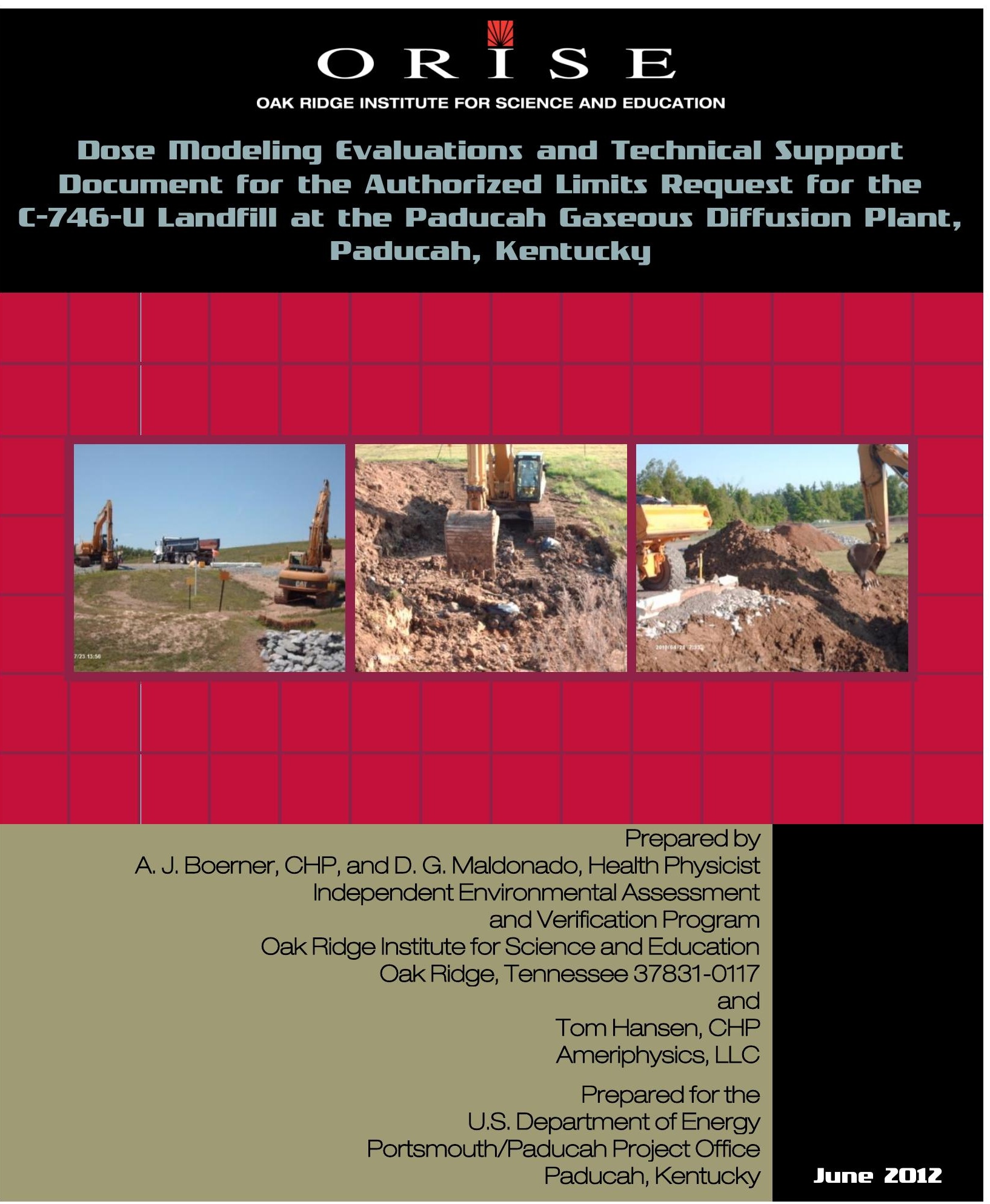

Disclaimer-The dose modeling software codes utilized in this report, RESRAD and RESRAD-OFFSITE, have undergone verification and validation (V\&V) testing by the Argonne National Laboratory Environmental Science Division (ANL/ESD). The RESRAD codes have been approved and used by the U.S. Department of Energy, Nuclear Regulatory Commission, and other regulatory agencies; however, ORISE takes no responsibility for the underlying accuracy of these codes.

Approved for public release; further dissemination unlimited. 
The Oak Ridge Institute for Science and Education (ORISE) is a U.S. Department of Energy institute focusing on scientific initiatives to research health risks from occupational hazards, assess environmental cleanup, respond to radiation medical emergencies, support national security and emergency preparedness, and educate the next generation of scientists. ORISE is managed by Oak Ridge Associated Universities.

\section{NOTICES}

The opinions expressed herein do not necessarily reflect the opinions of the sponsoring institutions of Oak Ridge Associated Universities.

This report was prepared as an account of work sponsored by the United States Government. Neither the United States Government nor the U.S. Department of Energy, nor any of their employees, makes any warranty, expressed or implied, or assumes any legal liability or responsibility for the accuracy, completeness, or usefulness of any information, apparatus, product, or process disclosed, or represents that its use would not infringe on privately owned rights. Reference herein to any specific commercial product, process, or service by trade name, mark, manufacturer, or otherwise, does not necessarily constitute or imply its endorsement or recommendation, or favor by the U.S. Government or any agency thereof. The views and opinions of authors expressed herein do not necessarily state or reflect those of the U.S. Government or any agency thereof. 


\section{Acknowledgments}

The Oak Ridge Institute for Science and Education (ORISE) appreciated the opportunity to provide technical support to the U.S. Department of Energy Portsmouth/Paducah Project Office (DOE-PPPO) at the Paducah Gaseous Diffusion Plant (PGDP), Paducah, Kentucky. ORISE supported the development of Authorized Limits (ALs) for the C-746-U Landfill at the PGDP.

The authors gratefully acknowledge the following individuals for their assistance and support with this challenging project:

Dr. Richard Bonczek, Mr. Donald Dihel, Mr. Tom Hines, and Mr. Reinhard Knerr of the DOE-PPPO; Mr. Orville Cypret, CHP (technical support consultant to DOE through Radiation Physics Solutions, LLC); and Mr. Raulie Casteel and Dr. John Volpe-technical support contractors to DOE through Performance Results Corporation (PRC).

Mr. David King, CHP (ORISE); and

Mr. Tom Hansen, CHP, Ameriphysics, LLC (ORISE technical consultant).

The DOE-PPPO team was of great assistance in providing historical and technical information about the PGDP and the C-746-U Landfill, including an extensive set of background project documents that defined the source term and permitted ORISE to evaluate and select appropriate site-specific input parameters for the dose modeling effort. Dr. Bonczek and Mr. Dihel played key roles on essentially a daily basis to ensure the project satisfied key objectives. Mr. Cypret, Mr. Casteel, and Dr. Volpe provided significant support regarding site-specific historical and technical input.

Mr. King provided significant technical input and reviews on key aspects of the project. Mr. Hansen was instrumental throughout the project, both with the conduct of the dose modeling effort and as a principal author of the report.

Finally, the following ORISE administrative and financial accountability staff members are sincerely acknowledged for their efforts to ensure the ORISE project milestones were satisfactorily achieved:

Ms. Ann Templon, Ms. Terina Bryant, Ms. Paige Benton, Ms. LaTosha Barton, Ms. Fleur Riva, and Ms. Karen Moore. Ms. Templon is the ORISE Quality Assurance Director and provided oversight of quality issues. Ms. Bryant, Ms. Benton, Ms. Barton, Ms. Riva, and Ms. Moore provided assistance with editorial reviews, report formatting and reproduction, schedule tracking, financial accountability and project reporting requirements. 
DOSE MODELING EVALUATIONS AND TECHNICAL SUPPORT DOCUMENT FOR THE AUTHORIZED LIMITS REQUEST FOR THE C-746-U LANDFILL AT THE PADUCAH GASEOUS DIFFUSION PLANT

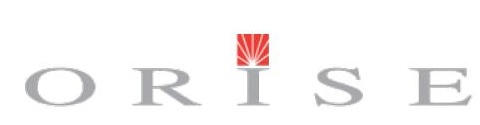

OAK RIDGE INSTITUTE FOR SCIENCE AND EDUCATION

Table of Contents

Executive Summary

1.0: Introduction

1.1 Purpose 5

1.2 Scope 5

1.3 Report Structure__ 5

1.4 Introduction to the Approach __ 7

1.5 Quality and Technical Reviews___ 12

2.0: Analytical Plan _ 13

2.1 General Approach for Soil Guidelines Derivation __ 13

2.2 DOE Regulations, Guidance, and Authorized Limits _ 14

2.2.1 DOE Order 5400.5, DOE Order 458.1, DOE G-441.1-XX, and 10 CFR Part $835 \ldots 14$

2.2.2 Definition of Authorized Limits _ 15

2.2.3 Current Authorized Limits_— 15

2.2.4 Rationale for New Authorized Limits __ 15

2.3 Waste Stream Characterization___ 15

2.4 Receptor Selection _ 16

2.5 Parameter Types _ 17

2.6 Priority Designations __ 18

2.7 Sensitivity Analyses __ 18

2.8 Deterministic Approach _ 19

2.9 Targeted Radionuclides __ 19

2.10 Source Term _ 21

2.11 Soil Guideline Output Methodology___ 21

3.0: PGDP and C-746-U Landfill Environmental Setting____ 23

3.1 General Environmental and Physical Site Characteristics___ 23

3.1.1 Geography and Physiography ___ 23

3.1.2 Population and Nearby Communities __ 24

3.1.3 Climatology and Meteorology____ 24

3.1.4 Geology 26

3.1.4.1 Bedrock and the Rubble Zone _ 26

3.1.4.2 McNairy and Clayton Formations___ 26

3.1.4.3 Porters Creek Clay _ 27

3.1.4.4 Eocene Sands__ 28

3.1.4.5 Continental Deposits _ 28

3.1.4.6 Surficial Deposits/Soils__ 30

3.1.5 Hydrology_ 30

3.1.5.1 Surface Water Hydrology _ 30

3.1.5.2 Groundwater Hydrology__ 33 
DOSE MODELING EVALUATIONS AND TECHNICAL

SUPPORT DOCUMENT FOR THE AUTHORIZED

LIMITS REQUEST FOR THE C-746-U LANDFILL AT

THE PADUCAH GASEOUS DIFFUSION PLANT

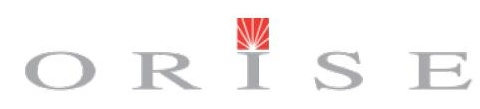

OAK RIDGE INSTITUTE FOR SCIENCE AND EDUCATION

Table of Contents

3.1.5.2.1 Bedrock Aquifer 33

3.1.5.2.2 McNairy Flow System 34

3.1.5.2.3 Terrace Gravel and Eocene Sands __ 34

3.1.5.2.4 Regional Gravel Aquifer __ 34

3.1.5.2.5 Upper Continental Recharge System __ 35

3.1.6 Ecological Resources___ 37

3.1.6.1 Terrestrial Systems__ 37

3.1.6.1.1 Vegetation__ 37

3.1.6.1.2 Wildlife__ 38

3.1.6.2 Aquatic Systems__ 38

3.1.6.3 Wetlands___ 38

3.1.6.4 Threatened and Endangered Species __ 39

4.0: C-746-ULandfill Description and Design Features___ 41

4.1 C-746-U Landfill Permitting ___ 41

4.2 North-South Diversion Ditch __ 42

4.3 C-746-U Landfill Construction and Design Features ___ 43

4.3.1 Periods of C-746-U Landfill Performance __ 45

4.3.2 Control of Surface Runoff___ 50

4.3.3 Leachate Collection and Storage System __ 52

4.3.4 Disposal Acceptance and Quantities ___ 53

4.3.5 C-746-U Landfill Capacity and Current Status ___ 53

5.0: Basis for the Derivation of Soil Guidelines____ 55

5.1 Target Dose Constraints ___ 55

5.2 Dose Modeling Assessment_General Basis____ 55

5.3 Conceptual Site Model____ 56

5.4 Receptor Selection, Scenarios, and Pathways __ 58

5.4.1 Operational Period ___ 58

5.4.1.1 Landfill Worker (Adult)_Plausible __ 58

5.4.1.2 Trespasser (Adult) —Implausible _ 58

5.4.2 Post-Institutional Control Period __ 59

5.4.2.1 Outdoor Worker (Adult)_Plausible__ 59

5.4.2.2 Recreational User (Teen)_Plausible __ 59

5.4.2.3 Resident Farmer (Adult)—Implausible __ 59

5.4.2.4 Resident Gardener (Adult)_Implausible___ 60

5.4.2.5 Offsite Resident Farmer (Adult)_Plausible___ 61

5.4.3 Exclusion of the Radon Pathway ___ 63

5.4.4 Receptor Summary___ 64

5.5 Computational Modeling (Project Dose Modeling Software) ___ 64

5.5.1 RESRAD 65

5.5.2 RESRAD-OFFSITE __ 65

5.5.3 Comparison of RESRAD and RESRAD-OFFSITE ___ 67

5.5.3.1 Same or Similar Submodels in RESRAD and RESRAD-OFFSITE __ 67

5.5.3.1.1 Groundwater Release Submodel __ 67

5.5.3.1.2 Surface Soil Mixing Submodel ___ 67

5.5.3.1.3 Dust Release Model ___ 68

5.5.3.1.4 Exposure Models__ 68 
DOSE MODELING EVALUATIONS AND TECHNICAL

SUPPORT DOCUMENT FOR THE AUTHORIZED

LIMITS REQUEST FOR THE C-746-U LANDFILL AT

THE PADUCAH GASEOUS DIFFUSION PLANT

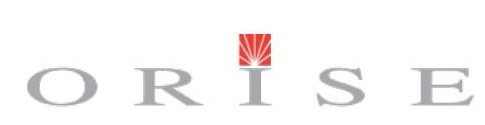

OAK RIDGE INSTITUTE FOR SCIENCE AND EDUCATION

Table of Contents

5.5.3.1.5 Advective Groundwater Transport Model 68

5.5.3.2 Additional Submodels in RESRAD-OFFSITE___ 68

5.5.3.2.1 Atmospheric Transport __ 68

5.5.3.2.2 Advective-Dispersive Groundwater Transport___ 69

5.5.3.2.3 Accumulation in Offsite Soil __ 69

5.5.3.2.4 Accumulation in a Surface Water Body __ 69

5.6 Establishing Parameter Inputs __ 70

5.6.1 Discussion of Parameters __ 70

5.6.2 Parameter Selection Hierarchy___ 75

5.6.2.1 Site-Specific Parameters _ 75

5.6.2.2 Calculated Input Values__ 75

5.6.2.3 Literature Values ___ 76

5.6.2.4 Default Parameters __ 76

5.6.3 Development of Input Parameter Tables ___ 76

5.7 Deterministic Analysis ___ 78

5.8 Sensitivity Analysis __ 78

6.0: Results and Discussion___ 79

6.1 General___ 79

6.2 Deterministic Results___ 79

6.2.1 Sensitivity Analysis _ 79

6.2.2 Single Radionuclide Soil Guidelines ___ 80

6.3 Derived Soil Guidelines ___ 82

6.4 Discussion of Derived Soil Guidelines ___ 83

6.4.1 Discussion of the Tc-99 Derived Soil Guideline __ 83

6.5 Peak Dose from Cumulative Radionuclide Inventory ___ 86

7.0: Summary, Conclusions, and Application of ORISE-Derived Soil Guidelines ___ 88

7.1 Uncertainties Associated with the RESRAD and RESRAD-OFFSTE Codes__ 89

7.2 Application of Derived Soil Guidelines___ 89

7.2.1 Unity Calculations___ 90

7.2.2 Shipment Limits _ 90

7.2.3 Radionuclide Inventory Management___ 90

8.0: References __ 93

Appendix A: RESRAD Table of Input Parameters for the C-746-U Landfill Onsite Receptor Scenarios

APPENDIX B: RESRAD-OFFSITE Table of Input Parameters for the C-746-U Landfill Offsite Resident Farmer Scenario___ $B$

Appendix C: RESRAD Summary Reports __ C

Appendix D: RESRAD-OFFSITE Summary Report____ _ D

Appendix E: Additional Documentation __E 
DOSE MODELING EVALUATIONS AND TECHNICAL SUPPORT DOCUMENT FOR THE AUTHORIZED LIMITS REQUEST FOR THE C-746-U LANDFILL AT THE PADUCAH GASEOUS DIFFUSION PLANT

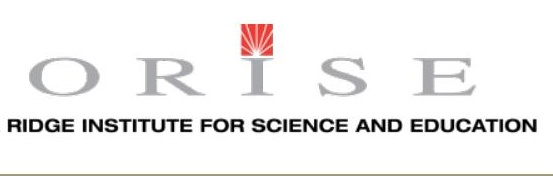

List of Tables

Table ES-1. ORISE Derived Radionuclide Soil Guidelines for the C-746-U Landfil 2

Table 2-1. List of Targeted Radionuclides___ 20

Table 5-1. Summary of Receptors and Active Pathways___ 64

Table 5-2. Parent Radionuclides and Progeny __ 71

Table 6-1. Single Radionuclide Soil Guidelines based on Receptor-Specific Target Dose 81

Table 6-2. ORISE-Derived Soil Guidelines for the C-746-U Landfill ___ _ 82

Table 6-3. Peak Dose from Cumulative Radionuclide Inventory (mrem/yr) ___ _ 87

Table 7-1. Projected Radionuclide Inventory for the C-746-U Landfill___ 92 
List of Figures

Figure 1-1. Location of the Paducah Gaseous Diffusion Plant and C-746-U Landfill 4

Figure 2-1. Concepts of Deterministic and Probabilistic Analysis (from NUREG/CR-6676, May 2000) 19

Figure 3-1. Communities in the Vicinity of the PGDP 25

Figure 3-2. Geologic Columnar Section in the Vicinity of the PGDP 27

Figure 3-3. Geologic Cross Section of the PGDP 28

Figure 3-4. Surface Water Features in the Vicinity of the PGDP 32

Figure 3-5. Hydrogeologic Units Beneath the PGDP 36

Figure 4-1. Wetlands and Floodplains in the Vicinity of the C-746-U Landfill 42

Figure 4-2. C-746-ULandfill Cross-Section 45

Figure 4-3. Schematic Model of DUST Model Layers and Materials for the Operational Period Under All Scenarios (from DOE 2003b)

Figure 4-4. Schematic Model of DUST Model Layers and Materials for the Institutional Control Period Under All Scenarios and for the Post-Institutional Control Period Under the No Failure Scenario (from DOE 2003b)

Figure 4-5. Schematic Model of DUST Model Layers and Materials for the Post-Institutional Control Period Under the Gradual Failure and Immediate Failure Scenarios (from DOE 2003b)

Figure 4-6. Close-up View of the C-746-ULandfill, Including Sediment Ponds and Borrow Areas 51

Figure 4-7. Sedimentation Pond at the C-746-ULandfil 52

Figure 4-8. C-746-U3 Landfill Leachate Tanks 53

Figure 4-9. C-746-U Construction, Design, and Planned Use Features 54

Figure 5-1. Onsite and Offsite ${ }^{a}$ Conceptual Site Model for the PGDP C-746-U Landfill __ 57

Figure 5-2. Location of the well for the Offsite Resident Farmer 62

Figure 5-3. RESRAD Exposure Pathways 65

Figure 5-4. RESRAD-OFFSITE Exposure Pathways 66

Figure 6-1. Dose to Offsite Resident Farmer from all Selected Targeted Radionuclides and Pathways

Figure 6-2. Dose to Offsite Resident Farmer from Tc-99 through Component Pathways 
DOSE MODELING EVALUATIONS AND TECHNICAL SUPPORT DOCUMENT FOR THE AUTHORIZED LIMITS REQUEST FOR THE C-746-U LANDFILL AT THE PADUCAH GASEOUS DIFFUSION PLANT

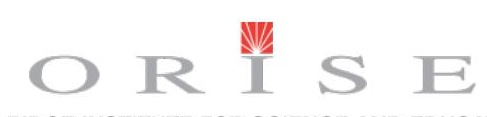

OAK RIDGE INSTITUTE FOR SCIENCE AND EDUCATION

Terms, Acronyms, and Abbreviations

\begin{tabular}{|c|c|}
\hline ACL & Administrative Control Level \\
\hline AEA & Atomic Energy Act \\
\hline $\mathrm{AL}$ & Authorized Limit(s) \\
\hline ALARA & As Low as Reasonably Achievable \\
\hline Am-241 & americium-241 \\
\hline amsl & above mean sea level \\
\hline ANL & Argonne National Laboratory \\
\hline ARRA & American Recovery and Reinvestment Act of 2009 \\
\hline bgs & below ground surface \\
\hline CERCLA & Comprehensive Environmental Response, Compensation, and Liability Act \\
\hline $\mathrm{Ci}$ & curies \\
\hline $\mathrm{cm}$ & centimeters \\
\hline $\mathrm{cm} / \mathrm{s}$ & centimeters per second \\
\hline Cs-137 & cesium-137 \\
\hline $\operatorname{csM}$ & Conceptual Site Model \\
\hline D\&D & Decontamination and Decommissioning \\
\hline DCF & Dose Conversion Factor \\
\hline DOA & Department of Energy Organization Act \\
\hline DOE & U.S. Department of Energy \\
\hline DOE-PPPO & DOE Portsmouth/Paducah Project Office \\
\hline $\mathrm{dpm} / 100 \mathrm{~cm}^{2}$ & disintegrations per minute per one hundred square centimeters \\
\hline DSR & Dose-to-Source Ratio \\
\hline DUST & Disposal Unit Source Term Model \\
\hline EM & Environmental Management \\
\hline EPA & U.S. Environmental Protection Agency \\
\hline FML & Flexible Membrane Linings \\
\hline $\mathrm{ft}$ & foot (feet) \\
\hline $\mathrm{ft}^{3}$ & cubic feet \\
\hline $\mathrm{g} / \mathrm{cm}^{3}$ & grams per cubic centimeter \\
\hline gal & gallon(s) \\
\hline HDPE & High-Density Polyethylene Membrane \\
\hline $\mathrm{hr}$ & hour(s) \\
\hline $\mathrm{HU}$ & Hydrogeologic Unit \\
\hline ICRP & International Commission on Radiological Protection \\
\hline IG & Implementation Guide \\
\hline in & inch(es) \\
\hline KAR & Kentucky Administrative Regulations \\
\hline$K d$ & distribution coefficient \\
\hline
\end{tabular}


DOSE MODELING EVALUATIONS AND TECHNICAL SUPPORT DOCUMENT FOR THE AUTHORIZED LIMITS REQUEST FOR THE C-746-U LANDFILL AT THE PADUCAH GASEOUS DIFFUSION PLANT

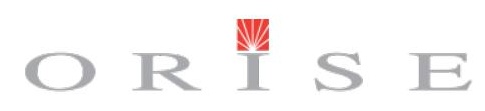

OAK RIDGE INSTITUTE FOR SCIENCE AND EDUCATION

Terms, Acronyms, and Abbreviations

\begin{tabular}{|c|c|}
\hline KDEP & Kentucky Department for Environmental Protection \\
\hline KDFWR & Kentucky Department of Fish and Wildlife Resources \\
\hline KDWM & Kentucky Division of Waste Management \\
\hline km & kilometer(s) \\
\hline $\mathrm{km}^{2}$ & kilometers squared (square kilometers) \\
\hline KOW & Kentucky Ordnance Works \\
\hline KRS & Kentucky Revised Statutes \\
\hline m & meter(s) \\
\hline $\mathrm{m} / \mathrm{m}$ & meters per meter \\
\hline $\mathrm{m}^{2}$ & square meter(s) \\
\hline $\mathrm{m}^{3}$ & cubic meter(s) \\
\hline mi & mile(s) \\
\hline $\mathrm{mi}^{2}$ & mile(s) squared (square miles) \\
\hline $\mathrm{mph}$ & miles per hour \\
\hline mrem & millirem \\
\hline $\mathrm{mrem} / \mathrm{yr}$ & millirem per year \\
\hline NCRP & National Council on Radiation Protection and Measurements \\
\hline NIOSH & National Institute for Occupational Safety and Health \\
\hline Np-237 & neptunium-237 \\
\hline NPL & National Priorities List \\
\hline NRC & Nuclear Regulatory Commission \\
\hline NSDD & North-South Diversion Ditch \\
\hline ORAU & Oak Ridge Associated Universities \\
\hline ORISE & Oak Ridge Institute for Science and Education \\
\hline ORO & Oak Ridge Office \\
\hline PCB & Polychlorinated Biphenyl \\
\hline $\mathrm{pCi} / \mathrm{g}$ & picocuries per gram \\
\hline PGDP & Paducah Gaseous Diffusion Plant \\
\hline ppm & parts per million \\
\hline PRS & Paducah Remediation Services \\
\hline Pu-238 & plutonium-238 \\
\hline Pu-239 & plutonium-239 \\
\hline Pu-240 & plutonium-240 \\
\hline Pu-241 & plutonium-241 \\
\hline RCRA & Resource Conservation and Recovery Act \\
\hline RGA & Regional Gravel Aquifer \\
\hline sow & Statement of Work \\
\hline T\&E & Threatened and Endangered \\
\hline Tc-99 & technetium-99 \\
\hline
\end{tabular}


DOSE MODELING EVALUATIONS AND TECHNICAL SUPPORT DOCUMENT FOR THE AUTHORIZED LIMITS REQUEST FOR THE C-746-U LANDFILL AT THE PADUCAH GASEOUS DIFFUSION PLANT

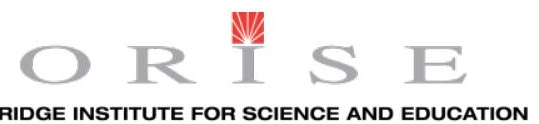

Terms, Acronyms, and Abbreviations

\begin{tabular}{ll}
\hline TCE & trichloroethylene \\
\hline TED & Total Effective Dose \\
\hline TEDE & Total Effective Dose Equivalent \\
\hline TENORM & Technologically Enhanced Naturally Occurring Radioactive Material \\
\hline Th-228 & thorium-228 \\
\hline Th-230 & thorium-230 \\
\hline Th-232 & thorium-232 \\
\hline TSCA & Toxic Substances Control Act \\
\hline TVA & Tennessee Valley Authority \\
\hline U-234 & uranium-234 \\
\hline U-235 & uranium-235 \\
\hline U-238 & uranium-238 \\
\hline UCRS & Upper Continental Recharge System \\
\hline USACE & U.S. Army Corp of Engineers \\
\hline USGS & U.S. Geological Survey \\
\hline UZ & Unsaturated Zone \\
\hline WKWMA & West Kentucky Wildlife Management Area \\
\hline WL & Working Level \\
\hline yr & year(s) \\
\hline
\end{tabular}


Executive Summary

\section{EXECUTME SUMMARY}

Environmental assessments and remediation activities are being conducted by the U.S. Department of Energy (DOE) at the Paducah Gaseous Diffusion Plant (PGDP), Paducah, Kentucky. The Oak Ridge Institute for Science and Education (ORISE), a DOE prime contractor, was contracted by the DOE Portsmouth/Paducah Project Office (DOE-PPPO) to conduct radiation dose modeling analyses and derive single radionuclide soil guidelines (soil guidelines) in support of the derivation of revised Authorized Limits (ALs) at the DOE Paducah C-746-U Landfill (Landfill). Relevant onsite and offsite receptors impacting current operational and projected future activities at the PGDP were evaluated. The DOE-PPPO is responsible for Environmental Management (EM) activities associated with the PGDP and serves as the lead agency for the conduct of remedial actions at the site.

The DOE has determined the need to close out existing ALs and develop, approve, and implement new limits. Several reasons exist for this action, including that current ALs are based on PGDP work activities projected in 2002, a 7-year (yr) waste projection; the American Recovery and Reinvestment Act of 2009 (ARRA) has expedited Decontamination and Decommissioning (D\&D) work at PGDP; clean-up activities have accelerated throughout the site; and with Landfill expansion, new ALs are needed to ensure appropriate disposal.

In support of soil guideline derivation, a Conceptual Site Model (CSM) was developed. The CSM listed radiation and contamination sources, release mechanisms, transport media, representative exposure pathways from residual radioactivity, six onsite receptors (under present and future use scenarios), and one offsite receptor. Plausible receptors included a Landfill Worker, Outdoor Worker, Recreational User, and Offsite Resident Farmer. Implausible receptors included a Trespasser, Resident Farmer (onsite), and Resident Gardener. The latter were considered implausible due to existing or planned controls for the operational and post-institutional control periods. The outputs of the various models are soil guidelines that can be used by DOE-PPPO to derive revised ALs. This document provides technical support for DOE to establish ALs. Derivation of the actual ALs is outside the scope of this report and will be handled separately by DOE-PPPO as a formal AL request.

Three target dose constraints (above background) - 1, 15, and 25 millirem per year ( $\mathrm{mrem} / \mathrm{yr}$ ) were considered in the soil guideline analysis. The $1 \mathrm{mrem} / \mathrm{yr}$ constraint represents a "walk-away" dose, that is, a dose that if satisfied, would eliminate the need for any remedial action at the end of the C-746-U Landfill's useful life. In addition, soil guideline derivation for specific receptors included a comparison to the $100 \mathrm{mrem} / \mathrm{yr}$ primary public dose limit (above background) cited in DOE Order 458.1, Radiation Protection of the Public and the Environment (DOE 2011). The primary dose 


\section{Executive Summary}

limit and As Low as Reasonably Achievable (ALARA) considerations were incorporated into the Landfill Worker receptor evaluation.

The most current RESRAD (Version 6.5) and RESRAD-OFFSITE (Version 2.5) computer codes available for the analysis were used for the detailed, deterministic technical assessments. These codes were developed by the Argonne National Laboratory (ANL). Modeling evaluations for any onsite structures were excluded from the ORISE Statement of Work (SOW). Using careful technical judgment and assessment of site-specific and literature references as well as correspondence with DOE project personnel, the computational models were parameterized with emphasis on site-specific input values. Model outputs were evaluated to ensure that physical site conditions and mathematical terms were consistent. A sensitivity analysis ensured that important exposure pathways and parameters were not overlooked.

In support of the forthcoming AL request, single radionuclide soil guidelines (outputs specified by the software modeling codes) were generated for each receptor and targeted radionuclides. These soil guidelines were based on satisfying a basic radiation public dose limit of $100 \mathrm{mrem} / \mathrm{yr}$ for implausible receptors, $100 \mathrm{mrem} / \mathrm{yr}$ for a Landfill Worker, and $1 \mathrm{mrem} / \mathrm{yr}$ for other plausible receptors. The Landfill Worker was specifically evaluated to meet the public dose limit —a limit well below the DOE Administrative Control Level (ACL) of 2,000 mrem/yr applicable to occupationally exposed workers. The most limiting (restrictive) single radionuclide soil guidelines across all receptors were then identified, rounded to two significant figures, and reported as the derived soil guidelines. The derived soil guidelines for the C-746-U Landfill are presented in Table ES-1.

Table ES-1. ORISE Derived Radionuclide Soil Guidelines for the C-746-U Landfill

\begin{tabular}{ccc}
\hline Radionuclide & Derived Soil Guidelines (pCi/g)* \\
\hline Am-241 & 3,500 \\
Cs-137 & 190 \\
Np-237 & 550 \\
Pu-238 & 3,900 \\
Pu-239 & 3,600 \\
Pu-240 & 3,600 \\
TC-99 & 28 \\
Th-228 & 74 \\
Th-230 & 1,200 \\
Th-232 & 38 \\
U-234 & 18,000 \\
U-235 & 820 \\
U-238 & 3,200
\end{tabular}

*The derived soil guidelines reflect above background concentrations of radioactive material. 


\section{Executive Summary}

These derived soil guidelines ensure that modeled receptors will not exceed the $100 \mathrm{mrem} / \mathrm{yr}$ and $1 \mathrm{mrem} / \mathrm{yr}$ target doses, will be protective of human health and the environment, and will meet the requirements of the DOE Order 458.1 and associated guidance. The derived soil guidelines reflect above background concentrations of radioactive material.

An additional evaluation was performed at the request of the DOE-PPPO to determine the maximum (peak) dose if all radionuclides were present at the derived soil guidelines. A time horizon of 1,050 yr was used for all receptors with the exception of the Trespasser and the Landfill Worker where a time horizon of $70 \mathrm{yr}$ was assumed. The highest projected dose $-1,030 \mathrm{mrem} / \mathrm{yr}$-occurred for the Landfill Worker and most likely overestimates the projected dose for actual workers. This argues for the conservatism in the modeling estimates.

Based on planned C-746-U Landfill waste receipts at the concentrations reflected by the derived soil guidelines, ORISE believes it is reasonable to expect that the target dose constraints will be satisfied at the end of the Landfill's operation and for 1,000 yr following closure.

This report contains the technical basis in support of the DOE's derivation of ALs for the Landfill. A complete description of the methodology, including an assessment of the input parameters, model inputs, and results is provided in this report. The derived soil guidelines presented in this report are provided to DOE-PPPO for consideration. This report also provides initial recommendations on applying the derived soil guidelines. The ORISE-derived soil guidelines are specifically applicable to the Landfill at the end of its operational life and are not intended to be used for individual, routine load shipments of the DOE-authorized materials to the Landfill. A suggested "upper bound" multiple of the derived soil guidelines for individual shipments is provided by ORISE for DOE-PPPO consideration based on the results of the analysis. Ultimately, it is the DOE's responsibility to develop and approve the AL request and operate the Landfill to implement the requested ALs. If the requested ALs are approved, the DOE would be responsible for the proper management of these limits under its AL program. 


\section{0: Introduction}

\section{0: INTRODUCTION}

The U.S. Department of Energy (DOE) Paducah Gaseous Diffusion Plant (PGDP) is an active uranium enrichment facility located approximately 10 miles (mi) west of Paducah, Kentucky and $3.5 \mathrm{mi}$ south of the Ohio River in the western part of McCracken County (Figure 1-1). The plant is situated on 3,424 acres. Approximately 748 acres comprise the industrial portion of PGDP, located within a fenced security area. This area is designated as secured industrial land use, and contains active and inactive production buildings, offices, equipment and material storage areas, active and inactive waste management units, and other support facilities. The remaining 2,676 acres consist of an unsecured industrial land "buffer zone" surrounding the plant, and land transferred to the Tennessee Valley Authority (TVA) for the Shawnee Steam Plant and to the Commonwealth of Kentucky for wildlife conservation and recreational purposes (ORAU 2007, PRS 2008a).

The PGDP limited area (i.e., the area inside the security fence) is heavily industrialized; however, the area surrounding the plant is mostly agricultural and open land, with some forested areas. The reasonably anticipated future land use of the PGDP limited area is industrial; however, final decisions associated with future land use will be made in conjunction with the remedial action process under the Comprehensive Environmental Response, Compensation, and Liability Act (CERCLA). The PGDP is posted government property and trespassing is prohibited. Access to the PGDP limited area is controlled by guarded checkpoints, a perimeter fence, and vehicle barriers and is subject to routine patrol and visual inspection by armed plant protective forces. The DOE Reservation surrounding the PGDP limited area includes 1,986 acres licensed to the Commonwealth of Kentucky Department of Fish and Wildlife Resources (KDFWR). This area is part of the West Kentucky Wildlife Management Area (WKWMA) and borders PGDP to the north, west, and south. The WKWMA is an important recreational resource for western Kentucky and is used by more than 10,000 people each year (yr). Major recreational activities include hunting, field trials for dogs and horses, trail riding, fishing, and skeet shooting. The TVA Shawnee Steam Plant, adjacent to the northeast border of the DOE Reservation, is the only other major industrial facility in the immediate area.

Environmental assessments and remediation activities are currently being conducted by the DOE at the PGDP. The Oak Ridge Institute for Science and Education (ORISE) was contracted by the DOE Portsmouth/Paducah Project Office (DOE-PPPO) to conduct dose modeling evaluations for relevant onsite and offsite receptors impacting current operational and projected future activities at the DOE Paducah C-746-U Landfill (Landfill).

The DOE-PPPO is responsible for Environmental Management (EM) activities associated with the PGDP and serves as the lead agency for the conduct of remedial actions at the PGDP. 


\section{0: Introduction}

The Atomic Energy Act (AEA), the Department of Energy Organization Act (DOA), and related statutes assign to the Department the responsibility to protect the public, the environment, and property from the hazards associated with its research, development, production, or other activities. This responsibility, which lacks any limit in time, includes protecting the public and environment from radiation or radioactive material (DOE 1999a).

The U.S. Environmental Protection Agency (EPA) Region 4 and the Kentucky Department for Environmental Protection (KDEP) serve as the regulatory oversight agencies for CERCLA and Resource Conservation and Recovery Act (RCRA) activities. The Kentucky Cabinet for Health and Family Services, Department for Public Health, Radiation Health Branch is the regulatory oversight agency for radiation in Kentucky.

As an essential component of these technical evaluations, ORISE was requested to develop an approach to support a separate DOE AL request by deriving single radionuclide soil guidelines for various Landfill scenarios.

The C-746-U Landfill was constructed from 1995 to 1997 by DOE for disposal of solid wastes that are not regulated as hazardous waste under the RCRA Subtitle $\mathrm{C}$ or as waste containing Polychlorinated Biphenyls (PCBs) under the Toxic Substances Control Act (TSCA). Construction of the Landfill was needed to continue onsite disposal of certain wastes generated at the PGDP after an older landfill at the PDGP was filled to capacity and closed in accordance with Kentucky requirements.

The C-746-U Landfill is located north of DOE Paducah's main plant area (Figure 1-1) and is permitted by the Kentucky Energy and Environment Cabinet, Department for Environmental Protection, Division of Waste Management (KDWM) in accordance with the requirements of its solid waste regulations-401 Kentucky Administrative Regulations (KAR) 48, Standards for Solid Waste Facilities — and Subtitle D of RCRA. The total permitted area of the Landfill is approximately 59 acres. Twenty-two of the 59 acres are currently designated to be developed for waste disposal. The potential disposal capacity is approximately 42.1 million cubic feet $\left(\mathrm{ft}^{3}\right)$ or 1.2 million cubic meters $\left(\mathrm{m}^{3}\right)$. The Landfill is lined, has a leachate collection system, and will contain a multilayer cap when closed. Construction of the facility and emplacement of wastes is currently proceeding from the southern end to the northern end of the Landfill. Additional details regarding the Landfill, including design features, which directly influenced the ORISE modeling analyses, are provided in Section 4.0, "C-746-U Landfill Description and Design Features," of this report.

As a permitted RCRA Subtitle D facility, post-operational care of the Landfill and limitations on future use of the Landfill are statutory. The Kentucky regulations (401 KAR 48:070, Section 15) require the operator of a contained solid waste landfill to close it in a manner that minimizes the 


\section{0: Introduction}

need for further maintenance and minimizes the closure care formation and release of leachate and explosive gases to air, groundwater, or surface water to the extent necessary to protect human health and the environment. In summary, the key provisions of the regulatory requirements contained in 401 KAR 48:070, Section 15 require the operator to:

Maintain the integrity and effectiveness of the cap

Conduct groundwater monitoring

Maintain and operate the leachate collection system until leachate no longer is generated

Conduct monitoring and routine maintenance activities that shall be carried out during the closure care period of at least thirty (30) years.

The closure plan is required to contain a description of the planned uses of the property during the closure care period. Closure care use of the property shall not be allowed to disturb the integrity of the final cap, liner(s), or any other components of the containment system, or the function of the monitoring systems, unless upon demonstration by the owner or operator, the cabinet determines that the activities shall not increase the potential threat to human health or the environment or the disturbance is necessary to reduce a threat to human health or the environment. The owner or operator shall obtain approval from the cabinet in order to remove any wastes or waste residues, the liner, or contaminated soils from the land.

The owner or operator is also required to record a notice in the deed that shall in perpetuity notify any potential purchaser of the property of the location and time of operation of the facility, the nature of the waste placed in the site and a caution against future disturbance of the area. Such notice shall be recorded in accordance with KRS Chapter 382 and proof of recording shall be submitted to the cabinet prior to the cabinet's acceptance of certification of closure. 
DOSE MODELING EVALUATIONS AND TECHNICAL SUPPORT DOCUMENT FOR THE AUTHORIZED LIMITS REQUEST FOR THE C-746-U LANDFILL AT THE PADUCAH GASEOUS DIFFUSION PLANT

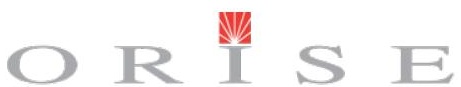

OAK RIDGE INSTITUTE FOR SCIENCE AND EDUCATION

\section{0: Introduction}

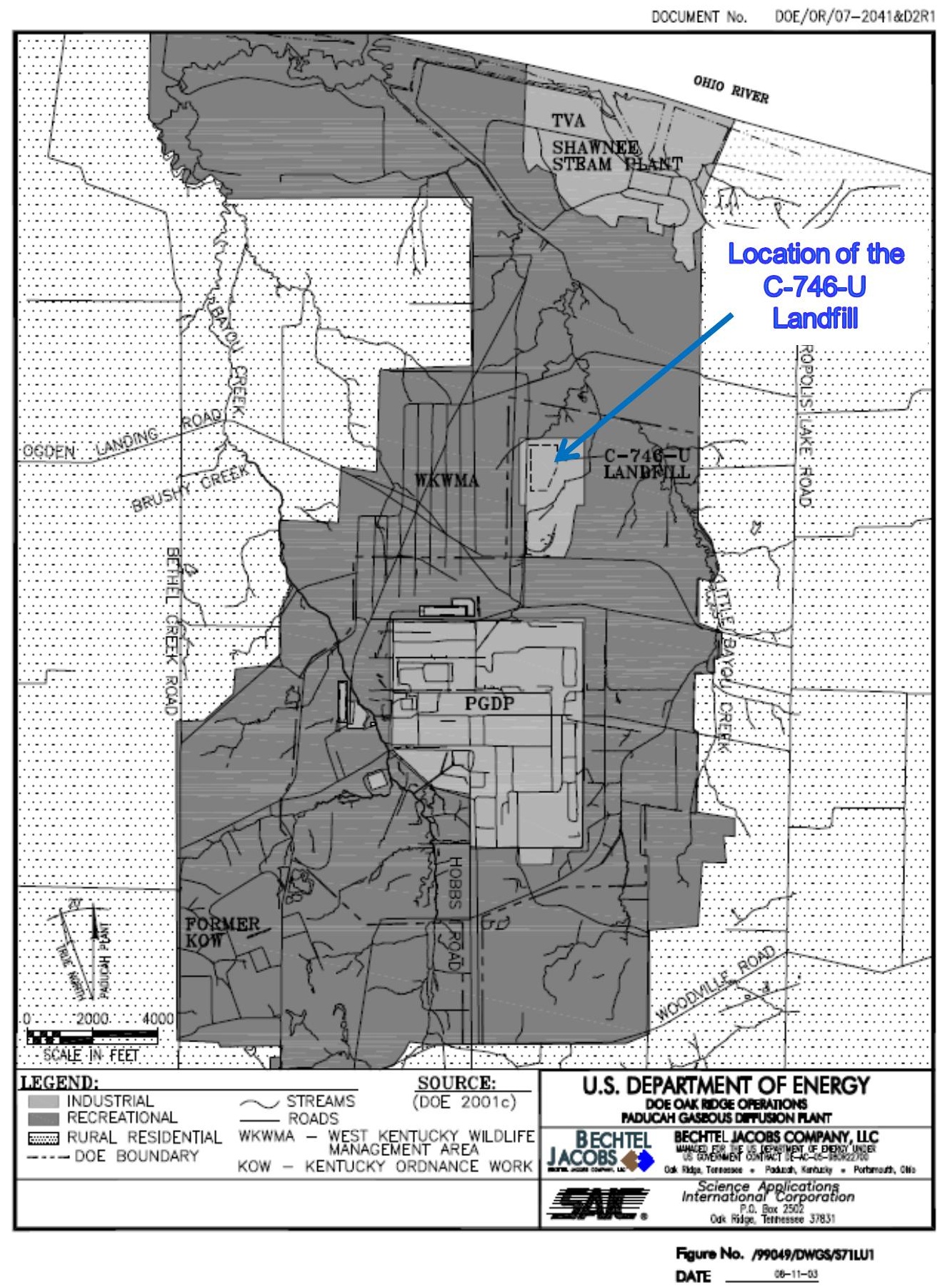

Figure 1-1. Location of the Paducah Gaseous Diffusion Plant and C-746-U Landfill 


\section{0: Introduction}

The purpose of the analyses presented in this report is to provide technical support for DOE-PPPO to establish revised site-specific ALs for the C-746-U Landfill in support of environmental remediation and waste disposition activities at the PGDP.

1.2

SCOPE

To support the request for site-specific ALs, a deterministic analysis for the C-746-U Landfill is presented in this report. The analysis included a review of the site-specific environmental parameters utilized in the analysis, the methodology used for calculating the ORISE-derived soil guideline numeric limits, and identification of sensitive parameters. These reviews were conducted to ensure that no individual parameter was overlooked in the model equations as it pertained to the environmental transport of residual contaminants and the resulting dose at receptor locations. The analysis was applied specifically to the following site radionuclides provided by DOE-PPPO to ORISE: Am-241, Cs-137, Np-237, Pu-238, Pu-239, Pu-240, Tc-99, Th-228, Th-230, Th-232, U-234, $\mathrm{U}-235$, and U-238.

Note: The soil guidelines derived by ORISE are specifically applicable to the C-746-U Landfill at the end of its operational life.

This report is organized into multiple sections:

\section{Executive Summary}

1.0: Introduction

2.0: Analytical Plan

3.0: PGDP and C-746-U Landfill Environmental Setting

4.0: C-746-U Landfill Description and Design Features

5.0: Basis for the Derivation of Soil Guidelines

6.0: Results and Discussions

7.0: Summary, Conclusions, and Application of ORISE-Derived Soil Guidelines

8.0: References

Appendices (e.g., parameter tables and supporting input documentation, input/output files, and additional documentation)

The ORISE Analytical Plan (Plan) approved by DOE-PPPO (and evaluated by EPA and Kentucky regulatory staff) was an essential component of this work effort. Per agreement with DOE-PPPO, the Plan was modified as the project evolved and new information was identified. The Plan is introduced in Section 2.0, "Analytical Plan." Supporting details are then captured in other sections 


\section{0: Introduction}

of this report (particularly Section 5.0, "Basis for the Derivation of Soil Guidelines"). The Plan explains the methodology used to determine soil guidelines.

Section 3.0, "PGDP and C-746-U Landfill Environmental Setting," extends the report's introduction about the PGDP site from a hydrological, topographical, and ecological perspective.

Details regarding the C-746-U Landfill, including specific design features, are described in Section 4.0, "C-746-U Landfill Description and Design Features." The DOE's Risk and Performance Evaluation of the C-746-U Landfill at the Paducah Gaseous Diffusion Plant, Paducah, Kentucky (DOE 2003b) was used as a primary reference for this information. Where applicable, design features influencing the ORISE modeling analysis are identified.

Section 5.0, "Basis for the Derivation of Soil Guidelines," serves as an important backdrop for the results and conclusions that follow. Details are provided regarding the Landfill's Conceptual Site Model (CSM) and selection of the site dose modeling codes and analyses conducted. Specifics related to various exposure scenarios, pathways, and the selection of deterministic input parameters for the modeling runs are included. In brief, Section 5.0 provides the requisite preliminary information to take the reviewer to the point where the software modeling codes are actually used to generate results.

Section 6.0, "Results and Discussion," provides the derived soil guidelines for the C-746-U Landfill on a radionuclide-specific basis for specified target doses, receptors, and exposure pathways. Results are provided for both onsite and offsite receptors. Derived soil guidelines were selected based on the most restrictive results for each radionuclide (selection of the lowest soil guidelines corresponded to the highest dose) relative to all receptors. Key sensitive parameters are described.

Section 7.0, "Summary, Conclusions, and Application of ORISE-Derived Soil Guidelines," summarizes the results of the dose modeling and AL analysis and provides recommendations on applying the soil guidelines at the PGDP.

An extensive set of references is compiled in Section 8.0, "References," encompassing regulatory and guidance-based documents, PGDP site and C-746-U Landfill information, and references associated with utilizing the software codes and evaluating input parameter selection. Extensive background site information was provided by DOE-PPPO staff in support of report preparation.

Appendices A through D are provided containing both the specifically chosen input parameters for the two utilized computer codes, supporting information for the selected inputs, and the code input/output results. Appendix E, "Additional Documentation," is included as a placeholder for certain technical support documents that DOE-PPPO would like to accompany their AL request. 
DOSE MODELING EVALUATIONS AND TECHNICAL

SUPPORT DOCUMENT FOR THE AUTHORIZED

LIMITS REQUEST FOR THE C-746-U LANDFILL AT THE PADUCAH GASEOUS DIFFUSION PLANT

\section{O R $\mathrm{N}$ E}

OAK RIDGE INSTITUTE FOR SCIENCE AND EDUCATION

\section{0: Introduction}

1.4

INTRODUCTIONTO THE APPROACH

This section introduces the general aspects of the approach used by ORISE to derive soil guidelines for the C-746-U Landfill. Supporting details are provided in Section 2.0, "Analytical Plan"; Section 5.0, "Basis for the Derivation of Soil Guidelines"; and Section 6.0, "Results and Discussion."

Three target dose constraints (above background) were considered in support of soil guideline development. The target dose constraints in this report will be discussed in terms of the Total Effective Dose (TED) received in a year; however, for simplicity the abbreviation “/yr" will be used. These dose constraints are:

1 millirem per year (mrem/yr): A DOE field element approval limitation and a dose considered negligible by the Commonwealth of Kentucky Radiation Health Branch.

$15 \mathrm{mrem} / \mathrm{yr}:$ The EPA protective cleanup level for radionuclide contamination cited in EPA OSWER No. 9200.4-18, Establishment of Cleanup Levels for CERCLA Sites with Radioactive Contamination (EPA 1997).

$25 \mathrm{mrem} / \mathrm{yr}$ : The DOE level of residual radioactive material for real property above background in any calendar year that must be applied to each specific clearance of property for any actual or likely future use of the property as cited in DOE Order 458.1, Radiation Protection of the Public and the Environment (Paragraph 4.k.(2), "Release and Clearance of Property") (DOE 2011). This dose level is consistent with the Kentucky Administrative Regulation (KAR) 902 KAR 100:042, Section 2, and the Nuclear Regulatory Commission (NRC) Title 10 of the Code of Federal Regulations (CFR), Part 20, Subpart E. However, the radiological release criteria of $25 \mathrm{mrem} / \mathrm{yr}$ cited in KAR and NRC regulations correspond to Total Effective Dose Equivalent (TEDE) and not TED as required in DOE Order 458.1 and 10 CFR 835.

The $1 \mathrm{mrem} / \mathrm{yr}$ constraint represents a "walk-away" dose level for the site and was of significant importance in this project. The term "walk-away dose" has been cited in the 2001 memorandum Risk versus Dose Cleanup Levels issued by the Kentucky Radiation Health and Toxic Agents Branch (currently the "Kentucky Radiation Health Branch") to the PGDP (Volpe 2001). This memorandum states the following: "It is the position of the Radiation Health and Toxic Agents Branch that dose assessments must be conducted and considered for all pathways and radionuclides" and that "regardless of the pathway, it is the position of the Radiation Health and Toxic Agents Branch that a $1 \mathrm{mrem} / \mathrm{yr}$ dose should be used as a walk away requirement where no further action is required to reduce the dose." 
DOSE MODELING EVALUATIONS AND TECHNICAL

SUPPORT DOCUMENT FOR THE AUTHORIZED

LIMITS REQUEST FOR THE C-746-U LANDFILL AT THE PADUCAH GASEOUS DIFFUSION PLANT

\section{$\mathrm{O} R \mathrm{~N} \mathrm{~N}$}

OAK RIDGE INSTITUTE FOR SCIENCE AND EDUCATION

\section{0: Introduction}

In this context, the $1 \mathrm{mrem} / \mathrm{yr}$ dose is considered a constraint that applies to any reasonable scenario in which a plausible receptor could be exposed to ionizing radiation from any contaminated media following Landfill closure.

In addition to these target dose constraints (applicable to some but not all receptors), the DOE primary public dose limit of $100 \mathrm{mrem} / \mathrm{yr}$ above background, cited in DOE Order 458.1, Radiation Protection of the Public and the Environment (DOE 2011), was also utilized for applicable receptors. The DOE describes Order 458.1 as the primary radiation protection standard used to protect the public and the environment from undue risk of radiation associated with DOE operations. The Order establishes requirements and the framework for the release of both real and personal property with residual radioactivity from DOE control.

Note: This work effort was initiated under DOE Order 5400.5, Radiation Protection of the Public and the Environment (DOE 1993) and DOE G 441.1-XX, Implementation Guide: Control and Release of Property with Residual Radioactive Material for use with DOE 5400.5 (DOE 2002). However, during the course of this work, DOE Order 5400.5 was replaced by DOE Order 458.1 with the same title. (The DOE-EM has indicated that DOE G 441.1-XX, originally issued in 2002, will be updated [Gelles 2009]). DOE Order 458.1 was issued on February 11, 2011 and cancelled DOE Order 5400.5 Chg 2, except for Chapter III, Derived Concentration Guidelines, and Figure IV-I, Surface Contamination Guidelines. A revision of the Order was required to promote consistency with the June 2007 amendments to DOE's 10 CFR 835, Occupational Radiation Protection (Wallo 2007). ORISE evaluated the changes in DOE Order 458.1 against DOE Order 5400.5 and determined that DOE Order 458.1 did not have an impact on this work effort from a dose modeling perspective. In particular, this is due to the fact that some of the modifications included in the Order (e.g., the use of TED vs. TEDE) that could have affected this work are consistent with 10 CFR 835, which was followed in this project.

Because the primary dose limit (100 mrem/yr) applies to all sources and pathways, a dose constraint of one quarter of the primary dose limit (i.e., $25 \mathrm{mrem} / \mathrm{yr}$ ) is applied to each DOE source or practice (as cited in draft DOE G 441.1-XX). Therefore, per this Implementation Guide (IG), ALs for annual dose from the release of property should be as far below $25 \mathrm{mrem} / \mathrm{yr}$ as is practicable. This dose constraint represents an upper bound or "cap" for As Low as Reasonably Achievable (ALARA)-based ALs for release of property containing residual radioactive material. As Kentucky is an Agreement State, this dose constraint ensures DOE real property releases are consistent with dose requirements in 902 KAR 100:042, Decommissioning and Financial Surety. (Requirements in 902 KAR 100:042 must be at least equivalent to those requirements found in 10 CFR 20, Subpart E, Radiological Criteria for License Termination, applicable to non-agreement states.) 
DOSE MODELING EVALUATIONS AND TECHNICAL

SUPPORT DOCUMENT FOR THE AUTHORIZED

LIMITS REQUEST FOR THE C-746-U LANDFILL AT THE PADUCAH GASEOUS DIFFUSION PLANT

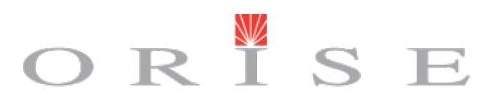

OAK RIDGE INSTITUTE FOR SCIENCE AND EDUCATION

\section{0: Introduction}

The ORISE work effort was affected by the DOE's July 9, 2010, implementation requirement in 10 CFR Part 835, Occupational Radiation Protection, to cite radiological units in TED in lieu of TEDE. Part 835 now incorporates more recent International Commission on Radiological Protection (ICRP) methodologies identified in ICRP Publication 60 (ICRP 1991) and ICRP Publication 68 (ICRP 1994), respectively, in support of the change to TED. The term "TEDE" has therefore been replaced in the regulation. Further discussion of this change and its impact on the dose modeling analyses can be found in Section 5.0, "Basis for the Derivation of Soil Guidelines."

A CSM was developed to identify primary and secondary sources of contamination and release mechanisms, transport media, exposure pathways, and representative receptors. These receptors were categorized first into onsite and offsite receptors. Onsite receptors were further divided into an operational period and future use period-i.e., an Institutional Control Period (and beyond). Receptors considered during the Operational Period consisted of the Landfill Worker and a Trespasser. Receptors included in the future use period were the Resident Farmer, Resident Gardener, Outdoor Worker, and Recreational User. For the offsite dose assessment, a Resident Farmer was selected.

The onsite Resident Farmer scenario was incorporated into the CSM for comparison to the $100 \mathrm{mrem} / \mathrm{yr}$ primary public dose limit. The Resident Farmer and his family were assumed to move onto the site after a DOE property release, build a house, grow crops, and raise livestock for consumption. A more complete discussion of this receptor, including the specific modeling assumptions and results for this receptor are discussed in Section 5.0, "Basis for the Derivation of Soil Guidelines," and Section 6.0, "Results and Discussion."

In addition to DOE Order 5400.5, DOE Order 458.1, and 10 CFR 835 requirements, many other regulatory and guidance documents were examined in this dose modeling and AL development report. References included DOE guidance documents, applicable Commonwealth of Kentucky requirements and guidance, Nuclear Regulatory Commission (i.e., NUREG) and EPA documentation, ICRP reports, and an extensive set of Paducah site-specific records provided by the DOE-PPPO. References used in this analysis are provided in Section 8.0, "References."

The most recent Argonne National Laboratory (ANL) RESRAD (Version 6.5) and RESRAD-OFFSITE (Version 2.5) computer codes available at the time were used for the C-746-U Landfill assessments. Consistent with guidance in the RESRAD Manual, exposure pathways considered in the modeling effort were receptor-specific. Where applicable, for example, the Onsite and Offsite Resident Farmer scenarios, the soil guideline determination included the groundwater pathway as an active pathway (refer to the CSM in Section 5.0, "Basis for the Derivation of Soil Guidelines," for supporting details). The radon pathway was deactivated in all cases (refer to Section 5.4.3, "Exclusion of the Radon Pathway," for supporting details). 


\section{0: Introduction}

Recognizing that the historical nature of PGDP operations primarily involved the processing of uranium isotopes, a primary assumption was made in this dose assessment that radionuclides from the uranium (U-238) and actinium (U-235) decay series did not exist in secular equilibrium with their decay products. Furthermore, the absence of secular equilibrium was also assumed for radionuclides associated with the thorium series (beginning with Th-232). None of the other targeted radionuclides in this analysis were members of a naturally occurring radioactive decay series. Thus, for purposes of this analysis, the uranium (U-238) and actinium (U-235) decay series did not exist in secular equilibrium with their decay products. This assumption is not related to the short-lived daughters, as ingrowth still occurs and that is considered in the model when deriving soil guidelines. In the analysis, this statement is meant to prevent long lived progeny, such as radium, from beginning at time " 0 " with an assigned activity (that is, they are allowed to grow in as well). If equilibrium is assumed, all the progeny will have the same activity as the parent at time " 0 ", that is, 1 picocurie per gram (pCi/g) in this case. This approach, if adopted, would have resulted in considerably lower soil guidelines.

A key component in the analysis was the parameterization of the model equations. ORISE conducted a thorough assessment to carefully review and determine an appropriate input for each parameter into the computer codes. Soil guideline derivations were aided by reviews of site records and available references. Available site-specific parameters were utilized as input to both computer codes. Selection of these parameters was influenced by two primary references - the DOE's Risk and Performance Evaluation of the C-746-U Landfill at the Paducah Gaseous Diffusion Plant, Paducah, Kentucky (DOE 2003b) and Methods for Conducting Risk. Assessments and Risk Evaluations at the Paducah Gaseous Diffusion Plant, Paducah, Kentucky (DOE 2009b). DOE contractor technical support staff was contacted as needed to discuss site-specific issues. When unavailable, other sources for input parameters - including RESRAD and RESRAD-OFFSITE default values-were utilized, based on an established selection hierarchy described in Section 5.0, "Basis for the Derivation of Soil Guidelines."

Unit (normalized) concentrations of 1 picocurie per gram (pCi/g) for each of the site's targeted radionuclides were used for the primary modeling evaluations. This approach provided initial Dose-to-Source Ratios (DSRs) as a dose per unit activity factor (mrem/yr per pCi/g), calculated for exposed individuals over a time period of 1,050 yr. An exception was allowed for receptors that would only be exposed during the Operational Period (i.e., the Trespasser and the Landfill Worker), and a time horizon of $70 \mathrm{yr}$ was used for these modeled cases.

A period of 1,000 $\mathrm{yr}$ represents the conventional period germane to AL derivations, per guidance cited in DOE/CH/8901, A Manual for Implementing Residual Radioactive Material Guidelines (DOE 1989) and discussions with ANL RESRAD staff members. The choice of 1,050 yr reflected the selection of 1960 as the starting year for modeling purposes. It is recognized that PGDP uranium enrichment 


\section{0: Introduction}

operations initially began in 1952 (ORAU 2007, PRS 2008a); however, the entire uranium inventory was not present in 1952 and is therefore not a reasonable starting time. ORISE selected 1960 to include some radioactive ingrowth in the conduct of the analysis.

In support of the forthcoming DOE AL request, single radionuclide soil guidelines (an output specified by the software codes) were generated for each receptor and targeted radionuclide. The results represented the codes' single radionuclide soil guidelines based on satisfying radiation doses of:

$100 \mathrm{mrem} / \mathrm{yr}$ for implausible receptors

$100 \mathrm{mrem} / \mathrm{yr}$ for a Landfill Worker (plausible receptor)

$1 \mathrm{mrem} / \mathrm{yr}$ for other plausible receptors

The Landfill Worker was specifically evaluated to meet the public dose limit-a limit well below the DOE Administrative Control Level (ACL) of 2,000 mrem/yr applicable to occupationally exposed workers. The most limiting (restrictive) single radionuclide soil guidelines across all receptors were then identified as ORISE-derived soil guidelines.

Following a careful evaluation of the receptors modeled using RESRAD and RESRAD-OFFSITE, the single radionuclide soil guidelines were then rounded to two significant figures and identified by ORISE as the derived soil guidelines (refer to Section 6.0, "Results and Discussion"). These derived soil guidelines ensured that modeled receptors would not exceed the doses described above. The derived soil guidelines are provided to DOE-PPPO for consideration. Ultimately, it is the DOE's responsibility to develop and approve the AL request and operate the Landfill to implement the requested ALs. If the requested ALs are approved, the DOE would be responsible for the proper management of these limits under its AL program.

Per a request from the DOE-PPPO, an additional evaluation was then conducted using the ORISE-derived soil guidelines. The evaluation consisted of taking each radionuclide-specific soil guideline as an individual input to the modeling codes and determining the maximum (peak) annual dose at 1,050 yr for each receptor. (As discussed, a time horizon of $70 \mathrm{yr}$ was assumed for the Trespasser and the Landfill Worker.)

The resultant doses for all receptors are provided in Section 6.0, "Results and Discussion." Conclusions regarding specifically satisfying the $1 \mathrm{mrem} / \mathrm{yr}$ walk-away dose constraint for this analysis — at the end of the Landfill's operation and for the 1,000 $\mathrm{yr}$ following closure-on planned Landfill waste inventory receipts at the concentrations reflected by the soil guidelines, are provided as well. 
DOSE MODELING EVALUATIONS AND TECHNICAL

SUPPORT DOCUMENT FOR THE AUTHORIZED

LIMITS REQUEST FOR THE C-746-U LANDFILL AT

THE PADUCAH GASEOUS DIFFUSION PLANT

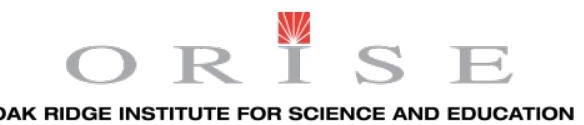

1.0: Introduction

1.5

QUALTYY AND TECHNICAL REVIEWS

The derivation of soil guidelines for the PGDP C-746-U Landfill required numerous discussions with the management team and thorough quality and technical reviews. In addition to internal (ORISE) staff reviews, DOE-PPPO and its contractor staff provided an external evaluation of the tables of parameters for the RESRAD and RESRAD-OFFSITE inputs. A DOE-PPPO contractor staff member with significant dose modeling expertise was also tasked with confirming the adequacy of a representative number of ORISE modeling runs to verify the codes' output results. 
DOSE MODELING EVALUATIONS AND TECHNICAL

SUPPORT DOCUMENT FOR THE AUTHORIZED

LIMITS REQUEST FOR THE C-746-U LANDFILL AT THE PADUCAH GASEOUS DIFFUSION PLANT

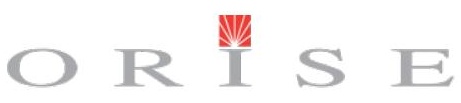

OAK RIDGE INSTITUTE FOR SCIENCE AND EDUCATION

2.0: Analytical Plan

2.0: ANALYTTCAL PLAN

Derivation of soil guidelines to support DOE's establishment of ALs for the C-746-U Landfill was a principal objective of this project. The Analytical Plan (Plan) described in this section contains the technical approach by which this project was organized and carried through to completion to satisfy this objective. Formal presentations on the Plan were provided to DOE, EPA, and Commonwealth of Kentucky Radiation Health Branch regulatory staff during an early phase of the project (March 2010). Per prior agreement with the DOE-PPPO, ORISE was authorized to modify the Plan when information was obtained that supported a technical rationale for required changes. Plan modifications did occur during the project and this report captures the culmination of that evolution.

This section contains introductory details about the Plan, consisting of the general approach for deriving soil guidelines; pertinent regulatory and guidance documents; the definition of an AL, history of existing ALs and applicable solid waste forms, and the need for revised ALs; PGDP waste stream characterization; the approach for receptor selection; identification of three general categories of parameters and priority designations using an Nuclear Regulatory Commission (NRC) NUREG classification; the conduct of a sensitivity analysis; a graphical depiction of a deterministic analysis; the radionuclides targeted for the dose modeling; source term information; and the general calculational methodology used to determine soil guidelines.

Supporting details are provided later in this document, particularly in Section 5.0, "Basis for the Derivation of Soil Guidelines," and Section 6.0, "Results and Discussion." These include the identification of key references such as regulatory and guidance drivers for this work effort, further information regarding the selected target dose constraints (including the $1 \mathrm{mrem} / \mathrm{yr}$ walk-away constraint), the conceptual site model developed for this project, discussion of the two utilized dose modeling software codes, and the approach used to prepare extensive tables of input parameters and supporting input documentation.

\subsection{GENERAL APPROACHFOR SOIL GUIDELINES DERIVATION}

In general, a technically defensible approach for conducting dose modeling-and deriving soil guidelines as an outcome-requires:

Understanding the modeled location

Establishing target radionuclides and dose constraints and limits

Developing a defined CSM to identify and justify the inclusion and exclusion of exposure scenarios (pathways and receptors) - i.e., who gets exposed, where, how, etc. 
DOSE MODELING EVALUATIONS AND TECHNICAL

SUPPORT DOCUMENT FOR THE AUTHORIZED

LIMITS REQUEST FOR THE C-746-U LANDFILL AT THE PADUCAH GASEOUS DIFFUSION PLANT

\section{OR"}

OAK RIDGE INSTITUTE FOR SCIENCE AND EDUCATION

\section{0: Analytical Plan}

Identifying the dose modeling approach and "tools" to conduct the analysis-i.e., what software code(s) will be utilized and the rationalization for their selection

Selecting and tabulating defensible user input parameters for the selected model/code to match the CSM based on hierarchy of 1) site-specific values, 2) calculated input values, 3) literature values, and 4) code-specific defaults

Incorporating sensitivity analyses results and conclusions and an established hierarchy as to which parameters are more "sensitive" than others

Refining/validating sensitive parameters

Providing the specific methodology for soil guideline derivation

Ensuring accurate computational derivation and appropriate interpretation of soil guidelines

In brief, many decisional dose modeling inputs are required to reach the end objective.

Developing site-specific soil guidelines for the C-746-U Landfill was a step-wise, iterative process. First, multiple site-specific references were reviewed and a thorough environmental assessment was made of the site to identify relevant parameters and parameter values for the computational analysis. This step required numerous discussions with the ORISE project team, DOE-PPPO staff, and DOE contractor support personnel (ORISE 2010). Second, results of the assessment and evaluation of site environmental parameters were input into a computational model to provide a deterministic result for the receptor dose as a function of time. Third, a sensitivity analysis was performed to evaluate the results of the model equations and the sensitivity of specific environmental parameters for the Landfill to ensure the most realistic and scientifically plausible parameter values were used.

The iterative process ensured the results presented from the computer model reflected actual environmental conditions of the site as much as practicable and more importantly, assured decision makers that no single lumped parameter of interest in the model was overlooked in the description and physical transport of the material.

2.2

DOE REGULATIONS, GUIDANCE, AND AUTHORIZED LIMITS

2.2 .1

DOE ORDER 5400.5, DOE ORDER 458.1, DOE G-441.1-XX, AND 10 CFRPART 835

Several primary DOE regulations, orders, and guidance documents influenced the soil guideline development effort. In particular, these included DOE's 10 CFR Part 835, DOE Order 5400.5, and DOE G-441.1-XX. However, as previously discussed in Section 1.0, "Introduction,"

DOE Order 5400.5 was cancelled and replaced in February 2011, by DOE Order 458.1. Because an 
DOSE MODELING EVALUATIONS AND TECHNICAL

SUPPORT DOCUMENT FOR THE AUTHORIZED

LIMITS REQUEST FOR THE C-746-U LANDFILL AT THE PADUCAH GASEOUS DIFFUSION PLANT

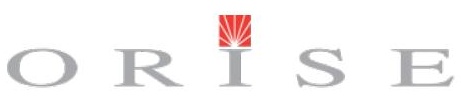

OAK RIDGE INSTITUTE FOR SCIENCE AND EDUCATION

\section{0: Analytical Plan}

updated dosimetric quantity (i.e., TED), cited in 10 CFR 835, was incorporated into the ORISE analysis, the changes incorporated in this new Order did not impact the ORISE work effort from a dose modeling perspective.

\subsubsection{DEFINITION OFAUTHORIZED LIMITS}

Per DOE Order 458.1, "An authorized limit is a limit on the concentration or quantity of residual radioactive material on the surfaces or within property that has been derived consistent with DOE directives including the ALARA process requirements. An authorized limit may also include conditions or measures that limit or control the disposition of property."

Note: The ORISE dose modeling evaluation assumes that the DOE has (and will continue to have) controls in place for the C-746-U Landfill. It is assumed the Landfill will not be released without restrictions as discussed in Section1.0: "Introduction."

\subsubsection{CURRENT AUTHORIZED LIMITS}

The current ALs for the C-746-U Landfill were approved by the DOE Oak Ridge Office (ORO) on February 6, 2003. These limits were applied to disposal of solid waste-nonhazardous soil and debris wastes generated from construction, maintenance, environmental restoration, and Decontamination and Decommissioning (D\&D) activities at the Landfill. The ALs included disposal volume projection estimates for $7 \mathrm{yr}$ of operation: $11,795 \mathrm{~m}^{3}$ in the first year and $5,000 \mathrm{~m}^{3}$ annually for years 2-7 (DOE 2003a).

\subsubsection{RATIONALEFORNEW AUTHORIZED LIMITS}

The DOE determined the need to close out existing ALs and develop, approve, and implement new limits. Several reasons exist(ed) for this action, including that current ALs were based on PGDP work activities projected in 2002; the American Recovery and Reinvestment Act of 2009 (ARRA) expedited D\&D work at PGDP; clean-up activities accelerated throughout the site; and with Landfill expansion, new ALs were needed to ensure appropriate disposal.

\subsection{WASTESTREAM CHARACTERIZATION}

Waste streams for disposal at the C-746-U Landfill are generated from activities at the PGDP. These include soils, wood, concrete, roofing and construction debris, and other nonhazardous sanitary and industrial wastes - e.g., paper, fly ash, treated medical waste, asbestos, cardboard, tires, animal carcasses, detectable PCBs less than 50 parts per million ( $\mathrm{ppm}$ ), personal protective equipment, plastic, alkaline batteries, and metals. The Landfill is not approved for disposal of RCRA hazardous, TSCA-regulated, or radioactive waste (Kentucky Energy and Environment Cabinet Solid Waste Permit \#: SW07300014, SW07300015, and SW07300045). DOE regulates radioactive waste under DOE Order 435.1, Radioactive W aste Management (and related guidance), and sends radioactive waste 


\section{0: Analytical Plan}

and mixed waste generated at the PGDP to facilities such as the DOE Nevada Test Site, the DOE Hanford Reservation, and a commercially operated facility near Clive, Utah.

Some waste streams currently disposed of at the C-746-U Landfill contain small quantities of residual radioactive materials resulting from either incidental process contamination or the presence of naturally occurring radioactive materials. DOE-PPPO currently accepts such waste for disposal at the Landfill on a case-by-case basis using the generic ALs for surface-contaminated materials from DOE Order 5400.5 and surface contamination limits in disintegrations per minute per 100 square centimeters $\left(\mathrm{dpm} / 100 \mathrm{~cm}^{2}\right)$ and volumetric concentration limits in $\mathrm{pCi} / \mathrm{g}$ for radionuclides cited in the current AL report, Authorized Limits Request for Solid Waste Disposal at Landfill C-746-U at the Paducah Gaseous Diffusion Plant (DOE 2003a).

Operation of the C-746-U Landfill is regulated by DOE under the authority of the AEA and the Commonwealth of Kentucky under authority delegated by the EPA to enforce implementing regulations for RCRA through provisions in regulations for solid waste landfills by the Commonwealth of Kentucky (401 KAR 48). Under the AEA, the DOE has the responsibility and authority to establish radiological limits for protection of the public and the environment, either in the form of release criteria for offsite disposition of waste it generates or for waste acceptance criteria for disposal of materials in a DOE-owned onsite landfill. ORISE examined waste stream characterization data in support of the development of revised ALs for the Landfill.

\section{4}

RECEPTOR SELECTION

Appropriate receptor selection is a key consideration for the C-746-U Landfill. Prior reports, issued by or for the DOE_-including but not limited to Risk and Performance Evaluation of the C-746-U Landfill at the Paducah Gaseous Diffusion Plant (DOE 2003b), Methods for Conducting Risk Assessments and Risk Evaluations at the Paducah Gaseous Diffusion Plant, Paducah, Kentucky, Volume 1. Human Health (DOE 2009b), and Authorized Limits Request for Solid Waste Disposal at Landfill C-746-U at the Paducab Gaseous Diffusion Plant (DOE 2003a) —identified several onsite and offsite receptors. In particular, Table 3.7 from DOE 2003b provided an excellent summary of quantitative and qualitative evaluations involving adult, teen, and child receptors under both current (operational) and future (institutional control period and beyond) and various media, exposure media, and exposure route scenarios. In each of these reports, DOE provided a rationale for the inclusion or elimination of these receptors.

ORISE evaluated these receptors relative to CSM development and soil guideline derivations. A primary determining factor in identifying credible receptors (exposure groups) included current and reasonably anticipated future land uses. Receptor selection has a direct influence on which exposure pathways are activated or are alternatively suppressed in the dose modeling codes. 


\section{0: Analytical Plan}

It should be recognized that both dose- and risk-based assessments have been previously conducted by the DOE at the PGDP — the latter has emphasized multiple age cohorts (adult, teen, and child) and a specified exposure duration. This modeling effort, however, was dose-based. The scenarios that follow, and the dose modeling conducted in support of soil guideline development, were applicable to adults in all cases except for the Recreational User and for an annual dose. Adults were generally selected due to higher inhalation and consumption rates (it is acknowledged that children are assumed to have higher soil ingestion rates).

Based on its evaluation, ORISE identified several human receptors and pathways for the dose modeling and soil guideline derivations. Specific receptors and pathways are identified in Section 5.0, "Basis for the Derivation of Soil Guidelines."

\subsection{PARAMETERTYPES}

An extensive set of input parameters was identified for each dose modeling code utilized in this project. (The parameter sets are provided in appendices to this report.) These parameters were first organized into three general categories: "Physical," "Behavioral," and "Metabolic." Per NUREG/CR-6697, Development of Probabilistic RESRAD 6.0 and RESRAD-BUILD 3.0 Computer Codes (Yu et al. 2000) and the User's Manual for RESRAD-OFFSITE Version 2 (Yu et al. 2007), they are defined as follows:

Physical - Any parameter whose value would not change if a different group of receptors were considered. These parameters are determined by the source, its location, and the geological characteristics of the site (these parameters are therefore "source"- and "site"-specific).

NUREG/CR-6697 (Chapter 3) illustrates that physical parameters predominate in dose modeling evaluations. For RESRAD, 89 physical parameters, 16 behavioral parameters, 10 metabolic parameters, 27 dual-type parameters, and three unclassified parameters were identified. These parameters are typically site-specific.

Examples of physical parameters include evapotranspiration coefficients, depth of soil mixing layer, mass loading, and wind speed.

Behavioral-Any parameter whose value depends on the receptor's behavior and the scenario definition. For the same group of receptors, a parameter value could change if the scenario changes (e.g., parameters for recreational use could be different from those for residential use).

Behavioral parameters include the outdoor time fraction, mass loading, depth of soil mixing layer, and quantity of water for household purposes. 
DOSE MODELING EVALUATIONS AND TECHNICAL

SUPPORT DOCUMENT FOR THE AUTHORIZED

LIMITS REQUEST FOR THE C-746-U LANDFILL AT THE PADUCAH GASEOUS DIFFUSION PLANT

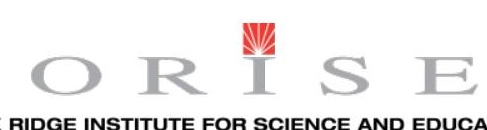

OAK RIDGE INSTITUTE FOR SCIENCE AND EDUCATION

2.0: Analytical Plan

Metabolic - A parameter that represents the metabolic characteristics of the potential receptor and is independent of the scenario. Parameter values may be different in different population age groups. Per ICRP Publication 43, Principles of Monitoring for the Radiation Protection of the

Population (ICRP 1985), parameters representing metabolic characteristics are defined by average values for the general population. These values would not be expected to be modified for a sitespecific analysis because the parameter values would be independent of site conditions.

Examples of metabolic parameters include consumption of fruit, vegetables, and grains, leafy vegetables, milk, meat and poultry, and fish; soil ingestion rate; drinking water intake; livestock fodder intake for meat and milk; livestock water intake for meat and milk; and livestock intake of soil.

\section{$2.6 \quad$ PRIORITY DESIGNATIONS}

NUREG/CR-6697 was also reviewed to establish an initial mechanism for the measure of an individual parameter's impact or importance. The NUREG assigns Priority Levels "1," "2," and “3." Level 1 indicates the highest priority; Level 2 represents a medium priority; and Level 3 represents the lowest priority. This ranking is valuable for examining the relative importance of a deterministic (or probabilistic) input.

Priority 1 designations provided as examples from NUREG/CR-6697 include the following: distribution coefficient, density of cover material, density of contaminated zone, density of saturated zone, saturated zone total porosity, saturated zone effective porosity, saturated zone hydraulic conductivity, unsaturated zone thickness, depth of roots, and plant transfer factors.

ORISE used Priority 1 designations as a starting point in the soil guideline development and for comparison to available C-746-U Landfill-specific information. Evaluations of Priority 2 and Priority 3 designations were also conducted. Evolution of these designations occurred during this project with eventual selection of several site-specific, physical parameters and emphasis on the outcome of sensitivity analyses to ensure key parameters were identified. The results of these evaluations, including technical justifications for final selections, are discussed in Section 5.0, "Basis for the Derivation of Soil Guidelines."

\subsection{SENSITIVITY ANALYSES}

A sensitivity analysis was employed to identify specific input parameters having a definitive influence on the dose output. Both modeling codes used in the ORISE analysis contain provisions for conducting such an analysis. However, RESRAD is limited to a maximum evaluation of five parameters at a time. In contrast, RESRAD-OFFSITE contains a significantly enhanced feature for conducting such an analysis. The code can evaluate all parameters (physical, behavioral, and 


\section{0: Analytical Plan}

metabolic), assign a percent range to each parameter, rank each parameter in importance, and provide the output results. Sensitivity analysis results are discussed later in this report.

2.8

DEIERMINISTIC APPROACH

Parameterization of the model was evaluated through the assessment described previously. Models were tested and parameters evaluated through a deterministic sensitivity analysis.

The approach for the deterministic analysis is depicted in Figure 2-1 from NUREG/CR-6676, Probabilistic Dose Analysis Using Parameter Distributions Developed for RESRAD and for RESRAD-BUILD Codes (Kamboj et al. 2000). In a deterministic analysis, a single input value results in a single output value. If the analysis is extended probabilistically (an analysis not formally conducted in this work effort), a distribution results around the input and output values.

Deterministic Analysis
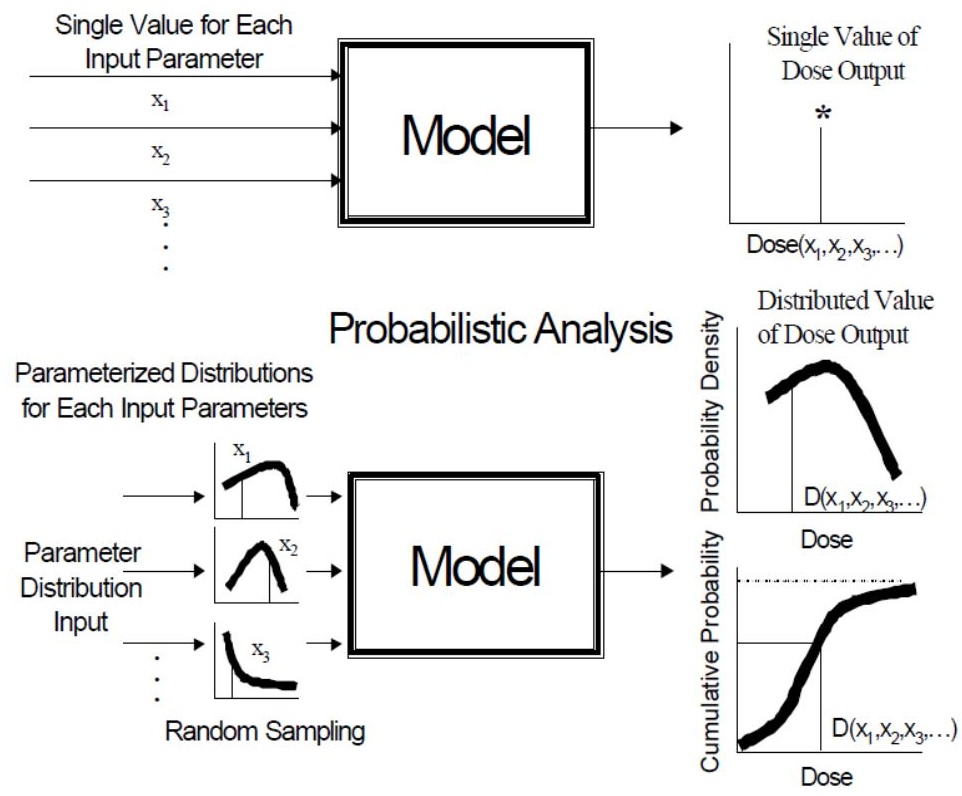

Figure 2-1. Concepts of Deterministic and Probabilistic Analysis (from NUREG/CR-6676, May 2000)

Principal radionuclides modeled for this project at the PGDP begin with uranium isotopes due to the plant's mission. Targeted radionuclides in the ORISE analysis consisted of U-235, U-238, and $\mathrm{U}-234$. Other radionuclides, not associated directly with uranium decay, appeared as a consequence of the enrichment process and PGDP commercial applications over its operating history. This 


\section{0: Analytical Plan}

included Tc-99, a radioactive fission product and principal contaminant offsite, which was introduced at the site when reprocessed uranium was introduced into the diffusion process. Neptunium-237 was also identified as early as 1957. Enrichment operations also eventually resulted in the appearance of plutonium, such as $\mathrm{Pu}-239$ and $\mathrm{Pu}-241$. Radioactive decay of $\mathrm{Pu}-241$ in turn produces Am-241. Additional information regarding these radionuclides, concentrations historically encountered at the PGDP, worker doses, exposure pathways, and risks, etc. can be found in the PGDP site profile prepared by Oak Ridge Associated Universities (ORAU) for the National Institute for Occupational Safety and Health (NIOSH) (ORAU 2007). Several of these radionuclides have also been detected outside the DOE limited area as a consequence of plant releases.

Cesium-137 and plutonium-239/240 have been detected in areas outside the DOE limited area. Cs137 may have also been used at the PGDP for a limited, specific application process.

Site- and process-related radionuclide selections were determined initially from the ORISE SOW. Following review of the Update to the End State Vision for the Paducah Gaseous Diffusion Plant, Paducah, Kentucky, (DOE 2008), Table 1.1, Significant Contaminants of Potential Concern at PGDP, and discussions with DOE-PPPO staff, Th-228 was added to the list of radionuclide contaminants of concern.

The final radionuclide listing utilized in this project, relevant to disposal operations at the C-746-U Landfill, are shown in Table 2-1.

Table 2-1. List of Targeted Radionuclides

\begin{tabular}{|cc|}
\hline & TARGETED RADIONUCLIDES \\
\hline Am-241 & Th-228 \\
\hline Cs-137 & Th-230 \\
Np-237 & Th-232 \\
Pu-238 & U-234 \\
Pu-239 & U-235 \\
Pu-240 & U-238 \\
Tc-99 & \\
\hline
\end{tabular}

Secular equilibrium is typically assumed in dose modeling analyses for members of the uranium (U-238), thorium (Th-232), and actinium (U-235) naturally occurring decay chains for the purpose of including contributions from radioactive progeny. However, secular equilibrium was not assumed in this project due to the nature of the PGDP's enrichment mission. This important assumption was verified with DOE-PPPO technical staff and inputs to the dose modeling codes accordingly reflected this decision. As described earlier, 1960 was selected as the initial year for modeling purposes, allowing the ingrowth of radioactive progeny from the three decay chains to begin at that time in the absence of an equilibrium condition. The contribution from progeny ingrowth is 


\section{0: Analytical Plan}

reflected in the single radionuclide soil guideline for the parent in each chain. These guideline values are generated as an output from the software codes (refer to Section 5.0, "Basis for the Derivation of Soil Guidelines," and Section 6.0, "Results and Discussion”).

\section{$2.10 \quad$ SOURCETERM}

The radiological source term (in addition to the radionuclide listing) was examined on the basis of waste stream characterization information and a waste inventory provided by DOE to ORISE. The inventory represented the amount of radioactive material disposed of (i.e., currently in the C-746-U Landfill as of the end of the Landfill's seventh year of operation). However, for purposes of the modeling evaluations, as will be described later, specific radioactive material quantities associated with individual radionuclides were not required as initial inputs to the modeling codes.

The following approach was applied to the dose modeling soil guideline outputs:

A normalized (unit) concentration of $1 \mathrm{pCi} / \mathrm{g}$ for each targeted radionuclide was input to the codes.

Doses were calculated (by radionuclide) as a function of time, up to 1,050 $\mathrm{yr}$, representing the conventional period used in these analyses for soil guideline determinations (1,000 yr) and an additional $50 \mathrm{yr}$ to begin the analysis as of the year 1960. The peak dose appearing within the time period of 1,050 $\mathrm{yr}$ was determined (per unit activity of the parent radionuclide).

As described previously, it is acknowledged that PGDP enrichment operations began as early as 1952; however, this represented a partial and intermittent start-up and did not reflect a total uranium material inventory, which if assumed would represent an overly conservative approach. Selection of 1960 represents a reasonable starting point for the analysis and allows for radioactive ingrowth from that time forward.

Resulting DSRs were compared to the DOE project established dose constraints, primary dose limit, and ACL (in mrem/yr) — associated respectively with specific receptors-resulting initially in single radionuclide soil guidelines. The following general equation illustrates use of the $1 \mathrm{mrem} / \mathrm{yr}$ dose constraint in the initial generation of single radionuclide soil guidelines, subsequently rounded for use as the derived soil guidelines $(\mathrm{pCi} / \mathrm{g})$ :

$$
\text { Soil Guideline }=\left(\frac{1 m r e m / y r}{D S R \frac{m r e m / y r}{p C i / g}}\right) \quad \text { (pCi/g) }
$$


DOSE MODELING EVALUATIONS AND TECHNICAL

SUPPORT DOCUMENT FOR THE AUTHORIZED

LIMITS REQUEST FOR THE C-746-U LANDFILL AT

THE PADUCAH GASEOUS DIFFUSION PLANT

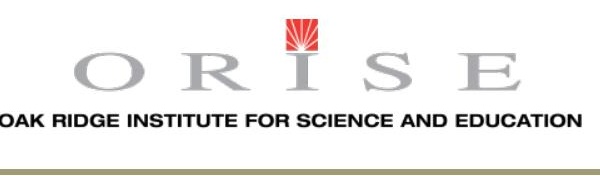

2.0: Analytical Plan

A detailed discussion describing the approach for soil guideline determinations and the resultant ORISE-derived soil guidelines, receptor-specific peak doses, and suggestions for application of the derived soil guidelines can be found in Section 5.0, "Basis for the Derivation of Soil Guidelines"; Section 6.0, "Results and Discussion"; and Section 7.0, "Summary, Conclusions, and Application of ORISE-Derived Soil Guidelines” of this report. 
DOSE MODELING EVALUATIONS AND TECHNICAL

SUPPORT DOCUMENT FOR THE AUTHORIZED

LIMITS REQUEST FOR THE C-746-U LANDFILL AT THE PADUCAH GASEOUS DIFFUSION PLANT

\section{$O \mathbb{R}$ 亚 $S$}

OAK RIDGE INSTITUTE FOR SCIENCE AND EDUCATION

\section{0: PGDP and C-746-U Landfill Environmental Setting}

\section{0: PGDP AND C-746-ULANDFILL ENVIRONMENTAL SEITING}

This section provides an overview of the DOE-owned property encompassing the PGDP site and the C-746-U Landfill with emphasis on environmental features. This information supported the radiation dose modeling analysis and soil guideline derivations described in this report. Descriptions are provided of the geography and physiography, demography and land use, climatology and meteorology, geology, hydrology, and ecological features.

The information provided in this section was excerpted from DOE 2003b. Minor editorial changes were made as appropriate. Reviewers should reference the DOE document for additional details, including supporting references, graphics, etc.

\subsection{GENERAL ENVIRONMENTAL AND PHYSICAL STIE CHARACTERISTICS}

\subsubsection{GEOGRAPHY AND PHYSIOGRAPHY}

The PGDP is located in western McCracken County, Kentucky, approximately 3 mi south of the Ohio River and approximately $10 \mathrm{mi}$ west of the City of Paducah. Approximately $90 \%$ of the area within a 5-mi radius of the plant is agricultural or forested land. Urban and industrial lands comprise less than $4 \%$ of the surrounding area, and surface-water bodies cover approximately $5 \%$.

The PGDP is located in the Jackson Purchase Region of western Kentucky, at the northern tip of the Mississippi Embayment portion of the Atlantic Coastal Plain physiographic province. The area is bounded on the north and east by the Highland Rim portion of the Interior Low Plateau physiographic province, an area of low plateaus on stratified sedimentary rock. The Mississippi Embayment is a large sedimentary trough oriented north-south that received sediments from the middle of the North American continent.

The PGDP is situated in an area characterized by low relief. Elevations on the DOE-owned property vary from approximately 350 to $390 \mathrm{ft}$ above mean sea level (amsl), with the ground surface sloping at a rate of approximately $27 \mathrm{ft} / \mathrm{mi}$ toward the Ohio River. Two main topographic features dominate the landscape in the surrounding area: the loess-covered plains, at an average elevation of $390 \mathrm{ft}$ amsl; and the Ohio River floodplain zone, dominated by alluvial sediments, at an average elevation of $315 \mathrm{ft}$ amsl. The terrain of the PGDP area is modified slightly by the dendritic (i.e., branching like a tree) drainage systems associated with the two principal streams in the area, Bayou Creek and Little Bayou Creek. These northerly flowing streams have eroded small valleys that are approximately $20 \mathrm{ft}$ below the adjacent plain. 
DOSE MODELING EVALUATIONS AND TECHNICAL

SUPPORT DOCUMENT FOR THE AUTHORIZED

LIMITS REQUEST FOR THE C-746-U LANDFILL AT THE PADUCAH GASEOUS DIFFUSION PLANT

\section{0: PGDP and C-746-U Landfill Environmental Setting}

\subsubsection{POPULATIONAND NEARBY COMMUNITIES}

The total population within a radius of $50 \mathrm{mi}(80.46 \mathrm{~km})$ radius of PGDP is approximately 500,000. An estimated 50,000 people live within $10 \mathrm{mi}(16.09 \mathrm{~km})$ of PGDP and homes are scattered along rural roads around the plant. The population of Paducah, Kentucky, based on the 2000 U.S. Census, is 26,307; the total population of McCracken County, which covers $251 \mathrm{mi}^{2}\left(650.4 \mathrm{~km}^{2}\right)$ is approximately 65,000. The closest communities to PGDP are the unincorporated towns of Grahamville, about $1 \mathrm{mi}(1.6 \mathrm{~km})$ to the east, and Heath, located about $1 \mathrm{mi}(1.6 \mathrm{~km})$ southeast (Figure 3-1).

Historically, groundwater was the primary source of drinking water for residents and industries in the vicinity of the plant area. Due to trichloroethylene (TCE) contamination in the underground plume from the PGDP, some area residents and industries have chosen to replace groundwater sources with water supplied by the West McCracken County Water District. In areas where the groundwater is either known to be contaminated or is suspected of becoming contaminated in the future, the PGDP continues to provide municipal water. Several residential out-of-service wells are utilized by the DOE for monitoring (per written agreements). Residential wells that no longer are sampled have been capped and locked.

The nearest community downstream of Paducah using surface water for drinking water is Cairo, Illinois, which is located at the confluence of the Upper Mississippi and Ohio Rivers.

\subsubsection{CLIMATOLOGY AND METEOROLOGY}

The climate of the PGDP area can be described as humid-continental. It is characterized by warm and humid summers and moderately cold and humid winters. Temperatures for the summer months average $85^{\circ} \mathrm{F}$, while winter temperatures average $36^{\circ} \mathrm{F}$. During the winter months, temperatures drop below freezing an average of 60 nights and 10 days. The summers average 40 days $/ \mathrm{yr}$ of $90^{\circ} \mathrm{F}$ or higher temperatures.

Precipitation is distributed relatively evenly throughout the year and averaged 50 inches per year (in/yr) from 1969 to 1989. The average annual precipitation for the region from 1984 to 1999 was $47.84 \mathrm{in} / \mathrm{yr}$. Most groundwater recharge and stream flooding occur between November and May, when evapotranspiration normally is less than the remainder of the year.

The average prevailing wind in the area is from the south to southwest at approximately 9.8 miles per hour (mph). Generally, stronger winds are observed when the winds are from the southwest or northwest. 
DOSE MODELING EVALUATIONS AND TECHNICAL SUPPORT DOCUMENT FOR THE AUTHORIZED LIMITS REQUEST FOR THE C-746-U LANDFILL AT THE PADUCAH GASEOUS DIFFUSION PLANT

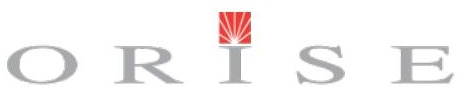

OAK RIDGE INSTITUTE FOR SCIENCE AND EDUCATION

\section{0: PGDP and C-746-U Landfill Environmental Setting}

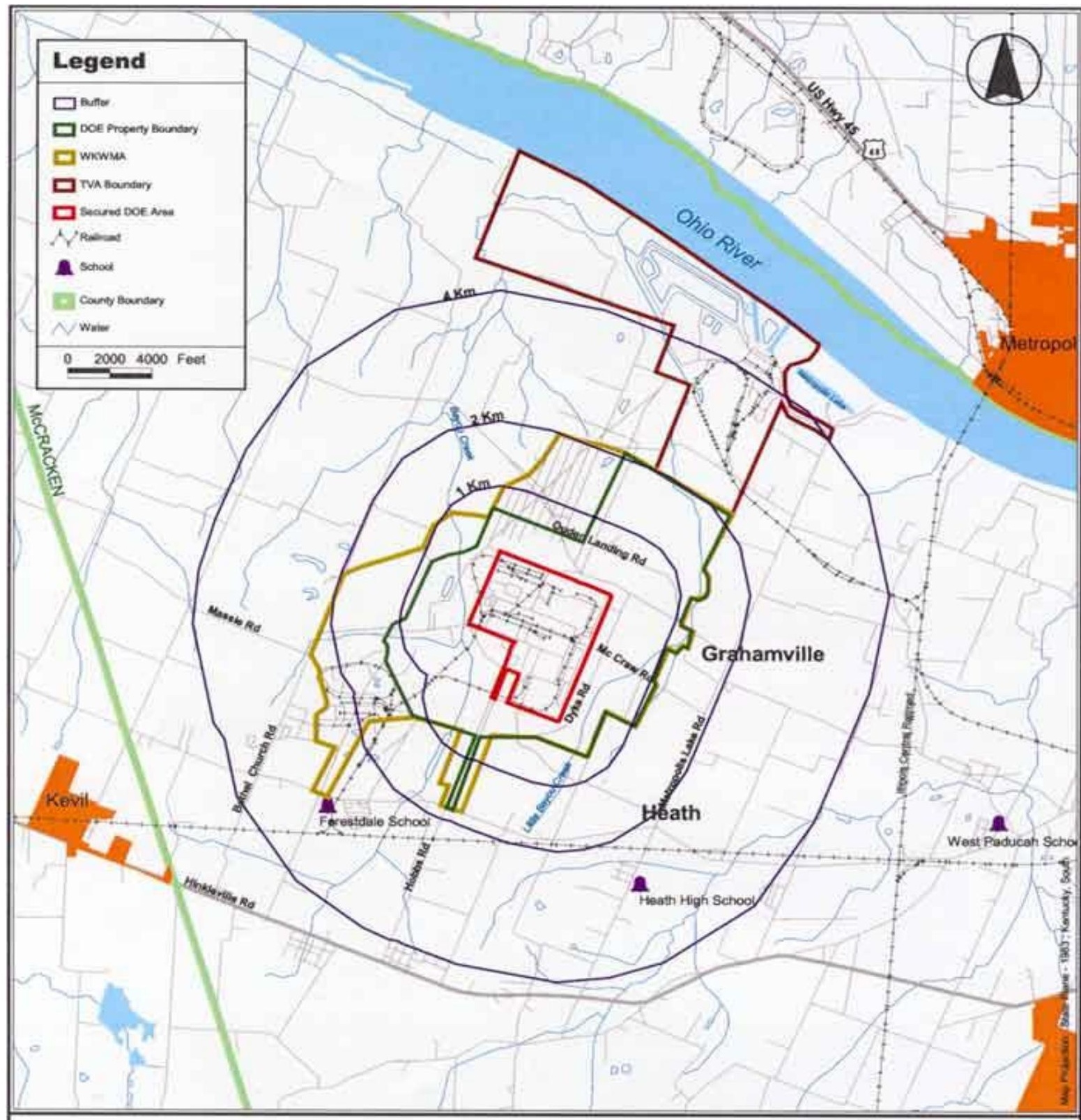

\section{Paducah Gaseous Diffusion Plant}

Paducah, Kentucky CERCLIS No. KY8890008982

Figure 3: Property Boundaries and Other Features
Site Location

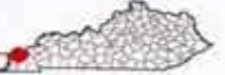

McCracken County, Kentucky

H. BSAAGIS]

Figure 3-1. Communities in the Vicinity of the PGDP 
DOSE MODELING EVALUATIONS AND TECHNICAL

SUPPORT DOCUMENT FOR THE AUTHORIZED

LIMITS REQUEST FOR THE C-746-U LANDFILL AT THE PADUCAH GASEOUS DIFFUSION PLANT

\section{OR R I E}

OAK RIDGE INSTITUTE FOR SCIENCE AND EDUCATION

\section{0: PGDP and C-746-U Landfill Environmental Setting}

\subsubsection{GEOLOGY}

The subsurface in the PGDP vicinity consists of approximately $350 \mathrm{ft}$ of Cretaceous, Tertiary, and Quaternary sediments unconformably overlying Paleozoic bedrock. In the PGDP vicinity, these sediments dip gently to the south-southwest toward the axis of the Mississippi Embayment and overlie northward-dipping Paleozoic bedrock. In ascending stratigraphic order, bedrock is overlaid by a rubble zone, the McNairy Formation, the Paleocene Porters Creek Clay, undifferentiated Eocene sediments, and Pliocene and Pleistocene continental deposits (Figure 3-2).

The erosion and subsequent fill of the ancestral Tennessee River Valley during the Pleistocene is a primary factor controlling the geologic units beneath the PGDP. During the Pleistocene, the ancestral Tennessee River occupied a position close to the present-day course of the Ohio River. The southern edge of the former Tennessee River Valley underlies the PGDP. Figure 3-3 presents a general north-south cross section of the geologic units extending from PGDP to the Ohio River.

Several engineering and environmental investigations have defined the geology of the DOE's PGDP reservation. A 1993 siting investigation for the C-746-U Landfill provides the site-specific information that follows.

\subsubsection{Bedrock and the Rubble Zone}

Deep borings at the PGDP have encountered Mississippian limestone bedrock approximately 335 to $350 \mathrm{ft}$ below ground surface (bgs). Immediately overlying bedrock at the PGDP is a rubble zone, which consists of a layer 5 - to 20 -ft thick of subangular chert and silicified limestone fragments.

\subsubsection{McNairy and Clayton Formations}

Overlying the rubble zone are the unconsolidated deposits of the Upper Cretaceous McNairy Formation. This formation is composed of interbedded and interlensing sand, silt accessory, and clay. The sands are well-sorted, fine-grained, micaceous (composed of mica, a group of aluminum silicate minerals), and often glauconitic (containing glauconite, a greenish mineral of the mica group composed of hydrous silicate of potassium, iron, aluminum, or manganese). Near the PGDP, the McNairy Formation can be subdivided into three lithologic members: 1) a 60-ft thick sand-dominant lower member; 2) a 100- to 130-ft thick middle member composed predominantly of silty and clayey fine sand; and 3) a 30- to 50-ft thick upper member consisting of interbedded sands, silts, clays, and occasional gravels. Deposits of the Clayton Formation overlie the McNairy Formation. Because of difficulties in distinguishing between the Clayton and McNairy Formations at the PGDP, these lithologies have been grouped together and termed the McNairy Formation. Total thickness of the McNairy Formation is approximately $225 \mathrm{ft}$. The McNairy Formation underlies the C-746-U Landfill site. 
DOSE MODELING EVALUATIONS AND TECHNICAL

SUPPORT DOCUMENT FOR THE AUTHORIZED

LIMITS REQUEST FOR THE C-746-U LANDFILL AT

THE PADUCAH GASEOUS DIFFUSION PLANT

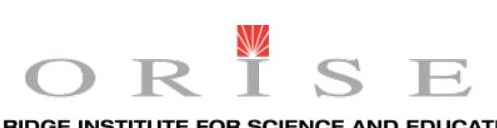

OAK RIDGE INSTITUTE FOR SCIENCE AND EDUCATION

\section{0: PGDP and C-746-U Landfill Environmental Setting}

\subsubsection{Porters Creek Clay}

Stratigraphically overlying the McNairy Formation, the Paleocene Porters Creek Clay occurs in southern portions of the site as a massive glauconitic clay with lesser interbeds of sand. A terrace slope of the ancestral Tennessee River completely cuts through the thickness of the Porters Creek Clay under the south end of the PGDP. The Porters Creek Clay is approximately $100-\mathrm{ft}$ thick immediately southwest of the PGDP but is absent, or present only as thin isolated remnants, to the north of the terrace slope.

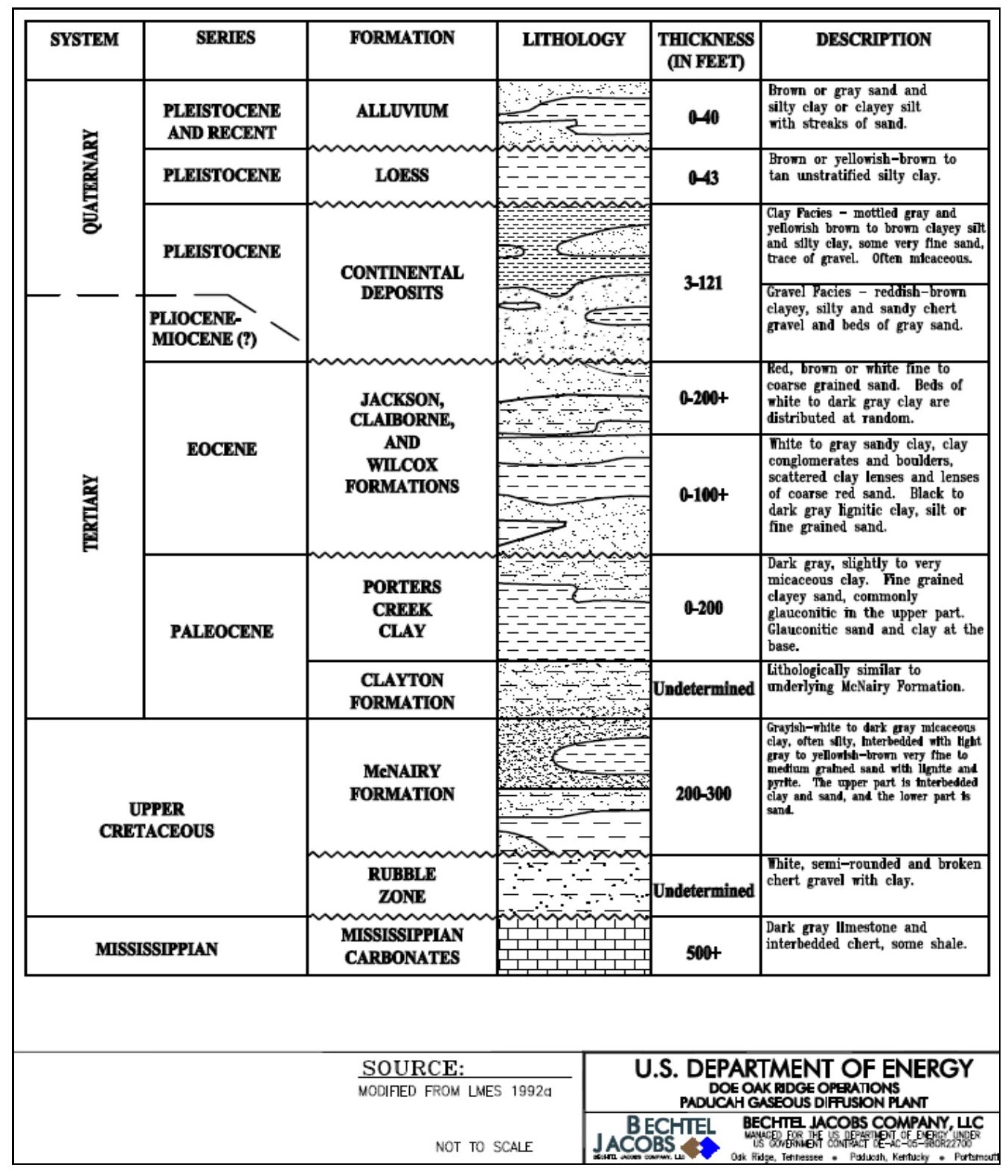

Figure 3-2. Geologic Columnar Section in the Vicinity of the PGDP 
DOSE MODELING EVALUATIONS AND TECHNICAL

SUPPORT DOCUMENT FOR THE AUTHORIZED

LIMITS REQUEST FOR THE C-746-U LANDFILL AT

THE PADUCAH GASEOUS DIFFUSION PLANT

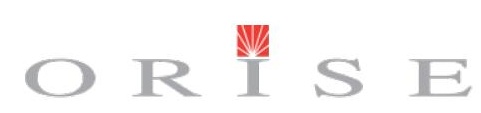

OAK RIDGE INSTITUTE FOR SCIENCE AND EDUCATION

3.0: PGDP and C-746-U Landfill Environmental Setting

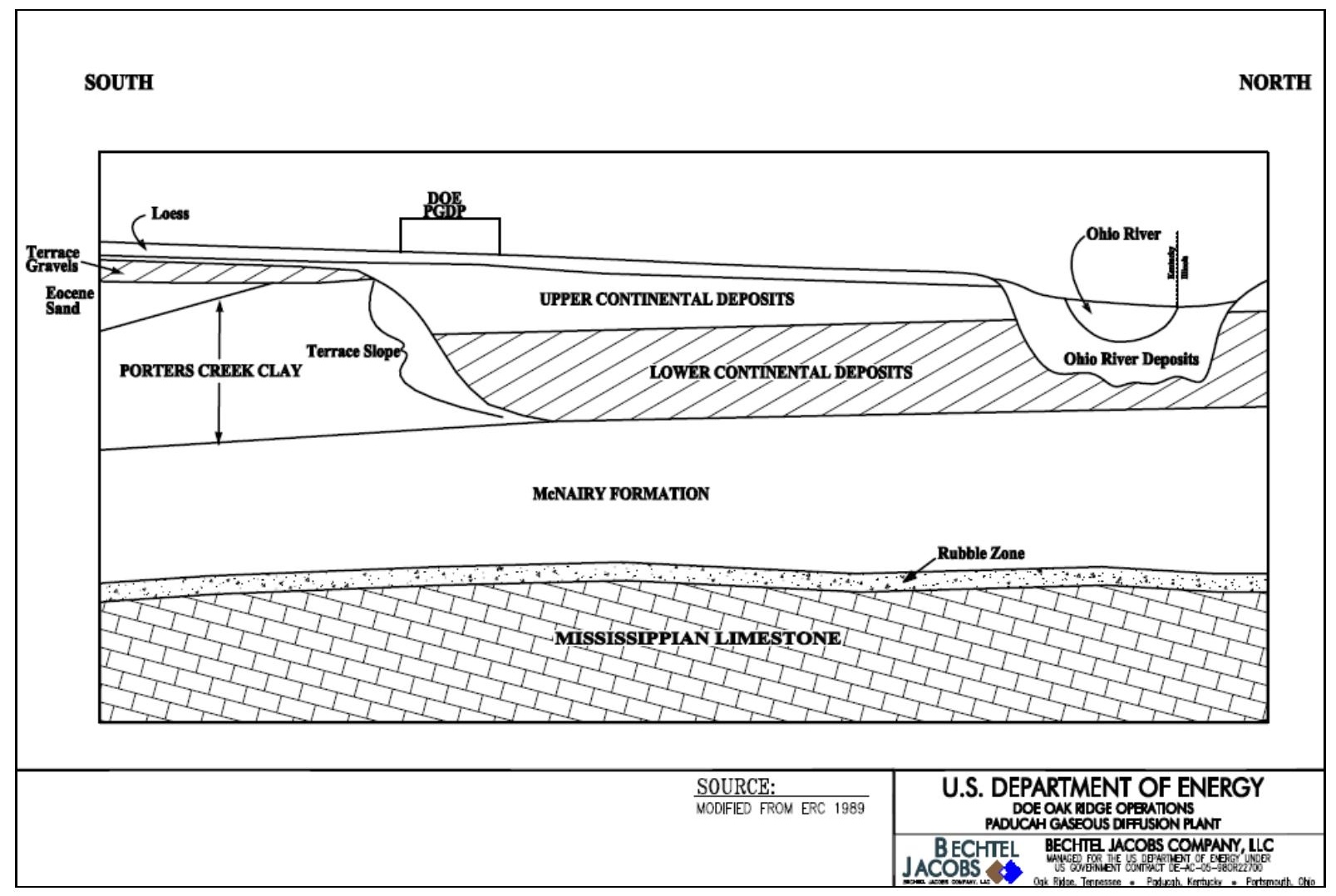

Figure 3-3. Geologic Cross Section of the PGDP

The top of the Porters Creek Clay south of the PGDP has significant topographic relief. A greater depth to the top of the Porters Creek Clay to the east of the PGDP permitted deposition of a thick, relatively permeable Pliocene gravel deposit near the surface. Because the C-746-U Landfill lies to the north of the terrace slope, Porters Creek Clay is not present at the Landfill site.

\subsubsection{Eocene Sands}

Eocene sands, silts, and clays overlie the Porters Creek Clay south of the PGDP. Researchers have not attributed these sediments to a specific formation. The thickness of the Eocene sands approaches zero near the terrace slope and increases southward to greater than $100 \mathrm{ft}$. As with the Porters Creek Clay, Eocene deposits do not underlie the Landfill.

\subsubsection{Continental Deposits}

Pliocene and Pleistocene continental deposits unconformably overlie the Cretaceous through Eocene strata in the vicinity of PGDP. The Pliocene deposits consist of lobes of poorly sorted, silty sand and gravel that occur south of PGDP (i.e., terrace gravels). These sediments represent an alluvial fan deposit that covered all of western Kentucky and parts of Tennessee and Illinois during the Pliocene Epoch. 
DOSE MODELING EVALUATIONS AND TECHNICAL

SUPPORT DOCUMENT FOR THE AUTHORIZED

LIMITS REQUEST FOR THE C-746-U LANDFILL AT THE PADUCAH GASEOUS DIFFUSION PLANT

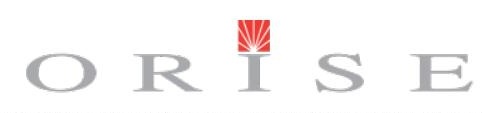

OAK RIDGE INSTITUTE FOR SCIENCE AND EDUCATION

\section{0: PGDP and C-746-U Landfill Environmental Setting}

Beginning near the southern boundary of the PGDP and extending north of the C-746-U Landfill, and subsequently beyond the Ohio River, a thick sequence of Pleistocene continental deposits fills the buried valley of the ancestral Tennessee River. This sediment package consists of a basal sand and gravel member, the lower continental deposits, an overlying finer-textured lithofacies, and the upper continental deposits. Where fully developed, the upper continental deposits include a bottom sand unit overlain by a thick silt and clay interval containing at least two horizons of sand and gravel.

Lower Continental Deposits - Pleistocene sand and gravel units, collectively averaging 30-ft thick, underlie most of PGDP and the northern portion of the DOE-owned property. Depth to the top of this lower member in the main plant area is approximately $60 \mathrm{ft}$. The matrix is characteristically medium to coarse sand and chert gravel of variable sorting. Thickness of the individual depositional units varies widely. The lateral continuity of the individual depositional units typically is limited. In the area of the Landfill, these deposits are 45- to 50-ft deep and average 35 -ft thick.

Upper Continental Deposits - The upper member sediments (Pleistocene) include a wide variety of textures within three depositional series. A basal sand unit is generally present, representing the transition from gravel and coarser sand of the lower member continental deposits to the overlying silty clay unit. The sand generally has a fining upward texture, becoming siltier toward the top of the unit.

An overlying interval of fine-textured sediments defines a middle unit. This unit occurs in most locations and is generally comprised of silty clay or clayey silt. However, a silty, fine sand facies is common. The thickness of the unit varies widely from $<10-40 \mathrm{ft}$ and is approximately $20-\mathrm{ft}$ thick at the Landfill.

Sand and gravel deposits define an upper unit. Texture and sorting are widely variable among the sand and gravel deposits. Where the unit is fully developed, three horizons are present: 1) a basal sand and gravel horizon; 2) a middle, finer-textured horizon, typically consisting of a silty, fine sand, or silt; and 3) an upper sand and gravel horizon. At the Landfill, the uppermost unit is present as a thin, sandy horizon.

Other than the broad lens-character of some sand and gravel units, the upper member continental deposits do not contain recognizable bedding features. Gradational textural changes are common. Silt and clay facies typically are mottled with frequent vertical traces filled with lighter colored silt or clay. 
DOSE MODELING EVALUATIONS AND TECHNICAL

SUPPORT DOCUMENT FOR THE AUTHORIZED

LIMITS REQUEST FOR THE C-746-U LANDFILL AT THE PADUCAH GASEOUS DIFFUSION PLANT

\section{0: PGDP and C-746-U Landfill Environmental Setting}

\subsubsection{Surficial Deposits/Soils}

Silt of the Pleistocene Peorian Loess and an older unit tentatively identified as the Roxanna Loess covers sediments both north and south of the buried terrace slope. The loess deposit is virtually indistinguishable from silt facies of the upper member of the continental deposits. Loess typically is 10- to 15-ft thick beneath most of PGDP; however, construction activities have excavated the loess or replaced the loess with fill material in many areas. Soils of the area are predominantly silt loams that are poorly drained, acidic, and have little organic content.

Six soil types are associated with the PGDP as mapped by the Natural Resources Conservation Service, formerly the Soil Conservation Service. These are Calloway silt loam, Grenada silt loam, Loring silt loam, Falaya-Collins silt loam, Vicksburg silt loam, and Henry silt loam. The dominant soil types, the Calloway and Henry silt loams, consist of nearly level, somewhat poorly drained to poorly drained soils that formed in deposits of loess and alluvium. These soils tend to have low organic content, low buffering capacity, and acidic $\mathrm{pH}$ ranging from 4.5 to 5.5. The Henry and Calloway series have a fragipan horizon, a compact and brittle silty clay loam layer that extends from 26 in bgs to a depth of 50 in or more. The fragipan reduces the vertical movement of water and causes a seasonally perched water table in some areas at the PGDP. In areas within the PGDP where past construction activities have disturbed the fragipan layer, the soils are best classified as "urban."

In the area of the C-746-U Landfill, the surficial deposits are approximately 6.5-ft thick, and the Calloway-Henry and Grenada-Calloway associations dominate. Construction of the Landfill and associated structures has eliminated any fragipan.

\subsubsection{HYDROLOGY}

The PGDP is in an area of abundant surface water and groundwater resources. Creeks that bound the east and west sides of the PGDP flow north from the PGDP to join with the Ohio River. The sands and gravels of the continental deposit form a shallow aquifer beneath most of the PGDP and the contiguous area to the north, beginning at the Porters Creek Clay Terrace under the south end of the PGDP and extending to the north beyond the Ohio River.

\subsubsection{Surface Water Hydrology}

The PGDP is located in the western portion of the Ohio River basin. The plant is within the drainage areas of Bayou and Little Bayou Creeks and is situated on the divide between the two creeks, with Bayou Creek on the west and Little Bayou Creek on the east (Figure 3-4). Surface-water bodies in the vicinity of the PGDP include the Ohio River to the north, Metropolis Lake (located east of Shawnee Steam Plant), Bayou Creek, Little Bayou Creek, numerous small tributaries and creeks, as well as surface-water ditches and lagoons located within the plant boundary. There is a 
DOSE MODELING EVALUATIONS AND TECHNICAL

SUPPORT DOCUMENT FOR THE AUTHORIZED

LIMITS REQUEST FOR THE C-746-U LANDFILL AT THE PADUCAH GASEOUS DIFFUSION PLANT

\section{OR"}

OAK RIDGE INSTITUTE FOR SCIENCE AND EDUCATION

\section{0: PGDP and C-746-U Landfill Environmental Setting}

marshy area, called the Tupelo Swamp, just south of the confluence of Bayou and Little Bayou Creeks. The smaller surface-water bodies are expected to have only localized effects on the regional groundwater flow pattern.

Bayou Creek is a perennial stream with a drainage area of approximately $18.6 \mathrm{mi}^{2}$ that flows generally northward to the Ohio River from approximately $2.5 \mathrm{mi}$ south of the plant. Little Bayou Creek, which becomes a perennial stream north of the plant due to the PGDP discharges, originates within the WKWMA and flows northward to the Ohio River. The approximate drainage area of Little Bayou Creek is $8.5 \mathrm{mi}^{2}$. The confluence of the two creeks is approximately $3 \mathrm{mi}$ north of the plant site (as measured over land), just upstream of the location at which the creeks discharge into the Ohio River. The drainage areas for both creeks generally are rural and located mostly within the properties of the WKWMA, PGDP, and the TVA Shawnee Steam Plant. However, they receive surface drainage from numerous swales that drain residential and commercial properties. A major portion of the flow in both creeks north of the PGDP is effluent water from the plant, discharged through Kentucky Pollutant Discharge Elimination System-permitted outfalls. The C-746-U Landfill is contained within the Little Bayou Creek drainage area.

The U.S. Geological Survey (USGS) maintains gauging stations on Bayou Creek, 4.1 and 7.3 river-mi from the Ohio River, and a station on Little Bayou Creek, 2.2 river-mi upstream from its confluence with Bayou Creek. The mean monthly discharge at Bayou Creek, including plant discharge, varies from 6.5 to $60.7 \mathrm{ft}^{3} / \mathrm{s}$. The mean monthly discharge on Little Bayou Creek, including plant discharge, ranges from 0.89 to $33.5 \mathrm{ft}^{3} / \mathrm{s}$.

Two studies have investigated the dynamics of interaction between surface water and groundwater in Bayou and Little Bayou Creeks. The USGS performed a seepage survey in Bayou and Little Bayou Creeks on August 15 and 16, 1989. Mr. Eric Wallin monitored indicators of seepage between the creeks and groundwater during the period from July 22, 1996, through October 12, 1997, as the subject for a Master of Science thesis at the University of Kentucky.

The 1989 USGS study determined a point on both Bayou and Little Bayou Creeks where the creeks changed from losing streams (Bayou Creek), or streams of no groundwater interaction (Little Bayou Creek), to gaining streams. On Bayou Creek, the gaining reach began approximately 3.5 river-mi upstream from the Ohio River. On Little Bayou Creek, the point where the creek became a gaining stream was located approximately 2.6 river-mi upstream from the Ohio River. The USGS researchers noted channel-bank seeps along the lower reaches of both creeks. 
DOSE MODELING EVALUATIONS AND TECHNICAL SUPPORT DOCUMENT FOR THE AUTHORIZED LIMITS REQUEST FOR THE C-746-U LANDFILL AT THE PADUCAH GASEOUS DIFFUSION PLANT

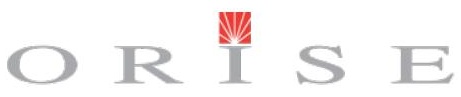

OAK RIDGE INSTITUTE FOR SCIENCE AND EDUCATION

\section{0: PGDP and C-746-U Landfill Environmental Setting}

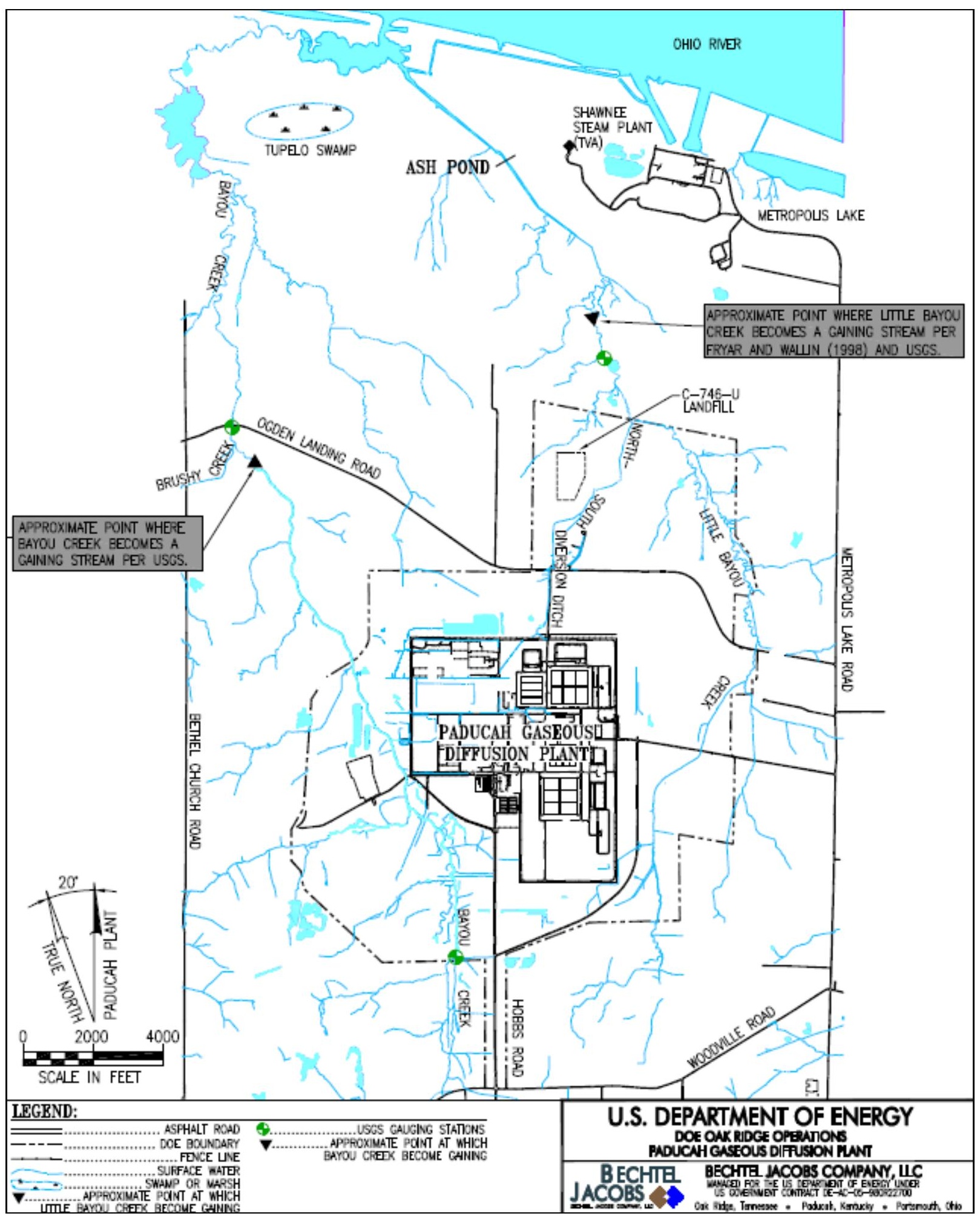

Figure 3-4. Surface Water Features in the Vicinity of the PGDP 
DOSE MODELING EVALUATIONS AND TECHNICAL

SUPPORT DOCUMENT FOR THE AUTHORIZED

LIMITS REQUEST FOR THE C-746-U LANDFILL AT THE PADUCAH GASEOUS DIFFUSION PLANT

\section{0: PGDP and C-746-U Landfill Environmental Setting}

The 1996-1997 study by Wallin assessed both spatial and temporal trends in stream-to-groundwater interaction along the creeks. This study assessed Bayou Creek from south of the PGDP to the Ohio River and Little Bayou Creek from the plant outfalls to the river. The investigation found that the magnitude of seepage varied with season, but it concurred with the 1989 survey location of the inflection point on Little Bayou Creek where the stream begins to gain. The Wallin study also found that gaining reaches on Bayou Creek are limited to the area south of the PGDP and the area near the Ohio River. The C-746-U Landfill is located in an area where Little Bayou Creek and surrounding minor creeks and ditches are expected to be losing; therefore, discharge of Landfill area groundwater to these creeks cannot reasonably be expected. Groundwater flowing from the area of the Landfill should not discharge to either the Bayou or Little Bayou Creeks. Man-made drainages receive storm water and effluent from the PGDP. The plant monitors 17 outfalls, which have a combined average daily flow of approximately 4.9 million gallons (gal) per day. Water flow in some of these ditches is intermittent based on seasonal rainfall. A significant man-made drainage located on the southern and eastern sides of the Landfill is the North-South Diversion Ditch (NSDD). The NSDD served as a major effluent channel from the industrialized PGDP until the mid-1990s when process water was diverted to treatment systems. Currently, the part of the NSDD located outside the secure area of the PGDP carries surface runoff to Little Bayou Creek.

\subsubsection{Groundwater Hydrology}

The Jackson Purchase Region is characterized by a thick sequence of unconsolidated Cretaceous through Holocene period sediments deposited on an erosionally truncated Paleozoic surface. The flow system in the vicinity of the PGDP exists primarily within unconsolidated sediments.

The regional groundwater flow systems occur within the Mississippian bedrock, Cretaceous McNairy Formation, Eocene sands, Pliocene terrace gravel, Pleistocene lower continental deposits, and upper continental deposits. Terms used to describe the hydrogeologic flow system are the Bedrock Aquifer, McNairy Flow System, Eocene Sands and Terrace Gravel, the Regional Gravel Aquifer (RGA), and the Upper Continental Recharge System (UCRS). Specific components for the regional groundwater flow system have been identified and are defined in the following subsections (refer to Figure 3-5).

\subsection{Bedrock Aquifer}

Limestone, which is believed to be Mississippian-age Warsaw Limestone, subcrops beneath the PGDP. Groundwater production from the bedrock aquifers comes from fissures and fractures and from the weathered rubble zone near the top of the bedrock. The bottom of the rubble zone generally marks the base of the active groundwater flow system beneath PGDP. 
DOSE MODELING EVALUATIONS AND TECHNICAL

SUPPORT DOCUMENT FOR THE AUTHORIZED

LIMITS REQUEST FOR THE C-746-U LANDFILL AT THE PADUCAH GASEOUS DIFFUSION PLANT

\section{0: PGDP and C-746-U Landfill Environmental Setting}

\subsection{McNairy Flow System}

This component, formerly termed the "deep groundwater system," consists of the interbedded and interlensing sand, silt, and clay of the Cretaceous McNairy Formation. The sand in the McNairy Formation is an excellent aquifer in the southeastern part of the Jackson Purchase Region; however, near the PGDP, the McNairy Formation contains significant amounts of silt and clay. Reported hydraulic conductivities for the McNairy Flow System range from 1.4E-8 to 4.7E-2 cm/s. Regionally, the McNairy Formation recharges along areas of outcrop in the eastern part of the region, near Kentucky Lake and Lake Barkley. Water movement is north and northwest toward discharge areas in Missouri and along the Ohio River.

The McNairy Formation subcrops beneath the plant at depths ranging from approximately 100-350 ft. Overall, sand facies account for 40-50\% of the total formation thickness of approximately $225 \mathrm{ft}$. The upper and middle McNairy members in the area of the PGDP are predominately silty and clayey fine sands. However, where the RGA is in direct hydraulic connection with coarser-grained sediments of the McNairy Formation, the McNairy flow is coincident with that of the RGA.

\subsection{Terrace Gravel and Eocene Sands}

Pliocene-age gravel deposits and Eocene sands overlie the Paleocene Porters Creek Clay in the southern portion of the DOE-owned property. A water table flow system developed in these units provides some through-flow to the north, across the Porters Creek Clay Terrace. Most of this through-flow is realized east of the PGDP, where the Pliocene Terrace Gravel is thickest adjacent to the Porters Creek Clay Terrace. The water table flow systems, immediately south and west of the PGDP, generally discharge to Bayou Creek because of the shallow depth of the Porters Creek Clay in those areas. However, closer to the northern limit of the terrace, through-flow provides recharge to the RGA. Reported hydraulic conductivities for these flow systems range from 1E-6 to $1.4 \mathrm{E}-3 \mathrm{~cm} / \mathrm{s}$. As noted earlier, these features are not present in the area of the C-746-U Landfill.

\subsection{Regional Gravel Aquifer}

The RGA consists primarily of the coarse sand and gravel facies of the lower continental deposits. Permeable sands of the upper continental deposits and the McNairy Formation, where they occur in contact with the lower continental deposits, are included in the RGA. The RGA is found throughout the plant area and to the north, but pinches out to the south, southeast, and southwest along the slope of the Porters Creek Clay terrace. Regionally, the RGA includes the Holocene-aged alluvium found adjacent to the Ohio River.

The RGA is the primary aquifer beneath the PGDP and is the dominant groundwater flow system in the area extending from the PGDP to the Ohio River, including the area of the C-746-U Landfill. 
DOSE MODELING EVALUATIONS AND TECHNICAL

SUPPORT DOCUMENT FOR THE AUTHORIZED

LIMITS REQUEST FOR THE C-746-U LANDFILL AT THE PADUCAH GASEOUS DIFFUSION PLANT

\section{0: PGDP and C-746-U Landfill Environmental Setting}

Regional groundwater flow within the RGA trends north-northeast toward a base level represented by the Ohio River. East-west heterogeneities within the lower continental deposits and leaks from the PGDP utilities cause groundwater flow to be directed locally to the northeast and northwest of the plant. Differences in permeability and aquifer thickness also affect the hydraulic gradient. Low gradients in the north-central portion of the plant site are the result of a thick section of the RGA containing higher fractions of coarse sand and gravel. Northward, near the Ohio River, the hydraulic gradient increases as a result either of a thinner section of RGA or of low-permeability bottom sediments in the Ohio River. The hydraulic gradient varies spatially but is on the order of 1.0E-4 to 1.0E-3 meters per meter $(\mathrm{m} / \mathrm{m})$. Hydraulic conductivities from the RGA have been reported as ranging from $1.0 \mathrm{E}-4$ to $1.0 \mathrm{E}+0 \mathrm{~cm} / \mathrm{s}$.

The RGA is the dominant pathway by which groundwater contamination migrates offsite. Contamination is also found in the upper portions of the McNairy Formation at the PGDP. However, the greater hydraulic conductivities in the RGA made the RGA the migration pathway of greatest importance in Risk and Performance Evaluation of the C-746-U Landfill at the Paducah Gaseous Diffusion Plant (DOE 2003b).

\subsection{Upper Continental Recharge System}

The UCRS consists of a thick, surface loess unit and the upper continental deposits. Hydrogeologists at the PGDP have differentiated the UCRS into three general horizons, or Hydrogeologic Units (HUs), which are as follows:

$\boldsymbol{H U} \mathbf{1}$ - an upper silt and clay interval (the surface loess unit)

$\boldsymbol{H U} 2$ - an intervening interval of common sand and gravel lenses

$\boldsymbol{H U} 3$ - a lower silt and clay interval

HU 1 and HU 3 are present in the area of the C-746-U Landfill, but HU 2 may be absent.

Groundwater flow in the UCRS is predominantly downward into the RGA, hence the term "recharge system." Vertical hydraulic gradients generally range from 0.5 to $1 \mathrm{~m} / \mathrm{m}$ where measured by wells completed at different depths in the UCRS. The presence of steep, but undetermined, vertical gradients for most areas of PGDP has limited the ability to map a water table at the PGDP. However, the available UCRS well network is sufficient to determine the main features of the water table. Regionally, the thickness of the saturated UCRS ranges from 0 to $50 \mathrm{ft}$. At the Landfill, the expected thickness of the UCRS is approximately $30 \mathrm{ft}$. Measurements of UCRS hydraulic conductivity range from $1.7 \mathrm{E}-08$ to $3.2 \mathrm{E}+00 \mathrm{~cm} / \mathrm{s}$. The range of eight orders of magnitude reflects the varied textures of the UCRS matrix. 
DOSE MODELING EVALUATIONS AND TECHNICAL

SUPPORT DOCUMENT FOR THE AUTHORIZED

LIMITS REQUEST FOR THE C-746-U LANDFILL AT

THE PADUCAH GASEOUS DIFFUSION PLANT

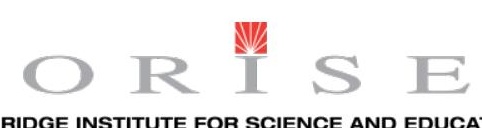

OAK RIDGE INSTITUTE FOR SCIENCE AND EDUCATION

3.0: PGDP and C-746-U Landfill Environmental Setting

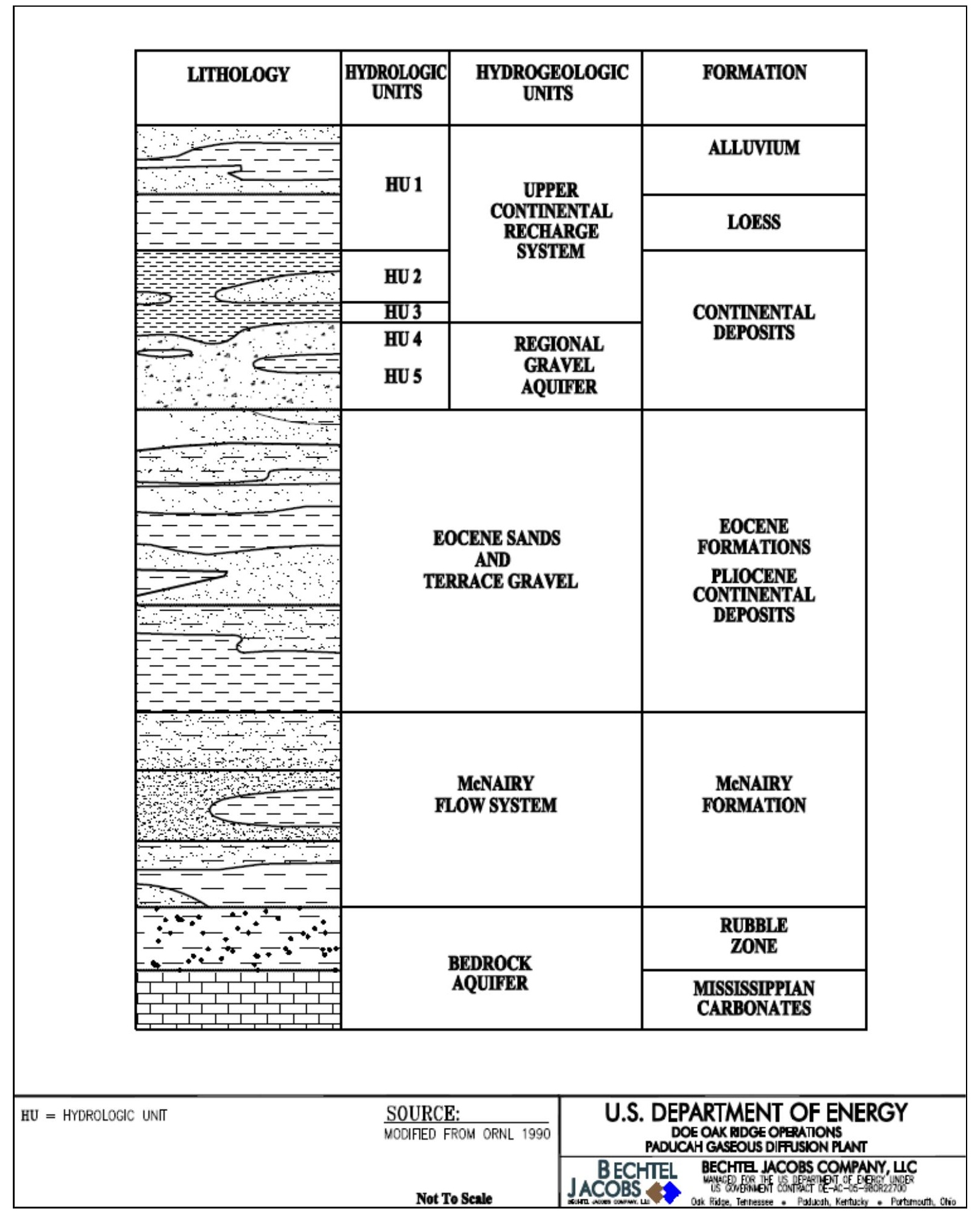

Figure 3-5. Hydrogeologic Units Beneath the PGDP 
DOSE MODELING EVALUATIONS AND TECHNICAL

SUPPORT DOCUMENT FOR THE AUTHORIZED

LIMITS REQUEST FOR THE C-746-U LANDFILL AT THE PADUCAH GASEOUS DIFFUSION PLANT

\section{0: PGDP and C-746-U Landfill Environmental Setting}

\subsection{6}

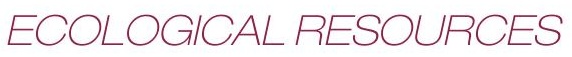

The PGDP and surrounding DOE-owned property are located in the Interior Low Plateau, Shawnee Hills Section of the Eastern Broadleaf Forest (Continental) Province of the Hot Continental Division of the Humid Temperate Domain. The vegetation types typical of this ecoregion are oak-hickory forests in the uplands and oak-gum-cypress forests in the bottomlands. The floodplain of the Ohio River in this area is dominated by sycamore, Kentucky Coffeetree, sugar berry, and honey locust with local tupelo and cypress swamp communities. Due to anthropogenic disturbances, the landscape now is a mosaic of primarily forest and agricultural lands. The ecological resources-i.e., terrestrial and aquatic flora and fauna, wetlands, and Threatened and Endangered (T\&E) species - in the PGDP vicinity are briefly summarized below. Each of these resources can be assumed to exist near the C-746-U Landfill because this site is surrounded by land managed by the WKWMA.

\subsubsection{Terrestrial Systems}

The upland habitats in the PGDP area support a variety of plant and wildlife species. Because much of the DOE-owned property and WKWMA terrestrial habitat is managed for multiple uses, the diversity of habitat is excellent. Forest and shrub tracts alternate with fencerows and transitional edge habitats (ecotones) along roads and transmission-line corridors. Fencerow communities are dominated by elm, locust, oak, and maple, with an often thick understory of sumac, honeysuckle, blackberry, and grape. Herbaceous growth in these areas includes clover, plantain, and numerous grasses. The numerous ditches, upland embankments along streams, and open areas around ponds in the area also provide diversity of habitat for wildlife and for recreational hunting.

\subsection{Vegetation}

The terrestrial community is described by the dominant vegetation sites that characterize the community. The communities range from oak-hickory forest, in areas that have been relatively undisturbed, to managed fencerows and agricultural lands. Detailed investigations of vegetation have been conducted for Ballard and McCracken Counties in Kentucky by the WKWMA and the U.S. Army Corps of Engineers (USACE). Significant areas of the DOE-owned property and WKWMA include vegetation managed for consumption by wildlife, especially deer. In addition, $26 \%$ of the total land area of Ballard County and $24 \%$ of McCracken County are designated as commercial forestland. Most of the area in the vicinity of the PGDP has been cleared of vegetation at some time. Approximately 2,000 acres in the WKWMA consist of old field grasslands. Approximately 800 acres within the WKWMA are in scrub or shrub habitat. The KDFWR staff mows 600 to 700 acres; control burns 200 to 400 acres; plants 150 acres of food plots (for wildlife); and sprays, strip-discs, or otherwise actively manages an additional 100 to 500 acres annually on the WKWMA. 
DOSE MODELING EVALUATIONS AND TECHNICAL

SUPPORT DOCUMENT FOR THE AUTHORIZED

LIMITS REQUEST FOR THE C-746-U LANDFILL AT THE PADUCAH GASEOUS DIFFUSION PLANT

\section{0: PGDP and C-746-U Landfill Environmental Setting}

\subsection{Wildlife}

Wildlife commonly found in the PGDP area consists of species indigenous to open grassland, thickets, and forest habitats. Observations by ecologists and WKWMA staff have provided a qualitative description of wildlife communities likely to inhabit the vegetation communities in the vicinity of PGDP. Open herbaceous areas are frequented by rabbits, mice, and a variety of other small mammals. Birds include red-winged blackbirds, quail, sparrows, and predators such as hawks and owls. In ecotones (including fencerows, low shrub, and young forests), a variety of wildlife is present including opossum, vole, mole, raccoon, and deer. Birds typical in the ecotones include red-winged blackbird, loggerhead shrike, mourning dove, northern bobwhite quail, wild turkey, northern cardinal, and western meadowlark. Several groups of coyotes also reside in the vicinity of the PGDP. In mature forests, squirrel, various songbirds, and great horned owls may be present. The primary game species hunted for food in the area are deer, wild turkey, northern bobwhite quail, rabbit, and squirrel. Opossums and raccoons are hunted for dog training and their pelts. Much of the area is attractive to game and nongame species because of the intense management program for game that has been implemented in the WKWMA.

\subsubsection{Aquatic Systems}

Both Bayou and Little Bayou Creeks and tributaries support a variety of aquatic life, including several species of sunfish, as well as spotted and largemouth bass, bullheads, and creek chub. Inhabitants of shallow streams, characteristic of the two main area creeks, are dominantly bluegill, green and longear sunfish, and central stonerollers.

In addition to stream habitats, approximately 13 fishing ponds are located primarily in the WKWMA. Most of the ponds north of the PGDP are used for public fishing. Ponds in the former Kentucky Ordnance Works (KOW) area have been posted with consumption warnings, due to contamination from the former KOW operations. Pond areas generally are dominated by largemouth bass, bluegill, and to a lesser extent, green sunfish. Prior to 1990, Little Bayou Creek also was fished; however, due to the detection of elevated concentrations of PCBs in fish taken from Little Bayou Creek, consumption warnings have been posted. Aquatic habitats are used by muskrat and beaver. Many species of water birds, including wood duck, geese, heron, and species of migratory birds, also use these areas. Numerous other smaller ponds and abandoned gravel pits usually contain water and may have functioning ecosystems.

\subsubsection{Wetlands}

Habitats that have soil and hydrology capable of supporting vegetation adapted for hydric environments are considered wetlands. These habitats include marshes (wetlands dominated by herbaceous species) and swamps (wetlands dominated by woody species), as well as many other ecotones between terrestrial and aquatic habitats. Near the PGDP, there are numerous areas where 
DOSE MODELING EVALUATIONS AND TECHNICAL

SUPPORT DOCUMENT FOR THE AUTHORIZED

LIMITS REQUEST FOR THE C-746-U LANDFILL AT THE PADUCAH GASEOUS DIFFUSION PLANT

\section{OR"}

OAK RIDGE INSTITUTE FOR SCIENCE AND EDUCATION

\section{0: PGDP and C-746-U Landfill Environmental Setting}

these conditions prevail, particularly in the region adjacent to the Ohio River. Within the WKWMA, approximately 4,000 acres have been identified as having hydric soil capable of supporting wetlands. Some of these systems include a special-status species, the water hickory. Approximately 400 acres of this area are Tupelo Swamp, and another 600 acres are bottomland hardwood. The Tupelo Swamp, which is located near the PGDP, is considered unusual by state and federal land managers and is thought to be only one of three similar systems left in the United States. Most of the remainder of the wetlands in the PGDP vicinity is in agricultural use or is in some stage of succession to wetland scrub. Other wetland habitats are found associated with the shorelines of ditches and creeks (riparian vegetation), although many of these are incised and have only marginal areas of wetlands. Most ponds also include shallow wetland systems along their shorelines and along contiguities with bottomland hardwood systems.

The 1994 USACE environmental investigations identified 11,728 acres of wetlands surrounding the PGDP. This investigation identified and grouped wetlands into vegetation cover types encompassing forested, scrub/shrub, and emergent wetlands. Wetlands inside the plant security fence are confined to portions of drainage ditches traversing the site. Functions and values of these areas inside the plant as wetlands are low to moderate with regard to groundwater recharge, floodwater retention, and sediment/toxicant retention. Other functions and values such as wildlife habitat/benefits are low. The wetlands closest to the C-746-U Landfill are located to the west. A small wetland, approximately 1 acre in area, is present near the northwest corner of the Landfill.

Flooding is associated with the Ohio River, Bayou Creek, and Little Bayou Creek. The majority of overland flooding is associated with the Ohio River floodplain. Bayou and Little Bayou Creek flooding is generally confined to the areas within, and immediately adjacent to, the channels of these streams. A floodplain analysis performed by the USACE in 1994 found that much of the built-up portions of the plant, including the Landfill, lie outside the 100- and 500-yr floodplains of these streams.

\subsubsection{Threatened and Endangered Species}

Potential habitat for federally listed T\&E species was evaluated for the area surrounding PGDP during the 1994 USACE environmental investigation of the PGDP and inside the fence of the PGDP during the 1994 investigation of sensitive resources at the PGDP. No T\&E species or potential habitat for any $\mathrm{T} \& \mathrm{E}$ species was observed during the inside-the-fence investigation. In 1999, five Indiana bats were captured near the lower downstream reaches of Bayou Creek.

Eleven federally listed, proposed, or candidate species have been identified as potentially occurring at or near the PGDP. None of the species has been reported as sighted on the DOE-owned property. Potential summer habitat exists on DOE-owned property for the Indiana bat based on roosting studies, and Indiana bats have been captured in the vicinity. Suitable forage habitat for the 
DOSE MODELING EVALUATIONS AND TECHNICAL

SUPPORT DOCUMENT FOR THE AUTHORIZED

LIMITS REQUEST FOR THE C-746-U LANDFILL AT

THE PADUCAH GASEOUS DIFFUSION PLANT

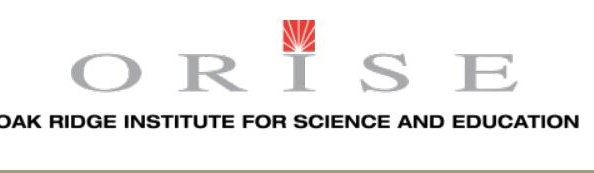

3.0: PGDP and C-746-U Landfill Environmental Setting

Indiana bat is present throughout the DOE-owned property. A subadult Copperbelly Water Snake was caught in the Tupelo Swamp on the WKWMA in the summer of 2000. No critical habitat for any of these species has been designated anywhere in the area of the C-746-U Landfill. 
DOSE MODELING EVALUATIONS AND TECHNICAL

SUPPORT DOCUMENT FOR THE AUTHORIZED

LIMITS REQUEST FOR THE C-746-U LANDFILL AT THE PADUCAH GASEOUS DIFFUSION PLANT

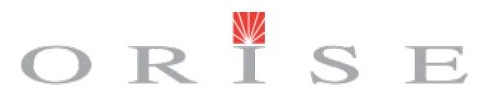

OAK RIDGE INSTITUTE FOR SCIENCE AND EDUCATION

4.0: C-746-U Landfill Description and Design Features

4.0: C-746-U LANDFILL DESCRIPTION AND DESIGN FEATURES

A general description of the C-746-U Landfill and its history was provided in Section 1.0, "Introduction," and is extended here to emphasize the Landfill's regulatory history and specific construction, design, and use features.

The information provided in this section was excerpted from Risk and Performance Evaluation of the C-746-U Landfill at the Paducah Gaseous Diffusion Plant (DOE 2003b). Minor editorial changes were made as appropriate. Reviewers should reference the DOE document for additional details, including supporting references, graphics, etc. Where applicable, ORISE incorporated Landfill design features into the modeling analysis. The Landfill's permanent cover depth was of particular importance in this regard.

C-746-U LANDFILLPERMITTING

The C-746-U Landfill is permitted by the Solid Waste Branch of the Kentucky Energy and Environment Cabinet and began operations in 1997 under its first Operational Solid Waste Permit \#073-00045 (effective date of November 4, 1996). The applicable regulations are outlined in 401 KAR Chapter 47, Solid Waste Facilities, and 401 KAR Chapter 48, Standards for Solid Waste Facilities. The regulations contain multiple requirements, including an environmental monitoring plan for all designs that meet $401 \mathrm{KAR}$ 48:300, a continuous impervious liner, a description of procedures and schedule for final closure, a description of the final cover, compliance with surface and groundwater monitoring requirements, erosion and sedimentation control measures, a Kentucky-licensed landfill manager and operator to be physically located and to control access at the disposal facility during posted operational hours, and no acceptance of free liquids or hazardous waste.

The C-746-U Landfill site encompasses 59.7 acres and is located in the buffer zone surrounding the industrialized portion of the PGDP (refer to Figure 1-1). Although surrounded by recreational use areas, the Landfill is in an area designated as unsecured and industrial (i.e., patrolled but outside the main security fence). 
DOSE MODELING EVALUATIONS AND TECHNICAL

SUPPORT DOCUMENT FOR THE AUTHORIZED

LIMITS REQUEST FOR THE C-746-U LANDFILL AT

THE PADUCAH GASEOUS DIFFUSION PLANT

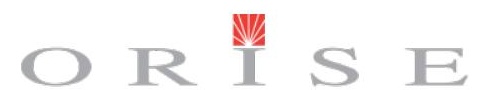

OAK RIDGE INSTITUTE FOR SCIENCE AND EDUCATION

\section{0: C-746-U Landfill Description and Design Features}

\section{2}

NORTH-SOUTHDIVERSIONDITCH

The NSDD lies near the southern and eastern boundary of the C-746-U Landfill site. An unnamed creek borders the northern edge of the Landfill (Figure 4-1). Both the unnamed creek and the NSDD empty into Little Bayou Creek. In the area of the Landfill, the NSDD and Little Bayou Creek are perennial streams that are assumed to provide aquatic habitat. The unnamed creek is intermittent and it is assumed to provide no aquatic habitat. Intermittent streams do provide habitat for amphibians and are a source of drinking water for wildlife. The areas surrounding the creeks form habitat for a variety of terrestrial wildlife, including the T\&E species discussed earlier.

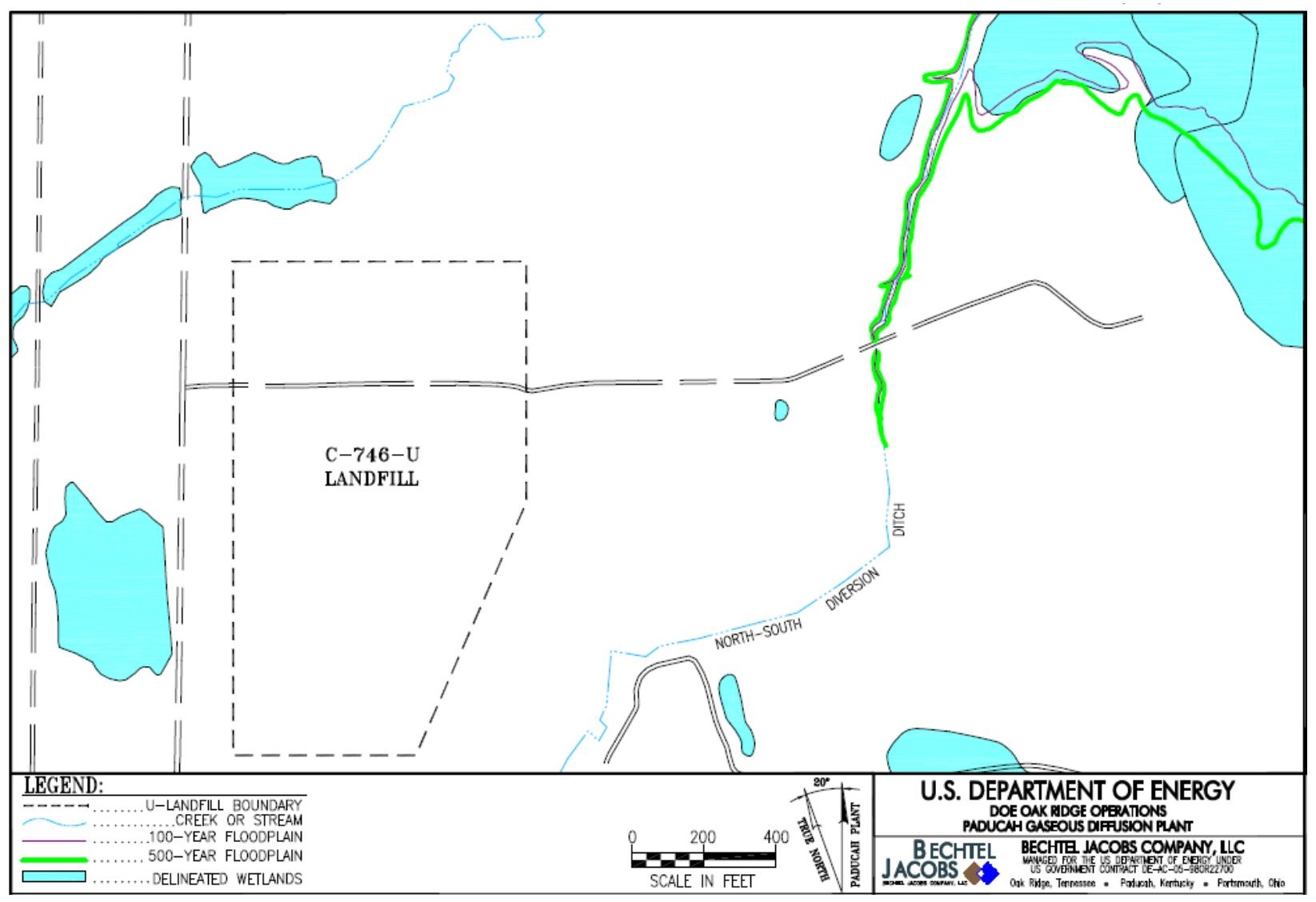

Figure 4-1. Wetlands and Floodplains in the Vicinity of the C-746-U Landfill

Groundwater flow at the C-746-U Landfill is similar to other locations at the PGDP located above the RGA. Groundwater flow in the UCRS is primarily vertical, and flow in the RGA is primarily lateral. Once groundwater reaches the RGA, flow is towards the north-northeast. Based upon water level measurements, groundwater reaching the RGA is assumed to pass under Little Bayou Creek, as it flows to the Ohio River, and not to discharge to this creek. The ultimate discharge point of RGA groundwater originating at the Landfill is the Ohio River. 
DOSE MODELING EVALUATIONS AND TECHNICAL

SUPPORT DOCUMENT FOR THE AUTHORIZED

LIMITS REQUEST FOR THE C-746-U LANDFILL AT THE PADUCAH GASEOUS DIFFUSION PLANT

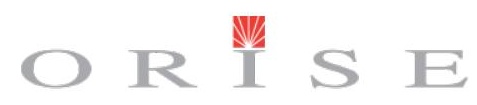

OAK RIDGE INSTITUTE FOR SCIENCE AND EDUCATION

4.0: C-746-U Landfill Description and Design Features

4.3

C-746-U LANDFILL CONSTRUCTION AND DESIGN FEATURES

This section describes construction, design, and current and future anticipated use and closure aspects of the C-746-U Landfill design used by ORISE in support of the development of the project's conceptual site model and to provide relevant inputs for the radiation dose fate and transport modeling. A cross-section of the Landfill is provided in Figure 4-2. C-746-U Landfill design features described here were excerpted from DOE 2003b, Section 3. This document in turn referenced two specific DOE sources of supporting information: Technical Application for Contained Solid Waste Landfill and the report Construction and Operation of the U.S. Department of Energy C-746-U Contained Landfill Solid Waste Permit No. 073-00045, Paducah, Kentucky.

With the exception of minor editorial changes, the text reflects DOE 2003b content. Where appropriate, ORISE provides input when it influenced the modeling analysis.

The conceptual design for the Landfill included the following key design elements.

Permanent Cover-The final cover planned for the C-746-U Landfill is designed to minimize infiltration. The final cover will have six layers with a total thickness of $5 \mathrm{ft}$. The cover will include, from top to bottom, a 3 -ft vegetative soil erosion prevention layer, a geotextile filter fabric above a 40 -mil low-density polyethylene membrane, a 0.5 -ft clay barrier, a 0.5 -ft sacrificial soil layer, and a 1 -ft sand gas-venting system. The average side slope of the top erosion prevention layer is planned to be approximately $18.25 \%$ (including storm water diversion benches). The final cover will be installed at the end of the active Landfill operating period. When installed, this cover will include a passive venting system composed of one vent per acre of cap.

Note: ORISE used the total cover thickness of $5 \mathrm{ft}(1.52 \mathrm{~m})$ in the modeling analysis.

Waste-When full, the C-746-U Landfill is projected to contain soil, concrete, scrap metal and lumber, roofing and construction debris, and other nonhazardous sanitary and industrial waste. Because the Landfill will have sloping sides, the waste thickness will vary. The maximum waste height in the Landfill is projected to be $76.4 \mathrm{ft}$ with an average thickness of $38 \mathrm{ft}$.

Note: According to DOE 2003b: "maximum waste height in the Landfill is projected to be $76.4 \mathrm{ft}$ with an average thickness of $38 \mathrm{ft}$." However, the Disposal Unit Source Term (DUST) model depicted in Figure 4.3 cites a layer thickness of $44 \mathrm{ft}$ based on the sum of the layer thicknesses for the four Waste Forms (soil, concrete, metal, and organic, respectively). For this evaluation, ORISE used $44 \mathrm{ft}$ as the average thickness of the waste. 
DOSE MODELING EVALUATIONS AND TECHNICAL

SUPPORT DOCUMENT FOR THE AUTHORIZED LIMITS REQUEST FOR THE C-746-U LANDFILL AT THE PADUCAH GASEOUS DIFFUSION PLANT

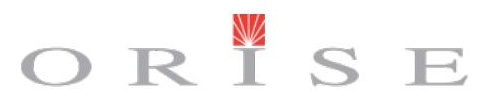

OAK RIDGE INSTITUTE FOR SCIENCE AND EDUCATION

\section{0: C-746-U Landfill Description and Design Features}

Wastes disposed of in the Landfill will be compacted and covered with clean cover soil, as permitted by the Commonwealth of Kentucky in accordance with the requirements of Kentucky solid waste regulations and Subtitle D of RCRA. The overall mixing of wastes and cover material is assumed to result in an 8:1 ratio of waste to soil within the Landfill, based on the placement of $0.5 \mathrm{ft}$ of daily cover for every 4 - $\mathrm{ft}$ lift of compacted waste. This ratio may be decreased (i.e., less waste placed per amount of soil) if waste is placed in the Landfill at a rate slower than projected.

Note: ORISE used a daily cover depth for the Operational Period of 6 in.

Multilayer Base Liner System - The purpose of the base liner is to prevent contaminants from migrating from the waste facility to groundwater. The liner for the C-746-U Landfill has five layers with a total thickness of approximately $5 \mathrm{ft}$ and is underlain by a 3 -ft compacted subgrade. The liner includes, from top to bottom, a 1-ft protective soil layer, a geotextile filter fabric, a 1-ft gravel drainage layer for primary leachate collection, a layer of geotextile fabric and an 80-mil high-density polyethylene (HDPE textured geomembrane), and a 3-ft clay liner. In order to facilitate leachate collection and transfer, the drainage layer also contains perforated pipes placed on a 1.6\% slope. Leachate is accumulated in a collection sump. The compacted subgrade is composed of $2 \mathrm{ft}$ of compacted "road base 2" gravel covered with $1 \mathrm{ft}$ of compacted native clay. (The subgrade was a design change made during construction of Landfill Phases 1-5 so that the cells would pass the proof rolling test.) During the Operational and Institutional Control Periods, the leachate is assumed to be sent to a wastewater treatment facility. 
DOSE MODELING EVALUATIONS AND TECHNICAL

SUPPORT DOCUMENT FOR THE AUTHORIZED

LIMITS REQUEST FOR THE C-746-U LANDFILL AT THE PADUCAH GASEOUS DIFFUSION PLANT

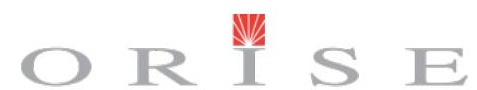

OAK RIDGE INSTITUTE FOR SCIENCE AND EDUCATION

4.0: C-746-U Landfill Description and Design Features

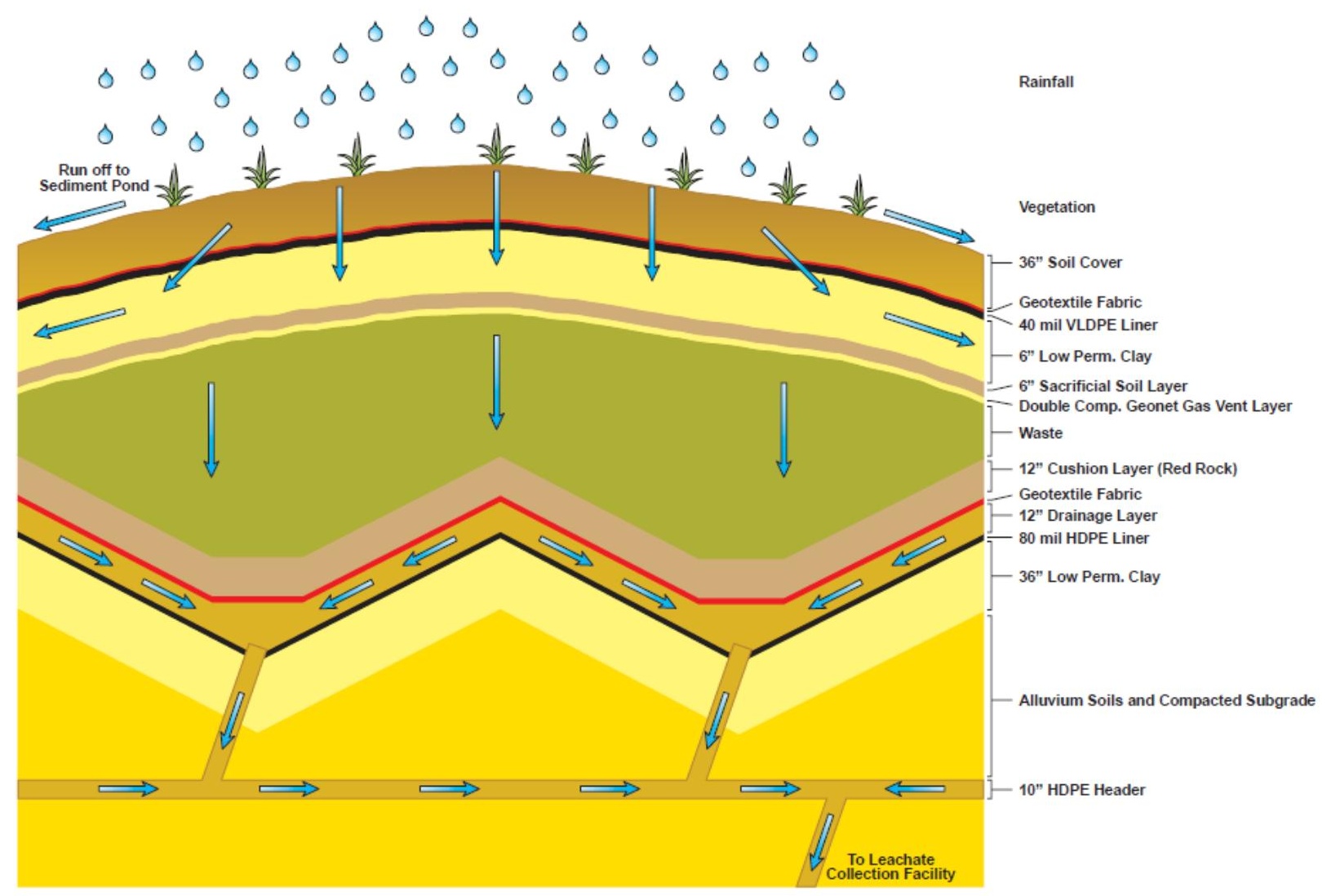

Figure 4-2. C-746-U Landfill Cross-Section

Geologic Buffer-A 34-ft geologic buffer layer composed of native soils (i.e., HU 3) is assumed to lie between the base liner and the uppermost aquifer at PGDP (the RGA). The buffer includes $6.5 \mathrm{ft}$ of alluvium soil and $27.5 \mathrm{ft}$ of clay to clayey silt.

Clean Fill Perimeter Dike-A clean-fill dike will be constructed around the C-746-U Landfill to provide stable lateral containment of wastes. The dike will tie together the cover and base liner components and provide for drainage ditches and a perimeter access road.

\subsubsection{PERIODS OFC-746-ULANDFILL PERFORMANCE}

Three periods of landfill performance (operational, institutional control, and post-institutional control) are expected under the current C-746-U Landfill design and rate of waste placement. Each of these periods is described below and depicted in Figures 4-3 through 4-5, respectively.

The Operational Period occurs during the first $20 \mathrm{yr}$ of Landfill operation. During this period, waste is placed in the Landfill until it is full, and $0.5 \mathrm{ft}$ of uncompacted soil is assumed to be used as interim daily cover for disposed waste. The waste must be covered within 2 hour (hr) of 
DOSE MODELING EVALUATIONS AND TECHNICAL

SUPPORT DOCUMENT FOR THE AUTHORIZED LIMITS REQUEST FOR THE C-746-U LANDFILL AT THE PADUCAH GASEOUS DIFFUSION PLANT

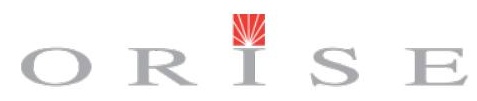

OAK RIDGE INSTITUTE FOR SCIENCE AND EDUCATION

4.0: C-746-U Landfill Description and Design Features

entering the Landfill. The multilayer base liner, including the leachate collection system, is assumed operational.

Note: The PGDP operates the Landfill through a permit issued under the provisions of Kentucky Revised Statutes (KRS) Chapter 224, Environmental Protection. To clarify the statement pertaining to the time period to cover waste once received at the Landfill, per the permitting requirements contained in 401 KAR 48:090 Section 9, Working Face Requirements, the 2-hr time limit actually applies to dumping the load following waste receipt. Per the regulation, the owner or operator shall spread wastes in loose layers not exceeding 24-in depth and compact it to the maximum practicable density. Per Section 3(1), "Daily cover," the owner or operator shall place a minimum of 6 in of cover over all exposed solid waste at the end of each working day.

The Institutional Control Period occurs between the years 20 and 50. During this period, all components of the solid waste C-746-U Landfill—liners, Flexible Membrane Linings (FMLs), drainage layer, and clay layers - are assumed to be in place. The final cover is assumed to operate successfully for $30 \mathrm{yr}$ after emplacement. Similarly, the multilayer base-liner system, including the leachate collection system, is assumed to operate during this period.

Note: ORISE assumed both a gradual and immediate failure in its modeling during this time period.

The Post-Institutional Control Period occurs between the years 50 and 10,000. During this period, it is assumed that infiltration of water through the cap and liner system increases due to degradation of some layers. However, it is also assumed DOE or another federal agency continues to control the C-746-U Landfill as an industrial site, which includes preventing cap erosion and addressing gradual changes that may occur in the Landfill. Therefore, access by the public will continue to be limited, and access for industrial purposes will be controlled with workers being protected. 
DOSE MODELING EVALUATIONS AND TECHNICAL SUPPORT DOCUMENT FOR THE AUTHORIZED LIMITS REQUEST FOR THE C-746-U LANDFILL AT THE PADUCAH GASEOUS DIFFUSION PLANT

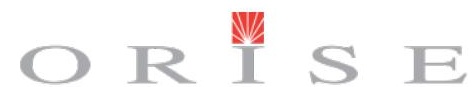

OAK RIDGE INSTITUTE FOR SCIENCE AND EDUCATION

4.0: C-746-U Landfill Description and Design Features

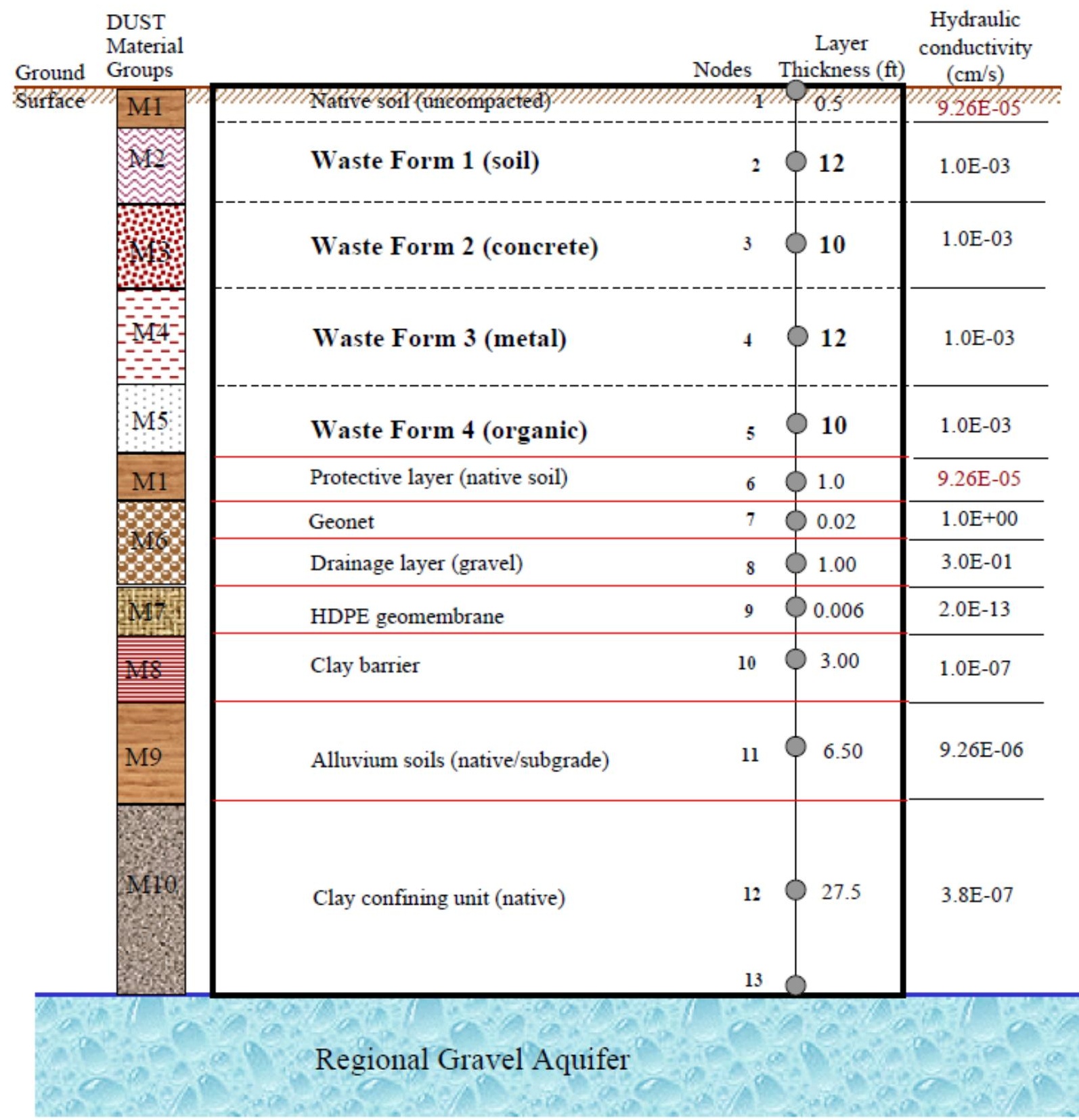

(not to scale)

Figure 4-3. Schematic Model of DUST Model Layers and Materials for the Operational Period Under All Scenarios (from DOE 2003b) 
DOSE MODELING EVALUATIONS AND TECHNICAL SUPPORT DOCUMENT FOR THE AUTHORIZED LIMITS REQUEST FOR THE C-746-U LANDFILL AT THE PADUCAH GASEOUS DIFFUSION PLANT

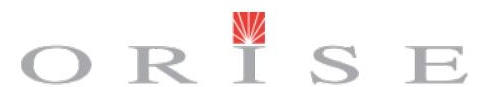

OAK RIDGE INSTITUTE FOR SCIENCE AND EDUCATION

4.0: C-746-U Landfill Description and Design Features

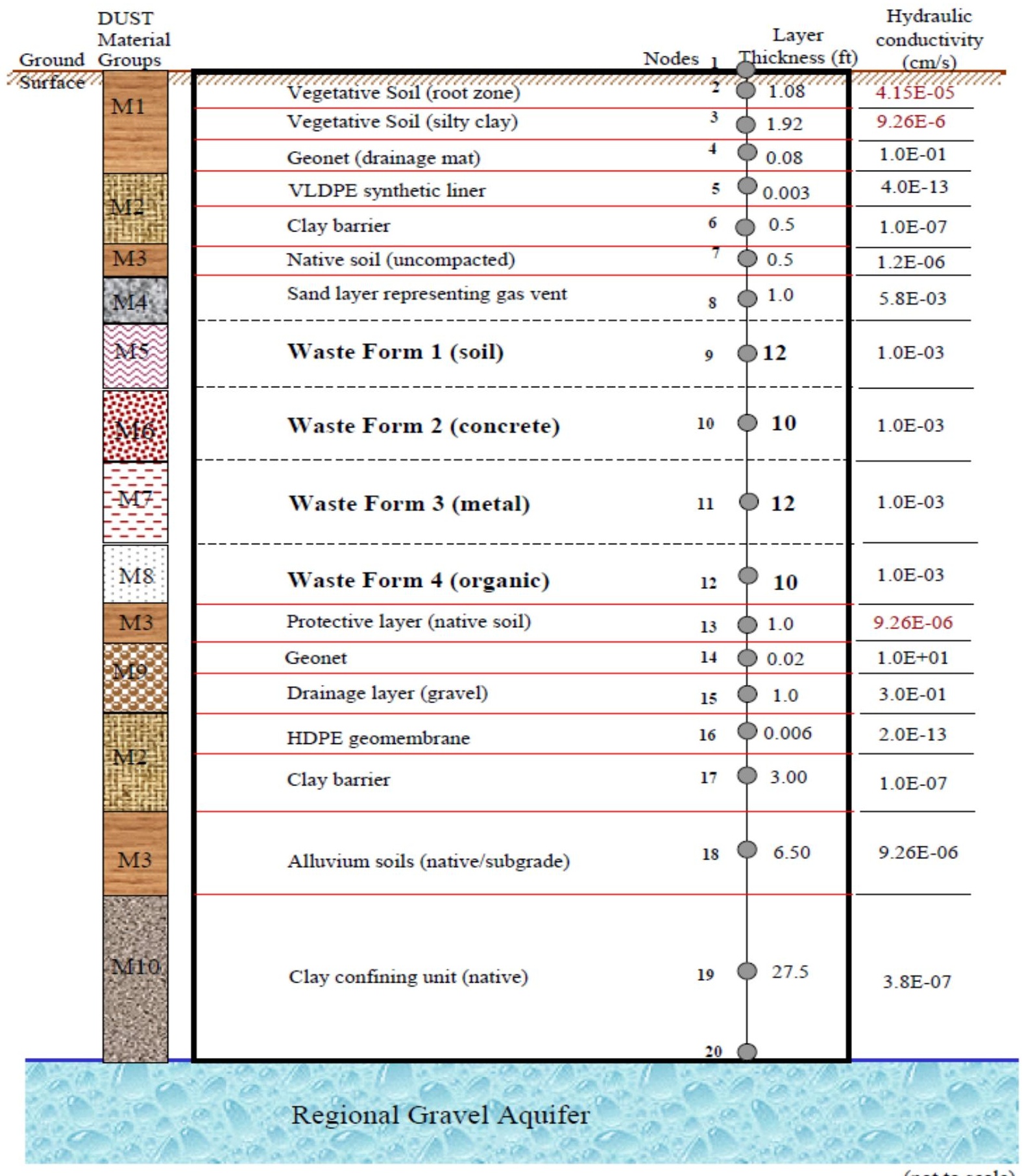

Figure 4-4. Schematic Model of DUST Model Layers and Materials for the Institutional Control Period Under All Scenarios and for the Post-Institutional Control Period Under the No Failure Scenario (from DOE 2003b) 
DOSE MODELING EVALUATIONS AND TECHNICAL SUPPORT DOCUMENT FOR THE AUTHORIZED LIMITS REQUEST FOR THE C-746-U LANDFILL AT THE PADUCAH GASEOUS DIFFUSION PLANT

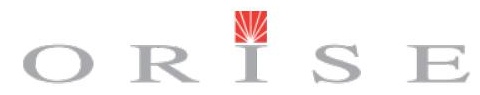

OAK RIDGE INSTITUTE FOR SCIENCE AND EDUCATION

4.0: C-746-U Landfill Description and Design Features

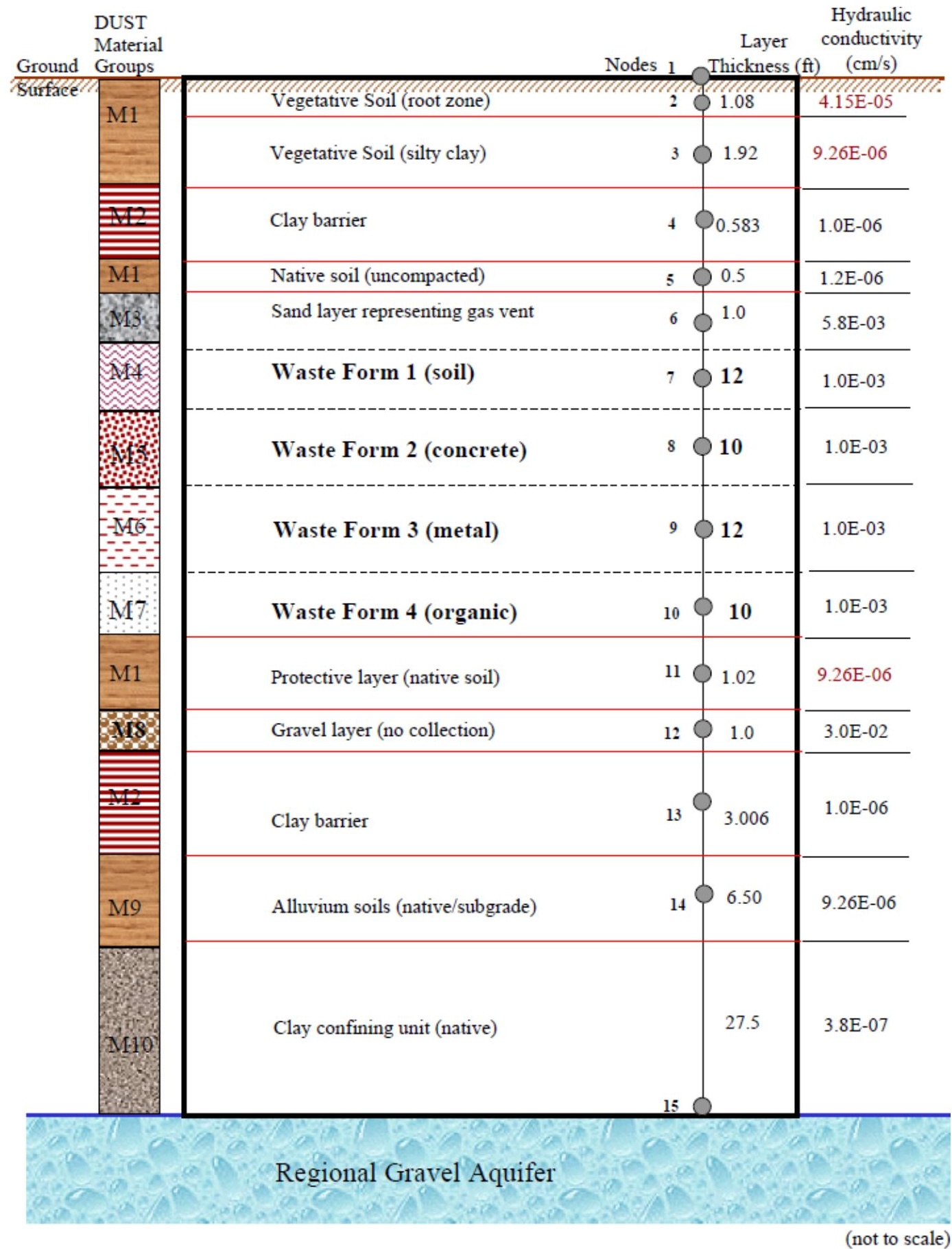

Figure 4-5. Schematic Model of DUST Model Layers and Materials for the Post-Institutional Control Period Under the Gradual Failure and Immediate Failure Scenarios (from DOE 2003b) 
DOSE MODELING EVALUATIONS AND TECHNICAL

SUPPORT DOCUMENT FOR THE AUTHORIZED

LIMITS REQUEST FOR THE C-746-U LANDFILL AT THE PADUCAH GASEOUS DIFFUSION PLANT

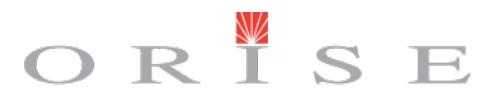

OAK RIDGE INSTITUTE FOR SCIENCE AND EDUCATION

\section{0: C-746-U Landfill Description and Design Features}

Per DOE 2003b, while all components of the waste disposal cell are assumed to be in place, some layers are assumed to degrade. The FMLs are assumed to degrade completely, and the hydraulic conductivity of the top and bottom clay barriers is assumed to increase by one order of magnitude. Additionally, the gravel layer in the base liner is assumed to no longer function as a drainage layer, and its hydraulic conductivity is assumed to decrease by one order of magnitude due to clogging with fine materials.

Although the cap and the liner system can reasonably be expected to degrade slowly, it is uncertain at what rate degradation will occur. Therefore, both a gradual failure rate and an immediate failure are considered in the modeling.

\subsubsection{CONTROL OFSURFACERUNOFF}

During the current operational period, surface runoff at the C-746-U Landfill is controlled using sedimentation (sediment) ponds (Figures 4-6 and 4-7). The area within the drainage boundary of the sedimentation ponds is maintained to prevent the erosion of perimeter ditches and to minimize the effects of runoff of contaminated soils and sediments to surrounding creeks. Forecast rainfall events are closely monitored to reduce the potential for rainfall/waste contact. A positive grade is maintained within the waste limits to prevent the ponding of storm water within these areas. Vegetative cover is continually maintained to ensure that impacts from storm events do not adversely affect the water quality within the sedimentation pond. The discharge of storm water from the sedimentation pond periodically occurs when volumes reach maximum holding capacities. 
DOSE MODELING EVALUATIONS AND TECHNICAL SUPPORT DOCUMENT FOR THE AUTHORIZED LIMITS REQUEST FOR THE C-746-U LANDFILL AT THE PADUCAH GASEOUS DIFFUSION PLANT

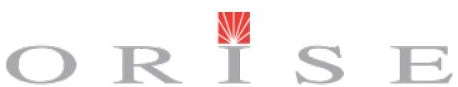

OAK RIDGE INSTITUTE FOR SCIENCE AND EDUCATION

\section{0: C-746-U Landfill Description and Design Features}

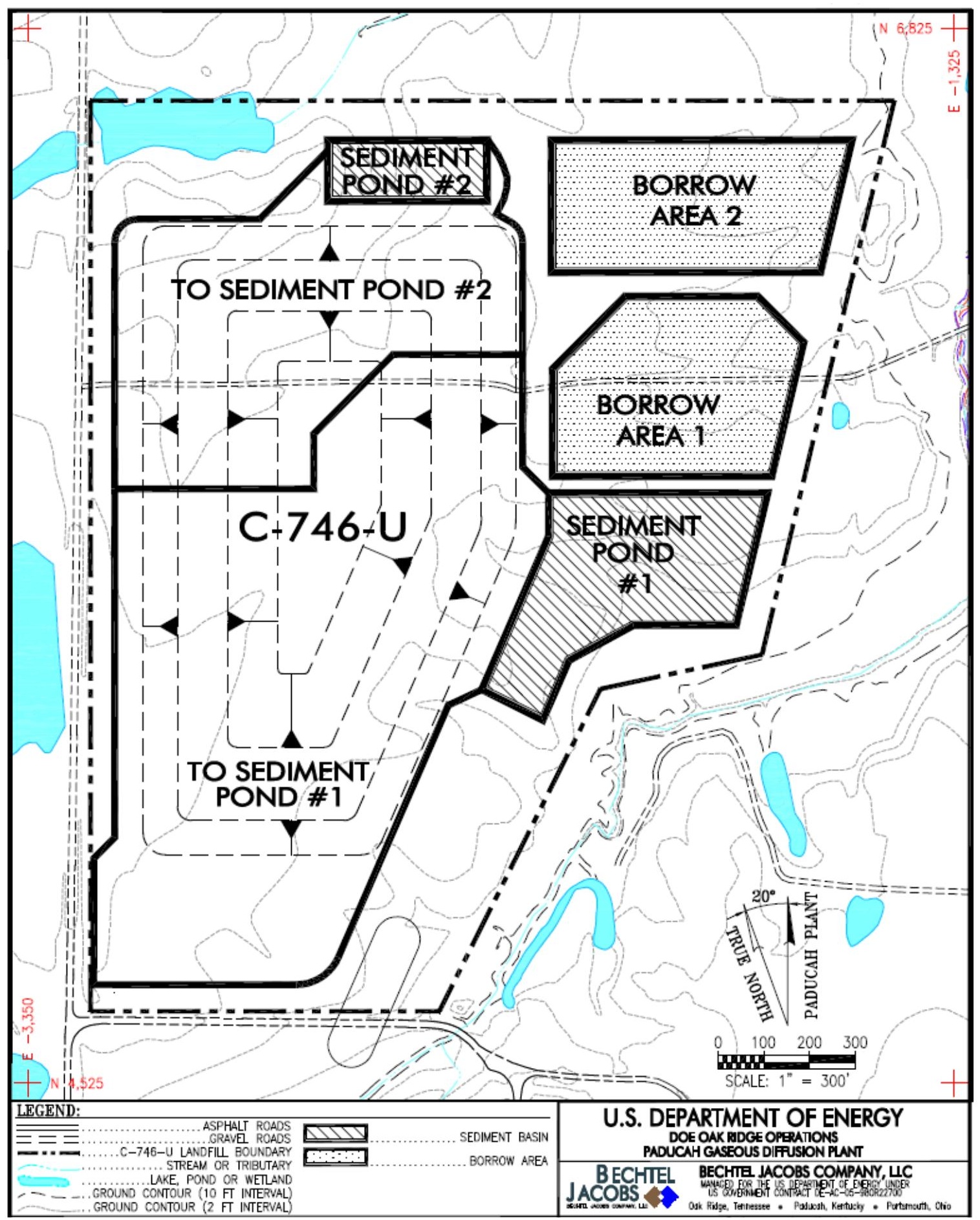

Figure 4-6. Close-up View of the C-746-U Landfill, Including Sediment Ponds and Borrow Areas 
DOSE MODELING EVALUATIONS AND TECHNICAL SUPPORT DOCUMENT FOR THE AUTHORIZED LIMITS REQUEST FOR THE C-746-U LANDFILL AT THE PADUCAH GASEOUS DIFFUSION PLANT

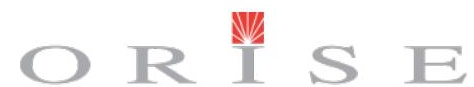

OAK RIDGE INSTITUTE FOR SCIENCE AND EDUCATION

4.0: C-746-U Landfill Description and Design Features

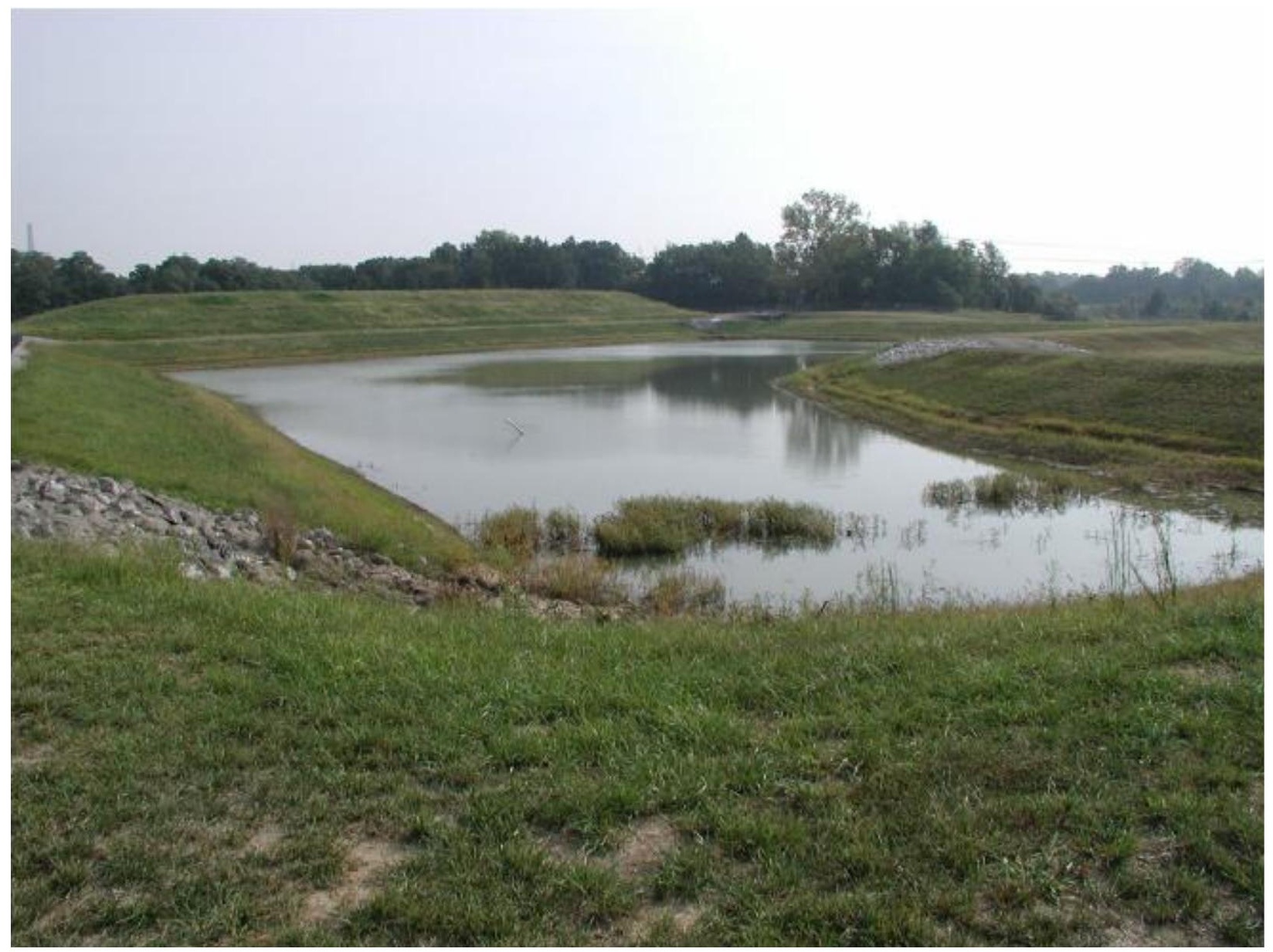

Figure 4-7. Sedimentation Pond at the C-746-U Landfill

\subsection{3 \\ LEACHATE COLLECTIONAND STORAGESYSTEM}

The C-746-U Landfill operates under a leachate management system. Per the KDWM regulations, the leachate collection system must be able to hold a minimum of 15 days of leachate collection and be greater than 1,000 gal in size. To meet that requirement, two 30,000-gal leachate storage tanks were constructed at the C-746-U3 leachate facility to contain leachate generated from the Landfill. Leachate is generated from the collection drainage network as shown in Figure 4-8. Leachate collection lines transport leachate to the below ground wet well pumping facility and then pump it into the 30,000-gal holding tanks from the wet well. Two leachate disposal options are allowed by the permit documents. The primary disposal option is the recirculation of Landfill leachate to the working phase of the Landfill. The second option is the disposal of leachate at the PGDP C-615 waste water treatment plant. Leachate is required to be sampled and characterized prior to disposal at C-615.

Note: ORISE did not consider leachate collection in the RESRAD modeling. ORISE assumed that all material disposed in the Landfill had an opportunity to migrate to groundwater based on the 
DOSE MODELING EVALUATIONS AND TECHNICAL SUPPORT DOCUMENT FOR THE AUTHORIZED LIMITS REQUEST FOR THE C-746-U LANDFILL AT THE PADUCAH GASEOUS DIFFUSION PLANT

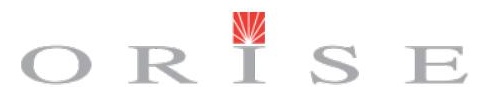

OAK RIDGE INSTITUTE FOR SCIENCE AND EDUCATION

\section{0: C-746-U Landfill Description and Design Features}

receptors and scenarios described in Section 5.4 and the Landfill hydrogeological properties. That is, the Landfill was modeled as if the leachate collection system did not exist.

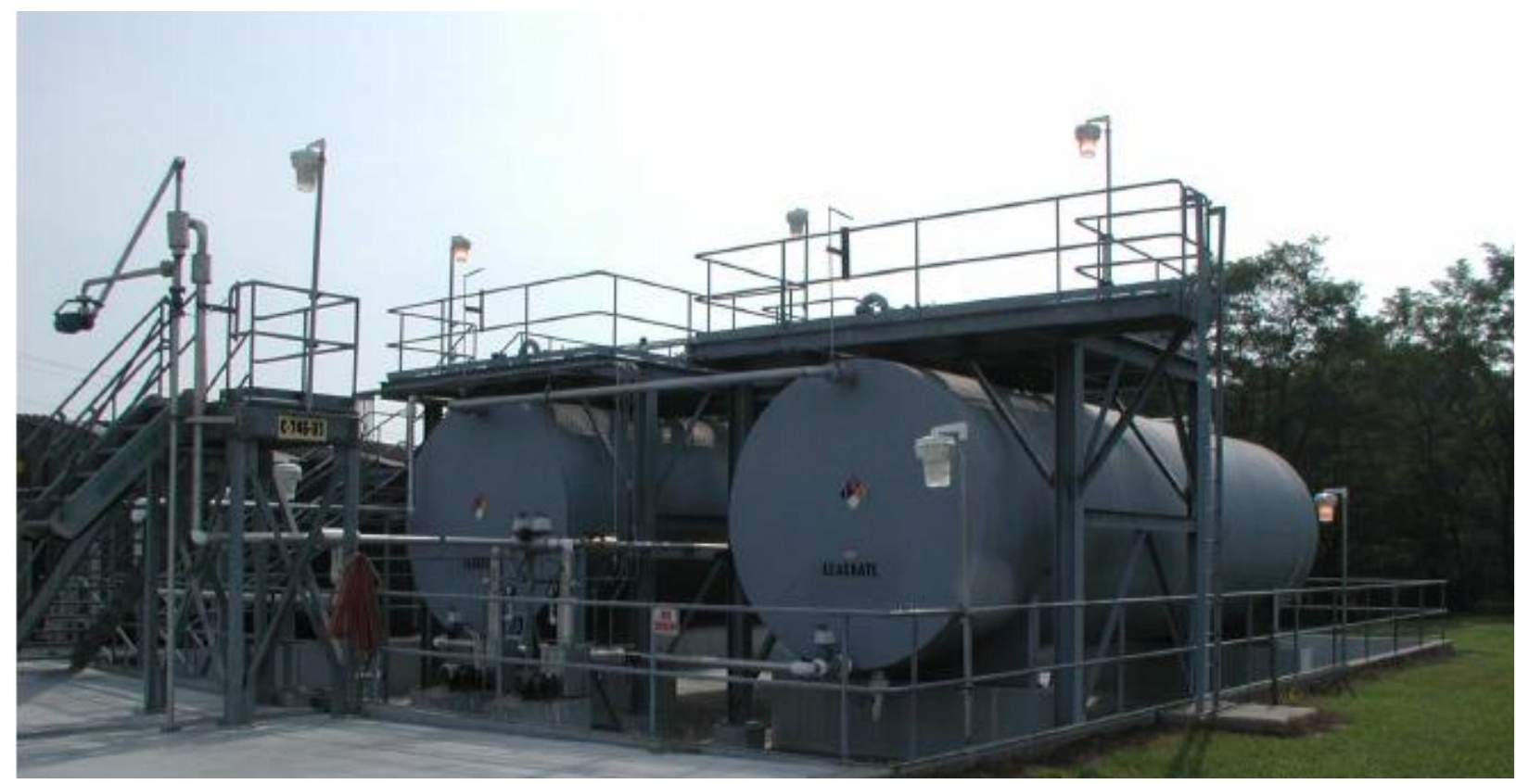

Figure 4-8. C-746-U3 Landfill Leachate Tanks

The sedimentation ponds described earlier are also involved in leachate collection. C-746-U Landfill personnel closely monitor the water quality of the sedimentation pond and initiate treatment activities if pond parameters exceed established discharge limits.

\subsubsection{DISPOSAL ACCEPTANCEAND QUANTITIES}

Only nonhazardous solid waste generated at the PGDP can be accepted for disposal at the C-746-U Landfill. Acceptable solid waste forms include construction and demolition wastes, commercial wastes, and industrial wastes. Of these, the majority have come from maintenance activities, with concrete and general construction debris (timbers and roofing material) forming the greatest portion of the waste.

\subsubsection{C-746-ULANDFILL CAPACITY AND CURRENT STATUS}

When filled, the C-746-U Landfill will encompass 22.1 acres; however, the total permitted Landfill site, including perimeter roads and support facilities, will encompass 59.7 acres. To date, five Landfill cells have been constructed covering approximately 5 of the 22.1 acres permitted for waste disposal. (Figure 4-9). These cells have a composite liner (consisting of a low-permeability, flexible membrane liner and a layer of compacted clay) and leachate management system designed to prevent and control the migration of contaminants from the unit. No Landfill cells have been closed to date. 
DOSE MODELING EVALUATIONS AND TECHNICAL SUPPORT DOCUMENT FOR THE AUTHORIZED LIMITS REQUEST FOR THE C-746-U LANDFILL AT THE PADUCAH GASEOUS DIFFUSION PLANT

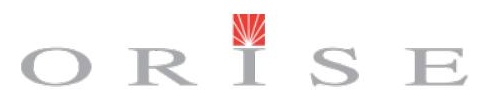

OAK RIDGE INSTITUTE FOR SCIENCE AND EDUCATION

\section{0: C-746-U Landfill Description and Design Features}

However, the planned closure cap will consist of a gas vent system and a multilayer cap composed of soil, clay, geomembrane, filter fabric, and re-vegetative soil.

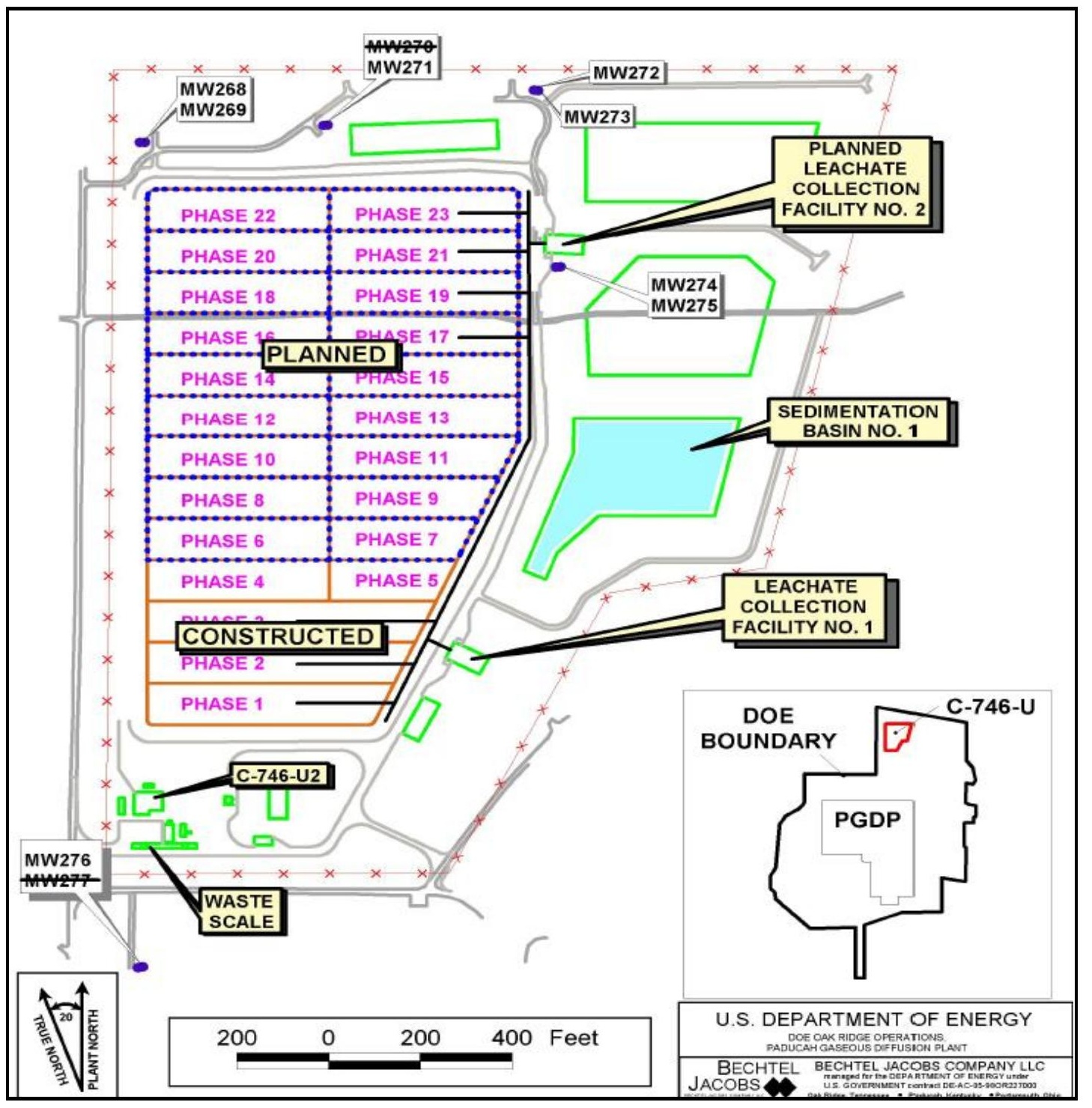

Figure 4-9. C-746-U Construction, Design, and Planned Use Features 
DOSE MODELING EVALUATIONS AND TECHNICAL

SUPPORT DOCUMENT FOR THE AUTHORIZED

LIMITS REQUEST FOR THE C-746-U LANDFILL AT THE PADUCAH GASEOUS DIFFUSION PLANT

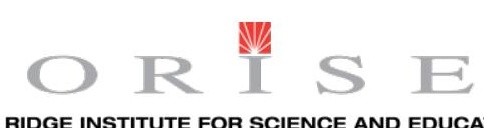

OAK RIDGE INSTITUTE FOR SCIENCE AND EDUCATION

5.0: Basis for the Derivation of Soil Guidelines

\section{O: BASIS FOR THEDERIVATION OF SOIL GUIDELINES}

\section{$5.1 \quad$ TARGET DOSE CONSTRAINTS}

The DOE's primary public dose limit is $100 \mathrm{mrem} / \mathrm{yr}$ above background; however, for plausible, nonoccupationally exposed receptors, the DOE-PPPO is adopting a $1 \mathrm{mrem} / \mathrm{yr}$ dose constraint (above background) in developing ALs for any wastes to be disposed at the C-746-U Landfill. The $1 \mathrm{mrem} / \mathrm{yr}$ dose constraint is referred to as a "walk-away" dose.

Derivation of the soil guidelines for the Landfill required a detailed pathway analysis to demonstrate that the dose constraints and limit introduced in Section 1.4, "Introduction to the Approach," were satisfied.

In addition to the $1 \mathrm{mrem} / \mathrm{yr}$ target dose constraint and the $100 \mathrm{mrem} / \mathrm{yr}$ dose limit, two additional dose constraints - 15 and $25 \mathrm{mrem} / \mathrm{yr}$ - were considered in the derivation of soil guidelines. As described in Section 1.0, "Introduction," these target dose constraints originated from two primary sources, respectively:

\section{EPA OSWER No. 9200.4-18 (EPA 1997)}

\section{DOE Order 458.1 (DOE 2011)}

\subsection{DOSE MODELING ASSESSMENT—GENERAL BASIS}

The following general assumptions formed the basis for the dose modeling assessments:

Only deterministic evaluations were performed to determine soil guidelines. The most recent versions of RESRAD and RESRAD-OFFSITE available at the time of soil guideline development were used for this assessment.

The single radionuclide soil guidelines generated by the RESRAD codes are nuclide-specific concentrations in $\mathrm{pCi} / \mathrm{g}$ that will comply with a user-selected radiation dose limit. In this report, the term "single radionuclide soil guidelines" is used to reflect the output of the RESRAD codes.

In this report, the word "onsite," relative to receptor selection, refers to receptors that would be physically located directly above, and potentially exposed to, the entire approximate 22.1 acre waste disposal area of the C-746-U Landfill. The word "offsite" refers to receptors that would be potentially exposed outside the waste disposal area of the Landfill.

Current and future use of the C-746-U Landfill was considered and seven different receptors were selected for dose modeling. Four of these receptors were determined to be plausible. The 
DOSE MODELING EVALUATIONS AND TECHNICAL

SUPPORT DOCUMENT FOR THE AUTHORIZED

LIMITS REQUEST FOR THE C-746-U LANDFILL AT THE PADUCAH GASEOUS DIFFUSION PLANT

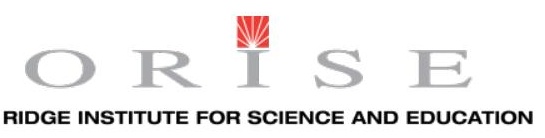

5.0: Basis for the Derivation of Soil Guidelines

remaining receptors are unlikely, because current DOE controls limit exposure or future Subtitle D Landfill requirements limit future use of the site of the Landfill.

The CSM is a fundamental and critical component of any dose modeling project. It addresses exposure pathways, receptor selection, and influences subsequent inputs to the selected dose modeling codes. For this project, available site information was evaluated and a model developed based on exposure routes to receptors identified for and appropriate to this task. The CSM provided in DOE 2003b was examined and modified for applicability to this project. A model was developed based on the presence of six onsite receptors and one offsite receptor. Adults were modeled for all scenarios with the exception of the Recreational User, which was modeled as a teen. These scenarios are discussed later in further detail. DOE-PPPO concurrence of the ORISE CSM was provided.

The CSM was developed using available environmental and waste inventory descriptions and C-746-U Landfill design information; knowledge of the projected waste inventory for the Landfill over the next $10 \mathrm{yr}$; evaluation of plausible receptors and exposure pathways used in the DOE 2003b; and consideration of target dose constraints, the public dose limit, and site radionuclides.

The ORISE project-specific CSM is provided in Figure 5-1. Essential components included the originating and secondary sources of the contamination, primary and secondary release mechanisms, transport media, receptors, and exposure routes. The latter included multiple exposure routes considered by the codes: incidental soil ingestion; ingestion of produce, meat, dairy products, and drinking water; dust inhalation; and external exposure. 
DOSE MODELING EVALUATIONS AND

TECHNICAL SUPPORT DOCUMENT FOR THE

AUTHORIZED LIMITS REQUEST FOR THE

C-746-U LANDFILL AT THE PADUCAH

GASEOUS DIFFUSION PLANT

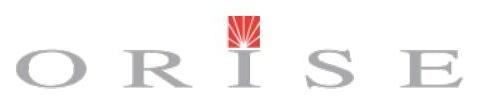

OAK RIDGE INSTITUTE FOR SCIENCE AND EDUCATION

5.0: Basis for the Derivation of Soil Guidelines

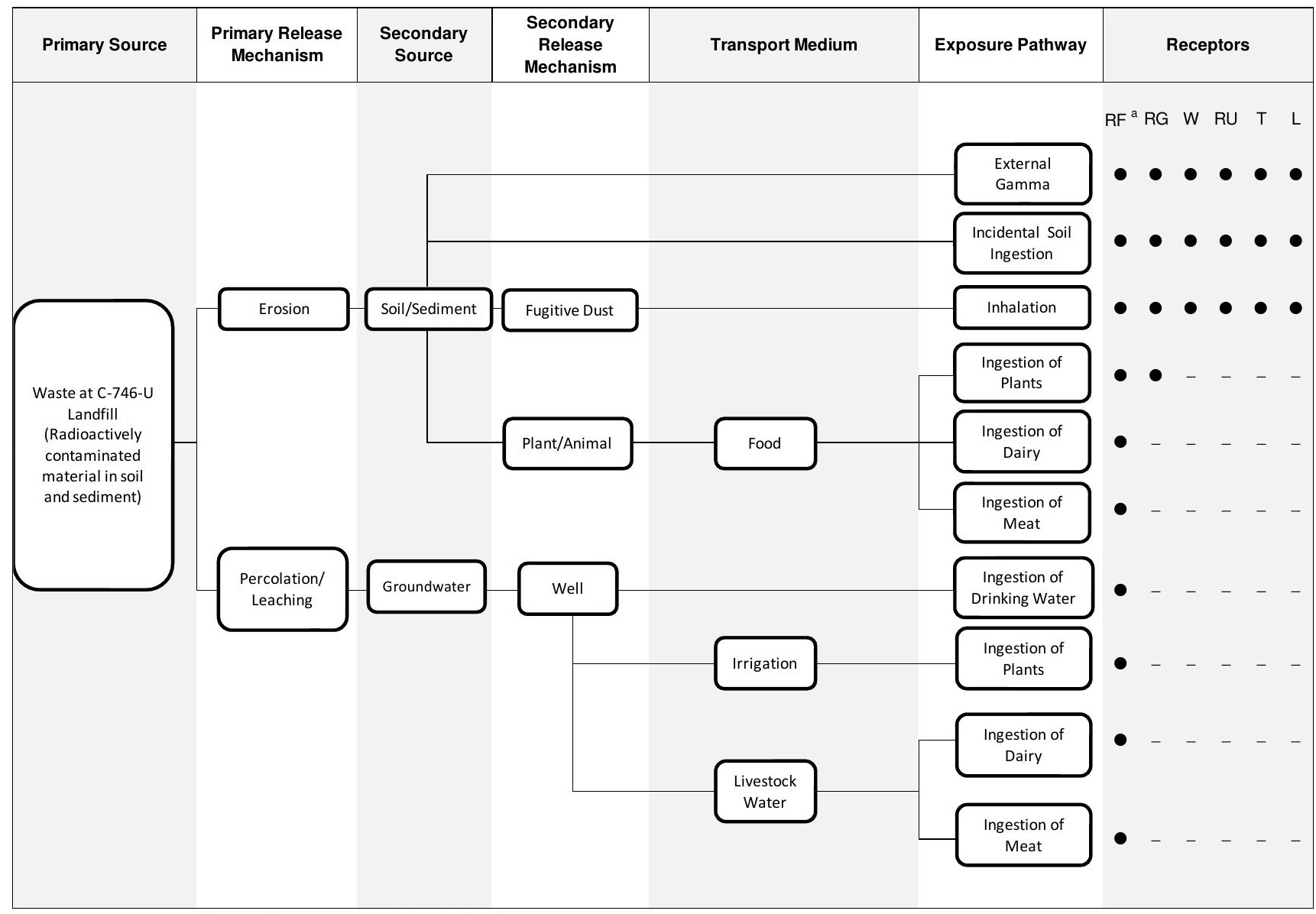

${ }^{\mathrm{a}}$ For the offsite scenario, only the Resident Farmer is considered.

$\mathrm{RF}=$ Resident Farmer

$\mathrm{L}=$ Landfill Worker

$\mathrm{T}=$ Trespasser

W= Outdoor Worker

$\mathrm{RU}=$ Teen Recreational User

- Complete Exposure Pathway

- Incomplete Pathway

Figure 5-1. Onsite and Offsite ${ }^{a}$ Conceptual Site Model for the PGDP C-746-U Landfill 
DOSE MODELING EVALUATIONS AND TECHNICAL

SUPPORT DOCUMENT FOR THE AUTHORIZED

LIMITS REQUEST FOR THE C-746-U LANDFILL AT THE PADUCAH GASEOUS DIFFUSION PLANT

\section{O R $\mathrm{N}$ E}

OAK RIDGE INSTITUTE FOR SCIENCE AND EDUCATION

\section{0: Basis for the Derivation of Soil Guidelines}

\section{4}

RECEPTOR SELECTION, SCENARIOS, AND PATHWAYS

Receptor-specific scenarios and exposure pathways were developed based on the model described in the project Analytical Plan. First, the site conditions were considered in terms of periods of C-746-U Landfill performance that were most appropriate for each receptor. Next, the likelihood of each scenario was considered in order to verify that the correct target dose constraint or limit was used in the derivation of soil guidelines.

\subsubsection{OPERATIONAL PERIOD}

The Operational Period occurs during the first $20 \mathrm{yr}$ of C-746-U Landfill operation. During this period, waste is placed in the Landfill until it reaches its authorized disposal capacity, and 6 in of uncompacted soil is assumed to be used as interim daily cover for disposed waste. The maximum amount of time the material can remain uncovered is $2 \mathrm{hr}$. (See Section 4.3.1, "Periods of C-746-U Landfill Performance," for a clarification from ORISE regarding the length of time waste may remain exposed.)

\subsubsection{Landfill Worker (Adult)_Plausible}

A prior DOE dose modeling and AL evaluation (DOE 2003a) subdivided Landfill Workers into "onsite landfill" (waste disposal) workers, "leachate collection" workers, and "waste receiving and sampling" workers, respectively. These receptors are important because the C-746-U Landfill is currently operating, thereby providing a source of exposure to these workers. Of the three worker categories, waste disposal workers received the highest dose per the DOE evaluation. Under 10 CFR 835, all Landfill Workers are Radiation Worker II qualified and therefore legally authorized to receive an annual dose of up to 5,000 mrem. According to DOE-PPPO staff, during the $7 \mathrm{yr}$ of operation under the current ALs, no Landfill Worker has had any detectable internal uptake of radioactive materials, nor has there been any detectable radiation exposure above background levels.

Based on the nature of the work and the projected onsite occupancy required to perform these work activities, ORISE concluded a Landfill Worker exposed to uncovered waste represented the worker receiving the highest dose. The individual spends $8 \mathrm{hr} /$ day outside, $185 \mathrm{days} / \mathrm{yr}$ for $25 \mathrm{yr}$ on the contaminated site (DOE 2009b). This individual performs moderate physical activities and is expected to disturb the soil; the soil ingestion rate for workers is higher than the other receptors evaluated (DOE 2009b). Exposure pathways included incidental soil ingestion, dust inhalation, and external gamma.

\subsubsection{Trespasser (Adult)—Implausible}

A transient individual accessing the C-746-U Landfill without authorization was modeled as a Trespasser. This individual is assumed to be an adult who trespasses $5 \mathrm{hr} / \mathrm{day}, 104$ days/yr for $12 \mathrm{yr}$ (DOE 2009b). Since this receptor trespasses during the Operational Period, there is only an interim 
DOSE MODELING EVALUATIONS AND TECHNICAL

SUPPORT DOCUMENT FOR THE AUTHORIZED

LIMITS REQUEST FOR THE C-746-U LANDFILL AT THE PADUCAH GASEOUS DIFFUSION PLANT

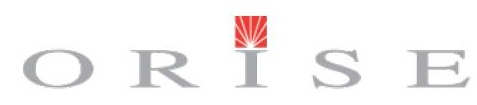

OAK RIDGE INSTITUTE FOR SCIENCE AND EDUCATION

\section{0: Basis for the Derivation of Soil Guidelines}

daily cover of 6 in placed over disposed waste. This individual is not anticipated to be ingesting plants, meat, aquatic food, milk, or water from the contaminated site. This receptor is expected to be performing moderate physical activities that will not include disturbing the soil. Exposure pathways evaluated were external gamma, dust inhalation, and incidental soil ingestion.

5.4 .2

POST-INSTITUTIONAL CONTROL PERIOD

The Post-Institutional Control Period occurs following an Institutional Control Period of $30 \mathrm{yr}$, between the years 50 and 10,000. During this period, it is assumed that infiltration of water through the cap and liner system increases due to degradation of some layers. However, it is also assumed the DOE, as the Landfill owner and operator under Subtitle D landfill requirements, continues to maintain the C-746-U Landfill as an industrial site, which includes preventing cap erosion and addressing gradual changes that may occur in the Landfill. Therefore, access by the public will continue to be limited, and access for industrial purposes will be controlled with workers being protected (DOE 2003b).

\subsubsection{Outdoor Worker (Adult)—Plausible}

Under this scenario, an adult Outdoor Worker builds or operates an industrial-use facility or could construct residential dwellings. The individual spends $8 \mathrm{hr} /$ day outside, 185 days/yr for $25 \mathrm{yr}$ on the contaminated site (DOE 2009b). This individual performs moderate physical activities and is expected to disturb the soil; the soil ingestion rate is higher for workers than the other receptors evaluated (DOE 2009b). Exposure pathways included external gamma, dust inhalation, and incidental soil ingestion.

\subsubsection{Recreational User (Teen)-Plausible}

Under this scenario, a teen Recreational User participates in several recreational activities such as jogging, hiking, cycling, etc. This teen spends $5 \mathrm{hr} /$ day, 140 days/yr for $12 \mathrm{yr}$ on the contaminated site (DOE 2009b). Exposure pathways included incidental soil ingestion, dust inhalation, and external gamma.

\subsubsection{Resident Farmer (Adult)—Implausible}

The Resident Farmer is assumed to be an adult who spends 350 days/yr for $24 \mathrm{yr}$ on the contaminated site (DOE 2009b). The individual spends $8 \mathrm{hr} /$ day outside and $16 \mathrm{hr} /$ day inside, which results in outdoor and indoor fractions of 0.32 and 0.64 , respectively. Under this scenario, the Resident Farmer builds a house, grows crops, and raises livestock on top of the cover. All the water for drinking, household use, livestock and irrigation of agricultural areas (i.e., fruit, grain, non-leafy and leafy vegetables) and livestock feed areas (i.e., fodder) is obtained from an onsite well located at the downgradient edge of the contaminated zone. Even though irrigation of fodder was not requested by DOE-PPPO to be included in the modeling, RESRAD (onsite) does not provide the 
DOSE MODELING EVALUATIONS AND TECHNICAL

SUPPORT DOCUMENT FOR THE AUTHORIZED

LIMITS REQUEST FOR THE C-746-U LANDFILL AT THE PADUCAH GASEOUS DIFFUSION PLANT

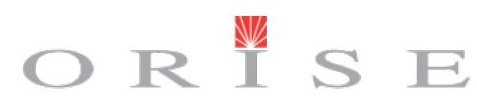

OAK RIDGE INSTITUTE FOR SCIENCE AND EDUCATION

\section{0: Basis for the Derivation of Soil Guidelines}

capability to adjust irrigation separately for different areas. In RESRAD (onsite) when the meat and milk ingestion pathways are activated and irrigation is considered, irrigation of fodder cannot be adjusted separately in contrast to RESRAD-OFFSITE. As a result, the code will consider irrigation of the agricultural areas as well as irrigation of fodder. This creates a discrepancy between the two Resident Farmers; however, it is acknowledged by DOE-PPPO and ORISE that this is a limitation of the RESRAD (onsite) code.

Ingestion of aquatic food is excluded in this scenario. Exposure pathways included incidental soil ingestion; consumption of home-grown fruits and vegetables, meat and dairy products, and drinking water; dust inhalation; and external gamma.

An important assumption for this receptor is that all activities occur on top of a cover that is designed to prevent intrusion into the waste (DOE 2003b). Other than normal erosion, the cover remains undisturbed. This approach, and the exposure pathways considered, was selected for consistency with a receptor modeled in conjunction with a previous AL request (DOE 2003a), but the consideration of this receptor disregards the statutory restrictions placed on the future use of Subtitle D landfills, which include deed restrictions (See Section 1.0, "Introduction").

\subsubsection{Resident Gardener (Adult)_Implausible}

Under this scenario, the Resident Gardener establishes a garden directly on top of the C-746-U Landfill. The Resident Gardener is similar to the Resident Farmer, except that this receptor does not raise livestock, and all water for drinking, household use, and irrigation of agricultural areas (i.e., fruit, grain, non-leafy and leafy vegetables) is obtained from an uncontaminated source such as a municipal water source. This receptor does not use or have a water well. The use of an alternate source of water, e.g., municipal water, in this future scenario is in accord with a description provided in ATSDR 2002 (as discussed in ATSDR 2002, "According to a June 1997 communication with the West McCracken County Water District, new homes being built in the area are served by municipal water through their local water districts, which receive water from the Ohio River.').

Irrigation from an uncontaminated water source is included for the agricultural areas (i.e., fruit, grain, non-leafy and leafy vegetables) only. Even though this receptor is modeled with RESRAD (onsite), irrigation of fodder will not be included for this receptor because the meat and milk ingestion pathways are excluded in this receptor scenario.

In addition, ingestion of aquatic food is excluded in this scenario. Exposure pathways included incidental soil ingestion, consumption of home-grown fruits and vegetables, dust inhalation, and external gamma. This scenario also disregards the statutory restrictions placed on the future use of Subtitle D landfills, which include deed restrictions (See Section 1.0, "Introduction"). 
DOSE MODELING EVALUATIONS AND TECHNICAL SUPPORT DOCUMENT FOR THE AUTHORIZED LIMITS REQUEST FOR THE C-746-U LANDFILL AT THE PADUCAH GASEOUS DIFFUSION PLANT

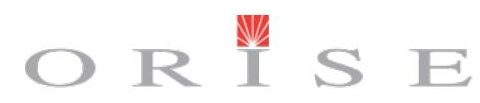

OAK RIDGE INSTITUTE FOR SCIENCE AND EDUCATION

\section{0: Basis for the Derivation of Soil Guidelines}

\subsubsection{Offsite Resident Farmer (Adult)_Plausible}

While all the other receptors were modeled using RESRAD, the RESRAD-OFFSITE code was used to model this receptor because RESRAD is limited to onsite receptors only.

Under this scenario, an Offsite Resident Farmer places a well 407 m north from the downgradient edge of the contaminated zone and builds a house, grows crops, and raises livestock near the DOE property boundary. This particular location was selected for consistency with a previously modeled offsite well (DOE 2003b). Figure 5-2 from DOE 2003b is included to show the location of the well. This individual is assumed to be an adult who spends 350 days/yr for $24 \mathrm{yr}$ adjacent to contaminated site (DOE 2009b). The individual spends $8 \mathrm{hr} /$ day outside and $16 \mathrm{hr} /$ day inside, which results in outdoor and indoor fractions of 0.32 and 0.64 , respectively. All the water for drinking, household use, livestock and irrigation of agricultural areas (i.e., fruit, grain, non-leafy and leafy vegetables) is obtained from a well downgradient of the contaminated zone. However, no irrigation is applied to the primary contaminated zone, livestock feed growing areas, and the offsite dwelling site. Ingestion of aquatic food is excluded in this scenario. Exposure pathways included incidental soil ingestion; consumption of home-grown fruits and vegetables, meat and dairy products, and drinking water; dust inhalation; and external gamma. 
DOSE MODELING EVALUATIONS AND TECHNICAL SUPPORT DOCUMENT FOR THE AUTHORIZED LIMITS REQUEST FOR THE C-746-U LANDFILL AT THE PADUCAH GASEOUS DIFFUSION PLANT

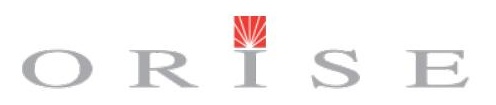

OAK RIDGE INSTITUTE FOR SCIENCE AND EDUCATION

\section{0: Basis for the Derivation of Soil Guidelines}

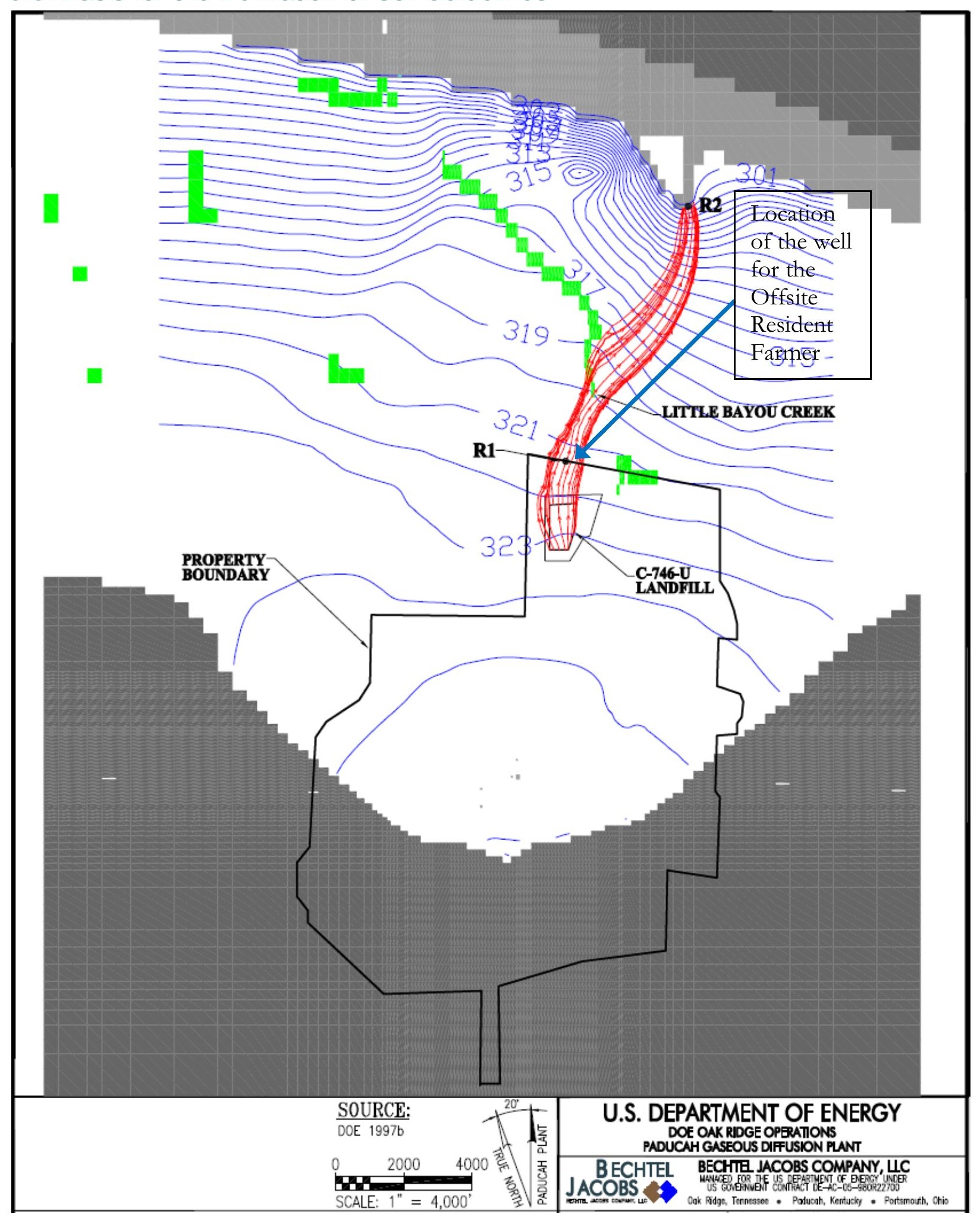

Figure 5-2. Location of the well for the Offsite Resident Farmer 
DOSE MODELING EVALUATIONS AND TECHNICAL

SUPPORT DOCUMENT FOR THE AUTHORIZED

LIMITS REQUEST FOR THE C-746-U LANDFILL AT THE PADUCAH GASEOUS DIFFUSION PLANT

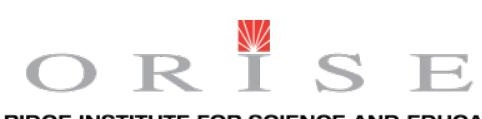

OAK RIDGE INSTITUTE FOR SCIENCE AND EDUCATION

\section{0: Basis for the Derivation of Soil Guidelines}

\subsubsection{EXCLUSION OF THERADONPATHWAY}

Dose limits for members of the public are presented in DOE Order 458.1. Specifically, the public dose limits are described in Paragraph 4.b., and apply to doses from exposures to radiation sources from radiological activities, including remedial actions and activities using Technologically Enhanced Naturally Occurring Radioactive Material (TENORM), released by DOE processes and operations. The dose limits also apply to the doses to individuals who are exposed to radiation or contamination by radionuclides at properties subsequent to remedial action and clearance of the property.

DOE Order 458.1 in Paragraph 4.b.(1)(a)1, excludes the dose from radon and its decay products in air [Radon is regulated separately e.g., under Paragraphs 4.f. and 4.h.(1)(d) in this Order and under Title 40 CFR Part 61, Subparts Q and T] from the primary dose limit. Radon and its decay products are addressed independently from the primary dose limit in Paragraph 4.f., as follows:

"Airborne Radioactive Effluents. Radiological activities must be conducted in a manner such that the release of radioactive material to the atmosphere will:

(1) Be evaluated using the ALARA process established in paragraph 4.d. of this Order;

(2) Not cause radon-222 flux rates to exceed $20 \mathrm{pCi}\left(0.7\right.$ [becquerel] Bq $\mathrm{m}^{-2} \sec ^{-1}$ averaged over the surface area overlaying waste, including the covering or other confinement structures, wherever radium-226 wastes are accepted for storage or disposal (See 40 CFR Part 61, Subparts Q and T);

(3) Meet compliance agreements under 40 CFR Part 61, Subparts H, Q, and T;

(4) Not cause the radon-220 and radon-222 decay product concentration, including background, to exceed 0.03 [Working Levels] WL in buildings that are being released from DOE control. Further, a reasonable effort must be made to meet a $0.02 \mathrm{WL}$ generic guideline for annual average radon-220 and radon-222 decay product concentration, including background, in such buildings; and

(5) Not exceed $3 \mathrm{pCi} / \mathrm{L}$ annual average radon-220 and radon-222 concentration, not including background, at the site boundary if DOE activities release radon-220 and radon-222 or their decay products."

Radon modeling is highly uncertain due to the localized environmental variability and problems with predicting future construction design. Modeling uncertainties are, therefore, considered too great to accurately predict results distinguishable from natural background in future hypothetical scenarios, and remediation to radium standards is assumed sufficient to address radon standards and 
DOSE MODELING EVALUATIONS AND TECHNICAL SUPPORT DOCUMENT FOR THE AUTHORIZED LIMITS REQUEST FOR THE C-746-U LANDFILL AT THE PADUCAH GASEOUS DIFFUSION PLANT

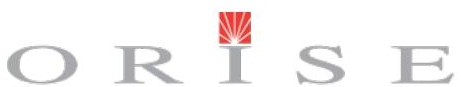

OAK RIDGE INSTITUTE FOR SCIENCE AND EDUCATION

\section{0: Basis for the Derivation of Soil Guidelines}

guidelines. Consequently, remediation to dose-based radium limits is assumed sufficient to satisfy the previously described generic guidelines for airborne radon decay products and the radon pathway is not considered in the derivation of single radionuclide soil guidelines. Although ORISE is not proposing radium clean up criteria, the single radionuclide soil guidelines for uranium and thorium consider ingrowth of radium and its progeny.

\subsubsection{RECEPTOR SUMMARY}

The following table summarizes the receptors and respective exposure pathways that were evaluated in conjunction with the modeling effort described in this section. Active pathways are indicated with a "check" in the column for the receptor; inactive pathways are marked with a "dash" and suppressed for the analyses.

Table 5-1. Summary of Receptors and Active Pathways

\begin{tabular}{|c|c|c|c|c|c|c|c|}
\hline \multirow[b]{2}{*}{$\begin{array}{l}\text { Attributes/ } \\
\text { Pathways }\end{array}$} & \multicolumn{7}{|c|}{ Receptors } \\
\hline & Trespasser & $\begin{array}{l}\text { Resident } \\
\text { Farmer }\end{array}$ & $\begin{array}{l}\text { Resident } \\
\text { Gardener }\end{array}$ & $\begin{array}{c}\text { Recreational } \\
\text { User }\end{array}$ & $\begin{array}{l}\text { Landffll } \\
\text { Worker }\end{array}$ & $\begin{array}{l}\text { Outdoor } \\
\text { Worker }\end{array}$ & $\begin{array}{c}\text { Offsite } \\
\text { Resident } \\
\text { Farmer }\end{array}$ \\
\hline Onsite or Offsite & Onsite & Onsite & Onsite & Onsite & Onsite & Onsite & Offsite \\
\hline $\begin{array}{l}\text { Plausible (P) or } \\
\text { Implausible (I) }\end{array}$ & I & I & I & $\mathrm{P}$ & $P$ & $P$ & $P$ \\
\hline $\begin{array}{l}\text { Target Dose } \\
\text { (mrem/yr) }\end{array}$ & 100 & 100 & 100 & 1 & 100 & 1 & 1 \\
\hline External Gamma & $\checkmark$ & $\checkmark$ & $\checkmark$ & $\checkmark$ & $\checkmark$ & $\checkmark$ & $\checkmark$ \\
\hline $\begin{array}{l}\text { Inhalation } \\
\text { (w/o Radon) }\end{array}$ & $\checkmark$ & $\checkmark$ & $\checkmark$ & $\checkmark$ & $\checkmark$ & $\checkmark$ & $\checkmark$ \\
\hline Plant Ingestion & - & $\checkmark$ & $\checkmark$ & - & - & - & $\checkmark$ \\
\hline Meat Ingestion & - & $\checkmark$ & - & - & - & - & $\checkmark$ \\
\hline Milk Ingestion & - & $\checkmark$ & - & - & - & - & $\checkmark$ \\
\hline $\begin{array}{l}\text { Aquatic Foods } \\
\text { Ingestion }\end{array}$ & - & - & - & - & - & - & - \\
\hline Drinking Water & - & $\checkmark$ & - & - & - & - & $\checkmark$ \\
\hline Soil Ingestion & $\checkmark$ & $\checkmark$ & $\checkmark$ & $\checkmark$ & $\checkmark$ & $\checkmark$ & $\checkmark$ \\
\hline Radon Inhalation & - & - & - & - & - & - & - \\
\hline
\end{tabular}

5.5

\section{COMPUTATIONAL MODELING (PROJECT DOSE MODELING SOFTWARE)}

The conceptual site model described previously was developed in support of the performance of dose assessments using available (and validated and verified) computer codes. Two codes, developed by ANL, were used for this project. 
DOSE MODELING EVALUATIONS AND TECHNICAL SUPPORT DOCUMENT FOR THE AUTHORIZED LIMITS REQUEST FOR THE C-746-U LANDFILL AT THE PADUCAH GASEOUS DIFFUSION PLANT

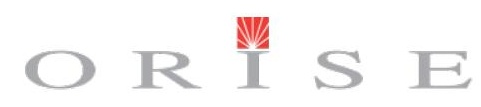

OAK RIDGE INSTITUTE FOR SCIENCE AND EDUCATION

\section{0: Basis for the Derivation of Soil Guidelines}

\subsubsection{RESRAD}

The RESRAD code was developed by ANL over $20 \mathrm{yr}$ ago and has been updated several times since its introduction. RESRAD is a computer model used to evaluate radiation doses and excess cancer risks to an individual exposed from residual radioactive materials in soil. Approximately 145 "principal" and "associated" radionuclides are included in the User's Manual for RESRAD Version 6 (Yu et al. 2001), which remains relevant to the latest user code, Version 6.5. RESRAD allows approximately 140 input parameters. The code is recognized by the DOE (e.g., in DOE Order 458.1) for use in dose modeling evaluations. The exposure pathways examined by RESRAD—taken from the RESRAD User's Manual—are illustrated in Figure 5-3.

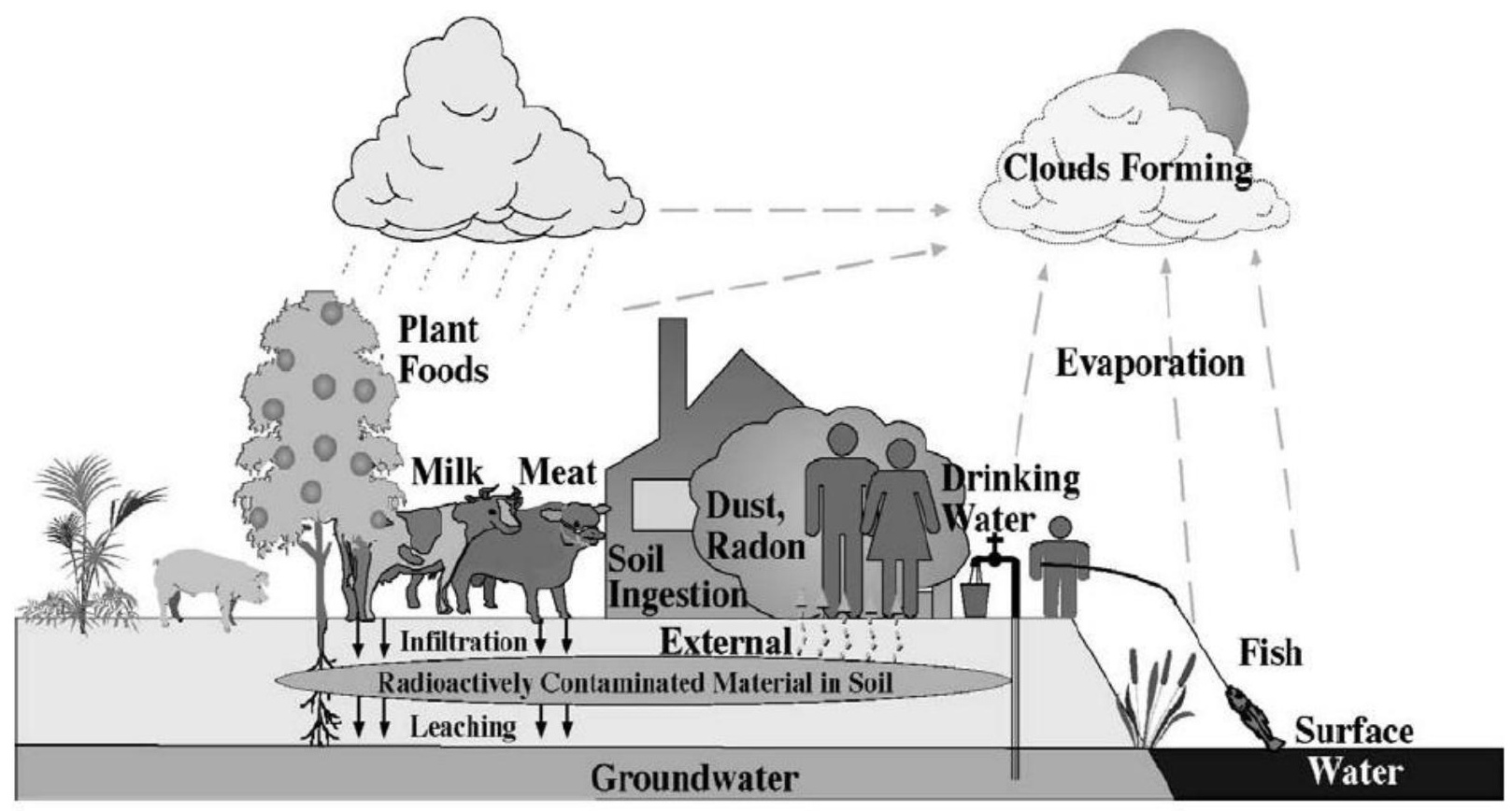

Figure 5-3. RESRAD Exposure Pathways

Note the location of the contaminated material in the figure (i.e., directly below the receptor). The position of the receptor along the horizontal plane can be altered relative to the source, but the receptor always remains within the boundary of primary contamination (i.e., above the source).

The RESRAD code was used in this project to model six onsite receptors, under both current (operational period) and future use scenarios (post-institutional control period).

\subsubsection{RESRAD-OFFSITE}

The RESRAD-OFFSITE dose modeling code was developed much more recently by ANL. RESRAD-OFFSITE is considered by ANL an evolution of RESRAD and is expected to replace RESRAD in the future. RESRAD-OFFSITE uses new models such as a three-dimensional 
DOSE MODELING EVALUATIONS AND TECHNICAL SUPPORT DOCUMENT FOR THE AUTHORIZED LIMITS REQUEST FOR THE C-746-U LANDFILL AT THE PADUCAH GASEOUS DIFFUSION PLANT

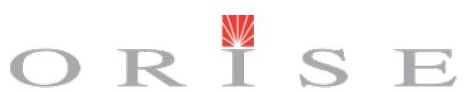

OAK RIDGE INSTITUTE FOR SCIENCE AND EDUCATION

\section{0: Basis for the Derivation of Soil Guidelines}

dispersion groundwater flow and radionuclide transport model, a Gaussian plume model for atmospheric dispersion, and a deposition model used to estimate the accumulation of radionuclides in offsite locations and in foods (Yu et al. 2007).

RESRAD-OFFSITE contains more than 400 input parameters-significantly more than RESRAD. Therefore, use of this code requires additional site-specific (or default) inputs.

The RESRAD-OFFSITE code evaluates the radiological dose and excess cancer risk to an individual who is exposed while located within or outside the area of initial (primary) contamination. The primary contamination, which is the source of all the releases modeled by the code, is assumed to be a layer of soil. The releases of contaminants from the primary contamination to the atmosphere, to surface runoff, and to groundwater are considered.

The code models the movement of the contaminants from the primary contamination to agricultural areas, pastures, a dwelling area, a well, and a surface water body. It also models the accumulation of the contaminants at those locations where appropriate. Any contribution of the contaminants from the water sources to the land-based locations is also modeled. As shown in Figure 5-4, the water sources and the land-based locations can be outside the boundary of the primary contamination. These locations are referred to as offsite locations in RESRAD-OFFSITE. Therefore, unlike RESRAD, RESRAD-OFFSITE can model both onsite and offsite receptors.

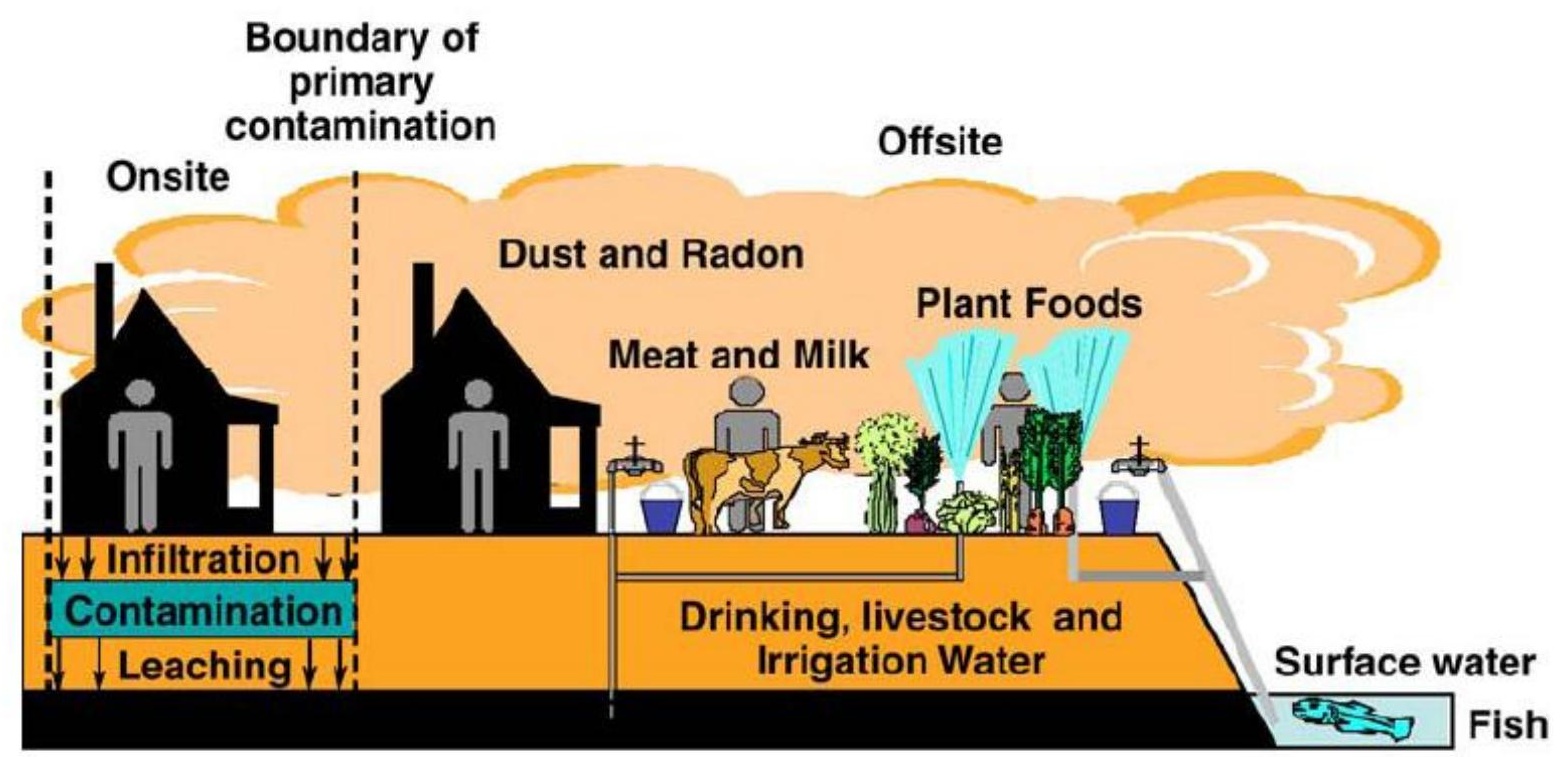

Figure 5-4. RESRAD-OFFSITE Exposure Pathways

As described within this section, the RESRAD-OFFSITE code was used to model the Resident Farmer who is located downgradient from the C-746-U Landfill and represents an offsite receptor. 
DOSE MODELING EVALUATIONS AND TECHNICAL

SUPPORT DOCUMENT FOR THE AUTHORIZED

LIMITS REQUEST FOR THE C-746-U LANDFILL AT THE PADUCAH GASEOUS DIFFUSION PLANT

\section{O R $\mathrm{N}$ E}

OAK RIDGE INSTITUTE FOR SCIENCE AND EDUCATION

\section{0: Basis for the Derivation of Soil Guidelines}

Note: This code was not available when the ALs requested in DOE 2003a were derived.

5.5.3 COMPARISON OF RESRAD AND RESRAD-OFFSITE

RESRAD-OFFSITE is a computer code that evaluates the radiological dose and excess cancer risk to an individual who is exposed while residing and/or working in or near an area where the soil is contaminated by radionuclides. It evolved from RESRAD during the BIOMOVS II model comparison, first by the addition of an offsite soil accumulation submodel (BIOMOVS II 1995) and then by the inclusion of an advective-dispersive groundwater transport submodel (BIOMOVS II 1996). The ability to accept a time series for the release from the contaminated soil was also added during this study. The advective-dispersive groundwater transport submodel was improved to better predict the transport of progeny produced in transit during participation in the multimedia model comparison study. Since then, an atmospheric transport submodel and a surface water body accumulation submodel have been added. Many of the submodels in RESRAD were modified during the addition of these submodels. The computational algorithm of the RESRAD-OFFSITE code also changed from that of RESRAD. RESRAD numerically evaluates the analytical expressions for concentration, dose, and risk at any desired time since the site survey; RESRAD-OFFSITE uses numerical methods to compute the concentration, dose, and risk progressively over time (Yu et al. 2006).

\subsubsection{Same or Similar Submodels in RESRAD and RESRAD-OFFSITE}

This subsection identifies the submodels in RESRAD-OFFSITE that are essentially the same as the corresponding ones in RESRAD. It also describes the differences in those submodels, which serve as a starting point for investigating the differences in the predictions of the two codes (Yu et al. 2006).

\subsection{Groundwater Release Submodel}

The release to groundwater is the only release that RESRAD explicitly considers. This is a first-order release model in which the flux of radionuclides released to the infiltrating water at any time is in direct proportion to the radionuclide inventory in the contaminated soil at that time. The same model was retained in RESRAD-OFFSITE, although the radionuclide inventory at any time is adjusted differently because of the modifications to the surface soil mixing submodel (Yu et al. 2007).

\subsection{Surface Soil Mixing Submodel}

The surface soil mixing submodel in RESRAD ignores the contaminants that were removed by erosion of the initially uncontaminated mixing layer. Although this model is appropriate for RESRAD because it does not address the surface soil release to offsite locations, it is not suitable for RESRAD-OFFSITE, which models the accumulation of the eroded material in a surface water body 
DOSE MODELING EVALUATIONS AND TECHNICAL

SUPPORT DOCUMENT FOR THE AUTHORIZED

LIMITS REQUEST FOR THE C-746-U LANDFILL AT THE PADUCAH GASEOUS DIFFUSION PLANT

\section{OR R I I E}

OAK RIDGE INSTITUTE FOR SCIENCE AND EDUCATION

\section{0: Basis for the Derivation of Soil Guidelines}

and offsite soils. The new model in RESRAD-OFFSITE maintains a mass balance of contaminants (Yu et al. 2007).

\subsection{Dust Release Model}

Although RESRAD does not explicitly model a release to the atmosphere, it does model the effects of a dust release (inhalation, foliar deposition) by using the concept of a mass loading factor. In RESRAD-OFFSITE, this concept has been extended to provide a release to the atmospheric transport model (Yu et al. 2007).

\subsection{Exposure Models}

All the exposure models in RESRAD_-direct external radiation; inhalation of dust and radon; and ingestion of vegetables, meat, milk, aquatic food, and soil-were retained in RESRAD-OFFSITE, with minor changes. In RESRAD-OFFSITE, these exposure models are applied at more locations and more contamination pathways - on primary contamination in agricultural and farmed areas because of contamination by irrigation and deposition of dust. The exposure models were changed to accommodate the numerical nature of the RESRAD-OFFSITE code and also to facilitate their application to the offsite locations (Yu et al. 2007).

\subsection{Advective Groundwater Transport Model}

The groundwater transport model in RESRAD considers the effects of the different transport rates of the progeny nuclides that are produced in transit. The option of using this advective transport model was retained in RESRAD-OFFSITE, in addition to the option of considering the effects of dispersive transport. Although the basic concepts are the same for both codes, each code implements them differently. The concentrations of nuclides in well and surface water at any time are expressed analytically in RESRAD, although these expressions are evaluated numerically. In RESRAD-OFFSITE, the nuclide transport is modeled zone by zone (each unsaturated zone and then the saturated zone) by numerically calculating the flux across each zone progressively over time (Yu et al. 2007).

\subsubsection{Additional Submodels in RESRAD-OFFSITE}

As mentioned previously, submodels to simulate the following were included in

RESRAD-OFFSITE: atmospheric transport, advective-dispersive groundwater transport, accumulation in offsite soil, and accumulation in a surface water body.

\subsection{Atmospheric Transport}

An area source air dispersion model was added to the RESRAD-OFFSITE computer code for the long-term analysis of downwind receptor impacts from area sources with chronic releases of radionuclides to the atmosphere. The air dispersion model is based on the standard Gaussian plume 
DOSE MODELING EVALUATIONS AND TECHNICAL

SUPPORT DOCUMENT FOR THE AUTHORIZED

LIMITS REQUEST FOR THE C-746-U LANDFILL AT THE PADUCAH GASEOUS DIFFUSION PLANT

\section{O R $\mathrm{N}$ E}

OAK RIDGE INSTITUTE FOR SCIENCE AND EDUCATION

\section{0: Basis for the Derivation of Soil Guidelines}

point source formulation and was adapted for use as an area source implementation. This submodel was benchmarked against CAP88-PC and ISCLT3 (Yu et al. 2006).

\subsection{Advective-Dispersive Groundwater Transport}

As radionuclides are transported through an aquifer or a partially saturated (or unsaturated) soil layer, some of the atoms will be transformed into their progeny continuously throughout the transport zone. Different radionuclides will travel at different speeds, depending on their interaction with the solid phase of the soil layer. In RESRAD-OFFSITE, this interaction is characterized by the distribution coefficient of the nuclide between the aqueous and solid phase of the soil. The groundwater transport algorithms in RESRAD-OFFSITE account for the effects of longitudinal and transverse dispersion when modeling the transport of atoms that enter and leave a transport zone as the same radionuclide. RESRAD-OFFSITE has algorithms that will consider either the longitudinal dispersion or the different rates of transport of the parent and progeny nuclides in order to model the transport of progeny produced in transit. Both algorithms account for transverse dispersion. If one or the other of these two processes is dominant, the choice of the algorithm is straightforward. When both processes are of comparable importance, RESRAD-OFFSITE offers the option of subdividing the transport zone into smaller subzones in order to better model the transport of the progeny produced in transit. When the transport zone is broken up into many smaller layers, the length of the region in which both processes must be modeled is reduced, and the significant transport processes will be considered over most of the transport path (Yu et al. 2006). The scheme was tested in RESRAD-OFFSITE during the multimedia model comparison study described in Gnanapragasam et al. (2000) (as cited in Yu et al. 2006).

\subsection{Accumulation in Offsite Soil}

The accumulation of contaminants in offsite surface soil due to irrigation with contaminated water and due to deposition of contaminated dust is considered. Radiological transformations, mixing of soil in the surface layer, erosion of the surface layer, and equilibrium desorption release are considered in computing the concentration in surface soil (Yu et al. 2007).

\subsection{Accumulation in a Surface Water Body}

The code considers three modes of contamination of an offsite surface water body: 1) the influx of contaminated soil removed from the primary contamination by surface erosion, 2) the contribution of contaminated groundwater entering a surface water body (lake), and 3) the deposition of dust from atmospheric transport. Radiological transformations, equilibrium adsorption/desorption between the deposited material and water, and removal of contaminants in the outflow from the lake are considered in computing the contaminant inventory in the lake (Yu et al. 2007). 
DOSE MODELING EVALUATIONS AND TECHNICAL

SUPPORT DOCUMENT FOR THE AUTHORIZED

LIMITS REQUEST FOR THE C-746-U LANDFILL AT THE PADUCAH GASEOUS DIFFUSION PLANT

\section{$O R \stackrel{\mathbb{N}}{\mathbf{l}} \mathrm{E}$}

OAK RIDGE INSTITUTE FOR SCIENCE AND EDUCATION

\section{0: Basis for the Derivation of Soil Guidelines}

5.6

ESTABLISHING PARAMETER INPUTS

Determining appropriate and reasonable input parameters for the models is an important first step in the derivation of soil guidelines. A review of site records and available references was conducted by personnel with previous dose assessment experience in order to develop a list of defensible inputs. Site-specific values, where available, were emphasized and used as input to the codes. While site-specific inputs are always preferable, it was anticipated that a number of default parameters would be necessary to run the code(s).

\subsubsection{DISCUSSION OFPARAMETERS}

The parameters utilized in the RESRAD and RESRAD-OFFSITE codes are included in respective tables of parameters as well as a justification for each input as necessary. These tables are provided in Appendices A and B. The following parameters were selected from the tables in Appendices A and $\mathrm{B}$ in order to provide further details that could not be included in the justification section of these tables.

Dose Conversion Factors - The Dose Conversion Factors (DCFs) from the ICRP 60 and 72 libraries (available in the RESRAD codes) were utilized in the dose modeling analysis in order to obtain results in TED rather than TEDE. 10 CFR 835 now incorporates ICRP 60 and 68 in support of the TED determinations, but does not incorporate ICRP 72 since this is applicable to members of the public.

The external and internal DCFs from ICRP 60 and 72 libraries, respectively, were used for the analysis. However, it is important to emphasize that ICRP 72 has age-dependent dose conversion factors and that the RESRAD codes have age-dependent libraries for ICRP 72 available for selection. The two ICRP 72 libraries used were "Adult" and "Age 15."

The Adult library was used for all the receptors with the exception of the Recreational User. The Recreational User was considered to be a teen; therefore, the Age 15 library was applicable. In order to use ICRP 60 in conjunction with the Age 15 library for the Recreational User, it was necessary to create a library in RESRAD by selecting ICRP 60 and the ICRP 72 Age 15 libraries. This had to be done since the RESRAD code automatically adds ICRP 72's Adult library when ICRP 60 is selected from the drop down menu.

The Landfill Worker is the only receptor in this analysis who receives occupational exposure; consequently, ICRP 60 and 68 methodologies are applicable. However, because an ICRP 68 library is not available in the RESRAD code, the ICRP 72 internal DCF library was used for the Landfill Worker while acknowledging this receptor is considered a radiation worker. This library was used because it is a selectable "drop-down" menu option in the RESRAD code whereas the ICRP 68 library with its corresponding set of internal DCFs is not an available option. 
DOSE MODELING EVALUATIONS AND TECHNICAL SUPPORT DOCUMENT FOR THE AUTHORIZED LIMITS REQUEST FOR THE C-746-U LANDFILL AT THE PADUCAH GASEOUS DIFFUSION PLANT

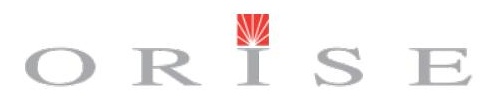

OAK RIDGE INSTITUTE FOR SCIENCE AND EDUCATION

\section{0: Basis for the Derivation of Soil Guidelines}

To understand this issue and defend the approach, ORISE compared applicable ICRP 72 internal DCF values against ICRP 68 values. Results using ICRP 72 were similar to those obtained with ICRP 68 internal DCF values. For the most part, the values in ICRP 72 for the targeted radionuclides and their progeny are slightly higher, which resulted in slightly lower DSRs. It was determined that differences in the values between ICRP 72 and 68 are negligible for the purposes of this project.

Radionuclide Concentrations - The targeted radionuclides consisted of Am-241, Np-237, Cs-137, Tc-99, Pu-238, Pu-239, Pu-240, Th-228, Th-230, Th-232, U-234, U-235, and U-238. As a result of the processes that led to the formation of the waste, it was assumed that secular equilibrium does not exist. Unit concentrations of $1 \mathrm{pCi} / \mathrm{g}$ for each radionuclide were used. The contaminated zone was treated as a uniformly contaminated area with a single radionuclide concentration at every point (Yu et al 2007). Parent radionuclides and their progeny with a half-life greater than 180 days are used by the codes in the computational analysis and are provided in Table $5-2$.

Table 5-2. Parent Radionuclides and Progeny

\begin{tabular}{|cc|}
\hline Parent Radionuclides & Progeny* \\
\hline Am-241 & Np-237, U-233, and Th-229 \\
\hline Np-237 & U-233 and Th-229 \\
\hline Cs-137 & None \\
\hline Tc-99 & None \\
\hline Pu-238 & U-234, Th-230, Ra-226, and Pb-210 \\
\hline Pu-239 & U-235, Pa-231, and Ac-227 \\
\hline Pu-240 & U-236, Th-232, Ra-228, and Th-228 \\
\hline Th-228 & None \\
Th-230 & Ra-226 and Pb-210 \\
Th-232 & Ra-228 and Th-228 \\
U-234 & Th-230, Ra-226, and Pb-210 \\
U-235 & Pa-231 and Ac-227 \\
U-238 & U-234, Th-230, Ra-226, and Pb-210 \\
\hline
\end{tabular}

*The default cutoff half life in the RESRAD code includes only the progeny with a half-life greater than 180 days. The same cutoff half life was selected for RESRAD-OFFSITE. The cutoff half-life is used to separate the "principal nuclides" from the "associated nuclides" (Yu et al. 2001).

Distribution Coefficients (Kds)-The distribution coefficient, $K d$, is the ratio of the concentration of the contaminant in the adsorbed phase in soil to the concentration of the contaminant in the aqueous phase of soil (Yu et. al 2007). Site-specific distribution coefficients were included for the parent radionuclides and their progeny. Some of the distribution coefficients were obtained from DOE 2003b and others were obtained through DOE project 
DOSE MODELING EVALUATIONS AND TECHNICAL

SUPPORT DOCUMENT FOR THE AUTHORIZED

LIMITS REQUEST FOR THE C-746-U LANDFILL AT THE PADUCAH GASEOUS DIFFUSION PLANT

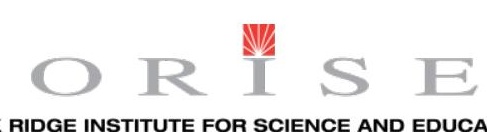

OAK RIDGE INSTITUTE FOR SCIENCE AND EDUCATION

\section{0: Basis for the Derivation of Soil Guidelines}

communications with the Waste Disposal Options Project Team from Paducah, KY. These values were included specifically for the contaminated, unsaturated, and saturated zones. The contaminated zone $K d s$ correspond to the $K d s$ of sand. The unsaturated zones $K d s$ are a combination of $K d s$ for sand and clay. Unsaturated zones (UZs) 1, 2, and 4 have $K d s$ for sand, and UZs 3 and 5 have $K d s$ for clay. The saturated zone $K d s$ correspond to the value of sand.

In addition to the contaminated zone, unsaturated zones, and saturated zone, the RESRAD-OFFSITE code allows the user to input distribution coefficients for the following parameters: Sediment in Surface Water Body; Fruit, Grain, Non-leafy Fields; Leafy Vegetable Fields; Pasture, Silage Growing Areas; Livestock Feed Grain Fields; and Dwelling Site. The RESRAD code does not contain these parameters. A brief description of these RESRAD-OFFSITE parameters is included.

- Sediment in Surface Water Body: This distribution coefficient is used to compute the concentration of the radionuclide in the surface water body.

- Fruit, Grain, Non-leafy Fields; Leafy Vegetable Fields; Pasture, Silage Growing Areas; Livestock Feed Grain Fields; and Dwelling Site: These five distribution coefficients for agricultural fields, pastures, and dwelling sites are used to account for leaching when accumulation in the fields, pastures, and dwelling sites is being computed.

The native soil distribution coefficients were used for these areas. The soil types at the Paducah site areas are predominantly silty loams that are poorly drained, acidic, and have little organic content (PRS 2008a). The site-specific distribution coefficients corresponding to this soil type are generally and conservatively similar to the defaults for a sandy soil type. Sandy soil exhibits the least retardation of downward migration (DOE 2009b).

Kd for $\boldsymbol{N p}$-237 in RESRAD - In a previous RESRAD study for the C-746-U Landfill included in DOE 2003b, the site-specific distribution coefficients for Np-237 were not used. However, in this project, the site-specific distribution coefficients for $\mathrm{Np}-237$ were input into the RESRAD code by unchecking the box for "use plant/soil ratio." This approach was verified with a RESRAD expert from ANL.

Unsaturated Zones - An unsaturated zone is defined as a horizontal uncontaminated layer located between the contaminated zone and the aquifer. There are five unsaturated zones (UZs) considered in the ORISE analysis, corresponding to the layers of the C-746-U Landfill during the Post-Institutional Period. These five zones are:

- $\boldsymbol{U Z} 1$ - Protective layer (native soil)

- UZ 2-Gravel layer (no collection) 
DOSE MODELING EVALUATIONS AND TECHNICAL

SUPPORT DOCUMENT FOR THE AUTHORIZED

LIMITS REQUEST FOR THE C-746-U LANDFILL AT THE PADUCAH GASEOUS DIFFUSION PLANT

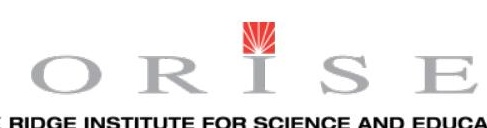

OAK RIDGE INSTITUTE FOR SCIENCE AND EDUCATION

\section{0: Basis for the Derivation of Soil Guidelines}

- UZ 3-Clay barrier

- $\boldsymbol{U Z} 4$-Alluvium soils (native/subgrade)

- UZ 5-Clay confining unit (native)

Area of Contamination Zone-The contaminated zone was assumed to be limited to the waste disposal area of the C-746-U Landfill. This area is described as 89,436 $\mathrm{m}^{2}$ (22.1 acres) within the permitted area of the Landfill. The area of the contaminated zone is a user input in RESRAD, but not in RESRAD-OFFSITE. The area of the contaminated zone is calculated by RESRAD-OFFSITE from the " $x$ " and " $y$ " dimensions of the primary contaminated area.

Thickness of Contaminated Zone-The contaminated zone is composed of four general disposal waste forms. These waste forms are identified as soil-like material, concrete, metal, and lumber/debris (DOE 2003b). The thickness of the contaminated zone used by ORISE is the sum of the thicknesses for all the waste forms which is $44 \mathrm{ft}(13.4 \mathrm{~m})$.

Cover Depth-The cover depth corresponds to the total thickness of the C-746-U Landfill cap. Different thicknesses were used for the operational period and post-institutional control period. During the operational period, the Landfill cover has a layer of vegetative soil and its depth is expected to be $0.5 \mathrm{ft}(0.152 \mathrm{~m})$. This layer is assumed to be used as interim daily cover for disposed waste (DOE 2003b). During the post-institutional control, the Landfill cover will have six layers with a total depth of $5 \mathrm{ft}(1.52 \mathrm{~m})$. This depth was used by ORISE in the modeling analysis. These layers constitute the final cover planned for the Landfill (DOE 2003b). For the Landfill Worker, it was assumed that no cover exists.

Density of Cover Material - The densities of both C-746-U Landfill covers corresponding to the operational and the post-institutional periods are 1.5 grams per cubic centimeters $\left(\mathrm{g} / \mathrm{cm}^{3}\right)$.

Density of Contaminated Zone-The density of the contaminated zone is the weighted average density calculated from using the densities of the waste forms and the total volume capacity in each waste layer. The weighted average density for the contaminated zone is $1.89 \mathrm{~g} / \mathrm{cm}^{3}$. This value was used in the ORISE analysis.

Irrigation Rate - Irrigation in the Paducah, Kentucky area is considered to be unlikely. In the event irrigation is necessary, the water will primarily come from surface water and not from groundwater (well). Information from the USGS shows that surface water is the main source of water used in Kentucky for irrigation (Kenny et al. 2009). The Paducah area (i.e., where PGDP is located) receives about an average of 49 inches (1.24 $\mathrm{m}$ ) of precipitation per year (PRS 2008a). According to ATSDR 2002, the farms in McCracken County, KY (i.e., where Paducah is located) rely on rainfall to water their crops. For conservatism in the modeling, and as 
DOSE MODELING EVALUATIONS AND TECHNICAL

SUPPORT DOCUMENT FOR THE AUTHORIZED

LIMITS REQUEST FOR THE C-746-U LANDFILL AT THE PADUCAH GASEOUS DIFFUSION PLANT

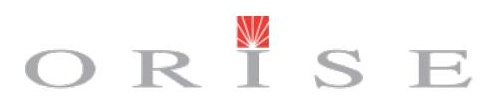

OAK RIDGE INSTITUTE FOR SCIENCE AND EDUCATION

\section{0: Basis for the Derivation of Soil Guidelines}

recommended by DOE-PPPO, it was assumed that both of the Resident Farmers use contaminated well water for irrigation of agricultural areas (i.e., fruit, grain, non-leafy and leafy vegetables). However, due to limitations in the RESRAD (onsite) code, the Resident Farmer (onsite) scenario includes irrigation of fodder besides the agricultural areas as explained previously. Alternatively, the Resident Gardener uses water for irrigation of plants (i.e., fruit, grain, non-leafy and leafy vegetables) from an uncontaminated source (e.g., municipal water source). An irrigation rate of $0.1 \mathrm{~m} / \mathrm{yr}$ is used for the Resident Farmer (onsite), the Resident Gardener and the Offsite Resident Farmer.

An irrigation rate of $0 \mathrm{~m} / \mathrm{yr}$ or no irrigation is assumed for the Landfill Worker, Trespasser, Recreational User, and Outdoor Worker.

Hydraulic Conductivity (Unsaturated Zone 5)_Difficulties were encountered with the RESRAD-OFFSITE code when using a site-specific hydraulic conductivity less than the code's calculated infiltration rate. According to DOE 2003b, Unsaturated Zone 5 has a hydraulic conductivity of $0.12 \mathrm{~m} / \mathrm{yr}$; however, the code displayed a message indicating that the calculated infiltration rate was $0.139 \mathrm{~m} / \mathrm{yr}$ - higher than the hydraulic conductivity_resulting in the code's inability to run. According to a RESRAD-OFFSITE expert from ANL, if water were to infiltrate at the calculated infiltration rate of $0.139 \mathrm{~m} / \mathrm{yr}$, it would have to accumulate on top of the Unsaturated Zone 5 with a hydraulic conductivity of $0.12 \mathrm{~m} / \mathrm{yr}$. Therefore, Unsaturated Zone 5 and all or part of Unsaturated Zone 4 will have to become saturated. This violates the conceptual model in both RESRAD and RESRAD-OFFSITE. The infiltration rate calculated by the code has to be less than the saturated hydraulic conductivity of the unsaturated layers.

In order to enable the RESRAD-OFFSITE code to run, the hydraulic conductivity of Unsaturated Zone 5 (which corresponds to the clay barrier) had to be adjusted. This is a parameter that makes most sense to change, among the other parameters that could have been adjusted (i.e., the evapotranspiration coefficient) run off coefficient and precipitation rate. The hydraulic conductivity was adjusted from $0.12 \mathrm{~m} / \mathrm{yr}$ to $0.14 \mathrm{~m} / \mathrm{yr}$ - the minimum required to execute the code.

Although, no difficulties were encountered in RESRAD (onsite) when using a hydraulic conductivity of $0.12 \mathrm{~m} / \mathrm{yr}$ for Unsaturated Zone 5 , this hydraulic conductivity was adjusted as well. The hydraulic conductivity for Unsaturated Zone 5 was adjusted to $0.24 \mathrm{~m} / \mathrm{yr}$ for the onsite receptors who irrigate (i.e., Resident Farmer and Resident Gardener) to ensure that the calculated infiltration rate of $0.238 \mathrm{~m} / \mathrm{yr}$ is less than the saturated hydraulic conductivity of the unsaturated layers. Other receptors in RESRAD (onsite) are not impacted by the hydraulic conductivity, since the food and drinking water pathways are not included. 
DOSE MODELING EVALUATIONS AND TECHNICAL

SUPPORT DOCUMENT FOR THE AUTHORIZED

LIMITS REQUEST FOR THE C-746-U LANDFILL AT THE PADUCAH GASEOUS DIFFUSION PLANT

\section{0: Basis for the Derivation of Soil Guidelines}

\subsubsection{PARAMETER SELECTIONHIERARCHY}

Parameters input to the dose modeling codes required a selection hierarchy. For this project, the following general selection order was utilized:

\subsubsection{Site-Specific Parameters}

Site-specific parameters are preferred over default values when the goal is to calculate reasonable exposures. The parameters were considered to be site-specific if they reflected attributes unique to the C-746-U Landfill, were obtained or derived from the references below, or were provided by the DOE. In some instances, site-specific values were converted (via calculation) into units appropriate for the dose modeling codes.

The references used to obtain site-specific parameters included:

DOE 2003b. Risk and Performance Evaluation of the C-746-U Landfill at the Paducah Gaseous Diffusion Plant, Paducah, Kentucky, DOE/OR/07-2041\&D2R1, U.S. Department of Energy, Paducah, KY.

DOE 2009b. Methods for Conducting Risk. Assessments and Risk Evaluations at the Paducah Gaseous Diffusion Plant, Paducah, Kentucky, Volume 1. Human Health, DOE/LX/07-0107\&D1/V1, U.S. Department of Energy, Paducah, KY.

DOE project communication with DOE-PPPO and DOE support contractors.

Lee, D. W., J. C. Wang, and D. C. Kocher 1995. Operating Limit Study for the Proposed Solid W aste Landfill at Paducah Gaseous Diffusion Plant, ORNL/TM-13008, Oak Ridge National Laboratory, Oak Ridge, TN.

PRS 2008a. Paducah Site Annual Site Environmental Report for Calendar Year 2006, PRS-ENM-0034, Volume I, Paducah Remediation Services, LLC, Paducah, KY.

\subsubsection{Calculated Input Values}

Some parameters were calculated based on site-specific information obtained from the previously mentioned references. The equations used to perform these calculations were obtained from the following references:

Yu, C., C. Loureiro, J. J. Cheng, L. G. Jones, Y. Y. Wang, Y. P. Chia, and E. Faillace 1993. Data Collection Handbook to Support Modeling Impacts of Radioactive Material in Soil, ANL/EAIS-8, Argonne National Laboratory, Environmental Assessment and Information Sciences Division, Argonne, IL.

King, D. A. and K. Keil 2006. "Comparison of Standard Radiological Risk Models and Using RESRAD to Derive Generic Risk-Based Area Factors for Final Status Surveys", Risk Analysis, Vol. 26, No. 1, pp. 175-183. 
DOSE MODELING EVALUATIONS AND TECHNICAL

SUPPORT DOCUMENT FOR THE AUTHORIZED

LIMITS REQUEST FOR THE C-746-U LANDFILL AT THE PADUCAH GASEOUS DIFFUSION PLANT

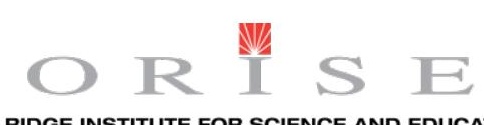

OAK RIDGE INSTITUTE FOR SCIENCE AND EDUCATION

\section{0: Basis for the Derivation of Soil Guidelines}

\subsubsection{Literature Values}

When site-specific values could not be determined using one of the previously mentioned sources, a search of pertinent literature was conducted and, in the absence of site-specific values, these literature values were selected over RESRAD or RESRAD-OFFSITE default values.

The following references contained values considered appropriate for the site:

Yu, C., C. Loureiro, J. J. Cheng, L. G. Jones, Y. Y. Wang, Y. P. Chia, and E. Faillace 1993. Data Collection Handbook to Support Modeling Impacts of Radioactive Material in Soil, ANL/EAIS-8, Argonne National Laboratory, Environmental Assessment and Information Sciences Division, Argonne, IL.

Yu, C., E. Gnanapragasam, B. M. Biwer, S. Kamboj, J. J. Cheng, T. Klett, D. LePoire, A. J. Zielen, S. Y. Chen, W. A. Williams, A. Wallo, S. Domotor, T. Mo, and A. Schwartzman 2007. User's Manual for RESRAD-OFFSITE Version 2, ANL/EVS/TM/07-1 (DOE/HS-0005, NUREG/CR-6937), Argonne National Laboratory, Environmental Science Division, Argonne, IL.

Wischmeier, W. H., and D. D. Smith 1978, Predicting Rainfall Erosion Losses: A Guide to Conservation Planning, U.S. Department of Agriculture, Agriculture Handbook No. 537.

\subsubsection{Default Parameters}

Default values are often required out of necessity as site-specific values may be unknown or costly to determine. However, they are the last choice in these evaluations. In several cases, RESRAD or RESRAD-OFFSITE defaults were considered necessary or adequate for this project.

These values were obtained from the references:

Yu, C., A. J. Zielen, J. J. Cheng, D. J. LePoire, E. Gnanapragasam, S. Kamboj, J. Arnish, A. Wallo, III, W. A. Williams, and H. Peterson 2001. User's Manual for RESRAD Version 6, ANL/EAD-4, Argonne National Laboratory, Environmental Assessment Division, Argonne, IL.

Yu, C., E. Gnanapragasam, B. M. Biwer, S. Kamboj, J. J. Cheng, T. Klett, D. LePoire, A. J. Zielen, S. Y. Chen, W. A. Williams, A. Wallo, S. Domotor, T. Mo, and A. Schwartzman 2007. User's Manual for RESRAD-OFFSITE Version 2, ANL/EVS/TM/07-1 (DOE/HS-0005, NUREG/CR-6937), Argonne National Laboratory, Environmental Science Division, Argonne, IL.

\subsubsection{DEVELOPMENT OF INPUTPARAMETERTABLES}

The parameter assessment culminated in evaluating and selecting hundreds of input parameters as inputs to the codes. The input parameters with corresponding information in the input/output files 
DOSE MODELING EVALUATIONS AND TECHNICAL

SUPPORT DOCUMENT FOR THE AUTHORIZED

LIMITS REQUEST FOR THE C-746-U LANDFILL AT THE PADUCAH GASEOUS DIFFUSION PLANT

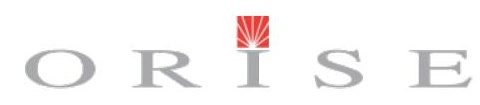

OAK RIDGE INSTITUTE FOR SCIENCE AND EDUCATION

\section{0: Basis for the Derivation of Soil Guidelines}

for all radionuclide soil guideline determinations were captured in appendices prepared for this report. A parameter-by-parameter assessment, including a rationale for parameter value assessment and selection, is included for RESRAD and RESRAD-OFFSITE as Appendices A and B, respectively. As discussed previously, identification of available site-specific parameters was based on review of the available literature, discussions with personnel familiar with the site (including DOE-PPPO provided environmental specialists), and other sources available to ORISE.

In many situations where dose modeling is conducted, site-specific values are difficult to obtain. Therefore, default parameters were utilized for this project as needed; however, ORISE examined all input values through sensitivity analyses to determine if any parameters, including defaults, used in support of the single radionuclide soil guideline determinations significantly impacted the results. Sensitivity analyses are discussed in greater detail in Section 5.8, "Sensitivity Analysis," and Section 6.0, "Results and Discussion."

Input deterministic parameters for each dose modeling code utilized in this project were captured in table format. Each table was populated with recommended (and justified) values. Each table included the following components:

Parameter Name (taken from the software codes)

Units (time, length, area, volume, density, no units, etc)

Default Values (specified in the software codes)

Code-Accepted Values (values the dose modeling code accepts as inputs)

Receptor Selection

Deterministic Values

Parameter Type (physical, behavioral, metabolic)

Parameter Justification

Reference(s)

The approach provided in NUREG/CR-6697 (ANL/EAD/TM-98), Development of Probabilistic RESRAD 6.0 and RESRAD-BUILD 3.0 Computer Codes (Yu et al. 2000), Table 2.1, Parameters and Their Default V alues Used in Version 6.0 of RESRAD, was initially followed. Because this NUREG did not contain an equivalent RESRAD-OFFSITE table, ORISE developed the table using information contained in the ANL User's Manual for RESRAD-OFFSITE Version 2 (Yu et al. 2007). As the project progressed, generic inputs provided in these tables were replaced with available projectspecific information.

The parameter tables are included in their entirety in Appendices A and B. 
DOSE MODELING EVALUATIONS AND TECHNICAL

SUPPORT DOCUMENT FOR THE AUTHORIZED

LIMITS REQUEST FOR THE C-746-U LANDFILL AT THE PADUCAH GASEOUS DIFFUSION PLANT

\section{0: Basis for the Derivation of Soil Guidelines}

\section{$5.7 \quad$ DETERMINISTIC ANALYSIS}

Once concurrence on the parameter table inputs was received from DOE-PPPO, the values were added to the respective codes. The codes were executed to establish preliminary deterministic outputs. The outputs are provided in Appendices C and D and discussed in detail in Section 6.0, "Results and Discussion."

\section{$5.8 \quad$ SENSTTIVITY ANALYSIS}

A sensitivity analysis was conducted based on the results of deterministic outputs to identify key parameters that impact total dose and the significance of this impact. In this respect, sensitivity analysis is a powerful tool that can be used to assess the robustness of the results returned by the model and may demonstrate that additional investigations would be beneficial.

Initially, all input values were scrutinized to determine the expected consequence of their use. In some instances, this evaluation was limited to a qualitative evaluation by an experienced health physicist; in others, the sensitivity tool in the respective code was used. Next, sensitive parameters were examined to determine the extent to which they would vary, and a range was developed for each. In instances where the anticipated variance was determined to be negligible because the input reflected engineered or verifiable values, additional analysis was not necessary. Some parameters were considered ineligible by the code for sensitivity analysis, because it did not make sense to perform sensitivity analysis on those parameters (Yu et al. 2007).

In the codes, sensitivity analysis is carried out after the deterministic calculations are completed by taking selected parameters and repeating the entire calculation with the parameter set at user-specified extremes (i.e., minimum and maximum values). Only a single test parameter is varied at a time. 
DOSE MODELING EVALUATIONS AND TECHNICAL

SUPPORT DOCUMENT FOR THE AUTHORIZED

LIMITS REQUEST FOR THE C-746-U LANDFILL AT THE PADUCAH GASEOUS DIFFUSION PLANT

\section{0: Results and Discussion}

\section{0: RESULTS ANDDISCUSSION}

\section{1}

GENERAL

This section provides a results and discussion of the dose assessments and soil guideline determinations that can be used by DOE to develop ALs for targeted radionuclides under a variety of exposure pathways and receptors. Many of the inputs to the modeling codes require the use of either intensive field or empirical determinations to establish site-specific inputs. While site-specific parameters are preferred for enhanced, site-specific models, the RESRAD User's Manual notes that it is not required to completely characterize transport and exposure processes to achieve improved modeling. Therefore, in many cases, the use of default parameters were necessary and considered acceptable for this project, considering many of the parameters evaluated during the soil guideline determination (through the use of sensitivity analyses described next) did not significantly impact the results. Appendices A and B provide a parameter-by-parameter assessment, including a justification for parameter value selection, for the receptors modeled by RESRAD and RESRAD-OFFSITE, respectively. The reports returned by the codes are called "Summary Reports" (RESRAD) and "Parent Dose Reports" (RESRAD-OFFSITE). These reports are provided in Appendices C and D. The results have been independently verified and validated by a third party DOE-PPPO contractor with dose-modeling experience.

\subsection{DEIERMINISTIC RESULTS}

A number of receptors and scenarios were modeled. Four of the receptors (i.e., Landfill Worker, Outdoor Worker, Recreational User, and Offsite Resident Farmer) were considered plausible. The remaining receptors (i.e., Trespasser, Resident Farmer, and Resident Gardener) were considered implausible due to existing or planned controls for the operational and post-institutional control periods. Scenarios associated with the post-institutional control period assume that as a RCRA permitted Subtitle D facility, post-operational care of the Landfill and limitations on future-use of the area of the Landfill are statutory.

\subsubsection{SENSITIMITY ANALYSIS}

The primary rationale behind sensitivity analyses is that key parameters may require additional investigation, particularly when default parameters are used. Section 5.0, "Basis for the Derivation of Soil Guidelines," contains a discussion of sensitivity analysis and the parameters evaluated with RESRAD and RESRAD-OFFSITE for the C-746-U Landfill.

In general, the sensitivity analysis revealed the following:

For the onsite receptors, attributes that impacted the cover proved to be most sensitive. These parameters included cover thickness, cover density, and cover erosion rate. Fraction of time 
DOSE MODELING EVALUATIONS AND TECHNICAL

SUPPORT DOCUMENT FOR THE AUTHORIZED

LIMITS REQUEST FOR THE C-746-U LANDFILL AT THE PADUCAH GASEOUS DIFFUSION PLANT

\section{0: Results and Discussion}

spent outdoors was determined to be sensitive, as were several other behavioral and/or metabolic parameters.

For the onsite Resident Farmer, the Tc-99 distribution coefficient of the contaminated zone; Tc-99 distribution coefficient of unsaturated zone 5; and the density, thickness, effective porosity, and total porosity of unsaturated zone 5 were sensitive relative to the dose from Tc-99. The depth or roots was sensitive for all radionuclides with the exception of Th-228. Depth of roots particularly impacted Th-230 and Th-232.

For the Offsite Resident Farmer, attributes that impacted Tc-99 groundwater transport proved to be most sensitive. These parameters included Tc-99 distribution coefficients for both the contaminated zone and unsaturated zone 5; evapotranspiration coefficient; precipitation rate; runoff coefficient; length of contamination parallel to aquifer flow; thickness and dry bulk density of the contaminated zone; longitudinal dispersivity of unsaturated zones 1 and 2; and thickness, dry bulk density, total porosity, effective porosity, and longitudinal dispersivity of unsaturated zone 5. Drinking water consumption rate was also sensitive as expected.

The impact of these parameters was straightforward-i.e., as the cover (shielding) was reducedexternal dose to onsite receptors increased, and as drinking water intake decreased, dose to the Offsite Resident Farmer decreased. Moreover, none of the parameters that demonstrated sensitivity are expected to be highly variable. As a result, it was concluded that the deterministic models were sufficiently rigorous, and the process of soil guideline derivation was continued without additional sensitivity or follow-on uncertainty analyses.

\subsubsection{SINGLERADIONUCLIDE SOIL GUIDELINES}

The single radionuclide soil guidelines returned by the codes are summarized in Table 6-1. The results presented in this table represent the codes' single radionuclide soil guidelines using a basic radiation dose of $100 \mathrm{mrem} / \mathrm{yr}$ (above background) for implausible receptors, $100 \mathrm{mrem} / \mathrm{yr}$ (above background) for a Landfill Worker, and $1 \mathrm{mrem} / \mathrm{yr}$ for other plausible receptors. The most limiting (restrictive) single radionuclide soil guidelines across all receptors were evaluated for use as the derived soil guidelines. 
Table 6-1. Single Radionuclide Soil Guidelines based on Receptor-Specific Target Dose

\begin{tabular}{|c|c|c|c|c|c|c|c|c|c|}
\hline \multirow{4}{*}{ Nuclide } & \multicolumn{7}{|c|}{ Receptors } & \multirow{3}{*}{\multicolumn{2}{|c|}{$\begin{array}{l}\text { Results and Pathways by which Radionuclides } \\
\text { Contribute Dose to Limiting Receptor }\end{array}$}} \\
\hline & \multirow{2}{*}{\multicolumn{3}{|c|}{$\begin{array}{c}\text { Implausible } \\
\text { (100 mrem/yr) }\end{array}$}} & \multicolumn{4}{|c|}{ Plausible } & & \\
\hline & & & & \multicolumn{3}{|c|}{ (1 mrem/yr) } & \multirow{2}{*}{$\begin{array}{c}\begin{array}{c}(100 \\
\text { mrem/yr) }\end{array} \\
\text { Landfill } \\
\text { Worker } \\
\text { (pCi/g) }\end{array}$} & & \\
\hline & $\begin{array}{l}\text { Trespasser } \\
\text { (pCi/g) }\end{array}$ & $\begin{array}{l}\text { Resident } \\
\text { Farmer } \\
\text { (pCi/g) }\end{array}$ & $\begin{array}{c}\text { Resident } \\
\text { Gardener } \\
\text { (pCi/g) }\end{array}$ & $\begin{array}{c}\text { Recreational } \\
\text { User } \\
\text { (pCi/g) }\end{array}$ & $\begin{array}{l}\text { Outdoor } \\
\text { Worker } \\
\text { (pCi/g) }\end{array}$ & $\begin{array}{l}\text { Offsite } \\
\text { Resident } \\
\text { Farmer } \\
\text { (pCi/g) }\end{array}$ & & $\begin{array}{l}\text { Limiting Single } \\
\text { Radionuclide Soil } \\
\text { Guideline (pCi/g) }\end{array}$ & $\begin{array}{l}\text { Pathways (in descending order } \\
\text { of contribution to dose if more } \\
\text { than one is listed) }\end{array}$ \\
\hline Am-241 & $2.448 \mathrm{E}+05$ & $5.181 \mathrm{E}+05$ & $5.044 \mathrm{E}+05$ & $8.235 E+11$ & $3.875 \mathrm{E}+11$ & $3.431 \mathrm{E}+12 *$ & $3.509 E+03$ & $3.509 E+03$ & $\begin{array}{l}\text { Soil ingestion, external gamma, } \\
\text { and inhalation }\end{array}$ \\
\hline Cs-137 & $4.856 \mathrm{E}+03$ & $7.867 \mathrm{E}+10$ & $7.925 \mathrm{E}+10$ & $8.242 \mathrm{E}+09$ & $3.879 \mathrm{E}+09$ & $8.704 \mathrm{E}+13^{*}$ & $1.900 \mathrm{E}+02$ & $1.900 E+02$ & $\begin{array}{l}\text { External gamma, soil ingestion, } \\
\text { and inhalation }\end{array}$ \\
\hline Np-237 & $1.320 \mathrm{E}+04$ & $9.749 E+03$ & $9.756 \mathrm{E}+03$ & $1.380 \mathrm{E}+08$ & $6.495 \mathrm{E}+07$ & $7.047 \mathrm{E}+08^{*}$ & $5.507 \mathrm{E}+02$ & $5.507 E+02$ & $\begin{array}{l}\text { External gamma, soil ingestion, } \\
\text { and inhalation }\end{array}$ \\
\hline Pu-238 & $3.400 E+05$ & $1.628 \mathrm{E}+08$ & $1.637 \mathrm{E}+08$ & $7.937 \mathrm{E}+10$ & $3.735 E+10$ & $1.712 \mathrm{E}+13^{*}$ & $3.926 \mathrm{E}+03$ & $3.926 E+03$ & $\begin{array}{l}\text { Soil ingestion, inhalation, } \\
\text { and external gamma }\end{array}$ \\
\hline Pu-239 & $1.792 \mathrm{E}+05$ & $8.096 E+04$ & $7.884 \mathrm{E}+04$ & $6.214 \mathrm{E}+10^{*}$ & $6.214 \mathrm{E}+10^{*}$ & $6.214 \mathrm{E}+10^{*}$ & $3.595 E+03$ & $3.595 E+03$ & $\begin{array}{l}\text { Soil ingestion, inhalation, } \\
\text { and external gamma }\end{array}$ \\
\hline $\mathrm{Pu}-240$ & $1.806 \mathrm{E}+05$ & $8.779 \mathrm{E}+04$ & $8.550 E+04$ & $2.278 \mathrm{E}+11^{*}$ & $2.278 \mathrm{E}+11^{*}$ & $2.278 \mathrm{E}+11 *$ & $3.598 \mathrm{E}+03$ & $3.598 E+03$ & $\begin{array}{l}\text { Soil ingestion, inhalation, } \\
\text { and external gamma }\end{array}$ \\
\hline Tc-99 & $1.359 \mathrm{E}+08$ & $2.453 \mathrm{E}+02$ & $7.545 \mathrm{E}+07$ & $1.697 \mathrm{E}+10^{*}$ & $1.697 \mathrm{E}+10^{*}$ & $2.783 E+01$ & $1.131 E+06$ & $2.783 E+01$ & $\begin{array}{l}\text { Drinking water, plant ingestion, } \\
\text { and milk ingestion }\end{array}$ \\
\hline Th-228 & $1.125 \mathrm{E}+03$ & $6.085 \mathrm{E}+07$ & $7.234 \mathrm{E}+07$ & $7.523 E+06$ & $3.540 \mathrm{E}+06$ & $1.190 \mathrm{E}+14$ & $7.351 E+01$ & $7.351 E+01$ & $\begin{array}{l}\text { External gamma, soil ingestion, } \\
\text { and inhalation }\end{array}$ \\
\hline Th-230 & $1.906 \mathrm{E}+04$ & $1.651 \mathrm{E}+03$ & $1.719 \mathrm{E}+03$ & $1.155 \mathrm{E}+05$ & $5.434 \mathrm{E}+04$ & $2.018 \mathrm{E}+10^{*}$ & $1.234 \mathrm{E}+03$ & $1.234 E+03$ & $\begin{array}{l}\text { External gamma, soil ingestion, } \\
\text { and inhalation }\end{array}$ \\
\hline Th-232 & $4.102 \mathrm{E}+02$ & $6.221 E+02$ & $6.708 \mathrm{E}+02$ & $1.124 \mathrm{E}+04$ & $5.287 E+03$ & $1.097 \mathrm{E}+05^{*}$ & $3.757 E+01$ & $3.757 E+01$ & $\begin{array}{l}\text { External gamma, soil ingestion, } \\
\text { and inhalation }\end{array}$ \\
\hline U-234 & $9.092 \mathrm{E}+05$ & $1.044 \mathrm{E}+05$ & $1.078 \mathrm{E}+05$ & $2.275 \mathrm{E}+07$ & $1.071 \mathrm{E}+07$ & $6.247 \mathrm{E}+09 *$ & $1.822 \mathrm{E}+04$ & $1.822 E+04$ & $\begin{array}{l}\text { Soil ingestion, external gamma, } \\
\text { and inhalation }\end{array}$ \\
\hline U-235 & $2.495 E+04$ & $5.340 \mathrm{E}+04$ & $5.658 \mathrm{E}+04$ & $2.161 \mathrm{E}+06^{*}$ & $2.161 \mathrm{E}+06^{*}$ & $2.161 \mathrm{E}+06^{*}$ & $8.218 \mathrm{E}+02$ & $8.218 E+02$ & $\begin{array}{l}\text { External gamma, soil ingestion, } \\
\text { and inhalation }\end{array}$ \\
\hline U-238 & $6.025 E+04$ & $1.533 \mathrm{E}+05$ & $1.578 \mathrm{E}+05$ & $3.361 \mathrm{E}+05^{*}$ & $3.361 \mathrm{E}+05^{*}$ & $3.361 \mathrm{E}+05^{*}$ & $3.196 \mathrm{E}+03$ & $3.196 E+03$ & $\begin{array}{l}\text { External gamma, soil ingestion, } \\
\text { and inhalation }\end{array}$ \\
\hline
\end{tabular}

*Value at the specific activity limit. 
DOSE MODELING EVALUATIONS AND TECHNICAL SUPPORT DOCUMENT FOR THE AUTHORIZED LIMITS REQUEST FOR THE C-746-U LANDFILL AT THE PADUCAH GASEOUS DIFFUSION PLANT

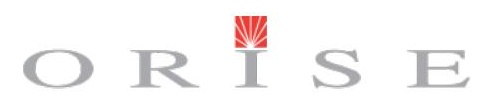

OAK RIDGE INSTITUTE FOR SCIENCE AND EDUCATION

\section{0: Results and Discussion}

\section{3}

DERIVED SOIL GUIDELINES

The single radionuclide soil guidelines in Table 6-1 are the nuclide-specific concentrations in $\mathrm{pCi} / \mathrm{g}$ that will comply with the target dose constraint of $1 \mathrm{mrem} / \mathrm{yr}$ for plausible, nonoccupationally exposed receptors and the $100 \mathrm{mrem} / \mathrm{yr}$ primary dose limit applicable to both the implausible receptors and a plausible, occupationally exposed Landfill Worker. The soil guidelines included in this table reflect above background concentrations of radioactive material. As a result, the most limiting single radionuclide soil guidelines are appropriate for translation into ALs as part of an AL request by $\mathrm{DOE}$.

RESRAD and RESRAD-OFFSITE report their output in scientific notation to four significant digits. DOE-PPPO was consulted, and for ease of application, single radionuclide soil guidelines were rounded to two significant figures in Table 6-2, which constitute the derived soil guidelines for the Landfill:

Table 6-2. ORISE-Derived Soil Guidelines for the C-746-U Landfill

\begin{tabular}{|cc|}
\hline Radionuclide & Derived Soil Guidelines (pCi/g)* \\
\hline Am-241 & 3,500 \\
\hline Cs-137 & 190 \\
\hline Np-237 & 550 \\
\hline Pu-238 & 3,900 \\
\hline Pu-239 & 3,600 \\
\hline Pu-240 & 3,600 \\
\hline Tc-99 & 28 \\
\hline Th-228 & 74 \\
\hline Th-230 & 1,200 \\
\hline Th-232 & 38 \\
U-234 & 18,000 \\
U-235 & 820 \\
U-238 & 3,200 \\
\hline
\end{tabular}

*The derived soil guidelines reflect above background concentrations of radioactive material. 
DOSE MODELING EVALUATIONS AND TECHNICAL

SUPPORT DOCUMENT FOR THE AUTHORIZED

LIMITS REQUEST FOR THE C-746-U LANDFILL AT THE PADUCAH GASEOUS DIFFUSION PLANT

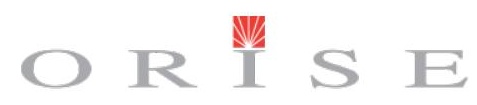

OAK RIDGE INSTITUTE FOR SCIENCE AND EDUCATION

\section{0: Results and Discussion}

\section{4}

DISCUSSION OF DERIVED SOIL GUIDELINES

For clarity, additional discussion regarding the ORISE-derived soil guidelines and their attributes for the C-746-U Landfill is provided as follows:

With the exception of the value for Tc-99, the ORISE derived soil guidelines are higher than previously recommended values (DOE 2003a). This attribute of the derived soil guidelines is due almost exclusively to the presence of a 1.52-m thick cover on the Landfill that remains undisturbed with the exception of normal erosion. This approach is consistent with the model used to derive the Landfill's current ALs; however, ORISE used the Landfill's actual cover depth, $5 \mathrm{ft}(1.52 \mathrm{~m})$, and the model upon which the current ALs were derived considered only a cover thickness of $1 \mathrm{~m}$ (DOE 2003a).

The Tc-99 derived soil guideline is lower than previously recommended limits due to the consideration of an Offsite Resident Farmer, evaluation of additional exposure pathways (refer to the CSM in Figure 5-1), and a target dose constraint of $1 \mathrm{mrem} / \mathrm{yr}$. This receptor's dose is attributed almost exclusively to ingestion of drinking water, plants and milk. However, the majority of the dose results from the ingestion of drinking water. The code used to model this receptor, RESRAD-OFFSITE, was not available when the current ALs were developed in DOE 2003a. A detailed discussion is included in Section 6.4.1, "Discussion of the Tc-99 Derived Soil Guideline.”

Soil guidelines relative to the $1 \mathrm{mrem} / \mathrm{yr}$ target dose constraint and the $100 \mathrm{mrem} / \mathrm{yr}$ primary public dose limit are on an isotope-specific basis. That is, it is expected that management of the Landfill using the derived soil guidelines will consider the sum of fractions (unity). Application of a unity calculation will be discussed in Section 7.0, "Summary, Conclusions, and Application of ORISE-Derived Soil Guidelines."

The derived soil guidelines for uranium isotopes were derived independently from one another based on the results of dose only. The codes used to accomplish dose modeling for this project do not consider enrichment; therefore, no conclusions should be made regarding authorized enrichments of uranium from the ORISE derived soil guidelines.

The derived soil guidelines reflect above background concentrations of radioactive material. To maximize the available radionuclide capacity of the Landfill, background correction measurements should be considered.

\subsubsection{DISCLSSION OFTHETC-99 DERIVED SOIL GUIDELINE}

The derived soil guidelines are higher relative to the current ALs for the C-746-U Landfill with the single exception of the derived soil guideline for Tc-99 that decreased from the current AL of 
DOSE MODELING EVALUATIONS AND TECHNICAL

SUPPORT DOCUMENT FOR THE AUTHORIZED

LIMITS REQUEST FOR THE C-746-U LANDFILL AT THE PADUCAH GASEOUS DIFFUSION PLANT

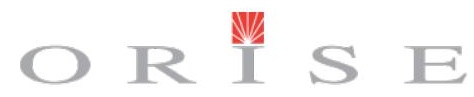

OAK RIDGE INSTITUTE FOR SCIENCE AND EDUCATION

\section{0: Results and Discussion}

$500 \mathrm{pCi} / \mathrm{g}$ (DOE 2003a). This radionuclide is worthy of discussion since it is a crucial radionuclide due to its mobility in the environment and potential impact to the public and the environment.

As discussed in Section 5.0, "Basis for the Derivation of Soil Guidelines," six onsite receptors were modeled with RESRAD and one offsite receptor (Offsite Resident Farmer) was modeled with RESRAD-OFFSITE. The selected and most restrictive value of $28 \mathrm{pCi} / \mathrm{g}$ for Tc-99 comes from the Offsite Resident Farmer scenario using a target dose constraint of $1 \mathrm{mrem} / \mathrm{yr}$. This is considered to be a plausible scenario.

The following graphics were obtained from the evaluation of the derived soil guidelines using the RESRAD-OFFSITE code. Figure 6-1 illustrates the contribution to dose from all targeted radionuclides and pathways for the Offsite Resident Farmer. Figure 6-2 illustrates the contribution to the dose for the Offsite Resident Farmer from specifically Tc-99 and the different pathways. As depicted in these figures, this receptor's dose is due almost entirely to Tc-99 through the drinking water, plant ingestion, and milk ingestion pathways with the maximum dose occurring at $772 \mathrm{yr}$. Further discussion about peak doses evaluated from the derived soil guidelines is included in Section 6.5, "Peak Dose from Cumulative Radionuclide Inventory." 
DOSE MODELING EVALUATIONS AND TECHNICAL SUPPORT DOCUMENT FOR THE AUTHORIZED LIMITS REQUEST FOR THE C-746-U LANDFILL AT THE PADUCAH GASEOUS DIFFUSION PLANT

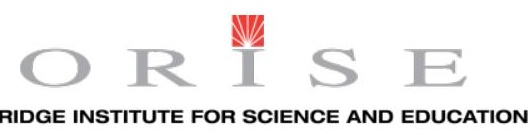

OAK RIDGE INSTITUTE FOR SCIENCE AND EDUCATION

\section{0: Results and Discussion}

DOSE: All Nuclides Summed, All Pathways Summed

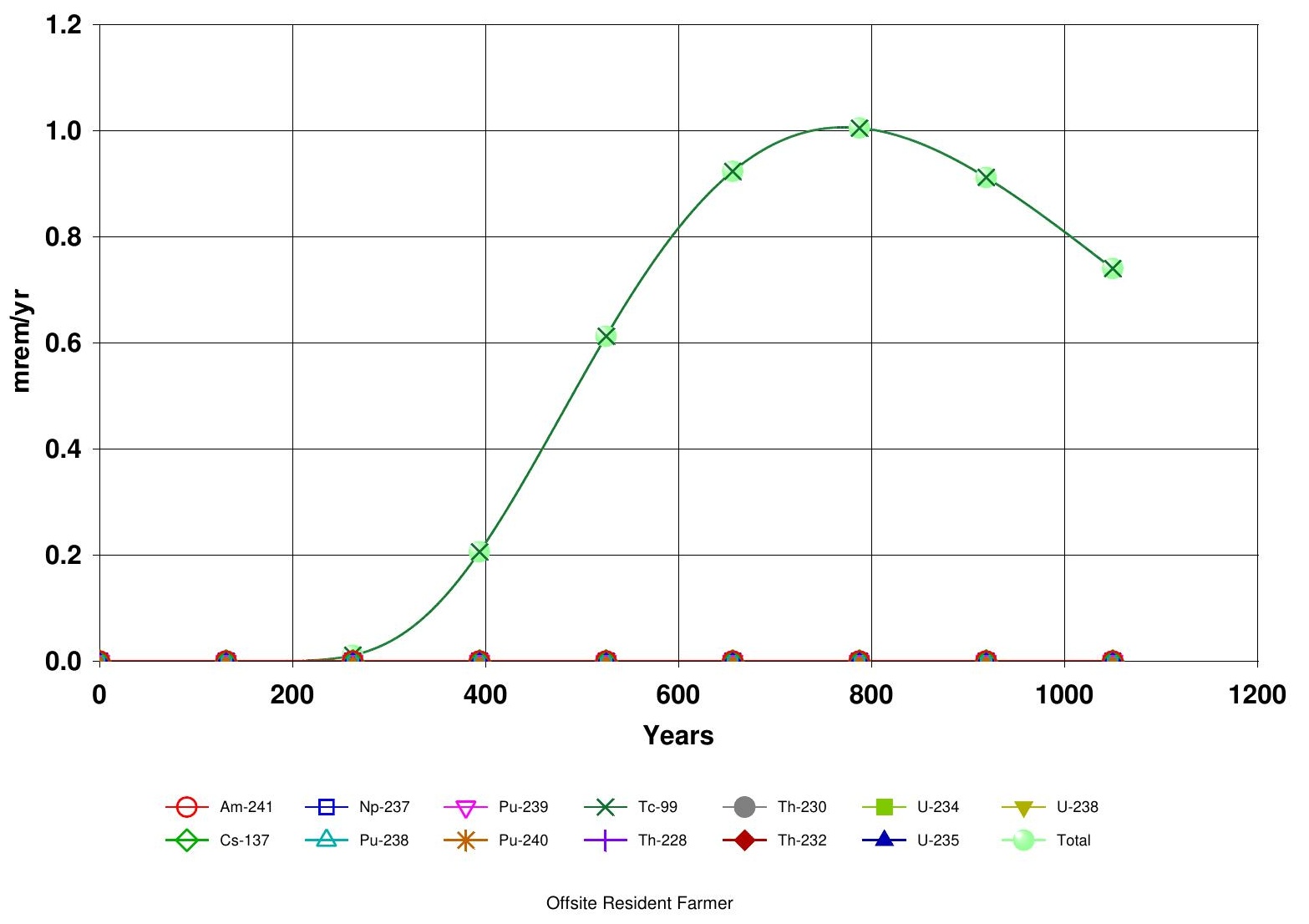

Figure 6-1. Dose to Offsite Resident Farmer from all Selected Targeted Radionuclides and Pathways 
DOSE MODELING EVALUATIONS AND TECHNICAL

SUPPORT DOCUMENT FOR THE AUTHORIZED

LIMITS REQUEST FOR THE C-746-U LANDFILL AT

THE PADUCAH GASEOUS DIFFUSION PLANT

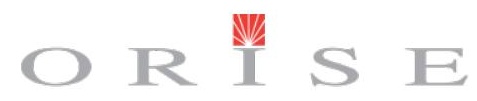

OAK RIDGE INSTITUTE FOR SCIENCE AND EDUCATION

6.0: Results and Discussion

DOSE: TC-99, Component Pathways

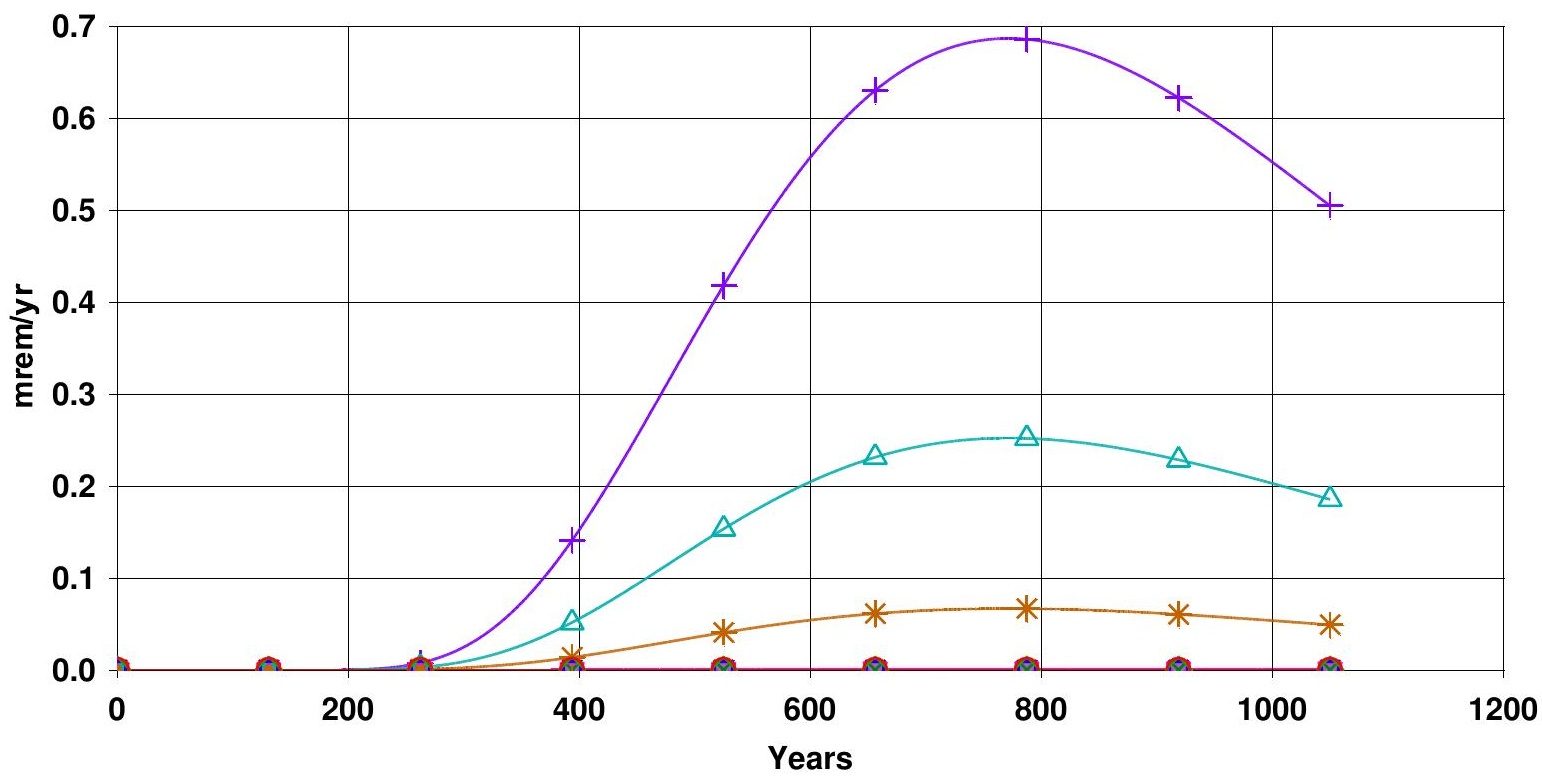

* Milk (waterborne)

$\leftarrow$ Soil ingestion (waterborne)

+ Water

$\square$ Radon (waterborne)

$\triangle$ Plant (waterborne)

$\nabla$ Meat (waterborne)
- Direct radiation from soil (direct \& airborne)

$\smile$ Inhalation

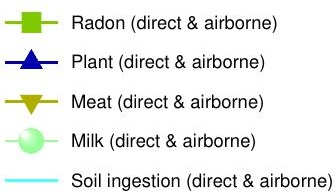

Offsite Resident Farmer

Figure 6-2. Dose to Offsite Resident Farmer from Tc-99 through Component Pathways

\subsection{PEAKDOSE FROM CUMULATIVE RADIONUCLIDE INVENTORY}

DOE-PPPO requested that ORISE perform an additional evaluation of potential peak dose to each receptor.

The evaluation involved the assessment of potential peak dose from the cumulative radionuclide inventory using maximum concentration values (i.e., all radionuclide concentrations at the derived soil guidelines listed in Table 6-2) and no consideration given to satisfying the unity rule. As each derived soil guideline was developed based on the premise that the concentration it reflects is sufficient to satisfy a target dose, it was expected that inputting each concentration at the derived soil guideline into the modeling codes would cumulatively exceed the target dose. The forward run was intended to determine the magnitude to which this occurred across all receptors. 
DOSE MODELING EVALUATIONS AND TECHNICAL SUPPORT DOCUMENT FOR THE AUTHORIZED LIMITS REQUEST FOR THE C-746-U LANDFILL AT THE PADUCAH GASEOUS DIFFUSION PLANT

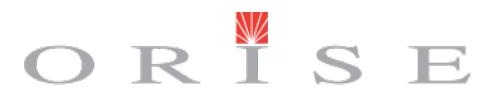

OAK RIDGE INSTITUTE FOR SCIENCE AND EDUCATION

\section{0: Results and Discussion}

The codes were run for each receptor using the derived soil guidelines as the input nuclide concentration and ignoring any unity rule corrections. A time horizon of 1,050 yr was assumed for all receptors except the Landfill Worker and the Trespasser; a time horizon of $70 \mathrm{yr}$ was assumed for these receptors.

The following output peak doses in Table 6-3 were returned:

Table 6-3. Peak Dose from Cumulative Radionuclide Inventory (mrem/yr)

\begin{tabular}{cccccccc}
\hline Receptor & Trespasser & $\begin{array}{c}\text { Resident } \\
\text { Farmer }\end{array}$ & $\begin{array}{c}\text { Resident } \\
\text { Gardener }\end{array}$ & $\begin{array}{c}\text { Landfill } \\
\text { Worker }\end{array}$ & $\begin{array}{c}\text { Recreational } \\
\text { User }\end{array}$ & $\begin{array}{c}\text { Outdoor } \\
\text { Worker }\end{array}$ & $\begin{array}{c}\text { Offsite } \\
\text { Resident } \\
\text { Farmer }\end{array}$ \\
\hline $\begin{array}{c}\text { Target Dose } \\
\text { (mrem/yr) }\end{array}$ & 100 & 100 & 100 & 100 & 1 & 1 & 1 \\
$\begin{array}{c}\text { Peak Dose } \\
\text { (mrem/yr) }\end{array}$ & 38 & 115 & 111 & 1,030 & 0.015 & 0.031 & 1.0 \\
$\begin{array}{c}\text { Time } \\
\text { (yr) }\end{array}$ & 70 & 1,050 & 1,050 & 0 & 1,050 & 1,050 & 772
\end{tabular}

As expected, the codes returned results that exceeded the target doses; however, the Resident Farmer and Resident Gardener are considered implausible receptors, and the Landfill Worker's dose is considerably below the DOE's 2,000 mrem/yr ACL. The peak dose results were rounded to two significant figures for all of the receptors except for the Resident Farmer, Resident Gardener and Landfill Worker. Results were rounded to three significant figures to capture relevant distinctions between these receptors (e.g., exposure pathways for the Resident Farmer and Gardener). The dose calculated for the Landfill Worker, 1,030 mrem/yr for year 0, most likely overestimates the projected dose for actual workers. This argues for the conservatism in the modeling estimates. 
DOSE MODELING EVALUATIONS AND TECHNICAL

SUPPORT DOCUMENT FOR THE AUTHORIZED

LIMITS REQUEST FOR THE C-746-U LANDFILL AT THE PADUCAH GASEOUS DIFFUSION PLANT

7.0: Summary, Conclusions, and Application Of ORISE-Derived Soil Guidelines

7.0: SUMMARY, CONCLUSIONS, AND APPLICATION OF ORISE-DERIVED SOIL GUIDELINES

ORISE was contracted by the DOE-PPPO to conduct dose modeling to support the derivation of revised ALs for the C-746-U Landfill at the PGDP. This technical report includes a complete description of the methodology, an assessment of the input parameters, model inputs, and results in support of the AL request. The derived soil guidelines are provided to DOE-PPPO for consideration. Ultimately, it is the DOE's responsibility to develop and approve the AL request and operate the Landfill to implement the requested ALs.

Per DOE Order 458.1, Radiation Protection of the Public and the Environment (DOE 2011), an AL represents a limit on the concentration or quantity of residual radioactive material on the surfaces or within property that has been derived consistent with DOE directives including the ALARA process requirements. An authorized limit may also include conditions or measures that limit or control the disposition of property. The DOE-PPPO administers oversight of the AL program.

The derivation of site-specific, deterministic soil guidelines for 13 targeted radionuclides of concern was assisted by reviewing site and other pertinent references, conducting an extensive environmental evaluation of the site (which identified multiple relevant site-specific environmental parameters for the computational model equations), developing a CSM and extensive parameter table sets, executing current versions of the ANL RESRAD and RESRAD-OFFSITE computer codes, and generating single radionuclide soil guidelines as code outputs. The sensitivity of input parameters was evaluated iteratively to examine their effect on the output results. The most limiting (restrictive) soil guidelines across all receptors were selected to identify ORISE-derived soil guidelines.

Radioactive secular equilibrium was not assumed in the analysis for the uranium, actinium, and thorium decay series due to the nature of the PGDP's uranium enrichment mission.

The computer codes and project CSM were used to evaluate six onsite and one offsite receptor under both current and future land use scenarios relative to the designated targeted radionuclides and project dose constraints of 1, 15, and $25 \mathrm{mrem} / \mathrm{yr}$, respectively. Both plausible and implausible exposure scenarios were evaluated. All implausible scenarios and a single, plausible scenario for an occupationally exposed Landfill Worker were evaluated against the $100 \mathrm{mrem} / \mathrm{yr}$ primary public dose limit above background, applicable to all sources and pathways, as cited in DOE Order 458.1. Particular emphasis was placed on the derivation of soil guidelines that satisfy a $1 \mathrm{mrem} / \mathrm{yr}$ dose constraint for plausible receptor scenarios. All plausible receptors, with the exception of the Landfill Worker, were evaluated against the $1 \mathrm{mrem} / \mathrm{yr}$ constraint.

The modeling runs used RESRAD and RESRAD-OFFSITE time horizons out to 1,050 yr-a time frame associated with the typical period associated with AL derivation (1,000 yr) and an additional 
DOSE MODELING EVALUATIONS AND TECHNICAL

SUPPORT DOCUMENT FOR THE AUTHORIZED

LIMITS REQUEST FOR THE C-746-U LANDFILL AT THE PADUCAH GASEOUS DIFFUSION PLANT

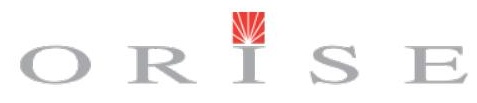

OAK RIDGE INSTITUTE FOR SCIENCE AND EDUCATION

7.0: Summary, Conclusions, and Application Of ORISE-Derived Soil Guidelines

$50 \mathrm{yr}$ (beginning in 1960) to capture the contribution of limited radioactive ingrowth relative to the plant's start-up operations in 1952.

The external dose pathway was identified as an important exposure pathway for onsite receptors while the drinking water pathway was important for the single, offsite receptor.

ORISE-derived soil guidelines for this project range from $28 \mathrm{pCi} / \mathrm{g}$ for Tc-99 to $18,000 \mathrm{pCi} / \mathrm{g}$ for U-234. These derived soil guidelines are specifically applicable to the C-746-U Landfill at the end of its operational life and are not intended to be used for individual, routine load shipments of DOE-authorized materials to the Landfill (refer to Section 7.2, "Application of Derived Soil Guidelines").

An additional evaluation was conducted at the request of the DOE-PPPO to determine the maximum (peak) dose for all radionuclides and dose scenarios at 1,050 $\mathrm{yr}$ for all receptors with the exception of the Landfill Worker and Trespasser where a time horizon of $70 \mathrm{yr}$ was assumed. This evaluation used the derived soil guidelines and the projected cumulative radionuclide inventory to determine peak dose. The highest dose across all receptors was 1,030 mrem/yr for year 0 (see Section 6.5, "Peak Dose from Cumulative Radionuclide Inventory"). This dose was received by the Landfill Worker.

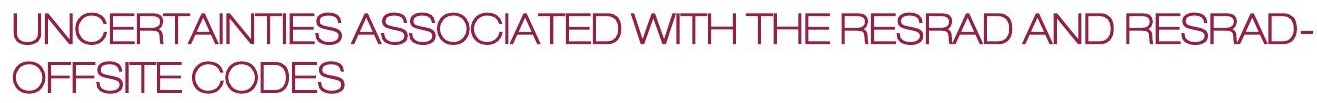

Differences exist between the RESRAD and RESRAD-OFFSITE modeling codes. As previously described, a primary difference is the groundwater model. Limitations exist as well. The RESRAD and RESRAD-OFFSITE codes utilize different groundwater models and the results obtained through this pathway are different, despite the fact the different scenarios were evaluated with both codes.

Differences in the codes can impact the results obtained. Caution should be taken when interpreting the results obtained from the codes, especially if many site-specific values are being input into the codes. Site-specific values can also impact the execution capability of the code. Difficulties trying to execute the RESRAD-OFFSITE code were experienced by ORISE when using site-specific values - particularly for one of the unsaturated zones (i.e., the site-specific hydraulic conductivity for unsaturated zone 5). The difficulties encountered with this parameter were discussed in Section 5.0, "Basis for the Derivation of Soil Guidelines."

\subsection{APPLICATION OF DERIVED SOIL GUIDELINES}

DOE is responsible for developing and approving the AL request and for operating the Landfill to implement the requested ALs. The derived soil guidelines can be used by DOE to support the 
DOSE MODELING EVALUATIONS AND TECHNICAL

SUPPORT DOCUMENT FOR THE AUTHORIZED

LIMITS REQUEST FOR THE C-746-U LANDFILL AT THE PADUCAH GASEOUS DIFFUSION PLANT

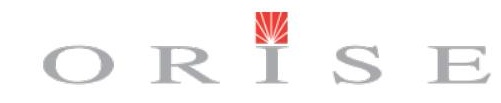

OAK RIDGE INSTITUTE FOR SCIENCE AND EDUCATION

7.0: Summary, Conclusions, and Application Of ORISE-Derived Soil Guidelines

establishment of ALs; therefore, ORISE has a number of recommendations regarding developing the $\mathrm{AL}$ request.

\subsubsection{UNITY CALCLLATIONS}

As each of the derived soil guidelines reflects a concentration that meets a target dose, a unity calculation is required to demonstrate compliance against target dose constraints and limits. The necessity of a unity calculation is demonstrated by the peak doses reported in Table 6-3 that show that the Resident Farmer and Resident Gardener, although implausible, would exceed the primary dose limit of $100 \mathrm{mrem} / \mathrm{yr}$ if unity is not considered. Unity is determined using the following equation:

$$
\frac{C_{1}}{S G_{1}}+\frac{C_{2}}{S G_{2}}+\ldots \frac{C_{n}}{S G_{n}} \leq 1 \text { (unity) }
$$

where $C$ is the concentration of an individual nuclide in $\mathrm{pCi} / \mathrm{g}$ and $S G$ is that nuclide's derived soil guideline.

\subsubsection{SHIPMENTLIMITS}

Another important aspect of development of the AL request is that the derived soil guidelines reflect the attributes of the C-746-U Landfill when it has reached its design capacity; therefore, they need not be applied on a "per shipment" basis. That is, it is assumed that individual shipments that otherwise meet the Landfill's waste acceptance criteria may exceed the derived soil guidelines, provided the projected maximum radionuclide inventory in curies (Ci) at the end of the Landfill's life is not exceeded.

Many of the derived soil guidelines are intrinsically based on limiting the occupational exposure of a Landfill Worker to $100 \mathrm{mrem} / \mathrm{yr}$; therefore, it is recommended that individual shipments be limited to twenty times the derived soil guideline to prevent exceeding a 2,000 mrem/yr ACL (i.e., $20 \times 100 \mathrm{mrem} / \mathrm{yr}=2,000 \mathrm{mrem} / \mathrm{yr}$ ). ORISE was not tasked to evaluate the operational health-physics aspects of receiving and handling shipments, and consideration of these aspects should be taken into account when authorizing any shipments that exceed a derived soil guideline, even those that conform to the "twenty times" recommendation.

\subsubsection{RADIONUCLIDEINVENTORY MANAGEMENT}

A projected maximum inventory for each radionuclide was calculated using the derived soil guidelines. The calculation involved the conversion of the derived soil guidelines into curies by multiplying the entire volume of the Landfill $\left(1.19 \mathrm{E}+12 \mathrm{~cm}^{3}\right)$ by the weighted average waste density $\left(1.89 \mathrm{~g} / \mathrm{cm}^{3}\right)$ and the appropriate activity conversion from $\mathrm{pCi}$ to $\mathrm{Ci}(1 \mathrm{E}-12 \mathrm{Ci} / \mathrm{pCi})$. Once the 
DOSE MODELING EVALUATIONS AND TECHNICAL

SUPPORT DOCUMENT FOR THE AUTHORIZED

LIMITS REQUEST FOR THE C-746-U LANDFILL AT THE PADUCAH GASEOUS DIFFUSION PLANT

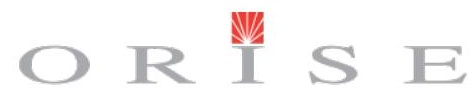

OAK RIDGE INSTITUTE FOR SCIENCE AND EDUCATION

7.0: Summary, Conclusions, and Application Of ORISE-Derived Soil Guidelines

projected maximum radionuclide inventory was calculated, the current quantity of radioactive material already in the Landfill was subtracted from the projected maximum radionuclide inventory to obtain the projected remaining inventory allowed in the Landfill. The current amount of radioactive material was determined from the quantity disposed of as of the end of the seventh year of operation (covering the period May 21, 2003 to May 21, 2010) (DOE 2010).

The seventh year inventory has separate total activity amounts for Am-241, Cs-137, Np-237, Pu-238, and Tc-99 and total activity amounts for Pu-239/240, total thorium, and total uranium. As a result, the amount of $\mathrm{Pu}-239 / 240$ was subtracted from the projected maximum inventory value of both $\mathrm{Pu}-239$ and $\mathrm{Pu}-240$. Then, in order to obtain values for each isotope of thorium, radionuclide specific activities from the sixth year inventory spreadsheet (DOE 2009a) were added to activities listed in the seventh year inventory to determine the total amount of Th-228, Th-230, and Th-232 to subtract from the projected maximum inventory for each of these nuclides. For uranium, the total uranium activity from the seventh year inventory was multiplied by the isotopic abundances of 49\% U-234, 2\% U-235, and 49\% U-238. These isotopic abundances were assumed in DOE 2003a.

Once the contribution of each uranium isotope was determined, then the amount of activity for each radionuclide was subtracted from the projected maximum inventory values for the uranium isotopes. The results are provided in the projected remaining inventory in Table 7-1.

Based on the assumptions regarding the anticipated volume and density of the C-746-U Landfill, the projected radionuclide inventory at the end of operation should not exceed the values from Table 7-1 with consideration given to unity except for Tc-99 as described previously. 
DOSE MODELING EVALUATIONS AND TECHNICAL SUPPORT DOCUMENT FOR THE AUTHORIZED LIMITS REQUEST FOR THE C-746-U LANDFILL AT THE PADUCAH GASEOUS DIFFUSION PLANT

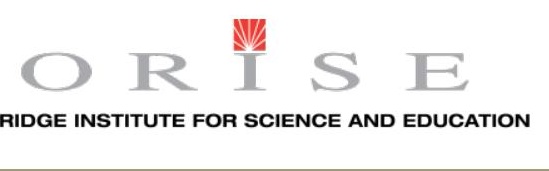

7.0: Summary, Conclusions, and Application Of ORISE-Derived Soil Guidelines

Table 7-1. Projected Radionuclide Inventory for the C-746-U Landfill

\begin{tabular}{|ccc|}
\hline Radionuclide & Projected Maximum Inventory (Ci) & Projected Remaining Inventory (Ci) \\
\hline Am-241 & 7,900 & 7,900 \\
\hline Cs-137 & 430 & 430 \\
\hline Np-237 & 1,200 & 1,200 \\
\hline Pu-238 & 8,800 & 8,800 \\
\hline Pu-239 & 8,100 & 8,100 \\
\hline Pu-240 & 8,100 & 8,100 \\
\hline Tc-99 & $63^{*}$ & $62^{*}$ \\
\hline Th-228 & 170 & 170 \\
\hline Th-230 & 2,700 & 2,700 \\
\hline Th-232 & 86 & 86 \\
U-234 & 41,000 & 41,000 \\
\hline U-235 & 1,800 & 1,800 \\
\hline U-238 & 7,200 & 7,200 \\
\hline
\end{tabular}

*Note: It is recognized that the values shown are the same for all nuclides except for Tc-99. This is due to the fact that the current radionuclide inventory is miniscule compared to the Projected Maximum Inventory; i.e., less than 1 Ci has been disposed at the Landfill for all nuclides except for Tc-99 of which 1.02 Ci has been disposed of as of May 21, 2010. As a result, the values for the two Projected Inventories are the same for all nuclides except for Tc-99 when rounded to two significant figures.

If individual shipments are allowed to exceed the derived soil guidelines, radionuclide inventory management is critical in order to ensure that target dose constraints and limits are met when the C-746-U Landfill closes. In application, inventory management should use actual volumes and densities rather than a priori values. 
DOSE MODELING EVALUATIONS AND TECHNICAL

SUPPORT DOCUMENT FOR THE AUTHORIZED

LIMITS REQUEST FOR THE C-746-U LANDFILL AT THE PADUCAH GASEOUS DIFFUSION PLANT

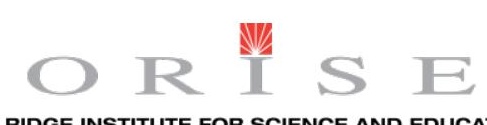

OAK RIDGE INSTITUTE FOR SCIENCE AND EDUCATION

8.0: References

8.0: REFERENCES

This report and the dose modeling it describes were supported by many regulatory, guidance, site-specific, and additional background documents. A listing of pertinent documents reviewed for this project is provided in this section.

\section{REGULATORY AND GUIDANCE-BASED}

10 CFR 20, Standards for Protection Against Radiation. Code of Federal Regulations (CFR), Title 10, Energy, Part 20, Subpart E, "Radiological Criteria for License Termination" (current version), U.S. Nuclear Regulatory Commission, Washington, DC.

10 CFR 835, Occupational Radiation Protection, (revised rule 2007). Code of Federal Regulations (CFR), Title 10, Energy, Part 835, U. S. Department of Energy, Washington, DC.

401 KAR 47, Kentucky Administrative Regulations, Title 401, Energy and Environment Cabinet Department for Environmental Protection, Chapter 47, Solid W aste Facilities.

401 KAR 48, Kentucky Administrative Regulations, Title 401, Energy and Environment Cabinet Department for Environmental Protection, Chapter 48, Standards for Solid Waste Facilities.

902 KAR 100:042, Kentucky Administrative Regulations, Title 902, Cabinet for Health and Family Services Department for Public Health, Chapter 100:042, Radiology: Decommissioning and Financial Surety.

DOE 1989. A Manual for Implementing Residual Radioactive Material Guidelines, DOE/CH/8901 (ANL/ES-160), U. S. Department of Energy, Office of Remedial Action and Waste Technology, June.

DOE 1999a. The Long-Term Control of Property: Overview of Requirements in Orders DOE 5400.1 and DOE 5400.5, DOE EH-412-0014/1099, U. S. Department of Energy, Washington, DC, October.

DOE 1999b. Implementation Guide for Use with DOE M 435.1-1, Radioactive W aste Management Manual, DOE G 435.1-1, U. S. Department of Energy, Washington, DC, July.

DOE 1993. Radiation Protection of the Public and the Environment, DOE Order 5400.5 (Chg 2), U. S. Department of Energy, Washington, DC, January.

DOE 2001a. Radioactive Waste Management, DOE Order 435.1 (Chg 1), U. S. Department of Energy, Washington, DC, August.

DOE 2001b. Radioactive Waste Management Manual, DOE M 435.1-1, U. S. Department of Energy, Washington, DC, June. 
DOSE MODELING EVALUATIONS AND TECHNICAL

SUPPORT DOCUMENT FOR THE AUTHORIZED

LIMITS REQUEST FOR THE C-746-U LANDFILL AT THE PADUCAH GASEOUS DIFFUSION PLANT

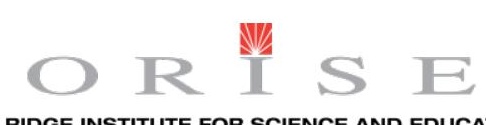

OAK RIDGE INSTITUTE FOR SCIENCE AND EDUCATION

\section{0: References}

DOE 2002. Implementation Guide: Control and Release of Property with Residual Radioactive Material for use with DOE 5400.5, Radiation Protection of the Public and the Environment, DOE G 441.1-XX, U. S. Department of Energy, Washington, DC, April.

DOE 2008. Environmental Protection Program, DOE Order 450.1A, U. S. Department of Energy, Washington, DC, June.

DOE 2011. Radiation Protection of the Public and the Environment, DOE Order 458.1, U. S. Department of Energy, Washington, DC, February.

EPA 1997. Establishment of Cleanup Levels for CERCLA Sites with Radioactive Contamination, Office of Solid Waste and Emergency Response (OSWER) No. 9200.4-18, U.S. Environmental Protection Agency, Washington, DC, August.

Gelles, C. 2009. Disposition of Low-Activity Waste within the U.S. Department of Energy, presentation at the Waste Management Conference, March.

ICRP 1985. Principles of Monitoring for the Radiation Protection of the Population, ICRP Publication 43, Annals of the ICRP, Vol. 15, No.1.

ICRP 1991. 1990 Recommendations of the International Commission on Radiological Protection, ICRP Publication 60, Annals of the ICRP, Vol. 21, No. 1-3.

ICRP 1994. Dose Coefficients for Intakes of Radionuclides by Workers, ICRP Publication 68, Annals of the ICRP, Vol. 24, No. 4.

ICRP 1995. Age-dependent Doses to the Members of the Public from Intake of Radionuclides - Part 5, Compilation of Ingestion and Inhalation Coefficients, ICRP Publication 72, Annals of the ICRP, Vol. 26, No. 1.

Kentucky Energy and Environment Cabinet, Department of Environmental Conservation, Division of Waste Management, Solid Waste Permit \#: SW07300014, SW07300015, SW07300045, permit issued $11 / 20 / 2008$.

NCRP 2009. Radiation Exposure of the Population of the United States, NCRP Report No. 160, Bethesda, Maryland.

MARSSIM 2001. Multi-Agency Radiation Survey and Site Investigation Manual (MARSSIM), U.S. Nuclear Regulatory Commission, NUREG-1575, Revision 1, U.S. Environmental Protection Agency, EPA 402-R-97-016 Revision 1, U.S. Department of Energy, DOE EH-0624 Revision 1,Washington, D.C. (August 2000 including June 2001 updates).

Volpe, J. 2001. Risk versus Dose Cleanup Levels (Memorandum), Kentucky Radiation Health and Toxic Agents Branch (currently the Kentucky Radiation Health Branch), March. 
DOSE MODELING EVALUATIONS AND TECHNICAL

SUPPORT DOCUMENT FOR THE AUTHORIZED

LIMITS REQUEST FOR THE C-746-U LANDFILL AT THE PADUCAH GASEOUS DIFFUSION PLANT

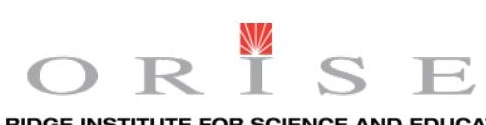

OAK RIDGE INSTITUTE FOR SCIENCE AND EDUCATION

\section{0: References}

Wallo, A. 2007. Radiological Control and Clearance of Property and DOE 5400.5-Part 835 Interface. U.S. Department of Energy, Washington, DC.

\section{SITE-SPECIFIC}

ATSDR 2002. Public Health Assessment for the Paducah Gaseous Diffusion Plant (USDOE) Paducah, McCracken County, Kentucky, May.

DOE 2001. Draft Environmental Assessment on the Implementation of the Authorized Limits Process for Waste Acceptance at the C-746-U Landfill, Paducah Gaseous Diffusion Plant, Paducah, Kentucky, March. [No DOE reference number was assigned to this document.]

DOE 2003a. Authorized Limits Request for Solid W aste Disposal at Landfill C-746-U at the Paducah Gaseous Diffusion Plant (November 2002; revised January 2003). [No DOE reference number was assigned to this document.]

DOE 2003b. Risk and Performance Evaluation of the C-746-U Landfill at the Paducab Gaseous Diffusion Plant, Paducah, Kentucky, DOE/OR/07-2041\&D2R1, U. S. Department of Energy, Paducah, KY, September.

DOE 2008. Update to the End State Vision for the Paducah Gaseous Diffusion Plant, Paducah, Kentucky, DOE/LX/07-0013\&D1, U.S. Department of Energy, Paducah, KY, February.

DOE 2009a. C-746-U Landfill inventory spreadsheet for total waste disposed from May 2003-May 2009.

DOE 2009b. Methods for Conducting Risk. Assessments and Risk Evaluations at the Paducah Gaseous Diffusion Plant Paducah, Kentucky, Volume 1. Human Health, DOE/LX/07-0107\&D1/V1, U.S. Department of Energy, Paducah, KY, July.

DOE 2009c. Statement of Work (SOW) for C-746-U Landfill provided to ORISE by DOE-PPPO in December.

DOE 2010. Seventh Year of Operation of C-746-U Landfill Under the Authorized Limits (Approved 2/6/03) May 2003-May 2010.

Kenny, J. F., N. L. Barber, S. S. Hutson, K. S. Linsey, J. K. Lovelace, and M. A. Maupin 2009. Estimated Use of Water in the United States in 2005, Circular 1344, U.S. Department of the Interior, U.S. Geological Survey.

Kentucky Radiation Health Branch 2009. Characterization and Assessment of Areas of Interest. Radiation/Environmental Monitoring Section, May.

King, D. A. and K. Keil 2006. "Comparison of Standard Radiological Risk Models and Using RESRAD to Derive Generic Risk-Based Area Factors for Final Status Surveys," Risk Analysis, Vol. 26, No. 1, pp. 175-183. 
DOSE MODELING EVALUATIONS AND TECHNICAL

SUPPORT DOCUMENT FOR THE AUTHORIZED

LIMITS REQUEST FOR THE C-746-U LANDFILL AT THE PADUCAH GASEOUS DIFFUSION PLANT

8.0: References

Lee, D. W., J. C. Wang, and D. C. Kocher 1995. Operating Limit Study for the Proposed Solid W aste Landfill at Paducah Gaseous Diffusion Plant, ORNL/TM-13008, Oak Ridge National Laboratory, Oak Ridge, TN, June.

ORAU 2007. Paducah Gaseous Diffusion Plant_Site Description, ORAU-TKBS-0019-2, Oak Ridge Associated Universities, Oak Ridge, TN, May.

ORISE 2010. Project Communications with DOE-PPPO and DOE support contractors (January-August).

PRS 2008a. Paducah Site Annual Site Environmental Report for Calendar Year 2006, PRS-ENM-0034 Volume I, Paducah Remediation Services, LLC, Paducah, KY, September.

PRS 2008b. Waste Acceptance Criteria for the Treatment, Storage and Disposal Facilities at the Paducah U.S. Department of Energy Site, PRS-WSD-0011, Paducah Remediation Services, LLC, Paducah, $\mathrm{KY}$, April.

Wischmeier, W. H., and D. D. Smith 1978. Predicting Rainfall Erosion Losses: A Guide to Conservation Planning, U.S. Department of Agriculture, Agriculture Handbook No. 537, December.

University of Kentucky 2007. Assessment of Radiation in Surface Water at the Paducab Gaseous Diffusion Plant, Kentucky Water Resources Research Institute, January. 
DOSE MODELING EVALUATIONS AND TECHNICAL

SUPPORT DOCUMENT FOR THE AUTHORIZED

LIMITS REQUEST FOR THE C-746-U LANDFILL AT THE PADUCAH GASEOUS DIFFUSION PLANT

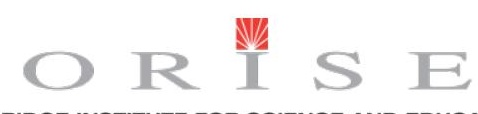

OAK RIDGE INSTITUTE FOR SCIENCE AND EDUCATION

\section{0: References}

\section{COMPUTATIONAL DOSE MODELING AND PARAMETERIZATION METHODS}

Army Corps of Engineers 2002. White Paper: Using RESRAD in a CERCLA Radiological Risk Assessment, Buffalo District Office, Formerly Utilized Sites Remedial Action Program, Buffalo, NY, October.

Beyeler, W. E., W. A. Hareland, F. A. Durán, T. J. Brown, E. Kalinina, D. P. Gallegos, P. A. Davis and C. Daily 1999. Residual Radioactive Contamination from Decommissioning, Parameter Analysis (Draft), NUREG/CR-5512 Vol. 3 (SAND99-2148), U.S. Nuclear Regulatory Commission, Washington, DC, August.

EPA1999a. Understanding Variation in Partition Coefficient, $K_{d} V$ alues, Volume 1, EPA 402-R-99-0004A, U.S. Environmental Protection Agency, Washington, DC, August.

EPA1999b. Understanding Variation in Partition Coefficient, $K_{d}$ Values, Volume 2, EPA 402-R-99-0004B, U.S. Environmental Protection Agency, Washington, DC, August.

Haaker, R. et al. 1999. Comparison of the Models and Assumptions used in the DandD 1.0, RESRAD 5.61, and RESRAD-Build 1.50 Computer Codes with Respect to the Residential Farmer and Industrial Occupant Scenarios Provided in NUREG/CR-5512, (Draft), NUREG/CR-5512, Vol. 4 (SAND99-2147), U.S. Nuclear Regulatory Commission, Washington, DC, August.

Kamboj, S., D. LePoire, E. Gnanapragasam, B. M. Biwer, J. Cheng, J. Arnish, C. Yu, and S. Y. Chen. 2000. Probabilistic Dose Analysis Using Parameter Distributions Developed for RESRAD and for RESRAD-BUILD Codes, NUREG/CR-6676 (ANL/EAD/TM-89), U.S. Nuclear Regulatory Commission, Washington, DC, May.

Kamboj, S., J.-J. Cheng and C. Yu . 2005. "Deterministic vs. Probabilistic Analyses to Identify Sensitive Parameters in Dose Assessment Using RESRAD”, Health Physics, Vol. 88, No. 5, pp. S104-S109.

Kennedy, W. E, and D. L. Strenge 1992. Residual Radioactive Contamination from Decommissioning, Technical Basis for Translating Contamination Levels to Annual Total Effective Dose Equivalent (Final) NUREG/CR-5512, Vol. 1 (PNL-7994), U.S. Nuclear Regulatory Commission, Washington, DC, September.

Napier, B. A., W. E. Kennedy, T. A. Ikenberry, M. M. Hunacek and A. M. Kennedy 2004. Technical Basis for the Derivation of Authorized Limits for Units of the Hanford Reach National Monument, PNNL-14531, Pacific Northwest National Laboratory, Richland, WA, March.

Robinson, D. G. 1998. A Survey of Probabilistic Methods Used in Reliability, Risk and Uncertainty Analysis: Analytical Techniques I, SAND98-1189, Sandia National Laboratories, Albuquerque, NM, June. 
DOSE MODELING EVALUATIONS AND TECHNICAL

SUPPORT DOCUMENT FOR THE AUTHORIZED

LIMITS REQUEST FOR THE C-746-U LANDFILL AT THE PADUCAH GASEOUS DIFFUSION PLANT

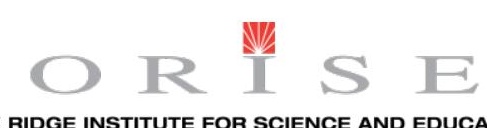

OAK RIDGE INSTITUTE FOR SCIENCE AND EDUCATION

\section{0: References}

Sheppard, M. I., and D. H Thibault 1990. "Default Soil Solid/Liquid Partition Coefficients, Kds, for Four Major Soil Types: A Compendium,” Health Physics, Vol. 59. No. 4, p. 471.

Wolbarst, A. B., B. M. Biwer, R. Cady, S.-Y. Chen, S. Domotor, P. Egidi, D. J. LePoire, T. Mo, J. Peterson, and S. Walker 2005. "ISCORS Catalog of References to Parameter Values and Distributions Used in Environmental Pathway Modeling for Cleanup of Sites Contaminated with Radioactivity," Health Physics, Vol. 89, No. 5, pp. S91-S99.

Yu ,C., C. Loureiro, J. J. Cheng, L. G. Jones, Y. Y. Wang, Y. P. Chia, and E. Faillace 1993. Data Collection Handbook to Support Modeling Impacts of Radioactive Material in Soil, ANL/EAIS-8, Argonne National Laboratory, Environmental Assessment and Information Sciences Division, Argonne, IL, April.

Yu, C, D. LePoire, E. Gnanapragasam, J. Arnish, S. Kamboj, B. M. Biwer, J.-J. Cheng, A. Zielen, and S.Y. Chen 2000. Development of Probabilistic RESRAD 6.0 and RESRAD-BUILD 3.0 Computer Codes, NUREG/CR-6697 (ANL/EAD/TM-98), U.S. Nuclear Regulatory Commission, Washington, DC, November.

Yu, C., A. J. Zielen, J. J. Cheng, D. J. LePoire, E. Gnanapragasam, S. Kamboj, J. Arnish, A. Wallo, III, W. A. Williams, and H. Peterson 2001. User's Manual for RESRAD Version 6, ANL/EAD-4, Argonne National Laboratory, Environmental Assessment Division, Argonne, IL, July.

Yu, C., E. Gnanapragasam, J-J. Cheng, and B. M Biwer 2006. Benchmarking of RESRAD-OFFSITE: Transition from RESRAD to RESR AD-OFFSITE and Comparison of the RESRAD-OFFSITE Predictions with Peer Codes, ANL/EVS/TM/06-3 (DOE/EH-0708), Argonne National Laboratory, Environmental Science Division, Argonne, IL, May.

Yu, C., E. Gnanapragasam, B. M. Biwer, S. Kamboj, J. J. Cheng, T. Klett, D. LePoire, A. J. Zielen, S. Y. Chen, W. A. Williams, A. Wallo, S. Domotor, T. Mo, and A. Schwartzman 2007. User's Manual for RESRAD-OFFSITE V ersion 2, ANL/EVS/TM/07-1 (DOE/HS-0005, NUREG/CR-6937), Argonne National Laboratory, Environmental Science Division, Argonne, IL, June.

Yu, C. et al. 2009. RESRAD for Windows, Version 6.5, Computer Modeling Code, Argonne National Laboratory, Environmental Assessment Division, Argonne, IL, October.

Yu, C. et al. 2009. RESRAD-OFFSITE for Windows, Version 2.5, Computer Modeling Code, Argonne National Laboratory, Environmental Assessment Division, Argonne, IL, October. 
DOSE MODELING EVALUATIONS AND TECHNICAL SUPPORT DOCUMENT FOR THE AUTHORIZED LIMITS REQUEST FOR THE C-746-U LANDFILL AT THE PADUCAH GASEOUS DIFFUSION PLANT

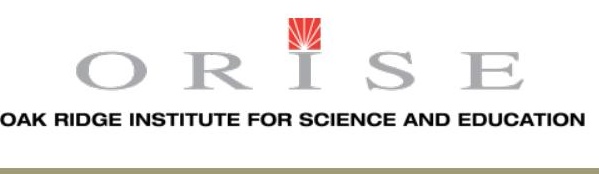

Appendix A: RESRAD Table of Input Parameters for the C-746-U Landfill Onsite Receptor Scenario 
THIS PAGE INTENTIONALLY LEFT BLANK 
RESRAD Table of Input Parameters for the C-746-U Landfill Onsite Receptor Scenarios

\begin{tabular}{|c|c|c|c|c|c|c|c|c|c|}
\hline $\begin{array}{c}\text { Input Screen Title } \\
\text { and Parameter } \\
\text { Name }\end{array}$ & Unit & $\begin{array}{c}\text { Code } \\
\text { Default } \\
\text { Value }\end{array}$ & $\begin{array}{c}\text { Code- } \\
\text { Accepted } \\
\text { Values }^{a}\end{array}$ & Receptor ${ }^{b}$ & $\begin{array}{c}\text { Deterministic } \\
\text { Value }\end{array}$ & Type $^{c}$ & Priority $^{d}$ & Justification & References \\
\hline \multicolumn{10}{|l|}{ Source } \\
\hline $\begin{array}{c}\text { Radionuclide } \\
\text { concentration }\end{array}$ & $\mathrm{pCi} / \mathrm{g}$ & $\begin{array}{l}100 \text { (Nuclide } \\
\text { specific) }\end{array}$ & Site specific & All & $\begin{array}{c}\text { Unit } \\
\text { concentration for: } \\
\text { Am-241 } \\
\text { Cs-137 } \\
\text { Np-237 } \\
\text { Pu-238 } \\
\text { Pu-239 } \\
\text { Pu-240 } \\
\text { Tc-99 } \\
\text { Th-228 } \\
\text { Th-230 } \\
\text { Th-232 } \\
\text { U-234 } \\
\text { U-235 } \\
\text { U-238 }\end{array}$ & $P$ & 2 & $\begin{array}{l}\text { The radionuclide concentration used is } 1 \mathrm{pCi} / \mathrm{g} \\
\text { for each parent radionuclide listed. Site- } \\
\text { specific values for the 6-year waste inventory } \\
\text { (May } 2003 \text { - May 2009) were not used as } \\
\text { input values. The list of radionuclides used } \\
\text { was provided to ORISE by DOE. Radioactive } \\
\text { secular equilibrium was not assumed in the } \\
\text { analysis for the uranium, actinium, and } \\
\text { thorium decay series due to the nature of the } \\
\text { PGDP's uranium enrichment mission. }\end{array}$ & $\begin{array}{c}\text { DOE 2003a } \\
\text { DOE SOW for } \\
\text { C-746-U landfill } \\
\text { and DOE } \\
\text { Project } \\
\text { Communication } \\
\text { (May 2010) }\end{array}$ \\
\hline
\end{tabular}

Transport Factors

\begin{tabular}{|c|c|c|c|c|c|c|c|c|c|}
\hline $\begin{array}{c}\text { Distribution } \\
\text { coefficients: } \\
\text { contaminated zone }\end{array}$ & $\mathrm{cm}^{3} / \mathrm{g}$ & $\begin{array}{l}\text { Nuclide } \\
\text { Specific } \\
\text { (Default } \\
\text { values } \\
\text { available) }\end{array}$ & $\begin{array}{l}\text { Nuclide } \\
\text { Specific }\end{array}$ & All & $\begin{array}{l}\text { Nuclide Specific } \\
\text { (See Attachment I) }\end{array}$ & $P$ & 1 & $\begin{array}{l}\text { Tables with site-specific distribution } \\
\text { coefficients for the parent and progeny } \\
\text { radionuclides are available in } \\
\text { Attachment I immediately following this table } \\
\text { of parameters. }\end{array}$ & $\begin{array}{c}\text { DOE 2003b } \\
\text { Table Att. 1, } \\
\text { page C3-314, } \\
\text { Table C.3.1., } \\
\text { page C3-301 } \\
\\
\text { DOE Project } \\
\text { Communication } \\
\text { (March 2010) }\end{array}$ \\
\hline $\begin{array}{c}\text { Distribution } \\
\text { coefficients: } \\
\text { unsaturated zones }\end{array}$ & $\mathrm{cm}^{3} / \mathrm{g}$ & $\begin{array}{l}\text { Nuclide } \\
\text { Specific } \\
\text { (Default } \\
\text { values } \\
\text { available) }\end{array}$ & $\begin{array}{l}\text { Nuclide } \\
\text { Specific }\end{array}$ & All & $\begin{array}{l}\text { Nuclide Specific } \\
\text { (See Attachment I) }\end{array}$ & $P$ & 1 & $\begin{array}{l}\text { Tables with site-specific distribution } \\
\text { coefficients for the parent and progeny } \\
\text { radionuclides are available in } \\
\text { Attachment I immediately following this table } \\
\text { of parameters. }\end{array}$ & $\begin{array}{c}\text { DOE 2003b } \\
\text { Table Att. 1, } \\
\text { page C3-314, } \\
\text { Table C.3.1., } \\
\text { page C3-301 } \\
\\
\text { DOE Project } \\
\text { Communication } \\
\text { (March 2010) }\end{array}$ \\
\hline $\begin{array}{c}\text { Distribution } \\
\text { coefficients: saturated } \\
\text { zones }\end{array}$ & $\mathrm{cm}^{3} / \mathrm{g}$ & $\begin{array}{l}\text { Nuclide } \\
\text { Specific } \\
\text { (Default } \\
\text { values }\end{array}$ & $\begin{array}{l}\text { Nuclide } \\
\text { Specific }\end{array}$ & All & $\begin{array}{l}\text { Nuclide Specific } \\
\text { (See Attachment I) }\end{array}$ & $P$ & 1 & $\begin{array}{l}\text { Tables with site-specific distribution } \\
\text { coefficients for the parent and daughter } \\
\text { radionuclides are available in } \\
\text { Attachment I immediately following this table }\end{array}$ & $\begin{array}{l}\text { DOE 2003b } \\
\text { Table Att. 1, } \\
\text { page C3-314, } \\
\text { Table C.3.1., }\end{array}$ \\
\hline
\end{tabular}


RESRAD Table of Input Parameters for the C-746-U Landfill Onsite Receptor Scenarios

\begin{tabular}{|c|c|c|c|c|c|c|c|c|c|}
\hline $\begin{array}{c}\text { Input Screen Title } \\
\text { and Parameter } \\
\text { Name }\end{array}$ & Unit & $\begin{array}{c}\text { Code } \\
\text { Default } \\
\text { Value }\end{array}$ & $\begin{array}{c}\text { Code- } \\
\text { Accepted } \\
\text { Values }^{a}\end{array}$ & Receptor ${ }^{b}$ & $\begin{array}{l}\text { Deterministic } \\
\text { Value }\end{array}$ & Type $^{c}$ & Priority $^{d}$ & Justification & References \\
\hline & & available) & & & & & & of parameters. & $\begin{array}{c}\text { page C3-301, } \\
\text { Table 4.7, } \\
\text { page 4-21 } \\
\\
\text { DOE Project } \\
\text { Communication } \\
\text { (March 2010) }\end{array}$ \\
\hline $\begin{array}{c}\text { Number of } \\
\text { unsaturated zones }\end{array}$ & $-{ }^{e}$ & 1 & $\begin{array}{l}0-5 \\
\text { (integer } \\
\text { value) }\end{array}$ & All & 5 & $P$ & 3 & $\begin{array}{l}\text { There are five unsaturated zones (UZ) } \\
\text { considered for receptors evaluated during the } \\
\text { Operational Period and the Post-Institutional } \\
\text { Control Period. These correspond to the } \\
\text { layers under waste. The maximum number of } \\
\text { layers accepted by the code is five. } \\
\text { Only the Landfill Worker and the Trespasser } \\
\text { are evaluated during the Operational Period, } \\
\text { the other receptors are evaluated during the } \\
\text { Post-Institutional Control Period. } \\
\text { It is important to note that even though the } \\
\text { UZ values input into the code correspond to } \\
\text { each receptor in accordance to its period of } \\
\text { evaluation, the UZ parameters will not be } \\
\text { applicable for the Trespasser, Outdoor } \\
\text { Worker, Recreational User or the Landfill } \\
\text { Worker. This is because the pathways } \\
\text { considering the UZ are suppressed as per the } \\
\text { conceptual site model. } \\
\text { Below are the five zones considered: } \\
\text { UZ 1= Protective layer (native soil) } \\
\text { UZ 2= Gravel layer } \\
\text { UZ } 3=\text { Clay barrier } \\
\text { UZ } 4=\text { Alluvium soils (native/subgrade) } \\
\text { UZ } 5=\text { Clay confining unit (native) }\end{array}$ & $\begin{array}{c}\text { DOE } 2003 \mathrm{~b} \\
\text { Fig. 4.3, } \\
\text { page 4-16, } \\
\text { Table 4.4, } \\
\text { page 4-9, } \\
\text { Fig. 4.5, } \\
\text { page 4-18, } \\
\text { Table Att.2, } \\
\text { page C3-315, }\end{array}$ \\
\hline $\begin{array}{l}\text { Time since placement } \\
\text { of material }\end{array}$ & $\mathrm{yr}$ & 0 & $0-100$ & All & 27 & $P$ & 3 & $\begin{array}{l}\text { It is assumed that waste material was initially } \\
\text { placed in the landfill on May } 2003 \text { and that } \\
\text { the landfill will close in } 2030 .\end{array}$ & $\begin{array}{c}\text { DOE Project } \\
\text { Communication } \\
\text { with DOE-PPPO } \\
\text { (May 2010) }\end{array}$ \\
\hline $\begin{array}{l}\text { Groundwater } \\
\text { concentration }\end{array}$ & $\mathrm{pCi} / \mathrm{L}$ & $\begin{array}{l}0^{f} \text { (Nuclide } \\
\text { specific) }\end{array}$ & $0-1 E+34$ & All & 0 & $\mathrm{P}$ & 3 & $\begin{array}{l}\text { The default value is assigned; however, it is } \\
\text { not used by the code. This parameter is one of } \\
\text { the options in RESRAD to derive distribution }\end{array}$ & Yu et al. 2001 \\
\hline
\end{tabular}


RESRAD Table of Input Parameters for the C-746-U Landfill Onsite Receptor Scenarios

\begin{tabular}{|c|c|c|c|c|c|c|c|c|c|}
\hline $\begin{array}{c}\text { Input Screen Title } \\
\text { and Parameter } \\
\text { Name }\end{array}$ & Unit & $\begin{array}{c}\text { Code } \\
\text { Default } \\
\text { Value }\end{array}$ & $\begin{array}{c}\text { Code- } \\
\text { Accepted } \\
\text { Values }^{a}\end{array}$ & Receptor ${ }^{b}$ & $\begin{array}{c}\text { Deterministic } \\
\text { Value }\end{array}$ & Type $^{c}$ & Priority $^{d}$ & Justification & References \\
\hline & & & & & & & & $\begin{array}{l}\text { coefficients (Kds) when site-specific data is } \\
\text { not available. In this case site-specific Kds are } \\
\text { available and are used by the code; therefore, } \\
\text { there was no need to use this option to derive } \\
\text { them. }\end{array}$ & \\
\hline Leach rate ${ }^{g}$ & $1 / \mathrm{yr}$ & $\begin{array}{l}0 \text { (Nuclide } \\
\text { specific) }\end{array}$ & $0-1 E+34$ & All & 0 & $\mathrm{P}$ & 3 & $\begin{array}{l}\text { The default value is assigned; however, it is } \\
\text { not used by the code. This parameter is one of } \\
\text { the options in RESRAD to derive distribution } \\
\text { coefficients (Kds) when site-specific data is } \\
\text { not available. In this case site-specific Kds are } \\
\text { available and are used by the code; therefore, } \\
\text { there was no need to use this option to derive } \\
\text { them. }\end{array}$ & Yu et al. 2001 \\
\hline Solubility limit & $\mathrm{mol} / \mathrm{L}$ & $\begin{array}{l}0 \text { (Nuclide } \\
\text { specific) }\end{array}$ & $0-1 E+34$ & All & 0 & $\mathrm{P}$ & 3 & $\begin{array}{l}\text { The default value is assigned; however, it is } \\
\text { not used by the code. This parameter is one of } \\
\text { the options in RESRAD to derive distribution } \\
\text { coefficients (Kds) when site-specific data is } \\
\text { not available. In this case site-specific Kds are } \\
\text { available and are used by the code; therefore, } \\
\text { there was no need to use this option to derive } \\
\text { them. }\end{array}$ & Yu et al. 2001 \\
\hline Use plant/soil ratio & check box & Yes/No & $N A^{h}$ & All & $\begin{array}{l}\text { Box checked for } \\
\text { all except Np-237 }\end{array}$ & NA & 3 & $\begin{array}{l}\text { The default value is "checked", but the code } \\
\text { will not allow input of site specific distribution } \\
\text { coefficients for Np- } 237 \text { unless the box is } \\
\text { unchecked. Confirmed that this approach was } \\
\text { appropriate with Dr. Charley Yu, ANL. }\end{array}$ & $\begin{array}{c}\text { Project } \\
\text { Communication } \\
\text { with } \\
\text { Dr. Charley Yu } \\
\text { (April 2010) }\end{array}$ \\
\hline
\end{tabular}

Calculation Parameters

\begin{tabular}{|c|c|c|c|c|c|c|c|c|c|}
\hline \multirow{2}{*}{$\begin{array}{l}\text { Basic radiation dose } \\
\text { limit }\end{array}$} & \multirow{2}{*}{$\mathrm{mrem} / \mathrm{yr}$} & \multirow{2}{*}{25} & \multirow{2}{*}{$\begin{array}{l}1 \mathrm{E}-2- \\
1 \mathrm{E}+4\end{array}$} & $\begin{array}{c}\text { RF } \\
\text { RG } \\
\mathrm{T} \\
\mathrm{L}\end{array}$ & 100 & \multirow{2}{*}{ NA } & \multirow{2}{*}{3} & \multirow{2}{*}{$\begin{array}{l}\text { Three target dose constraints of } 1,15,25 \\
\mathrm{mrem} / \mathrm{yr} \text { and a primary dose limit of } 100 \\
\mathrm{mrem} / \mathrm{yr} \text { are considered in this project. } \\
\text { However, a target dose constraint of } 1 \\
\mathrm{mrem} / \mathrm{yr} \text { and a primary dose limit of } 100 \\
\mathrm{mrem} / \mathrm{yr} \text { are used for the RESRAD runs. } \\
\\
\text { Note that changing the basic radiation dose } \\
\text { limit in the code will not change the Dose to } \\
\text { Source Ratio (DSR) which is used in the } \\
\text { calculation for single radionuclide soil } \\
\text { guidelines. }\end{array}$} & \multirow[t]{2}{*}{$\begin{array}{l}\text { DOE SOW to } \\
\text { ORISE for } \\
\text { C-746-U } \\
\text { landfill, } \\
\text { Section 2, } \\
\text { Item 3 }\end{array}$} \\
\hline & & & & $\begin{array}{l}\text { W } \\
\mathrm{RU}\end{array}$ & 1 & & & & \\
\hline
\end{tabular}


RESRAD Table of Input Parameters for the C-746-U Landfill Onsite Receptor Scenarios

\begin{tabular}{|c|c|c|c|c|c|c|c|c|c|}
\hline $\begin{array}{c}\text { Input Screen Title } \\
\text { and Parameter } \\
\text { Name }\end{array}$ & Unit & $\begin{array}{c}\text { Code } \\
\text { Default } \\
\text { Value }\end{array}$ & $\begin{array}{l}\text { Code- } \\
\text { Accepted } \\
\text { Values }^{a}\end{array}$ & Receptor ${ }^{b}$ & $\begin{array}{c}\text { Deterministic } \\
\text { Value }\end{array}$ & Type $^{c}$ & Priority $^{d}$ & Justification & References \\
\hline \multirow[b]{2}{*}{ Times for calculations } & \multirow[b]{2}{*}{$\mathrm{yr}$} & \multirow[b]{2}{*}{$\begin{array}{c}1,3,10,30 \\
100,300 \\
1000\end{array}$} & \multirow[b]{2}{*}{$0-1 E+5$} & $\begin{array}{l}\text { RF } \\
\text { RG } \\
W \\
\text { RU } \\
\end{array}$ & $\begin{array}{c}1,50,100,500 \\
1050\end{array}$ & \multirow[b]{2}{*}{$P$} & \multirow[b]{2}{*}{3} & \multirow{2}{*}{$\begin{array}{l}\text { A time horizon of } 1,050 \text { years is used in order } \\
\text { to calculate single radionuclide soil guidelines. } \\
\text { This is assumed to allow for ingrowth and } \\
\text { decay since PGDP has been in operation for } \\
\text { about } 50 \text { years (since about } 1960 \text { to2010). } \\
\text { A time horizon of } 70 \text { years is used for the } \\
\text { Landfill Worker and the Trespasser since } \\
\text { these receptors are modeled during the } \\
\text { Operational Period of the landfill. The } \\
\text { Operational Period of the landfill is considered } \\
\text { to be } 20 \text { years per DOE 2003b and } 50 \text { years } \\
\text { are included to allow for ingrowth and decay } \\
\text { due to PGDP being in operation for about } 50 \\
\text { years. }\end{array}$} & $\begin{array}{c}\mathrm{DOE} / \mathrm{CH} / 8901 \\
\text { and } \\
\text { DOE Order } \\
5400.5\end{array}$ \\
\hline & & & & $\begin{array}{l}\mathrm{T} \\
\mathrm{L}\end{array}$ & $1,50,70$ & & & & $\begin{array}{c}\text { Communication } \\
\text { (May } 2010 \text { and } \\
\text { July 2010) } \\
\text { DOE 2003b }\end{array}$ \\
\hline
\end{tabular}

Contaminated Zone Parameters

\begin{tabular}{|c|c|c|c|c|c|c|c|c|c|}
\hline $\begin{array}{l}\text { Area of contaminated } \\
\text { zone }\end{array}$ & $\mathrm{m}^{2}$ & 10,000 & $\begin{array}{l}1 E-4- \\
1 E+15\end{array}$ & All & 89,436 & $P$ & 2 & $\begin{array}{l}\text { The contaminated zone is composed of four } \\
\text { different waste forms. The waste forms types } \\
\text { are soil, concrete, metal, and organic (lumber } \\
\text { and debris). The total waste disposal area of } \\
\text { the landfill is used as the area of the } \\
\text { contaminated zone. When filled the landfill } \\
\text { disposal area will encompass } 22.1 \text { acres } \\
\text { (approximately } 89,436 \text { square meters). } \\
\text { However, the total permitted landfill site will } \\
\text { encompass } 59.7 \text { acres. }\end{array}$ & $\begin{array}{l}\text { DOE SOW for } \\
\text { C-746-U landfill } \\
\\
\text { DOE 2003b } \\
\text { Section 3.2, } \\
\text { page 3-11, } \\
\text { Table 4.5, } \\
\text { page 4-13 }\end{array}$ \\
\hline $\begin{array}{l}\text { Thickness of } \\
\text { contaminated zone }\end{array}$ & $\mathrm{m}$ & 2 & $\begin{array}{l}1 E-5- \\
1 E+3\end{array}$ & All & 13.4 & $P$ & 2 & $\begin{array}{l}\text { This value is the average thickness for the } \\
\text { waste forms when the landfill is full. }\end{array}$ & $\begin{array}{c}\text { DOE 2003b } \\
\text { Table 4.5, } \\
\text { page 4-13, } \\
\text { Table Att.3, } \\
\text { page C3-315 } \\
\end{array}$ \\
\hline $\begin{array}{l}\text { Length parallel to } \\
\text { aquifer flow }\end{array}$ & $\mathrm{m}$ & 100 & $\begin{array}{l}1 E-4- \\
1 E+6\end{array}$ & All & 399 & $P$ & 2 & $\begin{array}{l}\text { This value of } 399 \mathrm{~m} \text { is the conservative longest } \\
\text { dimension between the upgradient edge of } \\
\text { the contaminated zone and the downgradient } \\
\text { edge, parallel to the aquifer. }\end{array}$ & $\begin{array}{l}\text { Lee et al. } 1995 \\
\text { Fig 2-4, page } 17\end{array}$ \\
\hline
\end{tabular}

Cover and Contaminated Zone Hydrological Data 
RESRAD Table of Input Parameters for the C-746-U Landfill Onsite Receptor Scenarios

\begin{tabular}{|c|c|c|c|c|c|c|c|c|c|}
\hline $\begin{array}{l}\text { Input Screen Title } \\
\text { and Parameter } \\
\text { Name }\end{array}$ & Unit & $\begin{array}{l}\text { Code } \\
\text { Default } \\
\text { Value }\end{array}$ & $\begin{array}{l}\text { Code- } \\
\text { Accepted } \\
\text { Values }^{a}\end{array}$ & Receptor ${ }^{b}$ & $\begin{array}{l}\text { Deterministic } \\
\text { Value }\end{array}$ & Type ${ }^{c}$ & Priority $^{d}$ & Justification & References \\
\hline Cover depth & $\mathrm{m}$ & 0 & $0-100$ & $\begin{array}{l}\text { RF } \\
\text { RG } \\
\text { W } \\
\text { RU }\end{array}$ & 0.152 & $P$ & 2 & $\begin{array}{l}\text { For receptors exposed during the Post- } \\
\text { Institutional Control Period this value is the } \\
\text { depth of the final cover planned for the } \\
\text { landfill. The landfill cover will have six layers } \\
\text { with a total thickness of } 5 \mathrm{ft} \text { ( } 1.52 \text { meters). } \\
\text { This applies to all receptors except for the } \\
\text { Trespasser and Landfill Worker. The } \\
\text { Trespasser and the Landfill Worker are } \\
\text { exposed during the Operational Period. } \\
\text { During this period the cover has a layer of } \\
\text { vegetative soil and its depth is expected to be } \\
6 \text { inches ( } 0.152 \text { meters) A cover is assumed for } \\
\text { the Trespasser; however, no cover is assumed } \\
\text { for the Landfill Worker. }\end{array}$ & $\begin{array}{c}\text { DOE } 2003 b \\
\text { Section } 3.2, \\
\text { page } 3-11, \\
\text { page } 3-13, \\
\text { Fig. } 4.3, \\
\text { page } 4-16, \\
\text { Fig. } 4.5, \\
\text { page } 4-18\end{array}$ \\
\hline $\begin{array}{l}\text { Density of cover } \\
\text { material }\end{array}$ & $\mathrm{g} / \mathrm{cm} 3$ & 1.5 & $1 E-3-22.5$ & All & 1.5 & $P$ & 1 & $\begin{array}{l}\text { For receptors exposed during the Post- } \\
\text { Institutional Control Period the value for the } \\
\text { density of the cover was obtained from the } \\
\text { previous RESRAD study for the landfill } \\
\text { described in DOE 2003b. This applies to all } \\
\text { receptors except for the Trespasser and the } \\
\text { Landfill Worker. This value was also confirmed } \\
\text { with DOE to be a site specific value for the } \\
\text { final cover. The Trespasser is exposed during } \\
\text { the operational period and the density of the } \\
\text { cover is also } 1.5 \mathrm{~g} / \mathrm{cm}^{3} \text { as provided by } \\
\text { geologist and engineer. This parameter is not } \\
\text { applicable to the Landfill Worker since no } \\
\text { cover is assumed for this receptor. }\end{array}$ & $\begin{array}{c}\text { DOE 2003b } \\
\text { Table Att.5, } \\
\text { page C3-316 } \\
\text { DOE Project } \\
\text { Communication } \\
\text { with geologist } \\
\text { and engineer } \\
\text { (April 2010) }\end{array}$ \\
\hline Cover erosion rate & $\mathrm{m} / \mathrm{yr}$ & 0.001 & $0-5$ & All & 0.0006 & $P, B$ & 2 & $\begin{array}{l}\text { This value was obtained from the previous } \\
\text { RESRAD study for the landfill described in DOE } \\
\text { 2003b. }\end{array}$ & $\begin{array}{l}\text { DOE 2003b } \\
\text { Table Att.5, } \\
\text { page C3-316 }\end{array}$ \\
\hline $\begin{array}{c}\text { Density of } \\
\text { contaminated zone }\end{array}$ & $\mathrm{g} / \mathrm{cm} 3$ & 1.5 & $1 E-3-22.5$ & All & 1.89 & $\mathrm{P}$ & 1 & $\begin{array}{l}\text { The densities of the waste forms were used to } \\
\text { calculate the weighted average density for the } \\
\text { contaminated zone which is approximately } \\
1.89 \mathrm{~g} / \mathrm{cm}^{3} \text {. }\end{array}$ & $\begin{array}{l}\text { DOE } 2003 b \\
\text { Table } 4.5 \\
\text { page } 4-13\end{array}$ \\
\hline $\begin{array}{l}\text { Contaminated zone } \\
\text { total porosity }\end{array}$ & - & 0.4 & $1 E-5-1$ & All & 0.17 & $P$ & 2 & $\begin{array}{l}\text { The site-specific value available is } 0.168 \\
\mathrm{vol} / \mathrm{vol} \text {. }\end{array}$ & $\begin{array}{l}\text { DOE 2003b } \\
\text { Table 4.4, } \\
\text { page 4-9 }\end{array}$ \\
\hline $\begin{array}{l}\text { Contaminated zone } \\
\text { field capacity }\end{array}$ & - & 0.2 & $1 E-34-1$ & All & 0.07 & $P$ & 3 & $\begin{array}{l}\text { The site-specific value available is } 0.073 \\
\mathrm{vol} / \mathrm{vol} \text {. }\end{array}$ & $\begin{array}{l}\text { DOE 2003b } \\
\text { Table 4.4, } \\
\text { page 4-9 }\end{array}$ \\
\hline Contaminated zone & $\mathrm{m} / \mathrm{yr}$ & 0.001 & $0-5$ & All & 0.0006 & $P, B$ & 2 & This value was obtained from the previous & DOE 2003b \\
\hline
\end{tabular}


RESRAD Table of Input Parameters for the C-746-U Landfill Onsite Receptor Scenarios

\begin{tabular}{|c|c|c|c|c|c|c|c|c|c|}
\hline $\begin{array}{c}\text { Input Screen Title } \\
\text { and Parameter } \\
\text { Name }\end{array}$ & Unit & $\begin{array}{c}\text { Code } \\
\text { Default } \\
\text { Value }\end{array}$ & $\begin{array}{l}\text { Code- } \\
\text { Accepted }^{a} \\
\text { Values }^{a}\end{array}$ & Receptor ${ }^{b}$ & $\begin{array}{c}\text { Deterministic } \\
\text { Value }\end{array}$ & Type $^{c}$ & Priority $^{d}$ & Justification & References \\
\hline erosion rate & & & & & & & & $\begin{array}{l}\text { RESRAD study for the landfill described in DOE } \\
\text { 2003b. }\end{array}$ & $\begin{array}{l}\text { Table Att.3, } \\
\text { page C3-315 }\end{array}$ \\
\hline $\begin{array}{c}\text { Contaminated zone } \\
\text { hydraulic conductivity }\end{array}$ & $\mathrm{m} / \mathrm{yr}$ & 10 & $\begin{array}{l}1 E-3- \\
1 E+10\end{array}$ & All & 315.4 & $P$ & 2 & $\begin{array}{l}\text { The hydraulic conductivity for waste forms 1-4 } \\
\text { is } 1.0 \mathrm{E}-3 \mathrm{~cm} / \mathrm{s} \text { (approximately } 315.4 \mathrm{~m} / \mathrm{yr} \text { ). }\end{array}$ & $\begin{array}{l}\text { DOE 2003b } \\
\text { Fig. 4.5, } \\
\text { page 4-18 }\end{array}$ \\
\hline $\begin{array}{l}\text { Contaminated zone b } \\
\text { parameter }\end{array}$ & - & 5.3 & $0-15$ & All & 4.05 & $P$ & 2 & $\begin{array}{l}\text { DOE geologist determined that the most } \\
\text { appropriate value for the contaminated zone } \\
\text { b parameter available in Yu et al. } 1993 \text { is the } \\
\text { one for sand. It is known that the } \\
\text { contaminated zone (waste) will have high } \\
\text { porosity and high permeability. When } \\
\text { selecting a deterministic value for this input } \\
\text { parameter, the closest material and } \\
\text { corresponding Soil b Parameter, as developed } \\
\text { by Clapp and Hornberger (Yu et al. 1993), for } \\
\text { concrete, steel and soil waste is sand. Clapp \& } \\
\text { Hornberger do not offer a corresponding Soil } \\
\text { b Parameter for landfill waste. }\end{array}$ & $\begin{array}{c}\text { Yu et al. } 1993 \\
\text { page } 83 \\
\text { DOE Project } \\
\text { Communication } \\
\text { with geologist } \\
\text { (July 2010) }\end{array}$ \\
\hline \multirow{4}{*}{$\begin{array}{l}\text { Evapotranspiration } \\
\text { coefficient }\end{array}$} & \multirow{4}{*}{-} & \multirow{4}{*}{0.5} & \multirow{4}{*}{$0-0.999$} & $\begin{array}{l}\mathrm{RF} \\
\mathrm{RG}\end{array}$ & 0.74 & \multirow{4}{*}{$P$} & \multirow{4}{*}{2} & $\begin{array}{l}\text { The value for the Resident Farmer, Resident } \\
\text { Gardener, Worker and Recreational User were } \\
\text { calculated using the HELP Output data for the } \\
\text { Post-Institutional Control Period. }\end{array}$ & \multirow{4}{*}{$\begin{array}{c}\text { DOE } 2003 \mathrm{~b} \\
\text { pages, C3-93, } \\
\text { C3-243 } \\
\text { Yu et al. } 1993 \\
\text { page } 78\end{array}$} \\
\hline & & & & $\begin{array}{l}\text { W } \\
\text { RU }\end{array}$ & 0.83 & & & $\begin{array}{l}\text { The value for the Trespasser and the Landfill } \\
\text { Worker was calculated using the HELP Output } \\
\text { data for the Operational Period. }\end{array}$ & \\
\hline & & & & & & & & $\begin{array}{l}\text { The equation used to calculate these values is } \\
\text { available in Yu et al. } 1993 . \\
\text { The calculations are available in Attachment II } \\
\text { following this table. }\end{array}$ & \\
\hline & & & & $\begin{array}{l}\mathrm{T} \\
\mathrm{L}\end{array}$ & 0.69 & & & $\begin{array}{l}\text { The code initially did not run when using an } \\
\text { irrigation rate of } 0.1 \mathrm{~m} / \mathrm{yr} \text { and an } \\
\text { evapotranspiration coefficient of } 0.74 \text { for the } \\
\text { Resident Farmer. It generated an output file } \\
\text { with instructions to make appropriate } \\
\text { changes in order for it run. Adjustments had } \\
\text { to be made to the code's graphic points and } \\
\text { the number of dose points. The RESRAD } \\
\text { output file with the instructions is available in } \\
\text { Attachment III following this table. }\end{array}$ & \\
\hline
\end{tabular}


RESRAD Table of Input Parameters for the C-746-U Landfill Onsite Receptor Scenarios

\begin{tabular}{|c|c|c|c|c|c|c|c|c|c|}
\hline $\begin{array}{c}\text { Input Screen Title } \\
\text { and Parameter } \\
\text { Name }\end{array}$ & Unit & $\begin{array}{c}\text { Code } \\
\text { Default } \\
\text { Value }\end{array}$ & $\begin{array}{c}\text { Code- } \\
\text { Accepted } \\
\text { Values }^{a}\end{array}$ & Receptor $^{b}$ & $\begin{array}{l}\text { Deterministic } \\
\text { Value }\end{array}$ & Type $e^{c}$ & Priority $^{d}$ & Justification & References \\
\hline Wind speed & $\mathrm{m} / \mathrm{s}$ & 2 & $1 E-4-20$ & All & 4.5 & $\mathrm{P}$ & 2 & $\begin{array}{l}\text { The average prevailing wind at the PGDP is } \\
\text { from the south to southwest at approximately } \\
10 \mathrm{mph} \text { ( } 4.5 \text { meters/seconds). }\end{array}$ & $\begin{array}{l}\text { PRS } 2008 \\
\text { page 1-4 }\end{array}$ \\
\hline Precipitation rate & $\mathrm{m} / \mathrm{yr}$ & 1 & $0-10$ & All & 1.24 & $\mathrm{P}$ & 2 & $\begin{array}{l}\text { The yearly precipitation averages about } 49 \\
\text { inches ( } 1.24 \text { meters). }\end{array}$ & $\begin{array}{l}\text { PRS } 2008 \\
\text { page } 1-4\end{array}$ \\
\hline Irrigation rate & $\mathrm{m} / \mathrm{yr}$ & 0.2 & $0-10$ & $\begin{array}{l}\text { W } \\
\text { RU } \\
\text { T } \\
\text { L }\end{array}$ & 0.1 & B & 3 & $\begin{array}{l}\text { Irrigation in the Paducah, Kentucky area is } \\
\text { considered to be unlikely. In the event } \\
\text { irrigation is necessary, the water will primarily } \\
\text { come from uncontaminated surface water } \\
\text { and not from groundwater (well). Information } \\
\text { from the USGS shows that surface water is the } \\
\text { main source of water used in Kentucky for } \\
\text { irrigation (Kenny et al. 2009). The Paducah } \\
\text { area (i.e., where PGDP is located) receives } \\
\text { about an average of } 49 \text { inches (1.24 m) of } \\
\text { precipitation per year (PRS 2008). According } \\
\text { to ATSDR 2002, the farms in McCracken } \\
\text { County, KY (i.e., where Paducah is located) } \\
\text { rely on rainfall to water their crops. For } \\
\text { conservatism in the modeling, and as } \\
\text { recommended by DOE-PPPO, it was assumed } \\
\text { that the Resident Farmer uses contaminated } \\
\text { well water for irrigation of agricultural areas } \\
\text { (i.e., fruit, grain, non-leafy and leafy } \\
\text { vegetables). However, due to limitations in } \\
\text { the RESRAD (onsite) code, the Resident } \\
\text { Farmer (onsite) scenario includes irrigation of } \\
\text { fodder besides the agricultural areas. } \\
\text { Alternatively, the Resident Gardener uses } \\
\text { water for irrigation of plants (i.e., fruit, grain, } \\
\text { non-leafy and leafy vegetables) from an } \\
\text { uncontaminated source (e.g., municipal water } \\
\text { source). Even though this receptor is modeled } \\
\text { with RESRAD (onsite), irrigation of fodder will } \\
\text { not be included for this receptor because the } \\
\text { meat and milk ingestion pathways are } \\
\text { excluded in this receptor scenario. An } \\
\text { irrigation rate of } 0.1 \text { m/yr is used for the } \\
\text { Resident Farmer (onsite), and the Resident } \\
\text { Gardener. } \\
\text { An irrigation rate of } 0 \text { m/yr or no irrigation is }\end{array}$ & $\begin{array}{c}\text { DOE Project } \\
\text { Communication } \\
\text { with DOE-PPPO } \\
\text { (April 2011) } \\
\text { Kenny et al. } \\
2009 \\
\\
\text { ATSDR } 2002 \\
\text { page } 8\end{array}$ \\
\hline
\end{tabular}


RESRAD Table of Input Parameters for the C-746-U Landfill Onsite Receptor Scenarios

\begin{tabular}{|c|c|c|c|c|c|c|c|c|c|}
\hline $\begin{array}{l}\text { Input Screen Title } \\
\text { and Parameter } \\
\text { Name }\end{array}$ & Unit & $\begin{array}{l}\text { Code } \\
\text { Default } \\
\text { Value }\end{array}$ & $\begin{array}{l}\text { Code- } \\
\text { Accepted }^{a} \\
\text { Values }^{a}\end{array}$ & Receptor ${ }^{b}$ & $\begin{array}{c}\text { Deterministic } \\
\text { Value }\end{array}$ & Type ${ }^{c}$ & Priority $^{d}$ & Justification & References \\
\hline & & & & & & & & $\begin{array}{l}\text { assumed for the Landfill Worker, Trespasser, } \\
\text { Recreational User, and Outdoor Worker. } \\
\text { The code initially did not run when using an } \\
\text { irrigation rate of } 0.1 \mathrm{~m} / \mathrm{yr} \text { and an } \\
\text { evapotranspiration coefficient of } 0.74 \text { for the } \\
\text { Resident Farmer. It generated an output file } \\
\text { with instructions to make appropriate } \\
\text { changes in order for it run. Adjustments had } \\
\text { to be made to the code's graphic points and } \\
\text { the number of dose points. The RESRAD } \\
\text { output file with the instructions is available in } \\
\text { Attachment III following this table. }\end{array}$ & \\
\hline Irrigation mode & - & Overhead & $\begin{array}{l}\text { Overhead/ } \\
\text { ditch }\end{array}$ & All & Overhead & B & 3 & $\begin{array}{l}\text { The default input is used. } \\
\text { Irrigation is not applicable for the Workers, } \\
\text { Recreational User, or the Trespasser. In order } \\
\text { to suppress this parameter for these } \\
\text { receptors only the following pathways are } \\
\text { used: external gamma, inhalation, and soil } \\
\text { ingestion. }\end{array}$ & Yu et al. 2001 \\
\hline Runoff coefficient & - & 0.2 & $0-1$ & $\begin{array}{l}\text { RF } \\
\text { RG } \\
\text { W } \\
\text { RU }\end{array}$ & 0.34 & & 2 & $\begin{array}{l}\text { The values for the Resident Farmer, Resident } \\
\text { Gardener, Outdoor Worker and Recreational } \\
\text { User were calculated using the HELP Output } \\
\text { data for the Post-Institutional Control Period. } \\
\text { The value for the Trespasser and Landfill } \\
\text { Worker was calculated using the HELP Output } \\
\text { data for the Operational Period. } \\
\text { The equation used to calculate these values is } \\
\text { available in Yu et al. 1993. } \\
\text { The calculations are available in Attachment II } \\
\text { following this table. }\end{array}$ & $\begin{array}{c}\text { DOE } 2003 \mathrm{~b} \\
\text { pages C3-93, } \\
\text { C3-243 } \\
\text { Yu et al. } 1993 \\
\text { page } 73\end{array}$ \\
\hline $\begin{array}{l}\text { Watershed area for } \\
\text { nearby stream or pond }\end{array}$ & $\mathrm{m}^{2}$ & $1,000,000$ & $\begin{array}{l}1 E-4- \\
1 E+34\end{array}$ & All & $1,000,000$ & & 3 & $\begin{array}{l}\text { This parameter refers to the site-specific area } \\
\text { that drains into the nearby pond. } \\
\text { A default value is assumed. } \\
\text { No site-specific value available. }\end{array}$ & Yu et al. 2001 \\
\hline $\begin{array}{l}\text { Accuracy for water } \\
\text { soil computation }\end{array}$ & - & 0.001 & $0-0.1$ & All & 0.001 & NA & 3 & $\begin{array}{l}\text { This parameter refers to the fractional } \\
\text { accuracy desired (convergence criterion) in } \\
\text { the Romberg integration used to obtain } \\
\text { water/soil concentration ratios. }\end{array}$ & Yu et al. 2001 \\
\hline
\end{tabular}


RESRAD Table of Input Parameters for the C-746-U Landfill Onsite Receptor Scenarios

\begin{tabular}{|c|c|c|c|c|c|c|c|c|}
\hline $\begin{array}{c}\text { Input Screen Title } \\
\text { and Parameter } \\
\text { Name }\end{array}$ & Unit & $\begin{array}{c}\text { Code } \\
\text { Default } \\
\text { Value }\end{array}$ & $\begin{array}{c}\text { Code- } \\
\text { Accepted } \\
\text { Values }^{a}\end{array}$ & Receptor $^{b}$ & $\begin{array}{c}\text { Deterministic } \\
\text { Value }\end{array}$ & Type $^{c}$ & Priority & Justification \\
\hline & & & & & & & $\begin{array}{c}\text { A default value is assumed. No site-specific } \\
\text { value available. }\end{array}$ & \\
\hline
\end{tabular}

Saturated Zone Hydrological Data

\begin{tabular}{|c|c|c|c|c|c|c|c|c|c|}
\hline $\begin{array}{l}\text { Density of saturated } \\
\text { zone }\end{array}$ & $\mathrm{g} / \mathrm{cm}^{3}$ & 1.5 & $1 E-3-22.5$ & All & 1.67 & $P$ & 1 & $\begin{array}{l}\text { This value was obtained from the previous } \\
\text { RESRAD study for the landfill described in DOE } \\
\text { 2003b. }\end{array}$ & $\begin{array}{c}\text { DOE 2003b } \\
\text { Table 4.7, page } \\
\text { 4-21, Table } \\
\text { Att.4., page C3- } \\
315 \\
\end{array}$ \\
\hline $\begin{array}{l}\text { Saturated zone total } \\
\text { porosity }\end{array}$ & - & 0.4 & $1 \mathrm{E}-5-1$ & All & 0.34 & $P$ & 1 & $\begin{array}{l}\text { This value was obtained from the previous } \\
\text { RESRAD study for the landfill described in DOE } \\
\text { 2003b. }\end{array}$ & $\begin{array}{l}\text { DOE 2003b } \\
\text { Table Att.4., } \\
\text { page C3-315 }\end{array}$ \\
\hline $\begin{array}{l}\text { Saturated zone } \\
\text { effective porosity }\end{array}$ & - & 0.2 & $1 \mathrm{E}-34-1$ & All & 0.3 & $\mathrm{P}$ & 1 & $\begin{array}{l}\text { This value was obtained from the previous } \\
\text { RESRAD study for the landfill described in DOE } \\
\text { 2003b. }\end{array}$ & $\begin{array}{c}\text { DOE 2003b } \\
\text { Table 4.7, page } \\
\text { 4-21, Table } \\
\text { Att.4., page C3- } \\
315 \\
\end{array}$ \\
\hline $\begin{array}{l}\text { Saturated zone field } \\
\text { capacity }\end{array}$ & - & 0.2 & $1 E-34-1$ & All & 0.04 & $P$ & 3 & $\begin{array}{l}\text { This value was obtained from the previous } \\
\text { RESRAD study for the landfill described in DOE } \\
\text { 2003b. }\end{array}$ & $\begin{array}{l}\text { DOE 2003b } \\
\text { Table Att.4., } \\
\text { page C3-315 }\end{array}$ \\
\hline $\begin{array}{c}\text { Saturated zone } \\
\text { hydraulic conductivity }\end{array}$ & $\mathrm{m} / \mathrm{yr}$ & 100 & $\begin{array}{l}1 E-3- \\
1 E+10\end{array}$ & All & 55630 & $P$ & 1 & $\begin{array}{l}\text { This value was obtained from the previous } \\
\text { RESRAD study for the landfill described in DOE } \\
\text { 2003b. This value was verified by DOE } \\
\text { geologist. }\end{array}$ & $\begin{array}{c}\text { DOE 2003b } \\
\text { Table Att.4., } \\
\text { page C3-315 } \\
\\
\text { DOE Project } \\
\text { Communication } \\
\text { with geologist } \\
\text { and engineer } \\
\text { (April 2010) }\end{array}$ \\
\hline $\begin{array}{l}\text { Saturated zone } \\
\text { hydraulic gradient }\end{array}$ & - & 0.02 & $1 \mathrm{E}-10-10$ & All & 0.0011 & $\mathrm{P}$ & 2 & $\begin{array}{l}\text { This value was obtained from the previous } \\
\text { RESRAD study for the landfill described in DOE } \\
\text { 2003b. }\end{array}$ & $\begin{array}{l}\text { DOE 2003b } \\
\text { Table Att.4., } \\
\text { page C3-315 }\end{array}$ \\
\hline $\begin{array}{l}\text { Saturated zone } b \\
\text { parameter }\end{array}$ & - & 5.3 & $1 E-34-15$ & All & 4.05 & $P$ & 2 & $\begin{array}{l}\text { DOE geologist determined that saturated zone } \\
\text { consists of a mixture of gravel and sand and } \\
\text { recommended a value from Yu et al. } 1993 \\
\text { based on sand. }\end{array}$ & $\begin{array}{l}\text { Yu et al. } 1993 \\
\text { DOE Project } \\
\text { Communication } \\
\text { with geologist } \\
\text { (April 2010) }\end{array}$ \\
\hline Water table drop rate & $\mathrm{m} / \mathrm{yr}$ & 0.001 & $0-5$ & All & 0.001 & $P$ & 3 & $\begin{array}{l}\text { The default value is used. } \\
\text { No site-specific value was available. }\end{array}$ & Yu et al. 2001 \\
\hline Well pump intake & $\mathrm{m}$ & 10 & $1 \mathrm{E}-5-$ & All & 9.1 & $P$ & 2 & The value of $9.1 \mathrm{~m}$ is used for the Resident & DOE Project \\
\hline
\end{tabular}


RESRAD Table of Input Parameters for the C-746-U Landfill Onsite Receptor Scenarios

\begin{tabular}{|c|c|c|c|c|c|c|c|c|c|}
\hline $\begin{array}{c}\text { Input Screen Title } \\
\text { and Parameter } \\
\text { Name }\end{array}$ & Unit & $\begin{array}{c}\text { Code } \\
\text { Default } \\
\text { Value }\end{array}$ & $\begin{array}{c}\text { Code- } \\
\text { Accepted } \\
\text { Values }^{a}\end{array}$ & Receptor $^{b}$ & $\begin{array}{l}\text { Deterministic } \\
\text { Value }\end{array}$ & Type $^{c}$ & Priority $^{d}$ & Justification & References \\
\hline $\begin{array}{c}\text { depth (below water } \\
\text { table) }\end{array}$ & & & 1,000 & & & & & $\begin{array}{l}\text { Farmer since this value was recommended by } \\
\text { LATA (Los Alamos Technical Associates) } \\
\text { Kentucky. In addition, the value for the well } \\
\text { pump intake depth in RESRAD was modified in } \\
\text { order to achieve consistency with the depth } \\
\text { of aquifer contributing to well in RESRAD- } \\
\text { OFFSITE as suggested by Argonne National } \\
\text { Laboratory (ANL) expert. } \\
\text { This parameter is suppressed for the Resident } \\
\text { Gardener, Workers, Recreational User and the } \\
\text { Trespasser by choosing the applicable } \\
\text { pathways. }\end{array}$ & $\begin{array}{c}\text { Communicatior } \\
\text { with DOE } \\
\text { consultant } \\
\text { (November } \\
\text { 2010) }\end{array}$ \\
\hline $\begin{array}{l}\text { Model: nondispersion } \\
\text { (ND) or mass-balance } \\
\text { (MB) }\end{array}$ & - & ND & $\mathrm{ND} / \mathrm{MB}$ & All & ND & $\mathrm{P}$ & 3 & $\begin{array}{l}\text { A default model was assumed for the } \\
\text { Resident Farmer, since this is the only } \\
\text { receptor that will have a well and site specific } \\
\text { information is not available. } \\
\text { The meat, milk, plant and drinking water } \\
\text { ingestion pathways are suppressed for the } \\
\text { Workers, Recreational User, and Trespasser } \\
\text { since these pathways are not considered in } \\
\text { the conceptual site model for these receptors. } \\
\text { The meat, milk, and drinking water ingestion } \\
\text { pathways are suppressed for Resident } \\
\text { Gardener. The plant ingestion pathway is } \\
\text { active for this receptor; however, the water is } \\
\text { obtained from uncontaminated sources. }\end{array}$ & Yu et al. 2001 \\
\hline Well pumping rate & $\mathrm{m}^{3} / \mathrm{yr}$ & 250 & $0-1 E+10$ & All & 685 & $B, P$ & 2 & $\begin{array}{l}\text { This value is modified to achieve consistency } \\
\text { with the calculated well pumping rate in } \\
\text { RESRAD-OFFSITE. This applies to the Resident } \\
\text { Farmer and Resident Gardener. The value } \\
\text { calculated by RESRAD-OFFSITE for the well } \\
\text { pumping rate corresponds to } 685 \mathrm{~m}^{3} / \mathrm{yr} \text {. This } \\
\text { approach was suggested by ANL. } \\
\text { The meat, milk, plant and drinking water } \\
\text { ingestion pathways are suppressed for the } \\
\text { Workers, Recreational User, and Trespasser } \\
\text { since these pathways are not considered in } \\
\text { the conceptual site model for these receptors. }\end{array}$ & $\begin{array}{l}\text { DOE Project } \\
\text { Communication } \\
\text { with DOE } \\
\text { consultant } \\
\text { (November } \\
\text { 2010) }\end{array}$ \\
\hline
\end{tabular}


RESRAD Table of Input Parameters for the C-746-U Landfill Onsite Receptor Scenarios

\begin{tabular}{|c|c|c|c|c|c|c|c|c|}
\hline $\begin{array}{c}\text { Input Screen Title } \\
\text { and Parameter } \\
\text { Name }\end{array}$ & Unit & $\begin{array}{c}\text { Code } \\
\text { Default } \\
\text { Value }\end{array}$ & $\begin{array}{c}\text { Code- } \\
\text { Accepted } \\
\text { Values }^{a}\end{array}$ & Receptor & $\begin{array}{c}\text { Deterministic } \\
\text { Value }\end{array}$ & Type $^{c}$ & Priority $^{d}$ & References $^{\text {Justification }}$ \\
\hline & & & & & $\begin{array}{l}\text { The meat, milk, and drinking water ingestion } \\
\text { pathways are suppressed for Resident } \\
\text { Gardener. The plant ingestion pathway is } \\
\text { active for this receptor; however, the water is } \\
\text { obtained from uncontaminated sources. }\end{array}$ \\
\hline
\end{tabular}

Uncontaminated Unsaturated Zone Parameters

\begin{tabular}{|c|c|c|c|c|c|c|c|c|c|}
\hline $\begin{array}{l}\text { Unsaturated zone } \\
\text { thickness }\end{array}$ & $\mathrm{m}$ & 4 & $0-10,000$ & All & $\begin{array}{l}\text { Zone } 1=0.3 \\
\text { Zone } 2=0.3 \\
\text { Zone } 3=0.9 \\
\text { Zone } 4=2.0 \\
\text { Zone } 5=8.4\end{array}$ & $P$ & 1 & $\begin{array}{l}\text { These values were obtained from the previous } \\
\text { RESRAD study for the landfill described in DOE } \\
\text { 2003b. }\end{array}$ & $\begin{array}{l}\text { DOE 2003b } \\
\text { Table Att.2, } \\
\text { page C3-315 }\end{array}$ \\
\hline $\begin{array}{l}\text { Unsaturated zone } \\
\text { density }\end{array}$ & $\mathrm{g} / \mathrm{cm}^{3}$ & 1.5 & $1 \mathrm{E}-3-22.5$ & All & $\begin{array}{l}\text { Zone } 1=1.2 \\
\text { Zone } 2=1.5 \\
\text { Zone } 3=1.8 \\
\text { Zone } 4=1.5 \\
\text { Zone } 5=1.76\end{array}$ & $P$ & 2 & $\begin{array}{l}\text { These values were obtained from the previous } \\
\text { RESRAD study for the landfill described in DOE } \\
\text { 2003b. }\end{array}$ & $\begin{array}{l}\text { DOE 2003b } \\
\text { Table Att.2, } \\
\text { page C3-315 }\end{array}$ \\
\hline $\begin{array}{l}\text { Unsaturated zone } \\
\text { total porosity }\end{array}$ & - & 0.4 & $1 \mathrm{E}-5-1$ & All & $\begin{array}{c}\text { Zone } 1=0.45 \\
\text { Zone } 2=0.4 \\
\text { Zone } 3=0.43 \\
\text { Zone } 4=0.4 \\
\text { Zone } 5=0.45\end{array}$ & $\mathrm{P}$ & 2 & $\begin{array}{l}\text { These values were obtained from the previous } \\
\text { RESRAD study for the landfill described in DOE } \\
\text { 2003b. } \\
\text { The values for UZ } 1 \text { and UZ } 2 \text { were transposed } \\
\text { as recommended by DOE. }\end{array}$ & $\begin{array}{c}\text { DOE 2003b } \\
\text { Table Att.2, } \\
\text { page C3-315 } \\
\text { DOE Project } \\
\text { Communication } \\
\text { with DOE-PPPO } \\
\text { (October 2010) }\end{array}$ \\
\hline $\begin{array}{l}\text { Unsaturated zone } \\
\text { effective porosity }\end{array}$ & - & 0.2 & $1 \mathrm{E}-34-1$ & All & $\begin{array}{c}\text { Zone } 1=0.2 \\
\text { Zone } 2=0.2 \\
\text { Zone } 3=0.08 \\
\text { Zone } 4=0.2 \\
\text { Zone } 5=0.15\end{array}$ & $P$ & 2 & $\begin{array}{l}\text { These values were calculated using equation } \\
4.4 \text { from Yu et al. } 1993 \text { as this approach was } \\
\text { accepted by ANL rather than using the values } \\
\text { available in DOE } 2003 \text { b. This approach was } \\
\text { taken to ensure that the effective porosity } \\
\text { was less than the total porosity. }\end{array}$ & $\begin{array}{l}\text { Yu et al. } 1993 \\
\text { Project } \\
\text { Communication } \\
\text { with DOE } \\
\text { consultant } \\
\text { (October 2010) }\end{array}$ \\
\hline $\begin{array}{l}\text { Unsaturated zone } \\
\text { field capacity }\end{array}$ & - & 0.2 & $1 \mathrm{E}-34-1$ & All & $\begin{array}{c}\text { Zone } 1=0.25 \\
\text { Zone } 2=0.2 \\
\text { Zone } 3=0.35 \\
\text { Zone } 4=0.2 \\
\text { Zone } 5=0.3\end{array}$ & $P$ & 3 & $\begin{array}{l}\text { These values were obtained from the previous } \\
\text { RESRAD study for the landfill described in DOE } \\
\text { 2003b. } \\
\text { The values for UZ } 1 \text { and UZ } 2 \text { were transposed } \\
\text { as recommended by DOE. }\end{array}$ & $\begin{array}{c}\text { DOE 2003b } \\
\text { Table Att.2, } \\
\text { page C3-315 } \\
\text { Project } \\
\text { Communication } \\
\text { with DOE-PPPO } \\
\text { (October 2010) }\end{array}$ \\
\hline $\begin{array}{l}\text { Unsaturated zone, } \\
\text { soil-specific b } \\
\text { parameter }\end{array}$ & - & 5.3 & $0-15$ & All & $\begin{array}{l}\text { Zone } 1=7.75 \\
\text { Zone } 2=7.75 \\
\text { Zone } 3=11.4\end{array}$ & $P$ & 2 & $\begin{array}{l}\text { DOE evaluated the unsaturated zone and } \\
\text { determined that the value for Silty Clay Loam } \\
\text { from Yu et al. } 1993 \text { was most appropriate for }\end{array}$ & $\begin{array}{l}\text { Yu et al. } 1993 \\
\text { DOE Project }\end{array}$ \\
\hline
\end{tabular}


RESRAD Table of Input Parameters for the C-746-U Landfill Onsite Receptor Scenarios

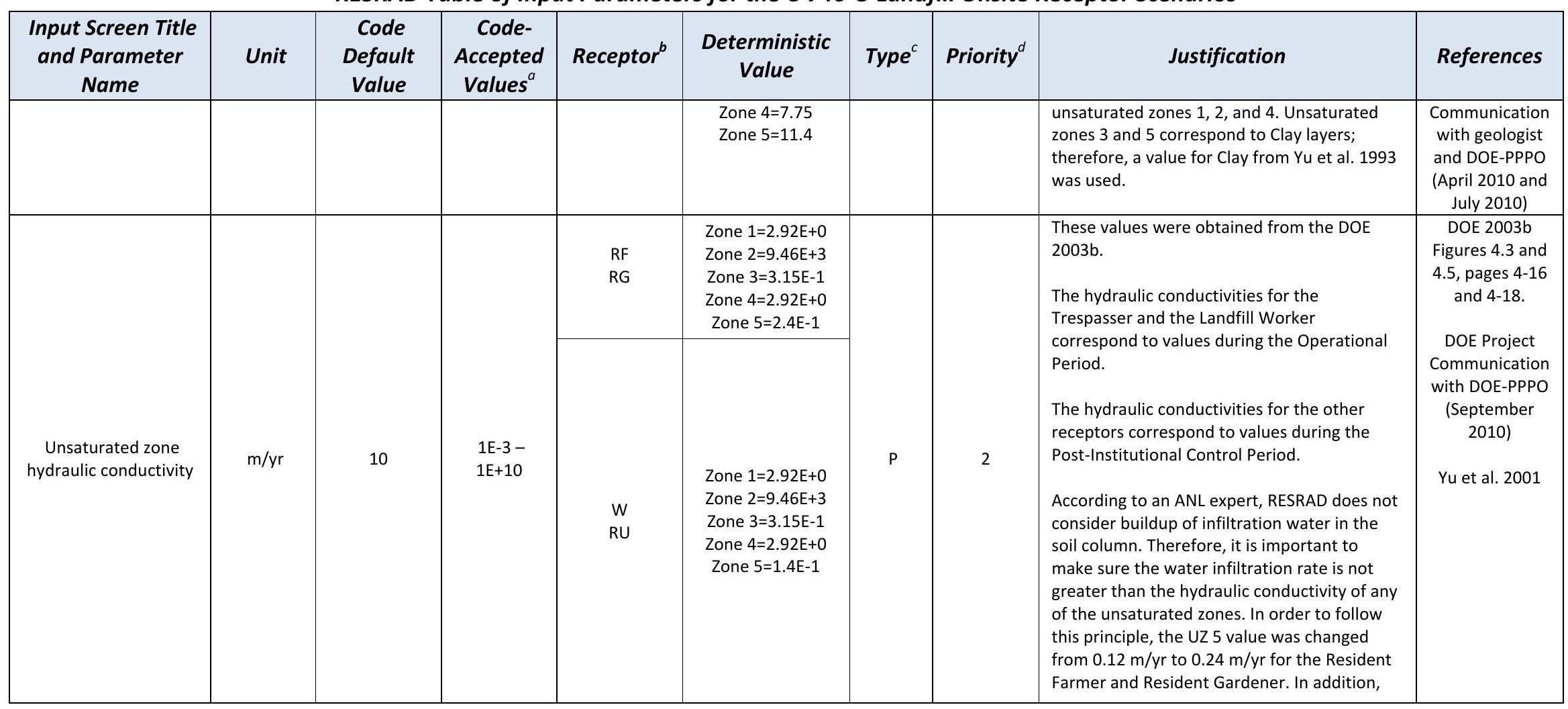


RESRAD Table of Input Parameters for the C-746-U Landfill Onsite Receptor Scenarios

\begin{tabular}{|c|c|c|c|c|c|c|c|c|c|}
\hline $\begin{array}{c}\text { Input Screen Title } \\
\text { and Parameter } \\
\text { Name }\end{array}$ & Unit & $\begin{array}{c}\text { Code } \\
\text { Default } \\
\text { Value }\end{array}$ & $\begin{array}{c}\text { Code- } \\
\text { Accepted } \\
\text { Values }^{a}\end{array}$ & Receptor ${ }^{b}$ & $\begin{array}{c}\text { Deterministic } \\
\text { Value }\end{array}$ & Type $^{c}$ & Priority $^{d}$ & Justification & References \\
\hline & & & & $\begin{array}{l}\mathrm{T} \\
\mathrm{L}\end{array}$ & $\begin{array}{l}\text { Zone } 1=2.92 \mathrm{E}+1 \\
\text { Zone } 2=9.46 \mathrm{E}+4 \\
\text { Zone } 3=2.81 \mathrm{E}-1 \\
\text { Zone } 4=2.92 \mathrm{E}+0 \\
\text { Zone } 5=2.81 \mathrm{E}-1\end{array}$ & & & $\begin{array}{l}\text { the UZ } 5 \text { value was changed from } 0.12 \mathrm{~m} / \mathrm{yr} \text { to } \\
0.14 \mathrm{~m} / \mathrm{yr} \text { for the Outdoor Worker and } \\
\text { Recreational User. For the Trespasser and } \\
\text { Landfill Worker the UZ } 3 \text { value was changed } \\
\text { besides the value of UZ } 5 \text { value since the } \\
\text { infiltration rate calculated was greater than } \\
\text { the value of the hydraulic conductivities for } \\
\text { these zones. The value for UZ } 3 \text { was changed } \\
\text { from } 0.0315 \mathrm{~m} / \mathrm{yr} \text { to } 0.281 \mathrm{~m} / \mathrm{yr} \text { and the value } \\
\text { for UZ } 5 \text { was changed from } 0.12 \mathrm{~m} / \mathrm{yr} \text { to } 0.281 \\
\mathrm{~m} / \mathrm{yr} \text {. } \\
\text { Although all the receptors have corresponding } \\
\text { hydraulic conductivities (that are greater than } \\
\text { the infiltration rate), these are only used by } \\
\text { the code in the Resident Farmer and Gardener } \\
\text { scenarios. In these scenarios, the code uses } \\
\text { the hydraulic conductivities (besides other } \\
\text { parameters related to the unsaturated zones), } \\
\text { when at least one of the following ingestion } \\
\text { pathways is active; drinking water, plant, milk, } \\
\text { and/or meat. In the case of the Resident } \\
\text { Farmer, all of these pathways are active and } \\
\text { in the case of the Resident Gardener the plant } \\
\text { ingestion pathway is active. For the Workers, } \\
\text { Recreational User and the Trespasser, these } \\
\text { ingestion pathways mentioned are } \\
\text { suppressed; therefore, the unsaturated zones } \\
\text { parameters are not used by the code. } \\
\text { The infiltration rate calculations are in } \\
\text { Attachment II following this table. }\end{array}$ & \\
\hline
\end{tabular}

Occupancy, Inhalation, and External Gamma Parameters

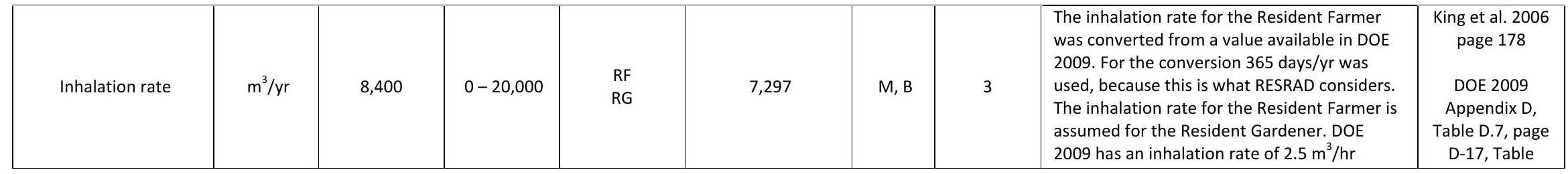


RESRAD Table of Input Parameters for the C-746-U Landfill Onsite Receptor Scenarios

\begin{tabular}{|c|c|c|c|c|c|c|c|c|c|}
\hline $\begin{array}{c}\text { Input Screen Title } \\
\text { and Parameter } \\
\text { Name }\end{array}$ & Unit & $\begin{array}{c}\text { Code } \\
\text { Default } \\
\text { Value }\end{array}$ & $\begin{array}{c}\text { Code- } \\
\text { Accepted } \\
\text { Values }^{a}\end{array}$ & Receptor ${ }^{b}$ & $\begin{array}{c}\text { Deterministic } \\
\text { Value }\end{array}$ & Type $^{c}$ & Priority $^{d}$ & Justification & References \\
\hline & & & & $\begin{array}{l}\text { W } \\
\text { RU } \\
\text { T } \\
\text { L }\end{array}$ & 20,000 & & & $\begin{array}{l}\left.\text { (21,900 } \mathrm{m}^{3} / \mathrm{yr}\right) \text { for the Workers, Recreational } \\
\text { User, and the Trespasser. The maximum value } \\
\text { allowed by RESRAD is } 20,000 \mathrm{~m}^{3} / \mathrm{yr} \text {, thus this } \\
\text { value is used. } \\
\text { See Attachment II following this table of } \\
\text { parameters. }\end{array}$ & $\begin{array}{c}\text { D.38, pages D- } \\
\text { 48, Table D.17, } \\
\text { page D-27 }\end{array}$ \\
\hline $\begin{array}{l}\text { Mass loading for } \\
\text { inhalation }\end{array}$ & $\mathrm{g} / \mathrm{m}^{3}$ & $1.00 \mathrm{E}-04$ & $0-2$ & $\begin{array}{l}\text { RF } \\
\text { RG } \\
\text { RU } \\
T\end{array}$ & 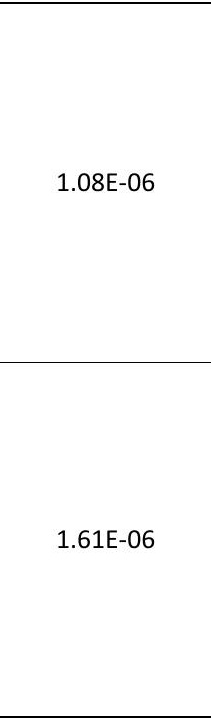 & $P, B$ & 2 & $\begin{array}{l}\text { The following equation was used to calculate } \\
\text { the Mass Loading for Inhalation or Air-to-Soil } \\
\text { concentration ratio (ASR): } \\
\text { ASR = 1/ PEF; PEF is the particulate emission } \\
\text { factor. } \\
\text { The PEF values used to calculate the mass } \\
\text { loading for inhalation are available in DOE } \\
\text { 2009. The PEF values were converted into } \\
\text { RESRAD compatible units. } \\
\text { The mass loading for inhalation for the } \\
\text { Resident Farmer is assumed for the Resident } \\
\text { Gardener. } \\
\text { The mass loading for inhalation for the } \\
\text { Recreational User is assumed for the } \\
\text { Trespasser. } \\
\text { See Attachment II following this table of } \\
\text { parameters }\end{array}$ & $\begin{array}{l}\text { King et al. } 2006 \\
\text { page } 178 \\
\text { DOE } 2009 \\
\text { Appendix D, } \\
\text { Table D.7, page } \\
\text { D-17, Table } \\
\text { D.38, pages D- } \\
\text { 48, Table D.17, } \\
\text { page D-27 }\end{array}$ \\
\hline Exposure duration & $\mathrm{yr}$ & 30 & $1-1,000$ & $\begin{array}{l}\mathrm{RF} \\
\mathrm{RG}\end{array}$ & 24 & B & 3 & $\begin{array}{l}\text { The exposure duration is the span of time, in } \\
\text { years, during which an individual is expected } \\
\text { to spend time on the site. This value is used in } \\
\text { calculating lifetime cancer risk from exposure } \\
\text { to radionuclide contamination. It is also used } \\
\text { to calculate time-integrated dose if the } \\
\text { exposure duration is less than a year. }\end{array}$ & $\begin{array}{c}\text { DOE } 2009 \\
\text { Appendix D, } \\
\text { Table D.8, page } \\
\text { D-18, Table } \\
\text { D.18, page D- } \\
\text { 28, Table D.40, } \\
\text { page D-50 }\end{array}$ \\
\hline
\end{tabular}


RESRAD Table of Input Parameters for the C-746-U Landfill Onsite Receptor Scenarios

\begin{tabular}{|c|c|c|c|c|c|c|c|c|c|}
\hline $\begin{array}{c}\text { Input Screen Title } \\
\text { and Parameter } \\
\text { Name }\end{array}$ & Unit & $\begin{array}{l}\text { Code } \\
\text { Default } \\
\text { Value }\end{array}$ & $\begin{array}{l}\text { Code- } \\
\text { Accepted } \\
\text { Values }^{a}\end{array}$ & Receptor $^{b}$ & $\begin{array}{c}\text { Deterministic } \\
\text { Value }\end{array}$ & Type $^{c}$ & Priority $^{d}$ & Justification & References \\
\hline & & & & 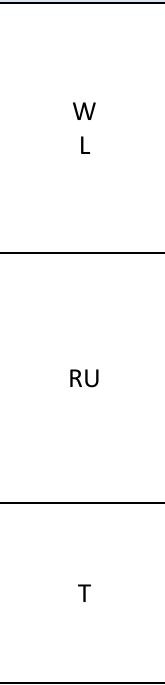 & 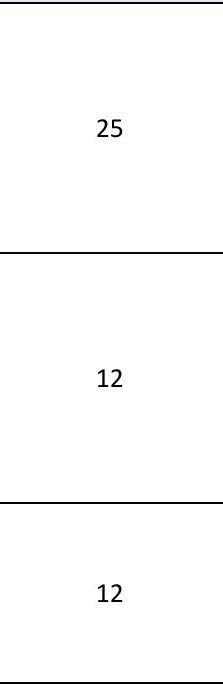 & & & $\begin{array}{l}\text { These values were obtained from DOE } 2009 . \\
\text { The exposure duration is available in the } \\
\text { tables of Appendix D. } \\
\text { For the Resident Farmer and the Resident } \\
\text { Gardener the adult value for "Rural Resident" } \\
\text { is used. } \\
\text { For the Workers the value for "Industrial } \\
\text { Worker or Excavation Worker" is used since } \\
\text { these values are equivalent. } \\
\text { For the Recreational User the value for the } \\
\text { "Recreational User (Teen)" is used. } \\
\text { For the Trespasser the value for the } \\
\text { "Recreational User (adult)" is used. } \\
\text { See Attachment II following this table of } \\
\text { parameters. }\end{array}$ & \\
\hline $\begin{array}{l}\text { Indoor dust filtration } \\
\text { factor }\end{array}$ & - & 0.4 & $0-1$ & All & 0.4 & $P, B$ & 2 & $\begin{array}{l}\text { The default value is used. Indoor time fraction } \\
\text { is the driver for application of this parameter. } \\
\text { In instances where there is no indoor } \\
\text { occupancy, this parameter will not be applied. }\end{array}$ & Yu et al. 2001 \\
\hline $\begin{array}{l}\text { External gamma } \\
\text { shielding factor }\end{array}$ & - & 0.7 & $0-1$ & $\begin{array}{l}\text { RF } \\
\text { RG } \\
W \\
L\end{array}$ & 0.8 & $P$ & 2 & $\begin{array}{l}\text { The external gamma shielding factors are } \\
\text { available for the Resident Farmer, Workers, } \\
\text { and Recreational User in DOE } 2009 \text {. The value } \\
\text { is } 0.2 \text { for all these receptors except for the } \\
\text { Recreational User which is } 0 \text {. The RESRAD } \\
\text { input values correspond to } 0.8 \text { and } 1 \text {. The } \\
\text { shielding factor of } 0.8 \text { implies that the indoor } \\
\text { levels of external radiation are } 20 \% \text { lower } \\
\text { than the outdoor levels. A shielding factor of } 1 \\
\text { implies that there is no shielding. } \\
\text { The Resident Gardener is assumed to have the } \\
\text { same shielding factor as the Resident Farmer. } \\
\text { The Trespasser is assumed to have the same } \\
\text { shielding factor as the Recreational User. } \\
\text { See Attachment II following this table of }\end{array}$ & $\begin{array}{c}\text { DOE } 2009 \\
\text { Appendix D, } \\
\text { Table D.8, page } \\
\text { D-18, Table } \\
\text { D.18, page D- } \\
\text { 28, and Table } \\
\text { D.40, page D-50 }\end{array}$ \\
\hline
\end{tabular}


RESRAD Table of Input Parameters for the C-746-U Landfill Onsite Receptor Scenarios

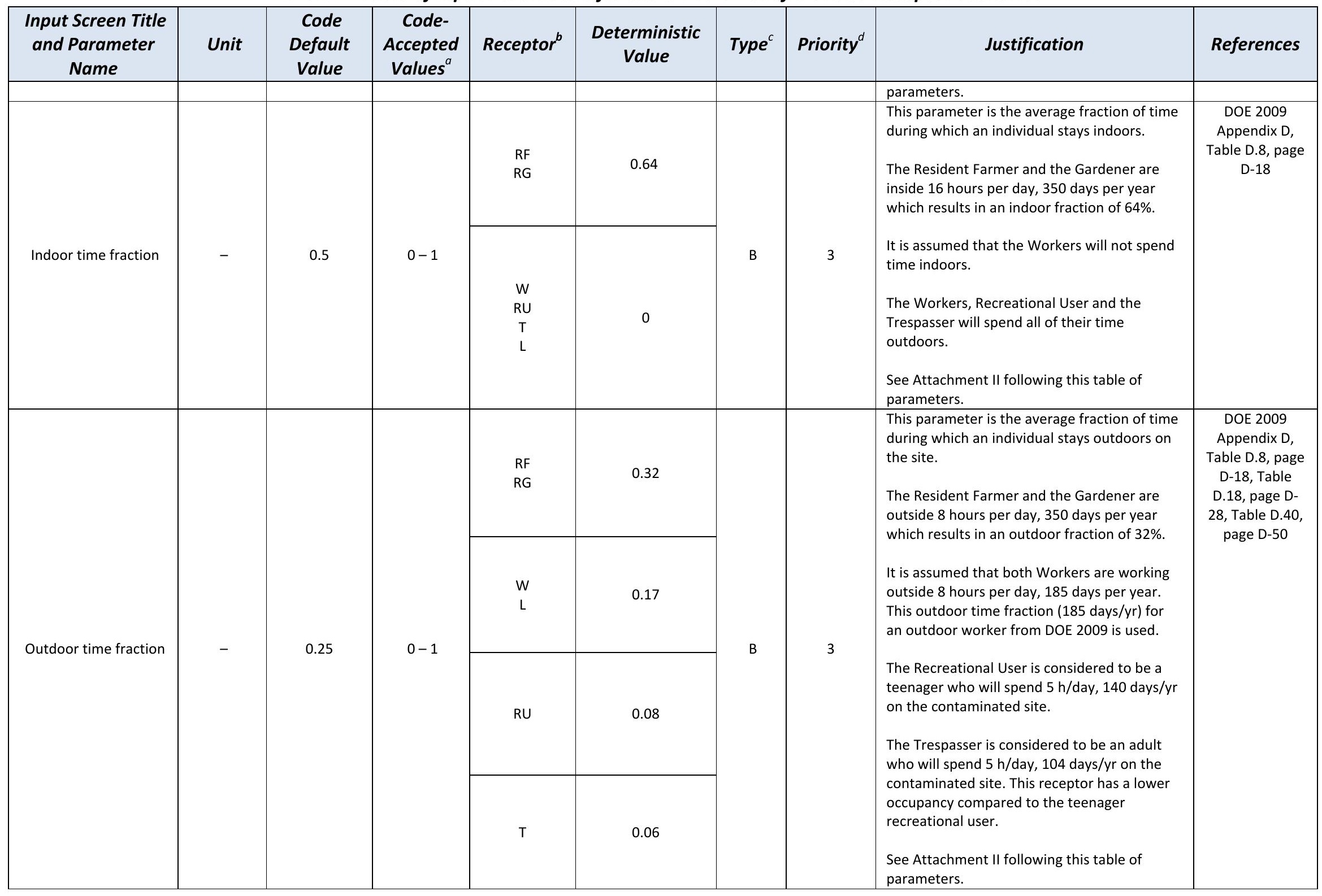


RESRAD Table of Input Parameters for the C-746-U Landfill Onsite Receptor Scenarios

\begin{tabular}{|c|c|c|c|c|c|c|c|c|c|}
\hline $\begin{array}{c}\text { Input Screen Title } \\
\text { and Parameter } \\
\text { Name }\end{array}$ & Unit & $\begin{array}{c}\text { Code } \\
\text { Default } \\
\text { Value }\end{array}$ & $\begin{array}{c}\text { Code- } \\
\text { Accepted } \\
\text { Values }^{a}\end{array}$ & Receptor ${ }^{b}$ & $\begin{array}{c}\text { Deterministic } \\
\text { Value }\end{array}$ & Type ${ }^{c}$ & Priority $^{d}$ & Justification & References \\
\hline $\begin{array}{l}\text { Shape of the } \\
\text { contaminated zone } \\
\text { (shape factor flag) }\end{array}$ & - & Circular & $\begin{array}{l}\text { Circular/ } \\
\text { non- } \\
\text { circular }\end{array}$ & All & Circular & $P$ & 3 & $\begin{array}{l}\text { It is assumed that the receptor is located in } \\
\text { the middle of the contaminated zone. } \\
\text { Therefore, the circular shape was assumed } \\
\text { instead of the noncircular shape. By default, } \\
\text { the receptor is assumed to be placed in the } \\
\text { middle of a circularly shaped contaminated } \\
\text { zone. }\end{array}$ & Yu et al. 2001 \\
\hline
\end{tabular}

Ingestion Pathway, Dietary Data

\begin{tabular}{|c|c|c|c|c|c|c|c|c|c|}
\hline $\begin{array}{l}\text { Fruit, vegetable, and } \\
\text { grain consumption }\end{array}$ & $\mathrm{kg} / \mathrm{yr}$ & 160 & $0-1,000$ & All & 231.7 & $M, B$ & 2 & $\begin{array}{l}\text { The value was converted from Table D.9 in } \\
\text { DOE 2009, which is for home grown } \\
\text { vegetables. It does not specify fruit, and grain, } \\
\text { thus for RESRAD a ratio was obtained to } \\
\text { assign a value for fruit, vegetable and grain } \\
\text { consumption and a value for leafy vegetable } \\
\text { consumption. } \\
\text { The calculation is included in Attachment II. } \\
\text { This parameter applies to the Resident Farmer } \\
\text { and Resident Gardener since the ingestion } \\
\text { pathway for plants/ home-grown produce is } \\
\text { applicable for these receptors. } \\
\text { The plant ingestion pathway is suppressed for } \\
\text { the Workers, Recreational User, and } \\
\text { Trespasser since this pathway is not } \\
\text { considered in the conceptual site model for } \\
\text { these receptors. } \\
\text { See Attachment II following this table of } \\
\text { parameters. }\end{array}$ & $\begin{array}{c}\text { DOE } 2009 \\
\text { Appendix D, } \\
\text { Table D.9, page } \\
\text { D-19 }\end{array}$ \\
\hline $\begin{array}{l}\text { Leafy vegetable } \\
\text { consumption }\end{array}$ & $\mathrm{kg} / \mathrm{yr}$ & 14 & $0-100$ & All & 20.3 & $\mathrm{M}, \mathrm{B}$ & 3 & $\begin{array}{l}\text { The value was converted from Table D.9 in } \\
\text { DOE 2009, which is for home grown } \\
\text { vegetables. It does not specify fruit, and grain, } \\
\text { thus for RESRAD a ratio was obtained to } \\
\text { assign a value for fruit, vegetable and grain } \\
\text { consumption and a value for leafy vegetable } \\
\text { consumption. } \\
\text { The calculation is included in Attachment II. } \\
\text { This parameter applies to the Resident Farmer } \\
\text { and Resident Gardener since the ingestion }\end{array}$ & $\begin{array}{c}\text { DOE } 2009 \\
\text { Appendix D, } \\
\text { Table D.9, page } \\
\text { D-19 }\end{array}$ \\
\hline
\end{tabular}


RESRAD Table of Input Parameters for the C-746-U Landfill Onsite Receptor Scenarios

\begin{tabular}{|c|c|c|c|c|c|c|c|c|c|}
\hline $\begin{array}{c}\text { Input Screen Title } \\
\text { and Parameter } \\
\text { Name }\end{array}$ & Unit & $\begin{array}{c}\text { Code } \\
\text { Default } \\
\text { Value }\end{array}$ & $\begin{array}{c}\text { Code- } \\
\text { Accepted } \\
\text { Values }^{a}\end{array}$ & Receptor $^{b}$ & $\begin{array}{c}\text { Deterministic } \\
\text { Value }\end{array}$ & Type $^{c}$ & Priority $^{d}$ & Justification & References \\
\hline & & & & & & & & $\begin{array}{l}\text { pathway for plants/ home-grown produce is } \\
\text { applicable for these receptors. } \\
\text { The plant ingestion pathway is suppressed for } \\
\text { the Workers, Recreational User, and } \\
\text { Trespasser since this pathway is not } \\
\text { considered in the conceptual site model for } \\
\text { these receptors. } \\
\text { See Attachment II following this table of } \\
\text { parameters. }\end{array}$ & \\
\hline Milk consumption & $\mathrm{L} / \mathrm{yr}$ & 92 & $0-1,000$ & All & 425 & $M, B$ & 2 & $\begin{array}{l}\text { This value was converted from Table D.11 in } \\
\text { DOE } 2009 . \\
\text { The density of whole milk, } 1030 \mathrm{~kg} / \mathrm{cubic} \\
\text { meter, was used to convert the value into } \\
\text { L/yr. } \\
\text { This parameter is applicable for the Resident } \\
\text { Farmer. } \\
\text { This parameter is not applicable for the } \\
\text { Resident Gardener, Workers, Recreational } \\
\text { User, or the Trespasser; therefore, the milk } \\
\text { ingestion pathway is suppressed. } \\
\text { See Attachment II following this table of } \\
\text { parameters. }\end{array}$ & $\begin{array}{c}\text { DOE } 2009 \\
\text { Appendix D, } \\
\text { Table D.11, } \\
\text { page D-21 }\end{array}$ \\
\hline $\begin{array}{l}\text { Meat and poultry } \\
\text { consumption }\end{array}$ & $\mathrm{kg} / \mathrm{yr}$ & 63 & $0-300$ & All & 154 & $M, B$ & 3 & $\begin{array}{l}\text { This value was converted from Table D.10, } \\
\text { D.12, and D.13 in DOE 2009. The value is the } \\
\text { sum of the values obtained for beef, pork and } \\
\text { poultry, since they are in separate tables. The } \\
\text { value for eggs is available, but eggs are not } \\
\text { considered poultry. } \\
\text { This parameter is applicable for the Resident } \\
\text { Farmer. } \\
\text { This parameter is not applicable for the } \\
\text { Resident Gardener, Workers, Recreational } \\
\text { User or the Trespasser; therefore, the meat } \\
\text { ingestion pathway is suppressed. } \\
\text { See Attachment II following this table of }\end{array}$ & $\begin{array}{c}\text { DOE } 2009 \\
\text { Appendix D, } \\
\text { Table D.10, } \\
\text { D.12, and D.13, } \\
\text { pages D-20, D- } \\
22 \text { and D-23 }\end{array}$ \\
\hline
\end{tabular}


RESRAD Table of Input Parameters for the C-746-U Landfill Onsite Receptor Scenarios

\begin{tabular}{|c|c|c|c|c|c|c|c|c|c|}
\hline $\begin{array}{c}\text { Input Screen Title } \\
\text { and Parameter } \\
\text { Name }\end{array}$ & Unit & $\begin{array}{l}\text { Code } \\
\text { Default } \\
\text { Value }\end{array}$ & $\begin{array}{l}\text { Code- } \\
\text { Accepted } \\
\text { Values }^{a}\end{array}$ & Receptor $^{b}$ & $\begin{array}{l}\text { Deterministic } \\
\text { Value }\end{array}$ & Type $^{c}$ & Priority $^{d}$ & Justification & References \\
\hline & & & & & & & & parameters. & \\
\hline Fish consumption & $\mathrm{kg} / \mathrm{yr}$ & 5.4 & $0-1,000$ & All & 5.4 & $\mathrm{M}, \mathrm{B}$ & 3 & $\begin{array}{l}\text { The aquatic foods ingestion pathway is } \\
\text { suppressed in RESRAD for all receptors } \\
\text { because it is not considered part of the } \\
\text { conceptual site model. }\end{array}$ & Yu et al. 2001 \\
\hline $\begin{array}{l}\text { Other seafood } \\
\text { consumption }\end{array}$ & $\mathrm{kg} / \mathrm{yr}$ & 0.9 & $0-100$ & All & 0.9 & $\mathrm{M}, \mathrm{B}$ & 3 & $\begin{array}{l}\text { The aquatic foods ingestion pathway is } \\
\text { suppressed in RESRAD for all receptors } \\
\text { because it is not considered part of the } \\
\text { conceptual site model. }\end{array}$ & Yu et al. 2001 \\
\hline \multirow[b]{2}{*}{ Soil ingestion rate } & \multirow[b]{2}{*}{$g / y r$} & \multirow[b]{2}{*}{36.5} & \multirow[b]{2}{*}{$0-10,000$} & $\begin{array}{l}\text { RF } \\
\text { RG } \\
\text { RU } \\
T\end{array}$ & 36.5 & \multirow[b]{2}{*}{$\mathrm{M}, \mathrm{B}$} & \multirow[b]{2}{*}{2} & \multirow{2}{*}{$\begin{array}{l}\text { This value was converted from Table D.5 in } \\
\text { DOE } 2009 . \\
\text { Reference DOE } 2009 \text { assumes a lower } \\
\text { ingestion rate for workers who spend part of } \\
\text { the day outdoors. It is assumed the Workers } \\
\text { are working outside and perform duties that } \\
\text { result in a higher soil ingestion rate. } \\
\text { For the Recreational User the value available } \\
\text { in Table D.15 in DOE } 2009 \text { is for ingestion of } \\
\text { sediment. This value was assumed for the soil } \\
\text { ingestion rate. } \\
\text { See Attachment II following this table of } \\
\text { parameters. }\end{array}$} & \multirow[t]{2}{*}{$\begin{array}{c}\text { DOE } 2009 \\
\text { Appendix D, } \\
\text { Table D.5, page } \\
\text { D-15, Table } \\
\text { D.15, page D- } \\
25 \text {, Table D.37 } \\
\text { page D-47 }\end{array}$} \\
\hline & & & & $\begin{array}{l}\text { W } \\
\mathrm{L}\end{array}$ & 175.2 & & & & \\
\hline Drinking water intake & $\mathrm{L} / \mathrm{yr}$ & 510 & $0-10,000$ & All & 700 & $\mathrm{M}, \mathrm{B}$ & 2 & $\begin{array}{l}\text { This value was converted from Table D. } 1 \text { in } \\
\text { DOE } 2009 \\
\text { This parameter is applicable for the Resident } \\
\text { Farmer. } \\
\text { This parameter is not applicable for the } \\
\text { Resident Gardener, Workers, Recreational } \\
\text { User or the Trespasser; therefore, the drinking } \\
\text { water ingestion pathway is suppressed. } \\
\text { See Attachment II following this table of } \\
\text { parameters. }\end{array}$ & $\begin{array}{c}\text { DOE } 2009 \\
\text { Appendix D, } \\
\text { Table D.1, page } \\
\text { D-11 }\end{array}$ \\
\hline $\begin{array}{l}\text { Drinking water } \\
\text { contaminated fraction }\end{array}$ & - & 1 & $0-1$ & All & 1 & $B, P$ & 3 & $\begin{array}{l}\text { This parameter allows specification of the } \\
\text { fraction of contaminated intake for the } \\
\text { drinking water pathway. The remaining } \\
\text { balance (if value }<1 \text { ) of the drinking water is }\end{array}$ & Yu et al. 2001 \\
\hline
\end{tabular}


RESRAD Table of Input Parameters for the C-746-U Landfill Onsite Receptor Scenarios

\begin{tabular}{|c|c|c|c|c|c|c|c|c|c|}
\hline $\begin{array}{c}\text { Input Screen Title } \\
\text { and Parameter } \\
\text { Name }\end{array}$ & Unit & $\begin{array}{c}\text { Code } \\
\text { Default } \\
\text { Value }\end{array}$ & $\begin{array}{c}\text { Code- } \\
\text { Accepted } \\
\text { Values }^{a}\end{array}$ & Receptor ${ }^{b}$ & $\begin{array}{c}\text { Deterministic } \\
\text { Value }\end{array}$ & Type & Priority $^{d}$ & Justification & References \\
\hline & & & & & & & & $\begin{array}{l}\text { from off-site sources, which are assumed to } \\
\text { be uncontaminated. } \\
\text { A default value of } 1 \text { was assumed for the } \\
\text { Resident Farmer. } \\
\text { This parameter is not applicable for the } \\
\text { Resident Gardener, Workers, Recreational } \\
\text { User or the Trespasser; therefore, the drinking } \\
\text { water ingestion pathway is suppressed. }\end{array}$ & \\
\hline $\begin{array}{l}\text { Household water } \\
\text { contaminated fraction }\end{array}$ & - & 1 & $0-1$ & All & 1 & $B, P$ & 3 & $\begin{array}{l}\text { A default value of } 1 \text { is assumed. This default } \\
\text { value of } 1 \text { indicates that all household water is } \\
\text { from an on-site source. However, this } \\
\text { parameter is not used by the code since it is } \\
\text { related to the radon pathway and this } \\
\text { pathway is deactivated. }\end{array}$ & Yu et al. 2001 \\
\hline $\begin{array}{l}\text { Livestock water } \\
\text { contaminated fraction }\end{array}$ & - & 1 & $0-1$ & All & 1 & $B, P$ & 3 & $\begin{array}{l}\text { A default value of } 1 \text { is assumed for the } \\
\text { Resident Farmer. This default value of } 1 \\
\text { indicates that all livestock water is from an } \\
\text { on-site source. } \\
\text { This parameter is related to the milk and meat } \\
\text { ingestion pathways and these pathways are } \\
\text { not applicable for the Resident Gardener, } \\
\text { Workers, Recreational User, or the } \\
\text { Trespasser. Therefore, the meat and milk } \\
\text { ingestion pathways are deactivated for these } \\
\text { receptors. }\end{array}$ & Yu et al. 2001 \\
\hline \multirow{2}{*}{$\begin{array}{l}\text { Irrigation water } \\
\text { contaminated fraction }\end{array}$} & \multirow[b]{2}{*}{-} & \multirow[b]{2}{*}{1} & \multirow[b]{2}{*}{$0-1$} & $\begin{array}{l}\text { RF } \\
\text { W } \\
\text { RU } \\
T \\
\text { L }\end{array}$ & 1 & \multirow[b]{2}{*}{$B, P$} & \multirow[b]{2}{*}{3} & $\begin{array}{l}\text { The default value of } 1 \text { is assumed for the } \\
\text { Resident Farmer. This default value of } 1 \\
\text { indicates that all irrigation water is from an } \\
\text { on-site source. } \\
\text { A value of " } 0 \text { " is used for the Resident }\end{array}$ & \multirow[t]{2}{*}{$\begin{array}{l}\text { DOE Project } \\
\text { Communication } \\
\text { with DOE-PPPO } \\
\text { (September } \\
\text { 2010) }\end{array}$} \\
\hline & & & & RG & 0 & & & $\begin{array}{l}\text { Gardener since this receptor will use an off- } \\
\text { site water source. } \\
\text { This parameter is related to the plant, meat, } \\
\text { and milk ingestion pathways and these are } \\
\text { not applicable for the Workers, Recreational } \\
\text { User, and the Trespasser. Therefore, the }\end{array}$ & \\
\hline
\end{tabular}


RESRAD Table of Input Parameters for the C-746-U Landfill Onsite Receptor Scenarios

\begin{tabular}{|c|c|c|c|c|c|c|c|c|c|}
\hline $\begin{array}{c}\text { Input Screen Title } \\
\text { and Parameter } \\
\text { Name }\end{array}$ & Unit & $\begin{array}{c}\text { Code } \\
\text { Default } \\
\text { Value }\end{array}$ & $\begin{array}{c}\text { Code- } \\
\text { Accepted } \\
\text { Values }^{a}\end{array}$ & Receptor $^{b}$ & $\begin{array}{c}\text { Deterministic } \\
\text { Value }\end{array}$ & Type $^{c}$ & Priority $^{d}$ & Justification & References \\
\hline & & & & & & & & $\begin{array}{l}\text { plant, meat and milk ingestion pathways are } \\
\text { suppressed for these receptors. }\end{array}$ & \\
\hline $\begin{array}{c}\text { Aquatic food } \\
\text { contaminated fraction }\end{array}$ & - & 0.5 & $0-1$ & All & 0.5 & $B, P$ & 2 & $\begin{array}{l}\text { A default value of } 0.5 \text { indicates that } 50 \% \text { of } \\
\text { aquatic food is being obtained from on-site } \\
\text { sources. } \\
\text { The aquatic food pathway is not considered in } \\
\text { the conceptual site model and it is } \\
\text { deactivated for all receptors. Therefore, this } \\
\text { parameter is not used by the code. }\end{array}$ & Yu et al. 2001 \\
\hline $\begin{array}{c}\text { Plant food } \\
\text { contaminated fraction }\end{array}$ & - & -1 & 0 to 1 or -1 & All & -1 & $B, P$ & 3 & $\begin{array}{l}\text { The default value of }-1 \text { specifies that the } \\
\text { contaminated fraction of plant food is } \\
\text { calculated from the appropriate area factor in } \\
\text { the code (see page A-8 of Yu et al. 2001). } \\
\text { The plant ingestion pathway is suppressed for } \\
\text { the Workers, Recreational User, and } \\
\text { Trespasser since this pathway is not } \\
\text { considered in the conceptual site model for } \\
\text { these receptors. }\end{array}$ & Yu et al. 2001 \\
\hline $\begin{array}{l}\text { Meat contaminated } \\
\text { fraction }\end{array}$ & - & -1 & 0 to 1 or -1 & All & -1 & $B, P$ & 3 & $\begin{array}{l}\text { A default value of - } 1 \text { was assumed for the } \\
\text { Resident Farmer. The default value of }-1 \\
\text { specifies that the contaminated fraction of } \\
\text { meat is calculated from the appropriate area } \\
\text { factor in the code. } \\
\text { The meat ingestion pathway is suppressed for } \\
\text { the Resident Gardener, Workers, Recreational } \\
\text { User, and Trespasser since this pathway is not } \\
\text { considered in the conceptual site model for } \\
\text { these receptors. }\end{array}$ & Yu et al. 2001 \\
\hline $\begin{array}{l}\text { Milk contaminated } \\
\text { fraction }\end{array}$ & - & -1 & 0 to 1 or -1 & All & -1 & $B, P$ & 3 & $\begin{array}{l}\text { The default value of }-1 \text { specifies that the } \\
\text { contaminated fraction of milk is calculated } \\
\text { from the appropriate area factor in the code. } \\
\text { The milk ingestion pathway is suppressed for } \\
\text { the Resident Gardener, Workers, Recreational } \\
\text { User, and Trespasser since this pathway is not }\end{array}$ & Yu et al. 2001 \\
\hline
\end{tabular}


RESRAD Table of Input Parameters for the C-746-U Landfill Onsite Receptor Scenarios

\begin{tabular}{|c|c|c|c|c|c|c|c|c|}
\hline $\begin{array}{c}\text { Input Screen Title } \\
\text { and Parameter } \\
\text { Name }\end{array}$ & Unit & $\begin{array}{c}\text { Code } \\
\text { Default } \\
\text { Value }\end{array}$ & $\begin{array}{c}\text { Code- } \\
\text { Accepted } \\
\text { Values }^{a}\end{array}$ & Receptor $^{b}$ & $\begin{array}{c}\text { Deterministic } \\
\text { Value }\end{array}$ & Type $^{c}$ & Priority & Justification \\
\hline & & & & & & & $\begin{array}{c}\text { considered in the conceptual site model for } \\
\text { these receptors. }\end{array}$ \\
\hline
\end{tabular}

Ingestion Pathway, Nondietary Data

\begin{tabular}{|c|c|c|c|c|c|c|c|c|c|}
\hline $\begin{array}{l}\text { Livestock fodder } \\
\text { intake for meat }\end{array}$ & $\mathrm{kg} / \mathrm{d}$ & 68 & $0-300$ & All & 25 & M & 3 & $\begin{array}{l}\text { This parameter is for the daily intake of } \\
\text { fodder by livestock kept for meat } \\
\text { consumption. The code uses the area factor to } \\
\text { calculate the contaminated intake. } \\
\text { The meat ingestion pathway is suppressed for } \\
\text { the Resident Gardener, Workers, Recreational } \\
\text { User, and Trespasser since this pathway is not } \\
\text { considered in the conceptual site model for } \\
\text { these receptors. }\end{array}$ & $\begin{array}{c}\text { DOE } 2009 \\
\text { Appendix D, } \\
\text { Table D.46, } \\
\text { page D-56 }\end{array}$ \\
\hline $\begin{array}{l}\text { Livestock fodder } \\
\text { intake for milk }\end{array}$ & $\mathrm{kg} / \mathrm{d}$ & 55 & $0-300$ & All & 25 & $\mathrm{M}$ & 3 & $\begin{array}{l}\text { This parameter is for the daily intake of } \\
\text { fodder by livestock kept for milk consumption. } \\
\text { The code uses the area factor to calculate the } \\
\text { contaminated intake. } \\
\text { The milk ingestion pathway is suppressed for } \\
\text { the Resident Gardener, Workers, Recreational } \\
\text { User, and Trespasser since this pathway is not } \\
\text { considered in the conceptual site model for } \\
\text { these receptors. }\end{array}$ & $\begin{array}{c}\text { DOE } 2009 \\
\text { Appendix D, } \\
\text { Table D.47, } \\
\text { page D-57 }\end{array}$ \\
\hline $\begin{array}{l}\text { Livestock water intake } \\
\text { for meat }\end{array}$ & $\mathrm{L} / \mathrm{d}$ & 50 & $0-500$ & All & 50 & $M$ & 3 & $\begin{array}{l}\text { This parameter is for the daily intake of water } \\
\text { by livestock kept for meat consumption. } \\
\text { The code uses the area factor to calculate the } \\
\text { contaminated intake. } \\
\text { The meat ingestion pathway is suppressed for } \\
\text { the Resident Gardener, Workers, Recreational } \\
\text { User, and Trespasser since this pathway is not } \\
\text { considered in the conceptual site model for } \\
\text { these receptors. }\end{array}$ & $\begin{array}{c}\text { DOE } 2009 \\
\text { Appendix D, } \\
\text { Table D.46, } \\
\text { page D-56 }\end{array}$ \\
\hline $\begin{array}{l}\text { Livestock water intake } \\
\text { for milk }\end{array}$ & $\mathrm{L} / \mathrm{d}$ & 160 & $0-500$ & All & 160 & M & 3 & $\begin{array}{l}\text { The default value is used for the Resident } \\
\text { Farmer. } \\
\text { The milk ingestion pathway is suppressed for } \\
\text { the Resident Gardener, Workers, Recreational } \\
\text { User, and Trespasser since this pathway is not } \\
\text { considered in the conceptual site model for }\end{array}$ & Yu et al. 2001 \\
\hline
\end{tabular}


RESRAD Table of Input Parameters for the C-746-U Landfill Onsite Receptor Scenarios

\begin{tabular}{|c|c|c|c|c|c|c|c|c|c|}
\hline $\begin{array}{c}\text { Input Screen Title } \\
\text { and Parameter } \\
\text { Name }\end{array}$ & Unit & $\begin{array}{c}\text { Code } \\
\text { Default } \\
\text { Value }\end{array}$ & $\begin{array}{c}\text { Code- } \\
\text { Accepted } \\
\text { Values }^{a}\end{array}$ & Receptor ${ }^{b}$ & $\begin{array}{c}\text { Deterministic } \\
\text { Value }\end{array}$ & Type $^{c}$ & Priority $^{d}$ & Justification & References \\
\hline & & & & & & & & these receptors. & \\
\hline Livestock intake of soil & $\mathrm{kg} / \mathrm{d}$ & 0.5 & $0-10$ & All & 1 & $M$ & 3 & $\begin{array}{l}\text { This parameter reflects the daily intake of soil } \\
\text { by livestock kept for meat or milk } \\
\text { consumption. } \\
\text { DOE } 2009 \text { has separate tables for livestock soil } \\
\text { ingestion. A value of } 1 \mathrm{~kg} / \mathrm{d} \text { is listed for beef } \\
\text { and dairy in each table, thus for the Resident } \\
\text { Farmer, this value will be used. } \\
\text { The meat and milk ingestion pathways are } \\
\text { suppressed for the Resident Gardener, } \\
\text { Workers, Recreational User, and Trespasser } \\
\text { since these pathways are not considered in } \\
\text { the conceptual site model for these receptors. }\end{array}$ & $\begin{array}{c}\text { DOE } 2009 \\
\text { Appendix D, } \\
\text { Table D.46 and } \\
\text { D.47, page D-56 } \\
\text { and D-57 }\end{array}$ \\
\hline $\begin{array}{l}\text { Mass loading for foliar } \\
\text { deposition }\end{array}$ & $\mathrm{g} / \mathrm{m}^{3}$ & $1.00 \mathrm{E}-04$ & $0-1$ & All & $1.00 \mathrm{E}-04$ & $P$ & 3 & $\begin{array}{l}\text { The average mass loading of airborne } \\
\text { contaminated soil particles in a garden during } \\
\text { the growing season. } \\
\text { A default value was assumed for the Resident } \\
\text { Farmer and the Resident Gardener, since } \\
\text { plant ingestion is a pathway for these } \\
\text { receptors and site specific information is not } \\
\text { available. } \\
\text { The plant ingestion pathway is suppressed for } \\
\text { the Workers, Recreational User, and } \\
\text { Trespasser since this pathway is not } \\
\text { considered in the conceptual site model for } \\
\text { these receptors. }\end{array}$ & Yu et al. 2001 \\
\hline $\begin{array}{c}\text { Depth of soil mixing } \\
\text { layer }\end{array}$ & $\mathrm{m}$ & 0.15 & $0-1$ & All & 0.15 & $P$ & 2 & $\begin{array}{l}\text { Used in calculating the depth factor for dust } \\
\text { inhalation and soil ingestion pathways and for } \\
\text { foliar deposition for the plant, meat, and milk } \\
\text { ingestion pathways. The depth factor is the } \\
\text { fraction of the resuspendable soil particles at } \\
\text { the ground surface that are contaminated. It } \\
\text { is calculated by assuming that mixing of soil } \\
\text { will occur in the soil mixing layer. } \\
\text { A default value was assumed and is applied to } \\
\text { all receptors since the inhalation and soil } \\
\text { ingestion pathways apply to all receptors and }\end{array}$ & Yu et al. 2001 \\
\hline
\end{tabular}


RESRAD Table of Input Parameters for the C-746-U Landfill Onsite Receptor Scenarios

\begin{tabular}{|c|c|c|c|c|c|c|c|c|c|}
\hline $\begin{array}{c}\text { Input Screen Title } \\
\text { and Parameter } \\
\text { Name }\end{array}$ & Unit & $\begin{array}{c}\text { Code } \\
\text { Default } \\
\text { Value }\end{array}$ & $\begin{array}{c}\text { Code- } \\
\text { Accepted } \\
\text { Values }^{a}\end{array}$ & Receptor ${ }^{b}$ & $\begin{array}{c}\text { Deterministic } \\
\text { Value }\end{array}$ & Type $^{c}$ & Priority $^{d}$ & Justification & References \\
\hline & & & & & & & & $\begin{array}{l}\text { site specific information is not available. } \\
\text { The meat, milk, and plant ingestion pathways } \\
\text { are suppressed for the Workers, Recreational } \\
\text { User, and Trespasser since these pathways } \\
\text { are not considered in the conceptual site } \\
\text { model for these receptors. } \\
\text { The meat and milk ingestion pathways are } \\
\text { suppressed for the Resident Gardener since } \\
\text { these pathways are not considered in the } \\
\text { conceptual site model for this receptor. }\end{array}$ & \\
\hline Depth of roots & $\mathrm{m}$ & 0.9 & $0-100$ & All & 0.9 & $P$ & 1 & $\begin{array}{l}\text { The maximum root depth below the ground } \\
\text { surface. } \\
\text { A default value was assumed for the Resident } \\
\text { Farmer, since meat, milk, and plant ingestion } \\
\text { are pathways for this receptor and site } \\
\text { specific information is not available. } \\
\text { The meat, milk, and plant ingestion pathways } \\
\text { are suppressed for the Workers, Recreational } \\
\text { User, and Trespasser since these pathways } \\
\text { are not considered in the conceptual site } \\
\text { model for these receptors. } \\
\text { The meat and milk ingestion pathways are } \\
\text { suppressed for the Resident Gardener since } \\
\text { these pathways are not considered in the } \\
\text { conceptual site model for this receptor. }\end{array}$ & Yu et al. 2001 \\
\hline $\begin{array}{l}\text { Groundwater } \\
\text { fractional usage for } \\
\text { drinking water }\end{array}$ & - & 1 & $0-1$ & All & 1 & $B, P$ & 3 & $\begin{array}{l}\text { The four groundwater fractional usage } \\
\text { parameters (drinking water, household water, } \\
\text { livestock water, and irrigation water) are } \\
\text { included primarily for all groundwater (well or } \\
\text { spring) and surface water (pond or river) } \\
\text { scenarios. Hence, the fractions will usually be } \\
\text { set at } 1 \text { or } 0 \text {. A value of } 1 \text { specifies } 100 \% \\
\text { groundwater usage and } 0 \text { specifies } 100 \% \\
\text { surface water usage. } \\
\text { A default value was assumed for the Resident } \\
\text { Farmer, since drinking water ingestion is a }\end{array}$ & Yu et al. 2001 \\
\hline
\end{tabular}


RESRAD Table of Input Parameters for the C-746-U Landfill Onsite Receptor Scenarios

\begin{tabular}{|c|c|c|c|c|c|c|c|c|c|}
\hline $\begin{array}{c}\text { Input Screen Title } \\
\text { and Parameter } \\
\text { Name }\end{array}$ & Unit & $\begin{array}{c}\text { Code } \\
\text { Default } \\
\text { Value }\end{array}$ & $\begin{array}{c}\text { Code- } \\
\text { Accepted } \\
\text { Values }^{a}\end{array}$ & Receptor $^{b}$ & $\begin{array}{l}\text { Deterministic } \\
\text { Value }\end{array}$ & Type $^{c}$ & Priority $^{d}$ & Justification & References \\
\hline & & & & & & & & $\begin{array}{l}\text { pathway for this receptor and site specific } \\
\text { information is not available. } \\
\text { The drinking water ingestion pathway is } \\
\text { suppressed for the Resident Gardener, } \\
\text { Workers, Recreational User, and Trespasser } \\
\text { since this pathway is not considered in the } \\
\text { conceptual site model for these receptors. }\end{array}$ & \\
\hline $\begin{array}{l}\text { Groundwater } \\
\text { fractional usage for } \\
\text { household water }\end{array}$ & - & 1 & $0-1$ & All & 1 & $B, P$ & 3 & $\begin{array}{l}\text { The four groundwater fractional usage } \\
\text { parameters (drinking water, household water, } \\
\text { livestock water, and irrigation water) are } \\
\text { included primarily for all groundwater (well or } \\
\text { spring) and surface water (pond or river) } \\
\text { scenarios. Hence, the fractions will usually be } \\
\text { set at } 1 \text { or } 0 \text {. A value of } 1 \text { specifies } 100 \% \\
\text { groundwater usage and } 0 \text { specifies } 100 \% \\
\text { surface water usage. } \\
\text { A default value was assumed for the Resident } \\
\text { Farmer, since it is reflected in the pathways } \\
\text { for this receptor and site specific information } \\
\text { is not available. } \\
\text { The meat, milk, and plant ingestion pathways } \\
\text { are suppressed for the Workers, Recreational } \\
\text { User, and Trespasser since these pathways } \\
\text { are not considered in the conceptual site } \\
\text { model for these receptors. } \\
\text { The meat and milk ingestion pathways are } \\
\text { suppressed for the Resident Gardener since } \\
\text { these pathways are not considered in the } \\
\text { conceptual site model for this receptor. }\end{array}$ & Yu et al. 2001 \\
\hline $\begin{array}{l}\text { Groundwater } \\
\text { fractional usage for } \\
\text { livestock water }\end{array}$ & - & 1 & $0-1$ & All & 1 & $B, P$ & 3 & $\begin{array}{l}\text { The four groundwater fractional usage } \\
\text { parameters (drinking water, household water, } \\
\text { livestock water, and irrigation water) are } \\
\text { included primarily for all groundwater (well or } \\
\text { spring) and surface water (pond or river) } \\
\text { scenarios. Hence, the fractions will usually be } \\
\text { set at } 1 \text { or } 0 \text {. A value of } 1 \text { specifies } 100 \% \\
\text { groundwater usage and } 0 \text { specifies } 100 \% \\
\text { surface water usage. }\end{array}$ & Yu et al. 2001 \\
\hline
\end{tabular}


RESRAD Table of Input Parameters for the C-746-U Landfill Onsite Receptor Scenarios

\begin{tabular}{|c|c|c|c|c|c|c|c|c|c|}
\hline $\begin{array}{c}\text { Input Screen Title } \\
\text { and Parameter } \\
\text { Name }\end{array}$ & Unit & $\begin{array}{c}\text { Code } \\
\text { Default } \\
\text { Value }\end{array}$ & $\begin{array}{c}\text { Code- } \\
\text { Accepted } \\
\text { Values }^{a}\end{array}$ & Receptor $^{b}$ & $\begin{array}{c}\text { Deterministic } \\
\text { Value }\end{array}$ & Type $e^{c}$ & Priority $^{d}$ & Justification & References \\
\hline & & & & & & & & $\begin{array}{l}\text { A default value was assumed for the Resident } \\
\text { Farmer since it is reflected in the pathways for } \\
\text { this receptor and site specific information is } \\
\text { not available. } \\
\text { The meat and milk ingestion pathways are } \\
\text { suppressed for the Resident Gardener, } \\
\text { Workers, Recreational User, and Trespasser } \\
\text { since these pathways are not considered in } \\
\text { the conceptual site model. }\end{array}$ & \\
\hline $\begin{array}{l}\text { Groundwater } \\
\text { fractional usage for } \\
\text { irrigation water }\end{array}$ & - & 1 & $0-1$ & $\begin{array}{c}\text { RF } \\
\text { W } \\
\text { RU } \\
\mathrm{T} \\
\mathrm{L}\end{array}$ & 0 & $B, P$ & 3 & $\begin{array}{l}\text { The four groundwater fractional usage } \\
\text { parameters (drinking water, household water, } \\
\text { livestock water, and irrigation water) are } \\
\text { included primarily for all groundwater (well or } \\
\text { spring) and surface water (pond or river) } \\
\text { scenarios. Hence, the fractions will usually be } \\
\text { set at } 1 \text { or } 0 \text {. A value of } 1 \text { specifies } 100 \% \\
\text { groundwater usage and } 0 \text { specifies } 100 \% \\
\text { surface water usage. } \\
\text { A value of } 1 \text { is used for the Resident Farmer } \\
\text { and because the conceptual site model } \\
\text { assumed this individual will obtain irrigation } \\
\text { water from groundwater. } \\
\text { A value of } 0 \text { is used the Resident Gardener } \\
\text { because the conceptual site model assumes } \\
\text { this individual will obtain uncontaminated } \\
\text { irrigation water from offsite (e.g., a municipal } \\
\text { water source). } \\
\text { The plant ingestion pathway is suppressed for } \\
\text { the Workers, Recreational User, and } \\
\text { Trespasser since this pathway is not } \\
\text { considered in the conceptual site model for } \\
\text { these receptors. }\end{array}$ & $\begin{array}{l}\text { Yu et al. } 2001 \\
\text { DOE Project } \\
\text { Communication } \\
\text { with DOE-PPPO } \\
\text { (September } \\
\text { 2010) }\end{array}$ \\
\hline
\end{tabular}

Plant Factors 
RESRAD Table of Input Parameters for the C-746-U Landfill Onsite Receptor Scenarios

\begin{tabular}{|c|c|c|c|c|c|c|c|c|c|}
\hline $\begin{array}{c}\text { Input Screen Title } \\
\text { and Parameter } \\
\text { Name }\end{array}$ & Unit & $\begin{array}{c}\text { Code } \\
\text { Default } \\
\text { Value }\end{array}$ & $\begin{array}{l}\text { Code- } \\
\text { Accepted } \\
\text { Values }^{a}\end{array}$ & Receptor ${ }^{b}$ & $\begin{array}{c}\text { Deterministic } \\
\text { Value }\end{array}$ & Type $^{c}$ & Priority $^{d}$ & Justification & References \\
\hline $\begin{array}{l}\text { Wet-weight crop } \\
\text { yields for non-leafy } \\
\text { vegetables }\end{array}$ & $\mathrm{kg} / \mathrm{m}^{2}$ & 0.7 & $0.01-3$ & All & 0.7 & $P$ & 2 & $\begin{array}{l}\text { The weight of the edible portion of plant food } \\
\text { produced per unit land area for different food } \\
\text { classes. The code has wet weight crop yield } \\
\text { for non-leafy, leafy, and fodder. Non-leafy and } \\
\text { leafy vegetables are for human consumption; } \\
\text { fodder is for animal consumption. } \\
\text { A default value was assumed for the Resident } \\
\text { Farmer and Resident Gardener since it is } \\
\text { reflected in the pathway for these receptors } \\
\text { and site specific information is not available. } \\
\text { The plant ingestion pathway is suppressed for } \\
\text { the Workers, Recreational User, and } \\
\text { Trespasser since this pathway is not } \\
\text { considered in the conceptual site model for } \\
\text { these receptors. }\end{array}$ & Yu et al. 2001 \\
\hline $\begin{array}{l}\text { Wet-weight crop } \\
\text { yields for leafy } \\
\text { vegetables }\end{array}$ & $\mathrm{kg} / \mathrm{m}^{2}$ & 1.5 & $0.01-3$ & All & 1.5 & $P$ & 3 & $\begin{array}{l}\text { A default value was assumed for the Resident } \\
\text { Farmer and Resident Gardener since the } \\
\text { ingestion pathway for home-grown produce is } \\
\text { applicable for these receptors and site specific } \\
\text { information is not available. } \\
\text { The plant ingestion pathway is suppressed for } \\
\text { the Workers, Recreational User, and } \\
\text { Trespasser since this pathway is not } \\
\text { considered in the conceptual site model for } \\
\text { these receptors. }\end{array}$ & Yu et al. 2001 \\
\hline $\begin{array}{l}\text { Wet-weight crop } \\
\text { yields for fodder }\end{array}$ & $\mathrm{kg} / \mathrm{m}^{2}$ & 1.1 & $0.01-3$ & All & 1.1 & $P$ & 3 & $\begin{array}{l}\text { A default value was assumed for the Resident } \\
\text { Farmer since meat and milk ingestion is } \\
\text { applicable and a site specific value is not } \\
\text { available. } \\
\text { The meat and milk ingestion pathways are } \\
\text { suppressed for the Resident Gardener, } \\
\text { Workers, Recreational User, and Trespasser } \\
\text { since these pathways are not considered in } \\
\text { the conceptual site model for these receptors. }\end{array}$ & Yu et al. 2001 \\
\hline $\begin{array}{l}\text { Length of growing } \\
\text { season for non-leafy } \\
\text { vegetables }\end{array}$ & $\mathrm{yr}$ & 0.17 & $0.01-1$ & All & 0.17 & $P$ & 3 & $\begin{array}{l}\text { The exposure time to contamination for the } \\
\text { plant food during the growing season. The } \\
\text { contamination can reach the edible portion of } \\
\text { the plant food through foliar deposition, root }\end{array}$ & Yu et al. 2001 \\
\hline
\end{tabular}


RESRAD Table of Input Parameters for the C-746-U Landfill Onsite Receptor Scenarios

\begin{tabular}{|c|c|c|c|c|c|c|c|c|c|}
\hline $\begin{array}{c}\text { Input Screen Title } \\
\text { and Parameter } \\
\text { Name }\end{array}$ & Unit & $\begin{array}{c}\text { Code } \\
\text { Default } \\
\text { Value }\end{array}$ & $\begin{array}{c}\text { Code- } \\
\text { Accepted } \\
\text { Values }^{a} \\
\end{array}$ & Receptor $^{b}$ & $\begin{array}{c}\text { Deterministic } \\
\text { Value }\end{array}$ & Type ${ }^{c}$ & Priority $^{d}$ & Justification & References \\
\hline & & & & & & & & $\begin{array}{l}\text { uptake, and water irrigation. } \\
\text { The code has length of growing season for } \\
\text { non-leafy vegetables, leafy vegetables, and } \\
\text { fodder. } \\
\text { A default value was assumed for the Resident } \\
\text { Farmer and Resident Gardener since plant } \\
\text { ingestion is applicable and a site specific value } \\
\text { is not available. } \\
\text { The plant ingestion pathway is suppressed for } \\
\text { the Workers, Recreational User, and } \\
\text { Trespasser since this pathway is not } \\
\text { considered in the conceptual site model for } \\
\text { these receptors. }\end{array}$ & \\
\hline $\begin{array}{l}\text { Length of growing } \\
\text { season for leafy } \\
\text { vegetables }\end{array}$ & $\mathrm{yr}$ & 0.25 & $0.01-1$ & All & 0.25 & $\mathrm{P}$ & 3 & $\begin{array}{l}\text { The exposure time to contamination for the } \\
\text { plant food during the growing season. The } \\
\text { contamination can reach the edible portion of } \\
\text { the plant food through foliar deposition, root } \\
\text { uptake, and water irrigation. } \\
\text { The code has length of growing season for } \\
\text { non-leafy vegetables, leafy vegetables, and } \\
\text { fodder. } \\
\text { A default value was assumed for the Resident } \\
\text { Farmer and Resident Gardener since plant } \\
\text { ingestion is applicable and a site specific value } \\
\text { is not available. } \\
\text { The plant ingestion pathway is suppressed for } \\
\text { the Workers, Recreational User, and } \\
\text { Trespasser since this pathway is not } \\
\text { considered in the conceptual site model for } \\
\text { these receptors. }\end{array}$ & Yu et al. 2001 \\
\hline $\begin{array}{l}\text { Length of growing } \\
\text { season for fodder }\end{array}$ & $\mathrm{yr}$ & 0.08 & $0.01-1$ & All & 0.08 & $P$ & 3 & $\begin{array}{l}\text { The exposure time to contamination for the } \\
\text { plant food during the growing season. The } \\
\text { contamination can reach the edible portion of } \\
\text { the plant food through foliar deposition, root } \\
\text { uptake, and water irrigation. }\end{array}$ & Yu et al. 2001 \\
\hline
\end{tabular}


RESRAD Table of Input Parameters for the C-746-U Landfill Onsite Receptor Scenarios

\begin{tabular}{|c|c|c|c|c|c|c|c|c|c|}
\hline $\begin{array}{c}\text { Input Screen Title } \\
\text { and Parameter } \\
\text { Name }\end{array}$ & Unit & $\begin{array}{c}\text { Code } \\
\text { Default } \\
\text { Value }\end{array}$ & $\begin{array}{c}\text { Code- } \\
\text { Accepted } \\
\text { Values }^{a}\end{array}$ & Receptor $^{b}$ & $\begin{array}{l}\text { Deterministic } \\
\text { Value }\end{array}$ & Type $^{c}$ & Priority $^{d}$ & Justification & References \\
\hline & & & & & & & & $\begin{array}{l}\text { The code has length of growing season for } \\
\text { non-leafy vegetables, leafy vegetables, and } \\
\text { fodder. } \\
\text { A default value was assumed for the Resident } \\
\text { Farmer because meat and milk ingestion are } \\
\text { applicable and a site specific value is not } \\
\text { available. } \\
\text { The meat and milk ingestion pathways are } \\
\text { suppressed for the Resident Gardener, } \\
\text { Workers, Recreational User, and Trespasser } \\
\text { since these pathways are not considered in } \\
\text { the conceptual site model for these receptors. }\end{array}$ & \\
\hline $\begin{array}{l}\text { Translocation factor } \\
\text { for non-leafy } \\
\text { vegetables }\end{array}$ & - & 0.1 & $0-1$ & All & 0.1 & $P$ & 3 & $\begin{array}{l}\text { The fraction of the contamination that is } \\
\text { retained on the foliage that is transferred to } \\
\text { the edible portion of the plant. } \\
\text { The code has three food categories, non-leafy } \\
\text { (includes non-leafy vegetables, fruit, and } \\
\text { grain) and leafy vegetables for human and } \\
\text { fodder for animal consumption. } \\
\text { A default value was assumed for the Resident } \\
\text { Farmer and Resident Gardener since plant } \\
\text { ingestion is applicable and a site specific value } \\
\text { is not available. } \\
\text { The plant ingestion pathway is suppressed for } \\
\text { the Workers, Recreational User, and } \\
\text { Trespasser since this pathway is not } \\
\text { considered in the conceptual site model for } \\
\text { these receptors. }\end{array}$ & Yu et al. 2001 \\
\hline $\begin{array}{l}\text { Translocation factor } \\
\text { for leafy vegetables }\end{array}$ & - & 1 & $0-1$ & All & 1 & $P$ & 3 & $\begin{array}{l}\text { The fraction of the contamination that is } \\
\text { retained on the foliage that is transferred to } \\
\text { the edible portion of the plant. } \\
\text { The code has three food categories, non-leafy } \\
\text { (includes non-leafy vegetables, fruit, and } \\
\text { grain) and leafy vegetables for human and } \\
\text { fodder for animal consumption. }\end{array}$ & Yu et al. 2001 \\
\hline
\end{tabular}


RESRAD Table of Input Parameters for the C-746-U Landfill Onsite Receptor Scenarios

\begin{tabular}{|c|c|c|c|c|c|c|c|c|c|}
\hline $\begin{array}{c}\text { Input Screen Title } \\
\text { and Parameter } \\
\text { Name }\end{array}$ & Unit & $\begin{array}{c}\text { Code } \\
\text { Default } \\
\text { Value }\end{array}$ & $\begin{array}{l}\text { Code- } \\
\text { Accepted } \\
\text { Values }^{a}\end{array}$ & Receptor ${ }^{b}$ & $\begin{array}{c}\text { Deterministic } \\
\text { Value }\end{array}$ & Type $^{c}$ & Priority $^{d}$ & Justification & References \\
\hline & & & & & & & & $\begin{array}{l}\text { A default value was assumed for the Resident } \\
\text { Farmer and Resident Gardener since plant } \\
\text { ingestion is applicable and a site specific value } \\
\text { is not available. } \\
\text { The plant ingestion pathway is suppressed for } \\
\text { the Workers, Recreational User, and } \\
\text { Trespasser since this pathway is not } \\
\text { considered in the conceptual site model for } \\
\text { these receptors. }\end{array}$ & \\
\hline $\begin{array}{l}\text { Translocation factor } \\
\text { for fodder }\end{array}$ & - & 1 & $0-1$ & All & 1 & P & 3 & $\begin{array}{l}\text { The fraction of the contamination that is } \\
\text { retained on the foliage that is transferred to } \\
\text { the edible portion of the plant. The code has } \\
\text { three food categories, non-leafy (includes } \\
\text { non-leafy vegetables, fruit, and grain) and } \\
\text { leafy vegetables for human and fodder for } \\
\text { animal consumption (in all three values). } \\
\text { A default value was assumed for the Resident } \\
\text { Farmer because meat and milk ingestion are } \\
\text { applicable and a site specific value is not } \\
\text { available. } \\
\text { The meat and milk ingestion pathways are } \\
\text { suppressed for the Resident Gardener, } \\
\text { Workers, Recreational User, and Trespasser } \\
\text { since these pathways are not considered in } \\
\text { the conceptual site model for these receptors. }\end{array}$ & Yu et al. 2001 \\
\hline $\begin{array}{l}\text { Weathering removal } \\
\text { constant }\end{array}$ & $1 / \mathrm{yr}$ & 20 & $1-40$ & All & 20 & P & 2 & $\begin{array}{l}\text { The weathering process would remove } \\
\text { contaminants from foliage of the plant food. } \\
\text { The process is characterized by a removal } \\
\text { constant and reduces the amount of } \\
\text { contaminants on foliage exponentially during } \\
\text { the exposure period. } \\
\text { A default value was assumed for the Resident } \\
\text { Farmer and Resident Gardener since plant } \\
\text { ingestion is applicable and a site specific value } \\
\text { is not available. } \\
\text { The plant ingestion pathway is suppressed for } \\
\text { the Workers, Recreational User, and }\end{array}$ & Yu et al. 2001 \\
\hline
\end{tabular}


RESRAD Table of Input Parameters for the C-746-U Landfill Onsite Receptor Scenarios

\begin{tabular}{|c|c|c|c|c|c|c|c|c|c|}
\hline $\begin{array}{c}\text { Input Screen Title } \\
\text { and Parameter } \\
\text { Name }\end{array}$ & Unit & $\begin{array}{c}\text { Code } \\
\text { Default } \\
\text { Value }\end{array}$ & $\begin{array}{c}\text { Code- } \\
\text { Accepted } \\
\text { Values }^{a}\end{array}$ & Receptor $^{b}$ & $\begin{array}{l}\text { Deterministic } \\
\text { Value }\end{array}$ & Type $^{c}$ & Priority $^{d}$ & Justification & References \\
\hline & & & & & & & & $\begin{array}{l}\text { Trespasser since this pathway is not } \\
\text { considered in the conceptual site model for } \\
\text { these receptors. }\end{array}$ & \\
\hline $\begin{array}{l}\text { Wet foliar } \\
\text { interception fraction } \\
\text { for non-leafy } \\
\text { vegetables }\end{array}$ & - & 0.25 & $0-1$ & All & 0.25 & $\mathrm{P}$ & 3 & $\begin{array}{l}\text { The fraction of deposited radionuclides that is } \\
\text { retained on the foliage of the plant food. Both } \\
\text { dry deposition (from airborne particulates) } \\
\text { and the wet deposition processes (from } \\
\text { irrigation) are considered. } \\
\text { The code has wet as well as dry foliar } \\
\text { interception fraction for non-leafy, leafy (for } \\
\text { human consumption), and fodder (for animal } \\
\text { consumption). } \\
\text { A default value was assumed for the Resident } \\
\text { Farmer and Resident Gardener since plant } \\
\text { ingestion is applicable and a site specific value } \\
\text { is not available. } \\
\text { The plant ingestion pathway is suppressed for } \\
\text { the Workers, Recreational User, and } \\
\text { Trespasser since this pathway is not } \\
\text { considered in the conceptual site model for } \\
\text { these receptors. }\end{array}$ & Yu et al. 2001 \\
\hline $\begin{array}{l}\text { Wet foliar } \\
\text { interception fraction } \\
\text { for leafy vegetables }\end{array}$ & - & 0.25 & $0-1$ & All & 0.25 & $\mathrm{P}$ & 2 & $\begin{array}{l}\text { The fraction of deposited radionuclides that is } \\
\text { retained on the foliage of the plant food. Both } \\
\text { dry deposition (from airborne particulates) } \\
\text { and the wet deposition processes (from } \\
\text { irrigation) are considered. } \\
\text { The code has wet as well as dry foliar } \\
\text { interception fraction for non-leafy, leafy (for } \\
\text { human consumption), and fodder (for animal } \\
\text { consumption). } \\
\text { A default value was assumed for the Resident } \\
\text { Farmer and Resident Gardener since plant } \\
\text { ingestion is applicable and a site specific value } \\
\text { is not available. } \\
\text { The plant ingestion pathway is suppressed for } \\
\text { the Workers, Recreational User, and }\end{array}$ & Yu et al. 2001 \\
\hline
\end{tabular}


RESRAD Table of Input Parameters for the C-746-U Landfill Onsite Receptor Scenarios

\begin{tabular}{|c|c|c|c|c|c|c|c|c|c|}
\hline $\begin{array}{c}\text { Input Screen Title } \\
\text { and Parameter } \\
\text { Name }\end{array}$ & Unit & $\begin{array}{c}\text { Code } \\
\text { Default } \\
\text { Value }\end{array}$ & $\begin{array}{c}\text { Code- } \\
\text { Accepted } \\
\text { Values }^{a}\end{array}$ & Receptor ${ }^{b}$ & $\begin{array}{l}\text { Deterministic } \\
\text { Value }\end{array}$ & Type $^{c}$ & Priority $^{d}$ & Justification & References \\
\hline & & & & & & & & $\begin{array}{l}\text { Trespasser since this pathway is not } \\
\text { considered in the conceptual site model for } \\
\text { these receptors. }\end{array}$ & \\
\hline $\begin{array}{l}\text { Wet foliar } \\
\text { interception fraction } \\
\text { for fodder }\end{array}$ & - & 0.25 & $0-1$ & All & 0.25 & $P$ & 3 & $\begin{array}{l}\text { The fraction of deposited radionuclides that is } \\
\text { retained on the foliage of the plant food. Both } \\
\text { dry deposition (from airborne particulates) } \\
\text { and the wet deposition processes (from } \\
\text { irrigation) are considered. } \\
\text { The code has wet as well as dry foliar } \\
\text { interception fraction for non-leafy, leafy (for } \\
\text { human consumption), and fodder (for animal } \\
\text { consumption). } \\
\text { A default value was assumed for the Resident } \\
\text { Farmer because meat and milk ingestion are } \\
\text { applicable and a site specific value is not } \\
\text { available. } \\
\text { The meat and milk ingestion pathways are } \\
\text { suppressed for the Resident Gardener, } \\
\text { Workers, Recreational User, and Trespasser } \\
\text { since these pathways are not considered in } \\
\text { the conceptual site model for these receptors. }\end{array}$ & Yu et al. 2001 \\
\hline $\begin{array}{l}\text { Dry foliar interception } \\
\text { fraction for non-leafy } \\
\text { vegetables }\end{array}$ & - & 0.25 & $0-1$ & All & 0.25 & $P$ & 3 & $\begin{array}{l}\text { The fraction of deposited radionuclides that is } \\
\text { retained on the foliage of the plant food. Both } \\
\text { the dry deposition (from airborne } \\
\text { particulates) and the wet deposition } \\
\text { processes (from irrigation) are considered. } \\
\text { The code has wet as well as dry foliar } \\
\text { interception fraction for non-leafy, leafy (for } \\
\text { human consumption), and fodder (for animal } \\
\text { consumption). } \\
\text { A default value was assumed for the Resident } \\
\text { Farmer and Resident Gardener since plant } \\
\text { ingestion is applicable and a site specific value } \\
\text { is not available. } \\
\text { The plant ingestion pathway is suppressed for } \\
\text { the Workers, Recreational User, and }\end{array}$ & Yu et al. 2001 \\
\hline
\end{tabular}


RESRAD Table of Input Parameters for the C-746-U Landfill Onsite Receptor Scenarios

\begin{tabular}{|c|c|c|c|c|c|c|c|c|c|}
\hline $\begin{array}{c}\text { Input Screen Title } \\
\text { and Parameter } \\
\text { Name }\end{array}$ & Unit & $\begin{array}{c}\text { Code } \\
\text { Default } \\
\text { Value }\end{array}$ & $\begin{array}{c}\text { Code- } \\
\text { Accepted } \\
\text { Values }^{a}\end{array}$ & Receptor ${ }^{b}$ & $\begin{array}{l}\text { Deterministic } \\
\text { Value }\end{array}$ & Type $^{c}$ & Priority $^{d}$ & Justification & References \\
\hline & & & & & & & & $\begin{array}{l}\text { Trespasser since this pathway is not } \\
\text { considered in the conceptual site model for } \\
\text { these receptors. }\end{array}$ & \\
\hline $\begin{array}{l}\text { Dry foliar interception } \\
\text { fraction for leafy } \\
\text { vegetables }\end{array}$ & - & 0.25 & $0-1$ & All & 0.25 & $P$ & 3 & $\begin{array}{l}\text { The fraction of deposited radionuclides that is } \\
\text { retained on the foliage of the plant food. Both } \\
\text { the dry deposition (from airborne } \\
\text { particulates) and the wet deposition } \\
\text { processes (from irrigation) are considered. } \\
\text { The code has wet as well as dry foliar } \\
\text { interception fraction for non-leafy, leafy (for } \\
\text { human consumption), and fodder (for animal } \\
\text { consumption). } \\
\text { A default value was assumed for the Resident } \\
\text { Farmer and Resident Gardener since plant } \\
\text { ingestion is applicable and a site specific value } \\
\text { is not available. } \\
\text { The plant ingestion pathway is suppressed for } \\
\text { the Workers, Recreational User, and } \\
\text { Trespasser since this pathway is not } \\
\text { considered in the conceptual site model for } \\
\text { these receptors. }\end{array}$ & Yu et al. 2001 \\
\hline $\begin{array}{l}\text { Dry foliar interception } \\
\text { fraction for fodder }\end{array}$ & - & 0.25 & $0-1$ & All & 0.25 & $\mathrm{P}$ & 3 & $\begin{array}{l}\text { The fraction of deposited radionuclides that is } \\
\text { retained on the foliage of the plant food. Both } \\
\text { the dry deposition (from airborne } \\
\text { particulates) and the wet deposition } \\
\text { processes (from irrigation) are considered. } \\
\text { The code has wet as well as dry foliar } \\
\text { interception fraction for non-leafy, leafy (for } \\
\text { human consumption), and fodder (for animal } \\
\text { consumption). } \\
\text { A default value was assumed for the Resident } \\
\text { Farmer because meat and milk ingestion are } \\
\text { applicable and a site specific value is not } \\
\text { available. } \\
\text { The meat and milk ingestion pathways are } \\
\text { suppressed for the Resident Gardener, }\end{array}$ & Yu et al. 2001 \\
\hline
\end{tabular}


RESRAD Table of Input Parameters for the C-746-U Landfill Onsite Receptor Scenarios

\begin{tabular}{|c|c|c|c|c|c|c|c|c|c|}
\hline $\begin{array}{c}\text { Input Screen Title } \\
\text { and Parameter } \\
\text { Name }\end{array}$ & Unit & $\begin{array}{c}\text { Code } \\
\text { Default } \\
\text { Value }\end{array}$ & $\begin{array}{c}\text { Code- } \\
\text { Accepted } \\
\text { Values }^{a}\end{array}$ & Receptor ${ }^{b}$ & $\begin{array}{l}\text { Deterministic } \\
\text { Value }\end{array}$ & Type $e^{c}$ & Priority $^{d}$ & Justification & References \\
\hline & & & & & & & & $\begin{array}{l}\text { Workers, Recreational User, and Trespasser } \\
\text { since these pathways are not considered in } \\
\text { the conceptual site model for these receptors. }\end{array}$ & \\
\hline
\end{tabular}

Storage Times before Use Data

\begin{tabular}{|c|c|c|c|c|c|c|c|c|c|}
\hline $\begin{array}{l}\text { Storage times for } \\
\text { fruits, non-leafy } \\
\text { vegetables, and grain }\end{array}$ & $d$ & 14 & $0-1 E+34$ & All & 14 & B & 3 & $\begin{array}{l}\text { The storage times are used to calculate } \\
\text { radioactive ingrowth and decay adjustment } \\
\text { factors for food and feed due to storage. } \\
\text { The code has values for fruits, non-leafy } \\
\text { vegetables, and grain (one category), leafy } \\
\text { vegetables, milk, well and surface water, } \\
\text { livestock fodder, meat, fish and crustacea; } \\
\text { and mollusks. } \\
\text { A default value was assumed for the Resident } \\
\text { Farmer and Resident Gardener since plant } \\
\text { ingestion is applicable and a site specific value } \\
\text { is not available. } \\
\text { The plant ingestion pathway is suppressed for } \\
\text { the Workers, Recreational User, and } \\
\text { Trespasser since this pathway is not } \\
\text { considered in the conceptual site model for } \\
\text { these receptors. }\end{array}$ & Yu et al. 2001 \\
\hline $\begin{array}{l}\text { Storage times for leafy } \\
\text { vegetables }\end{array}$ & $d$ & 1 & $0-1 E+34$ & All & 1 & B & 3 & $\begin{array}{l}\text { The storage times are used to calculate } \\
\text { radioactive ingrowth and decay adjustment } \\
\text { factors for food and feed due to storage. } \\
\text { The code has values for fruits, non-leafy } \\
\text { vegetables, and grain (one category), leafy } \\
\text { vegetables, milk, well and surface water, } \\
\text { livestock fodder, meat, fish and crustacea; } \\
\text { and mollusks. } \\
\text { A default value was assumed for the Resident } \\
\text { Farmer and Resident Gardener since plant } \\
\text { ingestion is applicable and a site specific value } \\
\text { is not available. } \\
\text { The plant ingestion pathway is suppressed for } \\
\text { the Workers, Recreational User, and }\end{array}$ & Yu et al. 2001 \\
\hline
\end{tabular}


RESRAD Table of Input Parameters for the C-746-U Landfill Onsite Receptor Scenarios

\begin{tabular}{|c|c|c|c|c|c|c|c|c|c|}
\hline $\begin{array}{c}\text { Input Screen Title } \\
\text { and Parameter } \\
\text { Name }\end{array}$ & Unit & $\begin{array}{c}\text { Code } \\
\text { Default } \\
\text { Value }\end{array}$ & $\begin{array}{c}\text { Code- } \\
\text { Accepted } \\
\text { Values }^{a}\end{array}$ & Receptor ${ }^{b}$ & $\begin{array}{l}\text { Deterministic } \\
\text { Value }\end{array}$ & Type $^{c}$ & Priority $^{d}$ & Justification & References \\
\hline & & & & & & & & $\begin{array}{l}\text { Trespasser since this pathway is not } \\
\text { considered in the conceptual site model for } \\
\text { these receptors. }\end{array}$ & \\
\hline Storage times for milk & d & 1 & $0-1 E+34$ & All & 1 & B & 3 & $\begin{array}{l}\text { The storage times are used to calculate } \\
\text { radioactive ingrowth and decay adjustment } \\
\text { factors for food and feed due to storage. } \\
\text { The code has values for fruits, non-leafy } \\
\text { vegetables, and grain (one category), leafy } \\
\text { vegetables, milk, well and surface water, } \\
\text { livestock fodder, meat, fish and crustacea; } \\
\text { and mollusks. } \\
\text { A default value was assumed for the Resident } \\
\text { Farmer since milk ingestion is applicable and a } \\
\text { site specific value is not available. } \\
\text { The milk ingestion pathway is suppressed for } \\
\text { the Residential Gardener, Workers, } \\
\text { Recreational User, and Trespasser since this } \\
\text { pathway is not considered in the conceptual } \\
\text { site model for these receptors. }\end{array}$ & Yu et al. 2001 \\
\hline $\begin{array}{l}\text { Storage times for } \\
\text { meat }\end{array}$ & $d$ & 20 & $0-1 E+34$ & All & 20 & B & 3 & $\begin{array}{l}\text { The storage times are used to calculate } \\
\text { radioactive ingrowth and decay adjustment } \\
\text { factors for food and feed due to storage. } \\
\text { The code has values for fruits, non-leafy } \\
\text { vegetables, and grain (one category), leafy } \\
\text { vegetables, milk, well and surface water, } \\
\text { livestock fodder, meat, fish and crustacea; } \\
\text { and mollusks. } \\
\text { A default value was assumed for the Resident } \\
\text { Farmer since meat ingestion is applicable and } \\
\text { a site specific value is not available. } \\
\text { The meat ingestion pathway is suppressed for } \\
\text { the Resident Gardner, Workers, Recreational } \\
\text { User, and Trespasser since this pathway is not } \\
\text { considered in the conceptual site model for } \\
\text { these receptors. }\end{array}$ & Yu et al. 2001 \\
\hline Storage times for fish & $d$ & 7 & $0-1 \mathrm{E}+34$ & All & 7 & $\mathrm{~B}$ & 3 & The storage times are used to calculate & Yu et al. 2001 \\
\hline
\end{tabular}


RESRAD Table of Input Parameters for the C-746-U Landfill Onsite Receptor Scenarios

\begin{tabular}{|c|c|c|c|c|c|c|c|c|c|}
\hline $\begin{array}{c}\text { Input Screen Title } \\
\text { and Parameter } \\
\text { Name }\end{array}$ & Unit & $\begin{array}{c}\text { Code } \\
\text { Default } \\
\text { Value }\end{array}$ & $\begin{array}{c}\text { Code- } \\
\text { Accepted } \\
\text { Values }^{a}\end{array}$ & Receptor ${ }^{b}$ & $\begin{array}{c}\text { Deterministic } \\
\text { Value }\end{array}$ & Type ${ }^{c}$ & Priority $^{d}$ & Justification & References \\
\hline & & & & & & & & $\begin{array}{l}\text { radioactive ingrowth and decay adjustment } \\
\text { factors for food and feed due to storage. } \\
\text { The code has values for fruits, non-leafy } \\
\text { vegetables, and grain (one category), leafy } \\
\text { vegetables, milk, well and surface water, } \\
\text { livestock fodder, meat, fish and crustacea; } \\
\text { and mollusks. } \\
\text { A default value was assumed; however, the } \\
\text { aquatic foods ingestion pathway is suppressed } \\
\text { for all receptors since this pathway is not } \\
\text { considered in the conceptual site model. }\end{array}$ & \\
\hline $\begin{array}{c}\text { Storage times for } \\
\text { crustacea and mollusks }\end{array}$ & $d$ & 7 & $0-1 E+34$ & All & 7 & B & 3 & $\begin{array}{l}\text { The storage times are used to calculate } \\
\text { radioactive ingrowth and decay adjustment } \\
\text { factors for food and feed due to storage. } \\
\text { The code has values for fruits, non-leafy } \\
\text { vegetables, and grain (one category), leafy } \\
\text { vegetables, milk, well and surface water, } \\
\text { livestock fodder, meat, fish and crustacea; } \\
\text { and mollusks. } \\
\text { A default value was assumed; however, the } \\
\text { aquatic foods ingestion pathway is suppressed } \\
\text { for all receptors since this pathway is not } \\
\text { considered in the conceptual site model. }\end{array}$ & Yu et al. 2001 \\
\hline $\begin{array}{l}\text { Storage times for well } \\
\text { water }\end{array}$ & $d$ & 1 & $0-1 E+34$ & All & 1 & B & 3 & $\begin{array}{l}\text { The storage times are used to calculate } \\
\text { radioactive ingrowth and decay adjustment } \\
\text { factors for food and feed due to storage. } \\
\text { The code has values for fruits, non-leafy } \\
\text { vegetables, and grain (one category), leafy } \\
\text { vegetables, milk, well and surface water, } \\
\text { livestock fodder, meat, fish and crustacea; } \\
\text { and mollusks. } \\
\text { A default value was assumed for the Resident } \\
\text { Farmer since this receptor would be } \\
\text { potentially affected by contaminated well } \\
\text { water and a site specific value is not available. }\end{array}$ & Yu et al. 2001 \\
\hline
\end{tabular}


RESRAD Table of Input Parameters for the C-746-U Landfill Onsite Receptor Scenarios

\begin{tabular}{|c|c|c|c|c|c|c|c|c|c|}
\hline $\begin{array}{c}\text { Input Screen Title } \\
\text { and Parameter } \\
\text { Name }\end{array}$ & Unit & $\begin{array}{c}\text { Code } \\
\text { Default } \\
\text { Value }\end{array}$ & $\begin{array}{c}\text { Code- } \\
\text { Accepted } \\
\text { Values }^{a}\end{array}$ & Receptor $^{b}$ & $\begin{array}{c}\text { Deterministic } \\
\text { Value }\end{array}$ & Type $^{c}$ & Priority $^{d}$ & Justification & References \\
\hline & & & & & & & & $\begin{array}{l}\text { The meat, milk, plant, and drinking water } \\
\text { ingestion pathways are suppressed for the } \\
\text { Workers, Recreational User, and Trespasser } \\
\text { since these pathways are not considered in } \\
\text { the conceptual site model for these receptors. } \\
\text { The meat, milk, and drinking water ingestion } \\
\text { pathways are suppressed for the Resident } \\
\text { Gardener since these pathways are not } \\
\text { considered in the conceptual site model for } \\
\text { this receptor. }\end{array}$ & \\
\hline $\begin{array}{l}\text { Storage times for } \\
\text { surface water }\end{array}$ & $d$ & 1 & $0-1 E+34$ & All & 1 & B & 3 & $\begin{array}{l}\text { The storage times are used to calculate } \\
\text { radioactive ingrowth and decay adjustment } \\
\text { factors for food and feed due to storage. } \\
\text { The code has values for fruits, non-leafy } \\
\text { vegetables, and grain (one category), leafy } \\
\text { vegetables, milk, well and surface water, } \\
\text { livestock fodder, meat, fish and crustacea; } \\
\text { and mollusks. } \\
\text { A default value was assumed for the Resident } \\
\text { Farmer since this receptor would be } \\
\text { potentially affected by contaminated surface } \\
\text { water and a site specific value is not available. } \\
\text { The meat, milk, plant, and drinking water } \\
\text { ingestion pathways are suppressed for the } \\
\text { Workers, Recreational User, and Trespasser } \\
\text { since these pathways are not considered in } \\
\text { the conceptual site model for these receptors. } \\
\text { The meat, milk, and drinking water ingestion } \\
\text { pathways are suppressed for the Resident } \\
\text { Gardener since these pathways are not } \\
\text { considered in the conceptual site model for } \\
\text { this receptor. }\end{array}$ & Yu et al. 2001 \\
\hline $\begin{array}{l}\text { Storage times for } \\
\text { livestock fodder }\end{array}$ & $d$ & 45 & $0-1 E+34$ & All & 45 & B & 3 & $\begin{array}{l}\text { For livestock fodder the storage time is an } \\
\text { annual average. The default value is obtained } \\
\text { by assuming } 6 \text { months of outside gazing and } 6 \\
\text { months of silage fodder with an average silo } \\
\text { time of } 3 \text { months. }\end{array}$ & Yu et al. 2001 \\
\hline
\end{tabular}


RESRAD Table of Input Parameters for the C-746-U Landfill Onsite Receptor Scenarios

\begin{tabular}{|c|c|c|c|c|c|c|c|c|c|}
\hline $\begin{array}{c}\text { Input Screen Title } \\
\text { and Parameter } \\
\text { Name }\end{array}$ & Unit & $\begin{array}{c}\text { Code } \\
\text { Default } \\
\text { Value }\end{array}$ & $\begin{array}{c}\text { Code- } \\
\text { Accepted } \\
\text { Values }^{a}\end{array}$ & Receptor ${ }^{b}$ & $\begin{array}{c}\text { Deterministic } \\
\text { Value }\end{array}$ & Type $e^{c}$ & Priority $^{d}$ & Justification & References \\
\hline & & & & & & & & $\begin{array}{l}\text { A default value was assumed for the Resident } \\
\text { Farmer because meat and milk ingestion are } \\
\text { applicable and a site specific value is not } \\
\text { available. } \\
\text { The meat and milk ingestion pathways are } \\
\text { suppressed for the Resident Gardener, } \\
\text { Workers, Recreational User, and Trespasser } \\
\text { since these pathways are not considered in } \\
\text { the conceptual site model for these receptors. }\end{array}$ & \\
\hline \multirow{2}{*}{$\begin{array}{l}\text { Inhalation dose } \\
\text { conversion factors }\end{array}$} & \multirow{2}{*}{$\mathrm{mrem} / \mathrm{pCi}$} & \multirow{2}{*}{$\begin{array}{c}\text { Nuclide } \\
\text { Specific } \\
\text { (Default } \\
\text { values } \\
\text { available) }\end{array}$} & \multirow{2}{*}{$\begin{array}{l}\text { Nuclide } \\
\text { Specific }\end{array}$} & $\begin{array}{l}\text { RF } \\
\text { RG } \\
W \\
T \\
L \\
\end{array}$ & $\begin{array}{l}\text { Nuclide Specific } \\
\text { (ICRP } 72 \text { (Adult)) }\end{array}$ & \multirow[t]{2}{*}{ M } & \multirow[t]{2}{*}{3} & \multirow{2}{*}{$\begin{array}{l}\text { The ICRP } 72 \text { Adult and Age } 15 \text { (internal dose } \\
\text { conversion factors) libraries are selected in } \\
\text { conjunction with the ICRP } 60 \text { (external dose } \\
\text { conversion factors) library to obtain results in } \\
\text { Total Effective Dose (TED). } \\
\text { The Recreational User is the only receptor } \\
\text { who is a teenager; therefore, the applicable } \\
\text { library is ICRP } 72 \text { (Age 15). }\end{array}$} & \multirow[t]{2}{*}{ Yu et al. 2001} \\
\hline & & & & RU & $\begin{array}{l}\text { Nuclide Specific } \\
\text { (ICRP } 72 \text { (Age 15)) }\end{array}$ & & & & \\
\hline \multirow{2}{*}{$\begin{array}{l}\text { Ingestion dose } \\
\text { conversion factors }\end{array}$} & \multirow{2}{*}{$\mathrm{mrem} / \mathrm{pCi}$} & \multirow{2}{*}{$\begin{array}{c}\text { Nuclide } \\
\text { Specific } \\
\text { (Default } \\
\text { values } \\
\text { available) }\end{array}$} & \multirow{2}{*}{$\begin{array}{l}\text { Nuclide } \\
\text { Specific }\end{array}$} & $\begin{array}{c}\text { RF } \\
\text { RG } \\
W \\
T \\
L \\
\end{array}$ & $\begin{array}{l}\text { Nuclide Specific } \\
\text { (ICRP } 72 \text { (Adult)) }\end{array}$ & \multirow[t]{2}{*}{ M } & \multirow[t]{2}{*}{3} & \multirow{2}{*}{$\begin{array}{l}\text { The ICRP } 72 \text { Adult and Age } 15 \text { (internal dose } \\
\text { conversion factors) libraries are selected in } \\
\text { conjunction with the ICRP } 60 \text { (external dose } \\
\text { conversion factors) library to obtain results in } \\
\text { Total Effective Dose (TED). } \\
\text { The Recreational User is the only receptor } \\
\text { who is a teenager; therefore, the applicable } \\
\text { library is ICRP } 72 \text { (Age 15). }\end{array}$} & \multirow[t]{2}{*}{ Yu et al. 2001} \\
\hline & & & & RU & $\begin{array}{l}\text { Nuclide Specific } \\
\text { (ICRP } 72 \text { (Age 15)) }\end{array}$ & & & & \\
\hline Slope factor- external & $\begin{array}{l}\text { (risk/yr)/ } \\
(\mathrm{pCi} / \mathrm{g})\end{array}$ & $\begin{array}{c}\text { Nuclide } \\
\text { Specific } \\
\text { (Default } \\
\text { values } \\
\text { available) }\end{array}$ & $\begin{array}{l}\text { Nuclide } \\
\text { Specific }\end{array}$ & All & $\begin{array}{l}\text { Nuclide Specific } \\
\text { (Default values) }\end{array}$ & M & 3 & Default value is used. & Yu et al. 2001 \\
\hline $\begin{array}{l}\text { Slope factor - } \\
\text { inhalation }\end{array}$ & risk/pCi & $\begin{array}{c}\text { Nuclide } \\
\text { Specific } \\
\text { (Default } \\
\text { values } \\
\text { available) }\end{array}$ & $\begin{array}{l}\text { Nuclide } \\
\text { Specific }\end{array}$ & All & $\begin{array}{l}\text { Nuclide Specific } \\
\text { (Default values) }\end{array}$ & M & 3 & Default value is used. & Yu et al. 2001 \\
\hline
\end{tabular}


RESRAD Table of Input Parameters for the C-746-U Landfill Onsite Receptor Scenarios

\begin{tabular}{|c|c|c|c|c|c|c|c|c|c|}
\hline $\begin{array}{c}\text { Input Screen Title } \\
\text { and Parameter } \\
\text { Name }\end{array}$ & Unit & $\begin{array}{c}\text { Code } \\
\text { Default } \\
\text { Value }\end{array}$ & $\begin{array}{c}\text { Code- } \\
\text { Accepted } \\
\text { Values }^{a}\end{array}$ & Receptor ${ }^{b}$ & $\begin{array}{c}\text { Deterministic } \\
\text { Value }\end{array}$ & Type ${ }^{c}$ & Priority $^{d}$ & Justification & References \\
\hline $\begin{array}{l}\text { Slope factor - } \\
\text { ingestion }\end{array}$ & risk/pCi & $\begin{array}{c}\text { Nuclide } \\
\text { Specific } \\
\text { (Default } \\
\text { values } \\
\text { available) } \\
\end{array}$ & $\begin{array}{l}\text { Nuclide } \\
\text { Specific }\end{array}$ & All & $\begin{array}{l}\text { Nuclide Specific } \\
\text { (Default values) }\end{array}$ & M & 3 & Default value is used. & Yu et al. 2001 \\
\hline Plant transfer factor & - & $\begin{array}{c}\text { Element } \\
\text { Specific } \\
\text { (Default } \\
\text { values } \\
\text { available) }\end{array}$ & $\begin{array}{l}\text { Element } \\
\text { Specific }\end{array}$ & All & $\begin{array}{l}\text { Nuclide Specific } \\
\text { (Default values) }\end{array}$ & $P$ & 1 & Default value is used. & Yu et al. 2001 \\
\hline Meat transfer factor & $\begin{array}{l}(\mathrm{pCi} / \mathrm{kg}) / \\
(\mathrm{pCi} / \mathrm{d})\end{array}$ & $\begin{array}{l}\text { Element } \\
\text { Specific } \\
\text { (Default } \\
\text { values } \\
\text { available) }\end{array}$ & $\begin{array}{l}\text { Element } \\
\text { Specific }\end{array}$ & All & $\begin{array}{l}\text { Nuclide Specific } \\
\text { (Default values) }\end{array}$ & $P$ & 2 & Default value is used. & Yu et al. 2001 \\
\hline Milk transfer factor & $\begin{array}{l}(\mathrm{pCi} / \mathrm{L}) / \\
(\mathrm{pCi} / \mathrm{d})\end{array}$ & $\begin{array}{c}\text { Element } \\
\text { Specific } \\
\text { (Default } \\
\text { values } \\
\text { available) } \\
\end{array}$ & $\begin{array}{l}\text { Element } \\
\text { Specific }\end{array}$ & All & $\begin{array}{l}\text { Nuclide Specific } \\
\text { (Default values) }\end{array}$ & $P$ & 2 & Default value is used. & Yu et al. 2001 \\
\hline $\begin{array}{l}\text { Bioaccumulation } \\
\text { factor for fish }\end{array}$ & $\begin{array}{l}(\mathrm{pCi} / \mathrm{kg}) / \\
(\mathrm{pCi} / \mathrm{L})\end{array}$ & $\begin{array}{c}\text { Element } \\
\text { Specific } \\
\text { (Default } \\
\text { values } \\
\text { available) }\end{array}$ & $\begin{array}{l}\text { Element } \\
\text { Specific }\end{array}$ & All & $\begin{array}{l}\text { Nuclide Specific } \\
\text { (Default values) }\end{array}$ & $P$ & 2 & Default value is used. & Yu et al. 2001 \\
\hline $\begin{array}{l}\text { Bioaccumulation } \\
\text { factor for crustacea } \\
\text { and mollusks }\end{array}$ & $\begin{array}{l}(\mathrm{pCi} / \mathrm{kg}) / \\
(\mathrm{pCi} / \mathrm{L})\end{array}$ & $\begin{array}{c}\text { Element } \\
\text { Specific } \\
\text { (Default } \\
\text { values } \\
\text { available) }\end{array}$ & $\begin{array}{l}\text { Element } \\
\text { Specific }\end{array}$ & All & $\begin{array}{l}\text { Nuclide Specific } \\
\text { (Default values }\end{array}$ & $P$ & 3 & Default value is used. & Yu et al. 2001 \\
\hline
\end{tabular}


a RESRAD does not provide code-accepted values for element- or nuclide-specific parameters

b The receptors considered for the selection of parameters are the Resident Farmer (RF), Resident Gardener (RG), Outdoor Worker (W), Recreational User (RU) Trespasser ( $\mathrm{T}$ ) and the Landfill Worker $(\mathrm{L})$

c $\mathrm{P}=$ physical, $\mathrm{B}=$ behavioral, $\mathrm{M}=$ metabolic; when more than one type is listed, the first is primary and the next is secondary. The RESRAD parameters that are not classified, because of their function in the code are considered as "NA= not applicable" in this table.

d According to NUREG/CR-6697, it is necessary to establish priorities about which parameters to collect data for and use for distribution analysis. The parameters were ranked into three levels of priority: 1 (high priority), 2 (medium priority), and 3 (low priority).

e " $\_$" indicates that the parameter is dimensionless.

$f$ Groundwater concentration can be input only if time since placement of material is $>0$.

g This parameter should be used only if radionuclide leach rates are known.

h $\quad \mathrm{NA}=$ not applicable.

The Radon and Carbon-14 parameters are not included as part of this table because these radionuclides are not included in the contaminants of concern for this project. RESRAD allows the user to edit radon parameters only when a radon parent for either Rn-222 (U-238, U-234, Th-230, or Ra-226) or Rn-220 (Th-232, Ra-228, or Th-228) is present as a contaminant. Similarly, a user will have access to carbon-14 (C-14) parameters only if C-14 is a contaminant.

Notes:

The template for the table of parameters was created based on information available in NUREG/CR-6697 (ANL/EAD/TM-98), Development of Probabilistic RESRAD 6.0 and RESRAD-Build 3.0 Computer Codes and the User's Manual for RESRAD Version 6.0. 
Attachment I

Distribution Coefficients 


\section{Distribution Coefficients $\left(K d s, \mathrm{~cm}^{3} / \mathrm{g}\right)^{a, b}$ for parent radionuclides in the contaminated zone, the unsaturated zones, and the saturated zone}

\begin{tabular}{|c|c|c|c|c|c|c|c|c|c|c|c|c|}
\hline Radionuclide & Am-241 & Cs-137 & Np-237 & Pu-238 & Pu-239/240 & Tc-99 & Th-228 & Th-230 & Th-232 & U-234 & U-235 & U-238 \\
\hline Contaminated Zone $^{c}$ & 1900 & 280 & 70 & 550 & 550 & 1 & 3200 & 3200 & 3200 & 410 & 410 & 410 \\
\hline $\begin{array}{l}\text { Unsaturated Zone } 1 \\
\text { (Protective layer } \\
\text { [native soil]) }\end{array}$ & 1900 & 280 & 70 & 550 & 550 & 0.2 & 3200 & 3200 & 3200 & 66.8 & 66.8 & 66.8 \\
\hline $\begin{array}{c}\text { Unsaturated Zone } 2 \\
\text { (Gravel layer) }\end{array}$ & 1900 & 280 & 70 & 550 & 550 & 0.2 & 3200 & 3200 & 3200 & 66.8 & 66.8 & 66.8 \\
\hline $\begin{array}{c}\text { Unsaturated Zone } 3 \\
\text { (Clay barrier) }\end{array}$ & 8400 & 1900 & 144 & 5100 & 5100 & 20 & 5800 & 5800 & 5800 & 3640 & 3640 & 3640 \\
\hline $\begin{array}{c}\text { Unsaturated Zone } 4 \\
\text { (Alluvium soils } \\
\text { [native/subgrade]) }\end{array}$ & 1900 & 280 & 70 & 550 & 550 & 0.2 & 3200 & 3200 & 3200 & 66.8 & 66.8 & 66.8 \\
\hline $\begin{array}{c}\text { Unsaturated Zone } 5 \\
\text { (Clay confining unit } \\
\text { [native]) }\end{array}$ & 8400 & 1900 & 144 & 5100 & 5100 & 20 & 5800 & 5800 & 5800 & 3640 & 3640 & 3640 \\
\hline Saturated Zone(RGA) & 1900 & 280 & 70 & 550 & 550 & 0.2 & 3200 & 3200 & 3200 & 66.8 & 66.8 & 66.8 \\
\hline
\end{tabular}

\footnotetext{
a Distribution coefficients for Am-241, Np-237, Th-230, Th-232, U-234 and U-238 were obtained from DOE 2003b, page C3-313 and Table Att. 1. Distribution coefficient of radionuclides and their daughter products in different zones, page C3-314. It was assumed that the Kd for U-235 was similar to the Kd for U-234 and U-238 since the Kds are chemical specific.

${ }^{b}$ Distribution coefficients for Cs-137, Th-228, Pu-238, Pu-239, and Pu-240 were obtained through "Project Communication" with the Waste Disposal Options Project Team from Paducah, KY. The distribution coefficients for Tc-99 are available in Table C.3.1. Chemical and physical properties of different classes of chemicals identified as COPCs for the C-746-U Landfill of DOE 2003b, page C3301. Table 4.5 DUST model input parameters, page 4-12, has Kds for Tc-99 and Uranium.

${ }^{c}$ The contaminated zone includes four Waste Forms such as: Soil (Waste Form 1), Concrete (Waste Form 2), Metal (Waste Form 3), and Organic (Waste Form 4). This information was obtained from figure Fig. 4.5. Schematic diagram of DUST model layers and materials for the Post-Institutional Control Period under the gradual failure and immediate failure scenarios of DOE 2003b, page 4-18.
} 
Distribution Coefficients $\left(K d s, \mathrm{~cm}^{3} / \mathrm{g}\right)^{d}$ for progeny radionuclides in the contaminated zone, the unsaturated zones and the saturated zone

\begin{tabular}{|c|c|c|c|c|c|c|c|c|}
\hline Radionuclide & Ac-227 & Pa-231 & $\mathrm{Pb}-210$ & Ra-226 & Ra-228 & Th-229 & U-233 & U-236 \\
\hline Contaminated Zone $^{\mathrm{e}}$ & 450 & 550 & 270 & 500 & 500 & 3200 & 410 & 410 \\
\hline $\begin{array}{c}\text { Unsaturated Zone } 1 \\
\text { (Protective layer [native soil]) }\end{array}$ & 450 & 550 & 270 & 500 & 500 & 3200 & 66.8 & 66.8 \\
\hline Unsaturated Zone 2 (Gravel layer) & 450 & 550 & 270 & 500 & 500 & 3200 & 66.8 & 66.8 \\
\hline $\begin{array}{l}\text { Unsaturated Zone } 3 \\
\text { (Clay barrier) }\end{array}$ & 2400 & 2700 & 550 & 9100 & 9100 & 5800 & 3640 & 3640 \\
\hline $\begin{array}{c}\text { Unsaturated Zone } 4 \\
\text { (Alluvium soils [native/subgrade]) }\end{array}$ & 450 & 550 & 270 & 500 & 500 & 3200 & 66.8 & 66.8 \\
\hline $\begin{array}{c}\text { Unsaturated Zone } 5 \\
\text { (Clay confining unit [native]) }\end{array}$ & 2400 & 2700 & 550 & 9100 & 9100 & 5800 & 3640 & 3640 \\
\hline Saturated Zone(RGA) & 450 & 550 & 270 & 500 & 500 & 3200 & 66.8 & 66.8 \\
\hline
\end{tabular}

\footnotetext{
d Distribution coefficients for Ac-227, Pa-231, Pb-210, Ra-226, Ra-228, Th-229, and U-236 were obtained through "Project Communication" with the Waste Disposal Options Project Team from Paducah, KY. It was assumed that the Kds for U-233 was similar to the Kds for the other uranium isotopes (i.e. U-234, U-235, U-236 and U-238), since the Kds are chemical specific.

The contaminated zone includes four Waste Forms such as: Soil (Waste Form 1), Concrete (Waste Form 2), Metal (Waste Form 3), and Organic (Waste Form 4). This information was obtained from figure Fig. 4.5. Schematic diagram of DUST model layers and materials for the Post Institutional Control Period under the gradual failure and immediate failure scenarios of DOE $2003 \mathrm{~b}$, page 4-18.
} 
Attachment II

Calculations and Applicable Parameters from DOE 2009, Appendix D, Converted into RESRAD Compatible Units 


\section{Section A. Runoff Coefficient and Evapotranspiration Coefficient Calculations}

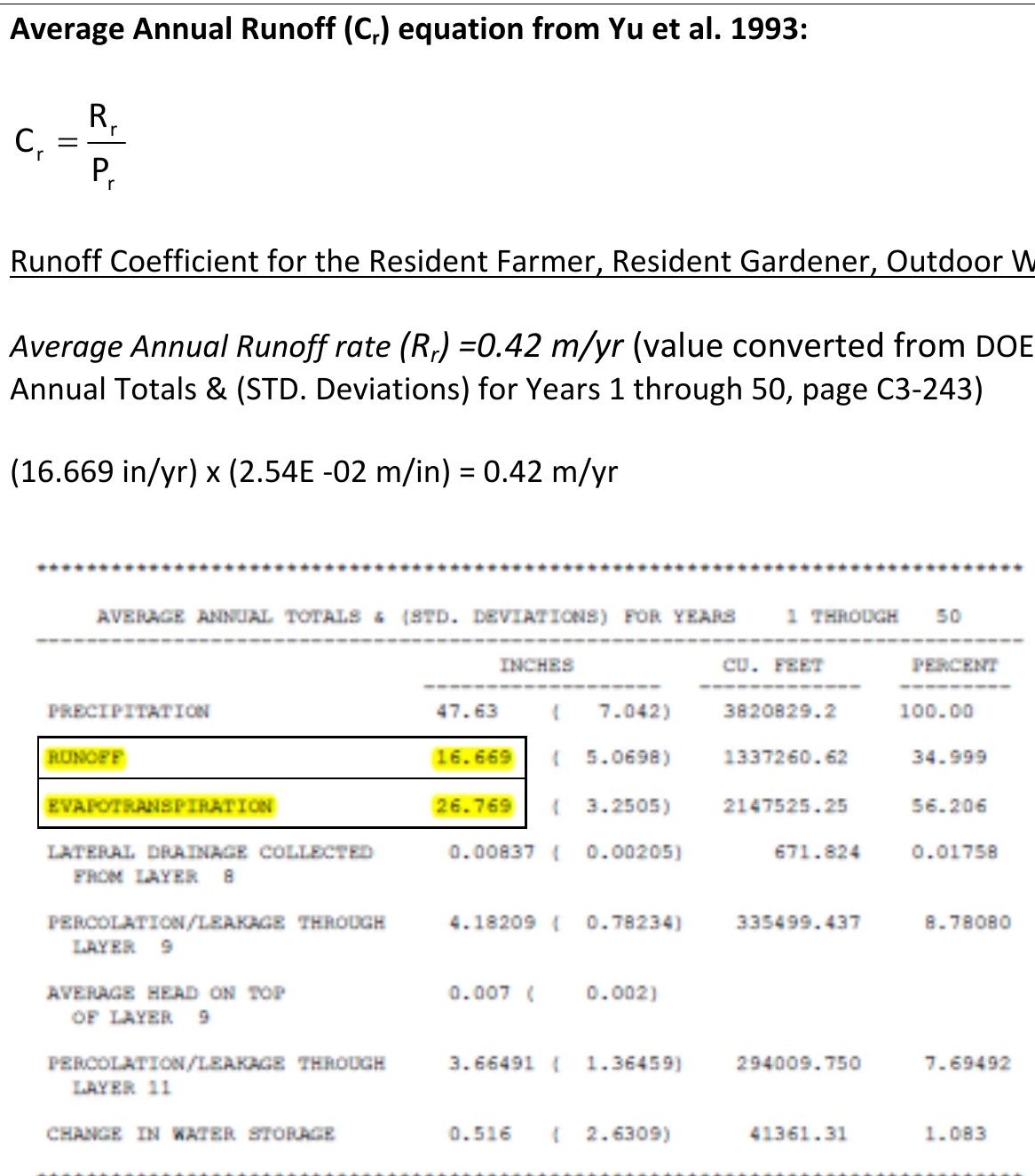

Note: The values from the HELP Output List 3 that were used to determine input parameters are highlighted. 


\section{Section A. Runoff Coefficient and Evapotranspiration Coefficient Calculations (cont.)}

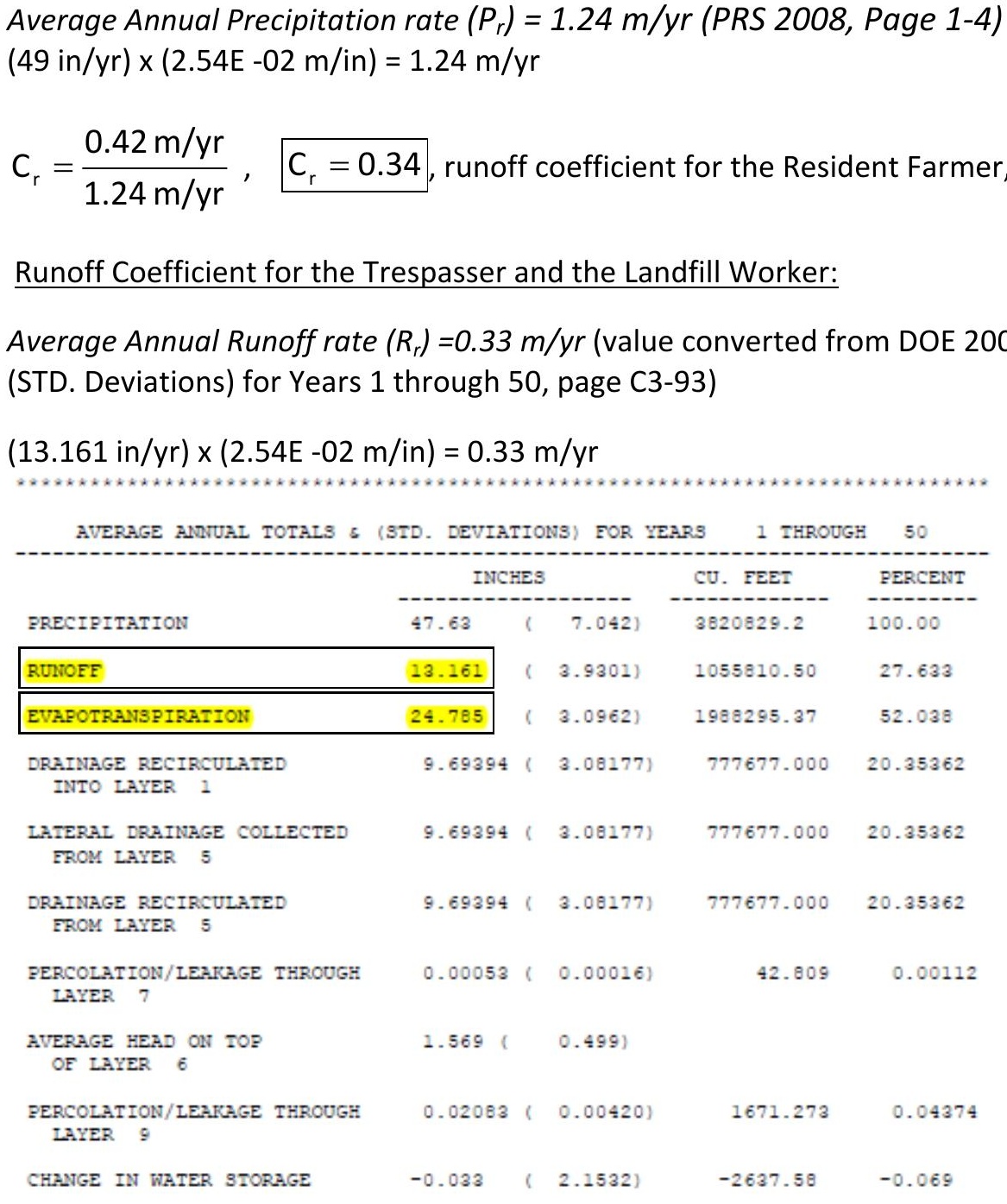

Note: The values from the HELP Output List 1 that were used to determine input parameters are highlighted. 


\section{Section A. Runoff Coefficient and Evapotranspiration Coefficient Calculations (cont.)}

Average Annual Precipitation rate $\left(P_{r}\right)=1.24 \mathrm{~m} / \mathrm{yr}$ (PRS 2008, Page 1-4)

$(49 \mathrm{in} / \mathrm{yr}) \times(2.54 \mathrm{E}-02 \mathrm{~m} / \mathrm{in})=1.24 \mathrm{~m} / \mathrm{yr}$

$C_{r}=\frac{0.33 \mathrm{~m} / \mathrm{yr}}{1.24 \mathrm{~m} / \mathrm{yr}}, \quad C_{r}=0.27$, runoff coefficient for the Trespasser and the Landfill Worker

Evapotranspiration coefficient $\left(C_{\mathrm{e}}\right)$ equation from Yu et al. 1993:

$C_{e}=\frac{E T_{r}}{\left(1-C_{r}\right) P_{r}+I R_{r}}$

Evapotranspiration Coefficient for the Resident Farmer, and Resident Gardener:

Evapotranspiration rate $\left(E T_{r}\right)=0.68 \mathrm{~m} / \mathrm{yr}$ (value converted from DOE 2003b, HELP Output List 3. Post-Institutional Control Period, Average Annual Totals \& (STD. Deviations) for Years 1 through 50, page C3-243)

$(26.769 \mathrm{in} / \mathrm{yr}) \times(2.54 \mathrm{E}-02 \mathrm{~m} / \mathrm{in})=0.68 \mathrm{~m} / \mathrm{yr}$

As recommended by DOE-PPPO, an irrigation rate of $0.1 \mathrm{~m} / \mathrm{yr}$ was assumed for the Resident Farmer, and Resident Gardener $I R_{r}=0.1 \mathrm{~m} / \mathrm{yr}$

$C_{e}=\frac{0.68 m / y r}{(1-0.34) 1.24 m / y r+0.1 m / y r}, \quad C_{e}=0.74$, evapotranspiration coefficient for the Resident Farmer, and Resident Gardener.

\section{Evapotranspiration Coefficient for the Outdoor Worker and Recreational User:}

Evapotranspiration rate $\left(E T_{r}\right)=0.68 \mathrm{~m} / \mathrm{yr}$ (value converted from DOE 2003b, HELP Output List 3. Post-Institutional Control Period, Average Annual Totals \& (STD. Deviations) for Years 1 through 50, page C3-243)

$(26.769 \mathrm{in} / \mathrm{yr}) \times(2.54 \mathrm{E}-02 \mathrm{~m} / \mathrm{in})=0.68 \mathrm{~m} / \mathrm{yr}$

An irrigation rate of $0 \mathrm{~m} / \mathrm{yr}$ was assumed for the Outdoor Worker, and Recreational User $\mathrm{IR}_{\mathrm{r}}=0 \mathrm{~m} / \mathrm{yr}$

$C_{e}=\frac{0.68 m / y r}{(1-0.34) 1.24 m / y r+0 m / y}, \quad C_{e}=0.83$, 


\section{Section A. Runoff Coefficient and Evapotranspiration Coefficient Calculations (cont.)}

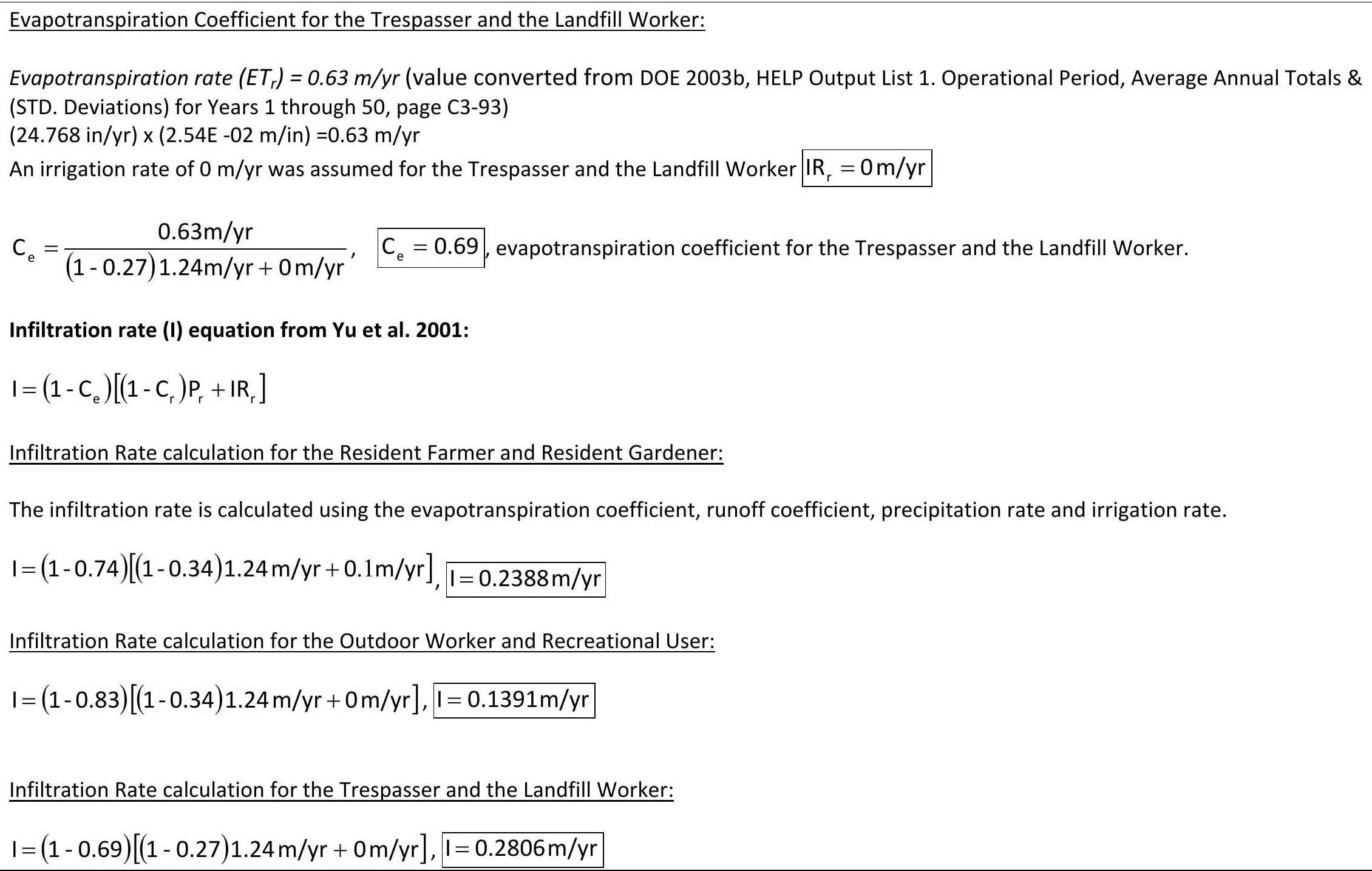




\section{Section B. Parameters Applicable to the Resident Farmer and the Resident Gardener}

\section{Drinking Water Intake}

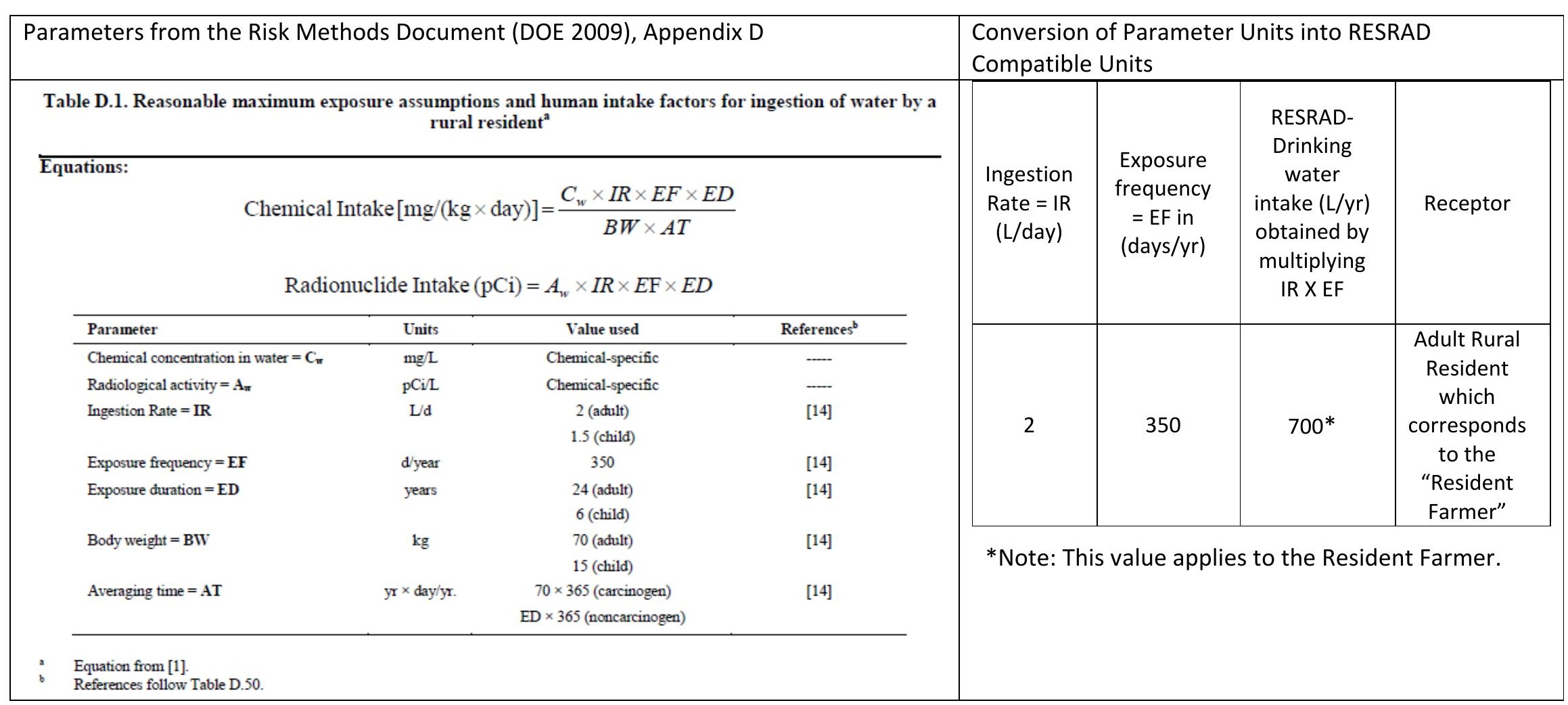




\section{Section B. Parameters Applicable to the Resident Farmer and the Resident Gardener (cont.)}

\section{Soil Ingestion Rate}

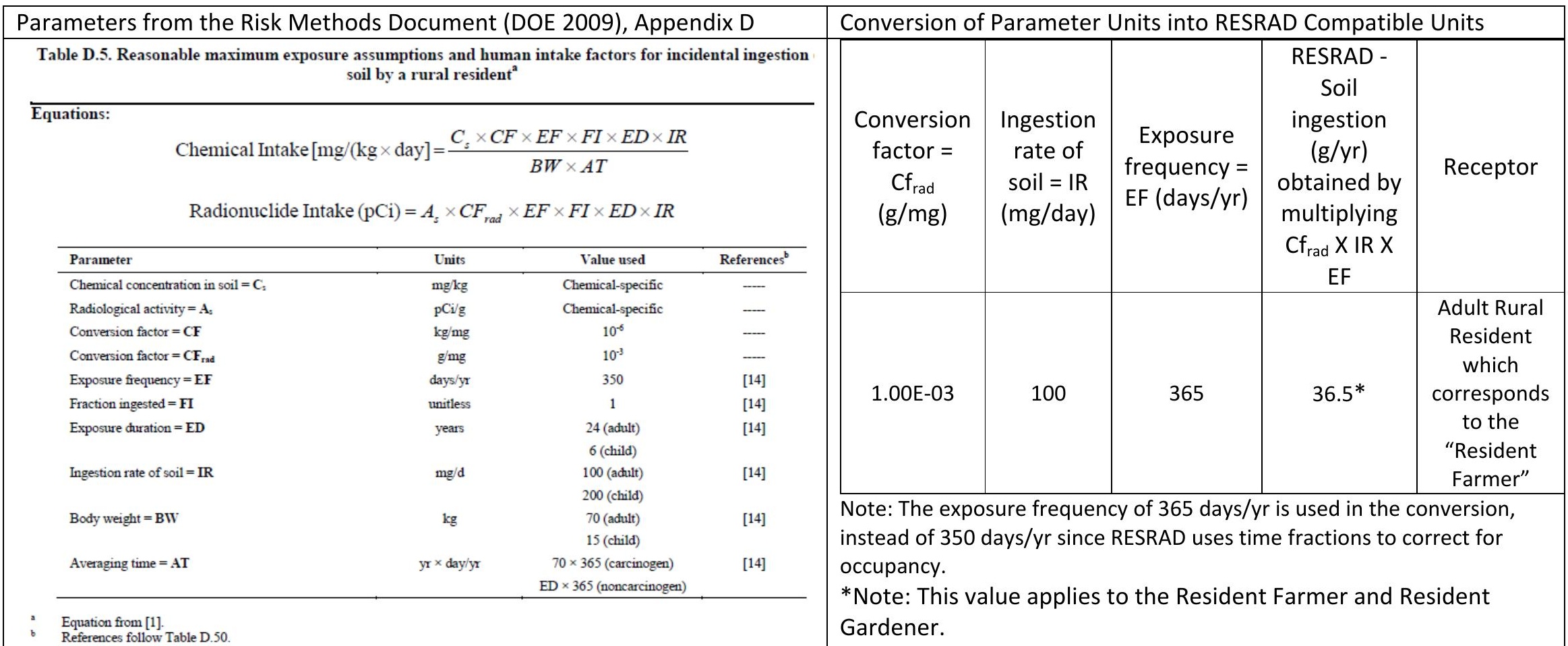




\section{Section B. Parameters Applicable to the Resident Farmer and the Resident Gardener (cont.)}

\section{Inhalation Rate and Mass Loading for Inhalation}

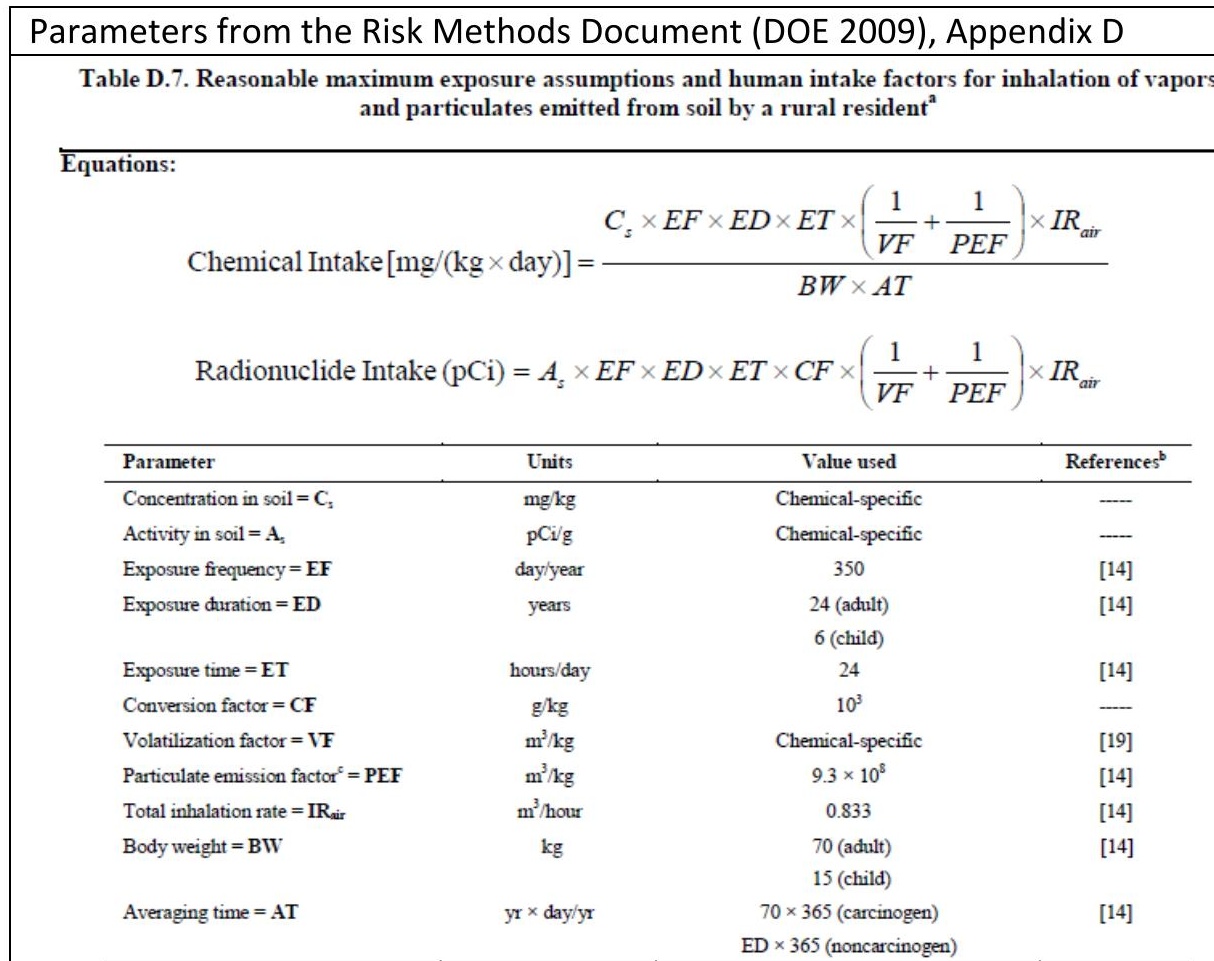

Conversion of Parameter Units into RESRAD Compatible Units

\begin{tabular}{|c|c|c|c|c|}
$\begin{array}{c}\text { Total } \\
\text { inhalation } \\
\text { rate }=I R_{\text {air }} \\
\left(\mathrm{m}^{3} / \text { hour) }\right.\end{array}$ & $\begin{array}{c}\text { Exposure } \\
\text { time = ET } \\
\text { (hours/ } \\
\text { day) }\end{array}$ & $\begin{array}{c}\text { Exposure } \\
\text { frequency } \\
=\mathrm{EF} \\
\text { (days/yr) }\end{array}$ & $\begin{array}{c}\text { RESRAD- } \\
\text { Inhalation } \\
\text { rate }\left(\mathrm{m}^{3} / \mathrm{yr}\right) \\
\text { obtained by } \\
\text { multiplying } \\
\text { IF X ET X EF }\end{array}$ & Receptor \\
\hline 0.833 & 24 & 365 & $7,297^{*}$ & $\begin{array}{c}\text { Adult Rural } \\
\text { Resident } \\
\text { which } \\
\text { corresponds } \\
\text { to the } \\
\text { "Resident } \\
\text { Farmer" }\end{array}$ \\
\hline
\end{tabular}

Note: The exposure frequency of 365 days/yr is used in the conversion, instead of 350 days/yr since RESRAD uses time fractions to correct for occupancy.

\begin{tabular}{|c|c|c|c|c|}
\hline $\begin{array}{c}\text { PEF } \\
\left(\mathrm{m}^{3} / \mathrm{kg}\right)\end{array}$ & $\begin{array}{c}\text { Conversion } \\
\text { from } \\
\mathrm{kg} \text { to g }\end{array}$ & $\begin{array}{c}\text { PEF } \\
\left(\mathrm{m}^{3} / \mathrm{g}\right)\end{array}$ & $\begin{array}{c}\text { RESRAD- } \\
\text { Mass } \\
\text { Loading for } \\
\text { Inhalation } \\
\left(\mathrm{g} / \mathrm{m}^{3}\right)= \\
1 / \mathrm{PEF}\end{array}$ & Receptor \\
\hline $9.30 \mathrm{E}+08$ & 1000 & 930000 & $1.08 \mathrm{E}-06^{*}$ & $\begin{array}{c}\text { Adult Rural } \\
\text { Resident } \\
\text { which } \\
\text { corresponds } \\
\text { to the } \\
\text { "Resident } \\
\text { Farmer" }\end{array}$ \\
\hline
\end{tabular}

*Note: These values apply to the Resident Farmer and Resident Gardener. 


\section{Section B. Parameters Applicable to the Resident Farmer and the Resident Gardener (cont.)}

\section{External Gamma Shielding Factor and Exposure Duration}

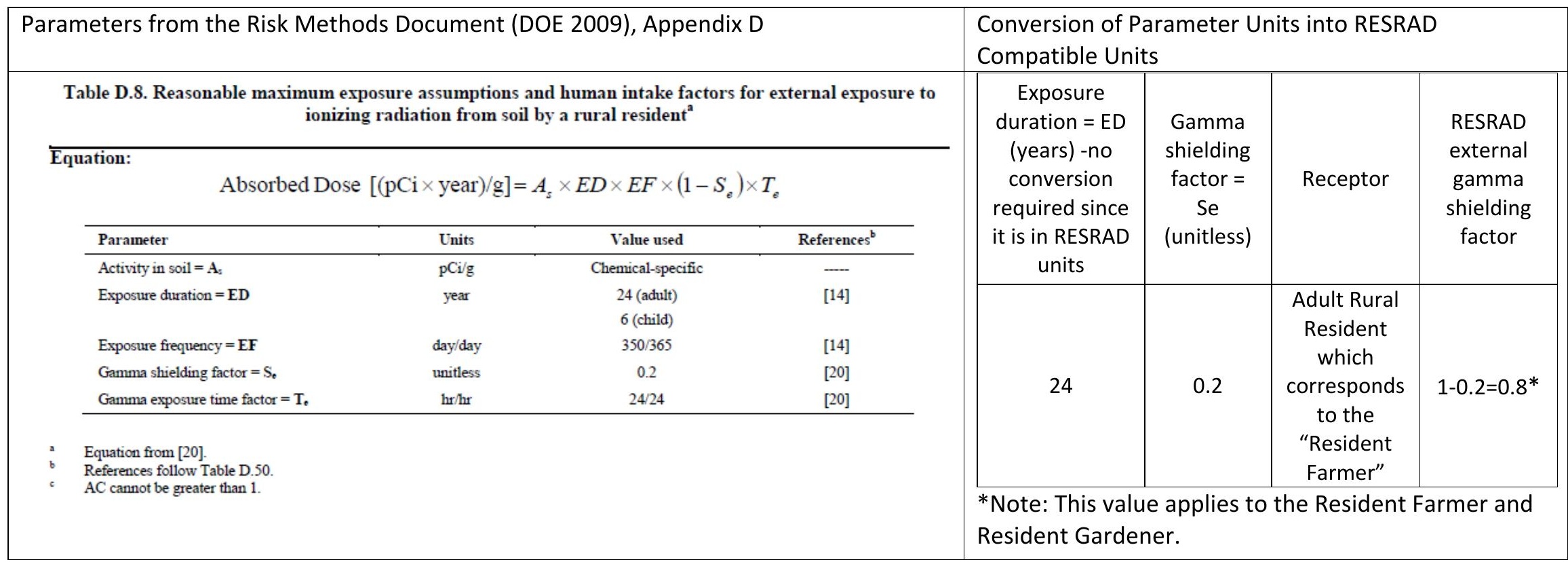

Indoor and Outdoor Occupancy Fractions

\begin{tabular}{|c|c|c|}
\hline \multicolumn{3}{|c|}{ Resident Farmer and Resident Gardener Occupancy fractions } \\
\hline & Days & Fractions for RESRAD \\
\hline $1 / 3$ of the time outdoors & 117 & 0.32 \\
\hline $2 / 3$ of the time indoors & 233 & 0.64 \\
\hline Total Days Onsite & 350 & \\
\hline Total Fraction & & 0.96 \\
\hline
\end{tabular}

Note: The Resident Farmer spends 350 days on site. 


\section{Section B. Parameters Applicable to the Resident Farmer and the Resident Gardener (cont.)}

\section{Fruit, Non-Leafy Vegetables, and Grain Consumption and Leafy Vegetables Consumption}

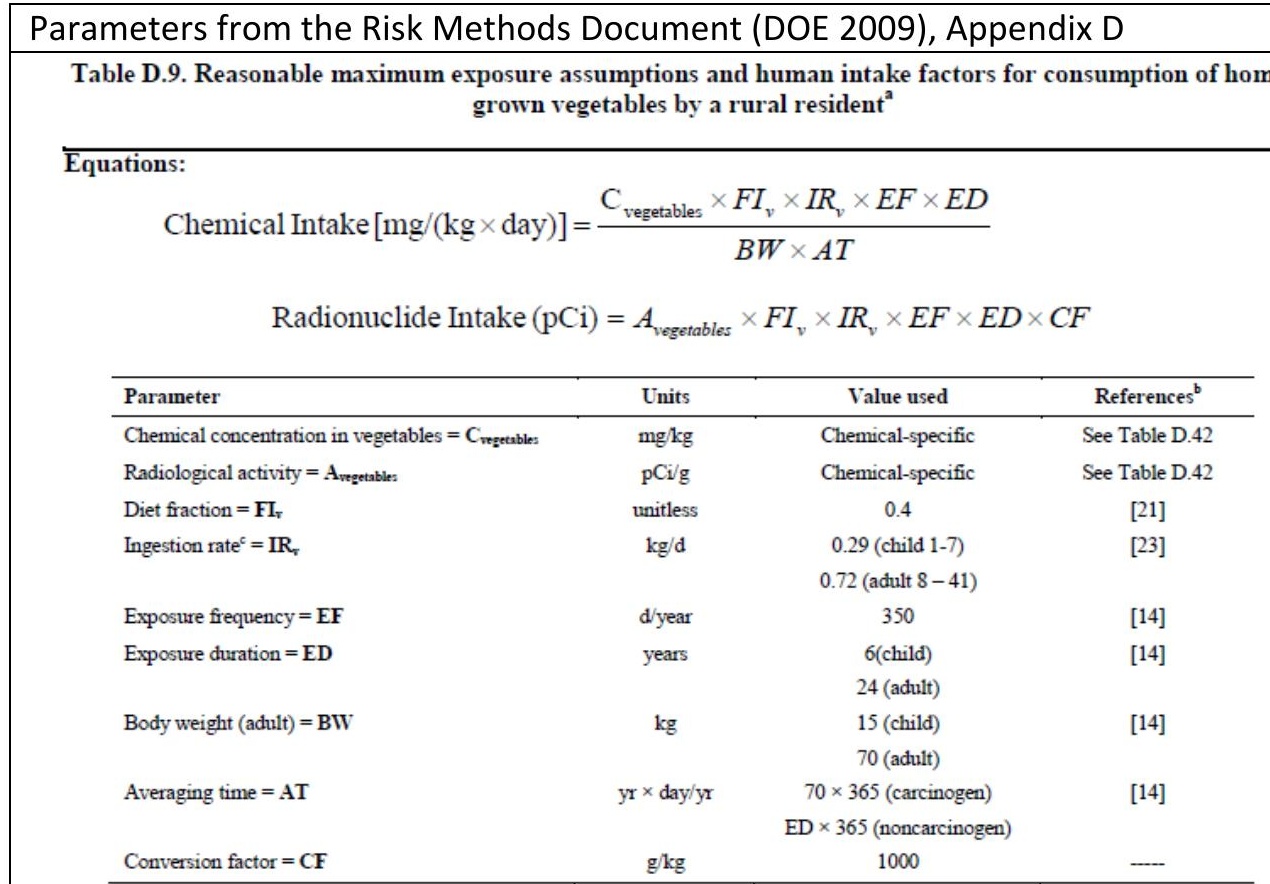

\section{Equation from [1].}

Ingestion values represent the $95^{\text {m }}$ percentile of individuals who consume this food group.

\begin{tabular}{|c|c|c|c|}
\hline \multicolumn{3}{|c|}{ Conversion of Parameter Units into RESRAD Compatible Units } \\
\begin{tabular}{|c|c|c|} 
Ingestion \\
rate $^{\mathrm{c}}=$ \\
$\mathrm{IR} \mathrm{R}_{\mathrm{v}}$ \\
$(\mathrm{kg} / \mathrm{day})$
\end{tabular} & $\begin{array}{c}\text { Exposure } \\
\text { frequency } \\
=\mathrm{EF} \\
\text { (days/yr) }\end{array}$ & $\begin{array}{c}\text { Home grown } \\
\text { vegetables } \\
\text { consumption } \\
\text { (kg/yr) } \\
\text { obtained by } \\
\text { multiplying IR } \\
\text { X EF }\end{array}$ & Receptor \\
0.72 & 350 & 252 & $\begin{array}{c}\text { Adult Rural } \\
\text { Resident which } \\
\text { corresponds to the } \\
\text { "Resident Farmer" }\end{array}$ \\
\hline
\end{tabular}

Note: This table is for home grown vegetables, it does not specify fruit, and grain. The ratio of this value is used for RESRAD as the Fruit, vegetables, and grain consumption (kg/yr) and for Leafy Vegetables (kg/yr).

\begin{tabular}{|l|c|c|c|}
\cline { 2 - 4 } \multicolumn{1}{c|}{} & $\begin{array}{c}\text { RESRAD } \\
\text { default }\end{array}$ & Calculation & $\begin{array}{c}\text { Ratio of } \\
\text { values for } \\
\text { RESRAD }\end{array}$ \\
\hline $\begin{array}{l}\text { Fruit, vegetable, and } \\
\text { grain consumption } \\
\text { (kg/yr) }\end{array}$ & 160 & $\frac{160}{174 \times 252}$ & $231.7^{*}$ \\
\hline $\begin{array}{l}\text { Leafy vegetables } \\
\text { consumption }(\mathrm{kg} / \mathrm{yr})\end{array}$ & 14 & $\frac{14}{174 \times 252}$ & $20.3^{*}$ \\
\hline Total $(\mathrm{kg} / \mathrm{yr})$ & 174 & NA & 252 \\
\hline
\end{tabular}

*Note: These values apply to the Resident Farmer and Resident Gardener. 


\section{Section B. Parameters Applicable to the Resident Farmer and the Resident Gardener (cont.)}

\section{Milk Consumption}

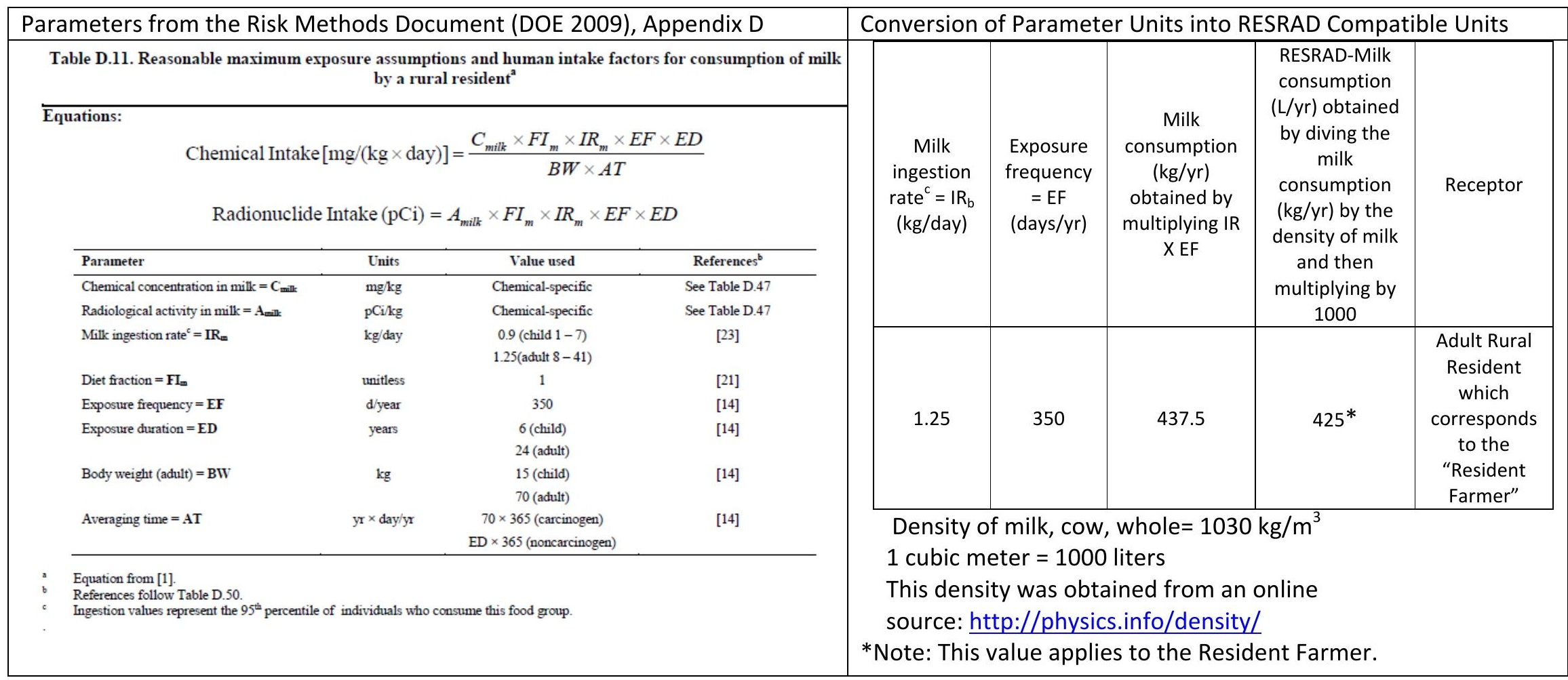




\section{Section B. Parameters Applicable to the Resident Farmer and the Resident Gardener (cont.)}

\section{Meat and Poultry Consumption}

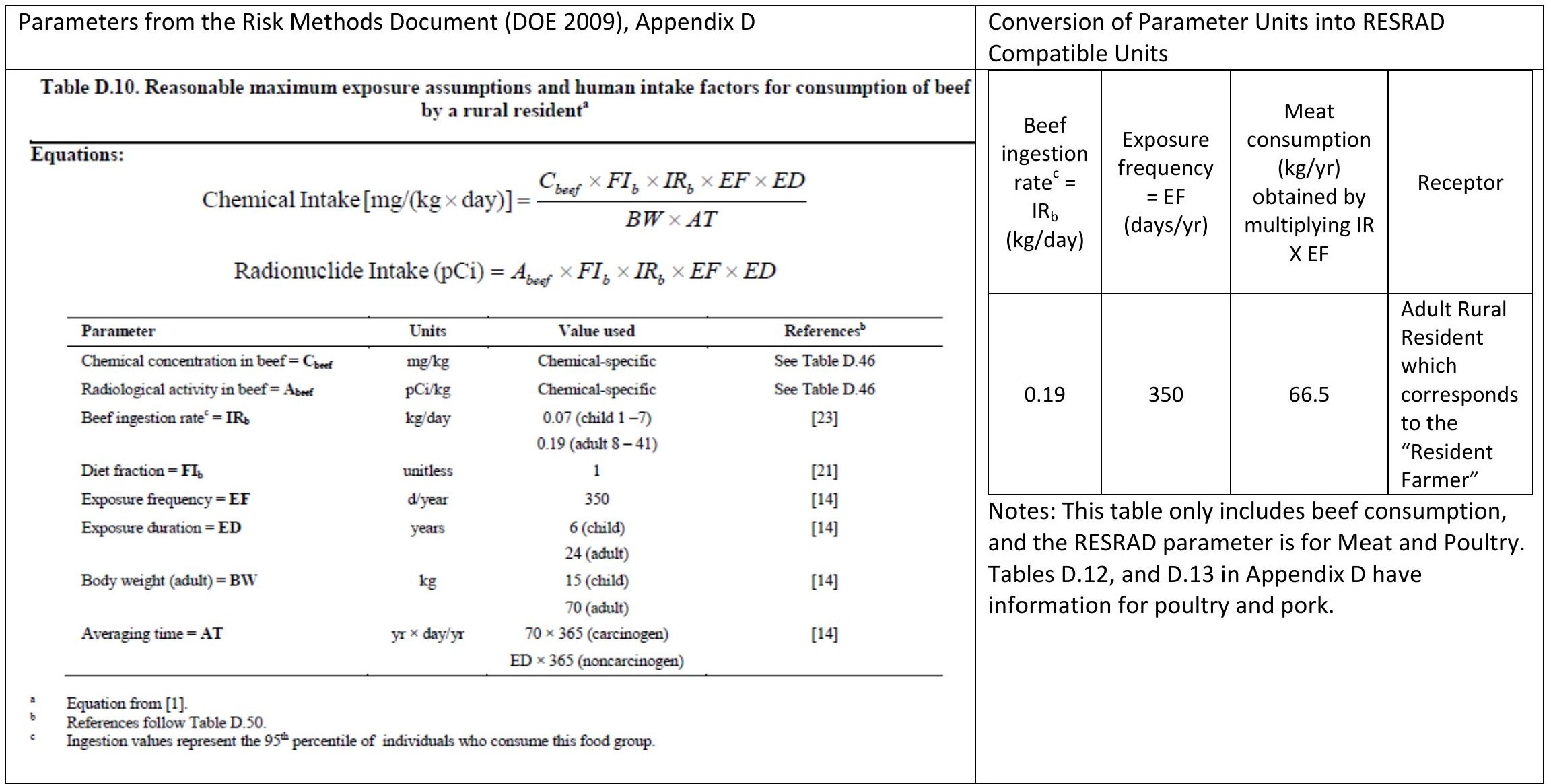




\section{Section B. Parameters Applicable to the Resident Farmer and the Resident Gardener (cont.)}

\section{Meat and Poultry Consumption (cont.)}

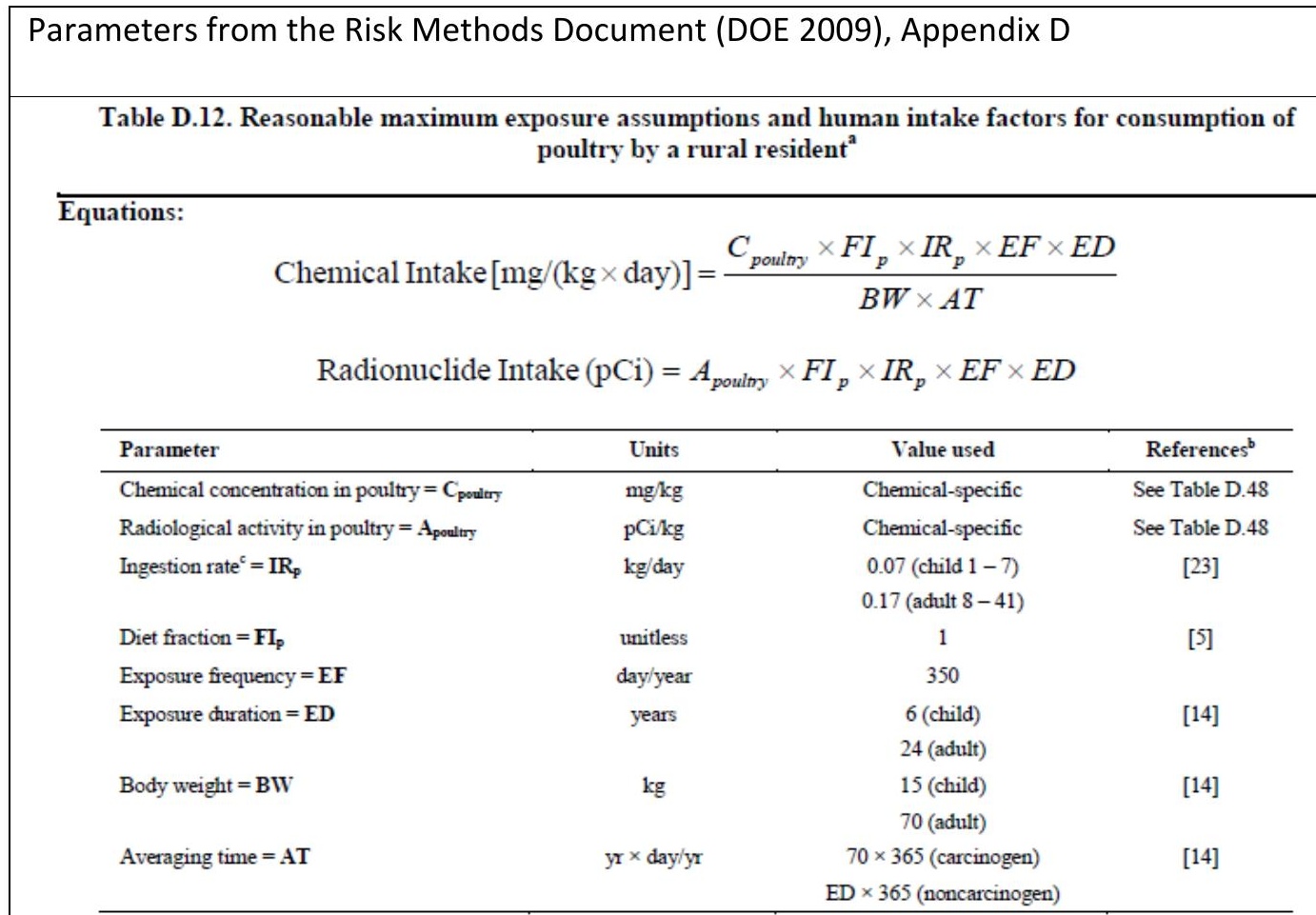

Conversion of Parameter Units into RESRAD Compatible Units

\begin{tabular}{|c|c|c|c|}
\hline $\begin{array}{c}\text { Poultry } \\
\text { ingestion } \\
\text { rate }^{\mathrm{c}}=\mathrm{IR}_{\mathrm{b}} \\
(\mathrm{kg} / \text { day) }\end{array}$ & $\begin{array}{c}\text { Exposure } \\
\text { frequency }\end{array}$ & $\begin{array}{c}\text { Poultry } \\
\text { consumption } \\
\text { (kg/yr) } \\
\text { obtained by } \\
\text { multiplying IR } \\
\text { X EF }\end{array}$ & Receptor \\
\hline 0.17 & 350 & 59.5 & $\begin{array}{c}\text { Adult Rural } \\
\text { Resident } \\
\text { which } \\
\text { corresponds } \\
\text { to the } \\
\text { "Resident } \\
\text { Farmer" }\end{array}$ \\
\hline
\end{tabular}

Notes: This table only includes poultry consumption, and the RESRAD parameter is for Meat and Poultry. Table D.10, and D.13 in Appendix D have information for beef and pork. 


\section{Section B. Parameters Applicable to the Resident Farmer and the Resident Gardener (cont.)}

\section{Meat and Poultry Consumption (cont.)}

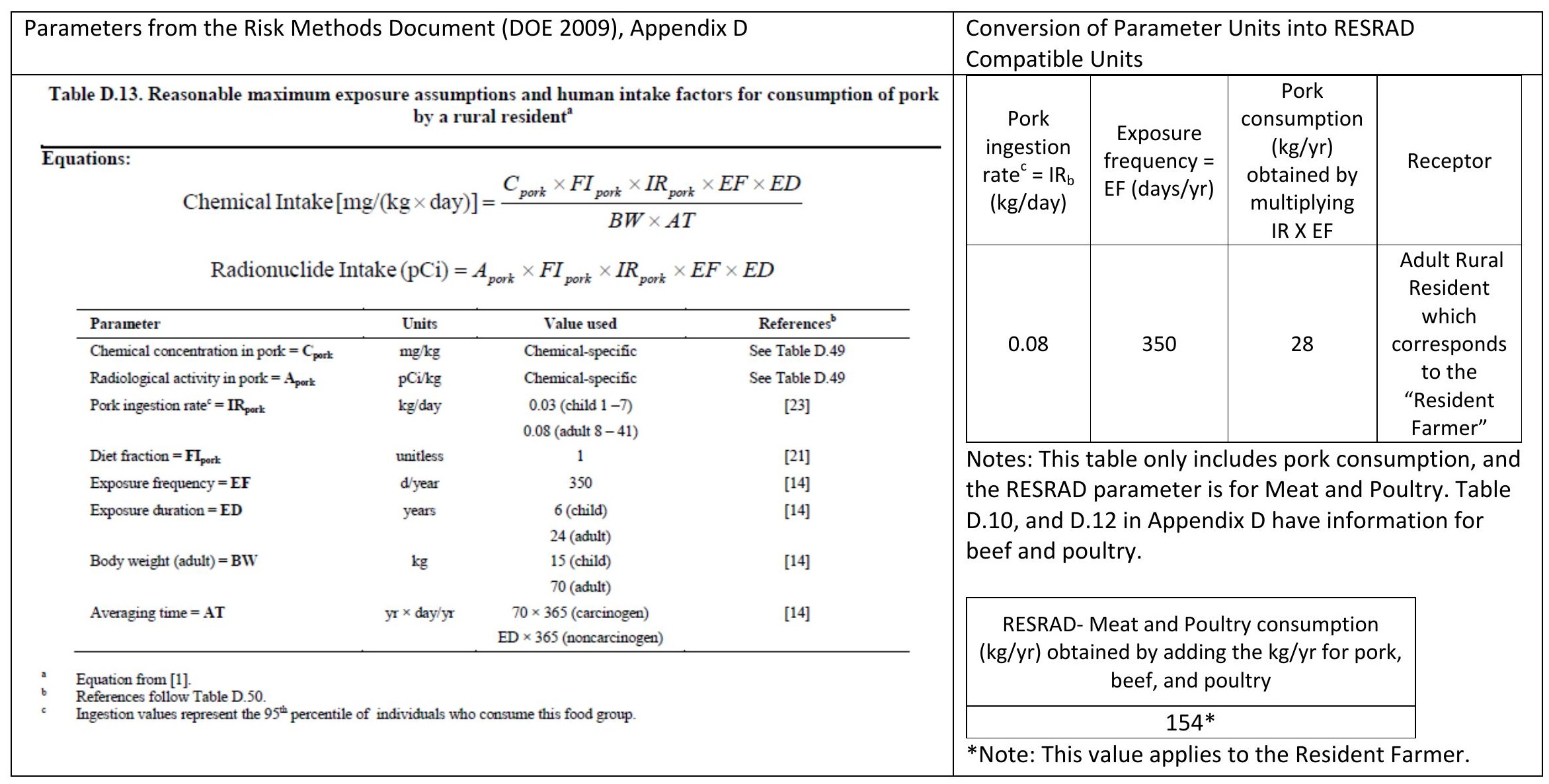




\section{Section C. Parameters Applicable to the Outdoor Worker and the Landfill Worker}

\section{Soil Ingestion Rate}

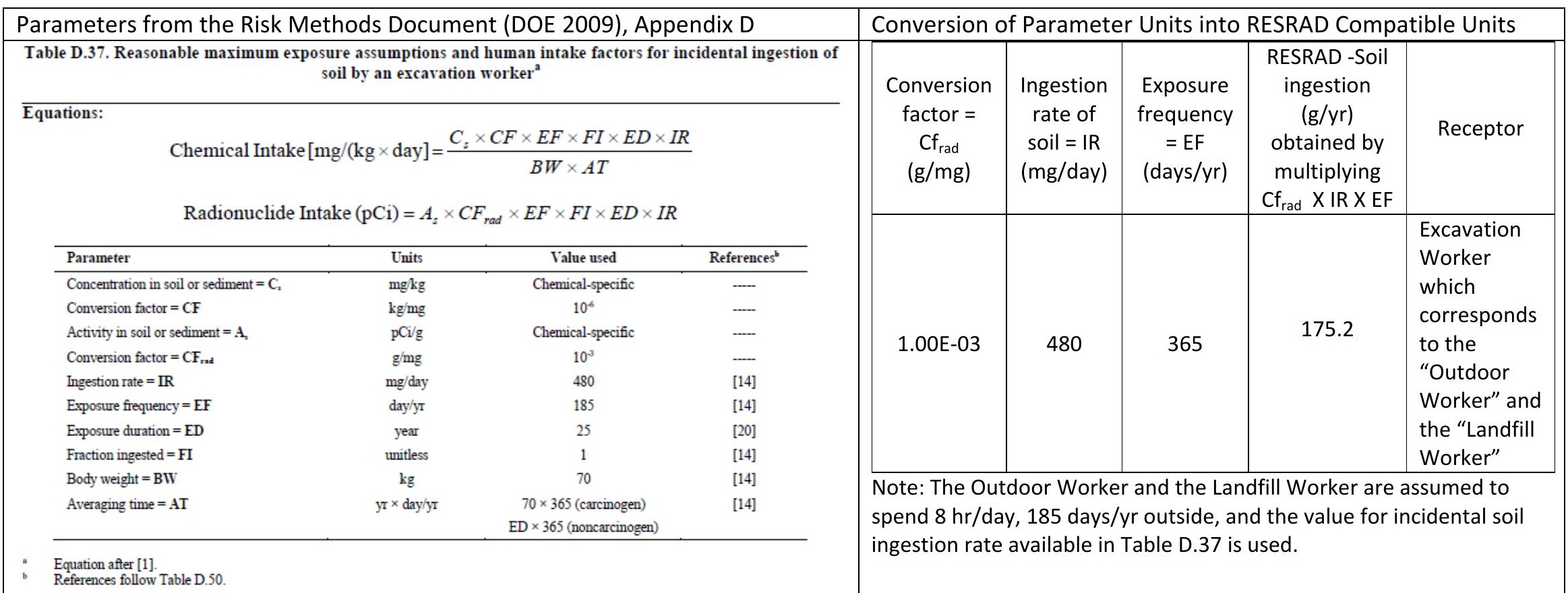




\section{Section C. Parameters Applicable to the Outdoor Worker and the Landfill Worker (cont.)}

\section{Inhalation Rate and Mass Loading for Inhalation}

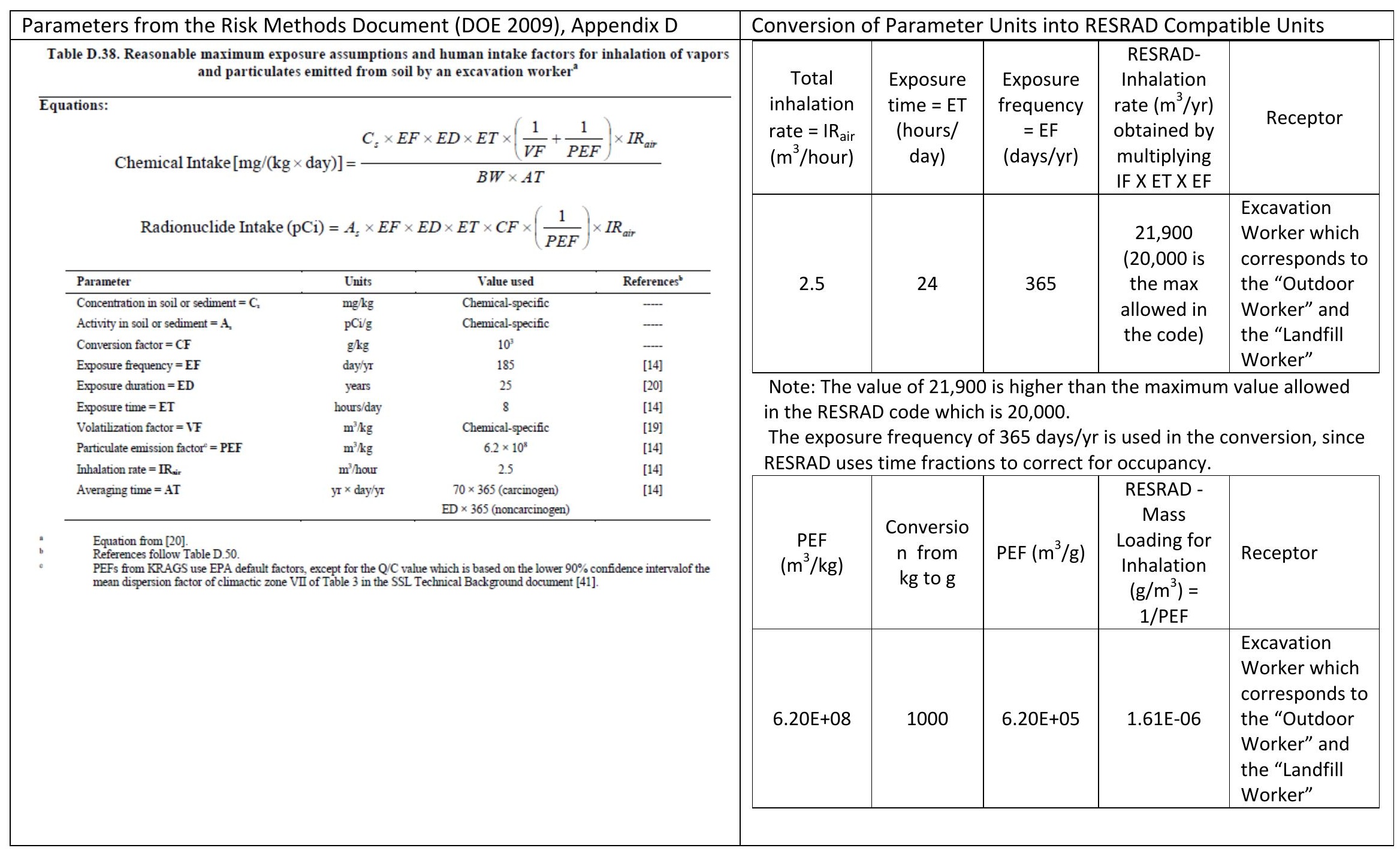




\section{Section C. Parameters Applicable to the Outdoor Worker and the Landfill Worker (cont.)}

\section{External Gamma Shielding Factor and Exposure Duration}

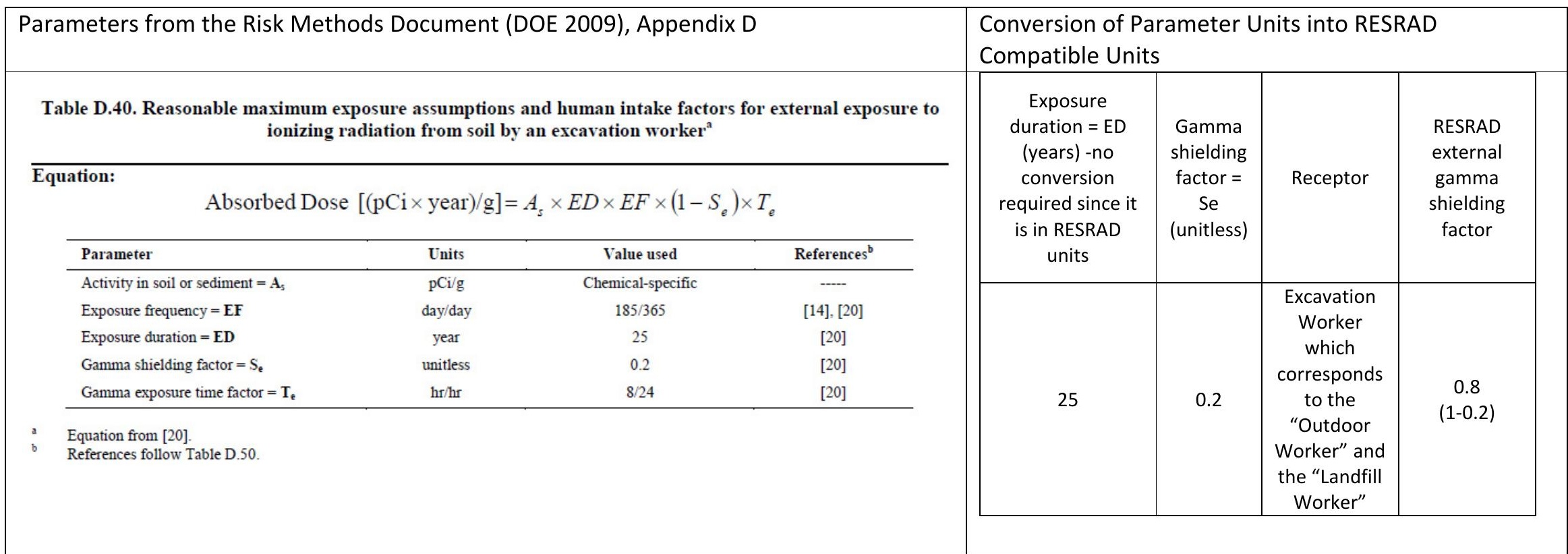




\section{Section C. Parameters Applicable to the Outdoor Worker and the Landfill Worker (cont.)}

\section{Outdoor Time Fraction}

\begin{tabular}{|c|c|c|c|c|c|}
\hline \multicolumn{4}{|c|}{ Parameters from the Risk Methods Document (DOE 2009), Appendix D } & \multicolumn{2}{|c|}{$\begin{array}{l}\text { Conversion of Parameter Units into RESRAD } \\
\text { Compatible Units }\end{array}$} \\
\hline \multirow{2}{*}{\multicolumn{4}{|c|}{$\begin{array}{l}\text { Table D.40. Reasonable maximum exposure assumptions and human intake factors for external exposure to } \\
\text { ionizing radiation from soil by an excavation worker }{ }^{a}\end{array}$}} & $185 \mathrm{~d} / \mathrm{yr} \div 365 \mathrm{~d} / \mathrm{yr}=$ & 0.51 \\
\hline & & & & $8 h \div 24 h=$ & 0.33 \\
\hline \multicolumn{4}{|l|}{ Equation: } & $\begin{array}{r}\text { Outdoor time fraction } \\
\text { for the Workers } 0.51 \\
\times 0.33=\end{array}$ & 0.17 \\
\hline Parameter & Units & Value used & References $^{b}$ & \multirow{7}{*}{\multicolumn{2}{|c|}{$\begin{array}{l}\text { Note: It is assumed the Outdoor Worker and } \\
\text { the Landfill Worker are outdoors } 185 \text { days/yr } \\
\text { and work } 8 \mathrm{hr} / \text { day. }\end{array}$}} \\
\hline Activity in soil or sediment $=\mathrm{A}_{\mathrm{s}}$ & $\mathrm{pCi} / \mathrm{g}$ & Chemical-specific & $-\cdots$ & & \\
\hline Exposure frequency $=\mathbf{E F}$ & day/day & $185 / 365$ & [14], [20] & & \\
\hline Exposure duration = ED & year & 25 & [20] & & \\
\hline Gamma shielding factor $=S_{e}$ & unitless & 0.2 & [20] & & \\
\hline Gamma exposure time factor $=\mathbf{T}_{e}$ & $\mathrm{hr} / \mathrm{hr}$ & $8 / 24$ & [20] & & \\
\hline $\begin{array}{ll}\text { a } & \text { Equation from [20]. } \\
\text { b } & \text { References follow Table D. } 50 .\end{array}$ & & & & & \\
\hline
\end{tabular}




\section{Section D. Parameters Applicable to the Recreational User and Trespasser}

\section{Soil Ingestion Rate}

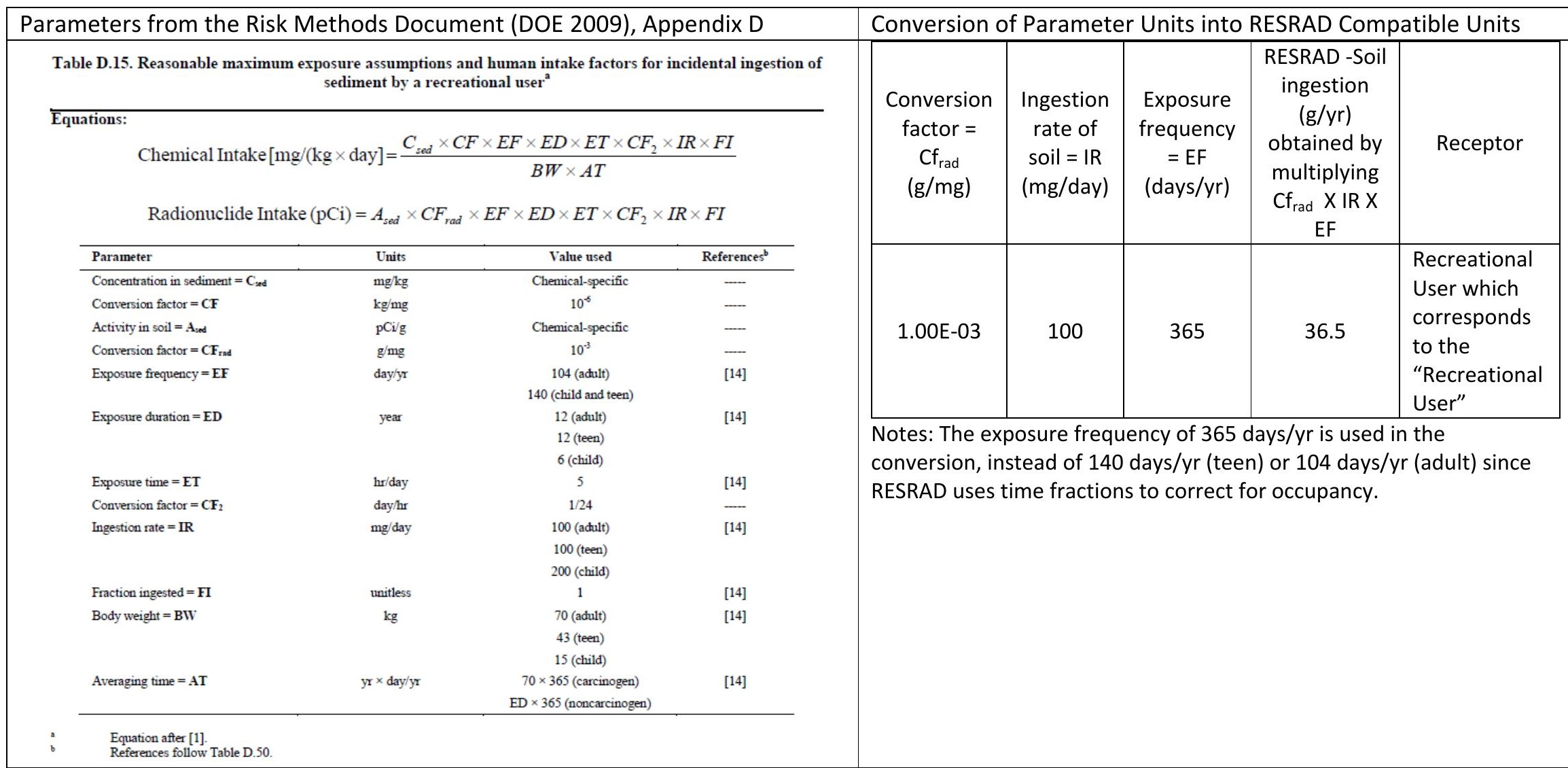




\section{Section D. Parameters Applicable to the Recreational User and Trespasser (cont.)}

\section{Inhalation Rate and Mass Loading for Inhalation}

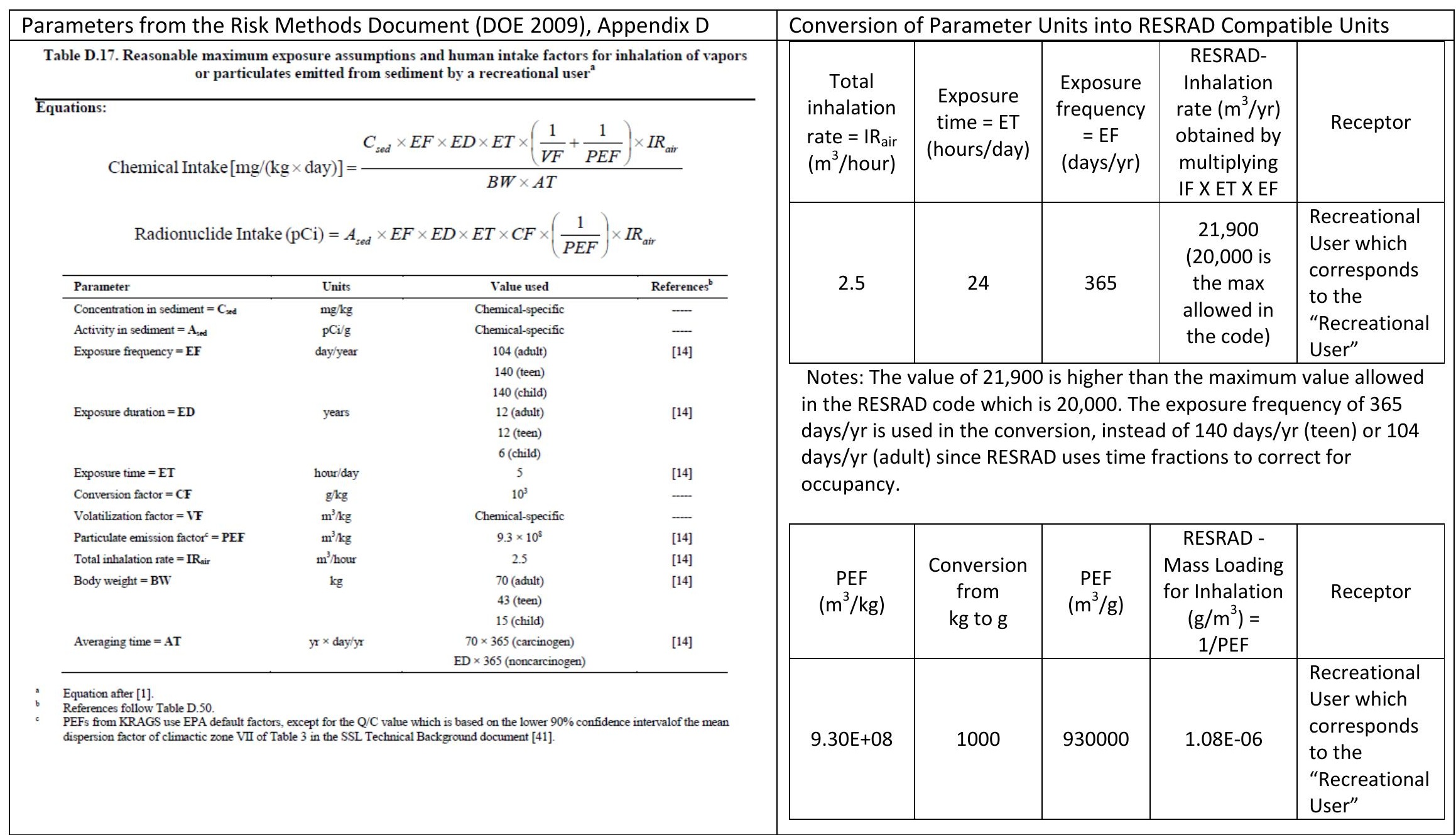




\section{Section D. Parameters Applicable to the Recreational User and Trespasser (cont.)}

\section{External Gamma Shielding Factor and Exposure Duration}

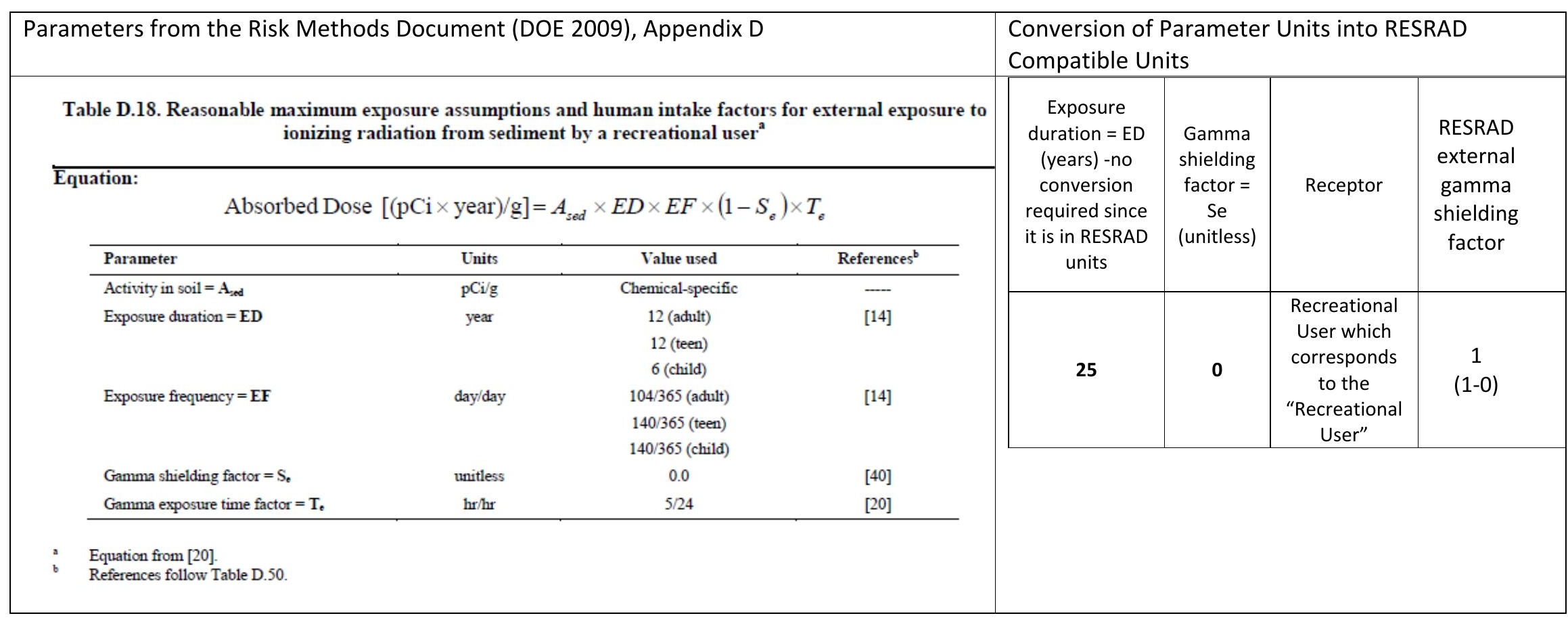

\section{Outdoor Time Fraction (Recreational User-Teenager)}

\begin{tabular}{|c|c|}
\hline $140 \mathrm{~d} / \mathrm{yr} \div 365 \mathrm{~d} / \mathrm{yr}=$ & 0.38 \\
\hline $5 \mathrm{~h} \div 24 \mathrm{~h}=$ & 0.21 \\
\hline $\begin{array}{c}\text { Outdoor time fraction for } \\
\text { the RU-teenager } \\
0.38 \times 0.21=\end{array}$ & 0.08 \\
\hline \multicolumn{2}{|c|}{$\begin{array}{l}\text { Note: The Recreational User is considered to be a teenager } \\
\text { who will spend } 5 \mathrm{~h} / \text { day, } 140 \text { days/yr on the contaminated site. }\end{array}$}
\end{tabular}




\section{Section D. Parameters Applicable to the Recreational User and Trespasser (cont.)}

Outdoor Time Fraction (Trespasser-Adult)

\begin{tabular}{|c|c|}
\hline $104 d / y r \div 365 d / y r=$ & 0.28 \\
\hline $5 \mathrm{~h} \div 24 \mathrm{~h}=$ & 0.21 \\
\hline $\begin{array}{r}\text { Outdoor time fraction for } \\
\text { the Trespasser-Adult } \\
0.28 \times 0.21=\end{array}$ & 0.06 \\
\hline \multicolumn{2}{|c|}{$\begin{array}{l}\text { Note: The Trespasser is considered to be an adult who will } \\
\text { spend } 5 \mathrm{~h} / \text { day, } 104 \text { days/yr on the contaminated site. This } \\
\text { receptor has a lower occupancy than the teen Recreationa } \\
\text { User. }\end{array}$} \\
\hline
\end{tabular}


Section E. Parameters applicable to beef and dairy from the Risk Methods Document (DOE 2009), Appendix D

Table D.46. Reasonable maximum exposure assumptions for concentration or activity of COPCs in beef

\begin{tabular}{|c|c|c|c|}
\hline \multicolumn{4}{|l|}{ Equations: } \\
\hline Parameter & Units & Value used & References $^{\mathrm{b}}$ \\
\hline Chemical concentration in beef $=\mathrm{C}_{\text {beef }}$ & $\mathrm{mg} / \mathrm{kg}$ or $\mathrm{pCi} / \mathrm{g}$ & Chemical-specific & Calculated \\
\hline Forage-beef transfer factor $=\mathbf{F}_{\text {beef }}$ & day $/ \mathrm{kg}$ & Chemical-specific & ---- \\
\hline Chemical concentration in pasture $=\mathrm{C}_{\text {forage }}$ & $\mathrm{mg} / \mathrm{kg}$ or $\mathrm{pCi} / \mathrm{g}$ & Chemical-specific & Calculated \\
\hline Area of $\operatorname{contact}^{\mathrm{c}}=\mathrm{AC}$ & unitless & $\mathrm{AS} / \mathrm{AD}$ & - \\
\hline Area of SWMU = AS & acres & SWMU-specific & --- \\
\hline Area of beef range $=\mathrm{AD}$ & acres & 2 & [29] \\
\hline Fraction of beef's food from site when on site $=f_{s}$ & unitless & 1.0 & [5] \\
\hline Quantity of pasture ingested daily by beef $=Q_{f}$ & $\mathrm{~kg} /$ day & 25 & [25] \\
\hline Chemical concentration in soil or sediment $=\mathrm{C}_{5}$ & $\mathrm{mg} / \mathrm{kg}$ or $\mathrm{pCi} / \mathrm{g}$ & Chemical-specific & $-\ldots$ \\
\hline Quantity of soil ingested daily by beef $=Q_{s}$ & $\mathrm{~kg} /$ day & 1 & [26] \\
\hline Contaminant concentration in water $=\mathrm{C}_{\mathrm{w}}$ & $\mathrm{mg} / \mathrm{L}$ or $\mathrm{pCi} / \mathrm{L}$ & Chemical-specific & $-\ldots$ \\
\hline Conversion factor for radionuclides $=\mathrm{CF}_{\mathrm{rad}}$ & $\mathrm{kg} / \mathrm{g}$ & $10^{-3}$ & --- \\
\hline Quantity of water ingested daily by beef $=Q_{w}$ & $\mathrm{~L}$ day & 50 & [25] \\
\hline Soil to plant uptake (dry) $=R_{\text {upp }}$ & unitless & $\begin{array}{l}\text { Chemical-specific } \\
\text { or } 38 \times \mathrm{K}_{\text {ow }}{ }^{-0.58}\end{array}$ & [8] \\
\hline Soil resuspension multiplier $=R_{e s}$ & unitless & 0.25 & [3] \\
\hline
\end{tabular}

Equations after [1], [2], [3], [4].

All references follow Table D. 50

$\mathrm{AC}$ cannot be greater than

All ingested water is considered to be from SWMU or SWMU area.

Note: The values that were used to determine input parameters are highlighted. 
Section E. Parameters applicable to beef and dairy from the Risk Methods Document (DOE 2009), Appendix D (cont.)

Table D.47. Reasonable maximum exposure assumptions for concentration or activity of COPCs in milk

\begin{tabular}{|c|c|c|c|}
\hline \multicolumn{4}{|l|}{$\begin{array}{l}\text { Equations: } \\
\qquad C_{\text {milk }}\end{array}$} \\
\hline Parameter & Units & Value used & References $^{\mathrm{b}}$ \\
\hline Chemical concentration in milk $=\mathrm{C}_{\text {milk }}$ & $\mathrm{mg} / \mathrm{kg}$ or $\mathrm{pCi} / \mathrm{g}$ & Chemical-specific & Calculated \\
\hline Forage-milk transfer factor $=\mathbf{F}_{\mathbf{m i l k}}$ & day $/ \mathrm{kg}$ & Chemical-specific & $\ldots$ \\
\hline Chemical concentration in pasture $=\mathrm{C}_{\text {forage }}$ & $\mathrm{mg} / \mathrm{kg}$ or $\mathrm{pCi} / \mathrm{g}$ & Chemical-specific & Calculated \\
\hline Area of contact $^{\mathrm{c}}=\mathrm{AC}$ & unitless & $\mathrm{AS} / \mathrm{AD}$ & $\ldots$ \\
\hline Area of $\mathrm{SWMU}=\mathrm{AS}$ & acres & SWMU-specific & $\ldots$ \\
\hline Area of dairy range $=\mathbf{A D}$ & acres & 2 & [29] \\
\hline Fraction of dairy's food from site when on site $=\mathbf{f}_{\mathrm{s}}$ & unitless & 1.0 & [5] \\
\hline Quantity of pasture ingested daily by dairy $=Q_{f}$ & $\mathrm{~kg} /$ day & 25 & [25] \\
\hline Chemical concentration in soil or sediment $=\mathrm{C}_{\mathrm{s}}$ & $\mathrm{mg} / \mathrm{kg}$ or $\mathrm{pCi} / \mathrm{g}$ & Chemical-specific & $\ldots$ \\
\hline Quantity of soil ingested daily by dairy $=Q_{s}$ & $\mathrm{~kg} /$ day & 1 & [26] \\
\hline Contaminant concentration in water $=\mathrm{C}_{\mathrm{w}}$ & $\mathrm{mg} / \mathrm{L}$ or $\mathrm{pCi} / \mathrm{L}$ & Chemical-specific & $\ldots$ \\
\hline Conversion factor for radionuclides $=\mathbf{C F}_{\mathrm{rad}}$ & $\mathrm{kg} / \mathrm{g}$ & $10^{-3}$ & $\ldots$ \\
\hline Quantity of water ingested daily by dairy $=Q_{w}$ & $L /$ day & 60 & [25] \\
\hline Soil to plant uptake (dry) $=\mathbf{R}_{\text {upp }}$ & unitless & $\begin{array}{l}\text { Chemical-specific } \\
\text { or } 38 \times \mathrm{K}_{\mathrm{ow}}^{-0.58}\end{array}$ & [8] \\
\hline Soil resuspension multiplier $=R_{e s}$ & unitless & 0.25 & [3] \\
\hline
\end{tabular}

Equations after [1], [2], [3], [4].

AC cannot be greater than 1

All ingested water is considered to be from SWMU or SWMU area.

Note: The values that were used to determine input parameters are highlighted. 


\section{Attachment III \\ RESRAD Error/OUTPUT File for the Resident Farmer}


The code displayed an error message for the Resident Farmer when running it with an irrigation rate of $0.1 \mathrm{~m} / \mathrm{yr}$ and an evapotranspiration coefficient of 0.74 . The message is below:
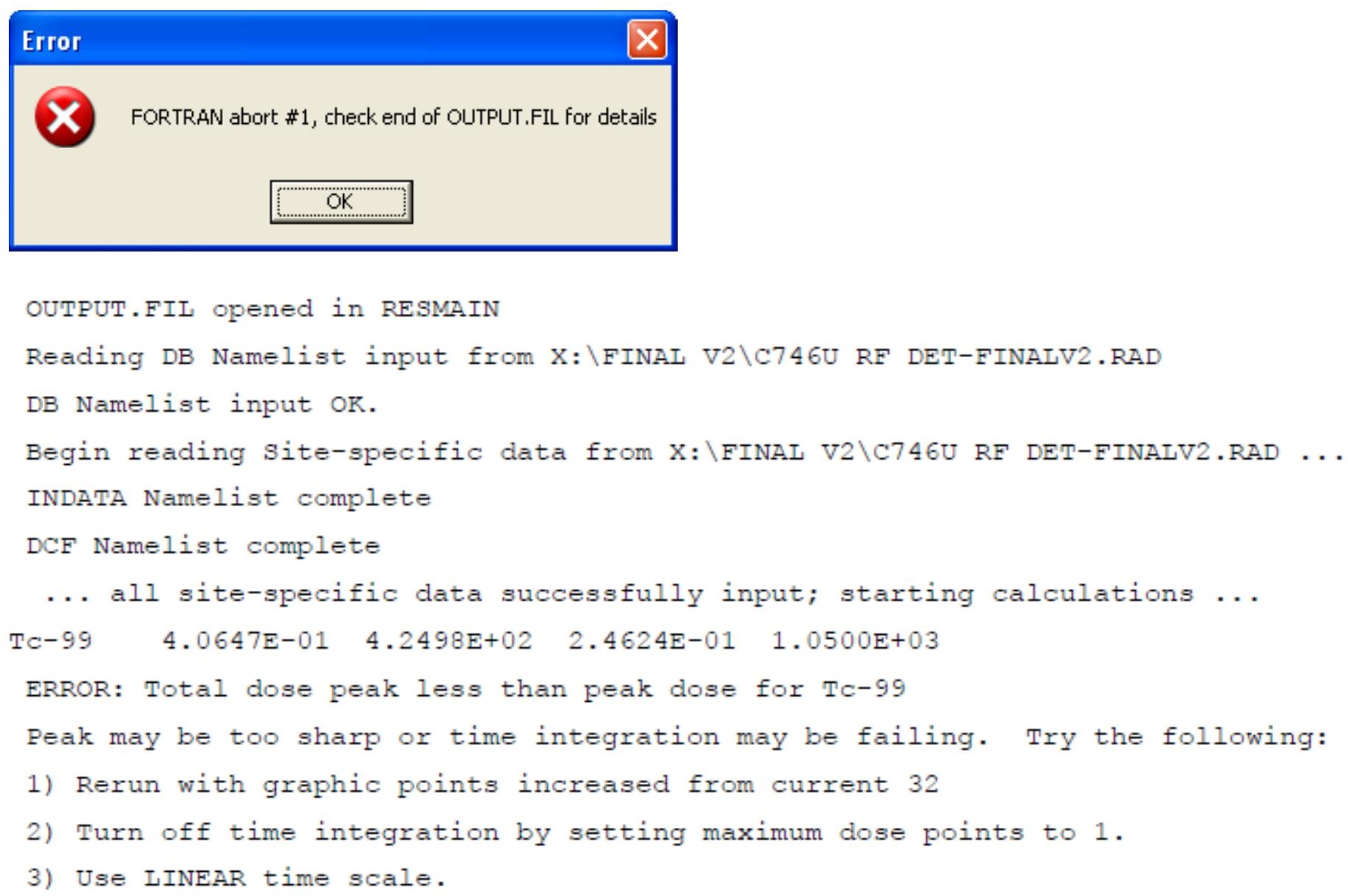

The code ran successfully after increasing the graphic points from 32 (default) to 64 and setting the maximum dose points from 17 (default) to 1 as indicated in the output file above. 


\section{References}

ATSDR 2002, Public Health Assessment for the Paducah Gaseous Diffusion Plant (USDOE) Paducah, McCracken County, Kentucky (May 2002).

DOE 2003a. Authorized Limits Request for Solid Waste Disposal at Landfill C-746-U at the Paducah Gaseous Diffusion Plant, (November 2002; revised January 2003).

DOE 2003b. Risk and Performance Evaluation of the C-746-U Landfill at the Paducah Gaseous Diffusion Plant, Paducah, Kentucky, DOE/OR/072041\&D2R1 (September 2003).

DOE 2009. Methods for Conducting Risk Assessments and Risk Evaluations at the Paducah Gaseous Diffusion Plant Paducah, Kentucky Volume 1. Human Health, DOE/LX/07-0107\&D1/V1 (July 2009).

DOE Statement of Work (SOW) for C-746-U Landfill provided to ORISE on December 2009.

DOE C-746-U landfill inventory spreadsheet for total waste disposed from May 2003 through May 2009.

DOE Project Communication with the Waste Disposal Operations Project Team from Paducah, KY, March 2010 (Email correspondence 03/29/2010 from Rich Bonczek).

DOE Project Communication with the Geologist from Paducah, KY, April 2010 (Email correspondence 04/05/2010 from Raulie Casteel).

DOE Project Communication with Geologist and Engineer from Paducah, KY, April 2010 (Email correspondence 04/07/2010 from Raulie Casteel).

DOE Project Communication with the Facility Representative DOE-PPPO from Paducah, KY, May 2010 (Email correspondence 05/05/2010 from Don Dihel).

DOE Project Communication May, 2010 (Discussion between ORISE and Rich Bonczek during a meeting held at ORISE on 05/17/2010).

DOE Project Communication June, 2010 (Email correspondence 06/02/2010 from ORISE to DOE).

DOE Project Communication July, 2010 (Discussion between ORISE and DOE-PPPO during a meeting held at ORISE on 07/12/2010).

DOE Project Communication September, 2010 (Discussion between ORISE and DOE-PPPO during a conference call held on 09/29/2010). 
DOE Project Communication October, 2010 (Discussion between ORISE and DOE-PPPO during a conference call held on 10/7/2010).

DOE Project Communication November, 2010 (Email correspondence 11/03/2010 from ORISE to DOE consultant).

DOE Project Communication April, 2011 (ORISE and DOE-PPPO biweekly conference call on 04/13/2011 and email correspondence 04/14/2011 from ORISE to DOE-PPPO).

DOE Order 458.1, Radiation Protection of the Public and the Environment (DOE 2011).

DOE Order 5400.5, Radiation Protection of the Public and the Environment (DOE 1993).

Kenny, J. F., N. L. Barber, S. S. Hutson, K. S. Linsey, J. K. Lovelace, and M. A. Maupin 2009. Estimated Use of Water in the United States in 2005, Circular 1344, U.S. Department of the Interior, U.S. Geological Survey.

King, David A. and Karen Keil, 2006. "Comparison of Standard Radiological Risk Models and Using RESRAD to Derive Generic Risk-Based Area Factors for Final Status Surveys," Risk Analysis, Vol. 26, No. 1, pp. 175-183.

Lee, D. W., J. C. Wang, and D. C. Kocher, 1995. Operating Limit Study for the Proposed Solid Waste Landfill at Paducah Gaseous Diffusion Plant, ORNL/TM-13008 (June 1995).

PRS 2008. 2006 Paducah Site Annual Site Environmental Report for Calendar Year 2006, PRS-ENM-0034 Volume I, Paducah Remediation Services, LLC (September 2008).

Yu, C., C. Loureiro, J. J. Cheng, L.G. Jones, Y.Y. Wang, Y.P. Chia, and E. Faillace 1993. Data Collection Handbook to Support Modeling Impacts of Radioactive Material in Soil, ANL/EAIS-8 (April 1993).

Yu C., D. LePoire, E. Gnanapragasam, J. Arnish, S. Kamboj, B.M. Biwer, J.-J. Cheng, A. Zielen, and S.Y. Chen 2000. Development of Probabilistic RESRAD 6.0 and RESRAD-Build 3.0 Computer Codes, NUREG/CR-6697 (ANL/EAD/TM-98) (November 2000).

Yu, C., A.J. Zielen, J.J. Cheng, D.J. LePoire, E. Gnanapragasam, S. Kamboj, J. Arnish, A. Wallo, III, W.A. Williams, and H. Peterson 2001. User's Manual for RESRAD Version 6, ANL/EAD-4 (July 2001). 
DOSE MODELING EVALUATIONS AND TECHNICAL

SUPPORT DOCUMENT FOR THE AUTHORIZED

LIMITS REQUEST FOR THE C-746-U LANDFILL AT THE PADUCAH GASEOUS DIFFUSION PLANT

OAK RIDGE INSTITUTE FOR SCIENCE AND EDUCATION

Appendix B: RESRAD-OFFSITE Table of Input Parameters for the

C-746-U Landfill Offsite Resident Farmer Scenario

APPENDIXB: RESRAD-OFFSITE TABLE OF INPUT PARAMEIERS FOR THE C-746-ULANDFILL OFFSITE RESIDENT FARMER SCENARIO 
THIS PAGE INTENTIONALLY LEFT BLANK 
RESRAD-OFFSITE Table of Input Parameters for the C-746-U Landfill Offsite Resident Farmer Scenario

\begin{tabular}{|l|c|c|c|c|c|c|c|}
\hline $\begin{array}{c}\text { Input Screen Title } \\
\text { and Parameter } \\
\text { Name }\end{array}$ & Units & $\begin{array}{c}\text { Default } \\
\text { Value }\end{array}$ & $\begin{array}{c}\text { Code-Accepted } \\
\text { Values }^{b} \\
\text { Physical or } \\
\text { Numerical } \\
\text { Range }\end{array}$ & $\begin{array}{c}\text { Deterministic } \\
\text { Value }\end{array}$ & Type $^{d}$ & Priority $^{e}$ & References \\
Title
\end{tabular}

\section{Preliminary Inputs}

\begin{tabular}{|c|c|c|c|c|c|c|c|c|c|}
\hline $\begin{array}{l}\text { Radiological units } \\
\text { for activity }\end{array}$ & $\begin{array}{c}\mathrm{Ci}, \mathrm{Bq} \\
\mathrm{dps}, \mathrm{dpm}\end{array}$ & $\mathrm{pCi}$ & $\begin{array}{l}\mathrm{Ci}, \mathrm{Bq}, \mathrm{dps} \\
\mathrm{dpm}\end{array}$ & & $\mathrm{pCi}$ & $N A^{f}$ & & Default units are used. & Yu et al. 2007 \\
\hline $\begin{array}{l}\text { Radiological units } \\
\text { for dose }\end{array}$ & $\begin{array}{l}\text { rem and } \\
\text { Sv }\end{array}$ & mrem & rem, Sv & & mrem & NA & & Default units are used. & Yu et al. 2007 \\
\hline $\begin{array}{l}\text { Basic radiation dose } \\
\text { limit }\end{array}$ & $\mathrm{mrem} / \mathrm{yr}$ & 25 & $\begin{array}{l}1 \mathrm{E}-34- \\
1 \mathrm{E}+34\end{array}$ & $\mathrm{~N}$ & 1 & NA & 3 & $\begin{array}{l}\text { The target dose constraints of } 1,15,25 \text { and } \\
100 \text { mrem/yr are considered in this project. However, } \\
\text { the basic radiation dose constraint used for the } \\
\text { RESRAD run is } 1 \mathrm{mrem} / \mathrm{yr} \text {. If the basic radiation dose } \\
\text { limit is changed it will not change the Dose to Source } \\
\text { Ratio (DSR) which is used in the calculation for single } \\
\text { radionuclide soil guidelines. }\end{array}$ & $\begin{array}{l}\text { DOE SOW for C- } \\
746-U \text { landfill, } \\
\text { Section } 2 \text {, item } 3\end{array}$ \\
\hline Exposure duration & $\mathrm{yr}$ & 30 & $1-1,000$ & & 24 & B & 3 & $\begin{array}{l}\text { The exposure duration is the span of time, in years, } \\
\text { during which an individual is expected to spend time } \\
\text { on the site. This value is used in calculating lifetime } \\
\text { cancer risk from exposure to radionuclide } \\
\text { contamination. It is also used to calculate time- } \\
\text { integrated dose if exposure duration is less than a } \\
\text { year. This value is obtained from DOE 2009. The } \\
\text { exposure duration is available in the tables of } \\
\text { Appendix D. For the Resident Farmer, the value for } \\
\text { "Rural Resident" is used. }\end{array}$ & $\begin{array}{c}\text { DOE } 2009 \\
\text { Appendix D,Table } \\
\text { D.8, page D-18 }\end{array}$ \\
\hline $\begin{array}{l}\text { Number of } \\
\text { unsaturated zone }\end{array}$ & $--\mathrm{g}$ & 1 & $0-5$ & $\mathrm{~N}$ & 5 & $P$ & 3 & $\begin{array}{l}\text { There are five unsaturated zones (UZ) considered. } \\
\text { These correspond to the layers under waste during } \\
\text { the Post-Institutional Control Period. Below are the } \\
\text { five zones: } \\
\text { UZ } 1=\text { Protective layer (native soil) } \\
\text { UZ } 2 \text { = Gravel layer } \\
\text { UZ } 3 \text { = Clay barrier } \\
\text { UZ } 4=\text { Alluvium soils (native/subgrade) } \\
\text { UZ } 5 \text { = Clay confining unit (native) }\end{array}$ & $\begin{array}{c}\text { DOE 2003b } \\
\text { Table 4.4, page 4- } \\
\text { 9, Fig. 4.5, page 4- } \\
\text { 18, Table Att.2, } \\
\text { page C3-315 }\end{array}$ \\
\hline \multicolumn{10}{|l|}{ Site Layout } \\
\hline Bearing of $X$ axis & degrees & 90 & $0-360$ & $P$ & 90 & $P$ & & Default value is used. & Yu et al. 2007 \\
\hline $\begin{array}{l}X \text { dimension of } \\
\text { Primary }\end{array}$ & $\mathrm{m}$ & 100 & $\begin{array}{l}-80,000- \\
+80,000\end{array}$ & & 256 & $P$ & 2 & $\begin{array}{l}\text { The primary contamination is modeled as a rectangle } \\
\text { for atmospheric release and transport calculations. }\end{array}$ & Lee et al. 1995 \\
\hline
\end{tabular}


RESRAD-OFFSITE Table of Input Parameters for the C-746-U Landfill Offsite Resident Farmer Scenario

\begin{tabular}{|c|c|c|c|c|c|c|c|c|}
\hline $\begin{array}{c}\text { Input Screen Title } \\
\text { and Parameter } \\
\text { Name }\end{array}$ & Units & $\begin{array}{l}\text { Default } \\
\text { Value }^{a}\end{array}$ & $\begin{array}{l}\text { Code-Accepted } \\
\text { Values }^{b} \\
\text { Physical or }^{\text {Numerical }} \text { (N) } \\
\text { Range } \\
\end{array}$ & $\begin{array}{c}\text { Deterministic } \\
\text { Value }\end{array}$ & Type $e^{d}$ & Priority $^{e}$ & Justification & References \\
\hline contamination & & & & & & & $\begin{array}{l}\text { The lengths of the sides of the rectangle are used to } \\
\text { define the rectangular region for the atmospheric } \\
\text { transport calculations. The area is no longer an input, } \\
\text { but is obtained as the product of these two } \\
\text { perpendicular dimensions. The landfill does not have } \\
\text { a rectangular shape; therefore, the two sides }(x, y) \text { of } \\
\text { the pentagon with maximum length were selected. }\end{array}$ & Yu et al. 2007 \\
\hline $\begin{array}{l}\text { Y dimension of } \\
\text { Primary } \\
\text { contamination }\end{array}$ & $\mathrm{m}$ & 100 & $\begin{array}{l}-80,000- \\
+80,000\end{array}$ & 399 & $P$ & 2 & $\begin{array}{l}\text { The primary contamination is modeled as a rectangle } \\
\text { for atmospheric release and transport calculations. } \\
\text { The lengths of the sides of the rectangle are used to } \\
\text { define the rectangular region for the atmospheric } \\
\text { transport calculations. The area is no longer an input, } \\
\text { but is obtained as the product of these two } \\
\text { perpendicular dimensions. The landfill does not have } \\
\text { a rectangular shape; therefore, the two sides }(x, y) \text { of } \\
\text { the pentagon with maximum length were selected. }\end{array}$ & $\begin{array}{l}\text { Lee et al. } 1995 \\
\text { Yu et al. } 2007\end{array}$ \\
\hline $\begin{array}{l}\text { Smaller } x \\
\text { coordinate of the } \\
\text { fruit, grain, } \\
\text { nonleafy vegetables } \\
\text { plot } \\
\end{array}$ & $\mathrm{m}$ & 34.375 & $\begin{array}{l}-80,000- \\
+80,000\end{array}$ & 34.375 & $P$ & 3 & \multirow[t]{4}{*}{$\begin{array}{l}\text { A plot, with an area }=1,000 \text { square meters (RESRAD } \\
\text { OFFSITE default), is located north of the } \\
\text { contaminated zone near the well (which is located } \\
407 \text { meters north/downgradient of the contaminated } \\
\text { zone). }\end{array}$} & \multirow[t]{4}{*}{ Yu et al. 2007} \\
\hline $\begin{array}{l}\text { Larger } x \text { coordinate } \\
\text { of the fruit, grain, } \\
\text { nonleafy vegetables } \\
\text { plot }\end{array}$ & $\mathrm{m}$ & 65.625 & $\begin{array}{l}-80,000- \\
+80,000\end{array}$ & 65.625 & $P$ & 3 & & \\
\hline $\begin{array}{l}\text { Smaller y } \\
\text { coordinate of the } \\
\text { fruit, grain, } \\
\text { nonleafy vegetables } \\
\text { plot } \\
\end{array}$ & $\mathrm{m}$ & 234 & $\begin{array}{l}-80,000- \\
+80,000\end{array}$ & 806 & $P$ & 3 & & \\
\hline $\begin{array}{l}\text { Larger y coordinate } \\
\text { of the fruit, grain, } \\
\text { nonleafy vegetables } \\
\text { plot }\end{array}$ & $\mathrm{m}$ & 266 & $\begin{array}{l}-80,000- \\
+80,000\end{array}$ & 838 & $P$ & 3 & & \\
\hline $\begin{array}{l}\text { Smaller } x \\
\text { coordinate of the } \\
\text { leafy vegetables } \\
\text { plot }\end{array}$ & $\mathrm{m}$ & 34.375 & $\begin{array}{l}-80,000- \\
+80,000\end{array}$ & 34.375 & $P$ & 3 & $\begin{array}{l}\text { A plot, with an area }=1,000 \text { square meters (RESRAD } \\
\text { OFFSITE default), is located north of the } \\
\text { contaminated zone near the well (which is located } \\
407 \text { meters north/downgradient of the contaminated } \\
\text { zone). }\end{array}$ & Yu et al. 2007 \\
\hline
\end{tabular}


RESRAD-OFFSITE Table of Input Parameters for the C-746-U Landfill Offsite Resident Farmer Scenario

\begin{tabular}{|c|c|c|c|c|c|c|c|c|}
\hline $\begin{array}{c}\text { Input Screen Title } \\
\text { and Parameter } \\
\text { Name }\end{array}$ & Units & $\begin{array}{l}\text { Default } \\
\text { Value }^{a}\end{array}$ & $\begin{array}{r}\text { Code-Acce, } \\
\text { Values } \\
\text { Physical } \\
\text { Numerical } \\
\text { Range }\end{array}$ & $\begin{array}{l}\text { Deterministic } \\
\text { Value }\end{array}$ & Type $^{d}$ & Priority $^{e}$ & Justification & References \\
\hline $\begin{array}{c}\text { Larger } x \text { coordinate } \\
\text { of the leafy } \\
\text { vegetables plot }\end{array}$ & $\mathrm{m}$ & 65.625 & $\begin{array}{l}-80,000- \\
+80,000\end{array}$ & 65.625 & $P$ & 3 & & \\
\hline $\begin{array}{c}\text { Smaller y } \\
\text { coordinate of the } \\
\text { leafy vegetables } \\
\text { plot }\end{array}$ & $\mathrm{m}$ & 268 & $\begin{array}{l}-80,000- \\
+80,000\end{array}$ & 840 & $P$ & 3 & & \\
\hline $\begin{array}{l}\text { Larger y coordinate } \\
\text { of the leafy } \\
\text { vegetables plot }\end{array}$ & $\mathrm{m}$ & 300 & $\begin{array}{l}-80,000- \\
+80,000\end{array}$ & 872 & $P$ & 3 & & \\
\hline $\begin{array}{c}\text { Smaller } x \\
\text { coordinate of the } \\
\text { pasture, silage } \\
\text { growing area } \\
\end{array}$ & $\mathrm{m}$ & 0 & $\begin{array}{l}-80,000- \\
+80,000\end{array}$ & 0 & $P$ & 3 & \multirow{4}{*}{$\begin{array}{l}\text { A plot, with an area }=10,000 \text { square meters (RESRAD } \\
\text { OFFSITE default), is located north of the } \\
\text { contaminated zone near the well (which is located } \\
407 \text { meters north/downgradient of the contaminated } \\
\text { zone). }\end{array}$} & \multirow[t]{4}{*}{ Yu et al. 2007} \\
\hline $\begin{array}{l}\text { Larger } x \text { coordinate } \\
\text { of the pasture, } \\
\text { silage growing area }\end{array}$ & $\mathrm{m}$ & 100 & $\begin{array}{l}-80,000- \\
+80,000\end{array}$ & 100 & $P$ & 3 & & \\
\hline $\begin{array}{c}\text { Smaller y } \\
\text { coordinate of the } \\
\text { pasture, silage } \\
\text { growing area }\end{array}$ & $\mathrm{m}$ & 450 & $\begin{array}{l}-80,000- \\
+80,000\end{array}$ & 706 & $P$ & 3 & & \\
\hline $\begin{array}{c}\text { Larger y coordinate } \\
\text { of the pasture, } \\
\text { silage growing area }\end{array}$ & $\mathrm{m}$ & 550 & $\begin{array}{l}-80,000- \\
+80,000\end{array}$ & 806 & $P$ & 3 & & \\
\hline $\begin{array}{l}\text { Smaller } x \\
\text { coordinate of the } \\
\text { grain fields }\end{array}$ & $\mathrm{m}$ & 0 & $\begin{array}{l}-80,000- \\
+80,000\end{array}$ & 192 & $P$ & 3 & \multirow{4}{*}{$\begin{array}{l}\text { A plot, with an area }=10,000 \text { square meters (RESRAD } \\
\text { OFFSITE default), is located north of the } \\
\text { contaminated zone near the well (which is located } \\
407 \text { meters north/downgradient of the contaminated } \\
\text { zone). }\end{array}$} & \multirow[t]{4}{*}{ Yu et al. 2007} \\
\hline $\begin{array}{l}\text { Larger } x \text { coordinate } \\
\text { of the grain fields }\end{array}$ & $\mathrm{m}$ & 100 & $\begin{array}{l}-80,000- \\
+80,000 \\
\end{array}$ & 292 & $P$ & 3 & & \\
\hline $\begin{array}{c}\text { Smaller y } \\
\text { coordinate of the } \\
\text { grain fields }\end{array}$ & $\mathrm{m}$ & 300 & $\begin{array}{l}-80,000- \\
+80,000\end{array}$ & 700 & $P$ & 3 & & \\
\hline $\begin{array}{l}\text { Larger y coordinate } \\
\text { of the grain fields }\end{array}$ & $\mathrm{m}$ & 400 & $\begin{array}{l}-80,000- \\
+80,000 \\
\end{array}$ & 800 & $P$ & 3 & & \\
\hline $\begin{array}{c}\text { Smaller } x \\
\text { coordinate of the } \\
\text { dwelling site }\end{array}$ & $\mathrm{m}$ & 34.375 & $\begin{array}{l}-80,000- \\
+80,000\end{array}$ & 34.375 & $P$ & 3 & \multirow{2}{*}{$\begin{array}{l}\text { A plot, with an area }=1,000 \text { square meters (RESRAD } \\
\text { OFFSITE default), is located north of the } \\
\text { contaminated zone near the well (which is located } \\
407 \text { meters north/downgradient of the contaminated } \\
\text { zone). }\end{array}$} & \multirow[t]{2}{*}{ Yu et al. 2007} \\
\hline $\begin{array}{l}\text { Larger } x \text { coordinate } \\
\text { of the dwelling site }\end{array}$ & $\mathrm{m}$ & 65.625 & $\begin{array}{l}-80,000- \\
+80,000\end{array}$ & 65.625 & $\mathrm{P}$ & 3 & & \\
\hline
\end{tabular}


RESRAD-OFFSITE Table of Input Parameters for the C-746-U Landfill Offsite Resident Farmer Scenario

\begin{tabular}{|c|c|c|c|c|c|c|c|c|}
\hline $\begin{array}{l}\text { Input Screen Title } \\
\text { and Parameter } \\
\text { Name }\end{array}$ & Units & $\begin{array}{l}\text { Default } \\
\text { Value }^{a}\end{array}$ & $\begin{array}{c}\text { Code-Accepted } \\
\text { Values }^{b} \\
\text { Physical or } \\
\text { Numerical }^{c} \text { (N) } \\
\text { Range }\end{array}$ & $\begin{array}{l}\text { Deterministic } \\
\text { Value }\end{array}$ & Type $^{d}$ & Priority $^{e}$ & Justification & References \\
\hline $\begin{array}{c}\text { Smaller y } \\
\text { coordinate of the } \\
\text { dwelling site }\end{array}$ & $\mathrm{m}$ & 134 & $\begin{array}{l}-80,000- \\
+80,000\end{array}$ & 636 & $\mathrm{P}$ & 3 & & \\
\hline $\begin{array}{l}\text { Larger y coordinate } \\
\text { of the dwelling site }\end{array}$ & $\mathrm{m}$ & 166 & $\begin{array}{l}-80,000- \\
+80,000\end{array}$ & 670 & $\mathrm{P}$ & 3 & & \\
\hline $\begin{array}{c}\text { Smaller } x \\
\text { coordinate of the } \\
\text { surface-water body }\end{array}$ & $\mathrm{m}$ & -100 & $\begin{array}{l}-80,000- \\
+80,000\end{array}$ & -100 & $P$ & 3 & \multirow{4}{*}{$\begin{array}{l}\text { A plot, with an area }=90,000 \text { square meters (RESRAD } \\
\text { OFFSITE default), is located south of the } \\
\text { contaminated zone/upgradient. The surface water } \\
\text { body is not included in the CSM. }\end{array}$} & \multirow[t]{4}{*}{ Yu et al. 2007} \\
\hline $\begin{array}{l}\text { Larger } x \text { coordinate } \\
\text { of the surface- } \\
\text { water body }\end{array}$ & $\mathrm{m}$ & 200 & $\begin{array}{l}-80,000- \\
+80,000\end{array}$ & 200 & $\mathrm{P}$ & 3 & & \\
\hline $\begin{array}{c}\text { Smaller y } \\
\text { coordinate of the } \\
\text { surface-water body }\end{array}$ & $\mathrm{m}$ & 550 & $\begin{array}{l}-80,000- \\
+80,000\end{array}$ & -850 & $P$ & 3 & & \\
\hline $\begin{array}{l}\text { Larger y coordinate } \\
\text { of the surface- } \\
\text { water body }\end{array}$ & $\mathrm{m}$ & 850 & $\begin{array}{l}-80,000- \\
+80,000\end{array}$ & -550 & $P$ & 3 & & \\
\hline
\end{tabular}

Source

\begin{tabular}{|c|c|c|c|c|c|c|c|c|c|}
\hline $\begin{array}{c}\text { Nuclide } \\
\text { concentration }\end{array}$ & $\mathrm{pCi} / \mathrm{g}$ & 100 & $0-1 \mathrm{E}+34$ & $\mathrm{~N}$ & $\begin{array}{c}\text { Unit } \\
\text { concentration } \\
\text { for: } \\
\text { Am-241 } \\
\text { Cs-137 } \\
\text { Np-237 } \\
\text { Pu-238 } \\
\text { Pu-239 } \\
\text { Pu-240 } \\
\text { Tc-99 } \\
\text { Th-228 } \\
\text { Th-230 } \\
\text { Th-232 } \\
\text { U-234 } \\
\text { U-235 } \\
\text { U-238 } \\
\end{array}$ & $P$ & 2 & $\begin{array}{l}\text { The radionuclide concentration used is } 1 \mathrm{pCi} / \mathrm{g} \text { for } \\
\text { each parent radionuclide listed. Site-specific values } \\
\text { for the 6-year waste inventory (May 2003- May 2009) } \\
\text { were not used as input values. The list of } \\
\text { radionuclides used was provided to ORISE by DOE. } \\
\text { Radioactive secular equilibrium was not assumed in } \\
\text { the analysis for the uranium, actinium, and thorium } \\
\text { decay series due to the nature of the PGDP's uranium } \\
\text { enrichment mission. }\end{array}$ & $\begin{array}{c}\text { DOE 2003a } \\
\text { DOE SOW for C- } \\
746-U \text { landfill and } \\
\text { DOE Project } \\
\text { Communication } \\
\text { (May 2010) }\end{array}$ \\
\hline \multicolumn{10}{|c|}{ Source Release and Deposition Velocity } \\
\hline $\begin{array}{c}\text { Release to } \\
\text { groundwater, leach }\end{array}$ & $1 / \mathrm{yr}$ & 0 & $0-1 E+34$ & $\mathrm{~N}$ & 0 & $P$ & 3 & $\begin{array}{l}\text { The fraction of the available radionuclide leached out } \\
\text { from the contaminated zone per unit of time. If a }\end{array}$ & Yu et al. 2007 \\
\hline
\end{tabular}


RESRAD-OFFSITE Table of Input Parameters for the C-746-U Landfill Offsite Resident Farmer Scenario

\begin{tabular}{|c|c|c|c|c|c|c|c|c|c|}
\hline $\begin{array}{c}\text { Input Screen Title } \\
\text { and Parameter } \\
\text { Name }\end{array}$ & Units & $\begin{array}{l}\text { Default } \\
\text { Value }^{a}\end{array}$ & $\begin{array}{r}\text { Code-Accep }^{\text {Aalues }^{b}} \\
\text { Physical }^{c} \\
\text { Numerical }^{c} \\
\text { Range }\end{array}$ & & $\begin{array}{c}\text { Deterministic } \\
\text { Value }\end{array}$ & Type $^{d}$ & Priority $^{e}$ & Justification & References \\
\hline rate & & & & & & & & $\begin{array}{l}\text { zero is entered, the code will estimate a release rate } \\
\text { on the basis of the equilibrium desorption } \\
\text { concentration. The default value is used. }\end{array}$ & \\
\hline Deposition velocity & $\mathrm{m} / \mathrm{s}$ & $\begin{array}{c}0.001 \\
0.01(\mathrm{Cl}, \mathrm{l}) \\
0(\mathrm{Xe})\end{array}$ & $0-1 E+34$ & $\mathrm{~N}$ & 0.001 & P & 2 & $\begin{array}{l}\text { For nuclides that are transported by contaminated } \\
\text { dust, it is the settling velocity of dust. If the nuclide is } \\
\text { being transported in the form of a gas (water vapor, } \\
\text { carbon dioxide, radon, etc.), a value of zero may be } \\
\text { entered. The default value is used. }\end{array}$ & Yu et al. 2007 \\
\hline
\end{tabular}

Distribution Coefficients

\begin{tabular}{|c|c|c|c|c|c|c|c|c|c|}
\hline Contaminated zone & $\mathrm{cm}^{3} / \mathrm{g}$ & $\begin{array}{l}\text { Nuclide- } \\
\text { dependent } \\
\text { (Default values } \\
\text { available) }\end{array}$ & $0-1 E+34$ & $\mathrm{~N}$ & $\begin{array}{l}\text { Nuclide- } \\
\text { dependent (see } \\
\text { Attachment I) }\end{array}$ & $P$ & 1 & $\begin{array}{l}\text { Tables with site-specific distribution coefficients for } \\
\text { the parent and daughter radionuclides are available } \\
\text { immediately following this table of parameters. }\end{array}$ & $\begin{array}{c}\text { DOE 2003b } \\
\text { Table Att. 1, page } \\
\text { C3-314, Table } \\
\text { C.3.1., page C3- } \\
301 \\
\\
\text { DOE Project } \\
\text { Communication } \\
\text { (March 2010) } \\
\text { Yu et al. } 2001 \\
\end{array}$ \\
\hline Unsaturated zone & $\mathrm{cm}^{3} / \mathrm{g}$ & $\begin{array}{l}\text { Nuclide- } \\
\text { dependent } \\
\text { (Default values } \\
\text { available) }\end{array}$ & $0-1 E+34$ & $\mathrm{~N}$ & $\begin{array}{l}\text { Nuclide- } \\
\text { dependent (see } \\
\text { Attachment I) }\end{array}$ & $P$ & 1 & $\begin{array}{l}\text { Tables with site-specific distribution coefficients for } \\
\text { the parent and daughter radionuclides are available } \\
\text { immediately following this table of parameters. }\end{array}$ & $\begin{array}{c}\text { DOE 2003b } \\
\text { Table Att. 1, page } \\
\text { C3-314, Table } \\
\text { C.3.1., page C3- } \\
301 \\
\\
\text { DOE Project } \\
\text { Communication } \\
\text { (March 2010) } \\
\text { Yu et al. } 2001\end{array}$ \\
\hline Saturated zone & $\mathrm{cm}^{3} / \mathrm{g}$ & $\begin{array}{l}\text { Nuclide- } \\
\text { dependent } \\
\text { (Default values } \\
\text { available) }\end{array}$ & $0-1 E+34$ & $\mathrm{~N}$ & $\begin{array}{l}\text { Nuclide- } \\
\text { dependent (see } \\
\text { Attachment I) }\end{array}$ & $P$ & 1 & $\begin{array}{l}\text { Tables with site-specific distribution coefficients for } \\
\text { the parent and daughter radionuclides are available } \\
\text { immediately following this table of parameters. }\end{array}$ & $\begin{array}{c}\text { DOE 2003b } \\
\text { Table Att. 1, page } \\
\text { C3-314, Table } \\
\text { C.3.1., page C3- } \\
\text { 301, } \\
\text { Table 4.7., page 4- } \\
21\end{array}$ \\
\hline
\end{tabular}


RESRAD-OFFSITE Table of Input Parameters for the C-746-U Landfill Offsite Resident Farmer Scenario

\begin{tabular}{|c|c|c|c|c|c|c|c|c|c|}
\hline \multirow[t]{2}{*}{$\begin{array}{l}\text { Input Screen Title } \\
\text { and Parameter } \\
\text { Name }\end{array}$} & \multirow[t]{2}{*}{ Units } & \multirow[t]{2}{*}{$\begin{array}{l}\text { Default } \\
\text { Value }^{a}\end{array}$} & \multicolumn{2}{|c|}{$\begin{array}{l}\text { Code-Accepted } \\
\text { Values }^{b} \\
\text { Physical or } \\
\text { Numerical }(\mathrm{N}) \\
\text { Range }\end{array}$} & \multirow[t]{2}{*}{$\begin{array}{c}\text { Deterministic } \\
\text { Value }\end{array}$} & \multirow[t]{2}{*}{ Type $e^{d}$} & \multirow[t]{2}{*}{ Priority $^{e}$} & \multirow[t]{2}{*}{ Justification } & \multirow{2}{*}{$\begin{array}{c}\text { References } \\
\\
\text { DOE Project } \\
\text { Communication } \\
\text { (March 2010) }\end{array}$} \\
\hline & & & & & & & & & \\
\hline $\begin{array}{l}\text { Sediment in surface } \\
\text { water body }\end{array}$ & $\mathrm{cm}^{3} / \mathrm{g}$ & $\begin{array}{c}\text { Nuclide- } \\
\text { dependent } \\
\text { (Default values } \\
\text { available) }\end{array}$ & $0-1 E+34$ & $\mathrm{~N}$ & $\begin{array}{l}\text { Nuclide- } \\
\text { dependent (see } \\
\text { Attachment I) }\end{array}$ & $P$ & 1 & $\begin{array}{l}\text { Tables with site-specific distribution coefficients for } \\
\text { the parent and daughter radionuclides are available } \\
\text { immediately following this table of parameters. }\end{array}$ & $\begin{array}{l}\text { DOE Project } \\
\text { Communication } \\
\text { (March 2010) }\end{array}$ \\
\hline $\begin{array}{l}\text { Fruit, grain, } \\
\text { nonleafy fields }\end{array}$ & $\mathrm{cm}^{3} / \mathrm{g}$ & $\begin{array}{c}\text { Nuclide- } \\
\text { dependent } \\
\text { (Default values } \\
\text { available) }\end{array}$ & $0-1 E+34$ & $\mathrm{~N}$ & $\begin{array}{l}\text { Nuclide- } \\
\text { dependent (see } \\
\text { Attachment I) }\end{array}$ & $P$ & 1 & $\begin{array}{l}\text { Tables with site-specific distribution coefficients for } \\
\text { the parent and daughter radionuclides are available } \\
\text { immediately following this table of parameters. }\end{array}$ & $\begin{array}{l}\text { DOE Project } \\
\text { Communication } \\
\text { (March 2010) }\end{array}$ \\
\hline $\begin{array}{l}\text { Leafy vegetable } \\
\text { fields }\end{array}$ & $\mathrm{cm}^{3} / \mathrm{g}$ & $\begin{array}{c}\text { Nuclide- } \\
\text { dependent } \\
\text { (Default values } \\
\text { available) }\end{array}$ & $0-1 E+34$ & $\mathrm{~N}$ & $\begin{array}{l}\text { Nuclide- } \\
\text { dependent (see } \\
\text { Attachment I) }\end{array}$ & $P$ & 1 & $\begin{array}{l}\text { Tables with site-specific distribution coefficients for } \\
\text { the parent and daughter radionuclides are available } \\
\text { immediately following this table of parameters. }\end{array}$ & $\begin{array}{l}\text { DOE Project } \\
\text { Communication } \\
\text { (March 2010) }\end{array}$ \\
\hline $\begin{array}{l}\text { Pasture, silage } \\
\text { growing areas }\end{array}$ & $\mathrm{cm}^{3} / \mathrm{g}$ & $\begin{array}{c}\text { Nuclide- } \\
\text { dependent } \\
\text { (Default values } \\
\text { available) }\end{array}$ & $0-1 E+34$ & $\mathrm{~N}$ & $\begin{array}{l}\text { Nuclide- } \\
\text { dependent (see } \\
\text { Attachment I) }\end{array}$ & $P$ & 1 & $\begin{array}{l}\text { Tables with site-specific distribution coefficients for } \\
\text { the parent and daughter radionuclides are available } \\
\text { immediately following this table of parameters. }\end{array}$ & $\begin{array}{l}\text { DOE Project } \\
\text { Communication } \\
\text { (March 2010) }\end{array}$ \\
\hline $\begin{array}{l}\text { Livestock feed grain } \\
\text { fields }\end{array}$ & $\mathrm{cm}^{3} / \mathrm{g}$ & $\begin{array}{c}\text { Nuclide- } \\
\text { dependent } \\
\text { (Default values } \\
\text { available) } \\
\end{array}$ & $0-1 E+34$ & $\mathrm{~N}$ & $\begin{array}{l}\text { Nuclide- } \\
\text { dependent (see } \\
\text { Attachment I) }\end{array}$ & $P$ & 1 & $\begin{array}{l}\text { Tables with site-specific distribution coefficients for } \\
\text { the parent and daughter radionuclides are available } \\
\text { immediately following this table of parameters. }\end{array}$ & $\begin{array}{l}\text { DOE Project } \\
\text { Communication } \\
\text { (March 2010) }\end{array}$ \\
\hline Offsite dwelling site & $\mathrm{cm}^{3} / \mathrm{g}$ & $\begin{array}{c}\text { Nuclide- } \\
\text { dependent } \\
\text { (Default values } \\
\text { available) }\end{array}$ & $0-1 E+34$ & $\mathrm{~N}$ & $\begin{array}{l}\text { Nuclide- } \\
\text { dependent (see } \\
\text { Attachment I) }\end{array}$ & $P$ & 1 & $\begin{array}{l}\text { Tables with site-specific distribution coefficients for } \\
\text { the parent and daughter radionuclides are available } \\
\text { immediately following this table of parameters. }\end{array}$ & $\begin{array}{l}\text { DOE Project } \\
\text { Communication } \\
\text { (March 2010) }\end{array}$ \\
\hline
\end{tabular}

Dose Conversion and Slope Factors

\begin{tabular}{|c|c|c|c|c|c|c|c|c|}
\hline $\begin{array}{c}\text { External dose } \\
\text { conversion factors }\end{array}$ & $\begin{array}{c}\text { (mrem/yr) } \\
\text { per } \\
(\mathrm{pCi} / \mathrm{g})\end{array}$ & $\begin{array}{l}\text { Nuclide- } \\
\text { specific } \\
\text { (default values } \\
\text { available) }\end{array}$ & $\begin{array}{c}\text { Nuclide- } \\
\text { specific } \\
\text { (default } \\
\text { values } \\
\text { available) }\end{array}$ & $\begin{array}{l}\text { Nuclide-specific } \\
\text { (ICRP } 60 \text { values } \\
\text { available) }\end{array}$ & $\mathrm{M}$ & 3 & $\begin{array}{l}\text { The ICRP } 60 \text { (external dose conversion factors) library } \\
\text { is selected in conjunction with the ICRP } 72 \text { Adult } \\
\text { (internal dose conversion factors) library to obtain } \\
\text { results in Total Effective Dose (TED). }\end{array}$ & Yu et al. 2007 \\
\hline $\begin{array}{l}\text { Inhalation dose } \\
\text { conversion factors }\end{array}$ & $\mathrm{mrem} / \mathrm{pCi}$ & $\begin{array}{l}\text { Nuclide- } \\
\text { specific } \\
\text { (default values } \\
\text { available) }\end{array}$ & $\begin{array}{c}\text { Nuclide- } \\
\text { specific } \\
\text { (default } \\
\text { values } \\
\text { available) }\end{array}$ & $\begin{array}{l}\text { Nuclide-specific } \\
\text { (ICRP } 72 \text { values } \\
\text { available) }\end{array}$ & $\mathrm{M}$ & 3 & $\begin{array}{l}\text { The ICRP } 72 \text { Adult (internal dose conversion factors) } \\
\text { library is selected in conjunction with the ICRP } 60 \\
\text { (external dose conversion factors) library to obtain } \\
\text { results in Total Effective Dose (TED). }\end{array}$ & Yu et al. 2007 \\
\hline
\end{tabular}


RESRAD-OFFSITE Table of Input Parameters for the C-746-U Landfill Offsite Resident Farmer Scenario

\begin{tabular}{|c|c|c|c|c|c|c|c|c|}
\hline $\begin{array}{l}\text { Input Screen Title } \\
\text { and Parameter } \\
\text { Name }\end{array}$ & Units & $\begin{array}{l}\text { Default } \\
\text { Value }^{a}\end{array}$ & $\begin{array}{r}\text { Code-Acce } \\
\text { Values } \\
\text { Physical } \\
\text { Numerical } \\
\text { Range }\end{array}$ & $\begin{array}{c}\text { Deterministic } \\
\text { Value }\end{array}$ & Type $^{d}$ & Priority $^{e}$ & Justification & References \\
\hline $\begin{array}{l}\text { Ingestion dose } \\
\text { conversion factors }\end{array}$ & $\mathrm{mrem} / \mathrm{pCi}$ & $\begin{array}{l}\text { Nuclide- } \\
\text { specific } \\
\text { (default values } \\
\text { available) }\end{array}$ & $\begin{array}{c}\text { Nuclide- } \\
\text { specific } \\
\text { (default } \\
\text { values } \\
\text { available) } \\
\end{array}$ & $\begin{array}{l}\text { Nuclide-specific } \\
\text { (ICRP } 72 \text { values } \\
\text { available) }\end{array}$ & $M$ & 3 & $\begin{array}{l}\text { The ICRP } 72 \text { Adult (internal dose conversion factors) } \\
\text { library is selected in conjunction with the ICRP } 60 \\
\text { (external dose conversion factors) library to obtain } \\
\text { results in Total Effective Dose (TED). }\end{array}$ & Yu et al. 2007 \\
\hline $\begin{array}{l}\text { Slope factor -- } \\
\text { external }\end{array}$ & $\begin{array}{l}\text { (risk/yr) } \\
\text { per } \\
(\mathrm{pCi} / \mathrm{g})\end{array}$ & $\begin{array}{l}\text { Nuclide- } \\
\text { specific } \\
\text { (default values } \\
\text { available) }\end{array}$ & $\begin{array}{c}\text { Nuclide- } \\
\text { specific } \\
\text { (default } \\
\text { values } \\
\text { available) }\end{array}$ & $\begin{array}{l}\text { Nuclide-specific } \\
\text { (default values } \\
\text { available) }\end{array}$ & $M$ & 3 & Default values are used. & Yu et al. 2007 \\
\hline $\begin{array}{l}\text { Slope factor -- } \\
\text { inhalation }\end{array}$ & risk/pCi & $\begin{array}{l}\text { Nuclide- } \\
\text { specific } \\
\text { (default values } \\
\text { available) }\end{array}$ & $\begin{array}{l}\text { Nuclide- } \\
\text { specific } \\
\text { (default } \\
\text { values } \\
\text { available) } \\
\end{array}$ & $\begin{array}{l}\text { Nuclide-specific } \\
\text { (default values } \\
\text { available) }\end{array}$ & $M$ & 3 & Default values are used. & Yu et al. 2007 \\
\hline $\begin{array}{l}\text { Slope factor -- food } \\
\text { ingestion }\end{array}$ & risk/pCi & $\begin{array}{l}\text { Nuclide- } \\
\text { specific } \\
\text { (default values } \\
\text { available) }\end{array}$ & $\begin{array}{c}\text { Nuclide- } \\
\text { specific } \\
\text { (default } \\
\text { values } \\
\text { available) }\end{array}$ & $\begin{array}{l}\text { Nuclide-specific } \\
\text { (default values } \\
\text { available) }\end{array}$ & M & 3 & Default values are used. & Yu et al. 2007 \\
\hline $\begin{array}{l}\text { Slope factor -- } \\
\text { water ingestion }\end{array}$ & risk/pCi & $\begin{array}{l}\text { Nuclide- } \\
\text { specific } \\
\text { (default values } \\
\text { available) }\end{array}$ & $\begin{array}{c}\text { Nuclide- } \\
\text { specific } \\
\text { (default } \\
\text { values } \\
\text { available) } \\
\end{array}$ & $\begin{array}{l}\text { Nuclide-specific } \\
\text { (default values } \\
\text { available) }\end{array}$ & M & 3 & Default values are used. & Yu et al. 2007 \\
\hline $\begin{array}{l}\text { Slope factor -- soil } \\
\text { ingestion }\end{array}$ & risk/pCi & $\begin{array}{l}\text { Nuclide- } \\
\text { specific } \\
\text { (default values } \\
\text { available) }\end{array}$ & $\begin{array}{l}\text { Nuclide- } \\
\text { specific } \\
\text { (default } \\
\text { values } \\
\text { available) }\end{array}$ & $\begin{array}{l}\text { Nuclide-specific } \\
\text { (default values } \\
\text { available) }\end{array}$ & $M$ & 3 & Default values are used. & Yu et al. 2007 \\
\hline
\end{tabular}

Transfer Factors

\begin{tabular}{|c|c|c|c|c|c|c|c|c|}
\hline $\begin{array}{c}\text { Fruit, grain, } \\
\text { nonleafy vegetables } \\
\text { transfer factor }\end{array}$ & $\begin{array}{c}(\mathrm{pCi} / \mathrm{kg}) / \\
(\mathrm{pCi} / \mathrm{kg})\end{array}$ & $\begin{array}{c}\text { Element- } \\
\text { dependent } \\
\text { (Default values } \\
\text { available) }\end{array}$ & $0-1 \mathrm{E}+34$ & $\mathrm{~N}$ & $\begin{array}{c}\text { Element- } \\
\text { dependent } \\
\text { (default values } \\
\text { available) }\end{array}$ & $\mathrm{P}$ & 1 & Default values are used. \\
\hline $\begin{array}{c}\text { Leafy vegetables } \\
\text { transfer factor }\end{array}$ & $\begin{array}{c}\text { (pCi/kg)/ } / \mathrm{kCi} / \mathrm{kg}) \\
\left(\begin{array}{c}\text { dement- } \\
\text { dependent } \\
\text { (Default values } \\
\text { available) }\end{array}\right.\end{array}$ & $0-1 \mathrm{E}+34$ & $\mathrm{~N}$ & $\begin{array}{c}\text { Element- } \\
\text { dependent } \\
\text { (default values } \\
\text { available) }\end{array}$ & $\mathrm{P}$ & 1 & Default values are used. \\
\hline
\end{tabular}


RESRAD-OFFSITE Table of Input Parameters for the C-746-U Landfill Offsite Resident Farmer Scenario

\begin{tabular}{|c|c|c|c|c|c|c|c|c|c|}
\hline $\begin{array}{c}\text { Input Screen Title } \\
\text { and Parameter } \\
\text { Name }\end{array}$ & Units & $\begin{array}{l}\text { Default } \\
\text { Value }^{a}\end{array}$ & $\begin{array}{r}\text { Code-Acce } \\
\text { Values } \\
\text { Physical } \\
\text { Numerica } \\
\text { Range }\end{array}$ & & $\begin{array}{c}\text { Deterministic } \\
\text { Value }\end{array}$ & Type $^{d}$ & Priority $^{e}$ & Justification & References \\
\hline $\begin{array}{l}\text { Pasture and silage } \\
\text { transfer factor }\end{array}$ & $\begin{array}{l}(\mathrm{pCi} / \mathrm{kg}) / \\
(\mathrm{pCi} / \mathrm{kg})\end{array}$ & $\begin{array}{c}\text { Element- } \\
\text { dependent } \\
\text { (Default values } \\
\text { available) }\end{array}$ & $0-1 E+34$ & $\mathrm{~N}$ & $\begin{array}{c}\text { Element- } \\
\text { dependent } \\
\text { (default values } \\
\text { available) }\end{array}$ & $\mathrm{P}$ & 1 & Default values are used. & Yu et al. 2007 \\
\hline $\begin{array}{l}\text { Livestock feed grain } \\
\text { transfer factor }\end{array}$ & $\begin{array}{l}(\mathrm{pCi} / \mathrm{kg}) / \\
(\mathrm{pCi} / \mathrm{kg})\end{array}$ & $\begin{array}{c}\text { Element- } \\
\text { dependent } \\
\text { (Default values } \\
\text { available) } \\
\end{array}$ & $0-1 E+34$ & $\mathrm{~N}$ & $\begin{array}{c}\text { Element- } \\
\text { dependent } \\
\text { (default values } \\
\text { available) } \\
\end{array}$ & $\mathrm{P}$ & 1 & Default values are used. & Yu et al. 2007 \\
\hline $\begin{array}{l}\text { Meat transfer } \\
\text { factor }\end{array}$ & $\begin{array}{l}(\mathrm{pCi} / \mathrm{kg}) / \\
(\mathrm{pCi} / \mathrm{d})\end{array}$ & $\begin{array}{c}\text { Element- } \\
\text { dependent } \\
\text { (Default values } \\
\text { available) } \\
\end{array}$ & $0-1 E+34$ & $\mathrm{~N}$ & $\begin{array}{c}\text { Element- } \\
\text { dependent } \\
\text { (default values } \\
\text { available) } \\
\end{array}$ & $\mathrm{P}$ & 2 & Default values are used. & Yu et al. 2007 \\
\hline Milk transfer factor & $\begin{array}{l}(\mathrm{pCi} / \mathrm{L}) / \\
(\mathrm{pCi} / \mathrm{d})\end{array}$ & $\begin{array}{c}\text { Element- } \\
\text { dependent } \\
\text { (Default values } \\
\text { available) }\end{array}$ & $0-1 E+34$ & $\mathrm{~N}$ & $\begin{array}{c}\text { Element- } \\
\text { dependent } \\
\text { (default values } \\
\text { available) }\end{array}$ & $P$ & 2 & Default values are used. & Yu et al. 2007 \\
\hline $\begin{array}{l}\text { Bioaccumulation } \\
\text { factor for fish }\end{array}$ & $\begin{array}{l}(\mathrm{pCi} / \mathrm{kg}) / \\
(\mathrm{pCi} / \mathrm{L})\end{array}$ & $\begin{array}{c}\text { Element- } \\
\text { dependent } \\
\text { (Default values } \\
\text { available) } \\
\end{array}$ & $0-1 E+34$ & $\mathrm{~N}$ & $\begin{array}{c}\text { Element- } \\
\text { dependent } \\
\text { (default values } \\
\text { available) } \\
\end{array}$ & $P$ & 2 & Default values are used. & Yu et al. 2007 \\
\hline $\begin{array}{l}\text { Bioaccumulation } \\
\text { factor for crustacea } \\
\text { and mollusks }\end{array}$ & $\begin{array}{l}(\mathrm{pCi} / \mathrm{kg}) / \\
(\mathrm{pCi} / \mathrm{L})\end{array}$ & $\begin{array}{c}\text { Element- } \\
\text { dependent } \\
\text { (Default values } \\
\text { available) }\end{array}$ & $0-1 E+34$ & $\mathrm{~N}$ & $\begin{array}{c}\text { Element- } \\
\text { dependent } \\
\text { (default values } \\
\text { available) }\end{array}$ & $\mathrm{P}$ & 3 & Default values are used. & Yu et al. 2007 \\
\hline
\end{tabular}

Reporting Times

\begin{tabular}{|c|c|c|c|c|c|c|c|c|}
\hline $\begin{array}{l}\text { Times at which } \\
\text { output is reported }\end{array}$ & $\mathrm{yr}$ & $\begin{array}{c}1,3,6,12,30 \\
75,175,420 \\
970\end{array}$ & $0-1 \mathrm{E}+5$ & $\begin{array}{c}1,50,100,500 \\
1026\end{array}$ & $P$ & 3 & $\begin{array}{l}\text { A time horizon of } 1,050 \text { years is used to calculate soil } \\
\text { guidelines. This is assumed to allow for ingrowth and } \\
\text { decay since the plant has been in operation for about } \\
50 \text { years (since about } 1960 \text { to } 2010 \text { ). } \\
\text { The time horizon is the sum of the maximum user- } \\
\text { specified reporting time and the exposure duration. } \\
\text { For instance, in this case for a time horizon of } 1050 \\
\text { yrs, the maximum reporting time is } 1026 \text { yrs for an } \\
\text { exposure duration of } 24 \text { yrs. }\end{array}$ & $\begin{array}{c}\text { DOE/CH/8901 and } \\
\text { DOE Order } 5400.5 \\
\text { DOE Project } \\
\text { Communication } \\
\text { (May 2010) }\end{array}$ \\
\hline
\end{tabular}

Storage Times

Storage time for

d

1

$0-1 \mathrm{E}+34$

1

B

3

Default value is used.

Yu et al. 2007 
RESRAD-OFFSITE Table of Input Parameters for the C-746-U Landfill Offsite Resident Farmer Scenario

\begin{tabular}{|c|c|c|c|c|c|c|c|c|c|}
\hline \multirow[t]{2}{*}{$\begin{array}{c}\text { Input Screen Title } \\
\text { and Parameter } \\
\text { Name }\end{array}$} & \multirow[t]{2}{*}{ Units } & \multirow[t]{2}{*}{$\begin{array}{l}\text { Default } \\
\text { Value }^{a}\end{array}$} & \multicolumn{2}{|c|}{$\begin{array}{l}\text { Code-Accepted } \\
\text { Values }^{b} \\
\text { Physical or } \\
\text { Numerical }^{c}(\mathrm{~N}) \\
\text { Range }\end{array}$} & \multirow[t]{2}{*}{$\begin{array}{l}\text { Deterministic } \\
\text { Value }\end{array}$} & \multirow[t]{2}{*}{ Type $^{d}$} & \multirow[t]{2}{*}{ Priority $^{e}$} & \multirow[t]{2}{*}{ Justification } & \multirow[t]{2}{*}{ References } \\
\hline & & & & & & & & & \\
\hline $\begin{array}{l}\text { Storage time for } \\
\text { well water }\end{array}$ & $d$ & 1 & $0-1 E+34$ & $\mathrm{~N}$ & 1 & B & 3 & Default value is used. & Yu et al. 2007 \\
\hline $\begin{array}{c}\text { Storage time for } \\
\text { fruits, grain, and } \\
\text { nonleafy vegetables }\end{array}$ & $d$ & 14 & $0-1 E+34$ & $\mathrm{~N}$ & 14 & B & 3 & Default value is used. & Yu et al. 2007 \\
\hline $\begin{array}{l}\text { Storage time for } \\
\text { leafy vegetables }\end{array}$ & $d$ & 1 & $0-1 E+34$ & $\mathrm{~N}$ & 1 & B & 3 & Default value is used. & Yu et al. 2007 \\
\hline $\begin{array}{c}\text { Storage time for } \\
\text { pasture and silage }\end{array}$ & $d$ & 1 & $0-1 E+34$ & $\mathrm{~N}$ & 1 & B & 3 & Default value is used. & Yu et al. 2007 \\
\hline $\begin{array}{l}\text { Storage time for } \\
\text { livestock feed grain }\end{array}$ & $d$ & 45 & $0-1 E+34$ & $\mathrm{~N}$ & 45 & B & 3 & Default value is used. & Yu et al. 2007 \\
\hline $\begin{array}{c}\text { Storage time for } \\
\text { meat }\end{array}$ & $d$ & 20 & $0-1 E+34$ & $\mathrm{~N}$ & 20 & B & 3 & Default value is used. & Yu et al. 2007 \\
\hline $\begin{array}{l}\text { Storage time for } \\
\text { milk }\end{array}$ & $d$ & 1 & $0-1 E+34$ & $\mathrm{~N}$ & 1 & B & 3 & Default value is used. & Yu et al. 2007 \\
\hline $\begin{array}{l}\text { Storage time for } \\
\text { fish }\end{array}$ & $d$ & 7 & $0-1 E+34$ & $\mathrm{~N}$ & 7 & B & 3 & Default value is used. & Yu et al. 2007 \\
\hline $\begin{array}{l}\text { Storage time for } \\
\text { crustacea and } \\
\text { mollusks }\end{array}$ & $d$ & 7 & $0-1 E+34$ & $\mathrm{~N}$ & 7 & B & 3 & Default value is used. & Yu et al. 2007 \\
\hline
\end{tabular}

Physical and

Hydrological

\begin{tabular}{|c|c|c|c|c|c|c|c|c|}
\hline Precipitation & $\mathrm{m} / \mathrm{yr}$ & 1 & $0-10$ & 1.24 & $P$ & 2 & $\begin{array}{l}\text { The yearly precipitation averages about } 49 \text { inches } \\
\text { (approximately } 1.24 \text { meters). }\end{array}$ & $\begin{array}{c}\text { PRS 2008a } \\
\text { page 1-4 } \\
\text { DOE 2003b } \\
\text { page 2-5 }\end{array}$ \\
\hline Wind speed & $\mathrm{m} / \mathrm{s}$ & 2 & $1 E-4-20$ & $\begin{array}{l}\text { Actual values } \\
\text { will be from } \\
\text { Paducah read } \\
\text { meteorological } \\
\text { star file }\end{array}$ & $P$ & 2 & $\begin{array}{l}\text { The STAR file selected from the RESRAD-OFFSITE } \\
\text { code is called KY_Paducah.str. } \\
\text { The wind speed is divided into six intervals in order to } \\
\text { specify the joint frequency distribution of wind speed } \\
\text { and atmospheric stability in each direction of a wind } \\
\text { rose. This is the average wind speed for the wind } \\
\text { speed interval. }\end{array}$ & Yu et al. 2007 \\
\hline
\end{tabular}

Primary

Contamination

Area of primary

$\mathrm{m}^{2}$

10,000

Calculated

Calculated

\begin{tabular}{l|l|l}
\hline $\mathrm{P}$ & 2 & The contaminated zone is composed of four different
\end{tabular}

DOE SOW for C- 
RESRAD-OFFSITE Table of Input Parameters for the C-746-U Landfill Offsite Resident Farmer Scenario

\begin{tabular}{|c|c|c|c|c|c|c|c|c|}
\hline $\begin{array}{l}\text { Input Screen Title } \\
\text { and Parameter } \\
\text { Name }\end{array}$ & Units & $\begin{array}{l}\text { Default } \\
\text { Value }^{a}\end{array}$ & $\begin{array}{c}\text { Code-Accepted } \\
\text { Values }^{b} \\
\text { Physical or } \\
\text { Numerical }^{c} \text { (N) } \\
\text { Range }\end{array}$ & $\begin{array}{l}\text { Deterministic } \\
\text { Value }\end{array}$ & Type $e^{d}$ & Priority $^{e}$ & Justification & References \\
\hline contamination & & & & & & & $\begin{array}{l}\text { waste forms. The waste forms types are soil, } \\
\text { concrete, metal, and organic (lumber and debris). The } \\
\text { total waste disposal area of the landfill is calculated } \\
\text { by the code, it is not an input. The calculated area of } \\
\text { the contaminated zone is approximately } 91,000 \\
\text { square meters (not exactly } 89,436 \text { square meters } \\
\text { which is the total disposal area when the landfill is } \\
\text { filled). The code calculated this area based on input } \\
\text { values from dimensions of the waste disposal area } \\
\text { available in Lee et al. } 1995 \text {. }\end{array}$ & $\begin{array}{l}\text { 746-U landfill } \\
\text { DOE 2003b } \\
\text { Section 3.2, } \\
\text { page 3-11, } \\
\text { Table 4.5, } \\
\text { page 4-13 } \\
\text { Lee et al. } 1995 \\
\text { Fig } 2-4, \\
\text { page } 17\end{array}$ \\
\hline $\begin{array}{l}\text { Length of } \\
\text { contamination } \\
\text { parallel to aquifer } \\
\text { flow }\end{array}$ & $\mathrm{m}$ & 100 & $1 E-4-1 E+6$ & 399 & $\mathrm{P}$ & 2 & $\begin{array}{l}\text { This value of } 399 \mathrm{~m} \text { is the conservative longest } \\
\text { dimension between the upgradient edge of the } \\
\text { contaminated zone and the downgradient edge, } \\
\text { parallel to the aquifer. }\end{array}$ & $\begin{array}{l}\text { Lee et al. } 1995 \\
\text { Fig } 2-4, \\
\text { page } 17\end{array}$ \\
\hline $\begin{array}{l}\text { Depth of soil mixing } \\
\text { layer }(m)\end{array}$ & $\mathrm{m}$ & 0.15 & $0-1$ & 0.15 & $P, B$ & 2 & Default value is used. & Yu et al. 2007 \\
\hline $\begin{array}{l}\text { Deposition velocity } \\
\text { of dust }(\mathrm{m} / \mathrm{s})\end{array}$ & $\mathrm{m} / \mathrm{s}$ & 0.001 & $0-0.01$ & 0.001 & $P$ & & $\begin{array}{l}\text { This is the average velocity with which dust settles } \\
\text { onto the contaminated zone. It is used to calculate } \\
\text { the release to the atmosphere. The default value is } \\
\text { used per communication with DOE geologist. }\end{array}$ & $\begin{array}{l}\text { Yu et al. } 2007 \\
\text { DOE Project } \\
\text { Communication } \\
\text { with geologist } \\
\text { (April 2010) }\end{array}$ \\
\hline $\begin{array}{l}\text { Irrigation applied } \\
\text { per year (m/yr) }\end{array}$ & $\mathrm{m} / \mathrm{yr}$ & 0.2 & $0-10$ & 0 & B & 3 & $\begin{array}{l}\text { The irrigation rate for the contaminated zone is set to } \\
\text { "0" since the Resident Farmer is located offsite. }\end{array}$ & Yu et al. 2007 \\
\hline $\begin{array}{l}\text { Evapotranspiration } \\
\text { coefficient }\end{array}$ & -- & 0.5 & $0-0.999$ & 0.83 & $\mathrm{P}$ & 2 & $\begin{array}{l}\text { This value was calculated from the HELP Output data } \\
\text { for the Post-Institutional Control Period. The } \\
\text { equation used to calculate the value is available in Yu } \\
\text { et al. } 1993 . \\
\text { The calculations are available in Attachment II } \\
\text { following this table. }\end{array}$ & $\begin{array}{l}\text { DOE } 2003 b \\
\text { page C3-243 } \\
\text { Yu et al.1993 } \\
\text { page } 78\end{array}$ \\
\hline Runoff coefficient & -- & 0.2 & $0-1$ & 0.34 & $\mathrm{P}$ & 2 & $\begin{array}{l}\text { This value was calculated from the HELP Output data } \\
\text { for the Post-Institutional Control Period. The } \\
\text { equation used to calculate the value is available in Yu } \\
\text { et al. } 1993 . \\
\text { The calculations are available in Attachment II } \\
\text { following this table. }\end{array}$ & $\begin{array}{l}\text { DOE 2003b } \\
\text { Page C3-243 } \\
\text { Yu et al. } 1993 \\
\text { page } 73\end{array}$ \\
\hline Rainfall and runoff & -- & 160 & $0-1,000$ & 250 & $\mathrm{P}$ & 2 & This value was obtained from Wischmeier et al. 1978 & Wischmeier et al. \\
\hline
\end{tabular}


RESRAD-OFFSITE Table of Input Parameters for the C-746-U Landfill Offsite Resident Farmer Scenario

\begin{tabular}{|c|c|c|c|c|c|c|c|c|}
\hline $\begin{array}{c}\text { Input Screen Title } \\
\text { and Parameter } \\
\text { Name }\end{array}$ & Units & $\begin{array}{l}\text { Default } \\
\text { Value }^{a}\end{array}$ & $\begin{array}{l}\text { Code-Accepted } \\
\text { Values }^{b} \\
\text { Physical or } \\
\text { Numerical }^{c}(\mathrm{~N}) \\
\text { Range }^{\text {Rang }}\end{array}$ & $\begin{array}{l}\text { Deterministic } \\
\text { Value }\end{array}$ & Type $e^{d}$ & Priority $^{e}$ & Justification & References \\
\hline & & & & & & & and agreed upon by DOE geologist. & $\begin{array}{c}1978 \\
\text { Figure 1, page 5 } \\
\text { (Predicting } \\
\text { Rainfall Erosion } \\
\text { Losses) } \\
\\
\text { DOE Project } \\
\text { Communication } \\
\text { with geologist } \\
\text { (April 2010) }\end{array}$ \\
\hline $\begin{array}{l}\text { Slope-length- } \\
\text { steepness factor }\end{array}$ & -- & 0.4 & $0-10$ & 0.4 & $\mathrm{P}$ & 2 & $\begin{array}{l}\text { DOE geologist recommended a value of } 0.4 \text { based on } \\
\text { site topography. }\end{array}$ & $\begin{array}{l}\text { Yu et al. } 2007 \\
\text { DOE Project } \\
\text { Communication } \\
\text { with geologist } \\
\text { (April 2010) }\end{array}$ \\
\hline $\begin{array}{c}\text { Cover and } \\
\text { management factor }\end{array}$ & -- & 0.003 & $0-1$ & 0.2 & $B, P$ & 2 & $\begin{array}{l}\text { DOE geologist recommended value based on no } \\
\text { appreciable canopy and } 20 \% \text { ground cover. }\end{array}$ & $\begin{array}{l}\text { Yu et al. } 2007 \\
\text { DOE Project } \\
\text { Communication } \\
\text { with geologist } \\
\text { (April 2010) }\end{array}$ \\
\hline $\begin{array}{l}\text { Support practice } \\
\text { factor }\end{array}$ & -- & 1 & $0-1$ & 0.5 & $B, P$ & 2 & DOE geologist recommended value. & $\begin{array}{l}\text { Yu et al. } 2007 \\
\text { DOE Project } \\
\text { Communication } \\
\text { with geologist } \\
\text { (July 2010) }\end{array}$ \\
\hline
\end{tabular}

Contaminated Zone

\begin{tabular}{|c|c|c|c|c|c|c|c|c|}
\hline $\begin{array}{c}\text { Thickness of } \\
\text { contaminated zone }\end{array}$ & $\mathrm{m}$ & 2 & $\begin{array}{c}1 \mathrm{E}-5- \\
1,000\end{array}$ & 13.4 & $\mathrm{P}$ & 2 & $\begin{array}{c}\text { This value is the average thickness for the waste } \\
\text { forms when the landfill is full. }\end{array}$ & $\begin{array}{c}\text { Table 4.5, } \\
\text { page 4-13, } \\
\text { Table Att.3, } \\
\text { page C3-315 }\end{array}$ \\
\hline $\begin{array}{c}\text { Total porosity of } \\
\text { contaminated zone }\end{array}$ & -- & 0.4 & $1 \mathrm{E}-5-1$ & 0.17 & $\mathrm{P}$ & 2 & $\begin{array}{c}\text { DOE 2003b } \\
\text { Table } 4.4, \\
\text { page 4-9 }\end{array}$ \\
\hline $\begin{array}{c}\text { Dry bulk density of } \\
\text { contaminated zone-specific value available is 0.168 vol/vol. }\end{array}$ & $\mathrm{g} / \mathrm{cm}^{3}$ & 1.5 & $1 \mathrm{E}-3-22.5$ & & 1.89 & $\mathrm{P}$ & 1 & $\begin{array}{c}\text { The densities of the waste forms were used to } \\
\text { calculate the weighted average density for the }\end{array}$ \\
\hline
\end{tabular}


RESRAD-OFFSITE Table of Input Parameters for the C-746-U Landfill Offsite Resident Farmer Scenario

\begin{tabular}{|c|c|c|c|c|c|c|c|c|}
\hline $\begin{array}{c}\text { Input Screen Title } \\
\text { and Parameter } \\
\text { Name }\end{array}$ & Units & $\begin{array}{l}\text { Default } \\
\text { Value }^{a}\end{array}$ & $\begin{array}{l}\text { Code-Accepted } \\
\text { Values }^{b} \\
\text { Physical or } \\
\text { Numerical }{ }^{C}(\mathrm{~N}) \\
\text { Range }\end{array}$ & $\begin{array}{l}\text { Deterministic } \\
\text { Value }\end{array}$ & Type $^{d}$ & Priority $^{e}$ & Justification & References \\
\hline & & & & & & & $\begin{array}{l}\text { contaminated zone which is approximately } \\
1.89 \mathrm{~g} / \mathrm{cm}^{3} \text {. }\end{array}$ & page 4-13 \\
\hline $\begin{array}{l}\text { Soil erodibility } \\
\text { factor of } \\
\text { contaminated zone }\end{array}$ & tons/acre & 0.4 & $0-0.5$ & 0.37 & $\mathrm{P}$ & 2 & $\begin{array}{l}\text { DOE geologist recommended value based on silty clay } \\
\text { loam and } 0.5 \% \text { organic matter. }\end{array}$ & $\begin{array}{c}\text { Yu et al. } 2007 \\
\text { Table 2.4-2, } \\
\text { page B-31 } \\
\\
\text { DOE Project } \\
\text { Communication } \\
\text { with geologist } \\
\text { (May 2010) }\end{array}$ \\
\hline $\begin{array}{l}\text { Field capacity of } \\
\text { contaminated zone }\end{array}$ & -- & 0.3 & $1 E-5-1$ & 0.07 & $\mathrm{P}$ & 3 & The site-specific value available is $0.073 \mathrm{vol} / \mathrm{vol}$. & $\begin{array}{l}\text { DOE 2003b } \\
\text { Table 4.4, } \\
\text { page 4-9 }\end{array}$ \\
\hline $\begin{array}{l}\text { Soil b parameter of } \\
\text { contaminated zone }\end{array}$ & -- & 5.3 & $0-15$ & 4.05 & $\mathrm{P}$ & 2 & $\begin{array}{l}\text { DOE geologist determined that the most appropriate } \\
\text { value for the contaminated zone b available in Yu et } \\
\text { al. } 1993 \text { is the one for sand. It is known that the } \\
\text { contaminated zone (waste) will have high porosity } \\
\text { and high permeability. When selecting a } \\
\text { deterministic value for this input parameter, the } \\
\text { closest material and corresponding Soil b Parameter, } \\
\text { as developed by Clapp \& and Hornberger (Yu et al. } \\
\text { 1993), for concrete, steel and soil waste is sand. } \\
\text { Clapp \& Hornberger do not offer a corresponding Soil } \\
\text { b Parameter for landfill waste material. This value } \\
\text { according to the geologist should be low. }\end{array}$ & $\begin{array}{l}\text { Yu et al. } 1993 \\
\text { page } 83 \\
\\
\text { DOE project } \\
\text { Communication } \\
\text { with geologist } \\
\text { (July 2010) }\end{array}$ \\
\hline $\begin{array}{c}\text { Hydraulic } \\
\text { conductivity of } \\
\text { contaminated zone }\end{array}$ & $\mathrm{m} / \mathrm{yr}$ & 10 & $\begin{array}{l}1 E-3- \\
1 E+10\end{array}$ & 315.4 & $\mathrm{P}$ & 2 & $\begin{array}{l}\text { The hydraulic conductivity for waste forms } 1-4 \text { is } \\
1.0 \mathrm{E}^{-3} \mathrm{~cm} / \mathrm{s}(315.4 \mathrm{~m} / \mathrm{yr}) \text {. }\end{array}$ & $\begin{array}{l}\text { DOE 2003b } \\
\text { Fig. } 4.5, \text { page } 4-18\end{array}$ \\
\hline
\end{tabular}

Clean Cover

\begin{tabular}{|c|c|c|c|c|c|c|c|c|}
\hline $\begin{array}{l}\text { Thickness of clean } \\
\text { cover }\end{array}$ & $\mathrm{m}$ & 0 & $0-100$ & 1.52 & $\mathrm{P}$ & 2 & $\begin{array}{l}\text { For receptors exposed during the post-institutional } \\
\text { control period this value is the depth of the final } \\
\text { cover planned for the landfill. The landfill cover will } \\
\text { have six layers with a total thickness of } 5 \mathrm{ft} \text { ( } 1.52 \\
\text { meters). }\end{array}$ & $\begin{array}{c}\text { DOE 2003b } \\
\text { Section 3.2, page } \\
\text { 3-11, Fig. 4.3, } \\
\text { page 4-16 } \\
\\
\text { DOE Project } \\
\text { Communication } \\
\text { with geologist and } \\
\text { engineer } \\
\text { (April 2010) }\end{array}$ \\
\hline
\end{tabular}


RESRAD-OFFSITE Table of Input Parameters for the C-746-U Landfill Offsite Resident Farmer Scenario

\begin{tabular}{|c|c|c|c|c|c|c|c|c|}
\hline $\begin{array}{c}\text { Input Screen Title } \\
\text { and Parameter } \\
\text { Name }\end{array}$ & Units & $\begin{array}{l}\text { Default } \\
\text { Value }^{a}\end{array}$ & $\begin{array}{l}\text { Code-Accepted } \\
\text { Values }^{b} \\
\text { Physical or }^{\text {Numerical }} \text { (N) } \\
\text { Range }\end{array}$ & $\begin{array}{l}\text { Deterministic } \\
\text { Value }\end{array}$ & Type $^{d}$ & Priority $^{e}$ & Justification & References \\
\hline $\begin{array}{l}\text { Total porosity of } \\
\text { clean cover }\end{array}$ & -- & 0.4 & $1 E-5-1$ & 0.3 & $\mathrm{P}$ & 2 & $\begin{array}{l}\text { DOE geologist recommended a value for vegetative } \\
\text { soil cover (root zone, layer 1) available in DOE 2003b. }\end{array}$ & $\begin{array}{l}\text { DOE Project } \\
\text { Communication } \\
\text { with geologist } \\
\text { (May 2010) and } \\
\text { DOE 2003b } \\
\text { Table 4.4 } \\
\end{array}$ \\
\hline $\begin{array}{l}\text { Dry bulk density of } \\
\text { clean cover }\end{array}$ & $\mathrm{g} / \mathrm{cm}^{3}$ & 1.5 & $1 E-3-22.5$ & 1.5 & $\mathrm{P}$ & 2 & $\begin{array}{l}\text { The value for the density of the cover was obtained } \\
\text { from the previous RESRAD study for the landfill } \\
\text { described in DOE 2003b. This value was also } \\
\text { confirmed with DOE to be a site specific value for the } \\
\text { final cover. }\end{array}$ & $\begin{array}{c}\text { DOE 2003b } \\
\text { Table Att.5, page } \\
\text { C3-316 } \\
\text { DOE Project } \\
\text { Communication } \\
\text { with geologist and } \\
\text { engineer } \\
\text { (April 2010) }\end{array}$ \\
\hline $\begin{array}{l}\text { Soil erodibility } \\
\text { factor of clean } \\
\text { cover }\end{array}$ & tons/acre & 0.4 & $0-0.5$ & 0.37 & $\mathrm{P}$ & 2 & $\begin{array}{l}\text { DOE geologist recommended value based on silty clay } \\
\text { loam and } 0.5 \% \text { organic matter. }\end{array}$ & $\begin{array}{c}\text { Yu et al. } 2007 \\
\text { Table 2.4-2, page } \\
\text { B-31 } \\
\text { DOE Project } \\
\text { Communication } \\
\text { with geologist } \\
\text { (May 2010) } \\
\end{array}$ \\
\hline $\begin{array}{c}\text { Volumetric water } \\
\text { content of clean } \\
\text { cover }\end{array}$ & -- & 0.05 & $0-1$ & 0.347 & $\mathrm{P}$ & 2 & $\begin{array}{l}\text { DOE geologist recommended value based on silty clay } \\
\text { loam and normal distribution. However, this } \\
\text { parameter is only used by the code when the radon } \\
\text { pathway is active and radon is included in the } \\
\text { conceptual site model. }\end{array}$ & $\begin{array}{l}\text { Yu et al. } 2007 \\
\text { DOE Project } \\
\text { Communication } \\
\text { with geologist } \\
\text { (April 2010) } \\
\end{array}$ \\
\hline
\end{tabular}

Agriculture Area Parameters

Fruit, Grain, and Non-leafy Vegetables Field

\begin{tabular}{|c|c|c|c|c|c|c|c|c|}
\hline $\begin{array}{l}\text { Area for fruit, grain, } \\
\text { and non-leafy } \\
\text { vegetables field }\end{array}$ & $\mathrm{m}^{2}$ & 1,000 & Calculated & $\begin{array}{l}\text { Calculated by } \\
\text { the code }\end{array}$ & B & 3 & $\begin{array}{l}\text { The fruit, grain and non-leafy vegetable growing area, } \\
\text { the leafy vegetable growing area, the pasture and } \\
\text { silage growing area, the livestock feed grain growing } \\
\text { area, and the dwelling site are all approximated by } \\
\text { rectangular shapes in the atmospheric transport } \\
\text { model. The sides of these rectangles must be parallel }\end{array}$ & Yu et al. 2007 \\
\hline
\end{tabular}


RESRAD-OFFSITE Table of Input Parameters for the C-746-U Landfill Offsite Resident Farmer Scenario

\begin{tabular}{|c|c|c|c|c|c|c|c|c|}
\hline $\begin{array}{c}\text { Input Screen Title } \\
\text { and Parameter } \\
\text { Name }\end{array}$ & Units & $\begin{array}{l}\text { Default } \\
\text { Value }^{a}\end{array}$ & $\begin{array}{c}\text { Code-Accepted } \\
\text { Values }^{b} \\
\text { Physical or } \\
\text { Numerical }{ }^{C}(\mathrm{~N}) \\
\text { Range }\end{array}$ & $\begin{array}{l}\text { Deterministic } \\
\text { Value }\end{array}$ & Type $e^{d}$ & Priority $^{e}$ & Justification & References \\
\hline & & & & & & & to the sides of the primary contamination. & \\
\hline $\begin{array}{l}\text { Fraction of area } \\
\text { directly over } \\
\text { primary } \\
\text { contamination for } \\
\text { fruit, grain, and } \\
\text { nonleafy vegetables } \\
\text { field } \\
\end{array}$ & -- & 0 & $0-1$ & 0 & $B, P$ & 3 & $\begin{array}{l}\text { Default value is used since the receptor is outside of } \\
\text { the contaminated zone. }\end{array}$ & Yu et al. 2007 \\
\hline $\begin{array}{l}\text { Irrigation applied } \\
\text { per year for fruit, } \\
\text { grain, and nonleafy } \\
\text { vegetables field }\end{array}$ & $\mathrm{m} / \mathrm{yr}$ & 0.2 & $0-10$ & 0.1 & B & 3 & $\begin{array}{l}\text { Irrigation in the Paducah, Kentucky area is considered } \\
\text { to be unlikely. In the event irrigation is necessary, the } \\
\text { water will primarily come from uncontaminated } \\
\text { surface water and not from groundwater (well). } \\
\text { Information from the USGS shows that surface water } \\
\text { is the main source of water used in Kentucky for } \\
\text { irrigation (Kenny et al. 2009). The Paducah area (i.e., } \\
\text { where PGDP is located) receives about an average of } \\
49 \text { inches (1.24 m) of precipitation per year (PRS } \\
2008 \text { a). According to ATSDR 2002, the farms in } \\
\text { McCracken County, KY (i.e., where Paducah is } \\
\text { located) rely on rainfall to water their crops. For } \\
\text { conservatism in the modeling, and as recommended } \\
\text { by DOE-PPPO, it was assumed that the Offsite } \\
\text { Resident Farmer uses contaminated well water for } \\
\text { irrigation of agricultural areas (i.e., fruit, grain, non- } \\
\text { leafy and leafy vegetables). An irrigation rate of } 0.1 \\
\text { m/yr is used for the Offsite Resident Farmer's } \\
\text { agricultural areas (i.e., fruit, grain, non-leafy and leafy } \\
\text { vegetables). } \\
\text { The fruits, grains, non-leafy vegetables, and leafy } \\
\text { vegetables are for human consumption. }\end{array}$ & $\begin{array}{c}\text { DOE Project } \\
\text { Communication } \\
\text { with DOE-PPPO } \\
\text { (April 2011) } \\
\text { PRS 2008a } \\
\text { page 1-4 } \\
\text { ATSDR } 2002 \\
\begin{array}{c}\text { Yu et al. } 1993 \\
\text { page } 75\end{array} \\
\text { Yu et al. } 2007 \\
\text { Kenny et al. } 2009\end{array}$ \\
\hline $\begin{array}{l}\text { Evapotranspiration } \\
\text { coefficient for fruit, } \\
\text { grain, and nonleafy } \\
\text { vegetables field }\end{array}$ & -- & 0.5 & $0-0.999$ & 0.74 & $P$ & 2 & $\begin{array}{l}\text { This value was calculated from the HELP Output data } \\
\text { for the Post-Institutional Control Period. The } \\
\text { equation used to calculate the value is available in } \\
\text { Yu et al. } 1993 . \\
\text { The calculations are available in Attachment II } \\
\text { following this table. }\end{array}$ & $\begin{array}{l}\text { DOE } 2003 \mathrm{~b} \\
\text { page C3-243 } \\
\text { Yu et al. } 1993 \\
\text { page } 78\end{array}$ \\
\hline $\begin{array}{l}\text { Runoff coefficient } \\
\text { for fruit, grain, and }\end{array}$ & -- & 0.2 & $0-1$ & 0.34 & $\mathrm{P}$ & 2 & $\begin{array}{l}\text { This value was calculated from the HELP Output data } \\
\text { for the Post-Institutional Control Period. The }\end{array}$ & $\begin{array}{l}\text { DOE 2003b } \\
\text { page C3-243 }\end{array}$ \\
\hline
\end{tabular}


RESRAD-OFFSITE Table of Input Parameters for the C-746-U Landfill Offsite Resident Farmer Scenario

\begin{tabular}{|c|c|c|c|c|c|c|c|c|}
\hline $\begin{array}{c}\text { Input Screen Title } \\
\text { and Parameter } \\
\text { Name }\end{array}$ & Units & $\begin{array}{l}\text { Default } \\
\text { Value }^{a}\end{array}$ & $\begin{array}{l}\text { Code-Accepted } \\
\text { Values }^{b} \\
\text { Physical or }^{\text {Numerical }} \text { (N) } \\
\text { Range } \\
\end{array}$ & $\begin{array}{l}\text { Deterministic } \\
\text { Value }\end{array}$ & Type $^{d}$ & Priority $^{e}$ & Justification & References \\
\hline $\begin{array}{l}\text { nonleafy vegetables } \\
\text { field }\end{array}$ & & & & & & & $\begin{array}{l}\text { calculated value is } 0.34 \text {. The equation used to } \\
\text { calculate the value is available in Yu et al. } 1993 . \\
\text { The calculations are available in Attachment II } \\
\text { following this table. }\end{array}$ & $\begin{array}{l}\text { Yu et al. } 1993 \\
\text { page } 73\end{array}$ \\
\hline $\begin{array}{l}\text { Depth of soil mixing } \\
\text { layer or plow layer } \\
\text { for fruit, grain, and } \\
\text { nonleafy vegetables } \\
\text { field }\end{array}$ & $\mathrm{m}$ & 0.15 & $0-1$ & 0.15 & $P, B$ & 2 & Default value is used. & Yu et al. 2007 \\
\hline $\begin{array}{l}\text { Volumetric water } \\
\text { content for fruit, } \\
\text { grain, and nonleafy } \\
\text { vegetables field }\end{array}$ & -- & 0.3 & $1 \mathrm{E}-5-1$ & 0.347 & $P$ & 2 & $\begin{array}{l}\text { DOE geologist recommended value based on silty clay } \\
\text { loam and normal distribution. }\end{array}$ & $\begin{array}{l}\text { Yu et al. } 2007 \\
\text { DOE project } \\
\text { communication } \\
\text { with geologist } \\
\text { (April 2010) }\end{array}$ \\
\hline $\begin{array}{l}\text { Dry bulk density of } \\
\text { soil for fruit, grain, } \\
\text { and nonleafy } \\
\text { vegetables field }\end{array}$ & $\mathrm{g} / \mathrm{cm}^{3}$ & 1.5 & $1 E-3-22.5$ & 1.5 & $P$ & 2 & Default value is used. & Yu et al. 2007 \\
\hline $\begin{array}{l}\text { Soil erodibility } \\
\text { factor for fruit, } \\
\text { grain, and nonleafy } \\
\text { vegetables field }\end{array}$ & tons/acre & 0.4 & $0-0.5$ & 0.37 & $\mathrm{P}$ & 2 & $\begin{array}{l}\text { DOE geologist recommended value based on silty clay } \\
\text { loam and } 0.5 \% \text { organic matter. }\end{array}$ & $\begin{array}{c}\text { Yu et al. } 2007 \\
\text { Table 2.4-2, page } \\
\text { B-31 } \\
\text { DOE Project } \\
\text { Communication } \\
\text { with geologist } \\
\text { (May 2010) } \\
\end{array}$ \\
\hline $\begin{array}{l}\text { Slope-length- } \\
\text { steepness factor for } \\
\text { fruit, grain, and } \\
\text { nonleafy vegetables } \\
\text { field }\end{array}$ & -- & 0.4 & $0-10$ & 0.4 & $P$ & 2 & $\begin{array}{l}\text { DOE geologist recommended using } 0.4 \text { based on site } \\
\text { topography. }\end{array}$ & $\begin{array}{l}\text { Yu et al. } 2007 \\
\text { DOE Project } \\
\text { Communication } \\
\text { with geologist } \\
\text { (April 2010) }\end{array}$ \\
\hline $\begin{array}{l}\text { Cover and } \\
\text { management factor } \\
\text { for fruit, grain, and } \\
\text { nonleafy vegetables } \\
\text { field }\end{array}$ & -- & 0.003 & $0-1$ & 0.2 & $B, P$ & 2 & $\begin{array}{l}\text { DOE geologist recommended value based on no } \\
\text { appreciable canopy and } 20 \% \text { ground cover. }\end{array}$ & $\begin{array}{l}\text { Yu et al. } 2007 \\
\text { DOE Project } \\
\text { Communication } \\
\text { with geologist } \\
\text { (April 2010) }\end{array}$ \\
\hline
\end{tabular}


RESRAD-OFFSITE Table of Input Parameters for the C-746-U Landfill Offsite Resident Farmer Scenario

\begin{tabular}{|c|c|c|c|c|c|c|c|}
\hline $\begin{array}{c}\text { Input Screen Title } \\
\text { and Parameter } \\
\text { Name }\end{array}$ & Units & $\begin{array}{c}\text { Default } \\
\text { Value }\end{array}$ & $\begin{array}{c}\text { Code-Accepted } \\
\text { Values } \\
\text { Physical or } \\
\text { Numerical' (N) } \\
\text { Range }\end{array}$ & $\begin{array}{c}\text { Deterministic } \\
\text { Value }\end{array}$ & Type $^{d}$ & Priority $^{e}$ & References \\
\hline $\begin{array}{c}\text { Support practice } \\
\text { factor for fruit, } \\
\text { grain, and nonleafy } \\
\text { vegetables field }\end{array}$ & -- & 1 & $0-1$ & 0.5 & B, P & 2 & DOEtification geologist recommended value. \\
$\begin{array}{c}\text { Communication } \\
\text { with geologist } \\
\text { (July 2010) }\end{array}$ \\
\hline
\end{tabular}

Leafy Vegetable Field

\begin{tabular}{|c|c|c|c|c|c|c|c|c|}
\hline $\begin{array}{l}\text { Area for leafy } \\
\text { vegetable field }\end{array}$ & $\mathrm{m}^{2}$ & 1,000 & Calculated & $\begin{array}{l}\text { Calculated by } \\
\text { the code }\end{array}$ & B & 3 & $\begin{array}{l}\text { The fruit, grain and non-leafy vegetable growing area, } \\
\text { the leafy vegetable growing area, the pasture and } \\
\text { silage growing area, the livestock feed grain growing } \\
\text { area, and the dwelling site are all approximated by } \\
\text { rectangular shapes in the atmospheric transport } \\
\text { model. The sides of these rectangles must be parallel } \\
\text { to the sides of the primary contamination. }\end{array}$ & Yu et al. 2007 \\
\hline $\begin{array}{l}\text { Fraction of area } \\
\text { directly over } \\
\text { primary } \\
\text { contamination for } \\
\text { leafy vegetable field }\end{array}$ & -- & 0 & $0-1$ & 0 & $B, P$ & 3 & $\begin{array}{l}\text { Default value is used since the receptor is located } \\
\text { outside the contaminated zone. }\end{array}$ & Yu et al. 2007 \\
\hline $\begin{array}{l}\text { Irrigation applied } \\
\text { per year for leafy } \\
\text { vegetable field }\end{array}$ & $\mathrm{m} / \mathrm{yr}$ & 0.2 & $0-10$ & 0.1 & B & 3 & $\begin{array}{l}\text { Irrigation in the Paducah, Kentucky area is considered } \\
\text { to be unlikely. In the event irrigation is necessary, the } \\
\text { water will primarily come from uncontaminated } \\
\text { surface water and not from groundwater (well). } \\
\text { Information from the USGS shows that surface water } \\
\text { is the main source of water used in Kentucky for } \\
\text { irrigation (Kenny et al. 2009). The Paducah area (i.e., } \\
\text { where PGDP is located) receives about an average of } \\
49 \text { inches ( } 1.24 \mathrm{~m} \text { ) of precipitation per year (PRS } \\
2008 \text { a). According to ATSDR 2002, the farms in } \\
\text { McCracken County, KY (i.e., where Paducah is } \\
\text { located) rely on rainfall to water their crops. For } \\
\text { conservatism in the modeling, and as recommended } \\
\text { by DOE-PPPO, it was assumed that the Offsite } \\
\text { Resident Farmer uses contaminated well water for } \\
\text { irrigation of agricultural areas (i.e., fruit, grain, non- } \\
\text { leafy and leafy vegetables). An irrigation rate of } \\
0.1 \text { m/yr is used for the Offsite Resident Farmer's } \\
\text { agricultural areas (i.e., fruit, grain, non-leafy and leafy } \\
\text { vegetables). }\end{array}$ & $\begin{array}{c}\text { DOE Project } \\
\text { Communication } \\
\text { with DOE-PPPO } \\
\text { (April 2011) } \\
\text { PRS 2008a } \\
\text { page 1-4 } \\
\text { ATSDR } 2002 \\
\text { page } 8 \\
\text { Yu et al. } 1993 \\
\text { page } 75 \\
\text { Yu et al. } 2007 \\
\text { Kenny et al. } 2009\end{array}$ \\
\hline
\end{tabular}


RESRAD-OFFSITE Table of Input Parameters for the C-746-U Landfill Offsite Resident Farmer Scenario

\begin{tabular}{|c|c|c|c|c|c|c|c|c|}
\hline $\begin{array}{c}\text { Input Screen Title } \\
\text { and Parameter } \\
\text { Name }\end{array}$ & Units & $\begin{array}{l}\text { Default } \\
\text { Value }^{a}\end{array}$ & $\begin{array}{c}\text { Code-Accepted } \\
\text { Values }^{b} \\
\text { Physical or } \\
\text { Numerical }^{c}(\mathrm{~N}) \\
\text { Range }\end{array}$ & $\begin{array}{l}\text { Deterministic } \\
\text { Value }\end{array}$ & Type $^{d}$ & Priority $^{e}$ & Justification & References \\
\hline & & & & & & & $\begin{array}{l}\text { The fruits, grains, non-leafy vegetables, and leafy } \\
\text { vegetables are for human consumption. }\end{array}$ & \\
\hline $\begin{array}{l}\text { Evapotranspiration } \\
\text { coefficient for leafy } \\
\text { vegetable field }\end{array}$ & -- & 0.5 & $0-0.999$ & 0.74 & $\mathrm{P}$ & 2 & $\begin{array}{l}\text { This value was calculated using the HELP Output data } \\
\text { for the Post-Institutional Control Period. The } \\
\text { equation used to calculate the value is available in } \\
\text { Yu et al. } 1993 . \\
\text { The calculations are available in Attachment II } \\
\text { following this table. }\end{array}$ & $\begin{array}{l}\text { DOE 2003b } \\
\text { page C3-243 } \\
\text { Yu et al. } 1993 \\
\text { page } 78\end{array}$ \\
\hline $\begin{array}{l}\text { Runoff coefficient } \\
\text { for leafy vegetable } \\
\text { field }\end{array}$ & -- & 0.2 & $0-1$ & 0.34 & $\mathrm{P}$ & 2 & $\begin{array}{l}\text { This value was calculated from the HELP Output data } \\
\text { for the Post-Institutional Control Period. The } \\
\text { calculated value is } 0.34 \text {. The equation used to } \\
\text { calculate the value is available in Yu et al. } 1993 \text {. } \\
\text { The calculations are available in Attachment II } \\
\text { following this table. }\end{array}$ & $\begin{array}{c}\text { DOE } 2003 \mathrm{~b} \\
\text { page C3-243 } \\
\text { Yu et al. } 1993 \\
\text { page } 73\end{array}$ \\
\hline $\begin{array}{c}\text { Depth of soil mixing } \\
\text { layer or plow layer } \\
\text { for leafy vegetable } \\
\text { field }\end{array}$ & $\mathrm{m}$ & 0.15 & $0-1$ & 0.15 & $P, B$ & 2 & Default value is used. & Yu et al. 2007 \\
\hline $\begin{array}{l}\text { Volumetric water } \\
\text { content for leafy } \\
\text { vegetable field }\end{array}$ & -- & 0.3 & $1 E-5-1$ & 0.347 & $\mathrm{P}$ & 2 & $\begin{array}{l}\text { DOE geologist recommended value based on silty clay } \\
\text { loam and normal distribution. }\end{array}$ & $\begin{array}{l}\text { Yu et al. } 2007 \\
\text { DOE Project } \\
\text { Communication } \\
\text { with geologist } \\
\text { (April 2010) }\end{array}$ \\
\hline $\begin{array}{l}\text { Dry bulk density of } \\
\text { soil for leafy } \\
\text { vegetable field }\end{array}$ & $\mathrm{g} / \mathrm{cm}^{3}$ & 1.5 & $1 E-3-22.5$ & 1.5 & $P$ & 2 & Default value is used. & Yu et al. 2007 \\
\hline $\begin{array}{l}\text { Soil erodibility } \\
\text { factor for leafy } \\
\text { vegetable field }\end{array}$ & tons/acre & 0.4 & $0-0.5$ & 0.37 & $P$ & 2 & $\begin{array}{l}\text { DOE geologist recommended value based on silty clay } \\
\text { loam and } 0.5 \% \text { organic matter. }\end{array}$ & $\begin{array}{l}\text { Yu et al. } 2007 \\
\text { Table 2.4-2, page } \\
\text { B-31 } \\
\text { DOE Project } \\
\text { Communication } \\
\text { with geologist } \\
\text { (May 2010) }\end{array}$ \\
\hline $\begin{array}{l}\text { Slope-length- } \\
\text { steepness factor for }\end{array}$ & -- & 0.4 & $0-10$ & 0.4 & $\mathrm{P}$ & 2 & $\begin{array}{l}\text { DOE geologist recommended a value of } 0.4 \text { based on } \\
\text { site topography. }\end{array}$ & Yu et al. 2007 \\
\hline
\end{tabular}


RESRAD-OFFSITE Table of Input Parameters for the C-746-U Landfill Offsite Resident Farmer Scenario

\begin{tabular}{|c|c|c|c|c|c|c|c|c|}
\hline $\begin{array}{c}\text { Input Screen Title } \\
\text { and Parameter } \\
\text { Name }\end{array}$ & Units & $\begin{array}{l}\text { Default } \\
\text { Value }^{a}\end{array}$ & $\begin{array}{c}\text { Code-Accepted } \\
\text { Values }^{b} \\
\text { Physical or } \\
\text { Numerical }{ }^{c}(\mathrm{~N}) \\
\text { Range }^{\text {Range }}\end{array}$ & $\begin{array}{l}\text { Deterministic } \\
\text { Value }\end{array}$ & Type $e^{d}$ & Priority $^{e}$ & Justification & References \\
\hline leafy vegetable field & & & & & & & & $\begin{array}{c}\text { DOE Project } \\
\text { Communication } \\
\text { with geologist } \\
\text { (April 2010) }\end{array}$ \\
\hline $\begin{array}{c}\text { Cover and } \\
\text { management factor } \\
\text { for leafy vegetable } \\
\text { field }\end{array}$ & -- & 0.003 & $0-1$ & 0.2 & $B, P$ & 2 & $\begin{array}{l}\text { DOE geologist recommended value based on no } \\
\text { appreciable canopy and } 20 \% \text { ground cover. }\end{array}$ & $\begin{array}{l}\text { Yu et al. } 2007 \\
\text { DOE Project } \\
\text { Communication } \\
\text { with geologist } \\
\text { (April 2010) }\end{array}$ \\
\hline $\begin{array}{l}\text { Support practice } \\
\text { factor for leafy } \\
\text { vegetable field }\end{array}$ & -- & 1 & $0-1$ & 0.5 & $B, P$ & 2 & DOE geologist recommended value. & $\begin{array}{l}\text { Yu et al. } 2007 \\
\text { DOE Project } \\
\text { Communication } \\
\text { with geologist } \\
\text { (July 2010) }\end{array}$ \\
\hline
\end{tabular}

\section{Livestock Feed Growing Area Parameters}

\section{Pasture and Silage Field}

\begin{tabular}{|c|c|c|c|c|c|c|c|c|}
\hline $\begin{array}{l}\text { Area for pasture } \\
\text { and silage field }\end{array}$ & $\mathrm{m}^{2}$ & 10,000 & Calculated & $\begin{array}{l}\text { Calculated by } \\
\text { the code }\end{array}$ & B & 3 & $\begin{array}{l}\text { The fruit, grain and non-leafy vegetable growing area, } \\
\text { the leafy vegetable growing area, the pasture and } \\
\text { silage growing area, the livestock feed grain growing } \\
\text { area, and the dwelling site are all approximated by } \\
\text { rectangular shapes in the atmospheric transport } \\
\text { model. The sides of these rectangles must be parallel } \\
\text { to the sides of the primary contamination. }\end{array}$ & Yu et al. 2007 \\
\hline $\begin{array}{l}\text { Fraction of area } \\
\text { directly over } \\
\text { primary } \\
\text { contamination for } \\
\text { pasture and silage } \\
\quad \text { field } \\
\end{array}$ & -- & 0 & $0-1$ & 0 & $B, P$ & 3 & $\begin{array}{l}\text { Default is used since the receptor is located outside } \\
\text { the contaminated zone. }\end{array}$ & Yu et al. 2007 \\
\hline $\begin{array}{l}\text { Irrigation applied } \\
\text { per year for pasture } \\
\text { and silage field }\end{array}$ & $\mathrm{m} / \mathrm{yr}$ & 0.2 & $0-10$ & 0 & B & 3 & $\begin{array}{l}\text { The irrigation rate was set to } 0 \mathrm{~m} / \mathrm{yr} \text { as requested by } \\
\text { DOE-PPPO, since no irrigation is being considered for } \\
\text { the pasture and silage field. Irrigation in the Paducah, } \\
\text { Kentucky area is considered to be unlikely. In the } \\
\text { event irrigation is necessary, the water will primarily } \\
\text { come from uncontaminated surface water and not }\end{array}$ & $\begin{array}{c}\text { DOE Project } \\
\text { Communication } \\
\text { with DOE-PPPO } \\
\text { (September 2010) } \\
\text { DOE Project }\end{array}$ \\
\hline
\end{tabular}


RESRAD-OFFSITE Table of Input Parameters for the C-746-U Landfill Offsite Resident Farmer Scenario

\begin{tabular}{|c|c|c|c|c|c|c|c|c|}
\hline $\begin{array}{c}\text { Input Screen Title } \\
\text { and Parameter } \\
\text { Name }\end{array}$ & Units & $\begin{array}{l}\text { Default } \\
\text { Value }^{a}\end{array}$ & $\begin{array}{l}\text { Code-Accepted } \\
\text { Values }^{b} \\
\text { Physical or }^{\text {Numerical }} \text { (N) } \\
\text { Range } \\
\end{array}$ & $\begin{array}{l}\text { Deterministic } \\
\text { Value }\end{array}$ & Type $^{d}$ & Priority $^{e}$ & Justification & References \\
\hline & & & & & & & $\begin{array}{l}\text { from groundwater (well). Information from the USGS } \\
\text { shows that surface water is the main source of water } \\
\text { used in Kentucky for irrigation (Kenny et al. 2009). } \\
\text { The pasture and silage and livestock feed grain are } \\
\text { for livestock consumption. }\end{array}$ & $\begin{array}{c}\text { Communication } \\
\text { with DOE-PPPO } \\
\text { (April 2011) } \\
\text { Kenny et al. } 2009\end{array}$ \\
\hline $\begin{array}{l}\text { Evapotranspiration } \\
\text { coefficient for } \\
\text { pasture and silage } \\
\text { field }\end{array}$ & -- & 0.5 & $0-0.999$ & 0.83 & $P$ & 2 & $\begin{array}{l}\text { This value was calculated using the HELP Output data } \\
\text { for the Post-Institutional Control Period. The } \\
\text { equation used to calculate the value is available in } \\
\text { Yu et al. } 1993 . \\
\text { The calculations are available in Attachment II } \\
\text { following this table. }\end{array}$ & $\begin{array}{l}\text { DOE } 2003 \mathrm{~b} \\
\text { page C3-243 } \\
\text { Yu et al. } 1993 \\
\text { page } 78\end{array}$ \\
\hline $\begin{array}{l}\text { Runoff coefficient } \\
\text { for pasture and } \\
\text { silage field }\end{array}$ & -- & 0.2 & $0-1$ & 0.34 & $P$ & 2 & $\begin{array}{l}\text { This value was calculated from the HELP Output data } \\
\text { for the Post-Institutional Control Period. The } \\
\text { calculated value is } 0.34 \text {. The equation used to } \\
\text { calculate the value is available in Yu et al. } 1993 \text {. } \\
\text { The calculations are available in Attachment II } \\
\text { following this table. }\end{array}$ & $\begin{array}{l}\text { DOE } 2003 b \\
\text { page C3-243 } \\
\text { Yu et al. } 1993 \\
\text { page } 73\end{array}$ \\
\hline $\begin{array}{l}\text { Depth of soil mixing } \\
\text { layer or plow layer } \\
\text { for pasture and } \\
\text { silage field }\end{array}$ & $\mathrm{m}$ & 0.15 & $0-1$ & 0.15 & $P, B$ & 2 & Default value is used. & Yu et al. 2007 \\
\hline $\begin{array}{l}\text { Volumetric water } \\
\text { content for pasture } \\
\text { and silage field }\end{array}$ & -- & 0.3 & $1 E-5-1$ & 0.347 & $P$ & 2 & $\begin{array}{l}\text { DOE geologist recommended value based on silty clay } \\
\text { loam and normal distribution. }\end{array}$ & $\begin{array}{l}\text { Yu et al. } 2007 \\
\text { DOE project } \\
\text { Communication } \\
\text { with geologist } \\
\text { (April 2010) } \\
\end{array}$ \\
\hline $\begin{array}{c}\text { Dry bulk density of } \\
\text { soil for pasture and } \\
\text { silage field }\end{array}$ & $\mathrm{g} / \mathrm{cm}^{3}$ & 1.5 & $1 \mathrm{E}-3-22.5$ & 1.5 & $P$ & 2 & Default value is used. & Yu et al. 2007 \\
\hline $\begin{array}{l}\text { Soil erodibility } \\
\text { factor for pasture } \\
\text { and silage field }\end{array}$ & tons/acre & 0.4 & $0-0.5$ & 0.37 & $P$ & 2 & $\begin{array}{l}\text { DOE geologist recommended value based on silty clay } \\
\text { loam and } 0.5 \% \text { organic matter. }\end{array}$ & $\begin{array}{c}\text { Yu et al. } 2007 \\
\text { Table 2.4-2, page } \\
\text { B-31 } \\
\text { DOE Project } \\
\text { Communication } \\
\text { with geologist }\end{array}$ \\
\hline
\end{tabular}


RESRAD-OFFSITE Table of Input Parameters for the C-746-U Landfill Offsite Resident Farmer Scenario

\begin{tabular}{|c|c|c|c|c|c|c|c|c|}
\hline $\begin{array}{c}\text { Input Screen Title } \\
\text { and Parameter } \\
\text { Name }\end{array}$ & Units & $\begin{array}{l}\text { Default } \\
\text { Value }^{a}\end{array}$ & $\begin{array}{l}\text { Code-Accepted } \\
\text { Values }^{b} \\
\text { Physical or } \\
\text { Numerical }^{c} \text { (N) } \\
\text { Range }\end{array}$ & $\begin{array}{l}\text { Deterministic } \\
\text { Value }\end{array}$ & Type $^{d}$ & Priority $^{e}$ & Justification & References \\
\hline & & & & & & & & (May 2010) \\
\hline $\begin{array}{l}\text { Slope-length- } \\
\text { steepness factor for } \\
\text { pasture and silage } \\
\text { field }\end{array}$ & -- & 0.4 & $0-10$ & 0.4 & P & 2 & $\begin{array}{l}\text { DOE geologist recommended using } 0.4 \text { based on site } \\
\text { topography. }\end{array}$ & $\begin{array}{l}\text { Yu et al. } 2007 \\
\\
\text { DOE Project } \\
\text { Communication } \\
\text { with geologist } \\
\text { (April 2010) }\end{array}$ \\
\hline $\begin{array}{l}\text { Cover and } \\
\text { management factor } \\
\text { for pasture and } \\
\text { silage field }\end{array}$ & -- & 0.003 & $0-1$ & 0.2 & $B, P$ & 2 & $\begin{array}{l}\text { DOE geologist recommended value based on no } \\
\text { appreciable canopy and } 20 \% \text { ground cover. }\end{array}$ & $\begin{array}{l}\text { Yu et al. } 2007 \\
\\
\text { DOE Project } \\
\text { Communication } \\
\text { with geologist } \\
\text { (April 2010) }\end{array}$ \\
\hline $\begin{array}{l}\text { Support practice } \\
\text { factor for pasture } \\
\text { and silage field }\end{array}$ & -- & 1 & $0-1$ & 0.5 & $B, P$ & 2 & DOE geologist recommended value. & $\begin{array}{l}\text { Yu et al. } 2007 \\
\text { DOE Project } \\
\text { Communication } \\
\text { with geologist } \\
\text { (July 2010) }\end{array}$ \\
\hline
\end{tabular}

Grain Field

\begin{tabular}{|c|c|c|c|c|c|c|c|c|}
\hline Area for grain field & $\mathrm{m}^{2}$ & 10,000 & Calculated & $\begin{array}{l}\text { Calculated by } \\
\text { the code }\end{array}$ & B & & $\begin{array}{l}\text { The fruit, grain and non-leafy vegetable growing area, } \\
\text { the leafy vegetable growing area, the pasture and } \\
\text { silage growing area, the livestock feed grain growing } \\
\text { area, and the dwelling site are all approximated by } \\
\text { rectangular shapes in the atmospheric transport } \\
\text { model. The sides of these rectangles must be parallel } \\
\text { to the sides of the primary contamination. }\end{array}$ & Yu et al. 2007 \\
\hline $\begin{array}{l}\text { Fraction of area } \\
\text { directly over } \\
\text { primary } \\
\text { contamination for } \\
\text { grain field } \\
\end{array}$ & -- & 0 & $0-1$ & 0 & $B, P$ & & $\begin{array}{l}\text { Default value is used since the receptor is outside the } \\
\text { contaminated zone. }\end{array}$ & Yu et al. 2007 \\
\hline $\begin{array}{l}\text { Irrigation applied } \\
\text { per year for grain } \\
\text { field }\end{array}$ & $\mathrm{m} / \mathrm{yr}$ & 0.2 & $0-10$ & 0 & B & 3 & $\begin{array}{l}\text { The irrigation rate was set to } 0 \mathrm{~m} / \mathrm{yr} \text { as requested by } \\
\text { DOE-PPPO, since no irrigation is being considered for } \\
\text { the grain field. Irrigation in the Paducah, Kentucky } \\
\text { area is considered to be unlikely. In the event } \\
\text { irrigation is necessary, the water will primarily come } \\
\text { from uncontaminated surface water and not from } \\
\text { groundwater (well). Information from the USGS }\end{array}$ & $\begin{array}{c}\text { DOE Project } \\
\text { Communication } \\
\text { with DOE-PPPO } \\
\text { (September 2010) } \\
\\
\text { DOE Project } \\
\text { Communication }\end{array}$ \\
\hline
\end{tabular}


RESRAD-OFFSITE Table of Input Parameters for the C-746-U Landfill Offsite Resident Farmer Scenario

\begin{tabular}{|c|c|c|c|c|c|c|c|c|}
\hline $\begin{array}{c}\text { Input Screen Title } \\
\text { and Parameter } \\
\text { Name }\end{array}$ & Units & $\begin{array}{l}\text { Default } \\
\text { Value }^{a}\end{array}$ & $\begin{array}{l}\text { Code-Accepted } \\
\text { Values }^{b} \\
\text { Physical or } \\
\text { Numerical }{ }^{c}(\mathrm{~N}) \\
\text { Range }\end{array}$ & $\begin{array}{l}\text { Deterministic } \\
\text { Value }\end{array}$ & Type $e^{d}$ & Priority $^{e}$ & Justification & References \\
\hline & & & & & & & $\begin{array}{l}\text { shows that surface water is the main source of water } \\
\text { used in Kentucky for irrigation (Kenny et al. 2009). } \\
\text { The pasture and silage and livestock feed grain are } \\
\text { for livestock consumption. }\end{array}$ & $\begin{array}{l}\text { with DOE-PPPO } \\
\text { (April 2011) } \\
\text { Kenny et al. } 2009 \\
\text { Yu et al. } 2007 \\
\end{array}$ \\
\hline $\begin{array}{l}\text { Evapotranspiration } \\
\text { coefficient for grain } \\
\text { field }\end{array}$ & -- & 0.5 & $0-0.999$ & 0.83 & $\mathrm{P}$ & 2 & $\begin{array}{l}\text { This value was calculated using the HELP Output data } \\
\text { for the Post-Institutional Control Period. The } \\
\text { equation used to calculate the value is available in } \\
\text { Yu et al. } 1993 . \\
\text { The calculations are available in Attachment II } \\
\text { following this table. }\end{array}$ & $\begin{array}{l}\text { DOE } 2003 b \\
\text { page C3-243 } \\
\text { Yu et al. } 1993 \\
\text { page } 78\end{array}$ \\
\hline $\begin{array}{l}\text { Runoff coefficient } \\
\text { for grain field }\end{array}$ & -- & 0.2 & $0-1$ & 0.34 & $\mathrm{P}$ & 2 & $\begin{array}{l}\text { This value was calculated from the HELP Output data } \\
\text { for the Post-Institutional Control Period. The } \\
\text { calculated value is } 0.34 \text {. The equation used to } \\
\text { calculate the value is available in Yu et al. } 1993 \text {. } \\
\text { The calculations are available in Attachment II } \\
\text { following this table. }\end{array}$ & $\begin{array}{l}\text { DOE } 2003 \mathrm{~b} \\
\text { page C3-243 } \\
\text { Yu et al. } 1993 \\
\text { page } 73\end{array}$ \\
\hline $\begin{array}{l}\text { Depth of soil mixing } \\
\text { layer or plow layer } \\
\text { for grain field }\end{array}$ & $\mathrm{m}$ & 0.15 & $0-1$ & 0.15 & $P, B$ & 2 & Default value is used. & Yu et al. 2007 \\
\hline $\begin{array}{l}\text { Volumetric water } \\
\text { content for grain } \\
\text { field }\end{array}$ & -- & 0.3 & $1 E-5-1$ & 0.347 & $P$ & 2 & $\begin{array}{l}\text { DOE geologist recommended value based on silty clay } \\
\text { loam and normal distribution. }\end{array}$ & $\begin{array}{l}\text { Yu et al. } 2007 \\
\text { DOE Project } \\
\text { Communication } \\
\text { with geologist } \\
\text { (April 2010) }\end{array}$ \\
\hline $\begin{array}{l}\text { Dry bulk density of } \\
\text { soil for grain field }\end{array}$ & $\mathrm{g} / \mathrm{cm}^{3}$ & 1.5 & $1 E-3-22.5$ & 1.5 & $\mathrm{P}$ & 2 & Default value is used. & Yu et al. 2007 \\
\hline $\begin{array}{l}\text { Soil erodibility } \\
\text { factor for grain field }\end{array}$ & tons/acre & 0.4 & $0-0.5$ & 0.37 & $P$ & 2 & $\begin{array}{l}\text { DOE geologist recommended value based on silty clay } \\
\text { loam and } 0.5 \% \text { organic matter. }\end{array}$ & $\begin{array}{l}\text { Yu et al. } 2007 \\
\text { Table 2.4-2, page } \\
\text { B-31 } \\
\text { DOE Project } \\
\text { Communication } \\
\text { with geologist } \\
\text { (May 2010) }\end{array}$ \\
\hline Slope-length- & -- & 0.4 & $0-10$ & 0.4 & $P$ & 2 & DOE geologist recommended a value of 0.4 based on & Yu et al. 2007 \\
\hline
\end{tabular}


RESRAD-OFFSITE Table of Input Parameters for the C-746-U Landfill Offsite Resident Farmer Scenario

\begin{tabular}{|c|c|c|c|c|c|c|c|c|}
\hline $\begin{array}{c}\text { Input Screen Title } \\
\text { and Parameter } \\
\text { Name }\end{array}$ & Units & $\begin{array}{l}\text { Default } \\
\text { Value }^{a}\end{array}$ & $\begin{array}{c}\text { Code-Accepted } \\
\text { Values }^{b} \\
\text { Physical or } \\
\text { Numerical }{ }^{c}(\mathrm{~N}) \\
\text { Range }^{\text {Range }}\end{array}$ & $\begin{array}{l}\text { Deterministic } \\
\text { Value }\end{array}$ & Type $^{d}$ & Priority $^{e}$ & Justification & References \\
\hline $\begin{array}{l}\text { steepness factor for } \\
\text { grain field }\end{array}$ & & & & & & & site topography. & $\begin{array}{c}\text { DOE Project } \\
\text { Communication } \\
\text { with geologist } \\
\text { (April 2010) }\end{array}$ \\
\hline $\begin{array}{c}\text { Cover and } \\
\text { management factor } \\
\text { for grain field }\end{array}$ & -- & 0.003 & $0-1$ & 0.2 & $B, P$ & 2 & $\begin{array}{l}\text { DOE geologist recommended value based on no } \\
\text { appreciable canopy and } 20 \% \text { ground cover. }\end{array}$ & $\begin{array}{l}\text { Yu et al. } 2007 \\
\text { DOE Project } \\
\text { Communication } \\
\text { with geologist } \\
\text { (April 2010) }\end{array}$ \\
\hline $\begin{array}{l}\text { Support practice } \\
\text { factor for grain field }\end{array}$ & -- & 1 & $0-1$ & 0.5 & $B, P$ & 2 & DOE geologist recommended value. & $\begin{array}{l}\text { Yu et al. } 2007 \\
\text { DOE Project } \\
\text { Communication } \\
\text { with geologist } \\
\text { (July 2010) }\end{array}$ \\
\hline
\end{tabular}

Offsite Dwelling Area Parameters

\begin{tabular}{|c|c|c|c|c|c|c|c|c|}
\hline $\begin{array}{l}\text { Area of offsite } \\
\text { dwelling site }\end{array}$ & $\mathrm{m}^{2}$ & 1,000 & Calculated & $\begin{array}{l}\text { Calculated by } \\
\text { the code }\end{array}$ & B & 3 & $\begin{array}{l}\text { The fruit, grain and non-leafy vegetable growing area, } \\
\text { the leafy vegetable growing area, the pasture and } \\
\text { silage growing area, the livestock feed grain growing } \\
\text { area, and the dwelling site are all approximated by } \\
\text { rectangular shapes in the atmospheric transport } \\
\text { model. The sides of these rectangles must be parallel } \\
\text { to the sides of the primary contamination. }\end{array}$ & Yu et al. 2007 \\
\hline $\begin{array}{l}\text { Irrigation applied } \\
\text { per year to home } \\
\text { garden or lawn }\end{array}$ & $\mathrm{m} / \mathrm{yr}$ & 0.2 & $0-10$ & 0 & B & 3 & $\begin{array}{l}\text { The irrigation rate was set to } 0 \mathrm{~m} / \mathrm{yr} \text { as requested by } \\
\text { DOE-PPPO, since no irrigation is being considered for } \\
\text { the dwelling site. Irrigation in the Paducah, Kentucky } \\
\text { area is considered to be unlikely. In the event } \\
\text { irrigation is necessary, the water will primarily come } \\
\text { from uncontaminated surface water and not from } \\
\text { groundwater (well). Information from the USGS } \\
\text { shows that surface water is the main source of water } \\
\text { used in Kentucky for irrigation (Kenny et al. 2009). }\end{array}$ & $\begin{array}{c}\text { DOE Project } \\
\text { Communication } \\
\text { with DOE-PPPO } \\
\text { (September 2010) } \\
\text { Kenny et al. } 2009\end{array}$ \\
\hline $\begin{array}{l}\text { Evapotranspiration } \\
\text { coefficient for } \\
\text { dwelling site }\end{array}$ & -- & 0.5 & $0-0.999$ & 0.83 & $P$ & 2 & $\begin{array}{l}\text { This value was calculated using the HELP Output data } \\
\text { for the Post-Institutional Control Period. The } \\
\text { equation used to calculate the value is available in } \\
\text { Yu et al. } 1993 .\end{array}$ & $\begin{array}{c}\text { DOE } 2003 b \\
\text { page C3-243 } \\
\text { Yu et al. } 1993 \\
\text { page } 78\end{array}$ \\
\hline
\end{tabular}


RESRAD-OFFSITE Table of Input Parameters for the C-746-U Landfill Offsite Resident Farmer Scenario

\begin{tabular}{|c|c|c|c|c|c|c|c|c|}
\hline $\begin{array}{c}\text { Input Screen Title } \\
\text { and Parameter } \\
\text { Name }\end{array}$ & Units & $\begin{array}{l}\text { Default } \\
\text { Value }^{a}\end{array}$ & $\begin{array}{c}\text { Code-Accepted } \\
\text { Values }^{b} \\
\text { Physical or }^{\text {Numerical }} \text { (N) } \\
\text { Range } \\
\text { Numb }\end{array}$ & $\begin{array}{l}\text { Deterministic } \\
\text { Value }\end{array}$ & Type $^{d}$ & Priority $^{e}$ & Justification & References \\
\hline & & & & & & & $\begin{array}{l}\text { The calculations are available in Attachment II } \\
\text { following this table. }\end{array}$ & \\
\hline $\begin{array}{l}\text { Runoff coefficient } \\
\text { for dwelling site }\end{array}$ & -- & 0.2 & $0-1$ & 0.34 & $P$ & 2 & $\begin{array}{l}\text { This value was calculated from the HELP Output data } \\
\text { for the Post-Institutional Control Period. The } \\
\text { calculated value is } 0.34 \text {. The equation used to } \\
\text { calculate the value is available in Yu et al. } 1993 \text {. } \\
\text { The calculations are available in Attachment II } \\
\text { following this table. }\end{array}$ & $\begin{array}{c}\text { DOE } 2003 b \\
\text { page C3-243 } \\
\text { Yu et al. } 1993 \\
\text { page } 73\end{array}$ \\
\hline $\begin{array}{l}\text { Depth of soil mixing } \\
\text { layer for dwelling } \\
\text { site }\end{array}$ & $\mathrm{m}$ & 0.15 & $0-1$ & 0.15 & $P, B$ & 2 & Default value is used. & Yu et al. 2007 \\
\hline $\begin{array}{l}\text { Volumetric water } \\
\text { content for dwelling } \\
\text { site }\end{array}$ & -- & 0.3 & $1 E-5-1$ & 0.347 & P & 2 & $\begin{array}{l}\text { DOE geologist recommended value based on silty clay } \\
\text { loam and normal distribution. }\end{array}$ & $\begin{array}{l}\text { Yu et al. } 2007 \\
\\
\text { DOE Project } \\
\text { Communication } \\
\text { with geologist } \\
\text { (April 2010) }\end{array}$ \\
\hline $\begin{array}{l}\text { Dry bulk density of } \\
\text { soil for dwelling site }\end{array}$ & $\mathrm{g} / \mathrm{cm}^{3}$ & 1.5 & $1 \mathrm{E}-3-22.5$ & 1.5 & $P$ & 2 & Default value is used. & Yu et al. 2007 \\
\hline $\begin{array}{c}\text { Soil erodibility } \\
\text { factor for dwelling } \\
\text { site }\end{array}$ & tons/acre & 0 & $0-0.5$ & 0.37 & $P$ & 2 & $\begin{array}{l}\text { DOE geologist recommended value based on silty clay } \\
\text { loam and } 0.5 \% \text { organic matter. }\end{array}$ & $\begin{array}{l}\text { Yu et al. } 2007 \\
\text { Table 2.4-2, page } \\
\text { B-31 } \\
\text { DOE Project } \\
\text { Communication } \\
\text { with geologist } \\
\text { (May 2010) } \\
\end{array}$ \\
\hline $\begin{array}{l}\text { Slope-length- } \\
\text { steepness factor for } \\
\text { dwelling site }\end{array}$ & -- & 0.4 & $0-10$ & 0.4 & $P$ & 2 & $\begin{array}{l}\text { DOE geologist recommended a value of } 0.4 \text { based on } \\
\text { site topography. }\end{array}$ & $\begin{array}{l}\text { Yu et al. } 2007 \\
\text { DOE Project } \\
\text { Communication } \\
\text { with geologist } \\
\text { (April 2010) }\end{array}$ \\
\hline $\begin{array}{c}\text { Cover and } \\
\text { management factor } \\
\text { for dwelling site }\end{array}$ & -- & 0.003 & $0-1$ & 0.2 & $B, P$ & 2 & $\begin{array}{l}\text { DOE geologist recommended value based on no } \\
\text { appreciable canopy and } 20 \% \text { ground cover. }\end{array}$ & $\begin{array}{l}\text { Yu et al. } 2007 \\
\text { DOE Project } \\
\text { Communication } \\
\text { with geologist } \\
\text { (April 2010) }\end{array}$ \\
\hline
\end{tabular}


RESRAD-OFFSITE Table of Input Parameters for the C-746-U Landfill Offsite Resident Farmer Scenario

\begin{tabular}{|c|c|c|c|c|c|c|c|c|}
\hline $\begin{array}{c}\text { Input Screen Title } \\
\text { and Parameter } \\
\text { Name }\end{array}$ & Units & $\begin{array}{l}\text { Default } \\
\text { Value }^{a}\end{array}$ & $\begin{array}{c}\text { Code-Accepted } \\
\text { Values }^{b} \\
\text { Physical or } \\
\text { Numerical }{ }^{c} \text { (N) } \\
\text { Range }\end{array}$ & $\begin{array}{l}\text { Deterministic } \\
\text { Value }\end{array}$ & Type $^{d}$ & Priority $^{e}$ & Justification & References \\
\hline $\begin{array}{l}\text { Support practice } \\
\text { factor for dwelling } \\
\text { site }\end{array}$ & -- & 1 & $0-1$ & 0.5 & $B, P$ & 2 & DOE geologist recommended value. & $\begin{array}{l}\text { Yu et al. } 2007 \\
\text { DOE Project } \\
\text { Communication } \\
\text { with geologist } \\
\text { (July 2010) }\end{array}$ \\
\hline
\end{tabular}

Atmospheric Transport

\begin{tabular}{|c|c|c|c|c|c|c|c|c|}
\hline Release height & $\mathrm{m}$ & 1 & $0-100$ & 0.1 & $P$ & 2 & $\begin{array}{l}\text { The code does not allow a value of less than } 0.1 \text { thus } \\
\text { this value is selected because the release height is } \\
\text { assumed to be at ground level. }\end{array}$ & Yu et al. 2007 \\
\hline Release heat flux & $\mathrm{cal} / \mathrm{s}$ & 0 & $0-1 \mathrm{E}+10$ & 0 & & 2 & Default value is used. & Yu et al. 2007 \\
\hline Anemometer height & $\mathrm{m}$ & 10 & $0-100$ & 10 & $P$ & 2 & Default value is used. & Yu et al. 2007 \\
\hline $\begin{array}{c}\text { Ambient } \\
\text { temperature }\end{array}$ & $\mathrm{K}$ & 285 & $250-320$ & 285 & $\mathrm{P}$ & 2 & Default value is used. & Yu et al. 2007 \\
\hline $\begin{array}{l}\text { AM atmospheric } \\
\text { mixing height }\end{array}$ & $\mathrm{m}$ & 400 & $0-3,000$ & 400 & $P$ & 2 & Default value is used. & Yu et al. 2007 \\
\hline $\begin{array}{l}\text { PM atmospheric } \\
\text { mixing height }\end{array}$ & $\mathrm{m}$ & 1,600 & $0-3,000$ & 1600 & $P$ & 2 & Default value is used. & Yu et al. 2007 \\
\hline $\begin{array}{l}\text { Dispersion model } \\
\text { coefficients }\end{array}$ & -- & Pasquill-Gifford & $\begin{array}{c}\text { Briggs } \\
\text { rural/urban, } \\
\text { Pasquill- } \\
\text { Gifford }\end{array}$ & Pasquill-Gifford & $\mathrm{P}$ & 2 & $\begin{array}{l}\text { Pasquill-Gifford should be used for releases at or near } \\
\text { ground level. }\end{array}$ & Yu et al. 2007 \\
\hline Windspeed Terrain & -- & Rural & $\begin{array}{l}\text { Rural, } \\
\text { urban }\end{array}$ & Rural & $P$ & 2 & Rural is appropriate for the terrain. & Yu et al. 2007 \\
\hline $\begin{array}{c}\text { Fruit, grain, } \\
\text { nonleafy vegetable } \\
\text { plot }\end{array}$ & $\mathrm{m}$ & 0 & $0-100$ & 0 & $\mathrm{P}$ & 2 & Default value is used. & Yu et al. 2007 \\
\hline Leafy vegetable plot & $\mathrm{m}$ & 0 & $0-100$ & 0 & $\mathrm{P}$ & 2 & Default value is used. & Yu et al. 2007 \\
\hline $\begin{array}{l}\text { Pasture, silage } \\
\text { growing area }\end{array}$ & $\mathrm{m}$ & 0 & $0-100$ & 0 & $\mathrm{P}$ & 2 & Default value is used. & Yu et al. 2007 \\
\hline Grain fields & $\mathrm{m}$ & 0 & $0-100$ & 0 & $\mathrm{P}$ & 2 & Default value is used. & Yu et al. 2007 \\
\hline Dwelling site & $\mathrm{m}$ & 0 & $0-100$ & 0 & $\mathrm{P}$ & 2 & Default value is used. & Yu et al. 2007 \\
\hline Surface water body & $\mathrm{m}$ & 0 & $0-100$ & 0 & $\mathrm{P}$ & 2 & Default value is used. & Yu et al. 2007 \\
\hline $\begin{array}{l}\text { Grid spacing for } \\
\text { areal integration }\end{array}$ & $\mathrm{m}$ & 10 & $0-500$ & 10 & $P$ & 2 & Default value is used. & Yu et al. 2007 \\
\hline $\begin{array}{l}\text { Joint frequency of } \\
\text { wind speed and } \\
\text { stability class for a }\end{array}$ & -- & $1(\mathrm{~S}$ to $\mathrm{N})$ & $0-1$ & $\begin{array}{l}\text { Actual values } \\
\text { will be from } \\
\text { Paducah, KY }\end{array}$ & $P$ & 3 & $\begin{array}{l}\text { When a star file is read in the information for all } 16 \\
\text { sectors is read in. This parameter indicates the joint } \\
\text { frequency that is displayed on the input screen; }\end{array}$ & Yu et al. 2007 \\
\hline
\end{tabular}


RESRAD-OFFSITE Table of Input Parameters for the C-746-U Landfill Offsite Resident Farmer Scenario

\begin{tabular}{|c|c|c|c|c|c|c|c|c|}
\hline $\begin{array}{c}\text { Input Screen Title } \\
\text { and Parameter } \\
\text { Name }\end{array}$ & Units & $\begin{array}{l}\text { Default } \\
\text { Value }^{a}\end{array}$ & $\begin{array}{l}\text { Code-Accepted } \\
\text { Values }^{b} \\
\text { Physical or } \\
\text { Numerical }{ }^{c} \text { (N) } \\
\text { Range } \\
\end{array}$ & $\begin{array}{l}\text { Deterministic } \\
\text { Value }\end{array}$ & Type $^{d}$ & Priority $^{e}$ & Justification & References \\
\hline 16 sector windrose & & & & $\begin{array}{c}\text { read } \\
\text { metereological } \\
\text { STAR file }\end{array}$ & & & $\begin{array}{l}\text { however all } 16 \text { sectors are used in the model. The } \\
\text { STAR file selected is called KY_Paducah.str. }\end{array}$ & \\
\hline Wind speed & $\mathrm{m} / \mathrm{s}$ & $\begin{array}{c}0.89,2.46 \\
4.47,6.93,9.61 \\
12.52\end{array}$ & $0.001-20$ & $\begin{array}{r}0.89,2.46,4.47 \\
6.93,9.61,12.52\end{array}$ & $P$ & 2 & $\begin{array}{l}\text { Default values are used. The wind speed is divided } \\
\text { into six intervals in order to specify the joint } \\
\text { frequency distribution of wind speed and } \\
\text { atmospheric stability in each direction of a wind rose. } \\
\text { This is the average wind speed for the wind speed } \\
\text { interval. }\end{array}$ & Yu et al. 2007 \\
\hline
\end{tabular}

Unsaturated Zone Parameters

\begin{tabular}{|c|c|c|c|c|c|c|c|c|}
\hline \multirow{5}{*}{$\begin{array}{l}\text { Unsaturated zone } \\
\text { thickness }\end{array}$} & \multirow{5}{*}{$\mathrm{m}$} & \multirow{5}{*}{4} & \multirow{5}{*}{$\begin{array}{r}0.01- \\
10,000\end{array}$} & Zone $1=0.3$ & \multirow{5}{*}{$P$} & \multirow{5}{*}{1} & \multirow{5}{*}{$\begin{array}{l}\text { This value was obtained from the previous RESRAD } \\
\text { study for the landfill described in DOE 2003b. }\end{array}$} & \multirow{5}{*}{$\begin{array}{c}\text { DOE 2003b } \\
\text { Table Att.2, page } \\
\text { C3-315 }\end{array}$} \\
\hline & & & & Zone $2=0.3$ & & & & \\
\hline & & & & Zone $3=0.9$ & & & & \\
\hline & & & & Zone $4=2.0$ & & & & \\
\hline & & & & Zone $5=8.4$ & & & & \\
\hline \multirow{5}{*}{$\begin{array}{l}\text { Unsaturated zone } \\
\text { dry bulk density }\end{array}$} & \multirow{5}{*}{$\mathrm{g} / \mathrm{cm}^{3}$} & \multirow{5}{*}{1.5} & \multirow{5}{*}{$1 E-3-22.5$} & Zone $1=1.2$ & \multirow{5}{*}{$P$} & \multirow{5}{*}{2} & \multirow{5}{*}{$\begin{array}{l}\text { This value was obtained from the previous RESRAD } \\
\text { study for the landfill described in DOE 2003b. }\end{array}$} & \multirow{5}{*}{$\begin{array}{c}\text { DOE 2003b } \\
\text { Table Att.2, page } \\
\text { C3-315 }\end{array}$} \\
\hline & & & & Zone $2=1.5$ & & & & \\
\hline & & & & Zone $3=1.8$ & & & & \\
\hline & & & & Zone $4=1.5$ & & & & \\
\hline & & & & Zone $5=1.76$ & & & & \\
\hline \multirow{5}{*}{$\begin{array}{l}\text { Unsaturated zone } \\
\text { total porosity }\end{array}$} & \multirow{5}{*}{--} & \multirow{5}{*}{0.4} & \multirow{5}{*}{$1 E-5-1$} & Zone $1=0.45$ & \multirow{5}{*}{$P$} & \multirow{5}{*}{2} & \multirow{5}{*}{$\begin{array}{l}\text { This value was obtained from the previous RESRAD } \\
\text { study for the landfill described in DOE 2003b. } \\
\text { The values for UZ1 and UZ2 were transposed as } \\
\text { recommended by DOE. }\end{array}$} & \multirow{5}{*}{$\begin{array}{c}\text { DOE 2003b } \\
\text { Table Att.2, page } \\
\text { C3-315 } \\
\text { DOE Project } \\
\text { Communication } \\
\text { with DOE-PPPO } \\
\text { (October 2010) }\end{array}$} \\
\hline & & & & Zone $2=0.4$ & & & & \\
\hline & & & & Zone $3=0.43$ & & & & \\
\hline & & & & Zone $4=0.4$ & & & & \\
\hline & & & & Zone $5=0.45$ & & & & \\
\hline \multirow{5}{*}{$\begin{array}{l}\text { Unsaturated zone } \\
\text { effective porosity }\end{array}$} & \multirow{5}{*}{--} & \multirow{5}{*}{0.2} & \multirow{5}{*}{$1 E-5-1$} & Zone 1= 0.2 & \multirow{5}{*}{$P$} & \multirow{5}{*}{2} & \multirow{5}{*}{$\begin{array}{l}\text { These values were calculated using equation } 4.4 \text { from } \\
\text { Yu et al. } 1993 \text { as this approach was accepted by ANL } \\
\text { rather than using the values available in DOE } 2003 \mathrm{~b} \text {. } \\
\text { This approach was taken to ensure that the effective } \\
\text { porosity was less than the total porosity. }\end{array}$} & \multirow{5}{*}{$\begin{array}{c}\text { Yu et al. } 1993 \\
\text { Project } \\
\text { Communication } \\
\text { with DOE } \\
\text { consultant } \\
\text { (October 2010) }\end{array}$} \\
\hline & & & & Zone $2=0.2$ & & & & \\
\hline & & & & Zone $3=0.08$ & & & & \\
\hline & & & & Zone $4=0.2$ & & & & \\
\hline & & & & Zone $5=0.15$ & & & & \\
\hline \multirow{2}{*}{$\begin{array}{l}\text { Unsaturated zone } \\
\text { field capacity }\end{array}$} & \multirow[b]{2}{*}{--} & & & Zone $1=0.25$ & & & These values were obtained from the previous & DOE 2003b \\
\hline & & 0.3 & $1 \mathrm{E}-5-1$ & Zone $2=0.2$ & $\mathrm{P}$ & 3 & RESRAD study for the landfill described in DOE 2003b. & Table Att.2, page \\
\hline
\end{tabular}


RESRAD-OFFSITE Table of Input Parameters for the C-746-U Landfill Offsite Resident Farmer Scenario

\begin{tabular}{|c|c|c|c|c|c|c|c|c|}
\hline $\begin{array}{l}\text { Input Screen Title } \\
\text { and Parameter } \\
\text { Name }\end{array}$ & Units & $\begin{array}{l}\text { Default } \\
\text { Value }^{a}\end{array}$ & $\begin{array}{l}\text { Code-Accepted } \\
\text { Values }^{b} \\
\text { Physical or } \\
\text { Numerical }^{c}(\mathrm{~N}) \\
\text { Range }^{\text {Rang }}\end{array}$ & $\begin{array}{l}\text { Deterministic } \\
\text { Value }\end{array}$ & Type $^{d}$ & Priority $^{e}$ & Justification & References \\
\hline & & & & Zone $3=0.35$ & & & & C3-315 \\
\hline & & & & Zone $4=0.2$ & & & $\begin{array}{l}\text { Ihe values for } U \angle 1 \text { and } U \angle Z \text { were transposed as } \\
\text { recommended by DOE. }\end{array}$ & DOE Project \\
\hline & & & & Zone $5=0.3$ & & & & $\begin{array}{l}\text { Communication } \\
\text { with DOE-PPPO } \\
\text { (July 2010) }\end{array}$ \\
\hline \multirow{5}{*}{$\begin{array}{l}\text { Unsaturated zone } \\
\text { hydraulic } \\
\text { conductivity }\end{array}$} & \multirow{5}{*}{$\mathrm{m} / \mathrm{yr}$} & \multirow{5}{*}{10} & \multirow{5}{*}{$1 E-3-1 E+6$} & Zone $1=2.92 \mathrm{E} 0$ & \multirow{5}{*}{$\mathrm{P}$} & \multirow{5}{*}{2} & \multirow{5}{*}{$\begin{array}{l}\text { This value was obtained from the previous RESRAD } \\
\text { study for the landfill described in DOE 2003b. The } \\
\text { value for unsaturated zone } 5 \text { was changed from } \\
0.12 \mathrm{~m} / \mathrm{yr} \text { to } 0.14 \mathrm{~m} / \mathrm{yr} \text { to allow the code to run as } \\
\text { agreed with DOE. }\end{array}$} & DOE 2003b \\
\hline & & & & Zone $2=9.46 \mathrm{E}+3$ & & & & Table Att.2, page \\
\hline & & & & Zone $3=3.15 \mathrm{E}-1$ & & & & C3-315 \\
\hline & & & & Zone 4= 2.92E0 & & & & \\
\hline & & & & Zone $5=1.4 \mathrm{E}-1$ & & & & $\begin{array}{l}\text { Communication } \\
\text { (June 2010) }\end{array}$ \\
\hline \multirow{5}{*}{$\begin{array}{l}\text { Unsaturated zone } \\
\text { soil b parameter }\end{array}$} & \multirow{5}{*}{--} & \multirow{5}{*}{5.3} & \multirow{5}{*}{$0-15$} & Zone $1=7.75$ & \multirow{5}{*}{$\mathrm{P}$} & \multirow{5}{*}{2} & \multirow{5}{*}{$\begin{array}{l}\text { DOE geologist evaluated the unsaturated zone and } \\
\text { determined that the value for Silty Clay Loam from } \\
\text { Yu et al. } 1993 \text { was most appropriate. }\end{array}$} & Yu et al. 1993 \\
\hline & & & & Zone $2=7.75$ & & & & \\
\hline & & & & Zone $3=11.4$ & & & & DOE Project \\
\hline & & & & Zone $4=7.75$ & & & & with geologist \\
\hline & & & & Zone $5=11.4$ & & & & \multirow{6}{*}{$\begin{array}{l}\text { Communication } \\
\text { with DOE } \\
\text { consultant } \\
\text { (November 2010) }\end{array}$} \\
\hline \multirow{5}{*}{$\begin{array}{l}\text { Unsaturated zone } \\
\text { longitudinal } \\
\text { dispersivity }\end{array}$} & \multirow{5}{*}{$\mathrm{m}$} & \multirow{5}{*}{0.1} & \multirow{5}{*}{$0-100$} & Zone $1=0.03$ & \multirow{5}{*}{$\mathrm{P}$} & \multirow{5}{*}{2} & \multirow{5}{*}{$\begin{array}{l}\text { According to ANL expert, in general, the value of this } \\
\text { parameter is dependent on the thickness of the } \\
\text { unsaturated zone, and ranges from one hundredth of } \\
\text { the thickness to the order of the thickness. A value of } \\
1 / 10 \text { of the thickness might be more appropriate for } \\
\text { this parameter. } \\
\text { A value of } 1 / 10 \text { of the thickness was used for each } \\
\text { unsaturated zone as suggested. }\end{array}$} & \\
\hline & & & & Zone $2=0.03$ & & & & \\
\hline & & & & Zone $3=0.09$ & & & & \\
\hline & & & & Zone $4=0.2$ & & & & \\
\hline & & & & Zone $5=0.84$ & & & & \\
\hline
\end{tabular}

Saturated Zone Hydrological Data

\begin{tabular}{|c|c|c|c|c|c|c|c|c|}
\hline $\begin{array}{c}\text { Thickness of } \\
\text { saturated zone }\end{array}$ & $\mathrm{m}$ & 100 & $0-1,000$ & DOE geologist recommended value. & Yu et al. 2007 & $\begin{array}{c}\text { DOE Project } \\
\text { Communication } \\
\text { with geologist } \\
\text { (April 2010) }\end{array}$ \\
\hline $\begin{array}{c}\text { Dry bulk density of } \\
\text { saturated zone }\end{array}$ & $\mathrm{g} / \mathrm{cm}^{3}$ & 1.5 & $1 \mathrm{E}-3-22.5$ & & 1.67 & $\mathrm{P}$ & 1 & $\begin{array}{c}\text { This value was obtained from the previous RESRAD } \\
\text { study for the landfill described in DOE 2003b. }\end{array}$ \\
\hline
\end{tabular}


RESRAD-OFFSITE Table of Input Parameters for the C-746-U Landfill Offsite Resident Farmer Scenario

\begin{tabular}{|c|c|c|c|c|c|c|c|c|}
\hline $\begin{array}{c}\text { Input Screen Title } \\
\text { and Parameter } \\
\text { Name }\end{array}$ & Units & $\begin{array}{l}\text { Default } \\
\text { Value }^{a}\end{array}$ & $\begin{array}{c}\text { Code-Accepted } \\
\text { Values }^{b} \\
\text { Physical or }^{\text {Phy }} \\
\text { Numerical }(\mathrm{N}) \\
\text { Range }\end{array}$ & $\begin{array}{l}\text { Deterministic } \\
\text { Value }\end{array}$ & Type ${ }^{d}$ & Priority $^{e}$ & Justification & References \\
\hline $\begin{array}{l}\text { Saturated zone } \\
\text { total porosity }\end{array}$ & -- & 0.4 & $1 E-5-1$ & 0.34 & $\mathrm{P}$ & 1 & $\begin{array}{l}\text { This value was obtained from the previous RESRAD } \\
\text { study for the landfill described in DOE 2003b. }\end{array}$ & $\begin{array}{c}\text { DOE 2003b } \\
\text { Table Att.4., page } \\
\text { C3-315 }\end{array}$ \\
\hline $\begin{array}{l}\text { Saturated zone } \\
\text { effective porosity }\end{array}$ & -- & 0.2 & $1 \mathrm{E}-5-1$ & 0.3 & P & 1 & $\begin{array}{l}\text { This value was obtained from the previous RESRAD } \\
\text { study for the landfill described in DOE 2003b. }\end{array}$ & $\begin{array}{c}\text { DOE 2003b } \\
\text { Table 4.7, page 4- } \\
\text { 21, Table Att.4., } \\
\text { page C3-315 }\end{array}$ \\
\hline $\begin{array}{l}\text { Saturated zone } \\
\text { hydraulic } \\
\text { conductivity }\end{array}$ & $\mathrm{m} / \mathrm{yr}$ & 100 & $\begin{array}{c}1 E-3- \\
1 E+10\end{array}$ & 55630 & P & 1 & $\begin{array}{l}\text { This value was obtained from the previous RESRAD } \\
\text { study for the landfill described in DOE 2003b. This } \\
\text { value was verified by DOE geologist. }\end{array}$ & $\begin{array}{l}\text { DOE 2003b } \\
\text { Table Att.4., page } \\
\text { C3-315 } \\
\text { DOE Project } \\
\text { Communication } \\
\text { with geologist and } \\
\text { engineer (April } \\
\text { 2010) } \\
\end{array}$ \\
\hline $\begin{array}{l}\text { Saturated zone } \\
\text { hydraulic gradient } \\
\text { to well }\end{array}$ & -- & 0.02 & $1 \mathrm{E}-10-10$ & 0.0011 & $\mathrm{P}$ & 2 & $\begin{array}{l}\text { This value was obtained from the previous RESRAD } \\
\text { study for the landfill described in DOE 2003b. }\end{array}$ & $\begin{array}{c}\text { DOE 2003b } \\
\text { Table Att.4., page } \\
\text { C3-315 } \\
\end{array}$ \\
\hline $\begin{array}{c}\text { Saturated } \\
\text { zone longitudinal } \\
\text { dispersivity to well }\end{array}$ & $\mathrm{m}$ & 3 & $0-1,000$ & 15 & P & 2 & $\begin{array}{l}\text { This value was obtained from DOE 2003b and agreed } \\
\text { upon by DOE geologist. } \\
\text { In addition, this value was provided by site modeling } \\
\text { experts in Paducah (i.e., the values for saturated zone } \\
\text { longitudinal, horizontal lateral and vertical lateral } \\
\text { dispersivity were provided by Chad Drummond, and } \\
\text { are used by Los Alamos Technical Associates (LATA) } \\
\text { KY for their modeling). }\end{array}$ & $\begin{array}{c}\text { DOE 2003b } \\
\text { Table 4.7, page 4- } \\
21 \\
\text { DOE Project } \\
\text { Communication } \\
\text { with geologist } \\
\text { (April 2010) } \\
\\
\text { PRS 2010 } \\
\text { Table 3.5, page 3- } \\
36 \\
\text { DOE Project } \\
\text { Communication } \\
\text { with DOE } \\
\text { consultant } \\
\text { (November 2010) } \\
\text { DOE Project } \\
\text { Communication } \\
\end{array}$ \\
\hline
\end{tabular}


RESRAD-OFFSITE Table of Input Parameters for the C-746-U Landfill Offsite Resident Farmer Scenario

\begin{tabular}{|c|c|c|c|c|c|c|c|c|}
\hline $\begin{array}{c}\text { Input Screen Title } \\
\text { and Parameter } \\
\text { Name }\end{array}$ & Units & $\begin{array}{l}\text { Default } \\
\text { Value }^{a}\end{array}$ & $\begin{array}{l}\text { Code-Accepted } \\
\text { Values }^{b} \\
\text { Physical or }^{\text {Numerical }} \text { (N) } \\
\text { Range }\end{array}$ & $\begin{array}{l}\text { Deterministic } \\
\text { Value }\end{array}$ & Type $^{d}$ & Priority $^{e}$ & Justification & References \\
\hline & & & & & & & & $\begin{array}{l}\text { with DOE-PPPO } \\
\text { (April 2011) }\end{array}$ \\
\hline $\begin{array}{c}\text { Saturated zone } \\
\text { horizontal lateral } \\
\text { dispersivity to well }\end{array}$ & $\mathrm{m}$ & 0.4 & $0-1,000$ & 1.5 & $\mathrm{P}$ & 2 & $\begin{array}{l}\text { This value was provided by site modeling experts in } \\
\text { Paducah (i.e., the values for saturated zone } \\
\text { longitudinal, horizontal lateral and vertical lateral } \\
\text { dispersivity were provided by Chad Drummond, and } \\
\text { are used by Los Alamos Technical Associates (LATA) } \\
\text { KY for their modeling). }\end{array}$ & $\begin{array}{c}\text { DOE Project } \\
\text { Communication } \\
\text { with DOE-PPPO } \\
\text { (April 2011) }\end{array}$ \\
\hline $\begin{array}{c}\text { Saturated zone } \\
\text { vertical lateral } \\
\text { dispersivity to well }\end{array}$ & $\mathrm{m}$ & 0.02 & $0-1,000$ & 0.15 & $\mathrm{P}$ & 2 & $\begin{array}{l}\text { This value was provided by site modeling experts in } \\
\text { Paducah (i.e., the values for saturated zone } \\
\text { longitudinal, horizontal lateral and vertical lateral } \\
\text { dispersivity were provided by Chad Drummond, and } \\
\text { are used by Los Alamos Technical Associates (LATA) } \\
\text { KY for their modeling). }\end{array}$ & $\begin{array}{c}\text { DOE Project } \\
\text { Communication } \\
\text { with DOE-PPPO } \\
\text { (April 2011) }\end{array}$ \\
\hline $\begin{array}{l}\text { Depth of aquifer } \\
\text { contributing to well }\end{array}$ & $\mathrm{m}$ & 10 & $\begin{array}{l}1 \mathrm{E}-4- \\
1,000\end{array}$ & 9.1 & $P$ & 2 & $\begin{array}{l}\text { The value of } 9.1 \mathrm{~m} \text { is used for the Resident Farmer } \\
\text { since this value was recommended by LATA (Los } \\
\text { Alamos Technical Associates) Kentucky. In addition, } \\
\text { the value for the well pump intake depth in RESRAD } \\
\text { was modified in order to achieve consistency with the } \\
\text { depth of aquifer contributing to well in RESRAD- } \\
\text { OFFSITE as suggested by Argonne National } \\
\text { Laboratory (ANL) expert. }\end{array}$ & $\begin{array}{c}\text { DOE Project } \\
\text { Communication } \\
\text { with DOE } \\
\text { consultant } \\
\text { (November 2010) }\end{array}$ \\
\hline $\begin{array}{c}\text { Saturated zone } \\
\text { hydraulic gradient } \\
\text { to surface water } \\
\text { body }\end{array}$ & -- & 0.02 & $1 \mathrm{E}-10-10$ & 0.0011 & $P$ & 3 & $\begin{array}{l}\text { Assumed to be the same as hydraulic gradient to the } \\
\text { well. }\end{array}$ & $\begin{array}{c}\text { DOE 2003b } \\
\text { Table Att.4., page } \\
\text { C3-315 }\end{array}$ \\
\hline $\begin{array}{l}\text { Saturated zone } \\
\text { longitudinal } \\
\text { dispersivity to } \\
\text { surface water body }\end{array}$ & $\mathrm{m}$ & 10 & $0-1,000$ & 15 & $P$ & 3 & $\begin{array}{l}\text { This value was obtained from DOE 2003b and agreed } \\
\text { upon by DOE geologist. } \\
\text { In addition, this value was recommended by Chad } \\
\text { Drummond (Los Alamos Technical Associates (LATA) } \\
\text { KY) in April } 2011 .\end{array}$ & $\begin{array}{c}\text { DOE 2003b } \\
\text { Table 4.7, page 4- } \\
21 \\
\text { DOE Project } \\
\text { Communication } \\
\text { with geologist } \\
\text { (April 2010) } \\
\text { DOE Project } \\
\text { Communication } \\
\text { with DOE-PPPO } \\
\text { (April 2011) }\end{array}$ \\
\hline
\end{tabular}


RESRAD-OFFSITE Table of Input Parameters for the C-746-U Landfill Offsite Resident Farmer Scenario

\begin{tabular}{|c|c|c|c|c|c|c|c|c|}
\hline $\begin{array}{c}\text { Input Screen Title } \\
\text { and Parameter } \\
\text { Name }\end{array}$ & Units & $\begin{array}{l}\text { Default } \\
\text { Value }^{a}\end{array}$ & $\begin{array}{c}\text { Code-Accepted } \\
\text { Values }^{b} \\
\text { Physical or } \\
\text { Numerical }^{c} \text { (N) } \\
\text { Range }\end{array}$ & $\begin{array}{l}\text { Deterministic } \\
\text { Value }\end{array}$ & Type & Priority $^{e}$ & Justification & References \\
\hline $\begin{array}{l}\text { Saturated zone } \\
\text { horizontal lateral } \\
\text { dispersivity to } \\
\text { surface water body }\end{array}$ & $\mathrm{m}$ & 1 & $0-1,000$ & 1.5 & $P$ & 3 & $\begin{array}{l}\text { This value was recommended by Chad Drummond } \\
\text { (Los Alamos Technical Associates (LATA) KY) in April } \\
2011 .\end{array}$ & $\begin{array}{c}\text { DOE Project } \\
\text { Communication } \\
\text { with DOE-PPPO } \\
\text { (April 2011) }\end{array}$ \\
\hline $\begin{array}{l}\text { Saturated zone } \\
\text { vertical lateral } \\
\text { dispersivity to } \\
\text { surface water body }\end{array}$ & $\mathrm{m}$ & 0.06 & $0-1,000$ & 0.15 & P & 3 & $\begin{array}{l}\text { This value was recommended by Chad Drummond } \\
\text { (Los Alamos Technical Associates (LATA) KY) in April } \\
2011 .\end{array}$ & $\begin{array}{c}\text { DOE Project } \\
\text { Communication } \\
\text { with DOE-PPPO } \\
\text { (April 2011) }\end{array}$ \\
\hline $\begin{array}{l}\text { Depth of aquifer } \\
\text { contributing to } \\
\text { surface water body }\end{array}$ & $\mathrm{m}$ & 10 & $0-1,000$ & 9.1 & P & 3 & $\begin{array}{l}\text { The value of } 9.1 \mathrm{~m} \text { was recommended by LATA (Los } \\
\text { Alamos Technical Associates) Kentucky for the depth } \\
\text { of aquifer contributing to well. However, this value is } \\
\text { assumed for the depth of aquifer contributing to } \\
\text { surface water body. This modification will not impact } \\
\text { the results since the surface water body is not } \\
\text { considered in the CSM. }\end{array}$ & $\begin{array}{c}\text { DOE Project } \\
\text { Communication } \\
\text { with DOE } \\
\text { consultant } \\
\text { (November 2010) }\end{array}$ \\
\hline
\end{tabular}

Surface Water Body Parameters

\begin{tabular}{|c|c|c|c|c|c|c|c|c|c|}
\hline $\begin{array}{l}\text { Sediment delivery } \\
\text { ratio }\end{array}$ & -- & 1 & $0-1$ & & 0 & $\mathrm{P}$ & 3 & $\begin{array}{l}\text { DOE geologist recommended a value of } 0 \text { since this is } \\
\text { the fraction of the contaminated soil that is eroded } \\
\text { from the area of primary contamination that reaches } \\
\text { the surface water body. }\end{array}$ & $\begin{array}{l}\text { Yu et al. } 2007 \\
\\
\text { DOE Project } \\
\text { Communication } \\
\text { with geologist } \\
\text { (April 2010) }\end{array}$ \\
\hline $\begin{array}{c}\text { Volume of surface } \\
\text { water body }\end{array}$ & $\mathrm{m}^{3}$ & 150,000 & $1-1 E+34$ & $\mathrm{~N}$ & 150000 & $\mathrm{P}$ & 3 & Default value is used. & Yu et al. 2007 \\
\hline $\begin{array}{c}\text { Mean residence } \\
\text { time of water in } \\
\text { surface water body }\end{array}$ & $\mathrm{yr}$ & 1 & $\begin{array}{l}1 E-4- \\
1 E+34\end{array}$ & $\mathrm{~N}$ & 1 & $\mathrm{P}$ & 3 & Default value is used. & Yu et al. 2007 \\
\hline
\end{tabular}

Groundwater Transport Parameters

Distance from Downgradient Edge of Contamination to:

\begin{tabular}{|c|c|c|c|c|c|c|c|c|}
\hline $\begin{array}{c}\text { Well in the } \\
\text { direction parallel to } \\
\text { aquifer flow }\end{array}$ & $\mathrm{m}$ & 100 & $\begin{array}{c}-16,000- \\
+16,000\end{array}$ & 407 & P, B & 2 & $\begin{array}{l}\text { This is the distance, in meters, between two lines that } \\
\text { are perpendicular to the direction of aquifer flow, } \\
\text { one at the down gradient edge of the primary } \\
\text { contamination and the other at the well. This value is }\end{array}$ & $\begin{array}{c}\text { Yu et at. 2007 } \\
\text { DOE 2003b } \\
\text { page 4-1 }\end{array}$ \\
\hline
\end{tabular}


RESRAD-OFFSITE Table of Input Parameters for the C-746-U Landfill Offsite Resident Farmer Scenario

\begin{tabular}{|c|c|c|c|c|c|c|c|c|}
\hline $\begin{array}{c}\text { Input Screen Title } \\
\text { and Parameter } \\
\text { Name }\end{array}$ & Units & $\begin{array}{l}\text { Default } \\
\text { Value }^{a}\end{array}$ & $\begin{array}{l}\text { Code-Accepted } \\
\text { Values }^{b} \\
\text { Physical or } \\
\text { Numerical }{ }^{C}(\mathrm{~N}) \\
\text { Range }\end{array}$ & $\begin{array}{l}\text { Deterministic } \\
\text { Value }\end{array}$ & Type $e^{d}$ & Priority $^{e}$ & Justification & References \\
\hline & & & & & & & $\begin{array}{l}\text { set at "0" for onsite receptors to put the well at } \\
\text { downgradient edge of the primary contaminated } \\
\text { zone. For the offsite receptor, the well is located at } \\
407 \mathrm{~m} \text { from the downgradient edge of the } \\
\text { contaminated zone. This point corresponds to an } \\
\text { exposure point previously evaluated by DOE at the } \\
\text { property boundary. }\end{array}$ & \\
\hline $\begin{array}{l}\text { Surface water body } \\
\text { in the direction } \\
\text { parallel to aquifer } \\
\text { flow }\end{array}$ & $\mathrm{m}$ & 600 & $\begin{array}{l}-16,000- \\
+16,000\end{array}$ & -1249 & $P$ & 3 & $\begin{array}{l}\text { Setting this to a negative value will cause the code to } \\
\text { skip the groundwater transport calculations to the } \\
\text { surface water body. } \\
\text { Surface water is not considered in the CSM. }\end{array}$ & Yu et at. 2007 \\
\hline $\begin{array}{l}\text { Well in the } \\
\text { direction } \\
\text { perpendicular to } \\
\text { aquifer flow }\end{array}$ & $\mathrm{m}$ & 0 & $\begin{array}{l}-16,000- \\
+16,000\end{array}$ & 0 & $P, B$ & 2 & $\begin{array}{l}\text { The well is located } 407 \text { meters downgradient to the } \\
\text { primary contaminated zone. }\end{array}$ & Yu et at. 2007 \\
\hline $\begin{array}{l}\text { Near edge of } \\
\text { surface water body } \\
\text { in the direction } \\
\text { perpendicular to } \\
\text { aquifer flow }\end{array}$ & $\mathrm{m}$ & -150 & $\begin{array}{l}-16,000- \\
+16,000\end{array}$ & -72 & $\mathrm{P}$ & 3 & $\begin{array}{l}\text { The surface water body is located upgradient to the } \\
\text { primary contaminated zone since it is not considered } \\
\text { in the CSM. }\end{array}$ & Yu et at. 2007 \\
\hline $\begin{array}{l}\text { Far edge of surface } \\
\text { water body in the } \\
\text { direction } \\
\text { perpendicular to } \\
\text { aquifer flow }\end{array}$ & $\mathrm{m}$ & 150 & $\begin{array}{l}-16,000- \\
+16,000\end{array}$ & 228 & $P$ & 3 & $\begin{array}{l}\text { The surface water body is located upgradient to the } \\
\text { primary contaminated zone since it is not considered } \\
\text { in the CSM. }\end{array}$ & Yu et at. 2007 \\
\hline $\begin{array}{l}\text { Convergence } \\
\text { criterion (fractional } \\
\text { accuracy desired) }\end{array}$ & -- & 0.001 & $0-0.1$ & 0.001 & $P$ & 3 & $\begin{array}{l}\text { Default value is used. The surface water body is } \\
\text { located upgradient to the primary contaminated zone } \\
\text { since it is not considered in the CSM. }\end{array}$ & Yu et at. 2007 \\
\hline $\begin{array}{l}\text { Main subzones in } \\
\text { saturated zone }\end{array}$ & -- & 1 & $1-1024$ & 1 & NA & 3 & Default value is used. & Yu et al. 2007 \\
\hline $\begin{array}{l}\text { Main subzones in } \\
\text { each partially } \\
\text { saturated zone }\end{array}$ & -- & 1 & $1-1024$ & 1 & NA & 3 & Default value is used. & Yu et al. 2007 \\
\hline
\end{tabular}


RESRAD-OFFSITE Table of Input Parameters for the C-746-U Landfill Offsite Resident Farmer Scenario

\begin{tabular}{|c|c|c|c|c|c|c|c|c|}
\hline $\begin{array}{l}\text { Input Screen Title } \\
\text { and Parameter } \\
\text { Name }\end{array}$ & Units & $\begin{array}{l}\text { Default } \\
\text { Value }^{a}\end{array}$ & $\begin{array}{c}\text { Code-Acceptec } \\
\text { Values }^{b} \\
\text { Physical or } \\
\text { Numerical }{ }^{c}(\mathrm{~N} \\
\text { Range }\end{array}$ & $\begin{array}{l}\text { Deterministic } \\
\text { Value }\end{array}$ & Type $^{d}$ & Priority $^{e}$ & Justification & References \\
\hline $\begin{array}{l}\text { Nuclide-specific } \\
\text { retardation in all } \\
\text { subzones, } \\
\text { longitudinal } \\
\text { dispersion in all but } \\
\text { the subzone of } \\
\text { transformation? }\end{array}$ & -- & Yes & Yes/No & Yes & NA & 3 & Default value is used. & Yu et at. 2007 \\
\hline $\begin{array}{l}\text { Longitudinal } \\
\text { dispersion in all } \\
\text { subzones, nuclide- } \\
\text { specific retardation } \\
\text { in all but the } \\
\text { subzone of } \\
\text { transformation, } \\
\text { parent retardation } \\
\text { in zone of } \\
\text { transformation? }\end{array}$ & -- & No & Yes/No & No & NA & 3 & Default value is used. & Yu et at. 2007 \\
\hline $\begin{array}{l}\text { Longitudinal } \\
\text { dispersion in all } \\
\text { subzones, nuclide- } \\
\text { specific retardation } \\
\text { in all but the } \\
\text { subzone of } \\
\text { transformation, } \\
\text { progeny retardation } \\
\text { in zone of } \\
\text { transformation? }\end{array}$ & -- & No & Yes/No & No & NA & 3 & Default value is used. & Yu et at. 2007 \\
\hline $\begin{array}{l}\text { Quantity of water } \\
\text { consumed by an } \\
\text { individual }\end{array}$ & $L / y r$ & 510 & $0-1,000$ & 700 & $\mathrm{M}, \mathrm{B}$ & 2 & $\begin{array}{l}\text { This value was converted from Table D.1 in DOE } \\
2009 . \\
\text { See Attachment II following this table of parameters. }\end{array}$ & $\begin{array}{c}\text { DOE } 2009 \\
\text { Appendix D, } \\
\text { Table D.1, page D- } \\
11 \\
\end{array}$ \\
\hline $\begin{array}{l}\text { Fraction of water } \\
\text { from surface body } \\
\text { for human } \\
\text { consumption }\end{array}$ & -- & 0 & $0-1$ & 0 & $B, P$ & 3 & $\begin{array}{l}\text { This parameter is the fraction of water that is } \\
\text { obtained from the contaminated surface water body } \\
\text { for the specific use. If water is obtained from other } \\
\text { sources (contaminated well, uncontaminated outside } \\
\text { source), the fraction will be less than one. } \\
\text { It is assumed that all drinking water will come from } \\
\text { the well; therefore, the fraction of water from } \\
\text { contaminated surface water body is } 0 \text {. }\end{array}$ & Yu et al. 2007 \\
\hline
\end{tabular}


RESRAD-OFFSITE Table of Input Parameters for the C-746-U Landfill Offsite Resident Farmer Scenario

\begin{tabular}{|c|c|c|c|c|c|c|c|c|}
\hline $\begin{array}{c}\text { Input Screen Title } \\
\text { and Parameter } \\
\text { Name }\end{array}$ & Units & $\begin{array}{l}\text { Default } \\
\text { Value }^{a}\end{array}$ & $\begin{array}{l}\text { Code-Accepted } \\
\text { Values }^{b} \\
\text { Physical or } \\
\text { Numerical }^{c} \text { (N) } \\
\text { Range }\end{array}$ & $\begin{array}{c}\text { Deterministic } \\
\text { Value }\end{array}$ & Type $e^{d}$ & Priority $^{e}$ & Justification & References \\
\hline $\begin{array}{l}\text { Fraction of water } \\
\text { from well for } \\
\text { human } \\
\text { consumption }\end{array}$ & -- & 1 & $0-1$ & 1 & $B, P$ & 2 & $\begin{array}{l}\text { This parameter is the fraction of water that is } \\
\text { obtained from the contaminated well for the specific } \\
\text { use. If water is obtained from other sources } \\
\text { (contaminated surface water body, uncontaminated } \\
\text { outside source), the fraction will be less than one. } \\
\text { It is assumed that all drinking water will come from } \\
\text { the well; therefore, the fraction of water from the } \\
\text { contaminated well is } 1 .\end{array}$ & Yu et al. 2007 \\
\hline $\begin{array}{l}\text { Number of } \\
\text { household } \\
\text { individuals } \\
\text { consuming and } \\
\text { using water } \\
\end{array}$ & -- & 4 & $0-1,000$ & 4 & B & 3 & $\begin{array}{l}\text { Default value is used. The number of individuals } \\
\text { consuming and using water from the well is used to } \\
\text { estimate the minimum amount of water that is being } \\
\text { extracted from the well. This is not used in the } \\
\text { computational code. }\end{array}$ & Yu et al. 2007 \\
\hline $\begin{array}{l}\text { Quantity of water } \\
\text { for use indoors of } \\
\text { dwelling per } \\
\text { individual }\end{array}$ & $\mathrm{L} / \mathrm{d}$ & 225 & $0-1,000$ & 225 & $M, B$ & 3 & $\begin{array}{l}\text { Default value is used. This is the total amount of } \\
\text { water used in the house. It includes water used for } \\
\text { cleaning, washing, showering/bathing, etc. } \\
\text { It is also used by the interface to estimate the volume } \\
\text { of water that needs to be extracted from the well to } \\
\text { satisfy the specified needs. }\end{array}$ & Yu et al. 2007 \\
\hline $\begin{array}{l}\text { Fraction of water } \\
\text { from surface body } \\
\text { for use indoors of } \\
\text { dwelling }\end{array}$ & -- & 0 & $0-1$ & 0 & $B, P$ & 3 & $\begin{array}{l}\text { This parameter is the fraction of water that is } \\
\text { obtained from the contaminated surface water body } \\
\text { for the specific use. If water is obtained from other } \\
\text { sources (contaminated well, uncontaminated outside } \\
\text { source), the fraction will be less than one. } \\
\text { It is assumed that all water will come from a } \\
\text { contaminated well. }\end{array}$ & Yu et al. 2007 \\
\hline $\begin{array}{l}\text { Fraction of water } \\
\text { from well for use } \\
\text { indoors of dwelling }\end{array}$ & -- & 1 & $0-1$ & 1 & $B, P$ & 2 & $\begin{array}{l}\text { This parameter is the fraction of water that is } \\
\text { obtained from the contaminated well for the specific } \\
\text { use. If water is obtained from other sources } \\
\text { (contaminated surface water body, uncontaminated } \\
\text { outside source), the fraction will be less than one. } \\
\text { It is assumed that all water will come from a } \\
\text { contaminated well. }\end{array}$ & Yu et al. 2007 \\
\hline \multicolumn{9}{|l|}{ Beef Cattle } \\
\hline $\begin{array}{l}\text { Quantity of water } \\
\text { for beef cattle }\end{array}$ & $L / d$ & 50 & $0-500$ & 50 & $M, B$ & 2 & $\begin{array}{l}\text { The value used corresponds to the quantity of water } \\
\text { ingested daily by beef, available in DOE } 2009 \text {. }\end{array}$ & $\begin{array}{c}\text { DOE } 2009 \\
\text { Appendix D, Table }\end{array}$ \\
\hline
\end{tabular}


RESRAD-OFFSITE Table of Input Parameters for the C-746-U Landfill Offsite Resident Farmer Scenario

\begin{tabular}{|c|c|c|c|c|c|c|c|c|}
\hline $\begin{array}{c}\text { Input Screen Title } \\
\text { and Parameter } \\
\text { Name }\end{array}$ & Units & $\begin{array}{l}\text { Default } \\
\text { Value }^{a}\end{array}$ & $\begin{array}{c}\text { Code-Accepted } \\
\text { Values }^{b} \\
\text { Physical or } \\
\text { Numerical }^{c} \text { (N) } \\
\text { Range }\end{array}$ & $\begin{array}{c}\text { Deterministic } \\
\text { Value }\end{array}$ & Type & Priority $^{e}$ & Justification & References \\
\hline & & & & & & & See Attachment II following this table of parameters. & D.46, Page D-56. \\
\hline $\begin{array}{l}\text { Fraction of water } \\
\text { from surface body } \\
\text { for beef cattle }\end{array}$ & -- & 0 & $0-1$ & 0 & $B, P$ & 3 & $\begin{array}{l}\text { This parameter is the fraction of water that is } \\
\text { obtained from the contaminated surface water body } \\
\text { for the specific use. If water is obtained from other } \\
\text { sources (contaminated well, uncontaminated outside } \\
\text { source), the fraction will be less than one. } \\
\text { It is assumed that all water will come from a } \\
\text { contaminated well. }\end{array}$ & Yu et al. 2007 \\
\hline $\begin{array}{l}\text { Fraction of water } \\
\text { from well for beef } \\
\text { cattle }\end{array}$ & -- & 1 & $0-1$ & 1 & $B, P$ & 2 & $\begin{array}{l}\text { This parameter is the fraction of water that is } \\
\text { obtained from the contaminated well for the specific } \\
\text { use. If water is obtained from other sources } \\
\text { (contaminated surface water body, uncontaminated } \\
\text { outside source), the fraction will be less than one. } \\
\text { It is assumed that all water will come from a } \\
\text { contaminated well. }\end{array}$ & Yu et al. 2007 \\
\hline $\begin{array}{l}\text { Number of cattle } \\
\text { for beef cattle }\end{array}$ & -- & 2 & $0-10$ & 2 & B & 3 & Default value is used. & Yu et al. 2007 \\
\hline
\end{tabular}

\section{Dairy Cows}

\begin{tabular}{|c|c|c|c|c|c|c|c|c|}
\hline $\begin{array}{l}\text { Quantity of water } \\
\text { for dairy cows }\end{array}$ & $L / d$ & 160 & $0-1,000$ & 160 & $M, B$ & 2 & Default value is used. & Yu et al. 2007 \\
\hline $\begin{array}{l}\text { Fraction of water } \\
\text { from surface body } \\
\text { for dairy cows }\end{array}$ & -- & 0 & $0-1$ & 0 & $B, P$ & 3 & $\begin{array}{l}\text { This parameter is the fraction of water that is } \\
\text { obtained from the contaminated surface water body } \\
\text { for the specific use. If water is obtained from other } \\
\text { sources (contaminated well, uncontaminated outside } \\
\text { source), the fraction will be less than one. } \\
\text { It is assumed that all water will come from a } \\
\text { contaminated well. }\end{array}$ & Yu et al. 2007 \\
\hline $\begin{array}{l}\text { Fraction of water } \\
\text { from well for dairy } \\
\text { cows }\end{array}$ & -- & 1 & $0-1$ & 1 & $B, P$ & 2 & $\begin{array}{l}\text { This parameter is the fraction of water that is } \\
\text { obtained from the contaminated well for the specific } \\
\text { use. If water is obtained from other sources } \\
\text { (contaminated surface water body, uncontaminated } \\
\text { outside source), the fraction will be less than one. } \\
\text { It is assumed that all water will come from a } \\
\text { contaminated well. }\end{array}$ & Yu et al. 2007 \\
\hline
\end{tabular}


RESRAD-OFFSITE Table of Input Parameters for the C-746-U Landfill Offsite Resident Farmer Scenario

\begin{tabular}{|c|c|c|c|c|c|c|c|c|}
\hline $\begin{array}{c}\text { Input Screen Title } \\
\text { and Parameter } \\
\text { Name }\end{array}$ & Units & $\begin{array}{l}\text { Default } \\
\text { Value }^{a}\end{array}$ & 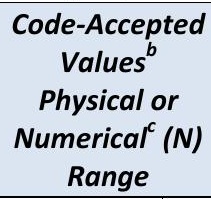 & $\begin{array}{l}\text { Deterministic } \\
\text { Value }\end{array}$ & Type $^{d}$ & Priority $^{e}$ & Justification & References \\
\hline $\begin{array}{c}\text { Number of cows for } \\
\text { dairy cows }\end{array}$ & -- & 2 & $0-10$ & 2 & B & 3 & Default value is used. & Yu et al. 2007 \\
\hline $\begin{array}{l}\text { Fraction of water } \\
\text { from surface body } \\
\text { for fruit, grain, and } \\
\text { nonleafy vegetables }\end{array}$ & -- & 0 & $0-1$ & 0 & $B, P$ & 3 & $\begin{array}{l}\text { This parameter is the fraction of water that is } \\
\text { obtained from the contaminated surface water body } \\
\text { for the specific use. If water is obtained from other } \\
\text { sources (contaminated well, uncontaminated outside } \\
\text { source), the fraction will be less than one. } \\
\text { It is assumed that all water will come from a } \\
\text { contaminated well. }\end{array}$ & $\begin{array}{c}\text { DOE Project } \\
\text { Communication } \\
\text { with DOE-PPPO } \\
\text { (April 2011) } \\
\text { Yu et al. } 2007\end{array}$ \\
\hline $\begin{array}{l}\text { Fraction of water } \\
\text { from well for fruit, } \\
\text { grain, and nonleafy } \\
\text { vegetables }\end{array}$ & -- & 1 & $0-1$ & 1 & $B, P$ & 2 & $\begin{array}{l}\text { This parameter is the fraction of water that is } \\
\text { obtained from the contaminated well for the specific } \\
\text { use. If water is obtained from other sources } \\
\text { (contaminated surface water body, uncontaminated } \\
\text { outside source), the fraction will be less than one. } \\
\text { It is assumed that all water will come from a } \\
\text { contaminated well. }\end{array}$ & $\begin{array}{c}\text { DOE Project } \\
\text { Communication } \\
\text { with DOE-PPPO } \\
\text { (April 2011) } \\
\text { Yu et al. } 2007\end{array}$ \\
\hline
\end{tabular}

Leafy Vegetables

\begin{tabular}{|c|c|c|c|c|c|c|c|c|}
\hline $\begin{array}{l}\text { Fraction of water } \\
\text { from surface body } \\
\text { for leafy vegetables }\end{array}$ & -- & 0 & $0-1$ & 0 & $\mathrm{~B}, \mathrm{P}$ & 3 & $\begin{array}{l}\text { This parameter is the fraction of water that is } \\
\text { obtained from the contaminated surface water body } \\
\text { for the specific use. If water is obtained from other } \\
\text { sources (contaminated well, uncontaminated outside } \\
\text { source), the fraction will be less than one. } \\
\text { It is assumed that all water will come from a } \\
\text { contaminated well. }\end{array}$ & $\begin{array}{c}\text { DOE Project } \\
\text { Communication } \\
\text { with DOE-PPPO } \\
\text { (April 2011) } \\
\text { Yu et al. } 2007\end{array}$ \\
\hline $\begin{array}{l}\text { Fraction of water } \\
\text { from well for leafy } \\
\text { vegetables }\end{array}$ & -- & 1 & $0-1$ & 1 & $\mathrm{~B}, \mathrm{P}$ & 2 & $\begin{array}{l}\text { This parameter is the fraction of water that is } \\
\text { obtained from the contaminated well for the specific } \\
\text { use. If water is obtained from other sources } \\
\text { (contaminated surface water body, uncontaminated } \\
\text { outside source), the fraction will be less than one. } \\
\text { It is assumed that all water will come from a } \\
\text { contaminated well. }\end{array}$ & $\begin{array}{c}\text { DOE Project } \\
\text { Communication } \\
\text { with DOE-PPPO } \\
\text { (April 2011) } \\
\text { Yu et al. } 2007\end{array}$ \\
\hline
\end{tabular}

Pasture and Silage

Fraction of water

0

$0-1$

0

$B, P$

\begin{tabular}{l|l}
3 & This is the fraction of water that is obtained from the
\end{tabular}

DOE Project 
RESRAD-OFFSITE Table of Input Parameters for the C-746-U Landfill Offsite Resident Farmer Scenario

\begin{tabular}{|c|c|c|c|c|c|c|c|c|}
\hline $\begin{array}{c}\text { Input Screen Title } \\
\text { and Parameter } \\
\text { Name }\end{array}$ & Units & $\begin{array}{l}\text { Default } \\
\text { Value }^{a}\end{array}$ & $\begin{array}{l}\text { Code-Accepted } \\
\text { Values }^{b} \\
\text { Physical or } \\
\text { Numerical }^{c}(\mathrm{~N}) \\
\text { Range }^{\text {Rang }}\end{array}$ & $\begin{array}{l}\text { Deterministic } \\
\text { Value }\end{array}$ & Type & Priority $^{e}$ & Justification & References \\
\hline $\begin{array}{l}\text { from surface body } \\
\text { for pasture and } \\
\text { silage }\end{array}$ & & & & & & & $\begin{array}{l}\text { contaminated surface water body for the specific use. } \\
\text { If water is obtained from other sources } \\
\text { (contaminated well, uncontaminated outside source), } \\
\text { the fraction will be less than one. } \\
\text { It is assumed that all water will come from an } \\
\text { uncontaminated outside source. }\end{array}$ & $\begin{array}{l}\text { Communication } \\
\text { with DOE-PPPO } \\
\text { (October 2010) } \\
\text { Yu et al. } 2007\end{array}$ \\
\hline $\begin{array}{l}\text { Fraction of water } \\
\text { from well for } \\
\text { pasture and silage }\end{array}$ & -- & 1 & $0-1$ & 0 & $B, P$ & 2 & $\begin{array}{l}\text { This parameter is the fraction of water that is } \\
\text { obtained from the contaminated well for the specific } \\
\text { use. If water is obtained from other sources } \\
\text { (contaminated surface water body, uncontaminated } \\
\text { outside source), the fraction will be less than one. } \\
\text { It is assumed that all water will come from an } \\
\text { uncontaminated outside source. }\end{array}$ & $\begin{array}{c}\text { DOE Project } \\
\text { Communication } \\
\text { with DOE-PPPO } \\
\text { (October 2010) } \\
\text { Yu et al. } 2007\end{array}$ \\
\hline
\end{tabular}

Livestock Feed Grain

\begin{tabular}{|c|c|c|c|c|c|c|c|c|}
\hline $\begin{array}{l}\text { Fraction of water } \\
\text { from surface body } \\
\text { for livestock feed } \\
\text { grain }\end{array}$ & -- & 0 & $0-1$ & 0 & $\mathrm{~B}, \mathrm{P}$ & 3 & $\begin{array}{l}\text { This is the fraction of water that is obtained from the } \\
\text { contaminated surface water body for the specific use. } \\
\text { If water is obtained from other sources } \\
\text { (contaminated well, uncontaminated outside source), } \\
\text { the fraction will be less than one. } \\
\text { It is assumed that all water will come from an } \\
\text { uncontaminated outside source. }\end{array}$ & $\begin{array}{c}\text { DOE Project } \\
\text { Communication } \\
\text { with DOE-PPPO } \\
\text { (October 2010) } \\
\text { Yu et al. } 2007\end{array}$ \\
\hline $\begin{array}{l}\text { Fraction of water } \\
\text { from well for } \\
\text { livestock feed grain }\end{array}$ & -- & 1 & $0-1$ & 0 & $\mathrm{~B}, \mathrm{P}$ & 2 & $\begin{array}{l}\text { This parameter is the fraction of water that is } \\
\text { obtained from the contaminated well for the specific } \\
\text { use. If water is obtained from other sources } \\
\text { (contaminated surface water body, uncontaminated } \\
\text { outside source), the fraction will be less than one. } \\
\text { It is assumed that all water will come from an } \\
\text { uncontaminated outside source. }\end{array}$ & $\begin{array}{c}\text { DOE Project } \\
\text { Communication } \\
\text { with DOE-PPPO } \\
\text { (October 2010) } \\
\text { Yu et al. } 2007\end{array}$ \\
\hline
\end{tabular}

Offsite Dwelling Site

\begin{tabular}{|c|c|c|c|c|c|c|c|c|}
\hline $\begin{array}{l}\text { Fraction of water } \\
\text { from surface body } \\
\text { for offsite dwelling } \\
\text { site }\end{array}$ & -- & 0 & $0-1$ & 0 & $\mathrm{~B}, \mathrm{P}$ & 3 & $\begin{array}{l}\text { This is the fraction of water that is obtained from the } \\
\text { contaminated surface water body for the specific use. } \\
\text { If water is obtained from other sources } \\
\text { (contaminated well, uncontaminated outside source), }\end{array}$ & $\begin{array}{l}\text { DOE Project } \\
\text { Communication } \\
\text { with DOE-PPPO } \\
\text { (October 2010) }\end{array}$ \\
\hline
\end{tabular}


RESRAD-OFFSITE Table of Input Parameters for the C-746-U Landfill Offsite Resident Farmer Scenario

\begin{tabular}{|c|c|c|c|c|c|c|c|c|}
\hline $\begin{array}{c}\text { Input Screen Title } \\
\text { and Parameter } \\
\text { Name }\end{array}$ & Units & $\begin{array}{l}\text { Default } \\
\text { Value }^{a}\end{array}$ & $\begin{array}{c}\text { Code-Accepted } \\
\text { Values }^{b} \\
\text { Physical or }^{\text {Putcal }} \\
\text { Numerical }^{c}(\mathrm{~N}) \\
\text { Range }\end{array}$ & $\begin{array}{c}\text { Deterministic } \\
\text { Value }\end{array}$ & Type $^{d}$ & Priority $^{e}$ & Justification & References \\
\hline & & & & & & & $\begin{array}{l}\text { the fraction will be less than one. } \\
\text { It is assumed that all water will come from an } \\
\text { uncontaminated outside source. }\end{array}$ & Yu et al. 2007 \\
\hline $\begin{array}{l}\text { Fraction of water } \\
\text { from well for offsite } \\
\text { dwelling site }\end{array}$ & -- & 1 & $0-1$ & 0 & $B, P$ & 2 & $\begin{array}{l}\text { This parameter is the fraction of water that is } \\
\text { obtained from the contaminated well for the specific } \\
\text { use. If water is obtained from other sources } \\
\text { (contaminated surface water body, uncontaminated } \\
\text { outside source), the fraction will be less than one. } \\
\text { It is assumed that all water will come from an } \\
\text { uncontaminated outside source. }\end{array}$ & $\begin{array}{c}\text { DOE Project } \\
\text { Communication } \\
\text { with DOE-PPPO } \\
\text { (October 2010) } \\
\text { Yu et al. } 2007\end{array}$ \\
\hline Well pumping rate & $\mathrm{m}^{3} / \mathrm{yr}$ & 5,100 & $0-100,000$ & $\begin{array}{l}\text { Calculated by } \\
\text { the code }\end{array}$ & $B, P$ & 2 & Calculated by the code. & Yu et al. 2007 \\
\hline $\begin{array}{l}\text { Well pumping rate } \\
\text { needed to specified } \\
\text { water use for } \\
\text { livestock feed grain }\end{array}$ & $\mathrm{m}^{3} / \mathrm{yr}$ & $5,084.17$ & Calculated & $\begin{array}{l}\text { Calculated by } \\
\text { the code }\end{array}$ & $B, P$ & 3 & Calculated by the code. & Yu et al. 2007 \\
\hline
\end{tabular}

\section{Ingestion Rates}

Consumption Rate

\begin{tabular}{|c|c|c|c|c|c|c|c|c|}
\hline $\begin{array}{l}\text { Drinking water } \\
\text { intake }\end{array}$ & $\mathrm{L} / \mathrm{yr}$ & 510 & $0-1,000$ & 700 & $\mathrm{M}, \mathrm{B}$ & 2 & $\begin{array}{l}\text { This value was converted from Table D.1 in DOE } \\
2009 . \\
\text { See Attachment II following this table of parameters. }\end{array}$ & $\begin{array}{c}\text { DOE } 2009 \\
\text { Appendix D, } \\
\text { Table D.1, page D- } \\
11 \\
\end{array}$ \\
\hline Fish consumption & $\mathrm{kg} / \mathrm{yr}$ & 5.4 & $0-1,000$ & 5.4 & $\mathrm{M}, \mathrm{B}$ & 3 & $\begin{array}{l}\text { The aquatic foods ingestion pathway is suppressed in } \\
\text { RESRAD OFFSITE for all receptors because it is not } \\
\text { considered part of the conceptual site model. }\end{array}$ & Yu et el. 2007 \\
\hline $\begin{array}{l}\text { Other aquatic food } \\
\text { consumption }\end{array}$ & $\mathrm{kg} / \mathrm{yr}$ & 0.9 & $0-100$ & 0.9 & $\mathrm{M}, \mathrm{B}$ & 3 & $\begin{array}{l}\text { The aquatic foods ingestion pathway is suppressed in } \\
\text { RESRAD OFFSITE for all receptors because it is not } \\
\text { considered part of the conceptual site model. }\end{array}$ & Yu et el. 2007 \\
\hline $\begin{array}{l}\text { Fruit, grain, } \\
\text { nonleafy vegetables } \\
\text { consumption }\end{array}$ & $\mathrm{kg} / \mathrm{yr}$ & 160 & $0-1,000$ & 231.7 & $\mathrm{M}, \mathrm{B}$ & 2 & $\begin{array}{l}\text { The value was converted from Table D.9 in DOE 2009, } \\
\text { which is for home grown vegetables. It does not } \\
\text { specify fruit, and grain, thus for RESRAD a ratio was } \\
\text { obtained to assign a value for fruit, vegetable and } \\
\text { grain consumption and a value for leafy vegetable } \\
\text { consumption. }\end{array}$ & $\begin{array}{c}\text { DOE } 2009 \\
\text { Appendix D, } \\
\text { Table D.9, page D- } \\
19\end{array}$ \\
\hline
\end{tabular}


RESRAD-OFFSITE Table of Input Parameters for the C-746-U Landfill Offsite Resident Farmer Scenario

\begin{tabular}{|c|c|c|c|c|c|c|c|c|}
\hline $\begin{array}{l}\text { Input Screen Title } \\
\text { and Parameter } \\
\text { Name }\end{array}$ & Units & $\begin{array}{l}\text { Default } \\
\text { Value }^{a}\end{array}$ & $\begin{array}{l}\text { Code-Accepted } \\
\text { Values }^{b} \\
\text { Physical or } \\
\text { Numerical }{ }^{C}(\mathrm{~N}) \\
\text { Range }\end{array}$ & $\begin{array}{c}\text { Deterministic } \\
\text { Value }\end{array}$ & Type $e^{d}$ & Priority $^{e}$ & Justification & References \\
\hline & & & & & & & The calculation is included in Attachment II. & \\
\hline $\begin{array}{l}\text { Leafy vegetables } \\
\text { consumption }\end{array}$ & $\mathrm{kg} / \mathrm{yr}$ & 14 & $0-100$ & 20.3 & $\mathrm{M}, \mathrm{B}$ & 3 & $\begin{array}{l}\text { The value was converted from Table D.9 in DOE 2009, } \\
\text { which is for home grown vegetables. It does not } \\
\text { specify fruit, and grain, thus for RESRAD a ratio was } \\
\text { obtained to assign a value for fruit, vegetable and } \\
\text { grain consumption and a value for leafy vegetable } \\
\text { consumption. } \\
\text { The calculation is included in Attachment II. }\end{array}$ & $\begin{array}{l}\text { DOE } 2009 \\
\text { Appendix D, Table } \\
\text { D.9, page D-19 }\end{array}$ \\
\hline Meat consumption & $\mathrm{kg} / \mathrm{yr}$ & 63 & $0-300$ & 154 & $M, B$ & 3 & $\begin{array}{l}\text { This value was converted from Table D.10, D.12, and } \\
\text { D.13 in DOE } 2009 \text {. The value is the sum of the values } \\
\text { obtained for beef, pork and poultry, since they are in } \\
\text { separate tables. The value for eggs is available, but } \\
\text { eggs are not considered poultry. } \\
\text { See Attachment II following this table of parameters. }\end{array}$ & $\begin{array}{l}\text { DOE } 2009 \\
\text { Appendix D, Table } \\
\text { D.10, D.12, and } \\
\text { D.13, pages D-20, } \\
\text { D-22 and D-23 }\end{array}$ \\
\hline Milk consumption & L/yr & 92 & $0-1,000$ & 425 & $\mathrm{M}, \mathrm{B}$ & 2 & $\begin{array}{l}\text { This value was converted from Table D. } 11 \text { in DOE } \\
\text { 2009. The density of whole milk, } 1030 \mathrm{~kg} / \mathrm{cubic} \\
\text { meter, was used to convert the value into } \mathrm{L} / \mathrm{yr} \text {. } \\
\text { See Attachment II following this table of parameters. }\end{array}$ & $\begin{array}{l}\text { DOE } 2009 \\
\text { Appendix D, } \\
\text { Table D.11, page } \\
\text { D-21 }\end{array}$ \\
\hline $\begin{array}{l}\text { Soil (incidental) } \\
\text { ingestion rate }\end{array}$ & $g / y r$ & 36.5 & $0-10,000$ & 36.5 & $\mathrm{M}, \mathrm{B}$ & 2 & $\begin{array}{l}\text { This value was converted from Table D.5 in } \\
\text { DOE } 2009 . \\
\text { See Attachment II following this table of parameters. }\end{array}$ & $\begin{array}{c}\text { DOE } 2009 \\
\text { Appendix D,Table } \\
\text { D.5, page D-15 }\end{array}$ \\
\hline $\begin{array}{l}\text { Drinking water } \\
\text { intake from } \\
\text { affected area }\end{array}$ & -- & 1 & $0-1$ & 1 & $B, P$ & 3 & $\begin{array}{l}\text { This is the fraction of drinking water consumed by an } \\
\text { individual that is obtained from the contaminated } \\
\text { source. }\end{array}$ & Yu et al. 2007 \\
\hline $\begin{array}{l}\text { Fish consumption } \\
\text { from affected area }\end{array}$ & -- & 0.5 & $0-1$ & 0.5 & $B, P$ & 2 & $\begin{array}{l}\text { This is the fraction of fish consumed by an individual } \\
\text { that is obtained from the contaminated surface water } \\
\text { body. } \\
\text { This parameter is suppressed by turning off the } \\
\text { aquatic food pathway because it is not considered in } \\
\text { the conceptual site model. }\end{array}$ & Yu et al. 2007 \\
\hline $\begin{array}{l}\text { Other aquatic food } \\
\text { consumption from } \\
\text { affected area }\end{array}$ & -- & 0.5 & $0-1$ & 0.5 & $B, P$ & 2 & $\begin{array}{l}\text { This is the fraction of the other aquatic food } \\
\text { consumed by an individual that is obtained from the } \\
\text { contaminated surface water body. The aquatic foods } \\
\text { ingestion pathway is suppressed in RESRAD for all } \\
\text { receptors because it is not considered part of the }\end{array}$ & Yu et al. 2007 \\
\hline
\end{tabular}


RESRAD-OFFSITE Table of Input Parameters for the C-746-U Landfill Offsite Resident Farmer Scenario

\begin{tabular}{|c|c|c|c|c|c|c|c|c|}
\hline $\begin{array}{c}\text { Input Screen Title } \\
\text { and Parameter } \\
\text { Name }\end{array}$ & Units & $\begin{array}{l}\text { Default } \\
\text { Value }^{a}\end{array}$ & $\begin{array}{c}\text { Code-Accepted } \\
\text { Values }^{b} \\
\text { Physical or }^{\text {Putcal }} \\
\text { Numerical }^{c}(\mathrm{~N}) \\
\text { Range }\end{array}$ & $\begin{array}{l}\text { Deterministic } \\
\text { Value }\end{array}$ & Type $e^{d}$ & Priority $^{e}$ & Justification & References \\
\hline & & & & & & & conceptual site model. & \\
\hline $\begin{array}{c}\text { Fruit, grain, } \\
\text { nonleafy vegetables } \\
\text { consumption from } \\
\text { affected area } \\
\end{array}$ & -- & 0.5 & $0-1$ & 0.5 & $B, P$ & 3 & $\begin{array}{l}\text { This is the fraction of fruit, non-leafy vegetables, or } \\
\text { grain consumed by an individual that is obtained } \\
\text { from contaminated agricultural areas. }\end{array}$ & Yu et al. 2007 \\
\hline $\begin{array}{l}\text { Leafy vegetables } \\
\text { consumption from } \\
\text { affected area }\end{array}$ & -- & 0.5 & $0-1$ & 0.5 & $B, P$ & 3 & $\begin{array}{l}\text { This is the fraction of leafy vegetables consumed by } \\
\text { an individual that is obtained from contaminated } \\
\text { agricultural areas. }\end{array}$ & Yu et al. 2007 \\
\hline $\begin{array}{l}\text { Meat consumption } \\
\text { from affected area }\end{array}$ & -- & 1 & $0-1$ & 1 & $B, P$ & 3 & $\begin{array}{l}\text { This is the fraction of meat consumed by an } \\
\text { individual that is produced using contaminated feed } \\
\text { and water. }\end{array}$ & Yu et al. 2007 \\
\hline $\begin{array}{l}\text { Milk consumption } \\
\text { from affected area }\end{array}$ & -- & 1 & $0-1$ & 1 & $B, P$ & 3 & $\begin{array}{l}\text { This is the fraction of milk consumed by an individual } \\
\text { that is produced using contaminated feed and water. }\end{array}$ & Yu et al. 2007 \\
\hline
\end{tabular}

\section{Livestock Intakes}

\begin{tabular}{|c|c|c|c|c|c|c|c|c|}
\hline \multicolumn{9}{|l|}{ Beef Cattle } \\
\hline $\begin{array}{l}\text { Water intake for } \\
\text { beef cattle }\end{array}$ & $\mathrm{L} / \mathrm{d}$ & 50 & $0-500$ & 50 & $\mathrm{M}$ & 3 & $\begin{array}{l}\text { The value used corresponds to the quantity of water } \\
\text { ingested daily by beef, available in DOE } 2009 . \\
\text { See Attachment II following this table of parameters. }\end{array}$ & $\begin{array}{c}\text { DOE } 2009 \\
\text { Appendix D, Table } \\
\text { D.46, Page D-56. }\end{array}$ \\
\hline $\begin{array}{l}\text { Pasture and silage } \\
\text { intake for beef } \\
\text { cattle }\end{array}$ & $\mathrm{kg} / \mathrm{d}$ & 14 & $0-300$ & 25 & $M$ & 3 & $\begin{array}{l}\text { The value used corresponds to the quantity of } \\
\text { pasture ingested daily by beef, available in DOE } 2009 . \\
\text { See Attachment II following this table of parameters. }\end{array}$ & $\begin{array}{c}\text { DOE } 2009 \\
\text { Appendix D, Table } \\
\text { D.46, Page D-56. }\end{array}$ \\
\hline $\begin{array}{c}\text { Grain intake for } \\
\text { beef cattle }\end{array}$ & $\mathrm{kg} / \mathrm{d}$ & 54 & $0-300$ & 54 & $M$ & 3 & $\begin{array}{l}\text { Default value is used because there is no site specific } \\
\text { value. }\end{array}$ & Yu et al. 2007 \\
\hline $\begin{array}{l}\text { Soil from pasture } \\
\text { and silage intake for } \\
\text { beef cattle }\end{array}$ & $\mathrm{kg} / \mathrm{d}$ & 0.1 & $0-10$ & 0.2 & M & 3 & $\begin{array}{l}\text { DOE } 2009 \text { specifies a value of } 1 \mathrm{~kg} / \mathrm{d} \text { for soil ingested } \\
\text { daily by beef. The default values were used to } \\
\text { develop a ratio, by which this value was calculated. } \\
\text { See Attachment II following this table of parameters. }\end{array}$ & $\begin{array}{c}\text { DOE 2009, } \\
\text { Appendix D, Table } \\
\text { D.46, page D-56 }\end{array}$ \\
\hline $\begin{array}{l}\text { Soil from grain } \\
\text { intake for beef } \\
\quad \text { cattle }\end{array}$ & $\mathrm{kg} / \mathrm{d}$ & 0.4 & $0-10$ & 0.8 & $M$ & 3 & $\begin{array}{l}\text { DOE } 2009 \text { specifies a value of } 1 \mathrm{~kg} / \mathrm{d} \text { for soil ingested } \\
\text { daily by beef. The default values were used to } \\
\text { develop a ratio, by which this value was calculated. } \\
\text { See Attachment II following this table of parameters. }\end{array}$ & $\begin{array}{c}\text { DOE 2009, } \\
\text { Appendix D, Table } \\
\text { D.46, page D-56 }\end{array}$ \\
\hline
\end{tabular}

Dairy Cows 
RESRAD-OFFSITE Table of Input Parameters for the C-746-U Landfill Offsite Resident Farmer Scenario

\begin{tabular}{|c|c|c|c|c|c|c|c|c|}
\hline $\begin{array}{c}\text { Input Screen Title } \\
\text { and Parameter } \\
\text { Name }\end{array}$ & Units & $\begin{array}{l}\text { Default } \\
\text { Value }^{a}\end{array}$ & $\begin{array}{l}\text { Code-Accepted } \\
\text { Values }^{b} \\
\text { Physical or } \\
\text { Numerical }{ }^{C}(\mathrm{~N}) \\
\text { Range }\end{array}$ & $\begin{array}{l}\text { Deterministic } \\
\text { Value }\end{array}$ & Type $e^{d}$ & Priority $^{e}$ & Justification & References \\
\hline $\begin{array}{l}\text { Water intake for } \\
\text { dairy cows }\end{array}$ & $L / d$ & 160 & $0-500$ & 160 & M & 3 & Default value is used. & Yu et al. 2007 \\
\hline $\begin{array}{l}\text { Pasture and silage } \\
\text { intake for dairy } \\
\text { cows }\end{array}$ & $\mathrm{kg} / \mathrm{d}$ & 44 & $0-300$ & 25 & M & 3 & $\begin{array}{l}\text { The value used corresponds to the quantity of } \\
\text { pasture ingested daily by dairy, available in DOE } \\
2009 \text {. } \\
\text { See Attachment II following this table of parameters. }\end{array}$ & $\begin{array}{c}\text { DOE } 2009 \\
\text { Appendix D, Table } \\
\text { D.47, Page D-57 }\end{array}$ \\
\hline $\begin{array}{l}\text { Grain intake for } \\
\text { dairy cows }\end{array}$ & $\mathrm{kg} / \mathrm{d}$ & 11 & $0-300$ & 11 & M & 3 & $\begin{array}{l}\text { Default value is used because there is no site specific } \\
\text { value. }\end{array}$ & Yu et al. 2007 \\
\hline $\begin{array}{l}\text { Soil from pasture } \\
\text { and silage intake for } \\
\text { dairy cows }\end{array}$ & $\mathrm{kg} / \mathrm{d}$ & 0.4 & $0-10$ & 0.8 & M & 3 & $\begin{array}{l}\text { DOE } 2009 \text { specifies a value of } 1 \mathrm{~kg} / \mathrm{d} \text { for soil ingested } \\
\text { daily by dairy. The default values were used to } \\
\text { develop a ratio, by which this value was calculated. } \\
\text { See Attachment II following this table of parameters. }\end{array}$ & $\begin{array}{c}\text { DOE 2009, } \\
\text { Appendix D, Table } \\
\text { D.47, page D-57 }\end{array}$ \\
\hline $\begin{array}{l}\text { Soil from grain } \\
\text { intake for dairy } \\
\text { cows }\end{array}$ & $\mathrm{kg} / \mathrm{d}$ & 0.1 & $0-10$ & 0.2 & M & 3 & $\begin{array}{l}\text { DOE } 2009 \text { specifies a value of } 1 \mathrm{~kg} / \mathrm{d} \text { for soil ingested } \\
\text { daily by dairy. The default values were used to } \\
\text { develop a ratio, by which this value was calculated. } \\
\text { See Attachment II following this table of parameters. }\end{array}$ & $\begin{array}{c}\text { DOE 2009, } \\
\text { Appendix D, Table } \\
\text { D.47, page D-57 }\end{array}$ \\
\hline
\end{tabular}

Livestock Feed Factors

Pasture and Silage
\begin{tabular}{|c|c|c|c|c|c|c|c|c|}
\hline $\begin{array}{c}\text { Wet weight crop } \\
\text { yield of pasture and } \\
\text { silage }\end{array}$ & $\mathrm{kg} / \mathrm{m}^{2}$ & 1.1 & $0.01-3$ & & 1.1 & $\mathrm{P}$ & 3 & Default value is used. \\
\hline $\begin{array}{c}\text { Duration of growing } \\
\text { season of pasture } \\
\text { and silage }\end{array}$ & $\mathrm{yr}$ & 0.08 & $0.01-1$ & & 0.08 & $\mathrm{P}$ & 3 & Default value is used. \\
\hline $\begin{array}{c}\text { Foliage to food } \\
\text { transfer coefficient } \\
\text { of pasture and } \\
\text { silage }\end{array}$ & -- & 1 & $0-1$ & 1 & & $\mathrm{P}$ & 3 & Ye07 et al. 2007 \\
\hline $\begin{array}{c}\text { Weathering } \\
\text { removal constant of } \\
\text { pasture and silage }\end{array}$ & $1 / \mathrm{yr}$ & 20 & $1-40$ & & 20 & $\mathrm{P}$ & 2 & Default value is used. \\
\hline $\begin{array}{c}\text { Foliar interception } \\
\text { factor for irrigation } \\
\text { of pasture and }\end{array}$ & -- & 0.25 & $0-1$ & & 0.25 & $\mathrm{P}$ & 3 & Default value is used. \\
\hline
\end{tabular}


RESRAD-OFFSITE Table of Input Parameters for the C-746-U Landfill Offsite Resident Farmer Scenario

\begin{tabular}{|c|c|c|c|c|c|c|c|c|}
\hline $\begin{array}{c}\text { Input Screen Title } \\
\text { and Parameter } \\
\text { Name }\end{array}$ & Units & $\begin{array}{l}\text { Default } \\
\text { Value }^{a}\end{array}$ & $\begin{array}{c}\text { Code-Accepted } \\
\text { Values }^{b} \\
\text { Physical or } \\
\text { Numerical }^{c} \text { (N) } \\
\text { Range }\end{array}$ & $\begin{array}{l}\text { Deterministic } \\
\text { Value }\end{array}$ & Type $^{d}$ & Priority $^{e}$ & Justification & References \\
\hline silage & & & & & & & & \\
\hline $\begin{array}{l}\text { Foliar interception } \\
\text { factor for dust of } \\
\text { pasture and silage }\end{array}$ & -- & 0.25 & $0-1$ & 0.25 & $P$ & 3 & Default value is used. & Yu et al. 2007 \\
\hline $\begin{array}{c}\text { Root depth of } \\
\text { pasture and silage }\end{array}$ & $\mathrm{m}$ & 0.9 & $0-3$ & 0.9 & $P$ & 1 & Default value is used. & Yu et al. 2007 \\
\hline
\end{tabular}

\section{Grain}

\begin{tabular}{|c|c|c|c|c|c|c|c|l|}
\hline $\begin{array}{c}\text { Wet weight crop } \\
\text { yield of grain }\end{array}$ & $\mathrm{kg} / \mathrm{m}^{2}$ & 0.7 & $0.01-3$ & 0.7 & $\mathrm{P}$ & 3 & Yefault value is used. \\
\hline $\begin{array}{c}\text { Duration of growing } \\
\text { season of grain }\end{array}$ & $\mathrm{yr}$ & 0.17 & $0.01-1$ & 0.17 & $\mathrm{P}$ & 3 & Default value is used. \\
\hline $\begin{array}{c}\text { Foliage to food } \\
\text { transfer coefficient } \\
\text { of grain }\end{array}$ & -- & 0.1 & $0-1$ & 0.1 & $\mathrm{P}$ & 3 & Default value is used. \\
\hline $\begin{array}{c}\text { Weathering } \\
\text { removal constant of } \\
\text { grain }\end{array}$ & $1 / \mathrm{yr}$ & 20 & $1-40$ & 20 & $\mathrm{P}$ & 2 & Yu et al. 2007 \\
\hline $\begin{array}{c}\text { Foliar interception } \\
\text { factor for irrigation } \\
\text { of grain }\end{array}$ & -- & 0.25 & $0-1$ & & 0.25 & $\mathrm{P}$ & 3 & Default value is used. \\
\hline $\begin{array}{c}\text { Foliar interception } \\
\text { factor for dust of } \\
\text { grain }\end{array}$ & -- & 0.25 & $0-1$ & & 0.25 & $\mathrm{P}$ & 3 & Yu et al. 2007 \\
\hline Root depth of grain & $\mathrm{m}$ & 1.2 & $0-10$ & & 1.2 & $\mathrm{P}$ & 1 & Default value is used. \\
\hline
\end{tabular}

\section{Plant Factors}

\begin{tabular}{|c|c|c|c|c|c|c|c|c|}
\hline $\begin{array}{l}\text { Wet weight crop } \\
\text { yield of fruit, grain, } \\
\text { and nonleafy } \\
\text { vegetables }\end{array}$ & $\mathrm{kg} / \mathrm{m}^{2}$ & 0.7 & $0.01-3$ & 0.7 & $P$ & 3 & $\begin{array}{l}\text { The weight of the edible portion of plant food } \\
\text { produced per unit land area for different food } \\
\text { classes. The code has wet weight crop yield for non- } \\
\text { leafy, leafy, and fodder. Non-leafy and leafy } \\
\text { vegetables are for human consumption; fodder is for } \\
\text { animal consumption. } \\
\text { Default value is used. }\end{array}$ & Yu et al. 2007 \\
\hline $\begin{array}{l}\text { Duration of growing } \\
\text { season of fruit, } \\
\text { grain, and nonleafy } \\
\text { vegetables }\end{array}$ & $\mathrm{yr}$ & 0.17 & $0.01-1$ & 0.17 & $P$ & 3 & $\begin{array}{l}\text { This is the period of time over which the crop is } \\
\text { grown. It is assumed that the plant is exposed to } \\
\text { contamination by foliar interception during this } \\
\text { period and that all the irrigation is applied during this }\end{array}$ & Yu et al. 2007 \\
\hline
\end{tabular}


RESRAD-OFFSITE Table of Input Parameters for the C-746-U Landfill Offsite Resident Farmer Scenario

\begin{tabular}{|c|c|c|c|c|c|c|c|c|}
\hline $\begin{array}{c}\text { Input Screen Title } \\
\text { and Parameter } \\
\text { Name }\end{array}$ & Units & $\begin{array}{l}\text { Default } \\
\text { Value }^{a}\end{array}$ & $\begin{array}{c}\text { Code-Accepted } \\
\text { Values }^{b} \\
\text { Physical or } \\
\text { Numerical }^{c}(\mathrm{~N}) \\
\text { Range }^{\text {Rang }}\end{array}$ & $\begin{array}{c}\text { Deterministic } \\
\text { Value }\end{array}$ & Type $^{d}$ & Priority $^{e}$ & Justification & References \\
\hline & & & & & & & $\begin{array}{l}\text { period. } \\
\text { Default value is used. }\end{array}$ & \\
\hline $\begin{array}{c}\text { Foliage to food } \\
\text { transfer coefficient } \\
\text { of fruit, grain, and } \\
\text { nonleafy vegetables }\end{array}$ & -- & 0.1 & $0-1$ & 0.1 & $P$ & 3 & Default value is used. & Yu et al. 2007 \\
\hline $\begin{array}{l}\text { Weathering } \\
\text { removal constant of } \\
\text { fruit, grain, and } \\
\text { nonleafy vegetables }\end{array}$ & $1 / \mathrm{yr}$ & 20 & $1-40$ & 20 & $P$ & 2 & Default value is used. & Yu et al. 2007 \\
\hline $\begin{array}{l}\text { Foliar interception } \\
\text { factor for irrigation } \\
\text { of fruit, grain, and } \\
\text { nonleafy vegetables }\end{array}$ & -- & 0.25 & $0-1$ & 0.25 & $\mathrm{P}$ & 2 & Default value is used. & Yu et al. 2007 \\
\hline $\begin{array}{l}\text { Foliar interception } \\
\text { factor for dust of } \\
\text { fruit, grain, and } \\
\text { nonleafy vegetables }\end{array}$ & -- & 0.25 & $0-1$ & 0.25 & $\mathrm{P}$ & 3 & Default value is used. & Yu et al. 2007 \\
\hline $\begin{array}{l}\text { Root depth of fruit, } \\
\text { grain, and nonleafy } \\
\text { vegetables }\end{array}$ & $\mathrm{m}$ & 1.2 & $0-10$ & 1.2 & $P$ & 1 & Default value is used. & Yu et al. 2007 \\
\hline
\end{tabular}

\section{Leafy Vegetables}

\begin{tabular}{|c|c|c|c|c|c|c|c|c|}
\hline $\begin{array}{c}\text { Wet weight crop } \\
\text { yield of leafy } \\
\text { vegetables }\end{array}$ & $\mathrm{kg} / \mathrm{m}^{2}$ & 1.5 & $0.01-3$ & 1.5 & $\mathrm{P}$ & 3 & Yu et al. 2007 \\
\hline $\begin{array}{c}\text { Duration of growing } \\
\text { season of leafy } \\
\text { vegetables }\end{array}$ & $\mathrm{yr}$ & 0.25 & $0.01-1$ & 0.25 & $\mathrm{P}$ & 3 & Default value is used. \\
\hline $\begin{array}{c}\text { Foliage to food } \\
\text { transfer coefficient } \\
\text { of leafy vegetables }\end{array}$ & -- & 1 & $0-1$ & 1 & $\mathrm{P}$ & 3 & Default value is used. \\
\hline $\begin{array}{c}\text { Weathering } \\
\text { removal constant of } \\
\text { leafy vegetables }\end{array}$ & $1 / \mathrm{yr}$ & 20 & $1-40$ & 2007 & Yu et al. 2007 \\
\hline $\begin{array}{c}\text { Foliar interception } \\
\text { factor for irrigation } \\
\text { of leafy vegetables }\end{array}$ & -- & 0.25 & $0-1$ & & 0.25 & $\mathrm{P}$ & 2 & Default value is used. \\
\hline
\end{tabular}


RESRAD-OFFSITE Table of Input Parameters for the C-746-U Landfill Offsite Resident Farmer Scenario

\begin{tabular}{|c|c|c|c|c|c|c|c|c|}
\hline $\begin{array}{c}\text { Input Screen Title } \\
\text { and Parameter } \\
\text { Name }\end{array}$ & Units & $\begin{array}{l}\text { Default } \\
\text { Value }^{a}\end{array}$ & $\begin{array}{c}\text { Code-Accepted } \\
\text { Values }^{b} \\
\text { Physical or } \\
\text { Numerical }^{c} \text { (N) } \\
\text { Range }\end{array}$ & $\begin{array}{l}\text { Deterministic } \\
\text { Value }\end{array}$ & Type $^{d}$ & Priority $^{e}$ & Justification & References \\
\hline $\begin{array}{l}\text { Foliar interception } \\
\text { factor for dust of } \\
\text { leafy vegetables }\end{array}$ & -- & 0.25 & $0-1$ & 0.25 & $P$ & 3 & Default value is used. & Yu et al. 2007 \\
\hline $\begin{array}{l}\text { Root depth of leafy } \\
\text { vegetables }\end{array}$ & $\mathrm{m}$ & 0.9 & $0-3$ & 0.9 & $P$ & 1 & Default value is used. & Yu et al. 2007 \\
\hline
\end{tabular}

Inhalation and External Gamma Data

\begin{tabular}{|c|c|c|c|c|c|c|c|c|}
\hline Inhalation rate & $\mathrm{m}^{3} / \mathrm{yr}$ & 8,400 & $0-20,000$ & 7,297 & $M, B$ & 3 & $\begin{array}{l}\text { The inhalation rate for the Resident Farmer was } \\
\text { converted from a value available in DOE 2009. For } \\
\text { the conversion } 365 \text { days/yr were used, because this is } \\
\text { what RESRAD considers. }\end{array}$ & $\begin{array}{c}\text { DOE } 2009 \\
\text { Appendix D, Table } \\
\text { D.7, page D-17 } \\
\\
\text { King et al. } 2006 \\
\text { Page } 178\end{array}$ \\
\hline $\begin{array}{l}\text { Mass loading for } \\
\text { inhalation }\end{array}$ & $\mathrm{g} / \mathrm{m}^{3}$ & 0.0001 & $0-2$ & $1.08 \mathrm{E}-06$ & $P, B$ & 2 & $\begin{array}{l}\text { The following equation was used to calculate the } \\
\text { Mass Loading for Inhalation or Air-to-Soil } \\
\text { Concentration Ratio (ASR): ASR = 1/ PEF. } \\
\text { The PEF values used to calculate the mass loading for } \\
\text { inhalation are available in DOE 2009. The PEF value } \\
\text { was converted into RESRAD compatible units. } \\
\text { See Attachment II following this table of parameters. }\end{array}$ & $\begin{array}{l}\text { King et al. } 2006 \\
\text { page } 178 \\
\\
\text { DOE } 2009 \\
\text { Appendix D, Table } \\
\text { D.7 (Resident } \\
\text { Farmer = Rural } \\
\text { Resident), page D- } \\
17 \\
\end{array}$ \\
\hline $\begin{array}{l}\text { Mean onsite mass } \\
\text { loading }\end{array}$ & $\mathrm{g} / \mathrm{m}^{3}$ & 0.0001 & $0-2$ & $1.08 \mathrm{E}-06$ & $P, B$ & 2 & $\begin{array}{l}\text { This is the average mass loading of airborne } \\
\text { contaminated soil particles, above the primary } \\
\text { contamination. It is used to estimate the contaminant } \\
\text { release rate to the atmosphere. }\end{array}$ & Yu et al. 2007 \\
\hline $\begin{array}{l}\text { Indoor dust } \\
\text { filtration factor } \\
\text { (indoor to outdoor } \\
\text { dust concentration) }\end{array}$ & -- & 0.4 & $0-1$ & 0.4 & $P, B$ & 2 & $\begin{array}{l}\text { The default value is used. Indoor time fraction is the } \\
\text { driver for application of this parameter. In instances } \\
\text { where there is no indoor occupancy, this parameter } \\
\text { will not be applied. }\end{array}$ & Yu et al. 2007 \\
\hline $\begin{array}{l}\text { External gamma } \\
\text { shielding } \\
\text { (penetration) factor }\end{array}$ & -- & 0.7 & $0-1$ & 0.8 & $P$ & 2 & $\begin{array}{l}\text { The external gamma shielding factor is available for } \\
\text { the Resident Farmer in DOE } 2009 \text {. } \\
\text { The value used in the code is actually the fraction of } \\
\text { outdoor gamma radiation that penetrates the } \\
\text { building. } \\
\text { See Attachment II following this table of parameters. }\end{array}$ & $\begin{array}{c}\text { DOE } 2009 \\
\text { Appendix D, Table } \\
\text { D.8, page D-18 } \\
\text { Yu et al. } 2007\end{array}$ \\
\hline
\end{tabular}


RESRAD-OFFSITE Table of Input Parameters for the C-746-U Landfill Offsite Resident Farmer Scenario

\begin{tabular}{|c|c|c|c|c|c|c|c|}
\hline $\begin{array}{c}\text { Input Screen Title } \\
\text { and Parameter } \\
\text { Name }\end{array}$ & Units & $\begin{array}{c}\text { Default } \\
\text { Value }^{a}\end{array}$ & $\begin{array}{c}\text { Code-Accepted } \\
\text { Values } \\
\text { Physical or } \\
\text { Numerical } \\
\text { Range }\end{array}$ & $\begin{array}{c}\text { Deterministic } \\
\text { Value }\end{array}$ & Type $^{d}$ & Priority $^{e}$ & References \\
\hline
\end{tabular}

External Radiation Shape and Area Factors

\begin{tabular}{|c|c|c|c|c|c|c|c|c|}
\hline Dwelling location & & Offsite & $\begin{array}{l}\text { Onsite or } \\
\text { offsite }\end{array}$ & Offsite & $P$ & 3 & $\begin{array}{l}\text { The receptor is located outside the contaminated } \\
\text { zone. }\end{array}$ & Yu et al. 2007 \\
\hline Scale & $\mathrm{m}$ & 200 & $>0-32,000$ & 1000 & $P$ & 3 & $\begin{array}{l}\text { This scale is chosen to fully encompass the primary } \\
\text { contamination. }\end{array}$ & Yu et al. 2007 \\
\hline $\begin{array}{l}\text { Dwelling location } \\
\text { coordinate in X- } \\
\text { direction }\end{array}$ & $\mathrm{m}$ & 100 & $\begin{array}{l}-16,000- \\
+16,000\end{array}$ & 190.375 & $P$ & 3 & $\begin{array}{l}\text { The dwelling is located near the well, north of the } \\
\text { contaminated zone. }\end{array}$ & \\
\hline $\begin{array}{l}\text { Dwelling location } \\
\text { coordinate in y- } \\
\text { direction }\end{array}$ & $\mathrm{m}$ & 0 & $\begin{array}{l}-16,000- \\
+16,000\end{array}$ & 670 & $P$ & 3 & $\begin{array}{l}\text { The dwelling is located near the well, } 300 \text { meters } \\
\text { north of the north edge of the contaminated zone. }\end{array}$ & \\
\hline \multirow{12}{*}{ Radius } & \multirow{12}{*}{$\mathrm{m}$} & 13.25 & \multirow{12}{*}{ Calculated } & Calculated & \multirow{12}{*}{$\mathrm{P}$} & \multirow{12}{*}{3} & \multirow[t]{12}{*}{ Calculated by the code. } & \multirow[t]{12}{*}{ Yu et al. 2007} \\
\hline & & 26.5 & & Calculated & & & & \\
\hline & & 39.75 & & Calculated & & & & \\
\hline & & 53 & & Calculated & & & & \\
\hline & & 66.25 & & Calculated & & & & \\
\hline & & 79.5 & & Calculated & & & & \\
\hline & & 92.75 & & Calculated & & & & \\
\hline & & 106 & & Calculated & & & & \\
\hline & & 119.25 & & Calculated & & & & \\
\hline & & 132.5 & & Calculated & & & & \\
\hline & & 145.75 & & Calculated & & & & \\
\hline & & 159 & & Calculated & & & & \\
\hline \multirow{12}{*}{ Fraction } & \multirow{12}{*}{--} & 0 & \multirow{12}{*}{ Calculated } & Calculated & \multirow{12}{*}{$\mathrm{P}$} & \multirow{12}{*}{3} & \multirow[t]{12}{*}{ Calculated by the code. } & \multirow[t]{12}{*}{ Yu et al. 2007} \\
\hline & & 0 & & Calculated & & & & \\
\hline & & 0 & & Calculated & & & & \\
\hline & & 0.024 & & Calculated & & & & \\
\hline & & 0.19 & & Calculated & & & & \\
\hline & & 0.24 & & Calculated & & & & \\
\hline & & 0.2 & & Calculated & & & & \\
\hline & & 0.17 & & Calculated & & & & \\
\hline & & 0.15 & & Calculated & & & & \\
\hline & & 0.13 & & Calculated & & & & \\
\hline & & 0.12 & & Calculated & & & & \\
\hline & & 0.052 & & Calculated & & & & \\
\hline
\end{tabular}


RESRAD-OFFSITE Table of Input Parameters for the C-746-U Landfill Offsite Resident Farmer Scenario

\begin{tabular}{|c|c|c|c|c|c|c|c|c|}
\hline $\begin{array}{c}\text { Input Screen Title } \\
\text { and Parameter } \\
\text { Name }\end{array}$ & Units & $\begin{array}{l}\text { Default } \\
\text { Value }^{a}\end{array}$ & $\begin{array}{c}\text { Code-Accepted } \\
\text { Values }^{b} \\
\text { Physical or } \\
\text { Numerical }{ }^{c}(\mathrm{~N}) \\
\text { Range }^{\text {Rang }}\end{array}$ & $\begin{array}{l}\text { Deterministic } \\
\text { Value }\end{array}$ & Type $^{d}$ & Priority $^{e}$ & Justification & References \\
\hline $\begin{array}{l}\text { Shape of the } \\
\text { primary } \\
\text { contamination }\end{array}$ & -- & Polygonal & $\begin{array}{l}\text { Circular or } \\
\text { polygonal }\end{array}$ & Polygonal & P & 3 & $\begin{array}{l}\text { The coordinates of the waste area were used to } \\
\text { create the shape of the contaminated area. }\end{array}$ & $\begin{array}{l}\text { Yu et al. } 2007 \\
\text { Lee et al. } 1995\end{array}$ \\
\hline $\begin{array}{l}\mathrm{X} \text { coordinate of the } \\
\text { vertices of polygon } \\
\text { of the primary } \\
\text { contamination }\end{array}$ & $\mathrm{m}$ & none & $\begin{array}{l}-16,000- \\
+16,000\end{array}$ & $\begin{array}{c}X 1=98, \\
X 2=256, \\
X 3=256, \\
X 4=0, \\
X 5=0, \\
X 6=98\end{array}$ & $P$ & 3 & $\begin{array}{l}\text { The coordinates of the waste area were used to } \\
\text { create the shape of the contaminated area. }\end{array}$ & Lee et al. 1995 \\
\hline $\begin{array}{l}Y \text { coordinate of the } \\
\text { vertices of polygon } \\
\text { of the primary } \\
\text { contamination }\end{array}$ & $\mathrm{m}$ & none & $\begin{array}{l}-16,000- \\
+16,000\end{array}$ & $\begin{array}{c}Y 1=0, \\
Y 2=0, \\
Y 3=399, \\
Y 4=399, \\
Y 5=210, \\
Y 6=0\end{array}$ & $P$ & 3 & $\begin{array}{l}\text { The coordinates of the waste area were used to } \\
\text { create the shape of the contaminated area. }\end{array}$ & Lee et al. 1995 \\
\hline
\end{tabular}

Occupancy Factors

\begin{tabular}{|c|c|c|c|c|c|c|c|c|}
\hline $\begin{array}{l}\text { Indoor time fraction } \\
\text { on primary } \\
\text { contamination }\end{array}$ & -- & 0 & $0-1$ & 0 & B & 3 & $\begin{array}{l}\text { This parameter is the average fraction of time during } \\
\text { which an individual stays indoors. } \\
\text { The default value is used. The Resident Farmer does } \\
\text { not spend any time onsite. }\end{array}$ & Yu et al. 2007 \\
\hline $\begin{array}{l}\text { Outdoor time } \\
\text { fraction on primary } \\
\text { contamination }\end{array}$ & -- & 0 & $0-1$ & 0 & B & 3 & $\begin{array}{l}\text { This parameter is the average fraction of time during } \\
\text { which an individual stays outdoors on the site. } \\
\text { The default value is used. The Resident Farmer does } \\
\text { not spend any time onsite. }\end{array}$ & Yu et al. 2007 \\
\hline $\begin{array}{l}\text { Indoor time fraction } \\
\text { on offsite dwelling } \\
\text { site }\end{array}$ & -- & 0.5 & $0-1$ & 0.64 & B & 3 & $\begin{array}{l}\text { This parameter is the average fraction of time during } \\
\text { which an individual stays indoors. } \\
\text { The Resident Farmer is inside } 16 \text { hours per day, } 350 \\
\text { days per year which results in an indoor fraction of } \\
64 \% \text {. }\end{array}$ & $\begin{array}{c}\text { DOE } 2009 \\
\text { Appendix D, } \\
\text { Table D.8, page D- } \\
18\end{array}$ \\
\hline $\begin{array}{l}\text { Outdoor time } \\
\text { fraction on offsite } \\
\text { dwelling site }\end{array}$ & -- & 0.1 & $0-1$ & 0.064 & B & 3 & $\begin{array}{l}\text { This parameter is the average fraction of time during } \\
\text { which an individual stays outdoors on the site. } \\
\text { The Resident Farmer is outside } 8 \text { hours per day, } 350 \\
\text { days per year which results in an outdoor fraction of } \\
32 \% \text {. }\end{array}$ & $\begin{array}{c}\text { DOE } 2009 \\
\text { Appendix D, Table } \\
\text { D.8, page D-18 }\end{array}$ \\
\hline
\end{tabular}


RESRAD-OFFSITE Table of Input Parameters for the C-746-U Landfill Offsite Resident Farmer Scenario

\begin{tabular}{|c|c|c|c|c|c|c|c|c|}
\hline $\begin{array}{c}\text { Input Screen Title } \\
\text { and Parameter } \\
\text { Name }\end{array}$ & Units & $\begin{array}{l}\text { Default } \\
\text { Value }^{a}\end{array}$ & $\begin{array}{c}\text { Code-Accepted } \\
\text { Values }^{b} \\
\text { Physical or } \\
\text { Numerical }^{c} \text { (N) } \\
\text { Range }\end{array}$ & $\begin{array}{c}\text { Deterministic } \\
\text { Value }\end{array}$ & Type $^{d}$ & Priority $^{e}$ & Justification & References \\
\hline & & & & & & & $\begin{array}{l}\text { The outdoor fraction of } 0.32 \text { is divided by the number } \\
\text { of outdoor locations (5) to determine the time } \\
\text { fraction. }\end{array}$ & \\
\hline $\begin{array}{c}\text { Time fraction in } \\
\text { fruit, grain, and } \\
\text { nonleafy vegetable } \\
\text { fields }\end{array}$ & -- & 0.1 & $0-1$ & 0.064 & B & 3 & $\begin{array}{l}\text { This parameter is the average fraction of time during } \\
\text { which an individual stays outdoors on the site. } \\
\text { The Resident Farmer is outside } 8 \text { hours per day, } 350 \\
\text { days per year which results in an outdoor fraction of } \\
32 \% \text {. } \\
\text { The outdoor fraction of } 0.32 \text { is divided by the number } \\
\text { of outdoor locations (5) to determine the time } \\
\text { fraction. }\end{array}$ & $\begin{array}{c}\text { DOE } 2009 \\
\text { Appendix D, Table } \\
\text { D.8, page D-18 }\end{array}$ \\
\hline $\begin{array}{l}\text { Time fraction in } \\
\text { leafy vegetable } \\
\text { fields }\end{array}$ & -- & 0.1 & $0-1$ & 0.064 & B & 3 & $\begin{array}{l}\text { This parameter is the average fraction of time during } \\
\text { which an individual stays outdoors on the site. } \\
\text { The Resident Farmer is outside } 8 \text { hours per day, } 350 \\
\text { days per year which results in an outdoor fraction of } \\
32 \% \text {. } \\
\text { The outdoor fraction of } 0.32 \text { is divided by the number } \\
\text { of outdoor locations (5) to determine the time } \\
\text { fraction. }\end{array}$ & $\begin{array}{c}\text { DOE } 2009 \\
\text { Appendix D, Table } \\
\text { D.8, page D-18 }\end{array}$ \\
\hline $\begin{array}{l}\text { Time fraction in } \\
\text { pasture and silage } \\
\text { fields }\end{array}$ & -- & 0.1 & $0-1$ & 0.064 & B & 3 & $\begin{array}{l}\text { This parameter is the average fraction of time during } \\
\text { which an individual stays outdoors on the site. } \\
\text { The Resident Farmer is outside } 8 \text { hours per day, } 350 \\
\text { days per year which results in an outdoor fraction of } \\
32 \% \text {. } \\
\text { The outdoor fraction of } 0.32 \text { is divided by the number } \\
\text { of outdoor locations (5) to determine the time } \\
\text { fraction. }\end{array}$ & $\begin{array}{c}\text { DOE } 2009 \\
\text { Appendix D, Table } \\
\text { D.8, page D-18 }\end{array}$ \\
\hline
\end{tabular}


RESRAD-OFFSITE Table of Input Parameters for the C-746-U Landfill Offsite Resident Farmer Scenario

\begin{tabular}{|c|c|c|c|c|c|c|c|c|}
\hline $\begin{array}{c}\text { Input Screen Title } \\
\text { and Parameter } \\
\text { Name }\end{array}$ & Units & $\begin{array}{l}\text { Default } \\
\text { Value }^{a}\end{array}$ & $\begin{array}{c}\text { Code-Accepted } \\
\text { Values }^{b} \\
\text { Physical or } \\
\text { Numerical }^{c}(\mathrm{~N}) \\
\text { Range }\end{array}$ & $\begin{array}{c}\text { Deterministic } \\
\text { Value }\end{array}$ & Type $^{d}$ & Priority $^{e}$ & Justification & References \\
\hline $\begin{array}{l}\text { Time fraction in } \\
\text { livestock grain fields }\end{array}$ & -- & 0.1 & $0-1$ & 0.064 & B & 3 & $\begin{array}{l}\text { This parameter is the average fraction of time during } \\
\text { which an individual stays outdoors on the site. } \\
\text { The Resident Farmer is outside } 8 \text { hours per day, } 350 \\
\text { days per year which results in an outdoor fraction of } \\
32 \% \text {. } \\
\text { The outdoor fraction of } 0.32 \text { is divided by the number } \\
\text { of outdoor locations (5) to determine the time } \\
\text { fraction. }\end{array}$ & $\begin{array}{c}\text { DOE } 2009 \\
\text { Appendix D, Table } \\
\text { D.8, page D-18 }\end{array}$ \\
\hline
\end{tabular}

a The default values listed in this table are the default values in the RESRAD-OFFSITE code Version 2.

b RESRAD-OFFSITE does not provide code-accepted values for element- or nuclide-specific parameters.

c Numerical range is the range defined in a program file to prevent code crashes.

d $\quad P=$ physical, $B=$ behavioral, $M=$ metabolic; when more than one type is listed, the first is primary and the next is secondary.

e According to NUREG/CR-6697, it is necessary to establish priorities about which parameters to collect data for and use for distribution analysis. The parameters were ranked into three levels of priority: 1 (high priority), 2 (medium priority), and 3 (low priority).

f $\quad \mathrm{NA}=$ not applicable.

g Two hyphens indicate that the parameter is dimensionless.

Notes: According to the RESRAD-OFFSITE manual, the Radon parameters can be changed only if a radon precursor is selected in the radionuclide list and the radon pathway is turned on. Similarly, a user will have access to carbon-14 (C-14) or tritium (H-3) parameters only if C-14 or $\mathrm{H}-3$ radionuclides are selected as a contaminant.

The template for the table of parameters was created based on information available information in the User's Manual for RESRAD-OFFSITE Version 2. 
Attachment I

Distribution Coefficients 


\section{Distribution Coefficients $\left(K d s, \mathrm{~cm}^{3} / \mathrm{g}\right)^{a, b}$ for parent radionuclides in the contaminated zone, the unsaturated zone, and the saturated zone}

\begin{tabular}{|c|c|c|c|c|c|c|c|c|c|c|c|c|}
\hline Radionuclide & Am-241 & Cs-137 & Np-237 & Pu-238 & Pu-239/240 & Tc-99 & Th-228 & Th-230 & Th-232 & U-234 & U-235 & U-238 \\
\hline Contaminated Zone $^{c}$ & 1900 & 280 & 70 & 550 & 550 & 1 & 3200 & 3200 & 3200 & 410 & 410 & 410 \\
\hline $\begin{array}{c}\text { Unsaturated Zone } 1 \\
\text { (Protective layer } \\
\text { [native soil]) }\end{array}$ & 1900 & 280 & 70 & 550 & 550 & 0.2 & 3200 & 3200 & 3200 & 66.8 & 66.8 & 66.8 \\
\hline $\begin{array}{l}\text { Unsaturated Zone } 2 \\
\text { (Gravel layer [no } \\
\text { collection]) }\end{array}$ & 1900 & 280 & 70 & 550 & 550 & 0.2 & 3200 & 3200 & 3200 & 66.8 & 66.8 & 66.8 \\
\hline $\begin{array}{c}\text { Unsaturated Zone } 3 \\
\text { (Clay barrier) }\end{array}$ & 8400 & 1900 & 144 & 5100 & 5100 & 20 & 5800 & 5800 & 5800 & 3640 & 3640 & 3640 \\
\hline $\begin{array}{c}\text { Unsaturated Zone } 4 \\
\text { (Alluvium soils } \\
\text { [native/subgrade]) }\end{array}$ & 1900 & 280 & 70 & 550 & 550 & 0.2 & 3200 & 3200 & 3200 & 66.8 & 66.8 & 66.8 \\
\hline $\begin{array}{c}\text { Unsaturated Zone } 5 \\
\text { (Clay confining unit } \\
\text { [native]) }\end{array}$ & 8400 & 1900 & 144 & 5100 & 5100 & 20 & 5800 & 5800 & 5800 & 3640 & 3640 & 3640 \\
\hline Saturated Zone(RGA) & 1900 & 280 & 70 & 550 & 550 & 0.2 & 3200 & 3200 & 3200 & 66.8 & 66.8 & 66.8 \\
\hline
\end{tabular}

\footnotetext{
a Distribution coefficients for Am-241, Np-237, Th-230, Th-232, U-234 and U-238 were obtained from DOE 2003b, page C3-313 and Table Att. 1. Distribution coefficient of radionuclides and their daughter products in different zones, page C3-314. It was assumed that the Kd for U-235 was similar to the Kd for U-234 and U-238 since the Kds are chemical specific.

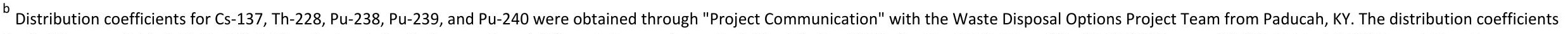
for Tc-99 are available in Table C.3.1. Chemical and physical properties of different classes of chemicals identified as COPCs for the C-746-U Landfill of DOE 2003b, page C3-301. Table 4.5 DUST model input parameters, page 4-12, has Kds for Tc-99 and Uranium.

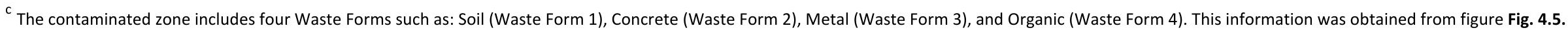
Schematic diagram of DUST model layers and materials for the Post-Institutional Control Period under the gradual failure and immediate failure scenarios of DOE 2003b, page 4-18.
} 
Distribution Coefficients $\left(\mathrm{Kds}, \mathrm{cm}^{3} / \mathrm{g}\right)^{d}$ for progeny radionuclides in the contaminated zone, the unsaturated zones, and the saturated zone

\begin{tabular}{|c|c|c|c|c|c|c|c|c|}
\hline Radionuclide & Ac-227 & $\mathrm{Pa}-231$ & $\mathrm{~Pb}-210$ & Ra-226 & Ra-228 & Th-229 & U-233 & U-236 \\
\hline Contaminated Zone $e^{e}$ & 450 & 550 & 270 & 500 & 500 & 3200 & 410 & 410 \\
\hline $\begin{array}{c}\text { Unsaturated Zone } 1 \\
\text { (Protective layer [native soil]) }\end{array}$ & 450 & 550 & 270 & 500 & 500 & 3200 & 66.8 & 66.8 \\
\hline $\begin{array}{c}\text { Unsaturated Zone } 2 \\
\text { (Gravel layer [no collection]) }\end{array}$ & 450 & 550 & 270 & 500 & 500 & 3200 & 66.8 & 66.8 \\
\hline $\begin{array}{l}\text { Unsaturated Zone } 3 \\
\quad \text { (Clay barrier) }\end{array}$ & 2400 & 2700 & 550 & 9100 & 9100 & 5800 & 3640 & 3640 \\
\hline $\begin{array}{c}\text { Unsaturated Zone } 4 \\
\text { (Alluvium soils [native/subgrade]) }\end{array}$ & 450 & 550 & 270 & 500 & 500 & 3200 & 66.8 & 66.8 \\
\hline $\begin{array}{c}\text { Unsaturated Zone } 5 \\
\text { (Clay confining unit [native]) }\end{array}$ & 2400 & 2700 & 550 & 9100 & 9100 & 5800 & 3640 & 3640 \\
\hline Saturated Zone (RGA) & 450 & 550 & 270 & 500 & 500 & 3200 & 66.8 & 66.8 \\
\hline
\end{tabular}

\footnotetext{
d Distribution coefficients for Ac-227, Pa-231, Pb-210, Ra-226, Ra-228, Th-229, and U-236 were obtained through "Project Communication" with the Waste Disposal Options Project Team from Paducah, KY. It was assumed that the Kds for U-233 was similar to the Kds for the other uranium isotopes (i.e. U-234, U-235, U-236 and U-238), since the Kds are chemical specific.

e The contaminated zone includes four Waste Forms such as: Soil (Waste Form 1), Concrete (Waste Form 2), Metal (Waste Form 3), and Organic (Waste Form 4). This information was obtained from figure Fig. 4.5. Schematic diagram of DUST model layers and materials for the Post Institutional Control Period under the gradual failure and immediate failure scenarios of DOE $2003 \mathrm{~b}$, page 4-18.
} 
Distribution Coefficients ( $K d s, \mathrm{~cm}^{3} / \mathrm{g}$ ) for parent radionuclides in the sediment in surface water body; fruit, grain, nonleafy fields; leafy vegetable fields; pasture, silage growing areas; livestock feed grain fields; and dwelling site $e^{f}$

\begin{tabular}{|c|c|c|c|c|c|c|c|c|c|c|c|c|}
\hline Radionuclide & Am-241 & Cs-137 & Np-237 & Pu-238 & $\mathrm{Pu}-239 / 240$ & Tc-99 & Th-228 & Th-230 & Th-232 & U-234 & U-235 & U-238 \\
\hline $\begin{array}{c}\text { Sediment in } \\
\text { Surface Water } \\
\text { Body }\end{array}$ & 1900 & 280 & 70 & 550 & 550 & 0.2 & 3200 & 3200 & 3200 & 66.8 & 66.8 & 66.8 \\
\hline $\begin{array}{c}\text { Fruit, Grain, } \\
\text { Non-Leafy Fields }\end{array}$ & 1900 & 280 & 70 & 550 & 550 & 0.2 & 3200 & 3200 & 3200 & 66.8 & 66.8 & 66.8 \\
\hline $\begin{array}{l}\text { Leafy Vegetable } \\
\text { Fields }\end{array}$ & 1900 & 280 & 70 & 550 & 550 & 0.2 & 3200 & 3200 & 3200 & 66.8 & 66.8 & 66.8 \\
\hline $\begin{array}{l}\text { Pasture, Silage } \\
\text { Growing Areas }\end{array}$ & 1900 & 280 & 70 & 550 & 550 & 0.2 & 3200 & 3200 & 3200 & 66.8 & 66.8 & 66.8 \\
\hline $\begin{array}{l}\text { Livestock Feed } \\
\text { Grain Fields }\end{array}$ & 1900 & 280 & 70 & 550 & 550 & 0.2 & 3200 & 3200 & 3200 & 66.8 & 66.8 & 66.8 \\
\hline Dwelling Site & 1900 & 280 & 70 & 550 & 550 & 0.2 & 3200 & 3200 & 3200 & 66.8 & 66.8 & 66.8 \\
\hline
\end{tabular}

\footnotetext{
${ }^{\mathrm{f}}$ The Kds for native soil (Unsaturated Zone 2) were assumed for these areas.
} 
Distribution Coefficients ( $K d s, \mathrm{~cm}^{3} / \mathrm{g}$ ) for progeny in the sediment in surface water body; fruit, grain, nonleafy fields; leafy vegetable fields; pasture, silage growing areas; livestock feed grain fields; and dwelling site

\begin{tabular}{|c|c|c|c|c|c|c|c|c|}
\hline Radionuclide & Ac-227 & $\mathrm{Pa}-231$ & $\mathrm{~Pb}-210$ & Ra-226 & Ra-228 & Th-229 & U-233 & U-236 \\
\hline Sediment in Surface Water Body & 450 & 550 & 270 & 500 & 500 & 3200 & 66.8 & 66.8 \\
\hline Fruit, Grain, Non-Leafy Fields & 450 & 550 & 270 & 500 & 500 & 3200 & 66.8 & 66.8 \\
\hline Pasture, Silage Growing Areas & 450 & 550 & 270 & 500 & 500 & 3200 & 66.8 & 66.8 \\
\hline Livestock Feed Grain Fields & 450 & 550 & 270 & 500 & 500 & 3200 & 66.8 & 66.8 \\
\hline Dwelling Site & 450 & 550 & 270 & 500 & 500 & 3200 & 66.8 & 66.8 \\
\hline
\end{tabular}


Attachment II

Calculations and Applicable Parameters from DOE 2009, Appendix D, Converted into RESRAD Compatible Units 


\section{Section A. Runoff Coefficient and Evapotranspiration Coefficient Calculations}

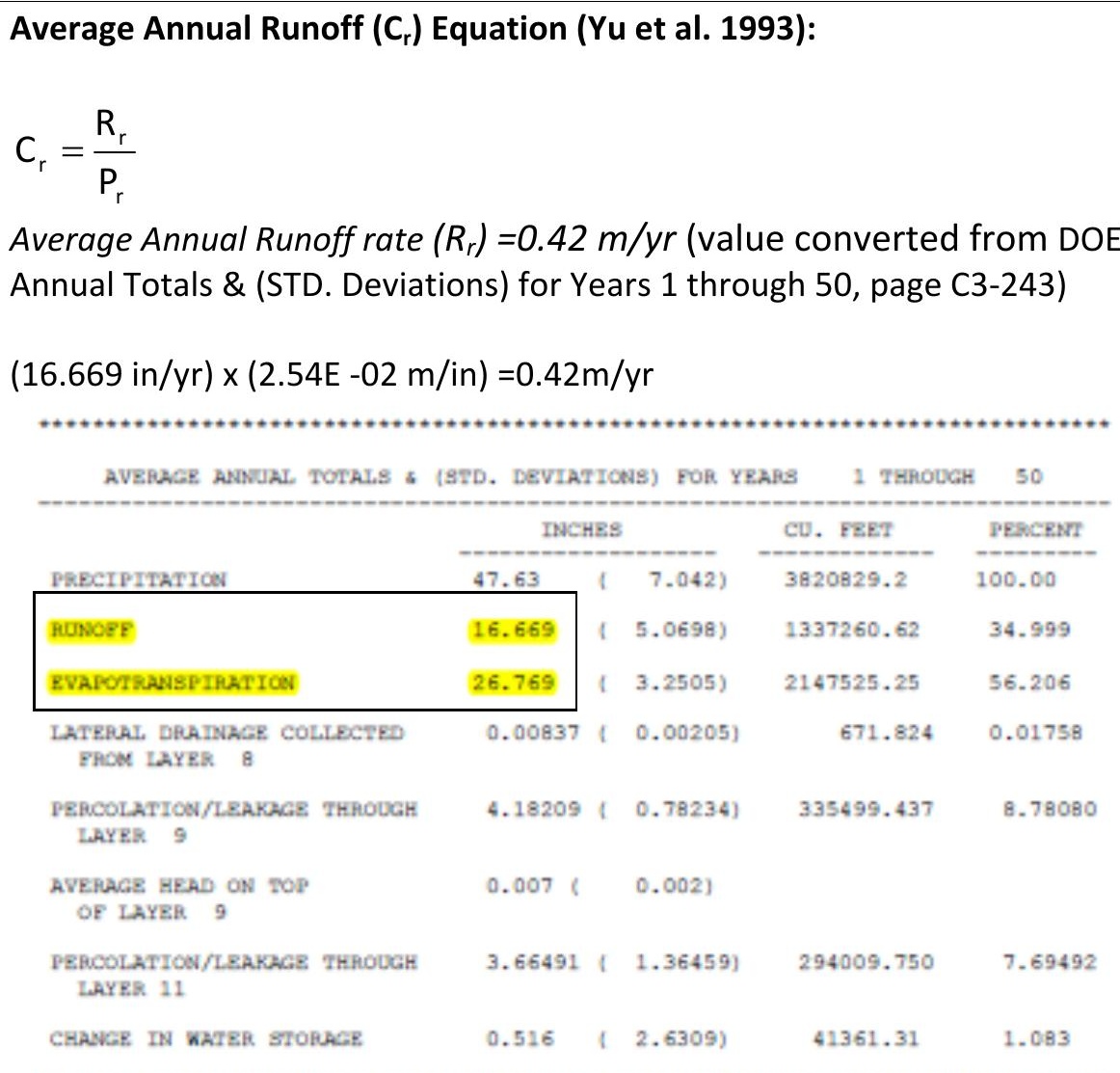




\section{Section A. Runoff Coefficient and Evapotranspiration Coefficient Calculations (cont.)}

$$
\begin{aligned}
& \text { Evapotranspiration Coefficient }\left(C_{e}\right) \text { Equation from Yu et al. 1993: } \\
& \text { The following evapotranspiration coefficient applies to areas including } \\
& \text { dwelling site: } \\
& C_{e}=\frac{E T_{r}}{\left(1-C_{r}\right) P_{r}+I R_{r}} \\
& C_{e}=\frac{0.68 \mathrm{~m} / \mathrm{yr}}{(1-0.34) 1.24 \mathrm{~m} / \mathrm{yr}+0 \mathrm{~m} / \mathrm{yr}}, C_{e}=0.83
\end{aligned}
$$

The following evapotranspiration coefficient applies to areas including the primary contaminated zone, livestock feed growing areas and offsite

The Evapotranspiration coefficient is $\mathbf{C}_{\mathrm{e}} \mathbf{=} \mathbf{0 . 8 3}$ assuming an Irrigation rate $\left(\mathrm{IR}_{\mathrm{r}}\right)$ of $0 \mathrm{~m} / \mathrm{yr}$, an Evapotranspiration rate $\left(\mathrm{ET}_{\mathrm{r}}\right)$ of $0.68 \mathrm{~m} / \mathrm{yr}$, a Precipitation rate of $1.24 \mathrm{~m} / \mathrm{yr}$, and a runoff coefficient of 0.34 .

Evapotranspiration rate $\left(E T_{r}\right)=0.68 \mathrm{~m} / \mathrm{yr}$ (value converted from DOE 2003b, HELP Output List 3. Post Institutional Control Period, Average Annual Totals \& (STD. Deviations) for Years 1 through 50, page C3-243)

$(26.769 \mathrm{in} / \mathrm{yr}) \times(2.54 \mathrm{E}-02 \mathrm{~m} / \mathrm{in})=0.68 \mathrm{~m} / \mathrm{yr}$

As recommended by DOE-PPPO, an irrigation rate of $0.1 \mathrm{~m} / \mathrm{yr}$ was assumed for the Offsite Resident Farmer agricultural areas (i.e., fruit, grain, non-leafy and leafy vegetables).

The following evapotranspiration coefficient applies to the agricultural areas:

$C_{e}=\frac{0.68 \mathrm{~m} / \mathrm{yr}}{(1-0.34) 1.24 \mathrm{~m} / \mathrm{yr}+0.1 \mathrm{~m} / \mathrm{yr}}, \quad C_{e}=0.74$

The Evapotranspiration coefficient is $\mathbf{C}_{\mathrm{e}} \mathbf{=} \mathbf{0 . 7 4}$ assuming an Irrigation rate $\left(I \mathrm{R}_{\mathrm{r}}\right)$ of $0.1 \mathrm{~m} / \mathrm{yr}$, an Evapotranspiration rate $\left(E T_{r}\right)$ of $0.68 \mathrm{~m} / \mathrm{yr}$, a Precipitation rate of $1.24 \mathrm{~m} / \mathrm{yr}$, and a runoff coefficient of 0.34 . 
Section B. Parameters Applicable to the Resident Farmer from DOE 2009, Appendix D Converted into RESRAD Compatible Units

\section{Drinking Water Intake}

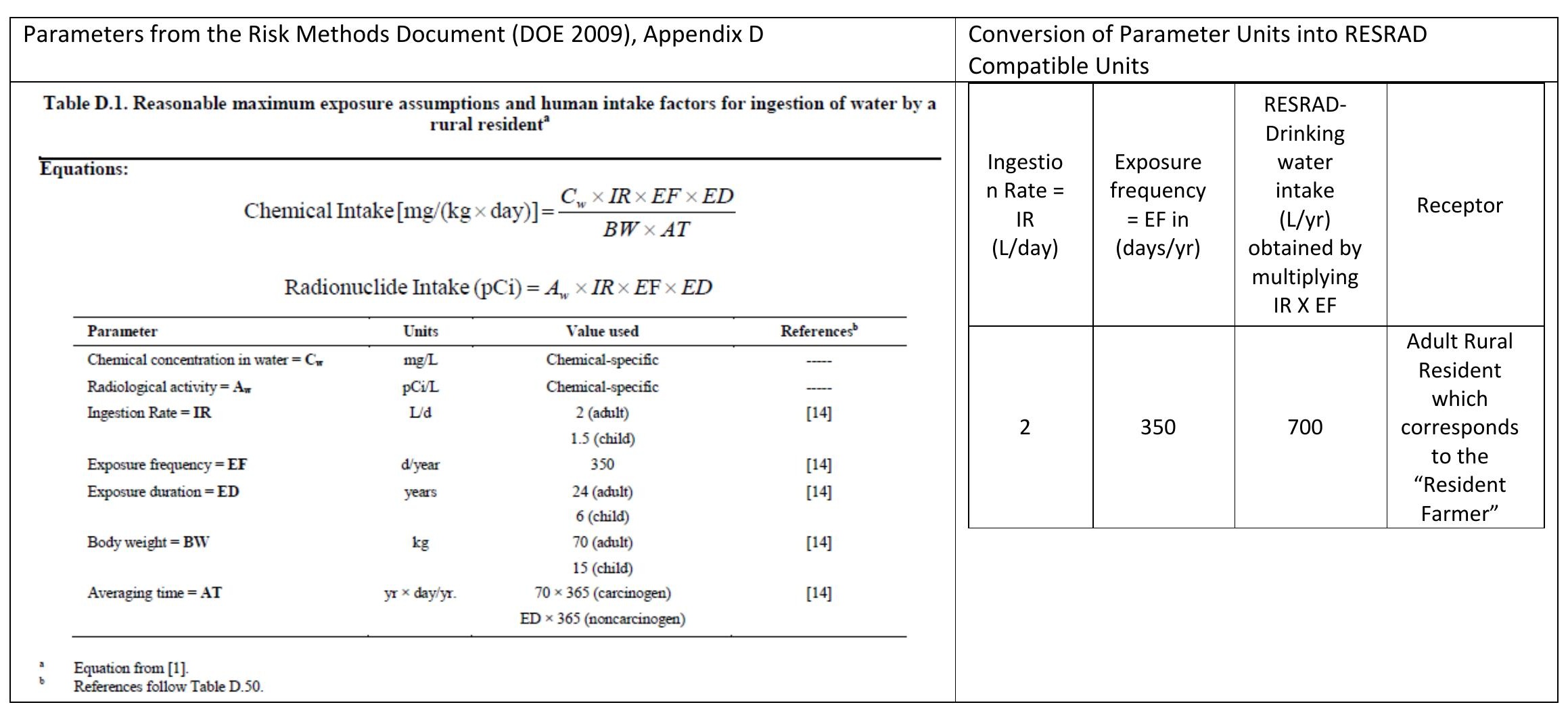


Section B. Parameters Applicable to the Resident Farmer from DOE 2009, Appendix D Converted into RESRAD Compatible Units (cont.)

\section{Soil Ingestion Rate}

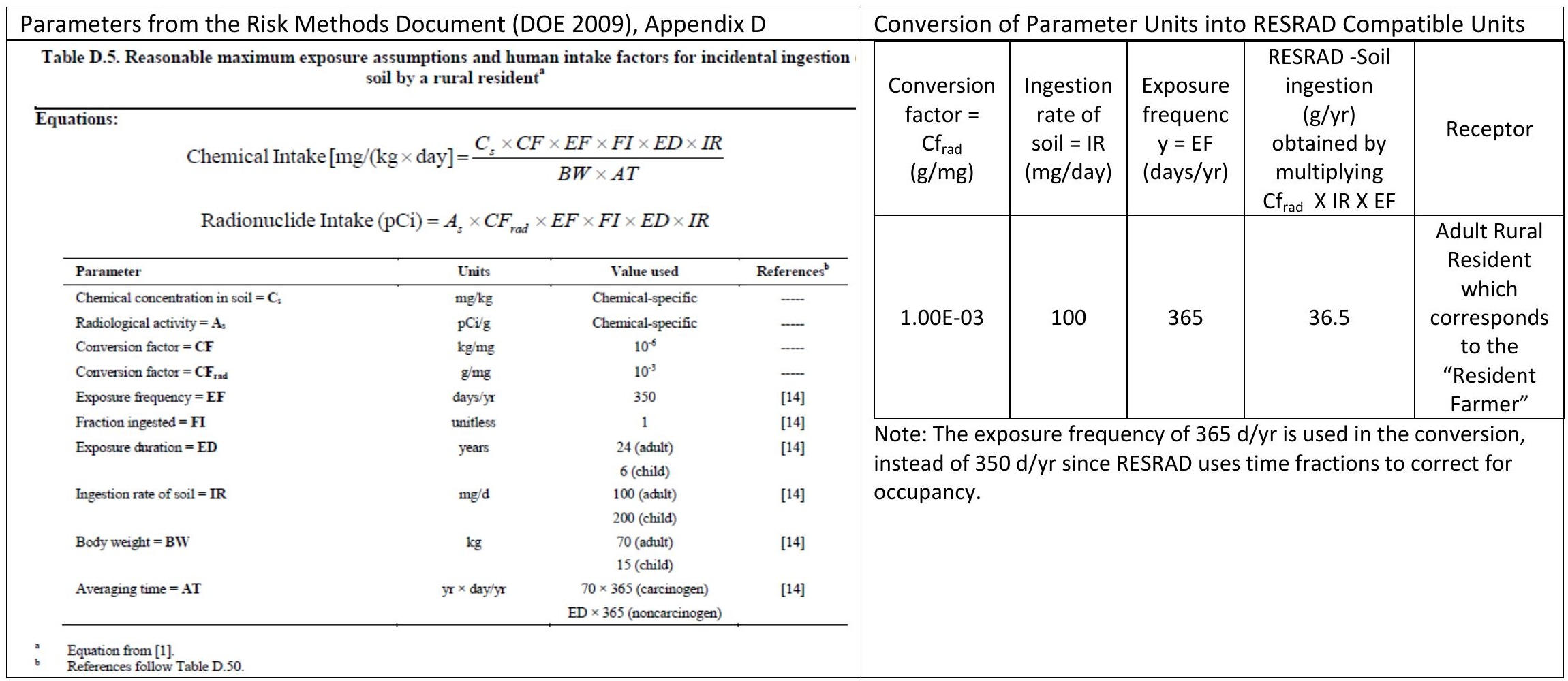




\section{Section B. Parameters Applicable to the Resident Farmer from DOE 2009, Appendix D Converted into RESRAD Compatible Units}

(cont.)

\section{Inhalation Rate and Mass Loading for Inhalation}

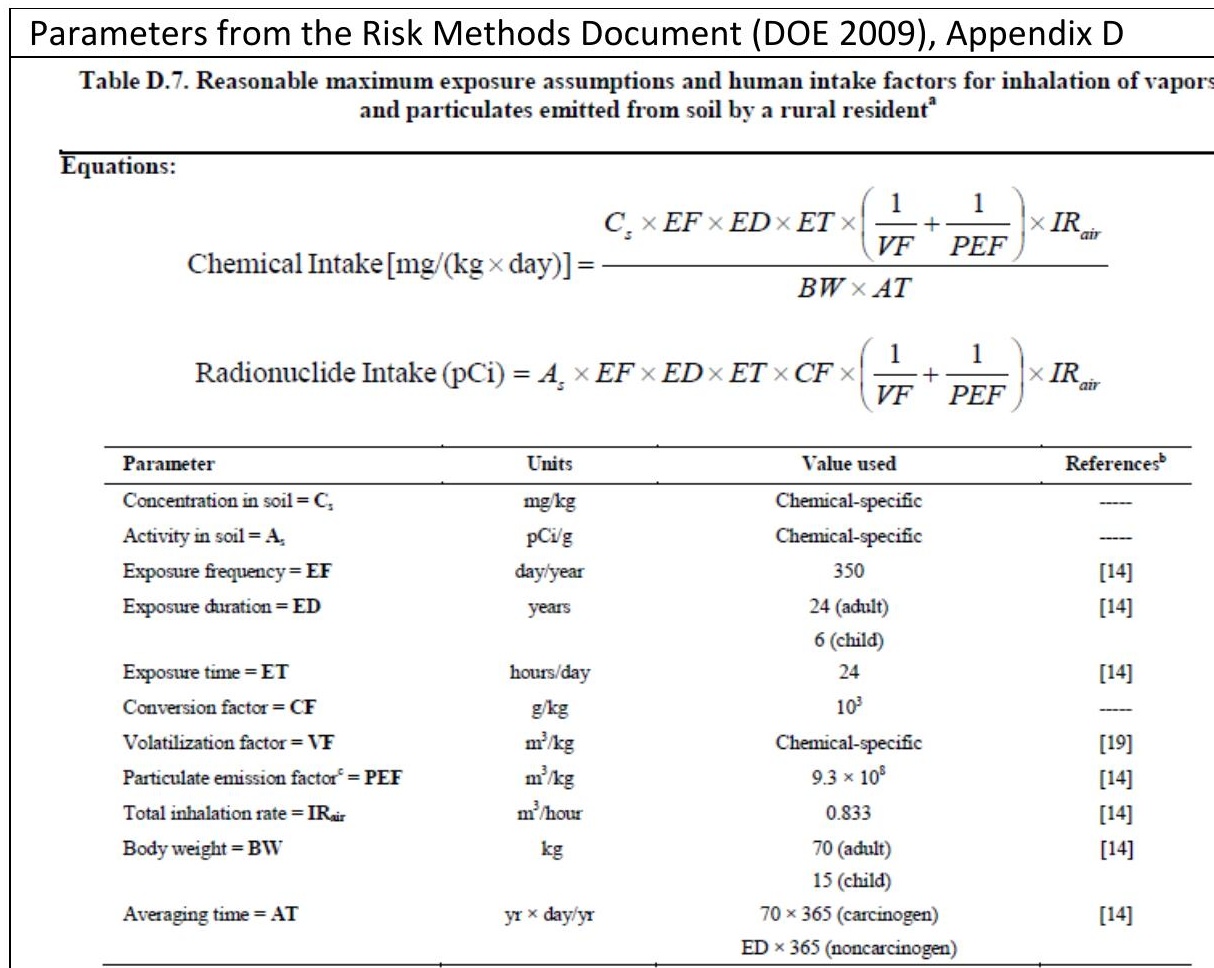

\begin{tabular}{|c|c|c|c|c|}
\hline \multicolumn{5}{|c|}{ Conversion of Parameter Units into RESRAD Compatible Units } \\
\hline $\begin{array}{c}\text { Total } \\
\text { inhalation } \\
\text { rate }=I R_{\text {air }} \\
\left.\text { ( } \mathrm{m}^{3} / \text { hour }\right)\end{array}$ & $\begin{array}{c}\text { Exposure } \\
\text { time = ET } \\
\text { (hours/ } \\
\text { day) }\end{array}$ & $\begin{array}{l}\text { Exposure } \\
\text { frequency } \\
=\mathrm{EF} \\
\text { (days/yr) }\end{array}$ & $\begin{array}{l}\text { RESRAD- } \\
\text { Inhalation } \\
\text { rate }\left(\mathrm{m}^{3} / \mathrm{yr}\right) \\
\text { obtained by } \\
\text { multiplying } \\
\text { IF X ET X EF }\end{array}$ & Receptor \\
\hline 0.833 & 24 & 365 & 7,297 & $\begin{array}{l}\text { Adult Rural } \\
\text { Resident } \\
\text { which } \\
\text { corresponds to } \\
\text { the "Resident } \\
\text { Farmer" }\end{array}$ \\
\hline
\end{tabular}

Note: The exposure frequency of $365 \mathrm{~d} / \mathrm{yr}$ is used in the conversion, instead of $350 \mathrm{~d} / \mathrm{yr}$ since RESRAD uses time fractions to correct for occupancy.

\begin{tabular}{|c|c|c|c|c|}
\hline $\begin{array}{c}\mathrm{PEF} \\
\left(\mathrm{m}^{3} / \mathrm{kg}\right)\end{array}$ & $\begin{array}{c}\text { Conversion } \\
\text { from } \\
\mathrm{kg} \text { to g }\end{array}$ & $\operatorname{PEF~}\left(\mathrm{m}^{3} / \mathrm{g}\right)$ & $\begin{array}{c}\text { RESRAD- } \\
\text { Mass } \\
\text { Loading for } \\
\text { Inhalation } \\
\left(\mathrm{g} / \mathrm{m}^{3}\right)= \\
1 / \mathrm{PEF}\end{array}$ & Receptor \\
\hline $9.30 \mathrm{E}+08$ & 1000 & 930000 & $1.08 \mathrm{E}-06$ & $\begin{array}{c}\text { Adult Rural } \\
\text { Resident } \\
\text { which } \\
\text { corresponds to } \\
\text { the "Resident } \\
\text { Farmer" }\end{array}$ \\
\hline
\end{tabular}


Section B. Parameters Applicable to the Resident Farmer from DOE 2009, Appendix D Converted into RESRAD Compatible Units (cont.)

\section{External Gamma Shielding Factor and Exposure Duration}

\begin{tabular}{|c|c|c|c|c|c|c|c|c|}
\hline \multirow{2}{*}{\multicolumn{5}{|c|}{$\begin{array}{l}\text { Parameters from the Risk Methods Document (DOE 2009), Appendix D } \\
\text { Table D.8. Reasonable maximum exposure assumptions and human intake factors for external exposure to } \\
\text { ionizing radiation from soil by a rural resident }{ }^{{ }^{2}}\end{array}$}} & \multicolumn{4}{|c|}{$\begin{array}{l}\text { Conversion of Parameter Units into RESRAD } \\
\text { Compatible Units }\end{array}$} \\
\hline & & & & & $\begin{array}{l}\text { Exposure } \\
\text { duration }=\end{array}$ & & \multirow{5}{*}{ Receptor } & \multirow{5}{*}{$\begin{array}{l}\text { RESRAD } \\
\text { external } \\
\text { gamma } \\
\text { shielding } \\
\text { factor }\end{array}$} \\
\hline \multicolumn{5}{|c|}{ Absorbed Dose $[(\mathrm{pCi} \times$ year $) / \mathrm{g}]=A_{s} \times E D \times E F \times\left(1-S_{e}\right) \times T_{e}$} & no & shielding & & \\
\hline & Parameter & Units & Value used & References $^{\mathrm{b}}$ & \multirow{3}{*}{$\begin{array}{c}\text { since it is in } \\
\text { RESRAD } \\
\text { units }\end{array}$} & \multirow{3}{*}{ (unitless) } & & \\
\hline & Activity in soil $=A_{4}$ & $\mathrm{pCi} / \mathrm{g}$ & Chemical-specific & - & & & & \\
\hline & Exposure duration $=$ ED & year & $\begin{array}{l}24 \text { (adult) } \\
6 \text { (child) }\end{array}$ & [14] & & & & \\
\hline & Exposure frequency $=\mathbf{E F}$ & day/day & $350 / 365$ & [14] & \multirow[b]{4}{*}{24} & \multirow[b]{4}{*}{0.2} & \multirow{4}{*}{$\begin{array}{l}\text { Adult Rural } \\
\text { Resident } \\
\text { which } \\
\text { corresponds } \\
\text { to the } \\
\text { "Resident } \\
\text { Farmer" }\end{array}$} & \multirow[b]{4}{*}{$1-0.2=0.8$} \\
\hline & Gamma shielding factor $=S_{e}$ & unitless & 0.2 & [20] & & & & \\
\hline & Gamma exposure time factor $=T_{0}$ & $\mathrm{hr} / \mathrm{hr}$ & $24 / 24$ & [20] & & & & \\
\hline $\begin{array}{l}\mathrm{a} \\
\mathrm{b} \\
\mathrm{c}\end{array}$ & $\begin{array}{l}\text { Equation from [20]. } \\
\text { References follow Table D. } 50 \text {. } \\
\text { AC cannot be greater than } 1 .\end{array}$ & & & & & & & \\
\hline
\end{tabular}


Section B. Parameters Applicable to the Resident Farmer from DOE 2009, Appendix D Converted into RESRAD Compatible Units (cont.)

Indoor and Outdoor Occupancy Fractions

\begin{tabular}{|c|c|c|}
\hline \multicolumn{3}{|c|}{ Resident Farmer Occupancy fractions } \\
\hline & Days & Fractions for RESRAD \\
\hline $1 / 3$ of the time outdoors & 117 & 0.32 \\
\hline $2 / 3$ of the time indoors & 233 & 0.64 \\
\hline Total Days Onsite & 350 & \\
\hline Total Fraction & & 0.96 \\
\hline \multicolumn{3}{|c|}{$\begin{array}{l}\text { Note: The Resident Farmer spends } 350 \text { days on site. The fraction } \\
\text { of time spent outdoors was divided by } 5 \text {, in order to equally } \\
\text { distribute the time spent outdoors and in the different farm } \\
\text { areas. This fraction was } 0.064 \text {. }\end{array}$} \\
\hline
\end{tabular}




\section{Section B. Parameters Applicable to the Resident Farmer from DOE 2009, Appendix D Converted into RESRAD Compatible Units}

(cont.)

\section{Fruit, Non-Leafy Vegetable, and Grain Consumption and Leafy Vegetables Consumption}

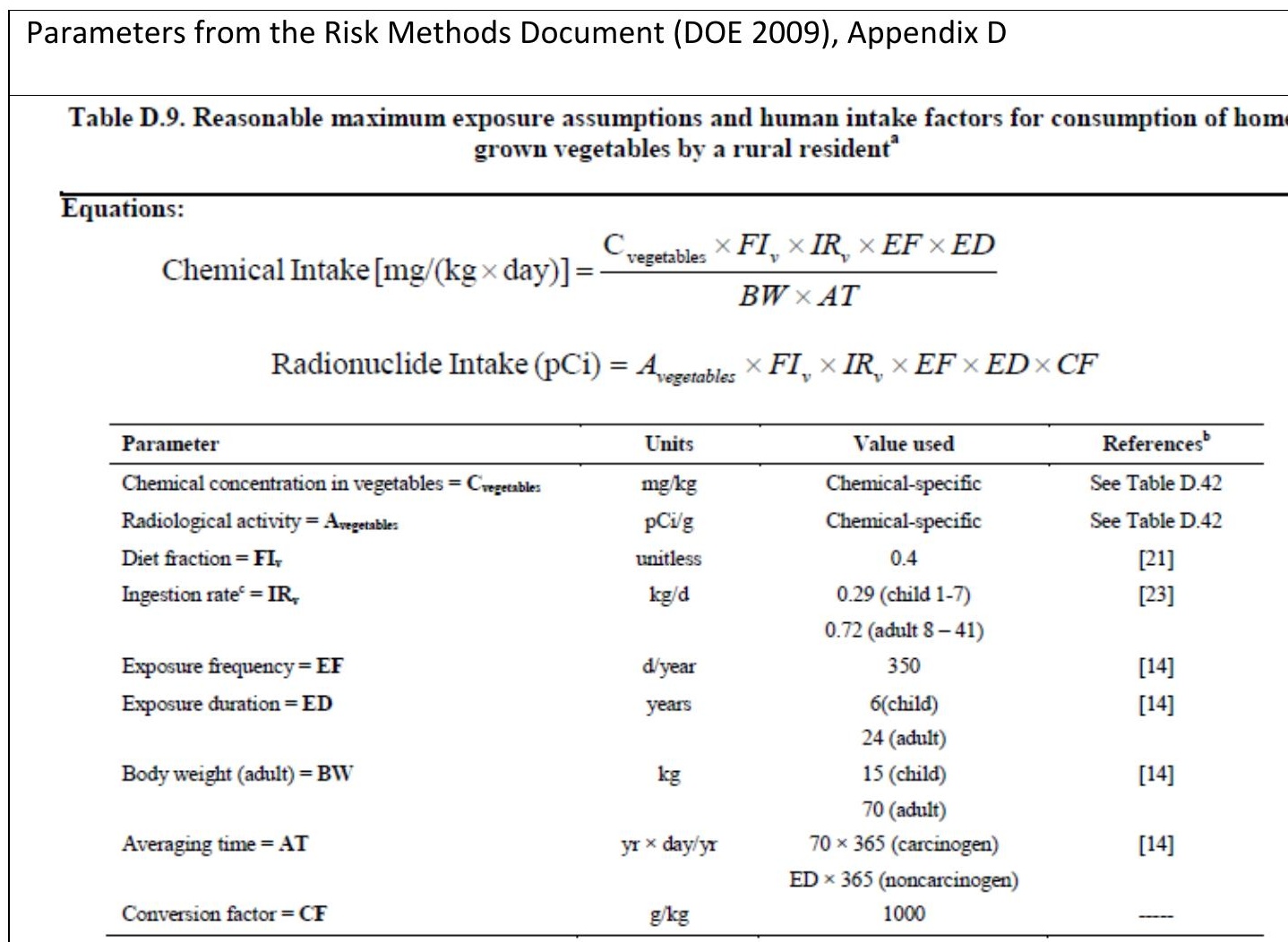

Conversion of Parameter Units into RESRAD Compatible Units

\begin{tabular}{|l|c|c|c|}
\hline $\begin{array}{c}\text { Ingestion } \\
\text { rate }^{\mathrm{c}}=\mathrm{IR}_{\mathrm{v}} \\
(\mathrm{kg} / \mathrm{day})\end{array}$ & $\begin{array}{c}\text { Exposure } \\
\text { frequency }=\end{array}$ & $\begin{array}{c}\text { Home grown } \\
\text { vegetables } \\
\text { consumption } \\
\text { (kg/yr) } \\
\text { obtained by } \\
\text { multiplying IR X } \\
\mathrm{EF}\end{array}$ & Receptor \\
\hline 0.72 & 350 & 252 & $\begin{array}{c}\text { Adult Rural } \\
\text { Resident which } \\
\text { corresponds to } \\
\text { the "Resident } \\
\text { Farmer" }\end{array}$ \\
\hline
\end{tabular}
(kg/yr).

\begin{tabular}{|c|c|c|c|}
\cline { 2 - 4 } \multicolumn{1}{c|}{} & $\begin{array}{c}\text { RESRAD } \\
\text { default }\end{array}$ & Calculation & $\begin{array}{c}\text { Ratio of values } \\
\text { to use in } \\
\text { RESRAD }\end{array}$ \\
\hline $\begin{array}{c}\text { Fruit, } \\
\text { vegetable, } \\
\text { and grain } \\
\text { consumption } \\
(\mathrm{kg} / \mathrm{yr})\end{array}$ & 160 & $\frac{160}{174 \times 252}$ & 231.7 \\
\hline $\begin{array}{c}\text { Leafy } \\
\text { vegetables } \\
\text { consumption } \\
(\mathrm{kg} / \mathrm{yr})\end{array}$ & 14 & $174 \times 252$ & 20.3 \\
\hline \begin{tabular}{c} 
Total $(\mathrm{kg} / \mathrm{yr})$ \\
\hline
\end{tabular} & 174 & NA & 252 \\
\hline
\end{tabular}


Section B. Parameters Applicable to the Resident Farmer from DOE 2009, Appendix D Converted into RESRAD Compatible Units (cont.)

\section{Milk Consumption}

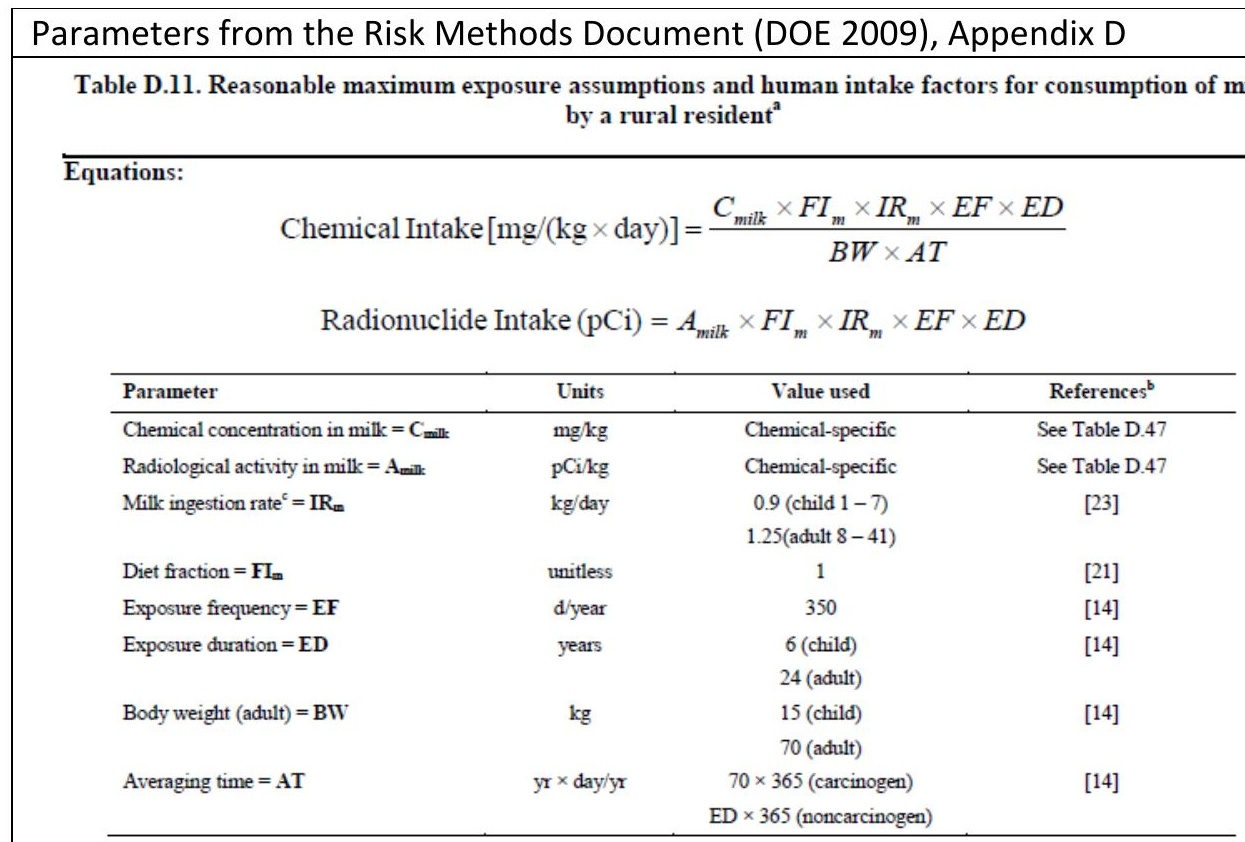

Conversion of Parameter Units into RESRAD Compatible Units

Equation from [1]

References follow Table D. 50 .

Ingestion values represent the $95^{\text {t' }}$ percentile of individuals who consume this food group.

\begin{tabular}{|c|c|c|c|c|}
\hline $\begin{array}{c}\text { Milk } \\
\text { ingestion } \\
\text { rate }^{c}= \\
I_{\mathrm{b}} \\
\text { (kg/day) }\end{array}$ & $\begin{array}{c}\text { Exposure } \\
\text { frequency } \\
=\mathrm{EF} \\
\text { (days/yr) }\end{array}$ & $\begin{array}{c}\text { Milk } \\
\text { consumption } \\
\text { (kg/yr) } \\
\text { obtained by } \\
\text { multiplying IR } \\
\text { X EF }\end{array}$ & $\begin{array}{l}\text { RESRAD-Milk } \\
\text { consumption } \\
\text { (L/yr) } \\
\text { obtained by } \\
\text { diving the } \\
\text { milk } \\
\text { consumption } \\
\text { (kg/yr) by the } \\
\text { density of } \\
\text { milk and then } \\
\text { multiplying by } \\
1000\end{array}$ & Receptor \\
\hline 1.25 & 350 & 437.5 & 425 & $\begin{array}{l}\text { Adult Rural } \\
\text { Resident } \\
\text { which } \\
\text { corresponds } \\
\text { to the } \\
\text { "Resident } \\
\text { Farmer" }\end{array}$ \\
\hline
\end{tabular}

Density of milk, cow, whole $=1030 \mathrm{~kg} / \mathrm{m}^{3}$

1 cubic meter $=1000$ liters

This density was obtained from an online

source: http://physics.info/density/ 
Section B. Parameters Applicable to the Resident Farmer from DOE 2009, Appendix D Converted into RESRAD Compatible Units (cont.)

\section{Meat and Poultry Consumption}

\begin{tabular}{|c|c|c|c|}
\hline \multicolumn{4}{|c|}{ Parameters from the Risk Methods Document (DOE 2009), Appendix D } \\
\hline \multicolumn{4}{|c|}{ Chemical Intake $[\mathrm{mg} /(\mathrm{kg} \times$ day $)]=\frac{C_{b e e f} \times F I_{b} \times I R_{b} \times E F \times E D}{B W \times A T}$} \\
\hline Parameter & Units & Value used & References $^{b}$ \\
\hline Chemical concentration in beef $=C_{\text {bef }}$ & $\mathrm{mg} / \mathrm{kg}$ & Chemical-specific & See Table D.46 \\
\hline Radiological activity in beef $=A_{b e e f}$ & $\mathrm{pCi} / \mathrm{kg}$ & Chemical-specific & See Table D.46 \\
\hline Beef ingestion rate ${ }^{c}=\mathrm{IR}_{b}$ & $\mathrm{~kg} /$ day & $\begin{array}{c}0.07 \text { (child } 1-7 \text { ) } \\
0.19 \text { (adult } 8-41 \text { ) }\end{array}$ & [23] \\
\hline Diet fraction $=\mathbf{F I}_{b}$ & unitless & 1 & [21] \\
\hline Exposure frequency $=\mathbf{E F}$ & $d /$ year & 350 & [14] \\
\hline Exposure curation $=\mathrm{ED}$ & years & $\begin{array}{l}6 \text { (child) } \\
24 \text { (adult) }\end{array}$ & [14] \\
\hline Body weight (adult) $=\mathrm{BW}$ & $\mathrm{kg}$ & $\begin{array}{l}15 \text { (child) } \\
70 \text { (adult) }\end{array}$ & [14] \\
\hline Averaging time $=\mathbf{A T}$ & $\mathrm{yr} \times$ day $/ \mathrm{yr}$ & $\begin{array}{c}70 \times 365 \text { (carcinogen) } \\
\text { ED × } 365 \text { (noncarcinogen) }\end{array}$ & [14] \\
\hline
\end{tabular}

Conversion of Parameter Units into RESRAD Compatible Units

\begin{tabular}{|c|c|c|c|}
\hline $\begin{array}{c}\text { Beef } \\
\text { ingestion } \\
\text { rate }^{c}= \\
\mathrm{IR}_{\mathrm{b}} \\
(\mathrm{kg} / \mathrm{day})\end{array}$ & $\begin{array}{c}\text { Exposure } \\
\text { frequency } \\
=\mathrm{EF} \\
\text { (days/yr) }\end{array}$ & $\begin{array}{c}\text { Meat } \\
\text { consumption } \\
\text { (kg/yr) } \\
\text { obtained by } \\
\text { multiplying IR } \\
\text { X EF }\end{array}$ & Receptor \\
\hline 0.19 & 350 & 66.5 & $\begin{array}{c}\text { Adult Rural } \\
\text { Resident } \\
\text { which } \\
\text { corresponds } \\
\text { to the } \\
\text { "Resident } \\
\text { Farmer" }\end{array}$ \\
\hline
\end{tabular}

Notes: This table only includes beef consumption, and the RESRAD parameter is for Meat and Poultry. Tables D.12, and D.13 in Appendix D have information for poultry and pork.

Equation from [1]

References follow Table D 50

Ingestion values represent the $95^{\text {m }}$ percentile of individuals who consume this food group. 
Section B. Parameters Applicable to the Resident Farmer from DOE 2009, Appendix D Converted into RESRAD Compatible Units (cont.)

\section{Meat and Poultry Consumption (cont.)}

\begin{tabular}{|c|c|c|c|}
\hline $\begin{array}{l}\text { Parameters from the Risk Metho } \\
\text { Table D.12. Reasonable maximum }\end{array}$ & $\begin{array}{c}\text { Table D.12. Reasonable maximum exposure assumptions and human intake factors for consumption of } \\
\text { poultry by a rural resident }{ }^{a}\end{array}$ & $\begin{array}{l}\text { 009), Appendix } \\
\text { human intake facto }_{\text {ent }^{\mathrm{a}}}\end{array}$ & consumption of \\
\hline \multicolumn{4}{|c|}{$\begin{array}{c}\text { Chemical Intake }[\mathrm{mg} /(\mathrm{kg} \times \text { day })]=\frac{C_{\text {poultry }} \times F I_{p} \times I R_{p} \times E F \times E D}{B W \times A T} \\
\text { Radionuclide Intake }(\mathrm{pCi})=A_{\text {poulty }} \times F I_{p} \times I R_{p} \times E F \times E D\end{array}$} \\
\hline Parameter & Units & Value used & References $^{b}$ \\
\hline Chemical concentration in poultry $=\mathrm{C}_{\text {poultry }}$ & $\mathrm{mg} / \mathrm{kg}$ & Chemical-specific & See Table D.48 \\
\hline Radiological activity in poultry $=A_{\text {poultry }}$ & $\mathrm{pCi} / \mathrm{kg}$ & Chemical-specific & See Table D.48 \\
\hline Ingestion rate ${ }^{c}=\mathrm{IR}_{\mathrm{p}}$ & $\mathrm{kg} /$ day & $\begin{array}{l}0.07 \text { (child } 1-7 \text { ) } \\
0.17 \text { (adult } 8-41 \text { ) }\end{array}$ & [23] \\
\hline Diet fraction $=\mathbf{F I}_{\mathbf{p}}$ & unitless & 1 & [5] \\
\hline Exposure frequency $=\mathbf{E F}$ & day/year & 350 & \\
\hline Exposure duration $=$ ED & years & $\begin{array}{c}6 \text { (child) } \\
24 \text { (adult) }\end{array}$ & [14] \\
\hline Body weight $=\mathrm{BW}$ & $\mathrm{kg}$ & $\begin{array}{l}15 \text { (child) } \\
70 \text { (adult) }\end{array}$ & [14] \\
\hline Averaging time $=\mathrm{AT}$ & $\mathrm{yr} \times$ day $/ \mathrm{yr}$ & $\begin{array}{r}70 \times 365 \text { (carcinogen) } \\
\mathrm{ED} \times 365 \text { (noncarcinoge }\end{array}$ & [14] \\
\hline
\end{tabular}

Conversion of Parameter Units into RESRAD Compatible Units

\begin{tabular}{|c|c|c|c|}
\hline $\begin{array}{c}\text { Poultry } \\
\text { ingestion } \\
\text { rate }^{\mathrm{c}}=\mathrm{IR}_{\mathrm{b}} \\
(\mathrm{kg} / \text { day) }\end{array}$ & $\begin{array}{c}\text { Exposure } \\
\text { frequency }=\end{array}$ & $\begin{array}{c}\text { Poultry } \\
\text { consumption } \\
\text { (kg/yr) } \\
\text { obtained by } \\
\text { multiplying IR } \\
\text { X EF }\end{array}$ & Receptor \\
\hline 0.17 & 350 & 59.5 & $\begin{array}{c}\text { Adult Rural } \\
\text { Resident } \\
\text { which } \\
\text { corresponds } \\
\text { to the } \\
\text { "Resident } \\
\text { Farmer" }\end{array}$ \\
\hline
\end{tabular}

Notes: This table only includes poultry consumption, and the RESRAD parameter is for Meat and Poultry. Table D.10, and D.13 in Appendix D have information for beef and pork.

Equation from [1]

References follow Table D. 50

Ingestion values represent the $95^{\text {th }}$ percentile of individuals who consume this food group. 


\section{Section B. Parameters Applicable to the Resident Farmer from DOE 2009, Appendix D Converted into RESRAD Compatible Units}

(cont.)

\section{Meat and Poultry Consumption (cont.)}

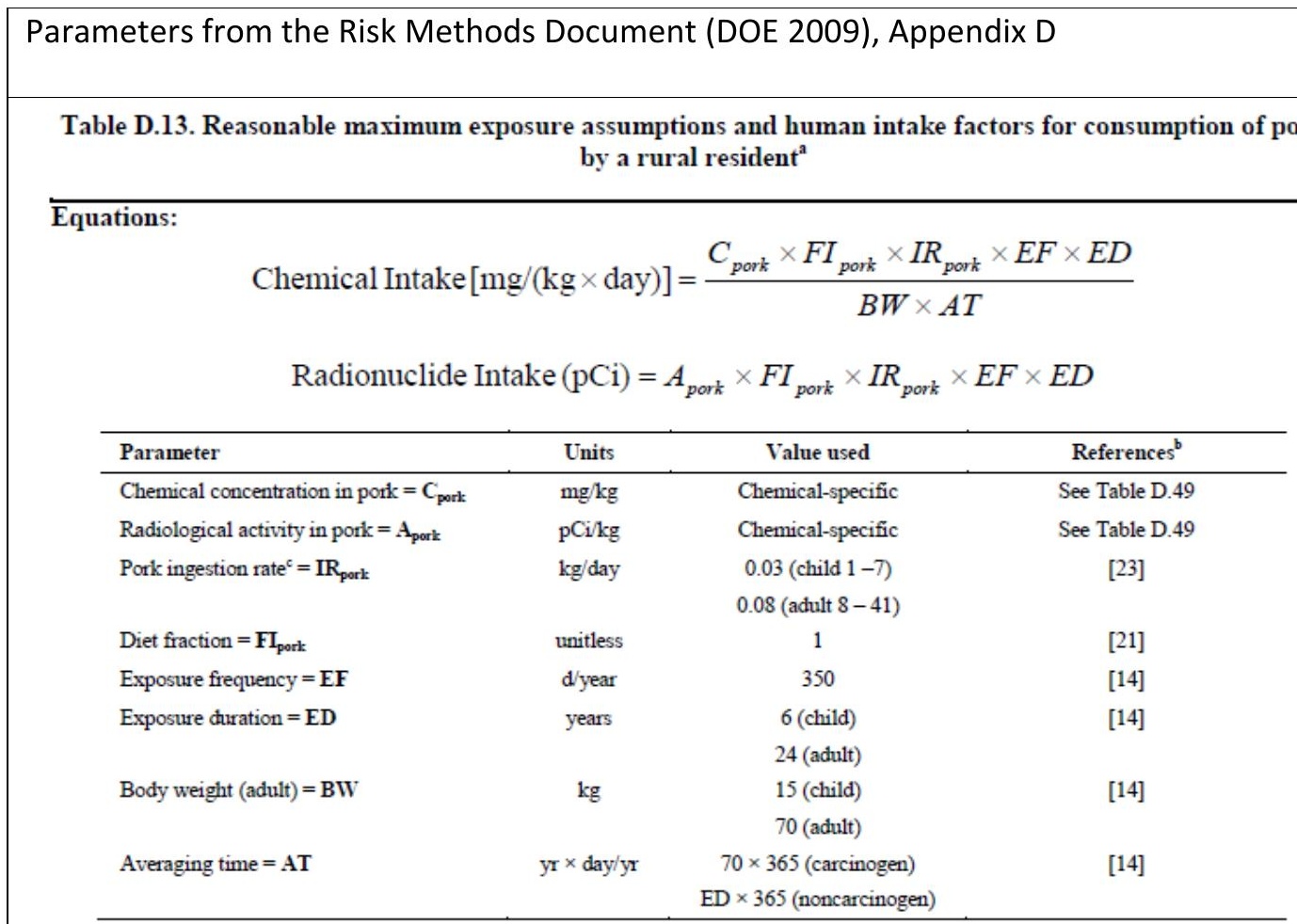

Conversion of Parameter Units into RESRAD Compatible Units

\begin{tabular}{|c|c|c|c|}
\hline $\begin{array}{c}\text { Pork } \\
\text { ingestion } \\
\text { rate }^{\mathrm{c}}=\mathrm{IR}_{\mathrm{b}} \\
(\mathrm{kg} / \mathrm{day})\end{array}$ & $\begin{array}{c}\text { Exposure } \\
\text { frequency } \\
=\mathrm{EF} \\
\text { (days/yr) }\end{array}$ & $\begin{array}{c}\text { Pork } \\
\text { consumption } \\
\text { (kg/yr) } \\
\text { obtained by } \\
\text { multiplying IR } \\
\text { X EF }\end{array}$ & Receptor \\
\hline 0.08 & 350 & 28 & $\begin{array}{c}\text { Adult Rural } \\
\text { Resident } \\
\text { which } \\
\text { corresponds } \\
\text { to the } \\
\text { "Resident } \\
\text { Farmer" }\end{array}$ \\
\hline
\end{tabular}

Notes: This table only includes pork consumption, and the RESRAD parameter is for Meat and Poultry. Table D.10, and D.12 in Appendix D have information for beef and poultry.

RESRAD- Meat and Poultry consumption ( $\mathrm{kg} / \mathrm{yr}$ ) obtained by adding of the $\mathrm{kg} / \mathrm{yr}$ for pork, beef and poultry 


\section{Section C. Parameters Applicable to Beef and Dairy from DOE 2009, Appendix D}

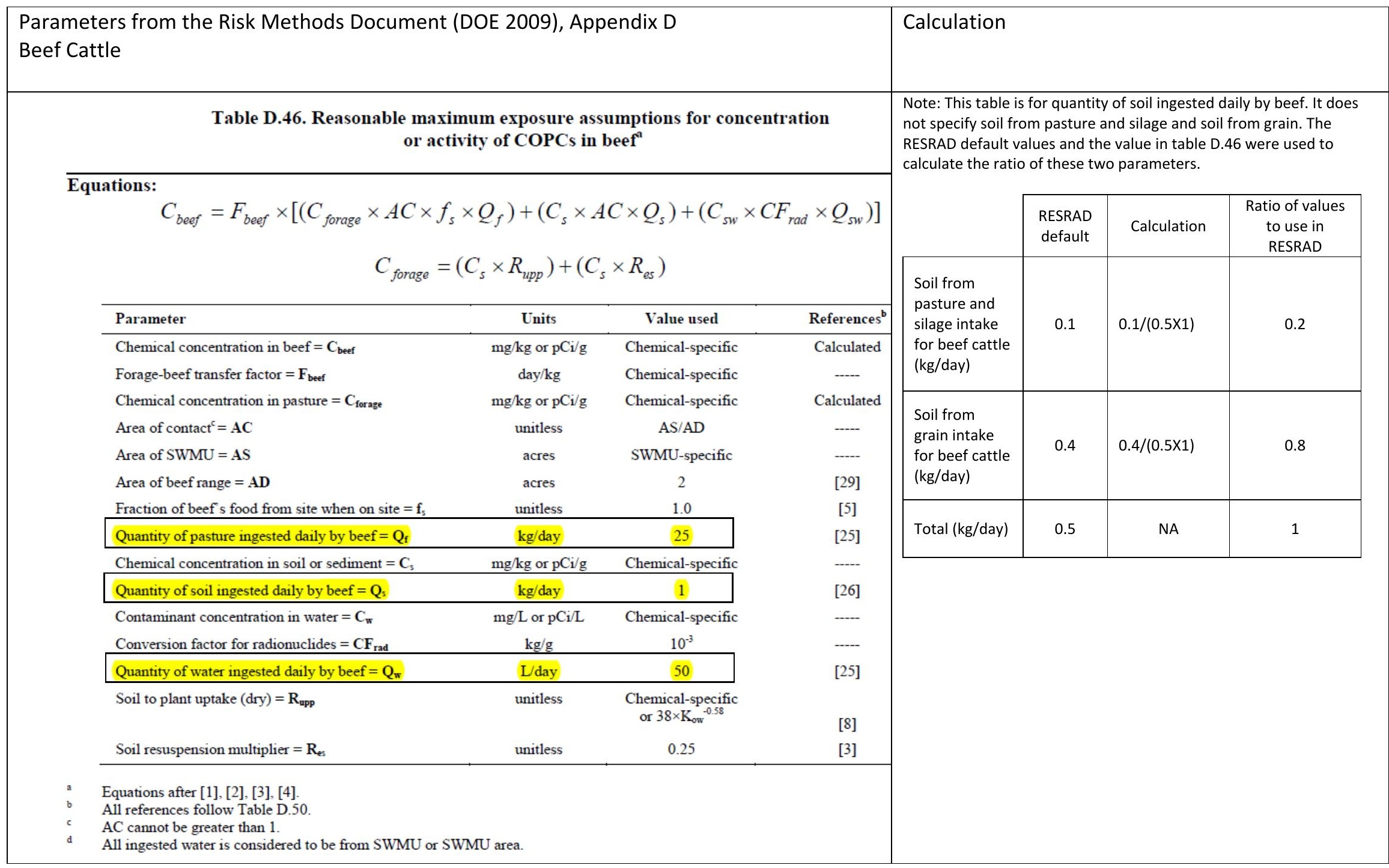

Note: The values that were used to determine input parameters are highlighted. 


\section{Section C. Parameters Applicable to Beef and Dairy from DOE 2009, Appendix D (cont.)}

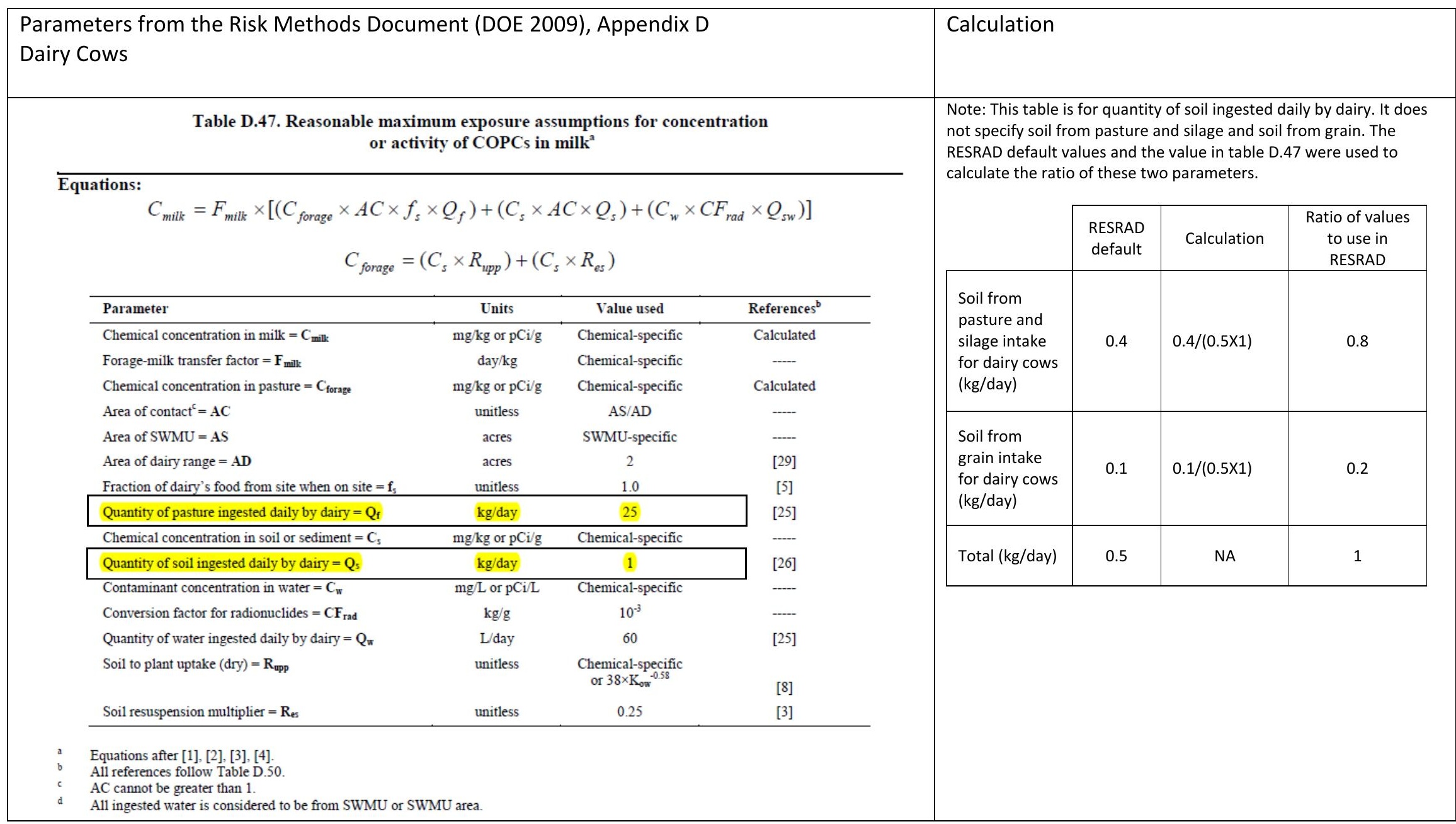

Note: The values that were used to determine input parameters are highlighted. 


\section{References}

ATSDR 2002, Public Health Assessment for the Paducah Gaseous Diffusion Plant (USDOE) Paducah, McCracken County, Kentucky (May 2002).

DOE 2003a. Authorized Limits Request for Solid Waste Disposal at Landfill C-746-U at the Paducah Gaseous Diffusion Plant, (November 2002; revised January 2003).

DOE 2003b. Risk and Performance Evaluation of the C-746-U Landfill at the Paducah Gaseous Diffusion Plant, Paducah, Kentucky, DOE/OR/072041\&D2R1 (September 2003).

DOE 2009. Methods for Conducting Risk Assessments and Risk Evaluations at the Paducah Gaseous Diffusion Plant Paducah, Kentucky Volume 1. Human Health, DOE/LX/07-0107\&D1/V1 (July 2009).

DOE Statement of Work (SOW) for C-746-U Landfill provided to ORISE on December 2009.

DOE C-746-U landfill inventory spreadsheet for total waste disposed from May 2003 through May 2009.

DOE Project Communication with the Waste Disposal Options Project Team from Paducah, KY, March 2010 (Latest email correspondence 03/29/2010 from Rich Bonczek).

DOE Project Communication with the Geologist from Paducah, KY, April 2010 (Latest email correspondence 04/05/2010 from Raulie Casteel).

DOE Project Communication with Geologist and Engineer from Paducah, KY, April 2010 (Latest email correspondence 04/07/2010 from Raulie Casteel).

DOE Project Communication with the Geologist from Paducah, KY, April 2010 (Latest email correspondence 04/28/2010 from Raulie Casteel).

DOE Project Communication May, 2010 (Discussion between ORISE and Rich Bonczek during a meeting held at ORISE on 05/17/2010).

DOE Project Communication June, 2010 (Email correspondence 06/02/2010 from ORISE to DOE).

DOE Project Communication July, 2010 (Discussion between ORISE and DOE-PPPO during a meeting held at ORISE on 07/12/2010).

DOE Project Communication September, 2010 (Discussion between ORISE and DOE-PPPO during a conference call held on 09/29/2010). 
DOE Project Communication October, 2010 (Discussion between ORISE and DOE-PPPO during a conference call held on 10/7/2010).

DOE Project Communication November, 2010 (Email correspondence 11/03/2010 from ORISE to DOE consultant).

DOE Project Communication April, 2011 (ORISE and DOE-PPPO biweekly conference call on 04/13/2011 and email correspondence 04/14/2011 from ORISE to DOE-PPPO).

DOE Project Communication April, 2011 (ORISE and DOE-PPPO email correspondence 04/8/2011 from Chad Drummond to DOE-PPPO from DOEPPPO to ORISE).

DOE Order 458.1, Radiation Protection of the Public and the Environment (DOE 2011).

DOE Order 5400.5, Radiation Protection of the Public and the Environment (DOE 1993).

Kenny, J. F., N. L. Barber, S. S. Hutson, K. S. Linsey, J. K. Lovelace, and M. A. Maupin 2009. Estimated Use of Water in the United States in 2005, Circular 1344, U.S. Department of the Interior, U.S. Geological Survey.

King, David A. and Karen Keil, 2006. "Comparison of Standard Radiological Risk Models and Using RESRAD to Derive Generic Risk-Based Area Factors for Final Status Surveys," Risk Analysis, Vol. 26, No. 1, pp. 175-183.

Lee, D. W., J. C. Wang, and D. C. Kocher, 1995. Operating Limit Study for the Proposed Solid Waste Landfill at Paducah Gaseous Diffusion Plant, ORNL/TM-13008 (June 1995).

PRS 2008a. 2006 Paducah Site Annual Site Environmental Report for Calendar Year 2006, PRS-ENM-0034 Volume I, Paducah Remediation Services, LLC (September 2008).

PRS 2010. 2008 Update of the Paducah Gaseous Diffusion Plant Sitewide Groundwater Flow Model, PRS-ENR-0028, Paducah Gaseous Diffusion Plant Site Groundwater Modeling Working Group (February 2010).

Wischmeier, W.H., and D.D. Smith 1978. Predicting Rainfall Erosion Losses: A Guide to Conservation Planning, U.S. Department of Agriculture, Agriculture Handbook No. 537 (December 1978).

Yu, C., C. Loureiro, J. J. Cheng, L.G. Jones, Y.Y. Wang, Y.P. Chia, and E. Faillace 1993. Data Collection Handbook to Support Modeling Impacts of Radioactive Material in Soil, ANL/EAIS-8 (April 1993). 
Yu C., D. LePoire, E. Gnanapragasam, J. Arnish, S. Kamboj, B.M. Biwer, J.-J. Cheng, A. Zielen, and S.Y. Chen 2000. Development of Probabilistic RESRAD 6.0 and RESRAD-Build 3.0 Computer Codes, NUREG/CR-6697 (ANL/EAD/TM-98) (November 2000).

Yu, C., A.J. Zielen, J.J. Cheng, D.J. LePoire, E. Gnanapragasam, S. Kamboj, J. Arnish, A. Wallo, III, W.A. Williams, and H. Peterson 2007. User's Manual for RESRAD OFFSITE Version 2, ANL/EVS/TM/07-1, (DOE /HS-0005, NUREG/CR-6937) (June 2007). 
DOSE MODELING EVALUATIONS AND TECHNICAL SUPPORT DOCUMENT FOR THE AUTHORIZED LIMITS REQUEST FOR THE C-746-U LANDFILL AT THE PADUCAH GASEOUS DIFFUSION PLANT

Appendix C: RESRAD Summary Reports 


\section{Table of Contents}

Trespasser: Unit Concentration for Targeted Radionuclides..................................... C-3

Trespasser: Peak Dose from Cumulative Radionuclide Inventory ......................... C-35

Resident Farmer: Unit Concentration for Targeted Radionuclides .........................6-67

Resident Farmer: Peak Dose from Cumulative Radionuclide Inventory ............. C-102

Resident Gardener: Unit Concentration for Targeted Radionuclides ................. C-136

Resident Gardener: Peak Dose from Cumulative Radionuclide Inventory ..........C-170

Recreational User: Unit Concentration for Targeted Radionuclides ......................-204

Recreational User: Peak Dose from Cumulative Radionuclide Inventory .............-238

Outdoor Worker: Unit Concentration for Targeted Radionuclides ........................-272

Outdoor Worker: Peak Dose from Cumulative Radionuclide Inventory................-306

Landfill Worker: Unit Concentration for Targeted Radionuclides .............................340

Landfill Worker: Peak Dose from Cumulative Radionuclide Inventory ....................373 


\section{Trespasser}

The following summary report includes the single radionuclide soil guidelines based on a unit concentration for targeted radionuclides. 
THIS PAGE INTENTIONALLY LEFT BLANK 
RESRAD, Version $6.5 \quad \mathrm{~T}^{1 / 2}$ Limit $=180$ days

Summary : C746U Trespasser Deterministic Run

File : $\mathrm{X}: \backslash$ FINAL V2 $\backslash \mathrm{C} 746 \mathrm{U} \mathrm{T}$ DET-FINALV2.RAD

Table of Contents

Part I: Mixture Sums and Single Radionuclide Guidelines

Dose Conversion Factor (and Related) Parameter Summary ... 2

Site-Specific Parameter Summary $\ldots \ldots \ldots \ldots \ldots \ldots \ldots \ldots \ldots$

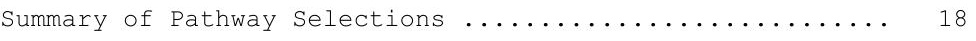

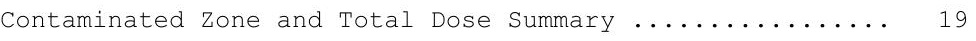

Total Dose Components

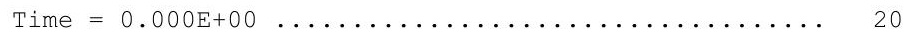

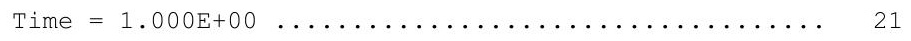

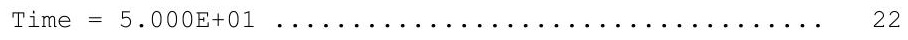

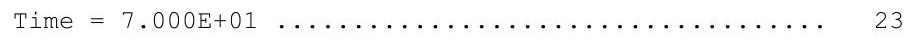

Dose/Source Ratios Summed Over All Pathways ............ 24

Single Radionuclide Soil Guidelines ............... 26

Dose Per Nuclide Summed Over All Pathways ............ 27

Soil Concentration Per Nuclide .................. 29 
RESRAD, Version $6.5 \quad \mathrm{~T}^{1 / 2}$ Limit $=180$ days

Summary : C746U Trespasser Deterministic Run

File : $\mathrm{X}: \backslash$ FINAL V2 $\backslash \mathrm{C} 746 \mathrm{U}$ T DET-FINALV2.RAD

Dose Conversion Factor (and Related) Parameter Summary

Dose Library: ICRP 60 \& ICRP 72 (Adult)

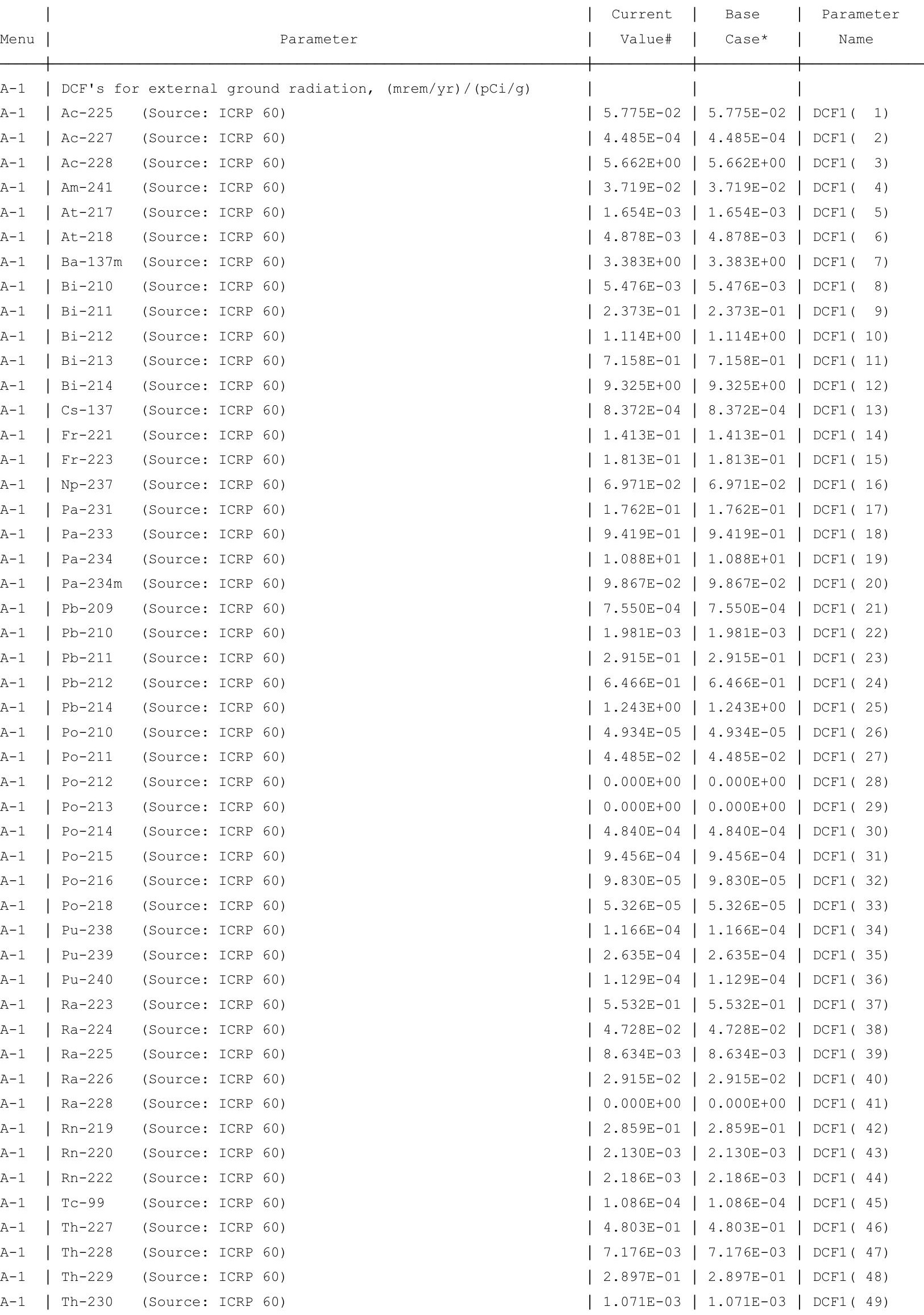


RESRAD, Version $6.5 \quad \mathrm{~T}^{1} / 2$ Limit $=180$ days

Summary : C746U Trespasser Deterministic Run

File : $\mathrm{X}: \backslash$ FINAL V2 $\backslash \mathrm{C} 746 \mathrm{U} \mathrm{T}$ DET-FINALV2.RAD

Dose Conversion Factor (and Related) Parameter Summary (continued)

Dose Library: ICRP 60 \& ICRP 72 (Adult)

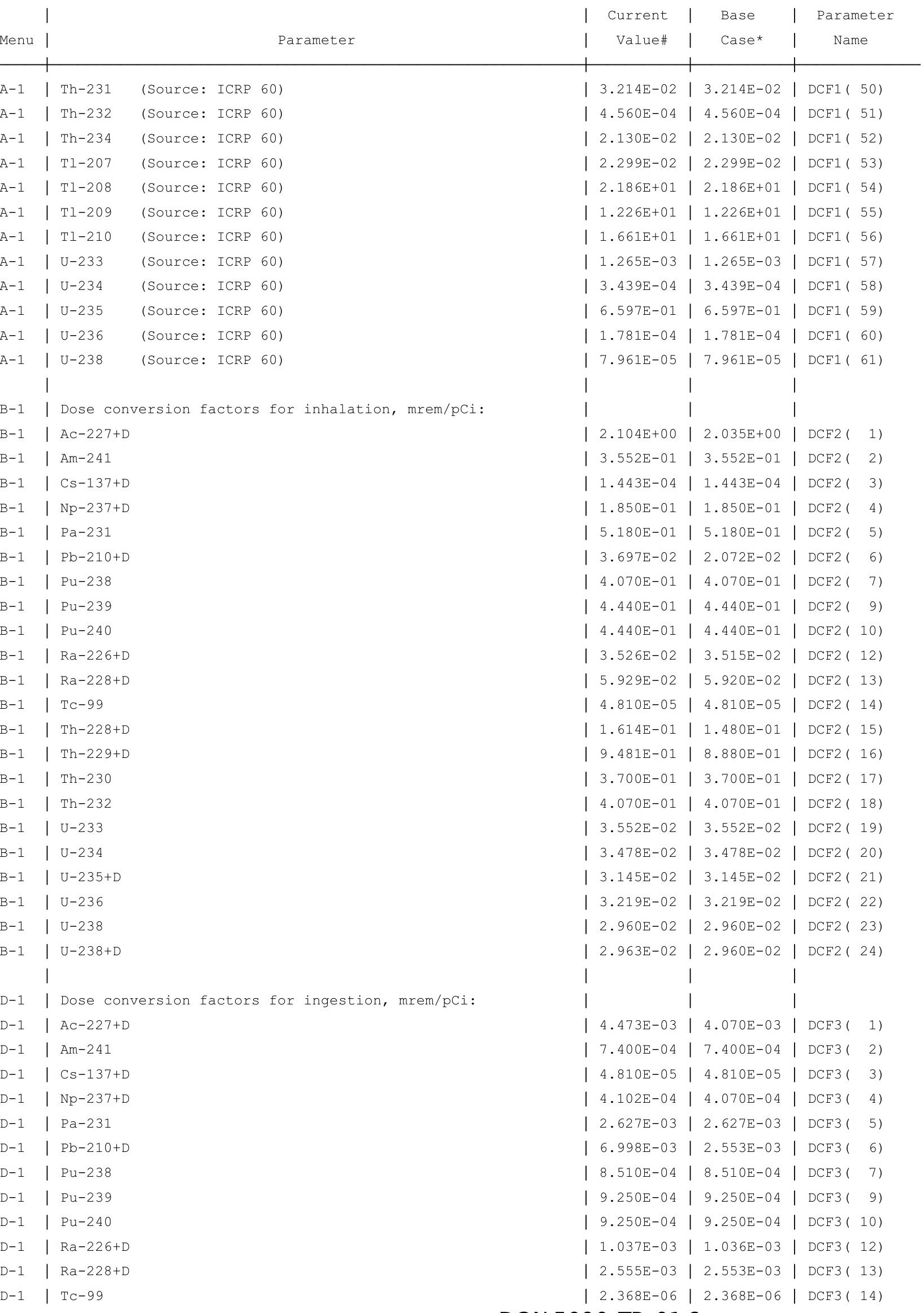


RESRAD, Version $6.5 \quad T^{1 / 2}$ Limit $=180$ days

Summary : C746U Trespasser Deterministic Run

File : $\mathrm{X}: \backslash$ FINAL V2\C746U T DET-FINALV2.RAD

Dose Conversion Factor (and Related) Parameter Summary (continued)

Dose Library: ICRP 60 \& ICRP 72 (Adult)

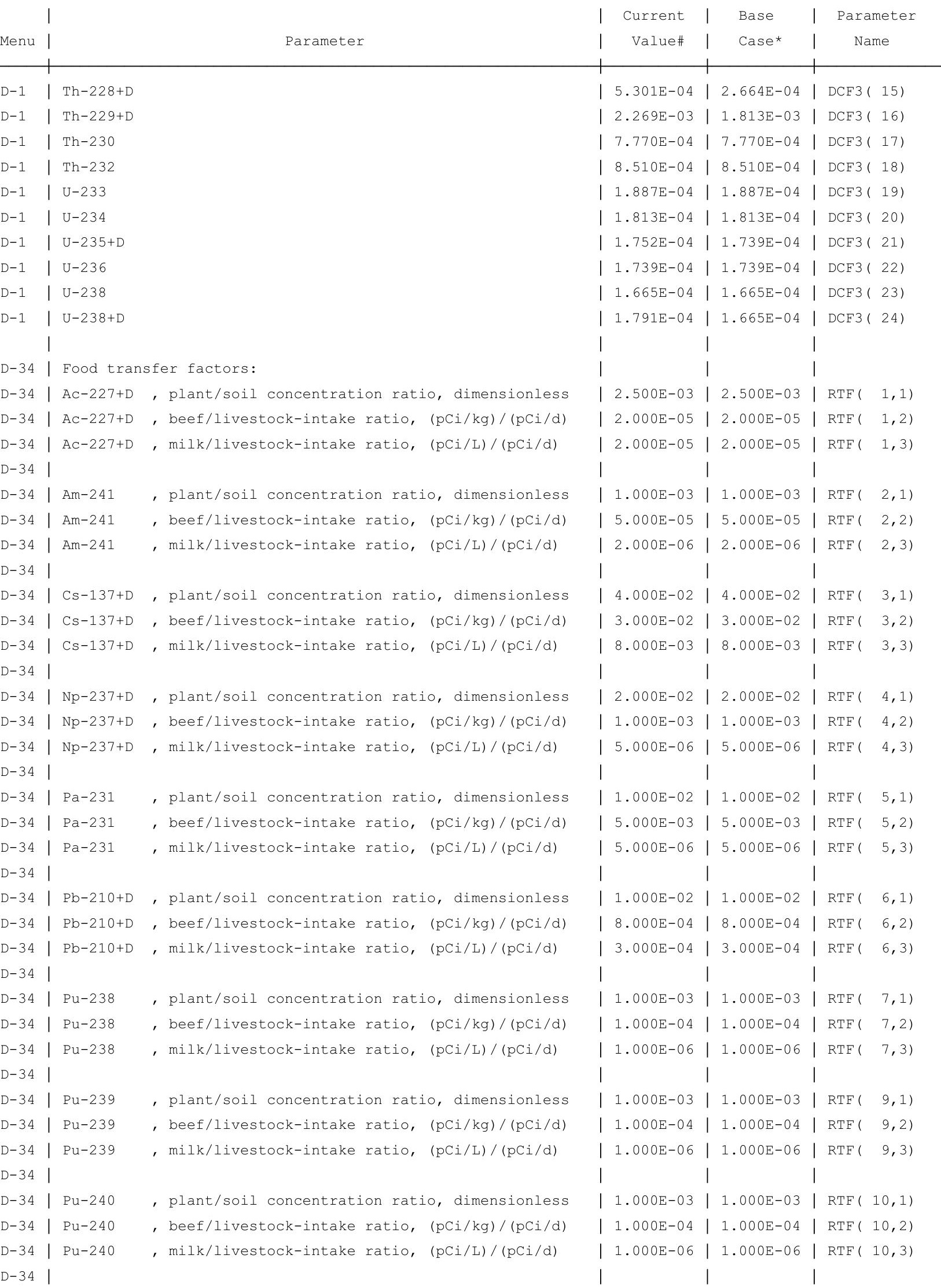


RESRAD, Version $6.5 \quad T^{1 / 2}$ Limit $=180$ days

Summary : C746U Trespasser Deterministic Run

File : $\mathrm{X}: \backslash$ FINAL V2\C746U T DET-FINALV2.RAD

Dose Conversion Factor (and Related) Parameter Summary (continued) Dose Library: ICRP 60 \& ICRP 72 (Adult)

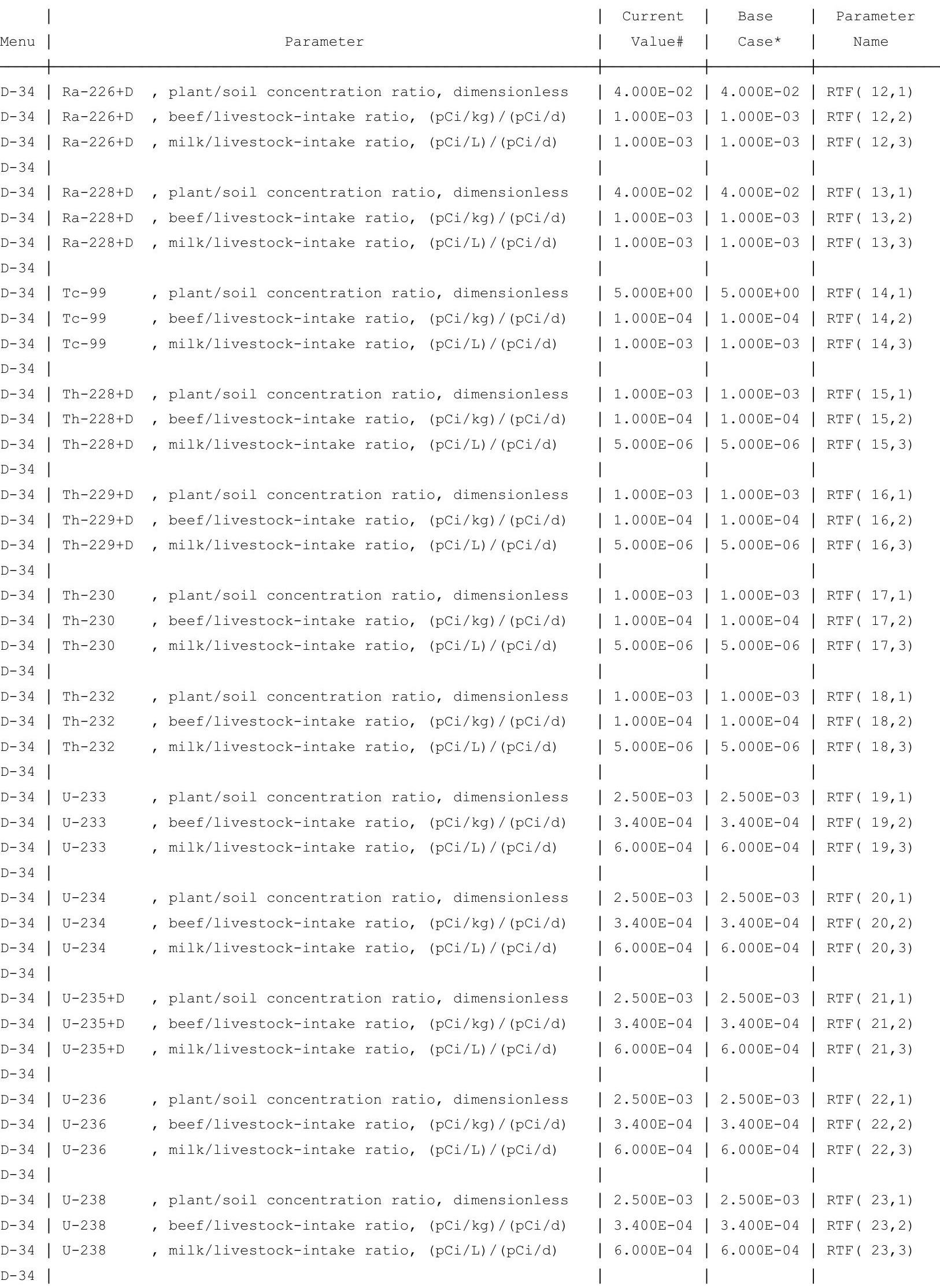


RESRAD, Version $6.5 \quad T^{1 / 2}$ Limit $=180$ days

Summary : C746U Trespasser Deterministic Run

File : $\mathrm{X}: \backslash$ FINAL V2 $\backslash \mathrm{C} 746 \mathrm{U} \mathrm{T}$ DET-FINALV2.RAD

Dose Conversion Factor (and Related) Parameter Summary (continued)

Dose Library: ICRP 60 \& ICRP 72 (Adult)

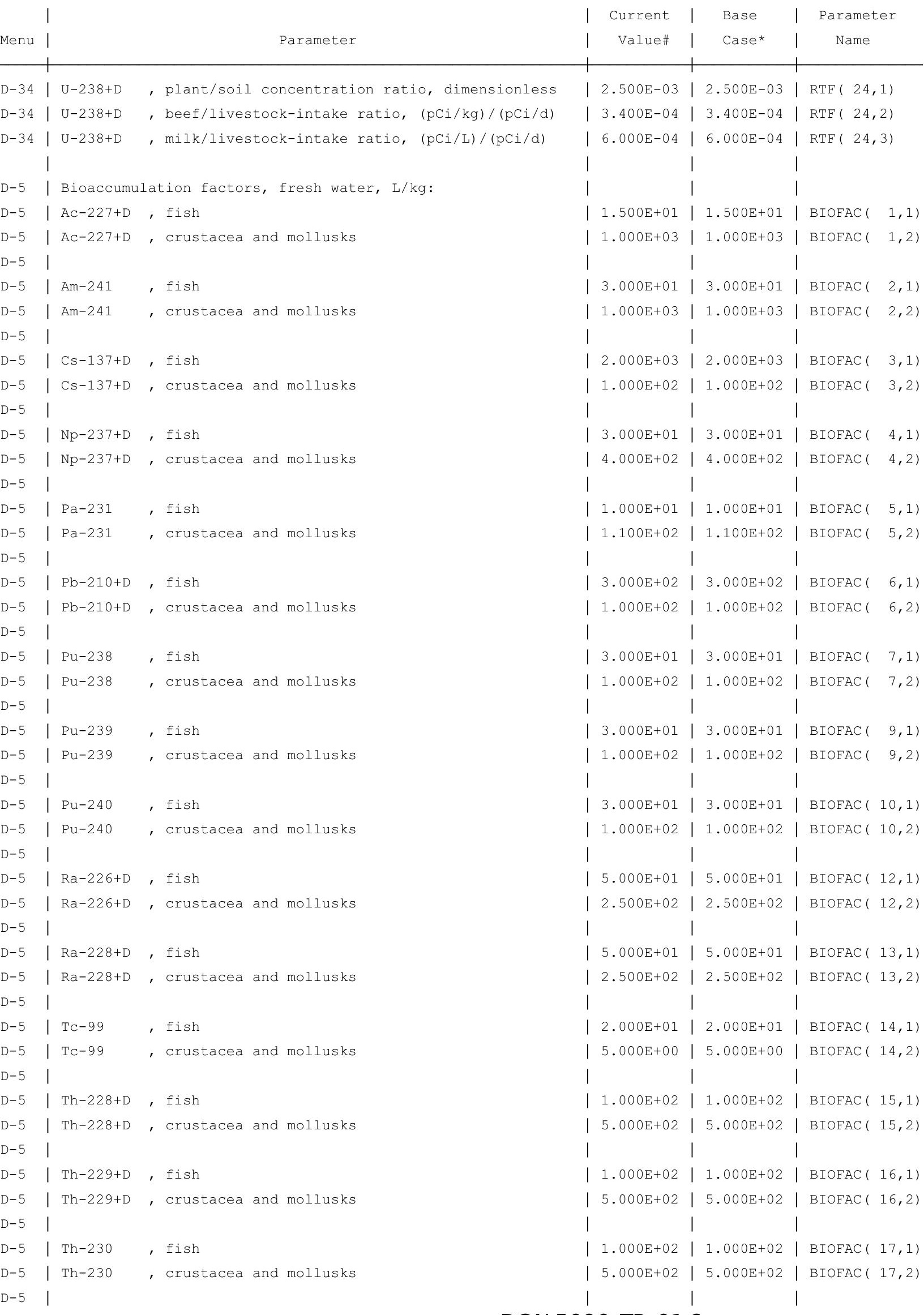


RESRAD, Version $6.5 \quad \mathrm{~T}^{1 / 2}$ Limit $=180$ days

Summary : C746U Trespasser Deterministic Run

File : $\mathrm{X}: \backslash$ FINAL V2 $\backslash \mathrm{C746U}$ T DET-FINALV2.RAD

Site-Specific Parameter Summary (continued)

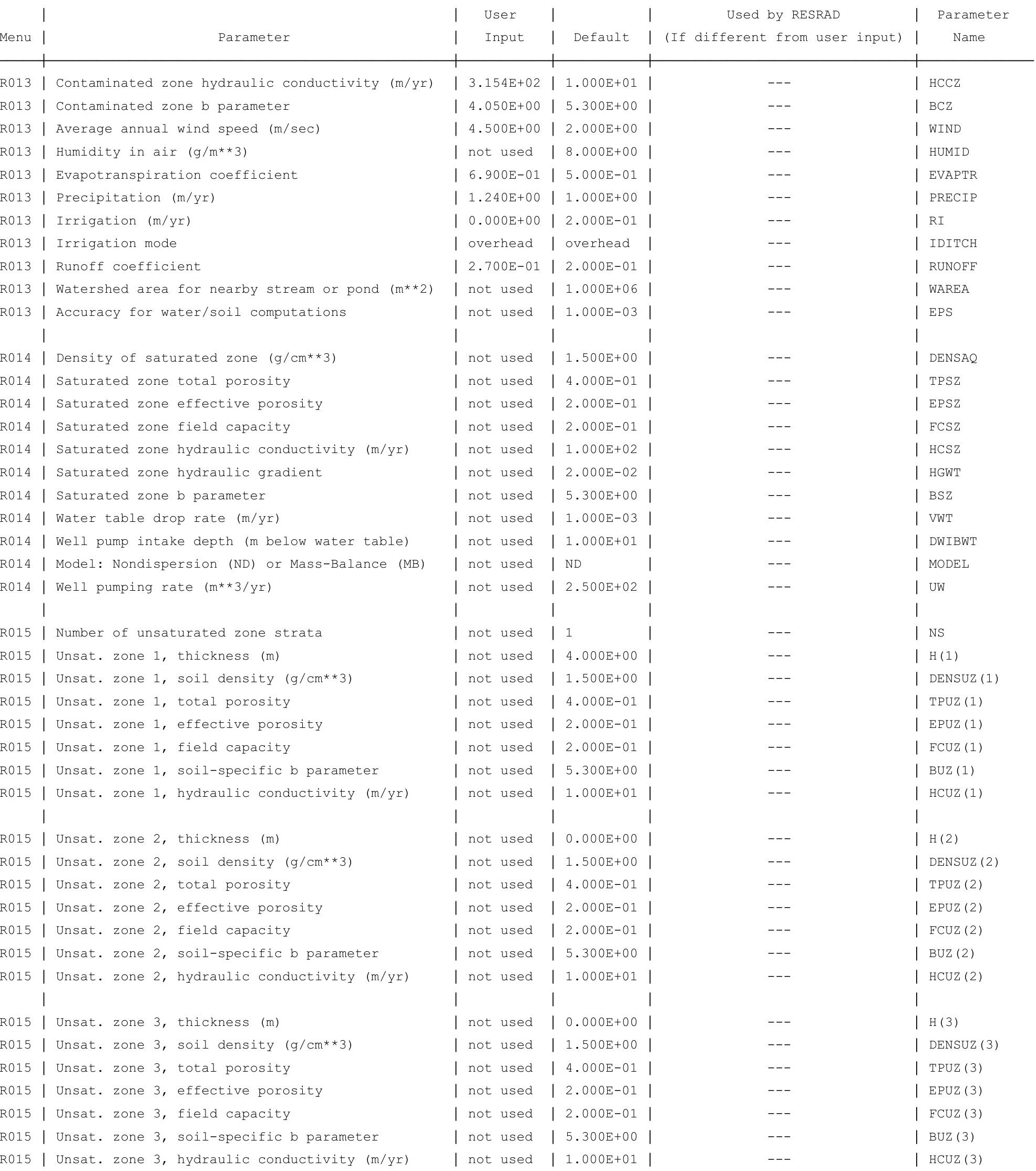


RESRAD, Version $6.5 \quad \mathrm{~T}^{1 / 2}$ Limit $=180$ days

Summary : C746U Trespasser Deterministic Run

File : $\mathrm{X}: \backslash$ FINAL V2 $\backslash \mathrm{C746U}$ T DET-FINALV2.RAD

Site-Specific Parameter Summary (continued)

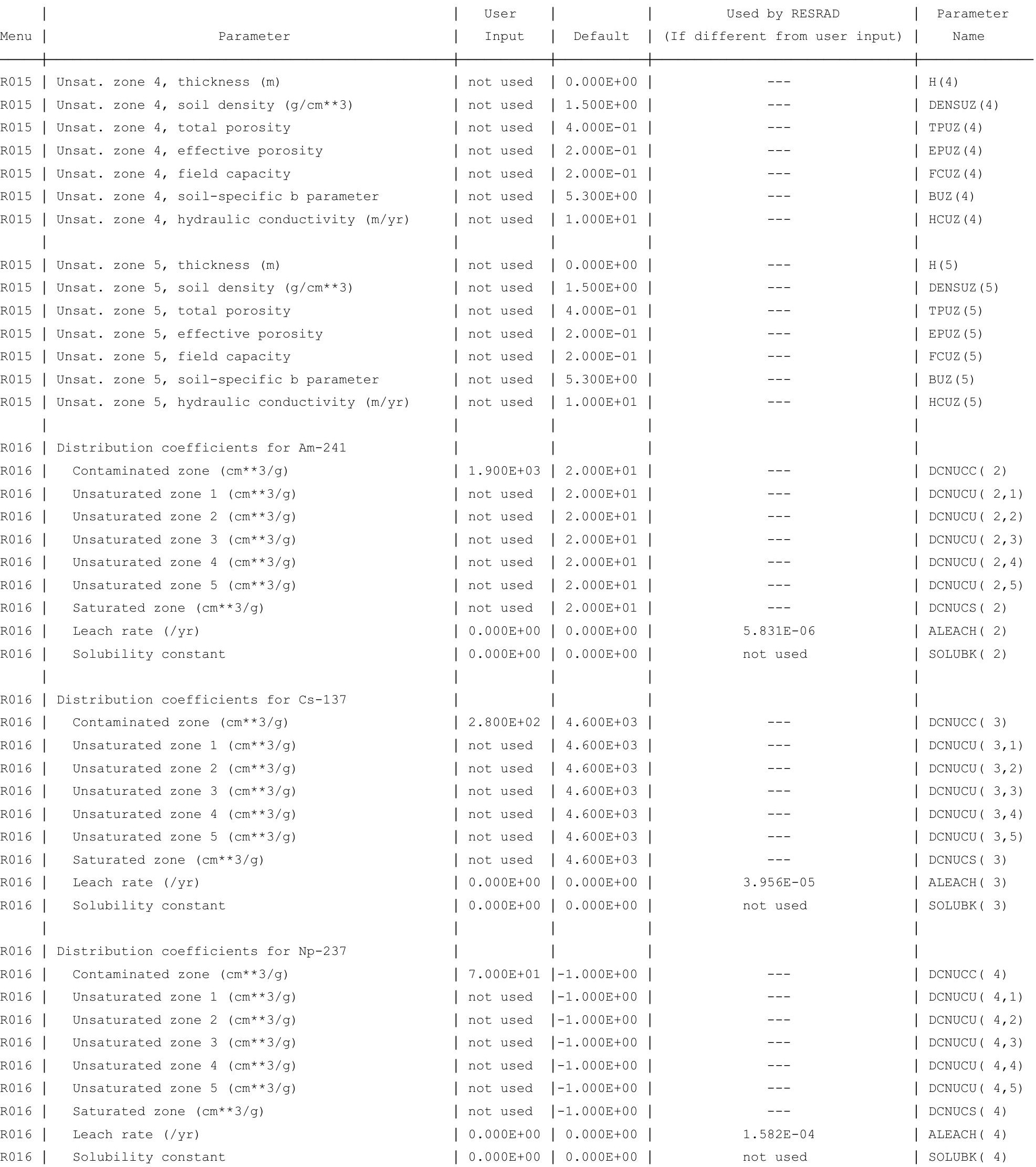


RESRAD, Version $6.5 \quad \mathrm{~T}^{1 / 2}$ Limit $=180$ days

Summary : C746U Trespasser Deterministic Run

File : $\mathrm{X}: \backslash$ FINAL V2 $\backslash \mathrm{C} 746 \mathrm{U}$ T DET-FINALV2.RAD

Site-Specific Parameter Summary (continued)

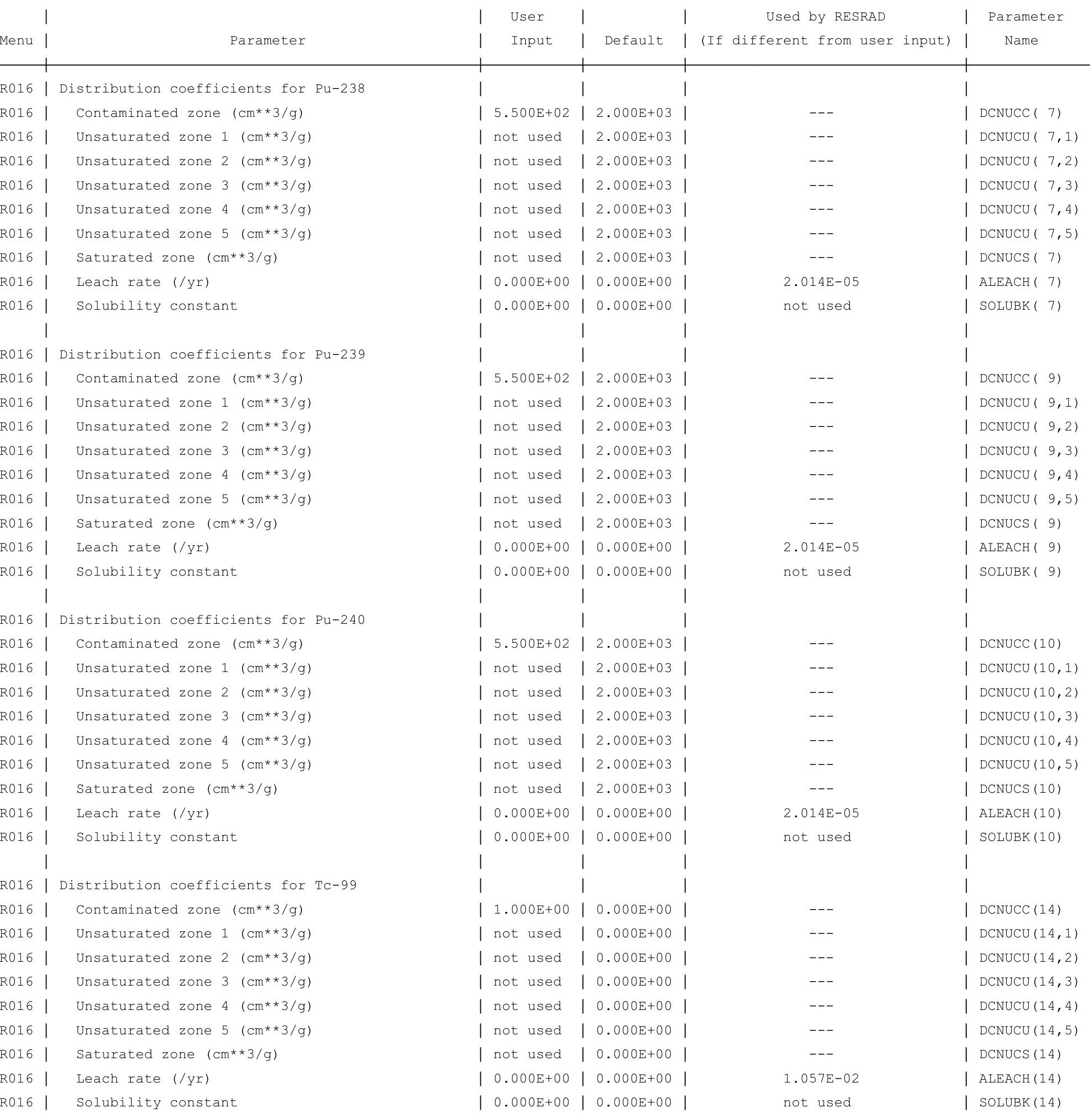


RESRAD, Version $6.5 \quad \mathrm{~T}^{1 / 2}$ Limit $=180$ days

Summary : C746U Trespasser Deterministic Run

File : $\mathrm{X}: \backslash$ FINAL V2 $\backslash \mathrm{C} 746 \mathrm{U}$ T DET-FINALV2.RAD

Site-Specific Parameter Summary (continued)

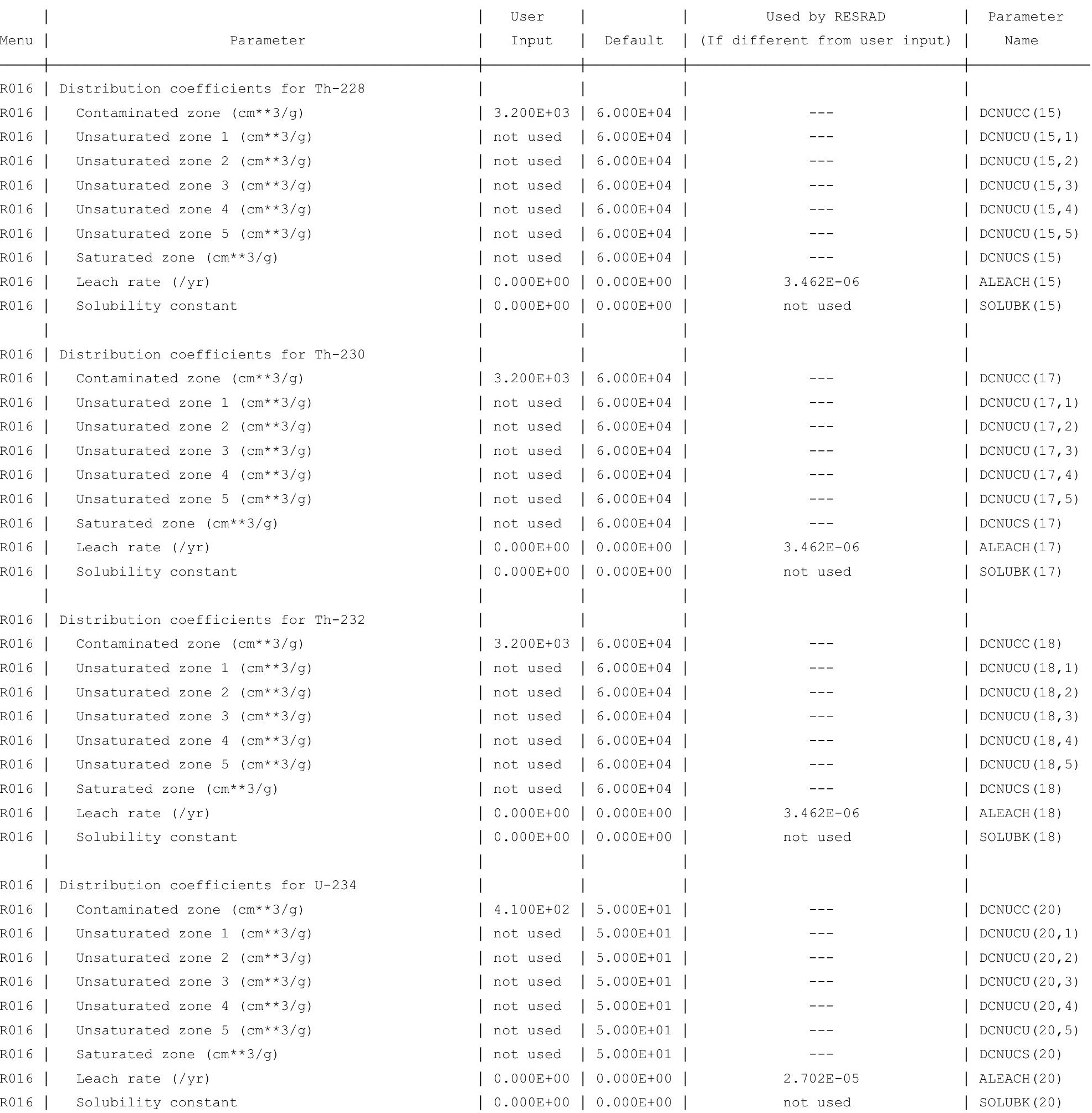


RESRAD, Version $6.5 \quad \mathrm{~T}^{1 / 2}$ Limit $=180$ days

Summary : C746U Trespasser Deterministic Run

File : $\mathrm{X}: \backslash$ FINAL V2 $\backslash \mathrm{C} 746 \mathrm{U}$ T DET-FINALV2.RAD

Site-Specific Parameter Summary (continued)

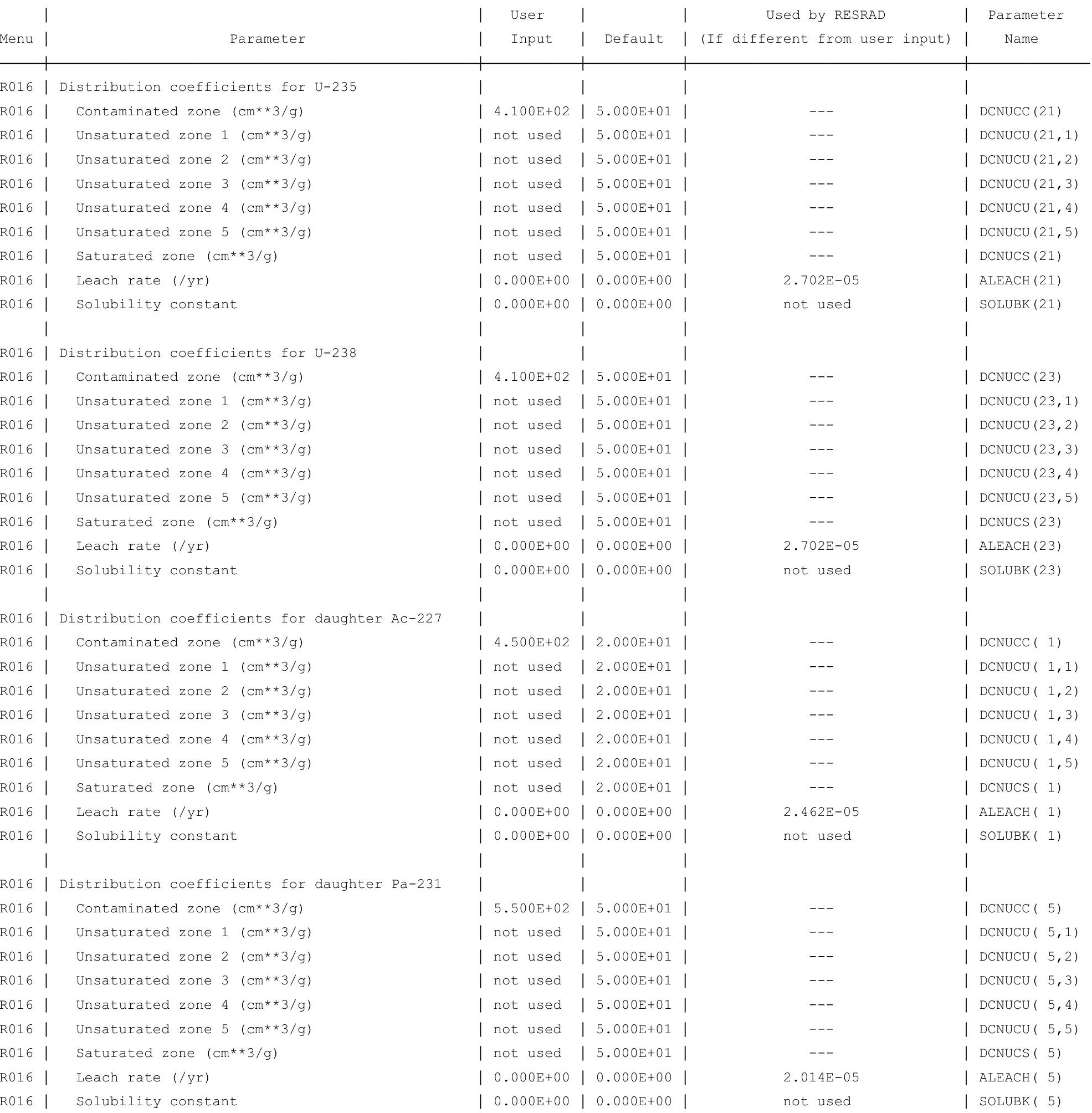


RESRAD, Version $6.5 \quad \mathrm{~T}^{1 / 2}$ Limit $=180$ days

Summary : C746U Trespasser Deterministic Run

File : $\mathrm{X}: \backslash$ FINAL V2 $\backslash \mathrm{C} 746 \mathrm{U}$ T DET-FINALV2.RAD

Site-Specific Parameter Summary (continued)

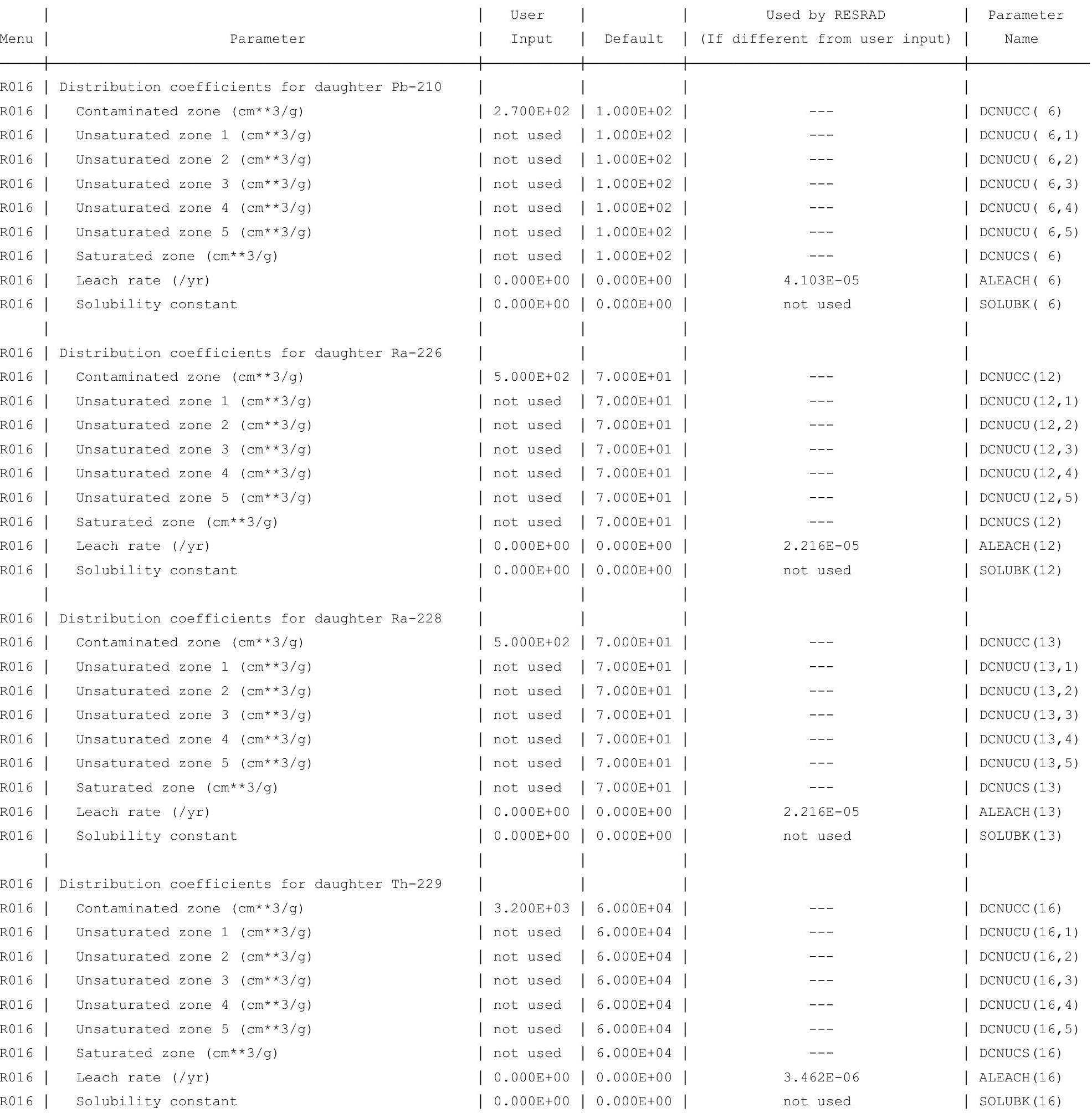


RESRAD, Version $6.5 \quad \mathrm{~T}^{1 / 2}$ Limit $=180$ days

Summary : C746U Trespasser Deterministic Run

File : $\mathrm{X}: \backslash$ FINAL V2 $\backslash \mathrm{C746U}$ T DET-FINALV2.RAD

Site-Specific Parameter Summary (continued)

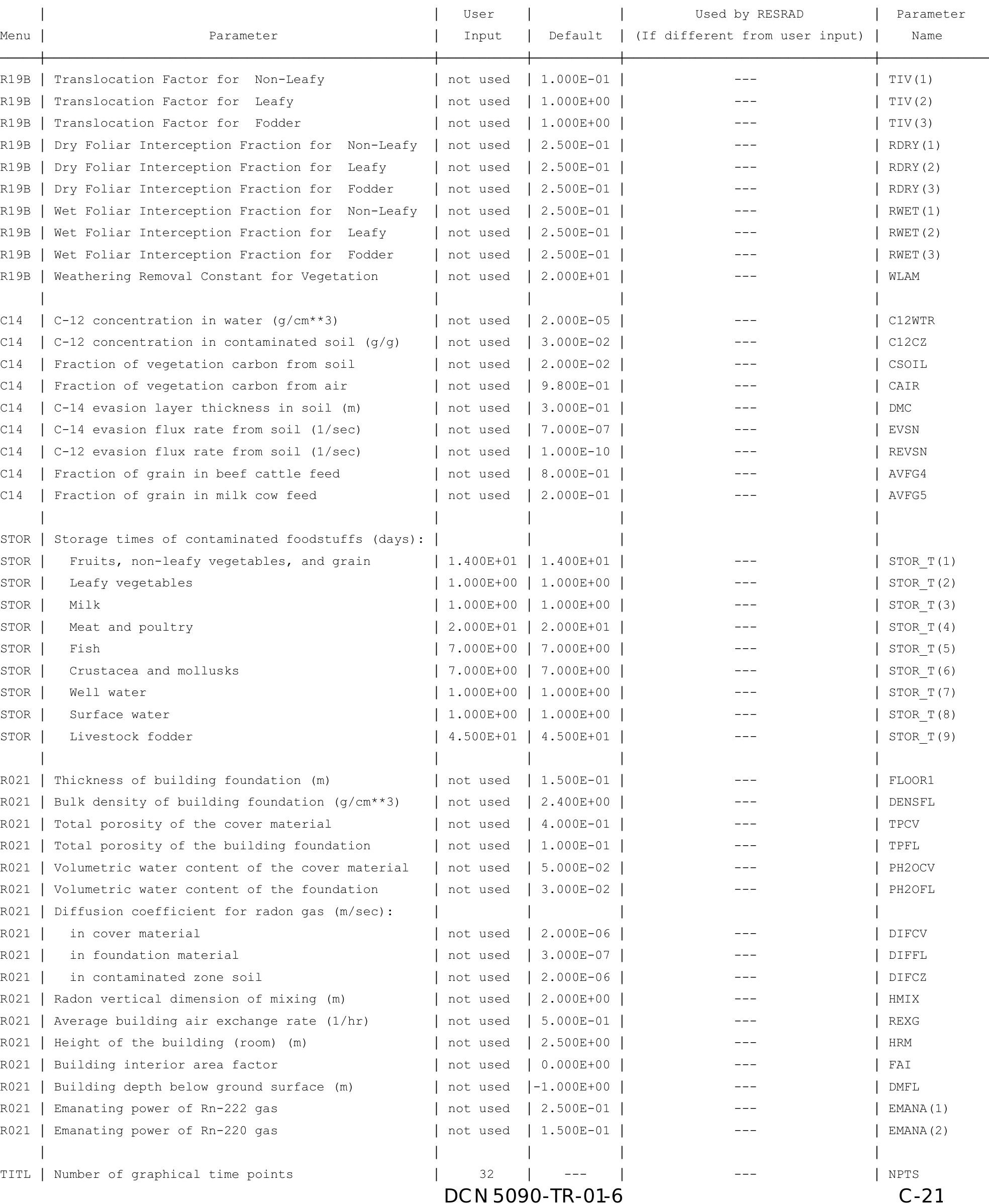


RESRAD, Version $6.5 \quad \mathrm{~T}^{1} \frac{1}{2}$ Limit $=180$ days

Summary : C746U Trespasser Deterministic Run

File : $\mathrm{X}: \backslash$ FINAL V2 $\backslash \mathrm{C} 746 \mathrm{U} T$ DET-FINALV2.RAD

Contaminated Zone Dimensions

Area: 89436.00 square meters

Thickness:

Cover Depth:
13.40 meters
0.15 meters
Initial Soil Concentrations, pCi/g

$\begin{array}{ll}\mathrm{Am}-241 & 1.000 \mathrm{E}+00 \\ \mathrm{Cs}-137 & 1.000 \mathrm{E}+00 \\ \mathrm{~Np}-237 & 1.000 \mathrm{E}+00 \\ \mathrm{Pu}-238 & 1.000 \mathrm{E}+00 \\ \mathrm{Pu}-239 & 1.000 \mathrm{E}+00 \\ \mathrm{Pu}-240 & 1.000 \mathrm{E}+00 \\ \mathrm{TC}-99 & 1.000 \mathrm{E}+00 \\ \mathrm{Th}-228 & 1.000 \mathrm{E}+00 \\ \mathrm{Th}-230 & 1.000 \mathrm{E}+00 \\ \mathrm{Th}-232 & 1.000 \mathrm{E}+00 \\ \mathrm{U}-234 & 1.000 \mathrm{E}+00 \\ \mathrm{U}-235 & 1.000 \mathrm{E}+00 \\ \mathrm{U}-238 & 1.000 \mathrm{E}+00\end{array}$

Total Dose TDOSE(t), mrem/yr

Basic Radiation Dose Limit $=1.000 \mathrm{E}+02 \mathrm{mrem} / \mathrm{yr}$

Total Mixture Sum $M(t)$ = Fraction of Basic Dose Limit Received at Time (t)

$\begin{array}{rllll}t \quad \text { years }): & 0.000 \mathrm{E}+00 & 1.000 \mathrm{E}+00 & 5.000 \mathrm{E}+01 & 7.000 \mathrm{E}+01 \\ \text { TDOSE }(t): & 1.188 \mathrm{E}-01 & 1.004 \mathrm{E}-01 & 2.374 \mathrm{E}-01 & 2.715 \mathrm{E}-01 \\ \mathrm{M}(\mathrm{t}): & 1.188 \mathrm{E}-03 & 1.004 \mathrm{E}-03 & 2.374 \mathrm{E}-03 & 2.715 \mathrm{E}-03\end{array}$

Maximum TDOSE $(t): 2.715 \mathrm{E}-01 \mathrm{mrem} / \mathrm{yr}$ at $t=7.000 \mathrm{E}+01$ years 
RESRAD, Version $6.5 \quad \mathrm{~T}^{1 / 2}$ Limit $=180$ days

Summary : C746U Trespasser Deterministic Run
File : $\mathrm{X}: \backslash$ FINAL V2 $\backslash \mathrm{C} 746 \mathrm{U} \mathrm{T}$ DET-FINALV2.RAD

Total Dose Contributions TDOSE(i,p,t) for Individual Radionuclides (i) and Pathways (p) As mrem/yr and Fraction of Total Dose At $t=0.000 \mathrm{E}+00$ years

Water Independent Pathways (Inhalation excludes radon)

\begin{tabular}{|c|c|c|}
\hline clide & mrem/yr & fract. \\
\hline-241 & $1.457 \mathrm{E}-06$ & 0.0000 \\
\hline-137 & $2.060 \mathrm{E}-02$ & 0.1734 \\
\hline-237 & $3.453 E-03$ & 0.0291 \\
\hline-238 & $2.641 \mathrm{E}-08$ & 0.0000 \\
\hline-239 & $6.302 \mathrm{E}-07$ & 0.0000 \\
\hline-240 & $2.567 \mathrm{E}-08$ & 0.0000 \\
\hline-99 & $4.063 \mathrm{E}-08$ & 0.0000 \\
\hline-228 & $8.889 \mathrm{E}-02$ & 0.7483 \\
\hline-230 & $2.131 \mathrm{E}-05$ & 0.0002 \\
\hline-232 & $3.329 \mathrm{E}-03$ & 0.0280 \\
\hline 34 & $1.754 \mathrm{E}-07$ & 0.0000 \\
\hline 35 & $1.627 \mathrm{E}-03$ & 0.0137 \\
\hline 38 & $8.774 \mathrm{E}-04$ & 0.0074 \\
\hline & $\mathrm{J}$ & 1.0000 \\
\hline
\end{tabular}

\begin{abstract}
Inhalation
\end{abstract}

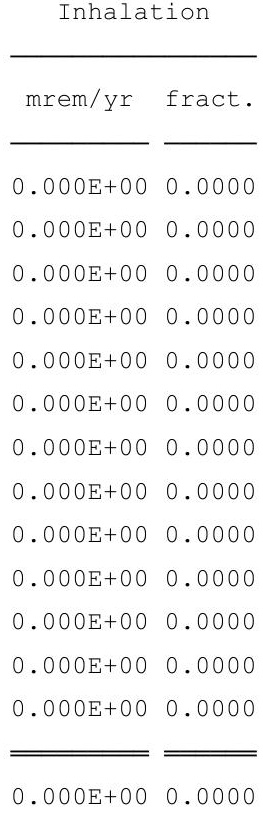

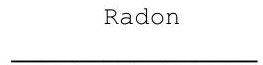
mrem/yr fract. $\overline{0.000 \mathrm{E}+00} \overline{0.0000}$ $0.000 \mathrm{E}+00 \quad 0.0000$ $0.000 E+00 \quad 0.0000$ $0.000 E+00 \quad 0.0000$ $0.000 \mathrm{E}+00 \quad 0.0000$ $0.000 E+00 \quad 0.0000$ $0.000 \mathrm{E}+00 \quad 0.0000$ $0.000 E+00 \quad 0.0000$ $0.000 \mathrm{E}+00 \quad 0.0000$ $0.000 \mathrm{E}+00 \quad 0.0000$ $0.000 E+00 \quad 0.0000$ $0.000 \mathrm{E}+00 \quad 0.0000$ $0.000 \mathrm{E}+00 \quad 0.0000$

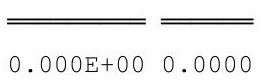

\begin{tabular}{|c|c|c|c|}
\hline \multicolumn{2}{|c|}{ Plant } & \multicolumn{2}{|c|}{ Meat } \\
\hline mrem/yr & fract. & mrem/yr & fract. \\
\hline $.000 \mathrm{E}+00$ & 0.0000 & $0.000 \mathrm{E}+00$ & 0.0000 \\
\hline $0.000 \mathrm{E}+00$ & 0.0000 & $0.000 \mathrm{E}+00$ & 0.0000 \\
\hline $0.000 \mathrm{E}+00$ & 0.0000 & $0.000 \mathrm{E}+00$ & 0.0000 \\
\hline $0.000 \mathrm{E}+00$ & 0.0000 & $0.000 \mathrm{E}+00$ & 0.0000 \\
\hline $0.000 \mathrm{E}+00$ & 0.0000 & $0.000 \mathrm{E}+00$ & 0.0000 \\
\hline $0.000 \mathrm{E}+00$ & 0.0000 & $0.000 \mathrm{E}+00$ & 0.0000 \\
\hline $0.000 \mathrm{E}+00$ & 0.0000 & $0.000 \mathrm{E}+00$ & 0.0000 \\
\hline $0.000 \mathrm{E}+00$ & 0.0000 & $0.000 \mathrm{E}+00$ & 0.0000 \\
\hline $0.000 \mathrm{E}+00$ & 0.0000 & $0.000 \mathrm{E}+00$ & 0.0000 \\
\hline $0.000 \mathrm{E}+00$ & 0.0000 & $0.000 \mathrm{E}+00$ & 0.0000 \\
\hline $0.000 \mathrm{E}+00$ & 0.0000 & $0.000 \mathrm{E}+00$ & 0.0000 \\
\hline $0.000 \mathrm{E}+00$ & 0.0000 & $0.000 \mathrm{E}+00$ & 0.0000 \\
\hline $0.000 \mathrm{E}+00$ & 0.0000 & $0.000 \mathrm{E}+00$ & 0.0000 \\
\hline & & 0.00 & . \\
\hline
\end{tabular}

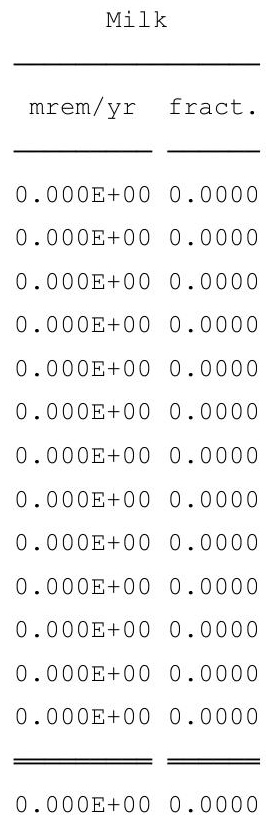

Soil mrem/yr fract. $0.000 \mathrm{E}+00 \quad 0.0000$ $0.000 \mathrm{E}+00 \quad 0.0000$ $0.000 \mathrm{E}+00 \quad 0.0000$ $0.000 \mathrm{E}+00 \quad 0.0000$ $0.000 \mathrm{E}+00 \quad 0.0000$ $0.000 \mathrm{E}+00 \quad 0.0000$ $0.000 \mathrm{E}+00 \quad 0.0000$ $0.000 \mathrm{E}+00 \quad 0.0000$ $0.000 \mathrm{E}+00 \quad 0.0000$ $0.000 \mathrm{E}+00 \quad 0.0000$ $0.000 \mathrm{E}+00 \quad 0.0000$ $0.000 \mathrm{E}+00 \quad 0.0000$ $0.000 \mathrm{E}+00 \quad 0.0000$ $0.000 \mathrm{E}+00 \quad 0.0000$

Total Dose Contributions TDOSE (i,p,t) for Individual Radionuclides (i) and Pathways (p) As mrem/yr and Fraction of Total Dose At $t=0.000 \mathrm{E}+00$ years

Water Dependent Pathways

\begin{tabular}{|c|c|c|c|c|c|c|}
\hline \multirow{2}{*}{$\begin{array}{l}\text { Radio- } \\
\text { Nuclide }\end{array}$} & \multicolumn{2}{|c|}{ Water } & \multicolumn{2}{|c|}{ Fish } & \multicolumn{2}{|c|}{ Radon } \\
\hline & $\mathrm{mrem} / \mathrm{yr}$ & fract. & mrem/yr & fract. & $\mathrm{mrem} / \mathrm{yr}$ & fract. \\
\hline-241 & $0.000 \mathrm{E}+00$ & 0.0000 & $0.000 \mathrm{E}+00$ & 0.0000 & $0.000 \mathrm{E}+00$ & 0.0000 \\
\hline-137 & $0.000 \mathrm{E}+00$ & 0.0000 & $0.000 \mathrm{E}+00$ & 0.0000 & $0.000 \mathrm{E}+00$ & 0.0000 \\
\hline 237 & $0.000 \mathrm{E}+00$ & 0.0000 & $0.000 \mathrm{E}+00$ & 0.0000 & $0.000 \mathrm{E}+00$ & 0.0000 \\
\hline-238 & $0.000 \mathrm{E}+00$ & 0.0000 & $0.000 \mathrm{E}+00$ & 0.0000 & $0.000 \mathrm{E}+00$ & 0.0000 \\
\hline 239 & $0.000 \mathrm{E}+00$ & 0.0000 & $0.000 \mathrm{E}+00$ & 0.0000 & $0.000 \mathrm{E}+00$ & 0.0000 \\
\hline-240 & $0.000 \mathrm{E}+00$ & 0.0000 & $0.000 \mathrm{E}+00$ & 0.0000 & $0.000 \mathrm{E}+00$ & 0.0000 \\
\hline 99 & $0.000 \mathrm{E}+00$ & 0.0000 & $0.000 \mathrm{E}+00$ & 0.0000 & $0.000 \mathrm{E}+00$ & 0.0000 \\
\hline 228 & $0.000 \mathrm{E}+00$ & 0.0000 & $0.000 \mathrm{E}+00$ & 0.0000 & $0.000 \mathrm{E}+00$ & 0.0000 \\
\hline 230 & $0.000 \mathrm{E}+00$ & 0.0000 & $0.000 \mathrm{E}+00$ & 0.0000 & $0.000 \mathrm{E}+00$ & 0.0000 \\
\hline 232 & $0.000 \mathrm{E}+00$ & 0.0000 & $0.000 \mathrm{E}+00$ & 0.0000 & $0.000 \mathrm{E}+00$ & 0.0000 \\
\hline 4 & $0.000 \mathrm{E}+00$ & 0.0000 & $0.000 \mathrm{E}+00$ & 0.0000 & $0.000 \mathrm{E}+00$ & 0.0000 \\
\hline & $0.000 \mathrm{E}+00$ & 0.0000 & $0.000 \mathrm{E}+00$ & 0.0000 & $0.000 \mathrm{E}+00$ & 0.0000 \\
\hline & $0.000 \mathrm{E}+00$ & 0.0000 & $0.000 \mathrm{E}+00$ & 0.0000 & $0.000 \mathrm{E}+00$ & 0.0000 \\
\hline & 00 & 00 & $.000 \mathrm{E}+00$ & 000 & $0.000 \mathrm{E}+00$ & 0.00 \\
\hline
\end{tabular}

\begin{tabular}{cc} 
Plant \\
\cline { 1 - 2 } mrem/yr fract. \\
\cline { 1 - 1 } 0.000E+00 & 0.0000 \\
$0.000 \mathrm{E}+00$ & 0.0000 \\
$0.000 \mathrm{E}+00$ & 0.0000 \\
$0.000 \mathrm{E}+00$ & 0.0000 \\
$0.000 \mathrm{E}+00$ & 0.0000 \\
$0.000 \mathrm{E}+00$ & 0.0000 \\
$0.000 \mathrm{E}+00$ & 0.0000 \\
$0.000 \mathrm{E}+00$ & 0.0000 \\
$0.000 \mathrm{E}+00$ & 0.0000 \\
$0.000 \mathrm{E}+00$ & 0.0000 \\
$0.000 \mathrm{E}+00$ & 0.0000 \\
$0.000 \mathrm{E}+00$ & 0.0000 \\
$0.000 \mathrm{E}+00$ & 0.0000 \\
\hline \hline
\end{tabular}

$0.000 \mathrm{E}+00 \quad 0.0000$

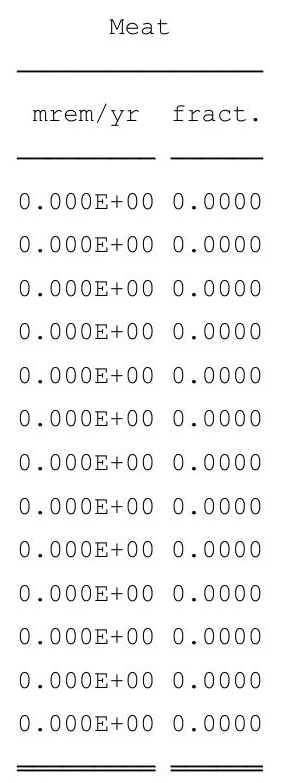

$0.000 \mathrm{E}+00 \quad 0.0000$

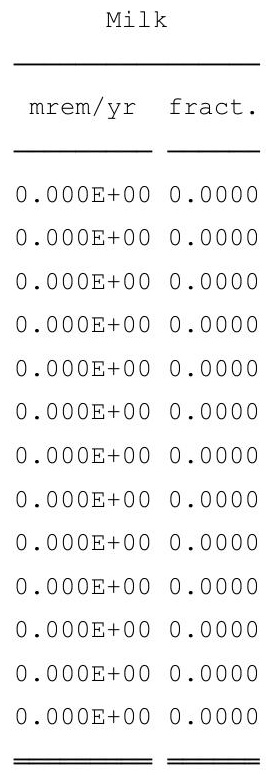

$0.000 \mathrm{E}+00 \quad 0.0000$
All Pathways* mrem/yr fract. $1.457 \mathrm{E}-06 \quad 0.0000$ $2.060 \mathrm{E}-02 \quad 0.1734$ $3.453 \mathrm{E}-03 \quad 0.0291$ $2.641 \mathrm{E}-08 \quad 0.0000$ $6.302 \mathrm{E}-07 \quad 0.0000$ $2.567 \mathrm{E}-08 \quad 0.0000$ $4.063 \mathrm{E}-08 \quad 0.0000$ $8.889 \mathrm{E}-02 \quad 0.7483$ $2.131 \mathrm{E}-05 \quad 0.0002$ $3.329 \mathrm{E}-03 \quad 0.0280$ $1.754 \mathrm{E}-07 \quad 0.0000$ $1.627 \mathrm{E}-03 \quad 0.0137$ $8.774 \mathrm{E}-04 \quad 0.0074$

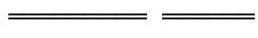
$1.188 \mathrm{E}-01 \quad 1.0000$

*Sum of all water independent and dependent pathways. 
RESRAD, Version $6.5 \quad \mathrm{~T}^{1 / 2}$ Limit $=180$ days

Summary : C746U Trespasser Deterministic Run
File : X: $\backslash$ FINAL V2 $\backslash$ C746U T DET-FINALV2.RAD

Total Dose Contributions TDOSE (i,p,t) for Individual Radionuclides (i) and Pathways (p) As mrem/yr and Fraction of Total Dose At $t=1.000 \mathrm{E}+00$ years

Water Independent Pathways (Inhalation excludes radon)

\begin{tabular}{|c|c|c|c|c|c|c|c|c|c|c|c|c|c|c|}
\hline \multirow{2}{*}{ Nuclide } & \multicolumn{2}{|c|}{ Ground } & \multicolumn{2}{|c|}{ Inhalation } & \multicolumn{2}{|c|}{ Radon } & \multicolumn{2}{|c|}{ Plant } & \multicolumn{2}{|c|}{ Meat } & \multicolumn{2}{|c|}{ Milk } & \multicolumn{2}{|c|}{ Soil } \\
\hline & mrem/yr & fract. & mrem/yr & fract. & mrem/yr & fract. & mrem/yr & fract. & mrem/yr & fract. & mrem/yr & fract. & mrem/yr & fract. \\
\hline-241 & $1.498 E-06$ & 0.0000 & $0.000 \mathrm{E}+00$ & 0.0000 & $0.000 \mathrm{E}+00$ & 0.0000 & $0.000 \mathrm{E}+00$ & 0.0000 & $0.000 \mathrm{E}+00$ & 0.0000 & $0.000 \mathrm{E}+00$ & 0.0000 & $0.000 \mathrm{E}+00$ & 0.0000 \\
\hline-137 & $2.029 E-02$ & 0.2020 & $0.000 \mathrm{E}+00$ & 0.0000 & $0.000 \mathrm{E}+00$ & 0.0000 & $0.000 \mathrm{E}+00$ & 0.0000 & $0.000 \mathrm{E}+00$ & 0.0000 & $0.000 \mathrm{E}+00$ & 0.0000 & $0.000 \mathrm{E}+00$ & 0.0000 \\
\hline-237 & $3.490 \mathrm{E}-03$ & 0.0347 & $0.000 \mathrm{E}+00$ & 0.0000 & $0.000 \mathrm{E}+00$ & 0.0000 & $0.000 \mathrm{E}+00$ & 0.0000 & $0.000 \mathrm{E}+00$ & 0.0000 & $0.000 \mathrm{E}+00$ & 0.0000 & $0.000 \mathrm{E}+00$ & 0.0000 \\
\hline-238 & $2.667 \mathrm{E}-08$ & 0.0000 & $0.000 \mathrm{E}+00$ & 0.0000 & $0.000 \mathrm{E}+00$ & 0.0000 & $0.000 \mathrm{E}+00$ & 0.0000 & $0.000 \mathrm{E}+00$ & 0.0000 & $0.000 \mathrm{E}+00$ & 0.0000 & $0.000 \mathrm{E}+00$ & 0.0000 \\
\hline-239 & $6.378 E-07$ & 0.0000 & $0.000 \mathrm{E}+00$ & 0.0000 & $0.000 \mathrm{E}+00$ & 0.0000 & $0.000 \mathrm{E}+00$ & 0.0000 & $0.000 \mathrm{E}+00$ & 0.0000 & $0.000 \mathrm{E}+00$ & 0.0000 & $0.000 \mathrm{E}+00$ & 0.0000 \\
\hline-240 & $2.612 \mathrm{E}-08$ & 0.0000 & $0.000 \mathrm{E}+00$ & 0.0000 & $0.000 \mathrm{E}+00$ & 0.0000 & $0.000 \mathrm{E}+00$ & 0.0000 & $0.000 \mathrm{E}+00$ & 0.0000 & $0.000 \mathrm{E}+00$ & 0.0000 & $0.000 \mathrm{E}+00$ & 0.0000 \\
\hline 99 & $4.098 E-08$ & 0.0000 & $0.000 \mathrm{E}+00$ & 0.0000 & $0.000 \mathrm{E}+00$ & 0.0000 & $0.000 \mathrm{E}+00$ & 0.0000 & $0.000 \mathrm{E}+00$ & 0.0000 & $0.000 \mathrm{E}+00$ & 0.0000 & $0.000 \mathrm{E}+00$ & 0.0000 \\
\hline-228 & $6.226 \mathrm{E}-02$ & 0.6198 & $0.000 \mathrm{E}+00$ & 0.0000 & $0.000 \mathrm{E}+00$ & 0.0000 & $0.000 \mathrm{E}+00$ & 0.0000 & $0.000 \mathrm{E}+00$ & 0.0000 & $0.000 \mathrm{E}+00$ & 0.0000 & $0.000 \mathrm{E}+00$ & 0.0000 \\
\hline-230 & $6.276 \mathrm{E}-05$ & 0.0006 & $0.000 \mathrm{E}+00$ & 0.0000 & $0.000 \mathrm{E}+00$ & 0.0000 & $0.000 \mathrm{E}+00$ & 0.0000 & $0.000 \mathrm{E}+00$ & 0.0000 & $0.000 \mathrm{E}+00$ & 0.0000 & $0.000 \mathrm{E}+00$ & 0.0000 \\
\hline-232 & $1.181 \mathrm{E}-02$ & 0.1176 & $0.000 \mathrm{E}+00$ & 0.0000 & $0.000 \mathrm{E}+00$ & 0.0000 & $0.000 \mathrm{E}+00$ & 0.0000 & $0.000 \mathrm{E}+00$ & 0.0000 & $0.000 \mathrm{E}+00$ & 0.0000 & $0.000 \mathrm{E}+00$ & 0.0000 \\
\hline 234 & $1.789 \mathrm{E}-07$ & 0.0000 & $0.000 \mathrm{E}+00$ & 0.0000 & $0.000 \mathrm{E}+00$ & 0.0000 & $0.000 \mathrm{E}+00$ & 0.0000 & $0.000 \mathrm{E}+00$ & 0.0000 & $0.000 \mathrm{E}+00$ & 0.0000 & $0.000 \mathrm{E}+00$ & 0.0000 \\
\hline 235 & $1.648 E-03$ & 0.0164 & $0.000 \mathrm{E}+00$ & 0.0000 & $0.000 \mathrm{E}+00$ & 0.0000 & $0.000 \mathrm{E}+00$ & 0.0000 & $0.000 \mathrm{E}+00$ & 0.0000 & $0.000 \mathrm{E}+00$ & 0.0000 & $0.000 \mathrm{E}+00$ & 0.0000 \\
\hline 38 & $8.846 E-04$ & 0.0088 & $0.000 \mathrm{E}+00$ & 0.0000 & $0.000 \mathrm{E}+00$ & 0.0000 & $0.000 \mathrm{E}+00$ & 0.0000 & $0.000 \mathrm{E}+00$ & 0.0000 & $0.000 \mathrm{E}+00$ & 0.0000 & $0.000 \mathrm{E}+00$ & 0.0000 \\
\hline & $1.004 \mathrm{E}-01$ & 1.0000 & $0.000 \mathrm{E}+00$ & 0.0000 & $0.000 \mathrm{E}+00$ & 0.0000 & $0.000 \mathrm{E}+00$ & 0.0000 & $0.000 \mathrm{E}+00$ & 0.0000 & $0.000 \mathrm{E}+00$ & 0.0000 & $.000 \mathrm{E}+00$ & 0.0000 \\
\hline
\end{tabular}

Total Dose Contributions TDOSE (i,p,t) for Individual Radionuclides (i) and Pathways (p) As mrem/yr and Fraction of Total Dose At $t=1.000 \mathrm{E}+00$ years

Water Dependent Pathways

\begin{tabular}{|c|c|c|c|c|c|c|c|c|c|c|c|c|c|c|}
\hline & \multicolumn{2}{|c|}{ Water } & \multicolumn{2}{|c|}{ Fish } & \multicolumn{2}{|c|}{ Radon } & \multicolumn{2}{|c|}{ Plant } & \multicolumn{2}{|c|}{ Meat } & \multicolumn{2}{|c|}{ Milk } & \multicolumn{2}{|c|}{ All Pathways* } \\
\hline clide & mrem/yr & fract. & mrem/yr & fract. & mrem/yr & fract. & mrem/yr & fract. & mrem/yr & fract. & mrem/yr & fract. & mrem/yr & fract. \\
\hline-241 & $0.000 \mathrm{E}+00$ & 0.0000 & $0.000 \mathrm{E}+00$ & 0.0000 & $0.000 \mathrm{E}+00$ & 0.0000 & $0.000 \mathrm{E}+00$ & 0.0000 & $0.000 \mathrm{E}+00$ & 0.0000 & $0.000 E+00$ & 0.0000 & $1.498 \mathrm{E}-06$ & 0.0000 \\
\hline-137 & $0.000 \mathrm{E}+00$ & 0.0000 & $0.000 \mathrm{E}+00$ & 0.0000 & $0.000 \mathrm{E}+00$ & 0.0000 & $0.000 \mathrm{E}+00$ & 0.0000 & $0.000 \mathrm{E}+00$ & 0.0000 & $0.000 \mathrm{E}+00$ & 0.0000 & $2.029 \mathrm{E}-02$ & 0.2020 \\
\hline-237 & $0.000 \mathrm{E}+00$ & 0.0000 & $0.000 \mathrm{E}+00$ & 0.0000 & $0.000 \mathrm{E}+00$ & 0.0000 & $0.000 \mathrm{E}+00$ & 0.0000 & $0.000 \mathrm{E}+00$ & 0.0000 & $0.000 \mathrm{E}+00$ & 0.0000 & $3.490 \mathrm{E}-03$ & 0.0347 \\
\hline 238 & $0.000 \mathrm{E}+00$ & 0.0000 & $0.000 \mathrm{E}+00$ & 0.0000 & $0.000 \mathrm{E}+00$ & 0.0000 & $0.000 \mathrm{E}+00$ & 0.0000 & $0.000 \mathrm{E}+00$ & 0.0000 & $0.000 \mathrm{E}+00$ & 0.0000 & $2.667 \mathrm{E}-08$ & 0.0000 \\
\hline 239 & $0.000 \mathrm{E}+00$ & 0.0000 & $0.000 \mathrm{E}+00$ & 0.0000 & $0.000 \mathrm{E}+00$ & 0.0000 & $0.000 \mathrm{E}+00$ & 0.0000 & $0.000 \mathrm{E}+00$ & 0.0000 & $0.000 \mathrm{E}+00$ & 0.0000 & $6.378 \mathrm{E}-07$ & 0.0000 \\
\hline 240 & $0.000 \mathrm{E}+00$ & 0.0000 & $0.000 \mathrm{E}+00$ & 0.0000 & $0.000 \mathrm{E}+00$ & 0.0000 & $0.000 \mathrm{E}+00$ & 0.0000 & $0.000 \mathrm{E}+00$ & 0.0000 & $0.000 \mathrm{E}+00$ & 0.0000 & $2.612 \mathrm{E}-08$ & 0.0000 \\
\hline 99 & $0.000 \mathrm{E}+00$ & 0.0000 & $0.000 \mathrm{E}+00$ & 0.0000 & $0.000 \mathrm{E}+00$ & 0.0000 & $0.000 \mathrm{E}+00$ & 0.0000 & $0.000 \mathrm{E}+00$ & 0.0000 & $0.000 \mathrm{E}+00$ & 0.0000 & $4.098 E-08$ & 0.0000 \\
\hline 228 & $0.000 \mathrm{E}+00$ & 0.0000 & $0.000 \mathrm{E}+00$ & 0.0000 & $0.000 \mathrm{E}+00$ & 0.0000 & $0.000 \mathrm{E}+00$ & 0.0000 & $0.000 \mathrm{E}+00$ & 0.0000 & $0.000 \mathrm{E}+00$ & 0.0000 & $6.226 \mathrm{E}-02$ & 0.6198 \\
\hline 230 & $0.000 \mathrm{E}+00$ & 0.0000 & $0.000 \mathrm{E}+00$ & 0.0000 & $0.000 \mathrm{E}+00$ & 0.0000 & $0.000 \mathrm{E}+00$ & 0.0000 & $0.000 \mathrm{E}+00$ & 0.0000 & $0.000 \mathrm{E}+00$ & 0.0000 & $6.276 \mathrm{E}-05$ & 0.0006 \\
\hline 232 & $0.000 \mathrm{E}+00$ & 0.0000 & $0.000 \mathrm{E}+00$ & 0.0000 & $0.000 \mathrm{E}+00$ & 0.0000 & $0.000 \mathrm{E}+00$ & 0.0000 & $0.000 \mathrm{E}+00$ & 0.0000 & $0.000 \mathrm{E}+00$ & 0.0000 & $1.181 \mathrm{E}-02$ & 0.1176 \\
\hline 34 & $0.000 \mathrm{E}+00$ & 0.0000 & $0.000 \mathrm{E}+00$ & 0.0000 & $0.000 \mathrm{E}+00$ & 0.0000 & $0.000 \mathrm{E}+00$ & 0.0000 & $0.000 \mathrm{E}+00$ & 0.0000 & $0.000 \mathrm{E}+00$ & 0.0000 & $1.789 \mathrm{E}-07$ & 0.0000 \\
\hline 35 & $0.000 \mathrm{E}+00$ & 0.0000 & $0.000 \mathrm{E}+00$ & 0.0000 & $0.000 \mathrm{E}+00$ & 0.0000 & $0.000 \mathrm{E}+00$ & 0.0000 & $0.000 \mathrm{E}+00$ & 0.0000 & $0.000 \mathrm{E}+00$ & 0.0000 & $1.648 \mathrm{E}-03$ & 0.0164 \\
\hline 38 & $0.000 \mathrm{E}+00$ & 0.0000 & $0.000 \mathrm{E}+00$ & 0.0000 & $0.000 \mathrm{E}+00$ & 0.0000 & $0.000 \mathrm{E}+00$ & 0.0000 & $0.000 \mathrm{E}+00$ & 0.0000 & $0.000 \mathrm{E}+00$ & 0.0000 & $8.846 \mathrm{E}-04$ & 0.0088 \\
\hline & $0.000 \mathrm{E}+00$ & 0.0000 & $0.000 \mathrm{E}+00$ & 0.0000 & $0.000 \mathrm{E}+00$ & 0.0000 & $0.000 \mathrm{E}+00$ & 0.0000 & $0.000 \mathrm{E}+00$ & 0.0000 & $0.000 \mathrm{E}+00$ & 000 & -01 & 1.0000 \\
\hline
\end{tabular}

* Sum of all water independent and dependent pathways. 
RESRAD, Version $6.5 \quad \mathrm{~T}^{1 / 2}$ Limit $=180$ days

Summary : C746U Trespasser Deterministic Run
File : $\mathrm{X}: \backslash$ FINAL V2 $\backslash \mathrm{C} 746 \mathrm{U} \mathrm{T}$ DET-FINALV2.RAD

Total Dose Contributions TDOSE(i,p,t) for Individual Radionuclides (i) and Pathways (p) As mrem/yr and Fraction of Total Dose At $t=5.000 \mathrm{E}+01$ years

Water Independent Pathways (Inhalation excludes radon)

\begin{tabular}{|c|c|c|c|c|c|c|c|c|c|c|c|c|c|c|}
\hline \multirow{2}{*}{ Nuclide } & \multicolumn{2}{|c|}{ Ground } & \multicolumn{2}{|c|}{ Inhalation } & \multicolumn{2}{|c|}{ Radon } & \multicolumn{2}{|c|}{ Plant } & \multicolumn{2}{|c|}{ Meat } & \multicolumn{2}{|c|}{ Milk } & \multicolumn{2}{|c|}{ Soil } \\
\hline & mrem/yr & fract. & mrem/yr & fract. & mrem/yr & fract. & mrem/yr & fract. & mrem/yr & fract. & mrem/yr & fract. & mrem/yr & fract. \\
\hline-241 & $5.626 \mathrm{E}-06$ & 0.0000 & $7.441 \mathrm{E}-06$ & 0.0000 & $0.000 \mathrm{E}+00$ & 0.0000 & $0.000 \mathrm{E}+00$ & 0.0000 & $0.000 \mathrm{E}+00$ & 0.0000 & $0.000 \mathrm{E}+00$ & 0.0000 & $2.819 E-04$ & 0.0012 \\
\hline-137 & $9.872 \mathrm{E}-03$ & 0.0416 & $1.019 \mathrm{E}-09$ & 0.0000 & $0.000 \mathrm{E}+00$ & 0.0000 & $0.000 \mathrm{E}+00$ & 0.0000 & $0.000 \mathrm{E}+00$ & 0.0000 & $0.000 \mathrm{E}+00$ & 0.0000 & $6.176 \mathrm{E}-06$ & 0.0000 \\
\hline-237 & $5.910 E-03$ & 0.0249 & $4.171 \mathrm{E}-06$ & 0.0000 & $0.000 \mathrm{E}+00$ & 0.0000 & $0.000 \mathrm{E}+00$ & 0.0000 & $0.000 \mathrm{E}+00$ & 0.0000 & $0.000 \mathrm{E}+00$ & 0.0000 & $1.682 \mathrm{E}-04$ & 0.0007 \\
\hline-238 & $4.307 E-08$ & 0.0000 & $6.200 \mathrm{E}-06$ & 0.0000 & $0.000 \mathrm{E}+00$ & 0.0000 & $0.000 \mathrm{E}+00$ & 0.0000 & $0.000 \mathrm{E}+00$ & 0.0000 & $0.000 \mathrm{E}+00$ & 0.0000 & $2.357 \mathrm{E}-04$ & 0.0010 \\
\hline-239 & $1.145 \mathrm{E}-06$ & 0.0000 & $1.006 \mathrm{E}-05$ & 0.0000 & $0.000 \mathrm{E}+00$ & 0.0000 & $0.000 \mathrm{E}+00$ & 0.0000 & $0.000 \mathrm{E}+00$ & 0.0000 & $0.000 \mathrm{E}+00$ & 0.0000 & $3.812 \mathrm{E}-04$ & 0.0016 \\
\hline-240 & $6.171 \mathrm{E}-08$ & 0.0000 & $1.003 \mathrm{E}-05$ & 0.0000 & $0.000 \mathrm{E}+00$ & 0.0000 & $0.000 \mathrm{E}+00$ & 0.0000 & $0.000 \mathrm{E}+00$ & 0.0000 & $0.000 \mathrm{E}+00$ & 0.0000 & $3.798 \mathrm{E}-04$ & 0.0016 \\
\hline-99 & $6.246 E-08$ & 0.0000 & $6.406 \mathrm{E}-10$ & 0.0000 & $0.000 \mathrm{E}+00$ & 0.0000 & $0.000 \mathrm{E}+00$ & 0.0000 & $0.000 \mathrm{E}+00$ & 0.0000 & $0.000 \mathrm{E}+00$ & 0.0000 & $5.735 \mathrm{E}-07$ & 0.0000 \\
\hline-228 & $1.646 \mathrm{E}-09$ & 0.0000 & $4.170 \mathrm{E}-14$ & 0.0000 & $0.000 \mathrm{E}+00$ & 0.0000 & $0.000 \mathrm{E}+00$ & 0.0000 & $0.000 \mathrm{E}+00$ & 0.0000 & $0.000 \mathrm{E}+00$ & 0.0000 & $2.490 \mathrm{E}-12$ & 0.0000 \\
\hline-230 & $2.923 E-03$ & 0.0123 & $8.429 \mathrm{E}-06$ & 0.0000 & $0.000 \mathrm{E}+00$ & 0.0000 & $0.000 \mathrm{E}+00$ & 0.0000 & $0.000 \mathrm{E}+00$ & 0.0000 & $0.000 \mathrm{E}+00$ & 0.0000 & $3.612 \mathrm{E}-04$ & 0.0015 \\
\hline-232 & $2.106 \mathrm{E}-01$ & 0.8872 & $1.424 \mathrm{E}-05$ & 0.0001 & $0.000 \mathrm{E}+00$ & 0.0000 & $0.000 \mathrm{E}+00$ & 0.0000 & $0.000 \mathrm{E}+00$ & 0.0000 & $0.000 \mathrm{E}+00$ & 0.0000 & $1.623 \mathrm{E}-03$ & 0.0068 \\
\hline 34 & $1.092 \mathrm{E}-06$ & 0.0000 & $7.930 \mathrm{E}-07$ & 0.0000 & $0.000 \mathrm{E}+00$ & 0.0000 & $0.000 \mathrm{E}+00$ & 0.0000 & $0.000 \mathrm{E}+00$ & 0.0000 & $0.000 \mathrm{E}+00$ & 0.0000 & 7. $495 \mathrm{E}-05$ & 0.0003 \\
\hline 35 & $3.036 \mathrm{E}-03$ & 0.0128 & $7.519 \mathrm{E}-07$ & 0.0000 & $0.000 \mathrm{E}+00$ & 0.0000 & $0.000 \mathrm{E}+00$ & 0.0000 & $0.000 \mathrm{E}+00$ & 0.0000 & $0.000 \mathrm{E}+00$ & 0.0000 & $7.442 \mathrm{E}-05$ & 0.0003 \\
\hline 38 & 1. $318 E-03$ & 0.0056 & $6.725 \mathrm{E}-07$ & 0.0000 & $0.000 \mathrm{E}+00$ & 0.0000 & $0.000 \mathrm{E}+00$ & 0.0000 & $0.000 \mathrm{E}+00$ & 0.0000 & $0.000 \mathrm{E}+00$ & 0.0000 & $7.390 \mathrm{E}-05$ & 0.0003 \\
\hline & $2.337 \mathrm{E}-01$ & 0.9843 & $6.279 \mathrm{E}-05$ & 0.0003 & $0.000 \mathrm{E}+00$ & 0.0000 & $0.000 \mathrm{E}+00$ & 0.0000 & $0.000 \mathrm{E}+00$ & 0.0000 & $0.000 \mathrm{E}+00$ & 0.0000 & 3. $660 \mathrm{E}-03$ & 0.0154 \\
\hline
\end{tabular}

Total Dose Contributions TDOSE(i,p,t) for Individual Radionuclides (i) and Pathways (p) As mrem/yr and Fraction of Total Dose At $t=5.000 \mathrm{E}+01$ years

Water Dependent Pathways

\begin{tabular}{|c|c|c|c|c|c|c|c|c|c|c|c|c|c|c|}
\hline \multirow{2}{*}{ Nuclide } & \multicolumn{2}{|c|}{ Water } & \multicolumn{2}{|c|}{ Fish } & \multicolumn{2}{|c|}{ Radon } & \multicolumn{2}{|c|}{ Plant } & \multicolumn{2}{|c|}{ Meat } & \multicolumn{2}{|c|}{ Milk } & \multicolumn{2}{|c|}{ All Pathways* } \\
\hline & mrem/yr & fract. & mrem/yr & fract. & mrem/yr & fract. & mrem/yr & fract. & mrem/yr & fract. & mrem/yr & fract. & mrem/yr & fract. \\
\hline-241 & $0.000 \mathrm{E}+00$ & 0.0000 & $0.000 \mathrm{E}+00$ & 0.0000 & $0.000 \mathrm{E}+00$ & 0.0000 & $0.000 \mathrm{E}+00$ & 0.0000 & $0.000 \mathrm{E}+00$ & 0.0000 & $0.000 E+00$ & 0.0000 & $2.950 \mathrm{E}-04$ & 0.0012 \\
\hline-137 & $0.000 \mathrm{E}+00$ & 0.0000 & $0.000 \mathrm{E}+00$ & 0.0000 & $0.000 \mathrm{E}+00$ & 0.0000 & $0.000 \mathrm{E}+00$ & 0.0000 & $0.000 \mathrm{E}+00$ & 0.0000 & $0.000 \mathrm{E}+00$ & 0.0000 & $9.878 \mathrm{E}-03$ & 0.0416 \\
\hline-237 & $0.000 \mathrm{E}+00$ & 0.0000 & $0.000 \mathrm{E}+00$ & 0.0000 & $0.000 \mathrm{E}+00$ & 0.0000 & $0.000 \mathrm{E}+00$ & 0.0000 & $0.000 \mathrm{E}+00$ & 0.0000 & $0.000 \mathrm{E}+00$ & 0.0000 & $6.082 \mathrm{E}-03$ & 0.0256 \\
\hline-238 & $0.000 \mathrm{E}+00$ & 0.0000 & $0.000 \mathrm{E}+00$ & 0.0000 & $0.000 \mathrm{E}+00$ & 0.0000 & $0.000 \mathrm{E}+00$ & 0.0000 & $0.000 \mathrm{E}+00$ & 0.0000 & $0.000 \mathrm{E}+00$ & 0.0000 & $2.420 \mathrm{E}-04$ & 0.0010 \\
\hline-239 & $0.000 \mathrm{E}+00$ & 0.0000 & $0.000 \mathrm{E}+00$ & 0.0000 & $0.000 \mathrm{E}+00$ & 0.0000 & $0.000 \mathrm{E}+00$ & 0.0000 & $0.000 \mathrm{E}+00$ & 0.0000 & $0.000 \mathrm{E}+00$ & 0.0000 & $3.925 \mathrm{E}-04$ & 0.0017 \\
\hline-240 & $0.000 \mathrm{E}+00$ & 0.0000 & $0.000 \mathrm{E}+00$ & 0.0000 & $0.000 \mathrm{E}+00$ & 0.0000 & $0.000 \mathrm{E}+00$ & 0.0000 & $0.000 \mathrm{E}+00$ & 0.0000 & $0.000 \mathrm{E}+00$ & 0.0000 & $3.899 \mathrm{E}-04$ & 0.0016 \\
\hline 99 & $0.000 \mathrm{E}+00$ & 0.0000 & $0.000 \mathrm{E}+00$ & 0.0000 & $0.000 \mathrm{E}+00$ & 0.0000 & $0.000 \mathrm{E}+00$ & 0.0000 & $0.000 \mathrm{E}+00$ & 0.0000 & $0.000 \mathrm{E}+00$ & 0.0000 & $6.366 \mathrm{E}-07$ & 0.0000 \\
\hline-228 & $0.000 \mathrm{E}+00$ & 0.0000 & $0.000 \mathrm{E}+00$ & 0.0000 & $0.000 \mathrm{E}+00$ & 0.0000 & $0.000 \mathrm{E}+00$ & 0.0000 & $0.000 \mathrm{E}+00$ & 0.0000 & $0.000 \mathrm{E}+00$ & 0.0000 & $1.649 \mathrm{E}-09$ & 0.0000 \\
\hline 230 & $0.000 \mathrm{E}+00$ & 0.0000 & $0.000 \mathrm{E}+00$ & 0.0000 & $0.000 \mathrm{E}+00$ & 0.0000 & $0.000 \mathrm{E}+00$ & 0.0000 & $0.000 \mathrm{E}+00$ & 0.0000 & $0.000 \mathrm{E}+00$ & 0.0000 & $3.293 E-03$ & 0.0139 \\
\hline 232 & $0.000 \mathrm{E}+00$ & 0.0000 & $0.000 \mathrm{E}+00$ & 0.0000 & $0.000 \mathrm{E}+00$ & 0.0000 & $0.000 \mathrm{E}+00$ & 0.0000 & $0.000 \mathrm{E}+00$ & 0.0000 & $0.000 \mathrm{E}+00$ & 0.0000 & $2.123 E-01$ & 0.8941 \\
\hline 34 & $0.000 \mathrm{E}+00$ & 0.0000 & $0.000 \mathrm{E}+00$ & 0.0000 & $0.000 \mathrm{E}+00$ & 0.0000 & $0.000 \mathrm{E}+00$ & 0.0000 & $0.000 \mathrm{E}+00$ & 0.0000 & $0.000 \mathrm{E}+00$ & 0.0000 & $7.683 \mathrm{E}-05$ & 0.0003 \\
\hline 35 & $0.000 \mathrm{E}+00$ & 0.0000 & $0.000 \mathrm{E}+00$ & 0.0000 & $0.000 \mathrm{E}+00$ & 0.0000 & $0.000 \mathrm{E}+00$ & 0.0000 & $0.000 \mathrm{E}+00$ & 0.0000 & $0.000 \mathrm{E}+00$ & 0.0000 & $3.111 \mathrm{E}-03$ & 0.0131 \\
\hline 38 & $0.000 \mathrm{E}+00$ & 0.0000 & $0.000 \mathrm{E}+00$ & 0.0000 & $0.000 \mathrm{E}+00$ & 0.0000 & $0.000 \mathrm{E}+00$ & 0.0000 & $0.000 \mathrm{E}+00$ & 0.0000 & $0.000 \mathrm{E}+00$ & 0.0000 & $1.393 \mathrm{E}-03$ & 0.0059 \\
\hline & $0.000 \mathrm{E}+00$ & 0.0000 & $0.000 \mathrm{E}+00$ & 0.0000 & $0.000 \mathrm{E}+00$ & 0.0000 & $0.000 \mathrm{E}+00$ & 0.0000 & $0.000 \mathrm{E}+00$ & 0.0000 & $0.000 \mathrm{E}+00$ & 0.0000 & $4 E-01$ & 1.0000 \\
\hline
\end{tabular}

* Sum of all water independent and dependent pathways. 
RESRAD, Version $6.5 \quad \mathrm{~T}^{1 / 2}$ Limit $=180$ days

Summary : C746U Trespasser Deterministic Run
File : $\mathrm{X}: \backslash$ FINAL V2 $\backslash \mathrm{C} 746 \mathrm{U} \mathrm{T}$ DET-FINALV2.RAD

Total Dose Contributions TDOSE(i,p,t) for Individual Radionuclides (i) and Pathways (p) As mrem/yr and Fraction of Total Dose At $t=7.000 \mathrm{E}+01$ years

Water Independent Pathways (Inhalation excludes radon)

\begin{tabular}{|c|c|c|c|c|c|c|c|c|c|c|c|c|c|c|}
\hline \multirow{2}{*}{ Nuclide } & \multicolumn{2}{|c|}{ Ground } & \multicolumn{2}{|c|}{ Inhalation } & \multicolumn{2}{|c|}{ Radon } & \multicolumn{2}{|c|}{ Plant } & \multicolumn{2}{|c|}{ Meat } & \multicolumn{2}{|c|}{ Milk } & \multicolumn{2}{|c|}{ Soil } \\
\hline & mrem/yr & fract. & mrem/yr & fract. & mrem/yr & fract. & mrem/yr & fract. & mrem/yr & fract. & mrem/yr & fract. & mrem/yr & fract. \\
\hline-241 & $9.593 E-06$ & 0.0000 & $1.026 \mathrm{E}-05$ & 0.0000 & $0.000 \mathrm{E}+00$ & 0.0000 & $0.000 \mathrm{E}+00$ & 0.0000 & $0.000 \mathrm{E}+00$ & 0.0000 & $0.000 \mathrm{E}+00$ & 0.0000 & $3.887 \mathrm{E}-04$ & 0.0014 \\
\hline-137 & $7.357 \mathrm{E}-03$ & 0.0271 & $9.133 \mathrm{E}-10$ & 0.0000 & $0.000 \mathrm{E}+00$ & 0.0000 & $0.000 \mathrm{E}+00$ & 0.0000 & $0.000 \mathrm{E}+00$ & 0.0000 & $0.000 \mathrm{E}+00$ & 0.0000 & $5.536 \mathrm{E}-06$ & 0.0000 \\
\hline-237 & $7.331 E-03$ & 0.0270 & $5.921 \mathrm{E}-06$ & 0.0000 & $0.000 \mathrm{E}+00$ & 0.0000 & $0.000 \mathrm{E}+00$ & 0.0000 & $0.000 \mathrm{E}+00$ & 0.0000 & $0.000 \mathrm{E}+00$ & 0.0000 & $2.387 \mathrm{E}-04$ & 0.0009 \\
\hline-238 & $5.243 E-08$ & 0.0000 & $7.535 \mathrm{E}-06$ & 0.0000 & $0.000 \mathrm{E}+00$ & 0.0000 & $0.000 \mathrm{E}+00$ & 0.0000 & $0.000 \mathrm{E}+00$ & 0.0000 & $0.000 \mathrm{E}+00$ & 0.0000 & $2.865 E-04$ & 0.0011 \\
\hline-239 & $1.453 \mathrm{E}-06$ & 0.0000 & $1.432 \mathrm{E}-05$ & 0.0001 & $0.000 \mathrm{E}+00$ & 0.0000 & $0.000 \mathrm{E}+00$ & 0.0000 & $0.000 \mathrm{E}+00$ & 0.0000 & $0.000 \mathrm{E}+00$ & 0.0000 & $5.424 \mathrm{E}-04$ & 0.0020 \\
\hline-240 & $8.764 \mathrm{E}-08$ & 0.0000 & $1.424 \mathrm{E}-05$ & 0.0001 & $0.000 \mathrm{E}+00$ & 0.0000 & $0.000 \mathrm{E}+00$ & 0.0000 & $0.000 \mathrm{E}+00$ & 0.0000 & $0.000 \mathrm{E}+00$ & 0.0000 & $5.394 \mathrm{E}-04$ & 0.0020 \\
\hline-99 & $7.418 \mathrm{E}-08$ & 0.0000 & 7. $383 \mathrm{E}-10$ & 0.0000 & $0.000 \mathrm{E}+00$ & 0.0000 & $0.000 \mathrm{E}+00$ & 0.0000 & $0.000 \mathrm{E}+00$ & 0.0000 & $0.000 \mathrm{E}+00$ & 0.0000 & $6.609 \mathrm{E}-07$ & 0.0000 \\
\hline-228 & 1. $330 \mathrm{E}-12$ & 0.0000 & $4.233 \mathrm{E}-17$ & 0.0000 & $0.000 \mathrm{E}+00$ & 0.0000 & $0.000 \mathrm{E}+00$ & 0.0000 & $0.000 \mathrm{E}+00$ & 0.0000 & $0.000 \mathrm{E}+00$ & 0.0000 & $2.528 \mathrm{E}-15$ & 0.0000 \\
\hline-230 & $4.685 \mathrm{E}-03$ & 0.0173 & $1.202 \mathrm{E}-05$ & 0.0000 & $0.000 \mathrm{E}+00$ & 0.0000 & $0.000 \mathrm{E}+00$ & 0.0000 & $0.000 \mathrm{E}+00$ & 0.0000 & $0.000 \mathrm{E}+00$ & 0.0000 & $5.489 \mathrm{E}-04$ & 0.0020 \\
\hline-232 & $2.414 \mathrm{E}-01$ & 0.8891 & $2.030 \mathrm{E}-05$ & 0.0001 & $0.000 \mathrm{E}+00$ & 0.0000 & $0.000 \mathrm{E}+00$ & 0.0000 & $0.000 \mathrm{E}+00$ & 0.0000 & $0.000 \mathrm{E}+00$ & 0.0000 & $2.314 \mathrm{E}-03$ & 0.0085 \\
\hline 34 & $2.099 E-06$ & 0.0000 & $1.131 \mathrm{E}-06$ & 0.0000 & $0.000 \mathrm{E}+00$ & 0.0000 & $0.000 \mathrm{E}+00$ & 0.0000 & $0.000 \mathrm{E}+00$ & 0.0000 & $0.000 \mathrm{E}+00$ & 0.0000 & $1.068 \mathrm{E}-04$ & 0.0004 \\
\hline 35 & $3.899 \mathrm{E}-03$ & 0.0144 & $1.102 \mathrm{E}-06$ & 0.0000 & $0.000 \mathrm{E}+00$ & 0.0000 & $0.000 \mathrm{E}+00$ & 0.0000 & $0.000 \mathrm{E}+00$ & 0.0000 & $0.000 \mathrm{E}+00$ & 0.0000 & $1.075 \mathrm{E}-04$ & 0.0004 \\
\hline 38 & $1.554 \mathrm{E}-03$ & 0.0057 & $9.572 \mathrm{E}-07$ & 0.0000 & $0.000 \mathrm{E}+00$ & 0.0000 & $0.000 \mathrm{E}+00$ & 0.0000 & $0.000 \mathrm{E}+00$ & 0.0000 & $0.000 \mathrm{E}+00$ & 0.0000 & $1.052 \mathrm{E}-04$ & 0.0004 \\
\hline & $2.663 \mathrm{E}-01$ & 0.9806 & $8.779 \mathrm{E}-05$ & 0.0003 & $0.000 \mathrm{E}+00$ & 0.0000 & $0.000 \mathrm{E}+00$ & 0.0000 & $0.000 \mathrm{E}+00$ & 0.0000 & $0.000 \mathrm{E}+00$ & 0.0000 & $5.185 \mathrm{E}-03$ & 0.0191 \\
\hline
\end{tabular}

Total Dose Contributions TDOSE(i,p,t) for Individual Radionuclides (i) and Pathways (p) As mrem/yr and Fraction of Total Dose At $t=7.000 \mathrm{E}+01$ years

Water Dependent Pathways

\begin{tabular}{|c|c|c|c|c|c|c|c|c|c|c|c|c|c|c|}
\hline \multirow{2}{*}{ Nuclide } & \multicolumn{2}{|c|}{ Water } & \multicolumn{2}{|c|}{ Fish } & \multicolumn{2}{|c|}{ Radon } & \multicolumn{2}{|c|}{ Plant } & \multicolumn{2}{|c|}{ Meat } & \multicolumn{2}{|c|}{ Milk } & \multicolumn{2}{|c|}{ All Pathways* } \\
\hline & mrem/yr & fract. & mrem/yr & fract. & mrem/yr & fract. & mrem/yr & fract. & mrem/yr & fract. & mrem/yr & fract. & mrem/yr & fract. \\
\hline-241 & $0.000 \mathrm{E}+00$ & 0.0000 & $0.000 \mathrm{E}+00$ & 0.0000 & $0.000 \mathrm{E}+00$ & 0.0000 & $0.000 \mathrm{E}+00$ & 0.0000 & $0.000 \mathrm{E}+00$ & 0.0000 & $0.000 E+00$ & 0.0000 & $4.086 \mathrm{E}-04$ & 0.0015 \\
\hline-137 & $0.000 \mathrm{E}+00$ & 0.0000 & $0.000 \mathrm{E}+00$ & 0.0000 & $0.000 \mathrm{E}+00$ & 0.0000 & $0.000 \mathrm{E}+00$ & 0.0000 & $0.000 \mathrm{E}+00$ & 0.0000 & $0.000 \mathrm{E}+00$ & 0.0000 & $7.362 \mathrm{E}-03$ & 0.0271 \\
\hline-237 & $0.000 \mathrm{E}+00$ & 0.0000 & $0.000 \mathrm{E}+00$ & 0.0000 & $0.000 \mathrm{E}+00$ & 0.0000 & $0.000 \mathrm{E}+00$ & 0.0000 & $0.000 \mathrm{E}+00$ & 0.0000 & $0.000 \mathrm{E}+00$ & 0.0000 & $7.575 E-03$ & 0.0279 \\
\hline-238 & $0.000 \mathrm{E}+00$ & 0.0000 & $0.000 \mathrm{E}+00$ & 0.0000 & $0.000 \mathrm{E}+00$ & 0.0000 & $0.000 \mathrm{E}+00$ & 0.0000 & $0.000 \mathrm{E}+00$ & 0.0000 & $0.000 \mathrm{E}+00$ & 0.0000 & $2.941 E-04$ & 0.0011 \\
\hline-239 & $0.000 \mathrm{E}+00$ & 0.0000 & $0.000 \mathrm{E}+00$ & 0.0000 & $0.000 \mathrm{E}+00$ & 0.0000 & $0.000 \mathrm{E}+00$ & 0.0000 & $0.000 \mathrm{E}+00$ & 0.0000 & $0.000 \mathrm{E}+00$ & 0.0000 & $5.581 \mathrm{E}-04$ & 0.0021 \\
\hline-240 & $0.000 \mathrm{E}+00$ & 0.0000 & $0.000 \mathrm{E}+00$ & 0.0000 & $0.000 \mathrm{E}+00$ & 0.0000 & $0.000 \mathrm{E}+00$ & 0.0000 & $0.000 \mathrm{E}+00$ & 0.0000 & $0.000 \mathrm{E}+00$ & 0.0000 & $5.538 \mathrm{E}-04$ & 0.0020 \\
\hline 99 & $0.000 \mathrm{E}+00$ & 0.0000 & $0.000 \mathrm{E}+00$ & 0.0000 & $0.000 \mathrm{E}+00$ & 0.0000 & $0.000 \mathrm{E}+00$ & 0.0000 & $0.000 \mathrm{E}+00$ & 0.0000 & $0.000 \mathrm{E}+00$ & 0.0000 & $7.359 \mathrm{E}-07$ & 0.0000 \\
\hline-228 & $0.000 \mathrm{E}+00$ & 0.0000 & $0.000 \mathrm{E}+00$ & 0.0000 & $0.000 \mathrm{E}+00$ & 0.0000 & $0.000 \mathrm{E}+00$ & 0.0000 & $0.000 \mathrm{E}+00$ & 0.0000 & $0.000 \mathrm{E}+00$ & 0.0000 & $1.333 \mathrm{E}-12$ & 0.0000 \\
\hline 230 & $0.000 \mathrm{E}+00$ & 0.0000 & $0.000 \mathrm{E}+00$ & 0.0000 & $0.000 \mathrm{E}+00$ & 0.0000 & $0.000 \mathrm{E}+00$ & 0.0000 & $0.000 \mathrm{E}+00$ & 0.0000 & $0.000 \mathrm{E}+00$ & 0.0000 & $5.246 \mathrm{E}-03$ & 0.0193 \\
\hline 232 & $0.000 \mathrm{E}+00$ & 0.0000 & $0.000 \mathrm{E}+00$ & 0.0000 & $0.000 \mathrm{E}+00$ & 0.0000 & $0.000 \mathrm{E}+00$ & 0.0000 & $0.000 \mathrm{E}+00$ & 0.0000 & $0.000 \mathrm{E}+00$ & 0.0000 & $2.438 E-01$ & 0.8977 \\
\hline 34 & $0.000 \mathrm{E}+00$ & 0.0000 & $0.000 \mathrm{E}+00$ & 0.0000 & $0.000 \mathrm{E}+00$ & 0.0000 & $0.000 \mathrm{E}+00$ & 0.0000 & $0.000 \mathrm{E}+00$ & 0.0000 & $0.000 \mathrm{E}+00$ & 0.0000 & $1.100 \mathrm{E}-04$ & 0.0004 \\
\hline 35 & $0.000 \mathrm{E}+00$ & 0.0000 & $0.000 \mathrm{E}+00$ & 0.0000 & $0.000 \mathrm{E}+00$ & 0.0000 & $0.000 \mathrm{E}+00$ & 0.0000 & $0.000 \mathrm{E}+00$ & 0.0000 & $0.000 \mathrm{E}+00$ & 0.0000 & $4.007 \mathrm{E}-03$ & 0.0148 \\
\hline 38 & $0.000 \mathrm{E}+00$ & 0.0000 & $0.000 \mathrm{E}+00$ & 0.0000 & $0.000 \mathrm{E}+00$ & 0.0000 & $0.000 \mathrm{E}+00$ & 0.0000 & $0.000 \mathrm{E}+00$ & 0.0000 & $0.000 \mathrm{E}+00$ & 0.0000 & $1.660 \mathrm{E}-03$ & 0.0061 \\
\hline & $0.000 \mathrm{E}+00$ & 0.0000 & $0.000 \mathrm{E}+00$ & 0.0000 & $0.000 \mathrm{E}+00$ & 0.0000 & $0.000 \mathrm{E}+00$ & 0.0000 & $0.000 \mathrm{E}+00$ & 0.0000 & $0.000 \mathrm{E}+00$ & 0.0000 & $5 E-01$ & 1.0000 \\
\hline
\end{tabular}

* Sum of all water independent and dependent pathways. 
RESRAD, Version $6.5 \quad \mathrm{~T}^{1 / 2}$ Limit $=180$ days

Summary : C746U Trespasser Deterministic Run

File : $\mathrm{X}: \backslash$ FINAL V2\C746U T DET-FINALV2.RAD

Dose/Source Ratios Summed Over All Pathways

Parent and Progeny Principal Radionuclide Contributions Indicated

Parent Product Thread DSR $(j, t)$ At Time in Years (mrem/yr)/ $(\mathrm{pCi} / \mathrm{g})$

(i) (j) Fraction 0.000E+00 1.000E+00 5.000E+01 7.000E+01

$\begin{array}{lllllll}\text { Am-241 } & 1.000 \mathrm{E}+00 & 1.457 \mathrm{E}-06 & 1.496 \mathrm{E}-06 & 2.949 \mathrm{E}-04 & 4.084 \mathrm{E}-04\end{array}$

$\begin{array}{lllllll}\mathrm{Np}-237+\mathrm{D} & 1.000 \mathrm{E}+00 & 5.599 \mathrm{E}-10 & 1.695 \mathrm{E}-09 & 9.593 \mathrm{E}-08 & 1.644 \mathrm{E}-07\end{array}$

$\begin{array}{llllll}\mathrm{U}-233 & 1.000 \mathrm{E}+00 & 6.695 \mathrm{E}-19 & 4.735 \mathrm{E}-18 & 1.474 \mathrm{E}-13 & 4.016 \mathrm{E}-13\end{array}$

$\begin{array}{llllll}\mathrm{Th}-229+\mathrm{D} & 1.000 \mathrm{E}+00 & 3.971 \mathrm{E}-20 & 5.999 \mathrm{E}-19 & 3.406 \mathrm{E}-14 & 1.120 \mathrm{E}-13\end{array}$

$\operatorname{\sum DSR}(j) \quad 1.457 \mathrm{E}-06 \quad 1.498 \mathrm{E}-06 \quad 2.950 \mathrm{E}-04 \quad 4.086 \mathrm{E}-04$

$\mathrm{Cs}-137+\mathrm{D} \quad 1.000 \mathrm{E}+00 \quad 2.060 \mathrm{E}-02 \quad 2.029 \mathrm{E}-02 \quad 9.878 \mathrm{E}-03 \quad 7.362 \mathrm{E}-03$

$\begin{array}{lllllll}\mathrm{Np}-237+\mathrm{D} & 1.000 \mathrm{E}+00 & 3.453 \mathrm{E}-03 & 3.490 \mathrm{E}-03 & 6.082 \mathrm{E}-03 & 7.575 \mathrm{E}-03\end{array}$

$\begin{array}{lllllll}\mathrm{U}-233 & 1.000 \mathrm{E}+00 & 6.197 \mathrm{E}-12 & 1.880 \mathrm{E}-11 & 1.848 \mathrm{E}-08 & 3.644 \mathrm{E}-08\end{array}$

$\begin{array}{llllllll}\mathrm{Th}-229+\mathrm{D} & 1.000 \mathrm{E}+00 \quad 4.903 \mathrm{E}-13 & 3.458 \mathrm{E}-12 & 6.366 \mathrm{E}-09 & 1.511 \mathrm{E}-08\end{array}$

$\operatorname{LDSR}(j) \quad 3.453 \mathrm{E}-03 \quad 3.490 \mathrm{E}-03 \quad 6.082 \mathrm{E}-03 \quad 7.575 \mathrm{E}-03$

$\begin{array}{llllll}\mathrm{Pu}-238 & 1.840 \mathrm{E}-09 & 4.859 \mathrm{E}-17 & 4.907 \mathrm{E}-17 & 4.452 \mathrm{E}-13 & 5.411 \mathrm{E}-13\end{array}$

$\begin{array}{llllll}\mathrm{Pu}-238 & 1.000 \mathrm{E}+00 & 2.641 \mathrm{E}-08 & 2.667 \mathrm{E}-08 & 2.419 \mathrm{E}-04 & 2.941 \mathrm{E}-04\end{array}$

$\begin{array}{lllllll}\mathrm{U}-234 & 1.000 \mathrm{E}+00 & 2.486 \mathrm{E}-13 & 7.549 \mathrm{E}-13 & 8.976 \mathrm{E}-09 & 1.658 \mathrm{E}-08\end{array}$

$\begin{array}{lllllll}\mathrm{Th}-230 & 1.000 \mathrm{E}+00 & 3.358 \mathrm{E}-18 & 2.380 \mathrm{E}-17 & 9.470 \mathrm{E}-12 & 2.502 \mathrm{E}-11\end{array}$

$\begin{array}{lllllll}\mathrm{Ra}-226+\mathrm{D} \quad 1.000 \mathrm{E}+00 \quad 4.363 \mathrm{E}-17 & 6.572 \mathrm{E}-16 & 2.901 \mathrm{E}-11 & 8.757 \mathrm{E}-11\end{array}$

$\mathrm{Pb}-210+\mathrm{D} \quad 1.000 \mathrm{E}+00 \quad 2.379 \mathrm{E}-23 \quad 7.401 \mathrm{E}-22 \quad 1.869 \mathrm{E}-13 \quad 8.845 \mathrm{E}-13$

$\operatorname{\sum DSR}(j) \quad 2.641 \mathrm{E}-08 \quad 2.667 \mathrm{E}-08 \quad 2.420 \mathrm{E}-04 \quad 2.941 \mathrm{E}-04$

$\begin{array}{lllllll}\mathrm{Pu}-239 & 1.000 \mathrm{E}+00 & 6.302 \mathrm{E}-07 & 6.378 \mathrm{E}-07 & 3.925 \mathrm{E}-04 & 5.581 \mathrm{E}-04\end{array}$

$\begin{array}{lllllll}\mathrm{U}-235+\mathrm{D} & 1.000 \mathrm{E}+00 & 8.030 \mathrm{E}-13 & 2.436 \mathrm{E}-12 & 1.542 \mathrm{E}-10 & 2.766 \mathrm{E}-10\end{array}$

$\begin{array}{lllllll}\mathrm{Pa}-231 & 1.000 \mathrm{E}+00 & 2.330 \mathrm{E}-18 & 1.646 \mathrm{E}-17 & 5.929 \mathrm{E}-14 & 1.534 \mathrm{E}-13\end{array}$

$\mathrm{AC}-227+\mathrm{D} \quad 1.000 \mathrm{E}+00 \quad 2.010 \mathrm{E}-19 \quad 3.022 \mathrm{E}-18 \quad 1.404 \mathrm{E}-13 \quad 4.252 \mathrm{E}-13$

$\operatorname{EDSR}(j) \quad 6.302 \mathrm{E}-07 \quad 6.378 \mathrm{E}-07 \quad 3.925 \mathrm{E}-04 \quad 5.581 \mathrm{E}-04$

Pu-240 4.950E-08 $1.271 \mathrm{E}-15 \quad 1.293 \mathrm{E}-15 \quad 1.930 \mathrm{E}-11 \quad 2.741 \mathrm{E}-11$

$\begin{array}{llllll}\mathrm{Pu}-240 \quad 1.000 \mathrm{E}+00 & 2.567 \mathrm{E}-08 & 2.612 \mathrm{E}-08 & 3.899 \mathrm{E}-04 & 5.538 \mathrm{E}-04\end{array}$

$\begin{array}{lllllll}\mathrm{U}-236 & 1.000 \mathrm{E}+00 & 1.038 \mathrm{E}-15 & 3.165 \mathrm{E}-15 & 1.083 \mathrm{E}-10 & 2.151 \mathrm{E}-10\end{array}$

Th-232 1.000E+00 4.987E-26 $3.547 \mathrm{E}-25 \quad 6.713 \mathrm{E}-19 \quad 1.861 \mathrm{E}-18$

$\begin{array}{lllllll}\mathrm{Ra}-228+\mathrm{D} & 1.000 \mathrm{E}+00 & 3.271 \mathrm{E}-22 & 4.816 \mathrm{E}-21 & 9.119 \mathrm{E}-17 & 2.265 \mathrm{E}-16\end{array}$

$\begin{array}{lllllll}\mathrm{Th}-228+\mathrm{D} \quad 1.000 \mathrm{E}+00 \quad 5.216 \mathrm{E}-23 & 1.501 \mathrm{E}-21 & 1.723 \mathrm{E}-16 & 4.318 \mathrm{E}-16\end{array}$

$\operatorname{\sum DSR}(j) \quad 2.567 \mathrm{E}-08 \quad 2.612 \mathrm{E}-08 \quad 3.899 \mathrm{E}-04 \quad 5.538 \mathrm{E}-04$

$\begin{array}{llllll}\mathrm{TC}-99 & 1.000 \mathrm{E}+00 & 4.063 \mathrm{E}-08 & 4.098 \mathrm{E}-08 & 6.366 \mathrm{E}-07 & 7.359 \mathrm{E}-07\end{array}$

Th-228+D 1.000E+00 8.889E-02 6.226E-02 $1.649 \mathrm{E}-09 \quad 1.333 \mathrm{E}-12$

$\begin{array}{llllll}\mathrm{Th}-230 & 1.000 \mathrm{E}+00 & 7.878 \mathrm{E}-07 & 8.012 \mathrm{E}-07 & 3.311 \mathrm{E}-04 & 4.713 \mathrm{E}-04\end{array}$

$\mathrm{Ra}-226+\mathrm{D} \quad 1.000 \mathrm{E}+00 \quad 2.053 \mathrm{E}-05 \quad 6.196 \mathrm{E}-05 \quad 2.931 \mathrm{E}-03 \quad 4.701 \mathrm{E}-03$

$\mathrm{Pb}-210+\mathrm{D} \quad 1.000 \mathrm{E}+00 \quad 1.860 \mathrm{E}-11 \quad 1.304 \mathrm{E}-10 \quad 3.123 \mathrm{E}-05 \quad 7.416 \mathrm{E}-05$

$\operatorname{LDSR}(j) \quad 2.131 \mathrm{E}-05 \quad 6.276 \mathrm{E}-05 \quad 3.293 \mathrm{E}-03 \quad 5.246 \mathrm{E}-03$ 
RESRAD, Version $6.5 \quad T^{1 / 2}$ Limit $=180$ days

Summary : C746U Trespasser Deterministic Run

File : $\mathrm{X}: \backslash$ FINAL V2 $\backslash$ C746U T DET-FINALV2.RAD

Dose/Source Ratios Summed Over All Pathways

Parent and Progeny Principal Radionuclide Contributions Indicated

\begin{tabular}{|c|c|c|c|c|c|c|}
\hline $\begin{array}{l}\text { Parent } \\
\text { (i) }\end{array}$ & $\begin{array}{c}\text { Product } \\
(j)\end{array}$ & $\begin{array}{c}\text { Thread } \\
\text { Fraction }\end{array}$ & $\begin{array}{l}\mathrm{SR}(j, t) \text { At } \\
0.000 \mathrm{E}+00\end{array}$ & $\begin{array}{l}\text { Time in Ye } \\
1.000 \mathrm{E}+00\end{array}$ & $\begin{array}{l}\text { ears (mre } \\
5.000 \mathrm{E}+01\end{array}$ & $\begin{array}{l}\mathrm{em} / \mathrm{yr}) /(\mathrm{pC} \\
7.000 \mathrm{E}+01\end{array}$ \\
\hline$h-232$ & Th-232 & $1.000 \mathrm{E}+00$ & $2.040 \mathrm{E}-07$ & $2.078 \mathrm{E}-07$ & $3.613 \mathrm{E}-04$ & $5.145 \mathrm{E}-04$ \\
\hline Th-232 & $\mathrm{Ra}-228+\mathrm{D}$ & $1.000 \mathrm{E}+00$ & $2.643 \mathrm{E}-03$ & $7.575 \mathrm{E}-03$ & $6.750 \mathrm{E}-02$ & $7.900 \mathrm{E}-02$ \\
\hline Th-232 & Th $-228+D$ & $1.000 \mathrm{E}+00$ & $6.862 \mathrm{E}-04$ & $4.233 \mathrm{E}-03$ & $1.444 \mathrm{E}-01$ & $1.642 \mathrm{E}-01$ \\
\hline Th-232 & $\sum \operatorname{DSR}(j)$ & & $3.329 \mathrm{E}-03$ & $1.181 \mathrm{E}-02$ & $2.123 \mathrm{E}-01$ & $2.438 \mathrm{E}-01$ \\
\hline $\mathrm{J}-234$ & $\mathrm{U}-234$ & $1.000 \mathrm{E}+00$ & $1.753 \mathrm{E}-07$ & $1.784 \mathrm{E}-07$ & $7.601 \mathrm{E}-05$ & $1.082 \mathrm{E}-04$ \\
\hline $\mathrm{U}-234$ & Th-230 & $1.000 \mathrm{E}+00$ & $3.556 \mathrm{E}-12$ & $1.083 \mathrm{E}-11$ & $1.504 \mathrm{E}-07$ & $2.989 \mathrm{E}-07$ \\
\hline-234 & $\mathrm{Ra}-226+\mathrm{D}$ & $1.000 \mathrm{E}+00$ & $6.163 \mathrm{E}-11$ & $4.340 \mathrm{E}-10$ & $6.684 \mathrm{E}-07$ & $1.499 \mathrm{E}-06$ \\
\hline $\mathrm{U}-234$ & $\mathrm{~Pb}-210+\mathrm{D}$ & $1.000 \mathrm{E}+00$ & $4.195 \mathrm{E}-17$ & $6.314 \mathrm{E}-16$ & $5.293 \mathrm{E}-09$ & $1.815 \mathrm{E}-08$ \\
\hline $\mathrm{U}-234$ & $\sum \operatorname{DSR}(j)$ & & $1.754 \mathrm{E}-07$ & $1.789 \mathrm{E}-07$ & $7.683 \mathrm{E}-05$ & $1.100 \mathrm{E}-04$ \\
\hline$U-235+D$ & $\mathrm{U}-235+\mathrm{D}$ & $1.000 \mathrm{E}+00$ & $1.627 \mathrm{E}-03$ & $1.648 \mathrm{E}-03$ & $3.101 \mathrm{E}-03$ & $3.987 \mathrm{E}-03$ \\
\hline$U-235+D$ & $\mathrm{~Pa}-231$ & $1.000 \mathrm{E}+00$ & $7.092 \mathrm{E}-09$ & $2.148 \mathrm{E}-08$ & $2.385 \mathrm{E}-06$ & $4.421 \mathrm{E}-06$ \\
\hline$U-235+D$ & $A c-227+D$ & $1.000 \mathrm{E}+00$ & $8.148 \mathrm{E}-10$ & $5.702 \mathrm{E}-09$ & $7.572 \mathrm{E}-06$ & $1.589 \mathrm{E}-05$ \\
\hline$U-235+D$ & $\sum \operatorname{DSR}(j)$ & & $1.627 \mathrm{E}-03$ & $1.648 \mathrm{E}-03$ & $3.111 \mathrm{E}-03$ & $4.007 \mathrm{E}-03$ \\
\hline $\mathrm{U}-238$ & $\mathrm{U}-238$ & $5.400 \mathrm{E}-05$ & $1.359 \mathrm{E}-15$ & $1.421 \mathrm{E}-15$ & $3.746 \mathrm{E}-09$ & $5.332 \mathrm{E}-09$ \\
\hline$U-238+D$ & $\mathrm{U}-238+\mathrm{D}$ & $9.999 \mathrm{E}-01$ & $8.774 \mathrm{E}-04$ & $8.846 \mathrm{E}-04$ & $1.393 \mathrm{E}-03$ & $1.660 \mathrm{E}-03$ \\
\hline$U-238+D$ & $\mathrm{U}-234$ & $9.999 \mathrm{E}-01$ & $2.492 \mathrm{E}-13$ & $7.595 \mathrm{E}-13$ & $1.088 \mathrm{E}-08$ & $2.162 \mathrm{E}-08$ \\
\hline$U-238+D$ & Th-230 & $9.999 \mathrm{E}-01$ & 3. $365 \mathrm{E}-18$ & $2.390 \mathrm{E}-17$ & $1.077 \mathrm{E}-11$ & $2.987 \mathrm{E}-11$ \\
\hline $\mathrm{U}-238+\mathrm{D}$ & $\mathrm{Ra}-226+\mathrm{D}$ & $9.999 \mathrm{E}-01$ & $4.369 \mathrm{E}-17$ & $6.593 \mathrm{E}-16$ & $3.196 \mathrm{E}-11$ & $1.001 \mathrm{E}-10$ \\
\hline $\mathrm{U}-238+\mathrm{D}$ & $\mathrm{Pb}-210+\mathrm{D}$ & $9.999 \mathrm{E}-01$ & $2.382 \mathrm{E}-23$ & $7.420 \mathrm{E}-22$ & $2.027 \mathrm{E}-13$ & $9.911 \mathrm{E}-13$ \\
\hline$U-238+D$ & $\sum \operatorname{DSR}(j)$ & & $8.774 \mathrm{E}-04$ & $8.846 \mathrm{E}-04$ & $1.393 \mathrm{E}-03$ & $1.660 \mathrm{E}-03$ \\
\hline
\end{tabular}

The DSR includes contributions from associated (half-life $\leq 180$ days) daughters. 
RESRAD, Version $6.5 \quad T^{1 / 2}$ Limit $=180$ days

Summary : C746U Trespasser Deterministic Run

File : $\mathrm{X}: \backslash$ FINAL V2 $\backslash$ C746U T DET-FINALV2.RAD

Single Radionuclide Soil Guidelines $G(i, t)$ in $\mathrm{pCi} / \mathrm{g}$

Basic Radiation Dose Limit $=1.000 \mathrm{E}+02 \mathrm{mrem} / \mathrm{yr}$

Nuclide

\begin{tabular}{cccccc} 
(i) & $\mathrm{t}=$ & $0.000 \mathrm{E}+00$ & $1.000 \mathrm{E}+00$ & $5.000 \mathrm{E}+01$ & $7.000 \mathrm{E}+01$ \\
\cline { 1 - 1 } $\mathrm{Am}-241$ & & $6.861 \mathrm{E}+07$ & $6.676 \mathrm{E}+07$ & $3.390 \mathrm{E}+05$ & $2.448 \mathrm{E}+05$ \\
$\mathrm{Cs}-137$ & & $4.856 \mathrm{E}+03$ & $4.927 \mathrm{E}+03$ & $1.012 \mathrm{E}+04$ & $1.358 \mathrm{E}+04$ \\
$\mathrm{~Np}-237$ & & $2.896 \mathrm{E}+04$ & $2.866 \mathrm{E}+04$ & $1.644 \mathrm{E}+04$ & $1.320 \mathrm{E}+04$ \\
$\mathrm{Pu}-238$ & & $3.787 \mathrm{E}+09$ & $3.750 \mathrm{E}+09$ & $4.133 \mathrm{E}+05$ & $3.400 \mathrm{E}+05$ \\
$\mathrm{Pu}-239$ & & $1.587 \mathrm{E}+08$ & $1.568 \mathrm{E}+08$ & $2.548 \mathrm{E}+05$ & $1.792 \mathrm{E}+05$ \\
$\mathrm{Pu}-240$ & & $3.896 \mathrm{E}+09$ & $3.828 \mathrm{E}+09$ & $2.565 \mathrm{E}+05$ & $1.806 \mathrm{E}+05$ \\
$\mathrm{TC}-99$ & & $2.461 \mathrm{E}+09$ & $2.440 \mathrm{E}+09$ & $1.571 \mathrm{E}+08$ & $1.359 \mathrm{E}+08$ \\
$\mathrm{Th}-228$ & & $1.125 \mathrm{E}+03$ & $1.606 \mathrm{E}+03$ & $6.065 \mathrm{E}+10$ & $7.505 \mathrm{E}+13$ \\
$\mathrm{Th}-230$ & & $4.692 \mathrm{E}+06$ & $1.593 \mathrm{E}+06$ & $3.037 \mathrm{E}+04$ & $1.906 \mathrm{E}+04$ \\
$\mathrm{Th}-232$ & & $3.004 \mathrm{E}+04$ & $8.469 \mathrm{E}+03$ & $4.711 \mathrm{E}+02$ & $4.102 \mathrm{E}+02$ \\
$\mathrm{U}-234$ & & $5.702 \mathrm{E}+08$ & $5.590 \mathrm{E}+08$ & $1.301 \mathrm{E}+06$ & $9.092 \mathrm{E}+05$ \\
$\mathrm{U}-235$ & $6.145 \mathrm{E}+04$ & $6.069 \mathrm{E}+04$ & $3.214 \mathrm{E}+04$ & $2.495 \mathrm{E}+04$ \\
$\mathrm{U}-238$ & $1.140 \mathrm{E}+05$ & $1.131 \mathrm{E}+05$ & $7.180 \mathrm{E}+04$ & $6.025 \mathrm{E}+04$ \\
\hline \hline & & & & &
\end{tabular}

Summed Dose/Source Ratios DSR(i,t) in (mrem/yr)/(pCi/g) and Single Radionuclide Soil Guidelines $\mathrm{G}(i, t)$ in $\mathrm{pCi} / \mathrm{g}$ at $\operatorname{tmin}=$ time of minimum single radionuclide soil guideline and at $\operatorname{tmax}=$ time of maximum total dose $=7.000 \mathrm{E}+01$ years

\begin{tabular}{|c|c|c|c|c|c|c|}
\hline $\begin{array}{l}\text { uclide } \\
\text { (i) }\end{array}$ & $\begin{array}{c}\text { Initial } \\
(\mathrm{pCi} / \mathrm{g})\end{array}$ & $\begin{array}{c}\text { tmin } \\
\text { (years) }\end{array}$ & $\operatorname{DSR}(i, \operatorname{tmin})$ & $\begin{array}{c}\mathrm{G}(i, \mathrm{tmin}) \\
(\mathrm{pCi} / \mathrm{g})\end{array}$ & $\operatorname{DSR}(i, \operatorname{tmax})$ & $\begin{array}{c}\mathrm{G}(i, \mathrm{tmax}) \\
(\mathrm{pCi} / \mathrm{g})\end{array}$ \\
\hline 241 & $1.000 \mathrm{E}+00$ & $7.000 \mathrm{E}+01$ & $4.086 \mathrm{E}-04$ & $2.448 E+05$ & $4.086 \mathrm{E}-04$ & $2.448 E+05$ \\
\hline-137 & $1.000 \mathrm{E}+00$ & $0.000 \mathrm{E}+00$ & $2.060 \mathrm{E}-02$ & $4.856 \mathrm{E}+03$ & $7.362 \mathrm{E}-03$ & $1.358 \mathrm{E}+04$ \\
\hline-237 & $1.000 \mathrm{E}+00$ & $7.000 \mathrm{E}+01$ & $7.575 \mathrm{E}-03$ & $1.320 \mathrm{E}+04$ & $7.575 E-03$ & $1.320 \mathrm{E}+04$ \\
\hline-238 & $1.000 \mathrm{E}+00$ & $7.000 \mathrm{E}+01$ & $2.941 E-04$ & $3.400 \mathrm{E}+05$ & $2.941 \mathrm{E}-04$ & $3.400 \mathrm{E}+05$ \\
\hline-239 & $1.000 \mathrm{E}+00$ & $7.000 \mathrm{E}+01$ & $5.581 \mathrm{E}-04$ & $1.792 \mathrm{E}+05$ & $5.581 \mathrm{E}-04$ & $1.792 \mathrm{E}+05$ \\
\hline-240 & $1.000 \mathrm{E}+00$ & $7.000 \mathrm{E}+01$ & $5.538 \mathrm{E}-04$ & $1.806 \mathrm{E}+05$ & $5.538 \mathrm{E}-04$ & $1.806 \mathrm{E}+05$ \\
\hline-99 & $1.000 \mathrm{E}+00$ & $7.000 \mathrm{E}+01$ & $7.359 \mathrm{E}-07$ & $1.359 \mathrm{E}+08$ & $7.359 \mathrm{E}-07$ & $1.359 \mathrm{E}+08$ \\
\hline-228 & $1.000 \mathrm{E}+00$ & $0.000 \mathrm{E}+00$ & $8.889 \mathrm{E}-02$ & $1.125 \mathrm{E}+03$ & $1.333 \mathrm{E}-12$ & $7.505 E+13$ \\
\hline 230 & $1.000 \mathrm{E}+00$ & $7.000 \mathrm{E}+01$ & $5.246 \mathrm{E}-03$ & $1.906 \mathrm{E}+04$ & $5.246 \mathrm{E}-03$ & $1.906 \mathrm{E}+04$ \\
\hline 232 & $1.000 \mathrm{E}+00$ & $7.000 \mathrm{E}+01$ & $2.438 \mathrm{E}-01$ & $4.102 \mathrm{E}+02$ & $2.438 \mathrm{E}-01$ & $4.102 E+02$ \\
\hline 234 & $1.000 \mathrm{E}+00$ & $7.000 \mathrm{E}+01$ & $1.100 \mathrm{E}-04$ & $9.092 \mathrm{E}+05$ & $1.100 \mathrm{E}-04$ & $9.092 \mathrm{E}+05$ \\
\hline 35 & $1.000 \mathrm{E}+00$ & $7.000 \mathrm{E}+01$ & $4.007 \mathrm{E}-03$ & $2.495 \mathrm{E}+04$ & $4.007 \mathrm{E}-03$ & $2.495 E+04$ \\
\hline 38 & $1.000 \mathrm{E}+00$ & $7.000 E+01$ & $1.660 \mathrm{E}-03$ & $6.025 E+04$ & $1.660 \mathrm{E}-03$ & $6.025 E+04$ \\
\hline
\end{tabular}


RESRAD, Version $6.5 \quad \mathrm{~T}^{1 / 2}$ Limit $=180$ days

Summary : C746U Trespasser Deterministic Run

File : $\mathrm{X}: \backslash$ FINAL V2 $\backslash$ C746U T DET-FINALV2.RAD

Individual Nuclide Dose Summed Over All Pathways

Parent Nuclide and Branch Fraction Indicated

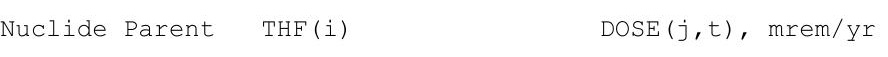

(j)

$\overline{m-241}$

$\mathrm{Am}-241 \quad \mathrm{Am}-241 \quad 1.000 \mathrm{E}+00$

Np-237 Am-241 $1.000 \mathrm{E}+00$

Np-237 Np-237 $1.000 \mathrm{E}+00$

Np-237 $\sum \operatorname{DOSE}(j)$

$\mathrm{U}-233 \quad \mathrm{Am}-241 \quad 1.000 \mathrm{E}+00$

$\mathrm{U}-233 \quad \mathrm{~Np}-237 \quad 1.000 \mathrm{E}+00$

$\mathrm{U}-233 \quad \sum \operatorname{DOSE}(j)$

Th-229

Th-229

Th-229

Cs -137

$\mathrm{Pu}-238$

$\mathrm{Pu}-238$

Pu-238

$\mathrm{U}-234$

$\mathrm{U}-234$

$\mathrm{U}-234$

$\mathrm{U}-234$

Th -230

$\mathrm{Th}-230$

Th -230

Th -230

$\mathrm{Th}-230$

$\mathrm{Ra}-226$

$\mathrm{Ra}-226$

$\mathrm{Ra}-226$

$\mathrm{Ra}-226$

$\operatorname{Ra}-226$

$\mathrm{Pb}-210$

$\mathrm{Pb}-210$

$\mathrm{Pb}-210$

$\mathrm{Pb}-210$

$\mathrm{Pb}-210$

$\mathrm{Pu}-23$

$\mathrm{U}-235$

$\mathrm{U}-235$

$\mathrm{U}-235$

$\mathrm{Am}-241 \quad 1.000 \mathrm{E}+00$

Np-237 1.000E+00

$\operatorname{LOSE}(j)$

Cs-137 $1.000 \mathrm{E}+00$

Pu-238 1.840E-09

$\mathrm{Pu}-238 \quad 1.000 \mathrm{E}+00$

$\sum \operatorname{DOSE}(j)$

$\begin{array}{ll}\mathrm{Pu}-238 & 1.000 \mathrm{E}+00 \\ \mathrm{U}-234 & 1.000 \mathrm{E}+00 \\ \mathrm{U}-238 & 9.999 \mathrm{E}-01 \\ \operatorname{\sum DOSE}(j) & \end{array}$

$\mathrm{Pu}-238 \quad 1.000 \mathrm{E}+00$

Th-230 1.000E+00

$\mathrm{U}-234 \quad 1.000 \mathrm{E}+00$

U-238 $9.999 \mathrm{E}-01$

$\sum \operatorname{DOSE}(j)$

$\mathrm{Pu}-238 \quad 1.000 \mathrm{E}+00$

Th-230 1.000E+00

$\mathrm{U}-234 \quad 1.000 \mathrm{E}+00$

$\mathrm{U}-238 \quad 9.999 \mathrm{E}-01$

$\sum \operatorname{DOSE}(j)$

Pu-238 1.000E+00

Th-230 1.000E+00

U-234 $1.000 \mathrm{E}+00$

U-238 $9.999 \mathrm{E}-01$

$\operatorname{LDOSE}(j)$

Pu-239 1.000E+00

Pu-239 1.000E+00

U-235 $1.000 \mathrm{E}+00$

¿DOSE (j) $\mathrm{t}=0.000 \mathrm{E}+00 \quad 1.000 \mathrm{E}+00 \quad 5.000 \mathrm{E}+01 \quad 7.000 \mathrm{E}+01$

$1.457 \mathrm{E}-06 \quad 1.496 \mathrm{E}-06 \quad 2.949 \mathrm{E}-04 \quad 4.084 \mathrm{E}-04$

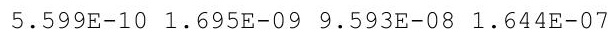

$3.453 \mathrm{E}-03 \quad 3.490 \mathrm{E}-03 \quad 6.082 \mathrm{E}-03 \quad 7.575 \mathrm{E}-03$

$3.453 \mathrm{E}-03 \quad 3.490 \mathrm{E}-03 \quad 6.082 \mathrm{E}-03 \quad 7.576 \mathrm{E}-03$

$6.695 E-19 \quad 4.735 E-18 \quad 1.474 E-13 \quad 4.016 E-13$

$6.197 \mathrm{E}-12 \quad 1.880 \mathrm{E}-11 \quad 1.848 \mathrm{E}-08 \quad 3.644 \mathrm{E}-08$

6.197E-12 $1.880 \mathrm{E}-11 \quad 1.848 \mathrm{E}-08 \quad 3.644 \mathrm{E}-08$

$3.971 \mathrm{E}-20 \quad 5.999 \mathrm{E}-19 \quad 3.406 \mathrm{E}-14 \quad 1.120 \mathrm{E}-13$

$\begin{array}{llll}4.903 \mathrm{E}-13 & 3.458 \mathrm{E}-12 & 6.366 \mathrm{E}-09 & 1.511 \mathrm{E}-08\end{array}$

$\begin{array}{lllll}4.903 \mathrm{E}-13 & 3.458 \mathrm{E}-12 & 6.366 \mathrm{E}-09 & 1.511 \mathrm{E}-08\end{array}$

$2.060 \mathrm{E}-02 \quad 2.029 \mathrm{E}-02 \quad 9.878 \mathrm{E}-03 \quad 7.362 \mathrm{E}-03$

$\begin{array}{llll}4.859 \mathrm{E}-17 & 4.907 \mathrm{E}-17 & 4.452 \mathrm{E}-13 & 5.411 \mathrm{E}-13\end{array}$

$2.641 \mathrm{E}-08 \quad 2.667 \mathrm{E}-08 \quad 2.419 \mathrm{E}-04 \quad 2.941 \mathrm{E}-04$

$\begin{array}{lllll}2.641 \mathrm{E}-08 & 2.667 \mathrm{E}-08 & 2.419 \mathrm{E}-04 & 2.941 \mathrm{E}-04\end{array}$

$2.486 \mathrm{E}-13 \quad 7.549 \mathrm{E}-13 \quad 8.976 \mathrm{E}-09 \quad 1.658 \mathrm{E}-08$

$\begin{array}{llll}1.753 \mathrm{E}-07 & 1.784 \mathrm{E}-07 \quad 7.601 \mathrm{E}-05 & 1.082 \mathrm{E}-04\end{array}$

$2.492 \mathrm{E}-13 \quad 7.595 \mathrm{E}-13 \quad 1.088 \mathrm{E}-08 \quad 2.162 \mathrm{E}-08$

$\begin{array}{llll}1.753 \mathrm{E}-07 & 1.784 \mathrm{E}-07 \quad 7.603 \mathrm{E}-05 & 1.082 \mathrm{E}-04\end{array}$

$\begin{array}{llll}3.358 \mathrm{E}-18 & 2.380 \mathrm{E}-17 & 9.470 \mathrm{E}-12 & 2.502 \mathrm{E}-11\end{array}$

$\begin{array}{llll}7.878 \mathrm{E}-07 & 8.012 \mathrm{E}-07 & 3.311 \mathrm{E}-04 & 4.713 \mathrm{E}-04\end{array}$

$3.556 \mathrm{E}-12 \quad 1.083 \mathrm{E}-11 \quad 1.504 \mathrm{E}-07 \quad 2.989 \mathrm{E}-07$

$\begin{array}{lllll}3.365 \mathrm{E}-18 & 2.390 \mathrm{E}-17 & 1.077 \mathrm{E}-11 & 2.987 \mathrm{E}-11\end{array}$

$\begin{array}{llll}7.878 \mathrm{E}-07 & 8.012 \mathrm{E}-07 & 3.312 \mathrm{E}-04 \quad 4.716 \mathrm{E}-04\end{array}$

$\begin{array}{llll}4.363 \mathrm{E}-17 & 6.572 \mathrm{E}-16 & 2.901 \mathrm{E}-11 & 8.757 \mathrm{E}-11\end{array}$

$2.053 \mathrm{E}-05 \quad 6.196 \mathrm{E}-05 \quad 2.931 \mathrm{E}-03 \quad 4.701 \mathrm{E}-03$

$\begin{array}{lllll}6.163 \mathrm{E}-11 & 4.340 \mathrm{E}-10 & 6.684 \mathrm{E}-07 & 1.499 \mathrm{E}-06\end{array}$

$\begin{array}{llll}4.369 \mathrm{E}-17 & 6.593 \mathrm{E}-16 & 3.196 \mathrm{E}-11 & 1.001 \mathrm{E}-10\end{array}$

2.053E-05 6.196E-05 2.931E-03 4.702E-03

$2.379 \mathrm{E}-23 \quad 7.401 \mathrm{E}-22 \quad 1.869 \mathrm{E}-13 \quad 8.845 \mathrm{E}-13$

$\begin{array}{llll}1.860 \mathrm{E}-11 & 1.304 \mathrm{E}-10 & 3.123 \mathrm{E}-05 & 7.416 \mathrm{E}-05\end{array}$

$\begin{array}{lllll}4.195 \mathrm{E}-17 & 6.314 \mathrm{E}-16 & 5.293 \mathrm{E}-09 & 1.815 \mathrm{E}-08\end{array}$

$\begin{array}{llll}2.382 \mathrm{E}-23 & 7.420 \mathrm{E}-22 & 2.027 \mathrm{E}-13 & 9.911 \mathrm{E}-13\end{array}$

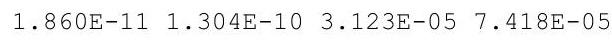

$6.302 \mathrm{E}-07 \quad 6.378 \mathrm{E}-07 \quad 3.925 \mathrm{E}-04 \quad 5.581 \mathrm{E}-04$

$\begin{array}{llll}8.030 \mathrm{E}-13 & 2.436 \mathrm{E}-12 & 1.542 \mathrm{E}-10 & 2.766 \mathrm{E}-10\end{array}$

$\begin{array}{llll}1.627 \mathrm{E}-03 & 1.648 \mathrm{E}-03 & 3.101 \mathrm{E}-03 & 3.987 \mathrm{E}-03\end{array}$

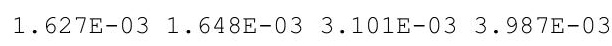


RESRAD, Version $6.5 \quad T^{1 / 2}$ Limit $=180$ days

Summary : C746U Trespasser Deterministic Run

File : X:\FINAL V2\C746U T DET-FINALV2.RAD

Individual Nuclide Dose Summed Over All Pathways

Parent Nuclide and Branch Fraction Indicated

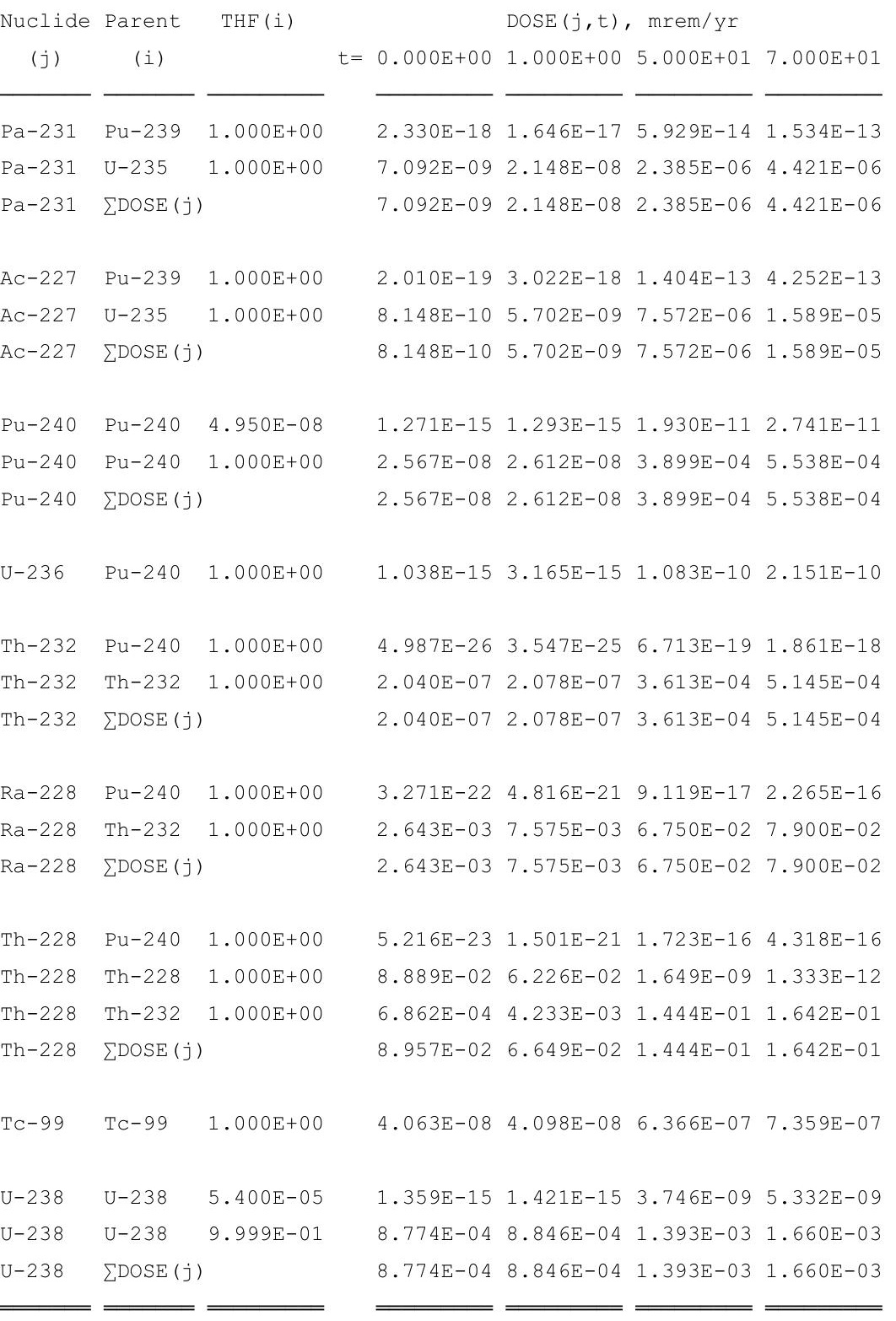

THF(i) is the thread fraction of the parent nuclide. 
RESRAD, Version $6.5 \quad T^{1 / 2}$ Limit $=180$ days

Summary : C746U Trespasser Deterministic Run

File : $\mathrm{X}: \backslash$ FINAL V2 $\backslash$ C746U T DET-FINALV2.RAD

Individual Nuclide Soil Concentration

Parent Nuclide and Branch Fraction Indicated

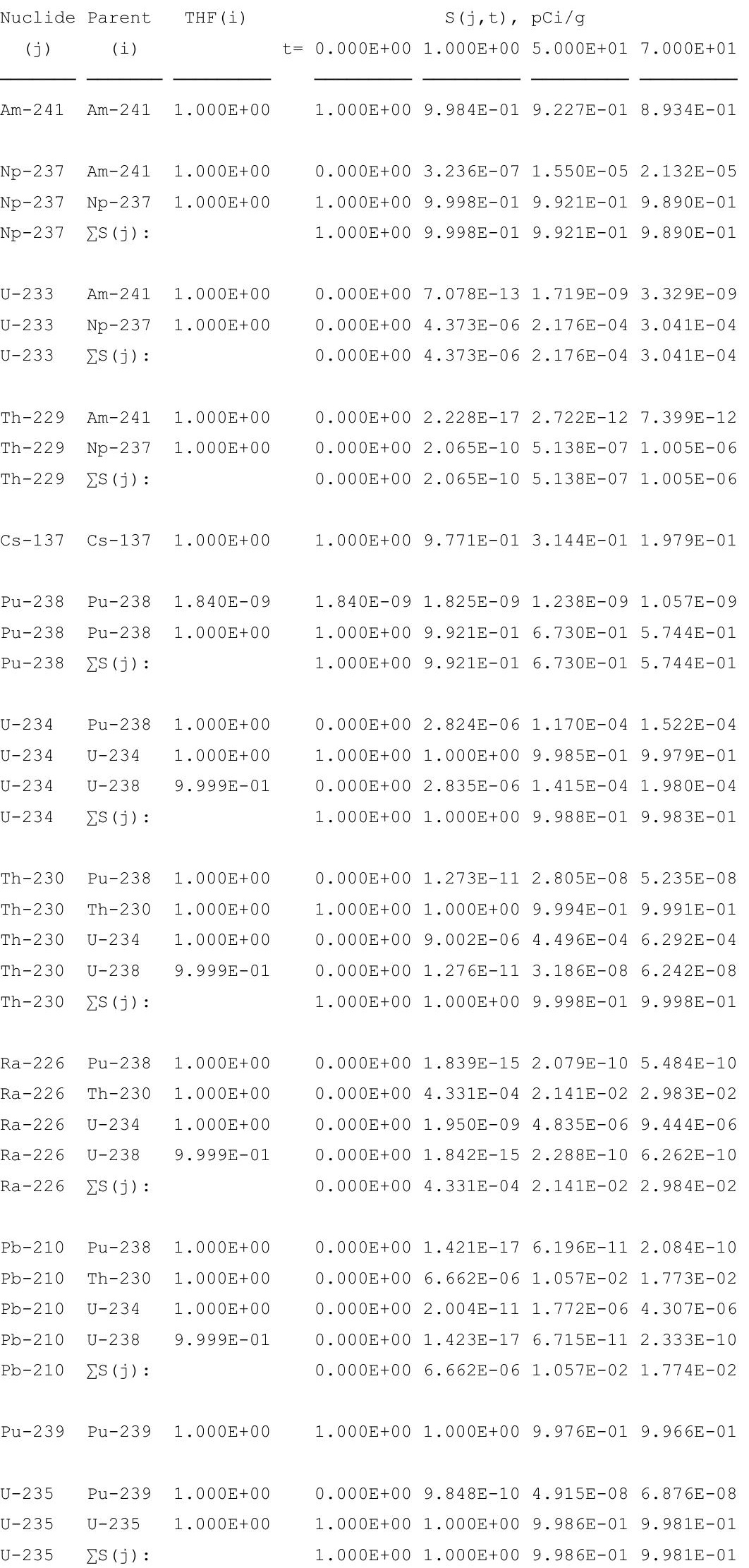


RESRAD, Version $6.5 \quad \mathrm{~T}^{1 / 2}$ Limit $=180$ days

Summary : C746U Trespasser Deterministic Run

File : $\mathrm{X}: \backslash$ FINAL V2 $\backslash$ C746U T DET-FINALV2.RAD

Individual Nuclide Soil Concentration

Parent Nuclide and Branch Fraction Indicated

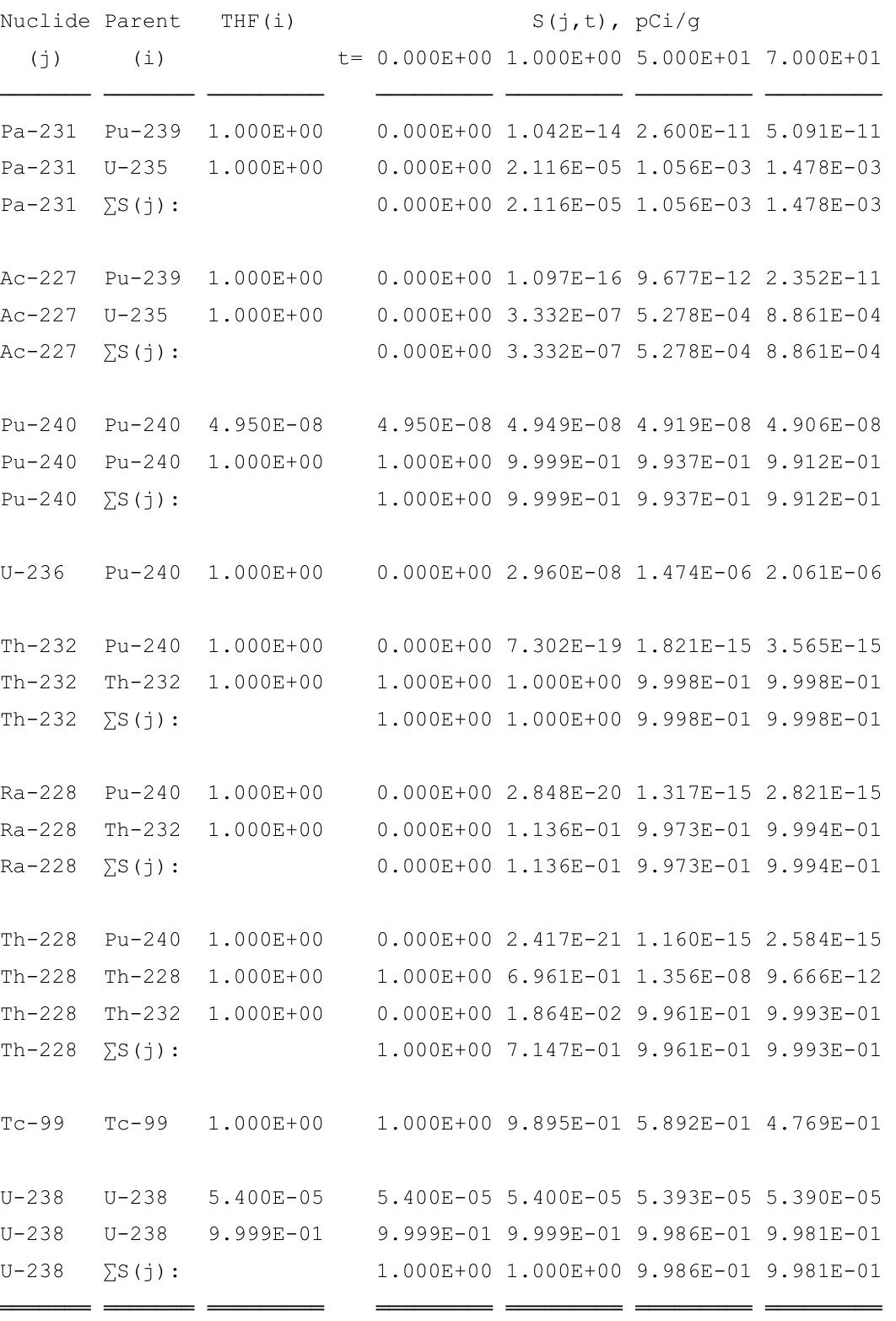

THF(i) is the thread fraction of the parent nuclide.

RESCALC.EXE execution time $=1.42$ seconds 


\section{Trespasser}

\section{The following summary report includes the peak dose from cumulative radionuclide inventory.}


THIS PAGE INTENTIONALLY LEFT BLANK 
RESRAD, Version $6.5 \quad \mathrm{~T}^{1 / 2}$ Limit $=180$ days

Summary : C746U Trespasser Deterministic Run

File : $\mathrm{X}: \backslash$ FINAL V2 $\backslash \mathrm{C} 746 \mathrm{U}$ T SG FWD-FINALV2.RAD

Dose Conversion Factor (and Related) Parameter Summary

Dose Library: ICRP 60 \& ICRP 72 (Adult)

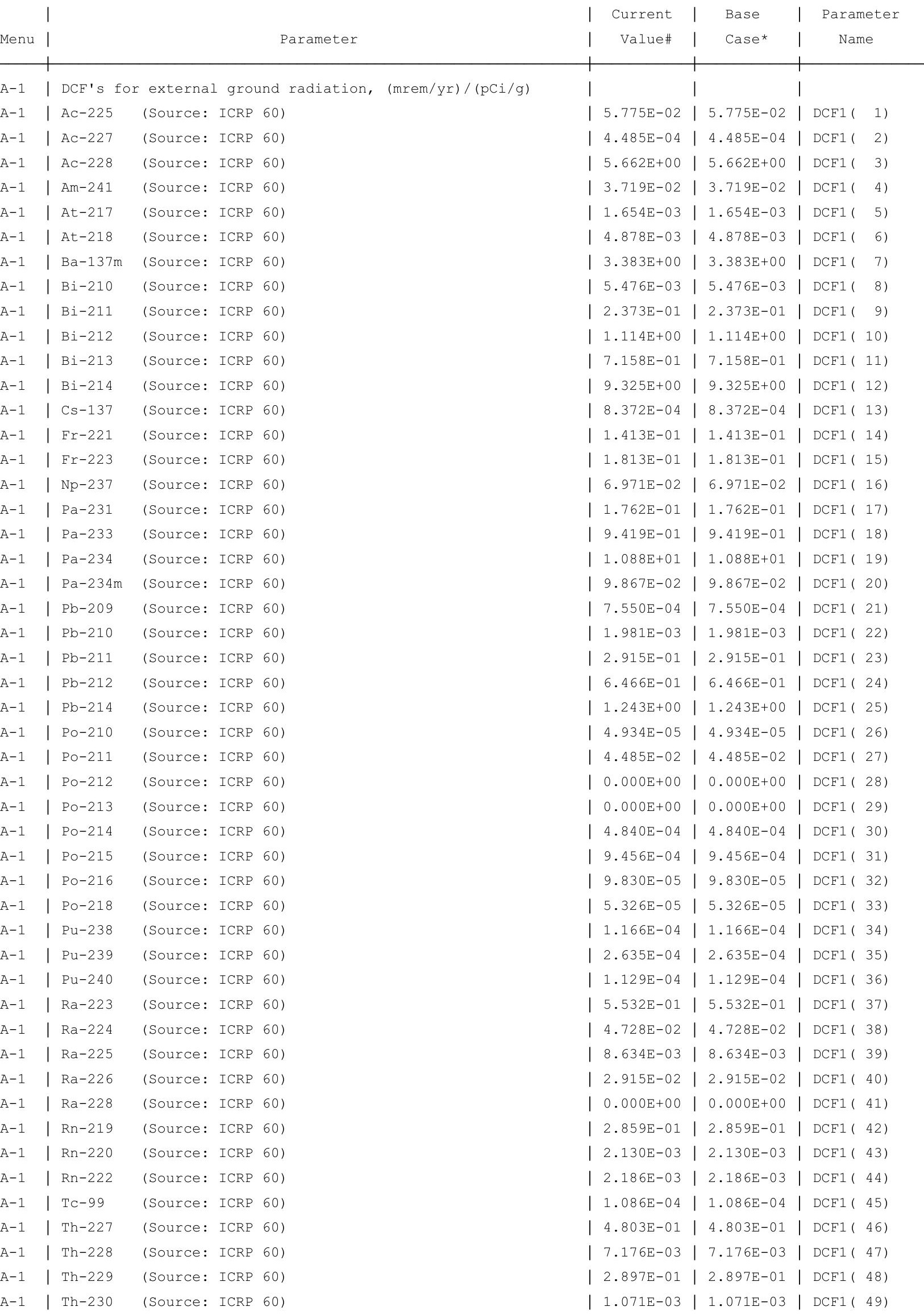


RESRAD, Version $6.5 \quad \mathrm{~T}^{1} / 2$ Limit $=180$ days

Summary : C746U Trespasser Deterministic Run

File : $\mathrm{X}: \backslash$ FINAL V2\C746U T SG FWD-FINALV2.RAD

Dose Conversion Factor (and Related) Parameter Summary (continued)

Dose Library: ICRP 60 \& ICRP 72 (Adult)

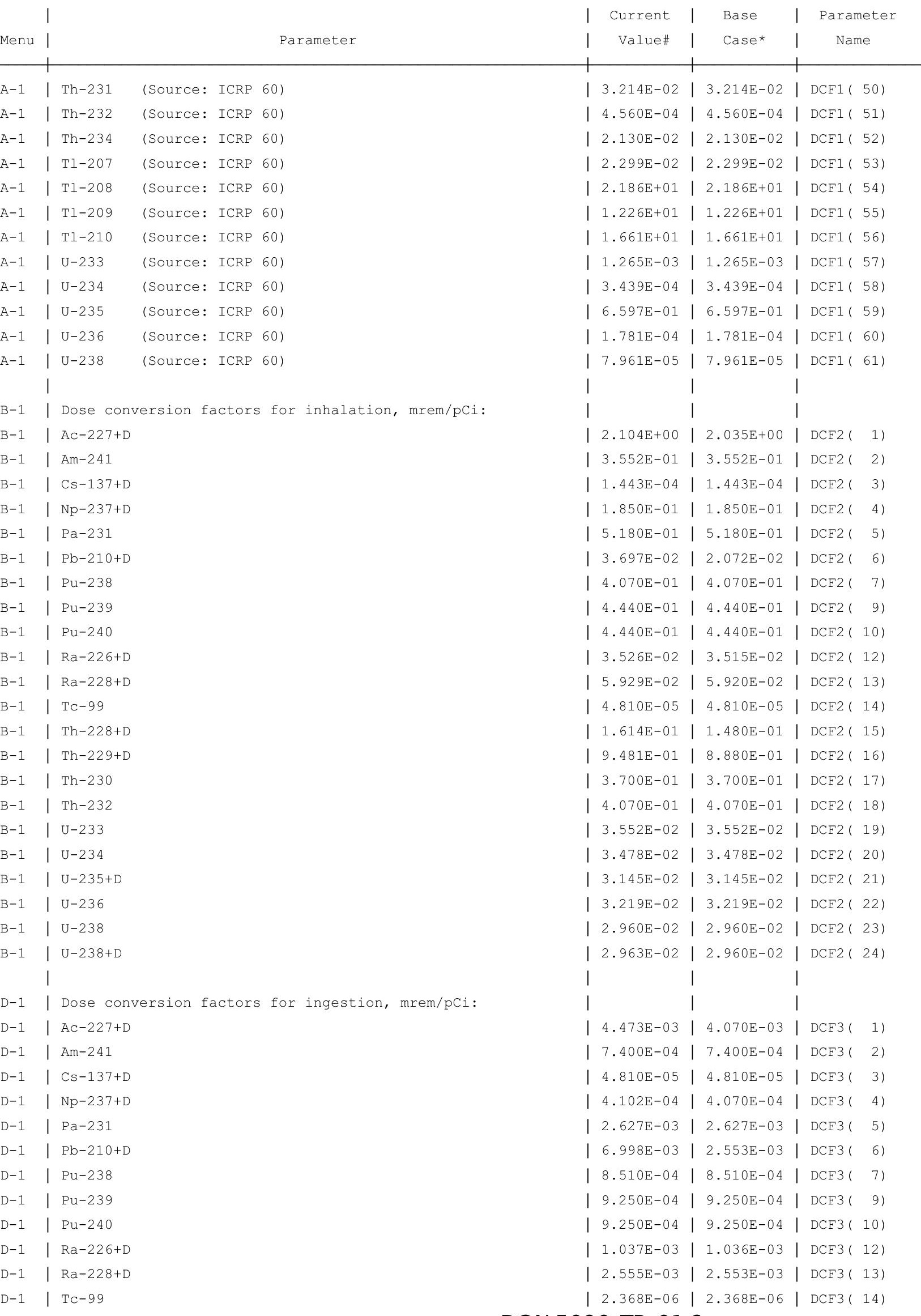


RESRAD, Version $6.5 \quad \mathrm{~T}^{1 / 2}$ Limit $=180$ days

Summary : C746U Trespasser Deterministic Run

File : X: \FINAL V2 \C746U T SG FWD-FINALV2.RAD

Dose Conversion Factor (and Related) Parameter Summary (continued) Dose Library: ICRP 60 \& ICRP 72 (Adult)

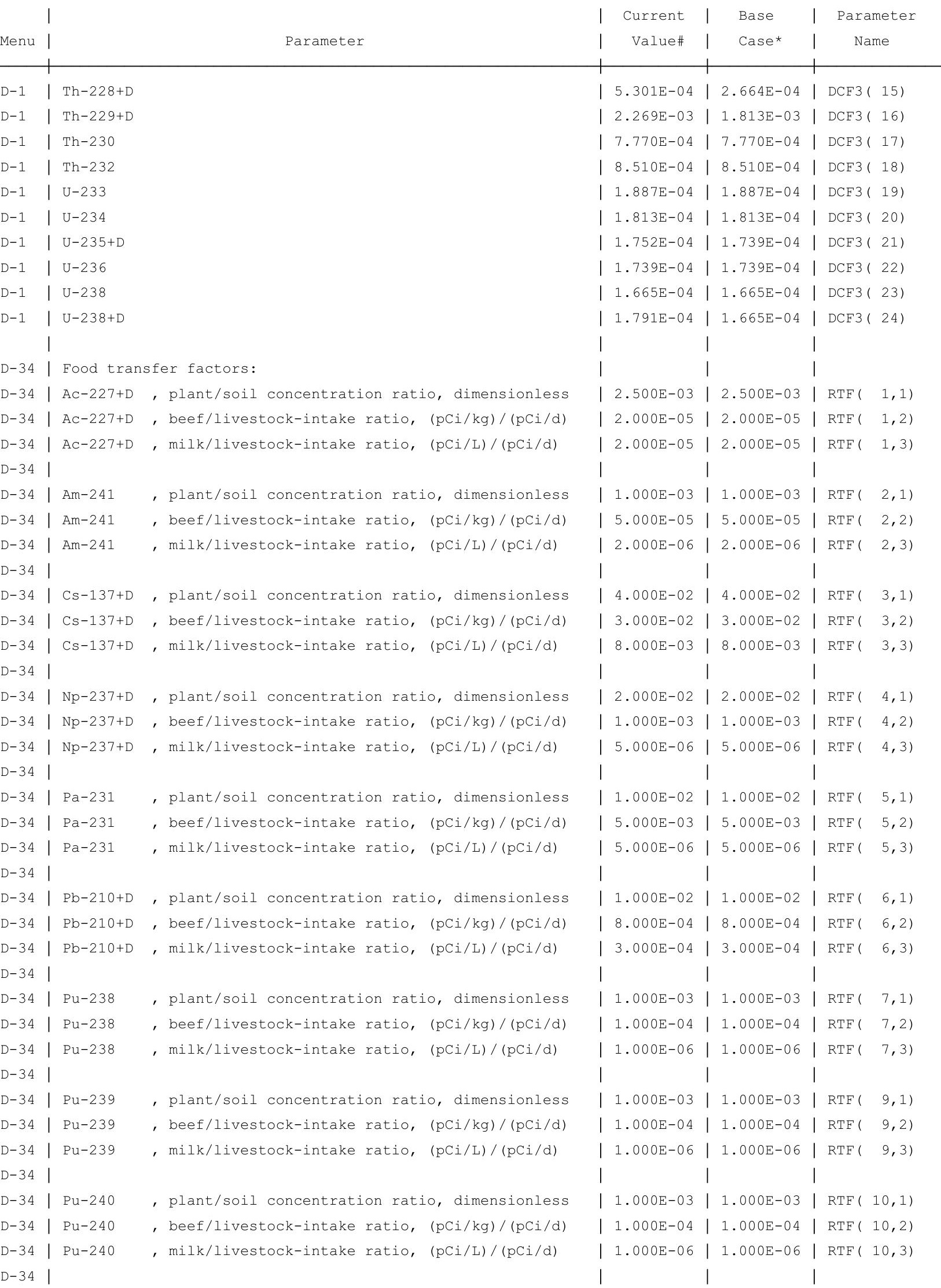


RESRAD, Version $6.5 \quad \mathrm{~T}^{1} / 2$ Limit $=180$ days

Summary : C746U Trespasser Deterministic Run

File : X: $\backslash$ FINAL V2 $\backslash$ C746U T SG FWD-FINALV2.RAD

Dose Conversion Factor (and Related) Parameter Summary (continued) Dose Library: ICRP 60 \& ICRP 72 (Adult)

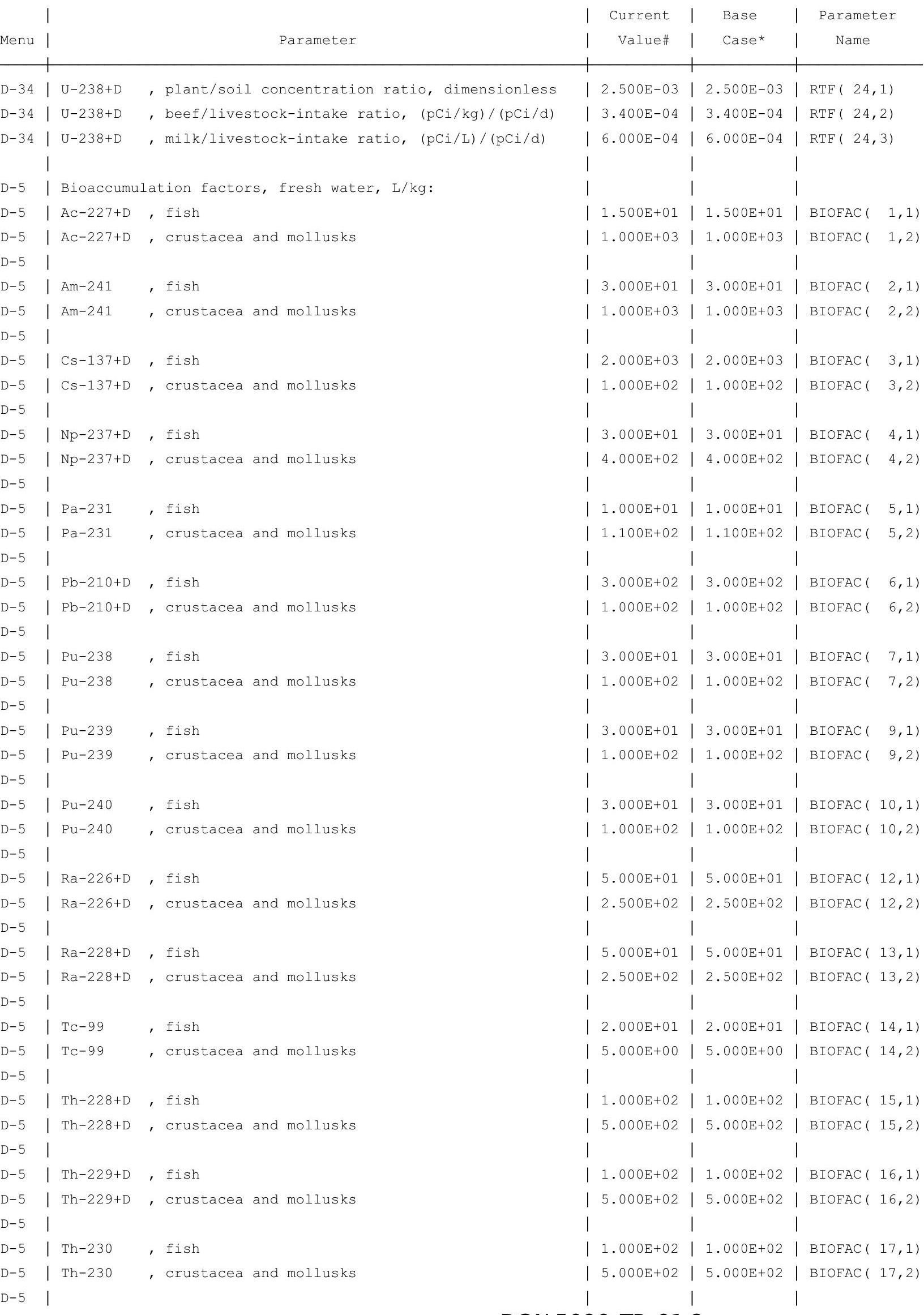


RESRAD, Version $6.5 \quad \mathrm{~T}^{1 / 2}$ Limit $=180$ days

Summary : C746U Trespasser Deterministic Run

File : $X: \backslash F I N A L$ V2 $\backslash C 746 U$ T SG FWD-FINALV2.RAD

Site-Specific Parameter Summary (continued)

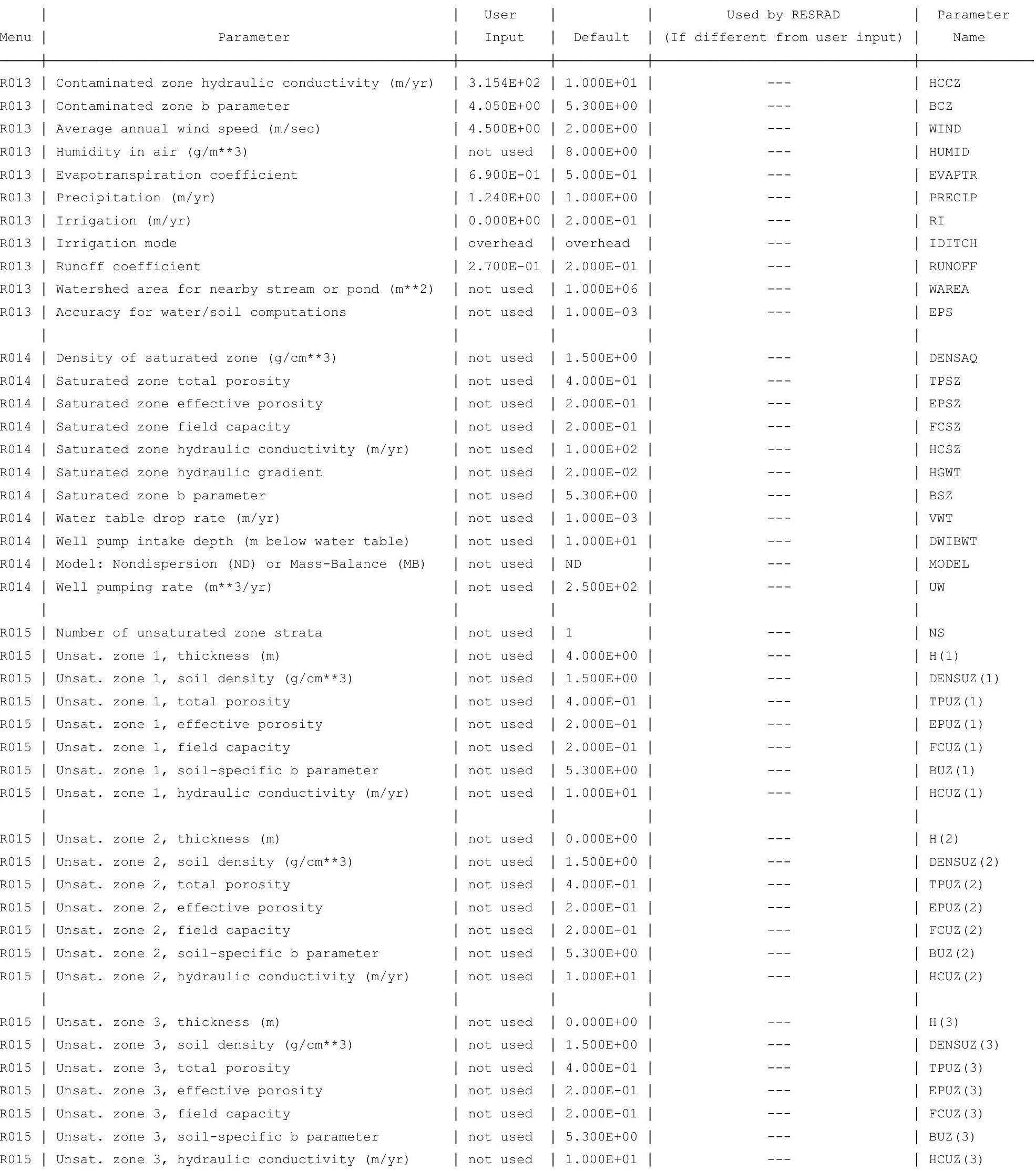


RESRAD, Version $6.5 \quad \mathrm{~T}^{1 / 2}$ Limit $=180$ days

Summary : C746U Trespasser Deterministic Run

File : $X: \backslash F I N A L$ V2 $\backslash C 746 U$ T SG FWD-FINALV2.RAD

Site-Specific Parameter Summary (continued)

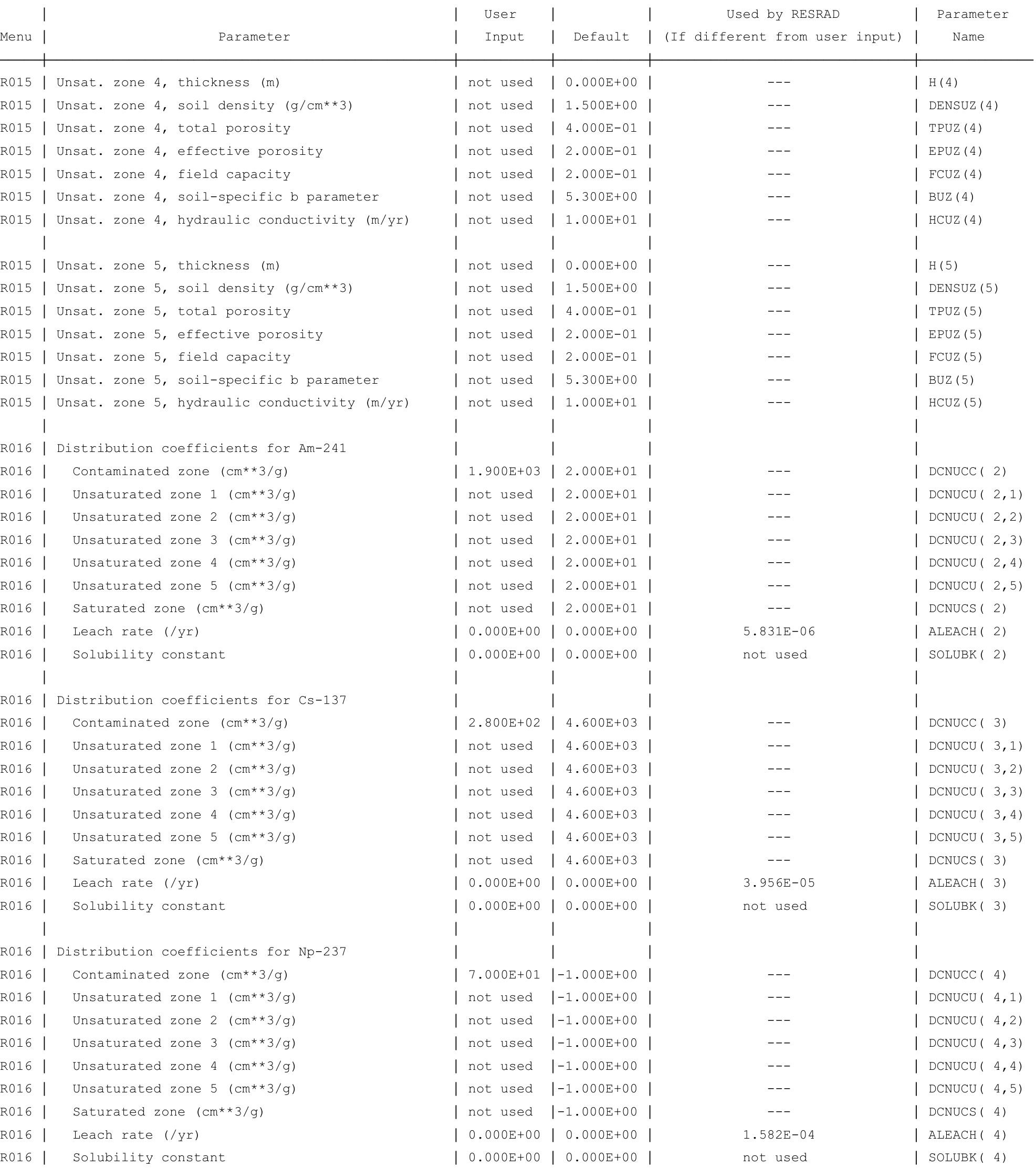


RESRAD, Version $6.5 \quad \mathrm{~T}^{1 / 2}$ Limit $=180$ days

Summary : C746U Trespasser Deterministic Run

File : $X: \backslash F I N A L$ V2 $\backslash C 746 U$ T SG FWD-FINALV2.RAD

Site-Specific Parameter Summary (continued)

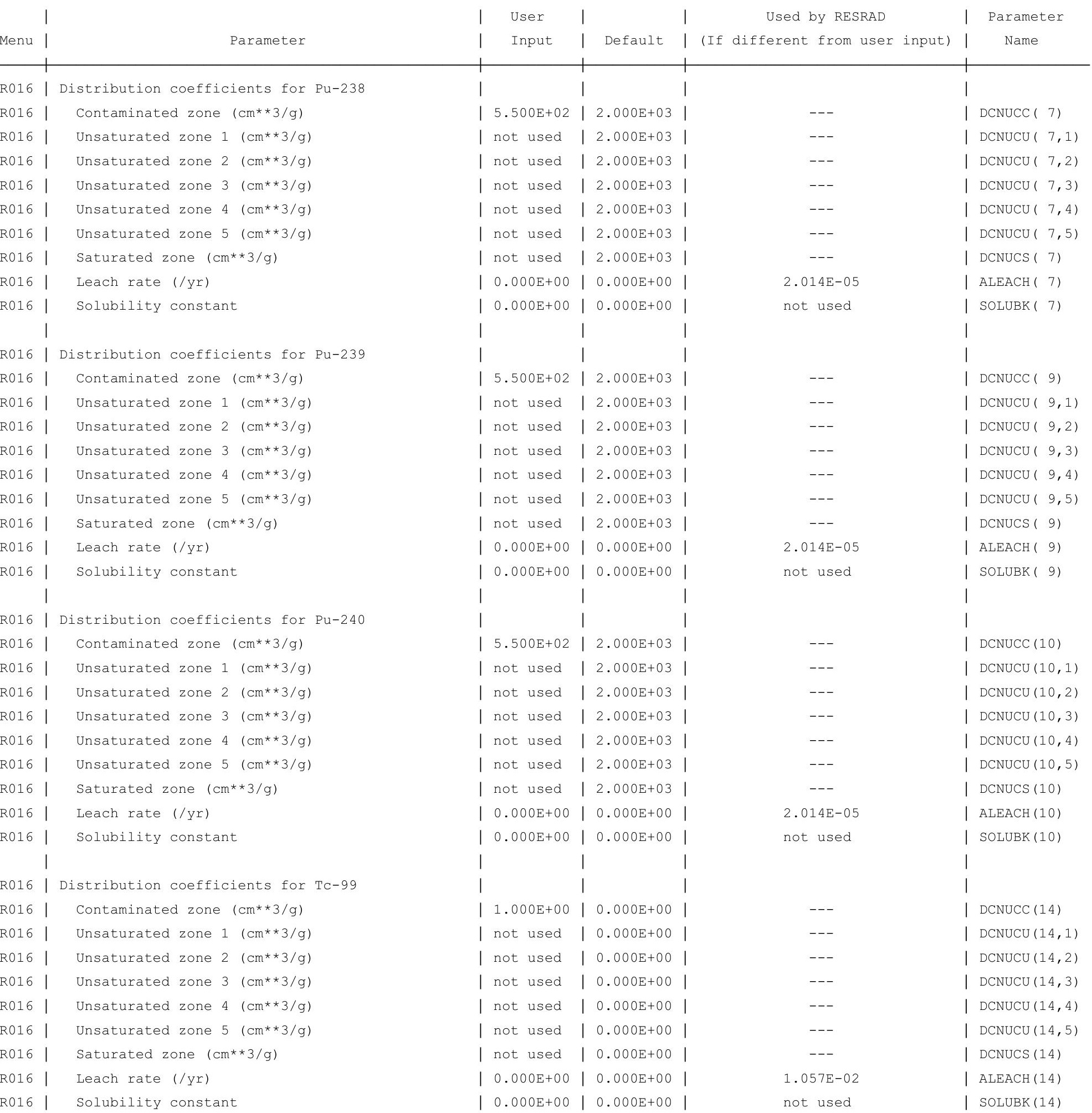


RESRAD, Version $6.5 \quad \mathrm{~T}^{1 / 2}$ Limit $=180$ days

Summary : C746U Trespasser Deterministic Run

File : $X: \backslash F I N A L$ V2 $\backslash C 746 U$ T SG FWD-FINALV2.RAD

Site-Specific Parameter Summary (continued)

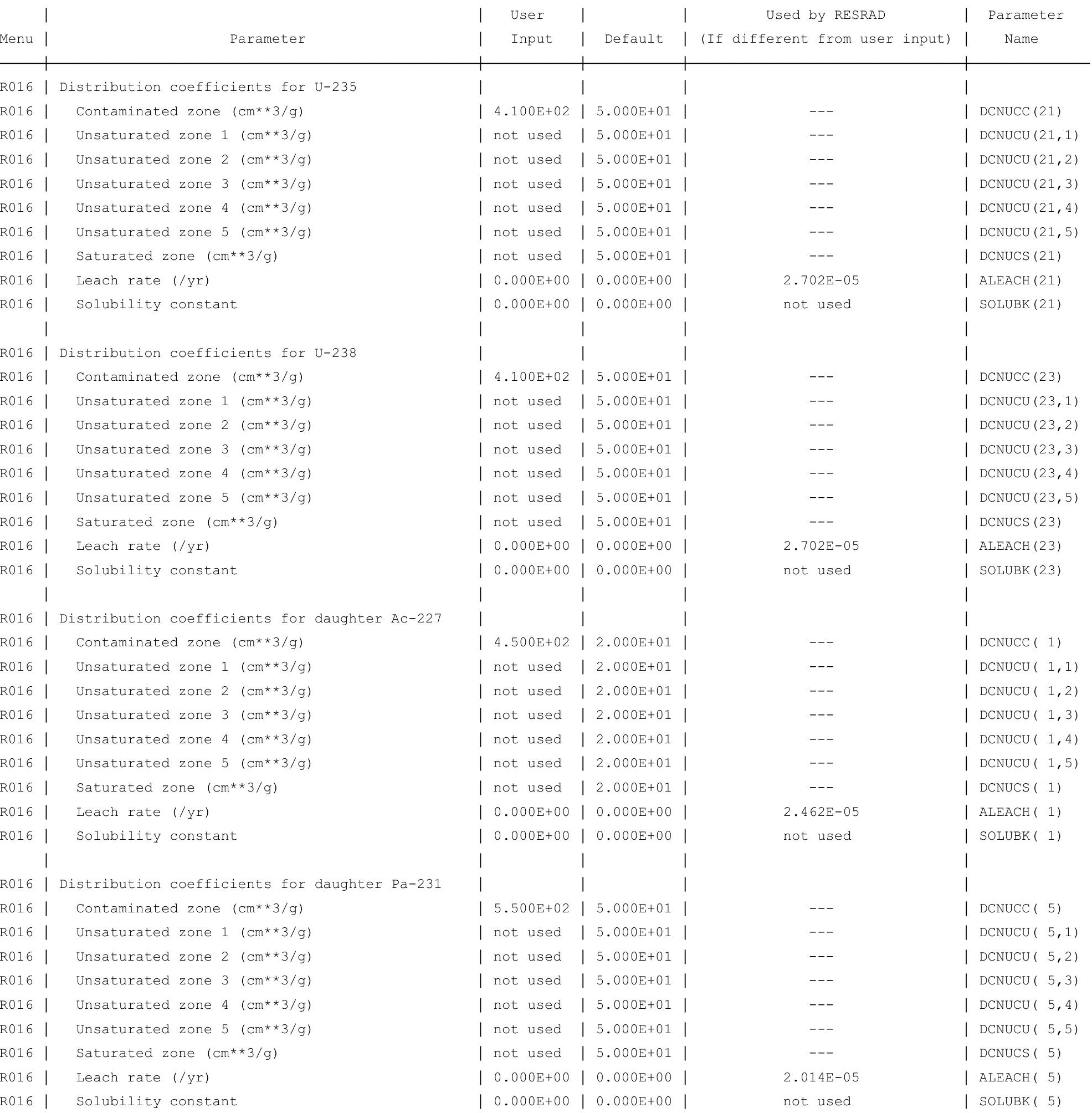


RESRAD, Version $6.5 \quad \mathrm{~T}^{1 / 2}$ Limit $=180$ days

Summary : C746U Trespasser Deterministic Run

File : $\mathrm{X}: \backslash$ FINAL V2 $\backslash \mathrm{C} 746 \mathrm{U}$ T SG FWD-FINALV2.RAD

Site-Specific Parameter Summary (continued)

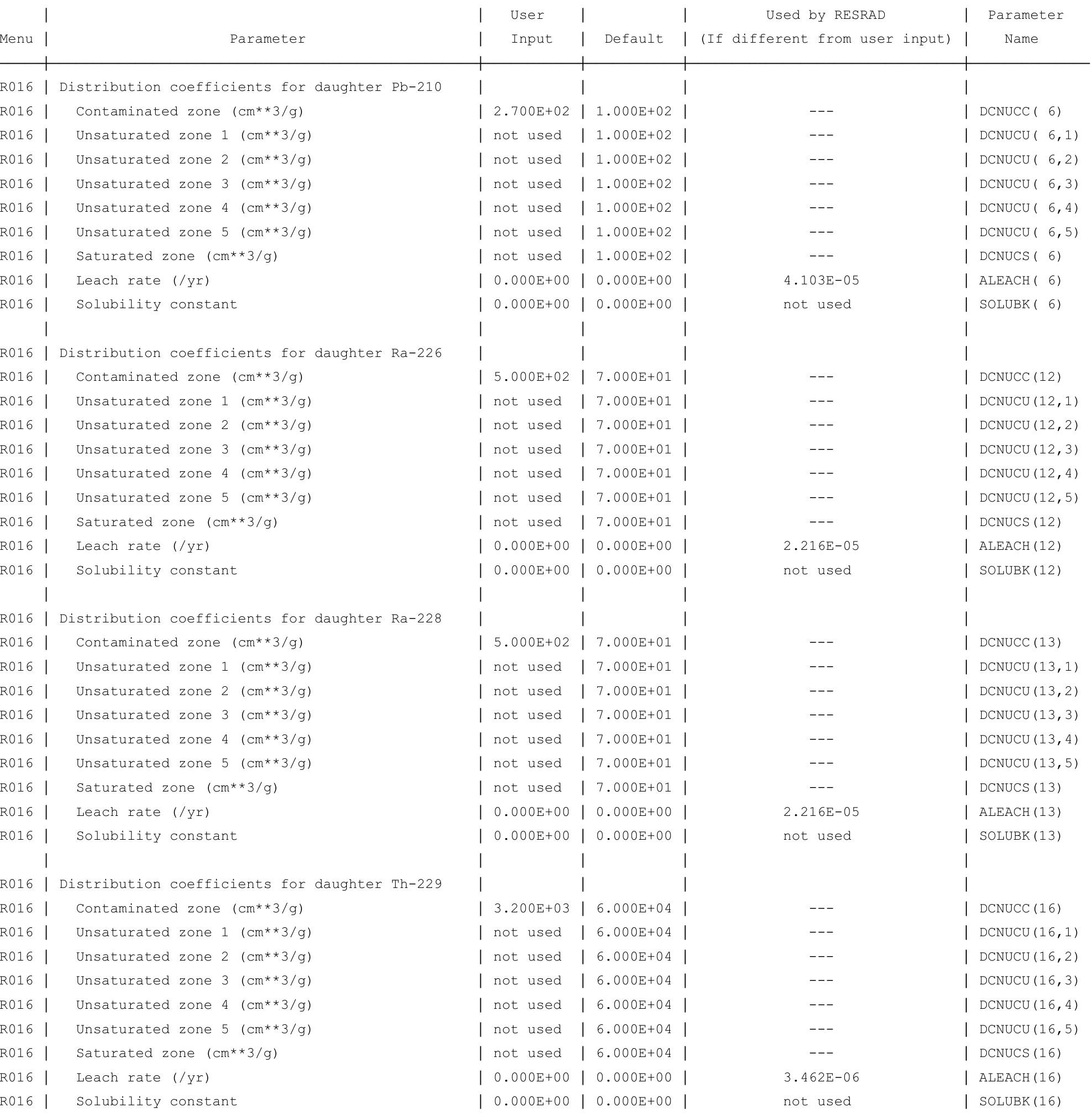


RESRAD, Version $6.5 \quad \mathrm{~T}^{1 / 2}$ Limit $=180$ days

Summary : C746U Trespasser Deterministic Run

File : $\mathrm{X}: \backslash$ FINAL V2 $\backslash \mathrm{C} 746 \mathrm{U}$ T SG FWD-FINALV2.RAD

Site-Specific Parameter Summary (continued)

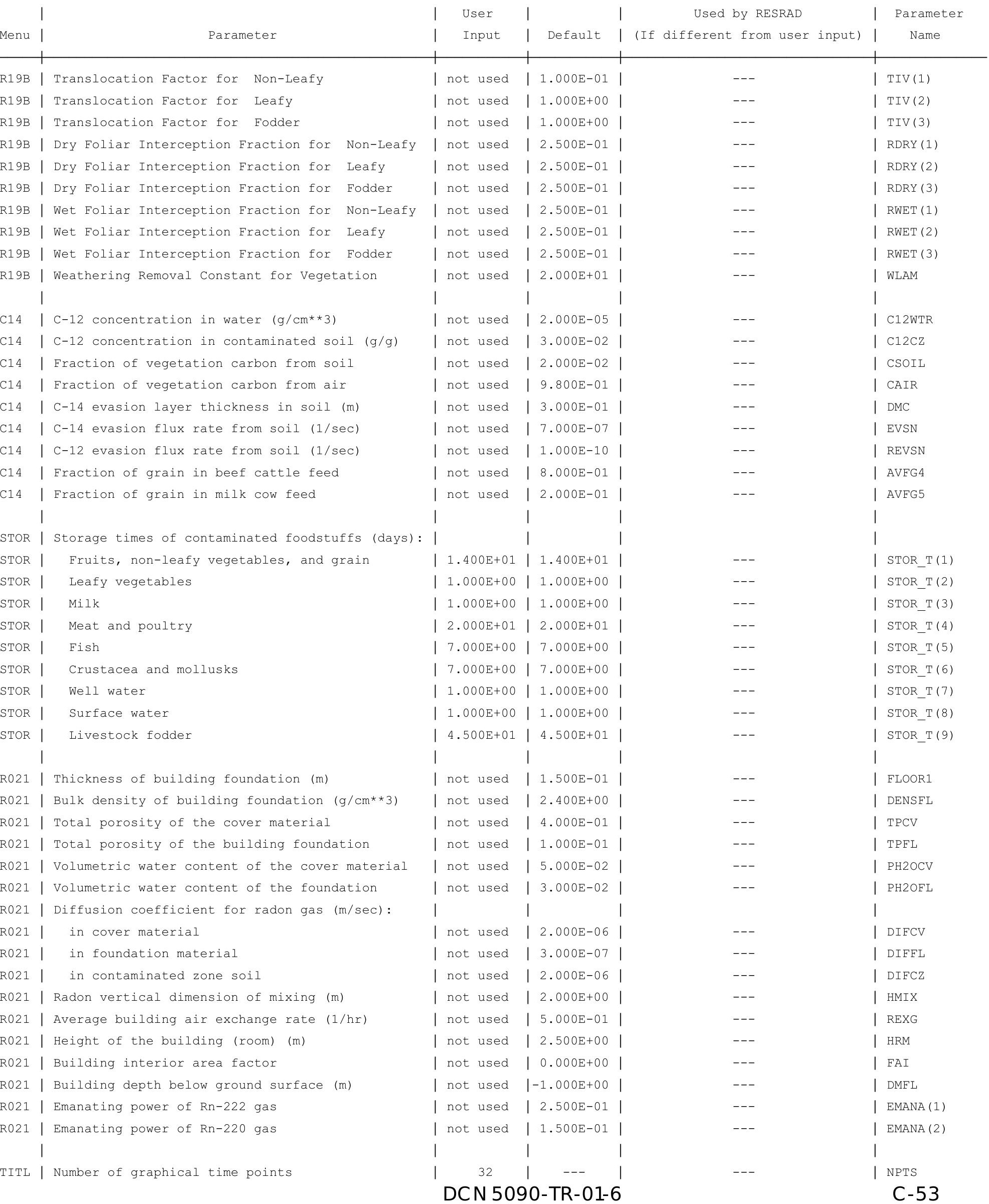


RESRAD, Version $6.5 \quad \mathrm{~T}^{1} \frac{1}{2}$ Limit $=180$ days

Summary : C746U Trespasser Deterministic Run

File : $\mathrm{X}: \backslash$ FINAL V2 $\backslash \mathrm{C} 746 \mathrm{U}$ T SG FWD-FINALV2.RAD

Contaminated Zone Dimensions

Area: $\quad 89436.00$ square meters

Thickness:

Cover Depth:

\begin{abstract}
13.40 meters
0.15 meters
\end{abstract}

Initial Soil Concentrations, pCi/g

$\begin{array}{ll}\text { Am-241 } & 3.500 \mathrm{E}+03 \\ \mathrm{Cs}-137 & 1.900 \mathrm{E}+02 \\ \mathrm{~Np}-237 & 5.500 \mathrm{E}+02 \\ \mathrm{Pu}-238 & 3.900 \mathrm{E}+03 \\ \mathrm{Pu}-239 & 3.600 \mathrm{E}+03 \\ \mathrm{Pu}-240 & 3.600 \mathrm{E}+03 \\ \mathrm{Tc}-99 & 2.800 \mathrm{E}+01 \\ \mathrm{Th}-228 & 7.400 \mathrm{E}+01 \\ \text { Th-230 } & 1.200 \mathrm{E}+03 \\ \text { Th-232 } & 3.800 \mathrm{E}+01 \\ \mathrm{U}-234 & 1.800 \mathrm{E}+04 \\ \mathrm{U}-235 & 8.200 \mathrm{E}+02 \\ \mathrm{U}-238 & 3.200 \mathrm{E}+03\end{array}$

Total Dose TDOSE(t), mrem/yr

Basic Radiation Dose Limit $=1.000 \mathrm{E}+02 \mathrm{mrem} / \mathrm{yr}$

Total Mixture Sum $M(t)$ = Fraction of Basic Dose Limit Received at Time (t)

$\begin{array}{rllll}t \quad \text { years }): & 0.000 \mathrm{E}+00 & 1.000 \mathrm{E}+00 & 5.000 \mathrm{E}+01 & 7.000 \mathrm{E}+01 \\ \text { TDOSE }(t): & 1.669 \mathrm{E}+01 & 1.510 \mathrm{E}+01 & 3.042 \mathrm{E}+01 & 3.828 \mathrm{E}+01 \\ \mathrm{M}(\mathrm{t}): & 1.669 \mathrm{E}-01 & 1.510 \mathrm{E}-01 & 3.042 \mathrm{E}-01 & 3.828 \mathrm{E}-01\end{array}$

Maximum TDOSE(t): $3.828 \mathrm{E}+01 \mathrm{mrem} / \mathrm{yr}$ at $t=7.000 \mathrm{E}+01$ years 
RESRAD, Version $6.5 \quad \mathrm{~T}^{1 / 2}$ Limit $=180$ days

Summary : C746U Trespasser Deterministic Run
File : $\mathrm{X}: \backslash$ FINAL V2 $\backslash C 746 \mathrm{U}$ T SG FWD-FINALV2.RAD

Total Dose Contributions TDOSE(i,p,t) for Individual Radionuclides (i) and Pathways (p) As mrem/yr and Fraction of Total Dose At $t=0.000 \mathrm{E}+00$ years

Water Independent Pathways (Inhalation excludes radon)

\begin{tabular}{|c|c|c|}
\hline clide & mrem/yr & fract. \\
\hline-241 & $5.101 \mathrm{E}-03$ & 0.0003 \\
\hline-137 & $3.913 E+00$ & 0.2344 \\
\hline-237 & $1.899 \mathrm{E}+00$ & 0.1137 \\
\hline-238 & $1.030 \mathrm{E}-04$ & 0.0000 \\
\hline-239 & $2.269 \mathrm{E}-03$ & 0.0001 \\
\hline-240 & $9.241 \mathrm{E}-05$ & 0.0000 \\
\hline-99 & $1.138 \mathrm{E}-06$ & 0.0000 \\
\hline-228 & $6.578 \mathrm{E}+00$ & 0.3940 \\
\hline-230 & $2.558 \mathrm{E}-02$ & 0.0015 \\
\hline-232 & $1.265 \mathrm{E}-01$ & 0.0076 \\
\hline 34 & $3.157 E-03$ & 0.0002 \\
\hline 35 & $1.334 \mathrm{E}+00$ & 0.0799 \\
\hline 238 & $2.808 \mathrm{E}+00$ & 0.1682 \\
\hline & 1.66 & 1. \\
\hline
\end{tabular}

Inhalation

\begin{tabular}{|c|c|}
\hline mrem/yr & fract. \\
\hline $0.000 \mathrm{E}+00$ & 0.0000 \\
\hline $0.000 \mathrm{E}+00$ & 0.0000 \\
\hline $0.000 \mathrm{E}+00$ & 0.0000 \\
\hline $0.000 \mathrm{E}+00$ & 0.0000 \\
\hline $0.000 \mathrm{E}+00$ & 0.0000 \\
\hline $0.000 \mathrm{E}+00$ & 0.0000 \\
\hline $0.000 \mathrm{E}+00$ & 0.0000 \\
\hline $0.000 \mathrm{E}+00$ & 0.0000 \\
\hline $0.000 \mathrm{E}+00$ & 0.0000 \\
\hline $0.000 \mathrm{E}+00$ & 0.0000 \\
\hline $0.000 \mathrm{E}+00$ & 0.0000 \\
\hline $0.000 \mathrm{E}+00$ & 0.0000 \\
\hline $0.000 \mathrm{E}+00$ & 0.0000 \\
\hline
\end{tabular}

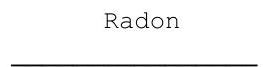
mrem/yr fract. $\overline{0.000 E+00} \overline{0.0000}$ $0.000 \mathrm{E}+00 \quad 0.0000$ $0.000 E+00 \quad 0.0000$ $0.000 E+00 \quad 0.0000$ $0.000 \mathrm{E}+00 \quad 0.0000$ $0.000 E+00 \quad 0.0000$ $0.000 \mathrm{E}+00 \quad 0.0000$ $0.000 E+00 \quad 0.0000$ $0.000 \mathrm{E}+00 \quad 0.0000$ $0.000 \mathrm{E}+00 \quad 0.0000$ $0.000 E+00 \quad 0.0000$ $0.000 \mathrm{E}+00 \quad 0.0000$ $0.000 \mathrm{E}+00 \quad 0.0000$

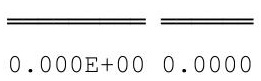

\begin{tabular}{|c|c|c|c|}
\hline \multicolumn{2}{|c|}{ Plant } & \multicolumn{2}{|c|}{ Meat } \\
\hline mrem/yr & fract. & mrem/yr & fract. \\
\hline $0.000 \mathrm{E}+00$ & 0.0000 & $0.000 \mathrm{E}+00$ & 0.0000 \\
\hline $0.000 \mathrm{E}+00$ & 0.0000 & $0.000 \mathrm{E}+00$ & 0.0000 \\
\hline $0.000 \mathrm{E}+00$ & 0.0000 & $0.000 \mathrm{E}+00$ & 0.0000 \\
\hline $0.000 \mathrm{E}+00$ & 0.0000 & $0.000 \mathrm{E}+00$ & 0.0000 \\
\hline $0.000 \mathrm{E}+00$ & 0.0000 & $0.000 \mathrm{E}+00$ & 0.0000 \\
\hline $0.000 \mathrm{E}+00$ & 0.0000 & $0.000 \mathrm{E}+00$ & 0.0000 \\
\hline $0.000 \mathrm{E}+00$ & 0.0000 & $0.000 \mathrm{E}+00$ & 0.0000 \\
\hline $0.000 \mathrm{E}+00$ & 0.0000 & $0.000 \mathrm{E}+00$ & 0.0000 \\
\hline $0.000 \mathrm{E}+00$ & 0.0000 & $0.000 \mathrm{E}+00$ & 0.0000 \\
\hline $0.000 \mathrm{E}+00$ & 0.0000 & $0.000 \mathrm{E}+00$ & 0.0000 \\
\hline $0.000 \mathrm{E}+00$ & 0.0000 & $0.000 \mathrm{E}+00$ & 0.0000 \\
\hline $0.000 \mathrm{E}+00$ & 0.0000 & $0.000 \mathrm{E}+00$ & 0.0000 \\
\hline $0.000 \mathrm{E}+00$ & 0.0000 & $0.000 \mathrm{E}+00$ & 0.0000 \\
\hline & & 0.00 & \\
\hline
\end{tabular}

\begin{tabular}{cc} 
Milk \\
\hline mrem/yr fract. \\
\cline { 1 - 2 } 0.000E+00 & 0.0000 \\
$0.000 \mathrm{E}+00$ & 0.0000 \\
$0.000 \mathrm{E}+00$ & 0.0000 \\
$0.000 \mathrm{E}+00$ & 0.0000 \\
$0.000 \mathrm{E}+00$ & 0.0000 \\
$0.000 \mathrm{E}+00$ & 0.0000 \\
$0.000 \mathrm{E}+00$ & 0.0000 \\
$0.000 \mathrm{E}+00$ & 0.0000 \\
$0.000 \mathrm{E}+00$ & 0.0000 \\
$0.000 \mathrm{E}+00$ & 0.0000 \\
$0.000 \mathrm{E}+00$ & 0.0000 \\
$0.000 \mathrm{E}+00$ & 0.0000 \\
$0.000 \mathrm{E}+00$ & 0.0000 \\
\hline \hline $0.000 \mathrm{E}+00$ & 0.0000
\end{tabular}

\begin{tabular}{cc} 
Soil \\
\cline { 1 - 2 } mrem/yr fract. & \multicolumn{1}{c}{ fran } \\
\cline { 1 - 2 } $0.000 \mathrm{E}+00$ & 0.0000 \\
$0.000 \mathrm{E}+00$ & 0.0000 \\
$0.000 \mathrm{E}+00$ & 0.0000 \\
$0.000 \mathrm{E}+00$ & 0.0000 \\
$0.000 \mathrm{E}+00$ & 0.0000 \\
$0.000 \mathrm{E}+00$ & 0.0000 \\
$0.000 \mathrm{E}+00$ & 0.0000 \\
$0.000 \mathrm{E}+00$ & 0.0000 \\
$0.000 \mathrm{E}+00$ & 0.0000 \\
$0.000 \mathrm{E}+00$ & 0.0000 \\
$0.000 \mathrm{E}+00$ & 0.0000 \\
$0.000 \mathrm{E}+00$ & 0.0000 \\
$0.000 \mathrm{E}+00$ & 0.0000 \\
\hline \hline $0.000 \mathrm{E}+00$ & 0.0000
\end{tabular}

Total Dose Contributions TDOSE (i,p,t) for Individual Radionuclides (i) and Pathways (p) As mrem/yr and Fraction of Total Dose At $t=0.000 \mathrm{E}+00$ years

Water Dependent Pathways

\begin{tabular}{|c|c|c|c|c|c|c|}
\hline & \multicolumn{2}{|c|}{ Water } & \multicolumn{2}{|c|}{ Fish } & \multicolumn{2}{|c|}{ Radon } \\
\hline clide & mrem/yr & fract. & mrem/yr & fract. & mrem/yr & fract. \\
\hline-241 & $0.000 \mathrm{E}+00$ & 0.0000 & $0.000 \mathrm{E}+00$ & 0.0000 & $0.000 \mathrm{E}+00$ & 0.0000 \\
\hline-137 & $0.000 \mathrm{E}+00$ & 0.0000 & $0.000 \mathrm{E}+00$ & 0.0000 & $0.000 \mathrm{E}+00$ & 0.0000 \\
\hline-237 & $0.000 \mathrm{E}+00$ & 0.0000 & $0.000 \mathrm{E}+00$ & 0.0000 & $0.000 \mathrm{E}+00$ & 0.0000 \\
\hline-238 & $0.000 \mathrm{E}+00$ & 0.0000 & $0.000 \mathrm{E}+00$ & 0.0000 & $0.000 \mathrm{E}+00$ & 0.0000 \\
\hline-239 & $0.000 \mathrm{E}+00$ & 0.0000 & $0.000 \mathrm{E}+00$ & 0.0000 & $0.000 \mathrm{E}+00$ & 0.0000 \\
\hline-240 & $0.000 \mathrm{E}+00$ & 0.0000 & $0.000 \mathrm{E}+00$ & 0.0000 & $0.000 \mathrm{E}+00$ & 0.0000 \\
\hline-99 & $0.000 \mathrm{E}+00$ & 0.0000 & $0.000 \mathrm{E}+00$ & 0.0000 & $0.000 \mathrm{E}+00$ & 0.0000 \\
\hline-228 & $0.000 \mathrm{E}+00$ & 0.0000 & $0.000 \mathrm{E}+00$ & 0.0000 & $0.000 \mathrm{E}+00$ & 0.0000 \\
\hline-230 & $0.000 \mathrm{E}+00$ & 0.0000 & $0.000 \mathrm{E}+00$ & 0.0000 & $0.000 \mathrm{E}+00$ & 0.0000 \\
\hline 232 & $0.000 \mathrm{E}+00$ & 0.0000 & $0.000 \mathrm{E}+00$ & 0.0000 & $0.000 \mathrm{E}+00$ & 0.0000 \\
\hline 34 & $0.000 \mathrm{E}+00$ & 0.0000 & $0.000 \mathrm{E}+00$ & 0.0000 & $0.000 \mathrm{E}+00$ & 0.0000 \\
\hline 35 & $0.000 \mathrm{E}+00$ & 0.0000 & $0.000 \mathrm{E}+00$ & 0.0000 & $0.000 \mathrm{E}+00$ & 0.0000 \\
\hline 238 & $0.000 \mathrm{E}+00$ & 0.0000 & $0.000 \mathrm{E}+00$ & 0.0000 & $0.000 \mathrm{E}+00$ & 0.0000 \\
\hline & $0.000 \mathrm{E}+00$ & 0.0000 & $0.000 \mathrm{E}+00$ & 0.0000 & $0.000 \mathrm{E}+00$ & 0.0000 \\
\hline
\end{tabular}

\begin{tabular}{|c|c|c|c|}
\hline \multicolumn{2}{|c|}{ Plant } & \multicolumn{2}{|c|}{ Meat } \\
\hline mrem/yr & fract. & mrem/yr & fract. \\
\hline $0.000 \mathrm{E}+00$ & 0.0000 & $0.000 \mathrm{E}+00$ & 0.0000 \\
\hline $0.000 \mathrm{E}+00$ & 0.0000 & $0.000 \mathrm{E}+00$ & 0.0000 \\
\hline $0.000 \mathrm{E}+00$ & 0.0000 & $0.000 \mathrm{E}+00$ & 0.0000 \\
\hline $0.000 \mathrm{E}+00$ & 0.0000 & $0.000 \mathrm{E}+00$ & 0.0000 \\
\hline $0.000 \mathrm{E}+00$ & 0.0000 & $0.000 \mathrm{E}+00$ & 0.0000 \\
\hline $0.000 \mathrm{E}+00$ & 0.0000 & $0.000 \mathrm{E}+00$ & 0.0000 \\
\hline $0.000 \mathrm{E}+00$ & 0.0000 & $0.000 \mathrm{E}+00$ & 0.0000 \\
\hline $0.000 \mathrm{E}+00$ & 0.0000 & $0.000 \mathrm{E}+00$ & 0.0000 \\
\hline $0.000 \mathrm{E}+00$ & 0.0000 & $0.000 \mathrm{E}+00$ & 0.0000 \\
\hline $0.000 \mathrm{E}+00$ & 0.0000 & $0.000 \mathrm{E}+00$ & 0.0000 \\
\hline $0.000 \mathrm{E}+00$ & 0.0000 & $0.000 \mathrm{E}+00$ & 0.0000 \\
\hline $0.000 \mathrm{E}+00$ & 0.0000 & $0.000 \mathrm{E}+00$ & 0.0000 \\
\hline $0.000 \mathrm{E}+00$ & 0.0000 & $0.000 \mathrm{E}+00$ & 0.0000 \\
\hline
\end{tabular}

$0.000 \mathrm{E}+00 \quad 0.0000$

$0.000 \mathrm{E}+00 \quad 0.0000$

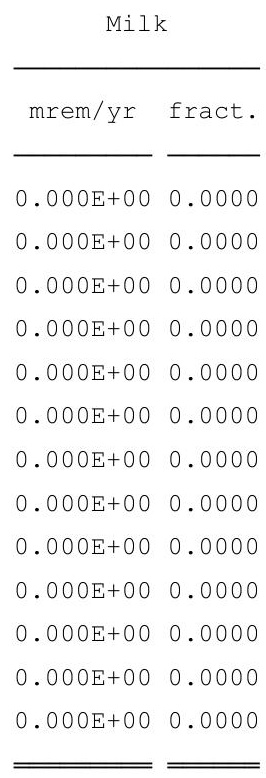

$0.000 \mathrm{E}+00 \quad 0.0000$
All Pathways* mrem/yr fract. 5.101E-03 0.0003 $3.913 \mathrm{E}+00 \quad 0.2344$ $1.899 \mathrm{E}+00 \quad 0.1137$ $1.030 \mathrm{E}-040.0000$ $2.269 \mathrm{E}-03 \quad 0.0001$ $9.241 \mathrm{E}-050.0000$ $1.138 \mathrm{E}-06 \quad 0.0000$ $6.578 \mathrm{E}+00 \quad 0.3940$ $2.558 \mathrm{E}-02 \quad 0.0015$ $1.265 \mathrm{E}-010.0076$ $3.157 \mathrm{E}-03 \quad 0.0002$ $1.334 \mathrm{E}+00 \quad 0.0799$ $2.808 \mathrm{E}+00 \quad 0.1682$ $1.669 \mathrm{E}+011.0000$

* Sum of all water independent and dependent pathways. 
RESRAD, Version $6.5 \quad \mathrm{~T}^{1 / 2}$ Limit $=180$ days

Total Dose Contributions TDOSE (i,p,t) for Individual Radionuclides (i) and Pathways (p) As mrem/yr and Fraction of Total Dose At $t=1.000 \mathrm{E}+00$ years

Water Independent Pathways (Inhalation excludes radon)

\begin{tabular}{|c|c|c|c|c|c|c|c|c|c|c|c|c|c|c|}
\hline \multirow{2}{*}{ Nuclide } & \multicolumn{2}{|c|}{ Ground } & \multicolumn{2}{|c|}{ Inhalation } & \multicolumn{2}{|c|}{ Radon } & \multicolumn{2}{|c|}{ Plant } & \multicolumn{2}{|c|}{ Meat } & \multicolumn{2}{|c|}{ Milk } & \multicolumn{2}{|c|}{ Soil } \\
\hline & mrem/yr & fract. & mrem/yr & fract. & mrem/yr & fract. & mrem/yr & fract. & mrem/yr & fract. & mrem/yr & fract. & mrem/yr & fract. \\
\hline-241 & $5.243 E-03$ & 0.0003 & $0.000 \mathrm{E}+00$ & 0.0000 & $0.000 \mathrm{E}+00$ & 0.0000 & $0.000 \mathrm{E}+00$ & 0.0000 & $0.000 \mathrm{E}+00$ & 0.0000 & $0.000 \mathrm{E}+00$ & 0.0000 & $0.000 \mathrm{E}+00$ & 0.0000 \\
\hline-137 & $3.856 \mathrm{E}+00$ & 0.2554 & $0.000 \mathrm{E}+00$ & 0.0000 & $0.000 \mathrm{E}+00$ & 0.0000 & $0.000 \mathrm{E}+00$ & 0.0000 & $0.000 \mathrm{E}+00$ & 0.0000 & $0.000 \mathrm{E}+00$ & 0.0000 & $0.000 \mathrm{E}+00$ & 0.0000 \\
\hline-237 & $1.919 \mathrm{E}+00$ & 0.1271 & $0.000 \mathrm{E}+00$ & 0.0000 & $0.000 \mathrm{E}+00$ & 0.0000 & $0.000 \mathrm{E}+00$ & 0.0000 & $0.000 \mathrm{E}+00$ & 0.0000 & $0.000 \mathrm{E}+00$ & 0.0000 & $0.000 \mathrm{E}+00$ & 0.0000 \\
\hline-238 & $1.040 \mathrm{E}-04$ & 0.0000 & $0.000 \mathrm{E}+00$ & 0.0000 & $0.000 \mathrm{E}+00$ & 0.0000 & $0.000 \mathrm{E}+00$ & 0.0000 & $0.000 \mathrm{E}+00$ & 0.0000 & $0.000 \mathrm{E}+00$ & 0.0000 & $0.000 \mathrm{E}+00$ & 0.0000 \\
\hline-239 & $2.296 \mathrm{E}-03$ & 0.0002 & $0.000 \mathrm{E}+00$ & 0.0000 & $0.000 \mathrm{E}+00$ & 0.0000 & $0.000 \mathrm{E}+00$ & 0.0000 & $0.000 \mathrm{E}+00$ & 0.0000 & $0.000 \mathrm{E}+00$ & 0.0000 & $0.000 \mathrm{E}+00$ & 0.0000 \\
\hline-240 & $9.405 \mathrm{E}-05$ & 0.0000 & $0.000 \mathrm{E}+00$ & 0.0000 & $0.000 \mathrm{E}+00$ & 0.0000 & $0.000 \mathrm{E}+00$ & 0.0000 & $0.000 \mathrm{E}+00$ & 0.0000 & $0.000 \mathrm{E}+00$ & 0.0000 & $0.000 \mathrm{E}+00$ & 0.0000 \\
\hline-99 & $1.147 \mathrm{E}-06$ & 0.0000 & $0.000 \mathrm{E}+00$ & 0.0000 & $0.000 \mathrm{E}+00$ & 0.0000 & $0.000 \mathrm{E}+00$ & 0.0000 & $0.000 \mathrm{E}+00$ & 0.0000 & $0.000 \mathrm{E}+00$ & 0.0000 & $0.000 \mathrm{E}+00$ & 0.0000 \\
\hline-228 & $4.607 \mathrm{E}+00$ & 0.3051 & $0.000 \mathrm{E}+00$ & 0.0000 & $0.000 \mathrm{E}+00$ & 0.0000 & $0.000 \mathrm{E}+00$ & 0.0000 & $0.000 \mathrm{E}+00$ & 0.0000 & $0.000 \mathrm{E}+00$ & 0.0000 & $0.000 \mathrm{E}+00$ & 0.0000 \\
\hline-230 & $7.531 \mathrm{E}-02$ & 0.0050 & $0.000 \mathrm{E}+00$ & 0.0000 & $0.000 \mathrm{E}+00$ & 0.0000 & $0.000 \mathrm{E}+00$ & 0.0000 & $0.000 \mathrm{E}+00$ & 0.0000 & $0.000 \mathrm{E}+00$ & 0.0000 & $0.000 \mathrm{E}+00$ & 0.0000 \\
\hline-232 & $4.487 E-01$ & 0.0297 & $0.000 \mathrm{E}+00$ & 0.0000 & $0.000 \mathrm{E}+00$ & 0.0000 & $0.000 \mathrm{E}+00$ & 0.0000 & $0.000 \mathrm{E}+00$ & 0.0000 & $0.000 \mathrm{E}+00$ & 0.0000 & $0.000 \mathrm{E}+00$ & 0.0000 \\
\hline 34 & $3.220 E-03$ & 0.0002 & $0.000 \mathrm{E}+00$ & 0.0000 & $0.000 \mathrm{E}+00$ & 0.0000 & $0.000 \mathrm{E}+00$ & 0.0000 & $0.000 \mathrm{E}+00$ & 0.0000 & $0.000 \mathrm{E}+00$ & 0.0000 & $0.000 \mathrm{E}+00$ & 0.0000 \\
\hline 35 & $1.351 \mathrm{E}+00$ & 0.0895 & $0.000 \mathrm{E}+00$ & 0.0000 & $0.000 \mathrm{E}+00$ & 0.0000 & $0.000 \mathrm{E}+00$ & 0.0000 & $0.000 \mathrm{E}+00$ & 0.0000 & $0.000 \mathrm{E}+00$ & 0.0000 & $0.000 \mathrm{E}+00$ & 0.0000 \\
\hline 38 & $2.831 \mathrm{E}+00$ & 0.1875 & $0.000 \mathrm{E}+00$ & 0.0000 & $0.000 \mathrm{E}+00$ & 0.0000 & $0.000 \mathrm{E}+00$ & 0.0000 & $0.000 \mathrm{E}+00$ & 0.0000 & $0.000 \mathrm{E}+00$ & 0.0000 & $0.000 \mathrm{E}+00$ & 0.0000 \\
\hline & $1.510 \mathrm{E}+01$ & 1.0000 & $0.000 \mathrm{E}+00$ & 0.0000 & $0.000 \mathrm{E}+00$ & 0.0000 & $0.000 \mathrm{E}+00$ & 0.0000 & $0.000 \mathrm{E}+00$ & 0.0000 & $0.000 \mathrm{E}+00$ & 0.0000 & $0.000 \mathrm{E}+00$ & 0.0000 \\
\hline
\end{tabular}

Total Dose Contributions TDOSE (i,p,t) for Individual Radionuclides (i) and Pathways (p) As mrem/yr and Fraction of Total Dose At $t=1.000 \mathrm{E}+00$ years

Water Dependent Pathways

\begin{tabular}{|c|c|c|c|c|c|c|c|c|c|c|c|c|c|c|}
\hline & \multicolumn{2}{|c|}{ Water } & \multicolumn{2}{|c|}{ Fish } & \multicolumn{2}{|c|}{ Radon } & \multicolumn{2}{|c|}{ Plant } & \multicolumn{2}{|c|}{ Meat } & \multicolumn{2}{|c|}{ Milk } & \multicolumn{2}{|c|}{ All Pathways* } \\
\hline clide & mrem/yr & fract. & mrem/yr & fract. & mrem/yr & fract. & mrem/yr & fract. & mrem/yr & fract. & mrem/yr & fract. & mrem/yr & fract. \\
\hline-241 & $0.000 \mathrm{E}+00$ & 0.0000 & $0.000 \mathrm{E}+00$ & 0.0000 & $0.000 \mathrm{E}+00$ & 0.0000 & $0.000 \mathrm{E}+00$ & 0.0000 & $0.000 \mathrm{E}+00$ & 0.0000 & $0.000 \mathrm{E}+00$ & 0.0000 & $5.243 E-03$ & 0.0003 \\
\hline-137 & $0.000 \mathrm{E}+00$ & 0.0000 & $0.000 \mathrm{E}+00$ & 0.0000 & $0.000 \mathrm{E}+00$ & 0.0000 & $0.000 \mathrm{E}+00$ & 0.0000 & $0.000 \mathrm{E}+00$ & 0.0000 & $0.000 \mathrm{E}+00$ & 0.0000 & $3.856 \mathrm{E}+00$ & 0.2554 \\
\hline-237 & $0.000 \mathrm{E}+00$ & 0.0000 & $0.000 \mathrm{E}+00$ & 0.0000 & $0.000 \mathrm{E}+00$ & 0.0000 & $0.000 \mathrm{E}+00$ & 0.0000 & $0.000 \mathrm{E}+00$ & 0.0000 & $0.000 \mathrm{E}+00$ & 0.0000 & $1.919 \mathrm{E}+00$ & 0.1271 \\
\hline 238 & $0.000 \mathrm{E}+00$ & 0.0000 & $0.000 \mathrm{E}+00$ & 0.0000 & $0.000 \mathrm{E}+00$ & 0.0000 & $0.000 \mathrm{E}+00$ & 0.0000 & $0.000 \mathrm{E}+00$ & 0.0000 & $0.000 \mathrm{E}+00$ & 0.0000 & $1.040 \mathrm{E}-04$ & 0.0000 \\
\hline 239 & $0.000 \mathrm{E}+00$ & 0.0000 & $0.000 \mathrm{E}+00$ & 0.0000 & $0.000 \mathrm{E}+00$ & 0.0000 & $0.000 \mathrm{E}+00$ & 0.0000 & $0.000 \mathrm{E}+00$ & 0.0000 & $0.000 \mathrm{E}+00$ & 0.0000 & $2.296 \mathrm{E}-03$ & 0.0002 \\
\hline 240 & $0.000 \mathrm{E}+00$ & 0.0000 & $0.000 \mathrm{E}+00$ & 0.0000 & $0.000 \mathrm{E}+00$ & 0.0000 & $0.000 \mathrm{E}+00$ & 0.0000 & $0.000 \mathrm{E}+00$ & 0.0000 & $0.000 \mathrm{E}+00$ & 0.0000 & $9.405 \mathrm{E}-05$ & 0.0000 \\
\hline 99 & $0.000 \mathrm{E}+00$ & 0.0000 & $0.000 \mathrm{E}+00$ & 0.0000 & $0.000 \mathrm{E}+00$ & 0.0000 & $0.000 \mathrm{E}+00$ & 0.0000 & $0.000 \mathrm{E}+00$ & 0.0000 & $0.000 \mathrm{E}+00$ & 0.0000 & $1.147 \mathrm{E}-06$ & 0.0000 \\
\hline 228 & $0.000 \mathrm{E}+00$ & 0.0000 & $0.000 \mathrm{E}+00$ & 0.0000 & $0.000 \mathrm{E}+00$ & 0.0000 & $0.000 \mathrm{E}+00$ & 0.0000 & $0.000 \mathrm{E}+00$ & 0.0000 & $0.000 \mathrm{E}+00$ & 0.0000 & $4.607 \mathrm{E}+00$ & 0.3051 \\
\hline 230 & $0.000 \mathrm{E}+00$ & 0.0000 & $0.000 \mathrm{E}+00$ & 0.0000 & $0.000 \mathrm{E}+00$ & 0.0000 & $0.000 \mathrm{E}+00$ & 0.0000 & $0.000 \mathrm{E}+00$ & 0.0000 & $0.000 \mathrm{E}+00$ & 0.0000 & $7.531 \mathrm{E}-02$ & 0.0050 \\
\hline 232 & $0.000 \mathrm{E}+00$ & 0.0000 & $0.000 \mathrm{E}+00$ & 0.0000 & $0.000 \mathrm{E}+00$ & 0.0000 & $0.000 \mathrm{E}+00$ & 0.0000 & $0.000 \mathrm{E}+00$ & 0.0000 & $0.000 \mathrm{E}+00$ & 0.0000 & $4.487 \mathrm{E}-01$ & 0.0297 \\
\hline 34 & $0.000 \mathrm{E}+00$ & 0.0000 & $0.000 \mathrm{E}+00$ & 0.0000 & $0.000 \mathrm{E}+00$ & 0.0000 & $0.000 \mathrm{E}+00$ & 0.0000 & $0.000 \mathrm{E}+00$ & 0.0000 & $0.000 \mathrm{E}+00$ & 0.0000 & $3.220 \mathrm{E}-03$ & 0.0002 \\
\hline 35 & $0.000 \mathrm{E}+00$ & 0.0000 & $0.000 \mathrm{E}+00$ & 0.0000 & $0.000 \mathrm{E}+00$ & 0.0000 & $0.000 \mathrm{E}+00$ & 0.0000 & $0.000 \mathrm{E}+00$ & 0.0000 & $0.000 \mathrm{E}+00$ & 0.0000 & $1.351 \mathrm{E}+00$ & 0.0895 \\
\hline 38 & $0.000 \mathrm{E}+00$ & 0.0000 & $0.000 \mathrm{E}+00$ & 0.0000 & $0.000 \mathrm{E}+00$ & 0.0000 & $0.000 \mathrm{E}+00$ & 0.0000 & $0.000 \mathrm{E}+00$ & 0.0000 & $0.000 \mathrm{E}+00$ & 0.0000 & $2.831 \mathrm{E}+00$ & 0.1875 \\
\hline & $0.000 \mathrm{E}+00$ & 0.0000 & $0.000 \mathrm{E}+00$ & 0.0000 & $0.000 \mathrm{E}+00$ & 0.0000 & $0.000 \mathrm{E}+00$ & 0.0000 & $0.000 \mathrm{E}+00$ & 0.0000 & $.000 \mathrm{E}+00$ & 000 & -01 & 1.0000 \\
\hline
\end{tabular}

* Sum of all water independent and dependent pathways. 
RESRAD, Version $6.5 \quad \mathrm{~T}^{1 / 2}$ Limit $=180$ days

Total Dose Contributions TDOSE (i,p,t) for Individual Radionuclides (i) and Pathways (p) As mrem/yr and Fraction of Total Dose At $t=5.000 \mathrm{E}+01$ years

Water Independent Pathways (Inhalation excludes radon)

\begin{tabular}{|c|c|c|c|c|c|c|c|c|c|c|c|c|c|c|}
\hline & \multicolumn{2}{|c|}{ Ground } & \multicolumn{2}{|c|}{ Inhalation } & \multicolumn{2}{|c|}{ Radon } & \multicolumn{2}{|c|}{ Plant } & \multicolumn{2}{|c|}{ Meat } & \multicolumn{2}{|c|}{ Milk } & \multicolumn{2}{|l|}{ Soil } \\
\hline Iide & mrem/yr & fract. & mrem/yr & fract. & mrem/yr & fract. & mrem/yr & fract. & mrem/yr & fract. & mrem/yr & fract. & mrem/yr & fract. \\
\hline-241 & $1.969 \mathrm{E}-02$ & 0.0006 & $2.604 \mathrm{E}-02$ & 0.0009 & $0.000 \mathrm{E}+00$ & 0.0000 & $0.000 \mathrm{E}+00$ & 0.0000 & $0.000 \mathrm{E}+00$ & 0.0000 & $0.000 \mathrm{E}+00$ & 0.0000 & $9.866 \mathrm{E}-01$ & 0.0324 \\
\hline-137 & $1.876 \mathrm{E}+00$ & 0.0617 & $1.936 \mathrm{E}-07$ & 0.0000 & $0.000 \mathrm{E}+00$ & 0.0000 & $0.000 \mathrm{E}+00$ & 0.0000 & $0.000 \mathrm{E}+00$ & 0.0000 & $0.000 \mathrm{E}+00$ & 0.0000 & $1.173 \mathrm{E}-03$ & 0.0000 \\
\hline-237 & $3.250 \mathrm{E}+00$ & 0.1068 & $2.294 E-03$ & 0.0001 & $0.000 \mathrm{E}+00$ & 0.0000 & $0.000 \mathrm{E}+00$ & 0.0000 & $0.000 \mathrm{E}+00$ & 0.0000 & $0.000 \mathrm{E}+00$ & 0.0000 & $9.249 \mathrm{E}-02$ & 0.0030 \\
\hline-238 & 1. $680 \mathrm{E}-04$ & 0.0000 & $2.418 \mathrm{E}-02$ & 0.0008 & $0.000 \mathrm{E}+00$ & 0.0000 & $0.000 \mathrm{E}+00$ & 0.0000 & $0.000 \mathrm{E}+00$ & 0.0000 & $0.000 \mathrm{E}+00$ & 0.0000 & $9.193 \mathrm{E}-01$ & 0.0302 \\
\hline 239 & $4.120 \mathrm{E}-03$ & 0.0001 & $3.623 \mathrm{E}-02$ & 0.0012 & $0.000 \mathrm{E}+00$ & 0.0000 & $0.000 \mathrm{E}+00$ & 0.0000 & $0.000 \mathrm{E}+00$ & 0.0000 & $0.000 \mathrm{E}+00$ & 0.0000 & $1.372 \mathrm{E}+00$ & 0.0451 \\
\hline 240 & $2.221 \mathrm{E}-04$ & 0.0000 & $3.609 \mathrm{E}-02$ & 0.0012 & $0.000 \mathrm{E}+00$ & 0.0000 & $0.000 \mathrm{E}+00$ & 0.0000 & $0.000 \mathrm{E}+00$ & 0.0000 & $0.000 \mathrm{E}+00$ & 0.0000 & $1.367 \mathrm{E}+00$ & 0.0449 \\
\hline 99 & $1.749 \mathrm{E}-06$ & 0.0000 & $1.794 \mathrm{E}-08$ & 0.0000 & $0.000 \mathrm{E}+00$ & 0.0000 & $0.000 \mathrm{E}+00$ & 0.0000 & $0.000 \mathrm{E}+00$ & 0.0000 & $0.000 \mathrm{E}+00$ & 0.0000 & $1.606 \mathrm{E}-05$ & 0.0000 \\
\hline 228 & $1.218 \mathrm{E}-07$ & 0.0000 & $3.086 \mathrm{E}-12$ & 0.0000 & $0.000 \mathrm{E}+00$ & 0.0000 & $0.000 \mathrm{E}+00$ & 0.0000 & $0.000 \mathrm{E}+00$ & 0.0000 & $0.000 \mathrm{E}+00$ & 0.0000 & $1.843 \mathrm{E}-10$ & 0.0000 \\
\hline 230 & $3.508 \mathrm{E}+00$ & 0.1153 & $1.011 \mathrm{E}-02$ & 0.0003 & $0.000 \mathrm{E}+00$ & 0.0000 & $0.000 \mathrm{E}+00$ & 0.0000 & $0.000 \mathrm{E}+00$ & 0.0000 & $0.000 \mathrm{E}+00$ & 0.0000 & $4.334 \mathrm{E}-01$ & 0.0142 \\
\hline 232 & $8.004 \mathrm{E}+00$ & 0.2631 & $5.413 E-04$ & 0.0000 & $0.000 \mathrm{E}+00$ & 0.0000 & $0.000 \mathrm{E}+00$ & 0.0000 & $0.000 \mathrm{E}+00$ & 0.0000 & $0.000 \mathrm{E}+00$ & 0.0000 & $6.166 \mathrm{E}-02$ & 0.0020 \\
\hline 34 & $1.965 E-02$ & 0.0006 & $1.427 \mathrm{E}-02$ & 0.0005 & $0.000 \mathrm{E}+00$ & 0.0000 & $0.000 \mathrm{E}+00$ & 0.0000 & $0.000 \mathrm{E}+00$ & 0.0000 & $0.000 \mathrm{E}+00$ & 0.0000 & $1.349 \mathrm{E}+00$ & 0.0443 \\
\hline 35 & $2.489 \mathrm{E}+00$ & 0.0818 & $6.166 \mathrm{E}-04$ & 0.0000 & $0.000 \mathrm{E}+00$ & 0.0000 & $0.000 \mathrm{E}+00$ & 0.0000 & $0.000 \mathrm{E}+00$ & 0.0000 & $0.000 \mathrm{E}+00$ & 0.0000 & $6.103 E-02$ & 0.0020 \\
\hline & $4.218 E+00$ & 0.1387 & $2.152 \mathrm{E}-03$ & 0.0001 & $0.000 \mathrm{E}+00$ & 0.0000 & $0.000 \mathrm{E}+00$ & 0.0000 & $0.000 \mathrm{E}+00$ & 0.0000 & $0.000 \mathrm{E}+00$ & 0.0000 & $2.365 \mathrm{E}-01$ & 0.0078 \\
\hline & $9 \mathrm{E}+01$ & 88 & $.525 \mathrm{E}-01$ & .0050 & $.000 \mathrm{E}+00$ & .0000 & $0.000 \mathrm{E}+00$ & 0.0000 & $0 \mathrm{E}+00$ & 000 & $0.000 \mathrm{E}+00$ & 0.0000 & $E+00$ & 262 \\
\hline
\end{tabular}

Total Dose Contributions TDOSE (i,p,t) for Individual Radionuclides (i) and Pathways (p) As mrem/yr and Fraction of Total Dose At $t=5.000 \mathrm{E}+01$ years

Water Dependent Pathways

\begin{tabular}{|c|c|c|c|c|c|c|c|c|c|c|c|c|c|c|}
\hline & \multicolumn{2}{|c|}{ Water } & \multicolumn{2}{|c|}{ Fish } & \multicolumn{2}{|c|}{ Radon } & \multicolumn{2}{|c|}{ Plant } & \multicolumn{2}{|c|}{ Meat } & \multicolumn{2}{|c|}{ Milk } & \multicolumn{2}{|c|}{ All Pathways* } \\
\hline clide & mrem/yr & fract. & mrem/yr & fract. & mrem/yr & fract. & mrem/yr & fract. & mrem/yr & fract. & mrem/yr & fract. & mrem/yr & fract. \\
\hline-241 & $0.000 \mathrm{E}+00$ & 0.0000 & $0.000 \mathrm{E}+00$ & 0.0000 & $0.000 \mathrm{E}+00$ & 0.0000 & $0.000 \mathrm{E}+00$ & 0.0000 & $0.000 \mathrm{E}+00$ & 0.0000 & $0.000 \mathrm{E}+00$ & 0.0000 & $1.032 \mathrm{E}+00$ & 0.0339 \\
\hline-137 & $0.000 \mathrm{E}+00$ & 0.0000 & $0.000 \mathrm{E}+00$ & 0.0000 & $0.000 \mathrm{E}+00$ & 0.0000 & $0.000 \mathrm{E}+00$ & 0.0000 & $0.000 \mathrm{E}+00$ & 0.0000 & $0.000 \mathrm{E}+00$ & 0.0000 & $1.877 \mathrm{E}+00$ & 0.0617 \\
\hline-237 & $0.000 \mathrm{E}+00$ & 0.0000 & $0.000 \mathrm{E}+00$ & 0.0000 & $0.000 \mathrm{E}+00$ & 0.0000 & $0.000 \mathrm{E}+00$ & 0.0000 & $0.000 \mathrm{E}+00$ & 0.0000 & $0.000 \mathrm{E}+00$ & 0.0000 & $3.345 E+00$ & 0.1100 \\
\hline-238 & $0.000 \mathrm{E}+00$ & 0.0000 & $0.000 \mathrm{E}+00$ & 0.0000 & $0.000 \mathrm{E}+00$ & 0.0000 & $0.000 \mathrm{E}+00$ & 0.0000 & $0.000 \mathrm{E}+00$ & 0.0000 & $0.000 \mathrm{E}+00$ & 0.0000 & $9.436 \mathrm{E}-01$ & 0.0310 \\
\hline-239 & $0.000 \mathrm{E}+00$ & 0.0000 & $0.000 \mathrm{E}+00$ & 0.0000 & $0.000 \mathrm{E}+00$ & 0.0000 & $0.000 \mathrm{E}+00$ & 0.0000 & $0.000 \mathrm{E}+00$ & 0.0000 & $0.000 E+00$ & 0.0000 & $1.413 \mathrm{E}+00$ & 0.0464 \\
\hline-240 & $0.000 \mathrm{E}+00$ & 0.0000 & $0.000 \mathrm{E}+00$ & 0.0000 & $0.000 \mathrm{E}+00$ & 0.0000 & $0.000 \mathrm{E}+00$ & 0.0000 & $0.000 \mathrm{E}+00$ & 0.0000 & $0.000 E+00$ & 0.0000 & $1.403 E+00$ & 0.0461 \\
\hline-99 & $0.000 \mathrm{E}+00$ & 0.0000 & $0.000 \mathrm{E}+00$ & 0.0000 & $0.000 \mathrm{E}+00$ & 0.0000 & $0.000 \mathrm{E}+00$ & 0.0000 & $0.000 \mathrm{E}+00$ & 0.0000 & $0.000 \mathrm{E}+00$ & 0.0000 & $1.782 \mathrm{E}-05$ & 0.0000 \\
\hline-228 & $0.000 \mathrm{E}+00$ & 0.0000 & $0.000 \mathrm{E}+00$ & 0.0000 & $0.000 \mathrm{E}+00$ & 0.0000 & $0.000 \mathrm{E}+00$ & 0.0000 & $0.000 \mathrm{E}+00$ & 0.0000 & $0.000 \mathrm{E}+00$ & 0.0000 & $1.220 \mathrm{E}-07$ & 0.0000 \\
\hline-230 & $0.000 \mathrm{E}+00$ & 0.0000 & $0.000 \mathrm{E}+00$ & 0.0000 & $0.000 \mathrm{E}+00$ & 0.0000 & $0.000 \mathrm{E}+00$ & 0.0000 & $0.000 \mathrm{E}+00$ & 0.0000 & $0.000 E+00$ & 0.0000 & $3.952 \mathrm{E}+00$ & 0.1299 \\
\hline 232 & $0.000 \mathrm{E}+00$ & 0.0000 & $0.000 \mathrm{E}+00$ & 0.0000 & $0.000 \mathrm{E}+00$ & 0.0000 & $0.000 \mathrm{E}+00$ & 0.0000 & $0.000 \mathrm{E}+00$ & 0.0000 & $0.000 \mathrm{E}+00$ & 0.0000 & $8.066 \mathrm{E}+00$ & 0.2651 \\
\hline 34 & $0.000 \mathrm{E}+00$ & 0.0000 & $0.000 \mathrm{E}+00$ & 0.0000 & $0.000 \mathrm{E}+00$ & 0.0000 & $0.000 \mathrm{E}+00$ & 0.0000 & $0.000 \mathrm{E}+00$ & 0.0000 & $0.000 \mathrm{E}+00$ & 0.0000 & $1.383 \mathrm{E}+00$ & 0.0455 \\
\hline 35 & $0.000 \mathrm{E}+00$ & 0.0000 & $0.000 \mathrm{E}+00$ & 0.0000 & $0.000 \mathrm{E}+00$ & 0.0000 & $0.000 \mathrm{E}+00$ & 0.0000 & $0.000 \mathrm{E}+00$ & 0.0000 & $0.000 E+00$ & 0.0000 & $2.551 \mathrm{E}+00$ & 0.0839 \\
\hline 38 & $0.000 \mathrm{E}+00$ & 0.0000 & $0.000 \mathrm{E}+00$ & 0.0000 & $0.000 \mathrm{E}+00$ & 0.0000 & $0.000 \mathrm{E}+00$ & 0.0000 & $0.000 \mathrm{E}+00$ & 0.0000 & $0.000 \mathrm{E}+00$ & 0.0000 & $4.457 \mathrm{E}+00$ & 0.1465 \\
\hline & $0.000 \mathrm{E}+00$ & 0.0000 & $0.000 \mathrm{E}+00$ & 0.0000 & $0.000 \mathrm{E}+00$ & 0.0000 & $0.000 \mathrm{E}+00$ & 0.0000 & $0.000 \mathrm{E}+00$ & 0.0000 & $0.000 \mathrm{E}+00$ & 0.0000 & $3.042 \mathrm{E}+01$ & 1. \\
\hline
\end{tabular}

* Sum of all water independent and dependent pathways. 
RESRAD, Version $6.5 \quad \mathrm{~T}^{1 / 2}$ Limit $=180$ days

Total Dose Contributions TDOSE (i,p,t) for Individual Radionuclides (i) and Pathways (p) As mrem/yr and Fraction of Total Dose At $t=7.000 \mathrm{E}+01$ years

Water Independent Pathways (Inhalation excludes radon)

\begin{tabular}{|c|c|c|c|c|c|c|c|c|c|c|c|c|c|c|}
\hline \multirow{2}{*}{ Nuclide } & \multicolumn{2}{|c|}{ Ground } & \multicolumn{2}{|c|}{ Inhalation } & \multicolumn{2}{|c|}{ Radon } & \multicolumn{2}{|c|}{ Plant } & \multicolumn{2}{|c|}{ Meat } & \multicolumn{2}{|c|}{ Milk } & \multicolumn{2}{|c|}{ Soil } \\
\hline & mrem/yr & fract. & mrem/yr & fract. & mrem/yr & fract. & mrem/yr & fract. & mrem/yr & fract. & mrem/yr & fract. & mrem/yr & fract. \\
\hline-241 & $3.358 E-02$ & 0.0009 & $3.591 \mathrm{E}-02$ & 0.0009 & $0.000 \mathrm{E}+00$ & 0.0000 & $0.000 \mathrm{E}+00$ & 0.0000 & $0.000 \mathrm{E}+00$ & 0.0000 & $0.000 \mathrm{E}+00$ & 0.0000 & $1.360 \mathrm{E}+00$ & 0.0355 \\
\hline-137 & $1.398 E+00$ & 0.0365 & $1.735 \mathrm{E}-07$ & 0.0000 & $0.000 \mathrm{E}+00$ & 0.0000 & $0.000 \mathrm{E}+00$ & 0.0000 & $0.000 \mathrm{E}+00$ & 0.0000 & $0.000 \mathrm{E}+00$ & 0.0000 & $1.052 \mathrm{E}-03$ & 0.0000 \\
\hline-237 & $4.032 E+00$ & 0.1053 & $3.256 \mathrm{E}-03$ & 0.0001 & $0.000 \mathrm{E}+00$ & 0.0000 & $0.000 \mathrm{E}+00$ & 0.0000 & $0.000 \mathrm{E}+00$ & 0.0000 & $0.000 \mathrm{E}+00$ & 0.0000 & $1.313 E-01$ & 0.0034 \\
\hline-238 & $2.045 E-04$ & 0.0000 & $2.939 E-02$ & 0.0008 & $0.000 \mathrm{E}+00$ & 0.0000 & $0.000 \mathrm{E}+00$ & 0.0000 & $0.000 \mathrm{E}+00$ & 0.0000 & $0.000 \mathrm{E}+00$ & 0.0000 & $1.117 \mathrm{E}+00$ & 0.0292 \\
\hline-239 & $5.231 E-03$ & 0.0001 & $5.154 \mathrm{E}-02$ & 0.0013 & $0.000 \mathrm{E}+00$ & 0.0000 & $0.000 \mathrm{E}+00$ & 0.0000 & $0.000 \mathrm{E}+00$ & 0.0000 & $0.000 \mathrm{E}+00$ & 0.0000 & $1.953 \mathrm{E}+00$ & 0.0510 \\
\hline-240 & $3.155 \mathrm{E}-04$ & 0.0000 & $5.126 \mathrm{E}-02$ & 0.0013 & $0.000 \mathrm{E}+00$ & 0.0000 & $0.000 \mathrm{E}+00$ & 0.0000 & $0.000 \mathrm{E}+00$ & 0.0000 & $0.000 \mathrm{E}+00$ & 0.0000 & $1.942 \mathrm{E}+00$ & 0.0507 \\
\hline-99 & $2.077 E-06$ & 0.0000 & $2.067 \mathrm{E}-08$ & 0.0000 & $0.000 \mathrm{E}+00$ & 0.0000 & $0.000 \mathrm{E}+00$ & 0.0000 & $0.000 \mathrm{E}+00$ & 0.0000 & $0.000 \mathrm{E}+00$ & 0.0000 & $1.851 \mathrm{E}-05$ & 0.0000 \\
\hline-228 & $9.842 \mathrm{E}-11$ & 0.0000 & $3.132 \mathrm{E}-15$ & 0.0000 & $0.000 \mathrm{E}+00$ & 0.0000 & $0.000 \mathrm{E}+00$ & 0.0000 & $0.000 \mathrm{E}+00$ & 0.0000 & $0.000 \mathrm{E}+00$ & 0.0000 & $1.871 \mathrm{E}-13$ & 0.0000 \\
\hline-230 & $5.622 \mathrm{E}+00$ & 0.1469 & $1.442 \mathrm{E}-02$ & 0.0004 & $0.000 \mathrm{E}+00$ & 0.0000 & $0.000 \mathrm{E}+00$ & 0.0000 & $0.000 \mathrm{E}+00$ & 0.0000 & $0.000 \mathrm{E}+00$ & 0.0000 & $6.587 \mathrm{E}-01$ & 0.0172 \\
\hline-232 & $9.174 \mathrm{E}+00$ & 0.2397 & $7.715 \mathrm{E}-04$ & 0.0000 & $0.000 \mathrm{E}+00$ & 0.0000 & $0.000 \mathrm{E}+00$ & 0.0000 & $0.000 \mathrm{E}+00$ & 0.0000 & $0.000 \mathrm{E}+00$ & 0.0000 & $8.795 E-02$ & 0.0023 \\
\hline 34 & $3.779 \mathrm{E}-02$ & 0.0010 & $2.035 E-02$ & 0.0005 & $0.000 \mathrm{E}+00$ & 0.0000 & $0.000 \mathrm{E}+00$ & 0.0000 & $0.000 \mathrm{E}+00$ & 0.0000 & $0.000 \mathrm{E}+00$ & 0.0000 & $1.922 \mathrm{E}+00$ & 0.0502 \\
\hline 35 & $3.197 \mathrm{E}+00$ & 0.0835 & $9.034 \mathrm{E}-04$ & 0.0000 & $0.000 \mathrm{E}+00$ & 0.0000 & $0.000 \mathrm{E}+00$ & 0.0000 & $0.000 \mathrm{E}+00$ & 0.0000 & $0.000 \mathrm{E}+00$ & 0.0000 & $8.817 \mathrm{E}-02$ & 0.0023 \\
\hline 38 & $4.971 E+00$ & 0.1299 & $3.063 E-03$ & 0.0001 & $0.000 \mathrm{E}+00$ & 0.0000 & $0.000 \mathrm{E}+00$ & 0.0000 & $0.000 \mathrm{E}+00$ & 0.0000 & $0.000 \mathrm{E}+00$ & 0.0000 & $3.366 \mathrm{E}-01$ & 0.0088 \\
\hline & $2.847 E+01$ & 0.7438 & $2.109 \mathrm{E}-01$ & 0.0055 & $0.000 \mathrm{E}+00$ & 0.0000 & $0.000 \mathrm{E}+00$ & 0.0000 & $0.000 \mathrm{E}+00$ & 0.0000 & $0.000 \mathrm{E}+00$ & 0.0000 & $9.598 \mathrm{E}+00$ & 0.2507 \\
\hline
\end{tabular}

Total Dose Contributions TDOSE (i,p,t) for Individual Radionuclides (i) and Pathways (p) As mrem/yr and Fraction of Total Dose At $t=7.000 \mathrm{E}+01$ years

Water Dependent Pathways

\begin{tabular}{|c|c|c|c|c|c|c|c|c|c|c|c|c|c|c|}
\hline & \multicolumn{2}{|c|}{ Water } & \multicolumn{2}{|c|}{ Fish } & \multicolumn{2}{|c|}{ Radon } & \multicolumn{2}{|c|}{ Plant } & \multicolumn{2}{|c|}{ Meat } & \multicolumn{2}{|c|}{ Milk } & \multicolumn{2}{|c|}{ All Pathways* } \\
\hline clide & mrem/yr & fract. & mrem/yr & fract. & mrem/yr & fract. & mrem/yr & fract. & mrem/yr & fract. & mrem/yr & fract. & mrem/yr & fract. \\
\hline-241 & $0.000 \mathrm{E}+00$ & 0.0000 & $0.000 \mathrm{E}+00$ & 0.0000 & $0.000 \mathrm{E}+00$ & 0.0000 & $0.000 \mathrm{E}+00$ & 0.0000 & $0.000 \mathrm{E}+00$ & 0.0000 & $0.000 \mathrm{E}+00$ & 0.0000 & $1.430 \mathrm{E}+00$ & 0.0374 \\
\hline-137 & $0.000 \mathrm{E}+00$ & 0.0000 & $0.000 \mathrm{E}+00$ & 0.0000 & $0.000 \mathrm{E}+00$ & 0.0000 & $0.000 \mathrm{E}+00$ & 0.0000 & $0.000 \mathrm{E}+00$ & 0.0000 & $0.000 \mathrm{E}+00$ & 0.0000 & $1.399 \mathrm{E}+00$ & 0.0365 \\
\hline-237 & $0.000 \mathrm{E}+00$ & 0.0000 & $0.000 \mathrm{E}+00$ & 0.0000 & $0.000 \mathrm{E}+00$ & 0.0000 & $0.000 \mathrm{E}+00$ & 0.0000 & $0.000 \mathrm{E}+00$ & 0.0000 & $0.000 \mathrm{E}+00$ & 0.0000 & $4.166 \mathrm{E}+00$ & 0.1088 \\
\hline-238 & $0.000 \mathrm{E}+00$ & 0.0000 & $0.000 \mathrm{E}+00$ & 0.0000 & $0.000 \mathrm{E}+00$ & 0.0000 & $0.000 \mathrm{E}+00$ & 0.0000 & $0.000 \mathrm{E}+00$ & 0.0000 & $0.000 \mathrm{E}+00$ & 0.0000 & $1.147 \mathrm{E}+00$ & 0.0300 \\
\hline-239 & $0.000 \mathrm{E}+00$ & 0.0000 & $0.000 \mathrm{E}+00$ & 0.0000 & $0.000 \mathrm{E}+00$ & 0.0000 & $0.000 \mathrm{E}+00$ & 0.0000 & $0.000 \mathrm{E}+00$ & 0.0000 & $0.000 E+00$ & 0.0000 & $2.009 \mathrm{E}+00$ & 0.0525 \\
\hline-240 & $0.000 \mathrm{E}+00$ & 0.0000 & $0.000 \mathrm{E}+00$ & 0.0000 & $0.000 \mathrm{E}+00$ & 0.0000 & $0.000 \mathrm{E}+00$ & 0.0000 & $0.000 \mathrm{E}+00$ & 0.0000 & $0.000 E+00$ & 0.0000 & $1.994 \mathrm{E}+00$ & 0.0521 \\
\hline-99 & $0.000 \mathrm{E}+00$ & 0.0000 & $0.000 \mathrm{E}+00$ & 0.0000 & $0.000 \mathrm{E}+00$ & 0.0000 & $0.000 \mathrm{E}+00$ & 0.0000 & $0.000 \mathrm{E}+00$ & 0.0000 & $0.000 \mathrm{E}+00$ & 0.0000 & $2.060 \mathrm{E}-05$ & 0.0000 \\
\hline-228 & $0.000 \mathrm{E}+00$ & 0.0000 & $0.000 \mathrm{E}+00$ & 0.0000 & $0.000 \mathrm{E}+00$ & 0.0000 & $0.000 \mathrm{E}+00$ & 0.0000 & $0.000 \mathrm{E}+00$ & 0.0000 & $0.000 \mathrm{E}+00$ & 0.0000 & $9.861 \mathrm{E}-11$ & 0.0000 \\
\hline-230 & $0.000 \mathrm{E}+00$ & 0.0000 & $0.000 \mathrm{E}+00$ & 0.0000 & $0.000 \mathrm{E}+00$ & 0.0000 & $0.000 \mathrm{E}+00$ & 0.0000 & $0.000 \mathrm{E}+00$ & 0.0000 & $0.000 E+00$ & 0.0000 & $6.295 \mathrm{E}+00$ & 0.1645 \\
\hline 232 & $0.000 \mathrm{E}+00$ & 0.0000 & $0.000 \mathrm{E}+00$ & 0.0000 & $0.000 \mathrm{E}+00$ & 0.0000 & $0.000 \mathrm{E}+00$ & 0.0000 & $0.000 \mathrm{E}+00$ & 0.0000 & $0.000 \mathrm{E}+00$ & 0.0000 & $9.263 \mathrm{E}+00$ & 0.2420 \\
\hline 34 & $0.000 \mathrm{E}+00$ & 0.0000 & $0.000 \mathrm{E}+00$ & 0.0000 & $0.000 \mathrm{E}+00$ & 0.0000 & $0.000 \mathrm{E}+00$ & 0.0000 & $0.000 \mathrm{E}+00$ & 0.0000 & $0.000 \mathrm{E}+00$ & 0.0000 & $1.980 \mathrm{E}+00$ & 0.0517 \\
\hline 35 & $0.000 \mathrm{E}+00$ & 0.0000 & $0.000 \mathrm{E}+00$ & 0.0000 & $0.000 \mathrm{E}+00$ & 0.0000 & $0.000 \mathrm{E}+00$ & 0.0000 & $0.000 \mathrm{E}+00$ & 0.0000 & $0.000 E+00$ & 0.0000 & $3.286 \mathrm{E}+00$ & 0.0858 \\
\hline 38 & $0.000 \mathrm{E}+00$ & 0.0000 & $0.000 \mathrm{E}+00$ & 0.0000 & $0.000 \mathrm{E}+00$ & 0.0000 & $0.000 \mathrm{E}+00$ & 0.0000 & $0.000 \mathrm{E}+00$ & 0.0000 & $0.000 \mathrm{E}+00$ & 0.0000 & $5.311 \mathrm{E}+00$ & 0.1387 \\
\hline & $0.000 \mathrm{E}+00$ & 0.0000 & $0.000 \mathrm{E}+00$ & 0.0000 & $0.000 \mathrm{E}+00$ & 0.0000 & $0.000 \mathrm{E}+00$ & 0.0000 & $0.000 \mathrm{E}+00$ & 0.0000 & $0.000 \mathrm{E}+00$ & 0.0000 & $B E+01$ & 1. \\
\hline
\end{tabular}

* Sum of all water independent and dependent pathways. 
RESRAD, Version $6.5 \quad \mathrm{~T}^{1 / 2}$ Limit $=180$ days

ummary : C746U Trespasser Deterministic Run

File : $\mathrm{X}: \backslash$ FINAL V2\C746U T SG FWD-FINALV2.RAD

Dose/Source Ratios Summed Over All Pathways

Parent and Progeny Principal Radionuclide Contributions Indicated

Parent Product Thread DSR $(j, t)$ At Time in Years (mrem/yr)/(pCi/g)

(i) (j) Fraction 0.000E+00 1.000E+00 5.000E+01 7.000E+01

$\begin{array}{lllllll}\mathrm{Am}-241 & 1.000 \mathrm{E}+00 & 1.457 \mathrm{E}-06 & 1.496 \mathrm{E}-06 & 2.949 \mathrm{E}-04 & 4.084 \mathrm{E}-04\end{array}$

$\begin{array}{lllllll}\mathrm{Np}-237+\mathrm{D} & 1.000 \mathrm{E}+00 & 5.599 \mathrm{E}-10 & 1.695 \mathrm{E}-09 & 9.593 \mathrm{E}-08 & 1.644 \mathrm{E}-07\end{array}$

$\begin{array}{llllll}\mathrm{U}-233 & 1.000 \mathrm{E}+00 & 6.695 \mathrm{E}-19 & 4.735 \mathrm{E}-18 & 1.474 \mathrm{E}-13 & 4.016 \mathrm{E}-13\end{array}$

$\begin{array}{lllllll}\mathrm{Th}-229+\mathrm{D} & 1.000 \mathrm{E}+00 & 3.971 \mathrm{E}-20 & 5.999 \mathrm{E}-19 & 3.406 \mathrm{E}-14 & 1.120 \mathrm{E}-13\end{array}$

$\operatorname{\sum DSR}(j) \quad 1.457 \mathrm{E}-06 \quad 1.498 \mathrm{E}-06 \quad 2.950 \mathrm{E}-04 \quad 4.086 \mathrm{E}-04$

$\mathrm{Cs}-137+\mathrm{D} \quad 1.000 \mathrm{E}+00 \quad 2.060 \mathrm{E}-02 \quad 2.029 \mathrm{E}-02 \quad 9.878 \mathrm{E}-03 \quad 7.362 \mathrm{E}-03$

$\begin{array}{lllllll}\mathrm{Np}-237+\mathrm{D} & 1.000 \mathrm{E}+00 & 3.453 \mathrm{E}-03 & 3.490 \mathrm{E}-03 & 6.082 \mathrm{E}-03 & 7.575 \mathrm{E}-03\end{array}$

$\begin{array}{lllllll}\mathrm{U}-233 & 1.000 \mathrm{E}+00 & 6.197 \mathrm{E}-12 & 1.880 \mathrm{E}-11 & 1.848 \mathrm{E}-08 & 3.644 \mathrm{E}-08\end{array}$

$\begin{array}{llllllll}\mathrm{Th}-229+\mathrm{D} & 1.000 \mathrm{E}+00 \quad 4.903 \mathrm{E}-13 & 3.458 \mathrm{E}-12 & 6.366 \mathrm{E}-09 & 1.511 \mathrm{E}-08\end{array}$

$\operatorname{LDSR}(j) \quad 3.453 \mathrm{E}-03 \quad 3.490 \mathrm{E}-03 \quad 6.082 \mathrm{E}-03 \quad 7.575 \mathrm{E}-03$

$\begin{array}{llllll}\mathrm{Pu}-238 & 1.840 \mathrm{E}-09 & 4.859 \mathrm{E}-17 & 4.907 \mathrm{E}-17 & 4.452 \mathrm{E}-13 & 5.411 \mathrm{E}-13\end{array}$

$\begin{array}{llllll}\mathrm{Pu}-238 & 1.000 \mathrm{E}+00 & 2.641 \mathrm{E}-08 & 2.667 \mathrm{E}-08 & 2.419 \mathrm{E}-04 & 2.941 \mathrm{E}-04\end{array}$

$\begin{array}{llllll}\mathrm{U}-234 & 1.000 \mathrm{E}+00 & 2.486 \mathrm{E}-13 & 7.549 \mathrm{E}-13 & 8.976 \mathrm{E}-09 & 1.658 \mathrm{E}-08\end{array}$

$\begin{array}{lllllll}\mathrm{Th}-230 & 1.000 \mathrm{E}+00 & 3.358 \mathrm{E}-18 & 2.380 \mathrm{E}-17 & 9.470 \mathrm{E}-12 & 2.502 \mathrm{E}-11\end{array}$

$\begin{array}{lllllll}\mathrm{Ra}-226+\mathrm{D} \quad 1.000 \mathrm{E}+00 \quad 4.363 \mathrm{E}-17 & 6.572 \mathrm{E}-16 & 2.901 \mathrm{E}-11 & 8.757 \mathrm{E}-11\end{array}$

$\mathrm{Pb}-210+\mathrm{D} \quad 1.000 \mathrm{E}+00 \quad 2.379 \mathrm{E}-23 \quad 7.401 \mathrm{E}-22 \quad 1.869 \mathrm{E}-13 \quad 8.845 \mathrm{E}-13$

$\operatorname{\sum DSR}(j) \quad 2.641 \mathrm{E}-08 \quad 2.667 \mathrm{E}-08 \quad 2.420 \mathrm{E}-04 \quad 2.941 \mathrm{E}-04$

$\begin{array}{lllllll}\mathrm{Pu}-239 & 1.000 \mathrm{E}+00 & 6.302 \mathrm{E}-07 & 6.378 \mathrm{E}-07 & 3.925 \mathrm{E}-04 & 5.581 \mathrm{E}-04\end{array}$

$\begin{array}{lllllll}\mathrm{U}-235+\mathrm{D} & 1.000 \mathrm{E}+00 & 8.030 \mathrm{E}-13 & 2.436 \mathrm{E}-12 & 1.542 \mathrm{E}-10 & 2.766 \mathrm{E}-10\end{array}$

$\begin{array}{lllllll}\mathrm{Pa}-231 & 1.000 \mathrm{E}+00 & 2.330 \mathrm{E}-18 & 1.646 \mathrm{E}-17 & 5.929 \mathrm{E}-14 & 1.534 \mathrm{E}-13\end{array}$

$\mathrm{AC}-227+\mathrm{D} \quad 1.000 \mathrm{E}+00 \quad 2.010 \mathrm{E}-19 \quad 3.022 \mathrm{E}-18 \quad 1.404 \mathrm{E}-13 \quad 4.252 \mathrm{E}-13$

$\operatorname{EDSR}(j) \quad 6.302 \mathrm{E}-07 \quad 6.378 \mathrm{E}-07 \quad 3.925 \mathrm{E}-04 \quad 5.581 \mathrm{E}-04$

Pu-240 4.950E-08 $1.271 \mathrm{E}-15 \quad 1.293 \mathrm{E}-15 \quad 1.930 \mathrm{E}-11 \quad 2.741 \mathrm{E}-11$

$\begin{array}{llllll}\mathrm{Pu}-240 \quad 1.000 \mathrm{E}+00 & 2.567 \mathrm{E}-08 & 2.612 \mathrm{E}-08 & 3.899 \mathrm{E}-04 & 5.538 \mathrm{E}-04\end{array}$

$\begin{array}{lllllll}\mathrm{U}-236 & 1.000 \mathrm{E}+00 & 1.038 \mathrm{E}-15 & 3.165 \mathrm{E}-15 & 1.083 \mathrm{E}-10 & 2.151 \mathrm{E}-10\end{array}$

Th-232 1.000E+00 4.987E-26 $3.547 \mathrm{E}-25 \quad 6.713 \mathrm{E}-19 \quad 1.861 \mathrm{E}-18$

$\begin{array}{lllllll}\mathrm{Ra}-228+\mathrm{D} & 1.000 \mathrm{E}+00 & 3.271 \mathrm{E}-22 & 4.816 \mathrm{E}-21 & 9.119 \mathrm{E}-17 & 2.265 \mathrm{E}-16\end{array}$

$\begin{array}{lllllll}\mathrm{Th}-228+\mathrm{D} \quad 1.000 \mathrm{E}+00 \quad 5.216 \mathrm{E}-23 & 1.501 \mathrm{E}-21 & 1.723 \mathrm{E}-16 & 4.318 \mathrm{E}-16\end{array}$

$\operatorname{\sum DSR}(j) \quad 2.567 \mathrm{E}-08 \quad 2.612 \mathrm{E}-08 \quad 3.899 \mathrm{E}-04 \quad 5.538 \mathrm{E}-04$

$\begin{array}{llllll}\mathrm{TC}-99 & 1.000 \mathrm{E}+00 & 4.063 \mathrm{E}-08 & 4.098 \mathrm{E}-08 & 6.366 \mathrm{E}-07 & 7.359 \mathrm{E}-07\end{array}$

Th-228+D 1.000E+00 8.889E-02 6.226E-02 $1.649 \mathrm{E}-09 \quad 1.333 \mathrm{E}-12$

$\begin{array}{llllll}\mathrm{Th}-230 & 1.000 \mathrm{E}+00 & 7.878 \mathrm{E}-07 & 8.012 \mathrm{E}-07 & 3.311 \mathrm{E}-04 & 4.713 \mathrm{E}-04\end{array}$

$\mathrm{Ra}-226+\mathrm{D} \quad 1.000 \mathrm{E}+00 \quad 2.053 \mathrm{E}-05 \quad 6.196 \mathrm{E}-05 \quad 2.931 \mathrm{E}-03 \quad 4.701 \mathrm{E}-03$

$\mathrm{Pb}-210+\mathrm{D} \quad 1.000 \mathrm{E}+00 \quad 1.860 \mathrm{E}-11 \quad 1.304 \mathrm{E}-10 \quad 3.123 \mathrm{E}-05 \quad 7.416 \mathrm{E}-05$

$\operatorname{LDSR}(j) \quad 2.131 \mathrm{E}-05 \quad 6.276 \mathrm{E}-05 \quad 3.293 \mathrm{E}-03 \quad 5.246 \mathrm{E}-03$ 
RESRAD, Version $6.5 \quad \mathrm{~T}^{1 / 2}$ Limit $=180$ days

Summary : C746U Trespasser Deterministic Run

File : $X: \backslash F I N A L$ V2 $\backslash C 746 U$ T SG FWD-FINALV2.RAD

Dose/Source Ratios Summed Over All Pathways

Parent and Progeny Principal Radionuclide Contributions Indicated

\begin{tabular}{|c|c|c|c|c|c|c|}
\hline Parent & Product & Thread & $\operatorname{SR}(j, t)$ At & Time in $Y e$ & ears & $\mathrm{m} / \mathrm{yr}) /(\mathrm{pCi}$ \\
\hline (i) & (j) & Fraction & $0.000 \mathrm{E}+00$ & $1.000 \mathrm{E}+00$ & $5.000 \mathrm{E}+01$ & $7.000 \mathrm{E}+01$ \\
\hline-232 & $\mathrm{Th}-232$ & $1.000 \mathrm{E}+00$ & $2.040 \mathrm{E}-07$ & $2.078 \mathrm{E}-07$ & $3.613 E-04$ & $5.145 \mathrm{E}-04$ \\
\hline$h-232$ & $\mathrm{Ra}-228+\mathrm{D}$ & $1.000 \mathrm{E}+00$ & $2.643 E-03$ & $7.575 E-03$ & $6.750 \mathrm{E}-02$ & 7. $900 \mathrm{E}-02$ \\
\hline Th-232 & $\mathrm{Th}-228+\mathrm{D}$ & $1.000 \mathrm{E}+00$ & $6.862 \mathrm{E}-04$ & $4.233 E-03$ & $1.444 \mathrm{E}-01$ & $1.642 \mathrm{E}-01$ \\
\hline$T h-232$ & $\sum \operatorname{DSR}(j)$ & & $3.329 \mathrm{E}-03$ & 1. $181 \mathrm{E}-02$ & $2.123 \mathrm{E}-01$ & $2.438 \mathrm{E}-01$ \\
\hline-234 & $U-234$ & $1.000 \mathrm{E}+00$ & $1.753 \mathrm{E}-07$ & $1.784 \mathrm{E}-07$ & $7.601 \mathrm{E}-05$ & $1.082 \mathrm{E}-04$ \\
\hline-234 & Th -230 & $1.000 \mathrm{E}+00$ & $3.556 \mathrm{E}-12$ & 1. $083 \mathrm{E}-11$ & $1.504 \mathrm{E}-07$ & $2.989 \mathrm{E}-07$ \\
\hline$J-234$ & $\mathrm{Ra}-226+\mathrm{D}$ & $1.000 \mathrm{E}+00$ & $6.163 \mathrm{E}-11$ & $4.340 \mathrm{E}-10$ & $6.684 \mathrm{E}-07$ & $1.499 \mathrm{E}-06$ \\
\hline$J-234$ & $\mathrm{~Pb}-210+\mathrm{D}$ & $1.000 \mathrm{E}+00$ & $4.195 \mathrm{E}-17$ & $6.314 \mathrm{E}-16$ & $5.293 E-09$ & $1.815 \mathrm{E}-08$ \\
\hline-234 & $\sum \operatorname{DSR}(j)$ & & $1.754 \mathrm{E}-07$ & $1.789 \mathrm{E}-07$ & $7.683 E-05$ & $1.100 \mathrm{E}-04$ \\
\hline$-235+D$ & $\mathrm{U}-235+\mathrm{D}$ & $1.000 \mathrm{E}+00$ & $1.627 \mathrm{E}-03$ & $1.648 \mathrm{E}-03$ & $3.101 \mathrm{E}-03$ & $3.987 \mathrm{E}-03$ \\
\hline$J-235+D$ & $\mathrm{~Pa}-231$ & $1.000 \mathrm{E}+00$ & $7.092 \mathrm{E}-09$ & $2.148 \mathrm{E}-08$ & $2.385 \mathrm{E}-06$ & $4.421 \mathrm{E}-06$ \\
\hline$J-235+D$ & $A C-227+D$ & $1.000 \mathrm{E}+00$ & $8.148 \mathrm{E}-10$ & $5.702 E-09$ & $7.572 \mathrm{E}-06$ & $1.589 \mathrm{E}-05$ \\
\hline$J-235+D$ & $\sum \operatorname{DSR}(j)$ & & $1.627 \mathrm{E}-03$ & $1.648 E-03$ & $3.111 \mathrm{E}-03$ & $4.007 E-03$ \\
\hline$J-238$ & $\mathrm{U}-238$ & $5.400 \mathrm{E}-05$ & 1. $359 \mathrm{E}-15$ & 1. $421 \mathrm{E}-15$ & $3.746 \mathrm{E}-09$ & $5.332 E-09$ \\
\hline$J-238+D$ & $\mathrm{U}-238+\mathrm{D}$ & $9.999 \mathrm{E}-01$ & $8.774 \mathrm{E}-04$ & $8.846 E-04$ & $1.393 E-03$ & $1.660 \mathrm{E}-03$ \\
\hline$J-238+D$ & $\mathrm{U}-234$ & $9.999 \mathrm{E}-01$ & $2.492 E-13$ & $7.595 \mathrm{E}-13$ & $1.088 \mathrm{E}-08$ & $2.162 \mathrm{E}-08$ \\
\hline$J-238+D$ & $T h-230$ & $9.999 \mathrm{E}-01$ & $3.365 E-18$ & $2.390 \mathrm{E}-17$ & $1.077 \mathrm{E}-11$ & $2.987 E-11$ \\
\hline$J-238+D$ & $\mathrm{Ra}-226+\mathrm{D}$ & $9.999 \mathrm{E}-01$ & $4.369 \mathrm{E}-17$ & $6.593 E-16$ & $3.196 \mathrm{E}-11$ & $1.001 \mathrm{E}-10$ \\
\hline$J-238+D$ & $\mathrm{~Pb}-210+\mathrm{D}$ & $9.999 \mathrm{E}-01$ & $2.382 E-23$ & $7.420 \mathrm{E}-22$ & $2.027 \mathrm{E}-13$ & $9.911 \mathrm{E}-13$ \\
\hline$J-238+D$ & $\sum \operatorname{DSR}(j)$ & & $8.774 \mathrm{E}-04$ & $8.846 \mathrm{E}-04$ & $1.393 E-03$ & $1.660 \mathrm{E}-03$ \\
\hline
\end{tabular}

The DSR includes contributions from associated (half-life $\leq 180$ days) daughters. 
RESRAD, Version $6.5 \quad \mathrm{~T}^{1 / 2}$ Limit $=180$ days

Summary : C746U Trespasser Deterministic Run

File : $X: \backslash F I N A L$ V2 $\backslash C 746 U$ T SG FWD-FINALV2.RAD

Single Radionuclide Soil Guidelines G(i,t) in pCi/g

Basic Radiation Dose Limit $=1.000 \mathrm{E}+02 \mathrm{mrem} / \mathrm{yr}$

Nuclide

\begin{tabular}{cccccc} 
(i) & $\mathrm{t}=$ & $0.000 \mathrm{E}+00$ & $1.000 \mathrm{E}+00$ & $5.000 \mathrm{E}+01$ & $7.000 \mathrm{E}+01$ \\
\cline { 1 - 1 } $\mathrm{Am}-241$ & & $6.861 \mathrm{E}+07$ & $6.676 \mathrm{E}+07$ & $3.390 \mathrm{E}+05$ & $2.448 \mathrm{E}+05$ \\
$\mathrm{Cs}-137$ & & $4.856 \mathrm{E}+03$ & $4.927 \mathrm{E}+03$ & $1.012 \mathrm{E}+04$ & $1.358 \mathrm{E}+04$ \\
$\mathrm{~Np}-237$ & & $2.896 \mathrm{E}+04$ & $2.866 \mathrm{E}+04$ & $1.644 \mathrm{E}+04$ & $1.320 \mathrm{E}+04$ \\
$\mathrm{Pu}-238$ & & $3.787 \mathrm{E}+09$ & $3.750 \mathrm{E}+09$ & $4.133 \mathrm{E}+05$ & $3.400 \mathrm{E}+05$ \\
$\mathrm{Pu}-239$ & & $1.587 \mathrm{E}+08$ & $1.568 \mathrm{E}+08$ & $2.548 \mathrm{E}+05$ & $1.792 \mathrm{E}+05$ \\
$\mathrm{Pu}-240$ & & $3.896 \mathrm{E}+09$ & $3.828 \mathrm{E}+09$ & $2.565 \mathrm{E}+05$ & $1.806 \mathrm{E}+05$ \\
$\mathrm{TC}-99$ & & $2.461 \mathrm{E}+09$ & $2.440 \mathrm{E}+09$ & $1.571 \mathrm{E}+08$ & $1.359 \mathrm{E}+08$ \\
$\mathrm{Th}-228$ & & $1.125 \mathrm{E}+03$ & $1.606 \mathrm{E}+03$ & $6.065 \mathrm{E}+10$ & $7.505 \mathrm{E}+13$ \\
$\mathrm{Th}-230$ & & $4.692 \mathrm{E}+06$ & $1.593 \mathrm{E}+06$ & $3.037 \mathrm{E}+04$ & $1.906 \mathrm{E}+04$ \\
$\mathrm{Th}-232$ & & $3.004 \mathrm{E}+04$ & $8.469 \mathrm{E}+03$ & $4.711 \mathrm{E}+02$ & $4.102 \mathrm{E}+02$ \\
$\mathrm{U}-234$ & $5.702 \mathrm{E}+08$ & $5.590 \mathrm{E}+08$ & $1.301 \mathrm{E}+06$ & $9.092 \mathrm{E}+05$ \\
$\mathrm{U}-235$ & $6.145 \mathrm{E}+04$ & $6.069 \mathrm{E}+04$ & $3.214 \mathrm{E}+04$ & $2.495 \mathrm{E}+04$ \\
$\mathrm{U}-238$ & $1.140 \mathrm{E}+05$ & $1.131 \mathrm{E}+05$ & $7.180 \mathrm{E}+04$ & $6.025 \mathrm{E}+04$ \\
\hline \hline
\end{tabular}

Summed Dose/Source Ratios DSR (i,t) in (mrem/yr)/(pCi/g) and Single Radionuclide Soil Guidelines G(i,t) in pCi/g at tmin = time of minimum single radionuclide soil guideline and at $\operatorname{tmax}=$ time of maximum total dose $=7.000 \mathrm{E}+01$ years

\begin{tabular}{|c|c|c|c|c|c|c|}
\hline $\begin{array}{l}\text { uclide } \\
\text { (i) }\end{array}$ & $\begin{array}{l}\text { Initial } \\
(\mathrm{pCi} / \mathrm{g})\end{array}$ & $\begin{array}{c}\text { tmin } \\
\text { (years) }\end{array}$ & $\operatorname{DSR}(i, \operatorname{tmin})$ & $\begin{array}{c}\mathrm{G}(\mathrm{i}, \mathrm{tmin}) \\
(\mathrm{pCi} / \mathrm{g})\end{array}$ & $\operatorname{DSR}(i, t \max )$ & $\begin{array}{c}G(i, t \max ) \\
(\mathrm{pCi} / \mathrm{g})\end{array}$ \\
\hline$n-241$ & $3.500 \mathrm{E}+03$ & $7.000 \mathrm{E}+01$ & $4.086 \mathrm{E}-04$ & $2.448 E+05$ & $4.086 E-04$ & $2.448 E+05$ \\
\hline-137 & $1.900 \mathrm{E}+02$ & $0.000 \mathrm{E}+00$ & $2.060 \mathrm{E}-02$ & $4.856 \mathrm{E}+03$ & $7.362 \mathrm{E}-03$ & 1. $358 \mathrm{E}+04$ \\
\hline-237 & $5.500 \mathrm{E}+02$ & $7.000 E+01$ & $7.575 \mathrm{E}-03$ & $1.320 \mathrm{E}+04$ & $7.575 E-03$ & $1.320 \mathrm{E}+04$ \\
\hline-238 & $3.900 \mathrm{E}+03$ & $7.000 E+01$ & $2.941 E-04$ & $3.400 \mathrm{E}+05$ & $2.941 E-04$ & $3.400 \mathrm{E}+05$ \\
\hline-239 & $3.600 \mathrm{E}+03$ & $7.000 \mathrm{E}+01$ & $5.581 \mathrm{E}-04$ & $1.792 \mathrm{E}+05$ & $5.581 \mathrm{E}-04$ & $1.792 \mathrm{E}+05$ \\
\hline$x-240$ & $3.600 \mathrm{E}+03$ & $7.000 \mathrm{E}+01$ & $5.538 \mathrm{E}-04$ & $1.806 \mathrm{E}+05$ & $5.538 \mathrm{E}-04$ & $1.806 \mathrm{E}+05$ \\
\hline-99 & $2.800 \mathrm{E}+01$ & $7.000 \mathrm{E}+01$ & 7. $359 \mathrm{E}-07$ & $1.359 \mathrm{E}+08$ & $7.359 \mathrm{E}-07$ & $1.359 \mathrm{E}+08$ \\
\hline-228 & $7.400 \mathrm{E}+01$ & $0.000 \mathrm{E}+00$ & $8.889 E-02$ & $1.125 \mathrm{E}+03$ & 1. $333 \mathrm{E}-12$ & $7.505 \mathrm{E}+13$ \\
\hline-230 & $1.200 \mathrm{E}+03$ & $7.000 \mathrm{E}+01$ & $5.246 \mathrm{E}-03$ & $1.906 \mathrm{E}+04$ & $5.246 \mathrm{E}-03$ & $1.906 \mathrm{E}+04$ \\
\hline-232 & $3.800 \mathrm{E}+01$ & $7.000 E+01$ & $2.438 \mathrm{E}-01$ & $4.102 \mathrm{E}+02$ & $2.438 E-01$ & $4.102 E+02$ \\
\hline-234 & $1.800 \mathrm{E}+04$ & $7.000 \mathrm{E}+01$ & $1.100 \mathrm{E}-04$ & $9.092 \mathrm{E}+05$ & $1.100 \mathrm{E}-04$ & $9.092 \mathrm{E}+05$ \\
\hline 235 & $8.200 \mathrm{E}+02$ & $7.000 \mathrm{E}+01$ & $4.007 \mathrm{E}-03$ & $2.495 \mathrm{E}+04$ & $4.007 E-03$ & $2.495 \mathrm{E}+04$ \\
\hline 238 & $3.200 E+03$ & $7.000 E+01$ & $1.660 \mathrm{E}-03$ & $6.025 E+04$ & $1.660 E-03$ & $6.025 E+04$ \\
\hline
\end{tabular}


RESRAD, Version $6.5 \quad \mathrm{~T}^{1 / 2}$ Limit $=180$ days

Summary : C746U Trespasser Deterministic Run

File : $\mathrm{X}: \backslash$ FINAL V2 $\backslash$ C746U T SG FWD-FINALV2.RAD

Individual Nuclide Dose Summed Over All Pathways

Parent Nuclide and Branch Fraction Indicated

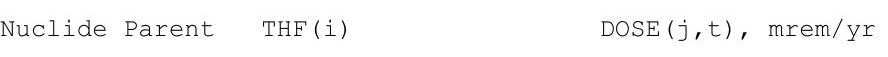

(j)

$+241$

$\mathrm{Am}-241 \quad \mathrm{Am}-241 \quad 1.000 \mathrm{E}+00$

Np-237 Am-241 $1.000 \mathrm{E}+00$

Np-237 Np-237 $1.000 E+00$

Np-237 $\sum \operatorname{DOSE}(j)$

$\mathrm{U}-233 \quad \mathrm{Am}-241 \quad 1.000 \mathrm{E}+00$

$\mathrm{U}-233 \quad \mathrm{~Np}-237 \quad 1.000 \mathrm{E}+00$

$\mathrm{U}-233 \quad \sum \operatorname{DOSE}(j)$

Th-229

Th-229

Th-229

Cs -137

$\mathrm{Pu}-238$

$\mathrm{Pu}-238$

Pu-238

$\mathrm{U}-234$

$\mathrm{U}-234$

$\mathrm{U}-234$

$\mathrm{U}-234$

Th -230

$\mathrm{Th}-230$

Th -230

Th -230

$\mathrm{Th}-230$

$\mathrm{Ra}-226$

$\mathrm{Ra}-226$

$\mathrm{Ra}-226$

$\mathrm{Ra}-226$

$\operatorname{Ra}-226$

$\mathrm{Pb}-210$

$\mathrm{Pb}-210$

$\mathrm{Pb}-210$

$\mathrm{Pb}-210$

$\mathrm{Pb}-210$

$\mathrm{Pu}-23$

$\mathrm{U}-235$

$\mathrm{U}-235$

$\mathrm{U}-235$

$\mathrm{Am}-241 \quad 1.000 \mathrm{E}+00$

Np-237 1.000E+00

$\operatorname{LOSE}(j)$

Cs-137 $1.000 \mathrm{E}+00$

Pu-238 1.840E-09

$\mathrm{Pu}-238 \quad 1.000 \mathrm{E}+00$

$\sum \operatorname{DOSE}(j)$

$\mathrm{Pu}-238 \quad 1.000 \mathrm{E}+00$

$\mathrm{U}-234 \quad 1.000 \mathrm{E}+00$

$\mathrm{U}-238 \quad 9.999 \mathrm{E}-01$

$\sum \operatorname{DOSE}(j)$

$\mathrm{Pu}-238 \quad 1.000 \mathrm{E}+00$

Th-230 1.000E+00

$\mathrm{U}-234 \quad 1.000 \mathrm{E}+00$

U-238 $9.999 \mathrm{E}-01$

$\sum \operatorname{DOSE}(j)$

$\mathrm{Pu}-238 \quad 1.000 \mathrm{E}+00$

Th-230 1.000E+00

$\mathrm{U}-234 \quad 1.000 \mathrm{E}+00$

$\mathrm{U}-238 \quad 9.999 \mathrm{E}-01$

$\sum \operatorname{DOSE}(j)$

Pu-238 1.000E+00

Th-230 1.000E+00

U-234 $1.000 \mathrm{E}+00$

$\mathrm{U}-238 \quad 9.999 \mathrm{E}-01$

$\sum \operatorname{DOSE}(j)$

Pu-239 1.000E+00

Pu-239 1.000E+00

$\mathrm{U}-2351.000 \mathrm{E}+00$

¿DOSE (j) $t=0.000 \mathrm{E}+00 \quad 1.000 \mathrm{E}+00 \quad 5.000 \mathrm{E}+01 \quad 7.000 \mathrm{E}+01$

$\begin{array}{llll}5.099 \mathrm{E}-03 & 5.237 \mathrm{E}-03 & 1.032 \mathrm{E}+00 & 1.429 \mathrm{E}+00\end{array}$

$1.960 \mathrm{E}-06 \quad 5.931 \mathrm{E}-06 \quad 3.357 \mathrm{E}-04 \quad 5.755 \mathrm{E}-04$

$1.899 \mathrm{E}+00 \quad 1.919 \mathrm{E}+00 \quad 3.345 \mathrm{E}+00 \quad 4.166 \mathrm{E}+00$

$\begin{array}{llll}1.899 \mathrm{E}+00 & 1.919 \mathrm{E}+00 & 3.345 \mathrm{E}+00 & 4.167 \mathrm{E}+00\end{array}$

$2.343 \mathrm{E}-15 \quad 1.657 \mathrm{E}-14 \quad 5.157 \mathrm{E}-10 \quad 1.406 \mathrm{E}-09$

3.408E-09 $1.034 \mathrm{E}-08 \quad 1.016 \mathrm{E}-05 \quad 2.004 \mathrm{E}-05$

3. 408E-09 1.034E-08 1.016E-05 2.004E-05

$\begin{array}{llll}1.390 \mathrm{E}-16 & 2.100 \mathrm{E}-15 & 1.192 \mathrm{E}-10 & 3.921 \mathrm{E}-10\end{array}$

$2.697 \mathrm{E}-10 \quad 1.902 \mathrm{E}-09 \quad 3.501 \mathrm{E}-06 \quad 8.311 \mathrm{E}-06$

$2.697 \mathrm{E}-10 \quad 1.902 \mathrm{E}-09 \quad 3.501 \mathrm{E}-06 \quad 8.311 \mathrm{E}-06$

$3.913 \mathrm{E}+00 \quad 3.856 \mathrm{E}+00 \quad 1.877 \mathrm{E}+00 \quad 1.399 \mathrm{E}+00$

$\begin{array}{llll}1.895 \mathrm{E}-13 & 1.914 \mathrm{E}-13 & 1.736 \mathrm{E}-09 & 2.110 \mathrm{E}-09\end{array}$

$1.030 \mathrm{E}-04 \quad 1.040 \mathrm{E}-04 \quad 9.436 \mathrm{E}-01 \quad 1.147 \mathrm{E}+00$

$1.030 \mathrm{E}-04 \quad 1.040 \mathrm{E}-04 \quad 9.436 \mathrm{E}-01 \quad 1.147 \mathrm{E}+00$

$9.694 \mathrm{E}-10 \quad 2.944 \mathrm{E}-09 \quad 3.501 \mathrm{E}-05 \quad 6.467 \mathrm{E}-05$
$3.156 \mathrm{E}-03$

$3.156 \mathrm{E}-03 \quad 3.212 \mathrm{E}-03 \quad 1.368 \mathrm{E}+00 \quad 1.947 \mathrm{E}+00$

$\begin{array}{llll}7.975 \mathrm{E}-10 & 2.430 \mathrm{E}-09 & 3.482 \mathrm{E}-05 & 6.919 \mathrm{E}-05\end{array}$

$\begin{array}{llll}3.156 \mathrm{E}-03 & 3.212 \mathrm{E}-03 & 1.368 \mathrm{E}+00 & 1.947 \mathrm{E}+00\end{array}$

$\begin{array}{lllll}1.310 \mathrm{E}-14 & 9.280 \mathrm{E}-14 & 3.693 \mathrm{E}-08 & 9.758 \mathrm{E}-08\end{array}$

$9.454 \mathrm{E}-04 \quad 9.614 \mathrm{E}-04 \quad 3.973 \mathrm{E}-01 \quad 5.655 \mathrm{E}-01$
$0.401 \mathrm{E}-08$

$6.401 \mathrm{E}-08 \quad 1.949 \mathrm{E}-07 \quad 2.708 \mathrm{E}-03 \quad 5.381 \mathrm{E}-03$

$\begin{array}{llll}1.077 \mathrm{E}-14 & 7.647 \mathrm{E}-14 & 3.446 \mathrm{E}-08 & 9.557 \mathrm{E}-08\end{array}$

9.455E-04 9.616E-04 4.000E-01 5.709E-01

$\begin{array}{llll}1.701 \mathrm{E}-13 & 2.563 \mathrm{E}-12 & 1.131 \mathrm{E}-07 & 3.415 \mathrm{E}-07\end{array}$

$2.463 \mathrm{E}-02 \quad 7.435 \mathrm{E}-02 \quad 3.517 \mathrm{E}+00 \quad 5.641 \mathrm{E}+00$

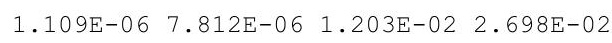

$\begin{array}{llll}1.398 \mathrm{E}-13 & 2.110 \mathrm{E}-12 & 1.023 \mathrm{E}-07 & 3.203 \mathrm{E}-07\end{array}$

$2.463 \mathrm{E}-02 \quad 7.436 \mathrm{E}-02 \quad 3.529 \mathrm{E}+00 \quad 5.668 \mathrm{E}+00$

$\begin{array}{llll}9.278 \mathrm{E}-20 & 2.886 \mathrm{E}-18 & 7.288 \mathrm{E}-10 & 3.449 \mathrm{E}-09\end{array}$

$2.232 \mathrm{E}-08 \quad 1.564 \mathrm{E}-07 \quad 3.747 \mathrm{E}-02 \quad 8.899 \mathrm{E}-02$

$\begin{array}{llll}7.550 \mathrm{E}-13 & 1.137 \mathrm{E}-11 & 9.527 \mathrm{E}-05 & 3.268 \mathrm{E}-04\end{array}$

$\begin{array}{lllll}7.622 \mathrm{E}-20 & 2.374 \mathrm{E}-18 & 6.486 \mathrm{E}-10 & 3.171 \mathrm{E}-09\end{array}$

$2.232 \mathrm{E}-08 \quad 1.564 \mathrm{E}-07 \quad 3.757 \mathrm{E}-02 \quad 8.932 \mathrm{E}-02$

$2.269 \mathrm{E}-03 \quad 2.296 \mathrm{E}-03 \quad 1.413 \mathrm{E}+00 \quad 2.009 \mathrm{E}+00$

$2.891 \mathrm{E}-09 \quad 8.769 \mathrm{E}-09 \quad 5.550 \mathrm{E}-07 \quad 9.958 \mathrm{E}-07$

$\begin{array}{llll}1.334 \mathrm{E}+00 & 1.351 \mathrm{E}+00 & 2.543 \mathrm{E}+00 & 3.269 \mathrm{E}+00\end{array}$

$\begin{array}{llll}1.334 \mathrm{E}+00 & 1.351 \mathrm{E}+00 & 2.543 \mathrm{E}+00 & 3.269 \mathrm{E}+00\end{array}$ 
RESRAD, Version $6.5 \quad \mathrm{~T}^{1 / 2}$ Limit $=180$ days

Summary : C746U Trespasser Deterministic Run

File : $\mathrm{X}: \backslash$ FINAL V2 $\backslash$ C746U T SG FWD-FINALV2.RAD

Individual Nuclide Dose Summed Over All Pathways

Parent Nuclide and Branch Fraction Indicated

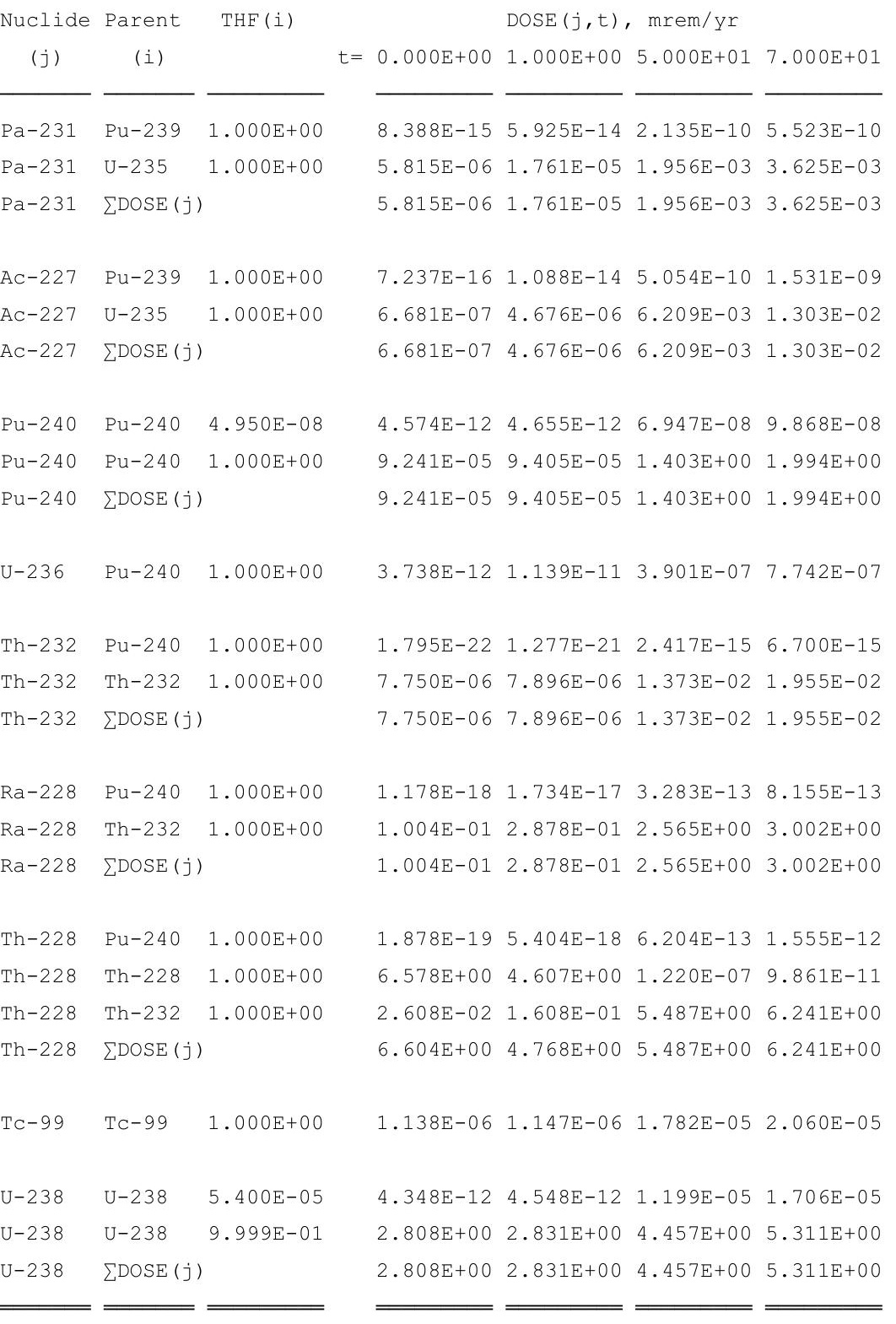

THF(i) is the thread fraction of the parent nuclide. 
RESRAD, Version $6.5 \quad T^{1 / 2}$ Limit $=180$ days

Summary : C746U Trespasser Deterministic Run

File : $\mathrm{X}: \backslash$ FINAL V2 $\backslash$ C746U T SG FWD-FINALV2.RAD

Individual Nuclide Soil Concentration

Parent Nuclide and Branch Fraction Indicated

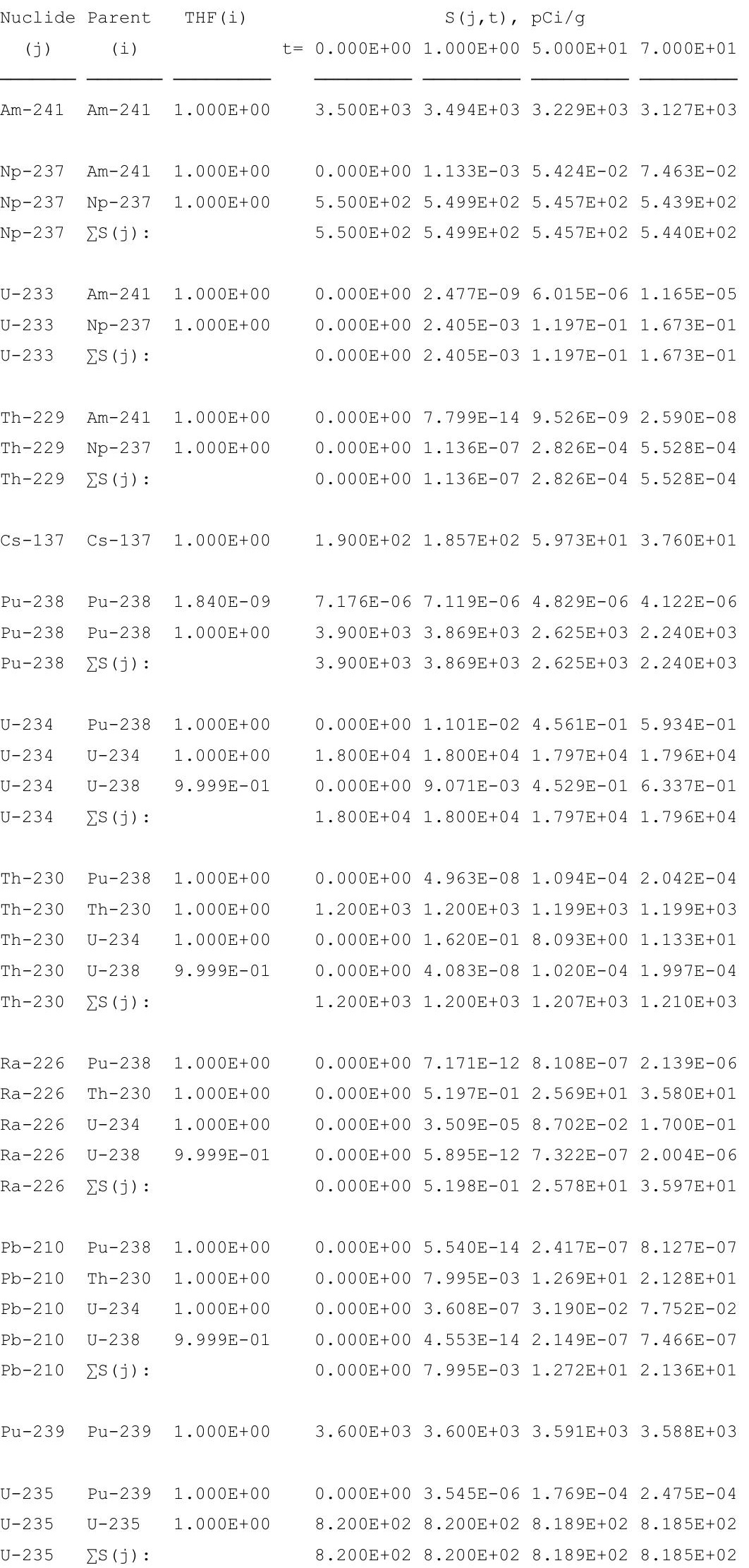


RESRAD, Version $6.5 \quad \mathrm{~T}^{1 / 2}$ Limit $=180$ days

Summary : C746U Trespasser Deterministic Run

File : $\mathrm{X}: \backslash$ FINAL V2 $\backslash$ C746U T SG FWD-FINALV2.RAD

Individual Nuclide Soil Concentration

Parent Nuclide and Branch Fraction Indicated

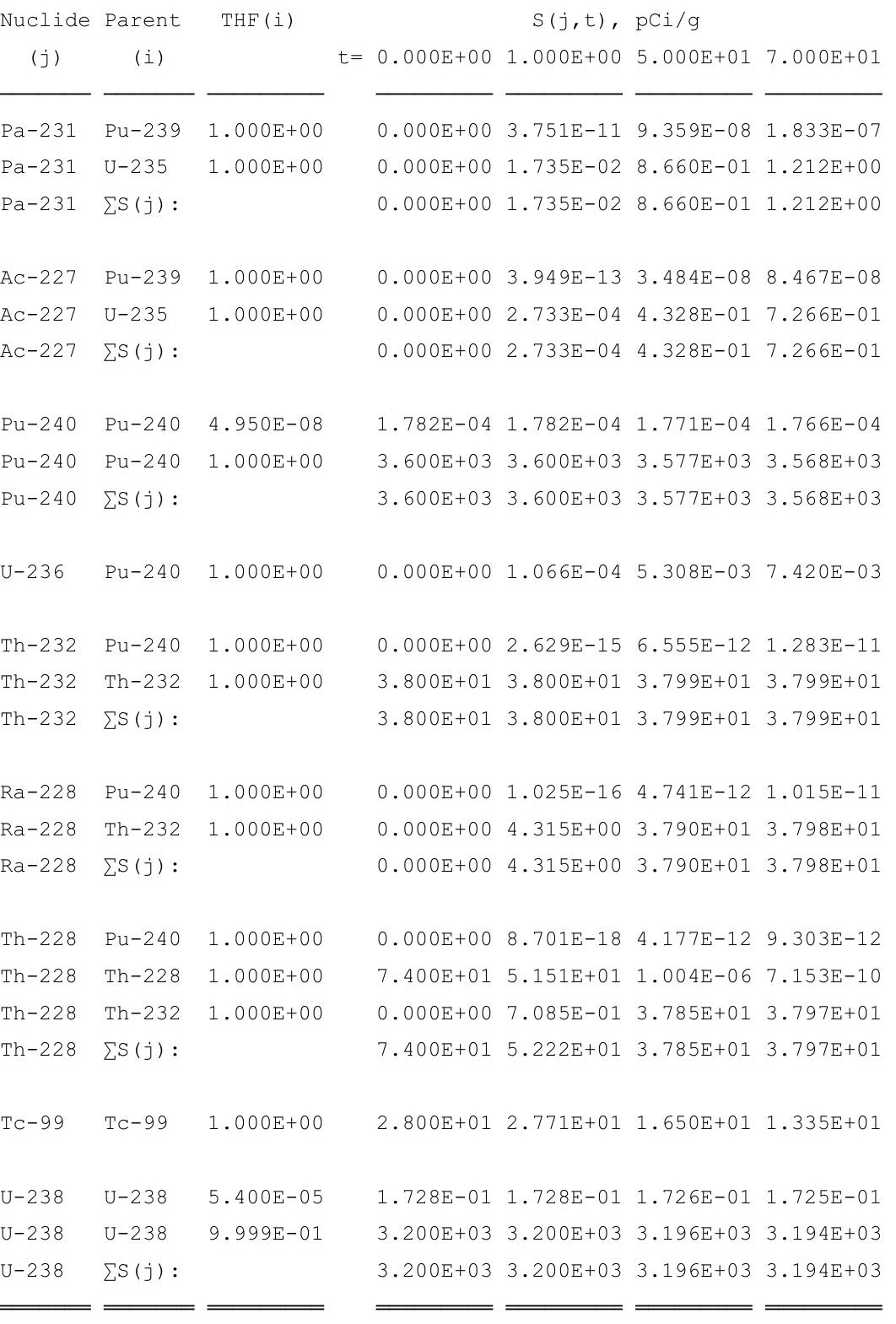

THF(i) is the thread fraction of the parent nuclide.

RESCALC.EXE execution time $=1.28$ seconds 


\section{Resident Farmer}

\section{The following summary report includes the single radionuclide soil guidelines based on a unit concentration for targeted radionuclides.}


THIS PAGE INTENTIONALLY LEFT BLANK 
RESRAD, Version $6.5 \quad T^{1 / 2}$ Limit $=180$ days

Summary : C746U Resident Farmer Deterministic Run

File : $\mathrm{x}: \backslash$ FINAL V2 $\backslash$ C746U RF DET-FINALV2.RAD

Table of Contents

Part I: Mixture Sums and Single Radionuclide Guidelines

Dose Conversion Factor (and Related) Parameter Summary ... 2

Site-Specific Parameter Summary $\ldots \ldots \ldots \ldots \ldots \ldots \ldots \ldots \ldots$

Summary of Pathway Selections $\ldots \ldots \ldots \ldots \ldots \ldots \ldots \ldots \ldots \ldots . \ldots \ldots$

Contaminated Zone and Total Dose Summary .............. 19

Total Dose Components

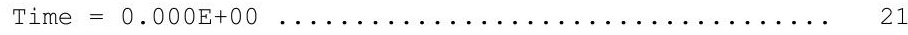

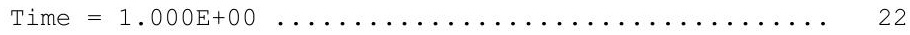

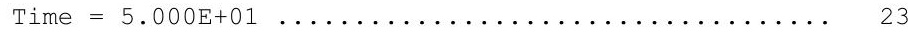

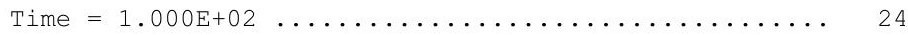

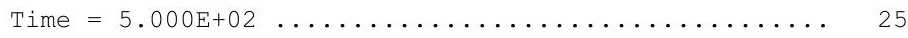

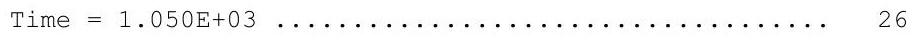

Dose/Source Ratios Summed Over All Pathways ........... 27

Single Radionuclide Soil Guidelines ............... 29

Dose Per Nuclide Summed Over All Pathways ............ 30

Soil Concentration Per Nuclide ................... 32 
RESRAD, Version $6.5 \quad \mathrm{~T}^{1 / 2}$ Limit $=180$ days

Summary : C746U Resident Farmer Deterministic Run

File : $\mathrm{X}: \backslash$ FINAL V2 $\backslash \mathrm{C746U}$ RF DET-FINALV2.RAD

Dose Conversion Factor (and Related) Parameter Summary Dose Library: ICRP 60 \& ICRP 72 (Adult)

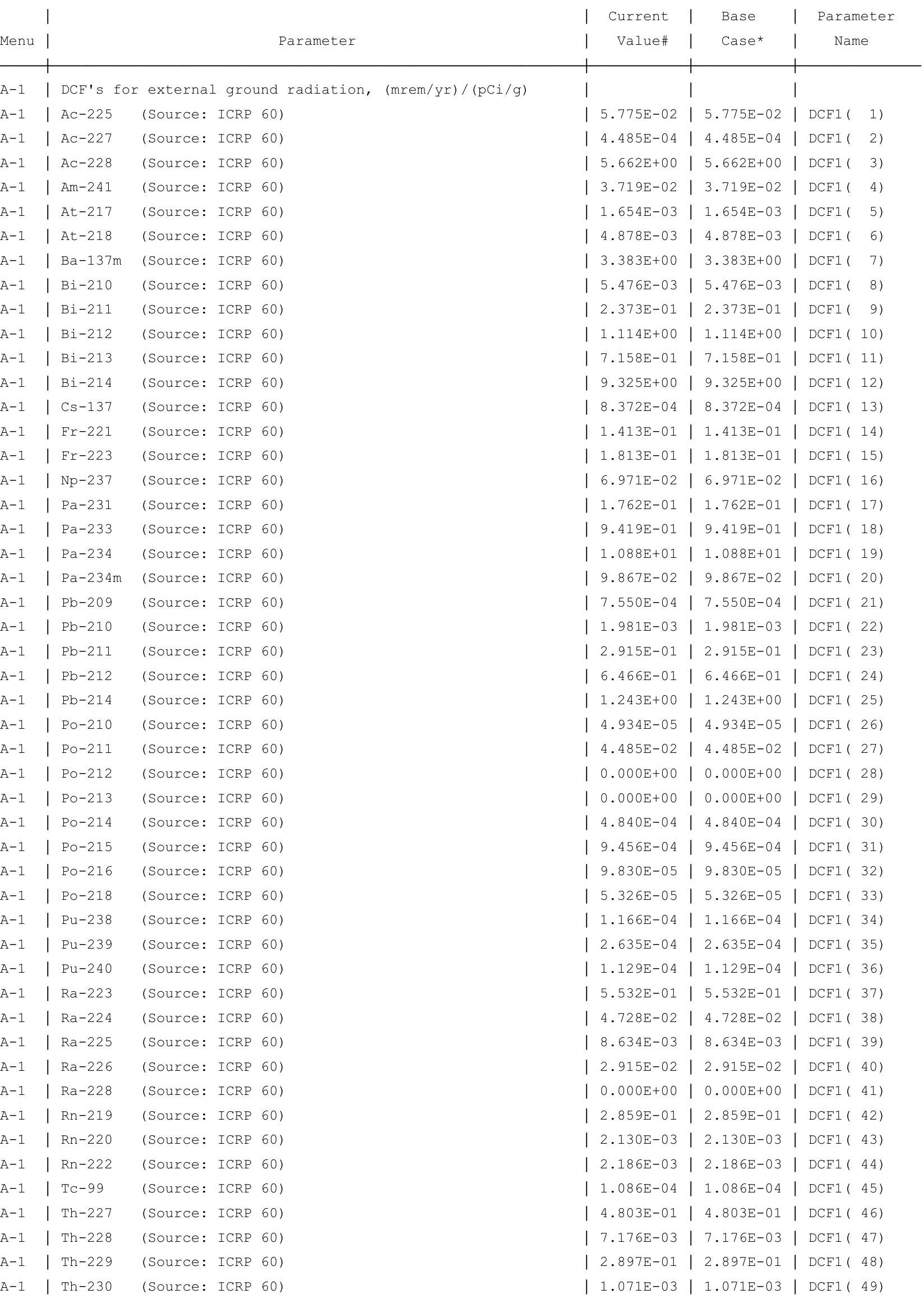


RESRAD, Version $6.5 \quad \mathrm{~T}^{1 / 2}$ Limit $=180$ days

Summary : C746U Resident Farmer Deterministic Run

File : $\mathrm{X}: \backslash$ FINAL V2 $\backslash$ C746U RF DET-FINALV2.RAD

Dose Conversion Factor (and Related) Parameter Summary (continued)

Dose Library: ICRP 60 \& ICRP 72 (Adult)

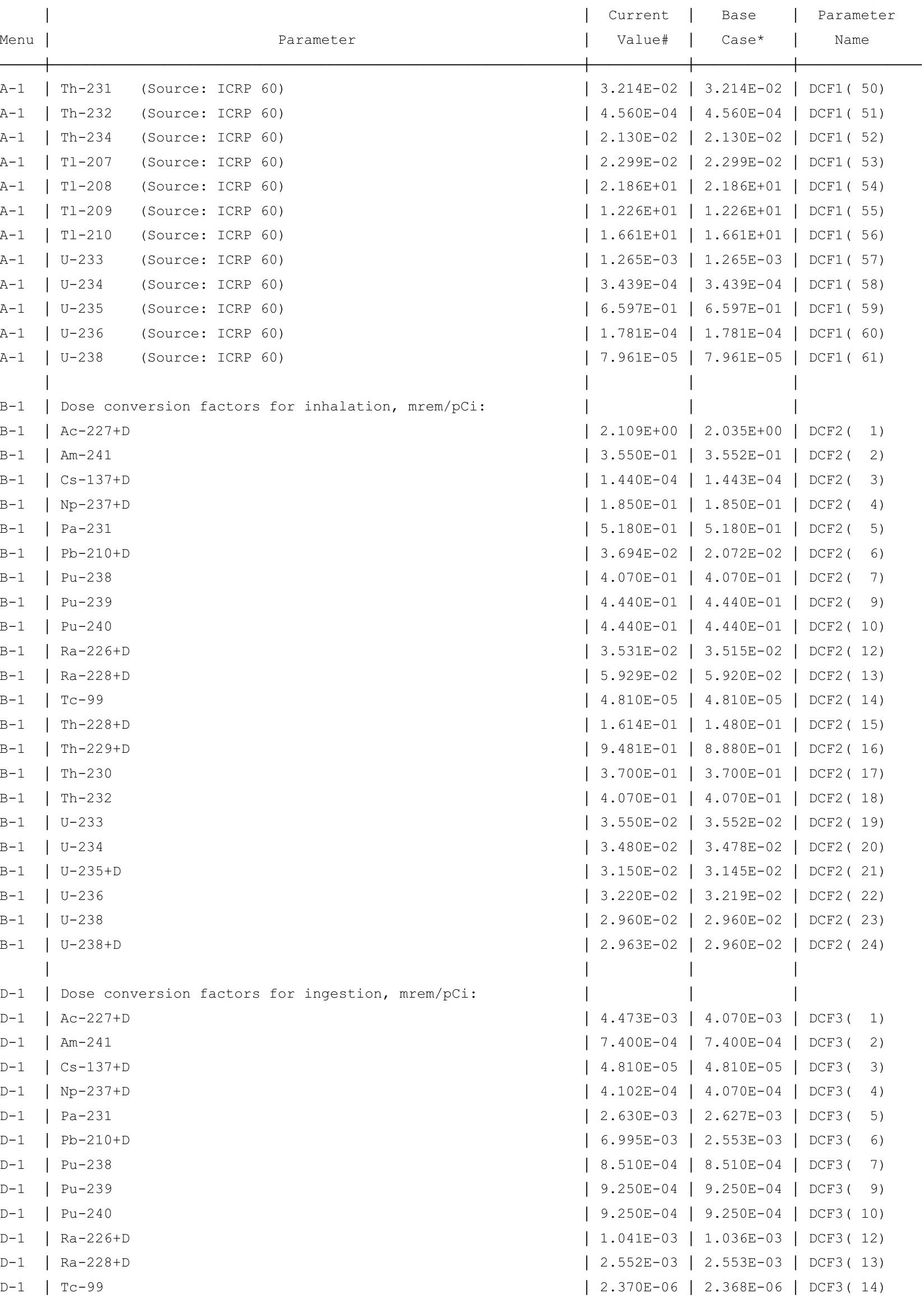


RESRAD, Version $6.5 \quad \mathrm{~T}^{1 / 2}$ Limit $=180$ days

Summary : C746U Resident Farmer Deterministic Run

File : $\mathrm{X}: \backslash$ FINAL V2 $\backslash \mathrm{C} 746 \mathrm{U}$ RF DET-FINALV2.RAD

Dose Conversion Factor (and Related) Parameter Summary (continued) Dose Library: ICRP 60 \& ICRP 72 (Adult)

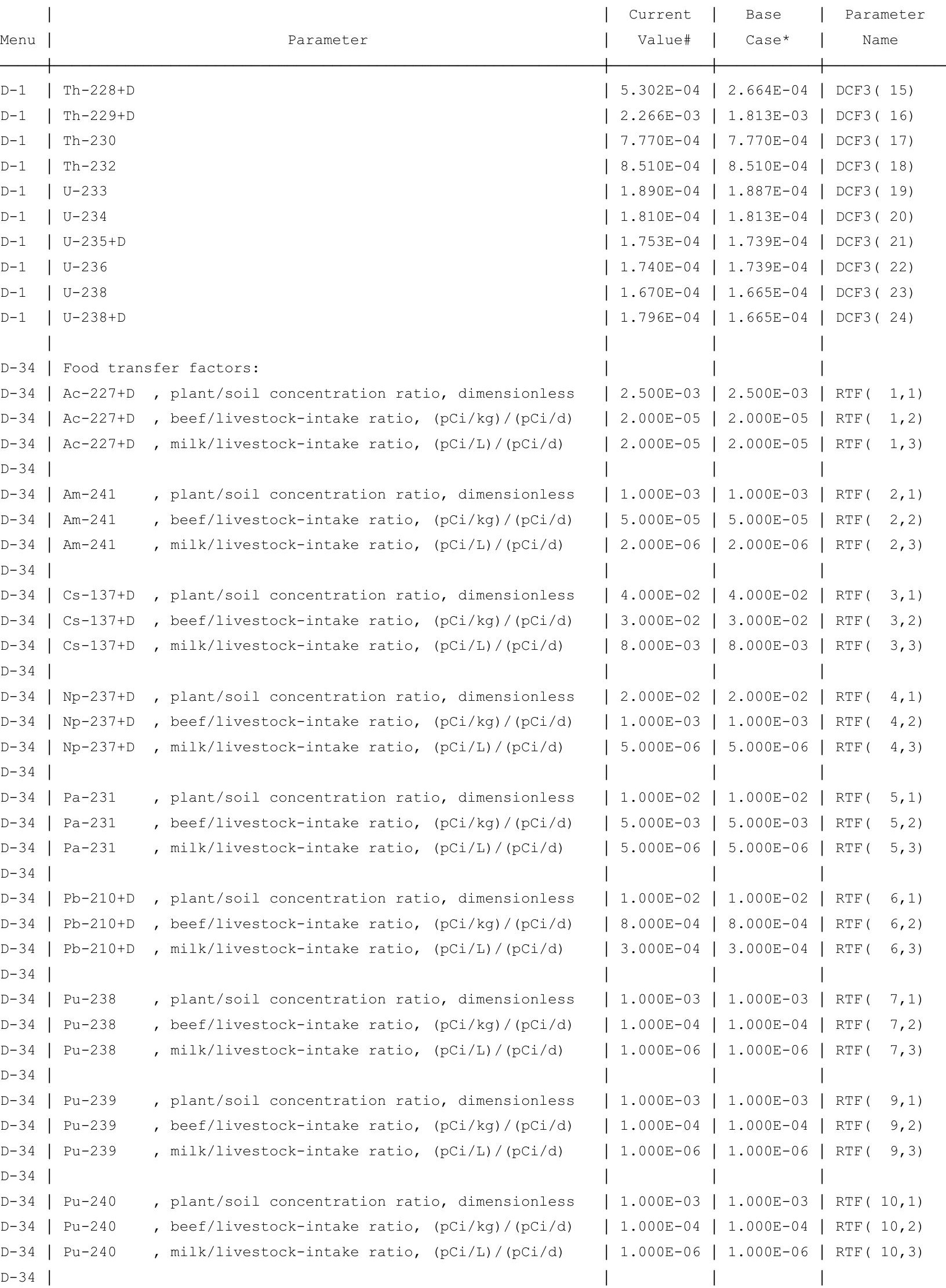


RESRAD, Version $6.5 \quad \mathrm{~T}^{1 / 2}$ Limit $=180$ days

Summary : C746U Resident Farmer Deterministic Run

File : $\mathrm{X}: \backslash$ FINAL V2 $\backslash \mathrm{C746U}$ RF DET-FINALV2.RAD

Dose Conversion Factor (and Related) Parameter Summary (continued) Dose Library: ICRP 60 \& ICRP 72 (Adult)

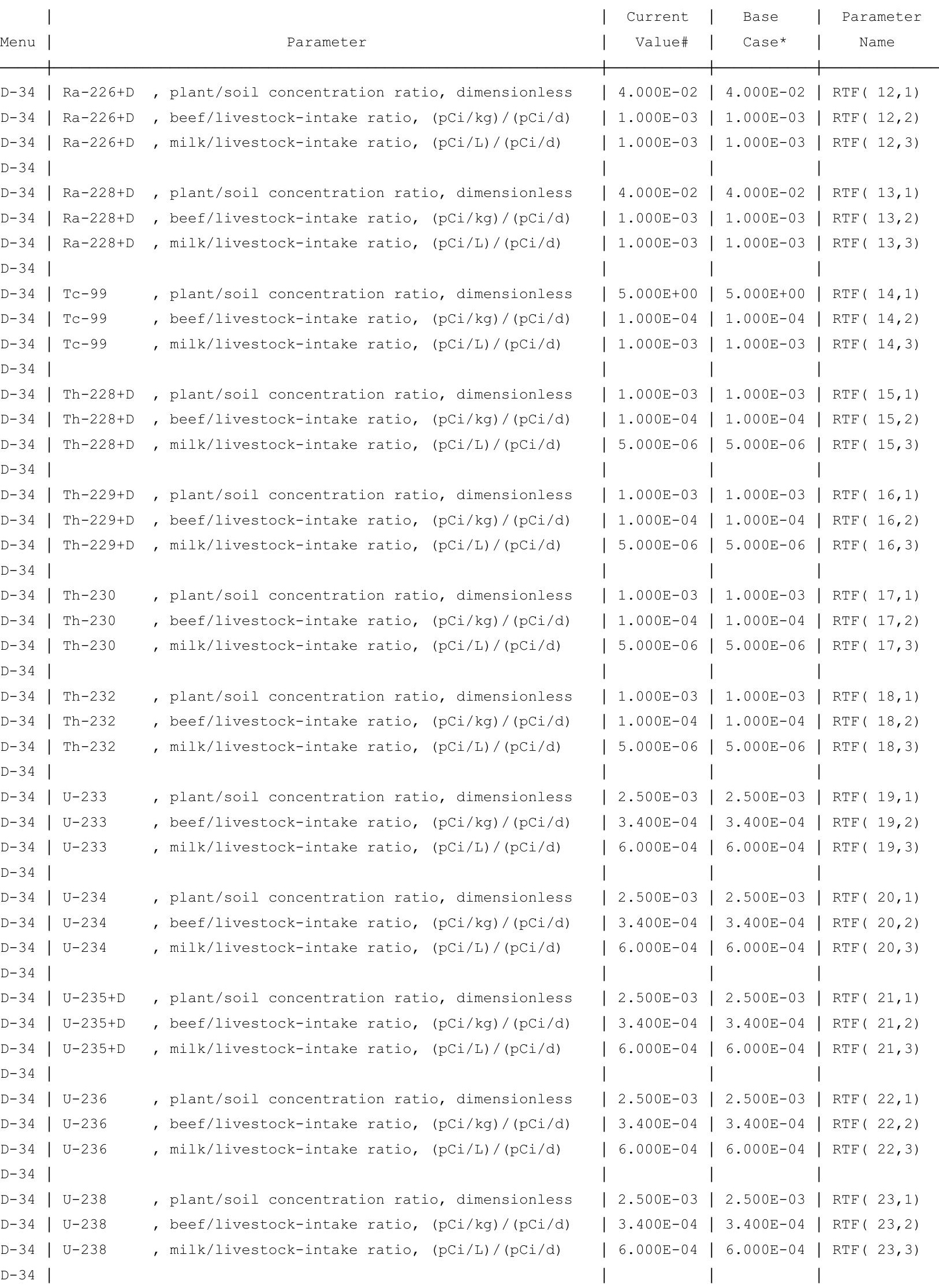


RESRAD, Version $6.5 \quad \mathrm{~T}^{1 / 2}$ Limit $=180$ days

Summary : C746U Resident Farmer Deterministic Run

File : $\mathrm{X}: \backslash$ FINAL V2 $\backslash \mathrm{C} 746 \mathrm{U}$ RF DET-FINALV2.RAD

Dose Conversion Factor (and Related) Parameter Summary (continued) Dose Library: ICRP 60 \& ICRP 72 (Adult)

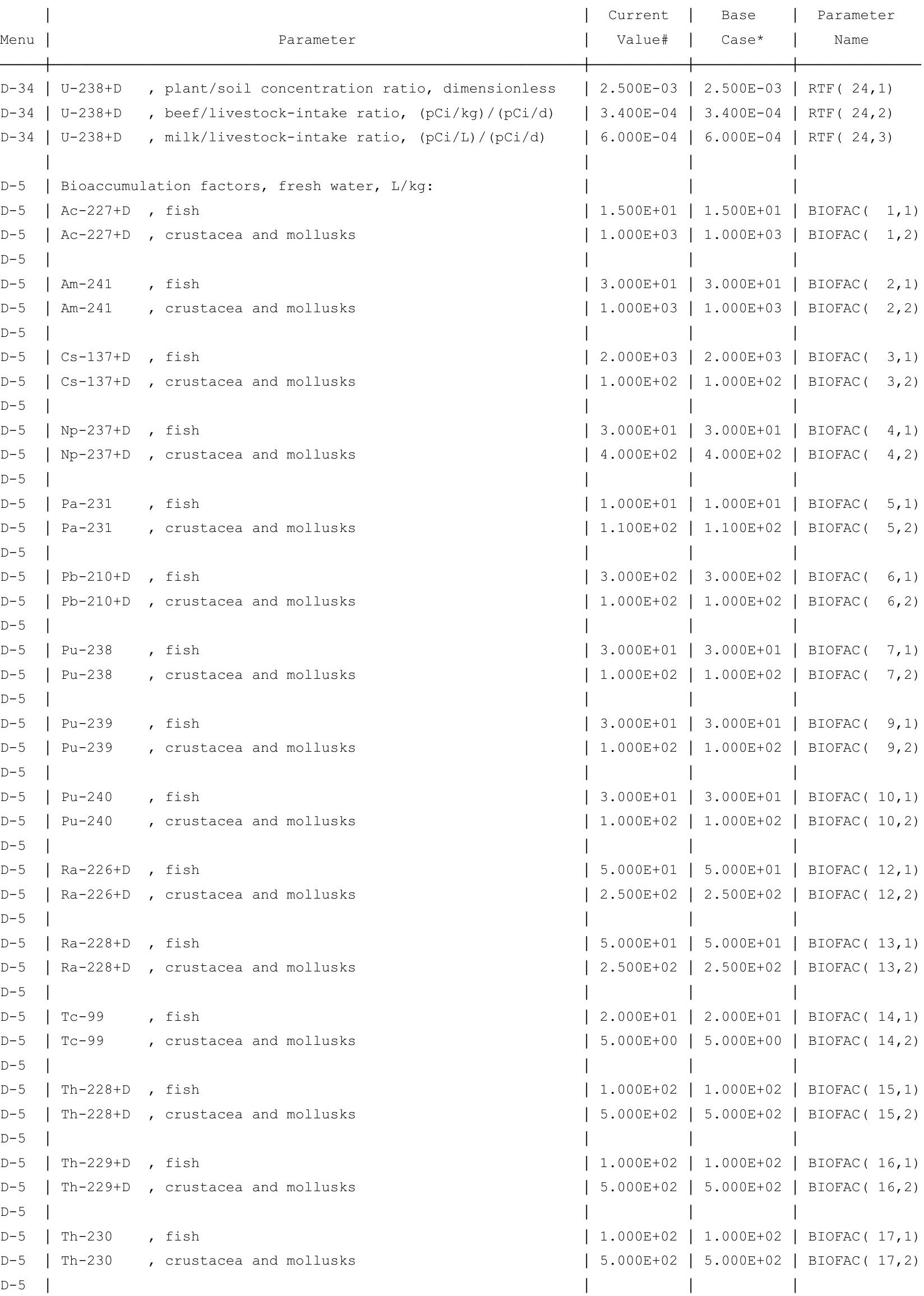


RESRAD, Version $6.5 \quad T^{1 / 2}$ Limit $=180$ days

Summary : C746U Resident Farmer Deterministic Run

File : $\mathrm{X}: \backslash$ FINAL V2 $\backslash$ C746U RF DET-FINALV2.RAD

Dose Conversion Factor (and Related) Parameter Summary (continued) Dose Library: ICRP 60 \& ICRP 72 (Adult)

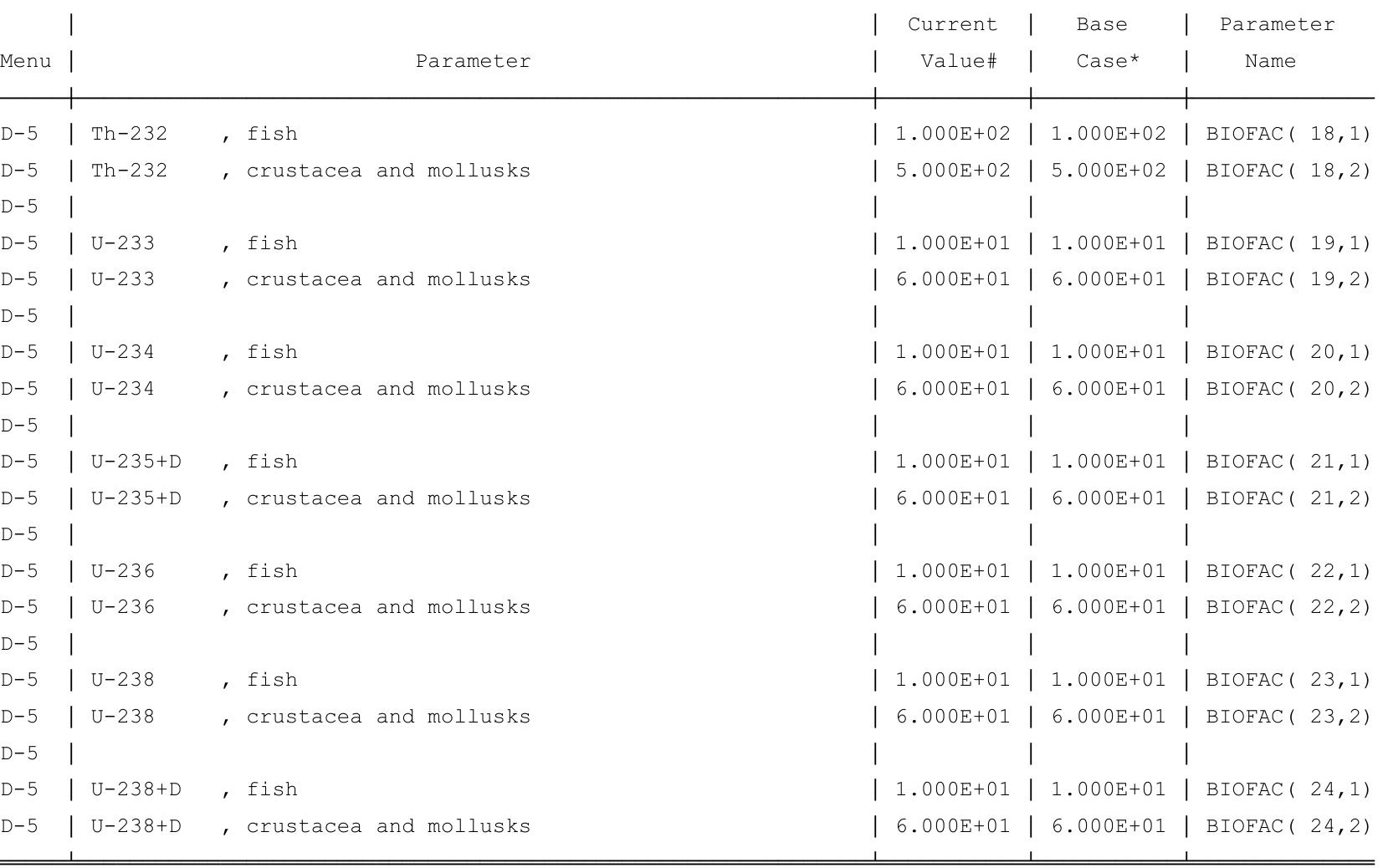

\#For DCFl(xxx) only, factors are for infinite depth \& area. See ETFG table in Ground Pathway of Detailed Report. *Base Case means Default.Lib w/o Associate Nuclide contributions. 
RESRAD, Version $6.5 \quad \mathrm{~T}^{1 / 2}$ Limit $=180$ days

Summary : C746U Resident Farmer Deterministic Run

File : $\mathrm{X}: \backslash$ FINAL V2 $\backslash \mathrm{C746U}$ RF DET-FINALV2.RAD

Site-Specific Parameter Summary

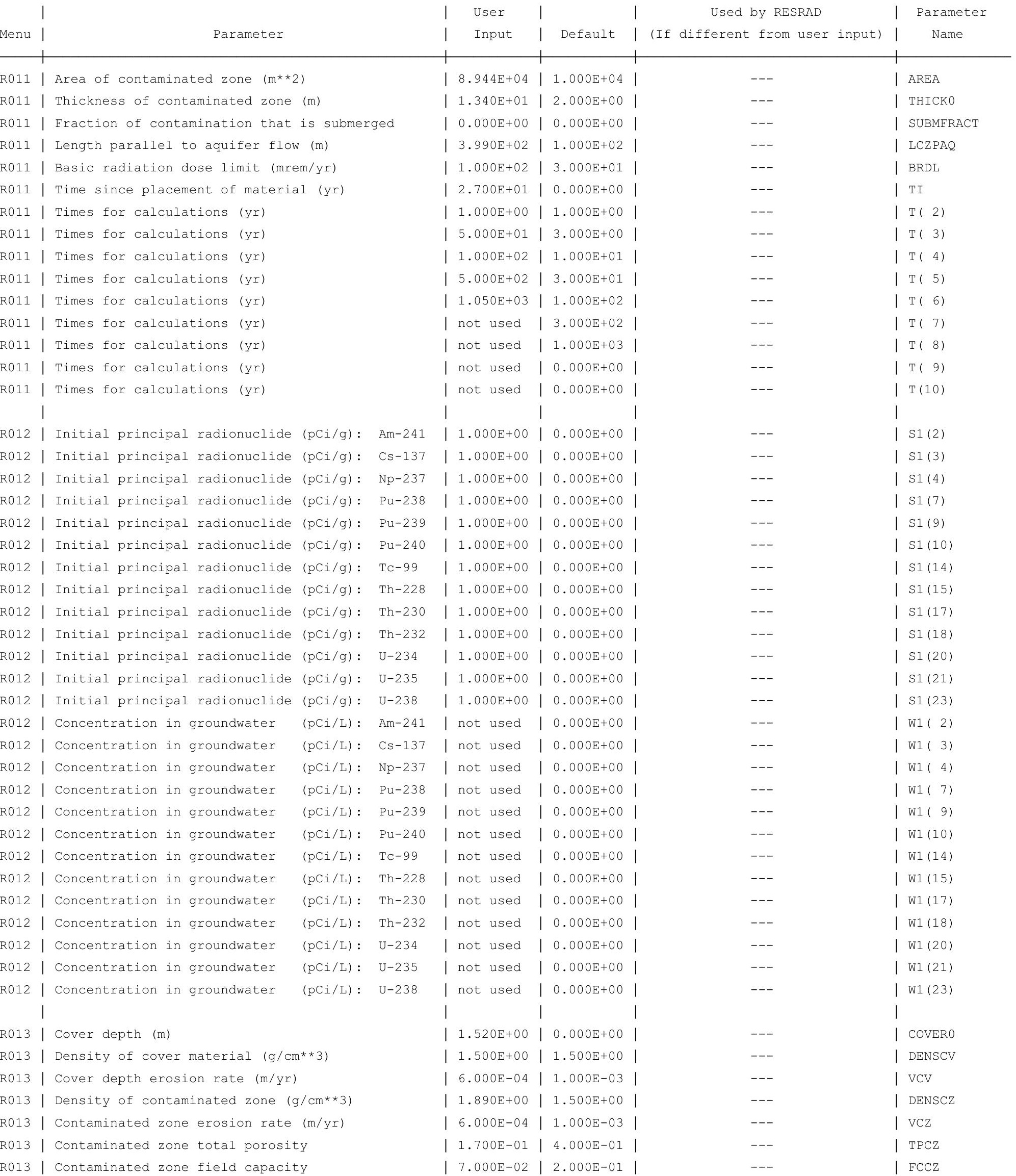


RESRAD, Version $6.5 \quad \mathrm{~T}^{1 / 2}$ Limit $=180$ days

Summary : C746U Resident Farmer Deterministic Run

File : $\mathrm{X}: \backslash \mathrm{FINAL}$ V2 $\backslash \mathrm{C746U}$ RF DET-FINALV2.RAD

Site-Specific Parameter Summary (continued)

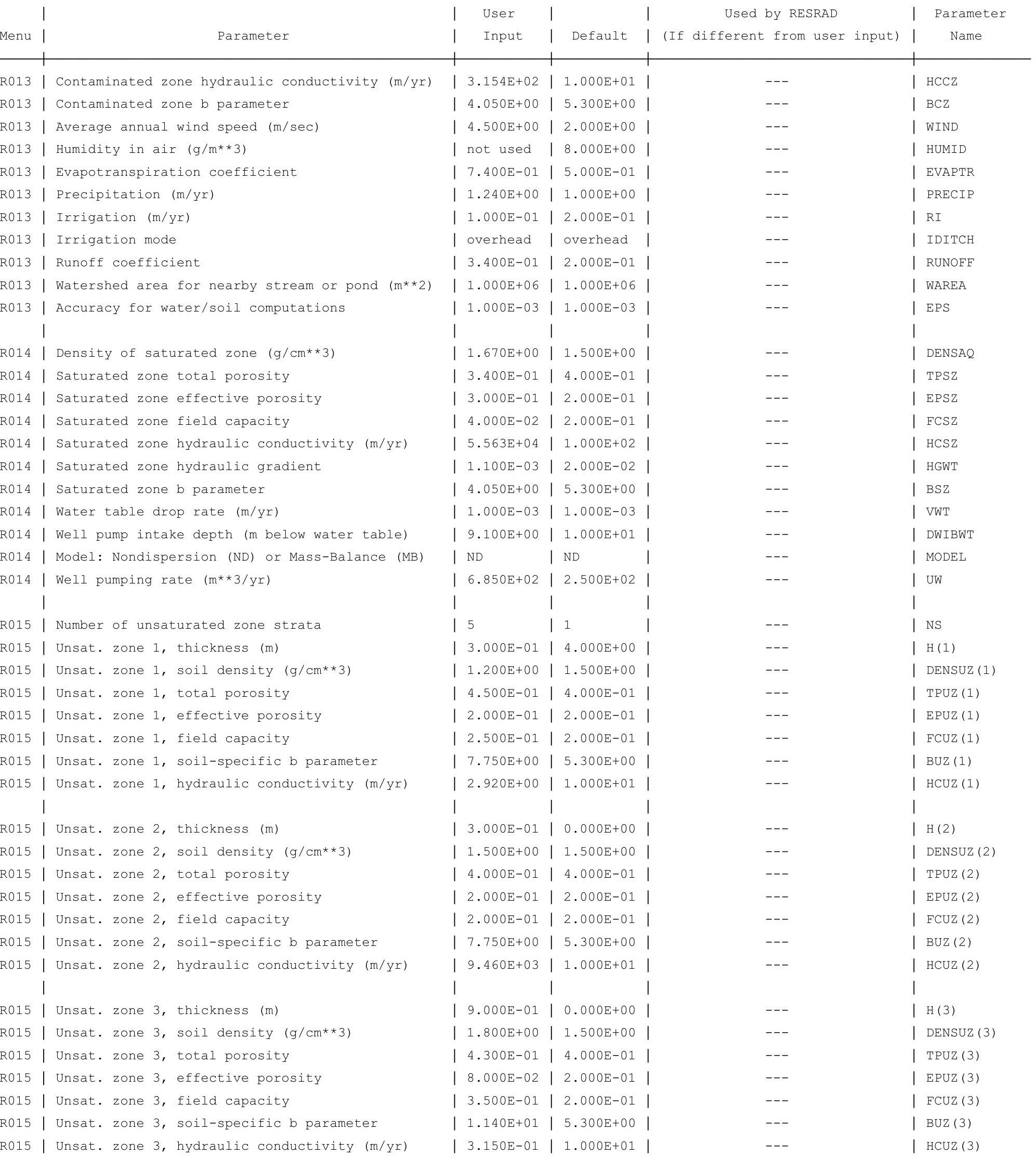


RESRAD, Version $6.5 \quad \mathrm{~T}^{1 / 2}$ Limit $=180$ days

Summary : C746U Resident Farmer Deterministic Run

File : $\mathrm{X}: \backslash \mathrm{FINAL}$ V2 $\backslash \mathrm{C} 746 \mathrm{U}$ RF DET-FINALV2.RAD

Site-Specific Parameter Summary (continued)

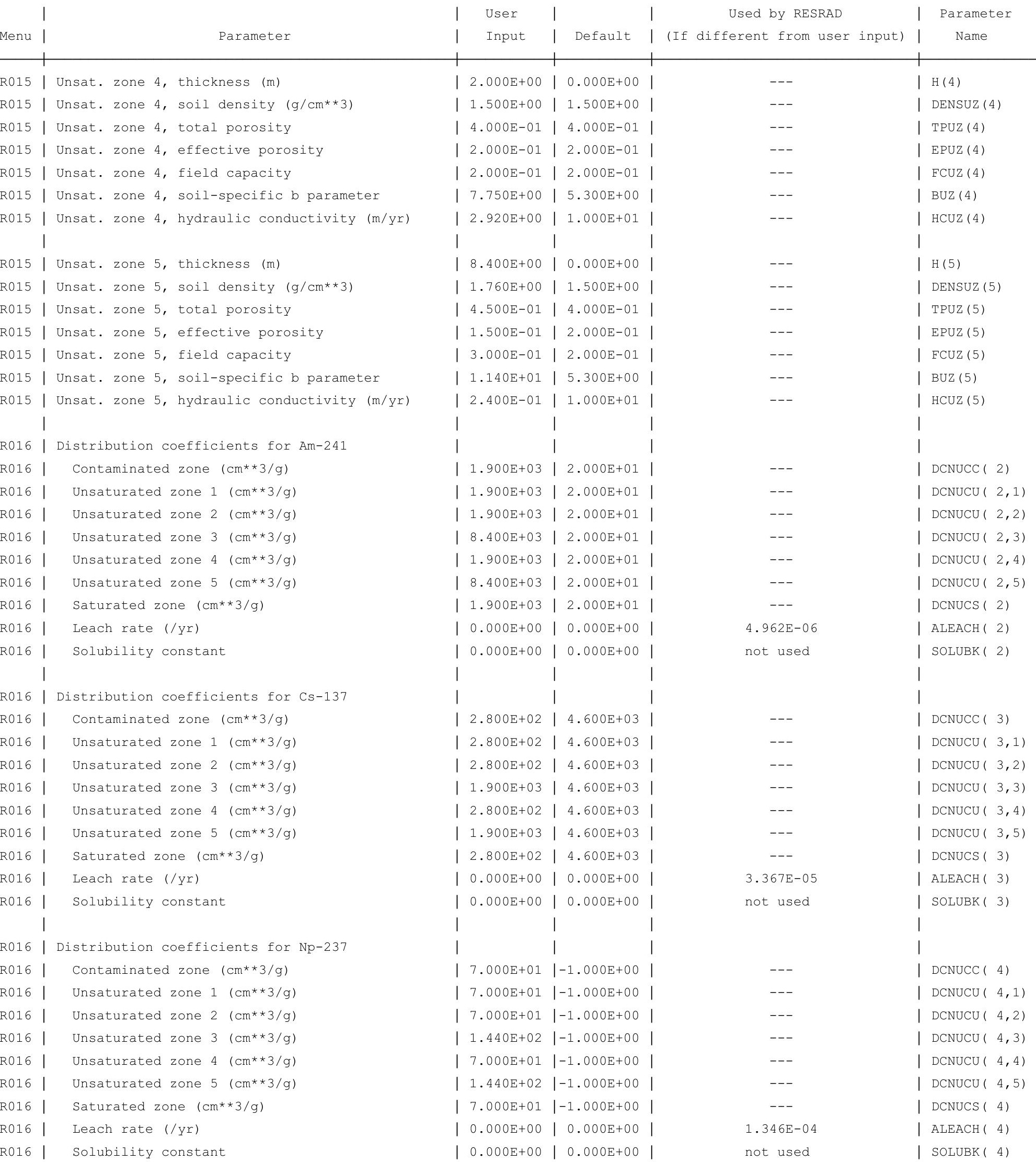


RESRAD, Version $6.5 \quad \mathrm{~T}^{1 / 2}$ Limit $=180$ days

Summary : C746U Resident Farmer Deterministic Run

File : $\mathrm{X}: \backslash \mathrm{FINAL}$ V2 $\backslash \mathrm{C746U}$ RF DET-FINALV2.RAD

Site-Specific Parameter Summary (continued)

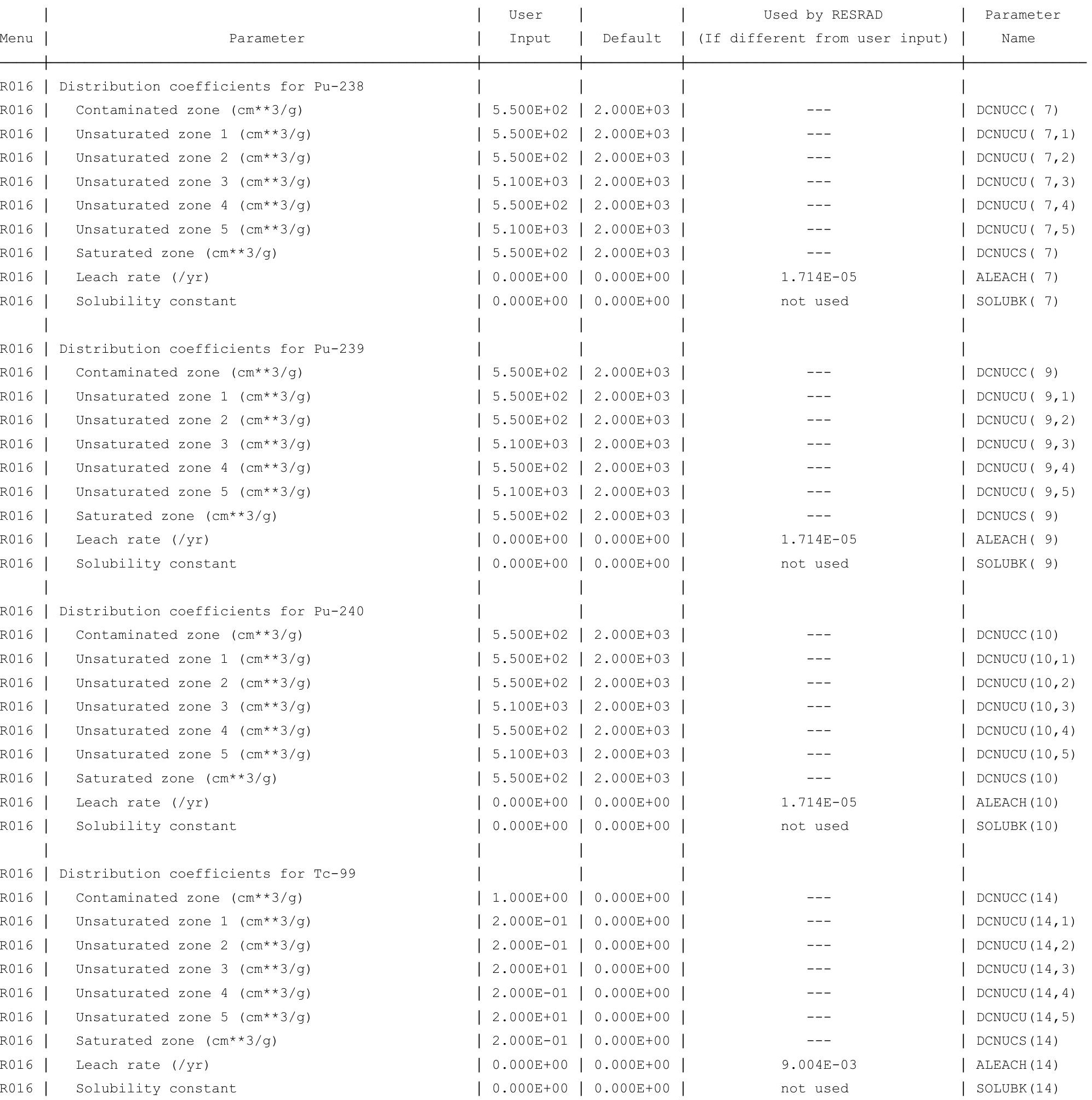


RESRAD, Version $6.5 \quad \mathrm{~T}^{1 / 2}$ Limit $=180$ days

Summary : C746U Resident Farmer Deterministic Run

File : $\mathrm{X}: \backslash \mathrm{FINAL}$ V2 $\backslash \mathrm{C} 746 \mathrm{U}$ RF DET-FINALV2.RAD

Site-Specific Parameter Summary (continued)

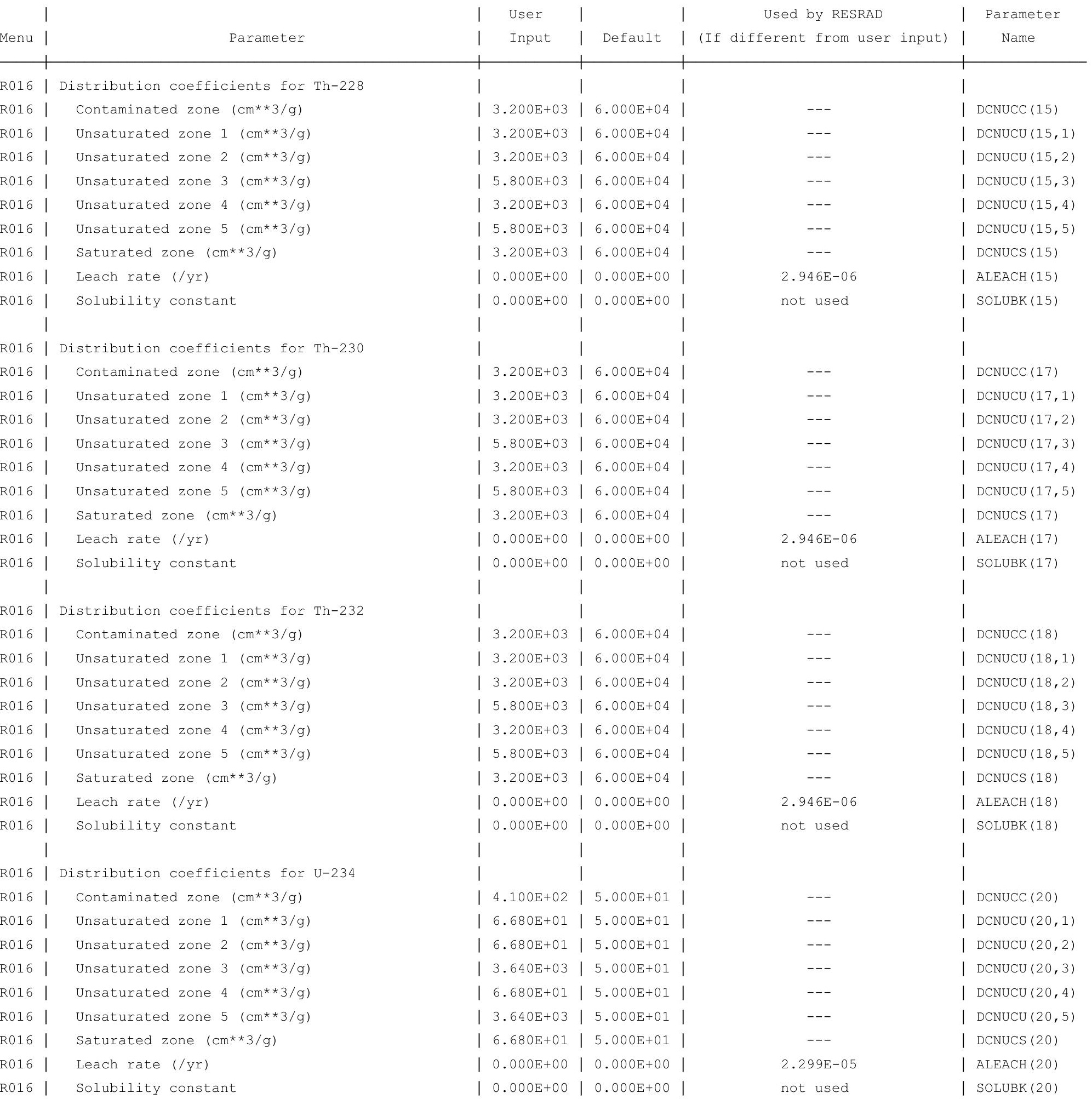


RESRAD, Version $6.5 \quad \mathrm{~T}^{1 / 2}$ Limit $=180$ days

Summary : C746U Resident Farmer Deterministic Run

File : $\mathrm{X}: \backslash \mathrm{FINAL}$ V2 $\backslash \mathrm{C} 746 \mathrm{U}$ RF DET-FINALV2.RAD

Site-Specific Parameter Summary (continued)

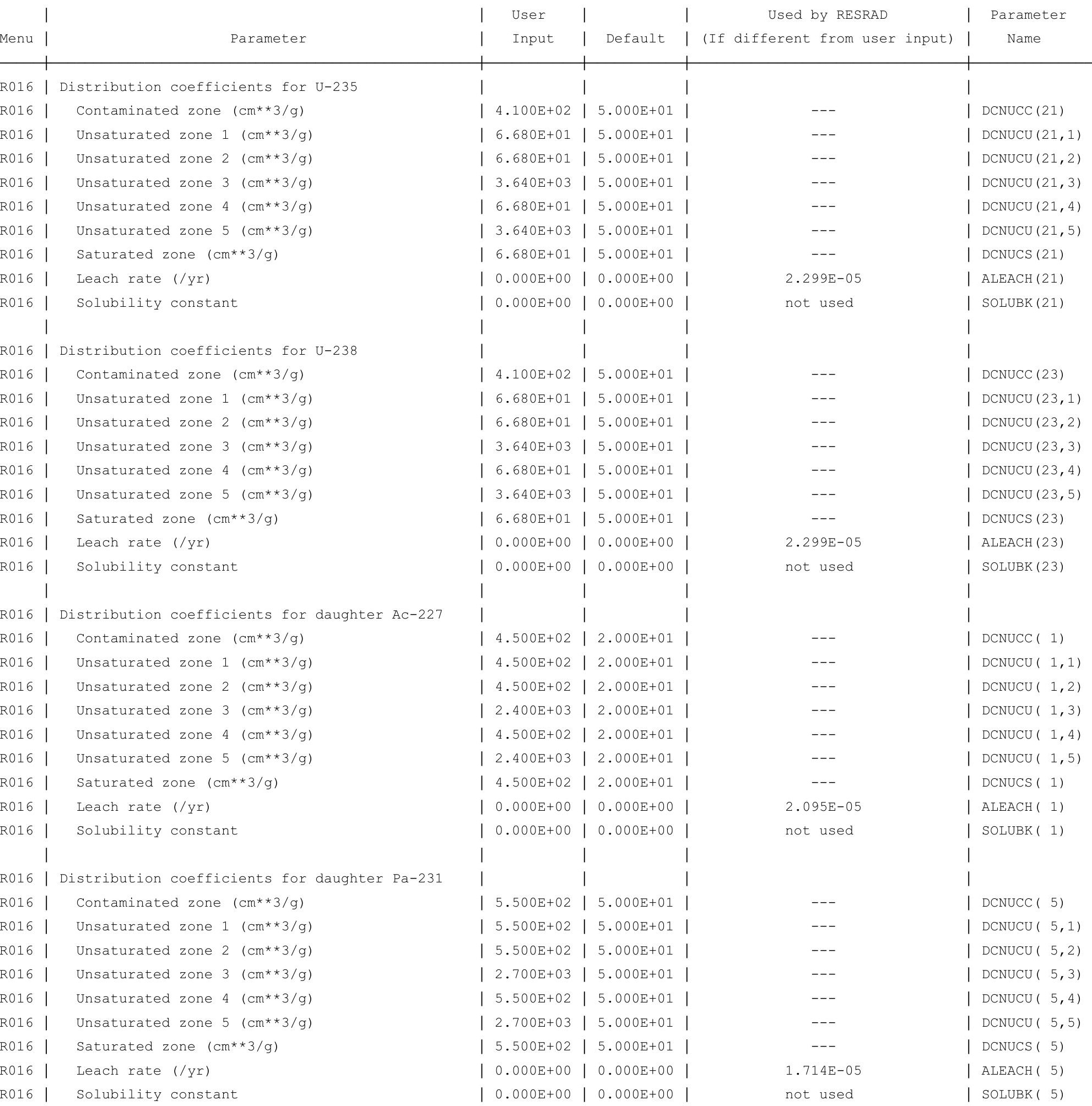


RESRAD, Version $6.5 \quad \mathrm{~T}^{1 / 2}$ Limit $=180$ days

Summary : C746U Resident Farmer Deterministic Run

File : $\mathrm{X}: \backslash \mathrm{FINAL}$ V2 $\backslash \mathrm{C} 746 \mathrm{U}$ RF DET-FINALV2.RAD

Site-Specific Parameter Summary (continued)

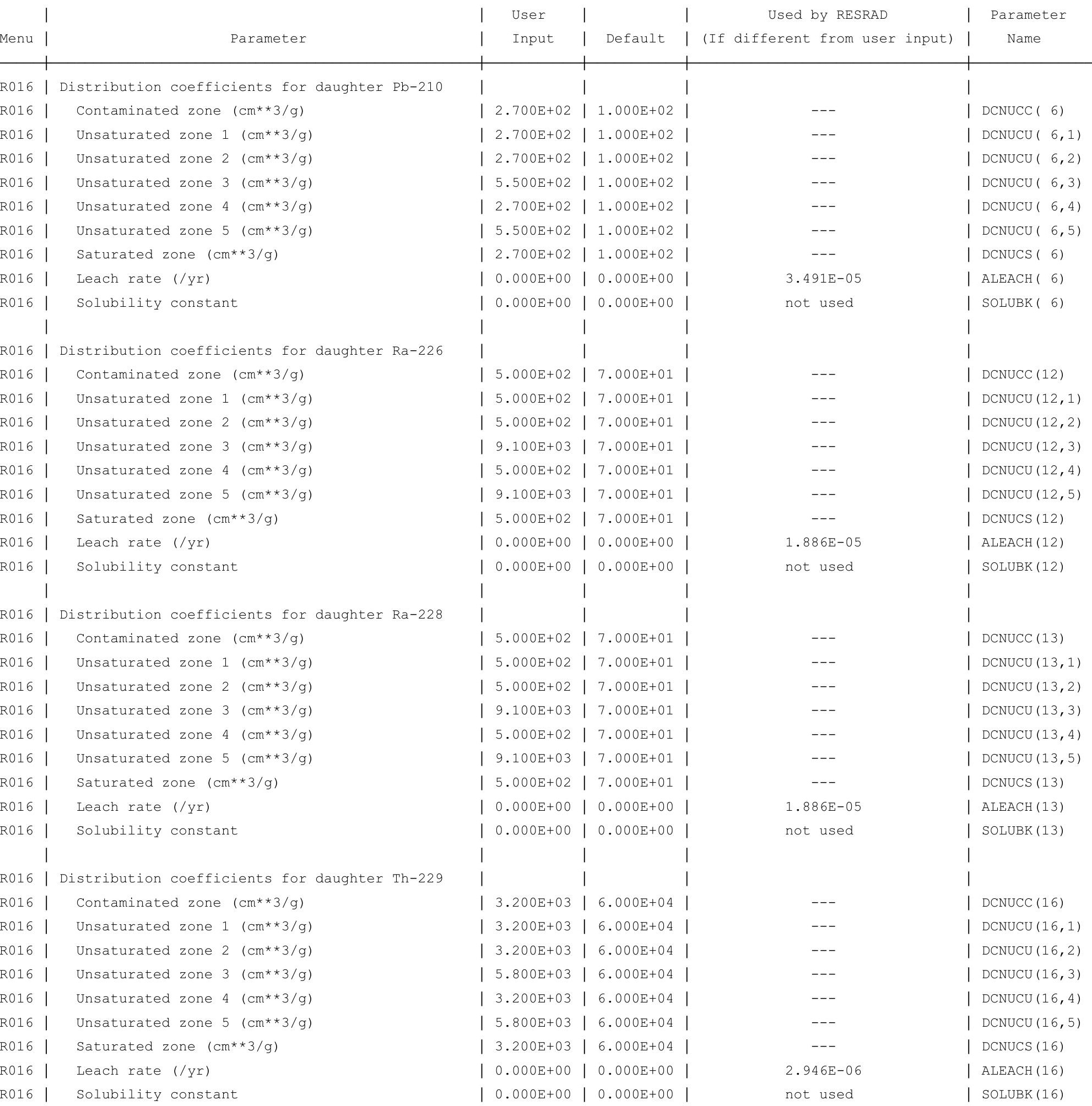


RESRAD, Version $6.5 \quad \mathrm{~T}^{1 / 2}$ Limit $=180$ days

Summary : C746U Resident Farmer Deterministic Run

File : $\mathrm{X}: \backslash \mathrm{FINAL}$ V2 $\backslash \mathrm{C} 746 \mathrm{U}$ RF DET-FINALV2.RAD

Site-Specific Parameter Summary (continued)

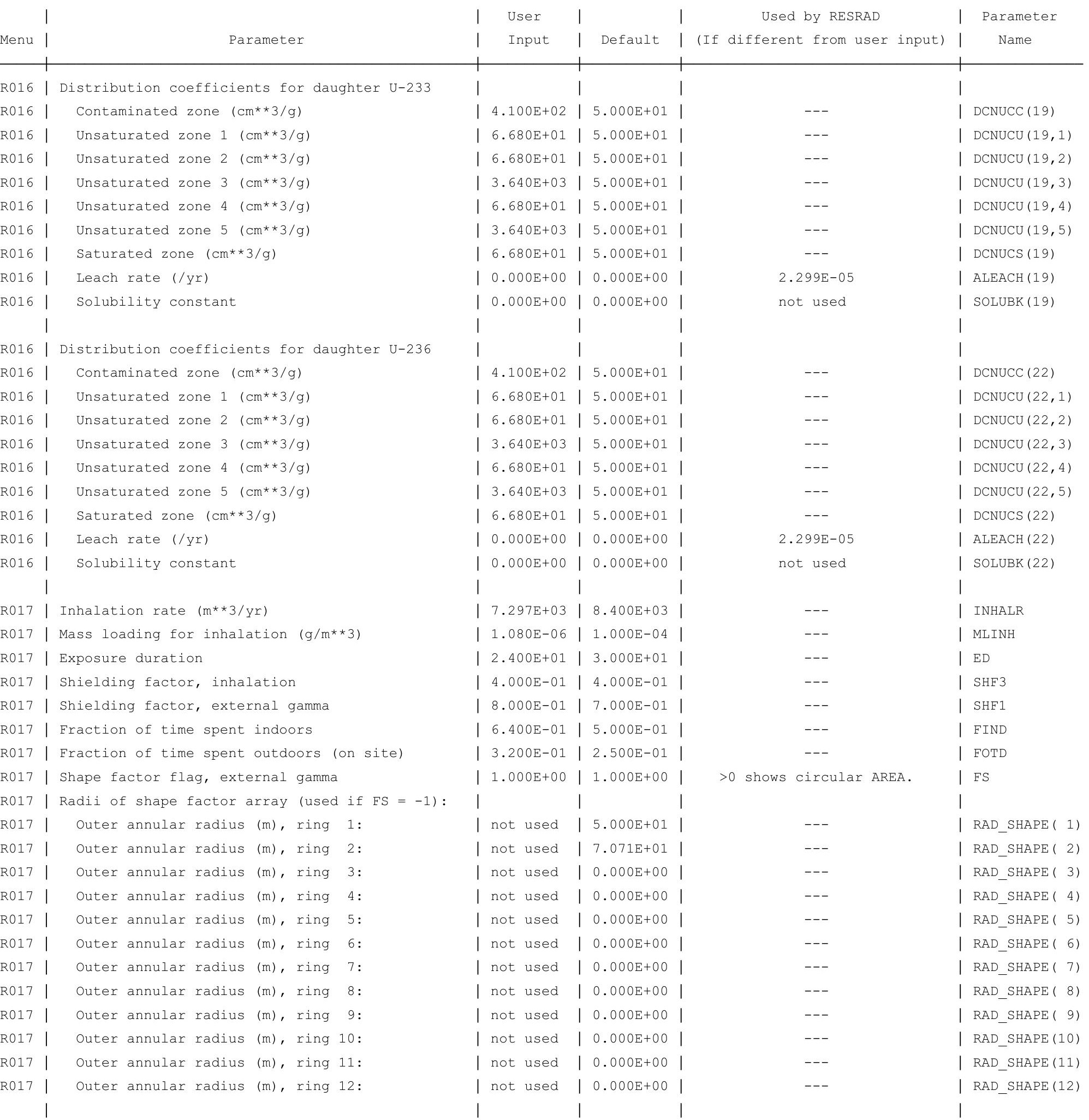


RESRAD, Version $6.5 \quad \mathrm{~T}^{1 / 2}$ Limit $=180$ days

Summary : C746U Resident Farmer Deterministic Run

File : $\mathrm{X}: \backslash$ FINAL V2 $\backslash \mathrm{C746U}$ RF DET-FINALV2.RAD

Contaminated Zone Dimensions

Area: 89436.00 square meters

Thickness:

Cover Depth:

\begin{abstract}
13.40 meters
1.52 meters
\end{abstract}

Initial Soil Concentrations, pCi/g

$\begin{array}{ll}\mathrm{Am}-241 & 1.000 \mathrm{E}+00 \\ \mathrm{Cs}-137 & 1.000 \mathrm{E}+00 \\ \mathrm{~Np}-237 & 1.000 \mathrm{E}+00 \\ \mathrm{Pu}-238 & 1.000 \mathrm{E}+00 \\ \mathrm{Pu}-239 & 1.000 \mathrm{E}+00 \\ \mathrm{Pu}-240 & 1.000 \mathrm{E}+00 \\ \mathrm{Tc}-99 & 1.000 \mathrm{E}+00 \\ \mathrm{Th}-228 & 1.000 \mathrm{E}+00 \\ \mathrm{Th}-230 & 1.000 \mathrm{E}+00 \\ \mathrm{Th}-232 & 1.000 \mathrm{E}+00 \\ \mathrm{U}-234 & 1.000 \mathrm{E}+00 \\ \mathrm{U}-235 & 1.000 \mathrm{E}+00 \\ \mathrm{U}-238 & 1.000 \mathrm{E}+00\end{array}$

Total Dose TDOSE(t), mrem/yr

Basic Radiation Dose Limit $=1.000 \mathrm{E}+02 \mathrm{mrem} / \mathrm{yr}$

Total Mixture Sum $M(t)$ = Fraction of Basic Dose Limit Received at Time (t)

$\begin{array}{rllllll}t \text { (years): } & 0.000 \mathrm{E}+00 & 1.000 \mathrm{E}+00 & 5.000 \mathrm{E}+01 & 1.000 \mathrm{E}+02 & 5.000 \mathrm{E}+02 & 1.050 \mathrm{E}+03 \\ \mathrm{TDOSE}(\mathrm{t}): & 1.645 \mathrm{E}-06 & 1.185 \mathrm{E}-06 & 2.240 \mathrm{E}-06 & 3.039 \mathrm{E}-06 & 2.080 \mathrm{E}-01 & 2.391 \mathrm{E}-01 \\ \mathrm{M}(\mathrm{t}): & 1.645 \mathrm{E}-08 & 1.185 \mathrm{E}-08 & 2.240 \mathrm{E}-08 & 3.039 \mathrm{E}-08 & 2.080 \mathrm{E}-03 & 2.391 \mathrm{E}-03\end{array}$

Maximum TDOSE $(t): 4.076 \mathrm{E}-01 \mathrm{mrem} / \mathrm{yr}$ at $t=425.2 \pm 0.9$ years

Total Dose Contributions TDOSE(i,p,t) for Individual Radionuclides (i) and Pathways (p)

As mrem/yr and Fraction of Total Dose At $t=4.252 \mathrm{E}+02$ years

Water Independent Pathways (Inhalation excludes radon)

\begin{tabular}{|c|c|c|c|c|c|c|c|c|c|c|c|c|c|c|}
\hline & \multicolumn{2}{|c|}{ Ground } & \multicolumn{2}{|c|}{ Inhalation } & \multicolumn{2}{|c|}{ Radon } & \multicolumn{2}{|c|}{ Plant } & \multicolumn{2}{|c|}{ Meat } & \multicolumn{2}{|c|}{ Milk } & \multicolumn{2}{|c|}{ Soil } \\
\hline clide & mrem/yr & fract. & mrem/yr & fract. & mrem/yr & fract. & mrem/yr & fract. & mrem/yr & fract. & mrem/yr & fract. & mrem/yr & fract. \\
\hline 241 & $9.162 \mathrm{E}-15$ & 0.0000 & $0.000 \mathrm{E}+00$ & 0.0000 & $0.000 \mathrm{E}+00$ & 0.0000 & $0.000 \mathrm{E}+00$ & 0.0000 & $0.000 \mathrm{E}+00$ & 0.0000 & $0.000 \mathrm{E}+00$ & 0.0000 & $0.000 \mathrm{E}+00$ & 0.0000 \\
\hline-137 & $2.453 \mathrm{E}-12$ & 0.0000 & $0.000 \mathrm{E}+00$ & 0.0000 & $0.000 \mathrm{E}+00$ & 0.0000 & $0.000 \mathrm{E}+00$ & 0.0000 & $0.000 \mathrm{E}+00$ & 0.0000 & $0.000 \mathrm{E}+00$ & 0.0000 & $0.000 \mathrm{E}+00$ & 0.0000 \\
\hline-237 & $9.140 \mathrm{E}-11$ & 0.0000 & $0.000 \mathrm{E}+00$ & 0.0000 & $0.000 \mathrm{E}+00$ & 0.0000 & $0.000 \mathrm{E}+00$ & 0.0000 & $0.000 \mathrm{E}+00$ & 0.0000 & $0.000 \mathrm{E}+00$ & 0.0000 & $0.000 \mathrm{E}+00$ & 0.0000 \\
\hline-238 & $2.257 \mathrm{E}-13$ & 0.0000 & $0.000 \mathrm{E}+00$ & 0.0000 & $0.000 \mathrm{E}+00$ & 0.0000 & $0.000 \mathrm{E}+00$ & 0.0000 & $0.000 \mathrm{E}+00$ & 0.0000 & $0.000 \mathrm{E}+00$ & 0.0000 & $0.000 \mathrm{E}+00$ & 0.0000 \\
\hline-239 & 1. $915 \mathrm{E}-15$ & 0.0000 & $0.000 \mathrm{E}+00$ & 0.0000 & $0.000 \mathrm{E}+00$ & 0.0000 & $0.000 \mathrm{E}+00$ & 0.0000 & $0.000 \mathrm{E}+00$ & 0.0000 & $0.000 \mathrm{E}+00$ & 0.0000 & $0.000 \mathrm{E}+00$ & 0.0000 \\
\hline-240 & $2.612 \mathrm{E}-18$ & 0.0000 & $0.000 \mathrm{E}+00$ & 0.0000 & $0.000 \mathrm{E}+00$ & 0.0000 & $0.000 \mathrm{E}+00$ & 0.0000 & $0.000 \mathrm{E}+00$ & 0.0000 & $0.000 \mathrm{E}+00$ & 0.0000 & $0.000 \mathrm{E}+00$ & 0.0000 \\
\hline 99 & $4.327 E-24$ & 0.0000 & $0.000 \mathrm{E}+00$ & 0.0000 & $0.000 \mathrm{E}+00$ & 0.0000 & $0.000 \mathrm{E}+00$ & 0.0000 & $0.000 \mathrm{E}+00$ & 0.0000 & $0.000 \mathrm{E}+00$ & 0.0000 & $0.000 \mathrm{E}+00$ & 0.0000 \\
\hline-228 & $0.000 \mathrm{E}+00$ & 0.0000 & $0.000 \mathrm{E}+00$ & 0.0000 & $0.000 \mathrm{E}+00$ & 0.0000 & $0.000 \mathrm{E}+00$ & 0.0000 & $0.000 \mathrm{E}+00$ & 0.0000 & $0.000 \mathrm{E}+00$ & 0.0000 & $0.000 \mathrm{E}+00$ & 0.0000 \\
\hline-230 & $5.495 \mathrm{E}-07$ & 0.0000 & $0.000 \mathrm{E}+00$ & 0.0000 & $0.000 \mathrm{E}+00$ & 0.0000 & $0.000 \mathrm{E}+00$ & 0.0000 & $0.000 \mathrm{E}+00$ & 0.0000 & $0.000 \mathrm{E}+00$ & 0.0000 & $0.000 \mathrm{E}+00$ & 0.0000 \\
\hline-232 & $2.123 E-05$ & 0.0001 & $0.000 \mathrm{E}+00$ & 0.0000 & $0.000 \mathrm{E}+00$ & 0.0000 & $0.000 \mathrm{E}+00$ & 0.0000 & $0.000 \mathrm{E}+00$ & 0.0000 & $0.000 \mathrm{E}+00$ & 0.0000 & $0.000 \mathrm{E}+00$ & 0.0000 \\
\hline 34 & $1.082 \mathrm{E}-09$ & 0.0000 & $0.000 \mathrm{E}+00$ & 0.0000 & $0.000 \mathrm{E}+00$ & 0.0000 & $0.000 \mathrm{E}+00$ & 0.0000 & $0.000 \mathrm{E}+00$ & 0.0000 & $0.000 \mathrm{E}+00$ & 0.0000 & $0.000 \mathrm{E}+00$ & 0.0000 \\
\hline 35 & $3.031 \mathrm{E}-11$ & 0.0000 & $0.000 \mathrm{E}+00$ & 0.0000 & $0.000 \mathrm{E}+00$ & 0.0000 & $0.000 \mathrm{E}+00$ & 0.0000 & $0.000 \mathrm{E}+00$ & 0.0000 & $0.000 \mathrm{E}+00$ & 0.0000 & $0.000 \mathrm{E}+00$ & 0.0000 \\
\hline 38 & $4.209 E-09$ & 0.0000 & $0.000 \mathrm{E}+00$ & 0.0000 & $0.000 \mathrm{E}+00$ & 0.0000 & $0.000 \mathrm{E}+00$ & 0.0000 & $0.000 \mathrm{E}+00$ & 0.0000 & $0.000 \mathrm{E}+00$ & 0.0000 & $0.000 \mathrm{E}+00$ & 0.0000 \\
\hline & $2.179 \mathrm{E}-05$ & 0. & $0.000 \mathrm{E}+00$ & 0.0000 & $0.000 \mathrm{E}+00$ & 0.0000 & $0.000 \mathrm{E}+00$ & 0.0000 & $0.000 \mathrm{E}+00$ & 0.0000 & $0.000 \mathrm{E}+00$ & 0.0000 & $0.000 \mathrm{E}+00$ & 0.0000 \\
\hline
\end{tabular}


RESRAD, Version $6.5 \quad \mathrm{~T}^{1 / 2}$ Limit $=180$ days

ummary : C746U Resident Farmer Deterministic Run

File : $\mathrm{X}: \backslash$ FINAL V2 $\backslash \mathrm{C} 746 \mathrm{U}$ RF DET-FINALV2.RAD

Total Dose Contributions TDOSE(i,p,t) for Individual Radionuclides (i) and Pathways (p) As mrem/yr and Fraction of Total Dose At $t=4.252 \mathrm{E}+02$ years

Water Dependent Pathways

\begin{tabular}{|c|c|c|c|c|c|c|c|c|c|c|c|c|c|c|}
\hline & \multicolumn{2}{|c|}{ Water } & \multicolumn{2}{|c|}{ Fish } & \multicolumn{2}{|c|}{ Radon } & \multicolumn{2}{|c|}{ Plant } & \multicolumn{2}{|c|}{ Meat } & \multicolumn{2}{|c|}{ Milk } & \multicolumn{2}{|c|}{ All Pathways* } \\
\hline clide & mrem/yr & fract. & mrem/yr & fract. & mrem/yr & fract. & mrem/yr & fract. & mrem/yr & fract. & mrem/yr & fract. & mrem/yr & fract. \\
\hline-241 & $0.000 \mathrm{E}+00$ & 0.0000 & $0.000 \mathrm{E}+00$ & 0.0000 & $0.000 \mathrm{E}+00$ & 0.0000 & $0.000 \mathrm{E}+00$ & 0.0000 & $0.000 \mathrm{E}+00$ & 0.0000 & $0.000 \mathrm{E}+00$ & 0.0000 & $9.162 \mathrm{E}-15$ & 0.0000 \\
\hline-137 & $0.000 \mathrm{E}+00$ & 0.0000 & $0.000 \mathrm{E}+00$ & 0.0000 & $0.000 \mathrm{E}+00$ & 0.0000 & $0.000 \mathrm{E}+00$ & 0.0000 & $0.000 \mathrm{E}+00$ & 0.0000 & $0.000 \mathrm{E}+00$ & 0.0000 & $2.453 \mathrm{E}-12$ & 0.0000 \\
\hline-237 & $0.000 \mathrm{E}+00$ & 0.0000 & $0.000 \mathrm{E}+00$ & 0.0000 & $0.000 \mathrm{E}+00$ & 0.0000 & $0.000 \mathrm{E}+00$ & 0.0000 & $0.000 \mathrm{E}+00$ & 0.0000 & $0.000 \mathrm{E}+00$ & 0.0000 & $9.140 \mathrm{E}-11$ & 0.0000 \\
\hline-238 & $0.000 \mathrm{E}+00$ & 0.0000 & $0.000 \mathrm{E}+00$ & 0.0000 & $0.000 \mathrm{E}+00$ & 0.0000 & $0.000 \mathrm{E}+00$ & 0.0000 & $0.000 \mathrm{E}+00$ & 0.0000 & $0.000 \mathrm{E}+00$ & 0.0000 & $2.257 \mathrm{E}-13$ & 0.0000 \\
\hline-239 & $0.000 \mathrm{E}+00$ & 0.0000 & $0.000 \mathrm{E}+00$ & 0.0000 & $0.000 \mathrm{E}+00$ & 0.0000 & $0.000 \mathrm{E}+00$ & 0.0000 & $0.000 \mathrm{E}+00$ & 0.0000 & $0.000 \mathrm{E}+00$ & 0.0000 & 1. $915 \mathrm{E}-15$ & 0.0000 \\
\hline-240 & $0.000 \mathrm{E}+00$ & 0.0000 & $0.000 \mathrm{E}+00$ & 0.0000 & $0.000 \mathrm{E}+00$ & 0.0000 & $0.000 \mathrm{E}+00$ & 0.0000 & $0.000 \mathrm{E}+00$ & 0.0000 & $0.000 \mathrm{E}+00$ & 0.0000 & $2.612 \mathrm{E}-18$ & 0.0000 \\
\hline-99 & $3.374 \mathrm{E}-01$ & 0.8277 & $0.000 \mathrm{E}+00$ & 0.0000 & $0.000 \mathrm{E}+00$ & 0.0000 & $3.154 \mathrm{E}-02$ & 0.0774 & $5.647 \mathrm{E}-04$ & 0.0014 & $3.811 \mathrm{E}-02$ & 0.0935 & $4.076 \mathrm{E}-01$ & 0.9999 \\
\hline-228 & $0.000 \mathrm{E}+00$ & 0.0000 & $0.000 \mathrm{E}+00$ & 0.0000 & $0.000 \mathrm{E}+00$ & 0.0000 & $0.000 \mathrm{E}+00$ & 0.0000 & $0.000 \mathrm{E}+00$ & 0.0000 & $0.000 \mathrm{E}+00$ & 0.0000 & $0.000 \mathrm{E}+00$ & 0.0000 \\
\hline-230 & $0.000 \mathrm{E}+00$ & 0.0000 & $0.000 \mathrm{E}+00$ & 0.0000 & $0.000 \mathrm{E}+00$ & 0.0000 & $0.000 \mathrm{E}+00$ & 0.0000 & $0.000 \mathrm{E}+00$ & 0.0000 & $0.000 \mathrm{E}+00$ & 0.0000 & $5.495 E-07$ & 0.0000 \\
\hline-232 & $0.000 \mathrm{E}+00$ & 0.0000 & $0.000 \mathrm{E}+00$ & 0.0000 & $0.000 \mathrm{E}+00$ & 0.0000 & $0.000 \mathrm{E}+00$ & 0.0000 & $0.000 \mathrm{E}+00$ & 0.0000 & $0.000 \mathrm{E}+00$ & 0.0000 & $2.123 E-05$ & 0.0001 \\
\hline 234 & $0.000 \mathrm{E}+00$ & 0.0000 & $0.000 \mathrm{E}+00$ & 0.0000 & $0.000 \mathrm{E}+00$ & 0.0000 & $0.000 \mathrm{E}+00$ & 0.0000 & $0.000 \mathrm{E}+00$ & 0.0000 & $0.000 \mathrm{E}+00$ & 0.0000 & $1.082 \mathrm{E}-09$ & 0.0000 \\
\hline 35 & $0.000 \mathrm{E}+00$ & 0.0000 & $0.000 \mathrm{E}+00$ & 0.0000 & $0.000 \mathrm{E}+00$ & 0.0000 & $0.000 \mathrm{E}+00$ & 0.0000 & $0.000 \mathrm{E}+00$ & 0.0000 & $0.000 \mathrm{E}+00$ & 0.0000 & $3.031 \mathrm{E}-11$ & 0.0000 \\
\hline 38 & $0.000 \mathrm{E}+00$ & 0.0000 & $0.000 \mathrm{E}+00$ & 0.0000 & $0.000 \mathrm{E}+00$ & 0.0000 & $0.000 \mathrm{E}+00$ & 0.0000 & $0.000 \mathrm{E}+00$ & 0.0000 & $0.000 \mathrm{E}+00$ & 0.0000 & $4.209 E-09$ & 0.0000 \\
\hline & $3.374 \mathrm{E}-01$ & 0.8277 & $0.000 \mathrm{E}+00$ & 0.0000 & $0.000 \mathrm{E}+00$ & 0.0000 & $3.154 \mathrm{E}-02$ & 0.0774 & $5.647 E-04$ & 0.0014 & $3.811 E-02$ & 0.0935 & $4.076 \mathrm{E}-01$ & 1.0000 \\
\hline
\end{tabular}

* Sum of all water independent and dependent pathways. 
RESRAD, Version $6.5 \quad \mathrm{~T}^{1 / 2}$ Limit $=180$ days

ummary : C746U Resident Farmer Deterministic Run

File : $\mathrm{X}: \backslash$ FINAL V2 $\backslash \mathrm{C} 746 \mathrm{U}$ RF DET-FINALV2.RAD

Total Dose Contributions TDOSE(i,p,t) for Individual Radionuclides (i) and Pathways (p) As mrem/yr and Fraction of Total Dose At $t=0.000 \mathrm{E}+00$ years

Water Independent Pathways (Inhalation excludes radon)

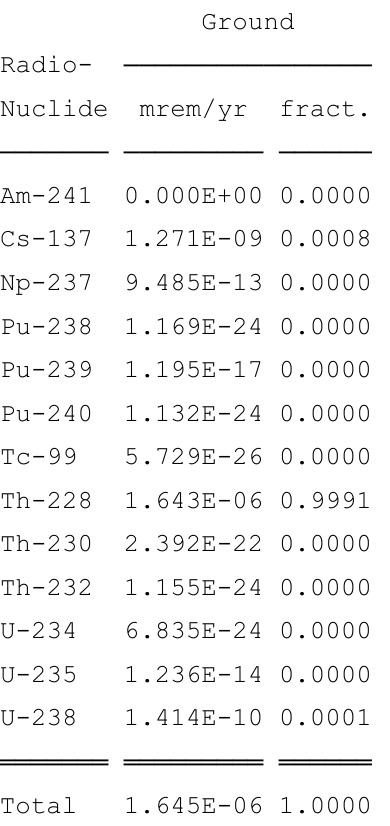

Inhalation

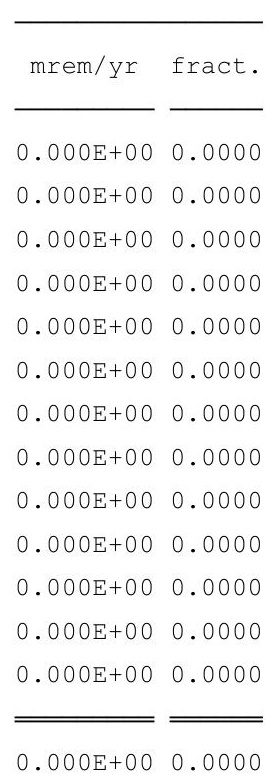

\begin{tabular}{ll} 
Radon \\
\hline mrem/yr fract. \\
\cline { 1 - 1 } 0.000E+00 & 0.0000 \\
$0.000 \mathrm{E}+00$ & 0.0000 \\
$0.000 \mathrm{E}+00$ & 0.0000 \\
$0.000 \mathrm{E}+00$ & 0.0000 \\
$0.000 \mathrm{E}+00$ & 0.0000 \\
$0.000 \mathrm{E}+00$ & 0.0000 \\
$0.000 \mathrm{E}+00$ & 0.0000 \\
$0.000 \mathrm{E}+00$ & 0.0000 \\
$0.000 \mathrm{E}+00$ & 0.0000 \\
$0.000 \mathrm{E}+00$ & 0.0000 \\
$0.000 \mathrm{E}+00$ & 0.0000 \\
$0.000 \mathrm{E}+00$ & 0.0000 \\
$0.000 \mathrm{E}+00$ & 0.0000 \\
\hline \hline $0.000 \mathrm{E}+00$ & 0.0000
\end{tabular}

\begin{tabular}{|c|c|}
\hline mrem/yr & fract. \\
\hline $0.000 \mathrm{E}+00$ & 0.0000 \\
\hline $0.000 \mathrm{E}+00$ & 0.0000 \\
\hline $0.000 \mathrm{E}+00$ & 0.0000 \\
\hline $0.000 \mathrm{E}+00$ & 0.0000 \\
\hline $0.000 \mathrm{E}+00$ & 0.0000 \\
\hline $0.000 \mathrm{E}+00$ & 0.0000 \\
\hline $0.000 \mathrm{E}+00$ & 0.0000 \\
\hline $0.000 \mathrm{E}+00$ & 0.0000 \\
\hline $0.000 \mathrm{E}+00$ & 0.0000 \\
\hline $0.000 \mathrm{E}+00$ & 0.0000 \\
\hline $0.000 \mathrm{E}+00$ & 0.0000 \\
\hline $0.000 \mathrm{E}+00$ & 0.0000 \\
\hline $0.000 \mathrm{E}+00$ & 0.0000 \\
\hline .000 & .000 \\
\hline
\end{tabular}

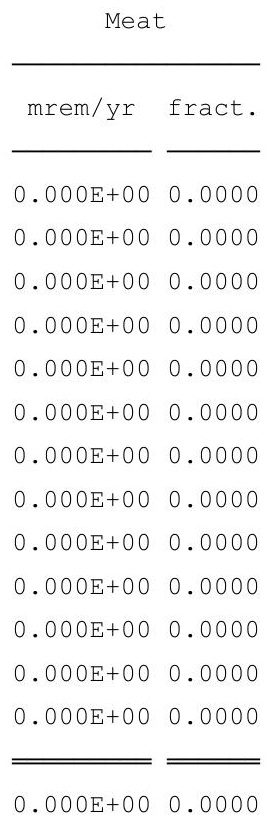

\begin{tabular}{cc} 
Milk \\
\cline { 1 - 1 } mrem/yr fract. \\
\cline { 1 - 1 } $0.000 \mathrm{E}+00$ & 0.0000 \\
$0.000 \mathrm{E}+00$ & 0.0000 \\
$0.000 \mathrm{E}+00$ & 0.0000 \\
$0.000 \mathrm{E}+00$ & 0.0000 \\
$0.000 \mathrm{E}+00$ & 0.0000 \\
$0.000 \mathrm{E}+00$ & 0.0000 \\
$0.000 \mathrm{E}+00$ & 0.0000 \\
$0.000 \mathrm{E}+00$ & 0.0000 \\
$0.000 \mathrm{E}+00$ & 0.0000 \\
$0.000 \mathrm{E}+00$ & 0.0000 \\
$0.000 \mathrm{E}+00$ & 0.0000 \\
$0.000 \mathrm{E}+00$ & 0.0000 \\
$0.000 \mathrm{E}+00$ & 0.0000 \\
\hline \hline $0.000 \mathrm{E}+00$ & 0.0000
\end{tabular}

Total Dose Contributions TDOSE(i,p,t) for Individual Radionuclides (i) and Pathways (p) As mrem/yr and Fraction of Total Dose At $t=0.000 \mathrm{E}+00$ years

Water Dependent Pathways

\begin{tabular}{llll} 
& & \multicolumn{2}{c}{ Water } \\
Radio- & & \\
Nuclide & mrem/yr & fract. \\
Am-241 & $0.000 \mathrm{E}+00$ & 0.0000 \\
Cs-137 & $0.000 \mathrm{E}+00$ & 0.0000 \\
$\mathrm{~Np}-237$ & $0.000 \mathrm{E}+00$ & 0.0000 \\
Pu-238 & $0.000 \mathrm{E}+00$ & 0.0000 \\
Pu-239 & $0.000 \mathrm{E}+00$ & 0.0000 \\
Pu-240 & $0.000 \mathrm{E}+00$ & 0.0000 \\
$\mathrm{TC}-99$ & $0.000 \mathrm{E}+00$ & 0.0000 \\
$\mathrm{Th}-228$ & $0.000 \mathrm{E}+00$ & 0.0000 \\
$\mathrm{Th}-230$ & $0.000 \mathrm{E}+00$ & 0.0000 \\
$\mathrm{Th}-232$ & $0.000 \mathrm{E}+00$ & 0.0000 \\
$\mathrm{U}-234$ & $0.000 \mathrm{E}+00$ & 0.0000 \\
$\mathrm{U}-235$ & $0.000 \mathrm{E}+00$ & 0.0000 \\
$\mathrm{U}-238$ & $0.000 \mathrm{E}+00$ & 0.0000 \\
\hline \hline
\end{tabular}

$0.000 \mathrm{E}+00 \quad 0.0000$

\begin{tabular}{cc} 
Fish \\
\cline { 1 - 2 } mrem/yr & fract. \\
\hline $0.000 \mathrm{E}+00$ & 0.0000 \\
$0.000 \mathrm{E}+00$ & 0.0000 \\
$0.000 \mathrm{E}+00$ & 0.0000 \\
$0.000 \mathrm{E}+00$ & 0.0000 \\
$0.000 \mathrm{E}+00$ & 0.0000 \\
$0.000 \mathrm{E}+00$ & 0.0000 \\
$0.000 \mathrm{E}+00$ & 0.0000 \\
$0.000 \mathrm{E}+00$ & 0.0000 \\
$0.000 \mathrm{E}+00$ & 0.0000 \\
$0.000 \mathrm{E}+00$ & 0.0000 \\
$0.000 \mathrm{E}+00$ & 0.0000 \\
$0.000 \mathrm{E}+00$ & 0.0000 \\
$0.000 \mathrm{E}+00$ & 0.0000 \\
\hline \hline
\end{tabular}

$0.000 \mathrm{E}+00 \quad 0.0000$

\begin{tabular}{cc} 
Radon \\
\cline { 1 - 2 } mrem/yr fract. \\
\cline { 1 - 2 } $0.000 \mathrm{E}+00$ & 0.0000 \\
$0.000 \mathrm{E}+00$ & 0.0000 \\
$0.000 \mathrm{E}+00$ & 0.0000 \\
$0.000 \mathrm{E}+00$ & 0.0000 \\
$0.000 \mathrm{E}+00$ & 0.0000 \\
$0.000 \mathrm{E}+00$ & 0.0000 \\
$0.000 \mathrm{E}+00$ & 0.0000 \\
$0.000 \mathrm{E}+00$ & 0.0000 \\
$0.000 \mathrm{E}+00$ & 0.0000 \\
$0.000 \mathrm{E}+00$ & 0.0000 \\
$0.000 \mathrm{E}+00$ & 0.0000 \\
$0.000 \mathrm{E}+00$ & 0.0000 \\
$0.000 \mathrm{E}+00$ & 0.0000 \\
\hline \hline
\end{tabular}

$0.000 \mathrm{E}+00 \quad 0.0000$

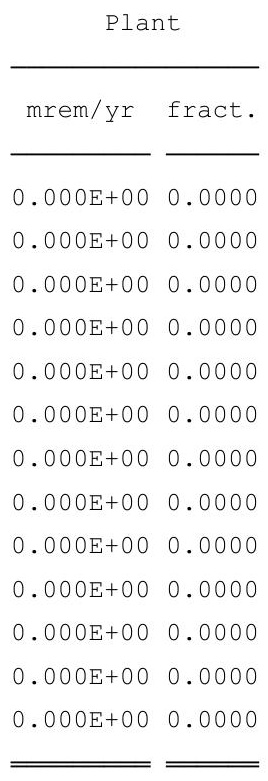

$0.000 \mathrm{E}+00 \quad 0.0000$

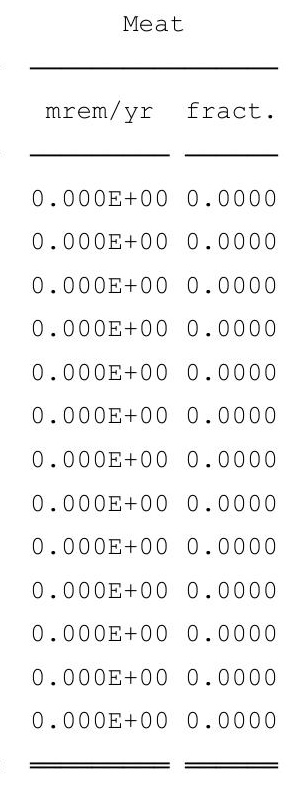

$0.000 \mathrm{E}+00 \quad 0.0000$

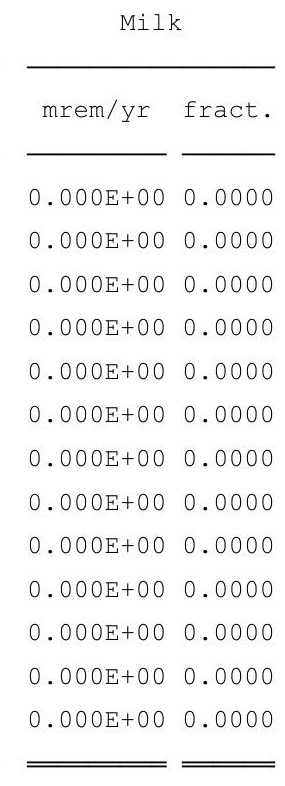

$0.000 E+00 \quad 0.0000$
Soil

\begin{tabular}{ccc} 
mrem/yr & fract. \\
\cline { 1 - 1 } $0.000 \mathrm{E}+00$ & 0.0000 \\
$0.000 \mathrm{E}+00$ & 0.0000 \\
$0.000 \mathrm{E}+00$ & 0.0000 \\
$0.000 \mathrm{E}+00$ & 0.0000 \\
$0.000 \mathrm{E}+00$ & 0.0000 \\
$0.000 \mathrm{E}+00$ & 0.0000 \\
$0.000 \mathrm{E}+00$ & 0.0000 \\
$0.000 \mathrm{E}+00$ & 0.0000 \\
$0.000 \mathrm{E}+00$ & 0.0000 \\
$0.000 \mathrm{E}+00$ & 0.0000 \\
$0.000 \mathrm{E}+00$ & 0.0000 \\
$0.000 \mathrm{E}+00$ & 0.0000 \\
$0.000 \mathrm{E}+00$ & 0.0000 \\
\hline \hline $0.000 \mathrm{E}+00$ & 0.0000
\end{tabular}

* Sum of all water independent and dependent pathways. 
RESRAD, Version $6.5 \quad \mathrm{~T}^{1 / 2}$ Limit $=180$ days

ummary : C746U Resident Farmer Deterministic Run

File : $\mathrm{X}: \backslash$ FINAL V2 $\backslash \mathrm{C} 746 \mathrm{U}$ RF DET-FINALV2.RAD

Total Dose Contributions TDOSE(i,p,t) for Individual Radionuclides (i) and Pathways (p) As mrem/yr and Fraction of Total Dose At $t=5.000 \mathrm{E}+01$ years

Water Independent Pathways (Inhalation excludes radon)

\begin{tabular}{|c|c|c|}
\hline ide & mrem/yr & fract. \\
\hline $1-241$ & $2.526 \mathrm{E}-17$ & 0.0000 \\
\hline-137 & $6.094 \mathrm{E}-10$ & 0.0003 \\
\hline-237 & $1.620 \mathrm{E}-12$ & 0.0000 \\
\hline-238 & $5.098 \mathrm{E}-17$ & 0.0000 \\
\hline-239 & $2.170 \mathrm{E}-17$ & 0.0000 \\
\hline-240 & $2.609 \mathrm{E}-21$ & 0.0000 \\
\hline-99 & $9.526 \mathrm{E}-26$ & 0.0000 \\
\hline-228 & $3.003 E-14$ & 0.0000 \\
\hline-230 & $5.249 \mathrm{E}-09$ & 0.0023 \\
\hline-232 & $2.234 \mathrm{E}-06$ & 0.9973 \\
\hline 34 & $1.185 \mathrm{E}-12$ & 0.0000 \\
\hline 35 & $9.085 \mathrm{E}-14$ & 0.0000 \\
\hline 238 & $2.107 \mathrm{E}-10$ & 0.0001 \\
\hline & 06 & $\perp$ \\
\hline
\end{tabular}

Inhalation

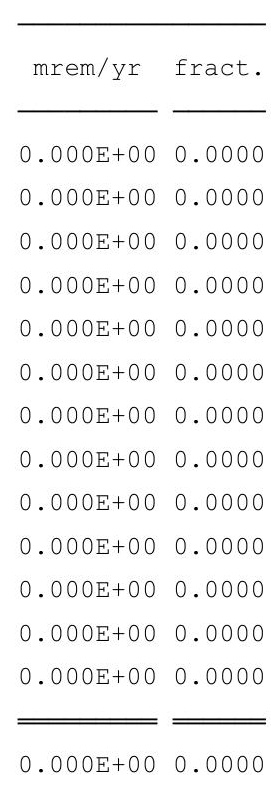

\begin{tabular}{cc} 
Radon \\
\cline { 1 - 2 } mrem/yr fract. \\
\cline { 1 - 2 } $0.000 \mathrm{E}+00$ & 0.0000 \\
$0.000 \mathrm{E}+00$ & 0.0000 \\
$0.000 \mathrm{E}+00$ & 0.0000 \\
$0.000 \mathrm{E}+00$ & 0.0000 \\
$0.000 \mathrm{E}+00$ & 0.0000 \\
$0.000 \mathrm{E}+00$ & 0.0000 \\
$0.000 \mathrm{E}+00$ & 0.0000 \\
$0.000 \mathrm{E}+00$ & 0.0000 \\
$0.000 \mathrm{E}+00$ & 0.0000 \\
$0.000 \mathrm{E}+00$ & 0.0000 \\
$0.000 \mathrm{E}+00$ & 0.0000 \\
$0.000 \mathrm{E}+00$ & 0.0000 \\
$0.000 \mathrm{E}+00$ & 0.0000 \\
\hline \hline $0.000 \mathrm{E}+00$ & 0.0000
\end{tabular}

\begin{tabular}{cc} 
Plant \\
\cline { 1 - 2 } mrem/yr fract. \\
\cline { 1 - 2 } $0.000 \mathrm{E}+00$ & 0.0000 \\
$0.000 \mathrm{E}+00$ & 0.0000 \\
$0.000 \mathrm{E}+00$ & 0.0000 \\
$0.000 \mathrm{E}+00$ & 0.0000 \\
$0.000 \mathrm{E}+00$ & 0.0000 \\
$0.000 \mathrm{E}+00$ & 0.0000 \\
$0.000 \mathrm{E}+00$ & 0.0000 \\
$0.000 \mathrm{E}+00$ & 0.0000 \\
$0.000 \mathrm{E}+00$ & 0.0000 \\
$0.000 \mathrm{E}+00$ & 0.0000 \\
$0.000 \mathrm{E}+00$ & 0.0000 \\
$0.000 \mathrm{E}+00$ & 0.0000 \\
$0.000 \mathrm{E}+00$ & 0.0000 \\
\hline \hline $0.000 \mathrm{E}+00$ & 0.0000
\end{tabular}

\begin{tabular}{cc} 
Meat \\
\hline mrem/yr fract. \\
\cline { 1 - 2 } 0.000E+00 & 0.0000 \\
$0.000 \mathrm{E}+00$ & 0.0000 \\
$0.000 \mathrm{E}+00$ & 0.0000 \\
$0.000 \mathrm{E}+00$ & 0.0000 \\
$0.000 \mathrm{E}+00$ & 0.0000 \\
$0.000 \mathrm{E}+00$ & 0.0000 \\
$0.000 \mathrm{E}+00$ & 0.0000 \\
$0.000 \mathrm{E}+00$ & 0.0000 \\
$0.000 \mathrm{E}+00$ & 0.0000 \\
$0.000 \mathrm{E}+00$ & 0.0000 \\
$0.000 \mathrm{E}+00$ & 0.0000 \\
$0.000 \mathrm{E}+00$ & 0.0000 \\
$0.000 \mathrm{E}+00$ & 0.0000 \\
\hline \hline $0.000 \mathrm{E}+00$ & 0.0000
\end{tabular}

\begin{tabular}{cc} 
Milk \\
\hline mrem/yr fract. \\
\cline { 1 - 2 } 0.000E+00 & 0.0000 \\
$0.000 \mathrm{E}+00$ & 0.0000 \\
$0.000 \mathrm{E}+00$ & 0.0000 \\
$0.000 \mathrm{E}+00$ & 0.0000 \\
$0.000 \mathrm{E}+00$ & 0.0000 \\
$0.000 \mathrm{E}+00$ & 0.0000 \\
$0.000 \mathrm{E}+00$ & 0.0000 \\
$0.000 \mathrm{E}+00$ & 0.0000 \\
$0.000 \mathrm{E}+00$ & 0.0000 \\
$0.000 \mathrm{E}+00$ & 0.0000 \\
$0.000 \mathrm{E}+00$ & 0.0000 \\
$0.000 \mathrm{E}+00$ & 0.0000 \\
$0.000 \mathrm{E}+00$ & 0.0000 \\
\hline \hline $0.000 \mathrm{E}+00$ & 0.0000
\end{tabular}

Total Dose Contributions TDOSE (i,p,t) for Individual Radionuclides (i) and Pathways (p) As mrem/yr and Fraction of Total Dose At $t=5.000 \mathrm{E}+01$ years

Water Dependent Pathways

\begin{tabular}{|c|c|c|}
\hline clide & mrem/yr & fract. \\
\hline-241 & $0.000 \mathrm{E}+00$ & 0.0000 \\
\hline-137 & $0.000 \mathrm{E}+00$ & 0.0000 \\
\hline-237 & $0.000 \mathrm{E}+00$ & 0.0000 \\
\hline-238 & $0.000 \mathrm{E}+00$ & 0.0000 \\
\hline-239 & $0.000 \mathrm{E}+00$ & 0.0000 \\
\hline-240 & $0.000 \mathrm{E}+00$ & 0.0000 \\
\hline-99 & $0.000 \mathrm{E}+00$ & 0.0000 \\
\hline-228 & $0.000 \mathrm{E}+00$ & 0.0000 \\
\hline-230 & $0.000 \mathrm{E}+00$ & 0.0000 \\
\hline-232 & $0.000 \mathrm{E}+00$ & 0.0000 \\
\hline 234 & $0.000 \mathrm{E}+00$ & 0.0000 \\
\hline 235 & $0.000 \mathrm{E}+00$ & 0.0000 \\
\hline 38 & $0.000 \mathrm{E}+00$ & 0.0000 \\
\hline
\end{tabular}

$0.000 \mathrm{E}+00 \quad 0.0000$

\begin{tabular}{|c|c|}
\hline mrem/yr & fract. \\
\hline $0.000 \mathrm{E}+00$ & 0.0000 \\
\hline $0.000 \mathrm{E}+00$ & 0.0000 \\
\hline $0.000 \mathrm{E}+00$ & 0.0000 \\
\hline $0.000 \mathrm{E}+00$ & 0.0000 \\
\hline $0.000 \mathrm{E}+00$ & 0.0000 \\
\hline $0.000 \mathrm{E}+00$ & 0.0000 \\
\hline $0.000 \mathrm{E}+00$ & 0.0000 \\
\hline $0.000 \mathrm{E}+00$ & 0.0000 \\
\hline $0.000 \mathrm{E}+00$ & 0.0000 \\
\hline $0.000 \mathrm{E}+00$ & 0.0000 \\
\hline $0.000 \mathrm{E}+00$ & 0.0000 \\
\hline $0.000 \mathrm{E}+00$ & 0.0000 \\
\hline $0.000 \mathrm{E}+00$ & 0.0000 \\
\hline
\end{tabular}

$0.000 \mathrm{E}+00 \quad 0.0000$

\begin{tabular}{|c|c|}
\hline mrem/yr & fract. \\
\hline $0.000 \mathrm{E}+00$ & 0.0000 \\
\hline $0.000 \mathrm{E}+00$ & 0.0000 \\
\hline $0.000 \mathrm{E}+00$ & 0.0000 \\
\hline $0.000 \mathrm{E}+00$ & 0.0000 \\
\hline $0.000 \mathrm{E}+00$ & 0.0000 \\
\hline $0.000 \mathrm{E}+00$ & 0.0000 \\
\hline $0.000 \mathrm{E}+00$ & 0.0000 \\
\hline $0.000 \mathrm{E}+00$ & 0.0000 \\
\hline $0.000 \mathrm{E}+00$ & 0.0000 \\
\hline $0.000 \mathrm{E}+00$ & 0.0000 \\
\hline $0.000 \mathrm{E}+00$ & 0.0000 \\
\hline $0.000 \mathrm{E}+00$ & 0.0000 \\
\hline $0.000 \mathrm{E}+00$ & 0.0000 \\
\hline
\end{tabular}

$0.000 \mathrm{E}+00 \quad 0.0000$

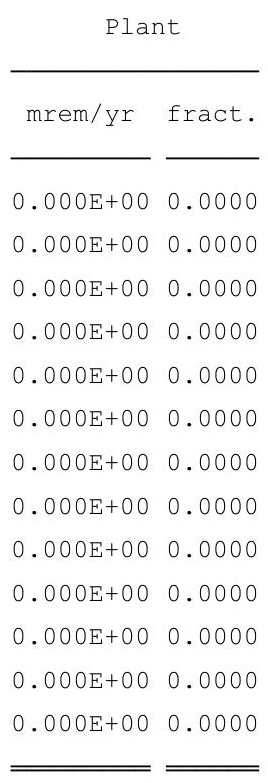

$0.000 \mathrm{E}+00 \quad 0.0000$

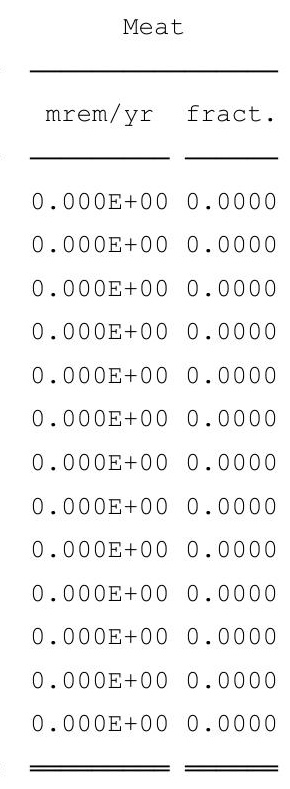

$0.000 \mathrm{E}+00 \quad 0.0000$

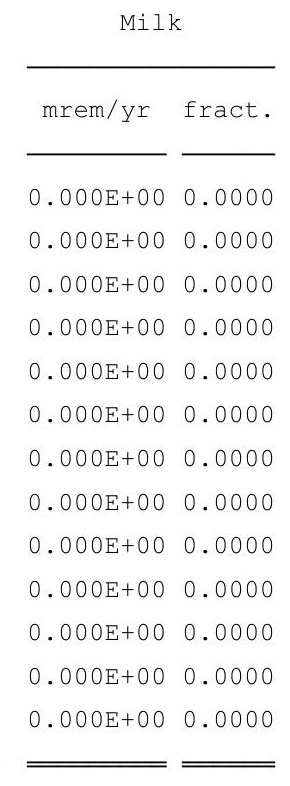

$0.000 \mathrm{E}+00 \quad 0.0000$
Soil

\begin{tabular}{ll} 
mrem/yr fract. & frn \\
\cline { 1 - 1 } $0.000 \mathrm{E}+00$ & 0.0000 \\
$0.000 \mathrm{E}+00$ & 0.0000 \\
$0.000 \mathrm{E}+00$ & 0.0000 \\
$0.000 \mathrm{E}+00$ & 0.0000 \\
$0.000 \mathrm{E}+00$ & 0.0000 \\
$0.000 \mathrm{E}+00$ & 0.0000 \\
$0.000 \mathrm{E}+00$ & 0.0000 \\
$0.000 \mathrm{E}+00$ & 0.0000 \\
$0.000 \mathrm{E}+00$ & 0.0000 \\
$0.000 \mathrm{E}+00$ & 0.0000 \\
$0.000 \mathrm{E}+00$ & 0.0000 \\
$0.000 \mathrm{E}+00$ & 0.0000 \\
$0.000 \mathrm{E}+00$ & 0.0000 \\
\hline \hline $0.000 \mathrm{E}+00$ & 0.0000
\end{tabular}

* Sum of all water independent and dependent pathways. 
RESRAD, Version $6.5 \quad \mathrm{~T}^{1 / 2}$ Limit $=180$ days

ummary : C746U Resident Farmer Deterministic Run

File : $\mathrm{X}: \backslash$ FINAL V2 $\backslash \mathrm{C} 746 \mathrm{U}$ RF DET-FINALV2.RAD

Total Dose Contributions TDOSE(i,p,t) for Individual Radionuclides (i) and Pathways (p) As mrem/yr and Fraction of Total Dose At $t=1.000 \mathrm{E}+02$ years

Water Independent Pathways (Inhalation excludes radon)

\begin{tabular}{|c|c|c|}
\hline ide & mrem/yr & fract. \\
\hline $1-241$ & $8.317 \mathrm{E}-17$ & 0.0000 \\
\hline-137 & 2. $922 \mathrm{E}-10$ & 0.0001 \\
\hline-237 & $2.773 \mathrm{E}-12$ & 0.0000 \\
\hline-238 & $5.231 \mathrm{E}-16$ & 0.0000 \\
\hline-239 & $3.943 \mathrm{E}-17$ & 0.0000 \\
\hline-240 & $1.758 \mathrm{E}-20$ & 0.0000 \\
\hline-99 & $1.584 \mathrm{E}-25$ & 0.0000 \\
\hline-228 & $5.489 \mathrm{E}-22$ & 0.0000 \\
\hline-230 & $1.467 \mathrm{E}-08$ & 0.0048 \\
\hline-232 & $3.024 \mathrm{E}-06$ & 0.9950 \\
\hline 234 & $6.647 \mathrm{E}-12$ & 0.0000 \\
\hline 35 & $3.352 \mathrm{E}-13$ & 0.0000 \\
\hline 238 & $3.141 \mathrm{E}-10$ & 0.0001 \\
\hline & 06 & \\
\hline
\end{tabular}

Inhalation

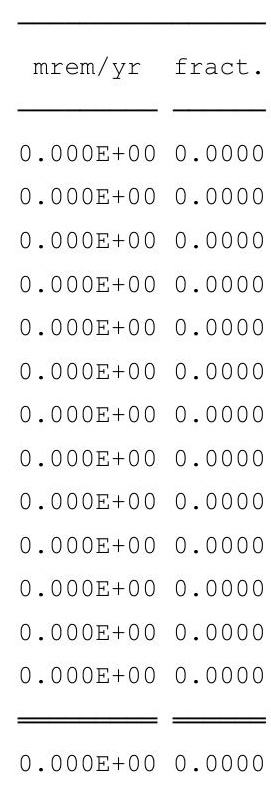

\begin{tabular}{ll} 
Radon \\
\hline mrem/yr fract. \\
\cline { 1 - 1 } 0.000E+00 & 0.0000 \\
$0.000 \mathrm{E}+00$ & 0.0000 \\
$0.000 \mathrm{E}+00$ & 0.0000 \\
$0.000 \mathrm{E}+00$ & 0.0000 \\
$0.000 \mathrm{E}+00$ & 0.0000 \\
$0.000 \mathrm{E}+00$ & 0.0000 \\
$0.000 \mathrm{E}+00$ & 0.0000 \\
$0.000 \mathrm{E}+00$ & 0.0000 \\
$0.000 \mathrm{E}+00$ & 0.0000 \\
$0.000 \mathrm{E}+00$ & 0.0000 \\
$0.000 \mathrm{E}+00$ & 0.0000 \\
$0.000 \mathrm{E}+00$ & 0.0000 \\
$0.000 \mathrm{E}+00$ & 0.0000 \\
\hline \hline $0.000 \mathrm{E}+00$ & 0.0000
\end{tabular}

\begin{tabular}{|c|c|}
\hline mrem/yr & fract. \\
\hline $0.000 \mathrm{E}+00$ & 0.0000 \\
\hline $0.000 \mathrm{E}+00$ & 0.0000 \\
\hline $0.000 \mathrm{E}+00$ & 0.0000 \\
\hline $0.000 \mathrm{E}+00$ & 0.0000 \\
\hline $0.000 \mathrm{E}+00$ & 0.0000 \\
\hline $0.000 \mathrm{E}+00$ & 0.0000 \\
\hline $0.000 \mathrm{E}+00$ & 0.0000 \\
\hline $0.000 \mathrm{E}+00$ & 0.0000 \\
\hline $0.000 \mathrm{E}+00$ & 0.0000 \\
\hline $0.000 \mathrm{E}+00$ & 0.0000 \\
\hline $0.000 \mathrm{E}+00$ & 0.0000 \\
\hline $0.000 \mathrm{E}+00$ & 0.0000 \\
\hline $0.000 \mathrm{E}+00$ & 0.0000 \\
\hline .000 & .000 \\
\hline
\end{tabular}

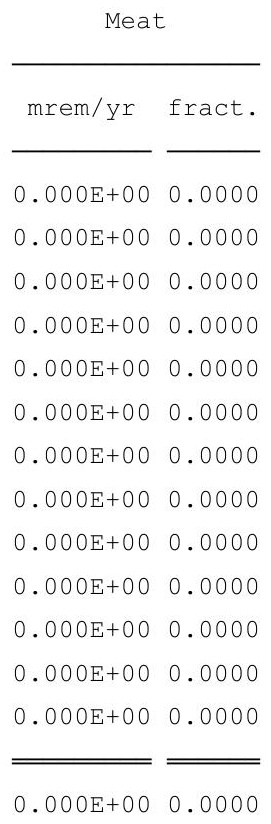

\begin{tabular}{cc} 
Milk \\
\cline { 1 - 1 } mrem/yr fract. \\
\cline { 1 - 1 } $0.000 \mathrm{E}+00$ & 0.0000 \\
$0.000 \mathrm{E}+00$ & 0.0000 \\
$0.000 \mathrm{E}+00$ & 0.0000 \\
$0.000 \mathrm{E}+00$ & 0.0000 \\
$0.000 \mathrm{E}+00$ & 0.0000 \\
$0.000 \mathrm{E}+00$ & 0.0000 \\
$0.000 \mathrm{E}+00$ & 0.0000 \\
$0.000 \mathrm{E}+00$ & 0.0000 \\
$0.000 \mathrm{E}+00$ & 0.0000 \\
$0.000 \mathrm{E}+00$ & 0.0000 \\
$0.000 \mathrm{E}+00$ & 0.0000 \\
$0.000 \mathrm{E}+00$ & 0.0000 \\
$0.000 \mathrm{E}+00$ & 0.0000 \\
\hline \hline $0.000 \mathrm{E}+00$ & 0.0000
\end{tabular}

Total Dose Contributions TDOSE (i,p,t) for Individual Radionuclides (i) and Pathways (p) As mrem/yr and Fraction of Total Dose At $t=1.000 \mathrm{E}+02$ years

Water Dependent Pathways

\begin{tabular}{llll} 
& & \multicolumn{2}{c}{ Water } \\
Radio- & & \\
Nuclide & mrem/yr & fract. \\
Am-241 & $0.000 \mathrm{E}+00$ & 0.0000 \\
Cs-137 & $0.000 \mathrm{E}+00$ & 0.0000 \\
$\mathrm{~Np}-237$ & $0.000 \mathrm{E}+00$ & 0.0000 \\
Pu-238 & $0.000 \mathrm{E}+00$ & 0.0000 \\
Pu-239 & $0.000 \mathrm{E}+00$ & 0.0000 \\
Pu-240 & $0.000 \mathrm{E}+00$ & 0.0000 \\
$\mathrm{TC}-99$ & $0.000 \mathrm{E}+00$ & 0.0000 \\
$\mathrm{Th}-228$ & $0.000 \mathrm{E}+00$ & 0.0000 \\
$\mathrm{Th}-230$ & $0.000 \mathrm{E}+00$ & 0.0000 \\
$\mathrm{Th}-232$ & $0.000 \mathrm{E}+00$ & 0.0000 \\
$\mathrm{U}-234$ & $0.000 \mathrm{E}+00$ & 0.0000 \\
$\mathrm{U}-235$ & $0.000 \mathrm{E}+00$ & 0.0000 \\
$\mathrm{U}-238$ & $0.000 \mathrm{E}+00$ & 0.0000 \\
\hline \hline
\end{tabular}

$0.000 \mathrm{E}+00 \quad 0.0000$

\begin{tabular}{cc} 
Fish \\
\cline { 1 - 2 } mrem/yr & fract. \\
\hline $0.000 \mathrm{E}+00$ & 0.0000 \\
$0.000 \mathrm{E}+00$ & 0.0000 \\
$0.000 \mathrm{E}+00$ & 0.0000 \\
$0.000 \mathrm{E}+00$ & 0.0000 \\
$0.000 \mathrm{E}+00$ & 0.0000 \\
$0.000 \mathrm{E}+00$ & 0.0000 \\
$0.000 \mathrm{E}+00$ & 0.0000 \\
$0.000 \mathrm{E}+00$ & 0.0000 \\
$0.000 \mathrm{E}+00$ & 0.0000 \\
$0.000 \mathrm{E}+00$ & 0.0000 \\
$0.000 \mathrm{E}+00$ & 0.0000 \\
$0.000 \mathrm{E}+00$ & 0.0000 \\
$0.000 \mathrm{E}+00$ & 0.0000 \\
\hline \hline
\end{tabular}

$0.000 \mathrm{E}+00 \quad 0.0000$

\begin{tabular}{cc} 
Radon \\
\cline { 1 - 2 } mrem/yr fract. \\
\cline { 1 - 2 } $0.000 \mathrm{E}+00$ & 0.0000 \\
$0.000 \mathrm{E}+00$ & 0.0000 \\
$0.000 \mathrm{E}+00$ & 0.0000 \\
$0.000 \mathrm{E}+00$ & 0.0000 \\
$0.000 \mathrm{E}+00$ & 0.0000 \\
$0.000 \mathrm{E}+00$ & 0.0000 \\
$0.000 \mathrm{E}+00$ & 0.0000 \\
$0.000 \mathrm{E}+00$ & 0.0000 \\
$0.000 \mathrm{E}+00$ & 0.0000 \\
$0.000 \mathrm{E}+00$ & 0.0000 \\
$0.000 \mathrm{E}+00$ & 0.0000 \\
$0.000 \mathrm{E}+00$ & 0.0000 \\
$0.000 \mathrm{E}+00$ & 0.0000 \\
\hline \hline
\end{tabular}

$0.000 \mathrm{E}+00 \quad 0.0000$

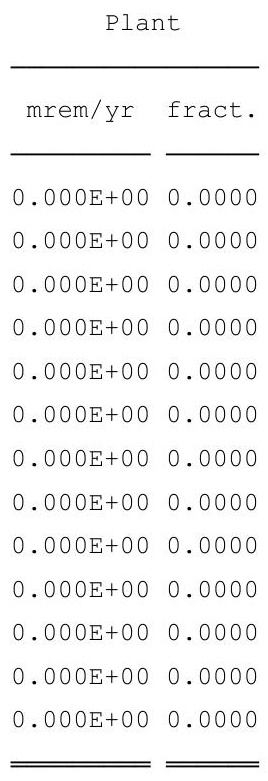

$0.000 \mathrm{E}+00 \quad 0.0000$

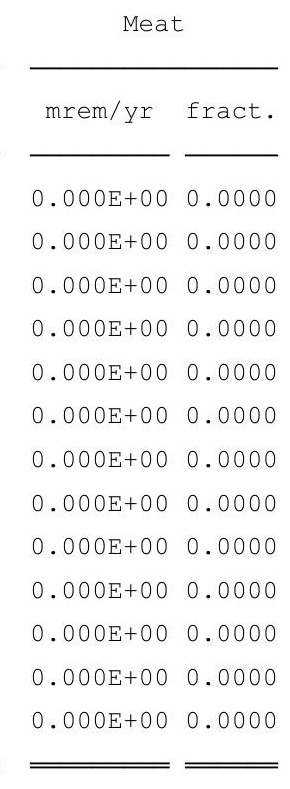

$0.000 \mathrm{E}+00 \quad 0.0000$

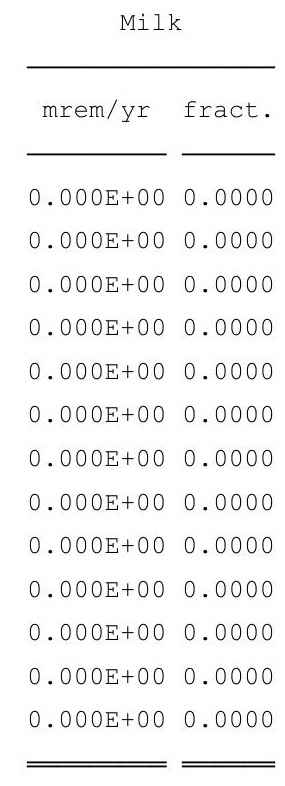

$0.000 E+00 \quad 0.0000$
Soil

\begin{tabular}{ccc} 
mrem/yr & fract. \\
\cline { 1 - 1 } $0.000 \mathrm{E}+00$ & 0.0000 \\
$0.000 \mathrm{E}+00$ & 0.0000 \\
$0.000 \mathrm{E}+00$ & 0.0000 \\
$0.000 \mathrm{E}+00$ & 0.0000 \\
$0.000 \mathrm{E}+00$ & 0.0000 \\
$0.000 \mathrm{E}+00$ & 0.0000 \\
$0.000 \mathrm{E}+00$ & 0.0000 \\
$0.000 \mathrm{E}+00$ & 0.0000 \\
$0.000 \mathrm{E}+00$ & 0.0000 \\
$0.000 \mathrm{E}+00$ & 0.0000 \\
$0.000 \mathrm{E}+00$ & 0.0000 \\
$0.000 \mathrm{E}+00$ & 0.0000 \\
$0.000 \mathrm{E}+00$ & 0.0000 \\
\hline \hline $0.000 \mathrm{E}+00$ & 0.0000
\end{tabular}

* Sum of all water independent and dependent pathways. 
RESRAD, Version $6.5 \quad \mathrm{~T}^{1 / 2}$ Limit $=180$ days

ummary : C746U Resident Farmer Deterministic Run

File : $\mathrm{X}: \backslash$ FINAL V2 $\backslash \mathrm{C} 746 \mathrm{U}$ RF DET-FINALV2.RAD

Total Dose Contributions TDOSE(i,p,t) for Individual Radionuclides (i) and Pathways (p) As mrem/yr and Fraction of Total Dose At $t=5.000 \mathrm{E}+02$ years

Water Independent Pathways (Inhalation excludes radon)

\begin{tabular}{|c|c|c|}
\hline ide & mrem/yr & fract. \\
\hline $1-241$ & $2.281 E-14$ & 0.0000 \\
\hline-137 & $8.163 \mathrm{E}-13$ & 0.0000 \\
\hline-237 & $2.033 \mathrm{E}-10$ & 0.0000 \\
\hline-238 & $5.574 \mathrm{E}-13$ & 0.0000 \\
\hline-239 & $4.680 \mathrm{E}-15$ & 0.0000 \\
\hline-240 & $5.690 \mathrm{E}-18$ & 0.0000 \\
\hline-99 & $9.262 \mathrm{E}-24$ & 0.0000 \\
\hline-228 & $0.000 \mathrm{E}+00$ & 0.0000 \\
\hline-230 & $1.066 \mathrm{E}-06$ & 0.0000 \\
\hline-232 & $3.328 \mathrm{E}-05$ & 0.0002 \\
\hline 234 & $2.482 E-09$ & 0.0000 \\
\hline 35 & $6.994 \mathrm{E}-11$ & 0.0000 \\
\hline 238 & $7.649 \mathrm{E}-09$ & 0.0000 \\
\hline & & \\
\hline
\end{tabular}

Inhalation

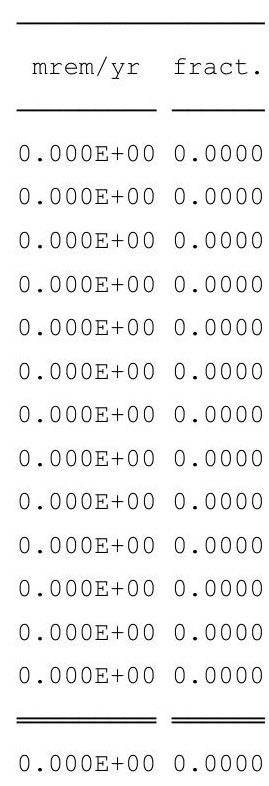

\begin{tabular}{ll} 
Radon \\
\hline mrem/yr fract. \\
\cline { 1 - 1 } 0.000E+00 & 0.0000 \\
$0.000 \mathrm{E}+00$ & 0.0000 \\
$0.000 \mathrm{E}+00$ & 0.0000 \\
$0.000 \mathrm{E}+00$ & 0.0000 \\
$0.000 \mathrm{E}+00$ & 0.0000 \\
$0.000 \mathrm{E}+00$ & 0.0000 \\
$0.000 \mathrm{E}+00$ & 0.0000 \\
$0.000 \mathrm{E}+00$ & 0.0000 \\
$0.000 \mathrm{E}+00$ & 0.0000 \\
$0.000 \mathrm{E}+00$ & 0.0000 \\
$0.000 \mathrm{E}+00$ & 0.0000 \\
$0.000 \mathrm{E}+00$ & 0.0000 \\
$0.000 \mathrm{E}+00$ & 0.0000 \\
\hline \hline $0.000 \mathrm{E}+00$ & 0.0000
\end{tabular}

\begin{tabular}{|c|c|}
\hline mrem/yr & fract. \\
\hline $0.000 \mathrm{E}+00$ & 0.0000 \\
\hline $0.000 \mathrm{E}+00$ & 0.0000 \\
\hline $0.000 \mathrm{E}+00$ & 0.0000 \\
\hline $0.000 \mathrm{E}+00$ & 0.0000 \\
\hline $0.000 \mathrm{E}+00$ & 0.0000 \\
\hline $0.000 \mathrm{E}+00$ & 0.0000 \\
\hline $0.000 \mathrm{E}+00$ & 0.0000 \\
\hline $0.000 \mathrm{E}+00$ & 0.0000 \\
\hline $0.000 \mathrm{E}+00$ & 0.0000 \\
\hline $0.000 \mathrm{E}+00$ & 0.0000 \\
\hline $0.000 \mathrm{E}+00$ & 0.0000 \\
\hline $0.000 \mathrm{E}+00$ & 0.0000 \\
\hline $0.000 \mathrm{E}+00$ & 0.0000 \\
\hline .000 & .000 \\
\hline
\end{tabular}

\begin{tabular}{cc} 
Meat \\
\hline mrem/yr fract. \\
\cline { 1 - 2 } 0.000E+00 & 0.0000 \\
$0.000 \mathrm{E}+00$ & 0.0000 \\
$0.000 \mathrm{E}+00$ & 0.0000 \\
$0.000 \mathrm{E}+00$ & 0.0000 \\
$0.000 \mathrm{E}+00$ & 0.0000 \\
$0.000 \mathrm{E}+00$ & 0.0000 \\
$0.000 \mathrm{E}+00$ & 0.0000 \\
$0.000 \mathrm{E}+00$ & 0.0000 \\
$0.000 \mathrm{E}+00$ & 0.0000 \\
$0.000 \mathrm{E}+00$ & 0.0000 \\
$0.000 \mathrm{E}+00$ & 0.0000 \\
$0.000 \mathrm{E}+00$ & 0.0000 \\
$0.000 \mathrm{E}+00$ & 0.0000 \\
\hline \hline $0.000 \mathrm{E}+00$ & 0.0000
\end{tabular}

\begin{tabular}{cc} 
Milk \\
\hline mrem/yr fract. \\
\cline { 1 - 2 } 0.000E+00 & 0.0000 \\
$0.000 \mathrm{E}+00$ & 0.0000 \\
$0.000 \mathrm{E}+00$ & 0.0000 \\
$0.000 \mathrm{E}+00$ & 0.0000 \\
$0.000 \mathrm{E}+00$ & 0.0000 \\
$0.000 \mathrm{E}+00$ & 0.0000 \\
$0.000 \mathrm{E}+00$ & 0.0000 \\
$0.000 \mathrm{E}+00$ & 0.0000 \\
$0.000 \mathrm{E}+00$ & 0.0000 \\
$0.000 \mathrm{E}+00$ & 0.0000 \\
$0.000 \mathrm{E}+00$ & 0.0000 \\
$0.000 \mathrm{E}+00$ & 0.0000 \\
$0.000 \mathrm{E}+00$ & 0.0000 \\
\hline \hline $0.000 \mathrm{E}+00$ & 0.0000
\end{tabular}

Total Dose Contributions TDOSE (i,p,t) for Individual Radionuclides (i) and Pathways (p) As mrem/yr and Fraction of Total Dose At $t=5.000 \mathrm{E}+02$ years

Water Dependent Pathways

\begin{tabular}{|c|c|c|}
\hline clide & mrem/yr & fract. \\
\hline-241 & $0.000 \mathrm{E}+00$ & 0.0000 \\
\hline-137 & $0.000 \mathrm{E}+00$ & 0.0000 \\
\hline-237 & $0.000 \mathrm{E}+00$ & 0.0000 \\
\hline-238 & $0.000 \mathrm{E}+00$ & 0.0000 \\
\hline-239 & $0.000 \mathrm{E}+00$ & 0.0000 \\
\hline-240 & $0.000 \mathrm{E}+00$ & 0.0000 \\
\hline-99 & $1.721 \mathrm{E}-01$ & 0.8276 \\
\hline-228 & $0.000 \mathrm{E}+00$ & 0.0000 \\
\hline-230 & $0.000 \mathrm{E}+00$ & 0.0000 \\
\hline-232 & $0.000 \mathrm{E}+00$ & 0.0000 \\
\hline 234 & $0.000 \mathrm{E}+00$ & 0.0000 \\
\hline 235 & $0.000 \mathrm{E}+00$ & 0.0000 \\
\hline 38 & $0.000 \mathrm{E}+00$ & 0.0000 \\
\hline
\end{tabular}

\begin{tabular}{ll} 
Fish \\
\hline mrem/yr fract. \\
\cline { 1 - 1 } & \\
\hline $0.000 \mathrm{E}+00$ & 0.0000 \\
$0.000 \mathrm{E}+00$ & 0.0000 \\
$0.000 \mathrm{E}+00$ & 0.0000 \\
$0.000 \mathrm{E}+00$ & 0.0000 \\
$0.000 \mathrm{E}+00$ & 0.0000 \\
$0.000 \mathrm{E}+00$ & 0.0000 \\
$0.000 \mathrm{E}+00$ & 0.0000 \\
$0.000 \mathrm{E}+00$ & 0.0000 \\
$0.000 \mathrm{E}+00$ & 0.0000 \\
$0.000 \mathrm{E}+00$ & 0.0000 \\
$0.000 \mathrm{E}+00$ & 0.0000 \\
$0.000 \mathrm{E}+00$ & 0.0000 \\
$0.000 \mathrm{E}+00$ & 0.0000 \\
\hline \hline & $=$ \\
\hline 0
\end{tabular}

$0.000 \mathrm{E}+00 \quad 0.0000$

\begin{tabular}{ll} 
Radon \\
\hline mrem/yr fract. \\
0.000E+00 & 0.0000 \\
$0.000 \mathrm{E}+00$ & 0.0000 \\
$0.000 \mathrm{E}+00$ & 0.0000 \\
$0.000 \mathrm{E}+00$ & 0.0000 \\
$0.000 \mathrm{E}+00$ & 0.0000 \\
$0.000 \mathrm{E}+00$ & 0.0000 \\
$0.000 \mathrm{E}+00$ & 0.0000 \\
$0.000 \mathrm{E}+00$ & 0.0000 \\
$0.000 \mathrm{E}+00$ & 0.0000 \\
$0.000 \mathrm{E}+00$ & 0.0000 \\
$0.000 \mathrm{E}+00$ & 0.0000 \\
$0.000 \mathrm{E}+00$ & 0.0000 \\
$0.000 \mathrm{E}+00$ & 0.0000 \\
\hline \hline
\end{tabular}

$0.000 \mathrm{E}+00 \quad 0.0000$

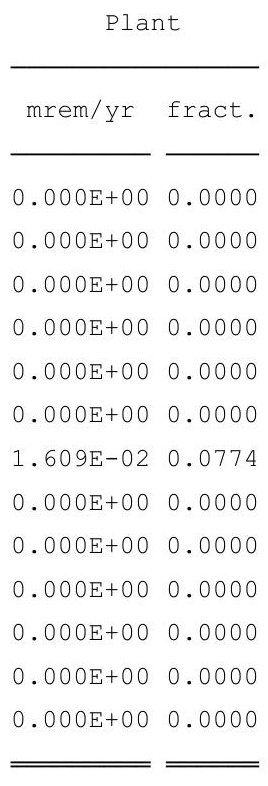

$1.609 \mathrm{E}-02 \quad 0.0774$

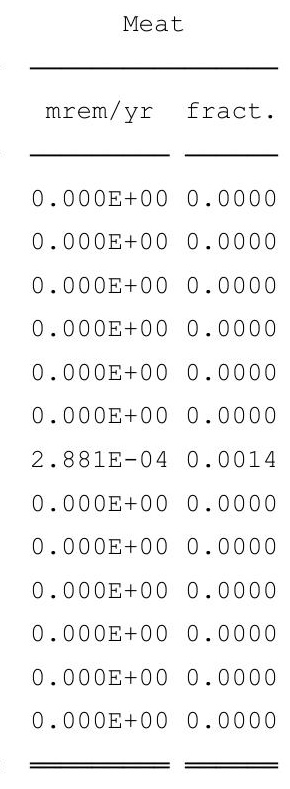

$2.881 \mathrm{E}-04 \quad 0.0014$

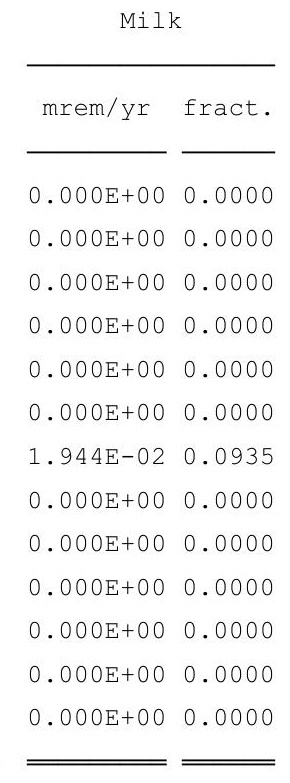

$1.944 \mathrm{E}-02 \quad 0.0935$
Soil

\begin{tabular}{ll} 
mrem/yr fract. & frn \\
\cline { 1 - 1 } $0.000 \mathrm{E}+00$ & 0.0000 \\
$0.000 \mathrm{E}+00$ & 0.0000 \\
$0.000 \mathrm{E}+00$ & 0.0000 \\
$0.000 \mathrm{E}+00$ & 0.0000 \\
$0.000 \mathrm{E}+00$ & 0.0000 \\
$0.000 \mathrm{E}+00$ & 0.0000 \\
$0.000 \mathrm{E}+00$ & 0.0000 \\
$0.000 \mathrm{E}+00$ & 0.0000 \\
$0.000 \mathrm{E}+00$ & 0.0000 \\
$0.000 \mathrm{E}+00$ & 0.0000 \\
$0.000 \mathrm{E}+00$ & 0.0000 \\
$0.000 \mathrm{E}+00$ & 0.0000 \\
$0.000 \mathrm{E}+00$ & 0.0000 \\
\hline \hline $0.000 \mathrm{E}+00$ & 0.0000
\end{tabular}

* Sum of all water independent and dependent pathways. 
RESRAD, Version $6.5 \quad \mathrm{~T}^{1 / 2}$ Limit $=180$ days

ummary : C746U Resident Farmer Deterministic Run

File : $\mathrm{X}: \backslash$ FINAL V2 $\backslash \mathrm{C} 746 \mathrm{U}$ RF DET-FINALV2.RAD

Total Dose Contributions TDOSE(i,p,t) for Individual Radionuclides (i) and Pathways (p) As mrem/yr and Fraction of Total Dose At $t=1.050 \mathrm{E}+03$ years

Water Independent Pathways (Inhalation excludes radon)

\begin{tabular}{|c|c|c|}
\hline ide & mrem/yr & fract. \\
\hline-241 & 1. $210 \mathrm{E}-11$ & 0.0000 \\
\hline-137 & $2.514 \mathrm{E}-16$ & 0.0000 \\
\hline-237 & $7.071 \mathrm{E}-08$ & 0.0000 \\
\hline-238 & 1. $296 \mathrm{E}-10$ & 0.0000 \\
\hline-239 & $3.318 \mathrm{E}-12$ & 0.0000 \\
\hline-240 & $8.057 \mathrm{E}-16$ & 0.0000 \\
\hline-99 & $2.490 \mathrm{E}-21$ & 0.0000 \\
\hline-228 & $0.000 \mathrm{E}+00$ & 0.0000 \\
\hline-230 & $8.932 \mathrm{E}-05$ & 0.0004 \\
\hline-232 & $9.216 \mathrm{E}-04$ & 0.0039 \\
\hline 234 & $4.523 E-07$ & 0.0000 \\
\hline 235 & $2.336 \mathrm{E}-08$ & 0.0000 \\
\hline 238 & $6.175 \mathrm{E}-07$ & 0.0000 \\
\hline & 03 & \\
\hline
\end{tabular}

Inhalation

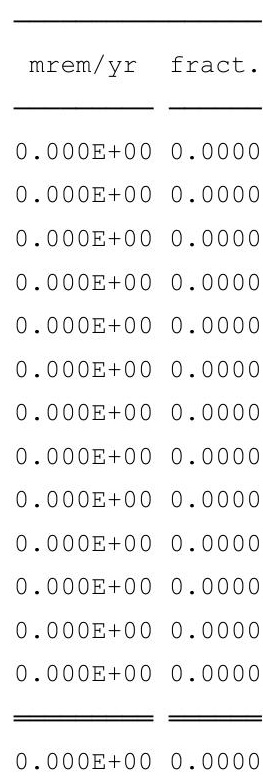

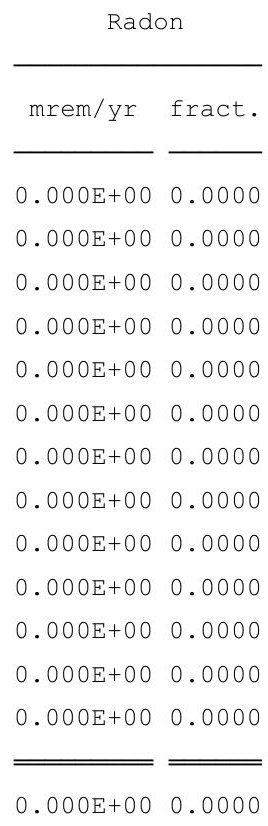

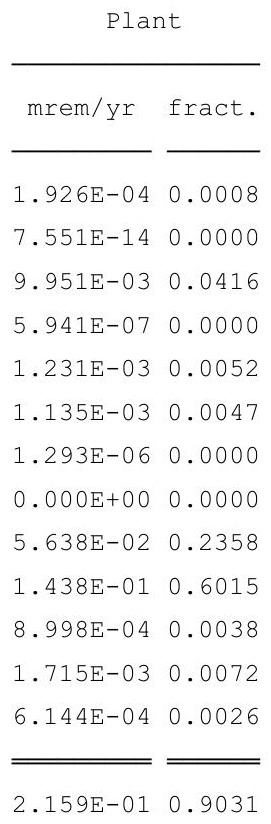

\begin{tabular}{ll} 
Meat \\
\hline mrem/yr fract. \\
\cline { 1 - 2 } $3.413 \mathrm{E}-07$ & 0.0000 \\
$6.863 \mathrm{E}-14$ & 0.0000 \\
$3.014 \mathrm{E}-04$ & 0.0013 \\
$5.269 \mathrm{E}-09$ & 0.0000 \\
$3.730 \mathrm{E}-06$ & 0.0000 \\
$3.440 \mathrm{E}-06$ & 0.0000 \\
$3.921 \mathrm{E}-09$ & 0.0000 \\
$0.000 \mathrm{E}+00$ & 0.0000 \\
$1.483 \mathrm{E}-03$ & 0.0062 \\
$4.243 \mathrm{E}-03$ & 0.0177 \\
$1.373 \mathrm{E}-05$ & 0.0001 \\
$1.264 \mathrm{E}-04$ & 0.0005 \\
$6.333 \mathrm{E}-06$ & 0.0000 \\
\hline \hline $6.181 \mathrm{E}-03$ & 0.0259 \\
\hline \hline
\end{tabular}

\begin{tabular}{cc} 
Milk \\
\cline { 1 - 2 } mrem/yr fract. \\
\cline { 1 - 1 } $3.276 \mathrm{E}-08$ & 0.0000 \\
$5.066 \mathrm{E}-14$ & 0.0000 \\
$4.312 \mathrm{E}-06$ & 0.0000 \\
$1.491 \mathrm{E}-08$ & 0.0000 \\
$1.033 \mathrm{E}-07$ & 0.0000 \\
$9.611 \mathrm{E}-08$ & 0.0000 \\
$1.085 \mathrm{E}-07$ & 0.0000 \\
$0.000 \mathrm{E}+00$ & 0.0000 \\
$2.628 \mathrm{E}-03$ & 0.0110 \\
$1.175 \mathrm{E}-02$ & 0.0491 \\
$4.413 \mathrm{E}-05$ & 0.0002 \\
$3.095 \mathrm{E}-05$ & 0.0001 \\
$3.092 \mathrm{E}-05$ & 0.0001 \\
\hline \hline $1.449 \mathrm{E}-02$ & 0.0606
\end{tabular}

Total Dose Contributions TDOSE (i,p,t) for Individual Radionuclides (i) and Pathways (p) As mrem/yr and Fraction of Total Dose At $t=1.050 \mathrm{E}+03$ years

Water Dependent Pathways

\begin{tabular}{llll} 
& & \multicolumn{2}{c}{ Water } \\
Radio- & & \\
Nuclide & mrem/yr & fract. \\
& & & \\
Am-241 & $0.000 \mathrm{E}+00$ & 0.0000 \\
$\mathrm{Cs}-137$ & $0.000 \mathrm{E}+00$ & 0.0000 \\
$\mathrm{~Np}-237$ & $0.000 \mathrm{E}+00$ & 0.0000 \\
Pu-238 & $0.000 \mathrm{E}+00$ & 0.0000 \\
Pu-239 & $0.000 \mathrm{E}+00$ & 0.0000 \\
Pu-240 & $0.000 \mathrm{E}+00$ & 0.0000 \\
$\mathrm{TC}-99$ & $1.224 \mathrm{E}-03$ & 0.0051 \\
$\mathrm{Th}-228$ & $0.000 \mathrm{E}+00$ & 0.0000 \\
$\mathrm{Th}-230$ & $0.000 \mathrm{E}+00$ & 0.0000 \\
$\mathrm{Th}-232$ & $0.000 \mathrm{E}+00$ & 0.0000 \\
$\mathrm{U}-234$ & $0.000 \mathrm{E}+00$ & 0.0000 \\
$\mathrm{U}-235$ & $0.000 \mathrm{E}+00$ & 0.0000 \\
$\mathrm{U}-238$ & $0.000 \mathrm{E}+00$ & 0.0000 \\
\hline \hline
\end{tabular}

Total

$1.224 \mathrm{E}-03 \quad 0.0051$

\begin{tabular}{cc} 
Fish \\
\cline { 1 - 2 } mrem/yr & fract. \\
\hline $0.000 \mathrm{E}+00$ & 0.0000 \\
$0.000 \mathrm{E}+00$ & 0.0000 \\
$0.000 \mathrm{E}+00$ & 0.0000 \\
$0.000 \mathrm{E}+00$ & 0.0000 \\
$0.000 \mathrm{E}+00$ & 0.0000 \\
$0.000 \mathrm{E}+00$ & 0.0000 \\
$0.000 \mathrm{E}+00$ & 0.0000 \\
$0.000 \mathrm{E}+00$ & 0.0000 \\
$0.000 \mathrm{E}+00$ & 0.0000 \\
$0.000 \mathrm{E}+00$ & 0.0000 \\
$0.000 \mathrm{E}+00$ & 0.0000 \\
$0.000 \mathrm{E}+00$ & 0.0000 \\
$0.000 \mathrm{E}+00$ & 0.0000 \\
\hline \hline
\end{tabular}

$0.000 \mathrm{E}+00 \quad 0.0000$

\begin{tabular}{|c|c|}
\hline $\mathrm{mrem} / \mathrm{yr}$ & fract \\
\hline $0.000 \mathrm{E}+00$ & 0.0000 \\
\hline $0.000 \mathrm{E}+00$ & 0.0000 \\
\hline $0.000 \mathrm{E}+00$ & 0.0000 \\
\hline $0.000 \mathrm{E}+00$ & 0.0000 \\
\hline $0.000 \mathrm{E}+00$ & 0.0000 \\
\hline $0.000 \mathrm{E}+00$ & 0.0000 \\
\hline $0.000 \mathrm{E}+00$ & 0.0000 \\
\hline $0.000 \mathrm{E}+00$ & 0.0000 \\
\hline $0.000 \mathrm{E}+00$ & 0.0000 \\
\hline $0.000 \mathrm{E}+00$ & 0.0000 \\
\hline $0.000 \mathrm{E}+00$ & 0.0000 \\
\hline $0.000 \mathrm{E}+00$ & 0.0000 \\
\hline $0.000 \mathrm{E}+00$ & 0.0000 \\
\hline
\end{tabular}

$0.000 \mathrm{E}+00 \quad 0.0000$

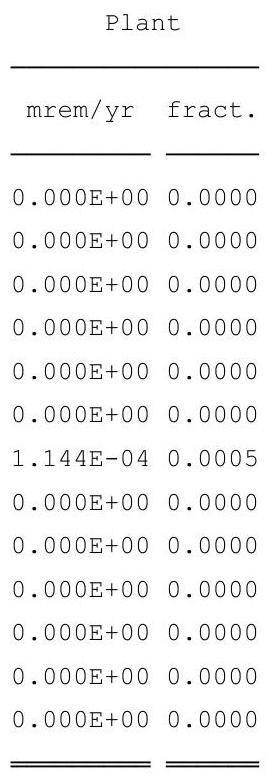

$1.144 \mathrm{E}-04 \quad 0.0005$

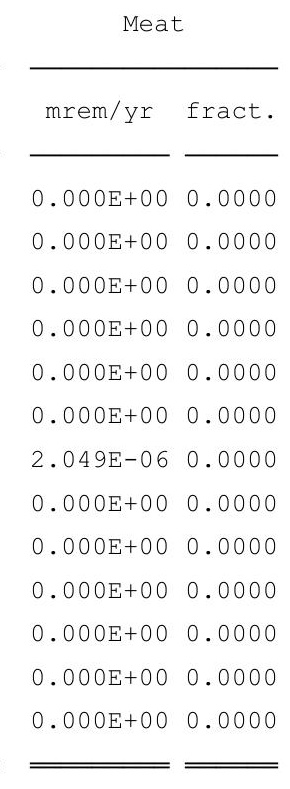

$2.049 \mathrm{E}-06 \quad 0.0000$

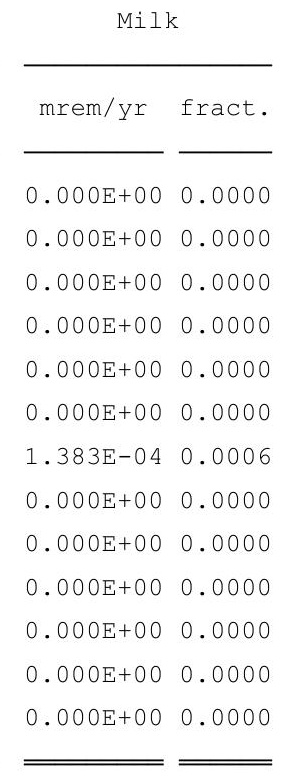

$1.383 \mathrm{E}-04 \quad 0.0006$
Soil

\begin{tabular}{lll} 
mrem/yr & fract. \\
\cline { 1 - 1 } $0.000 \mathrm{E}+00$ & 0.0000 \\
$0.000 \mathrm{E}+00$ & 0.0000 \\
$0.000 \mathrm{E}+00$ & 0.0000 \\
$0.000 \mathrm{E}+00$ & 0.0000 \\
$0.000 \mathrm{E}+00$ & 0.0000 \\
$0.000 \mathrm{E}+00$ & 0.0000 \\
$0.000 \mathrm{E}+00$ & 0.0000 \\
$0.000 \mathrm{E}+00$ & 0.0000 \\
$0.000 \mathrm{E}+00$ & 0.0000 \\
$0.000 \mathrm{E}+00$ & 0.0000 \\
$0.000 \mathrm{E}+00$ & 0.0000 \\
$0.000 \mathrm{E}+00$ & 0.0000 \\
$0.000 \mathrm{E}+00$ & 0.0000 \\
\hline \hline $0.000 \mathrm{E}+00$ & 0.0000
\end{tabular}

* Sum of all water independent and dependent pathways. 
RESRAD, Version $6.5 \quad \mathrm{~T}^{1 / 2}$ Limit $=180$ days

Summary : C746U Resident Farmer Deterministic Run

File : $\mathrm{X}: \backslash$ FINAL V2 $\backslash \mathrm{C746U}$ RF DET-FINALV2.RAD

Dose/Source Ratios Summed Over All Pathways

Parent and Progeny Principal Radionuclide Contributions Indicated

\begin{tabular}{|c|c|c|c|c|c|c|c|c|}
\hline Parent & Product & Thread & DSR & $(j, t)$ At & ime in Year & (mrer & $\mathrm{yr}) /(\mathrm{pCi} / \mathrm{c}$ & \\
\hline (i) & (j) & Fraction & $0.000 \mathrm{E}+00$ & $1.000 \mathrm{E}+00$ & $5.000 \mathrm{E}+01$ & $1.000 \mathrm{E}+02$ & $5.000 \mathrm{E}+02$ & $1.050 \mathrm{E}+03$ \\
\hline-241 & $A m-241$ & $1.000 \mathrm{E}+00$ & $1.910 \mathrm{E}-33$ & $1.962 \mathrm{E}-33$ & $7.255 E-33$ & $2.755 E-32$ & $1.192 \mathrm{E}-27$ & $1.912 \mathrm{E}-04$ \\
\hline-241 & $N p-237+D$ & $1.000 \mathrm{E}+00$ & $0.000 \mathrm{E}+00$ & $3.103 \mathrm{E}-19$ & $2.524 \mathrm{E}-17$ & $8.299 \mathrm{E}-17$ & $2.249 E-14$ & $1.774 \mathrm{E}-06$ \\
\hline-241 & $U-233$ & $1.000 \mathrm{E}+00$ & $0.000 \mathrm{E}+00$ & $1.055 \mathrm{E}-29$ & $4.739 E-26$ & $3.448 \mathrm{E}-25$ & $1.045 E-21$ & $3.144 \mathrm{E}-10$ \\
\hline $1-241$ & $\mathrm{Th}-229+\mathrm{D}$ & $1.000 \mathrm{E}+00$ & $0.000 \mathrm{E}+00$ & $9.607 \mathrm{E}-26$ & $1.654 \mathrm{E}-20$ & $1.834 \mathrm{E}-19$ & $3.175 E-16$ & $5.257 \mathrm{E}-11$ \\
\hline-241 & $\sum \operatorname{DSR}(j)$ & & $1.910 \mathrm{E}-33$ & $3.103 E-19$ & $2.526 \mathrm{E}-17$ & $8.317 \mathrm{E}-17$ & $2.281 E-14$ & $1.930 \mathrm{E}-04$ \\
\hline$-137+D$ & $\mathrm{Cs}-137+\mathrm{D}$ & $1.000 \mathrm{E}+00$ & $1.271 \mathrm{E}-09$ & $1.253 \mathrm{E}-09$ & $6.094 \mathrm{E}-10$ & $2.922 \mathrm{E}-10$ & $8.163 E-13$ & $1.950 \mathrm{E}-13$ \\
\hline$-237+D$ & $N p-237+D$ & $1.000 \mathrm{E}+00$ & $9.485 \mathrm{E}-13$ & $9.587 \mathrm{E}-13$ & 1. $617 \mathrm{E}-12$ & $2.756 \mathrm{E}-12$ & 1. $963 \mathrm{E}-10$ & $1.025 \mathrm{E}-02$ \\
\hline$-237+D$ & $\mathrm{U}-233$ & $1.000 \mathrm{E}+00$ & $0.000 \mathrm{E}+00$ & $6.517 \mathrm{E}-23$ & $6.002 E-21$ & $2.239 \mathrm{E}-20$ & 1. $638 \mathrm{E}-17$ & $2.955 E-06$ \\
\hline$-237+D$ & $\mathrm{Th}-229+\mathrm{D}$ & $1.000 \mathrm{E}+00$ & $0.000 \mathrm{E}+00$ & $8.902 \mathrm{E}-19$ & $3.122 \mathrm{E}-15$ & $1.764 \mathrm{E}-14$ & $7.041 \mathrm{E}-12$ & $6.620 \mathrm{E}-07$ \\
\hline$-237+D$ & $\sum \operatorname{DSR}(j)$ & & $9.485 E-13$ & $9.587 \mathrm{E}-13$ & 1. $620 \mathrm{E}-12$ & $2.773 \mathrm{E}-12$ & $2.033 E-10$ & $1.026 \mathrm{E}-02$ \\
\hline$x-238$ & $\mathrm{Pu}-238$ & $1.840 \mathrm{E}-09$ & $2.151 E-33$ & $2.172 \mathrm{E}-33$ & $3.503 E-33$ & $5.703 E-33$ & $2.817 \mathrm{E}-31$ & $5.383 E-16$ \\
\hline-238 & $\mathrm{Pu}-238$ & $1.000 \mathrm{E}+00$ & $1.169 \mathrm{E}-24$ & $1.181 \mathrm{E}-24$ & $1.904 \mathrm{E}-24$ & $3.100 \mathrm{E}-24$ & 1. $531 \mathrm{E}-22$ & $2.925 E-07$ \\
\hline-238 & $\mathrm{U}-234$ & $1.000 \mathrm{E}+00$ & $0.000 \mathrm{E}+00$ & $1.965 E-29$ & $1.939 \mathrm{E}-27$ & $7.864 \mathrm{E}-27$ & $1.675 E-23$ & $2.344 \mathrm{E}-07$ \\
\hline-238 & $T h-230$ & $1.000 \mathrm{E}+00$ & $0.000 \mathrm{E}+00$ & $3.096 E-33$ & $1.556 \mathrm{E}-29$ & $1.280 \mathrm{E}-28$ & $1.293 E-24$ & $3.186 \mathrm{E}-09$ \\
\hline-238 & $\mathrm{Ra}-226+\mathrm{D}$ & $1.000 \mathrm{E}+00$ & $0.000 \mathrm{E}+00$ & $3.212 \mathrm{E}-22$ & $5.098 \mathrm{E}-17$ & $5.231 \mathrm{E}-16$ & $5.574 \mathrm{E}-13$ & $3.395 E-08$ \\
\hline$x-238$ & $\mathrm{~Pb}-210+\mathrm{D}$ & $1.000 \mathrm{E}+00$ & $0.000 \mathrm{E}+00$ & $1.163 E-30$ & $7.464 \mathrm{E}-24$ & 1. $287 \mathrm{E}-22$ & $3.648 E-19$ & $5.037 \mathrm{E}-08$ \\
\hline$x-238$ & $\sum \operatorname{DSR}(j)$ & & $1.169 \mathrm{E}-24$ & $3.223 E-22$ & $5.098 \mathrm{E}-17$ & $5.231 \mathrm{E}-16$ & $5.574 E-13$ & $6.144 \mathrm{E}-07$ \\
\hline-239 & $\mathrm{Pu}-239$ & $1.000 \mathrm{E}+00$ & 1. $195 \mathrm{E}-17$ & 1. $209 \mathrm{E}-17$ & $2.170 \mathrm{E}-17$ & $3.941 \mathrm{E}-17$ & $4.662 E-15$ & 1. $235 \mathrm{E}-03$ \\
\hline$x-239$ & $\mathrm{U}-235+\mathrm{D}$ & $1.000 \mathrm{E}+00$ & $0.000 \mathrm{E}+00$ & 1. $232 \mathrm{E}-23$ & 1. $128 \mathrm{E}-21$ & $4.180 \mathrm{E}-21$ & $2.910 \mathrm{E}-18$ & $6.475 \mathrm{E}-10$ \\
\hline-239 & $\mathrm{~Pa}-231$ & $1.000 \mathrm{E}+00$ & $0.000 \mathrm{E}+00$ & $2.903 E-27$ & $1.220 \mathrm{E}-23$ & $8.286 \mathrm{E}-23$ & $1.434 \mathrm{E}-19$ & 4. $682 \mathrm{E}-10$ \\
\hline-239 & $A C-227+D$ & $1.000 \mathrm{E}+00$ & $0.000 \mathrm{E}+00$ & $9.153 \mathrm{E}-27$ & $1.237 \mathrm{E}-21$ & 1. $150 \mathrm{E}-20$ & $1.466 \mathrm{E}-17$ & $1.640 \mathrm{E}-10$ \\
\hline$x-239$ & $\sum \operatorname{DSR}(j)$ & & $1.195 \mathrm{E}-17$ & $1.209 \mathrm{E}-17$ & $2.170 \mathrm{E}-17$ & $3.943 E-17$ & $4.680 E-15$ & $1.235 \mathrm{E}-03$ \\
\hline-240 & $\mathrm{Pu}-240$ & $4.950 E-08$ & $5.604 \mathrm{E}-32$ & $5.703 E-32$ & $1.347 \mathrm{E}-31$ & $3.239 E-31$ & $3.615 E-28$ & $5.638 E-11$ \\
\hline-240 & $\mathrm{Pu}-240$ & $1.000 \mathrm{E}+00$ & $1.132 \mathrm{E}-24$ & $1.152 \mathrm{E}-24$ & $2.722 E-24$ & $6.543 E-24$ & 7. $302 E-21$ & $1.139 \mathrm{E}-03$ \\
\hline-240 & $\mathrm{U}-236$ & $1.000 \mathrm{E}+00$ & $0.000 \mathrm{E}+00$ & $4.350 E-32$ & $5.235 E-30$ & $2.566 \mathrm{E}-29$ & $1.669 E-25$ & $1.856 \mathrm{E}-08$ \\
\hline$x-240$ & Th-232 & $1.000 \mathrm{E}+00$ & $0.000 \mathrm{E}+00$ & $8.590 E-43$ & $5.322 \mathrm{E}-39$ & $5.373 E-38$ & $2.213 E-33$ & $9.120 \mathrm{E}-16$ \\
\hline-240 & $\mathrm{Ra}-228+\mathrm{D}$ & $1.000 \mathrm{E}+00$ & $0.000 \mathrm{E}+00$ & $5.459 \mathrm{E}-28$ & $3.662 \mathrm{E}-23$ & $2.505 E-22$ & 1. $461 \mathrm{E}-19$ & 1. $189 \mathrm{E}-13$ \\
\hline-240 & $T h-228+D$ & $1.000 \mathrm{E}+00$ & $0.000 \mathrm{E}+00$ & $3.996 \mathrm{E}-27$ & $2.570 \mathrm{E}-21$ & $1.733 E-20$ & $5.536 \mathrm{E}-18$ & $1.502 \mathrm{E}-15$ \\
\hline-240 & $\sum \operatorname{DSR}(j)$ & & $1.132 \mathrm{E}-24$ & $1.157 \mathrm{E}-24$ & $2.609 \mathrm{E}-21$ & 1. $758 \mathrm{E}-20$ & $5.690 E-18$ & $1.139 \mathrm{E}-03$ \\
\hline$=-99$ & $\mathrm{TC}-99$ & $1.000 \mathrm{E}+00$ & $5.729 \mathrm{E}-26$ & $5.787 \mathrm{E}-26$ & $9.526 \mathrm{E}-26$ & 1. $584 \mathrm{E}-25$ & $2.080 E-01$ & $1.480 \mathrm{E}-03$ \\
\hline$-228+D$ & $T h-228+D$ & $1.000 \mathrm{E}+00$ & $1.643 E-06$ & $1.151 \mathrm{E}-06$ & $3.003 E-14$ & $5.489 \mathrm{E}-22$ & $0.000 \mathrm{E}+00$ & $0.000 \mathrm{E}+00$ \\
\hline 230 & $T h-230$ & $1.000 \mathrm{E}+00$ & $2.392 \mathrm{E}-22$ & $2.432 \mathrm{E}-22$ & $5.543 E-22$ & 1. $285 \mathrm{E}-21$ & $1.069 \mathrm{E}-18$ & $1.076 \mathrm{E}-03$ \\
\hline 230 & $\mathrm{Ra}-226+\mathrm{D}$ & $1.000 \mathrm{E}+00$ & $0.000 \mathrm{E}+00$ & $7.565 \mathrm{E}-11$ & $5.249 \mathrm{E}-09$ & $1.467 \mathrm{E}-08$ & $1.066 E-06$ & $2.340 E-02$ \\
\hline-230 & $\mathrm{~Pb}-210+\mathrm{D}$ & $1.000 \mathrm{E}+00$ & $0.000 \mathrm{E}+00$ & $5.454 \mathrm{E}-19$ & $1.273 E-15$ & $5.257 \mathrm{E}-15$ & $7.641 \mathrm{E}-13$ & $3.610 \mathrm{E}-02$ \\
\hline 230 & $\sum \operatorname{DSR}(j)$ & & $2.392 \mathrm{E}-22$ & $7.565 \mathrm{E}-11$ & $5.249 E-09$ & $1.467 \mathrm{E}-08$ & $1.066 \mathrm{E}-06$ & $6.058 \mathrm{E}-02$ \\
\hline
\end{tabular}


RESRAD, Version $6.5 \quad \mathrm{~T}^{1} \frac{1}{2}$ Limit $=180$ days

Summary : C746U Resident Farmer Deterministic Run

File : $\mathrm{X}: \backslash$ FINAL V2 $\backslash \mathrm{C746U}$ RF DET-FINALV2.RAD

Dose/Source Ratios Summed Over All Pathways

Parent and Progeny Principal Radionuclide Contributions Indicated

\begin{tabular}{|c|c|c|c|c|c|c|c|c|}
\hline Parent & Product & Thread & DSR & $(j, t)$ At & ime in Yea & (mrem) & $/ \mathrm{yr}) /(\mathrm{pCi} /$ & \\
\hline (i) & (j) & Fraction & $0.000 \mathrm{E}+00$ & $1.000 \mathrm{E}+00$ & $5.000 \mathrm{E}+01$ & $1.000 \mathrm{E}+02$ & $5.000 \mathrm{E}+02$ & $1.050 \mathrm{E}+03$ \\
\hline-232 & Th-232 & $1.000 \mathrm{E}+00$ & $1.155 \mathrm{E}-24$ & $1.177 E-24$ & $2.922 E-24$ & 7. $393 E-24$ & $1.241 \mathrm{E}-20$ & $1.189 \mathrm{E}-03$ \\
\hline$h-232$ & $\mathrm{Ra}-228+\mathrm{D}$ & $1.000 \mathrm{E}+00$ & $0.000 \mathrm{E}+00$ & $2.177 \mathrm{E}-09$ & $2.773 E-08$ & $4.064 \mathrm{E}-08$ & $8.465 \mathrm{E}-07$ & $1.576 \mathrm{E}-01$ \\
\hline$h-232$ & $\mathrm{Th}-228+\mathrm{D}$ & $1.000 \mathrm{E}+00$ & $0.000 \mathrm{E}+00$ & $3.082 \mathrm{E}-08$ & $2.206 E-06$ & $2.983 E-06$ & $3.244 \mathrm{E}-05$ & $1.998 E-03$ \\
\hline$h-232$ & $\sum \operatorname{DSR}(j)$ & & $1.155 \mathrm{E}-24$ & $3.300 E-08$ & $2.234 E-06$ & $3.024 \mathrm{E}-06$ & $3.328 E-05$ & $1.607 \mathrm{E}-01$ \\
\hline-234 & $\mathrm{U}-234$ & $1.000 \mathrm{E}+00$ & $6.835 E-24$ & $6.957 \mathrm{E}-24$ & $1.656 \mathrm{E}-23$ & $4.011 E-23$ & $4.756 \mathrm{E}-20$ & $6.525 E-04$ \\
\hline-234 & $\mathrm{Th}-230$ & $1.000 \mathrm{E}+00$ & $0.000 \mathrm{E}+00$ & $2.190 \mathrm{E}-27$ & $2.494 \mathrm{E}-25$ & $1.156 \mathrm{E}-24$ & 4. $793 E-21$ & $1.009 \mathrm{E}-05$ \\
\hline-234 & $\mathrm{Ra}-226+\mathrm{D}$ & $1.000 \mathrm{E}+00$ & $0.000 \mathrm{E}+00$ & $3.405 E-16$ & $1.185 \mathrm{E}-12$ & $6.647 \mathrm{E}-12$ & $2.482 \mathrm{E}-09$ & $1.185 \mathrm{E}-04$ \\
\hline-234 & $\mathrm{~Pb}-210+\mathrm{D}$ & $1.000 \mathrm{E}+00$ & $0.000 \mathrm{E}+00$ & 1. $641 \mathrm{E}-24$ & $2.135 E-19$ & $1.903 \mathrm{E}-18$ & $1.668 \mathrm{E}-15$ & $1.770 \mathrm{E}-04$ \\
\hline-234 & $\sum \operatorname{DSR}(j)$ & & $6.835 E-24$ & $3.405 E-16$ & $1.185 \mathrm{E}-12$ & $6.647 \mathrm{E}-12$ & $2.482 E-09$ & $9.581 \mathrm{E}-04$ \\
\hline$-235+D$ & $\mathrm{U}-235+\mathrm{D}$ & $1.000 \mathrm{E}+00$ & $1.236 \mathrm{E}-14$ & 1. $251 \mathrm{E}-14$ & $2.291 E-14$ & $4.249 \mathrm{E}-14$ & $5.944 \mathrm{E}-12$ & $6.337 E-04$ \\
\hline$-235+D$ & $\mathrm{~Pa}-231$ & $1.000 \mathrm{E}+00$ & $0.000 \mathrm{E}+00$ & $5.896 \mathrm{E}-18$ & 4. $955 \mathrm{E}-16$ & $1.684 \mathrm{E}-15$ & $5.839 \mathrm{E}-13$ & $9.104 \mathrm{E}-04$ \\
\hline$-235+D$ & $A C-227+D$ & $1.000 \mathrm{E}+00$ & $0.000 \mathrm{E}+00$ & $2.781 \mathrm{E}-17$ & $6.744 \mathrm{E}-14$ & $2.910 \mathrm{E}-13$ & $6.341 \mathrm{E}-11$ & $3.284 \mathrm{E}-04$ \\
\hline$-235+D$ & $\sum \operatorname{DSR}(j)$ & & $1.236 \mathrm{E}-14$ & $1.254 \mathrm{E}-14$ & $9.085 E-14$ & $3.352 E-13$ & $6.994 \mathrm{E}-11$ & $1.873 E-03$ \\
\hline-238 & $\mathrm{U}-238$ & $5.400 \mathrm{E}-05$ & $0.000 \mathrm{E}+00$ & $0.000 \mathrm{E}+00$ & $0.000 \mathrm{E}+00$ & $0.000 \mathrm{E}+00$ & $0.000 \mathrm{E}+00$ & $3.261 \mathrm{E}-08$ \\
\hline$-238+D$ & $U-238+D$ & $9.999 \mathrm{E}-01$ & $1.414 \mathrm{E}-10$ & $1.425 \mathrm{E}-10$ & $2.107 \mathrm{E}-10$ & $3.141 \mathrm{E}-10$ & $7.648 \mathrm{E}-09$ & $6.500 \mathrm{E}-04$ \\
\hline$-238+D$ & $\mathrm{U}-234$ & $9.999 \mathrm{E}-01$ & $0.000 \mathrm{E}+00$ & $1.972 \mathrm{E}-29$ & $2.347 E-27$ & $1.137 \mathrm{E}-26$ & $6.745 E-23$ & $1.945 E-06$ \\
\hline$-238+D$ & $T h-230$ & $9.999 \mathrm{E}-01$ & $0.000 \mathrm{E}+00$ & $3.104 \mathrm{E}-33$ & $1.767 \mathrm{E}-29$ & $1.638 \mathrm{E}-28$ & $3.394 \mathrm{E}-24$ & $1.500 \mathrm{E}-08$ \\
\hline$-238+D$ & $\mathrm{Ra}-226+\mathrm{D}$ & $9.999 \mathrm{E}-01$ & $0.000 \mathrm{E}+00$ & $3.218 \mathrm{E}-22$ & $5.610 \mathrm{E}-17$ & $6.303 E-16$ & $1.193 \mathrm{E}-12$ & $1.217 \mathrm{E}-07$ \\
\hline$-238+D$ & $\mathrm{~Pb}-210+\mathrm{D}$ & $9.999 \mathrm{E}-01$ & $0.000 \mathrm{E}+00$ & $1.165 \mathrm{E}-30$ & $8.088 E-24$ & $1.513 E-22$ & 7. $559 \mathrm{E}-19$ & $1.765 \mathrm{E}-07$ \\
\hline$-238+D$ & $\sum \operatorname{DSR}(j)$ & & $1.414 \mathrm{E}-10$ & 1. $425 \mathrm{E}-10$ & $2.107 \mathrm{E}-10$ & $3.141 \mathrm{E}-10$ & $7.649 \mathrm{E}-09$ & $6.523 E-04$ \\
\hline
\end{tabular}

The DSR includes contributions from associated (half-life $\leq 180$ days) daughters. 
RESRAD, Version $6.5 \quad \mathrm{~T}^{1 / 2}$ Limit $=180$ days

ummary : C746U Resident Farmer Deterministic Run

File : $\mathrm{X}: \backslash \mathrm{FINAL}$ V2 $\backslash \mathrm{C746U}$ RF DET-FINALV2.RAD

Single Radionuclide Soil Guidelines G(i,t) in pCi/g

Basic Radiation Dose Limit $=1.000 \mathrm{E}+02 \mathrm{mrem} / \mathrm{yr}$

Nuclide

\begin{tabular}{|c|c|c|c|c|c|c|}
\hline (i) & $t=0.000 E+00$ & $1.000 \mathrm{E}+00$ & $5.000 E+01$ & $1.000 \mathrm{E}+02$ & $5.000 \mathrm{E}+02$ & $1.050 \mathrm{E}+03$ \\
\hline$n-241$ & $\star 3.431 \mathrm{E}+12$ & $\star 3.431 \mathrm{E}+12$ & $\star 3.431 \mathrm{E}+12$ & $\star 3.431 \mathrm{E}+12$ & $\star 3.431 \mathrm{E}+12$ & $5.181 \mathrm{E}+05$ \\
\hline$s-137$ & $7.867 \mathrm{E}+10$ & $7.984 \mathrm{E}+10$ & $1.641 \mathrm{E}+11$ & $3.422 \mathrm{E}+11$ & $\star 8.704 \mathrm{E}+13$ & $\star 8.704 \mathrm{E}+13$ \\
\hline$p-237$ & $\star 7.047 \mathrm{E}+08$ & $\star 7.047 \mathrm{E}+08$ & $\star 7.047 \mathrm{E}+08$ & $\star 7.047 \mathrm{E}+08$ & $\star 7.047 \mathrm{E}+08$ & $9.749 \mathrm{E}+03$ \\
\hline$u-238$ & $\star 1.712 \mathrm{E}+13$ & $\star 1.712 \mathrm{E}+13$ & $\star 1.712 \mathrm{E}+13$ & $\star 1.712 \mathrm{E}+13$ & $\star 1.712 \mathrm{E}+13$ & $1.628 \mathrm{E}+08$ \\
\hline$u-239$ & $\star 6.214 \mathrm{E}+10$ & $\star 6.214 \mathrm{E}+10$ & $\star 6.214 \mathrm{E}+10$ & $\star 6.214 \mathrm{E}+10$ & $\star 6.214 \mathrm{E}+10$ & $8.096 \mathrm{E}+04$ \\
\hline$u-240$ & $\star 2.278 \mathrm{E}+11$ & $\star 2.278 \mathrm{E}+11$ & $\star 2.278 \mathrm{E}+11$ & $\star 2.278 \mathrm{E}+11$ & $\star 2.278 \mathrm{E}+11$ & $8.779 \mathrm{E}+04$ \\
\hline$c-99$ & $\star 1.697 \mathrm{E}+10$ & $\star 1.697 \mathrm{E}+10$ & $\star 1.697 \mathrm{E}+10$ & $\star 1.697 \mathrm{E}+10$ & $4.808 E+02$ & $6.756 \mathrm{E}+04$ \\
\hline Th-228 & $6.085 \mathrm{E}+07$ & $8.690 \mathrm{E}+07$ & $\star 8.195 \mathrm{E}+14$ & $\star 8.195 \mathrm{E}+14$ & $\star 8.195 \mathrm{E}+14$ & $\star 8.195 \mathrm{E}+14$ \\
\hline Th-230 & $\star 2.018 \mathrm{E}+10$ & $\star 2.018 \mathrm{E}+10$ & $1.905 \mathrm{E}+10$ & $6.818 E+09$ & $9.377 \mathrm{E}+07$ & $1.651 \mathrm{E}+03$ \\
\hline Th-232 & $\star 1.097 \mathrm{E}+05$ & $* 1.097 \mathrm{E}+05$ & $\star 1.097 \mathrm{E}+05$ & $\star 1.097 \mathrm{E}+05$ & $\star 1.097 \mathrm{E}+05$ & $6.221 \mathrm{E}+02$ \\
\hline$U-234$ & $* 6.247 \mathrm{E}+09$ & $* 6.247 \mathrm{E}+09$ & $* 6.247 \mathrm{E}+09$ & $\star 6.247 \mathrm{E}+09$ & $\star 6.247 \mathrm{E}+09$ & $1.044 \mathrm{E}+05$ \\
\hline$U-235$ & $\star 2.161 \mathrm{E}+06$ & $\star 2.161 \mathrm{E}+06$ & $\star 2.161 \mathrm{E}+06$ & $\star 2.161 \mathrm{E}+06$ & $\star 2.161 \mathrm{E}+06$ & $5.340 \mathrm{E}+04$ \\
\hline$J-238$ & $\star 3.361 \mathrm{E}+05$ & $\star 3.361 \mathrm{E}+05$ & $\star 3.361 \mathrm{E}+05$ & $\star 3.361 \mathrm{E}+05$ & $\star 3.361 \mathrm{E}+05$ & $1.533 \mathrm{E}+05$ \\
\hline
\end{tabular}

*At specific activity limit

Summed Dose/Source Ratios DSR (i,t) in (mrem/yr)/(pCi/g) and Single Radionuclide Soil Guidelines $G(i, t)$ in pCi/g

at $\operatorname{tmin}=$ time of minimum single radionuclide soil guideline and at $\operatorname{tmax}=$ time of maximum total dose $=425.2 \pm 0.9$ years

\begin{tabular}{|c|c|c|c|c|c|c|}
\hline $\begin{array}{l}\text { uclide } \\
\text { (i) }\end{array}$ & $\begin{array}{l}\text { Initial } \\
(\mathrm{pCi} / \mathrm{g})\end{array}$ & $\begin{array}{c}\text { tmin } \\
\text { (years) }\end{array}$ & $\operatorname{DSR}(i, \operatorname{tmin})$ & $\begin{array}{c}\mathrm{G}(\mathrm{i}, \mathrm{tmin}) \\
(\mathrm{pCi} / \mathrm{g})\end{array}$ & $\operatorname{DSR}(i, t \max )$ & $\begin{array}{c}G(i, t \max ) \\
(\mathrm{pC} i / g)\end{array}$ \\
\hline$n-241$ & $1.000 \mathrm{E}+00$ & $1.050 \mathrm{E}+03$ & $1.930 \mathrm{E}-04$ & $5.181 \mathrm{E}+05$ & $9.162 \mathrm{E}-15$ & $\star 3.431 \mathrm{E}+12$ \\
\hline-137 & $1.000 \mathrm{E}+00$ & $0.000 \mathrm{E}+00$ & $1.271 E-09$ & $7.867 \mathrm{E}+10$ & $2.453 E-12$ & $4.077 E+13$ \\
\hline-237 & $1.000 \mathrm{E}+00$ & $1.050 \mathrm{E}+03$ & $1.026 \mathrm{E}-02$ & $9.749 \mathrm{E}+03$ & $9.140 \mathrm{E}-11$ & $\star 7.047 \mathrm{E}+08$ \\
\hline-238 & $1.000 \mathrm{E}+00$ & $1.050 \mathrm{E}+03$ & $6.144 \mathrm{E}-07$ & $1.628 \mathrm{E}+08$ & $2.257 \mathrm{E}-13$ & $\star 1.712 \mathrm{E}+13$ \\
\hline-239 & $1.000 \mathrm{E}+00$ & $1.050 \mathrm{E}+03$ & $1.235 E-03$ & $8.096 \mathrm{E}+04$ & $1.915 \mathrm{E}-15$ & $\star 6.214 \mathrm{E}+10$ \\
\hline-240 & $1.000 \mathrm{E}+00$ & $1.050 \mathrm{E}+03$ & $1.139 \mathrm{E}-03$ & $8.779 \mathrm{E}+04$ & $2.612 \mathrm{E}-18$ & $\star 2.278 \mathrm{E}+11$ \\
\hline$z-99$ & $1.000 \mathrm{E}+00$ & $425.2 \pm 0.9$ & $4.076 \mathrm{E}-01$ & $2.453 E+02$ & $4.076 \mathrm{E}-01$ & $2.453 E+02$ \\
\hline-228 & $1.000 \mathrm{E}+00$ & $0.000 \mathrm{E}+00$ & $1.643 E-06$ & $6.085 E+07$ & $0.000 \mathrm{E}+00$ & $\star 8.195 \mathrm{E}+14$ \\
\hline-230 & $1.000 \mathrm{E}+00$ & $1.050 \mathrm{E}+03$ & $6.058 E-02$ & $1.651 \mathrm{E}+03$ & $5.495 \mathrm{E}-07$ & $1.820 \mathrm{E}+08$ \\
\hline-232 & $1.000 \mathrm{E}+00$ & $1.050 \mathrm{E}+03$ & $1.607 E-01$ & $6.221 E+02$ & $2.123 E-05$ & $\star 1.097 \mathrm{E}+05$ \\
\hline 234 & $1.000 \mathrm{E}+00$ & $1.050 \mathrm{E}+03$ & $9.581 E-04$ & $1.044 \mathrm{E}+05$ & $1.082 E-09$ & $\star 6.247 \mathrm{E}+09$ \\
\hline 235 & $1.000 \mathrm{E}+00$ & $1.050 \mathrm{E}+03$ & $1.873 E-03$ & $5.340 \mathrm{E}+04$ & $3.031 \mathrm{E}-11$ & $\star 2.161 \mathrm{E}+06$ \\
\hline 238 & $1.000 \mathrm{E}+00$ & $1.050 \mathrm{E}+03$ & $6.523 \mathrm{E}-04$ & $1.533 \mathrm{E}+05$ & $4.209 \mathrm{E}-09$ & $\star 3.361 \mathrm{E}+05$ \\
\hline
\end{tabular}

*At specific activity limit 
RESRAD, Version $6.5 \quad \mathrm{~T}^{1 / 2}$ Limit $=180$ days

Summary : C746U Resident Farmer Deterministic Run

File : $\mathrm{X}: \backslash$ FINAL V2 $\backslash \mathrm{C746U}$ RF DET-FINALV2.RAD

Individual Nuclide Dose Summed Over All Pathways

Parent Nuclide and Branch Fraction Indicated

Nuclide Parent THF(i) DOSE $(j, t)$, mrem/yr

\begin{tabular}{|c|c|c|c|c|c|c|c|c|c|}
\hline (j) & (i) & & $t=$ & $0.000 \mathrm{E}+00$ & $1.000 \mathrm{E}+00$ & $5.000 \mathrm{E}+01$ & $1.000 \mathrm{E}+02$ & $5.000 \mathrm{E}+02$ & $1.050 \mathrm{E}+03$ \\
\hline$A m-241$ & Am-241 & $1.000 \mathrm{E}+00$ & & $0.000 E+00$ & $0.000 \mathrm{E}+00$ & $0.000 \mathrm{E}+00$ & $0.000 \mathrm{E}+00$ & $1.192 \mathrm{E}-27$ & 1.912E-04 \\
\hline
\end{tabular}

$\mathrm{Np}-237 \quad \mathrm{Am}-241 \quad 1.000 \mathrm{E}+00$

$\mathrm{Np}-237 \quad \mathrm{~Np}-237 \quad 1.000 \mathrm{E}+00$

Np-237 $\sum$ DOSE $(j)$

$\mathrm{U}-233$ Am-241 1.000E+00

$\mathrm{U}-233 \mathrm{~Np}-237 \quad 1.000 \mathrm{E}+00$

U-233 $\sum \mathrm{DOSE}(j)$

Th-229 Am-241 1.000E+00

Th-229 Np-237 1.000E+00

Th-229 ¿DOSE $(j)$

Cs-137 Cs $-137 \quad 1.000 E+00$

Pu-238 Pu-238 1.840E-09

$\mathrm{Pu}-238 \quad \mathrm{Pu}-238 \quad 1.000 \mathrm{E}+00$

$\mathrm{Pu}-238 \quad \sum \mathrm{DOSE}(j)$

$\mathrm{U}-234$

$\mathrm{U}-234$

$\mathrm{U}-234$

$\mathrm{U}-234$

$\mathrm{Th}-230$

$\mathrm{Th}-230$

$\mathrm{Th}-230$

$\mathrm{Th}-230$

$\mathrm{Th}-230$

$\mathrm{Ra}-226$

$\mathrm{Ra}-226$

$\mathrm{Ra}-226$

$\mathrm{Ra}-226$

$\mathrm{Ra}-226$

$\mathrm{Pb}-210$

$\mathrm{Pb}-210$

$\mathrm{Pb}-210$

$\mathrm{Pb}-210$

$\mathrm{Pb}-210$

$\mathrm{Pu}-239$

$\mathrm{Pu}-238$ 1.000E+00

$\mathrm{U}-234 \quad 1.000 \mathrm{E}+00$

$\mathrm{U}-238 \quad 9.999 \mathrm{E}-01$

$\sum \operatorname{DOSE}(j)$

$\mathrm{Pu}-238 \quad 1.000 \mathrm{E}+00$

Th-230 1.000E+00

$\mathrm{U}-234 \quad 1.000 \mathrm{E}+00$

$\mathrm{U}-238 \quad 9.999 \mathrm{E}-01$

$\sum \operatorname{DOSE}(j)$

$\mathrm{Pu}-238 \quad 1.000 \mathrm{E}+00$

Th-230 1.000E+00

$\mathrm{U}-234 \quad 1.000 \mathrm{E}+00$

U-238 9.999E-01

$\sum \operatorname{DOSE}(j)$

$\mathrm{Pu}-238$ 1.000E+00

Th-230 1.000E+00

$\mathrm{U}-234 \quad 1.000 \mathrm{E}+00$

U-238 9.999E-01

¿DOSE (j)

Pu-239 1.000E+00

$\mathrm{Pu}-239$ 1.000E+00

$\mathrm{U}-2351.000 \mathrm{E}+00$

$\sum \operatorname{DOSE}(j)$ $\begin{array}{lllllll}0.000 \mathrm{E}+00 & 3.103 \mathrm{E}-19 & 2.524 \mathrm{E}-17 & 8.299 \mathrm{E}-17 & 2.249 \mathrm{E}-14 & 1.774 \mathrm{E}-06\end{array}$

$9.485 \mathrm{E}-13 \quad 9.587 \mathrm{E}-13 \quad 1.617 \mathrm{E}-12 \quad 2.756 \mathrm{E}-12 \quad 1.963 \mathrm{E}-10 \quad 1.025 \mathrm{E}-02$ $9.485 \mathrm{E}-13 \quad 9.587 \mathrm{E}-13 \quad 1.617 \mathrm{E}-12 \quad 2.756 \mathrm{E}-12 \quad 1.963 \mathrm{E}-10 \quad 1.026 \mathrm{E}-02$

$0.000 \mathrm{E}+00 \quad 1.055 \mathrm{E}-29 \quad 4.739 \mathrm{E}-26 \quad 3.448 \mathrm{E}-25 \quad 1.045 \mathrm{E}-21 \quad 3.144 \mathrm{E}-10$ $0.000 \mathrm{E}+00 \quad 6.517 \mathrm{E}-23 \quad 6.002 \mathrm{E}-21 \quad 2.239 \mathrm{E}-20 \quad 1.638 \mathrm{E}-17 \quad 2.955 \mathrm{E}-06$ $\begin{array}{lllllll}0.000 \mathrm{E}+00 & 6.517 \mathrm{E}-23 & 6.002 \mathrm{E}-21 & 2.239 \mathrm{E}-20 & 1.638 \mathrm{E}-17 & 2.955 \mathrm{E}-06\end{array}$

$0.000 \mathrm{E}+00 \quad 9.607 \mathrm{E}-26 \quad 1.654 \mathrm{E}-20 \quad 1.834 \mathrm{E}-19 \quad 3.175 \mathrm{E}-16 \quad 5.257 \mathrm{E}-11$ $0.000 \mathrm{E}+00 \quad 8.902 \mathrm{E}-19 \quad 3.122 \mathrm{E}-15 \quad 1.764 \mathrm{E}-14 \quad 7.041 \mathrm{E}-12 \quad 6.620 \mathrm{E}-07$ $0.000 \mathrm{E}+00 \quad 8.902 \mathrm{E}-19 \quad 3.122 \mathrm{E}-15 \quad 1.764 \mathrm{E}-14 \quad 7.041 \mathrm{E}-12 \quad 6.620 \mathrm{E}-07$ $\begin{array}{llllll}1.271 E-09 & 1.253 E-09 & 6.094 E-10 & 2.922 E-10 & 8.163 E-13 & 1.950 E-13\end{array}$ $\begin{array}{llllll}0.000 \mathrm{E}+00 & 0.000 \mathrm{E}+00 & 0.000 \mathrm{E}+00 & 0.000 \mathrm{E}+00 & 0.000 \mathrm{E}+00 & 5.383 \mathrm{E}-16\end{array}$ $\begin{array}{llllll}1.169 \mathrm{E}-24 & 1.181 \mathrm{E}-24 & 1.904 \mathrm{E}-24 & 3.100 \mathrm{E}-24 & 1.531 \mathrm{E}-22 & 2.925 \mathrm{E}-07\end{array}$

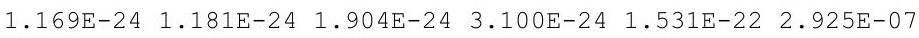

$0.000 \mathrm{E}+00 \quad 1.965 \mathrm{E}-29 \quad 1.939 \mathrm{E}-27 \quad 7.864 \mathrm{E}-27 \quad 1.675 \mathrm{E}-23 \quad 2.344 \mathrm{E}-07$ $6.835 \mathrm{E}-24 \quad 6.957 \mathrm{E}-24 \quad 1.656 \mathrm{E}-23 \quad 4.011 \mathrm{E}-23 \quad 4.756 \mathrm{E}-20 \quad 6.525 \mathrm{E}-04$ $\begin{array}{llllll}0.000 \mathrm{E}+00 & 1.972 \mathrm{E}-29 & 2.347 \mathrm{E}-27 & 1.137 \mathrm{E}-26 & 6.745 \mathrm{E}-23 & 1.945 \mathrm{E}-06\end{array}$ $\begin{array}{lllllll}6.835 E-24 & 6.957 E-24 & 1.656 E-23 & 4.013 E-23 & 4.764 E-20 & 6.547 E-04\end{array}$

$0.000 \mathrm{E}+00 \quad 0.000 \mathrm{E}+00 \quad 1.556 \mathrm{E}-29 \quad 1.280 \mathrm{E}-28 \quad 1.293 \mathrm{E}-24 \quad 3.186 \mathrm{E}-09$ $2.392 \mathrm{E}-22 \quad 2.432 \mathrm{E}-22 \quad 5.543 \mathrm{E}-22 \quad 1.285 \mathrm{E}-21 \quad 1.069 \mathrm{E}-18 \quad 1.076 \mathrm{E}-03$ $0.000 \mathrm{E}+00 \quad 2.190 \mathrm{E}-27 \quad 2.494 \mathrm{E}-25 \quad 1.156 \mathrm{E}-24 \quad 4.793 \mathrm{E}-21 \quad 1.009 \mathrm{E}-05$ $0.000 \mathrm{E}+00 \quad 0.000 \mathrm{E}+00 \quad 1.767 \mathrm{E}-29 \quad 1.638 \mathrm{E}-28 \quad 3.394 \mathrm{E}-24 \quad 1.500 \mathrm{E}-08$ $2.392 \mathrm{E}-22 \quad 2.432 \mathrm{E}-22 \quad 5.546 \mathrm{E}-22 \quad 1.286 \mathrm{E}-21 \quad 1.073 \mathrm{E}-18 \quad 1.086 \mathrm{E}-03$

$0.000 \mathrm{E}+00 \quad 3.212 \mathrm{E}-22 \quad 5.098 \mathrm{E}-17 \quad 5.231 \mathrm{E}-16 \quad 5.574 \mathrm{E}-13 \quad 3.395 \mathrm{E}-08$ $0.000 \mathrm{E}+00 \quad 7.565 \mathrm{E}-11 \quad 5.249 \mathrm{E}-09 \quad 1.467 \mathrm{E}-08 \quad 1.066 \mathrm{E}-06 \quad 2.340 \mathrm{E}-02$ $\begin{array}{lllllll}0.000 \mathrm{E}+00 & 3.405 \mathrm{E}-16 & 1.185 \mathrm{E}-12 & 6.647 \mathrm{E}-12 & 2.482 \mathrm{E}-09 & 1.185 \mathrm{E}-04\end{array}$ $0.000 \mathrm{E}+00 \quad 3.218 \mathrm{E}-22 \quad 5.610 \mathrm{E}-17 \quad 6.303 \mathrm{E}-16 \quad 1.193 \mathrm{E}-12 \quad 1.217 \mathrm{E}-07$ $0.000 \mathrm{E}+00 \quad 7.565 \mathrm{E}-11 \quad 5.250 \mathrm{E}-09 \quad 1.467 \mathrm{E}-08 \quad 1.069 \mathrm{E}-06 \quad 2.352 \mathrm{E}-02$

$0.000 \mathrm{E}+00 \quad 1.163 \mathrm{E}-30 \quad 7.464 \mathrm{E}-24 \quad 1.287 \mathrm{E}-22 \quad 3.648 \mathrm{E}-19 \quad 5.037 \mathrm{E}-08$ $0.000 \mathrm{E}+00 \quad 5.454 \mathrm{E}-19 \quad 1.273 \mathrm{E}-15 \quad 5.257 \mathrm{E}-15 \quad 7.641 \mathrm{E}-13 \quad 3.610 \mathrm{E}-02$ $0.000 \mathrm{E}+00 \quad 1.641 \mathrm{E}-24 \quad 2.135 \mathrm{E}-19 \quad 1.903 \mathrm{E}-18 \quad 1.668 \mathrm{E}-15 \quad 1.770 \mathrm{E}-04$ $0.000 \mathrm{E}+00 \quad 1.165 \mathrm{E}-30 \quad 8.088 \mathrm{E}-24 \quad 1.513 \mathrm{E}-22 \quad 7.559 \mathrm{E}-19 \quad 1.765 \mathrm{E}-07$ $0.000 \mathrm{E}+00 \quad 5.454 \mathrm{E}-19 \quad 1.274 \mathrm{E}-15 \quad 5.259 \mathrm{E}-15 \quad 7.657 \mathrm{E}-13 \quad 3.628 \mathrm{E}-02$ $1.195 \mathrm{E}-17 \quad 1.209 \mathrm{E}-17 \quad 2.170 \mathrm{E}-17 \quad 3.941 \mathrm{E}-17 \quad 4.662 \mathrm{E}-15 \quad 1.235 \mathrm{E}-03$ $0.000 \mathrm{E}+00 \quad 1.232 \mathrm{E}-23 \quad 1.128 \mathrm{E}-21 \quad 4.180 \mathrm{E}-21 \quad 2.910 \mathrm{E}-18 \quad 6.475 \mathrm{E}-10$ $\begin{array}{lllllll}1.236 \mathrm{E}-14 & 1.251 \mathrm{E}-14 & 2.291 \mathrm{E}-14 & 4.249 \mathrm{E}-14 & 5.944 \mathrm{E}-12 & 6.337 \mathrm{E}-04\end{array}$ $\begin{array}{lllllll}1.236 \mathrm{E}-14 & 1.251 \mathrm{E}-14 & 2.291 \mathrm{E}-14 & 4.249 \mathrm{E}-14 & 5.944 \mathrm{E}-12 & 6.337 \mathrm{E}-04\end{array}$ 
RESRAD, Version $6.5 \quad \mathrm{~T}^{1 / 2}$ Limit $=180$ days

Summary : C746U Resident Farmer Deterministic Run

File : $\mathrm{X}: \backslash$ FINAL V2 $\backslash \mathrm{C} 746 \mathrm{U}$ RF DET-FINALV2.RAD

Individual Nuclide Dose Summed Over All Pathways

Parent Nuclide and Branch Fraction Indicated

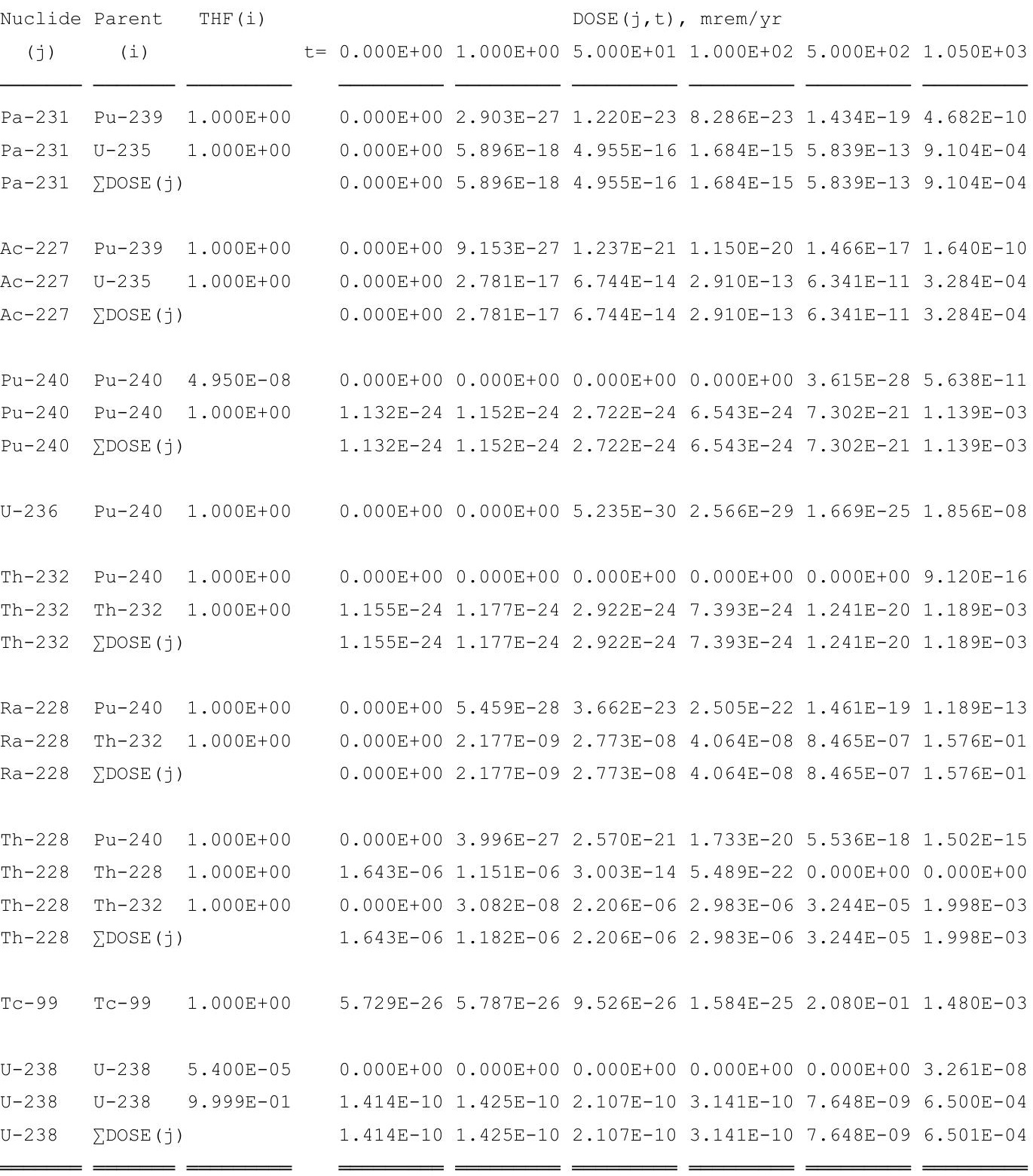

THF(i) is the thread fraction of the parent nuclide. 
RESRAD, Version $6.5 \quad \mathrm{~T}^{1 / 2}$ Limit $=180$ days

Summary : C746U Resident Farmer Deterministic Run

File : $\mathrm{X}: \backslash \mathrm{FINAL}$ V2 $\backslash \mathrm{C} 746 \mathrm{U}$ RF DET-FINALV2.RAD

Individual Nuclide Soil Concentration

Parent Nuclide and Branch Fraction Indicated

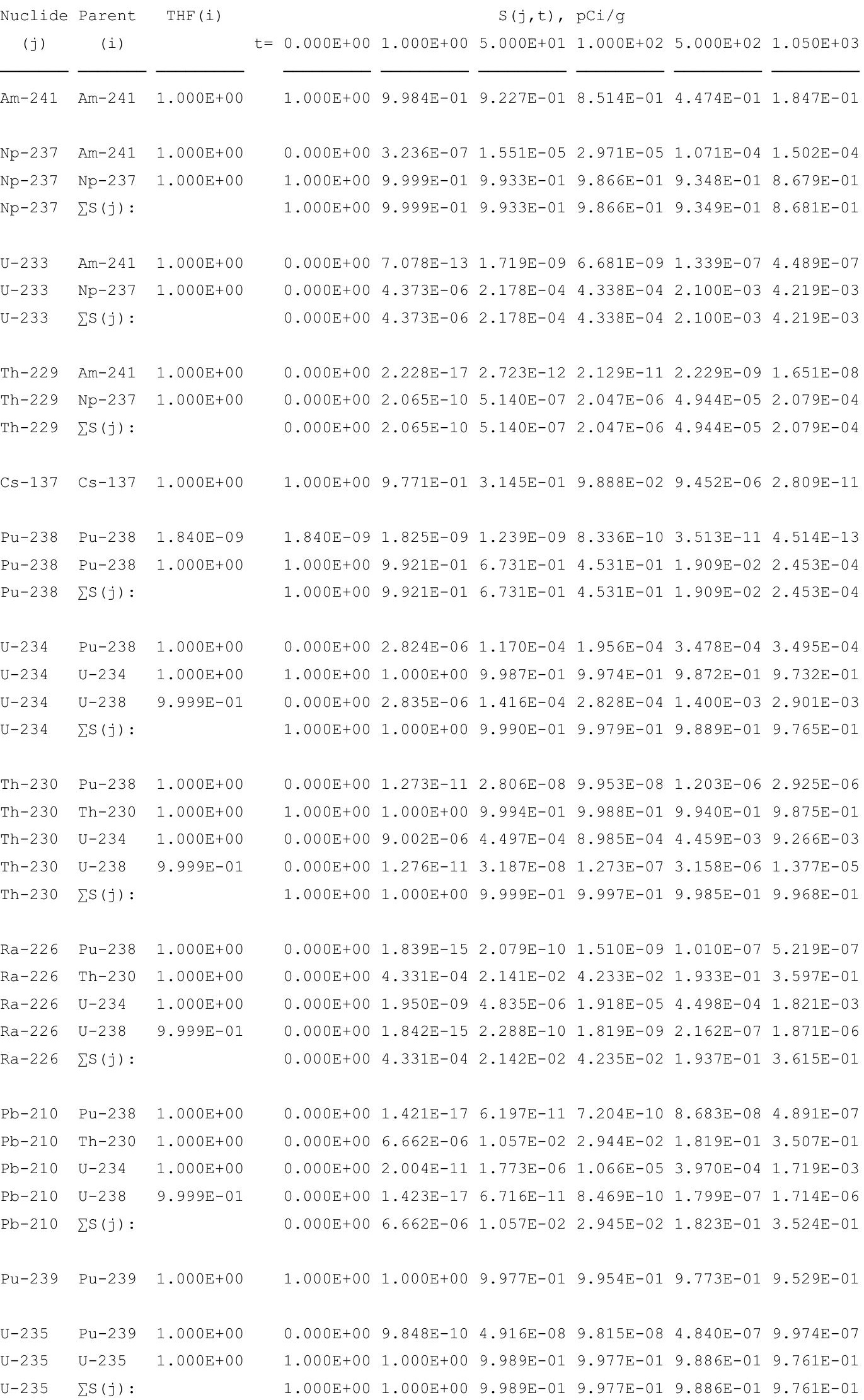


RESRAD, Version $6.5 \quad \mathrm{~T}^{1 / 2}$ Limit $=180$ days

Summary : C746U Resident Farmer Deterministic Run

File : $\mathrm{X}: \backslash$ FINAL V2 $\backslash \mathrm{C} 746 \mathrm{U}$ RF DET-FINALV2.RAD

Individual Nuclide Soil Concentration

Parent Nuclide and Branch Fraction Indicated

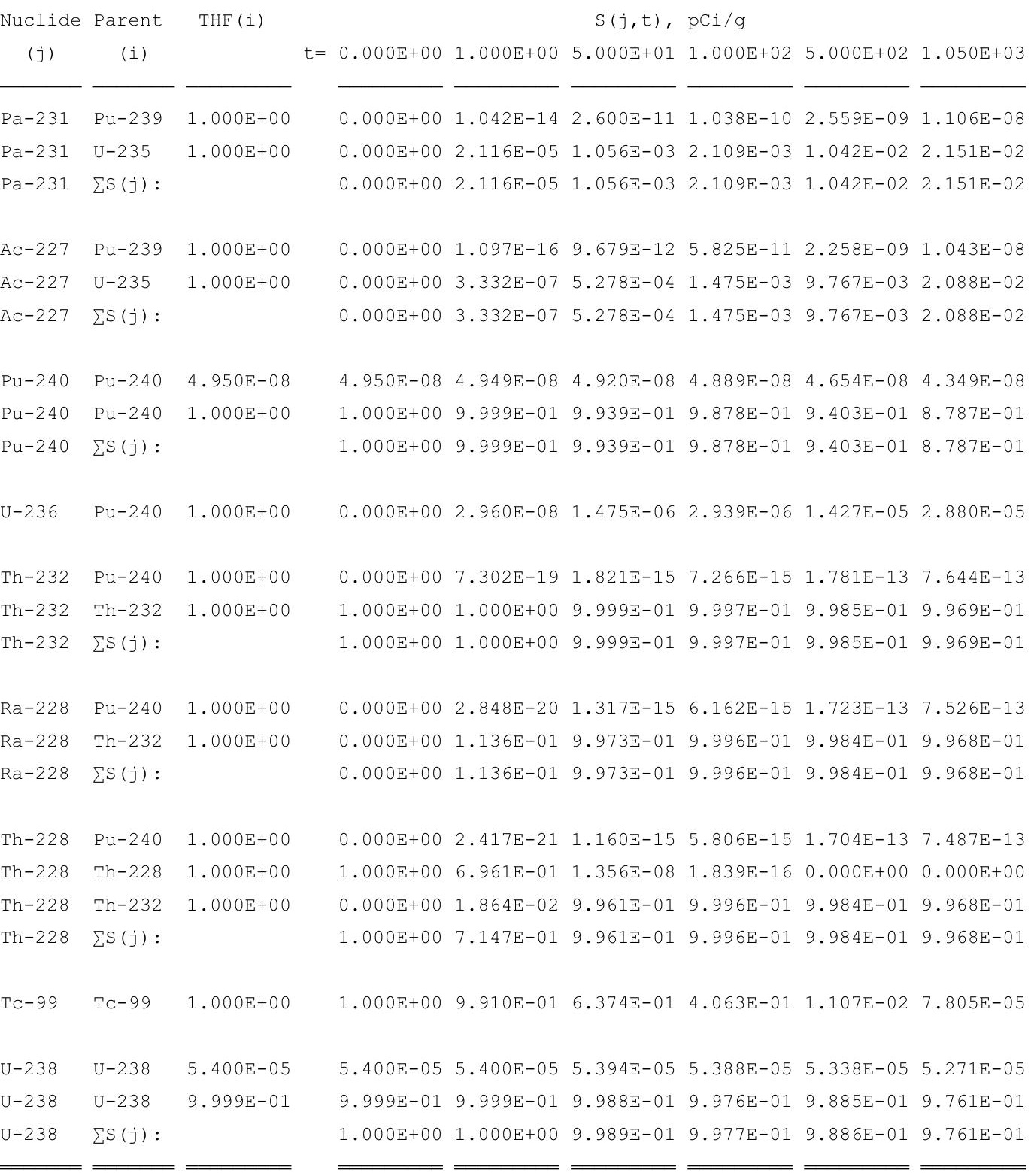

THF(i) is the thread fraction of the parent nuclide.

RESCALC.EXE execution time $=13.02$ seconds 


\section{Resident Farmer}

\section{The following summary report includes the peak dose from cumulative radionuclide inventory.}


THIS PAGE INTENTIONALLY LEFT BLANK 
RESRAD, Version $6.5 \quad T^{1 / 2}$ Limit $=180$ days

05/06/2011 12:46 Page

Summary : C746U Resident Farmer Deterministic Run

File : $\mathrm{X}: \backslash$ FINAL V2 $\backslash C 746 \mathrm{U}$ RF SG FWD-FINALV2.RAD

Table of Contents

Part I: Mixture Sums and Single Radionuclide Guidelines

Dose Conversion Factor (and Related) Parameter Summary ... 2

Site-Specific Parameter Summary ............... 8

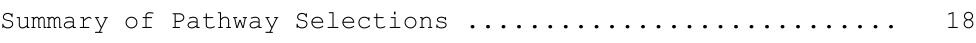

Contaminated zone and Total Dose Summary ............. 19

Total Dose Components

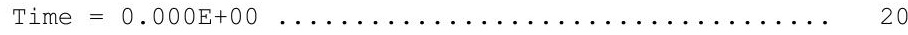

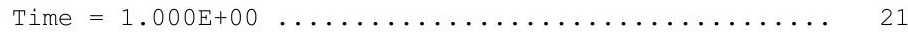

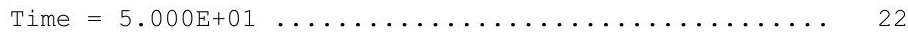

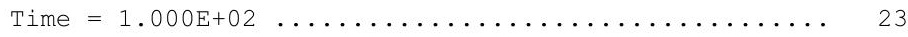

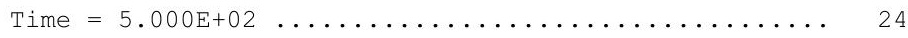

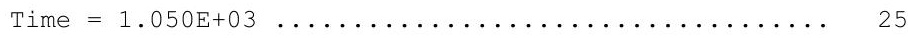

Dose/Source Ratios Summed Over All Pathways ........... 26

Single Radionuclide Soil Guidelines ............... 28

Dose Per Nuclide Summed Over All Pathways ............ 29

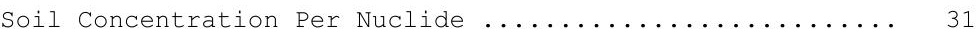


RESRAD, Version $6.5 \quad \mathrm{~T}^{1} \frac{1}{2}$ Limit $=180$ days

Summary : C746U Resident Farmer Deterministic Run

File : $\mathrm{X}: \backslash$ FINAL V2 $\backslash$ C746U RF SG FWD-FINALV2.RAD

Dose Conversion Factor (and Related) Parameter Summary (continued)

Dose Library: ICRP 60 \& ICRP 72 (Adult)

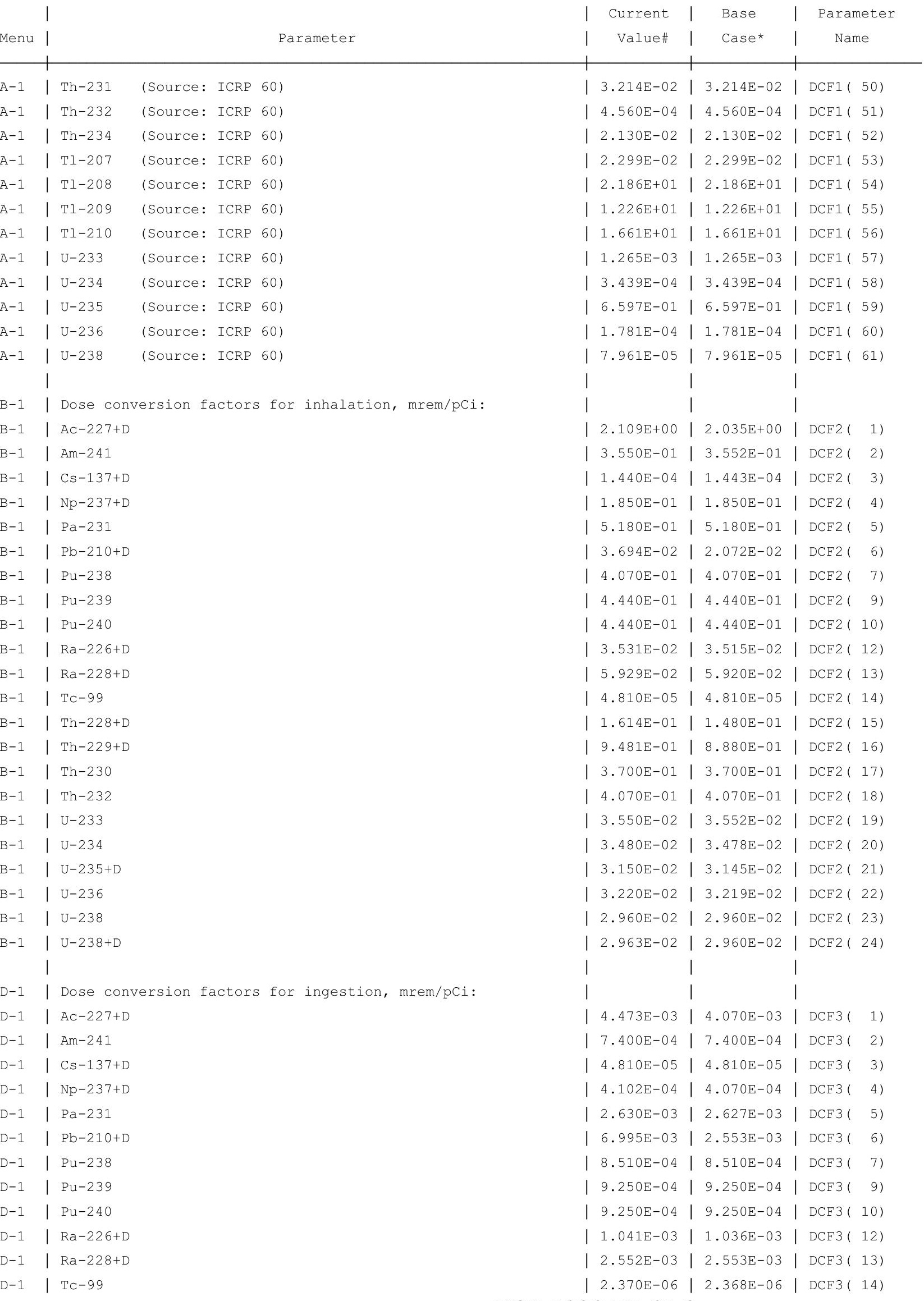


RESRAD, Version $6.5 \quad \mathrm{~T}^{1} \frac{1}{2}$ Limit $=180$ days

ummary : C746U Resident Farmer Deterministic Run

File : $\mathrm{X}: \backslash$ FINAL V2 $\backslash$ C746U RF SG FWD-FINALV2.RAD

Dose Conversion Factor (and Related) Parameter Summary (continued) Dose Library: ICRP 60 \& ICRP 72 (Adult)

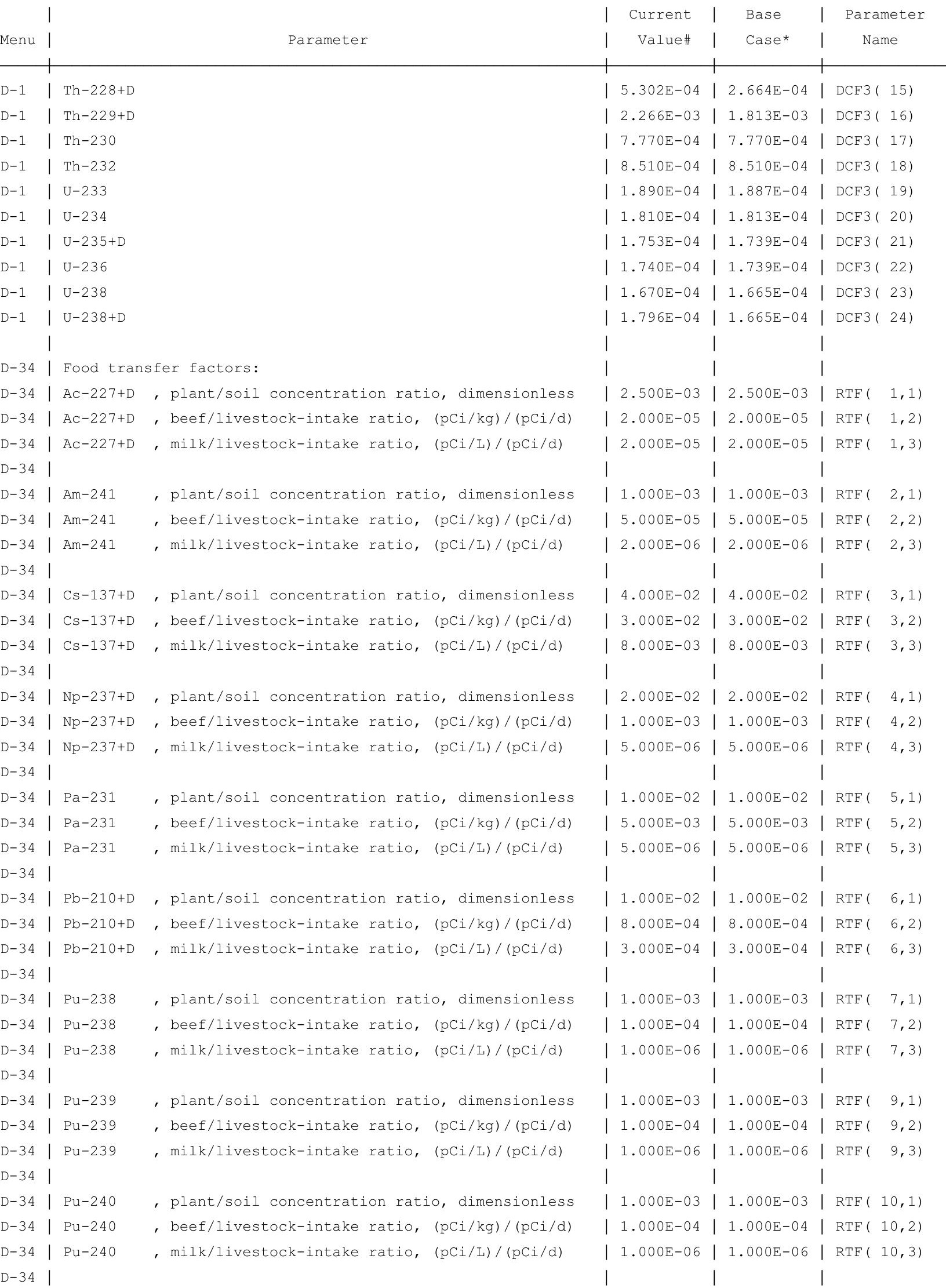


RESRAD, Version $6.5 \quad \mathrm{~T}^{1} \frac{1}{2}$ Limit $=180$ days

ummary : C746U Resident Farmer Deterministic Run

File : $\mathrm{X}: \backslash$ FINAL V2 $\backslash \mathrm{C746U}$ RF SG FWD-FINALV2.RAD

Dose Conversion Factor (and Related) Parameter Summary (continued) Dose Library: ICRP 60 \& ICRP 72 (Adult)

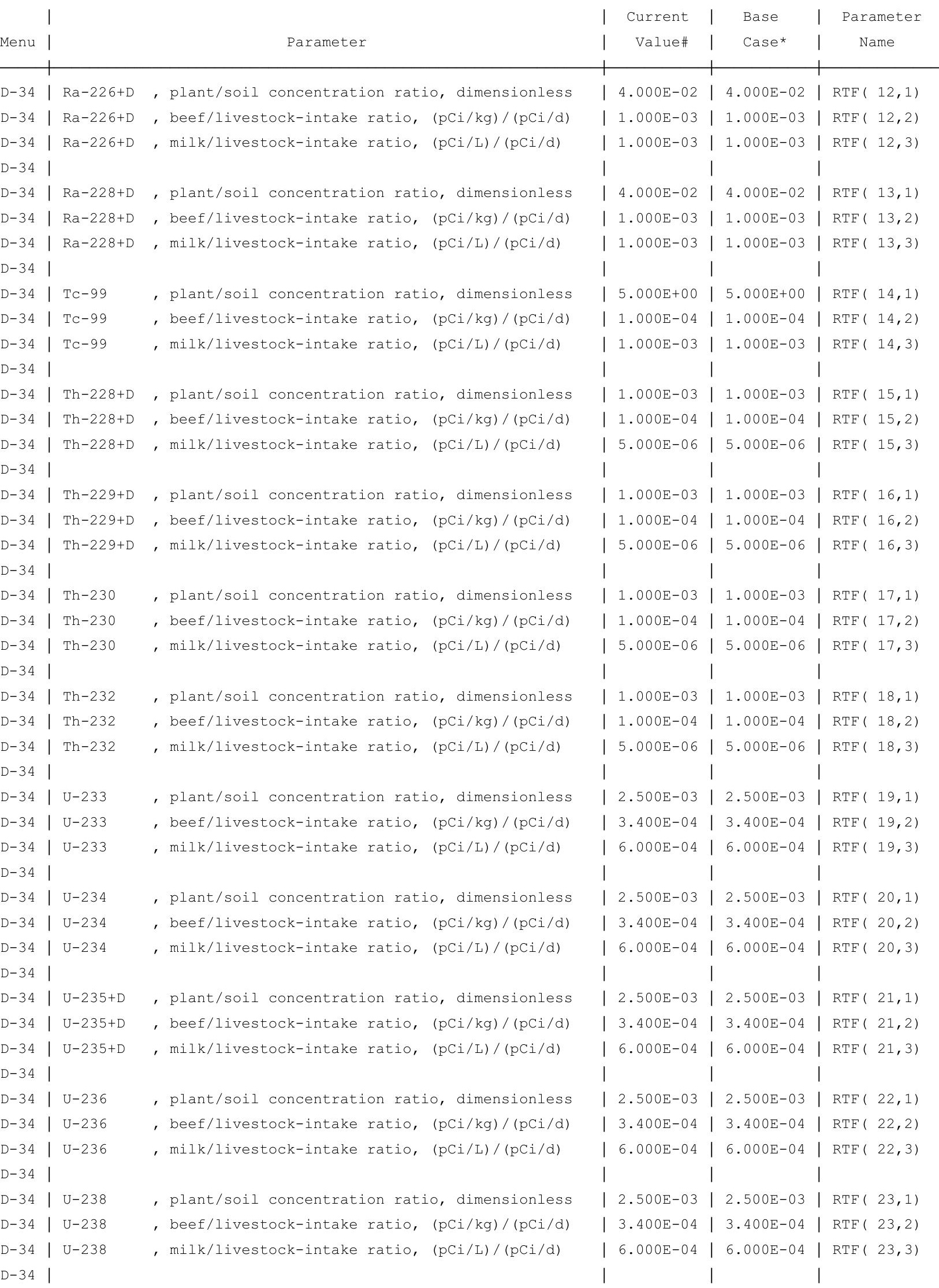


RESRAD, Version $6.5 \quad \mathrm{~T}^{1 / 2}$ Limit $=180$ days

ummary : C746U Resident Farmer Deterministic Run

File : $\mathrm{X}: \backslash$ FINAL V2 $\backslash$ C746U RF SG FWD-FINALV2.RAD

Dose Conversion Factor (and Related) Parameter Summary (continued) Dose Library: ICRP 60 \& ICRP 72 (Adult)

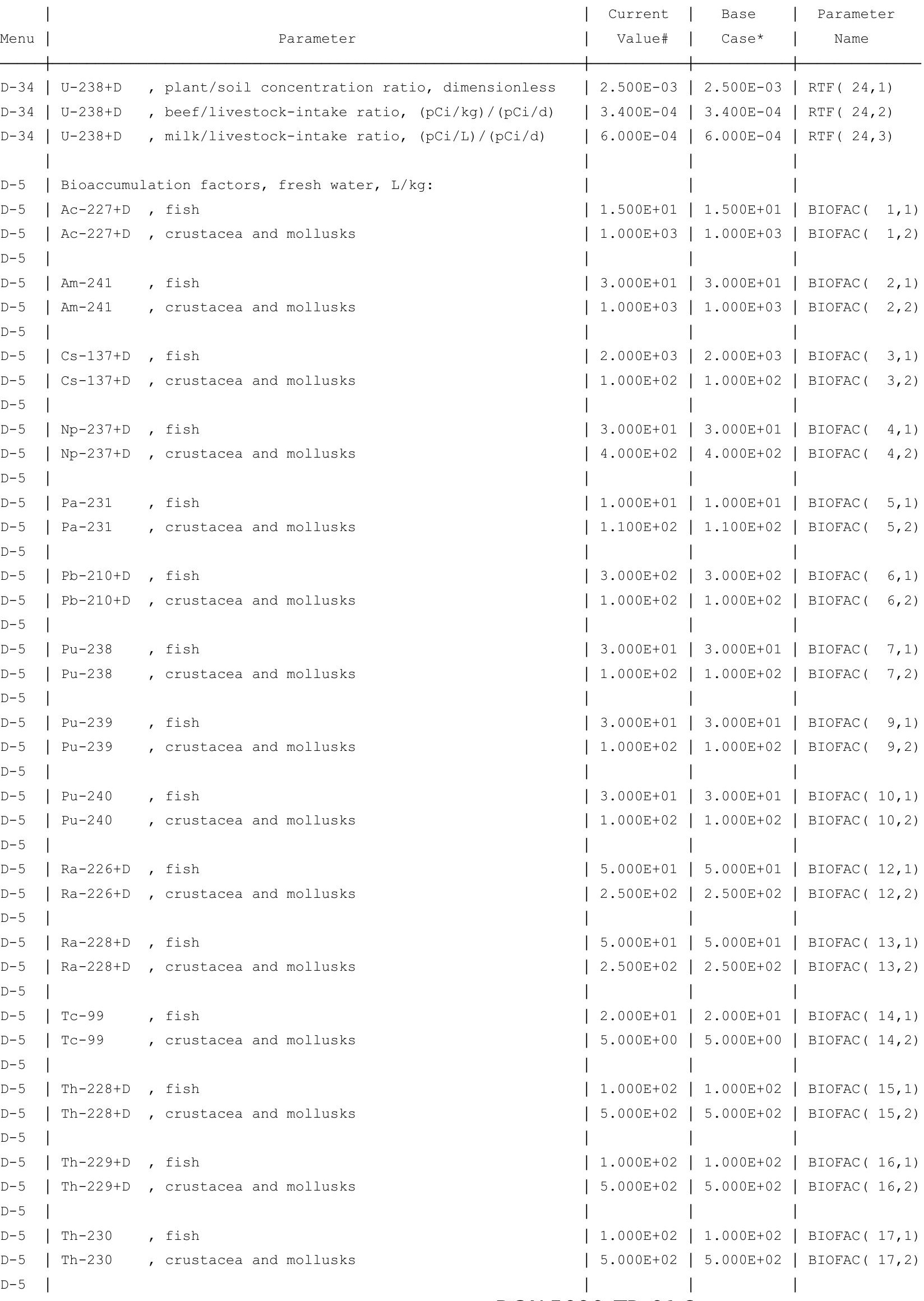


RESRAD, Version $6.5 \quad \mathrm{~T}^{1 / 2}$ Limit $=180$ days

05/06/2011 12:46 Page

Summary : C746U Resident Farmer Deterministic Run

File : $\mathrm{X}: \backslash$ FINAL V2 $\backslash$ C746U RF SG FWD-FINALV2.RAD

Dose Conversion Factor (and Related) Parameter Summary (continued) Dose Library: ICRP 60 \& ICRP 72 (Adult)

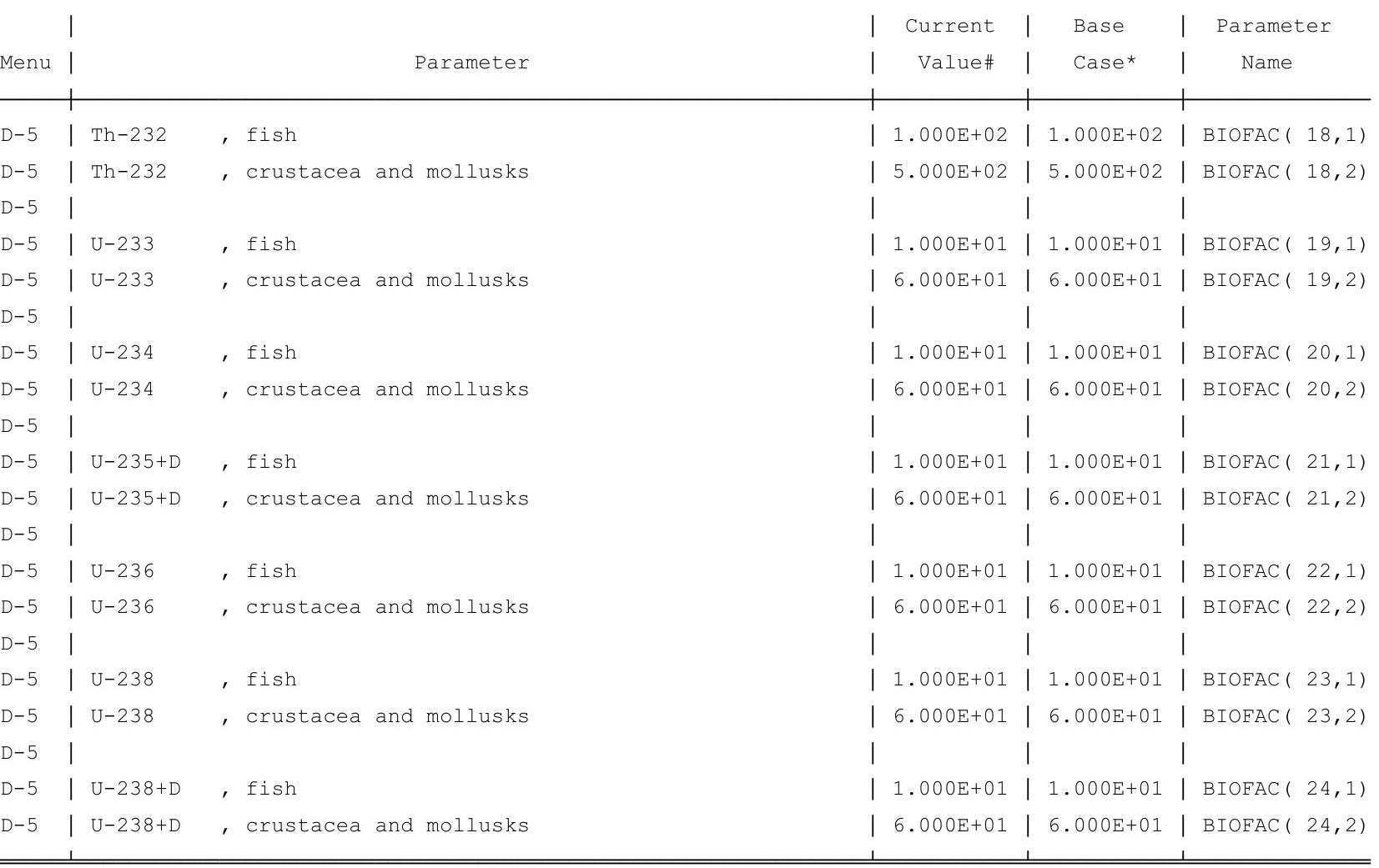

\#For DCFl(xxx) only, factors are for infinite depth \& area. See ETFG table in Ground Pathway of Detailed Report. *Base Case means Default.Lib w/o Associate Nuclide contributions. 
RESRAD, Version $6.5 \quad \mathrm{~T}^{1 / 2}$ Limit $=180$ days

Summary : C746U Resident Farmer Deterministic Run

File : $\mathrm{X}: \backslash$ FINAL V2 $\backslash$ C746U RF SG FWD-FINALV2.RAD

Site-Specific Parameter Summary (continued)

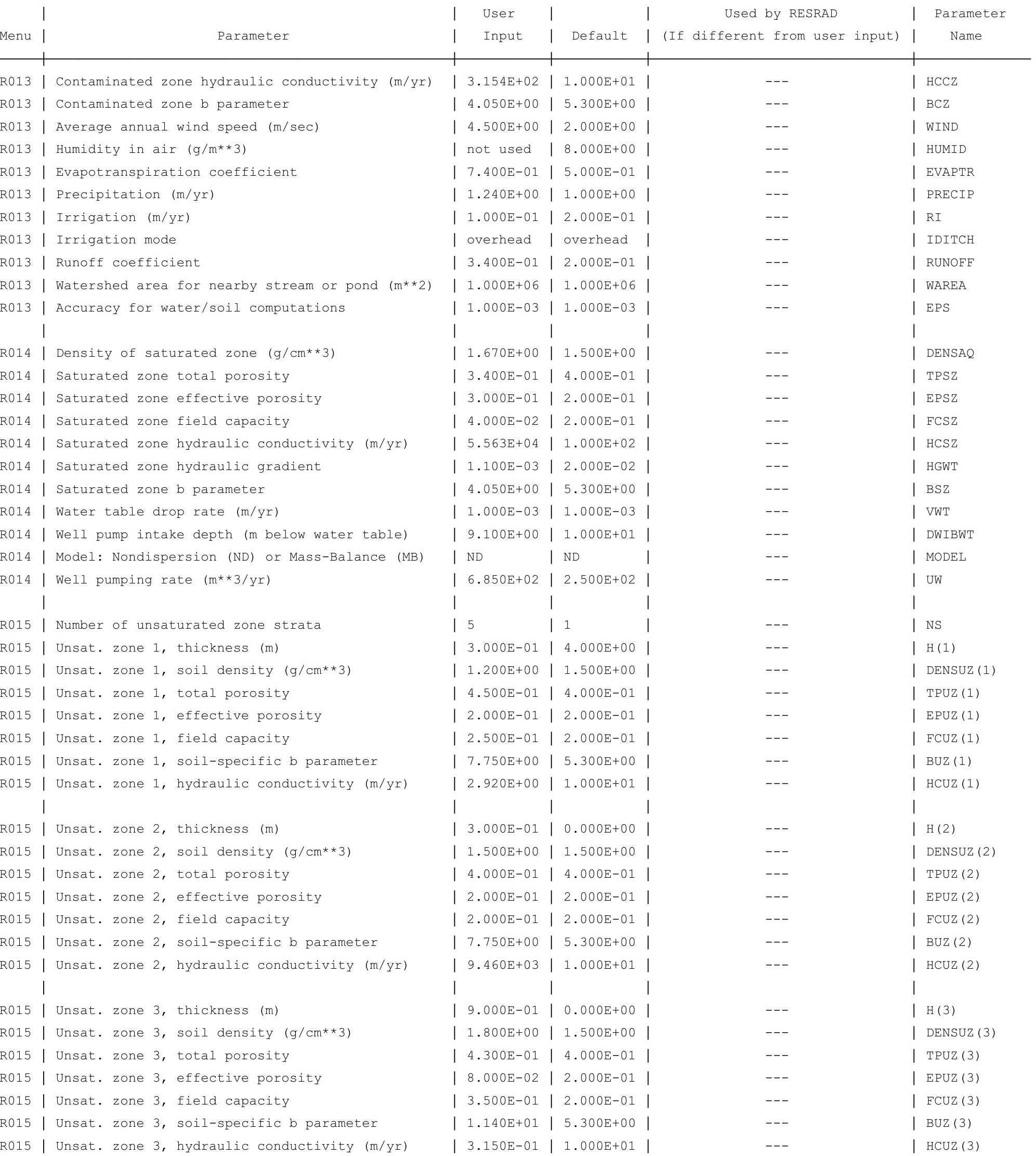


RESRAD, Version $6.5 \quad \mathrm{~T}^{1 / 2}$ Limit $=180$ days 
RESRAD, Version $6.5 \quad \mathrm{~T}^{1 / 2}$ Limit $=180$ days

Summary : C746U Resident Farmer Deterministic Run

File : $\mathrm{X}: \backslash$ FINAL V2 $\backslash \mathrm{C} 746 \mathrm{U}$ RF SG FWD-FINALV2.RAD

Site-Specific Parameter Summary (continued)

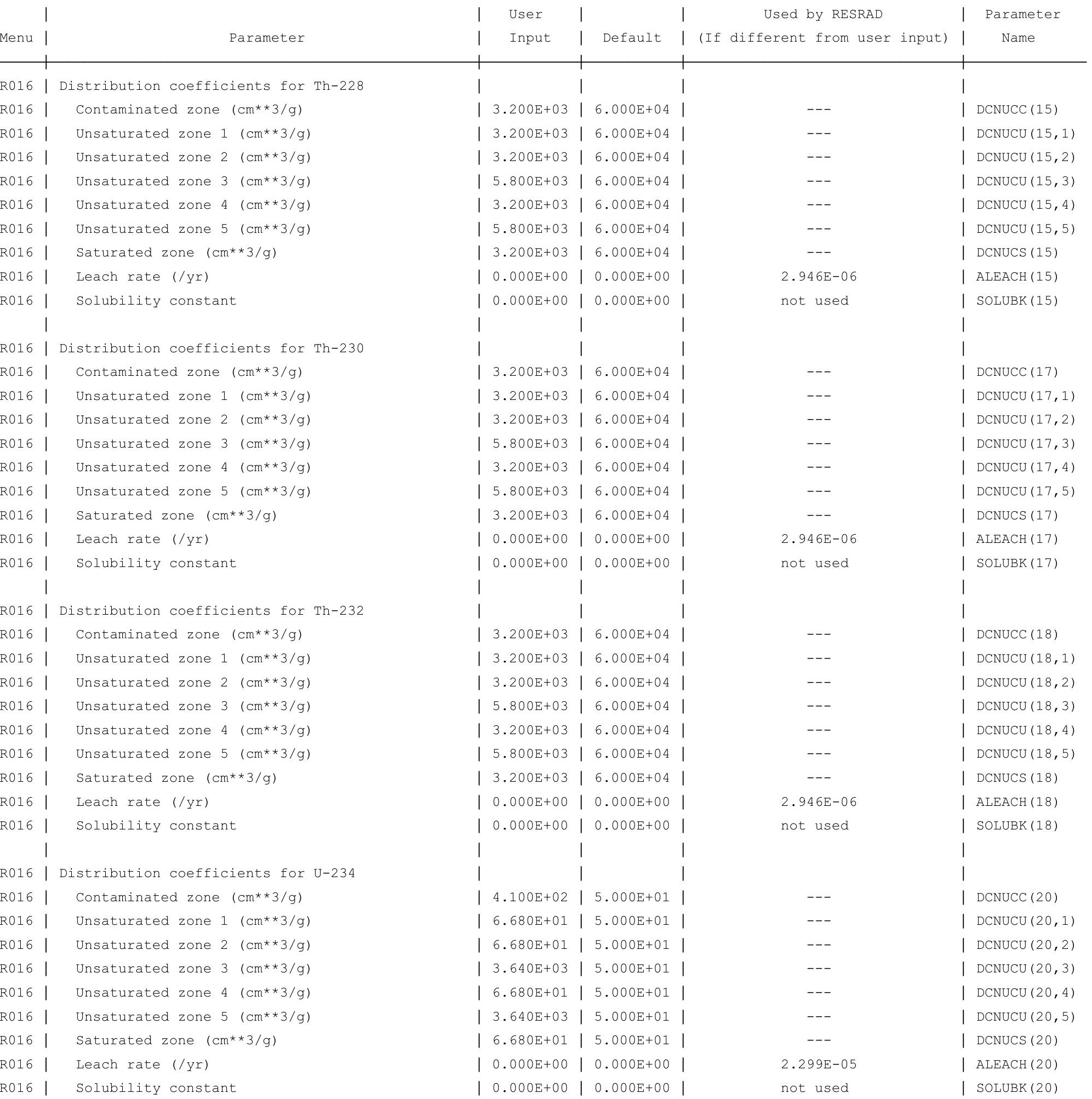


RESRAD, Version $6.5 \quad \mathrm{~T}^{1 / 2}$ Limit $=180$ days

Summary : C746U Resident Farmer Deterministic Run

File : $\mathrm{X}: \backslash$ FINAL V2 $\backslash \mathrm{C} 746 \mathrm{U}$ RF SG FWD-FINALV2.RAD

Site-Specific Parameter Summary (continued)

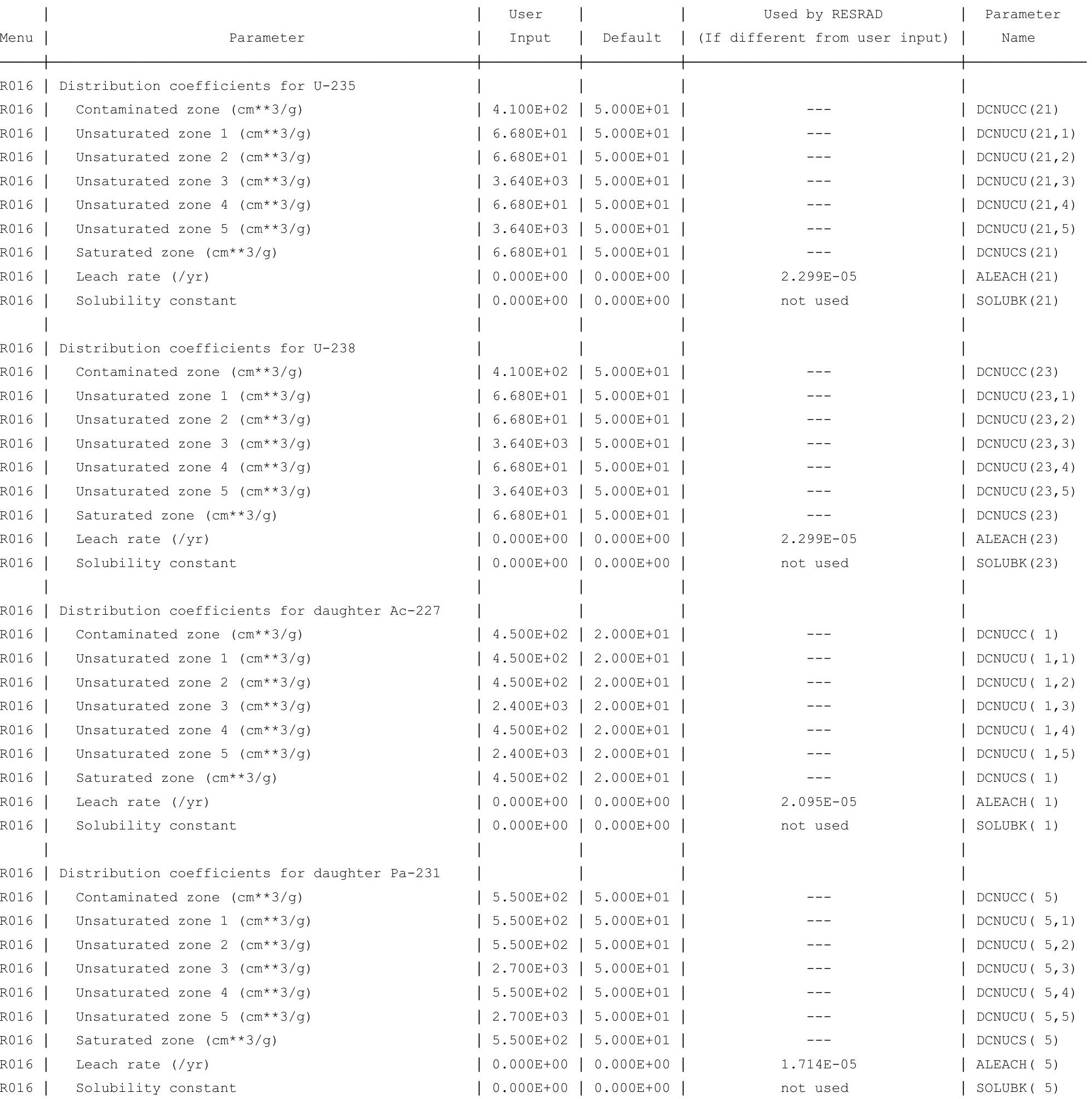


RESRAD, Version $6.5 \quad \mathrm{~T}^{1 / 2}$ Limit $=180$ days

Summary : C746U Resident Farmer Deterministic Run

File : $\mathrm{X}: \backslash$ FINAL V2 $\backslash \mathrm{C} 746 \mathrm{U}$ RF SG FWD-FINALV2.RAD

Site-Specific Parameter Summary (continued)

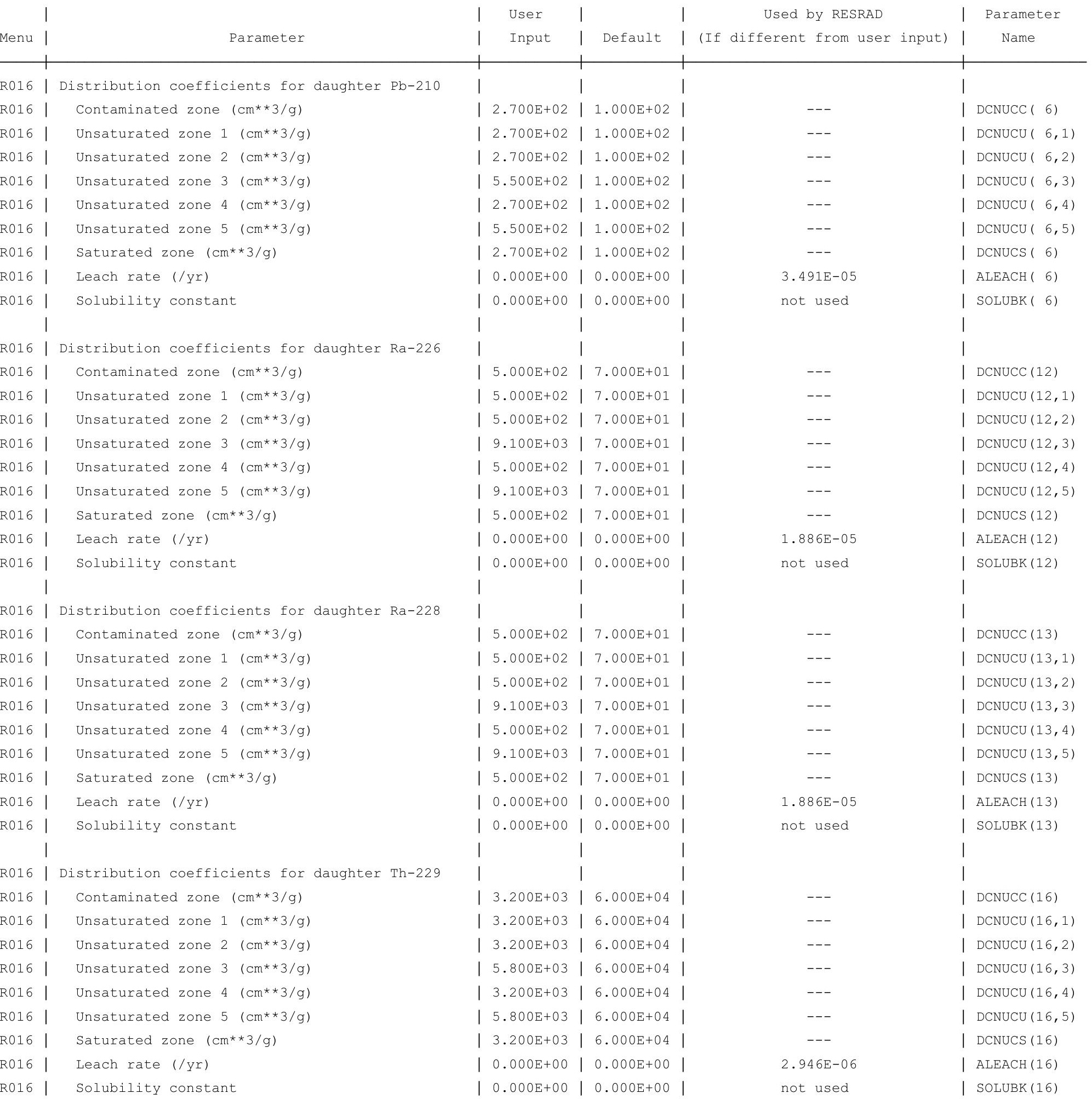


RESRAD, Version $6.5 \quad \mathrm{~T}^{1 / 2}$ Limit $=180$ days

Summary : C746U Resident Farmer Deterministic Run

File : $\mathrm{X}: \backslash$ FINAL V2 $\backslash \mathrm{C} 746 \mathrm{U}$ RF SG FWD-FINALV2.RAD

Site-Specific Parameter Summary (continued)

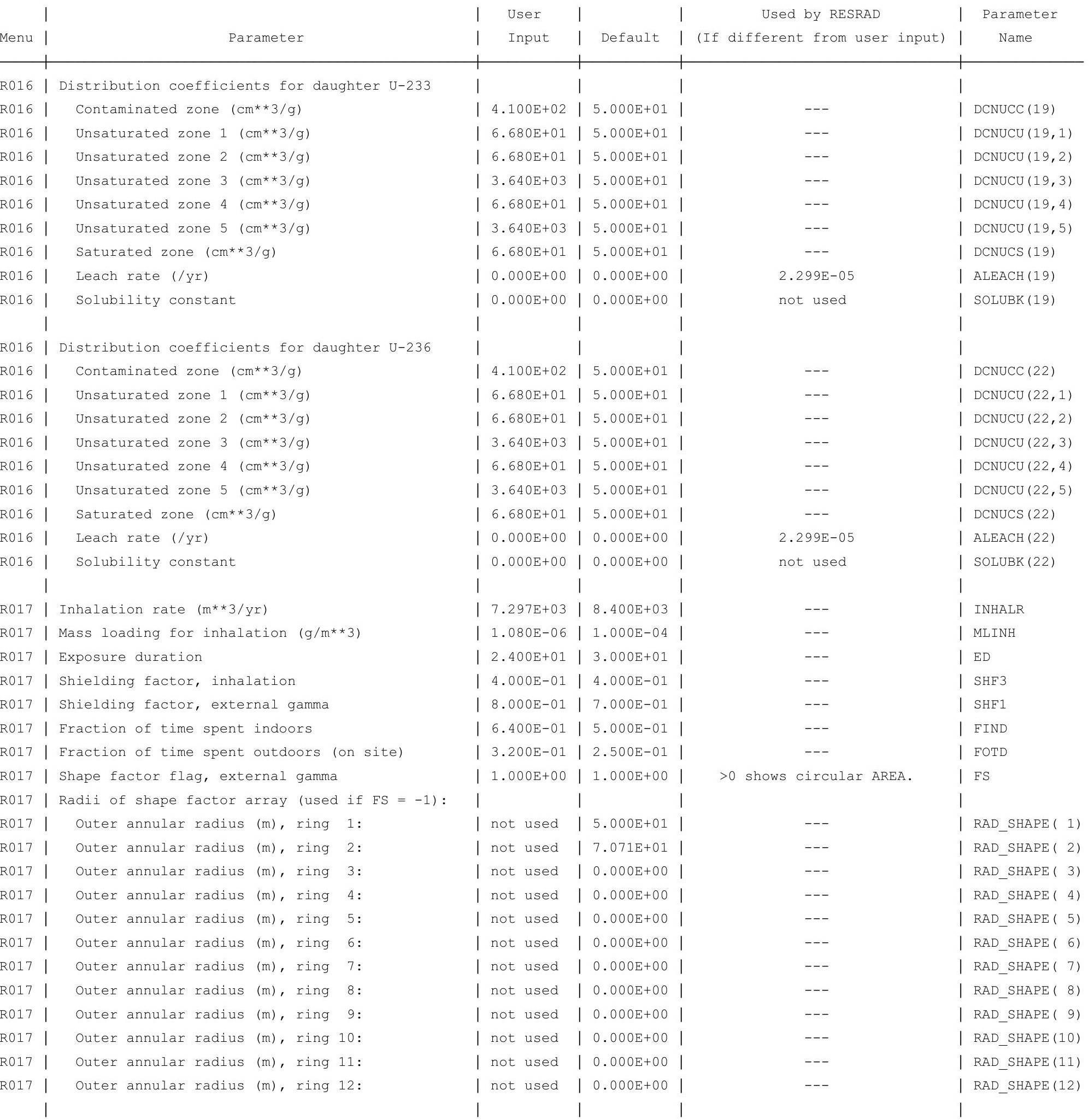


RESRAD, Version $6.5 \quad \mathrm{~T}^{1 / 2}$ Limit $=180$ days

Summary : C746U Resident Farmer Deterministic Run

File : $\mathrm{X}: \backslash \mathrm{FINAL}$ V2 $\backslash \mathrm{C746U}$ RF SG FWD-FINALV2.RAD

Site-Specific Parameter Summary (continued)

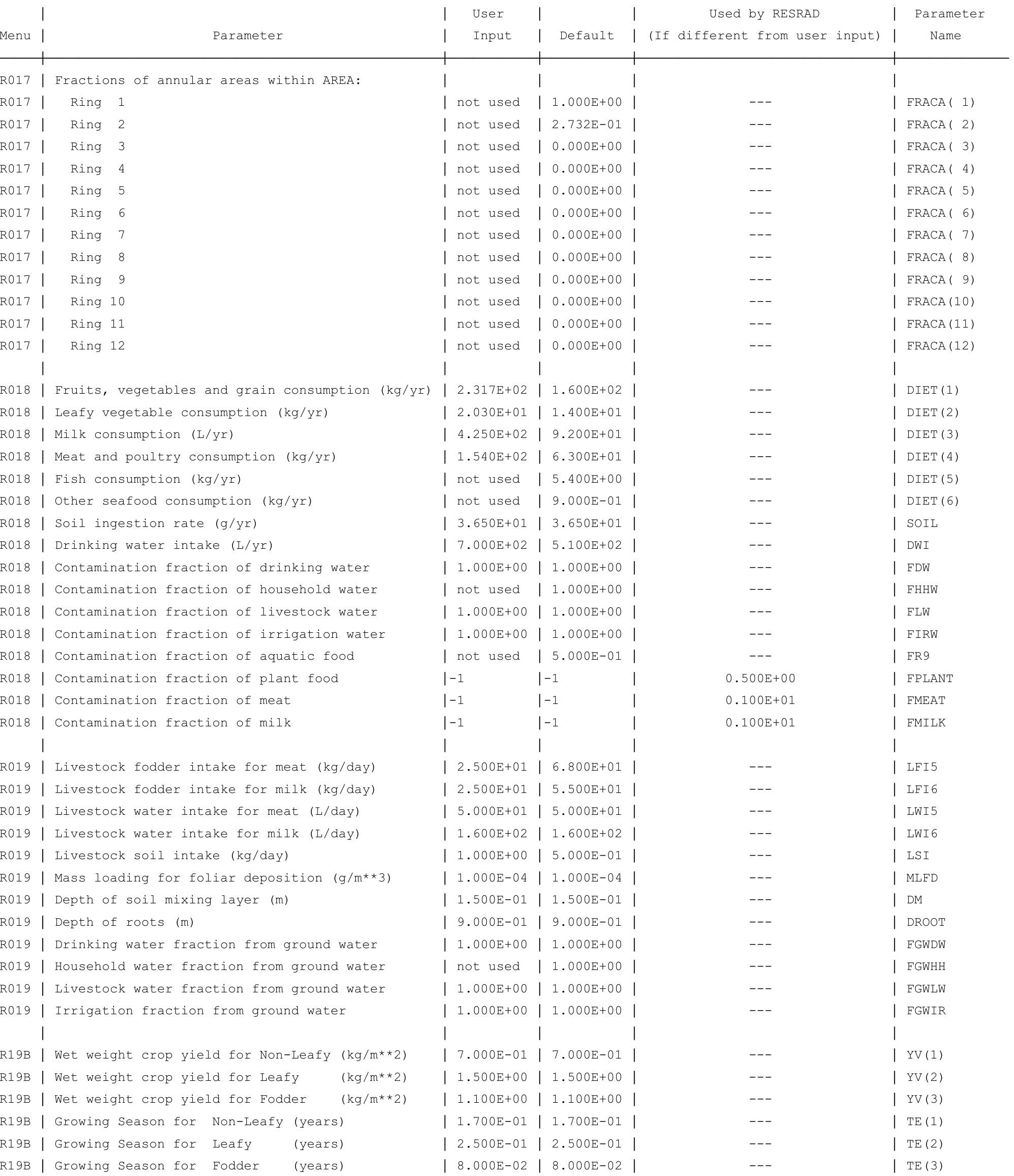


RESRAD, Version $6.5 \quad \mathrm{~T}^{1 / 2}$ Limit $=180$ days 
RESRAD, Version $6.5 \quad \mathrm{~T}^{1 / 2}$ Limit $=180$ days

05/06/2011 12:46 Page

Summary : C746U Resident Farmer Deterministic Run

File : $\mathrm{X}: \backslash \mathrm{FINAL}$ V2 $\backslash \mathrm{C746U}$ RF SG FWD-FINALV2.RAD

Contaminated Zone Dimensions

Initial Soil Concentrations, pCi/g

Area: 89436.00 square meters

$\begin{array}{ll}\mathrm{Am}-241 & 3.500 \mathrm{E}+03 \\ \mathrm{Cs}-137 & 1.900 \mathrm{E}+02 \\ \mathrm{~Np}-237 & 5.500 \mathrm{E}+02 \\ \mathrm{Pu}-238 & 3.900 \mathrm{E}+03 \\ \mathrm{Pu}-239 & 3.600 \mathrm{E}+03 \\ \mathrm{Pu}-240 & 3.600 \mathrm{E}+03 \\ \mathrm{Tc}-99 & 2.800 \mathrm{E}+01 \\ \mathrm{Th}-228 & 7.400 \mathrm{E}+01 \\ \mathrm{Th}-230 & 1.200 \mathrm{E}+03 \\ \mathrm{Th}-232 & 3.800 \mathrm{E}+01 \\ \mathrm{U}-234 & 1.800 \mathrm{E}+04 \\ \mathrm{U}-235 & 8.200 \mathrm{E}+02 \\ \mathrm{U}-238 & 3.200 \mathrm{E}+03\end{array}$

Total Dose TDOSE(t), mrem/yr

Basic Radiation Dose Limit $=1.000 \mathrm{E}+02 \mathrm{mrem} / \mathrm{yr}$

Total Mixture Sum $M(t)$ = Fraction of Basic Dose Limit Received at Time (t)

$\begin{array}{rllllll}t \text { (years }): & 0.000 \mathrm{E}+00 & 1.000 \mathrm{E}+00 & 5.000 \mathrm{E}+01 & 1.000 \mathrm{E}+02 & 5.000 \mathrm{E}+02 & 1.050 \mathrm{E}+03 \\ \mathrm{TDOSE}(\mathrm{t}): & 1.223 \mathrm{E}-04 & 8.719 \mathrm{E}-05 & 9.199 \mathrm{E}-05 & 1.337 \mathrm{E}-04 & 5.826 \mathrm{E}+00 & 1.146 \mathrm{E}+02 \\ \mathrm{M}(\mathrm{t}): & 1.223 \mathrm{E}-06 & 8.719 \mathrm{E}-07 & 9.199 \mathrm{E}-07 & 1.337 \mathrm{E}-06 & 5.826 \mathrm{E}-02 & 1.146 \mathrm{E}+00\end{array}$

Maximum TDOSE(t): $1.146 \mathrm{E}+02 \mathrm{mrem} / \mathrm{yr}$ at $t=1.050 \mathrm{E}+03$ years 


\section{RESRAD, Version $6.5 \quad \mathrm{~T}^{1 / 2}$ Limit $=180$ days}

Summary : C746U Resident Farmer Deterministic Run

: $\mathrm{X}: \backslash \mathrm{FINAL}$ V2 \C746U RF SG FWD-FINALV2.RAD

Total Dose Contributions TDOSE(i,p,t) for Individual Radionuclides (i) and Pathways (p) As mrem/yr and Fraction of Total Dose At $t=0.000 \mathrm{E}+00$ years

Water Independent Pathways (Inhalation excludes radon)

\begin{tabular}{|c|c|c|}
\hline ide & mrem/yr & fract. \\
\hline-241 & $0.000 \mathrm{E}+00$ & 0.0000 \\
\hline-137 & $2.415 \mathrm{E}-07$ & 0.0020 \\
\hline-237 & $5.217 \mathrm{E}-10$ & 0.0000 \\
\hline-238 & 4. $560 \mathrm{E}-21$ & 0.0000 \\
\hline-239 & $4.302 \mathrm{E}-14$ & 0.0000 \\
\hline-240 & $4.075 E-21$ & 0.0000 \\
\hline-99 & $1.604 \mathrm{E}-24$ & 0.0000 \\
\hline-228 & $1.216 \mathrm{E}-04$ & 0.9943 \\
\hline-230 & $2.870 \mathrm{E}-19$ & 0.0000 \\
\hline-232 & $4.389 \mathrm{E}-23$ & 0.0000 \\
\hline 34 & $1.230 \mathrm{E}-19$ & 0.0000 \\
\hline 35 & $1.013 \mathrm{E}-11$ & 0.0000 \\
\hline 238 & $4.525 \mathrm{E}-07$ & 0.0037 \\
\hline & 04 & $\perp$. \\
\hline
\end{tabular}

Inhalation

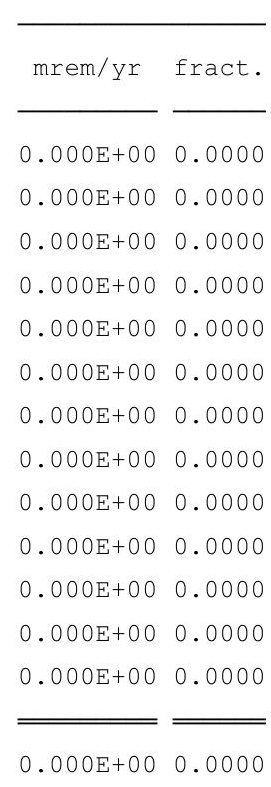

\begin{tabular}{ll} 
Radon \\
mrem/yr fract. \\
\cline { 1 - 1 } 0.000E+00 & 0.0000 \\
$0.000 \mathrm{E}+00$ & 0.0000 \\
$0.000 \mathrm{E}+00$ & 0.0000 \\
$0.000 \mathrm{E}+00$ & 0.0000 \\
$0.000 \mathrm{E}+00$ & 0.0000 \\
$0.000 \mathrm{E}+00$ & 0.0000 \\
$0.000 \mathrm{E}+00$ & 0.0000 \\
$0.000 \mathrm{E}+00$ & 0.0000 \\
$0.000 \mathrm{E}+00$ & 0.0000 \\
$0.000 \mathrm{E}+00$ & 0.0000 \\
$0.000 \mathrm{E}+00$ & 0.0000 \\
$0.000 \mathrm{E}+00$ & 0.0000 \\
$0.000 \mathrm{E}+00$ & 0.0000 \\
\hline \hline $0.000 \mathrm{E}+00$ & 0.0000
\end{tabular}

\begin{tabular}{|c|c|}
\hline mrem/yr & fract. \\
\hline $0.000 \mathrm{E}+00$ & 0.0000 \\
\hline $0.000 \mathrm{E}+00$ & 0.0000 \\
\hline $0.000 \mathrm{E}+00$ & 0.0000 \\
\hline $0.000 \mathrm{E}+00$ & 0.0000 \\
\hline $0.000 \mathrm{E}+00$ & 0.0000 \\
\hline $0.000 \mathrm{E}+00$ & 0.0000 \\
\hline $0.000 \mathrm{E}+00$ & 0.0000 \\
\hline $0.000 \mathrm{E}+00$ & 0.0000 \\
\hline $0.000 \mathrm{E}+00$ & 0.0000 \\
\hline $0.000 \mathrm{E}+00$ & 0.0000 \\
\hline $0.000 \mathrm{E}+00$ & 0.0000 \\
\hline $0.000 \mathrm{E}+00$ & 0.0000 \\
\hline $0.000 \mathrm{E}+00$ & 0.0000 \\
\hline .000 & .000 \\
\hline
\end{tabular}

\begin{tabular}{cc} 
Meat \\
\hline mrem/yr fract. \\
\cline { 1 - 2 } 0.000E+00 & 0.0000 \\
$0.000 \mathrm{E}+00$ & 0.0000 \\
$0.000 \mathrm{E}+00$ & 0.0000 \\
$0.000 \mathrm{E}+00$ & 0.0000 \\
$0.000 \mathrm{E}+00$ & 0.0000 \\
$0.000 \mathrm{E}+00$ & 0.0000 \\
$0.000 \mathrm{E}+00$ & 0.0000 \\
$0.000 \mathrm{E}+00$ & 0.0000 \\
$0.000 \mathrm{E}+00$ & 0.0000 \\
$0.000 \mathrm{E}+00$ & 0.0000 \\
$0.000 \mathrm{E}+00$ & 0.0000 \\
$0.000 \mathrm{E}+00$ & 0.0000 \\
$0.000 \mathrm{E}+00$ & 0.0000 \\
\hline \hline $0.000 \mathrm{E}+00$ & 0.0000
\end{tabular}

\begin{tabular}{cc} 
Milk \\
\hline mrem/yr fract. \\
\cline { 1 - 2 } 0.000E+00 & 0.0000 \\
$0.000 \mathrm{E}+00$ & 0.0000 \\
$0.000 \mathrm{E}+00$ & 0.0000 \\
$0.000 \mathrm{E}+00$ & 0.0000 \\
$0.000 \mathrm{E}+00$ & 0.0000 \\
$0.000 \mathrm{E}+00$ & 0.0000 \\
$0.000 \mathrm{E}+00$ & 0.0000 \\
$0.000 \mathrm{E}+00$ & 0.0000 \\
$0.000 \mathrm{E}+00$ & 0.0000 \\
$0.000 \mathrm{E}+00$ & 0.0000 \\
$0.000 \mathrm{E}+00$ & 0.0000 \\
$0.000 \mathrm{E}+00$ & 0.0000 \\
$0.000 \mathrm{E}+00$ & 0.0000 \\
\hline \hline $0.000 \mathrm{E}+00$ & 0.0000
\end{tabular}

Total Dose Contributions TDOSE(i,p,t) for Individual Radionuclides (i) and Pathways (p) As mrem/yr and Fraction of Total Dose At $t=0.000 \mathrm{E}+00$ years

Water Dependent Pathways

\begin{tabular}{|c|c|c|}
\hline clide & mrem/yr & fract. \\
\hline-241 & $0.000 \mathrm{E}+00$ & 0.0000 \\
\hline-137 & $0.000 \mathrm{E}+00$ & 0.0000 \\
\hline-237 & $0.000 \mathrm{E}+00$ & 0.0000 \\
\hline-238 & $0.000 \mathrm{E}+00$ & 0.0000 \\
\hline-239 & $0.000 \mathrm{E}+00$ & 0.0000 \\
\hline-240 & $0.000 \mathrm{E}+00$ & 0.0000 \\
\hline-99 & $0.000 \mathrm{E}+00$ & 0.0000 \\
\hline-228 & $0.000 \mathrm{E}+00$ & 0.0000 \\
\hline-230 & $0.000 \mathrm{E}+00$ & 0.0000 \\
\hline-232 & $0.000 \mathrm{E}+00$ & 0.0000 \\
\hline 234 & $0.000 \mathrm{E}+00$ & 0.0000 \\
\hline 235 & $0.000 \mathrm{E}+00$ & 0.0000 \\
\hline 38 & $0.000 \mathrm{E}+00$ & 0.0000 \\
\hline
\end{tabular}

$0.000 \mathrm{E}+00 \quad 0.0000$

\begin{tabular}{|c|c|}
\hline mrem/yr & fract. \\
\hline $0.000 \mathrm{E}+00$ & 0.0000 \\
\hline $0.000 \mathrm{E}+00$ & 0.0000 \\
\hline $0.000 \mathrm{E}+00$ & 0.0000 \\
\hline $0.000 \mathrm{E}+00$ & 0.0000 \\
\hline $0.000 \mathrm{E}+00$ & 0.0000 \\
\hline $0.000 \mathrm{E}+00$ & 0.0000 \\
\hline $0.000 \mathrm{E}+00$ & 0.0000 \\
\hline $0.000 \mathrm{E}+00$ & 0.0000 \\
\hline $0.000 \mathrm{E}+00$ & 0.0000 \\
\hline $0.000 \mathrm{E}+00$ & 0.0000 \\
\hline $0.000 \mathrm{E}+00$ & 0.0000 \\
\hline $0.000 \mathrm{E}+00$ & 0.0000 \\
\hline $0.000 \mathrm{E}+00$ & 0.0000 \\
\hline
\end{tabular}

$0.000 \mathrm{E}+00 \quad 0.0000$

\begin{tabular}{|c|c|}
\hline mrem/yr & fract. \\
\hline $0.000 \mathrm{E}+00$ & 0.0000 \\
\hline $0.000 \mathrm{E}+00$ & 0.0000 \\
\hline $0.000 \mathrm{E}+00$ & 0.0000 \\
\hline $0.000 \mathrm{E}+00$ & 0.0000 \\
\hline $0.000 \mathrm{E}+00$ & 0.0000 \\
\hline $0.000 \mathrm{E}+00$ & 0.0000 \\
\hline $0.000 \mathrm{E}+00$ & 0.0000 \\
\hline $0.000 \mathrm{E}+00$ & 0.0000 \\
\hline $0.000 \mathrm{E}+00$ & 0.0000 \\
\hline $0.000 \mathrm{E}+00$ & 0.0000 \\
\hline $0.000 \mathrm{E}+00$ & 0.0000 \\
\hline $0.000 \mathrm{E}+00$ & 0.0000 \\
\hline $0.000 \mathrm{E}+00$ & 0.0000 \\
\hline
\end{tabular}

$0.000 \mathrm{E}+00 \quad 0.0000$

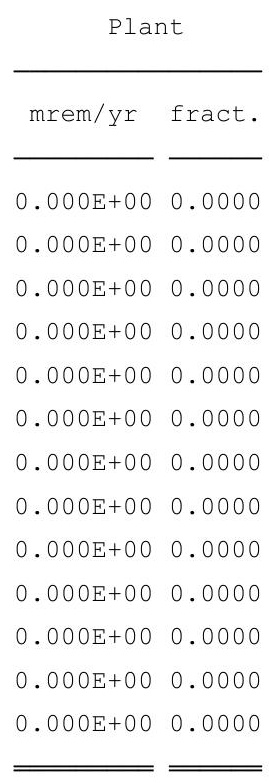

$0.000 \mathrm{E}+00 \quad 0.0000$

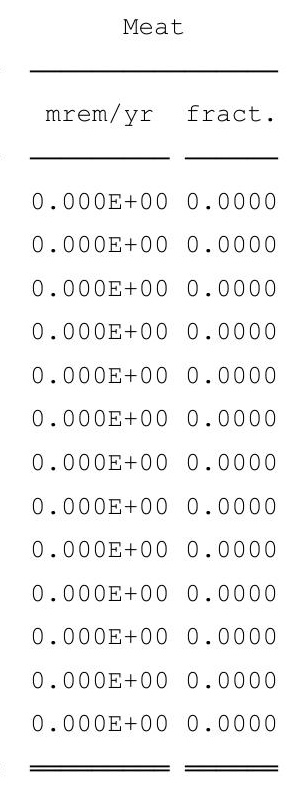

$0.000 \mathrm{E}+00 \quad 0.0000$

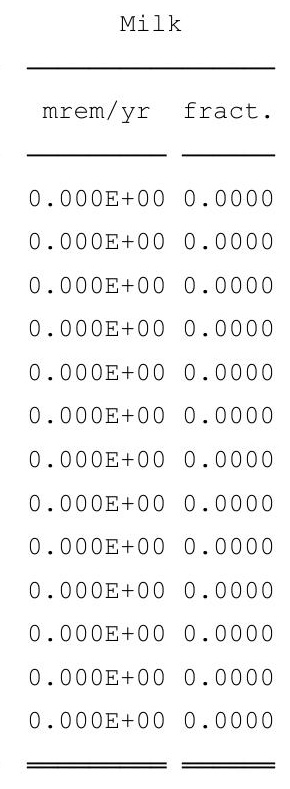

$0.000 \mathrm{E}+00 \quad 0.0000$
Soil

\begin{tabular}{ll} 
mrem/yr fract. & frn \\
\cline { 1 - 1 } $0.000 \mathrm{E}+00$ & 0.0000 \\
$0.000 \mathrm{E}+00$ & 0.0000 \\
$0.000 \mathrm{E}+00$ & 0.0000 \\
$0.000 \mathrm{E}+00$ & 0.0000 \\
$0.000 \mathrm{E}+00$ & 0.0000 \\
$0.000 \mathrm{E}+00$ & 0.0000 \\
$0.000 \mathrm{E}+00$ & 0.0000 \\
$0.000 \mathrm{E}+00$ & 0.0000 \\
$0.000 \mathrm{E}+00$ & 0.0000 \\
$0.000 \mathrm{E}+00$ & 0.0000 \\
$0.000 \mathrm{E}+00$ & 0.0000 \\
$0.000 \mathrm{E}+00$ & 0.0000 \\
$0.000 \mathrm{E}+00$ & 0.0000 \\
\hline \hline $0.000 \mathrm{E}+00$ & 0.0000
\end{tabular}

* Sum of all water independent and dependent pathways. 


\section{RESRAD, Version $6.5 \quad \mathrm{~T}^{1 / 2}$ Limit $=180$ days}

Summary : C746U Resident Farmer Deterministic Run

: $\mathrm{X}: \backslash \mathrm{FINAL}$ V2 \C746U RF SG FWD-FINALV2.RAD

Total Dose Contributions TDOSE(i,p,t) for Individual Radionuclides (i) and Pathways (p) As mrem/yr and Fraction of Total Dose At $t=1.000 \mathrm{E}+00$ years

Water Independent Pathways (Inhalation excludes radon)

\begin{tabular}{|c|c|c|}
\hline ide & mrem/yr & fract. \\
\hline $1-241$ & $1.086 \mathrm{E}-15$ & 0.0000 \\
\hline-137 & $2.380 \mathrm{E}-07$ & 0.0027 \\
\hline-237 & $5.273 \mathrm{E}-10$ & 0.0000 \\
\hline-238 & 1. $257 \mathrm{E}-18$ & 0.0000 \\
\hline-239 & 4. $354 \mathrm{E}-14$ & 0.0000 \\
\hline-240 & $4.164 \mathrm{E}-21$ & 0.0000 \\
\hline-99 & 1. $620 \mathrm{E}-24$ & 0.0000 \\
\hline-228 & $8.515 E-05$ & 0.9766 \\
\hline-230 & $9.078 \mathrm{E}-08$ & 0.0010 \\
\hline-232 & $1.254 \mathrm{E}-06$ & 0.0144 \\
\hline 34 & $6.129 \mathrm{E}-12$ & 0.0000 \\
\hline 35 & $1.029 \mathrm{E}-11$ & 0.0000 \\
\hline 238 & $4.561 \mathrm{E}-07$ & 0.0052 \\
\hline & 05 & 1.000 \\
\hline
\end{tabular}

Inhalation

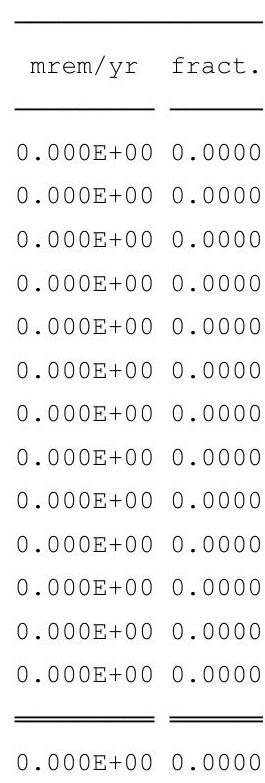

\begin{tabular}{ll} 
Radon \\
\hline mrem/yr fract. \\
\cline { 1 - 1 } 0.000E+00 & 0.0000 \\
$0.000 \mathrm{E}+00$ & 0.0000 \\
$0.000 \mathrm{E}+00$ & 0.0000 \\
$0.000 \mathrm{E}+00$ & 0.0000 \\
$0.000 \mathrm{E}+00$ & 0.0000 \\
$0.000 \mathrm{E}+00$ & 0.0000 \\
$0.000 \mathrm{E}+00$ & 0.0000 \\
$0.000 \mathrm{E}+00$ & 0.0000 \\
$0.000 \mathrm{E}+00$ & 0.0000 \\
$0.000 \mathrm{E}+00$ & 0.0000 \\
$0.000 \mathrm{E}+00$ & 0.0000 \\
$0.000 \mathrm{E}+00$ & 0.0000 \\
$0.000 \mathrm{E}+00$ & 0.0000 \\
\hline \hline $0.000 \mathrm{E}+00$ & 0.0000
\end{tabular}

\begin{tabular}{|c|c|}
\hline mrem/yr & fract. \\
\hline $0.000 \mathrm{E}+00$ & 0.0000 \\
\hline $0.000 \mathrm{E}+00$ & 0.0000 \\
\hline $0.000 \mathrm{E}+00$ & 0.0000 \\
\hline $0.000 \mathrm{E}+00$ & 0.0000 \\
\hline $0.000 \mathrm{E}+00$ & 0.0000 \\
\hline $0.000 \mathrm{E}+00$ & 0.0000 \\
\hline $0.000 \mathrm{E}+00$ & 0.0000 \\
\hline $0.000 \mathrm{E}+00$ & 0.0000 \\
\hline $0.000 \mathrm{E}+00$ & 0.0000 \\
\hline $0.000 \mathrm{E}+00$ & 0.0000 \\
\hline $0.000 \mathrm{E}+00$ & 0.0000 \\
\hline $0.000 \mathrm{E}+00$ & 0.0000 \\
\hline $0.000 \mathrm{E}+00$ & 0.0000 \\
\hline .000 & .000 \\
\hline
\end{tabular}

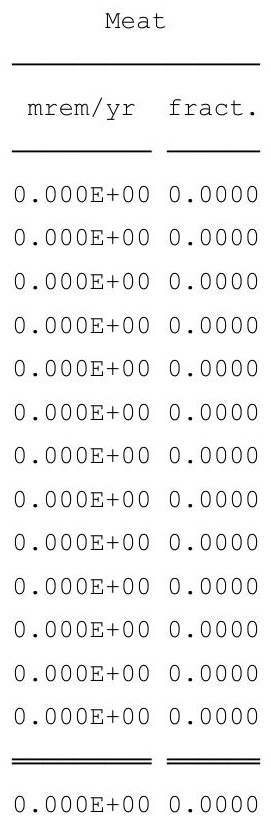

\begin{tabular}{cc} 
Milk \\
\cline { 1 - 1 } mrem/yr fract. \\
\cline { 1 - 1 } $0.000 \mathrm{E}+00$ & 0.0000 \\
$0.000 \mathrm{E}+00$ & 0.0000 \\
$0.000 \mathrm{E}+00$ & 0.0000 \\
$0.000 \mathrm{E}+00$ & 0.0000 \\
$0.000 \mathrm{E}+00$ & 0.0000 \\
$0.000 \mathrm{E}+00$ & 0.0000 \\
$0.000 \mathrm{E}+00$ & 0.0000 \\
$0.000 \mathrm{E}+00$ & 0.0000 \\
$0.000 \mathrm{E}+00$ & 0.0000 \\
$0.000 \mathrm{E}+00$ & 0.0000 \\
$0.000 \mathrm{E}+00$ & 0.0000 \\
$0.000 \mathrm{E}+00$ & 0.0000 \\
$0.000 \mathrm{E}+00$ & 0.0000 \\
\hline \hline $0.000 \mathrm{E}+00$ & 0.0000
\end{tabular}

Total Dose Contributions TDOSE (i,p,t) for Individual Radionuclides (i) and Pathways (p) As mrem/yr and Fraction of Total Dose At $t=1.000 \mathrm{E}+00$ years

Water Dependent Pathways

\begin{tabular}{llll} 
& & \multicolumn{2}{c}{ Water } \\
Radio- & & \\
Nuclide & mrem/yr & fract. \\
Am-241 & $0.000 \mathrm{E}+00$ & 0.0000 \\
Cs-137 & $0.000 \mathrm{E}+00$ & 0.0000 \\
$\mathrm{~Np}-237$ & $0.000 \mathrm{E}+00$ & 0.0000 \\
Pu-238 & $0.000 \mathrm{E}+00$ & 0.0000 \\
Pu-239 & $0.000 \mathrm{E}+00$ & 0.0000 \\
Pu-240 & $0.000 \mathrm{E}+00$ & 0.0000 \\
$\mathrm{TC}-99$ & $0.000 \mathrm{E}+00$ & 0.0000 \\
$\mathrm{Th}-228$ & $0.000 \mathrm{E}+00$ & 0.0000 \\
$\mathrm{Th}-230$ & $0.000 \mathrm{E}+00$ & 0.0000 \\
$\mathrm{Th}-232$ & $0.000 \mathrm{E}+00$ & 0.0000 \\
$\mathrm{U}-234$ & $0.000 \mathrm{E}+00$ & 0.0000 \\
$\mathrm{U}-235$ & $0.000 \mathrm{E}+00$ & 0.0000 \\
$\mathrm{U}-238$ & $0.000 \mathrm{E}+00$ & 0.0000 \\
\hline \hline
\end{tabular}

$0.000 \mathrm{E}+00 \quad 0.0000$

\begin{tabular}{cc} 
Fish \\
\cline { 1 - 2 } mrem/yr & fract. \\
\hline $0.000 \mathrm{E}+00$ & 0.0000 \\
$0.000 \mathrm{E}+00$ & 0.0000 \\
$0.000 \mathrm{E}+00$ & 0.0000 \\
$0.000 \mathrm{E}+00$ & 0.0000 \\
$0.000 \mathrm{E}+00$ & 0.0000 \\
$0.000 \mathrm{E}+00$ & 0.0000 \\
$0.000 \mathrm{E}+00$ & 0.0000 \\
$0.000 \mathrm{E}+00$ & 0.0000 \\
$0.000 \mathrm{E}+00$ & 0.0000 \\
$0.000 \mathrm{E}+00$ & 0.0000 \\
$0.000 \mathrm{E}+00$ & 0.0000 \\
$0.000 \mathrm{E}+00$ & 0.0000 \\
$0.000 \mathrm{E}+00$ & 0.0000 \\
\hline \hline
\end{tabular}

$0.000 \mathrm{E}+00 \quad 0.0000$

\begin{tabular}{cc} 
Radon \\
\cline { 1 - 1 } mrem/yr fract. \\
\hline $0.000 \mathrm{E}+00$ & 0.0000 \\
$0.000 \mathrm{E}+00$ & 0.0000 \\
$0.000 \mathrm{E}+00$ & 0.0000 \\
$0.000 \mathrm{E}+00$ & 0.0000 \\
$0.000 \mathrm{E}+00$ & 0.0000 \\
$0.000 \mathrm{E}+00$ & 0.0000 \\
$0.000 \mathrm{E}+00$ & 0.0000 \\
$0.000 \mathrm{E}+00$ & 0.0000 \\
$0.000 \mathrm{E}+00$ & 0.0000 \\
$0.000 \mathrm{E}+00$ & 0.0000 \\
$0.000 \mathrm{E}+00$ & 0.0000 \\
$0.000 \mathrm{E}+00$ & 0.0000 \\
$0.000 \mathrm{E}+00$ & 0.0000 \\
\hline \hline
\end{tabular}

$0.000 \mathrm{E}+00 \quad 0.0000$

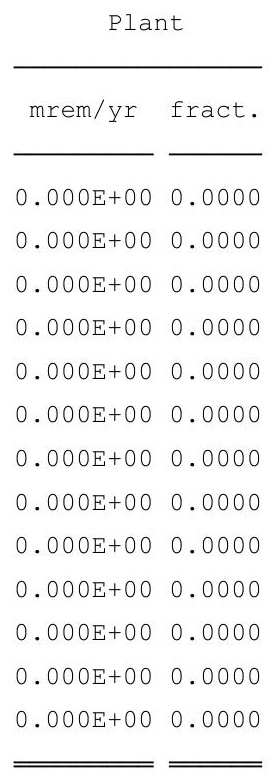

$0.000 \mathrm{E}+00 \quad 0.0000$

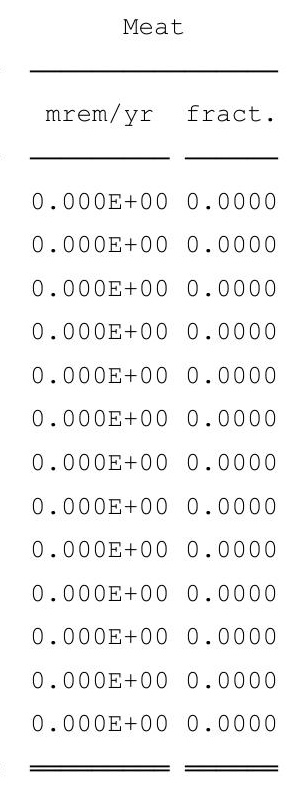

$0.000 \mathrm{E}+00 \quad 0.0000$

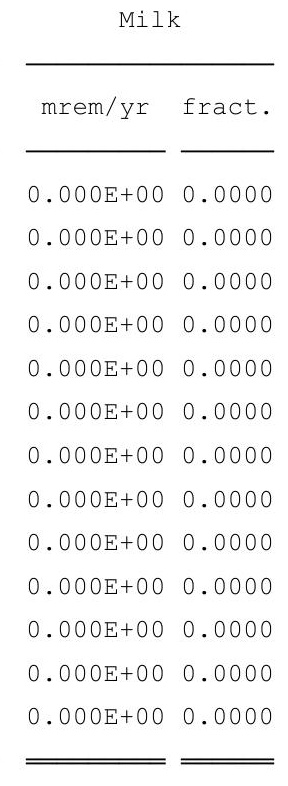

$0.000 E+00 \quad 0.0000$
Soil

\begin{tabular}{ccc} 
mrem/yr & fract. \\
\cline { 1 - 1 } $0.000 \mathrm{E}+00$ & 0.0000 \\
$0.000 \mathrm{E}+00$ & 0.0000 \\
$0.000 \mathrm{E}+00$ & 0.0000 \\
$0.000 \mathrm{E}+00$ & 0.0000 \\
$0.000 \mathrm{E}+00$ & 0.0000 \\
$0.000 \mathrm{E}+00$ & 0.0000 \\
$0.000 \mathrm{E}+00$ & 0.0000 \\
$0.000 \mathrm{E}+00$ & 0.0000 \\
$0.000 \mathrm{E}+00$ & 0.0000 \\
$0.000 \mathrm{E}+00$ & 0.0000 \\
$0.000 \mathrm{E}+00$ & 0.0000 \\
$0.000 \mathrm{E}+00$ & 0.0000 \\
$0.000 \mathrm{E}+00$ & 0.0000 \\
\hline \hline $0.000 \mathrm{E}+00$ & 0.0000
\end{tabular}

* Sum of all water independent and dependent pathways. 


\section{RESRAD, Version $6.5 \quad \mathrm{~T}^{1 / 2}$ Limit $=180$ days}

Summary : C746U Resident Farmer Deterministic Run

: $\mathrm{X}: \backslash \mathrm{FINAL}$ V2 \C746U RF SG FWD-FINALV2.RAD

Total Dose Contributions TDOSE(i,p,t) for Individual Radionuclides (i) and Pathways (p) As mrem/yr and Fraction of Total Dose At $t=5.000 \mathrm{E}+01$ years

Water Independent Pathways (Inhalation excludes radon)

\begin{tabular}{|c|c|c|c|c|c|c|c|c|c|c|c|c|}
\hline \multirow[b]{2}{*}{ Nuclide } & \multicolumn{2}{|c|}{ Ground } & \multicolumn{2}{|c|}{ Inhalation } & \multicolumn{2}{|c|}{ Radon } & \multicolumn{2}{|c|}{ Plant } & \multicolumn{2}{|c|}{ Meat } & \multicolumn{2}{|c|}{ Milk } \\
\hline & mrem/yr & fract. & mrem/yr & fract. & mrem/yr & fract. & mrem/yr & fract. & mrem/yr & fract. & mrem/yr & fract. \\
\hline-241 & $8.840 \mathrm{E}-14$ & 0.0000 & $0.000 \mathrm{E}+00$ & 0.0000 & $0.000 \mathrm{E}+00$ & 0.0000 & $0.000 \mathrm{E}+00$ & 0.0000 & $0.000 \mathrm{E}+00$ & 0.0000 & $0.000 \mathrm{E}+00$ & 0.0000 \\
\hline-137 & $1.158 \mathrm{E}-07$ & 0.0013 & $0.000 \mathrm{E}+00$ & 0.0000 & $0.000 \mathrm{E}+00$ & 0.0000 & $0.000 \mathrm{E}+00$ & 0.0000 & $0.000 \mathrm{E}+00$ & 0.0000 & $0.000 \mathrm{E}+00$ & 0.0000 \\
\hline-237 & $8.909 \mathrm{E}-10$ & 0.0000 & $0.000 \mathrm{E}+00$ & 0.0000 & $0.000 \mathrm{E}+00$ & 0.0000 & $0.000 \mathrm{E}+00$ & 0.0000 & $0.000 \mathrm{E}+00$ & 0.0000 & $0.000 \mathrm{E}+00$ & 0.0000 \\
\hline-238 & 1. $988 \mathrm{E}-13$ & 0.0000 & $0.000 \mathrm{E}+00$ & 0.0000 & $0.000 \mathrm{E}+00$ & 0.0000 & $0.000 \mathrm{E}+00$ & 0.0000 & $0.000 \mathrm{E}+00$ & 0.0000 & $0.000 \mathrm{E}+00$ & 0.0000 \\
\hline-239 & $7.814 \mathrm{E}-14$ & 0.0000 & $0.000 \mathrm{E}+00$ & 0.0000 & $0.000 \mathrm{E}+00$ & 0.0000 & $0.000 \mathrm{E}+00$ & 0.0000 & $0.000 \mathrm{E}+00$ & 0.0000 & $0.000 \mathrm{E}+00$ & 0.0000 \\
\hline-240 & $9.393 E-18$ & 0.0000 & $0.000 \mathrm{E}+00$ & 0.0000 & $0.000 \mathrm{E}+00$ & 0.0000 & $0.000 \mathrm{E}+00$ & 0.0000 & $0.000 \mathrm{E}+00$ & 0.0000 & $0.000 \mathrm{E}+00$ & 0.0000 \\
\hline-99 & $2.667 E-24$ & 0.0000 & $0.000 \mathrm{E}+00$ & 0.0000 & $0.000 \mathrm{E}+00$ & 0.0000 & $0.000 \mathrm{E}+00$ & 0.0000 & $0.000 \mathrm{E}+00$ & 0.0000 & $0.000 \mathrm{E}+00$ & 0.0000 \\
\hline-228 & $2.223 E-12$ & 0.0000 & $0.000 \mathrm{E}+00$ & 0.0000 & $0.000 \mathrm{E}+00$ & 0.0000 & $0.000 \mathrm{E}+00$ & 0.0000 & $0.000 \mathrm{E}+00$ & 0.0000 & $0.000 \mathrm{E}+00$ & 0.0000 \\
\hline-230 & $6.299 \mathrm{E}-06$ & 0.0685 & $0.000 \mathrm{E}+00$ & 0.0000 & $0.000 \mathrm{E}+00$ & 0.0000 & $0.000 \mathrm{E}+00$ & 0.0000 & $0.000 \mathrm{E}+00$ & 0.0000 & $0.000 \mathrm{E}+00$ & 0.0000 \\
\hline 232 & $8.488 E-05$ & 0.9227 & $0.000 \mathrm{E}+00$ & 0.0000 & $0.000 \mathrm{E}+00$ & 0.0000 & $0.000 \mathrm{E}+00$ & 0.0000 & $0.000 \mathrm{E}+00$ & 0.0000 & $0.000 \mathrm{E}+00$ & 0.0000 \\
\hline 34 & $2.134 \mathrm{E}-08$ & 0.0002 & $0.000 \mathrm{E}+00$ & 0.0000 & $0.000 \mathrm{E}+00$ & 0.0000 & $0.000 \mathrm{E}+00$ & 0.0000 & $0.000 \mathrm{E}+00$ & 0.0000 & $0.000 \mathrm{E}+00$ & 0.0000 \\
\hline 35 & $7.450 \mathrm{E}-11$ & 0.0000 & $0.000 \mathrm{E}+00$ & 0.0000 & $0.000 \mathrm{E}+00$ & 0.0000 & $0.000 \mathrm{E}+00$ & 0.0000 & $0.000 \mathrm{E}+00$ & 0.0000 & $0.000 \mathrm{E}+00$ & 0.0000 \\
\hline 38 & $6.743 E-07$ & 0.0073 & $0.000 \mathrm{E}+00$ & 0.0000 & $0.000 \mathrm{E}+00$ & 0.0000 & $0.000 \mathrm{E}+00$ & 0.0000 & $0.000 \mathrm{E}+00$ & 0.0000 & $0.000 \mathrm{E}+00$ & 0.0000 \\
\hline & $9.199 \mathrm{E}-05$ & 1.0000 & $0.000 \mathrm{E}+00$ & 0.0000 & $0.000 \mathrm{E}+00$ & 0.0000 & $0.000 \mathrm{E}+00$ & 0.0000 & $0.000 \mathrm{E}+00$ & 0.0000 & $0.000 \mathrm{E}+00$ & 0.0000 \\
\hline
\end{tabular}

Total Dose Contributions TDOSE (i,p,t) for Individual Radionuclides (i) and Pathways (p) As mrem/yr and Fraction of Total Dose At $t=5.000 \mathrm{E}+01$ years

Water Dependent Pathways

\begin{tabular}{llll} 
& & \multicolumn{2}{c}{ Water } \\
Radio- & & \\
Nuclide & mrem/yr & fract. \\
Am-241 & $0.000 \mathrm{E}+00$ & 0.0000 \\
Cs-137 & $0.000 \mathrm{E}+00$ & 0.0000 \\
$\mathrm{~Np}-237$ & $0.000 \mathrm{E}+00$ & 0.0000 \\
Pu-238 & $0.000 \mathrm{E}+00$ & 0.0000 \\
Pu-239 & $0.000 \mathrm{E}+00$ & 0.0000 \\
Pu-240 & $0.000 \mathrm{E}+00$ & 0.0000 \\
$\mathrm{TC}-99$ & $0.000 \mathrm{E}+00$ & 0.0000 \\
$\mathrm{Th}-228$ & $0.000 \mathrm{E}+00$ & 0.0000 \\
$\mathrm{Th}-230$ & $0.000 \mathrm{E}+00$ & 0.0000 \\
$\mathrm{Th}-232$ & $0.000 \mathrm{E}+00$ & 0.0000 \\
$\mathrm{U}-234$ & $0.000 \mathrm{E}+00$ & 0.0000 \\
$\mathrm{U}-235$ & $0.000 \mathrm{E}+00$ & 0.0000 \\
$\mathrm{U}-238$ & $0.000 \mathrm{E}+00$ & 0.0000 \\
\hline \hline
\end{tabular}

Total

$0.000 \mathrm{E}+00 \quad 0.0000$

\begin{tabular}{|c|c|}
\hline mrem/yr & fract. \\
\hline $000 \mathrm{E}+00$ & 0.0000 \\
\hline $.000 \mathrm{E}+00$ & 0.0000 \\
\hline $.000 \mathrm{E}+00$ & 0.0000 \\
\hline $.000 \mathrm{E}+00$ & 0.0000 \\
\hline $.000 \mathrm{E}+00$ & 0.0000 \\
\hline $0.000 \mathrm{E}+00$ & 0.0000 \\
\hline $0.000 \mathrm{E}+00$ & 0.0000 \\
\hline $0.000 \mathrm{E}+00$ & 0.0000 \\
\hline $0.000 \mathrm{E}+00$ & 0.0000 \\
\hline $0.000 \mathrm{E}+00$ & 0.0000 \\
\hline $0.000 \mathrm{E}+00$ & 0.0000 \\
\hline $0.000 \mathrm{E}+00$ & 0.0000 \\
\hline $0.000 \mathrm{E}+00$ & 0.0000 \\
\hline
\end{tabular}

$0.000 \mathrm{E}+00 \quad 0.0000$

\begin{tabular}{cc} 
Radon \\
\cline { 1 - 2 } mrem/yr fract. \\
\hline $0.000 \mathrm{E}+00$ & 0.0000 \\
$0.000 \mathrm{E}+00$ & 0.0000 \\
$0.000 \mathrm{E}+00$ & 0.0000 \\
$0.000 \mathrm{E}+00$ & 0.0000 \\
$0.000 \mathrm{E}+00$ & 0.0000 \\
$0.000 \mathrm{E}+00$ & 0.0000 \\
$0.000 \mathrm{E}+00$ & 0.0000 \\
$0.000 \mathrm{E}+00$ & 0.0000 \\
$0.000 \mathrm{E}+00$ & 0.0000 \\
$0.000 \mathrm{E}+00$ & 0.0000 \\
$0.000 \mathrm{E}+00$ & 0.0000 \\
$0.000 \mathrm{E}+00$ & 0.0000 \\
$0.000 \mathrm{E}+00$ & 0.0000 \\
\hline \hline
\end{tabular}

$0.000 \mathrm{E}+00 \quad 0.0000$

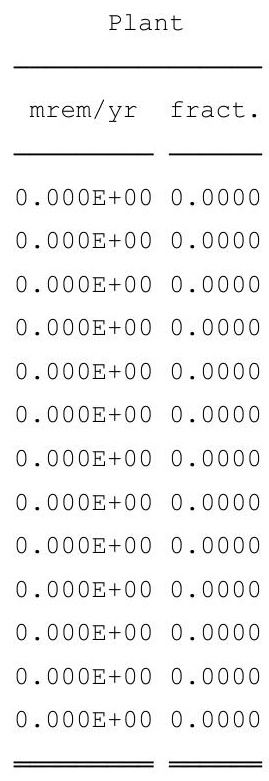

$0.000 \mathrm{E}+00 \quad 0.0000$

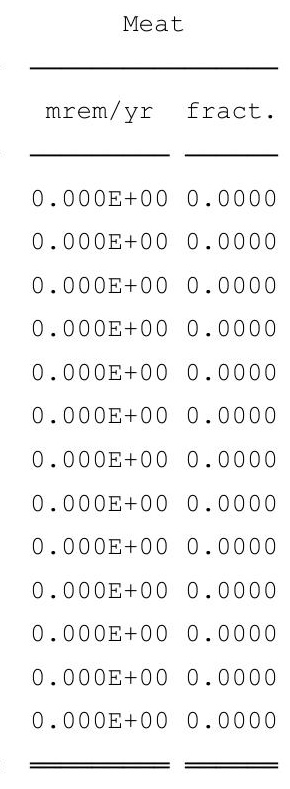

$0.000 \mathrm{E}+00 \quad 0.0000$

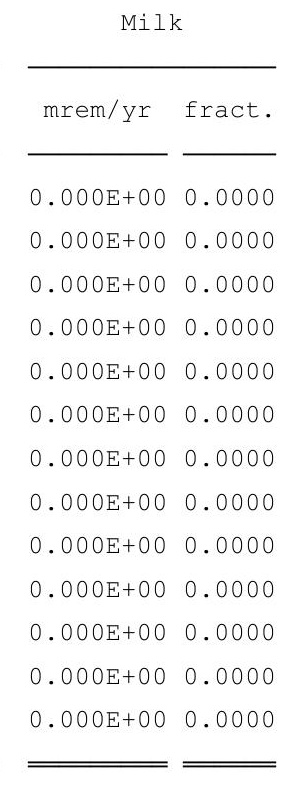

$0.000 \mathrm{E}+00 \quad 0.0000$
Soil

\begin{tabular}{lll} 
mrem/yr & fract. \\
\cline { 1 - 1 } $0.000 \mathrm{E}+00$ & 0.0000 \\
$0.000 \mathrm{E}+00$ & 0.0000 \\
$0.000 \mathrm{E}+00$ & 0.0000 \\
$0.000 \mathrm{E}+00$ & 0.0000 \\
$0.000 \mathrm{E}+00$ & 0.0000 \\
$0.000 \mathrm{E}+00$ & 0.0000 \\
$0.000 \mathrm{E}+00$ & 0.0000 \\
$0.000 \mathrm{E}+00$ & 0.0000 \\
$0.000 \mathrm{E}+00$ & 0.0000 \\
$0.000 \mathrm{E}+00$ & 0.0000 \\
$0.000 \mathrm{E}+00$ & 0.0000 \\
$0.000 \mathrm{E}+00$ & 0.0000 \\
$0.000 \mathrm{E}+00$ & 0.0000 \\
\hline \hline $0.000 \mathrm{E}+00$ & 0.0000
\end{tabular}

*Sum of all water independent and dependent pathways. 


\section{RESRAD, Version $6.5 \quad \mathrm{~T}^{1 / 2}$ Limit $=180$ days}

Summary : C746U Resident Farmer Deterministic Run

: $\mathrm{X}: \backslash \mathrm{FINAL}$ V2 \C746U RF SG FWD-FINALV2.RAD

Total Dose Contributions TDOSE(i,p,t) for Individual Radionuclides (i) and Pathways (p) As mrem/yr and Fraction of Total Dose At $t=1.000 \mathrm{E}+02$ years

Water Independent Pathways (Inhalation excludes radon)

\begin{tabular}{|c|c|c|}
\hline ide & mrem/yr & fract. \\
\hline-241 & $2.911 \mathrm{E}-13$ & 0.0000 \\
\hline-137 & $5.552 \mathrm{E}-08$ & 0.0004 \\
\hline-237 & $1.525 \mathrm{E}-09$ & 0.0000 \\
\hline-238 & $2.040 \mathrm{E}-12$ & 0.0000 \\
\hline-239 & $1.419 \mathrm{E}-13$ & 0.0000 \\
\hline-240 & $6.330 \mathrm{E}-17$ & 0.0000 \\
\hline-99 & $4.436 \mathrm{E}-24$ & 0.0000 \\
\hline-228 & $4.062 \mathrm{E}-20$ & 0.0000 \\
\hline-230 & $1.760 \mathrm{E}-05$ & 0.1317 \\
\hline-232 & $1.149 \mathrm{E}-04$ & 0.8595 \\
\hline 34 & $1.197 \mathrm{E}-07$ & 0.0009 \\
\hline 35 & $2.749 \mathrm{E}-10$ & 0.0000 \\
\hline 238 & $1.005 \mathrm{E}-06$ & 0.0075 \\
\hline & 04 & 1 \\
\hline
\end{tabular}

Inhalation

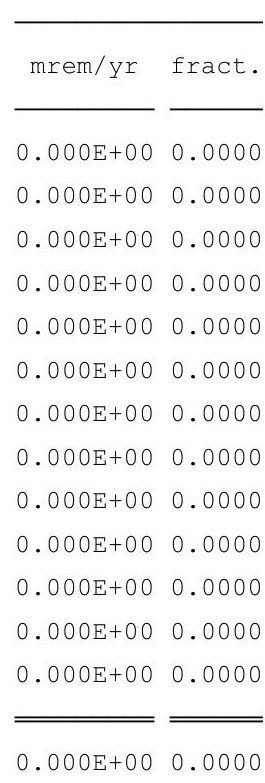

\begin{tabular}{ll} 
Radon \\
\hline mrem/yr fract. \\
\cline { 1 - 1 } 0.000E+00 & 0.0000 \\
$0.000 \mathrm{E}+00$ & 0.0000 \\
$0.000 \mathrm{E}+00$ & 0.0000 \\
$0.000 \mathrm{E}+00$ & 0.0000 \\
$0.000 \mathrm{E}+00$ & 0.0000 \\
$0.000 \mathrm{E}+00$ & 0.0000 \\
$0.000 \mathrm{E}+00$ & 0.0000 \\
$0.000 \mathrm{E}+00$ & 0.0000 \\
$0.000 \mathrm{E}+00$ & 0.0000 \\
$0.000 \mathrm{E}+00$ & 0.0000 \\
$0.000 \mathrm{E}+00$ & 0.0000 \\
$0.000 \mathrm{E}+00$ & 0.0000 \\
$0.000 \mathrm{E}+00$ & 0.0000 \\
\hline \hline $0.000 \mathrm{E}+00$ & 0.0000
\end{tabular}

\begin{tabular}{|c|c|}
\hline mrem/yr & fract. \\
\hline $0.000 \mathrm{E}+00$ & 0.0000 \\
\hline $0.000 \mathrm{E}+00$ & 0.0000 \\
\hline $0.000 \mathrm{E}+00$ & 0.0000 \\
\hline $0.000 \mathrm{E}+00$ & 0.0000 \\
\hline $0.000 \mathrm{E}+00$ & 0.0000 \\
\hline $0.000 \mathrm{E}+00$ & 0.0000 \\
\hline $0.000 \mathrm{E}+00$ & 0.0000 \\
\hline $0.000 \mathrm{E}+00$ & 0.0000 \\
\hline $0.000 \mathrm{E}+00$ & 0.0000 \\
\hline $0.000 \mathrm{E}+00$ & 0.0000 \\
\hline $0.000 \mathrm{E}+00$ & 0.0000 \\
\hline $0.000 \mathrm{E}+00$ & 0.0000 \\
\hline $0.000 \mathrm{E}+00$ & 0.0000 \\
\hline .000 & .000 \\
\hline
\end{tabular}

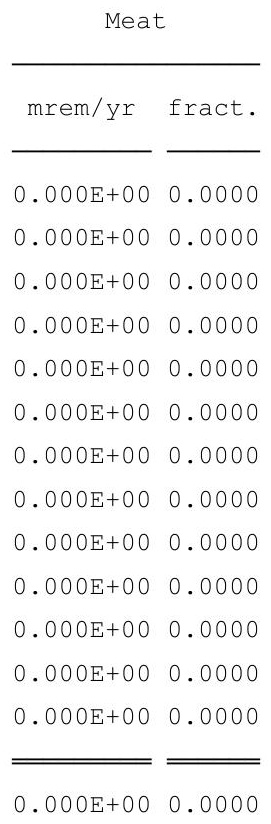

\begin{tabular}{cc} 
Milk \\
\cline { 1 - 1 } mrem/yr fract. \\
\cline { 1 - 1 } $0.000 \mathrm{E}+00$ & 0.0000 \\
$0.000 \mathrm{E}+00$ & 0.0000 \\
$0.000 \mathrm{E}+00$ & 0.0000 \\
$0.000 \mathrm{E}+00$ & 0.0000 \\
$0.000 \mathrm{E}+00$ & 0.0000 \\
$0.000 \mathrm{E}+00$ & 0.0000 \\
$0.000 \mathrm{E}+00$ & 0.0000 \\
$0.000 \mathrm{E}+00$ & 0.0000 \\
$0.000 \mathrm{E}+00$ & 0.0000 \\
$0.000 \mathrm{E}+00$ & 0.0000 \\
$0.000 \mathrm{E}+00$ & 0.0000 \\
$0.000 \mathrm{E}+00$ & 0.0000 \\
$0.000 \mathrm{E}+00$ & 0.0000 \\
\hline \hline $0.000 \mathrm{E}+00$ & 0.0000
\end{tabular}

Total Dose Contributions TDOSE (i,p,t) for Individual Radionuclides (i) and Pathways (p) As mrem/yr and Fraction of Total Dose At $t=1.000 \mathrm{E}+02$ years

Water Dependent Pathways

\begin{tabular}{llll} 
& & \multicolumn{2}{c}{ Water } \\
Radio- & & \\
Nuclide & mrem/yr & fract. \\
Am-241 & $0.000 \mathrm{E}+00$ & 0.0000 \\
Cs-137 & $0.000 \mathrm{E}+00$ & 0.0000 \\
$\mathrm{~Np}-237$ & $0.000 \mathrm{E}+00$ & 0.0000 \\
Pu-238 & $0.000 \mathrm{E}+00$ & 0.0000 \\
Pu-239 & $0.000 \mathrm{E}+00$ & 0.0000 \\
Pu-240 & $0.000 \mathrm{E}+00$ & 0.0000 \\
$\mathrm{TC}-99$ & $0.000 \mathrm{E}+00$ & 0.0000 \\
$\mathrm{Th}-228$ & $0.000 \mathrm{E}+00$ & 0.0000 \\
$\mathrm{Th}-230$ & $0.000 \mathrm{E}+00$ & 0.0000 \\
$\mathrm{Th}-232$ & $0.000 \mathrm{E}+00$ & 0.0000 \\
$\mathrm{U}-234$ & $0.000 \mathrm{E}+00$ & 0.0000 \\
$\mathrm{U}-235$ & $0.000 \mathrm{E}+00$ & 0.0000 \\
$\mathrm{U}-238$ & $0.000 \mathrm{E}+00$ & 0.0000 \\
\hline \hline
\end{tabular}

$0.000 \mathrm{E}+00 \quad 0.0000$

\begin{tabular}{cc} 
Fish \\
\cline { 1 - 2 } mrem/yr & fract. \\
\hline $0.000 \mathrm{E}+00$ & 0.0000 \\
$0.000 \mathrm{E}+00$ & 0.0000 \\
$0.000 \mathrm{E}+00$ & 0.0000 \\
$0.000 \mathrm{E}+00$ & 0.0000 \\
$0.000 \mathrm{E}+00$ & 0.0000 \\
$0.000 \mathrm{E}+00$ & 0.0000 \\
$0.000 \mathrm{E}+00$ & 0.0000 \\
$0.000 \mathrm{E}+00$ & 0.0000 \\
$0.000 \mathrm{E}+00$ & 0.0000 \\
$0.000 \mathrm{E}+00$ & 0.0000 \\
$0.000 \mathrm{E}+00$ & 0.0000 \\
$0.000 \mathrm{E}+00$ & 0.0000 \\
$0.000 \mathrm{E}+00$ & 0.0000 \\
\hline \hline
\end{tabular}

$0.000 \mathrm{E}+00 \quad 0.0000$

\begin{tabular}{cc} 
Radon \\
\hline mrem/yr fract. \\
\hline $0.000 \mathrm{E}+00$ & 0.0000 \\
$0.000 \mathrm{E}+00$ & 0.0000 \\
$0.000 \mathrm{E}+00$ & 0.0000 \\
$0.000 \mathrm{E}+00$ & 0.0000 \\
$0.000 \mathrm{E}+00$ & 0.0000 \\
$0.000 \mathrm{E}+00$ & 0.0000 \\
$0.000 \mathrm{E}+00$ & 0.0000 \\
$0.000 \mathrm{E}+00$ & 0.0000 \\
$0.000 \mathrm{E}+00$ & 0.0000 \\
$0.000 \mathrm{E}+00$ & 0.0000 \\
$0.000 \mathrm{E}+00$ & 0.0000 \\
$0.000 \mathrm{E}+00$ & 0.0000 \\
$0.000 \mathrm{E}+00$ & 0.0000 \\
\hline \hline
\end{tabular}

$0.000 \mathrm{E}+00 \quad 0.0000$

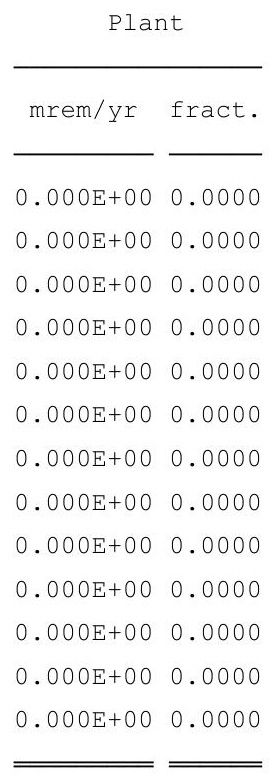

$0.000 \mathrm{E}+00 \quad 0.0000$

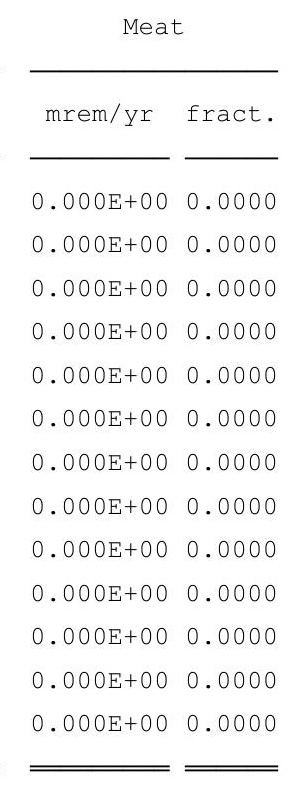

$0.000 \mathrm{E}+00 \quad 0.0000$

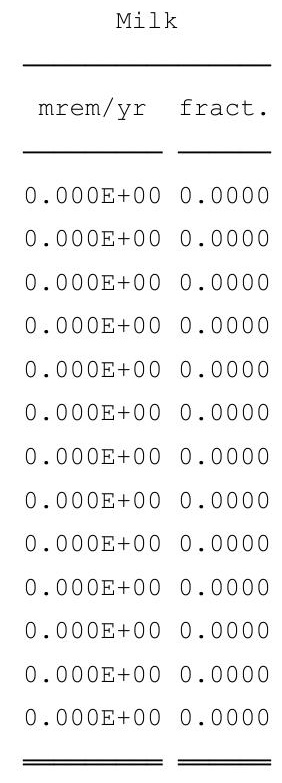

$0.000 E+00 \quad 0.0000$
Soil

\begin{tabular}{ccc} 
mrem/yr & fract. \\
\cline { 1 - 1 } $0.000 \mathrm{E}+00$ & 0.0000 \\
$0.000 \mathrm{E}+00$ & 0.0000 \\
$0.000 \mathrm{E}+00$ & 0.0000 \\
$0.000 \mathrm{E}+00$ & 0.0000 \\
$0.000 \mathrm{E}+00$ & 0.0000 \\
$0.000 \mathrm{E}+00$ & 0.0000 \\
$0.000 \mathrm{E}+00$ & 0.0000 \\
$0.000 \mathrm{E}+00$ & 0.0000 \\
$0.000 \mathrm{E}+00$ & 0.0000 \\
$0.000 \mathrm{E}+00$ & 0.0000 \\
$0.000 \mathrm{E}+00$ & 0.0000 \\
$0.000 \mathrm{E}+00$ & 0.0000 \\
$0.000 \mathrm{E}+00$ & 0.0000 \\
\hline \hline $0.000 \mathrm{E}+00$ & 0.0000
\end{tabular}

* Sum of all water independent and dependent pathways. 


\section{RESRAD, Version $6.5 \quad \mathrm{~T}^{1 / 2}$ Limit $=180$ days}

Summary : C746U Resident Farmer Deterministic Run

: $\mathrm{X}: \backslash \mathrm{FINAL}$ V2 \C746U RF SG FWD-FINALV2.RAD

Total Dose Contributions TDOSE(i,p,t) for Individual Radionuclides (i) and Pathways (p) As mrem/yr and Fraction of Total Dose At $t=5.000 \mathrm{E}+02$ years

Water Independent Pathways (Inhalation excludes radon)

\begin{tabular}{|c|c|c|}
\hline ide & mrem/yr & fract. \\
\hline-241 & 7. $984 \mathrm{E}-11$ & 0.0000 \\
\hline-137 & $1.551 \mathrm{E}-10$ & 0.0000 \\
\hline-237 & $1.118 \mathrm{E}-07$ & 0.0000 \\
\hline-238 & $2.174 \mathrm{E}-09$ & 0.0000 \\
\hline-239 & $1.685 \mathrm{E}-11$ & 0.0000 \\
\hline-240 & $2.048 E-14$ & 0.0000 \\
\hline-99 & $2.593 E-22$ & 0.0000 \\
\hline-228 & $0.000 \mathrm{E}+00$ & 0.0000 \\
\hline-230 & 1. $280 \mathrm{E}-03$ & 0.0002 \\
\hline-232 & $1.265 E-03$ & 0.0002 \\
\hline 234 & $4.468 E-05$ & 0.0000 \\
\hline 5 & $5.735 E-08$ & 0.0000 \\
\hline 38 & $2.448 E-05$ & 0.0000 \\
\hline & 03 & 0. \\
\hline
\end{tabular}

Inhalation

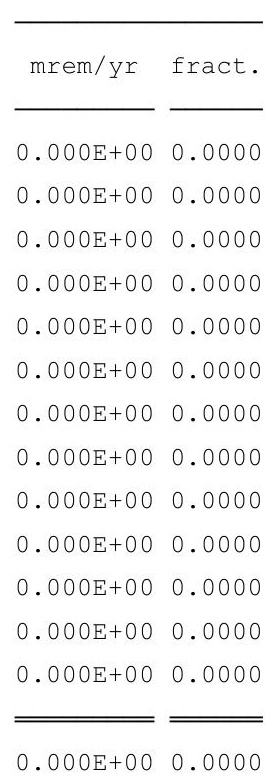

\begin{tabular}{ll} 
Radon \\
\hline mrem/yr fract. \\
\cline { 1 - 1 } 0.000E+00 & 0.0000 \\
$0.000 \mathrm{E}+00$ & 0.0000 \\
$0.000 \mathrm{E}+00$ & 0.0000 \\
$0.000 \mathrm{E}+00$ & 0.0000 \\
$0.000 \mathrm{E}+00$ & 0.0000 \\
$0.000 \mathrm{E}+00$ & 0.0000 \\
$0.000 \mathrm{E}+00$ & 0.0000 \\
$0.000 \mathrm{E}+00$ & 0.0000 \\
$0.000 \mathrm{E}+00$ & 0.0000 \\
$0.000 \mathrm{E}+00$ & 0.0000 \\
$0.000 \mathrm{E}+00$ & 0.0000 \\
$0.000 \mathrm{E}+00$ & 0.0000 \\
$0.000 \mathrm{E}+00$ & 0.0000 \\
\hline \hline $0.000 \mathrm{E}+00$ & 0.0000
\end{tabular}

\begin{tabular}{|c|c|}
\hline mrem/yr & fract. \\
\hline $0.000 \mathrm{E}+00$ & 0.0000 \\
\hline $0.000 \mathrm{E}+00$ & 0.0000 \\
\hline $0.000 \mathrm{E}+00$ & 0.0000 \\
\hline $0.000 \mathrm{E}+00$ & 0.0000 \\
\hline $0.000 \mathrm{E}+00$ & 0.0000 \\
\hline $0.000 \mathrm{E}+00$ & 0.0000 \\
\hline $0.000 \mathrm{E}+00$ & 0.0000 \\
\hline $0.000 \mathrm{E}+00$ & 0.0000 \\
\hline $0.000 \mathrm{E}+00$ & 0.0000 \\
\hline $0.000 \mathrm{E}+00$ & 0.0000 \\
\hline $0.000 \mathrm{E}+00$ & 0.0000 \\
\hline $0.000 \mathrm{E}+00$ & 0.0000 \\
\hline $0.000 \mathrm{E}+00$ & 0.0000 \\
\hline .000 & .000 \\
\hline
\end{tabular}

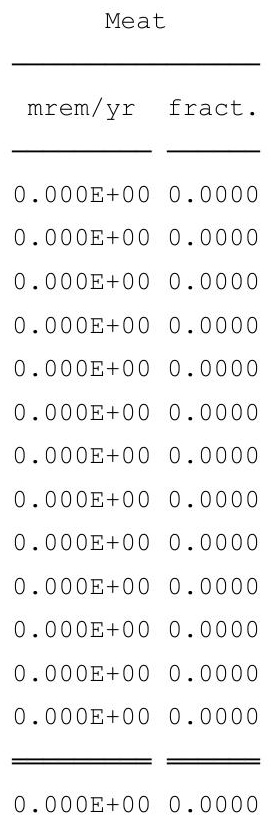

\begin{tabular}{cc} 
Milk \\
\cline { 1 - 1 } mrem/yr fract. \\
\cline { 1 - 1 } $0.000 \mathrm{E}+00$ & 0.0000 \\
$0.000 \mathrm{E}+00$ & 0.0000 \\
$0.000 \mathrm{E}+00$ & 0.0000 \\
$0.000 \mathrm{E}+00$ & 0.0000 \\
$0.000 \mathrm{E}+00$ & 0.0000 \\
$0.000 \mathrm{E}+00$ & 0.0000 \\
$0.000 \mathrm{E}+00$ & 0.0000 \\
$0.000 \mathrm{E}+00$ & 0.0000 \\
$0.000 \mathrm{E}+00$ & 0.0000 \\
$0.000 \mathrm{E}+00$ & 0.0000 \\
$0.000 \mathrm{E}+00$ & 0.0000 \\
$0.000 \mathrm{E}+00$ & 0.0000 \\
$0.000 \mathrm{E}+00$ & 0.0000 \\
\hline \hline $0.000 \mathrm{E}+00$ & 0.0000
\end{tabular}

Total Dose Contributions TDOSE (i,p,t) for Individual Radionuclides (i) and Pathways (p) As mrem/yr and Fraction of Total Dose At $t=5.000 \mathrm{E}+02$ years

Water Dependent Pathways

\begin{tabular}{|c|c|c|}
\hline de & $\mathrm{mrem} / \mathrm{yr}$ & fract. \\
\hline-241 & $0.000 \mathrm{E}+00$ & 0.0000 \\
\hline 137 & $0.000 \mathrm{E}+00$ & 0.0000 \\
\hline 237 & $0.000 \mathrm{E}+00$ & 0.0000 \\
\hline-238 & $0.000 \mathrm{E}+00$ & 0.0000 \\
\hline 239 & $0.000 \mathrm{E}+00$ & 0.0000 \\
\hline 240 & $0.000 \mathrm{E}+00$ & 0.0000 \\
\hline & $4.820 \mathrm{E}+00$ & 0.8274 \\
\hline 228 & $0.000 \mathrm{E}+00$ & 0.0000 \\
\hline 230 & $0.000 \mathrm{E}+00$ & 0.0000 \\
\hline 232 & $0.000 \mathrm{E}+00$ & 0.0000 \\
\hline & $0.000 \mathrm{E}+00$ & 0.0000 \\
\hline & $0.000 \mathrm{E}+00$ & 0.0000 \\
\hline & $0.000 \mathrm{E}+00$ & 0.0000 \\
\hline
\end{tabular}

\begin{tabular}{cc} 
Fish \\
\cline { 1 - 2 } mrem/yr & fract. \\
\hline $0.000 \mathrm{E}+00$ & 0.0000 \\
$0.000 \mathrm{E}+00$ & 0.0000 \\
$0.000 \mathrm{E}+00$ & 0.0000 \\
$0.000 \mathrm{E}+00$ & 0.0000 \\
$0.000 \mathrm{E}+00$ & 0.0000 \\
$0.000 \mathrm{E}+00$ & 0.0000 \\
$0.000 \mathrm{E}+00$ & 0.0000 \\
$0.000 \mathrm{E}+00$ & 0.0000 \\
$0.000 \mathrm{E}+00$ & 0.0000 \\
$0.000 \mathrm{E}+00$ & 0.0000 \\
$0.000 \mathrm{E}+00$ & 0.0000 \\
$0.000 \mathrm{E}+00$ & 0.0000 \\
$0.000 \mathrm{E}+00$ & 0.0000 \\
\hline \hline
\end{tabular}

$0.000 \mathrm{E}+00 \quad 0.0000$

\begin{tabular}{cc} 
Radon \\
\cline { 1 - 2 } mrem/yr fract. \\
\cline { 1 - 2 } $0.000 \mathrm{E}+00$ & 0.0000 \\
$0.000 \mathrm{E}+00$ & 0.0000 \\
$0.000 \mathrm{E}+00$ & 0.0000 \\
$0.000 \mathrm{E}+00$ & 0.0000 \\
$0.000 \mathrm{E}+00$ & 0.0000 \\
$0.000 \mathrm{E}+00$ & 0.0000 \\
$0.000 \mathrm{E}+00$ & 0.0000 \\
$0.000 \mathrm{E}+00$ & 0.0000 \\
$0.000 \mathrm{E}+00$ & 0.0000 \\
$0.000 \mathrm{E}+00$ & 0.0000 \\
$0.000 \mathrm{E}+00$ & 0.0000 \\
$0.000 \mathrm{E}+00$ & 0.0000 \\
$0.000 \mathrm{E}+00$ & 0.0000 \\
\hline \hline
\end{tabular}

$0.000 \mathrm{E}+00 \quad 0.0000$

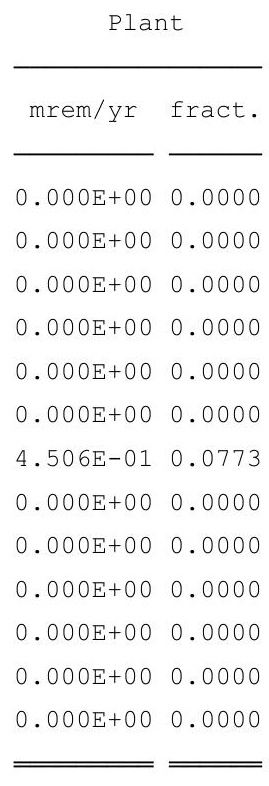

$4.506 \mathrm{E}-01 \quad 0.0773$

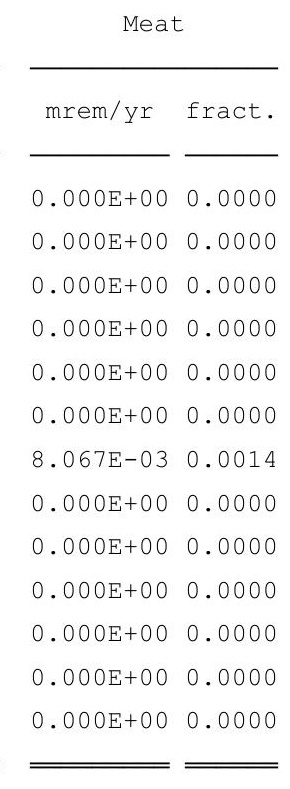

$8.067 \mathrm{E}-03 \quad 0.0014$

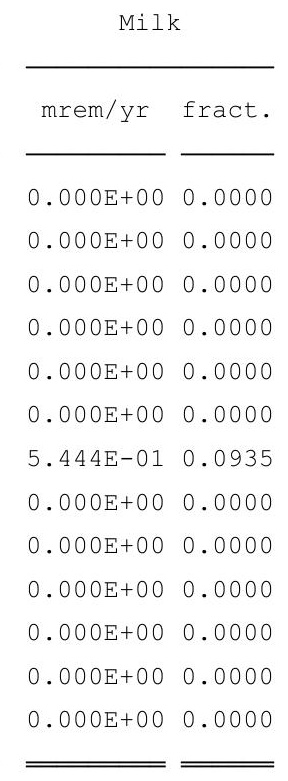

$5.444 \mathrm{E}-01 \quad 0.0935$
Soil

\begin{tabular}{ccc} 
mrem/yr & fract. \\
\cline { 1 - 1 } $0.000 \mathrm{E}+00$ & 0.0000 \\
$0.000 \mathrm{E}+00$ & 0.0000 \\
$0.000 \mathrm{E}+00$ & 0.0000 \\
$0.000 \mathrm{E}+00$ & 0.0000 \\
$0.000 \mathrm{E}+00$ & 0.0000 \\
$0.000 \mathrm{E}+00$ & 0.0000 \\
$0.000 \mathrm{E}+00$ & 0.0000 \\
$0.000 \mathrm{E}+00$ & 0.0000 \\
$0.000 \mathrm{E}+00$ & 0.0000 \\
$0.000 \mathrm{E}+00$ & 0.0000 \\
$0.000 \mathrm{E}+00$ & 0.0000 \\
$0.000 \mathrm{E}+00$ & 0.0000 \\
$0.000 \mathrm{E}+00$ & 0.0000 \\
\hline \hline $0.000 \mathrm{E}+00$ & 0.0000
\end{tabular}

* Sum of all water independent and dependent pathways. 


\section{RESRAD, Version $6.5 \quad \mathrm{~T}^{1 / 2}$ Limit $=180$ days}

Summary : C746U Resident Farmer Deterministic Run

: $\mathrm{X}: \backslash \mathrm{FINAL}$ V2 \C746U RF SG FWD-FINALV2.RAD

Total Dose Contributions TDOSE(i,p,t) for Individual Radionuclides (i) and Pathways (p) As mrem/yr and Fraction of Total Dose At $t=1.050 \mathrm{E}+03$ years

Water Independent Pathways (Inhalation excludes radon)

\begin{tabular}{|c|c|c|c|c|c|c|c|c|c|c|c|c|}
\hline \multirow{2}{*}{ Nuclide } & \multicolumn{2}{|c|}{ Ground } & \multicolumn{2}{|c|}{ Inhalation } & \multicolumn{2}{|c|}{ Radon } & \multicolumn{2}{|c|}{ Plant } & \multicolumn{2}{|c|}{ Meat } & \multicolumn{2}{|c|}{ Milk } \\
\hline & mrem/yr & fract. & mrem/yr & fract. & mrem/yr & fract. & mrem/yr & fract. & mrem/yr & fract. & mrem/yr & fract. \\
\hline-241 & $4.234 \mathrm{E}-08$ & 0.0000 & $0.000 \mathrm{E}+00$ & 0.0000 & $0.000 \mathrm{E}+00$ & 0.0000 & $6.742 \mathrm{E}-01$ & 0.0059 & $1.195 \mathrm{E}-03$ & 0.0000 & $1.147 \mathrm{E}-04$ & 0.0000 \\
\hline-137 & $4.776 \mathrm{E}-14$ & 0.0000 & $0.000 \mathrm{E}+00$ & 0.0000 & $0.000 \mathrm{E}+00$ & 0.0000 & 1. $435 \mathrm{E}-11$ & 0.0000 & $1.304 \mathrm{E}-11$ & 0.0000 & $9.626 \mathrm{E}-12$ & 0.0000 \\
\hline 237 & $3.889 \mathrm{E}-05$ & 0.0000 & $0.000 \mathrm{E}+00$ & 0.0000 & $0.000 \mathrm{E}+00$ & 0.0000 & $5.473 E+00$ & 0.0478 & $1.658 \mathrm{E}-01$ & 0.0014 & $2.372 E-03$ & 0.0000 \\
\hline-238 & $5.054 \mathrm{E}-07$ & 0.0000 & $0.000 \mathrm{E}+00$ & 0.0000 & $0.000 \mathrm{E}+00$ & 0.0000 & $2.317 \mathrm{E}-03$ & 0.0000 & $2.055 E-05$ & 0.0000 & $5.814 \mathrm{E}-05$ & 0.0000 \\
\hline-239 & $1.194 \mathrm{E}-08$ & 0.0000 & $0.000 \mathrm{E}+00$ & 0.0000 & $0.000 \mathrm{E}+00$ & 0.0000 & $4.433 E+00$ & 0.0387 & $1.343 E-02$ & 0.0001 & $3.719 \mathrm{E}-04$ & 0.0000 \\
\hline-240 & $2.901 \mathrm{E}-12$ & 0.0000 & $0.000 \mathrm{E}+00$ & 0.0000 & $0.000 \mathrm{E}+00$ & 0.0000 & $4.088 E+00$ & 0.0357 & $1.238 \mathrm{E}-02$ & 0.0001 & $3.460 \mathrm{E}-04$ & 0.0000 \\
\hline-99 & $6.973 E-20$ & 0.0000 & $0.000 \mathrm{E}+00$ & 0.0000 & $0.000 \mathrm{E}+00$ & 0.0000 & $3.619 \mathrm{E}-05$ & 0.0000 & $1.098 \mathrm{E}-07$ & 0.0000 & $3.038 E-06$ & 0.0000 \\
\hline-228 & $0.000 \mathrm{E}+00$ & 0.0000 & $0.000 \mathrm{E}+00$ & 0.0000 & $0.000 \mathrm{E}+00$ & 0.0000 & $0.000 \mathrm{E}+00$ & 0.0000 & $0.000 \mathrm{E}+00$ & 0.0000 & $0.000 \mathrm{E}+00$ & 0.0000 \\
\hline-230 & $1.072 \mathrm{E}-01$ & 0.0009 & $0.000 \mathrm{E}+00$ & 0.0000 & $0.000 \mathrm{E}+00$ & 0.0000 & $6.765 \mathrm{E}+01$ & 0.5904 & $1.780 \mathrm{E}+00$ & 0.0155 & $3.154 \mathrm{E}+00$ & 0.0275 \\
\hline-232 & $3.502 \mathrm{E}-02$ & 0.0003 & $0.000 \mathrm{E}+00$ & 0.0000 & $0.000 \mathrm{E}+00$ & 0.0000 & $5.465 \mathrm{E}+00$ & 0.0477 & $1.612 \mathrm{E}-01$ & 0.0014 & $4.464 \mathrm{E}-01$ & 0.0039 \\
\hline 234 & $8.141 \mathrm{E}-03$ & 0.0001 & $0.000 \mathrm{E}+00$ & 0.0000 & $0.000 \mathrm{E}+00$ & 0.0000 & $1.620 \mathrm{E}+01$ & 0.1414 & $2.471 \mathrm{E}-01$ & 0.0022 & $7.943 \mathrm{E}-01$ & 0.0069 \\
\hline 235 & $1.916 \mathrm{E}-05$ & 0.0000 & $0.000 \mathrm{E}+00$ & 0.0000 & $0.000 \mathrm{E}+00$ & 0.0000 & $1.406 \mathrm{E}+00$ & 0.0123 & $1.037 \mathrm{E}-01$ & 0.0009 & $2.538 \mathrm{E}-02$ & 0.0002 \\
\hline 38 & $1.976 \mathrm{E}-03$ & 0.0000 & $0.000 \mathrm{E}+00$ & 0.0000 & $0.000 \mathrm{E}+00$ & 0.0000 & $1.966 \mathrm{E}+00$ & 0.0172 & $2.027 E-02$ & 0.0002 & $9.894 \mathrm{E}-02$ & 0.0009 \\
\hline & $1.524 \mathrm{E}-01$ & 0.0013 & $0.000 \mathrm{E}+00$ & 0.0000 & $0.000 \mathrm{E}+00$ & 0.0000 & $1.074 \mathrm{E}+02$ & 0.9370 & $2.505 E+00$ & 0.0219 & $4.522 \mathrm{E}+00$ & 0.0395 \\
\hline
\end{tabular}

Total Dose Contributions TDOSE (i,p,t) for Individual Radionuclides (i) and Pathways (p) As mrem/yr and Fraction of Total Dose At $t=1.050 \mathrm{E}+03$ years

Water Dependent Pathways

\begin{tabular}{|c|c|c|c|c|c|c|c|c|c|c|c|c|c|c|}
\hline & \multicolumn{2}{|c|}{ Water } & \multicolumn{2}{|c|}{ Fish } & \multicolumn{2}{|c|}{ Radon } & \multicolumn{2}{|c|}{ Plant } & \multicolumn{2}{|c|}{ Meat } & \multicolumn{2}{|c|}{ Milk } & \multicolumn{2}{|c|}{ All Pathways* } \\
\hline clide & mrem/yr & fract. & mrem/yr & fract. & mrem/yr & fract. & mrem/yr & fract. & mrem/yr & fract. & mrem/yr & fract. & mrem/yr & fract. \\
\hline-241 & $0.000 \mathrm{E}+00$ & 0.0000 & $0.000 \mathrm{E}+00$ & 0.0000 & $0.000 \mathrm{E}+00$ & 0.0000 & $0.000 \mathrm{E}+00$ & 0.0000 & $0.000 \mathrm{E}+00$ & 0.0000 & $0.000 \mathrm{E}+00$ & 0.0000 & $6.755 \mathrm{E}-01$ & 0.0059 \\
\hline-137 & $0.000 \mathrm{E}+00$ & 0.0000 & $0.000 \mathrm{E}+00$ & 0.0000 & $0.000 \mathrm{E}+00$ & 0.0000 & $0.000 \mathrm{E}+00$ & 0.0000 & $0.000 \mathrm{E}+00$ & 0.0000 & $0.000 \mathrm{E}+00$ & 0.0000 & $3.706 \mathrm{E}-11$ & 0.0000 \\
\hline-237 & $0.000 \mathrm{E}+00$ & 0.0000 & $0.000 \mathrm{E}+00$ & 0.0000 & $0.000 \mathrm{E}+00$ & 0.0000 & $0.000 \mathrm{E}+00$ & 0.0000 & $0.000 \mathrm{E}+00$ & 0.0000 & $0.000 \mathrm{E}+00$ & 0.0000 & $5.641 \mathrm{E}+00$ & 0.0492 \\
\hline-238 & $0.000 \mathrm{E}+00$ & 0.0000 & $0.000 \mathrm{E}+00$ & 0.0000 & $0.000 \mathrm{E}+00$ & 0.0000 & $0.000 \mathrm{E}+00$ & 0.0000 & $0.000 \mathrm{E}+00$ & 0.0000 & $0.000 \mathrm{E}+00$ & 0.0000 & $2.396 \mathrm{E}-03$ & 0.0000 \\
\hline 239 & $0.000 \mathrm{E}+00$ & 0.0000 & $0.000 \mathrm{E}+00$ & 0.0000 & $0.000 \mathrm{E}+00$ & 0.0000 & $0.000 \mathrm{E}+00$ & 0.0000 & $0.000 \mathrm{E}+00$ & 0.0000 & $0.000 \mathrm{E}+00$ & 0.0000 & $4.447 \mathrm{E}+00$ & 0.0388 \\
\hline-240 & $0.000 \mathrm{E}+00$ & 0.0000 & $0.000 \mathrm{E}+00$ & 0.0000 & $0.000 \mathrm{E}+00$ & 0.0000 & $0.000 \mathrm{E}+00$ & 0.0000 & $0.000 \mathrm{E}+00$ & 0.0000 & $0.000 \mathrm{E}+00$ & 0.0000 & $4.101 \mathrm{E}+00$ & 0.0358 \\
\hline 99 & $3.428 E-02$ & 0.0003 & $0.000 \mathrm{E}+00$ & 0.0000 & $0.000 \mathrm{E}+00$ & 0.0000 & $3.204 \mathrm{E}-03$ & 0.0000 & $5.736 \mathrm{E}-05$ & 0.0000 & $3.871 \mathrm{E}-03$ & 0.0000 & $4.145 \mathrm{E}-02$ & 0.0004 \\
\hline-228 & $0.000 \mathrm{E}+00$ & 0.0000 & $0.000 \mathrm{E}+00$ & 0.0000 & $0.000 \mathrm{E}+00$ & 0.0000 & $0.000 \mathrm{E}+00$ & 0.0000 & $0.000 \mathrm{E}+00$ & 0.0000 & $0.000 \mathrm{E}+00$ & 0.0000 & $0.000 \mathrm{E}+00$ & 0.0000 \\
\hline-230 & $0.000 \mathrm{E}+00$ & 0.0000 & $0.000 \mathrm{E}+00$ & 0.0000 & $0.000 \mathrm{E}+00$ & 0.0000 & $0.000 \mathrm{E}+00$ & 0.0000 & $0.000 \mathrm{E}+00$ & 0.0000 & $0.000 \mathrm{E}+00$ & 0.0000 & $7.269 \mathrm{E}+01$ & 0.6344 \\
\hline 232 & $0.000 \mathrm{E}+00$ & 0.0000 & $0.000 \mathrm{E}+00$ & 0.0000 & $0.000 \mathrm{E}+00$ & 0.0000 & $0.000 \mathrm{E}+00$ & 0.0000 & $0.000 \mathrm{E}+00$ & 0.0000 & $0.000 \mathrm{E}+00$ & 0.0000 & $6.108 \mathrm{E}+00$ & 0.0533 \\
\hline 34 & $0.000 \mathrm{E}+00$ & 0.0000 & $0.000 \mathrm{E}+00$ & 0.0000 & $0.000 \mathrm{E}+00$ & 0.0000 & $0.000 \mathrm{E}+00$ & 0.0000 & $0.000 \mathrm{E}+00$ & 0.0000 & $0.000 \mathrm{E}+00$ & 0.0000 & $1.725 \mathrm{E}+01$ & 0.1505 \\
\hline 35 & $0.000 \mathrm{E}+00$ & 0.0000 & $0.000 \mathrm{E}+00$ & 0.0000 & $0.000 \mathrm{E}+00$ & 0.0000 & $0.000 \mathrm{E}+00$ & 0.0000 & $0.000 \mathrm{E}+00$ & 0.0000 & $0.000 \mathrm{E}+00$ & 0.0000 & $1.535 \mathrm{E}+00$ & 0.0134 \\
\hline 38 & $0.000 \mathrm{E}+00$ & 0.0000 & $0.000 \mathrm{E}+00$ & 0.0000 & $0.000 \mathrm{E}+00$ & 0.0000 & $0.000 \mathrm{E}+00$ & 0.0000 & $0.000 \mathrm{E}+00$ & 0.0000 & $0.000 \mathrm{E}+00$ & 0.0000 & $2.087 \mathrm{E}+00$ & 0.0182 \\
\hline & $3.428 \mathrm{E}-02$ & 0.0003 & $0.000 \mathrm{E}+00$ & 0.0000 & $0.000 \mathrm{E}+00$ & 0.0000 & $3.204 \mathrm{E}-03$ & 0.0000 & $5.736 E-05$ & 0.0000 & $3.871 E-03$ & 0.0000 & +02 & 1.0000 \\
\hline
\end{tabular}

* Sum of all water independent and dependent pathways. 
RESRAD, Version $6.5 \quad \mathrm{~T}^{1} \frac{1}{2}$ Limit $=180$ days

Summary : C746U Resident Farmer Deterministic Run

File : $\mathrm{X}: \backslash$ FINAL V2 $\backslash \mathrm{C} 746 \mathrm{U}$ RF SG FWD-FINALV2.RAD

Dose/Source Ratios Summed Over All Pathways

Parent and Progeny Principal Radionuclide Contributions Indicated

\begin{tabular}{|c|c|c|c|c|c|c|c|c|}
\hline Parent & Product & Thread & DSR & $(j, t)$ At & me in Year & (mrem) & $/ \mathrm{yr}) /(\mathrm{pCi} / \mathrm{g}$ & \\
\hline (i) & (j) & Fraction & $0.000 \mathrm{E}+00$ & $1.000 \mathrm{E}+00$ & $5.000 \mathrm{E}+01$ & $1.000 \mathrm{E}+02$ & $5.000 \mathrm{E}+02$ & $1.050 \mathrm{E}+03$ \\
\hline $1-241$ & Am-241 & $1.000 \mathrm{E}+00$ & $1.910 \mathrm{E}-33$ & $1.962 \mathrm{E}-33$ & $7.255 E-33$ & $2.755 E-32$ & $1.192 \mathrm{E}-27$ & 1. $912 \mathrm{E}-04$ \\
\hline$n-241$ & $\mathrm{~Np}-237+\mathrm{D}$ & $1.000 \mathrm{E}+00$ & $0.000 \mathrm{E}+00$ & $3.103 \mathrm{E}-19$ & $2.524 \mathrm{E}-17$ & $8.299 \mathrm{E}-17$ & $2.249 \mathrm{E}-14$ & $1.774 \mathrm{E}-06$ \\
\hline $1-241$ & $U-233$ & $1.000 \mathrm{E}+00$ & $0.000 \mathrm{E}+00$ & $1.055 \mathrm{E}-29$ & $4.739 E-26$ & $3.448 E-25$ & $1.045 E-21$ & $3.144 \mathrm{E}-10$ \\
\hline$n-241$ & $T h-229+D$ & $1.000 \mathrm{E}+00$ & $0.000 \mathrm{E}+00$ & $9.607 E-26$ & $1.654 \mathrm{E}-20$ & $1.834 \mathrm{E}-19$ & $3.175 E-16$ & $5.257 \mathrm{E}-11$ \\
\hline$n-241$ & $\sum \operatorname{DSR}(j)$ & & $1.910 E-33$ & $3.103 E-19$ & $2.526 E-17$ & $8.317 E-17$ & $2.281 E-14$ & $1.930 \mathrm{E}-04$ \\
\hline$-137+D$ & $\mathrm{Cs}-137+\mathrm{D}$ & $1.000 \mathrm{E}+00$ & $1.271 E-09$ & $1.253 E-09$ & $6.094 \mathrm{E}-10$ & $2.922 E-10$ & $8.163 E-13$ & $1.950 \mathrm{E}-13$ \\
\hline$-237+D$ & $N p-237+D$ & $1.000 \mathrm{E}+00$ & $9.485 E-13$ & $9.587 \mathrm{E}-13$ & 1. $617 \mathrm{E}-12$ & $2.756 E-12$ & $1.963 \mathrm{E}-10$ & $1.025 \mathrm{E}-02$ \\
\hline$-237+D$ & $U-233$ & $1.000 \mathrm{E}+00$ & $0.000 \mathrm{E}+00$ & $6.517 \mathrm{E}-23$ & $6.002 E-21$ & $2.239 E-20$ & $1.638 \mathrm{E}-17$ & $2.955 E-06$ \\
\hline$-237+D$ & $T h-229+D$ & $1.000 \mathrm{E}+00$ & $0.000 \mathrm{E}+00$ & $8.902 \mathrm{E}-19$ & $3.122 \mathrm{E}-15$ & $1.764 \mathrm{E}-14$ & $7.041 E-12$ & $6.620 \mathrm{E}-07$ \\
\hline$-237+D$ & $\sum \operatorname{DSR}(j)$ & & $9.485 \mathrm{E}-13$ & $9.587 \mathrm{E}-13$ & 1. $620 \mathrm{E}-12$ & $2.773 \mathrm{E}-12$ & $2.033 E-10$ & $1.026 \mathrm{E}-02$ \\
\hline-238 & $\mathrm{Pu}-238$ & $1.840 E-09$ & $2.151 E-33$ & $2.172 \mathrm{E}-33$ & $3.503 E-33$ & $5.703 E-33$ & $2.817 E-31$ & $5.383 E-16$ \\
\hline-238 & $\mathrm{Pu}-238$ & $1.000 \mathrm{E}+00$ & $1.169 \mathrm{E}-24$ & $1.181 \mathrm{E}-24$ & $1.904 \mathrm{E}-24$ & $3.100 \mathrm{E}-24$ & 1. $531 \mathrm{E}-22$ & $2.925 E-07$ \\
\hline-238 & $U-234$ & $1.000 \mathrm{E}+00$ & $0.000 \mathrm{E}+00$ & $1.965 \mathrm{E}-29$ & $1.939 \mathrm{E}-27$ & $7.864 \mathrm{E}-27$ & $1.675 E-23$ & $2.344 \mathrm{E}-07$ \\
\hline$x-238$ & Th-230 & $1.000 \mathrm{E}+00$ & $0.000 \mathrm{E}+00$ & $3.096 \mathrm{E}-33$ & $1.556 \mathrm{E}-29$ & 1. $280 \mathrm{E}-28$ & $1.293 E-24$ & $3.186 \mathrm{E}-09$ \\
\hline$x-238$ & $\mathrm{Ra}-226+\mathrm{D}$ & $1.000 \mathrm{E}+00$ & $0.000 \mathrm{E}+00$ & $3.212 E-22$ & $5.098 E-17$ & $5.231 E-16$ & $5.574 \mathrm{E}-13$ & $3.395 E-08$ \\
\hline$x-238$ & $\mathrm{~Pb}-210+\mathrm{D}$ & $1.000 \mathrm{E}+00$ & $0.000 \mathrm{E}+00$ & $1.163 \mathrm{E}-30$ & $7.464 \mathrm{E}-24$ & $1.287 \mathrm{E}-22$ & $3.648 E-19$ & $5.037 E-08$ \\
\hline-238 & $\sum \operatorname{DSR}(j)$ & & $1.169 \mathrm{E}-24$ & $3.223 E-22$ & $5.098 \mathrm{E}-17$ & $5.231 \mathrm{E}-16$ & $5.574 \mathrm{E}-13$ & $6.144 \mathrm{E}-07$ \\
\hline-239 & $\mathrm{Pu}-239$ & $1.000 \mathrm{E}+00$ & $1.195 \mathrm{E}-17$ & 1. $209 \mathrm{E}-17$ & $2.170 \mathrm{E}-17$ & $3.941 \mathrm{E}-17$ & $4.662 E-15$ & $1.235 \mathrm{E}-03$ \\
\hline $1-239$ & $U-235+D$ & $1.000 \mathrm{E}+00$ & $0.000 \mathrm{E}+00$ & 1. $232 \mathrm{E}-23$ & 1. $128 \mathrm{E}-21$ & $4.180 \mathrm{E}-21$ & $2.910 \mathrm{E}-18$ & $6.475 \mathrm{E}-10$ \\
\hline$x-239$ & $\mathrm{~Pa}-231$ & $1.000 \mathrm{E}+00$ & $0.000 \mathrm{E}+00$ & $2.903 E-27$ & 1. $220 \mathrm{E}-23$ & $8.286 E-23$ & $1.434 \mathrm{E}-19$ & $4.682 \mathrm{E}-10$ \\
\hline-239 & $A C-227+D$ & $1.000 \mathrm{E}+00$ & $0.000 \mathrm{E}+00$ & $9.153 \mathrm{E}-27$ & 1. $237 \mathrm{E}-21$ & 1. $150 \mathrm{E}-20$ & 1. $466 \mathrm{E}-17$ & $1.640 \mathrm{E}-10$ \\
\hline-239 & $\sum \operatorname{DSR}(j)$ & & $1.195 \mathrm{E}-17$ & 1. $209 \mathrm{E}-17$ & $2.170 \mathrm{E}-17$ & $3.943 E-17$ & $4.680 \mathrm{E}-15$ & $1.235 \mathrm{E}-03$ \\
\hline-240 & $\mathrm{Pu}-240$ & $4.950 \mathrm{E}-08$ & $5.604 \mathrm{E}-32$ & $5.703 E-32$ & 1. $347 \mathrm{E}-31$ & $3.239 E-31$ & $3.615 E-28$ & $5.638 \mathrm{E}-11$ \\
\hline-240 & $\mathrm{Pu}-240$ & $1.000 \mathrm{E}+00$ & $1.132 \mathrm{E}-24$ & $1.152 \mathrm{E}-24$ & $2.722 E-24$ & $6.543 E-24$ & $7.302 E-21$ & $1.139 \mathrm{E}-03$ \\
\hline-240 & $\mathrm{U}-236$ & $1.000 \mathrm{E}+00$ & $0.000 \mathrm{E}+00$ & $4.350 \mathrm{E}-32$ & $5.235 E-30$ & $2.566 \mathrm{E}-29$ & $1.669 \mathrm{E}-25$ & $1.856 \mathrm{E}-08$ \\
\hline $1-240$ & $T h-232$ & $1.000 \mathrm{E}+00$ & $0.000 \mathrm{E}+00$ & $8.590 E-43$ & $5.322 E-39$ & $5.373 E-38$ & $2.213 E-33$ & $9.120 \mathrm{E}-16$ \\
\hline-240 & $\mathrm{Ra}-228+\mathrm{D}$ & $1.000 \mathrm{E}+00$ & $0.000 \mathrm{E}+00$ & $5.459 \mathrm{E}-28$ & $3.662 E-23$ & $2.505 E-22$ & $1.461 \mathrm{E}-19$ & $1.189 \mathrm{E}-13$ \\
\hline-240 & $T h-228+D$ & $1.000 \mathrm{E}+00$ & $0.000 \mathrm{E}+00$ & $3.996 \mathrm{E}-27$ & $2.570 \mathrm{E}-21$ & $1.733 \mathrm{E}-20$ & $5.536 \mathrm{E}-18$ & $1.502 \mathrm{E}-15$ \\
\hline-240 & $\sum \operatorname{DSR}(j)$ & & $1.132 \mathrm{E}-24$ & $1.157 \mathrm{E}-24$ & $2.609 \mathrm{E}-21$ & 1. $758 \mathrm{E}-20$ & $5.690 \mathrm{E}-18$ & $1.139 \mathrm{E}-03$ \\
\hline-99 & $\mathrm{TC}-99$ & $1.000 \mathrm{E}+00$ & $5.729 \mathrm{E}-26$ & $5.787 \mathrm{E}-26$ & $9.526 E-26$ & $1.584 \mathrm{E}-25$ & $2.080 E-01$ & $1.480 \mathrm{E}-03$ \\
\hline$-228+D$ & $T h-228+D$ & $1.000 \mathrm{E}+00$ & $1.643 \mathrm{E}-06$ & $1.151 \mathrm{E}-06$ & $3.003 E-14$ & $5.489 \mathrm{E}-22$ & $0.000 \mathrm{E}+00$ & $0.000 \mathrm{E}+00$ \\
\hline-230 & $\mathrm{Th}-230$ & $1.000 \mathrm{E}+00$ & $2.392 \mathrm{E}-22$ & $2.432 \mathrm{E}-22$ & $5.543 E-22$ & $1.285 \mathrm{E}-21$ & $1.069 \mathrm{E}-18$ & $1.076 \mathrm{E}-03$ \\
\hline 30 & $\mathrm{Ra}-226+\mathrm{D}$ & $1.000 \mathrm{E}+00$ & $0.000 \mathrm{E}+00$ & $7.565 \mathrm{E}-11$ & $5.249 E-09$ & $1.467 \mathrm{E}-08$ & $1.066 \mathrm{E}-06$ & $2.340 E-02$ \\
\hline 30 & $\mathrm{~Pb}-210+\mathrm{D}$ & $1.000 \mathrm{E}+00$ & $0.000 \mathrm{E}+00$ & $5.454 \mathrm{E}-19$ & $1.273 \mathrm{E}-15$ & $5.257 \mathrm{E}-15$ & $7.641 \mathrm{E}-13$ & $3.610 \mathrm{E}-02$ \\
\hline 30 & $\sum \operatorname{DSR}(j)$ & & $2.392 E-22$ & $7.565 \mathrm{E}-11$ & $5.249 E-09$ & $1.467 \mathrm{E}-08$ & $1.066 E-06$ & $6.058 \mathrm{E}-02$ \\
\hline
\end{tabular}


RESRAD, Version $6.5 \quad \mathrm{~T}^{1} \frac{1}{2}$ Limit $=180$ days

Summary : C746U Resident Farmer Deterministic Run

File : $\mathrm{X}: \backslash$ FINAL V2 $\backslash$ C746U RF SG FWD-FINALV2.RAD

Dose/Source Ratios Summed Over All Pathways

Parent and Progeny Principal Radionuclide Contributions Indicated

\begin{tabular}{|c|c|c|c|c|c|c|c|c|}
\hline Parent & Product & Thread & DSF & $(j, t)$ At & ime in Year & (mrem, & $(\mathrm{yr}) /(\mathrm{pCi} / \mathrm{g}$ & \\
\hline (i) & (j) & Fraction & $0.000 \mathrm{E}+00$ & $1.000 \mathrm{E}+00$ & $5.000 \mathrm{E}+01$ & $1.000 \mathrm{E}+02$ & $5.000 \mathrm{E}+02$ & $1.050 \mathrm{E}+03$ \\
\hline-232 & $T h-232$ & $1.000 \mathrm{E}+00$ & $1.155 \mathrm{E}-24$ & $1.177 \mathrm{E}-24$ & $2.922 \mathrm{E}-24$ & 7. $393 E-24$ & 1. $241 \mathrm{E}-20$ & 1. $189 \mathrm{E}-03$ \\
\hline$h-232$ & $\mathrm{Ra}-228+\mathrm{D}$ & $1.000 \mathrm{E}+00$ & $0.000 \mathrm{E}+00$ & $2.177 \mathrm{E}-09$ & $2.773 E-08$ & $4.064 \mathrm{E}-08$ & $8.465 E-07$ & $1.576 \mathrm{E}-01$ \\
\hline$h-232$ & $T h-228+D$ & $1.000 \mathrm{E}+00$ & $0.000 \mathrm{E}+00$ & $3.082 \mathrm{E}-08$ & $2.206 \mathrm{E}-06$ & $2.983 \mathrm{E}-06$ & $3.244 \mathrm{E}-05$ & $1.998 \mathrm{E}-03$ \\
\hline$h-232$ & $\sum \operatorname{DSR}(j)$ & & $1.155 \mathrm{E}-24$ & $3.300 \mathrm{E}-08$ & $2.234 \mathrm{E}-06$ & $3.024 \mathrm{E}-06$ & $3.328 E-05$ & $1.607 \mathrm{E}-01$ \\
\hline-234 & $U-234$ & $1.000 \mathrm{E}+00$ & $6.835 \mathrm{E}-24$ & $6.957 \mathrm{E}-24$ & $1.656 \mathrm{E}-23$ & $4.011 \mathrm{E}-23$ & $4.756 \mathrm{E}-20$ & $6.525 \mathrm{E}-04$ \\
\hline-234 & Th-230 & $1.000 \mathrm{E}+00$ & $0.000 \mathrm{E}+00$ & $2.190 \mathrm{E}-27$ & $2.494 \mathrm{E}-25$ & $1.156 \mathrm{E}-24$ & $4.793 E-21$ & $1.009 E-05$ \\
\hline-234 & $\mathrm{Ra}-226+\mathrm{D}$ & $1.000 \mathrm{E}+00$ & $0.000 \mathrm{E}+00$ & $3.405 \mathrm{E}-16$ & 1. $185 \mathrm{E}-12$ & $6.647 \mathrm{E}-12$ & $2.482 E-09$ & $1.185 \mathrm{E}-04$ \\
\hline-234 & $\mathrm{~Pb}-210+\mathrm{D}$ & $1.000 \mathrm{E}+00$ & $0.000 \mathrm{E}+00$ & $1.641 \mathrm{E}-24$ & $2.135 \mathrm{E}-19$ & 1. $903 \mathrm{E}-18$ & 1. $668 \mathrm{E}-15$ & $1.770 \mathrm{E}-04$ \\
\hline-234 & $\sum \operatorname{DSR}(j)$ & & $6.835 E-24$ & $3.405 E-16$ & $1.185 \mathrm{E}-12$ & $6.647 E-12$ & $2.482 E-09$ & $9.581 \mathrm{E}-04$ \\
\hline$-235+D$ & $\mathrm{U}-235+\mathrm{D}$ & $1.000 \mathrm{E}+00$ & $1.236 \mathrm{E}-14$ & 1. $251 \mathrm{E}-14$ & $2.291 \mathrm{E}-14$ & $4.249 \mathrm{E}-14$ & $5.944 \mathrm{E}-12$ & $6.337 \mathrm{E}-04$ \\
\hline$-235+D$ & $\mathrm{~Pa}-231$ & $1.000 \mathrm{E}+00$ & $0.000 \mathrm{E}+00$ & $5.896 \mathrm{E}-18$ & $4.955 E-16$ & $1.684 \mathrm{E}-15$ & $5.839 E-13$ & $9.104 \mathrm{E}-04$ \\
\hline$-235+D$ & $A C-227+D$ & $1.000 \mathrm{E}+00$ & $0.000 \mathrm{E}+00$ & $2.781 \mathrm{E}-17$ & $6.744 \mathrm{E}-14$ & $2.910 \mathrm{E}-13$ & $6.341 E-11$ & $3.284 E-04$ \\
\hline$-235+D$ & $\sum \operatorname{DSR}(j)$ & & $1.236 \mathrm{E}-14$ & 1. $254 \mathrm{E}-14$ & $9.085 \mathrm{E}-14$ & $3.352 E-13$ & $6.994 \mathrm{E}-11$ & $1.873 E-03$ \\
\hline-238 & $U-238$ & $5.400 \mathrm{E}-05$ & $0.000 \mathrm{E}+00$ & $0.000 \mathrm{E}+00$ & $0.000 \mathrm{E}+00$ & $0.000 \mathrm{E}+00$ & $0.000 \mathrm{E}+00$ & $3.261 \mathrm{E}-08$ \\
\hline$-238+D$ & $\mathrm{U}-238+\mathrm{D}$ & $9.999 \mathrm{E}-01$ & $1.414 \mathrm{E}-10$ & 1. $425 \mathrm{E}-10$ & $2.107 \mathrm{E}-10$ & $3.141 \mathrm{E}-10$ & $7.648 E-09$ & $6.500 \mathrm{E}-04$ \\
\hline$-238+D$ & $\mathrm{U}-234$ & $9.999 E-01$ & $0.000 \mathrm{E}+00$ & $1.972 \mathrm{E}-29$ & $2.347 E-27$ & $1.137 \mathrm{E}-26$ & $6.745 E-23$ & $1.945 E-06$ \\
\hline$U-238+D$ & $\mathrm{Th}-230$ & $9.999 E-01$ & $0.000 \mathrm{E}+00$ & $3.104 \mathrm{E}-33$ & $1.767 \mathrm{E}-29$ & $1.638 \mathrm{E}-28$ & $3.394 \mathrm{E}-24$ & $1.500 \mathrm{E}-08$ \\
\hline$U-238+D$ & $\mathrm{Ra}-226+\mathrm{D}$ & $9.999 \mathrm{E}-01$ & $0.000 \mathrm{E}+00$ & $3.218 \mathrm{E}-22$ & $5.610 \mathrm{E}-17$ & $6.303 E-16$ & 1. $193 \mathrm{E}-12$ & 1. $217 \mathrm{E}-07$ \\
\hline$-238+D$ & $\mathrm{~Pb}-210+\mathrm{D}$ & $9.999 E-01$ & $0.000 \mathrm{E}+00$ & $1.165 \mathrm{E}-30$ & $8.088 E-24$ & 1. $513 E-22$ & $7.559 \mathrm{E}-19$ & $1.765 \mathrm{E}-07$ \\
\hline$-238+D$ & $\sum \operatorname{DSR}(j)$ & & $1.414 \mathrm{E}-10$ & 1. $425 \mathrm{E}-10$ & $2.107 \mathrm{E}-10$ & $3.141 \mathrm{E}-10$ & $7.649 E-09$ & $6.523 E-04$ \\
\hline
\end{tabular}

The DSR includes contributions from associated (half-life $\leq 180$ days) daughters. 
RESRAD, Version $6.5 \quad \mathrm{~T}^{1 / 2}$ Limit $=180$ days

Summary : C746U Resident Farmer Deterministic Run

File : $\mathrm{X}: \backslash$ FINAL V2 $\backslash \mathrm{C} 746 \mathrm{U}$ RF SG FWD-FINALV2.RAD

Single Radionuclide Soil Guidelines G(i,t) in pCi/g

Basic Radiation Dose Limit $=1.000 \mathrm{E}+02 \mathrm{mrem} / \mathrm{yr}$

Nuclide

\begin{tabular}{|c|c|c|c|c|c|c|}
\hline (i) & $t=0.000 \mathrm{E}+00$ & $1.000 \mathrm{E}+00$ & $5.000 \mathrm{E}+01$ & $1.000 \mathrm{E}+02$ & $5.000 \mathrm{E}+02$ & $1.050 \mathrm{E}+03$ \\
\hline$n-241$ & $\star 3.431 \mathrm{E}+12$ & $\star 3.431 \mathrm{E}+12$ & $\star 3.431 \mathrm{E}+12$ & $\star 3.431 \mathrm{E}+12$ & $\star 3.431 \mathrm{E}+12$ & $5.181 \mathrm{E}+05$ \\
\hline$s-137$ & $7.867 \mathrm{E}+10$ & $7.984 \mathrm{E}+10$ & $1.641 \mathrm{E}+11$ & $3.422 \mathrm{E}+11$ & $\star 8.704 \mathrm{E}+13$ & $\star 8.704 \mathrm{E}+13$ \\
\hline-237 & $\star 7.047 \mathrm{E}+08$ & $\star 7.047 \mathrm{E}+08$ & $\star 7.047 \mathrm{E}+08$ & $\star 7.047 \mathrm{E}+08$ & $\star 7.047 \mathrm{E}+08$ & $9.749 \mathrm{E}+03$ \\
\hline$u-238$ & $\star 1.712 \mathrm{E}+13$ & $\star 1.712 \mathrm{E}+13$ & $\star 1.712 \mathrm{E}+13$ & $\star 1.712 \mathrm{E}+13$ & $\star 1.712 \mathrm{E}+13$ & $1.628 \mathrm{E}+08$ \\
\hline$u-239$ & $\star 6.214 \mathrm{E}+10$ & $\star 6.214 \mathrm{E}+10$ & $\star 6.214 \mathrm{E}+10$ & $\star 6.214 \mathrm{E}+10$ & $* 6.214 \mathrm{E}+10$ & $8.096 \mathrm{E}+04$ \\
\hline $\mathrm{Pu}-240$ & $\star 2.278 \mathrm{E}+11$ & $\star 2.278 \mathrm{E}+11$ & $\star 2.278 \mathrm{E}+11$ & $\star 2.278 \mathrm{E}+11$ & $\star 2.278 \mathrm{E}+11$ & $8.779 \mathrm{E}+04$ \\
\hline $\mathrm{TC}-99$ & $* 1.697 \mathrm{E}+10$ & $\star 1.697 \mathrm{E}+10$ & $\star 1.697 \mathrm{E}+10$ & $\star 1.697 \mathrm{E}+10$ & $4.808 \mathrm{E}+02$ & $6.756 E+04$ \\
\hline$T h-228$ & $6.085 E+07$ & $8.690 \mathrm{E}+07$ & $\star 8.195 \mathrm{E}+14$ & $\star 8.195 \mathrm{E}+14$ & $\star 8.195 \mathrm{E}+14$ & $\star 8.195 \mathrm{E}+14$ \\
\hline$T h-230$ & $\star 2.018 \mathrm{E}+10$ & $\star 2.018 \mathrm{E}+10$ & $1.905 \mathrm{E}+10$ & $6.818 \mathrm{E}+09$ & $9.377 \mathrm{E}+07$ & $1.651 \mathrm{E}+03$ \\
\hline Th-232 & $* 1.097 \mathrm{E}+05$ & $\star 1.097 \mathrm{E}+05$ & $\star 1.097 \mathrm{E}+05$ & $* 1.097 \mathrm{E}+05$ & $* 1.097 \mathrm{E}+05$ & $6.221 \mathrm{E}+02$ \\
\hline $\mathrm{U}-234$ & $\star 6.247 \mathrm{E}+09$ & $\star 6.247 \mathrm{E}+09$ & $\star 6.247 \mathrm{E}+09$ & $\star 6.247 \mathrm{E}+09$ & $\star 6.247 \mathrm{E}+09$ & $1.044 \mathrm{E}+05$ \\
\hline 35 & $\star 2.161 \mathrm{E}+06$ & $\star 2.161 \mathrm{E}+06$ & $\star 2.161 \mathrm{E}+06$ & $\star 2.161 \mathrm{E}+06$ & $\star 2.161 \mathrm{E}+06$ & $5.340 \mathrm{E}+04$ \\
\hline 238 & $\star 3.361 \mathrm{E}+05$ & $\star 3.361 \mathrm{E}+05$ & $\star 3.361 E+05$ & $\star 3.361 \mathrm{E}+05$ & $\star 3.361 \mathrm{E}+05$ & $1.533 \mathrm{E}+05$ \\
\hline
\end{tabular}

*At specific activity limit

Summed Dose/Source Ratios DSR (i,t) in (mrem/yr)/(pCi/g) and Single Radionuclide Soil Guidelines $G(i, t)$ in pCi/g

at $\operatorname{tmin}=$ time of minimum single radionuclide soil guideline and at $\operatorname{tmax}=$ time of maximum total dose $=1.050 \mathrm{E}+03$ years

\begin{tabular}{|c|c|c|c|c|c|c|}
\hline $\begin{array}{l}\text { uclide } \\
\text { (i) }\end{array}$ & $\begin{array}{l}\text { Initial } \\
(\mathrm{pCi} / \mathrm{g})\end{array}$ & $\begin{array}{c}\text { tmin } \\
\text { (years) }\end{array}$ & $\operatorname{DSR}(i, \operatorname{tmin})$ & $\begin{array}{c}\mathrm{G}(\mathrm{i}, \mathrm{tmin}) \\
(\mathrm{pCi} / \mathrm{g})\end{array}$ & $\operatorname{DSR}(i, \operatorname{tmax})$ & $\begin{array}{c}G(i, t \max ) \\
(\mathrm{pCi} / \mathrm{g})\end{array}$ \\
\hline$m-241$ & $3.500 \mathrm{E}+03$ & $1.050 \mathrm{E}+03$ & $1.930 \mathrm{E}-04$ & $5.181 E+05$ & $1.930 \mathrm{E}-04$ & $5.181 \mathrm{E}+05$ \\
\hline $5-137$ & $1.900 \mathrm{E}+02$ & $0.000 \mathrm{E}+00$ & $1.271 \mathrm{E}-09$ & $7.867 \mathrm{E}+10$ & $1.950 \mathrm{E}-13$ & $\star 8.704 \mathrm{E}+13$ \\
\hline-237 & $5.500 \mathrm{E}+02$ & $1.050 \mathrm{E}+03$ & $1.026 \mathrm{E}-02$ & $9.749 \mathrm{E}+03$ & $1.026 \mathrm{E}-02$ & $9.749 \mathrm{E}+03$ \\
\hline$u-238$ & $3.900 \mathrm{E}+03$ & $1.050 \mathrm{E}+03$ & $6.144 \mathrm{E}-07$ & $1.628 \mathrm{E}+08$ & $6.144 \mathrm{E}-07$ & 1. $628 \mathrm{E}+08$ \\
\hline$u-239$ & $3.600 E+03$ & $1.050 \mathrm{E}+03$ & $1.235 E-03$ & $8.096 \mathrm{E}+04$ & $1.235 E-03$ & $8.096 \mathrm{E}+04$ \\
\hline$x-240$ & $3.600 \mathrm{E}+03$ & $1.050 \mathrm{E}+03$ & $1.139 \mathrm{E}-03$ & $8.779 \mathrm{E}+04$ & $1.139 \mathrm{E}-03$ & $8.779 \mathrm{E}+04$ \\
\hline$=-99$ & $2.800 \mathrm{E}+01$ & $425.2 \pm 0.9$ & $4.076 \mathrm{E}-01$ & $2.453 E+02$ & $1.480 \mathrm{E}-03$ & $6.756 \mathrm{E}+04$ \\
\hline-228 & $7.400 \mathrm{E}+01$ & $0.000 \mathrm{E}+00$ & $1.643 E-06$ & $6.085 E+07$ & $0.000 \mathrm{E}+00$ & $\star 8.195 \mathrm{E}+14$ \\
\hline-230 & $1.200 \mathrm{E}+03$ & $1.050 \mathrm{E}+03$ & $6.058 \mathrm{E}-02$ & $1.651 \mathrm{E}+03$ & $6.058 \mathrm{E}-02$ & $1.651 \mathrm{E}+03$ \\
\hline-232 & $3.800 \mathrm{E}+01$ & $1.050 \mathrm{E}+03$ & $1.607 \mathrm{E}-01$ & $6.221 E+02$ & $1.607 \mathrm{E}-01$ & $6.221 \mathrm{E}+02$ \\
\hline-234 & $1.800 \mathrm{E}+04$ & $1.050 \mathrm{E}+03$ & $9.581 \mathrm{E}-04$ & $1.044 \mathrm{E}+05$ & $9.581 \mathrm{E}-04$ & $1.044 \mathrm{E}+05$ \\
\hline-235 & $8.200 \mathrm{E}+02$ & $1.050 \mathrm{E}+03$ & $1.873 E-03$ & $5.340 \mathrm{E}+04$ & $1.873 \mathrm{E}-03$ & $5.340 \mathrm{E}+04$ \\
\hline-238 & $3.200 E+03$ & $1.050 \mathrm{E}+03$ & $6.523 E-04$ & $1.533 E+05$ & $6.523 E-04$ & $1.533 E+05$ \\
\hline
\end{tabular}

*At specific activity limit 
RESRAD, Version $6.5 \quad \mathrm{~T}^{1 / 2}$ Limit $=180$ days 
RESRAD, Version $6.5 \quad \mathrm{~T}^{1} \frac{1}{2}$ Limit $=180$ days

Summary : C746U Resident Farmer Deterministic Run

File : $\mathrm{X}: \backslash \mathrm{FINAL}$ V2 $\backslash \mathrm{C746U}$ RF SG FWD-FINALV2.RAD

Individual Nuclide Soil Concentration

Parent Nuclide and Branch Fraction Indicated

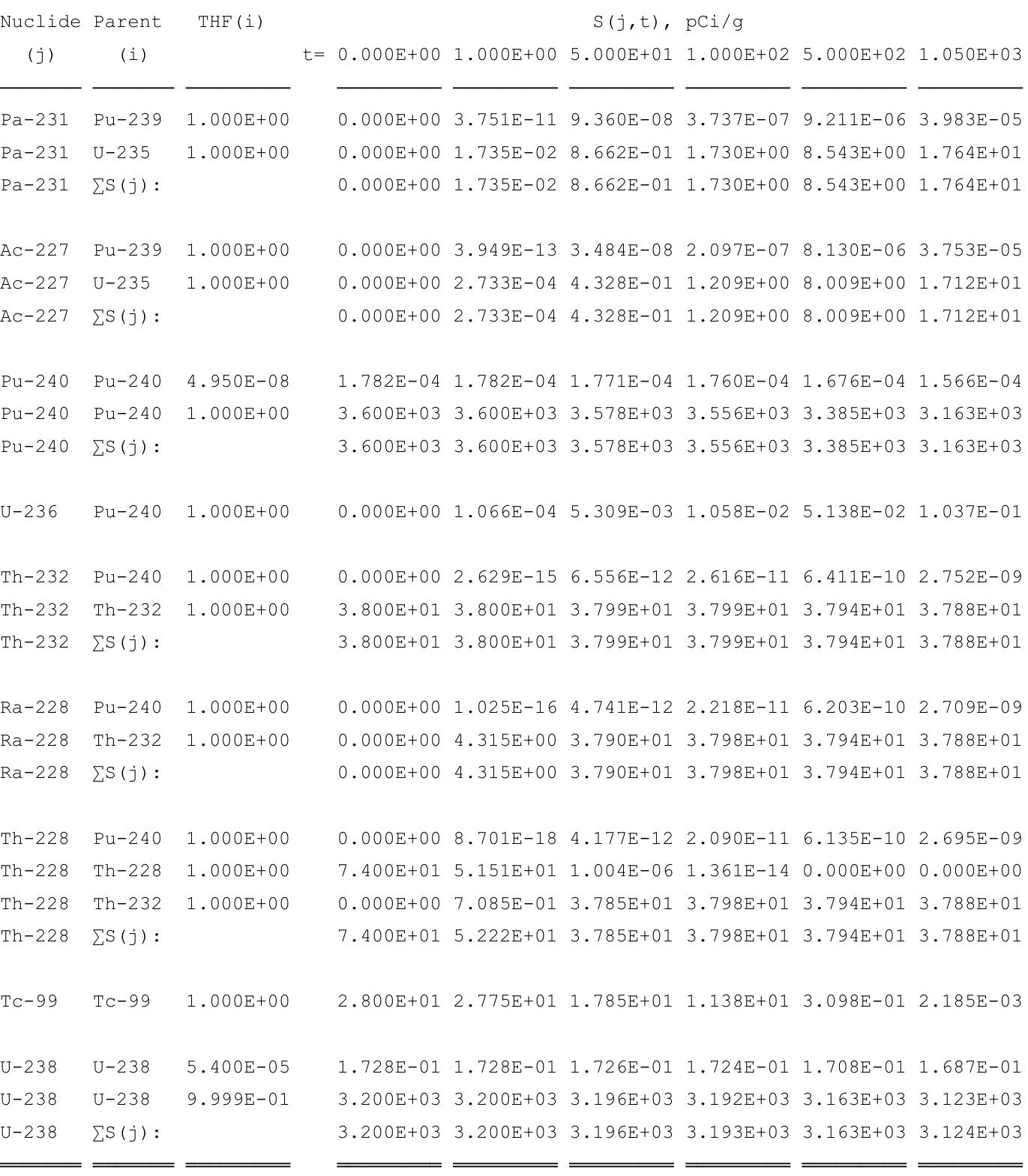

THF(i) is the thread fraction of the parent nuclide.

RESCALC.EXE execution time $=9.89$ seconds 


\section{Resident Gardener}

The following summary report includes the single radionuclide soil guidelines based on a unit concentration for targeted radionuclides. 
THIS PAGE INTENTIONALLY LEFT BLANK 
RESRAD, Version $6.5 \quad \mathrm{~T}^{1 / 2}$ Limit $=180$ days

Summary : C746U Resident Gardener Deterministic Run

File : $\mathrm{X}: \backslash$ FINAL V2 $\backslash$ C746U RG DET-FINALV2.RAD

Table of Contents

Part I: Mixture Sums and Single Radionuclide Guidelines

Dose Conversion Factor (and Related) Parameter Summary ... 2

Site-Specific Parameter Summary ............... 8

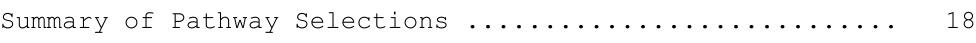

Contaminated zone and Total Dose Summary ............. 19

Total Dose Components

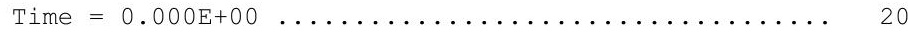

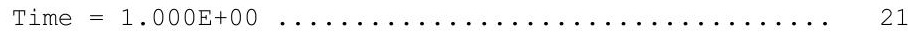

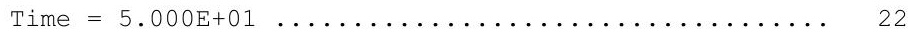

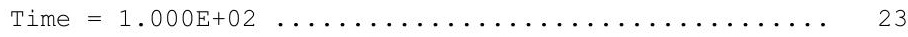

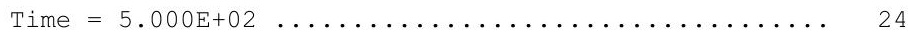

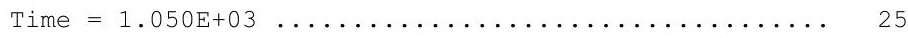

Dose/Source Ratios Summed Over All Pathways ........... 26

Single Radionuclide Soil Guidelines ............... 28

Dose Per Nuclide Summed Over All Pathways ............ 29

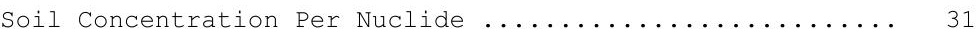


RESRAD, Version $6.5 \quad \mathrm{~T}^{1 / 2}$ Limit $=180$ days

Summary : C746U Resident Gardener Deterministic Run

File : $\mathrm{X}: \backslash$ FINAL V2 $\backslash$ C746U RG DET-FINALV2.RAD

Dose Conversion Factor (and Related) Parameter Summary (continued)

Dose Library: ICRP 60 \& ICRP 72 (Adult)

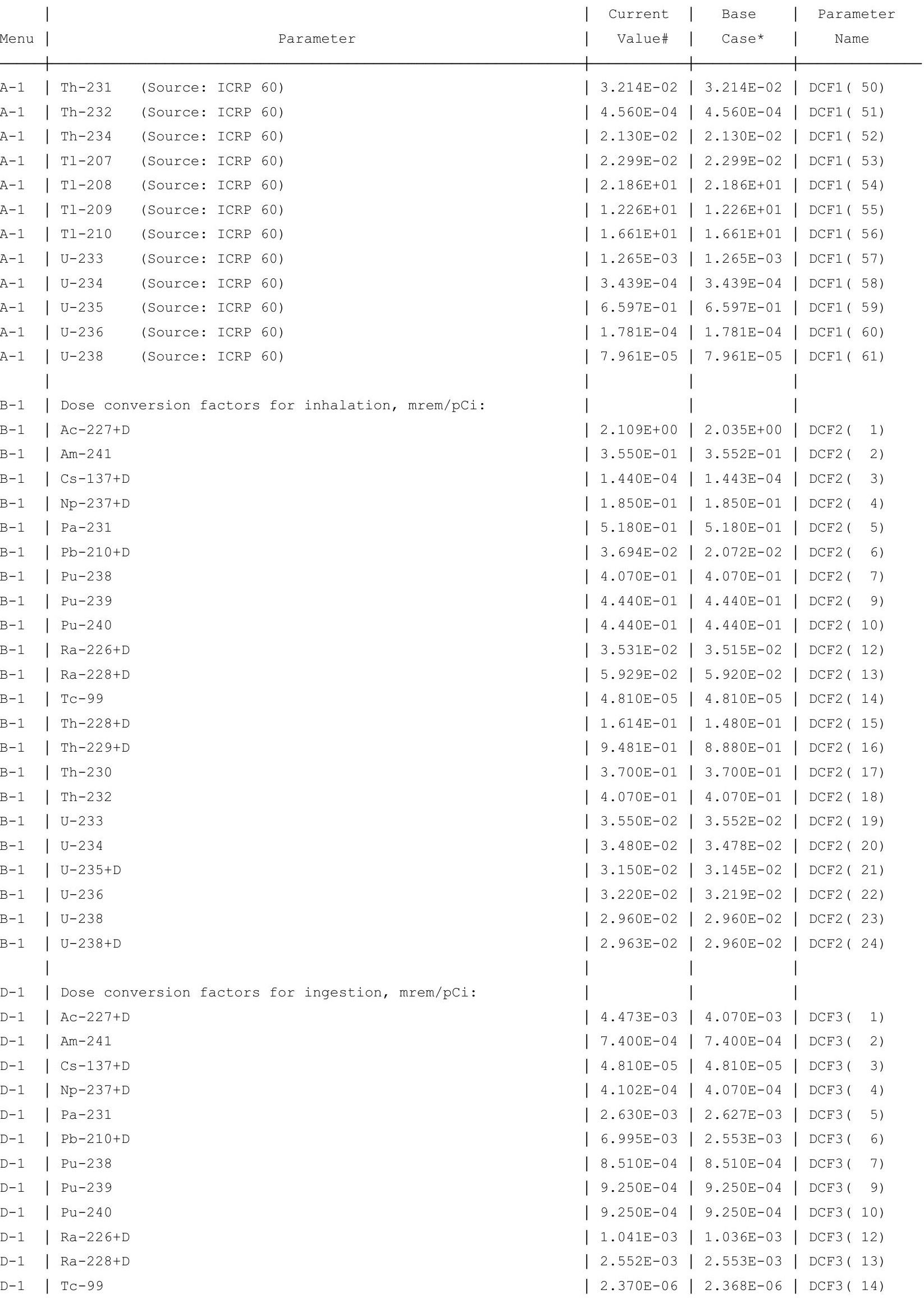


RESRAD, Version $6.5 \quad \mathrm{~T}^{1 / 2}$ Limit $=180$ days

Summary : C746U Resident Gardener Deterministic Run

File : $\mathrm{X}: \backslash$ FINAL V2 $\backslash$ C746U RG DET-FINALV2.RAD

Dose Conversion Factor (and Related) Parameter Summary (continued) Dose Library: ICRP 60 \& ICRP 72 (Adult)

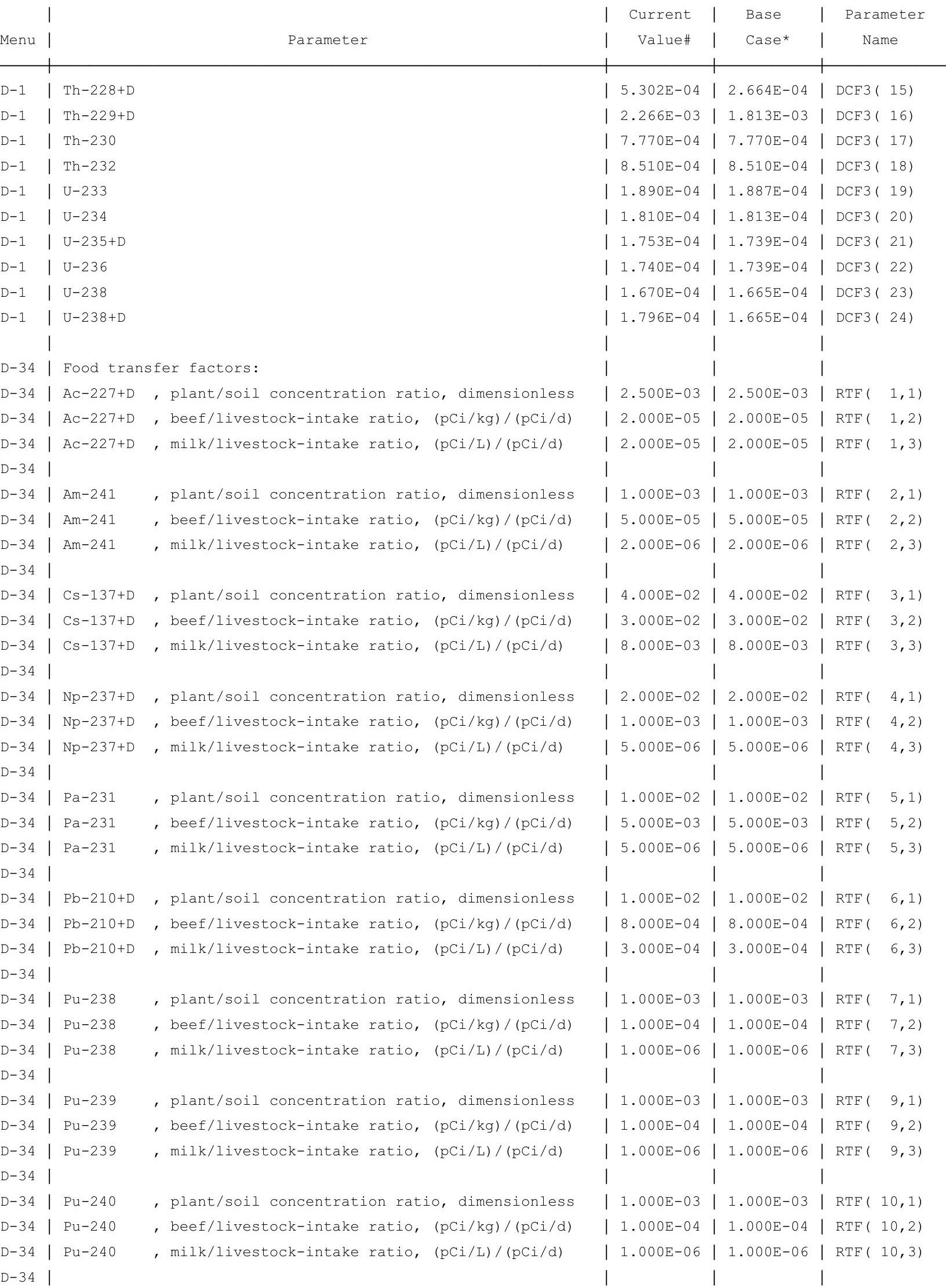


RESRAD, Version $6.5 \quad T^{1 / 2}$ Limit $=180$ days

Summary : C746U Resident Gardener Deterministic Run

File : $\mathrm{X}: \backslash$ FINAL V2 $\backslash \mathrm{C746U}$ RG DET-FINALV2.RAD

Dose Conversion Factor (and Related) Parameter Summary (continued) Dose Library: ICRP 60 \& ICRP 72 (Adult)

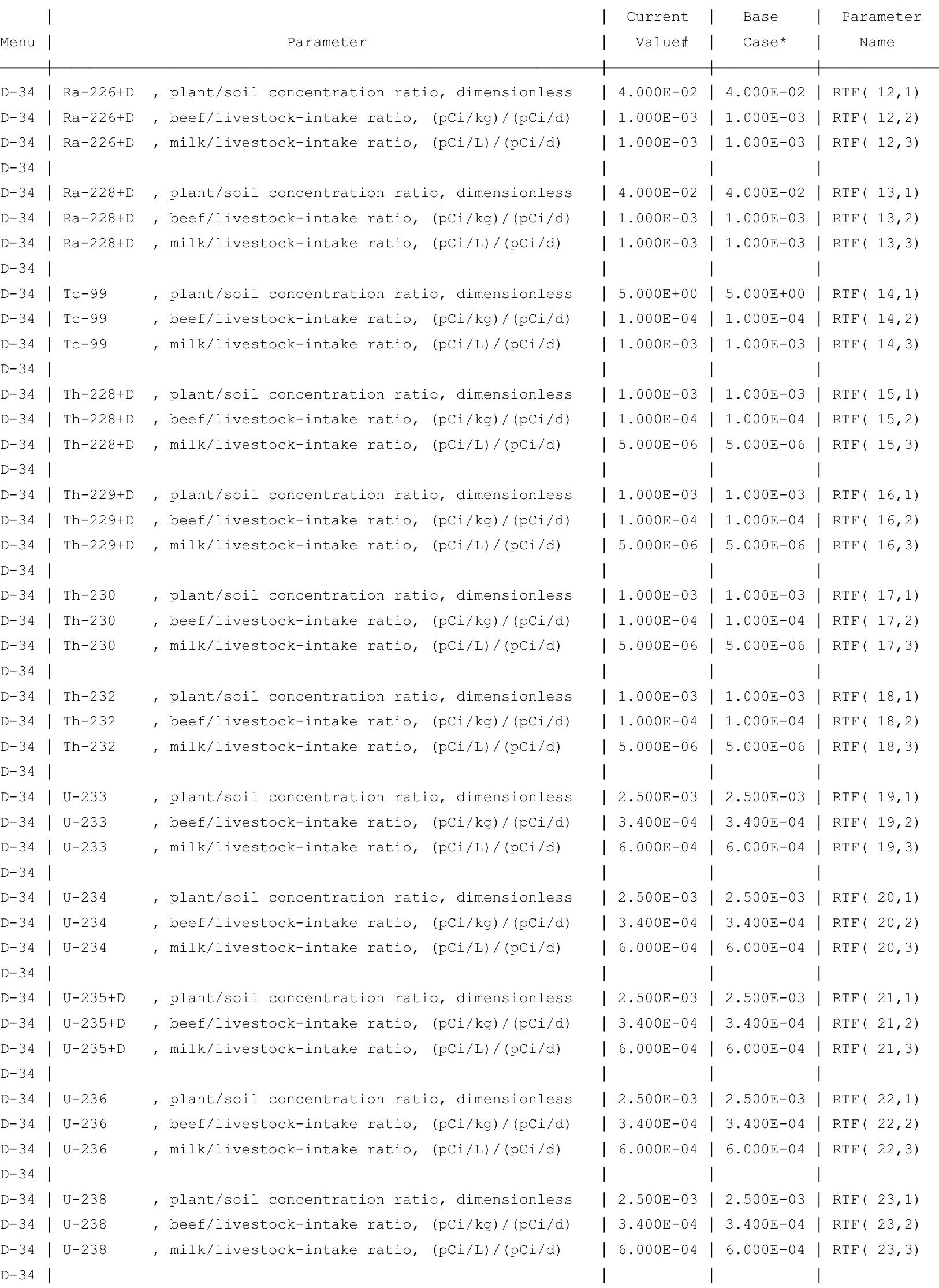


RESRAD, Version $6.5 \quad \mathrm{~T}^{1 / 2}$ Limit $=180$ days

Summary : C746U Resident Gardener Deterministic Run

File : $\mathrm{X}: \backslash$ FINAL V2 $\backslash$ C746U RG DET-FINALV2.RAD

Dose Conversion Factor (and Related) Parameter Summary (continued) Dose Library: ICRP 60 \& ICRP 72 (Adult)

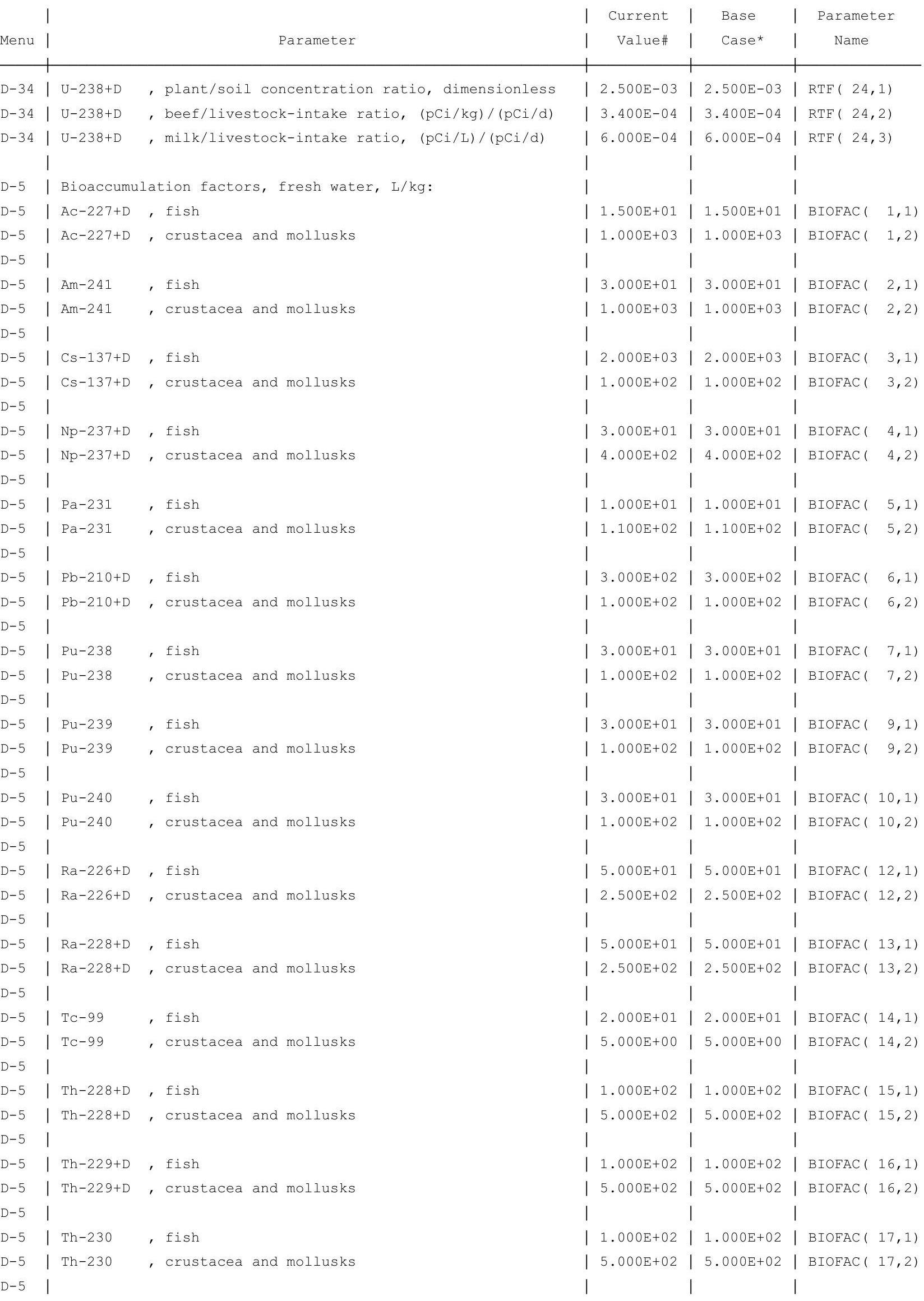


RESRAD, Version $6.5 \quad T^{1 / 2}$ Limit $=180$ days

Summary : C746U Resident Gardener Deterministic Run

File : $\mathrm{X}: \backslash$ FINAL V2\C746U RG DET-FINALV2.RAD

Dose Conversion Factor (and Related) Parameter Summary (continued) Dose Library: ICRP 60 \& ICRP 72 (Adult)

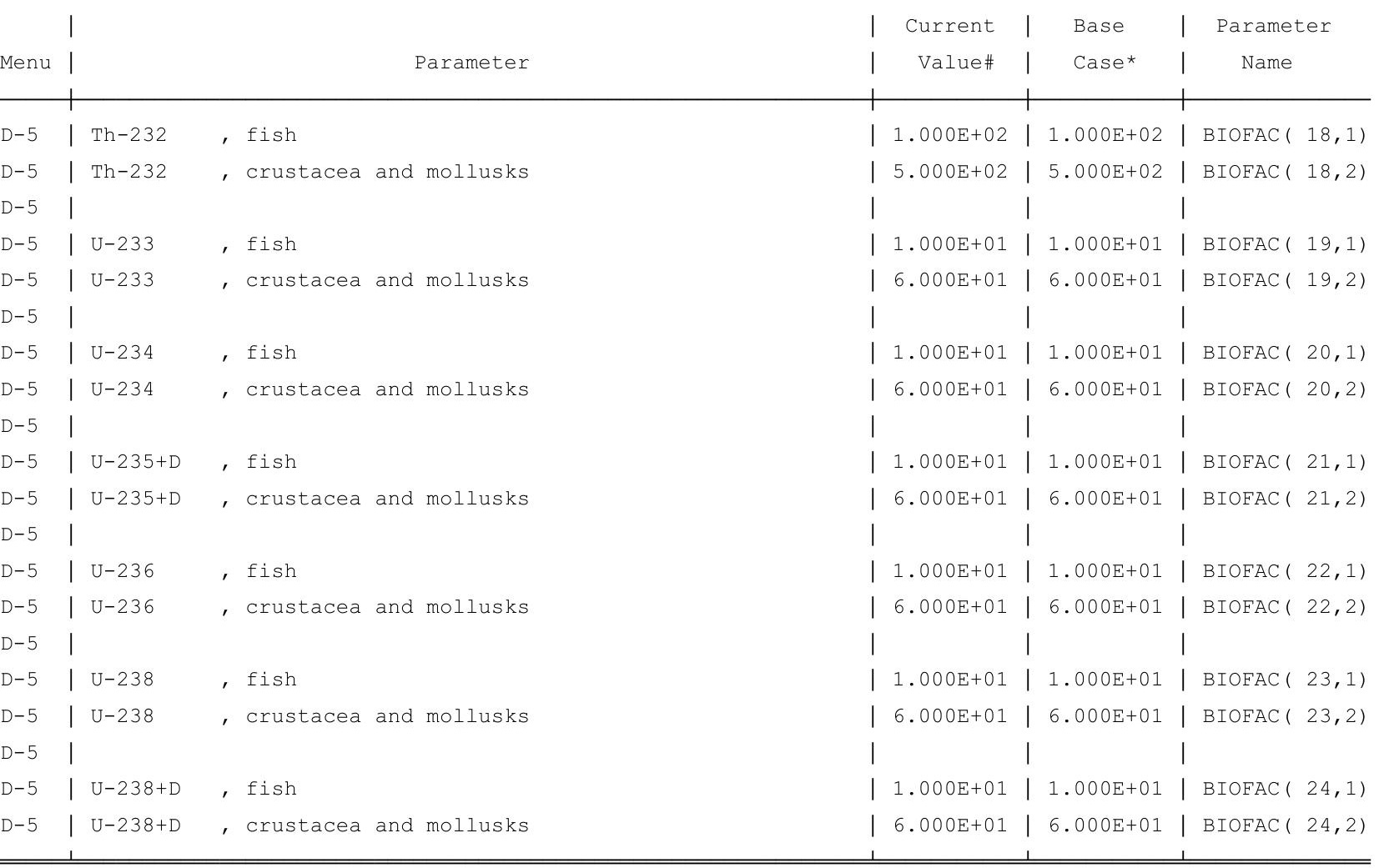

\#For DCFl(xxx) only, factors are for infinite depth \& area. See ETFG table in Ground Pathway of Detailed Report. *Base Case means Default.Lib w/o Associate Nuclide contributions. 
RESRAD, Version $6.5 \quad \mathrm{~T}^{1 / 2}$ Limit $=180$ days

Summary : C746U Resident Gardener Deterministic Run

File : X: $\backslash$ FINAL V2\C746U RG DET-FINALV2.RAD

Site-Specific Parameter Summary

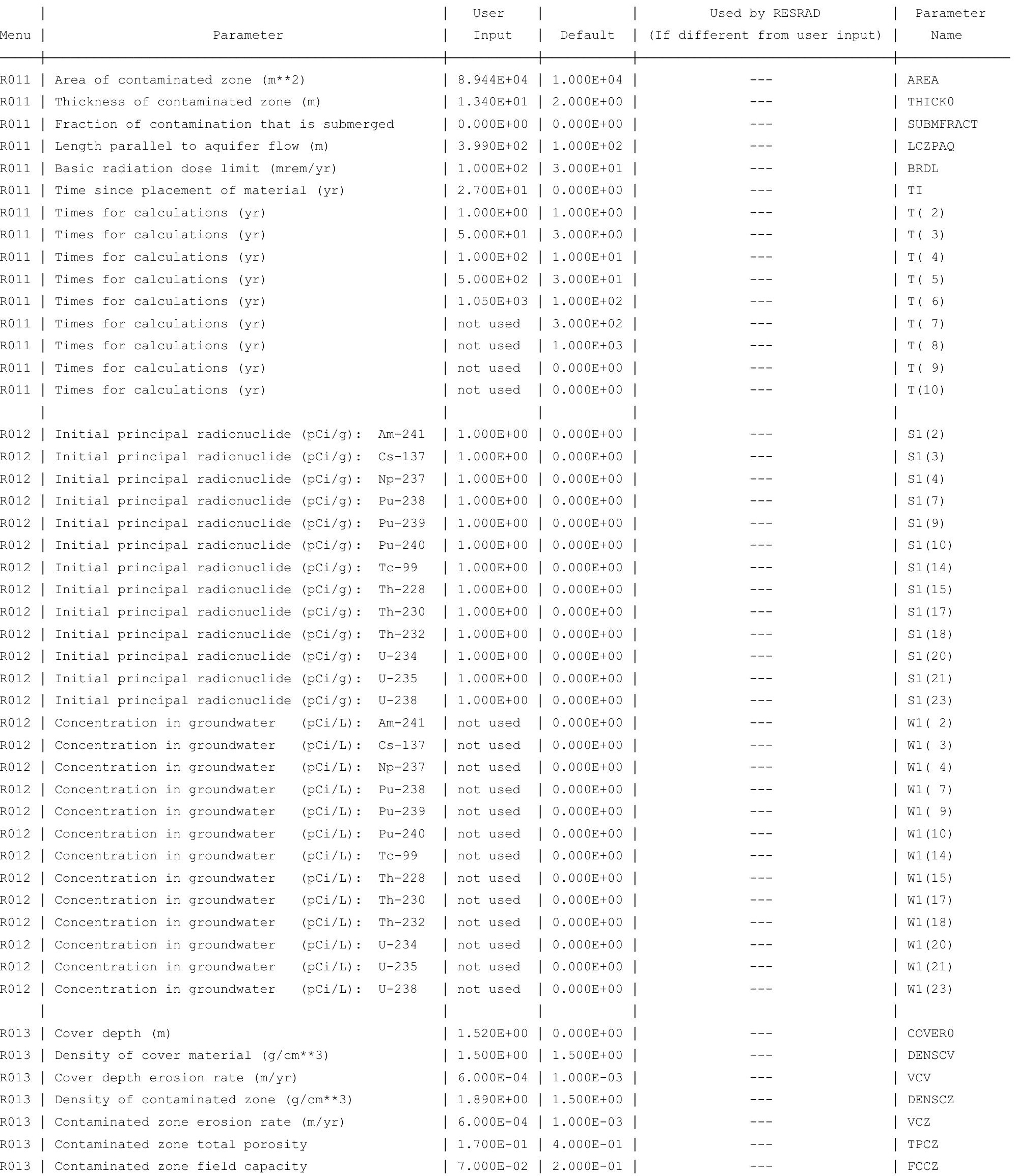


RESRAD, Version $6.5 \quad \mathrm{~T}^{1 / 2}$ Limit $=180$ days

Summary : C746U Resident Gardener Deterministic Run

File : $\mathrm{X}: \backslash$ FINAL V2\C746U RG DET-FINALV2.RAD

Site-Specific Parameter Summary (continued)

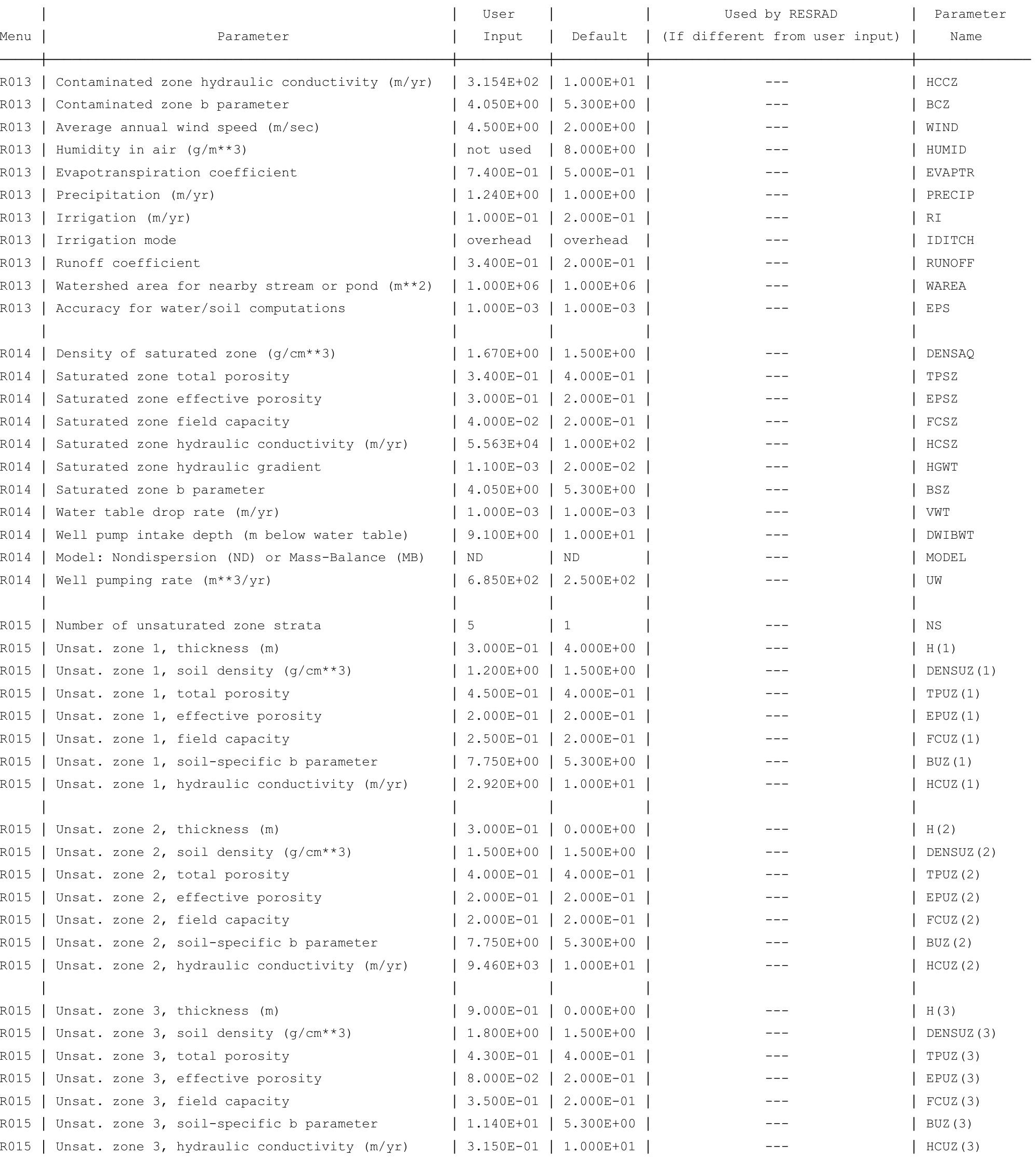


RESRAD, Version $6.5 \quad \mathrm{~T}^{1 / 2}$ Limit $=180$ days

Summary : C746U Resident Gardener Deterministic Run

File : $\mathrm{X}: \backslash$ FINAL V2\C746U RG DET-FINALV2.RAD

Site-Specific Parameter Summary (continued)

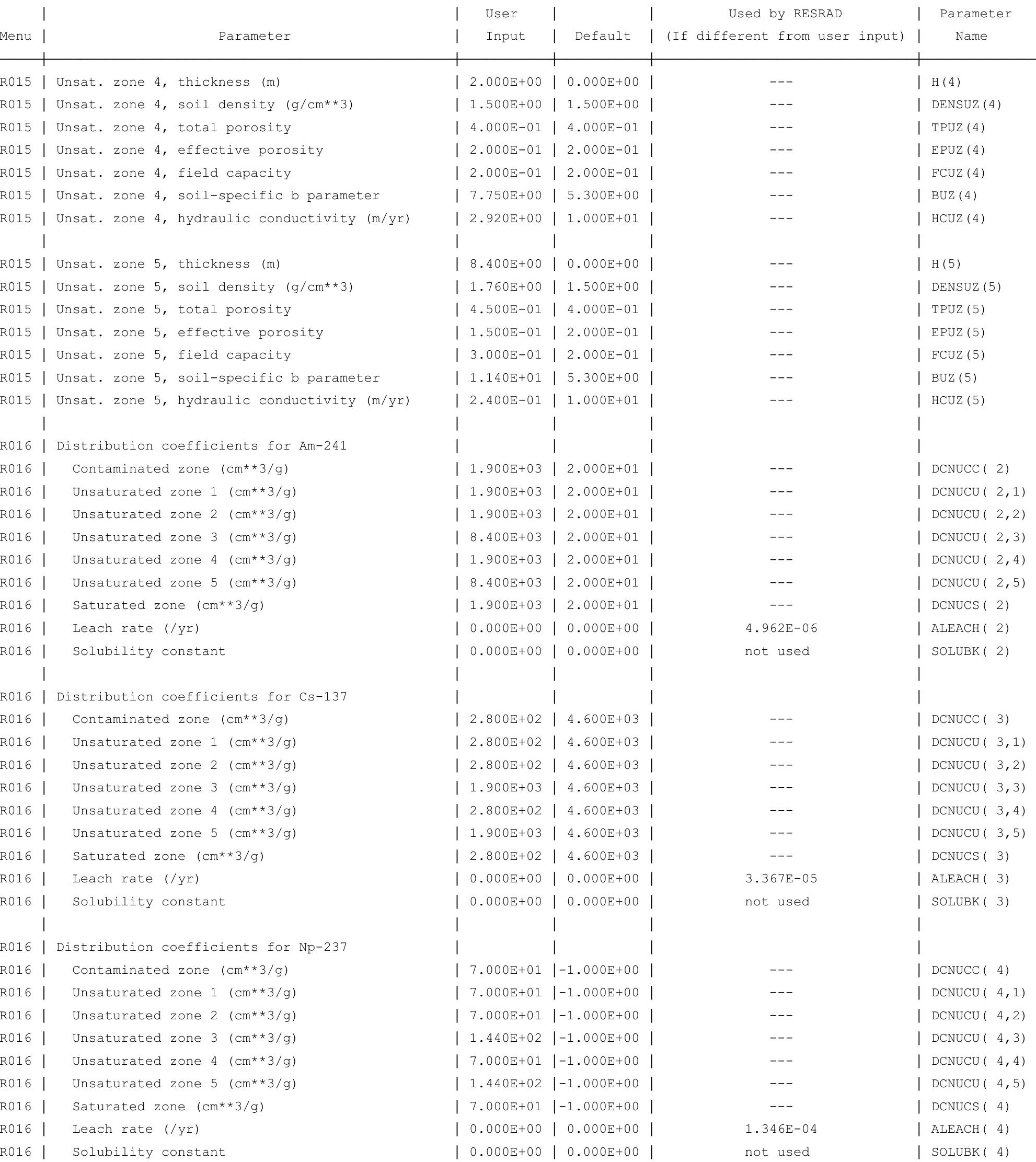


RESRAD, Version $6.5 \quad \mathrm{~T}^{1 / 2}$ Limit $=180$ days

Summary : C746U Resident Gardener Deterministic Run

File : $\mathrm{X}: \backslash$ FINAL V2 $\backslash \mathrm{C} 746 \mathrm{U}$ RG DET-FINALV2.RAD

Site-Specific Parameter Summary (continued)

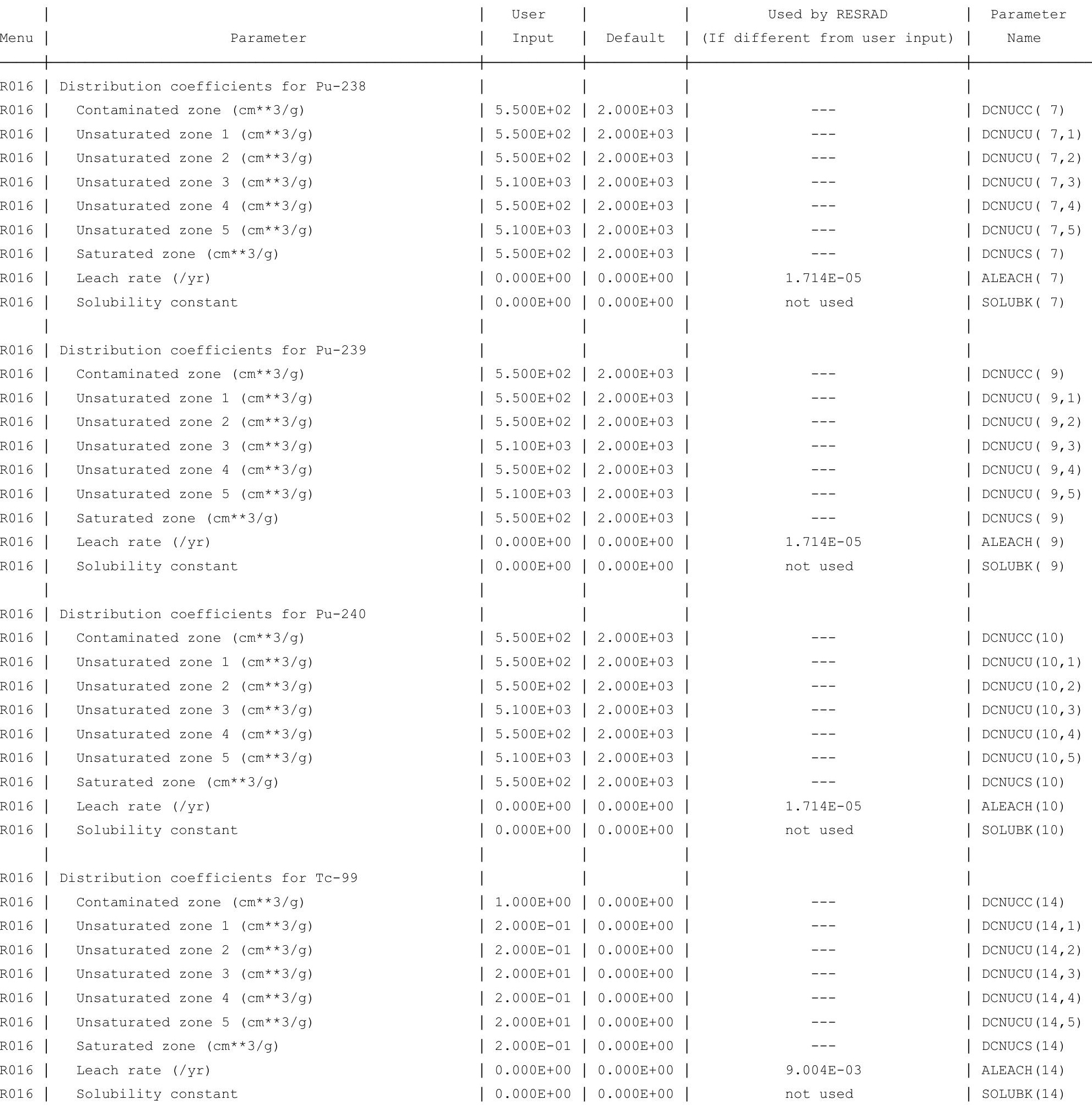


RESRAD, Version $6.5 \quad \mathrm{~T}^{1 / 2}$ Limit $=180$ days

Summary : C746U Resident Gardener Deterministic Run

File : $\mathrm{X}: \backslash \mathrm{FINAL}$ V2 $\backslash \mathrm{C746U}$ RG DET-FINALV2.RAD

Site-Specific Parameter Summary (continued)

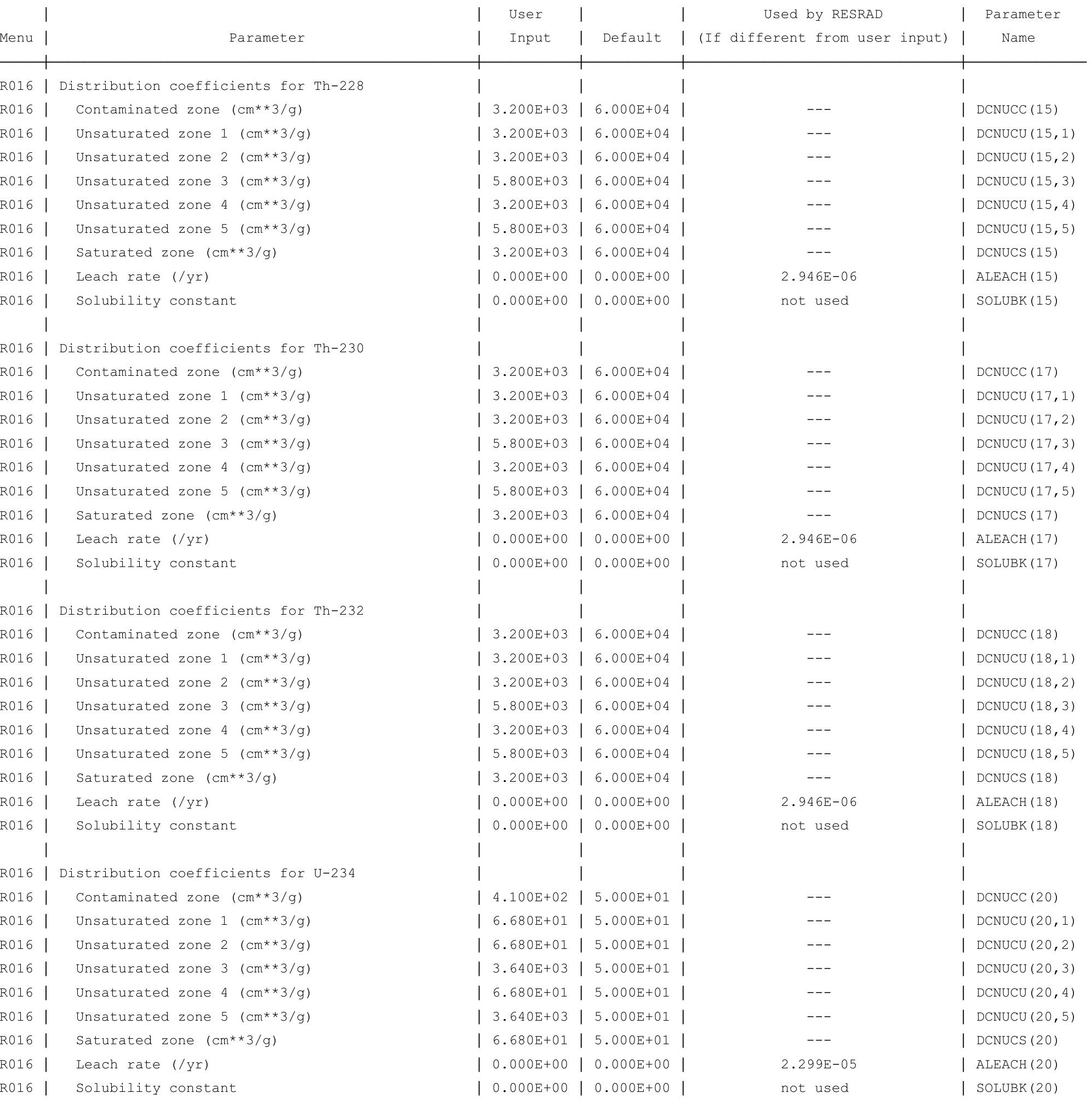


RESRAD, Version $6.5 \quad \mathrm{~T}^{1 / 2}$ Limit $=180$ days

Summary : C746U Resident Gardener Deterministic Run

File : $\mathrm{X}: \backslash \mathrm{FINAL}$ V2 $\backslash \mathrm{C746U}$ RG DET-FINALV2.RAD

Site-Specific Parameter Summary (continued)

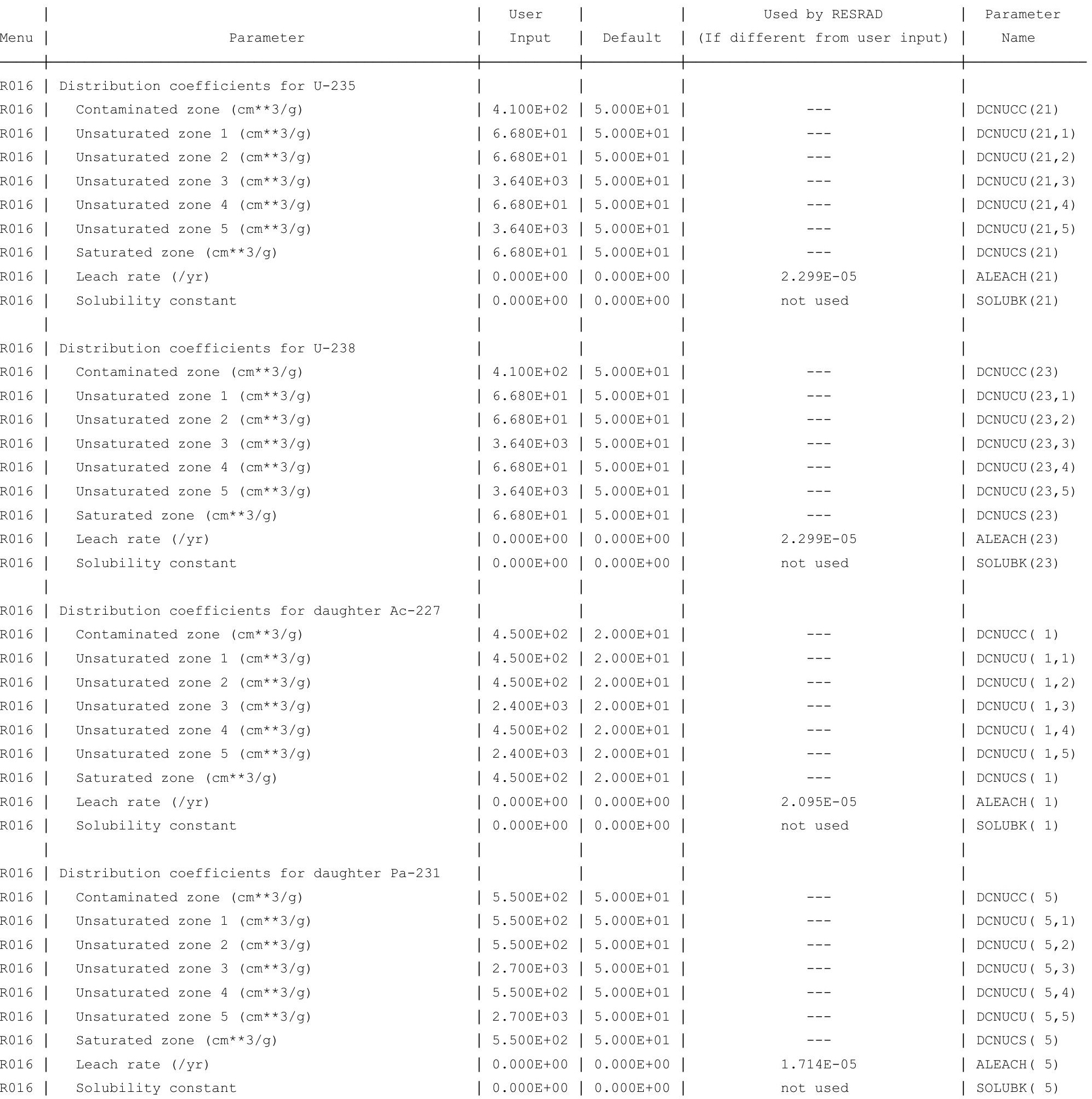


RESRAD, Version $6.5 \quad \mathrm{~T}^{1 / 2}$ Limit $=180$ days

Summary : C746U Resident Gardener Deterministic Run

File : $\mathrm{X}: \backslash$ FINAL V2\C746U RG DET-FINALV2.RAD

Site-Specific Parameter Summary (continued)

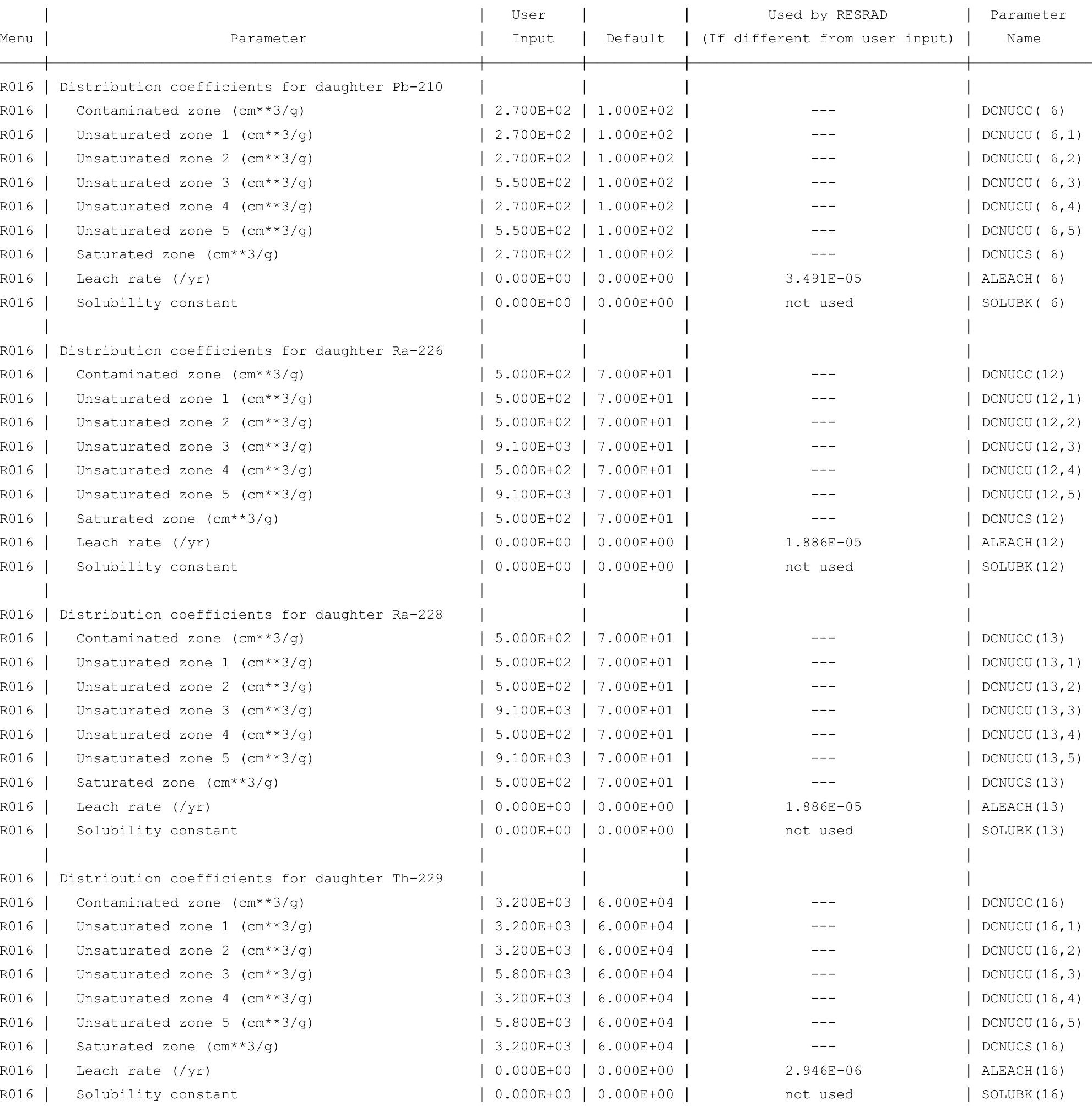


RESRAD, Version $6.5 \quad \mathrm{~T}^{1 / 2}$ Limit $=180$ days

Summary : C746U Resident Gardener Deterministic Run

File : $\mathrm{X}: \backslash$ FINAL V2\C746U RG DET-FINALV2.RAD

Site-Specific Parameter Summary (continued)

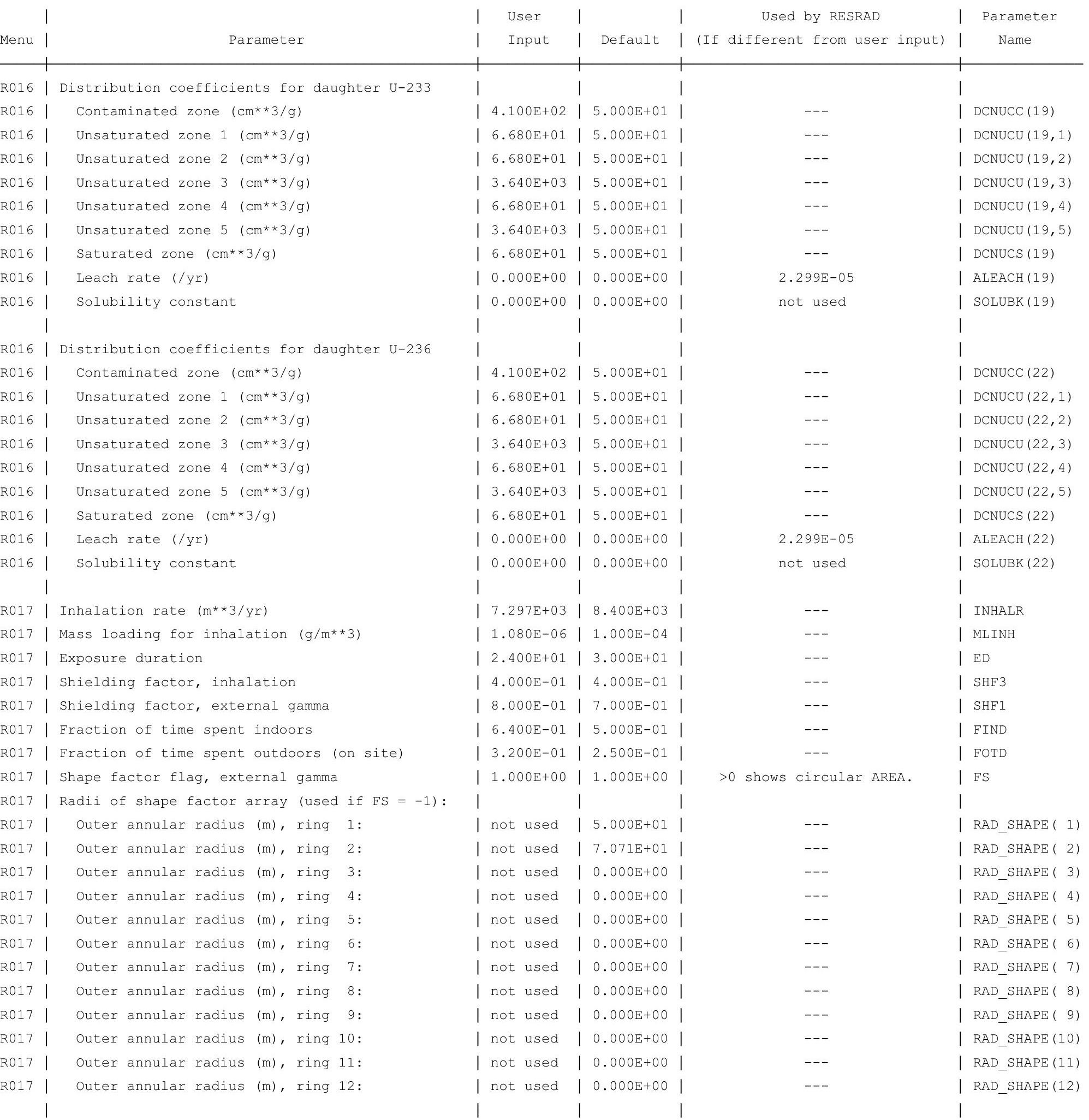


RESRAD, Version $6.5 \quad \mathrm{~T}^{1 / 2}$ Limit $=180$ days

Summary : C746U Resident Gardener Deterministic Run

File : $X: \backslash F I N A L$ V2 \C746U RG DET-FINALV2.RAD

Site-Specific Parameter Summary (continued)

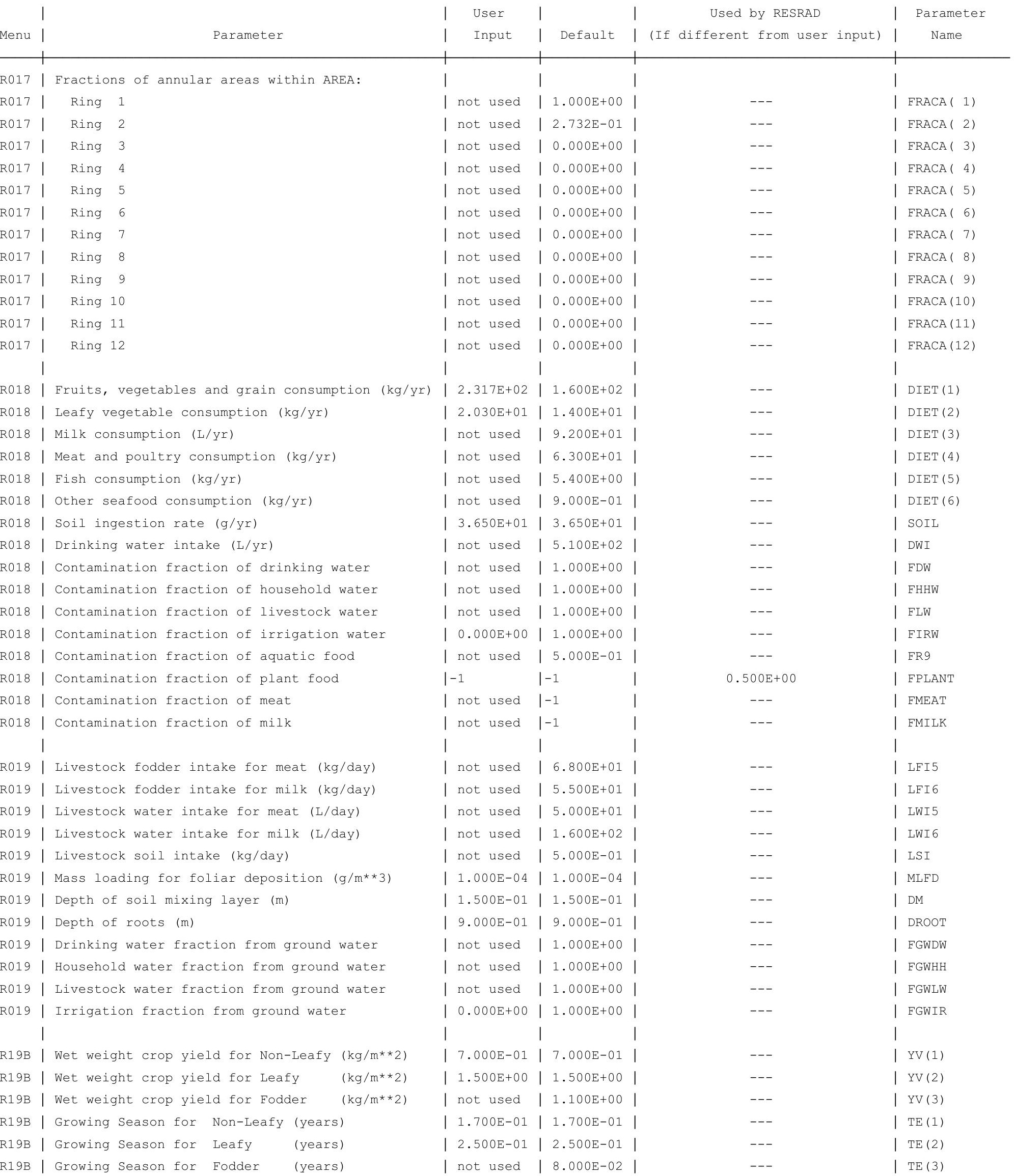


RESRAD, Version $6.5 \quad \mathrm{~T}^{1 / 2}$ Limit $=180$ days

Summary : C746U Resident Gardener Deterministic Run

File : $\mathrm{X}: \backslash$ FINAL V2\C746U RG DET-FINALV2.RAD

Site-Specific Parameter Summary (continued)

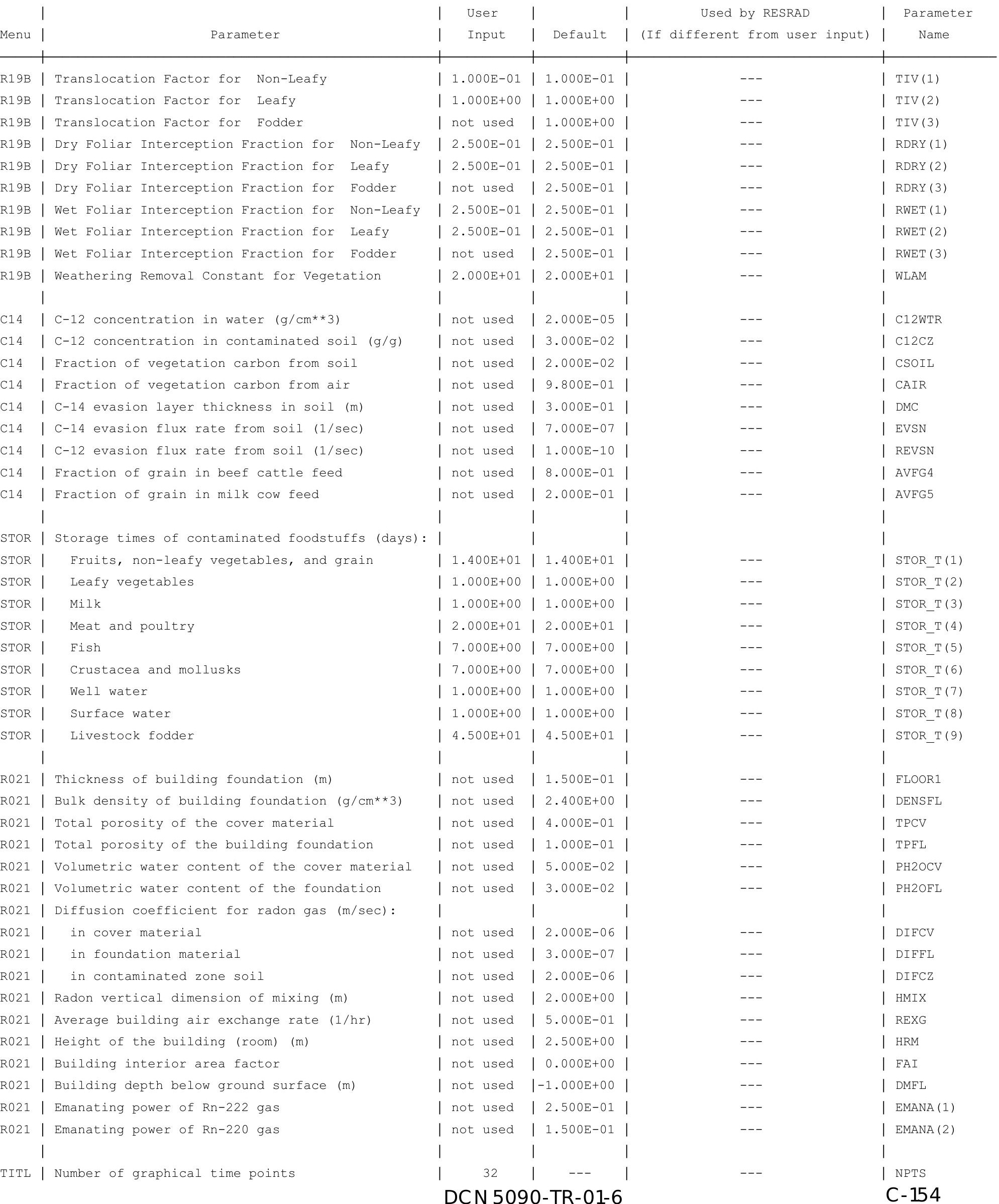


RESRAD, Version $6.5 \quad \mathrm{~T}^{1 / 2}$ Limit $=180$ days

Summary : C746U Resident Gardener Deterministic Run

File : $\mathrm{X}: \backslash$ FINAL V2 $\backslash \mathrm{C746U}$ RG DET-FINALV2.RAD

Contaminated Zone Dimensions

Area: 89436.00 square meters

Thickness:

Cover Depth:

\begin{abstract}
13.40 meters
1.52 meters
\end{abstract}

Initial Soil Concentrations, pCi/g

$\begin{array}{ll}\mathrm{Am}-241 & 1.000 \mathrm{E}+00 \\ \mathrm{Cs}-137 & 1.000 \mathrm{E}+00 \\ \mathrm{~Np}-237 & 1.000 \mathrm{E}+00 \\ \mathrm{Pu}-238 & 1.000 \mathrm{E}+00 \\ \mathrm{Pu}-239 & 1.000 \mathrm{E}+00 \\ \mathrm{Pu}-240 & 1.000 \mathrm{E}+00 \\ \mathrm{TC}-99 & 1.000 \mathrm{E}+00 \\ \mathrm{Th}-228 & 1.000 \mathrm{E}+00 \\ \mathrm{Th}-230 & 1.000 \mathrm{E}+00 \\ \mathrm{Th}-232 & 1.000 \mathrm{E}+00 \\ \mathrm{U}-234 & 1.000 \mathrm{E}+00 \\ \mathrm{U}-235 & 1.000 \mathrm{E}+00 \\ \mathrm{U}-238 & 1.000 \mathrm{E}+00\end{array}$

Total Dose TDOSE(t), mrem/yr

Basic Radiation Dose Limit $=1.000 \mathrm{E}+02 \mathrm{mrem} / \mathrm{yr}$

Total Mixture Sum $M(t)$ = Fraction of Basic Dose Limit Received at Time (t)

$\begin{array}{rllllll}t \text { (years) : } & 0.000 \mathrm{E}+00 & 1.000 \mathrm{E}+00 & 5.000 \mathrm{E}+01 & 1.000 \mathrm{E}+02 & 5.000 \mathrm{E}+02 & 1.050 \mathrm{E}+03 \\ \mathrm{TDOSE}(\mathrm{t}): & 1.396 \mathrm{E}-06 & 1.038 \mathrm{E}-06 & 2.247 \mathrm{E}-06 & 3.048 \mathrm{E}-06 & 3.446 \mathrm{E}-05 & 2.235 \mathrm{E}-01 \\ \mathrm{M}(\mathrm{t}): & 1.396 \mathrm{E}-08 & 1.038 \mathrm{E}-08 & 2.247 \mathrm{E}-08 & 3.048 \mathrm{E}-08 & 3.446 \mathrm{E}-07 & 2.235 \mathrm{E}-03\end{array}$

Maximum TDOSE $(t): 2.235 \mathrm{E}-01 \mathrm{mrem} / \mathrm{yr}$ at $t=1.050 \mathrm{E}+03$ years 
RESRAD, Version $6.5 \quad \mathrm{~T}^{1 / 2}$ Limit $=180$ days

ummary : C746U Resident Gardener Deterministic Run

File : $\mathrm{X}: \backslash$ FINAL V2 $\backslash$ C746U RG DET-FINALV2.RAD

Total Dose Contributions TDOSE(i,p,t) for Individual Radionuclides (i) and Pathways (p) As mrem/yr and Fraction of Total Dose At $t=0.000 \mathrm{E}+00$ years

Water Independent Pathways (Inhalation excludes radon)

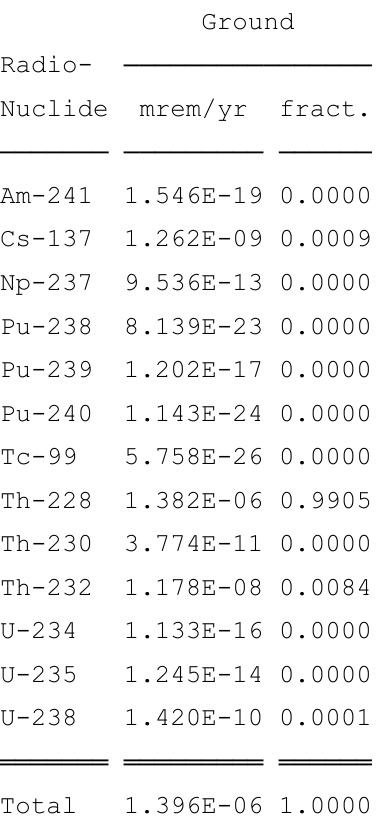

Inhalation

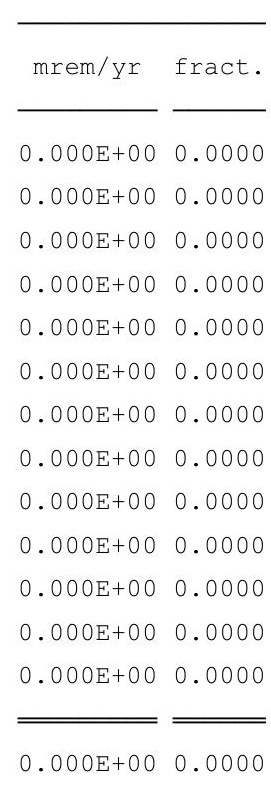

\begin{tabular}{ll} 
Radon \\
\hline mrem/yr fract. \\
\cline { 1 - 1 } 0.000E+00 & 0.0000 \\
$0.000 \mathrm{E}+00$ & 0.0000 \\
$0.000 \mathrm{E}+00$ & 0.0000 \\
$0.000 \mathrm{E}+00$ & 0.0000 \\
$0.000 \mathrm{E}+00$ & 0.0000 \\
$0.000 \mathrm{E}+00$ & 0.0000 \\
$0.000 \mathrm{E}+00$ & 0.0000 \\
$0.000 \mathrm{E}+00$ & 0.0000 \\
$0.000 \mathrm{E}+00$ & 0.0000 \\
$0.000 \mathrm{E}+00$ & 0.0000 \\
$0.000 \mathrm{E}+00$ & 0.0000 \\
$0.000 \mathrm{E}+00$ & 0.0000 \\
$0.000 \mathrm{E}+00$ & 0.0000 \\
\hline \hline $0.000 \mathrm{E}+00$ & 0.0000
\end{tabular}

\begin{tabular}{|c|c|}
\hline mrem/yr & fract. \\
\hline $0.000 \mathrm{E}+00$ & 0.0000 \\
\hline $0.000 \mathrm{E}+00$ & 0.0000 \\
\hline $0.000 \mathrm{E}+00$ & 0.0000 \\
\hline $0.000 \mathrm{E}+00$ & 0.0000 \\
\hline $0.000 \mathrm{E}+00$ & 0.0000 \\
\hline $0.000 \mathrm{E}+00$ & 0.0000 \\
\hline $0.000 \mathrm{E}+00$ & 0.0000 \\
\hline $0.000 \mathrm{E}+00$ & 0.0000 \\
\hline $0.000 \mathrm{E}+00$ & 0.0000 \\
\hline $0.000 \mathrm{E}+00$ & 0.0000 \\
\hline $0.000 \mathrm{E}+00$ & 0.0000 \\
\hline $0.000 \mathrm{E}+00$ & 0.0000 \\
\hline $0.000 \mathrm{E}+00$ & 0.0000 \\
\hline .000 & .000 \\
\hline
\end{tabular}

\begin{tabular}{|c|c|}
\hline mrem/yr & fract. \\
\hline $0.000 \mathrm{E}+00$ & 0.0000 \\
\hline $0.000 \mathrm{E}+00$ & 0.0000 \\
\hline $0.000 \mathrm{E}+00$ & 0.0000 \\
\hline $0.000 \mathrm{E}+00$ & 0.0000 \\
\hline $0.000 \mathrm{E}+00$ & 0.0000 \\
\hline $0.000 \mathrm{E}+00$ & 0.0000 \\
\hline $0.000 \mathrm{E}+00$ & 0.0000 \\
\hline $0.000 \mathrm{E}+00$ & 0.0000 \\
\hline $0.000 \mathrm{E}+00$ & 0.0000 \\
\hline $0.000 \mathrm{E}+00$ & 0.0000 \\
\hline $0.000 \mathrm{E}+00$ & 0.0000 \\
\hline $0.000 \mathrm{E}+00$ & 0.0000 \\
\hline $0.000 \mathrm{E}+00$ & 0.0000 \\
\hline
\end{tabular}

\begin{tabular}{cc} 
Milk \\
\cline { 1 - 1 } mrem/yr & fract. \\
\cline { 1 - 1 } $0.000 \mathrm{E}+00$ & 0.0000 \\
$0.000 \mathrm{E}+00$ & 0.0000 \\
$0.000 \mathrm{E}+00$ & 0.0000 \\
$0.000 \mathrm{E}+00$ & 0.0000 \\
$0.000 \mathrm{E}+00$ & 0.0000 \\
$0.000 \mathrm{E}+00$ & 0.0000 \\
$0.000 \mathrm{E}+00$ & 0.0000 \\
$0.000 \mathrm{E}+00$ & 0.0000 \\
$0.000 \mathrm{E}+00$ & 0.0000 \\
$0.000 \mathrm{E}+00$ & 0.0000 \\
$0.000 \mathrm{E}+00$ & 0.0000 \\
$0.000 \mathrm{E}+00$ & 0.0000 \\
$0.000 \mathrm{E}+00$ & 0.0000 \\
\hline \hline $0.000 \mathrm{E}+00$ & 0.0000
\end{tabular}

Total Dose Contributions TDOSE (i,p,t) for Individual Radionuclides (i) and Pathways (p) As mrem/yr and Fraction of Total Dose At $t=0.000 \mathrm{E}+00$ years

Water Dependent Pathways

\begin{tabular}{llll} 
& & \multicolumn{2}{c}{ Water } \\
Radio- & & \\
Nuclide & mrem/yr & fract. \\
Am-241 & $0.000 \mathrm{E}+00$ & 0.0000 \\
Cs-137 & $0.000 \mathrm{E}+00$ & 0.0000 \\
$\mathrm{~Np}-237$ & $0.000 \mathrm{E}+00$ & 0.0000 \\
Pu-238 & $0.000 \mathrm{E}+00$ & 0.0000 \\
Pu-239 & $0.000 \mathrm{E}+00$ & 0.0000 \\
Pu-240 & $0.000 \mathrm{E}+00$ & 0.0000 \\
$\mathrm{TC}-99$ & $0.000 \mathrm{E}+00$ & 0.0000 \\
$\mathrm{Th}-228$ & $0.000 \mathrm{E}+00$ & 0.0000 \\
$\mathrm{Th}-230$ & $0.000 \mathrm{E}+00$ & 0.0000 \\
$\mathrm{Th}-232$ & $0.000 \mathrm{E}+00$ & 0.0000 \\
$\mathrm{U}-234$ & $0.000 \mathrm{E}+00$ & 0.0000 \\
$\mathrm{U}-235$ & $0.000 \mathrm{E}+00$ & 0.0000 \\
$\mathrm{U}-238$ & $0.000 \mathrm{E}+00$ & 0.0000 \\
\hline \hline
\end{tabular}

Total

$0.000 \mathrm{E}+00 \quad 0.0000$

\begin{tabular}{cc} 
Fish \\
\cline { 1 - 2 } mrem/yr & fract. \\
\hline $0.000 \mathrm{E}+00$ & 0.0000 \\
$0.000 \mathrm{E}+00$ & 0.0000 \\
$0.000 \mathrm{E}+00$ & 0.0000 \\
$0.000 \mathrm{E}+00$ & 0.0000 \\
$0.000 \mathrm{E}+00$ & 0.0000 \\
$0.000 \mathrm{E}+00$ & 0.0000 \\
$0.000 \mathrm{E}+00$ & 0.0000 \\
$0.000 \mathrm{E}+00$ & 0.0000 \\
$0.000 \mathrm{E}+00$ & 0.0000 \\
$0.000 \mathrm{E}+00$ & 0.0000 \\
$0.000 \mathrm{E}+00$ & 0.0000 \\
$0.000 \mathrm{E}+00$ & 0.0000 \\
$0.000 \mathrm{E}+00$ & 0.0000 \\
\hline \hline
\end{tabular}

$0.000 \mathrm{E}+00 \quad 0.0000$

\begin{tabular}{cc} 
Radon \\
\cline { 1 - 1 } mrem/yr fract. \\
\hline $0.000 \mathrm{E}+00$ & 0.0000 \\
$0.000 \mathrm{E}+00$ & 0.0000 \\
$0.000 \mathrm{E}+00$ & 0.0000 \\
$0.000 \mathrm{E}+00$ & 0.0000 \\
$0.000 \mathrm{E}+00$ & 0.0000 \\
$0.000 \mathrm{E}+00$ & 0.0000 \\
$0.000 \mathrm{E}+00$ & 0.0000 \\
$0.000 \mathrm{E}+00$ & 0.0000 \\
$0.000 \mathrm{E}+00$ & 0.0000 \\
$0.000 \mathrm{E}+00$ & 0.0000 \\
$0.000 \mathrm{E}+00$ & 0.0000 \\
$0.000 \mathrm{E}+00$ & 0.0000 \\
$0.000 \mathrm{E}+00$ & 0.0000 \\
\hline \hline
\end{tabular}

$0.000 \mathrm{E}+00 \quad 0.0000$

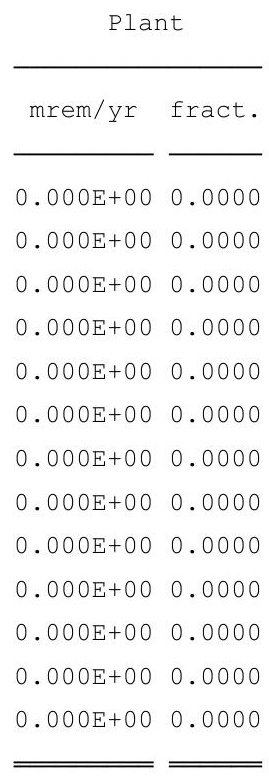

$0.000 \mathrm{E}+00 \quad 0.0000$

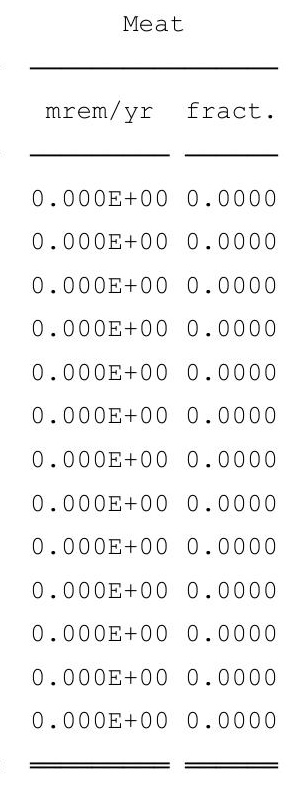

$0.000 \mathrm{E}+00 \quad 0.0000$

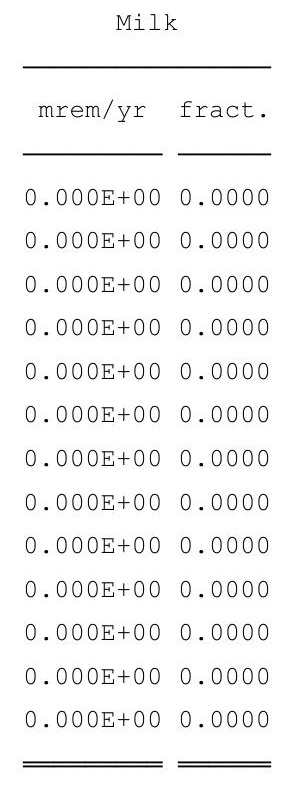

$0.000 \mathrm{E}+00 \quad 0.0000$
Soil

\begin{tabular}{ccc} 
mrem/yr & fract. \\
\cline { 1 - 1 } $0.000 \mathrm{E}+00$ & 0.0000 \\
$0.000 \mathrm{E}+00$ & 0.0000 \\
$0.000 \mathrm{E}+00$ & 0.0000 \\
$0.000 \mathrm{E}+00$ & 0.0000 \\
$0.000 \mathrm{E}+00$ & 0.0000 \\
$0.000 \mathrm{E}+00$ & 0.0000 \\
$0.000 \mathrm{E}+00$ & 0.0000 \\
$0.000 \mathrm{E}+00$ & 0.0000 \\
$0.000 \mathrm{E}+00$ & 0.0000 \\
$0.000 \mathrm{E}+00$ & 0.0000 \\
$0.000 \mathrm{E}+00$ & 0.0000 \\
$0.000 \mathrm{E}+00$ & 0.0000 \\
$0.000 \mathrm{E}+00$ & 0.0000 \\
\hline \hline $0.000 \mathrm{E}+00$ & 0.0000
\end{tabular}

* Sum of all water independent and dependent pathways. 
RESRAD, Version $6.5 \quad \mathrm{~T}^{1 / 2}$ Limit $=180$ days

ummary : C746U Resident Gardener Deterministic Run

File : $\mathrm{X}: \backslash$ FINAL V2 $\backslash$ C746U RG DET-FINALV2.RAD

Total Dose Contributions TDOSE(i,p,t) for Individual Radionuclides (i) and Pathways (p) As mrem/yr and Fraction of Total Dose At $t=1.000 \mathrm{E}+00$ years

Water Independent Pathways (Inhalation excludes radon)

\begin{tabular}{|c|c|c|}
\hline ide & mrem/yr & fract. \\
\hline $1-241$ & 4. $680 \mathrm{E}-19$ & 0.0000 \\
\hline-137 & $1.243 \mathrm{E}-09$ & 0.0012 \\
\hline-237 & $9.638 \mathrm{E}-13$ & 0.0000 \\
\hline-238 & 1. $209 \mathrm{E}-21$ & 0.0000 \\
\hline-239 & 1. $217 \mathrm{E}-17$ & 0.0000 \\
\hline-240 & $1.188 \mathrm{E}-24$ & 0.0000 \\
\hline-99 & $5.817 \mathrm{E}-26$ & 0.0000 \\
\hline-228 & $9.680 \mathrm{E}-07$ & 0.9321 \\
\hline-230 & $1.139 \mathrm{E}-10$ & 0.0001 \\
\hline-232 & $6.899 \mathrm{E}-08$ & 0.0664 \\
\hline 234 & $7.978 \mathrm{E}-16$ & 0.0000 \\
\hline 5 & $1.266 \mathrm{E}-14$ & 0.0000 \\
\hline 238 & $1.431 \mathrm{E}-10$ & 0.0001 \\
\hline & 06 & \\
\hline
\end{tabular}

Inhalation

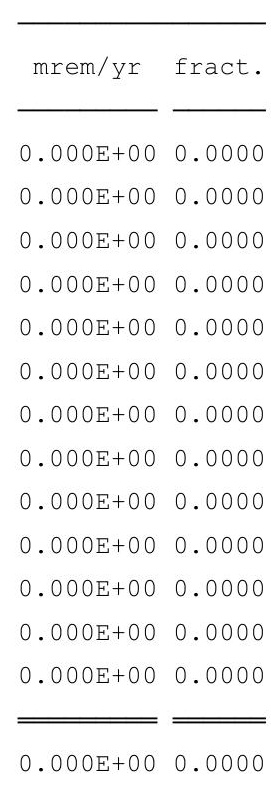

\begin{tabular}{ll} 
Radon \\
\hline mrem/yr fract. \\
\cline { 1 - 1 } 0.000E+00 & 0.0000 \\
$0.000 \mathrm{E}+00$ & 0.0000 \\
$0.000 \mathrm{E}+00$ & 0.0000 \\
$0.000 \mathrm{E}+00$ & 0.0000 \\
$0.000 \mathrm{E}+00$ & 0.0000 \\
$0.000 \mathrm{E}+00$ & 0.0000 \\
$0.000 \mathrm{E}+00$ & 0.0000 \\
$0.000 \mathrm{E}+00$ & 0.0000 \\
$0.000 \mathrm{E}+00$ & 0.0000 \\
$0.000 \mathrm{E}+00$ & 0.0000 \\
$0.000 \mathrm{E}+00$ & 0.0000 \\
$0.000 \mathrm{E}+00$ & 0.0000 \\
$0.000 \mathrm{E}+00$ & 0.0000 \\
\hline \hline $0.000 \mathrm{E}+00$ & 0.0000
\end{tabular}

\begin{tabular}{|c|c|}
\hline mrem/yr & fract. \\
\hline $0.000 \mathrm{E}+00$ & 0.0000 \\
\hline $0.000 \mathrm{E}+00$ & 0.0000 \\
\hline $0.000 \mathrm{E}+00$ & 0.0000 \\
\hline $0.000 \mathrm{E}+00$ & 0.0000 \\
\hline $0.000 \mathrm{E}+00$ & 0.0000 \\
\hline $0.000 \mathrm{E}+00$ & 0.0000 \\
\hline $0.000 \mathrm{E}+00$ & 0.0000 \\
\hline $0.000 \mathrm{E}+00$ & 0.0000 \\
\hline $0.000 \mathrm{E}+00$ & 0.0000 \\
\hline $0.000 \mathrm{E}+00$ & 0.0000 \\
\hline $0.000 \mathrm{E}+00$ & 0.0000 \\
\hline $0.000 \mathrm{E}+00$ & 0.0000 \\
\hline $0.000 \mathrm{E}+00$ & 0.0000 \\
\hline .000 & .000 \\
\hline
\end{tabular}

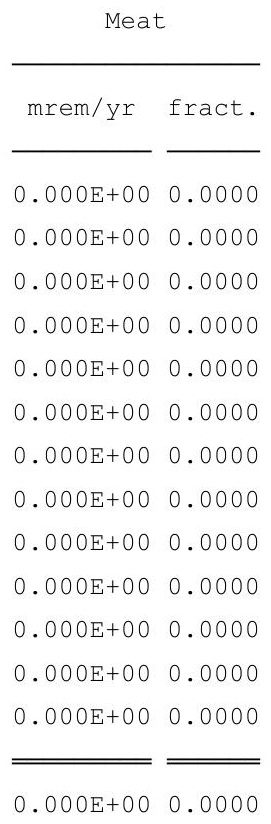

\begin{tabular}{cc} 
Milk \\
\cline { 1 - 1 } mrem/yr fract. \\
\cline { 1 - 1 } $0.000 \mathrm{E}+00$ & 0.0000 \\
$0.000 \mathrm{E}+00$ & 0.0000 \\
$0.000 \mathrm{E}+00$ & 0.0000 \\
$0.000 \mathrm{E}+00$ & 0.0000 \\
$0.000 \mathrm{E}+00$ & 0.0000 \\
$0.000 \mathrm{E}+00$ & 0.0000 \\
$0.000 \mathrm{E}+00$ & 0.0000 \\
$0.000 \mathrm{E}+00$ & 0.0000 \\
$0.000 \mathrm{E}+00$ & 0.0000 \\
$0.000 \mathrm{E}+00$ & 0.0000 \\
$0.000 \mathrm{E}+00$ & 0.0000 \\
$0.000 \mathrm{E}+00$ & 0.0000 \\
$0.000 \mathrm{E}+00$ & 0.0000 \\
\hline \hline $0.000 \mathrm{E}+00$ & 0.0000
\end{tabular}

Total Dose Contributions TDOSE (i,p,t) for Individual Radionuclides (i) and Pathways (p) As mrem/yr and Fraction of Total Dose At $t=1.000 \mathrm{E}+00$ years

Water Dependent Pathways

\begin{tabular}{llll} 
& & \multicolumn{2}{c}{ Water } \\
Radio- & & \\
Nuclide & mrem/yr & fract. \\
Am-241 & $0.000 \mathrm{E}+00$ & 0.0000 \\
Cs-137 & $0.000 \mathrm{E}+00$ & 0.0000 \\
$\mathrm{~Np}-237$ & $0.000 \mathrm{E}+00$ & 0.0000 \\
Pu-238 & $0.000 \mathrm{E}+00$ & 0.0000 \\
Pu-239 & $0.000 \mathrm{E}+00$ & 0.0000 \\
Pu-240 & $0.000 \mathrm{E}+00$ & 0.0000 \\
$\mathrm{TC}-99$ & $0.000 \mathrm{E}+00$ & 0.0000 \\
$\mathrm{Th}-228$ & $0.000 \mathrm{E}+00$ & 0.0000 \\
$\mathrm{Th}-230$ & $0.000 \mathrm{E}+00$ & 0.0000 \\
$\mathrm{Th}-232$ & $0.000 \mathrm{E}+00$ & 0.0000 \\
$\mathrm{U}-234$ & $0.000 \mathrm{E}+00$ & 0.0000 \\
$\mathrm{U}-235$ & $0.000 \mathrm{E}+00$ & 0.0000 \\
$\mathrm{U}-238$ & $0.000 \mathrm{E}+00$ & 0.0000 \\
\hline \hline
\end{tabular}

$0.000 \mathrm{E}+00 \quad 0.0000$

\begin{tabular}{cc} 
Fish \\
\cline { 1 - 2 } mrem/yr & fract. \\
\hline $0.000 \mathrm{E}+00$ & 0.0000 \\
$0.000 \mathrm{E}+00$ & 0.0000 \\
$0.000 \mathrm{E}+00$ & 0.0000 \\
$0.000 \mathrm{E}+00$ & 0.0000 \\
$0.000 \mathrm{E}+00$ & 0.0000 \\
$0.000 \mathrm{E}+00$ & 0.0000 \\
$0.000 \mathrm{E}+00$ & 0.0000 \\
$0.000 \mathrm{E}+00$ & 0.0000 \\
$0.000 \mathrm{E}+00$ & 0.0000 \\
$0.000 \mathrm{E}+00$ & 0.0000 \\
$0.000 \mathrm{E}+00$ & 0.0000 \\
$0.000 \mathrm{E}+00$ & 0.0000 \\
$0.000 \mathrm{E}+00$ & 0.0000 \\
\hline \hline
\end{tabular}

$0.000 \mathrm{E}+00 \quad 0.0000$

\begin{tabular}{cc} 
Radon \\
\cline { 1 - 1 } mrem/yr fract. \\
\hline $0.000 \mathrm{E}+00$ & 0.0000 \\
$0.000 \mathrm{E}+00$ & 0.0000 \\
$0.000 \mathrm{E}+00$ & 0.0000 \\
$0.000 \mathrm{E}+00$ & 0.0000 \\
$0.000 \mathrm{E}+00$ & 0.0000 \\
$0.000 \mathrm{E}+00$ & 0.0000 \\
$0.000 \mathrm{E}+00$ & 0.0000 \\
$0.000 \mathrm{E}+00$ & 0.0000 \\
$0.000 \mathrm{E}+00$ & 0.0000 \\
$0.000 \mathrm{E}+00$ & 0.0000 \\
$0.000 \mathrm{E}+00$ & 0.0000 \\
$0.000 \mathrm{E}+00$ & 0.0000 \\
$0.000 \mathrm{E}+00$ & 0.0000 \\
\hline \hline
\end{tabular}

$0.000 \mathrm{E}+00 \quad 0.0000$

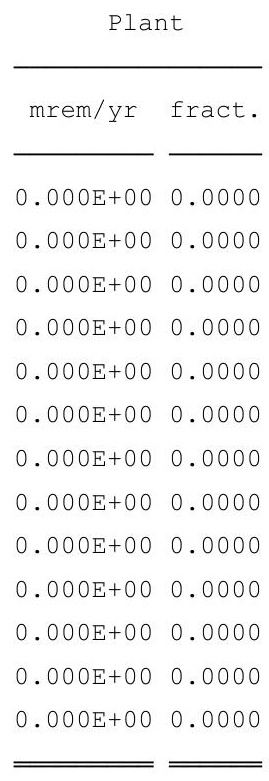

$0.000 \mathrm{E}+00 \quad 0.0000$

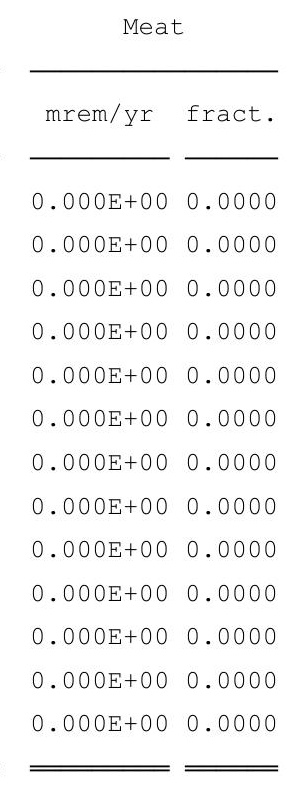

$0.000 \mathrm{E}+00 \quad 0.0000$

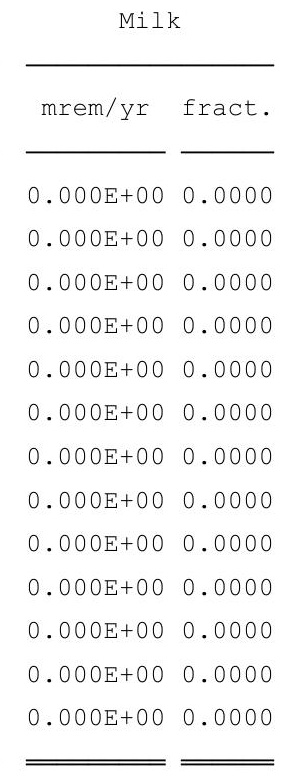

$0.000 \mathrm{E}+00 \quad 0.0000$
Soil

\begin{tabular}{lll} 
mrem/yr & fract. \\
\cline { 1 - 1 } $0.000 \mathrm{E}+00$ & 0.0000 \\
$0.000 \mathrm{E}+00$ & 0.0000 \\
$0.000 \mathrm{E}+00$ & 0.0000 \\
$0.000 \mathrm{E}+00$ & 0.0000 \\
$0.000 \mathrm{E}+00$ & 0.0000 \\
$0.000 \mathrm{E}+00$ & 0.0000 \\
$0.000 \mathrm{E}+00$ & 0.0000 \\
$0.000 \mathrm{E}+00$ & 0.0000 \\
$0.000 \mathrm{E}+00$ & 0.0000 \\
$0.000 \mathrm{E}+00$ & 0.0000 \\
$0.000 \mathrm{E}+00$ & 0.0000 \\
$0.000 \mathrm{E}+00$ & 0.0000 \\
$0.000 \mathrm{E}+00$ & 0.0000 \\
\hline \hline $0.000 \mathrm{E}+00$ & 0.0000
\end{tabular}

* Sum of all water independent and dependent pathways. 
RESRAD, Version $6.5 \quad \mathrm{~T}^{1 / 2}$ Limit $=180$ days

ummary : C746U Resident Gardener Deterministic Run

File : $\mathrm{X}: \backslash$ FINAL V2 $\backslash$ C746U RG DET-FINALV2.RAD

Total Dose Contributions TDOSE(i,p,t) for Individual Radionuclides (i) and Pathways (p) As mrem/yr and Fraction of Total Dose At $t=5.000 \mathrm{E}+01$ years

Water Independent Pathways (Inhalation excludes radon)

\begin{tabular}{|c|c|c|}
\hline ide & mrem/yr & fract. \\
\hline-241 & $2.564 \mathrm{E}-17$ & 0.0000 \\
\hline-137 & $6.050 \mathrm{E}-10$ & 0.0003 \\
\hline-237 & 1. $629 \mathrm{E}-12$ & 0.0000 \\
\hline-238 & $5.266 \mathrm{E}-17$ & 0.0000 \\
\hline-239 & $2.183 \mathrm{E}-17$ & 0.0000 \\
\hline-240 & $2.681 \mathrm{E}-21$ & 0.0000 \\
\hline-99 & $9.575 \mathrm{E}-26$ & 0.0000 \\
\hline-228 & $2.527 \mathrm{E}-14$ & 0.0000 \\
\hline-230 & $5.320 \mathrm{E}-09$ & 0.0024 \\
\hline-232 & $2.241 \mathrm{E}-06$ & 0.9973 \\
\hline 34 & 1.213E-12 & 0.0000 \\
\hline 35 & $9.238 \mathrm{E}-14$ & 0.0000 \\
\hline 238 & $2.116 \mathrm{E}-10$ & 0.0001 \\
\hline & 06 & $\perp$ \\
\hline
\end{tabular}

Inhalation

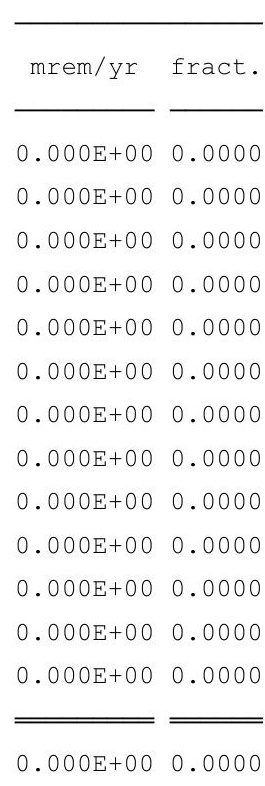

\begin{tabular}{cc} 
Radon \\
\cline { 1 - 2 } mrem/yr fract. \\
\cline { 1 - 2 } $0.000 \mathrm{E}+00$ & 0.0000 \\
$0.000 \mathrm{E}+00$ & 0.0000 \\
$0.000 \mathrm{E}+00$ & 0.0000 \\
$0.000 \mathrm{E}+00$ & 0.0000 \\
$0.000 \mathrm{E}+00$ & 0.0000 \\
$0.000 \mathrm{E}+00$ & 0.0000 \\
$0.000 \mathrm{E}+00$ & 0.0000 \\
$0.000 \mathrm{E}+00$ & 0.0000 \\
$0.000 \mathrm{E}+00$ & 0.0000 \\
$0.000 \mathrm{E}+00$ & 0.0000 \\
$0.000 \mathrm{E}+00$ & 0.0000 \\
$0.000 \mathrm{E}+00$ & 0.0000 \\
$0.000 \mathrm{E}+00$ & 0.0000 \\
\hline \hline $0.000 \mathrm{E}+00$ & 0.0000
\end{tabular}

\begin{tabular}{cc} 
Plant \\
\cline { 1 - 2 } mrem/yr fract. \\
\cline { 1 - 2 } $0.000 \mathrm{E}+00$ & 0.0000 \\
$0.000 \mathrm{E}+00$ & 0.0000 \\
$0.000 \mathrm{E}+00$ & 0.0000 \\
$0.000 \mathrm{E}+00$ & 0.0000 \\
$0.000 \mathrm{E}+00$ & 0.0000 \\
$0.000 \mathrm{E}+00$ & 0.0000 \\
$0.000 \mathrm{E}+00$ & 0.0000 \\
$0.000 \mathrm{E}+00$ & 0.0000 \\
$0.000 \mathrm{E}+00$ & 0.0000 \\
$0.000 \mathrm{E}+00$ & 0.0000 \\
$0.000 \mathrm{E}+00$ & 0.0000 \\
$0.000 \mathrm{E}+00$ & 0.0000 \\
$0.000 \mathrm{E}+00$ & 0.0000 \\
\hline \hline $0.000 \mathrm{E}+00$ & 0.0000
\end{tabular}

\begin{tabular}{|c|c|}
\hline mrem/yr & fract. \\
\hline $0.000 \mathrm{E}+00$ & 0.0000 \\
\hline $0.000 \mathrm{E}+00$ & 0.0000 \\
\hline $0.000 \mathrm{E}+00$ & 0.0000 \\
\hline $0.000 \mathrm{E}+00$ & 0.0000 \\
\hline $0.000 \mathrm{E}+00$ & 0.0000 \\
\hline $0.000 \mathrm{E}+00$ & 0.0000 \\
\hline $0.000 \mathrm{E}+00$ & 0.0000 \\
\hline $0.000 \mathrm{E}+00$ & 0.0000 \\
\hline $0.000 \mathrm{E}+00$ & 0.0000 \\
\hline $0.000 \mathrm{E}+00$ & 0.0000 \\
\hline $0.000 \mathrm{E}+00$ & 0.0000 \\
\hline $0.000 \mathrm{E}+00$ & 0.0000 \\
\hline $0.000 \mathrm{E}+00$ & 0.0000 \\
\hline
\end{tabular}

\begin{tabular}{cc} 
Milk \\
\cline { 1 - 1 } mrem/yr & fract. \\
\cline { 1 - 1 } $0.000 \mathrm{E}+00$ & 0.0000 \\
$0.000 \mathrm{E}+00$ & 0.0000 \\
$0.000 \mathrm{E}+00$ & 0.0000 \\
$0.000 \mathrm{E}+00$ & 0.0000 \\
$0.000 \mathrm{E}+00$ & 0.0000 \\
$0.000 \mathrm{E}+00$ & 0.0000 \\
$0.000 \mathrm{E}+00$ & 0.0000 \\
$0.000 \mathrm{E}+00$ & 0.0000 \\
$0.000 \mathrm{E}+00$ & 0.0000 \\
$0.000 \mathrm{E}+00$ & 0.0000 \\
$0.000 \mathrm{E}+00$ & 0.0000 \\
$0.000 \mathrm{E}+00$ & 0.0000 \\
$0.000 \mathrm{E}+00$ & 0.0000 \\
\hline \hline $0.000 \mathrm{E}+00$ & 0.0000
\end{tabular}

Total Dose Contributions TDOSE (i,p,t) for Individual Radionuclides (i) and Pathways (p) As mrem/yr and Fraction of Total Dose At $t=5.000 \mathrm{E}+01$ years

Water Dependent Pathways

\begin{tabular}{llll} 
& & \multicolumn{2}{c}{ Water } \\
Radio- & & \\
Nuclide & mrem/yr & fract. \\
Am-241 & $0.000 \mathrm{E}+00$ & 0.0000 \\
Cs-137 & $0.000 \mathrm{E}+00$ & 0.0000 \\
$\mathrm{~Np}-237$ & $0.000 \mathrm{E}+00$ & 0.0000 \\
Pu-238 & $0.000 \mathrm{E}+00$ & 0.0000 \\
Pu-239 & $0.000 \mathrm{E}+00$ & 0.0000 \\
Pu-240 & $0.000 \mathrm{E}+00$ & 0.0000 \\
$\mathrm{TC}-99$ & $0.000 \mathrm{E}+00$ & 0.0000 \\
$\mathrm{Th}-228$ & $0.000 \mathrm{E}+00$ & 0.0000 \\
$\mathrm{Th}-230$ & $0.000 \mathrm{E}+00$ & 0.0000 \\
$\mathrm{Th}-232$ & $0.000 \mathrm{E}+00$ & 0.0000 \\
$\mathrm{U}-234$ & $0.000 \mathrm{E}+00$ & 0.0000 \\
$\mathrm{U}-235$ & $0.000 \mathrm{E}+00$ & 0.0000 \\
$\mathrm{U}-238$ & $0.000 \mathrm{E}+00$ & 0.0000 \\
\hline \hline
\end{tabular}

Total

$0.000 \mathrm{E}+00 \quad 0.0000$

\begin{tabular}{cc} 
Fish \\
\cline { 1 - 2 } mrem/yr & fract. \\
\hline $0.000 \mathrm{E}+00$ & 0.0000 \\
$0.000 \mathrm{E}+00$ & 0.0000 \\
$0.000 \mathrm{E}+00$ & 0.0000 \\
$0.000 \mathrm{E}+00$ & 0.0000 \\
$0.000 \mathrm{E}+00$ & 0.0000 \\
$0.000 \mathrm{E}+00$ & 0.0000 \\
$0.000 \mathrm{E}+00$ & 0.0000 \\
$0.000 \mathrm{E}+00$ & 0.0000 \\
$0.000 \mathrm{E}+00$ & 0.0000 \\
$0.000 \mathrm{E}+00$ & 0.0000 \\
$0.000 \mathrm{E}+00$ & 0.0000 \\
$0.000 \mathrm{E}+00$ & 0.0000 \\
$0.000 \mathrm{E}+00$ & 0.0000 \\
\hline \hline
\end{tabular}

$0.000 \mathrm{E}+00 \quad 0.0000$

\begin{tabular}{cc} 
Radon \\
\cline { 1 - 1 } mrem/yr fract. \\
\hline $0.000 \mathrm{E}+00$ & 0.0000 \\
$0.000 \mathrm{E}+00$ & 0.0000 \\
$0.000 \mathrm{E}+00$ & 0.0000 \\
$0.000 \mathrm{E}+00$ & 0.0000 \\
$0.000 \mathrm{E}+00$ & 0.0000 \\
$0.000 \mathrm{E}+00$ & 0.0000 \\
$0.000 \mathrm{E}+00$ & 0.0000 \\
$0.000 \mathrm{E}+00$ & 0.0000 \\
$0.000 \mathrm{E}+00$ & 0.0000 \\
$0.000 \mathrm{E}+00$ & 0.0000 \\
$0.000 \mathrm{E}+00$ & 0.0000 \\
$0.000 \mathrm{E}+00$ & 0.0000 \\
$0.000 \mathrm{E}+00$ & 0.0000 \\
\hline \hline
\end{tabular}

$0.000 \mathrm{E}+00 \quad 0.0000$

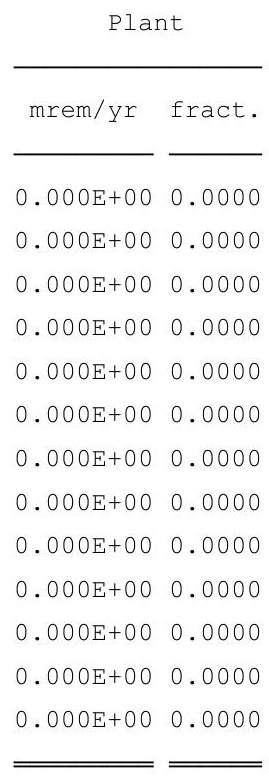

$0.000 \mathrm{E}+00 \quad 0.0000$

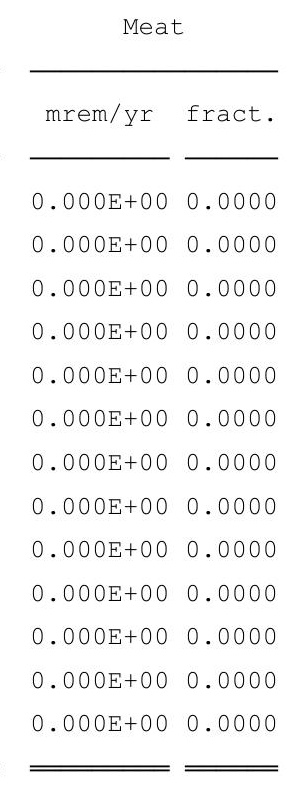

$0.000 \mathrm{E}+00 \quad 0.0000$

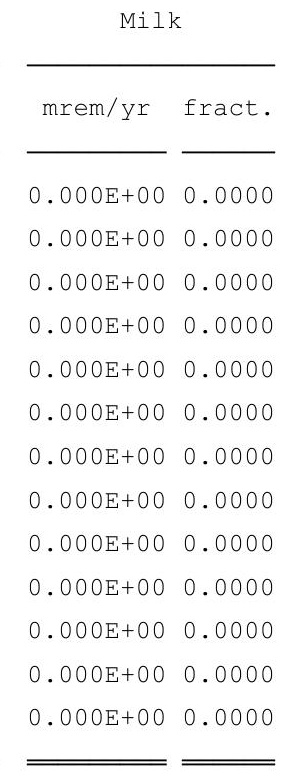

$0.000 \mathrm{E}+00 \quad 0.0000$
Soil

\begin{tabular}{ccc} 
mrem/yr & fract. \\
\cline { 1 - 1 } $0.000 \mathrm{E}+00$ & 0.0000 \\
$0.000 \mathrm{E}+00$ & 0.0000 \\
$0.000 \mathrm{E}+00$ & 0.0000 \\
$0.000 \mathrm{E}+00$ & 0.0000 \\
$0.000 \mathrm{E}+00$ & 0.0000 \\
$0.000 \mathrm{E}+00$ & 0.0000 \\
$0.000 \mathrm{E}+00$ & 0.0000 \\
$0.000 \mathrm{E}+00$ & 0.0000 \\
$0.000 \mathrm{E}+00$ & 0.0000 \\
$0.000 \mathrm{E}+00$ & 0.0000 \\
$0.000 \mathrm{E}+00$ & 0.0000 \\
$0.000 \mathrm{E}+00$ & 0.0000 \\
$0.000 \mathrm{E}+00$ & 0.0000 \\
\hline \hline $0.000 \mathrm{E}+00$ & 0.0000
\end{tabular}

* Sum of all water independent and dependent pathways. 
RESRAD, Version $6.5 \quad \mathrm{~T}^{1 / 2}$ Limit $=180$ days

ummary : C746U Resident Gardener Deterministic Run

File : $\mathrm{X}: \backslash$ FINAL V2 $\backslash$ C746U RG DET-FINALV2.RAD

Total Dose Contributions TDOSE(i,p,t) for Individual Radionuclides (i) and Pathways (p) As mrem/yr and Fraction of Total Dose At $t=1.000 \mathrm{E}+02$ years

Water Independent Pathways (Inhalation excludes radon)

\begin{tabular}{|c|c|c|}
\hline ide & mrem/yr & fract. \\
\hline $1-241$ & $8.401 \mathrm{E}-17$ & 0.0000 \\
\hline-137 & $2.901 \mathrm{E}-10$ & 0.0001 \\
\hline-237 & $2.788 \mathrm{E}-12$ & 0.0000 \\
\hline-238 & $5.323 E-16$ & 0.0000 \\
\hline-239 & $3.966 \mathrm{E}-17$ & 0.0000 \\
\hline-240 & 1. $783 \mathrm{E}-20$ & 0.0000 \\
\hline-99 & $1.592 \mathrm{E}-25$ & 0.0000 \\
\hline-228 & $4.618 \mathrm{E}-22$ & 0.0000 \\
\hline-230 & $1.479 \mathrm{E}-08$ & 0.0049 \\
\hline-232 & $3.033 \mathrm{E}-06$ & 0.9949 \\
\hline 234 & $6.737 \mathrm{E}-12$ & 0.0000 \\
\hline 35 & $3.388 \mathrm{E}-13$ & 0.0000 \\
\hline 238 & $3.153 \mathrm{E}-10$ & 0.0001 \\
\hline & 06 & \\
\hline
\end{tabular}

Inhalation

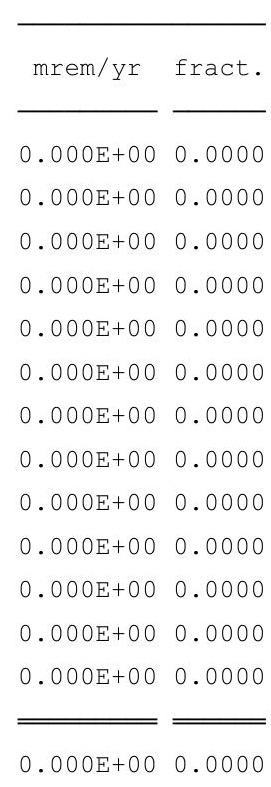

\begin{tabular}{ll} 
Radon \\
\hline mrem/yr fract. \\
\cline { 1 - 1 } 0.000E+00 & 0.0000 \\
$0.000 \mathrm{E}+00$ & 0.0000 \\
$0.000 \mathrm{E}+00$ & 0.0000 \\
$0.000 \mathrm{E}+00$ & 0.0000 \\
$0.000 \mathrm{E}+00$ & 0.0000 \\
$0.000 \mathrm{E}+00$ & 0.0000 \\
$0.000 \mathrm{E}+00$ & 0.0000 \\
$0.000 \mathrm{E}+00$ & 0.0000 \\
$0.000 \mathrm{E}+00$ & 0.0000 \\
$0.000 \mathrm{E}+00$ & 0.0000 \\
$0.000 \mathrm{E}+00$ & 0.0000 \\
$0.000 \mathrm{E}+00$ & 0.0000 \\
$0.000 \mathrm{E}+00$ & 0.0000 \\
\hline \hline $0.000 \mathrm{E}+00$ & 0.0000
\end{tabular}

\begin{tabular}{|c|c|}
\hline mrem/yr & fract. \\
\hline $0.000 \mathrm{E}+00$ & 0.0000 \\
\hline $0.000 \mathrm{E}+00$ & 0.0000 \\
\hline $0.000 \mathrm{E}+00$ & 0.0000 \\
\hline $0.000 \mathrm{E}+00$ & 0.0000 \\
\hline $0.000 \mathrm{E}+00$ & 0.0000 \\
\hline $0.000 \mathrm{E}+00$ & 0.0000 \\
\hline $0.000 \mathrm{E}+00$ & 0.0000 \\
\hline $0.000 \mathrm{E}+00$ & 0.0000 \\
\hline $0.000 \mathrm{E}+00$ & 0.0000 \\
\hline $0.000 \mathrm{E}+00$ & 0.0000 \\
\hline $0.000 \mathrm{E}+00$ & 0.0000 \\
\hline $0.000 \mathrm{E}+00$ & 0.0000 \\
\hline $0.000 \mathrm{E}+00$ & 0.0000 \\
\hline .000 & .000 \\
\hline
\end{tabular}

\begin{tabular}{|c|c|}
\hline mrem/yr & fract. \\
\hline $0.000 \mathrm{E}+00$ & 0.0000 \\
\hline $0.000 \mathrm{E}+00$ & 0.0000 \\
\hline $0.000 \mathrm{E}+00$ & 0.0000 \\
\hline $0.000 \mathrm{E}+00$ & 0.0000 \\
\hline $0.000 \mathrm{E}+00$ & 0.0000 \\
\hline $0.000 \mathrm{E}+00$ & 0.0000 \\
\hline $0.000 \mathrm{E}+00$ & 0.0000 \\
\hline $0.000 \mathrm{E}+00$ & 0.0000 \\
\hline $0.000 \mathrm{E}+00$ & 0.0000 \\
\hline $0.000 \mathrm{E}+00$ & 0.0000 \\
\hline $0.000 \mathrm{E}+00$ & 0.0000 \\
\hline $0.000 \mathrm{E}+00$ & 0.0000 \\
\hline $0.000 \mathrm{E}+00$ & 0.0000 \\
\hline
\end{tabular}

\begin{tabular}{cc} 
Milk \\
\cline { 1 - 1 } mrem/yr & fract. \\
\cline { 1 - 1 } $0.000 \mathrm{E}+00$ & 0.0000 \\
$0.000 \mathrm{E}+00$ & 0.0000 \\
$0.000 \mathrm{E}+00$ & 0.0000 \\
$0.000 \mathrm{E}+00$ & 0.0000 \\
$0.000 \mathrm{E}+00$ & 0.0000 \\
$0.000 \mathrm{E}+00$ & 0.0000 \\
$0.000 \mathrm{E}+00$ & 0.0000 \\
$0.000 \mathrm{E}+00$ & 0.0000 \\
$0.000 \mathrm{E}+00$ & 0.0000 \\
$0.000 \mathrm{E}+00$ & 0.0000 \\
$0.000 \mathrm{E}+00$ & 0.0000 \\
$0.000 \mathrm{E}+00$ & 0.0000 \\
$0.000 \mathrm{E}+00$ & 0.0000 \\
\hline \hline $0.000 \mathrm{E}+00$ & 0.0000
\end{tabular}

Total Dose Contributions TDOSE (i,p,t) for Individual Radionuclides (i) and Pathways (p) As mrem/yr and Fraction of Total Dose At $t=1.000 \mathrm{E}+02$ years

Water Dependent Pathways

\begin{tabular}{llll} 
& & \multicolumn{2}{c}{ Water } \\
Radio- & & \\
Nuclide & mrem/yr & fract. \\
Am-241 & $0.000 \mathrm{E}+00$ & 0.0000 \\
Cs-137 & $0.000 \mathrm{E}+00$ & 0.0000 \\
$\mathrm{~Np}-237$ & $0.000 \mathrm{E}+00$ & 0.0000 \\
Pu-238 & $0.000 \mathrm{E}+00$ & 0.0000 \\
Pu-239 & $0.000 \mathrm{E}+00$ & 0.0000 \\
Pu-240 & $0.000 \mathrm{E}+00$ & 0.0000 \\
$\mathrm{TC}-99$ & $0.000 \mathrm{E}+00$ & 0.0000 \\
$\mathrm{Th}-228$ & $0.000 \mathrm{E}+00$ & 0.0000 \\
$\mathrm{Th}-230$ & $0.000 \mathrm{E}+00$ & 0.0000 \\
$\mathrm{Th}-232$ & $0.000 \mathrm{E}+00$ & 0.0000 \\
$\mathrm{U}-234$ & $0.000 \mathrm{E}+00$ & 0.0000 \\
$\mathrm{U}-235$ & $0.000 \mathrm{E}+00$ & 0.0000 \\
$\mathrm{U}-238$ & $0.000 \mathrm{E}+00$ & 0.0000 \\
\hline \hline
\end{tabular}

Total

$0.000 \mathrm{E}+00 \quad 0.0000$

\begin{tabular}{cc} 
Fish \\
\cline { 1 - 2 } mrem/yr & fract. \\
\hline $0.000 \mathrm{E}+00$ & 0.0000 \\
$0.000 \mathrm{E}+00$ & 0.0000 \\
$0.000 \mathrm{E}+00$ & 0.0000 \\
$0.000 \mathrm{E}+00$ & 0.0000 \\
$0.000 \mathrm{E}+00$ & 0.0000 \\
$0.000 \mathrm{E}+00$ & 0.0000 \\
$0.000 \mathrm{E}+00$ & 0.0000 \\
$0.000 \mathrm{E}+00$ & 0.0000 \\
$0.000 \mathrm{E}+00$ & 0.0000 \\
$0.000 \mathrm{E}+00$ & 0.0000 \\
$0.000 \mathrm{E}+00$ & 0.0000 \\
$0.000 \mathrm{E}+00$ & 0.0000 \\
$0.000 \mathrm{E}+00$ & 0.0000 \\
\hline \hline
\end{tabular}

$0.000 \mathrm{E}+00 \quad 0.0000$

\begin{tabular}{cc} 
Radon \\
\cline { 1 - 1 } mrem/yr fract. \\
\hline $0.000 \mathrm{E}+00$ & 0.0000 \\
$0.000 \mathrm{E}+00$ & 0.0000 \\
$0.000 \mathrm{E}+00$ & 0.0000 \\
$0.000 \mathrm{E}+00$ & 0.0000 \\
$0.000 \mathrm{E}+00$ & 0.0000 \\
$0.000 \mathrm{E}+00$ & 0.0000 \\
$0.000 \mathrm{E}+00$ & 0.0000 \\
$0.000 \mathrm{E}+00$ & 0.0000 \\
$0.000 \mathrm{E}+00$ & 0.0000 \\
$0.000 \mathrm{E}+00$ & 0.0000 \\
$0.000 \mathrm{E}+00$ & 0.0000 \\
$0.000 \mathrm{E}+00$ & 0.0000 \\
$0.000 \mathrm{E}+00$ & 0.0000 \\
\hline \hline
\end{tabular}

$0.000 \mathrm{E}+00 \quad 0.0000$

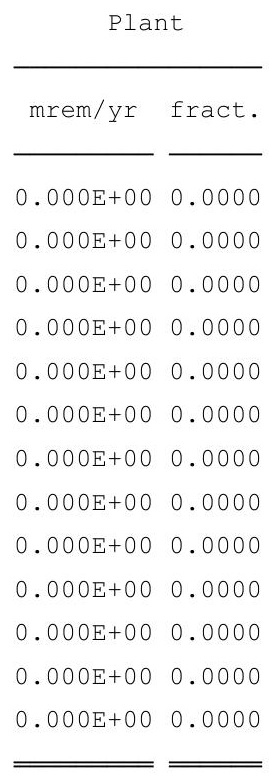

$0.000 \mathrm{E}+00 \quad 0.0000$

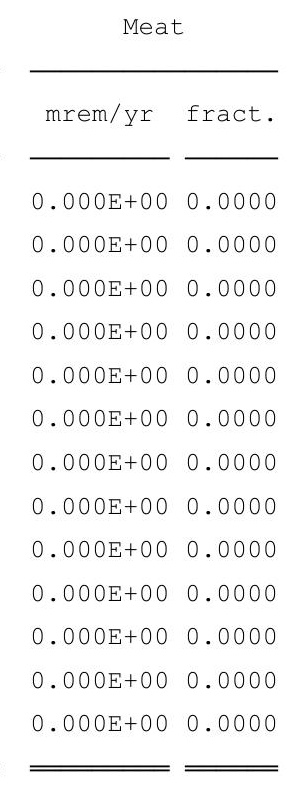

$0.000 \mathrm{E}+00 \quad 0.0000$

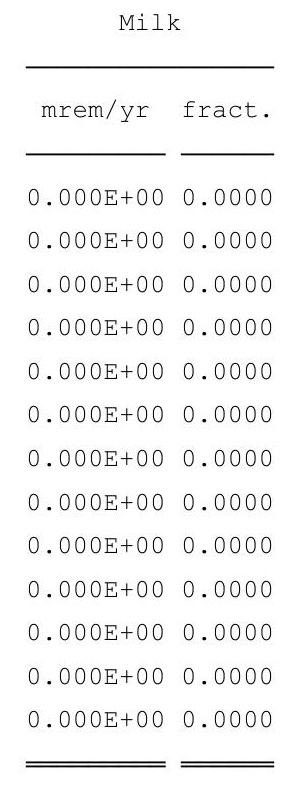

$0.000 \mathrm{E}+00 \quad 0.0000$
Soil

\begin{tabular}{ccc} 
mrem/yr & fract. \\
\cline { 1 - 1 } $0.000 \mathrm{E}+00$ & 0.0000 \\
$0.000 \mathrm{E}+00$ & 0.0000 \\
$0.000 \mathrm{E}+00$ & 0.0000 \\
$0.000 \mathrm{E}+00$ & 0.0000 \\
$0.000 \mathrm{E}+00$ & 0.0000 \\
$0.000 \mathrm{E}+00$ & 0.0000 \\
$0.000 \mathrm{E}+00$ & 0.0000 \\
$0.000 \mathrm{E}+00$ & 0.0000 \\
$0.000 \mathrm{E}+00$ & 0.0000 \\
$0.000 \mathrm{E}+00$ & 0.0000 \\
$0.000 \mathrm{E}+00$ & 0.0000 \\
$0.000 \mathrm{E}+00$ & 0.0000 \\
$0.000 \mathrm{E}+00$ & 0.0000 \\
\hline \hline $0.000 \mathrm{E}+00$ & 0.0000
\end{tabular}

* Sum of all water independent and dependent pathways. 
RESRAD, Version $6.5 \quad \mathrm{~T}^{1 / 2}$ Limit $=180$ days

ummary : C746U Resident Gardener Deterministic Run

File : $\mathrm{X}: \backslash$ FINAL V2 $\backslash$ C746U RG DET-FINALV2.RAD

Total Dose Contributions TDOSE(i,p,t) for Individual Radionuclides (i) and Pathways (p) As mrem/yr and Fraction of Total Dose At $t=5.000 \mathrm{E}+02$ years

Water Independent Pathways (Inhalation excludes radon)

\begin{tabular}{|c|c|c|}
\hline ide & mrem/yr & fract. \\
\hline $1-241$ & $2.295 E-14$ & 0.0000 \\
\hline-137 & $8.104 \mathrm{E}-13$ & 0.0000 \\
\hline-237 & $2.044 \mathrm{E}-10$ & 0.0000 \\
\hline-238 & $5.607 \mathrm{E}-13$ & 0.0000 \\
\hline-239 & $4.708 \mathrm{E}-15$ & 0.0000 \\
\hline-240 & $5.719 \mathrm{E}-18$ & 0.0000 \\
\hline-99 & $9.310 \mathrm{E}-24$ & 0.0000 \\
\hline-228 & $0.000 \mathrm{E}+00$ & 0.0000 \\
\hline-230 & $1.071 \mathrm{E}-06$ & 0.0311 \\
\hline-232 & $3.338 \mathrm{E}-05$ & 0.9686 \\
\hline 234 & $2.496 \mathrm{E}-09$ & 0.0001 \\
\hline 35 & $7.033 \mathrm{E}-11$ & 0.0000 \\
\hline 238 & $7.680 \mathrm{E}-09$ & 0.0002 \\
\hline & & $\perp$. \\
\hline
\end{tabular}

Inhalation

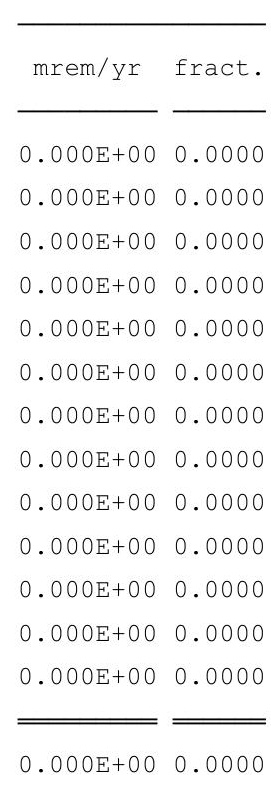

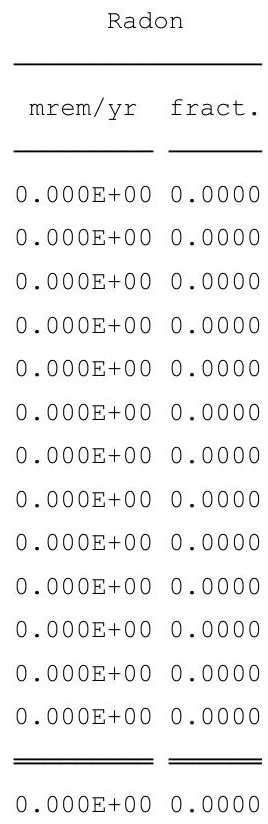

\begin{tabular}{cc} 
Plant \\
\cline { 1 - 2 } mrem/yr fract. & - \\
\hline $0.000 \mathrm{E}+00$ & 0.0000 \\
$0.000 \mathrm{E}+00$ & 0.0000 \\
$0.000 \mathrm{E}+00$ & 0.0000 \\
$0.000 \mathrm{E}+00$ & 0.0000 \\
$0.000 \mathrm{E}+00$ & 0.0000 \\
$0.000 \mathrm{E}+00$ & 0.0000 \\
$0.000 \mathrm{E}+00$ & 0.0000 \\
$0.000 \mathrm{E}+00$ & 0.0000 \\
$0.000 \mathrm{E}+00$ & 0.0000 \\
$0.000 \mathrm{E}+00$ & 0.0000 \\
$0.000 \mathrm{E}+00$ & 0.0000 \\
$0.000 \mathrm{E}+00$ & 0.0000 \\
$0.000 \mathrm{E}+00$ & 0.0000 \\
\hline \hline $0.000 \mathrm{E}+00$ & 0.0000
\end{tabular}

\begin{tabular}{cc} 
Meat \\
\cline { 1 - 2 } mrem/yr fract. \\
\cline { 1 - 1 } $0.000 \mathrm{E}+00$ & 0.0000 \\
$0.000 \mathrm{E}+00$ & 0.0000 \\
$0.000 \mathrm{E}+00$ & 0.0000 \\
$0.000 \mathrm{E}+00$ & 0.0000 \\
$0.000 \mathrm{E}+00$ & 0.0000 \\
$0.000 \mathrm{E}+00$ & 0.0000 \\
$0.000 \mathrm{E}+00$ & 0.0000 \\
$0.000 \mathrm{E}+00$ & 0.0000 \\
$0.000 \mathrm{E}+00$ & 0.0000 \\
$0.000 \mathrm{E}+00$ & 0.0000 \\
$0.000 \mathrm{E}+00$ & 0.0000 \\
$0.000 \mathrm{E}+00$ & 0.0000 \\
$0.000 \mathrm{E}+00$ & 0.0000 \\
\hline \hline $0.000 \mathrm{E}+00$ & 0.0000
\end{tabular}

\begin{tabular}{cc} 
Milk \\
\cline { 1 - 1 } mrem/yr & fract. \\
\cline { 1 - 1 } $0.000 \mathrm{E}+00$ & 0.0000 \\
$0.000 \mathrm{E}+00$ & 0.0000 \\
$0.000 \mathrm{E}+00$ & 0.0000 \\
$0.000 \mathrm{E}+00$ & 0.0000 \\
$0.000 \mathrm{E}+00$ & 0.0000 \\
$0.000 \mathrm{E}+00$ & 0.0000 \\
$0.000 \mathrm{E}+00$ & 0.0000 \\
$0.000 \mathrm{E}+00$ & 0.0000 \\
$0.000 \mathrm{E}+00$ & 0.0000 \\
$0.000 \mathrm{E}+00$ & 0.0000 \\
$0.000 \mathrm{E}+00$ & 0.0000 \\
$0.000 \mathrm{E}+00$ & 0.0000 \\
$0.000 \mathrm{E}+00$ & 0.0000 \\
\hline \hline $0.000 \mathrm{E}+00$ & 0.0000
\end{tabular}

Total Dose Contributions TDOSE (i,p,t) for Individual Radionuclides (i) and Pathways (p) As mrem/yr and Fraction of Total Dose At $t=5.000 \mathrm{E}+02$ years

Water Dependent Pathways

\begin{tabular}{llll} 
& & \multicolumn{2}{c}{ Water } \\
Radio- & & \\
Nuclide & mrem/yr & fract. \\
Am-241 & $0.000 \mathrm{E}+00$ & 0.0000 \\
Cs-137 & $0.000 \mathrm{E}+00$ & 0.0000 \\
$\mathrm{~Np}-237$ & $0.000 \mathrm{E}+00$ & 0.0000 \\
Pu-238 & $0.000 \mathrm{E}+00$ & 0.0000 \\
Pu-239 & $0.000 \mathrm{E}+00$ & 0.0000 \\
Pu-240 & $0.000 \mathrm{E}+00$ & 0.0000 \\
$\mathrm{TC}-99$ & $0.000 \mathrm{E}+00$ & 0.0000 \\
$\mathrm{Th}-228$ & $0.000 \mathrm{E}+00$ & 0.0000 \\
$\mathrm{Th}-230$ & $0.000 \mathrm{E}+00$ & 0.0000 \\
$\mathrm{Th}-232$ & $0.000 \mathrm{E}+00$ & 0.0000 \\
$\mathrm{U}-234$ & $0.000 \mathrm{E}+00$ & 0.0000 \\
$\mathrm{U}-235$ & $0.000 \mathrm{E}+00$ & 0.0000 \\
$\mathrm{U}-238$ & $0.000 \mathrm{E}+00$ & 0.0000 \\
\hline \hline
\end{tabular}

$0.000 \mathrm{E}+00 \quad 0.0000$

\begin{tabular}{cc} 
Fish \\
\hline mrem/yr fract. \\
\hline $0.000 \mathrm{E}+00$ & 0.0000 \\
$0.000 \mathrm{E}+00$ & 0.0000 \\
$0.000 \mathrm{E}+00$ & 0.0000 \\
$0.000 \mathrm{E}+00$ & 0.0000 \\
$0.000 \mathrm{E}+00$ & 0.0000 \\
$0.000 \mathrm{E}+00$ & 0.0000 \\
$0.000 \mathrm{E}+00$ & 0.0000 \\
$0.000 \mathrm{E}+00$ & 0.0000 \\
$0.000 \mathrm{E}+00$ & 0.0000 \\
$0.000 \mathrm{E}+00$ & 0.0000 \\
$0.000 \mathrm{E}+00$ & 0.0000 \\
$0.000 \mathrm{E}+00$ & 0.0000 \\
$0.000 \mathrm{E}+00$ & 0.0000 \\
\hline \hline
\end{tabular}

$0.000 \mathrm{E}+00 \quad 0.0000$

\begin{tabular}{cc} 
Radon \\
\cline { 1 - 2 } mrem/yr & fract. \\
\hline $0.000 \mathrm{E}+00$ & 0.0000 \\
$0.000 \mathrm{E}+00$ & 0.0000 \\
$0.000 \mathrm{E}+00$ & 0.0000 \\
$0.000 \mathrm{E}+00$ & 0.0000 \\
$0.000 \mathrm{E}+00$ & 0.0000 \\
$0.000 \mathrm{E}+00$ & 0.0000 \\
$0.000 \mathrm{E}+00$ & 0.0000 \\
$0.000 \mathrm{E}+00$ & 0.0000 \\
$0.000 \mathrm{E}+00$ & 0.0000 \\
$0.000 \mathrm{E}+00$ & 0.0000 \\
$0.000 \mathrm{E}+00$ & 0.0000 \\
$0.000 \mathrm{E}+00$ & 0.0000 \\
$0.000 \mathrm{E}+00$ & 0.0000 \\
\hline \hline
\end{tabular}

$0.000 \mathrm{E}+00 \quad 0.0000$

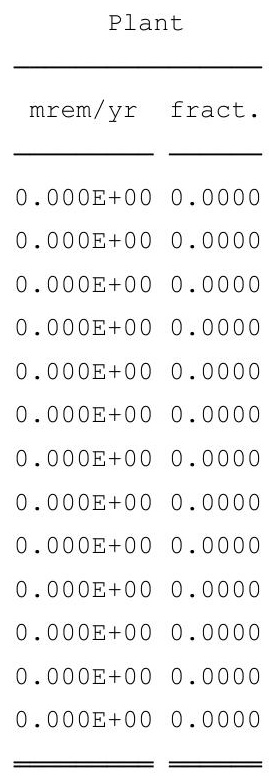

$0.000 \mathrm{E}+00 \quad 0.0000$

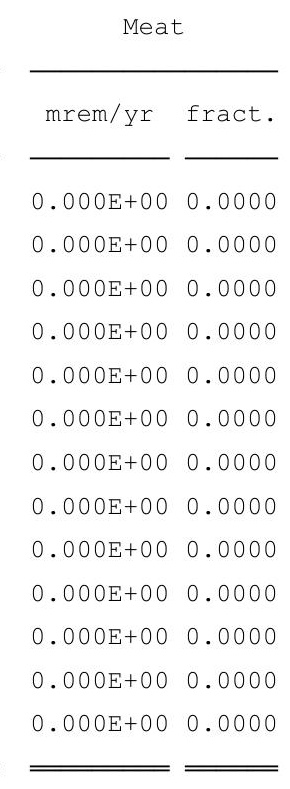

$0.000 \mathrm{E}+00 \quad 0.0000$

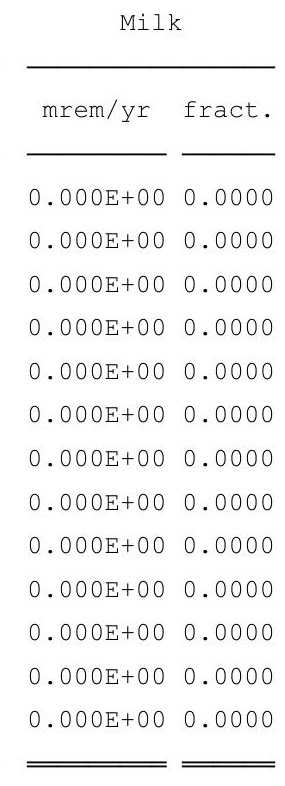

$0.000 \mathrm{E}+00 \quad 0.0000$
Soil

\begin{tabular}{ccc} 
mrem/yr & fract. \\
\cline { 1 - 1 } $0.000 \mathrm{E}+00$ & 0.0000 \\
$0.000 \mathrm{E}+00$ & 0.0000 \\
$0.000 \mathrm{E}+00$ & 0.0000 \\
$0.000 \mathrm{E}+00$ & 0.0000 \\
$0.000 \mathrm{E}+00$ & 0.0000 \\
$0.000 \mathrm{E}+00$ & 0.0000 \\
$0.000 \mathrm{E}+00$ & 0.0000 \\
$0.000 \mathrm{E}+00$ & 0.0000 \\
$0.000 \mathrm{E}+00$ & 0.0000 \\
$0.000 \mathrm{E}+00$ & 0.0000 \\
$0.000 \mathrm{E}+00$ & 0.0000 \\
$0.000 \mathrm{E}+00$ & 0.0000 \\
$0.000 \mathrm{E}+00$ & 0.0000 \\
\hline \hline $0.000 \mathrm{E}+00$ & 0.0000
\end{tabular}

* Sum of all water independent and dependent pathways. 
RESRAD, Version $6.5 \quad \mathrm{~T}^{1 / 2}$ Limit $=180$ days

ummary : C746U Resident Gardener Deterministic Run

File : $\mathrm{X}: \backslash$ FINAL V2 $\backslash$ C746U RG DET-FINALV2.RAD

Total Dose Contributions TDOSE(i,p,t) for Individual Radionuclides (i) and Pathways (p) As mrem/yr and Fraction of Total Dose At $t=1.050 \mathrm{E}+03$ years

Water Independent Pathways (Inhalation excludes radon)

\begin{tabular}{|c|c|c|c|c|c|c|c|c|c|c|c|c|}
\hline \multirow{2}{*}{ Nuclide } & \multicolumn{2}{|c|}{ Ground } & \multicolumn{2}{|c|}{ Inhalation } & \multicolumn{2}{|c|}{ Radon } & \multicolumn{2}{|c|}{ Plant } & \multicolumn{2}{|c|}{ Meat } & \multicolumn{2}{|c|}{ Milk } \\
\hline & mrem/yr & fract. & mrem/yr & fract. & mrem/yr & fract. & mrem/yr & fract. & mrem/yr & fract. & mrem/yr & fract. \\
\hline-241 & $1.216 \mathrm{E}-11$ & 0.0000 & $0.000 \mathrm{E}+00$ & 0.0000 & $0.000 \mathrm{E}+00$ & 0.0000 & 1. $983 E-04$ & 0.0009 & $0.000 \mathrm{E}+00$ & 0.0000 & $0.000 \mathrm{E}+00$ & 0.0000 \\
\hline-137 & $2.495 \mathrm{E}-16$ & 0.0000 & $0.000 \mathrm{E}+00$ & 0.0000 & $0.000 \mathrm{E}+00$ & 0.0000 & 7. $688 \mathrm{E}-14$ & 0.0000 & $0.000 \mathrm{E}+00$ & 0.0000 & $0.000 \mathrm{E}+00$ & 0.0000 \\
\hline 237 & $7.109 \mathrm{E}-08$ & 0.0000 & $0.000 \mathrm{E}+00$ & 0.0000 & $0.000 \mathrm{E}+00$ & 0.0000 & $1.025 \mathrm{E}-02$ & 0.0459 & $0.000 \mathrm{E}+00$ & 0.0000 & $0.000 \mathrm{E}+00$ & 0.0000 \\
\hline-238 & 1. $302 \mathrm{E}-10$ & 0.0000 & $0.000 \mathrm{E}+00$ & 0.0000 & $0.000 \mathrm{E}+00$ & 0.0000 & $6.108 \mathrm{E}-07$ & 0.0000 & $0.000 \mathrm{E}+00$ & 0.0000 & $0.000 \mathrm{E}+00$ & 0.0000 \\
\hline-239 & $3.338 \mathrm{E}-12$ & 0.0000 & $0.000 \mathrm{E}+00$ & 0.0000 & $0.000 \mathrm{E}+00$ & 0.0000 & $1.268 \mathrm{E}-03$ & 0.0057 & $0.000 \mathrm{E}+00$ & 0.0000 & $0.000 \mathrm{E}+00$ & 0.0000 \\
\hline-240 & $8.095 E-16$ & 0.0000 & $0.000 \mathrm{E}+00$ & 0.0000 & $0.000 \mathrm{E}+00$ & 0.0000 & $1.170 \mathrm{E}-03$ & 0.0052 & $0.000 \mathrm{E}+00$ & 0.0000 & $0.000 \mathrm{E}+00$ & 0.0000 \\
\hline 99 & $2.503 E-21$ & 0.0000 & $0.000 \mathrm{E}+00$ & 0.0000 & $0.000 \mathrm{E}+00$ & 0.0000 & 1. $325 \mathrm{E}-06$ & 0.0000 & $0.000 \mathrm{E}+00$ & 0.0000 & $0.000 \mathrm{E}+00$ & 0.0000 \\
\hline-228 & $0.000 \mathrm{E}+00$ & 0.0000 & $0.000 \mathrm{E}+00$ & 0.0000 & $0.000 \mathrm{E}+00$ & 0.0000 & $0.000 \mathrm{E}+00$ & 0.0000 & $0.000 \mathrm{E}+00$ & 0.0000 & $0.000 \mathrm{E}+00$ & 0.0000 \\
\hline-230 & $8.967 \mathrm{E}-05$ & 0.0004 & $0.000 \mathrm{E}+00$ & 0.0000 & $0.000 \mathrm{E}+00$ & 0.0000 & $5.809 \mathrm{E}-02$ & 0.2600 & $0.000 \mathrm{E}+00$ & 0.0000 & $0.000 \mathrm{E}+00$ & 0.0000 \\
\hline-232 & $9.244 \mathrm{E}-04$ & 0.0041 & $0.000 \mathrm{E}+00$ & 0.0000 & $0.000 \mathrm{E}+00$ & 0.0000 & 1. $481 \mathrm{E}-01$ & 0.6629 & $0.000 \mathrm{E}+00$ & 0.0000 & $0.000 \mathrm{E}+00$ & 0.0000 \\
\hline 234 & $4.542 \mathrm{E}-07$ & 0.0000 & $0.000 \mathrm{E}+00$ & 0.0000 & $0.000 \mathrm{E}+00$ & 0.0000 & $9.271 \mathrm{E}-04$ & 0.0041 & $0.000 \mathrm{E}+00$ & 0.0000 & $0.000 \mathrm{E}+00$ & 0.0000 \\
\hline 235 & $2.349 \mathrm{E}-08$ & 0.0000 & $0.000 \mathrm{E}+00$ & 0.0000 & $0.000 \mathrm{E}+00$ & 0.0000 & $1.767 \mathrm{E}-03$ & 0.0079 & $0.000 \mathrm{E}+00$ & 0.0000 & $0.000 \mathrm{E}+00$ & 0.0000 \\
\hline 38 & $6.200 \mathrm{E}-07$ & 0.0000 & $0.000 \mathrm{E}+00$ & 0.0000 & $0.000 \mathrm{E}+00$ & 0.0000 & $6.329 \mathrm{E}-04$ & 0.0028 & $0.000 \mathrm{E}+00$ & 0.0000 & $0.000 \mathrm{E}+00$ & 0.0000 \\
\hline & $1.015 \mathrm{E}-03$ & 0.0045 & $0.000 \mathrm{E}+00$ & 0.0000 & $0.000 \mathrm{E}+00$ & 0.0000 & $2.225 E-01$ & 0.9955 & $0.000 \mathrm{E}+00$ & 0.0000 & $0.000 \mathrm{E}+00$ & 0.0000 \\
\hline
\end{tabular}

Total Dose Contributions TDOSE(i,p,t) for Individual Radionuclides (i) and Pathways (p) As mrem/yr and Fraction of Total Dose At $t=1.050 \mathrm{E}+03$ years

Water Dependent Pathways

\begin{tabular}{|c|c|c|c|c|c|c|c|c|c|c|c|c|c|c|}
\hline \multirow{2}{*}{ Nuclide } & \multicolumn{2}{|c|}{ Water } & \multicolumn{2}{|c|}{ Fish } & \multicolumn{2}{|c|}{ Radon } & \multicolumn{2}{|c|}{ Plant } & \multicolumn{2}{|c|}{ Meat } & \multicolumn{2}{|c|}{ Milk } & \multicolumn{2}{|c|}{ All Pathways* } \\
\hline & mrem/yr & fract. & mrem/yr & fract. & mrem/yr & fract. & mrem/yr & fract. & mrem/yr & fract. & mrem/yr & fract. & mrem/yr & fract. \\
\hline-241 & $0.000 \mathrm{E}+00$ & 0.0000 & $0.000 \mathrm{E}+00$ & 0.0000 & $0.000 \mathrm{E}+00$ & 0.0000 & $0.000 \mathrm{E}+00$ & 0.0000 & $0.000 \mathrm{E}+00$ & 0.0000 & $0.000 \mathrm{E}+00$ & 0.0000 & $1.983 \mathrm{E}-04$ & 0.0009 \\
\hline-137 & $0.000 \mathrm{E}+00$ & 0.0000 & $0.000 \mathrm{E}+00$ & 0.0000 & $0.000 \mathrm{E}+00$ & 0.0000 & $0.000 \mathrm{E}+00$ & 0.0000 & $0.000 \mathrm{E}+00$ & 0.0000 & $0.000 \mathrm{E}+00$ & 0.0000 & 7. $713 \mathrm{E}-14$ & 0.0000 \\
\hline-237 & $0.000 \mathrm{E}+00$ & 0.0000 & $0.000 \mathrm{E}+00$ & 0.0000 & $0.000 \mathrm{E}+00$ & 0.0000 & $0.000 \mathrm{E}+00$ & 0.0000 & $0.000 \mathrm{E}+00$ & 0.0000 & $0.000 \mathrm{E}+00$ & 0.0000 & $1.025 \mathrm{E}-02$ & 0.0459 \\
\hline-238 & $0.000 \mathrm{E}+00$ & 0.0000 & $0.000 \mathrm{E}+00$ & 0.0000 & $0.000 \mathrm{E}+00$ & 0.0000 & $0.000 \mathrm{E}+00$ & 0.0000 & $0.000 \mathrm{E}+00$ & 0.0000 & $0.000 \mathrm{E}+00$ & 0.0000 & $6.110 \mathrm{E}-07$ & 0.0000 \\
\hline 239 & $0.000 \mathrm{E}+00$ & 0.0000 & $0.000 \mathrm{E}+00$ & 0.0000 & $0.000 \mathrm{E}+00$ & 0.0000 & $0.000 \mathrm{E}+00$ & 0.0000 & $0.000 \mathrm{E}+00$ & 0.0000 & $0.000 \mathrm{E}+00$ & 0.0000 & $1.268 \mathrm{E}-03$ & 0.0057 \\
\hline-240 & $0.000 \mathrm{E}+00$ & 0.0000 & $0.000 \mathrm{E}+00$ & 0.0000 & $0.000 \mathrm{E}+00$ & 0.0000 & $0.000 \mathrm{E}+00$ & 0.0000 & $0.000 \mathrm{E}+00$ & 0.0000 & $0.000 \mathrm{E}+00$ & 0.0000 & $1.170 \mathrm{E}-03$ & 0.0052 \\
\hline 99 & $0.000 \mathrm{E}+00$ & 0.0000 & $0.000 \mathrm{E}+00$ & 0.0000 & $0.000 \mathrm{E}+00$ & 0.0000 & $0.000 \mathrm{E}+00$ & 0.0000 & $0.000 \mathrm{E}+00$ & 0.0000 & $0.000 \mathrm{E}+00$ & 0.0000 & $1.325 \mathrm{E}-06$ & 0.0000 \\
\hline-228 & $0.000 \mathrm{E}+00$ & 0.0000 & $0.000 \mathrm{E}+00$ & 0.0000 & $0.000 \mathrm{E}+00$ & 0.0000 & $0.000 \mathrm{E}+00$ & 0.0000 & $0.000 \mathrm{E}+00$ & 0.0000 & $0.000 \mathrm{E}+00$ & 0.0000 & $0.000 \mathrm{E}+00$ & 0.0000 \\
\hline-230 & $0.000 \mathrm{E}+00$ & 0.0000 & $0.000 \mathrm{E}+00$ & 0.0000 & $0.000 \mathrm{E}+00$ & 0.0000 & $0.000 \mathrm{E}+00$ & 0.0000 & $0.000 \mathrm{E}+00$ & 0.0000 & $0.000 \mathrm{E}+00$ & 0.0000 & $5.818 \mathrm{E}-02$ & 0.2604 \\
\hline 232 & $0.000 \mathrm{E}+00$ & 0.0000 & $0.000 \mathrm{E}+00$ & 0.0000 & $0.000 \mathrm{E}+00$ & 0.0000 & $0.000 \mathrm{E}+00$ & 0.0000 & $0.000 \mathrm{E}+00$ & 0.0000 & $0.000 \mathrm{E}+00$ & 0.0000 & 1. $491 \mathrm{E}-01$ & 0.6671 \\
\hline 34 & $0.000 \mathrm{E}+00$ & 0.0000 & $0.000 \mathrm{E}+00$ & 0.0000 & $0.000 \mathrm{E}+00$ & 0.0000 & $0.000 \mathrm{E}+00$ & 0.0000 & $0.000 \mathrm{E}+00$ & 0.0000 & $0.000 \mathrm{E}+00$ & 0.0000 & $9.276 \mathrm{E}-04$ & 0.0042 \\
\hline 35 & $0.000 \mathrm{E}+00$ & 0.0000 & $0.000 \mathrm{E}+00$ & 0.0000 & $0.000 \mathrm{E}+00$ & 0.0000 & $0.000 \mathrm{E}+00$ & 0.0000 & $0.000 \mathrm{E}+00$ & 0.0000 & $0.000 \mathrm{E}+00$ & 0.0000 & $1.767 \mathrm{E}-03$ & 0.0079 \\
\hline 38 & $0.000 \mathrm{E}+00$ & 0.0000 & $0.000 \mathrm{E}+00$ & 0.0000 & $0.000 \mathrm{E}+00$ & 0.0000 & $0.000 \mathrm{E}+00$ & 0.0000 & $0.000 \mathrm{E}+00$ & 0.0000 & $0.000 \mathrm{E}+00$ & 0.0000 & $6.335 \mathrm{E}-04$ & 0.0028 \\
\hline & $0.000 \mathrm{E}+00$ & 0.0000 & $0.000 \mathrm{E}+00$ & 0.0000 & $0.000 \mathrm{E}+00$ & 0.0000 & $0.000 \mathrm{E}+00$ & 0.0000 & $0.000 \mathrm{E}+00$ & 0.0000 & $0.000 \mathrm{E}+00$ & 0.0000 & -01 & 1.0000 \\
\hline
\end{tabular}

* Sum of all water independent and dependent pathways. 
RESRAD, Version $6.5 \quad T^{1 / 2}$ Limit $=180$ days

Summary : C746U Resident Gardener Deterministic Run

File : $\mathrm{X}: \backslash$ FINAL V2 $\backslash$ C746U RG DET-FINALV2.RAD

Dose/Source Ratios Summed Over All Pathways

Parent and Progeny Principal Radionuclide Contributions Indicated

\begin{tabular}{|c|c|c|c|c|c|c|c|c|}
\hline Parent & Product & Thread & DSR & $(j, t)$ At $T i$ & ime in Year & (mre & $\mathrm{r}) /(\mathrm{pCi} / \mathrm{c}$ & \\
\hline (i) & (j) & Fraction & $0.000 \mathrm{E}+00$ & $1.000 \mathrm{E}+00$ & $5.000 E+01$ & $1.000 \mathrm{E}+02$ & $5.000 \mathrm{E}+02$ & $1.050 \mathrm{E}+03$ \\
\hline-241 & $A m-241$ & $1.000 \mathrm{E}+00$ & $1.936 \mathrm{E}-33$ & $1.989 \mathrm{E}-33$ & $7.353 E-33$ & $2.792 E-32$ & $1.208 E-27$ & $1.965 \mathrm{E}-04$ \\
\hline-241 & $N p-237+D$ & $1.000 \mathrm{E}+00$ & $1.546 \mathrm{E}-19$ & $4.680 \mathrm{E}-19$ & $2.562 \mathrm{E}-17$ & $8.382 \mathrm{E}-17$ & $2.263 E-14$ & $1.773 \mathrm{E}-06$ \\
\hline-241 & $\mathrm{U}-233$ & $1.000 \mathrm{E}+00$ & $3.506 \mathrm{E}-30$ & $2.479 E-29$ & $4.863 E-26$ & $3.503 E-25$ & $1.053 E-21$ & $3.056 \mathrm{E}-10$ \\
\hline-241 & $\mathrm{Th}-229+\mathrm{D}$ & $1.000 \mathrm{E}+00$ & $2.399 E-26$ & $3.618 \mathrm{E}-25$ & $1.710 \mathrm{E}-20$ & $1.868 \mathrm{E}-19$ & $3.195 E-16$ & $5.403 \mathrm{E}-11$ \\
\hline-241 & $\sum \operatorname{DSR}(j)$ & & $1.546 \mathrm{E}-19$ & 4. $680 \mathrm{E}-19$ & $2.564 \mathrm{E}-17$ & $8.401 \mathrm{E}-17$ & $2.295 E-14$ & $1.983 \mathrm{E}-04$ \\
\hline$-137+D$ & $\mathrm{Cs}-137+\mathrm{D}$ & $1.000 \mathrm{E}+00$ & $1.262 \mathrm{E}-09$ & $1.243 \mathrm{E}-09$ & $6.050 \mathrm{E}-10$ & $2.901 \mathrm{E}-10$ & $8.104 \mathrm{E}-13$ & 7. $713 \mathrm{E}-14$ \\
\hline$-237+D$ & $N p-237+D$ & $1.000 \mathrm{E}+00$ & $9.536 \mathrm{E}-13$ & $9.638 \mathrm{E}-13$ & 1. $625 \mathrm{E}-12$ & $2.770 \mathrm{E}-12$ & $1.974 \mathrm{E}-10$ & $1.025 \mathrm{E}-02$ \\
\hline$-237+D$ & $\mathrm{U}-233$ & $1.000 \mathrm{E}+00$ & $3.245 E-23$ & $9.844 \mathrm{E}-23$ & $6.100 \mathrm{E}-21$ & $2.264 \mathrm{E}-20$ & 1. $650 \mathrm{E}-17$ & $2.871 E-06$ \\
\hline$-237+D$ & $\mathrm{Th}-229+\mathrm{D}$ & $1.000 \mathrm{E}+00$ & $2.962 \mathrm{E}-19$ & $2.086 \mathrm{E}-18$ & $3.196 \mathrm{E}-15$ & 1. $788 \mathrm{E}-14$ & $7.080 \mathrm{E}-12$ & $6.801 \mathrm{E}-07$ \\
\hline$-237+D$ & $\sum \operatorname{DSR}(j)$ & & $9.536 \mathrm{E}-13$ & $9.638 \mathrm{E}-13$ & 1. $629 \mathrm{E}-12$ & $2.788 \mathrm{E}-12$ & $2.044 \mathrm{E}-10$ & $1.025 \mathrm{E}-02$ \\
\hline$x-238$ & $\mathrm{Pu}-238$ & $1.840 \mathrm{E}-09$ & $2.162 \mathrm{E}-33$ & $2.183 E-33$ & $3.520 E-33$ & $5.731 E-33$ & $2.831 E-31$ & $5.505 \mathrm{E}-16$ \\
\hline-238 & $\mathrm{Pu}-238$ & $1.000 \mathrm{E}+00$ & $1.175 \mathrm{E}-24$ & $1.186 \mathrm{E}-24$ & $1.913 \mathrm{E}-24$ & $3.115 \mathrm{E}-24$ & 1. $539 \mathrm{E}-22$ & $2.992 \mathrm{E}-07$ \\
\hline-238 & $\mathrm{U}-234$ & $1.000 \mathrm{E}+00$ & $9.778 \mathrm{E}-30$ & $2.969 E-29$ & $1.973 \mathrm{E}-27$ & 7. $960 \mathrm{E}-27$ & $1.690 \mathrm{E}-23$ & $2.276 \mathrm{E}-07$ \\
\hline-238 & $T h-230$ & $1.000 \mathrm{E}+00$ & $1.028 \mathrm{E}-33$ & 7. $286 \mathrm{E}-33$ & $1.599 \mathrm{E}-29$ & 1. $302 \mathrm{E}-28$ & 1. $306 \mathrm{E}-24$ & $3.273 E-09$ \\
\hline$x-238$ & $\mathrm{Ra}-226+\mathrm{D}$ & $1.000 \mathrm{E}+00$ & $8.021 \mathrm{E}-23$ & $1.208 \mathrm{E}-21$ & $5.266 \mathrm{E}-17$ & $5.323 E-16$ & $5.607 \mathrm{E}-13$ & $3.143 \mathrm{E}-08$ \\
\hline$x-238$ & $\mathrm{~Pb}-210+\mathrm{D}$ & $1.000 \mathrm{E}+00$ & $2.326 \mathrm{E}-31$ & 7. $210 \mathrm{E}-30$ & $7.772 \mathrm{E}-24$ & 1. $314 \mathrm{E}-22$ & $3.671 E-19$ & $4.946 \mathrm{E}-08$ \\
\hline$x-238$ & $\sum \operatorname{DSR}(j)$ & & $8.139 \mathrm{E}-23$ & $1.209 E-21$ & $5.266 \mathrm{E}-17$ & $5.323 E-16$ & $5.607 \mathrm{E}-13$ & $6.110 \mathrm{E}-07$ \\
\hline-239 & $\mathrm{Pu}-239$ & $1.000 \mathrm{E}+00$ & $1.202 \mathrm{E}-17$ & 1. $217 \mathrm{E}-17$ & $2.183 \mathrm{E}-17$ & $3.965 \mathrm{E}-17$ & $4.690 E-15$ & $1.268 \mathrm{E}-03$ \\
\hline$x-239$ & $\mathrm{U}-235+\mathrm{D}$ & $1.000 \mathrm{E}+00$ & $6.135 \mathrm{E}-24$ & $1.861 \mathrm{E}-23$ & $1.146 \mathrm{E}-21$ & $4.227 \mathrm{E}-21$ & $2.931 \mathrm{E}-18$ & $6.291 \mathrm{E}-10$ \\
\hline-239 & $\mathrm{~Pa}-231$ & $1.000 \mathrm{E}+00$ & $9.652 \mathrm{E}-28$ & $6.818 \mathrm{E}-27$ & $1.251 \mathrm{E}-23$ & $8.414 \mathrm{E}-23$ & 1. $444 \mathrm{E}-19$ & $4.191 \mathrm{E}-10$ \\
\hline$x-239$ & $A C-227+D$ & $1.000 \mathrm{E}+00$ & $2.288 E-27$ & $3.434 \mathrm{E}-26$ & $1.276 \mathrm{E}-21$ & 1. $169 \mathrm{E}-20$ & $1.476 \mathrm{E}-17$ & 1. $686 \mathrm{E}-10$ \\
\hline$x-239$ & $\sum \operatorname{DSR}(j)$ & & $1.202 \mathrm{E}-17$ & $1.217 \mathrm{E}-17$ & $2.183 E-17$ & $3.966 \mathrm{E}-17$ & $4.708 \mathrm{E}-15$ & $1.268 \mathrm{E}-03$ \\
\hline-240 & $\mathrm{Pu}-240$ & $4.950 E-08$ & $5.653 E-32$ & $5.753 E-32$ & $1.359 \mathrm{E}-31$ & $3.267 E-31$ & $3.647 E-28$ & $5.789 \mathrm{E}-11$ \\
\hline-240 & $\mathrm{Pu}-240$ & $1.000 \mathrm{E}+00$ & $1.142 \mathrm{E}-24$ & $1.162 \mathrm{E}-24$ & $2.746 E-24$ & $6.601 \mathrm{E}-24$ & 7. $367 \mathrm{E}-21$ & $1.170 \mathrm{E}-03$ \\
\hline$x-240$ & $\mathrm{U}-236$ & $1.000 \mathrm{E}+00$ & $2.162 E-32$ & $6.590 \mathrm{E}-32$ & $5.335 E-30$ & $2.602 E-29$ & $1.686 E-25$ & $1.804 \mathrm{E}-08$ \\
\hline$x-240$ & Th-232 & $1.000 \mathrm{E}+00$ & $2.845 E-43$ & $2.028 E-42$ & $5.480 E-39$ & $5.478 E-38$ & $2.238 E-33$ & $9.371 \mathrm{E}-16$ \\
\hline-240 & $\mathrm{Ra}-228+\mathrm{D}$ & $1.000 \mathrm{E}+00$ & $1.371 \mathrm{E}-28$ & $2.018 \mathrm{E}-27$ & $3.762 \mathrm{E}-23$ & $2.542 E-22$ & $1.470 \mathrm{E}-19$ & $1.102 \mathrm{E}-13$ \\
\hline-240 & $T h-228+D$ & $1.000 \mathrm{E}+00$ & $8.111 \mathrm{E}-28$ & $2.334 \mathrm{E}-26$ & $2.641 \mathrm{E}-21$ & $1.757 \mathrm{E}-20$ & $5.564 \mathrm{E}-18$ & 1. $510 \mathrm{E}-15$ \\
\hline-240 & $\sum \operatorname{DSR}(j)$ & & $1.143 E-24$ & $1.188 \mathrm{E}-24$ & $2.681 \mathrm{E}-21$ & $1.783 \mathrm{E}-20$ & $5.719 E-18$ & $1.170 \mathrm{E}-03$ \\
\hline$=-99$ & $\mathrm{TC}-99$ & $1.000 \mathrm{E}+00$ & $5.758 E-26$ & $5.817 \mathrm{E}-26$ & $9.575 E-26$ & $1.592 \mathrm{E}-25$ & $9.310 E-24$ & $1.325 E-06$ \\
\hline$-228+D$ & $T h-228+D$ & $1.000 \mathrm{E}+00$ & $1.382 \mathrm{E}-06$ & $9.680 \mathrm{E}-07$ & $2.527 E-14$ & $4.618 \mathrm{E}-22$ & $0.000 \mathrm{E}+00$ & $0.000 \mathrm{E}+00$ \\
\hline-230 & $T h-230$ & $1.000 \mathrm{E}+00$ & $2.412 \mathrm{E}-22$ & $2.453 \mathrm{E}-22$ & $5.590 \mathrm{E}-22$ & 1. $295 \mathrm{E}-21$ & $1.078 \mathrm{E}-18$ & $1.104 \mathrm{E}-03$ \\
\hline 230 & $\mathrm{Ra}-226+\mathrm{D}$ & $1.000 \mathrm{E}+00$ & $3.774 \mathrm{E}-11$ & $1.139 \mathrm{E}-10$ & $5.320 \mathrm{E}-09$ & $1.479 \mathrm{E}-08$ & $1.071 E-06$ & $2.165 \mathrm{E}-02$ \\
\hline-230 & $\mathrm{~Pb}-210+\mathrm{D}$ & $1.000 \mathrm{E}+00$ & $1.819 \mathrm{E}-19$ & $1.271 \mathrm{E}-18$ & $1.299 \mathrm{E}-15$ & $5.314 E-15$ & $7.678 E-13$ & $3.543 E-02$ \\
\hline-230 & $\sum \operatorname{DSR}(j)$ & & $3.774 \mathrm{E}-11$ & $1.139 \mathrm{E}-10$ & $5.320 E-09$ & $1.479 \mathrm{E}-08$ & $1.071 \mathrm{E}-06$ & $5.818 \mathrm{E}-02$ \\
\hline
\end{tabular}


RESRAD, Version 6.5

Summary : C746U Resident Gardener Deterministic Run

File : $\mathrm{x}: \backslash$ FINAL V2 $\backslash$ C746U RG DET-FINALV2.RAD

Dose/Source Ratios Summed Over All Pathways

Parent and Progeny Principal Radionuclide Contributions Indicated

\begin{tabular}{|c|c|c|c|c|c|c|c|c|}
\hline Parent & Product & Thread & DSH & $(j, t)$ At & ime in Year & (mrem, & $(\mathrm{yr}) /(\mathrm{pCi} / \mathrm{g}$ & \\
\hline (i) & (j) & Fraction & $0.000 \mathrm{E}+00$ & $1.000 \mathrm{E}+00$ & $5.000 \mathrm{E}+01$ & $1.000 \mathrm{E}+02$ & $5.000 \mathrm{E}+02$ & $1.050 \mathrm{E}+03$ \\
\hline-232 & $T h-232$ & $1.000 \mathrm{E}+00$ & $1.166 \mathrm{E}-24$ & $1.188 \mathrm{E}-24$ & $2.949 \mathrm{E}-24$ & $7.462 \mathrm{E}-24$ & 1. $252 \mathrm{E}-20$ & 1. $221 \mathrm{E}-03$ \\
\hline$h-232$ & $\mathrm{Ra}-228+\mathrm{D}$ & $1.000 \mathrm{E}+00$ & $1.107 E-09$ & $3.174 \mathrm{E}-09$ & $2.784 \mathrm{E}-08$ & $4.079 E-08$ & $8.497 E-07$ & $1.458 \mathrm{E}-01$ \\
\hline$h-232$ & $T h-228+D$ & $1.000 \mathrm{E}+00$ & $1.067 \mathrm{E}-08$ & $6.581 \mathrm{E}-08$ & $2.213 \mathrm{E}-06$ & $2.992 \mathrm{E}-06$ & $3.253 E-05$ & $2.007 \mathrm{E}-03$ \\
\hline$h-232$ & $\sum \operatorname{DSR}(j)$ & & $1.178 \mathrm{E}-08$ & $6.899 \mathrm{E}-08$ & $2.241 \mathrm{E}-06$ & $3.033 E-06$ & $3.338 E-05$ & $1.491 \mathrm{E}-01$ \\
\hline-234 & $U-234$ & $1.000 \mathrm{E}+00$ & $6.896 \mathrm{E}-24$ & $7.019 \mathrm{E}-24$ & $1.670 \mathrm{E}-23$ & $4.047 E-23$ & $4.798 E-20$ & $6.337 \mathrm{E}-04$ \\
\hline-234 & Th-230 & $1.000 \mathrm{E}+00$ & $1.089 \mathrm{E}-27$ & $3.315 E-27$ & $2.540 \mathrm{E}-25$ & 1. $171 \mathrm{E}-24$ & $4.838 E-21$ & $1.037 E-05$ \\
\hline-234 & $\mathrm{Ra}-226+\mathrm{D}$ & $1.000 \mathrm{E}+00$ & $1.133 \mathrm{E}-16$ & $7.978 E-16$ & 1. $213 \mathrm{E}-12$ & $6.737 \mathrm{E}-12$ & $2.496 E-09$ & $1.097 \mathrm{E}-04$ \\
\hline-234 & $\mathrm{~Pb}-210+\mathrm{D}$ & $1.000 \mathrm{E}+00$ & $4.102 \mathrm{E}-25$ & $6.153 E-24$ & $2.201 \mathrm{E}-19$ & 1. $935 \mathrm{E}-18$ & $1.678 E-15$ & $1.738 \mathrm{E}-04$ \\
\hline-234 & $\sum \operatorname{DSR}(j)$ & & $1.133 \mathrm{E}-16$ & $7.978 E-16$ & 1. $213 \mathrm{E}-12$ & $6.737 E-12$ & $2.496 E-09$ & $9.276 E-04$ \\
\hline$-235+D$ & $\mathrm{U}-235+\mathrm{D}$ & $1.000 \mathrm{E}+00$ & 1. $243 E-14$ & $1.259 \mathrm{E}-14$ & $2.306 \mathrm{E}-14$ & $4.276 \mathrm{E}-14$ & $5.981 \mathrm{E}-12$ & $6.155 \mathrm{E}-04$ \\
\hline$-235+D$ & $\mathrm{~Pa}-231$ & $1.000 \mathrm{E}+00$ & $2.937 E-18$ & $8.896 \mathrm{E}-18$ & $5.031 \mathrm{E}-16$ & $1.701 \mathrm{E}-15$ & $5.876 E-13$ & $8.145 E-04$ \\
\hline$-235+D$ & $A C-227+D$ & $1.000 \mathrm{E}+00$ & $9.274 \mathrm{E}-18$ & $6.481 \mathrm{E}-17$ & $6.882 \mathrm{E}-14$ & $2.943 E-13$ & $6.376 \mathrm{E}-11$ & $3.373 E-04$ \\
\hline$-235+D$ & $\sum \operatorname{DSR}(j)$ & & 1. $245 \mathrm{E}-14$ & $1.266 \mathrm{E}-14$ & $9.238 \mathrm{E}-14$ & $3.388 E-13$ & $7.033 E-11$ & $1.767 \mathrm{E}-03$ \\
\hline-238 & $\mathrm{U}-238$ & $5.400 E-05$ & $0.000 \mathrm{E}+00$ & $0.000 \mathrm{E}+00$ & $0.000 \mathrm{E}+00$ & $0.000 \mathrm{E}+00$ & $0.000 \mathrm{E}+00$ & $3.167 \mathrm{E}-08$ \\
\hline$-238+D$ & $\mathrm{U}-238+\mathrm{D}$ & $9.999 \mathrm{E}-01$ & 1. $420 \mathrm{E}-10$ & $1.431 \mathrm{E}-10$ & $2.116 \mathrm{E}-10$ & $3.153 \mathrm{E}-10$ & $7.678 E-09$ & $6.313 E-04$ \\
\hline$J-238+D$ & $\mathrm{U}-234$ & $9.999 \mathrm{E}-01$ & $9.803 E-30$ & $2.988 E-29$ & $2.392 E-27$ & $1.153 \mathrm{E}-26$ & $6.812 \mathrm{E}-23$ & $1.890 \mathrm{E}-06$ \\
\hline$J-238+D$ & Th-230 & $9.999 E-01$ & $1.030 E-33$ & $7.316 E-33$ & $1.818 \mathrm{E}-29$ & 1. $668 \mathrm{E}-28$ & $3.430 E-24$ & $1.541 \mathrm{E}-08$ \\
\hline$J-238+D$ & $\mathrm{Ra}-226+\mathrm{D}$ & $9.999 \mathrm{E}-01$ & $8.034 \mathrm{E}-23$ & $1.212 \mathrm{E}-21$ & $5.801 \mathrm{E}-17$ & $6.420 \mathrm{E}-16$ & 1. $201 \mathrm{E}-12$ & $1.127 \mathrm{E}-07$ \\
\hline$J-238+D$ & $\mathrm{~Pb}-210+\mathrm{D}$ & $9.999 \mathrm{E}-01$ & $2.329 E-31$ & $7.229 \mathrm{E}-30$ & $8.430 \mathrm{E}-24$ & 1. $546 \mathrm{E}-22$ & 7. $612 \mathrm{E}-19$ & $1.734 \mathrm{E}-07$ \\
\hline$-238+D$ & $\sum \operatorname{DSR}(j)$ & & $1.420 \mathrm{E}-10$ & $1.431 \mathrm{E}-10$ & $2.116 \mathrm{E}-10$ & $3.153 E-10$ & $7.680 E-09$ & $6.335 E-04$ \\
\hline
\end{tabular}

The DSR includes contributions from associated (half-life $\leq 180$ days) daughters. 
RESRAD, Version $6.5 \quad \mathrm{~T}^{1 / 2}$ Limit $=180$ days

Summary : C746U Resident Gardener Deterministic Run

File : $\mathrm{x}: \backslash$ FINAL V2\C746U RG DET-FINALV2.RAD

Single Radionuclide Soil Guidelines G(i,t) in $\mathrm{pCi} / \mathrm{g}$

Basic Radiation Dose Limit $=1.000 \mathrm{E}+02 \mathrm{mrem} / \mathrm{yr}$

Nuclide

\begin{tabular}{|c|c|c|c|c|c|c|}
\hline (i) & $t=0.000 \mathrm{E}+00$ & $1.000 \mathrm{E}+00$ & $5.000 \mathrm{E}+01$ & $1.000 \mathrm{E}+02$ & $5.000 \mathrm{E}+02$ & $1.050 \mathrm{E}+03$ \\
\hline $1-241$ & $\star 3.431 \mathrm{E}+12$ & $\star 3.431 \mathrm{E}+12$ & $\star 3.431 \mathrm{E}+12$ & $\star 3.431 \mathrm{E}+12$ & $\star 3.431 \mathrm{E}+12$ & $5.044 \mathrm{E}+05$ \\
\hline$s-137$ & $7.925 \mathrm{E}+10$ & $8.043 E+10$ & $1.653 \mathrm{E}+11$ & $3.447 \mathrm{E}+11$ & $\star 8.704 \mathrm{E}+13$ & $\star 8.704 \mathrm{E}+13$ \\
\hline-237 & $\star 7.047 \mathrm{E}+08$ & $\star 7.047 \mathrm{E}+08$ & $\star 7.047 \mathrm{E}+08$ & $\star 7.047 \mathrm{E}+08$ & $\star 7.047 \mathrm{E}+08$ & $9.756 \mathrm{E}+03$ \\
\hline$a-238$ & $* 1.712 \mathrm{E}+13$ & $\star 1.712 \mathrm{E}+13$ & $\star 1.712 \mathrm{E}+13$ & $\star 1.712 \mathrm{E}+13$ & $* 1.712 \mathrm{E}+13$ & $1.637 \mathrm{E}+08$ \\
\hline-239 & $\star 6.214 \mathrm{E}+10$ & $\star 6.214 \mathrm{E}+10$ & $\star 6.214 \mathrm{E}+10$ & $\star 6.214 \mathrm{E}+10$ & $* 6.214 \mathrm{E}+10$ & $7.884 \mathrm{E}+04$ \\
\hline$u-240$ & $\star 2.278 \mathrm{E}+11$ & $\star 2.278 \mathrm{E}+11$ & $\star 2.278 \mathrm{E}+11$ & $\star 2.278 \mathrm{E}+11$ & $\star 2.278 \mathrm{E}+11$ & $8.550 \mathrm{E}+04$ \\
\hline$c-99$ & $* 1.697 \mathrm{E}+10$ & $\star 1.697 \mathrm{E}+10$ & $\star 1.697 \mathrm{E}+10$ & $\star 1.697 \mathrm{E}+10$ & $\star 1.697 \mathrm{E}+10$ & $7.545 \mathrm{E}+07$ \\
\hline$h-228$ & $7.234 \mathrm{E}+07$ & $1.033 \mathrm{E}+08$ & $\star 8.195 \mathrm{E}+14$ & $\star 8.195 \mathrm{E}+14$ & $\star 8.195 \mathrm{E}+14$ & $\star 8.195 \mathrm{E}+14$ \\
\hline$h-230$ & $\star 2.018 \mathrm{E}+10$ & $\star 2.018 \mathrm{E}+10$ & $1.880 \mathrm{E}+10$ & $6.761 \mathrm{E}+09$ & $9.336 \mathrm{E}+07$ & $1.719 \mathrm{E}+03$ \\
\hline Th-232 & $\star 1.097 \mathrm{E}+05$ & $\star 1.097 \mathrm{E}+05$ & $\star 1.097 \mathrm{E}+05$ & $\star 1.097 \mathrm{E}+05$ & $* 1.097 \mathrm{E}+05$ & $6.708 \mathrm{E}+02$ \\
\hline$J-234$ & $* 6.247 \mathrm{E}+09$ & $\star 6.247 \mathrm{E}+09$ & $* 6.247 \mathrm{E}+09$ & $* 6.247 \mathrm{E}+09$ & $* 6.247 \mathrm{E}+09$ & $1.078 \mathrm{E}+05$ \\
\hline$J-235$ & $\star 2.161 \mathrm{E}+06$ & $\star 2.161 \mathrm{E}+06$ & $\star 2.161 \mathrm{E}+06$ & $\star 2.161 \mathrm{E}+06$ & $\star 2.161 \mathrm{E}+06$ & $5.658 E+04$ \\
\hline-238 & $* 3.361 \mathrm{E}+05$ & $\star 3.361 \mathrm{E}+05$ & $\star 3.361 \mathrm{E}+05$ & $\star 3.361 \mathrm{E}+05$ & $* 3.361 \mathrm{E}+05$ & $1.578 \mathrm{E}+05$ \\
\hline
\end{tabular}

*At specific activity limit

Summed Dose/Source Ratios DSR(i,t) in (mrem/yr)/(pCi/g) and Single Radionuclide Soil Guidelines $G(i, t)$ in $\mathrm{pCi} / \mathrm{g}$

at $\operatorname{tmin}=$ time of minimum single radionuclide soil guideline and at $\operatorname{tmax}=$ time of maximum total dose $=1.050 \mathrm{E}+03$ years

\begin{tabular}{|c|c|c|c|c|c|c|}
\hline $\begin{array}{l}\text { uclide } \\
\text { (i) }\end{array}$ & $\begin{array}{l}\text { Initial } \\
(\mathrm{pCi} / \mathrm{g})\end{array}$ & $\begin{array}{c}\text { tmin } \\
\text { (years) }\end{array}$ & $\operatorname{DSR}(i, \operatorname{tmin})$ & $\begin{array}{c}\mathrm{G}(i, \operatorname{tmin}) \\
(\mathrm{pCi} / \mathrm{g})\end{array}$ & $\operatorname{DSR}(i, \operatorname{tmax})$ & $\begin{array}{c}\mathrm{G}(i, \operatorname{tmax}) \\
(\mathrm{pC} i / \mathrm{g})\end{array}$ \\
\hline 241 & $1.000 \mathrm{E}+00$ & $1.050 \mathrm{E}+03$ & $1.983 \mathrm{E}-04$ & $5.044 \mathrm{E}+05$ & $1.983 \mathrm{E}-04$ & $5.044 \mathrm{E}+05$ \\
\hline-137 & $1.000 \mathrm{E}+00$ & $0.000 \mathrm{E}+00$ & $1.262 \mathrm{E}-09$ & $7.925 E+10$ & $7.713 \mathrm{E}-14$ & $\star 8.704 \mathrm{E}+13$ \\
\hline 237 & $1.000 \mathrm{E}+00$ & $1.050 \mathrm{E}+03$ & $1.025 \mathrm{E}-02$ & $9.756 \mathrm{E}+03$ & $1.025 \mathrm{E}-02$ & $9.756 \mathrm{E}+03$ \\
\hline-238 & $1.000 \mathrm{E}+00$ & $1.050 \mathrm{E}+03$ & $6.110 \mathrm{E}-07$ & $1.637 \mathrm{E}+08$ & $6.110 \mathrm{E}-07$ & $1.637 \mathrm{E}+08$ \\
\hline-239 & $1.000 \mathrm{E}+00$ & $1.050 \mathrm{E}+03$ & $1.268 \mathrm{E}-03$ & $7.884 \mathrm{E}+04$ & $1.268 \mathrm{E}-03$ & $7.884 \mathrm{E}+04$ \\
\hline-240 & $1.000 \mathrm{E}+00$ & $1.050 \mathrm{E}+03$ & $1.170 \mathrm{E}-03$ & $8.550 E+04$ & $1.170 \mathrm{E}-03$ & $8.550 E+04$ \\
\hline-99 & $1.000 \mathrm{E}+00$ & $1.050 \mathrm{E}+03$ & $1.325 \mathrm{E}-06$ & $7.545 \mathrm{E}+07$ & $1.325 \mathrm{E}-06$ & $7.545 E+07$ \\
\hline Th-228 & $1.000 \mathrm{E}+00$ & $0.000 \mathrm{E}+00$ & $1.382 \mathrm{E}-06$ & $7.234 E+07$ & $0.000 \mathrm{E}+00$ & $\star 8.195 \mathrm{E}+14$ \\
\hline-230 & $1.000 \mathrm{E}+00$ & $1.050 \mathrm{E}+03$ & $5.818 \mathrm{E}-02$ & $1.719 \mathrm{E}+03$ & $5.818 \mathrm{E}-02$ & $1.719 \mathrm{E}+03$ \\
\hline-232 & $1.000 \mathrm{E}+00$ & $1.050 \mathrm{E}+03$ & $1.491 \mathrm{E}-01$ & $6.708 \mathrm{E}+02$ & $1.491 \mathrm{E}-01$ & $6.708 \mathrm{E}+02$ \\
\hline 34 & $1.000 \mathrm{E}+00$ & $1.050 \mathrm{E}+03$ & $9.276 \mathrm{E}-04$ & $1.078 \mathrm{E}+05$ & $9.276 \mathrm{E}-04$ & $1.078 \mathrm{E}+05$ \\
\hline 35 & $1.000 \mathrm{E}+00$ & $1.050 \mathrm{E}+03$ & $1.767 \mathrm{E}-03$ & $5.658 \mathrm{E}+04$ & $1.767 \mathrm{E}-03$ & $5.658 \mathrm{E}+04$ \\
\hline 38 & $1.000 \mathrm{E}+00$ & $1.050 \mathrm{E}+03$ & $6.335 \mathrm{E}-04$ & $1.578 \mathrm{E}+05$ & $6.335 E-04$ & $1.578 E+05$ \\
\hline
\end{tabular}

*At specific activity limit 
RESRAD, Version $6.5 \quad \mathrm{~T}^{1 / 2}$ Limit $=180$ days

Summary : C746U Resident Gardener Deterministic Run

File : $\mathrm{X}: \backslash$ FINAL V2 $\backslash$ C746U RG DET-FINALV2.RAD

Individual Nuclide Dose Summed Over All Pathways

Parent Nuclide and Branch Fraction Indicated

Nuclide Parent THF(i) DOSE $(j, t)$, mrem/yr

\begin{tabular}{|c|c|c|c|c|c|c|c|c|c|}
\hline (j) & (i) & & $t=$ & $0.000 \mathrm{E}+00$ & $1.000 \mathrm{E}+00$ & $5.000 \mathrm{E}+01$ & $1.000 \mathrm{E}+02$ & $5.000 \mathrm{E}+02$ & $1.050 \mathrm{E}+03$ \\
\hline$A m-241$ & Am-241 & $1.000 \mathrm{E}+00$ & & $0.000 E+00$ & $0.000 \mathrm{E}+00$ & $0.000 \mathrm{E}+00$ & $0.000 \mathrm{E}+00$ & $1.208 E-27$ & $1.965 E-04$ \\
\hline
\end{tabular}

$\mathrm{Np}-237 \quad \mathrm{Am}-241 \quad 1.000 \mathrm{E}+00$

$\mathrm{Np}-237 \quad \mathrm{~Np}-237 \quad 1.000 \mathrm{E}+00$

Np-237 SDOSE (j)

$\mathrm{U}-233$ Am-241 1.000E+00

$\mathrm{U}-233 \mathrm{~Np}-237 \quad 1.000 \mathrm{E}+00$

U-233 $\sum \mathrm{DOSE}(j)$

Th-229 Am-241 1.000E+00

$\mathrm{Th}-229 \quad \mathrm{~Np}-237 \quad 1.000 \mathrm{E}+00$

Th-229 ¿DOSE $(j)$

Cs-137 Cs $-137 \quad 1.000 E+00$

Pu-238 Pu-238 1.840E-09

$\mathrm{Pu}-238 \quad \mathrm{Pu}-238 \quad 1.000 \mathrm{E}+00$

$\mathrm{Pu}-238 \quad \sum \mathrm{DOSE}(j)$

$\mathrm{U}-234$

$\mathrm{U}-234$

$\mathrm{U}-234$

$\mathrm{U}-234$

$\mathrm{Th}-230$

$\mathrm{Th}-230$

$\mathrm{Th}-230$

$\mathrm{Th}-230$

$\mathrm{Th}-230$

$\mathrm{Ra}-226$

$\mathrm{Ra}-226$

$\mathrm{Ra}-226$

$\mathrm{Ra}-226$

$\mathrm{Ra}-226$

$\mathrm{Pb}-210$

$\mathrm{Pb}-210$

$\mathrm{Pb}-210$

$\mathrm{Pb}-210$

$\mathrm{Pb}-210$

$\mathrm{Pu}-239$

$\mathrm{Pu}-238 \quad 1.000 \mathrm{E}+00$

$\mathrm{U}-234 \quad 1.000 \mathrm{E}+00$

$\mathrm{U}-238 \quad 9.999 \mathrm{E}-01$

$\sum \operatorname{DOSE}(j)$

$\mathrm{Pu}-238 \quad 1.000 \mathrm{E}+00$

Th-230 1.000E+00

$\mathrm{U}-234 \quad 1.000 \mathrm{E}+00$

$\mathrm{U}-238 \quad 9.999 \mathrm{E}-01$

$\sum \operatorname{DOSE}(j)$

$\mathrm{Pu}-238 \quad 1.000 \mathrm{E}+00$

Th-230 1.000E+00

$\mathrm{U}-234 \quad 1.000 \mathrm{E}+00$

$\mathrm{U}-238 \quad 9.999 \mathrm{E}-01$

$\sum \operatorname{DOSE}(j)$

$\mathrm{Pu}-238$ 1.000E+00

Th-230 1.000E+00

$\mathrm{U}-234 \quad 1.000 \mathrm{E}+00$

U-238 9.999E-01

$\sum \operatorname{DOSE}(j)$

Pu-239 1.000E+00

$\mathrm{Pu}-239$ 1.000E+00

$\mathrm{U}-2351.000 \mathrm{E}+00$

$\sum \operatorname{DOSE}(j)$ $\begin{array}{llllllll}1.546 \mathrm{E}-19 & 4.680 \mathrm{E}-19 & 2.562 \mathrm{E}-17 & 8.382 \mathrm{E}-17 & 2.263 \mathrm{E}-14 & 1.773 \mathrm{E}-06\end{array}$ $\begin{array}{lllllll}9.536 \mathrm{E}-13 & 9.638 \mathrm{E}-13 & 1.625 \mathrm{E}-12 & 2.770 \mathrm{E}-12 & 1.974 \mathrm{E}-10 & 1.025 \mathrm{E}-02\end{array}$ $\begin{array}{llllll}9.536 \mathrm{E}-13 & 9.638 \mathrm{E}-13 & 1.625 \mathrm{E}-12 & 2.770 \mathrm{E}-12 & 1.974 \mathrm{E}-10 & 1.025 \mathrm{E}-02\end{array}$

$3.506 \mathrm{E}-30 \quad 2.479 \mathrm{E}-29 \quad 4.863 \mathrm{E}-26 \quad 3.503 \mathrm{E}-25 \quad 1.053 \mathrm{E}-21 \quad 3.056 \mathrm{E}-10$ $3.245 \mathrm{E}-23 \quad 9.844 \mathrm{E}-23 \quad 6.100 \mathrm{E}-21 \quad 2.264 \mathrm{E}-20 \quad 1.650 \mathrm{E}-17 \quad 2.871 \mathrm{E}-06$ $3.245 \mathrm{E}-23 \quad 9.844 \mathrm{E}-23 \quad 6.100 \mathrm{E}-21 \quad 2.264 \mathrm{E}-20 \quad 1.650 \mathrm{E}-17 \quad 2.871 \mathrm{E}-06$

$2.399 \mathrm{E}-26 \quad 3.618 \mathrm{E}-25 \quad 1.710 \mathrm{E}-20 \quad 1.868 \mathrm{E}-19 \quad 3.195 \mathrm{E}-16 \quad 5.403 \mathrm{E}-11$ $2.962 \mathrm{E}-192.086 \mathrm{E}-18 \quad 3.196 \mathrm{E}-15 \quad 1.788 \mathrm{E}-14 \quad 7.080 \mathrm{E}-12 \quad 6.801 \mathrm{E}-07$ $2.962 \mathrm{E}-19 \quad 2.086 \mathrm{E}-18 \quad 3.196 \mathrm{E}-15 \quad 1.788 \mathrm{E}-14 \quad 7.080 \mathrm{E}-12 \quad 6.802 \mathrm{E}-07$

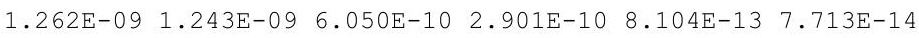
$\begin{array}{llllll}0.000 \mathrm{E}+00 & 0.000 \mathrm{E}+00 & 0.000 \mathrm{E}+00 & 0.000 \mathrm{E}+00 & 0.000 \mathrm{E}+00 \quad 5.505 \mathrm{E}-16\end{array}$ $\begin{array}{llllll}1.175 \mathrm{E}-24 & 1.186 \mathrm{E}-24 & 1.913 \mathrm{E}-24 & 3.115 \mathrm{E}-24 & 1.539 \mathrm{E}-22 & 2.992 \mathrm{E}-07\end{array}$ $\begin{array}{llllll}1.175 E-24 & 1.186 \mathrm{E}-24 & 1.913 \mathrm{E}-24 & 3.115 \mathrm{E}-24 & 1.539 \mathrm{E}-22 & 2.992 \mathrm{E}-07\end{array}$

$9.778 \mathrm{E}-30 \quad 2.969 \mathrm{E}-29 \quad 1.973 \mathrm{E}-27 \quad 7.960 \mathrm{E}-27 \quad 1.690 \mathrm{E}-23 \quad 2.276 \mathrm{E}-07$ $\begin{array}{lllllll}6.896 \mathrm{E}-24 & 7.019 \mathrm{E}-24 & 1.670 \mathrm{E}-23 & 4.047 \mathrm{E}-23 & 4.798 \mathrm{E}-20 & 6.337 \mathrm{E}-04\end{array}$ $9.803 \mathrm{E}-30 \quad 2.988 \mathrm{E}-29 \quad 2.392 \mathrm{E}-27 \quad 1.153 \mathrm{E}-26 \quad 6.812 \mathrm{E}-23 \quad 1.890 \mathrm{E}-06$ $\begin{array}{lllllll}6.896 \mathrm{E}-24 & 7.019 \mathrm{E}-24 & 1.671 \mathrm{E}-23 & 4.049 \mathrm{E}-23 & 4.806 \mathrm{E}-20 & 6.358 \mathrm{E}-04\end{array}$

$0.000 \mathrm{E}+00 \quad 0.000 \mathrm{E}+00 \quad 1.599 \mathrm{E}-29 \quad 1.302 \mathrm{E}-28 \quad 1.306 \mathrm{E}-24 \quad 3.273 \mathrm{E}-09$ $2.412 \mathrm{E}-22 \quad 2.453 \mathrm{E}-22 \quad 5.590 \mathrm{E}-22 \quad 1.295 \mathrm{E}-21 \quad 1.078 \mathrm{E}-18 \quad 1.104 \mathrm{E}-03$ $\begin{array}{lllllll}1.089 \mathrm{E}-27 & 3.315 \mathrm{E}-27 & 2.540 \mathrm{E}-25 & 1.171 \mathrm{E}-24 & 4.838 \mathrm{E}-21 & 1.037 \mathrm{E}-05\end{array}$ $0.000 \mathrm{E}+00 \quad 0.000 \mathrm{E}+00 \quad 1.818 \mathrm{E}-29 \quad 1.668 \mathrm{E}-28 \quad 3.430 \mathrm{E}-24 \quad 1.541 \mathrm{E}-08$ $2.412 \mathrm{E}-22 \quad 2.453 \mathrm{E}-22 \quad 5.592 \mathrm{E}-22 \quad 1.297 \mathrm{E}-21 \quad 1.082 \mathrm{E}-18 \quad 1.115 \mathrm{E}-03$

$\begin{array}{llllll}8.021 \mathrm{E}-23 & 1.208 \mathrm{E}-21 & 5.266 \mathrm{E}-17 & 5.323 \mathrm{E}-16 & 5.607 \mathrm{E}-13 & 3.143 \mathrm{E}-08\end{array}$ $\begin{array}{lllllll}3.774 \mathrm{E}-11 & 1.139 \mathrm{E}-10 & 5.320 \mathrm{E}-09 & 1.479 \mathrm{E}-08 & 1.071 \mathrm{E}-06 & 2.165 \mathrm{E}-02\end{array}$ $\begin{array}{lllllll}1.133 \mathrm{E}-16 & 7.978 \mathrm{E}-16 & 1.213 \mathrm{E}-12 & 6.737 \mathrm{E}-12 & 2.496 \mathrm{E}-09 & 1.097 \mathrm{E}-04\end{array}$ $8.034 \mathrm{E}-23 \quad 1.212 \mathrm{E}-21 \quad 5.801 \mathrm{E}-17 \quad 6.420 \mathrm{E}-16 \quad 1.201 \mathrm{E}-12 \quad 1.127 \mathrm{E}-07$ $3.774 \mathrm{E}-11 \quad 1.139 \mathrm{E}-10 \quad 5.321 \mathrm{E}-09 \quad 1.480 \mathrm{E}-08 \quad 1.074 \mathrm{E}-06 \quad 2.176 \mathrm{E}-02$

$0.000 \mathrm{E}+00 \quad 7.210 \mathrm{E}-30 \quad 7.772 \mathrm{E}-24 \quad 1.314 \mathrm{E}-22 \quad 3.671 \mathrm{E}-19 \quad 4.946 \mathrm{E}-08$ $\begin{array}{llllll}1.819 \mathrm{E}-19 & 1.271 \mathrm{E}-18 & 1.299 \mathrm{E}-15 & 5.314 \mathrm{E}-15 & 7.678 \mathrm{E}-13 & 3.543 \mathrm{E}-02\end{array}$ $\begin{array}{lllllll}4.102 \mathrm{E}-25 & 6.153 \mathrm{E}-24 & 2.201 \mathrm{E}-19 & 1.935 \mathrm{E}-18 & 1.678 \mathrm{E}-15 & 1.738 \mathrm{E}-04\end{array}$ $0.000 \mathrm{E}+00 \quad 7.229 \mathrm{E}-30 \quad 8.430 \mathrm{E}-24 \quad 1.546 \mathrm{E}-22 \quad 7.612 \mathrm{E}-19 \quad 1.734 \mathrm{E}-07$ $\begin{array}{llllll}1.819 \mathrm{E}-19 & 1.271 \mathrm{E}-18 & 1.299 \mathrm{E}-15 & 5.316 \mathrm{E}-15 & 7.695 \mathrm{E}-13 & 3.560 \mathrm{E}-02\end{array}$ $\begin{array}{llllll}1.202 \mathrm{E}-17 & 1.217 \mathrm{E}-17 & 2.183 \mathrm{E}-17 & 3.965 \mathrm{E}-17 & 4.690 \mathrm{E}-15 & 1.268 \mathrm{E}-03\end{array}$ $\begin{array}{lllllll}6.135 \mathrm{E}-24 & 1.861 \mathrm{E}-23 & 1.146 \mathrm{E}-21 & 4.227 \mathrm{E}-21 & 2.931 \mathrm{E}-18 & 6.291 \mathrm{E}-10\end{array}$ $\begin{array}{lllllll}1.243 \mathrm{E}-14 & 1.259 \mathrm{E}-14 & 2.306 \mathrm{E}-14 & 4.276 \mathrm{E}-14 & 5.981 \mathrm{E}-12 & 6.155 \mathrm{E}-04\end{array}$ $1.243 \mathrm{E}-14 \quad 1.259 \mathrm{E}-14 \quad 2.306 \mathrm{E}-14 \quad 4.276 \mathrm{E}-14 \quad 5.981 \mathrm{E}-12 \quad 6.155 \mathrm{E}-04$ 
RESRAD, Version $6.5 \quad \mathrm{~T}^{1 / 2}$ Limit $=180$ days

Summary : C746U Resident Gardener Deterministic Run

File : $\mathrm{X}: \backslash$ FINAL V2 $\backslash \mathrm{C} 746 \mathrm{U}$ RG DET-FINALV2.RAD

Individual Nuclide Soil Concentration

Parent Nuclide and Branch Fraction Indicated

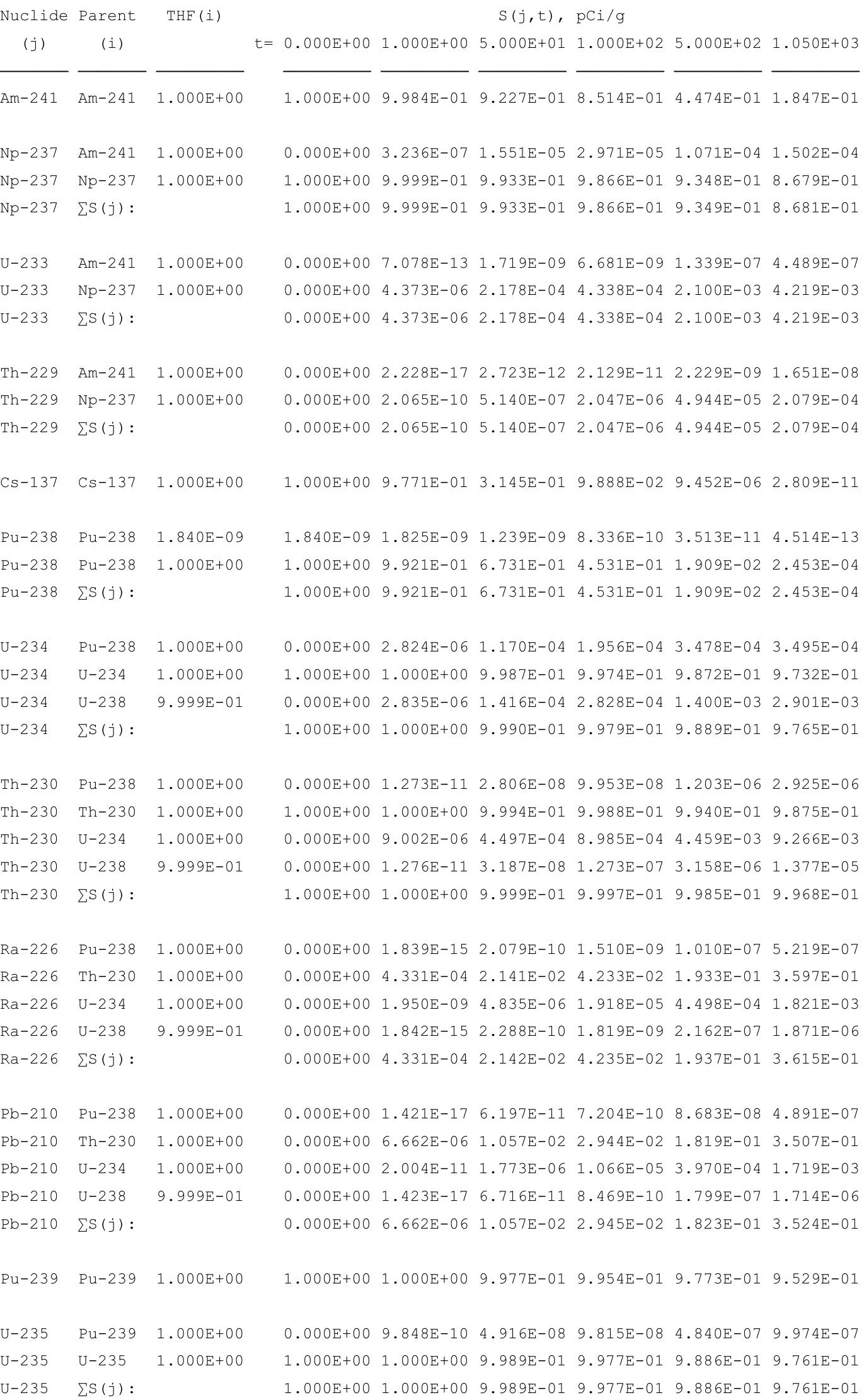


RESRAD, Version $6.5 \quad \mathrm{~T}^{1 / 2}$ Limit $=180$ days

Summary : C746U Resident Gardener Deterministic Run

File : $\mathrm{X}: \backslash$ FINAL V2 $\backslash \mathrm{C} 746 \mathrm{U}$ RG DET-FINALV2.RAD

Individual Nuclide Soil Concentration

Parent Nuclide and Branch Fraction Indicated

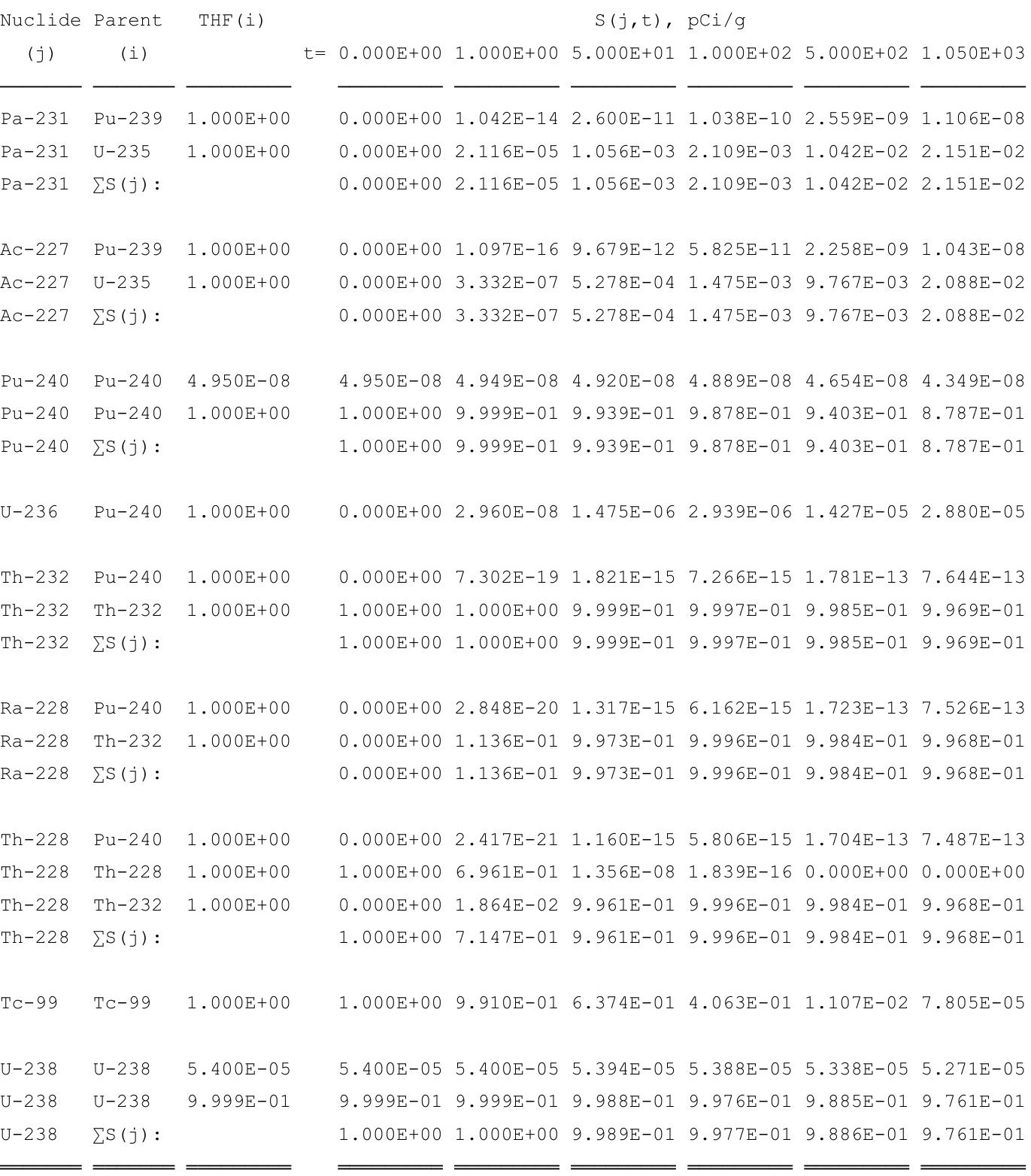

THF(i) is the thread fraction of the parent nuclide.

RESCALC.EXE execution time $=\quad 6.05$ seconds 


\section{Resident Gardener}

\section{The following summary report includes the peak dose from cumulative radionuclide inventory.}


THIS PAGE INTENTIONALLY LEFT BLANK 
RESRAD, Version $6.5 \quad T^{1 / 2}$ Limit $=180$ days

Summary : C746U Resident Gardener Deterministic Run

File : $\mathrm{X}: \backslash$ FINAL V2 $\backslash$ C746U RG SG FWD-FINALV2.RAD

Table of Contents

Part I: Mixture Sums and Single Radionuclide Guidelines

Dose Conversion Factor (and Related) Parameter Summary ... 2

Site-Specific Parameter Summary ............... 8

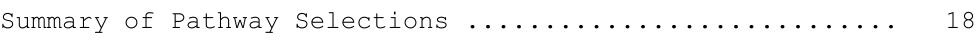

Contaminated zone and Total Dose Summary ............. 19

Total Dose Components

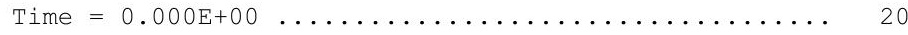

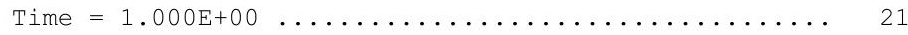

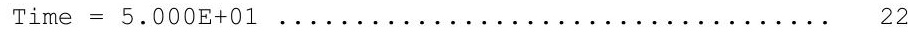

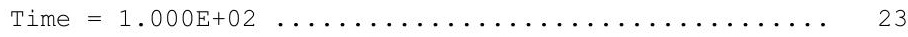

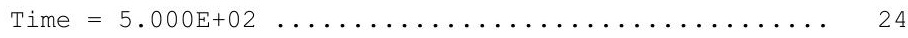

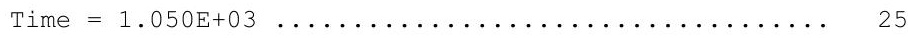

Dose/Source Ratios Summed Over All Pathways ........... 26

Single Radionuclide Soil Guidelines ............... 28

Dose Per Nuclide Summed Over All Pathways ............ 29

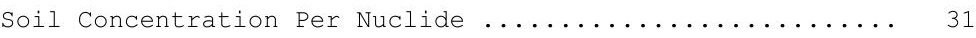


RESRAD, Version $6.5 \quad \mathrm{~T}^{1 / 2}$ Limit $=180$ days

Summary : C746U Resident Gardener Deterministic Run

File : $\mathrm{X}: \backslash$ FINAL V2 $\backslash$ C746U RG SG FWD-FINALV2.RAD

Dose Conversion Factor (and Related) Parameter Summary (continued)

Dose Library: ICRP 60 \& ICRP 72 (Adult)

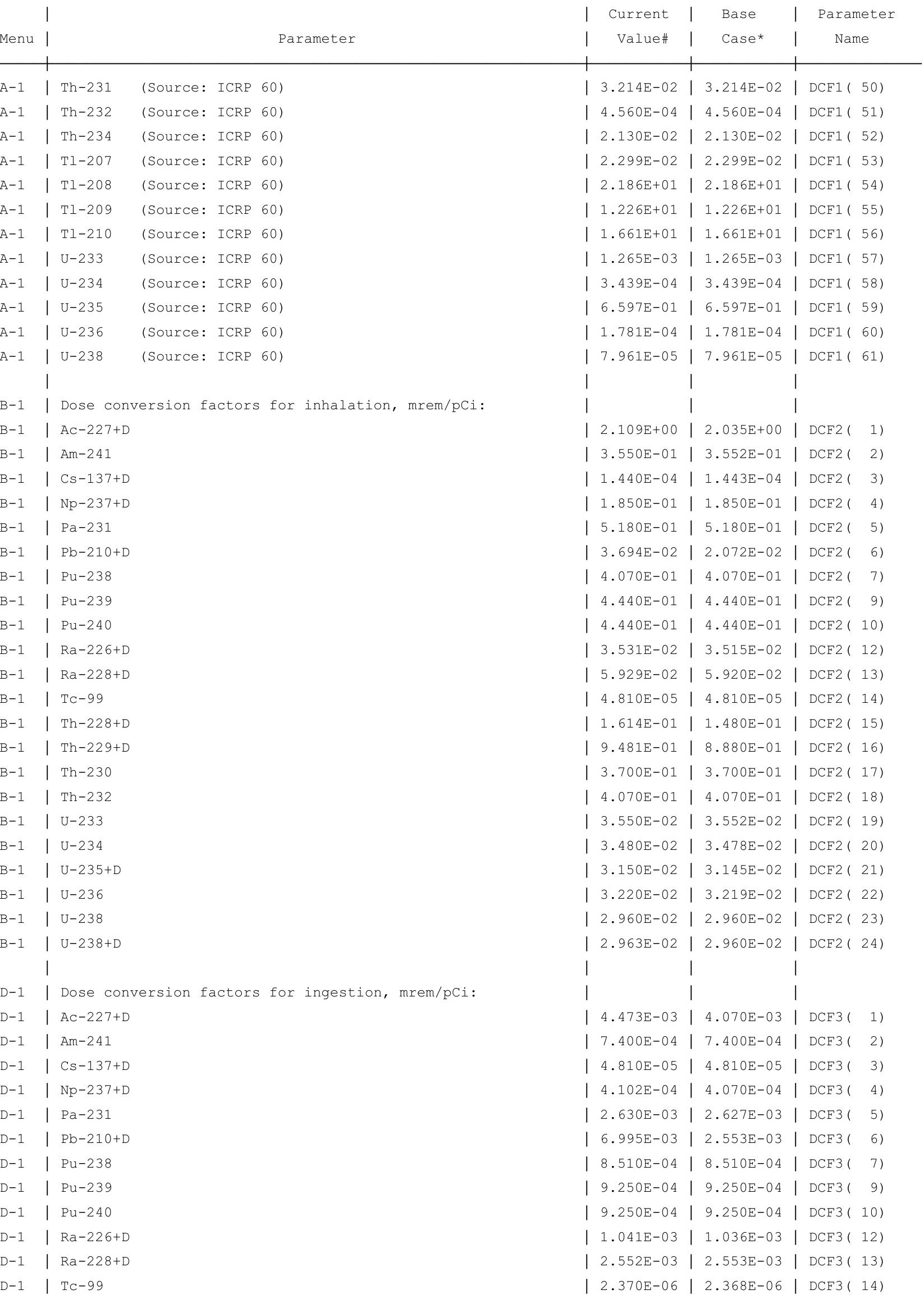


RESRAD, Version $6.5 \quad \mathrm{~T}^{1 / 2}$ Limit $=180$ days

Sumary : C746U Resident Gardener Deterministic Run

File : $\mathrm{X}: \backslash$ FINAL V2 $\backslash$ C746U RG SG FWD-FINALV2.RAD

Dose Conversion Factor (and Related) Parameter Summary (continued) Dose Library: ICRP 60 \& ICRP 72 (Adult)

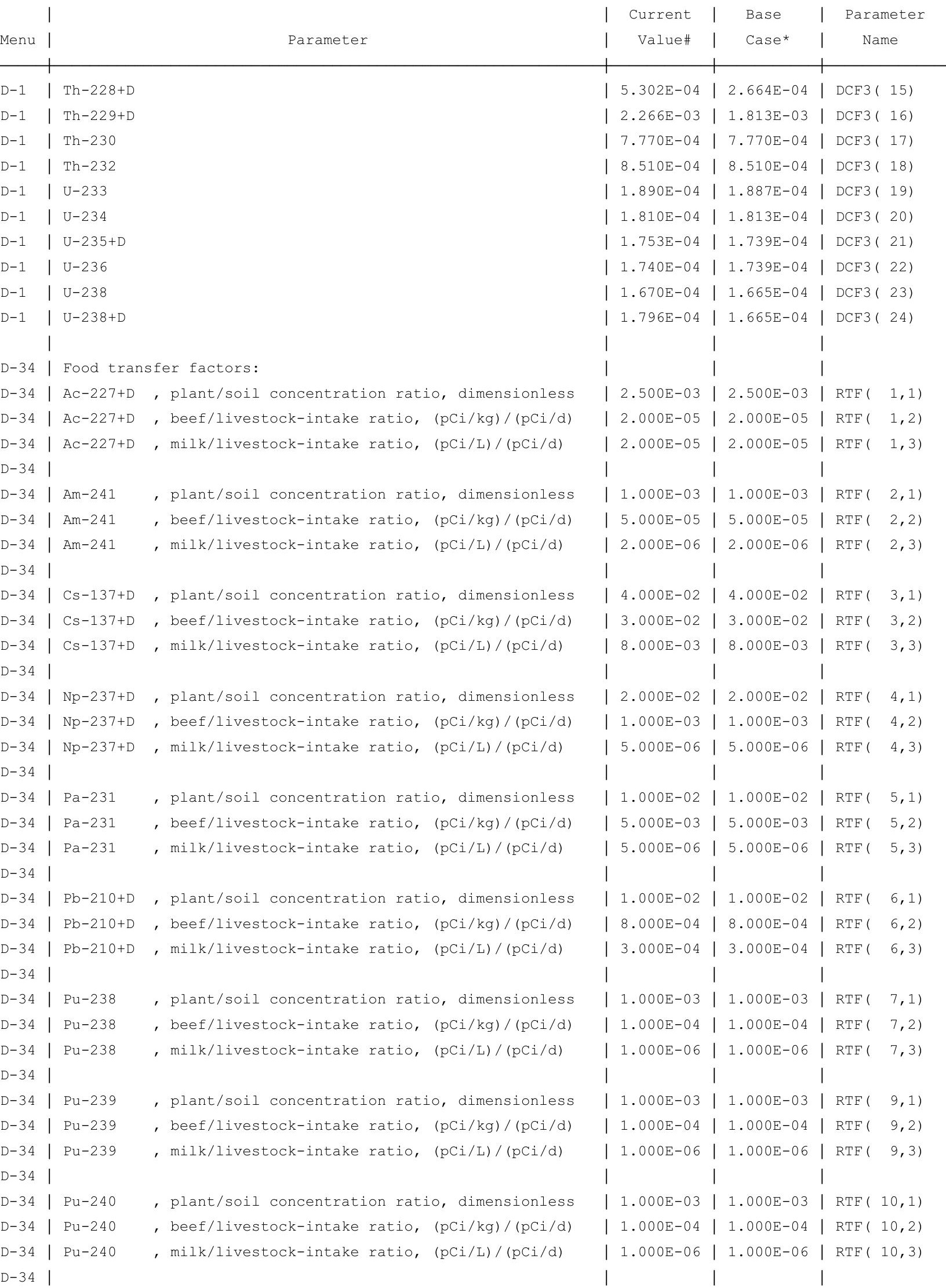


RESRAD, Version $6.5 \quad \mathrm{~T}^{1 / 2}$ Limit $=180$ days

ummary : C746U Resident Gardener Deterministic Run

File : $\mathrm{X}: \backslash$ FINAL V2 $\backslash$ C746U RG SG FWD-FINALV2.RAD

Dose Conversion Factor (and Related) Parameter Summary (continued) Dose Library: ICRP 60 \& ICRP 72 (Adult)

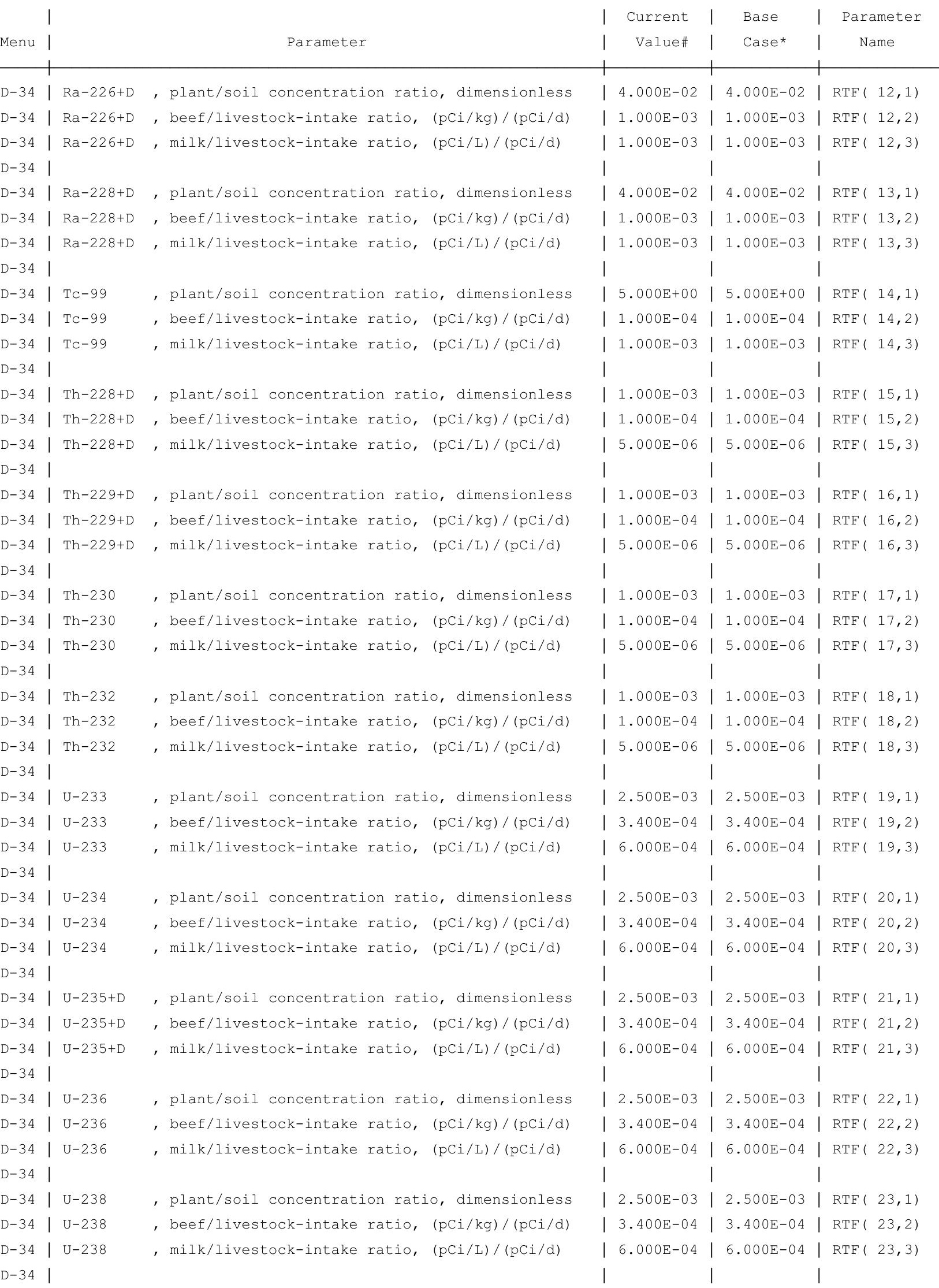


RESRAD, Version $6.5 \quad T^{1 / 2}$ Limit $=180$ days

Summary : C746U Resident Gardener Deterministic Run

File : $X: \backslash F I N A L$ V2 $\backslash C 746 U$ RG SG FWD-FINALV2.RAD

Dose Conversion Factor (and Related) Parameter Summary (continued) Dose Library: ICRP 60 \& ICRP 72 (Adult)

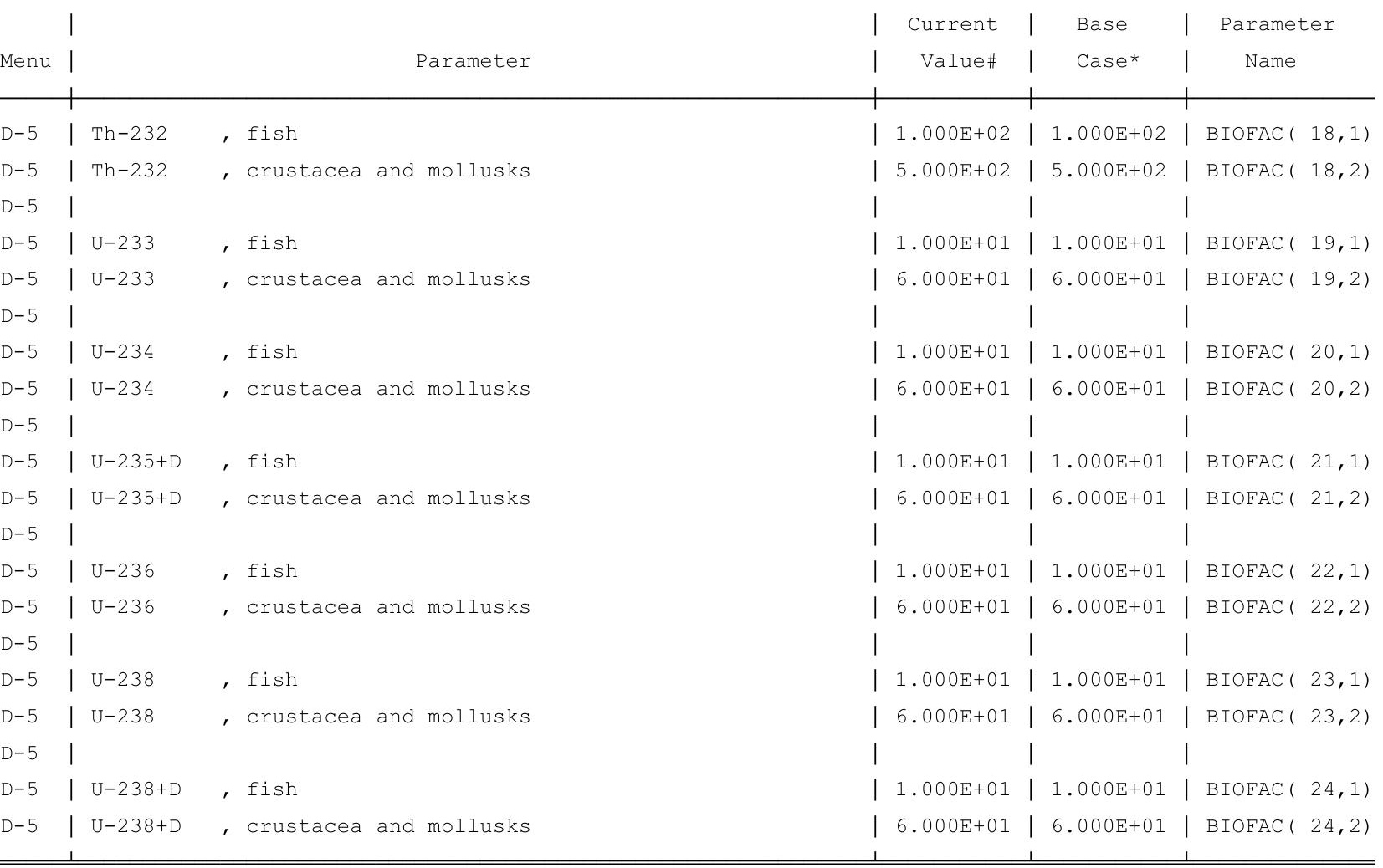

\#For DCFl(xxx) only, factors are for infinite depth \& area. See ETFG table in Ground Pathway of Detailed Report. *Base Case means Default.Lib w/o Associate Nuclide contributions. 
RESRAD, Version $6.5 \quad \mathrm{~T}^{1 / 2}$ Limit $=180$ days

Summary : C746U Resident Gardener Deterministic Run

File : $\mathrm{X}: \backslash$ FINAL V2 $\backslash \mathrm{C746U}$ RG SG FWD-FINALV2.RAD

Site-Specific Parameter Summary

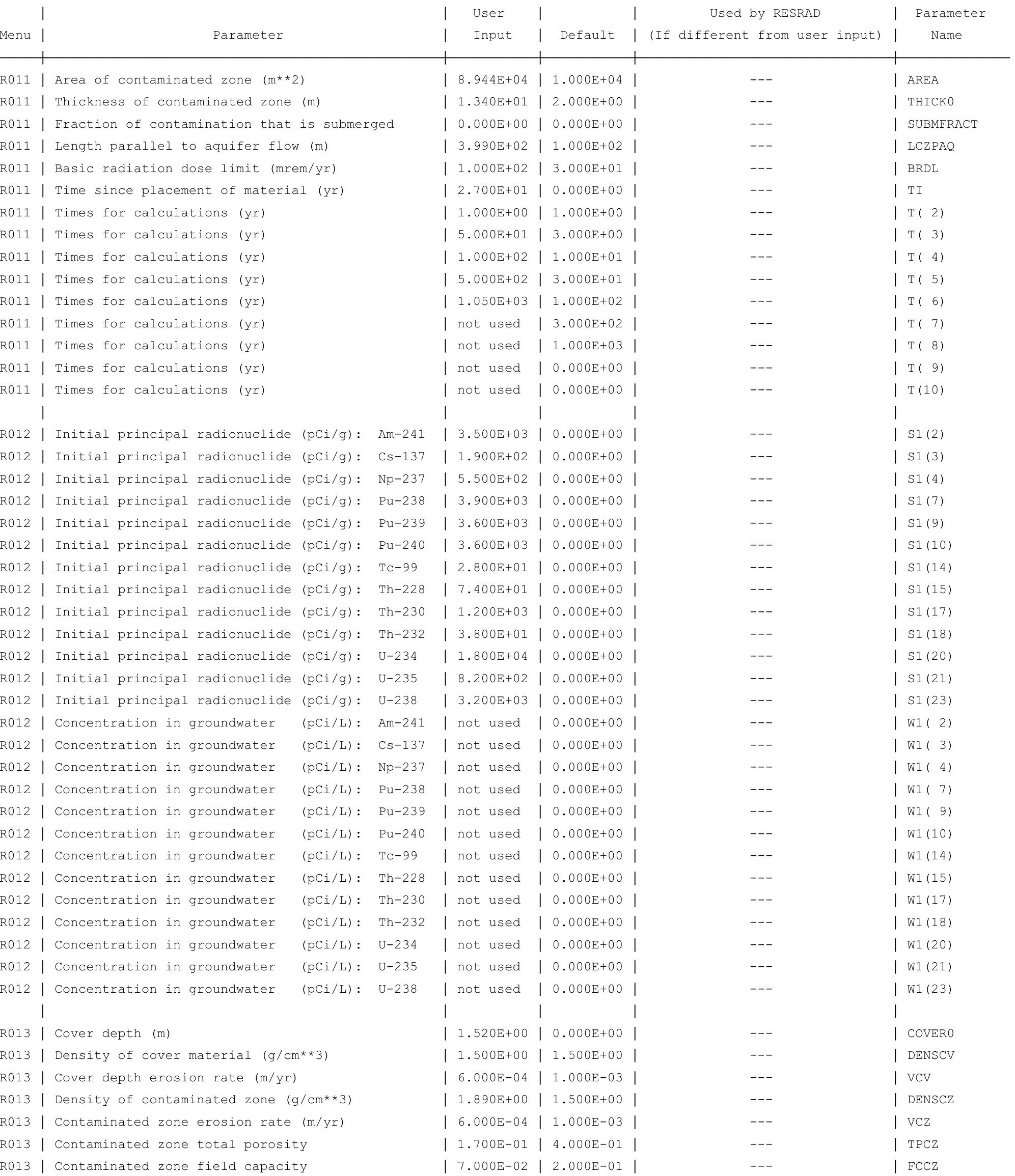


RESRAD, Version $6.5 \quad \mathrm{~T}^{1 / 2}$ Limit $=180$ days

Summary : C746U Resident Gardener Deterministic Run

File : $\mathrm{X}: \backslash$ FINAL V2 $\backslash$ C746U RG SG FWD-FINALV2.RAD

Site-Specific Parameter Summary (continued)

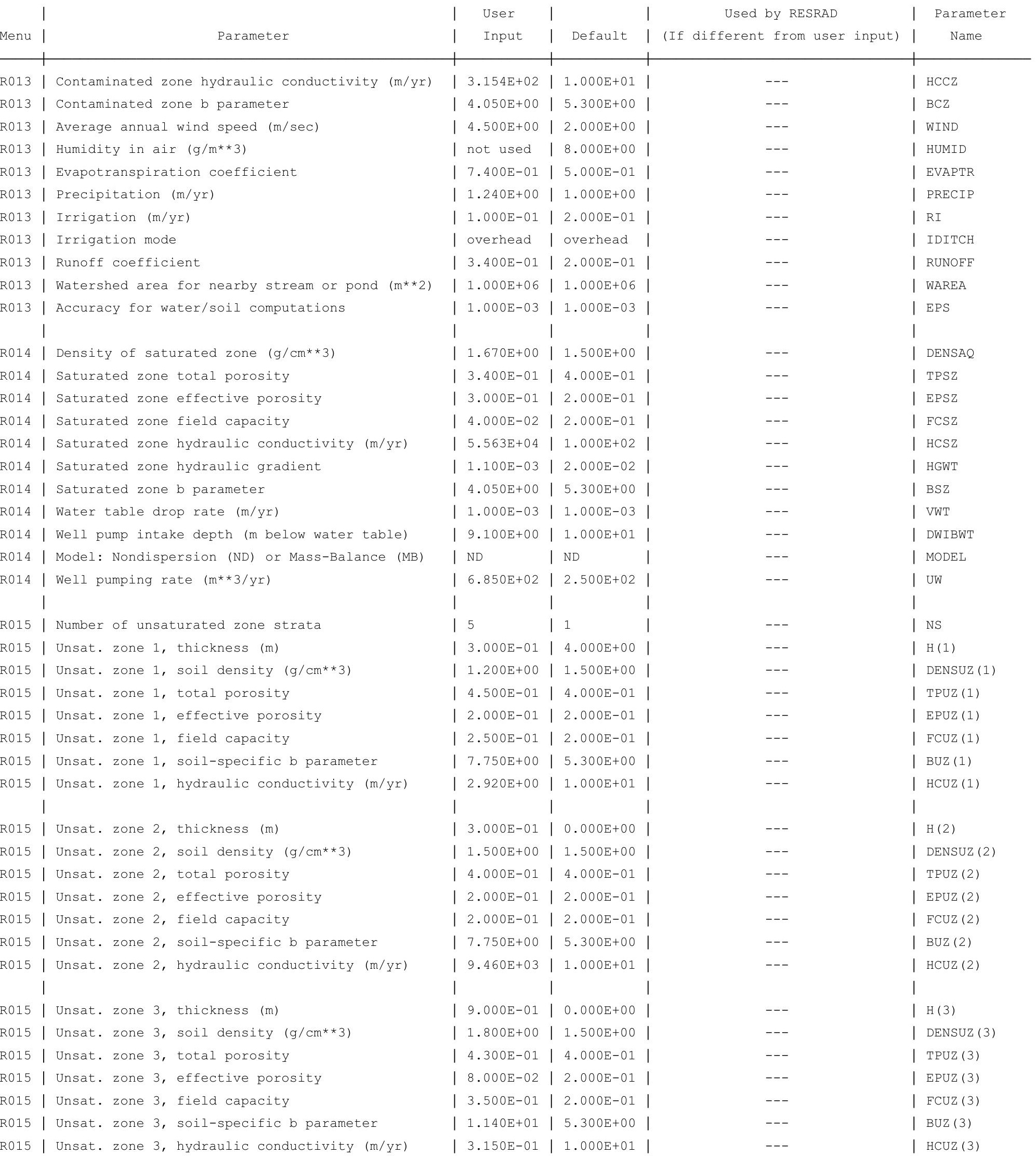


RESRAD, Version $6.5 \quad \mathrm{~T}^{1 / 2}$ Limit $=180$ days 
RESRAD, Version $6.5 \quad \mathrm{~T}^{1 / 2}$ Limit $=180$ days

05/23/2011 08:35 Page 12

Summary : C746U Resident Gardener Deterministic Run

File : $\mathrm{X}: \backslash$ FINAL V2 $\backslash \mathrm{C} 746 \mathrm{U}$ RG SG FWD-FINALV2.RAD

Site-Specific Parameter Summary (continued)

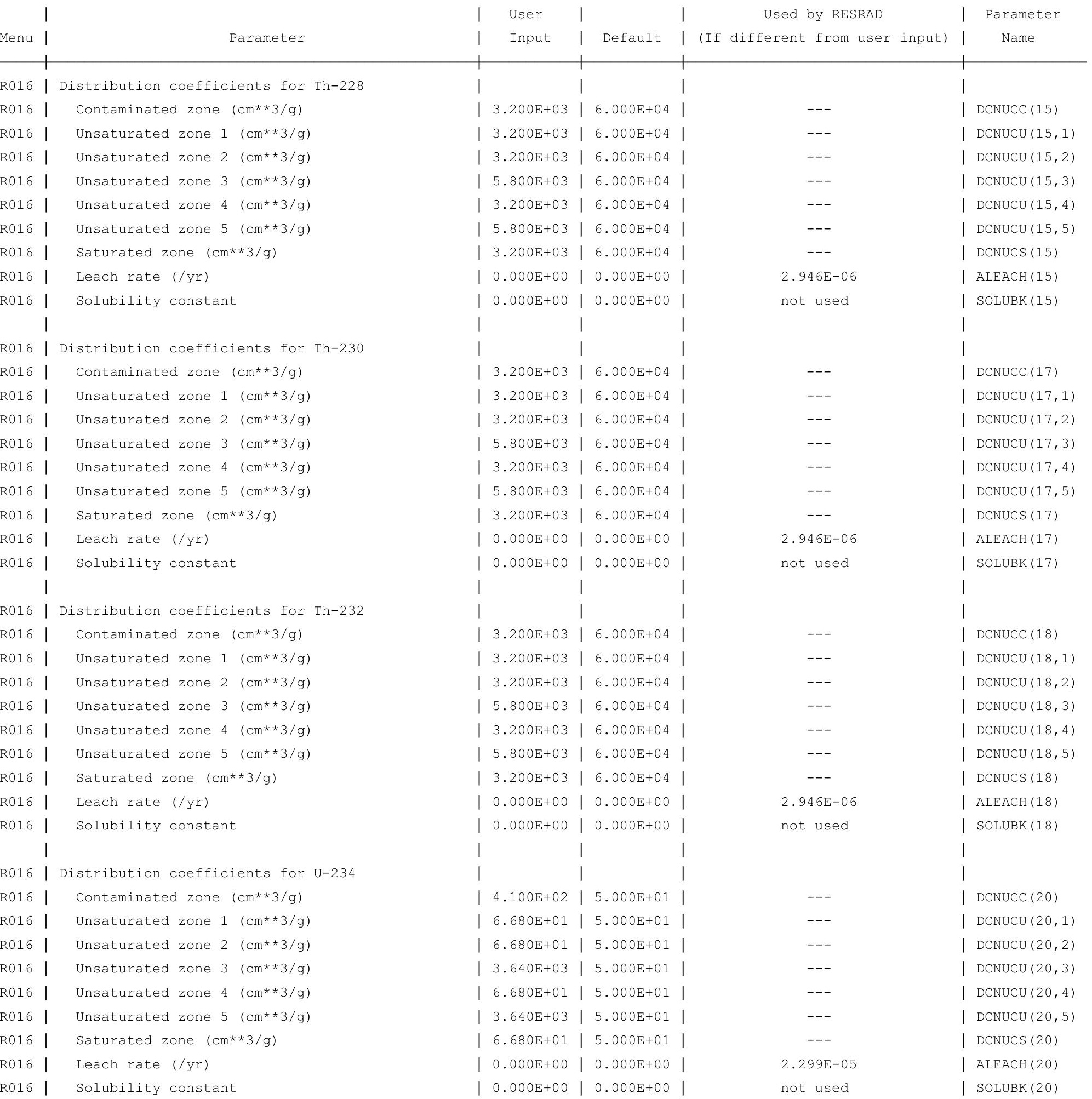


RESRAD, Version $6.5 \quad \mathrm{~T}^{1 / 2}$ Limit $=180$ days

Summary : C746U Resident Gardener Deterministic Run

File : $\mathrm{X}: \backslash F I N A L$ V2 $\backslash C 746 \mathrm{U}$ RG SG FWD-FINALV2.RAD

Site-Specific Parameter Summary (continued)

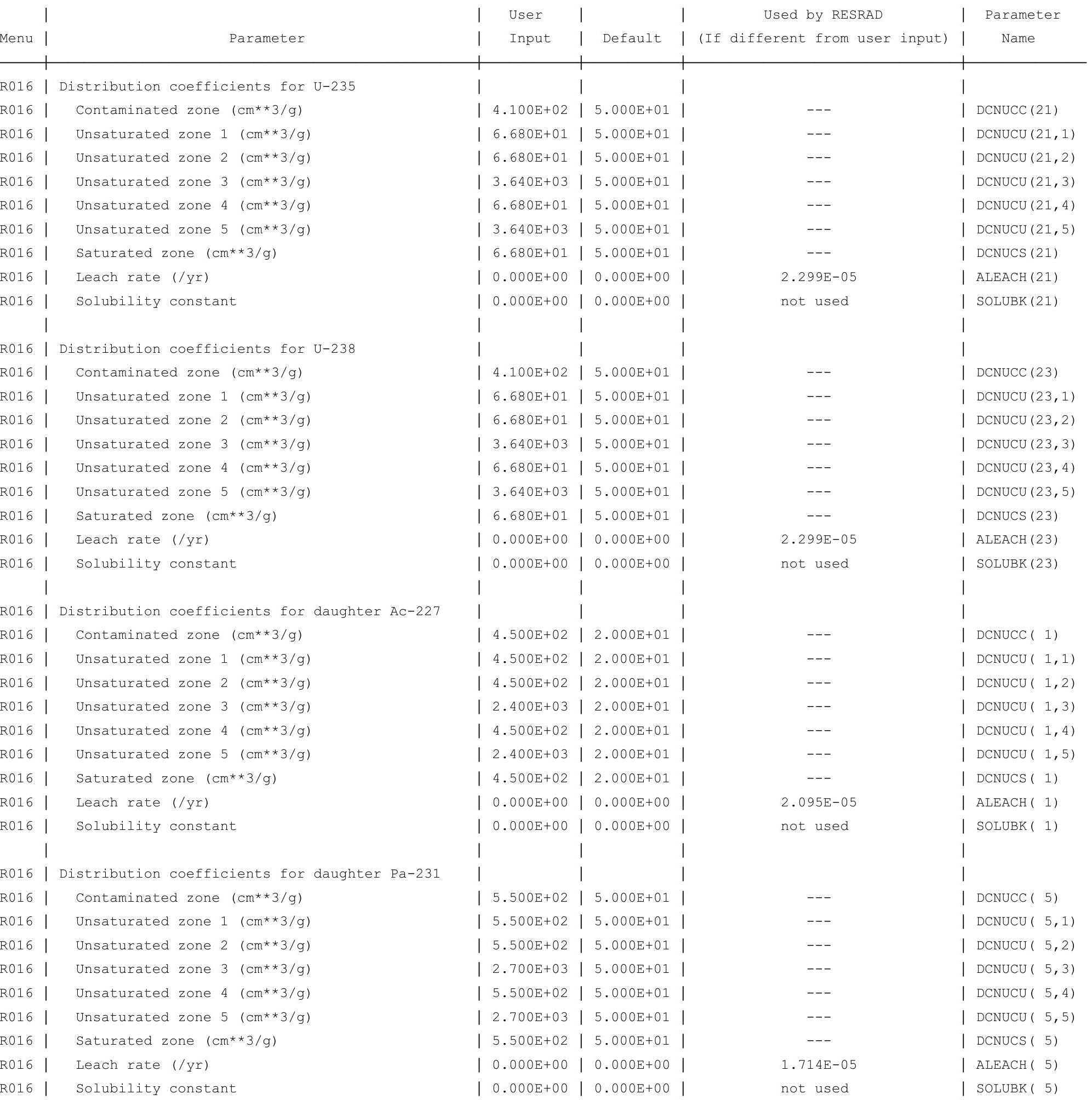


RESRAD, Version $6.5 \quad \mathrm{~T}^{1 / 2}$ Limit $=180$ days

Summary : C746U Resident Gardener Deterministic Run

File : $\mathrm{X}: \backslash$ FINAL V2 $\backslash C 746 \mathrm{U}$ RG SG FWD-FINALV2.RAD

Site-Specific Parameter Summary (continued)

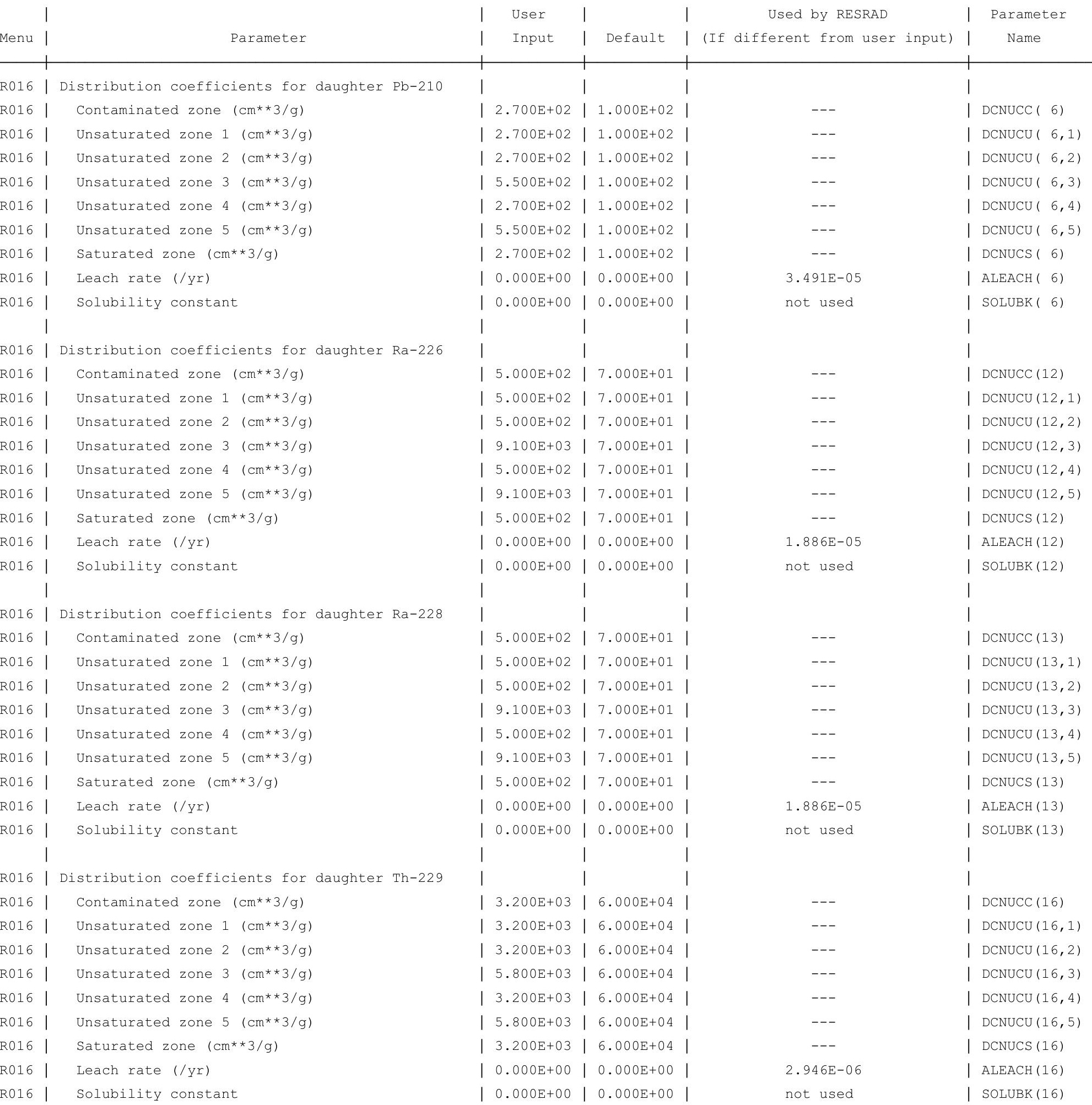


RESRAD, Version $6.5 \quad \mathrm{~T}^{1 / 2}$ Limit $=180$ days

Summary : C746U Resident Gardener Deterministic Run

File : $\mathrm{X}: \backslash$ FINAL V2 $\backslash \mathrm{C} 746 \mathrm{U}$ RG SG FWD-FINALV2.RAD

Site-Specific Parameter Summary (continued)

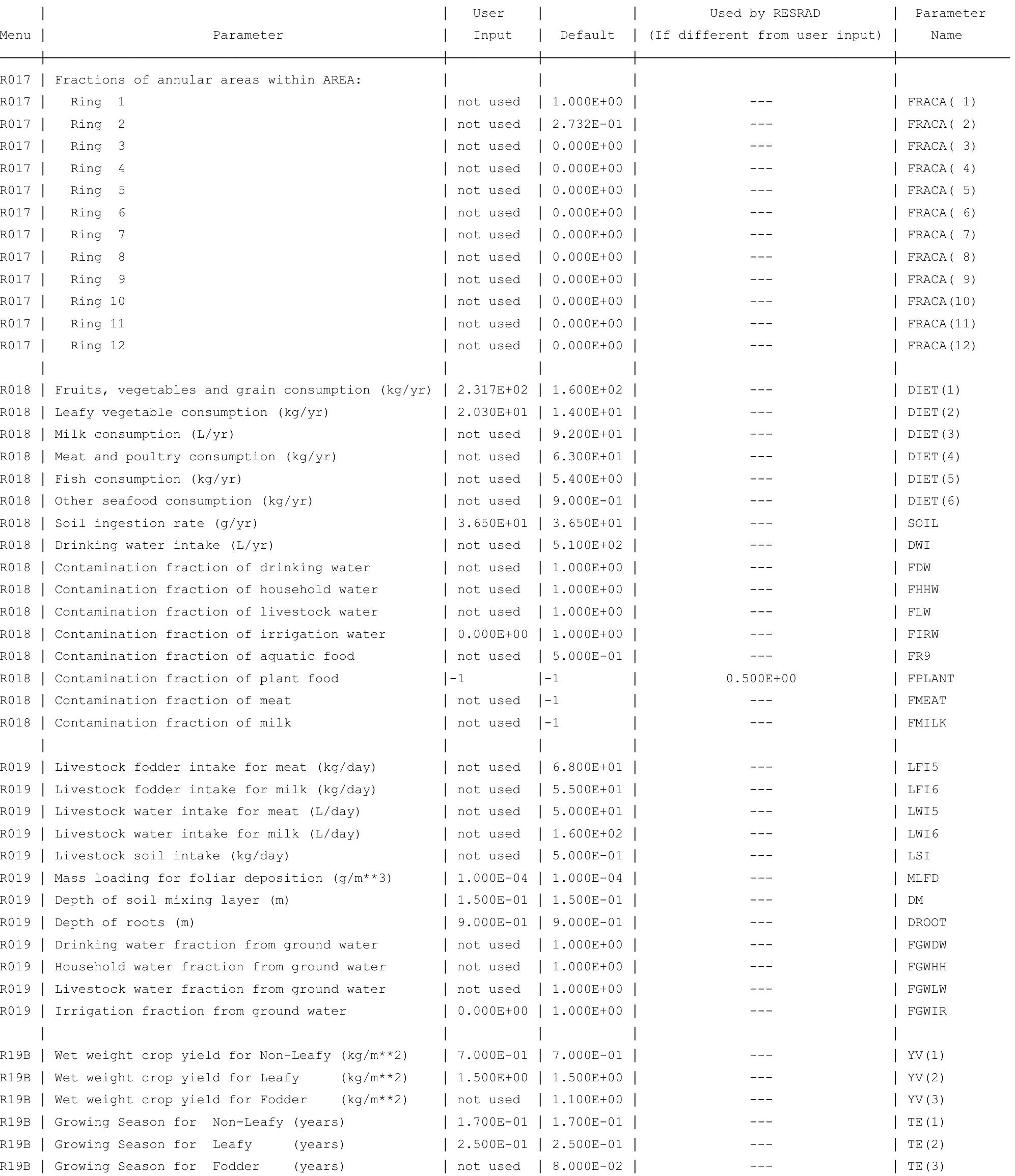


RESRAD, Version $6.5 \quad \mathrm{~T}^{1 / 2}$ Limit $=180$ days 
RESRAD, Version $6.5 \quad \mathrm{~T}^{1 / 2}$ Limit $=180$ days

05/23/2011 $08: 35$ Page 18

Summary : C746U Resident Gardener Deterministic Run

File : $X: \backslash F I N A L$ V2 $\backslash C 746 U$ RG SG FWD-FINALV2.RAD

Site-Specific Parameter Summary (continued)

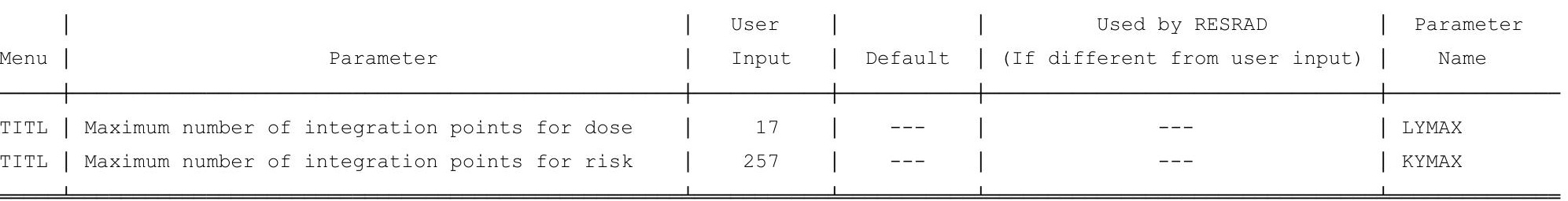

Summary of Pathway Selections

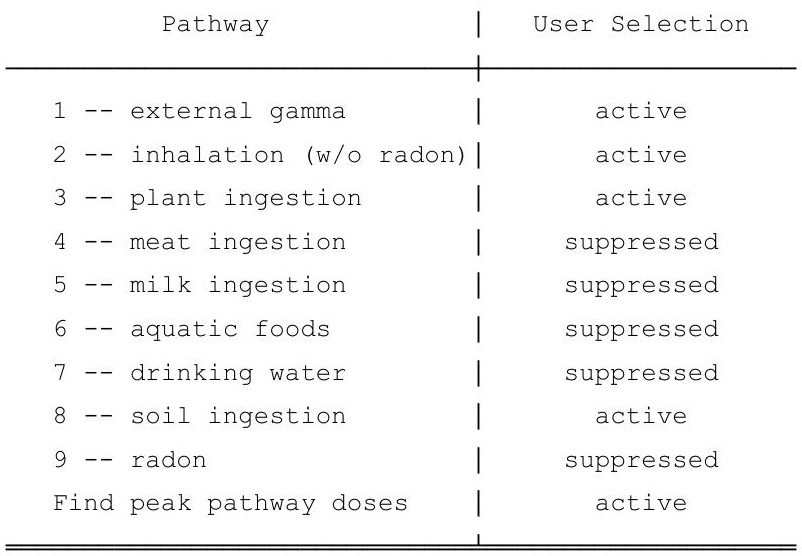


RESRAD, Version $6.5 \quad \mathrm{~T}^{1 / 2}$ Limit $=180$ days

Summary : C746U Resident Gardener Deterministic Run

File : $\mathrm{X}: \backslash$ FINAL V2 $\backslash \mathrm{C746U}$ RG SG FWD-FINALV2.RAD

Contaminated Zone Dimensions

Area: 89436.00 square meters

Thickness:

Cover Depth:

\begin{abstract}
13.40 meters
1.52 meters
\end{abstract}

Initial Soil Concentrations, pCi/g

$\begin{array}{ll}\mathrm{Am}-241 & 3.500 \mathrm{E}+03 \\ \mathrm{Cs}-137 & 1.900 \mathrm{E}+02 \\ \mathrm{~Np}-237 & 5.500 \mathrm{E}+02 \\ \mathrm{Pu}-238 & 3.900 \mathrm{E}+03 \\ \mathrm{Pu}-239 & 3.600 \mathrm{E}+03 \\ \mathrm{Pu}-240 & 3.600 \mathrm{E}+03 \\ \mathrm{TC}-99 & 2.800 \mathrm{E}+01 \\ \mathrm{Th}-228 & 7.400 \mathrm{E}+01 \\ \mathrm{Th}-230 & 1.200 \mathrm{E}+03 \\ \mathrm{Th}-232 & 3.800 \mathrm{E}+01 \\ \mathrm{U}-234 & 1.800 \mathrm{E}+04 \\ \mathrm{U}-235 & 8.200 \mathrm{E}+02 \\ \mathrm{U}-238 & 3.200 \mathrm{E}+03\end{array}$

Total Dose TDOSE(t), mrem/yr

Basic Radiation Dose Limit $=1.000 \mathrm{E}+02 \mathrm{mrem} / \mathrm{yr}$

Total Mixture Sum $M(t)=$ Fraction of Basic Dose Limit Received at Time (t)

$\begin{array}{rllllll}t \text { (years) }: & 0.000 \mathrm{E}+00 & 1.000 \mathrm{E}+00 & 5.000 \mathrm{E}+01 & 1.000 \mathrm{E}+02 & 5.000 \mathrm{E}+02 & 1.050 \mathrm{E}+03 \\ \mathrm{TDOSE}(\mathrm{t}): & 1.035 \mathrm{E}-04 & 7.509 \mathrm{E}-05 & 9.235 \mathrm{E}-05 & 1.342 \mathrm{E}-04 & 2.624 \mathrm{E}-03 & 1.108 \mathrm{E}+02 \\ \mathrm{M}(\mathrm{t}): & 1.035 \mathrm{E}-06 & 7.509 \mathrm{E}-07 & 9.235 \mathrm{E}-07 & 1.342 \mathrm{E}-06 & 2.624 \mathrm{E}-05 & 1.108 \mathrm{E}+00\end{array}$

Maximum TDOSE(t): $1.108 \mathrm{E}+02 \mathrm{mrem} / \mathrm{yr}$ at $t=1.050 \mathrm{E}+03$ years 
RESRAD, Version $6.5 \quad \mathrm{~T}^{1 / 2}$ Limit $=180$ days

ummary : C746U Resident Gardener Deterministic Run

File : $\mathrm{X}: \backslash$ FINAL V2 $\backslash$ C746U RG SG FWD-FINALV2.RAD

Total Dose Contributions TDOSE(i,p,t) for Individual Radionuclides (i) and Pathways (p) As mrem/yr and Fraction of Total Dose At $t=0.000 \mathrm{E}+00$ years

Water Independent Pathways (Inhalation excludes radon)

\begin{tabular}{|c|c|c|}
\hline ide & mrem/yr & fract. \\
\hline $1-241$ & $5.412 \mathrm{E}-16$ & 0.0000 \\
\hline-137 & $2.397 \mathrm{E}-07$ & 0.0023 \\
\hline-237 & $5.245 \mathrm{E}-10$ & 0.0000 \\
\hline-238 & $3.174 \mathrm{E}-19$ & 0.0000 \\
\hline-239 & 4. $328 \mathrm{E}-14$ & 0.0000 \\
\hline-240 & $4.115 \mathrm{E}-21$ & 0.0000 \\
\hline-99 & 1. $612 \mathrm{E}-24$ & 0.0000 \\
\hline-228 & $1.023 \mathrm{E}-04$ & 0.9885 \\
\hline-230 & $4.529 \mathrm{E}-08$ & 0.0004 \\
\hline-232 & $4.476 \mathrm{E}-07$ & 0.0043 \\
\hline 34 & $2.040 E-12$ & 0.0000 \\
\hline 35 & $1.020 \mathrm{E}-11$ & 0.0000 \\
\hline 238 & $4.543 E-07$ & 0.0044 \\
\hline & 04 & $\perp$ \\
\hline
\end{tabular}

Inhalation

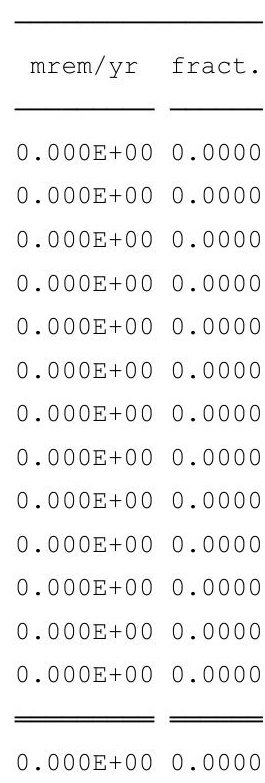

\begin{tabular}{ll} 
Radon \\
\hline mrem/yr fract. \\
\cline { 1 - 1 } 0.000E+00 & 0.0000 \\
$0.000 \mathrm{E}+00$ & 0.0000 \\
$0.000 \mathrm{E}+00$ & 0.0000 \\
$0.000 \mathrm{E}+00$ & 0.0000 \\
$0.000 \mathrm{E}+00$ & 0.0000 \\
$0.000 \mathrm{E}+00$ & 0.0000 \\
$0.000 \mathrm{E}+00$ & 0.0000 \\
$0.000 \mathrm{E}+00$ & 0.0000 \\
$0.000 \mathrm{E}+00$ & 0.0000 \\
$0.000 \mathrm{E}+00$ & 0.0000 \\
$0.000 \mathrm{E}+00$ & 0.0000 \\
$0.000 \mathrm{E}+00$ & 0.0000 \\
$0.000 \mathrm{E}+00$ & 0.0000 \\
\hline \hline $0.000 \mathrm{E}+00$ & 0.0000
\end{tabular}

\begin{tabular}{|c|c|}
\hline mrem/yr & fract. \\
\hline $0.000 \mathrm{E}+00$ & 0.0000 \\
\hline $0.000 \mathrm{E}+00$ & 0.0000 \\
\hline $0.000 \mathrm{E}+00$ & 0.0000 \\
\hline $0.000 \mathrm{E}+00$ & 0.0000 \\
\hline $0.000 \mathrm{E}+00$ & 0.0000 \\
\hline $0.000 \mathrm{E}+00$ & 0.0000 \\
\hline $0.000 \mathrm{E}+00$ & 0.0000 \\
\hline $0.000 \mathrm{E}+00$ & 0.0000 \\
\hline $0.000 \mathrm{E}+00$ & 0.0000 \\
\hline $0.000 \mathrm{E}+00$ & 0.0000 \\
\hline $0.000 \mathrm{E}+00$ & 0.0000 \\
\hline $0.000 \mathrm{E}+00$ & 0.0000 \\
\hline $0.000 \mathrm{E}+00$ & 0.0000 \\
\hline .000 & .000 \\
\hline
\end{tabular}

\begin{tabular}{|c|c|}
\hline mrem/yr & fract. \\
\hline $0.000 \mathrm{E}+00$ & 0.0000 \\
\hline $0.000 \mathrm{E}+00$ & 0.0000 \\
\hline $0.000 \mathrm{E}+00$ & 0.0000 \\
\hline $0.000 \mathrm{E}+00$ & 0.0000 \\
\hline $0.000 \mathrm{E}+00$ & 0.0000 \\
\hline $0.000 \mathrm{E}+00$ & 0.0000 \\
\hline $0.000 \mathrm{E}+00$ & 0.0000 \\
\hline $0.000 \mathrm{E}+00$ & 0.0000 \\
\hline $0.000 \mathrm{E}+00$ & 0.0000 \\
\hline $0.000 \mathrm{E}+00$ & 0.0000 \\
\hline $0.000 \mathrm{E}+00$ & 0.0000 \\
\hline $0.000 \mathrm{E}+00$ & 0.0000 \\
\hline $0.000 \mathrm{E}+00$ & 0.0000 \\
\hline
\end{tabular}

\begin{tabular}{cc} 
Milk \\
\cline { 1 - 1 } mrem/yr fract. \\
\cline { 1 - 1 } $0.000 \mathrm{E}+00$ & 0.0000 \\
$0.000 \mathrm{E}+00$ & 0.0000 \\
$0.000 \mathrm{E}+00$ & 0.0000 \\
$0.000 \mathrm{E}+00$ & 0.0000 \\
$0.000 \mathrm{E}+00$ & 0.0000 \\
$0.000 \mathrm{E}+00$ & 0.0000 \\
$0.000 \mathrm{E}+00$ & 0.0000 \\
$0.000 \mathrm{E}+00$ & 0.0000 \\
$0.000 \mathrm{E}+00$ & 0.0000 \\
$0.000 \mathrm{E}+00$ & 0.0000 \\
$0.000 \mathrm{E}+00$ & 0.0000 \\
$0.000 \mathrm{E}+00$ & 0.0000 \\
$0.000 \mathrm{E}+00$ & 0.0000 \\
\hline \hline $0.000 \mathrm{E}+00$ & 0.0000
\end{tabular}

Total Dose Contributions TDOSE (i,p,t) for Individual Radionuclides (i) and Pathways (p) As mrem/yr and Fraction of Total Dose At $t=0.000 \mathrm{E}+00$ years

Water Dependent Pathways

\begin{tabular}{llll} 
& & \multicolumn{2}{c}{ Water } \\
Radio- & & \\
Nuclide & mrem/yr & fract. \\
Am-241 & $0.000 \mathrm{E}+00$ & 0.0000 \\
Cs-137 & $0.000 \mathrm{E}+00$ & 0.0000 \\
$\mathrm{~Np}-237$ & $0.000 \mathrm{E}+00$ & 0.0000 \\
Pu-238 & $0.000 \mathrm{E}+00$ & 0.0000 \\
Pu-239 & $0.000 \mathrm{E}+00$ & 0.0000 \\
Pu-240 & $0.000 \mathrm{E}+00$ & 0.0000 \\
$\mathrm{TC}-99$ & $0.000 \mathrm{E}+00$ & 0.0000 \\
$\mathrm{Th}-228$ & $0.000 \mathrm{E}+00$ & 0.0000 \\
$\mathrm{Th}-230$ & $0.000 \mathrm{E}+00$ & 0.0000 \\
$\mathrm{Th}-232$ & $0.000 \mathrm{E}+00$ & 0.0000 \\
$\mathrm{U}-234$ & $0.000 \mathrm{E}+00$ & 0.0000 \\
$\mathrm{U}-235$ & $0.000 \mathrm{E}+00$ & 0.0000 \\
$\mathrm{U}-238$ & $0.000 \mathrm{E}+00$ & 0.0000 \\
\hline \hline
\end{tabular}

$0.000 \mathrm{E}+00 \quad 0.0000$

\begin{tabular}{cc} 
Fish \\
\hline mrem/yr fract. \\
\hline $0.000 \mathrm{E}+00$ & 0.0000 \\
$0.000 \mathrm{E}+00$ & 0.0000 \\
$0.000 \mathrm{E}+00$ & 0.0000 \\
$0.000 \mathrm{E}+00$ & 0.0000 \\
$0.000 \mathrm{E}+00$ & 0.0000 \\
$0.000 \mathrm{E}+00$ & 0.0000 \\
$0.000 \mathrm{E}+00$ & 0.0000 \\
$0.000 \mathrm{E}+00$ & 0.0000 \\
$0.000 \mathrm{E}+00$ & 0.0000 \\
$0.000 \mathrm{E}+00$ & 0.0000 \\
$0.000 \mathrm{E}+00$ & 0.0000 \\
$0.000 \mathrm{E}+00$ & 0.0000 \\
$0.000 \mathrm{E}+00$ & 0.0000 \\
\hline \hline
\end{tabular}

$0.000 \mathrm{E}+00 \quad 0.0000$

\begin{tabular}{cc} 
Radon \\
\cline { 1 - 1 } mrem/yr fract. \\
\hline $0.000 \mathrm{E}+00$ & 0.0000 \\
$0.000 \mathrm{E}+00$ & 0.0000 \\
$0.000 \mathrm{E}+00$ & 0.0000 \\
$0.000 \mathrm{E}+00$ & 0.0000 \\
$0.000 \mathrm{E}+00$ & 0.0000 \\
$0.000 \mathrm{E}+00$ & 0.0000 \\
$0.000 \mathrm{E}+00$ & 0.0000 \\
$0.000 \mathrm{E}+00$ & 0.0000 \\
$0.000 \mathrm{E}+00$ & 0.0000 \\
$0.000 \mathrm{E}+00$ & 0.0000 \\
$0.000 \mathrm{E}+00$ & 0.0000 \\
$0.000 \mathrm{E}+00$ & 0.0000 \\
$0.000 \mathrm{E}+00$ & 0.0000 \\
\hline \hline
\end{tabular}

$0.000 \mathrm{E}+00 \quad 0.0000$

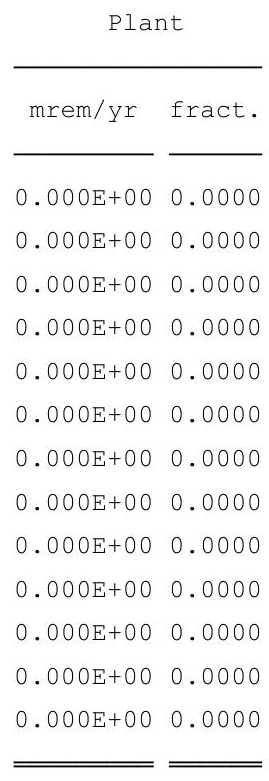

$0.000 \mathrm{E}+00 \quad 0.0000$

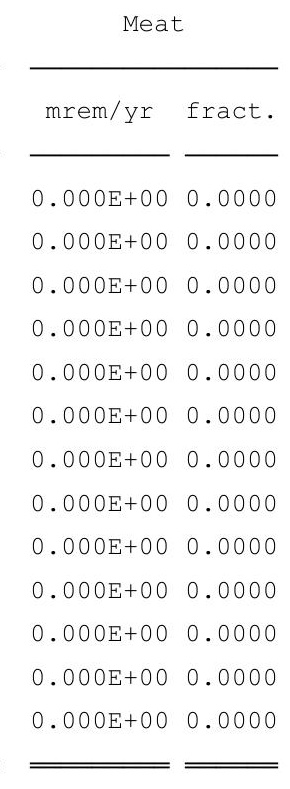

$0.000 \mathrm{E}+00 \quad 0.0000$

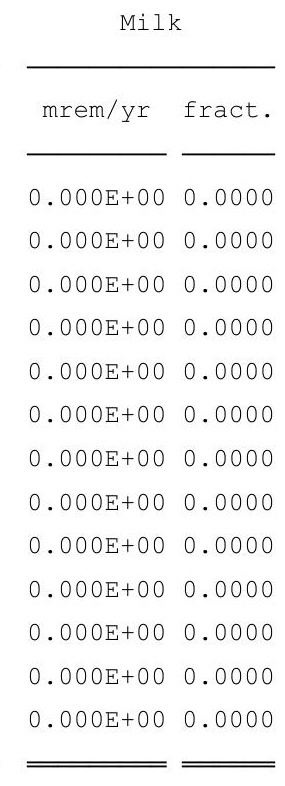

$0.000 E+00 \quad 0.0000$
Soil

\begin{tabular}{ccc} 
mrem/yr & fract. \\
\cline { 1 - 1 } $0.000 \mathrm{E}+00$ & 0.0000 \\
$0.000 \mathrm{E}+00$ & 0.0000 \\
$0.000 \mathrm{E}+00$ & 0.0000 \\
$0.000 \mathrm{E}+00$ & 0.0000 \\
$0.000 \mathrm{E}+00$ & 0.0000 \\
$0.000 \mathrm{E}+00$ & 0.0000 \\
$0.000 \mathrm{E}+00$ & 0.0000 \\
$0.000 \mathrm{E}+00$ & 0.0000 \\
$0.000 \mathrm{E}+00$ & 0.0000 \\
$0.000 \mathrm{E}+00$ & 0.0000 \\
$0.000 \mathrm{E}+00$ & 0.0000 \\
$0.000 \mathrm{E}+00$ & 0.0000 \\
$0.000 \mathrm{E}+00$ & 0.0000 \\
\hline \hline $0.000 \mathrm{E}+00$ & 0.0000
\end{tabular}

* Sum of all water independent and dependent pathways. 
RESRAD, Version $6.5 \quad \mathrm{~T}^{1 / 2}$ Limit $=180$ days

ummary : C746U Resident Gardener Deterministic Run

File : $\mathrm{X}: \backslash$ FINAL V2 $\backslash$ C746U RG SG FWD-FINALV2.RAD

Total Dose Contributions TDOSE(i,p,t) for Individual Radionuclides (i) and Pathways (p) As mrem/yr and Fraction of Total Dose At $t=1.000 \mathrm{E}+00$ years

Water Independent Pathways (Inhalation excludes radon)

\begin{tabular}{|c|c|c|}
\hline ide & mrem/yr & fract. \\
\hline $1-241$ & $1.638 \mathrm{E}-15$ & 0.0000 \\
\hline-137 & $2.362 \mathrm{E}-07$ & 0.0031 \\
\hline-237 & $5.301 \mathrm{E}-10$ & 0.0000 \\
\hline-238 & 4. $717 \mathrm{E}-18$ & 0.0000 \\
\hline-239 & $4.380 \mathrm{E}-14$ & 0.0000 \\
\hline-240 & $4.275 E-21$ & 0.0000 \\
\hline-99 & 1. $629 \mathrm{E}-24$ & 0.0000 \\
\hline-228 & $7.163 \mathrm{E}-05$ & 0.9540 \\
\hline-230 & $1.367 \mathrm{E}-07$ & 0.0018 \\
\hline-232 & $2.622 \mathrm{E}-06$ & 0.0349 \\
\hline 34 & $1.436 \mathrm{E}-11$ & 0.0000 \\
\hline 35 & $1.038 \mathrm{E}-11$ & 0.0000 \\
\hline 238 & $4.579 \mathrm{E}-07$ & 0.0061 \\
\hline & & \\
\hline
\end{tabular}

Inhalation

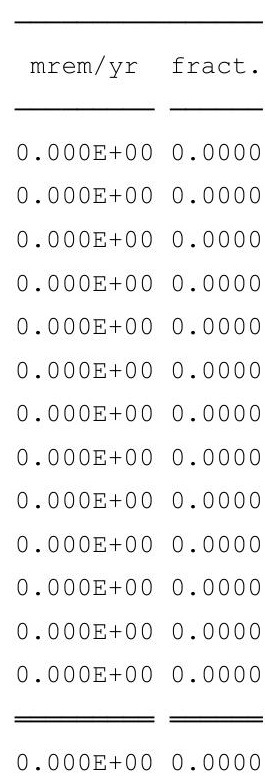

\begin{tabular}{ll} 
Radon \\
\hline mrem/yr fract. \\
\cline { 1 - 1 } 0.000E+00 & 0.0000 \\
$0.000 \mathrm{E}+00$ & 0.0000 \\
$0.000 \mathrm{E}+00$ & 0.0000 \\
$0.000 \mathrm{E}+00$ & 0.0000 \\
$0.000 \mathrm{E}+00$ & 0.0000 \\
$0.000 \mathrm{E}+00$ & 0.0000 \\
$0.000 \mathrm{E}+00$ & 0.0000 \\
$0.000 \mathrm{E}+00$ & 0.0000 \\
$0.000 \mathrm{E}+00$ & 0.0000 \\
$0.000 \mathrm{E}+00$ & 0.0000 \\
$0.000 \mathrm{E}+00$ & 0.0000 \\
$0.000 \mathrm{E}+00$ & 0.0000 \\
$0.000 \mathrm{E}+00$ & 0.0000 \\
\hline \hline $0.000 \mathrm{E}+00$ & 0.0000
\end{tabular}

\begin{tabular}{|c|c|}
\hline mrem/yr & fract. \\
\hline $0.000 \mathrm{E}+00$ & 0.0000 \\
\hline $0.000 \mathrm{E}+00$ & 0.0000 \\
\hline $0.000 \mathrm{E}+00$ & 0.0000 \\
\hline $0.000 \mathrm{E}+00$ & 0.0000 \\
\hline $0.000 \mathrm{E}+00$ & 0.0000 \\
\hline $0.000 \mathrm{E}+00$ & 0.0000 \\
\hline $0.000 \mathrm{E}+00$ & 0.0000 \\
\hline $0.000 \mathrm{E}+00$ & 0.0000 \\
\hline $0.000 \mathrm{E}+00$ & 0.0000 \\
\hline $0.000 \mathrm{E}+00$ & 0.0000 \\
\hline $0.000 \mathrm{E}+00$ & 0.0000 \\
\hline $0.000 \mathrm{E}+00$ & 0.0000 \\
\hline $0.000 \mathrm{E}+00$ & 0.0000 \\
\hline .000 & .000 \\
\hline
\end{tabular}

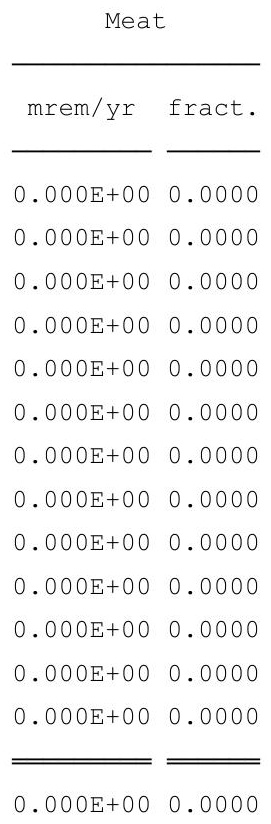

\begin{tabular}{cc} 
Milk \\
\cline { 1 - 1 } mrem/yr fract. \\
\cline { 1 - 1 } $0.000 \mathrm{E}+00$ & 0.0000 \\
$0.000 \mathrm{E}+00$ & 0.0000 \\
$0.000 \mathrm{E}+00$ & 0.0000 \\
$0.000 \mathrm{E}+00$ & 0.0000 \\
$0.000 \mathrm{E}+00$ & 0.0000 \\
$0.000 \mathrm{E}+00$ & 0.0000 \\
$0.000 \mathrm{E}+00$ & 0.0000 \\
$0.000 \mathrm{E}+00$ & 0.0000 \\
$0.000 \mathrm{E}+00$ & 0.0000 \\
$0.000 \mathrm{E}+00$ & 0.0000 \\
$0.000 \mathrm{E}+00$ & 0.0000 \\
$0.000 \mathrm{E}+00$ & 0.0000 \\
$0.000 \mathrm{E}+00$ & 0.0000 \\
\hline \hline $0.000 \mathrm{E}+00$ & 0.0000
\end{tabular}

Total Dose Contributions TDOSE (i,p,t) for Individual Radionuclides (i) and Pathways (p) As mrem/yr and Fraction of Total Dose At $t=1.000 \mathrm{E}+00$ years

Water Dependent Pathways

\begin{tabular}{llll} 
& & \multicolumn{2}{c}{ Water } \\
Radio- & & \\
Nuclide & mrem/yr & fract. \\
Am-241 & $0.000 \mathrm{E}+00$ & 0.0000 \\
Cs-137 & $0.000 \mathrm{E}+00$ & 0.0000 \\
$\mathrm{~Np}-237$ & $0.000 \mathrm{E}+00$ & 0.0000 \\
Pu-238 & $0.000 \mathrm{E}+00$ & 0.0000 \\
Pu-239 & $0.000 \mathrm{E}+00$ & 0.0000 \\
Pu-240 & $0.000 \mathrm{E}+00$ & 0.0000 \\
$\mathrm{TC}-99$ & $0.000 \mathrm{E}+00$ & 0.0000 \\
$\mathrm{Th}-228$ & $0.000 \mathrm{E}+00$ & 0.0000 \\
$\mathrm{Th}-230$ & $0.000 \mathrm{E}+00$ & 0.0000 \\
$\mathrm{Th}-232$ & $0.000 \mathrm{E}+00$ & 0.0000 \\
$\mathrm{U}-234$ & $0.000 \mathrm{E}+00$ & 0.0000 \\
$\mathrm{U}-235$ & $0.000 \mathrm{E}+00$ & 0.0000 \\
$\mathrm{U}-238$ & $0.000 \mathrm{E}+00$ & 0.0000 \\
\hline \hline
\end{tabular}

$0.000 \mathrm{E}+00 \quad 0.0000$

\begin{tabular}{cc} 
Fish \\
\cline { 1 - 2 } mrem/yr & fract. \\
\hline $0.000 \mathrm{E}+00$ & 0.0000 \\
$0.000 \mathrm{E}+00$ & 0.0000 \\
$0.000 \mathrm{E}+00$ & 0.0000 \\
$0.000 \mathrm{E}+00$ & 0.0000 \\
$0.000 \mathrm{E}+00$ & 0.0000 \\
$0.000 \mathrm{E}+00$ & 0.0000 \\
$0.000 \mathrm{E}+00$ & 0.0000 \\
$0.000 \mathrm{E}+00$ & 0.0000 \\
$0.000 \mathrm{E}+00$ & 0.0000 \\
$0.000 \mathrm{E}+00$ & 0.0000 \\
$0.000 \mathrm{E}+00$ & 0.0000 \\
$0.000 \mathrm{E}+00$ & 0.0000 \\
$0.000 \mathrm{E}+00$ & 0.0000 \\
\hline \hline
\end{tabular}

$0.000 \mathrm{E}+00 \quad 0.0000$

\begin{tabular}{cc} 
Radon \\
\cline { 1 - 1 } mrem/yr fract. \\
\hline $0.000 \mathrm{E}+00$ & 0.0000 \\
$0.000 \mathrm{E}+00$ & 0.0000 \\
$0.000 \mathrm{E}+00$ & 0.0000 \\
$0.000 \mathrm{E}+00$ & 0.0000 \\
$0.000 \mathrm{E}+00$ & 0.0000 \\
$0.000 \mathrm{E}+00$ & 0.0000 \\
$0.000 \mathrm{E}+00$ & 0.0000 \\
$0.000 \mathrm{E}+00$ & 0.0000 \\
$0.000 \mathrm{E}+00$ & 0.0000 \\
$0.000 \mathrm{E}+00$ & 0.0000 \\
$0.000 \mathrm{E}+00$ & 0.0000 \\
$0.000 \mathrm{E}+00$ & 0.0000 \\
$0.000 \mathrm{E}+00$ & 0.0000 \\
\hline \hline
\end{tabular}

$0.000 \mathrm{E}+00 \quad 0.0000$

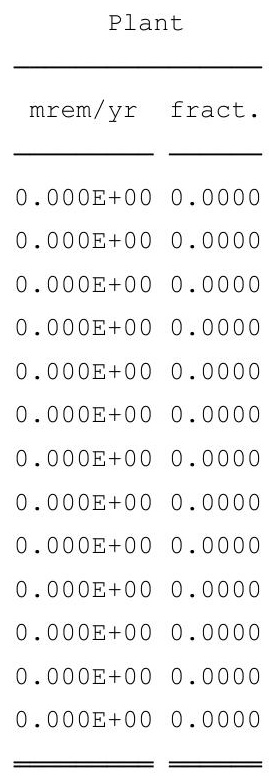

$0.000 \mathrm{E}+00 \quad 0.0000$

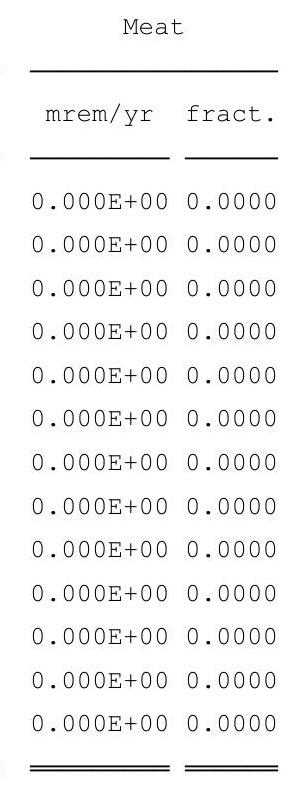

$0.000 \mathrm{E}+00 \quad 0.0000$

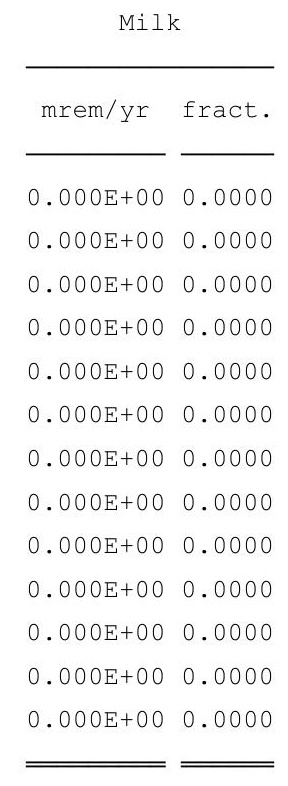

$0.000 E+00 \quad 0.0000$
Soil

\begin{tabular}{ccc} 
mrem/yr & fract. \\
\cline { 1 - 1 } $0.000 \mathrm{E}+00$ & 0.0000 \\
$0.000 \mathrm{E}+00$ & 0.0000 \\
$0.000 \mathrm{E}+00$ & 0.0000 \\
$0.000 \mathrm{E}+00$ & 0.0000 \\
$0.000 \mathrm{E}+00$ & 0.0000 \\
$0.000 \mathrm{E}+00$ & 0.0000 \\
$0.000 \mathrm{E}+00$ & 0.0000 \\
$0.000 \mathrm{E}+00$ & 0.0000 \\
$0.000 \mathrm{E}+00$ & 0.0000 \\
$0.000 \mathrm{E}+00$ & 0.0000 \\
$0.000 \mathrm{E}+00$ & 0.0000 \\
$0.000 \mathrm{E}+00$ & 0.0000 \\
$0.000 \mathrm{E}+00$ & 0.0000 \\
\hline \hline $0.000 \mathrm{E}+00$ & 0.0000
\end{tabular}

* Sum of all water independent and dependent pathways. 
RESRAD, Version $6.5 \quad \mathrm{~T}^{1 / 2}$ Limit $=180$ days

ummary : C746U Resident Gardener Deterministic Run

File : $\mathrm{X}: \backslash$ FINAL V2 $\backslash$ C746U RG SG FWD-FINALV2.RAD

Total Dose Contributions TDOSE(i,p,t) for Individual Radionuclides (i) and Pathways (p) As mrem/yr and Fraction of Total Dose At $t=5.000 \mathrm{E}+01$ years

Water Independent Pathways (Inhalation excludes radon)

\begin{tabular}{|c|c|c|}
\hline ide & mrem/yr & fract. \\
\hline $1-241$ & $8.973 E-14$ & 0.0000 \\
\hline-137 & $1.149 \mathrm{E}-07$ & 0.0012 \\
\hline-237 & $8.957 \mathrm{E}-10$ & 0.0000 \\
\hline-238 & $2.054 \mathrm{E}-13$ & 0.0000 \\
\hline-239 & $7.861 \mathrm{E}-14$ & 0.0000 \\
\hline-240 & $9.653 \mathrm{E}-18$ & 0.0000 \\
\hline-99 & $2.681 \mathrm{E}-24$ & 0.0000 \\
\hline-228 & $1.870 \mathrm{E}-12$ & 0.0000 \\
\hline-230 & $6.384 \mathrm{E}-06$ & 0.0691 \\
\hline-232 & $8.515 \mathrm{E}-05$ & 0.9221 \\
\hline 234 & $2.184 \mathrm{E}-08$ & 0.0002 \\
\hline 5 & $7.575 \mathrm{E}-11$ & 0.0000 \\
\hline 38 & $6.770 \mathrm{E}-07$ & 0.0073 \\
\hline & 05 & 1 \\
\hline
\end{tabular}

Inhalation

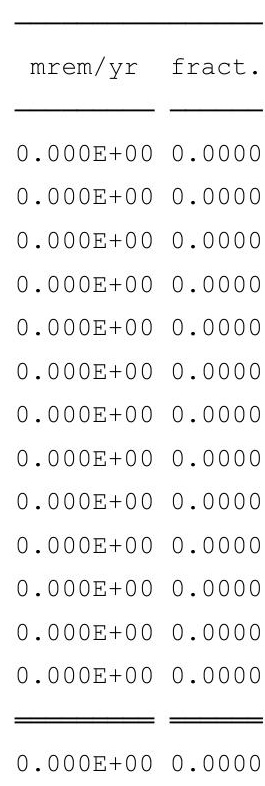

\begin{tabular}{ll} 
Radon \\
\hline mrem/yr fract. \\
\cline { 1 - 1 } 0.000E+00 & 0.0000 \\
$0.000 \mathrm{E}+00$ & 0.0000 \\
$0.000 \mathrm{E}+00$ & 0.0000 \\
$0.000 \mathrm{E}+00$ & 0.0000 \\
$0.000 \mathrm{E}+00$ & 0.0000 \\
$0.000 \mathrm{E}+00$ & 0.0000 \\
$0.000 \mathrm{E}+00$ & 0.0000 \\
$0.000 \mathrm{E}+00$ & 0.0000 \\
$0.000 \mathrm{E}+00$ & 0.0000 \\
$0.000 \mathrm{E}+00$ & 0.0000 \\
$0.000 \mathrm{E}+00$ & 0.0000 \\
$0.000 \mathrm{E}+00$ & 0.0000 \\
$0.000 \mathrm{E}+00$ & 0.0000 \\
\hline \hline $0.000 \mathrm{E}+00$ & 0.0000
\end{tabular}

\begin{tabular}{|c|c|}
\hline mrem/yr & fract. \\
\hline $0.000 \mathrm{E}+00$ & 0.0000 \\
\hline $0.000 \mathrm{E}+00$ & 0.0000 \\
\hline $0.000 \mathrm{E}+00$ & 0.0000 \\
\hline $0.000 \mathrm{E}+00$ & 0.0000 \\
\hline $0.000 \mathrm{E}+00$ & 0.0000 \\
\hline $0.000 \mathrm{E}+00$ & 0.0000 \\
\hline $0.000 \mathrm{E}+00$ & 0.0000 \\
\hline $0.000 \mathrm{E}+00$ & 0.0000 \\
\hline $0.000 \mathrm{E}+00$ & 0.0000 \\
\hline $0.000 \mathrm{E}+00$ & 0.0000 \\
\hline $0.000 \mathrm{E}+00$ & 0.0000 \\
\hline $0.000 \mathrm{E}+00$ & 0.0000 \\
\hline $0.000 \mathrm{E}+00$ & 0.0000 \\
\hline .000 & .000 \\
\hline
\end{tabular}

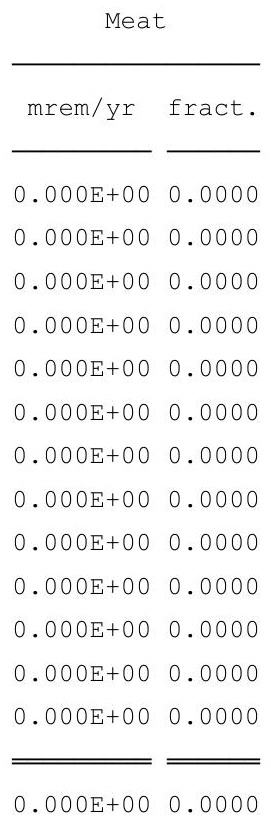

\begin{tabular}{cc} 
Milk \\
\cline { 1 - 1 } mrem/yr fract. \\
\cline { 1 - 1 } $0.000 \mathrm{E}+00$ & 0.0000 \\
$0.000 \mathrm{E}+00$ & 0.0000 \\
$0.000 \mathrm{E}+00$ & 0.0000 \\
$0.000 \mathrm{E}+00$ & 0.0000 \\
$0.000 \mathrm{E}+00$ & 0.0000 \\
$0.000 \mathrm{E}+00$ & 0.0000 \\
$0.000 \mathrm{E}+00$ & 0.0000 \\
$0.000 \mathrm{E}+00$ & 0.0000 \\
$0.000 \mathrm{E}+00$ & 0.0000 \\
$0.000 \mathrm{E}+00$ & 0.0000 \\
$0.000 \mathrm{E}+00$ & 0.0000 \\
$0.000 \mathrm{E}+00$ & 0.0000 \\
$0.000 \mathrm{E}+00$ & 0.0000 \\
\hline \hline $0.000 \mathrm{E}+00$ & 0.0000
\end{tabular}

Total Dose Contributions TDOSE (i,p,t) for Individual Radionuclides (i) and Pathways (p) As mrem/yr and Fraction of Total Dose At $t=5.000 \mathrm{E}+01$ years

Water Dependent Pathways

\begin{tabular}{llll} 
& & \multicolumn{2}{c}{ Water } \\
Radio- & & \\
Nuclide & mrem/yr & fract. \\
Am-241 & $0.000 \mathrm{E}+00$ & 0.0000 \\
Cs-137 & $0.000 \mathrm{E}+00$ & 0.0000 \\
$\mathrm{~Np}-237$ & $0.000 \mathrm{E}+00$ & 0.0000 \\
Pu-238 & $0.000 \mathrm{E}+00$ & 0.0000 \\
Pu-239 & $0.000 \mathrm{E}+00$ & 0.0000 \\
Pu-240 & $0.000 \mathrm{E}+00$ & 0.0000 \\
$\mathrm{TC}-99$ & $0.000 \mathrm{E}+00$ & 0.0000 \\
$\mathrm{Th}-228$ & $0.000 \mathrm{E}+00$ & 0.0000 \\
$\mathrm{Th}-230$ & $0.000 \mathrm{E}+00$ & 0.0000 \\
$\mathrm{Th}-232$ & $0.000 \mathrm{E}+00$ & 0.0000 \\
$\mathrm{U}-234$ & $0.000 \mathrm{E}+00$ & 0.0000 \\
$\mathrm{U}-235$ & $0.000 \mathrm{E}+00$ & 0.0000 \\
$\mathrm{U}-238$ & $0.000 \mathrm{E}+00$ & 0.0000 \\
\hline \hline
\end{tabular}

$0.000 \mathrm{E}+00 \quad 0.0000$

\begin{tabular}{cc} 
Fish \\
\cline { 1 - 2 } mrem/yr & fract. \\
\hline $0.000 \mathrm{E}+00$ & 0.0000 \\
$0.000 \mathrm{E}+00$ & 0.0000 \\
$0.000 \mathrm{E}+00$ & 0.0000 \\
$0.000 \mathrm{E}+00$ & 0.0000 \\
$0.000 \mathrm{E}+00$ & 0.0000 \\
$0.000 \mathrm{E}+00$ & 0.0000 \\
$0.000 \mathrm{E}+00$ & 0.0000 \\
$0.000 \mathrm{E}+00$ & 0.0000 \\
$0.000 \mathrm{E}+00$ & 0.0000 \\
$0.000 \mathrm{E}+00$ & 0.0000 \\
$0.000 \mathrm{E}+00$ & 0.0000 \\
$0.000 \mathrm{E}+00$ & 0.0000 \\
$0.000 \mathrm{E}+00$ & 0.0000 \\
\hline \hline
\end{tabular}

$0.000 \mathrm{E}+00 \quad 0.0000$

\begin{tabular}{cc} 
Radon \\
\cline { 1 - 1 } mrem/yr fract. \\
\hline $0.000 \mathrm{E}+00$ & 0.0000 \\
$0.000 \mathrm{E}+00$ & 0.0000 \\
$0.000 \mathrm{E}+00$ & 0.0000 \\
$0.000 \mathrm{E}+00$ & 0.0000 \\
$0.000 \mathrm{E}+00$ & 0.0000 \\
$0.000 \mathrm{E}+00$ & 0.0000 \\
$0.000 \mathrm{E}+00$ & 0.0000 \\
$0.000 \mathrm{E}+00$ & 0.0000 \\
$0.000 \mathrm{E}+00$ & 0.0000 \\
$0.000 \mathrm{E}+00$ & 0.0000 \\
$0.000 \mathrm{E}+00$ & 0.0000 \\
$0.000 \mathrm{E}+00$ & 0.0000 \\
$0.000 \mathrm{E}+00$ & 0.0000 \\
\hline \hline
\end{tabular}

$0.000 \mathrm{E}+00 \quad 0.0000$

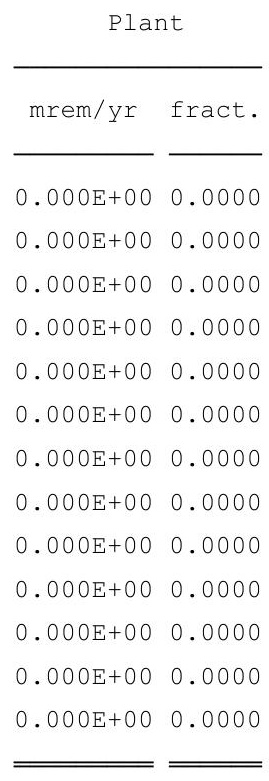

$0.000 \mathrm{E}+00 \quad 0.0000$

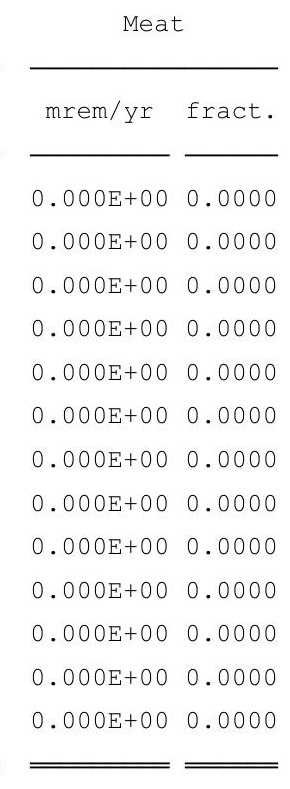

$0.000 \mathrm{E}+00 \quad 0.0000$

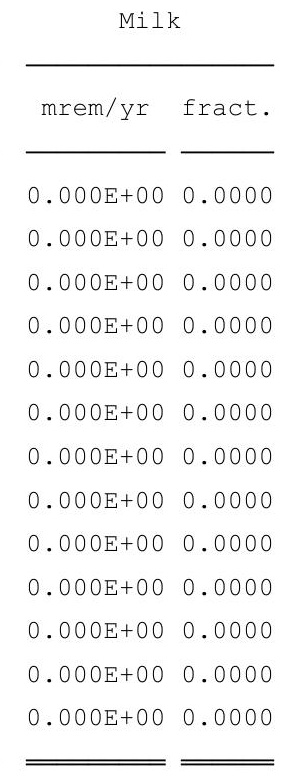

$0.000 E+00 \quad 0.0000$
Soil

\begin{tabular}{ccc} 
mrem/yr & fract. \\
\cline { 1 - 1 } $0.000 \mathrm{E}+00$ & 0.0000 \\
$0.000 \mathrm{E}+00$ & 0.0000 \\
$0.000 \mathrm{E}+00$ & 0.0000 \\
$0.000 \mathrm{E}+00$ & 0.0000 \\
$0.000 \mathrm{E}+00$ & 0.0000 \\
$0.000 \mathrm{E}+00$ & 0.0000 \\
$0.000 \mathrm{E}+00$ & 0.0000 \\
$0.000 \mathrm{E}+00$ & 0.0000 \\
$0.000 \mathrm{E}+00$ & 0.0000 \\
$0.000 \mathrm{E}+00$ & 0.0000 \\
$0.000 \mathrm{E}+00$ & 0.0000 \\
$0.000 \mathrm{E}+00$ & 0.0000 \\
$0.000 \mathrm{E}+00$ & 0.0000 \\
\hline \hline $0.000 \mathrm{E}+00$ & 0.0000
\end{tabular}

* Sum of all water independent and dependent pathways. 
RESRAD, Version $6.5 \quad \mathrm{~T}^{1 / 2}$ Limit $=180$ days

ummary : C746U Resident Gardener Deterministic Run

File : $\mathrm{X}: \backslash$ FINAL V2 $\backslash$ C746U RG SG FWD-FINALV2.RAD

Total Dose Contributions TDOSE(i,p,t) for Individual Radionuclides (i) and Pathways (p) As mrem/yr and Fraction of Total Dose At $t=1.000 \mathrm{E}+02$ years

Water Independent Pathways (Inhalation excludes radon)

\begin{tabular}{|c|c|c|}
\hline ide & mrem/yr & fract. \\
\hline $1-241$ & $2.940 \mathrm{E}-13$ & 0.0000 \\
\hline-137 & $5.512 \mathrm{E}-08$ & 0.0004 \\
\hline-237 & $1.534 \mathrm{E}-09$ & 0.0000 \\
\hline-238 & $2.076 \mathrm{E}-12$ & 0.0000 \\
\hline-239 & $1.428 \mathrm{E}-13$ & 0.0000 \\
\hline-240 & $6.420 \mathrm{E}-17$ & 0.0000 \\
\hline-99 & $4.458 E-24$ & 0.0000 \\
\hline-228 & $3.417 \mathrm{E}-20$ & 0.0000 \\
\hline-230 & $1.775 \mathrm{E}-05$ & 0.1323 \\
\hline-232 & $1.152 \mathrm{E}-04$ & 0.8589 \\
\hline 34 & $1.213 E-07$ & 0.0009 \\
\hline 35 & $2.778 \mathrm{E}-10$ & 0.0000 \\
\hline 238 & $1.009 \mathrm{E}-06$ & 0.0075 \\
\hline & 04 & $\perp$ \\
\hline
\end{tabular}

Inhalation

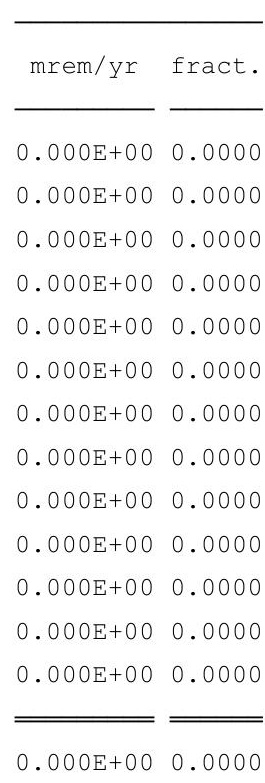

\begin{tabular}{ll} 
Radon \\
\hline mrem/yr fract. \\
\cline { 1 - 1 } 0.000E+00 & 0.0000 \\
$0.000 \mathrm{E}+00$ & 0.0000 \\
$0.000 \mathrm{E}+00$ & 0.0000 \\
$0.000 \mathrm{E}+00$ & 0.0000 \\
$0.000 \mathrm{E}+00$ & 0.0000 \\
$0.000 \mathrm{E}+00$ & 0.0000 \\
$0.000 \mathrm{E}+00$ & 0.0000 \\
$0.000 \mathrm{E}+00$ & 0.0000 \\
$0.000 \mathrm{E}+00$ & 0.0000 \\
$0.000 \mathrm{E}+00$ & 0.0000 \\
$0.000 \mathrm{E}+00$ & 0.0000 \\
$0.000 \mathrm{E}+00$ & 0.0000 \\
$0.000 \mathrm{E}+00$ & 0.0000 \\
\hline \hline $0.000 \mathrm{E}+00$ & 0.0000
\end{tabular}

\begin{tabular}{|c|c|}
\hline mrem/yr & fract. \\
\hline $0.000 \mathrm{E}+00$ & 0.0000 \\
\hline $0.000 \mathrm{E}+00$ & 0.0000 \\
\hline $0.000 \mathrm{E}+00$ & 0.0000 \\
\hline $0.000 \mathrm{E}+00$ & 0.0000 \\
\hline $0.000 \mathrm{E}+00$ & 0.0000 \\
\hline $0.000 \mathrm{E}+00$ & 0.0000 \\
\hline $0.000 \mathrm{E}+00$ & 0.0000 \\
\hline $0.000 \mathrm{E}+00$ & 0.0000 \\
\hline $0.000 \mathrm{E}+00$ & 0.0000 \\
\hline $0.000 \mathrm{E}+00$ & 0.0000 \\
\hline $0.000 \mathrm{E}+00$ & 0.0000 \\
\hline $0.000 \mathrm{E}+00$ & 0.0000 \\
\hline $0.000 \mathrm{E}+00$ & 0.0000 \\
\hline .000 & .000 \\
\hline
\end{tabular}

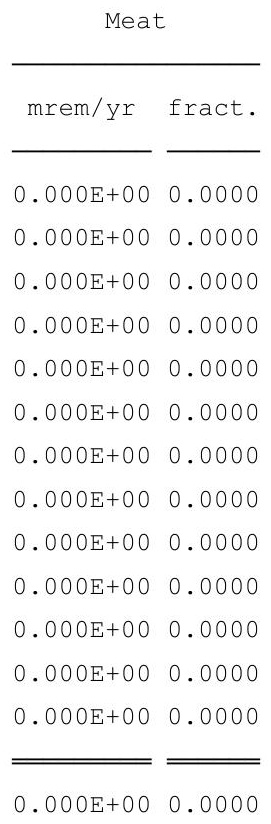

\begin{tabular}{cc} 
Milk \\
\cline { 1 - 1 } mrem/yr fract. \\
\cline { 1 - 1 } $0.000 \mathrm{E}+00$ & 0.0000 \\
$0.000 \mathrm{E}+00$ & 0.0000 \\
$0.000 \mathrm{E}+00$ & 0.0000 \\
$0.000 \mathrm{E}+00$ & 0.0000 \\
$0.000 \mathrm{E}+00$ & 0.0000 \\
$0.000 \mathrm{E}+00$ & 0.0000 \\
$0.000 \mathrm{E}+00$ & 0.0000 \\
$0.000 \mathrm{E}+00$ & 0.0000 \\
$0.000 \mathrm{E}+00$ & 0.0000 \\
$0.000 \mathrm{E}+00$ & 0.0000 \\
$0.000 \mathrm{E}+00$ & 0.0000 \\
$0.000 \mathrm{E}+00$ & 0.0000 \\
$0.000 \mathrm{E}+00$ & 0.0000 \\
\hline \hline $0.000 \mathrm{E}+00$ & 0.0000
\end{tabular}

Total Dose Contributions TDOSE (i,p,t) for Individual Radionuclides (i) and Pathways (p) As mrem/yr and Fraction of Total Dose At $t=1.000 \mathrm{E}+02$ years

Water Dependent Pathways

\begin{tabular}{llll} 
& & \multicolumn{2}{c}{ Water } \\
Radio- & & \\
Nuclide & mrem/yr & fract. \\
Am-241 & $0.000 \mathrm{E}+00$ & 0.0000 \\
Cs-137 & $0.000 \mathrm{E}+00$ & 0.0000 \\
$\mathrm{~Np}-237$ & $0.000 \mathrm{E}+00$ & 0.0000 \\
Pu-238 & $0.000 \mathrm{E}+00$ & 0.0000 \\
Pu-239 & $0.000 \mathrm{E}+00$ & 0.0000 \\
Pu-240 & $0.000 \mathrm{E}+00$ & 0.0000 \\
$\mathrm{TC}-99$ & $0.000 \mathrm{E}+00$ & 0.0000 \\
$\mathrm{Th}-228$ & $0.000 \mathrm{E}+00$ & 0.0000 \\
$\mathrm{Th}-230$ & $0.000 \mathrm{E}+00$ & 0.0000 \\
$\mathrm{Th}-232$ & $0.000 \mathrm{E}+00$ & 0.0000 \\
$\mathrm{U}-234$ & $0.000 \mathrm{E}+00$ & 0.0000 \\
$\mathrm{U}-235$ & $0.000 \mathrm{E}+00$ & 0.0000 \\
$\mathrm{U}-238$ & $0.000 \mathrm{E}+00$ & 0.0000 \\
\hline \hline
\end{tabular}

$0.000 \mathrm{E}+00 \quad 0.0000$

\begin{tabular}{cc} 
Fish \\
\cline { 1 - 2 } mrem/yr & fract. \\
\hline $0.000 \mathrm{E}+00$ & 0.0000 \\
$0.000 \mathrm{E}+00$ & 0.0000 \\
$0.000 \mathrm{E}+00$ & 0.0000 \\
$0.000 \mathrm{E}+00$ & 0.0000 \\
$0.000 \mathrm{E}+00$ & 0.0000 \\
$0.000 \mathrm{E}+00$ & 0.0000 \\
$0.000 \mathrm{E}+00$ & 0.0000 \\
$0.000 \mathrm{E}+00$ & 0.0000 \\
$0.000 \mathrm{E}+00$ & 0.0000 \\
$0.000 \mathrm{E}+00$ & 0.0000 \\
$0.000 \mathrm{E}+00$ & 0.0000 \\
$0.000 \mathrm{E}+00$ & 0.0000 \\
$0.000 \mathrm{E}+00$ & 0.0000 \\
\hline \hline
\end{tabular}

$0.000 \mathrm{E}+00 \quad 0.0000$

\begin{tabular}{cc} 
Radon \\
\cline { 1 - 1 } mrem/yr fract. \\
\hline $0.000 \mathrm{E}+00$ & 0.0000 \\
$0.000 \mathrm{E}+00$ & 0.0000 \\
$0.000 \mathrm{E}+00$ & 0.0000 \\
$0.000 \mathrm{E}+00$ & 0.0000 \\
$0.000 \mathrm{E}+00$ & 0.0000 \\
$0.000 \mathrm{E}+00$ & 0.0000 \\
$0.000 \mathrm{E}+00$ & 0.0000 \\
$0.000 \mathrm{E}+00$ & 0.0000 \\
$0.000 \mathrm{E}+00$ & 0.0000 \\
$0.000 \mathrm{E}+00$ & 0.0000 \\
$0.000 \mathrm{E}+00$ & 0.0000 \\
$0.000 \mathrm{E}+00$ & 0.0000 \\
$0.000 \mathrm{E}+00$ & 0.0000 \\
\hline \hline
\end{tabular}

$0.000 \mathrm{E}+00 \quad 0.0000$

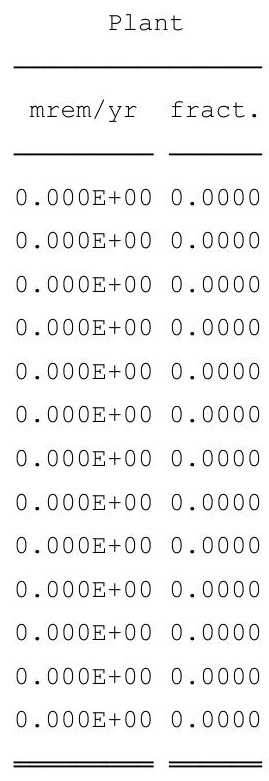

$0.000 \mathrm{E}+00 \quad 0.0000$

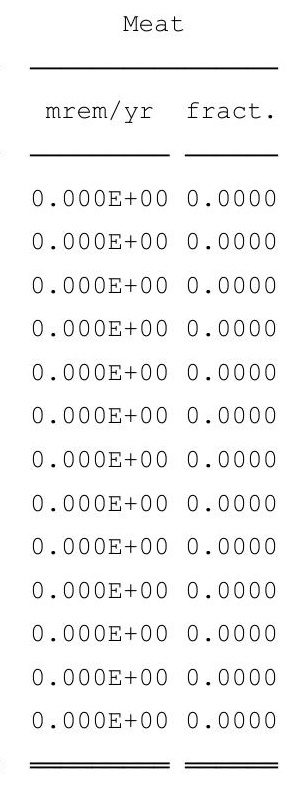

$0.000 \mathrm{E}+00 \quad 0.0000$

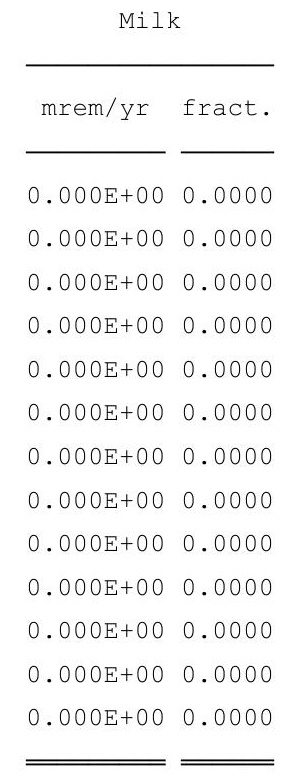

$0.000 E+00 \quad 0.0000$
Soil

\begin{tabular}{lll} 
mrem/yr & fract. \\
\cline { 1 - 1 } $0.000 \mathrm{E}+00$ & 0.0000 \\
$0.000 \mathrm{E}+00$ & 0.0000 \\
$0.000 \mathrm{E}+00$ & 0.0000 \\
$0.000 \mathrm{E}+00$ & 0.0000 \\
$0.000 \mathrm{E}+00$ & 0.0000 \\
$0.000 \mathrm{E}+00$ & 0.0000 \\
$0.000 \mathrm{E}+00$ & 0.0000 \\
$0.000 \mathrm{E}+00$ & 0.0000 \\
$0.000 \mathrm{E}+00$ & 0.0000 \\
$0.000 \mathrm{E}+00$ & 0.0000 \\
$0.000 \mathrm{E}+00$ & 0.0000 \\
$0.000 \mathrm{E}+00$ & 0.0000 \\
$0.000 \mathrm{E}+00$ & 0.0000 \\
\hline \hline $0.000 \mathrm{E}+00$ & 0.0000
\end{tabular}

* Sum of all water independent and dependent pathways. 
RESRAD, Version $6.5 \quad \mathrm{~T}^{1 / 2}$ Limit $=180$ days

ummary : C746U Resident Gardener Deterministic Run

File : $\mathrm{X}: \backslash$ FINAL V2 $\backslash$ C746U RG SG FWD-FINALV2.RAD

Total Dose Contributions TDOSE(i,p,t) for Individual Radionuclides (i) and Pathways (p) As mrem/yr and Fraction of Total Dose At $t=5.000 \mathrm{E}+02$ years

Water Independent Pathways (Inhalation excludes radon)

\begin{tabular}{|c|c|c|}
\hline ide & mrem/yr & fract. \\
\hline-241 & $8.032 \mathrm{E}-11$ & 0.0000 \\
\hline-137 & 1. $540 \mathrm{E}-10$ & 0.0000 \\
\hline-237 & $1.124 \mathrm{E}-07$ & 0.0000 \\
\hline-238 & $2.187 \mathrm{E}-09$ & 0.0000 \\
\hline-239 & $1.695 \mathrm{E}-11$ & 0.0000 \\
\hline-240 & $2.059 \mathrm{E}-14$ & 0.0000 \\
\hline-99 & $2.607 \mathrm{E}-22$ & 0.0000 \\
\hline-228 & $0.000 \mathrm{E}+00$ & 0.0000 \\
\hline-230 & $1.285 \mathrm{E}-03$ & 0.4899 \\
\hline-232 & $1.269 \mathrm{E}-03$ & 0.4835 \\
\hline 234 & $4.492 E-05$ & 0.0171 \\
\hline 235 & $5.767 \mathrm{E}-08$ & 0.0000 \\
\hline 238 & $2.457 \mathrm{E}-05$ & 0.0094 \\
\hline & 03 & 1.0 \\
\hline
\end{tabular}

Inhalation

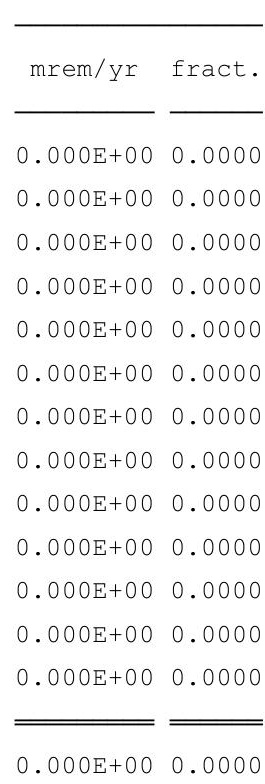

\begin{tabular}{ll} 
Radon \\
\hline mrem/yr fract. \\
\cline { 1 - 1 } 0.000E+00 & 0.0000 \\
$0.000 \mathrm{E}+00$ & 0.0000 \\
$0.000 \mathrm{E}+00$ & 0.0000 \\
$0.000 \mathrm{E}+00$ & 0.0000 \\
$0.000 \mathrm{E}+00$ & 0.0000 \\
$0.000 \mathrm{E}+00$ & 0.0000 \\
$0.000 \mathrm{E}+00$ & 0.0000 \\
$0.000 \mathrm{E}+00$ & 0.0000 \\
$0.000 \mathrm{E}+00$ & 0.0000 \\
$0.000 \mathrm{E}+00$ & 0.0000 \\
$0.000 \mathrm{E}+00$ & 0.0000 \\
$0.000 \mathrm{E}+00$ & 0.0000 \\
$0.000 \mathrm{E}+00$ & 0.0000 \\
\hline \hline $0.000 \mathrm{E}+00$ & 0.0000
\end{tabular}

\begin{tabular}{|c|c|}
\hline mrem/yr & fract. \\
\hline $0.000 \mathrm{E}+00$ & 0.0000 \\
\hline $0.000 \mathrm{E}+00$ & 0.0000 \\
\hline $0.000 \mathrm{E}+00$ & 0.0000 \\
\hline $0.000 \mathrm{E}+00$ & 0.0000 \\
\hline $0.000 \mathrm{E}+00$ & 0.0000 \\
\hline $0.000 \mathrm{E}+00$ & 0.0000 \\
\hline $0.000 \mathrm{E}+00$ & 0.0000 \\
\hline $0.000 \mathrm{E}+00$ & 0.0000 \\
\hline $0.000 \mathrm{E}+00$ & 0.0000 \\
\hline $0.000 \mathrm{E}+00$ & 0.0000 \\
\hline $0.000 \mathrm{E}+00$ & 0.0000 \\
\hline $0.000 \mathrm{E}+00$ & 0.0000 \\
\hline $0.000 \mathrm{E}+00$ & 0.0000 \\
\hline .000 & .000 \\
\hline
\end{tabular}

\begin{tabular}{|c|c|}
\hline mrem/yr & fract. \\
\hline $0.000 \mathrm{E}+00$ & 0.0000 \\
\hline $0.000 \mathrm{E}+00$ & 0.0000 \\
\hline $0.000 \mathrm{E}+00$ & 0.0000 \\
\hline $0.000 \mathrm{E}+00$ & 0.0000 \\
\hline $0.000 \mathrm{E}+00$ & 0.0000 \\
\hline $0.000 \mathrm{E}+00$ & 0.0000 \\
\hline $0.000 \mathrm{E}+00$ & 0.0000 \\
\hline $0.000 \mathrm{E}+00$ & 0.0000 \\
\hline $0.000 \mathrm{E}+00$ & 0.0000 \\
\hline $0.000 \mathrm{E}+00$ & 0.0000 \\
\hline $0.000 \mathrm{E}+00$ & 0.0000 \\
\hline $0.000 \mathrm{E}+00$ & 0.0000 \\
\hline $0.000 \mathrm{E}+00$ & 0.0000 \\
\hline
\end{tabular}

\begin{tabular}{cc} 
Milk \\
\cline { 1 - 1 } mrem/yr fract. \\
\cline { 1 - 1 } $0.000 \mathrm{E}+00$ & 0.0000 \\
$0.000 \mathrm{E}+00$ & 0.0000 \\
$0.000 \mathrm{E}+00$ & 0.0000 \\
$0.000 \mathrm{E}+00$ & 0.0000 \\
$0.000 \mathrm{E}+00$ & 0.0000 \\
$0.000 \mathrm{E}+00$ & 0.0000 \\
$0.000 \mathrm{E}+00$ & 0.0000 \\
$0.000 \mathrm{E}+00$ & 0.0000 \\
$0.000 \mathrm{E}+00$ & 0.0000 \\
$0.000 \mathrm{E}+00$ & 0.0000 \\
$0.000 \mathrm{E}+00$ & 0.0000 \\
$0.000 \mathrm{E}+00$ & 0.0000 \\
$0.000 \mathrm{E}+00$ & 0.0000 \\
\hline \hline $0.000 \mathrm{E}+00$ & 0.0000
\end{tabular}

Total Dose Contributions TDOSE (i,p,t) for Individual Radionuclides (i) and Pathways (p) As mrem/yr and Fraction of Total Dose At $t=5.000 \mathrm{E}+02$ years

Water Dependent Pathways

\begin{tabular}{llll} 
& & \multicolumn{2}{c}{ Water } \\
Radio- & & \\
Nuclide & mrem/yr & fract. \\
Am-241 & $0.000 \mathrm{E}+00$ & 0.0000 \\
Cs-137 & $0.000 \mathrm{E}+00$ & 0.0000 \\
$\mathrm{~Np}-237$ & $0.000 \mathrm{E}+00$ & 0.0000 \\
Pu-238 & $0.000 \mathrm{E}+00$ & 0.0000 \\
Pu-239 & $0.000 \mathrm{E}+00$ & 0.0000 \\
Pu-240 & $0.000 \mathrm{E}+00$ & 0.0000 \\
$\mathrm{TC}-99$ & $0.000 \mathrm{E}+00$ & 0.0000 \\
$\mathrm{Th}-228$ & $0.000 \mathrm{E}+00$ & 0.0000 \\
$\mathrm{Th}-230$ & $0.000 \mathrm{E}+00$ & 0.0000 \\
$\mathrm{Th}-232$ & $0.000 \mathrm{E}+00$ & 0.0000 \\
$\mathrm{U}-234$ & $0.000 \mathrm{E}+00$ & 0.0000 \\
$\mathrm{U}-235$ & $0.000 \mathrm{E}+00$ & 0.0000 \\
$\mathrm{U}-238$ & $0.000 \mathrm{E}+00$ & 0.0000 \\
\hline \hline
\end{tabular}

$0.000 \mathrm{E}+00 \quad 0.0000$

\begin{tabular}{cc} 
Fish \\
\cline { 1 - 2 } mrem/yr & fract. \\
\hline $0.000 \mathrm{E}+00$ & 0.0000 \\
$0.000 \mathrm{E}+00$ & 0.0000 \\
$0.000 \mathrm{E}+00$ & 0.0000 \\
$0.000 \mathrm{E}+00$ & 0.0000 \\
$0.000 \mathrm{E}+00$ & 0.0000 \\
$0.000 \mathrm{E}+00$ & 0.0000 \\
$0.000 \mathrm{E}+00$ & 0.0000 \\
$0.000 \mathrm{E}+00$ & 0.0000 \\
$0.000 \mathrm{E}+00$ & 0.0000 \\
$0.000 \mathrm{E}+00$ & 0.0000 \\
$0.000 \mathrm{E}+00$ & 0.0000 \\
$0.000 \mathrm{E}+00$ & 0.0000 \\
$0.000 \mathrm{E}+00$ & 0.0000 \\
\hline \hline
\end{tabular}

$0.000 \mathrm{E}+00 \quad 0.0000$

\begin{tabular}{cc} 
Radon \\
\cline { 1 - 1 } mrem/yr fract. \\
\hline $0.000 \mathrm{E}+00$ & 0.0000 \\
$0.000 \mathrm{E}+00$ & 0.0000 \\
$0.000 \mathrm{E}+00$ & 0.0000 \\
$0.000 \mathrm{E}+00$ & 0.0000 \\
$0.000 \mathrm{E}+00$ & 0.0000 \\
$0.000 \mathrm{E}+00$ & 0.0000 \\
$0.000 \mathrm{E}+00$ & 0.0000 \\
$0.000 \mathrm{E}+00$ & 0.0000 \\
$0.000 \mathrm{E}+00$ & 0.0000 \\
$0.000 \mathrm{E}+00$ & 0.0000 \\
$0.000 \mathrm{E}+00$ & 0.0000 \\
$0.000 \mathrm{E}+00$ & 0.0000 \\
$0.000 \mathrm{E}+00$ & 0.0000 \\
\hline \hline
\end{tabular}

$0.000 \mathrm{E}+00 \quad 0.0000$

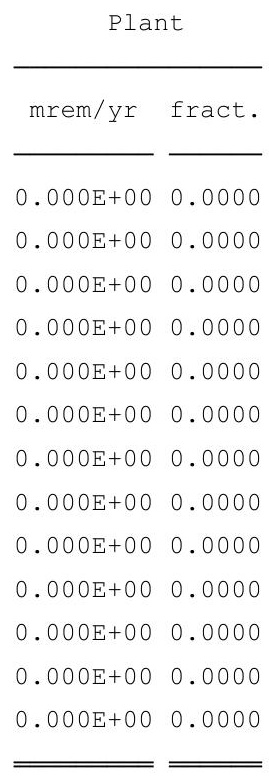

$0.000 \mathrm{E}+00 \quad 0.0000$

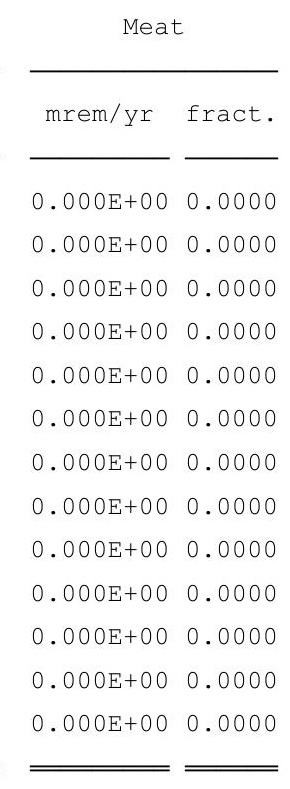

$0.000 \mathrm{E}+00 \quad 0.0000$

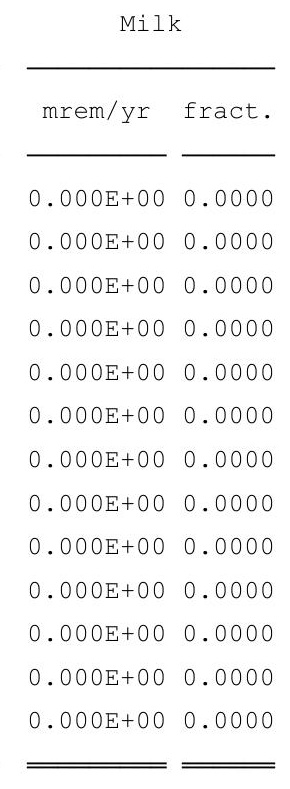

$0.000 E+00 \quad 0.0000$
Soil

\begin{tabular}{ccc} 
mrem/yr & fract. \\
\cline { 1 - 1 } $0.000 \mathrm{E}+00$ & 0.0000 \\
$0.000 \mathrm{E}+00$ & 0.0000 \\
$0.000 \mathrm{E}+00$ & 0.0000 \\
$0.000 \mathrm{E}+00$ & 0.0000 \\
$0.000 \mathrm{E}+00$ & 0.0000 \\
$0.000 \mathrm{E}+00$ & 0.0000 \\
$0.000 \mathrm{E}+00$ & 0.0000 \\
$0.000 \mathrm{E}+00$ & 0.0000 \\
$0.000 \mathrm{E}+00$ & 0.0000 \\
$0.000 \mathrm{E}+00$ & 0.0000 \\
$0.000 \mathrm{E}+00$ & 0.0000 \\
$0.000 \mathrm{E}+00$ & 0.0000 \\
$0.000 \mathrm{E}+00$ & 0.0000 \\
\hline \hline $0.000 \mathrm{E}+00$ & 0.0000
\end{tabular}

* Sum of all water independent and dependent pathways. 
RESRAD, Version $6.5 \quad \mathrm{~T}^{1 / 2}$ Limit $=180$ days

ummary : C746U Resident Gardener Deterministic Run

File : $\mathrm{X}: \backslash$ FINAL V2 $\backslash$ C746U RG SG FWD-FINALV2.RAD

Total Dose Contributions TDOSE(i,p,t) for Individual Radionuclides (i) and Pathways (p) As mrem/yr and Fraction of Total Dose At $t=1.050 \mathrm{E}+03$ years

Water Independent Pathways (Inhalation excludes radon)

\begin{tabular}{|c|c|c|c|c|c|c|c|c|c|c|c|c|}
\hline \multirow[b]{2}{*}{ Nuclide } & \multicolumn{2}{|c|}{ Ground } & \multicolumn{2}{|c|}{ Inhalation } & \multicolumn{2}{|c|}{ Radon } & \multicolumn{2}{|c|}{ Plant } & \multicolumn{2}{|c|}{ Meat } & \multicolumn{2}{|c|}{ Milk } \\
\hline & mrem/yr & fract. & mrem/yr & fract. & mrem/yr & fract. & mrem/yr & fract. & mrem/yr & fract. & mrem/yr & fract. \\
\hline-241 & $4.257 \mathrm{E}-08$ & 0.0000 & $0.000 \mathrm{E}+00$ & 0.0000 & $0.000 \mathrm{E}+00$ & 0.0000 & $6.939 \mathrm{E}-01$ & 0.0063 & $0.000 \mathrm{E}+00$ & 0.0000 & $0.000 \mathrm{E}+00$ & 0.0000 \\
\hline-137 & $4.741 \mathrm{E}-14$ & 0.0000 & $0.000 \mathrm{E}+00$ & 0.0000 & $0.000 \mathrm{E}+00$ & 0.0000 & $1.461 \mathrm{E}-11$ & 0.0000 & $0.000 \mathrm{E}+00$ & 0.0000 & $0.000 \mathrm{E}+00$ & 0.0000 \\
\hline-237 & $3.910 \mathrm{E}-05$ & 0.0000 & $0.000 \mathrm{E}+00$ & 0.0000 & $0.000 \mathrm{E}+00$ & 0.0000 & $5.637 \mathrm{E}+00$ & 0.0509 & $0.000 \mathrm{E}+00$ & 0.0000 & $0.000 \mathrm{E}+00$ & 0.0000 \\
\hline-238 & $5.077 \mathrm{E}-07$ & 0.0000 & $0.000 \mathrm{E}+00$ & 0.0000 & $0.000 \mathrm{E}+00$ & 0.0000 & $2.382 \mathrm{E}-03$ & 0.0000 & $0.000 \mathrm{E}+00$ & 0.0000 & $0.000 \mathrm{E}+00$ & 0.0000 \\
\hline-239 & $1.202 \mathrm{E}-08$ & 0.0000 & $0.000 \mathrm{E}+00$ & 0.0000 & $0.000 \mathrm{E}+00$ & 0.0000 & $4.566 \mathrm{E}+00$ & 0.0412 & $0.000 \mathrm{E}+00$ & 0.0000 & $0.000 \mathrm{E}+00$ & 0.0000 \\
\hline-240 & $2.914 \mathrm{E}-12$ & 0.0000 & $0.000 \mathrm{E}+00$ & 0.0000 & $0.000 \mathrm{E}+00$ & 0.0000 & $4.210 \mathrm{E}+00$ & 0.0380 & $0.000 \mathrm{E}+00$ & 0.0000 & $0.000 \mathrm{E}+00$ & 0.0000 \\
\hline-99 & $7.008 E-20$ & 0.0000 & $0.000 \mathrm{E}+00$ & 0.0000 & $0.000 \mathrm{E}+00$ & 0.0000 & $3.711 \mathrm{E}-05$ & 0.0000 & $0.000 \mathrm{E}+00$ & 0.0000 & $0.000 \mathrm{E}+00$ & 0.0000 \\
\hline-228 & $0.000 \mathrm{E}+00$ & 0.0000 & $0.000 \mathrm{E}+00$ & 0.0000 & $0.000 \mathrm{E}+00$ & 0.0000 & $0.000 \mathrm{E}+00$ & 0.0000 & $0.000 \mathrm{E}+00$ & 0.0000 & $0.000 \mathrm{E}+00$ & 0.0000 \\
\hline-230 & $1.076 \mathrm{E}-01$ & 0.0010 & $0.000 \mathrm{E}+00$ & 0.0000 & $0.000 \mathrm{E}+00$ & 0.0000 & $6.971 E+01$ & 0.6294 & $0.000 \mathrm{E}+00$ & 0.0000 & $0.000 \mathrm{E}+00$ & 0.0000 \\
\hline 232 & $3.513 E-02$ & 0.0003 & $0.000 \mathrm{E}+00$ & 0.0000 & $0.000 \mathrm{E}+00$ & 0.0000 & $5.630 \mathrm{E}+00$ & 0.0508 & $0.000 \mathrm{E}+00$ & 0.0000 & $0.000 \mathrm{E}+00$ & 0.0000 \\
\hline 34 & $8.176 \mathrm{E}-03$ & 0.0001 & $0.000 \mathrm{E}+00$ & 0.0000 & $0.000 \mathrm{E}+00$ & 0.0000 & $1.669 \mathrm{E}+01$ & 0.1507 & $0.000 \mathrm{E}+00$ & 0.0000 & $0.000 \mathrm{E}+00$ & 0.0000 \\
\hline 35 & $1.926 \mathrm{E}-05$ & 0.0000 & $0.000 \mathrm{E}+00$ & 0.0000 & $0.000 \mathrm{E}+00$ & 0.0000 & $1.449 \mathrm{E}+00$ & 0.0131 & $0.000 \mathrm{E}+00$ & 0.0000 & $0.000 \mathrm{E}+00$ & 0.0000 \\
\hline 38 & $1.984 \mathrm{E}-03$ & 0.0000 & $0.000 \mathrm{E}+00$ & 0.0000 & $0.000 \mathrm{E}+00$ & 0.0000 & $2.025 \mathrm{E}+00$ & 0.0183 & $0.000 \mathrm{E}+00$ & 0.0000 & $0.000 \mathrm{E}+00$ & 0.0000 \\
\hline & $1.529 \mathrm{E}-01$ & 0.0014 & $0.000 \mathrm{E}+00$ & 0.0000 & $0.000 \mathrm{E}+00$ & 0.0000 & $1.106 \mathrm{E}+02$ & 0.9986 & $0.000 \mathrm{E}+00$ & 0.0000 & $0.000 \mathrm{E}+00$ & 0.0000 \\
\hline
\end{tabular}

Total Dose Contributions TDOSE (i,p,t) for Individual Radionuclides (i) and Pathways (p) As mrem/yr and Fraction of Total Dose At $t=1.050 \mathrm{E}+03$ years

Water Dependent Pathways

\begin{tabular}{llll} 
& & Water \\
Radio- & & \\
Nuclide & mrem/yr & fract. \\
Am-241 & $0.000 \mathrm{E}+00$ & 0.0000 \\
$\mathrm{Cs}-137$ & $0.000 \mathrm{E}+00$ & 0.0000 \\
$\mathrm{~Np}-237$ & $0.000 \mathrm{E}+00$ & 0.0000 \\
Pu-238 & $0.000 \mathrm{E}+00$ & 0.0000 \\
Pu-239 & $0.000 \mathrm{E}+00$ & 0.0000 \\
Pu-240 & $0.000 \mathrm{E}+00$ & 0.0000 \\
$\mathrm{TC}-99$ & $0.000 \mathrm{E}+00$ & 0.0000 \\
$\mathrm{Th}-228$ & $0.000 \mathrm{E}+00$ & 0.0000 \\
$\mathrm{Th}-230$ & $0.000 \mathrm{E}+00$ & 0.0000 \\
$\mathrm{Th}-232$ & $0.000 \mathrm{E}+00$ & 0.0000 \\
$\mathrm{U}-234$ & $0.000 \mathrm{E}+00$ & 0.0000 \\
$\mathrm{U}-235$ & $0.000 \mathrm{E}+00$ & 0.0000 \\
$\mathrm{U}-238$ & $0.000 \mathrm{E}+00$ & 0.0000 \\
\hline \hline
\end{tabular}

Total

$0.000 \mathrm{E}+00 \quad 0.0000$

\begin{tabular}{cc} 
Fish \\
\hline mrem/yr fract. \\
\cline { 1 - 1 } 0.000E+00 & 0.0000 \\
$0.000 \mathrm{E}+00$ & 0.0000 \\
$0.000 \mathrm{E}+00$ & 0.0000 \\
$0.000 \mathrm{E}+00$ & 0.0000 \\
$0.000 \mathrm{E}+00$ & 0.0000 \\
$0.000 \mathrm{E}+00$ & 0.0000 \\
$0.000 \mathrm{E}+00$ & 0.0000 \\
$0.000 \mathrm{E}+00$ & 0.0000 \\
$0.000 \mathrm{E}+00$ & 0.0000 \\
$0.000 \mathrm{E}+00$ & 0.0000 \\
$0.000 \mathrm{E}+00$ & 0.0000 \\
$0.000 \mathrm{E}+00$ & 0.0000 \\
$0.000 \mathrm{E}+00$ & 0.0000 \\
\hline \hline
\end{tabular}

$0.000 E+00 \quad 0.0000$

\begin{tabular}{cc} 
Radon \\
\cline { 1 - 2 } mrem/yr fract. \\
\hline $0.000 \mathrm{E}+00$ & 0.0000 \\
$0.000 \mathrm{E}+00$ & 0.0000 \\
$0.000 \mathrm{E}+00$ & 0.0000 \\
$0.000 \mathrm{E}+00$ & 0.0000 \\
$0.000 \mathrm{E}+00$ & 0.0000 \\
$0.000 \mathrm{E}+00$ & 0.0000 \\
$0.000 \mathrm{E}+00$ & 0.0000 \\
$0.000 \mathrm{E}+00$ & 0.0000 \\
$0.000 \mathrm{E}+00$ & 0.0000 \\
$0.000 \mathrm{E}+00$ & 0.0000 \\
$0.000 \mathrm{E}+00$ & 0.0000 \\
$0.000 \mathrm{E}+00$ & 0.0000 \\
$0.000 \mathrm{E}+00$ & 0.0000 \\
\hline \hline
\end{tabular}

$0.000 \mathrm{E}+00 \quad 0.0000$

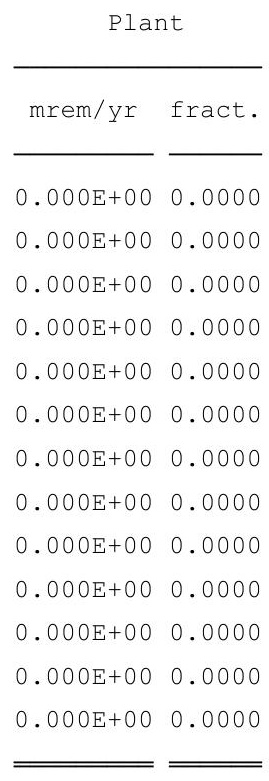

$0.000 \mathrm{E}+00 \quad 0.0000$

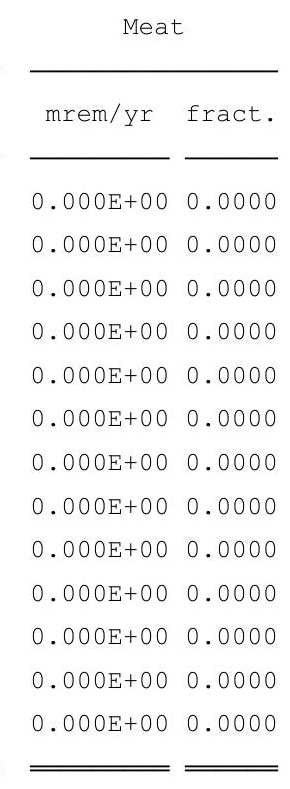

$0.000 \mathrm{E}+00 \quad 0.0000$

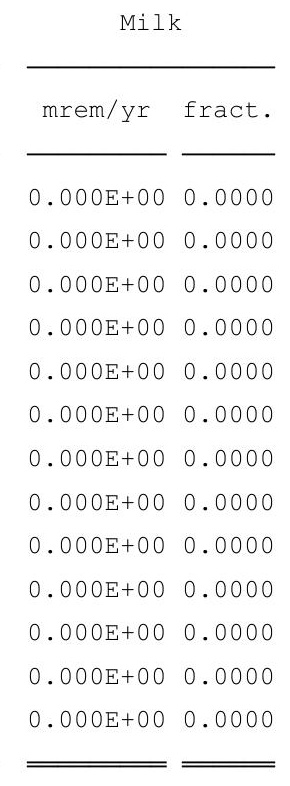

$0.000 \mathrm{E}+00 \quad 0.0000$
Soil

\begin{tabular}{lll} 
mrem/yr & fract. \\
\cline { 1 - 1 } $0.000 \mathrm{E}+00$ & 0.0000 \\
$0.000 \mathrm{E}+00$ & 0.0000 \\
$0.000 \mathrm{E}+00$ & 0.0000 \\
$0.000 \mathrm{E}+00$ & 0.0000 \\
$0.000 \mathrm{E}+00$ & 0.0000 \\
$0.000 \mathrm{E}+00$ & 0.0000 \\
$0.000 \mathrm{E}+00$ & 0.0000 \\
$0.000 \mathrm{E}+00$ & 0.0000 \\
$0.000 \mathrm{E}+00$ & 0.0000 \\
$0.000 \mathrm{E}+00$ & 0.0000 \\
$0.000 \mathrm{E}+00$ & 0.0000 \\
$0.000 \mathrm{E}+00$ & 0.0000 \\
$0.000 \mathrm{E}+00$ & 0.0000 \\
\hline \hline $0.000 \mathrm{E}+00$ & 0.0000
\end{tabular}

*Sum of all water independent and dependent pathways. 
RESRAD, Version $6.5 \quad \mathrm{~T}^{1 / 2}$ Limit $=180$ days

Sumary : C746U Resident Gardener Deterministic Run

File : $\mathrm{X}: \backslash$ FINAL V2 $\backslash \mathrm{C} 746 \mathrm{U}$ RG SG FWD-FINALV2.RAD

Dose/Source Ratios Summed Over All Pathways

Parent and Progeny Principal Radionuclide Contributions Indicated

\begin{tabular}{|c|c|c|c|c|c|c|c|c|}
\hline Parent & Product & Thread & DSH & $(j, t)$ At & ime in Year & (mrem, & $(\mathrm{yr}) /(\mathrm{pCi} / \mathrm{g}$ & \\
\hline (i) & (j) & Fraction & $0.000 \mathrm{E}+00$ & $1.000 \mathrm{E}+00$ & $5.000 \mathrm{E}+01$ & $1.000 \mathrm{E}+02$ & $5.000 \mathrm{E}+02$ & $1.050 \mathrm{E}+03$ \\
\hline-232 & $T h-232$ & $1.000 \mathrm{E}+00$ & $1.166 \mathrm{E}-24$ & $1.188 \mathrm{E}-24$ & $2.949 \mathrm{E}-24$ & $7.462 \mathrm{E}-24$ & 1. $252 \mathrm{E}-20$ & 1. $221 \mathrm{E}-03$ \\
\hline$h-232$ & $\mathrm{Ra}-228+\mathrm{D}$ & $1.000 \mathrm{E}+00$ & $1.107 E-09$ & $3.174 \mathrm{E}-09$ & $2.784 \mathrm{E}-08$ & $4.079 E-08$ & $8.497 E-07$ & $1.458 \mathrm{E}-01$ \\
\hline$h-232$ & $T h-228+D$ & $1.000 \mathrm{E}+00$ & $1.067 \mathrm{E}-08$ & $6.581 \mathrm{E}-08$ & $2.213 \mathrm{E}-06$ & $2.992 \mathrm{E}-06$ & $3.253 E-05$ & $2.007 \mathrm{E}-03$ \\
\hline$h-232$ & $\sum \operatorname{DSR}(j)$ & & $1.178 \mathrm{E}-08$ & $6.899 \mathrm{E}-08$ & $2.241 \mathrm{E}-06$ & $3.033 E-06$ & $3.338 E-05$ & $1.491 \mathrm{E}-01$ \\
\hline-234 & $U-234$ & $1.000 \mathrm{E}+00$ & $6.896 \mathrm{E}-24$ & $7.019 \mathrm{E}-24$ & $1.670 \mathrm{E}-23$ & $4.047 E-23$ & $4.798 E-20$ & $6.337 \mathrm{E}-04$ \\
\hline-234 & Th-230 & $1.000 \mathrm{E}+00$ & $1.089 \mathrm{E}-27$ & $3.315 E-27$ & $2.540 \mathrm{E}-25$ & 1. $171 \mathrm{E}-24$ & $4.838 E-21$ & $1.037 E-05$ \\
\hline-234 & $\mathrm{Ra}-226+\mathrm{D}$ & $1.000 \mathrm{E}+00$ & $1.133 \mathrm{E}-16$ & $7.978 E-16$ & 1. $213 \mathrm{E}-12$ & $6.737 \mathrm{E}-12$ & $2.496 E-09$ & $1.097 \mathrm{E}-04$ \\
\hline-234 & $\mathrm{~Pb}-210+\mathrm{D}$ & $1.000 \mathrm{E}+00$ & $4.102 \mathrm{E}-25$ & $6.153 E-24$ & $2.201 \mathrm{E}-19$ & 1. $935 \mathrm{E}-18$ & $1.678 E-15$ & $1.738 \mathrm{E}-04$ \\
\hline-234 & $\sum \operatorname{DSR}(j)$ & & $1.133 \mathrm{E}-16$ & $7.978 E-16$ & 1. $213 \mathrm{E}-12$ & $6.737 E-12$ & $2.496 E-09$ & $9.276 E-04$ \\
\hline$-235+D$ & $\mathrm{U}-235+\mathrm{D}$ & $1.000 \mathrm{E}+00$ & 1. $243 E-14$ & $1.259 \mathrm{E}-14$ & $2.306 \mathrm{E}-14$ & $4.276 \mathrm{E}-14$ & $5.981 \mathrm{E}-12$ & $6.155 \mathrm{E}-04$ \\
\hline$-235+D$ & $\mathrm{~Pa}-231$ & $1.000 \mathrm{E}+00$ & $2.937 E-18$ & $8.896 \mathrm{E}-18$ & $5.031 \mathrm{E}-16$ & $1.701 \mathrm{E}-15$ & $5.876 E-13$ & $8.145 E-04$ \\
\hline$-235+D$ & $A C-227+D$ & $1.000 \mathrm{E}+00$ & $9.274 \mathrm{E}-18$ & $6.481 \mathrm{E}-17$ & $6.882 \mathrm{E}-14$ & $2.943 E-13$ & $6.376 \mathrm{E}-11$ & $3.373 E-04$ \\
\hline$-235+D$ & $\sum \operatorname{DSR}(j)$ & & 1. $245 \mathrm{E}-14$ & $1.266 \mathrm{E}-14$ & $9.238 \mathrm{E}-14$ & $3.388 E-13$ & $7.033 E-11$ & $1.767 \mathrm{E}-03$ \\
\hline-238 & $\mathrm{U}-238$ & $5.400 E-05$ & $0.000 \mathrm{E}+00$ & $0.000 \mathrm{E}+00$ & $0.000 \mathrm{E}+00$ & $0.000 \mathrm{E}+00$ & $0.000 \mathrm{E}+00$ & $3.167 \mathrm{E}-08$ \\
\hline$-238+D$ & $\mathrm{U}-238+\mathrm{D}$ & $9.999 \mathrm{E}-01$ & 1. $420 \mathrm{E}-10$ & $1.431 \mathrm{E}-10$ & $2.116 \mathrm{E}-10$ & $3.153 \mathrm{E}-10$ & $7.678 E-09$ & $6.313 E-04$ \\
\hline$J-238+D$ & $\mathrm{U}-234$ & $9.999 \mathrm{E}-01$ & $9.803 E-30$ & $2.988 E-29$ & $2.392 E-27$ & $1.153 \mathrm{E}-26$ & $6.812 \mathrm{E}-23$ & $1.890 \mathrm{E}-06$ \\
\hline$J-238+D$ & Th-230 & $9.999 E-01$ & $1.030 E-33$ & $7.316 E-33$ & $1.818 \mathrm{E}-29$ & 1. $668 \mathrm{E}-28$ & $3.430 E-24$ & $1.541 \mathrm{E}-08$ \\
\hline$J-238+D$ & $\mathrm{Ra}-226+\mathrm{D}$ & $9.999 \mathrm{E}-01$ & $8.034 \mathrm{E}-23$ & $1.212 \mathrm{E}-21$ & $5.801 \mathrm{E}-17$ & $6.420 \mathrm{E}-16$ & 1. $201 \mathrm{E}-12$ & $1.127 \mathrm{E}-07$ \\
\hline$J-238+D$ & $\mathrm{~Pb}-210+\mathrm{D}$ & $9.999 \mathrm{E}-01$ & $2.329 E-31$ & $7.229 \mathrm{E}-30$ & $8.430 \mathrm{E}-24$ & 1. $546 \mathrm{E}-22$ & 7. $612 \mathrm{E}-19$ & $1.734 \mathrm{E}-07$ \\
\hline$-238+D$ & $\sum \operatorname{DSR}(j)$ & & $1.420 \mathrm{E}-10$ & $1.431 \mathrm{E}-10$ & $2.116 \mathrm{E}-10$ & $3.153 E-10$ & $7.680 E-09$ & $6.335 E-04$ \\
\hline
\end{tabular}

The DSR includes contributions from associated (half-life $\leq 180$ days) daughters. 
RESRAD, Version $6.5 \quad \mathrm{~T}^{1 / 2}$ Limit $=180$ days

Summary : C746U Resident Gardener Deterministic Run

File : $\mathrm{X}: \backslash$ FINAL V2 $\backslash \mathrm{C} 746 \mathrm{U}$ RG SG FWD-FINALV2.RAD

Single Radionuclide Soil Guidelines G(i,t) in pCi/g

Basic Radiation Dose Limit $=1.000 \mathrm{E}+02 \mathrm{mrem} / \mathrm{yr}$

Nuclide

\begin{tabular}{|c|c|c|c|c|c|c|}
\hline (i) & $t=0.000 \mathrm{E}+00$ & $1.000 \mathrm{E}+00$ & $5.000 \mathrm{E}+01$ & $1.000 \mathrm{E}+02$ & $5.000 \mathrm{E}+02$ & $1.050 \mathrm{E}+03$ \\
\hline $1-241$ & $\star 3.431 \mathrm{E}+12$ & $\star 3.431 \mathrm{E}+12$ & $\star 3.431 \mathrm{E}+12$ & $\star 3.431 \mathrm{E}+12$ & $\star 3.431 \mathrm{E}+12$ & $5.044 \mathrm{E}+05$ \\
\hline$s-137$ & $7.925 \mathrm{E}+10$ & $8.043 E+10$ & $1.653 \mathrm{E}+11$ & $3.447 \mathrm{E}+11$ & $\star 8.704 \mathrm{E}+13$ & $\star 8.704 \mathrm{E}+13$ \\
\hline-237 & $\star 7.047 \mathrm{E}+08$ & $\star 7.047 \mathrm{E}+08$ & $\star 7.047 \mathrm{E}+08$ & $\star 7.047 \mathrm{E}+08$ & $\star 7.047 \mathrm{E}+08$ & $9.756 \mathrm{E}+03$ \\
\hline$a-238$ & $* 1.712 \mathrm{E}+13$ & $\star 1.712 \mathrm{E}+13$ & $\star 1.712 \mathrm{E}+13$ & $\star 1.712 \mathrm{E}+13$ & $* 1.712 \mathrm{E}+13$ & $1.637 \mathrm{E}+08$ \\
\hline-239 & $\star 6.214 \mathrm{E}+10$ & $\star 6.214 \mathrm{E}+10$ & $\star 6.214 \mathrm{E}+10$ & $\star 6.214 \mathrm{E}+10$ & $* 6.214 \mathrm{E}+10$ & $7.884 \mathrm{E}+04$ \\
\hline$u-240$ & $\star 2.278 \mathrm{E}+11$ & $\star 2.278 \mathrm{E}+11$ & $\star 2.278 \mathrm{E}+11$ & $\star 2.278 \mathrm{E}+11$ & $\star 2.278 \mathrm{E}+11$ & $8.550 \mathrm{E}+04$ \\
\hline$c-99$ & $* 1.697 \mathrm{E}+10$ & $\star 1.697 \mathrm{E}+10$ & $\star 1.697 \mathrm{E}+10$ & $\star 1.697 \mathrm{E}+10$ & $\star 1.697 \mathrm{E}+10$ & $7.545 \mathrm{E}+07$ \\
\hline$h-228$ & $7.234 \mathrm{E}+07$ & $1.033 \mathrm{E}+08$ & $\star 8.195 \mathrm{E}+14$ & $\star 8.195 \mathrm{E}+14$ & $\star 8.195 \mathrm{E}+14$ & $\star 8.195 \mathrm{E}+14$ \\
\hline$h-230$ & $\star 2.018 \mathrm{E}+10$ & $\star 2.018 \mathrm{E}+10$ & $1.880 \mathrm{E}+10$ & $6.761 \mathrm{E}+09$ & $9.336 \mathrm{E}+07$ & $1.719 \mathrm{E}+03$ \\
\hline Th-232 & $\star 1.097 \mathrm{E}+05$ & $\star 1.097 \mathrm{E}+05$ & $\star 1.097 \mathrm{E}+05$ & $\star 1.097 \mathrm{E}+05$ & $* 1.097 \mathrm{E}+05$ & $6.708 \mathrm{E}+02$ \\
\hline$J-234$ & $* 6.247 \mathrm{E}+09$ & $\star 6.247 \mathrm{E}+09$ & $* 6.247 \mathrm{E}+09$ & $* 6.247 \mathrm{E}+09$ & $* 6.247 \mathrm{E}+09$ & $1.078 \mathrm{E}+05$ \\
\hline$J-235$ & $\star 2.161 \mathrm{E}+06$ & $\star 2.161 \mathrm{E}+06$ & $\star 2.161 \mathrm{E}+06$ & $\star 2.161 \mathrm{E}+06$ & $\star 2.161 \mathrm{E}+06$ & $5.658 E+04$ \\
\hline-238 & $* 3.361 \mathrm{E}+05$ & $\star 3.361 \mathrm{E}+05$ & $\star 3.361 \mathrm{E}+05$ & $\star 3.361 \mathrm{E}+05$ & $* 3.361 \mathrm{E}+05$ & $1.578 \mathrm{E}+05$ \\
\hline
\end{tabular}

*At specific activity limit

Summed Dose/Source Ratios DSR (i,t) in (mrem/yr)/(pCi/g) and Single Radionuclide Soil Guidelines $G(i, t)$ in pCi/g

at $\operatorname{tmin}=$ time of minimum single radionuclide soil guideline and at $\operatorname{tmax}=$ time of maximum total dose $=1.050 \mathrm{E}+03$ years

\begin{tabular}{|c|c|c|c|c|c|c|}
\hline $\begin{array}{l}\text { uclide } \\
\text { (i) }\end{array}$ & $\begin{array}{l}\text { Initial } \\
(\mathrm{pCi} / \mathrm{g})\end{array}$ & $\begin{array}{c}\text { tmin } \\
\text { (years) }\end{array}$ & $\operatorname{DSR}(i, \operatorname{tmin})$ & $\begin{array}{c}\mathrm{G}(\mathrm{i}, \mathrm{tmin}) \\
(\mathrm{pCi} / \mathrm{g})\end{array}$ & $\operatorname{DSR}(i, \operatorname{tmax})$ & $\begin{array}{c}\mathrm{G}(\mathrm{i}, \mathrm{tmax}) \\
(\mathrm{pCi} / \mathrm{g})\end{array}$ \\
\hline$m-241$ & $3.500 \mathrm{E}+03$ & $1.050 \mathrm{E}+03$ & $1.983 E-04$ & $5.044 E+05$ & $1.983 E-04$ & $5.044 \mathrm{E}+05$ \\
\hline $5-137$ & $1.900 \mathrm{E}+02$ & $0.000 \mathrm{E}+00$ & $1.262 \mathrm{E}-09$ & $7.925 \mathrm{E}+10$ & $7.713 \mathrm{E}-14$ & $\star 8.704 \mathrm{E}+13$ \\
\hline-237 & $5.500 \mathrm{E}+02$ & $1.050 \mathrm{E}+03$ & $1.025 \mathrm{E}-02$ & $9.756 \mathrm{E}+03$ & $1.025 \mathrm{E}-02$ & $9.756 \mathrm{E}+03$ \\
\hline$u-238$ & $3.900 \mathrm{E}+03$ & $1.050 \mathrm{E}+03$ & $6.110 \mathrm{E}-07$ & $1.637 \mathrm{E}+08$ & $6.110 \mathrm{E}-07$ & $1.637 \mathrm{E}+08$ \\
\hline$u-239$ & $3.600 E+03$ & $1.050 \mathrm{E}+03$ & $1.268 E-03$ & $7.884 \mathrm{E}+04$ & $1.268 E-03$ & $7.884 \mathrm{E}+04$ \\
\hline$x-240$ & $3.600 \mathrm{E}+03$ & $1.050 \mathrm{E}+03$ & $1.170 \mathrm{E}-03$ & $8.550 \mathrm{E}+04$ & $1.170 \mathrm{E}-03$ & $8.550 \mathrm{E}+04$ \\
\hline$=-99$ & $2.800 \mathrm{E}+01$ & $1.050 \mathrm{E}+03$ & 1. $325 E-06$ & $7.545 E+07$ & 1. $325 E-06$ & $7.545 \mathrm{E}+07$ \\
\hline-228 & $7.400 \mathrm{E}+01$ & $0.000 E+00$ & $1.382 E-06$ & $7.234 \mathrm{E}+07$ & $0.000 \mathrm{E}+00$ & $\star 8.195 E+14$ \\
\hline-230 & $1.200 \mathrm{E}+03$ & $1.050 \mathrm{E}+03$ & $5.818 \mathrm{E}-02$ & $1.719 \mathrm{E}+03$ & $5.818 \mathrm{E}-02$ & 1. $719 \mathrm{E}+03$ \\
\hline-232 & $3.800 \mathrm{E}+01$ & $1.050 \mathrm{E}+03$ & $1.491 E-01$ & $6.708 \mathrm{E}+02$ & $1.491 \mathrm{E}-01$ & $6.708 \mathrm{E}+02$ \\
\hline-234 & $1.800 \mathrm{E}+04$ & $1.050 \mathrm{E}+03$ & $9.276 \mathrm{E}-04$ & $1.078 \mathrm{E}+05$ & $9.276 \mathrm{E}-04$ & $1.078 E+05$ \\
\hline-235 & $8.200 \mathrm{E}+02$ & $1.050 \mathrm{E}+03$ & $1.767 \mathrm{E}-03$ & $5.658 \mathrm{E}+04$ & $1.767 \mathrm{E}-03$ & $5.658 \mathrm{E}+04$ \\
\hline-238 & $3.200 E+03$ & $1.050 E+03$ & $6.335 E-04$ & $1.578 \mathrm{E}+05$ & $6.335 E-04$ & $1.578 \mathrm{E}+05$ \\
\hline
\end{tabular}

*At specific activity limit 
RESRAD, Version $6.5 \quad \mathrm{~T}^{1 / 2}$ Limit $=180$ days

Summary : C746U Resident Gardener Deterministic Run

File : $\mathrm{X}: \backslash$ FINAL V2 $\backslash$ C746U RG SG FWD-FINALV2.RAD

Individual Nuclide Dose Summed Over All Pathways

Parent Nuclide and Branch Fraction Indicated

Nuclide Parent THF(i) DOSE $(j, t)$, mrem/yr

\begin{tabular}{|c|c|c|c|c|c|c|c|c|}
\hline (j) & (i) & & $t=0.000 E+00$ & $1.000 \mathrm{E}+00$ & $5.000 \mathrm{E}+01$ & $1.000 \mathrm{E}+02$ & $5.000 \mathrm{E}+02$ & $1.050 \mathrm{E}+03$ \\
\hline$A m-241$ & $A m-241$ & $1.000 \mathrm{E}+00$ & $0.000 \mathrm{E}+00$ & $0.000 \mathrm{E}+00$ & $0.000 \mathrm{E}+00$ & $0.000 \mathrm{E}+00$ & $4.227 E-24$ & $6.877 \mathrm{E}-01$ \\
\hline$N p-237$ & Am-241 & $1.000 \mathrm{E}+00$ & $5.412 \mathrm{E}-16$ & 1. $638 \mathrm{E}-15$ & $8.967 \mathrm{E}-14$ & $2.934 \mathrm{E}-13$ & 7. $921 \mathrm{E}-11$ & $6.206 E-03$ \\
\hline$N p-237$ & $N p-237$ & $1.000 \mathrm{E}+00$ & $5.245 E-10$ & $5.301 \mathrm{E}-10$ & $8.939 \mathrm{E}-10$ & $1.524 \mathrm{E}-09$ & $1.085 \mathrm{E}-07$ & $5.635 E+00$ \\
\hline$N p-237$ & $\sum \operatorname{DOSE}(j)$ & & $5.245 \mathrm{E}-10$ & $5.301 \mathrm{E}-10$ & $8.940 \mathrm{E}-10$ & $1.524 \mathrm{E}-09$ & $1.086 \mathrm{E}-07$ & $5.642 \mathrm{E}+00$ \\
\hline
\end{tabular}

$\mathrm{U}-233 \mathrm{Am}-241 \quad 1.000 \mathrm{E}+00$

$\begin{array}{lllllll}1.227 \mathrm{E}-26 & 8.678 \mathrm{E}-26 & 1.702 \mathrm{E}-22 & 1.226 \mathrm{E}-21 & 3.685 \mathrm{E}-18 & 1.069 \mathrm{E}-06\end{array}$ $\mathrm{Np}-237 \quad 1.000 \mathrm{E}+00$ $\begin{array}{llllll}1.785 \mathrm{E}-20 & 5.414 \mathrm{E}-20 & 3.355 \mathrm{E}-18 & 1.245 \mathrm{E}-17 & 9.076 \mathrm{E}-15 & 1.579 \mathrm{E}-03\end{array}$ $\begin{array}{lllllll}1.785 \mathrm{E}-20 & 5.414 \mathrm{E}-20 & 3.355 \mathrm{E}-18 & 1.245 \mathrm{E}-17 & 9.079 \mathrm{E}-15 & 1.580 \mathrm{E}-03\end{array}$

8.395E-23 1.266E-21 5.984E-17 6.539E-16 $1.118 \mathrm{E}-12 \quad 1.891 \mathrm{E}-07$ $1.629 \mathrm{E}-16 \quad 1.147 \mathrm{E}-15 \quad 1.758 \mathrm{E}-12 \quad 9.834 \mathrm{E}-12 \quad 3.894 \mathrm{E}-09 \quad 3.741 \mathrm{E}-04$ $1.629 \mathrm{E}-16 \quad 1.147 \mathrm{E}-15 \quad 1.758 \mathrm{E}-12 \quad 9.835 \mathrm{E}-12 \quad 3.895 \mathrm{E}-09 \quad 3.743 \mathrm{E}-04$ $2.397 \mathrm{E}-07 \quad 2.362 \mathrm{E}-07 \quad 1.149 \mathrm{E}-07 \quad 5.512 \mathrm{E}-08 \quad 1.540 \mathrm{E}-10 \quad 1.465 \mathrm{E}-11$ $\begin{array}{llllll}0.000 \mathrm{E}+00 & 0.000 \mathrm{E}+00 & 0.000 \mathrm{E}+00 & 0.000 \mathrm{E}+00 & 0.000 \mathrm{E}+00 & 2.147 \mathrm{E}-12\end{array}$ $\begin{array}{lllllll}4.582 \mathrm{E}-21 & 4.627 \mathrm{E}-21 & 7.461 \mathrm{E}-21 & 1.215 \mathrm{E}-20 & 6.001 \mathrm{E}-19 & 1.167 \mathrm{E}-03\end{array}$ $\begin{array}{llllll}4.582 \mathrm{E}-21 & 4.627 \mathrm{E}-21 & 7.461 \mathrm{E}-21 & 1.215 \mathrm{E}-20 & 6.001 \mathrm{E}-19 & 1.167 \mathrm{E}-03\end{array}$ $3.813 \mathrm{E}-26 \quad 1.158 \mathrm{E}-25 \quad 7.693 \mathrm{E}-24 \quad 3.104 \mathrm{E}-23 \quad 6.593 \mathrm{E}-20 \quad 8.877 \mathrm{E}-04$ $\begin{array}{lllllll}1.241 \mathrm{E}-19 & 1.263 \mathrm{E}-19 & 3.007 \mathrm{E}-19 & 7.284 \mathrm{E}-19 & 8.636 \mathrm{E}-16 & 1.141 \mathrm{E}+01\end{array}$ $3.137 \mathrm{E}-26 \quad 9.560 \mathrm{E}-26 \quad 7.653 \mathrm{E}-24 \quad 3.690 \mathrm{E}-23 \quad 2.180 \mathrm{E}-19 \quad 6.048 \mathrm{E}-03$ $\begin{array}{llllll}1.241 \mathrm{E}-19 & 1.263 \mathrm{E}-19 & 3.007 \mathrm{E}-19 & 7.285 \mathrm{E}-19 & 8.639 \mathrm{E}-16 & 1.141 \mathrm{E}+01\end{array}$

$0.000 \mathrm{E}+00 \quad 0.000 \mathrm{E}+00 \quad 6.236 \mathrm{E}-26 \quad 5.079 \mathrm{E}-25 \quad 5.092 \mathrm{E}-21 \quad 1.276 \mathrm{E}-05$ $2.895 \mathrm{E}-192.944 \mathrm{E}-19 \quad 6.708 \mathrm{E}-19 \quad 1.554 \mathrm{E}-18 \quad 1.293 \mathrm{E}-15 \quad 1.325 \mathrm{E}+00$ $1.960 \mathrm{E}-23 \quad 5.968 \mathrm{E}-23 \quad 4.573 \mathrm{E}-21 \quad 2.108 \mathrm{E}-20 \quad 8.708 \mathrm{E}-17 \quad 1.866 \mathrm{E}-01$ $0.000 \mathrm{E}+00 \quad 0.000 \mathrm{E}+00 \quad 5.819 \mathrm{E}-26 \quad 5.338 \mathrm{E}-25 \quad 1.098 \mathrm{E}-20 \quad 4.933 \mathrm{E}-05$ $2.895 \mathrm{E}-19 \quad 2.944 \mathrm{E}-19 \quad 6.754 \mathrm{E}-19 \quad 1.576 \mathrm{E}-18 \quad 1.380 \mathrm{E}-15 \quad 1.512 \mathrm{E}+00$

$\begin{array}{llllll}3.128 \mathrm{E}-19 & 4.712 \mathrm{E}-18 & 2.054 \mathrm{E}-13 & 2.076 \mathrm{E}-12 & 2.187 \mathrm{E}-09 & 1.226 \mathrm{E}-04\end{array}$ $\begin{array}{lllllll}4.529 \mathrm{E}-08 & 1.367 \mathrm{E}-07 & 6.384 \mathrm{E}-06 & 1.775 \mathrm{E}-05 & 1.285 \mathrm{E}-03 & 2.598 \mathrm{E}+01\end{array}$ $2.040 \mathrm{E}-12 \quad 1.436 \mathrm{E}-11 \quad 2.184 \mathrm{E}-08 \quad 1.213 \mathrm{E}-07 \quad 4.492 \mathrm{E}-05 \quad 1.974 \mathrm{E}+00$ $2.571 \mathrm{E}-19 \quad 3.879 \mathrm{E}-18 \quad 1.856 \mathrm{E}-13 \quad 2.055 \mathrm{E}-12 \quad 3.842 \mathrm{E}-09 \quad 3.607 \mathrm{E}-04$ $\begin{array}{llllll}4.529 \mathrm{E}-08 & 1.367 \mathrm{E}-07 & 6.405 \mathrm{E}-06 & 1.787 \mathrm{E}-05 & 1.330 \mathrm{E}-03 & 2.795 \mathrm{E}+01\end{array}$

$0.000 \mathrm{E}+00 \quad 2.812 \mathrm{E}-26 \quad 3.031 \mathrm{E}-20 \quad 5.124 \mathrm{E}-19 \quad 1.432 \mathrm{E}-15 \quad 1.929 \mathrm{E}-04$ $\begin{array}{lllllll}2.183 \mathrm{E}-16 & 1.525 \mathrm{E}-15 & 1.559 \mathrm{E}-12 & 6.377 \mathrm{E}-12 & 9.214 \mathrm{E}-10 & 4.252 \mathrm{E}+01\end{array}$ $\begin{array}{llllll}7.383 \mathrm{E}-21 & 1.108 \mathrm{E}-19 & 3.962 \mathrm{E}-15 & 3.482 \mathrm{E}-14 & 3.021 \mathrm{E}-11 & 3.129 \mathrm{E}+00\end{array}$ $0.000 \mathrm{E}+00 \quad 2.313 \mathrm{E}-26 \quad 2.698 \mathrm{E}-20 \quad 4.947 \mathrm{E}-19 \quad 2.436 \mathrm{E}-15 \quad 5.548 \mathrm{E}-04$ $2.183 \mathrm{E}-16 \quad 1.525 \mathrm{E}-15 \quad 1.563 \mathrm{E}-12 \quad 6.412 \mathrm{E}-12 \quad 9.516 \mathrm{E}-10 \quad 4.565 \mathrm{E}+01$

4.328E-14 4.380E-14 7.860E-14 $1.427 \mathrm{E}-13 \quad 1.689 \mathrm{E}-11 \quad 4.566 \mathrm{E}+00$

$2.209 E-20 \quad 6.699 E-20 \quad 4.126 E-18 \quad 1.522 E-17 \quad 1.055 E-14 \quad 2.265 E-06$ $\begin{array}{llllll}1.019 \mathrm{E}-11 & 1.032 \mathrm{E}-11 & 1.891 \mathrm{E}-11 & 3.506 \mathrm{E}-11 & 4.904 \mathrm{E}-09 & 5.047 \mathrm{E}-01\end{array}$ $\begin{array}{llllll}1.019 E-11 & 1.032 E-11 & 1.891 E-11 & 3.506 E-11 & 4.904 E-09 & 5.047 E-01\end{array}$ 
RESRAD, Version $6.5 \quad \mathrm{~T}^{1 / 2} / 2$ Limit $=180$ days

Summary : C746U Resident Gardener Deterministic Run

File : $\mathrm{X}: \backslash$ FINAL V2 $\backslash \mathrm{C} 746 \mathrm{U}$ RG SG FWD-FINALV2.RAD

Individual Nuclide Soil Concentration

Parent Nuclide and Branch Fraction Indicated

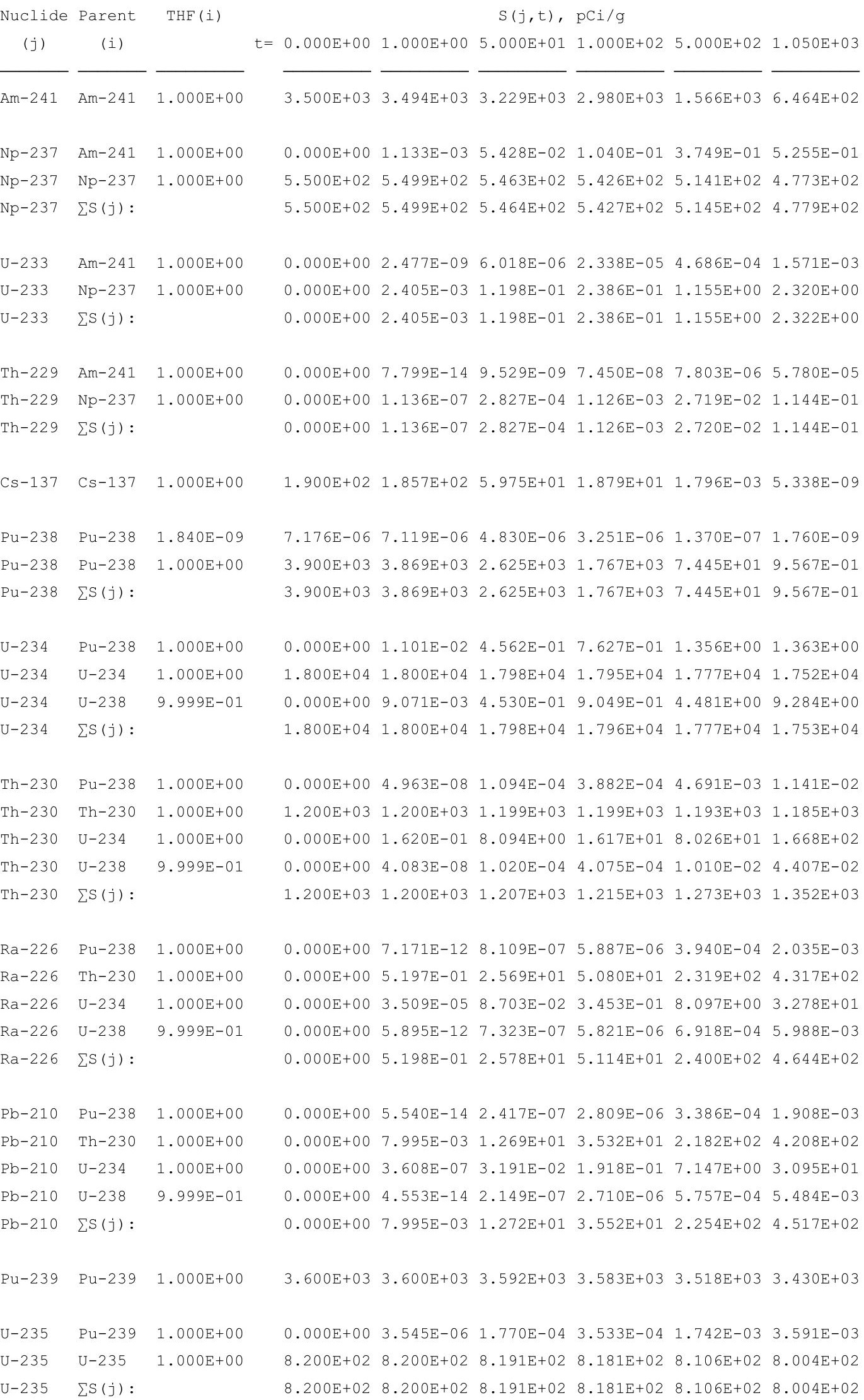


RESRAD, Version $6.5 \quad \mathrm{~T}^{1 / 2}$ Limit $=180$ days

Summary : C746U Resident Gardener Deterministic Run

File : $X: \backslash F I N A L$ V2 $\backslash C 746 U$ RG SG FWD-FINALV2.RAD

Individual Nuclide Soil Concentration

Parent Nuclide and Branch Fraction Indicated

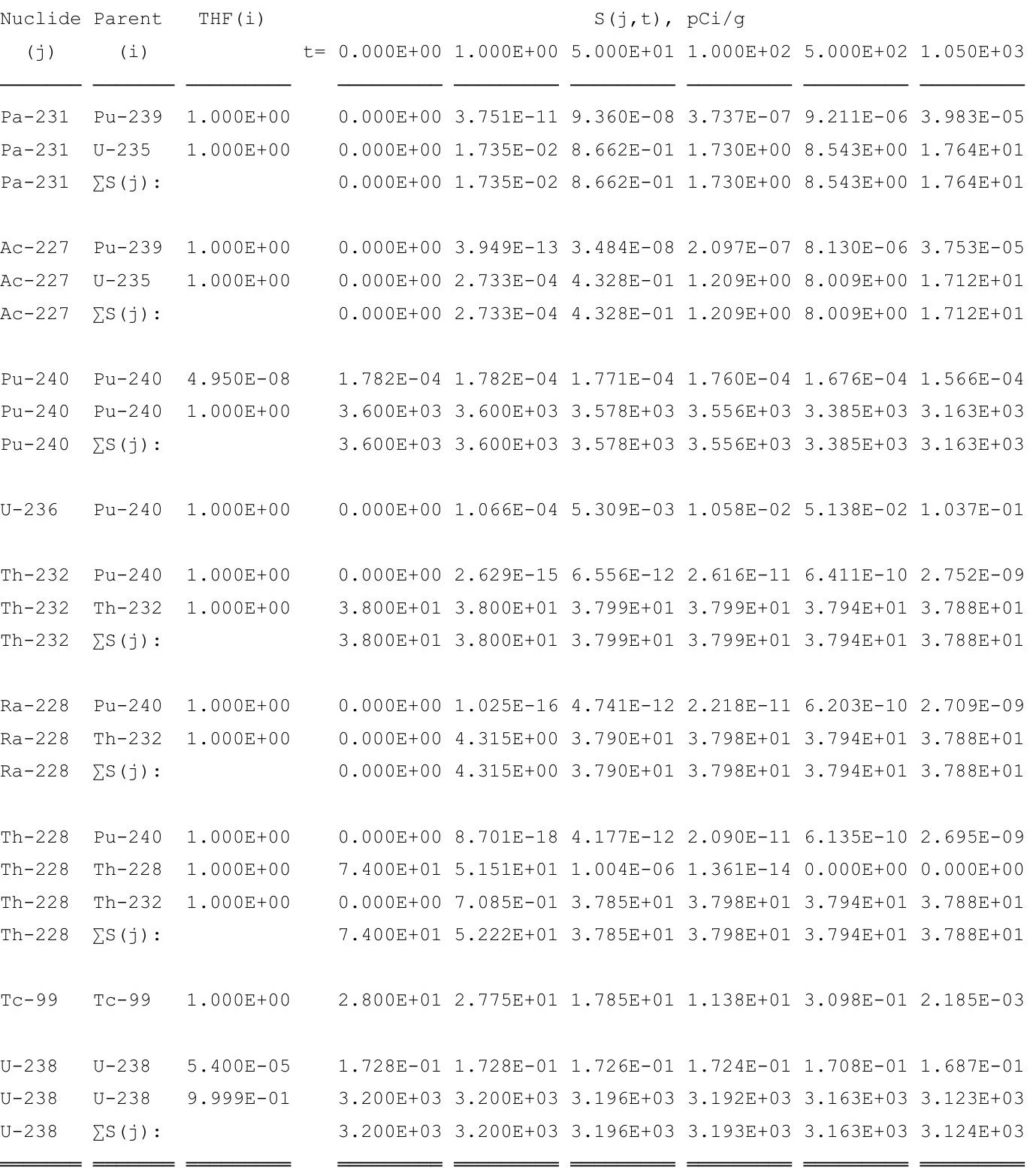

THF (i) is the thread fraction of the parent nuclide.

RESCALC.EXE execution time $=\quad 3.97$ seconds 


\section{Recreational User}

The following summary report includes the single radionuclide soil guidelines based on a unit concentration for targeted radionuclides. 
THIS PAGE INTENTIONALLY LEFT BLANK 
RESRAD, Version $6.5 \quad \mathrm{~T}^{1} \frac{1}{2}$ Limit $=180$ days

Summary : C746U Recreational User Deterministic Run

File : $\mathrm{X}: \backslash$ FINAL V2 $\backslash \mathrm{C746U}$ RU DET-FINALV2.RAD

Table of Contents

Part I: Mixture Sums and Single Radionuclide Guidelines

Dose Conversion Factor (and Related) Parameter Summary ... 2

Site-Specific Parameter Summary ................. 8

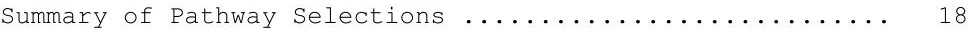

Contaminated Zone and Total Dose Summary ............. 19

Total Dose Components

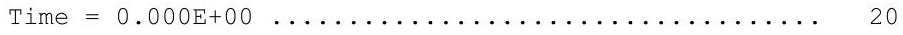

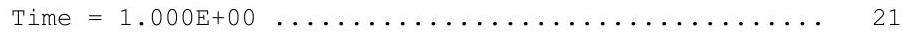

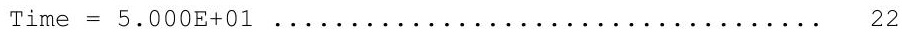

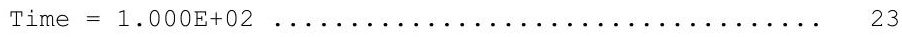

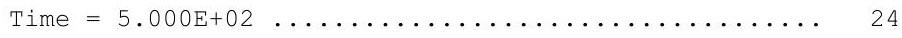

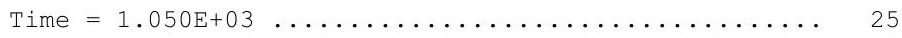

Dose/Source Ratios Summed Over All Pathways .......... 26

Single Radionuclide Soil Guidelines ............... 28

Dose Per Nuclide Summed Over All Pathways ............ 29

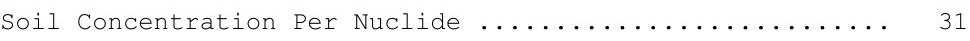


RESRAD, Version $6.5 \quad T^{1 / 2}$ Limit $=180$ days

Summary : C746U Recreational User Deterministic Run

File : $\mathrm{X}: \backslash$ FINAL V2 $\backslash \mathrm{C746U}$ RU DET-FINALV2.RAD

Dose Conversion Factor (and Related) Parameter Summary

Dose Library: Teen Recreational User Plus ICRP 60 \& ICRP 72 (Age 15)

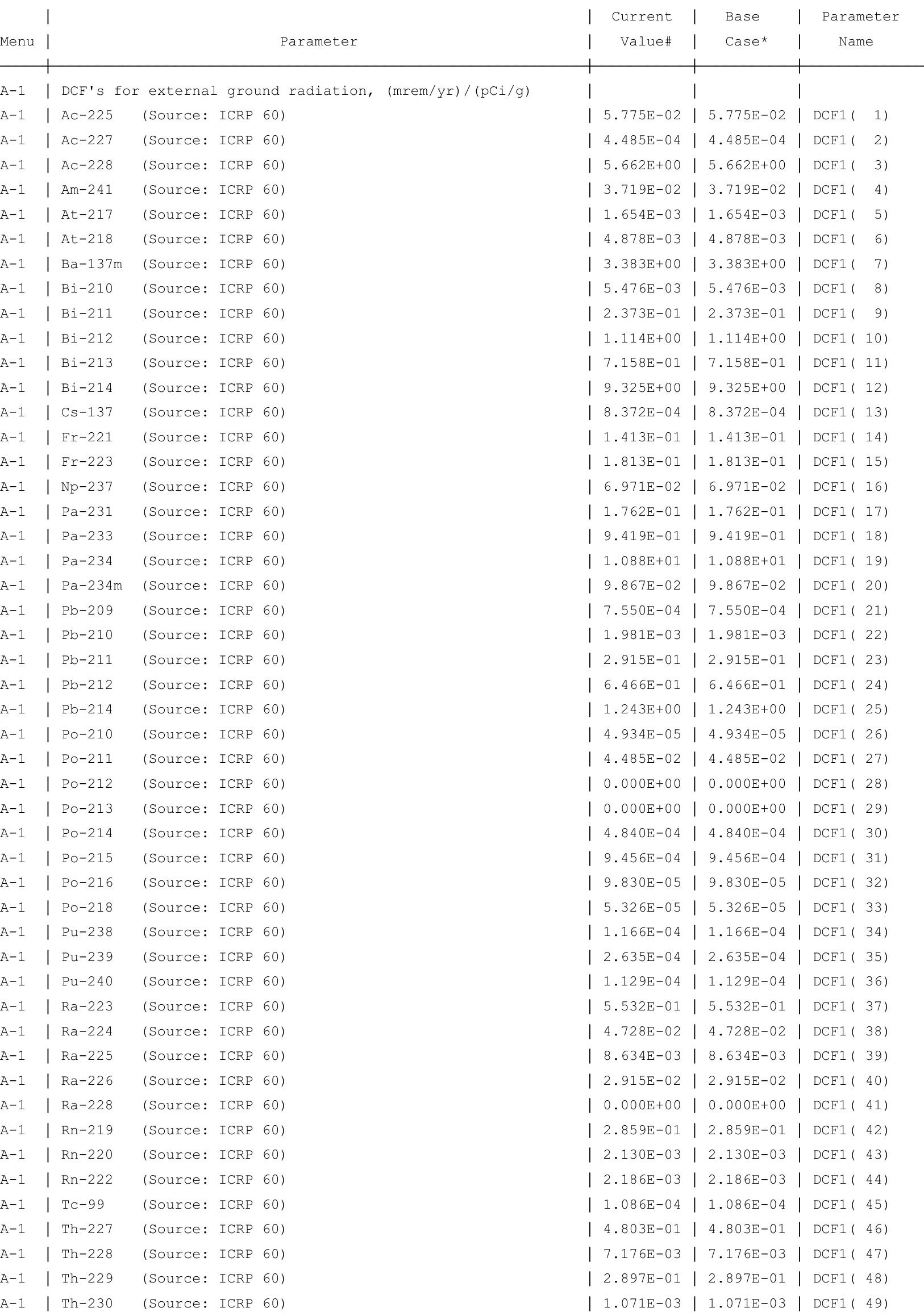


RESRAD, Version $6.5 \quad T^{1 / 2}$ Limit $=180$ days

Summary : C746U Recreational User Deterministic Run

File : $\mathrm{X}: \backslash$ FINAL V2\C746U RU DET-FINALV2.RAD

Dose Conversion Factor (and Related) Parameter Summary (continued)

Dose Library: Teen Recreational User Plus ICRP 60 \& ICRP 72 (Age 15)

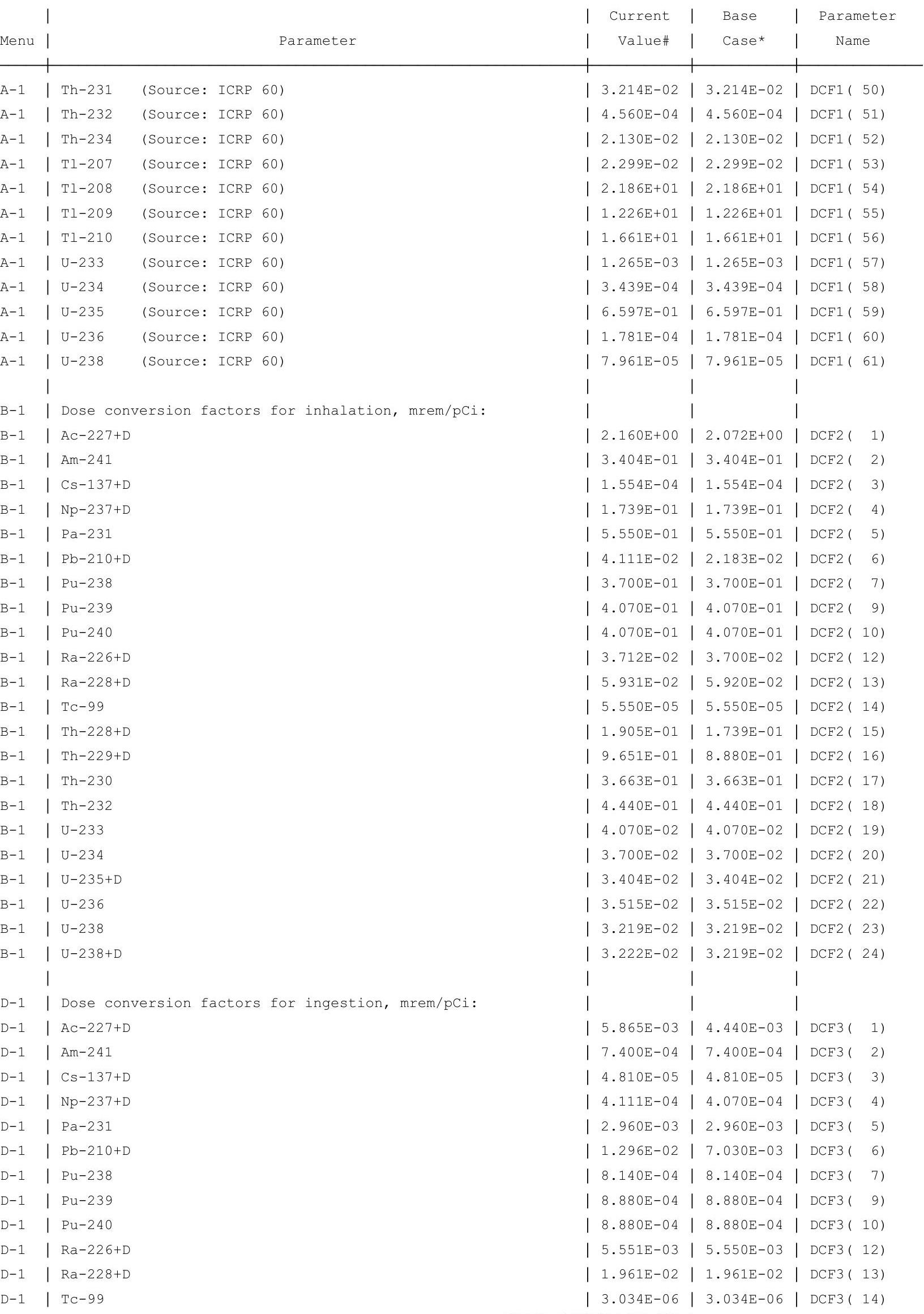


RESRAD, Version $6.5 \quad \mathrm{~T}^{1 / 2}$ Limit $=180$ days

Summary : C746U Recreational User Deterministic Run

File : $\mathrm{X}: \backslash$ FINAL V2 $\backslash \mathrm{C746U}$ RU DET-FINALV2.RAD

Dose Conversion Factor (and Related) Parameter Summary (continued)

Dose Library: Teen Recreational User Plus ICRP 60 \& ICRP 72 (Age 15)

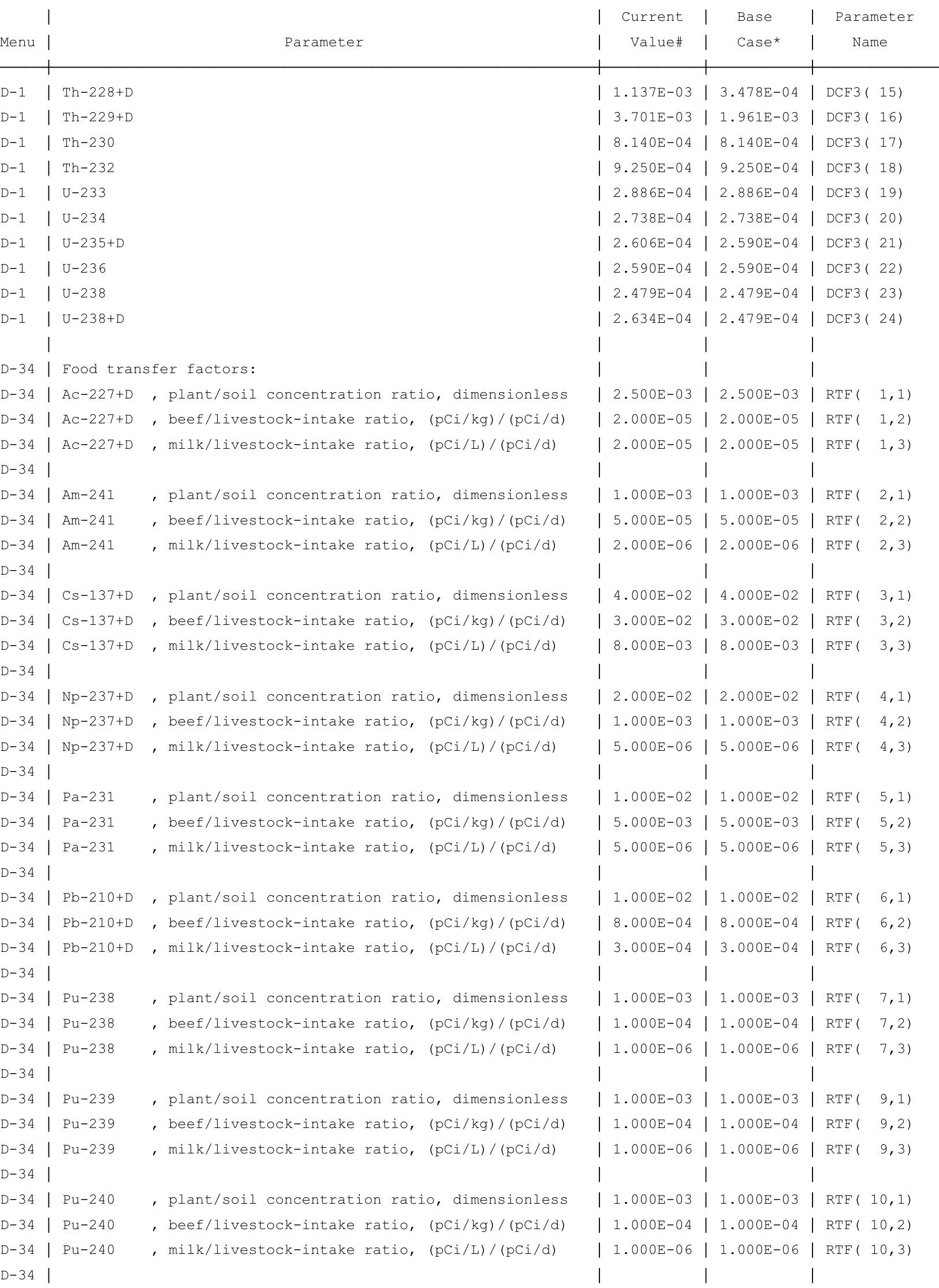


RESRAD, Version $6.5 \quad \mathrm{~T}^{1 / 2}$ Limit $=180$ days

Summary : C746U Recreational User Deterministic Run

File : $\mathrm{X}: \backslash$ FINAL V2 $\backslash$ C746U RU DET-FINALV2.RAD

Dose Conversion Factor (and Related) Parameter Summary (continued)

Dose Library: Teen Recreational User Plus ICRP 60 \& ICRP 72 (Age 15)

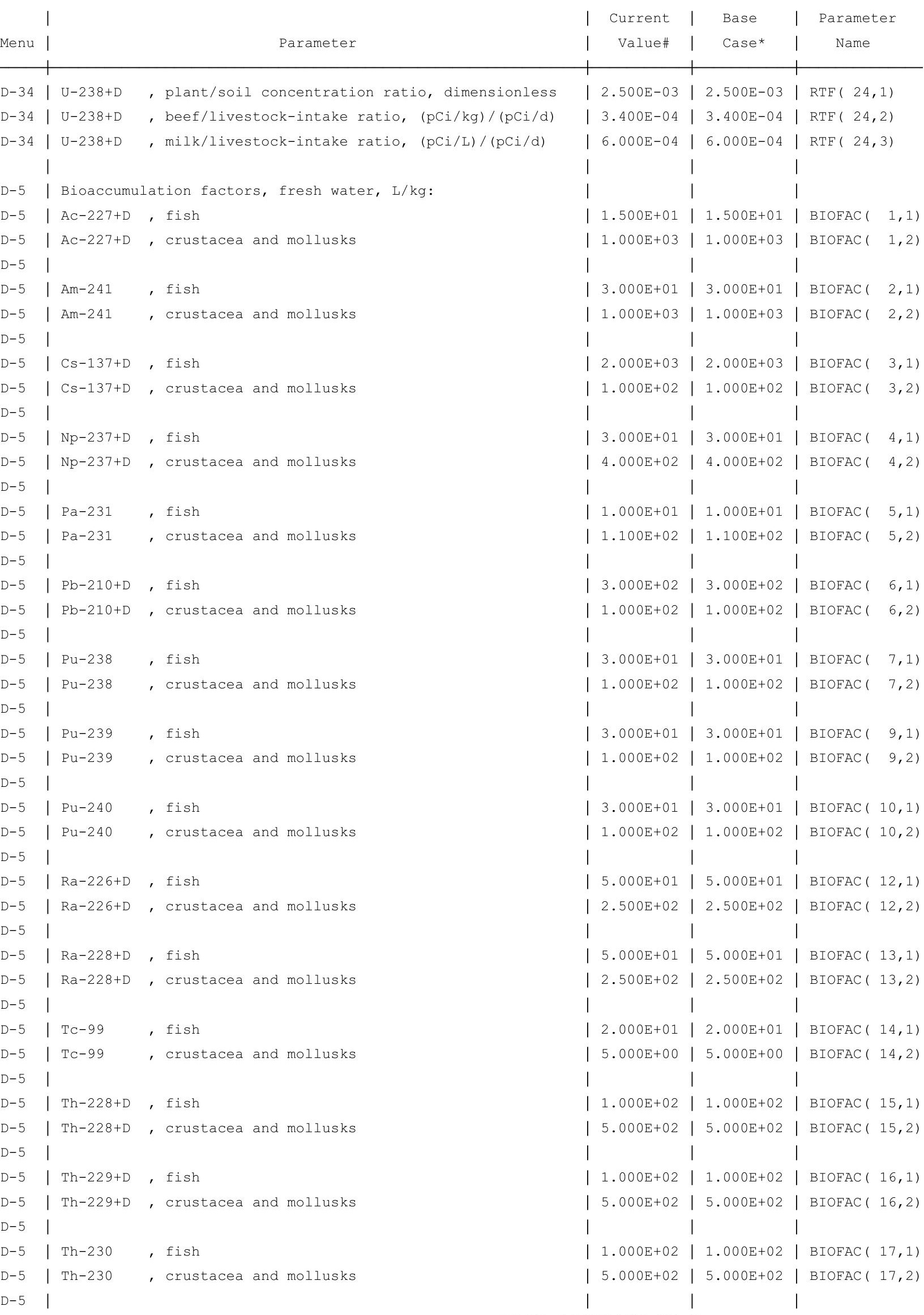


RESRAD, Version $6.5 \quad T^{1 / 2}$ Limit $=180$ days

Summary : C746U Recreational User Deterministic Run

File : $\mathrm{x}: \backslash$ FINAL V2\C746U RU DET-FINALV2.RAD

Dose Conversion Factor (and Related) Parameter Summary (continued)

Dose Library: Teen Recreational User Plus ICRP 60 \& ICRP 72 (Age 15)

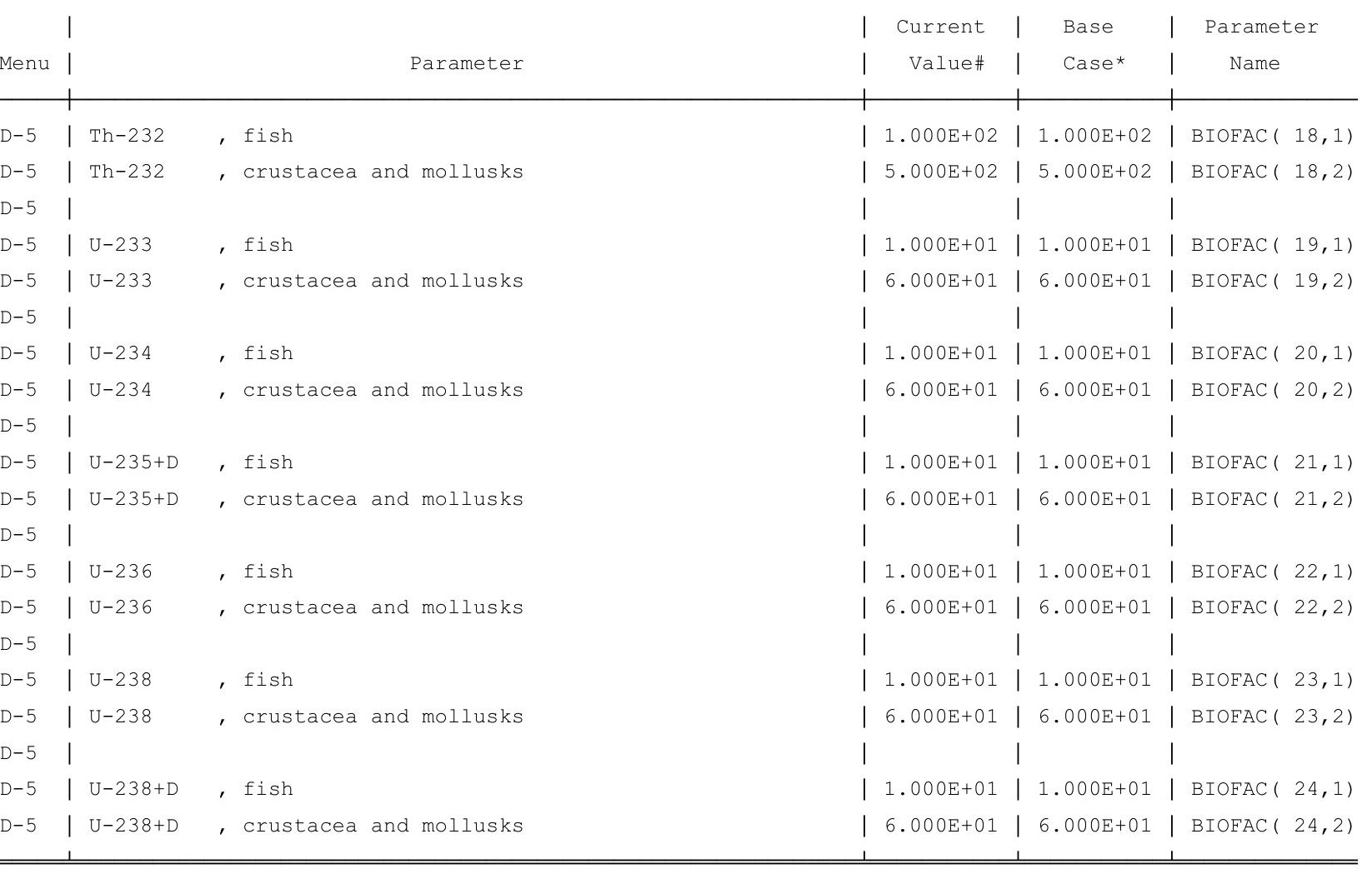

\#For DCFl(xxx) only, factors are for infinite depth \& area. See ETFG table in Ground Pathway of Detailed Report. *Base Case means Default.Lib w/o Associate Nuclide contributions. 
RESRAD, Version $6.5 \quad T^{1 / 2}$ Limit $=180$ days

Summary : C746U Recreational User Deterministic Run

File : $X: \backslash F I N A L$ V2 $\backslash C 746 U$ RU DET-FINALV2.RAD

Site-Specific Parameter Summary (continued)

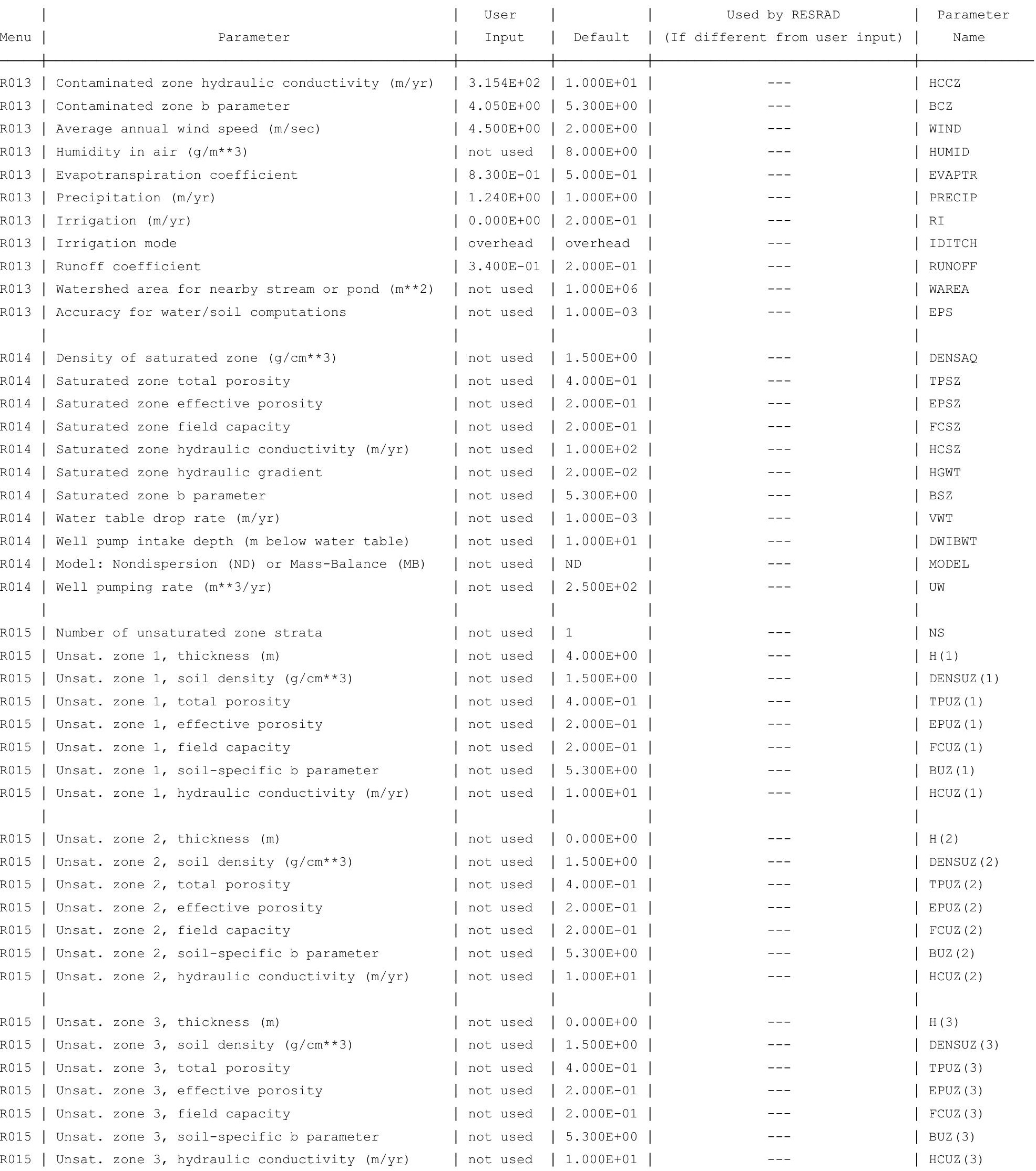


RESRAD, Version $6.5 \quad T^{1 / 2}$ Limit $=180$ days

Summary : C746U Recreational User Deterministic Run

File : $\mathrm{X}: \backslash$ FINAL V2 $\backslash \mathrm{C} 746 \mathrm{U}$ RU DET-FINALV2.RAD

Site-Specific Parameter Summary (continued)

\begin{tabular}{|c|c|c|c|c|c|c|}
\hline । & & User & । & । & Used by RESRAD & I Parameter \\
\hline nu $\mid$ & Parameter & Input & I Default & | (If & different from user input) & Name \\
\hline 161 & Distribution coefficients for Pu-238 & l & | & | & & | \\
\hline 161 & Contaminated zone $(\mathrm{cm} * * 3 / \mathrm{g})$ & $5.500 \mathrm{E}+02$ & $2.000 \mathrm{E}+03$ & | & --- & | $\operatorname{DCNUCC}(7)$ \\
\hline 161 & Unsaturated zone $1(\mathrm{~cm} * * 3 / \mathrm{g})$ & I not used & $2.000 \mathrm{E}+03$ & | & --- & DCNUCU $(7,1$ \\
\hline 161 & Unsaturated zone $2(\mathrm{~cm} * * 3 / \mathrm{g})$ & I not used & | $2.000 \mathrm{E}+03$ & | & --- & I DCNUCU $(7,2$ \\
\hline 161 & Unsaturated zone $3(\mathrm{~cm} * * 3 / \mathrm{g})$ & I not used & | $2.000 \mathrm{E}+03$ & | & --- & DCNUCU $(7,3$ \\
\hline 161 & Unsaturated zone $4\left(\mathrm{~cm}^{\star \star} 3 / \mathrm{g}\right)$ & I not used & $2.000 \mathrm{E}+03$ & l & --- & I $\operatorname{DCNUCU}(7,4$ \\
\hline $16 \mid$ & Unsaturated zone $5(\mathrm{~cm} * * 3 / \mathrm{g})$ & I not used & | $2.000 \mathrm{E}+03$ & | & --- & DCNUCU $(7,5$ \\
\hline 161 & Saturated zone $(\mathrm{cm} * * 3 / \mathrm{g})$ & I not used & $2.000 \mathrm{E}+03$ & | & --- & | DCNUCS ( 7) \\
\hline 161 & Leach rate (/yr) & $10.000 \mathrm{E}+00$ & $10.000 \mathrm{E}+00$ & | & $9.987 \mathrm{E}-06$ & | ALEACH ( 7) \\
\hline 161 & Solubility constant & $10.000 \mathrm{E}+00$ & $0.000 \mathrm{E}+00$ & । & not used & | SOLUBK ( 7) \\
\hline । & & । & । & । & & । \\
\hline 161 & Distribution coefficients for Pu-239 & | & | & | & & | \\
\hline 161 & Contaminated zone $(\mathrm{cm} * * 3 / \mathrm{g})$ & $5.500 \mathrm{E}+02$ & $2.000 \mathrm{E}+03$ & | & --- & | $\operatorname{DCNUCC}(9)$ \\
\hline 161 & Unsaturated zone $1(\mathrm{~cm} * \star 3 / \mathrm{g})$ & I not used & $2.000 \mathrm{E}+03$ & | & --- & I DCNUCU $(9,1$ \\
\hline 161 & Unsaturated zone $2(\mathrm{~cm} * \star 3 / \mathrm{g})$ & I not used & $2.000 \mathrm{E}+03$ & | & --- & I DCNUCU $(9,2$ \\
\hline 161 & Unsaturated zone $3\left(\mathrm{~cm}^{* * 3 / \mathrm{g})}\right.$ & I not used & $2.000 \mathrm{E}+03$ & | & --- & I DCNUCU( 9,3 \\
\hline 161 & Unsaturated zone $4(\mathrm{~cm} * \star 3 / \mathrm{g})$ & I not used & $2.000 \mathrm{E}+03$ & | & --- & I DCNUCU $(9,4$ \\
\hline 161 & Unsaturated zone $5(\mathrm{~cm} * * 3 / \mathrm{g})$ & I not used & | $2.000 \mathrm{E}+03$ & । & --- & I DCNUCU $(9,5$ \\
\hline$|6|$ & Saturated zone $(\mathrm{cm} * * 3 / \mathrm{g})$ & I not used & $2.000 \mathrm{E}+03$ & । & --- & | DCNUCS ( 9) \\
\hline 61 & Leach rate (/yr) & $10.000 \mathrm{E}+00$ & $0.000 \mathrm{E}+00$ & | & $9.987 \mathrm{E}-06$ & | $\operatorname{ALEACH}(9)$ \\
\hline 61 & Solubility constant & $10.000 \mathrm{E}+00$ & $10.000 \mathrm{E}+00$ & | & not used & | SOLUBK (9) \\
\hline | & & l & । & | & & | \\
\hline 161 & Distribution coefficients for $\mathrm{Pu}-240$ & l & । & | & & I \\
\hline 61 & Contaminated zone $\left(\mathrm{cm}^{* * 3 / \mathrm{g})}\right.$ & $5.500 \mathrm{E}+02$ & $2.000 \mathrm{E}+03$ & | & --- & I DCNUCC (10) \\
\hline 61 & Unsaturated zone $1(\mathrm{~cm} * \star 3 / \mathrm{g})$ & I not used & $2.000 \mathrm{E}+03$ & | & --- & I $\operatorname{DCNUCU}(10,1$ \\
\hline 61 & Unsaturated zone $2(\mathrm{~cm} * * 3 / \mathrm{g})$ & I not used & $2.000 \mathrm{E}+03$ & | & --- & I $\operatorname{DCNUCU}(10,2$ \\
\hline 61 & Unsaturated zone $3(\mathrm{~cm} * \star 3 / \mathrm{g})$ & I not used & | $2.000 \mathrm{E}+03$ & । & --- & I $\operatorname{DCNUCU}(10,3$ \\
\hline 61 & Unsaturated zone $4(\mathrm{~cm} * \star 3 / \mathrm{g})$ & I not used & $2.000 \mathrm{E}+03$ & | & --- & I DCNUCU $(10,4$ \\
\hline 61 & Unsaturated zone $5(\mathrm{~cm} * * 3 / \mathrm{g})$ & I not used & $2.000 \mathrm{E}+03$ & | & --- & I $\operatorname{DCNUCU}(10,5$ \\
\hline 61 & Saturated zone $\left(\mathrm{cm}^{* * 3 / \mathrm{g})}\right.$ & I not used & $2.000 \mathrm{E}+03$ & | & --- & | DCNUCS (10) \\
\hline 61 & Leach rate (/yr) & $10.000 \mathrm{E}+00$ & $10.000 \mathrm{E}+00$ & | & $9.987 \mathrm{E}-06$ & | ALEACH (10) \\
\hline 61 & Solubility constant & $10.000 \mathrm{E}+00$ & $10.000 \mathrm{E}+00$ & | & not used & I SOLUBK (10) \\
\hline | & & l & | & | & & I \\
\hline | & Distribution coefficients for TC-99 & | & | & | & & I \\
\hline | & Contaminated zone $(\mathrm{cm} * \star 3 / \mathrm{g})$ & $1.000 \mathrm{E}+00$ & $10.000 \mathrm{E}+00$ & I & --- & I DCNUCC (14) \\
\hline 61 & Unsaturated zone $1(\mathrm{~cm} * * 3 / \mathrm{g})$ & I not used & $0.000 \mathrm{E}+00$ & । & --- & I DCNUCU $(14,1$ \\
\hline 61 & Unsaturated zone $2(\mathrm{~cm} * \star 3 / \mathrm{g})$ & I not used & $10.000 \mathrm{E}+00$ & | & --- & | $\operatorname{DCNUCU}(14,2$ \\
\hline 61 & Unsaturated zone $3\left(\mathrm{~cm}^{* *} 3 / \mathrm{g}\right)$ & I not used & $10.000 \mathrm{E}+00$ & | & --- & I DCNUCU $(14,3$ \\
\hline 61 & Unsaturated zone $4(\mathrm{~cm} * * 3 / \mathrm{g})$ & I not used & $10.000 \mathrm{E}+00$ & | & --- & I $\operatorname{DCNUCU}(14,4$ \\
\hline 61 & Unsaturated zone $5(\mathrm{~cm} * \star 3 / \mathrm{g})$ & I not used & $0.000 \mathrm{E}+00$ & । & --- & I DCNUCU $(14,5$ \\
\hline | & Saturated zone $(\mathrm{cm} * \star 3 / \mathrm{g})$ & I not used & $10.000 \mathrm{E}+00$ & | & --- & I DCNUCS (14) \\
\hline & Leach rate $(/ y r)$ & $10.000 \mathrm{E}+00$ & $10.000 \mathrm{E}+00$ & I & $5.258 \mathrm{E}-03$ & I ALEACH (14) \\
\hline & Solubility constant & $10.000 \mathrm{E}+00$ & $10.000 \mathrm{E}+00$ & & not used & I SOLUBK (14) \\
\hline
\end{tabular}


RESRAD, Version $6.5 \quad T^{1 / 2}$ Limit $=180$ days

Summary : C746U Recreational User Deterministic Run

File : $\mathrm{X}: \backslash$ FINAL V2 $\backslash \mathrm{C} 746 \mathrm{U}$ RU DET-FINALV2.RAD

Site-Specific Parameter Summary (continued)

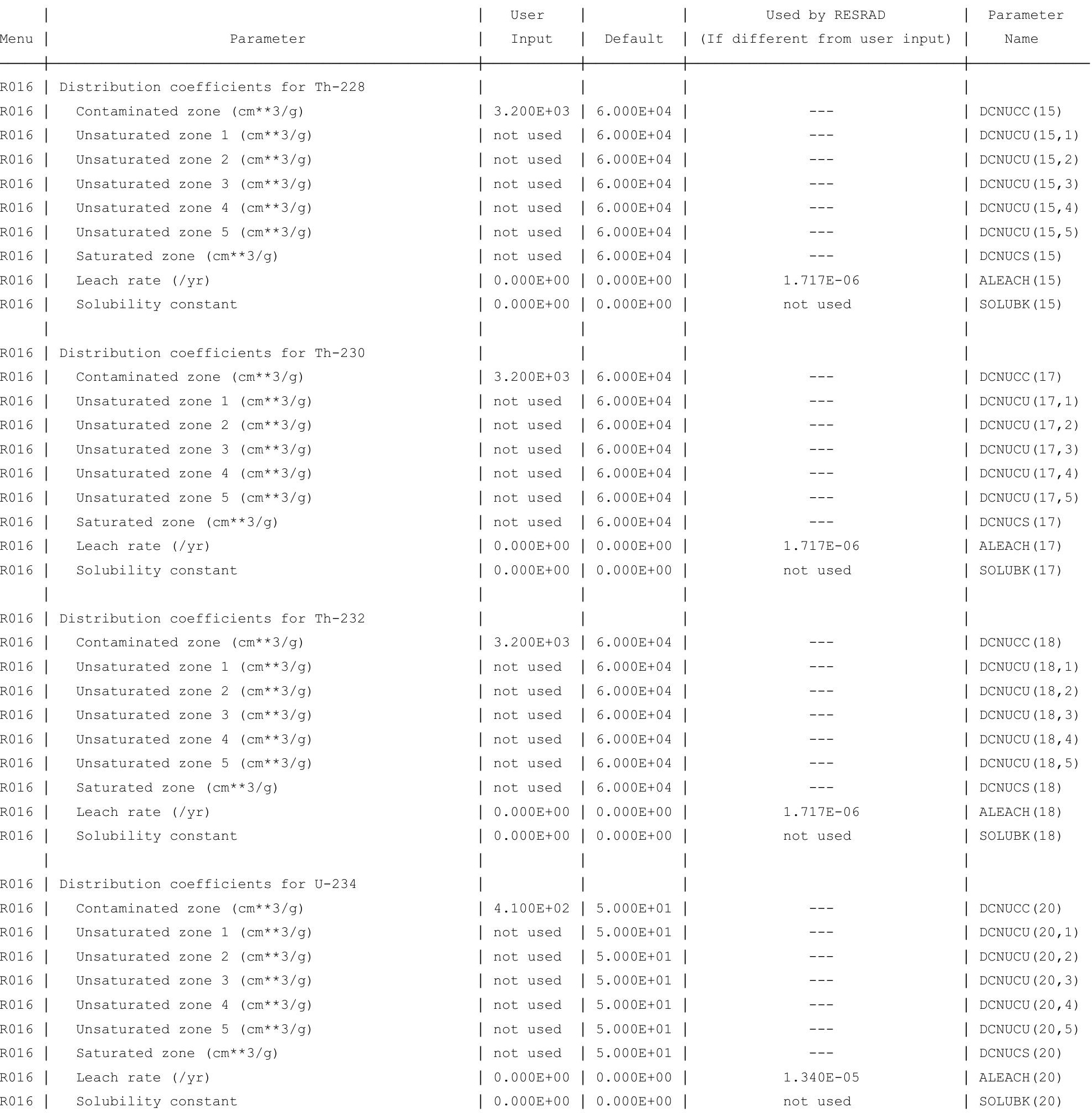


RESRAD, Version $6.5 \quad T^{1 / 2}$ Limit $=180$ days

Summary : C746U Recreational User Deterministic Run

File : $\mathrm{X}: \backslash$ FINAL V2 $\backslash \mathrm{C} 746 \mathrm{U}$ RU DET-FINALV2.RAD

Site-Specific Parameter Summary (continued)

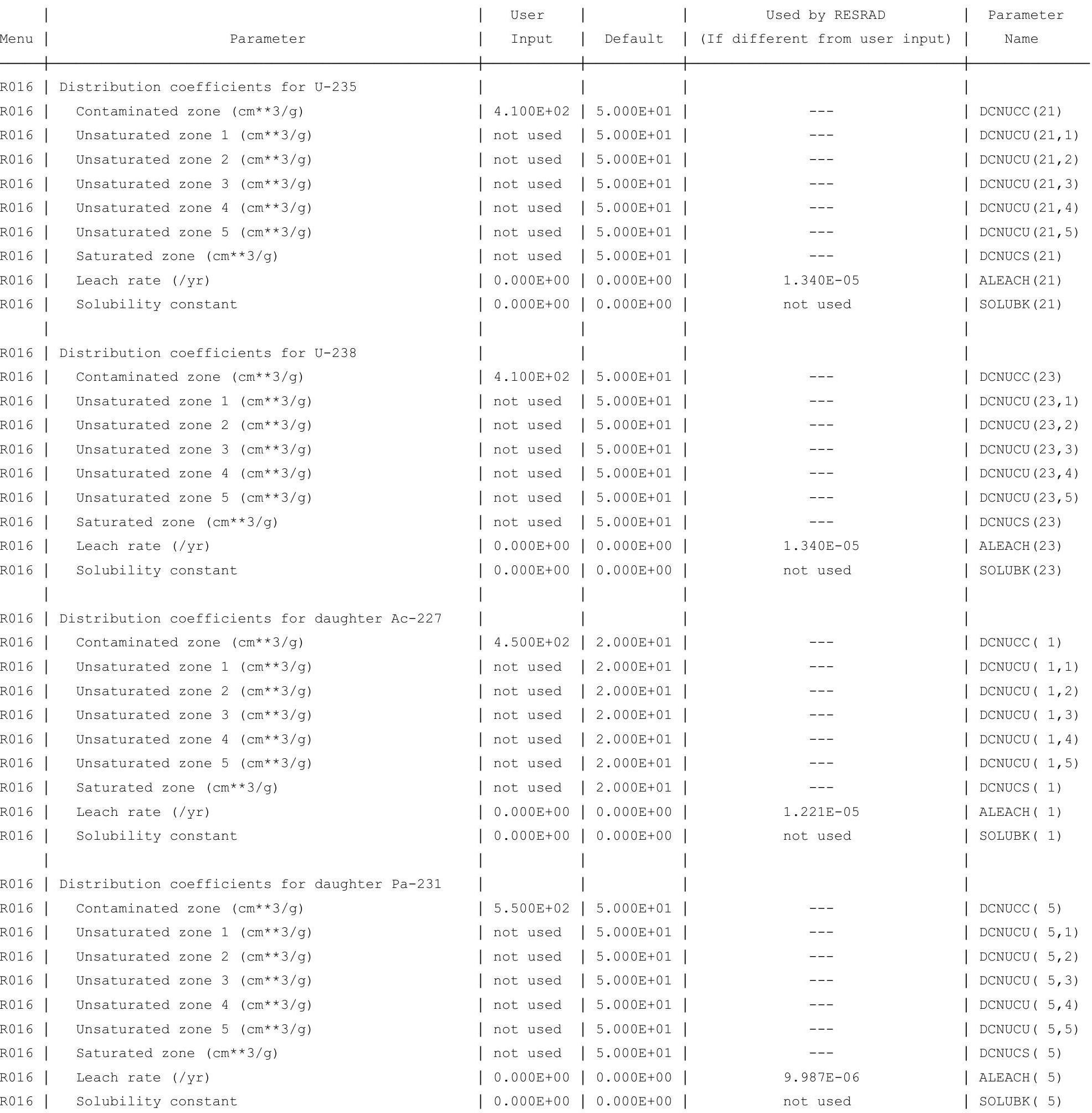


RESRAD, Version $6.5 \quad T^{1 / 2}$ Limit $=180$ days

Summary : C746U Recreational User Deterministic Run

File : $\mathrm{x}: \backslash$ FINAL V2 $\backslash \mathrm{C} 746 \mathrm{U}$ RU DET-FINALV2.RAD

Site-Specific Parameter Summary (continued)

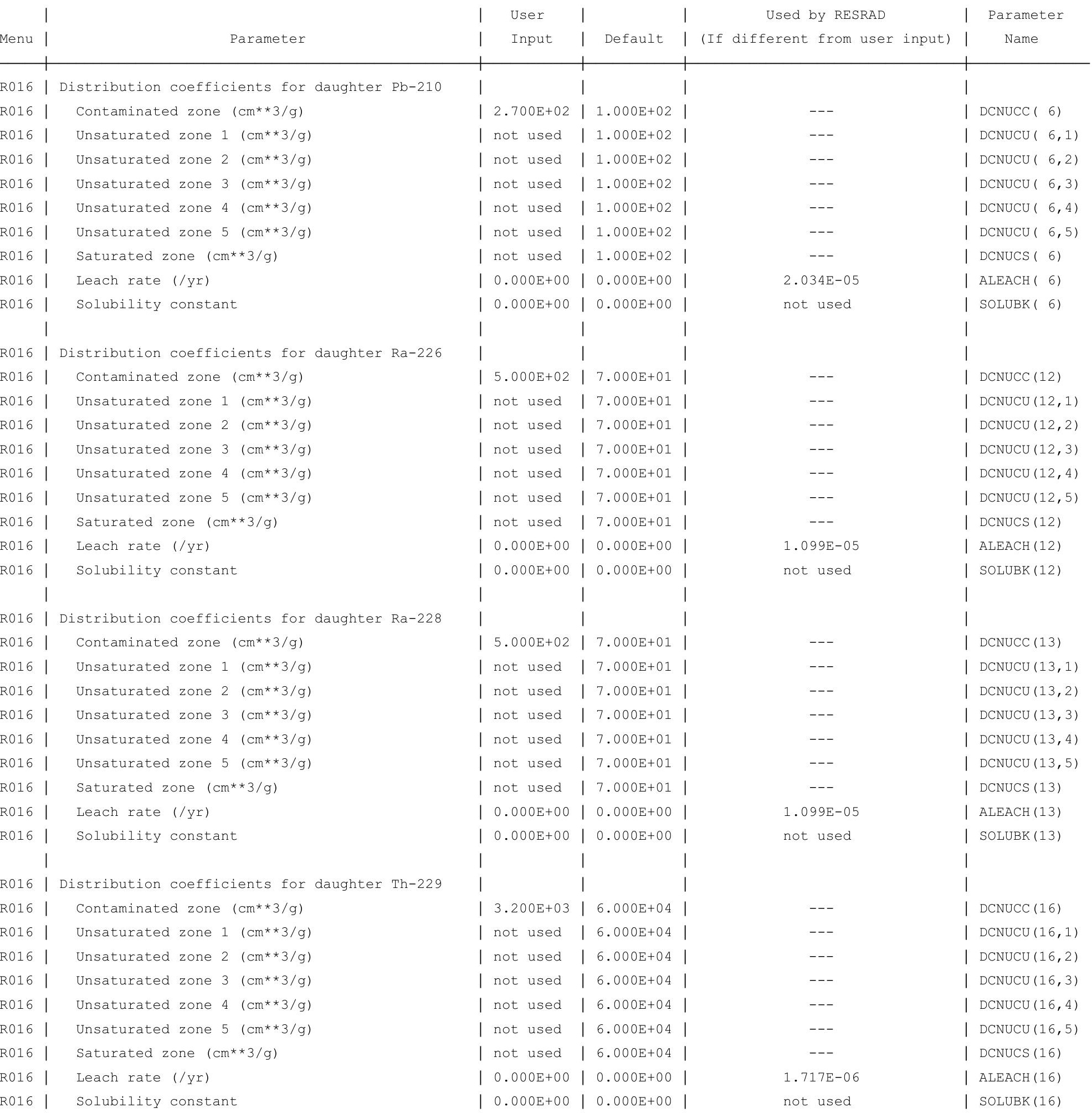


RESRAD, Version $6.5 \quad T^{1 / 2}$ Limit $=180$ days

Summary : C746U Recreational User Deterministic Run

File : $X: \backslash F I N A L$ V2 $\backslash C 746 U$ RU DET-FINALV2.RAD

Site-Specific Parameter Summary (continued)

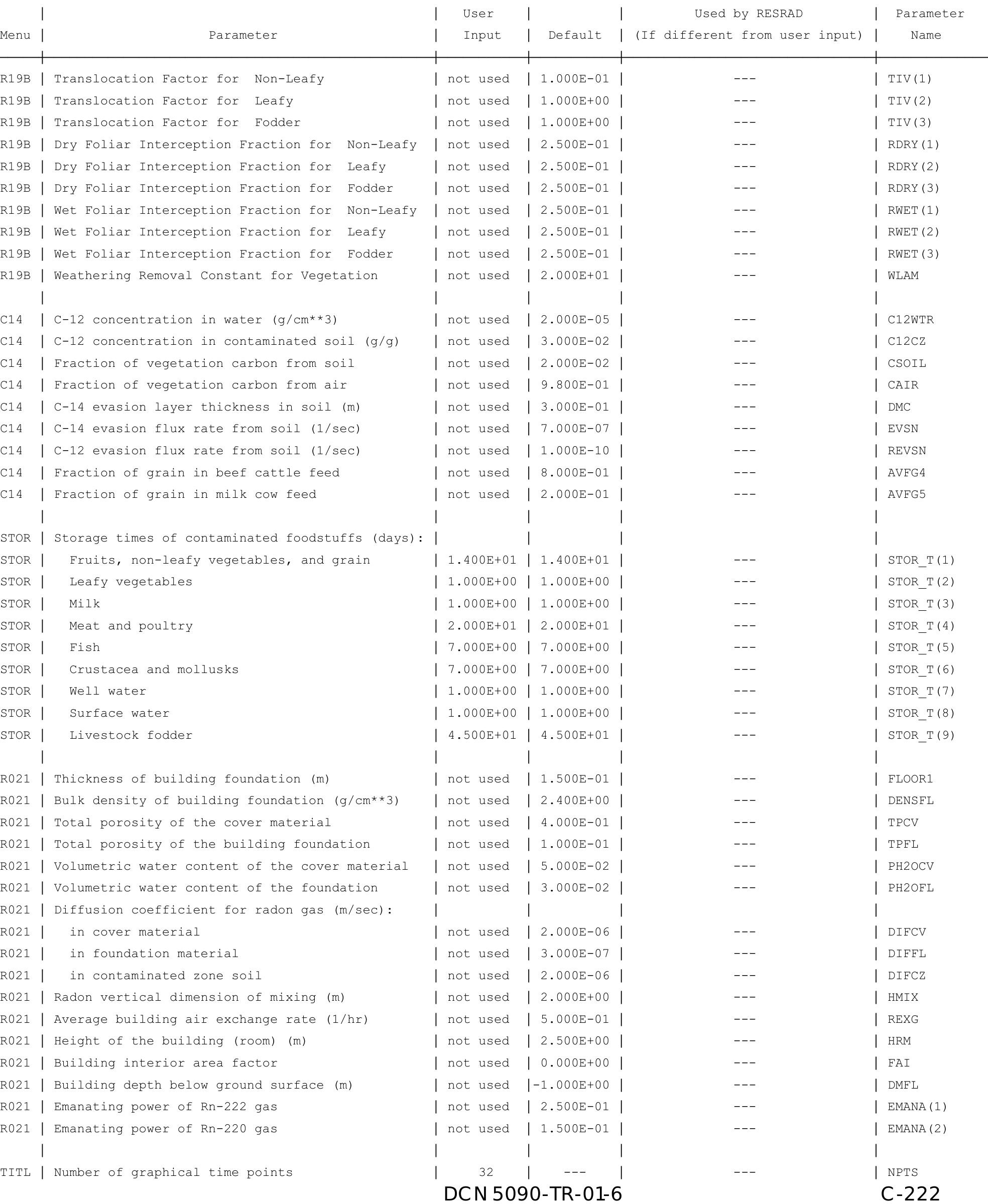


RESRAD, Version $6.5 \quad \mathrm{~T}^{1 / 2}$ Limit $=180$ days

Summary : C746U Recreational User Deterministic Run

File : $\mathrm{X}: \backslash F I N A L$ V2 $\backslash \mathrm{C} 746 \mathrm{U}$ RU DET-FINALV2.RAD

Contaminated Zone Dimensions

Area: $\quad 89436.00$ square meters

Thickness:

Cover Depth:
Initial Soil Concentrations, pci/g

$\begin{array}{ll}\mathrm{Am}-241 & 1.000 \mathrm{E}+00 \\ \mathrm{Cs}-137 & 1.000 \mathrm{E}+00 \\ \mathrm{~Np}-237 & 1.000 \mathrm{E}+00 \\ \mathrm{Pu}-238 & 1.000 \mathrm{E}+00 \\ \mathrm{Pu}-239 & 1.000 \mathrm{E}+00 \\ \mathrm{Pu}-240 & 1.000 \mathrm{E}+00 \\ \mathrm{TC}-99 & 1.000 \mathrm{E}+00 \\ \mathrm{Th}-228 & 1.000 \mathrm{E}+00 \\ \mathrm{Th}-230 & 1.000 \mathrm{E}+00 \\ \mathrm{Th}-232 & 1.000 \mathrm{E}+00 \\ \mathrm{U}-234 & 1.000 \mathrm{E}+00 \\ \mathrm{U}-235 & 1.000 \mathrm{E}+00 \\ \mathrm{U}-238 & 1.000 \mathrm{E}+00\end{array}$

Total Dose TDOSE(t), mrem/yr

Basic Radiation Dose Limit $=1.000 \mathrm{E}+00 \mathrm{mrem} / \mathrm{yr}$

Total Mixture Sum $M(t)$ = Fraction of Basic Dose Limit Received at Time (t)

$\begin{array}{rllllll}t \text { (years): } & 0.000 \mathrm{E}+00 & 1.000 \mathrm{E}+00 & 5.000 \mathrm{E}+01 & 1.000 \mathrm{E}+02 & 5.000 \mathrm{E}+02 & 1.050 \mathrm{E}+03 \\ \text { TDOSE }(\mathrm{t}): & 1.342 \mathrm{E}-07 & 9.986 \mathrm{E}-08 & 2.161 \mathrm{E}-07 & 2.931 \mathrm{E}-07 & 3.316 \mathrm{E}-06 & 9.778 \mathrm{E}-05 \\ \mathrm{M}(\mathrm{t}): & 1.342 \mathrm{E}-07 & 9.986 \mathrm{E}-08 & 2.161 \mathrm{E}-07 & 2.931 \mathrm{E}-07 & 3.316 \mathrm{E}-06 & 9.778 \mathrm{E}-05\end{array}$

Maximum TDOSE $(t): 9.778 \mathrm{E}-05 \mathrm{mrem} / \mathrm{yr}$ at $t=1.050 \mathrm{E}+03$ years 
RESRAD, Version 6.5

$\mathrm{T}^{1 / 2}$ Limit $=180$ days

ummary : C746U Recreational User Deterministic Run

: $\mathrm{X}: \backslash F I N A L$ V2 \C746U RU DET-FINALV2.RAD

Total Dose Contributions TDOSE (i,p,t) for Individual Radionuclides (i) and Pathways (p) As mrem/yr and Fraction of Total Dose At $t=0.000 \mathrm{E}+00$ years

Water Independent Pathways (Inhalation excludes radon)

\begin{tabular}{|c|c|c|c|c|c|c|c|c|c|c|c|c|c|c|}
\hline \multirow{2}{*}{ Nuclide } & \multicolumn{2}{|c|}{ Ground } & \multicolumn{2}{|c|}{ Inhalation } & \multicolumn{2}{|c|}{ Radon } & \multicolumn{2}{|c|}{ Plant } & \multicolumn{2}{|c|}{ Meat } & \multicolumn{2}{|c|}{ Milk } & \multicolumn{2}{|c|}{ Soil } \\
\hline & mrem/yr & fract. & mrem/yr & fract. & mrem/yr & fract. & mrem/yr & fract. & mrem/yr & fract. & mrem/yr & fract. & mrem/yr & fract. \\
\hline-241 & $1.487 \mathrm{E}-20$ & 0.0000 & $0.000 \mathrm{E}+00$ & 0.0000 & $0.000 \mathrm{E}+00$ & 0.0000 & $0.000 \mathrm{E}+00$ & 0.0000 & $0.000 \mathrm{E}+00$ & 0.0000 & $0.000 \mathrm{E}+00$ & 0.0000 & $0.000 \mathrm{E}+00$ & 0.0000 \\
\hline-137 & $1.213 \mathrm{E}-10$ & 0.0009 & $0.000 \mathrm{E}+00$ & 0.0000 & $0.000 \mathrm{E}+00$ & 0.0000 & $0.000 \mathrm{E}+00$ & 0.0000 & $0.000 \mathrm{E}+00$ & 0.0000 & $0.000 \mathrm{E}+00$ & 0.0000 & $0.000 \mathrm{E}+00$ & 0.0000 \\
\hline-237 & $9.169 \mathrm{E}-14$ & 0.0000 & $0.000 \mathrm{E}+00$ & 0.0000 & $0.000 \mathrm{E}+00$ & 0.0000 & $0.000 \mathrm{E}+00$ & 0.0000 & $0.000 \mathrm{E}+00$ & 0.0000 & $0.000 \mathrm{E}+00$ & 0.0000 & $0.000 \mathrm{E}+00$ & 0.0000 \\
\hline-238 & $7.826 E-24$ & 0.0000 & $0.000 \mathrm{E}+00$ & 0.0000 & $0.000 \mathrm{E}+00$ & 0.0000 & $0.000 \mathrm{E}+00$ & 0.0000 & $0.000 \mathrm{E}+00$ & 0.0000 & $0.000 \mathrm{E}+00$ & 0.0000 & $0.000 \mathrm{E}+00$ & 0.0000 \\
\hline-239 & $1.156 \mathrm{E}-18$ & 0.0000 & $0.000 \mathrm{E}+00$ & 0.0000 & $0.000 \mathrm{E}+00$ & 0.0000 & $0.000 \mathrm{E}+00$ & 0.0000 & $0.000 \mathrm{E}+00$ & 0.0000 & $0.000 \mathrm{E}+00$ & 0.0000 & $0.000 \mathrm{E}+00$ & 0.0000 \\
\hline-240 & $1.099 \mathrm{E}-25$ & 0.0000 & $0.000 \mathrm{E}+00$ & 0.0000 & $0.000 \mathrm{E}+00$ & 0.0000 & $0.000 \mathrm{E}+00$ & 0.0000 & $0.000 \mathrm{E}+00$ & 0.0000 & $0.000 \mathrm{E}+00$ & 0.0000 & $0.000 \mathrm{E}+00$ & 0.0000 \\
\hline 99 & $5.547 \mathrm{E}-27$ & 0.0000 & $0.000 \mathrm{E}+00$ & 0.0000 & $0.000 \mathrm{E}+00$ & 0.0000 & $0.000 \mathrm{E}+00$ & 0.0000 & $0.000 \mathrm{E}+00$ & 0.0000 & $0.000 \mathrm{E}+00$ & 0.0000 & $0.000 \mathrm{E}+00$ & 0.0000 \\
\hline-228 & $1.329 \mathrm{E}-07$ & 0.9905 & $0.000 \mathrm{E}+00$ & 0.0000 & $0.000 \mathrm{E}+00$ & 0.0000 & $0.000 \mathrm{E}+00$ & 0.0000 & $0.000 \mathrm{E}+00$ & 0.0000 & $0.000 \mathrm{E}+00$ & 0.0000 & $0.000 \mathrm{E}+00$ & 0.0000 \\
\hline-230 & $3.629 \mathrm{E}-12$ & 0.0000 & $0.000 \mathrm{E}+00$ & 0.0000 & $0.000 \mathrm{E}+00$ & 0.0000 & $0.000 \mathrm{E}+00$ & 0.0000 & $0.000 \mathrm{E}+00$ & 0.0000 & $0.000 \mathrm{E}+00$ & 0.0000 & $0.000 \mathrm{E}+00$ & 0.0000 \\
\hline-232 & $1.133 E-09$ & 0.0084 & $0.000 \mathrm{E}+00$ & 0.0000 & $0.000 \mathrm{E}+00$ & 0.0000 & $0.000 \mathrm{E}+00$ & 0.0000 & $0.000 \mathrm{E}+00$ & 0.0000 & $0.000 \mathrm{E}+00$ & 0.0000 & $0.000 \mathrm{E}+00$ & 0.0000 \\
\hline 234 & $1.090 \mathrm{E}-17$ & 0.0000 & $0.000 \mathrm{E}+00$ & 0.0000 & $0.000 \mathrm{E}+00$ & 0.0000 & $0.000 \mathrm{E}+00$ & 0.0000 & $0.000 \mathrm{E}+00$ & 0.0000 & $0.000 \mathrm{E}+00$ & 0.0000 & $0.000 \mathrm{E}+00$ & 0.0000 \\
\hline 235 & $1.197 \mathrm{E}-15$ & 0.0000 & $0.000 \mathrm{E}+00$ & 0.0000 & $0.000 \mathrm{E}+00$ & 0.0000 & $0.000 \mathrm{E}+00$ & 0.0000 & $0.000 \mathrm{E}+00$ & 0.0000 & $0.000 \mathrm{E}+00$ & 0.0000 & $0.000 \mathrm{E}+00$ & 0.0000 \\
\hline 38 & $1.365 E-11$ & 0.0001 & $0.000 \mathrm{E}+00$ & 0.0000 & $0.000 \mathrm{E}+00$ & 0.0000 & $0.000 \mathrm{E}+00$ & 0.0000 & $0.000 \mathrm{E}+00$ & 0.0000 & $0.000 \mathrm{E}+00$ & 0.0000 & $0.000 \mathrm{E}+00$ & 0.0000 \\
\hline & 1. $342 \mathrm{E}-07$ & 1.0000 & $0.000 \mathrm{E}+00$ & 0.0000 & $0.000 \mathrm{E}+00$ & 0.0000 & $0.000 \mathrm{E}+00$ & 0.0000 & $0.000 \mathrm{E}+00$ & 0.0000 & $0.000 \mathrm{E}+00$ & 0.0000 & $.000 \mathrm{E}+00$ & 0.0000 \\
\hline
\end{tabular}

Total Dose Contributions TDOSE (i,p,t) for Individual Radionuclides (i) and Pathways (p) As mrem/yr and Fraction of Total Dose At $t=0.000 \mathrm{E}+00$ years

Water Dependent Pathways

\begin{tabular}{|c|c|c|c|c|c|c|c|c|c|c|c|c|c|c|}
\hline & \multicolumn{2}{|c|}{ Water } & \multicolumn{2}{|c|}{ Fish } & \multicolumn{2}{|c|}{ Radon } & \multicolumn{2}{|c|}{ Plant } & \multicolumn{2}{|c|}{ Meat } & \multicolumn{2}{|c|}{ Milk } & \multicolumn{2}{|c|}{ All Pathways* } \\
\hline clide & mrem/yr & fract. & mrem/yr & fract. & mrem/yr & fract. & mrem/yr & fract. & mrem/yr & fract. & mrem/yr & fract. & mrem/yr & fract. \\
\hline-241 & $0.000 \mathrm{E}+00$ & 0.0000 & $0.000 \mathrm{E}+00$ & 0.0000 & $0.000 \mathrm{E}+00$ & 0.0000 & $0.000 \mathrm{E}+00$ & 0.0000 & $0.000 \mathrm{E}+00$ & 0.0000 & $0.000 \mathrm{E}+00$ & 0.0000 & $1.487 \mathrm{E}-20$ & 0.0000 \\
\hline-137 & $0.000 \mathrm{E}+00$ & 0.0000 & $0.000 \mathrm{E}+00$ & 0.0000 & $0.000 \mathrm{E}+00$ & 0.0000 & $0.000 \mathrm{E}+00$ & 0.0000 & $0.000 \mathrm{E}+00$ & 0.0000 & $0.000 \mathrm{E}+00$ & 0.0000 & 1. $213 \mathrm{E}-10$ & 0.0009 \\
\hline-237 & $0.000 \mathrm{E}+00$ & 0.0000 & $0.000 \mathrm{E}+00$ & 0.0000 & $0.000 \mathrm{E}+00$ & 0.0000 & $0.000 \mathrm{E}+00$ & 0.0000 & $0.000 \mathrm{E}+00$ & 0.0000 & $0.000 \mathrm{E}+00$ & 0.0000 & $9.169 \mathrm{E}-14$ & 0.0000 \\
\hline 238 & $0.000 \mathrm{E}+00$ & 0.0000 & $0.000 \mathrm{E}+00$ & 0.0000 & $0.000 \mathrm{E}+00$ & 0.0000 & $0.000 \mathrm{E}+00$ & 0.0000 & $0.000 \mathrm{E}+00$ & 0.0000 & $0.000 \mathrm{E}+00$ & 0.0000 & $7.826 \mathrm{E}-24$ & 0.0000 \\
\hline 239 & $0.000 \mathrm{E}+00$ & 0.0000 & $0.000 \mathrm{E}+00$ & 0.0000 & $0.000 \mathrm{E}+00$ & 0.0000 & $0.000 \mathrm{E}+00$ & 0.0000 & $0.000 \mathrm{E}+00$ & 0.0000 & $0.000 \mathrm{E}+00$ & 0.0000 & $1.156 \mathrm{E}-18$ & 0.0000 \\
\hline 240 & $0.000 \mathrm{E}+00$ & 0.0000 & $0.000 \mathrm{E}+00$ & 0.0000 & $0.000 \mathrm{E}+00$ & 0.0000 & $0.000 \mathrm{E}+00$ & 0.0000 & $0.000 \mathrm{E}+00$ & 0.0000 & $0.000 \mathrm{E}+00$ & 0.0000 & $1.099 \mathrm{E}-25$ & 0.0000 \\
\hline 99 & $0.000 \mathrm{E}+00$ & 0.0000 & $0.000 \mathrm{E}+00$ & 0.0000 & $0.000 \mathrm{E}+00$ & 0.0000 & $0.000 \mathrm{E}+00$ & 0.0000 & $0.000 \mathrm{E}+00$ & 0.0000 & $0.000 \mathrm{E}+00$ & 0.0000 & $5.547 \mathrm{E}-27$ & 0.0000 \\
\hline 228 & $0.000 \mathrm{E}+00$ & 0.0000 & $0.000 \mathrm{E}+00$ & 0.0000 & $0.000 \mathrm{E}+00$ & 0.0000 & $0.000 \mathrm{E}+00$ & 0.0000 & $0.000 \mathrm{E}+00$ & 0.0000 & $0.000 \mathrm{E}+00$ & 0.0000 & $1.329 \mathrm{E}-07$ & 0.9905 \\
\hline 230 & $0.000 \mathrm{E}+00$ & 0.0000 & $0.000 \mathrm{E}+00$ & 0.0000 & $0.000 \mathrm{E}+00$ & 0.0000 & $0.000 \mathrm{E}+00$ & 0.0000 & $0.000 \mathrm{E}+00$ & 0.0000 & $0.000 \mathrm{E}+00$ & 0.0000 & $3.629 \mathrm{E}-12$ & 0.0000 \\
\hline 232 & $0.000 \mathrm{E}+00$ & 0.0000 & $0.000 \mathrm{E}+00$ & 0.0000 & $0.000 \mathrm{E}+00$ & 0.0000 & $0.000 \mathrm{E}+00$ & 0.0000 & $0.000 \mathrm{E}+00$ & 0.0000 & $0.000 \mathrm{E}+00$ & 0.0000 & $1.133 \mathrm{E}-09$ & 0.0084 \\
\hline 34 & $0.000 \mathrm{E}+00$ & 0.0000 & $0.000 \mathrm{E}+00$ & 0.0000 & $0.000 \mathrm{E}+00$ & 0.0000 & $0.000 \mathrm{E}+00$ & 0.0000 & $0.000 \mathrm{E}+00$ & 0.0000 & $0.000 \mathrm{E}+00$ & 0.0000 & $1.090 \mathrm{E}-17$ & 0.0000 \\
\hline 35 & $0.000 \mathrm{E}+00$ & 0.0000 & $0.000 \mathrm{E}+00$ & 0.0000 & $0.000 \mathrm{E}+00$ & 0.0000 & $0.000 \mathrm{E}+00$ & 0.0000 & $0.000 \mathrm{E}+00$ & 0.0000 & $0.000 \mathrm{E}+00$ & 0.0000 & $1.197 \mathrm{E}-15$ & 0.0000 \\
\hline 38 & $0.000 \mathrm{E}+00$ & 0.0000 & $0.000 \mathrm{E}+00$ & 0.0000 & $0.000 \mathrm{E}+00$ & 0.0000 & $0.000 \mathrm{E}+00$ & 0.0000 & $0.000 \mathrm{E}+00$ & 0.0000 & $0.000 \mathrm{E}+00$ & 0.0000 & 1. $365 \mathrm{E}-11$ & 0.0001 \\
\hline & $0.000 \mathrm{E}+00$ & 0.0000 & $0.000 \mathrm{E}+00$ & 0.0000 & $0.000 \mathrm{E}+00$ & 0.0000 & $0.000 \mathrm{E}+00$ & 0.0000 & $0.000 \mathrm{E}+00$ & 0.0000 & $0.000 \mathrm{E}+00$ & 000 & -07 & 1.0000 \\
\hline
\end{tabular}

* Sum of all water independent and dependent pathways. 
RESRAD, Version 6.5

$\mathrm{T}^{1 / 2}$ Limit $=180$ days

ummary : C746U Recreational User Deterministic Run

: $X: \backslash F I N A L$ V2 $\backslash C 746 U$ RU DET-FINALV2.RAD

Total Dose Contributions TDOSE (i,p,t) for Individual Radionuclides (i) and Pathways (p) As mrem/yr and Fraction of Total Dose At $t=1.000 \mathrm{E}+00$ years

Water Independent Pathways (Inhalation excludes radon)

\begin{tabular}{|c|c|c|c|c|c|c|c|c|c|c|c|c|c|c|}
\hline \multirow{2}{*}{ Nuclide } & \multicolumn{2}{|c|}{ Ground } & \multicolumn{2}{|c|}{ Inhalation } & \multicolumn{2}{|c|}{ Radon } & \multicolumn{2}{|c|}{ Plant } & \multicolumn{2}{|c|}{ Meat } & \multicolumn{2}{|c|}{ Milk } & \multicolumn{2}{|c|}{ Soil } \\
\hline & mrem/yr & fract. & mrem/yr & fract. & mrem/yr & fract. & mrem/yr & fract. & mrem/yr & fract. & mrem/yr & fract. & mrem/yr & fract. \\
\hline-241 & $4.500 \mathrm{E}-20$ & 0.0000 & $0.000 \mathrm{E}+00$ & 0.0000 & $0.000 \mathrm{E}+00$ & 0.0000 & $0.000 \mathrm{E}+00$ & 0.0000 & $0.000 \mathrm{E}+00$ & 0.0000 & $0.000 \mathrm{E}+00$ & 0.0000 & $0.000 \mathrm{E}+00$ & 0.0000 \\
\hline-137 & $1.196 \mathrm{E}-10$ & 0.0012 & $0.000 \mathrm{E}+00$ & 0.0000 & $0.000 \mathrm{E}+00$ & 0.0000 & $0.000 \mathrm{E}+00$ & 0.0000 & $0.000 \mathrm{E}+00$ & 0.0000 & $0.000 \mathrm{E}+00$ & 0.0000 & $0.000 \mathrm{E}+00$ & 0.0000 \\
\hline-237 & $9.268 \mathrm{E}-14$ & 0.0000 & $0.000 \mathrm{E}+00$ & 0.0000 & $0.000 \mathrm{E}+00$ & 0.0000 & $0.000 \mathrm{E}+00$ & 0.0000 & $0.000 \mathrm{E}+00$ & 0.0000 & $0.000 \mathrm{E}+00$ & 0.0000 & $0.000 \mathrm{E}+00$ & 0.0000 \\
\hline-238 & $1.163 E-22$ & 0.0000 & $0.000 \mathrm{E}+00$ & 0.0000 & $0.000 \mathrm{E}+00$ & 0.0000 & $0.000 \mathrm{E}+00$ & 0.0000 & $0.000 \mathrm{E}+00$ & 0.0000 & $0.000 \mathrm{E}+00$ & 0.0000 & $0.000 \mathrm{E}+00$ & 0.0000 \\
\hline-239 & $1.170 \mathrm{E}-18$ & 0.0000 & $0.000 \mathrm{E}+00$ & 0.0000 & $0.000 \mathrm{E}+00$ & 0.0000 & $0.000 \mathrm{E}+00$ & 0.0000 & $0.000 \mathrm{E}+00$ & 0.0000 & $0.000 \mathrm{E}+00$ & 0.0000 & $0.000 \mathrm{E}+00$ & 0.0000 \\
\hline-240 & $1.142 \mathrm{E}-25$ & 0.0000 & $0.000 \mathrm{E}+00$ & 0.0000 & $0.000 \mathrm{E}+00$ & 0.0000 & $0.000 \mathrm{E}+00$ & 0.0000 & $0.000 \mathrm{E}+00$ & 0.0000 & $0.000 \mathrm{E}+00$ & 0.0000 & $0.000 \mathrm{E}+00$ & 0.0000 \\
\hline 99 & $5.625 E-27$ & 0.0000 & $0.000 \mathrm{E}+00$ & 0.0000 & $0.000 \mathrm{E}+00$ & 0.0000 & $0.000 \mathrm{E}+00$ & 0.0000 & $0.000 \mathrm{E}+00$ & 0.0000 & $0.000 \mathrm{E}+00$ & 0.0000 & $0.000 \mathrm{E}+00$ & 0.0000 \\
\hline-228 & $9.308 \mathrm{E}-08$ & 0.9321 & $0.000 \mathrm{E}+00$ & 0.0000 & $0.000 \mathrm{E}+00$ & 0.0000 & $0.000 \mathrm{E}+00$ & 0.0000 & $0.000 \mathrm{E}+00$ & 0.0000 & $0.000 \mathrm{E}+00$ & 0.0000 & $0.000 \mathrm{E}+00$ & 0.0000 \\
\hline-230 & $1.095 \mathrm{E}-11$ & 0.0001 & $0.000 \mathrm{E}+00$ & 0.0000 & $0.000 \mathrm{E}+00$ & 0.0000 & $0.000 \mathrm{E}+00$ & 0.0000 & $0.000 \mathrm{E}+00$ & 0.0000 & $0.000 \mathrm{E}+00$ & 0.0000 & $0.000 \mathrm{E}+00$ & 0.0000 \\
\hline-232 & $6.633 E-09$ & 0.0664 & $0.000 \mathrm{E}+00$ & 0.0000 & $0.000 \mathrm{E}+00$ & 0.0000 & $0.000 \mathrm{E}+00$ & 0.0000 & $0.000 \mathrm{E}+00$ & 0.0000 & $0.000 \mathrm{E}+00$ & 0.0000 & $0.000 \mathrm{E}+00$ & 0.0000 \\
\hline 234 & $7.671 \mathrm{E}-17$ & 0.0000 & $0.000 \mathrm{E}+00$ & 0.0000 & $0.000 \mathrm{E}+00$ & 0.0000 & $0.000 \mathrm{E}+00$ & 0.0000 & $0.000 \mathrm{E}+00$ & 0.0000 & $0.000 \mathrm{E}+00$ & 0.0000 & $0.000 \mathrm{E}+00$ & 0.0000 \\
\hline 235 & $1.217 \mathrm{E}-15$ & 0.0000 & $0.000 \mathrm{E}+00$ & 0.0000 & $0.000 \mathrm{E}+00$ & 0.0000 & $0.000 \mathrm{E}+00$ & 0.0000 & $0.000 \mathrm{E}+00$ & 0.0000 & $0.000 \mathrm{E}+00$ & 0.0000 & $0.000 \mathrm{E}+00$ & 0.0000 \\
\hline 38 & $1.376 \mathrm{E}-11$ & 0.0001 & $0.000 \mathrm{E}+00$ & 0.0000 & $0.000 \mathrm{E}+00$ & 0.0000 & $0.000 \mathrm{E}+00$ & 0.0000 & $0.000 \mathrm{E}+00$ & 0.0000 & $0.000 \mathrm{E}+00$ & 0.0000 & $0.000 \mathrm{E}+00$ & 0.0000 \\
\hline & $9.986 E-08$ & 1.0000 & $0.000 \mathrm{E}+00$ & 0.0000 & $0.000 \mathrm{E}+00$ & 0.0000 & $0.000 \mathrm{E}+00$ & 0.0000 & $0.000 \mathrm{E}+00$ & 0.0000 & $0.000 \mathrm{E}+00$ & 0.0000 & $.000 \mathrm{E}+00$ & 0.0000 \\
\hline
\end{tabular}

Total Dose Contributions TDOSE (i,p,t) for Individual Radionuclides (i) and Pathways (p) As mrem/yr and Fraction of Total Dose At $t=1.000 \mathrm{E}+00$ years

Water Dependent Pathways

\begin{tabular}{|c|c|c|c|c|c|c|c|c|c|c|c|c|c|c|}
\hline & \multicolumn{2}{|c|}{ Water } & \multicolumn{2}{|c|}{ Fish } & \multicolumn{2}{|c|}{ Radon } & \multicolumn{2}{|c|}{ Plant } & \multicolumn{2}{|c|}{ Meat } & \multicolumn{2}{|c|}{ Milk } & \multicolumn{2}{|c|}{ All Pathways* } \\
\hline clide & mrem/yr & fract. & mrem/yr & fract. & mrem/yr & fract. & mrem/yr & fract. & mrem/yr & fract. & mrem/yr & fract. & mrem/yr & fract. \\
\hline-241 & $0.000 \mathrm{E}+00$ & 0.0000 & $0.000 \mathrm{E}+00$ & 0.0000 & $0.000 \mathrm{E}+00$ & 0.0000 & $0.000 \mathrm{E}+00$ & 0.0000 & $0.000 \mathrm{E}+00$ & 0.0000 & $0.000 E+00$ & 0.0000 & $4.500 \mathrm{E}-20$ & 0.0000 \\
\hline-137 & $0.000 \mathrm{E}+00$ & 0.0000 & $0.000 \mathrm{E}+00$ & 0.0000 & $0.000 \mathrm{E}+00$ & 0.0000 & $0.000 \mathrm{E}+00$ & 0.0000 & $0.000 \mathrm{E}+00$ & 0.0000 & $0.000 \mathrm{E}+00$ & 0.0000 & $1.196 \mathrm{E}-10$ & 0.0012 \\
\hline-237 & $0.000 \mathrm{E}+00$ & 0.0000 & $0.000 \mathrm{E}+00$ & 0.0000 & $0.000 \mathrm{E}+00$ & 0.0000 & $0.000 \mathrm{E}+00$ & 0.0000 & $0.000 \mathrm{E}+00$ & 0.0000 & $0.000 \mathrm{E}+00$ & 0.0000 & $9.268 \mathrm{E}-14$ & 0.0000 \\
\hline 238 & $0.000 \mathrm{E}+00$ & 0.0000 & $0.000 \mathrm{E}+00$ & 0.0000 & $0.000 \mathrm{E}+00$ & 0.0000 & $0.000 \mathrm{E}+00$ & 0.0000 & $0.000 \mathrm{E}+00$ & 0.0000 & $0.000 \mathrm{E}+00$ & 0.0000 & $1.163 \mathrm{E}-22$ & 0.0000 \\
\hline 239 & $0.000 \mathrm{E}+00$ & 0.0000 & $0.000 \mathrm{E}+00$ & 0.0000 & $0.000 \mathrm{E}+00$ & 0.0000 & $0.000 \mathrm{E}+00$ & 0.0000 & $0.000 \mathrm{E}+00$ & 0.0000 & $0.000 \mathrm{E}+00$ & 0.0000 & $1.170 \mathrm{E}-18$ & 0.0000 \\
\hline 240 & $0.000 \mathrm{E}+00$ & 0.0000 & $0.000 \mathrm{E}+00$ & 0.0000 & $0.000 \mathrm{E}+00$ & 0.0000 & $0.000 \mathrm{E}+00$ & 0.0000 & $0.000 \mathrm{E}+00$ & 0.0000 & $0.000 \mathrm{E}+00$ & 0.0000 & $1.142 \mathrm{E}-25$ & 0.0000 \\
\hline 99 & $0.000 \mathrm{E}+00$ & 0.0000 & $0.000 \mathrm{E}+00$ & 0.0000 & $0.000 \mathrm{E}+00$ & 0.0000 & $0.000 \mathrm{E}+00$ & 0.0000 & $0.000 \mathrm{E}+00$ & 0.0000 & $0.000 \mathrm{E}+00$ & 0.0000 & $5.625 \mathrm{E}-27$ & 0.0000 \\
\hline 228 & $0.000 \mathrm{E}+00$ & 0.0000 & $0.000 \mathrm{E}+00$ & 0.0000 & $0.000 \mathrm{E}+00$ & 0.0000 & $0.000 \mathrm{E}+00$ & 0.0000 & $0.000 \mathrm{E}+00$ & 0.0000 & $0.000 \mathrm{E}+00$ & 0.0000 & $9.308 \mathrm{E}-08$ & 0.9321 \\
\hline 230 & $0.000 \mathrm{E}+00$ & 0.0000 & $0.000 \mathrm{E}+00$ & 0.0000 & $0.000 \mathrm{E}+00$ & 0.0000 & $0.000 \mathrm{E}+00$ & 0.0000 & $0.000 \mathrm{E}+00$ & 0.0000 & $0.000 \mathrm{E}+00$ & 0.0000 & $1.095 \mathrm{E}-11$ & 0.0001 \\
\hline 232 & $0.000 \mathrm{E}+00$ & 0.0000 & $0.000 \mathrm{E}+00$ & 0.0000 & $0.000 \mathrm{E}+00$ & 0.0000 & $0.000 \mathrm{E}+00$ & 0.0000 & $0.000 \mathrm{E}+00$ & 0.0000 & $0.000 \mathrm{E}+00$ & 0.0000 & $6.633 E-09$ & 0.0664 \\
\hline 34 & $0.000 \mathrm{E}+00$ & 0.0000 & $0.000 \mathrm{E}+00$ & 0.0000 & $0.000 \mathrm{E}+00$ & 0.0000 & $0.000 \mathrm{E}+00$ & 0.0000 & $0.000 \mathrm{E}+00$ & 0.0000 & $0.000 \mathrm{E}+00$ & 0.0000 & $7.671 \mathrm{E}-17$ & 0.0000 \\
\hline 35 & $0.000 \mathrm{E}+00$ & 0.0000 & $0.000 \mathrm{E}+00$ & 0.0000 & $0.000 \mathrm{E}+00$ & 0.0000 & $0.000 \mathrm{E}+00$ & 0.0000 & $0.000 \mathrm{E}+00$ & 0.0000 & $0.000 \mathrm{E}+00$ & 0.0000 & $1.217 \mathrm{E}-15$ & 0.0000 \\
\hline 38 & $0.000 \mathrm{E}+00$ & 0.0000 & $0.000 \mathrm{E}+00$ & 0.0000 & $0.000 \mathrm{E}+00$ & 0.0000 & $0.000 \mathrm{E}+00$ & 0.0000 & $0.000 \mathrm{E}+00$ & 0.0000 & $0.000 \mathrm{E}+00$ & 0.0000 & $1.376 \mathrm{E}-11$ & 0.0001 \\
\hline & $0.000 \mathrm{E}+00$ & 0.0000 & $0.000 \mathrm{E}+00$ & 0.0000 & $0.000 \mathrm{E}+00$ & 0.0000 & $0.000 \mathrm{E}+00$ & 0.0000 & $0.000 \mathrm{E}+00$ & 0.0000 & $0.000 \mathrm{E}+00$ & 000 & -08 & 1.0000 \\
\hline
\end{tabular}

* Sum of all water independent and dependent pathways. 
RESRAD, Version 6.5

$\mathrm{T}^{1 / 2}$ Limit $=180$ days

ummary : C746U Recreational User Deterministic Run

: $\mathrm{X}: \backslash F I N A L$ V2 \C746U RU DET-FINALV2.RAD

Total Dose Contributions TDOSE (i,p,t) for Individual Radionuclides (i) and Pathways (p) As mrem/yr and Fraction of Total Dose At $t=5.000 \mathrm{E}+01$ years

Water Independent Pathways (Inhalation excludes radon)

\begin{tabular}{|c|c|c|c|c|c|c|c|c|c|c|c|c|c|c|}
\hline \multirow{2}{*}{ Nuclide } & \multicolumn{2}{|c|}{ Ground } & \multicolumn{2}{|c|}{ Inhalation } & \multicolumn{2}{|c|}{ Radon } & \multicolumn{2}{|c|}{ Plant } & \multicolumn{2}{|c|}{ Meat } & \multicolumn{2}{|c|}{ Milk } & \multicolumn{2}{|c|}{ Soil } \\
\hline & mrem/yr & fract. & mrem/yr & fract. & mrem/yr & fract. & mrem/yr & fract. & mrem/yr & fract. & mrem/yr & fract. & mrem/yr & fract. \\
\hline-241 & $2.469 \mathrm{E}-18$ & 0.0000 & $0.000 \mathrm{E}+00$ & 0.0000 & $0.000 \mathrm{E}+00$ & 0.0000 & $0.000 \mathrm{E}+00$ & 0.0000 & $0.000 \mathrm{E}+00$ & 0.0000 & $0.000 \mathrm{E}+00$ & 0.0000 & $0.000 \mathrm{E}+00$ & 0.0000 \\
\hline-137 & $5.821 E-11$ & 0.0003 & $0.000 \mathrm{E}+00$ & 0.0000 & $0.000 \mathrm{E}+00$ & 0.0000 & $0.000 \mathrm{E}+00$ & 0.0000 & $0.000 \mathrm{E}+00$ & 0.0000 & $0.000 \mathrm{E}+00$ & 0.0000 & $0.000 \mathrm{E}+00$ & 0.0000 \\
\hline-237 & $1.570 \mathrm{E}-13$ & 0.0000 & $0.000 \mathrm{E}+00$ & 0.0000 & $0.000 \mathrm{E}+00$ & 0.0000 & $0.000 \mathrm{E}+00$ & 0.0000 & $0.000 \mathrm{E}+00$ & 0.0000 & $0.000 \mathrm{E}+00$ & 0.0000 & $0.000 \mathrm{E}+00$ & 0.0000 \\
\hline-238 & $5.065 E-18$ & 0.0000 & $0.000 \mathrm{E}+00$ & 0.0000 & $0.000 \mathrm{E}+00$ & 0.0000 & $0.000 \mathrm{E}+00$ & 0.0000 & $0.000 \mathrm{E}+00$ & 0.0000 & $0.000 \mathrm{E}+00$ & 0.0000 & $0.000 \mathrm{E}+00$ & 0.0000 \\
\hline-239 & $2.100 \mathrm{E}-18$ & 0.0000 & $0.000 \mathrm{E}+00$ & 0.0000 & $0.000 \mathrm{E}+00$ & 0.0000 & $0.000 \mathrm{E}+00$ & 0.0000 & $0.000 \mathrm{E}+00$ & 0.0000 & $0.000 \mathrm{E}+00$ & 0.0000 & $0.000 \mathrm{E}+00$ & 0.0000 \\
\hline-240 & $2.579 E-22$ & 0.0000 & $0.000 \mathrm{E}+00$ & 0.0000 & $0.000 \mathrm{E}+00$ & 0.0000 & $0.000 \mathrm{E}+00$ & 0.0000 & $0.000 \mathrm{E}+00$ & 0.0000 & $0.000 \mathrm{E}+00$ & 0.0000 & $0.000 \mathrm{E}+00$ & 0.0000 \\
\hline 99 & $1.112 \mathrm{E}-26$ & 0.0000 & $0.000 \mathrm{E}+00$ & 0.0000 & $0.000 \mathrm{E}+00$ & 0.0000 & $0.000 \mathrm{E}+00$ & 0.0000 & $0.000 \mathrm{E}+00$ & 0.0000 & $0.000 \mathrm{E}+00$ & 0.0000 & $0.000 \mathrm{E}+00$ & 0.0000 \\
\hline-228 & $2.430 \mathrm{E}-15$ & 0.0000 & $0.000 \mathrm{E}+00$ & 0.0000 & $0.000 \mathrm{E}+00$ & 0.0000 & $0.000 \mathrm{E}+00$ & 0.0000 & $0.000 \mathrm{E}+00$ & 0.0000 & $0.000 \mathrm{E}+00$ & 0.0000 & $0.000 \mathrm{E}+00$ & 0.0000 \\
\hline-230 & $5.116 \mathrm{E}-10$ & 0.0024 & $0.000 \mathrm{E}+00$ & 0.0000 & $0.000 \mathrm{E}+00$ & 0.0000 & $0.000 \mathrm{E}+00$ & 0.0000 & $0.000 \mathrm{E}+00$ & 0.0000 & $0.000 \mathrm{E}+00$ & 0.0000 & $0.000 \mathrm{E}+00$ & 0.0000 \\
\hline-232 & $2.155 E-07$ & 0.9973 & $0.000 \mathrm{E}+00$ & 0.0000 & $0.000 \mathrm{E}+00$ & 0.0000 & $0.000 \mathrm{E}+00$ & 0.0000 & $0.000 \mathrm{E}+00$ & 0.0000 & $0.000 \mathrm{E}+00$ & 0.0000 & $0.000 \mathrm{E}+00$ & 0.0000 \\
\hline 234 & $1.167 \mathrm{E}-13$ & 0.0000 & $0.000 \mathrm{E}+00$ & 0.0000 & $0.000 \mathrm{E}+00$ & 0.0000 & $0.000 \mathrm{E}+00$ & 0.0000 & $0.000 \mathrm{E}+00$ & 0.0000 & $0.000 \mathrm{E}+00$ & 0.0000 & $0.000 \mathrm{E}+00$ & 0.0000 \\
\hline 235 & $8.886 \mathrm{E}-15$ & 0.0000 & $0.000 \mathrm{E}+00$ & 0.0000 & $0.000 \mathrm{E}+00$ & 0.0000 & $0.000 \mathrm{E}+00$ & 0.0000 & $0.000 \mathrm{E}+00$ & 0.0000 & $0.000 \mathrm{E}+00$ & 0.0000 & $0.000 \mathrm{E}+00$ & 0.0000 \\
\hline 38 & $2.035 E-11$ & 0.0001 & $0.000 \mathrm{E}+00$ & 0.0000 & $0.000 \mathrm{E}+00$ & 0.0000 & $0.000 \mathrm{E}+00$ & 0.0000 & $0.000 \mathrm{E}+00$ & 0.0000 & $0.000 \mathrm{E}+00$ & 0.0000 & $0.000 \mathrm{E}+00$ & 0.0000 \\
\hline & $2.161 \mathrm{E}-07$ & 1.0000 & $0.000 \mathrm{E}+00$ & 0.0000 & $0.000 \mathrm{E}+00$ & 0.0000 & $0.000 \mathrm{E}+00$ & 0.0000 & $0.000 \mathrm{E}+00$ & 0.0000 & $0.000 \mathrm{E}+00$ & 0.0000 & $.000 \mathrm{E}+00$ & 0.0000 \\
\hline
\end{tabular}

Total Dose Contributions TDOSE (i,p,t) for Individual Radionuclides (i) and Pathways (p) As mrem/yr and Fraction of Total Dose At $t=5.000 \mathrm{E}+01$ years

Water Dependent Pathways

\begin{tabular}{|c|c|c|c|c|c|c|c|c|c|c|c|c|c|c|}
\hline & \multicolumn{2}{|c|}{ Water } & \multicolumn{2}{|c|}{ Fish } & \multicolumn{2}{|c|}{ Radon } & \multicolumn{2}{|c|}{ Plant } & \multicolumn{2}{|c|}{ Meat } & \multicolumn{2}{|c|}{ Milk } & \multicolumn{2}{|c|}{ All Pathways* } \\
\hline clide & mrem/yr & fract. & mrem/yr & fract. & mrem/yr & fract. & mrem/yr & fract. & mrem/yr & fract. & mrem/yr & fract. & mrem/yr & fract. \\
\hline-241 & $0.000 \mathrm{E}+00$ & 0.0000 & $0.000 \mathrm{E}+00$ & 0.0000 & $0.000 \mathrm{E}+00$ & 0.0000 & $0.000 \mathrm{E}+00$ & 0.0000 & $0.000 \mathrm{E}+00$ & 0.0000 & $0.000 \mathrm{E}+00$ & 0.0000 & $2.469 \mathrm{E}-18$ & 0.0000 \\
\hline-137 & $0.000 \mathrm{E}+00$ & 0.0000 & $0.000 \mathrm{E}+00$ & 0.0000 & $0.000 \mathrm{E}+00$ & 0.0000 & $0.000 \mathrm{E}+00$ & 0.0000 & $0.000 \mathrm{E}+00$ & 0.0000 & $0.000 \mathrm{E}+00$ & 0.0000 & $5.821 \mathrm{E}-11$ & 0.0003 \\
\hline-237 & $0.000 \mathrm{E}+00$ & 0.0000 & $0.000 \mathrm{E}+00$ & 0.0000 & $0.000 \mathrm{E}+00$ & 0.0000 & $0.000 \mathrm{E}+00$ & 0.0000 & $0.000 \mathrm{E}+00$ & 0.0000 & $0.000 \mathrm{E}+00$ & 0.0000 & $1.570 \mathrm{E}-13$ & 0.0000 \\
\hline 238 & $0.000 \mathrm{E}+00$ & 0.0000 & $0.000 \mathrm{E}+00$ & 0.0000 & $0.000 \mathrm{E}+00$ & 0.0000 & $0.000 \mathrm{E}+00$ & 0.0000 & $0.000 \mathrm{E}+00$ & 0.0000 & $0.000 \mathrm{E}+00$ & 0.0000 & $5.065 \mathrm{E}-18$ & 0.0000 \\
\hline 239 & $0.000 \mathrm{E}+00$ & 0.0000 & $0.000 \mathrm{E}+00$ & 0.0000 & $0.000 \mathrm{E}+00$ & 0.0000 & $0.000 \mathrm{E}+00$ & 0.0000 & $0.000 \mathrm{E}+00$ & 0.0000 & $0.000 \mathrm{E}+00$ & 0.0000 & $2.100 \mathrm{E}-18$ & 0.0000 \\
\hline 240 & $0.000 \mathrm{E}+00$ & 0.0000 & $0.000 \mathrm{E}+00$ & 0.0000 & $0.000 \mathrm{E}+00$ & 0.0000 & $0.000 \mathrm{E}+00$ & 0.0000 & $0.000 \mathrm{E}+00$ & 0.0000 & $0.000 \mathrm{E}+00$ & 0.0000 & $2.579 E-22$ & 0.0000 \\
\hline 99 & $0.000 \mathrm{E}+00$ & 0.0000 & $0.000 \mathrm{E}+00$ & 0.0000 & $0.000 \mathrm{E}+00$ & 0.0000 & $0.000 \mathrm{E}+00$ & 0.0000 & $0.000 \mathrm{E}+00$ & 0.0000 & $0.000 \mathrm{E}+00$ & 0.0000 & $1.112 \mathrm{E}-26$ & 0.0000 \\
\hline 228 & $0.000 \mathrm{E}+00$ & 0.0000 & $0.000 \mathrm{E}+00$ & 0.0000 & $0.000 \mathrm{E}+00$ & 0.0000 & $0.000 \mathrm{E}+00$ & 0.0000 & $0.000 \mathrm{E}+00$ & 0.0000 & $0.000 \mathrm{E}+00$ & 0.0000 & $2.430 \mathrm{E}-15$ & 0.0000 \\
\hline 230 & $0.000 \mathrm{E}+00$ & 0.0000 & $0.000 \mathrm{E}+00$ & 0.0000 & $0.000 \mathrm{E}+00$ & 0.0000 & $0.000 \mathrm{E}+00$ & 0.0000 & $0.000 \mathrm{E}+00$ & 0.0000 & $0.000 \mathrm{E}+00$ & 0.0000 & $5.116 \mathrm{E}-10$ & 0.0024 \\
\hline 232 & $0.000 \mathrm{E}+00$ & 0.0000 & $0.000 \mathrm{E}+00$ & 0.0000 & $0.000 \mathrm{E}+00$ & 0.0000 & $0.000 \mathrm{E}+00$ & 0.0000 & $0.000 \mathrm{E}+00$ & 0.0000 & $0.000 \mathrm{E}+00$ & 0.0000 & $2.155 \mathrm{E}-07$ & 0.9973 \\
\hline 34 & $0.000 \mathrm{E}+00$ & 0.0000 & $0.000 \mathrm{E}+00$ & 0.0000 & $0.000 \mathrm{E}+00$ & 0.0000 & $0.000 \mathrm{E}+00$ & 0.0000 & $0.000 \mathrm{E}+00$ & 0.0000 & $0.000 \mathrm{E}+00$ & 0.0000 & $1.167 \mathrm{E}-13$ & 0.0000 \\
\hline 35 & $0.000 \mathrm{E}+00$ & 0.0000 & $0.000 \mathrm{E}+00$ & 0.0000 & $0.000 \mathrm{E}+00$ & 0.0000 & $0.000 \mathrm{E}+00$ & 0.0000 & $0.000 \mathrm{E}+00$ & 0.0000 & $0.000 \mathrm{E}+00$ & 0.0000 & $8.886 \mathrm{E}-15$ & 0.0000 \\
\hline 38 & $0.000 \mathrm{E}+00$ & 0.0000 & $0.000 \mathrm{E}+00$ & 0.0000 & $0.000 \mathrm{E}+00$ & 0.0000 & $0.000 \mathrm{E}+00$ & 0.0000 & $0.000 \mathrm{E}+00$ & 0.0000 & $0.000 \mathrm{E}+00$ & 0.0000 & $2.035 E-11$ & 0.0001 \\
\hline & $0.000 \mathrm{E}+00$ & 0.0000 & $0.000 \mathrm{E}+00$ & 0.0000 & $0.000 \mathrm{E}+00$ & 0.0000 & $0.000 \mathrm{E}+00$ & 0.0000 & $0.000 \mathrm{E}+00$ & 0.0000 & $0.000 \mathrm{E}+00$ & 000 & -07 & 1.0000 \\
\hline
\end{tabular}

* Sum of all water independent and dependent pathways. 
RESRAD, Version 6.5

$\mathrm{T}^{1 / 2}$ Limit $=180$ days

ummary : C746U Recreational User Deterministic Run

: $\mathrm{X}: \backslash F I N A L$ V2 $\backslash C 746 \mathrm{U}$ RU DET-FINALV2.RAD

Total Dose Contributions TDOSE (i,p,t) for Individual Radionuclides (i) and Pathways (p) As mrem/yr and Fraction of Total Dose At $t=1.000 \mathrm{E}+02$ years

Water Independent Pathways (Inhalation excludes radon)

\begin{tabular}{|c|c|c|c|c|c|c|c|c|c|c|c|c|c|c|}
\hline \multirow{2}{*}{ Nuclide } & \multicolumn{2}{|c|}{ Ground } & \multicolumn{2}{|c|}{ Inhalation } & \multicolumn{2}{|c|}{ Radon } & \multicolumn{2}{|c|}{ Plant } & \multicolumn{2}{|c|}{ Meat } & \multicolumn{2}{|c|}{ Milk } & \multicolumn{2}{|c|}{ Soil } \\
\hline & mrem/yr & fract. & mrem/yr & fract. & mrem/yr & fract. & mrem/yr & fract. & mrem/yr & fract. & mrem/yr & fract. & mrem/yr & fract. \\
\hline-241 & $8.102 \mathrm{E}-18$ & 0.0000 & $0.000 \mathrm{E}+00$ & 0.0000 & $0.000 \mathrm{E}+00$ & 0.0000 & $0.000 \mathrm{E}+00$ & 0.0000 & $0.000 \mathrm{E}+00$ & 0.0000 & $0.000 \mathrm{E}+00$ & 0.0000 & $0.000 \mathrm{E}+00$ & 0.0000 \\
\hline-137 & $2.793 E-11$ & 0.0001 & $0.000 \mathrm{E}+00$ & 0.0000 & $0.000 \mathrm{E}+00$ & 0.0000 & $0.000 \mathrm{E}+00$ & 0.0000 & $0.000 \mathrm{E}+00$ & 0.0000 & $0.000 \mathrm{E}+00$ & 0.0000 & $0.000 \mathrm{E}+00$ & 0.0000 \\
\hline-237 & $2.696 \mathrm{E}-13$ & 0.0000 & $0.000 \mathrm{E}+00$ & 0.0000 & $0.000 \mathrm{E}+00$ & 0.0000 & $0.000 \mathrm{E}+00$ & 0.0000 & $0.000 \mathrm{E}+00$ & 0.0000 & $0.000 \mathrm{E}+00$ & 0.0000 & $0.000 \mathrm{E}+00$ & 0.0000 \\
\hline-238 & $5.122 \mathrm{E}-17$ & 0.0000 & $0.000 \mathrm{E}+00$ & 0.0000 & $0.000 \mathrm{E}+00$ & 0.0000 & $0.000 \mathrm{E}+00$ & 0.0000 & $0.000 \mathrm{E}+00$ & 0.0000 & $0.000 \mathrm{E}+00$ & 0.0000 & $0.000 \mathrm{E}+00$ & 0.0000 \\
\hline-239 & $3.817 \mathrm{E}-18$ & 0.0000 & $0.000 \mathrm{E}+00$ & 0.0000 & $0.000 \mathrm{E}+00$ & 0.0000 & $0.000 \mathrm{E}+00$ & 0.0000 & $0.000 \mathrm{E}+00$ & 0.0000 & $0.000 \mathrm{E}+00$ & 0.0000 & $0.000 \mathrm{E}+00$ & 0.0000 \\
\hline-240 & 1. $716 \mathrm{E}-21$ & 0.0000 & $0.000 \mathrm{E}+00$ & 0.0000 & $0.000 \mathrm{E}+00$ & 0.0000 & $0.000 \mathrm{E}+00$ & 0.0000 & $0.000 \mathrm{E}+00$ & 0.0000 & $0.000 \mathrm{E}+00$ & 0.0000 & $0.000 \mathrm{E}+00$ & 0.0000 \\
\hline 99 & $2.231 E-26$ & 0.0000 & $0.000 \mathrm{E}+00$ & 0.0000 & $0.000 \mathrm{E}+00$ & 0.0000 & $0.000 \mathrm{E}+00$ & 0.0000 & $0.000 \mathrm{E}+00$ & 0.0000 & $0.000 \mathrm{E}+00$ & 0.0000 & $0.000 \mathrm{E}+00$ & 0.0000 \\
\hline-228 & $4.441 E-23$ & 0.0000 & $0.000 \mathrm{E}+00$ & 0.0000 & $0.000 \mathrm{E}+00$ & 0.0000 & $0.000 \mathrm{E}+00$ & 0.0000 & $0.000 \mathrm{E}+00$ & 0.0000 & $0.000 \mathrm{E}+00$ & 0.0000 & $0.000 \mathrm{E}+00$ & 0.0000 \\
\hline-230 & 1. $423 E-09$ & 0.0049 & $0.000 \mathrm{E}+00$ & 0.0000 & $0.000 \mathrm{E}+00$ & 0.0000 & $0.000 \mathrm{E}+00$ & 0.0000 & $0.000 \mathrm{E}+00$ & 0.0000 & $0.000 \mathrm{E}+00$ & 0.0000 & $0.000 \mathrm{E}+00$ & 0.0000 \\
\hline-232 & $2.917 \mathrm{E}-07$ & 0.9949 & $0.000 \mathrm{E}+00$ & 0.0000 & $0.000 \mathrm{E}+00$ & 0.0000 & $0.000 \mathrm{E}+00$ & 0.0000 & $0.000 \mathrm{E}+00$ & 0.0000 & $0.000 \mathrm{E}+00$ & 0.0000 & $0.000 \mathrm{E}+00$ & 0.0000 \\
\hline 234 & $6.482 \mathrm{E}-13$ & 0.0000 & $0.000 \mathrm{E}+00$ & 0.0000 & $0.000 \mathrm{E}+00$ & 0.0000 & $0.000 \mathrm{E}+00$ & 0.0000 & $0.000 \mathrm{E}+00$ & 0.0000 & $0.000 \mathrm{E}+00$ & 0.0000 & $0.000 \mathrm{E}+00$ & 0.0000 \\
\hline 235 & $3.260 \mathrm{E}-14$ & 0.0000 & $0.000 \mathrm{E}+00$ & 0.0000 & $0.000 \mathrm{E}+00$ & 0.0000 & $0.000 \mathrm{E}+00$ & 0.0000 & $0.000 \mathrm{E}+00$ & 0.0000 & $0.000 \mathrm{E}+00$ & 0.0000 & $0.000 \mathrm{E}+00$ & 0.0000 \\
\hline 238 & $3.035 E-11$ & 0.0001 & $0.000 \mathrm{E}+00$ & 0.0000 & $0.000 \mathrm{E}+00$ & 0.0000 & $0.000 \mathrm{E}+00$ & 0.0000 & $0.000 \mathrm{E}+00$ & 0.0000 & $0.000 \mathrm{E}+00$ & 0.0000 & $0.000 \mathrm{E}+00$ & 0.0000 \\
\hline & $2.931 E-07$ & 1.0000 & $0.000 \mathrm{E}+00$ & 0.0000 & $0.000 \mathrm{E}+00$ & 0.0000 & $0.000 \mathrm{E}+00$ & 0.0000 & $0.000 \mathrm{E}+00$ & 0.0000 & $0.000 \mathrm{E}+00$ & 0.0000 & $.000 \mathrm{E}+00$ & 0.0000 \\
\hline
\end{tabular}

Total Dose Contributions TDOSE (i,p,t) for Individual Radionuclides (i) and Pathways (p) As mrem/yr and Fraction of Total Dose At $t=1.000 \mathrm{E}+02$ years

Water Dependent Pathways

\begin{tabular}{|c|c|c|c|c|c|c|c|c|c|c|c|c|c|c|}
\hline & \multicolumn{2}{|c|}{ Water } & \multicolumn{2}{|c|}{ Fish } & \multicolumn{2}{|c|}{ Radon } & \multicolumn{2}{|c|}{ Plant } & \multicolumn{2}{|c|}{ Meat } & \multicolumn{2}{|c|}{ Milk } & \multicolumn{2}{|c|}{ All Pathways* } \\
\hline clide & mrem/yr & fract. & mrem/yr & fract. & mrem/yr & fract. & mrem/yr & fract. & mrem/yr & fract. & mrem/yr & fract. & mrem/yr & fract. \\
\hline-241 & $0.000 \mathrm{E}+00$ & 0.0000 & $0.000 \mathrm{E}+00$ & 0.0000 & $0.000 \mathrm{E}+00$ & 0.0000 & $0.000 \mathrm{E}+00$ & 0.0000 & $0.000 \mathrm{E}+00$ & 0.0000 & $0.000 \mathrm{E}+00$ & 0.0000 & $8.102 \mathrm{E}-18$ & 0.0000 \\
\hline-137 & $0.000 \mathrm{E}+00$ & 0.0000 & $0.000 \mathrm{E}+00$ & 0.0000 & $0.000 \mathrm{E}+00$ & 0.0000 & $0.000 \mathrm{E}+00$ & 0.0000 & $0.000 \mathrm{E}+00$ & 0.0000 & $0.000 \mathrm{E}+00$ & 0.0000 & $2.793 E-11$ & 0.0001 \\
\hline-237 & $0.000 \mathrm{E}+00$ & 0.0000 & $0.000 \mathrm{E}+00$ & 0.0000 & $0.000 \mathrm{E}+00$ & 0.0000 & $0.000 \mathrm{E}+00$ & 0.0000 & $0.000 \mathrm{E}+00$ & 0.0000 & $0.000 \mathrm{E}+00$ & 0.0000 & $2.696 \mathrm{E}-13$ & 0.0000 \\
\hline-238 & $0.000 \mathrm{E}+00$ & 0.0000 & $0.000 \mathrm{E}+00$ & 0.0000 & $0.000 \mathrm{E}+00$ & 0.0000 & $0.000 \mathrm{E}+00$ & 0.0000 & $0.000 \mathrm{E}+00$ & 0.0000 & $0.000 \mathrm{E}+00$ & 0.0000 & $5.122 \mathrm{E}-17$ & 0.0000 \\
\hline-239 & $0.000 \mathrm{E}+00$ & 0.0000 & $0.000 \mathrm{E}+00$ & 0.0000 & $0.000 \mathrm{E}+00$ & 0.0000 & $0.000 \mathrm{E}+00$ & 0.0000 & $0.000 \mathrm{E}+00$ & 0.0000 & $0.000 \mathrm{E}+00$ & 0.0000 & $3.817 E-18$ & 0.0000 \\
\hline 240 & $0.000 \mathrm{E}+00$ & 0.0000 & $0.000 \mathrm{E}+00$ & 0.0000 & $0.000 \mathrm{E}+00$ & 0.0000 & $0.000 \mathrm{E}+00$ & 0.0000 & $0.000 \mathrm{E}+00$ & 0.0000 & $0.000 \mathrm{E}+00$ & 0.0000 & $1.716 \mathrm{E}-21$ & 0.0000 \\
\hline 99 & $0.000 \mathrm{E}+00$ & 0.0000 & $0.000 \mathrm{E}+00$ & 0.0000 & $0.000 \mathrm{E}+00$ & 0.0000 & $0.000 \mathrm{E}+00$ & 0.0000 & $0.000 \mathrm{E}+00$ & 0.0000 & $0.000 \mathrm{E}+00$ & 0.0000 & $2.231 E-26$ & 0.0000 \\
\hline 228 & $0.000 \mathrm{E}+00$ & 0.0000 & $0.000 \mathrm{E}+00$ & 0.0000 & $0.000 \mathrm{E}+00$ & 0.0000 & $0.000 \mathrm{E}+00$ & 0.0000 & $0.000 \mathrm{E}+00$ & 0.0000 & $0.000 \mathrm{E}+00$ & 0.0000 & $4.441 \mathrm{E}-23$ & 0.0000 \\
\hline 230 & $0.000 \mathrm{E}+00$ & 0.0000 & $0.000 \mathrm{E}+00$ & 0.0000 & $0.000 \mathrm{E}+00$ & 0.0000 & $0.000 \mathrm{E}+00$ & 0.0000 & $0.000 \mathrm{E}+00$ & 0.0000 & $0.000 \mathrm{E}+00$ & 0.0000 & $1.423 E-09$ & 0.0049 \\
\hline 232 & $0.000 \mathrm{E}+00$ & 0.0000 & $0.000 \mathrm{E}+00$ & 0.0000 & $0.000 \mathrm{E}+00$ & 0.0000 & $0.000 \mathrm{E}+00$ & 0.0000 & $0.000 \mathrm{E}+00$ & 0.0000 & $0.000 \mathrm{E}+00$ & 0.0000 & $2.917 \mathrm{E}-07$ & 0.9949 \\
\hline & $0.000 \mathrm{E}+00$ & 0.0000 & $0.000 \mathrm{E}+00$ & 0.0000 & $0.000 \mathrm{E}+00$ & 0.0000 & $0.000 \mathrm{E}+00$ & 0.0000 & $0.000 \mathrm{E}+00$ & 0.0000 & $0.000 \mathrm{E}+00$ & 0.0000 & $6.482 \mathrm{E}-13$ & 0.0000 \\
\hline 35 & $0.000 \mathrm{E}+00$ & 0.0000 & $0.000 \mathrm{E}+00$ & 0.0000 & $0.000 \mathrm{E}+00$ & 0.0000 & $0.000 \mathrm{E}+00$ & 0.0000 & $0.000 \mathrm{E}+00$ & 0.0000 & $0.000 \mathrm{E}+00$ & 0.0000 & $3.260 \mathrm{E}-14$ & 0.0000 \\
\hline 38 & $0.000 \mathrm{E}+00$ & 0.0000 & $0.000 \mathrm{E}+00$ & 0.0000 & $0.000 \mathrm{E}+00$ & 0.0000 & $0.000 \mathrm{E}+00$ & 0.0000 & $0.000 \mathrm{E}+00$ & 0.0000 & $0.000 \mathrm{E}+00$ & 0.0000 & $3.035 \mathrm{E}-11$ & 0.0001 \\
\hline & $0.000 \mathrm{E}+00$ & 0.0000 & $0.000 \mathrm{E}+00$ & 0.0000 & $0.000 \mathrm{E}+00$ & 0.0000 & $0.000 \mathrm{E}+00$ & 0.0000 & $0.000 \mathrm{E}+00$ & 0.0000 & $0.000 \mathrm{E}+00$ & 000 & -07 & 000 \\
\hline
\end{tabular}

* Sum of all water independent and dependent pathways. 
RESRAD, Version 6.5

$\mathrm{T}^{1 / 2}$ Limit $=180$ days

ummary : C746U Recreational User Deterministic Run

: $\mathrm{X}: \backslash F I N A L$ V2 $\backslash C 746 \mathrm{U}$ RU DET-FINALV2.RAD

Total Dose Contributions TDOSE (i,p,t) for Individual Radionuclides (i) and Pathways (p) As mrem/yr and Fraction of Total Dose At $t=5.000 \mathrm{E}+02$ years

Water Independent Pathways (Inhalation excludes radon)

\begin{tabular}{|c|c|c|c|c|c|c|c|c|c|c|c|c|c|c|}
\hline \multirow{2}{*}{ Nuclide } & \multicolumn{2}{|c|}{ Ground } & \multicolumn{2}{|c|}{ Inhalation } & \multicolumn{2}{|c|}{ Radon } & \multicolumn{2}{|c|}{ Plant } & \multicolumn{2}{|c|}{ Meat } & \multicolumn{2}{|c|}{ Milk } & \multicolumn{2}{|c|}{ Soil } \\
\hline & mrem/yr & fract. & mrem/yr & fract. & mrem/yr & fract. & mrem/yr & fract. & mrem/yr & fract. & mrem/yr & fract. & mrem/yr & fract. \\
\hline-241 & $2.243 E-15$ & 0.0000 & $0.000 \mathrm{E}+00$ & 0.0000 & $0.000 \mathrm{E}+00$ & 0.0000 & $0.000 \mathrm{E}+00$ & 0.0000 & $0.000 \mathrm{E}+00$ & 0.0000 & $0.000 \mathrm{E}+00$ & 0.0000 & $0.000 \mathrm{E}+00$ & 0.0000 \\
\hline-137 & $7.847 E-14$ & 0.0000 & $0.000 \mathrm{E}+00$ & 0.0000 & $0.000 \mathrm{E}+00$ & 0.0000 & $0.000 \mathrm{E}+00$ & 0.0000 & $0.000 \mathrm{E}+00$ & 0.0000 & $0.000 \mathrm{E}+00$ & 0.0000 & $0.000 \mathrm{E}+00$ & 0.0000 \\
\hline-237 & $2.021 E-11$ & 0.0000 & $0.000 \mathrm{E}+00$ & 0.0000 & $0.000 \mathrm{E}+00$ & 0.0000 & $0.000 \mathrm{E}+00$ & 0.0000 & $0.000 \mathrm{E}+00$ & 0.0000 & $0.000 \mathrm{E}+00$ & 0.0000 & $0.000 \mathrm{E}+00$ & 0.0000 \\
\hline-238 & $5.408 E-14$ & 0.0000 & $0.000 \mathrm{E}+00$ & 0.0000 & $0.000 \mathrm{E}+00$ & 0.0000 & $0.000 \mathrm{E}+00$ & 0.0000 & $0.000 \mathrm{E}+00$ & 0.0000 & $0.000 \mathrm{E}+00$ & 0.0000 & $0.000 \mathrm{E}+00$ & 0.0000 \\
\hline-239 & $4.543 E-16$ & 0.0000 & $0.000 \mathrm{E}+00$ & 0.0000 & $0.000 \mathrm{E}+00$ & 0.0000 & $0.000 \mathrm{E}+00$ & 0.0000 & $0.000 \mathrm{E}+00$ & 0.0000 & $0.000 \mathrm{E}+00$ & 0.0000 & $0.000 \mathrm{E}+00$ & 0.0000 \\
\hline-240 & $5.515 \mathrm{E}-19$ & 0.0000 & $0.000 \mathrm{E}+00$ & 0.0000 & $0.000 \mathrm{E}+00$ & 0.0000 & $0.000 \mathrm{E}+00$ & 0.0000 & $0.000 \mathrm{E}+00$ & 0.0000 & $0.000 \mathrm{E}+00$ & 0.0000 & $0.000 \mathrm{E}+00$ & 0.0000 \\
\hline 99 & $5.839 E-24$ & 0.0000 & $0.000 \mathrm{E}+00$ & 0.0000 & $0.000 \mathrm{E}+00$ & 0.0000 & $0.000 \mathrm{E}+00$ & 0.0000 & $0.000 \mathrm{E}+00$ & 0.0000 & $0.000 \mathrm{E}+00$ & 0.0000 & $0.000 \mathrm{E}+00$ & 0.0000 \\
\hline-228 & $0.000 \mathrm{E}+00$ & 0.0000 & $0.000 \mathrm{E}+00$ & 0.0000 & $0.000 \mathrm{E}+00$ & 0.0000 & $0.000 \mathrm{E}+00$ & 0.0000 & $0.000 \mathrm{E}+00$ & 0.0000 & $0.000 \mathrm{E}+00$ & 0.0000 & $0.000 \mathrm{E}+00$ & 0.0000 \\
\hline-230 & $1.032 \mathrm{E}-07$ & 0.0311 & $0.000 \mathrm{E}+00$ & 0.0000 & $0.000 \mathrm{E}+00$ & 0.0000 & $0.000 \mathrm{E}+00$ & 0.0000 & $0.000 \mathrm{E}+00$ & 0.0000 & $0.000 \mathrm{E}+00$ & 0.0000 & $0.000 \mathrm{E}+00$ & 0.0000 \\
\hline-232 & $3.212 \mathrm{E}-06$ & 0.9686 & $0.000 \mathrm{E}+00$ & 0.0000 & $0.000 \mathrm{E}+00$ & 0.0000 & $0.000 \mathrm{E}+00$ & 0.0000 & $0.000 \mathrm{E}+00$ & 0.0000 & $0.000 \mathrm{E}+00$ & 0.0000 & $0.000 \mathrm{E}+00$ & 0.0000 \\
\hline 234 & $2.407 \mathrm{E}-10$ & 0.0001 & $0.000 \mathrm{E}+00$ & 0.0000 & $0.000 \mathrm{E}+00$ & 0.0000 & $0.000 \mathrm{E}+00$ & 0.0000 & $0.000 \mathrm{E}+00$ & 0.0000 & $0.000 \mathrm{E}+00$ & 0.0000 & $0.000 \mathrm{E}+00$ & 0.0000 \\
\hline 235 & $6.791 \mathrm{E}-12$ & 0.0000 & $0.000 \mathrm{E}+00$ & 0.0000 & $0.000 \mathrm{E}+00$ & 0.0000 & $0.000 \mathrm{E}+00$ & 0.0000 & $0.000 \mathrm{E}+00$ & 0.0000 & $0.000 \mathrm{E}+00$ & 0.0000 & $0.000 \mathrm{E}+00$ & 0.0000 \\
\hline 38 & $7.420 \mathrm{E}-10$ & 0.0002 & $0.000 \mathrm{E}+00$ & 0.0000 & $0.000 \mathrm{E}+00$ & 0.0000 & $0.000 \mathrm{E}+00$ & 0.0000 & $0.000 \mathrm{E}+00$ & 0.0000 & $0.000 \mathrm{E}+00$ & 0.0000 & $0.000 \mathrm{E}+00$ & 0.0000 \\
\hline & $3.316 E-06$ & 1.0000 & $0.000 \mathrm{E}+00$ & 0.0000 & $0.000 \mathrm{E}+00$ & 0.0000 & $0.000 \mathrm{E}+00$ & 0.0000 & $0.000 \mathrm{E}+00$ & 0.0000 & $0.000 \mathrm{E}+00$ & 0.0000 & $.000 \mathrm{E}+00$ & 0.0000 \\
\hline
\end{tabular}

Total Dose Contributions TDOSE (i,p,t) for Individual Radionuclides (i) and Pathways (p) As mrem/yr and Fraction of Total Dose At $t=5.000 \mathrm{E}+02$ years

Water Dependent Pathways

\begin{tabular}{|c|c|c|c|c|c|c|c|c|c|c|c|c|c|c|}
\hline & \multicolumn{2}{|c|}{ Water } & \multicolumn{2}{|c|}{ Fish } & \multicolumn{2}{|c|}{ Radon } & \multicolumn{2}{|c|}{ Plant } & \multicolumn{2}{|c|}{ Meat } & \multicolumn{2}{|c|}{ Milk } & \multicolumn{2}{|c|}{ All Pathways* } \\
\hline clide & mrem/yr & fract. & mrem/yr & fract. & mrem/yr & fract. & mrem/yr & fract. & mrem/yr & fract. & mrem/yr & fract. & mrem/yr & fract. \\
\hline-241 & $0.000 \mathrm{E}+00$ & 0.0000 & $0.000 \mathrm{E}+00$ & 0.0000 & $0.000 \mathrm{E}+00$ & 0.0000 & $0.000 \mathrm{E}+00$ & 0.0000 & $0.000 \mathrm{E}+00$ & 0.0000 & $0.000 \mathrm{E}+00$ & 0.0000 & $2.243 E-15$ & 0.0000 \\
\hline-137 & $0.000 \mathrm{E}+00$ & 0.0000 & $0.000 \mathrm{E}+00$ & 0.0000 & $0.000 \mathrm{E}+00$ & 0.0000 & $0.000 \mathrm{E}+00$ & 0.0000 & $0.000 \mathrm{E}+00$ & 0.0000 & $0.000 \mathrm{E}+00$ & 0.0000 & $7.847 \mathrm{E}-14$ & 0.0000 \\
\hline-237 & $0.000 \mathrm{E}+00$ & 0.0000 & $0.000 \mathrm{E}+00$ & 0.0000 & $0.000 \mathrm{E}+00$ & 0.0000 & $0.000 \mathrm{E}+00$ & 0.0000 & $0.000 \mathrm{E}+00$ & 0.0000 & $0.000 \mathrm{E}+00$ & 0.0000 & $2.021 \mathrm{E}-11$ & 0.0000 \\
\hline 238 & $0.000 \mathrm{E}+00$ & 0.0000 & $0.000 \mathrm{E}+00$ & 0.0000 & $0.000 \mathrm{E}+00$ & 0.0000 & $0.000 \mathrm{E}+00$ & 0.0000 & $0.000 \mathrm{E}+00$ & 0.0000 & $0.000 \mathrm{E}+00$ & 0.0000 & $5.408 E-14$ & 0.0000 \\
\hline 239 & $0.000 \mathrm{E}+00$ & 0.0000 & $0.000 \mathrm{E}+00$ & 0.0000 & $0.000 \mathrm{E}+00$ & 0.0000 & $0.000 \mathrm{E}+00$ & 0.0000 & $0.000 \mathrm{E}+00$ & 0.0000 & $0.000 \mathrm{E}+00$ & 0.0000 & $4.543 E-16$ & 0.0000 \\
\hline 240 & $0.000 \mathrm{E}+00$ & 0.0000 & $0.000 \mathrm{E}+00$ & 0.0000 & $0.000 \mathrm{E}+00$ & 0.0000 & $0.000 \mathrm{E}+00$ & 0.0000 & $0.000 \mathrm{E}+00$ & 0.0000 & $0.000 \mathrm{E}+00$ & 0.0000 & $5.515 \mathrm{E}-19$ & 0.0000 \\
\hline 99 & $0.000 \mathrm{E}+00$ & 0.0000 & $0.000 \mathrm{E}+00$ & 0.0000 & $0.000 \mathrm{E}+00$ & 0.0000 & $0.000 \mathrm{E}+00$ & 0.0000 & $0.000 \mathrm{E}+00$ & 0.0000 & $0.000 \mathrm{E}+00$ & 0.0000 & $5.839 E-24$ & 0.0000 \\
\hline 228 & $0.000 \mathrm{E}+00$ & 0.0000 & $0.000 \mathrm{E}+00$ & 0.0000 & $0.000 \mathrm{E}+00$ & 0.0000 & $0.000 \mathrm{E}+00$ & 0.0000 & $0.000 \mathrm{E}+00$ & 0.0000 & $0.000 \mathrm{E}+00$ & 0.0000 & $0.000 \mathrm{E}+00$ & 0.0000 \\
\hline 230 & $0.000 \mathrm{E}+00$ & 0.0000 & $0.000 \mathrm{E}+00$ & 0.0000 & $0.000 \mathrm{E}+00$ & 0.0000 & $0.000 \mathrm{E}+00$ & 0.0000 & $0.000 \mathrm{E}+00$ & 0.0000 & $0.000 \mathrm{E}+00$ & 0.0000 & $1.032 \mathrm{E}-07$ & 0.0311 \\
\hline 232 & $0.000 \mathrm{E}+00$ & 0.0000 & $0.000 \mathrm{E}+00$ & 0.0000 & $0.000 \mathrm{E}+00$ & 0.0000 & $0.000 \mathrm{E}+00$ & 0.0000 & $0.000 \mathrm{E}+00$ & 0.0000 & $0.000 \mathrm{E}+00$ & 0.0000 & $3.212 \mathrm{E}-06$ & 0.9686 \\
\hline 34 & $0.000 \mathrm{E}+00$ & 0.0000 & $0.000 \mathrm{E}+00$ & 0.0000 & $0.000 \mathrm{E}+00$ & 0.0000 & $0.000 \mathrm{E}+00$ & 0.0000 & $0.000 \mathrm{E}+00$ & 0.0000 & $0.000 \mathrm{E}+00$ & 0.0000 & $2.407 \mathrm{E}-10$ & 0.0001 \\
\hline 35 & $0.000 \mathrm{E}+00$ & 0.0000 & $0.000 \mathrm{E}+00$ & 0.0000 & $0.000 \mathrm{E}+00$ & 0.0000 & $0.000 \mathrm{E}+00$ & 0.0000 & $0.000 \mathrm{E}+00$ & 0.0000 & $0.000 \mathrm{E}+00$ & 0.0000 & $6.791 \mathrm{E}-12$ & 0.0000 \\
\hline 38 & $0.000 \mathrm{E}+00$ & 0.0000 & $0.000 \mathrm{E}+00$ & 0.0000 & $0.000 \mathrm{E}+00$ & 0.0000 & $0.000 \mathrm{E}+00$ & 0.0000 & $0.000 \mathrm{E}+00$ & 0.0000 & $0.000 \mathrm{E}+00$ & 0.0000 & 7. $420 \mathrm{E}-10$ & 0.0002 \\
\hline & $0.000 \mathrm{E}+00$ & 0.0000 & $0.000 \mathrm{E}+00$ & 0.0000 & $0.000 \mathrm{E}+00$ & 0.0000 & $0.000 \mathrm{E}+00$ & 0.0000 & $0.000 \mathrm{E}+00$ & 0.0000 & $0.000 \mathrm{E}+00$ & 000 & -06 & 1.0000 \\
\hline
\end{tabular}

* Sum of all water independent and dependent pathways. 
RESRAD, Version 6.5

$\mathrm{T}^{1 / 2}$ Limit $=180$ days

ummary : C746U Recreational User Deterministic Run

: $\mathrm{X}: \backslash F I N A L$ V2 \C746U RU DET-FINALV2.RAD

Total Dose Contributions TDOSE (i,p,t) for Individual Radionuclides (i) and Pathways (p) As mrem/yr and Fraction of Total Dose At $t=1.050 \mathrm{E}+03$ years

Water Independent Pathways (Inhalation excludes radon)

\begin{tabular}{|c|c|c|c|c|c|c|c|c|c|c|c|c|c|c|}
\hline \multirow{2}{*}{ Nuclide } & \multicolumn{2}{|c|}{ Ground } & \multicolumn{2}{|c|}{ Inhalation } & \multicolumn{2}{|c|}{ Radon } & \multicolumn{2}{|c|}{ Plant } & \multicolumn{2}{|c|}{ Meat } & \multicolumn{2}{|c|}{ Milk } & \multicolumn{2}{|c|}{ Soil } \\
\hline & mrem/yr & fract. & mrem/yr & fract. & mrem/yr & fract. & mrem/yr & fract. & mrem/yr & fract. & mrem/yr & fract. & mrem/yr & fract. \\
\hline-241 & 1. $214 \mathrm{E}-12$ & 0.0000 & $0.000 \mathrm{E}+00$ & 0.0000 & $0.000 \mathrm{E}+00$ & 0.0000 & $0.000 \mathrm{E}+00$ & 0.0000 & $0.000 \mathrm{E}+00$ & 0.0000 & $0.000 \mathrm{E}+00$ & 0.0000 & $0.000 \mathrm{E}+00$ & 0.0000 \\
\hline-137 & $2.435 E-17$ & 0.0000 & $0.000 \mathrm{E}+00$ & 0.0000 & $0.000 \mathrm{E}+00$ & 0.0000 & $0.000 \mathrm{E}+00$ & 0.0000 & $0.000 \mathrm{E}+00$ & 0.0000 & $0.000 \mathrm{E}+00$ & 0.0000 & $0.000 \mathrm{E}+00$ & 0.0000 \\
\hline-237 & $7.245 E-09$ & 0.0001 & $0.000 \mathrm{E}+00$ & 0.0000 & $0.000 \mathrm{E}+00$ & 0.0000 & $0.000 \mathrm{E}+00$ & 0.0000 & $0.000 \mathrm{E}+00$ & 0.0000 & $0.000 \mathrm{E}+00$ & 0.0000 & $0.000 \mathrm{E}+00$ & 0.0000 \\
\hline-238 & $1.260 \mathrm{E}-11$ & 0.0000 & $0.000 \mathrm{E}+00$ & 0.0000 & $0.000 \mathrm{E}+00$ & 0.0000 & $0.000 \mathrm{E}+00$ & 0.0000 & $0.000 \mathrm{E}+00$ & 0.0000 & $0.000 \mathrm{E}+00$ & 0.0000 & $0.000 \mathrm{E}+00$ & 0.0000 \\
\hline-239 & $3.234 \mathrm{E}-13$ & 0.0000 & $0.000 \mathrm{E}+00$ & 0.0000 & $0.000 \mathrm{E}+00$ & 0.0000 & $0.000 \mathrm{E}+00$ & 0.0000 & $0.000 \mathrm{E}+00$ & 0.0000 & $0.000 \mathrm{E}+00$ & 0.0000 & $0.000 \mathrm{E}+00$ & 0.0000 \\
\hline-240 & $7.834 \mathrm{E}-17$ & 0.0000 & $0.000 \mathrm{E}+00$ & 0.0000 & $0.000 \mathrm{E}+00$ & 0.0000 & $0.000 \mathrm{E}+00$ & 0.0000 & $0.000 \mathrm{E}+00$ & 0.0000 & $0.000 \mathrm{E}+00$ & 0.0000 & $0.000 \mathrm{E}+00$ & 0.0000 \\
\hline 99 & $1.233 E-20$ & 0.0000 & $0.000 \mathrm{E}+00$ & 0.0000 & $0.000 \mathrm{E}+00$ & 0.0000 & $0.000 \mathrm{E}+00$ & 0.0000 & $0.000 \mathrm{E}+00$ & 0.0000 & $0.000 \mathrm{E}+00$ & 0.0000 & $0.000 \mathrm{E}+00$ & 0.0000 \\
\hline-228 & $0.000 \mathrm{E}+00$ & 0.0000 & $0.000 \mathrm{E}+00$ & 0.0000 & $0.000 \mathrm{E}+00$ & 0.0000 & $0.000 \mathrm{E}+00$ & 0.0000 & $0.000 \mathrm{E}+00$ & 0.0000 & $0.000 \mathrm{E}+00$ & 0.0000 & $0.000 \mathrm{E}+00$ & 0.0000 \\
\hline-230 & $8.661 \mathrm{E}-06$ & 0.0886 & $0.000 \mathrm{E}+00$ & 0.0000 & $0.000 \mathrm{E}+00$ & 0.0000 & $0.000 \mathrm{E}+00$ & 0.0000 & $0.000 \mathrm{E}+00$ & 0.0000 & $0.000 \mathrm{E}+00$ & 0.0000 & $0.000 \mathrm{E}+00$ & 0.0000 \\
\hline-232 & $8.900 E-05$ & 0.9103 & $0.000 \mathrm{E}+00$ & 0.0000 & $0.000 \mathrm{E}+00$ & 0.0000 & $0.000 \mathrm{E}+00$ & 0.0000 & $0.000 \mathrm{E}+00$ & 0.0000 & $0.000 \mathrm{E}+00$ & 0.0000 & $0.000 \mathrm{E}+00$ & 0.0000 \\
\hline 234 & $4.396 \mathrm{E}-08$ & 0.0004 & $0.000 \mathrm{E}+00$ & 0.0000 & $0.000 \mathrm{E}+00$ & 0.0000 & $0.000 \mathrm{E}+00$ & 0.0000 & $0.000 \mathrm{E}+00$ & 0.0000 & $0.000 \mathrm{E}+00$ & 0.0000 & $0.000 \mathrm{E}+00$ & 0.0000 \\
\hline 235 & $2.279 E-09$ & 0.0000 & $0.000 \mathrm{E}+00$ & 0.0000 & $0.000 \mathrm{E}+00$ & 0.0000 & $0.000 \mathrm{E}+00$ & 0.0000 & $0.000 \mathrm{E}+00$ & 0.0000 & $0.000 \mathrm{E}+00$ & 0.0000 & $0.000 \mathrm{E}+00$ & 0.0000 \\
\hline 38 & $6.021 E-08$ & 0.0006 & $0.000 \mathrm{E}+00$ & 0.0000 & $0.000 \mathrm{E}+00$ & 0.0000 & $0.000 \mathrm{E}+00$ & 0.0000 & $0.000 \mathrm{E}+00$ & 0.0000 & $0.000 \mathrm{E}+00$ & 0.0000 & $0.000 \mathrm{E}+00$ & 0.0000 \\
\hline & $9.778 E-05$ & 1.0000 & $0.000 \mathrm{E}+00$ & 0.0000 & $0.000 \mathrm{E}+00$ & 0.0000 & $0.000 \mathrm{E}+00$ & 0.0000 & $0.000 \mathrm{E}+00$ & 0.0000 & $0.000 \mathrm{E}+00$ & 0.0000 & $.000 \mathrm{E}+00$ & 0.0000 \\
\hline
\end{tabular}

Total Dose Contributions TDOSE (i,p,t) for Individual Radionuclides (i) and Pathways (p) As mrem/yr and Fraction of Total Dose At $t=1.050 \mathrm{E}+03$ years

Water Dependent Pathways

\begin{tabular}{|c|c|c|c|c|c|c|c|c|c|c|c|c|c|c|}
\hline & \multicolumn{2}{|c|}{ Water } & \multicolumn{2}{|c|}{ Fish } & \multicolumn{2}{|c|}{ Radon } & \multicolumn{2}{|c|}{ Plant } & \multicolumn{2}{|c|}{ Meat } & \multicolumn{2}{|c|}{ Milk } & \multicolumn{2}{|c|}{ All Pathways* } \\
\hline clide & mrem/yr & fract. & mrem/yr & fract. & mrem/yr & fract. & mrem/yr & fract. & mrem/yr & fract. & mrem/yr & fract. & mrem/yr & fract. \\
\hline-241 & $0.000 \mathrm{E}+00$ & 0.0000 & $0.000 \mathrm{E}+00$ & 0.0000 & $0.000 \mathrm{E}+00$ & 0.0000 & $0.000 \mathrm{E}+00$ & 0.0000 & $0.000 \mathrm{E}+00$ & 0.0000 & $0.000 \mathrm{E}+00$ & 0.0000 & 1. $214 \mathrm{E}-12$ & 0.0000 \\
\hline-137 & $0.000 \mathrm{E}+00$ & 0.0000 & $0.000 \mathrm{E}+00$ & 0.0000 & $0.000 \mathrm{E}+00$ & 0.0000 & $0.000 \mathrm{E}+00$ & 0.0000 & $0.000 \mathrm{E}+00$ & 0.0000 & $0.000 \mathrm{E}+00$ & 0.0000 & $2.435 \mathrm{E}-17$ & 0.0000 \\
\hline-237 & $0.000 \mathrm{E}+00$ & 0.0000 & $0.000 \mathrm{E}+00$ & 0.0000 & $0.000 \mathrm{E}+00$ & 0.0000 & $0.000 \mathrm{E}+00$ & 0.0000 & $0.000 \mathrm{E}+00$ & 0.0000 & $0.000 \mathrm{E}+00$ & 0.0000 & $7.245 E-09$ & 0.0001 \\
\hline 238 & $0.000 \mathrm{E}+00$ & 0.0000 & $0.000 \mathrm{E}+00$ & 0.0000 & $0.000 \mathrm{E}+00$ & 0.0000 & $0.000 \mathrm{E}+00$ & 0.0000 & $0.000 \mathrm{E}+00$ & 0.0000 & $0.000 \mathrm{E}+00$ & 0.0000 & $1.260 \mathrm{E}-11$ & 0.0000 \\
\hline 239 & $0.000 \mathrm{E}+00$ & 0.0000 & $0.000 \mathrm{E}+00$ & 0.0000 & $0.000 \mathrm{E}+00$ & 0.0000 & $0.000 \mathrm{E}+00$ & 0.0000 & $0.000 \mathrm{E}+00$ & 0.0000 & $0.000 \mathrm{E}+00$ & 0.0000 & $3.234 \mathrm{E}-13$ & 0.0000 \\
\hline 240 & $0.000 \mathrm{E}+00$ & 0.0000 & $0.000 \mathrm{E}+00$ & 0.0000 & $0.000 \mathrm{E}+00$ & 0.0000 & $0.000 \mathrm{E}+00$ & 0.0000 & $0.000 \mathrm{E}+00$ & 0.0000 & $0.000 \mathrm{E}+00$ & 0.0000 & $7.834 \mathrm{E}-17$ & 0.0000 \\
\hline 99 & $0.000 \mathrm{E}+00$ & 0.0000 & $0.000 \mathrm{E}+00$ & 0.0000 & $0.000 \mathrm{E}+00$ & 0.0000 & $0.000 \mathrm{E}+00$ & 0.0000 & $0.000 \mathrm{E}+00$ & 0.0000 & $0.000 \mathrm{E}+00$ & 0.0000 & $1.233 \mathrm{E}-20$ & 0.0000 \\
\hline 228 & $0.000 \mathrm{E}+00$ & 0.0000 & $0.000 \mathrm{E}+00$ & 0.0000 & $0.000 \mathrm{E}+00$ & 0.0000 & $0.000 \mathrm{E}+00$ & 0.0000 & $0.000 \mathrm{E}+00$ & 0.0000 & $0.000 \mathrm{E}+00$ & 0.0000 & $0.000 \mathrm{E}+00$ & 0.0000 \\
\hline 230 & $0.000 \mathrm{E}+00$ & 0.0000 & $0.000 \mathrm{E}+00$ & 0.0000 & $0.000 \mathrm{E}+00$ & 0.0000 & $0.000 \mathrm{E}+00$ & 0.0000 & $0.000 \mathrm{E}+00$ & 0.0000 & $0.000 \mathrm{E}+00$ & 0.0000 & $8.661 \mathrm{E}-06$ & 0.0886 \\
\hline 232 & $0.000 \mathrm{E}+00$ & 0.0000 & $0.000 \mathrm{E}+00$ & 0.0000 & $0.000 \mathrm{E}+00$ & 0.0000 & $0.000 \mathrm{E}+00$ & 0.0000 & $0.000 \mathrm{E}+00$ & 0.0000 & $0.000 \mathrm{E}+00$ & 0.0000 & $8.900 \mathrm{E}-05$ & 0.9103 \\
\hline 34 & $0.000 \mathrm{E}+00$ & 0.0000 & $0.000 \mathrm{E}+00$ & 0.0000 & $0.000 \mathrm{E}+00$ & 0.0000 & $0.000 \mathrm{E}+00$ & 0.0000 & $0.000 \mathrm{E}+00$ & 0.0000 & $0.000 \mathrm{E}+00$ & 0.0000 & $4.396 \mathrm{E}-08$ & 0.0004 \\
\hline 35 & $0.000 \mathrm{E}+00$ & 0.0000 & $0.000 \mathrm{E}+00$ & 0.0000 & $0.000 \mathrm{E}+00$ & 0.0000 & $0.000 \mathrm{E}+00$ & 0.0000 & $0.000 \mathrm{E}+00$ & 0.0000 & $0.000 \mathrm{E}+00$ & 0.0000 & $2.279 \mathrm{E}-09$ & 0.0000 \\
\hline 38 & $0.000 \mathrm{E}+00$ & 0.0000 & $0.000 \mathrm{E}+00$ & 0.0000 & $0.000 \mathrm{E}+00$ & 0.0000 & $0.000 \mathrm{E}+00$ & 0.0000 & $0.000 \mathrm{E}+00$ & 0.0000 & $0.000 \mathrm{E}+00$ & 0.0000 & $6.021 \mathrm{E}-08$ & 0.0006 \\
\hline & $0.000 \mathrm{E}+00$ & 0.0000 & $0.000 \mathrm{E}+00$ & 0.0000 & $0.000 \mathrm{E}+00$ & 0.0000 & $0.000 \mathrm{E}+00$ & 0.0000 & $0.000 \mathrm{E}+00$ & 0.0000 & $0.000 \mathrm{E}+00$ & 000 & -05 & 1.0000 \\
\hline
\end{tabular}

* Sum of all water independent and dependent pathways. 
RESRAD, Version 6.5

$\mathrm{T}^{1 / 2}$ Limit $=180$ days

Summary : C746U Recreational User Deterministic Run

File : $\mathrm{X}: \backslash$ FINAL V2 $\backslash$ C746U RU DET-FINALV2.RAD

Dose/Source Ratios Summed Over All Pathways

Parent and Progeny Principal Radionuclide Contributions Indicated

Parent Product Thread DSR $(j, t)$ At Time in Years (mrem/yr)/(pCi/g)

(i)

(j)

$\begin{array}{ll}\mathrm{Am}-241 & 1.000 \mathrm{E}+00 \\ \mathrm{~Np}-237+\mathrm{D} & 1.000 \mathrm{E}+00 \\ \mathrm{U}-233 & 1.000 \mathrm{E}+00 \\ \mathrm{Th}-229+\mathrm{D} & 1.000 \mathrm{E}+00 \\ \operatorname{\sum DSR}(j) & \end{array}$

Cs $-137+D$

$\mathrm{Np}-237+\mathrm{D}$

U-233

Th-229+D

$\sum \operatorname{DSR}(j)$

$\mathrm{Pu}-238$

Pu-238

U-234

Th-230

Ra-226+D

$\mathrm{Pb}-210+\mathrm{D}$

$\sum \operatorname{DSR}(j)$

Pu-239

$\mathrm{U}-235+\mathrm{D}$

$\mathrm{Pa}-231$

AC-227+D

$\sum \operatorname{DSR}(j)$

Pu-2 40

\section{Pu-240}

U-236

Th-232

$\mathrm{Ra}-228+\mathrm{D}$

Th-228+D

$\sum \mathrm{DSR}(j)$

TC-99

Th-228+D

Th-230

Ra-226+D

$\mathrm{Pb}-210+\mathrm{D}$

$\sum \mathrm{DSR}(j)$ $\begin{array}{lllllllll}1.000 \mathrm{E}+00 & 1.213 \mathrm{E}-10 & 1.196 \mathrm{E}-10 & 5.821 \mathrm{E}-11 & 2.793 \mathrm{E}-11 & 7.847 \mathrm{E}-14 & 2.435 \mathrm{E}-17\end{array}$

$\begin{array}{lllllll}1.000 \mathrm{E}+00 & 9.169 \mathrm{E}-14 & 9.268 \mathrm{E}-14 & 1.567 \mathrm{E}-13 & 2.679 \mathrm{E}-13 & 1.952 \mathrm{E}-11 & 7.101 \mathrm{E}-09\end{array}$

$\begin{array}{lllllll}1.000 \mathrm{E}+00 \quad 3.120 \mathrm{E}-24 & 9.466 \mathrm{E}-24 & 5.875 \mathrm{E}-22 & 2.184 \mathrm{E}-21 & 1.613 \mathrm{E}-18 & 3.273 \mathrm{E}-15\end{array}$

$\begin{array}{lllllll}1.000 \mathrm{E}+00 & 2.848 \mathrm{E}-20 & 2.006 \mathrm{E}-19 & 3.076 \mathrm{E}-16 & 1.723 \mathrm{E}-15 & 6.884 \mathrm{E}-13 & 1.443 \mathrm{E}-10\end{array}$ $\begin{array}{lllllll}9.169 \mathrm{E}-14 & 9.268 \mathrm{E}-14 & 1.570 \mathrm{E}-13 & 2.696 \mathrm{E}-13 & 2.021 \mathrm{E}-11 & 7.245 \mathrm{E}-09\end{array}$

$\begin{array}{lllllll}1.840 E-09 & 2.079 E-34 & 2.099 E-34 & 3.386 E-34 & 5.515 E-34 & 2.732 E-32 & 5.849 E-30\end{array}$

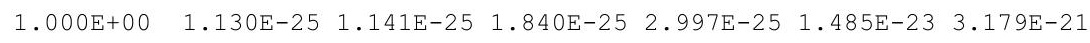

$\begin{array}{llllllll}1.000 \mathrm{E}+00 & 9.402 \mathrm{E}-31 & 2.855 \mathrm{E}-30 & 1.897 \mathrm{E}-28 & 7.660 \mathrm{E}-28 & 1.633 \mathrm{E}-24 & 2.820 \mathrm{E}-20\end{array}$

$\begin{array}{lllllll}1.000 \mathrm{E}+00 & 9.887 \mathrm{E}-35 & 7.005 \mathrm{E}-34 & 1.538 \mathrm{E}-30 & 1.253 \mathrm{E}-29 & 1.259 \mathrm{E}-25 & 3.198 \mathrm{E}-21\end{array}$

$\begin{array}{llllllll}1.000 \mathrm{E}+00 & 7.713 \mathrm{E}-24 & 1.162 \mathrm{E}-22 & 5.065 \mathrm{E}-18 & 5.122 \mathrm{E}-17 & 5.408 \mathrm{E}-14 & 1.260 \mathrm{E}-11\end{array}$

$\begin{array}{llllllll}1.000 \mathrm{E}+00 & 2.237 \mathrm{E}-32 & 6.933 \mathrm{E}-31 & 7.476 \mathrm{E}-25 & 1.264 \mathrm{E}-23 & 3.542 \mathrm{E}-20 & 1.664 \mathrm{E}-17\end{array}$

$\begin{array}{lllllll}7.826 \mathrm{E}-24 & 1.163 \mathrm{E}-22 & 5.065 \mathrm{E}-18 & 5.122 \mathrm{E}-17 & 5.408 \mathrm{E}-14 & 1.260 \mathrm{E}-11\end{array}$

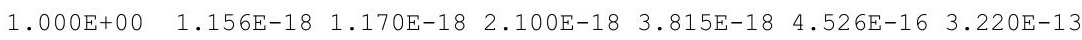

$\begin{array}{llllll}1.000 \mathrm{E}+00 \quad 5.899 \mathrm{E}-25 & 1.789 \mathrm{E}-24 & 1.102 \mathrm{E}-22 & 4.068 \mathrm{E}-22 & 2.830 \mathrm{E}-19 & 5.291 \mathrm{E}-16\end{array}$

$\begin{array}{llllllll}1.000 \mathrm{E}+00 & 9.281 \mathrm{E}-29 & 6.556 \mathrm{E}-28 & 1.203 \mathrm{E}-24 & 8.097 \mathrm{E}-24 & 1.394 \mathrm{E}-20 & 2.092 \mathrm{E}-17\end{array}$

$\begin{array}{lllllll}1.000 \mathrm{E}+00 & 2.200 \mathrm{E}-28 & 3.302 \mathrm{E}-27 & 1.227 \mathrm{E}-22 & 1.125 \mathrm{E}-21 & 1.425 \mathrm{E}-18 & 8.591 \mathrm{E}-16\end{array}$

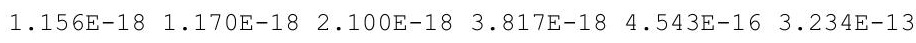

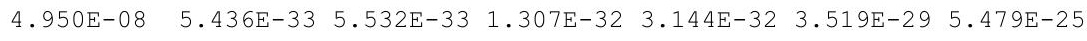

$\begin{array}{lllllll}1.000 \mathrm{E}+00 & 1.098 \mathrm{E}-25 & 1.118 \mathrm{E}-25 & 2.641 \mathrm{E}-25 & 6.352 \mathrm{E}-25 & 7.109 \mathrm{E}-22 & 1.107 \mathrm{E}-17\end{array}$

$\begin{array}{llllllll}1.000 \mathrm{E}+00 & 2.079 \mathrm{E}-33 & 6.337 \mathrm{E}-33 & 5.132 \mathrm{E}-31 & 2.504 \mathrm{E}-30 & 1.628 \mathrm{E}-26 & 6.574 \mathrm{E}-22\end{array}$

$\begin{array}{llllllll}1.000 E+00 & 2.803 E-44 & 1.948 E-43 & 5.271 E-40 & 5.270 E-39 & 2.159 E-34 & 2.528 E-29\end{array}$

$\begin{array}{lllllll}1.000 \mathrm{E}+00 & 1.318 \mathrm{E}-29 & 1.940 \mathrm{E}-28 & 3.618 \mathrm{E}-24 & 2.445 \mathrm{E}-23 & 1.417 \mathrm{E}-20 & 4.042 \mathrm{E}-18\end{array}$

$\begin{array}{llllllll}1.000 \mathrm{E}+00 \quad 7.799 \mathrm{E}-29 & 2.244 \mathrm{E}-27 & 2.540 \mathrm{E}-22 & 1.691 \mathrm{E}-21 & 5.366 \mathrm{E}-19 & 6.323 \mathrm{E}-17\end{array}$

$\begin{array}{llllll}1.099 \mathrm{E}-25 & 1.142 \mathrm{E}-25 & 2.579 \mathrm{E}-22 & 1.716 \mathrm{E}-21 & 5.515 \mathrm{E}-19 & 7.834 \mathrm{E}-17\end{array}$

$\begin{array}{lllllll}1.000 \mathrm{E}+00 & 5.547 \mathrm{E}-27 & 5.625 \mathrm{E}-27 & 1.112 \mathrm{E}-26 & 2.231 \mathrm{E}-26 & 5.839 \mathrm{E}-24 & 1.233 \mathrm{E}-20\end{array}$

$\begin{array}{lllllll}1.000 \mathrm{E}+00 & 1.329 \mathrm{E}-07 & 9.308 \mathrm{E}-08 & 2.430 \mathrm{E}-15 & 4.441 \mathrm{E}-23 & 0.000 \mathrm{E}+00 \quad 0.000 \mathrm{E}+00\end{array}$

$\begin{array}{llllllll}1.000 \mathrm{E}+00 & 2.319 \mathrm{E}-23 & 2.359 \mathrm{E}-23 & 5.375 \mathrm{E}-23 & 1.246 \mathrm{E}-22 & 1.037 \mathrm{E}-19 & 1.074 \mathrm{E}-15\end{array}$

$\begin{array}{llllllll}1.000 \mathrm{E}+00 & 3.629 \mathrm{E}-12 & 1.095 \mathrm{E}-11 & 5.116 \mathrm{E}-10 & 1.423 \mathrm{E}-09 & 1.032 \mathrm{E}-07 & 8.661 \mathrm{E}-06\end{array}$

$\begin{array}{lllllll}1.000 \mathrm{E}+00 & 1.749 \mathrm{E}-20 & 1.222 \mathrm{E}-19 & 1.249 \mathrm{E}-16 & 5.113 \mathrm{E}-16 & 7.402 \mathrm{E}-14 & 1.190 \mathrm{E}-11\end{array}$

$3.629 \mathrm{E}-12$ 1.095E-11 $5.116 \mathrm{E}-10 \quad 1.423 \mathrm{E}-09 \quad 1.032 \mathrm{E}-07 \quad 8.661 \mathrm{E}-06$ 
RESRAD, Version 6.5

Summary : C746U Recreational User Deterministic Run

File : $\mathrm{X}: \backslash F I N A L$ V2 $\backslash C 746 \mathrm{U}$ RU DET-FINALV2.RAD

Dose/Source Ratios Summed Over All Pathways

Parent and Progeny Principal Radionuclide Contributions Indicated

\begin{tabular}{|c|c|c|c|c|c|c|c|c|}
\hline $\begin{array}{l}\text { Parent } \\
\text { (i) }\end{array}$ & $\begin{array}{l}\text { Product } \\
\text { (j) }\end{array}$ & $\begin{array}{l}\text { Thread } \\
\text { Fraction }\end{array}$ & $\begin{array}{r}\text { DSR } \\
0.000 \mathrm{E}+00\end{array}$ & $\begin{array}{l}(j, t) \text { At } T \\
1.000 E+00\end{array}$ & $\begin{array}{l}\text { ime in Yea } \\
5.000 \mathrm{E}+01\end{array}$ & $\begin{array}{l}\text { rs (mrem, } \\
1.000 \mathrm{E}+02\end{array}$ & $\begin{array}{l}(\mathrm{yr}) /(\mathrm{pCi} / \mathrm{g} \\
5.000 \mathrm{E}+02\end{array}$ & $\begin{array}{l}\text { g) } \\
1.050 \mathrm{E}+03\end{array}$ \\
\hline-232 & $\mathrm{Th}-232$ & $1.000 \mathrm{E}+00$ & $1.121 \mathrm{E}-25$ & $1.142 \mathrm{E}-25$ & $2.836 \mathrm{E}-25$ & $7.176 \mathrm{E}-25$ & 1. $205 E-21$ & $3.277 \mathrm{E}-17$ \\
\hline-232 & $\mathrm{Ra}-228+\mathrm{D}$ & $1.000 \mathrm{E}+00$ & $1.065 \mathrm{E}-10$ & $3.052 \mathrm{E}-10$ & $2.678 \mathrm{E}-09$ & $3.923 \mathrm{E}-09$ & $8.176 \mathrm{E}-08$ & $5.322 \mathrm{E}-06$ \\
\hline $1-232$ & $T h-228+D$ & $1.000 \mathrm{E}+00$ & $1.026 \mathrm{E}-09$ & $6.328 E-09$ & $2.128 \mathrm{E}-07$ & $2.877 \mathrm{E}-07$ & $3.130 \mathrm{E}-06$ & $8.368 E-05$ \\
\hline-232 & $\sum \operatorname{DSR}(j)$ & & $1.133 E-09$ & $6.633 E-09$ & $2.155 \mathrm{E}-07$ & $2.917 \mathrm{E}-07$ & $3.212 \mathrm{E}-06$ & $8.900 \mathrm{E}-05$ \\
\hline-234 & $\mathrm{U}-234$ & $1.000 \mathrm{E}+00$ & $6.631 E-25$ & $6.749 \mathrm{E}-25$ & 1. $607 \mathrm{E}-24$ & $3.895 E-24$ & $4.636 \mathrm{E}-21$ & $7.854 \mathrm{E}-17$ \\
\hline-234 & Th-230 & $1.000 \mathrm{E}+00$ & $1.047 \mathrm{E}-28$ & $3.188 \mathrm{E}-28$ & $2.443 E-26$ & $1.127 \mathrm{E}-25$ & $4.665 E-22$ & $1.013 \mathrm{E}-17$ \\
\hline-234 & $\mathrm{Ra}-226+\mathrm{D}$ & $1.000 \mathrm{E}+00$ & $1.090 \mathrm{E}-17$ & $7.671 \mathrm{E}-17$ & $1.167 \mathrm{E}-13$ & $6.482 \mathrm{E}-13$ & $2.407 \mathrm{E}-10$ & 4. 396E-08 \\
\hline-234 & $\mathrm{~Pb}-210+\mathrm{D}$ & $1.000 \mathrm{E}+00$ & $3.944 \mathrm{E}-26$ & $5.916 \mathrm{E}-25$ & $2.118 \mathrm{E}-20$ & $1.862 \mathrm{E}-19$ & $1.619 \mathrm{E}-16$ & $5.847 \mathrm{E}-14$ \\
\hline-234 & $\sum \operatorname{DSR}(j)$ & & $1.090 \mathrm{E}-17$ & $7.671 \mathrm{E}-17$ & $1.167 \mathrm{E}-13$ & $6.482 \mathrm{E}-13$ & $2.407 \mathrm{E}-10$ & $4.396 \mathrm{E}-08$ \\
\hline$-235+D$ & $\mathrm{U}-235+\mathrm{D}$ & $1.000 \mathrm{E}+00$ & $1.195 \mathrm{E}-15$ & $1.210 \mathrm{E}-15$ & $2.218 E-15$ & $4.115 \mathrm{E}-15$ & $5.779 \mathrm{E}-13$ & $5.183 \mathrm{E}-10$ \\
\hline$-235+D$ & $\mathrm{~Pa}-231$ & $1.000 \mathrm{E}+00$ & $2.825 E-19$ & $8.554 \mathrm{E}-19$ & $4.840 \mathrm{E}-17$ & $1.637 \mathrm{E}-16$ & $5.673 \mathrm{E}-14$ & $4.068 \mathrm{E}-11$ \\
\hline$-235+D$ & $A C-227+D$ & $1.000 \mathrm{E}+00$ & $8.917 \mathrm{E}-19$ & $6.232 \mathrm{E}-18$ & $6.620 \mathrm{E}-15$ & $2.832 \mathrm{E}-14$ & $6.156 \mathrm{E}-12$ & $1.720 \mathrm{E}-09$ \\
\hline$-235+D$ & $\sum \operatorname{DSR}(j)$ & & $1.197 \mathrm{E}-15$ & $1.217 \mathrm{E}-15$ & $8.886 \mathrm{E}-15$ & $3.260 \mathrm{E}-14$ & $6.791 \mathrm{E}-12$ & $2.279 \mathrm{E}-09$ \\
\hline-238 & $U-238$ & $5.400 E-05$ & $0.000 \mathrm{E}+00$ & $0.000 \mathrm{E}+00$ & $0.000 \mathrm{E}+00$ & $0.000 \mathrm{E}+00$ & $0.000 \mathrm{E}+00$ & $1.636 \mathrm{E}-39$ \\
\hline$-238+D$ & $\mathrm{U}-238+\mathrm{D}$ & $9.999 \mathrm{E}-01$ & 1. $365 \mathrm{E}-11$ & 1. $376 \mathrm{E}-11$ & $2.035 \mathrm{E}-11$ & $3.035 \mathrm{E}-11$ & 7. $419 \mathrm{E}-10$ & $6.017 \mathrm{E}-08$ \\
\hline$-238+D$ & $\mathrm{U}-234$ & $9.999 \mathrm{E}-01$ & $9.426 \mathrm{E}-31$ & $2.873 E-30$ & $2.301 \mathrm{E}-28$ & $1.110 \mathrm{E}-27$ & $6.582 \mathrm{E}-24$ & $2.342 \mathrm{E}-19$ \\
\hline$-238+D$ & $\mathrm{Th}-230$ & $9.999 E-01$ & $9.906 \mathrm{E}-35$ & $7.035 \mathrm{E}-34$ & $1.749 \mathrm{E}-30$ & $1.605 \mathrm{E}-29$ & $3.309 \mathrm{E}-25$ & $1.508 \mathrm{E}-20$ \\
\hline$-238+D$ & $\mathrm{Ra}-226+\mathrm{D}$ & $9.999 \mathrm{E}-01$ & $7.725 E-24$ & $1.165 E-22$ & $5.580 \mathrm{E}-18$ & $6.178 \mathrm{E}-17$ & $1.159 \mathrm{E}-13$ & $4.523 E-11$ \\
\hline$-238+D$ & $\mathrm{~Pb}-210+\mathrm{D}$ & $9.999 \mathrm{E}-01$ & $2.239 \mathrm{E}-32$ & $6.951 \mathrm{E}-31$ & $8.109 \mathrm{E}-25$ & $1.488 \mathrm{E}-23$ & 7. $347 \mathrm{E}-20$ & $5.837 \mathrm{E}-17$ \\
\hline$-238+D$ & $\sum \operatorname{DSR}(j)$ & & $1.365 \mathrm{E}-11$ & 1. $376 \mathrm{E}-11$ & $2.035 \mathrm{E}-11$ & $3.035 \mathrm{E}-11$ & $7.420 \mathrm{E}-10$ & $6.021 \mathrm{E}-08$ \\
\hline
\end{tabular}

The DSR includes contributions from associated (half-life $\leq 180$ days) daughters. 
RESRAD, Version $6.5 \quad \mathrm{~T}^{1 / 2}$ Limit $=180$ days

Summary : C746U Recreational User Deterministic Run

File : $X: \backslash F I N A L$ V2 $\backslash C 746 U$ RU DET-FINALV2.RAD

Single Radionuclide Soil Guidelines G(i,t) in pCi/g

Basic Radiation Dose Limit $=1.000 \mathrm{E}+00 \mathrm{mrem} / \mathrm{yr}$

Nuclide

\begin{tabular}{|c|c|c|c|c|c|c|}
\hline (i) & $t=0.000 E+00$ & $1.000 \mathrm{E}+00$ & $5.000 \mathrm{E}+01$ & $1.000 \mathrm{E}+02$ & $5.000 \mathrm{E}+02$ & $1.050 \mathrm{E}+03$ \\
\hline-241 & $\star 3.431 \mathrm{E}+12$ & $\star 3.431 \mathrm{E}+12$ & $\star 3.431 \mathrm{E}+12$ & $\star 3.431 \mathrm{E}+12$ & $\star 3.431 \mathrm{E}+12$ & $8.235 E+11$ \\
\hline$s-137$ & $8.242 \mathrm{E}+09$ & $8.364 \mathrm{E}+09$ & $1.718 \mathrm{E}+10$ & $3.580 \mathrm{E}+10$ & $1.274 \mathrm{E}+13$ & $\star 8.704 \mathrm{E}+13$ \\
\hline$p-237$ & $\star 7.047 \mathrm{E}+08$ & $\star 7.047 \mathrm{E}+08$ & $\star 7.047 \mathrm{E}+08$ & $\star 7.047 \mathrm{E}+08$ & $\star 7.047 \mathrm{E}+08$ & $1.380 \mathrm{E}+08$ \\
\hline$u-238$ & $\star 1.712 \mathrm{E}+13$ & $\star 1.712 \mathrm{E}+13$ & $\star 1.712 \mathrm{E}+13$ & $\star 1.712 \mathrm{E}+13$ & $\star 1.712 \mathrm{E}+13$ & $7.937 \mathrm{E}+10$ \\
\hline$u-239$ & $* 6.214 \mathrm{E}+10$ & $* 6.214 \mathrm{E}+10$ & $* 6.214 \mathrm{E}+10$ & $\star 6.214 \mathrm{E}+10$ & $\star 6.214 \mathrm{E}+10$ & $* 6.214 \mathrm{E}+10$ \\
\hline$u-240$ & $\star 2.278 \mathrm{E}+11$ & $\star 2.278 \mathrm{E}+11$ & $\star 2.278 \mathrm{E}+11$ & $\star 2.278 \mathrm{E}+11$ & $\star 2.278 \mathrm{E}+11$ & $\star 2.278 \mathrm{E}+11$ \\
\hline$c-99$ & $* 1.697 \mathrm{E}+10$ & $\star 1.697 \mathrm{E}+10$ & $\star 1.697 \mathrm{E}+10$ & $\star 1.697 \mathrm{E}+10$ & $\star 1.697 \mathrm{E}+10$ & $\star 1.697 \mathrm{E}+10$ \\
\hline Th-228 & $7.523 \mathrm{E}+06$ & $1.074 \mathrm{E}+07$ & $4.116 \mathrm{E}+14$ & $\star 8.195 \mathrm{E}+14$ & $\star 8.195 E+14$ & $\star 8.195 \mathrm{E}+14$ \\
\hline Th -230 & $\star 2.018 \mathrm{E}+10$ & $\star 2.018 \mathrm{E}+10$ & $1.955 \mathrm{E}+09$ & $7.028 \mathrm{E}+08$ & $9.688 \mathrm{E}+06$ & $1.155 \mathrm{E}+05$ \\
\hline Th-232 & $* 1.097 \mathrm{E}+05$ & $\star 1.097 \mathrm{E}+05$ & $* 1.097 \mathrm{E}+05$ & *1.097E+05 & $* 1.097 \mathrm{E}+05$ & $1.124 \mathrm{E}+04$ \\
\hline $\mathrm{U}-234$ & $* 6.247 \mathrm{E}+09$ & $\star 6.247 \mathrm{E}+09$ & $\star 6.247 \mathrm{E}+09$ & $\star 6.247 \mathrm{E}+09$ & $4.154 \mathrm{E}+09$ & $2.275 \mathrm{E}+07$ \\
\hline-235 & $\star 2.161 \mathrm{E}+06$ & $\star 2.161 \mathrm{E}+06$ & $\star 2.161 \mathrm{E}+06$ & $\star 2.161 \mathrm{E}+06$ & $\star 2.161 \mathrm{E}+06$ & $\star 2.161 \mathrm{E}+06$ \\
\hline 238 & $\star 3.361 \mathrm{E}+05$ & $\star 3.361 \mathrm{E}+05$ & $\star 3.361 \mathrm{E}+05$ & $\star 3.361 \mathrm{E}+05$ & $\star 3.361 \mathrm{E}+05$ & $\star 3.361 \mathrm{E}+05$ \\
\hline
\end{tabular}

*At specific activity limit

Summed Dose/Source Ratios DSR(i,t) in (mrem/yr)/(pCi/g) and Single Radionuclide Soil Guidelines $\mathrm{G}(i, t)$ in $\mathrm{pCi} / \mathrm{g}$

at tmin $=$ time of minimum single radionuclide soil guideline and at tmax $=$ time of maximum total dose $=1.050 \mathrm{E}+03$ years

\begin{tabular}{|c|c|c|c|c|c|c|}
\hline $\begin{array}{l}\text { Uclide } \\
\text { (i) }\end{array}$ & $\begin{array}{l}\text { Initial } \\
(\mathrm{pCi} / \mathrm{g})\end{array}$ & $\begin{array}{c}\text { tmin } \\
\text { (years) }\end{array}$ & $\operatorname{DSR}(i, \operatorname{tmin})$ & $\begin{array}{c}\mathrm{G}(\mathrm{i}, \mathrm{tmin}) \\
(\mathrm{pCi} / \mathrm{g})\end{array}$ & $\operatorname{DSR}(i, \operatorname{tmax})$ & $\begin{array}{l}G(i, t \max ) \\
(\mathrm{pCi} / \mathrm{g})\end{array}$ \\
\hline-241 & $1.000 \mathrm{E}+00$ & $1.050 \mathrm{E}+03$ & $1.214 \mathrm{E}-12$ & $8.235 E+11$ & $1.214 \mathrm{E}-12$ & $8.235 E+11$ \\
\hline 137 & $1.000 \mathrm{E}+00$ & $0.000 \mathrm{E}+00$ & $1.213 \mathrm{E}-10$ & $8.242 E+09$ & $2.435 \mathrm{E}-17$ & $\star 8.704 \mathrm{E}+13$ \\
\hline 237 & $1.000 \mathrm{E}+00$ & $1.050 \mathrm{E}+03$ & $7.245 E-09$ & $1.380 \mathrm{E}+08$ & $7.245 \mathrm{E}-09$ & $1.380 \mathrm{E}+08$ \\
\hline-238 & $1.000 \mathrm{E}+00$ & $1.050 \mathrm{E}+03$ & $1.260 \mathrm{E}-11$ & $7.937 \mathrm{E}+10$ & $1.260 \mathrm{E}-11$ & $7.937 \mathrm{E}+10$ \\
\hline $\mathrm{Pu}-239$ & $1.000 \mathrm{E}+00$ & $1.050 \mathrm{E}+03$ & $3.234 \mathrm{E}-13$ & $* 6.214 \mathrm{E}+10$ & $3.234 \mathrm{E}-13$ & $\star 6.214 \mathrm{E}+10$ \\
\hline$u-240$ & $1.000 \mathrm{E}+00$ & $1.050 \mathrm{E}+03$ & $7.834 \mathrm{E}-17$ & $\star 2.278 \mathrm{E}+11$ & $7.834 \mathrm{E}-17$ & $\star 2.278 \mathrm{E}+11$ \\
\hline TC-99 & $1.000 \mathrm{E}+00$ & $1.050 \mathrm{E}+03$ & $1.233 \mathrm{E}-20$ & $\star 1.697 \mathrm{E}+10$ & $1.233 \mathrm{E}-20$ & $\star 1.697 \mathrm{E}+10$ \\
\hline Th-228 & $1.000 \mathrm{E}+00$ & $0.000 \mathrm{E}+00$ & $1.329 \mathrm{E}-07$ & $7.523 \mathrm{E}+06$ & $0.000 \mathrm{E}+00$ & $\star 8.195 \mathrm{E}+14$ \\
\hline$T h-230$ & $1.000 \mathrm{E}+00$ & $1.050 \mathrm{E}+03$ & $8.661 \mathrm{E}-06$ & $1.155 \mathrm{E}+05$ & $8.661 \mathrm{E}-06$ & $1.155 \mathrm{E}+05$ \\
\hline 232 & $1.000 \mathrm{E}+00$ & $1.050 \mathrm{E}+03$ & $8.900 E-05$ & $1.124 \mathrm{E}+04$ & $8.900 \mathrm{E}-05$ & $1.124 \mathrm{E}+04$ \\
\hline 34 & $1.000 \mathrm{E}+00$ & $1.050 \mathrm{E}+03$ & $4.396 \mathrm{E}-08$ & $2.275 \mathrm{E}+07$ & $4.396 \mathrm{E}-08$ & $2.275 E+07$ \\
\hline 35 & $1.000 \mathrm{E}+00$ & $1.050 \mathrm{E}+03$ & $2.279 \mathrm{E}-09$ & $\star 2.161 \mathrm{E}+06$ & $2.279 \mathrm{E}-09$ & $\star 2.161 \mathrm{E}+06$ \\
\hline 238 & $1.000 \mathrm{E}+00$ & $1.050 \mathrm{E}+03$ & $6.021 \mathrm{E}-08$ & $\star 3.361 \mathrm{E}+05$ & $6.021 \mathrm{E}-08$ & $\star 3.361 \mathrm{E}+05$ \\
\hline
\end{tabular}

*At specific activity limit 
RESRAD, Version 6.5

Summary : C746U Recreational User Deterministic Run

File : $\mathrm{X}: \backslash$ FINAL V2 $\backslash$ C746U RU DET-FINALV2.RAD

Individual Nuclide Dose Summed Over All Pathways

Parent Nuclide and Branch Fraction Indicated

Nuclide Parent THF(i) DOSE $(j, t)$, mrem/yr

\begin{tabular}{|c|c|c|}
\hline (j) & (i) & \\
\hline$A m-241$ & $A m-241$ & $1.000 \mathrm{E}+00$ \\
\hline$p-237$ & $A m-241$ & $1.000 \mathrm{E}+00$ \\
\hline $\mathrm{Np}-237$ & $\mathrm{~Np}-237$ & $1.000 \mathrm{E}+00$ \\
\hline $\mathrm{Np}-237$ & $\sum \operatorname{DOSE}(j$ & \\
\hline
\end{tabular}

$\mathrm{U}-233 \quad \mathrm{Am}-241 \quad 1.000 \mathrm{E}+00$

$\mathrm{U}-233 \quad \mathrm{~Np}-237 \quad 1.000 \mathrm{E}+00$

U-233 $\quad$ DOSE $(j)$

Th-229

Th-229

Th-229

Cs -137

$\mathrm{Pu}-238$

$\mathrm{Pu}-238$

$\mathrm{Pu}-238$

$\mathrm{U}-234$

$\mathrm{U}-234$

$\mathrm{U}-234$

$\mathrm{U}-234$

Th-230

Th -230

Th -230

Th -230

$\mathrm{Th}-230$

$\mathrm{Ra}-226$

$\mathrm{Ra}-226$

$\mathrm{Ra}-226$

$\mathrm{Ra}-226$

$\operatorname{Ra}-226$

$\mathrm{Pb}-210$

$\mathrm{Pb}-210$

$\mathrm{Pb}-210$

$\mathrm{Pb}-210$

$\mathrm{Pb}-210$

$\mathrm{Pu}-239$

$\mathrm{U}-235$

$\mathrm{U}-235$

$\mathrm{U}-235$
Am-241 1.000E+00

$\mathrm{Np}-237 \quad 1.000 \mathrm{E}+00$

$\sum \operatorname{DOSE}(j)$

Cs-137 1.000E+00

Pu-238 1.840E-09

Pu-238 $1.000 \mathrm{E}+00$

$\sum \operatorname{DOSE}(j)$

$\mathrm{Pu}-238 \quad 1.000 \mathrm{E}+00$

$\mathrm{U}-234 \quad 1.000 \mathrm{E}+00$

$\operatorname{LDOSE}(j)$

Pu-238 1.000E+00

Th-230 1.000E+00

$\mathrm{U}-234 \quad 1.000 \mathrm{E}+00$

$\sum \operatorname{DOSE}(j)$

$\mathrm{Pu}-238 \quad 1.000 \mathrm{E}+00$

Th-230 1.000E+00

$\mathrm{U}-238 \quad 9.999 \mathrm{E}-01$

$\sum \operatorname{DOSE}(j)$

$\mathrm{Pu}-238 \quad 1.000 \mathrm{E}+00$

Th-230 $1.000 \mathrm{E}+00$

U-234 $1.000 \mathrm{E}+00$

U-238 $9.999 \mathrm{E}-01$

$\operatorname{LDOSE}(j)$

$\mathrm{Pu}-239 \quad 1.000 \mathrm{E}+00$

$\mathrm{Pu}-239 \quad 1.000 \mathrm{E}+00$

¿DOSE $(j)$
U-238 9.999E-01

$\mathrm{U}-238 \quad 9.999 \mathrm{E}-01$

$\mathrm{U}-234 \quad 1.000 \mathrm{E}+00$

U-235 $1.000 \mathrm{E}+00$ $t=0.000 \mathrm{E}+00 \quad 1.000 \mathrm{E}+00 \quad 5.000 \mathrm{E}+01 \quad 1.000 \mathrm{E}+02 \quad 5.000 \mathrm{E}+02 \quad 1.050 \mathrm{E}+03$

$\begin{array}{llllll}0.000 \mathrm{E}+00 & 0.000 \mathrm{E}+00 & 0.000 \mathrm{E}+00 & 0.000 \mathrm{E}+00 & 1.163 \mathrm{E}-28 & 2.757 \mathrm{E}-22\end{array}$

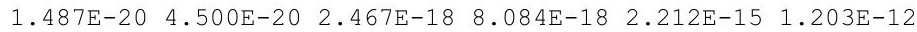

$\begin{array}{llllll}9.169 \mathrm{E}-14 & 9.268 \mathrm{E}-14 & 1.567 \mathrm{E}-13 & 2.679 \mathrm{E}-13 & 1.952 \mathrm{E}-11 & 7.101 \mathrm{E}-09\end{array}$

$\begin{array}{llllll}9.169 \mathrm{E}-14 & 9.268 \mathrm{E}-14 & 1.567 \mathrm{E}-13 & 2.679 \mathrm{E}-13 & 1.952 \mathrm{E}-11 & 7.102 \mathrm{E}-09\end{array}$

$\begin{array}{llllll}0.000 \mathrm{E}+00 & 2.384 \mathrm{E}-30 & 4.682 \mathrm{E}-27 & 3.376 \mathrm{E}-26 & 1.025 \mathrm{E}-22 & 3.455 \mathrm{E}-19\end{array}$

$\begin{array}{llllll}3.120 \mathrm{E}-24 & 9.466 \mathrm{E}-24 & 5.875 \mathrm{E}-22 & 2.184 \mathrm{E}-21 & 1.613 \mathrm{E}-18 & 3.273 \mathrm{E}-15\end{array}$

$\begin{array}{llllll}3.120 \mathrm{E}-24 & 9.466 \mathrm{E}-24 & 5.875 \mathrm{E}-22 & 2.184 \mathrm{E}-21 & 1.613 \mathrm{E}-18 & 3.273 \mathrm{E}-15\end{array}$

$2.306 \mathrm{E}-27 \quad 3.479 \mathrm{E}-26 \quad 1.645 \mathrm{E}-21 \quad 1.799 \mathrm{E}-20 \quad 3.100 \mathrm{E}-17 \quad 1.142 \mathrm{E}-14$

$2.848 \mathrm{E}-20 \quad 2.006 \mathrm{E}-19 \quad 3.076 \mathrm{E}-16 \quad 1.723 \mathrm{E}-15 \quad 6.884 \mathrm{E}-13 \quad 1.443 \mathrm{E}-10$

$2.848 \mathrm{E}-20 \quad 2.006 \mathrm{E}-19 \quad 3.076 \mathrm{E}-16 \quad 1.723 \mathrm{E}-15 \quad 6.884 \mathrm{E}-13 \quad 1.443 \mathrm{E}-10$

$\begin{array}{llllll}1.213 \mathrm{E}-10 & 1.196 \mathrm{E}-10 & 5.821 \mathrm{E}-11 & 2.793 \mathrm{E}-11 & 7.847 \mathrm{E}-14 & 2.435 \mathrm{E}-17\end{array}$

$\begin{array}{llllll}0.000 \mathrm{E}+00 & 0.000 \mathrm{E}+00 & 0.000 \mathrm{E}+00 & 0.000 \mathrm{E}+00 & 0.000 \mathrm{E}+00 & 5.849 \mathrm{E}-30\end{array}$

$\begin{array}{llllll}1.130 \mathrm{E}-25 & 1.141 \mathrm{E}-25 & 1.840 \mathrm{E}-25 & 2.997 \mathrm{E}-25 & 1.485 \mathrm{E}-23 & 3.179 \mathrm{E}-21\end{array}$

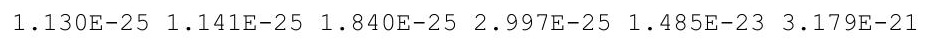

$\begin{array}{llllll}0.000 \mathrm{E}+00 & 2.855 \mathrm{E}-30 & 1.897 \mathrm{E}-28 & 7.660 \mathrm{E}-28 & 1.633 \mathrm{E}-24 & 2.820 \mathrm{E}-20\end{array}$

$\begin{array}{lllllll}6.631 \mathrm{E}-25 & 6.749 \mathrm{E}-25 & 1.607 \mathrm{E}-24 & 3.895 \mathrm{E}-24 & 4.636 \mathrm{E}-21 & 7.854 \mathrm{E}-17\end{array}$

$\begin{array}{llllll}0.000 E+00 & 2.873 E-30 & 2.301 E-28 & 1.110 E-27 & 6.582 E-24 & 2.342 E-19\end{array}$

$\begin{array}{llllll}6.631 \mathrm{E}-25 & 6.749 \mathrm{E}-25 & 1.607 \mathrm{E}-24 & 3.897 \mathrm{E}-24 & 4.644 \mathrm{E}-21 & 7.880 \mathrm{E}-17\end{array}$

$\begin{array}{llllll}0.000 \mathrm{E}+00 & 0.000 \mathrm{E}+00 & 1.538 \mathrm{E}-30 & 1.253 \mathrm{E}-29 & 1.259 \mathrm{E}-25 & 3.198 \mathrm{E}-21\end{array}$

$\begin{array}{llllll}2.319 \mathrm{E}-23 & 2.359 \mathrm{E}-23 & 5.375 \mathrm{E}-23 & 1.246 \mathrm{E}-22 & 1.037 \mathrm{E}-19 & 1.074 \mathrm{E}-15\end{array}$

$1.047 \mathrm{E}-28 \quad 3.188 \mathrm{E}-28 \quad 2.443 \mathrm{E}-26 \quad 1.127 \mathrm{E}-25 \quad 4.665 \mathrm{E}-22 \quad 1.013 \mathrm{E}-17$

$\begin{array}{llllll}0.000 \mathrm{E}+00 & 0.000 \mathrm{E}+00 & 1.749 \mathrm{E}-30 & 1.605 \mathrm{E}-29 & 3.309 \mathrm{E}-25 & 1.508 \mathrm{E}-20\end{array}$

$\begin{array}{llllll}2.319 \mathrm{E}-23 & 2.359 \mathrm{E}-23 & 5.378 \mathrm{E}-23 & 1.247 \mathrm{E}-22 & 1.041 \mathrm{E}-19 & 1.084 \mathrm{E}-15\end{array}$

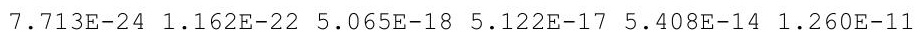

$\begin{array}{llllll}3.629 \mathrm{E}-12 & 1.095 \mathrm{E}-11 & 5.116 \mathrm{E}-10 & 1.423 \mathrm{E}-09 & 1.032 \mathrm{E}-07 & 8.661 \mathrm{E}-06\end{array}$

$\begin{array}{lllllll}1.090 \mathrm{E}-17 & 7.671 \mathrm{E}-17 & 1.167 \mathrm{E}-13 & 6.482 \mathrm{E}-13 & 2.407 \mathrm{E}-10 & 4.396 \mathrm{E}-08\end{array}$

$\begin{array}{llllll}7.725 \mathrm{E}-24 & 1.165 \mathrm{E}-22 & 5.580 \mathrm{E}-18 & 6.178 \mathrm{E}-17 & 1.159 \mathrm{E}-13 & 4.523 \mathrm{E}-11\end{array}$

$\begin{array}{llllll}3.629 \mathrm{E}-12 & 1.095 \mathrm{E}-11 & 5.117 \mathrm{E}-10 & 1.423 \mathrm{E}-09 & 1.035 \mathrm{E}-07 & 8.705 \mathrm{E}-06\end{array}$

$\begin{array}{llllll}0.000 \mathrm{E}+00 & 0.000 \mathrm{E}+00 & 7.476 \mathrm{E}-25 & 1.264 \mathrm{E}-23 & 3.542 \mathrm{E}-20 & 1.664 \mathrm{E}-17\end{array}$ $\begin{array}{llllll}1.749 \mathrm{E}-20 & 1.222 \mathrm{E}-19 & 1.249 \mathrm{E}-16 & 5.113 \mathrm{E}-16 & 7.402 \mathrm{E}-14 & 1.190 \mathrm{E}-11\end{array}$ $\begin{array}{llllll}3.944 \mathrm{E}-26 & 5.916 \mathrm{E}-25 & 2.118 \mathrm{E}-20 & 1.862 \mathrm{E}-19 & 1.619 \mathrm{E}-16 & 5.847 \mathrm{E}-14\end{array}$ $0.000 \mathrm{E}+00 \quad 0.000 \mathrm{E}+00 \quad 8.109 \mathrm{E}-25 \quad 1.488 \mathrm{E}-23 \quad 7.347 \mathrm{E}-20 \quad 5.837 \mathrm{E}-17$ $\begin{array}{llllll}1.749 \mathrm{E}-20 & 1.222 \mathrm{E}-19 & 1.250 \mathrm{E}-16 & 5.115 \mathrm{E}-16 & 7.418 \mathrm{E}-14 & 1.196 \mathrm{E}-11\end{array}$

$\begin{array}{llllll}1.156 \mathrm{E}-18 & 1.170 \mathrm{E}-18 & 2.100 \mathrm{E}-18 & 3.815 \mathrm{E}-18 & 4.526 \mathrm{E}-16 & 3.220 \mathrm{E}-13\end{array}$

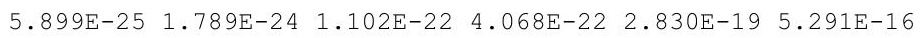
$\begin{array}{llllll}1.195 \mathrm{E}-15 & 1.210 \mathrm{E}-15 & 2.218 \mathrm{E}-15 & 4.115 \mathrm{E}-15 & 5.779 \mathrm{E}-13 & 5.183 \mathrm{E}-10\end{array}$

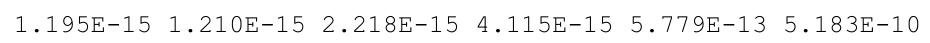


RESRAD, Version $6.5 \quad T^{1 / 2}$ Limit $=180$ days

Summary : C746U Recreational User Deterministic Run

File : $X: \backslash F I N A L$ V2 $\backslash C 746 U$ RU DET-FINALV2.RAD

Individual Nuclide Dose Summed Over All Pathways

Parent Nuclide and Branch Fraction Indicated

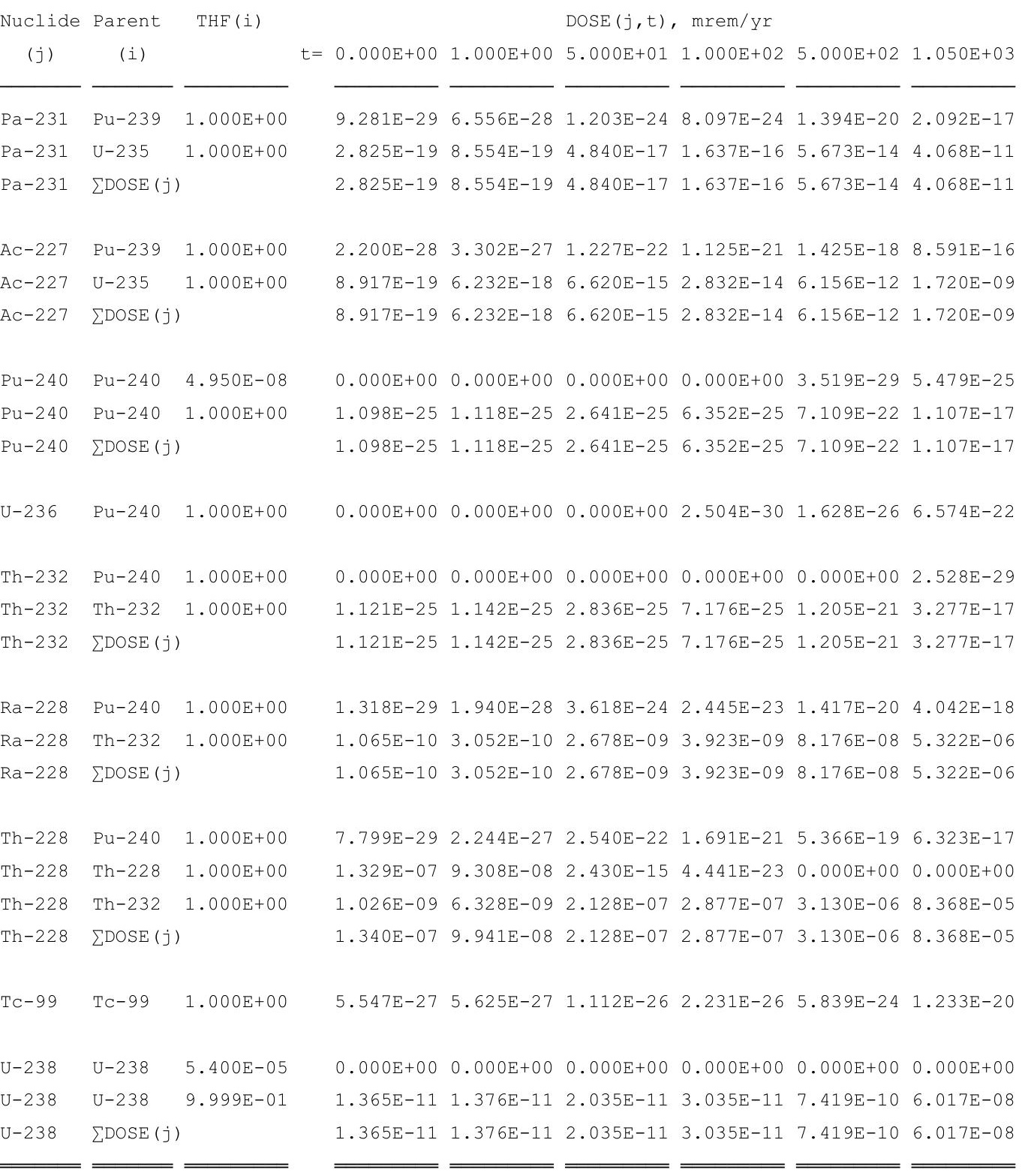

THF(i) is the thread fraction of the parent nuclide. 
RESRAD, Version $6.5 \quad T^{1 / 2}$ Limit $=180$ days

Summary : C746U Recreational User Deterministic Run

File : $\mathrm{X}: \backslash$ FINAL V2 $\backslash \mathrm{C746U}$ RU DET-FINALV2.RAD

Individual Nuclide Soil Concentration

Parent Nuclide and Branch Fraction Indicated

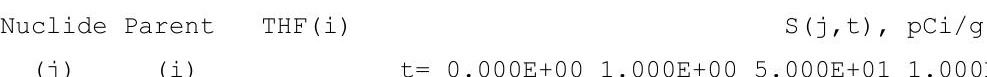

\section{(j)}

(i)

Am-241 Am-241 1.000E+00

$\mathrm{Np}-237 \quad \mathrm{Am}-241 \quad 1.000 \mathrm{E}+00$

$\mathrm{Np}-237 \quad \mathrm{~Np}-237 \quad 1.000 \mathrm{E}+00$

Np-237 $\sum S(j):$

$\mathrm{U}-233 \quad \mathrm{Am}-241 \quad 1.000 \mathrm{E}+00$

$\mathrm{U}-233 \mathrm{~Np}-237 \quad 1.000 \mathrm{E}+00$

$\mathrm{U}-233 \sum \mathrm{S}(j)$ :

Th-229

$\mathrm{Th}-229$

$\mathrm{Th}-229$

Cs -137

$\mathrm{Pu}-238$

$\mathrm{Pu}-238$

$\mathrm{Pu}-238$

$\mathrm{U}-234$

$\mathrm{U}-234$

$\mathrm{U}-234$

$\mathrm{U}-234$

Th-230

Th-230

Th-230

$\mathrm{Th}-230$

Th-230

$\mathrm{Ra}-226$

$\mathrm{Ra}-226$

$\mathrm{Ra}-226$

$\mathrm{Ra}-226$

$\mathrm{Ra}-226$

$\mathrm{Pb}-210$

$\mathrm{Pb}-210$

$\mathrm{Pb}-210$

$\mathrm{Pb}-210$

$\mathrm{Pb}-210$

Pu-239

Am-241 1.000E+00

$\mathrm{Np}-237 \quad 1.000 \mathrm{E}+00$

$\sum S(j):$

Cs-137 1.000E+00

Pu-238 1.840E-09

$\mathrm{Pu}-238 \quad 1.000 \mathrm{E}+00$

$\sum S(j):$

$\mathrm{Pu}-238 \quad 1.000 \mathrm{E}+00$

$\mathrm{U}-234 \quad 1.000 \mathrm{E}+00$

U-238 9.999E-01

$\sum S(j):$

$\mathrm{Pu}-238 \quad 1.000 \mathrm{E}+00$

Th-230 1.000E+00

U-234 $1.000 \mathrm{E}+00$

U-238 9.999E-01

$\sum S(j):$

$\mathrm{Pu}-238 \quad 1.000 \mathrm{E}+00$

Th-230 1.000E+00

$\mathrm{U}-234 \quad 1.000 \mathrm{E}+00$

U-238 9.999E-01

$\sum S(j):$

$\mathrm{Pu}-238 \quad 1.000 \mathrm{E}+00$

Th-230 1.000E+00

$\mathrm{U}-234 \quad 1.000 \mathrm{E}+00$

U-238 9.999E-01

$\sum S(j):$

$\mathrm{Pu}-239 \quad 1.000 \mathrm{E}+00$

$\mathrm{Pu}-239 \quad 1.000 \mathrm{E}+00$

$\mathrm{U}-235 \quad 1.000 \mathrm{E}+00$

$\sum S(j):$
$=0.000 \mathrm{E}+001.000 \mathrm{E}+00 \quad 5.000 \mathrm{E}+01 \quad 1.000 \mathrm{E}+02 \quad 5.000 \mathrm{E}+02 \quad 1.050 \mathrm{E}+03$

$\begin{array}{lllllll}1.000 \mathrm{E}+00 & 9.984 \mathrm{E}-01 & 9.228 \mathrm{E}-01 & 8.516 \mathrm{E}-01 & 4.478 \mathrm{E}-01 & 1.851 \mathrm{E}-01\end{array}$

$\begin{array}{lllllll}0.000 \mathrm{E}+00 & 3.236 \mathrm{E}-07 & 1.553 \mathrm{E}-05 & 2.980 \mathrm{E}-05 & 1.089 \mathrm{E}-04 & 1.559 \mathrm{E}-04\end{array}$

$\begin{array}{lllllll}1.000 \mathrm{E}+00 & 9.999 \mathrm{E}-01 & 9.961 \mathrm{E}-01 & 9.922 \mathrm{E}-01 & 9.614 \mathrm{E}-01 & 9.206 \mathrm{E}-01\end{array}$

$\begin{array}{llllll}1.000 \mathrm{E}+00 & 9.999 \mathrm{E}-01 & 9.961 \mathrm{E}-01 & 9.922 \mathrm{E}-01 & 9.615 \mathrm{E}-01 & 9.208 \mathrm{E}-01\end{array}$

$0.000 \mathrm{E}+00 \quad 7.078 \mathrm{E}-13 \quad 1.721 \mathrm{E}-09 \quad 6.696 \mathrm{E}-09 \quad 1.355 \mathrm{E}-07 \quad 4.608 \mathrm{E}-07$

$0.000 \mathrm{E}+00 \quad 4.373 \mathrm{E}-06 \quad 2.181 \mathrm{E}-04 \quad 4.352 \mathrm{E}-04 \quad 2.135 \mathrm{E}-03 \quad 4.366 \mathrm{E}-03$

$0.000 \mathrm{E}+00 \quad 4.373 \mathrm{E}-06 \quad 2.181 \mathrm{E}-04 \quad 4.352 \mathrm{E}-04 \quad 2.135 \mathrm{E}-03 \quad 4.366 \mathrm{E}-03$

$\begin{array}{llllllll}0.000 \mathrm{E}+00 & 2.228 \mathrm{E}-17 & 2.725 \mathrm{E}-12 & 2.132 \mathrm{E}-11 & 2.249 \mathrm{E}-09 & 1.683 \mathrm{E}-08\end{array}$

$0.000 \mathrm{E}+00 \quad 2.065 \mathrm{E}-10 \quad 5.146 \mathrm{E}-07 \quad 2.052 \mathrm{E}-06 \quad 4.999 \mathrm{E}-05 \quad 2.128 \mathrm{E}-04$

$0.000 \mathrm{E}+00 \quad 2.065 \mathrm{E}-10 \quad 5.146 \mathrm{E}-07 \quad 2.052 \mathrm{E}-06 \quad 4.999 \mathrm{E}-05 \quad 2.129 \mathrm{E}-04$

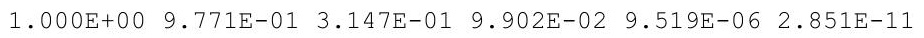

$\begin{array}{lllllll}1.840 \mathrm{E}-09 & 1.826 \mathrm{E}-09 & 1.239 \mathrm{E}-09 & 8.342 \mathrm{E}-10 & 3.525 \mathrm{E}-11 & 4.548 \mathrm{E}-13\end{array}$

$\begin{array}{lllllll}1.000 \mathrm{E}+00 & 9.921 \mathrm{E}-01 & 6.733 \mathrm{E}-01 & 4.534 \mathrm{E}-01 & 1.916 \mathrm{E}-02 & 2.472 \mathrm{E}-04\end{array}$

$\begin{array}{llllll}1.000 \mathrm{E}+00 & 9.921 \mathrm{E}-01 & 6.733 \mathrm{E}-01 & 4.534 \mathrm{E}-01 & 1.916 \mathrm{E}-02 & 2.472 \mathrm{E}-04\end{array}$

$\begin{array}{lllllll}0.000 \mathrm{E}+00 & 2.824 \mathrm{E}-06 & 1.170 \mathrm{E}-04 & 1.957 \mathrm{E}-04 & 3.494 \mathrm{E}-04 & 3.530 \mathrm{E}-04\end{array}$

$\begin{array}{lllllll}1.000 \mathrm{E}+00 & 1.000 \mathrm{E}+00 & 9.992 \mathrm{E}-01 & 9.984 \mathrm{E}-01 & 9.919 \mathrm{E}-01 & 9.831 \mathrm{E}-01\end{array}$

$\begin{array}{llllll}0.000 \mathrm{E}+00 & 2.835 \mathrm{E}-06 & 1.416 \mathrm{E}-04 & 2.831 \mathrm{E}-04 & 1.407 \mathrm{E}-03 & 2.931 \mathrm{E}-03\end{array}$

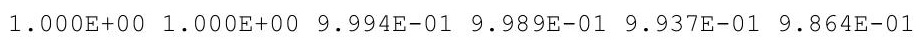

$\begin{array}{llllll}0.000 \mathrm{E}+00 & 1.273 \mathrm{E}-11 & 2.807 \mathrm{E}-08 & 9.959 \mathrm{E}-08 & 1.206 \mathrm{E}-06 & 2.942 \mathrm{E}-06\end{array}$ $\begin{array}{lllllll}1.000 \mathrm{E}+00 & 1.000 \mathrm{E}+00 & 9.995 \mathrm{E}-01 & 9.989 \mathrm{E}-01 & 9.947 \mathrm{E}-01 & 9.888 \mathrm{E}-01\end{array}$ $0.000 \mathrm{E}+00 \quad 9.002 \mathrm{E}-06 \quad 4.498 \mathrm{E}-04 \quad 8.990 \mathrm{E}-04 \quad 4.471 \mathrm{E}-03 \quad 9.319 \mathrm{E}-03$ $\begin{array}{lllllll}0.000 \mathrm{E}+00 & 1.276 \mathrm{E}-11 & 3.188 \mathrm{E}-08 & 1.274 \mathrm{E}-07 & 3.168 \mathrm{E}-06 & 1.387 \mathrm{E}-05\end{array}$

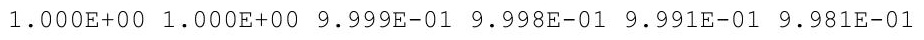

$0.000 \mathrm{E}+00 \quad 1.839 \mathrm{E}-15 \quad 2.080 \mathrm{E}-10 \quad 1.511 \mathrm{E}-09 \quad 1.013 \mathrm{E}-07 \quad 5.253 \mathrm{E}-07$ $0.000 \mathrm{E}+00 \quad 4.331 \mathrm{E}-04 \quad 2.142 \mathrm{E}-02 \quad 4.235 \mathrm{E}-02 \quad 1.937 \mathrm{E}-01 \quad 3.613 \mathrm{E}-01$ $0.000 \mathrm{E}+00 \quad 1.950 \mathrm{E}-09 \quad 4.837 \mathrm{E}-06 \quad 1.920 \mathrm{E}-05 \quad 4.512 \mathrm{E}-04 \quad 1.833 \mathrm{E}-03$ $0.000 \mathrm{E}+00 \quad 1.842 \mathrm{E}-15 \quad 2.289 \mathrm{E}-10 \quad 1.820 \mathrm{E}-09 \quad 2.170 \mathrm{E}-07 \quad 1.885 \mathrm{E}-06$ $0.000 \mathrm{E}+00 \quad 4.331 \mathrm{E}-04 \quad 2.142 \mathrm{E}-02 \quad 4.237 \mathrm{E}-02 \quad 1.942 \mathrm{E}-01 \quad 3.632 \mathrm{E}-01$

$0.000 \mathrm{E}+00 \quad 1.421 \mathrm{E}-17 \quad 6.200 \mathrm{E}-11 \quad 7.209 \mathrm{E}-10 \quad 8.712 \mathrm{E}-08 \quad 4.925 \mathrm{E}-07$ $0.000 \mathrm{E}+00 \quad 6.663 \mathrm{E}-06 \quad 1.058 \mathrm{E}-02 \quad 2.946 \mathrm{E}-02 \quad 1.823 \mathrm{E}-01 \quad 3.524 \mathrm{E}-01$ $0.000 \mathrm{E}+00 \quad 2.004 \mathrm{E}-11 \quad 1.773 \mathrm{E}-06 \quad 1.066 \mathrm{E}-05 \quad 3.984 \mathrm{E}-04 \quad 1.731 \mathrm{E}-03$ $0.000 \mathrm{E}+00 \quad 1.423 \mathrm{E}-17 \quad 6.719 \mathrm{E}-11 \quad 8.476 \mathrm{E}-10 \quad 1.806 \mathrm{E}-07 \quad 1.727 \mathrm{E}-06$ $0.000 \mathrm{E}+00 \quad 6.663 \mathrm{E}-06 \quad 1.058 \mathrm{E}-02 \quad 2.947 \mathrm{E}-02 \quad 1.827 \mathrm{E}-01 \quad 3.541 \mathrm{E}-01$ $\begin{array}{llllll}1.000 \mathrm{E}+00 & 1.000 \mathrm{E}+00 & 9.981 \mathrm{E}-01 & 9.961 \mathrm{E}-01 & 9.808 \mathrm{E}-01 & 9.601 \mathrm{E}-01\end{array}$ $0.000 \mathrm{E}+00 \quad 9.848 \mathrm{E}-10 \quad 4.918 \mathrm{E}-08 \quad 9.823 \mathrm{E}-08 \quad 4.861 \mathrm{E}-07 \quad 1.006 \mathrm{E}-06$ $\begin{array}{lllllll}1.000 \mathrm{E}+00 & 1.000 \mathrm{E}+00 & 9.993 \mathrm{E}-01 & 9.987 \mathrm{E}-01 & 9.933 \mathrm{E}-01 & 9.860 \mathrm{E}-01\end{array}$ $\begin{array}{llllll}1.000 \mathrm{E}+00 & 1.000 \mathrm{E}+00 & 9.993 \mathrm{E}-01 & 9.987 \mathrm{E}-01 & 9.933 \mathrm{E}-01 & 9.860 \mathrm{E}-01\end{array}$ 
RESRAD, Version $6.5 \quad T^{1 / 2}$ Limit $=180$ days

Summary : C746U Recreational User Deterministic Run

File : X: \FINAL V2 \C746U RU DET-FINALV2.RAD

Individual Nuclide Soil Concentration

Parent Nuclide and Branch Fraction Indicated

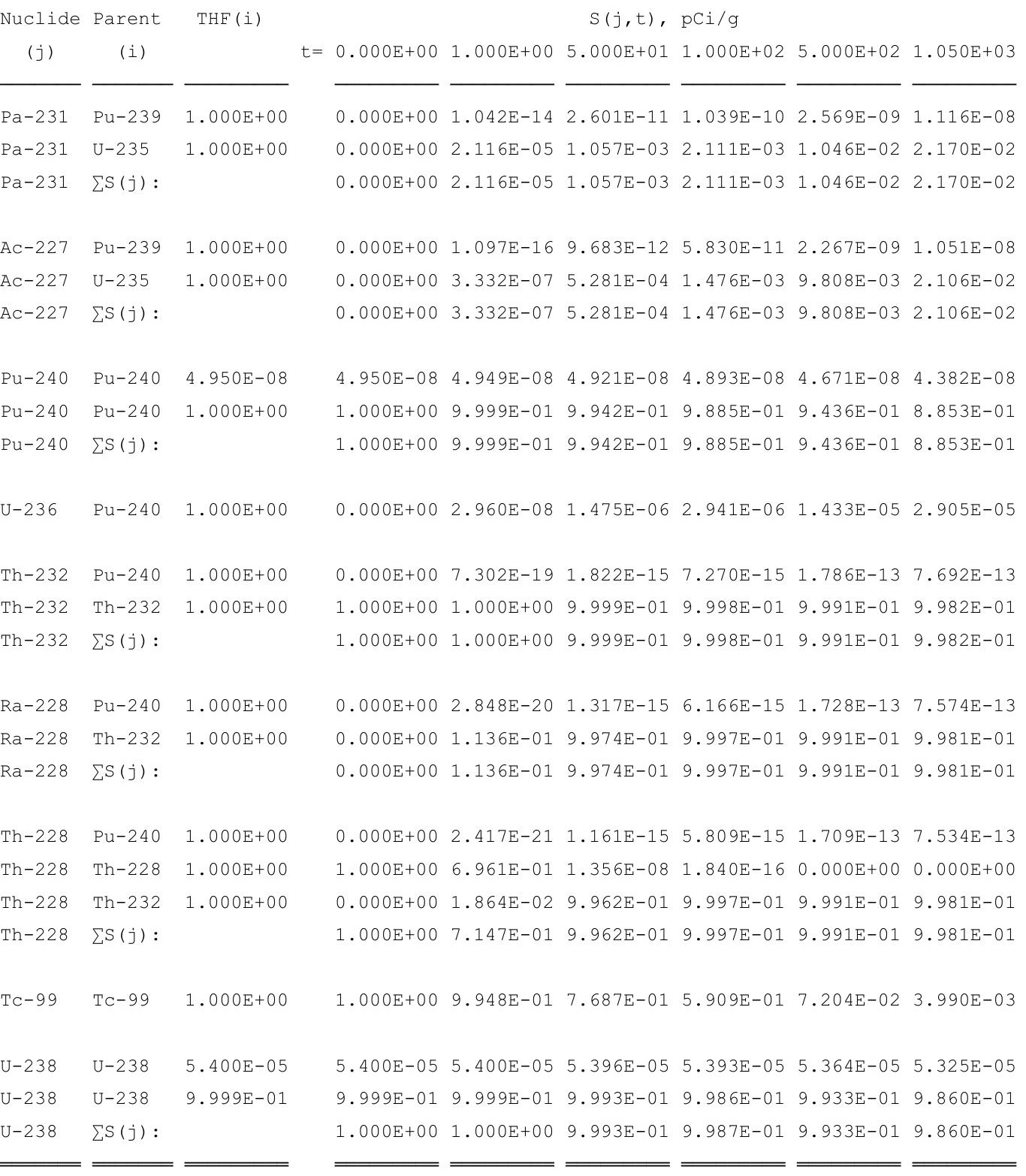

THF(i) is the thread fraction of the parent nuclide.

RESCALC.EXE execution time $=\quad 5.03$ seconds 


\section{Recreational User}

\section{The following summary report includes the peak dose from cumulative radionuclide inventory.}


THIS PAGE INTENTIONALLY LEFT BLANK 
RESRAD, Version $6.5 \quad \mathrm{~T}^{1} \frac{1}{2}$ Limit $=180$ days

05/03/2011 16:09 Page

Summary : C746U Recreational User Deterministic Run

File : $\mathrm{X}: \backslash$ FINAL V2 $\backslash \mathrm{C} 746 \mathrm{U}$ RU SG FWD-FINALV2.RAD

Table of Contents

Part I: Mixture Sums and Single Radionuclide Guidelines

Dose Conversion Factor (and Related) Parameter Summary ... 2

Site-Specific Parameter Summary ................. 8

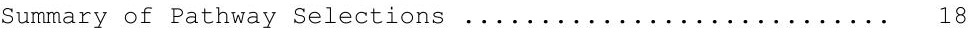

Contaminated Zone and Total Dose Summary ............. 19

Total Dose Components

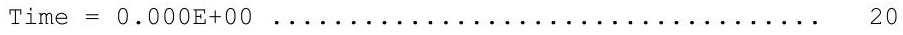

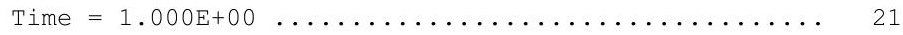

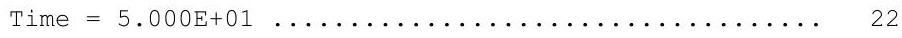

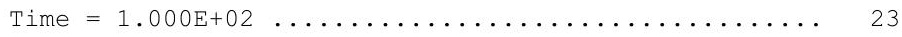

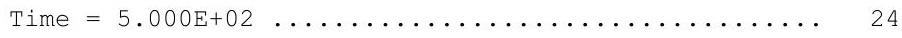

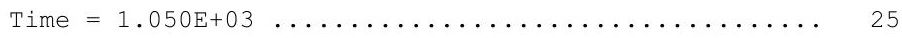

Dose/Source Ratios Summed Over All Pathways .......... 26

Single Radionuclide Soil Guidelines ............... 28

Dose Per Nuclide Summed Over All Pathways ............ 29

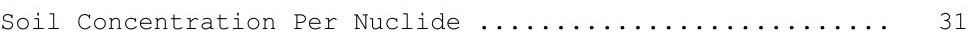


RESRAD, Version $6.5 \quad T^{1 / 2}$ Limit $=180$ days

Summary : C746U Recreational User Deterministic Run

File : $\mathrm{X}: \backslash$ FINAL V2 $\backslash \mathrm{C} 746 \mathrm{U}$ RU SG FWD-FINALV2.RAD

Dose Conversion Factor (and Related) Parameter Summary

Dose Library: Teen Recreational User Plus ICRP 60 \& ICRP 72 (Age 15)

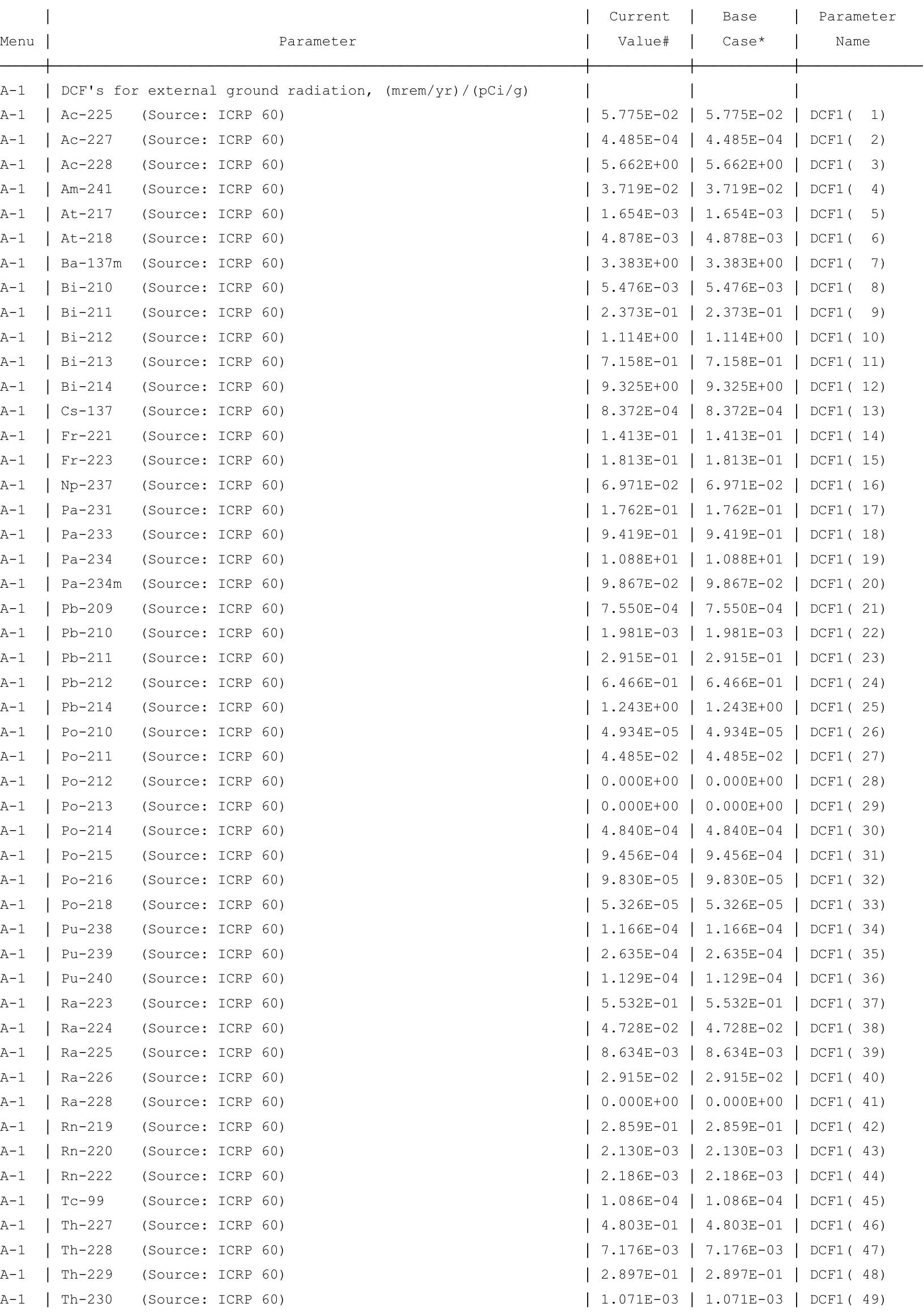


RESRAD, Version $6.5 \quad \mathrm{~T}^{1 / 2}$ Limit $=180$ days

Summary : C746U Recreational User Deterministic Run

File : $\mathrm{X}: \backslash$ FINAL V2 $\backslash \mathrm{C} 746 \mathrm{U}$ RU SG FWD-FINALV2.RAD

Dose Conversion Factor (and Related) Parameter Summary (continued)

Dose Library: Teen Recreational User Plus ICRP 60 \& ICRP 72 (Age 15)

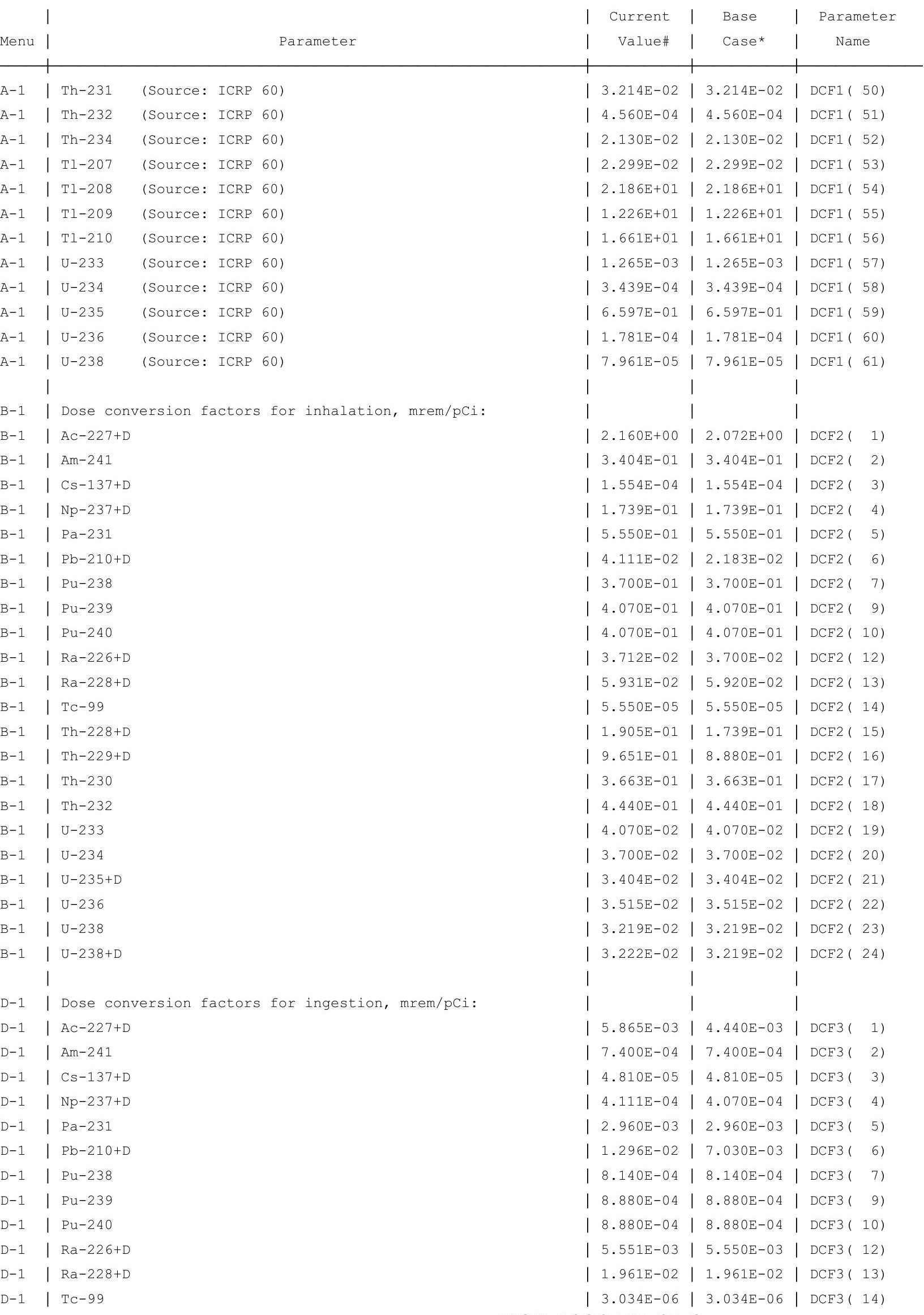


RESRAD, Version $6.5 \quad T^{1 / 2}$ Limit $=180$ days

Summary : C746U Recreational User Deterministic Run

File : $\mathrm{X}: \backslash$ FINAL V2 $\backslash \mathrm{C} 746 \mathrm{U}$ RU SG FWD-FINALV2.RAD

Dose Conversion Factor (and Related) Parameter Summary (continued)

Dose Library: Teen Recreational User Plus ICRP 60 \& ICRP 72 (Age 15)

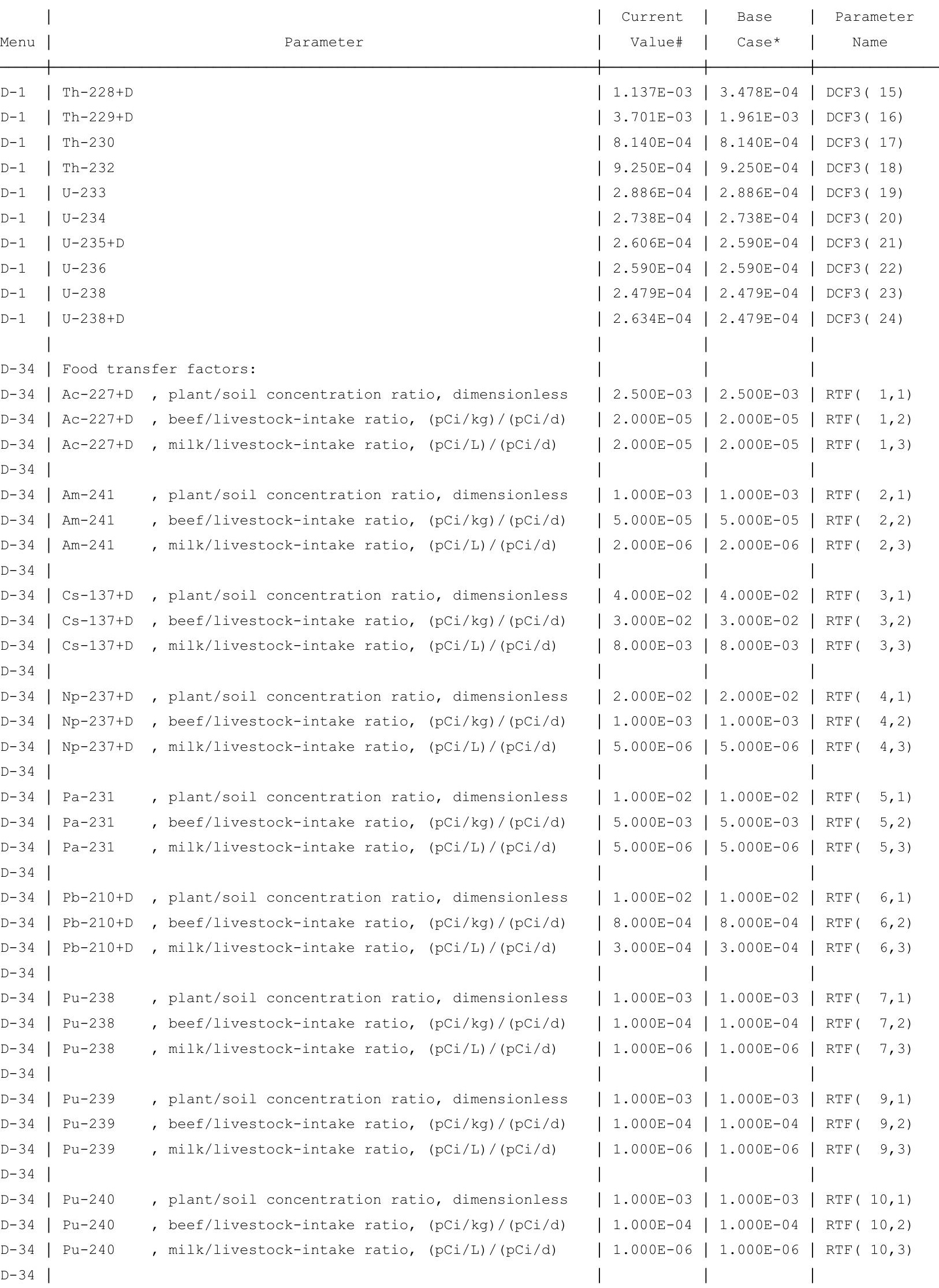


RESRAD, Version $6.5 \quad T^{1 / 2}$ Limit $=180$ days

ummary : C746U Recreational User Deterministic Run

File : $\mathrm{X}: \backslash$ FINAL V2 $\backslash \mathrm{C746U}$ RU SG FWD-FINALV2.RAD

Dose Conversion Factor (and Related) Parameter Summary (continued) Dose Library: Teen Recreational User Plus ICRP 60 \& ICRP 72 (Age 15)

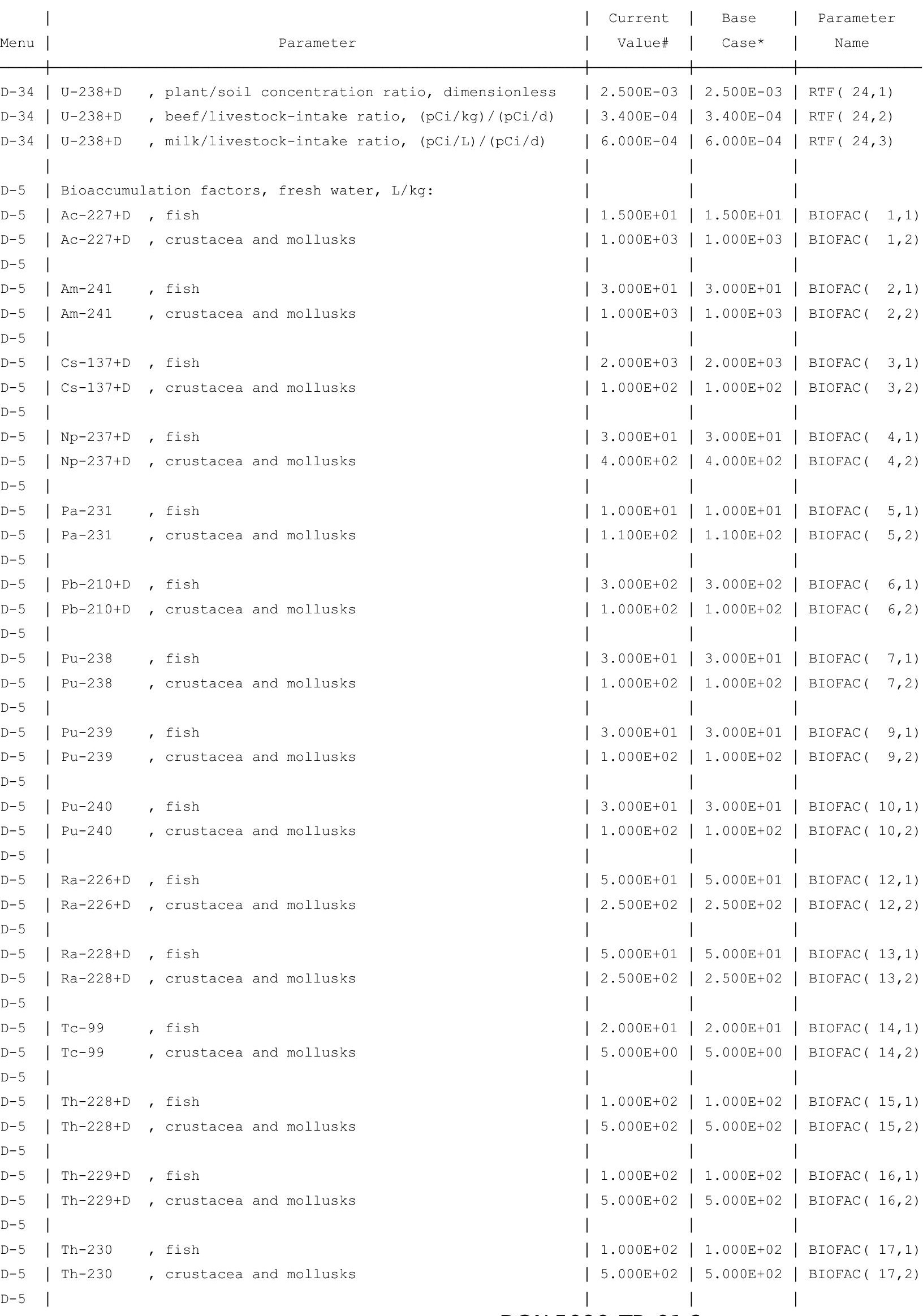


RESRAD, Version $6.5 \quad T^{13 / 2}$ Limit $=180$ days

05/03/2011 16:09 Page

Summary : C746U Recreational User Deterministic Run

File : $\mathrm{X}: \backslash$ FINAL V2\C746U RU SG FWD-FINALV2.RAD

Dose Conversion Factor (and Related) Parameter Summary (continued)

Dose Library: Teen Recreational User Plus ICRP 60 \& ICRP 72 (Age 15)

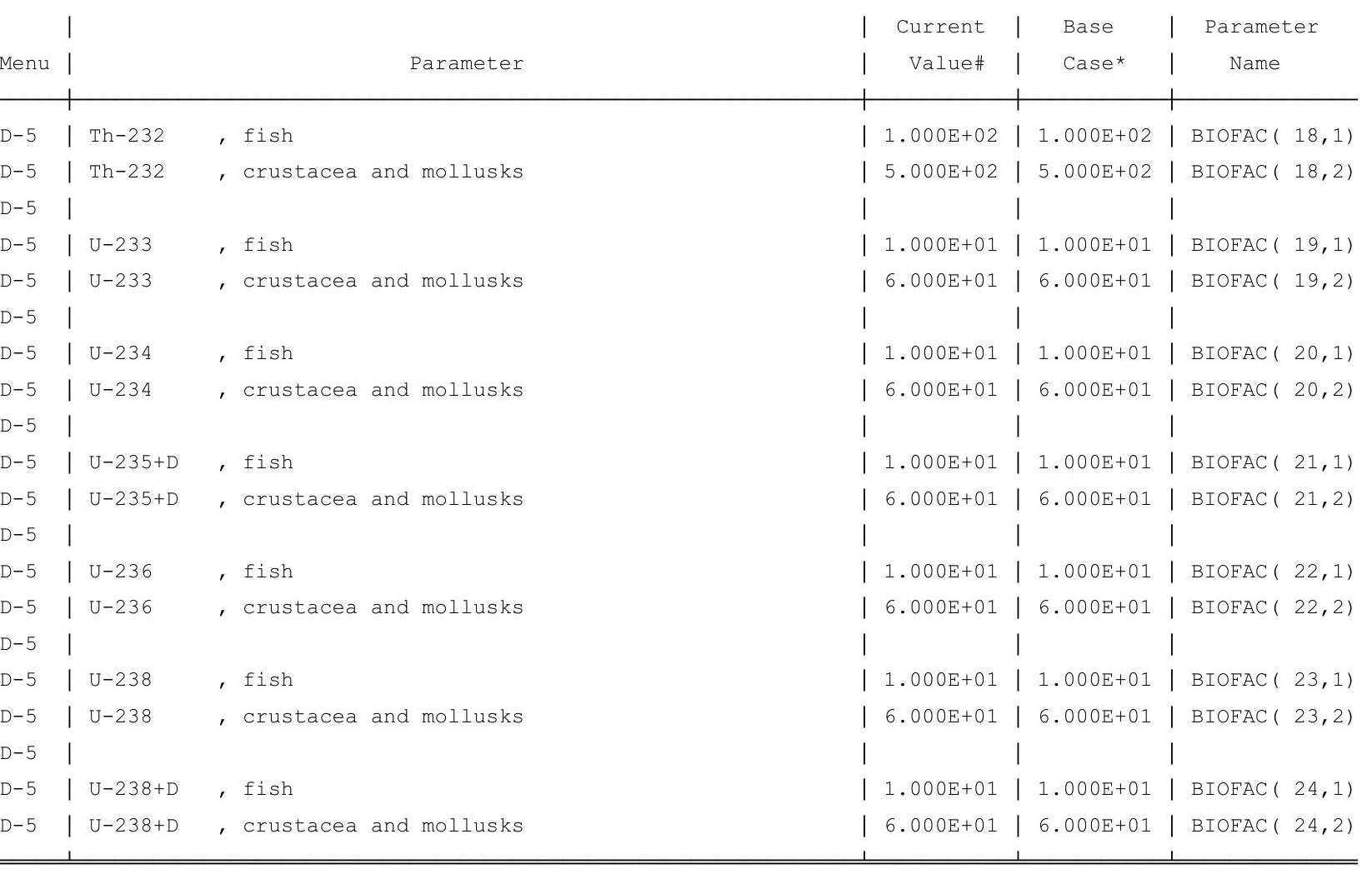

\#For DCFl(xxx) only, factors are for infinite depth \& area. See ETFG table in Ground Pathway of Detailed Report. *Base Case means Default.Lib w/o Associate Nuclide contributions. 
RESRAD, Version $6.5 \quad T^{1 / 2}$ Limit $=180$ days

Summary : C746U Recreational User Deterministic Run

File : $\mathrm{X}: \backslash \mathrm{FINAL}$ V2 $\backslash \mathrm{C} 746 \mathrm{U}$ RU SG FWD-FINALV2.RAD

Site-Specific Parameter Summary (continued)

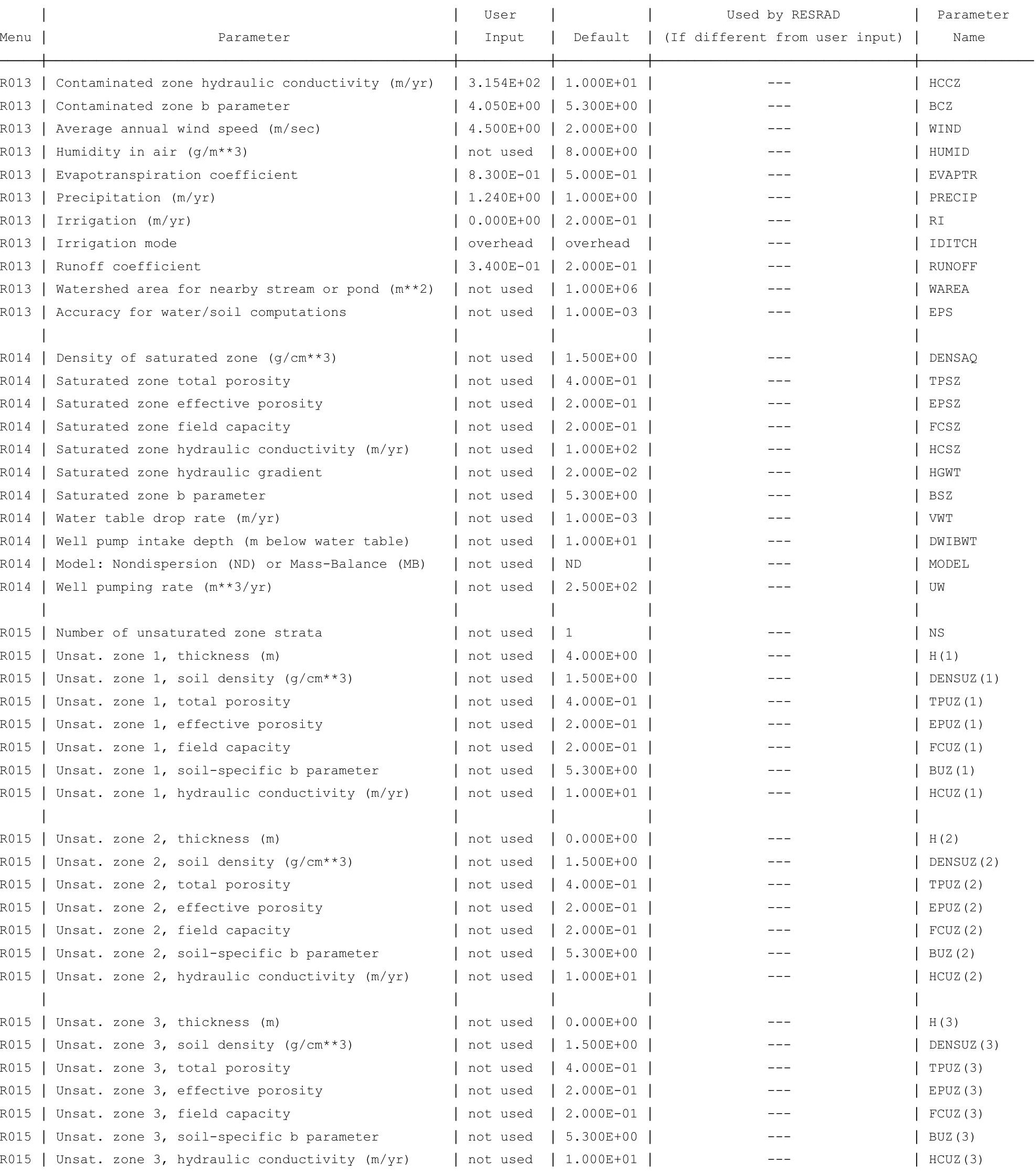


RESRAD, Version $6.5 \quad T^{1 / 2}$ Limit $=180$ days

Summary : C746U Recreational User Deterministic Run

File : $\mathrm{X}: \backslash$ FINAL V2 $\backslash \mathrm{C746U}$ RU SG FWD-FINALV2.RAD

Site-Specific Parameter Summary (continued)

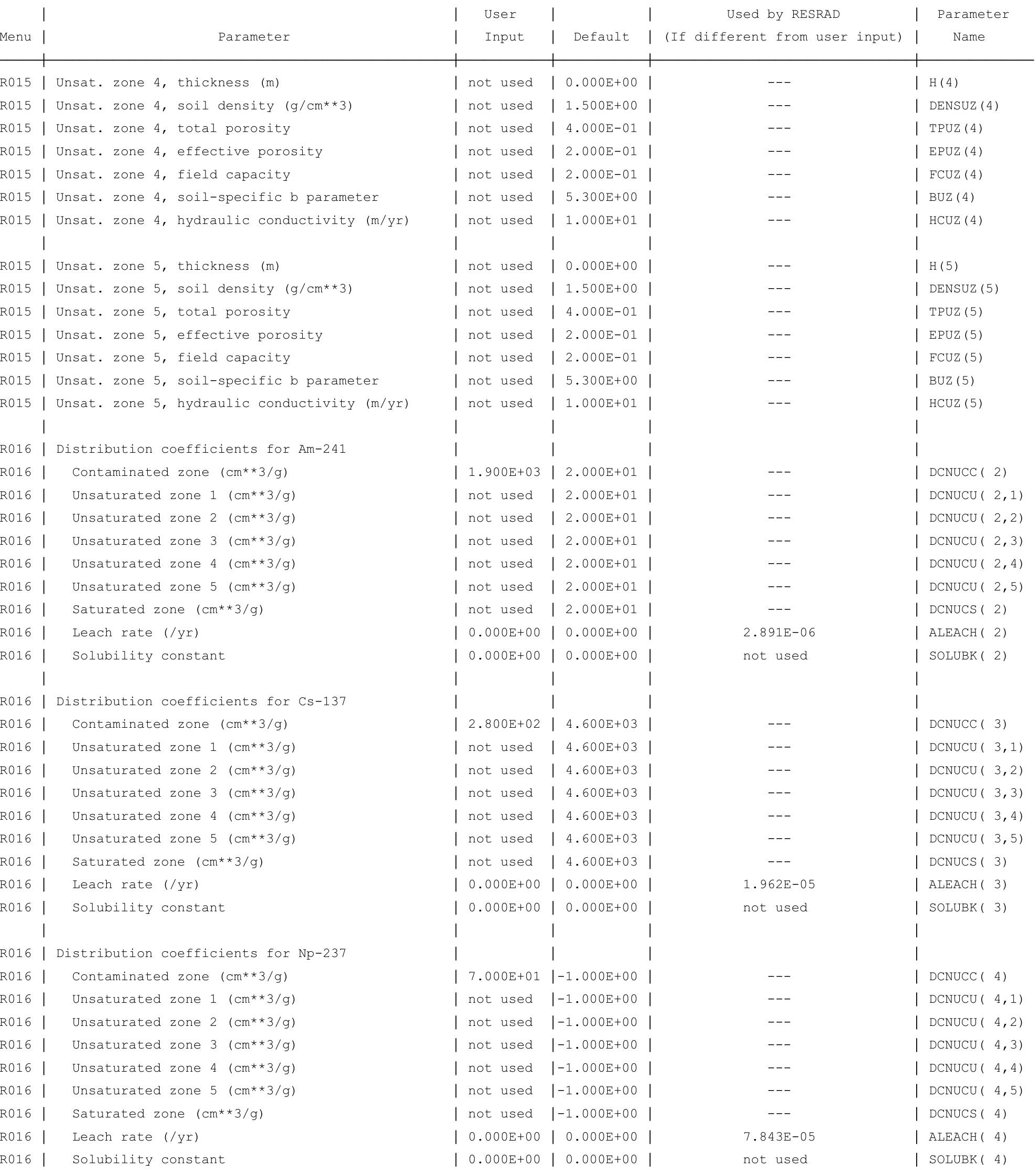


RESRAD, Version $6.5 \quad T^{1 / 2}$ Limit $=180$ days

Summary : C746U Recreational User Deterministic Run

File : $\mathrm{X}: \backslash$ FINAL V2 $\backslash \mathrm{C746U}$ RU SG FWD-FINALV2.RAD

Site-Specific Parameter Summary (continued)

\begin{tabular}{|c|c|c|c|c|c|c|}
\hline । & & User & । & । & Used by RESRAD & I Parameter \\
\hline nu $\mid$ & Parameter & Input & I Default & | (If & different from user input) & Name \\
\hline 161 & Distribution coefficients for Pu-238 & l & | & | & & | \\
\hline 161 & Contaminated zone $(\mathrm{cm} * * 3 / \mathrm{g})$ & $5.500 \mathrm{E}+02$ & $2.000 \mathrm{E}+03$ & | & --- & | $\operatorname{DCNUCC}(7)$ \\
\hline 161 & Unsaturated zone $1(\mathrm{~cm} * * 3 / \mathrm{g})$ & I not used & $2.000 \mathrm{E}+03$ & | & --- & DCNUCU $(7,1$ \\
\hline 161 & Unsaturated zone $2(\mathrm{~cm} * * 3 / \mathrm{g})$ & I not used & | $2.000 \mathrm{E}+03$ & | & --- & I DCNUCU $(7,2$ \\
\hline 161 & Unsaturated zone $3(\mathrm{~cm} * * 3 / \mathrm{g})$ & I not used & | $2.000 \mathrm{E}+03$ & | & --- & DCNUCU $(7,3$ \\
\hline 161 & Unsaturated zone $4\left(\mathrm{~cm}^{\star \star} 3 / \mathrm{g}\right)$ & I not used & $2.000 \mathrm{E}+03$ & l & --- & I $\operatorname{DCNUCU}(7,4$ \\
\hline $16 \mid$ & Unsaturated zone $5(\mathrm{~cm} * * 3 / \mathrm{g})$ & I not used & | $2.000 \mathrm{E}+03$ & | & --- & DCNUCU $(7,5$ \\
\hline 161 & Saturated zone $(\mathrm{cm} * * 3 / \mathrm{g})$ & I not used & $2.000 \mathrm{E}+03$ & | & --- & | DCNUCS ( 7) \\
\hline 161 & Leach rate (/yr) & $10.000 \mathrm{E}+00$ & $10.000 \mathrm{E}+00$ & | & $9.987 \mathrm{E}-06$ & | ALEACH ( 7) \\
\hline 161 & Solubility constant & $10.000 \mathrm{E}+00$ & $0.000 \mathrm{E}+00$ & । & not used & | SOLUBK ( 7) \\
\hline । & & । & । & । & & । \\
\hline 161 & Distribution coefficients for Pu-239 & | & | & | & & | \\
\hline 161 & Contaminated zone $(\mathrm{cm} * * 3 / \mathrm{g})$ & $5.500 \mathrm{E}+02$ & $2.000 \mathrm{E}+03$ & | & --- & | $\operatorname{DCNUCC}(9)$ \\
\hline 161 & Unsaturated zone $1(\mathrm{~cm} * \star 3 / \mathrm{g})$ & I not used & $2.000 \mathrm{E}+03$ & | & --- & I DCNUCU $(9,1$ \\
\hline 161 & Unsaturated zone $2(\mathrm{~cm} * \star 3 / \mathrm{g})$ & I not used & $2.000 \mathrm{E}+03$ & | & --- & I DCNUCU $(9,2$ \\
\hline 161 & Unsaturated zone $3\left(\mathrm{~cm}^{* * 3 / \mathrm{g})}\right.$ & I not used & $2.000 \mathrm{E}+03$ & | & --- & I DCNUCU( 9,3 \\
\hline 161 & Unsaturated zone $4(\mathrm{~cm} * \star 3 / \mathrm{g})$ & I not used & $2.000 \mathrm{E}+03$ & | & --- & I DCNUCU $(9,4$ \\
\hline 161 & Unsaturated zone $5(\mathrm{~cm} * * 3 / \mathrm{g})$ & I not used & | $2.000 \mathrm{E}+03$ & । & --- & I DCNUCU $(9,5$ \\
\hline$|6|$ & Saturated zone $(\mathrm{cm} * * 3 / \mathrm{g})$ & I not used & $2.000 \mathrm{E}+03$ & । & --- & | DCNUCS ( 9) \\
\hline 61 & Leach rate (/yr) & $10.000 \mathrm{E}+00$ & $0.000 \mathrm{E}+00$ & | & $9.987 \mathrm{E}-06$ & | $\operatorname{ALEACH}(9)$ \\
\hline 61 & Solubility constant & $10.000 \mathrm{E}+00$ & $10.000 \mathrm{E}+00$ & | & not used & | SOLUBK (9) \\
\hline | & & l & । & | & & | \\
\hline 161 & Distribution coefficients for $\mathrm{Pu}-240$ & l & । & | & & I \\
\hline 61 & Contaminated zone $\left(\mathrm{cm}^{* * 3 / \mathrm{g})}\right.$ & $5.500 \mathrm{E}+02$ & $2.000 \mathrm{E}+03$ & | & --- & I DCNUCC (10) \\
\hline 61 & Unsaturated zone $1(\mathrm{~cm} * \star 3 / \mathrm{g})$ & I not used & $2.000 \mathrm{E}+03$ & | & --- & I $\operatorname{DCNUCU}(10,1$ \\
\hline 61 & Unsaturated zone $2(\mathrm{~cm} * * 3 / \mathrm{g})$ & I not used & $2.000 \mathrm{E}+03$ & | & --- & I $\operatorname{DCNUCU}(10,2$ \\
\hline 61 & Unsaturated zone $3(\mathrm{~cm} * \star 3 / \mathrm{g})$ & I not used & | $2.000 \mathrm{E}+03$ & । & --- & I $\operatorname{DCNUCU}(10,3$ \\
\hline 61 & Unsaturated zone $4(\mathrm{~cm} * \star 3 / \mathrm{g})$ & I not used & $2.000 \mathrm{E}+03$ & | & --- & I DCNUCU $(10,4$ \\
\hline 61 & Unsaturated zone $5(\mathrm{~cm} * * 3 / \mathrm{g})$ & I not used & $2.000 \mathrm{E}+03$ & | & --- & I $\operatorname{DCNUCU}(10,5$ \\
\hline 61 & Saturated zone $\left(\mathrm{cm}^{* * 3 / \mathrm{g})}\right.$ & I not used & $2.000 \mathrm{E}+03$ & | & --- & | DCNUCS (10) \\
\hline 61 & Leach rate (/yr) & $10.000 \mathrm{E}+00$ & $10.000 \mathrm{E}+00$ & | & $9.987 \mathrm{E}-06$ & | ALEACH (10) \\
\hline 61 & Solubility constant & $10.000 \mathrm{E}+00$ & $10.000 \mathrm{E}+00$ & | & not used & I SOLUBK (10) \\
\hline | & & l & | & | & & I \\
\hline | & Distribution coefficients for TC-99 & | & | & | & & I \\
\hline | & Contaminated zone $(\mathrm{cm} * \star 3 / \mathrm{g})$ & $1.000 \mathrm{E}+00$ & $10.000 \mathrm{E}+00$ & I & --- & I DCNUCC (14) \\
\hline 61 & Unsaturated zone $1(\mathrm{~cm} * * 3 / \mathrm{g})$ & I not used & $0.000 \mathrm{E}+00$ & । & --- & I DCNUCU $(14,1$ \\
\hline 61 & Unsaturated zone $2(\mathrm{~cm} * \star 3 / \mathrm{g})$ & I not used & $10.000 \mathrm{E}+00$ & | & --- & | $\operatorname{DCNUCU}(14,2$ \\
\hline 61 & Unsaturated zone $3\left(\mathrm{~cm}^{* *} 3 / \mathrm{g}\right)$ & I not used & $10.000 \mathrm{E}+00$ & | & --- & I DCNUCU $(14,3$ \\
\hline 61 & Unsaturated zone $4(\mathrm{~cm} * * 3 / \mathrm{g})$ & I not used & $10.000 \mathrm{E}+00$ & | & --- & I $\operatorname{DCNUCU}(14,4$ \\
\hline 61 & Unsaturated zone $5(\mathrm{~cm} * \star 3 / \mathrm{g})$ & I not used & $0.000 \mathrm{E}+00$ & । & --- & I DCNUCU $(14,5$ \\
\hline | & Saturated zone $(\mathrm{cm} * \star 3 / \mathrm{g})$ & I not used & $10.000 \mathrm{E}+00$ & | & --- & I DCNUCS (14) \\
\hline & Leach rate $(/ y r)$ & $10.000 \mathrm{E}+00$ & $10.000 \mathrm{E}+00$ & I & $5.258 \mathrm{E}-03$ & I ALEACH (14) \\
\hline & Solubility constant & $10.000 \mathrm{E}+00$ & $10.000 \mathrm{E}+00$ & & not used & I SOLUBK (14) \\
\hline
\end{tabular}


RESRAD, Version $6.5 \quad T^{11 / 2}$ Limit $=180$ days

Summary : C746U Recreational User Deterministic Run

File : $\mathrm{X}: \backslash$ FINAL V2 $\backslash \mathrm{C746U}$ RU SG FWD-FINALV2.RAD

Site-Specific Parameter Summary (continued)

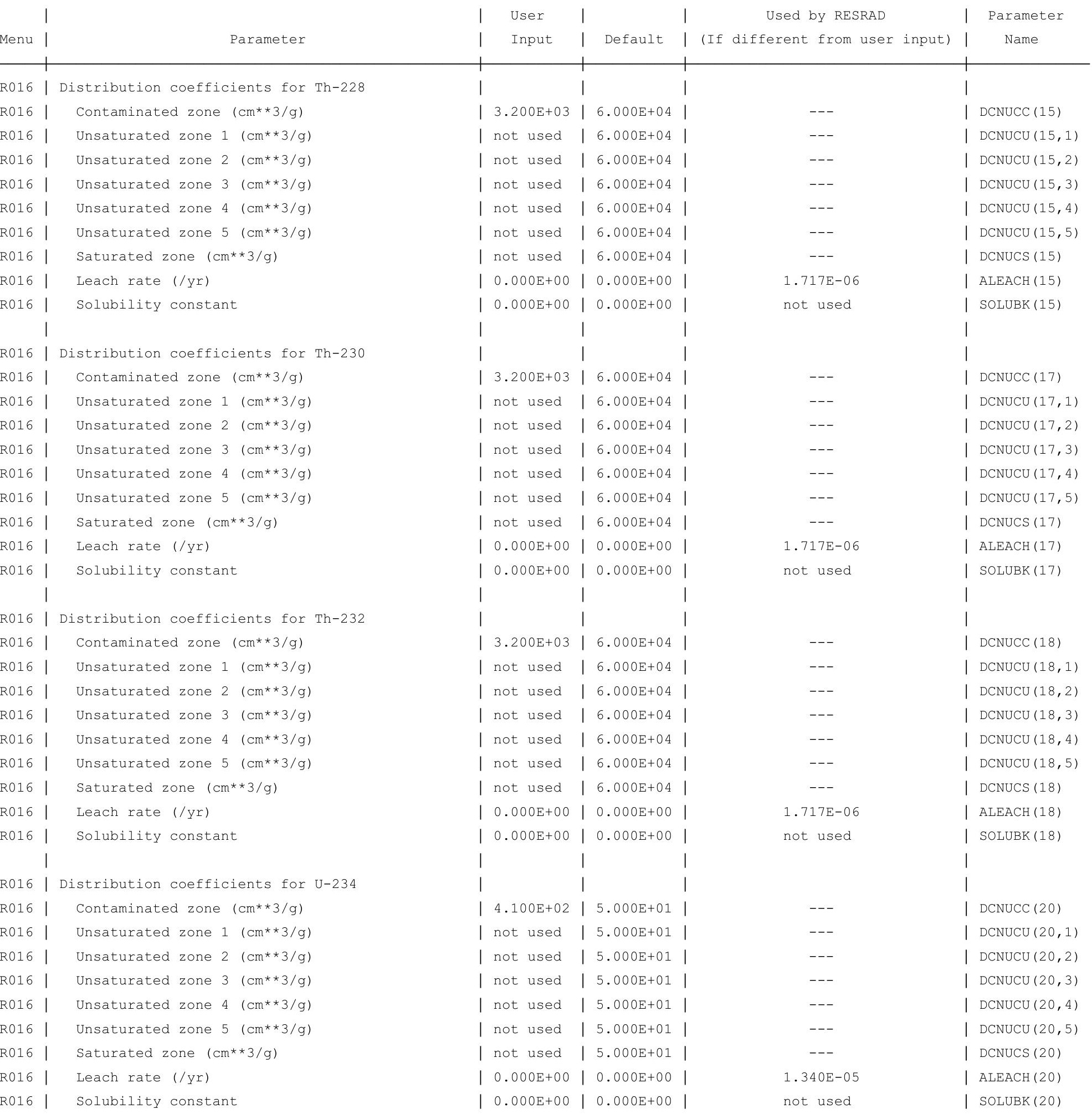


RESRAD, Version $6.5 \quad T^{11 / 2}$ Limit $=180$ days

Summary : C746U Recreational User Deterministic Run

File : $\mathrm{X}: \backslash$ FINAL V2 $\backslash \mathrm{C746U}$ RU SG FWD-FINALV2.RAD

Site-Specific Parameter Summary (continued)

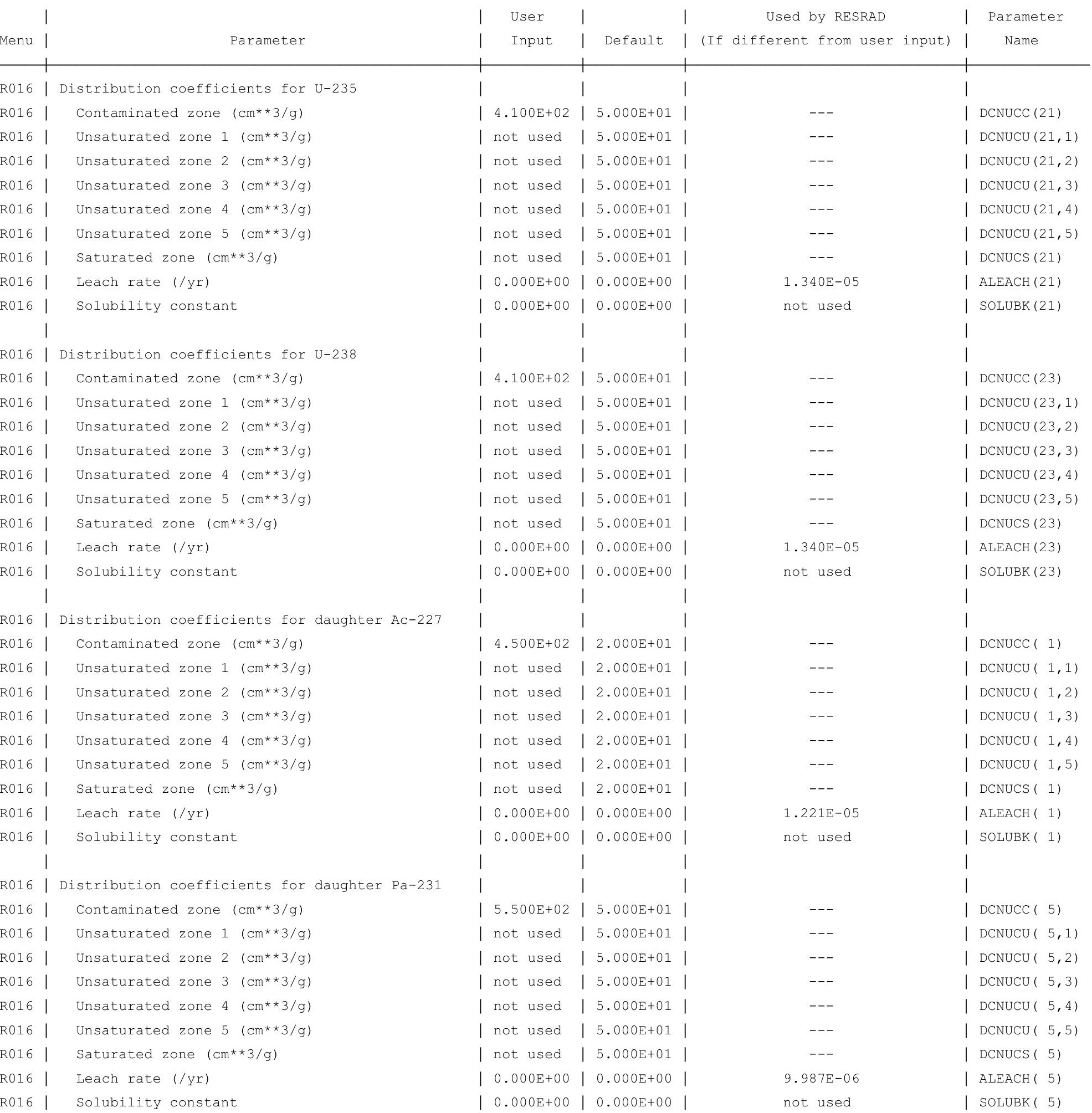


RESRAD, Version $6.5 \quad T^{1 / 2}$ Limit $=180$ days

Summary : C746U Recreational User Deterministic Run

File : $\mathrm{X}: \backslash F I N A L$ V2 $\backslash \mathrm{C} 746 \mathrm{U}$ RU SG FWD-FINALV2.RAD

Site-Specific Parameter Summary (continued)

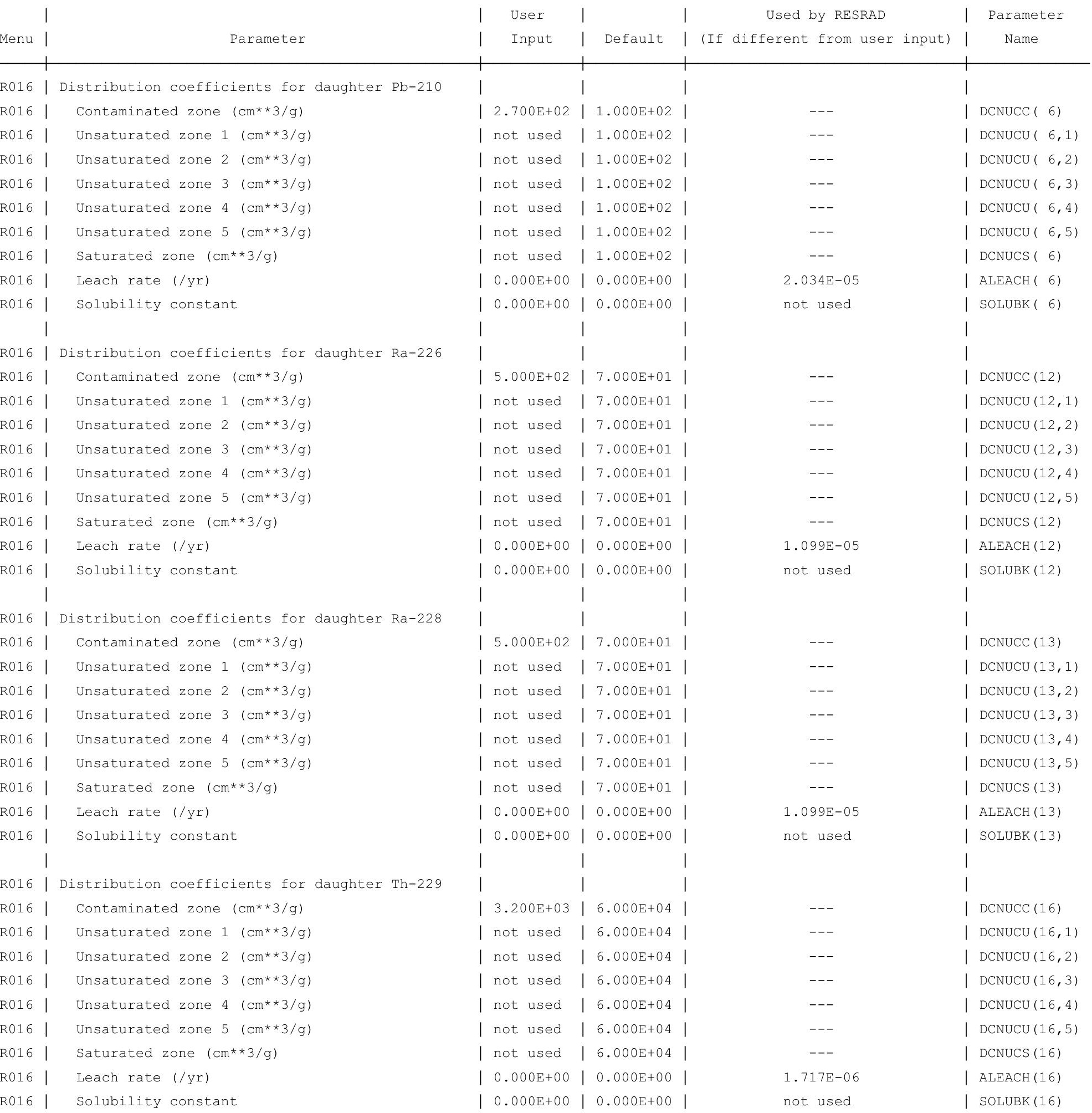


RESRAD, Version $6.5 \quad T^{1 / 2}$ Limit $=180$ days

Summary : C746U Recreational User Deterministic Run

File : $\mathrm{X}: \backslash$ FINAL V2\C746U RU SG FWD-FINALV2.RAD

Site-Specific Parameter Summary (continued)

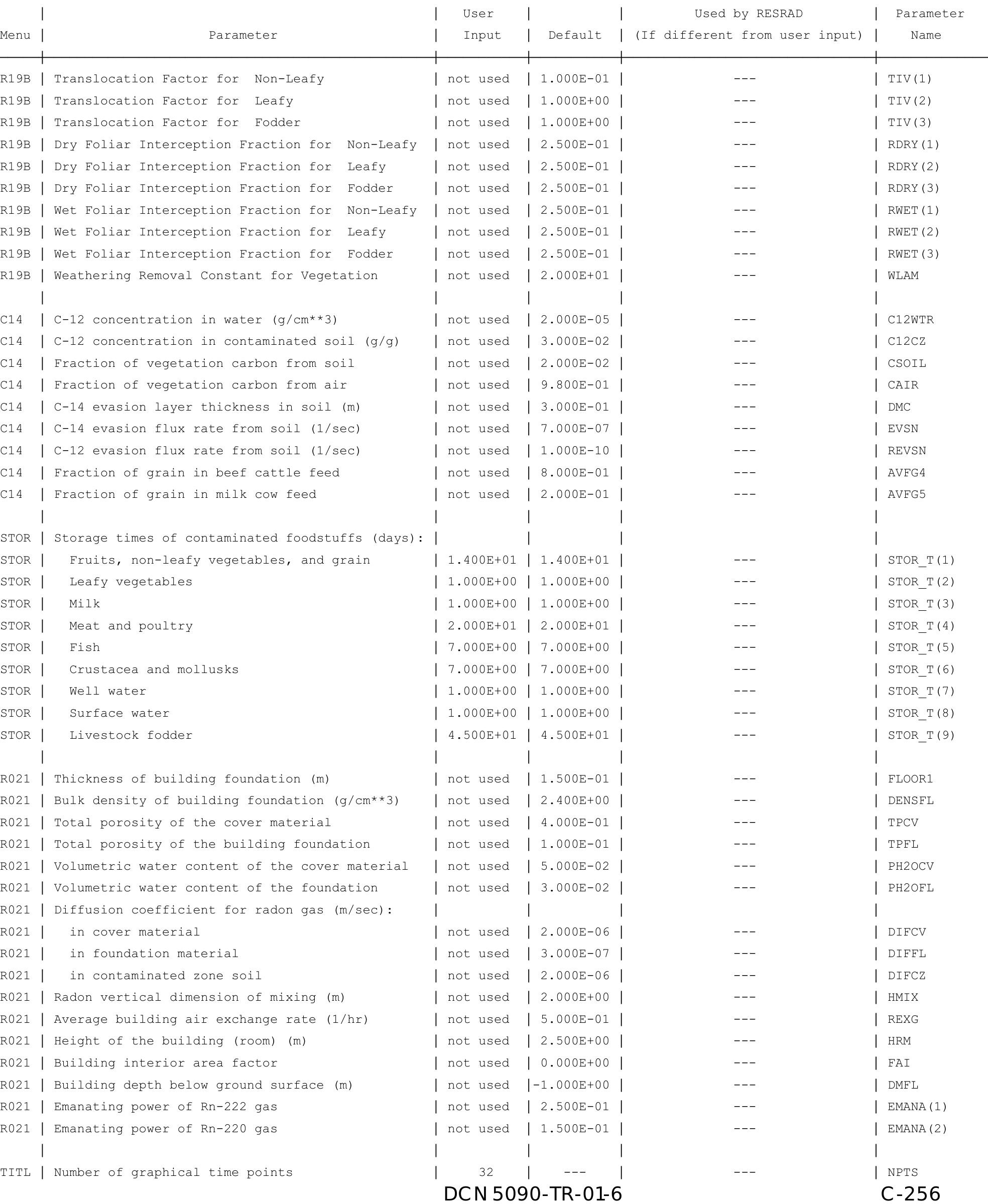


RESRAD, Version $6.5 \quad \mathrm{~T}^{1 / 2}$ Limit $=180$ days

Summary : C746U Recreational User Deterministic Run

File : $\mathrm{X}: \backslash F I N A L$ V2 $\backslash \mathrm{C} 746 \mathrm{U}$ RU SG FWD-FINALV2.RAD

Contaminated Zone Dimensions

Area: $\quad 89436.00$ square meters

Thickness:

Cover Depth:
Initial Soil Concentrations, pCi/g

$\begin{array}{ll}\mathrm{Am}-241 & 3.500 \mathrm{E}+03 \\ \mathrm{Cs}-137 & 1.900 \mathrm{E}+02 \\ \mathrm{~Np}-237 & 5.500 \mathrm{E}+02 \\ \mathrm{Pu}-238 & 3.900 \mathrm{E}+03 \\ \mathrm{Pu}-239 & 3.600 \mathrm{E}+03 \\ \mathrm{Pu}-240 & 3.600 \mathrm{E}+03 \\ \mathrm{TC}-99 & 2.800 \mathrm{E}+01 \\ \mathrm{Th}-228 & 7.400 \mathrm{E}+01 \\ \mathrm{Th}-230 & 1.200 \mathrm{E}+03 \\ \mathrm{Th}-232 & 3.800 \mathrm{E}+01 \\ \mathrm{U}-234 & 1.800 \mathrm{E}+04 \\ \mathrm{U}-235 & 8.200 \mathrm{E}+02 \\ \mathrm{U}-238 & 3.200 \mathrm{E}+03\end{array}$

Total Dose TDOSE(t), mrem/yr

Basic Radiation Dose Limit $=1.000 \mathrm{E}+00 \mathrm{mrem} / \mathrm{yr}$

Total Mixture Sum $M(t)$ = Fraction of Basic Dose Limit Received at Time (t)

$\begin{array}{rllllll}t \text { (years): } & 0.000 \mathrm{E}+00 & 1.000 \mathrm{E}+00 & 5.000 \mathrm{E}+01 & 1.000 \mathrm{E}+02 & 5.000 \mathrm{E}+02 & 1.050 \mathrm{E}+03 \\ \text { TDOSE }(\mathrm{t}): & 9.951 \mathrm{E}-06 & 7.220 \mathrm{E}-06 & 8.881 \mathrm{E}-06 & 1.290 \mathrm{E}-05 & 2.526 \mathrm{E}-04 & 1.476 \mathrm{E}-02 \\ \mathrm{M}(\mathrm{t}): & 9.951 \mathrm{E}-06 & 7.220 \mathrm{E}-06 & 8.881 \mathrm{E}-06 & 1.290 \mathrm{E}-05 & 2.526 \mathrm{E}-04 & 1.476 \mathrm{E}-02\end{array}$

Maximum TDOSE $(\mathrm{t}): 1.476 \mathrm{E}-02 \mathrm{mrem} / \mathrm{yr}$ at $t=1.050 \mathrm{E}+03$ years 
RESRAD, Version 6.5

$\mathrm{T}^{1 / 2}$ Limit $=180$ days

ummary : C746U Recreational User Deterministic Run

: $\mathrm{X}: \backslash F I N A L$ V2 \C746U RU SG FWD-FINALV2.RAD

Total Dose Contributions TDOSE(i,p,t) for Individual Radionuclides (i) and Pathways (p) As mrem/yr and Fraction of Total Dose At $t=0.000 \mathrm{E}+00$ years

Water Independent Pathways (Inhalation excludes radon)

\begin{tabular}{|c|c|c|c|c|c|c|c|c|c|c|c|c|c|c|}
\hline \multirow{2}{*}{ Nuclide } & \multicolumn{2}{|c|}{ Ground } & \multicolumn{2}{|c|}{ Inhalation } & \multicolumn{2}{|c|}{ Radon } & \multicolumn{2}{|c|}{ Plant } & \multicolumn{2}{|c|}{ Meat } & \multicolumn{2}{|c|}{ Milk } & \multicolumn{2}{|c|}{ Soil } \\
\hline & mrem/yr & fract. & mrem/yr & fract. & mrem/yr & fract. & mrem/yr & fract. & mrem/yr & fract. & mrem/yr & fract. & mrem/yr & fract. \\
\hline-241 & $5.204 \mathrm{E}-17$ & 0.0000 & $0.000 \mathrm{E}+00$ & 0.0000 & $0.000 \mathrm{E}+00$ & 0.0000 & $0.000 \mathrm{E}+00$ & 0.0000 & $0.000 \mathrm{E}+00$ & 0.0000 & $0.000 \mathrm{E}+00$ & 0.0000 & $0.000 \mathrm{E}+00$ & 0.0000 \\
\hline-137 & $2.305 E-08$ & 0.0023 & $0.000 \mathrm{E}+00$ & 0.0000 & $0.000 \mathrm{E}+00$ & 0.0000 & $0.000 \mathrm{E}+00$ & 0.0000 & $0.000 \mathrm{E}+00$ & 0.0000 & $0.000 \mathrm{E}+00$ & 0.0000 & $0.000 \mathrm{E}+00$ & 0.0000 \\
\hline-237 & $5.043 E-11$ & 0.0000 & $0.000 \mathrm{E}+00$ & 0.0000 & $0.000 \mathrm{E}+00$ & 0.0000 & $0.000 \mathrm{E}+00$ & 0.0000 & $0.000 \mathrm{E}+00$ & 0.0000 & $0.000 \mathrm{E}+00$ & 0.0000 & $0.000 \mathrm{E}+00$ & 0.0000 \\
\hline-238 & $3.052 \mathrm{E}-20$ & 0.0000 & $0.000 \mathrm{E}+00$ & 0.0000 & $0.000 \mathrm{E}+00$ & 0.0000 & $0.000 \mathrm{E}+00$ & 0.0000 & $0.000 \mathrm{E}+00$ & 0.0000 & $0.000 \mathrm{E}+00$ & 0.0000 & $0.000 \mathrm{E}+00$ & 0.0000 \\
\hline-239 & $4.161 \mathrm{E}-15$ & 0.0000 & $0.000 \mathrm{E}+00$ & 0.0000 & $0.000 \mathrm{E}+00$ & 0.0000 & $0.000 \mathrm{E}+00$ & 0.0000 & $0.000 \mathrm{E}+00$ & 0.0000 & $0.000 \mathrm{E}+00$ & 0.0000 & $0.000 \mathrm{E}+00$ & 0.0000 \\
\hline-240 & $3.957 \mathrm{E}-22$ & 0.0000 & $0.000 \mathrm{E}+00$ & 0.0000 & $0.000 \mathrm{E}+00$ & 0.0000 & $0.000 \mathrm{E}+00$ & 0.0000 & $0.000 \mathrm{E}+00$ & 0.0000 & $0.000 \mathrm{E}+00$ & 0.0000 & $0.000 \mathrm{E}+00$ & 0.0000 \\
\hline 99 & $1.553 E-25$ & 0.0000 & $0.000 \mathrm{E}+00$ & 0.0000 & $0.000 \mathrm{E}+00$ & 0.0000 & $0.000 \mathrm{E}+00$ & 0.0000 & $0.000 \mathrm{E}+00$ & 0.0000 & $0.000 \mathrm{E}+00$ & 0.0000 & $0.000 \mathrm{E}+00$ & 0.0000 \\
\hline-228 & $9.836 \mathrm{E}-06$ & 0.9885 & $0.000 \mathrm{E}+00$ & 0.0000 & $0.000 \mathrm{E}+00$ & 0.0000 & $0.000 \mathrm{E}+00$ & 0.0000 & $0.000 \mathrm{E}+00$ & 0.0000 & $0.000 \mathrm{E}+00$ & 0.0000 & $0.000 \mathrm{E}+00$ & 0.0000 \\
\hline-230 & $4.355 E-09$ & 0.0004 & $0.000 \mathrm{E}+00$ & 0.0000 & $0.000 \mathrm{E}+00$ & 0.0000 & $0.000 \mathrm{E}+00$ & 0.0000 & $0.000 \mathrm{E}+00$ & 0.0000 & $0.000 \mathrm{E}+00$ & 0.0000 & $0.000 \mathrm{E}+00$ & 0.0000 \\
\hline-232 & $4.304 E-08$ & 0.0043 & $0.000 \mathrm{E}+00$ & 0.0000 & $0.000 \mathrm{E}+00$ & 0.0000 & $0.000 \mathrm{E}+00$ & 0.0000 & $0.000 \mathrm{E}+00$ & 0.0000 & $0.000 \mathrm{E}+00$ & 0.0000 & $0.000 \mathrm{E}+00$ & 0.0000 \\
\hline 234 & $1.961 \mathrm{E}-13$ & 0.0000 & $0.000 \mathrm{E}+00$ & 0.0000 & $0.000 \mathrm{E}+00$ & 0.0000 & $0.000 \mathrm{E}+00$ & 0.0000 & $0.000 \mathrm{E}+00$ & 0.0000 & $0.000 \mathrm{E}+00$ & 0.0000 & $0.000 \mathrm{E}+00$ & 0.0000 \\
\hline 235 & $9.812 \mathrm{E}-13$ & 0.0000 & $0.000 \mathrm{E}+00$ & 0.0000 & $0.000 \mathrm{E}+00$ & 0.0000 & $0.000 \mathrm{E}+00$ & 0.0000 & $0.000 \mathrm{E}+00$ & 0.0000 & $0.000 \mathrm{E}+00$ & 0.0000 & $0.000 \mathrm{E}+00$ & 0.0000 \\
\hline 38 & $4.368 E-08$ & 0.0044 & $0.000 \mathrm{E}+00$ & 0.0000 & $0.000 \mathrm{E}+00$ & 0.0000 & $0.000 \mathrm{E}+00$ & 0.0000 & $0.000 \mathrm{E}+00$ & 0.0000 & $0.000 \mathrm{E}+00$ & 0.0000 & $0.000 \mathrm{E}+00$ & 0.0000 \\
\hline & $9.951 \mathrm{E}-06$ & 1.0000 & $0.000 \mathrm{E}+00$ & 0.0000 & $0.000 \mathrm{E}+00$ & 0.0000 & $0.000 \mathrm{E}+00$ & 0.0000 & $0.000 \mathrm{E}+00$ & 0.0000 & $0.000 \mathrm{E}+00$ & 0.0000 & $.000 \mathrm{E}+00$ & 0.0000 \\
\hline
\end{tabular}

Total Dose Contributions TDOSE (i,p,t) for Individual Radionuclides (i) and Pathways (p) As mrem/yr and Fraction of Total Dose At $t=0.000 \mathrm{E}+00$ years

Water Dependent Pathways

\begin{tabular}{|c|c|c|c|c|c|c|c|c|c|c|c|c|c|c|}
\hline & \multicolumn{2}{|c|}{ Water } & \multicolumn{2}{|c|}{ Fish } & \multicolumn{2}{|c|}{ Radon } & \multicolumn{2}{|c|}{ Plant } & \multicolumn{2}{|c|}{ Meat } & \multicolumn{2}{|c|}{ Milk } & \multicolumn{2}{|c|}{ All Pathways* } \\
\hline clide & mrem/yr & fract. & mrem/yr & fract. & mrem/yr & fract. & mrem/yr & fract. & mrem/yr & fract. & mrem/yr & fract. & mrem/yr & fract. \\
\hline-241 & $0.000 \mathrm{E}+00$ & 0.0000 & $0.000 \mathrm{E}+00$ & 0.0000 & $0.000 \mathrm{E}+00$ & 0.0000 & $0.000 \mathrm{E}+00$ & 0.0000 & $0.000 \mathrm{E}+00$ & 0.0000 & $0.000 E+00$ & 0.0000 & $5.204 \mathrm{E}-17$ & 0.0000 \\
\hline-137 & $0.000 \mathrm{E}+00$ & 0.0000 & $0.000 \mathrm{E}+00$ & 0.0000 & $0.000 \mathrm{E}+00$ & 0.0000 & $0.000 \mathrm{E}+00$ & 0.0000 & $0.000 \mathrm{E}+00$ & 0.0000 & $0.000 \mathrm{E}+00$ & 0.0000 & $2.305 E-08$ & 0.0023 \\
\hline-237 & $0.000 \mathrm{E}+00$ & 0.0000 & $0.000 \mathrm{E}+00$ & 0.0000 & $0.000 \mathrm{E}+00$ & 0.0000 & $0.000 \mathrm{E}+00$ & 0.0000 & $0.000 \mathrm{E}+00$ & 0.0000 & $0.000 \mathrm{E}+00$ & 0.0000 & $5.043 E-11$ & 0.0000 \\
\hline 238 & $0.000 \mathrm{E}+00$ & 0.0000 & $0.000 \mathrm{E}+00$ & 0.0000 & $0.000 \mathrm{E}+00$ & 0.0000 & $0.000 \mathrm{E}+00$ & 0.0000 & $0.000 \mathrm{E}+00$ & 0.0000 & $0.000 \mathrm{E}+00$ & 0.0000 & $3.052 \mathrm{E}-20$ & 0.0000 \\
\hline 239 & $0.000 \mathrm{E}+00$ & 0.0000 & $0.000 \mathrm{E}+00$ & 0.0000 & $0.000 \mathrm{E}+00$ & 0.0000 & $0.000 \mathrm{E}+00$ & 0.0000 & $0.000 \mathrm{E}+00$ & 0.0000 & $0.000 \mathrm{E}+00$ & 0.0000 & $4.161 \mathrm{E}-15$ & 0.0000 \\
\hline 240 & $0.000 \mathrm{E}+00$ & 0.0000 & $0.000 \mathrm{E}+00$ & 0.0000 & $0.000 \mathrm{E}+00$ & 0.0000 & $0.000 \mathrm{E}+00$ & 0.0000 & $0.000 \mathrm{E}+00$ & 0.0000 & $0.000 \mathrm{E}+00$ & 0.0000 & $3.957 \mathrm{E}-22$ & 0.0000 \\
\hline 99 & $0.000 \mathrm{E}+00$ & 0.0000 & $0.000 \mathrm{E}+00$ & 0.0000 & $0.000 \mathrm{E}+00$ & 0.0000 & $0.000 \mathrm{E}+00$ & 0.0000 & $0.000 \mathrm{E}+00$ & 0.0000 & $0.000 \mathrm{E}+00$ & 0.0000 & $1.553 \mathrm{E}-25$ & 0.0000 \\
\hline 228 & $0.000 \mathrm{E}+00$ & 0.0000 & $0.000 \mathrm{E}+00$ & 0.0000 & $0.000 \mathrm{E}+00$ & 0.0000 & $0.000 \mathrm{E}+00$ & 0.0000 & $0.000 \mathrm{E}+00$ & 0.0000 & $0.000 \mathrm{E}+00$ & 0.0000 & $9.836 \mathrm{E}-06$ & 0.9885 \\
\hline 230 & $0.000 \mathrm{E}+00$ & 0.0000 & $0.000 \mathrm{E}+00$ & 0.0000 & $0.000 \mathrm{E}+00$ & 0.0000 & $0.000 \mathrm{E}+00$ & 0.0000 & $0.000 \mathrm{E}+00$ & 0.0000 & $0.000 \mathrm{E}+00$ & 0.0000 & $4.355 E-09$ & 0.0004 \\
\hline 232 & $0.000 \mathrm{E}+00$ & 0.0000 & $0.000 \mathrm{E}+00$ & 0.0000 & $0.000 \mathrm{E}+00$ & 0.0000 & $0.000 \mathrm{E}+00$ & 0.0000 & $0.000 \mathrm{E}+00$ & 0.0000 & $0.000 \mathrm{E}+00$ & 0.0000 & $4.304 \mathrm{E}-08$ & 0.0043 \\
\hline 34 & $0.000 \mathrm{E}+00$ & 0.0000 & $0.000 \mathrm{E}+00$ & 0.0000 & $0.000 \mathrm{E}+00$ & 0.0000 & $0.000 \mathrm{E}+00$ & 0.0000 & $0.000 \mathrm{E}+00$ & 0.0000 & $0.000 \mathrm{E}+00$ & 0.0000 & $1.961 \mathrm{E}-13$ & 0.0000 \\
\hline 35 & $0.000 \mathrm{E}+00$ & 0.0000 & $0.000 \mathrm{E}+00$ & 0.0000 & $0.000 \mathrm{E}+00$ & 0.0000 & $0.000 \mathrm{E}+00$ & 0.0000 & $0.000 \mathrm{E}+00$ & 0.0000 & $0.000 \mathrm{E}+00$ & 0.0000 & $9.812 \mathrm{E}-13$ & 0.0000 \\
\hline 38 & $0.000 \mathrm{E}+00$ & 0.0000 & $0.000 \mathrm{E}+00$ & 0.0000 & $0.000 \mathrm{E}+00$ & 0.0000 & $0.000 \mathrm{E}+00$ & 0.0000 & $0.000 \mathrm{E}+00$ & 0.0000 & $0.000 \mathrm{E}+00$ & 0.0000 & $4.368 \mathrm{E}-08$ & 0.0044 \\
\hline & $0.000 \mathrm{E}+00$ & 0.0000 & $0.000 \mathrm{E}+00$ & 0.0000 & $0.000 \mathrm{E}+00$ & 0.0000 & $0.000 \mathrm{E}+00$ & 0.0000 & $0.000 \mathrm{E}+00$ & 0.0000 & $0.000 \mathrm{E}+00$ & 000 & -06 & 1.0000 \\
\hline
\end{tabular}

* Sum of all water independent and dependent pathways. 
RESRAD, Version 6.5

$\mathrm{T}^{1 / 2}$ Limit $=180$ days

ummary : C746U Recreational User Deterministic Run

: $\mathrm{X}: \backslash F I N A L$ V2 \C746U RU SG FWD-FINALV2.RAD

Total Dose Contributions TDOSE (i,p,t) for Individual Radionuclides (i) and Pathways (p) As mrem/yr and Fraction of Total Dose At $t=1.000 \mathrm{E}+00$ years

Water Independent Pathways (Inhalation excludes radon)

\begin{tabular}{|c|c|c|c|c|c|c|c|c|c|c|c|c|c|c|}
\hline \multirow{2}{*}{ Nuclide } & \multicolumn{2}{|c|}{ Ground } & \multicolumn{2}{|c|}{ Inhalation } & \multicolumn{2}{|c|}{ Radon } & \multicolumn{2}{|c|}{ Plant } & \multicolumn{2}{|c|}{ Meat } & \multicolumn{2}{|c|}{ Milk } & \multicolumn{2}{|c|}{ Soil } \\
\hline & mrem/yr & fract. & mrem/yr & fract. & mrem/yr & fract. & mrem/yr & fract. & mrem/yr & fract. & mrem/yr & fract. & mrem/yr & fract. \\
\hline-241 & $1.575 \mathrm{E}-16$ & 0.0000 & $0.000 \mathrm{E}+00$ & 0.0000 & $0.000 \mathrm{E}+00$ & 0.0000 & $0.000 \mathrm{E}+00$ & 0.0000 & $0.000 \mathrm{E}+00$ & 0.0000 & $0.000 \mathrm{E}+00$ & 0.0000 & $0.000 \mathrm{E}+00$ & 0.0000 \\
\hline-137 & $2.272 E-08$ & 0.0031 & $0.000 \mathrm{E}+00$ & 0.0000 & $0.000 \mathrm{E}+00$ & 0.0000 & $0.000 \mathrm{E}+00$ & 0.0000 & $0.000 \mathrm{E}+00$ & 0.0000 & $0.000 \mathrm{E}+00$ & 0.0000 & $0.000 \mathrm{E}+00$ & 0.0000 \\
\hline-237 & $5.097 \mathrm{E}-11$ & 0.0000 & $0.000 \mathrm{E}+00$ & 0.0000 & $0.000 \mathrm{E}+00$ & 0.0000 & $0.000 \mathrm{E}+00$ & 0.0000 & $0.000 \mathrm{E}+00$ & 0.0000 & $0.000 \mathrm{E}+00$ & 0.0000 & $0.000 \mathrm{E}+00$ & 0.0000 \\
\hline-238 & $4.535 E-19$ & 0.0000 & $0.000 \mathrm{E}+00$ & 0.0000 & $0.000 \mathrm{E}+00$ & 0.0000 & $0.000 \mathrm{E}+00$ & 0.0000 & $0.000 \mathrm{E}+00$ & 0.0000 & $0.000 \mathrm{E}+00$ & 0.0000 & $0.000 \mathrm{E}+00$ & 0.0000 \\
\hline-239 & $4.211 E-15$ & 0.0000 & $0.000 \mathrm{E}+00$ & 0.0000 & $0.000 \mathrm{E}+00$ & 0.0000 & $0.000 \mathrm{E}+00$ & 0.0000 & $0.000 \mathrm{E}+00$ & 0.0000 & $0.000 \mathrm{E}+00$ & 0.0000 & $0.000 \mathrm{E}+00$ & 0.0000 \\
\hline-240 & $4.111 \mathrm{E}-22$ & 0.0000 & $0.000 \mathrm{E}+00$ & 0.0000 & $0.000 \mathrm{E}+00$ & 0.0000 & $0.000 \mathrm{E}+00$ & 0.0000 & $0.000 \mathrm{E}+00$ & 0.0000 & $0.000 \mathrm{E}+00$ & 0.0000 & $0.000 \mathrm{E}+00$ & 0.0000 \\
\hline 99 & $1.575 E-25$ & 0.0000 & $0.000 \mathrm{E}+00$ & 0.0000 & $0.000 \mathrm{E}+00$ & 0.0000 & $0.000 \mathrm{E}+00$ & 0.0000 & $0.000 \mathrm{E}+00$ & 0.0000 & $0.000 \mathrm{E}+00$ & 0.0000 & $0.000 \mathrm{E}+00$ & 0.0000 \\
\hline-228 & $6.888 \mathrm{E}-06$ & 0.9540 & $0.000 \mathrm{E}+00$ & 0.0000 & $0.000 \mathrm{E}+00$ & 0.0000 & $0.000 \mathrm{E}+00$ & 0.0000 & $0.000 \mathrm{E}+00$ & 0.0000 & $0.000 \mathrm{E}+00$ & 0.0000 & $0.000 \mathrm{E}+00$ & 0.0000 \\
\hline-230 & 1. $314 \mathrm{E}-08$ & 0.0018 & $0.000 \mathrm{E}+00$ & 0.0000 & $0.000 \mathrm{E}+00$ & 0.0000 & $0.000 \mathrm{E}+00$ & 0.0000 & $0.000 \mathrm{E}+00$ & 0.0000 & $0.000 \mathrm{E}+00$ & 0.0000 & $0.000 \mathrm{E}+00$ & 0.0000 \\
\hline-232 & $2.521 E-07$ & 0.0349 & $0.000 \mathrm{E}+00$ & 0.0000 & $0.000 \mathrm{E}+00$ & 0.0000 & $0.000 \mathrm{E}+00$ & 0.0000 & $0.000 \mathrm{E}+00$ & 0.0000 & $0.000 \mathrm{E}+00$ & 0.0000 & $0.000 \mathrm{E}+00$ & 0.0000 \\
\hline 234 & 1. $381 \mathrm{E}-12$ & 0.0000 & $0.000 \mathrm{E}+00$ & 0.0000 & $0.000 \mathrm{E}+00$ & 0.0000 & $0.000 \mathrm{E}+00$ & 0.0000 & $0.000 \mathrm{E}+00$ & 0.0000 & $0.000 \mathrm{E}+00$ & 0.0000 & $0.000 \mathrm{E}+00$ & 0.0000 \\
\hline 235 & $9.983 E-13$ & 0.0000 & $0.000 \mathrm{E}+00$ & 0.0000 & $0.000 \mathrm{E}+00$ & 0.0000 & $0.000 \mathrm{E}+00$ & 0.0000 & $0.000 \mathrm{E}+00$ & 0.0000 & $0.000 \mathrm{E}+00$ & 0.0000 & $0.000 \mathrm{E}+00$ & 0.0000 \\
\hline 38 & $4.403 E-08$ & 0.0061 & $0.000 \mathrm{E}+00$ & 0.0000 & $0.000 \mathrm{E}+00$ & 0.0000 & $0.000 \mathrm{E}+00$ & 0.0000 & $0.000 \mathrm{E}+00$ & 0.0000 & $0.000 \mathrm{E}+00$ & 0.0000 & $0.000 \mathrm{E}+00$ & 0.0000 \\
\hline & 7. $220 \mathrm{E}-06$ & 1.0000 & $0.000 \mathrm{E}+00$ & 0.0000 & $0.000 \mathrm{E}+00$ & 0.0000 & $0.000 \mathrm{E}+00$ & 0.0000 & $0.000 \mathrm{E}+00$ & 0.0000 & $0.000 \mathrm{E}+00$ & 0.0000 & $.000 \mathrm{E}+00$ & 0.0000 \\
\hline
\end{tabular}

Total Dose Contributions TDOSE (i,p,t) for Individual Radionuclides (i) and Pathways (p) As mrem/yr and Fraction of Total Dose At $t=1.000 \mathrm{E}+00$ years

Water Dependent Pathways

\begin{tabular}{|c|c|c|c|c|c|c|c|c|c|c|c|c|c|c|}
\hline & \multicolumn{2}{|c|}{ Water } & \multicolumn{2}{|c|}{ Fish } & \multicolumn{2}{|c|}{ Radon } & \multicolumn{2}{|c|}{ Plant } & \multicolumn{2}{|c|}{ Meat } & \multicolumn{2}{|c|}{ Milk } & \multicolumn{2}{|c|}{ All Pathways* } \\
\hline clide & mrem/yr & fract. & mrem/yr & fract. & mrem/yr & fract. & mrem/yr & fract. & mrem/yr & fract. & mrem/yr & fract. & mrem/yr & fract. \\
\hline-241 & $0.000 \mathrm{E}+00$ & 0.0000 & $0.000 \mathrm{E}+00$ & 0.0000 & $0.000 \mathrm{E}+00$ & 0.0000 & $0.000 \mathrm{E}+00$ & 0.0000 & $0.000 \mathrm{E}+00$ & 0.0000 & $0.000 \mathrm{E}+00$ & 0.0000 & $1.575 \mathrm{E}-16$ & 0.0000 \\
\hline-137 & $0.000 \mathrm{E}+00$ & 0.0000 & $0.000 \mathrm{E}+00$ & 0.0000 & $0.000 \mathrm{E}+00$ & 0.0000 & $0.000 \mathrm{E}+00$ & 0.0000 & $0.000 \mathrm{E}+00$ & 0.0000 & $0.000 \mathrm{E}+00$ & 0.0000 & $2.272 \mathrm{E}-08$ & 0.0031 \\
\hline-237 & $0.000 \mathrm{E}+00$ & 0.0000 & $0.000 \mathrm{E}+00$ & 0.0000 & $0.000 \mathrm{E}+00$ & 0.0000 & $0.000 \mathrm{E}+00$ & 0.0000 & $0.000 \mathrm{E}+00$ & 0.0000 & $0.000 \mathrm{E}+00$ & 0.0000 & $5.097 \mathrm{E}-11$ & 0.0000 \\
\hline 238 & $0.000 \mathrm{E}+00$ & 0.0000 & $0.000 \mathrm{E}+00$ & 0.0000 & $0.000 \mathrm{E}+00$ & 0.0000 & $0.000 \mathrm{E}+00$ & 0.0000 & $0.000 \mathrm{E}+00$ & 0.0000 & $0.000 \mathrm{E}+00$ & 0.0000 & $4.535 E-19$ & 0.0000 \\
\hline 239 & $0.000 \mathrm{E}+00$ & 0.0000 & $0.000 \mathrm{E}+00$ & 0.0000 & $0.000 \mathrm{E}+00$ & 0.0000 & $0.000 \mathrm{E}+00$ & 0.0000 & $0.000 \mathrm{E}+00$ & 0.0000 & $0.000 \mathrm{E}+00$ & 0.0000 & $4.211 \mathrm{E}-15$ & 0.0000 \\
\hline 240 & $0.000 \mathrm{E}+00$ & 0.0000 & $0.000 \mathrm{E}+00$ & 0.0000 & $0.000 \mathrm{E}+00$ & 0.0000 & $0.000 \mathrm{E}+00$ & 0.0000 & $0.000 \mathrm{E}+00$ & 0.0000 & $0.000 \mathrm{E}+00$ & 0.0000 & $4.111 \mathrm{E}-22$ & 0.0000 \\
\hline 99 & $0.000 \mathrm{E}+00$ & 0.0000 & $0.000 \mathrm{E}+00$ & 0.0000 & $0.000 \mathrm{E}+00$ & 0.0000 & $0.000 \mathrm{E}+00$ & 0.0000 & $0.000 \mathrm{E}+00$ & 0.0000 & $0.000 \mathrm{E}+00$ & 0.0000 & $1.575 \mathrm{E}-25$ & 0.0000 \\
\hline 228 & $0.000 \mathrm{E}+00$ & 0.0000 & $0.000 \mathrm{E}+00$ & 0.0000 & $0.000 \mathrm{E}+00$ & 0.0000 & $0.000 \mathrm{E}+00$ & 0.0000 & $0.000 \mathrm{E}+00$ & 0.0000 & $0.000 \mathrm{E}+00$ & 0.0000 & $6.888 \mathrm{E}-06$ & 0.9540 \\
\hline 230 & $0.000 \mathrm{E}+00$ & 0.0000 & $0.000 \mathrm{E}+00$ & 0.0000 & $0.000 \mathrm{E}+00$ & 0.0000 & $0.000 \mathrm{E}+00$ & 0.0000 & $0.000 \mathrm{E}+00$ & 0.0000 & $0.000 \mathrm{E}+00$ & 0.0000 & $1.314 \mathrm{E}-08$ & 0.0018 \\
\hline 232 & $0.000 \mathrm{E}+00$ & 0.0000 & $0.000 \mathrm{E}+00$ & 0.0000 & $0.000 \mathrm{E}+00$ & 0.0000 & $0.000 \mathrm{E}+00$ & 0.0000 & $0.000 \mathrm{E}+00$ & 0.0000 & $0.000 \mathrm{E}+00$ & 0.0000 & $2.521 \mathrm{E}-07$ & 0.0349 \\
\hline 34 & $0.000 \mathrm{E}+00$ & 0.0000 & $0.000 \mathrm{E}+00$ & 0.0000 & $0.000 \mathrm{E}+00$ & 0.0000 & $0.000 \mathrm{E}+00$ & 0.0000 & $0.000 \mathrm{E}+00$ & 0.0000 & $0.000 \mathrm{E}+00$ & 0.0000 & 1. $381 \mathrm{E}-12$ & 0.0000 \\
\hline 35 & $0.000 \mathrm{E}+00$ & 0.0000 & $0.000 \mathrm{E}+00$ & 0.0000 & $0.000 \mathrm{E}+00$ & 0.0000 & $0.000 \mathrm{E}+00$ & 0.0000 & $0.000 \mathrm{E}+00$ & 0.0000 & $0.000 \mathrm{E}+00$ & 0.0000 & $9.983 \mathrm{E}-13$ & 0.0000 \\
\hline 38 & $0.000 \mathrm{E}+00$ & 0.0000 & $0.000 \mathrm{E}+00$ & 0.0000 & $0.000 \mathrm{E}+00$ & 0.0000 & $0.000 \mathrm{E}+00$ & 0.0000 & $0.000 \mathrm{E}+00$ & 0.0000 & $0.000 \mathrm{E}+00$ & 0.0000 & $4.403 E-08$ & 0.0061 \\
\hline & $0.000 \mathrm{E}+00$ & 0.0000 & $0.000 \mathrm{E}+00$ & 0.0000 & $0.000 \mathrm{E}+00$ & 0.0000 & $0.000 \mathrm{E}+00$ & 0.0000 & $0.000 \mathrm{E}+00$ & 0.0000 & $0.000 \mathrm{E}+00$ & 000 & -06 & 1.0000 \\
\hline
\end{tabular}

* Sum of all water independent and dependent pathways. 
RESRAD, Version 6.5

$\mathrm{T}^{1 / 2}$ Limit $=180$ days

ummary : C746U Recreational User Deterministic Run

: $\mathrm{X}: \backslash F I N A L$ V2 \C746U RU SG FWD-FINALV2.RAD

Total Dose Contributions TDOSE (i,p,t) for Individual Radionuclides (i) and Pathways (p) As mrem/yr and Fraction of Total Dose At $t=5.000 \mathrm{E}+01$ years

Water Independent Pathways (Inhalation excludes radon)

\begin{tabular}{|c|c|c|c|c|c|c|c|c|c|c|c|c|c|c|}
\hline \multirow{2}{*}{ Nuclide } & \multicolumn{2}{|c|}{ Ground } & \multicolumn{2}{|c|}{ Inhalation } & \multicolumn{2}{|c|}{ Radon } & \multicolumn{2}{|c|}{ Plant } & \multicolumn{2}{|c|}{ Meat } & \multicolumn{2}{|c|}{ Milk } & \multicolumn{2}{|c|}{ Soil } \\
\hline & mrem/yr & fract. & mrem/yr & fract. & mrem/yr & fract. & mrem/yr & fract. & mrem/yr & fract. & mrem/yr & fract. & mrem/yr & fract. \\
\hline-241 & $8.641 E-15$ & 0.0000 & $0.000 \mathrm{E}+00$ & 0.0000 & $0.000 \mathrm{E}+00$ & 0.0000 & $0.000 \mathrm{E}+00$ & 0.0000 & $0.000 \mathrm{E}+00$ & 0.0000 & $0.000 \mathrm{E}+00$ & 0.0000 & $0.000 \mathrm{E}+00$ & 0.0000 \\
\hline-137 & $1.106 \mathrm{E}-08$ & 0.0012 & $0.000 \mathrm{E}+00$ & 0.0000 & $0.000 \mathrm{E}+00$ & 0.0000 & $0.000 \mathrm{E}+00$ & 0.0000 & $0.000 \mathrm{E}+00$ & 0.0000 & $0.000 \mathrm{E}+00$ & 0.0000 & $0.000 \mathrm{E}+00$ & 0.0000 \\
\hline-237 & $8.637 E-11$ & 0.0000 & $0.000 \mathrm{E}+00$ & 0.0000 & $0.000 \mathrm{E}+00$ & 0.0000 & $0.000 \mathrm{E}+00$ & 0.0000 & $0.000 \mathrm{E}+00$ & 0.0000 & $0.000 \mathrm{E}+00$ & 0.0000 & $0.000 \mathrm{E}+00$ & 0.0000 \\
\hline-238 & $1.975 E-14$ & 0.0000 & $0.000 \mathrm{E}+00$ & 0.0000 & $0.000 \mathrm{E}+00$ & 0.0000 & $0.000 \mathrm{E}+00$ & 0.0000 & $0.000 \mathrm{E}+00$ & 0.0000 & $0.000 \mathrm{E}+00$ & 0.0000 & $0.000 \mathrm{E}+00$ & 0.0000 \\
\hline-239 & $7.561 E-15$ & 0.0000 & $0.000 \mathrm{E}+00$ & 0.0000 & $0.000 \mathrm{E}+00$ & 0.0000 & $0.000 \mathrm{E}+00$ & 0.0000 & $0.000 \mathrm{E}+00$ & 0.0000 & $0.000 \mathrm{E}+00$ & 0.0000 & $0.000 \mathrm{E}+00$ & 0.0000 \\
\hline-240 & $9.285 \mathrm{E}-19$ & 0.0000 & $0.000 \mathrm{E}+00$ & 0.0000 & $0.000 \mathrm{E}+00$ & 0.0000 & $0.000 \mathrm{E}+00$ & 0.0000 & $0.000 \mathrm{E}+00$ & 0.0000 & $0.000 \mathrm{E}+00$ & 0.0000 & $0.000 \mathrm{E}+00$ & 0.0000 \\
\hline 99 & $3.115 E-25$ & 0.0000 & $0.000 \mathrm{E}+00$ & 0.0000 & $0.000 \mathrm{E}+00$ & 0.0000 & $0.000 \mathrm{E}+00$ & 0.0000 & $0.000 \mathrm{E}+00$ & 0.0000 & $0.000 \mathrm{E}+00$ & 0.0000 & $0.000 \mathrm{E}+00$ & 0.0000 \\
\hline-228 & $1.798 \mathrm{E}-13$ & 0.0000 & $0.000 \mathrm{E}+00$ & 0.0000 & $0.000 \mathrm{E}+00$ & 0.0000 & $0.000 \mathrm{E}+00$ & 0.0000 & $0.000 \mathrm{E}+00$ & 0.0000 & $0.000 \mathrm{E}+00$ & 0.0000 & $0.000 \mathrm{E}+00$ & 0.0000 \\
\hline-230 & $6.139 \mathrm{E}-07$ & 0.0691 & $0.000 \mathrm{E}+00$ & 0.0000 & $0.000 \mathrm{E}+00$ & 0.0000 & $0.000 \mathrm{E}+00$ & 0.0000 & $0.000 \mathrm{E}+00$ & 0.0000 & $0.000 \mathrm{E}+00$ & 0.0000 & $0.000 \mathrm{E}+00$ & 0.0000 \\
\hline-232 & $8.189 E-06$ & 0.9220 & $0.000 \mathrm{E}+00$ & 0.0000 & $0.000 \mathrm{E}+00$ & 0.0000 & $0.000 \mathrm{E}+00$ & 0.0000 & $0.000 \mathrm{E}+00$ & 0.0000 & $0.000 \mathrm{E}+00$ & 0.0000 & $0.000 \mathrm{E}+00$ & 0.0000 \\
\hline 234 & $2.101 E-09$ & 0.0002 & $0.000 \mathrm{E}+00$ & 0.0000 & $0.000 \mathrm{E}+00$ & 0.0000 & $0.000 \mathrm{E}+00$ & 0.0000 & $0.000 \mathrm{E}+00$ & 0.0000 & $0.000 \mathrm{E}+00$ & 0.0000 & $0.000 \mathrm{E}+00$ & 0.0000 \\
\hline 235 & 7. $287 \mathrm{E}-12$ & 0.0000 & $0.000 \mathrm{E}+00$ & 0.0000 & $0.000 \mathrm{E}+00$ & 0.0000 & $0.000 \mathrm{E}+00$ & 0.0000 & $0.000 \mathrm{E}+00$ & 0.0000 & $0.000 \mathrm{E}+00$ & 0.0000 & $0.000 \mathrm{E}+00$ & 0.0000 \\
\hline 38 & $6.513 E-08$ & 0.0073 & $0.000 \mathrm{E}+00$ & 0.0000 & $0.000 \mathrm{E}+00$ & 0.0000 & $0.000 \mathrm{E}+00$ & 0.0000 & $0.000 \mathrm{E}+00$ & 0.0000 & $0.000 \mathrm{E}+00$ & 0.0000 & $0.000 \mathrm{E}+00$ & 0.0000 \\
\hline & $8.881 E-06$ & 1.0000 & $0.000 \mathrm{E}+00$ & 0.0000 & $0.000 \mathrm{E}+00$ & 0.0000 & $0.000 \mathrm{E}+00$ & 0.0000 & $0.000 \mathrm{E}+00$ & 0.0000 & $0.000 \mathrm{E}+00$ & 0.0000 & $.000 \mathrm{E}+00$ & 0.0000 \\
\hline
\end{tabular}

Total Dose Contributions TDOSE (i,p,t) for Individual Radionuclides (i) and Pathways (p) As mrem/yr and Fraction of Total Dose At $t=5.000 \mathrm{E}+01$ years

Water Dependent Pathways

\begin{tabular}{|c|c|c|c|c|c|c|c|c|c|c|c|c|c|c|}
\hline & \multicolumn{2}{|c|}{ Water } & \multicolumn{2}{|c|}{ Fish } & \multicolumn{2}{|c|}{ Radon } & \multicolumn{2}{|c|}{ Plant } & \multicolumn{2}{|c|}{ Meat } & \multicolumn{2}{|c|}{ Milk } & \multicolumn{2}{|c|}{ All Pathways* } \\
\hline clide & mrem/yr & fract. & mrem/yr & fract. & mrem/yr & fract. & mrem/yr & fract. & mrem/yr & fract. & mrem/yr & fract. & mrem/yr & fract. \\
\hline-241 & $0.000 \mathrm{E}+00$ & 0.0000 & $0.000 \mathrm{E}+00$ & 0.0000 & $0.000 \mathrm{E}+00$ & 0.0000 & $0.000 \mathrm{E}+00$ & 0.0000 & $0.000 \mathrm{E}+00$ & 0.0000 & $0.000 \mathrm{E}+00$ & 0.0000 & $8.641 E-15$ & 0.0000 \\
\hline-137 & $0.000 \mathrm{E}+00$ & 0.0000 & $0.000 \mathrm{E}+00$ & 0.0000 & $0.000 \mathrm{E}+00$ & 0.0000 & $0.000 \mathrm{E}+00$ & 0.0000 & $0.000 \mathrm{E}+00$ & 0.0000 & $0.000 \mathrm{E}+00$ & 0.0000 & $1.106 \mathrm{E}-08$ & 0.0012 \\
\hline-237 & $0.000 \mathrm{E}+00$ & 0.0000 & $0.000 \mathrm{E}+00$ & 0.0000 & $0.000 \mathrm{E}+00$ & 0.0000 & $0.000 \mathrm{E}+00$ & 0.0000 & $0.000 \mathrm{E}+00$ & 0.0000 & $0.000 \mathrm{E}+00$ & 0.0000 & $8.637 \mathrm{E}-11$ & 0.0000 \\
\hline-238 & $0.000 \mathrm{E}+00$ & 0.0000 & $0.000 \mathrm{E}+00$ & 0.0000 & $0.000 \mathrm{E}+00$ & 0.0000 & $0.000 \mathrm{E}+00$ & 0.0000 & $0.000 \mathrm{E}+00$ & 0.0000 & $0.000 \mathrm{E}+00$ & 0.0000 & $1.975 \mathrm{E}-14$ & 0.0000 \\
\hline-239 & $0.000 \mathrm{E}+00$ & 0.0000 & $0.000 \mathrm{E}+00$ & 0.0000 & $0.000 \mathrm{E}+00$ & 0.0000 & $0.000 \mathrm{E}+00$ & 0.0000 & $0.000 \mathrm{E}+00$ & 0.0000 & $0.000 E+00$ & 0.0000 & $7.561 \mathrm{E}-15$ & 0.0000 \\
\hline-240 & $0.000 \mathrm{E}+00$ & 0.0000 & $0.000 \mathrm{E}+00$ & 0.0000 & $0.000 \mathrm{E}+00$ & 0.0000 & $0.000 \mathrm{E}+00$ & 0.0000 & $0.000 \mathrm{E}+00$ & 0.0000 & $0.000 E+00$ & 0.0000 & $9.285 \mathrm{E}-19$ & 0.0000 \\
\hline-99 & $0.000 \mathrm{E}+00$ & 0.0000 & $0.000 \mathrm{E}+00$ & 0.0000 & $0.000 \mathrm{E}+00$ & 0.0000 & $0.000 \mathrm{E}+00$ & 0.0000 & $0.000 \mathrm{E}+00$ & 0.0000 & $0.000 \mathrm{E}+00$ & 0.0000 & $3.115 \mathrm{E}-25$ & 0.0000 \\
\hline-228 & $0.000 \mathrm{E}+00$ & 0.0000 & $0.000 \mathrm{E}+00$ & 0.0000 & $0.000 \mathrm{E}+00$ & 0.0000 & $0.000 \mathrm{E}+00$ & 0.0000 & $0.000 \mathrm{E}+00$ & 0.0000 & $0.000 \mathrm{E}+00$ & 0.0000 & $1.798 \mathrm{E}-13$ & 0.0000 \\
\hline-230 & $0.000 \mathrm{E}+00$ & 0.0000 & $0.000 \mathrm{E}+00$ & 0.0000 & $0.000 \mathrm{E}+00$ & 0.0000 & $0.000 \mathrm{E}+00$ & 0.0000 & $0.000 \mathrm{E}+00$ & 0.0000 & $0.000 E+00$ & 0.0000 & $6.139 \mathrm{E}-07$ & 0.0691 \\
\hline 232 & $0.000 \mathrm{E}+00$ & 0.0000 & $0.000 \mathrm{E}+00$ & 0.0000 & $0.000 \mathrm{E}+00$ & 0.0000 & $0.000 \mathrm{E}+00$ & 0.0000 & $0.000 \mathrm{E}+00$ & 0.0000 & $0.000 \mathrm{E}+00$ & 0.0000 & $8.189 \mathrm{E}-06$ & 0.9220 \\
\hline 34 & $0.000 \mathrm{E}+00$ & 0.0000 & $0.000 \mathrm{E}+00$ & 0.0000 & $0.000 \mathrm{E}+00$ & 0.0000 & $0.000 \mathrm{E}+00$ & 0.0000 & $0.000 \mathrm{E}+00$ & 0.0000 & $0.000 \mathrm{E}+00$ & 0.0000 & $2.101 \mathrm{E}-09$ & 0.0002 \\
\hline 35 & $0.000 \mathrm{E}+00$ & 0.0000 & $0.000 \mathrm{E}+00$ & 0.0000 & $0.000 \mathrm{E}+00$ & 0.0000 & $0.000 \mathrm{E}+00$ & 0.0000 & $0.000 \mathrm{E}+00$ & 0.0000 & $0.000 E+00$ & 0.0000 & $7.287 \mathrm{E}-12$ & 0.0000 \\
\hline 38 & $0.000 \mathrm{E}+00$ & 0.0000 & $0.000 \mathrm{E}+00$ & 0.0000 & $0.000 \mathrm{E}+00$ & 0.0000 & $0.000 \mathrm{E}+00$ & 0.0000 & $0.000 \mathrm{E}+00$ & 0.0000 & $0.000 \mathrm{E}+00$ & 0.0000 & $6.513 E-08$ & 0.0073 \\
\hline & $0.000 \mathrm{E}+00$ & 0.0000 & $0.000 \mathrm{E}+00$ & 0.0000 & $0.000 \mathrm{E}+00$ & 0.0000 & $0.000 \mathrm{E}+00$ & 0.0000 & $0.000 \mathrm{E}+00$ & 0.0000 & $0.000 \mathrm{E}+00$ & 0.0000 & $31 E-06$ & 1.0000 \\
\hline
\end{tabular}

* Sum of all water independent and dependent pathways. 
RESRAD, Version 6.5

$\mathrm{T}^{1 / 2}$ Limit $=180$ days

ummary : C746U Recreational User Deterministic Run

: $\mathrm{X}: \backslash F I N A L$ V2 \C746U RU SG FWD-FINALV2.RAD

Total Dose Contributions TDOSE (i,p,t) for Individual Radionuclides (i) and Pathways (p) As mrem/yr and Fraction of Total Dose At $t=1.000 \mathrm{E}+02$ years

Water Independent Pathways (Inhalation excludes radon)

\begin{tabular}{|c|c|c|c|c|c|c|c|c|c|c|c|c|c|c|}
\hline \multirow{2}{*}{ Nuclide } & \multicolumn{2}{|c|}{ Ground } & \multicolumn{2}{|c|}{ Inhalation } & \multicolumn{2}{|c|}{ Radon } & \multicolumn{2}{|c|}{ Plant } & \multicolumn{2}{|c|}{ Meat } & \multicolumn{2}{|c|}{ Milk } & \multicolumn{2}{|c|}{ Soil } \\
\hline & mrem/yr & fract. & mrem/yr & fract. & mrem/yr & fract. & mrem/yr & fract. & mrem/yr & fract. & mrem/yr & fract. & mrem/yr & fract. \\
\hline-241 & $2.836 \mathrm{E}-14$ & 0.0000 & $0.000 \mathrm{E}+00$ & 0.0000 & $0.000 \mathrm{E}+00$ & 0.0000 & $0.000 \mathrm{E}+00$ & 0.0000 & $0.000 \mathrm{E}+00$ & 0.0000 & $0.000 \mathrm{E}+00$ & 0.0000 & $0.000 \mathrm{E}+00$ & 0.0000 \\
\hline-137 & $5.307 E-09$ & 0.0004 & $0.000 \mathrm{E}+00$ & 0.0000 & $0.000 \mathrm{E}+00$ & 0.0000 & $0.000 \mathrm{E}+00$ & 0.0000 & $0.000 \mathrm{E}+00$ & 0.0000 & $0.000 \mathrm{E}+00$ & 0.0000 & $0.000 \mathrm{E}+00$ & 0.0000 \\
\hline-237 & $1.483 \mathrm{E}-10$ & 0.0000 & $0.000 \mathrm{E}+00$ & 0.0000 & $0.000 \mathrm{E}+00$ & 0.0000 & $0.000 \mathrm{E}+00$ & 0.0000 & $0.000 \mathrm{E}+00$ & 0.0000 & $0.000 \mathrm{E}+00$ & 0.0000 & $0.000 \mathrm{E}+00$ & 0.0000 \\
\hline-238 & $1.997 \mathrm{E}-13$ & 0.0000 & $0.000 \mathrm{E}+00$ & 0.0000 & $0.000 \mathrm{E}+00$ & 0.0000 & $0.000 \mathrm{E}+00$ & 0.0000 & $0.000 \mathrm{E}+00$ & 0.0000 & $0.000 \mathrm{E}+00$ & 0.0000 & $0.000 \mathrm{E}+00$ & 0.0000 \\
\hline-239 & $1.374 \mathrm{E}-14$ & 0.0000 & $0.000 \mathrm{E}+00$ & 0.0000 & $0.000 \mathrm{E}+00$ & 0.0000 & $0.000 \mathrm{E}+00$ & 0.0000 & $0.000 \mathrm{E}+00$ & 0.0000 & $0.000 \mathrm{E}+00$ & 0.0000 & $0.000 \mathrm{E}+00$ & 0.0000 \\
\hline-240 & $6.177 \mathrm{E}-18$ & 0.0000 & $0.000 \mathrm{E}+00$ & 0.0000 & $0.000 \mathrm{E}+00$ & 0.0000 & $0.000 \mathrm{E}+00$ & 0.0000 & $0.000 \mathrm{E}+00$ & 0.0000 & $0.000 \mathrm{E}+00$ & 0.0000 & $0.000 \mathrm{E}+00$ & 0.0000 \\
\hline 99 & $6.247 E-25$ & 0.0000 & $0.000 \mathrm{E}+00$ & 0.0000 & $0.000 \mathrm{E}+00$ & 0.0000 & $0.000 \mathrm{E}+00$ & 0.0000 & $0.000 \mathrm{E}+00$ & 0.0000 & $0.000 \mathrm{E}+00$ & 0.0000 & $0.000 \mathrm{E}+00$ & 0.0000 \\
\hline-228 & $3.286 \mathrm{E}-21$ & 0.0000 & $0.000 \mathrm{E}+00$ & 0.0000 & $0.000 \mathrm{E}+00$ & 0.0000 & $0.000 \mathrm{E}+00$ & 0.0000 & $0.000 \mathrm{E}+00$ & 0.0000 & $0.000 \mathrm{E}+00$ & 0.0000 & $0.000 \mathrm{E}+00$ & 0.0000 \\
\hline-230 & $1.707 \mathrm{E}-06$ & 0.1323 & $0.000 \mathrm{E}+00$ & 0.0000 & $0.000 \mathrm{E}+00$ & 0.0000 & $0.000 \mathrm{E}+00$ & 0.0000 & $0.000 \mathrm{E}+00$ & 0.0000 & $0.000 \mathrm{E}+00$ & 0.0000 & $0.000 \mathrm{E}+00$ & 0.0000 \\
\hline-232 & $1.108 E-05$ & 0.8588 & $0.000 \mathrm{E}+00$ & 0.0000 & $0.000 \mathrm{E}+00$ & 0.0000 & $0.000 \mathrm{E}+00$ & 0.0000 & $0.000 \mathrm{E}+00$ & 0.0000 & $0.000 \mathrm{E}+00$ & 0.0000 & $0.000 \mathrm{E}+00$ & 0.0000 \\
\hline 234 & $1.167 \mathrm{E}-08$ & 0.0009 & $0.000 \mathrm{E}+00$ & 0.0000 & $0.000 \mathrm{E}+00$ & 0.0000 & $0.000 \mathrm{E}+00$ & 0.0000 & $0.000 \mathrm{E}+00$ & 0.0000 & $0.000 \mathrm{E}+00$ & 0.0000 & $0.000 \mathrm{E}+00$ & 0.0000 \\
\hline 235 & $2.673 E-11$ & 0.0000 & $0.000 \mathrm{E}+00$ & 0.0000 & $0.000 \mathrm{E}+00$ & 0.0000 & $0.000 \mathrm{E}+00$ & 0.0000 & $0.000 \mathrm{E}+00$ & 0.0000 & $0.000 \mathrm{E}+00$ & 0.0000 & $0.000 \mathrm{E}+00$ & 0.0000 \\
\hline 38 & $9.712 \mathrm{E}-08$ & 0.0075 & $0.000 \mathrm{E}+00$ & 0.0000 & $0.000 \mathrm{E}+00$ & 0.0000 & $0.000 \mathrm{E}+00$ & 0.0000 & $0.000 \mathrm{E}+00$ & 0.0000 & $0.000 \mathrm{E}+00$ & 0.0000 & $0.000 \mathrm{E}+00$ & 0.0000 \\
\hline & $1.290 \mathrm{E}-05$ & 1.0000 & $0.000 \mathrm{E}+00$ & 0.0000 & $0.000 \mathrm{E}+00$ & 0.0000 & $0.000 \mathrm{E}+00$ & 0.0000 & $0.000 \mathrm{E}+00$ & 0.0000 & $0.000 \mathrm{E}+00$ & 0.0000 & $.000 \mathrm{E}+00$ & 0.0000 \\
\hline
\end{tabular}

Total Dose Contributions TDOSE (i,p,t) for Individual Radionuclides (i) and Pathways (p) As mrem/yr and Fraction of Total Dose At $t=1.000 \mathrm{E}+02$ years

Water Dependent Pathways

\begin{tabular}{|c|c|c|c|c|c|c|c|c|c|c|c|c|c|c|}
\hline & \multicolumn{2}{|c|}{ Water } & \multicolumn{2}{|c|}{ Fish } & \multicolumn{2}{|c|}{ Radon } & \multicolumn{2}{|c|}{ Plant } & \multicolumn{2}{|c|}{ Meat } & \multicolumn{2}{|c|}{ Milk } & \multicolumn{2}{|c|}{ All Pathways* } \\
\hline clide & mrem/yr & fract. & mrem/yr & fract. & mrem/yr & fract. & mrem/yr & fract. & mrem/yr & fract. & mrem/yr & fract. & mrem/yr & fract. \\
\hline-241 & $0.000 \mathrm{E}+00$ & 0.0000 & $0.000 \mathrm{E}+00$ & 0.0000 & $0.000 \mathrm{E}+00$ & 0.0000 & $0.000 \mathrm{E}+00$ & 0.0000 & $0.000 \mathrm{E}+00$ & 0.0000 & $0.000 \mathrm{E}+00$ & 0.0000 & $2.836 \mathrm{E}-14$ & 0.0000 \\
\hline-137 & $0.000 \mathrm{E}+00$ & 0.0000 & $0.000 \mathrm{E}+00$ & 0.0000 & $0.000 \mathrm{E}+00$ & 0.0000 & $0.000 \mathrm{E}+00$ & 0.0000 & $0.000 \mathrm{E}+00$ & 0.0000 & $0.000 \mathrm{E}+00$ & 0.0000 & $5.307 \mathrm{E}-09$ & 0.0004 \\
\hline-237 & $0.000 \mathrm{E}+00$ & 0.0000 & $0.000 \mathrm{E}+00$ & 0.0000 & $0.000 \mathrm{E}+00$ & 0.0000 & $0.000 \mathrm{E}+00$ & 0.0000 & $0.000 \mathrm{E}+00$ & 0.0000 & $0.000 \mathrm{E}+00$ & 0.0000 & $1.483 \mathrm{E}-10$ & 0.0000 \\
\hline 238 & $0.000 \mathrm{E}+00$ & 0.0000 & $0.000 \mathrm{E}+00$ & 0.0000 & $0.000 \mathrm{E}+00$ & 0.0000 & $0.000 \mathrm{E}+00$ & 0.0000 & $0.000 \mathrm{E}+00$ & 0.0000 & $0.000 \mathrm{E}+00$ & 0.0000 & $1.997 \mathrm{E}-13$ & 0.0000 \\
\hline 239 & $0.000 \mathrm{E}+00$ & 0.0000 & $0.000 \mathrm{E}+00$ & 0.0000 & $0.000 \mathrm{E}+00$ & 0.0000 & $0.000 \mathrm{E}+00$ & 0.0000 & $0.000 \mathrm{E}+00$ & 0.0000 & $0.000 \mathrm{E}+00$ & 0.0000 & $1.374 \mathrm{E}-14$ & 0.0000 \\
\hline 240 & $0.000 \mathrm{E}+00$ & 0.0000 & $0.000 \mathrm{E}+00$ & 0.0000 & $0.000 \mathrm{E}+00$ & 0.0000 & $0.000 \mathrm{E}+00$ & 0.0000 & $0.000 \mathrm{E}+00$ & 0.0000 & $0.000 \mathrm{E}+00$ & 0.0000 & $6.177 \mathrm{E}-18$ & 0.0000 \\
\hline 99 & $0.000 \mathrm{E}+00$ & 0.0000 & $0.000 \mathrm{E}+00$ & 0.0000 & $0.000 \mathrm{E}+00$ & 0.0000 & $0.000 \mathrm{E}+00$ & 0.0000 & $0.000 \mathrm{E}+00$ & 0.0000 & $0.000 \mathrm{E}+00$ & 0.0000 & $6.247 \mathrm{E}-25$ & 0.0000 \\
\hline 228 & $0.000 \mathrm{E}+00$ & 0.0000 & $0.000 \mathrm{E}+00$ & 0.0000 & $0.000 \mathrm{E}+00$ & 0.0000 & $0.000 \mathrm{E}+00$ & 0.0000 & $0.000 \mathrm{E}+00$ & 0.0000 & $0.000 \mathrm{E}+00$ & 0.0000 & $3.286 \mathrm{E}-21$ & 0.0000 \\
\hline 230 & $0.000 \mathrm{E}+00$ & 0.0000 & $0.000 \mathrm{E}+00$ & 0.0000 & $0.000 \mathrm{E}+00$ & 0.0000 & $0.000 \mathrm{E}+00$ & 0.0000 & $0.000 \mathrm{E}+00$ & 0.0000 & $0.000 \mathrm{E}+00$ & 0.0000 & $1.707 \mathrm{E}-06$ & 0.1323 \\
\hline 232 & $0.000 \mathrm{E}+00$ & 0.0000 & $0.000 \mathrm{E}+00$ & 0.0000 & $0.000 \mathrm{E}+00$ & 0.0000 & $0.000 \mathrm{E}+00$ & 0.0000 & $0.000 \mathrm{E}+00$ & 0.0000 & $0.000 \mathrm{E}+00$ & 0.0000 & $1.108 \mathrm{E}-05$ & 0.8588 \\
\hline 34 & $0.000 \mathrm{E}+00$ & 0.0000 & $0.000 \mathrm{E}+00$ & 0.0000 & $0.000 \mathrm{E}+00$ & 0.0000 & $0.000 \mathrm{E}+00$ & 0.0000 & $0.000 \mathrm{E}+00$ & 0.0000 & $0.000 \mathrm{E}+00$ & 0.0000 & $1.167 \mathrm{E}-08$ & 0.0009 \\
\hline 35 & $0.000 \mathrm{E}+00$ & 0.0000 & $0.000 \mathrm{E}+00$ & 0.0000 & $0.000 \mathrm{E}+00$ & 0.0000 & $0.000 \mathrm{E}+00$ & 0.0000 & $0.000 \mathrm{E}+00$ & 0.0000 & $0.000 \mathrm{E}+00$ & 0.0000 & $2.673 E-11$ & 0.0000 \\
\hline 38 & $0.000 \mathrm{E}+00$ & 0.0000 & $0.000 \mathrm{E}+00$ & 0.0000 & $0.000 \mathrm{E}+00$ & 0.0000 & $0.000 \mathrm{E}+00$ & 0.0000 & $0.000 \mathrm{E}+00$ & 0.0000 & $0.000 \mathrm{E}+00$ & 0.0000 & $9.712 \mathrm{E}-08$ & 0.0075 \\
\hline & $0.000 \mathrm{E}+00$ & 0.0000 & $0.000 \mathrm{E}+00$ & 0.0000 & $0.000 \mathrm{E}+00$ & 0.0000 & $0.000 \mathrm{E}+00$ & 0.0000 & $0.000 \mathrm{E}+00$ & 0.0000 & $0.000 \mathrm{E}+00$ & 000 & -05 & 1.0000 \\
\hline
\end{tabular}

* Sum of all water independent and dependent pathways. 
RESRAD, Version 6.5

$\mathrm{T}^{1 / 2}$ Limit $=180$ days

ummary : C746U Recreational User Deterministic Run

: $\mathrm{X}: \backslash F I N A L$ V2 \C746U RU SG FWD-FINALV2.RAD

Total Dose Contributions TDOSE (i,p,t) for Individual Radionuclides (i) and Pathways (p) As mrem/yr and Fraction of Total Dose At $t=5.000 \mathrm{E}+02$ years

Water Independent Pathways (Inhalation excludes radon)

\begin{tabular}{|c|c|c|c|c|c|c|c|c|c|c|c|c|c|c|}
\hline \multirow{2}{*}{ Nuclide } & \multicolumn{2}{|c|}{ Ground } & \multicolumn{2}{|c|}{ Inhalation } & \multicolumn{2}{|c|}{ Radon } & \multicolumn{2}{|c|}{ Plant } & \multicolumn{2}{|c|}{ Meat } & \multicolumn{2}{|c|}{ Milk } & \multicolumn{2}{|c|}{ Soil } \\
\hline & mrem/yr & fract. & mrem/yr & fract. & mrem/yr & fract. & mrem/yr & fract. & mrem/yr & fract. & mrem/yr & fract. & mrem/yr & fract. \\
\hline-241 & $7.849 \mathrm{E}-12$ & 0.0000 & $0.000 \mathrm{E}+00$ & 0.0000 & $0.000 \mathrm{E}+00$ & 0.0000 & $0.000 \mathrm{E}+00$ & 0.0000 & $0.000 \mathrm{E}+00$ & 0.0000 & $0.000 \mathrm{E}+00$ & 0.0000 & $0.000 \mathrm{E}+00$ & 0.0000 \\
\hline-137 & $1.491 \mathrm{E}-11$ & 0.0000 & $0.000 \mathrm{E}+00$ & 0.0000 & $0.000 \mathrm{E}+00$ & 0.0000 & $0.000 \mathrm{E}+00$ & 0.0000 & $0.000 \mathrm{E}+00$ & 0.0000 & $0.000 \mathrm{E}+00$ & 0.0000 & $0.000 \mathrm{E}+00$ & 0.0000 \\
\hline-237 & $1.111 \mathrm{E}-08$ & 0.0000 & $0.000 \mathrm{E}+00$ & 0.0000 & $0.000 \mathrm{E}+00$ & 0.0000 & $0.000 \mathrm{E}+00$ & 0.0000 & $0.000 \mathrm{E}+00$ & 0.0000 & $0.000 \mathrm{E}+00$ & 0.0000 & $0.000 \mathrm{E}+00$ & 0.0000 \\
\hline-238 & $2.109 \mathrm{E}-10$ & 0.0000 & $0.000 \mathrm{E}+00$ & 0.0000 & $0.000 \mathrm{E}+00$ & 0.0000 & $0.000 \mathrm{E}+00$ & 0.0000 & $0.000 \mathrm{E}+00$ & 0.0000 & $0.000 \mathrm{E}+00$ & 0.0000 & $0.000 \mathrm{E}+00$ & 0.0000 \\
\hline-239 & 1. $636 \mathrm{E}-12$ & 0.0000 & $0.000 \mathrm{E}+00$ & 0.0000 & $0.000 \mathrm{E}+00$ & 0.0000 & $0.000 \mathrm{E}+00$ & 0.0000 & $0.000 \mathrm{E}+00$ & 0.0000 & $0.000 \mathrm{E}+00$ & 0.0000 & $0.000 \mathrm{E}+00$ & 0.0000 \\
\hline-240 & 1. $985 \mathrm{E}-15$ & 0.0000 & $0.000 \mathrm{E}+00$ & 0.0000 & $0.000 \mathrm{E}+00$ & 0.0000 & $0.000 \mathrm{E}+00$ & 0.0000 & $0.000 \mathrm{E}+00$ & 0.0000 & $0.000 \mathrm{E}+00$ & 0.0000 & $0.000 \mathrm{E}+00$ & 0.0000 \\
\hline 99 & $1.635 E-22$ & 0.0000 & $0.000 \mathrm{E}+00$ & 0.0000 & $0.000 \mathrm{E}+00$ & 0.0000 & $0.000 \mathrm{E}+00$ & 0.0000 & $0.000 \mathrm{E}+00$ & 0.0000 & $0.000 \mathrm{E}+00$ & 0.0000 & $0.000 \mathrm{E}+00$ & 0.0000 \\
\hline-228 & $0.000 \mathrm{E}+00$ & 0.0000 & $0.000 \mathrm{E}+00$ & 0.0000 & $0.000 \mathrm{E}+00$ & 0.0000 & $0.000 \mathrm{E}+00$ & 0.0000 & $0.000 \mathrm{E}+00$ & 0.0000 & $0.000 \mathrm{E}+00$ & 0.0000 & $0.000 \mathrm{E}+00$ & 0.0000 \\
\hline-230 & $1.239 \mathrm{E}-04$ & 0.4903 & $0.000 \mathrm{E}+00$ & 0.0000 & $0.000 \mathrm{E}+00$ & 0.0000 & $0.000 \mathrm{E}+00$ & 0.0000 & $0.000 \mathrm{E}+00$ & 0.0000 & $0.000 \mathrm{E}+00$ & 0.0000 & $0.000 \mathrm{E}+00$ & 0.0000 \\
\hline-232 & $1.221 E-04$ & 0.4831 & $0.000 \mathrm{E}+00$ & 0.0000 & $0.000 \mathrm{E}+00$ & 0.0000 & $0.000 \mathrm{E}+00$ & 0.0000 & $0.000 \mathrm{E}+00$ & 0.0000 & $0.000 \mathrm{E}+00$ & 0.0000 & $0.000 \mathrm{E}+00$ & 0.0000 \\
\hline 234 & $4.333 E-06$ & 0.0171 & $0.000 \mathrm{E}+00$ & 0.0000 & $0.000 \mathrm{E}+00$ & 0.0000 & $0.000 \mathrm{E}+00$ & 0.0000 & $0.000 \mathrm{E}+00$ & 0.0000 & $0.000 \mathrm{E}+00$ & 0.0000 & $0.000 \mathrm{E}+00$ & 0.0000 \\
\hline 235 & $5.569 \mathrm{E}-09$ & 0.0000 & $0.000 \mathrm{E}+00$ & 0.0000 & $0.000 \mathrm{E}+00$ & 0.0000 & $0.000 \mathrm{E}+00$ & 0.0000 & $0.000 \mathrm{E}+00$ & 0.0000 & $0.000 \mathrm{E}+00$ & 0.0000 & $0.000 \mathrm{E}+00$ & 0.0000 \\
\hline 38 & $2.374 E-06$ & 0.0094 & $0.000 \mathrm{E}+00$ & 0.0000 & $0.000 \mathrm{E}+00$ & 0.0000 & $0.000 \mathrm{E}+00$ & 0.0000 & $0.000 \mathrm{E}+00$ & 0.0000 & $0.000 \mathrm{E}+00$ & 0.0000 & $0.000 \mathrm{E}+00$ & 0.0000 \\
\hline & $2.526 E-04$ & 1.0000 & $0.000 \mathrm{E}+00$ & 0.0000 & $0.000 \mathrm{E}+00$ & 0.0000 & $0.000 \mathrm{E}+00$ & 0.0000 & $0.000 \mathrm{E}+00$ & 0.0000 & $0.000 \mathrm{E}+00$ & 0.0000 & $.000 \mathrm{E}+00$ & 0.0000 \\
\hline
\end{tabular}

Total Dose Contributions TDOSE (i,p,t) for Individual Radionuclides (i) and Pathways (p) As mrem/yr and Fraction of Total Dose At $t=5.000 \mathrm{E}+02$ years

Water Dependent Pathways

\begin{tabular}{|c|c|c|c|c|c|c|c|c|c|c|c|c|c|c|}
\hline & \multicolumn{2}{|c|}{ Water } & \multicolumn{2}{|c|}{ Fish } & \multicolumn{2}{|c|}{ Radon } & \multicolumn{2}{|c|}{ Plant } & \multicolumn{2}{|c|}{ Meat } & \multicolumn{2}{|c|}{ Milk } & \multicolumn{2}{|c|}{ All Pathways* } \\
\hline clide & mrem/yr & fract. & mrem/yr & fract. & mrem/yr & fract. & mrem/yr & fract. & mrem/yr & fract. & mrem/yr & fract. & mrem/yr & fract. \\
\hline-241 & $0.000 \mathrm{E}+00$ & 0.0000 & $0.000 \mathrm{E}+00$ & 0.0000 & $0.000 \mathrm{E}+00$ & 0.0000 & $0.000 \mathrm{E}+00$ & 0.0000 & $0.000 \mathrm{E}+00$ & 0.0000 & $0.000 \mathrm{E}+00$ & 0.0000 & $7.849 \mathrm{E}-12$ & 0.0000 \\
\hline-137 & $0.000 \mathrm{E}+00$ & 0.0000 & $0.000 \mathrm{E}+00$ & 0.0000 & $0.000 \mathrm{E}+00$ & 0.0000 & $0.000 \mathrm{E}+00$ & 0.0000 & $0.000 \mathrm{E}+00$ & 0.0000 & $0.000 \mathrm{E}+00$ & 0.0000 & $1.491 \mathrm{E}-11$ & 0.0000 \\
\hline-237 & $0.000 \mathrm{E}+00$ & 0.0000 & $0.000 \mathrm{E}+00$ & 0.0000 & $0.000 \mathrm{E}+00$ & 0.0000 & $0.000 \mathrm{E}+00$ & 0.0000 & $0.000 \mathrm{E}+00$ & 0.0000 & $0.000 \mathrm{E}+00$ & 0.0000 & $1.111 \mathrm{E}-08$ & 0.0000 \\
\hline 238 & $0.000 \mathrm{E}+00$ & 0.0000 & $0.000 \mathrm{E}+00$ & 0.0000 & $0.000 \mathrm{E}+00$ & 0.0000 & $0.000 \mathrm{E}+00$ & 0.0000 & $0.000 \mathrm{E}+00$ & 0.0000 & $0.000 \mathrm{E}+00$ & 0.0000 & $2.109 \mathrm{E}-10$ & 0.0000 \\
\hline 239 & $0.000 \mathrm{E}+00$ & 0.0000 & $0.000 \mathrm{E}+00$ & 0.0000 & $0.000 \mathrm{E}+00$ & 0.0000 & $0.000 \mathrm{E}+00$ & 0.0000 & $0.000 \mathrm{E}+00$ & 0.0000 & $0.000 \mathrm{E}+00$ & 0.0000 & $1.636 \mathrm{E}-12$ & 0.0000 \\
\hline 240 & $0.000 \mathrm{E}+00$ & 0.0000 & $0.000 \mathrm{E}+00$ & 0.0000 & $0.000 \mathrm{E}+00$ & 0.0000 & $0.000 \mathrm{E}+00$ & 0.0000 & $0.000 \mathrm{E}+00$ & 0.0000 & $0.000 \mathrm{E}+00$ & 0.0000 & $1.985 \mathrm{E}-15$ & 0.0000 \\
\hline 99 & $0.000 \mathrm{E}+00$ & 0.0000 & $0.000 \mathrm{E}+00$ & 0.0000 & $0.000 \mathrm{E}+00$ & 0.0000 & $0.000 \mathrm{E}+00$ & 0.0000 & $0.000 \mathrm{E}+00$ & 0.0000 & $0.000 \mathrm{E}+00$ & 0.0000 & $1.635 \mathrm{E}-22$ & 0.0000 \\
\hline 228 & $0.000 \mathrm{E}+00$ & 0.0000 & $0.000 \mathrm{E}+00$ & 0.0000 & $0.000 \mathrm{E}+00$ & 0.0000 & $0.000 \mathrm{E}+00$ & 0.0000 & $0.000 \mathrm{E}+00$ & 0.0000 & $0.000 \mathrm{E}+00$ & 0.0000 & $0.000 \mathrm{E}+00$ & 0.0000 \\
\hline 230 & $0.000 \mathrm{E}+00$ & 0.0000 & $0.000 \mathrm{E}+00$ & 0.0000 & $0.000 \mathrm{E}+00$ & 0.0000 & $0.000 \mathrm{E}+00$ & 0.0000 & $0.000 \mathrm{E}+00$ & 0.0000 & $0.000 \mathrm{E}+00$ & 0.0000 & $1.239 \mathrm{E}-04$ & 0.4903 \\
\hline 232 & $0.000 \mathrm{E}+00$ & 0.0000 & $0.000 \mathrm{E}+00$ & 0.0000 & $0.000 \mathrm{E}+00$ & 0.0000 & $0.000 \mathrm{E}+00$ & 0.0000 & $0.000 \mathrm{E}+00$ & 0.0000 & $0.000 \mathrm{E}+00$ & 0.0000 & $1.221 \mathrm{E}-04$ & 0.4831 \\
\hline 34 & $0.000 \mathrm{E}+00$ & 0.0000 & $0.000 \mathrm{E}+00$ & 0.0000 & $0.000 \mathrm{E}+00$ & 0.0000 & $0.000 \mathrm{E}+00$ & 0.0000 & $0.000 \mathrm{E}+00$ & 0.0000 & $0.000 \mathrm{E}+00$ & 0.0000 & $4.333 E-06$ & 0.0171 \\
\hline 35 & $0.000 \mathrm{E}+00$ & 0.0000 & $0.000 \mathrm{E}+00$ & 0.0000 & $0.000 \mathrm{E}+00$ & 0.0000 & $0.000 \mathrm{E}+00$ & 0.0000 & $0.000 \mathrm{E}+00$ & 0.0000 & $0.000 \mathrm{E}+00$ & 0.0000 & $5.569 \mathrm{E}-09$ & 0.0000 \\
\hline 38 & $0.000 \mathrm{E}+00$ & 0.0000 & $0.000 \mathrm{E}+00$ & 0.0000 & $0.000 \mathrm{E}+00$ & 0.0000 & $0.000 \mathrm{E}+00$ & 0.0000 & $0.000 \mathrm{E}+00$ & 0.0000 & $0.000 \mathrm{E}+00$ & 0.0000 & $2.374 \mathrm{E}-06$ & 0.0094 \\
\hline & $0.000 \mathrm{E}+00$ & 0.0000 & $0.000 \mathrm{E}+00$ & 0.0000 & $0.000 \mathrm{E}+00$ & 0.0000 & $0.000 \mathrm{E}+00$ & 0.0000 & $0.000 \mathrm{E}+00$ & 0.0000 & $0.000 \mathrm{E}+00$ & 000 & -04 & 1.0000 \\
\hline
\end{tabular}

* Sum of all water independent and dependent pathways. 
RESRAD, Version 6.5

$\mathrm{T}^{1 / 2}$ Limit $=180$ days

ummary : C746U Recreational User Deterministic Run

: $\mathrm{X}: \backslash F I N A L$ V2 \C746U RU SG FWD-FINALV2.RAD

Total Dose Contributions TDOSE (i,p,t) for Individual Radionuclides (i) and Pathways (p) As mrem/yr and Fraction of Total Dose At $t=1.050 \mathrm{E}+03$ years

Water Independent Pathways (Inhalation excludes radon)

\begin{tabular}{|c|c|c|c|c|c|c|c|c|c|c|c|c|c|c|}
\hline \multirow{2}{*}{ Nuclide } & \multicolumn{2}{|c|}{ Ground } & \multicolumn{2}{|c|}{ Inhalation } & \multicolumn{2}{|c|}{ Radon } & \multicolumn{2}{|c|}{ Plant } & \multicolumn{2}{|c|}{ Meat } & \multicolumn{2}{|c|}{ Milk } & \multicolumn{2}{|c|}{ Soil } \\
\hline & mrem/yr & fract. & mrem/yr & fract. & mrem/yr & fract. & mrem/yr & fract. & mrem/yr & fract. & mrem/yr & fract. & mrem/yr & fract. \\
\hline-241 & $4.250 E-09$ & 0.0000 & $0.000 \mathrm{E}+00$ & 0.0000 & $0.000 \mathrm{E}+00$ & 0.0000 & $0.000 \mathrm{E}+00$ & 0.0000 & $0.000 \mathrm{E}+00$ & 0.0000 & $0.000 \mathrm{E}+00$ & 0.0000 & $0.000 \mathrm{E}+00$ & 0.0000 \\
\hline-137 & $4.627 E-15$ & 0.0000 & $0.000 \mathrm{E}+00$ & 0.0000 & $0.000 \mathrm{E}+00$ & 0.0000 & $0.000 \mathrm{E}+00$ & 0.0000 & $0.000 \mathrm{E}+00$ & 0.0000 & $0.000 \mathrm{E}+00$ & 0.0000 & $0.000 \mathrm{E}+00$ & 0.0000 \\
\hline-237 & $3.985 E-06$ & 0.0003 & $0.000 \mathrm{E}+00$ & 0.0000 & $0.000 \mathrm{E}+00$ & 0.0000 & $0.000 \mathrm{E}+00$ & 0.0000 & $0.000 \mathrm{E}+00$ & 0.0000 & $0.000 \mathrm{E}+00$ & 0.0000 & $0.000 \mathrm{E}+00$ & 0.0000 \\
\hline-238 & $4.914 \mathrm{E}-08$ & 0.0000 & $0.000 \mathrm{E}+00$ & 0.0000 & $0.000 \mathrm{E}+00$ & 0.0000 & $0.000 \mathrm{E}+00$ & 0.0000 & $0.000 \mathrm{E}+00$ & 0.0000 & $0.000 \mathrm{E}+00$ & 0.0000 & $0.000 \mathrm{E}+00$ & 0.0000 \\
\hline-239 & $1.164 \mathrm{E}-09$ & 0.0000 & $0.000 \mathrm{E}+00$ & 0.0000 & $0.000 \mathrm{E}+00$ & 0.0000 & $0.000 \mathrm{E}+00$ & 0.0000 & $0.000 \mathrm{E}+00$ & 0.0000 & $0.000 \mathrm{E}+00$ & 0.0000 & $0.000 \mathrm{E}+00$ & 0.0000 \\
\hline-240 & $2.820 \mathrm{E}-13$ & 0.0000 & $0.000 \mathrm{E}+00$ & 0.0000 & $0.000 \mathrm{E}+00$ & 0.0000 & $0.000 \mathrm{E}+00$ & 0.0000 & $0.000 \mathrm{E}+00$ & 0.0000 & $0.000 \mathrm{E}+00$ & 0.0000 & $0.000 \mathrm{E}+00$ & 0.0000 \\
\hline 99 & $3.451 \mathrm{E}-19$ & 0.0000 & $0.000 \mathrm{E}+00$ & 0.0000 & $0.000 \mathrm{E}+00$ & 0.0000 & $0.000 \mathrm{E}+00$ & 0.0000 & $0.000 \mathrm{E}+00$ & 0.0000 & $0.000 \mathrm{E}+00$ & 0.0000 & $0.000 \mathrm{E}+00$ & 0.0000 \\
\hline-228 & $0.000 \mathrm{E}+00$ & 0.0000 & $0.000 \mathrm{E}+00$ & 0.0000 & $0.000 \mathrm{E}+00$ & 0.0000 & $0.000 \mathrm{E}+00$ & 0.0000 & $0.000 \mathrm{E}+00$ & 0.0000 & $0.000 \mathrm{E}+00$ & 0.0000 & $0.000 \mathrm{E}+00$ & 0.0000 \\
\hline-230 & $1.039 \mathrm{E}-02$ & 0.7039 & $0.000 \mathrm{E}+00$ & 0.0000 & $0.000 \mathrm{E}+00$ & 0.0000 & $0.000 \mathrm{E}+00$ & 0.0000 & $0.000 \mathrm{E}+00$ & 0.0000 & $0.000 \mathrm{E}+00$ & 0.0000 & $0.000 \mathrm{E}+00$ & 0.0000 \\
\hline-232 & $3.382 E-03$ & 0.2291 & $0.000 \mathrm{E}+00$ & 0.0000 & $0.000 \mathrm{E}+00$ & 0.0000 & $0.000 \mathrm{E}+00$ & 0.0000 & $0.000 \mathrm{E}+00$ & 0.0000 & $0.000 \mathrm{E}+00$ & 0.0000 & $0.000 \mathrm{E}+00$ & 0.0000 \\
\hline 234 & $7.913 E-04$ & 0.0536 & $0.000 \mathrm{E}+00$ & 0.0000 & $0.000 \mathrm{E}+00$ & 0.0000 & $0.000 \mathrm{E}+00$ & 0.0000 & $0.000 \mathrm{E}+00$ & 0.0000 & $0.000 \mathrm{E}+00$ & 0.0000 & $0.000 \mathrm{E}+00$ & 0.0000 \\
\hline 235 & $1.869 \mathrm{E}-06$ & 0.0001 & $0.000 \mathrm{E}+00$ & 0.0000 & $0.000 \mathrm{E}+00$ & 0.0000 & $0.000 \mathrm{E}+00$ & 0.0000 & $0.000 \mathrm{E}+00$ & 0.0000 & $0.000 \mathrm{E}+00$ & 0.0000 & $0.000 \mathrm{E}+00$ & 0.0000 \\
\hline 38 & $1.927 \mathrm{E}-04$ & 0.0131 & $0.000 \mathrm{E}+00$ & 0.0000 & $0.000 \mathrm{E}+00$ & 0.0000 & $0.000 \mathrm{E}+00$ & 0.0000 & $0.000 \mathrm{E}+00$ & 0.0000 & $0.000 \mathrm{E}+00$ & 0.0000 & $0.000 \mathrm{E}+00$ & 0.0000 \\
\hline & $1.476 \mathrm{E}-02$ & 1.0000 & $0.000 \mathrm{E}+00$ & 0.0000 & $0.000 \mathrm{E}+00$ & 0.0000 & $0.000 \mathrm{E}+00$ & 0.0000 & $0.000 \mathrm{E}+00$ & 0.0000 & $0.000 \mathrm{E}+00$ & 0.0000 & $.000 \mathrm{E}+00$ & 0.0000 \\
\hline
\end{tabular}

Total Dose Contributions TDOSE (i,p,t) for Individual Radionuclides (i) and Pathways (p) As mrem/yr and Fraction of Total Dose At $t=1.050 \mathrm{E}+03$ years

Water Dependent Pathways

\begin{tabular}{|c|c|c|c|c|c|c|c|c|c|c|c|c|c|c|}
\hline & \multicolumn{2}{|c|}{ Water } & \multicolumn{2}{|c|}{ Fish } & \multicolumn{2}{|c|}{ Radon } & \multicolumn{2}{|c|}{ Plant } & \multicolumn{2}{|c|}{ Meat } & \multicolumn{2}{|c|}{ Milk } & \multicolumn{2}{|c|}{ All Pathways* } \\
\hline clide & mrem/yr & fract. & mrem/yr & fract. & mrem/yr & fract. & mrem/yr & fract. & mrem/yr & fract. & mrem/yr & fract. & mrem/yr & fract. \\
\hline-241 & $0.000 \mathrm{E}+00$ & 0.0000 & $0.000 \mathrm{E}+00$ & 0.0000 & $0.000 \mathrm{E}+00$ & 0.0000 & $0.000 \mathrm{E}+00$ & 0.0000 & $0.000 \mathrm{E}+00$ & 0.0000 & $0.000 E+00$ & 0.0000 & $4.250 \mathrm{E}-09$ & 0.0000 \\
\hline-137 & $0.000 \mathrm{E}+00$ & 0.0000 & $0.000 \mathrm{E}+00$ & 0.0000 & $0.000 \mathrm{E}+00$ & 0.0000 & $0.000 \mathrm{E}+00$ & 0.0000 & $0.000 \mathrm{E}+00$ & 0.0000 & $0.000 \mathrm{E}+00$ & 0.0000 & $4.627 \mathrm{E}-15$ & 0.0000 \\
\hline-237 & $0.000 \mathrm{E}+00$ & 0.0000 & $0.000 \mathrm{E}+00$ & 0.0000 & $0.000 \mathrm{E}+00$ & 0.0000 & $0.000 \mathrm{E}+00$ & 0.0000 & $0.000 \mathrm{E}+00$ & 0.0000 & $0.000 \mathrm{E}+00$ & 0.0000 & $3.985 E-06$ & 0.0003 \\
\hline 238 & $0.000 \mathrm{E}+00$ & 0.0000 & $0.000 \mathrm{E}+00$ & 0.0000 & $0.000 \mathrm{E}+00$ & 0.0000 & $0.000 \mathrm{E}+00$ & 0.0000 & $0.000 \mathrm{E}+00$ & 0.0000 & $0.000 \mathrm{E}+00$ & 0.0000 & $4.914 \mathrm{E}-08$ & 0.0000 \\
\hline 239 & $0.000 \mathrm{E}+00$ & 0.0000 & $0.000 \mathrm{E}+00$ & 0.0000 & $0.000 \mathrm{E}+00$ & 0.0000 & $0.000 \mathrm{E}+00$ & 0.0000 & $0.000 \mathrm{E}+00$ & 0.0000 & $0.000 \mathrm{E}+00$ & 0.0000 & $1.164 \mathrm{E}-09$ & 0.0000 \\
\hline 240 & $0.000 \mathrm{E}+00$ & 0.0000 & $0.000 \mathrm{E}+00$ & 0.0000 & $0.000 \mathrm{E}+00$ & 0.0000 & $0.000 \mathrm{E}+00$ & 0.0000 & $0.000 \mathrm{E}+00$ & 0.0000 & $0.000 \mathrm{E}+00$ & 0.0000 & $2.820 \mathrm{E}-13$ & 0.0000 \\
\hline 99 & $0.000 \mathrm{E}+00$ & 0.0000 & $0.000 \mathrm{E}+00$ & 0.0000 & $0.000 \mathrm{E}+00$ & 0.0000 & $0.000 \mathrm{E}+00$ & 0.0000 & $0.000 \mathrm{E}+00$ & 0.0000 & $0.000 \mathrm{E}+00$ & 0.0000 & $3.451 \mathrm{E}-19$ & 0.0000 \\
\hline 228 & $0.000 \mathrm{E}+00$ & 0.0000 & $0.000 \mathrm{E}+00$ & 0.0000 & $0.000 \mathrm{E}+00$ & 0.0000 & $0.000 \mathrm{E}+00$ & 0.0000 & $0.000 \mathrm{E}+00$ & 0.0000 & $0.000 \mathrm{E}+00$ & 0.0000 & $0.000 \mathrm{E}+00$ & 0.0000 \\
\hline 230 & $0.000 \mathrm{E}+00$ & 0.0000 & $0.000 \mathrm{E}+00$ & 0.0000 & $0.000 \mathrm{E}+00$ & 0.0000 & $0.000 \mathrm{E}+00$ & 0.0000 & $0.000 \mathrm{E}+00$ & 0.0000 & $0.000 \mathrm{E}+00$ & 0.0000 & $1.039 \mathrm{E}-02$ & 0.7039 \\
\hline 232 & $0.000 \mathrm{E}+00$ & 0.0000 & $0.000 \mathrm{E}+00$ & 0.0000 & $0.000 \mathrm{E}+00$ & 0.0000 & $0.000 \mathrm{E}+00$ & 0.0000 & $0.000 \mathrm{E}+00$ & 0.0000 & $0.000 \mathrm{E}+00$ & 0.0000 & $3.382 \mathrm{E}-03$ & 0.2291 \\
\hline 34 & $0.000 \mathrm{E}+00$ & 0.0000 & $0.000 \mathrm{E}+00$ & 0.0000 & $0.000 \mathrm{E}+00$ & 0.0000 & $0.000 \mathrm{E}+00$ & 0.0000 & $0.000 \mathrm{E}+00$ & 0.0000 & $0.000 \mathrm{E}+00$ & 0.0000 & 7. $913 \mathrm{E}-04$ & 0.0536 \\
\hline 35 & $0.000 \mathrm{E}+00$ & 0.0000 & $0.000 \mathrm{E}+00$ & 0.0000 & $0.000 \mathrm{E}+00$ & 0.0000 & $0.000 \mathrm{E}+00$ & 0.0000 & $0.000 \mathrm{E}+00$ & 0.0000 & $0.000 \mathrm{E}+00$ & 0.0000 & $1.869 \mathrm{E}-06$ & 0.0001 \\
\hline 38 & $0.000 \mathrm{E}+00$ & 0.0000 & $0.000 \mathrm{E}+00$ & 0.0000 & $0.000 \mathrm{E}+00$ & 0.0000 & $0.000 \mathrm{E}+00$ & 0.0000 & $0.000 \mathrm{E}+00$ & 0.0000 & $0.000 \mathrm{E}+00$ & 0.0000 & $1.927 \mathrm{E}-04$ & 0.0131 \\
\hline & $0.000 \mathrm{E}+00$ & 0.0000 & $0.000 \mathrm{E}+00$ & 0.0000 & $0.000 \mathrm{E}+00$ & 0.0000 & $0.000 \mathrm{E}+00$ & 0.0000 & $0.000 \mathrm{E}+00$ & 0.0000 & $0.000 \mathrm{E}+00$ & 000 & -02 & 1.0000 \\
\hline
\end{tabular}

* Sum of all water independent and dependent pathways. 
RESRAD, Version $6.5 \quad \mathrm{~T}^{1 / 2}$ Limit $=180$ days

Summary : C746U Recreational User Deterministic Run

File : $\mathrm{X}: \backslash$ FINAL V2\C746U RU SG FWD-FINALV2.RAD

Dose/Source Ratios Summed Over All Pathways

Parent and Progeny Principal Radionuclide Contributions Indicated

Parent Product Thread DSR $(j, t)$ At Time in Years (mrem/yr)/(pCi/g)

(i)

(j)

$\begin{array}{ll}\mathrm{Am}-241 & 1.000 \mathrm{E}+00 \\ \mathrm{~Np}-237+\mathrm{D} & 1.000 \mathrm{E}+00 \\ \mathrm{U}-233 & 1.000 \mathrm{E}+00 \\ \mathrm{Th}-229+\mathrm{D} & 1.000 \mathrm{E}+00 \\ \operatorname{\sum DSR}(j) & \end{array}$

Cs $-137+D$

$\mathrm{Np}-237+\mathrm{D}$

U-233

Th-229+D

$\sum \operatorname{DSR}(j)$

$\mathrm{Pu}-238$

Pu-238

U-234

Th-230

Ra-226+D

$\mathrm{Pb}-210+\mathrm{D}$

$\sum \operatorname{DSR}(j)$

Pu-239

$\mathrm{U}-235+\mathrm{D}$

$\mathrm{Pa}-231$

AC-227+D

$\sum \operatorname{DSR}(j)$

Pu-2 40

\section{Pu-240}

U-236

Th-232

$\mathrm{Ra}-228+\mathrm{D}$

Th-228+D

$\sum \mathrm{DSR}(j)$

TC-99

Th-228+D

Th-230

$\mathrm{Ra}-226+\mathrm{D}$

$\mathrm{Pb}-210+\mathrm{D}$

$\sum \mathrm{DSR}(j)$ $\begin{array}{lllllllll}1.000 \mathrm{E}+00 & 1.213 \mathrm{E}-10 & 1.196 \mathrm{E}-10 & 5.821 \mathrm{E}-11 & 2.793 \mathrm{E}-11 & 7.847 \mathrm{E}-14 & 2.435 \mathrm{E}-17\end{array}$

$\begin{array}{lllllll}1.000 \mathrm{E}+00 & 9.169 \mathrm{E}-14 & 9.268 \mathrm{E}-14 & 1.567 \mathrm{E}-13 & 2.679 \mathrm{E}-13 & 1.952 \mathrm{E}-11 & 7.101 \mathrm{E}-09\end{array}$

$\begin{array}{lllllll}1.000 \mathrm{E}+00 \quad 3.120 \mathrm{E}-24 & 9.466 \mathrm{E}-24 & 5.875 \mathrm{E}-22 & 2.184 \mathrm{E}-21 & 1.613 \mathrm{E}-18 & 3.273 \mathrm{E}-15\end{array}$

$\begin{array}{lllllll}1.000 \mathrm{E}+00 & 2.848 \mathrm{E}-20 & 2.006 \mathrm{E}-19 & 3.076 \mathrm{E}-16 & 1.723 \mathrm{E}-15 & 6.884 \mathrm{E}-13 & 1.443 \mathrm{E}-10\end{array}$ $\begin{array}{lllllll}9.169 \mathrm{E}-14 & 9.268 \mathrm{E}-14 & 1.570 \mathrm{E}-13 & 2.696 \mathrm{E}-13 & 2.021 \mathrm{E}-11 & 7.245 \mathrm{E}-09\end{array}$

$\begin{array}{lllllll}1.840 E-09 & 2.079 E-34 & 2.099 E-34 & 3.386 E-34 & 5.515 E-34 & 2.732 E-32 & 5.849 E-30\end{array}$

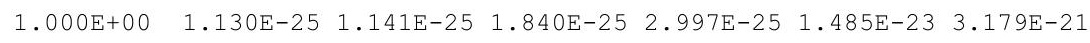

$\begin{array}{llllllll}1.000 \mathrm{E}+00 & 9.402 \mathrm{E}-31 & 2.855 \mathrm{E}-30 & 1.897 \mathrm{E}-28 & 7.660 \mathrm{E}-28 & 1.633 \mathrm{E}-24 & 2.820 \mathrm{E}-20\end{array}$

$\begin{array}{lllllll}1.000 \mathrm{E}+00 & 9.887 \mathrm{E}-35 & 7.005 \mathrm{E}-34 & 1.538 \mathrm{E}-30 & 1.253 \mathrm{E}-29 & 1.259 \mathrm{E}-25 & 3.198 \mathrm{E}-21\end{array}$

$\begin{array}{llllllll}1.000 \mathrm{E}+00 & 7.713 \mathrm{E}-24 & 1.162 \mathrm{E}-22 & 5.065 \mathrm{E}-18 & 5.122 \mathrm{E}-17 & 5.408 \mathrm{E}-14 & 1.260 \mathrm{E}-11\end{array}$

$\begin{array}{llllllll}1.000 \mathrm{E}+00 & 2.237 \mathrm{E}-32 & 6.933 \mathrm{E}-31 & 7.476 \mathrm{E}-25 & 1.264 \mathrm{E}-23 & 3.542 \mathrm{E}-20 & 1.664 \mathrm{E}-17\end{array}$

$\begin{array}{lllllll}7.826 \mathrm{E}-24 & 1.163 \mathrm{E}-22 & 5.065 \mathrm{E}-18 & 5.122 \mathrm{E}-17 & 5.408 \mathrm{E}-14 & 1.260 \mathrm{E}-11\end{array}$

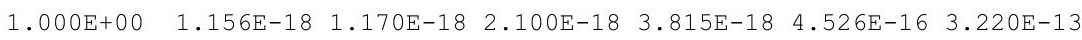

$\begin{array}{llllll}1.000 \mathrm{E}+00 \quad 5.899 \mathrm{E}-25 & 1.789 \mathrm{E}-24 & 1.102 \mathrm{E}-22 & 4.068 \mathrm{E}-22 & 2.830 \mathrm{E}-19 & 5.291 \mathrm{E}-16\end{array}$

$\begin{array}{llllllll}1.000 \mathrm{E}+00 & 9.281 \mathrm{E}-29 & 6.556 \mathrm{E}-28 & 1.203 \mathrm{E}-24 & 8.097 \mathrm{E}-24 & 1.394 \mathrm{E}-20 & 2.092 \mathrm{E}-17\end{array}$

$\begin{array}{lllllll}1.000 \mathrm{E}+00 & 2.200 \mathrm{E}-28 & 3.302 \mathrm{E}-27 & 1.227 \mathrm{E}-22 & 1.125 \mathrm{E}-21 & 1.425 \mathrm{E}-18 & 8.591 \mathrm{E}-16\end{array}$

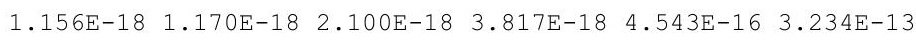

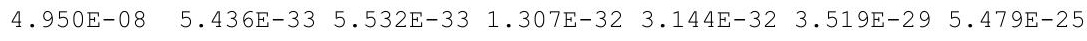

$\begin{array}{llllllll}1.000 \mathrm{E}+00 & 1.098 \mathrm{E}-25 & 1.118 \mathrm{E}-25 & 2.641 \mathrm{E}-25 & 6.352 \mathrm{E}-25 & 7.109 \mathrm{E}-22 & 1.107 \mathrm{E}-17\end{array}$

$\begin{array}{llllllll}1.000 \mathrm{E}+00 & 2.079 \mathrm{E}-33 & 6.337 \mathrm{E}-33 & 5.132 \mathrm{E}-31 & 2.504 \mathrm{E}-30 & 1.628 \mathrm{E}-26 & 6.574 \mathrm{E}-22\end{array}$

$\begin{array}{llllllll}1.000 E+00 & 2.803 E-44 & 1.948 E-43 & 5.271 E-40 & 5.270 E-39 & 2.159 E-34 & 2.528 E-29\end{array}$

$\begin{array}{lllllll}1.000 \mathrm{E}+00 & 1.318 \mathrm{E}-29 & 1.940 \mathrm{E}-28 & 3.618 \mathrm{E}-24 & 2.445 \mathrm{E}-23 & 1.417 \mathrm{E}-20 & 4.042 \mathrm{E}-18\end{array}$

$\begin{array}{llllllll}1.000 \mathrm{E}+00 \quad 7.799 \mathrm{E}-29 & 2.244 \mathrm{E}-27 & 2.540 \mathrm{E}-22 & 1.691 \mathrm{E}-21 & 5.366 \mathrm{E}-19 & 6.323 \mathrm{E}-17\end{array}$

$\begin{array}{llllll}1.099 \mathrm{E}-25 & 1.142 \mathrm{E}-25 & 2.579 \mathrm{E}-22 & 1.716 \mathrm{E}-21 & 5.515 \mathrm{E}-19 & 7.834 \mathrm{E}-17\end{array}$

$\begin{array}{lllllll}1.000 \mathrm{E}+00 & 5.547 \mathrm{E}-27 & 5.625 \mathrm{E}-27 & 1.112 \mathrm{E}-26 & 2.231 \mathrm{E}-26 & 5.839 \mathrm{E}-24 & 1.233 \mathrm{E}-20\end{array}$

$\begin{array}{lllllll}1.000 \mathrm{E}+00 & 1.329 \mathrm{E}-07 & 9.308 \mathrm{E}-08 & 2.430 \mathrm{E}-15 & 4.441 \mathrm{E}-23 & 0.000 \mathrm{E}+00 \quad 0.000 \mathrm{E}+00\end{array}$

$\begin{array}{llllllll}1.000 \mathrm{E}+00 & 2.319 \mathrm{E}-23 & 2.359 \mathrm{E}-23 & 5.375 \mathrm{E}-23 & 1.246 \mathrm{E}-22 & 1.037 \mathrm{E}-19 & 1.074 \mathrm{E}-15\end{array}$

$\begin{array}{llllllll}1.000 \mathrm{E}+00 & 3.629 \mathrm{E}-12 & 1.095 \mathrm{E}-11 & 5.116 \mathrm{E}-10 & 1.423 \mathrm{E}-09 & 1.032 \mathrm{E}-07 & 8.661 \mathrm{E}-06\end{array}$

$\begin{array}{lllllll}1.000 \mathrm{E}+00 & 1.749 \mathrm{E}-20 & 1.222 \mathrm{E}-19 & 1.249 \mathrm{E}-16 & 5.113 \mathrm{E}-16 & 7.402 \mathrm{E}-14 & 1.190 \mathrm{E}-11\end{array}$

$3.629 \mathrm{E}-12$ 1.095E-11 $5.116 \mathrm{E}-10 \quad 1.423 \mathrm{E}-09 \quad 1.032 \mathrm{E}-07 \quad 8.661 \mathrm{E}-06$ 
RESRAD, Version 6.5

Summary : C746U Recreational User Deterministic Run

File : $\mathrm{X}: \backslash$ FINAL V2\C746U RU SG FWD-FINALV2.RAD

Dose/Source Ratios Summed Over All Pathways

Parent and Progeny Principal Radionuclide Contributions Indicated

\begin{tabular}{|c|c|c|c|c|c|c|c|c|}
\hline $\begin{array}{l}\text { Parent } \\
\text { (i) }\end{array}$ & $\begin{array}{l}\text { Product } \\
\text { (j) }\end{array}$ & $\begin{array}{l}\text { Thread } \\
\text { Fraction }\end{array}$ & $\begin{array}{r}\text { DSR } \\
0.000 \mathrm{E}+00\end{array}$ & $\begin{array}{l}(j, t) \text { At } T \\
1.000 E+00\end{array}$ & $\begin{array}{l}\text { ime in Yea } \\
5.000 \mathrm{E}+01\end{array}$ & $\begin{array}{l}\text { rs (mrem, } \\
1.000 \mathrm{E}+02\end{array}$ & $\begin{array}{l}(\mathrm{yr}) /(\mathrm{pCi} / \mathrm{g} \\
5.000 \mathrm{E}+02\end{array}$ & $\begin{array}{l}\text { g) } \\
1.050 \mathrm{E}+03\end{array}$ \\
\hline-232 & $\mathrm{Th}-232$ & $1.000 \mathrm{E}+00$ & $1.121 \mathrm{E}-25$ & $1.142 \mathrm{E}-25$ & $2.836 \mathrm{E}-25$ & $7.176 \mathrm{E}-25$ & 1. $205 E-21$ & $3.277 \mathrm{E}-17$ \\
\hline-232 & $\mathrm{Ra}-228+\mathrm{D}$ & $1.000 \mathrm{E}+00$ & $1.065 \mathrm{E}-10$ & $3.052 \mathrm{E}-10$ & $2.678 \mathrm{E}-09$ & $3.923 \mathrm{E}-09$ & $8.176 \mathrm{E}-08$ & $5.322 \mathrm{E}-06$ \\
\hline $1-232$ & $T h-228+D$ & $1.000 \mathrm{E}+00$ & $1.026 \mathrm{E}-09$ & $6.328 E-09$ & $2.128 \mathrm{E}-07$ & $2.877 \mathrm{E}-07$ & $3.130 \mathrm{E}-06$ & $8.368 E-05$ \\
\hline-232 & $\sum \operatorname{DSR}(j)$ & & $1.133 E-09$ & $6.633 E-09$ & $2.155 \mathrm{E}-07$ & $2.917 \mathrm{E}-07$ & $3.212 \mathrm{E}-06$ & $8.900 \mathrm{E}-05$ \\
\hline-234 & $\mathrm{U}-234$ & $1.000 \mathrm{E}+00$ & $6.631 E-25$ & $6.749 \mathrm{E}-25$ & 1. $607 \mathrm{E}-24$ & $3.895 E-24$ & $4.636 \mathrm{E}-21$ & $7.854 \mathrm{E}-17$ \\
\hline-234 & Th-230 & $1.000 \mathrm{E}+00$ & $1.047 \mathrm{E}-28$ & $3.188 \mathrm{E}-28$ & $2.443 E-26$ & $1.127 \mathrm{E}-25$ & $4.665 E-22$ & $1.013 \mathrm{E}-17$ \\
\hline-234 & $\mathrm{Ra}-226+\mathrm{D}$ & $1.000 \mathrm{E}+00$ & $1.090 \mathrm{E}-17$ & $7.671 \mathrm{E}-17$ & $1.167 \mathrm{E}-13$ & $6.482 \mathrm{E}-13$ & $2.407 \mathrm{E}-10$ & 4. 396E-08 \\
\hline-234 & $\mathrm{~Pb}-210+\mathrm{D}$ & $1.000 \mathrm{E}+00$ & $3.944 \mathrm{E}-26$ & $5.916 \mathrm{E}-25$ & $2.118 \mathrm{E}-20$ & $1.862 \mathrm{E}-19$ & $1.619 \mathrm{E}-16$ & $5.847 \mathrm{E}-14$ \\
\hline-234 & $\sum \operatorname{DSR}(j)$ & & $1.090 \mathrm{E}-17$ & $7.671 \mathrm{E}-17$ & $1.167 \mathrm{E}-13$ & $6.482 \mathrm{E}-13$ & $2.407 \mathrm{E}-10$ & $4.396 \mathrm{E}-08$ \\
\hline$-235+D$ & $\mathrm{U}-235+\mathrm{D}$ & $1.000 \mathrm{E}+00$ & $1.195 \mathrm{E}-15$ & $1.210 \mathrm{E}-15$ & $2.218 E-15$ & $4.115 \mathrm{E}-15$ & $5.779 \mathrm{E}-13$ & $5.183 \mathrm{E}-10$ \\
\hline$-235+D$ & $\mathrm{~Pa}-231$ & $1.000 \mathrm{E}+00$ & $2.825 E-19$ & $8.554 \mathrm{E}-19$ & $4.840 \mathrm{E}-17$ & $1.637 \mathrm{E}-16$ & $5.673 \mathrm{E}-14$ & $4.068 \mathrm{E}-11$ \\
\hline$-235+D$ & $A C-227+D$ & $1.000 \mathrm{E}+00$ & $8.917 \mathrm{E}-19$ & $6.232 \mathrm{E}-18$ & $6.620 \mathrm{E}-15$ & $2.832 \mathrm{E}-14$ & $6.156 \mathrm{E}-12$ & $1.720 \mathrm{E}-09$ \\
\hline$-235+D$ & $\sum \operatorname{DSR}(j)$ & & $1.197 \mathrm{E}-15$ & $1.217 \mathrm{E}-15$ & $8.886 \mathrm{E}-15$ & $3.260 \mathrm{E}-14$ & $6.791 \mathrm{E}-12$ & $2.279 \mathrm{E}-09$ \\
\hline-238 & $U-238$ & $5.400 E-05$ & $0.000 \mathrm{E}+00$ & $0.000 \mathrm{E}+00$ & $0.000 \mathrm{E}+00$ & $0.000 \mathrm{E}+00$ & $0.000 \mathrm{E}+00$ & $1.636 \mathrm{E}-39$ \\
\hline$-238+D$ & $\mathrm{U}-238+\mathrm{D}$ & $9.999 \mathrm{E}-01$ & 1. $365 \mathrm{E}-11$ & 1. $376 \mathrm{E}-11$ & $2.035 \mathrm{E}-11$ & $3.035 \mathrm{E}-11$ & 7. $419 \mathrm{E}-10$ & $6.017 \mathrm{E}-08$ \\
\hline$-238+D$ & $\mathrm{U}-234$ & $9.999 \mathrm{E}-01$ & $9.426 \mathrm{E}-31$ & $2.873 E-30$ & $2.301 \mathrm{E}-28$ & $1.110 \mathrm{E}-27$ & $6.582 \mathrm{E}-24$ & $2.342 \mathrm{E}-19$ \\
\hline$-238+D$ & $\mathrm{Th}-230$ & $9.999 E-01$ & $9.906 \mathrm{E}-35$ & $7.035 \mathrm{E}-34$ & $1.749 \mathrm{E}-30$ & $1.605 \mathrm{E}-29$ & $3.309 \mathrm{E}-25$ & $1.508 \mathrm{E}-20$ \\
\hline$-238+D$ & $\mathrm{Ra}-226+\mathrm{D}$ & $9.999 \mathrm{E}-01$ & $7.725 E-24$ & $1.165 E-22$ & $5.580 \mathrm{E}-18$ & $6.178 \mathrm{E}-17$ & $1.159 \mathrm{E}-13$ & $4.523 E-11$ \\
\hline$-238+D$ & $\mathrm{~Pb}-210+\mathrm{D}$ & $9.999 \mathrm{E}-01$ & $2.239 \mathrm{E}-32$ & $6.951 \mathrm{E}-31$ & $8.109 \mathrm{E}-25$ & $1.488 \mathrm{E}-23$ & 7. $347 \mathrm{E}-20$ & $5.837 \mathrm{E}-17$ \\
\hline$-238+D$ & $\sum \operatorname{DSR}(j)$ & & $1.365 \mathrm{E}-11$ & 1. $376 \mathrm{E}-11$ & $2.035 \mathrm{E}-11$ & $3.035 \mathrm{E}-11$ & $7.420 \mathrm{E}-10$ & $6.021 \mathrm{E}-08$ \\
\hline
\end{tabular}

The DSR includes contributions from associated (half-life $\leq 180$ days) daughters. 
RESRAD, Version $6.5 \quad \mathrm{~T}^{1 / 2}$ Limit $=180$ days

Summary : C746U Recreational User Deterministic Run

File : $\mathrm{X}: \backslash$ FINAL V2\C746U RU SG FWD-FINALV2.RAD

Single Radionuclide Soil Guidelines G(i,t) in pCi/g

Basic Radiation Dose Limit $=1.000 \mathrm{E}+00 \mathrm{mrem} / \mathrm{yr}$

\begin{tabular}{|c|c|c|c|c|c|c|}
\hline (i) & $t=0.000 E+00$ & $1.000 \mathrm{E}+00$ & $5.000 \mathrm{E}+01$ & $1.000 \mathrm{E}+02$ & $5.000 \mathrm{E}+02$ & $1.050 \mathrm{E}+03$ \\
\hline-241 & $\star 3.431 \mathrm{E}+12$ & $\star 3.431 \mathrm{E}+12$ & $\star 3.431 \mathrm{E}+12$ & $\star 3.431 \mathrm{E}+12$ & $* 3.431 \mathrm{E}+12$ & $8.235 E+11$ \\
\hline-137 & $8.242 E+09$ & $8.364 \mathrm{E}+09$ & $1.718 \mathrm{E}+10$ & $3.580 \mathrm{E}+10$ & $1.274 \mathrm{E}+13$ & $\star 8.704 \mathrm{E}+13$ \\
\hline-237 & $\star 7.047 \mathrm{E}+08$ & $\star 7.047 \mathrm{E}+08$ & $\star 7.047 \mathrm{E}+08$ & $\star 7.047 \mathrm{E}+08$ & $\star 7.047 \mathrm{E}+08$ & $1.380 \mathrm{E}+08$ \\
\hline-238 & $\star 1.712 \mathrm{E}+13$ & $\star 1.712 \mathrm{E}+13$ & $\star 1.712 \mathrm{E}+13$ & $\star 1.712 \mathrm{E}+13$ & $\star 1.712 \mathrm{E}+13$ & $7.937 \mathrm{E}+10$ \\
\hline Pu-239 & $\star 6.214 \mathrm{E}+10$ & $* 6.214 \mathrm{E}+10$ & $\star 6.214 \mathrm{E}+10$ & $\star 6.214 \mathrm{E}+10$ & $\star 6.214 \mathrm{E}+10$ & $* 6.214 \mathrm{E}+10$ \\
\hline $\mathrm{Pu}-240$ & $\star 2.278 \mathrm{E}+11$ & $\star 2.278 \mathrm{E}+11$ & $\star 2.278 \mathrm{E}+11$ & $\star 2.278 \mathrm{E}+11$ & $\star 2.278 \mathrm{E}+11$ & $\star 2.278 \mathrm{E}+11$ \\
\hline$c-99$ & $\star 1.697 \mathrm{E}+10$ & $\star 1.697 \mathrm{E}+10$ & $\star 1.697 \mathrm{E}+10$ & $* 1.697 \mathrm{E}+10$ & $\star 1.697 \mathrm{E}+10$ & $\star 1.697 \mathrm{E}+10$ \\
\hline-228 & $7.523 E+06$ & $1.074 E+07$ & $4.116 \mathrm{E}+14$ & $\star 8.195 \mathrm{E}+14$ & $\star 8.195 \mathrm{E}+14$ & $* 8.195 \mathrm{E}+14$ \\
\hline-230 & $\star 2.018 \mathrm{E}+10$ & $\star 2.018 \mathrm{E}+10$ & $1.955 \mathrm{E}+09$ & $7.028 \mathrm{E}+08$ & $9.688 \mathrm{E}+06$ & $1.155 \mathrm{E}+05$ \\
\hline 232 & $\star 1.097 \mathrm{E}+05$ & $\star 1.097 \mathrm{E}+05$ & $\star 1.097 \mathrm{E}+05$ & $\star 1.097 \mathrm{E}+05$ & *1.097E+05 & $1.124 \mathrm{E}+04$ \\
\hline 34 & $* 6.247 \mathrm{E}+09$ & $* 6.247 \mathrm{E}+09$ & $* 6.247 \mathrm{E}+09$ & $\star 6.247 \mathrm{E}+09$ & $4.154 \mathrm{E}+09$ & $2.275 E+07$ \\
\hline 35 & $\star 2.161 \mathrm{E}+06$ & $\star 2.161 \mathrm{E}+06$ & $\star 2.161 \mathrm{E}+06$ & $\star 2.161 \mathrm{E}+06$ & $\star 2.161 \mathrm{E}+06$ & $\star 2.161 \mathrm{E}+06$ \\
\hline 238 & $\star 3.361 \mathrm{E}+05$ & $\star 3.361 \mathrm{E}+05$ & $\star 3.361 \mathrm{E}+05$ & $\star 3.361 \mathrm{E}+05$ & $\star 3.361 \mathrm{E}+05$ & $\star 3.361 \mathrm{E}+05$ \\
\hline
\end{tabular}

*At specific activity limit

Summed Dose/Source Ratios DSR(i,t) in (mrem/yr)/(pCi/g)

and Single Radionuclide Soil Guidelines $\mathrm{G}(i, t)$ in $\mathrm{pCi} / \mathrm{g}$

at tmin $=$ time of minimum single radionuclide soil guideline

and at tmax $=$ time of maximum total dose $=1.050 \mathrm{E}+03$ years

\begin{tabular}{|c|c|c|c|c|c|c|}
\hline $\begin{array}{l}\text { Uclide } \\
\text { (i) }\end{array}$ & $\begin{array}{l}\text { Initial } \\
(\mathrm{pCi} / \mathrm{g})\end{array}$ & $\begin{array}{c}\text { tmin } \\
\text { (years) }\end{array}$ & $\operatorname{DSR}(i, \operatorname{tmin})$ & $\begin{array}{c}\mathrm{G}(\mathrm{i}, \mathrm{tmin}) \\
(\mathrm{pCi} / \mathrm{g})\end{array}$ & $\operatorname{DSR}(i, \operatorname{tmax})$ & $\begin{aligned} & \mathrm{G}(i, \mathrm{tmax}) \\
&(\mathrm{pCi} / \mathrm{g})\end{aligned}$ \\
\hline-241 & $3.500 \mathrm{E}+03$ & $1.050 \mathrm{E}+03$ & $1.214 \mathrm{E}-12$ & $8.235 E+11$ & $1.214 \mathrm{E}-12$ & $8.235 \mathrm{E}+11$ \\
\hline 137 & $1.900 \mathrm{E}+02$ & $0.000 \mathrm{E}+00$ & $1.213 \mathrm{E}-10$ & $8.242 E+09$ & $2.435 \mathrm{E}-17$ & $\star 8.704 \mathrm{E}+13$ \\
\hline 237 & $5.500 \mathrm{E}+02$ & $1.050 \mathrm{E}+03$ & $7.245 \mathrm{E}-09$ & $1.380 \mathrm{E}+08$ & $7.245 \mathrm{E}-09$ & $1.380 \mathrm{E}+08$ \\
\hline-238 & $3.900 \mathrm{E}+03$ & $1.050 \mathrm{E}+03$ & $1.260 \mathrm{E}-11$ & $7.937 \mathrm{E}+10$ & $1.260 \mathrm{E}-11$ & $7.937 \mathrm{E}+10$ \\
\hline $\mathrm{Pu}-239$ & $3.600 E+03$ & $1.050 \mathrm{E}+03$ & $3.234 \mathrm{E}-13$ & $* 6.214 \mathrm{E}+10$ & $3.234 \mathrm{E}-13$ & $\star 6.214 \mathrm{E}+10$ \\
\hline $1-240$ & $3.600 \mathrm{E}+03$ & $1.050 \mathrm{E}+03$ & $7.834 \mathrm{E}-17$ & $\star 2.278 \mathrm{E}+11$ & $7.834 \mathrm{E}-17$ & $\star 2.278 \mathrm{E}+11$ \\
\hline TC-99 & $2.800 E+01$ & $1.050 \mathrm{E}+03$ & $1.233 \mathrm{E}-20$ & $\star 1.697 \mathrm{E}+10$ & $1.233 \mathrm{E}-20$ & $\star 1.697 \mathrm{E}+10$ \\
\hline Th-228 & $7.400 \mathrm{E}+01$ & $0.000 \mathrm{E}+00$ & $1.329 \mathrm{E}-07$ & $7.523 \mathrm{E}+06$ & $0.000 \mathrm{E}+00$ & $\star 8.195 \mathrm{E}+14$ \\
\hline$T h-230$ & $1.200 \mathrm{E}+03$ & $1.050 \mathrm{E}+03$ & $8.661 \mathrm{E}-06$ & $1.155 \mathrm{E}+05$ & $8.661 \mathrm{E}-06$ & $1.155 \mathrm{E}+05$ \\
\hline 232 & $3.800 \mathrm{E}+01$ & $1.050 \mathrm{E}+03$ & $8.900 \mathrm{E}-05$ & $1.124 \mathrm{E}+04$ & $8.900 \mathrm{E}-05$ & $1.124 \mathrm{E}+04$ \\
\hline 34 & $1.800 \mathrm{E}+04$ & $1.050 \mathrm{E}+03$ & $4.396 \mathrm{E}-08$ & $2.275 \mathrm{E}+07$ & $4.396 \mathrm{E}-08$ & $2.275 E+07$ \\
\hline 35 & $8.200 \mathrm{E}+02$ & $1.050 \mathrm{E}+03$ & $2.279 \mathrm{E}-09$ & $\star 2.161 \mathrm{E}+06$ & $2.279 \mathrm{E}-09$ & $\star 2.161 \mathrm{E}+06$ \\
\hline 238 & $3.200 \mathrm{E}+03$ & $1.050 \mathrm{E}+03$ & $6.021 \mathrm{E}-08$ & $\star 3.361 \mathrm{E}+05$ & $6.021 \mathrm{E}-08$ & $\star 3.361 \mathrm{E}+05$ \\
\hline
\end{tabular}

*At specific activity limit 
RESRAD, Version 6.5

Summary : C746U Recreational User Deterministic Run

File : $\mathrm{X}: \backslash$ FINAL V2 $\backslash \mathrm{C} 746 \mathrm{U}$ RU SG FWD-FINALV2.RAD

Individual Nuclide Dose Summed Over All Pathways

Parent Nuclide and Branch Fraction Indicated

Nuclide Parent THF(i) DOSE $(j, t)$, mrem/yr

\begin{tabular}{|c|c|c|}
\hline$(j)$ & (i) & \\
\hline-241 & $A m-241$ & $1.000 \mathrm{E}+00$ \\
\hline$p-237$ & $A m-241$ & $1.000 \mathrm{E}+00$ \\
\hline $\mathrm{Np}-237$ & $\mathrm{~Np}-237$ & $1.000 \mathrm{E}+00$ \\
\hline Np-237 & $\sum \operatorname{DOSE}(j$ & \\
\hline
\end{tabular}

$\mathrm{U}-233 \quad \mathrm{Am}-241 \quad 1.000 \mathrm{E}+00$

$\mathrm{U}-233 \quad \mathrm{~Np}-237 \quad 1.000 \mathrm{E}+00$

U-233 $\quad$ DOSE $(j)$

Th-229

Th-229

Th-229

Cs -137

$\mathrm{Pu}-238$

$\mathrm{Pu}-238$

$\mathrm{Pu}-238$

$\mathrm{U}-234$

$\mathrm{U}-234$

$\mathrm{U}-234$

$\mathrm{U}-234$

Th -230

Th -230

Th -230

Th-230

Th -230

$\mathrm{Ra}-226$

$\mathrm{Ra}-226$

$\mathrm{Ra}-226$

$\mathrm{Ra}-226$

$\mathrm{Ra}-226$

$\mathrm{Pb}-210$

$\mathrm{Pb}-210$

$\mathrm{Pb}-210$

$\mathrm{Pb}-210$

$\mathrm{Pb}-210$

$\mathrm{Pu}-239$

Pu-239 $1.000 \mathrm{E}+00$ $\mathrm{U}-2351.000 \mathrm{E}+00$

$\sum \operatorname{DOSE}(j)$ $\mathrm{t}=0.000 \mathrm{E}+00 \quad 1.000 \mathrm{E}+00 \quad 5.000 \mathrm{E}+01 \quad 1.000 \mathrm{E}+02 \quad 5.000 \mathrm{E}+02 \quad 1.050 \mathrm{E}+03$

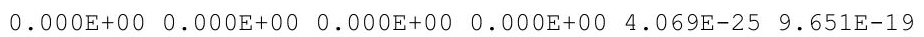

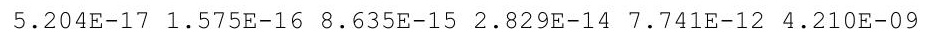

$\begin{array}{llllll}5.043 \mathrm{E}-11 & 5.097 \mathrm{E}-11 & 8.620 \mathrm{E}-11 & 1.473 \mathrm{E}-10 & 1.073 \mathrm{E}-08 & 3.906 \mathrm{E}-06\end{array}$

$\begin{array}{llllll}5.043 \mathrm{E}-11 & 5.097 \mathrm{E}-11 & 8.621 \mathrm{E}-11 & 1.474 \mathrm{E}-10 & 1.074 \mathrm{E}-08 & 3.910 \mathrm{E}-06\end{array}$

$0.000 \mathrm{E}+00 \quad 8.344 \mathrm{E}-27 \quad 1.639 \mathrm{E}-23 \quad 1.182 \mathrm{E}-22 \quad 3.586 \mathrm{E}-19 \quad 1.209 \mathrm{E}-15$

$\begin{array}{llllll}1.716 \mathrm{E}-21 & 5.206 \mathrm{E}-21 & 3.231 \mathrm{E}-19 & 1.201 \mathrm{E}-18 & 8.871 \mathrm{E}-16 & 1.800 \mathrm{E}-12\end{array}$

$\begin{array}{llllll}1.716 \mathrm{E}-21 & 5.206 \mathrm{E}-21 & 3.231 \mathrm{E}-19 & 1.201 \mathrm{E}-18 & 8.874 \mathrm{E}-16 & 1.801 \mathrm{E}-12\end{array}$

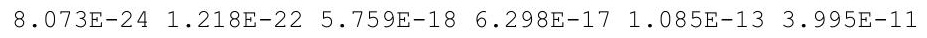

$\begin{array}{llllll}1.567 \mathrm{E}-17 & 1.103 \mathrm{E}-16 & 1.692 \mathrm{E}-13 & 9.477 \mathrm{E}-13 & 3.786 \mathrm{E}-10 & 7.936 \mathrm{E}-08\end{array}$

$\begin{array}{llllll}1.567 \mathrm{E}-17 & 1.103 \mathrm{E}-16 & 1.692 \mathrm{E}-13 & 9.478 \mathrm{E}-13 & 3.787 \mathrm{E}-10 & 7.940 \mathrm{E}-08\end{array}$

$2.305 \mathrm{E}-08 \quad 2.272 \mathrm{E}-08 \quad 1.106 \mathrm{E}-08 \quad 5.307 \mathrm{E}-09 \quad 1.491 \mathrm{E}-11 \quad 4.627 \mathrm{E}-15$

$\begin{array}{llllll}0.000 \mathrm{E}+00 & 0.000 \mathrm{E}+00 & 0.000 \mathrm{E}+00 & 0.000 \mathrm{E}+00 & 0.000 \mathrm{E}+00 & 2.281 \mathrm{E}-26\end{array}$

$\begin{array}{llllll}4.406 \mathrm{E}-22 & 4.449 \mathrm{E}-22 & 7.176 \mathrm{E}-22 & 1.169 \mathrm{E}-21 & 5.791 \mathrm{E}-20 & 1.240 \mathrm{E}-17\end{array}$

$\begin{array}{llllll}4.406 \mathrm{E}-22 & 4.449 \mathrm{E}-22 & 7.176 \mathrm{E}-22 & 1.169 \mathrm{E}-21 & 5.791 \mathrm{E}-20 & 1.240 \mathrm{E}-17\end{array}$

$0.000 \mathrm{E}+00 \quad 1.114 \mathrm{E}-26 \quad 7.400 \mathrm{E}-25 \quad 2.988 \mathrm{E}-24 \quad 6.368 \mathrm{E}-21 \quad 1.100 \mathrm{E}-16$

$\begin{array}{llllll}1.194 \mathrm{E}-20 & 1.215 \mathrm{E}-20 & 2.893 \mathrm{E}-20 & 7.010 \mathrm{E}-20 & 8.344 \mathrm{E}-17 & 1.414 \mathrm{E}-12\end{array}$

$\begin{array}{llllll}0.000 \mathrm{E}+00 & 9.193 \mathrm{E}-27 & 7.363 \mathrm{E}-25 & 3.551 \mathrm{E}-24 & 2.106 \mathrm{E}-20 & 7.496 \mathrm{E}-16\end{array}$

$\begin{array}{llllll}1.194 \mathrm{E}-20 & 1.215 \mathrm{E}-20 & 2.893 \mathrm{E}-20 & 7.011 \mathrm{E}-20 & 8.347 \mathrm{E}-17 & 1.415 \mathrm{E}-12\end{array}$

$\begin{array}{llllll}0.000 \mathrm{E}+00 & 0.000 \mathrm{E}+00 & 5.998 \mathrm{E}-27 & 4.887 \mathrm{E}-26 & 4.910 \mathrm{E}-22 & 1.247 \mathrm{E}-17\end{array}$ $\begin{array}{llllll}2.783 \mathrm{E}-20 & 2.830 \mathrm{E}-20 & 6.450 \mathrm{E}-20 & 1.495 \mathrm{E}-19 & 1.244 \mathrm{E}-16 & 1.289 \mathrm{E}-12\end{array}$ $\begin{array}{llllll}1.884 \mathrm{E}-24 & 5.738 \mathrm{E}-24 & 4.398 \mathrm{E}-22 & 2.028 \mathrm{E}-21 & 8.396 \mathrm{E}-18 & 1.823 \mathrm{E}-13\end{array}$ $\begin{array}{lllllll}0.000 \mathrm{E}+00 & 0.000 \mathrm{E}+00 & 5.597 \mathrm{E}-27 & 5.136 \mathrm{E}-26 & 1.059 \mathrm{E}-21 & 4.825 \mathrm{E}-17\end{array}$ $\begin{array}{llllll}2.783 \mathrm{E}-20 & 2.831 \mathrm{E}-20 & 6.494 \mathrm{E}-20 & 1.515 \mathrm{E}-19 & 1.328 \mathrm{E}-16 & 1.471 \mathrm{E}-12\end{array}$

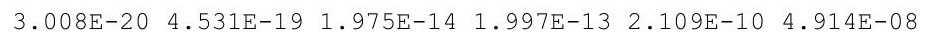
$\begin{array}{llllll}4.355 \mathrm{E}-09 & 1.314 \mathrm{E}-08 & 6.139 \mathrm{E}-07 & 1.707 \mathrm{E}-06 & 1.239 \mathrm{E}-04 & 1.039 \mathrm{E}-02\end{array}$ $\begin{array}{llllll}1.961 \mathrm{E}-13 & 1.381 \mathrm{E}-12 & 2.101 \mathrm{E}-09 & 1.167 \mathrm{E}-08 & 4.333 \mathrm{E}-06 & 7.913 \mathrm{E}-04\end{array}$ $2.472 \mathrm{E}-20 \quad 3.729 \mathrm{E}-19 \quad 1.786 \mathrm{E}-14 \quad 1.977 \mathrm{E}-13 \quad 3.707 \mathrm{E}-10 \quad 1.447 \mathrm{E}-07$ $\begin{array}{llllll}4.355 \mathrm{E}-09 & 1.314 \mathrm{E}-08 & 6.160 \mathrm{E}-07 & 1.719 \mathrm{E}-06 & 1.282 \mathrm{E}-04 & 1.118 \mathrm{E}-02\end{array}$

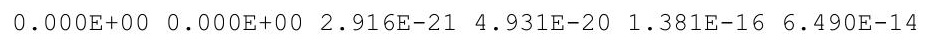
$\begin{array}{llllll}2.099 \mathrm{E}-17 & 1.466 \mathrm{E}-16 & 1.499 \mathrm{E}-13 & 6.136 \mathrm{E}-13 & 8.882 \mathrm{E}-11 & 1.428 \mathrm{E}-08\end{array}$ $\begin{array}{llllll}7.099 \mathrm{E}-22 & 1.065 \mathrm{E}-20 & 3.812 \mathrm{E}-16 & 3.351 \mathrm{E}-15 & 2.914 \mathrm{E}-12 & 1.053 \mathrm{E}-09\end{array}$ $\begin{array}{llllll}0.000 \mathrm{E}+00 & 0.000 \mathrm{E}+00 & 2.595 \mathrm{E}-21 & 4.761 \mathrm{E}-20 & 2.351 \mathrm{E}-16 & 1.868 \mathrm{E}-13\end{array}$ $2.099 \mathrm{E}-17 \quad 1.466 \mathrm{E}-16 \quad 1.503 \mathrm{E}-13 \quad 6.169 \mathrm{E}-13 \quad 9.173 \mathrm{E}-11 \quad 1.533 \mathrm{E}-08$

$\begin{array}{llllll}4.161 \mathrm{E}-15 & 4.211 \mathrm{E}-15 & 7.560 \mathrm{E}-15 & 1.373 \mathrm{E}-14 & 1.629 \mathrm{E}-12 & 1.159 \mathrm{E}-09\end{array}$

$2.124 \mathrm{E}-21 \quad 6.441 \mathrm{E}-21 \quad 3.969 \mathrm{E}-19 \quad 1.465 \mathrm{E}-18 \quad 1.019 \mathrm{E}-15 \quad 1.905 \mathrm{E}-12$ $\begin{array}{lllllll}9.803 \mathrm{E}-13 & 9.925 \mathrm{E}-13 & 1.819 \mathrm{E}-12 & 3.375 \mathrm{E}-12 & 4.739 \mathrm{E}-10 & 4.250 \mathrm{E}-07\end{array}$ $\begin{array}{llllll}9.803 \mathrm{E}-13 & 9.925 \mathrm{E}-13 & 1.819 \mathrm{E}-12 & 3.375 \mathrm{E}-12 & 4.739 \mathrm{E}-10 & 4.250 \mathrm{E}-07\end{array}$ 
RESRAD, Version $6.5 \quad \mathrm{~T}^{1 / 2}$ Limit $=180$ days

umary : C746U Recreational User Deterministic Run

File : $X: \backslash F I N A L$ V2 $\backslash C 746 U$ RU SG FWD-FINALV2.RAD

Individual Nuclide Dose Summed Over All Pathways

Parent Nuclide and Branch Fraction Indicated

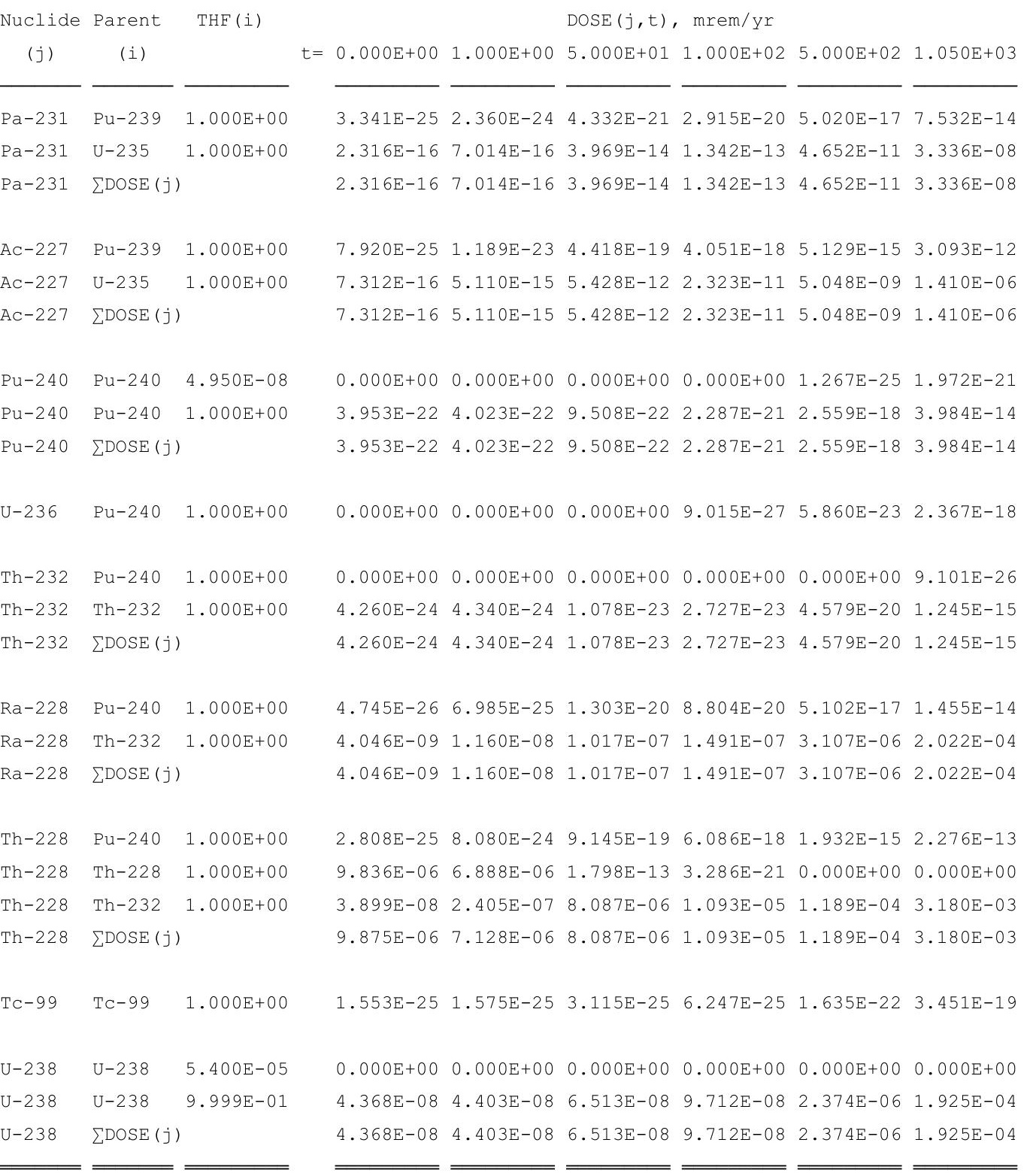

THF(i) is the thread fraction of the parent nuclide. 
RESRAD, Version $6.5 \quad \mathrm{~T}^{1 / 2}$ Limit $=180$ days

Summary : C746U Recreational User Deterministic Run

File : $\mathrm{X}: \backslash F I N A L$ V2 $\backslash \mathrm{C} 746 \mathrm{U}$ RU SG FWD-FINALV2.RAD

Individual Nuclide Soil Concentration

Parent Nuclide and Branch Fraction Indicated

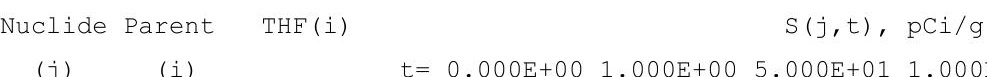

\section{(j)}

Am-241 Am-241 1.000E+00

$\mathrm{Np}-237 \quad \mathrm{Am}-241 \quad 1.000 \mathrm{E}+00$

$\mathrm{Np}-237 \quad \mathrm{~Np}-237 \quad 1.000 \mathrm{E}+00$

Np-237 $\sum S(j):$

$\mathrm{U}-233 \quad \mathrm{Am}-241 \quad 1.000 \mathrm{E}+00$

$\mathrm{U}-233 \mathrm{~Np}-237 \quad 1.000 \mathrm{E}+00$

U-233 $\quad \sum S(j):$

Th-229

$\mathrm{Th}-229$

$\mathrm{Th}-229$

Cs -137

$\mathrm{Pu}-238$

$\mathrm{Pu}-238$

$\mathrm{Pu}-238$

$\mathrm{U}-234$

$\mathrm{U}-234$

$\mathrm{U}-234$

$\mathrm{U}-234$

Th-230

$\mathrm{Th}-230$

$\mathrm{Th}-230$

$\mathrm{Th}-230$

Th-230

$\mathrm{Ra}-226$

$\mathrm{Ra}-226$

$\mathrm{Ra}-226$

$\mathrm{Ra}-226$

$\mathrm{Ra}-226$

$\mathrm{Pb}-210$

$\mathrm{Pb}-210$

$\mathrm{Pb}-210$

$\mathrm{Pb}-210$

$\mathrm{Pb}-210$

Pu-239

Am-241 1.000E+00

$\mathrm{Np}-237 \quad 1.000 \mathrm{E}+00$

$\sum S(j):$

Cs-137 1.000E+00

Pu-238 1.840E-09

$\mathrm{Pu}-238 \quad 1.000 \mathrm{E}+00$

$\sum S(j):$

$\mathrm{Pu}-238 \quad 1.000 \mathrm{E}+00$

$\mathrm{U}-234 \quad 1.000 \mathrm{E}+00$

U-238 9.999E-01

$\sum S(j):$

$\mathrm{Pu}-238 \quad 1.000 \mathrm{E}+00$

Th-230 1.000E+00

U-234 $1.000 \mathrm{E}+00$

U-238 9.999E-01

$\sum S(j):$

$\mathrm{Pu}-238 \quad 1.000 \mathrm{E}+00$

Th-230 1.000E+00

$\mathrm{U}-2341.000 \mathrm{E}+00$

U-238 9.999E-01

$\sum S(j):$

$\mathrm{Pu}-238 \quad 1.000 \mathrm{E}+00$

Th-230 1.000E+00

$\mathrm{U}-234 \quad 1.000 \mathrm{E}+00$

U-238 9.999E-01

$\sum S(j):$

Pu-239 1.000E+00

$\mathrm{Pu}-239 \quad 1.000 \mathrm{E}+00$

$\mathrm{U}-235 \quad 1.000 \mathrm{E}+00$

$\sum S(j):$
$=0.000 \mathrm{E}+001.000 \mathrm{E}+00 \quad 5.000 \mathrm{E}+01 \quad 1.000 \mathrm{E}+02 \quad 5.000 \mathrm{E}+02 \quad 1.050 \mathrm{E}+03$

$\begin{array}{llllll}3.500 \mathrm{E}+03 & 3.494 \mathrm{E}+03 & 3.230 \mathrm{E}+03 & 2.981 \mathrm{E}+03 & 1.567 \mathrm{E}+03 & 6.478 \mathrm{E}+02\end{array}$

$0.000 \mathrm{E}+00$ 1.133E-03 5.436E-02 1.043E-01 3.810E-01 5.458E-01

$5.500 \mathrm{E}+02 \quad 5.500 \mathrm{E}+02 \quad 5.478 \mathrm{E}+02 \quad 5.457 \mathrm{E}+02 \quad 5.288 \mathrm{E}+02 \quad 5.064 \mathrm{E}+02$

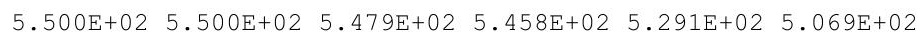

$0.000 \mathrm{E}+00 \quad 2.477 \mathrm{E}-09 \quad 6.025 \mathrm{E}-06 \quad 2.344 \mathrm{E}-05 \quad 4.742 \mathrm{E}-04 \quad 1.613 \mathrm{E}-03$

$\begin{array}{lllllll}0.000 \mathrm{E}+00 & 2.405 \mathrm{E}-03 & 1.200 \mathrm{E}-01 & 2.394 \mathrm{E}-01 & 1.174 \mathrm{E}+00 & 2.401 \mathrm{E}+00\end{array}$

$\begin{array}{lllllll}0.000 \mathrm{E}+00 & 2.405 \mathrm{E}-03 & 1.200 \mathrm{E}-01 & 2.394 \mathrm{E}-01 & 1.174 \mathrm{E}+00 & 2.403 \mathrm{E}+00\end{array}$

$0.000 \mathrm{E}+00 \quad 7.799 \mathrm{E}-14 \quad 9.538 \mathrm{E}-09 \quad 7.463 \mathrm{E}-08 \quad 7.873 \mathrm{E}-06 \quad 5.891 \mathrm{E}-05$

$0.000 \mathrm{E}+00 \quad 1.136 \mathrm{E}-07 \quad 2.830 \mathrm{E}-04 \quad 1.128 \mathrm{E}-03 \quad 2.750 \mathrm{E}-02 \quad 1.171 \mathrm{E}-01$

$0.000 \mathrm{E}+00 \quad 1.136 \mathrm{E}-07 \quad 2.830 \mathrm{E}-04 \quad 1.128 \mathrm{E}-03 \quad 2.750 \mathrm{E}-02 \quad 1.171 \mathrm{E}-01$

$\begin{array}{lllll}1.900 \mathrm{E}+02 & 1.857 \mathrm{E}+02 & 5.979 \mathrm{E}+01 & 1.881 \mathrm{E}+01 & 1.809 \mathrm{E}-03 \quad 5.417 \mathrm{E}-09\end{array}$

7.176E-06 7.119E-06 4.832E-06 3.254E-06 $1.375 \mathrm{E}-07 \quad 1.774 \mathrm{E}-09$

$\begin{array}{llllll}3.900 \mathrm{E}+03 & 3.869 \mathrm{E}+03 & 2.626 \mathrm{E}+03 & 1.768 \mathrm{E}+03 & 7.472 \mathrm{E}+01 & 9.639 \mathrm{E}-01\end{array}$

$\begin{array}{llllll}3.900 \mathrm{E}+03 & 3.869 \mathrm{E}+03 & 2.626 \mathrm{E}+03 & 1.768 \mathrm{E}+03 & 7.472 \mathrm{E}+01 & 9.639 \mathrm{E}-01\end{array}$

$0.000 \mathrm{E}+00 \quad 1.101 \mathrm{E}-02 \quad 4.564 \mathrm{E}-01 \quad 7.633 \mathrm{E}-01 \quad 1.362 \mathrm{E}+00 \quad 1.377 \mathrm{E}+00$

$\begin{array}{lllllll}1.800 \mathrm{E}+04 & 1.800 \mathrm{E}+04 & 1.799 \mathrm{E}+04 & 1.797 \mathrm{E}+04 & 1.785 \mathrm{E}+04 & 1.770 \mathrm{E}+04\end{array}$

$0.000 \mathrm{E}+00 \quad 9.071 \mathrm{E}-03 \quad 4.532 \mathrm{E}-01 \quad 9.058 \mathrm{E}-01 \quad 4.502 \mathrm{E}+00 \quad 9.378 \mathrm{E}+00$

$\begin{array}{llllll}1.800 \mathrm{E}+04 & 1.800 \mathrm{E}+04 & 1.799 \mathrm{E}+04 & 1.797 \mathrm{E}+04 & 1.786 \mathrm{E}+04 & 1.771 \mathrm{E}+04\end{array}$

$0.000 \mathrm{E}+00 \quad 4.963 \mathrm{E}-08 \quad 1.095 \mathrm{E}-04 \quad 3.884 \mathrm{E}-04 \quad 4.705 \mathrm{E}-03 \quad 1.147 \mathrm{E}-02$

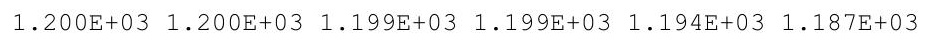
$0.000 \mathrm{E}+00 \quad 1.620 \mathrm{E}-01 \quad 8.096 \mathrm{E}+00 \quad 1.618 \mathrm{E}+01 \quad 8.047 \mathrm{E}+01 \quad 1.677 \mathrm{E}+02$ $0.000 \mathrm{E}+00 \quad 4.083 \mathrm{E}-08 \quad 1.020 \mathrm{E}-04 \quad 4.077 \mathrm{E}-04 \quad 1.014 \mathrm{E}-02 \quad 4.438 \mathrm{E}-02$

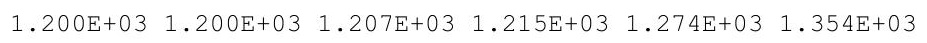

$0.000 \mathrm{E}+00 \quad 7.171 \mathrm{E}-12 \quad 8.112 \mathrm{E}-07 \quad 5.891 \mathrm{E}-06 \quad 3.952 \mathrm{E}-04 \quad 2.049 \mathrm{E}-03$ $\begin{array}{lllllllll}0.000 \mathrm{E}+00 & 5.197 \mathrm{E}-01 & 2.570 \mathrm{E}+01 & 5.082 \mathrm{E}+01 & 2.324 \mathrm{E}+02 & 4.336 \mathrm{E}+02\end{array}$ $\begin{array}{llllll}0.000 \mathrm{E}+00 & 3.509 \mathrm{E}-05 & 8.706 \mathrm{E}-02 & 3.455 \mathrm{E}-01 & 8.122 \mathrm{E}+00 & 3.300 \mathrm{E}+01\end{array}$ $0.000 \mathrm{E}+00 \quad 5.895 \mathrm{E}-12 \quad 7.326 \mathrm{E}-07 \quad 5.825 \mathrm{E}-06 \quad 6.943 \mathrm{E}-04 \quad 6.033 \mathrm{E}-03$ $\begin{array}{lllllll}0.000 \mathrm{E}+00 & 5.198 \mathrm{E}-01 & 2.579 \mathrm{E}+01 & 5.117 \mathrm{E}+01 & 2.406 \mathrm{E}+02 & 4.666 \mathrm{E}+02\end{array}$

$\begin{array}{lllllll}0.000 \mathrm{E}+00 & 5.540 \mathrm{E}-14 & 2.418 \mathrm{E}-07 & 2.812 \mathrm{E}-06 & 3.398 \mathrm{E}-04 & 1.921 \mathrm{E}-03\end{array}$ $0.000 \mathrm{E}+00 \quad 7.995 \mathrm{E}-03 \quad 1.269 \mathrm{E}+01 \quad 3.535 \mathrm{E}+01 \quad 2.188 \mathrm{E}+02 \quad 4.228 \mathrm{E}+02$ $\begin{array}{llllll}0.000 \mathrm{E}+00 & 3.608 \mathrm{E}-07 & 3.192 \mathrm{E}-02 & 1.920 \mathrm{E}-01 & 7.171 \mathrm{E}+00 & 3.116 \mathrm{E}+01\end{array}$ $\begin{array}{lllllll}0.000 \mathrm{E}+00 & 4.553 \mathrm{E}-14 & 2.150 \mathrm{E}-07 & 2.712 \mathrm{E}-06 & 5.779 \mathrm{E}-04 & 5.526 \mathrm{E}-03\end{array}$ $\begin{array}{llllll}0.000 \mathrm{E}+00 & 7.995 \mathrm{E}-03 & 1.272 \mathrm{E}+01 & 3.554 \mathrm{E}+01 & 2.260 \mathrm{E}+02 \quad 4.540 \mathrm{E}+02\end{array}$

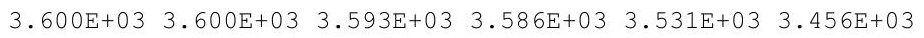
$0.000 \mathrm{E}+00 \quad 3.545 \mathrm{E}-06 \quad 1.770 \mathrm{E}-04 \quad 3.536 \mathrm{E}-04 \quad 1.750 \mathrm{E}-03 \quad 3.622 \mathrm{E}-03$ $8.200 \mathrm{E}+02 \quad 8.200 \mathrm{E}+02 \quad 8.195 \mathrm{E}+02 \quad 8.189 \mathrm{E}+02 \quad 8.145 \mathrm{E}+02 \quad 8.085 \mathrm{E}+02$ $8.200 \mathrm{E}+02 \quad 8.200 \mathrm{E}+02 \quad 8.195 \mathrm{E}+02 \quad 8.189 \mathrm{E}+02 \quad 8.145 \mathrm{E}+02 \quad 8.085 \mathrm{E}+02$ 
RESRAD, Version $6.5 \quad \mathrm{~T}^{1 / 2}$ Limit $=180$ days

ummary : C746U Recreational User Deterministic Run

File : $\mathrm{X}: \backslash F I N A L$ V2 $\backslash \mathrm{C} 746 \mathrm{U}$ RU SG FWD-FINALV2.RAD

Individual Nuclide Soil Concentration

Parent Nuclide and Branch Fraction Indicated

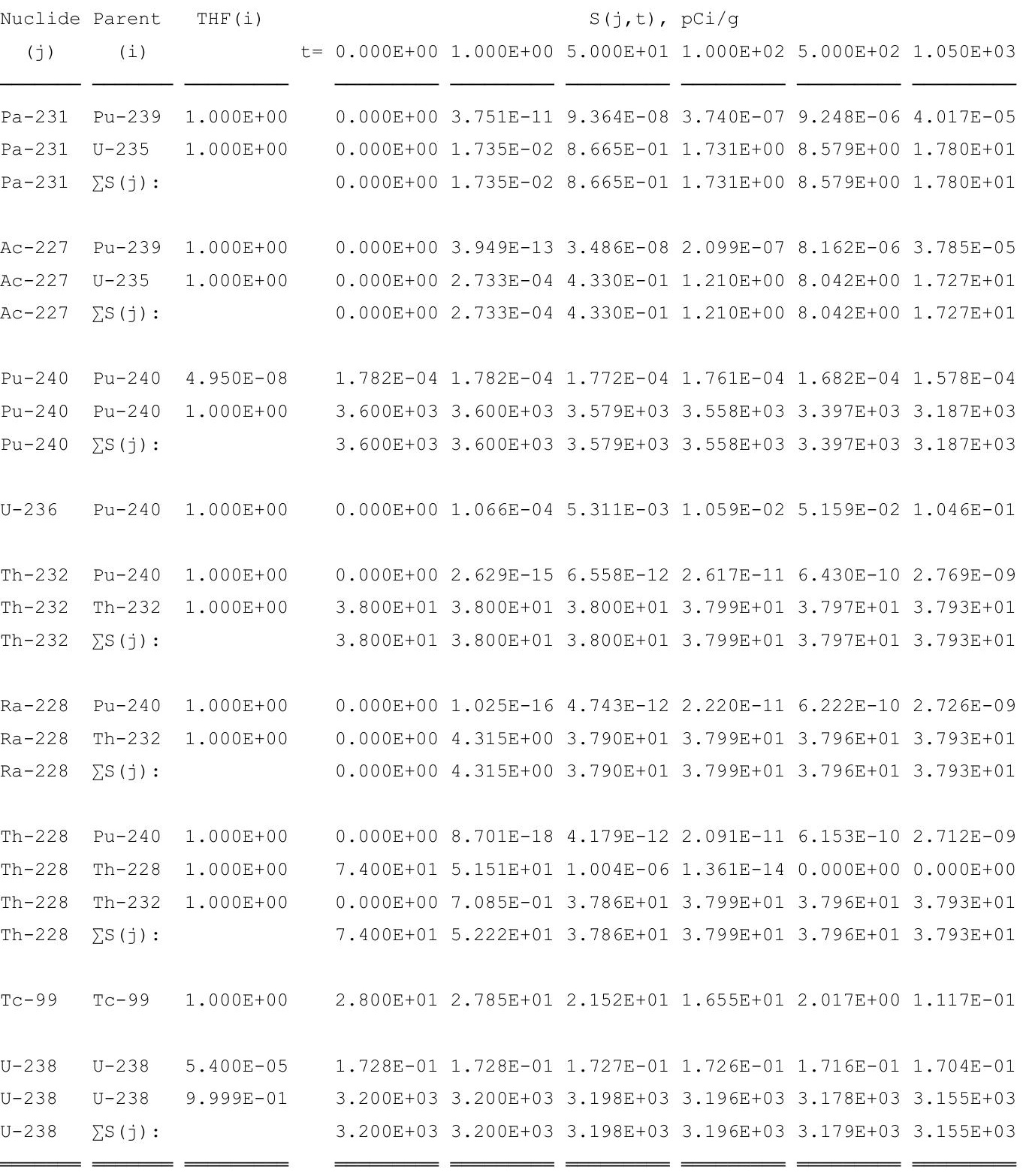

THF(i) is the thread fraction of the parent nuclide.

RESCALC.EXE execution time $=2.65$ seconds 


\section{Outdoor Worker}

The following summary report includes the single radionuclide soil guidelines based on a unit concentration for targeted radionuclides. 
THIS PAGE INTENTIONALLY LEFT BLANK 
RESRAD, Version 6.5

Summary : C746U Worker Deterministic Run

File : X: \FINAL V2\C746U W DET-FINALV2.RAD

Table of Contents

Part I: Mixture Sums and Single Radionuclide Guidelines

Dose Conversion Factor (and Related) Parameter Summary ... 2

Site-Specific Parameter Summary $\ldots \ldots \ldots \ldots \ldots \ldots \ldots \ldots \ldots$

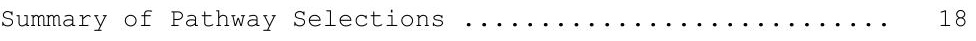

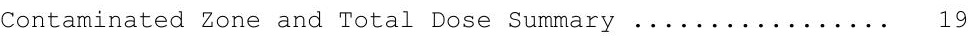

Total Dose Components

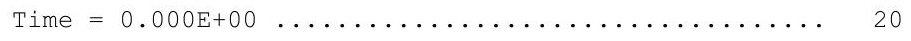

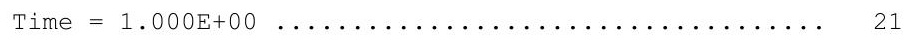

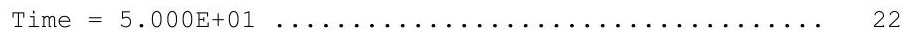

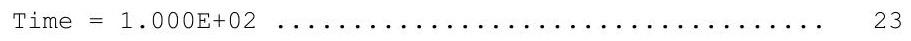

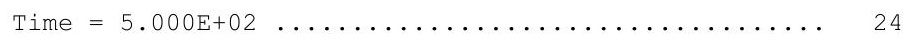

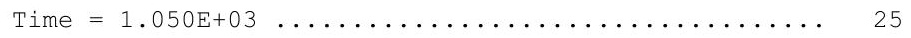

Dose/Source Ratios Summed Over All Pathways ............ 26

Single Radionuclide Soil Guidelines ............... 28

Dose Per Nuclide Summed Over All Pathways ............. 29

Soil Concentration Per Nuclide .................. 31 
RESRAD, Version $6.5 \quad T^{1 / 2}$ Limit $=180$ days

05/03/2011 16:14 Page

Summary : C746U Worker Deterministic Run

File : $\mathrm{X}: \backslash$ FINAL V2 $\backslash \mathrm{C} 746 \mathrm{U}$ W DET-FINALV2.RAD

Dose Conversion Factor (and Related) Parameter Summary

Dose Library: ICRP 60 \& ICRP 72 (Adult)

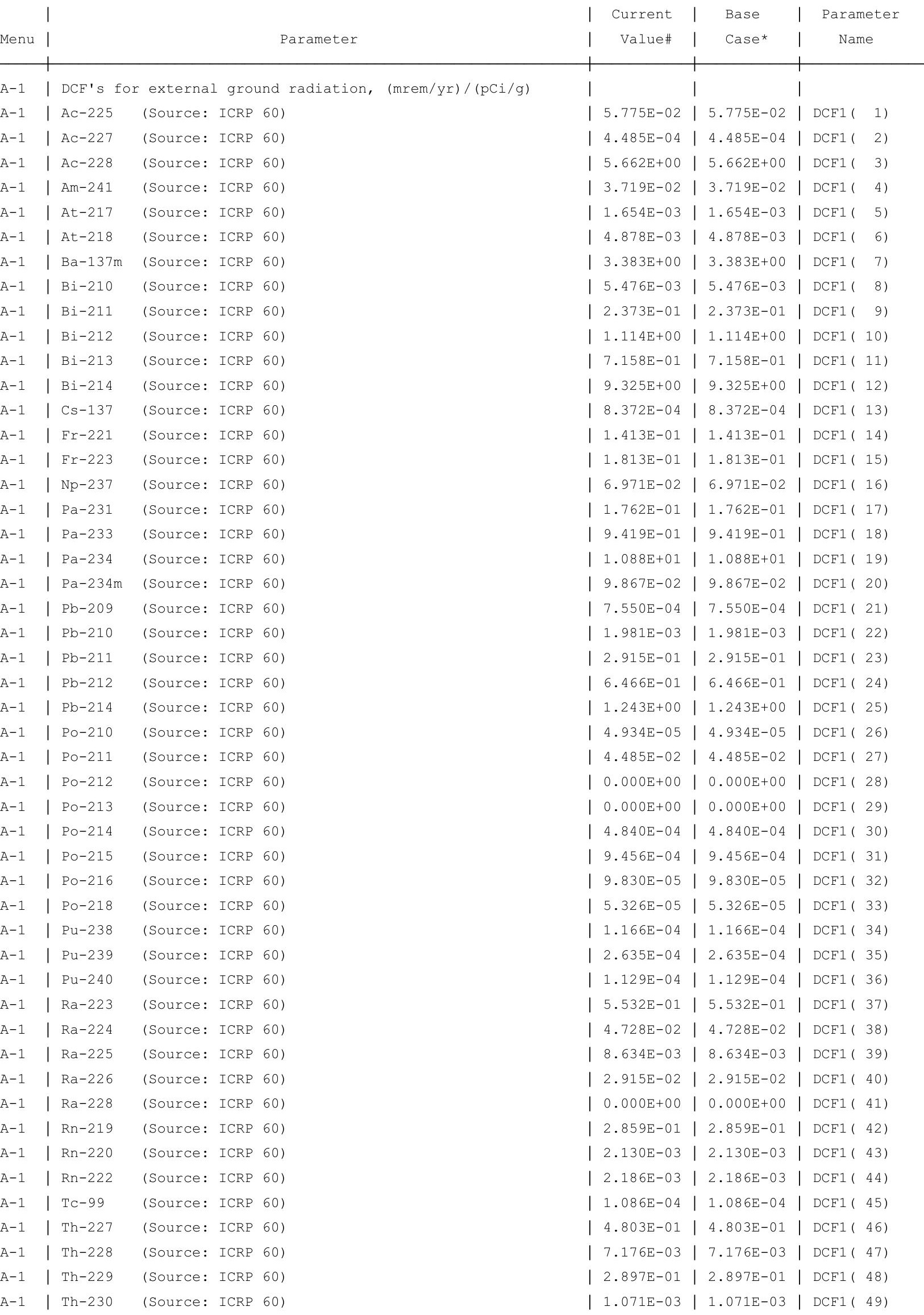


RESRAD, Version $6.5 \quad T^{3 / 2}$ Limit $=180$ days

Summary : C746U Worker Deterministic Run

File : X: \FINAL V2\C746U W DET-FINALV2.RAD

Dose Conversion Factor (and Related) Parameter Summary (continued)

Dose Library: ICRP 60 \& ICRP 72 (Adult)

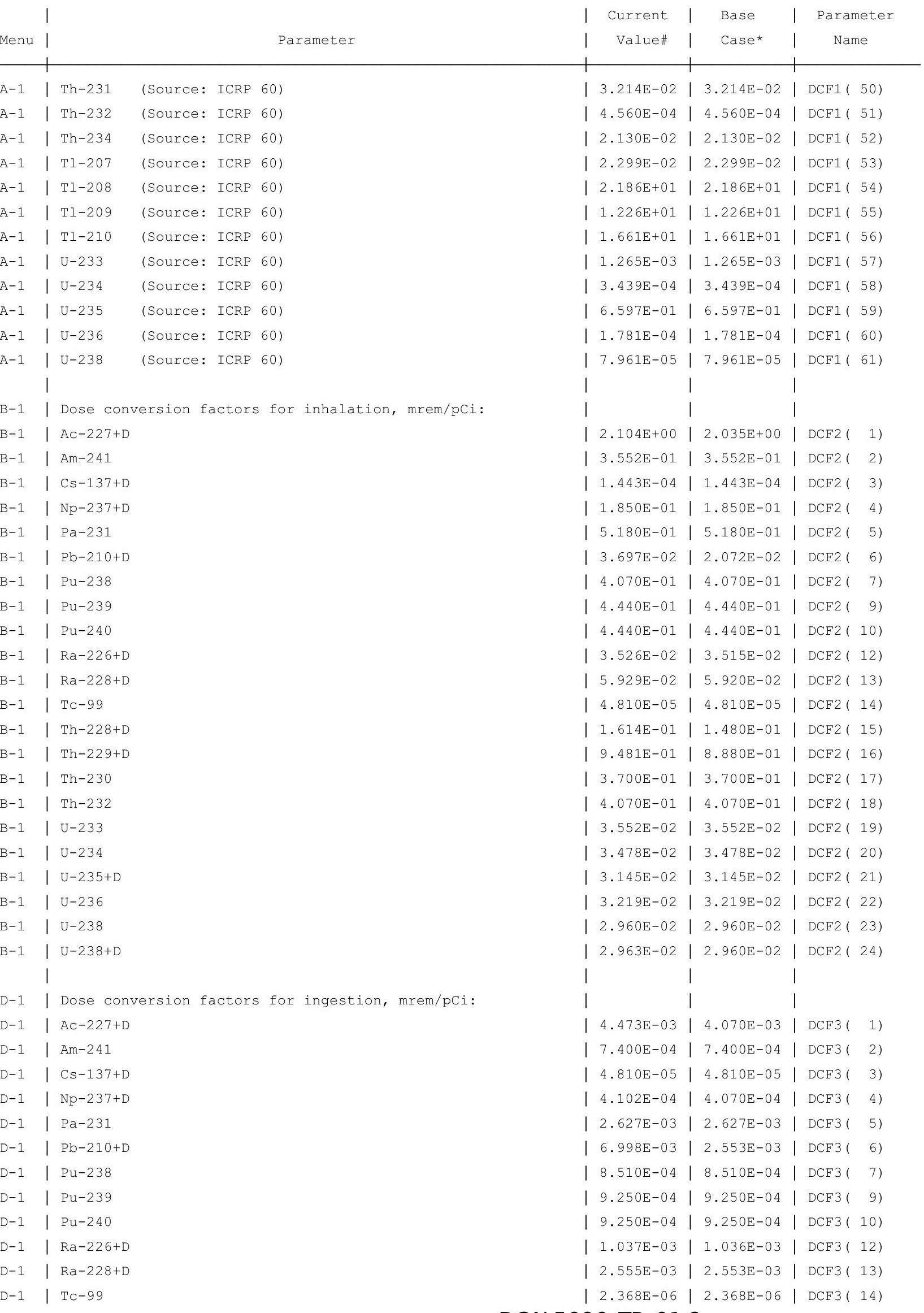


RESRAD, Version $6.5 \quad \mathrm{~T}^{1 / 2}$ Limit $=180$ days

Summary : C746U Worker Deterministic Run

File : $\mathrm{X}: \backslash$ FINAL V2 $\backslash \mathrm{C} 746 \mathrm{U}$ W DET-FINALV2.RAD

Dose Conversion Factor (and Related) Parameter Summary (continued) Dose Library: ICRP 60 \& ICRP 72 (Adult)

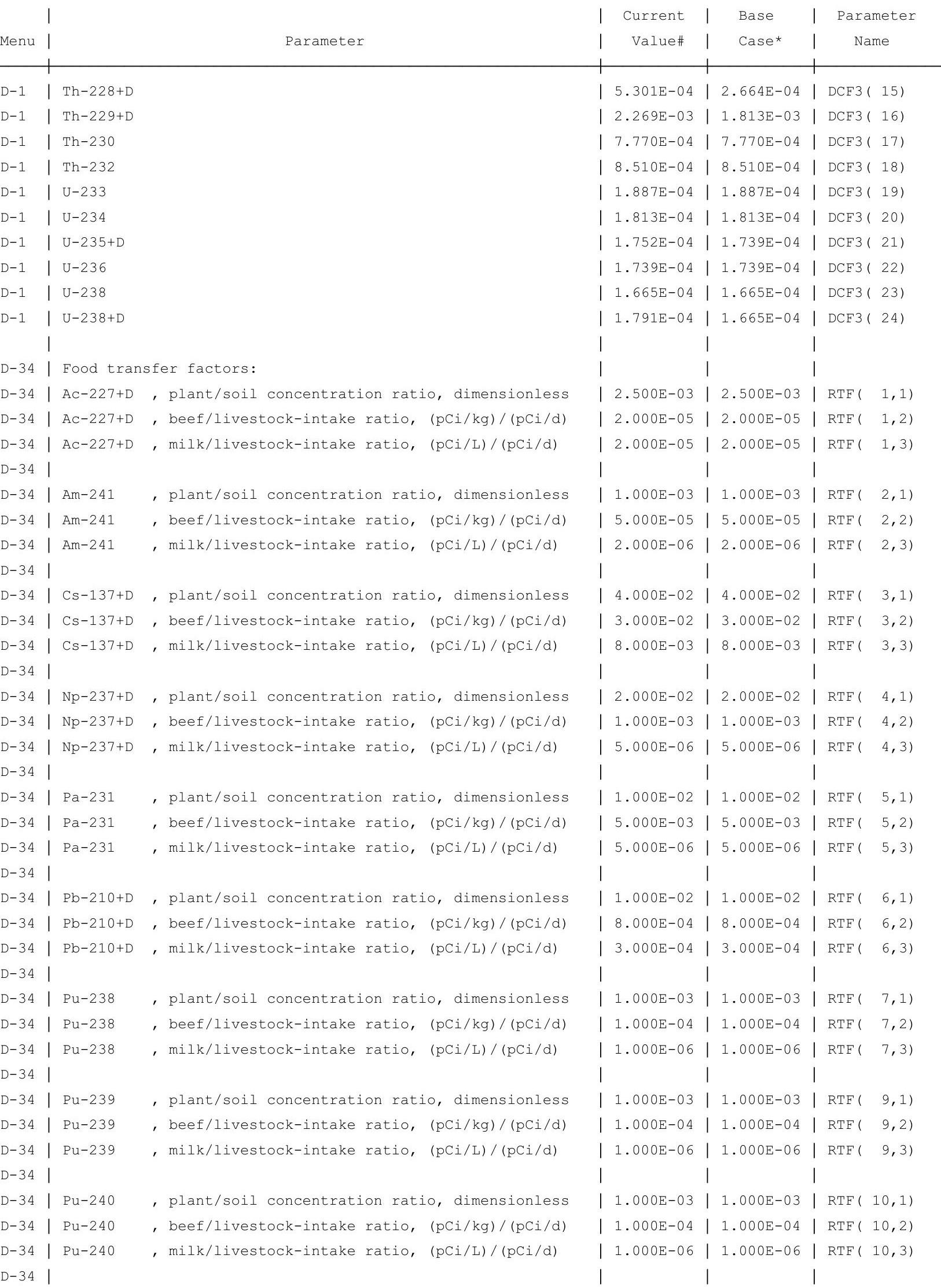


RESRAD, Version $6.5 \quad \mathrm{~T}^{1 / 2}$ Limit $=180$ days

Summary : C746U Worker Deterministic Run

File : $\mathrm{X}: \backslash$ FINAL V2\C746U W DET-FINALV2.RAD

Dose Conversion Factor (and Related) Parameter Summary (continued)

Dose Library: ICRP 60 \& ICRP 72 (Adult)

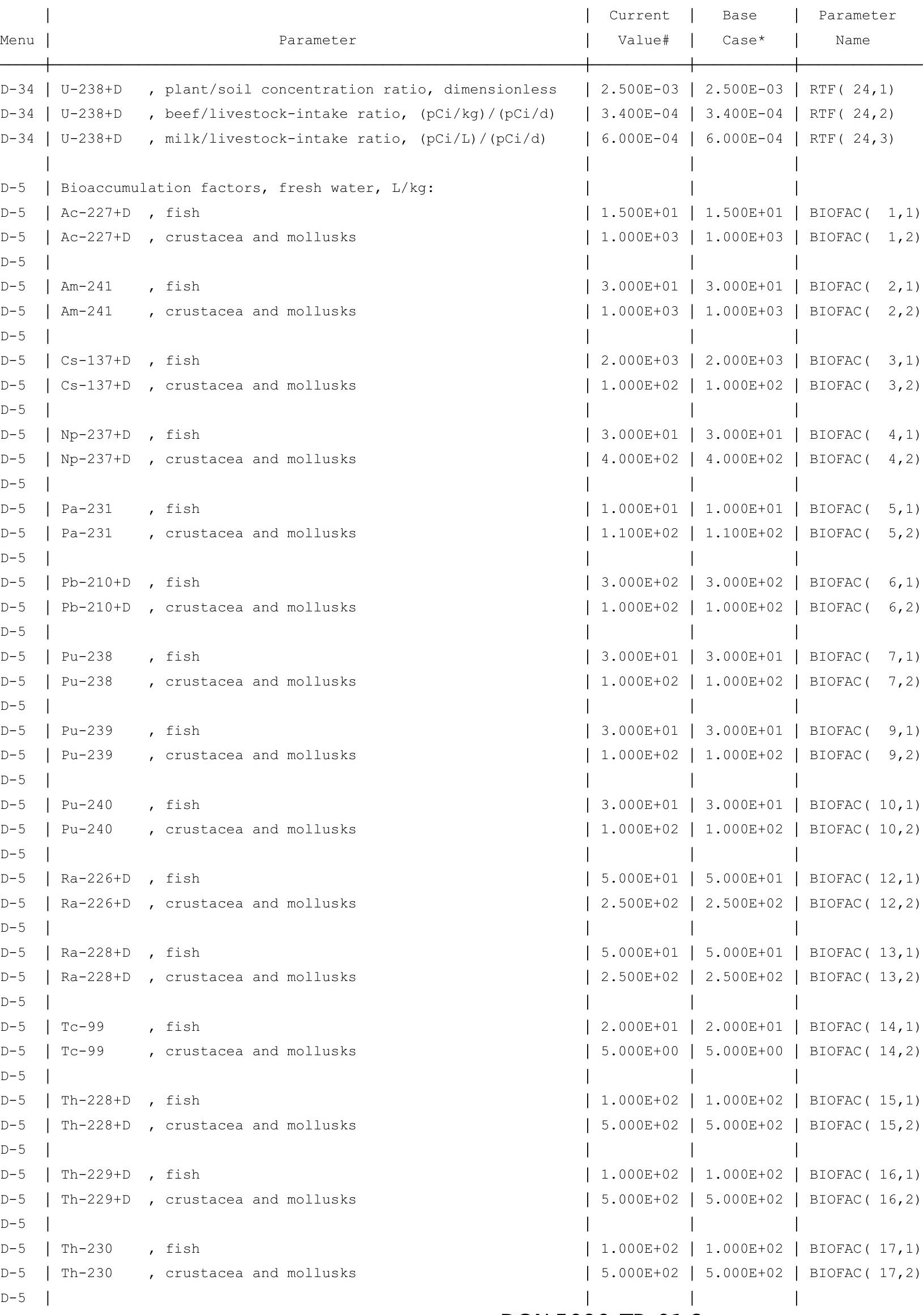


RESRAD, Version $6.5 \quad T^{1 / 2}$ Limit $=180$ days

Summary : C746U Worker Deterministic Run

File : $\mathrm{X}: \backslash$ FINAL V2\C746U W DET-FINALV2.RAD

Dose Conversion Factor (and Related) Parameter Summary (continued)

Dose Library: ICRP 60 \& ICRP 72 (Adult)

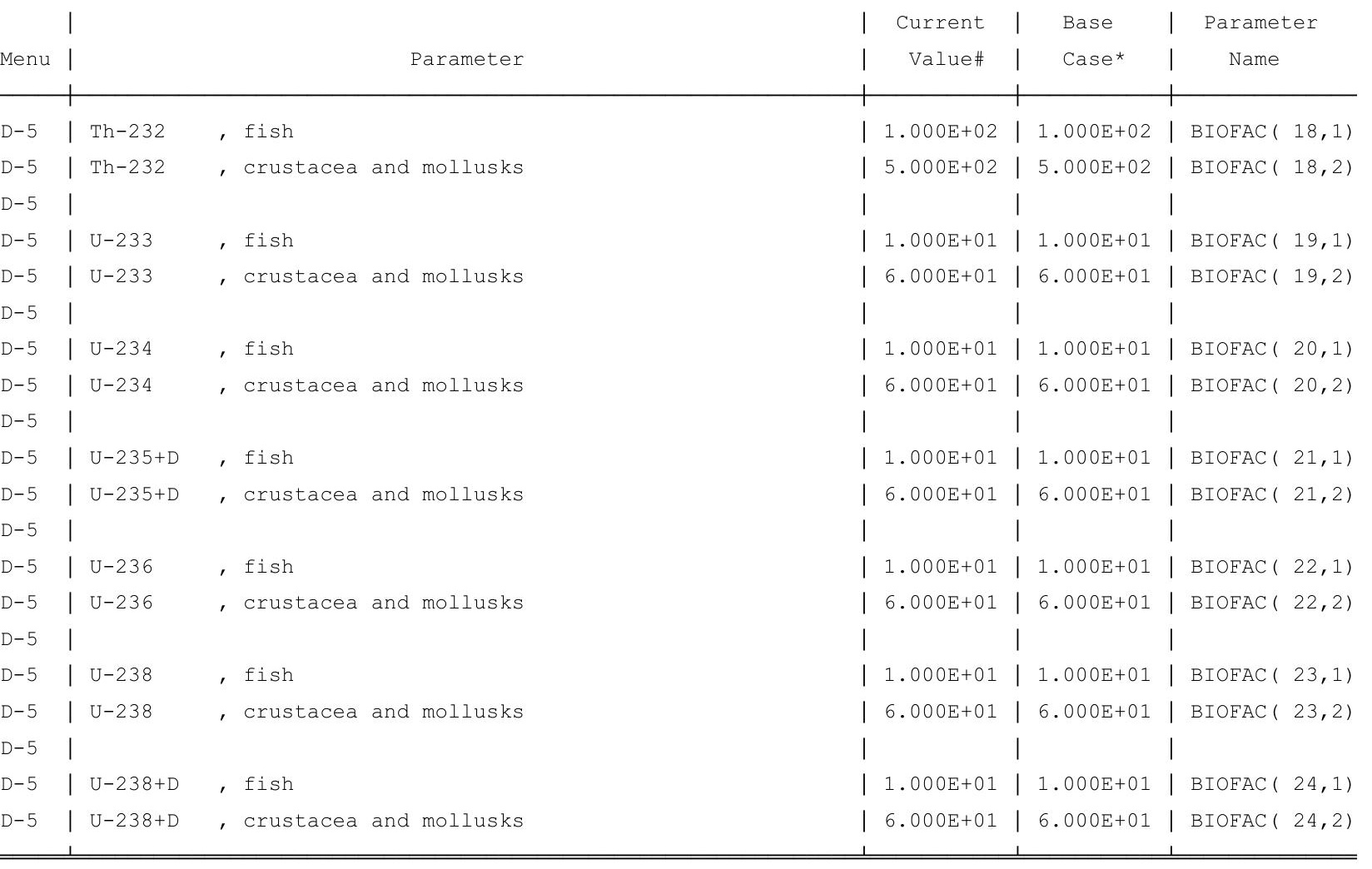

\#For DCFl(xxx) only, factors are for infinite depth \& area. See ETFG table in Ground Pathway of Detailed Report. *Base Case means Default.Lib w/o Associate Nuclide contributions. 
RESRAD, Version $6.5 \quad \mathrm{~T}^{1 / 2}$ Limit $=180$ days

Summary : C746U Worker Deterministic Run

File : $X: \backslash F I N A L$ V2 $\backslash C 746 U$ W DET-FINALV2.RAD

Site-Specific Parameter Summary (continued)

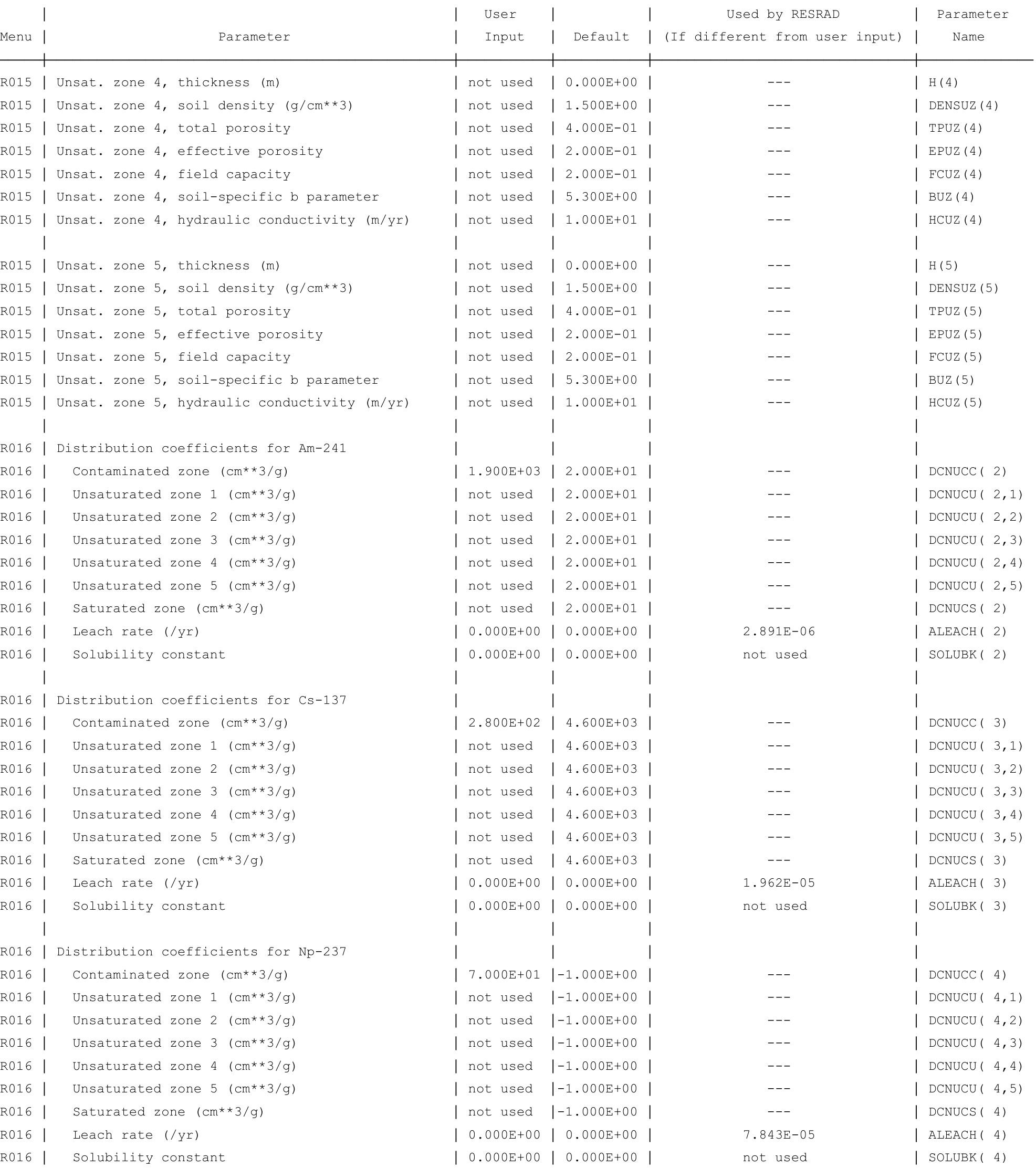


RESRAD, Version $6.5 \quad \mathrm{~T}^{1} 1 / 2$ Limit $=180$ days

Summary : C746U Worker Deterministic Run

File : $X: \backslash F I N A L$ V2 $\backslash C 746 U$ W DET-FINALV2.RAD

Site-Specific Parameter Summary (continued)

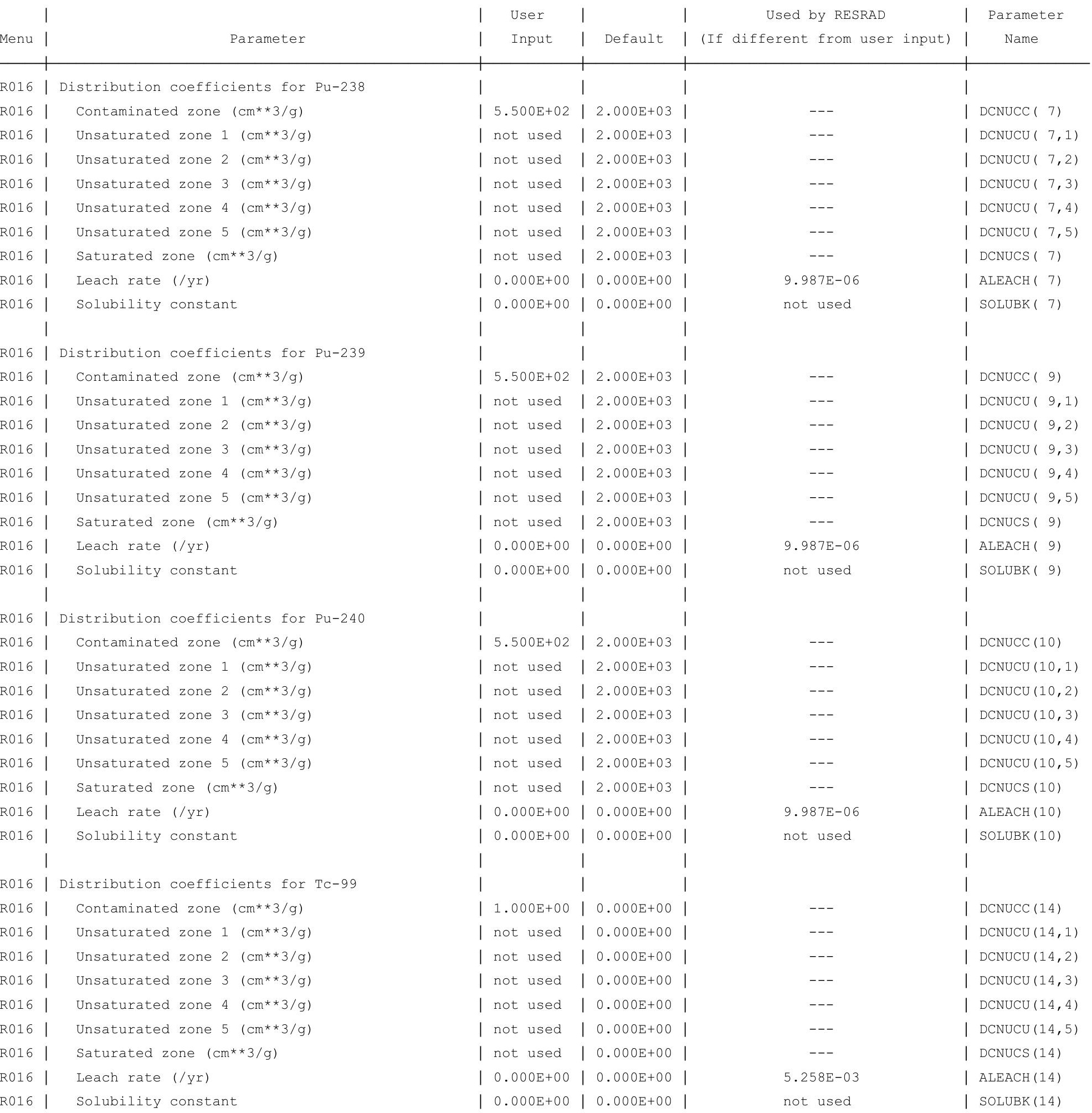


RESRAD, Version $6.5 \quad \mathrm{~T}^{1} 1 / 2$ Limit $=180$ days

Summary : C746U Worker Deterministic Run

File : $\mathrm{X}: \backslash$ FINAL V2 $\backslash \mathrm{C} 746 \mathrm{U}$ W DET-FINALV2.RAD

Site-Specific Parameter Summary (continued)

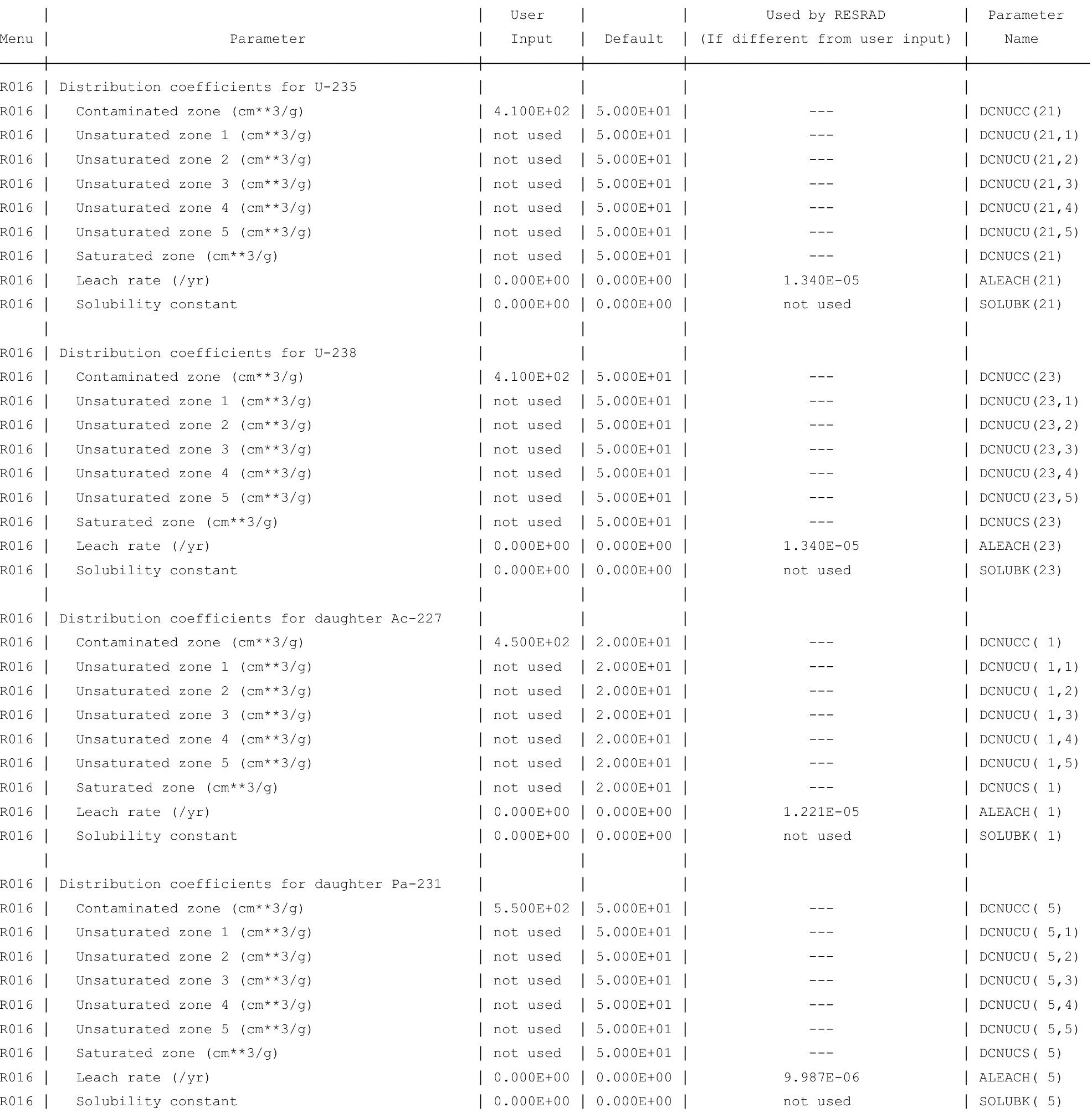


RESRAD, Version $6.5 \quad \mathrm{~T}^{1} 1 / 2$ Limit $=180$ days

Summary : C746U Worker Deterministic Run

File : $\mathrm{X}: \backslash$ FINAL V2 $\backslash \mathrm{C} 746 \mathrm{U}$ W DET-FINALV2.RAD

Site-Specific Parameter Summary (continued)

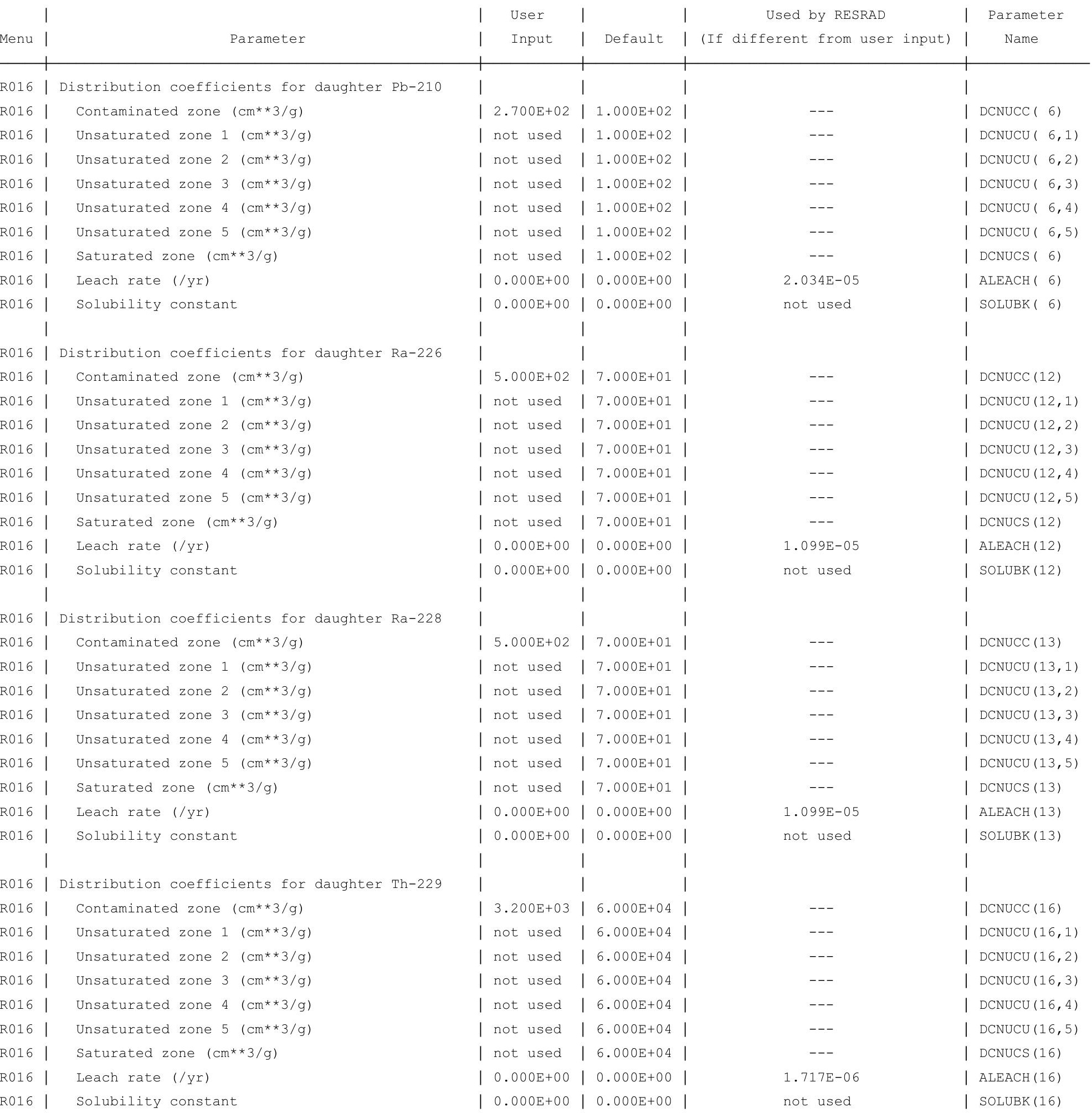


RESRAD, Version $6.5 \quad \mathrm{~T}^{1 / 2}$ Limit $=180$ days

Summary : C746U Worker Deterministic Run

File : $\mathrm{X}: \backslash$ FINAL V2 $\backslash \mathrm{C} 746 \mathrm{U}$ W DET-FINALV2.RAD

Site-Specific Parameter Summary (continued)

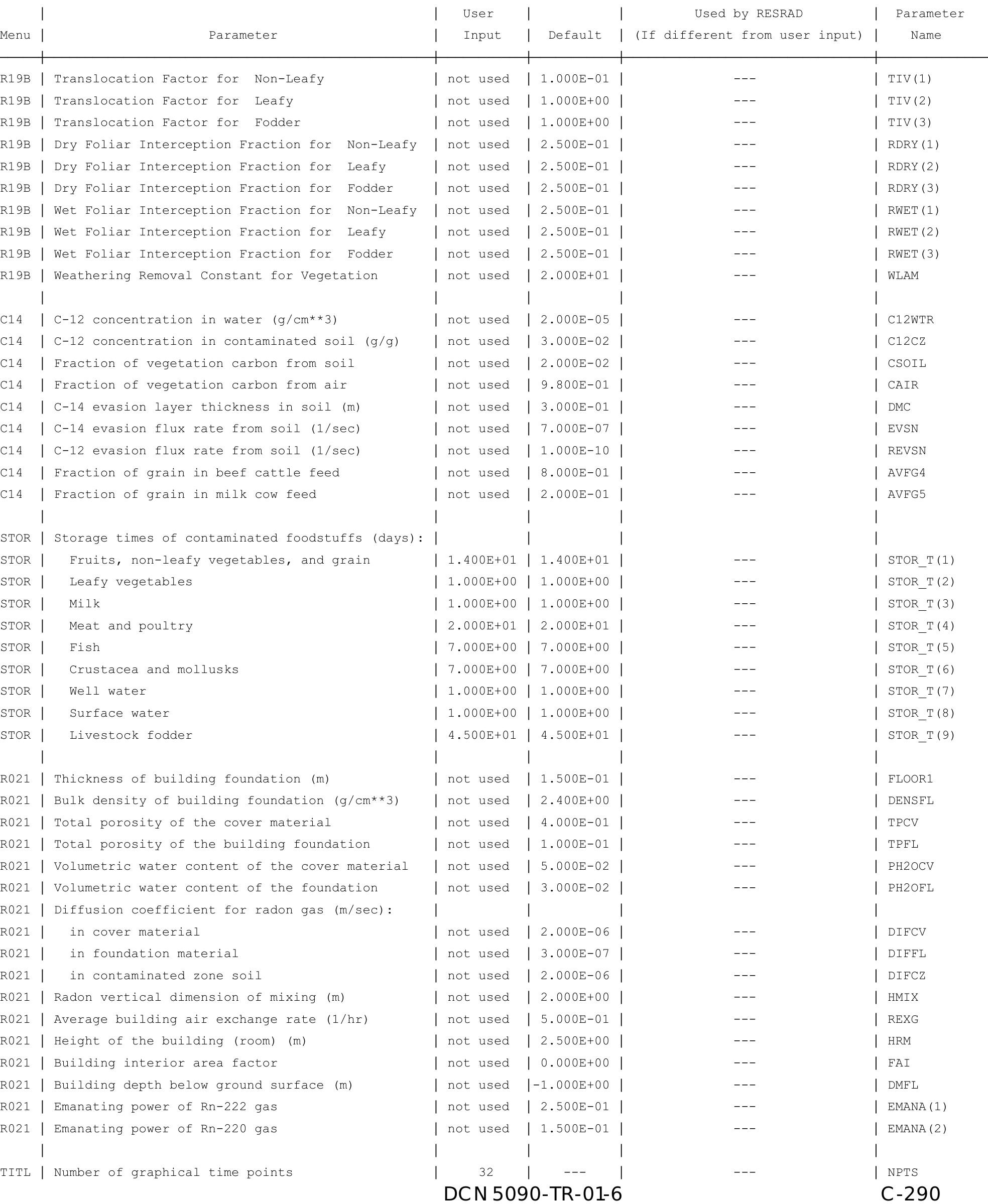


RESRAD, Version 6.5

$\mathrm{T}^{1 / 2}$ Limit $=180$ days

Summary : C746U Worker Deterministic Run

File : $\mathrm{X}: \backslash$ FINAL V2 $\backslash \mathrm{C} 746 \mathrm{U} W \mathrm{WET}$-FINALV2.RAD

Site-Specific Parameter Summary (continued)

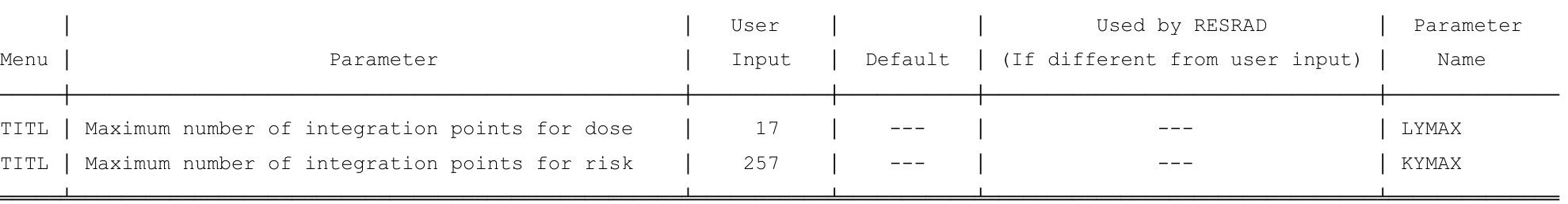

Summary of Pathway Selections

\begin{tabular}{|c|c|c|}
\hline & Pathway & User Selection \\
\hline 1 & -- external gamma & active \\
\hline 2 & -- inhalation (w/o radon) & active \\
\hline 3 & -- plant ingestion & suppressed \\
\hline 4 & -- meat ingestion & suppressed \\
\hline 5 & -- milk ingestion & suppressed \\
\hline 6 & -- aquatic foods & suppressed \\
\hline 7 & -- drinking water & suppressed \\
\hline 8 & -- soil ingestion & active \\
\hline 9 & -- radon & suppressed \\
\hline & ind peak pathway doses & active \\
\hline
\end{tabular}


RESRAD, Version $6.5 \quad \mathrm{~T}^{1 / 2}$ Limit $=180$ days

Summary : C746U Worker Deterministic Run

File : $\mathrm{X}: \backslash$ FINAL V2 $\backslash$ C746U W DET-FINALV2.RAD

Contaminated Zone Dimensions

Area: 89436.00 square meters

Thickness:

Cover Depth:

\begin{abstract}
13.40 meters
1.52 meters
\end{abstract}

Initial Soil Concentrations, pCi/g

$\begin{array}{ll}\mathrm{Am}-241 & 1.000 \mathrm{E}+00 \\ \mathrm{Cs}-137 & 1.000 \mathrm{E}+00 \\ \mathrm{~Np}-237 & 1.000 \mathrm{E}+00 \\ \mathrm{Pu}-238 & 1.000 \mathrm{E}+00 \\ \mathrm{Pu}-239 & 1.000 \mathrm{E}+00 \\ \mathrm{Pu}-240 & 1.000 \mathrm{E}+00 \\ \mathrm{TC}-99 & 1.000 \mathrm{E}+00 \\ \mathrm{Th}-228 & 1.000 \mathrm{E}+00 \\ \mathrm{Th}-230 & 1.000 \mathrm{E}+00 \\ \mathrm{Th}-232 & 1.000 \mathrm{E}+00 \\ \mathrm{U}-234 & 1.000 \mathrm{E}+00 \\ \mathrm{U}-235 & 1.000 \mathrm{E}+00 \\ \mathrm{U}-238 & 1.000 \mathrm{E}+00\end{array}$

Total Dose TDOSE(t), mrem/yr

Basic Radiation Dose Limit $=1.000 \mathrm{E}+00 \mathrm{mrem} / \mathrm{yr}$

Total Mixture Sum $M(t)$ = Fraction of Basic Dose Limit Received at Time (t)

$\begin{array}{rllllll}t \text { (years }): & 0.000 \mathrm{E}+00 & 1.000 \mathrm{E}+00 & 5.000 \mathrm{E}+01 & 1.000 \mathrm{E}+02 & 5.000 \mathrm{E}+02 & 1.050 \mathrm{E}+03 \\ \text { TDOSE }(t): & 2.852 \mathrm{E}-07 & 2.122 \mathrm{E}-07 & 4.592 \mathrm{E}-07 & 6.229 \mathrm{E}-07 & 7.047 \mathrm{E}-06 & 2.078 \mathrm{E}-04 \\ \mathrm{M}(\mathrm{t}): & 2.852 \mathrm{E}-07 & 2.122 \mathrm{E}-07 & 4.592 \mathrm{E}-07 & 6.229 \mathrm{E}-07 & 7.047 \mathrm{E}-06 & 2.078 \mathrm{E}-04\end{array}$

Maximum TDOSE $(\mathrm{t}): 2.078 \mathrm{E}-04 \mathrm{mrem} / \mathrm{yr}$ at $t=1.050 \mathrm{E}+03$ years 
RESRAD, Version 6.5

$\mathrm{T}^{1 / 2}$ Limit $=180$ days

Summary : C746U Worker Deterministic Run

File : $\mathrm{X}: \backslash$ FINAL V2\C746U W DET-FINALV2.RAD

Total Dose Contributions TDOSE(i,p,t) for Individual Radionuclides (i) and Pathways (p) As mrem/yr and Fraction of Total Dose At $t=0.000 \mathrm{E}+00$ years

Water Independent Pathways (Inhalation excludes radon)

\begin{tabular}{|c|c|c|c|c|c|c|c|c|c|c|c|c|c|c|}
\hline \multirow[b]{2}{*}{ clide } & \multicolumn{2}{|c|}{ Ground } & \multicolumn{2}{|c|}{ Inhalation } & \multicolumn{2}{|c|}{ Radon } & \multicolumn{2}{|c|}{ Plant } & \multicolumn{2}{|c|}{ Meat } & \multicolumn{2}{|c|}{ Milk } & \multicolumn{2}{|c|}{ Soil } \\
\hline & mrem/yr & fract. & mrem/yr & fract. & mrem/yr & fract. & mrem/yr & fract. & mrem/yr & fract. & mrem/yr & fract. & mrem/yr & fract. \\
\hline 41 & $3.160 \mathrm{E}-20$ & 0.0000 & $0.000 \mathrm{E}+00$ & 0.0000 & $0.000 \mathrm{E}+00$ & 0.0000 & $0.000 \mathrm{E}+00$ & 0.0000 & $0.000 \mathrm{E}+00$ & 0.0000 & $0.000 \mathrm{E}+00$ & 0.0000 & $0.000 \mathrm{E}+00$ & 0.0000 \\
\hline 37 & $2.578 \mathrm{E}-10$ & 0.0009 & $0.000 \mathrm{E}+00$ & 0.0000 & $0.000 \mathrm{E}+00$ & 0.0000 & $0.000 \mathrm{E}+00$ & 0.0000 & $0.000 \mathrm{E}+00$ & 0.0000 & $0.000 \mathrm{E}+00$ & 0.0000 & $0.000 \mathrm{E}+00$ & 0.0000 \\
\hline 37 & $1.948 \mathrm{E}-13$ & 0.0000 & $0.000 \mathrm{E}+00$ & 0.0000 & $0.000 \mathrm{E}+00$ & 0.0000 & $0.000 \mathrm{E}+00$ & 0.0000 & $0.000 \mathrm{E}+00$ & 0.0000 & $0.000 \mathrm{E}+00$ & 0.0000 & $0.000 \mathrm{E}+00$ & 0.0000 \\
\hline 238 & $1.663 \mathrm{E}-23$ & 0.0000 & $0.000 \mathrm{E}+00$ & 0.0000 & $0.000 \mathrm{E}+00$ & 0.0000 & $0.000 \mathrm{E}+00$ & 0.0000 & $0.000 \mathrm{E}+00$ & 0.0000 & $0.000 \mathrm{E}+00$ & 0.0000 & $0.000 \mathrm{E}+00$ & 0.0000 \\
\hline 239 & $2.456 \mathrm{E}-18$ & 0.0000 & $0.000 \mathrm{E}+00$ & 0.0000 & $0.000 \mathrm{E}+00$ & 0.0000 & $0.000 \mathrm{E}+00$ & 0.0000 & $0.000 \mathrm{E}+00$ & 0.0000 & $0.000 \mathrm{E}+00$ & 0.0000 & $0.000 \mathrm{E}+00$ & 000 \\
\hline 2 & $2.335 \mathrm{E}-25$ & 0 & $0.000 \mathrm{E}$ & 0 & $0.000 \mathrm{E}+00$ & 0 & $0.000 \mathrm{E}+00$ & 0 & $0.000 \mathrm{E}+00$ & 0 & $0.000 \mathrm{E}+00$ & 0 & $0.000 \mathrm{E}+00$ & 000 \\
\hline 99 & $1.179 \mathrm{E}-26$ & 0.0000 & $0.000 \mathrm{E}+00$ & 0.0000 & $0.000 \mathrm{E}+00$ & 0.0000 & $0.000 \mathrm{E}+00$ & 0.0000 & $0.000 \mathrm{E}+00$ & 0.0000 & $0.000 \mathrm{E}+00$ & 0.0000 & $0.000 \mathrm{E}+00$ & 0.0000 \\
\hline 20 & $2.825 \mathrm{E}-07$ & 0.9905 & $0.000 \mathrm{E}+00$ & 0.0000 & $0.000 \mathrm{E}+00$ & 0.0000 & $0.000 \mathrm{E}+00$ & 0.0000 & $0.000 \mathrm{E}+00$ & 0.0000 & $0.000 \mathrm{E}+00$ & 0.0000 & $0.000 \mathrm{E}+00$ & 0.0000 \\
\hline 230 & 7. $712 \mathrm{E}-12$ & 0.0000 & $0.000 \mathrm{E}+00$ & 0.0000 & $0.000 \mathrm{E}+00$ & 0.0000 & $0.000 \mathrm{E}+00$ & 0.0000 & $0.000 \mathrm{E}+00$ & 0.0000 & $0.000 \mathrm{E}+00$ & 0.0000 & $0.000 \mathrm{E}+00$ & 0.0000 \\
\hline & $2.407 \mathrm{E}-09$ & 0.0084 & $0.000 \mathrm{E}+00$ & 0.0000 & $0.000 \mathrm{E}+00$ & 0.0000 & $0.000 \mathrm{E}+00$ & 0.0000 & $0.000 \mathrm{E}+00$ & 0.0000 & $0.000 \mathrm{E}+00$ & 0.0000 & $0.000 \mathrm{E}+00$ & 0.0000 \\
\hline & $2.315 \mathrm{E}-17$ & 0.0000 & $0.000 \mathrm{E}+00$ & 0.0000 & $0.000 \mathrm{E}+00$ & 0.0000 & $0.000 \mathrm{E}+00$ & 0.0000 & $0.000 \mathrm{E}+00$ & 0.0000 & $0.000 \mathrm{E}+00$ & 0.0000 & $0.000 \mathrm{E}+00$ & 0.0000 \\
\hline & $2.543 E-15$ & 0.0000 & $0.000 \mathrm{E}+00$ & 0.0000 & $0.000 \mathrm{E}+00$ & 0.0000 & $0.000 \mathrm{E}+00$ & 0.0000 & $0.000 \mathrm{E}+00$ & 0.0000 & $0.000 \mathrm{E}+00$ & 0.0000 & $0.000 \mathrm{E}+00$ & 0.0000 \\
\hline & $2.901 \mathrm{E}-11$ & 0.0001 & $0.000 \mathrm{E}+00$ & 0.0000 & $0.000 \mathrm{E}+00$ & 0.0000 & $0.000 \mathrm{E}+00$ & 0.0000 & $0.000 \mathrm{E}+00$ & 0.0000 & $0.000 \mathrm{E}+00$ & 0.0000 & $0.000 \mathrm{E}+00$ & 0.0000 \\
\hline & 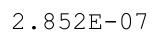 & 1.0000 & $0.000 \mathrm{E}+00$ & 0.0000 & $0.000 \mathrm{E}+00$ & 0.0000 & $0.000 \mathrm{E}+00$ & 0.0000 & $0.000 \mathrm{E}+00$ & 0. & $0.000 \mathrm{E}+00$ & 0.0000 & $E+00$ & 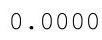 \\
\hline
\end{tabular}

Total Dose Contributions TDOSE (i,p,t) for Individual Radionuclides (i) and Pathways (p) As mrem/yr and Fraction of Total Dose At $t=0.000 \mathrm{E}+00$ years

Water Dependent Pathways

\begin{tabular}{|c|c|c|c|c|c|c|c|c|c|c|c|c|c|c|}
\hline \multirow[b]{2}{*}{ Nuclide } & \multicolumn{2}{|c|}{ Water } & \multicolumn{2}{|c|}{ Fish } & \multicolumn{2}{|c|}{ Radon } & \multicolumn{2}{|c|}{ Plant } & \multicolumn{2}{|c|}{ Meat } & \multicolumn{2}{|c|}{ Milk } & \multicolumn{2}{|c|}{ All Pathways* } \\
\hline & mrem/yr & fract. & $\mathrm{mrem} / \mathrm{yr}$ & fract. & $\mathrm{mrem} / \mathrm{yr}$ & fract. & mrem/yr & fract. & mrem/yr & fract. & $\mathrm{mrem} / \mathrm{yr}$ & fract. & $\mathrm{mrem} / \mathrm{yr}$ & fract. \\
\hline-241 & $0.000 \mathrm{E}+00$ & 0.0000 & $0.000 \mathrm{E}+00$ & 0.0000 & $0.000 \mathrm{E}+00$ & 0.0000 & $0.000 \mathrm{E}+00$ & 0.0000 & $0.000 \mathrm{E}+00$ & 0.0000 & $0.000 \mathrm{E}+00$ & 0.0000 & $3.160 \mathrm{E}-20$ & 0.0000 \\
\hline 37 & $0.000 \mathrm{E}+00$ & 0.0000 & $0.000 \mathrm{E}+00$ & 0.0000 & $0.000 \mathrm{E}+00$ & 0.0000 & $0.000 \mathrm{E}+00$ & 0.0000 & $0.000 \mathrm{E}+00$ & 0.0000 & $0.000 \mathrm{E}+00$ & 0.0000 & $2.578 \mathrm{E}-10$ & 0.0009 \\
\hline 37 & $0.000 \mathrm{E}+00$ & 0.0000 & $0.000 \mathrm{E}+00$ & 0.0000 & $0.000 \mathrm{E}+00$ & 0.0000 & $0.000 \mathrm{E}+00$ & 0.0000 & $0.000 \mathrm{E}+00$ & 0.0000 & $0.000 \mathrm{E}+00$ & 0.0000 & $1.948 \mathrm{E}-13$ & 0.0000 \\
\hline 238 & $0.000 \mathrm{E}+00$ & 0.0000 & $0.000 \mathrm{E}+00$ & 0.0000 & $0.000 \mathrm{E}+00$ & 0.0000 & $0.000 \mathrm{E}+00$ & 0.0000 & $0.000 \mathrm{E}+00$ & 0.0000 & $0.000 \mathrm{E}+00$ & 0.0000 & $1.663 \mathrm{E}-23$ & 0.0000 \\
\hline 239 & $0.000 \mathrm{E}+00$ & 0.0000 & $0.000 \mathrm{E}+00$ & 0.0000 & $0.000 \mathrm{E}+00$ & 0.0000 & $0.000 \mathrm{E}+00$ & 0.0000 & $0.000 \mathrm{E}+00$ & 0.0000 & $0.000 \mathrm{E}+00$ & 0.0000 & $2.456 \mathrm{E}-18$ & 0.0000 \\
\hline 240 & $0.000 \mathrm{E}+00$ & 0.0 & $0.000 \mathrm{E}+00$ & 0 & $0.000 \mathrm{E}+00$ & 0. & $0.000 \mathrm{E}+00$ & 0 & 0 & 0 & $0.000 \mathrm{E}+00$ & 0 & -25 & 000 \\
\hline 年 & $0.000 \mathrm{E}+00$ & 0 & $0.000 \mathrm{E}+00$ & 0 & $0.000 \mathrm{E}+00$ & 0 & $0.000 \mathrm{E}+00$ & 0.00 & $0.000 \mathrm{E}+00$ & 00 & $0.000 \mathrm{E}+00$ & 0 & $1.179 \mathrm{E}-26$ & 0.0000 \\
\hline-228 & $0.000 \mathrm{E}+00$ & 0.0000 & $0.000 \mathrm{E}+00$ & 0.0000 & $0.000 \mathrm{E}+00$ & 0.0000 & $0.000 \mathrm{E}+00$ & 0.0000 & $0.000 \mathrm{E}+00$ & 0.0000 & $0.000 \mathrm{E}+00$ & 0.0000 & $2.825 \mathrm{E}-07$ & 0.9905 \\
\hline 230 & $0.000 \mathrm{E}+00$ & 0.0000 & $0.000 \mathrm{E}+00$ & 0.0000 & $0.000 \mathrm{E}+00$ & 0.0000 & $0.000 \mathrm{E}+00$ & 0.0000 & $0.000 \mathrm{E}+00$ & 0.0000 & $0.000 \mathrm{E}+00$ & 0.0000 & $7.712 \mathrm{E}-12$ & 0.0000 \\
\hline 232 & $0.000 \mathrm{E}+00$ & 0.0000 & $0.000 \mathrm{E}+00$ & 0.0000 & $0.000 \mathrm{E}+00$ & 0.0000 & $0.000 \mathrm{E}+00$ & 0.0000 & $0.000 \mathrm{E}+00$ & 0.0000 & $0.000 \mathrm{E}+00$ & 0.0000 & $2.407 \mathrm{E}-09$ & 0.0084 \\
\hline & $0.000 \mathrm{E}+00$ & 0.0000 & $0.000 \mathrm{E}+00$ & 0.0000 & $0.000 \mathrm{E}+00$ & 0.0000 & $0.000 \mathrm{E}+00$ & 0.0000 & $0.000 \mathrm{E}+00$ & 0.0000 & $0.000 \mathrm{E}+00$ & 0.0000 & $2.315 \mathrm{E}-17$ & 0.0000 \\
\hline & $0.000 \mathrm{E}+00$ & 0.0000 & $0.000 \mathrm{E}+00$ & 0.0000 & $0.000 \mathrm{E}+00$ & 0.0000 & $0.000 \mathrm{E}+00$ & 0.0000 & $0.000 \mathrm{E}+00$ & 0.0000 & $0.000 \mathrm{E}+00$ & 0.0000 & $2.543 \mathrm{E}-15$ & 0.0000 \\
\hline 38 & $0.000 \mathrm{E}+00$ & 0.0000 & $0.000 \mathrm{E}+00$ & 0.0000 & $0.000 \mathrm{E}+00$ & 0.0000 & $0.000 \mathrm{E}+00$ & 0.0000 & $0.000 \mathrm{E}+00$ & 0.0000 & $0.000 \mathrm{E}+00$ & 0.0000 & $2.901 \mathrm{E}-11$ & 0.0001 \\
\hline & & 0 & $.000 \mathrm{E}+00$ & 000 & $E+00$ & 0.0000 & $.000 \mathrm{E}+00$ & .0000 & $.000 \mathrm{E}+00$ & 0 & $\mathrm{E}+\mathrm{O}$ & & $2.852 \mathrm{E}-01$ & \\
\hline
\end{tabular}

*Sum of all water independent and dependent pathways. 
RESRAD, Version 6.5

Summary : C746U Worker Deterministic Run

File : $\mathrm{X}: \backslash$ FINAL V2\C746U W DET-FINALV2.RAD

Total Dose Contributions TDOSE(i,p,t) for Individual Radionuclides (i) and Pathways (p) As mrem/yr and Fraction of Total Dose At $t=1.000 \mathrm{E}+00$ years

Water Independent Pathways (Inhalation excludes radon)

\begin{tabular}{|c|c|c|}
\hline clide & mrem/yr & fract. \\
\hline-241 & $9.563 E-20$ & 0.0000 \\
\hline-137 & $2.541 \mathrm{E}-10$ & 0.0012 \\
\hline-237 & $1.969 \mathrm{E}-13$ & 0.0000 \\
\hline-238 & $2.471 \mathrm{E}-22$ & 0.0000 \\
\hline-239 & $2.486 \mathrm{E}-18$ & 0.0000 \\
\hline-240 & $2.427 \mathrm{E}-25$ & 0.0000 \\
\hline-99 & $1.195 \mathrm{E}-26$ & 0.0000 \\
\hline-228 & $1.978 \mathrm{E}-07$ & 0.9321 \\
\hline-230 & $2.327 \mathrm{E}-11$ & 0.0001 \\
\hline-232 & $1.410 \mathrm{E}-08$ & 0.0664 \\
\hline 34 & $1.630 \mathrm{E}-16$ & 0.0000 \\
\hline 35 & $2.587 \mathrm{E}-15$ & 0.0000 \\
\hline 38 & $2.924 \mathrm{E}-11$ & 0.0001 \\
\hline & 07 & 1.0000 \\
\hline
\end{tabular}

Inhalation

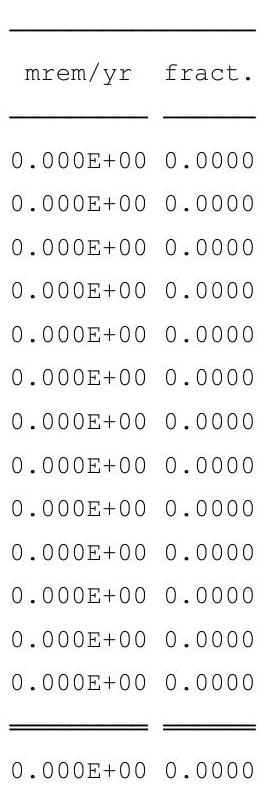

Radon

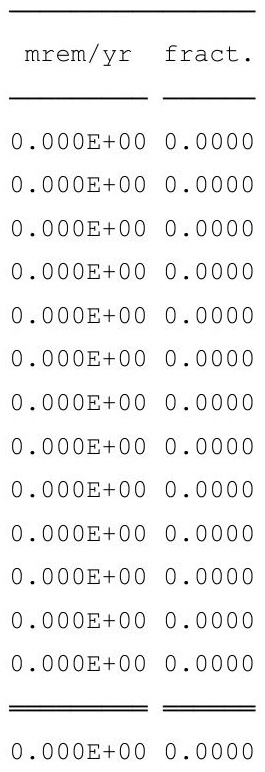

Plant

\begin{tabular}{ll}
\hline mrem/yr fract. \\
\hline $0.000 \mathrm{E}+00$ & 0.0000 \\
$0.000 \mathrm{E}+00$ & 0.0000 \\
$0.000 \mathrm{E}+00$ & 0.0000 \\
$0.000 \mathrm{E}+00$ & 0.0000 \\
$0.000 \mathrm{E}+00$ & 0.0000 \\
$0.000 \mathrm{E}+00$ & 0.0000 \\
$0.000 \mathrm{E}+00$ & 0.0000 \\
$0.000 \mathrm{E}+00$ & 0.0000 \\
$0.000 \mathrm{E}+00$ & 0.0000 \\
$0.000 \mathrm{E}+00$ & 0.0000 \\
$0.000 \mathrm{E}+00$ & 0.0000 \\
$0.000 \mathrm{E}+00$ & 0.0000 \\
$0.000 \mathrm{E}+00$ & 0.0000 \\
\hline \hline $0.000 \mathrm{E}+00$ & 0.0000 \\
\hline
\end{tabular}

\begin{tabular}{ll} 
Meat \\
\hline mrem/yr fract. \\
\cline { 1 - 2 } & \\
$0.000 \mathrm{E}+00$ & 0.0000 \\
$0.000 \mathrm{E}+00$ & 0.0000 \\
$0.000 \mathrm{E}+00$ & 0.0000 \\
$0.000 \mathrm{E}+00$ & 0.0000 \\
$0.000 \mathrm{E}+00$ & 0.0000 \\
$0.000 \mathrm{E}+00$ & 0.0000 \\
$0.000 \mathrm{E}+00$ & 0.0000 \\
$0.000 \mathrm{E}+00$ & 0.0000 \\
$0.000 \mathrm{E}+00$ & 0.0000 \\
$0.000 \mathrm{E}+00$ & 0.0000 \\
$0.000 \mathrm{E}+00$ & 0.0000 \\
$0.000 \mathrm{E}+00$ & 0.0000 \\
$0.000 \mathrm{E}+00$ & 0.0000 \\
\hline \hline $0.000 \mathrm{E}+00$ & 0.0000
\end{tabular}

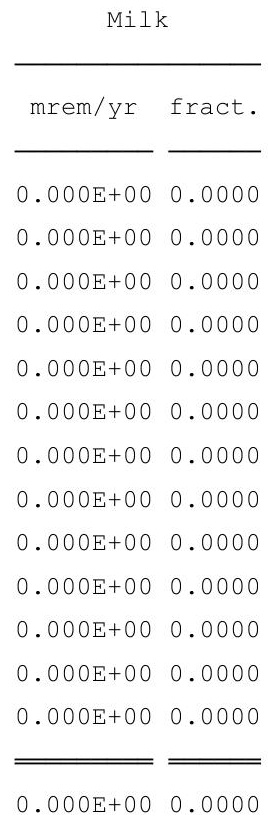

Soil mrem/yr fract. $0.000 \mathrm{E}+00 \quad 0.0000$ $0.000 \mathrm{E}+00 \quad 0.0000$ $0.000 \mathrm{E}+00 \quad 0.0000$ $0.000 \mathrm{E}+00 \quad 0.0000$ $0.000 \mathrm{E}+00 \quad 0.0000$ $0.000 \mathrm{E}+00 \quad 0.0000$ $0.000 \mathrm{E}+00 \quad 0.0000$ $0.000 \mathrm{E}+00 \quad 0.0000$ $0.000 \mathrm{E}+00 \quad 0.0000$ $0.000 \mathrm{E}+00 \quad 0.0000$ $0.000 \mathrm{E}+00 \quad 0.0000$ $0.000 \mathrm{E}+00 \quad 0.0000$ $0.000 \mathrm{E}+00 \quad 0.0000$ $0.000 \mathrm{E}+00 \quad 0.0000$

Total Dose Contributions TDOSE (i,p,t) for Individual Radionuclides (i) and Pathways (p) As mrem/yr and Fraction of Total Dose At $t=1.000 \mathrm{E}+00$ years

Water Dependent Pathways

\begin{tabular}{|c|c|c|c|c|c|c|}
\hline \multirow{2}{*}{$\begin{array}{l}\text { Radio- } \\
\text { Nuclide }\end{array}$} & \multicolumn{2}{|c|}{ Water } & \multicolumn{2}{|c|}{ Fish } & \multicolumn{2}{|c|}{ Radon } \\
\hline & $\mathrm{mrem} / \mathrm{yr}$ & fract. & mrem/yr & fract. & $\mathrm{mrem} / \mathrm{yr}$ & fract. \\
\hline-241 & $0.000 \mathrm{E}+00$ & 0.0000 & $0.000 \mathrm{E}+00$ & 0.0000 & $0.000 \mathrm{E}+00$ & 0.0000 \\
\hline-137 & $0.000 \mathrm{E}+00$ & 0.0000 & $0.000 \mathrm{E}+00$ & 0.0000 & $0.000 \mathrm{E}+00$ & 0.0000 \\
\hline 237 & $0.000 \mathrm{E}+00$ & 0.0000 & $0.000 \mathrm{E}+00$ & 0.0000 & $0.000 \mathrm{E}+00$ & 0.0000 \\
\hline-238 & $0.000 \mathrm{E}+00$ & 0.0000 & $0.000 \mathrm{E}+00$ & 0.0000 & $0.000 \mathrm{E}+00$ & 0.0000 \\
\hline 239 & $0.000 \mathrm{E}+00$ & 0.0000 & $0.000 \mathrm{E}+00$ & 0.0000 & $0.000 \mathrm{E}+00$ & 0.0000 \\
\hline-240 & $0.000 \mathrm{E}+00$ & 0.0000 & $0.000 \mathrm{E}+00$ & 0.0000 & $0.000 \mathrm{E}+00$ & 0.0000 \\
\hline 99 & $0.000 \mathrm{E}+00$ & 0.0000 & $0.000 \mathrm{E}+00$ & 0.0000 & $0.000 \mathrm{E}+00$ & 0.0000 \\
\hline 228 & $0.000 \mathrm{E}+00$ & 0.0000 & $0.000 \mathrm{E}+00$ & 0.0000 & $0.000 \mathrm{E}+00$ & 0.0000 \\
\hline 230 & $0.000 \mathrm{E}+00$ & 0.0000 & $0.000 \mathrm{E}+00$ & 0.0000 & $0.000 \mathrm{E}+00$ & 0.0000 \\
\hline 232 & $0.000 \mathrm{E}+00$ & 0.0000 & $0.000 \mathrm{E}+00$ & 0.0000 & $0.000 \mathrm{E}+00$ & 0.0000 \\
\hline 4 & $0.000 \mathrm{E}+00$ & 0.0000 & $0.000 \mathrm{E}+00$ & 0.0000 & $0.000 \mathrm{E}+00$ & 0.0000 \\
\hline & $0.000 \mathrm{E}+00$ & 0.0000 & $0.000 \mathrm{E}+00$ & 0.0000 & $0.000 \mathrm{E}+00$ & 0.0000 \\
\hline & $0.000 \mathrm{E}+00$ & 0.0000 & $0.000 \mathrm{E}+00$ & 0.0000 & $0.000 \mathrm{E}+00$ & 0.0000 \\
\hline & 00 & 00 & $.000 \mathrm{E}+00$ & 000 & $0.000 \mathrm{E}+00$ & 0.00 \\
\hline
\end{tabular}

*Sum of all water independent and dependent pathways.

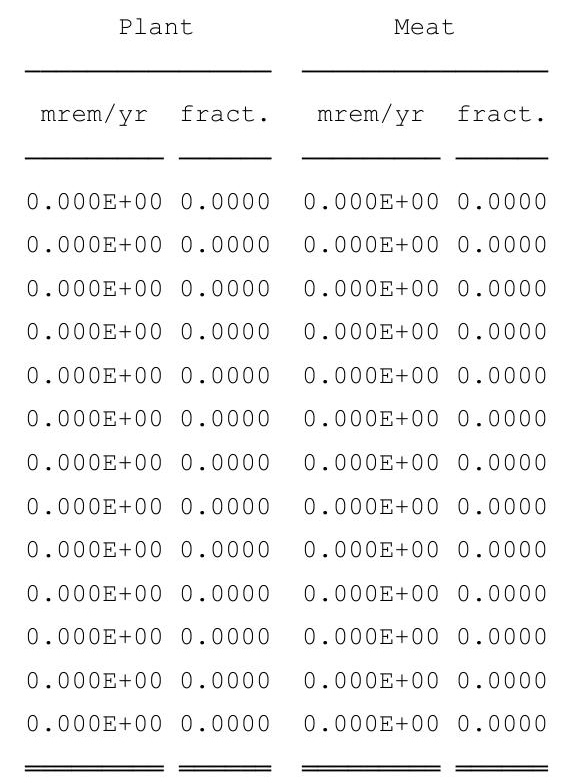

$0.000 \mathrm{E}+00 \quad 0.0000 \quad 0.000 \mathrm{E}+00 \quad 0.0000$

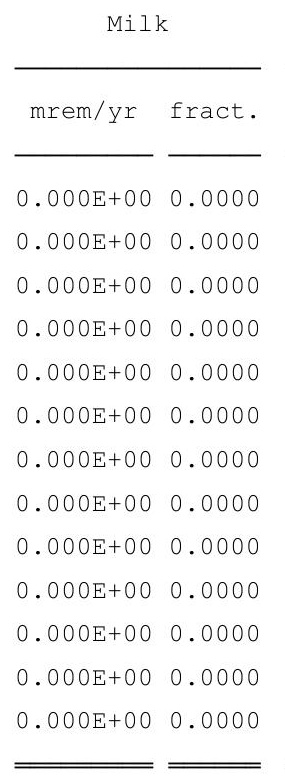

$0.000 \mathrm{E}+00 \quad 0.0000$
All Pathways* mrem/yr fract. $9.563 \mathrm{E}-20 \quad 0.0000$ $2.541 \mathrm{E}-10 \quad 0.0012$ $1.969 \mathrm{E}-13 \quad 0.0000$ $2.471 \mathrm{E}-22 \quad 0.0000$ $2.486 \mathrm{E}-18 \quad 0.0000$ $2.427 \mathrm{E}-25 \quad 0.0000$ $1.195 \mathrm{E}-26 \quad 0.0000$ $1.978 \mathrm{E}-07 \quad 0.9321$ $2.327 \mathrm{E}-11 \quad 0.0001$ $1.410 \mathrm{E}-08 \quad 0.0664$ $1.630 \mathrm{E}-16 \quad 0.0000$ $2.587 \mathrm{E}-15 \quad 0.0000$ $2.924 \mathrm{E}-11 \quad 0.0001$ $2.122 \mathrm{E}-07 \quad 1.0000$ 
RESRAD, Version 6.5

$\mathrm{T}^{1 / 2}$ Limit $=180$ days

Summary : C746U Worker Deterministic Run

File : $\mathrm{X}: \backslash$ FINAL V2\C746U W DET-FINALV2.RAD

Total Dose Contributions TDOSE(i,p,t) for Individual Radionuclides (i) and Pathways (p) As mrem/yr and Fraction of Total Dose At $t=5.000 \mathrm{E}+01$ years

Water Independent Pathways (Inhalation excludes radon)

\begin{tabular}{|c|c|c|c|c|c|c|c|c|c|c|c|c|c|c|}
\hline \multirow[b]{2}{*}{ clide } & \multicolumn{2}{|c|}{ Ground } & \multicolumn{2}{|c|}{ Inhalation } & \multicolumn{2}{|c|}{ Radon } & \multicolumn{2}{|c|}{ Plant } & \multicolumn{2}{|c|}{ Meat } & \multicolumn{2}{|c|}{ Milk } & \multicolumn{2}{|c|}{ Soil } \\
\hline & mrem/yr & fract. & mrem/yr & fract. & mrem/yr & fract. & mrem/yr & fract. & mrem/yr & fract. & mrem/yr & fract. & mrem/yr & fract. \\
\hline 41 & $5.246 \mathrm{E}-18$ & 0.0000 & $0.000 \mathrm{E}+00$ & 0.0000 & $0.000 \mathrm{E}+00$ & 0.0000 & $0.000 \mathrm{E}+00$ & 0.0000 & $0.000 \mathrm{E}+00$ & 0.0000 & $0.000 \mathrm{E}+00$ & 0.0000 & $0.000 \mathrm{E}+00$ & 0.0000 \\
\hline 37 & $1.237 \mathrm{E}-10$ & 0.0003 & $0.000 \mathrm{E}+00$ & 0.0000 & $0.000 \mathrm{E}+00$ & 0.0000 & $0.000 \mathrm{E}+00$ & 0.0000 & $0.000 \mathrm{E}+00$ & 0.0000 & $0.000 \mathrm{E}+00$ & 0.0000 & $0.000 \mathrm{E}+00$ & 0.0000 \\
\hline 37 & $3.337 \mathrm{E}-13$ & 0.0000 & $0.000 \mathrm{E}+00$ & 0.0000 & $0.000 \mathrm{E}+00$ & 0.0000 & $0.000 \mathrm{E}+00$ & 0.0000 & $0.000 \mathrm{E}+00$ & 0.0000 & $0.000 \mathrm{E}+00$ & 0.0000 & $0.000 \mathrm{E}+00$ & 0.0000 \\
\hline 238 & $1.076 \mathrm{E}-17$ & 0.0000 & $0.000 \mathrm{E}+00$ & 0.0000 & $0.000 \mathrm{E}+00$ & 0.0000 & $0.000 \mathrm{E}+00$ & 0.0000 & $0.000 \mathrm{E}+00$ & 0.0000 & $0.000 \mathrm{E}+00$ & 0.0000 & $0.000 \mathrm{E}+00$ & 0.0000 \\
\hline 239 & $4.463 \mathrm{E}-18$ & 0.0000 & $0.000 \mathrm{E}+00$ & 0.0000 & $0.000 \mathrm{E}+00$ & 0.0000 & $0.000 \mathrm{E}+00$ & 0.0000 & $0.000 \mathrm{E}+00$ & 0.0000 & $0.000 \mathrm{E}+00$ & 0.0000 & $0.000 \mathrm{E}+00$ & 0.0000 \\
\hline 240 & $5.480 \mathrm{E}-22$ & 0 & $0.000 \mathrm{E}$ & 0 & $0.000 \mathrm{E}+00$ & 0 & $0.000 \mathrm{E}+00$ & 0 & $0.000 \mathrm{E}+00$ & 0 & $0.000 \mathrm{E}+00$ & 0 & $0.000 \mathrm{E}+00$ & 000 \\
\hline-99 & $2.364 \mathrm{E}-26$ & 0.0000 & $0.000 \mathrm{E}+00$ & 0.0000 & $0.000 \mathrm{E}+00$ & 0.0000 & $0.000 \mathrm{E}+00$ & 0.00 & $0.000 \mathrm{E}+00$ & 0.00 & $0.000 \mathrm{E}+00$ & 0.0 & $0.000 \mathrm{E}+00$ & 0.0000 \\
\hline 20 & $5.163 \mathrm{E}-15$ & 0.0000 & $0.000 \mathrm{E}+00$ & 0.0000 & $0.000 \mathrm{E}+00$ & 0.0000 & $0.000 \mathrm{E}+00$ & 0.0000 & $0.000 \mathrm{E}+00$ & 0.0000 & $0.000 \mathrm{E}+00$ & 0.0000 & $0.000 \mathrm{E}+00$ & 0.0000 \\
\hline 230 & $1.087 \mathrm{E}-09$ & 0.0024 & $0.000 \mathrm{E}+00$ & 0.0000 & $0.000 \mathrm{E}+00$ & 0.0000 & $0.000 \mathrm{E}+00$ & 0.0000 & $0.000 \mathrm{E}+00$ & 0.0000 & $0.000 \mathrm{E}+00$ & 0.0000 & $0.000 \mathrm{E}+00$ & 0.0000 \\
\hline & $4.579 \mathrm{E}-07$ & 0.9973 & $0.000 \mathrm{E}+00$ & 0.0000 & $0.000 \mathrm{E}+00$ & 0.0000 & $0.000 \mathrm{E}+00$ & 0.0000 & $0.000 \mathrm{E}+00$ & 0.0000 & $0.000 \mathrm{E}+00$ & 0.0000 & $0.000 \mathrm{E}+00$ & 0.0000 \\
\hline & $2.480 \mathrm{E}-13$ & 0.0000 & $0.000 \mathrm{E}+00$ & 0.0000 & $0.000 \mathrm{E}+00$ & 0.0000 & $0.000 \mathrm{E}+00$ & 0.0000 & $0.000 \mathrm{E}+00$ & 0.0000 & $0.000 \mathrm{E}+00$ & 0.0000 & $0.000 \mathrm{E}+00$ & 0.0000 \\
\hline & $1.888 \mathrm{E}-14$ & 0.0000 & $0.000 \mathrm{E}+00$ & 0.0000 & $0.000 \mathrm{E}+00$ & 0.0000 & $0.000 \mathrm{E}+00$ & 0.0000 & $0.000 \mathrm{E}+00$ & 0.0000 & $0.000 \mathrm{E}+00$ & 0.0000 & $0.000 \mathrm{E}+00$ & 0.0000 \\
\hline & $4.325 \mathrm{E}-11$ & 0.0001 & $0.000 \mathrm{E}+00$ & 0.0000 & $0.000 \mathrm{E}+00$ & 0.0000 & $0.000 \mathrm{E}+00$ & 0.0000 & $0.000 \mathrm{E}+00$ & 0.0000 & $0.000 \mathrm{E}+00$ & 0.0000 & $0.000 \mathrm{E}+00$ & 0.0000 \\
\hline & & 00 & $0.000 \mathrm{E}+00$ & 0.0000 & $0.000 \mathrm{E}+00$ & 0.0000 & $0.000 \mathrm{E}+00$ & 0.0000 & $0.000 \mathrm{E}+00$ & 0.0000 & $0.000 \mathrm{E}+00$ & 0.0000 & $E+00$ & .0 \\
\hline
\end{tabular}

Total Dose Contributions TDOSE (i,p,t) for Individual Radionuclides (i) and Pathways (p) As mrem/yr and Fraction of Total Dose At $t=5.000 \mathrm{E}+01$ years

Water Dependent Pathways

\begin{tabular}{|c|c|c|c|c|c|c|c|c|c|c|c|c|c|c|}
\hline \multirow[b]{2}{*}{ Nuclide } & \multicolumn{2}{|c|}{ Water } & \multicolumn{2}{|c|}{ Fish } & \multicolumn{2}{|c|}{ Radon } & \multicolumn{2}{|c|}{ Plant } & \multicolumn{2}{|c|}{ Meat } & \multicolumn{2}{|c|}{ Milk } & \multicolumn{2}{|c|}{ All Pathways* } \\
\hline & mrem/yr & fract. & $\mathrm{mrem} / \mathrm{yr}$ & fract. & $\mathrm{mrem} / \mathrm{yr}$ & fract. & mrem/yr & fract. & mrem/yr & fract. & $\mathrm{mrem} / \mathrm{yr}$ & fract. & $\mathrm{mrem} / \mathrm{yr}$ & fract. \\
\hline-241 & $0.000 \mathrm{E}+00$ & 0.0000 & $0.000 \mathrm{E}+00$ & 0.0000 & $0.000 \mathrm{E}+00$ & 0.0000 & $0.000 \mathrm{E}+00$ & 0.0000 & $0.000 \mathrm{E}+00$ & 0.0000 & $0.000 \mathrm{E}+00$ & 0.0000 & $5.246 \mathrm{E}-18$ & 0.0000 \\
\hline 137 & $0.000 \mathrm{E}+00$ & 0.0000 & $0.000 \mathrm{E}+00$ & 0.0000 & $0.000 \mathrm{E}+00$ & 0.0000 & $0.000 \mathrm{E}+00$ & 0.0000 & $0.000 \mathrm{E}+00$ & 0.0000 & $0.000 \mathrm{E}+00$ & 0.0000 & $1.237 \mathrm{E}-10$ & 0.0003 \\
\hline 37 & $0.000 \mathrm{E}+00$ & 0.0000 & $0.000 \mathrm{E}+00$ & 0.0000 & $0.000 \mathrm{E}+00$ & 0.0000 & $0.000 \mathrm{E}+00$ & 0.0000 & $0.000 \mathrm{E}+00$ & 0.0000 & $0.000 \mathrm{E}+00$ & 0.0000 & $3.337 \mathrm{E}-13$ & 0.0000 \\
\hline 238 & $0.000 \mathrm{E}+00$ & 0.0000 & $0.000 \mathrm{E}+00$ & 0.0000 & $0.000 \mathrm{E}+00$ & 0.0000 & $0.000 \mathrm{E}+00$ & 0.0000 & $0.000 \mathrm{E}+00$ & 0.0000 & $0.000 \mathrm{E}+00$ & 0.0000 & $1.076 \mathrm{E}-17$ & 0.0000 \\
\hline 239 & $0.000 \mathrm{E}+00$ & 0.0000 & $0.000 \mathrm{E}+00$ & 0.0000 & $0.000 \mathrm{E}+00$ & 0.0000 & $0.000 \mathrm{E}+00$ & 0.0000 & $0.000 \mathrm{E}+00$ & 0.0000 & $0.000 \mathrm{E}+00$ & 0.0000 & $4.463 \mathrm{E}-18$ & 0.0000 \\
\hline 240 & $0.000 \mathrm{E}+00$ & 0.0 & $0.000 \mathrm{E}+00$ & 0 & $0.000 \mathrm{E}+00$ & 0. & $0.000 \mathrm{E}+00$ & 0 & 0 & 0 & $0.000 \mathrm{E}+00$ & 0 & $80 \mathrm{E}-22$ & 0000 \\
\hline 年 & $0.000 \mathrm{E}+00$ & 0 & $0.000 \mathrm{E}+00$ & 0 & $0.000 \mathrm{E}+00$ & 0 & $0.000 \mathrm{E}+00$ & 0.00 & $0.000 \mathrm{E}+00$ & 00 & $0.000 \mathrm{E}+00$ & 0 & $2.364 \mathrm{E}-26$ & 0.0000 \\
\hline-228 & $0.000 \mathrm{E}+00$ & 0.0000 & $0.000 \mathrm{E}+00$ & 0.0000 & $0.000 \mathrm{E}+00$ & 0.0000 & $0.000 \mathrm{E}+00$ & 0.0000 & $0.000 \mathrm{E}+00$ & 0.0000 & $0.000 \mathrm{E}+00$ & 0.0000 & $5.163 \mathrm{E}-15$ & 0.0000 \\
\hline 230 & $0.000 \mathrm{E}+00$ & 0.0000 & $0.000 \mathrm{E}+00$ & 0.0000 & $0.000 \mathrm{E}+00$ & 0.0000 & $0.000 \mathrm{E}+00$ & 0.0000 & $0.000 \mathrm{E}+00$ & 0.0000 & $0.000 \mathrm{E}+00$ & 0.0000 & $1.087 \mathrm{E}-09$ & 0.0024 \\
\hline 232 & $0.000 \mathrm{E}+00$ & 0.0000 & $0.000 \mathrm{E}+00$ & 0.0000 & $0.000 \mathrm{E}+00$ & 0.0000 & $0.000 \mathrm{E}+00$ & 0.0000 & $0.000 \mathrm{E}+00$ & 0.0000 & $0.000 \mathrm{E}+00$ & 0.0000 & $4.579 \mathrm{E}-07$ & 0.9973 \\
\hline & $0.000 \mathrm{E}+00$ & 0.0000 & $0.000 \mathrm{E}+00$ & 0.0000 & $0.000 \mathrm{E}+00$ & 0.0000 & $0.000 \mathrm{E}+00$ & 0.0000 & $0.000 \mathrm{E}+00$ & 0.0000 & $0.000 \mathrm{E}+00$ & 0.0000 & $2.480 \mathrm{E}-13$ & 0.0000 \\
\hline & $0.000 \mathrm{E}+00$ & 0.0000 & $0.000 \mathrm{E}+00$ & 0.0000 & $0.000 \mathrm{E}+00$ & 0.0000 & $0.000 \mathrm{E}+00$ & 0.0000 & $0.000 \mathrm{E}+00$ & 0.0000 & $0.000 \mathrm{E}+00$ & 0.0000 & $1.888 \mathrm{E}-14$ & 0.0000 \\
\hline 38 & $0.000 \mathrm{E}+00$ & 0.0000 & $0.000 \mathrm{E}+00$ & 0.0000 & $0.000 \mathrm{E}+00$ & 0.0000 & $0.000 \mathrm{E}+00$ & 0.0000 & $0.000 \mathrm{E}+00$ & 0.0000 & $0.000 \mathrm{E}+00$ & 0.0000 & $4.325 \mathrm{E}-11$ & 0.0001 \\
\hline & & 0 & $.000 \mathrm{E}+00$ & 000 & $E+00$ & 0.0000 & $.000 \mathrm{E}+00$ & .0000 & $.000 \mathrm{E}+00$ & 0 & $\mathrm{E}+\mathrm{O}$ & & $4.39 \angle \mathrm{E}-U T$ & \\
\hline
\end{tabular}

*Sum of all water independent and dependent pathways. 
RESRAD, Version 6.5

$\mathrm{T}^{1 / 2}$ Limit $=180$ days

Summary : C746U Worker Deterministic Run

File : $\mathrm{X}: \backslash$ FINAL V2 $\backslash C 746 \mathrm{U} W$ DET-FINALV2.RAD

Total Dose Contributions TDOSE (i,p,t) for Individual Radionuclides (i) and Pathways (p) As mrem/yr and Fraction of Total Dose At $t=1.000 \mathrm{E}+02$ years

Water Independent Pathways (Inhalation excludes radon)

\begin{tabular}{|c|c|c|c|c|c|c|c|c|c|c|c|c|c|c|}
\hline \multirow[b]{2}{*}{ clide } & \multicolumn{2}{|c|}{ Ground } & \multicolumn{2}{|c|}{ Inhalation } & \multicolumn{2}{|c|}{ Radon } & \multicolumn{2}{|c|}{ Plant } & \multicolumn{2}{|c|}{ Meat } & \multicolumn{2}{|c|}{ Milk } & \multicolumn{2}{|c|}{ Soil } \\
\hline & mrem/yr & fract. & mrem/yr & fract. & mrem/yr & fract. & mrem/yr & fract. & mrem/yr & fract. & mrem/yr & fract. & mrem/yr & fract. \\
\hline 1 & $1.722 \mathrm{E}-17$ & 0.0000 & $0.000 \mathrm{E}+00$ & 0.0000 & $0.000 \mathrm{E}+00$ & 0.0000 & $0.000 \mathrm{E}+00$ & 0.0000 & $0.000 \mathrm{E}+00$ & 0.0000 & $0.000 \mathrm{E}+00$ & 0.0000 & $0.000 \mathrm{E}+00$ & 0.0000 \\
\hline 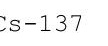 & $5.936 \mathrm{E}-11$ & 0.0001 & $0.000 \mathrm{E}+00$ & 0.0000 & $0.000 \mathrm{E}+00$ & 0.0000 & $0.000 \mathrm{E}+00$ & 0.0000 & $0.000 \mathrm{E}+00$ & 0.0000 & $0.000 \mathrm{E}+00$ & 0.0000 & $0.000 \mathrm{E}+00$ & 0.0000 \\
\hline 37 & $5.729 \mathrm{E}-13$ & 0.0000 & $0.000 \mathrm{E}+00$ & 0.0000 & $0.000 \mathrm{E}+00$ & 0.0000 & $0.000 \mathrm{E}+00$ & 0.0000 & $0.000 \mathrm{E}+00$ & 0.0000 & $0.000 \mathrm{E}+00$ & 0.0000 & $0.000 \mathrm{E}+00$ & 0.0000 \\
\hline 8 & $1.088 \mathrm{E}-16$ & 0.0000 & $0.000 \mathrm{E}+00$ & 0.0000 & $0.000 \mathrm{E}+00$ & 0.0000 & $0.000 \mathrm{E}+00$ & 0.0000 & $0.000 \mathrm{E}+00$ & 0.0000 & $0.000 \mathrm{E}+00$ & 0.0000 & $0.000 \mathrm{E}+00$ & 0.0000 \\
\hline & $8.110 \mathrm{E}-18$ & 0.0 & $0.000 \mathrm{E}$ & 0. & $0.000 \mathrm{E}+00$ & 0 & $0.000 \mathrm{E}+00$ & 0 & & & $0.000 \mathrm{E}+00$ & & $.000 \mathrm{E}+00$ & \\
\hline & $6 E-21$ & 0 & 0. & 0.0 & $0.000 \mathrm{E}+00$ & 0.00 & $0.000 \mathrm{E}+00$ & 0.0 & $E+00$ & 0 & $0.000 \mathrm{E}+00$ & 00 & $000 \mathrm{E}+00$ & 000 \\
\hline & $4.741 \mathrm{E}-26$ & 0.0000 & $0.000 \mathrm{E}+00$ & 0.0000 & $0.000 \mathrm{E}+00$ & 0.0000 & $0.000 \mathrm{E}+00$ & 0.0000 & $0.000 \mathrm{E}+00$ & 0.0000 & $0.000 \mathrm{E}+00$ & 0.0000 & $0.000 \mathrm{E}+00$ & 0.0000 \\
\hline 8 & $9.437 \mathrm{E}-23$ & 0.0000 & $0.000 \mathrm{E}+00$ & 0.0000 & $0.000 \mathrm{E}+00$ & 0.0000 & $0.000 \mathrm{E}+00$ & 0.0000 & $0.000 \mathrm{E}+00$ & 0.0000 & $0.000 \mathrm{E}+00$ & 0.0000 & $0.000 \mathrm{E}+00$ & 0.0000 \\
\hline & $3.024 \mathrm{E}-09$ & 0.0049 & $0.000 \mathrm{E}+00$ & 0.0000 & $0.000 \mathrm{E}+00$ & 0.0000 & $0.000 \mathrm{E}+00$ & 0.0000 & $0.000 \mathrm{E}+00$ & 0.0000 & $0.000 \mathrm{E}+00$ & 0.0000 & $0.000 \mathrm{E}+00$ & 0.0000 \\
\hline & $6.198 \mathrm{E}-07$ & 0.9949 & $0.000 \mathrm{E}+00$ & 0.0000 & $0.000 \mathrm{E}+00$ & 0.0000 & $0.000 \mathrm{E}+00$ & 0.0000 & $0.000 \mathrm{E}+00$ & 0.0000 & $0.000 \mathrm{E}+00$ & 0.0000 & $0.000 \mathrm{E}+00$ & 0.0000 \\
\hline & $1.377 \mathrm{E}-12$ & 0.0000 & $0.000 \mathrm{E}+00$ & 0.0000 & $0.000 \mathrm{E}+00$ & 0.0000 & $0.000 \mathrm{E}+00$ & 0.0000 & $0.000 \mathrm{E}+00$ & 0.0000 & $0.000 \mathrm{E}+00$ & 0.0000 & $0.000 \mathrm{E}+00$ & 0.0000 \\
\hline & $6.928 \mathrm{E}-14$ & 0.0000 & $0.000 \mathrm{E}+00$ & 0.0000 & $0.000 \mathrm{E}+00$ & 0.0000 & $0.000 \mathrm{E}+00$ & 0.0000 & $0.000 \mathrm{E}+00$ & 0.0000 & $0.000 \mathrm{E}+00$ & 0.0000 & $0.000 \mathrm{E}+00$ & 0.0000 \\
\hline & $6.449 \mathrm{E}-11$ & 0.0001 & $0.000 \mathrm{E}+00$ & 0.0000 & $0.000 \mathrm{E}+00$ & 0.0000 & $0.000 \mathrm{E}+00$ & 0.0000 & $0.000 \mathrm{E}+00$ & 0.0000 & $0.000 \mathrm{E}+00$ & 0.0000 & $0.000 \mathrm{E}+00$ & 0.0000 \\
\hline & & & $\mathrm{E}+00$ & 0.0000 & +00 & 0.0000 & +00 & & $E+00$ & & $0.000 \mathrm{E}+00$ & 0.0 & $E+00$ & c \\
\hline
\end{tabular}

Total Dose Contributions TDOSE (i,p,t) for Individual Radionuclides (i) and Pathways (p) As mrem/yr and Fraction of Total Dose At $t=1.000 \mathrm{E}+02$ years

Water Dependent Pathways

\begin{tabular}{|c|c|c|c|c|c|c|c|c|c|c|c|c|c|c|}
\hline \multirow[b]{2}{*}{ Nuclide } & \multicolumn{2}{|c|}{ Water } & \multicolumn{2}{|c|}{ Fish } & \multicolumn{2}{|c|}{ Radon } & \multicolumn{2}{|c|}{ Plant } & \multicolumn{2}{|c|}{ Meat } & \multicolumn{2}{|c|}{ Milk } & \multicolumn{2}{|c|}{ All Pathways* } \\
\hline & mrem/yr & fract. & $\mathrm{mrem} / \mathrm{yr}$ & fract. & $\mathrm{mrem} / \mathrm{yr}$ & fract. & mrem/yr & fract. & mrem/yr & fract. & $\mathrm{mrem} / \mathrm{yr}$ & fract. & $\mathrm{mrem} / \mathrm{yr}$ & fract. \\
\hline-241 & $0.000 \mathrm{E}+00$ & 0.0000 & $0.000 \mathrm{E}+00$ & 0.0000 & $0.000 \mathrm{E}+00$ & 0.0000 & $0.000 \mathrm{E}+00$ & 0.0000 & $0.000 \mathrm{E}+00$ & 0.0000 & $0.000 \mathrm{E}+00$ & 0.0000 & $1.722 \mathrm{E}-17$ & 0.0000 \\
\hline 137 & $0.000 \mathrm{E}+00$ & 0.0000 & $0.000 \mathrm{E}+00$ & 0.0000 & $0.000 \mathrm{E}+00$ & 0.0000 & $0.000 \mathrm{E}+00$ & 0.0000 & $0.000 \mathrm{E}+00$ & 0.0000 & $0.000 \mathrm{E}+00$ & 0.0000 & $5.936 \mathrm{E}-11$ & 0.0001 \\
\hline 37 & $0.000 \mathrm{E}+00$ & 0.0000 & $0.000 \mathrm{E}+00$ & 0.0000 & $0.000 \mathrm{E}+00$ & 0.0000 & $0.000 \mathrm{E}+00$ & 0.0000 & $0.000 \mathrm{E}+00$ & 0.0000 & $0.000 \mathrm{E}+00$ & 0.0000 & $5.729 \mathrm{E}-13$ & 0.0000 \\
\hline 238 & $0.000 \mathrm{E}+00$ & 0.0000 & $0.000 \mathrm{E}+00$ & 0.0000 & $0.000 \mathrm{E}+00$ & 0.0000 & $0.000 \mathrm{E}+00$ & 0.0000 & $0.000 \mathrm{E}+00$ & 0.0000 & $0.000 \mathrm{E}+00$ & 0.0000 & $1.088 \mathrm{E}-16$ & 0.0000 \\
\hline 239 & $0.000 \mathrm{E}+00$ & 0.0000 & $0.000 \mathrm{E}+00$ & 0.0000 & $0.000 \mathrm{E}+00$ & 0.0000 & $0.000 \mathrm{E}+00$ & 0.0000 & $0.000 \mathrm{E}+00$ & 0.0000 & $0.000 \mathrm{E}+00$ & 0.0000 & $8.110 \mathrm{E}-18$ & 0.0000 \\
\hline 240 & $0.000 \mathrm{E}+00$ & 0.0 & $0.000 \mathrm{E}+00$ & 0 & $0.000 \mathrm{E}+00$ & 0. & $0.000 \mathrm{E}+00$ & 0 & 0 & 0 & $0.000 \mathrm{E}+00$ & 0 & -21 & 000 \\
\hline 年 & $0.000 \mathrm{E}+00$ & 0 & $0.000 \mathrm{E}+00$ & 0 & $0.000 \mathrm{E}+00$ & 0 & $0.000 \mathrm{E}+00$ & 0.00 & $0.000 \mathrm{E}+00$ & 00 & $0.000 \mathrm{E}+00$ & 0 & $.741 \mathrm{E}-26$ & 0.0000 \\
\hline-228 & $0.000 \mathrm{E}+00$ & 0.0000 & $0.000 \mathrm{E}+00$ & 0.0000 & $0.000 \mathrm{E}+00$ & 0.0000 & $0.000 \mathrm{E}+00$ & 0.0000 & $0.000 \mathrm{E}+00$ & 0.0000 & $0.000 \mathrm{E}+00$ & 0.0000 & $9.437 \mathrm{E}-23$ & 0.0000 \\
\hline 230 & $0.000 \mathrm{E}+00$ & 0.0000 & $0.000 \mathrm{E}+00$ & 0.0000 & $0.000 \mathrm{E}+00$ & 0.0000 & $0.000 \mathrm{E}+00$ & 0.0000 & $0.000 \mathrm{E}+00$ & 0.0000 & $0.000 \mathrm{E}+00$ & 0.0000 & $3.024 \mathrm{E}-09$ & 0.0049 \\
\hline 232 & $0.000 \mathrm{E}+00$ & 0.0000 & $0.000 \mathrm{E}+00$ & 0.0000 & $0.000 \mathrm{E}+00$ & 0.0000 & $0.000 \mathrm{E}+00$ & 0.0000 & $0.000 \mathrm{E}+00$ & 0.0000 & $0.000 \mathrm{E}+00$ & 0.0000 & $6.198 \mathrm{E}-07$ & 0.9949 \\
\hline & $0.000 \mathrm{E}+00$ & 0.0000 & $0.000 \mathrm{E}+00$ & 0.0000 & $0.000 \mathrm{E}+00$ & 0.0000 & $0.000 \mathrm{E}+00$ & 0.0000 & $0.000 \mathrm{E}+00$ & 0.0000 & $0.000 \mathrm{E}+00$ & 0.0000 & $1.377 \mathrm{E}-12$ & 0.0000 \\
\hline & $0.000 \mathrm{E}+00$ & 0.0000 & $0.000 \mathrm{E}+00$ & 0.0000 & $0.000 \mathrm{E}+00$ & 0.0000 & $0.000 \mathrm{E}+00$ & 0.0000 & $0.000 \mathrm{E}+00$ & 0.0000 & $0.000 \mathrm{E}+00$ & 0.0000 & $6.928 \mathrm{E}-14$ & 0.0000 \\
\hline 38 & $0.000 \mathrm{E}+00$ & 0.0000 & $0.000 \mathrm{E}+00$ & 0.0000 & $0.000 \mathrm{E}+00$ & 0.0000 & $0.000 \mathrm{E}+00$ & 0.0000 & $0.000 \mathrm{E}+00$ & 0.0000 & $0.000 \mathrm{E}+00$ & 0.0000 & $6.449 \mathrm{E}-11$ & 0.0001 \\
\hline & & 0 & $.000 \mathrm{E}+00$ & 000 & $.000 \mathrm{E}+00$ & 0.0000 & $.000 \mathrm{E}+00$ & .0000 & $.000 \mathrm{E}+00$ & 0 & $\mathrm{E}+\mathrm{O}$ & & $6.229 \mathrm{E}-01$ & \\
\hline
\end{tabular}

*Sum of all water independent and dependent pathways. 
RESRAD, Version 6.5

$\mathrm{T}^{1 / 2}$ Limit $=180$ days

Summary : C746U Worker Deterministic Run

File : $\mathrm{X}: \backslash$ FINAL V2 $\backslash C 746 \mathrm{U} W$ DET-FINALV2.RAD

Total Dose Contributions TDOSE (i,p,t) for Individual Radionuclides (i) and Pathways (p) As mrem/yr and Fraction of Total Dose At $t=5.000 \mathrm{E}+02$ years

Water Independent Pathways (Inhalation excludes radon)

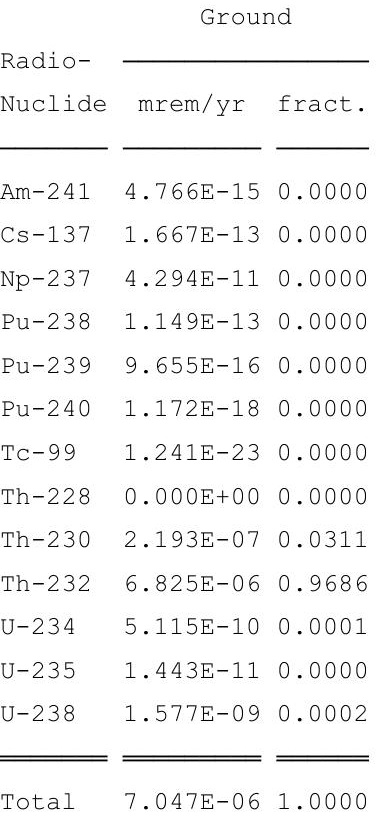

Radio-

Total

\begin{abstract}
Inhalation
\end{abstract}

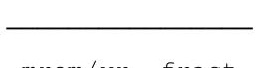

mrem/yr fract. mrem/yr fract.

$\overline{0.000 \mathrm{E}+00} \overline{0.0000}$

$0.000 \mathrm{E}+00 \quad 0.0000$

$0.000 \mathrm{E}+00 \quad 0.0000$

$0.000 \mathrm{E}+00 \quad 0.0000$

$0.000 \mathrm{E}+00 \quad 0.0000$

$0.000 \mathrm{E}+00 \quad 0.0000$

$0.000 \mathrm{E}+00 \quad 0.0000$

$0.000 \mathrm{E}+00 \quad 0.0000$

$0.000 \mathrm{E}+00 \quad 0.0000$

$0.000 \mathrm{E}+00 \quad 0.0000$

$0.000 \mathrm{E}+00 \quad 0.0000$

$0.000 \mathrm{E}+00 \quad 0.0000$

$0.000 \mathrm{E}+00 \quad 0.0000$

$\overline{0.000 \mathrm{E}+00} \overline{0.0000}$

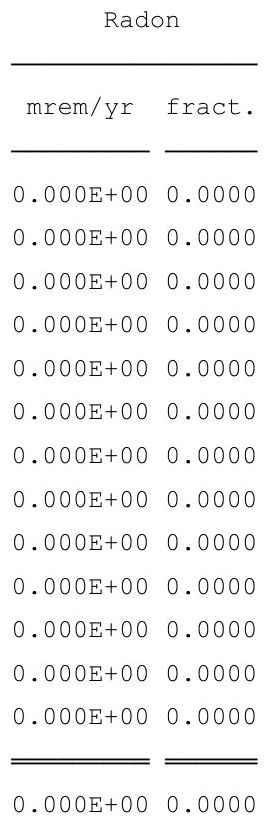

$0.000 \mathrm{E}+00 \quad 0.0000$

\begin{tabular}{ccccc} 
Plant & & Meat \\
\cline { 1 - 1 } mrem/yr fract. & & mrem/yr fract. & & \\
\cline { 1 - 1 } $0.000 \mathrm{E}+00$ & 0.0000 & & $0.000 \mathrm{E}+00$ & 0.0000 \\
$0.000 \mathrm{E}+00$ & 0.0000 & $0.000 \mathrm{E}+00$ & 0.0000 \\
$0.000 \mathrm{E}+00$ & 0.0000 & $0.000 \mathrm{E}+00$ & 0.0000 \\
$0.000 \mathrm{E}+00$ & 0.0000 & $0.000 \mathrm{E}+00$ & 0.0000 \\
$0.000 \mathrm{E}+00$ & 0.0000 & & $0.000 \mathrm{E}+00$ & 0.0000 \\
$0.000 \mathrm{E}+00$ & 0.0000 & $0.000 \mathrm{E}+00$ & 0.0000 \\
$0.000 \mathrm{E}+00$ & 0.0000 & $0.000 \mathrm{E}+00$ & 0.0000 \\
$0.000 \mathrm{E}+00$ & 0.0000 & $0.000 \mathrm{E}+00$ & 0.0000 \\
$0.000 \mathrm{E}+00$ & 0.0000 & $0.000 \mathrm{E}+00$ & 0.0000 \\
$0.000 \mathrm{E}+00$ & 0.0000 & $0.000 \mathrm{E}+00$ & 0.0000 \\
$0.000 \mathrm{E}+00$ & 0.0000 & $0.000 \mathrm{E}+00$ & 0.0000 \\
$0.000 \mathrm{E}+00$ & 0.0000 & $0.000 \mathrm{E}+00$ & 0.0000 \\
$0.000 \mathrm{E}+00$ & 0.0000 & $0.000 \mathrm{E}+00$ & 0.0000 \\
\hline \hline $0.000 \mathrm{E}+00$ & 0.0000 & $0.000 \mathrm{E}+00$ & 0.0000
\end{tabular}

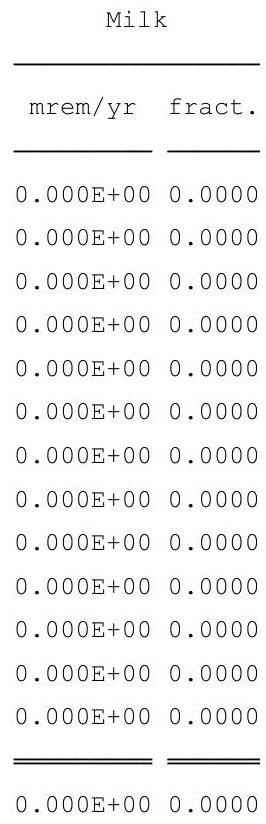

Soil mrem/yr fract. $0.000 \mathrm{E}+00 \quad 0.0000$ $0.000 \mathrm{E}+00 \quad 0.0000$ $0.000 \mathrm{E}+00 \quad 0.0000$ $0.000 \mathrm{E}+00 \quad 0.0000$ $0.000 \mathrm{E}+00 \quad 0.0000$ $0.000 \mathrm{E}+00 \quad 0.0000$ $0.000 \mathrm{E}+00 \quad 0.0000$ $0.000 \mathrm{E}+00 \quad 0.0000$ $0.000 \mathrm{E}+00 \quad 0.0000$ $0.000 \mathrm{E}+00 \quad 0.0000$ $0.000 \mathrm{E}+00 \quad 0.0000$ $0.000 \mathrm{E}+00 \quad 0.0000$ $0.000 \mathrm{E}+00 \quad 0.0000$ $0.000 \mathrm{E}+00 \quad 0.0000$

Total Dose Contributions TDOSE (i,p,t) for Individual Radionuclides (i) and Pathways (p) As mrem/yr and Fraction of Total Dose At $t=5.000 \mathrm{E}+02$ years

Water Dependent Pathways

\begin{tabular}{|c|c|c|c|c|c|c|}
\hline \multirow{2}{*}{$\begin{array}{l}\text { Radio- } \\
\text { Nuclide }\end{array}$} & \multicolumn{2}{|c|}{ Water } & \multicolumn{2}{|c|}{ Fish } & \multicolumn{2}{|c|}{ Radon } \\
\hline & $\mathrm{mrem} / \mathrm{yr}$ & fract. & mrem/yr & fract. & $\mathrm{mrem} / \mathrm{yr}$ & fract. \\
\hline-241 & $0.000 \mathrm{E}+00$ & 0.0000 & $0.000 \mathrm{E}+00$ & 0.0000 & $0.000 \mathrm{E}+00$ & 0.0000 \\
\hline-137 & $0.000 \mathrm{E}+00$ & 0.0000 & $0.000 \mathrm{E}+00$ & 0.0000 & $0.000 \mathrm{E}+00$ & 0.0000 \\
\hline 237 & $0.000 \mathrm{E}+00$ & 0.0000 & $0.000 \mathrm{E}+00$ & 0.0000 & $0.000 \mathrm{E}+00$ & 0.0000 \\
\hline-238 & $0.000 \mathrm{E}+00$ & 0.0000 & $0.000 \mathrm{E}+00$ & 0.0000 & $0.000 \mathrm{E}+00$ & 0.0000 \\
\hline 239 & $0.000 \mathrm{E}+00$ & 0.0000 & $0.000 \mathrm{E}+00$ & 0.0000 & $0.000 \mathrm{E}+00$ & 0.0000 \\
\hline-240 & $0.000 \mathrm{E}+00$ & 0.0000 & $0.000 \mathrm{E}+00$ & 0.0000 & $0.000 \mathrm{E}+00$ & 0.0000 \\
\hline 99 & $0.000 \mathrm{E}+00$ & 0.0000 & $0.000 \mathrm{E}+00$ & 0.0000 & $0.000 \mathrm{E}+00$ & 0.0000 \\
\hline 228 & $0.000 \mathrm{E}+00$ & 0.0000 & $0.000 \mathrm{E}+00$ & 0.0000 & $0.000 \mathrm{E}+00$ & 0.0000 \\
\hline 230 & $0.000 \mathrm{E}+00$ & 0.0000 & $0.000 \mathrm{E}+00$ & 0.0000 & $0.000 \mathrm{E}+00$ & 0.0000 \\
\hline 232 & $0.000 \mathrm{E}+00$ & 0.0000 & $0.000 \mathrm{E}+00$ & 0.0000 & $0.000 \mathrm{E}+00$ & 0.0000 \\
\hline 4 & $0.000 \mathrm{E}+00$ & 0.0000 & $0.000 \mathrm{E}+00$ & 0.0000 & $0.000 \mathrm{E}+00$ & 0.0000 \\
\hline & $0.000 \mathrm{E}+00$ & 0.0000 & $0.000 \mathrm{E}+00$ & 0.0000 & $0.000 \mathrm{E}+00$ & 0.0000 \\
\hline & $0.000 \mathrm{E}+00$ & 0.0000 & $0.000 \mathrm{E}+00$ & 0.0000 & $0.000 \mathrm{E}+00$ & 0.0000 \\
\hline & 00 & 00 & $.000 \mathrm{E}+00$ & 000 & $0.000 \mathrm{E}+00$ & 0.00 \\
\hline
\end{tabular}

\begin{tabular}{cc} 
Plant \\
\hline mrem/yr fract. \\
\cline { 1 - 1 } 0.000E+00 & 0.0000 \\
$0.000 \mathrm{E}+00$ & 0.0000 \\
$0.000 \mathrm{E}+00$ & 0.0000 \\
$0.000 \mathrm{E}+00$ & 0.0000 \\
$0.000 \mathrm{E}+00$ & 0.0000 \\
$0.000 \mathrm{E}+00$ & 0.0000 \\
$0.000 \mathrm{E}+00$ & 0.0000 \\
$0.000 \mathrm{E}+00$ & 0.0000 \\
$0.000 \mathrm{E}+00$ & 0.0000 \\
$0.000 \mathrm{E}+00$ & 0.0000 \\
$0.000 \mathrm{E}+00$ & 0.0000 \\
$0.000 \mathrm{E}+00$ & 0.0000 \\
$0.000 \mathrm{E}+00$ & 0.0000 \\
\hline \hline
\end{tabular}

$0.000 \mathrm{E}+00 \quad 0.0000$

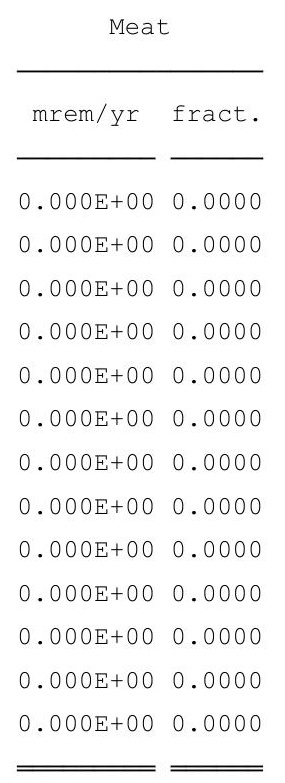

$0.000 \mathrm{E}+00 \quad 0.0000$

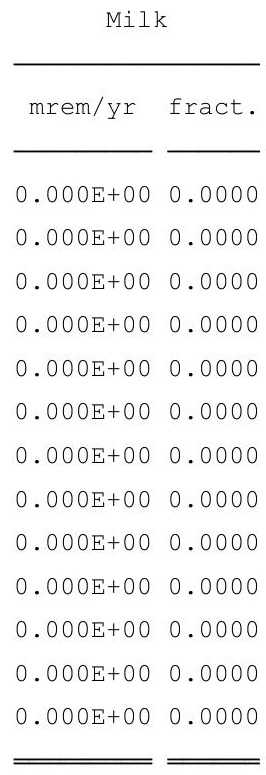

$0.000 \mathrm{E}+00 \quad 0.0000$
All Pathways* mrem/yr fract.

$4.766 \mathrm{E}-150.0000$ $1.667 \mathrm{E}-13 \quad 0.0000$ $4.294 \mathrm{E}-110.0000$ $1.149 \mathrm{E}-13 \quad 0.0000$ $9.655 \mathrm{E}-16 \quad 0.0000$ $1.172 \mathrm{E}-18 \quad 0.0000$ $1.241 \mathrm{E}-23 \quad 0.0000$ $0.000 \mathrm{E}+00 \quad 0.0000$ $2.193 \mathrm{E}-07 \quad 0.0311$ $6.825 \mathrm{E}-06 \quad 0.9686$ $5.115 \mathrm{E}-10 \quad 0.0001$ $1.443 \mathrm{E}-11 \quad 0.0000$ $1.577 \mathrm{E}-09 \quad 0.0002$ $7.047 \mathrm{E}-06 \quad 1.0000$

*Sum of all water independent and dependent pathways. 
RESRAD, Version 6.5

$\mathrm{T}^{1 / 2}$ Limit $=180$ days

\section{File : X: \FINAL V2\C746U W DET-FINALV2.RAD}

Total Dose Contributions TDOSE (i,p,t) for Individual Radionuclides (i) and Pathways (p) As mrem/yr and Fraction of Total Dose At $t=1.050 \mathrm{E}+03$ years

Water Independent Pathways (Inhalation excludes radon)

\begin{tabular}{|c|c|c|}
\hline clide & mrem/yr & fract. \\
\hline 241 & $2.581 \mathrm{E}-12$ & 0.0000 \\
\hline-137 & $5.175 \mathrm{E}-17$ & 0.0000 \\
\hline-237 & $1.540 \mathrm{E}-08$ & 0.0001 \\
\hline-238 & $2.677 \mathrm{E}-11$ & 0.0000 \\
\hline-239 & $6.871 \mathrm{E}-13$ & 0.0000 \\
\hline-240 & $1.665 \mathrm{E}-16$ & 0.0000 \\
\hline-99 & $2.619 \mathrm{E}-20$ & 0.0000 \\
\hline-228 & $0.000 \mathrm{E}+00$ & 0.0000 \\
\hline-230 & $1.840 \mathrm{E}-05$ & 0.0886 \\
\hline-232 & $1.891 \mathrm{E}-04$ & 0.9103 \\
\hline 34 & $9.341 E-08$ & 0.0004 \\
\hline 35 & $4.843 E-09$ & 0.0000 \\
\hline 38 & $1.280 \mathrm{E}-07$ & 0.0006 \\
\hline & 04 & 1.0000 \\
\hline
\end{tabular}

Inhalation

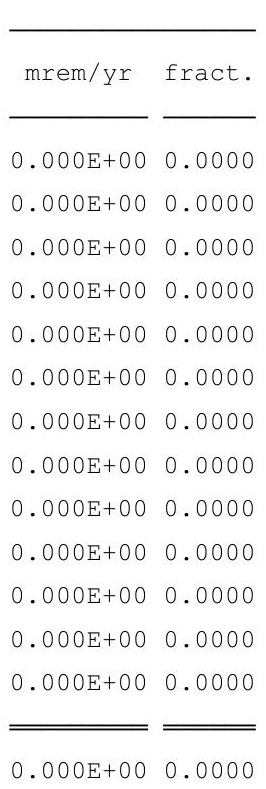

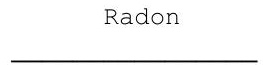
mrem/yr fract. $\overline{0.000 E+00} 0.0000$ $0.000 E+00 \quad 0.0000$ $0.000 E+00 \quad 0.0000$ $0.000 E+00 \quad 0.0000$ $0.000 \mathrm{E}+00 \quad 0.0000$ $0.000 E+00 \quad 0.0000$ $0.000 \mathrm{E}+00 \quad 0.0000$ $0.000 E+00 \quad 0.0000$ $0.000 \mathrm{E}+00 \quad 0.0000$ $0.000 \mathrm{E}+00 \quad 0.0000$ $0.000 E+00 \quad 0.0000$ $0.000 \mathrm{E}+00 \quad 0.0000$ $0.000 \mathrm{E}+00 \quad 0.0000$

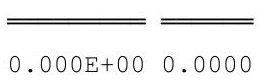

\begin{tabular}{|c|c|c|c|}
\hline \multicolumn{2}{|c|}{ Plant } & \multicolumn{2}{|c|}{ Meat } \\
\hline mrem/yr & fract. & mrem/yr & fract. \\
\hline $0.000 \mathrm{E}+00$ & 0.0000 & $0.000 \mathrm{E}+00$ & 0.0000 \\
\hline $0.000 \mathrm{E}+00$ & 0.0000 & $0.000 \mathrm{E}+00$ & 0.0000 \\
\hline $0.000 \mathrm{E}+00$ & 0.0000 & $0.000 \mathrm{E}+00$ & 0.0000 \\
\hline $0.000 \mathrm{E}+00$ & 0.0000 & $0.000 \mathrm{E}+00$ & 0.0000 \\
\hline $0.000 \mathrm{E}+00$ & 0.0000 & $0.000 \mathrm{E}+00$ & 0.0000 \\
\hline $0.000 \mathrm{E}+00$ & 0.0000 & $0.000 \mathrm{E}+00$ & 0.0000 \\
\hline $0.000 \mathrm{E}+00$ & 0.0000 & $0.000 \mathrm{E}+00$ & 0.0000 \\
\hline $0.000 \mathrm{E}+00$ & 0.0000 & $0.000 \mathrm{E}+00$ & 0.0000 \\
\hline $0.000 \mathrm{E}+00$ & 0.0000 & $0.000 \mathrm{E}+00$ & 0.0000 \\
\hline $0.000 \mathrm{E}+00$ & 0.0000 & $0.000 \mathrm{E}+00$ & 0.0000 \\
\hline $0.000 \mathrm{E}+00$ & 0.0000 & $0.000 \mathrm{E}+00$ & 0.0000 \\
\hline $0.000 \mathrm{E}+00$ & 0.0000 & $0.000 \mathrm{E}+00$ & 0.0000 \\
\hline $0.000 \mathrm{E}+00$ & 0.0000 & $0.000 \mathrm{E}+00$ & 0.0000 \\
\hline & & 0.00 & \\
\hline
\end{tabular}

\begin{tabular}{cc} 
Milk \\
\cline { 1 - 2 } mrem/yr fract. & \\
\cline { 1 - 2 } $0.000 \mathrm{E}+00$ & 0.0000 \\
$0.000 \mathrm{E}+00$ & 0.0000 \\
$0.000 \mathrm{E}+00$ & 0.0000 \\
$0.000 \mathrm{E}+00$ & 0.0000 \\
$0.000 \mathrm{E}+00$ & 0.0000 \\
$0.000 \mathrm{E}+00$ & 0.0000 \\
$0.000 \mathrm{E}+00$ & 0.0000 \\
$0.000 \mathrm{E}+00$ & 0.0000 \\
$0.000 \mathrm{E}+00$ & 0.0000 \\
$0.000 \mathrm{E}+00$ & 0.0000 \\
$0.000 \mathrm{E}+00$ & 0.0000 \\
$0.000 \mathrm{E}+00$ & 0.0000 \\
$0.000 \mathrm{E}+00$ & 0.0000 \\
\hline \hline $0.000 \mathrm{E}+00$ & 0.0000
\end{tabular}

Soil mrem/yr fract. $0.000 \mathrm{E}+00 \quad 0.0000$ $0.000 \mathrm{E}+00 \quad 0.0000$ $0.000 \mathrm{E}+00 \quad 0.0000$ $0.000 \mathrm{E}+00 \quad 0.0000$ $0.000 \mathrm{E}+00 \quad 0.0000$ $0.000 \mathrm{E}+00 \quad 0.0000$ $0.000 \mathrm{E}+00 \quad 0.0000$ $0.000 \mathrm{E}+00 \quad 0.0000$ $0.000 \mathrm{E}+00 \quad 0.0000$ $0.000 \mathrm{E}+00 \quad 0.0000$ $0.000 \mathrm{E}+00 \quad 0.0000$ $0.000 \mathrm{E}+00 \quad 0.0000$ $0.000 \mathrm{E}+00 \quad 0.0000$ $0.000 \mathrm{E}+00 \quad 0.0000$

Total Dose Contributions TDOSE (i,p,t) for Individual Radionuclides (i) and Pathways (p) As mrem/yr and Fraction of Total Dose At $t=1.050 \mathrm{E}+03$ years

Water Dependent Pathways

\begin{tabular}{|c|c|c|c|c|c|c|}
\hline \multirow{2}{*}{ Juclide } & \multicolumn{2}{|c|}{ Water } & \multicolumn{2}{|c|}{ Fish } & \multicolumn{2}{|c|}{ Radon } \\
\hline & mrem/yr & fract. & mrem/yr & fract. & mrem/yr & fract. \\
\hline-241 & $0.000 \mathrm{E}+00$ & 0.0000 & $0.000 \mathrm{E}+00$ & 0.0000 & $0.000 \mathrm{E}+00$ & 0.0000 \\
\hline-137 & $0.000 \mathrm{E}+00$ & 0.0000 & $0.000 \mathrm{E}+00$ & 0.0000 & $0.000 \mathrm{E}+00$ & 0.0000 \\
\hline-237 & $0.000 \mathrm{E}+00$ & 0.0000 & $0.000 \mathrm{E}+00$ & 0.0000 & $0.000 \mathrm{E}+00$ & 0.0000 \\
\hline-238 & $0.000 \mathrm{E}+00$ & 0.0000 & $0.000 \mathrm{E}+00$ & 0.0000 & $0.000 \mathrm{E}+00$ & 0.0000 \\
\hline 239 & $0.000 \mathrm{E}+00$ & 0.0000 & $0.000 \mathrm{E}+00$ & 0.0000 & $0.000 \mathrm{E}+00$ & 0.0000 \\
\hline 240 & $0.000 \mathrm{E}+00$ & 0.0000 & $0.000 \mathrm{E}+00$ & 0.0000 & $0.000 \mathrm{E}+00$ & 0.0000 \\
\hline 99 & $0.000 \mathrm{E}+00$ & 0.0000 & $0.000 \mathrm{E}+00$ & 0.0000 & $0.000 \mathrm{E}+00$ & 0.0000 \\
\hline 228 & $0.000 \mathrm{E}+00$ & 0.0000 & $0.000 \mathrm{E}+00$ & 0.0000 & $0.000 \mathrm{E}+00$ & 0.0000 \\
\hline 230 & $0.000 \mathrm{E}+00$ & 0.0000 & $0.000 \mathrm{E}+00$ & 0.0000 & $0.000 \mathrm{E}+00$ & 0.0000 \\
\hline 32 & $0.000 \mathrm{E}+00$ & 0.0000 & $0.000 \mathrm{E}+00$ & 0.0000 & $0.000 \mathrm{E}+00$ & 0.0000 \\
\hline 34 & $0.000 \mathrm{E}+00$ & 0.0000 & $0.000 \mathrm{E}+00$ & 0.0000 & $0.000 \mathrm{E}+00$ & 0.0000 \\
\hline 35 & $0.000 \mathrm{E}+00$ & 0.0000 & $0.000 \mathrm{E}+00$ & 0.0000 & $0.000 \mathrm{E}+00$ & 0.0000 \\
\hline & $0.000 \mathrm{E}+00$ & 0.0000 & $0.000 \mathrm{E}+00$ & 0.0000 & $0.000 \mathrm{E}+00$ & 0.0000 \\
\hline
\end{tabular}

\begin{tabular}{cc} 
Plant \\
\cline { 1 - 2 } mrem/yr fract. \\
\cline { 1 - 1 } 0.000E+00 & 0.0000 \\
$0.000 \mathrm{E}+00$ & 0.0000 \\
$0.000 \mathrm{E}+00$ & 0.0000 \\
$0.000 \mathrm{E}+00$ & 0.0000 \\
$0.000 \mathrm{E}+00$ & 0.0000 \\
$0.000 \mathrm{E}+00$ & 0.0000 \\
$0.000 \mathrm{E}+00$ & 0.0000 \\
$0.000 \mathrm{E}+00$ & 0.0000 \\
$0.000 \mathrm{E}+00$ & 0.0000 \\
$0.000 \mathrm{E}+00$ & 0.0000 \\
$0.000 \mathrm{E}+00$ & 0.0000 \\
$0.000 \mathrm{E}+00$ & 0.0000 \\
$0.000 \mathrm{E}+00$ & 0.0000 \\
\hline \hline
\end{tabular}

$0.000 \mathrm{E}+00 \quad 0.0000$

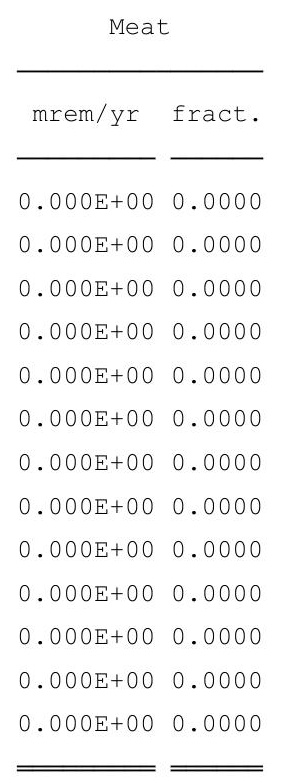

$0.000 \mathrm{E}+00 \quad 0.0000$

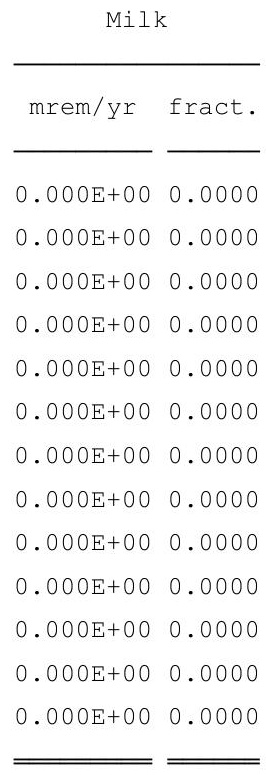

$0.000 \mathrm{E}+00 \quad 0.0000$
All Pathways* mrem/yr fract. $2.581 \mathrm{E}-12 \quad 0.0000$ $5.175 \mathrm{E}-17 \quad 0.0000$ $1.540 \mathrm{E}-08 \quad 0.0001$ $2.677 \mathrm{E}-110.0000$ $6.871 \mathrm{E}-13 \quad 0.0000$ $1.665 \mathrm{E}-16 \quad 0.0000$ $2.619 \mathrm{E}-20 \quad 0.0000$ $0.000 \mathrm{E}+00 \quad 0.0000$ $1.840 \mathrm{E}-05 \quad 0.0886$ $1.891 \mathrm{E}-04 \quad 0.9103$ $9.341 \mathrm{E}-08 \quad 0.0004$ $4.843 \mathrm{E}-09 \quad 0.0000$ $1.280 \mathrm{E}-07 \quad 0.0006$ $2.078 \mathrm{E}-04 \quad 1.0000$

*Sum of all water independent and dependent pathways. 
RESRAD, Version 6.5

\section{ummary : C746U Worker Deterministic Run \\ File : $\mathrm{X}: \backslash$ FINAL V2 $\backslash \mathrm{C} 746 \mathrm{U}$ W DET-FINALV2.RAD}

Dose/Source Ratios Summed Over All Pathways

Parent and Progeny Principal Radionuclide Contributions Indicated

\begin{tabular}{|c|c|c|c|c|c|c|c|c|}
\hline $\begin{array}{l}\text { Parent } \\
\text { (i) }\end{array}$ & $\begin{array}{l}\text { Product } \\
(j)\end{array}$ & $\begin{array}{c}\text { Thread } \\
\text { Fraction }\end{array}$ & $\begin{array}{r}\text { DSR } \\
0.000 \mathrm{E}+00\end{array}$ & $\begin{array}{l}(j, t) \text { At } T \\
1.000 \mathrm{E}+00\end{array}$ & $\begin{array}{l}\text { ime in Yea } \\
5.000 \mathrm{E}+01\end{array}$ & $\begin{array}{l}\text { rs (mrem } \\
1.000 \mathrm{E}+02\end{array}$ & $\begin{array}{l}/ \mathrm{yr}) /(\mathrm{pCi} / \\
5.000 \mathrm{E}+02\end{array}$ & $\begin{array}{l}\text { g) } \\
1.050 \mathrm{E}+03\end{array}$ \\
\hline-241 & $A m-241$ & $1.000 \mathrm{E}+00$ & $3.956 E-34$ & $4.063 E-34$ & $1.503 E-33$ & $5.707 E-33$ & $2.471 E-28$ & $5.859 E-22$ \\
\hline-241 & $N p-237+D$ & $1.000 \mathrm{E}+00$ & $3.160 \mathrm{E}-20$ & $9.563 \mathrm{E}-20$ & $5.243 \mathrm{E}-18$ & $1.718 \mathrm{E}-17$ & $4.700 \mathrm{E}-15$ & $2.556 \mathrm{E}-12$ \\
\hline-241 & $\mathrm{U}-233$ & $1.000 \mathrm{E}+00$ & $7.164 \mathrm{E}-31$ & $5.066 \mathrm{E}-30$ & $9.948 \mathrm{E}-27$ & $7.175 \mathrm{E}-26$ & $2.177 \mathrm{E}-22$ & $7.342 \mathrm{E}-19$ \\
\hline$n-241$ & $\mathrm{Th}-229+\mathrm{D}$ & $1.000 \mathrm{E}+00$ & $4.901 \mathrm{E}-27$ & 7. $393 E-26$ & $3.496 \mathrm{E}-21$ & $3.824 \mathrm{E}-20$ & $6.587 \mathrm{E}-17$ & $2.426 \mathrm{E}-14$ \\
\hline-241 & $\sum \operatorname{DSR}(j)$ & & $3.160 \mathrm{E}-20$ & $9.563 \mathrm{E}-20$ & $5.246 \mathrm{E}-18$ & $1.722 \mathrm{E}-17$ & $4.766 \mathrm{E}-15$ & $2.581 \mathrm{E}-12$ \\
\hline$-137+D$ & $\mathrm{Cs}-137+\mathrm{D}$ & $1.000 \mathrm{E}+00$ & $2.578 \mathrm{E}-10$ & $2.541 \mathrm{E}-10$ & $1.237 \mathrm{E}-10$ & $5.936 \mathrm{E}-11$ & $1.667 \mathrm{E}-13$ & $5.175 \mathrm{E}-17$ \\
\hline$-237+D$ & $N p-237+D$ & $1.000 \mathrm{E}+00$ & $1.948 \mathrm{E}-13$ & $1.969 \mathrm{E}-13$ & $3.330 \mathrm{E}-13$ & $5.693 \mathrm{E}-13$ & $4.147 \mathrm{E}-11$ & $1.509 \mathrm{E}-08$ \\
\hline$-237+D$ & $\mathrm{U}-233$ & $1.000 \mathrm{E}+00$ & $6.631 \mathrm{E}-24$ & $2.011 \mathrm{E}-23$ & $1.248 \mathrm{E}-21$ & 4. $641 \mathrm{E}-21$ & $3.427 \mathrm{E}-18$ & $6.954 \mathrm{E}-15$ \\
\hline$-237+D$ & $\mathrm{Th}-229+\mathrm{D}$ & $1.000 \mathrm{E}+00$ & $6.053 \mathrm{E}-20$ & 4. $262 \mathrm{E}-19$ & $6.537 \mathrm{E}-16$ & $3.662 \mathrm{E}-15$ & $1.463 \mathrm{E}-12$ & $3.066 \mathrm{E}-10$ \\
\hline$-237+D$ & $\sum \operatorname{DSR}(j)$ & & $1.948 \mathrm{E}-13$ & $1.969 \mathrm{E}-13$ & $3.337 E-13$ & $5.729 \mathrm{E}-13$ & $4.294 \mathrm{E}-11$ & $1.540 \mathrm{E}-08$ \\
\hline$x-238$ & $\mathrm{Pu}-238$ & $1.840 \mathrm{E}-09$ & $4.417 E-34$ & $4.460 \mathrm{E}-34$ & $7.195 \mathrm{E}-34$ & $1.172 \mathrm{E}-33$ & $5.806 \mathrm{E}-32$ & $1.243 E-29$ \\
\hline$x-238$ & $\mathrm{Pu}-238$ & $1.000 \mathrm{E}+00$ & $2.401 \mathrm{E}-25$ & $2.424 \mathrm{E}-25$ & $3.910 \mathrm{E}-25$ & $6.369 \mathrm{E}-25$ & $3.155 \mathrm{E}-23$ & $6.755 E-21$ \\
\hline$x-238$ & $\mathrm{U}-234$ & $1.000 \mathrm{E}+00$ & $1.998 \mathrm{E}-30$ & $6.068 \mathrm{E}-30$ & $4.032 \mathrm{E}-28$ & $1.628 \mathrm{E}-27$ & $3.470 \mathrm{E}-24$ & $5.993 E-20$ \\
\hline-238 & Th-230 & $1.000 \mathrm{E}+00$ & $2.101 E-34$ & $1.489 E-33$ & $3.268 E-30$ & $2.663 E-29$ & $2.676 \mathrm{E}-25$ & $6.795 E-21$ \\
\hline-238 & $\mathrm{Ra}-226+\mathrm{D}$ & $1.000 \mathrm{E}+00$ & $1.639 \mathrm{E}-23$ & $2.469 \mathrm{E}-22$ & $1.076 \mathrm{E}-17$ & $1.088 \mathrm{E}-16$ & $1.149 \mathrm{E}-13$ & $2.677 \mathrm{E}-11$ \\
\hline-238 & $\mathrm{~Pb}-210+\mathrm{D}$ & $1.000 \mathrm{E}+00$ & $4.753 E-32$ & $1.473 \mathrm{E}-30$ & $1.589 \mathrm{E}-24$ & $2.687 \mathrm{E}-23$ & $7.527 \mathrm{E}-20$ & $3.536 \mathrm{E}-17$ \\
\hline-238 & $\sum \operatorname{DSR}(j)$ & & $1.663 E-23$ & $2.471 E-22$ & $1.076 \mathrm{E}-17$ & $1.088 \mathrm{E}-16$ & $1.149 \mathrm{E}-13$ & $2.677 E-11$ \\
\hline
\end{tabular}

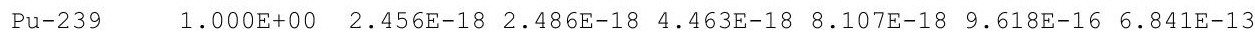

$\mathrm{U}-235+\mathrm{D} \quad 1.000 \mathrm{E}+00 \quad 1.254 \mathrm{E}-24 \quad 3.802 \mathrm{E}-24 \quad 2.343 \mathrm{E}-22 \quad 8.645 \mathrm{E}-22 \quad 6.015 \mathrm{E}-19 \quad 1.124 \mathrm{E}-15$

$\begin{array}{lllllllll}\mathrm{Pa}-231 & 1.000 \mathrm{E}+00 & 1.972 \mathrm{E}-28 & 1.393 \mathrm{E}-27 & 2.557 \mathrm{E}-24 & 1.721 \mathrm{E}-23 & 2.963 \mathrm{E}-20 & 4.446 \mathrm{E}-17\end{array}$

$\mathrm{AC}-227+\mathrm{D} \quad 1.000 \mathrm{E}+00 \quad 4.675 \mathrm{E}-28 \quad 7.017 \mathrm{E}-27 \quad 2.608 \mathrm{E}-22 \quad 2.391 \mathrm{E}-21 \quad 3.028 \mathrm{E}-18 \quad 1.826 \mathrm{E}-15$

$\operatorname{LDSR}(j) \quad 2.456 \mathrm{E}-18 \quad 2.486 \mathrm{E}-18 \quad 4.463 \mathrm{E}-18 \quad 8.110 \mathrm{E}-18 \quad 9.655 \mathrm{E}-16 \quad 6.871 \mathrm{E}-13$

$\mathrm{Pu}-240 \quad 4.950 \mathrm{E}-08 \quad 1.155 \mathrm{E}-32 \quad 1.176 \mathrm{E}-32 \quad 2.778 \mathrm{E}-32 \quad 6.681 \mathrm{E}-32 \quad 7.478 \mathrm{E}-29 \quad 1.164 \mathrm{E}-24$

$\begin{array}{llllllll}\mathrm{Pu}-240 & 1.000 \mathrm{E}+00 & 2.334 \mathrm{E}-25 & 2.375 \mathrm{E}-25 & 5.612 \mathrm{E}-25 & 1.350 \mathrm{E}-24 & 1.511 \mathrm{E}-21 & 2.352 \mathrm{E}-17\end{array}$

U-236 1.000E+00 4.417E-33 $1.347 \mathrm{E}-32 \quad 1.091 \mathrm{E}-30 \quad 5.321 \mathrm{E}-30 \quad 3.459 \mathrm{E}-26 \quad 1.397 \mathrm{E}-21$

Th-232 1.000E+00 5.745E-44 4.148E-43 $1.120 \mathrm{E}-39 \quad 1.120 \mathrm{E}-38 \quad 4.587 \mathrm{E}-34 \quad 5.372 \mathrm{E}-29$

$\mathrm{Ra}-228+\mathrm{D} \quad 1.000 \mathrm{E}+00 \quad 2.801 \mathrm{E}-29 \quad 4.123 \mathrm{E}-28 \quad 7.689 \mathrm{E}-24 \quad 5.197 \mathrm{E}-23 \quad 3.012 \mathrm{E}-20 \quad 8.590 \mathrm{E}-18$

$\mathrm{Th}-228+\mathrm{D} \quad 1.000 \mathrm{E}+00 \quad 1.657 \mathrm{E}-28 \quad 4.769 \mathrm{E}-27 \quad 5.398 \mathrm{E}-22 \quad 3.593 \mathrm{E}-21 \quad 1.140 \mathrm{E}-18 \quad 1.344 \mathrm{E}-16$

$\operatorname{LDSR}(j) \quad 2.335 \mathrm{E}-25 \quad 2.427 \mathrm{E}-25 \quad 5.480 \mathrm{E}-22 \quad 3.646 \mathrm{E}-21 \quad 1.172 \mathrm{E}-18 \quad 1.665 \mathrm{E}-16$

TC-99 1.000E+00 1.179E-26 $1.195 \mathrm{E}-26 \quad 2.364 \mathrm{E}-26 \quad 4.741 \mathrm{E}-26 \quad 1.241 \mathrm{E}-23 \quad 2.619 \mathrm{E}-20$

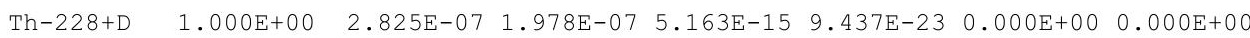

Th-230 1.000E+00 4.929E-23 5.012E-23 $1.142 \mathrm{E}-22 \quad 2.647 \mathrm{E}-22 \quad 2.203 \mathrm{E}-19 \quad 2.282 \mathrm{E}-15$

$\mathrm{Ra}-226+\mathrm{D} \quad 1.000 \mathrm{E}+00 \quad 7.712 \mathrm{E}-12 \quad 2.327 \mathrm{E}-11 \quad 1.087 \mathrm{E}-09 \quad 3.024 \mathrm{E}-09 \quad 2.193 \mathrm{E}-07 \quad 1.840 \mathrm{E}-05$

$\mathrm{Pb}-210+\mathrm{D} \quad 1.000 \mathrm{E}+00 \quad 3.717 \mathrm{E}-20 \quad 2.596 \mathrm{E}-19 \quad 2.655 \mathrm{E}-16 \quad 1.087 \mathrm{E}-15 \quad 1.573 \mathrm{E}-13 \quad 2.528 \mathrm{E}-11$

$\operatorname{LDSR}(j) \quad 7.712 \mathrm{E}-12 \quad 2.327 \mathrm{E}-11 \quad 1.087 \mathrm{E}-09 \quad 3.024 \mathrm{E}-09 \quad 2.193 \mathrm{E}-07 \quad 1.840 \mathrm{E}-05$ 
RESRAD, Version 6.5

Summary : C746U Worker Deterministic Run

File : $\mathrm{X}: \backslash F I N A L$ V2 $\backslash C 746 \mathrm{U} W$ DET-FINALV2.RAD

Dose/Source Ratios Summed Over All Pathways

Parent and Progeny Principal Radionuclide Contributions Indicated

\begin{tabular}{|c|c|c|c|c|c|c|c|c|}
\hline $\begin{array}{c}\text { Parent } \\
\text { (i) }\end{array}$ & $\begin{array}{l}\text { Product } \\
(j)\end{array}$ & $\begin{array}{l}\text { Thread } \\
\text { Fraction }\end{array}$ & $\begin{array}{r}\text { DSR } \\
0.000 \mathrm{E}+00\end{array}$ & $\begin{array}{l}(j, t) \text { At } T \\
1.000 \mathrm{E}+00\end{array}$ & $\begin{array}{l}\text { ime in Yea } \\
5.000 \mathrm{E}+01\end{array}$ & $\begin{array}{l}\text { Es (mrem/ } \\
1.000 \mathrm{E}+02\end{array}$ & $\begin{array}{l}/ \mathrm{yr}) /(\mathrm{pCi} / \\
5.000 \mathrm{E}+02\end{array}$ & $\begin{array}{l}\text { g) } \\
1.050 \mathrm{E}+03\end{array}$ \\
\hline-232 & $\mathrm{Th}-232$ & $1.000 \mathrm{E}+00$ & $2.382 \mathrm{E}-25$ & $2.427 E-25$ & $6.027 \mathrm{E}-25$ & $1.525 E-24$ & $2.561 \mathrm{E}-21$ & $6.965 E-17$ \\
\hline-232 & $\mathrm{Ra}-228+\mathrm{D}$ & $1.000 \mathrm{E}+00$ & $2.263 E-10$ & $6.486 \mathrm{E}-10$ & $5.690 \mathrm{E}-09$ & $8.336 \mathrm{E}-09$ & $1.737 \mathrm{E}-07$ & $1.131 \mathrm{E}-05$ \\
\hline $1-232$ & $T h-228+D$ & $1.000 \mathrm{E}+00$ & $2.181 E-09$ & $1.345 \mathrm{E}-08$ & $4.522 \mathrm{E}-07$ & $6.114 \mathrm{E}-07$ & $6.652 E-06$ & $1.778 \mathrm{E}-04$ \\
\hline-232 & $\sum \operatorname{DSR}(j)$ & & $2.407 E-09$ & $1.410 \mathrm{E}-08$ & $4.579 \mathrm{E}-07$ & $6.198 \mathrm{E}-07$ & $6.825 E-06$ & $1.891 \mathrm{E}-04$ \\
\hline-234 & $\mathrm{U}-234$ & $1.000 \mathrm{E}+00$ & $1.409 \mathrm{E}-24$ & $1.434 \mathrm{E}-24$ & $3.415 \mathrm{E}-24$ & $8.276 \mathrm{E}-24$ & $9.851 E-21$ & $1.669 \mathrm{E}-16$ \\
\hline-234 & Th-230 & $1.000 \mathrm{E}+00$ & $2.225 E-28$ & $6.774 \mathrm{E}-28$ & $5.192 \mathrm{E}-26$ & $2.394 \mathrm{E}-25$ & $9.912 \mathrm{E}-22$ & $2.152 \mathrm{E}-17$ \\
\hline-234 & $\mathrm{Ra}-226+\mathrm{D}$ & $1.000 \mathrm{E}+00$ & $2.315 E-17$ & $1.630 \mathrm{E}-16$ & $2.480 \mathrm{E}-13$ & $1.377 \mathrm{E}-12$ & $5.115 \mathrm{E}-10$ & $9.341 \mathrm{E}-08$ \\
\hline-234 & $\mathrm{~Pb}-210+\mathrm{D}$ & $1.000 \mathrm{E}+00$ & $8.381 E-26$ & $1.257 \mathrm{E}-24$ & $4.500 \mathrm{E}-20$ & $3.956 \mathrm{E}-19$ & $3.440 \mathrm{E}-16$ & 1. $243 \mathrm{E}-13$ \\
\hline-234 & $\sum \operatorname{DSR}(j)$ & & $2.315 \mathrm{E}-17$ & $1.630 \mathrm{E}-16$ & $2.480 \mathrm{E}-13$ & $1.377 \mathrm{E}-12$ & $5.115 \mathrm{E}-10$ & $9.341 \mathrm{E}-08$ \\
\hline$-235+D$ & $\mathrm{U}-235+\mathrm{D}$ & $1.000 \mathrm{E}+00$ & $2.540 \mathrm{E}-15$ & $2.572 \mathrm{E}-15$ & $4.713 E-15$ & $8.745 E-15$ & 1. $228 \mathrm{E}-12$ & $1.101 \mathrm{E}-09$ \\
\hline$-235+D$ & $\mathrm{~Pa}-231$ & $1.000 \mathrm{E}+00$ & $6.002 \mathrm{E}-19$ & $1.818 \mathrm{E}-18$ & $1.028 \mathrm{E}-16$ & $3.478 \mathrm{E}-16$ & 1. $206 \mathrm{E}-13$ & $8.644 \mathrm{E}-11$ \\
\hline$-235+D$ & $A C-227+D$ & $1.000 \mathrm{E}+00$ & 1. $895 \mathrm{E}-18$ & 1. $324 \mathrm{E}-17$ & $1.407 \mathrm{E}-14$ & $6.019 \mathrm{E}-14$ & $1.308 \mathrm{E}-11$ & $3.655 \mathrm{E}-09$ \\
\hline$-235+D$ & $\sum \operatorname{DSR}(j)$ & & $2.543 E-15$ & $2.587 \mathrm{E}-15$ & $1.888 \mathrm{E}-14$ & $6.928 \mathrm{E}-14$ & $1.443 E-11$ & $4.843 E-09$ \\
\hline-238 & $U-238$ & $5.400 E-05$ & $0.000 \mathrm{E}+00$ & $0.000 \mathrm{E}+00$ & $0.000 \mathrm{E}+00$ & $0.000 \mathrm{E}+00$ & $0.000 \mathrm{E}+00$ & $3.476 \mathrm{E}-39$ \\
\hline$-238+D$ & $\mathrm{U}-238+\mathrm{D}$ & $9.999 \mathrm{E}-01$ & $2.901 \mathrm{E}-11$ & $2.924 \mathrm{E}-11$ & 4. $325 E-11$ & $6.449 \mathrm{E}-11$ & $1.576 \mathrm{E}-09$ & $1.279 \mathrm{E}-07$ \\
\hline$-238+D$ & $\mathrm{U}-234$ & $9.999 \mathrm{E}-01$ & $2.003 E-30$ & $6.105 \mathrm{E}-30$ & $4.889 \mathrm{E}-28$ & $2.358 \mathrm{E}-27$ & $1.399 \mathrm{E}-23$ & 4. $978 \mathrm{E}-19$ \\
\hline$-238+D$ & $\mathrm{Th}-230$ & $9.999 E-01$ & $2.105 E-34$ & $1.495 \mathrm{E}-33$ & $3.717 \mathrm{E}-30$ & $3.411 \mathrm{E}-29$ & $7.032 \mathrm{E}-25$ & $3.204 \mathrm{E}-20$ \\
\hline$-238+D$ & $\mathrm{Ra}-226+\mathrm{D}$ & $9.999 \mathrm{E}-01$ & $1.642 \mathrm{E}-23$ & $2.477 \mathrm{E}-22$ & $1.186 \mathrm{E}-17$ & $1.313 E-16$ & $2.462 \mathrm{E}-13$ & $9.612 \mathrm{E}-11$ \\
\hline$-238+D$ & $\mathrm{~Pb}-210+\mathrm{D}$ & $9.999 \mathrm{E}-01$ & $4.759 E-32$ & $1.477 \mathrm{E}-30$ & $1.723 E-24$ & $3.161 \mathrm{E}-23$ & $1.561 \mathrm{E}-19$ & 1. $240 \mathrm{E}-16$ \\
\hline$-238+D$ & $\sum \operatorname{DSR}(j)$ & & $2.901 \mathrm{E}-11$ & $2.924 \mathrm{E}-11$ & $4.325 \mathrm{E}-11$ & $6.449 \mathrm{E}-11$ & $1.577 \mathrm{E}-09$ & $1.280 \mathrm{E}-07$ \\
\hline
\end{tabular}

The DSR includes contributions from associated (half-life $\leq 180$ days) daughters. 
RESRAD, Version $6.5 \quad T^{3 / 2}$ Limit $=180$ days

Summary : C746U Worker Deterministic Run

File : $\mathrm{X}: \backslash$ FINAL V2 $\backslash \mathrm{C} 746 \mathrm{U}$ W DET-FINALV2.RAD

Single Radionuclide Soil Guidelines G(i,t) in pCi/g

Basic Radiation Dose Limit $=1.000 \mathrm{E}+00 \mathrm{mrem} / \mathrm{yr}$

\begin{tabular}{|c|c|c|c|c|c|c|}
\hline (i) & $t=0.000 E+00$ & $1.000 \mathrm{E}+00$ & $5.000 \mathrm{E}+01$ & $1.000 \mathrm{E}+02$ & $5.000 \mathrm{E}+02$ & $1.050 \mathrm{E}+03$ \\
\hline-241 & $\star 3.431 \mathrm{E}+12$ & $\star 3.431 \mathrm{E}+12$ & $\star 3.431 \mathrm{E}+12$ & $\star 3.431 \mathrm{E}+12$ & $* 3.431 \mathrm{E}+12$ & $3.875 E+11$ \\
\hline-137 & $3.879 \mathrm{E}+09$ & $3.936 \mathrm{E}+09$ & $8.084 \mathrm{E}+09$ & $1.685 \mathrm{E}+10$ & $5.997 \mathrm{E}+12$ & $\star 8.704 \mathrm{E}+13$ \\
\hline-237 & $\star 7.047 \mathrm{E}+08$ & $\star 7.047 \mathrm{E}+08$ & $\star 7.047 \mathrm{E}+08$ & $\star 7.047 \mathrm{E}+08$ & $\star 7.047 \mathrm{E}+08$ & $6.495 \mathrm{E}+07$ \\
\hline 238 & $\star 1.712 \mathrm{E}+13$ & $\star 1.712 \mathrm{E}+13$ & $\star 1.712 \mathrm{E}+13$ & $\star 1.712 \mathrm{E}+13$ & $8.701 \mathrm{E}+12$ & $3.735 E+10$ \\
\hline Pu-239 & $\star 6.214 \mathrm{E}+10$ & $* 6.214 \mathrm{E}+10$ & $\star 6.214 \mathrm{E}+10$ & $\star 6.214 \mathrm{E}+10$ & $\star 6.214 \mathrm{E}+10$ & $* 6.214 \mathrm{E}+10$ \\
\hline $\mathrm{Pu}-240$ & $\star 2.278 \mathrm{E}+11$ & $\star 2.278 \mathrm{E}+11$ & $\star 2.278 \mathrm{E}+11$ & $\star 2.278 \mathrm{E}+11$ & $\star 2.278 \mathrm{E}+11$ & $\star 2.278 \mathrm{E}+11$ \\
\hline$c-99$ & $\star 1.697 \mathrm{E}+10$ & $\star 1.697 \mathrm{E}+10$ & $\star 1.697 \mathrm{E}+10$ & $* 1.697 \mathrm{E}+10$ & $\star 1.697 \mathrm{E}+10$ & $\star 1.697 \mathrm{E}+10$ \\
\hline-228 & $3.540 \mathrm{E}+06$ & $5.056 \mathrm{E}+06$ & $1.937 \mathrm{E}+14$ & $\star 8.195 \mathrm{E}+14$ & $\star 8.195 \mathrm{E}+14$ & $* 8.195 \mathrm{E}+14$ \\
\hline-230 & $\star 2.018 \mathrm{E}+10$ & $\star 2.018 \mathrm{E}+10$ & $9.198 \mathrm{E}+08$ & $3.307 \mathrm{E}+08$ & $4.559 \mathrm{E}+06$ & $5.434 \mathrm{E}+04$ \\
\hline 232 & $\star 1.097 \mathrm{E}+05$ & $\star 1.097 \mathrm{E}+05$ & $\star 1.097 \mathrm{E}+05$ & $\star 1.097 \mathrm{E}+05$ & *1.097E+05 & $5.287 \mathrm{E}+03$ \\
\hline 34 & $* 6.247 \mathrm{E}+09$ & $* 6.247 \mathrm{E}+09$ & $* 6.247 \mathrm{E}+09$ & $\star 6.247 \mathrm{E}+09$ & $1.955 \mathrm{E}+09$ & $1.071 \mathrm{E}+07$ \\
\hline 35 & $\star 2.161 \mathrm{E}+06$ & $\star 2.161 \mathrm{E}+06$ & $\star 2.161 \mathrm{E}+06$ & $\star 2.161 \mathrm{E}+06$ & $\star 2.161 \mathrm{E}+06$ & $\star 2.161 \mathrm{E}+06$ \\
\hline 238 & $* 3.361 \mathrm{E}+05$ & $\star 3.361 \mathrm{E}+05$ & $\star 3.361 \mathrm{E}+05$ & $\star 3.361 \mathrm{E}+05$ & $\star 3.361 \mathrm{E}+05$ & $* 3.361 \mathrm{E}+05$ \\
\hline
\end{tabular}

*At specific activity limit

Summed Dose/Source Ratios DSR(i,t) in (mrem/yr)/(pCi/g)

and Single Radionuclide Soil Guidelines G(i,t) in pCi/g

at tmin = time of minimum single radionuclide soil guideline

and at $\operatorname{tmax}=$ time of maximum total dose $=1.050 \mathrm{E}+03$ years

\begin{tabular}{|c|c|c|c|c|c|c|}
\hline $\begin{array}{l}\text { uclide } \\
\text { (i) }\end{array}$ & $\begin{array}{l}\text { Initial } \\
(\mathrm{pCi} / \mathrm{g})\end{array}$ & $\begin{array}{c}\text { tmin } \\
\text { (years) }\end{array}$ & $\operatorname{DSR}(i, \operatorname{tmin})$ & $\begin{array}{c}\mathrm{G}(\mathrm{i}, \mathrm{tmin}) \\
(\mathrm{pCi} / \mathrm{g})\end{array}$ & $\operatorname{DSR}(i, t \max )$ & $\begin{array}{c}\mathrm{G}(\mathrm{i}, \mathrm{tmax}) \\
(\mathrm{pci} / \mathrm{g})\end{array}$ \\
\hline $1-241$ & $1.000 \mathrm{E}+00$ & $1.050 E+03$ & $2.581 E-12$ & $3.875 E+11$ & $2.581 E-12$ & $3.875 \mathrm{E}+11$ \\
\hline-137 & $1.000 \mathrm{E}+00$ & $0.000 \mathrm{E}+00$ & $2.578 \mathrm{E}-10$ & $3.879 E+09$ & $5.175 \mathrm{E}-17$ & $\star 8.704 \mathrm{E}+13$ \\
\hline-237 & $1.000 \mathrm{E}+00$ & $1.050 \mathrm{E}+03$ & $1.540 \mathrm{E}-08$ & $6.495 \mathrm{E}+07$ & $1.540 \mathrm{E}-08$ & $6.495 \mathrm{E}+07$ \\
\hline$x-238$ & $1.000 \mathrm{E}+00$ & $1.050 E+03$ & $2.677 \mathrm{E}-11$ & $3.735 E+10$ & $2.677 \mathrm{E}-11$ & $3.735 \mathrm{E}+10$ \\
\hline$x-239$ & $1.000 \mathrm{E}+00$ & $1.050 \mathrm{E}+03$ & $6.871 \mathrm{E}-13$ & $\star 6.214 \mathrm{E}+10$ & $6.871 \mathrm{E}-13$ & $* 6.214 \mathrm{E}+10$ \\
\hline-240 & $1.000 \mathrm{E}+00$ & $1.050 \mathrm{E}+03$ & $1.665 \mathrm{E}-16$ & $\star 2.278 \mathrm{E}+11$ & 1. $665 \mathrm{E}-16$ & $\star 2.278 \mathrm{E}+11$ \\
\hline-99 & $1.000 \mathrm{E}+00$ & $1.050 E+03$ & $2.619 \mathrm{E}-20$ & $\star 1.697 \mathrm{E}+10$ & $2.619 \mathrm{E}-20$ & $\star 1.697 \mathrm{E}+10$ \\
\hline-228 & $1.000 \mathrm{E}+00$ & $0.000 \mathrm{E}+00$ & $2.825 E-07$ & $3.540 E+06$ & $0.000 \mathrm{E}+00$ & $\star 8.195 \mathrm{E}+14$ \\
\hline-230 & $1.000 \mathrm{E}+00$ & $1.050 \mathrm{E}+03$ & $1.840 \mathrm{E}-05$ & $5.434 \mathrm{E}+04$ & $1.840 \mathrm{E}-05$ & $5.434 \mathrm{E}+04$ \\
\hline-232 & $1.000 \mathrm{E}+00$ & $1.050 \mathrm{E}+03$ & $1.891 \mathrm{E}-04$ & $5.287 E+03$ & $1.891 \mathrm{E}-04$ & $5.287 \mathrm{E}+03$ \\
\hline 234 & $1.000 \mathrm{E}+00$ & $1.050 E+03$ & $9.341 \mathrm{E}-08$ & $1.071 E+07$ & $9.341 E-08$ & $1.071 \mathrm{E}+07$ \\
\hline 235 & $1.000 \mathrm{E}+00$ & $1.050 \mathrm{E}+03$ & $4.843 E-09$ & $\star 2.161 \mathrm{E}+06$ & $4.843 E-09$ & $\star 2.161 \mathrm{E}+06$ \\
\hline-238 & $1.000 \mathrm{E}+00$ & $1.050 \mathrm{E}+03$ & $1.280 \mathrm{E}-07$ & $\star 3.361 \mathrm{E}+05$ & $1.280 \mathrm{E}-07$ & $\star 3.361 \mathrm{E}+05$ \\
\hline
\end{tabular}

*At specific activity limit 
RESRAD, Version $6.5 \quad T^{1 / 2}$ Limit $=180$ days

Summary : C746U Worker Deterministic Run
File : X: $\backslash$ FINAL V2 $\backslash C 746 U$ W DET-FINALV2.RAD

Individual Nuclide Dose Summed Over All Pathways

Parent Nuclide and Branch Fraction Indicated

Nuclide Parent THF(i) DOSE $(j, t)$, mrem/yr

\begin{tabular}{|c|c|c|}
\hline$(j)$ & (i) & \\
\hline$m-241$ & $A m-241$ & $1.000 \mathrm{E}+00$ \\
\hline$p-237$ & $A m-241$ & $1.000 \mathrm{E}+00$ \\
\hline-237 & $\mathrm{~Np}-237$ & $1.000 \mathrm{E}+00$ \\
\hline 237 & $\sum \mathrm{DOSE}$ & \\
\hline
\end{tabular}

$\mathrm{U}-233 \mathrm{Am}-241 \quad 1.000 \mathrm{E}+00$

$\mathrm{U}-233 \mathrm{~Np}-237 \quad 1.000 \mathrm{E}+00$

U-233 $\quad$ DOSE $(j)$

Th-229

$\mathrm{Th}-229$

$\mathrm{Th}-229$

Cs -137

$\mathrm{Pu}-238$

$\mathrm{Pu}-238$

$\mathrm{Pu}-238$

$\mathrm{U}-234$

$\mathrm{U}-234$

$\mathrm{U}-234$

$\mathrm{U}-234$

Th-230

$\mathrm{Th}-230$

Th-230

$\mathrm{Th}-230$

$\mathrm{Th}-230$

$\mathrm{Ra}-226$

$\mathrm{Ra}-226$

$\mathrm{Ra}-226$

$\mathrm{Ra}-226$

$\mathrm{Ra}-226$

$\mathrm{Pb}-210$

$\mathrm{Pb}-210$

$\mathrm{Pb}-210$

$\mathrm{Pb}-210$

$\mathrm{Pb}-210$

Pu-239

Am-241 1.000E+00

$\mathrm{Np}-237 \quad 1.000 \mathrm{E}+00$

$\sum \operatorname{DOSE}(j)$

Cs $-137 \quad 1.000 \mathrm{E}+00$

Pu-238 1.840E-09

$\mathrm{Pu}-238 \quad 1.000 \mathrm{E}+00$

$\sum \operatorname{DOSE}(j)$

$\mathrm{Pu}-238 \quad 1.000 \mathrm{E}+00$

$\mathrm{U}-234 \quad 1.000 \mathrm{E}+00$

U-238 9.999E-01

$\sum \operatorname{DOSE}(j)$

$\mathrm{Pu}-238 \quad 1.000 \mathrm{E}+00$

Th-230 1.000E+00

$\mathrm{U}-234 \quad 1.000 \mathrm{E}+00$

$\mathrm{U}-238 \quad 9.999 \mathrm{E}-01$

$\sum \operatorname{DOSE}(j)$

$\mathrm{Pu}-238 \quad 1.000 \mathrm{E}+00$

Th-230 1.000E+00

$\mathrm{U}-234 \quad 1.000 \mathrm{E}+00$

U-238 9.999E-01

$\sum \operatorname{DOSE}(j)$

$\mathrm{Pu}-238 \quad 1.000 \mathrm{E}+00$

Th-230 1.000E+00

$\mathrm{U}-234 \quad 1.000 \mathrm{E}+00$

U-238 9.999E-01

$\sum \operatorname{DOSE}(j)$

$\mathrm{Pu}-239 \quad 1.000 \mathrm{E}+00$

$\mathrm{Pu}-239 \quad 1.000 \mathrm{E}+00$

U-235 $1.000 \mathrm{E}+00$

¿DOSE $(j)$
$\mathrm{E}=0.000 \mathrm{E}+00 \quad 1.000 \mathrm{E}+00 \quad 5.000 \mathrm{E}+01 \quad 1.000 \mathrm{E}+02 \quad 5.000 \mathrm{E}+02 \quad 1.050 \mathrm{E}+03$

$0.000 \mathrm{E}+00 \quad 0.000 \mathrm{E}+00 \quad 0.000 \mathrm{E}+00 \quad 0.000 \mathrm{E}+00 \quad 2.471 \mathrm{E}-28 \quad 5.859 \mathrm{E}-22$

$3.160 \mathrm{E}-20 \quad 9.563 \mathrm{E}-20 \quad 5.243 \mathrm{E}-18 \quad 1.718 \mathrm{E}-17 \quad 4.700 \mathrm{E}-15 \quad 2.556 \mathrm{E}-12$

$1.948 \mathrm{E}-13 \quad 1.969 \mathrm{E}-13 \quad 3.330 \mathrm{E}-13 \quad 5.693 \mathrm{E}-13 \quad 4.147 \mathrm{E}-11 \quad 1.509 \mathrm{E}-08$

$\begin{array}{llllll}1.948 \mathrm{E}-13 & 1.969 \mathrm{E}-13 & 3.330 \mathrm{E}-13 & 5.693 \mathrm{E}-13 & 4.148 \mathrm{E}-11 & 1.509 \mathrm{E}-08\end{array}$

$0.000 \mathrm{E}+00 \quad 5.066 \mathrm{E}-30 \quad 9.948 \mathrm{E}-27 \quad 7.175 \mathrm{E}-26 \quad 2.177 \mathrm{E}-22 \quad 7.342 \mathrm{E}-19$

$6.631 \mathrm{E}-24 \quad 2.011 \mathrm{E}-23 \quad 1.248 \mathrm{E}-21 \quad 4.641 \mathrm{E}-21 \quad 3.427 \mathrm{E}-18 \quad 6.954 \mathrm{E}-15$

$6.631 \mathrm{E}-24 \quad 2.011 \mathrm{E}-23 \quad 1.248 \mathrm{E}-21 \quad 4.641 \mathrm{E}-21 \quad 3.428 \mathrm{E}-18 \quad 6.955 \mathrm{E}-15$

$\begin{array}{llllll}4.901 \mathrm{E}-27 & 7.393 \mathrm{E}-26 & 3.496 \mathrm{E}-21 & 3.824 \mathrm{E}-20 & 6.587 \mathrm{E}-17 & 2.426 \mathrm{E}-14\end{array}$

$6.053 \mathrm{E}-20 \quad 4.262 \mathrm{E}-19 \quad 6.537 \mathrm{E}-16 \quad 3.662 \mathrm{E}-15 \quad 1.463 \mathrm{E}-12 \quad 3.066 \mathrm{E}-10$

$6.053 \mathrm{E}-20 \quad 4.262 \mathrm{E}-19 \quad 6.537 \mathrm{E}-16 \quad 3.662 \mathrm{E}-15 \quad 1.463 \mathrm{E}-12 \quad 3.067 \mathrm{E}-10$

$2.578 \mathrm{E}-10 \quad 2.541 \mathrm{E}-10 \quad 1.237 \mathrm{E}-10 \quad 5.936 \mathrm{E}-11 \quad 1.667 \mathrm{E}-13 \quad 5.175 \mathrm{E}-17$

$\begin{array}{lllllll}0.000 \mathrm{E}+00 & 0.000 \mathrm{E}+00 & 0.000 \mathrm{E}+00 & 0.000 \mathrm{E}+00 & 0.000 \mathrm{E}+00 & 1.243 \mathrm{E}-29\end{array}$

$2.401 \mathrm{E}-25 \quad 2.424 \mathrm{E}-25 \quad 3.910 \mathrm{E}-25 \quad 6.369 \mathrm{E}-25 \quad 3.155 \mathrm{E}-23 \quad 6.755 \mathrm{E}-21$

$2.401 \mathrm{E}-25 \quad 2.424 \mathrm{E}-25 \quad 3.910 \mathrm{E}-25 \quad 6.369 \mathrm{E}-25 \quad 3.155 \mathrm{E}-23 \quad 6.755 \mathrm{E}-21$

$\begin{array}{llllll}1.998 E-30 & 6.068 \mathrm{E}-30 & 4.032 \mathrm{E}-28 & 1.628 \mathrm{E}-27 & 3.470 \mathrm{E}-24 & 5.993 \mathrm{E}-20\end{array}$

$\begin{array}{lllllll}1.409 \mathrm{E}-24 & 1.434 \mathrm{E}-24 & 3.415 \mathrm{E}-24 & 8.276 \mathrm{E}-24 & 9.851 \mathrm{E}-21 & 1.669 \mathrm{E}-16\end{array}$

$2.003 \mathrm{E}-30 \quad 6.105 \mathrm{E}-30 \quad 4.889 \mathrm{E}-28 \quad 2.358 \mathrm{E}-27 \quad 1.399 \mathrm{E}-23 \quad 4.978 \mathrm{E}-19$

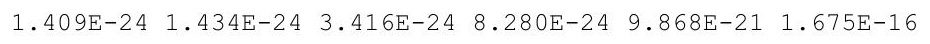

$\begin{array}{llllll}0.000 \mathrm{E}+00 & 0.000 \mathrm{E}+00 & 3.268 \mathrm{E}-30 & 2.663 \mathrm{E}-29 & 2.676 \mathrm{E}-25 & 6.795 \mathrm{E}-21\end{array}$

$\begin{array}{llllll}4.929 \mathrm{E}-23 & 5.012 \mathrm{E}-23 & 1.142 \mathrm{E}-22 & 2.647 \mathrm{E}-22 & 2.203 \mathrm{E}-19 & 2.282 \mathrm{E}-15\end{array}$

$\begin{array}{lllllll}2.225 \mathrm{E}-28 & 6.774 \mathrm{E}-28 & 5.192 \mathrm{E}-26 & 2.394 \mathrm{E}-25 & 9.912 \mathrm{E}-22 & 2.152 \mathrm{E}-17\end{array}$

$0.000 \mathrm{E}+00 \quad 0.000 \mathrm{E}+00 \quad 3.717 \mathrm{E}-30 \quad 3.411 \mathrm{E}-29 \quad 7.032 \mathrm{E}-25 \quad 3.204 \mathrm{E}-20$

$\begin{array}{llllll}4.929 E-23 & 5.012 \mathrm{E}-23 & 1.143 \mathrm{E}-22 & 2.650 \mathrm{E}-22 & 2.213 \mathrm{E}-19 & 2.304 \mathrm{E}-15\end{array}$

$\begin{array}{lllllll}1.639 \mathrm{E}-23 & 2.469 \mathrm{E}-22 & 1.076 \mathrm{E}-17 & 1.088 \mathrm{E}-16 & 1.149 \mathrm{E}-13 & 2.677 \mathrm{E}-11\end{array}$

$\begin{array}{lllllll}7.712 \mathrm{E}-12 & 2.327 \mathrm{E}-11 & 1.087 \mathrm{E}-09 & 3.024 \mathrm{E}-09 & 2.193 \mathrm{E}-07 & 1.840 \mathrm{E}-05\end{array}$

$\begin{array}{lllllll}2.315 \mathrm{E}-17 & 1.630 \mathrm{E}-16 & 2.480 \mathrm{E}-13 & 1.377 \mathrm{E}-12 & 5.115 \mathrm{E}-10 & 9.341 \mathrm{E}-08\end{array}$

$\begin{array}{llllll}1.642 \mathrm{E}-23 & 2.477 \mathrm{E}-22 & 1.186 \mathrm{E}-17 & 1.313 \mathrm{E}-16 & 2.462 \mathrm{E}-13 & 9.612 \mathrm{E}-11\end{array}$

$\begin{array}{lllllll}7.712 \mathrm{E}-12 & 2.327 \mathrm{E}-11 & 1.087 \mathrm{E}-09 & 3.025 \mathrm{E}-09 & 2.199 \mathrm{E}-07 & 1.850 \mathrm{E}-05\end{array}$

$0.000 \mathrm{E}+00 \quad 1.473 \mathrm{E}-30 \quad 1.589 \mathrm{E}-24 \quad 2.687 \mathrm{E}-23 \quad 7.527 \mathrm{E}-20 \quad 3.536 \mathrm{E}-17$

$\begin{array}{llllll}3.717 \mathrm{E}-20 & 2.596 \mathrm{E}-19 & 2.655 \mathrm{E}-16 & 1.087 \mathrm{E}-15 & 1.573 \mathrm{E}-13 & 2.528 \mathrm{E}-11\end{array}$

$8.381 \mathrm{E}-26 \quad 1.257 \mathrm{E}-24 \quad 4.500 \mathrm{E}-20 \quad 3.956 \mathrm{E}-19 \quad 3.440 \mathrm{E}-16 \quad 1.243 \mathrm{E}-13$

$0.000 \mathrm{E}+00 \quad 1.477 \mathrm{E}-30 \quad 1.723 \mathrm{E}-24 \quad 3.161 \mathrm{E}-23 \quad 1.561 \mathrm{E}-19 \quad 1.240 \mathrm{E}-16$

$\begin{array}{lllllll}3.717 \mathrm{E}-20 & 2.596 \mathrm{E}-19 & 2.655 \mathrm{E}-16 & 1.087 \mathrm{E}-15 & 1.576 \mathrm{E}-13 & 2.541 \mathrm{E}-11\end{array}$

$2.456 \mathrm{E}-18 \quad 2.486 \mathrm{E}-18 \quad 4.463 \mathrm{E}-18 \quad 8.107 \mathrm{E}-18 \quad 9.618 \mathrm{E}-16 \quad 6.841 \mathrm{E}-13$

$\begin{array}{llllll}1.254 E-24 & 3.802 E-24 & 2.343 E-22 & 8.645 E-22 & 6.015 E-19 & 1.124 E-15\end{array}$

$2.540 \mathrm{E}-15 \quad 2.572 \mathrm{E}-15 \quad 4.713 \mathrm{E}-15 \quad 8.745 \mathrm{E}-15 \quad 1.228 \mathrm{E}-12 \quad 1.101 \mathrm{E}-09$

$2.540 \mathrm{E}-15 \quad 2.572 \mathrm{E}-15 \quad 4.713 \mathrm{E}-15 \quad 8.745 \mathrm{E}-15 \quad 1.228 \mathrm{E}-12 \quad 1.101 \mathrm{E}-09$ 
RESRAD, Version $6.5 \quad T^{3 / 2}$ Limit $=180$ days

Summary : C746U Worker Deterministic Run

File : $\mathrm{X}: \backslash$ FINAL V2 $\backslash \mathrm{C} 746 \mathrm{U}$ W DET-FINALV2.RAD

Individual Nuclide Soil Concentration

Parent Nuclide and Branch Fraction Indicated

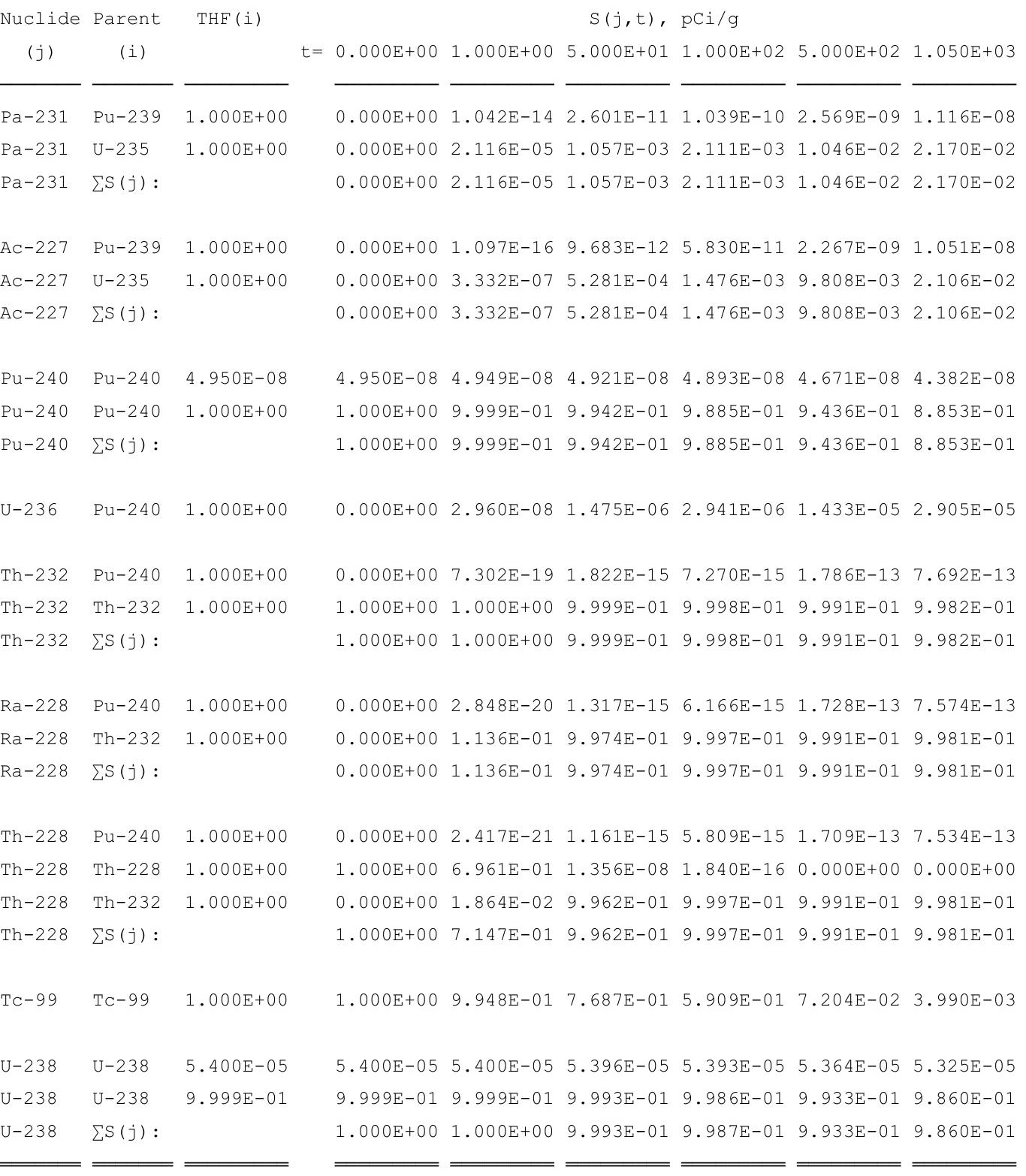

THF(i) is the thread fraction of the parent nuclide.

RESCALC.EXE execution time $=\quad 7.11$ seconds 


\section{Outdoor Worker}

\section{The following summary report includes the peak dose from cumulative radionuclide inventory.}


THIS PAGE INTENTIONALLY LEFT BLANK 
RESRAD, Version 6.5

Summary : C746U Worker Deterministic Run

File : $\mathrm{X}: \backslash$ FINAL V2 $\backslash$ C746U W SG FWD-FINALV2.RAD

Table of Contents

Part I: Mixture Sums and Single Radionuclide Guidelines

Dose Conversion Factor (and Related) Parameter Summary ... 2

Site-Specific Parameter Summary $\ldots \ldots \ldots \ldots \ldots \ldots \ldots \ldots \ldots$

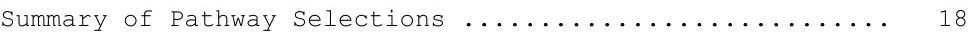

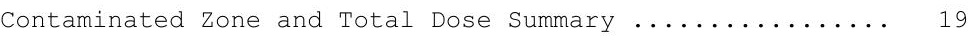

Total Dose Components

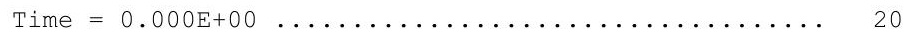

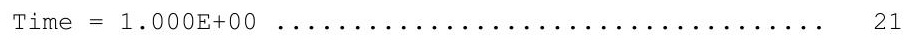

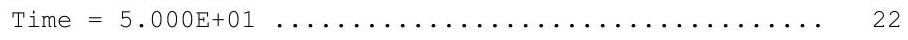

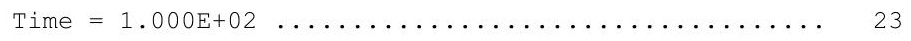

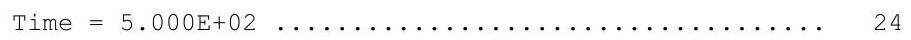

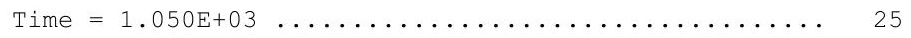

Dose/Source Ratios Summed Over All Pathways ............ 26

Single Radionuclide Soil Guidelines ............... 28

Dose Per Nuclide Summed Over All Pathways ............. 29

Soil Concentration Per Nuclide .................. 31 
RESRAD, Version $6.5 \quad T^{1 / 2}$ Limit $=180$ days

Summary : C746U Worker Deterministic Run
File : X: $\backslash$ FINAL V2 $\backslash$ C746U W SG FWD-FINALV2.RAD

Dose Conversion Factor (and Related) Parameter Summary

Dose Library: ICRP 60 \& ICRP 72 (Adult)

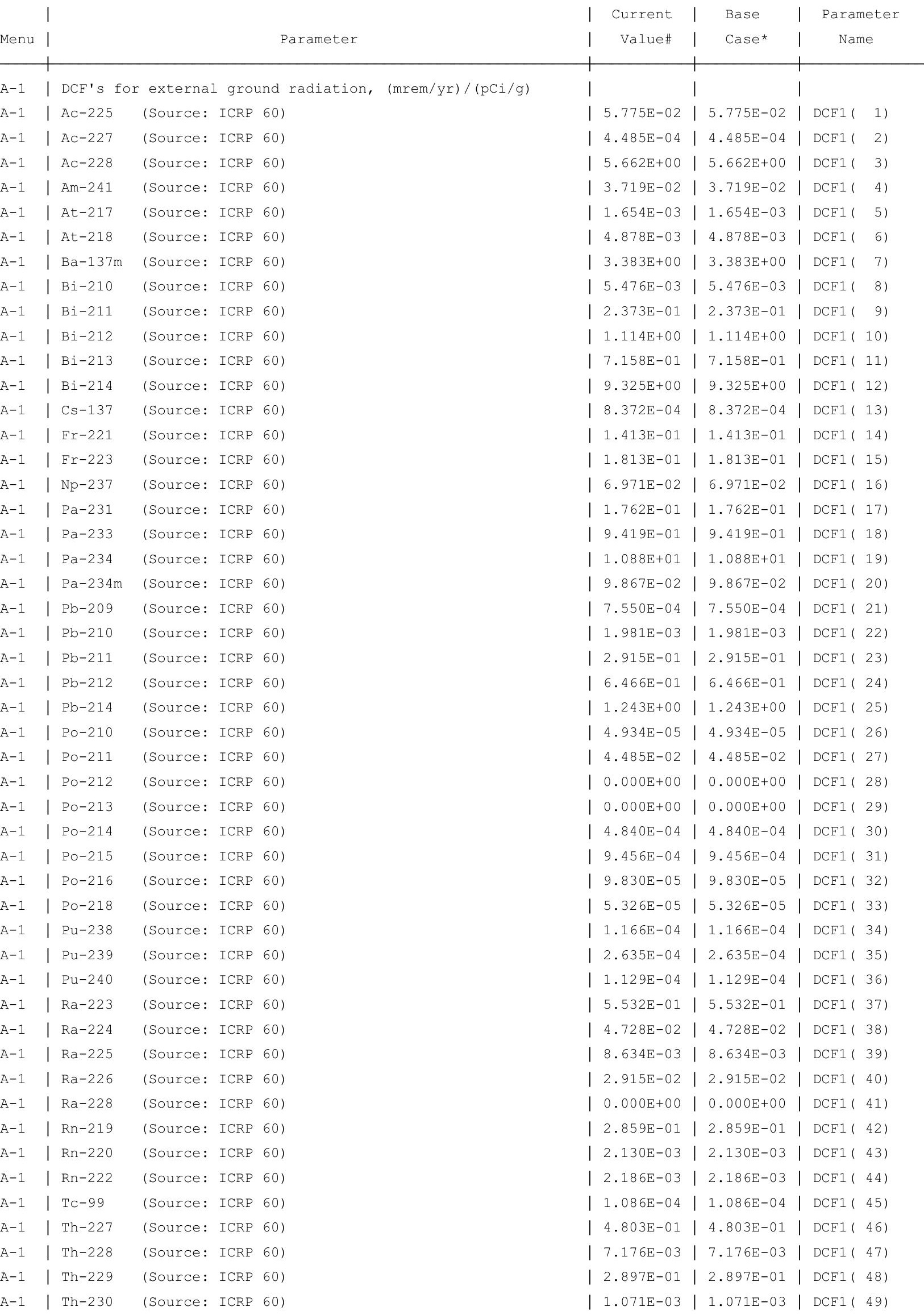


RESRAD, Version $6.5 \quad T^{1 / 2}$ Limit $=180$ days

Summary : C746U Worker Deterministic Run

File : $\mathrm{X}: \backslash$ FINAL V2 $\backslash \mathrm{C} 746 \mathrm{U}$ W SG FWD-FINALV2.RAD

Dose Conversion Factor (and Related) Parameter Summary (continued) Dose Library: ICRP 60 \& ICRP 72 (Adult)

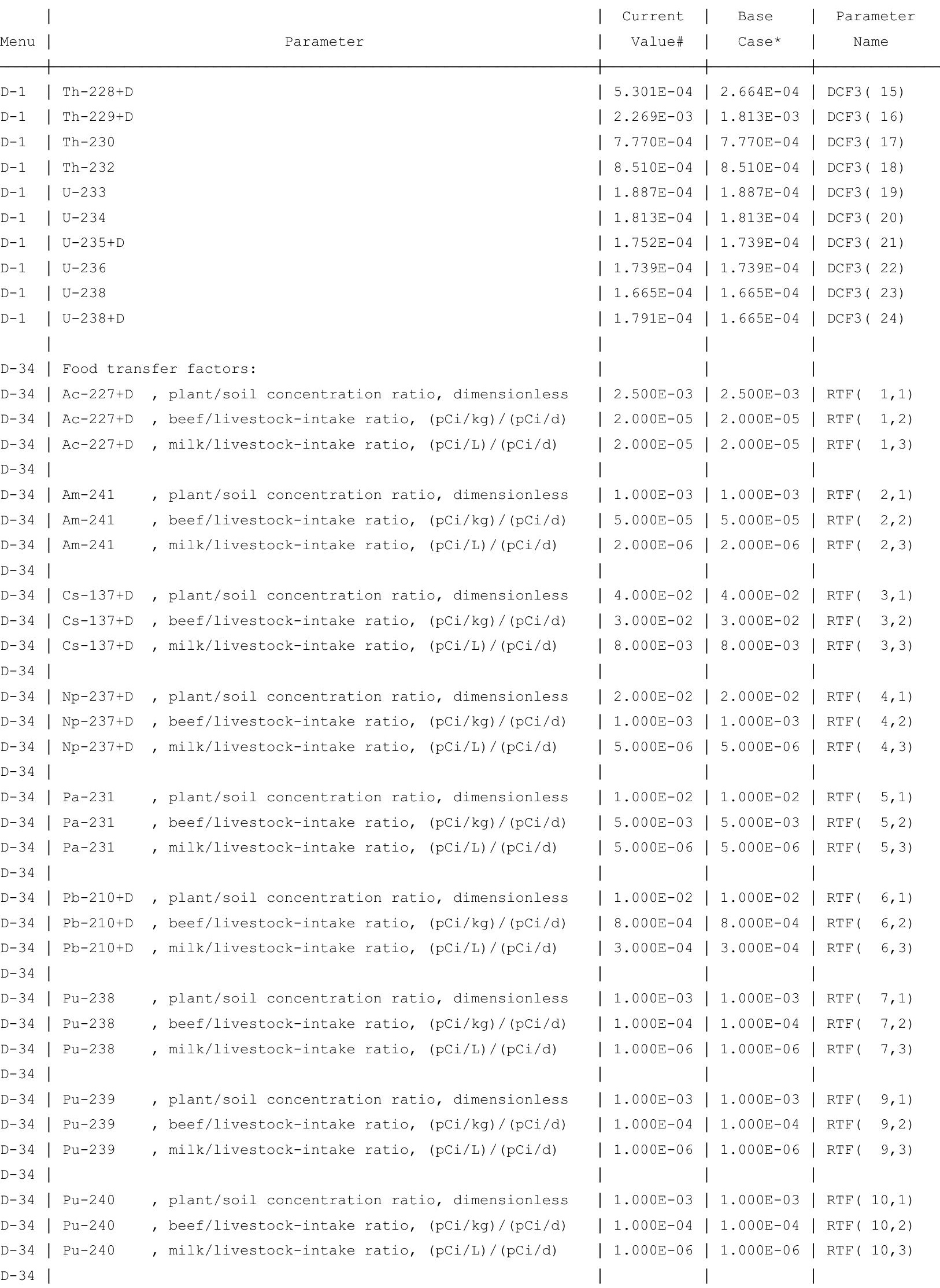


RESRAD, Version $6.5 \quad \mathrm{~T}^{1 / 2}$ Limit $=180$ days

Summary : C746U Worker Deterministic Run

File : $\mathrm{X}: \backslash$ FINAL V2 $\backslash$ C746U W SG FWD-FINALV2.RAD

Dose Conversion Factor (and Related) Parameter Summary (continued)

Dose Library: ICRP 60 \& ICRP 72 (Adult)

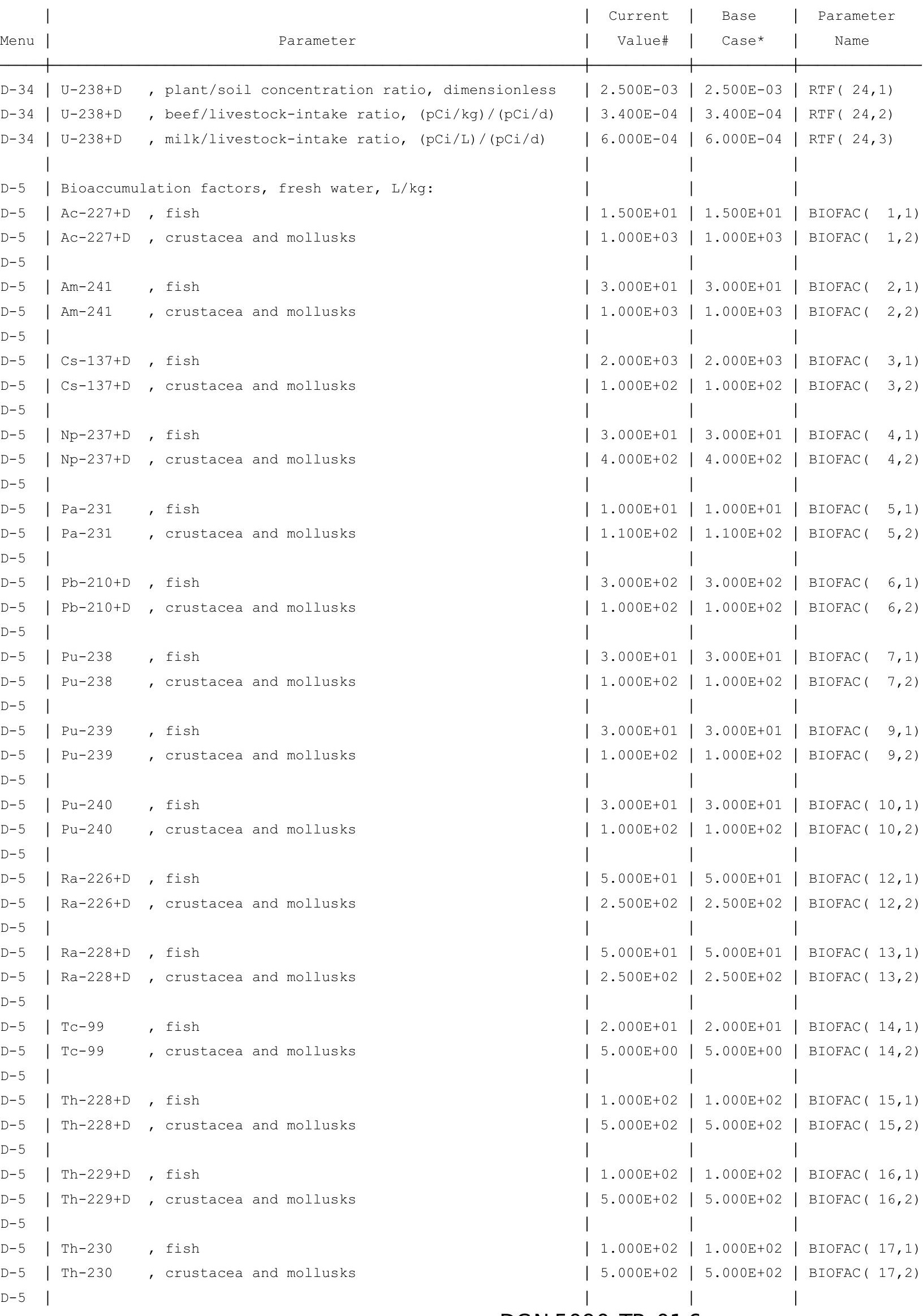


RESRAD, Version $6.5 \quad \mathrm{~T}^{1 / 2}$ Limit $=180$ days

Summary : C746U Worker Deterministic Run

File : $X: \backslash F I N A L$ V2 $\backslash C 746 U$ W SG FWD-FINALV2.RAD

Dose Conversion Factor (and Related) Parameter Summary (continued)

Dose Library: ICRP 60 \& ICRP 72 (Adult)

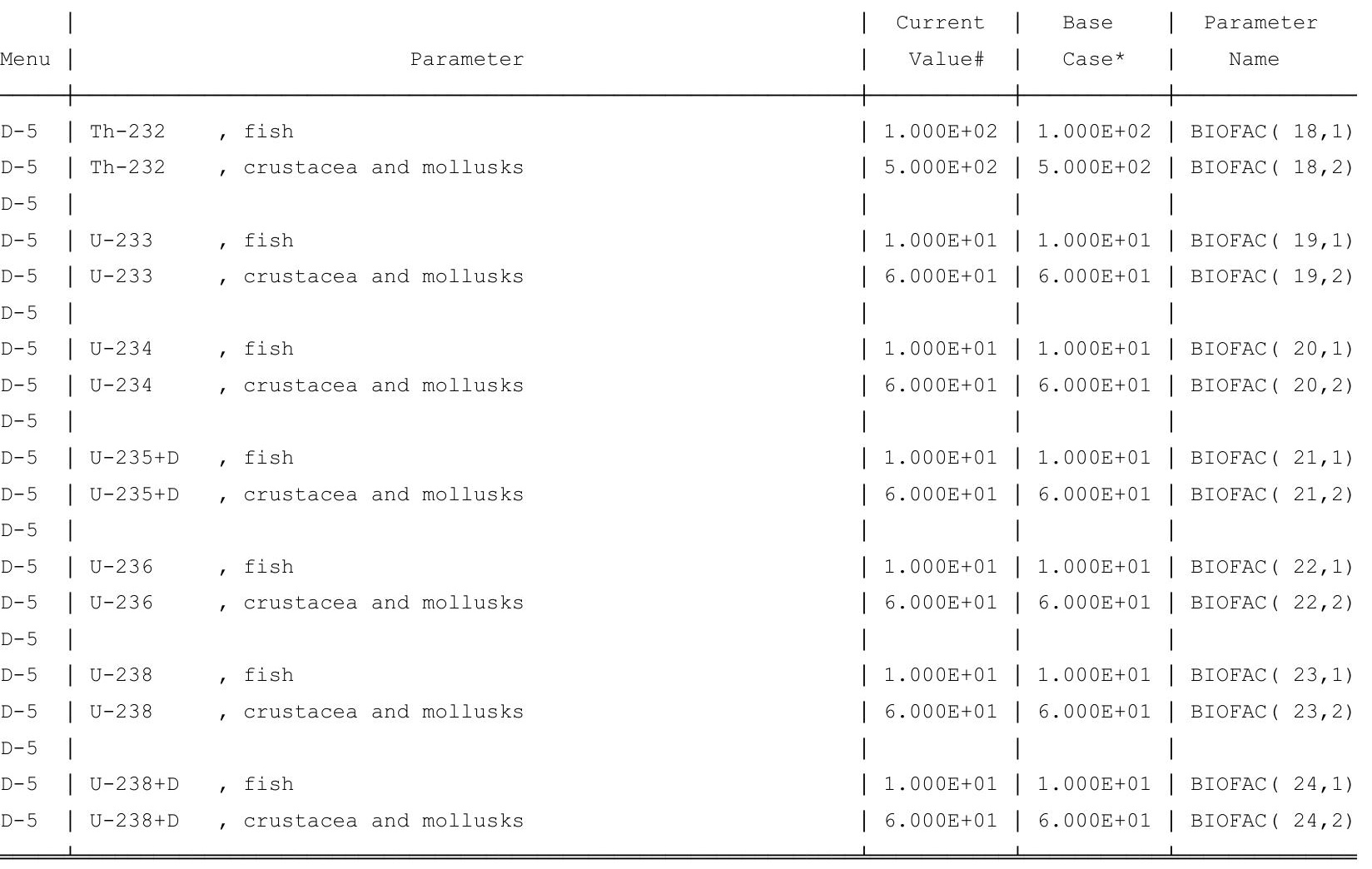

\#For DCFl(xxx) only, factors are for infinite depth \& area. See ETFG table in Ground Pathway of Detailed Report. *Base Case means Default.Lib w/o Associate Nuclide contributions. 
RESRAD, Version $6.5 \quad \mathrm{~T}^{1 / 2}$ Limit $=180$ days

Summary : C746U Worker Deterministic Run
File : $\mathrm{X}: \backslash$ FINAL V2 $\backslash \mathrm{C} 746 \mathrm{U}$ W SG FWD-FINALV2.RAD

Site-Specific Parameter Summary (continued)

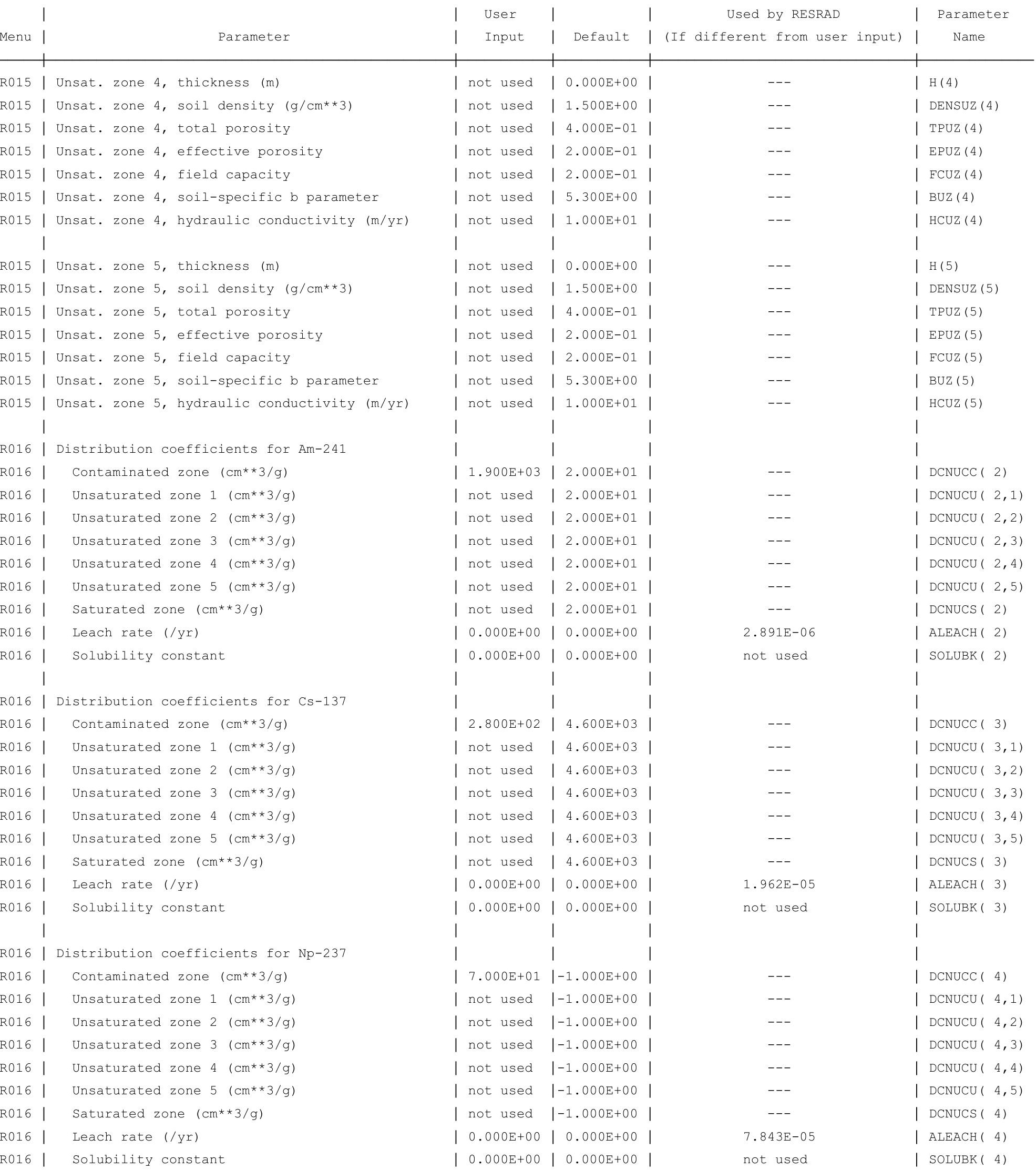


RESRAD, Version $6.5 \quad \mathrm{~T}^{1 / 2}$ Limit $=180$ days

Summary : C746U Worker Deterministic Run

File : $\mathrm{X}: \backslash$ FINAL V2 $\backslash \mathrm{C} 746 \mathrm{U}$ W SG FWD-FINALV2.RAD

Site-Specific Parameter Summary (continued)

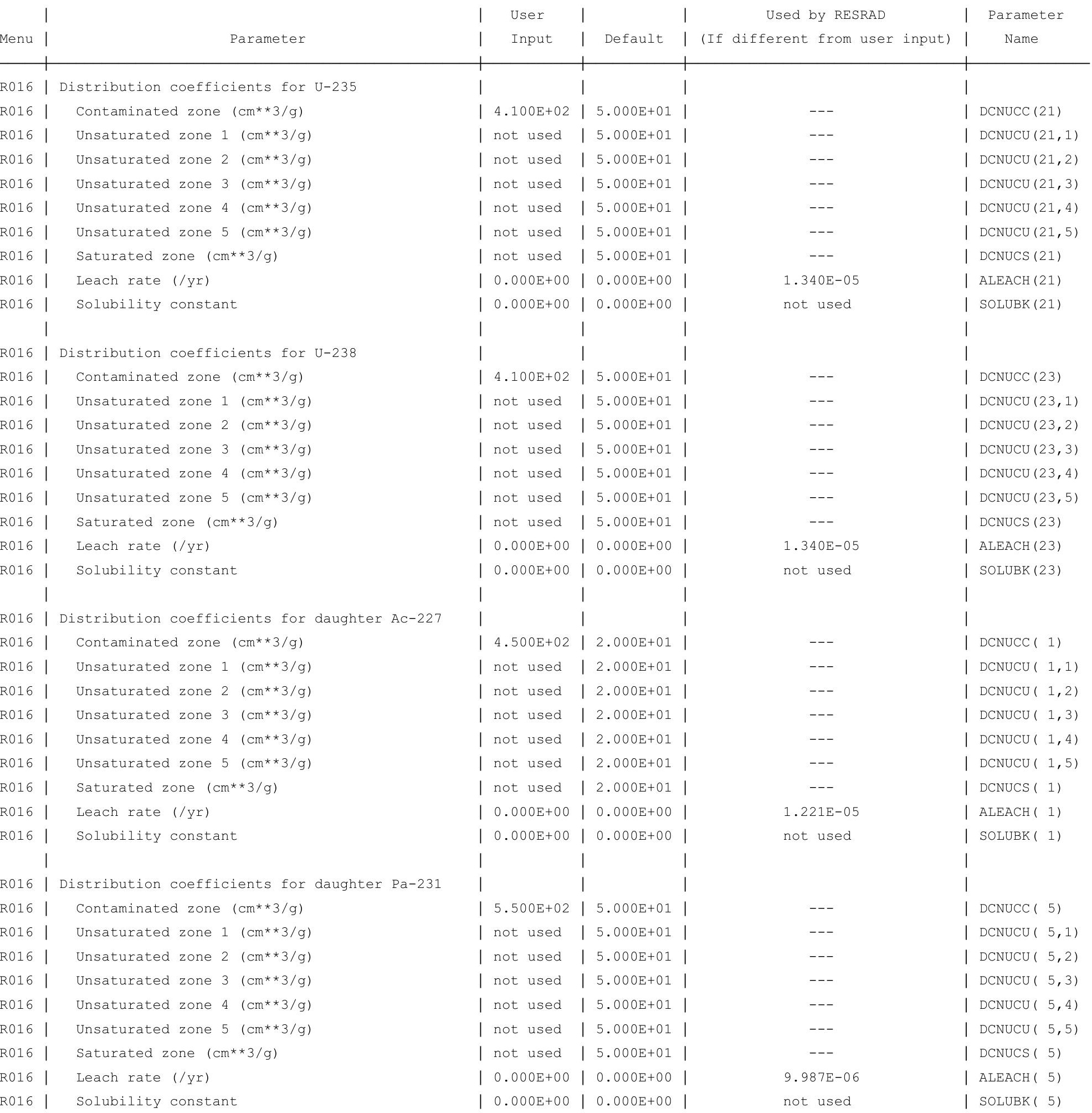


RESRAD, Version $6.5 \quad \mathrm{~T}^{1 / 2}$ Limit $=180$ days

Summary : C746U Worker Deterministic Run

File : $\mathrm{X}: \backslash$ FINAL V2 $\backslash \mathrm{C} 746 \mathrm{U}$ W SG FWD-FINALV2.RAD

Site-Specific Parameter Summary (continued)

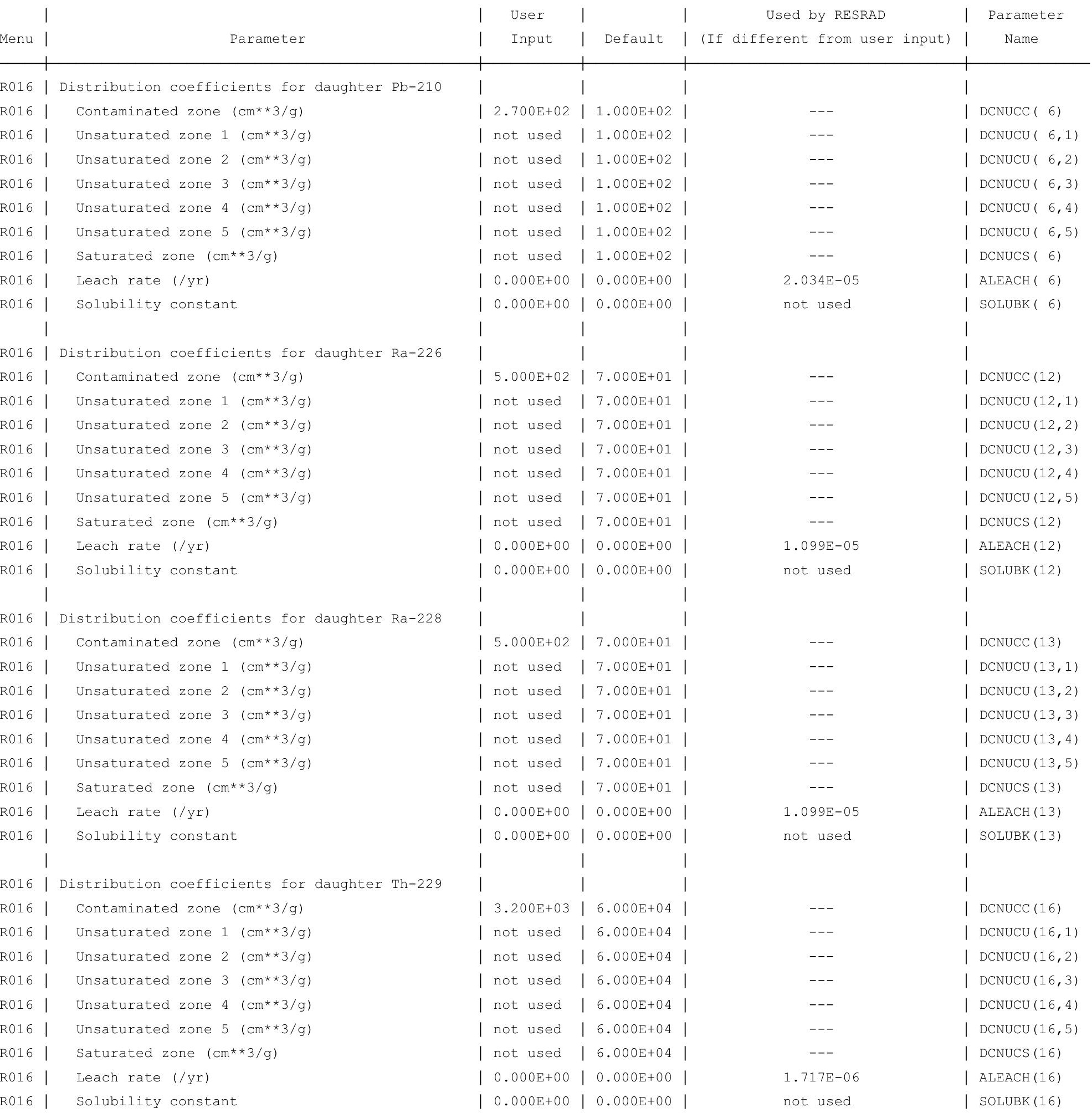


RESRAD, Version $6.5 \quad \mathrm{~T}^{1 / 2}$ Limit $=180$ days

Summary : C746U Worker Deterministic Run

File : $X: \backslash F I N A L$ V2 $\backslash C 746 U$ W SG FWD-FINALV2.RAD

Contaminated Zone Dimensions

Area: 89436.00 square meters

Thickness:

Cover Depth:

\begin{abstract}
13.40 meters
1.52 meters
\end{abstract}

Initial Soil Concentrations, pCi/g

$\begin{array}{ll}\mathrm{Am}-241 & 3.500 \mathrm{E}+03 \\ \mathrm{Cs}-137 & 1.900 \mathrm{E}+02 \\ \mathrm{~Np}-237 & 5.500 \mathrm{E}+02 \\ \mathrm{Pu}-238 & 3.900 \mathrm{E}+03 \\ \mathrm{Pu}-239 & 3.600 \mathrm{E}+03 \\ \mathrm{Pu}-240 & 3.600 \mathrm{E}+03 \\ \mathrm{TC}-99 & 2.800 \mathrm{E}+01 \\ \mathrm{Th}-228 & 7.400 \mathrm{E}+01 \\ \mathrm{Th}-230 & 1.200 \mathrm{E}+03 \\ \mathrm{Th}-232 & 3.800 \mathrm{E}+01 \\ \mathrm{U}-234 & 1.800 \mathrm{E}+04 \\ \mathrm{U}-235 & 8.200 \mathrm{E}+02 \\ \mathrm{U}-238 & 3.200 \mathrm{E}+03\end{array}$

Total Dose TDOSE(t), mrem/yr

Basic Radiation Dose Limit $=1.000 \mathrm{E}+00 \mathrm{mrem} / \mathrm{yr}$

Total Mixture Sum $M(t)$ = Fraction of Basic Dose Limit Received at Time (t)

$\begin{array}{rllllll}t \text { (years): } & 0.000 \mathrm{E}+00 & 1.000 \mathrm{E}+00 & 5.000 \mathrm{E}+01 & 1.000 \mathrm{E}+02 & 5.000 \mathrm{E}+02 & 1.050 \mathrm{E}+03 \\ \text { TDOSE }(\mathrm{t}): & 2.115 \mathrm{E}-05 & 1.534 \mathrm{E}-05 & 1.887 \mathrm{E}-05 & 2.742 \mathrm{E}-05 & 5.369 \mathrm{E}-04 & 3.138 \mathrm{E}-02 \\ \mathrm{M}(\mathrm{t}): & 2.115 \mathrm{E}-05 & 1.534 \mathrm{E}-05 & 1.887 \mathrm{E}-05 & 2.742 \mathrm{E}-05 & 5.369 \mathrm{E}-04 & 3.138 \mathrm{E}-02\end{array}$

Maximum TDOSE $(\mathrm{t}): \quad 3.138 \mathrm{E}-02 \mathrm{mrem} / \mathrm{yr}$ at $t=1.050 \mathrm{E}+03$ years 
RESRAD, Version 6.5

$\mathrm{T}^{1 / 2}$ Limit $=180$ days

Summary : C746U Worker Deterministic Run
File : X: $\backslash$ FINAL V2 \C746U W SG FWD-FINALV2.RAD

Total Dose Contributions TDOSE (i,p,t) for Individual Radionuclides (i) and Pathways (p) As mrem/yr and Fraction of Total Dose At $t=0.000 \mathrm{E}+00$ years

Water Independent Pathways (Inhalation excludes radon)

\begin{tabular}{|c|c|c|}
\hline clide & mrem/yr & fract. \\
\hline-241 & $1.106 \mathrm{E}-16$ & 0.0000 \\
\hline-137 & $4.898 \mathrm{E}-08$ & 0.0023 \\
\hline-237 & $1.072 \mathrm{E}-10$ & 0.0000 \\
\hline-238 & $6.486 \mathrm{E}-20$ & 0.0000 \\
\hline-239 & $8.843 E-15$ & 0.0000 \\
\hline-240 & $8.408 E-22$ & 0.0000 \\
\hline-99 & $3.300 \mathrm{E}-25$ & 0.0000 \\
\hline-228 & $2.090 \mathrm{E}-05$ & 0.9885 \\
\hline-230 & $9.254 \mathrm{E}-09$ & 0.0004 \\
\hline-232 & $9.146 \mathrm{E}-08$ & 0.0043 \\
\hline 234 & $4.168 \mathrm{E}-13$ & 0.0000 \\
\hline 235 & $2.085 \mathrm{E}-12$ & 0.0000 \\
\hline 38 & $9.282 \mathrm{E}-08$ & 0.0044 \\
\hline & $2 \cdot 113$ & 1.0000 \\
\hline
\end{tabular}

Inhalation

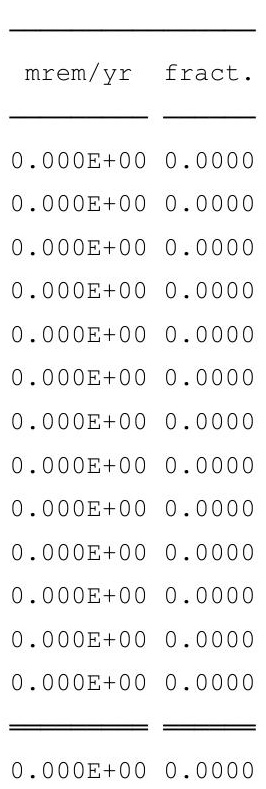

Radon

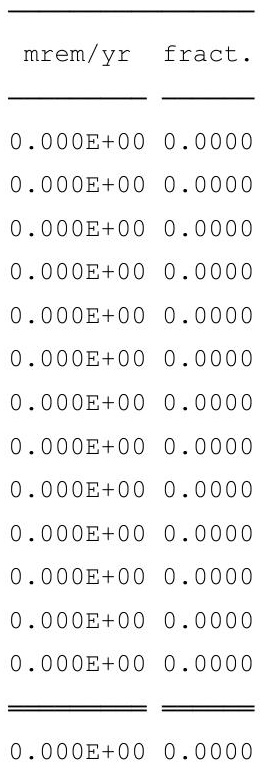

Plant

\begin{tabular}{ll}
\hline mrem/yr fract. \\
\hline $0.000 \mathrm{E}+00$ & 0.0000 \\
$0.000 \mathrm{E}+00$ & 0.0000 \\
$0.000 \mathrm{E}+00$ & 0.0000 \\
$0.000 \mathrm{E}+00$ & 0.0000 \\
$0.000 \mathrm{E}+00$ & 0.0000 \\
$0.000 \mathrm{E}+00$ & 0.0000 \\
$0.000 \mathrm{E}+00$ & 0.0000 \\
$0.000 \mathrm{E}+00$ & 0.0000 \\
$0.000 \mathrm{E}+00$ & 0.0000 \\
$0.000 \mathrm{E}+00$ & 0.0000 \\
$0.000 \mathrm{E}+00$ & 0.0000 \\
$0.000 \mathrm{E}+00$ & 0.0000 \\
$0.000 \mathrm{E}+00$ & 0.0000 \\
\hline \hline $0.000 \mathrm{E}+00$ & 0.0000 \\
\hline
\end{tabular}

\begin{tabular}{ll} 
Meat \\
\hline mrem/yr fract. \\
\cline { 1 - 2 } & \\
$0.000 \mathrm{E}+00$ & 0.0000 \\
$0.000 \mathrm{E}+00$ & 0.0000 \\
$0.000 \mathrm{E}+00$ & 0.0000 \\
$0.000 \mathrm{E}+00$ & 0.0000 \\
$0.000 \mathrm{E}+00$ & 0.0000 \\
$0.000 \mathrm{E}+00$ & 0.0000 \\
$0.000 \mathrm{E}+00$ & 0.0000 \\
$0.000 \mathrm{E}+00$ & 0.0000 \\
$0.000 \mathrm{E}+00$ & 0.0000 \\
$0.000 \mathrm{E}+00$ & 0.0000 \\
$0.000 \mathrm{E}+00$ & 0.0000 \\
$0.000 \mathrm{E}+00$ & 0.0000 \\
$0.000 \mathrm{E}+00$ & 0.0000 \\
\hline \hline $0.000 \mathrm{E}+00$ & 0.0000
\end{tabular}

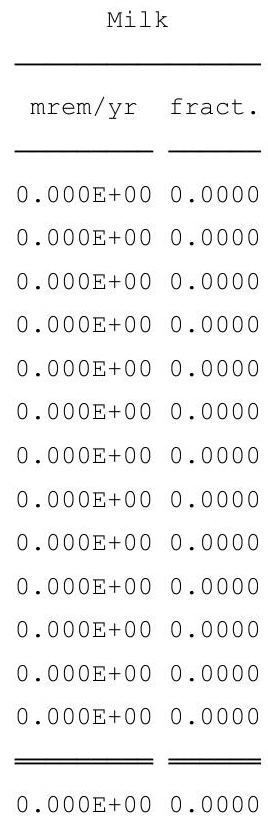

Soil mrem/yr fract. $0.000 \mathrm{E}+00 \quad 0.0000$ $0.000 \mathrm{E}+00 \quad 0.0000$ $0.000 \mathrm{E}+00 \quad 0.0000$ $0.000 \mathrm{E}+00 \quad 0.0000$ $0.000 \mathrm{E}+00 \quad 0.0000$ $0.000 \mathrm{E}+00 \quad 0.0000$ $0.000 \mathrm{E}+00 \quad 0.0000$ $0.000 \mathrm{E}+00 \quad 0.0000$ $0.000 \mathrm{E}+00 \quad 0.0000$ $0.000 \mathrm{E}+00 \quad 0.0000$ $0.000 \mathrm{E}+00 \quad 0.0000$ $0.000 \mathrm{E}+00 \quad 0.0000$ $0.000 \mathrm{E}+00 \quad 0.0000$ $0.000 \mathrm{E}+00 \quad 0.0000$

Total Dose Contributions TDOSE (i,p,t) for Individual Radionuclides (i) and Pathways (p) As mrem/yr and Fraction of Total Dose At $t=0.000 \mathrm{E}+00$ years

Water Dependent Pathways

\begin{tabular}{|c|c|c|c|c|c|c|}
\hline \multirow{2}{*}{ Nuclide } & \multicolumn{2}{|c|}{ Water } & \multicolumn{2}{|c|}{ Fish } & \multicolumn{2}{|c|}{ Radon } \\
\hline & mrem/yr & fract. & mrem/yr & fract. & mrem/yr & fract. \\
\hline-241 & $0.000 \mathrm{E}+00$ & 0.0000 & $0.000 \mathrm{E}+00$ & 0.0000 & $0.000 \mathrm{E}+00$ & 0.0000 \\
\hline-137 & $0.000 \mathrm{E}+00$ & 0.0000 & $0.000 \mathrm{E}+00$ & 0.0000 & $0.000 \mathrm{E}+00$ & 0.0000 \\
\hline-237 & $0.000 \mathrm{E}+00$ & 0.0000 & $0.000 \mathrm{E}+00$ & 0.0000 & $0.000 \mathrm{E}+00$ & 0.0000 \\
\hline 238 & $0.000 \mathrm{E}+00$ & 0.0000 & $0.000 \mathrm{E}+00$ & 0.0000 & $0.000 \mathrm{E}+00$ & 0.0000 \\
\hline 239 & $0.000 \mathrm{E}+00$ & 0.0000 & $0.000 \mathrm{E}+00$ & 0.0000 & $0.000 \mathrm{E}+00$ & 0.0000 \\
\hline 240 & $0.000 \mathrm{E}+00$ & 0.0000 & $0.000 \mathrm{E}+00$ & 0.0000 & $0.000 \mathrm{E}+00$ & 0.0000 \\
\hline 99 & $0.000 \mathrm{E}+00$ & 0.0000 & $0.000 \mathrm{E}+00$ & 0.0000 & $0.000 \mathrm{E}+00$ & 0.0000 \\
\hline 228 & $0.000 \mathrm{E}+00$ & 0.0000 & $0.000 \mathrm{E}+00$ & 0.0000 & $0.000 \mathrm{E}+00$ & 0.0000 \\
\hline 30 & $0.000 \mathrm{E}+00$ & 0.0000 & $0.000 \mathrm{E}+00$ & 0.0000 & $0.000 \mathrm{E}+00$ & 0.0000 \\
\hline 232 & $0.000 \mathrm{E}+00$ & 0.0000 & $0.000 \mathrm{E}+00$ & 0.0000 & $0.000 \mathrm{E}+00$ & 0.0000 \\
\hline 4 & $0.000 \mathrm{E}+00$ & 0.0000 & $0.000 \mathrm{E}+00$ & 0.0000 & $0.000 \mathrm{E}+00$ & 0.0000 \\
\hline 235 & $0.000 \mathrm{E}+00$ & 0.0000 & $0.000 \mathrm{E}+00$ & 0.0000 & $0.000 \mathrm{E}+00$ & 0.0000 \\
\hline & $0.000 \mathrm{E}+00$ & 0.0000 & $0.000 \mathrm{E}+00$ & 0.0000 & $0.000 \mathrm{E}+00$ & 0.0000 \\
\hline & $0.000 \mathrm{E}+00$ & 0.0000 & $0.000 \mathrm{E}+00$ & 0 & +00 & 0000 \\
\hline
\end{tabular}

*Sum of all water independent and dependent pathways.

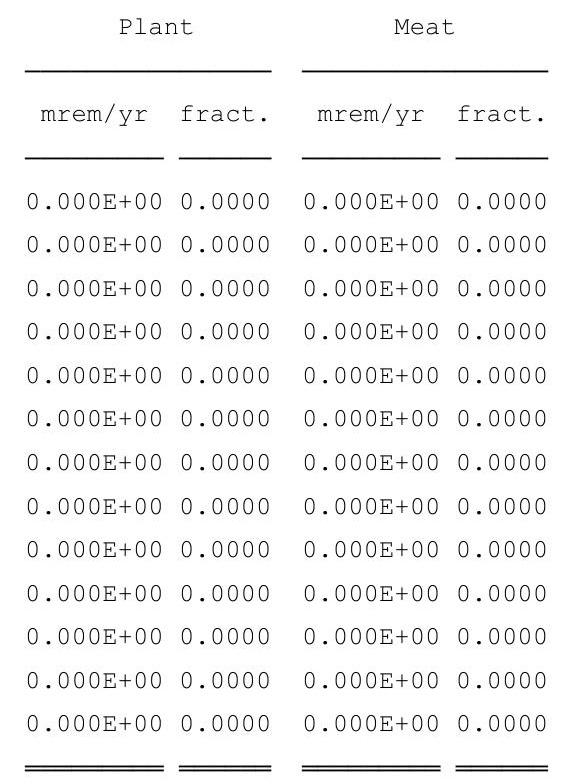

$0.000 \mathrm{E}+00 \quad 0.0000 \quad 0.000 \mathrm{E}+00 \quad 0.0000$

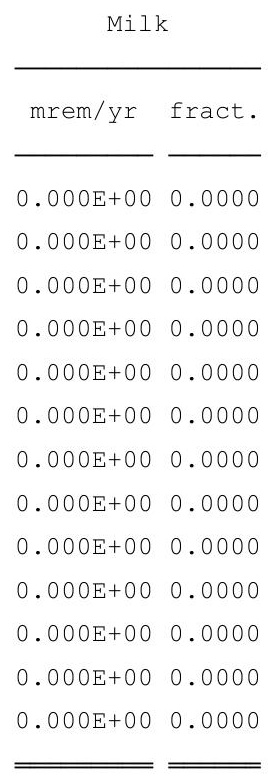

$0.000 \mathrm{E}+00 \quad 0.0000$
All Pathways* mrem/yr fract. $1.106 \mathrm{E}-16 \quad 0.0000$ $4.898 \mathrm{E}-08 \quad 0.0023$ $1.072 \mathrm{E}-10 \quad 0.0000$ $6.486 \mathrm{E}-20 \quad 0.0000$ $8.843 \mathrm{E}-15 \quad 0.0000$ $8.408 \mathrm{E}-22 \quad 0.0000$ $3.300 \mathrm{E}-25 \quad 0.0000$ $2.090 \mathrm{E}-05 \quad 0.9885$ $9.254 \mathrm{E}-09 \quad 0.0004$ $9.146 \mathrm{E}-08 \quad 0.0043$ $4.168 \mathrm{E}-13 \quad 0.0000$ $2.085 \mathrm{E}-12 \quad 0.0000$ $9.282 \mathrm{E}-08 \quad 0.0044$ $2.115 \mathrm{E}-05 \quad 1.0000$ 
RESRAD, Version 6.5

$\mathrm{T}^{1 / 2}$ Limit $=180$ days

Summary : C746U Worker Deterministic Run

File : $\mathrm{X}: \backslash$ FINAL V2 $\backslash$ C746U W SG FWD-FINALV2.RAD

Total Dose Contributions TDOSE(i,p,t) for Individual Radionuclides (i) and Pathways (p) As mrem/yr and Fraction of Total Dose At $t=1.000 \mathrm{E}+00$ years

Water Independent Pathways (Inhalation excludes radon)

\begin{tabular}{|c|c|c|}
\hline clide & mrem/yr & fract. \\
\hline-241 & $3.347 \mathrm{E}-16$ & 0.0000 \\
\hline-137 & $4.827 E-08$ & 0.0031 \\
\hline-237 & $1.083 \mathrm{E}-10$ & 0.0000 \\
\hline-238 & $9.637 E-19$ & 0.0000 \\
\hline-239 & $8.949 \mathrm{E}-15$ & 0.0000 \\
\hline-240 & $8.736 \mathrm{E}-22$ & 0.0000 \\
\hline-99 & $3.347 E-25$ & 0.0000 \\
\hline-228 & $1.464 \mathrm{E}-05$ & 0.9540 \\
\hline-230 & $2.793 E-08$ & 0.0018 \\
\hline 232 & $5.356 \mathrm{E}-07$ & 0.0349 \\
\hline 34 & $2.934 E-12$ & 0.0000 \\
\hline 35 & $2.121 E-12$ & 0.0000 \\
\hline 238 & $9.357 E-08$ & 0.0061 \\
\hline & $1.334 \mathrm{E}-05$ & 1. \\
\hline
\end{tabular}

\begin{abstract}
Inhalation
\end{abstract}

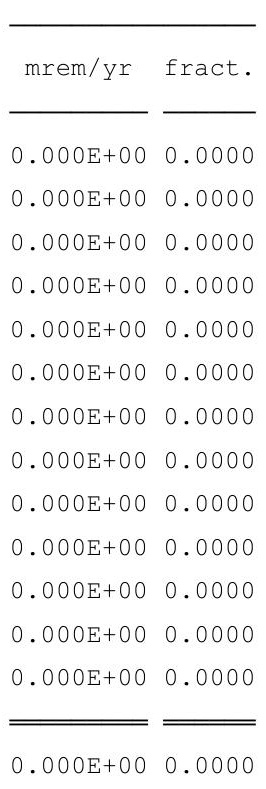

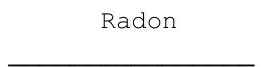
mrem/yr fract. $\overline{0.000 E+00} 0.0000$ $0.000 E+00 \quad 0.0000$ $0.000 E+00 \quad 0.0000$ $0.000 \mathrm{E}+00 \quad 0.0000$ $0.000 E+00 \quad 0.0000$ $0.000 E+00 \quad 0.0000$ $0.000 \mathrm{E}+00 \quad 0.0000$ $0.000 E+00 \quad 0.0000$ $0.000 E+00 \quad 0.0000$ $0.000 E+00 \quad 0.0000$ $0.000 \mathrm{E}+00 \quad 0.0000$ $0.000 E+00 \quad 0.0000$ $0.000 \mathrm{E}+00 \quad 0.0000$

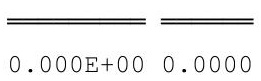

\begin{tabular}{|c|c|c|c|}
\hline \multicolumn{2}{|c|}{ Plant } & \multicolumn{2}{|c|}{ Meat } \\
\hline mrem/yr & fract. & mrem/yr & fract. \\
\hline $.000 \mathrm{E}+00$ & 0.0000 & $0.000 \mathrm{E}+00$ & 0.0000 \\
\hline $0.000 \mathrm{E}+00$ & 0.0000 & $0.000 \mathrm{E}+00$ & 0.0000 \\
\hline $0.000 \mathrm{E}+00$ & 0.0000 & $0.000 \mathrm{E}+00$ & 0.0000 \\
\hline $0.000 \mathrm{E}+00$ & 0.0000 & $0.000 \mathrm{E}+00$ & 0.0000 \\
\hline $0.000 \mathrm{E}+00$ & 0.0000 & $0.000 \mathrm{E}+00$ & 0.0000 \\
\hline $0.000 \mathrm{E}+00$ & 0.0000 & $0.000 \mathrm{E}+00$ & 0.0000 \\
\hline $0.000 \mathrm{E}+00$ & 0.0000 & $0.000 \mathrm{E}+00$ & 0.0000 \\
\hline $0.000 \mathrm{E}+00$ & 0.0000 & $0.000 \mathrm{E}+00$ & 0.0000 \\
\hline $0.000 \mathrm{E}+00$ & 0.0000 & $0.000 \mathrm{E}+00$ & 0.0000 \\
\hline $0.000 \mathrm{E}+00$ & 0.0000 & $0.000 \mathrm{E}+00$ & 0.0000 \\
\hline $0.000 \mathrm{E}+00$ & 0.0000 & $0.000 \mathrm{E}+00$ & 0.0000 \\
\hline $0.000 \mathrm{E}+00$ & 0.0000 & $0.000 \mathrm{E}+00$ & 0.0000 \\
\hline $0.000 \mathrm{E}+00$ & 0.0000 & $0.000 \mathrm{E}+00$ & 0.0000 \\
\hline & & 0.00 & . \\
\hline
\end{tabular}

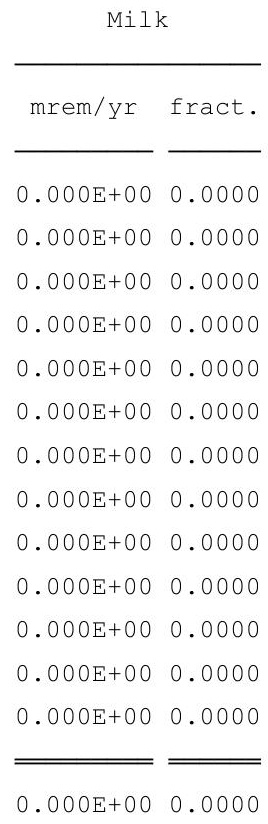

Soil mrem/yr fract. $0.000 \mathrm{E}+00 \quad 0.0000$ $0.000 \mathrm{E}+00 \quad 0.0000$ $0.000 \mathrm{E}+00 \quad 0.0000$ $0.000 \mathrm{E}+00 \quad 0.0000$ $0.000 \mathrm{E}+00 \quad 0.0000$ $0.000 \mathrm{E}+00 \quad 0.0000$ $0.000 \mathrm{E}+00 \quad 0.0000$ $0.000 \mathrm{E}+00 \quad 0.0000$ $0.000 \mathrm{E}+00 \quad 0.0000$ $0.000 \mathrm{E}+00 \quad 0.0000$ $0.000 \mathrm{E}+00 \quad 0.0000$ $0.000 \mathrm{E}+00 \quad 0.0000$ $0.000 \mathrm{E}+00 \quad 0.0000$ $0.000 \mathrm{E}+00 \quad 0.0000$

Total Dose Contributions TDOSE(i,p,t) for Individual Radionuclides (i) and Pathways (p) As mrem/yr and Fraction of Total Dose At $t=1.000 \mathrm{E}+00$ years

Water Dependent Pathways

\begin{tabular}{|c|c|c|c|c|c|c|}
\hline \multirow{2}{*}{$\begin{array}{l}\text { Radio- } \\
\text { Nuclide }\end{array}$} & \multicolumn{2}{|c|}{ Water } & \multicolumn{2}{|c|}{ Fish } & \multicolumn{2}{|c|}{ Radon } \\
\hline & mrem/yr & fract. & mrem/yr & fract. & mrem/yr & fract. \\
\hline-241 & $0.000 \mathrm{E}+00$ & 0.0000 & $0.000 \mathrm{E}+00$ & 0.0000 & $0.000 \mathrm{E}+00$ & 0.0000 \\
\hline-137 & $0.000 \mathrm{E}+00$ & 0.0000 & $0.000 \mathrm{E}+00$ & 0.0000 & $0.000 \mathrm{E}+00$ & 0.0000 \\
\hline 237 & $0.000 \mathrm{E}+00$ & 0.0000 & $0.000 \mathrm{E}+00$ & 0.0000 & $0.000 \mathrm{E}+00$ & 0.0000 \\
\hline-238 & $0.000 \mathrm{E}+00$ & 0.0000 & $0.000 \mathrm{E}+00$ & 0.0000 & $0.000 \mathrm{E}+00$ & 0.0000 \\
\hline 239 & $0.000 \mathrm{E}+00$ & 0.0000 & $0.000 \mathrm{E}+00$ & 0.0000 & $0.000 \mathrm{E}+00$ & 0.0000 \\
\hline-240 & $0.000 \mathrm{E}+00$ & 0.0000 & $0.000 \mathrm{E}+00$ & 0.0000 & $0.000 \mathrm{E}+00$ & 0.0000 \\
\hline 99 & $0.000 \mathrm{E}+00$ & 0.0000 & $0.000 \mathrm{E}+00$ & 0.0000 & $0.000 \mathrm{E}+00$ & 0.0000 \\
\hline 228 & $0.000 \mathrm{E}+00$ & 0.0000 & $0.000 \mathrm{E}+00$ & 0.0000 & $0.000 \mathrm{E}+00$ & 0.0000 \\
\hline 230 & $0.000 \mathrm{E}+00$ & 0.0000 & $0.000 \mathrm{E}+00$ & 0.0000 & $0.000 \mathrm{E}+00$ & 0.0000 \\
\hline 232 & $0.000 \mathrm{E}+00$ & 0.0000 & $0.000 \mathrm{E}+00$ & 0.0000 & $0.000 \mathrm{E}+00$ & 0.0000 \\
\hline 4 & $0.000 \mathrm{E}+00$ & 0.0000 & $0.000 \mathrm{E}+00$ & 0.0000 & $0.000 \mathrm{E}+00$ & 0.0000 \\
\hline & $0.000 \mathrm{E}+00$ & 0.0000 & $0.000 \mathrm{E}+00$ & 0.0000 & $0.000 \mathrm{E}+00$ & 0.0000 \\
\hline & $0.000 \mathrm{E}+00$ & 0.0000 & $0.000 \mathrm{E}+00$ & 0.0000 & $0.000 \mathrm{E}+00$ & 0.0000 \\
\hline & 0 & 00 & $.000 \mathrm{E}+00$ & 000 & $0.000 \mathrm{E}+00$ & 0.00 \\
\hline
\end{tabular}

*Sum of all water independent and dependent pathways.

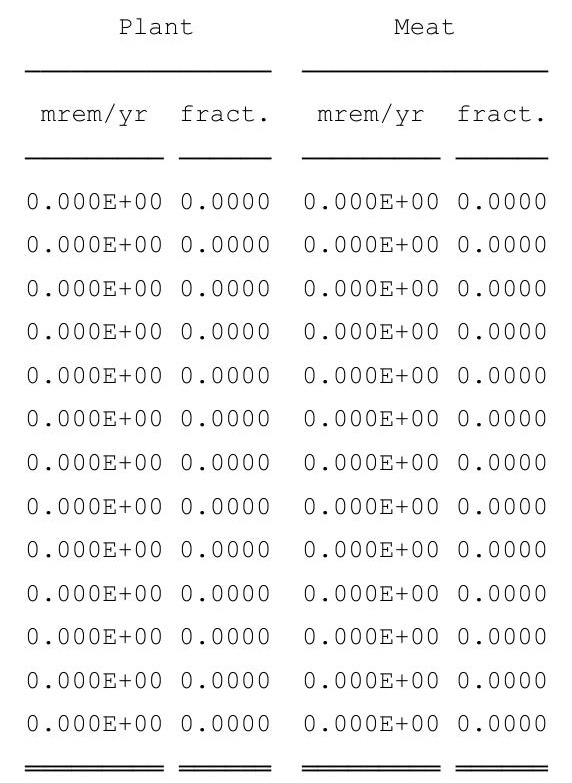

$0.000 \mathrm{E}+00 \quad 0.0000 \quad 0.000 \mathrm{E}+00 \quad 0.0000$

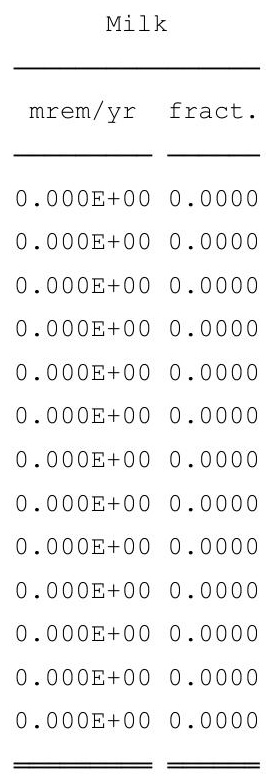

$0.000 \mathrm{E}+00 \quad 0.0000$
All Pathways* mrem/yr fract. $3.347 \mathrm{E}-16 \quad 0.0000$ $4.827 \mathrm{E}-08 \quad 0.0031$ $1.083 \mathrm{E}-10 \quad 0.0000$ $9.637 \mathrm{E}-19 \quad 0.0000$ $8.949 \mathrm{E}-15 \quad 0.0000$ $8.736 \mathrm{E}-22 \quad 0.0000$ $3.347 \mathrm{E}-25 \quad 0.0000$ $1.464 \mathrm{E}-05 \quad 0.9540$ $2.793 \mathrm{E}-08 \quad 0.0018$ $5.356 \mathrm{E}-07 \quad 0.0349$ $2.934 \mathrm{E}-12 \quad 0.0000$ $2.121 \mathrm{E}-12 \quad 0.0000$ $9.357 \mathrm{E}-08 \quad 0.0061$ $1.534 \mathrm{E}-05 \quad 1.0000$ 
RESRAD, Version 6.5

$\mathrm{T}^{1 / 2}$ Limit $=180$ days

Summary : C746U Worker Deterministic Run
File : X: $\backslash$ FINAL V2 \C746U W SG FWD-FINALV2.RAD

Total Dose Contributions TDOSE (i,p,t) for Individual Radionuclides (i) and Pathways (p) As mrem/yr and Fraction of Total Dose At $t=5.000 \mathrm{E}+01$ years

Water Independent Pathways (Inhalation excludes radon)

\begin{tabular}{|c|c|c|}
\hline clide & mrem/yr & fract. \\
\hline-241 & $1.836 \mathrm{E}-14$ & 0.0000 \\
\hline-137 & $2.350 \mathrm{E}-08$ & 0.0012 \\
\hline-237 & $1.835 \mathrm{E}-10$ & 0.0000 \\
\hline-238 & $4.197 \mathrm{E}-14$ & 0.0000 \\
\hline-239 & $1.607 \mathrm{E}-14$ & 0.0000 \\
\hline-240 & 1. $973 \mathrm{E}-18$ & 0.0000 \\
\hline-99 & $6.619 \mathrm{E}-25$ & 0.0000 \\
\hline-228 & $3.821 \mathrm{E}-13$ & 0.0000 \\
\hline-230 & $1.305 \mathrm{E}-06$ & 0.0691 \\
\hline-232 & $1.740 \mathrm{E}-05$ & 0.9220 \\
\hline 34 & $4.464 E-09$ & 0.0002 \\
\hline 235 & $1.548 \mathrm{E}-11$ & 0.0000 \\
\hline 38 & $1.384 \mathrm{E}-07$ & 0.0073 \\
\hline & 1. & 1.0000 \\
\hline
\end{tabular}

Inhalation

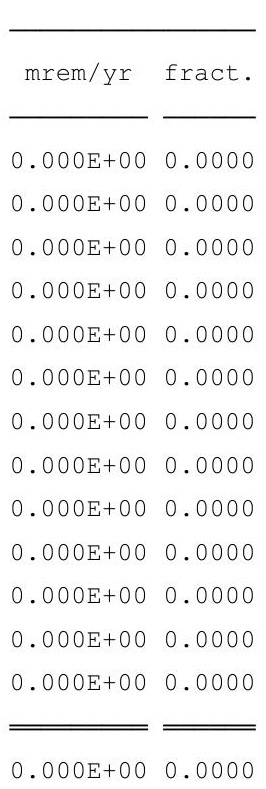

Radon

$\longrightarrow$

mrem/yr fract.

$0.000 \mathrm{E}+00 \quad 0.0000$

$0.000 E+00 \quad 0.0000$

$0.000 \mathrm{E}+00 \quad 0.0000$

$0.000 E+00 \quad 0.0000$

$0.000 \mathrm{E}+00 \quad 0.0000$

$0.000 E+00 \quad 0.0000$

$0.000 E+00 \quad 0.0000$

$0.000 E+00 \quad 0.0000$

$0.000 E+00 \quad 0.0000$

$0.000 \mathrm{E}+00 \quad 0.0000$

$0.000 E+00 \quad 0.0000$

$0.000 E+00 \quad 0.0000$

$0.000 \mathrm{E}+00 \quad 0.0000$

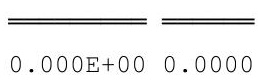

Plant

\section{mrem/yr fract.}

$\longrightarrow$

$0.000 \mathrm{E}+00 \quad 0.0000$

$0.000 \mathrm{E}+00 \quad 0.0000$

$0.000 \mathrm{E}+00 \quad 0.0000$

$0.000 \mathrm{E}+00 \quad 0.0000$

$0.000 \mathrm{E}+00 \quad 0.0000$

$0.000 \mathrm{E}+00 \quad 0.0000$

$0.000 \mathrm{E}+00 \quad 0.0000$

$0.000 \mathrm{E}+00 \quad 0.0000$

$0.000 \mathrm{E}+00 \quad 0.0000$

$0.000 \mathrm{E}+00 \quad 0.0000$

$0.000 \mathrm{E}+00 \quad 0.0000$

$0.000 \mathrm{E}+00 \quad 0.0000$

$0.000 \mathrm{E}+00 \quad 0.0000$

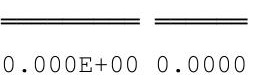

\begin{tabular}{|c|c|}
\hline mrem/yr & fract. \\
\hline $0.000 \mathrm{E}+00$ & 0.0000 \\
\hline $0.000 \mathrm{E}+00$ & 0.0000 \\
\hline $0.000 \mathrm{E}+00$ & 0.0000 \\
\hline $0.000 \mathrm{E}+00$ & 0.0000 \\
\hline $0.000 \mathrm{E}+00$ & 0.0000 \\
\hline $0.000 \mathrm{E}+00$ & 0.0000 \\
\hline $0.000 \mathrm{E}+00$ & 0.0000 \\
\hline $0.000 \mathrm{E}+00$ & 0.0000 \\
\hline $0.000 \mathrm{E}+00$ & 0.0000 \\
\hline $0.000 \mathrm{E}+00$ & 0.0000 \\
\hline $0.000 \mathrm{E}+00$ & 0.0000 \\
\hline $0.000 \mathrm{E}+00$ & 0.0000 \\
\hline $0.000 \mathrm{E}+00$ & 0.0000 \\
\hline $.000 \mathrm{E}$ & .000 \\
\hline
\end{tabular}

\begin{tabular}{cc} 
Milk \\
\hline mrem/yr fract. \\
\cline { 1 - 2 } $0.000 \mathrm{E}+00$ & 0.0000 \\
$0.000 \mathrm{E}+00$ & 0.0000 \\
$0.000 \mathrm{E}+00$ & 0.0000 \\
$0.000 \mathrm{E}+00$ & 0.0000 \\
$0.000 \mathrm{E}+00$ & 0.0000 \\
$0.000 \mathrm{E}+00$ & 0.0000 \\
$0.000 \mathrm{E}+00$ & 0.0000 \\
$0.000 \mathrm{E}+00$ & 0.0000 \\
$0.000 \mathrm{E}+00$ & 0.0000 \\
$0.000 \mathrm{E}+00$ & 0.0000 \\
$0.000 \mathrm{E}+00$ & 0.0000 \\
$0.000 \mathrm{E}+00$ & 0.0000 \\
$0.000 \mathrm{E}+00$ & 0.0000 \\
\hline \hline $0.000 \mathrm{E}+00$ & 0.0000
\end{tabular}

Soil

mrem/yr fract.

$0.000 \mathrm{E}+00 \quad 0.0000$

$0.000 \mathrm{E}+00 \quad 0.0000$

$0.000 \mathrm{E}+00 \quad 0.0000$

$0.000 \mathrm{E}+00 \quad 0.0000$

$0.000 \mathrm{E}+00 \quad 0.0000$

$0.000 \mathrm{E}+00 \quad 0.0000$

$0.000 \mathrm{E}+00 \quad 0.0000$

$0.000 \mathrm{E}+00 \quad 0.0000$

$0.000 \mathrm{E}+00 \quad 0.0000$

$0.000 \mathrm{E}+00 \quad 0.0000$

$0.000 \mathrm{E}+00 \quad 0.0000$

$0.000 \mathrm{E}+00 \quad 0.0000$

$0.000 \mathrm{E}+00 \quad 0.0000$

$0.000 \mathrm{E}+00 \quad 0.0000$

Total Dose Contributions TDOSE (i,p,t) for Individual Radionuclides (i) and Pathways (p) As mrem/yr and Fraction of Total Dose At $t=5.000 \mathrm{E}+01$ years

Water Dependent Pathways

\begin{tabular}{|c|c|c|c|c|c|c|}
\hline & \multicolumn{2}{|c|}{ Water } & \multicolumn{2}{|c|}{ Fish } & \multicolumn{2}{|c|}{ Radon } \\
\hline clide & mrem/yr & fract. & mrem/yr & fract. & mrem/yr & fract. \\
\hline 41 & $0.000 \mathrm{E}+00$ & 0.0000 & $0.000 \mathrm{E}+00$ & 0.0000 & $0.000 \mathrm{E}+00$ & 0.0000 \\
\hline-137 & $0.000 \mathrm{E}+00$ & 0.0000 & $0.000 \mathrm{E}+00$ & 0.0000 & $0.000 \mathrm{E}+00$ & 0.0000 \\
\hline-237 & $0.000 \mathrm{E}+00$ & 0.0000 & $0.000 \mathrm{E}+00$ & 0.0000 & $0.000 \mathrm{E}+00$ & 0.0000 \\
\hline-238 & $0.000 \mathrm{E}+00$ & 0.0000 & $0.000 \mathrm{E}+00$ & 0.0000 & $0.000 \mathrm{E}+00$ & 0.0000 \\
\hline-239 & $0.000 \mathrm{E}+00$ & 0.0000 & $0.000 \mathrm{E}+00$ & 0.0000 & $0.000 \mathrm{E}+00$ & 0.0000 \\
\hline-240 & $0.000 \mathrm{E}+00$ & 0.0000 & $0.000 \mathrm{E}+00$ & 0.0000 & $0.000 \mathrm{E}+00$ & 0.0000 \\
\hline-99 & $0.000 \mathrm{E}+00$ & 0.0000 & $0.000 \mathrm{E}+00$ & 0.0000 & $0.000 \mathrm{E}+00$ & 0.0000 \\
\hline-228 & $0.000 \mathrm{E}+00$ & 0.0000 & $0.000 \mathrm{E}+00$ & 0.0000 & $0.000 \mathrm{E}+00$ & 0.0000 \\
\hline-230 & $0.000 \mathrm{E}+00$ & 0.0000 & $0.000 \mathrm{E}+00$ & 0.0000 & $0.000 \mathrm{E}+00$ & 0.0000 \\
\hline-232 & $0.000 \mathrm{E}+00$ & 0.0000 & $0.000 \mathrm{E}+00$ & 0.0000 & $0.000 \mathrm{E}+00$ & 0.0000 \\
\hline 234 & $0.000 \mathrm{E}+00$ & 0.0000 & $0.000 \mathrm{E}+00$ & 0.0000 & $0.000 \mathrm{E}+00$ & 0.0000 \\
\hline 35 & $0.000 \mathrm{E}+00$ & 0.0000 & $0.000 \mathrm{E}+00$ & 0.0000 & $0.000 \mathrm{E}+00$ & 0.0000 \\
\hline 38 & $0.000 \mathrm{E}+00$ & 0.0000 & $0.000 \mathrm{E}+00$ & 0.0000 & $0.000 \mathrm{E}+00$ & 0.0000 \\
\hline & $0.000 \mathrm{E}+00$ & 0.0000 & $0.000 \mathrm{E}+00$ & 0.0000 & $0.000 \mathrm{E}+00$ & 0.0000 \\
\hline
\end{tabular}

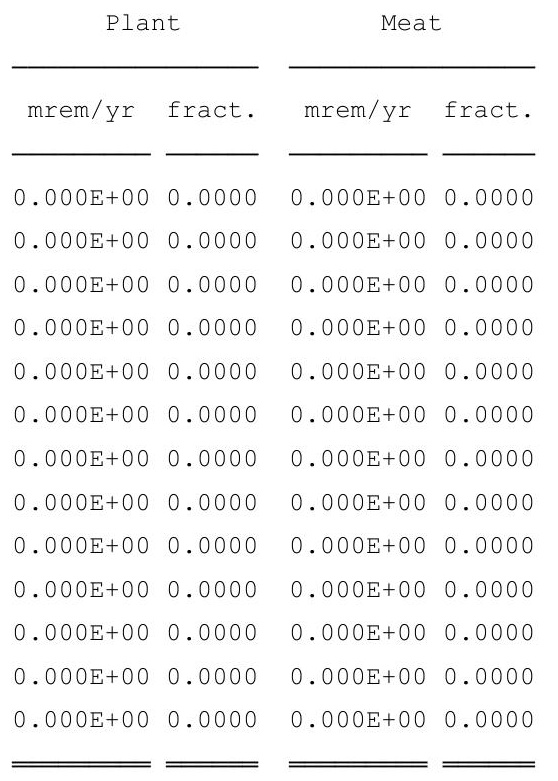

$0.000 \mathrm{E}+00 \quad 0.0000$

$0.000 \mathrm{E}+00 \quad 0.0000$

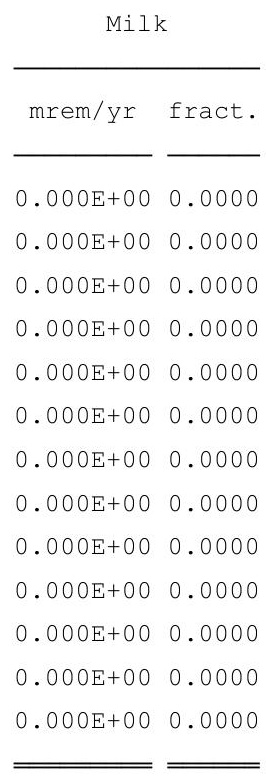

$0.000 \mathrm{E}+00 \quad 0.0000$
All Pathways * mrem/yr fract.

$1.836 \mathrm{E}-14 \quad 0.0000$ $2.350 \mathrm{E}-08 \quad 0.0012$ $1.835 \mathrm{E}-10 \quad 0.0000$ $4.197 \mathrm{E}-14 \quad 0.0000$ $1.607 \mathrm{E}-14 \quad 0.0000$ $1.973 \mathrm{E}-18 \quad 0.0000$ $6.619 \mathrm{E}-250.0000$ $3.821 \mathrm{E}-13 \quad 0.0000$ $1.305 \mathrm{E}-06 \quad 0.0691$ $1.740 \mathrm{E}-050.9220$ $4.464 \mathrm{E}-090.0002$ $1.548 \mathrm{E}-110.0000$ $1.384 \mathrm{E}-07 \quad 0.0073$ $1.887 \mathrm{E}-051.0000$

* Sum of all water independent and dependent pathways. 
RESRAD, Version 6.5

$\mathrm{T}^{1 / 2}$ Limit $=180$ days

Summary : C746U Worker Deterministic Run
File : X: $\backslash$ FINAL V2 \C746U W SG FWD-FINALV2.RAD

Total Dose Contributions TDOSE (i,p,t) for Individual Radionuclides (i) and Pathways (p) As mrem/yr and Fraction of Total Dose At $t=1.000 \mathrm{E}+02$ years

Water Independent Pathways (Inhalation excludes radon)

\begin{tabular}{|c|c|c|c|c|c|c|c|c|c|c|c|c|c|c|}
\hline \multirow[b]{2}{*}{ clide } & \multicolumn{2}{|c|}{ Ground } & \multicolumn{2}{|c|}{ Inhalation } & \multicolumn{2}{|c|}{ Radon } & \multicolumn{2}{|c|}{ Plant } & \multicolumn{2}{|c|}{ Meat } & \multicolumn{2}{|c|}{ Milk } & \multicolumn{2}{|c|}{ Soil } \\
\hline & mrem/yr & fract. & mrem/yr & fract. & mrem/yr & fract. & mrem/yr & fract. & mrem/yr & fract. & mrem/yr & fract. & mrem/yr & fract. \\
\hline 1 & $6.026 \mathrm{E}-14$ & 0.0000 & $0.000 \mathrm{E}+00$ & 0.0000 & $0.000 \mathrm{E}+00$ & 0.0000 & $0.000 \mathrm{E}+00$ & 0.0000 & $0.000 \mathrm{E}+00$ & 0.0000 & $0.000 \mathrm{E}+00$ & 0.0000 & $0.000 \mathrm{E}+00$ & 0.0000 \\
\hline 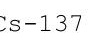 & $1.128 \mathrm{E}-08$ & 0.0004 & $0.000 \mathrm{E}+00$ & 0.0000 & $0.000 \mathrm{E}+00$ & 0.0000 & $0.000 \mathrm{E}+00$ & 0.0000 & $0.000 \mathrm{E}+00$ & 0.0000 & $0.000 \mathrm{E}+00$ & 0.0000 & $0.000 \mathrm{E}+00$ & 0.0000 \\
\hline 37 & $3.151 \mathrm{E}-10$ & 0.0000 & $0.000 \mathrm{E}+00$ & 0.0000 & $0.000 \mathrm{E}+00$ & 0.0000 & $0.000 \mathrm{E}+00$ & 0.0000 & $0.000 \mathrm{E}+00$ & 0.0000 & $0.000 \mathrm{E}+00$ & 0.0000 & $0.000 \mathrm{E}+00$ & 0.0000 \\
\hline 8 & $4.245 \mathrm{E}-13$ & 0.0000 & $0.000 \mathrm{E}+00$ & 0.0000 & $0.000 \mathrm{E}+00$ & 0.0000 & $0.000 \mathrm{E}+00$ & 0.0000 & $0.000 \mathrm{E}+00$ & 0.0000 & $0.000 \mathrm{E}+00$ & 0.0000 & $0.000 \mathrm{E}+00$ & 0.0000 \\
\hline & $2.920 \mathrm{E}-14$ & 0.0 & $0.000 \mathrm{E}+00$ & 0.0 & $0.000 \mathrm{E}+00$ & 0 & $0.000 \mathrm{E}+00$ & 0 & 00 & & $0.000 \mathrm{E}+00$ & & $.000 \mathrm{E}+00$ & \\
\hline & $1.313 \mathrm{E}-17$ & 0.0 & 0. & 0.0 & $0.000 \mathrm{E}+00$ & 0.0000 & $0.000 \mathrm{E}+00$ & 0.0 & $E+00$ & 0 & $0.000 \mathrm{E}+00$ & 00 & $000 \mathrm{E}+00$ & 000 \\
\hline & $1.327 \mathrm{E}-24$ & 0.0000 & $0.000 \mathrm{E}+00$ & 0.0000 & $0.000 \mathrm{E}+00$ & 0.0000 & $0.000 \mathrm{E}+00$ & 0.0000 & $0.000 \mathrm{E}+00$ & 0.0000 & $0.000 \mathrm{E}+00$ & 0.0000 & $0.000 \mathrm{E}+00$ & 0.0000 \\
\hline 8 & $6.983 \mathrm{E}-21$ & 0.0000 & $0.000 \mathrm{E}+00$ & 0.0000 & $0.000 \mathrm{E}+00$ & 0.0000 & $0.000 \mathrm{E}+00$ & 0.0000 & $0.000 \mathrm{E}+00$ & 0.0000 & $0.000 \mathrm{E}+00$ & 0.0000 & $0.000 \mathrm{E}+00$ & 0.0000 \\
\hline & $3.628 \mathrm{E}-06$ & 0.1323 & $0.000 \mathrm{E}+00$ & 0.0000 & $0.000 \mathrm{E}+00$ & 0.0000 & $0.000 \mathrm{E}+00$ & 0.0000 & $0.000 \mathrm{E}+00$ & 0.0000 & $0.000 \mathrm{E}+00$ & 0.0000 & $0.000 \mathrm{E}+00$ & 0.0000 \\
\hline 32 & $2.355 \mathrm{E}-05$ & 0.8588 & $0.000 \mathrm{E}+00$ & 0.0000 & $0.000 \mathrm{E}+00$ & 0.0000 & $0.000 \mathrm{E}+00$ & 0.0000 & $0.000 \mathrm{E}+00$ & 0.0000 & $0.000 \mathrm{E}+00$ & 0.0000 & $0.000 \mathrm{E}+00$ & 0.0000 \\
\hline & $2.479 \mathrm{E}-08$ & 0.0009 & $0.000 \mathrm{E}+00$ & 0.0000 & $0.000 \mathrm{E}+00$ & 0.0000 & $0.000 \mathrm{E}+00$ & 0.0000 & $0.000 \mathrm{E}+00$ & 0.0000 & $0.000 \mathrm{E}+00$ & 0.0000 & $0.000 \mathrm{E}+00$ & 0.0000 \\
\hline & $5.681 \mathrm{E}-11$ & 0.0000 & $0.000 \mathrm{E}+00$ & 0.0000 & $0.000 \mathrm{E}+00$ & 0.0000 & $0.000 \mathrm{E}+00$ & 0.0000 & $0.000 \mathrm{E}+00$ & 0.0000 & $0.000 \mathrm{E}+00$ & 0.0000 & $0.000 \mathrm{E}+00$ & 0.0000 \\
\hline & $2.064 \mathrm{E}-07$ & 0.0075 & $0.000 \mathrm{E}+00$ & 0.0000 & $0.000 \mathrm{E}+00$ & 0.0000 & $0.000 \mathrm{E}+00$ & 0.0000 & $0.000 \mathrm{E}+00$ & 0.0000 & $0.000 \mathrm{E}+00$ & 0.0000 & $0.000 \mathrm{E}+00$ & 0.0000 \\
\hline & & & +00 & 00 & +00 & 000 & +00 & & +00 & & +00 & & -00 & \\
\hline
\end{tabular}

Total Dose Contributions TDOSE (i,p,t) for Individual Radionuclides (i) and Pathways (p) As mrem/yr and Fraction of Total Dose At $t=1.000 \mathrm{E}+02$ years

Water Dependent Pathways

\begin{tabular}{|c|c|c|c|c|c|c|c|c|c|c|c|c|c|c|}
\hline \multirow[b]{2}{*}{ clide } & \multicolumn{2}{|c|}{ Water } & \multicolumn{2}{|c|}{ Fish } & \multicolumn{2}{|c|}{ Radon } & \multicolumn{2}{|c|}{ Plant } & \multicolumn{2}{|c|}{ Meat } & \multicolumn{2}{|c|}{ Milk } & \multicolumn{2}{|c|}{ All Pathways* } \\
\hline & mrem/yr & fract. & mrem/yr & fract. & mrem/yr & fract. & mrem/yr & fract. & mrem/yr & fract. & mrem/yr & fract. & mrem/yr & fract. \\
\hline-241 & $0.000 \mathrm{E}+00$ & 0.0000 & $0.000 \mathrm{E}+00$ & 0.0000 & $0.000 \mathrm{E}+00$ & 0.0000 & $0.000 \mathrm{E}+00$ & 0.0000 & $0.000 \mathrm{E}+00$ & 0.0000 & $0.000 \mathrm{E}+00$ & 0.0000 & $6.026 \mathrm{E}-14$ & 0.0000 \\
\hline - & $0.000 \mathrm{E}+00$ & 0.0000 & $0.000 \mathrm{E}+00$ & 0.0000 & $0.000 \mathrm{E}+00$ & 0.0000 & $0.000 \mathrm{E}+00$ & 0.0000 & $0.000 \mathrm{E}+00$ & 0.0000 & $0.000 \mathrm{E}+00$ & 0.0000 & $1.128 \mathrm{E}-08$ & 0.0004 \\
\hline 237 & $0.000 \mathrm{E}+00$ & 0.0 & $0.000 \mathrm{E}+00$ & 0 & $0.000 \mathrm{E}+00$ & 0 & $0.000 \mathrm{E}+00$ & 0 & $0.000 \mathrm{E}+00$ & 0 & $0.000 \mathrm{E}+00$ & 0 & $151 \mathrm{E}-10$ & 00 \\
\hline & $0.000 \mathrm{E}+00$ & 0 & $0.000 \mathrm{E}+00$ & 0 & $0.000 \mathrm{E}+00$ & 0 & $0.000 \mathrm{E}+00$ & 0 & $0.000 \mathrm{E}+00$ & 00 & $0.000 \mathrm{E}+00$ & 0 & -13 & 0000 \\
\hline 239 & $0.000 \mathrm{E}+00$ & 0.0000 & $0.000 \mathrm{E}+00$ & 0.0000 & $0.000 \mathrm{E}+00$ & 0.0000 & $0.000 \mathrm{E}+00$ & 0.0000 & $0.000 \mathrm{E}+00$ & 0.0000 & $0.000 \mathrm{E}+00$ & 0.0000 & $2.920 \mathrm{E}-14$ & 0.0000 \\
\hline 240 & $0.000 \mathrm{E}+00$ & 0.0000 & $0.000 \mathrm{E}+00$ & 0.0000 & $0.000 \mathrm{E}+00$ & 0.0000 & $0.000 \mathrm{E}+00$ & 0.0000 & $0.000 \mathrm{E}+00$ & 0.0000 & $0.000 \mathrm{E}+00$ & 0.0000 & $1.313 \mathrm{E}-17$ & 0.0000 \\
\hline & $0.000 \mathrm{E}+00$ & 0.0000 & $0.000 \mathrm{E}+00$ & 0.0000 & $0.000 \mathrm{E}+00$ & 0.0000 & $0.000 \mathrm{E}+00$ & 0.0000 & $0.000 \mathrm{E}+00$ & 0.0000 & $0.000 \mathrm{E}+00$ & 0.0000 & $1.327 \mathrm{E}-24$ & 0.0000 \\
\hline & $0.000 \mathrm{E}+00$ & 0.0000 & $0.000 \mathrm{E}+00$ & 0.0000 & $0.000 \mathrm{E}+00$ & 0.0000 & $0.000 \mathrm{E}+00$ & 0.0000 & $0.000 \mathrm{E}+00$ & 0.0000 & $0.000 \mathrm{E}+00$ & 0.0000 & $6.983 \mathrm{E}-21$ & 0.0000 \\
\hline & $0.000 \mathrm{E}+00$ & 0.0000 & $0.000 \mathrm{E}+00$ & 0.0000 & $0.000 \mathrm{E}+00$ & 0.0000 & $0.000 \mathrm{E}+00$ & 0.0000 & $0.000 \mathrm{E}+00$ & 0.0000 & $0.000 \mathrm{E}+00$ & 0.0000 & $3.628 \mathrm{E}-06$ & 0.1323 \\
\hline & $0.000 \mathrm{E}+00$ & 0.0000 & $0.000 \mathrm{E}+00$ & 0.0000 & $0.000 \mathrm{E}+00$ & 0.0000 & $0.000 \mathrm{E}+00$ & 0.0000 & $0.000 \mathrm{E}+00$ & 0.0000 & $0.000 \mathrm{E}+00$ & 0.0000 & $2.355 \mathrm{E}-05$ & 0.8588 \\
\hline & $0.000 \mathrm{E}+00$ & 0.0000 & $0.000 \mathrm{E}+00$ & 0.0000 & $0.000 \mathrm{E}+00$ & 0.0000 & $0.000 \mathrm{E}+00$ & 0.0000 & $0.000 \mathrm{E}+00$ & 0.0000 & $0.000 \mathrm{E}+00$ & 0.0000 & $2.479 \mathrm{E}-08$ & 0.0009 \\
\hline & $0.000 \mathrm{E}+00$ & 0.0000 & $0.000 \mathrm{E}+00$ & 0.0000 & $0.000 \mathrm{E}+00$ & 0.0000 & $0.000 \mathrm{E}+00$ & 0.0000 & $0.000 \mathrm{E}+00$ & 0.0000 & $0.000 \mathrm{E}+00$ & 0.0000 & $5.681 \mathrm{E}-11$ & 0.0000 \\
\hline & $0.000 \mathrm{E}+00$ & 0.0000 & $0.000 \mathrm{E}+00$ & 0.0000 & $0.000 \mathrm{E}+00$ & 0.0000 & $0.000 \mathrm{E}+00$ & 0.0000 & $0.000 \mathrm{E}+00$ & 0.0000 & $0.000 \mathrm{E}+00$ & 0.0000 & $2.064 \mathrm{E}-07$ & 0.0075 \\
\hline & . & 0000 & $.000 \mathrm{E}+00$ & 0.0000 & $0.000 \mathrm{E}+00$ & 0.0000 & $0.000 \mathrm{E}+00$ & 0.0000 & $0.000 \mathrm{E}+00$ & 0.0000 & $0.000 \mathrm{E}+00$ & 0.0000 & $2.742 \mathrm{E}-05$ & 1.0000 \\
\hline
\end{tabular}

*Sum of all water independent and dependent pathways. 
RESRAD, Version 6.5

$\mathrm{T}^{1 / 2}$ Limit $=180$ days

Summary : C746U Worker Deterministic Run
File : X: $\backslash$ FINAL V2 $\backslash C 746 U$ W SG FWD-FINALV2.RAD

Total Dose Contributions TDOSE (i,p,t) for Individual Radionuclides (i) and Pathways (p) As mrem/yr and Fraction of Total Dose At $t=5.000 \mathrm{E}+02$ years

Water Independent Pathways (Inhalation excludes radon)

\begin{tabular}{|c|c|c|c|c|c|c|c|c|c|c|c|c|c|c|}
\hline \multirow{2}{*}{ Nuclide } & \multicolumn{2}{|c|}{ Ground } & \multicolumn{2}{|c|}{ Inhalation } & \multicolumn{2}{|c|}{ Radon } & \multicolumn{2}{|c|}{ Plant } & \multicolumn{2}{|c|}{ Meat } & \multicolumn{2}{|c|}{ Milk } & \multicolumn{2}{|c|}{ Soil } \\
\hline & mrem/yr & fract. & mrem/yr & fract. & mrem/yr & fract. & mrem/yr & fract. & mrem/yr & fract. & mrem/yr & fract. & mrem/yr & fract. \\
\hline-241 & 1. $668 \mathrm{E}-11$ & 0.0000 & $0.000 \mathrm{E}+00$ & 0.0000 & $0.000 \mathrm{E}+00$ & 0.0000 & $0.000 \mathrm{E}+00$ & 0.0000 & $0.000 \mathrm{E}+00$ & 0.0000 & $0.000 \mathrm{E}+00$ & 0.0000 & $0.000 \mathrm{E}+00$ & 0.0000 \\
\hline-137 & $3.168 \mathrm{E}-11$ & 0.0000 & $0.000 \mathrm{E}+00$ & 0.0000 & $0.000 \mathrm{E}+00$ & 0.0000 & $0.000 \mathrm{E}+00$ & 0.0000 & $0.000 \mathrm{E}+00$ & 0.0000 & $0.000 \mathrm{E}+00$ & 0.0000 & $0.000 \mathrm{E}+00$ & 0.0000 \\
\hline-237 & $2.362 E-08$ & 0.0000 & $0.000 \mathrm{E}+00$ & 0.0000 & $0.000 \mathrm{E}+00$ & 0.0000 & $0.000 \mathrm{E}+00$ & 0.0000 & $0.000 \mathrm{E}+00$ & 0.0000 & $0.000 \mathrm{E}+00$ & 0.0000 & $0.000 \mathrm{E}+00$ & 0.0000 \\
\hline-238 & $4.482 \mathrm{E}-10$ & 0.0000 & $0.000 \mathrm{E}+00$ & 0.0000 & $0.000 \mathrm{E}+00$ & 0.0000 & $0.000 \mathrm{E}+00$ & 0.0000 & $0.000 \mathrm{E}+00$ & 0.0000 & $0.000 \mathrm{E}+00$ & 0.0000 & $0.000 \mathrm{E}+00$ & 0.0000 \\
\hline-239 & $3.476 \mathrm{E}-12$ & 0.0000 & $0.000 \mathrm{E}+00$ & 0.0000 & $0.000 \mathrm{E}+00$ & 0.0000 & $0.000 \mathrm{E}+00$ & 0.0000 & $0.000 \mathrm{E}+00$ & 0.0000 & $0.000 \mathrm{E}+00$ & 0.0000 & $0.000 \mathrm{E}+00$ & 0.0000 \\
\hline-240 & $4.219 \mathrm{E}-15$ & 0.0000 & $0.000 \mathrm{E}+00$ & 0.0000 & $0.000 \mathrm{E}+00$ & 0.0000 & $0.000 \mathrm{E}+00$ & 0.0000 & $0.000 \mathrm{E}+00$ & 0.0000 & $0.000 \mathrm{E}+00$ & 0.0000 & $0.000 \mathrm{E}+00$ & 0.0000 \\
\hline-99 & $3.474 \mathrm{E}-22$ & 0.0000 & $0.000 \mathrm{E}+00$ & 0.0000 & $0.000 \mathrm{E}+00$ & 0.0000 & $0.000 \mathrm{E}+00$ & 0.0000 & $0.000 \mathrm{E}+00$ & 0.0000 & $0.000 \mathrm{E}+00$ & 0.0000 & $0.000 \mathrm{E}+00$ & 0.0000 \\
\hline-228 & $0.000 \mathrm{E}+00$ & 0.0000 & $0.000 \mathrm{E}+00$ & 0.0000 & $0.000 \mathrm{E}+00$ & 0.0000 & $0.000 \mathrm{E}+00$ & 0.0000 & $0.000 \mathrm{E}+00$ & 0.0000 & $0.000 \mathrm{E}+00$ & 0.0000 & $0.000 \mathrm{E}+00$ & 0.0000 \\
\hline-230 & $2.632 \mathrm{E}-04$ & 0.4903 & $0.000 \mathrm{E}+00$ & 0.0000 & $0.000 \mathrm{E}+00$ & 0.0000 & $0.000 \mathrm{E}+00$ & 0.0000 & $0.000 \mathrm{E}+00$ & 0.0000 & $0.000 \mathrm{E}+00$ & 0.0000 & $0.000 \mathrm{E}+00$ & 0.0000 \\
\hline-232 & $2.594 \mathrm{E}-04$ & 0.4831 & $0.000 \mathrm{E}+00$ & 0.0000 & $0.000 \mathrm{E}+00$ & 0.0000 & $0.000 \mathrm{E}+00$ & 0.0000 & $0.000 \mathrm{E}+00$ & 0.0000 & $0.000 \mathrm{E}+00$ & 0.0000 & $0.000 \mathrm{E}+00$ & 0.0000 \\
\hline 34 & $9.207 E-06$ & 0.0171 & $0.000 \mathrm{E}+00$ & 0.0000 & $0.000 \mathrm{E}+00$ & 0.0000 & $0.000 \mathrm{E}+00$ & 0.0000 & $0.000 \mathrm{E}+00$ & 0.0000 & $0.000 \mathrm{E}+00$ & 0.0000 & $0.000 \mathrm{E}+00$ & 0.0000 \\
\hline 35 & $1.183 \mathrm{E}-08$ & 0.0000 & $0.000 \mathrm{E}+00$ & 0.0000 & $0.000 \mathrm{E}+00$ & 0.0000 & $0.000 \mathrm{E}+00$ & 0.0000 & $0.000 \mathrm{E}+00$ & 0.0000 & $0.000 \mathrm{E}+00$ & 0.0000 & $0.000 \mathrm{E}+00$ & 0.0000 \\
\hline 38 & $5.045 E-06$ & 0.0094 & $0.000 \mathrm{E}+00$ & 0.0000 & $0.000 \mathrm{E}+00$ & 0.0000 & $0.000 \mathrm{E}+00$ & 0.0000 & $0.000 \mathrm{E}+00$ & 0.0000 & $0.000 \mathrm{E}+00$ & 0.0000 & $0.000 \mathrm{E}+00$ & 0.0000 \\
\hline & $5.369 \mathrm{E}-04$ & 1.0000 & $0.000 \mathrm{E}+00$ & 0.0000 & $0.000 \mathrm{E}+00$ & 0.0000 & $0.000 \mathrm{E}+00$ & 0.0000 & $0.000 \mathrm{E}+00$ & 0.0000 & $0.000 \mathrm{E}+00$ & 0.0000 & $0.000 \mathrm{E}+00$ & 0.0000 \\
\hline
\end{tabular}

Total Dose Contributions TDOSE (i,p,t) for Individual Radionuclides (i) and Pathways (p) As mrem/yr and Fraction of Total Dose At $t=5.000 \mathrm{E}+02$ years

Water Dependent Pathways

\begin{tabular}{|c|c|c|c|c|c|c|c|c|c|c|c|c|c|c|}
\hline & \multicolumn{2}{|c|}{ Water } & \multicolumn{2}{|c|}{ Fish } & \multicolumn{2}{|c|}{ Radon } & \multicolumn{2}{|c|}{ Plant } & \multicolumn{2}{|c|}{ Meat } & \multicolumn{2}{|c|}{ Milk } & \multicolumn{2}{|c|}{ All Pathways* } \\
\hline clide & mrem/yr & fract. & mrem/yr & fract. & mrem/yr & fract. & mrem/yr & fract. & mrem/yr & fract. & mrem/yr & fract. & mrem/yr & fract. \\
\hline-241 & $0.000 \mathrm{E}+00$ & 0.0000 & $0.000 \mathrm{E}+00$ & 0.0000 & $0.000 \mathrm{E}+00$ & 0.0000 & $0.000 \mathrm{E}+00$ & 0.0000 & $0.000 \mathrm{E}+00$ & 0.0000 & $0.000 \mathrm{E}+00$ & 0.0000 & $1.668 \mathrm{E}-11$ & 0.0000 \\
\hline-137 & $0.000 \mathrm{E}+00$ & 0.0000 & $0.000 \mathrm{E}+00$ & 0.0000 & $0.000 \mathrm{E}+00$ & 0.0000 & $0.000 \mathrm{E}+00$ & 0.0000 & $0.000 \mathrm{E}+00$ & 0.0000 & $0.000 \mathrm{E}+00$ & 0.0000 & $3.168 \mathrm{E}-11$ & 0.0000 \\
\hline-237 & $0.000 \mathrm{E}+00$ & 0.0000 & $0.000 \mathrm{E}+00$ & 0.0000 & $0.000 \mathrm{E}+00$ & 0.0000 & $0.000 \mathrm{E}+00$ & 0.0000 & $0.000 \mathrm{E}+00$ & 0.0000 & $0.000 \mathrm{E}+00$ & 0.0000 & $2.362 \mathrm{E}-08$ & 0.0000 \\
\hline 238 & $0.000 \mathrm{E}+00$ & 0.0000 & $0.000 \mathrm{E}+00$ & 0.0000 & $0.000 \mathrm{E}+00$ & 0.0000 & $0.000 \mathrm{E}+00$ & 0.0000 & $0.000 \mathrm{E}+00$ & 0.0000 & $0.000 \mathrm{E}+00$ & 0.0000 & $4.482 \mathrm{E}-10$ & 0.0000 \\
\hline 239 & $0.000 \mathrm{E}+00$ & 0.0000 & $0.000 \mathrm{E}+00$ & 0.0000 & $0.000 \mathrm{E}+00$ & 0.0000 & $0.000 \mathrm{E}+00$ & 0.0000 & $0.000 \mathrm{E}+00$ & 0.0000 & $0.000 \mathrm{E}+00$ & 0.0000 & $3.476 \mathrm{E}-12$ & 0.0000 \\
\hline 240 & $0.000 \mathrm{E}+00$ & 0.0000 & $0.000 \mathrm{E}+00$ & 0.0000 & $0.000 \mathrm{E}+00$ & 0.0000 & $0.000 \mathrm{E}+00$ & 0.0000 & $0.000 \mathrm{E}+00$ & 0.0000 & $0.000 \mathrm{E}+00$ & 0.0000 & $4.219 \mathrm{E}-15$ & 0.0000 \\
\hline 99 & $0.000 \mathrm{E}+00$ & 0.0000 & $0.000 \mathrm{E}+00$ & 0.0000 & $0.000 \mathrm{E}+00$ & 0.0000 & $0.000 \mathrm{E}+00$ & 0.0000 & $0.000 \mathrm{E}+00$ & 0.0000 & $0.000 \mathrm{E}+00$ & 0.0000 & $3.474 \mathrm{E}-22$ & 0.0000 \\
\hline 228 & $0.000 \mathrm{E}+00$ & 0.0000 & $0.000 \mathrm{E}+00$ & 0.0000 & $0.000 \mathrm{E}+00$ & 0.0000 & $0.000 \mathrm{E}+00$ & 0.0000 & $0.000 \mathrm{E}+00$ & 0.0000 & $0.000 \mathrm{E}+00$ & 0.0000 & $0.000 \mathrm{E}+00$ & 0.0000 \\
\hline 230 & $0.000 \mathrm{E}+00$ & 0.0000 & $0.000 \mathrm{E}+00$ & 0.0000 & $0.000 \mathrm{E}+00$ & 0.0000 & $0.000 \mathrm{E}+00$ & 0.0000 & $0.000 \mathrm{E}+00$ & 0.0000 & $0.000 \mathrm{E}+00$ & 0.0000 & $2.632 \mathrm{E}-04$ & 0.4903 \\
\hline 232 & $0.000 \mathrm{E}+00$ & 0.0000 & $0.000 \mathrm{E}+00$ & 0.0000 & $0.000 \mathrm{E}+00$ & 0.0000 & $0.000 \mathrm{E}+00$ & 0.0000 & $0.000 \mathrm{E}+00$ & 0.0000 & $0.000 \mathrm{E}+00$ & 0.0000 & $2.594 \mathrm{E}-04$ & 0.4831 \\
\hline 34 & $0.000 \mathrm{E}+00$ & 0.0000 & $0.000 \mathrm{E}+00$ & 0.0000 & $0.000 \mathrm{E}+00$ & 0.0000 & $0.000 \mathrm{E}+00$ & 0.0000 & $0.000 \mathrm{E}+00$ & 0.0000 & $0.000 \mathrm{E}+00$ & 0.0000 & $9.207 \mathrm{E}-06$ & 0.0171 \\
\hline 35 & $0.000 \mathrm{E}+00$ & 0.0000 & $0.000 \mathrm{E}+00$ & 0.0000 & $0.000 \mathrm{E}+00$ & 0.0000 & $0.000 \mathrm{E}+00$ & 0.0000 & $0.000 \mathrm{E}+00$ & 0.0000 & $0.000 \mathrm{E}+00$ & 0.0000 & $1.183 \mathrm{E}-08$ & 0.0000 \\
\hline 38 & $0.000 \mathrm{E}+00$ & 0.0000 & $0.000 \mathrm{E}+00$ & 0.0000 & $0.000 \mathrm{E}+00$ & 0.0000 & $0.000 \mathrm{E}+00$ & 0.0000 & $0.000 \mathrm{E}+00$ & 0.0000 & $0.000 \mathrm{E}+00$ & 0.0000 & $5.045 \mathrm{E}-06$ & 0.0094 \\
\hline & $0.000 \mathrm{E}+00$ & 0.0000 & $0.000 \mathrm{E}+00$ & 0.0000 & $0.000 \mathrm{E}+00$ & 0.0000 & $0.000 \mathrm{E}+00$ & 0.0000 & $0.000 \mathrm{E}+00$ & 0.0000 & $0.000 \mathrm{E}+00$ & 000 & -04 & 1.0000 \\
\hline
\end{tabular}

* Sum of all water independent and dependent pathways. 
RESRAD, Version 6.5

$\mathrm{T}^{1 / 2}$ Limit $=180$ days

Summary : C746U Worker Deterministic Run
File : X: $\backslash$ FINAL V2 \C746U W SG FWD-FINALV2.RAD

Total Dose Contributions TDOSE(i,p,t) for Individual Radionuclides (i) and Pathways (p) As mrem/yr and Fraction of Total Dose At $t=1.050 \mathrm{E}+03$ years

Water Independent Pathways (Inhalation excludes radon)

\begin{tabular}{|c|c|c|}
\hline clide & mrem/yr & fract. \\
\hline-241 & $9.032 E-09$ & 0.0000 \\
\hline-137 & $9.832 \mathrm{E}-15$ & 0.0000 \\
\hline-237 & $8.468 E-06$ & 0.0003 \\
\hline-238 & $1.044 \mathrm{E}-07$ & 0.0000 \\
\hline-239 & $2.474 \mathrm{E}-09$ & 0.0000 \\
\hline-240 & $5.993 \mathrm{E}-13$ & 0.0000 \\
\hline-99 & $7.334 \mathrm{E}-19$ & 0.0000 \\
\hline-228 & $0.000 \mathrm{E}+00$ & 0.0000 \\
\hline-230 & $2.208 E-02$ & 0.7039 \\
\hline-232 & $7.187 \mathrm{E}-03$ & 0.2291 \\
\hline 34 & $1.681 \mathrm{E}-03$ & 0.0536 \\
\hline 235 & $3.971 E-06$ & 0.0001 \\
\hline 38 & $4.095 E-04$ & 0.0131 \\
\hline & $\mathrm{J} 2$ & 1.0000 \\
\hline
\end{tabular}

Inhalation

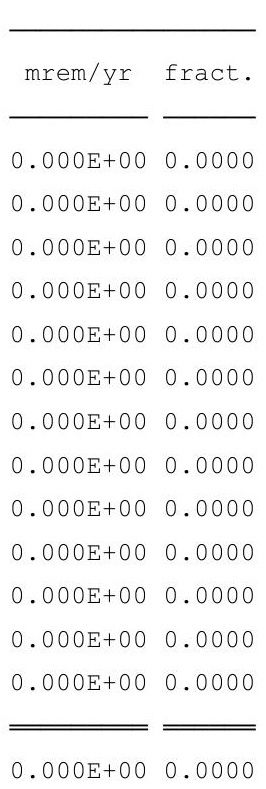

Radon

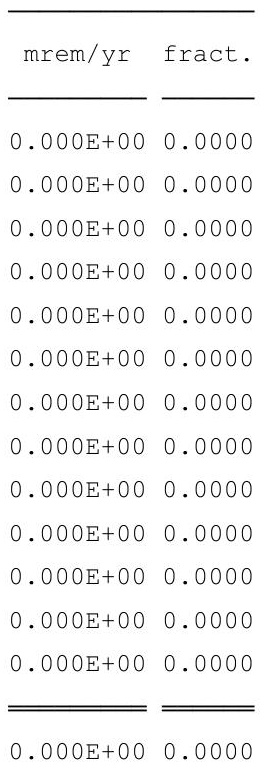

\begin{tabular}{|c|c|c|c|}
\hline \multicolumn{2}{|c|}{ Plant } & \multicolumn{2}{|c|}{ Meat } \\
\hline mrem/yr & fract. & mrem/yr & fract. \\
\hline $0.000 \mathrm{E}+00$ & 0.0000 & $0.000 \mathrm{E}+00$ & 0.0000 \\
\hline $0.000 \mathrm{E}+00$ & 0.0000 & $0.000 \mathrm{E}+00$ & 0.0000 \\
\hline $0.000 \mathrm{E}+00$ & 0.0000 & $0.000 \mathrm{E}+00$ & 0.0000 \\
\hline $0.000 \mathrm{E}+00$ & 0.0000 & $0.000 \mathrm{E}+00$ & 0.0000 \\
\hline $0.000 \mathrm{E}+00$ & 0.0000 & $0.000 \mathrm{E}+00$ & 0.0000 \\
\hline $0.000 \mathrm{E}+00$ & 0.0000 & $0.000 \mathrm{E}+00$ & 0.0000 \\
\hline $0.000 \mathrm{E}+00$ & 0.0000 & $0.000 \mathrm{E}+00$ & 0.0000 \\
\hline $0.000 \mathrm{E}+00$ & 0.0000 & $0.000 \mathrm{E}+00$ & 0.0000 \\
\hline $0.000 \mathrm{E}+00$ & 0.0000 & $0.000 \mathrm{E}+00$ & 0.0000 \\
\hline $0.000 \mathrm{E}+00$ & 0.0000 & $0.000 \mathrm{E}+00$ & 0.0000 \\
\hline $0.000 \mathrm{E}+00$ & 0.0000 & $0.000 \mathrm{E}+00$ & 0.0000 \\
\hline $0.000 \mathrm{E}+00$ & 0.0000 & $0.000 \mathrm{E}+00$ & 0.0000 \\
\hline $0.000 \mathrm{E}+00$ & 0.0000 & $0.000 \mathrm{E}+00$ & 0.0000 \\
\hline $0.000 \mathrm{E}+00$ & 0.0000 & $0.000 \mathrm{E}+00$ & 0.0000 \\
\hline
\end{tabular}

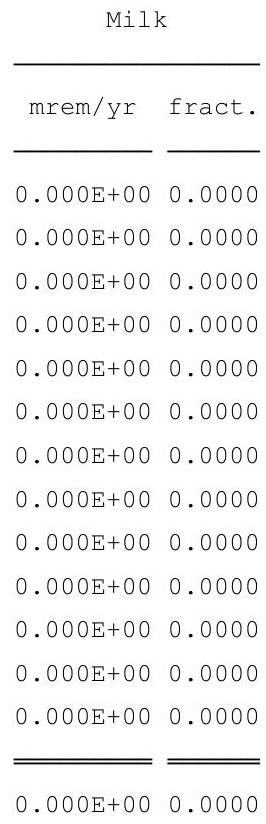

Soil mrem/yr fract. $0.000 \mathrm{E}+00 \quad 0.0000$ $0.000 \mathrm{E}+00 \quad 0.0000$ $0.000 \mathrm{E}+00 \quad 0.0000$ $0.000 \mathrm{E}+00 \quad 0.0000$ $0.000 \mathrm{E}+00 \quad 0.0000$ $0.000 \mathrm{E}+00 \quad 0.0000$ $0.000 \mathrm{E}+00 \quad 0.0000$ $0.000 \mathrm{E}+00 \quad 0.0000$ $0.000 \mathrm{E}+00 \quad 0.0000$ $0.000 \mathrm{E}+00 \quad 0.0000$ $0.000 \mathrm{E}+00 \quad 0.0000$ $0.000 \mathrm{E}+00 \quad 0.0000$ $0.000 \mathrm{E}+00 \quad 0.0000$ $0.000 E+00 \quad 0.0000$

Total Dose Contributions TDOSE (i,p,t) for Individual Radionuclides (i) and Pathways (p) As mrem/yr and Fraction of Total Dose At $t=1.050 \mathrm{E}+03$ years

Water Dependent Pathways

\begin{tabular}{|c|c|c|c|c|c|c|}
\hline \multirow[b]{2}{*}{ Nuclide } & \multicolumn{2}{|c|}{ Water } & \multicolumn{2}{|c|}{ Fish } & \multicolumn{2}{|c|}{ Radon } \\
\hline & mrem/yr & fract. & mrem/yr & fract. & mrem/yr & fract. \\
\hline-241 & $0.000 \mathrm{E}+00$ & 0.0000 & $0.000 \mathrm{E}+00$ & 0.0000 & $0.000 \mathrm{E}+00$ & 0.0000 \\
\hline-137 & $0.000 \mathrm{E}+00$ & 0.0000 & $0.000 \mathrm{E}+00$ & 0.0000 & $0.000 \mathrm{E}+00$ & 0.0000 \\
\hline-237 & $0.000 \mathrm{E}+00$ & 0.0000 & $0.000 \mathrm{E}+00$ & 0.0000 & $0.000 \mathrm{E}+00$ & 0.0000 \\
\hline 238 & $0.000 \mathrm{E}+00$ & 0.0000 & $0.000 \mathrm{E}+00$ & 0.0000 & $0.000 \mathrm{E}+00$ & 0.0000 \\
\hline 239 & $0.000 \mathrm{E}+00$ & 0.0000 & $0.000 \mathrm{E}+00$ & 0.0000 & $0.000 \mathrm{E}+00$ & 0.0000 \\
\hline 240 & $0.000 \mathrm{E}+00$ & 0.0000 & $0.000 \mathrm{E}+00$ & 0.0000 & $0.000 \mathrm{E}+00$ & 0.0000 \\
\hline 99 & $0.000 \mathrm{E}+00$ & 0.0000 & $0.000 \mathrm{E}+00$ & 0.0000 & $0.000 \mathrm{E}+00$ & 0.0000 \\
\hline 228 & $0.000 \mathrm{E}+00$ & 0.0000 & $0.000 \mathrm{E}+00$ & 0.0000 & $0.000 \mathrm{E}+00$ & 0.0000 \\
\hline 30 & $0.000 \mathrm{E}+00$ & 0.0000 & $0.000 \mathrm{E}+00$ & 0.0000 & $0.000 \mathrm{E}+00$ & 0.0000 \\
\hline 232 & $0.000 \mathrm{E}+00$ & 0.0000 & $0.000 \mathrm{E}+00$ & 0.0000 & $0.000 \mathrm{E}+00$ & 0.0000 \\
\hline 4 & $0.000 \mathrm{E}+00$ & 0.0000 & $0.000 \mathrm{E}+00$ & 0.0000 & $0.000 \mathrm{E}+00$ & 0.0000 \\
\hline 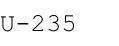 & $0.000 \mathrm{E}+00$ & 0.0000 & $0.000 \mathrm{E}+00$ & 0.0000 & $0.000 \mathrm{E}+00$ & 0.0000 \\
\hline & $0.000 \mathrm{E}+00$ & 0.0000 & $0.000 \mathrm{E}+00$ & 0.0000 & $0.000 \mathrm{E}+00$ & 0.0000 \\
\hline & $0.000 \mathrm{E}+00$ & 00 & $.000 \mathrm{E}+00$ & 000 & $0.000 \mathrm{E}+00$ & 0 \\
\hline
\end{tabular}

*Sum of all water independent and dependent pathways.

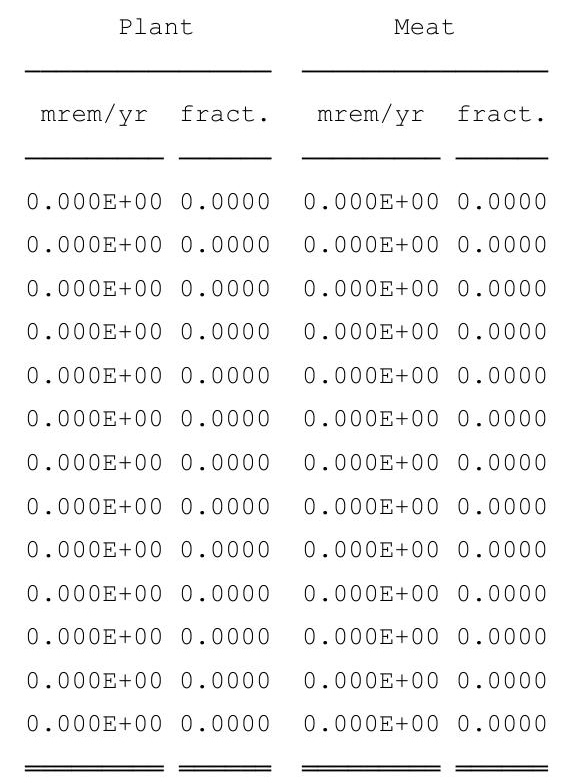

$\begin{array}{llll}0.000 E+00 & 0.0000 & 0.000 E+00 & 0.0000\end{array}$

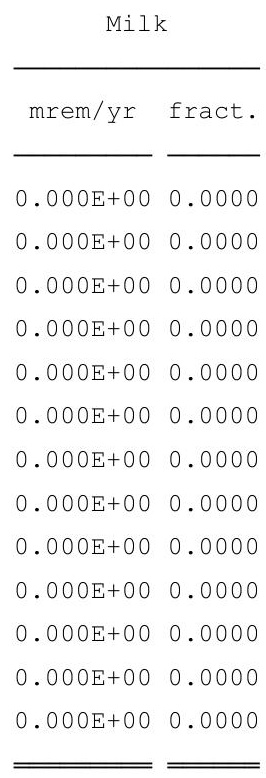

$0.000 \mathrm{E}+00 \quad 0.0000$
All Pathways* mrem/yr fract. $9.032 \mathrm{E}-09 \quad 0.0000$ $9.832 \mathrm{E}-15 \quad 0.0000$ $8.468 \mathrm{E}-06 \quad 0.0003$ $1.044 \mathrm{E}-07 \quad 0.0000$ $2.474 \mathrm{E}-09 \quad 0.0000$ $5.993 \mathrm{E}-13 \quad 0.0000$ $7.334 \mathrm{E}-19 \quad 0.0000$ $0.000 \mathrm{E}+00 \quad 0.0000$ $2.208 \mathrm{E}-02 \quad 0.7039$ $7.187 \mathrm{E}-03 \quad 0.2291$ $1.681 \mathrm{E}-03 \quad 0.0536$ $3.971 \mathrm{E}-06 \quad 0.0001$ $4.095 \mathrm{E}-04 \quad 0.0131$

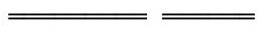
$3.138 \mathrm{E}-02 \quad 1.0000$ 
RESRAD, Version 6.5

Summary : C746U Worker Deterministic Run

File : $\mathrm{X}: \backslash$ FINAL V2 $\backslash$ C746U W SG FWD-FINALV2.RAD

Dose/Source Ratios Summed Over All Pathways

Parent and Progeny Principal Radionuclide Contributions Indicated

Parent Product Thread DSR $(j, t)$ At Time in Years (mrem/yr)/(pCi/g)

(i)

(j)

$\begin{array}{ll}\mathrm{Am}-241 & 1.000 \mathrm{E}+00 \\ \mathrm{~Np}-237+\mathrm{D} & 1.000 \mathrm{E}+00 \\ \mathrm{U}-233 & 1.000 \mathrm{E}+00 \\ \mathrm{Th}-229+\mathrm{D} & 1.000 \mathrm{E}+00 \\ \operatorname{MDSR}(j) & \end{array}$

Cs $-137+D$

$\mathrm{Np}-237+\mathrm{D}$

$\mathrm{U}-233$

Th-229+D

$\sum \operatorname{DSR}(j)$

$\mathrm{Pu}-238$

Pu-238

U-234

Th-230

Ra-226+D

$\mathrm{Pb}-210+\mathrm{D}$

$\sum \operatorname{DSR}(j)$

Pu-239

$\mathrm{U}-235+\mathrm{D}$

$\mathrm{Pa}-231$

AC-227+D

$\sum \operatorname{DSR}(j)$

Pu-2 40

$\mathrm{Pu}-240$

U-236

Th-232

$\mathrm{Ra}-228+\mathrm{D}$

Th-228+D

$\sum \operatorname{DSR}(j)$

TC-99

Th-228+D

1. $000 \mathrm{E}+00$

Th-230

1. $000 \mathrm{E}+00$

Ra-226+D

1. $000 \mathrm{E}+00$

$\mathrm{Pb}-210+\mathrm{D}$

$\sum \operatorname{DSR}(j)$

1. $000 \mathrm{E}+00$

1. $000 \mathrm{E}+00$

1. $000 \mathrm{E}+00$
$0.000 \mathrm{E}+00 \quad 1.000 \mathrm{E}+00 \quad 5.000 \mathrm{E}+01 \quad 1.000 \mathrm{E}+02 \quad 5.000 \mathrm{E}+02 \quad 1.050 \mathrm{E}+03$

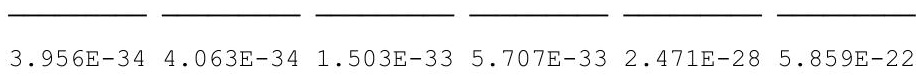

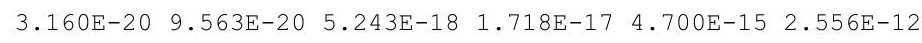

$\begin{array}{llllll}7.164 \mathrm{E}-31 & 5.066 \mathrm{E}-30 & 9.948 \mathrm{E}-27 & 7.175 \mathrm{E}-26 & 2.177 \mathrm{E}-22 & 7.342 \mathrm{E}-19\end{array}$

$\begin{array}{llllll}4.901 \mathrm{E}-27 & 7.393 \mathrm{E}-26 & 3.496 \mathrm{E}-21 & 3.824 \mathrm{E}-20 & 6.587 \mathrm{E}-17 & 2.426 \mathrm{E}-14\end{array}$

$3.160 \mathrm{E}-20 \quad 9.563 \mathrm{E}-20 \quad 5.246 \mathrm{E}-18 \quad 1.722 \mathrm{E}-17 \quad 4.766 \mathrm{E}-15 \quad 2.581 \mathrm{E}-12$

$\begin{array}{llllllll}1.000 \mathrm{E}+00 & 2.578 \mathrm{E}-10 & 2.541 \mathrm{E}-10 & 1.237 \mathrm{E}-10 & 5.936 \mathrm{E}-11 & 1.667 \mathrm{E}-13 & 5.175 \mathrm{E}-17\end{array}$

$\begin{array}{lllllll}1.000 \mathrm{E}+00 & 1.948 \mathrm{E}-13 & 1.969 \mathrm{E}-13 & 3.330 \mathrm{E}-13 & 5.693 \mathrm{E}-13 & 4.147 \mathrm{E}-11 & 1.509 \mathrm{E}-08\end{array}$

$1.000 \mathrm{E}+00 \quad 6.631 \mathrm{E}-24 \quad 2.011 \mathrm{E}-23 \quad 1.248 \mathrm{E}-21 \quad 4.641 \mathrm{E}-21 \quad 3.427 \mathrm{E}-18 \quad 6.954 \mathrm{E}-15$

$6.053 \mathrm{E}-20 \quad 4.262 \mathrm{E}-19 \quad 6.537 \mathrm{E}-16 \quad 3.662 \mathrm{E}-15 \quad 1.463 \mathrm{E}-12 \quad 3.066 \mathrm{E}-10$

$\begin{array}{llllll}1.948 \mathrm{E}-13 & 1.969 \mathrm{E}-13 & 3.337 \mathrm{E}-13 & 5.729 \mathrm{E}-13 & 4.294 \mathrm{E}-11 & 1.540 \mathrm{E}-08\end{array}$

$\begin{array}{lllllll}1.840 \mathrm{E}-09 & 4.417 \mathrm{E}-34 & 4.460 \mathrm{E}-34 & 7.195 \mathrm{E}-34 & 1.172 \mathrm{E}-33 & 5.806 \mathrm{E}-32 & 1.243 \mathrm{E}-29\end{array}$

$\begin{array}{lllllll}1.000 \mathrm{E}+00 & 2.401 \mathrm{E}-25 & 2.424 \mathrm{E}-25 & 3.910 \mathrm{E}-25 & 6.369 \mathrm{E}-25 & 3.155 \mathrm{E}-23 & 6.755 \mathrm{E}-21\end{array}$

$\begin{array}{lllllll}1.000 \mathrm{E}+00 & 1.998 \mathrm{E}-30 & 6.068 \mathrm{E}-30 & 4.032 \mathrm{E}-28 & 1.628 \mathrm{E}-27 & 3.470 \mathrm{E}-24 & 5.993 \mathrm{E}-20\end{array}$

$\begin{array}{llllllll}1.000 \mathrm{E}+00 & 2.101 \mathrm{E}-34 & 1.489 \mathrm{E}-33 & 3.268 \mathrm{E}-30 & 2.663 \mathrm{E}-29 & 2.676 \mathrm{E}-25 & 6.795 \mathrm{E}-21\end{array}$

$\begin{array}{lllllllll}1.000 \mathrm{E}+00 & 1.639 \mathrm{E}-23 & 2.469 \mathrm{E}-22 & 1.076 \mathrm{E}-17 & 1.088 \mathrm{E}-16 & 1.149 \mathrm{E}-13 & 2.677 \mathrm{E}-11\end{array}$

$\begin{array}{lllllll}4.753 E-32 & 1.473 E-30 & 1.589 E-24 & 2.687 \mathrm{E}-23 & 7.527 \mathrm{E}-20 & 3.536 \mathrm{E}-17\end{array}$

$\begin{array}{llllll}1.663 \mathrm{E}-23 & 2.471 \mathrm{E}-22 & 1.076 \mathrm{E}-17 & 1.088 \mathrm{E}-16 & 1.149 \mathrm{E}-13 & 2.677 \mathrm{E}-11\end{array}$

$\begin{array}{lllllll}1.000 \mathrm{E}+00 \quad 2.456 \mathrm{E}-18 & 2.486 \mathrm{E}-18 \quad 4.463 \mathrm{E}-18 & 8.107 \mathrm{E}-18 & 9.618 \mathrm{E}-16 & 6.841 \mathrm{E}-13\end{array}$

$\begin{array}{lllllll}1.000 \mathrm{E}+00 & 1.254 \mathrm{E}-24 & 3.802 \mathrm{E}-24 & 2.343 \mathrm{E}-22 & 8.645 \mathrm{E}-22 & 6.015 \mathrm{E}-19 & 1.124 \mathrm{E}-15\end{array}$

$\begin{array}{llllllll}1.000 \mathrm{E}+00 & 1.972 \mathrm{E}-28 & 1.393 \mathrm{E}-27 & 2.557 \mathrm{E}-24 & 1.721 \mathrm{E}-23 & 2.963 \mathrm{E}-20 & 4.446 \mathrm{E}-17\end{array}$

$\begin{array}{lllllll}4.675 \mathrm{E}-28 & 7.017 \mathrm{E}-27 & 2.608 \mathrm{E}-22 & 2.391 \mathrm{E}-21 & 3.028 \mathrm{E}-18 & 1.826 \mathrm{E}-15\end{array}$

$2.456 \mathrm{E}-18 \quad 2.486 \mathrm{E}-18 \quad 4.463 \mathrm{E}-18 \quad 8.110 \mathrm{E}-18 \quad 9.655 \mathrm{E}-16 \quad 6.871 \mathrm{E}-13$

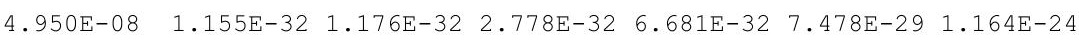

$\begin{array}{lllllll}1.000 E+00 \quad 2.334 E-25 & 2.375 E-25 & 5.612 E-25 & 1.350 E-24 & 1.511 E-21 & 2.352 E-17\end{array}$

$\begin{array}{lllllll}1.000 E+00 \quad 4.417 E-33 & 1.347 E-32 & 1.091 E-30 & 5.321 E-30 & 3.459 E-26 & 1.397 E-21\end{array}$

$\begin{array}{llllllll}1.000 \mathrm{E}+00 & 5.745 \mathrm{E}-44 & 4.148 \mathrm{E}-43 & 1.120 \mathrm{E}-39 & 1.120 \mathrm{E}-38 & 4.587 \mathrm{E}-34 & 5.372 \mathrm{E}-29\end{array}$

$\begin{array}{lllllll}1.000 \mathrm{E}+00 & 2.801 \mathrm{E}-29 & 4.123 \mathrm{E}-28 & 7.689 \mathrm{E}-24 & 5.197 \mathrm{E}-23 & 3.012 \mathrm{E}-20 & 8.590 \mathrm{E}-18\end{array}$

$\begin{array}{llllllll}1.000 \mathrm{E}+00 & 1.657 \mathrm{E}-28 & 4.769 \mathrm{E}-27 & 5.398 \mathrm{E}-22 & 3.593 \mathrm{E}-21 & 1.140 \mathrm{E}-18 & 1.344 \mathrm{E}-16\end{array}$

$2.335 \mathrm{E}-25 \quad 2.427 \mathrm{E}-25 \quad 5.480 \mathrm{E}-22 \quad 3.646 \mathrm{E}-21 \quad 1.172 \mathrm{E}-18 \quad 1.665 \mathrm{E}-16$

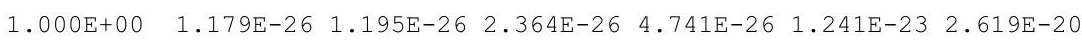

$\begin{array}{lllllll}3.717 \mathrm{E}-20 & 2.596 \mathrm{E}-19 & 2.655 \mathrm{E}-16 & 1.087 \mathrm{E}-15 & 1.573 \mathrm{E}-13 & 2.528 \mathrm{E}-11\end{array}$

$\begin{array}{llllll}7.712 E-12 & 2.327 E-11 & 1.087 E-09 & 3.024 E-09 & 2.193 E-07 & 1.840 E-05\end{array}$ 
RESRAD, Version 6.5

Summary : C746U Worker Deterministic Run

File : $\mathrm{X}: \backslash$ FINAL V2 $\backslash \mathrm{C} 746 \mathrm{U} W \mathrm{WG}$ FWD-FINALV2.RAD

Dose/Source Ratios Summed Over All Pathways

Parent and Progeny Principal Radionuclide Contributions Indicated

\begin{tabular}{|c|c|c|c|c|c|c|c|c|}
\hline $\begin{array}{c}\text { Parent } \\
\text { (i) }\end{array}$ & $\begin{array}{l}\text { Product } \\
(j)\end{array}$ & $\begin{array}{l}\text { Thread } \\
\text { Fraction }\end{array}$ & $\begin{array}{r}\text { DSR } \\
0.000 \mathrm{E}+00\end{array}$ & $\begin{array}{l}(j, t) \text { At } T \\
1.000 \mathrm{E}+00\end{array}$ & $\begin{array}{l}\text { ime in Yea } \\
5.000 \mathrm{E}+01\end{array}$ & $\begin{array}{l}\text { Es (mrem/ } \\
1.000 \mathrm{E}+02\end{array}$ & $\begin{array}{l}/ \mathrm{yr}) /(\mathrm{pCi} / \\
5.000 \mathrm{E}+02\end{array}$ & $\begin{array}{l}\text { g) } \\
1.050 \mathrm{E}+03\end{array}$ \\
\hline-232 & $\mathrm{Th}-232$ & $1.000 \mathrm{E}+00$ & $2.382 \mathrm{E}-25$ & $2.427 E-25$ & $6.027 \mathrm{E}-25$ & $1.525 E-24$ & $2.561 \mathrm{E}-21$ & $6.965 E-17$ \\
\hline-232 & $\mathrm{Ra}-228+\mathrm{D}$ & $1.000 \mathrm{E}+00$ & $2.263 E-10$ & $6.486 \mathrm{E}-10$ & $5.690 \mathrm{E}-09$ & $8.336 \mathrm{E}-09$ & $1.737 \mathrm{E}-07$ & $1.131 \mathrm{E}-05$ \\
\hline $1-232$ & $T h-228+D$ & $1.000 \mathrm{E}+00$ & $2.181 E-09$ & $1.345 \mathrm{E}-08$ & $4.522 \mathrm{E}-07$ & $6.114 \mathrm{E}-07$ & $6.652 E-06$ & $1.778 \mathrm{E}-04$ \\
\hline-232 & $\sum \operatorname{DSR}(j)$ & & $2.407 E-09$ & $1.410 \mathrm{E}-08$ & $4.579 \mathrm{E}-07$ & $6.198 \mathrm{E}-07$ & $6.825 E-06$ & $1.891 \mathrm{E}-04$ \\
\hline-234 & $\mathrm{U}-234$ & $1.000 \mathrm{E}+00$ & $1.409 \mathrm{E}-24$ & $1.434 \mathrm{E}-24$ & $3.415 \mathrm{E}-24$ & $8.276 \mathrm{E}-24$ & $9.851 E-21$ & $1.669 \mathrm{E}-16$ \\
\hline-234 & Th-230 & $1.000 \mathrm{E}+00$ & $2.225 E-28$ & $6.774 \mathrm{E}-28$ & $5.192 \mathrm{E}-26$ & $2.394 \mathrm{E}-25$ & $9.912 \mathrm{E}-22$ & $2.152 \mathrm{E}-17$ \\
\hline-234 & $\mathrm{Ra}-226+\mathrm{D}$ & $1.000 \mathrm{E}+00$ & $2.315 E-17$ & $1.630 \mathrm{E}-16$ & $2.480 \mathrm{E}-13$ & $1.377 \mathrm{E}-12$ & $5.115 \mathrm{E}-10$ & $9.341 \mathrm{E}-08$ \\
\hline-234 & $\mathrm{~Pb}-210+\mathrm{D}$ & $1.000 \mathrm{E}+00$ & $8.381 E-26$ & $1.257 \mathrm{E}-24$ & $4.500 \mathrm{E}-20$ & $3.956 \mathrm{E}-19$ & $3.440 \mathrm{E}-16$ & 1. $243 \mathrm{E}-13$ \\
\hline-234 & $\sum \operatorname{DSR}(j)$ & & $2.315 \mathrm{E}-17$ & $1.630 \mathrm{E}-16$ & $2.480 \mathrm{E}-13$ & $1.377 \mathrm{E}-12$ & $5.115 \mathrm{E}-10$ & $9.341 \mathrm{E}-08$ \\
\hline$-235+D$ & $\mathrm{U}-235+\mathrm{D}$ & $1.000 \mathrm{E}+00$ & $2.540 \mathrm{E}-15$ & $2.572 \mathrm{E}-15$ & $4.713 E-15$ & $8.745 E-15$ & 1. $228 \mathrm{E}-12$ & $1.101 \mathrm{E}-09$ \\
\hline$-235+D$ & $\mathrm{~Pa}-231$ & $1.000 \mathrm{E}+00$ & $6.002 \mathrm{E}-19$ & $1.818 \mathrm{E}-18$ & $1.028 \mathrm{E}-16$ & $3.478 \mathrm{E}-16$ & 1. $206 \mathrm{E}-13$ & $8.644 \mathrm{E}-11$ \\
\hline$-235+D$ & $A C-227+D$ & $1.000 \mathrm{E}+00$ & 1. $895 \mathrm{E}-18$ & 1. $324 \mathrm{E}-17$ & $1.407 \mathrm{E}-14$ & $6.019 \mathrm{E}-14$ & $1.308 \mathrm{E}-11$ & $3.655 \mathrm{E}-09$ \\
\hline$-235+D$ & $\sum \operatorname{DSR}(j)$ & & $2.543 E-15$ & $2.587 \mathrm{E}-15$ & $1.888 \mathrm{E}-14$ & $6.928 \mathrm{E}-14$ & $1.443 E-11$ & $4.843 E-09$ \\
\hline-238 & $U-238$ & $5.400 E-05$ & $0.000 \mathrm{E}+00$ & $0.000 \mathrm{E}+00$ & $0.000 \mathrm{E}+00$ & $0.000 \mathrm{E}+00$ & $0.000 \mathrm{E}+00$ & $3.476 \mathrm{E}-39$ \\
\hline$-238+D$ & $\mathrm{U}-238+\mathrm{D}$ & $9.999 \mathrm{E}-01$ & $2.901 \mathrm{E}-11$ & $2.924 \mathrm{E}-11$ & 4. $325 E-11$ & $6.449 \mathrm{E}-11$ & $1.576 \mathrm{E}-09$ & $1.279 \mathrm{E}-07$ \\
\hline$-238+D$ & $\mathrm{U}-234$ & $9.999 \mathrm{E}-01$ & $2.003 E-30$ & $6.105 \mathrm{E}-30$ & $4.889 \mathrm{E}-28$ & $2.358 \mathrm{E}-27$ & $1.399 \mathrm{E}-23$ & 4. $978 \mathrm{E}-19$ \\
\hline$-238+D$ & $\mathrm{Th}-230$ & $9.999 E-01$ & $2.105 E-34$ & $1.495 \mathrm{E}-33$ & $3.717 \mathrm{E}-30$ & $3.411 \mathrm{E}-29$ & $7.032 \mathrm{E}-25$ & $3.204 \mathrm{E}-20$ \\
\hline$-238+D$ & $\mathrm{Ra}-226+\mathrm{D}$ & $9.999 \mathrm{E}-01$ & $1.642 \mathrm{E}-23$ & $2.477 \mathrm{E}-22$ & $1.186 \mathrm{E}-17$ & $1.313 E-16$ & $2.462 \mathrm{E}-13$ & $9.612 \mathrm{E}-11$ \\
\hline$-238+D$ & $\mathrm{~Pb}-210+\mathrm{D}$ & $9.999 \mathrm{E}-01$ & $4.759 E-32$ & $1.477 \mathrm{E}-30$ & $1.723 E-24$ & $3.161 \mathrm{E}-23$ & $1.561 \mathrm{E}-19$ & 1. $240 \mathrm{E}-16$ \\
\hline$-238+D$ & $\sum \operatorname{DSR}(j)$ & & $2.901 \mathrm{E}-11$ & $2.924 \mathrm{E}-11$ & $4.325 \mathrm{E}-11$ & $6.449 \mathrm{E}-11$ & $1.577 \mathrm{E}-09$ & $1.280 \mathrm{E}-07$ \\
\hline
\end{tabular}

The DSR includes contributions from associated (half-life $\leq 180$ days) daughters. 
RESRAD, Version $6.5 \quad T^{3} / 2$ Limit $=180$ days

Summary : C746U Worker Deterministic Run

File : $\mathrm{X}: \backslash$ FINAL V2 $\backslash$ C746U W SG FWD-FINALV2.RAD

Single Radionuclide Soil Guidelines G(i,t) in pCi/g

Basic Radiation Dose Limit $=1.000 \mathrm{E}+00 \mathrm{mrem} / \mathrm{yr}$

Nuclide

\begin{tabular}{|c|c|c|c|c|c|c|}
\hline (i) & $t=0.000 E+00$ & $1.000 \mathrm{E}+00$ & $5.000 \mathrm{E}+01$ & $1.000 \mathrm{E}+02$ & $5.000 \mathrm{E}+02$ & $1.050 \mathrm{E}+03$ \\
\hline $1-241$ & $\star 3.431 \mathrm{E}+12$ & $\star 3.431 \mathrm{E}+12$ & $\star 3.431 \mathrm{E}+12$ & $\star 3.431 \mathrm{E}+12$ & $\star 3.431 \mathrm{E}+12$ & $3.875 \mathrm{E}+11$ \\
\hline$s-137$ & $3.879 E+09$ & $3.936 \mathrm{E}+09$ & $8.084 E+09$ & $1.685 \mathrm{E}+10$ & $5.997 \mathrm{E}+12$ & $\star 8.704 \mathrm{E}+13$ \\
\hline-237 & $\star 7.047 \mathrm{E}+08$ & $\star 7.047 \mathrm{E}+08$ & $\star 7.047 \mathrm{E}+08$ & $\star 7.047 \mathrm{E}+08$ & $\star 7.047 \mathrm{E}+08$ & $6.495 \mathrm{E}+07$ \\
\hline$u-238$ & $\star 1.712 \mathrm{E}+13$ & $\star 1.712 \mathrm{E}+13$ & $\star 1.712 \mathrm{E}+13$ & $\star 1.712 \mathrm{E}+13$ & $8.701 \mathrm{E}+12$ & $3.735 \mathrm{E}+10$ \\
\hline $\mathrm{Pu}-239$ & $\star 6.214 \mathrm{E}+10$ & $\star 6.214 \mathrm{E}+10$ & $\star 6.214 \mathrm{E}+10$ & $\star 6.214 \mathrm{E}+10$ & $\star 6.214 \mathrm{E}+10$ & $\star 6.214 \mathrm{E}+10$ \\
\hline $\mathrm{Pu}-240$ & $\star 2.278 \mathrm{E}+11$ & $\star 2.278 \mathrm{E}+11$ & $\star 2.278 \mathrm{E}+11$ & $\star 2.278 \mathrm{E}+11$ & $\star 2.278 \mathrm{E}+11$ & $\star 2.278 \mathrm{E}+11$ \\
\hline TC-99 & $* 1.697 \mathrm{E}+10$ & $* 1.697 \mathrm{E}+10$ & $\star 1.697 \mathrm{E}+10$ & $* 1.697 \mathrm{E}+10$ & $\star 1.697 \mathrm{E}+10$ & $\star 1.697 \mathrm{E}+10$ \\
\hline Th-228 & $3.540 \mathrm{E}+06$ & $5.056 \mathrm{E}+06$ & $1.937 \mathrm{E}+14$ & $\star 8.195 \mathrm{E}+14$ & $\star 8.195 \mathrm{E}+14$ & $\star 8.195 \mathrm{E}+14$ \\
\hline Th -230 & $\star 2.018 \mathrm{E}+10$ & $\star 2.018 \mathrm{E}+10$ & $9.198 \mathrm{E}+08$ & $3.307 \mathrm{E}+08$ & $4.559 \mathrm{E}+06$ & $5.434 \mathrm{E}+04$ \\
\hline$T h-232$ & $\star 1.097 \mathrm{E}+05$ & $\star 1.097 \mathrm{E}+05$ & $\star 1.097 \mathrm{E}+05$ & $\star 1.097 \mathrm{E}+05$ & $\star 1.097 \mathrm{E}+05$ & $5.287 \mathrm{E}+03$ \\
\hline $\mathrm{U}-234$ & $\star 6.247 \mathrm{E}+09$ & $\star 6.247 \mathrm{E}+09$ & $\star 6.247 \mathrm{E}+09$ & $\star 6.247 \mathrm{E}+09$ & $1.955 E+09$ & $1.071 \mathrm{E}+07$ \\
\hline 35 & $\star 2.161 \mathrm{E}+06$ & $\star 2.161 \mathrm{E}+06$ & $\star 2.161 \mathrm{E}+06$ & $\star 2.161 \mathrm{E}+06$ & $\star 2.161 \mathrm{E}+06$ & $\star 2.161 \mathrm{E}+06$ \\
\hline 238 & $\star 3.361 \mathrm{E}+05$ & $\star 3.361 \mathrm{E}+05$ & $\star 3.361 \mathrm{E}+05$ & $\star 3.361 \mathrm{E}+05$ & $\star 3.361 \mathrm{E}+05$ & $\star 3.361 \mathrm{E}+05$ \\
\hline
\end{tabular}

*At specific activity limit

Summed Dose/Source Ratios DSR (i,t) in (mrem/yr)/(pCi/g)

and Single Radionuclide Soil Guidelines G(i,t) in pCi/g

at $\operatorname{tmin}=$ time of minimum single radionuclide soil guideline

and at $\operatorname{tmax}=$ time of maximum total dose $=1.050 \mathrm{E}+03$ years

\begin{tabular}{|c|c|c|c|c|c|c|}
\hline $\begin{array}{l}\text { uclide } \\
\text { (i) }\end{array}$ & $\begin{array}{l}\text { Initial } \\
(\mathrm{pCi} / \mathrm{g})\end{array}$ & $\begin{array}{c}\text { tmin } \\
\text { (years) }\end{array}$ & $\operatorname{DSR}(i, \operatorname{tmin})$ & $\begin{array}{c}\mathrm{G}(\mathrm{i}, \mathrm{tmin}) \\
(\mathrm{pCi} / \mathrm{g})\end{array}$ & $\operatorname{DSR}(i, t \max )$ & $\begin{array}{c}G(i, t \max ) \\
(\mathrm{pCi} / \mathrm{g})\end{array}$ \\
\hline $1-241$ & $3.500 \mathrm{E}+03$ & $1.050 \mathrm{E}+03$ & $2.581 E-12$ & $3.875 E+11$ & $2.581 \mathrm{E}-12$ & $3.875 E+11$ \\
\hline-137 & $1.900 \mathrm{E}+02$ & $0.000 \mathrm{E}+00$ & $2.578 \mathrm{E}-10$ & $3.879 \mathrm{E}+09$ & $5.175 \mathrm{E}-17$ & $\star 8.704 \mathrm{E}+13$ \\
\hline-237 & $5.500 \mathrm{E}+02$ & $1.050 \mathrm{E}+03$ & $1.540 \mathrm{E}-08$ & $6.495 \mathrm{E}+07$ & $1.540 \mathrm{E}-08$ & $6.495 \mathrm{E}+07$ \\
\hline$x-238$ & $3.900 \mathrm{E}+03$ & $1.050 \mathrm{E}+03$ & $2.677 \mathrm{E}-11$ & $3.735 \mathrm{E}+10$ & $2.677 \mathrm{E}-11$ & $3.735 E+10$ \\
\hline$x-239$ & $3.600 \mathrm{E}+03$ & $1.050 \mathrm{E}+03$ & $6.871 \mathrm{E}-13$ & $* 6.214 \mathrm{E}+10$ & $6.871 \mathrm{E}-13$ & $* 6.214 \mathrm{E}+10$ \\
\hline-240 & $3.600 \mathrm{E}+03$ & $1.050 \mathrm{E}+03$ & $1.665 \mathrm{E}-16$ & $\star 2.278 \mathrm{E}+11$ & $1.665 \mathrm{E}-16$ & $\star 2.278 \mathrm{E}+11$ \\
\hline-99 & $2.800 \mathrm{E}+01$ & $1.050 \mathrm{E}+03$ & $2.619 \mathrm{E}-20$ & $\star 1.697 \mathrm{E}+10$ & $2.619 \mathrm{E}-20$ & $\star 1.697 \mathrm{E}+10$ \\
\hline-228 & $7.400 \mathrm{E}+01$ & $0.000 \mathrm{E}+00$ & $2.825 E-07$ & $3.540 \mathrm{E}+06$ & $0.000 \mathrm{E}+00$ & $\star 8.195 \mathrm{E}+14$ \\
\hline-230 & $1.200 \mathrm{E}+03$ & $1.050 \mathrm{E}+03$ & $1.840 \mathrm{E}-05$ & $5.434 \mathrm{E}+04$ & $1.840 \mathrm{E}-05$ & $5.434 \mathrm{E}+04$ \\
\hline-232 & $3.800 \mathrm{E}+01$ & $1.050 \mathrm{E}+03$ & $1.891 \mathrm{E}-04$ & $5.287 E+03$ & $1.891 \mathrm{E}-04$ & $5.287 \mathrm{E}+03$ \\
\hline 234 & $1.800 \mathrm{E}+04$ & $1.050 \mathrm{E}+03$ & $9.341 \mathrm{E}-08$ & $1.071 E+07$ & $9.341 E-08$ & $1.071 E+07$ \\
\hline 235 & $8.200 \mathrm{E}+02$ & $1.050 \mathrm{E}+03$ & $4.843 E-09$ & $\star 2.161 \mathrm{E}+06$ & $4.843 E-09$ & $* 2.161 \mathrm{E}+06$ \\
\hline-238 & $3.200 E+03$ & $1.050 \mathrm{E}+03$ & $1.280 \mathrm{E}-07$ & $\star 3.361 \mathrm{E}+05$ & $1.280 \mathrm{E}-07$ & $\star 3.361 \mathrm{E}+05$ \\
\hline
\end{tabular}

*At specific activity limit 
RESRAD, Version 6.5

Summary : C746U Worker Deterministic Run

File : $X: \backslash F I N A L$ V2 $\backslash$ C746U W SG FWD-FINALV2.RAD

Individual Nuclide Dose Summed Over All Pathways

Parent Nuclide and Branch Fraction Indicated

Nuclide Parent THF(i) DOSE $(j, t)$, mrem/yr

\begin{tabular}{|c|c|c|}
\hline$(j)$ & (i) & \\
\hline-241 & $A m-241$ & $1.000 \mathrm{E}+00$ \\
\hline$p-237$ & $A m-241$ & $1.000 \mathrm{E}+00$ \\
\hline $\mathrm{Np}-237$ & $\mathrm{~Np}-237$ & $1.000 \mathrm{E}+00$ \\
\hline Np-237 & $\sum \operatorname{DOSE}(j$ & \\
\hline
\end{tabular}

$\mathrm{U}-233 \quad \mathrm{Am}-241 \quad 1.000 \mathrm{E}+00$

$\mathrm{U}-233 \quad \mathrm{~Np}-237 \quad 1.000 \mathrm{E}+00$

U-233 $\quad$ DOSE $(j)$

Th-229

Th-229

Th-229

Cs -137

$\mathrm{Pu}-238$

$\mathrm{Pu}-238$

$\mathrm{Pu}-238$

$\mathrm{U}-234$

$\mathrm{U}-234$

$\mathrm{U}-234$

$\mathrm{U}-234$

Th -230

Th -230

Th -230

Th -230

$\mathrm{Th}-230$

$\mathrm{Ra}-226$

$\mathrm{Ra}-226$

$\mathrm{Ra}-226$

$\mathrm{Ra}-226$

$\mathrm{Ra}-226$

$\mathrm{Pb}-210$

$\mathrm{Pb}-210$

$\mathrm{Pb}-210$

$\mathrm{Pb}-210$

$\mathrm{Pb}-210$

$\mathrm{Pu}-239$

$\mathrm{U}-235$

$\mathrm{U}-235$

$\mathrm{U}-235$
Am-241 1.000E+00

Np-237 1.000E+00

$\sum \operatorname{DOSE}(j)$

Cs-137 $1.000 \mathrm{E}+00$

Pu-238 1.840E-09

$\sum \operatorname{DOSE}(j)$

$\mathrm{Pu}-238 \quad 1.000 \mathrm{E}+00$

$\mathrm{U}-234 \quad 1.000 \mathrm{E}+00$

$\operatorname{LDOSE}(j)$

$\mathrm{Pu}-238 \quad 1.000 \mathrm{E}+00$

Th-230 1.000E+00

$\mathrm{U}-234 \quad 1.000 \mathrm{E}+00$

$\sum \operatorname{DOSE}(j)$

$\mathrm{Pu}-238 \quad 1.000 \mathrm{E}+00$

Th-230 1.000E+00

$\mathrm{U}-234 \quad 1.000 \mathrm{E}+00$

$\mathrm{U}-238 \quad 9.999 \mathrm{E}-01$

$\sum \operatorname{DOSE}(j)$

Pu-238 $1.000 \mathrm{E}+00$

Th-230 1.000E+00

$\mathrm{U}-2341.000 \mathrm{E}+00$

U-238 9.999E-01

$\operatorname{LDOSE}(j)$

$\mathrm{Pu}-239 \quad 1.000 \mathrm{E}+00$

Pu-239 1.000E+00

U-235 1.000E+00

¿DOSE $(j)$
Pu-238 $1.000 \mathrm{E}+00$

U-238 9.999E-01

$\mathrm{U}-238 \quad 9.999 \mathrm{E}-01$ $t=0.000 \mathrm{E}+00 \quad 1.000 \mathrm{E}+00 \quad 5.000 \mathrm{E}+01 \quad 1.000 \mathrm{E}+02 \quad 5.000 \mathrm{E}+02 \quad 1.050 \mathrm{E}+03$

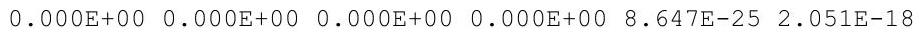

$1.106 \mathrm{E}-16 \quad 3.347 \mathrm{E}-16 \quad 1.835 \mathrm{E}-14 \quad 6.012 \mathrm{E}-14 \quad 1.645 \mathrm{E}-11 \quad 8.947 \mathrm{E}-09$

$\begin{array}{llllll}1.072 \mathrm{E}-10 & 1.083 \mathrm{E}-10 & 1.832 \mathrm{E}-10 & 3.131 \mathrm{E}-10 & 2.281 \mathrm{E}-08 & 8.299 \mathrm{E}-06\end{array}$

$\begin{array}{llllll}1.072 \mathrm{E}-10 & 1.083 \mathrm{E}-10 & 1.832 \mathrm{E}-10 & 3.132 \mathrm{E}-10 & 2.283 \mathrm{E}-08 & 8.308 \mathrm{E}-06\end{array}$

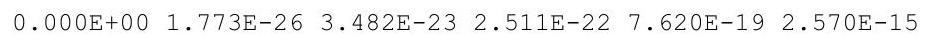

$\begin{array}{llllll}3.647 \mathrm{E}-21 & 1.106 \mathrm{E}-20 & 6.866 \mathrm{E}-19 & 2.553 \mathrm{E}-18 & 1.885 \mathrm{E}-15 & 3.825 \mathrm{E}-12\end{array}$

$\begin{array}{llllll}3.647 \mathrm{E}-21 & 1.106 \mathrm{E}-20 & 6.867 \mathrm{E}-19 & 2.553 \mathrm{E}-18 & 1.886 \mathrm{E}-15 & 3.827 \mathrm{E}-12\end{array}$

$\begin{array}{llllll}1.715 \mathrm{E}-23 & 2.588 \mathrm{E}-22 & 1.224 \mathrm{E}-17 & 1.338 \mathrm{E}-16 & 2.306 \mathrm{E}-13 & 8.490 \mathrm{E}-11\end{array}$

$\begin{array}{llllll}3.329 \mathrm{E}-17 & 2.344 \mathrm{E}-16 & 3.596 \mathrm{E}-13 & 2.014 \mathrm{E}-12 & 8.046 \mathrm{E}-10 & 1.686 \mathrm{E}-07\end{array}$

$\begin{array}{llllll}3.329 \mathrm{E}-17 & 2.344 \mathrm{E}-16 & 3.596 \mathrm{E}-13 & 2.014 \mathrm{E}-12 & 8.048 \mathrm{E}-10 & 1.687 \mathrm{E}-07\end{array}$

$\begin{array}{llllll}4.898 \mathrm{E}-08 & 4.827 \mathrm{E}-08 & 2.350 \mathrm{E}-08 & 1.128 \mathrm{E}-08 & 3.168 \mathrm{E}-11 & 9.832 \mathrm{E}-15\end{array}$

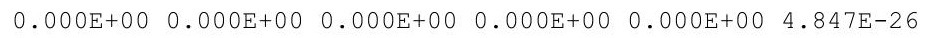

$\begin{array}{llllll}9.362 \mathrm{E}-22 & 9.454 \mathrm{E}-22 & 1.525 \mathrm{E}-21 & 2.484 \mathrm{E}-21 & 1.231 \mathrm{E}-19 & 2.634 \mathrm{E}-17\end{array}$ $\begin{array}{llllll}9.362 \mathrm{E}-22 & 9.454 \mathrm{E}-22 & 1.525 \mathrm{E}-21 & 2.484 \mathrm{E}-21 & 1.231 \mathrm{E}-19 & 2.634 \mathrm{E}-17\end{array}$

$\begin{array}{llllll}7.792 \mathrm{E}-27 & 2.366 \mathrm{E}-26 & 1.573 \mathrm{E}-24 & 6.349 \mathrm{E}-24 & 1.353 \mathrm{E}-20 & 2.337 \mathrm{E}-16\end{array}$

$\begin{array}{llllll}2.536 \mathrm{E}-20 & 2.582 \mathrm{E}-20 & 6.147 \mathrm{E}-20 & 1.490 \mathrm{E}-19 & 1.773 \mathrm{E}-16 & 3.004 \mathrm{E}-12\end{array}$

$6.410 \mathrm{E}-27 \quad 1.953 \mathrm{E}-26 \quad 1.565 \mathrm{E}-24 \quad 7.546 \mathrm{E}-24 \quad 4.476 \mathrm{E}-20 \quad 1.593 \mathrm{E}-15$

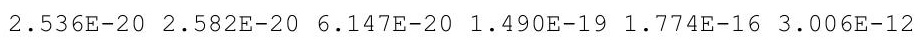

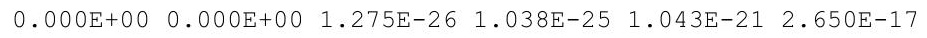
$\begin{array}{llllll}5.914 \mathrm{E}-20 & 6.015 \mathrm{E}-20 & 1.371 \mathrm{E}-19 & 3.177 \mathrm{E}-19 & 2.644 \mathrm{E}-16 & 2.739 \mathrm{E}-12\end{array}$ $4.004 \mathrm{E}-24 \quad 1.219 \mathrm{E}-23 \quad 9.346 \mathrm{E}-22 \quad 4.310 \mathrm{E}-21 \quad 1.784 \mathrm{E}-17 \quad 3.874 \mathrm{E}-13$ $0.000 \mathrm{E}+00 \quad 0.000 \mathrm{E}+00 \quad 1.189 \mathrm{E}-26 \quad 1.091 \mathrm{E}-25 \quad 2.250 \mathrm{E}-21 \quad 1.025 \mathrm{E}-16$ $\begin{array}{llllll}5.915 \mathrm{E}-20 & 6.016 \mathrm{E}-20 & 1.380 \mathrm{E}-19 & 3.220 \mathrm{E}-19 & 2.822 \mathrm{E}-16 & 3.126 \mathrm{E}-12\end{array}$

$6.392 \mathrm{E}-20 \quad 9.628 \mathrm{E}-19 \quad 4.197 \mathrm{E}-14 \quad 4.245 \mathrm{E}-13 \quad 4.482 \mathrm{E}-10 \quad 1.044 \mathrm{E}-07$ $\begin{array}{llllll}9.254 \mathrm{E}-09 & 2.793 \mathrm{E}-08 & 1.305 \mathrm{E}-06 & 3.628 \mathrm{E}-06 & 2.632 \mathrm{E}-04 & 2.208 \mathrm{E}-02\end{array}$ $\begin{array}{llllll}4.168 \mathrm{E}-13 & 2.934 \mathrm{E}-12 & 4.464 \mathrm{E}-09 & 2.479 \mathrm{E}-08 & 9.207 \mathrm{E}-06 & 1.681 \mathrm{E}-03\end{array}$ $\begin{array}{llllll}5.253 \mathrm{E}-20 & 7.925 \mathrm{E}-19 & 3.794 \mathrm{E}-14 & 4.201 \mathrm{E}-13 & 7.878 \mathrm{E}-10 & 3.076 \mathrm{E}-07\end{array}$ $\begin{array}{llllll}9.254 \mathrm{E}-09 & 2.793 \mathrm{E}-08 & 1.309 \mathrm{E}-06 & 3.653 \mathrm{E}-06 & 2.724 \mathrm{E}-04 & 2.377 \mathrm{E}-02\end{array}$

$\begin{array}{llllll}0.000 \mathrm{E}+00 & 5.746 \mathrm{E}-27 & 6.196 \mathrm{E}-21 & 1.048 \mathrm{E}-19 & 2.936 \mathrm{E}-16 & 1.379 \mathrm{E}-13\end{array}$ $\begin{array}{llllll}4.460 \mathrm{E}-17 & 3.115 \mathrm{E}-16 & 3.186 \mathrm{E}-13 & 1.304 \mathrm{E}-12 & 1.887 \mathrm{E}-10 & 3.034 \mathrm{E}-08\end{array}$ $\begin{array}{llllll}1.509 \mathrm{E}-21 & 2.263 \mathrm{E}-20 & 8.100 \mathrm{E}-16 & 7.121 \mathrm{E}-15 & 6.193 \mathrm{E}-12 & 2.237 \mathrm{E}-09\end{array}$ $0.000 \mathrm{E}+00 \quad 4.727 \mathrm{E}-27 \quad 5.514 \mathrm{E}-21 \quad 1.012 \mathrm{E}-19 \quad 4.996 \mathrm{E}-16 \quad 3.969 \mathrm{E}-13$ $\begin{array}{llllll}4.460 \mathrm{E}-17 & 3.115 \mathrm{E}-16 & 3.194 \mathrm{E}-13 & 1.311 \mathrm{E}-12 & 1.949 \mathrm{E}-10 & 3.258 \mathrm{E}-08\end{array}$

$\begin{array}{llllll}8.843 \mathrm{E}-15 & 8.949 \mathrm{E}-15 & 1.607 \mathrm{E}-14 & 2.919 \mathrm{E}-14 & 3.463 \mathrm{E}-12 & 2.463 \mathrm{E}-09\end{array}$

$4.513 \mathrm{E}-21 \quad 1.369 \mathrm{E}-20 \quad 8.434 \mathrm{E}-19 \quad 3.112 \mathrm{E}-18 \quad 2.165 \mathrm{E}-15 \quad 4.048 \mathrm{E}-12$ $\begin{array}{llllll}2.083 \mathrm{E}-12 & 2.109 \mathrm{E}-12 & 3.865 \mathrm{E}-12 & 7.171 \mathrm{E}-12 & 1.007 \mathrm{E}-09 & 9.031 \mathrm{E}-07\end{array}$ $\begin{array}{llllll}2.083 \mathrm{E}-12 & 2.109 \mathrm{E}-12 & 3.865 \mathrm{E}-12 & 7.171 \mathrm{E}-12 & 1.007 \mathrm{E}-09 & 9.031 \mathrm{E}-07\end{array}$ 
RESRAD, Version $6.5 \quad T^{3 / 2}$ Limit $=180$ days

ummary : C746U Worker Deterministic Run

File : $\mathrm{X}: \backslash$ FINAL V2 $\backslash \mathrm{C} 746 \mathrm{U}$ W SG FWD-FINALV2.RAD

Individual Nuclide Dose Summed Over All Pathways

Parent Nuclide and Branch Fraction Indicated

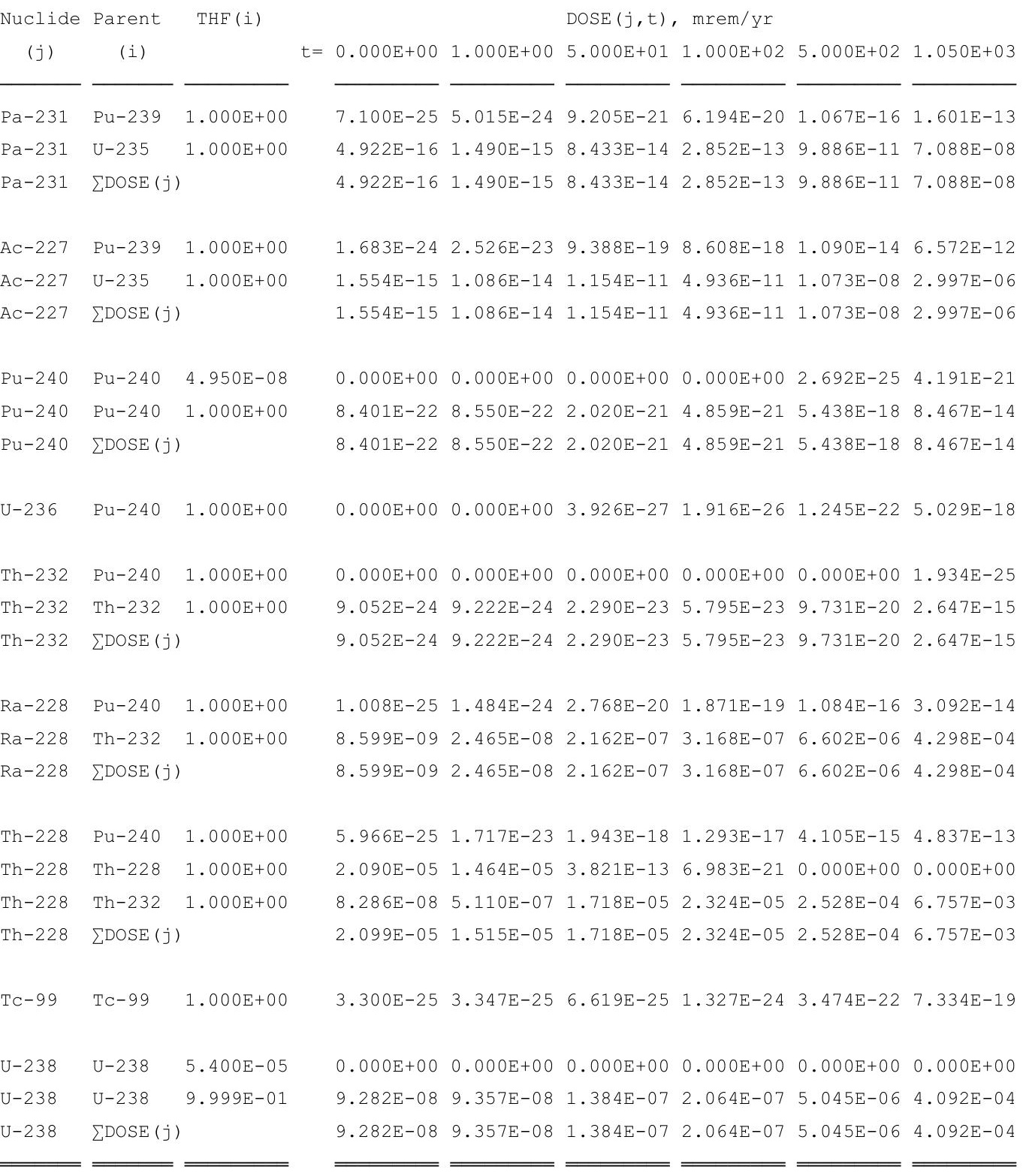

THF(i) is the thread fraction of the parent nuclide. 
RESRAD, Version $6.5 \quad T^{1 / 2}$ Limit $=180$ days

Summary : C746U Worker Deterministic Run

File : $\mathrm{X}: \backslash$ FINAL V2 $\backslash \mathrm{C} 746 \mathrm{U}$ W SG FWD-FINALV2.RAD

Individual Nuclide Soil Concentration

Parent Nuclide and Branch Fraction Indicated

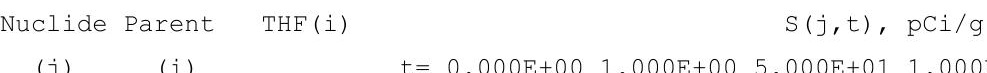

\section{(j)}

Am-241 Am-241 1.000E+00

$\mathrm{Np}-237 \mathrm{Am}-241 \quad 1.000 \mathrm{E}+00$

$\mathrm{Np}-237 \quad \mathrm{~Np}-237 \quad 1.000 \mathrm{E}+00$

Np-237 $\sum S(j):$

$\mathrm{U}-233 \mathrm{Am}-241 \quad 1.000 \mathrm{E}+00$

$\mathrm{U}-233 \mathrm{~Np}-237 \quad 1.000 \mathrm{E}+00$

$\mathrm{U}-233 \sum \mathrm{S}(j)$ :

Th-229

$\mathrm{Th}-229$

Th -229

$\mathrm{Cs}-137$

$\mathrm{Pu}-238$

$\mathrm{Pu}-238$

$\mathrm{Pu}-238$

$\mathrm{U}-234$

$\mathrm{U}-234$

$\mathrm{U}-234$

$\mathrm{U}-234$

Th -230

$\mathrm{Th}-230$

$\mathrm{Th}-230$

$\mathrm{Th}-230$

$\mathrm{Th}-230$

$\mathrm{Ra}-226$

$\mathrm{Ra}-226$

$\mathrm{Ra}-226$

$\mathrm{Ra}-226$

$\mathrm{Ra}-226$

$\mathrm{Pb}-210$

$\mathrm{Pb}-210$

$\mathrm{Pb}-210$

$\mathrm{Pb}-210$

$\mathrm{Pb}-210$

Pu-239

Am-241 1.000E+00

$\mathrm{Np}-237 \quad 1.000 \mathrm{E}+00$

$\sum S(j):$

Cs-137 1.000E+00

Pu-238 1.840E-09

$\mathrm{Pu}-238 \quad 1.000 \mathrm{E}+00$

$\sum S(j):$

$\mathrm{Pu}-238 \quad 1.000 \mathrm{E}+00$

$\mathrm{U}-234 \quad 1.000 \mathrm{E}+00$

U-238 9.999E-01

$\sum S(j):$

$\mathrm{Pu}-238 \quad 1.000 \mathrm{E}+00$

Th-230 1.000E+00

U-234 $1.000 \mathrm{E}+00$

U-238 9.999E-01

$\sum S(j):$

$\mathrm{Pu}-238 \quad 1.000 \mathrm{E}+00$

Th-230 1.000E+00

$\mathrm{U}-234 \quad 1.000 \mathrm{E}+00$

U-238 9.999E-01

$\sum S(j):$

$\mathrm{Pu}-238 \quad 1.000 \mathrm{E}+00$

Th-230 1.000E+00

$\mathrm{U}-234 \quad 1.000 \mathrm{E}+00$

$\mathrm{U}-2389.999 \mathrm{E}-01$

$\sum S(j):$

Pu-239 1.000E+00

$\mathrm{Pu}-239 \quad 1.000 \mathrm{E}+00$

$\mathrm{U}-2351.000 \mathrm{E}+00$

$\sum S(j):$
$=0.000 \mathrm{E}+001.000 \mathrm{E}+00 \quad 5.000 \mathrm{E}+01 \quad 1.000 \mathrm{E}+02 \quad 5.000 \mathrm{E}+02 \quad 1.050 \mathrm{E}+03$

$\begin{array}{lllll}3.500 \mathrm{E}+03 & 3.494 \mathrm{E}+03 & 3.230 \mathrm{E}+03 & 2.981 \mathrm{E}+03 & 1.567 \mathrm{E}+03 \quad 6.478 \mathrm{E}+02\end{array}$

$0.000 \mathrm{E}+00$ 1.133E-03 5.436E-02 1.043E-01 3.810E-01 5.458E-01

$5.500 \mathrm{E}+02 \quad 5.500 \mathrm{E}+02 \quad 5.478 \mathrm{E}+02 \quad 5.457 \mathrm{E}+02 \quad 5.288 \mathrm{E}+02 \quad 5.064 \mathrm{E}+02$

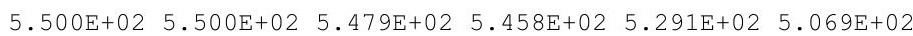

$0.000 \mathrm{E}+00 \quad 2.477 \mathrm{E}-09 \quad 6.025 \mathrm{E}-06 \quad 2.344 \mathrm{E}-05 \quad 4.742 \mathrm{E}-04 \quad 1.613 \mathrm{E}-03$

$\begin{array}{lllllll}0.000 \mathrm{E}+00 & 2.405 \mathrm{E}-03 & 1.200 \mathrm{E}-01 & 2.394 \mathrm{E}-01 & 1.174 \mathrm{E}+00 & 2.401 \mathrm{E}+00\end{array}$

$\begin{array}{lllllll}0.000 \mathrm{E}+00 & 2.405 \mathrm{E}-03 & 1.200 \mathrm{E}-01 & 2.394 \mathrm{E}-01 & 1.174 \mathrm{E}+00 & 2.403 \mathrm{E}+00\end{array}$

$0.000 \mathrm{E}+00 \quad 7.799 \mathrm{E}-14 \quad 9.538 \mathrm{E}-09 \quad 7.463 \mathrm{E}-08 \quad 7.873 \mathrm{E}-06 \quad 5.891 \mathrm{E}-05$

$\begin{array}{lllllll}0.000 \mathrm{E}+00 & 1.136 \mathrm{E}-07 & 2.830 \mathrm{E}-04 & 1.128 \mathrm{E}-03 & 2.750 \mathrm{E}-02 & 1.171 \mathrm{E}-01\end{array}$

$0.000 \mathrm{E}+00 \quad 1.136 \mathrm{E}-07 \quad 2.830 \mathrm{E}-04 \quad 1.128 \mathrm{E}-03 \quad 2.750 \mathrm{E}-02 \quad 1.171 \mathrm{E}-01$

$\begin{array}{lllll}1.900 \mathrm{E}+02 & 1.857 \mathrm{E}+02 & 5.979 \mathrm{E}+01 & 1.881 \mathrm{E}+01 & 1.809 \mathrm{E}-03 \quad 5.417 \mathrm{E}-09\end{array}$

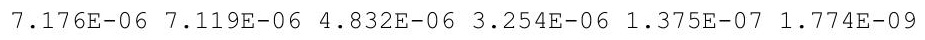

$\begin{array}{llllll}3.900 \mathrm{E}+03 & 3.869 \mathrm{E}+03 & 2.626 \mathrm{E}+03 & 1.768 \mathrm{E}+03 & 7.472 \mathrm{E}+01 & 9.639 \mathrm{E}-01\end{array}$

$\begin{array}{llllll}3.900 \mathrm{E}+03 & 3.869 \mathrm{E}+03 & 2.626 \mathrm{E}+03 & 1.768 \mathrm{E}+03 & 7.472 \mathrm{E}+01 & 9.639 \mathrm{E}-01\end{array}$

$0.000 \mathrm{E}+00 \quad 1.101 \mathrm{E}-02 \quad 4.564 \mathrm{E}-01 \quad 7.633 \mathrm{E}-01 \quad 1.362 \mathrm{E}+00 \quad 1.377 \mathrm{E}+00$

$\begin{array}{lllllll}1.800 \mathrm{E}+04 & 1.800 \mathrm{E}+04 & 1.799 \mathrm{E}+04 & 1.797 \mathrm{E}+04 & 1.785 \mathrm{E}+04 & 1.770 \mathrm{E}+04\end{array}$

$\begin{array}{lllllll}0.000 \mathrm{E}+00 & 9.071 \mathrm{E}-03 & 4.532 \mathrm{E}-01 & 9.058 \mathrm{E}-01 & 4.502 \mathrm{E}+00 & 9.378 \mathrm{E}+00\end{array}$

$\begin{array}{llllll}1.800 \mathrm{E}+04 & 1.800 \mathrm{E}+04 & 1.799 \mathrm{E}+04 & 1.797 \mathrm{E}+04 & 1.786 \mathrm{E}+04 & 1.771 \mathrm{E}+04\end{array}$

$0.000 \mathrm{E}+00 \quad 4.963 \mathrm{E}-08 \quad 1.095 \mathrm{E}-04 \quad 3.884 \mathrm{E}-04 \quad 4.705 \mathrm{E}-03 \quad 1.147 \mathrm{E}-02$

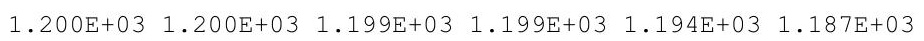
$0.000 \mathrm{E}+00 \quad 1.620 \mathrm{E}-01 \quad 8.096 \mathrm{E}+00 \quad 1.618 \mathrm{E}+01 \quad 8.047 \mathrm{E}+01 \quad 1.677 \mathrm{E}+02$ $0.000 \mathrm{E}+00 \quad 4.083 \mathrm{E}-08 \quad 1.020 \mathrm{E}-04 \quad 4.077 \mathrm{E}-04 \quad 1.014 \mathrm{E}-02 \quad 4.438 \mathrm{E}-02$

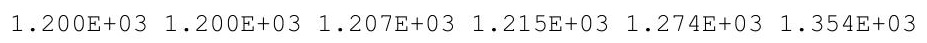

$0.000 \mathrm{E}+00 \quad 7.171 \mathrm{E}-12 \quad 8.112 \mathrm{E}-07 \quad 5.891 \mathrm{E}-06 \quad 3.952 \mathrm{E}-04 \quad 2.049 \mathrm{E}-03$ $\begin{array}{lllllllll}0.000 E+00 \quad 5.197 E-01 & 2.570 E+01 & 5.082 E+01 & 2.324 E+02 & 4.336 E+02\end{array}$ $\begin{array}{llllll}0.000 \mathrm{E}+00 & 3.509 \mathrm{E}-05 & 8.706 \mathrm{E}-02 & 3.455 \mathrm{E}-01 & 8.122 \mathrm{E}+00 & 3.300 \mathrm{E}+01\end{array}$ $0.000 \mathrm{E}+00 \quad 5.895 \mathrm{E}-12 \quad 7.326 \mathrm{E}-07 \quad 5.825 \mathrm{E}-06 \quad 6.943 \mathrm{E}-04 \quad 6.033 \mathrm{E}-03$ $\begin{array}{lllllll}0.000 \mathrm{E}+00 & 5.198 \mathrm{E}-01 & 2.579 \mathrm{E}+01 & 5.117 \mathrm{E}+01 & 2.406 \mathrm{E}+02 \quad 4.666 \mathrm{E}+02\end{array}$

$\begin{array}{lllllll}0.000 \mathrm{E}+00 & 5.540 \mathrm{E}-14 & 2.418 \mathrm{E}-07 & 2.812 \mathrm{E}-06 & 3.398 \mathrm{E}-04 & 1.921 \mathrm{E}-03\end{array}$ $0.000 \mathrm{E}+00 \quad 7.995 \mathrm{E}-03 \quad 1.269 \mathrm{E}+01 \quad 3.535 \mathrm{E}+01 \quad 2.188 \mathrm{E}+02 \quad 4.228 \mathrm{E}+02$ $\begin{array}{llllll}0.000 \mathrm{E}+00 & 3.608 \mathrm{E}-07 & 3.192 \mathrm{E}-02 & 1.920 \mathrm{E}-01 & 7.171 \mathrm{E}+00 & 3.116 \mathrm{E}+01\end{array}$ $\begin{array}{lllllll}0.000 \mathrm{E}+00 & 4.553 \mathrm{E}-14 & 2.150 \mathrm{E}-07 & 2.712 \mathrm{E}-06 & 5.779 \mathrm{E}-04 & 5.526 \mathrm{E}-03\end{array}$ $\begin{array}{llllll}0.000 \mathrm{E}+00 & 7.995 \mathrm{E}-03 & 1.272 \mathrm{E}+01 & 3.554 \mathrm{E}+01 & 2.260 \mathrm{E}+02 \quad 4.540 \mathrm{E}+02\end{array}$

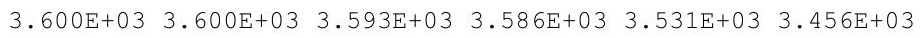
$0.000 \mathrm{E}+00 \quad 3.545 \mathrm{E}-06 \quad 1.770 \mathrm{E}-04 \quad 3.536 \mathrm{E}-04 \quad 1.750 \mathrm{E}-03 \quad 3.622 \mathrm{E}-03$ $8.200 \mathrm{E}+02 \quad 8.200 \mathrm{E}+02 \quad 8.195 \mathrm{E}+02 \quad 8.189 \mathrm{E}+02 \quad 8.145 \mathrm{E}+02 \quad 8.085 \mathrm{E}+02$ $8.200 \mathrm{E}+02 \quad 8.200 \mathrm{E}+02 \quad 8.195 \mathrm{E}+02 \quad 8.189 \mathrm{E}+02 \quad 8.145 \mathrm{E}+02 \quad 8.085 \mathrm{E}+02$ 
RESRAD, Version $6.5 \quad T^{3 / 2}$ Limit $=180$ days

Summary : C746U Worker Deterministic Run

File : $\mathrm{X}: \backslash$ FINAL V2 $\backslash \mathrm{C} 746 \mathrm{U}$ W SG FWD-FINALV2.RAD

Individual Nuclide Soil Concentration

Parent Nuclide and Branch Fraction Indicated

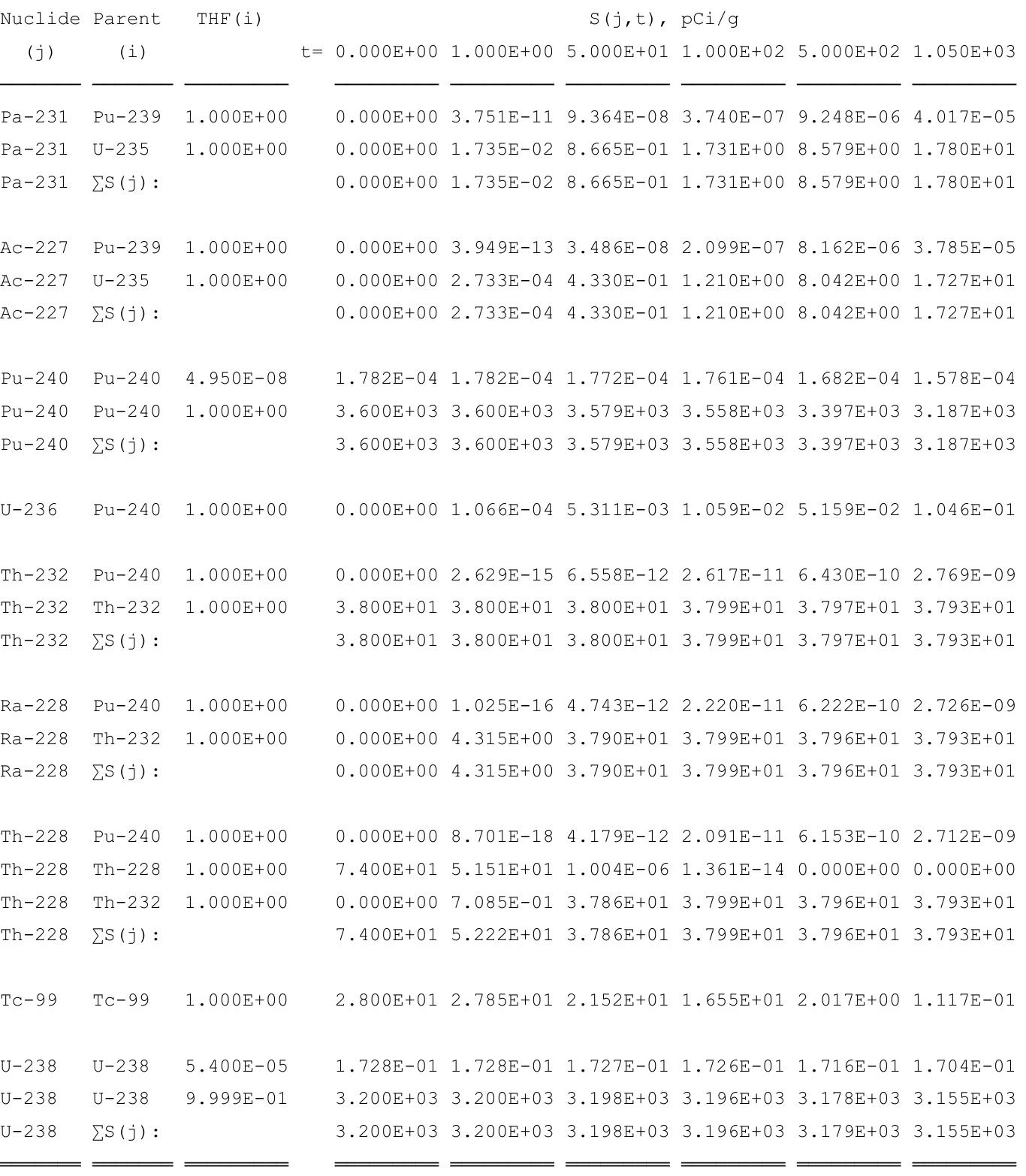

THF(i) is the thread fraction of the parent nuclide.

RESCALC.EXE execution time $=2.81$ seconds 


\section{Landfill Worker}

The following summary report includes the single radionuclide soil guidelines based on a unit concentration for targeted radionuclides. 
THIS PAGE INTENTIONALLY LEFT BLANK 
RESRAD, Version $6.5 \quad T^{1 / 2}$ Limit $=180$ days

Summary : C746U Landfill Worker Deterministic Run

File : $\mathrm{X}: \backslash$ FINAL V2 $\backslash \mathrm{C746U}$ LANDFILL WORKER DET-FINALV2.RAD

Table of Contents

Part I: Mixture Sums and Single Radionuclide Guidelines

Dose Conversion Factor (and Related) Parameter Summary ... 2

Site-Specific Parameter Summary $\ldots \ldots \ldots \ldots \ldots \ldots \ldots \ldots \ldots$

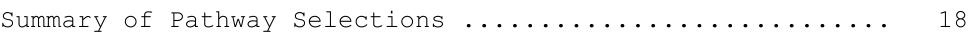

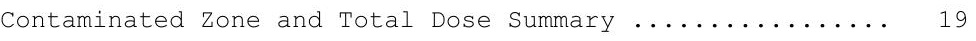

Total Dose Components

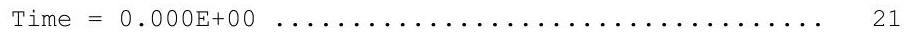

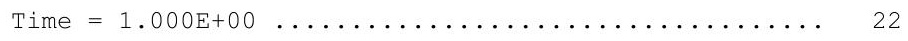

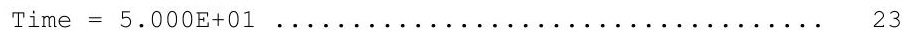

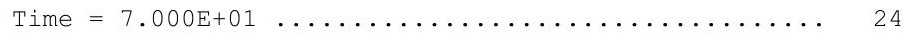

Dose/Source Ratios Summed Over All Pathways ............ 25

Single Radionuclide Soil Guidelines ............... 27

Dose Per Nuclide Summed Over All Pathways ............ 28

Soil Concentration Per Nuclide ................. 30 
RESRAD, Version $6.5 \quad \mathrm{~T}^{1} \frac{1}{2}$ Limit $=180$ days

Summary : C746U Landfill Worker Deterministic Run

File : $\mathrm{X}: \backslash$ FINAL V2 $\backslash \mathrm{C} 746 \mathrm{U}$ LANDFILL WORKER DET-FINALV2.RAD

Dose Conversion Factor (and Related) Parameter Summary

Dose Library: ICRP 60 \& ICRP 72 (Adult)

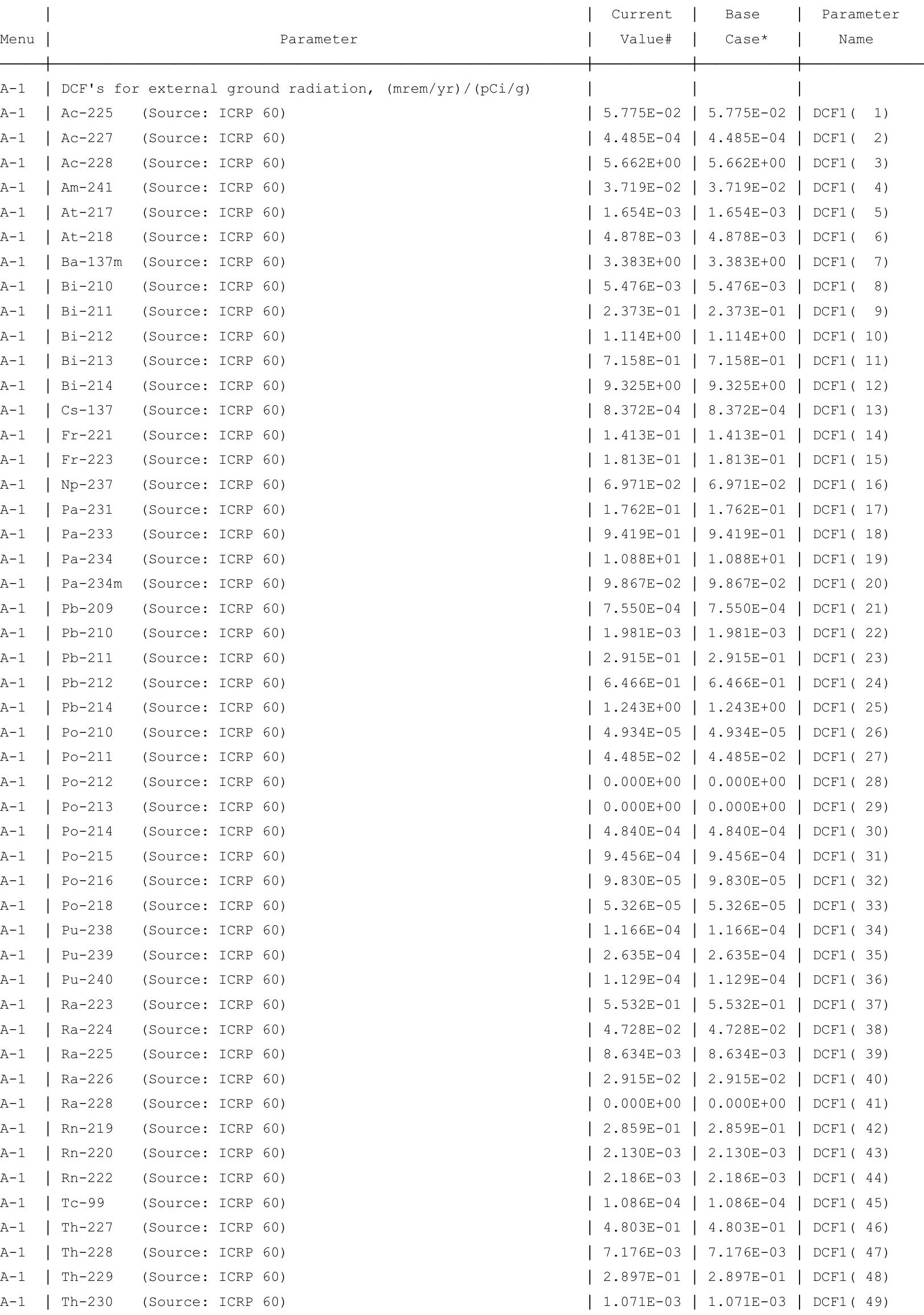


RESRAD, Version $6.5 \quad \mathrm{~T}^{1} \frac{1}{2}$ Limit $=180$ days

05/03/2011 15:49 Page

Summary : C746U Landfill Worker Deterministic Run

File : $\mathrm{X}: \backslash$ FINAL V2 $\backslash \mathrm{C} 746 \mathrm{U}$ LANDFILL WORKER DET-FINALV2.RAD

Dose Conversion Factor (and Related) Parameter Summary (continued)

Dose Library: ICRP 60 \& ICRP 72 (Adult)

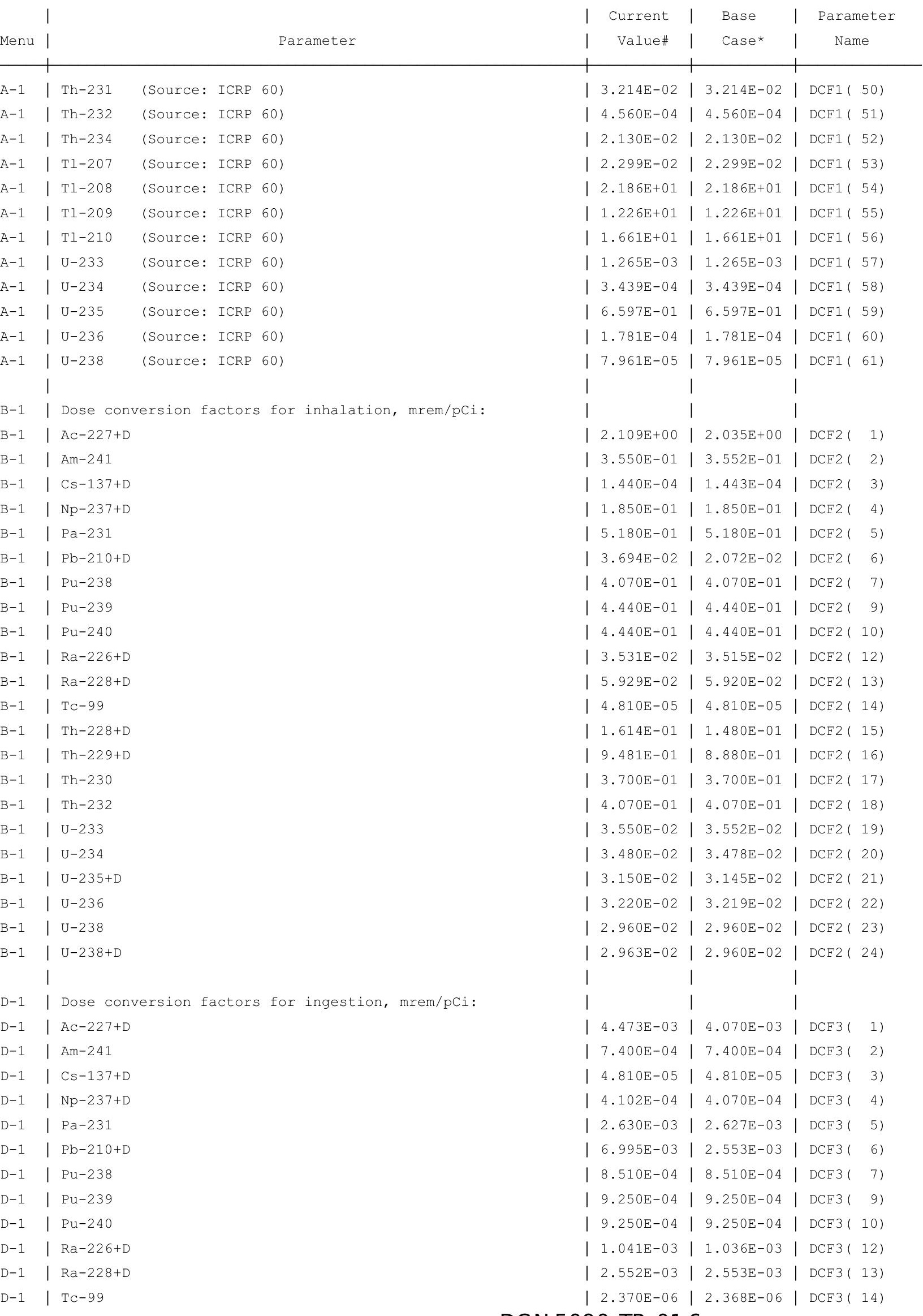


RESRAD, Version $6.5 \quad \mathrm{~T}^{1} \frac{1}{2}$ Limit $=180$ days

ummary : C746U Landfill Worker Deterministic Run

File : $\mathrm{X}: \backslash$ FINAL V2 $\backslash \mathrm{C} 746 \mathrm{U}$ LANDFILL WORKER DET-FINALV2.RAD

Dose Conversion Factor (and Related) Parameter Summary (continued)

Dose Library: ICRP 60 \& ICRP 72 (Adult)

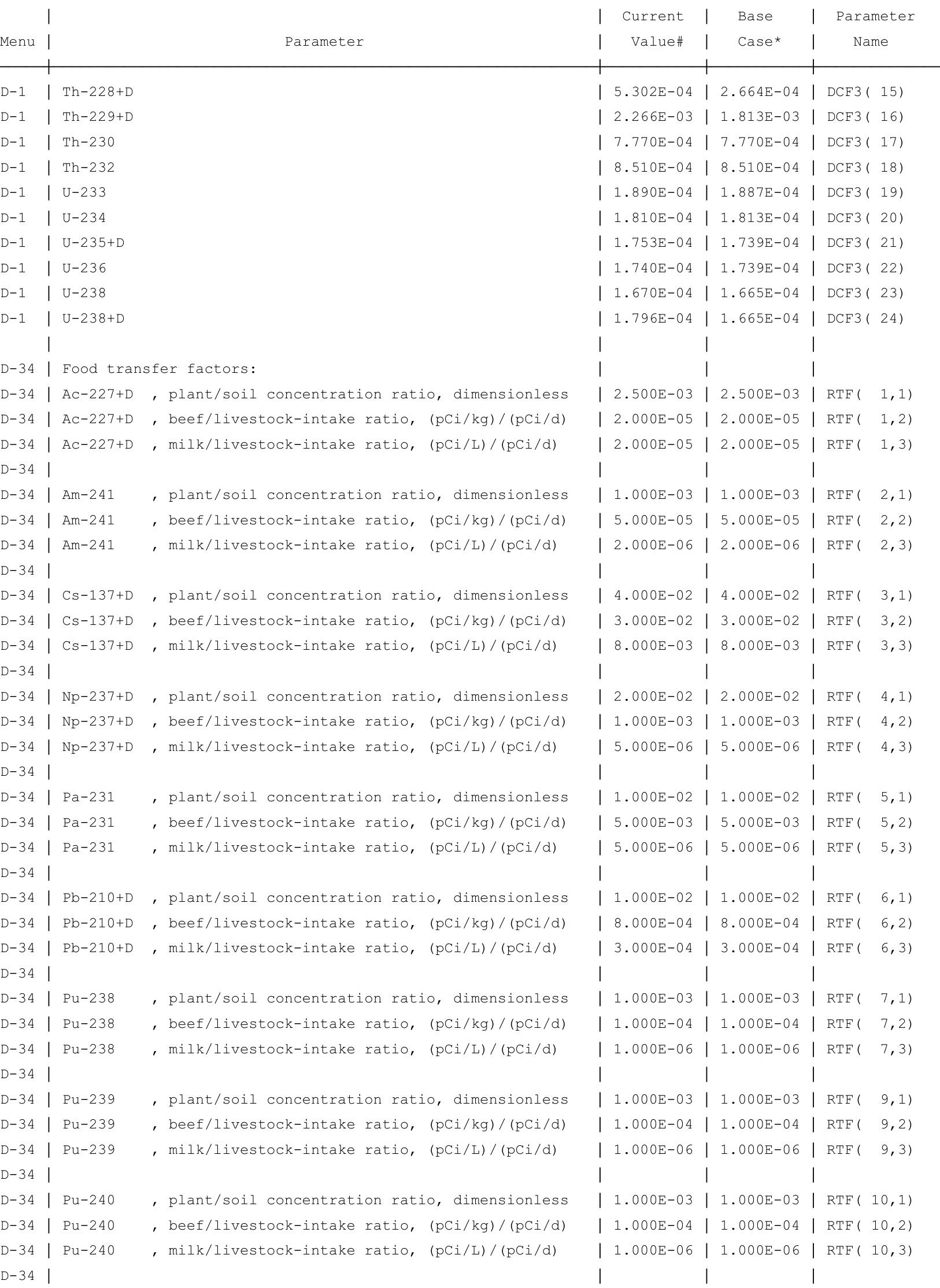


RESRAD, Version $6.5 \quad T^{1 / 2}$ Limit $=180$ days

05/03/2011 15:49 Page

Summary : C746U Landfill Worker Deterministic Run

File : X: \FINAL V2\C746U LANDFILL WORKER DET-FINALV2.RAD

Dose Conversion Factor (and Related) Parameter Summary (continued)

Dose Library: ICRP 60 \& ICRP 72 (Adult)

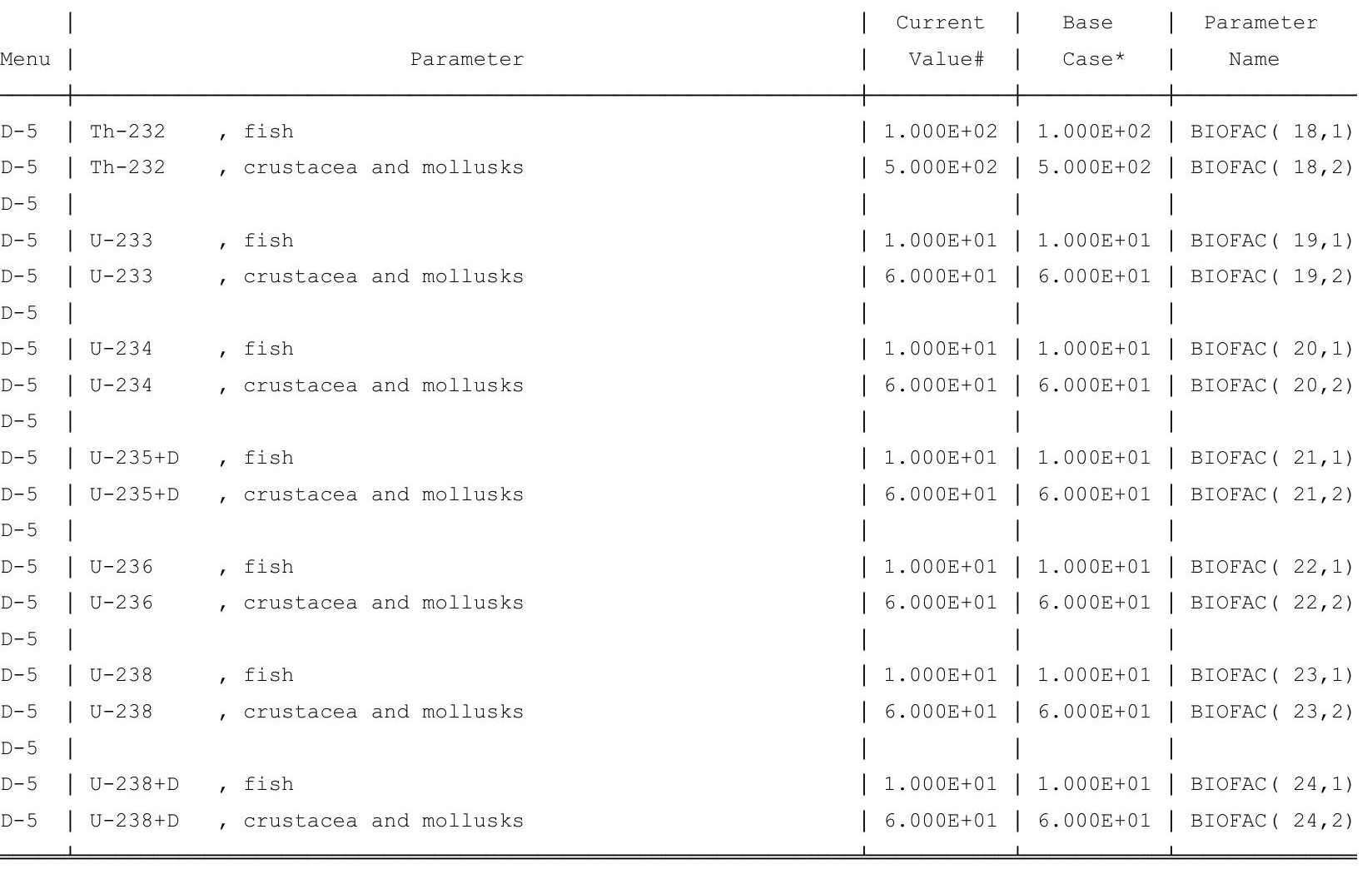

\#For DCFl(xxx) only, factors are for infinite depth \& area. See ETFG table in Ground Pathway of Detailed Report. *Base Case means Default.Lib w/o Associate Nuclide contributions. 
RESRAD, Version $6.5 \quad T^{1 / 2}$ Limit $=180$ days

Summary : C746U Landfill Worker Deterministic Run

File : $\mathrm{X}: \backslash$ FINAL V2 $\backslash$ C746U LANDFILL WORKER DET-FINALV2.RAD

Site-Specific Parameter Summary (continued)

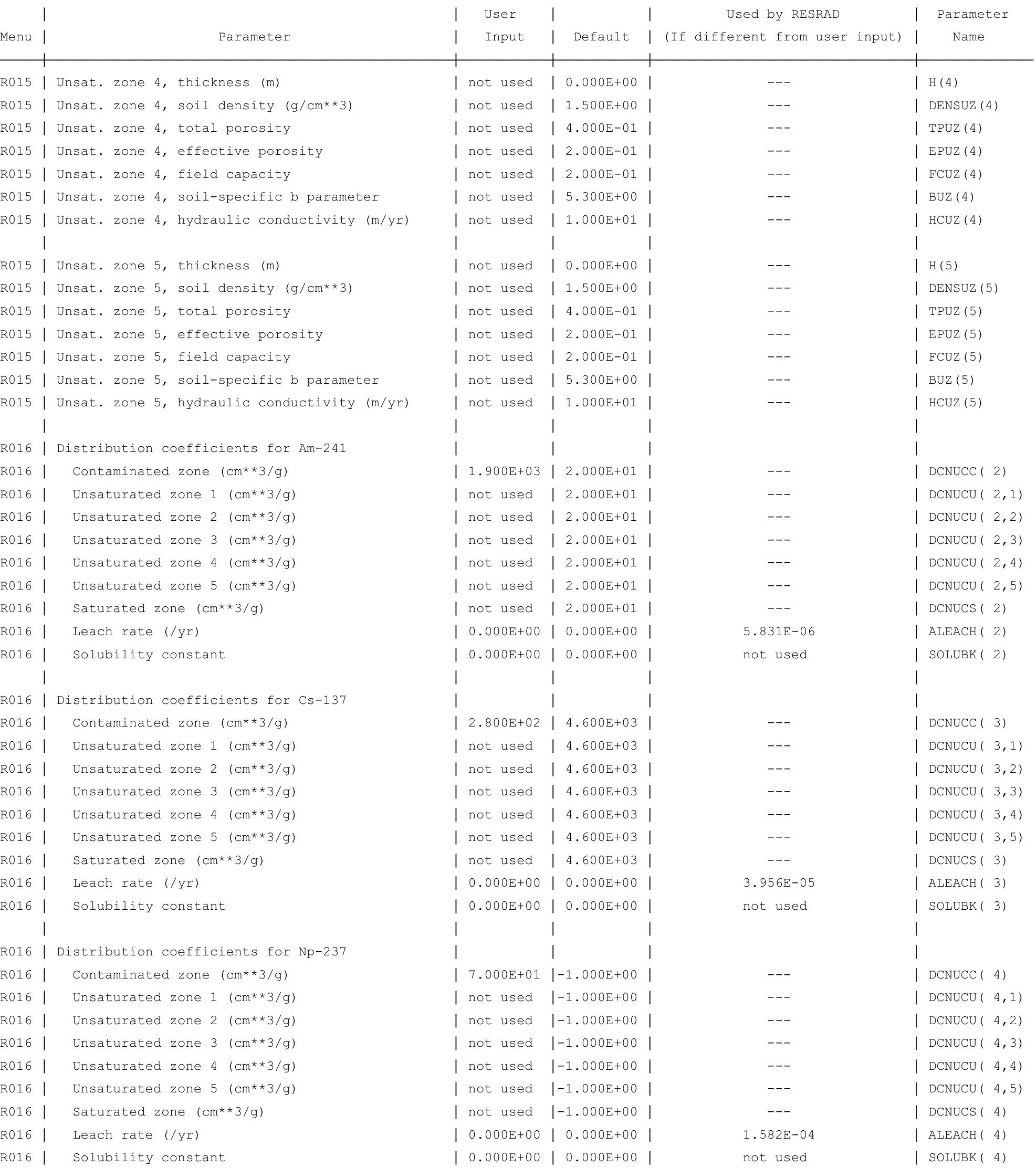


RESRAD, Version $6.5 \quad T^{1 / 2}$ Limit $=180$ days

05/03/2011 15:49 Page 12

Summary : C746U Landfill Worker Deterministic Run

File : $\mathrm{X}: \backslash$ FINAL V2 $\backslash \mathrm{C} 746 \mathrm{U}$ LANDFILL WORKER DET-FINALV2.RAD

Site-Specific Parameter Summary (continued)

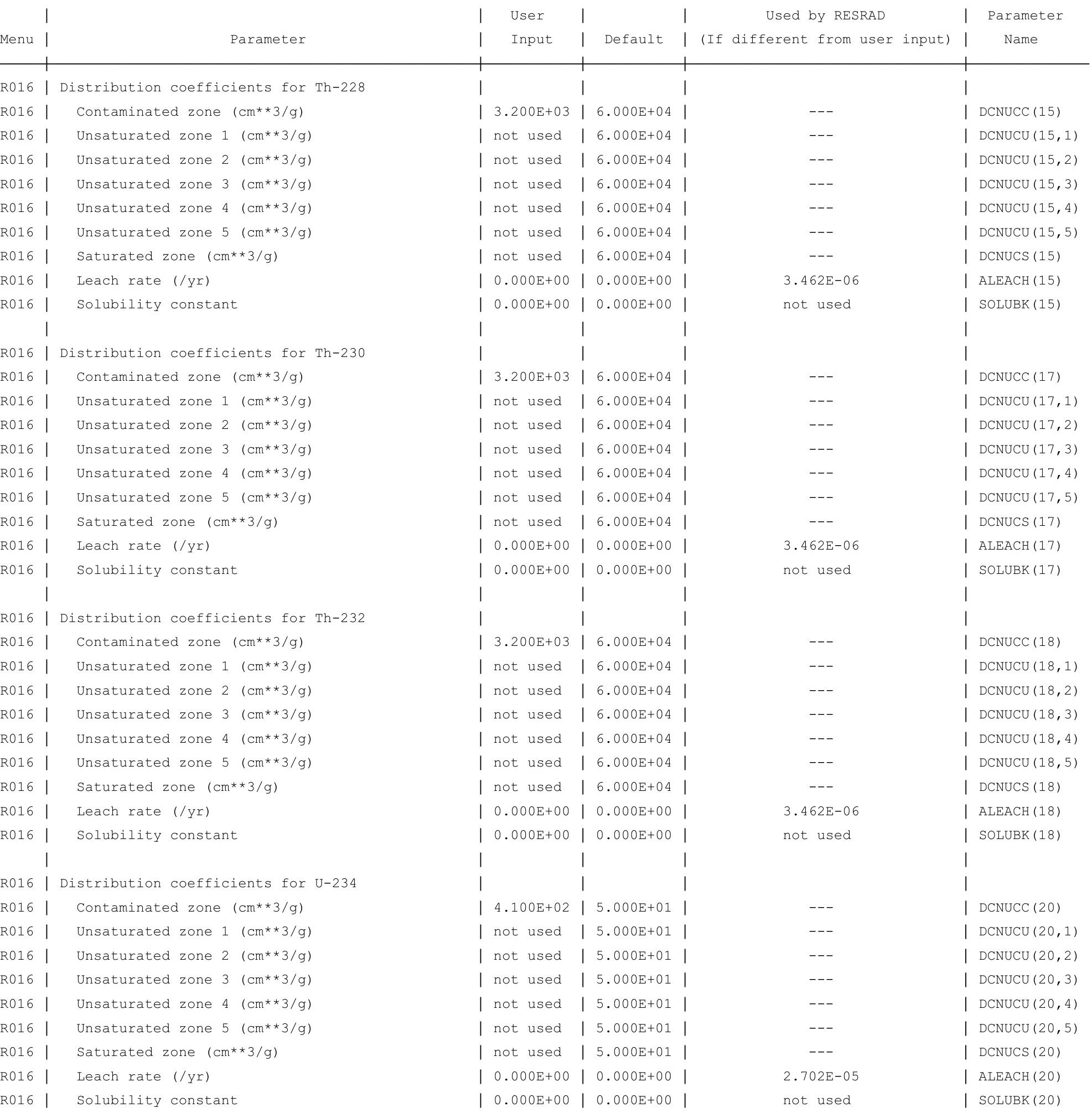


RESRAD, Version $6.5 \quad T^{1 / 2}$ Limit $=180$ days

Summary : C746U Landfill Worker Deterministic Run

File : $\mathrm{X}: \backslash F I N A L$ V2 $\backslash C 746 \mathrm{U}$ LANDFILL WORKER DET-FINALV2.RAD

Site-Specific Parameter Summary (continued)

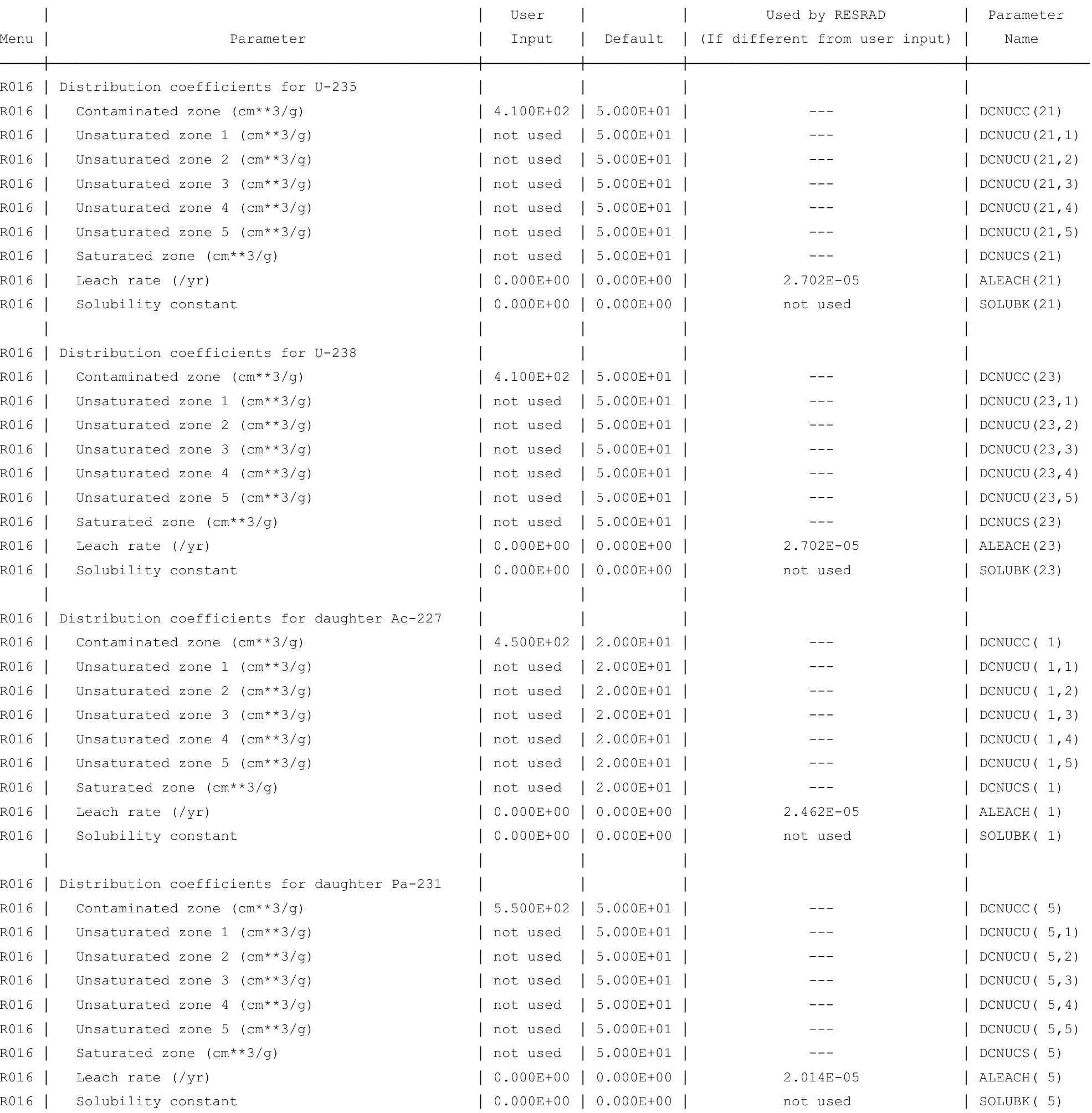


RESRAD, Version $6.5 \quad T^{1 / 2}$ Limit $=180$ days

Summary : C746U Landfill Worker Deterministic Run

File : $\mathrm{X}: \backslash$ FINAL V2 $\backslash \mathrm{C} 746 \mathrm{U}$ LANDFILL WORKER DET-FINALV2.RAD

Site-Specific Parameter Summary (continued)

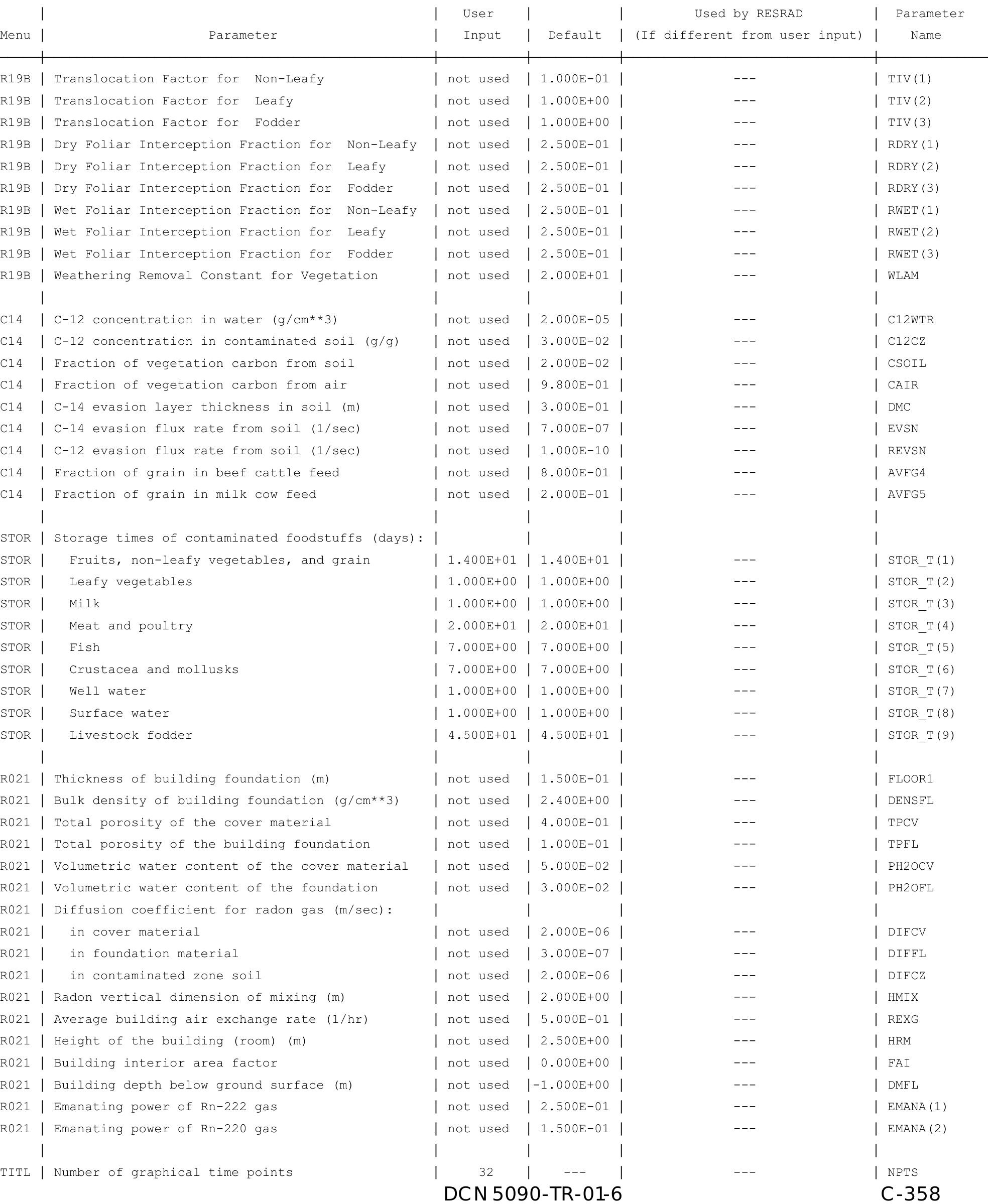


RESRAD, Version $6.5 \quad T^{1 / 2}$ Limit $=180$ days

Summary : C746U Landfill Worker Deterministic Run

File : $\mathrm{X}: \backslash$ FINAL V2 $\backslash \mathrm{C} 746 \mathrm{U}$ LANDFILL WORKER DET-FINALV2.RAD

Contaminated Zone Dimensions

Area: 89436.00 square meters

Thickness:

Cover Depth:

$$
\begin{array}{r}
13.40 \text { meters } \\
0.00 \text { meters }
\end{array}
$$

Initial Soil Concentrations, pCi/g

$\begin{array}{ll}\mathrm{Am}-241 & 1.000 \mathrm{E}+00 \\ \mathrm{Cs}-137 & 1.000 \mathrm{E}+00 \\ \mathrm{~Np}-237 & 1.000 \mathrm{E}+00 \\ \mathrm{Pu}-238 & 1.000 \mathrm{E}+00 \\ \mathrm{Pu}-239 & 1.000 \mathrm{E}+00 \\ \mathrm{Pu}-240 & 1.000 \mathrm{E}+00 \\ \mathrm{TC}-99 & 1.000 \mathrm{E}+00 \\ \mathrm{Th}-228 & 1.000 \mathrm{E}+00 \\ \mathrm{Th}-230 & 1.000 \mathrm{E}+00 \\ \mathrm{Th}-232 & 1.000 \mathrm{E}+00 \\ \mathrm{U}-234 & 1.000 \mathrm{E}+00 \\ \mathrm{U}-235 & 1.000 \mathrm{E}+00 \\ \mathrm{U}-238 & 1.000 \mathrm{E}+00\end{array}$

Total Dose TDOSE(t), mrem/yr

Basic Radiation Dose Limit $=1.000 \mathrm{E}+02 \mathrm{mrem} / \mathrm{yr}$

Total Mixture Sum $M(t)$ = Fraction of Basic Dose Limit Received at Time (t)

$\begin{array}{rllll}t \text { (years }): & 0.000 \mathrm{E}+00 & 1.000 \mathrm{E}+00 & 5.000 \mathrm{E}+01 & 7.000 \mathrm{E}+01 \\ \text { TDOSE }(t): & 2.455 \mathrm{E}+00 & 2.192 \mathrm{E}+00 & 3.322 \mathrm{E}+00 & 3.281 \mathrm{E}+00 \\ \mathrm{M}(\mathrm{t}): & 2.455 \mathrm{E}-02 & 2.192 \mathrm{E}-02 & 3.322 \mathrm{E}-02 & 3.281 \mathrm{E}-02\end{array}$

Maximum TDOSE $(t): \quad 3.343 E+00 \mathrm{mrem} / \mathrm{yr}$ at $t=36.83 \pm 0.07$ years

Total Dose Contributions TDOSE (i,p,t) for Individual Radionuclides (i) and Pathways (p) As mrem/yr and Fraction of Total Dose At $t=3.683 \mathrm{E}+01$ years

\begin{tabular}{|c|c|c|c|c|c|c|c|c|c|c|c|c|c|c|}
\hline & \multicolumn{2}{|c|}{ Ground } & \multicolumn{2}{|c|}{ Inhalation } & \multicolumn{2}{|c|}{ Radon } & \multicolumn{2}{|c|}{ Plant } & \multicolumn{2}{|c|}{ Meat } & \multicolumn{2}{|c|}{ Milk } & \multicolumn{2}{|c|}{ Soil } \\
\hline clide & mrem/yr & fract. & mrem/yr & fract. & mrem/yr & fract. & mrem/yr & fract. & mrem/yr & fract. & mrem/yr & fract. & mrem/yr & fract. \\
\hline 241 & $5.936 E-03$ & 0.0018 & $1.701 \mathrm{E}-04$ & 0.0001 & $0.000 \mathrm{E}+00$ & 0.0000 & $0.000 \mathrm{E}+00$ & 0.0000 & $0.000 \mathrm{E}+00$ & 0.0000 & $0.000 \mathrm{E}+00$ & 0.0000 & $2.075 E-02$ & 0.0062 \\
\hline-137 & $2.238 E-01$ & 0.0669 & $3.087 \mathrm{E}-08$ & 0.0000 & $0.000 \mathrm{E}+00$ & 0.0000 & $0.000 \mathrm{E}+00$ & 0.0000 & $0.000 \mathrm{E}+00$ & 0.0000 & $0.000 \mathrm{E}+00$ & 0.0000 & $6.038 \mathrm{E}-04$ & 0.0002 \\
\hline-237 & $1.683 E-01$ & 0.0503 & $9.357 \mathrm{E}-05$ & 0.0000 & $0.000 \mathrm{E}+00$ & 0.0000 & $0.000 \mathrm{E}+00$ & 0.0000 & $0.000 \mathrm{E}+00$ & 0.0000 & $0.000 \mathrm{E}+00$ & 0.0000 & $1.215 E-02$ & 0.0036 \\
\hline-238 & $1.474 \mathrm{E}-05$ & 0.0000 & $1.541 \mathrm{E}-04$ & 0.0000 & $0.000 \mathrm{E}+00$ & 0.0000 & $0.000 \mathrm{E}+00$ & 0.0000 & $0.000 \mathrm{E}+00$ & 0.0000 & $0.000 \mathrm{E}+00$ & 0.0000 & $1.886 \mathrm{E}-02$ & 0.0056 \\
\hline-239 & $4.414 \mathrm{E}-05$ & 0.0000 & $2.255 \mathrm{E}-04$ & 0.0001 & $0.000 \mathrm{E}+00$ & 0.0000 & $0.000 \mathrm{E}+00$ & 0.0000 & $0.000 \mathrm{E}+00$ & 0.0000 & $0.000 \mathrm{E}+00$ & 0.0000 & $2.750 \mathrm{E}-02$ & 0.0082 \\
\hline-240 & $1.905 E-05$ & 0.0000 & $2.248 E-04$ & 0.0001 & $0.000 \mathrm{E}+00$ & 0.0000 & $0.000 \mathrm{E}+00$ & 0.0000 & $0.000 \mathrm{E}+00$ & 0.0000 & $0.000 \mathrm{E}+00$ & 0.0000 & $2.742 \mathrm{E}-02$ & 0.0082 \\
\hline 99 & $1.233 E-05$ & 0.0000 & $1.649 \mathrm{E}-08$ & 0.0000 & $0.000 \mathrm{E}+00$ & 0.0000 & $0.000 \mathrm{E}+00$ & 0.0000 & $0.000 \mathrm{E}+00$ & 0.0000 & $0.000 \mathrm{E}+00$ & 0.0000 & $4.756 \mathrm{E}-05$ & 0.0000 \\
\hline-228 & $2.155 E-06$ & 0.0000 & $1.102 \mathrm{E}-10$ & 0.0000 & $0.000 \mathrm{E}+00$ & 0.0000 & $0.000 \mathrm{E}+00$ & 0.0000 & $0.000 \mathrm{E}+00$ & 0.0000 & $0.000 \mathrm{E}+00$ & 0.0000 & $2.119 \mathrm{E}-08$ & 0.0000 \\
\hline-230 & $2.840 E-02$ & 0.0085 & $1.886 \mathrm{E}-04$ & 0.0001 & $0.000 \mathrm{E}+00$ & 0.0000 & $0.000 \mathrm{E}+00$ & 0.0000 & $0.000 \mathrm{E}+00$ & 0.0000 & $0.000 \mathrm{E}+00$ & 0.0000 & $2.499 \mathrm{E}-02$ & 0.0075 \\
\hline-232 & $2.508 \mathrm{E}+00$ & 0.7504 & $3.176 \mathrm{E}-04$ & 0.0001 & $0.000 \mathrm{E}+00$ & 0.0000 & $0.000 \mathrm{E}+00$ & 0.0000 & $0.000 \mathrm{E}+00$ & 0.0000 & $0.000 \mathrm{E}+00$ & 0.0000 & $1.160 \mathrm{E}-01$ & 0.0347 \\
\hline 4 & $6.281 E-05$ & 0.0000 & $1.775 E-05$ & 0.0000 & $0.000 \mathrm{E}+00$ & 0.0000 & $0.000 \mathrm{E}+00$ & 0.0000 & $0.000 \mathrm{E}+00$ & 0.0000 & $0.000 E+00$ & 0.0000 & $5.393 E-03$ & 0.0016 \\
\hline 35 & $1.161 \mathrm{E}-01$ & 0.0347 & $1.657 \mathrm{E}-05$ & 0.0000 & $0.000 \mathrm{E}+00$ & 0.0000 & $0.000 \mathrm{E}+00$ & 0.0000 & $0.000 \mathrm{E}+00$ & 0.0000 & $0.000 \mathrm{E}+00$ & 0.0000 & $5.320 E-03$ & 0.0016 \\
\hline 38 & $2.590 \mathrm{E}-02$ & 0.0077 & $1.506 \mathrm{E}-05$ & 0.0000 & $0.000 \mathrm{E}+00$ & 0.0000 & $0.000 \mathrm{E}+00$ & 0.0000 & $0.000 \mathrm{E}+00$ & 0.0000 & $0.000 \mathrm{E}+00$ & 0.0000 & $5.345 E-03$ & 0.0016 \\
\hline & $3.077 \mathrm{E}+00$ & 0.9 & $1.424 \mathrm{E}-03$ & 0.0004 & $0.000 \mathrm{E}+00$ & 0.0000 & $0.000 \mathrm{E}+00$ & 000 & $0.000 \mathrm{E}+00$ & 000 & $0.000 \mathrm{E}+00$ & 00 & -01 & 0 \\
\hline
\end{tabular}

Water Independent Pathways (Inhalation excludes radon) 
RESRAD, Version $6.5 \quad \mathrm{~T}^{1 / 2}$ Limit $=180$ days

ummary : C746U Landfill Worker Deterministic Run

File : $\mathrm{X}: \backslash$ FINAL V2\C746U LANDFILL WORKER DET-FINALV2.RAD

Total Dose Contributions TDOSE(i,p,t) for Individual Radionuclides (i) and Pathways (p) As mrem/yr and Fraction of Total Dose At $t=3.683 \mathrm{E}+01$ years

Water Dependent Pathways

\begin{tabular}{|c|c|c|c|c|c|c|c|c|c|c|c|c|c|c|}
\hline & \multicolumn{2}{|c|}{ Water } & \multicolumn{2}{|c|}{ Fish } & \multicolumn{2}{|c|}{ Radon } & \multicolumn{2}{|c|}{ Plant } & \multicolumn{2}{|c|}{ Meat } & \multicolumn{2}{|c|}{ Milk } & \multicolumn{2}{|c|}{ All Pathways* } \\
\hline clide & mrem/yr & fract. & mrem/yr & fract. & mrem/yr & fract. & mrem/yr & fract. & mrem/yr & fract. & mrem/yr & fract. & mrem/yr & fract. \\
\hline 241 & $0.000 \mathrm{E}+00$ & 0.0000 & $0.000 \mathrm{E}+00$ & 0.0000 & $0.000 \mathrm{E}+00$ & 0.0000 & $0.000 \mathrm{E}+00$ & 0.0000 & $0.000 \mathrm{E}+00$ & 0.0000 & $0.000 \mathrm{E}+00$ & 0.0000 & $2.686 \mathrm{E}-02$ & 0.0080 \\
\hline-137 & $0.000 \mathrm{E}+00$ & 0.0000 & $0.000 \mathrm{E}+00$ & 0.0000 & $0.000 \mathrm{E}+00$ & 0.0000 & $0.000 \mathrm{E}+00$ & 0.0000 & $0.000 \mathrm{E}+00$ & 0.0000 & $0.000 \mathrm{E}+00$ & 0.0000 & $2.244 \mathrm{E}-01$ & 0.0671 \\
\hline-237 & $0.000 \mathrm{E}+00$ & 0.0000 & $0.000 \mathrm{E}+00$ & 0.0000 & $0.000 \mathrm{E}+00$ & 0.0000 & $0.000 \mathrm{E}+00$ & 0.0000 & $0.000 \mathrm{E}+00$ & 0.0000 & $0.000 \mathrm{E}+00$ & 0.0000 & $1.805 \mathrm{E}-01$ & 0.0540 \\
\hline-238 & $0.000 \mathrm{E}+00$ & 0.0000 & $0.000 \mathrm{E}+00$ & 0.0000 & $0.000 \mathrm{E}+00$ & 0.0000 & $0.000 \mathrm{E}+00$ & 0.0000 & $0.000 \mathrm{E}+00$ & 0.0000 & $0.000 \mathrm{E}+00$ & 0.0000 & $1.903 E-02$ & 0.0057 \\
\hline-239 & $0.000 \mathrm{E}+00$ & 0.0000 & $0.000 \mathrm{E}+00$ & 0.0000 & $0.000 \mathrm{E}+00$ & 0.0000 & $0.000 \mathrm{E}+00$ & 0.0000 & $0.000 \mathrm{E}+00$ & 0.0000 & $0.000 \mathrm{E}+00$ & 0.0000 & $2.777 \mathrm{E}-02$ & 0.0083 \\
\hline-240 & $0.000 \mathrm{E}+00$ & 0.0000 & $0.000 \mathrm{E}+00$ & 0.0000 & $0.000 \mathrm{E}+00$ & 0.0000 & $0.000 \mathrm{E}+00$ & 0.0000 & $0.000 \mathrm{E}+00$ & 0.0000 & $0.000 \mathrm{E}+00$ & 0.0000 & $2.766 \mathrm{E}-02$ & 0.0083 \\
\hline 99 & $0.000 \mathrm{E}+00$ & 0.0000 & $0.000 \mathrm{E}+00$ & 0.0000 & $0.000 \mathrm{E}+00$ & 0.0000 & $0.000 \mathrm{E}+00$ & 0.0000 & $0.000 \mathrm{E}+00$ & 0.0000 & $0.000 \mathrm{E}+00$ & 0.0000 & $5.990 \mathrm{E}-05$ & 0.0000 \\
\hline 228 & $0.000 \mathrm{E}+00$ & 0.0000 & $0.000 \mathrm{E}+00$ & 0.0000 & $0.000 \mathrm{E}+00$ & 0.0000 & $0.000 \mathrm{E}+00$ & 0.0000 & $0.000 \mathrm{E}+00$ & 0.0000 & $0.000 \mathrm{E}+00$ & 0.0000 & $2.176 \mathrm{E}-06$ & 0.0000 \\
\hline 230 & $0.000 \mathrm{E}+00$ & 0.0000 & $0.000 \mathrm{E}+00$ & 0.0000 & $0.000 \mathrm{E}+00$ & 0.0000 & $0.000 \mathrm{E}+00$ & 0.0000 & $0.000 \mathrm{E}+00$ & 0.0000 & $0.000 \mathrm{E}+00$ & 0.0000 & $5.358 \mathrm{E}-02$ & 0.0160 \\
\hline 232 & $0.000 \mathrm{E}+00$ & 0.0000 & $0.000 \mathrm{E}+00$ & 0.0000 & $0.000 \mathrm{E}+00$ & 0.0000 & $0.000 \mathrm{E}+00$ & 0.0000 & $0.000 \mathrm{E}+00$ & 0.0000 & $0.000 \mathrm{E}+00$ & 0.0000 & $2.625 \mathrm{E}+00$ & 0.7852 \\
\hline 34 & $0.000 \mathrm{E}+00$ & 0.0000 & $0.000 \mathrm{E}+00$ & 0.0000 & $0.000 \mathrm{E}+00$ & 0.0000 & $0.000 \mathrm{E}+00$ & 0.0000 & $0.000 \mathrm{E}+00$ & 0.0000 & $0.000 \mathrm{E}+00$ & 0.0000 & $5.473 E-03$ & 0.0016 \\
\hline & $0.000 \mathrm{E}+00$ & 0.0000 & $0.000 \mathrm{E}+00$ & 0.0000 & $0.000 \mathrm{E}+00$ & 0.0000 & $0.000 \mathrm{E}+00$ & 0.0000 & $0.000 \mathrm{E}+00$ & 0.0000 & $0.000 \mathrm{E}+00$ & 0.0000 & $1.215 \mathrm{E}-01$ & 0.0363 \\
\hline & $0.000 \mathrm{E}+00$ & 0.0000 & $0.000 \mathrm{E}+00$ & 0.0000 & $0.000 \mathrm{E}+00$ & 0.0000 & $0.000 \mathrm{E}+00$ & 0.0000 & $0.000 \mathrm{E}+00$ & 0.0000 & $0.000 \mathrm{E}+00$ & 0.0000 & $3.126 \mathrm{E}-02$ & 0.0094 \\
\hline & $0.000 \mathrm{E}+00$ & 0.0000 & $0.000 \mathrm{E}+00$ & 0.0000 & $0.000 \mathrm{E}+00$ & 0.0000 & $0.000 \mathrm{E}+00$ & 0.0000 & $0.000 \mathrm{E}+00$ & 0.0000 & $0.000 \mathrm{E}+00$ & 000 & $3 E+00$ & 1 . \\
\hline
\end{tabular}

* Sum of all water independent and dependent pathways. 
RESRAD, Version 6.5

$\mathrm{T}^{1 / 2}$ Limit $=180$ days

05/03/2011 15:49 Page 21

Summary : C746U Landfill Worker Deterministic Run
File : X: \FINAL V2 \C746U LANDFILL WORKER DET-FINALV2.RAD

Total Dose Contributions TDOSE(i,p,t) for Individual Radionuclides (i) and Pathways (p) As mrem/yr and Fraction of Total Dose At $t=0.000 \mathrm{E}+00$ years

Water Independent Pathways (Inhalation excludes radon)

\begin{tabular}{|c|c|c|c|c|c|c|c|c|c|c|c|c|c|c|}
\hline \multirow{2}{*}{ Nuclide } & \multicolumn{2}{|c|}{ Ground } & \multicolumn{2}{|c|}{ Inhalation } & \multicolumn{2}{|c|}{ Radon } & \multicolumn{2}{|c|}{ Plant } & \multicolumn{2}{|c|}{ Meat } & \multicolumn{2}{|c|}{ Milk } & \multicolumn{2}{|c|}{ Soil } \\
\hline & mrem/yr & fract. & mrem/yr & fract. & mrem/yr & fract. & mrem/yr & fract. & mrem/yr & fract. & mrem/yr & fract. & mrem/yr & fract. \\
\hline-241 & $6.297 E-03$ & 0.0026 & $1.805 \mathrm{E}-04$ & 0.0001 & $0.000 \mathrm{E}+00$ & 0.0000 & $0.000 \mathrm{E}+00$ & 0.0000 & $0.000 \mathrm{E}+00$ & 0.0000 & $0.000 \mathrm{E}+00$ & 0.0000 & $2.202 E-02$ & 0.0090 \\
\hline-137 & $5.248 E-01$ & 0.2138 & $7.242 \mathrm{E}-08$ & 0.0000 & $0.000 \mathrm{E}+00$ & 0.0000 & $0.000 \mathrm{E}+00$ & 0.0000 & $0.000 \mathrm{E}+00$ & 0.0000 & $0.000 \mathrm{E}+00$ & 0.0000 & $1.416 \mathrm{E}-03$ & 0.0006 \\
\hline-237 & $1.693 E-01$ & 0.0690 & $9.411 \mathrm{E}-05$ & 0.0000 & $0.000 \mathrm{E}+00$ & 0.0000 & $0.000 \mathrm{E}+00$ & 0.0000 & $0.000 \mathrm{E}+00$ & 0.0000 & $0.000 \mathrm{E}+00$ & 0.0000 & $1.222 \mathrm{E}-02$ & 0.0050 \\
\hline-238 & $1.972 \mathrm{E}-05$ & 0.0000 & $2.062 E-04$ & 0.0001 & $0.000 \mathrm{E}+00$ & 0.0000 & $0.000 \mathrm{E}+00$ & 0.0000 & $0.000 \mathrm{E}+00$ & 0.0000 & $0.000 \mathrm{E}+00$ & 0.0000 & $2.525 \mathrm{E}-02$ & 0.0103 \\
\hline-239 & $4.422 \mathrm{E}-05$ & 0.0000 & $2.259 \mathrm{E}-04$ & 0.0001 & $0.000 \mathrm{E}+00$ & 0.0000 & $0.000 \mathrm{E}+00$ & 0.0000 & $0.000 \mathrm{E}+00$ & 0.0000 & $0.000 \mathrm{E}+00$ & 0.0000 & $2.755 \mathrm{E}-02$ & 0.0112 \\
\hline-240 & $1.913 \mathrm{E}-05$ & 0.0000 & $2.259 \mathrm{E}-04$ & 0.0001 & $0.000 \mathrm{E}+00$ & 0.0000 & $0.000 \mathrm{E}+00$ & 0.0000 & $0.000 \mathrm{E}+00$ & 0.0000 & $0.000 \mathrm{E}+00$ & 0.0000 & $2.755 \mathrm{E}-02$ & 0.0112 \\
\hline-99 & $1.820 \mathrm{E}-05$ & 0.0000 & $2.434 \mathrm{E}-08$ & 0.0000 & $0.000 \mathrm{E}+00$ & 0.0000 & $0.000 \mathrm{E}+00$ & 0.0000 & $0.000 \mathrm{E}+00$ & 0.0000 & $0.000 \mathrm{E}+00$ & 0.0000 & $7.022 \mathrm{E}-05$ & 0.0000 \\
\hline-228 & $1.347 \mathrm{E}+00$ & 0.5487 & $6.889 \mathrm{E}-05$ & 0.0000 & $0.000 \mathrm{E}+00$ & 0.0000 & $0.000 \mathrm{E}+00$ & 0.0000 & $0.000 \mathrm{E}+00$ & 0.0000 & $0.000 \mathrm{E}+00$ & 0.0000 & 1. $325 \mathrm{E}-02$ & 0.0054 \\
\hline-230 & $5.615 E-04$ & 0.0002 & $1.882 \mathrm{E}-04$ & 0.0001 & $0.000 \mathrm{E}+00$ & 0.0000 & $0.000 \mathrm{E}+00$ & 0.0000 & $0.000 \mathrm{E}+00$ & 0.0000 & $0.000 \mathrm{E}+00$ & 0.0000 & $2.315 E-02$ & 0.0094 \\
\hline-232 & $6.493 E-02$ & 0.0264 & $2.093 E-04$ & 0.0001 & $0.000 \mathrm{E}+00$ & 0.0000 & $0.000 \mathrm{E}+00$ & 0.0000 & $0.000 \mathrm{E}+00$ & 0.0000 & $0.000 \mathrm{E}+00$ & 0.0000 & $2.985 \mathrm{E}-02$ & 0.0122 \\
\hline 34 & $5.807 E-05$ & 0.0000 & $1.770 \mathrm{E}-05$ & 0.0000 & $0.000 \mathrm{E}+00$ & 0.0000 & $0.000 \mathrm{E}+00$ & 0.0000 & $0.000 \mathrm{E}+00$ & 0.0000 & $0.000 \mathrm{E}+00$ & 0.0000 & $5.391 \mathrm{E}-03$ & 0.0022 \\
\hline 35 & $1.161 \mathrm{E}-01$ & 0.0473 & $1.603 \mathrm{E}-05$ & 0.0000 & $0.000 \mathrm{E}+00$ & 0.0000 & $0.000 \mathrm{E}+00$ & 0.0000 & $0.000 \mathrm{E}+00$ & 0.0000 & $0.000 \mathrm{E}+00$ & 0.0000 & $5.221 \mathrm{E}-03$ & 0.0021 \\
\hline 38 & $2.593 E-02$ & 0.0106 & $1.507 \mathrm{E}-05$ & 0.0000 & $0.000 \mathrm{E}+00$ & 0.0000 & $0.000 \mathrm{E}+00$ & 0.0000 & $0.000 \mathrm{E}+00$ & 0.0000 & $0.000 \mathrm{E}+00$ & 0.0000 & $5.349 \mathrm{E}-03$ & 0.0022 \\
\hline & $2.255 \mathrm{E}+00$ & 0.9186 & $1.448 \mathrm{E}-03$ & 0.0006 & $0.000 \mathrm{E}+00$ & 0.0000 & $0.000 \mathrm{E}+00$ & 0.0000 & $0.000 \mathrm{E}+00$ & 0.0000 & $0.000 \mathrm{E}+00$ & 0.0000 & 1. $983 \mathrm{E}-01$ & 0.0808 \\
\hline
\end{tabular}

Total Dose Contributions TDOSE(i,p,t) for Individual Radionuclides (i) and Pathways (p) As mrem/yr and Fraction of Total Dose At $t=0.000 \mathrm{E}+00$ years

Water Dependent Pathways

\begin{tabular}{|c|c|c|c|c|c|c|c|c|c|c|c|c|c|c|}
\hline \multirow{2}{*}{ Nuclide } & \multicolumn{2}{|c|}{ Water } & \multicolumn{2}{|c|}{ Fish } & \multicolumn{2}{|c|}{ Radon } & \multicolumn{2}{|c|}{ Plant } & \multicolumn{2}{|c|}{ Meat } & \multicolumn{2}{|c|}{ Milk } & \multicolumn{2}{|c|}{ All Pathways* } \\
\hline & mrem/yr & fract. & mrem/yr & fract. & mrem/yr & fract. & mrem/yr & fract. & mrem/yr & fract. & mrem/yr & fract. & mrem/yr & fract. \\
\hline-241 & $0.000 \mathrm{E}+00$ & 0.0000 & $0.000 \mathrm{E}+00$ & 0.0000 & $0.000 \mathrm{E}+00$ & 0.0000 & $0.000 \mathrm{E}+00$ & 0.0000 & $0.000 \mathrm{E}+00$ & 0.0000 & $0.000 E+00$ & 0.0000 & $2.850 \mathrm{E}-02$ & 0.0116 \\
\hline-137 & $0.000 \mathrm{E}+00$ & 0.0000 & $0.000 \mathrm{E}+00$ & 0.0000 & $0.000 \mathrm{E}+00$ & 0.0000 & $0.000 \mathrm{E}+00$ & 0.0000 & $0.000 \mathrm{E}+00$ & 0.0000 & $0.000 \mathrm{E}+00$ & 0.0000 & $5.262 \mathrm{E}-01$ & 0.2144 \\
\hline-237 & $0.000 \mathrm{E}+00$ & 0.0000 & $0.000 \mathrm{E}+00$ & 0.0000 & $0.000 \mathrm{E}+00$ & 0.0000 & $0.000 \mathrm{E}+00$ & 0.0000 & $0.000 \mathrm{E}+00$ & 0.0000 & $0.000 \mathrm{E}+00$ & 0.0000 & $1.816 \mathrm{E}-01$ & 0.0740 \\
\hline-238 & $0.000 \mathrm{E}+00$ & 0.0000 & $0.000 \mathrm{E}+00$ & 0.0000 & $0.000 \mathrm{E}+00$ & 0.0000 & $0.000 \mathrm{E}+00$ & 0.0000 & $0.000 \mathrm{E}+00$ & 0.0000 & $0.000 \mathrm{E}+00$ & 0.0000 & $2.547 \mathrm{E}-02$ & 0.0104 \\
\hline-239 & $0.000 \mathrm{E}+00$ & 0.0000 & $0.000 \mathrm{E}+00$ & 0.0000 & $0.000 \mathrm{E}+00$ & 0.0000 & $0.000 \mathrm{E}+00$ & 0.0000 & $0.000 \mathrm{E}+00$ & 0.0000 & $0.000 \mathrm{E}+00$ & 0.0000 & $2.782 \mathrm{E}-02$ & 0.0113 \\
\hline-240 & $0.000 \mathrm{E}+00$ & 0.0000 & $0.000 \mathrm{E}+00$ & 0.0000 & $0.000 \mathrm{E}+00$ & 0.0000 & $0.000 \mathrm{E}+00$ & 0.0000 & $0.000 \mathrm{E}+00$ & 0.0000 & $0.000 \mathrm{E}+00$ & 0.0000 & $2.779 \mathrm{E}-02$ & 0.0113 \\
\hline 99 & $0.000 \mathrm{E}+00$ & 0.0000 & $0.000 \mathrm{E}+00$ & 0.0000 & $0.000 \mathrm{E}+00$ & 0.0000 & $0.000 \mathrm{E}+00$ & 0.0000 & $0.000 \mathrm{E}+00$ & 0.0000 & $0.000 \mathrm{E}+00$ & 0.0000 & $8.844 \mathrm{E}-05$ & 0.0000 \\
\hline-228 & $0.000 \mathrm{E}+00$ & 0.0000 & $0.000 \mathrm{E}+00$ & 0.0000 & $0.000 \mathrm{E}+00$ & 0.0000 & $0.000 \mathrm{E}+00$ & 0.0000 & $0.000 \mathrm{E}+00$ & 0.0000 & $0.000 \mathrm{E}+00$ & 0.0000 & $1.360 \mathrm{E}+00$ & 0.5542 \\
\hline 230 & $0.000 \mathrm{E}+00$ & 0.0000 & $0.000 \mathrm{E}+00$ & 0.0000 & $0.000 \mathrm{E}+00$ & 0.0000 & $0.000 \mathrm{E}+00$ & 0.0000 & $0.000 \mathrm{E}+00$ & 0.0000 & $0.000 \mathrm{E}+00$ & 0.0000 & $2.390 \mathrm{E}-02$ & 0.0097 \\
\hline 232 & $0.000 \mathrm{E}+00$ & 0.0000 & $0.000 \mathrm{E}+00$ & 0.0000 & $0.000 \mathrm{E}+00$ & 0.0000 & $0.000 \mathrm{E}+00$ & 0.0000 & $0.000 \mathrm{E}+00$ & 0.0000 & $0.000 \mathrm{E}+00$ & 0.0000 & $9.499 \mathrm{E}-02$ & 0.0387 \\
\hline 34 & $0.000 \mathrm{E}+00$ & 0.0000 & $0.000 \mathrm{E}+00$ & 0.0000 & $0.000 \mathrm{E}+00$ & 0.0000 & $0.000 \mathrm{E}+00$ & 0.0000 & $0.000 \mathrm{E}+00$ & 0.0000 & $0.000 \mathrm{E}+00$ & 0.0000 & $5.467 \mathrm{E}-03$ & 0.0022 \\
\hline 35 & $0.000 \mathrm{E}+00$ & 0.0000 & $0.000 \mathrm{E}+00$ & 0.0000 & $0.000 \mathrm{E}+00$ & 0.0000 & $0.000 \mathrm{E}+00$ & 0.0000 & $0.000 \mathrm{E}+00$ & 0.0000 & $0.000 \mathrm{E}+00$ & 0.0000 & $1.213 \mathrm{E}-01$ & 0.0494 \\
\hline 38 & $0.000 \mathrm{E}+00$ & 0.0000 & $0.000 \mathrm{E}+00$ & 0.0000 & $0.000 \mathrm{E}+00$ & 0.0000 & $0.000 \mathrm{E}+00$ & 0.0000 & $0.000 \mathrm{E}+00$ & 0.0000 & $0.000 \mathrm{E}+00$ & 0.0000 & $3.129 \mathrm{E}-02$ & 0.0127 \\
\hline & $0.000 \mathrm{E}+00$ & 0.0000 & $0.000 \mathrm{E}+00$ & 0.0000 & $0.000 \mathrm{E}+00$ & 0.0000 & $0.000 \mathrm{E}+00$ & 0.0000 & $0.000 \mathrm{E}+00$ & 0.0000 & $0.000 \mathrm{E}+00$ & 0.0000 & $5 E+00$ & 1.0000 \\
\hline
\end{tabular}

* Sum of all water independent and dependent pathways. 
RESRAD, Version 6.5

$\mathrm{T}^{1 / 2}$ Limit $=180$ days

05/03/2011 15:49 Page 22

Summary : C746U Landfill Worker Deterministic Run
File : X: \FINAL V2 \C746U LANDFILL WORKER DET-FINALV2.RAD

Total Dose Contributions TDOSE (i,p,t) for Individual Radionuclides (i) and Pathways (p) As mrem/yr and Fraction of Total Dose At $t=1.000 \mathrm{E}+00$ years

Water Independent Pathways (Inhalation excludes radon)

\begin{tabular}{|c|c|c|c|c|c|c|c|c|c|c|c|c|c|c|}
\hline \multirow{2}{*}{ Nuclide } & \multicolumn{2}{|c|}{ Ground } & \multicolumn{2}{|c|}{ Inhalation } & \multicolumn{2}{|c|}{ Radon } & \multicolumn{2}{|c|}{ Plant } & \multicolumn{2}{|c|}{ Meat } & \multicolumn{2}{|c|}{ Milk } & \multicolumn{2}{|c|}{ Soil } \\
\hline & mrem/yr & fract. & mrem/yr & fract. & mrem/yr & fract. & mrem/yr & fract. & mrem/yr & fract. & mrem/yr & fract. & mrem/yr & fract. \\
\hline-241 & $6.287 E-03$ & 0.0029 & $1.802 \mathrm{E}-04$ & 0.0001 & $0.000 \mathrm{E}+00$ & 0.0000 & $0.000 \mathrm{E}+00$ & 0.0000 & $0.000 \mathrm{E}+00$ & 0.0000 & $0.000 \mathrm{E}+00$ & 0.0000 & $2.199 \mathrm{E}-02$ & 0.0100 \\
\hline-137 & $5.128 E-01$ & 0.2339 & $7.076 \mathrm{E}-08$ & 0.0000 & $0.000 \mathrm{E}+00$ & 0.0000 & $0.000 \mathrm{E}+00$ & 0.0000 & $0.000 \mathrm{E}+00$ & 0.0000 & $0.000 \mathrm{E}+00$ & 0.0000 & $1.384 \mathrm{E}-03$ & 0.0006 \\
\hline-237 & $1.693 E-01$ & 0.0772 & $9.410 \mathrm{E}-05$ & 0.0000 & $0.000 \mathrm{E}+00$ & 0.0000 & $0.000 \mathrm{E}+00$ & 0.0000 & $0.000 \mathrm{E}+00$ & 0.0000 & $0.000 \mathrm{E}+00$ & 0.0000 & $1.222 \mathrm{E}-02$ & 0.0056 \\
\hline-238 & $1.956 \mathrm{E}-05$ & 0.0000 & $2.046 \mathrm{E}-04$ & 0.0001 & $0.000 \mathrm{E}+00$ & 0.0000 & $0.000 \mathrm{E}+00$ & 0.0000 & $0.000 \mathrm{E}+00$ & 0.0000 & $0.000 \mathrm{E}+00$ & 0.0000 & $2.505 \mathrm{E}-02$ & 0.0114 \\
\hline-239 & $4.422 \mathrm{E}-05$ & 0.0000 & $2.259 \mathrm{E}-04$ & 0.0001 & $0.000 \mathrm{E}+00$ & 0.0000 & $0.000 \mathrm{E}+00$ & 0.0000 & $0.000 \mathrm{E}+00$ & 0.0000 & $0.000 \mathrm{E}+00$ & 0.0000 & $2.755 \mathrm{E}-02$ & 0.0126 \\
\hline-240 & $1.913 \mathrm{E}-05$ & 0.0000 & $2.258 \mathrm{E}-04$ & 0.0001 & $0.000 \mathrm{E}+00$ & 0.0000 & $0.000 \mathrm{E}+00$ & 0.0000 & $0.000 \mathrm{E}+00$ & 0.0000 & $0.000 \mathrm{E}+00$ & 0.0000 & $2.754 \mathrm{E}-02$ & 0.0126 \\
\hline-99 & $1.801 \mathrm{E}-05$ & 0.0000 & $2.408 \mathrm{E}-08$ & 0.0000 & $0.000 \mathrm{E}+00$ & 0.0000 & $0.000 \mathrm{E}+00$ & 0.0000 & $0.000 \mathrm{E}+00$ & 0.0000 & $0.000 \mathrm{E}+00$ & 0.0000 & $6.948 \mathrm{E}-05$ & 0.0000 \\
\hline-228 & $9.377 \mathrm{E}-01$ & 0.4277 & $4.795 \mathrm{E}-05$ & 0.0000 & $0.000 \mathrm{E}+00$ & 0.0000 & $0.000 \mathrm{E}+00$ & 0.0000 & $0.000 \mathrm{E}+00$ & 0.0000 & $0.000 \mathrm{E}+00$ & 0.0000 & $9.220 \mathrm{E}-03$ & 0.0042 \\
\hline-230 & $1.323 E-03$ & 0.0006 & $1.882 \mathrm{E}-04$ & 0.0001 & $0.000 \mathrm{E}+00$ & 0.0000 & $0.000 \mathrm{E}+00$ & 0.0000 & $0.000 \mathrm{E}+00$ & 0.0000 & $0.000 \mathrm{E}+00$ & 0.0000 & $2.317 \mathrm{E}-02$ & 0.0106 \\
\hline-232 & $2.189 \mathrm{E}-01$ & 0.0998 & $2.153 E-04$ & 0.0001 & $0.000 \mathrm{E}+00$ & 0.0000 & $0.000 \mathrm{E}+00$ & 0.0000 & $0.000 \mathrm{E}+00$ & 0.0000 & $0.000 \mathrm{E}+00$ & 0.0000 & $3.850 \mathrm{E}-02$ & 0.0176 \\
\hline 34 & $5.807 E-05$ & 0.0000 & $1.771 \mathrm{E}-05$ & 0.0000 & $0.000 \mathrm{E}+00$ & 0.0000 & $0.000 \mathrm{E}+00$ & 0.0000 & $0.000 \mathrm{E}+00$ & 0.0000 & $0.000 \mathrm{E}+00$ & 0.0000 & $5.391 \mathrm{E}-03$ & 0.0025 \\
\hline 35 & $1.161 \mathrm{E}-01$ & 0.0530 & $1.603 \mathrm{E}-05$ & 0.0000 & $0.000 \mathrm{E}+00$ & 0.0000 & $0.000 \mathrm{E}+00$ & 0.0000 & $0.000 \mathrm{E}+00$ & 0.0000 & $0.000 \mathrm{E}+00$ & 0.0000 & $5.222 \mathrm{E}-03$ & 0.0024 \\
\hline 38 & $2.593 E-02$ & 0.0118 & $1.507 \mathrm{E}-05$ & 0.0000 & $0.000 \mathrm{E}+00$ & 0.0000 & $0.000 \mathrm{E}+00$ & 0.0000 & $0.000 \mathrm{E}+00$ & 0.0000 & $0.000 \mathrm{E}+00$ & 0.0000 & $5.349 \mathrm{E}-03$ & 0.0024 \\
\hline & $1.988 \mathrm{E}+00$ & 0.9069 & $1.431 \mathrm{E}-03$ & 0.0007 & $0.000 \mathrm{E}+00$ & 0.0000 & $0.000 \mathrm{E}+00$ & 0.0000 & $0.000 \mathrm{E}+00$ & 0.0000 & $0.000 \mathrm{E}+00$ & 0.0000 & $.026 \mathrm{E}-01$ & 0.0924 \\
\hline
\end{tabular}

Total Dose Contributions TDOSE(i,p,t) for Individual Radionuclides (i) and Pathways (p) As mrem/yr and Fraction of Total Dose At $t=1.000 \mathrm{E}+00$ years

Water Dependent Pathways

\begin{tabular}{|c|c|c|c|c|c|c|c|c|c|c|c|c|c|c|}
\hline \multirow{2}{*}{ Nuclide } & \multicolumn{2}{|c|}{ Water } & \multicolumn{2}{|c|}{ Fish } & \multicolumn{2}{|c|}{ Radon } & \multicolumn{2}{|c|}{ Plant } & \multicolumn{2}{|c|}{ Meat } & \multicolumn{2}{|c|}{ Milk } & \multicolumn{2}{|c|}{ All Pathways* } \\
\hline & mrem/yr & fract. & mrem/yr & fract. & mrem/yr & fract. & mrem/yr & fract. & mrem/yr & fract. & mrem/yr & fract. & mrem/yr & fract. \\
\hline-241 & $0.000 \mathrm{E}+00$ & 0.0000 & $0.000 \mathrm{E}+00$ & 0.0000 & $0.000 \mathrm{E}+00$ & 0.0000 & $0.000 \mathrm{E}+00$ & 0.0000 & $0.000 \mathrm{E}+00$ & 0.0000 & $0.000 E+00$ & 0.0000 & $2.845 E-02$ & 0.0130 \\
\hline-137 & $0.000 \mathrm{E}+00$ & 0.0000 & $0.000 \mathrm{E}+00$ & 0.0000 & $0.000 \mathrm{E}+00$ & 0.0000 & $0.000 \mathrm{E}+00$ & 0.0000 & $0.000 \mathrm{E}+00$ & 0.0000 & $0.000 \mathrm{E}+00$ & 0.0000 & $5.142 \mathrm{E}-01$ & 0.2345 \\
\hline-237 & $0.000 \mathrm{E}+00$ & 0.0000 & $0.000 \mathrm{E}+00$ & 0.0000 & $0.000 \mathrm{E}+00$ & 0.0000 & $0.000 \mathrm{E}+00$ & 0.0000 & $0.000 \mathrm{E}+00$ & 0.0000 & $0.000 \mathrm{E}+00$ & 0.0000 & $1.816 \mathrm{E}-01$ & 0.0828 \\
\hline-238 & $0.000 \mathrm{E}+00$ & 0.0000 & $0.000 \mathrm{E}+00$ & 0.0000 & $0.000 \mathrm{E}+00$ & 0.0000 & $0.000 \mathrm{E}+00$ & 0.0000 & $0.000 \mathrm{E}+00$ & 0.0000 & $0.000 \mathrm{E}+00$ & 0.0000 & $2.527 \mathrm{E}-02$ & 0.0115 \\
\hline-239 & $0.000 \mathrm{E}+00$ & 0.0000 & $0.000 \mathrm{E}+00$ & 0.0000 & $0.000 \mathrm{E}+00$ & 0.0000 & $0.000 \mathrm{E}+00$ & 0.0000 & $0.000 \mathrm{E}+00$ & 0.0000 & $0.000 \mathrm{E}+00$ & 0.0000 & $2.782 \mathrm{E}-02$ & 0.0127 \\
\hline-240 & $0.000 \mathrm{E}+00$ & 0.0000 & $0.000 \mathrm{E}+00$ & 0.0000 & $0.000 \mathrm{E}+00$ & 0.0000 & $0.000 \mathrm{E}+00$ & 0.0000 & $0.000 \mathrm{E}+00$ & 0.0000 & $0.000 \mathrm{E}+00$ & 0.0000 & $2.779 \mathrm{E}-02$ & 0.0127 \\
\hline 99 & $0.000 \mathrm{E}+00$ & 0.0000 & $0.000 \mathrm{E}+00$ & 0.0000 & $0.000 \mathrm{E}+00$ & 0.0000 & $0.000 \mathrm{E}+00$ & 0.0000 & $0.000 \mathrm{E}+00$ & 0.0000 & $0.000 \mathrm{E}+00$ & 0.0000 & $8.751 E-05$ & 0.0000 \\
\hline-228 & $0.000 \mathrm{E}+00$ & 0.0000 & $0.000 \mathrm{E}+00$ & 0.0000 & $0.000 \mathrm{E}+00$ & 0.0000 & $0.000 \mathrm{E}+00$ & 0.0000 & $0.000 \mathrm{E}+00$ & 0.0000 & $0.000 \mathrm{E}+00$ & 0.0000 & $9.469 \mathrm{E}-01$ & 0.4319 \\
\hline 230 & $0.000 \mathrm{E}+00$ & 0.0000 & $0.000 \mathrm{E}+00$ & 0.0000 & $0.000 \mathrm{E}+00$ & 0.0000 & $0.000 \mathrm{E}+00$ & 0.0000 & $0.000 \mathrm{E}+00$ & 0.0000 & $0.000 \mathrm{E}+00$ & 0.0000 & $2.468 E-02$ & 0.0113 \\
\hline 232 & $0.000 \mathrm{E}+00$ & 0.0000 & $0.000 \mathrm{E}+00$ & 0.0000 & $0.000 \mathrm{E}+00$ & 0.0000 & $0.000 \mathrm{E}+00$ & 0.0000 & $0.000 \mathrm{E}+00$ & 0.0000 & $0.000 \mathrm{E}+00$ & 0.0000 & $2.576 \mathrm{E}-01$ & 0.1175 \\
\hline 34 & $0.000 \mathrm{E}+00$ & 0.0000 & $0.000 \mathrm{E}+00$ & 0.0000 & $0.000 \mathrm{E}+00$ & 0.0000 & $0.000 \mathrm{E}+00$ & 0.0000 & $0.000 \mathrm{E}+00$ & 0.0000 & $0.000 \mathrm{E}+00$ & 0.0000 & $5.467 \mathrm{E}-03$ & 0.0025 \\
\hline 35 & $0.000 \mathrm{E}+00$ & 0.0000 & $0.000 \mathrm{E}+00$ & 0.0000 & $0.000 \mathrm{E}+00$ & 0.0000 & $0.000 \mathrm{E}+00$ & 0.0000 & $0.000 \mathrm{E}+00$ & 0.0000 & $0.000 \mathrm{E}+00$ & 0.0000 & $1.213 \mathrm{E}-01$ & 0.0553 \\
\hline 38 & $0.000 \mathrm{E}+00$ & 0.0000 & $0.000 \mathrm{E}+00$ & 0.0000 & $0.000 \mathrm{E}+00$ & 0.0000 & $0.000 \mathrm{E}+00$ & 0.0000 & $0.000 \mathrm{E}+00$ & 0.0000 & $0.000 \mathrm{E}+00$ & 0.0000 & $3.129 \mathrm{E}-02$ & 0.0143 \\
\hline & $0.000 \mathrm{E}+00$ & 0.0000 & $0.000 \mathrm{E}+00$ & 0.0000 & $0.000 \mathrm{E}+00$ & 0.0000 & $0.000 \mathrm{E}+00$ & 0.0000 & $0.000 \mathrm{E}+00$ & 0.0000 & $0.000 \mathrm{E}+00$ & 0.0000 & $2 \mathrm{E}+00$ & 1.0000 \\
\hline
\end{tabular}

* Sum of all water independent and dependent pathways. 
RESRAD, Version 6.5

$\mathrm{T}^{1 / 2}$ Limit $=180$ days

05/03/2011 15:49 Page 23

Summary : C746U Landfill Worker Deterministic Run
File : X: \FINAL V2 \C746U LANDFILL WORKER DET-FINALV2.RAD

Total Dose Contributions TDOSE(i,p,t) for Individual Radionuclides (i) and Pathways (p) As mrem/yr and Fraction of Total Dose At $t=5.000 \mathrm{E}+01$ years

Water Independent Pathways (Inhalation excludes radon)

\begin{tabular}{|c|c|c|c|c|c|c|c|c|c|c|c|c|c|c|}
\hline \multirow{2}{*}{ Nuclide } & \multicolumn{2}{|c|}{ Ground } & \multicolumn{2}{|c|}{ Inhalation } & \multicolumn{2}{|c|}{ Radon } & \multicolumn{2}{|c|}{ Plant } & \multicolumn{2}{|c|}{ Meat } & \multicolumn{2}{|c|}{ Milk } & \multicolumn{2}{|c|}{ Soil } \\
\hline & mrem/yr & fract. & mrem/yr & fract. & mrem/yr & fract. & mrem/yr & fract. & mrem/yr & fract. & mrem/yr & fract. & mrem/yr & fract. \\
\hline-241 & $5.812 \mathrm{E}-03$ & 0.0017 & $1.665 \mathrm{E}-04$ & 0.0001 & $0.000 \mathrm{E}+00$ & 0.0000 & $0.000 \mathrm{E}+00$ & 0.0000 & $0.000 \mathrm{E}+00$ & 0.0000 & $0.000 \mathrm{E}+00$ & 0.0000 & $2.032 E-02$ & 0.0061 \\
\hline-137 & $1.650 \mathrm{E}-01$ & 0.0497 & $2.276 \mathrm{E}-08$ & 0.0000 & $0.000 \mathrm{E}+00$ & 0.0000 & $0.000 \mathrm{E}+00$ & 0.0000 & $0.000 \mathrm{E}+00$ & 0.0000 & $0.000 \mathrm{E}+00$ & 0.0000 & $4.452 \mathrm{E}-04$ & 0.0001 \\
\hline-237 & $1.680 \mathrm{E}-01$ & 0.0506 & $9.338 \mathrm{E}-05$ & 0.0000 & $0.000 \mathrm{E}+00$ & 0.0000 & $0.000 \mathrm{E}+00$ & 0.0000 & $0.000 \mathrm{E}+00$ & 0.0000 & $0.000 \mathrm{E}+00$ & 0.0000 & $1.212 \mathrm{E}-02$ & 0.0036 \\
\hline-238 & 1. $328 \mathrm{E}-05$ & 0.0000 & $1.388 \mathrm{E}-04$ & 0.0000 & $0.000 \mathrm{E}+00$ & 0.0000 & $0.000 \mathrm{E}+00$ & 0.0000 & $0.000 \mathrm{E}+00$ & 0.0000 & $0.000 \mathrm{E}+00$ & 0.0000 & $1.699 \mathrm{E}-02$ & 0.0051 \\
\hline-239 & $4.412 \mathrm{E}-05$ & 0.0000 & $2.253 E-04$ & 0.0001 & $0.000 \mathrm{E}+00$ & 0.0000 & $0.000 \mathrm{E}+00$ & 0.0000 & $0.000 \mathrm{E}+00$ & 0.0000 & $0.000 \mathrm{E}+00$ & 0.0000 & $2.748 \mathrm{E}-02$ & 0.0083 \\
\hline-240 & $1.901 \mathrm{E}-05$ & 0.0000 & $2.244 \mathrm{E}-04$ & 0.0001 & $0.000 \mathrm{E}+00$ & 0.0000 & $0.000 \mathrm{E}+00$ & 0.0000 & $0.000 \mathrm{E}+00$ & 0.0000 & $0.000 \mathrm{E}+00$ & 0.0000 & $2.738 \mathrm{E}-02$ & 0.0082 \\
\hline-99 & $1.072 \mathrm{E}-05$ & 0.0000 & $1.434 \mathrm{E}-08$ & 0.0000 & $0.000 \mathrm{E}+00$ & 0.0000 & $0.000 \mathrm{E}+00$ & 0.0000 & $0.000 \mathrm{E}+00$ & 0.0000 & $0.000 \mathrm{E}+00$ & 0.0000 & $4.137 \mathrm{E}-05$ & 0.0000 \\
\hline-228 & $1.827 \mathrm{E}-08$ & 0.0000 & $9.342 \mathrm{E}-13$ & 0.0000 & $0.000 \mathrm{E}+00$ & 0.0000 & $0.000 \mathrm{E}+00$ & 0.0000 & $0.000 \mathrm{E}+00$ & 0.0000 & $0.000 \mathrm{E}+00$ & 0.0000 & $1.796 \mathrm{E}-10$ & 0.0000 \\
\hline-230 & $3.824 \mathrm{E}-02$ & 0.0115 & $1.887 \mathrm{E}-04$ & 0.0001 & $0.000 \mathrm{E}+00$ & 0.0000 & $0.000 \mathrm{E}+00$ & 0.0000 & $0.000 \mathrm{E}+00$ & 0.0000 & $0.000 \mathrm{E}+00$ & 0.0000 & $2.604 \mathrm{E}-02$ & 0.0078 \\
\hline-232 & $2.538 \mathrm{E}+00$ & 0.7639 & $3.189 \mathrm{E}-04$ & 0.0001 & $0.000 \mathrm{E}+00$ & 0.0000 & $0.000 \mathrm{E}+00$ & 0.0000 & $0.000 \mathrm{E}+00$ & 0.0000 & $0.000 \mathrm{E}+00$ & 0.0000 & $1.169 \mathrm{E}-01$ & 0.0352 \\
\hline 34 & $6.674 \mathrm{E}-05$ & 0.0000 & $1.776 \mathrm{E}-05$ & 0.0000 & $0.000 \mathrm{E}+00$ & 0.0000 & $0.000 \mathrm{E}+00$ & 0.0000 & $0.000 \mathrm{E}+00$ & 0.0000 & $0.000 \mathrm{E}+00$ & 0.0000 & $5.394 \mathrm{E}-03$ & 0.0016 \\
\hline 35 & $1.162 \mathrm{E}-01$ & 0.0350 & $1.686 \mathrm{E}-05$ & 0.0000 & $0.000 \mathrm{E}+00$ & 0.0000 & $0.000 \mathrm{E}+00$ & 0.0000 & $0.000 \mathrm{E}+00$ & 0.0000 & $0.000 \mathrm{E}+00$ & 0.0000 & $5.368 \mathrm{E}-03$ & 0.0016 \\
\hline 38 & $2.589 \mathrm{E}-02$ & 0.0078 & $1.505 \mathrm{E}-05$ & 0.0000 & $0.000 \mathrm{E}+00$ & 0.0000 & $0.000 \mathrm{E}+00$ & 0.0000 & $0.000 \mathrm{E}+00$ & 0.0000 & $0.000 \mathrm{E}+00$ & 0.0000 & $5.343 E-03$ & 0.0016 \\
\hline & $3.057 \mathrm{E}+00$ & 0.9202 & $1.406 \mathrm{E}-03$ & 0.0004 & $0.000 \mathrm{E}+00$ & 0.0000 & $0.000 \mathrm{E}+00$ & 0.0000 & $0.000 \mathrm{E}+00$ & 0.0000 & $0.000 \mathrm{E}+00$ & 0.0000 & 2. $638 \mathrm{E}-01$ & 0.0794 \\
\hline
\end{tabular}

Total Dose Contributions TDOSE(i,p,t) for Individual Radionuclides (i) and Pathways (p) As mrem/yr and Fraction of Total Dose At $t=5.000 \mathrm{E}+01$ years

Water Dependent Pathways

\begin{tabular}{|c|c|c|c|c|c|c|c|c|c|c|c|c|c|c|}
\hline \multirow{2}{*}{ Nuclide } & \multicolumn{2}{|c|}{ Water } & \multicolumn{2}{|c|}{ Fish } & \multicolumn{2}{|c|}{ Radon } & \multicolumn{2}{|c|}{ Plant } & \multicolumn{2}{|c|}{ Meat } & \multicolumn{2}{|c|}{ Milk } & \multicolumn{2}{|c|}{ All Pathways* } \\
\hline & mrem/yr & fract. & mrem/yr & fract. & mrem/yr & fract. & mrem/yr & fract. & mrem/yr & fract. & mrem/yr & fract. & mrem/yr & fract. \\
\hline-241 & $0.000 \mathrm{E}+00$ & 0.0000 & $0.000 \mathrm{E}+00$ & 0.0000 & $0.000 \mathrm{E}+00$ & 0.0000 & $0.000 \mathrm{E}+00$ & 0.0000 & $0.000 \mathrm{E}+00$ & 0.0000 & $0.000 \mathrm{E}+00$ & 0.0000 & $2.630 \mathrm{E}-02$ & 0.0079 \\
\hline-137 & $0.000 \mathrm{E}+00$ & 0.0000 & $0.000 \mathrm{E}+00$ & 0.0000 & $0.000 \mathrm{E}+00$ & 0.0000 & $0.000 \mathrm{E}+00$ & 0.0000 & $0.000 \mathrm{E}+00$ & 0.0000 & $0.000 \mathrm{E}+00$ & 0.0000 & $1.654 \mathrm{E}-01$ & 0.0498 \\
\hline-237 & $0.000 \mathrm{E}+00$ & 0.0000 & $0.000 \mathrm{E}+00$ & 0.0000 & $0.000 \mathrm{E}+00$ & 0.0000 & $0.000 \mathrm{E}+00$ & 0.0000 & $0.000 \mathrm{E}+00$ & 0.0000 & $0.000 \mathrm{E}+00$ & 0.0000 & $1.802 \mathrm{E}-01$ & 0.0542 \\
\hline-238 & $0.000 \mathrm{E}+00$ & 0.0000 & $0.000 \mathrm{E}+00$ & 0.0000 & $0.000 \mathrm{E}+00$ & 0.0000 & $0.000 \mathrm{E}+00$ & 0.0000 & $0.000 \mathrm{E}+00$ & 0.0000 & $0.000 \mathrm{E}+00$ & 0.0000 & $1.714 \mathrm{E}-02$ & 0.0052 \\
\hline-239 & $0.000 \mathrm{E}+00$ & 0.0000 & $0.000 \mathrm{E}+00$ & 0.0000 & $0.000 \mathrm{E}+00$ & 0.0000 & $0.000 \mathrm{E}+00$ & 0.0000 & $0.000 \mathrm{E}+00$ & 0.0000 & $0.000 \mathrm{E}+00$ & 0.0000 & $2.775 \mathrm{E}-02$ & 0.0084 \\
\hline-240 & $0.000 \mathrm{E}+00$ & 0.0000 & $0.000 \mathrm{E}+00$ & 0.0000 & $0.000 \mathrm{E}+00$ & 0.0000 & $0.000 \mathrm{E}+00$ & 0.0000 & $0.000 \mathrm{E}+00$ & 0.0000 & $0.000 \mathrm{E}+00$ & 0.0000 & $2.762 \mathrm{E}-02$ & 0.0083 \\
\hline-99 & $0.000 \mathrm{E}+00$ & 0.0000 & $0.000 \mathrm{E}+00$ & 0.0000 & $0.000 \mathrm{E}+00$ & 0.0000 & $0.000 \mathrm{E}+00$ & 0.0000 & $0.000 \mathrm{E}+00$ & 0.0000 & $0.000 \mathrm{E}+00$ & 0.0000 & $5.211 \mathrm{E}-05$ & 0.0000 \\
\hline-228 & $0.000 \mathrm{E}+00$ & 0.0000 & $0.000 \mathrm{E}+00$ & 0.0000 & $0.000 \mathrm{E}+00$ & 0.0000 & $0.000 \mathrm{E}+00$ & 0.0000 & $0.000 \mathrm{E}+00$ & 0.0000 & $0.000 \mathrm{E}+00$ & 0.0000 & $1.845 \mathrm{E}-08$ & 0.0000 \\
\hline 230 & $0.000 \mathrm{E}+00$ & 0.0000 & $0.000 \mathrm{E}+00$ & 0.0000 & $0.000 \mathrm{E}+00$ & 0.0000 & $0.000 \mathrm{E}+00$ & 0.0000 & $0.000 \mathrm{E}+00$ & 0.0000 & $0.000 \mathrm{E}+00$ & 0.0000 & $6.446 \mathrm{E}-02$ & 0.0194 \\
\hline 232 & $0.000 \mathrm{E}+00$ & 0.0000 & $0.000 \mathrm{E}+00$ & 0.0000 & $0.000 \mathrm{E}+00$ & 0.0000 & $0.000 \mathrm{E}+00$ & 0.0000 & $0.000 \mathrm{E}+00$ & 0.0000 & $0.000 \mathrm{E}+00$ & 0.0000 & $2.655 \mathrm{E}+00$ & 0.7992 \\
\hline 34 & $0.000 \mathrm{E}+00$ & 0.0000 & $0.000 \mathrm{E}+00$ & 0.0000 & $0.000 \mathrm{E}+00$ & 0.0000 & $0.000 \mathrm{E}+00$ & 0.0000 & $0.000 \mathrm{E}+00$ & 0.0000 & $0.000 \mathrm{E}+00$ & 0.0000 & $5.478 E-03$ & 0.0016 \\
\hline 35 & $0.000 \mathrm{E}+00$ & 0.0000 & $0.000 \mathrm{E}+00$ & 0.0000 & $0.000 \mathrm{E}+00$ & 0.0000 & $0.000 \mathrm{E}+00$ & 0.0000 & $0.000 \mathrm{E}+00$ & 0.0000 & $0.000 \mathrm{E}+00$ & 0.0000 & $1.215 \mathrm{E}-01$ & 0.0366 \\
\hline 38 & $0.000 \mathrm{E}+00$ & 0.0000 & $0.000 \mathrm{E}+00$ & 0.0000 & $0.000 \mathrm{E}+00$ & 0.0000 & $0.000 \mathrm{E}+00$ & 0.0000 & $0.000 \mathrm{E}+00$ & 0.0000 & $0.000 \mathrm{E}+00$ & 0.0000 & $3.125 \mathrm{E}-02$ & 0.0094 \\
\hline & $0.000 \mathrm{E}+00$ & 0.0000 & $0.000 \mathrm{E}+00$ & 0.0000 & $0.000 \mathrm{E}+00$ & 0.0000 & $0.000 \mathrm{E}+00$ & 0.0000 & $0.000 \mathrm{E}+00$ & 0.0000 & $0.000 \mathrm{E}+00$ & 0.0000 & $2 E+00$ & 1.0000 \\
\hline
\end{tabular}

* Sum of all water independent and dependent pathways. 
RESRAD, Version 6.5

$\mathrm{T}^{1 / 2}$ Limit $=180$ days

05/03/2011 15:49 Page 24

Summary : C746U Landfill Worker Deterministic Run
File : X: \FINAL V2 \C746U LANDFILL WORKER DET-FINALV2.RAD

Total Dose Contributions TDOSE(i,p,t) for Individual Radionuclides (i) and Pathways (p) As mrem/yr and Fraction of Total Dose At $t=7.000 \mathrm{E}+01$ years

Water Independent Pathways (Inhalation excludes radon)

\begin{tabular}{|c|c|c|c|c|c|c|c|c|c|c|c|c|c|c|}
\hline \multirow{2}{*}{ Nuclide } & \multicolumn{2}{|c|}{ Ground } & \multicolumn{2}{|c|}{ Inhalation } & \multicolumn{2}{|c|}{ Radon } & \multicolumn{2}{|c|}{ Plant } & \multicolumn{2}{|c|}{ Meat } & \multicolumn{2}{|c|}{ Milk } & \multicolumn{2}{|c|}{ Soil } \\
\hline & mrem/yr & fract. & mrem/yr & fract. & mrem/yr & fract. & mrem/yr & fract. & mrem/yr & fract. & mrem/yr & fract. & mrem/yr & fract. \\
\hline-241 & $5.629 \mathrm{E}-03$ & 0.0017 & $1.612 \mathrm{E}-04$ & 0.0000 & $0.000 \mathrm{E}+00$ & 0.0000 & $0.000 \mathrm{E}+00$ & 0.0000 & $0.000 \mathrm{E}+00$ & 0.0000 & $0.000 \mathrm{E}+00$ & 0.0000 & $1.968 \mathrm{E}-02$ & 0.0060 \\
\hline-137 & $1.038 E-01$ & 0.0317 & $1.433 \mathrm{E}-08$ & 0.0000 & $0.000 \mathrm{E}+00$ & 0.0000 & $0.000 \mathrm{E}+00$ & 0.0000 & $0.000 \mathrm{E}+00$ & 0.0000 & $0.000 \mathrm{E}+00$ & 0.0000 & $2.802 \mathrm{E}-04$ & 0.0001 \\
\hline-237 & $1.674 \mathrm{E}-01$ & 0.0510 & $9.308 \mathrm{E}-05$ & 0.0000 & $0.000 \mathrm{E}+00$ & 0.0000 & $0.000 \mathrm{E}+00$ & 0.0000 & $0.000 \mathrm{E}+00$ & 0.0000 & $0.000 \mathrm{E}+00$ & 0.0000 & $1.208 \mathrm{E}-02$ & 0.0037 \\
\hline-238 & $1.134 \mathrm{E}-05$ & 0.0000 & $1.185 \mathrm{E}-04$ & 0.0000 & $0.000 \mathrm{E}+00$ & 0.0000 & $0.000 \mathrm{E}+00$ & 0.0000 & $0.000 \mathrm{E}+00$ & 0.0000 & $0.000 \mathrm{E}+00$ & 0.0000 & $1.450 \mathrm{E}-02$ & 0.0044 \\
\hline-239 & $4.408 E-05$ & 0.0000 & $2.251 \mathrm{E}-04$ & 0.0001 & $0.000 \mathrm{E}+00$ & 0.0000 & $0.000 \mathrm{E}+00$ & 0.0000 & $0.000 \mathrm{E}+00$ & 0.0000 & $0.000 \mathrm{E}+00$ & 0.0000 & $2.746 \mathrm{E}-02$ & 0.0084 \\
\hline-240 & $1.897 \mathrm{E}-05$ & 0.0000 & $2.239 \mathrm{E}-04$ & 0.0001 & $0.000 \mathrm{E}+00$ & 0.0000 & $0.000 \mathrm{E}+00$ & 0.0000 & $0.000 \mathrm{E}+00$ & 0.0000 & $0.000 \mathrm{E}+00$ & 0.0000 & $2.731 \mathrm{E}-02$ & 0.0083 \\
\hline-99 & $8.680 E-06$ & 0.0000 & $1.161 \mathrm{E}-08$ & 0.0000 & $0.000 \mathrm{E}+00$ & 0.0000 & $0.000 \mathrm{E}+00$ & 0.0000 & $0.000 \mathrm{E}+00$ & 0.0000 & $0.000 \mathrm{E}+00$ & 0.0000 & $3.349 \mathrm{E}-05$ & 0.0000 \\
\hline-228 & $1.302 \mathrm{E}-11$ & 0.0000 & $6.659 \mathrm{E}-16$ & 0.0000 & $0.000 \mathrm{E}+00$ & 0.0000 & $0.000 \mathrm{E}+00$ & 0.0000 & $0.000 \mathrm{E}+00$ & 0.0000 & $0.000 \mathrm{E}+00$ & 0.0000 & $1.280 \mathrm{E}-13$ & 0.0000 \\
\hline-230 & $5.307 \mathrm{E}-02$ & 0.0162 & $1.889 \mathrm{E}-04$ & 0.0001 & $0.000 \mathrm{E}+00$ & 0.0000 & $0.000 \mathrm{E}+00$ & 0.0000 & $0.000 \mathrm{E}+00$ & 0.0000 & $0.000 \mathrm{E}+00$ & 0.0000 & $2.779 \mathrm{E}-02$ & 0.0085 \\
\hline-232 & $2.545 E+00$ & 0.7757 & $3.192 \mathrm{E}-04$ & 0.0001 & $0.000 \mathrm{E}+00$ & 0.0000 & $0.000 \mathrm{E}+00$ & 0.0000 & $0.000 \mathrm{E}+00$ & 0.0000 & $0.000 \mathrm{E}+00$ & 0.0000 & $1.171 \mathrm{E}-01$ & 0.0357 \\
\hline 34 & $7.492 \mathrm{E}-05$ & 0.0000 & $1.779 \mathrm{E}-05$ & 0.0000 & $0.000 \mathrm{E}+00$ & 0.0000 & $0.000 \mathrm{E}+00$ & 0.0000 & $0.000 \mathrm{E}+00$ & 0.0000 & $0.000 \mathrm{E}+00$ & 0.0000 & $5.395 \mathrm{E}-03$ & 0.0016 \\
\hline 35 & $1.162 \mathrm{E}-01$ & 0.0354 & $1.735 \mathrm{E}-05$ & 0.0000 & $0.000 \mathrm{E}+00$ & 0.0000 & $0.000 \mathrm{E}+00$ & 0.0000 & $0.000 \mathrm{E}+00$ & 0.0000 & $0.000 \mathrm{E}+00$ & 0.0000 & $5.446 \mathrm{E}-03$ & 0.0017 \\
\hline 38 & $2.588 E-02$ & 0.0079 & $1.505 \mathrm{E}-05$ & 0.0000 & $0.000 \mathrm{E}+00$ & 0.0000 & $0.000 \mathrm{E}+00$ & 0.0000 & $0.000 \mathrm{E}+00$ & 0.0000 & $0.000 \mathrm{E}+00$ & 0.0000 & $5.340 \mathrm{E}-03$ & 0.0016 \\
\hline & $3.017 \mathrm{E}+00$ & 0.9196 & $1.380 \mathrm{E}-03$ & 0.0004 & $0.000 \mathrm{E}+00$ & 0.0000 & $0.000 \mathrm{E}+00$ & 0.0000 & $0.000 \mathrm{E}+00$ & 0.0000 & $0.000 \mathrm{E}+00$ & 0.0000 & 2. $624 \mathrm{E}-01$ & 0.0800 \\
\hline
\end{tabular}

Total Dose Contributions TDOSE(i,p,t) for Individual Radionuclides (i) and Pathways (p) As mrem/yr and Fraction of Total Dose At $t=7.000 \mathrm{E}+01$ years

Water Dependent Pathways

\begin{tabular}{|c|c|c|c|c|c|c|c|c|c|c|c|c|c|c|}
\hline & \multicolumn{2}{|c|}{ Water } & \multicolumn{2}{|c|}{ Fish } & \multicolumn{2}{|c|}{ Radon } & \multicolumn{2}{|c|}{ Plant } & \multicolumn{2}{|c|}{ Meat } & \multicolumn{2}{|c|}{ Milk } & \multicolumn{2}{|c|}{ All Pathways* } \\
\hline clide & mrem/yr & fract. & mrem/yr & fract. & mrem/yr & fract. & mrem/yr & fract. & mrem/yr & fract. & mrem/yr & fract. & mrem/yr & fract. \\
\hline 241 & $0.000 \mathrm{E}+00$ & 0.0000 & $0.000 \mathrm{E}+00$ & 0.0000 & $0.000 \mathrm{E}+00$ & 0.0000 & $0.000 \mathrm{E}+00$ & 0.0000 & $0.000 \mathrm{E}+00$ & 0.0000 & $0.000 \mathrm{E}+00$ & 0.0000 & $2.547 \mathrm{E}-02$ & 0.0078 \\
\hline-137 & $0.000 \mathrm{E}+00$ & 0.0000 & $0.000 \mathrm{E}+00$ & 0.0000 & $0.000 \mathrm{E}+00$ & 0.0000 & $0.000 \mathrm{E}+00$ & 0.0000 & $0.000 \mathrm{E}+00$ & 0.0000 & $0.000 \mathrm{E}+00$ & 0.0000 & $1.041 \mathrm{E}-01$ & 0.0317 \\
\hline-237 & $0.000 \mathrm{E}+00$ & 0.0000 & $0.000 \mathrm{E}+00$ & 0.0000 & $0.000 \mathrm{E}+00$ & 0.0000 & $0.000 \mathrm{E}+00$ & 0.0000 & $0.000 \mathrm{E}+00$ & 0.0000 & $0.000 \mathrm{E}+00$ & 0.0000 & $1.796 \mathrm{E}-01$ & 0.0547 \\
\hline-238 & $0.000 \mathrm{E}+00$ & 0.0000 & $0.000 \mathrm{E}+00$ & 0.0000 & $0.000 \mathrm{E}+00$ & 0.0000 & $0.000 \mathrm{E}+00$ & 0.0000 & $0.000 \mathrm{E}+00$ & 0.0000 & $0.000 \mathrm{E}+00$ & 0.0000 & $1.463 \mathrm{E}-02$ & 0.0045 \\
\hline-239 & $0.000 \mathrm{E}+00$ & 0.0000 & $0.000 \mathrm{E}+00$ & 0.0000 & $0.000 \mathrm{E}+00$ & 0.0000 & $0.000 \mathrm{E}+00$ & 0.0000 & $0.000 \mathrm{E}+00$ & 0.0000 & $0.000 E+00$ & 0.0000 & $2.772 \mathrm{E}-02$ & 0.0085 \\
\hline-240 & $0.000 \mathrm{E}+00$ & 0.0000 & $0.000 \mathrm{E}+00$ & 0.0000 & $0.000 \mathrm{E}+00$ & 0.0000 & $0.000 \mathrm{E}+00$ & 0.0000 & $0.000 \mathrm{E}+00$ & 0.0000 & $0.000 E+00$ & 0.0000 & $2.755 \mathrm{E}-02$ & 0.0084 \\
\hline-99 & $0.000 \mathrm{E}+00$ & 0.0000 & $0.000 \mathrm{E}+00$ & 0.0000 & $0.000 \mathrm{E}+00$ & 0.0000 & $0.000 \mathrm{E}+00$ & 0.0000 & $0.000 \mathrm{E}+00$ & 0.0000 & $0.000 \mathrm{E}+00$ & 0.0000 & $4.218 E-05$ & 0.0000 \\
\hline-228 & $0.000 \mathrm{E}+00$ & 0.0000 & $0.000 \mathrm{E}+00$ & 0.0000 & $0.000 \mathrm{E}+00$ & 0.0000 & $0.000 \mathrm{E}+00$ & 0.0000 & $0.000 \mathrm{E}+00$ & 0.0000 & $0.000 \mathrm{E}+00$ & 0.0000 & 1. $315 \mathrm{E}-11$ & 0.0000 \\
\hline-230 & $0.000 \mathrm{E}+00$ & 0.0000 & $0.000 \mathrm{E}+00$ & 0.0000 & $0.000 \mathrm{E}+00$ & 0.0000 & $0.000 \mathrm{E}+00$ & 0.0000 & $0.000 \mathrm{E}+00$ & 0.0000 & $0.000 E+00$ & 0.0000 & $8.104 \mathrm{E}-02$ & 0.0247 \\
\hline-232 & $0.000 \mathrm{E}+00$ & 0.0000 & $0.000 \mathrm{E}+00$ & 0.0000 & $0.000 \mathrm{E}+00$ & 0.0000 & $0.000 \mathrm{E}+00$ & 0.0000 & $0.000 \mathrm{E}+00$ & 0.0000 & $0.000 \mathrm{E}+00$ & 0.0000 & $2.662 \mathrm{E}+00$ & 0.8114 \\
\hline 34 & $0.000 \mathrm{E}+00$ & 0.0000 & $0.000 \mathrm{E}+00$ & 0.0000 & $0.000 \mathrm{E}+00$ & 0.0000 & $0.000 \mathrm{E}+00$ & 0.0000 & $0.000 \mathrm{E}+00$ & 0.0000 & $0.000 \mathrm{E}+00$ & 0.0000 & $5.488 E-03$ & 0.0017 \\
\hline 35 & $0.000 \mathrm{E}+00$ & 0.0000 & $0.000 \mathrm{E}+00$ & 0.0000 & $0.000 \mathrm{E}+00$ & 0.0000 & $0.000 \mathrm{E}+00$ & 0.0000 & $0.000 \mathrm{E}+00$ & 0.0000 & $0.000 \mathrm{E}+00$ & 0.0000 & $1.217 \mathrm{E}-01$ & 0.0371 \\
\hline 38 & $0.000 \mathrm{E}+00$ & 0.0000 & $0.000 \mathrm{E}+00$ & 0.0000 & $0.000 \mathrm{E}+00$ & 0.0000 & $0.000 \mathrm{E}+00$ & 0.0000 & $0.000 \mathrm{E}+00$ & 0.0000 & $0.000 \mathrm{E}+00$ & 0.0000 & $3.123 E-02$ & 0.0095 \\
\hline & $0.000 \mathrm{E}+00$ & 0.0000 & $0.000 \mathrm{E}+00$ & 0.0000 & $0.000 \mathrm{E}+00$ & 0.0000 & $0.000 \mathrm{E}+00$ & 0.0000 & $0.000 \mathrm{E}+00$ & 0.0000 & $0.000 \mathrm{E}+00$ & 0.0000 & $3.281 \mathrm{E}+00$ & 1. \\
\hline
\end{tabular}

* Sum of all water independent and dependent pathways. 
RESRAD, Version $6.5 \quad \mathrm{~T}^{1 / 2}$ Limit $=180$ days

ummary : C746U Landfill Worker Deterministic Run

File : $\mathrm{X}: \backslash$ FINAL V2 $\backslash \mathrm{C} 746 \mathrm{U}$ LANDFILL WORKER DET-FINALV2.RAD

Dose/Source Ratios Summed Over All Pathways

Parent and Progeny Principal Radionuclide Contributions Indicated

Parent Product Thread DSR $(j, t)$ At Time in Years (mrem/yr)/(pCi/g)

(i) (j) Fraction 0.000E+00 1.000E+00 5.000E+01 7.000E+01

Am-241

Am-241

Am-241

Am-241

Am-241

\begin{tabular}{|c|c|c|c|c|c|}
\hline Am-241 & $1.000 \mathrm{E}+00$ & $2.850 \mathrm{E}-02$ & $2.845 \mathrm{E}-02$ & $2.630 \mathrm{E}-02$ & $2.546 \mathrm{E}-02$ \\
\hline$N p-237+D$ & $1.000 \mathrm{E}+00$ & $2.940 \mathrm{E}-08$ & $8.812 \mathrm{E}-08$ & $2.842 E-06$ & $3.898 \mathrm{E}-06$ \\
\hline $\mathrm{U}-233$ & $1.000 \mathrm{E}+00$ & $1.383 E-15$ & $9.674 \mathrm{E}-15$ & $1.027 \mathrm{E}-11$ & $1.978 \mathrm{E}-11$ \\
\hline$T h-229+D$ & $1.000 \mathrm{E}+00$ & $1.756 \mathrm{E}-18$ & $2.633 \mathrm{E}-17$ & $8.837 \mathrm{E}-13$ & 2. $382 \mathrm{E}-12$ \\
\hline$\sum \operatorname{DSR}(j)$ & & $2.850 \mathrm{E}-02$ & $2.845 \mathrm{E}-02$ & $2.630 \mathrm{E}-02$ & $2.547 \mathrm{E}-02$ \\
\hline
\end{tabular}

$\mathrm{Cs}-137+\mathrm{D} \quad \mathrm{Cs}-137+\mathrm{D} \quad 1.000 \mathrm{E}+00 \quad 5.262 \mathrm{E}-01 \quad 5.142 \mathrm{E}-01 \quad 1.654 \mathrm{E}-01 \quad 1.041 \mathrm{E}-01$

$\mathrm{Np}-237+\mathrm{D} \quad \mathrm{Np}-237+\mathrm{D} \quad 1.000 \mathrm{E}+00 \quad 1.816 \mathrm{E}-01 \quad 1.816 \mathrm{E}-01 \quad 1.802 \mathrm{E}-01 \quad 1.796 \mathrm{E}-01$

$\mathrm{Np}-237+\mathrm{D} \quad \mathrm{U}-233 \quad 1.000 \mathrm{E}+00 \quad 1.281 \mathrm{E}-08 \quad 3.843 \mathrm{E}-08 \quad 1.288 \mathrm{E}-06 \quad 1.795 \mathrm{E}-06$

$\mathrm{Np}-237+\mathrm{D} \quad \mathrm{Th}-229+\mathrm{D} \quad 1.000 \mathrm{E}+00 \quad 2.169 \mathrm{E}-11 \quad 1.518 \mathrm{E}-10 \quad 1.652 \mathrm{E}-07 \quad 3.213 \mathrm{E}-07$

$\mathrm{Np}-237+\mathrm{D} \quad \sum \mathrm{DSR}(j) \quad 1.816 \mathrm{E}-01 \quad 1.816 \mathrm{E}-011.802 \mathrm{E}-011.796 \mathrm{E}-01$

Pu-238 Pu-238 1.840E-09 4.687E-11 4.650E-11 3.154E-11 2.692E-11

Pu-238 Pu-238 1.000E+00 2.547E-02 2.527E-02 $1.714 \mathrm{E}-02 \quad 1.463 \mathrm{E}-02$

$\begin{array}{llllllll}\mathrm{Pu}-238 \mathrm{U}-234 & 1.000 \mathrm{E}+00 & 7.728 \mathrm{E}-09 & 2.310 \mathrm{E}-08 & 6.445 \mathrm{E}-07 & 8.363 \mathrm{E}-07\end{array}$

Pu-238 Th-230 1.000E+00 9.980E-14 6.970E-13 $6.720 \mathrm{E}-10 \quad 1.247 \mathrm{E}-09$

$\mathrm{Pu}-238 \quad \mathrm{Ra}-226+\mathrm{D} \quad 1.000 \mathrm{E}+00 \quad 8.234 \mathrm{E}-16 \quad 1.233 \mathrm{E}-14 \quad 3.832 \mathrm{E}-10 \quad 1.002 \mathrm{E}-09$

$\mathrm{Pu}-238 \quad \mathrm{~Pb}-210+\mathrm{D} \quad 1.000 \mathrm{E}+00 \quad 5.964 \mathrm{E}-19 \quad 1.836 \mathrm{E}-17 \quad 1.347 \mathrm{E}-11 \quad 4.480 \mathrm{E}-11$

Pu-238 $\quad \sum \operatorname{DSR}(j) \quad 2.547 \mathrm{E}-02 \quad 2.527 \mathrm{E}-02 \quad 1.714 \mathrm{E}-02 \quad 1.463 \mathrm{E}-02$

$\mathrm{Pu}-239$

$\mathrm{Pu}-239$

$\mathrm{Pu}-239$

$\mathrm{Pu}-239$

$\mathrm{Pu}-239$

$\begin{array}{llllll}\mathrm{Pu}-239 & 1.000 \mathrm{E}+00 & 2.782 \mathrm{E}-02 & 2.782 \mathrm{E}-02 & 2.775 \mathrm{E}-02 & 2.772 \mathrm{E}-02\end{array}$

$\begin{array}{llllll}\mathrm{U}-235+\mathrm{D} & 1.000 \mathrm{E}+00 & 5.975 \mathrm{E}-11 & 1.793 \mathrm{E}-10 & 6.024 \mathrm{E}-09 & 8.403 \mathrm{E}-09\end{array}$

$\begin{array}{llllll}\mathrm{Pa}-231 & 1.000 \mathrm{E}+00 & 3.752 \mathrm{E}-16 & 2.626 \mathrm{E}-15 & 2.865 \mathrm{E}-12 & 5.580 \mathrm{E}-12\end{array}$

$\mathrm{AC}-227+\mathrm{D} \quad 1.000 \mathrm{E}+00 \quad 1.227 \mathrm{E}-17 \quad 1.828 \mathrm{E}-16 \quad 4.441 \mathrm{E}-12 \quad 1.071 \mathrm{E}-11$

$\operatorname{LDSR}(j) \quad 2.782 \mathrm{E}-02 \quad 2.782 \mathrm{E}-02 \quad 2.775 \mathrm{E}-02 \quad 2.772 \mathrm{E}-02$

$\begin{array}{lllllll}\mathrm{Pu}-240 \quad 4.950 \mathrm{E}-08 & 1.376 \mathrm{E}-09 & 1.376 \mathrm{E}-09 & 1.367 \mathrm{E}-09 & 1.364 \mathrm{E}-09\end{array}$

$\begin{array}{llllll}\mathrm{Pu}-240 & 1.000 \mathrm{E}+00 & 2.779 \mathrm{E}-02 & 2.779 \mathrm{E}-02 & 2.762 \mathrm{E}-02 & 2.755 \mathrm{E}-02\end{array}$

$\begin{array}{lllllll}\mathrm{U}-236 & 1.000 \mathrm{E}+00 & 7.739 \mathrm{E}-11 & 2.322 \mathrm{E}-10 & 7.787 \mathrm{E}-09 & 1.085 \mathrm{E}-08\end{array}$

$\begin{array}{llllll}\mathrm{Th}-232 & 1.000 \mathrm{E}+00 & 6.238 \mathrm{E}-21 & 4.367 \mathrm{E}-20 & 4.761 \mathrm{E}-17 & 9.268 \mathrm{E}-17\end{array}$

$\mathrm{Ra}-228+\mathrm{D} \quad 1.000 \mathrm{E}+00 \quad 7.279 \mathrm{E}-21 \quad 1.065 \mathrm{E}-19 \quad 1.370 \mathrm{E}-15 \quad 2.913 \mathrm{E}-15$

$\begin{array}{lllllll}\mathrm{Th}-228+\mathrm{D} & 1.000 \mathrm{E}+00 & 7.965 \mathrm{E}-22 & 2.280 \mathrm{E}-20 & 1.928 \mathrm{E}-15 & 4.261 \mathrm{E}-15\end{array}$

$\operatorname{LDSR}(j) \quad 2.779 \mathrm{E}-02 \quad 2.779 \mathrm{E}-02 \quad 2.762 \mathrm{E}-02 \quad 2.755 \mathrm{E}-02$

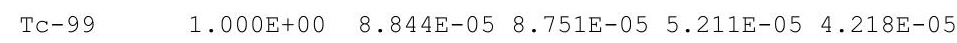

$\begin{array}{lllllll}\mathrm{Th}-228+\mathrm{D} & 1.000 \mathrm{E}+00 & 1.360 \mathrm{E}+00 & 9.469 \mathrm{E}-01 & 1.845 \mathrm{E}-08 & 1.315 \mathrm{E}-11\end{array}$

$\begin{array}{llllll}\mathrm{Th}-230 & 1.000 \mathrm{E}+00 & 2.351 \mathrm{E}-02 & 2.351 \mathrm{E}-02 & 2.350 \mathrm{E}-02 & 2.349 \mathrm{E}-02\end{array}$

$\mathrm{Ra}-226+\mathrm{D} \quad 1.000 \mathrm{E}+00 \quad 3.878 \mathrm{E}-04 \quad 1.163 \mathrm{E}-03 \quad 3.871 \mathrm{E}-02 \quad 5.379 \mathrm{E}-02$

$\mathrm{Pb}-210+\mathrm{D} \quad 1.000 \mathrm{E}+00 \quad 4.667 \mathrm{E}-07 \quad 3.238 \mathrm{E}-06 \quad 2.251 \mathrm{E}-03 \quad 3.757 \mathrm{E}-03$

$\operatorname{LDSR}(j) \quad 2.390 \mathrm{E}-02 \quad 2.468 \mathrm{E}-02 \quad 6.446 \mathrm{E}-02 \quad 8.104 \mathrm{E}-02$ 


\section{RESRAD, Version $6.5 \quad \mathrm{~T}^{1 / 2}$ Limit $=180$ days}

Summary : C746U Landfill Worker Deterministic Run

File : $\mathrm{X}: \backslash$ FINAL V2 $\backslash$ C746U LANDFILL WORKER DET-FINALV2.RAD

Dose/Source Ratios Summed Over All Pathways

Parent and Progeny Principal Radionuclide Contributions Indicated

\begin{tabular}{|c|c|c|c|c|c|c|}
\hline Parent & Product & Thread & $R(j, t) \quad A t$ & Time in $Y$ & (mre & $\mathrm{em} / \mathrm{yr}) /(\mathrm{pCi}$ \\
\hline (i) & $(j)$ & Fraction & $0.000 \mathrm{E}+00$ & $1.000 \mathrm{E}+00$ & $5.000 \mathrm{E}+01$ & $7.000 \mathrm{E}+01$ \\
\hline-232 & Th-232 & $1.000 \mathrm{E}+00$ & $2.563 E-02$ & $2.563 E-02$ & $2.563 E-02$ & $2.562 \mathrm{E}-02$ \\
\hline-232 & $\mathrm{Ra}-228+\mathrm{D}$ & $1.000 \mathrm{E}+00$ & $5.887 \mathrm{E}-02$ & $1.676 \mathrm{E}-01$ & $1.014 \mathrm{E}+00$ & $1.016 \mathrm{E}+00$ \\
\hline-232 & $\mathrm{Th}-228+\mathrm{D}$ & $1.000 \mathrm{E}+00$ & $1.049 \mathrm{E}-02$ & $6.433 E-02$ & $1.616 \mathrm{E}+00$ & $1.621 \mathrm{E}+00$ \\
\hline-232 & $\sum \operatorname{DSR}(j)$ & & $9.499 \mathrm{E}-02$ & $2.576 \mathrm{E}-01$ & $2.655 \mathrm{E}+00$ & $2.662 \mathrm{E}+00$ \\
\hline-234 & $\mathrm{U}-234$ & $1.000 \mathrm{E}+00$ & $5.467 \mathrm{E}-03$ & $5.466 \mathrm{E}-03$ & $5.458 \mathrm{E}-03$ & $5.455 \mathrm{E}-03$ \\
\hline-234 & Th-230 & $1.000 \mathrm{E}+00$ & $1.058 \mathrm{E}-07$ & $3.175 E-07$ & $1.068 \mathrm{E}-05$ & $1.490 \mathrm{E}-05$ \\
\hline-234 & $\mathrm{Ra}-226+\mathrm{D}$ & $1.000 \mathrm{E}+00$ & $1.164 \mathrm{E}-09$ & $8.144 \mathrm{E}-09$ & $8.830 \mathrm{E}-06$ & $1.715 \mathrm{E}-05$ \\
\hline-234 & $\mathrm{~Pb}-210+\mathrm{D}$ & $1.000 \mathrm{E}+00$ & 1. 052E-12 & 1. $567 \mathrm{E}-11$ & $3.816 \mathrm{E}-07$ & $9.196 \mathrm{E}-07$ \\
\hline-234 & $\sum \operatorname{DSR}(j)$ & & $5.467 \mathrm{E}-03$ & $5.467 \mathrm{E}-03$ & $5.478 E-03$ & $5.488 E-03$ \\
\hline$-235+D$ & $\mathrm{U}-235+\mathrm{D}$ & $1.000 \mathrm{E}+00$ & $1.213 \mathrm{E}-01$ & 1. $213 \mathrm{E}-01$ & 1. $212 \mathrm{E}-01$ & 1. $211 \mathrm{E}-01$ \\
\hline$-235+D$ & $\mathrm{~Pa}-231$ & $1.000 \mathrm{E}+00$ & $1.143 E-06$ & $3.429 \mathrm{E}-06$ & $1.152 \mathrm{E}-04$ & $1.608 \mathrm{E}-04$ \\
\hline$-235+D$ & $A c-227+D$ & $1.000 \mathrm{E}+00$ & $4.976 \mathrm{E}-08$ & $3.452 \mathrm{E}-07$ & $2.396 \mathrm{E}-04$ & $4.001 \mathrm{E}-04$ \\
\hline$-235+D$ & $\sum \operatorname{DSR}(j)$ & & $1.213 \mathrm{E}-01$ & 1. $213 E-01$ & $1.215 \mathrm{E}-01$ & $1.217 \mathrm{E}-01$ \\
\hline-238 & $\mathrm{U}-238$ & $5.400 E-05$ & $2.701 \mathrm{E}-07$ & $2.701 E-07$ & $2.698 E-07$ & $2.696 \mathrm{E}-07$ \\
\hline$-238+D$ & $\mathrm{U}-238+\mathrm{D}$ & $9.999 \mathrm{E}-01$ & $3.129 \mathrm{E}-02$ & $3.129 \mathrm{E}-02$ & $3.125 \mathrm{E}-02$ & $3.123 \mathrm{E}-02$ \\
\hline$J-238+D$ & $\mathrm{U}-234$ & $9.999 \mathrm{E}-01$ & $7.748 E-09$ & $2.324 \mathrm{E}-08$ & $7.815 \mathrm{E}-07$ & $1.090 \mathrm{E}-06$ \\
\hline$J-238+D$ & $T h-230$ & $9.999 \mathrm{E}-01$ & $9.999 \mathrm{E}-14$ & $6.999 \mathrm{E}-13$ & $7.642 \mathrm{E}-10$ & $1.489 \mathrm{E}-09$ \\
\hline$-238+D$ & $\mathrm{Ra}-226+\mathrm{D}$ & $9.999 \mathrm{E}-01$ & $8.247 \mathrm{E}-16$ & 1. $237 \mathrm{E}-14$ & $4.221 \mathrm{E}-10$ & $1.145 \mathrm{E}-09$ \\
\hline$-238+D$ & $\mathrm{~Pb}-210+\mathrm{D}$ & $9.999 \mathrm{E}-01$ & $5.972 \mathrm{E}-19$ & $1.841 \mathrm{E}-17$ & $1.461 \mathrm{E}-11$ & $5.020 \mathrm{E}-11$ \\
\hline$-238+D$ & $\sum \operatorname{DSR}(j)$ & & $3.129 \mathrm{E}-02$ & $3.129 \mathrm{E}-02$ & $3.125 \mathrm{E}-02$ & $3.123 E-02$ \\
\hline
\end{tabular}

The DSR includes contributions from associated (half-life $\leq 180$ days) daughters. 
RESRAD, Version $6.5 \quad \mathrm{~T}^{1 / 2}$ Limit $=180$ days

Summary : C746U Landfill Worker Deterministic Run

File : $\mathrm{X}: \backslash$ FINAL V2 $\backslash \mathrm{C} 746 \mathrm{U}$ LANDFILL WORKER DET-FINALV2.RAD

Single Radionuclide Soil Guidelines G(i,t) in pCi/g

Basic Radiation Dose Limit $=1.000 \mathrm{E}+02 \mathrm{mrem} / \mathrm{yr}$

Nuclide

\begin{tabular}{|c|c|c|c|c|c|}
\hline (i) & $t=$ & $0.000 \mathrm{E}+00$ & $1.000 \mathrm{E}+00$ & $5.000 \mathrm{E}+01$ & $7.000 \mathrm{E}+01$ \\
\hline Am-241 & & $3.509 \mathrm{E}+03$ & $3.514 \mathrm{E}+03$ & $3.802 \mathrm{E}+03$ & $3.927 \mathrm{E}+03$ \\
\hline $\mathrm{Cs}-137$ & & $1.900 \mathrm{E}+02$ & 1. $945 \mathrm{E}+02$ & $6.045 \mathrm{E}+02$ & $9.603 E+02$ \\
\hline$N p-237$ & & $5.507 \mathrm{E}+02$ & $5.507 \mathrm{E}+02$ & $5.550 \mathrm{E}+02$ & $5.568 \mathrm{E}+02$ \\
\hline $\mathrm{Pu}-238$ & & $3.926 \mathrm{E}+03$ & $3.957 \mathrm{E}+03$ & $5.833 \mathrm{E}+03$ & $6.834 \mathrm{E}+03$ \\
\hline Pu-239 & & $3.595 \mathrm{E}+03$ & $3.595 \mathrm{E}+03$ & $3.603 \mathrm{E}+03$ & $3.607 \mathrm{E}+03$ \\
\hline$P u-240$ & & $3.598 \mathrm{E}+03$ & $3.598 \mathrm{E}+03$ & $3.621 \mathrm{E}+03$ & $3.630 \mathrm{E}+03$ \\
\hline $\mathrm{TC}-99$ & & $1.131 \mathrm{E}+06$ & $1.143 \mathrm{E}+06$ & $1.919 \mathrm{E}+06$ & $2.371 \mathrm{E}+06$ \\
\hline Th -228 & & 7. $351 E+01$ & $1.056 \mathrm{E}+02$ & $5.420 \mathrm{E}+09$ & 7. $604 \mathrm{E}+12$ \\
\hline Th -230 & & $4.184 \mathrm{E}+03$ & $4.052 E+03$ & $1.551 \mathrm{E}+03$ & $1.234 \mathrm{E}+03$ \\
\hline Th-232 & & $1.053 \mathrm{E}+03$ & $3.882 \mathrm{E}+02$ & $3.766 \mathrm{E}+01$ & $3.757 \mathrm{E}+01$ \\
\hline $\mathrm{U}-234$ & & $1.829 \mathrm{E}+04$ & $1.829 \mathrm{E}+04$ & $1.825 \mathrm{E}+04$ & $1.822 \mathrm{E}+04$ \\
\hline$U-235$ & & $8.241 E+02$ & $8.241 E+02$ & $8.228 E+02$ & $8.218 E+02$ \\
\hline$U-238$ & & $3.196 \mathrm{E}+03$ & $3.196 \mathrm{E}+03$ & $3.200 \mathrm{E}+03$ & $3.202 \mathrm{E}+03$ \\
\hline
\end{tabular}

Summed Dose/Source Ratios DSR (i,t) in (mrem/yr)/(pCi/g) and Single Radionuclide Soil Guidelines G(i,t) in pCi/g at $\operatorname{tmin}=$ time of minimum single radionuclide soil guideline and at $\operatorname{tmax}=$ time of maximum total dose $=36.83 \pm 0.07$ years

\begin{tabular}{|c|c|c|c|c|c|c|}
\hline $\begin{array}{l}\text { Juclide } \\
\text { (i) }\end{array}$ & $\begin{array}{l}\text { Initial } \\
(\mathrm{pCi} / \mathrm{g})\end{array}$ & $\begin{array}{c}\text { tmin } \\
\text { (years) }\end{array}$ & $\operatorname{DSR}(i, \operatorname{tmin})$ & $\begin{array}{c}\mathrm{G}(\mathrm{i}, \mathrm{tmin}) \\
(\mathrm{pCi} / \mathrm{g})\end{array}$ & $\operatorname{DSR}(i, t \max )$ & $\begin{array}{c}\mathrm{G}(\mathrm{i}, \mathrm{tmax}) \\
(\mathrm{pCi} / \mathrm{g})\end{array}$ \\
\hline$m-241$ & $1.000 \mathrm{E}+00$ & $0.000 \mathrm{E}+00$ & $2.850 \mathrm{E}-02$ & $3.509 E+03$ & $2.686 \mathrm{E}-02$ & $3.723 E+03$ \\
\hline $8-137$ & $1.000 \mathrm{E}+00$ & $0.000 \mathrm{E}+00$ & $5.262 \mathrm{E}-01$ & $1.900 \mathrm{E}+02$ & $2.244 \mathrm{E}-01$ & $4.457 \mathrm{E}+02$ \\
\hline-237 & $1.000 \mathrm{E}+00$ & $0.000 \mathrm{E}+00$ & $1.816 \mathrm{E}-01$ & $5.507 \mathrm{E}+02$ & $1.805 \mathrm{E}-01$ & $5.539 \mathrm{E}+02$ \\
\hline$u-238$ & $1.000 \mathrm{E}+00$ & $0.000 \mathrm{E}+00$ & $2.547 \mathrm{E}-02$ & $3.926 \mathrm{E}+03$ & $1.903 E-02$ & $5.256 \mathrm{E}+03$ \\
\hline$u-239$ & $1.000 \mathrm{E}+00$ & $0.000 \mathrm{E}+00$ & $2.782 \mathrm{E}-02$ & $3.595 \mathrm{E}+03$ & $2.777 \mathrm{E}-02$ & $3.601 E+03$ \\
\hline-240 & $1.000 \mathrm{E}+00$ & $0.000 \mathrm{E}+00$ & $2.779 \mathrm{E}-02$ & $3.598 \mathrm{E}+03$ & $2.766 \mathrm{E}-02$ & $3.615 \mathrm{E}+03$ \\
\hline-99 & $1.000 \mathrm{E}+00$ & $0.000 \mathrm{E}+00$ & $8.844 \mathrm{E}-05$ & $1.131 \mathrm{E}+06$ & $5.990 \mathrm{E}-05$ & $1.669 \mathrm{E}+06$ \\
\hline-228 & $1.000 \mathrm{E}+00$ & $0.000 E+00$ & $1.360 \mathrm{E}+00$ & 7. $351 E+01$ & $2.176 \mathrm{E}-06$ & $4.595 E+07$ \\
\hline-230 & $1.000 \mathrm{E}+00$ & $7.000 \mathrm{E}+01$ & $8.104 \mathrm{E}-02$ & $1.234 \mathrm{E}+03$ & $5.358 \mathrm{E}-02$ & $1.866 \mathrm{E}+03$ \\
\hline $1-232$ & $1.000 \mathrm{E}+00$ & $7.000 \mathrm{E}+01$ & $2.662 \mathrm{E}+00$ & $3.757 \mathrm{E}+01$ & $2.625 \mathrm{E}+00$ & $3.810 \mathrm{E}+01$ \\
\hline-234 & $1.000 \mathrm{E}+00$ & $7.000 \mathrm{E}+01$ & $5.488 \mathrm{E}-03$ & $1.822 \mathrm{E}+04$ & $5.473 E-03$ & $1.827 \mathrm{E}+04$ \\
\hline 235 & $1.000 \mathrm{E}+00$ & $7.000 \mathrm{E}+01$ & $1.217 \mathrm{E}-01$ & $8.218 E+02$ & 1. $215 \mathrm{E}-01$ & $8.233 E+02$ \\
\hline 238 & $1.000 \mathrm{E}+00$ & $0.000 \mathrm{E}+00$ & $3.129 \mathrm{E}-02$ & $3.196 \mathrm{E}+03$ & $3.126 \mathrm{E}-02$ & $3.199 \mathrm{E}+03$ \\
\hline
\end{tabular}


RESRAD, Version $6.5 \quad \mathrm{~T}^{1 / 2}$ Limit $=180$ days

Summary : C746U Landfill Worker Deterministic Run
File : $\mathrm{X}: \backslash$ FINAL V2 $\backslash$ C746U LANDFILL WORKER DET-FINALV2.RAD

Individual Nuclide Dose Summed Over All Pathways

Parent Nuclide and Branch Fraction Indicated

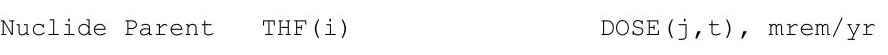

(j)

$-241$

(i)

$\overline{A m-241} \overline{1.000 E+00}$

$\mathrm{Am}-241 \quad 1.000 \mathrm{E}+00$

$\mathrm{Np}-237 \quad 1.000 \mathrm{E}+00$

$\sum \operatorname{DOSE}(j)$

Am-241 1.000E+00

$\mathrm{Np}-237 \quad 1.000 \mathrm{E}+00$

$\sum \operatorname{DOSE}(j)$

Am-241 1.000E+00

$\mathrm{Np}-237 \quad 1.000 \mathrm{E}+00$

$\sum \operatorname{DOSE}(j)$

Cs -137 1.000E+00

$\mathrm{Pu}-238 \quad 1.840 \mathrm{E}-09$

$\mathrm{Pu}-238 \quad 1.000 \mathrm{E}+00$

¿DOSE (j)

$\mathrm{Pu}-238 \quad 1.000 \mathrm{E}+00$

U-234 $1.000 \mathrm{E}+00$

U-238 9.999E-01

$\sum \operatorname{DOSE}(j)$

$\mathrm{Pu}-238 \quad 1.000 \mathrm{E}+00$

Th-230 1.000E+00

U-234 $1.000 \mathrm{E}+00$

$\mathrm{U}-238 \quad 9.999 \mathrm{E}-01$

$\sum \operatorname{DOSE}(j)$

$\mathrm{Pu}-238$ 1.000E+00

Th-230 1.000E+00

$\mathrm{U}-2341.000 \mathrm{E}+00$

$\mathrm{U}-238 \quad 9.999 \mathrm{E}-01$

$\sum \operatorname{DOSE}(j)$

$\mathrm{Pu}-238 \quad 1.000 \mathrm{E}+00$

$\mathrm{Th}-230 \quad 1.000 \mathrm{E}+00$

U-234 $1.000 \mathrm{E}+00$

U-238 9.999E-01

$\sum \operatorname{DOSE}(j)$

Pu-239 1.000E+00

$\mathrm{Pu}-239 \quad 1.000 \mathrm{E}+00$

U-235 $1.000 \mathrm{E}+00$

¿DOSE $(j)$ $\mathrm{t}=0.000 \mathrm{E}+00 \quad 1.000 \mathrm{E}+00 \quad 5.000 \mathrm{E}+01 \quad 7.000 \mathrm{E}+01$

$2.850 \mathrm{E}-02 \quad 2.845 \mathrm{E}-02 \quad 2.630 \mathrm{E}-02 \quad 2.546 \mathrm{E}-02$

$2.940 \mathrm{E}-08 \quad 8.812 \mathrm{E}-08 \quad 2.842 \mathrm{E}-06 \quad 3.898 \mathrm{E}-06$

$\begin{array}{llll}1.816 \mathrm{E}-01 & 1.816 \mathrm{E}-01 & 1.802 \mathrm{E}-01 & 1.796 \mathrm{E}-01\end{array}$

$1.816 \mathrm{E}-01$ 1.816E-01 1.802E-01 1.796E-01

$1.383 \mathrm{E}-15 \quad 9.674 \mathrm{E}-15 \quad 1.027 \mathrm{E}-11 \quad 1.978 \mathrm{E}-11$

$1.281 \mathrm{E}-08 \quad 3.843 \mathrm{E}-08 \quad 1.288 \mathrm{E}-06 \quad 1.795 \mathrm{E}-06$

$\begin{array}{llll}1.281 \mathrm{E}-08 & 3.843 \mathrm{E}-08 & 1.288 \mathrm{E}-06 & 1.795 \mathrm{E}-06\end{array}$

$\begin{array}{lllll}1.756 \mathrm{E}-18 & 2.633 \mathrm{E}-17 & 8.837 \mathrm{E}-13 & 2.382 \mathrm{E}-12\end{array}$

$2.169 \mathrm{E}-11 \quad 1.518 \mathrm{E}-10 \quad 1.652 \mathrm{E}-07 \quad 3.213 \mathrm{E}-07$

$2.169 \mathrm{E}-11 \quad 1.518 \mathrm{E}-10 \quad 1.652 \mathrm{E}-07 \quad 3.213 \mathrm{E}-07$

5.262E-01 5.142E-01 1.654E-01 1.041E-01

$\begin{array}{lllll}4.687 E-11 & 4.650 E-11 & 3.154 E-11 & 2.692 E-11\end{array}$

$2.547 \mathrm{E}-02 \quad 2.527 \mathrm{E}-02 \quad 1.714 \mathrm{E}-02 \quad 1.463 \mathrm{E}-02$

$2.547 \mathrm{E}-02 \quad 2.527 \mathrm{E}-02 \quad 1.714 \mathrm{E}-02 \quad 1.463 \mathrm{E}-02$

$\begin{array}{llll}7.728 E-09 & 2.310 E-08 & 6.445 E-07 & 8.363 E-07\end{array}$

$5.467 \mathrm{E}-03 \quad 5.466 \mathrm{E}-03 \quad 5.458 \mathrm{E}-03 \quad 5.455 \mathrm{E}-03$

$\begin{array}{llll}7.748 \mathrm{E}-09 & 2.324 \mathrm{E}-08 & 7.815 \mathrm{E}-07 & 1.090 \mathrm{E}-06\end{array}$

$5.467 \mathrm{E}-03 \quad 5.466 \mathrm{E}-03 \quad 5.460 \mathrm{E}-03 \quad 5.457 \mathrm{E}-03$

$9.980 \mathrm{E}-14 \quad 6.970 \mathrm{E}-13 \quad 6.720 \mathrm{E}-10 \quad 1.247 \mathrm{E}-09$

$\begin{array}{llll}2.351 E-02 & 2.351 E-02 & 2.350 E-02 & 2.349 E-02\end{array}$

$1.058 \mathrm{E}-07 \quad 3.175 \mathrm{E}-07 \quad 1.068 \mathrm{E}-05 \quad 1.490 \mathrm{E}-05$

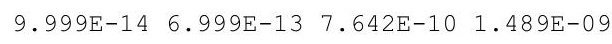

$\begin{array}{llll}2.351 E-02 & 2.351 E-02 & 2.351 E-02 & 2.351 E-02\end{array}$

$8.234 \mathrm{E}-16 \quad 1.233 \mathrm{E}-14 \quad 3.832 \mathrm{E}-10 \quad 1.002 \mathrm{E}-09$

$3.878 \mathrm{E}-04 \quad 1.163 \mathrm{E}-03 \quad 3.871 \mathrm{E}-02 \quad 5.379 \mathrm{E}-02$

$1.164 \mathrm{E}-09 \quad 8.144 \mathrm{E}-09 \quad 8.830 \mathrm{E}-06 \quad 1.715 \mathrm{E}-05$

8.247E-16 1.237E-14 4.221E-10 1.145E-09

$3.878 \mathrm{E}-04 \quad 1.163 \mathrm{E}-03 \quad 3.872 \mathrm{E}-02 \quad 5.381 \mathrm{E}-02$

$5.964 \mathrm{E}-19 \quad 1.836 \mathrm{E}-17 \quad 1.347 \mathrm{E}-11 \quad 4.480 \mathrm{E}-11$

$\begin{array}{llll}4.667 \mathrm{E}-07 & 3.238 \mathrm{E}-06 & 2.251 \mathrm{E}-03 & 3.757 \mathrm{E}-03\end{array}$

$\begin{array}{llll}1.052 \mathrm{E}-12 & 1.567 \mathrm{E}-11 & 3.816 \mathrm{E}-07 & 9.196 \mathrm{E}-07\end{array}$

$5.972 \mathrm{E}-19 \quad 1.841 \mathrm{E}-17 \quad 1.461 \mathrm{E}-11 \quad 5.020 \mathrm{E}-11$

$\begin{array}{llll}4.667 \mathrm{E}-07 & 3.238 \mathrm{E}-06 & 2.252 \mathrm{E}-03 & 3.758 \mathrm{E}-03\end{array}$

$\begin{array}{llll}2.782 E-02 & 2.782 E-02 & 2.775 E-02 & 2.772 E-02\end{array}$

5.975E-11 1.793E-10 6.024E-09 8.403E-09

$\begin{array}{llll}1.213 \mathrm{E}-01 & 1.213 \mathrm{E}-01 & 1.212 \mathrm{E}-01 & 1.211 \mathrm{E}-01\end{array}$

$1.213 \mathrm{E}-01$ 1.213E-01 1.212E-01 1.211E-01 


\section{RESRAD, Version $6.5 \quad T^{1 / 2}$ Limit $=180$ days}

Summary : C746U Landfill Worker Deterministic Run

File : $\mathrm{X}: \backslash$ FINAL V2 $\backslash \mathrm{C} 746 \mathrm{U}$ LANDFILL WORKER DET-FINALV2.RAD

Individual Nuclide Dose Summed Over All Pathways

Parent Nuclide and Branch Fraction Indicated

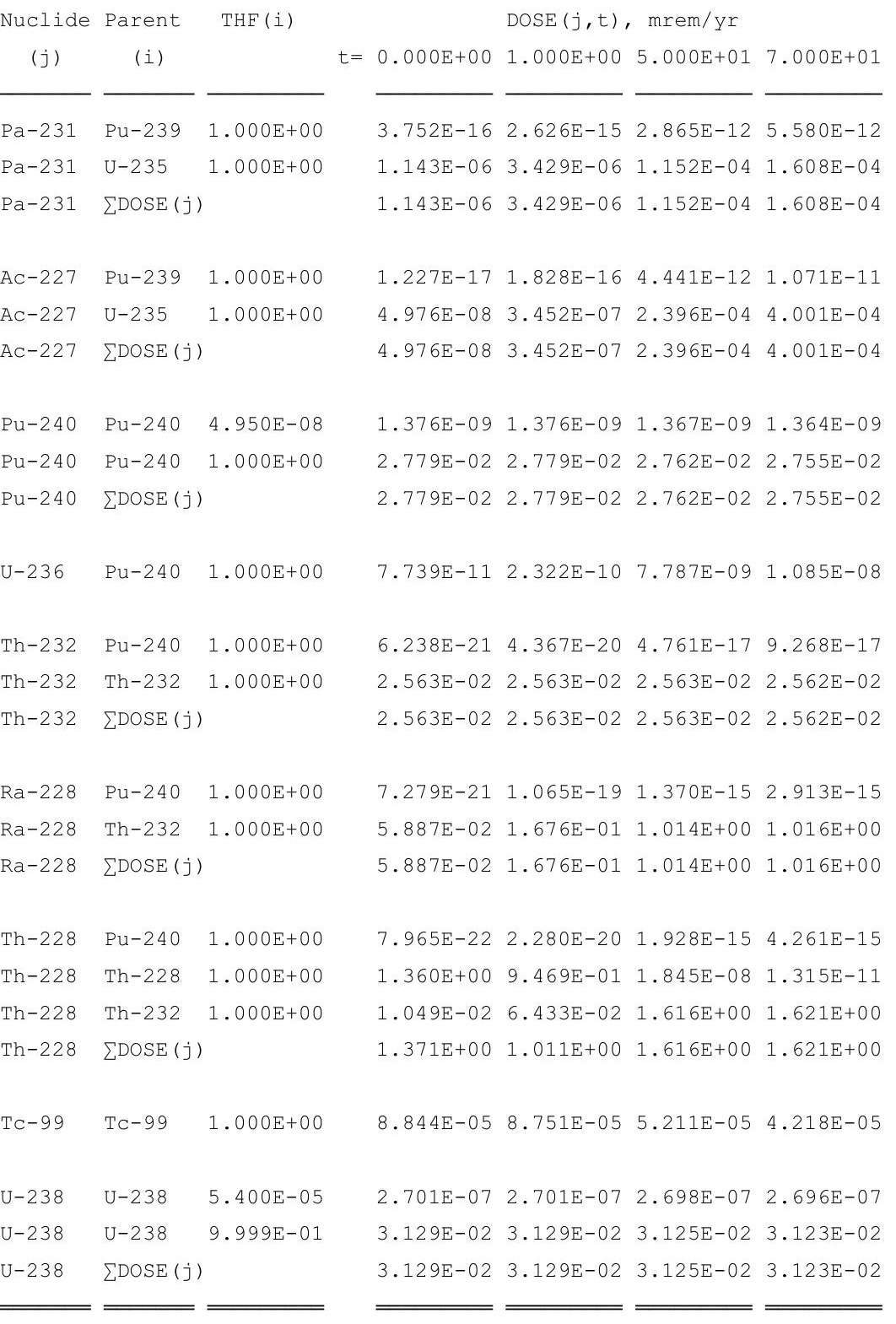

THF(i) is the thread fraction of the parent nuclide. 
RESRAD, Version $6.5 \quad \mathrm{~T}^{1 / 2}$ Limit $=180$ days

Summary : C746U Landfill Worker Deterministic Run

File : $\mathrm{X}: \backslash$ FINAL V2 $\backslash \mathrm{C} 746 \mathrm{U}$ LANDFILL WORKER DET-FINALV2.RAD

Individual Nuclide Soil Concentration

Parent Nuclide and Branch Fraction Indicated

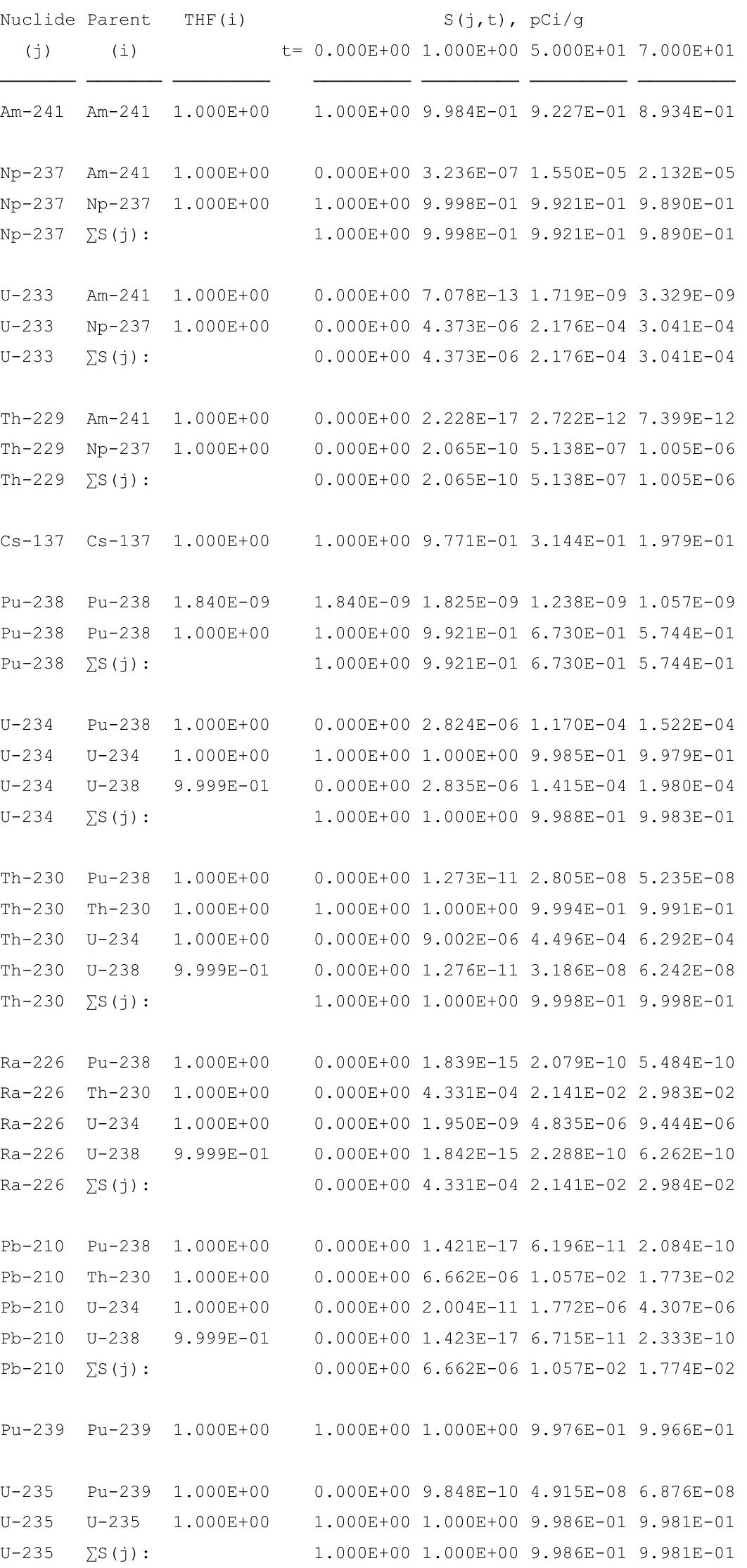




\section{RESRAD, Version $6.5 \quad T^{1 / 2}$ Limit $=180$ days}

Summary : C746U Landfill Worker Deterministic Run

File : $\mathrm{X}: \backslash$ FINAL V2 $\backslash \mathrm{C} 746 \mathrm{U}$ LANDFILL WORKER DET-FINALV2.RAD

Individual Nuclide Soil Concentration

Parent Nuclide and Branch Fraction Indicated

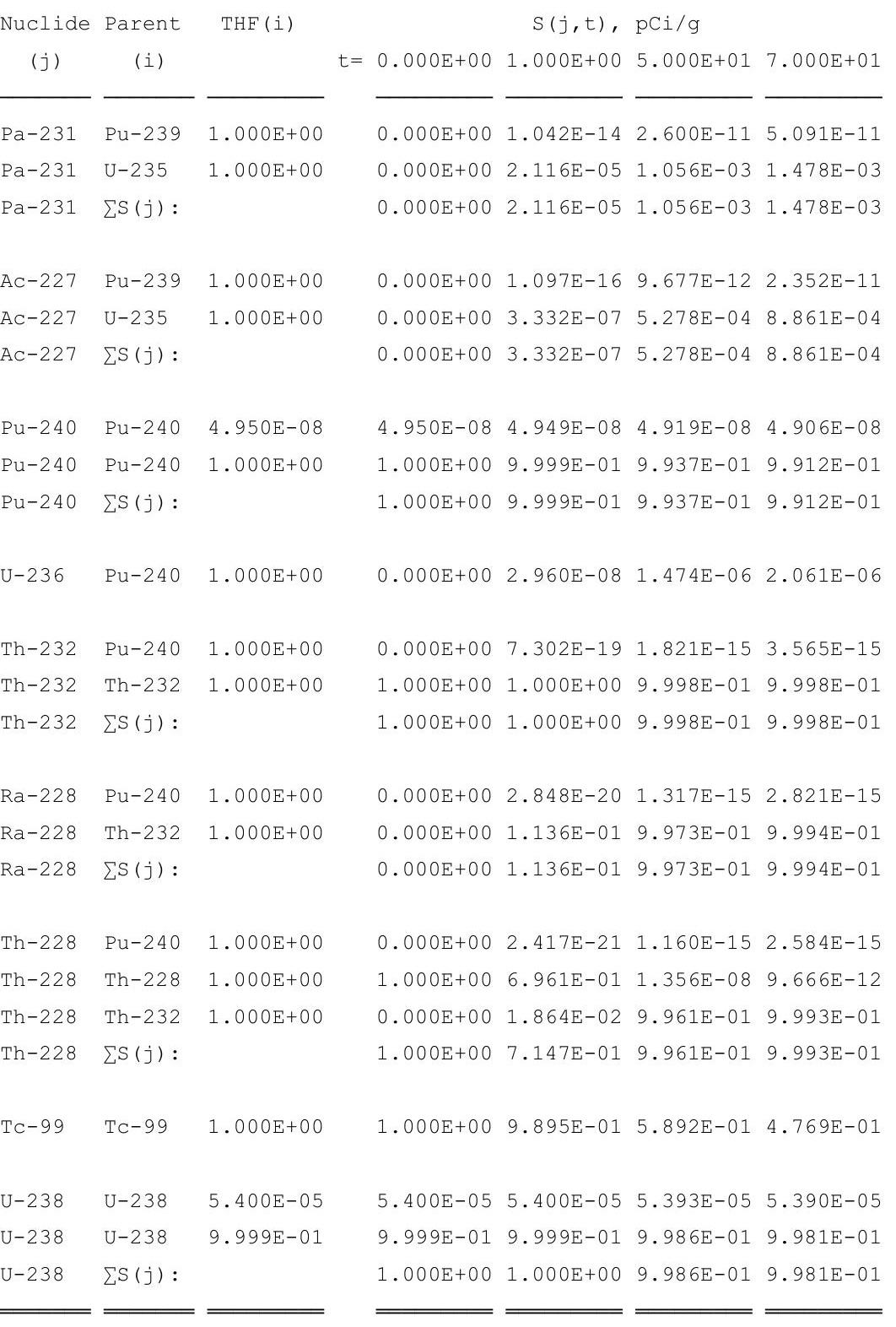

THF(i) is the thread fraction of the parent nuclide.

RESCALC.EXE execution time = 1.58 seconds 


\section{Landfill Worker}

\section{The following summary report includes the peak dose from cumulative radionuclide inventory.}


THIS PAGE INTENTIONALLY LEFT BLANK 
RESRAD, Version $6.5 \quad T^{1 / 2}$ Limit $=180$ days

Summary : C746U Landfill Worker Deterministic Run

File : $\mathrm{X}: \backslash$ FINAL V2 $\backslash \mathrm{C} 746 \mathrm{U}$ LANDFILL WORKER SG FWD-FINALV2.RAD

Table of Contents

Part I: Mixture Sums and Single Radionuclide Guidelines

Dose Conversion Factor (and Related) Parameter Summary ... 2

Site-Specific Parameter Summary $\ldots \ldots \ldots \ldots \ldots \ldots \ldots \ldots \ldots$

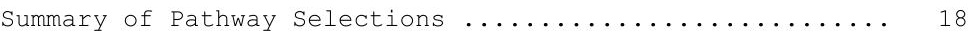

Contaminated Zone and Total Dose Summary ................ 19

Total Dose Components

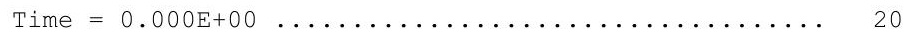

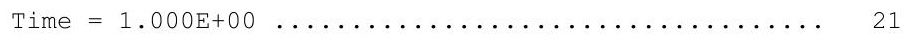

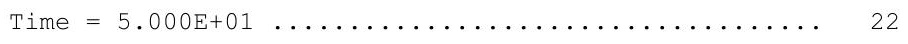

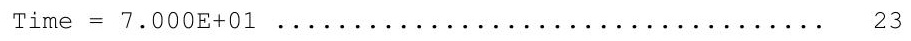

Dose/Source Ratios Summed Over All Pathways ............ 24

Single Radionuclide Soil Guidelines ............... 26

Dose Per Nuclide Summed Over All Pathways ............ 27

Soil Concentration Per Nuclide .................. 29 
RESRAD, Version $6.5 \quad \mathrm{~T}^{1} \frac{1}{2}$ Limit $=180$ days

Summary : C746U Landfill Worker Deterministic Run

File : $\mathrm{X}: \backslash$ FINAL V2 $\backslash \mathrm{C} 746 \mathrm{U}$ LANDFILL WORKER SG FWD-FINALV2.RAD

Dose Conversion Factor (and Related) Parameter Summary

Dose Library: ICRP 60 \& ICRP 72 (Adult)

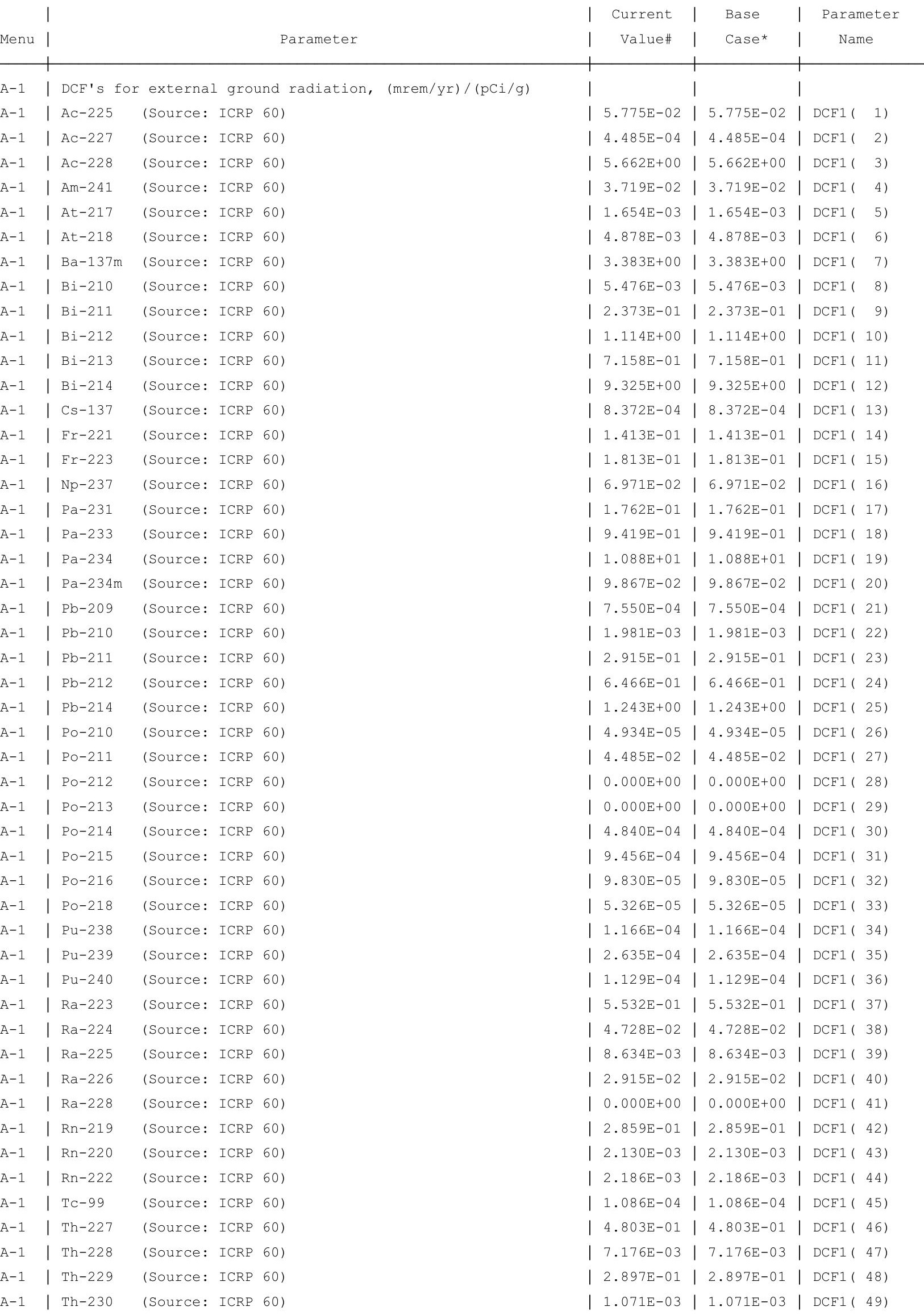


RESRAD, Version $6.5 \quad \mathrm{~T}^{1} \frac{1}{2}$ Limit $=180$ days

Summary : C746U Landfill Worker Deterministic Run

File : $\mathrm{X}: \backslash$ FINAL V2 $\backslash \mathrm{C} 746 \mathrm{U}$ LANDFILL WORKER SG FWD-FINALV2.RAD

Dose Conversion Factor (and Related) Parameter Summary (continued)

Dose Library: ICRP 60 \& ICRP 72 (Adult)

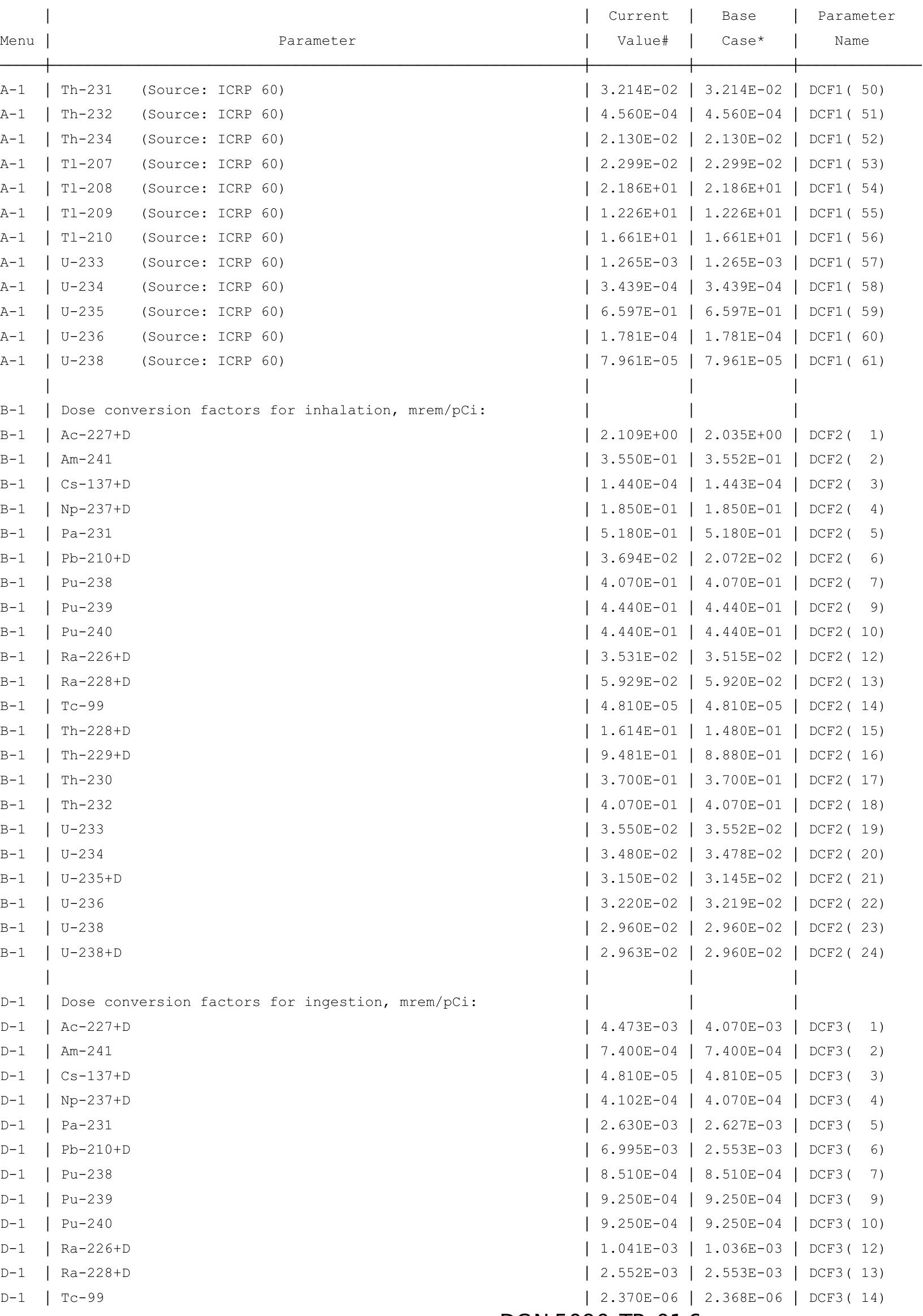


RESRAD, Version $6.5 \quad \mathrm{~T}^{1} \frac{1}{2}$ Limit $=180$ days

ummary : C746U Landfill Worker Deterministic Run

File : $\mathrm{X}: \backslash$ FINAL V2 $\backslash \mathrm{C} 746 \mathrm{U}$ LANDFILL WORKER SG FWD-FINALV2.RAD

Dose Conversion Factor (and Related) Parameter Summary (continued)

Dose Library: ICRP 60 \& ICRP 72 (Adult)

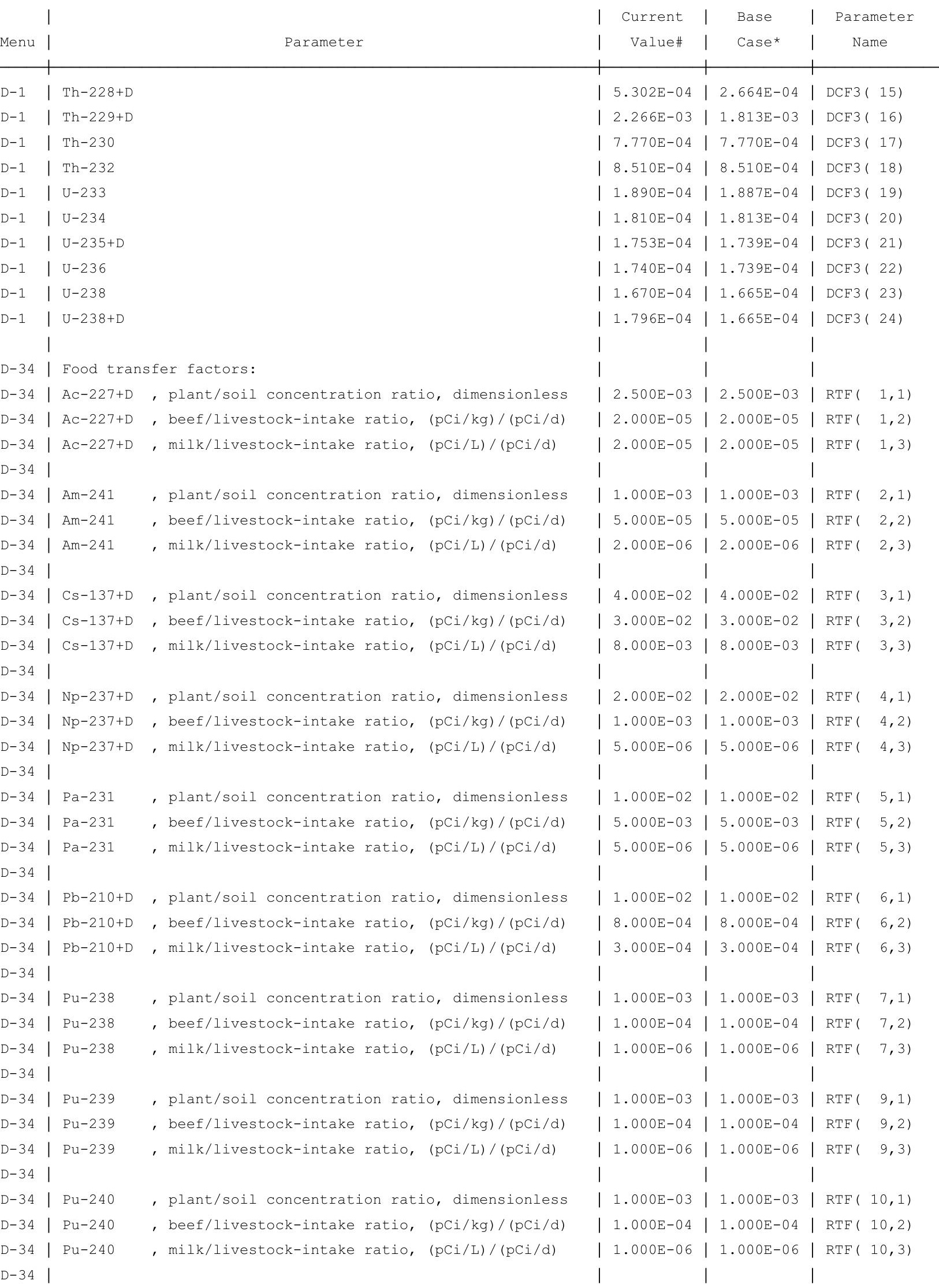


RESRAD, Version $6.5 \quad \mathrm{~T}^{1} \frac{1}{2}$ Limit $=180$ days

Summary : C746U Landfill Worker Deterministic Run

File : $\mathrm{X}: \backslash F I N A L$ V2\C746U LANDFILL WORKER SG FWD-FINALV2.RAD

Dose Conversion Factor (and Related) Parameter Summary (continued)

Dose Library: ICRP 60 \& ICRP 72 (Adult)

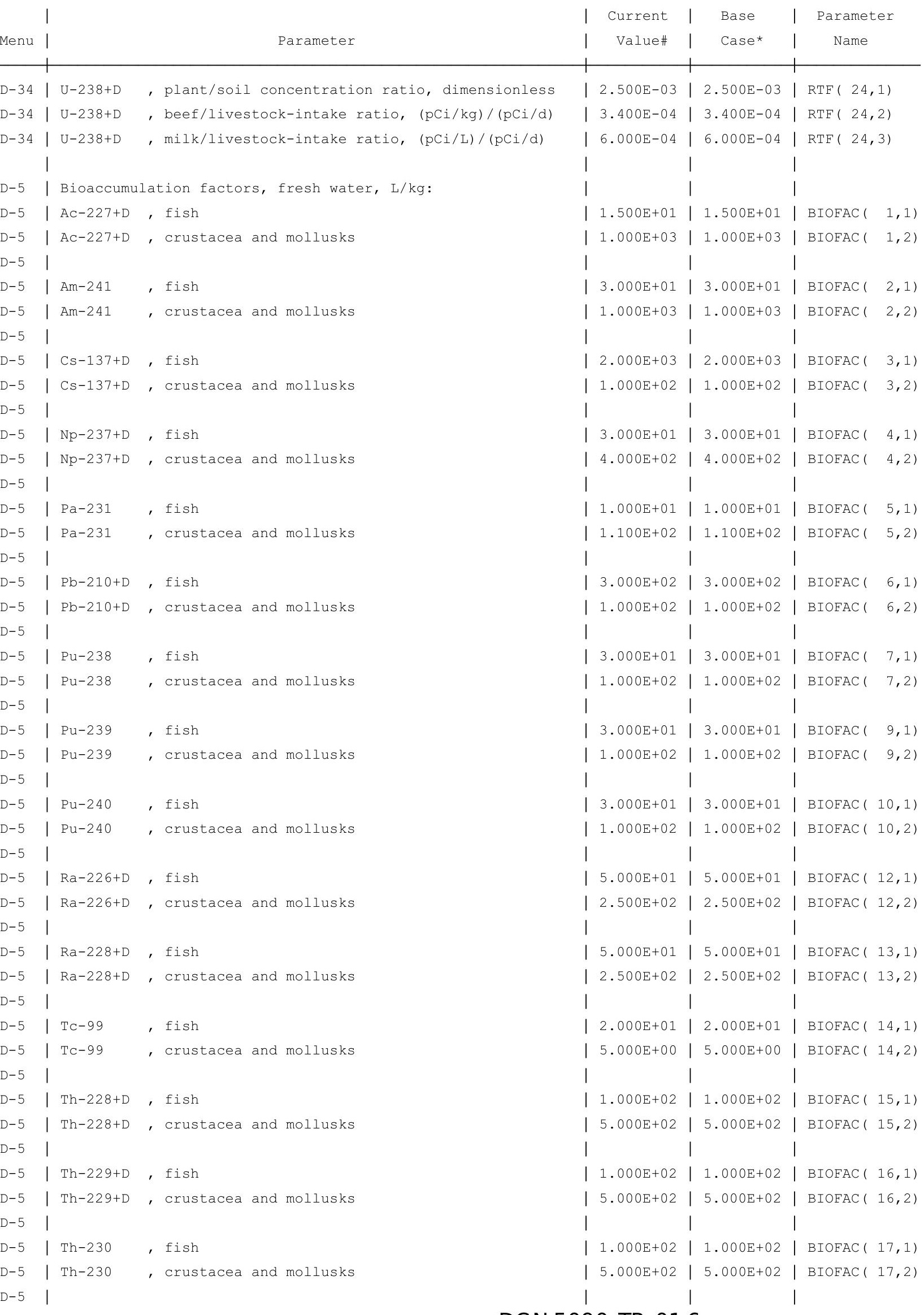


RESRAD, Version $6.5 \quad \mathrm{~T}^{1 / 2}$ Limit $=180$ days

05/03/2011 15:55 Page

ummary : C746U Landfill Worker Deterministic Run

File : $\mathrm{X}: \backslash F$ INAL V2\C746U LANDFILL WORKER SG FWD-FINALV2.RAD

Dose Conversion Factor (and Related) Parameter Summary (continued)

Dose Library: ICRP 60 \& ICRP 72 (Adult)

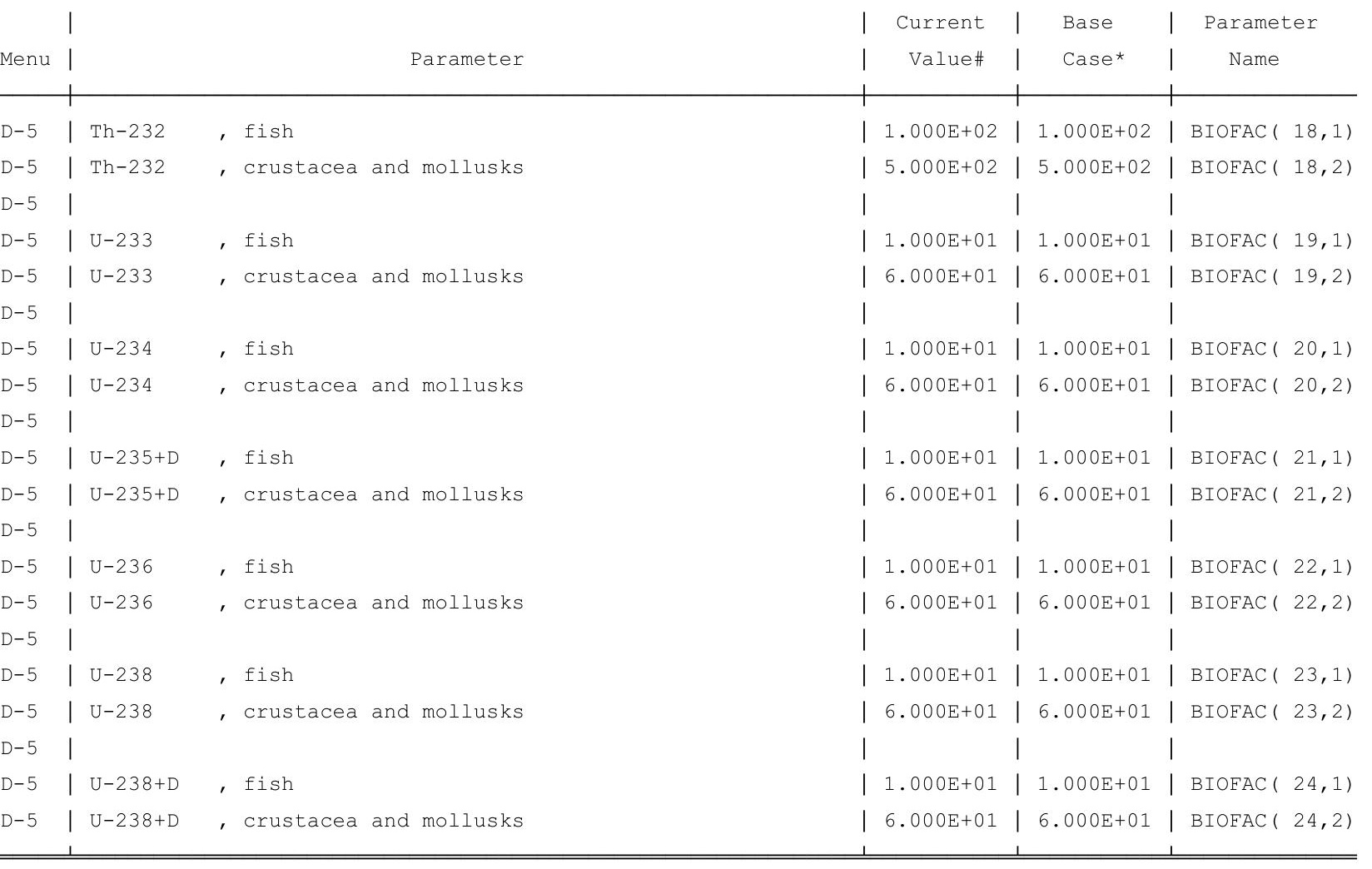

\#For DCFl(xxx) only, factors are for infinite depth \& area. See ETFG table in Ground Pathway of Detailed Report. *Base Case means Default.Lib w/o Associate Nuclide contributions. 
RESRAD, Version $6.5 \quad T^{1 / 2}$ Limit $=180$ days

05/03/2011 15:55 Page

Summary : C746U Landfill Worker Deterministic Run

File : $\mathrm{X}: \backslash F I N A L$ V2 $\backslash C 746 U$ LANDFILL WORKER SG FWD-FINALV2.RAD

Site-Specific Parameter Summary (continued)

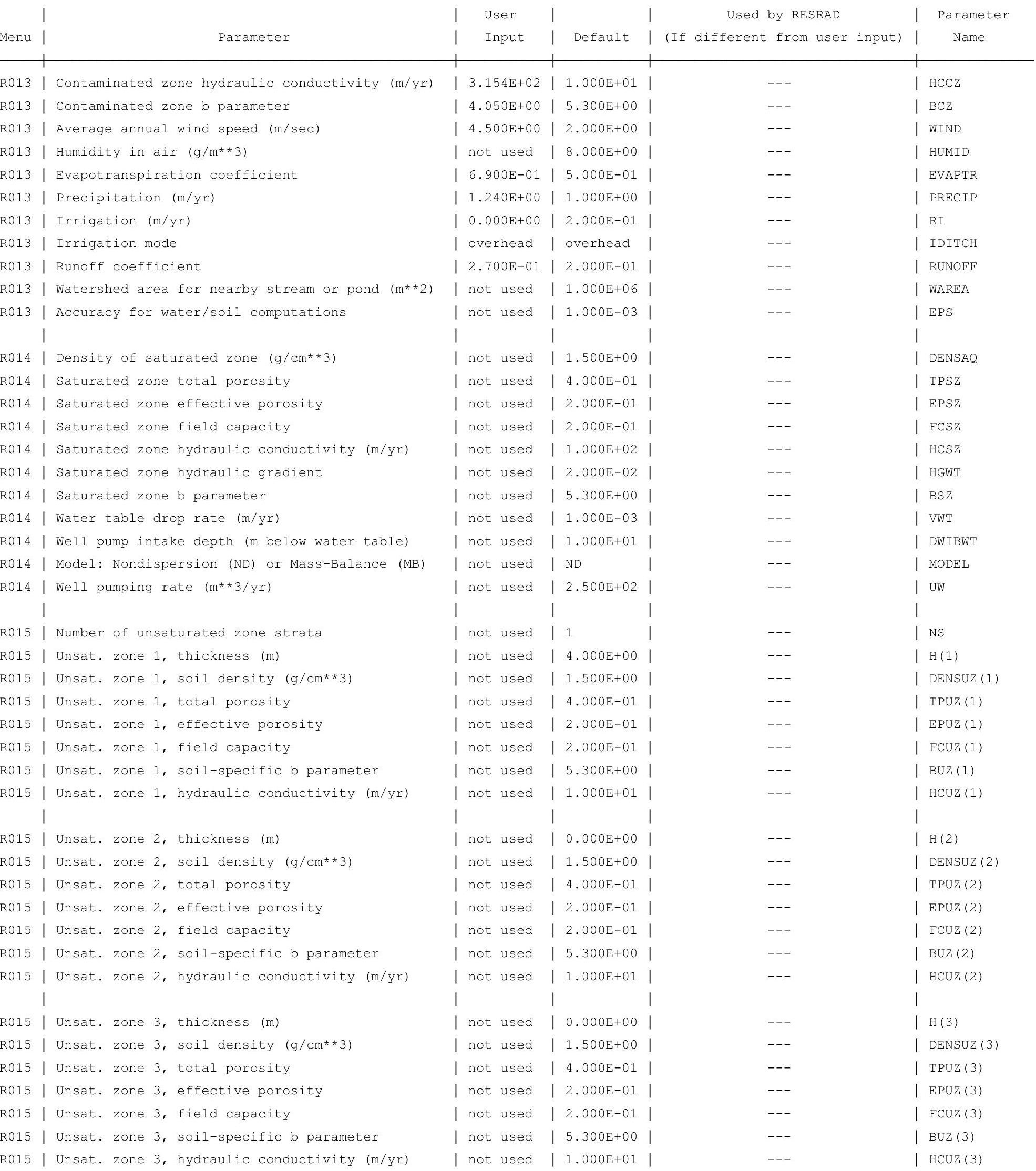


RESRAD, Version $6.5 \quad T^{1 / 2}$ Limit $=180$ days

Summary : C746U Landfill Worker Deterministic Run

File : $\mathrm{X}: \backslash$ FINAL V2 $\backslash \mathrm{C} 746 \mathrm{U}$ LANDFILL WORKER SG FWD-FINALV2.RAD

Site-Specific Parameter Summary (continued)

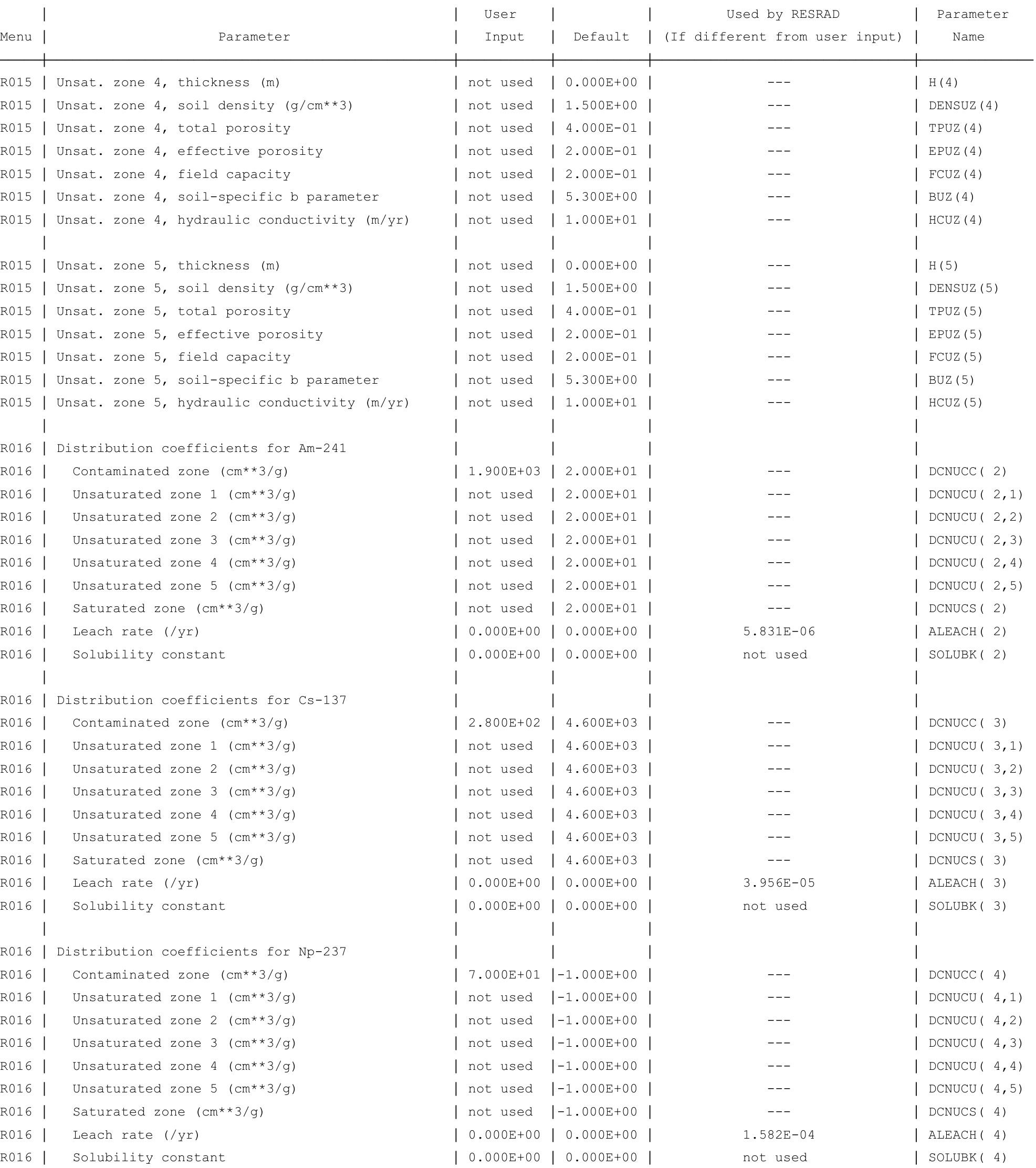


RESRAD, Version $6.5 \quad T^{1 / 2}$ Limit $=180$ days

05/03/2011 15:55 Page 12

Summary : C746U Landfill Worker Deterministic Run

File : $\mathrm{X}: \backslash F I N A L$ V2 $\backslash C 746 U$ LANDFILL WORKER SG FWD-FINALV2.RAD

Site-Specific Parameter Summary (continued)

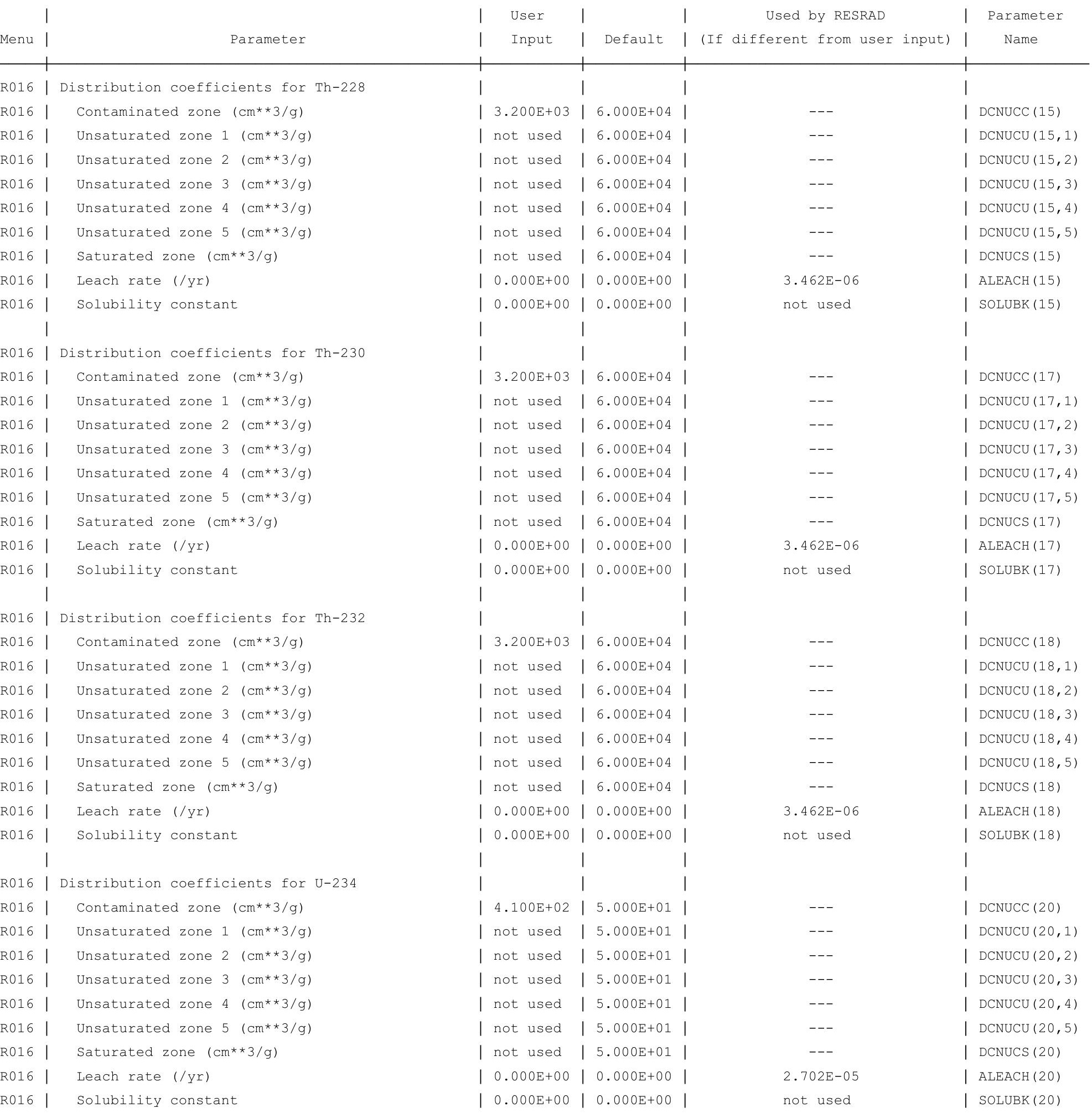


RESRAD, Version $6.5 \quad \mathrm{~T}^{1 / 2}$ Limit $=180$ days

Summary : C746U Landfill Worker Deterministic Run
File : X: $\backslash$ FINAL V2 $\backslash C 746 U$ LANDFILL WORKER SG FWD-FINALV2.RAD

Site-Specific Parameter Summary (continued)

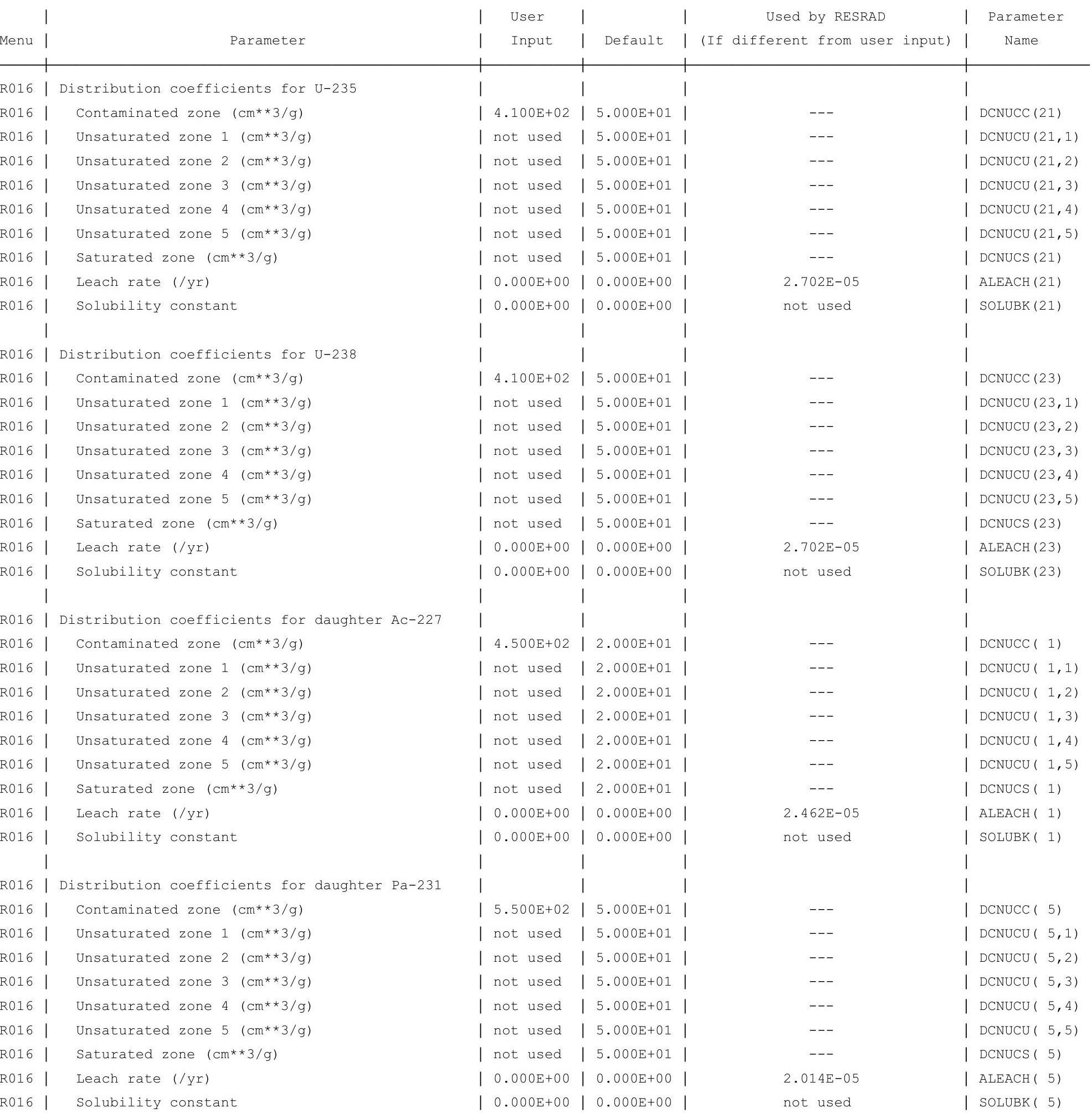


RESRAD, Version $6.5 \quad \mathrm{~T}^{1 / 2}$ Limit $=180$ days

Summary : C746U Landfill Worker Deterministic Run
File : X: $\backslash$ FINAL V2 $\backslash C 746 U$ LANDFILL WORKER SG FWD-FINALV2.RAD

Site-Specific Parameter Summary (continued)

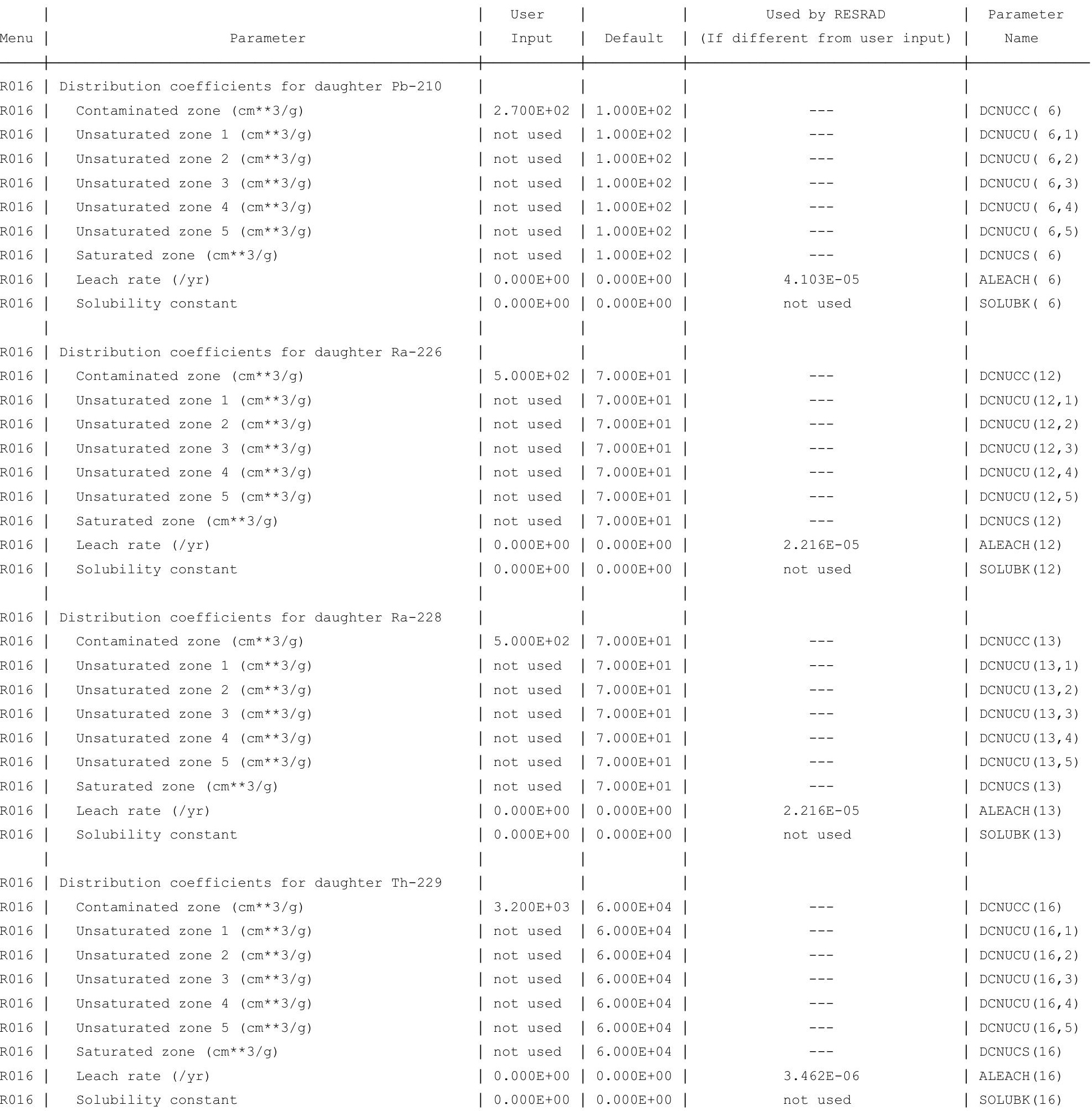


RESRAD, Version $6.5 \quad T^{1 / 2}$ Limit $=180$ days

Summary : C746U Landfill Worker Deterministic Run

File : $\mathrm{X}: \backslash$ FINAL V2 $\backslash$ C746U LANDFILL WORKER SG FWD-FINALV2.RAD

Site-Specific Parameter Summary (continued)

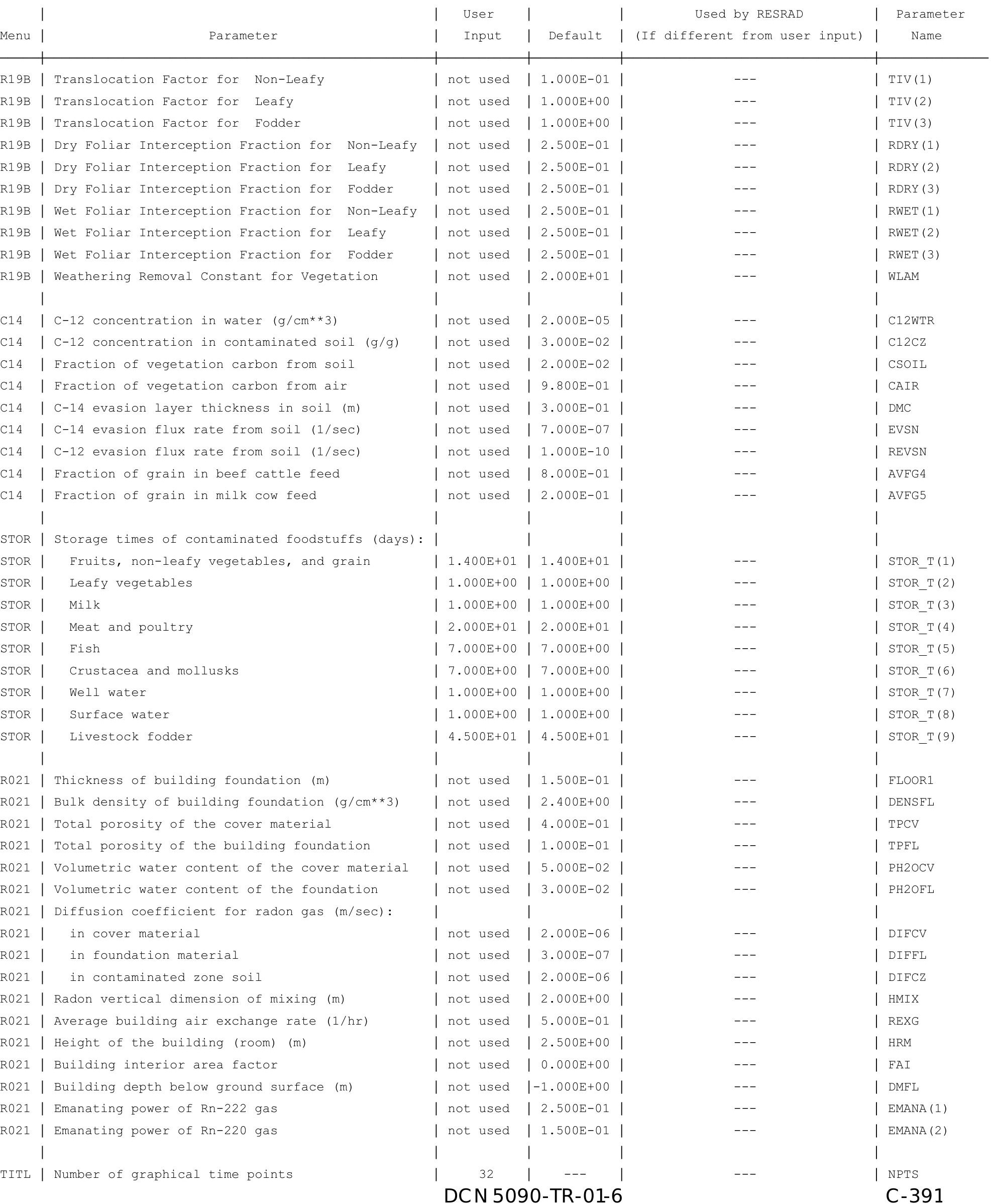


RESRAD, Version $6.5 \quad \mathrm{~T}^{1 / 2}$ Limit $=180$ days

Summary : C746U Landfill Worker Deterministic Run

File : $\mathrm{X}: \backslash$ FINAL V2 $\backslash C 746 \mathrm{U}$ LANDFILL WORKER SG FWD-FINALV2.RAD

Contaminated Zone Dimensions

Area: 89436.00 square meters

Thickness:

Cover Depth:
Initial Soil Concentrations, pCi/g

$\begin{array}{ll}\mathrm{Am}-241 & 3.500 \mathrm{E}+03 \\ \mathrm{Cs}-137 & 1.900 \mathrm{E}+02 \\ \mathrm{~Np}-237 & 5.500 \mathrm{E}+02 \\ \mathrm{Pu}-238 & 3.900 \mathrm{E}+03 \\ \mathrm{Pu}-239 & 3.600 \mathrm{E}+03 \\ \mathrm{Pu}-240 & 3.600 \mathrm{E}+03 \\ \mathrm{TC}-99 & 2.800 \mathrm{E}+01 \\ \mathrm{Th}-228 & 7.400 \mathrm{E}+01 \\ \mathrm{Th}-230 & 1.200 \mathrm{E}+03 \\ \mathrm{Th}-232 & 3.800 \mathrm{E}+01 \\ \mathrm{U}-234 & 1.800 \mathrm{E}+04 \\ \mathrm{U}-235 & 8.200 \mathrm{E}+02 \\ \mathrm{U}-238 & 3.200 \mathrm{E}+03\end{array}$

Total Dose TDOSE(t), mrem/yr

Basic Radiation Dose Limit $=1.000 \mathrm{E}+02 \mathrm{mrem} / \mathrm{yr}$

Total Mixture Sum $M(t)$ = Fraction of Basic Dose Limit Received at Time (t)

$\begin{array}{rllll}t \quad \text { years }): & 0.000 \mathrm{E}+00 & 1.000 \mathrm{E}+00 & 5.000 \mathrm{E}+01 & 7.000 \mathrm{E}+01 \\ \mathrm{TDOSE}(\mathrm{t}): & 1.030 \mathrm{E}+03 & 1.003 \mathrm{E}+03 & 9.653 \mathrm{E}+02 & 9.607 \mathrm{E}+02 \\ \mathrm{M}(\mathrm{t}): & 1.030 \mathrm{E}+01 & 1.003 \mathrm{E}+01 & 9.653 \mathrm{E}+00 & 9.607 \mathrm{E}+00\end{array}$

Maximum TDOSE $(\mathrm{t}): 1.030 \mathrm{E}+03 \mathrm{mrem} / \mathrm{yr}$ at $\mathrm{t}=0.000 \mathrm{E}+00$ years 
RESRAD, Version 6.5

$\mathrm{T}^{1 / 2}$ Limit $=180$ days

05/03/2011 15:55 Page 20

Summary : C746U Landfill Worker Deterministic Run
File : X: $\backslash$ FINAL V2 $\backslash C 746 U$ LANDFILL WORKER SG FWD-FINALV2.RAD

Total Dose Contributions TDOSE(i,p,t) for Individual Radionuclides (i) and Pathways (p) As mrem/yr and Fraction of Total Dose At $t=0.000 \mathrm{E}+00$ years

Water Independent Pathways (Inhalation excludes radon)

\begin{tabular}{|c|c|c|c|c|c|c|c|c|c|c|c|c|c|c|}
\hline \multirow{2}{*}{ Nuclide } & \multicolumn{2}{|c|}{ Ground } & \multicolumn{2}{|c|}{ Inhalation } & \multicolumn{2}{|c|}{ Radon } & \multicolumn{2}{|c|}{ Plant } & \multicolumn{2}{|c|}{ Meat } & \multicolumn{2}{|c|}{ Milk } & \multicolumn{2}{|c|}{ Soil } \\
\hline & mrem/yr & fract. & mrem/yr & fract. & mrem/yr & fract. & mrem/yr & fract. & mrem/yr & fract. & mrem/yr & fract. & mrem/yr & fract. \\
\hline-241 & $2.204 E+01$ & 0.0214 & $6.316 \mathrm{E}-01$ & 0.0006 & $0.000 \mathrm{E}+00$ & 0.0000 & $0.000 \mathrm{E}+00$ & 0.0000 & $0.000 \mathrm{E}+00$ & 0.0000 & $0.000 \mathrm{E}+00$ & 0.0000 & $7.708 \mathrm{E}+01$ & 0.0748 \\
\hline-137 & $9.972 \mathrm{E}+01$ & 0.0968 & $1.376 \mathrm{E}-05$ & 0.0000 & $0.000 \mathrm{E}+00$ & 0.0000 & $0.000 \mathrm{E}+00$ & 0.0000 & $0.000 \mathrm{E}+00$ & 0.0000 & $0.000 \mathrm{E}+00$ & 0.0000 & $2.691 \mathrm{E}-01$ & 0.0003 \\
\hline-237 & $9.311 E+01$ & 0.0904 & $5.176 \mathrm{E}-02$ & 0.0001 & $0.000 \mathrm{E}+00$ & 0.0000 & $0.000 \mathrm{E}+00$ & 0.0000 & $0.000 \mathrm{E}+00$ & 0.0000 & $0.000 \mathrm{E}+00$ & 0.0000 & $6.719 E+00$ & 0.0065 \\
\hline-238 & $7.691 \mathrm{E}-02$ & 0.0001 & $8.043 E-01$ & 0.0008 & $0.000 \mathrm{E}+00$ & 0.0000 & $0.000 \mathrm{E}+00$ & 0.0000 & $0.000 \mathrm{E}+00$ & 0.0000 & $0.000 \mathrm{E}+00$ & 0.0000 & $9.846 \mathrm{E}+01$ & 0.0956 \\
\hline-239 & $1.592 \mathrm{E}-01$ & 0.0002 & $8.131 \mathrm{E}-01$ & 0.0008 & $0.000 \mathrm{E}+00$ & 0.0000 & $0.000 \mathrm{E}+00$ & 0.0000 & $0.000 \mathrm{E}+00$ & 0.0000 & $0.000 \mathrm{E}+00$ & 0.0000 & $9.918 \mathrm{E}+01$ & 0.0963 \\
\hline-240 & $6.888 \mathrm{E}-02$ & 0.0001 & $8.131 \mathrm{E}-01$ & 0.0008 & $0.000 \mathrm{E}+00$ & 0.0000 & $0.000 \mathrm{E}+00$ & 0.0000 & $0.000 \mathrm{E}+00$ & 0.0000 & $0.000 \mathrm{E}+00$ & 0.0000 & $9.917 \mathrm{E}+01$ & 0.0963 \\
\hline-99 & $5.096 \mathrm{E}-04$ & 0.0000 & $6.815 \mathrm{E}-07$ & 0.0000 & $0.000 \mathrm{E}+00$ & 0.0000 & $0.000 \mathrm{E}+00$ & 0.0000 & $0.000 \mathrm{E}+00$ & 0.0000 & $0.000 \mathrm{E}+00$ & 0.0000 & $1.966 \mathrm{E}-03$ & 0.0000 \\
\hline-228 & $9.969 \mathrm{E}+01$ & 0.0968 & $5.098 \mathrm{E}-03$ & 0.0000 & $0.000 \mathrm{E}+00$ & 0.0000 & $0.000 \mathrm{E}+00$ & 0.0000 & $0.000 \mathrm{E}+00$ & 0.0000 & $0.000 \mathrm{E}+00$ & 0.0000 & $9.802 \mathrm{E}-01$ & 0.0010 \\
\hline-230 & $6.738 \mathrm{E}-01$ & 0.0007 & $2.259 \mathrm{E}-01$ & 0.0002 & $0.000 \mathrm{E}+00$ & 0.0000 & $0.000 \mathrm{E}+00$ & 0.0000 & $0.000 \mathrm{E}+00$ & 0.0000 & $0.000 \mathrm{E}+00$ & 0.0000 & $2.778 \mathrm{E}+01$ & 0.0270 \\
\hline-232 & $2.467 E+00$ & 0.0024 & $7.954 \mathrm{E}-03$ & 0.0000 & $0.000 \mathrm{E}+00$ & 0.0000 & $0.000 \mathrm{E}+00$ & 0.0000 & $0.000 \mathrm{E}+00$ & 0.0000 & $0.000 \mathrm{E}+00$ & 0.0000 & $1.134 \mathrm{E}+00$ & 0.0011 \\
\hline 34 & $1.045 \mathrm{E}+00$ & 0.0010 & $3.187 \mathrm{E}-01$ & 0.0003 & $0.000 \mathrm{E}+00$ & 0.0000 & $0.000 \mathrm{E}+00$ & 0.0000 & $0.000 \mathrm{E}+00$ & 0.0000 & $0.000 \mathrm{E}+00$ & 0.0000 & $9.704 \mathrm{E}+01$ & 0.0942 \\
\hline 35 & $9.521 \mathrm{E}+01$ & 0.0924 & $1.314 \mathrm{E}-02$ & 0.0000 & $0.000 \mathrm{E}+00$ & 0.0000 & $0.000 \mathrm{E}+00$ & 0.0000 & $0.000 \mathrm{E}+00$ & 0.0000 & $0.000 \mathrm{E}+00$ & 0.0000 & $4.281 E+00$ & 0.0042 \\
\hline 38 & $8.296 \mathrm{E}+01$ & 0.0805 & $4.823 E-02$ & 0.0000 & $0.000 \mathrm{E}+00$ & 0.0000 & $0.000 \mathrm{E}+00$ & 0.0000 & $0.000 \mathrm{E}+00$ & 0.0000 & $0.000 \mathrm{E}+00$ & 0.0000 & $1.712 \mathrm{E}+01$ & 0.0166 \\
\hline & $4.972 \mathrm{E}+02$ & 0.4827 & $3.733 \mathrm{E}+00$ & 0.0036 & $0.000 \mathrm{E}+00$ & 0.0000 & $0.000 \mathrm{E}+00$ & 0.0000 & $0.000 \mathrm{E}+00$ & 0.0000 & $0.000 \mathrm{E}+00$ & 0.0000 & $.292 \mathrm{E}+02$ & 0.5137 \\
\hline
\end{tabular}

Total Dose Contributions TDOSE(i,p,t) for Individual Radionuclides (i) and Pathways (p) As mrem/yr and Fraction of Total Dose At $t=0.000 \mathrm{E}+00$ years

Water Dependent Pathways

\begin{tabular}{|c|c|c|c|c|c|c|c|c|c|c|c|c|c|c|}
\hline \multirow{2}{*}{ Nuclide } & \multicolumn{2}{|c|}{ Water } & \multicolumn{2}{|c|}{ Fish } & \multicolumn{2}{|c|}{ Radon } & \multicolumn{2}{|c|}{ Plant } & \multicolumn{2}{|c|}{ Meat } & \multicolumn{2}{|c|}{ Milk } & \multicolumn{2}{|c|}{ All Pathways* } \\
\hline & mrem/yr & fract. & mrem/yr & fract. & mrem/yr & fract. & mrem/yr & fract. & mrem/yr & fract. & mrem/yr & fract. & mrem/yr & fract. \\
\hline-241 & $0.000 \mathrm{E}+00$ & 0.0000 & $0.000 \mathrm{E}+00$ & 0.0000 & $0.000 \mathrm{E}+00$ & 0.0000 & $0.000 \mathrm{E}+00$ & 0.0000 & $0.000 \mathrm{E}+00$ & 0.0000 & $0.000 \mathrm{E}+00$ & 0.0000 & $9.975 \mathrm{E}+01$ & 0.0968 \\
\hline-137 & $0.000 \mathrm{E}+00$ & 0.0000 & $0.000 \mathrm{E}+00$ & 0.0000 & $0.000 \mathrm{E}+00$ & 0.0000 & $0.000 \mathrm{E}+00$ & 0.0000 & $0.000 \mathrm{E}+00$ & 0.0000 & $0.000 \mathrm{E}+00$ & 0.0000 & $9.998 \mathrm{E}+01$ & 0.0971 \\
\hline-237 & $0.000 \mathrm{E}+00$ & 0.0000 & $0.000 \mathrm{E}+00$ & 0.0000 & $0.000 \mathrm{E}+00$ & 0.0000 & $0.000 \mathrm{E}+00$ & 0.0000 & $0.000 \mathrm{E}+00$ & 0.0000 & $0.000 \mathrm{E}+00$ & 0.0000 & $9.988 \mathrm{E}+01$ & 0.0970 \\
\hline-238 & $0.000 \mathrm{E}+00$ & 0.0000 & $0.000 \mathrm{E}+00$ & 0.0000 & $0.000 \mathrm{E}+00$ & 0.0000 & $0.000 \mathrm{E}+00$ & 0.0000 & $0.000 \mathrm{E}+00$ & 0.0000 & $0.000 \mathrm{E}+00$ & 0.0000 & $9.934 \mathrm{E}+01$ & 0.0964 \\
\hline-239 & $0.000 \mathrm{E}+00$ & 0.0000 & $0.000 \mathrm{E}+00$ & 0.0000 & $0.000 \mathrm{E}+00$ & 0.0000 & $0.000 \mathrm{E}+00$ & 0.0000 & $0.000 \mathrm{E}+00$ & 0.0000 & $0.000 \mathrm{E}+00$ & 0.0000 & $1.002 \mathrm{E}+02$ & 0.0972 \\
\hline-240 & $0.000 \mathrm{E}+00$ & 0.0000 & $0.000 \mathrm{E}+00$ & 0.0000 & $0.000 \mathrm{E}+00$ & 0.0000 & $0.000 \mathrm{E}+00$ & 0.0000 & $0.000 \mathrm{E}+00$ & 0.0000 & $0.000 \mathrm{E}+00$ & 0.0000 & $1.001 \mathrm{E}+02$ & 0.0971 \\
\hline-99 & $0.000 \mathrm{E}+00$ & 0.0000 & $0.000 \mathrm{E}+00$ & 0.0000 & $0.000 \mathrm{E}+00$ & 0.0000 & $0.000 \mathrm{E}+00$ & 0.0000 & $0.000 \mathrm{E}+00$ & 0.0000 & $0.000 \mathrm{E}+00$ & 0.0000 & $2.476 \mathrm{E}-03$ & 0.0000 \\
\hline-228 & $0.000 \mathrm{E}+00$ & 0.0000 & $0.000 \mathrm{E}+00$ & 0.0000 & $0.000 \mathrm{E}+00$ & 0.0000 & $0.000 \mathrm{E}+00$ & 0.0000 & $0.000 \mathrm{E}+00$ & 0.0000 & $0.000 \mathrm{E}+00$ & 0.0000 & $1.007 \mathrm{E}+02$ & 0.0977 \\
\hline 230 & $0.000 \mathrm{E}+00$ & 0.0000 & $0.000 \mathrm{E}+00$ & 0.0000 & $0.000 \mathrm{E}+00$ & 0.0000 & $0.000 \mathrm{E}+00$ & 0.0000 & $0.000 \mathrm{E}+00$ & 0.0000 & $0.000 \mathrm{E}+00$ & 0.0000 & $2.868 E+01$ & 0.0278 \\
\hline 232 & $0.000 \mathrm{E}+00$ & 0.0000 & $0.000 \mathrm{E}+00$ & 0.0000 & $0.000 \mathrm{E}+00$ & 0.0000 & $0.000 \mathrm{E}+00$ & 0.0000 & $0.000 \mathrm{E}+00$ & 0.0000 & $0.000 \mathrm{E}+00$ & 0.0000 & $3.610 \mathrm{E}+00$ & 0.0035 \\
\hline 34 & $0.000 \mathrm{E}+00$ & 0.0000 & $0.000 \mathrm{E}+00$ & 0.0000 & $0.000 \mathrm{E}+00$ & 0.0000 & $0.000 \mathrm{E}+00$ & 0.0000 & $0.000 \mathrm{E}+00$ & 0.0000 & $0.000 \mathrm{E}+00$ & 0.0000 & $9.840 \mathrm{E}+01$ & 0.0955 \\
\hline 35 & $0.000 \mathrm{E}+00$ & 0.0000 & $0.000 \mathrm{E}+00$ & 0.0000 & $0.000 \mathrm{E}+00$ & 0.0000 & $0.000 \mathrm{E}+00$ & 0.0000 & $0.000 \mathrm{E}+00$ & 0.0000 & $0.000 \mathrm{E}+00$ & 0.0000 & $9.950 \mathrm{E}+01$ & 0.0966 \\
\hline 38 & $0.000 \mathrm{E}+00$ & 0.0000 & $0.000 \mathrm{E}+00$ & 0.0000 & $0.000 \mathrm{E}+00$ & 0.0000 & $0.000 \mathrm{E}+00$ & 0.0000 & $0.000 \mathrm{E}+00$ & 0.0000 & $0.000 \mathrm{E}+00$ & 0.0000 & $1.001 \mathrm{E}+02$ & 0.0972 \\
\hline & $0.000 \mathrm{E}+00$ & 0.0000 & $0.000 \mathrm{E}+00$ & 0.0000 & $0.000 \mathrm{E}+00$ & 0.0000 & $0.000 \mathrm{E}+00$ & 0.0000 & $0.000 \mathrm{E}+00$ & 0.0000 & $0.000 \mathrm{E}+00$ & 0.0000 & $0 E+03$ & 1.0000 \\
\hline
\end{tabular}

* Sum of all water independent and dependent pathways. 
RESRAD, Version 6.5

$\mathrm{T}^{1 / 2}$ Limit $=180$ days

05/03/2011 15:55 Page 21

Summary : C746U Landfill Worker Deterministic Run
File : X: $\backslash$ FINAL V2 $\backslash C 746 U$ LANDFILL WORKER SG FWD-FINALV2.RAD

Total Dose Contributions TDOSE(i,p,t) for Individual Radionuclides (i) and Pathways (p) As mrem/yr and Fraction of Total Dose At $t=1.000 \mathrm{E}+00$ years

Water Independent Pathways (Inhalation excludes radon)

\begin{tabular}{|c|c|c|c|c|c|c|c|c|c|c|c|c|c|c|}
\hline \multirow{2}{*}{ Nuclide } & \multicolumn{2}{|c|}{ Ground } & \multicolumn{2}{|c|}{ Inhalation } & \multicolumn{2}{|c|}{ Radon } & \multicolumn{2}{|c|}{ Plant } & \multicolumn{2}{|c|}{ Meat } & \multicolumn{2}{|c|}{ Milk } & \multicolumn{2}{|c|}{ Soil } \\
\hline & mrem/yr & fract. & mrem/yr & fract. & mrem/yr & fract. & mrem/yr & fract. & mrem/yr & fract. & mrem/yr & fract. & mrem/yr & fract. \\
\hline-241 & $2.200 E+01$ & 0.0219 & $6.306 \mathrm{E}-01$ & 0.0006 & $0.000 \mathrm{E}+00$ & 0.0000 & $0.000 \mathrm{E}+00$ & 0.0000 & $0.000 \mathrm{E}+00$ & 0.0000 & $0.000 \mathrm{E}+00$ & 0.0000 & $7.695 \mathrm{E}+01$ & 0.0767 \\
\hline-137 & $9.743 E+01$ & 0.0971 & $1.344 \mathrm{E}-05$ & 0.0000 & $0.000 \mathrm{E}+00$ & 0.0000 & $0.000 \mathrm{E}+00$ & 0.0000 & $0.000 \mathrm{E}+00$ & 0.0000 & $0.000 \mathrm{E}+00$ & 0.0000 & $2.629 \mathrm{E}-01$ & 0.0003 \\
\hline-237 & $9.309 E+01$ & 0.0928 & $5.175 \mathrm{E}-02$ & 0.0001 & $0.000 \mathrm{E}+00$ & 0.0000 & $0.000 \mathrm{E}+00$ & 0.0000 & $0.000 \mathrm{E}+00$ & 0.0000 & $0.000 \mathrm{E}+00$ & 0.0000 & $6.718 \mathrm{E}+00$ & 0.0067 \\
\hline-238 & $7.630 \mathrm{E}-02$ & 0.0001 & 7. $980 \mathrm{E}-01$ & 0.0008 & $0.000 \mathrm{E}+00$ & 0.0000 & $0.000 \mathrm{E}+00$ & 0.0000 & $0.000 \mathrm{E}+00$ & 0.0000 & $0.000 \mathrm{E}+00$ & 0.0000 & $9.768 \mathrm{E}+01$ & 0.0974 \\
\hline-239 & $1.592 \mathrm{E}-01$ & 0.0002 & $8.131 \mathrm{E}-01$ & 0.0008 & $0.000 \mathrm{E}+00$ & 0.0000 & $0.000 \mathrm{E}+00$ & 0.0000 & $0.000 \mathrm{E}+00$ & 0.0000 & $0.000 \mathrm{E}+00$ & 0.0000 & $9.917 \mathrm{E}+01$ & 0.0988 \\
\hline-240 & $6.888 \mathrm{E}-02$ & 0.0001 & $8.130 \mathrm{E}-01$ & 0.0008 & $0.000 \mathrm{E}+00$ & 0.0000 & $0.000 \mathrm{E}+00$ & 0.0000 & $0.000 \mathrm{E}+00$ & 0.0000 & $0.000 \mathrm{E}+00$ & 0.0000 & $9.916 \mathrm{E}+01$ & 0.0988 \\
\hline-99 & $5.043 E-04$ & 0.0000 & $6.744 \mathrm{E}-07$ & 0.0000 & $0.000 \mathrm{E}+00$ & 0.0000 & $0.000 \mathrm{E}+00$ & 0.0000 & $0.000 \mathrm{E}+00$ & 0.0000 & $0.000 \mathrm{E}+00$ & 0.0000 & $1.945 \mathrm{E}-03$ & 0.0000 \\
\hline-228 & $6.939 \mathrm{E}+01$ & 0.0692 & $3.548 \mathrm{E}-03$ & 0.0000 & $0.000 \mathrm{E}+00$ & 0.0000 & $0.000 \mathrm{E}+00$ & 0.0000 & $0.000 \mathrm{E}+00$ & 0.0000 & $0.000 \mathrm{E}+00$ & 0.0000 & $6.823 \mathrm{E}-01$ & 0.0007 \\
\hline-230 & $1.588 \mathrm{E}+00$ & 0.0016 & $2.259 \mathrm{E}-01$ & 0.0002 & $0.000 \mathrm{E}+00$ & 0.0000 & $0.000 \mathrm{E}+00$ & 0.0000 & $0.000 \mathrm{E}+00$ & 0.0000 & $0.000 \mathrm{E}+00$ & 0.0000 & $2.780 \mathrm{E}+01$ & 0.0277 \\
\hline-232 & $8.316 \mathrm{E}+00$ & 0.0083 & $8.181 \mathrm{E}-03$ & 0.0000 & $0.000 \mathrm{E}+00$ & 0.0000 & $0.000 \mathrm{E}+00$ & 0.0000 & $0.000 \mathrm{E}+00$ & 0.0000 & $0.000 \mathrm{E}+00$ & 0.0000 & $1.463 \mathrm{E}+00$ & 0.0015 \\
\hline 34 & $1.045 \mathrm{E}+00$ & 0.0010 & $3.187 \mathrm{E}-01$ & 0.0003 & $0.000 \mathrm{E}+00$ & 0.0000 & $0.000 \mathrm{E}+00$ & 0.0000 & $0.000 \mathrm{E}+00$ & 0.0000 & $0.000 \mathrm{E}+00$ & 0.0000 & $9.704 \mathrm{E}+01$ & 0.0967 \\
\hline 35 & $9.521 \mathrm{E}+01$ & 0.0949 & $1.315 \mathrm{E}-02$ & 0.0000 & $0.000 \mathrm{E}+00$ & 0.0000 & $0.000 \mathrm{E}+00$ & 0.0000 & $0.000 \mathrm{E}+00$ & 0.0000 & $0.000 \mathrm{E}+00$ & 0.0000 & $4.282 \mathrm{E}+00$ & 0.0043 \\
\hline 38 & $8.296 \mathrm{E}+01$ & 0.0827 & $4.823 E-02$ & 0.0000 & $0.000 \mathrm{E}+00$ & 0.0000 & $0.000 \mathrm{E}+00$ & 0.0000 & $0.000 \mathrm{E}+00$ & 0.0000 & $0.000 \mathrm{E}+00$ & 0.0000 & $1.712 \mathrm{E}+01$ & 0.0171 \\
\hline & $4.713 E+02$ & 0.4697 & $3.724 \mathrm{E}+00$ & 0.0037 & $0.000 \mathrm{E}+00$ & 0.0000 & $0.000 \mathrm{E}+00$ & 0.0000 & $0.000 \mathrm{E}+00$ & 0.0000 & $0.000 \mathrm{E}+00$ & 0.0000 & $5.283 E+02$ & 0.5265 \\
\hline
\end{tabular}

Total Dose Contributions TDOSE(i,p,t) for Individual Radionuclides (i) and Pathways (p) As mrem/yr and Fraction of Total Dose At $t=1.000 \mathrm{E}+00$ years

Water Dependent Pathways

\begin{tabular}{|c|c|c|c|c|c|c|c|c|c|c|c|c|c|c|}
\hline \multirow{2}{*}{ Nuclide } & \multicolumn{2}{|c|}{ Water } & \multicolumn{2}{|c|}{ Fish } & \multicolumn{2}{|c|}{ Radon } & \multicolumn{2}{|c|}{ Plant } & \multicolumn{2}{|c|}{ Meat } & \multicolumn{2}{|c|}{ Milk } & \multicolumn{2}{|c|}{ All Pathways* } \\
\hline & mrem/yr & fract. & mrem/yr & fract. & mrem/yr & fract. & mrem/yr & fract. & mrem/yr & fract. & mrem/yr & fract. & mrem/yr & fract. \\
\hline-241 & $0.000 \mathrm{E}+00$ & 0.0000 & $0.000 \mathrm{E}+00$ & 0.0000 & $0.000 \mathrm{E}+00$ & 0.0000 & $0.000 \mathrm{E}+00$ & 0.0000 & $0.000 \mathrm{E}+00$ & 0.0000 & $0.000 \mathrm{E}+00$ & 0.0000 & $9.959 \mathrm{E}+01$ & 0.0993 \\
\hline-137 & $0.000 \mathrm{E}+00$ & 0.0000 & $0.000 \mathrm{E}+00$ & 0.0000 & $0.000 \mathrm{E}+00$ & 0.0000 & $0.000 \mathrm{E}+00$ & 0.0000 & $0.000 \mathrm{E}+00$ & 0.0000 & $0.000 \mathrm{E}+00$ & 0.0000 & $9.770 \mathrm{E}+01$ & 0.0974 \\
\hline-237 & $0.000 \mathrm{E}+00$ & 0.0000 & $0.000 \mathrm{E}+00$ & 0.0000 & $0.000 \mathrm{E}+00$ & 0.0000 & $0.000 \mathrm{E}+00$ & 0.0000 & $0.000 \mathrm{E}+00$ & 0.0000 & $0.000 \mathrm{E}+00$ & 0.0000 & $9.986 \mathrm{E}+01$ & 0.0995 \\
\hline-238 & $0.000 \mathrm{E}+00$ & 0.0000 & $0.000 \mathrm{E}+00$ & 0.0000 & $0.000 \mathrm{E}+00$ & 0.0000 & $0.000 \mathrm{E}+00$ & 0.0000 & $0.000 \mathrm{E}+00$ & 0.0000 & $0.000 \mathrm{E}+00$ & 0.0000 & $9.856 \mathrm{E}+01$ & 0.0982 \\
\hline-239 & $0.000 \mathrm{E}+00$ & 0.0000 & $0.000 \mathrm{E}+00$ & 0.0000 & $0.000 \mathrm{E}+00$ & 0.0000 & $0.000 \mathrm{E}+00$ & 0.0000 & $0.000 \mathrm{E}+00$ & 0.0000 & $0.000 \mathrm{E}+00$ & 0.0000 & $1.001 \mathrm{E}+02$ & 0.0998 \\
\hline-240 & $0.000 \mathrm{E}+00$ & 0.0000 & $0.000 \mathrm{E}+00$ & 0.0000 & $0.000 \mathrm{E}+00$ & 0.0000 & $0.000 \mathrm{E}+00$ & 0.0000 & $0.000 \mathrm{E}+00$ & 0.0000 & $0.000 \mathrm{E}+00$ & 0.0000 & $1.000 \mathrm{E}+02$ & 0.0997 \\
\hline-99 & $0.000 \mathrm{E}+00$ & 0.0000 & $0.000 \mathrm{E}+00$ & 0.0000 & $0.000 \mathrm{E}+00$ & 0.0000 & $0.000 \mathrm{E}+00$ & 0.0000 & $0.000 \mathrm{E}+00$ & 0.0000 & $0.000 \mathrm{E}+00$ & 0.0000 & $2.450 \mathrm{E}-03$ & 0.0000 \\
\hline-228 & $0.000 \mathrm{E}+00$ & 0.0000 & $0.000 \mathrm{E}+00$ & 0.0000 & $0.000 \mathrm{E}+00$ & 0.0000 & $0.000 \mathrm{E}+00$ & 0.0000 & $0.000 \mathrm{E}+00$ & 0.0000 & $0.000 \mathrm{E}+00$ & 0.0000 & $7.007 \mathrm{E}+01$ & 0.0698 \\
\hline 230 & $0.000 \mathrm{E}+00$ & 0.0000 & $0.000 \mathrm{E}+00$ & 0.0000 & $0.000 \mathrm{E}+00$ & 0.0000 & $0.000 \mathrm{E}+00$ & 0.0000 & $0.000 \mathrm{E}+00$ & 0.0000 & $0.000 \mathrm{E}+00$ & 0.0000 & $2.961 \mathrm{E}+01$ & 0.0295 \\
\hline 232 & $0.000 \mathrm{E}+00$ & 0.0000 & $0.000 \mathrm{E}+00$ & 0.0000 & $0.000 \mathrm{E}+00$ & 0.0000 & $0.000 \mathrm{E}+00$ & 0.0000 & $0.000 \mathrm{E}+00$ & 0.0000 & $0.000 \mathrm{E}+00$ & 0.0000 & $9.788 \mathrm{E}+00$ & 0.0098 \\
\hline 34 & $0.000 \mathrm{E}+00$ & 0.0000 & $0.000 \mathrm{E}+00$ & 0.0000 & $0.000 \mathrm{E}+00$ & 0.0000 & $0.000 \mathrm{E}+00$ & 0.0000 & $0.000 \mathrm{E}+00$ & 0.0000 & $0.000 \mathrm{E}+00$ & 0.0000 & $9.840 \mathrm{E}+01$ & 0.0981 \\
\hline 35 & $0.000 \mathrm{E}+00$ & 0.0000 & $0.000 \mathrm{E}+00$ & 0.0000 & $0.000 \mathrm{E}+00$ & 0.0000 & $0.000 \mathrm{E}+00$ & 0.0000 & $0.000 \mathrm{E}+00$ & 0.0000 & $0.000 \mathrm{E}+00$ & 0.0000 & $9.950 \mathrm{E}+01$ & 0.0992 \\
\hline 38 & $0.000 \mathrm{E}+00$ & 0.0000 & $0.000 \mathrm{E}+00$ & 0.0000 & $0.000 \mathrm{E}+00$ & 0.0000 & $0.000 \mathrm{E}+00$ & 0.0000 & $0.000 \mathrm{E}+00$ & 0.0000 & $0.000 \mathrm{E}+00$ & 0.0000 & $1.001 \mathrm{E}+02$ & 0.0998 \\
\hline & $0.000 \mathrm{E}+00$ & 0.0000 & $0.000 \mathrm{E}+00$ & 0.0000 & $0.000 \mathrm{E}+00$ & 0.0000 & $0.000 \mathrm{E}+00$ & 0.0000 & $0.000 \mathrm{E}+00$ & 0.0000 & $0.000 \mathrm{E}+00$ & 0.0000 & $3 E+03$ & 1.0000 \\
\hline
\end{tabular}

* Sum of all water independent and dependent pathways. 
RESRAD, Version 6.5

$\mathrm{T}^{1 / 2}$ Limit $=180$ days

05/03/2011 15:55 Page 22

Summary : C746U Landfill Worker Deterministic Run
File : X: $\backslash$ FINAL V2 $\backslash C 746 U$ LANDFILL WORKER SG FWD-FINALV2.RAD

Total Dose Contributions TDOSE(i,p,t) for Individual Radionuclides (i) and Pathways (p) As mrem/yr and Fraction of Total Dose At $t=5.000 \mathrm{E}+01$ years

Water Independent Pathways (Inhalation excludes radon)

\begin{tabular}{|c|c|c|c|c|c|c|c|c|c|c|c|c|}
\hline & \multicolumn{2}{|c|}{ Ground } & \multicolumn{2}{|c|}{ Inhalation } & \multicolumn{2}{|c|}{ Radon } & \multicolumn{2}{|c|}{ Plant } & \multicolumn{2}{|c|}{ Meat } & \multicolumn{2}{|c|}{ Milk } \\
\hline clide & mrem/yr & fract. & mrem/yr & fract. & mrem/yr & fract. & mrem/yr & fract. & mrem/yr & fract. & mrem/yr & fract. \\
\hline 41 & $2.034 E+01$ & 0.0211 & $5.827 \mathrm{E}-01$ & 0.0006 & $0.000 \mathrm{E}+00$ & 0.0000 & $0.000 \mathrm{E}+00$ & 0.0000 & $0.000 \mathrm{E}+00$ & 0.0000 & $0.000 \mathrm{E}+00$ & 0.0000 \\
\hline-137 & $3.135 E+01$ & 0.0325 & $4.325 E-06$ & 0.0000 & $0.000 \mathrm{E}+00$ & 0.0000 & $0.000 \mathrm{E}+00$ & 0.0000 & $0.000 \mathrm{E}+00$ & 0.0000 & $0.000 \mathrm{E}+00$ & 0.0000 \\
\hline-237 & $9.237 E+01$ & 0.0957 & $5.136 \mathrm{E}-02$ & 0.0001 & $0.000 \mathrm{E}+00$ & 0.0000 & $0.000 \mathrm{E}+00$ & 0.0000 & $0.000 \mathrm{E}+00$ & 0.0000 & $0.000 \mathrm{E}+00$ & 0.0000 \\
\hline-238 & $5.179 E-02$ & 0.0001 & $5.413 E-01$ & 0.0006 & $0.000 \mathrm{E}+00$ & 0.0000 & $0.000 \mathrm{E}+00$ & 0.0000 & $0.000 \mathrm{E}+00$ & 0.0000 & $0.000 \mathrm{E}+00$ & 0.0000 \\
\hline-239 & $1.588 \mathrm{E}-01$ & 0.0002 & $8.111 \mathrm{E}-01$ & 0.0008 & $0.000 \mathrm{E}+00$ & 0.0000 & $0.000 \mathrm{E}+00$ & 0.0000 & $0.000 \mathrm{E}+00$ & 0.0000 & $0.000 \mathrm{E}+00$ & 0.0000 \\
\hline-240 & $6.845 E-02$ & 0.0001 & $8.080 \mathrm{E}-01$ & 0.0008 & $0.000 \mathrm{E}+00$ & 0.0000 & $0.000 \mathrm{E}+00$ & 0.0000 & $0.000 \mathrm{E}+00$ & 0.0000 & $0.000 \mathrm{E}+00$ & 0.0000 \\
\hline-99 & $3.003 E-04$ & 0.0000 & $4.016 \mathrm{E}-07$ & 0.0000 & $0.000 \mathrm{E}+00$ & 0.0000 & $0.000 \mathrm{E}+00$ & 0.0000 & $0.000 \mathrm{E}+00$ & 0.0000 & $0.000 \mathrm{E}+00$ & 0.0000 \\
\hline-228 & $1.352 \mathrm{E}-06$ & 0.0000 & $6.913 \mathrm{E}-11$ & 0.0000 & $0.000 \mathrm{E}+00$ & 0.0000 & $0.000 \mathrm{E}+00$ & 0.0000 & $0.000 \mathrm{E}+00$ & 0.0000 & $0.000 \mathrm{E}+00$ & 0.0000 \\
\hline-230 & $4.588 \mathrm{E}+01$ & 0.0475 & $2.264 \mathrm{E}-01$ & 0.0002 & $0.000 \mathrm{E}+00$ & 0.0000 & $0.000 \mathrm{E}+00$ & 0.0000 & $0.000 \mathrm{E}+00$ & 0.0000 & $0.000 \mathrm{E}+00$ & 0.0000 \\
\hline-232 & $9.644 \mathrm{E}+01$ & 0.0999 & $1.212 \mathrm{E}-02$ & 0.0000 & $0.000 \mathrm{E}+00$ & 0.0000 & $0.000 \mathrm{E}+00$ & 0.0000 & $0.000 \mathrm{E}+00$ & 0.0000 & $0.000 \mathrm{E}+00$ & 0.0000 \\
\hline 234 & $1.201 \mathrm{E}+00$ & 0.0012 & $3.197 \mathrm{E}-01$ & 0.0003 & $0.000 \mathrm{E}+00$ & 0.0000 & $0.000 \mathrm{E}+00$ & 0.0000 & $0.000 \mathrm{E}+00$ & 0.0000 & $0.000 E+00$ & 0.0000 \\
\hline 250 & $9.524 \mathrm{E}+01$ & 0.0987 & $1.383 \mathrm{E}-02$ & 0.0000 & $0.000 \mathrm{E}+00$ & 0.0000 & $0.000 \mathrm{E}+00$ & 0.0000 & $0.000 \mathrm{E}+00$ & 0.0000 & $0.000 \mathrm{E}+00$ & 0.0000 \\
\hline 38 & $8.285 E+01$ & 0.0858 & $4.818 E-02$ & 0.0000 & $0.000 \mathrm{E}+00$ & 0.0000 & $0.000 \mathrm{E}+00$ & 0.0000 & $0.000 \mathrm{E}+00$ & 0.0000 & $0.000 \mathrm{E}+00$ & 0.0000 \\
\hline & $4.660 \mathrm{E}+02$ & 0.4827 & $3.415 \mathrm{E}+00$ & 0.0035 & $0.000 \mathrm{E}+00$ & 0.0000 & $0.000 \mathrm{E}+00$ & 0.0000 & $0.000 \mathrm{E}+00$ & 0.0000 & $0.000 \mathrm{E}+00$ & 0.0000 \\
\hline
\end{tabular}

Total Dose Contributions TDOSE (i,p,t) for Individual Radionuclides (i) and Pathways (p) As mrem/yr and Fraction of Total Dose At $t=5.000 \mathrm{E}+01$ years

Water Dependent Pathways

\begin{tabular}{|c|c|c|c|c|c|c|c|c|c|c|c|c|c|c|}
\hline & \multicolumn{2}{|c|}{ Water } & \multicolumn{2}{|c|}{ Fish } & \multicolumn{2}{|c|}{ Radon } & \multicolumn{2}{|c|}{ Plant } & \multicolumn{2}{|c|}{ Meat } & \multicolumn{2}{|c|}{ Milk } & \multicolumn{2}{|c|}{ All Pathways* } \\
\hline clide & mrem/yr & fract. & mrem/yr & fract. & mrem/yr & fract. & mrem/yr & fract. & mrem/yr & fract. & mrem/yr & fract. & mrem/yr & fract. \\
\hline-241 & $0.000 \mathrm{E}+00$ & 0.0000 & $0.000 \mathrm{E}+00$ & 0.0000 & $0.000 \mathrm{E}+00$ & 0.0000 & $0.000 \mathrm{E}+00$ & 0.0000 & $0.000 \mathrm{E}+00$ & 0.0000 & $0.000 \mathrm{E}+00$ & 0.0000 & $9.205 \mathrm{E}+01$ & 0.0954 \\
\hline-137 & $0.000 \mathrm{E}+00$ & 0.0000 & $0.000 \mathrm{E}+00$ & 0.0000 & $0.000 \mathrm{E}+00$ & 0.0000 & $0.000 \mathrm{E}+00$ & 0.0000 & $0.000 \mathrm{E}+00$ & 0.0000 & $0.000 \mathrm{E}+00$ & 0.0000 & $3.143 E+01$ & 0.0326 \\
\hline-237 & $0.000 \mathrm{E}+00$ & 0.0000 & $0.000 \mathrm{E}+00$ & 0.0000 & $0.000 \mathrm{E}+00$ & 0.0000 & $0.000 \mathrm{E}+00$ & 0.0000 & $0.000 \mathrm{E}+00$ & 0.0000 & $0.000 \mathrm{E}+00$ & 0.0000 & $9.909 \mathrm{E}+01$ & 0.1027 \\
\hline-238 & $0.000 \mathrm{E}+00$ & 0.0000 & $0.000 \mathrm{E}+00$ & 0.0000 & $0.000 \mathrm{E}+00$ & 0.0000 & $0.000 \mathrm{E}+00$ & 0.0000 & $0.000 \mathrm{E}+00$ & 0.0000 & $0.000 \mathrm{E}+00$ & 0.0000 & $6.686 \mathrm{E}+01$ & 0.0693 \\
\hline-239 & $0.000 \mathrm{E}+00$ & 0.0000 & $0.000 \mathrm{E}+00$ & 0.0000 & $0.000 \mathrm{E}+00$ & 0.0000 & $0.000 \mathrm{E}+00$ & 0.0000 & $0.000 \mathrm{E}+00$ & 0.0000 & $0.000 E+00$ & 0.0000 & $9.991 \mathrm{E}+01$ & 0.1035 \\
\hline-240 & $0.000 \mathrm{E}+00$ & 0.0000 & $0.000 \mathrm{E}+00$ & 0.0000 & $0.000 \mathrm{E}+00$ & 0.0000 & $0.000 \mathrm{E}+00$ & 0.0000 & $0.000 \mathrm{E}+00$ & 0.0000 & $0.000 E+00$ & 0.0000 & $9.943 \mathrm{E}+01$ & 0.1030 \\
\hline-99 & $0.000 \mathrm{E}+00$ & 0.0000 & $0.000 \mathrm{E}+00$ & 0.0000 & $0.000 \mathrm{E}+00$ & 0.0000 & $0.000 \mathrm{E}+00$ & 0.0000 & $0.000 \mathrm{E}+00$ & 0.0000 & $0.000 \mathrm{E}+00$ & 0.0000 & $1.459 \mathrm{E}-03$ & 0.0000 \\
\hline-228 & $0.000 \mathrm{E}+00$ & 0.0000 & $0.000 \mathrm{E}+00$ & 0.0000 & $0.000 \mathrm{E}+00$ & 0.0000 & $0.000 \mathrm{E}+00$ & 0.0000 & $0.000 \mathrm{E}+00$ & 0.0000 & $0.000 \mathrm{E}+00$ & 0.0000 & $1.365 \mathrm{E}-06$ & 0.0000 \\
\hline-230 & $0.000 \mathrm{E}+00$ & 0.0000 & $0.000 \mathrm{E}+00$ & 0.0000 & $0.000 \mathrm{E}+00$ & 0.0000 & $0.000 \mathrm{E}+00$ & 0.0000 & $0.000 \mathrm{E}+00$ & 0.0000 & $0.000 E+00$ & 0.0000 & $7.735 \mathrm{E}+01$ & 0.0801 \\
\hline-232 & $0.000 \mathrm{E}+00$ & 0.0000 & $0.000 \mathrm{E}+00$ & 0.0000 & $0.000 \mathrm{E}+00$ & 0.0000 & $0.000 \mathrm{E}+00$ & 0.0000 & $0.000 \mathrm{E}+00$ & 0.0000 & $0.000 \mathrm{E}+00$ & 0.0000 & $1.009 \mathrm{E}+02$ & 0.1045 \\
\hline 34 & $0.000 \mathrm{E}+00$ & 0.0000 & $0.000 \mathrm{E}+00$ & 0.0000 & $0.000 \mathrm{E}+00$ & 0.0000 & $0.000 \mathrm{E}+00$ & 0.0000 & $0.000 \mathrm{E}+00$ & 0.0000 & $0.000 \mathrm{E}+00$ & 0.0000 & $9.861 \mathrm{E}+01$ & 0.1022 \\
\hline 35 & $0.000 \mathrm{E}+00$ & 0.0000 & $0.000 \mathrm{E}+00$ & 0.0000 & $0.000 \mathrm{E}+00$ & 0.0000 & $0.000 \mathrm{E}+00$ & 0.0000 & $0.000 \mathrm{E}+00$ & 0.0000 & $0.000 \mathrm{E}+00$ & 0.0000 & $9.966 \mathrm{E}+01$ & 0.1032 \\
\hline 38 & $0.000 \mathrm{E}+00$ & 0.0000 & $0.000 \mathrm{E}+00$ & 0.0000 & $0.000 \mathrm{E}+00$ & 0.0000 & $0.000 \mathrm{E}+00$ & 0.0000 & $0.000 \mathrm{E}+00$ & 0.0000 & $0.000 \mathrm{E}+00$ & 0.0000 & $1.000 \mathrm{E}+02$ & 0.1036 \\
\hline & $0.000 \mathrm{E}+00$ & 0.0000 & $0.000 \mathrm{E}+00$ & 0.0000 & $0.000 \mathrm{E}+00$ & 0.0000 & $0.000 \mathrm{E}+00$ & 0.0000 & $0.000 \mathrm{E}+00$ & 0.0000 & $0.000 \mathrm{E}+00$ & 0.0000 & $3 E+02$ & 1. \\
\hline
\end{tabular}

* Sum of all water independent and dependent pathways. 
RESRAD, Version 6.5

$\mathrm{T}^{1 / 2}$ Limit $=180$ days

Summary : C746U Landfill Worker Deterministic Run
File : X: $\backslash$ FINAL V2 $\backslash C 746 U$ LANDFILL WORKER SG FWD-FINALV2.RAD

Total Dose Contributions TDOSE (i,p,t) for Individual Radionuclides (i) and Pathways (p) As mrem/yr and Fraction of Total Dose At $t=7.000 \mathrm{E}+01$ years

Water Independent Pathways (Inhalation excludes radon)

\begin{tabular}{|c|c|c|}
\hline clide & mrem/yr & fract. \\
\hline-241 & $1.970 \mathrm{E}+01$ & 0.0205 \\
\hline-137 & $1.973 E+01$ & 0.0205 \\
\hline-237 & $9.208 \mathrm{E}+01$ & 0.0959 \\
\hline-238 & $4.422 \mathrm{E}-02$ & 0.0000 \\
\hline-239 & $1.587 \mathrm{E}-01$ & 0.0002 \\
\hline-240 & $6.828 \mathrm{E}-02$ & 0.0001 \\
\hline-99 & $2.430 \mathrm{E}-04$ & 0.0000 \\
\hline-228 & $9.636 \mathrm{E}-10$ & 0.0000 \\
\hline-230 & $6.368 \mathrm{E}+01$ & 0.0663 \\
\hline-232 & $9.669 \mathrm{E}+01$ & 0.1007 \\
\hline 234 & $1.349 \mathrm{E}+00$ & 0.0014 \\
\hline 235 & $9.530 \mathrm{E}+01$ & 0.0992 \\
\hline 38 & $8.281 E+01$ & 0.0862 \\
\hline & $4.716 \mathrm{E}+02$ & 0.4909 \\
\hline
\end{tabular}

\begin{abstract}
Inhalation
\end{abstract}
$\longrightarrow$

mrem/yr fract. mrem/yr fract.

$\overline{5.643 \mathrm{E}-01} \overline{0.0006}$

$2.723 \mathrm{E}-06 \quad 0.0000$

$5.119 \mathrm{E}-02 \quad 0.0001$

4. $620 \mathrm{E}-010.0005$

8.103E-01 0.0008

$8.059 \mathrm{E}-010.0008$

$3.250 \mathrm{E}-07 \quad 0.0000$

$4.927 \mathrm{E}-14 \quad 0.0000$

$2.267 \mathrm{E}-010.0002$

$1.213 \mathrm{E}-02 \quad 0.0000$

$3.201 \mathrm{E}-010.0003$

$1.423 \mathrm{E}-02 \quad 0.0000$

4.815E-02 0.0001

$\overline{\overline{3.315 \mathrm{E}+00}} \overline{\overline{0.0035}}$

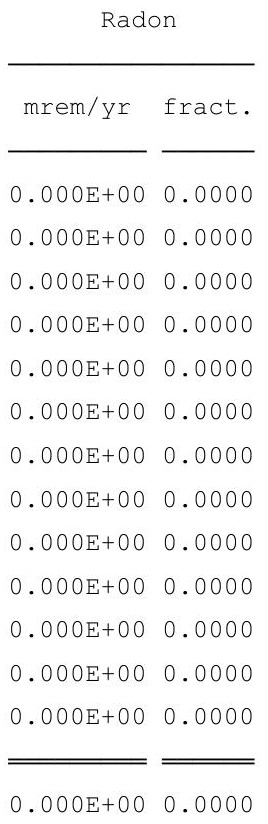

Plant

mrem/yr fract.

$0.000 \mathrm{E}+00 \quad 0.0000$

$0.000 \mathrm{E}+00 \quad 0.0000$

$0.000 \mathrm{E}+00 \quad 0.0000$

$0.000 \mathrm{E}+00 \quad 0.0000$

$0.000 \mathrm{E}+00 \quad 0.0000$

$0.000 \mathrm{E}+00 \quad 0.0000$

$0.000 \mathrm{E}+00 \quad 0.0000$

$0.000 \mathrm{E}+00 \quad 0.0000$

$0.000 \mathrm{E}+00 \quad 0.0000$

$0.000 \mathrm{E}+00 \quad 0.0000$

$0.000 \mathrm{E}+00 \quad 0.0000$

$0.000 \mathrm{E}+00 \quad 0.0000$

$0.000 \mathrm{E}+00 \quad 0.0000$

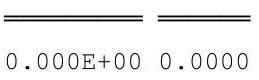

\begin{tabular}{ll} 
Meat \\
\hline mrem/yr fract. \\
\cline { 1 - 1 } 0.000E+00 & 0.0000 \\
$0.000 \mathrm{E}+00$ & 0.0000 \\
$0.000 \mathrm{E}+00$ & 0.0000 \\
$0.000 \mathrm{E}+00$ & 0.0000 \\
$0.000 \mathrm{E}+00$ & 0.0000 \\
$0.000 \mathrm{E}+00$ & 0.0000 \\
$0.000 \mathrm{E}+00$ & 0.0000 \\
$0.000 \mathrm{E}+00$ & 0.0000 \\
$0.000 \mathrm{E}+00$ & 0.0000 \\
$0.000 \mathrm{E}+00$ & 0.0000 \\
$0.000 \mathrm{E}+00$ & 0.0000 \\
$0.000 \mathrm{E}+00$ & 0.0000 \\
$0.000 \mathrm{E}+00$ & 0.0000 \\
\hline \hline $0.000 \mathrm{E}+00$ & 0.0000
\end{tabular}

\begin{tabular}{cc} 
Milk \\
\hline mrem/yr fract. \\
\cline { 1 - 2 } 0.000E+00 & 0.0000 \\
$0.000 \mathrm{E}+00$ & 0.0000 \\
$0.000 \mathrm{E}+00$ & 0.0000 \\
$0.000 \mathrm{E}+00$ & 0.0000 \\
$0.000 \mathrm{E}+00$ & 0.0000 \\
$0.000 \mathrm{E}+00$ & 0.0000 \\
$0.000 \mathrm{E}+00$ & 0.0000 \\
$0.000 \mathrm{E}+00$ & 0.0000 \\
$0.000 \mathrm{E}+00$ & 0.0000 \\
$0.000 \mathrm{E}+00$ & 0.0000 \\
$0.000 \mathrm{E}+00$ & 0.0000 \\
$0.000 \mathrm{E}+00$ & 0.0000 \\
$0.000 \mathrm{E}+00$ & 0.0000 \\
\hline \hline $0.000 \mathrm{E}+00$ & 0.0000
\end{tabular}

Soil

mrem/yr fract.

$6.887 \mathrm{E}+010.0717$

$5.324 \mathrm{E}-020.0001$

$6.646 \mathrm{E}+00 \quad 0.0069$

$5.656 \mathrm{E}+010.0589$

$9.884 \mathrm{E}+010.1029$

$9.830 \mathrm{E}+010.1023$

$9.376 \mathrm{E}-04 \quad 0.0000$

$9.475 \mathrm{E}-120.0000$

$3.334 \mathrm{E}+010.0347$

$4.449 \mathrm{E}+00 \quad 0.0046$

$9.712 \mathrm{E}+010.1011$

$4.466 \mathrm{E}+00 \quad 0.0046$

$1.709 \mathrm{E}+010.0178$

$4.857 \mathrm{E}+02 \quad 0.5056$

Total Dose Contributions TDOSE (i,p,t) for Individual Radionuclides (i) and Pathways (p) As mrem/yr and Fraction of Total Dose At $t=7.000 \mathrm{E}+01$ years

Water Dependent Pathways

\begin{tabular}{|c|c|c|c|c|c|c|}
\hline & \multicolumn{2}{|c|}{ Water } & \multicolumn{2}{|c|}{ Fish } & \multicolumn{2}{|c|}{ Radon } \\
\hline clide & mrem/yr & fract. & mrem/yr & fract. & mrem/yr & fract. \\
\hline 41 & $0.000 \mathrm{E}+00$ & 0.0000 & $0.000 \mathrm{E}+00$ & 0.0000 & $0.000 \mathrm{E}+00$ & 0.0000 \\
\hline-137 & $0.000 \mathrm{E}+00$ & 0.0000 & $0.000 \mathrm{E}+00$ & 0.0000 & $0.000 \mathrm{E}+00$ & 0.0000 \\
\hline-237 & $0.000 \mathrm{E}+00$ & 0.0000 & $0.000 \mathrm{E}+00$ & 0.0000 & $0.000 \mathrm{E}+00$ & 0.0000 \\
\hline-238 & $0.000 \mathrm{E}+00$ & 0.0000 & $0.000 \mathrm{E}+00$ & 0.0000 & $0.000 \mathrm{E}+00$ & 0.0000 \\
\hline-239 & $0.000 \mathrm{E}+00$ & 0.0000 & $0.000 \mathrm{E}+00$ & 0.0000 & $0.000 \mathrm{E}+00$ & 0.0000 \\
\hline-240 & $0.000 \mathrm{E}+00$ & 0.0000 & $0.000 \mathrm{E}+00$ & 0.0000 & $0.000 \mathrm{E}+00$ & 0.0000 \\
\hline-99 & $0.000 \mathrm{E}+00$ & 0.0000 & $0.000 \mathrm{E}+00$ & 0.0000 & $0.000 \mathrm{E}+00$ & 0.0000 \\
\hline-228 & $0.000 \mathrm{E}+00$ & 0.0000 & $0.000 \mathrm{E}+00$ & 0.0000 & $0.000 \mathrm{E}+00$ & 0.0000 \\
\hline-230 & $0.000 \mathrm{E}+00$ & 0.0000 & $0.000 \mathrm{E}+00$ & 0.0000 & $0.000 \mathrm{E}+00$ & 0.0000 \\
\hline-232 & $0.000 \mathrm{E}+00$ & 0.0000 & $0.000 \mathrm{E}+00$ & 0.0000 & $0.000 \mathrm{E}+00$ & 0.0000 \\
\hline 234 & $0.000 \mathrm{E}+00$ & 0.0000 & $0.000 \mathrm{E}+00$ & 0.0000 & $0.000 \mathrm{E}+00$ & 0.0000 \\
\hline 35 & $0.000 \mathrm{E}+00$ & 0.0000 & $0.000 \mathrm{E}+00$ & 0.0000 & $0.000 \mathrm{E}+00$ & 0.0000 \\
\hline 38 & $0.000 \mathrm{E}+00$ & 0.0000 & $0.000 \mathrm{E}+00$ & 0.0000 & $0.000 \mathrm{E}+00$ & 0.0000 \\
\hline & $0.000 \mathrm{E}+00$ & 0.0000 & $0.000 \mathrm{E}+00$ & 0.0000 & $0.000 \mathrm{E}+00$ & 0.0000 \\
\hline
\end{tabular}

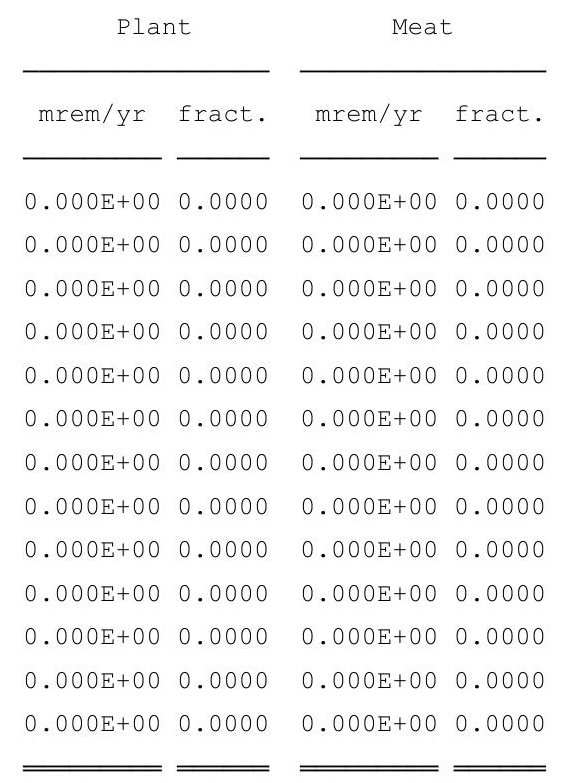

$0.000 \mathrm{E}+00 \quad 0.0000$

$0.000 \mathrm{E}+00 \quad 0.0000$

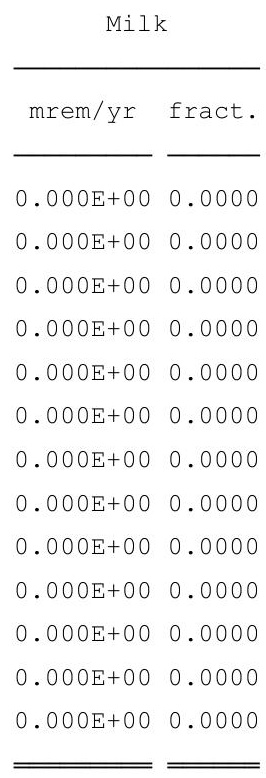

$0.000 \mathrm{E}+00 \quad 0.0000$
All Pathways * mrem/yr fract. $8.913 \mathrm{E}+010.0928$ $1.978 \mathrm{E}+010.0206$ $9.878 \mathrm{E}+010.1028$ $5.707 \mathrm{E}+01 \quad 0.0594$ $9.981 \mathrm{E}+010.1039$ $9.918 \mathrm{E}+010.1032$ $1.181 \mathrm{E}-03 \quad 0.0000$ $9.731 \mathrm{E}-10 \quad 0.0000$ $9.725 \mathrm{E}+010.1012$ $1.012 \mathrm{E}+020.1053$ $9.879 \mathrm{E}+010.1028$ $9.977 \mathrm{E}+010.1039$ $9.995 \mathrm{E}+010.1040$ $9.607 \mathrm{E}+02 \quad 1.0000$

* Sum of all water independent and dependent pathways. 
RESRAD, Version $6.5 \quad \mathrm{~T}^{1 / 2}$ Limit $=180$ days

ummary : C746U Landfill Worker Deterministic Run

File : $\mathrm{X}: \backslash$ FINAL V2 $\backslash C 746 \mathrm{U}$ LANDFILL WORKER SG FWD-FINALV2.RAD

Dose/Source Ratios Summed Over All Pathways

Parent and Progeny Principal Radionuclide Contributions Indicated

Parent Product Thread DSR $(j, t)$ At Time in Years (mrem/yr)/(pCi/g)

(i) (j) Fraction $0.000 \mathrm{E}+001.000 \mathrm{E}+00 \quad 5.000 \mathrm{E}+017.000 \mathrm{E}+01$

Am-241

Am-241

Am-241

Am-241

Am-241

$C s-137+D$

$\mathrm{Np}-237+\mathrm{D}$

$\mathrm{Np}-237+\mathrm{D}$

$\mathrm{Np}-237+\mathrm{D}$

$\mathrm{Np}-237+\mathrm{D}$

$\mathrm{Pu}-238$

$\mathrm{Pu}-238$

1. $840 E-09$

$\begin{array}{llllll}\text { Am-241 } & 1.000 \mathrm{E}+00 & 2.850 \mathrm{E}-02 & 2.845 \mathrm{E}-02 & 2.630 \mathrm{E}-02 & 2.546 \mathrm{E}-02\end{array}$

$\begin{array}{lllllll}\mathrm{Np}-237+\mathrm{D} & 1.000 \mathrm{E}+00 & 2.940 \mathrm{E}-08 & 8.812 \mathrm{E}-08 & 2.842 \mathrm{E}-06 & 3.898 \mathrm{E}-06\end{array}$

$\begin{array}{lllllll}\mathrm{U}-233 & 1.000 \mathrm{E}+00 & 1.383 \mathrm{E}-15 & 9.674 \mathrm{E}-15 & 1.027 \mathrm{E}-11 & 1.978 \mathrm{E}-11\end{array}$

$\begin{array}{llllllll}\mathrm{Th}-229+\mathrm{D} & 1.000 \mathrm{E}+00 & 1.756 \mathrm{E}-18 & 2.633 \mathrm{E}-17 & 8.837 \mathrm{E}-13 & 2.382 \mathrm{E}-12\end{array}$

$\sum \operatorname{DSR}(j)$

$2.850 \mathrm{E}-02 \quad 2.845 \mathrm{E}-02 \quad 2.630 \mathrm{E}-02 \quad 2.547 \mathrm{E}-02$

$\mathrm{Cs}-137+\mathrm{D} \quad 1.000 \mathrm{E}+00 \quad 5.262 \mathrm{E}-01 \quad 5.142 \mathrm{E}-01 \quad 1.654 \mathrm{E}-01 \quad 1.041 \mathrm{E}-01$

$\mathrm{Np}-237+\mathrm{D} \quad 1.000 \mathrm{E}+00 \quad 1.816 \mathrm{E}-01 \quad 1.816 \mathrm{E}-01 \quad 1.802 \mathrm{E}-01 \quad 1.796 \mathrm{E}-01$

U-233 1.000E+00 1.281E-08 3.843E-08 $1.288 \mathrm{E}-06 \quad 1.795 \mathrm{E}-06$

$\begin{array}{llllllll}\mathrm{Th}-229+\mathrm{D} \quad 1.000 \mathrm{E}+00 \quad 2.169 \mathrm{E}-11 & 1.518 \mathrm{E}-10 & 1.652 \mathrm{E}-07 & 3.213 \mathrm{E}-07\end{array}$

$\operatorname{\sum DSR}(j) \quad 1.816 \mathrm{E}-011.816 \mathrm{E}-011.802 \mathrm{E}-01 \quad 1.796 \mathrm{E}-01$

$\mathrm{Pu}-238$

$\begin{array}{lllllll}\mathrm{Pu}-238 & 1.000 \mathrm{E}+00 & 2.547 \mathrm{E}-02 & 2.527 \mathrm{E}-02 & 1.714 \mathrm{E}-02 & 1.463 \mathrm{E}-02\end{array}$

$\begin{array}{lllllll}\mathrm{U}-234 & 1.000 \mathrm{E}+00 & 7.728 \mathrm{E}-09 & 2.310 \mathrm{E}-08 & 6.445 \mathrm{E}-07 & 8.363 \mathrm{E}-07\end{array}$

$\begin{array}{llllll}\mathrm{Th}-230 & 1.000 \mathrm{E}+00 & 9.980 \mathrm{E}-14 & 6.970 \mathrm{E}-13 & 6.720 \mathrm{E}-10 & 1.247 \mathrm{E}-09\end{array}$

$\mathrm{Ra}-226+\mathrm{D} \quad 1.000 \mathrm{E}+00 \quad 8.234 \mathrm{E}-16 \quad 1.233 \mathrm{E}-14 \quad 3.832 \mathrm{E}-10 \quad 1.002 \mathrm{E}-09$

$\mathrm{Pb}-210+\mathrm{D} \quad 1.000 \mathrm{E}+00 \quad 5.964 \mathrm{E}-19 \quad 1.836 \mathrm{E}-17 \quad 1.347 \mathrm{E}-11 \quad 4.480 \mathrm{E}-11$

$\operatorname{LDSR}(j) \quad 2.547 \mathrm{E}-02 \quad 2.527 \mathrm{E}-02 \quad 1.714 \mathrm{E}-02 \quad 1.463 \mathrm{E}-02$

$\begin{array}{llllll}\mathrm{Pu}-239 & 1.000 \mathrm{E}+00 & 2.782 \mathrm{E}-02 & 2.782 \mathrm{E}-02 & 2.775 \mathrm{E}-02 & 2.772 \mathrm{E}-02\end{array}$

$\begin{array}{lllllll}\mathrm{U}-235+\mathrm{D} & 1.000 \mathrm{E}+00 & 5.975 \mathrm{E}-11 & 1.793 \mathrm{E}-10 & 6.024 \mathrm{E}-09 & 8.403 \mathrm{E}-09\end{array}$

$\begin{array}{lllllll}\mathrm{Pa}-231 & 1.000 \mathrm{E}+00 & 3.752 \mathrm{E}-16 & 2.626 \mathrm{E}-15 & 2.865 \mathrm{E}-12 & 5.580 \mathrm{E}-12\end{array}$

$\mathrm{AC}-227+\mathrm{D} \quad 1.000 \mathrm{E}+00 \quad 1.227 \mathrm{E}-17 \quad 1.828 \mathrm{E}-16 \quad 4.441 \mathrm{E}-12 \quad 1.071 \mathrm{E}-11$

$\operatorname{\sum DSR}(j) \quad 2.782 \mathrm{E}-02 \quad 2.782 \mathrm{E}-02 \quad 2.775 \mathrm{E}-02 \quad 2.772 \mathrm{E}-02$

Pu-240 4.950E-08 1.376E-09 $1.376 E-09 \quad 1.367 E-09 \quad 1.364 E-09$

$\begin{array}{llllll}\mathrm{Pu}-240 \quad 1.000 \mathrm{E}+00 & 2.779 \mathrm{E}-02 & 2.779 \mathrm{E}-02 & 2.762 \mathrm{E}-02 & 2.755 \mathrm{E}-02\end{array}$

$\begin{array}{lllllll}\mathrm{U}-236 & 1.000 \mathrm{E}+00 & 7.739 \mathrm{E}-11 & 2.322 \mathrm{E}-10 & 7.787 \mathrm{E}-09 & 1.085 \mathrm{E}-08\end{array}$

$\begin{array}{llllll}\mathrm{Th}-232 & 1.000 \mathrm{E}+00 & 6.238 \mathrm{E}-21 & 4.367 \mathrm{E}-20 & 4.761 \mathrm{E}-17 & 9.268 \mathrm{E}-17\end{array}$

$\mathrm{Ra}-228+\mathrm{D} \quad 1.000 \mathrm{E}+00 \quad 7.279 \mathrm{E}-21 \quad 1.065 \mathrm{E}-19 \quad 1.370 \mathrm{E}-15 \quad 2.913 \mathrm{E}-15$

$\begin{array}{lllllll}\mathrm{Th}-228+\mathrm{D} & 1.000 \mathrm{E}+00 & 7.965 \mathrm{E}-22 & 2.280 \mathrm{E}-20 & 1.928 \mathrm{E}-15 & 4.261 \mathrm{E}-15\end{array}$

$\begin{array}{llllll}\operatorname{DDSR}(j) & 2.779 \mathrm{E}-02 & 2.779 \mathrm{E}-02 & 2.762 \mathrm{E}-02 & 2.755 \mathrm{E}-02\end{array}$

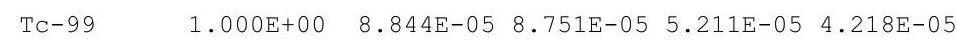

Th-228+D 1.000E+00 1.360E+00 9.469E-01 $1.845 \mathrm{E}-08 \quad 1.315 \mathrm{E}-11$

$\begin{array}{llllll}\mathrm{Th}-230 & 1.000 \mathrm{E}+00 & 2.351 \mathrm{E}-02 & 2.351 \mathrm{E}-02 & 2.350 \mathrm{E}-02 & 2.349 \mathrm{E}-02\end{array}$

$\mathrm{Ra}-226+\mathrm{D} \quad 1.000 \mathrm{E}+00 \quad 3.878 \mathrm{E}-04 \quad 1.163 \mathrm{E}-03 \quad 3.871 \mathrm{E}-02 \quad 5.379 \mathrm{E}-02$

$\mathrm{Pb}-210+\mathrm{D} \quad 1.000 \mathrm{E}+00 \quad 4.667 \mathrm{E}-07 \quad 3.238 \mathrm{E}-06 \quad 2.251 \mathrm{E}-03 \quad 3.757 \mathrm{E}-03$

$\operatorname{LDSR}(j) \quad 2.390 \mathrm{E}-02 \quad 2.468 \mathrm{E}-02 \quad 6.446 \mathrm{E}-02 \quad 8.104 \mathrm{E}-02$ 
RESRAD, Version $6.5 \quad \mathrm{~T}^{1 / 2}$ Limit $=180$ days

ummary : C746U Landfill Worker Deterministic Run

File : $\mathrm{X}: \backslash$ FINAL V2\C746U LANDFILL WORKER SG FWD-FINALV2.RAD

Dose/Source Ratios Summed Over All Pathways

Parent and Progeny Principal Radionuclide Contributions Indicated

\begin{tabular}{|c|c|c|c|c|c|c|}
\hline Parent & Product & Thread & $\operatorname{SR}(j, t)$ At & Time in $Y \epsilon$ & ears & $\mathrm{em} / \mathrm{yr}) /(\mathrm{pCi}$ \\
\hline (i) & (j) & Fraction & $0.000 \mathrm{E}+00$ & $1.000 \mathrm{E}+00$ & $5.000 \mathrm{E}+01$ & $7.000 \mathrm{E}+01$ \\
\hline-232 & Th-232 & $1.000 \mathrm{E}+00$ & $2.563 E-02$ & $2.563 E-02$ & $2.563 E-02$ & $2.562 E-02$ \\
\hline$h-232$ & $\mathrm{Ra}-228+\mathrm{D}$ & $1.000 \mathrm{E}+00$ & $5.887 \mathrm{E}-02$ & $1.676 \mathrm{E}-01$ & $1.014 \mathrm{E}+00$ & $1.016 \mathrm{E}+00$ \\
\hline$h-232$ & $\mathrm{Th}-228+\mathrm{D}$ & $1.000 \mathrm{E}+00$ & $1.049 \mathrm{E}-02$ & $6.433 E-02$ & $1.616 \mathrm{E}+00$ & $1.621 \mathrm{E}+00$ \\
\hline$h-232$ & $\sum \operatorname{DSR}(j)$ & & $9.499 \mathrm{E}-02$ & $2.576 \mathrm{E}-01$ & $2.655 E+00$ & $2.662 E+00$ \\
\hline$J-234$ & $\mathrm{U}-234$ & $1.000 \mathrm{E}+00$ & $5.467 \mathrm{E}-03$ & $5.466 \mathrm{E}-03$ & $5.458 E-03$ & $5.455 \mathrm{E}-03$ \\
\hline-234 & $T h-230$ & $1.000 \mathrm{E}+00$ & $1.058 \mathrm{E}-07$ & $3.175 E-07$ & $1.068 \mathrm{E}-05$ & $1.490 \mathrm{E}-05$ \\
\hline-234 & $\mathrm{Ra}-226+\mathrm{D}$ & $1.000 \mathrm{E}+00$ & $1.164 \mathrm{E}-09$ & $8.144 E-09$ & $8.830 \mathrm{E}-06$ & $1.715 E-05$ \\
\hline$J-234$ & $\mathrm{~Pb}-210+\mathrm{D}$ & $1.000 \mathrm{E}+00$ & 1. $052 \mathrm{E}-12$ & $1.567 \mathrm{E}-11$ & $3.816 \mathrm{E}-07$ & $9.196 \mathrm{E}-07$ \\
\hline-234 & $\sum \operatorname{DSR}(j)$ & & $5.467 \mathrm{E}-03$ & $5.467 \mathrm{E}-03$ & $5.478 E-03$ & $5.488 E-03$ \\
\hline$-235+D$ & $\mathrm{U}-235+\mathrm{D}$ & $1.000 \mathrm{E}+00$ & $1.213 E-01$ & $1.213 \mathrm{E}-01$ & 1. $212 \mathrm{E}-01$ & $1.211 \mathrm{E}-01$ \\
\hline$-235+D$ & $\mathrm{~Pa}-231$ & $1.000 \mathrm{E}+00$ & $1.143 \mathrm{E}-06$ & $3.429 \mathrm{E}-06$ & $1.152 \mathrm{E}-04$ & $1.608 \mathrm{E}-04$ \\
\hline$J-235+D$ & $A C-227+D$ & $1.000 \mathrm{E}+00$ & $4.976 \mathrm{E}-08$ & $3.452 \mathrm{E}-07$ & $2.396 \mathrm{E}-04$ & $4.001 E-04$ \\
\hline$-235+D$ & $\sum \operatorname{DSR}(j)$ & & $1.213 E-01$ & $1.213 E-01$ & $1.215 E-01$ & $1.217 \mathrm{E}-01$ \\
\hline$J-238$ & $\mathrm{U}-238$ & $5.400 \mathrm{E}-05$ & $2.701 \mathrm{E}-07$ & $2.701 \mathrm{E}-07$ & $2.698 \mathrm{E}-07$ & $2.696 \mathrm{E}-07$ \\
\hline$-238+D$ & $\mathrm{U}-238+\mathrm{D}$ & $9.999 \mathrm{E}-01$ & $3.129 E-02$ & $3.129 \mathrm{E}-02$ & $3.125 \mathrm{E}-02$ & $3.123 E-02$ \\
\hline$-238+D$ & $\mathrm{U}-234$ & $9.999 \mathrm{E}-01$ & $7.748 \mathrm{E}-09$ & $2.324 \mathrm{E}-08$ & $7.815 \mathrm{E}-07$ & $1.090 \mathrm{E}-06$ \\
\hline$-238+D$ & $T h-230$ & $9.999 \mathrm{E}-01$ & $9.999 \mathrm{E}-14$ & $6.999 \mathrm{E}-13$ & 7. $642 \mathrm{E}-10$ & $1.489 \mathrm{E}-09$ \\
\hline$-238+D$ & $\mathrm{Ra}-226+\mathrm{D}$ & $9.999 \mathrm{E}-01$ & $8.247 E-16$ & $1.237 \mathrm{E}-14$ & $4.221 \mathrm{E}-10$ & $1.145 \mathrm{E}-09$ \\
\hline$-238+D$ & $\mathrm{~Pb}-210+\mathrm{D}$ & $9.999 \mathrm{E}-01$ & $5.972 \mathrm{E}-19$ & $1.841 \mathrm{E}-17$ & $1.461 \mathrm{E}-11$ & $5.020 \mathrm{E}-11$ \\
\hline$-238+D$ & $\sum \operatorname{DSR}(j)$ & & $3.129 \mathrm{E}-02$ & $3.129 \mathrm{E}-02$ & $3.125 \mathrm{E}-02$ & $3.123 E-02$ \\
\hline
\end{tabular}

The DSR includes contributions from associated (half-life $\leq 180$ days) daughters. 
RESRAD, Version $6.5 \quad \mathrm{~T}^{1 / 2}$ Limit $=180$ days

Summary : C746U Landfill Worker Deterministic Run

File : $\mathrm{X}: \backslash$ FINAL V2 $\backslash \mathrm{C} 746 \mathrm{U}$ LANDFILL WORKER SG FWD-FINALV2.RAD

Single Radionuclide Soil Guidelines G(i,t) in pCi/g

Basic Radiation Dose Limit $=1.000 \mathrm{E}+02 \mathrm{mrem} / \mathrm{yr}$

Nuclide

\begin{tabular}{cccccc} 
(i) & $\mathrm{t}=$ & $0.000 \mathrm{E}+00$ & $1.000 \mathrm{E}+00$ & $5.000 \mathrm{E}+01$ & $7.000 \mathrm{E}+01$ \\
\cline { 1 - 1 } $\mathrm{Am}-241$ & & $3.509 \mathrm{E}+03$ & $3.514 \mathrm{E}+03$ & $3.802 \mathrm{E}+03$ & $3.927 \mathrm{E}+03$ \\
$\mathrm{Cs}-137$ & & $1.900 \mathrm{E}+02$ & $1.945 \mathrm{E}+02$ & $6.045 \mathrm{E}+02$ & $9.603 \mathrm{E}+02$ \\
$\mathrm{~Np}-237$ & $5.507 \mathrm{E}+02$ & $5.507 \mathrm{E}+02$ & $5.550 \mathrm{E}+02$ & $5.568 \mathrm{E}+02$ \\
$\mathrm{Pu}-238$ & $3.926 \mathrm{E}+03$ & $3.957 \mathrm{E}+03$ & $5.833 \mathrm{E}+03$ & $6.834 \mathrm{E}+03$ \\
$\mathrm{Pu}-239$ & $3.595 \mathrm{E}+03$ & $3.595 \mathrm{E}+03$ & $3.603 \mathrm{E}+03$ & $3.607 \mathrm{E}+03$ \\
$\mathrm{Pu}-240$ & $3.598 \mathrm{E}+03$ & $3.598 \mathrm{E}+03$ & $3.621 \mathrm{E}+03$ & $3.630 \mathrm{E}+03$ \\
$\mathrm{TC}-99$ & & $1.131 \mathrm{E}+06$ & $1.143 \mathrm{E}+06$ & $1.919 \mathrm{E}+06$ & $2.371 \mathrm{E}+06$ \\
$\mathrm{Th}-228$ & $7.351 \mathrm{E}+01$ & $1.056 \mathrm{E}+02$ & $5.420 \mathrm{E}+09$ & $7.604 \mathrm{E}+12$ \\
$\mathrm{Th}-230$ & $4.184 \mathrm{E}+03$ & $4.052 \mathrm{E}+03$ & $1.551 \mathrm{E}+03$ & $1.234 \mathrm{E}+03$ \\
$\mathrm{Th}-232$ & $1.053 \mathrm{E}+03$ & $3.882 \mathrm{E}+02$ & $3.766 \mathrm{E}+01$ & $3.757 \mathrm{E}+01$ \\
$\mathrm{U}-234$ & $1.829 \mathrm{E}+04$ & $1.829 \mathrm{E}+04$ & $1.825 \mathrm{E}+04$ & $1.822 \mathrm{E}+04$ \\
$\mathrm{U}-235$ & $8.241 \mathrm{E}+02$ & $8.241 \mathrm{E}+02$ & $8.228 \mathrm{E}+02$ & $8.218 \mathrm{E}+02$ \\
$\mathrm{U}-238$ & $3.196 \mathrm{E}+03$ & $3.196 \mathrm{E}+03$ & $3.200 \mathrm{E}+03$ & $3.202 \mathrm{E}+03$ \\
\hline \hline
\end{tabular}

Summed Dose/Source Ratios DSR (i,t) in (mrem/yr)/(pCi/g) and Single Radionuclide Soil Guidelines G(i,t) in pCi/g at tmin = time of minimum single radionuclide soil guideline and at $\operatorname{tmax}=$ time of maximum total dose $=0.000 \mathrm{E}+00$ years

\begin{tabular}{|c|c|c|c|c|c|c|}
\hline $\begin{array}{l}\text { uclide } \\
\text { (i) }\end{array}$ & $\begin{array}{l}\text { Initial } \\
(\mathrm{pCi} / \mathrm{g})\end{array}$ & $\begin{array}{c}\text { tmin } \\
\text { (years) }\end{array}$ & $\operatorname{DSR}(i, \operatorname{tmin})$ & $\begin{array}{c}\mathrm{G}(\mathrm{i}, \mathrm{tmin}) \\
(\mathrm{pCi} / \mathrm{g})\end{array}$ & $\operatorname{DSR}(i, t \max )$ & $\begin{array}{c}G(i, t \max ) \\
(\mathrm{pCi} / \mathrm{g})\end{array}$ \\
\hline$n-241$ & $3.500 \mathrm{E}+03$ & $0.000 \mathrm{E}+00$ & $2.850 \mathrm{E}-02$ & $3.509 \mathrm{E}+03$ & $2.850 \mathrm{E}-02$ & $3.509 E+03$ \\
\hline-137 & $1.900 \mathrm{E}+02$ & $0.000 \mathrm{E}+00$ & $5.262 \mathrm{E}-01$ & $1.900 \mathrm{E}+02$ & $5.262 \mathrm{E}-01$ & $1.900 \mathrm{E}+02$ \\
\hline-237 & $5.500 \mathrm{E}+02$ & $0.000 \mathrm{E}+00$ & $1.816 \mathrm{E}-01$ & $5.507 \mathrm{E}+02$ & $1.816 E-01$ & $5.507 \mathrm{E}+02$ \\
\hline-238 & $3.900 \mathrm{E}+03$ & $0.000 \mathrm{E}+00$ & $2.547 \mathrm{E}-02$ & $3.926 \mathrm{E}+03$ & $2.547 E-02$ & $3.926 \mathrm{E}+03$ \\
\hline-239 & $3.600 \mathrm{E}+03$ & $0.000 \mathrm{E}+00$ & $2.782 \mathrm{E}-02$ & $3.595 E+03$ & $2.782 \mathrm{E}-02$ & $3.595 \mathrm{E}+03$ \\
\hline$x-240$ & $3.600 \mathrm{E}+03$ & $0.000 \mathrm{E}+00$ & $2.779 \mathrm{E}-02$ & $3.598 \mathrm{E}+03$ & $2.779 \mathrm{E}-02$ & $3.598 \mathrm{E}+03$ \\
\hline-99 & $2.800 \mathrm{E}+01$ & $0.000 \mathrm{E}+00$ & $8.844 \mathrm{E}-05$ & $1.131 \mathrm{E}+06$ & $8.844 E-05$ & $1.131 \mathrm{E}+06$ \\
\hline-228 & $7.400 \mathrm{E}+01$ & $0.000 \mathrm{E}+00$ & $1.360 \mathrm{E}+00$ & 7. $351 E+01$ & $1.360 \mathrm{E}+00$ & $7.351 \mathrm{E}+01$ \\
\hline-230 & $1.200 \mathrm{E}+03$ & $7.000 \mathrm{E}+01$ & $8.104 \mathrm{E}-02$ & $1.234 \mathrm{E}+03$ & $2.390 \mathrm{E}-02$ & $4.184 \mathrm{E}+03$ \\
\hline-232 & $3.800 \mathrm{E}+01$ & $7.000 E+01$ & $2.662 \mathrm{E}+00$ & $3.757 \mathrm{E}+01$ & $9.499 \mathrm{E}-02$ & $1.053 E+03$ \\
\hline-234 & $1.800 \mathrm{E}+04$ & $7.000 \mathrm{E}+01$ & $5.488 \mathrm{E}-03$ & $1.822 \mathrm{E}+04$ & $5.467 \mathrm{E}-03$ & $1.829 \mathrm{E}+04$ \\
\hline 235 & $8.200 \mathrm{E}+02$ & $7.000 \mathrm{E}+01$ & $1.217 \mathrm{E}-01$ & $8.218 \mathrm{E}+02$ & 1. $213 E-01$ & $8.241 \mathrm{E}+02$ \\
\hline 238 & $3.200 \mathrm{E}+03$ & $0.000 \mathrm{E}+00$ & $3.129 \mathrm{E}-02$ & $3.196 \mathrm{E}+03$ & $3.129 \mathrm{E}-02$ & $3.196 \mathrm{E}+03$ \\
\hline
\end{tabular}


RESRAD, Version $6.5 \quad \mathrm{~T}^{1 / 2}$ Limit $=180$ days

Summary : C746U Landfill Worker Deterministic Run

File : $\mathrm{X}: \backslash$ FINAL V2 $\backslash \mathrm{C} 746 \mathrm{U}$ LANDFILL WORKER SG FWD-FINALV2.RAD

Individual Nuclide Dose Summed Over All Pathways

Parent Nuclide and Branch Fraction Indicated

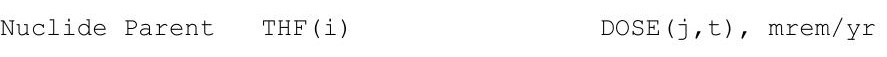




\section{RESRAD, Version $6.5 \quad T^{1 / 2}$ Limit $=180$ days}

Summary : C746U Landfill Worker Deterministic Run

File : $\mathrm{X}: \backslash$ FINAL V2 $\backslash \mathrm{C} 746 \mathrm{U}$ LANDFILL WORKER SG FWD-FINALV2.RAD

Individual Nuclide Dose Summed Over All Pathways

Parent Nuclide and Branch Fraction Indicated

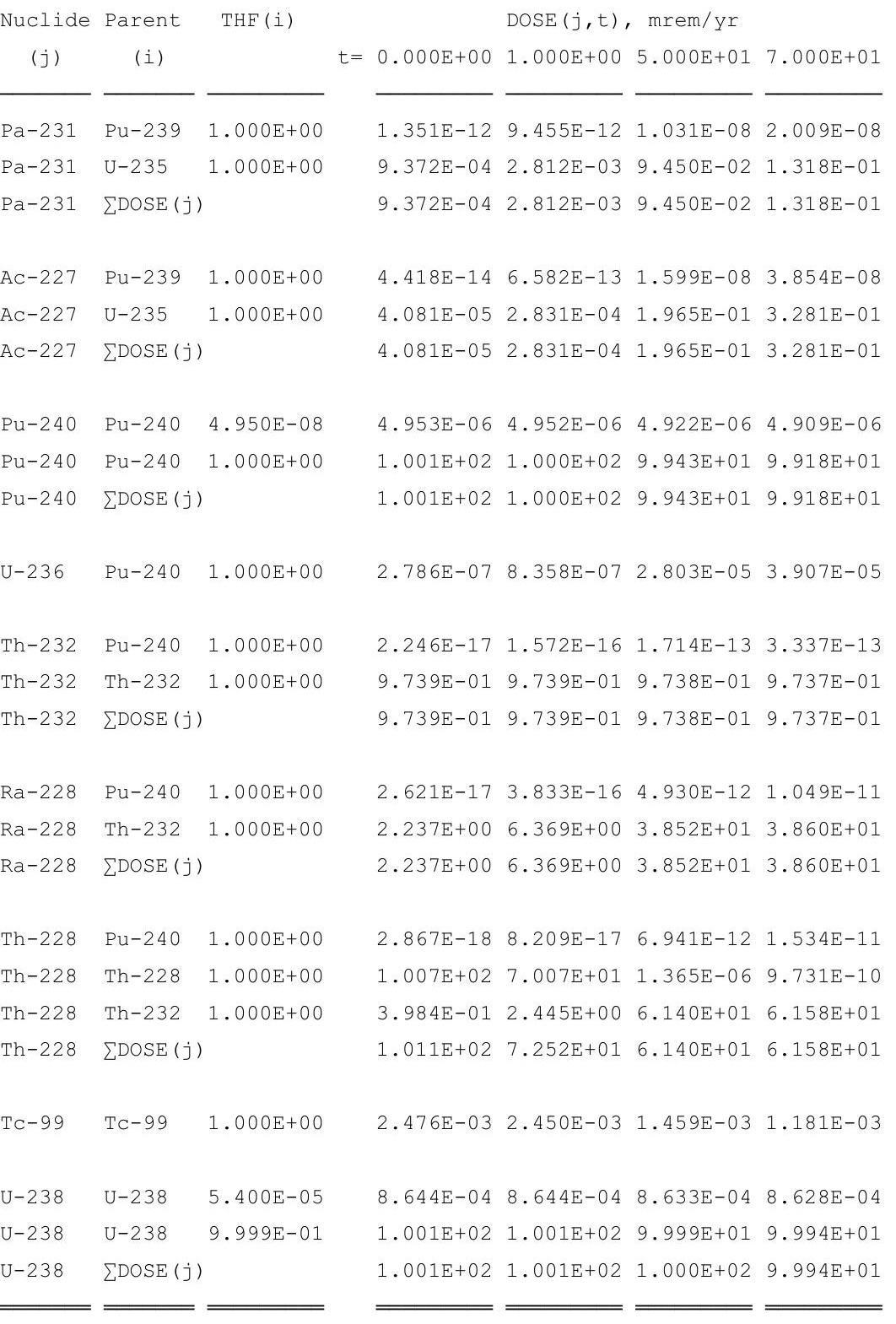

THF(i) is the thread fraction of the parent nuclide. 
RESRAD, Version $6.5 \quad \mathrm{~T}^{1 / 2}$ Limit $=180$ days

Summary : C746U Landfill Worker Deterministic Run
File : X: $\backslash$ FINAL V2 $\backslash C 746 U$ LANDFILL WORKER SG FWD-FINALV2.RAD

Individual Nuclide Soil Concentration

Parent Nuclide and Branch Fraction Indicated

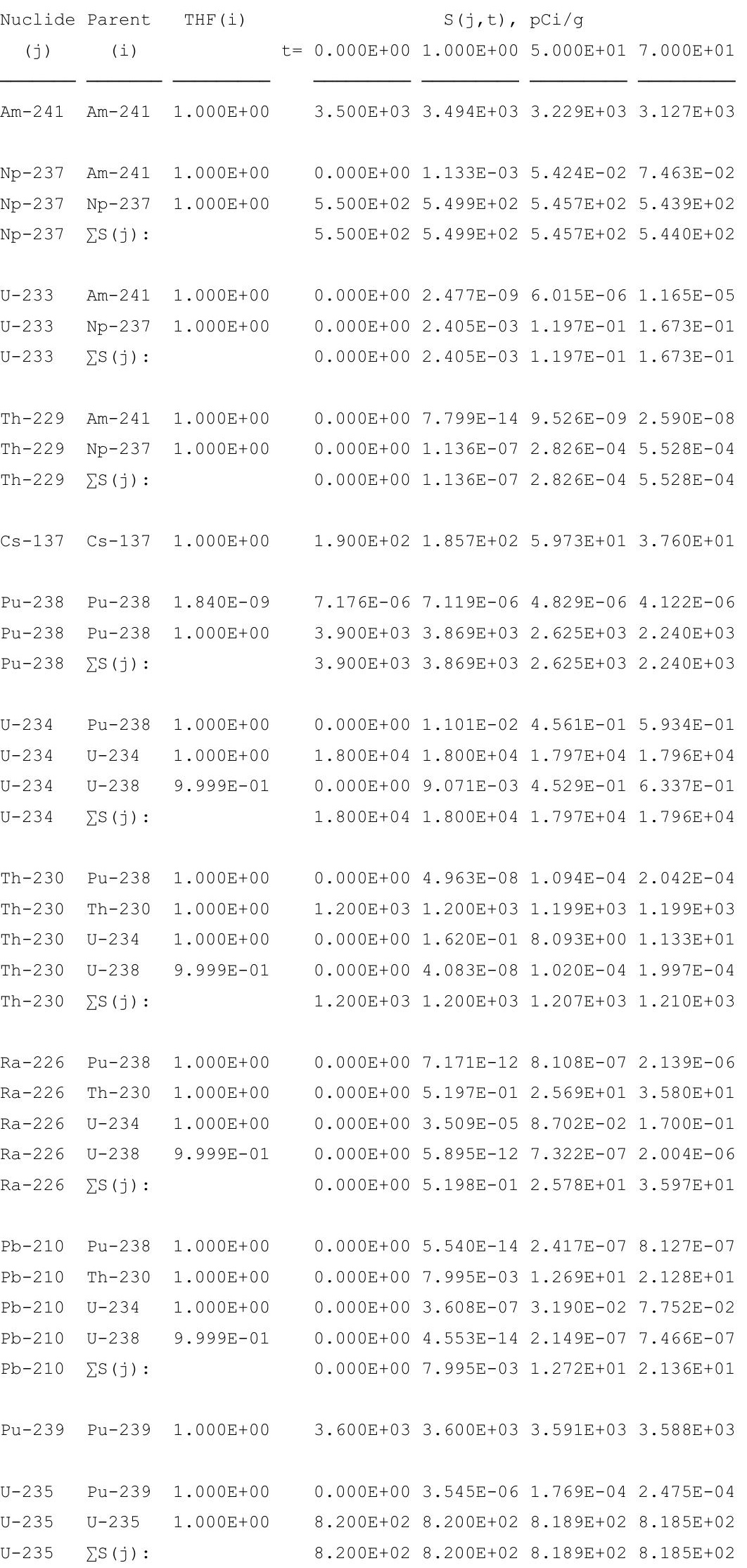




\section{RESRAD, Version $6.5 \quad T^{1 / 2}$ Limit $=180$ days}

Summary : C746U Landfill Worker Deterministic Run

File : $\mathrm{X}: \backslash F I N A L$ V2 $\backslash C 746 U$ LANDFILL WORKER SG FWD-FINALV2.RAD

Individual Nuclide Soil Concentration

Parent Nuclide and Branch Fraction Indicated

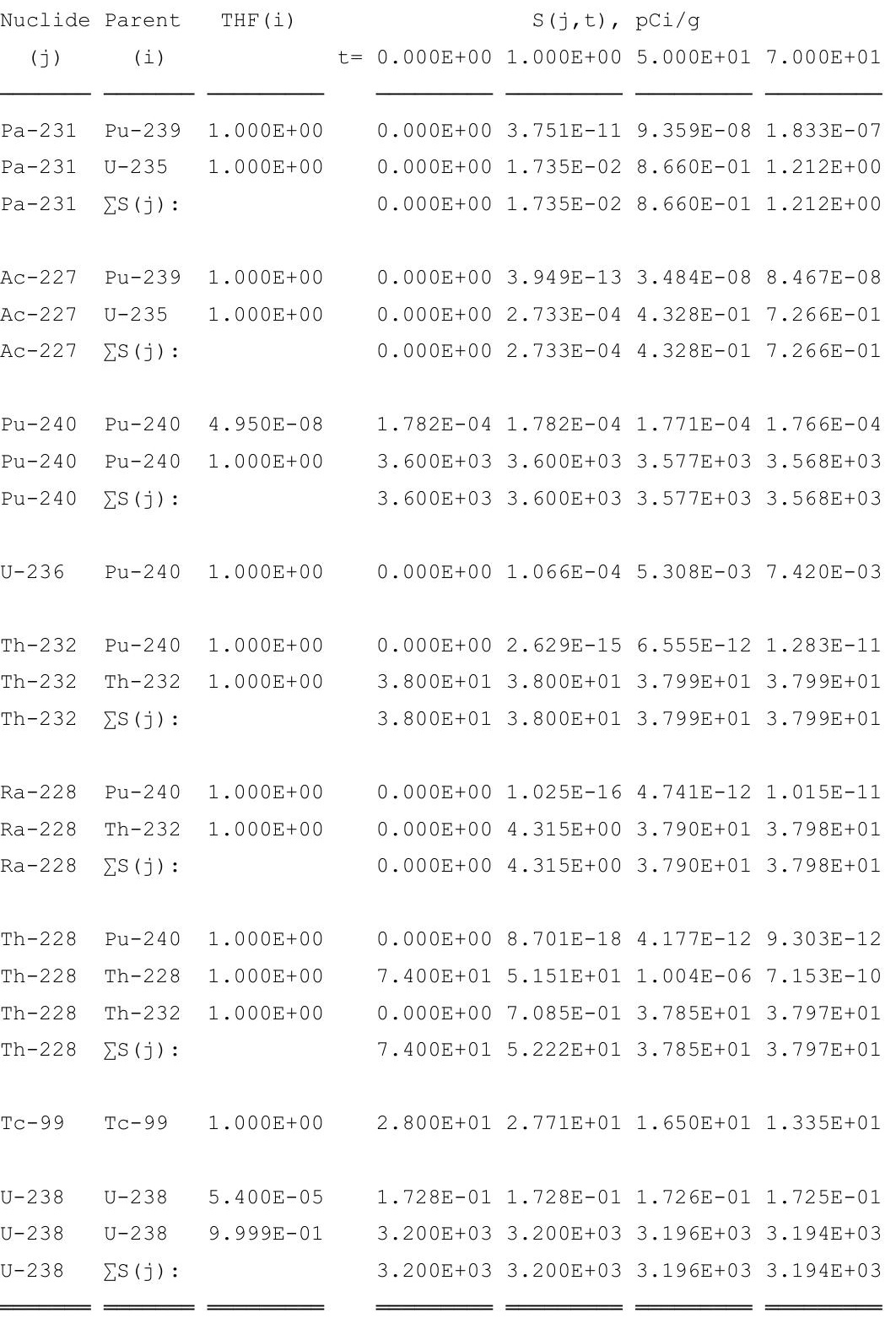

THF(i) is the thread fraction of the parent nuclide.

RESCALC.EXE execution time $=1.25$ seconds 
DOSE MODELING EVALUATIONS AND TECHNICAL SUPPORT DOCUMENT FOR THE AUTHORIZED LIMITS REQUEST FOR THE C-746-U LANDFILL AT THE PADUCAH GASEOUS DIFFUSION PLANT

Appendix D: RESRAD-OFFSITE Summary Reports 


\section{Table of Contents}

Offsite Resident Farmer: Unit Concentration for Targeted Radionuclides ............. D-3

Offsite Resident Farmer: Peak Dose from Cumulative Radionuclide Inventory...D-69 


\section{Offsite Resident Farmer}

The following summary report includes the single radionuclide soil guidelines based on a unit concentration for targeted radionuclides. 
THIS PAGE INTENTIONALLY LEFT BLANK 
RESRAD-OFFSITE, Version $2.5 \quad \mathrm{~T}^{1 / 2}$ Limit $=180$ days

Parent Dose Report

Title : Offsite Resident Farmer Deterministic Run

File : RF FINAL v2.ROF

Table of Contents

Part I: Mixture Sums and Single Radionuclide Guidelines

Dose Conversion Factor (and Related) Parameter Summary ... 2

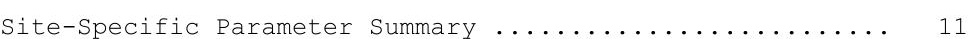

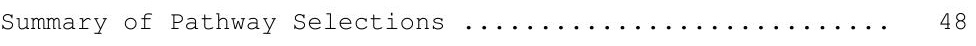

Contaminated Zone and Total Dose Summary ............ 49

Total Dose Components

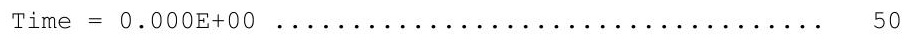

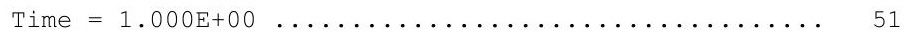

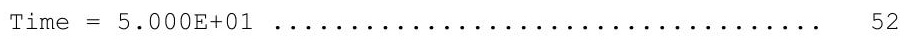

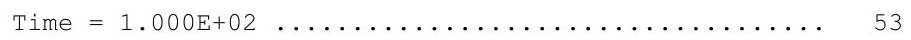

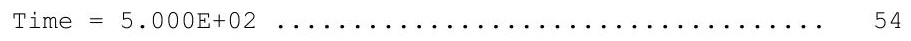

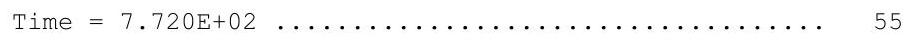

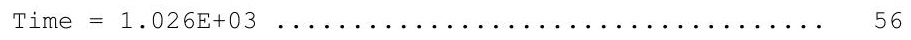

Dose/Source Ratios Summed Over All Pathways ............ 57

Single Radionuclide Soil Guidelines ............... 59

Dose Per Nuclide Summed Over All Pathways ............ 60

Soil Concentration Per Nuclide $\ldots \ldots \ldots \ldots \ldots \ldots \ldots \ldots \ldots .62$

Run Time Information $\ldots \ldots \ldots \ldots \ldots \ldots \ldots \ldots \ldots \ldots \ldots \ldots \ldots \ldots \ldots \ldots \ldots$

DCN 5090-TR-01-6 D-5 
RESRAD-OFFSITE, Version 2.5

Parent Dose Report

Title : Offsite Resident Farmer Deterministic Run

File : RF FINAL v2.ROF

Dose Conversion Factor (and Related) Parameter Summary

Current Library: ICRP 60

Default Library: ICRP 60

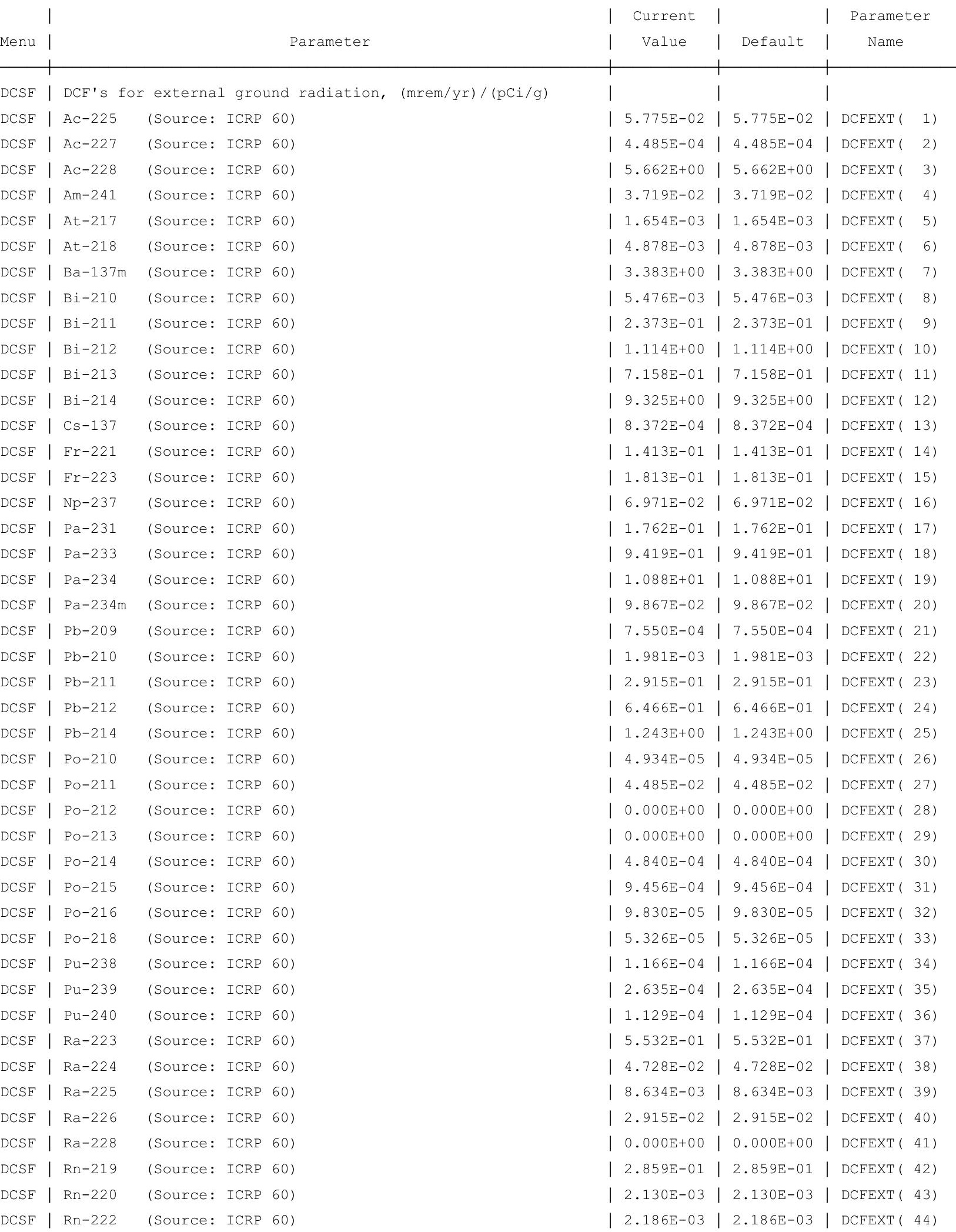


RESRAD-OFFSITE, Version $2.5 \quad \mathrm{~T}^{1 / 2}$ Limit $=180$ days

Parent Dose Report

Title : Offsite Resident Farmer Deterministic Run

File : RF FINAL v2.ROF

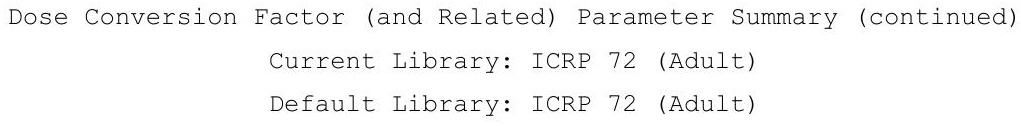

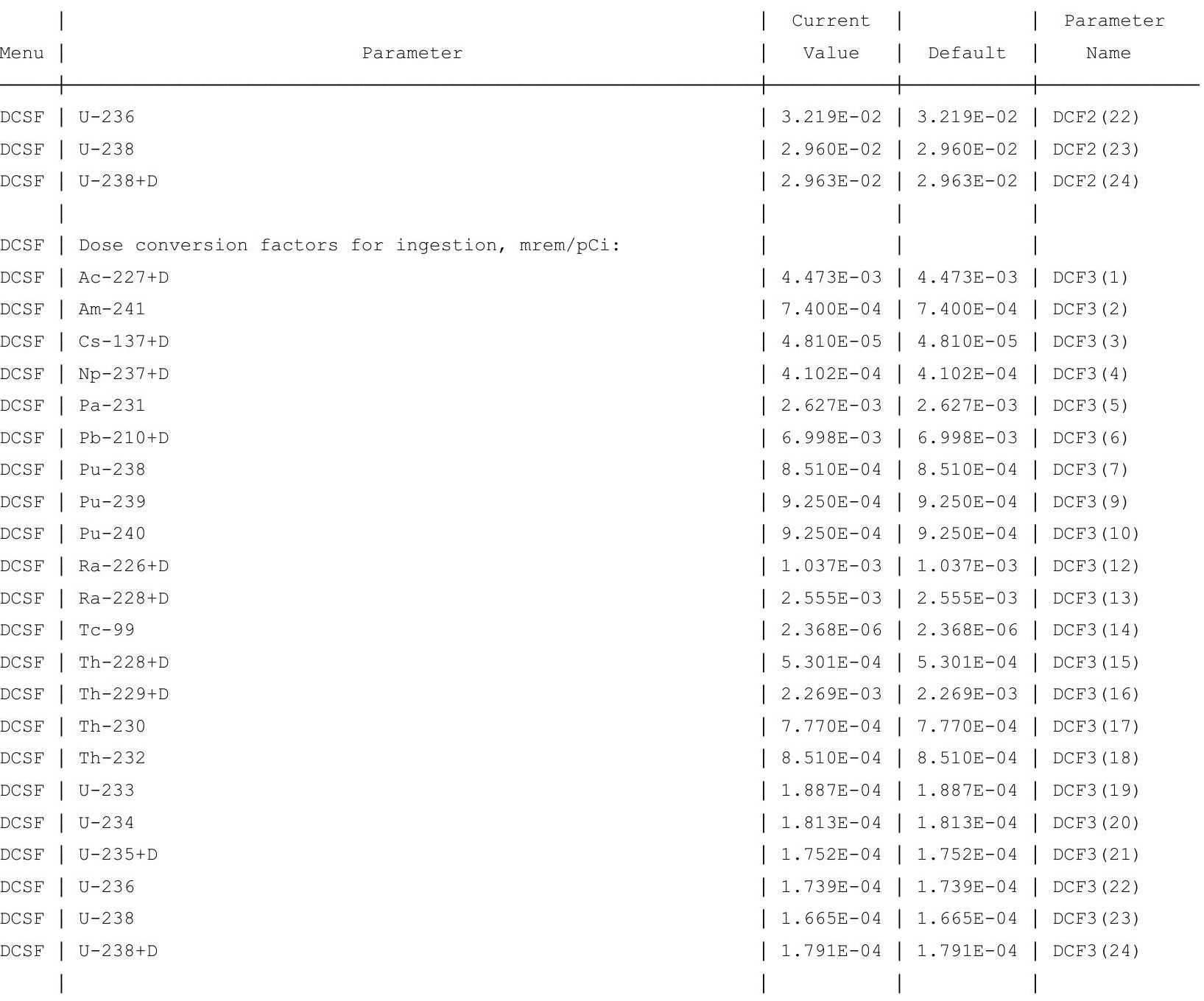


RESRAD-OFFSITE, Version 2.5

arent Dose Report

Title : Offsite Resident Farmer Deterministic Run

File : RF FINAL v2.ROF

Dose Conversion Factor (and Related) Parameter Summary (continued) Current Library: RESRAD Default Transfer factors Default Library: RESRAD Default Transfer factors

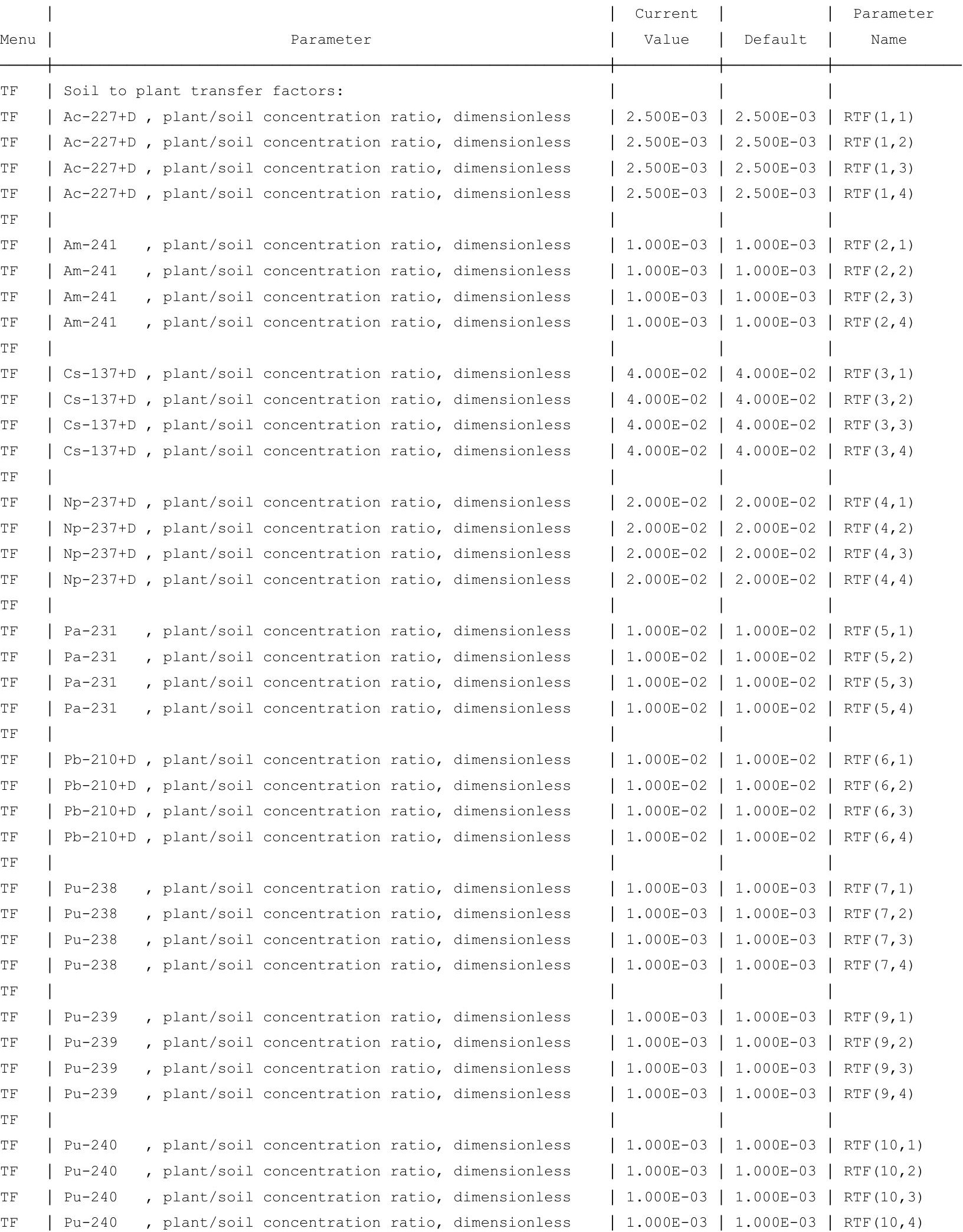


RESRAD-OFFSITE, Version 2.5

Parent Dose Report

Title : Offsite Resident Farmer Deterministic Run

File : RF FINAL v2.ROF

Dose Conversion Factor (and Related) Parameter Summary (continued)

Current Library: RESRAD Default Transfer factors

Default Library: RESRAD Default Transfer factors

Menu
M


RESRAD-OFFSITE, Version $2.5 \quad \mathrm{~T}^{1 / 2}$ Limit $=180$ days

Parent Dose Report

Title : Offsite Resident Farmer Deterministic Run

File : RF FINAL v2.ROF

Site-Specific Parameter Summary

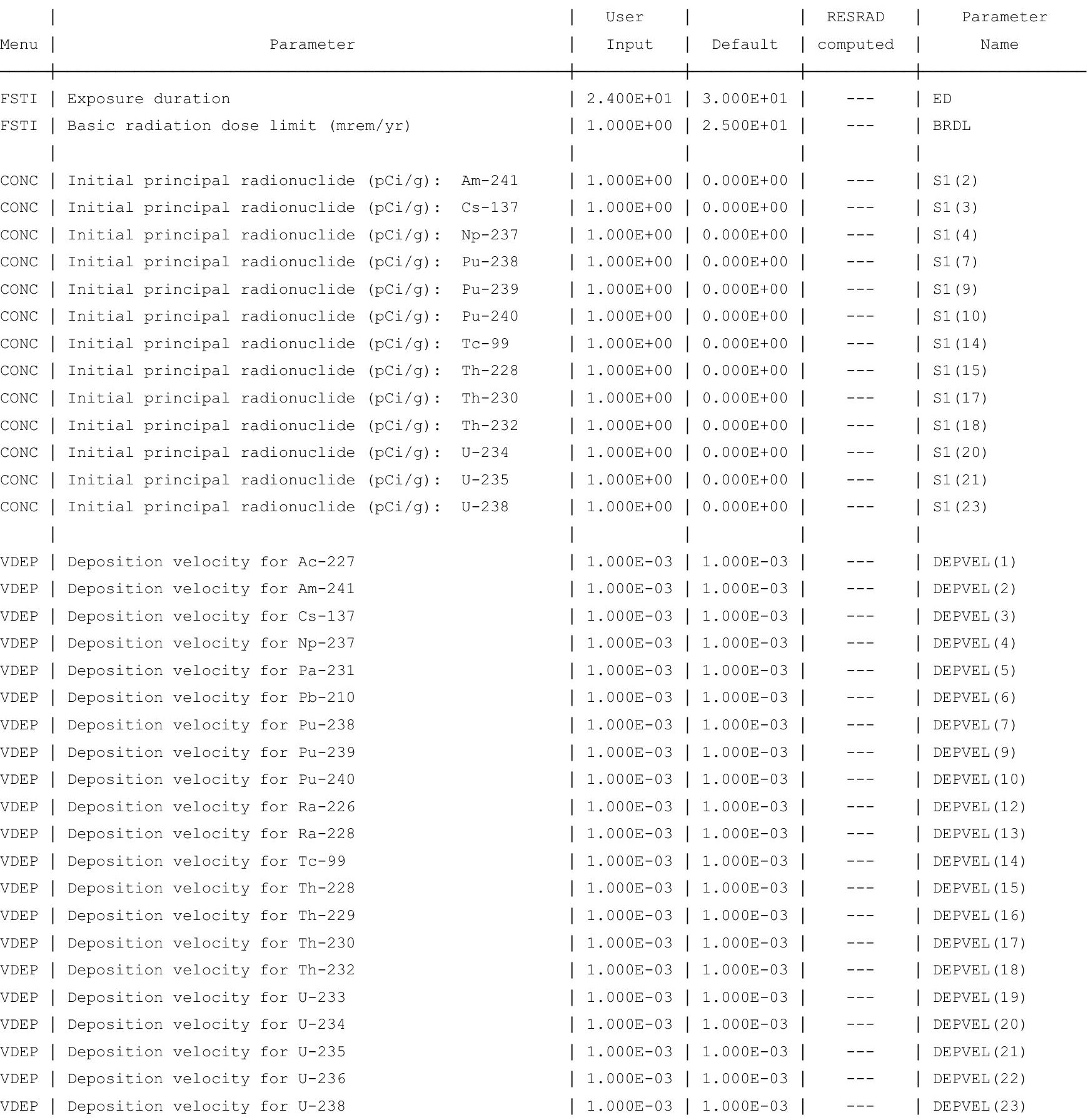


RESRAD-OFFSITE, Version $2.5 \quad \mathrm{~T}^{1 / 2}$ Limit $=180$ days

Parent Dose Report

Title : Offsite Resident Farmer Deterministic Run

File : RF FINAL v2.ROF

Site-Specific Parameter Summary (continued)

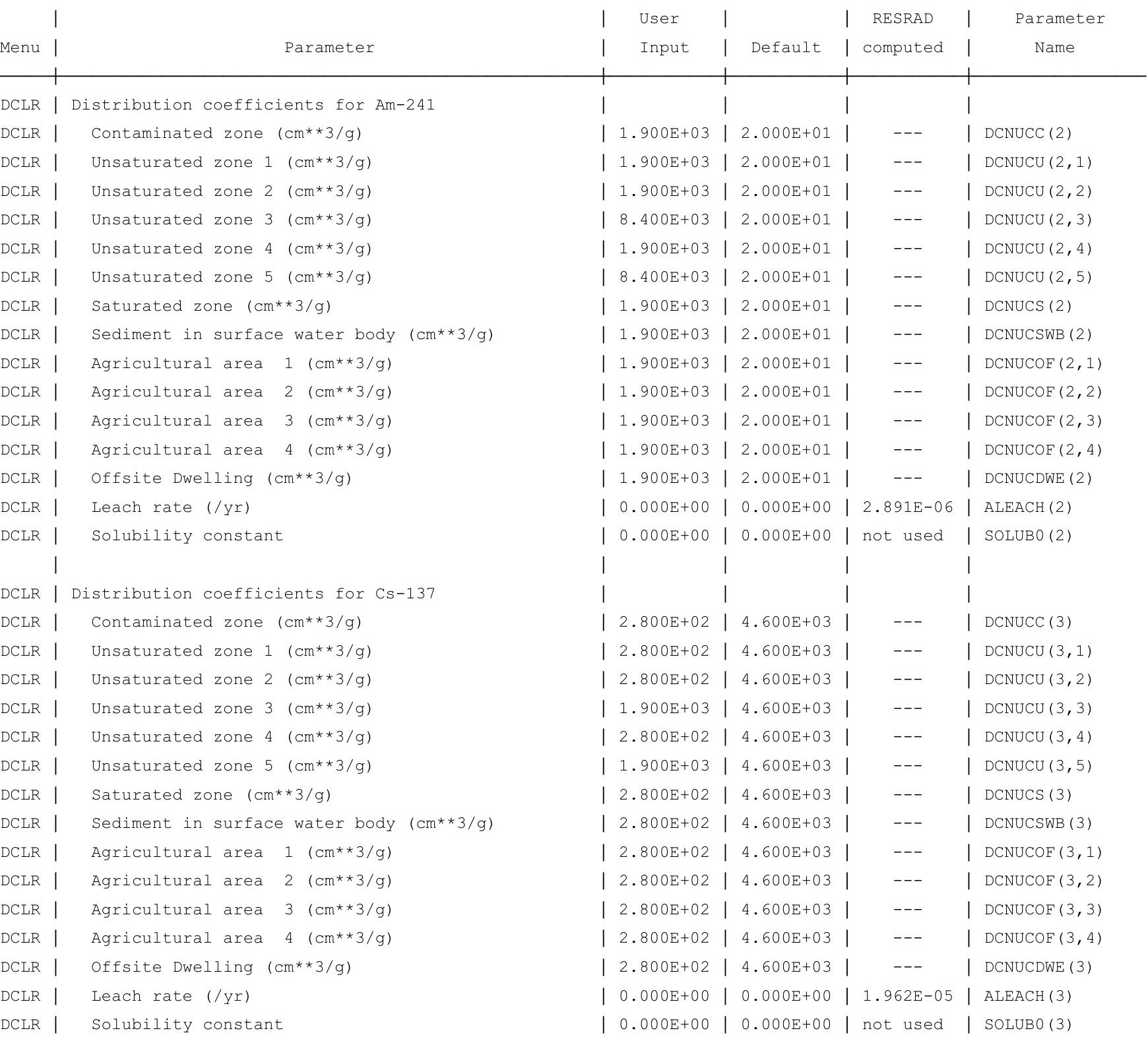


RESRAD-OFFSITE, Version $2.5, \quad \mathrm{~T}^{1 / 2}$ Limit $=180$ days

Parent Dose Report

Title : Offsite Resident Farmer Deterministic Run

File : RF FINAL v2.ROF

Site-Specific Parameter Summary (continued)

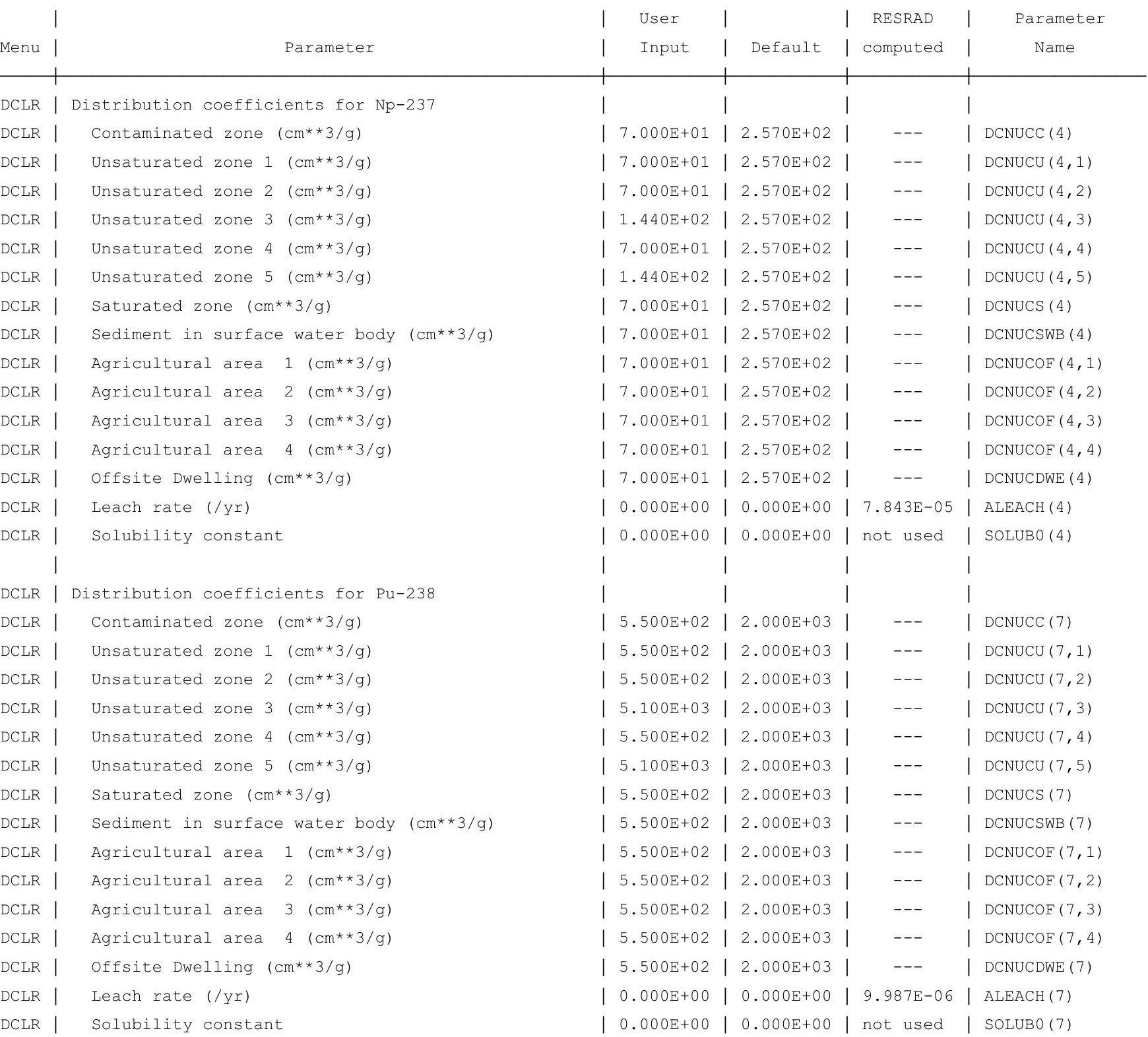


RESRAD-OFFSITE, Version $2.5, \quad \mathrm{~T}^{1 / 2}$ Limit $=180$ days

Parent Dose Report

Title : Offsite Resident Farmer Deterministic Run

File : RF FINAL v2.ROF

Site-Specific Parameter Summary (continued)

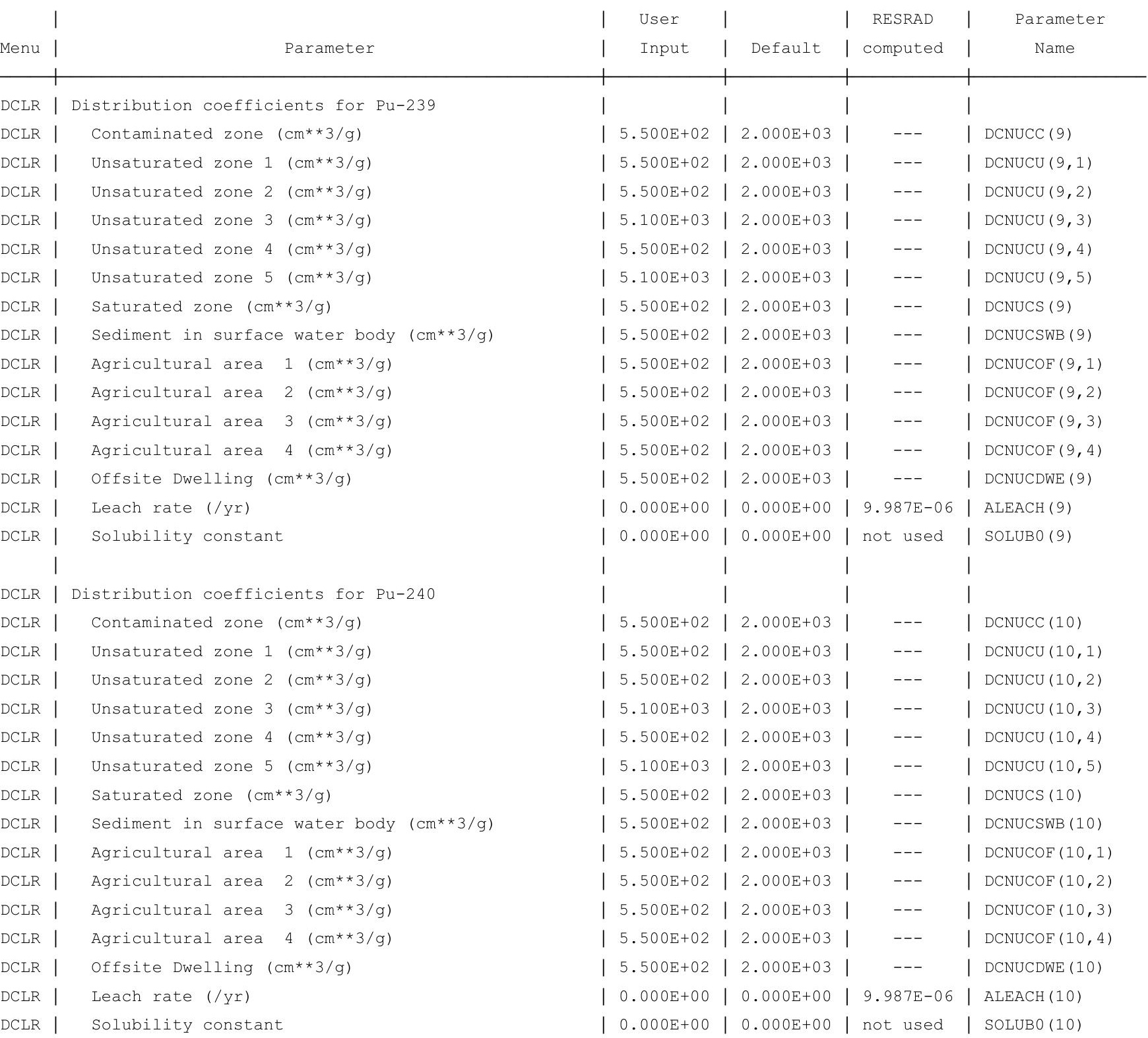


RESRAD-OFFSITE, Version $2.5, \quad \mathrm{~T}^{1 / 2}$ Limit $=180$ days

Parent Dose Report

Title : Offsite Resident Farmer Deterministic Run

File : RF FINAL v2.ROF

Site-Specific Parameter Summary (continued)

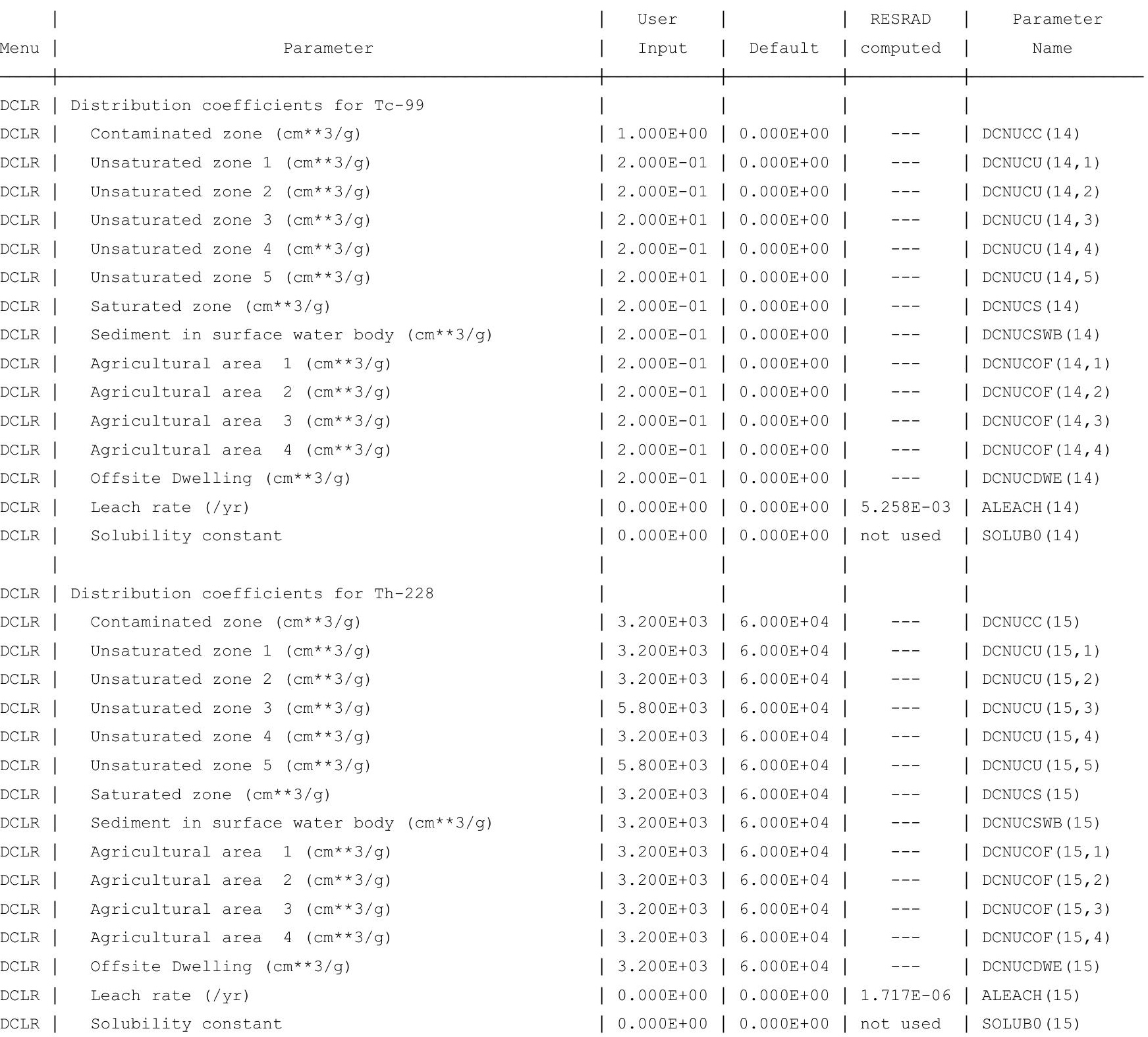


RESRAD-OFFSITE, Version $2.5 \quad \mathrm{~T}^{1 / 2}$ Limit $=180$ days

Parent Dose Report

Title : Offsite Resident Farmer Deterministic Run

File : RF FINAL v2.ROF

Site-Specific Parameter Summary (continued)

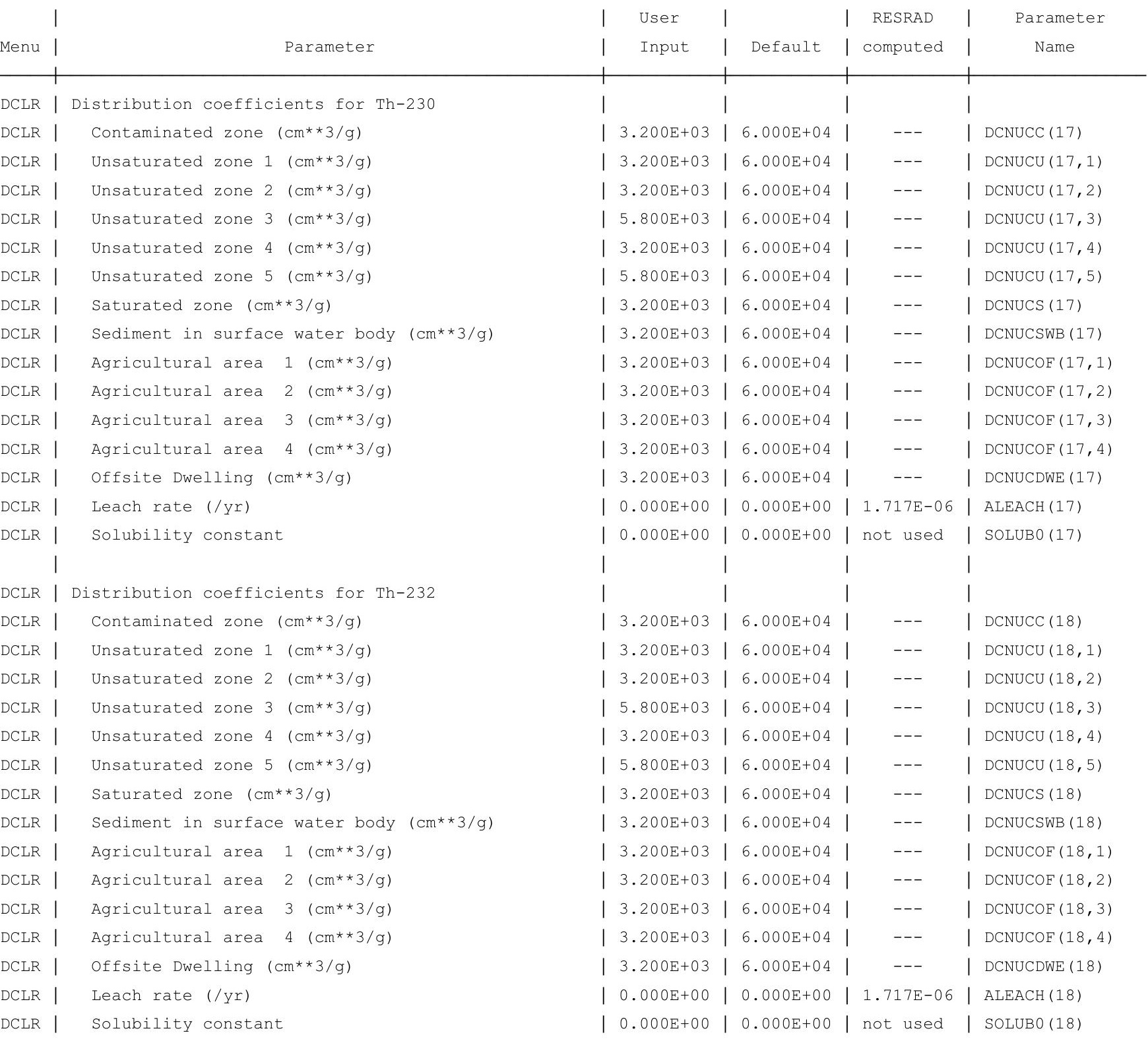


RESRAD-OFFSITE, Version $2.5, \quad \mathrm{~T}^{1 / 2}$ Limit $=180$ days

Parent Dose Report

Title : Offsite Resident Farmer Deterministic Run

File : RF FINAL v2.ROF

Site-Specific Parameter Summary (continued)

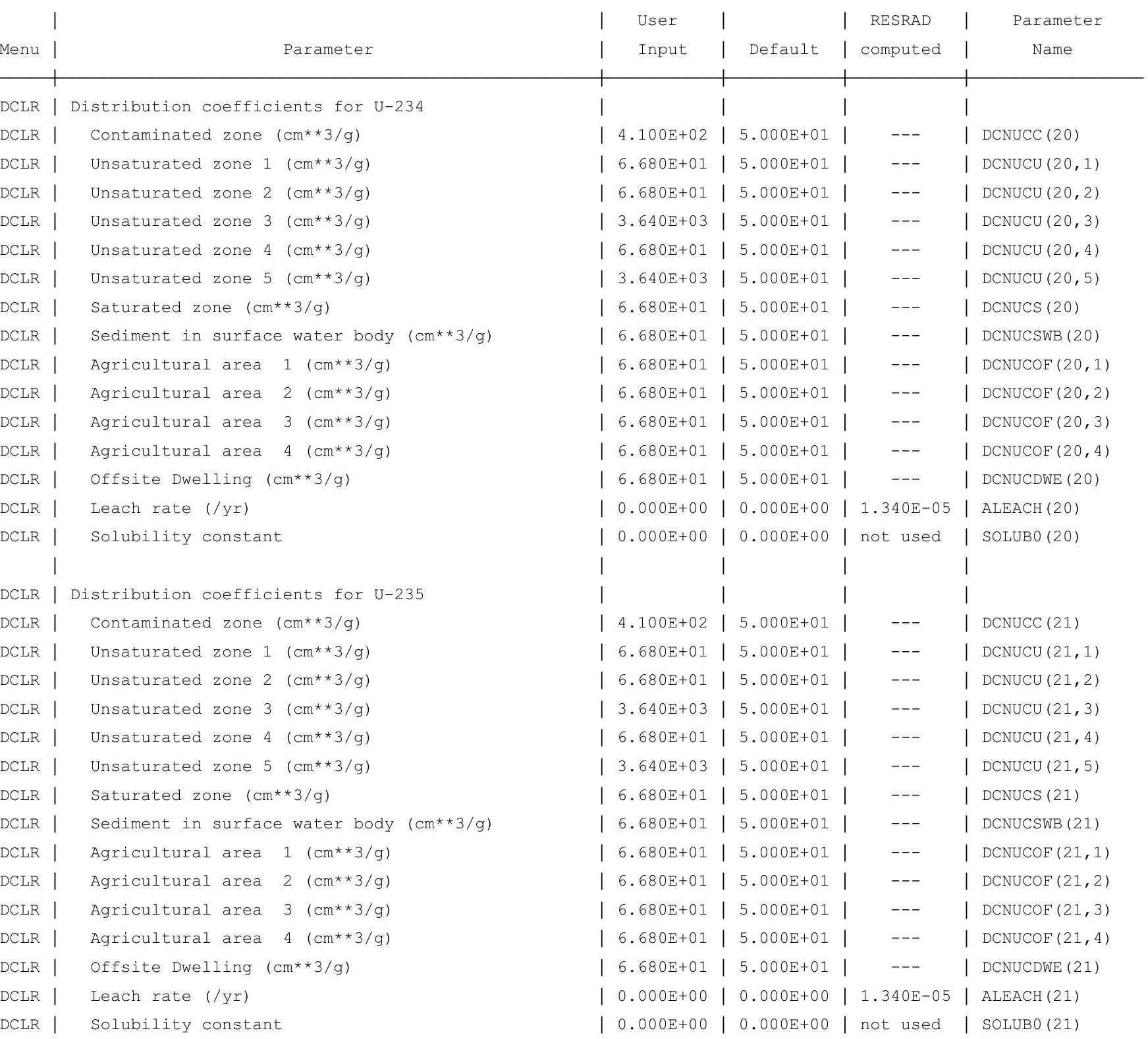


RESRAD-OFFSITE, Version $2.5, \quad \mathrm{~T}^{1 / 2}$ Limit $=180$ days

Parent Dose Report

Title : Offsite Resident Farmer Deterministic Run

File : RF FINAL v2.ROF

Site-Specific Parameter Summary (continued)

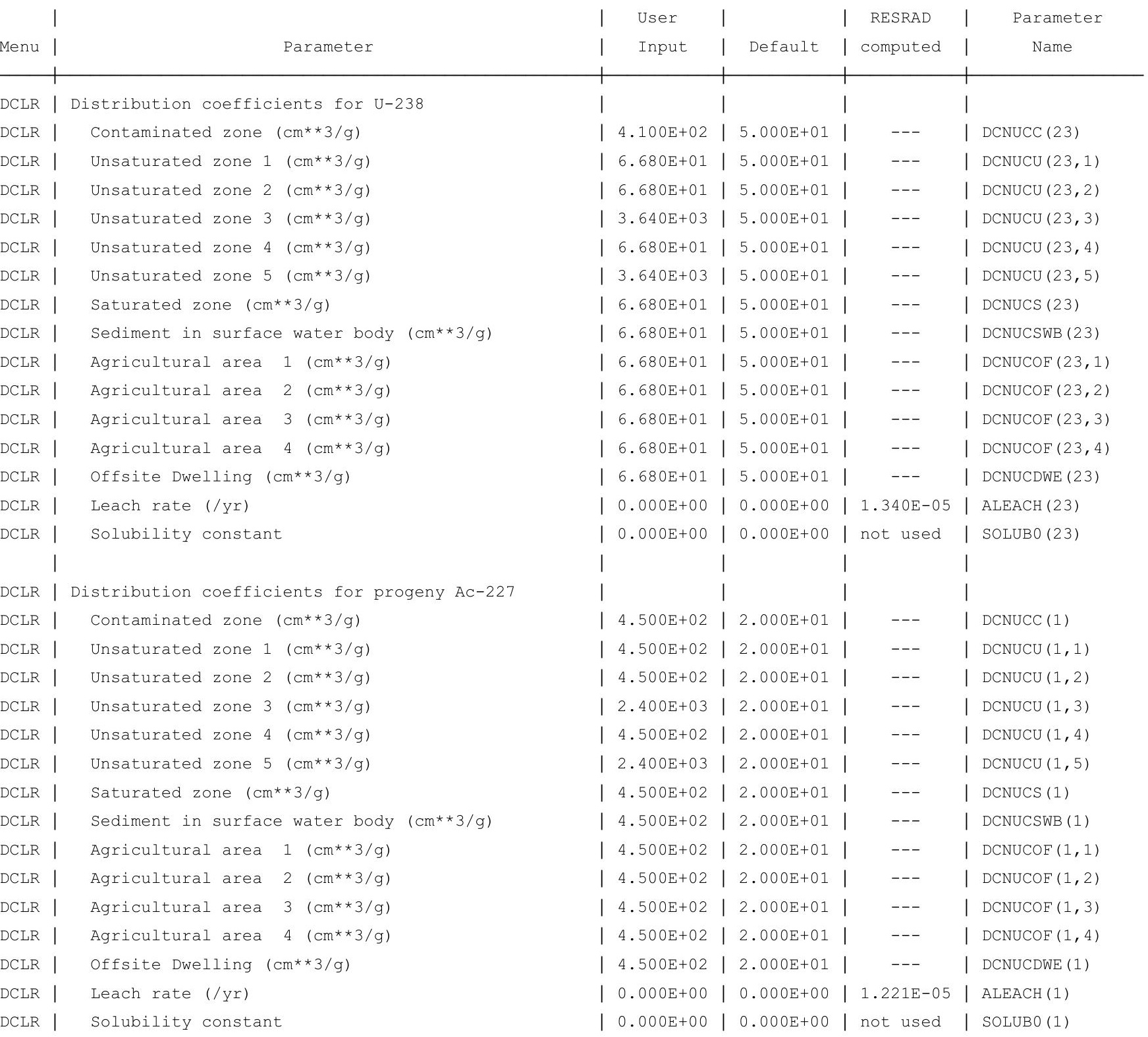


RESRAD-OFFSITE, Version $2.5 \quad \mathrm{~T}^{1 / 2}$ Limit $=180$ days

Parent Dose Report

Title : Offsite Resident Farmer Deterministic Run

File : RF FINAL v2.ROF

Site-Specific Parameter Summary (continued)

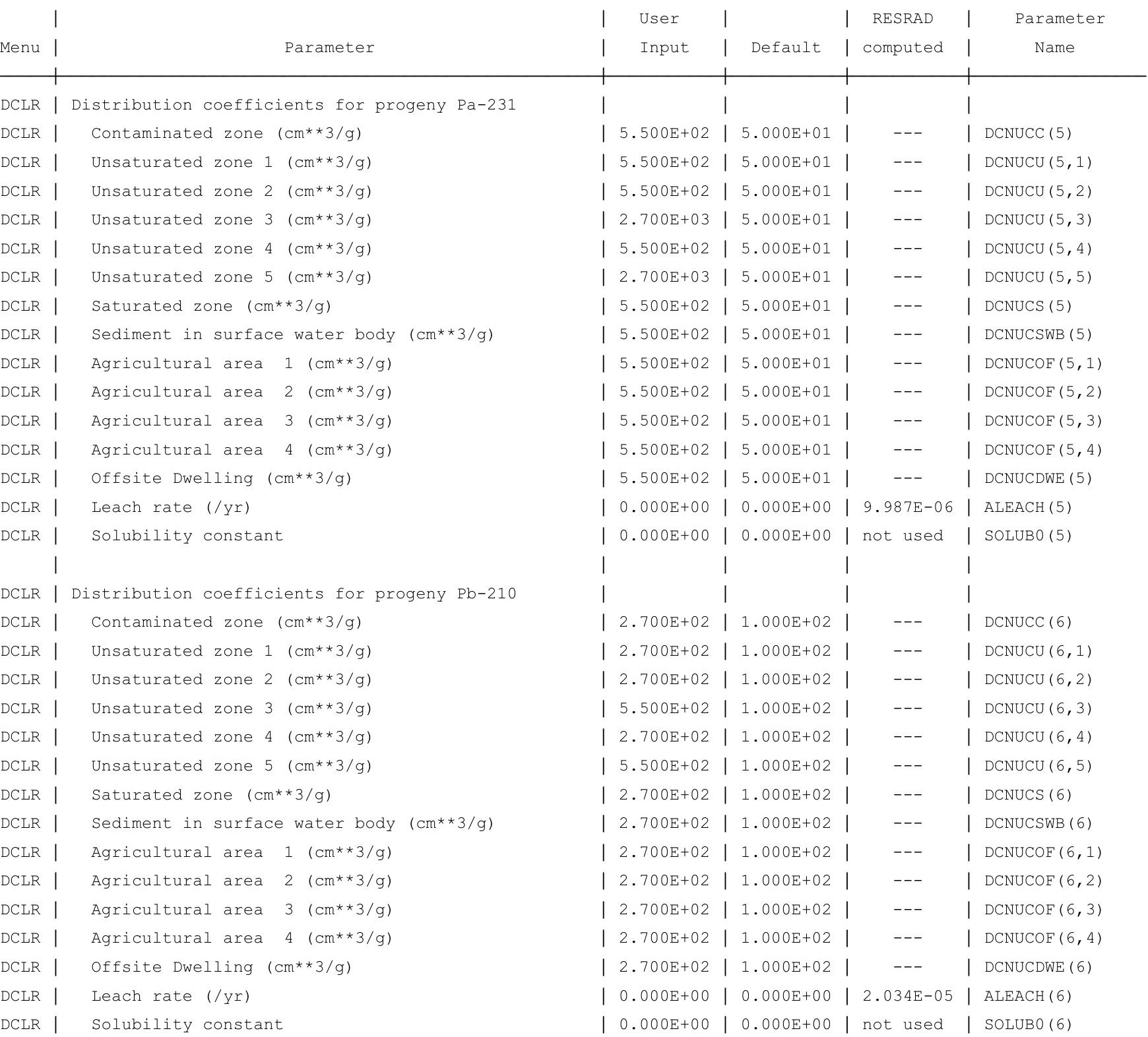


RESRAD-OFFSITE, Version $2.5, \quad \mathrm{~T}^{1 / 2}$ Limit $=180$ days

Parent Dose Report

Title : Offsite Resident Farmer Deterministic Run

File : RF FINAL v2.ROF

Site-Specific Parameter Summary (continued)

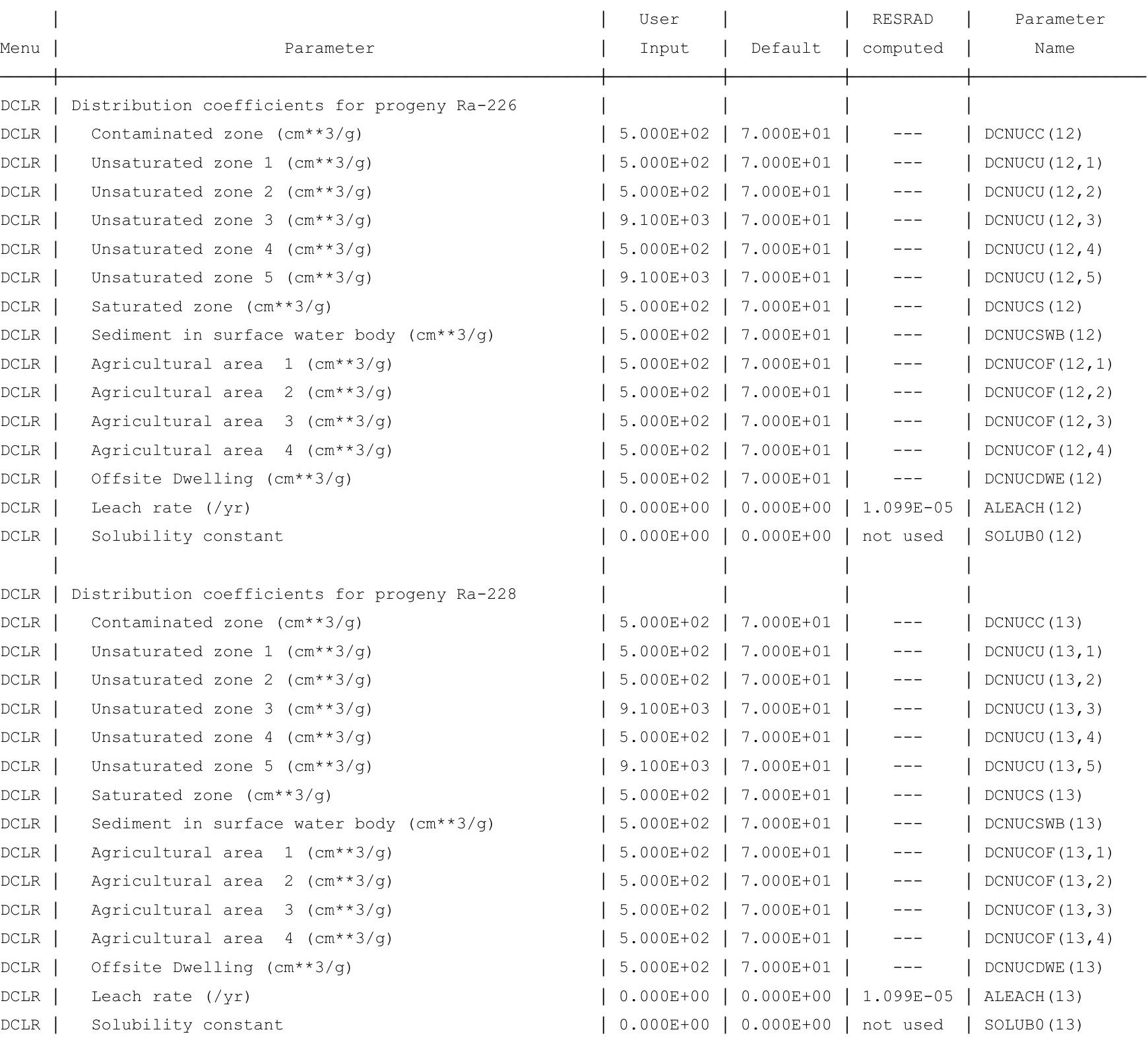


RESRAD-OFFSITE, Version $2.5 \quad \mathrm{~T}^{1 / 2}$ Limit $=180$ days

Parent Dose Report

Title : Offsite Resident Farmer Deterministic Run

File : RF FINAL v2.ROF

Site-Specific Parameter Summary (continued)

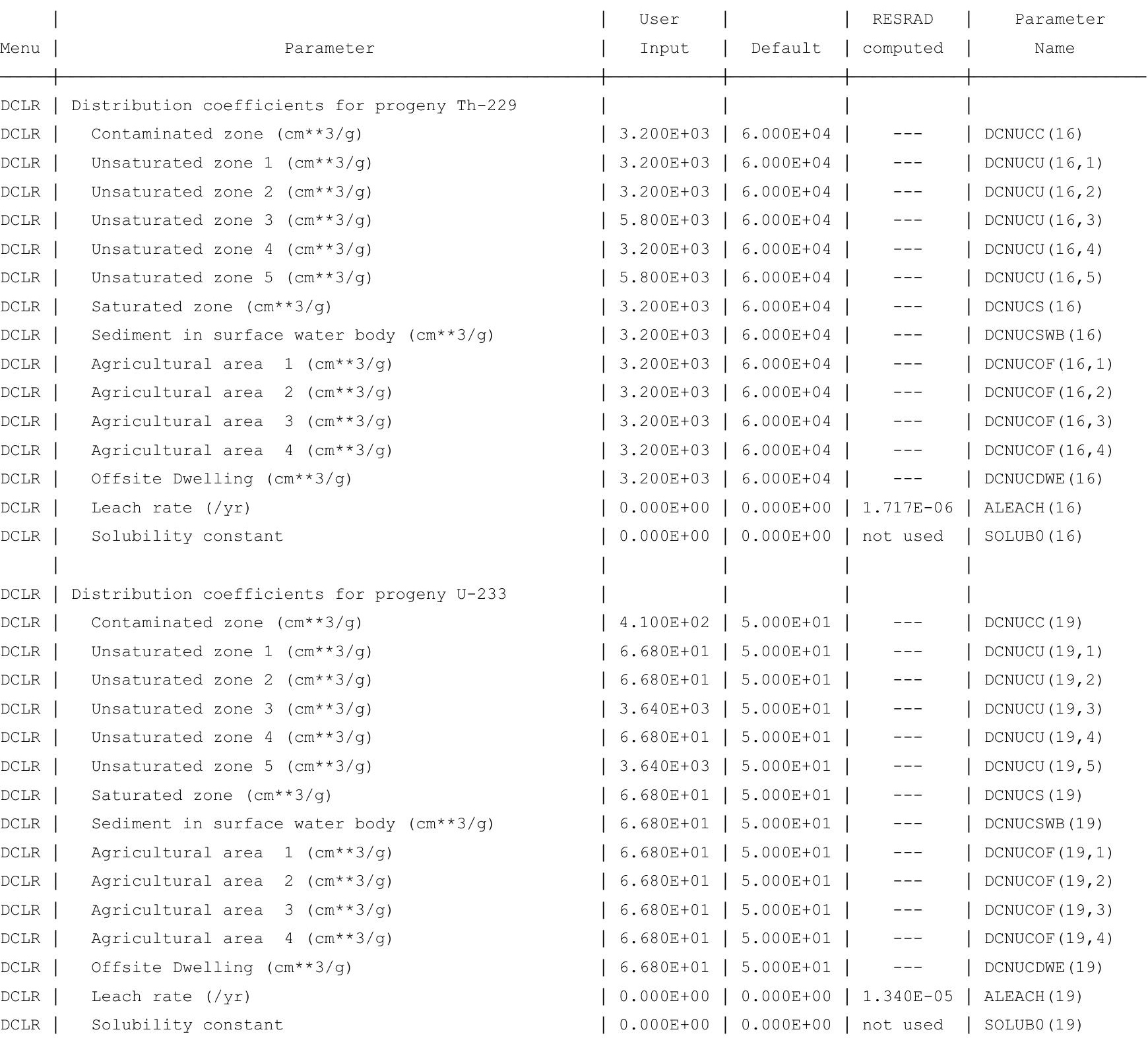


RESRAD-OFFSITE, Version 2.5

Parent Dose Report

Title : Offsite Resident Farmer Deterministic Run

File : RF FINAL v2.ROF

Site-Specific Parameter Summary (continued)

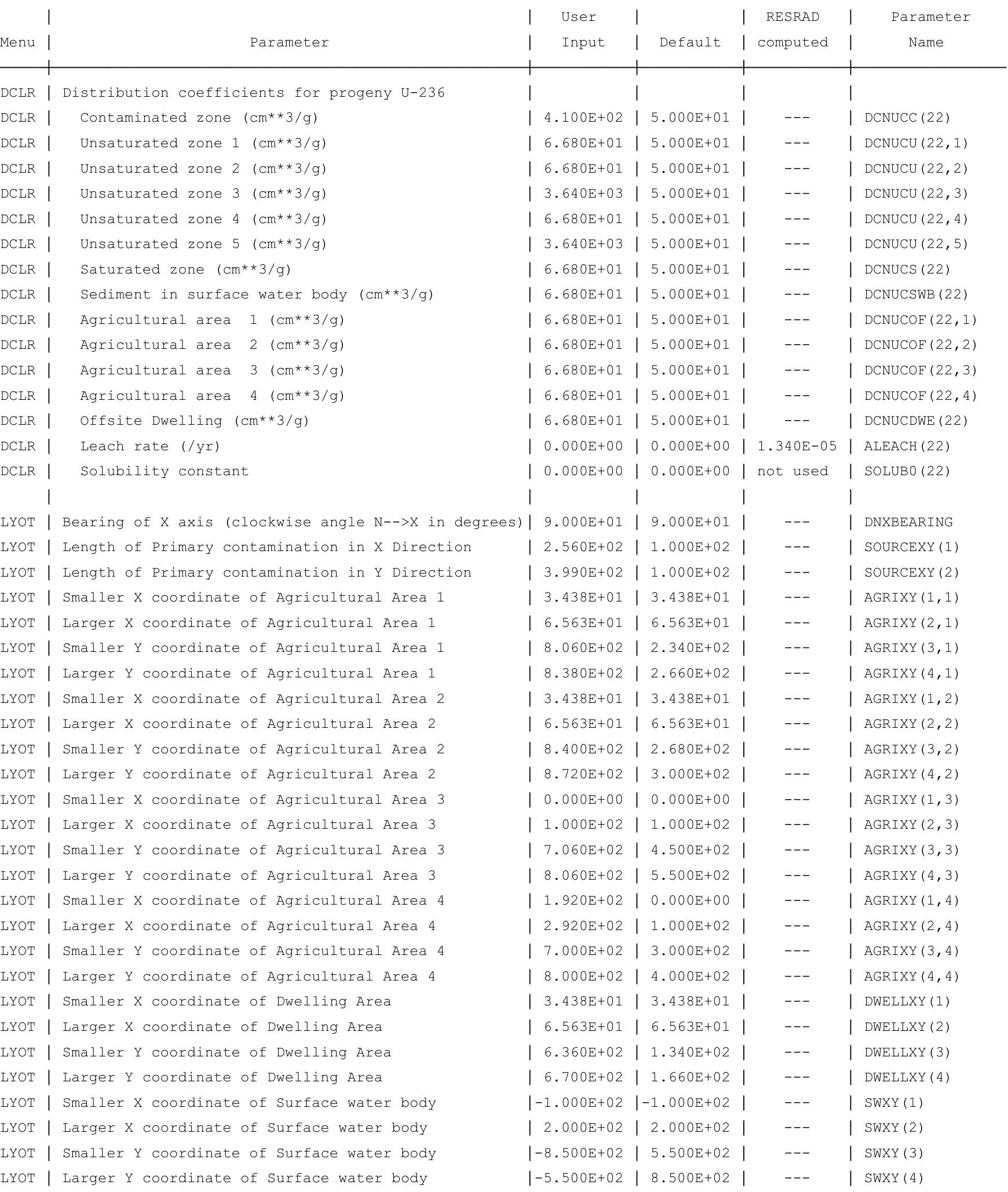


RESRAD-OFFSITE, Version 2.

Parent Dose Report

Title : Offsite Resident Farmer Deterministic Run

File : RF FINAL v2.ROF

Site-Specific Parameter Summary (continued)

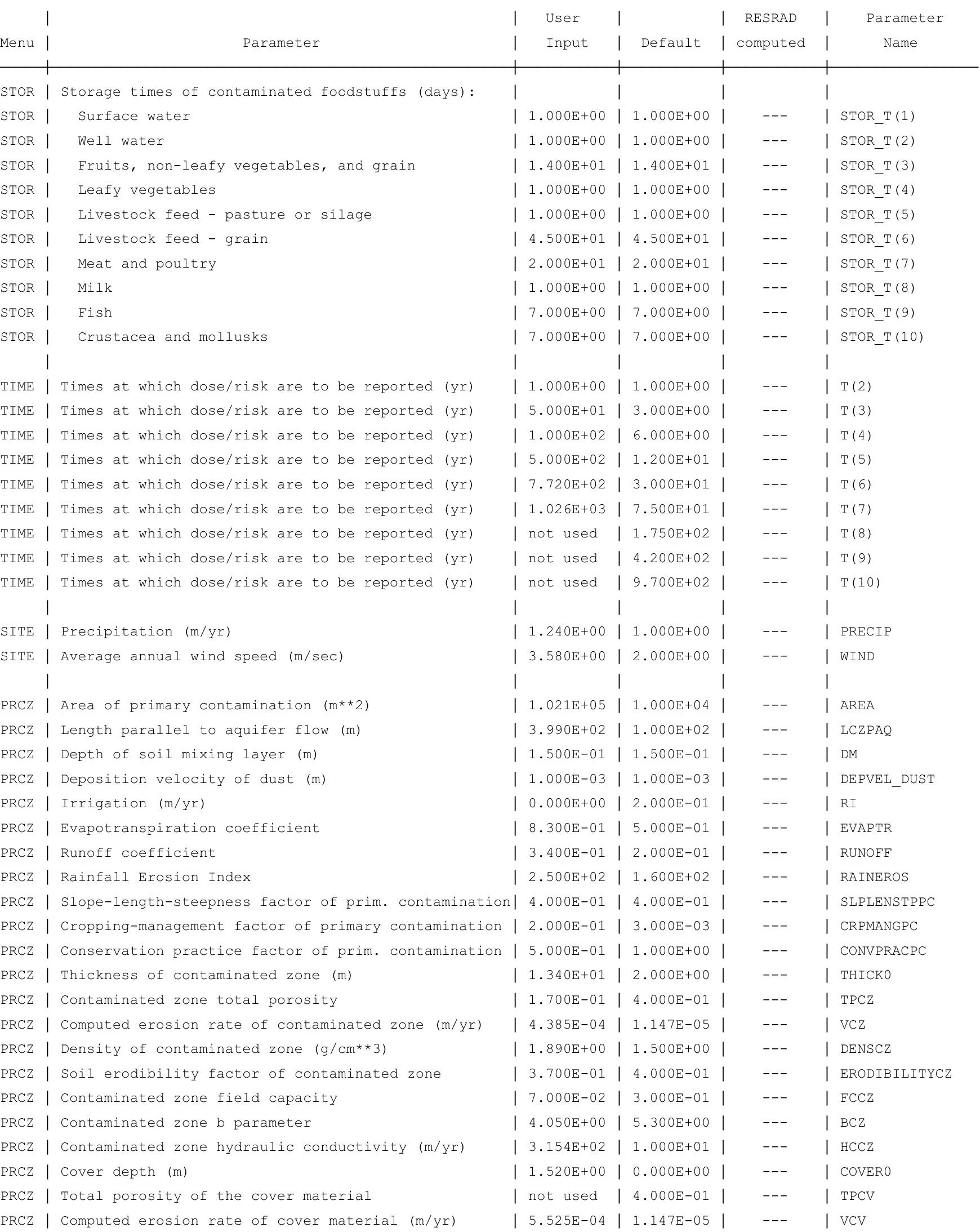


RESRAD-OFFSITE, Version 2.5

Parent Dose Report

Title : Offsite Resident Farmer Deterministic Run

File : RF FINAL v2.ROF

Site-Specific Parameter Summary (continued)

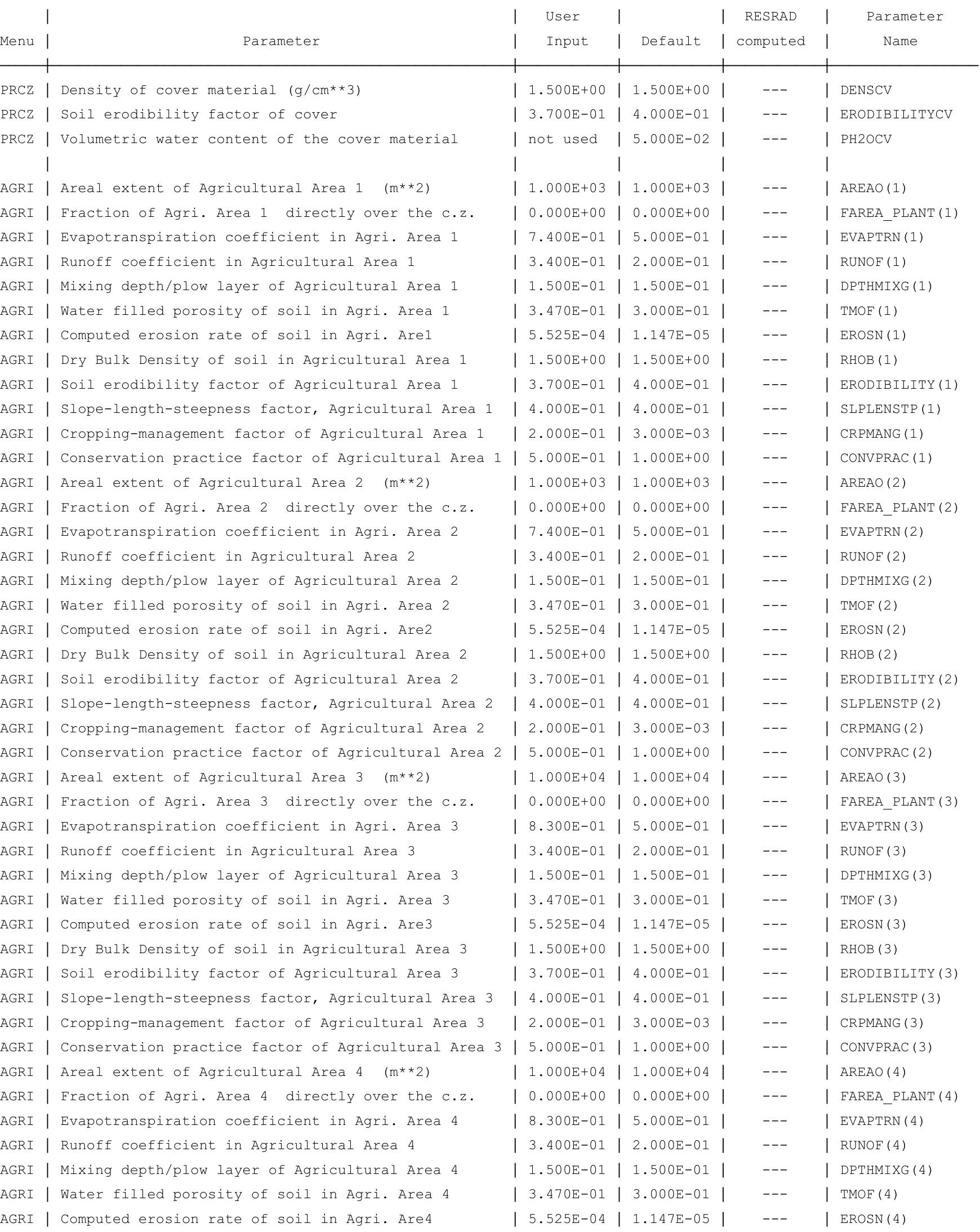


RESRAD-OFFSITE, Version 2.5

Parent Dose Report

Title : Offsite Resident Farmer Deterministic Run

File : RF FINAL v2.ROF

Site-Specific Parameter Summary (continued)

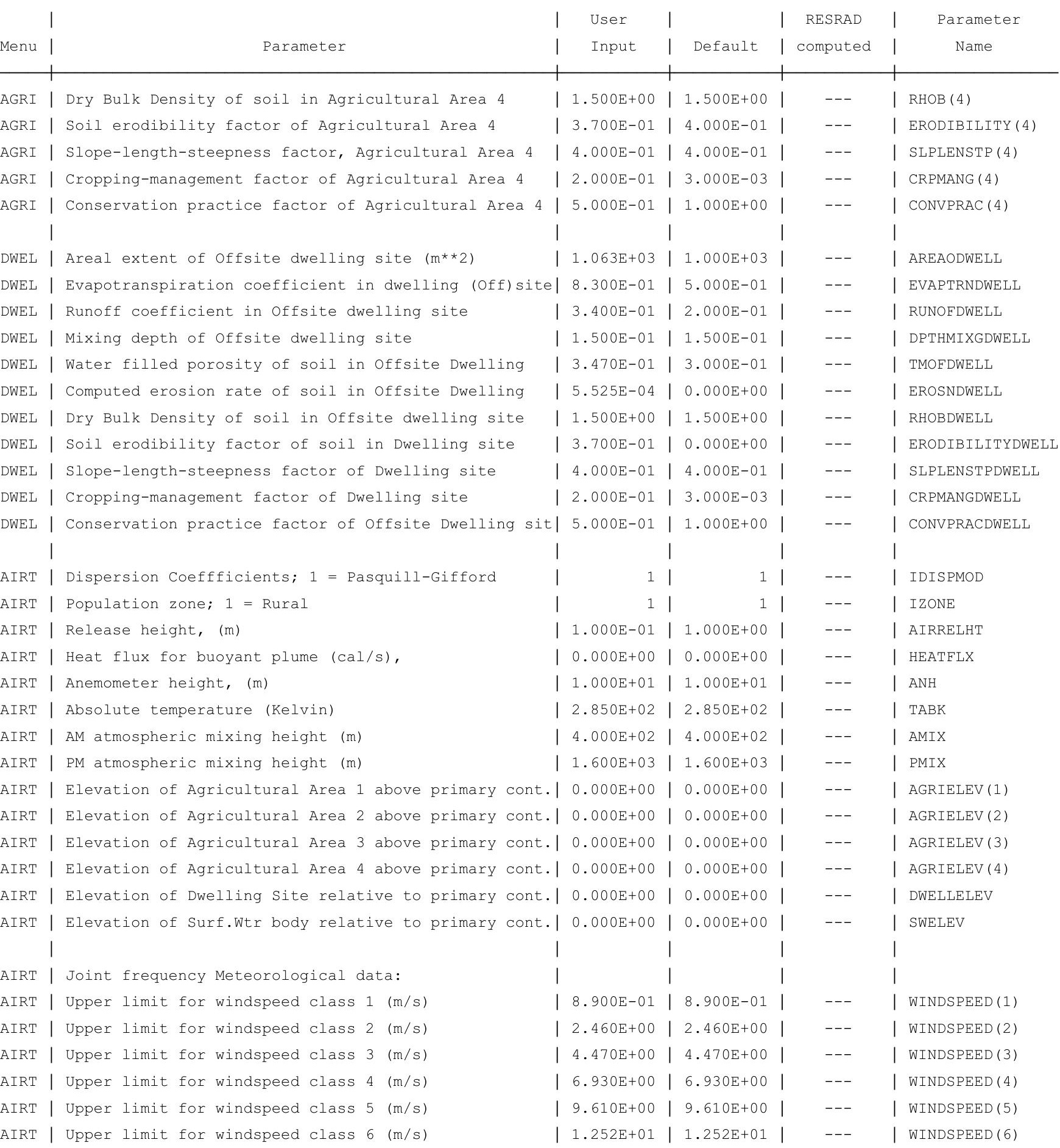


RESRAD-OFFSITE, Version 2.

Parent Dose Report

Title : Offsite Resident Farmer Deterministic Run

File : RF FINAL v2.ROF

Site-Specific Parameter Summary (continued)

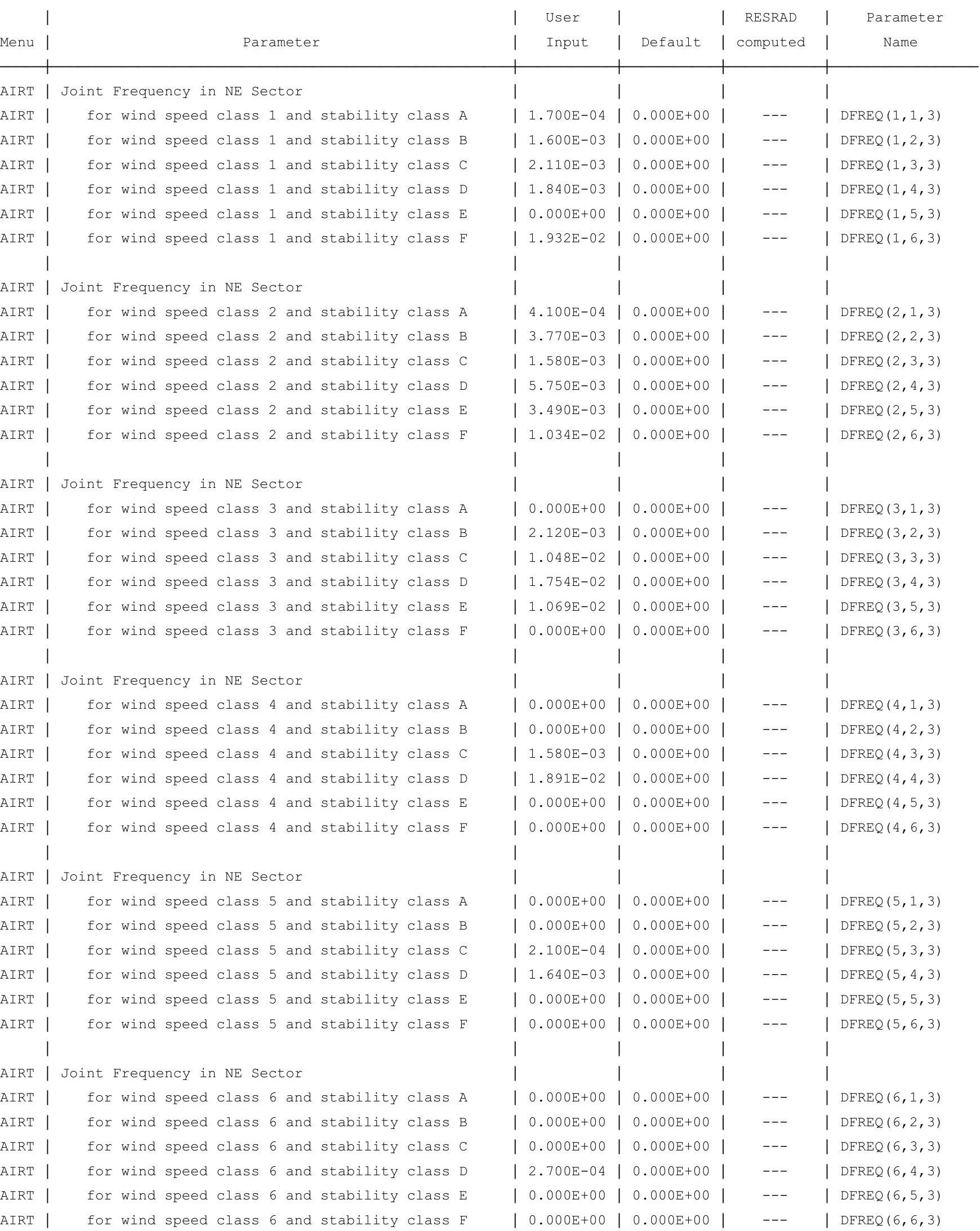


RESRAD-OFFSITE, Version 2.

Parent Dose Report

Title : Offsite Resident Farmer Deterministic Run

File : RF FINAL v2.ROF

Site-Specific Parameter Summary (continued)

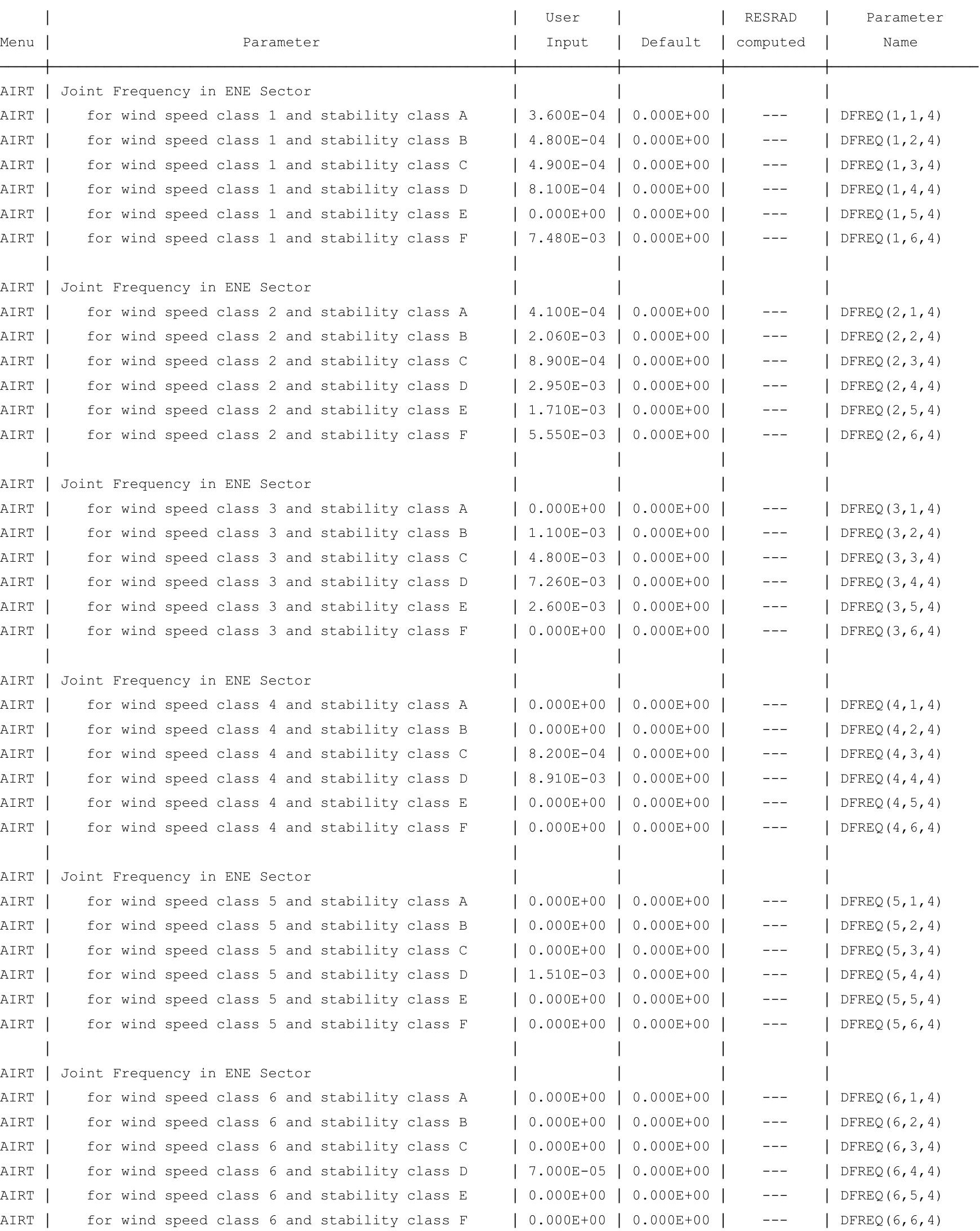


RESRAD-OFFSITE, Version 2.

Parent Dose Report

Title : Offsite Resident Farmer Deterministic Run

File : RF FINAL v2.ROF

Site-Specific Parameter Summary (continued)

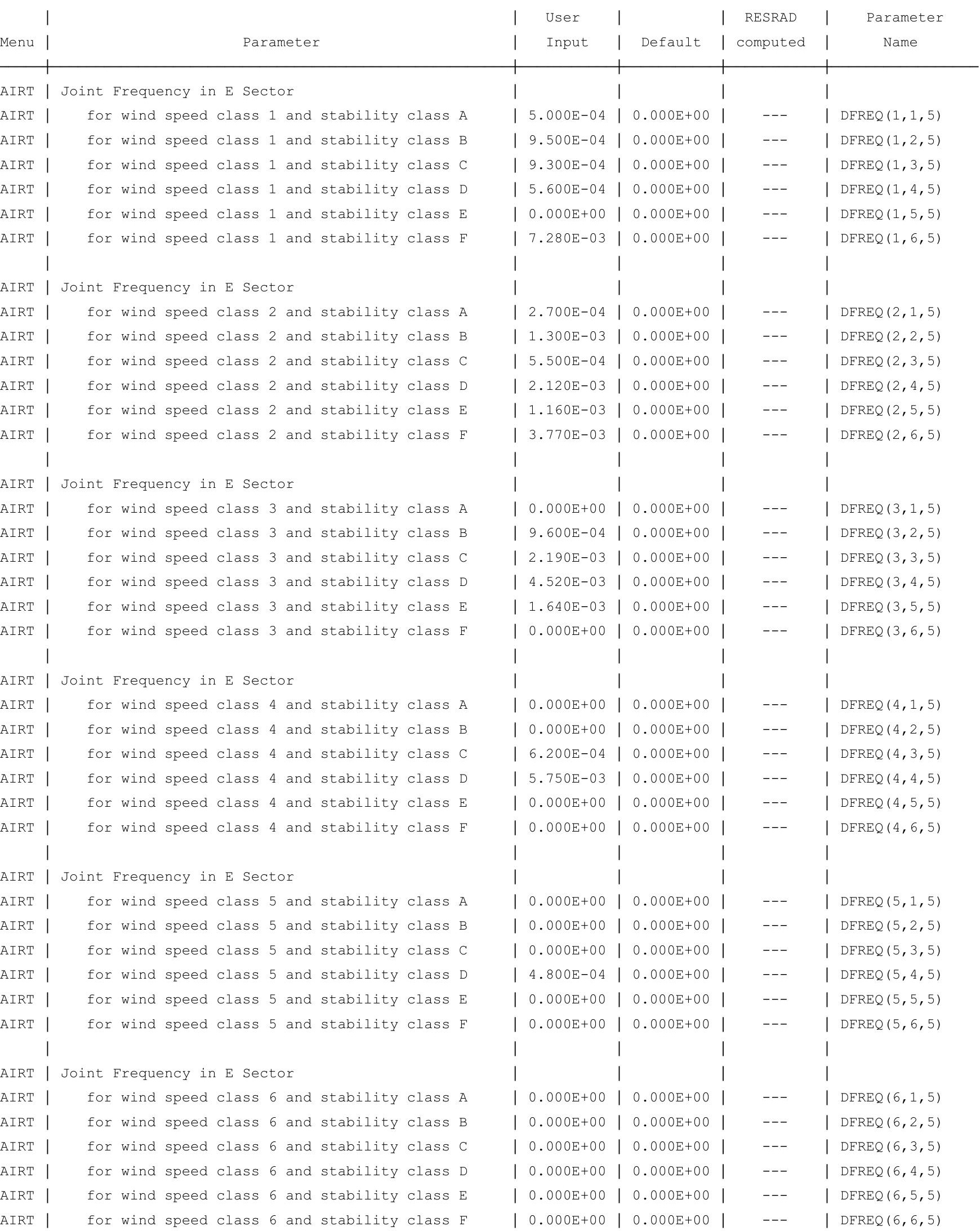


RESRAD-OFFSITE, Version 2.

Parent Dose Report

Title : Offsite Resident Farmer Deterministic Run

File : RF FINAL v2.ROF

Site-Specific Parameter Summary (continued)

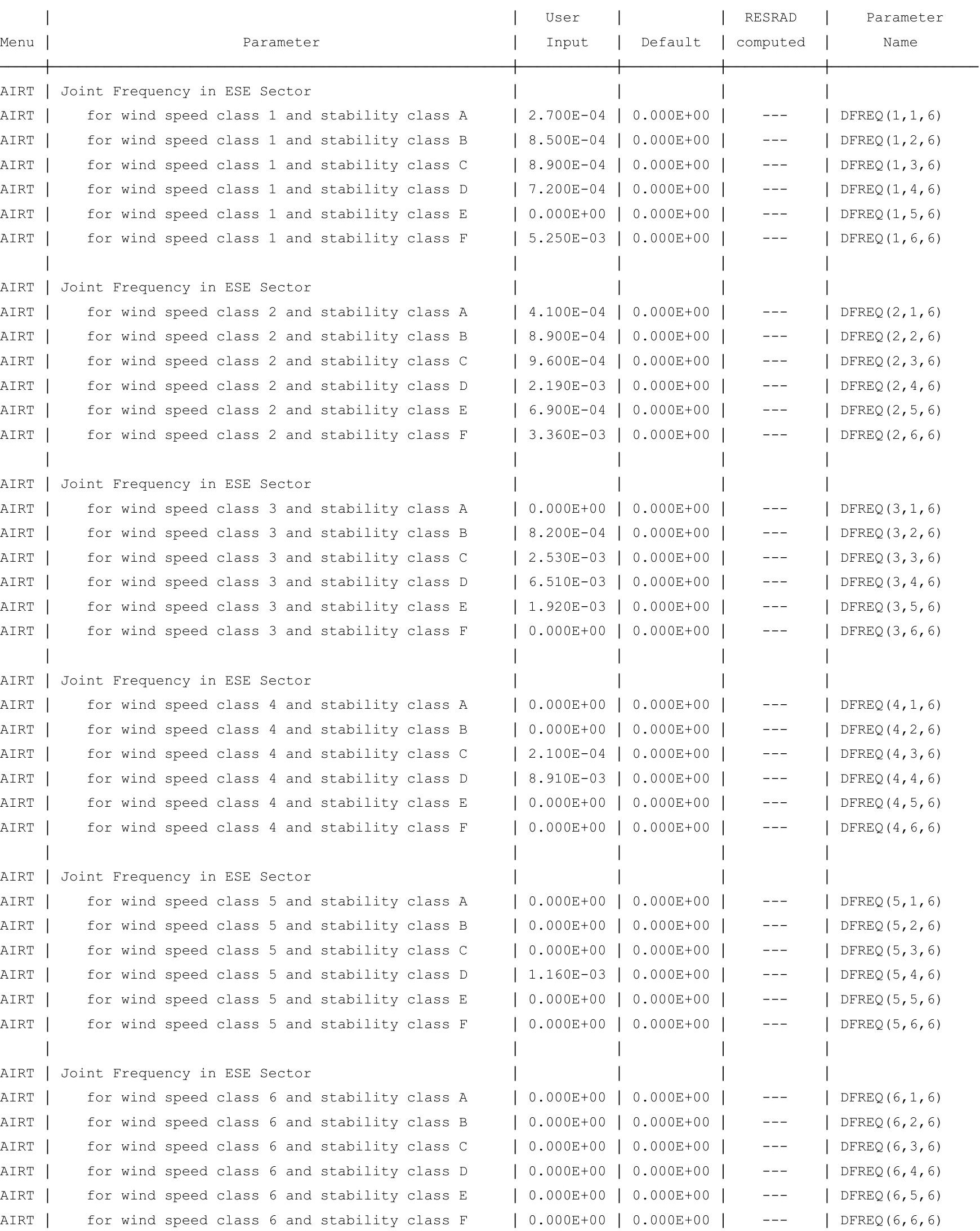


RESRAD-OFFSITE, Version 2.

Parent Dose Report

Title : Offsite Resident Farmer Deterministic Run

File : RF FINAL v2.ROF

Site-Specific Parameter Summary (continued)

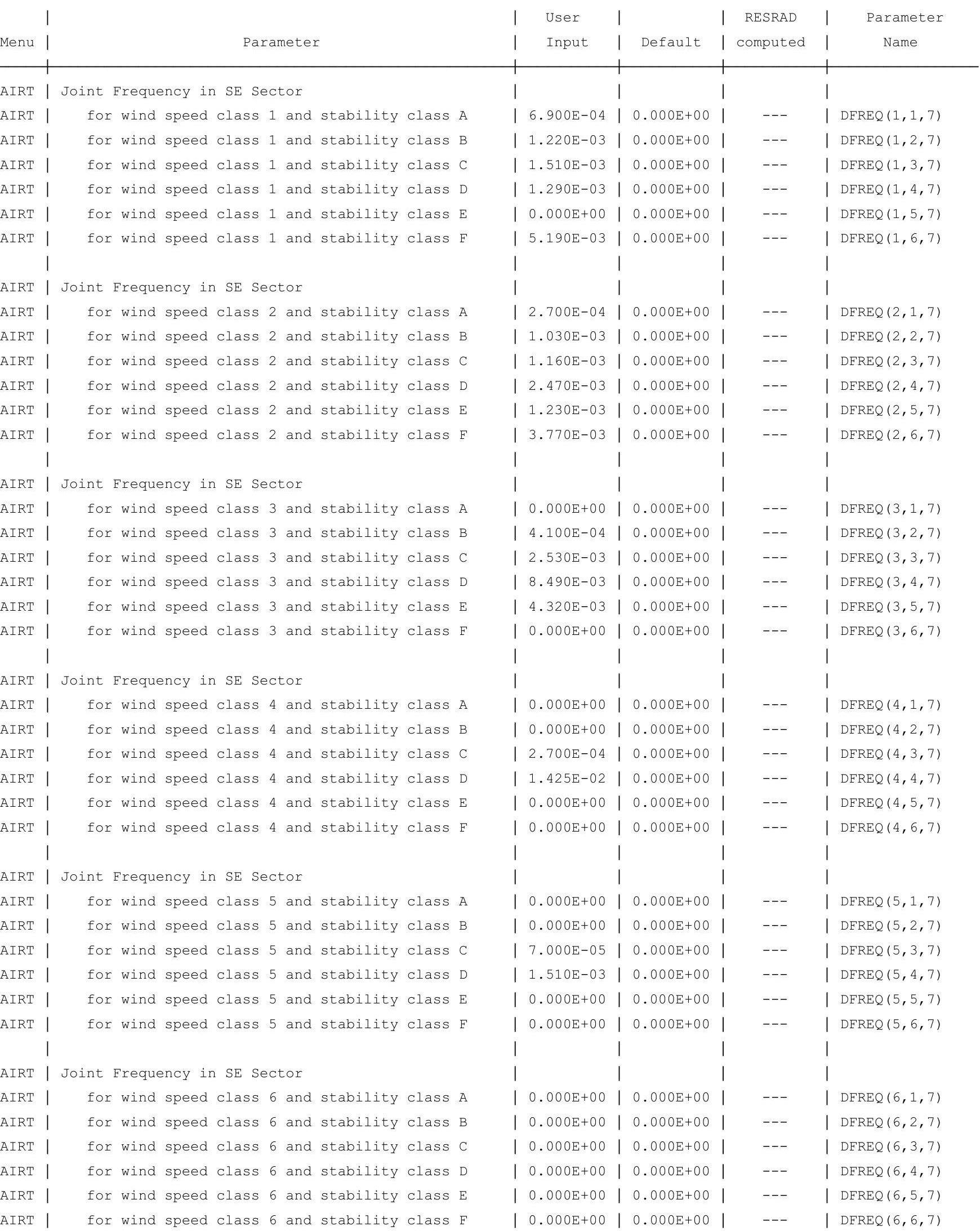


RESRAD-OFFSITE, Version 2.

Parent Dose Report

Title : Offsite Resident Farmer Deterministic Run

File : RF FINAL v2.ROF

Site-Specific Parameter Summary (continued)

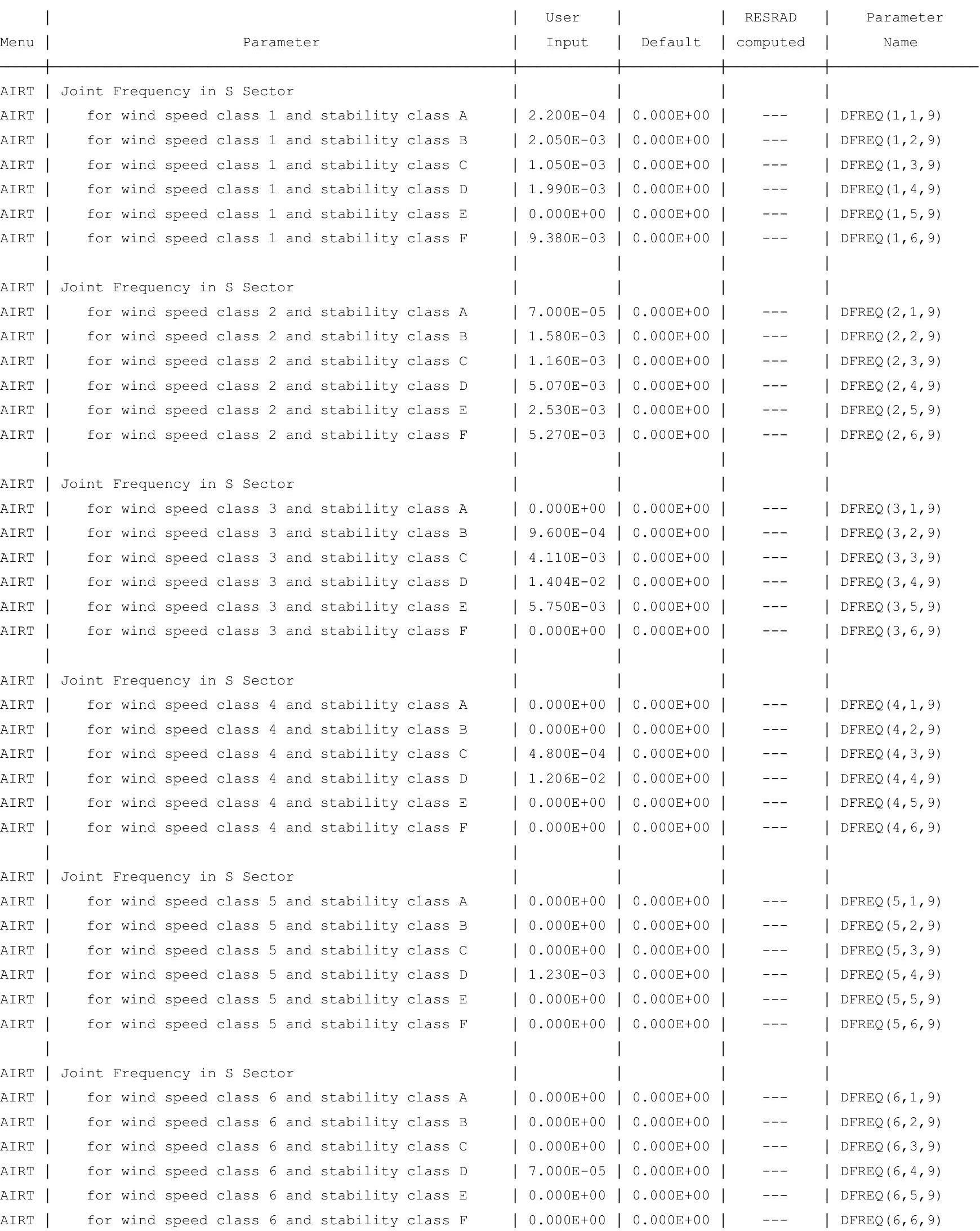


RESRAD-OFFSITE, Version 2.

Parent Dose Report

Title : Offsite Resident Farmer Deterministic Run

File : RF FINAL v2.ROF

Site-Specific Parameter Summary (continued)

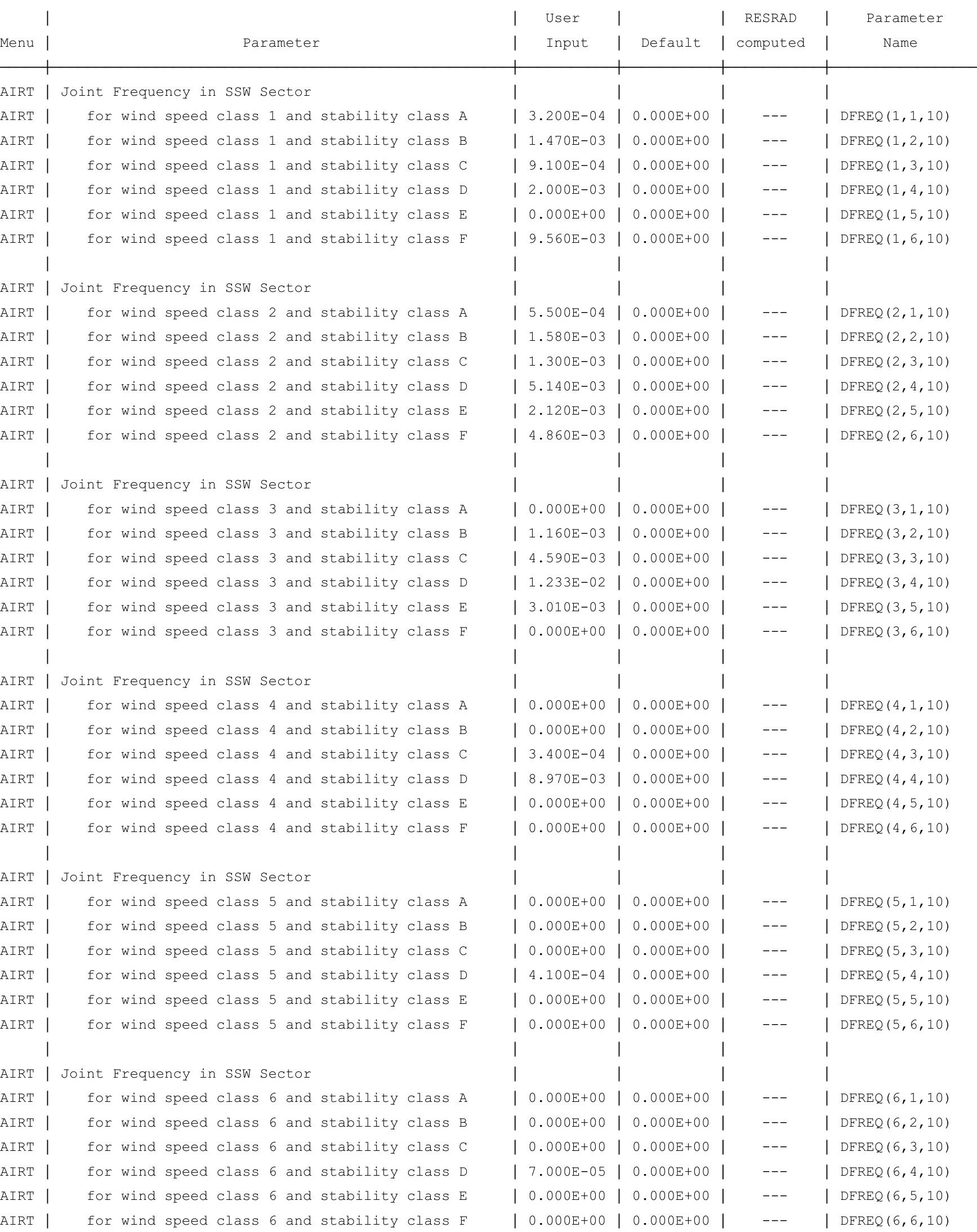


RESRAD-OFFSITE, Version 2.

Parent Dose Report

Title : Offsite Resident Farmer Deterministic Run

File : RF FINAL v2.ROF

Site-Specific Parameter Summary (continued)

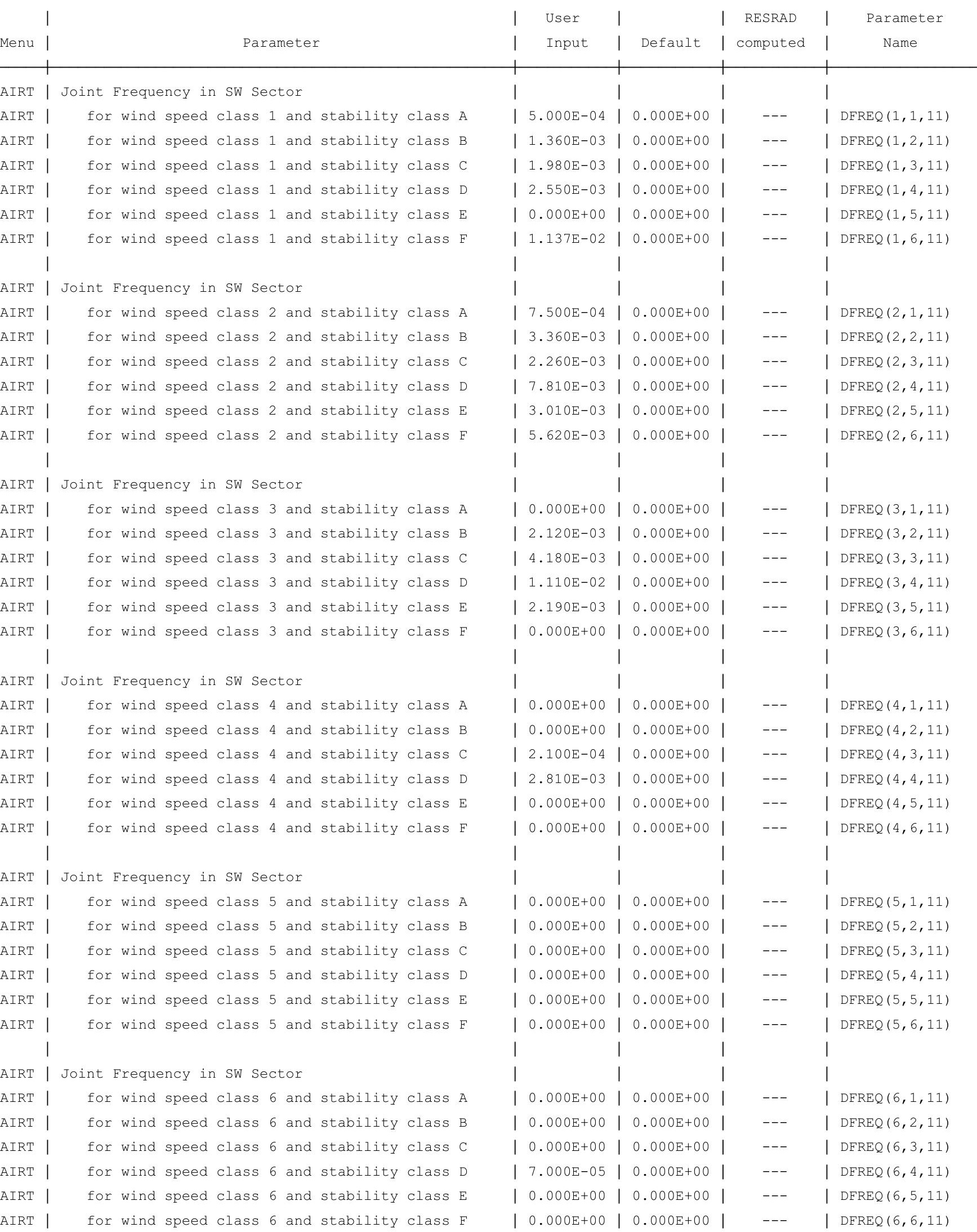


RESRAD-OFFSITE, Version 2.

Parent Dose Report

Title : Offsite Resident Farmer Deterministic Run

File : RF FINAL v2.ROF

Site-Specific Parameter Summary (continued)

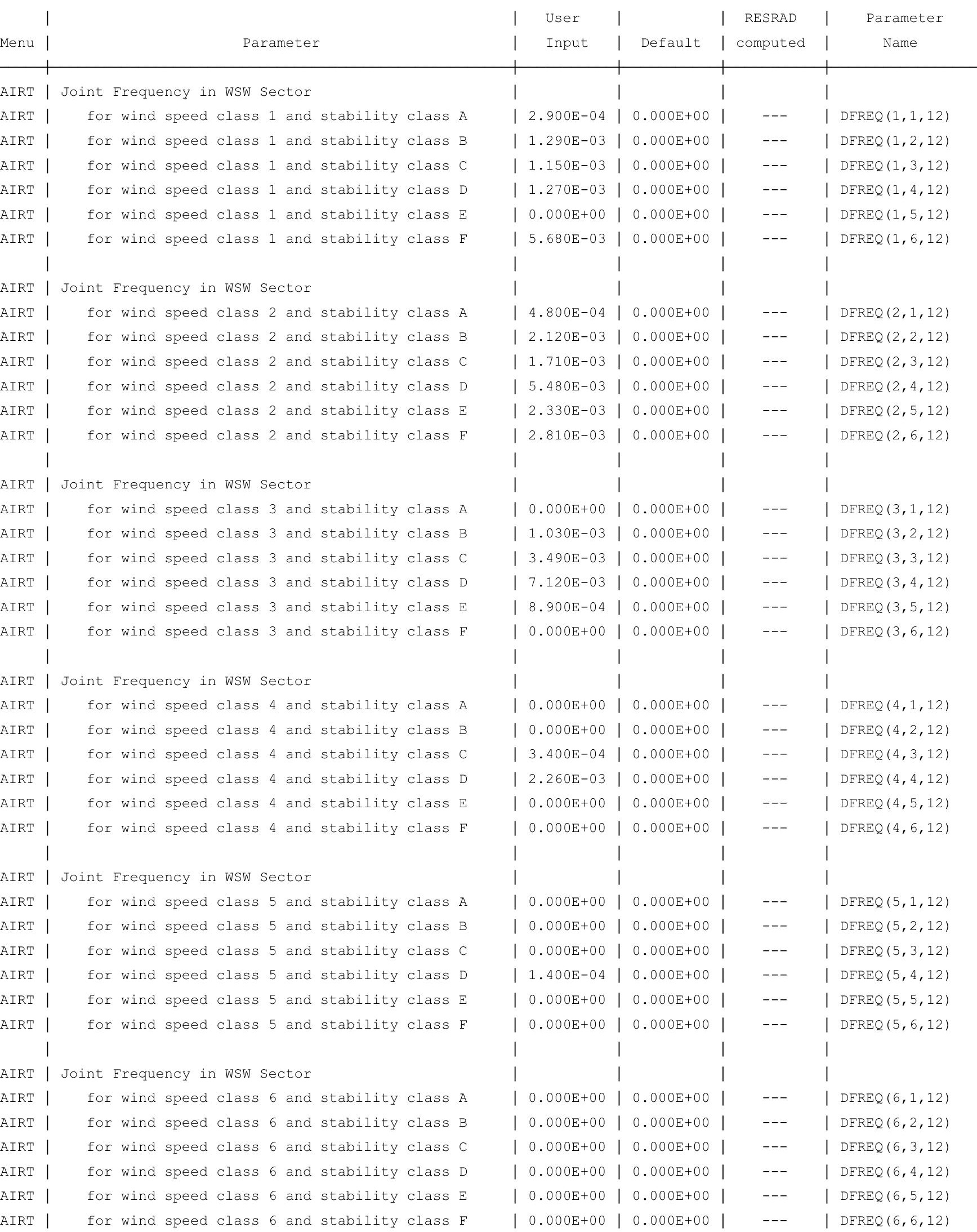


RESRAD-OFFSITE, Version 2.

Parent Dose Report

Title : Offsite Resident Farmer Deterministic Run

File : RF FINAL v2.ROF

Site-Specific Parameter Summary (continued)

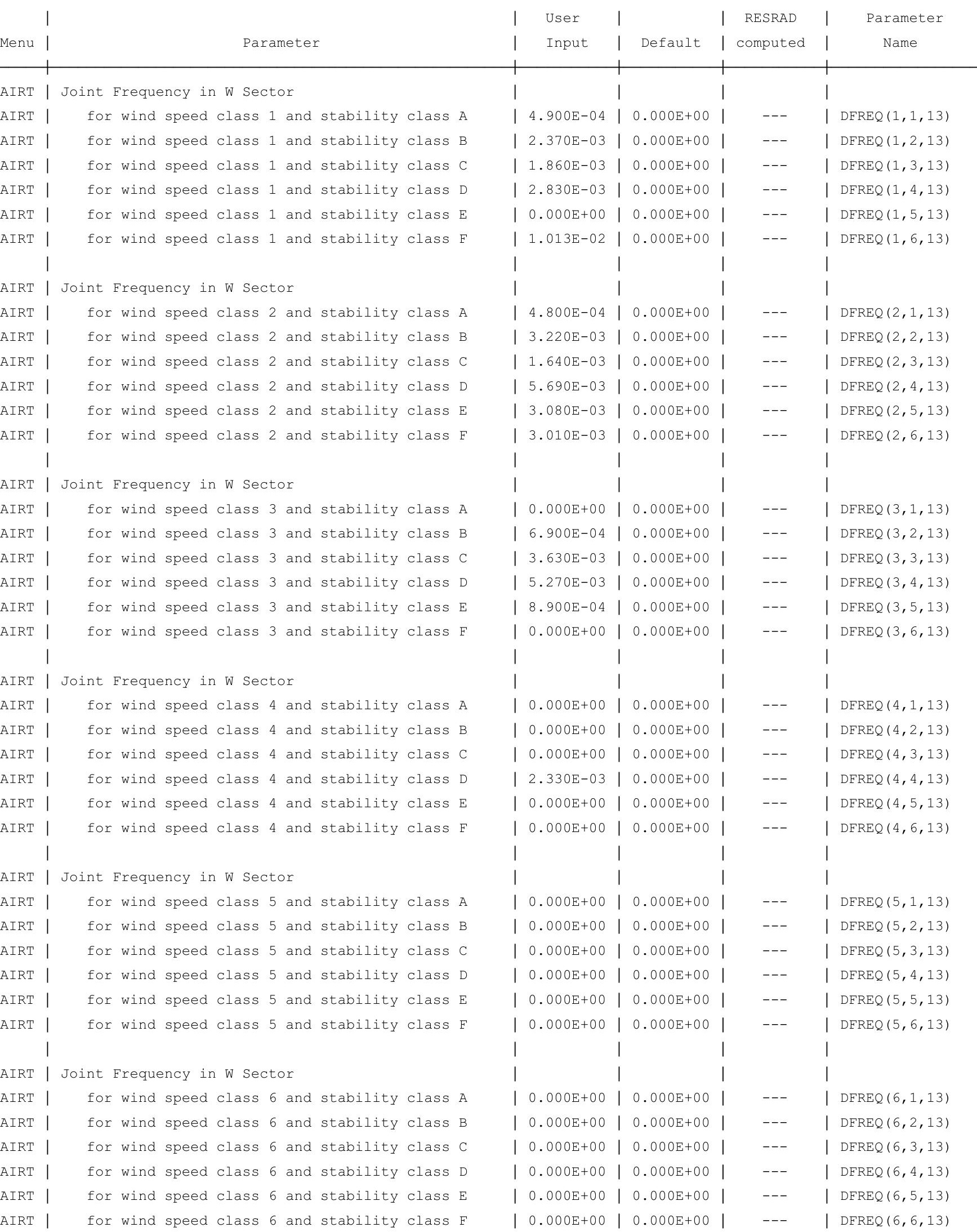


RESRAD-OFFSITE, Version 2.

Parent Dose Report

Title : Offsite Resident Farmer Deterministic Run

File : RF FINAL V2.ROF

Site-Specific Parameter Summary (continued)

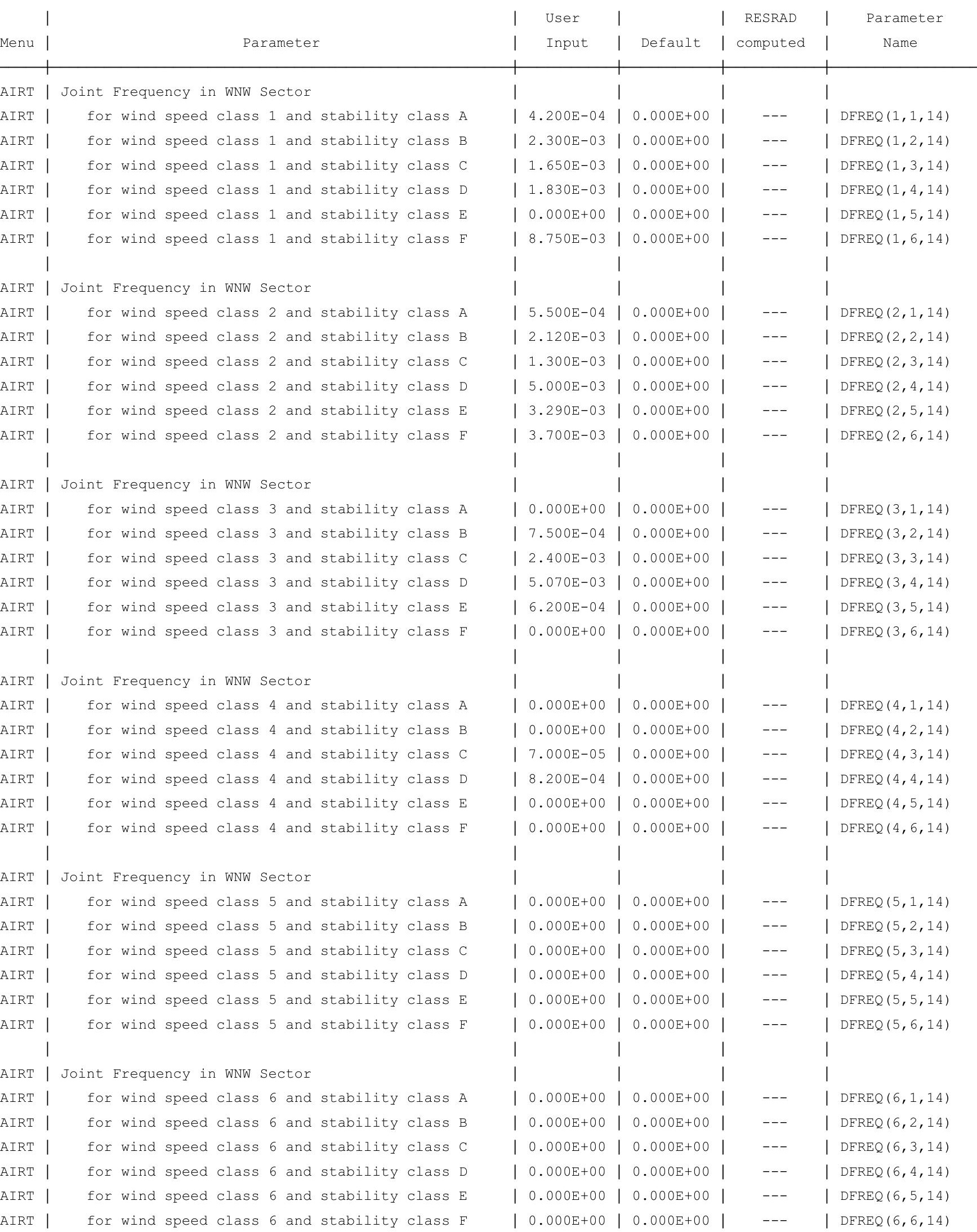


RESRAD-OFFSITE, Version 2.

Parent Dose Report

Title : Offsite Resident Farmer Deterministic Run

File : RF FINAL v2.ROF

Site-Specific Parameter Summary (continued)

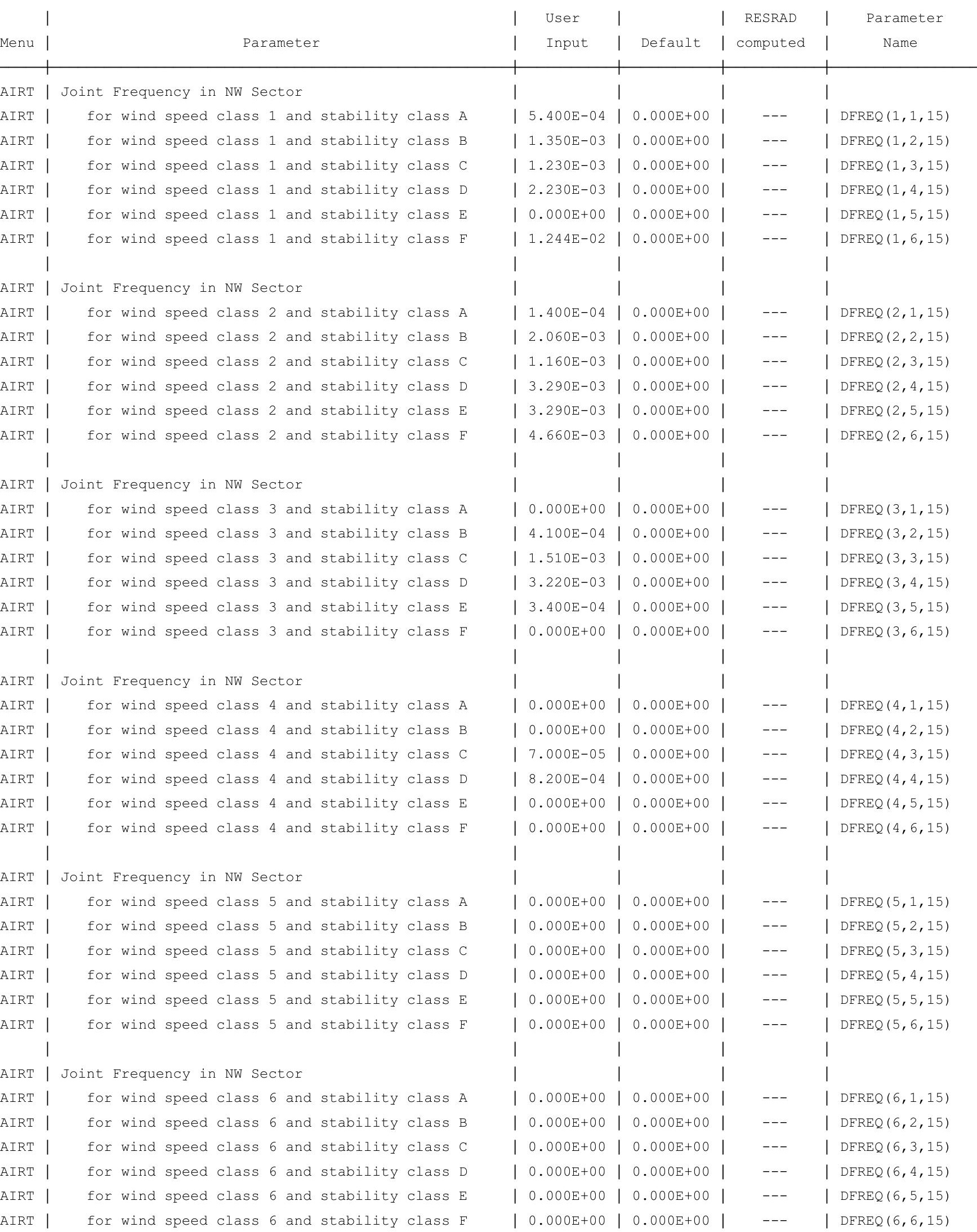


RESRAD-OFFSITE, Version 2.

Parent Dose Report

Title : Offsite Resident Farmer Deterministic Run

File : RF FINAL V2.ROF

Site-Specific Parameter Summary (continued)

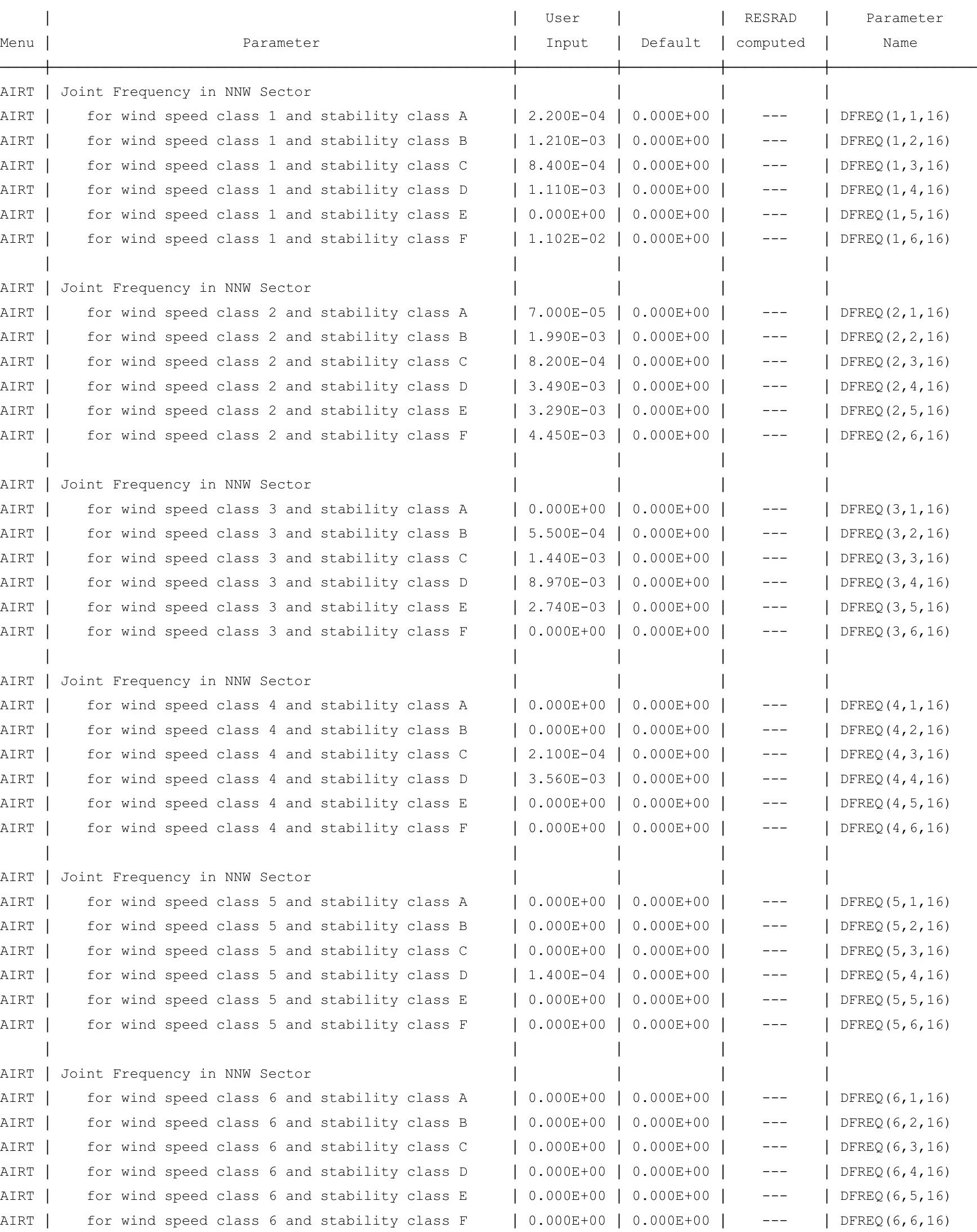


RESRAD-OFFSITE, Version 2.5

Parent Dose Report

Title : Offsite Resident Farmer Deterministic Run

File : RF FINAL v2.ROF

Site-Specific Parameter Summary (continued)

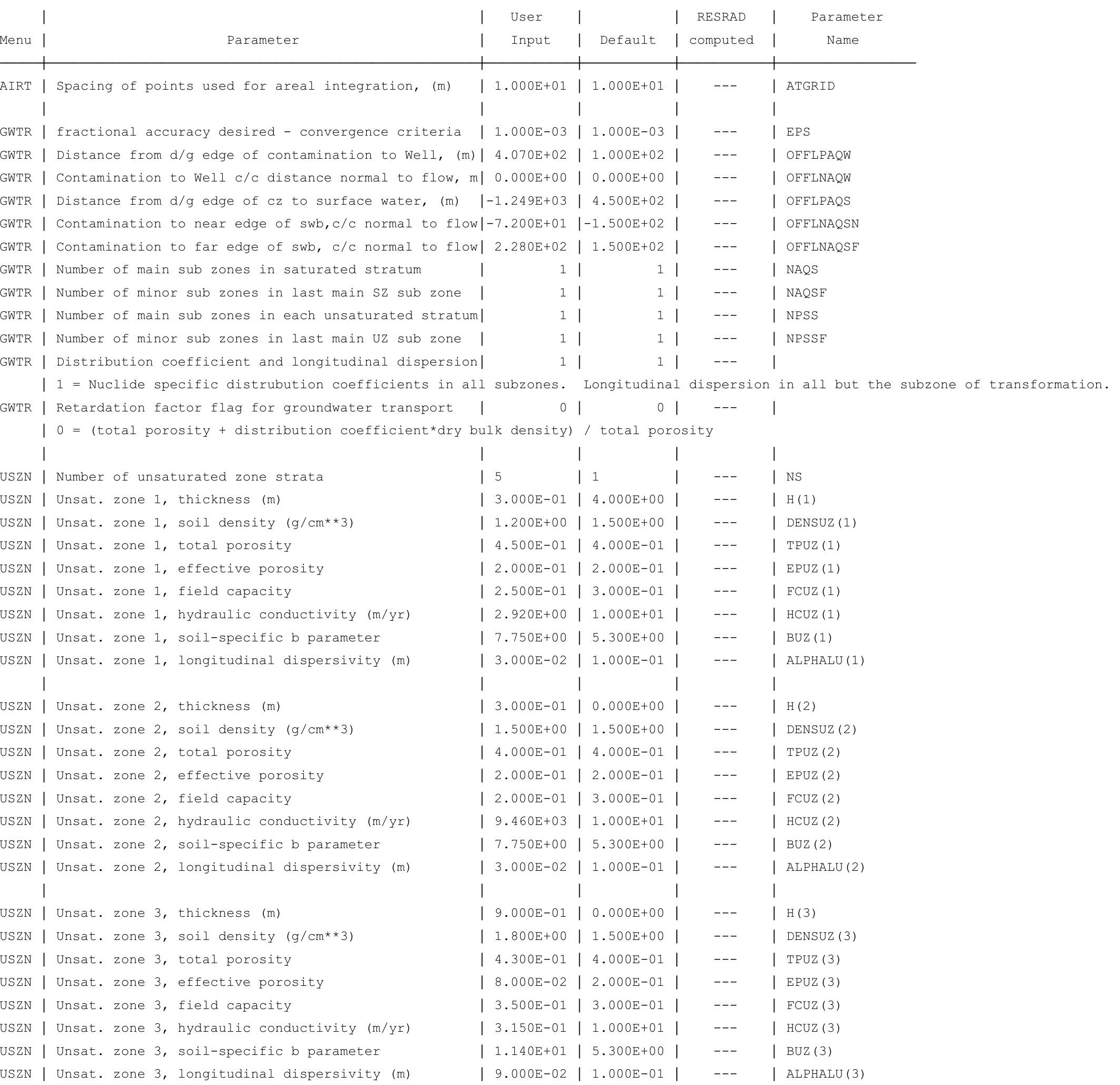


RESRAD-OFFSITE, Version 2.5

Parent Dose Report

Title : Offsite Resident Farmer Deterministic Run

File : RF FINAL v2.ROF

Site-Specific Parameter Summary (continued)

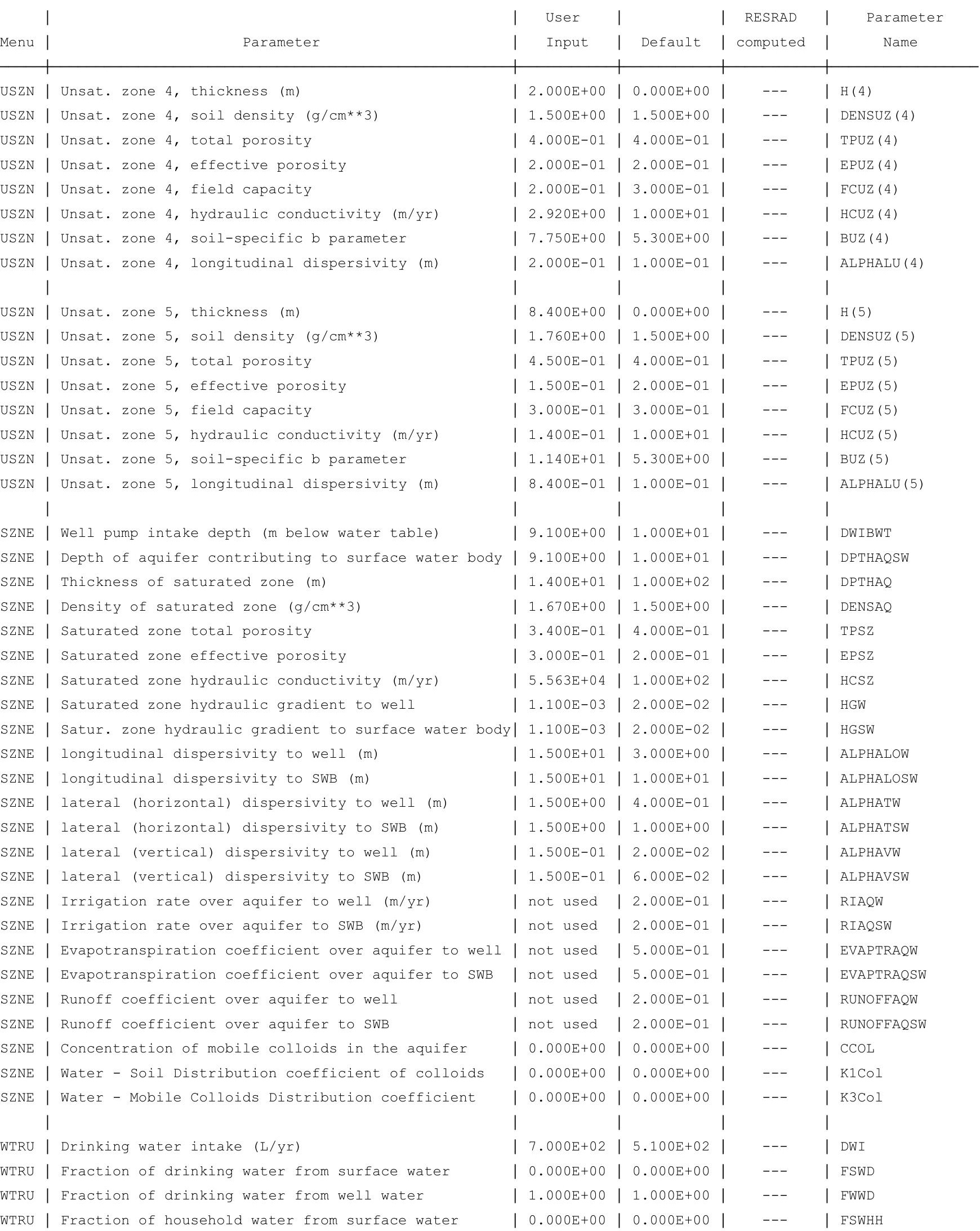


RESRAD-OFFSITE, Version 2.5

Parent Dose Report

Title : Offsite Resident Farmer Deterministic Run

File : RF FINAL v2.ROF

Site-Specific Parameter Summary (continued)

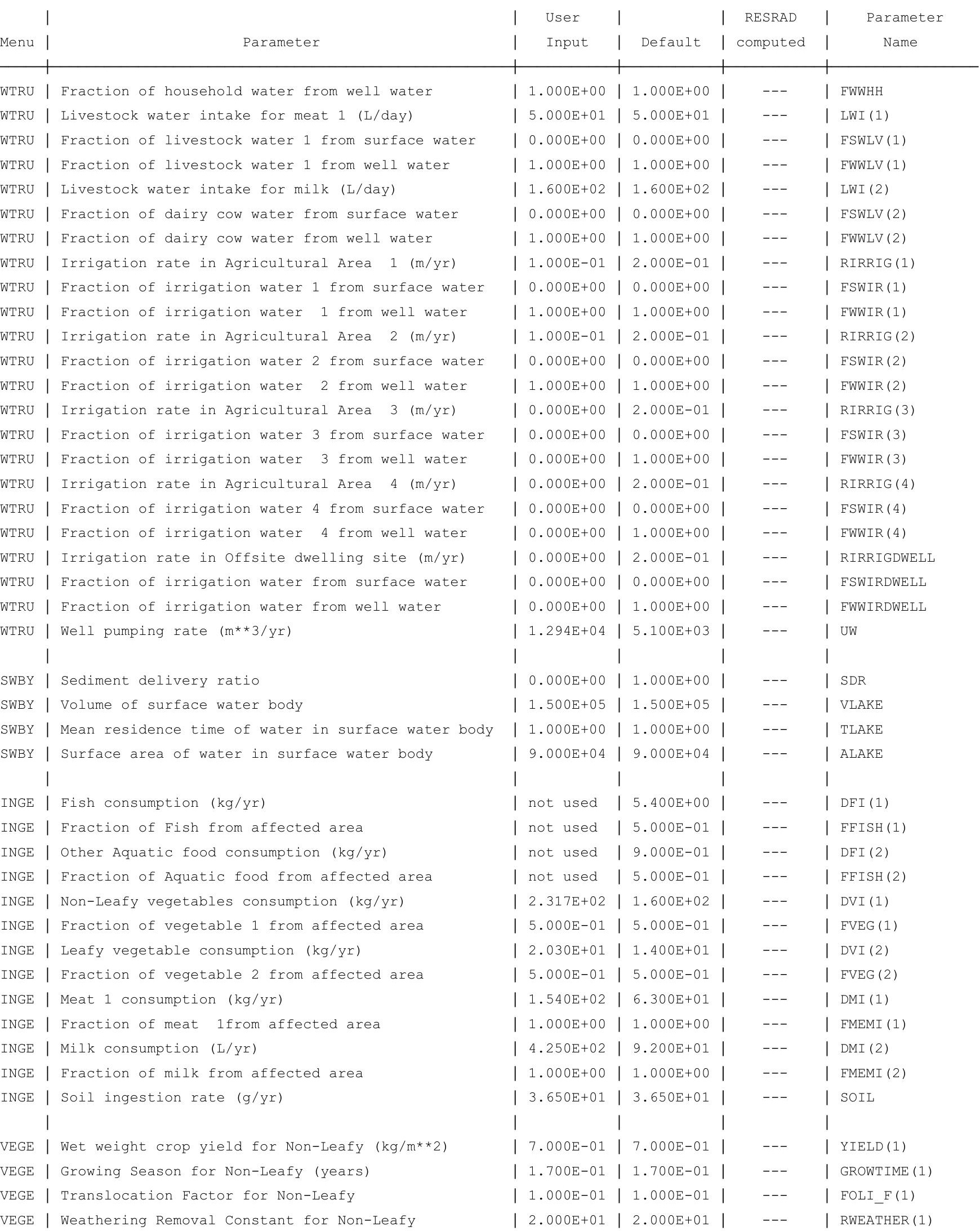


RESRAD-OFFSITE, Version 2.5

Parent Dose Report

Title : Offsite Resident Farmer Deterministic Run

File : RF FINAL v2.ROF

Site-Specific Parameter Summary (continued)

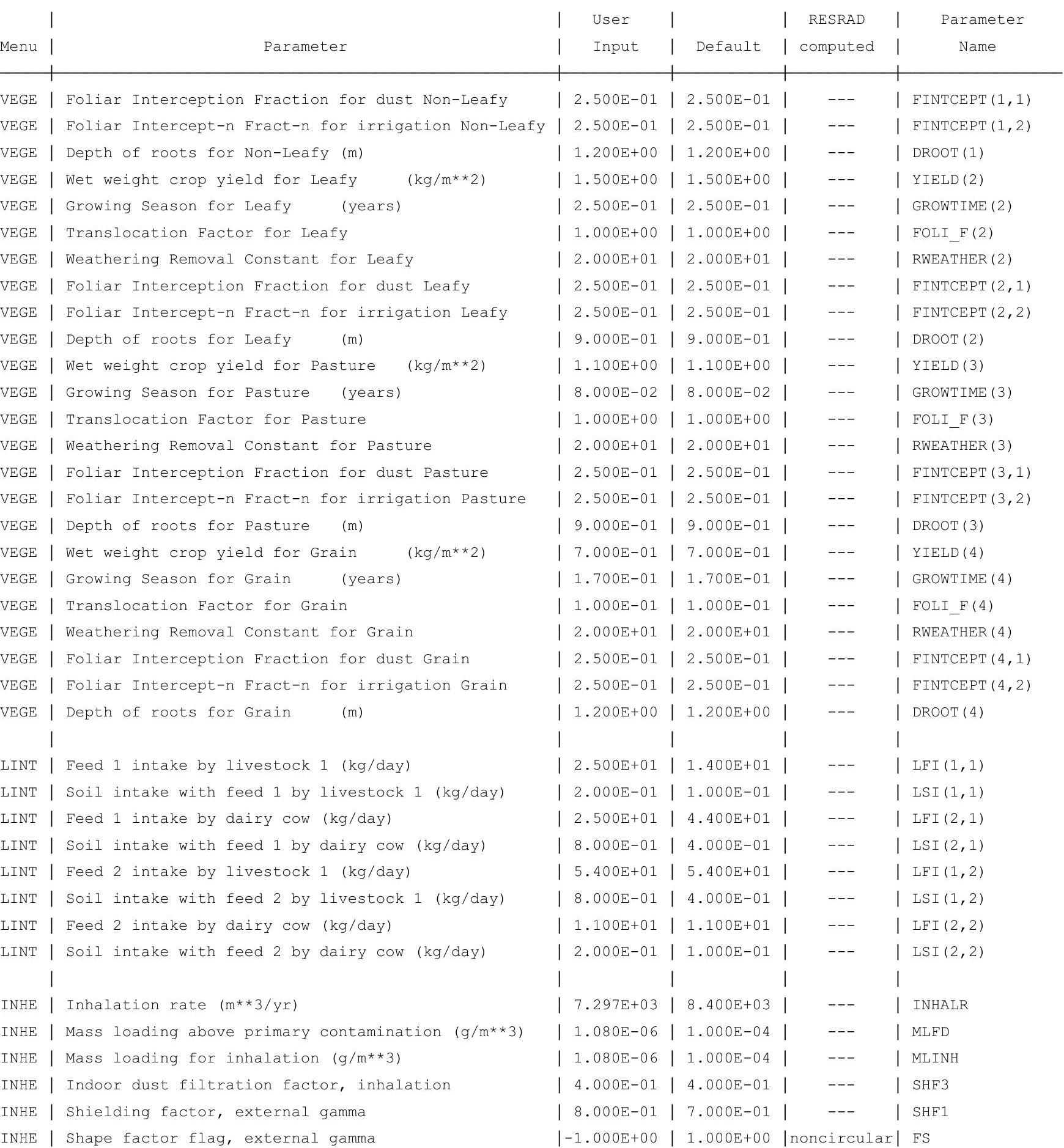


RESRAD-OFFSITE, Version 2.5

$\mathrm{T}^{1 / 2}$ Limit $=180$ days

05/02/2011 15:18 Page

46

rent Dose Report

Title : Offsite Resident Farmer Deterministic Run

File : RF FINAL v2.ROF

Site-Specific Parameter Summary (continued)

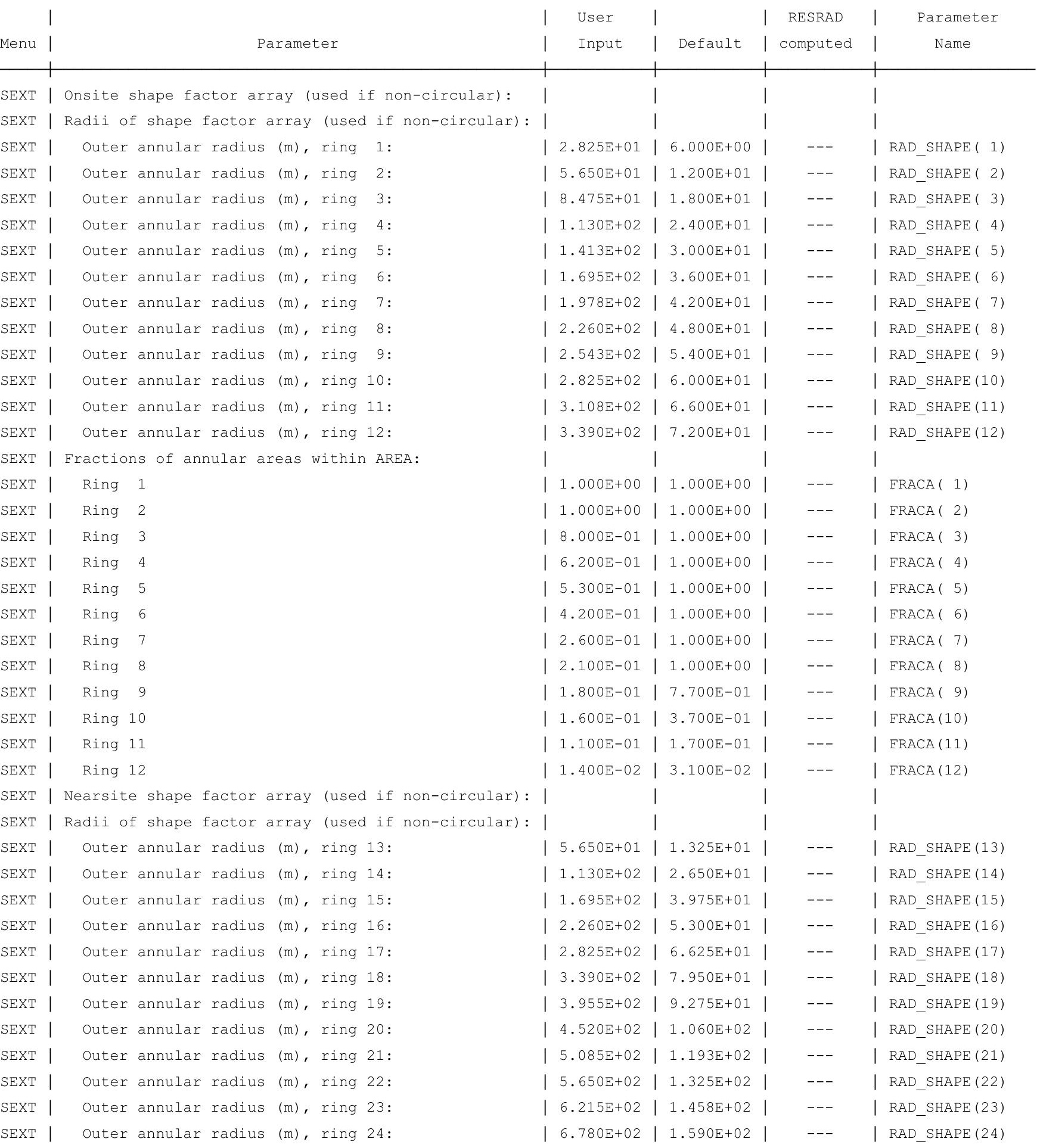


RESRAD-OFFSITE, Version 2.5

Parent Dose Report

Title : Offsite Resident Farmer Deterministic Run

File : RF FINAL v2.ROF

Site-Specific Parameter Summary (continued)

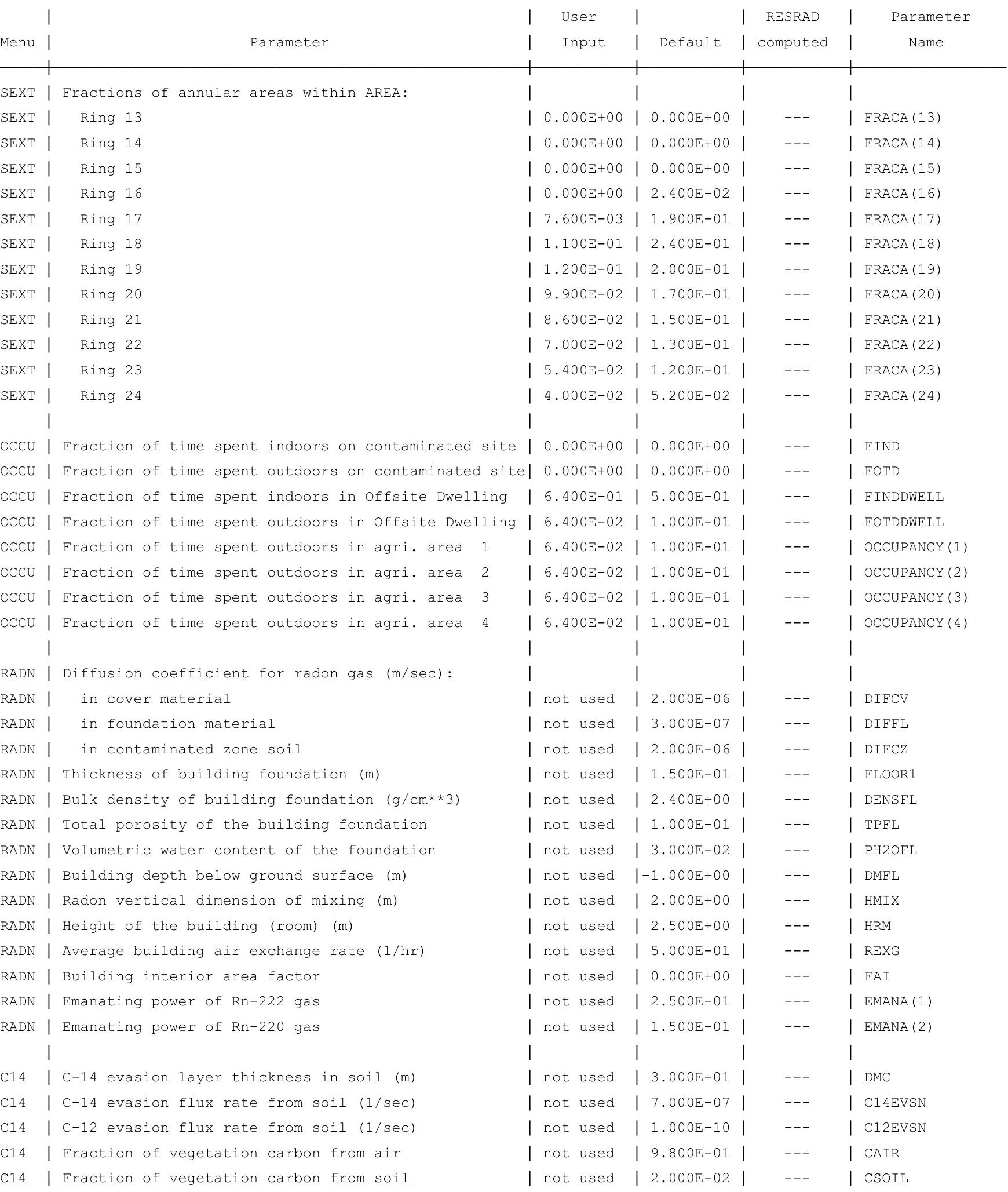


RESRAD-OFFSITE, Version 2.5

Parent Dose Report

Title : Offsite Resident Farmer Deterministic Run

File : RF FINAL v2.ROF

Site-Specific Parameter Summary (continued)

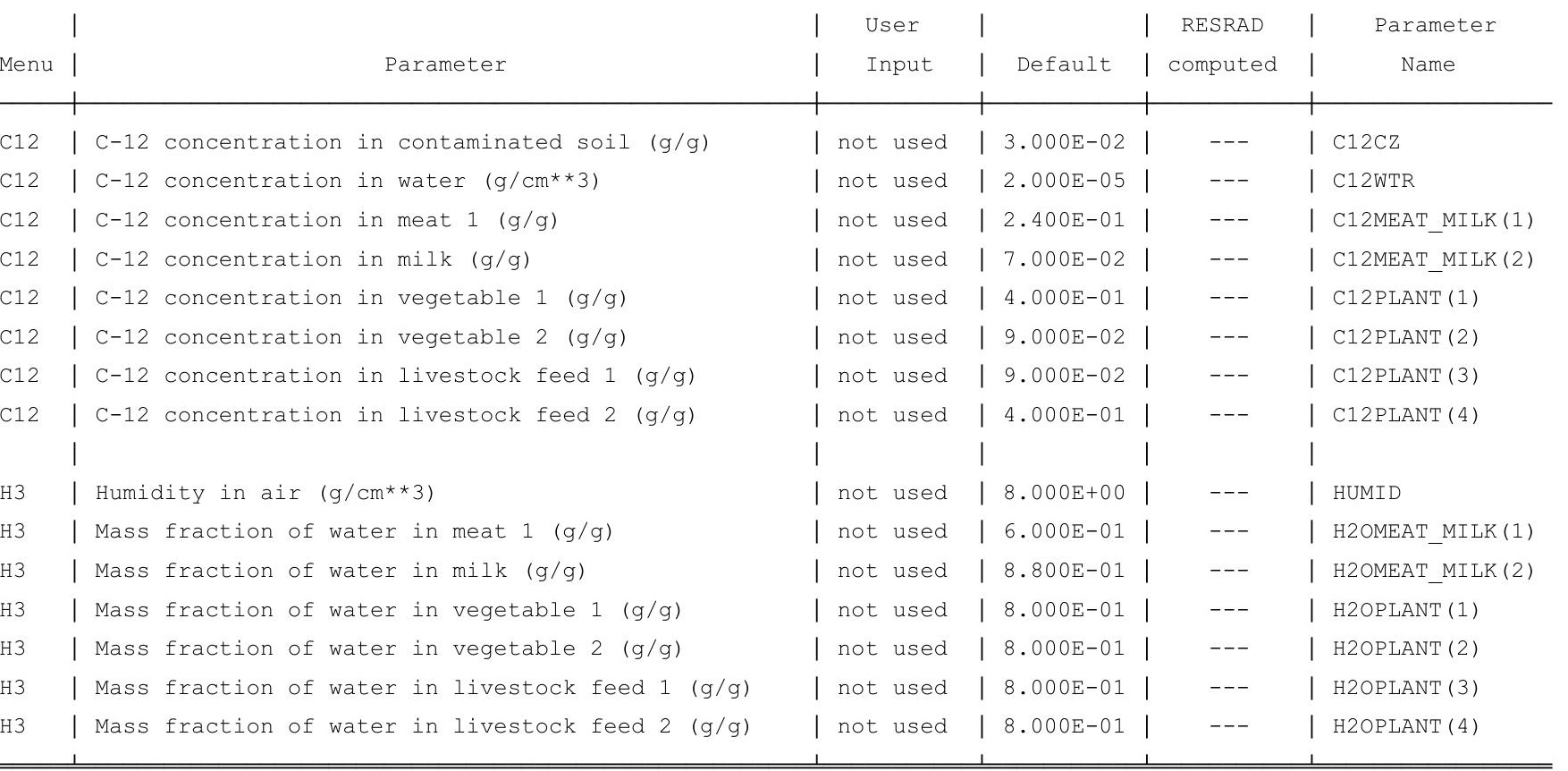

Summary of Pathway Selections

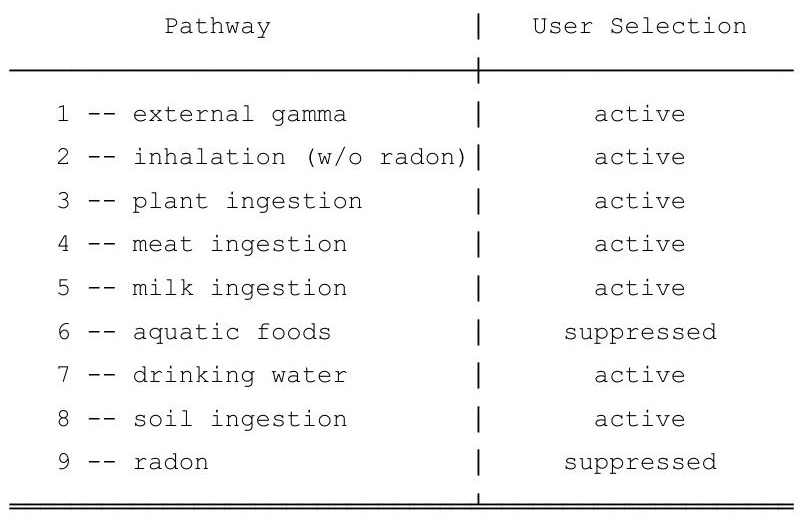


RESRAD-OFFSITE, Version $2.5 \quad \mathrm{~T}^{1 / 2}$ Limit $=180$ days

Parent Dose Report

Title : Offsite Resident Farmer Deterministic Run

File : RF FINAL v2.ROF

\section{Contaminated Zone Dimensions}

Area: 102144.00 square meters

Thickness: $\quad 13.40$ meters

Cover Depth: $\quad 1.52$ meters
Initial Soil Concentrations, pci/g

$\begin{array}{ll}\mathrm{Am}-241 & 1.000 \mathrm{E}+00 \\ \mathrm{Cs}-137 & 1.000 \mathrm{E}+00 \\ \mathrm{~Np}-237 & 1.000 \mathrm{E}+00 \\ \mathrm{Pu}-238 & 1.000 \mathrm{E}+00 \\ \mathrm{Pu}-239 & 1.000 \mathrm{E}+00 \\ \mathrm{Pu}-240 & 1.000 \mathrm{E}+00 \\ \mathrm{TC}-99 & 1.000 \mathrm{E}+00 \\ \mathrm{Th}-228 & 1.000 \mathrm{E}+00 \\ \mathrm{Th}-230 & 1.000 \mathrm{E}+00 \\ \mathrm{Th}-232 & 1.000 \mathrm{E}+00 \\ \mathrm{U}-234 & 1.000 \mathrm{E}+00 \\ \mathrm{U}-235 & 1.000 \mathrm{E}+00 \\ \mathrm{U}-238 & 1.000 \mathrm{E}+00\end{array}$

Total Dose TDOSE(t), mrem/yr

Basic Radiation Dose Limit $=1.000 \mathrm{E}+00 \mathrm{mrem} / \mathrm{yr}$

Total Mixture Sum $M(t)$ = Eraction of Basic Dose Limit Received at Time (t)

$\begin{array}{rllllllll}t \text { (years) }: & 0.000 \mathrm{E}+00 & 1.000 \mathrm{E}+00 & 5.000 \mathrm{E}+01 & 1.000 \mathrm{E}+02 & 5.000 \mathrm{E}+02 & 7.720 \mathrm{E}+02 & 1.026 \mathrm{E}+03 \\ \text { TDOSE }(\mathrm{t}): & 8.493 \mathrm{E}-15 & 6.320 \mathrm{E}-15 & 1.330 \mathrm{E}-14 & 1.763 \mathrm{E}-14 & 1.906 \mathrm{E}-02 & 3.593 \mathrm{E}-02 & 2.761 \mathrm{E}-02 \\ \mathrm{M}(\mathrm{t}): & 8.493 \mathrm{E}-15 & 6.320 \mathrm{E}-15 & 1.330 \mathrm{E}-14 & 1.763 \mathrm{E}-14 & 1.906 \mathrm{E}-02 & 3.593 \mathrm{E}-02 & 2.761 \mathrm{E}-02\end{array}$

Maximum TDOSE (t): $3.593 \mathrm{E}-02 \mathrm{mrem} / \mathrm{yr}$ at $t=772$ years

DCN 5090-TR-01-6 
RESRAD-OFFSITE, Version 2 .

Parent Dose Report

Title : Offsite Resident Farmer Deterministic Run

File : RF FINAL v2.ROF

Total Dose Contributions TDOSE (i,p,t) for Individual Radionuclides (i) and Pathways (p) in mrem/yr and as a Percentage of Total Dose at $t=0$ years

From releases to ground water and to surface water

\begin{tabular}{|c|c|c|c|c|c|c|c|c|c|c|c|c|c|c|c|c|}
\hline & \multicolumn{2}{|c|}{ Ground } & \multicolumn{2}{|l|}{ Fish } & \multicolumn{2}{|c|}{ Radon } & \multicolumn{2}{|c|}{ Plant } & \multicolumn{2}{|l|}{ Meat } & \multicolumn{2}{|l|}{ Milk } & \multicolumn{2}{|l|}{ Soil } & \multicolumn{2}{|c|}{ Water } \\
\hline clide & Dose & \% & Dose & $\%$ & Dose & \% & Dose & \% & Dose & \% & Dose & \% & Dose & \% & Dose & $\%$ \\
\hline-241 & $0.00 \mathrm{E}+00$ & 0 & $0.00 \mathrm{E}+00$ & 0 & $0.00 \mathrm{E}+00$ & 0 & $0.00 \mathrm{E}+00$ & 0 & $0.00 \mathrm{E}+00$ & 0 & $0.00 \mathrm{E}+00$ & 0 & $0.00 \mathrm{E}+00$ & 0 & $0.00 \mathrm{E}+00$ & 0 \\
\hline-137 & $0.00 \mathrm{E}+00$ & 0 & $0.00 \mathrm{E}+00$ & 0 & $0.00 \mathrm{E}+00$ & 0 & $0.00 \mathrm{E}+00$ & 0 & $0.00 \mathrm{E}+00$ & 0 & $0.00 \mathrm{E}+00$ & 0 & $0.00 \mathrm{E}+00$ & 0 & $0.00 \mathrm{E}+00$ & 0 \\
\hline-237 & $0.00 \mathrm{E}+00$ & 0 & $0.00 \mathrm{E}+00$ & 0 & $0.00 \mathrm{E}+00$ & 0 & $0.00 \mathrm{E}+00$ & 0 & $0.00 \mathrm{E}+00$ & 0 & $0.00 \mathrm{E}+00$ & 0 & $0.00 \mathrm{E}+00$ & 0 & $0.00 \mathrm{E}+00$ & 0 \\
\hline-238 & $0.00 \mathrm{E}+00$ & 0 & $0.00 \mathrm{E}+00$ & 0 & $0.00 \mathrm{E}+00$ & 0 & $0.00 \mathrm{E}+00$ & 0 & $0.00 \mathrm{E}+00$ & 0 & $0.00 \mathrm{E}+00$ & 0 & $0.00 \mathrm{E}+00$ & 0 & $0.00 \mathrm{E}+00$ & 0 \\
\hline-239 & $0.00 \mathrm{E}+00$ & 0 & $0.00 \mathrm{E}+00$ & 0 & $0.00 \mathrm{E}+00$ & 0 & $0.00 \mathrm{E}+00$ & 0 & $0.00 \mathrm{E}+00$ & 0 & $0.00 E+00$ & 0 & $0.00 \mathrm{E}+00$ & 0 & $0.00 \mathrm{E}+00$ & 0 \\
\hline-240 & $0.00 \mathrm{E}+00$ & 0 & $0.00 \mathrm{E}+00$ & 0 & $0.00 \mathrm{E}+00$ & 0 & $0.00 \mathrm{E}+00$ & 0 & $0.00 \mathrm{E}+00$ & 0 & $0.00 \mathrm{E}+00$ & 0 & $0.00 \mathrm{E}+00$ & 0 & $0.00 \mathrm{E}+00$ & 0 \\
\hline-99 & $0.00 \mathrm{E}+00$ & 0 & $0.00 E+00$ & 0 & $0.00 E+00$ & 0 & $0.00 \mathrm{E}+00$ & 0 & $0.00 \mathrm{E}+00$ & 0 & $0.00 E+00$ & 0 & $0.00 \mathrm{E}+00$ & 0 & $0.00 \mathrm{E}+00$ & 0 \\
\hline-228 & $0.00 \mathrm{E}+00$ & 0 & $0.00 \mathrm{E}+00$ & 0 & $0.00 \mathrm{E}+00$ & 0 & $0.00 \mathrm{E}+00$ & 0 & $0.00 \mathrm{E}+00$ & 0 & $0.00 \mathrm{E}+00$ & 0 & $0.00 \mathrm{E}+00$ & 0 & $0.00 \mathrm{E}+00$ & 0 \\
\hline-230 & $0.00 \mathrm{E}+00$ & 0 & $0.00 \mathrm{E}+00$ & 0 & $0.00 \mathrm{E}+00$ & 0 & $0.00 \mathrm{E}+00$ & 0 & $0.00 \mathrm{E}+00$ & 0 & $0.00 \mathrm{E}+00$ & 0 & $0.00 \mathrm{E}+00$ & 0 & $0.00 \mathrm{E}+00$ & 0 \\
\hline-232 & $0.00 \mathrm{E}+00$ & 0 & $0.00 \mathrm{E}+00$ & 0 & $0.00 \mathrm{E}+00$ & 0 & $0.00 \mathrm{E}+00$ & 0 & $0.00 \mathrm{E}+00$ & 0 & $0.00 \mathrm{E}+00$ & 0 & $0.00 \mathrm{E}+00$ & 0 & $0.00 \mathrm{E}+00$ & 0 \\
\hline 234 & $0.00 \mathrm{E}+00$ & 0 & $0.00 \mathrm{E}+00$ & 0 & $0.00 \mathrm{E}+00$ & 0 & $0.00 \mathrm{E}+00$ & 0 & $0.00 \mathrm{E}+00$ & 0 & $0.00 \mathrm{E}+00$ & 0 & $0.00 \mathrm{E}+00$ & 0 & $0.00 \mathrm{E}+00$ & 0 \\
\hline 235 & $0.00 \mathrm{E}+00$ & 0 & $0.00 \mathrm{E}+00$ & 0 & $0.00 \mathrm{E}+00$ & 0 & $0.00 \mathrm{E}+00$ & 0 & $0.00 \mathrm{E}+00$ & 0 & $0.00 E+00$ & 0 & $0.00 \mathrm{E}+00$ & 0 & $0.00 \mathrm{E}+00$ & 0 \\
\hline 38 & $0.00 \mathrm{E}+00$ & 0 & $0.00 \mathrm{E}+00$ & 0 & $0.00 \mathrm{E}+00$ & 0 & $0.00 \mathrm{E}+00$ & 0 & $0.00 \mathrm{E}+00$ & 0 & $0.00 \mathrm{E}+00$ & 0 & $0.00 \mathrm{E}+00$ & 0 & $0.00 \mathrm{E}+00$ & 0 \\
\hline & $0.00 \mathrm{E}+00$ & 0 & $0.00 \mathrm{E}+00$ & 0 & $0.00 \mathrm{E}+00$ & 0 & $0.00 \mathrm{E}+00$ & 0 & $0.00 \mathrm{E}+00$ & 0 & $0.00 \mathrm{E}+00$ & 0 & $0.00 \mathrm{E}+00$ & 0 & $0.00 \mathrm{E}+00$ & 0 \\
\hline
\end{tabular}

Total Dose Contributions TDOSE (i,p,t) for Individual Radionuclides (i) and Pathways (p)

in mrem/yr and as a Percentage of Total Dose at $t=0$ years

Directly from primary contamination and from release to atmosphere (Inhalation excludes radon)

\begin{tabular}{|c|c|c|c|c|c|c|c|c|c|c|c|c|c|c|c|c|}
\hline & \multicolumn{2}{|c|}{ Ground } & \multicolumn{2}{|c|}{ Inhalation } & \multicolumn{2}{|c|}{ Radon } & \multicolumn{2}{|c|}{ Plant } & \multicolumn{2}{|l|}{ Meat } & \multicolumn{2}{|l|}{ Milk } & \multicolumn{2}{|l|}{ Soil } & \multicolumn{2}{|c|}{ All Pathways* } \\
\hline ide & Dose & $\%$ & Dose & $\%$ & Dose & $\%$ & Dose & 음 & Dose & $\%$ & Dose & 음 & Dose & $\%$ & Dose & $\%$ \\
\hline-241 & $9.38 \mathrm{E}-28$ & 0 & $0.00 \mathrm{E}+00$ & 0 & $0.00 \mathrm{E}+00$ & 0 & $0.00 \mathrm{E}+00$ & 0 & $0.00 \mathrm{E}+00$ & 0 & $0.00 \mathrm{E}+00$ & 0 & $0.00 \mathrm{E}+00$ & 0 & $9.38 E-28$ & 0 \\
\hline-137 & $7.65 E-18$ & 0 & $0.00 E+00$ & 0 & $0.00 E+00$ & 0 & $0.00 \mathrm{E}+00$ & 0 & $0.00 \mathrm{E}+00$ & 0 & $0.00 E+00$ & 0 & $0.00 \mathrm{E}+00$ & 0 & 7. $65 \mathrm{E}-18$ & 0 \\
\hline-237 & $5.78 E-21$ & 0 & $0.00 \mathrm{E}+00$ & 0 & $0.00 E+00$ & 0 & $0.00 \mathrm{E}+00$ & 0 & $0.00 \mathrm{E}+00$ & 0 & $0.00 E+00$ & 0 & $0.00 \mathrm{E}+00$ & 0 & $5.78 E-21$ & 0 \\
\hline-238 & $6.27 E-31$ & 0 & $0.00 \mathrm{E}+00$ & 0 & $0.00 \mathrm{E}+00$ & 0 & $0.00 \mathrm{E}+00$ & 0 & $0.00 \mathrm{E}+00$ & 0 & $0.00 \mathrm{E}+00$ & 0 & $0.00 \mathrm{E}+00$ & 0 & $6.27 E-31$ & 0 \\
\hline-239 & $7.29 E-26$ & 0 & $0.00 \mathrm{E}+00$ & 0 & $0.00 \mathrm{E}+00$ & 0 & $0.00 \mathrm{E}+00$ & 0 & $0.00 \mathrm{E}+00$ & 0 & $0.00 \mathrm{E}+00$ & 0 & $0.00 \mathrm{E}+00$ & 0 & $7.29 \mathrm{E}-26$ & 0 \\
\hline-240 & $6.93 E-33$ & 0 & $0.00 \mathrm{E}+00$ & 0 & $0.00 \mathrm{E}+00$ & 0 & $0.00 \mathrm{E}+00$ & 0 & $0.00 \mathrm{E}+00$ & 0 & $0.00 \mathrm{E}+00$ & 0 & $0.00 \mathrm{E}+00$ & 0 & $6.93 E-33$ & 0 \\
\hline-99 & $3.50 E-34$ & 0 & $0.00 \mathrm{E}+00$ & 0 & $0.00 \mathrm{E}+00$ & 0 & $0.00 \mathrm{E}+00$ & 0 & $0.00 \mathrm{E}+00$ & 0 & $0.00 E+00$ & 0 & $0.00 \mathrm{E}+00$ & 0 & $3.50 E-34$ & 0 \\
\hline-228 & $8.40 \mathrm{E}-15$ & 99 & $0.00 \mathrm{E}+00$ & 0 & $0.00 \mathrm{E}+00$ & 0 & $0.00 \mathrm{E}+00$ & 0 & $0.00 \mathrm{E}+00$ & 0 & $0.00 \mathrm{E}+00$ & 0 & $0.00 \mathrm{E}+00$ & 0 & $8.40 \mathrm{E}-15$ & 99 \\
\hline-230 & $2.29 E-19$ & 0 & $0.00 E+00$ & 0 & $0.00 \mathrm{E}+00$ & 0 & $0.00 \mathrm{E}+00$ & 0 & $0.00 \mathrm{E}+00$ & 0 & $0.00 E+00$ & 0 & $0.00 \mathrm{E}+00$ & 0 & $2.29 \mathrm{E}-19$ & 0 \\
\hline-232 & $7.91 \mathrm{E}-17$ & 1 & $0.00 \mathrm{E}+00$ & 0 & $0.00 \mathrm{E}+00$ & 0 & $0.00 \mathrm{E}+00$ & 0 & $0.00 \mathrm{E}+00$ & 0 & $0.00 \mathrm{E}+00$ & 0 & $0.00 \mathrm{E}+00$ & 0 & $7.91 \mathrm{E}-17$ & 1 \\
\hline 34 & $7.79 E-25$ & 0 & $0.00 \mathrm{E}+00$ & 0 & $0.00 \mathrm{E}+00$ & 0 & $0.00 \mathrm{E}+00$ & 0 & $0.00 \mathrm{E}+00$ & 0 & $0.00 \mathrm{E}+00$ & 0 & $0.00 \mathrm{E}+00$ & 0 & $7.79 \mathrm{E}-25$ & 0 \\
\hline 235 & $7.54 \mathrm{E}-23$ & 0 & $0.00 \mathrm{E}+00$ & 0 & $0.00 \mathrm{E}+00$ & 0 & $0.00 \mathrm{E}+00$ & 0 & $0.00 \mathrm{E}+00$ & 0 & $0.00 \mathrm{E}+00$ & 0 & $0.00 \mathrm{E}+00$ & 0 & $7.54 \mathrm{E}-23$ & 0 \\
\hline 38 & $8.61 E-19$ & 0 & $0.00 \mathrm{E}+00$ & 0 & $0.00 \mathrm{E}+00$ & 0 & $0.00 \mathrm{E}+00$ & 0 & $0.00 \mathrm{E}+00$ & 0 & $0.00 E+00$ & 0 & $0.00 \mathrm{E}+00$ & 0 & 8. $61 \mathrm{E}-19$ & 0 \\
\hline & $8.49 \mathrm{E}-15$ & 100 & $0.00 \mathrm{E}+00$ & 0 & $0.00 \mathrm{E}+00$ & 0 & $0.00 \mathrm{E}+00$ & 0 & $0.00 \mathrm{E}+00$ & 0 & $0.00 E+00$ & 0 & $0.00 \mathrm{E}+00$ & 0 & $8.49 \mathrm{E}-15$ & 100 \\
\hline
\end{tabular}

* Sum of dose from all releases and from primary contamination. 
RESRAD-OFFSITE, Version 2 .

Parent Dose Report

Title : Offsite Resident Farmer Deterministic Run

File : RF FINAL v2.ROF

Total Dose Contributions TDOSE (i,p,t) for Individual Radionuclides (i) and Pathways (p) in mrem/yr and as a Percentage of Total Dose at $t=1$ years

From releases to ground water and to surface water

\begin{tabular}{|c|c|c|c|c|c|c|c|c|c|c|c|c|c|c|c|c|}
\hline & \multicolumn{2}{|c|}{ Ground } & \multicolumn{2}{|l|}{ Fish } & \multicolumn{2}{|c|}{ Radon } & \multicolumn{2}{|c|}{ Plant } & \multicolumn{2}{|l|}{ Meat } & \multicolumn{2}{|l|}{ Milk } & \multicolumn{2}{|l|}{ Soil } & \multicolumn{2}{|c|}{ Water } \\
\hline clide & Dose & \% & Dose & $\%$ & Dose & \% & Dose & \% & Dose & \% & Dose & \% & Dose & \% & Dose & $\%$ \\
\hline-241 & $0.00 \mathrm{E}+00$ & 0 & $0.00 \mathrm{E}+00$ & 0 & $0.00 \mathrm{E}+00$ & 0 & $0.00 \mathrm{E}+00$ & 0 & $0.00 \mathrm{E}+00$ & 0 & $0.00 \mathrm{E}+00$ & 0 & $0.00 \mathrm{E}+00$ & 0 & $0.00 \mathrm{E}+00$ & 0 \\
\hline-137 & $0.00 \mathrm{E}+00$ & 0 & $0.00 \mathrm{E}+00$ & 0 & $0.00 \mathrm{E}+00$ & 0 & $0.00 \mathrm{E}+00$ & 0 & $0.00 \mathrm{E}+00$ & 0 & $0.00 \mathrm{E}+00$ & 0 & $0.00 \mathrm{E}+00$ & 0 & $0.00 \mathrm{E}+00$ & 0 \\
\hline-237 & $0.00 \mathrm{E}+00$ & 0 & $0.00 \mathrm{E}+00$ & 0 & $0.00 \mathrm{E}+00$ & 0 & $0.00 \mathrm{E}+00$ & 0 & $0.00 \mathrm{E}+00$ & 0 & $0.00 \mathrm{E}+00$ & 0 & $0.00 \mathrm{E}+00$ & 0 & $0.00 \mathrm{E}+00$ & 0 \\
\hline-238 & $0.00 \mathrm{E}+00$ & 0 & $0.00 \mathrm{E}+00$ & 0 & $0.00 \mathrm{E}+00$ & 0 & $0.00 \mathrm{E}+00$ & 0 & $0.00 \mathrm{E}+00$ & 0 & $0.00 \mathrm{E}+00$ & 0 & $0.00 \mathrm{E}+00$ & 0 & $0.00 \mathrm{E}+00$ & 0 \\
\hline-239 & $0.00 \mathrm{E}+00$ & 0 & $0.00 \mathrm{E}+00$ & 0 & $0.00 \mathrm{E}+00$ & 0 & $0.00 \mathrm{E}+00$ & 0 & $0.00 \mathrm{E}+00$ & 0 & $0.00 E+00$ & 0 & $0.00 \mathrm{E}+00$ & 0 & $0.00 \mathrm{E}+00$ & 0 \\
\hline-240 & $0.00 \mathrm{E}+00$ & 0 & $0.00 \mathrm{E}+00$ & 0 & $0.00 \mathrm{E}+00$ & 0 & $0.00 \mathrm{E}+00$ & 0 & $0.00 \mathrm{E}+00$ & 0 & $0.00 \mathrm{E}+00$ & 0 & $0.00 \mathrm{E}+00$ & 0 & $0.00 \mathrm{E}+00$ & 0 \\
\hline-99 & $0.00 \mathrm{E}+00$ & 0 & $0.00 E+00$ & 0 & $0.00 E+00$ & 0 & $0.00 \mathrm{E}+00$ & 0 & $0.00 \mathrm{E}+00$ & 0 & $0.00 E+00$ & 0 & $0.00 \mathrm{E}+00$ & 0 & $0.00 \mathrm{E}+00$ & 0 \\
\hline-228 & $0.00 \mathrm{E}+00$ & 0 & $0.00 \mathrm{E}+00$ & 0 & $0.00 \mathrm{E}+00$ & 0 & $0.00 \mathrm{E}+00$ & 0 & $0.00 \mathrm{E}+00$ & 0 & $0.00 \mathrm{E}+00$ & 0 & $0.00 \mathrm{E}+00$ & 0 & $0.00 \mathrm{E}+00$ & 0 \\
\hline-230 & $0.00 \mathrm{E}+00$ & 0 & $0.00 \mathrm{E}+00$ & 0 & $0.00 \mathrm{E}+00$ & 0 & $0.00 \mathrm{E}+00$ & 0 & $0.00 \mathrm{E}+00$ & 0 & $0.00 \mathrm{E}+00$ & 0 & $0.00 \mathrm{E}+00$ & 0 & $0.00 \mathrm{E}+00$ & 0 \\
\hline-232 & $0.00 \mathrm{E}+00$ & 0 & $0.00 \mathrm{E}+00$ & 0 & $0.00 \mathrm{E}+00$ & 0 & $0.00 \mathrm{E}+00$ & 0 & $0.00 \mathrm{E}+00$ & 0 & $0.00 \mathrm{E}+00$ & 0 & $0.00 \mathrm{E}+00$ & 0 & $0.00 \mathrm{E}+00$ & 0 \\
\hline 234 & $0.00 \mathrm{E}+00$ & 0 & $0.00 \mathrm{E}+00$ & 0 & $0.00 \mathrm{E}+00$ & 0 & $0.00 \mathrm{E}+00$ & 0 & $0.00 \mathrm{E}+00$ & 0 & $0.00 \mathrm{E}+00$ & 0 & $0.00 \mathrm{E}+00$ & 0 & $0.00 \mathrm{E}+00$ & 0 \\
\hline 235 & $0.00 \mathrm{E}+00$ & 0 & $0.00 \mathrm{E}+00$ & 0 & $0.00 \mathrm{E}+00$ & 0 & $0.00 \mathrm{E}+00$ & 0 & $0.00 \mathrm{E}+00$ & 0 & $0.00 E+00$ & 0 & $0.00 \mathrm{E}+00$ & 0 & $0.00 \mathrm{E}+00$ & 0 \\
\hline 38 & $0.00 \mathrm{E}+00$ & 0 & $0.00 \mathrm{E}+00$ & 0 & $0.00 \mathrm{E}+00$ & 0 & $0.00 \mathrm{E}+00$ & 0 & $0.00 \mathrm{E}+00$ & 0 & $0.00 \mathrm{E}+00$ & 0 & $0.00 \mathrm{E}+00$ & 0 & $0.00 \mathrm{E}+00$ & 0 \\
\hline & $0.00 \mathrm{E}+00$ & 0 & $0.00 \mathrm{E}+00$ & 0 & $0.00 \mathrm{E}+00$ & 0 & $0.00 \mathrm{E}+00$ & 0 & $0.00 \mathrm{E}+00$ & 0 & $0.00 \mathrm{E}+00$ & 0 & $0.00 \mathrm{E}+00$ & 0 & $0.00 \mathrm{E}+00$ & 0 \\
\hline
\end{tabular}

Total Dose Contributions TDOSE (i,p,t) for Individual Radionuclides (i) and Pathways (p)

in mrem/yr and as a Percentage of Total Dose at $t=1$ years

Directly from primary contamination and from release to atmosphere (Inhalation excludes radon)

\begin{tabular}{|c|c|c|c|c|c|c|c|c|c|c|c|c|c|c|c|c|}
\hline & \multicolumn{2}{|c|}{ Ground } & \multicolumn{2}{|c|}{ Inhalation } & \multicolumn{2}{|c|}{ Radon } & \multicolumn{2}{|c|}{ Plant } & \multicolumn{2}{|l|}{ Meat } & \multicolumn{2}{|l|}{ Milk } & \multicolumn{2}{|l|}{ Soil } & \multicolumn{2}{|c|}{ All Pathways* } \\
\hline clide & Dose & \% & Dose & $\%$ & Dose & $\%$ & Dose & 음 & Dose & $\%$ & Dose & $\%$ & Dose & \% & Dose & $\frac{\circ}{0}$ \\
\hline-241 & $2.84 E-27$ & 0 & $0.00 E+00$ & 0 & $0.00 \mathrm{E}+00$ & 0 & $0.00 \mathrm{E}+00$ & 0 & $0.00 \mathrm{E}+00$ & 0 & $0.00 \mathrm{E}+00$ & 0 & $0.00 \mathrm{E}+00$ & 0 & $2.84 \mathrm{E}-27$ & 0 \\
\hline-137 & $7.53 \mathrm{E}-18$ & 0 & $0.00 \mathrm{E}+00$ & 0 & $0.00 \mathrm{E}+00$ & 0 & $0.00 \mathrm{E}+00$ & 0 & $0.00 \mathrm{E}+00$ & 0 & $0.00 \mathrm{E}+00$ & 0 & $0.00 \mathrm{E}+00$ & 0 & 7. $53 \mathrm{E}-18$ & 0 \\
\hline-237 & $5.84 \mathrm{E}-21$ & 0 & $0.00 \mathrm{E}+00$ & 0 & $0.00 \mathrm{E}+00$ & 0 & $0.00 \mathrm{E}+00$ & 0 & $0.00 \mathrm{E}+00$ & 0 & $0.00 \mathrm{E}+00$ & 0 & $0.00 \mathrm{E}+00$ & 0 & $5.84 \mathrm{E}-21$ & 0 \\
\hline-238 & $7.82 \mathrm{E}-30$ & 0 & $0.00 \mathrm{E}+00$ & 0 & $0.00 \mathrm{E}+00$ & 0 & $0.00 \mathrm{E}+00$ & 0 & $0.00 \mathrm{E}+00$ & 0 & $0.00 \mathrm{E}+00$ & 0 & $0.00 \mathrm{E}+00$ & 0 & $7.82 \mathrm{E}-30$ & 0 \\
\hline-239 & $7.37 \mathrm{E}-26$ & 0 & $0.00 \mathrm{E}+00$ & 0 & $0.00 \mathrm{E}+00$ & 0 & $0.00 \mathrm{E}+00$ & 0 & $0.00 \mathrm{E}+00$ & 0 & $0.00 \mathrm{E}+00$ & 0 & $0.00 \mathrm{E}+00$ & 0 & $7.37 \mathrm{E}-26$ & 0 \\
\hline-240 & $7.20 E-33$ & 0 & $0.00 \mathrm{E}+00$ & 0 & $0.00 \mathrm{E}+00$ & 0 & $0.00 \mathrm{E}+00$ & 0 & $0.00 \mathrm{E}+00$ & 0 & $0.00 \mathrm{E}+00$ & 0 & $0.00 \mathrm{E}+00$ & 0 & $7.20 E-33$ & 0 \\
\hline-99 & $3.54 E-34$ & 0 & $0.00 \mathrm{E}+00$ & 0 & $0.00 \mathrm{E}+00$ & 0 & $0.00 E+00$ & 0 & $0.00 \mathrm{E}+00$ & 0 & $0.00 \mathrm{E}+00$ & 0 & $0.00 \mathrm{E}+00$ & 0 & $3.54 E-34$ & 0 \\
\hline-228 & $5.89 \mathrm{E}-15$ & 93 & $0.00 \mathrm{E}+00$ & 0 & $0.00 \mathrm{E}+00$ & 0 & $0.00 \mathrm{E}+00$ & 0 & $0.00 \mathrm{E}+00$ & 0 & $0.00 \mathrm{E}+00$ & 0 & $0.00 \mathrm{E}+00$ & 0 & $5.89 E-15$ & 93 \\
\hline-230 & $6.90 \mathrm{E}-19$ & 0 & $0.00 \mathrm{E}+00$ & 0 & $0.00 \mathrm{E}+00$ & 0 & $0.00 \mathrm{E}+00$ & 0 & $0.00 \mathrm{E}+00$ & 0 & $0.00 \mathrm{E}+00$ & 0 & $0.00 \mathrm{E}+00$ & 0 & $6.90 \mathrm{E}-19$ & 0 \\
\hline-232 & $4.24 \mathrm{E}-16$ & 7 & $0.00 \mathrm{E}+00$ & 0 & $0.00 \mathrm{E}+00$ & 0 & $0.00 \mathrm{E}+00$ & 0 & $0.00 \mathrm{E}+00$ & 0 & $0.00 \mathrm{E}+00$ & 0 & $0.00 \mathrm{E}+00$ & 0 & $4.24 \mathrm{E}-16$ & 7 \\
\hline 234 & $4.95 E-24$ & 0 & $0.00 E+00$ & 0 & $0.00 \mathrm{E}+00$ & 0 & $0.00 E+00$ & 0 & $0.00 \mathrm{E}+00$ & 0 & $0.00 \mathrm{E}+00$ & 0 & $0.00 \mathrm{E}+00$ & 0 & $4.95 E-24$ & 0 \\
\hline 235 & $7.67 \mathrm{E}-23$ & 0 & $0.00 \mathrm{E}+00$ & 0 & $0.00 \mathrm{E}+00$ & 0 & $0.00 \mathrm{E}+00$ & 0 & $0.00 \mathrm{E}+00$ & 0 & $0.00 \mathrm{E}+00$ & 0 & $0.00 \mathrm{E}+00$ & 0 & $7.67 \mathrm{E}-23$ & 0 \\
\hline 38 & $8.67 \mathrm{E}-19$ & 0 & $0.00 \mathrm{E}+00$ & 0 & $0.00 \mathrm{E}+00$ & 0 & $0.00 \mathrm{E}+00$ & 0 & $0.00 \mathrm{E}+00$ & 0 & $0.00 \mathrm{E}+00$ & 0 & $0.00 \mathrm{E}+00$ & 0 & $8.67 \mathrm{E}-19$ & 0 \\
\hline & $6.32 \mathrm{E}-15$ & 100 & $0.00 \mathrm{E}+00$ & 0 & $0.00 \mathrm{E}+00$ & 0 & $0.00 \mathrm{E}+00$ & 0 & $0.00 \mathrm{E}+00$ & 0 & $0.00 \mathrm{E}+00$ & 0 & $0.00 \mathrm{E}+00$ & 0 & $6.32 \mathrm{E}-15$ & 100 \\
\hline
\end{tabular}

* Sum of dose from all releases and from primary contamination. 
RESRAD-OFFSITE, Version 2 .

Parent Dose Report

Title : Offsite Resident Farmer Deterministic Run

File : RF FINAL v2.ROF

Total Dose Contributions TDOSE (i,p,t) for Individual Radionuclides (i) and Pathways (p) in mrem/yr and as a Percentage of Total Dose at $t=50$ years

From releases to ground water and to surface water

\begin{tabular}{|c|c|c|c|c|c|c|c|c|c|c|c|c|c|c|c|c|}
\hline & \multicolumn{2}{|c|}{ Ground } & \multicolumn{2}{|l|}{ Fish } & \multicolumn{2}{|c|}{ Radon } & \multicolumn{2}{|c|}{ Plant } & \multicolumn{2}{|l|}{ Meat } & \multicolumn{2}{|l|}{ Milk } & \multicolumn{2}{|l|}{ Soil } & \multicolumn{2}{|c|}{ Water } \\
\hline ide & Dose & $\%$ & Dose & $\%$ & Dose & 응 & Dose & $\frac{\circ}{0}$ & Dose & 응 & Dose & 응 & Dose & $\%$ & Dose & $\%$ \\
\hline-241 & $0.00 \mathrm{E}+00$ & 0 & $0.00 E+00$ & 0 & $0.00 \mathrm{E}+00$ & 0 & $0.00 \mathrm{E}+00$ & 0 & $0.00 \mathrm{E}+00$ & 0 & $0.00 \mathrm{E}+00$ & 0 & $0.00 \mathrm{E}+00$ & 0 & $0.00 \mathrm{E}+00$ & 0 \\
\hline-137 & $0.00 \mathrm{E}+00$ & 0 & $0.00 \mathrm{E}+00$ & 0 & $0.00 \mathrm{E}+00$ & 0 & $0.00 \mathrm{E}+00$ & 0 & $0.00 \mathrm{E}+00$ & 0 & $0.00 \mathrm{E}+00$ & 0 & $0.00 \mathrm{E}+00$ & 0 & $0.00 \mathrm{E}+00$ & 0 \\
\hline-237 & $0.00 \mathrm{E}+00$ & 0 & $0.00 \mathrm{E}+00$ & 0 & $0.00 \mathrm{E}+00$ & 0 & $0.00 \mathrm{E}+00$ & 0 & $0.00 \mathrm{E}+00$ & 0 & $0.00 \mathrm{E}+00$ & 0 & $0.00 \mathrm{E}+00$ & 0 & $0.00 \mathrm{E}+00$ & 0 \\
\hline-238 & $0.00 \mathrm{E}+00$ & 0 & $0.00 \mathrm{E}+00$ & 0 & $0.00 E+00$ & 0 & $0.00 \mathrm{E}+00$ & 0 & $0.00 \mathrm{E}+00$ & 0 & $0.00 E+00$ & 0 & $0.00 \mathrm{E}+00$ & 0 & $0.00 \mathrm{E}+00$ & 0 \\
\hline-239 & $0.00 \mathrm{E}+00$ & 0 & $0.00 \mathrm{E}+00$ & 0 & $0.00 \mathrm{E}+00$ & 0 & $0.00 \mathrm{E}+00$ & 0 & $0.00 \mathrm{E}+00$ & 0 & $0.00 \mathrm{E}+00$ & 0 & $0.00 \mathrm{E}+00$ & 0 & $0.00 \mathrm{E}+00$ & 0 \\
\hline-240 & $0.00 \mathrm{E}+00$ & 0 & $0.00 \mathrm{E}+00$ & 0 & $0.00 \mathrm{E}+00$ & 0 & $0.00 \mathrm{E}+00$ & 0 & $0.00 \mathrm{E}+00$ & 0 & $0.00 \mathrm{E}+00$ & 0 & $0.00 \mathrm{E}+00$ & 0 & $0.00 \mathrm{E}+00$ & 0 \\
\hline-99 & $0.00 \mathrm{E}+00$ & 0 & $0.00 \mathrm{E}+00$ & 0 & $0.00 \mathrm{E}+00$ & 0 & $0.00 \mathrm{E}+00$ & 0 & $0.00 \mathrm{E}+00$ & 0 & $0.00 E+00$ & 0 & $0.00 \mathrm{E}+00$ & 0 & $0.00 \mathrm{E}+00$ & 0 \\
\hline-228 & $0.00 \mathrm{E}+00$ & 0 & $0.00 \mathrm{E}+00$ & 0 & $0.00 \mathrm{E}+00$ & 0 & $0.00 \mathrm{E}+00$ & 0 & $0.00 \mathrm{E}+00$ & 0 & $0.00 \mathrm{E}+00$ & 0 & $0.00 \mathrm{E}+00$ & 0 & $0.00 \mathrm{E}+00$ & 0 \\
\hline-230 & $0.00 \mathrm{E}+00$ & 0 & $0.00 \mathrm{E}+00$ & 0 & $0.00 \mathrm{E}+00$ & 0 & $0.00 \mathrm{E}+00$ & 0 & $0.00 \mathrm{E}+00$ & 0 & $0.00 \mathrm{E}+00$ & 0 & $0.00 \mathrm{E}+00$ & 0 & $0.00 \mathrm{E}+00$ & 0 \\
\hline-232 & $0.00 \mathrm{E}+00$ & 0 & $0.00 \mathrm{E}+00$ & 0 & $0.00 \mathrm{E}+00$ & 0 & $0.00 \mathrm{E}+00$ & 0 & $0.00 \mathrm{E}+00$ & 0 & $0.00 \mathrm{E}+00$ & 0 & $0.00 \mathrm{E}+00$ & 0 & $0.00 \mathrm{E}+00$ & 0 \\
\hline 34 & $0.00 \mathrm{E}+00$ & 0 & $0.00 \mathrm{E}+00$ & 0 & $0.00 \mathrm{E}+00$ & 0 & $0.00 \mathrm{E}+00$ & 0 & $0.00 \mathrm{E}+00$ & 0 & $0.00 \mathrm{E}+00$ & 0 & $0.00 \mathrm{E}+00$ & 0 & $0.00 \mathrm{E}+00$ & 0 \\
\hline 35 & $0.00 \mathrm{E}+00$ & 0 & $0.00 \mathrm{E}+00$ & 0 & $0.00 \mathrm{E}+00$ & 0 & $0.00 \mathrm{E}+00$ & 0 & $0.00 \mathrm{E}+00$ & 0 & $0.00 \mathrm{E}+00$ & 0 & $0.00 \mathrm{E}+00$ & 0 & $0.00 \mathrm{E}+00$ & 0 \\
\hline 38 & $0.00 \mathrm{E}+00$ & 0 & $0.00 \mathrm{E}+00$ & 0 & $0.00 E+00$ & 0 & $0.00 \mathrm{E}+00$ & 0 & $0.00 \mathrm{E}+00$ & 0 & $0.00 E+00$ & 0 & $0.00 \mathrm{E}+00$ & 0 & $0.00 \mathrm{E}+00$ & 0 \\
\hline & $0.00 \mathrm{E}+00$ & 0 & $0.00 E+00$ & 0 & $0.00 \mathrm{E}+00$ & 0 & $0.00 \mathrm{E}+00$ & 0 & $0.00 \mathrm{E}+00$ & 0 & $0.00 \mathrm{E}+00$ & 0 & $0.00 \mathrm{E}+00$ & 0 & $0.00 \mathrm{E}+00$ & 0 \\
\hline
\end{tabular}

Total Dose Contributions TDOSE(i,p,t) for Individual Radionuclides (i) and Pathways (p) in mrem/yr and as a Percentage of Total Dose at $t=50$ years

Directly from primary contamination and from release to atmosphere (Inhalation excludes radon)

\begin{tabular}{|c|c|c|c|c|c|c|c|c|c|c|c|c|c|c|c|c|}
\hline & \multicolumn{2}{|c|}{ Ground } & \multicolumn{2}{|c|}{ Inhalation } & \multicolumn{2}{|c|}{ Radon } & \multicolumn{2}{|c|}{ Plant } & \multicolumn{2}{|l|}{ Meat } & \multicolumn{2}{|l|}{ Milk } & \multicolumn{2}{|l|}{ Soil } & \multicolumn{2}{|c|}{ All Pathways* } \\
\hline clide & Dose & $\%$ & Dose & \% & Dose & $\%$ & Dose & 음 & Dose & $\%$ & Dose & 음 & Dose & $\%$ & Dose & $\%$ \\
\hline-241 & 1. $49 \mathrm{E}-25$ & 0 & $0.00 \mathrm{E}+00$ & 0 & $0.00 \mathrm{E}+00$ & 0 & $0.00 \mathrm{E}+00$ & 0 & $0.00 \mathrm{E}+00$ & 0 & $0.00 \mathrm{E}+00$ & 0 & $0.00 \mathrm{E}+00$ & 0 & $1.49 \mathrm{E}-25$ & 0 \\
\hline-137 & $3.55 E-18$ & 0 & $0.00 E+00$ & 0 & $0.00 E+00$ & 0 & $0.00 \mathrm{E}+00$ & 0 & $0.00 \mathrm{E}+00$ & 0 & $0.00 E+00$ & 0 & $0.00 \mathrm{E}+00$ & 0 & $3.55 E-18$ & 0 \\
\hline-237 & $9.49 E-21$ & 0 & $0.00 \mathrm{E}+00$ & 0 & $0.00 E+00$ & 0 & $0.00 \mathrm{E}+00$ & 0 & $0.00 \mathrm{E}+00$ & 0 & $0.00 E+00$ & 0 & $0.00 \mathrm{E}+00$ & 0 & $9.49 \mathrm{E}-21$ & 0 \\
\hline-238 & $3.11 E-25$ & 0 & $0.00 \mathrm{E}+00$ & 0 & $0.00 \mathrm{E}+00$ & 0 & $0.00 \mathrm{E}+00$ & 0 & $0.00 \mathrm{E}+00$ & 0 & $0.00 \mathrm{E}+00$ & 0 & $0.00 \mathrm{E}+00$ & 0 & $3.11 \mathrm{E}-25$ & 0 \\
\hline-239 & 1. $26 \mathrm{E}-25$ & 0 & $0.00 \mathrm{E}+00$ & 0 & $0.00 \mathrm{E}+00$ & 0 & $0.00 \mathrm{E}+00$ & 0 & $0.00 \mathrm{E}+00$ & 0 & $0.00 \mathrm{E}+00$ & 0 & $0.00 \mathrm{E}+00$ & 0 & $1.26 \mathrm{E}-25$ & 0 \\
\hline-240 & $1.59 \mathrm{E}-29$ & 0 & $0.00 \mathrm{E}+00$ & 0 & $0.00 \mathrm{E}+00$ & 0 & $0.00 \mathrm{E}+00$ & 0 & $0.00 \mathrm{E}+00$ & 0 & $0.00 E+00$ & 0 & $0.00 \mathrm{E}+00$ & 0 & $1.59 \mathrm{E}-29$ & 0 \\
\hline-99 & $6.50 E-34$ & 0 & $0.00 \mathrm{E}+00$ & 0 & $0.00 \mathrm{E}+00$ & 0 & $0.00 \mathrm{E}+00$ & 0 & $0.00 \mathrm{E}+00$ & 0 & $0.00 E+00$ & 0 & $0.00 \mathrm{E}+00$ & 0 & $6.50 E-34$ & 0 \\
\hline-228 & 1. $51 \mathrm{E}-22$ & 0 & $0.00 \mathrm{E}+00$ & 0 & $0.00 \mathrm{E}+00$ & 0 & $0.00 \mathrm{E}+00$ & 0 & $0.00 \mathrm{E}+00$ & 0 & $0.00 \mathrm{E}+00$ & 0 & $0.00 \mathrm{E}+00$ & 0 & 1. $51 \mathrm{E}-22$ & 0 \\
\hline-230 & $3.14 \mathrm{E}-17$ & 0 & $0.00 \mathrm{E}+00$ & 0 & $0.00 \mathrm{E}+00$ & 0 & $0.00 \mathrm{E}+00$ & 0 & $0.00 \mathrm{E}+00$ & 0 & $0.00 \mathrm{E}+00$ & 0 & $0.00 \mathrm{E}+00$ & 0 & $3.14 \mathrm{E}-17$ & 0 \\
\hline-232 & $1.33 E-14$ & 100 & $0.00 \mathrm{E}+00$ & 0 & $0.00 \mathrm{E}+00$ & 0 & $0.00 \mathrm{E}+00$ & 0 & $0.00 \mathrm{E}+00$ & 0 & $0.00 \mathrm{E}+00$ & 0 & $0.00 \mathrm{E}+00$ & 0 & 1. $33 \mathrm{E}-14$ & 100 \\
\hline 34 & $7.16 \mathrm{E}-21$ & 0 & $0.00 \mathrm{E}+00$ & 0 & $0.00 \mathrm{E}+00$ & 0 & $0.00 \mathrm{E}+00$ & 0 & $0.00 \mathrm{E}+00$ & 0 & $0.00 \mathrm{E}+00$ & 0 & $0.00 \mathrm{E}+00$ & 0 & $7.16 \mathrm{E}-21$ & 0 \\
\hline 35 & $5.39 \mathrm{E}-22$ & 0 & $0.00 \mathrm{E}+00$ & 0 & $0.00 \mathrm{E}+00$ & 0 & $0.00 \mathrm{E}+00$ & 0 & $0.00 \mathrm{E}+00$ & 0 & $0.00 \mathrm{E}+00$ & 0 & $0.00 \mathrm{E}+00$ & 0 & $5.39 \mathrm{E}-22$ & 0 \\
\hline 38 & 1. $24 \mathrm{E}-18$ & 0 & $0.00 \mathrm{E}+00$ & 0 & $0.00 \mathrm{E}+00$ & 0 & $0.00 \mathrm{E}+00$ & 0 & $0.00 \mathrm{E}+00$ & 0 & $0.00 E+00$ & 0 & $0.00 \mathrm{E}+00$ & 0 & 1. $24 \mathrm{E}-18$ & 0 \\
\hline & 1. $33 \mathrm{E}-14$ & 100 & $0.00 \mathrm{E}+00$ & 0 & $0.00 \mathrm{E}+00$ & 0 & $0.00 \mathrm{E}+00$ & 0 & $0.00 \mathrm{E}+00$ & 0 & $0.00 \mathrm{E}+00$ & 0 & $0.00 \mathrm{E}+00$ & 0 & 1. $33 \mathrm{E}-14$ & 100 \\
\hline
\end{tabular}

* Sum of dose from all releases and from primary contamination. 
RESRAD-OFFSITE, Version 2.

Parent Dose Report

Title : Offsite Resident Farmer Deterministic Run

File : RF FINAL v2.ROF

Total Dose Contributions TDOSE (i,p,t) for Individual Radionuclides (i) and Pathways (p) in mrem/yr and as a Percentage of Total Dose at $t=100$ years

From releases to ground water and to surface water

\begin{tabular}{|c|c|c|c|c|c|c|c|c|c|c|c|c|c|c|c|c|}
\hline & \multicolumn{2}{|c|}{ Ground } & \multicolumn{2}{|l|}{ Fish } & \multicolumn{2}{|c|}{ Radon } & \multicolumn{2}{|c|}{ Plant } & \multicolumn{2}{|l|}{ Meat } & \multicolumn{2}{|l|}{ Milk } & \multicolumn{2}{|l|}{ Soil } & \multicolumn{2}{|c|}{ Water } \\
\hline ide & Dose & $\%$ & Dose & $\%$ & Dose & 응 & Dose & $\frac{\circ}{0}$ & Dose & 응 & Dose & 응 & Dose & $\%$ & Dose & $\%$ \\
\hline-241 & $0.00 \mathrm{E}+00$ & 0 & $0.00 E+00$ & 0 & $0.00 \mathrm{E}+00$ & 0 & $0.00 \mathrm{E}+00$ & 0 & $0.00 \mathrm{E}+00$ & 0 & $0.00 \mathrm{E}+00$ & 0 & $0.00 \mathrm{E}+00$ & 0 & $0.00 \mathrm{E}+00$ & 0 \\
\hline-137 & $0.00 \mathrm{E}+00$ & 0 & $0.00 \mathrm{E}+00$ & 0 & $0.00 \mathrm{E}+00$ & 0 & $0.00 \mathrm{E}+00$ & 0 & $0.00 \mathrm{E}+00$ & 0 & $0.00 \mathrm{E}+00$ & 0 & $0.00 \mathrm{E}+00$ & 0 & $0.00 \mathrm{E}+00$ & 0 \\
\hline-237 & $0.00 \mathrm{E}+00$ & 0 & $0.00 \mathrm{E}+00$ & 0 & $0.00 \mathrm{E}+00$ & 0 & $0.00 \mathrm{E}+00$ & 0 & $0.00 \mathrm{E}+00$ & 0 & $0.00 \mathrm{E}+00$ & 0 & $0.00 \mathrm{E}+00$ & 0 & $0.00 \mathrm{E}+00$ & 0 \\
\hline-238 & $0.00 \mathrm{E}+00$ & 0 & $0.00 \mathrm{E}+00$ & 0 & $0.00 E+00$ & 0 & $0.00 \mathrm{E}+00$ & 0 & $0.00 \mathrm{E}+00$ & 0 & $0.00 E+00$ & 0 & $0.00 \mathrm{E}+00$ & 0 & $0.00 \mathrm{E}+00$ & 0 \\
\hline-239 & $0.00 \mathrm{E}+00$ & 0 & $0.00 \mathrm{E}+00$ & 0 & $0.00 \mathrm{E}+00$ & 0 & $0.00 \mathrm{E}+00$ & 0 & $0.00 \mathrm{E}+00$ & 0 & $0.00 \mathrm{E}+00$ & 0 & $0.00 \mathrm{E}+00$ & 0 & $0.00 \mathrm{E}+00$ & 0 \\
\hline-240 & $0.00 \mathrm{E}+00$ & 0 & $0.00 \mathrm{E}+00$ & 0 & $0.00 \mathrm{E}+00$ & 0 & $0.00 \mathrm{E}+00$ & 0 & $0.00 \mathrm{E}+00$ & 0 & $0.00 \mathrm{E}+00$ & 0 & $0.00 \mathrm{E}+00$ & 0 & $0.00 \mathrm{E}+00$ & 0 \\
\hline-99 & $0.00 \mathrm{E}+00$ & 0 & $0.00 \mathrm{E}+00$ & 0 & $0.00 \mathrm{E}+00$ & 0 & $0.00 \mathrm{E}+00$ & 0 & $0.00 \mathrm{E}+00$ & 0 & $0.00 E+00$ & 0 & $0.00 \mathrm{E}+00$ & 0 & $0.00 \mathrm{E}+00$ & 0 \\
\hline-228 & $0.00 \mathrm{E}+00$ & 0 & $0.00 \mathrm{E}+00$ & 0 & $0.00 \mathrm{E}+00$ & 0 & $0.00 \mathrm{E}+00$ & 0 & $0.00 \mathrm{E}+00$ & 0 & $0.00 \mathrm{E}+00$ & 0 & $0.00 \mathrm{E}+00$ & 0 & $0.00 \mathrm{E}+00$ & 0 \\
\hline-230 & $0.00 \mathrm{E}+00$ & 0 & $0.00 \mathrm{E}+00$ & 0 & $0.00 \mathrm{E}+00$ & 0 & $0.00 \mathrm{E}+00$ & 0 & $0.00 \mathrm{E}+00$ & 0 & $0.00 \mathrm{E}+00$ & 0 & $0.00 \mathrm{E}+00$ & 0 & $0.00 \mathrm{E}+00$ & 0 \\
\hline-232 & $0.00 \mathrm{E}+00$ & 0 & $0.00 \mathrm{E}+00$ & 0 & $0.00 \mathrm{E}+00$ & 0 & $0.00 \mathrm{E}+00$ & 0 & $0.00 \mathrm{E}+00$ & 0 & $0.00 \mathrm{E}+00$ & 0 & $0.00 \mathrm{E}+00$ & 0 & $0.00 \mathrm{E}+00$ & 0 \\
\hline 34 & $0.00 \mathrm{E}+00$ & 0 & $0.00 \mathrm{E}+00$ & 0 & $0.00 \mathrm{E}+00$ & 0 & $0.00 \mathrm{E}+00$ & 0 & $0.00 \mathrm{E}+00$ & 0 & $0.00 \mathrm{E}+00$ & 0 & $0.00 \mathrm{E}+00$ & 0 & $0.00 \mathrm{E}+00$ & 0 \\
\hline 35 & $0.00 \mathrm{E}+00$ & 0 & $0.00 \mathrm{E}+00$ & 0 & $0.00 \mathrm{E}+00$ & 0 & $0.00 \mathrm{E}+00$ & 0 & $0.00 \mathrm{E}+00$ & 0 & $0.00 \mathrm{E}+00$ & 0 & $0.00 \mathrm{E}+00$ & 0 & $0.00 \mathrm{E}+00$ & 0 \\
\hline 38 & $0.00 \mathrm{E}+00$ & 0 & $0.00 \mathrm{E}+00$ & 0 & $0.00 E+00$ & 0 & $0.00 \mathrm{E}+00$ & 0 & $0.00 \mathrm{E}+00$ & 0 & $0.00 E+00$ & 0 & $0.00 \mathrm{E}+00$ & 0 & $0.00 \mathrm{E}+00$ & 0 \\
\hline & $0.00 \mathrm{E}+00$ & 0 & $0.00 E+00$ & 0 & $0.00 \mathrm{E}+00$ & 0 & $0.00 \mathrm{E}+00$ & 0 & $0.00 \mathrm{E}+00$ & 0 & $0.00 \mathrm{E}+00$ & 0 & $0.00 \mathrm{E}+00$ & 0 & $0.00 \mathrm{E}+00$ & 0 \\
\hline
\end{tabular}

Total Dose Contributions TDOSE(i,p,t) for Individual Radionuclides (i) and Pathways (p) in mrem/yr and as a Percentage of Total Dose at $t=100$ years

Directly from primary contamination and from release to atmosphere (Inhalation excludes radon)

\begin{tabular}{|c|c|c|c|c|c|c|c|c|c|c|c|c|c|c|c|c|}
\hline & \multicolumn{2}{|c|}{ Ground } & \multicolumn{2}{|c|}{ Inhalation } & \multicolumn{2}{|c|}{ Radon } & \multicolumn{2}{|c|}{ Plant } & \multicolumn{2}{|l|}{ Meat } & \multicolumn{2}{|l|}{ Milk } & \multicolumn{2}{|l|}{ Soil } & \multicolumn{2}{|c|}{ All Pathways* } \\
\hline clide & Dose & $\%$ & Dose & $\%$ & Dose & $\%$ & Dose & 음 & Dose & $\%$ & Dose & 음 & Dose & $\%$ & Dose & $\%$ \\
\hline-241 & $4.69 \mathrm{E}-25$ & 0 & $0.00 \mathrm{E}+00$ & 0 & $0.00 \mathrm{E}+00$ & 0 & $0.00 \mathrm{E}+00$ & 0 & $0.00 \mathrm{E}+00$ & 0 & $0.00 \mathrm{E}+00$ & 0 & $0.00 \mathrm{E}+00$ & 0 & $4.69 \mathrm{E}-25$ & 0 \\
\hline-137 & 1. $65 \mathrm{E}-18$ & 0 & $0.00 E+00$ & 0 & $0.00 E+00$ & 0 & $0.00 \mathrm{E}+00$ & 0 & $0.00 \mathrm{E}+00$ & 0 & $0.00 E+00$ & 0 & $0.00 \mathrm{E}+00$ & 0 & 1. $65 \mathrm{E}-18$ & 0 \\
\hline-237 & $1.56 \mathrm{E}-20$ & 0 & $0.00 E+00$ & 0 & $0.00 E+00$ & 0 & $0.00 \mathrm{E}+00$ & 0 & $0.00 \mathrm{E}+00$ & 0 & $0.00 E+00$ & 0 & $0.00 \mathrm{E}+00$ & 0 & $1.56 \mathrm{E}-20$ & 0 \\
\hline-238 & $3.06 \mathrm{E}-24$ & 0 & $0.00 E+00$ & 0 & $0.00 \mathrm{E}+00$ & 0 & $0.00 \mathrm{E}+00$ & 0 & $0.00 \mathrm{E}+00$ & 0 & $0.00 \mathrm{E}+00$ & 0 & $0.00 \mathrm{E}+00$ & 0 & $3.06 \mathrm{E}-24$ & 0 \\
\hline-239 & $2.19 \mathrm{E}-25$ & 0 & $0.00 \mathrm{E}+00$ & 0 & $0.00 \mathrm{E}+00$ & 0 & $0.00 \mathrm{E}+00$ & 0 & $0.00 \mathrm{E}+00$ & 0 & $0.00 \mathrm{E}+00$ & 0 & $0.00 \mathrm{E}+00$ & 0 & $2.19 \mathrm{E}-25$ & 0 \\
\hline-240 & $1.03 E-28$ & 0 & $0.00 \mathrm{E}+00$ & 0 & $0.00 \mathrm{E}+00$ & 0 & $0.00 \mathrm{E}+00$ & 0 & $0.00 \mathrm{E}+00$ & 0 & $0.00 \mathrm{E}+00$ & 0 & $0.00 \mathrm{E}+00$ & 0 & $1.03 E-28$ & 0 \\
\hline-99 & $1.21 E-33$ & 0 & $0.00 E+00$ & 0 & $0.00 \mathrm{E}+00$ & 0 & $0.00 \mathrm{E}+00$ & 0 & $0.00 \mathrm{E}+00$ & 0 & $0.00 E+00$ & 0 & $0.00 \mathrm{E}+00$ & 0 & 1. $21 \mathrm{E}-33$ & 0 \\
\hline-228 & $2.68 \mathrm{E}-30$ & 0 & $0.00 \mathrm{E}+00$ & 0 & $0.00 \mathrm{E}+00$ & 0 & $0.00 \mathrm{E}+00$ & 0 & $0.00 \mathrm{E}+00$ & 0 & $0.00 \mathrm{E}+00$ & 0 & $0.00 \mathrm{E}+00$ & 0 & $2.68 \mathrm{E}-30$ & 0 \\
\hline-230 & $8.49 \mathrm{E}-17$ & 0 & $0.00 \mathrm{E}+00$ & 0 & $0.00 \mathrm{E}+00$ & 0 & $0.00 \mathrm{E}+00$ & 0 & $0.00 \mathrm{E}+00$ & 0 & $0.00 \mathrm{E}+00$ & 0 & $0.00 \mathrm{E}+00$ & 0 & $8.49 \mathrm{E}-17$ & 0 \\
\hline-232 & $1.75 \mathrm{E}-14$ & 99 & $0.00 E+00$ & 0 & $0.00 \mathrm{E}+00$ & 0 & $0.00 \mathrm{E}+00$ & 0 & $0.00 \mathrm{E}+00$ & 0 & $0.00 \mathrm{E}+00$ & 0 & $0.00 \mathrm{E}+00$ & 0 & 1. $75 \mathrm{E}-14$ & 99 \\
\hline 34 & $3.87 E-20$ & 0 & $0.00 \mathrm{E}+00$ & 0 & $0.00 \mathrm{E}+00$ & 0 & $0.00 \mathrm{E}+00$ & 0 & $0.00 \mathrm{E}+00$ & 0 & $0.00 \mathrm{E}+00$ & 0 & $0.00 \mathrm{E}+00$ & 0 & $3.87 \mathrm{E}-20$ & 0 \\
\hline 35 & $1.91 \mathrm{E}-21$ & 0 & $0.00 \mathrm{E}+00$ & 0 & $0.00 \mathrm{E}+00$ & 0 & $0.00 \mathrm{E}+00$ & 0 & $0.00 \mathrm{E}+00$ & 0 & $0.00 \mathrm{E}+00$ & 0 & $0.00 \mathrm{E}+00$ & 0 & $1.91 \mathrm{E}-21$ & 0 \\
\hline 38 & $1.80 \mathrm{E}-18$ & 0 & $0.00 E+00$ & 0 & $0.00 \mathrm{E}+00$ & 0 & $0.00 \mathrm{E}+00$ & 0 & $0.00 \mathrm{E}+00$ & 0 & $0.00 E+00$ & 0 & $0.00 \mathrm{E}+00$ & 0 & 1. $80 \mathrm{E}-18$ & 0 \\
\hline & $1.76 \mathrm{E}-14$ & 100 & $0.00 \mathrm{E}+00$ & 0 & $0.00 \mathrm{E}+00$ & 0 & $0.00 \mathrm{E}+00$ & 0 & $0.00 \mathrm{E}+00$ & 0 & $0.00 \mathrm{E}+00$ & 0 & $0.00 \mathrm{E}+00$ & 0 & $1.76 \mathrm{E}-14$ & 100 \\
\hline
\end{tabular}

* Sum of dose from all releases and from primary contamination. 
RESRAD-OFFSITE, Version 2 .

Parent Dose Report

Title : Offsite Resident Farmer Deterministic Run

File : RF FINAL v2.ROF

Total Dose Contributions TDOSE (i,p,t) for Individual Radionuclides (i) and Pathways (p) in mrem/yr and as a Percentage of Total Dose at $t=500$ years

From releases to ground water and to surface water

\begin{tabular}{|c|c|c|c|c|c|c|c|c|c|c|c|c|c|c|c|c|}
\hline & \multicolumn{2}{|c|}{ Ground } & \multicolumn{2}{|l|}{ Fish } & \multicolumn{2}{|c|}{ Radon } & \multicolumn{2}{|c|}{ Plant } & \multicolumn{2}{|l|}{ Meat } & \multicolumn{2}{|l|}{ Milk } & \multicolumn{2}{|l|}{ Soil } & \multicolumn{2}{|c|}{ Water } \\
\hline ide & Dose & $\%$ & Dose & $\%$ & Dose & 응 & Dose & $\frac{\circ}{0}$ & Dose & 응 & Dose & 응 & Dose & $\%$ & Dose & $\%$ \\
\hline-241 & $0.00 \mathrm{E}+00$ & 0 & $0.00 E+00$ & 0 & $0.00 \mathrm{E}+00$ & 0 & $0.00 \mathrm{E}+00$ & 0 & $0.00 \mathrm{E}+00$ & 0 & $0.00 \mathrm{E}+00$ & 0 & $0.00 \mathrm{E}+00$ & 0 & $0.00 \mathrm{E}+00$ & 0 \\
\hline-137 & $0.00 \mathrm{E}+00$ & 0 & $0.00 \mathrm{E}+00$ & 0 & $0.00 \mathrm{E}+00$ & 0 & $0.00 \mathrm{E}+00$ & 0 & $0.00 \mathrm{E}+00$ & 0 & $0.00 \mathrm{E}+00$ & 0 & $0.00 \mathrm{E}+00$ & 0 & $0.00 \mathrm{E}+00$ & 0 \\
\hline-237 & $0.00 \mathrm{E}+00$ & 0 & $0.00 \mathrm{E}+00$ & 0 & $0.00 \mathrm{E}+00$ & 0 & $0.00 \mathrm{E}+00$ & 0 & $0.00 \mathrm{E}+00$ & 0 & $0.00 \mathrm{E}+00$ & 0 & $0.00 \mathrm{E}+00$ & 0 & $0.00 \mathrm{E}+00$ & 0 \\
\hline-238 & $0.00 \mathrm{E}+00$ & 0 & $0.00 \mathrm{E}+00$ & 0 & $0.00 E+00$ & 0 & $0.00 E+00$ & 0 & $0.00 \mathrm{E}+00$ & 0 & $0.00 E+00$ & 0 & $0.00 \mathrm{E}+00$ & 0 & $0.00 \mathrm{E}+00$ & 0 \\
\hline-239 & $0.00 \mathrm{E}+00$ & 0 & $0.00 \mathrm{E}+00$ & 0 & $0.00 \mathrm{E}+00$ & 0 & $0.00 \mathrm{E}+00$ & 0 & $0.00 \mathrm{E}+00$ & 0 & $0.00 \mathrm{E}+00$ & 0 & $0.00 \mathrm{E}+00$ & 0 & $0.00 \mathrm{E}+00$ & 0 \\
\hline-240 & $0.00 \mathrm{E}+00$ & 0 & $0.00 \mathrm{E}+00$ & 0 & $0.00 \mathrm{E}+00$ & 0 & $0.00 \mathrm{E}+00$ & 0 & $0.00 \mathrm{E}+00$ & 0 & $0.00 \mathrm{E}+00$ & 0 & $0.00 \mathrm{E}+00$ & 0 & $0.00 \mathrm{E}+00$ & 0 \\
\hline-99 & $1.74 \mathrm{E}-08$ & 0 & $0.00 \mathrm{E}+00$ & 0 & $0.00 \mathrm{E}+00$ & 0 & $4.77 E-03$ & 25 & $1.43 E-05$ & 0 & $1.26 E-03$ & 7 & $1.47 \mathrm{E}-08$ & 0 & $1.30 \mathrm{E}-02$ & 68 \\
\hline-228 & $0.00 \mathrm{E}+00$ & 0 & $0.00 \mathrm{E}+00$ & 0 & $0.00 \mathrm{E}+00$ & 0 & $0.00 \mathrm{E}+00$ & 0 & $0.00 \mathrm{E}+00$ & 0 & $0.00 \mathrm{E}+00$ & 0 & $0.00 \mathrm{E}+00$ & 0 & $0.00 \mathrm{E}+00$ & 0 \\
\hline-230 & $0.00 \mathrm{E}+00$ & 0 & $0.00 \mathrm{E}+00$ & 0 & $0.00 \mathrm{E}+00$ & 0 & $0.00 \mathrm{E}+00$ & 0 & $0.00 \mathrm{E}+00$ & 0 & $0.00 \mathrm{E}+00$ & 0 & $0.00 \mathrm{E}+00$ & 0 & $0.00 \mathrm{E}+00$ & 0 \\
\hline-232 & $0.00 \mathrm{E}+00$ & 0 & $0.00 \mathrm{E}+00$ & 0 & $0.00 \mathrm{E}+00$ & 0 & $0.00 \mathrm{E}+00$ & 0 & $0.00 \mathrm{E}+00$ & 0 & $0.00 \mathrm{E}+00$ & 0 & $0.00 \mathrm{E}+00$ & 0 & $0.00 \mathrm{E}+00$ & 0 \\
\hline 34 & $0.00 \mathrm{E}+00$ & 0 & $0.00 \mathrm{E}+00$ & 0 & $0.00 \mathrm{E}+00$ & 0 & $0.00 \mathrm{E}+00$ & 0 & $0.00 \mathrm{E}+00$ & 0 & $0.00 \mathrm{E}+00$ & 0 & $0.00 \mathrm{E}+00$ & 0 & $0.00 \mathrm{E}+00$ & 0 \\
\hline 35 & $0.00 \mathrm{E}+00$ & 0 & $0.00 \mathrm{E}+00$ & 0 & $0.00 \mathrm{E}+00$ & 0 & $0.00 \mathrm{E}+00$ & 0 & $0.00 \mathrm{E}+00$ & 0 & $0.00 \mathrm{E}+00$ & 0 & $0.00 \mathrm{E}+00$ & 0 & $0.00 \mathrm{E}+00$ & 0 \\
\hline 38 & $0.00 \mathrm{E}+00$ & 0 & $0.00 \mathrm{E}+00$ & 0 & $0.00 E+00$ & 0 & $0.00 E+00$ & 0 & $0.00 \mathrm{E}+00$ & 0 & $0.00 E+00$ & 0 & $0.00 \mathrm{E}+00$ & 0 & $0.00 \mathrm{E}+00$ & 0 \\
\hline & $1.74 \mathrm{E}-08$ & 0 & $0.00 E+00$ & 0 & $0.00 \mathrm{E}+00$ & 0 & $4.77 E-03$ & 25 & $1.43 E-05$ & 0 & $1.26 E-03$ & 7 & $1.47 E-08$ & 0 & $1.30 \mathrm{E}-02$ & 68 \\
\hline
\end{tabular}

Total Dose Contributions TDOSE(i,p,t) for Individual Radionuclides (i) and Pathways (p) in mrem/yr and as a Percentage of Total Dose at $t=500$ years

Directly from primary contamination and from release to atmosphere (Inhalation excludes radon)

\begin{tabular}{|c|c|c|c|c|c|c|c|c|c|c|c|c|c|c|c|c|}
\hline & \multicolumn{2}{|c|}{ Ground } & \multicolumn{2}{|c|}{ Inhalation } & \multicolumn{2}{|c|}{ Radon } & \multicolumn{2}{|c|}{ Plant } & \multicolumn{2}{|l|}{ Meat } & \multicolumn{2}{|l|}{ Milk } & \multicolumn{2}{|l|}{ Soil } & \multicolumn{2}{|c|}{ All Pathways* } \\
\hline ide & Dose & $\%$ & Dose & $\%$ & Dose & $\%$ & Dose & 음 & Dose & $\%$ & Dose & 음 & Dose & $\%$ & Dose & $\%$ \\
\hline-241 & $9.24 E-23$ & 0 & $0.00 E+00$ & 0 & $0.00 E+00$ & 0 & $0.00 \mathrm{E}+00$ & 0 & $0.00 \mathrm{E}+00$ & 0 & $0.00 \mathrm{E}+00$ & 0 & $0.00 \mathrm{E}+00$ & 0 & $9.24 \mathrm{E}-23$ & 0 \\
\hline-137 & $3.54 E-21$ & 0 & $0.00 E+00$ & 0 & $0.00 E+00$ & 0 & $0.00 \mathrm{E}+00$ & 0 & $0.00 \mathrm{E}+00$ & 0 & $0.00 E+00$ & 0 & $0.00 \mathrm{E}+00$ & 0 & $3.54 \mathrm{E}-21$ & 0 \\
\hline-237 & $8.35 E-19$ & 0 & $0.00 E+00$ & 0 & $0.00 E+00$ & 0 & $0.00 \mathrm{E}+00$ & 0 & $0.00 \mathrm{E}+00$ & 0 & $0.00 E+00$ & 0 & $0.00 \mathrm{E}+00$ & 0 & $8.35 E-19$ & 0 \\
\hline-238 & $2.59 E-21$ & 0 & $0.00 E+00$ & 0 & $0.00 \mathrm{E}+00$ & 0 & $0.00 \mathrm{E}+00$ & 0 & $0.00 \mathrm{E}+00$ & 0 & $0.00 \mathrm{E}+00$ & 0 & $0.00 \mathrm{E}+00$ & 0 & $2.59 E-21$ & 0 \\
\hline-239 & $1.78 E-23$ & 0 & $0.00 \mathrm{E}+00$ & 0 & $0.00 \mathrm{E}+00$ & 0 & $0.00 \mathrm{E}+00$ & 0 & $0.00 \mathrm{E}+00$ & 0 & $0.00 \mathrm{E}+00$ & 0 & $0.00 \mathrm{E}+00$ & 0 & 1. $78 \mathrm{E}-23$ & 0 \\
\hline-240 & $2.74 \mathrm{E}-26$ & 0 & $0.00 \mathrm{E}+00$ & 0 & $0.00 \mathrm{E}+00$ & 0 & $0.00 \mathrm{E}+00$ & 0 & $0.00 \mathrm{E}+00$ & 0 & $0.00 \mathrm{E}+00$ & 0 & $0.00 \mathrm{E}+00$ & 0 & $2.74 \mathrm{E}-26$ & 0 \\
\hline-99 & 1. $72 E-31$ & 0 & $0.00 E+00$ & 0 & $0.00 \mathrm{E}+00$ & 0 & $0.00 \mathrm{E}+00$ & 0 & $0.00 \mathrm{E}+00$ & 0 & $0.00 E+00$ & 0 & $0.00 \mathrm{E}+00$ & 0 & 1. $91 \mathrm{E}-02$ & 100 \\
\hline-228 & $0.00 \mathrm{E}+00$ & 0 & $0.00 \mathrm{E}+00$ & 0 & $0.00 \mathrm{E}+00$ & 0 & $0.00 \mathrm{E}+00$ & 0 & $0.00 \mathrm{E}+00$ & 0 & $0.00 \mathrm{E}+00$ & 0 & $0.00 \mathrm{E}+00$ & 0 & $0.00 \mathrm{E}+00$ & 0 \\
\hline-230 & $4.95 E-15$ & 0 & $0.00 E+00$ & 0 & $0.00 \mathrm{E}+00$ & 0 & $0.00 \mathrm{E}+00$ & 0 & $0.00 \mathrm{E}+00$ & 0 & $0.00 E+00$ & 0 & $0.00 \mathrm{E}+00$ & 0 & 4. $95 E-15$ & 0 \\
\hline-232 & $1.60 \mathrm{E}-13$ & 0 & $0.00 E+00$ & 0 & $0.00 \mathrm{E}+00$ & 0 & $0.00 \mathrm{E}+00$ & 0 & $0.00 \mathrm{E}+00$ & 0 & $0.00 \mathrm{E}+00$ & 0 & $0.00 \mathrm{E}+00$ & 0 & $1.60 \mathrm{E}-13$ & 0 \\
\hline 34 & $1.15 \mathrm{E}-17$ & 0 & $0.00 \mathrm{E}+00$ & 0 & $0.00 \mathrm{E}+00$ & 0 & $0.00 \mathrm{E}+00$ & 0 & $0.00 \mathrm{E}+00$ & 0 & $0.00 \mathrm{E}+00$ & 0 & $0.00 \mathrm{E}+00$ & 0 & $1.15 \mathrm{E}-17$ & 0 \\
\hline 235 & $2.99 \mathrm{E}-19$ & 0 & $0.00 \mathrm{E}+00$ & 0 & $0.00 \mathrm{E}+00$ & 0 & $0.00 \mathrm{E}+00$ & 0 & $0.00 \mathrm{E}+00$ & 0 & $0.00 \mathrm{E}+00$ & 0 & $0.00 \mathrm{E}+00$ & 0 & $2.99 \mathrm{E}-19$ & 0 \\
\hline 38 & $3.41 E-17$ & 0 & $0.00 E+00$ & 0 & $0.00 \mathrm{E}+00$ & 0 & $0.00 \mathrm{E}+00$ & 0 & $0.00 \mathrm{E}+00$ & 0 & $0.00 E+00$ & 0 & $0.00 \mathrm{E}+00$ & 0 & $3.41 \mathrm{E}-17$ & 0 \\
\hline & $1.65 \mathrm{E}-13$ & 0 & $0.00 E+00$ & 0 & $0.00 E+00$ & 0 & $0.00 \mathrm{E}+00$ & 0 & $0.00 \mathrm{E}+00$ & 0 & $0.00 E+00$ & 0 & $0.00 \mathrm{E}+00$ & 0 & 1.91E-02 & 100 \\
\hline
\end{tabular}

* Sum of dose from all releases and from primary contamination. 
RESRAD-OFFSITE, Version 2 .

Parent Dose Report

Title : Offsite Resident Farmer Deterministic Run

File : RF FINAL v2.ROF

Total Dose Contributions TDOSE (i,p,t) for Individual Radionuclides (i) and Pathways (p) in mrem/yr and as a Percentage of Total Dose at $t=772$ years

From releases to ground water and to surface water

\begin{tabular}{|c|c|c|c|c|c|c|c|c|c|c|c|c|c|c|c|c|}
\hline & \multicolumn{2}{|c|}{ Ground } & \multicolumn{2}{|l|}{ Fish } & \multicolumn{2}{|c|}{ Radon } & \multicolumn{2}{|c|}{ Plant } & \multicolumn{2}{|l|}{ Meat } & \multicolumn{2}{|l|}{ Milk } & \multicolumn{2}{|l|}{ Soil } & \multicolumn{2}{|c|}{ Water } \\
\hline ide & Dose & $\%$ & Dose & $\%$ & Dose & 응 & Dose & $\frac{\circ}{0}$ & Dose & 응 & Dose & 응 & Dose & $\%$ & Dose & $\%$ \\
\hline-241 & $0.00 \mathrm{E}+00$ & 0 & $0.00 E+00$ & 0 & $0.00 \mathrm{E}+00$ & 0 & $0.00 \mathrm{E}+00$ & 0 & $0.00 \mathrm{E}+00$ & 0 & $0.00 \mathrm{E}+00$ & 0 & $0.00 \mathrm{E}+00$ & 0 & $0.00 \mathrm{E}+00$ & 0 \\
\hline-137 & $0.00 \mathrm{E}+00$ & 0 & $0.00 \mathrm{E}+00$ & 0 & $0.00 \mathrm{E}+00$ & 0 & $0.00 \mathrm{E}+00$ & 0 & $0.00 \mathrm{E}+00$ & 0 & $0.00 \mathrm{E}+00$ & 0 & $0.00 \mathrm{E}+00$ & 0 & $0.00 \mathrm{E}+00$ & 0 \\
\hline-237 & $0.00 \mathrm{E}+00$ & 0 & $0.00 \mathrm{E}+00$ & 0 & $0.00 \mathrm{E}+00$ & 0 & $0.00 \mathrm{E}+00$ & 0 & $0.00 \mathrm{E}+00$ & 0 & $0.00 \mathrm{E}+00$ & 0 & $0.00 \mathrm{E}+00$ & 0 & $0.00 \mathrm{E}+00$ & 0 \\
\hline-238 & $0.00 \mathrm{E}+00$ & 0 & $0.00 \mathrm{E}+00$ & 0 & $0.00 E+00$ & 0 & $0.00 E+00$ & 0 & $0.00 \mathrm{E}+00$ & 0 & $0.00 E+00$ & 0 & $0.00 \mathrm{E}+00$ & 0 & $0.00 \mathrm{E}+00$ & 0 \\
\hline-239 & $0.00 \mathrm{E}+00$ & 0 & $0.00 \mathrm{E}+00$ & 0 & $0.00 \mathrm{E}+00$ & 0 & $0.00 \mathrm{E}+00$ & 0 & $0.00 \mathrm{E}+00$ & 0 & $0.00 \mathrm{E}+00$ & 0 & $0.00 \mathrm{E}+00$ & 0 & $0.00 \mathrm{E}+00$ & 0 \\
\hline-240 & $0.00 \mathrm{E}+00$ & 0 & $0.00 \mathrm{E}+00$ & 0 & $0.00 \mathrm{E}+00$ & 0 & $0.00 \mathrm{E}+00$ & 0 & $0.00 \mathrm{E}+00$ & 0 & $0.00 \mathrm{E}+00$ & 0 & $0.00 \mathrm{E}+00$ & 0 & $0.00 \mathrm{E}+00$ & 0 \\
\hline-99 & $3.29 \mathrm{E}-08$ & 0 & $0.00 \mathrm{E}+00$ & 0 & $0.00 \mathrm{E}+00$ & 0 & $9.00 E-03$ & 25 & $2.70 E-05$ & 0 & $2.38 E-03$ & 7 & $2.77 E-08$ & 0 & $2.45 E-02$ & 68 \\
\hline-228 & $0.00 \mathrm{E}+00$ & 0 & $0.00 \mathrm{E}+00$ & 0 & $0.00 \mathrm{E}+00$ & 0 & $0.00 \mathrm{E}+00$ & 0 & $0.00 \mathrm{E}+00$ & 0 & $0.00 \mathrm{E}+00$ & 0 & $0.00 \mathrm{E}+00$ & 0 & $0.00 \mathrm{E}+00$ & 0 \\
\hline-230 & $0.00 \mathrm{E}+00$ & 0 & $0.00 \mathrm{E}+00$ & 0 & $0.00 \mathrm{E}+00$ & 0 & $0.00 \mathrm{E}+00$ & 0 & $0.00 \mathrm{E}+00$ & 0 & $0.00 \mathrm{E}+00$ & 0 & $0.00 \mathrm{E}+00$ & 0 & $0.00 \mathrm{E}+00$ & 0 \\
\hline-232 & $0.00 \mathrm{E}+00$ & 0 & $0.00 \mathrm{E}+00$ & 0 & $0.00 \mathrm{E}+00$ & 0 & $0.00 \mathrm{E}+00$ & 0 & $0.00 \mathrm{E}+00$ & 0 & $0.00 \mathrm{E}+00$ & 0 & $0.00 \mathrm{E}+00$ & 0 & $0.00 \mathrm{E}+00$ & 0 \\
\hline 34 & $0.00 \mathrm{E}+00$ & 0 & $0.00 \mathrm{E}+00$ & 0 & $0.00 \mathrm{E}+00$ & 0 & $0.00 \mathrm{E}+00$ & 0 & $0.00 \mathrm{E}+00$ & 0 & $0.00 \mathrm{E}+00$ & 0 & $0.00 \mathrm{E}+00$ & 0 & $0.00 \mathrm{E}+00$ & 0 \\
\hline 35 & $0.00 \mathrm{E}+00$ & 0 & $0.00 \mathrm{E}+00$ & 0 & $0.00 \mathrm{E}+00$ & 0 & $0.00 \mathrm{E}+00$ & 0 & $0.00 \mathrm{E}+00$ & 0 & $0.00 \mathrm{E}+00$ & 0 & $0.00 \mathrm{E}+00$ & 0 & $0.00 \mathrm{E}+00$ & 0 \\
\hline 38 & $0.00 \mathrm{E}+00$ & 0 & $0.00 \mathrm{E}+00$ & 0 & $0.00 E+00$ & 0 & $0.00 E+00$ & 0 & $0.00 \mathrm{E}+00$ & 0 & $0.00 E+00$ & 0 & $0.00 \mathrm{E}+00$ & 0 & $0.00 \mathrm{E}+00$ & 0 \\
\hline & $3.29 \mathrm{E}-08$ & 0 & $0.00 E+00$ & 0 & $0.00 \mathrm{E}+00$ & 0 & $9.00 E-03$ & 25 & $2.70 E-05$ & 0 & $2.38 E-03$ & 7 & $2.77 E-08$ & 0 & $2.45 E-02$ & 68 \\
\hline
\end{tabular}

Total Dose Contributions TDOSE(i,p,t) for Individual Radionuclides (i) and Pathways (p) in mrem/yr and as a Percentage of Total Dose at $t=772$ years

Directly from primary contamination and from release to atmosphere (Inhalation excludes radon)

\begin{tabular}{|c|c|c|c|c|c|c|c|c|c|c|c|c|c|c|c|c|}
\hline & \multicolumn{2}{|c|}{ Ground } & \multicolumn{2}{|c|}{ Inhalation } & \multicolumn{2}{|c|}{ Radon } & \multicolumn{2}{|c|}{ Plant } & \multicolumn{2}{|l|}{ Meat } & \multicolumn{2}{|l|}{ Milk } & \multicolumn{2}{|l|}{ Soil } & \multicolumn{2}{|c|}{ All Pathways* } \\
\hline ide & Dose & $\%$ & Dose & $\%$ & Dose & $\%$ & Dose & 음 & Dose & $\%$ & Dose & 음 & Dose & $\%$ & Dose & $\%$ \\
\hline-241 & 1. $75 \mathrm{E}-21$ & 0 & $0.00 \mathrm{E}+00$ & 0 & $0.00 E+00$ & 0 & $0.00 \mathrm{E}+00$ & 0 & $0.00 \mathrm{E}+00$ & 0 & $0.00 \mathrm{E}+00$ & 0 & $0.00 \mathrm{E}+00$ & 0 & 1. $75 \mathrm{E}-21$ & 0 \\
\hline-137 & $5.44 E-23$ & 0 & $0.00 E+00$ & 0 & $0.00 E+00$ & 0 & $0.00 \mathrm{E}+00$ & 0 & $0.00 \mathrm{E}+00$ & 0 & $0.00 E+00$ & 0 & $0.00 \mathrm{E}+00$ & 0 & $5.44 E-23$ & 0 \\
\hline-237 & $1.22 \mathrm{E}-17$ & 0 & $0.00 E+00$ & 0 & $0.00 E+00$ & 0 & $0.00 \mathrm{E}+00$ & 0 & $0.00 \mathrm{E}+00$ & 0 & $0.00 E+00$ & 0 & $0.00 \mathrm{E}+00$ & 0 & 1. $22 \mathrm{E}-17$ & 0 \\
\hline-238 & $3.94 E-20$ & 0 & $0.00 E+00$ & 0 & $0.00 \mathrm{E}+00$ & 0 & $0.00 \mathrm{E}+00$ & 0 & $0.00 \mathrm{E}+00$ & 0 & $0.00 \mathrm{E}+00$ & 0 & $0.00 \mathrm{E}+00$ & 0 & $3.94 \mathrm{E}-20$ & 0 \\
\hline-239 & $3.55 \mathrm{E}-22$ & 0 & $0.00 \mathrm{E}+00$ & 0 & $0.00 \mathrm{E}+00$ & 0 & $0.00 \mathrm{E}+00$ & 0 & $0.00 \mathrm{E}+00$ & 0 & $0.00 \mathrm{E}+00$ & 0 & $0.00 \mathrm{E}+00$ & 0 & $3.55 \mathrm{E}-22$ & 0 \\
\hline-240 & $2.98 E-25$ & 0 & $0.00 \mathrm{E}+00$ & 0 & $0.00 \mathrm{E}+00$ & 0 & $0.00 \mathrm{E}+00$ & 0 & $0.00 \mathrm{E}+00$ & 0 & $0.00 \mathrm{E}+00$ & 0 & $0.00 \mathrm{E}+00$ & 0 & $2.98 E-25$ & 0 \\
\hline-99 & $5.03 E-30$ & 0 & $0.00 E+00$ & 0 & $0.00 \mathrm{E}+00$ & 0 & $0.00 \mathrm{E}+00$ & 0 & $0.00 \mathrm{E}+00$ & 0 & $0.00 E+00$ & 0 & $0.00 \mathrm{E}+00$ & 0 & $3.59 \mathrm{E}-02$ & 100 \\
\hline-228 & $0.00 \mathrm{E}+00$ & 0 & $0.00 \mathrm{E}+00$ & 0 & $0.00 \mathrm{E}+00$ & 0 & $0.00 \mathrm{E}+00$ & 0 & $0.00 \mathrm{E}+00$ & 0 & $0.00 \mathrm{E}+00$ & 0 & $0.00 \mathrm{E}+00$ & 0 & $0.00 \mathrm{E}+00$ & 0 \\
\hline-230 & $4.07 E-14$ & 0 & $0.00 E+00$ & 0 & $0.00 \mathrm{E}+00$ & 0 & $0.00 \mathrm{E}+00$ & 0 & $0.00 \mathrm{E}+00$ & 0 & $0.00 E+00$ & 0 & $0.00 \mathrm{E}+00$ & 0 & $4.07 E-14$ & 0 \\
\hline-232 & $7.21 \mathrm{E}-13$ & 0 & $0.00 E+00$ & 0 & $0.00 \mathrm{E}+00$ & 0 & $0.00 \mathrm{E}+00$ & 0 & $0.00 \mathrm{E}+00$ & 0 & $0.00 \mathrm{E}+00$ & 0 & $0.00 \mathrm{E}+00$ & 0 & 7. $21 \mathrm{E}-13$ & 0 \\
\hline 34 & $1.49 \mathrm{E}-16$ & 0 & $0.00 \mathrm{E}+00$ & 0 & $0.00 \mathrm{E}+00$ & 0 & $0.00 \mathrm{E}+00$ & 0 & $0.00 \mathrm{E}+00$ & 0 & $0.00 \mathrm{E}+00$ & 0 & $0.00 \mathrm{E}+00$ & 0 & 1. $49 \mathrm{E}-16$ & 0 \\
\hline 35 & 4. $44 \mathrm{E}-18$ & 0 & $0.00 \mathrm{E}+00$ & 0 & $0.00 \mathrm{E}+00$ & 0 & $0.00 \mathrm{E}+00$ & 0 & $0.00 \mathrm{E}+00$ & 0 & $0.00 \mathrm{E}+00$ & 0 & $0.00 \mathrm{E}+00$ & 0 & 4. $44 \mathrm{E}-18$ & 0 \\
\hline 38 & $2.52 E-16$ & 0 & $0.00 E+00$ & 0 & $0.00 \mathrm{E}+00$ & 0 & $0.00 \mathrm{E}+00$ & 0 & $0.00 \mathrm{E}+00$ & 0 & $0.00 E+00$ & 0 & $0.00 \mathrm{E}+00$ & 0 & $2.52 \mathrm{E}-16$ & 0 \\
\hline & 7. $62 \mathrm{E}-13$ & 0 & $0.00 E+00$ & 0 & $0.00 E+00$ & 0 & $0.00 \mathrm{E}+00$ & 0 & $0.00 \mathrm{E}+00$ & 0 & $0.00 E+00$ & 0 & $0.00 \mathrm{E}+00$ & 0 & $3.59 \mathrm{E}-02$ & 100 \\
\hline
\end{tabular}

* Sum of dose from all releases and from primary contamination. 
RESRAD-OFFSITE, Version 2 .

Parent Dose Report

Title : Offsite Resident Farmer Deterministic Run

File : RF FINAL v2.ROF

Total Dose Contributions TDOSE (i,p,t) for Individual Radionuclides (i) and Pathways (p) in mrem/yr and as a Percentage of Total Dose at $t=1026$ years

From releases to ground water and to surface water

\begin{tabular}{|c|c|c|c|c|c|c|c|c|c|c|c|c|c|c|c|c|}
\hline & \multicolumn{2}{|c|}{ Ground } & \multicolumn{2}{|l|}{ Fish } & \multicolumn{2}{|l|}{ Radon } & \multicolumn{2}{|c|}{ Plant } & \multicolumn{2}{|l|}{ Meat } & \multicolumn{2}{|l|}{ Milk } & \multicolumn{2}{|l|}{ Soil } & \multicolumn{2}{|c|}{ Water } \\
\hline clide & Dose & \% & Dose & $\%$ & Dose & 음 & Dose & $\%$ & Dose & \% & Dose & $\%$ & Dose & 응 & Dose & \% \\
\hline-241 & $0.00 \mathrm{E}+00$ & 0 & $0.00 \mathrm{E}+00$ & 0 & $0.00 \mathrm{E}+00$ & 0 & $0.00 \mathrm{E}+00$ & 0 & $0.00 \mathrm{E}+00$ & 0 & $0.00 \mathrm{E}+00$ & 0 & $0.00 \mathrm{E}+00$ & 0 & $0.00 \mathrm{E}+00$ & 0 \\
\hline-137 & $0.00 \mathrm{E}+00$ & 0 & $0.00 \mathrm{E}+00$ & 0 & $0.00 \mathrm{E}+00$ & 0 & $0.00 \mathrm{E}+00$ & 0 & $0.00 \mathrm{E}+00$ & 0 & $0.00 \mathrm{E}+00$ & 0 & $0.00 \mathrm{E}+00$ & 0 & $0.00 \mathrm{E}+00$ & 0 \\
\hline-237 & $0.00 \mathrm{E}+00$ & 0 & $0.00 \mathrm{E}+00$ & 0 & $0.00 \mathrm{E}+00$ & 0 & $0.00 \mathrm{E}+00$ & 0 & $0.00 \mathrm{E}+00$ & 0 & $0.00 \mathrm{E}+00$ & 0 & $0.00 \mathrm{E}+00$ & 0 & $0.00 \mathrm{E}+00$ & 0 \\
\hline-238 & $0.00 \mathrm{E}+00$ & 0 & $0.00 E+00$ & 0 & $0.00 \mathrm{E}+00$ & 0 & $0.00 \mathrm{E}+00$ & 0 & $0.00 \mathrm{E}+00$ & 0 & $0.00 \mathrm{E}+00$ & 0 & $0.00 \mathrm{E}+00$ & 0 & $0.00 \mathrm{E}+00$ & 0 \\
\hline-239 & $0.00 \mathrm{E}+00$ & 0 & $0.00 E+00$ & 0 & $0.00 \mathrm{E}+00$ & 0 & $0.00 \mathrm{E}+00$ & 0 & $0.00 \mathrm{E}+00$ & 0 & $0.00 \mathrm{E}+00$ & 0 & $0.00 \mathrm{E}+00$ & 0 & $0.00 \mathrm{E}+00$ & 0 \\
\hline-240 & $0.00 \mathrm{E}+00$ & 0 & $0.00 \mathrm{E}+00$ & 0 & $0.00 \mathrm{E}+00$ & 0 & $0.00 \mathrm{E}+00$ & 0 & $0.00 \mathrm{E}+00$ & 0 & $0.00 \mathrm{E}+00$ & 0 & $0.00 \mathrm{E}+00$ & 0 & $0.00 \mathrm{E}+00$ & 0 \\
\hline-99 & $2.53 \mathrm{E}-08$ & 0 & $0.00 \mathrm{E}+00$ & 0 & $0.00 \mathrm{E}+00$ & 0 & $6.92 \mathrm{E}-03$ & 25 & $2.07 E-05$ & 0 & $1.83 \mathrm{E}-03$ & 7 & $2.13 \mathrm{E}-08$ & 0 & $1.88 \mathrm{E}-02$ & 68 \\
\hline-228 & $0.00 \mathrm{E}+00$ & 0 & $0.00 \mathrm{E}+00$ & 0 & $0.00 \mathrm{E}+00$ & 0 & $0.00 \mathrm{E}+00$ & 0 & $0.00 \mathrm{E}+00$ & 0 & $0.00 \mathrm{E}+00$ & 0 & $0.00 \mathrm{E}+00$ & 0 & $0.00 \mathrm{E}+00$ & 0 \\
\hline-230 & $0.00 \mathrm{E}+00$ & 0 & $0.00 \mathrm{E}+00$ & 0 & $0.00 \mathrm{E}+00$ & 0 & $0.00 \mathrm{E}+00$ & 0 & $0.00 \mathrm{E}+00$ & 0 & $0.00 \mathrm{E}+00$ & 0 & $0.00 \mathrm{E}+00$ & 0 & $0.00 \mathrm{E}+00$ & 0 \\
\hline-232 & $0.00 \mathrm{E}+00$ & 0 & $0.00 E+00$ & 0 & $0.00 \mathrm{E}+00$ & 0 & $0.00 \mathrm{E}+00$ & 0 & $0.00 \mathrm{E}+00$ & 0 & $0.00 \mathrm{E}+00$ & 0 & $0.00 \mathrm{E}+00$ & 0 & $0.00 \mathrm{E}+00$ & 0 \\
\hline 234 & $0.00 \mathrm{E}+00$ & 0 & $0.00 \mathrm{E}+00$ & 0 & $0.00 \mathrm{E}+00$ & 0 & $0.00 \mathrm{E}+00$ & 0 & $0.00 \mathrm{E}+00$ & 0 & $0.00 \mathrm{E}+00$ & 0 & $0.00 \mathrm{E}+00$ & 0 & $0.00 \mathrm{E}+00$ & 0 \\
\hline 35 & $0.00 \mathrm{E}+00$ & 0 & $0.00 E+00$ & 0 & $0.00 \mathrm{E}+00$ & 0 & $0.00 \mathrm{E}+00$ & 0 & $0.00 \mathrm{E}+00$ & 0 & $0.00 \mathrm{E}+00$ & 0 & $0.00 \mathrm{E}+00$ & 0 & $0.00 \mathrm{E}+00$ & 0 \\
\hline 238 & $0.00 \mathrm{E}+00$ & 0 & $0.00 E+00$ & 0 & $0.00 \mathrm{E}+00$ & 0 & $0.00 \mathrm{E}+00$ & 0 & $0.00 \mathrm{E}+00$ & 0 & $0.00 \mathrm{E}+00$ & 0 & $0.00 \mathrm{E}+00$ & 0 & $0.00 \mathrm{E}+00$ & 0 \\
\hline & $2.53 E-08$ & 0 & $0.00 \mathrm{E}+00$ & 0 & $0.00 \mathrm{E}+00$ & 0 & $6.92 \mathrm{E}-03$ & 25 & $2.07 E-05$ & 0 & $1.83 \mathrm{E}-03$ & 7 & $2.13 E-08$ & 0 & $1.88 \mathrm{E}-02$ & 68 \\
\hline
\end{tabular}

Total Dose Contributions TDOSE (i,p,t) for Individual Radionuclides (i) and Pathways (p)

in mrem/yr and as a Percentage of Total Dose at $t=1026$ years

Directly from primary contamination and from release to atmosphere (Inhalation excludes radon)

\begin{tabular}{|c|c|c|c|c|c|c|c|c|c|c|c|c|c|c|c|c|}
\hline & \multicolumn{2}{|c|}{ Ground } & \multicolumn{2}{|c|}{ Inhalation } & \multicolumn{2}{|c|}{ Radon } & \multicolumn{2}{|c|}{ Plant } & \multicolumn{2}{|l|}{ Meat } & \multicolumn{2}{|l|}{ Milk } & \multicolumn{2}{|l|}{ Soil } & \multicolumn{2}{|c|}{ All Pathways* } \\
\hline clide & Dose & \% & Dose & $\%$ & Dose & $\%$ & Dose & 음 & Dose & $\%$ & Dose & $\%$ & Dose & \% & Dose & $\frac{\circ}{0}$ \\
\hline-241 & $2.45 E-20$ & 0 & $0.00 \mathrm{E}+00$ & 0 & $0.00 \mathrm{E}+00$ & 0 & $0.00 \mathrm{E}+00$ & 0 & $0.00 \mathrm{E}+00$ & 0 & $0.00 \mathrm{E}+00$ & 0 & $0.00 \mathrm{E}+00$ & 0 & $2.45 E-20$ & 0 \\
\hline-137 & 1. $10 \mathrm{E}-24$ & 0 & $0.00 \mathrm{E}+00$ & 0 & $0.00 \mathrm{E}+00$ & 0 & $0.00 \mathrm{E}+00$ & 0 & $0.00 \mathrm{E}+00$ & 0 & $0.00 \mathrm{E}+00$ & 0 & $0.00 \mathrm{E}+00$ & 0 & 1.10E-24 & 0 \\
\hline-237 & 1. $48 \mathrm{E}-16$ & 0 & $0.00 \mathrm{E}+00$ & 0 & $0.00 \mathrm{E}+00$ & 0 & $0.00 \mathrm{E}+00$ & 0 & $0.00 \mathrm{E}+00$ & 0 & $0.00 \mathrm{E}+00$ & 0 & $0.00 \mathrm{E}+00$ & 0 & $1.48 \mathrm{E}-16$ & 0 \\
\hline-238 & $3.65 \mathrm{E}-19$ & 0 & $0.00 \mathrm{E}+00$ & 0 & $0.00 \mathrm{E}+00$ & 0 & $0.00 \mathrm{E}+00$ & 0 & $0.00 \mathrm{E}+00$ & 0 & $0.00 \mathrm{E}+00$ & 0 & $0.00 \mathrm{E}+00$ & 0 & $3.65 E-19$ & 0 \\
\hline-239 & $5.79 \mathrm{E}-21$ & 0 & $0.00 \mathrm{E}+00$ & 0 & $0.00 \mathrm{E}+00$ & 0 & $0.00 \mathrm{E}+00$ & 0 & $0.00 \mathrm{E}+00$ & 0 & $0.00 \mathrm{E}+00$ & 0 & $0.00 \mathrm{E}+00$ & 0 & $5.79 \mathrm{E}-21$ & 0 \\
\hline-240 & $2.25 E-24$ & 0 & $0.00 \mathrm{E}+00$ & 0 & $0.00 \mathrm{E}+00$ & 0 & $0.00 \mathrm{E}+00$ & 0 & $0.00 \mathrm{E}+00$ & 0 & $0.00 \mathrm{E}+00$ & 0 & $0.00 \mathrm{E}+00$ & 0 & $2.25 E-24$ & 0 \\
\hline-99 & $1.17 \mathrm{E}-28$ & 0 & $0.00 \mathrm{E}+00$ & 0 & $0.00 \mathrm{E}+00$ & 0 & $0.00 E+00$ & 0 & $0.00 \mathrm{E}+00$ & 0 & $0.00 \mathrm{E}+00$ & 0 & $0.00 \mathrm{E}+00$ & 0 & $2.76 \mathrm{E}-02$ & 100 \\
\hline-228 & $0.00 \mathrm{E}+00$ & 0 & $0.00 E+00$ & 0 & $0.00 \mathrm{E}+00$ & 0 & $0.00 \mathrm{E}+00$ & 0 & $0.00 \mathrm{E}+00$ & 0 & $0.00 \mathrm{E}+00$ & 0 & $0.00 \mathrm{E}+00$ & 0 & $0.00 \mathrm{E}+00$ & 0 \\
\hline-230 & $2.59 \mathrm{E}-13$ & 0 & $0.00 \mathrm{E}+00$ & 0 & $0.00 \mathrm{E}+00$ & 0 & $0.00 \mathrm{E}+00$ & 0 & $0.00 \mathrm{E}+00$ & 0 & $0.00 \mathrm{E}+00$ & 0 & $0.00 \mathrm{E}+00$ & 0 & $2.59 \mathrm{E}-13$ & 0 \\
\hline-232 & $2.96 \mathrm{E}-12$ & 0 & $0.00 \mathrm{E}+00$ & 0 & $0.00 \mathrm{E}+00$ & 0 & $0.00 \mathrm{E}+00$ & 0 & $0.00 \mathrm{E}+00$ & 0 & $0.00 \mathrm{E}+00$ & 0 & $0.00 \mathrm{E}+00$ & 0 & $2.96 \mathrm{E}-12$ & 0 \\
\hline 234 & $1.28 \mathrm{E}-15$ & 0 & $0.00 E+00$ & 0 & $0.00 \mathrm{E}+00$ & 0 & $0.00 E+00$ & 0 & $0.00 \mathrm{E}+00$ & 0 & $0.00 \mathrm{E}+00$ & 0 & $0.00 \mathrm{E}+00$ & 0 & 1. $28 \mathrm{E}-15$ & 0 \\
\hline 235 & $5.11 \mathrm{E}-17$ & 0 & $0.00 \mathrm{E}+00$ & 0 & $0.00 \mathrm{E}+00$ & 0 & $0.00 \mathrm{E}+00$ & 0 & $0.00 \mathrm{E}+00$ & 0 & $0.00 \mathrm{E}+00$ & 0 & $0.00 \mathrm{E}+00$ & 0 & $5.11 \mathrm{E}-17$ & 0 \\
\hline 38 & $1.64 E-15$ & 0 & $0.00 E+00$ & 0 & $0.00 E+00$ & 0 & $0.00 \mathrm{E}+00$ & 0 & $0.00 \mathrm{E}+00$ & 0 & $0.00 E+00$ & 0 & $0.00 \mathrm{E}+00$ & 0 & 1. $64 \mathrm{E}-15$ & 0 \\
\hline & $3.23 E-12$ & 0 & $0.00 \mathrm{E}+00$ & 0 & $0.00 \mathrm{E}+00$ & 0 & $0.00 \mathrm{E}+00$ & 0 & $0.00 \mathrm{E}+00$ & 0 & $0.00 \mathrm{E}+00$ & 0 & $0.00 \mathrm{E}+00$ & 0 & $2.76 \mathrm{E}-02$ & 100 \\
\hline
\end{tabular}

* Sum of dose from all releases and from primary contamination. 
RESRAD-OFFSITE, Version 2.

Parent Dose Report

Title : Offsite Resident Farmer Deterministic Run

File : RF FINAL v2.ROF

Dose/Source Ratios Summed Over All Pathways

Parent and Progeny Principal Radionuclide Contributions Indicated

\begin{tabular}{|c|c|c|c|c|c|c|c|c|c|}
\hline Parent & Product & Thread & & & $\operatorname{SR}(j, t) \quad(\mathrm{m}$ & $\mathrm{em} / \mathrm{yr}) /(\mathrm{pc}$ & i/g) & & \\
\hline (i) & $(j)$ & Fraction & $0.000 \mathrm{E}+00$ & $1.000 \mathrm{E}+00$ & $5.000 \mathrm{E}+01$ & $1.000 \mathrm{E}+02$ & $5.000 \mathrm{E}+02$ & $7.720 E+02$ & $1.026 \mathrm{E}+03$ \\
\hline-241 & $A m-241$ & $1.000 \mathrm{E}+00$ & $1.173 \mathrm{E}-41$ & $1.202 \mathrm{E}-41$ & $3.982 E-41$ & 1. $352 \mathrm{E}-40$ & $2.391 E-36$ & $1.849 E-33$ & $9.208 E-31$ \\
\hline-241 & $N p-237+D$ & $1.000 \mathrm{E}+00$ & $9.379 E-28$ & $2.835 E-27$ & $1.490 \mathrm{E}-25$ & $4.678 E-25$ & $9.095 E-23$ & $1.726 \mathrm{E}-21$ & $2.417 \mathrm{E}-20$ \\
\hline $1-241$ & $\mathrm{U}-233$ & $1.000 \mathrm{E}+00$ & $2.412 E-38$ & $1.539 \mathrm{E}-37$ & $2.808 E-34$ & $1.927 E-33$ & $3.932 E-30$ & $1.900 \mathrm{E}-28$ & $5.618 E-27$ \\
\hline $1-241$ & $T h-229+D$ & $1.000 \mathrm{E}+00$ & $1.854 \mathrm{E}-34$ & $2.341 E-33$ & 1. $009 \mathrm{E}-28$ & $1.073 \mathrm{E}-27$ & $1.480 \mathrm{E}-24$ & $2.852 E-23$ & $3.195 \mathrm{E}-22$ \\
\hline $1-241$ & $\sum \operatorname{DSR}(j)$ & & $9.379 E-28$ & $2.835 E-27$ & $1.491 \mathrm{E}-25$ & $4.689 \mathrm{E}-25$ & $9.243 E-23$ & $1.754 \mathrm{E}-21$ & $2.449 \mathrm{E}-20$ \\
\hline$-137+D$ & $\mathrm{Cs}-137+\mathrm{D}$ & $1.000 \mathrm{E}+00$ & $7.649 \mathrm{E}-18$ & 7. $532 \mathrm{E}-18$ & $3.550 \mathrm{E}-18$ & $1.647 \mathrm{E}-18$ & $3.543 E-21$ & $5.440 E-23$ & $1.101 \mathrm{E}-24$ \\
\hline$-237+D$ & $\mathrm{~Np}-237+\mathrm{D}$ & $1.000 \mathrm{E}+00$ & $5.780 \mathrm{E}-21$ & $5.837 \mathrm{E}-21$ & $9.466 \mathrm{E}-21$ & 1. $550 \mathrm{E}-20$ & $8.026 \mathrm{E}-19$ & $1.175 \mathrm{E}-17$ & 1. $440 \mathrm{E}-16$ \\
\hline$-237+D$ & $\mathrm{U}-233$ & $1.000 \mathrm{E}+00$ & $1.969 \mathrm{E}-31$ & $5.963 \mathrm{E}-31$ & $3.524 \mathrm{E}-29$ & $1.247 \mathrm{E}-28$ & $6.189 \mathrm{E}-26$ & $2.184 \mathrm{E}-24$ & $5.394 \mathrm{E}-23$ \\
\hline$-237+D$ & $\mathrm{Th}-229+\mathrm{D}$ & $1.000 \mathrm{E}+00$ & $2.038 E-27$ & 1. $295 \mathrm{E}-26$ & $1.887 \mathrm{E}-23$ & $1.028 \mathrm{E}-22$ & $3.287 \mathrm{E}-20$ & $4.493 E-19$ & $4.103 E-18$ \\
\hline-237 & $\sum \operatorname{DSR}(j)$ & & $5.780 \mathrm{E}-21$ & $5.837 \mathrm{E}-21$ & $9.485 \mathrm{E}-21$ & $1.561 \mathrm{E}-20$ & $8.354 \mathrm{E}-19$ & $1.220 \mathrm{E}-17$ & $1.481 \mathrm{E}-16$ \\
\hline-238 & $\mathrm{Pu}-238$ & $1.840 \mathrm{E}-09$ & $1.310 \mathrm{E}-41$ & 1. $321 \mathrm{E}-41$ & $1.990 \mathrm{E}-41$ & $3.022 E-41$ & $8.560 E-40$ & $8.317 E-39$ & $6.951 E-38$ \\
\hline-238 & $\mathrm{Pu}-238$ & $1.000 \mathrm{E}+00$ & $7.119 E-33$ & $7.179 E-33$ & $1.081 \mathrm{E}-32$ & $1.642 E-32$ & $4.652 E-31$ & $4.520 E-30$ & $3.778 \mathrm{E}-29$ \\
\hline-238 & $\mathrm{U}-234$ & $1.000 \mathrm{E}+00$ & $5.930 \mathrm{E}-38$ & $1.798 \mathrm{E}-37$ & $1.115 \mathrm{E}-35$ & $4.196 \mathrm{E}-35$ & $5.105 E-32$ & $4.378 E-30$ & $2.757 \mathrm{E}-28$ \\
\hline-238 & $\mathrm{Th}-230$ & $1.000 \mathrm{E}+00$ & $7.074 \mathrm{E}-42$ & $4.520 \mathrm{E}-41$ & $9.070 \mathrm{E}-38$ & $6.913 E-37$ & $4.079 E-33$ & $4.717 \mathrm{E}-31$ & $3.348 E-29$ \\
\hline-238 & $\mathrm{Ra}-226+\mathrm{D}$ & $1.000 \mathrm{E}+00$ & $6.200 E-31$ & $7.815 E-30$ & $3.107 E-25$ & $3.056 \mathrm{E}-24$ & $2.593 E-21$ & $3.938 E-20$ & $3.654 \mathrm{E}-19$ \\
\hline-238 & $\mathrm{~Pb}-210+\mathrm{D}$ & $1.000 \mathrm{E}+00$ & $2.070 E-39$ & 4. $917 \mathrm{E}-38$ & $4.570 \mathrm{E}-32$ & $7.489 \mathrm{E}-31$ & $1.633 E-27$ & $3.395 E-26$ & $4.208 E-25$ \\
\hline-238 & $\sum \operatorname{DSR}(j)$ & & $6.271 \mathrm{E}-31$ & $7.822 \mathrm{E}-30$ & $3.107 \mathrm{E}-25$ & $3.056 \mathrm{E}-24$ & $2.593 E-21$ & $3.938 E-20$ & $3.654 \mathrm{E}-19$ \\
\hline-239 & $\mathrm{Pu}-239$ & $1.000 \mathrm{E}+00$ & $7.287 \mathrm{E}-26$ & 7. $367 \mathrm{E}-26$ & $1.262 \mathrm{E}-25$ & $2.187 \mathrm{E}-25$ & $1.776 \mathrm{E}-23$ & $3.532 E-22$ & $5.763 \mathrm{E}-21$ \\
\hline-239 & $\mathrm{U}-235+\mathrm{D}$ & $1.000 \mathrm{E}+00$ & $3.721 \mathrm{E}-32$ & $1.127 \mathrm{E}-31$ & $6.617 \mathrm{E}-30$ & $2.325 E-29$ & $1.094 \mathrm{E}-26$ & $3.719 \mathrm{E}-25$ & $8.874 \mathrm{E}-24$ \\
\hline-239 & $\mathrm{~Pa}-231$ & $1.000 \mathrm{E}+00$ & $6.641 \mathrm{E}-36$ & $4.233 E-35$ & $7.273 E-32$ & $4.692 \mathrm{E}-31$ & $5.773 E-28$ & $1.956 \mathrm{E}-26$ & $4.121 \mathrm{E}-25$ \\
\hline-239 & $A C-227+D$ & $1.000 \mathrm{E}+00$ & $1.768 E-35$ & $2.220 E-34$ & $7.476 \mathrm{E}-30$ & $6.622 E-29$ & $6.350 E-26$ & $1.419 \mathrm{E}-24$ & $2.019 \mathrm{E}-23$ \\
\hline-239 & $\sum \operatorname{DSR}(j)$ & & $7.287 \mathrm{E}-26$ & $7.367 \mathrm{E}-26$ & $1.263 E-25$ & $2.188 \mathrm{E}-25$ & $1.784 \mathrm{E}-23$ & $3.550 \mathrm{E}-22$ & $5.792 \mathrm{E}-21$ \\
\hline-240 & $\mathrm{Pu}-240$ & $4.950 \mathrm{E}-08$ & $3.426 \mathrm{E}-40$ & $3.481 \mathrm{E}-40$ & 7. $683 \mathrm{E}-40$ & $1.723 E-39$ & $1.103 E-36$ & $8.924 E-35$ & $5.401 \mathrm{E}-33$ \\
\hline-240 & $\mathrm{Pu}-240$ & $1.000 \mathrm{E}+00$ & $6.921 E-33$ & $7.033 E-33$ & $1.552 \mathrm{E}-32$ & $3.481 E-32$ & $2.227 E-29$ & $1.803 E-27$ & $1.091 \mathrm{E}-25$ \\
\hline-240 & $\mathrm{U}-236$ & $1.000 \mathrm{E}+00$ & 1. $312 \mathrm{E}-40$ & $3.990 \mathrm{E}-40$ & $3.012 \mathrm{E}-38$ & $1.369 \mathrm{E}-37$ & $5.033 E-34$ & $6.932 \mathrm{E}-32$ & $6.106 \mathrm{E}-30$ \\
\hline-240 & Th-232 & $1.000 \mathrm{E}+00$ & $0.000 \mathrm{E}+00$ & $0.000 \mathrm{E}+00$ & $0.000 \mathrm{E}+00$ & $0.000 \mathrm{E}+00$ & $6.527 E-42$ & 1. $608 \mathrm{E}-39$ & $2.161 \mathrm{E}-37$ \\
\hline-240 & $\mathrm{Ra}-228+\mathrm{D}$ & $1.000 \mathrm{E}+00$ & $1.056 \mathrm{E}-36$ & $1.302 \mathrm{E}-35$ & $2.214 \mathrm{E}-31$ & $1.452 \mathrm{E}-30$ & $6.617 \mathrm{E}-28$ & $1.056 \mathrm{E}-26$ & $1.096 \mathrm{E}-25$ \\
\hline-240 & $T h-228+D$ & $1.000 \mathrm{E}+00$ & $7.082 E-36$ & $1.578 \mathrm{E}-34$ & $1.564 \mathrm{E}-29$ & $1.017 \mathrm{E}-28$ & $2.672 \mathrm{E}-26$ & $2.852 E-25$ & $2.030 \mathrm{E}-24$ \\
\hline-240 & $\sum \operatorname{DSR}(j)$ & & $6.929 E-33$ & $7.204 E-33$ & $1.588 \mathrm{E}-29$ & $1.032 \mathrm{E}-28$ & $2.740 E-26$ & $2.976 E-25$ & $2.249 E-24$ \\
\hline-99 & $\mathrm{TC}-99$ & $1.000 \mathrm{E}+00$ & $3.496 \mathrm{E}-34$ & $3.539 \mathrm{E}-34$ & $6.498 E-34$ & $1.208 E-33$ & $1.906 \mathrm{E}-02$ & $3.593 E-02$ & $2.761 \mathrm{E}-02$ \\
\hline $28+D$ & $\mathrm{Th}-228+\mathrm{D}$ & $1.000 \mathrm{E}+00$ & $8.405 E-15$ & $5.887 \mathrm{E}-15$ & $1.507 \mathrm{E}-22$ & $2.680 \mathrm{E}-30$ & $0.000 \mathrm{E}+00$ & $0.000 \mathrm{E}+00$ & $0.000 \mathrm{E}+00$ \\
\hline
\end{tabular}


RESRAD-OFFSITE, Version 2.

Parent Dose Report

Title : Offsite Resident Farmer Deterministic Run

File : RF FINAL v2.ROF

Dose/Source Ratios Summed Over All Pathways

Parent and Progeny Principal Radionuclide Contributions Indicated

\begin{tabular}{|c|c|c|c|c|c|c|c|c|c|}
\hline Parent & Product & Thread & & & $\mathrm{SR}(j, \mathrm{t}) \quad(\mathrm{mr}$ & $\mathrm{m} / \mathrm{yr}) /(\mathrm{p}$ & $i / g)$ & & \\
\hline (i) & $(j)$ & Fraction & $0.000 \mathrm{E}+00$ & $1.000 \mathrm{E}+00$ & $5.000 \mathrm{E}+01$ & $1.000 \mathrm{E}+02$ & $5.000 \mathrm{E}+02$ & $7.720 E+02$ & $1.026 \mathrm{E}+03$ \\
\hline-230 & $\mathrm{Th}-230$ & $1.000 \mathrm{E}+00$ & $1.462 \mathrm{E}-30$ & 1. $485 \mathrm{E}-30$ & $3.170 \mathrm{E}-30$ & $6.873 E-30$ & $3.359 \mathrm{E}-27$ & $2.263 E-25$ & $1.154 \mathrm{E}-23$ \\
\hline-230 & $\mathrm{Ra}-226+\mathrm{D}$ & $1.000 \mathrm{E}+00$ & $2.288 E-19$ & $6.901 E-19$ & $3.138 \mathrm{E}-17$ & $8.491 \mathrm{E}-17$ & $4.948 E-15$ & $4.074 E-14$ & $2.589 \mathrm{E}-13$ \\
\hline-230 & $\mathrm{~Pb}-210+\mathrm{D}$ & $1.000 \mathrm{E}+00$ & $1.250 \mathrm{E}-27$ & $7.883 \mathrm{E}-27$ & $7.635 \mathrm{E}-24$ & $3.029 \mathrm{E}-23$ & $3.412 \mathrm{E}-21$ & $3.713 E-20$ & $3.104 \mathrm{E}-19$ \\
\hline-230 & $\sum \operatorname{DSR}(j)$ & & $2.288 E-19$ & $6.901 \mathrm{E}-19$ & $3.138 \mathrm{E}-17$ & $8.491 \mathrm{E}-17$ & $4.948 E-15$ & $4.074 \mathrm{E}-14$ & $2.589 \mathrm{E}-13$ \\
\hline $1-232$ & Th-232 & $1.000 \mathrm{E}+00$ & $7.064 \mathrm{E}-33$ & $7.186 \mathrm{E}-33$ & $1.661 \mathrm{E}-32$ & $3.904 \mathrm{E}-32$ & $3.643 E-29$ & $3.811 \mathrm{E}-27$ & $2.931 E-25$ \\
\hline-232 & $\mathrm{Ra}-228+\mathrm{D}$ & $1.000 \mathrm{E}+00$ & $6.681 \mathrm{E}-18$ & 1.919E-17 & $1.638 \mathrm{E}-16$ & $2.329 \mathrm{E}-16$ & $3.817 \mathrm{E}-15$ & $2.557 \mathrm{E}-14$ & 1. $510 \mathrm{E}-13$ \\
\hline-232 & $T h-228+D$ & $1.000 \mathrm{E}+00$ & $7.238 E-17$ & $4.048 \mathrm{E}-16$ & 1. $310 \mathrm{E}-14$ & $1.731 \mathrm{E}-14$ & 1. $558 \mathrm{E}-13$ & $6.953 E-13$ & $2.813 \mathrm{E}-12$ \\
\hline $1-232$ & $\sum \operatorname{DSR}(j)$ & & $7.906 \mathrm{E}-17$ & $4.240 \mathrm{E}-16$ & $1.327 \mathrm{E}-14$ & $1.754 \mathrm{E}-14$ & $1.597 \mathrm{E}-13$ & $7.209 \mathrm{E}-13$ & $2.964 \mathrm{E}-12$ \\
\hline-234 & $\mathrm{U}-234$ & $1.000 \mathrm{E}+00$ & $4.179 \mathrm{E}-32$ & $4.247 E-32$ & $9.442 \mathrm{E}-32$ & $2.133 E-31$ & 1. $449 \mathrm{E}-28$ & $1.222 \mathrm{E}-26$ & $7.680 \mathrm{E}-25$ \\
\hline-234 & $T h-230$ & $1.000 \mathrm{E}+00$ & $6.605 E-36$ & $2.007 E-35$ & $1.441 E-33$ & $6.216 E-33$ & $1.511 \mathrm{E}-29$ & $1.571 E-27$ & $1.064 \mathrm{E}-25$ \\
\hline-234 & $\mathrm{Ra}-226+\mathrm{D}$ & $1.000 \mathrm{E}+00$ & $7.794 \mathrm{E}-25$ & $4.953 E-24$ & $7.158 \mathrm{E}-21$ & $3.868 \mathrm{E}-20$ & $1.154 \mathrm{E}-17$ & 1. $493 E-16$ & 1. $282 \mathrm{E}-15$ \\
\hline-234 & $\mathrm{~Pb}-210+\mathrm{D}$ & $1.000 \mathrm{E}+00$ & $3.169 \mathrm{E}-33$ & $3.978 E-32$ & $1.294 \mathrm{E}-27$ & $1.103 E-26$ & $7.464 \mathrm{E}-24$ & $1.304 \mathrm{E}-22$ & 1. $487 \mathrm{E}-21$ \\
\hline-234 & $\sum \operatorname{DSR}(j)$ & & $7.794 E-25$ & $4.953 E-24$ & $7.158 \mathrm{E}-21$ & $3.868 E-20$ & $1.154 \mathrm{E}-17$ & 1. $493 E-16$ & 1. $282 \mathrm{E}-15$ \\
\hline$-235+D$ & $\mathrm{U}-235+\mathrm{D}$ & $1.000 \mathrm{E}+00$ & $7.535 E-23$ & 7. $622 \mathrm{E}-23$ & 1. $331 \mathrm{E}-22$ & $2.352 \mathrm{E}-22$ & $2.233 E-20$ & $4.936 E-19$ & $8.893 \mathrm{E}-18$ \\
\hline$-235+D$ & $\mathrm{~Pa}-231$ & $1.000 \mathrm{E}+00$ & 1. $782 \mathrm{E}-26$ & $5.389 \mathrm{E}-26$ & $2.925 \mathrm{E}-24$ & $9.486 \mathrm{E}-24$ & $2.349 \mathrm{E}-21$ & $5.164 \mathrm{E}-20$ & $8.198 \mathrm{E}-19$ \\
\hline$-235+D$ & $A C-227+D$ & $1.000 \mathrm{E}+00$ & $6.374 \mathrm{E}-26$ & $4.021 E-25$ & $4.032 E-22$ & $1.667 \mathrm{E}-21$ & $2.744 \mathrm{E}-19$ & $3.897 E-18$ & $4.140 \mathrm{E}-17$ \\
\hline-235 & $\sum \operatorname{DSR}(j)$ & & $7.544 \mathrm{E}-23$ & $7.667 \mathrm{E}-23$ & $5.393 E-22$ & $1.912 \mathrm{E}-21$ & $2.991 E-19$ & $4.443 E-18$ & $5.111 \mathrm{E}-17$ \\
\hline-238 & $\mathrm{U}-238$ & $5.400 \mathrm{E}-05$ & $0.000 \mathrm{E}+00$ & $0.000 \mathrm{E}+00$ & $0.000 \mathrm{E}+00$ & $0.000 \mathrm{E}+00$ & $0.000 \mathrm{E}+00$ & $0.000 \mathrm{E}+00$ & $0.000 \mathrm{E}+00$ \\
\hline$-238+D$ & $\mathrm{U}-238+\mathrm{D}$ & $9.999 \mathrm{E}-01$ & $8.606 \mathrm{E}-19$ & $8.669 \mathrm{E}-19$ & 1. $243 \mathrm{E}-18$ & $1.796 \mathrm{E}-18$ & $3.408 \mathrm{E}-17$ & $2.522 E-16$ & 1. $635 \mathrm{E}-15$ \\
\hline$-238+D$ & $\mathrm{U}-234$ & $9.999 E-01$ & $5.948 E-38$ & $1.809 E-37$ & $1.352 E-35$ & $6.079 E-35$ & $2.058 E-31$ & $2.678 E-29$ & $2.238 E-27$ \\
\hline $38+D$ & $\mathrm{Th}-230$ & $9.999 \mathrm{E}-01$ & $7.089 E-42$ & $4.540 E-41$ & $1.031 \mathrm{E}-37$ & $8.855 E-37$ & $1.072 \mathrm{E}-32$ & $1.720 \mathrm{E}-30$ & $1.548 \mathrm{E}-28$ \\
\hline$-238+D$ & $\mathrm{Ra}-226+\mathrm{D}$ & $9.999 \mathrm{E}-01$ & $5.589 \mathrm{E}-31$ & $7.732 E-30$ & $3.423 E-25$ & $3.687 E-24$ & $5.554 \mathrm{E}-21$ & $1.120 \mathrm{E}-19$ & 1. $288 \mathrm{E}-18$ \\
\hline$-238+D$ & $\mathrm{~Pb}-210+\mathrm{D}$ & $9.999 \mathrm{E}-01$ & $7.472 E-39$ & $3.324 E-38$ & $4.957 E-32$ & $8.813 E-31$ & $3.387 E-27$ & $9.392 E-26$ & 1. $449 \mathrm{E}-24$ \\
\hline-238 & $\sum \operatorname{DSR}(j)$ & & $8.606 \mathrm{E}-19$ & $8.669 \mathrm{E}-19$ & $1.243 \mathrm{E}-18$ & 1. $796 \mathrm{E}-18$ & $3.408 \mathrm{E}-17$ & $2.523 E-16$ & $1.636 \mathrm{E}-15$ \\
\hline
\end{tabular}

The DSR includes contributions from associated (half-life $\leq 180$ days) daughters. 
RESRAD-OFFSITE, Version 2.

Parent Dose Report

Title : Offsite Resident Farmer Deterministic Run

File : RF FINAL v2.ROF

Single Radionuclide Soil Guidelines G(i,t) in pCi/g

Basic Radiation Dose Limit $=1.000 \mathrm{E}+00 \mathrm{mrem} / \mathrm{yr}$

Nuclide

\begin{tabular}{|c|c|c|c|c|c|c|c|}
\hline (i) & $t=0.000 \mathrm{E}+00$ & $1.000 \mathrm{E}+00$ & $5.000 \mathrm{E}+01$ & $1.000 \mathrm{E}+02$ & $5.000 \mathrm{E}+02$ & $7.720 \mathrm{E}+02$ & $26 E+03$ \\
\hline-241 & $\star 3.431 \mathrm{E}+12$ & $\star 3.431 \mathrm{E}+12$ & $\star 3.431 \mathrm{E}+12$ & $\star 3.431 \mathrm{E}+12$ & $\star 3.431 \mathrm{E}+12$ & $\star 3.431 E+12$ & $\star 3.431 E+12$ \\
\hline-137 & $\star 8.704 \mathrm{E}+13$ & $\star 8.704 \mathrm{E}+13$ & $\star 8.704 \mathrm{E}+13$ & $\star 8.704 \mathrm{E}+13$ & $\star 8.704 \mathrm{E}+13$ & $\star 8.704 \mathrm{E}+13$ & $\star 8.704 \mathrm{E}+13$ \\
\hline-237 & $\star 7.047 \mathrm{E}+08$ & $\star 7.047 \mathrm{E}+08$ & $\star 7.047 \mathrm{E}+08$ & $\star 7.047 \mathrm{E}+08$ & $\star 7.047 \mathrm{E}+08$ & $\star 7.047 \mathrm{E}+08$ & $\star 7.047 \mathrm{E}+08$ \\
\hline-238 & $\star 1.712 \mathrm{E}+13$ & $\star 1.712 \mathrm{E}+13$ & $\star 1.712 \mathrm{E}+13$ & $\star 1.712 \mathrm{E}+13$ & $\star 1.712 \mathrm{E}+13$ & $\star 1.712 \mathrm{E}+13$ & $\star 1.712 \mathrm{E}+13$ \\
\hline-239 & $\star 6.214 \mathrm{E}+10$ & $\star 6.214 \mathrm{E}+10$ & $\star 6.214 \mathrm{E}+10$ & $\star 6.214 \mathrm{E}+10$ & $\star 6.214 \mathrm{E}+10$ & $* 6.214 \mathrm{E}+10$ & $\star 6.214 \mathrm{E}+10$ \\
\hline-2 & $\star 2.278 \mathrm{E}+11$ & $\star 2.278 \mathrm{E}+11$ & $\star 2.278 \mathrm{E}+11$ & & & $8 E+11$ & $\star 2.278 \mathrm{E}+11$ \\
\hline-99 & $\star 1.697 \mathrm{E}+10$ & $\star 1.697 \mathrm{E}+10$ & $\star 1.697 \mathrm{E}+10$ & $\star 1.697 \mathrm{E}+10$ & $5.247 E+01$ & $2.783 E+01$ & $3.621 \mathrm{E}+01$ \\
\hline-228 & $1.190 \mathrm{E}+14$ & $1.699 \mathrm{E}+14$ & $\star 8.195 \mathrm{E}+14$ & $\star 8.195 E+14$ & $\star 8.195 \mathrm{E}+14$ & $\star 8.195 \mathrm{E}+14$ & $\star 8.195 \mathrm{E}+14$ \\
\hline-230 & $\star 2.018 \mathrm{E}+10$ & $\star 2.018 \mathrm{E}+10$ & $\star 2.018 \mathrm{E}+10$ & $\star 2.018 \mathrm{E}+10$ & $\star 2.018 \mathrm{E}+10$ & $\star 2.018 \mathrm{E}+10$ & $\star 2.018 \mathrm{E}+10$ \\
\hline-232 & $* 1.097 \mathrm{E}+05$ & $\star 1.097 \mathrm{E}+05$ & $\star 1.097 \mathrm{E}+05$ & $\star 1.097 \mathrm{E}+05$ & $\star 1.097 \mathrm{E}+05$ & $\star 1.097 \mathrm{E}+05$ & $\star 1.097 \mathrm{E}+05$ \\
\hline 234 & $\star 6.247 \mathrm{E}+09$ & $\star 6.247 \mathrm{E}+09$ & $\star 6.247 \mathrm{E}+09$ & $\star 6.247 \mathrm{E}+09$ & $\star 6.247 \mathrm{E}+09$ & $\star 6.247 \mathrm{E}+09$ & $\star 6.247 \mathrm{E}+09$ \\
\hline 35 & $\star 2.161 \mathrm{E}+06$ & $\star 2.161 \mathrm{E}+06$ & $\star 2.161 \mathrm{E}+06$ & $\star 2.161 \mathrm{E}+06$ & $\star 2.161 \mathrm{E}+06$ & $\star 2.161 \mathrm{E}+06$ & $\star 2.161 \mathrm{E}+06$ \\
\hline 38 & $\star 3.361 \mathrm{E}+05$ & $\star 3.361 \mathrm{E}+05$ & $* 3.361 \mathrm{E}+05$ & $\star 3.361 \mathrm{E}+05$ & $\star 3.361 \mathrm{E}+05$ & $\star 3.361 \mathrm{E}+05$ & $\star 3.361 \mathrm{E}+05$ \\
\hline
\end{tabular}

*At specific activity limit

Summed Dose/Source Ratios DSR(i,t) in (mrem/yr)/(pCi/g)

and Single Radionuclide Soil Guidelines $G(i, t)$ in pCi/g

at tmin = time of minimum single radionuclide soil guideline

and at $\operatorname{tmax}=$ time of maximum total dose $=772$ years

\begin{tabular}{|c|c|c|c|c|c|c|}
\hline $\begin{array}{l}\text { Juclide } \\
\text { (i) }\end{array}$ & $\begin{array}{l}\text { Initial } \\
(\mathrm{pCi} / \mathrm{g})\end{array}$ & $\begin{array}{c}\text { tmin } \\
\text { (years) }\end{array}$ & $\operatorname{DSR}(i, \operatorname{tmin})$ & $\begin{array}{c}G(i, \operatorname{tmin}) \\
(\mathrm{pCi} / \mathrm{g})\end{array}$ & $\operatorname{DSR}(i, \operatorname{tmax})$ & $\begin{array}{c}G(i, t \max ) \\
(\mathrm{pCi} / \mathrm{g})\end{array}$ \\
\hline-241 & $1.000 \mathrm{E}+00$ & 1050 & $3.116 \mathrm{E}-20$ & $\star 3.431 \mathrm{E}+12$ & $1.747 \mathrm{E}-21$ & $\star 3.431 \mathrm{E}+12$ \\
\hline$s-137$ & $1.000 \mathrm{E}+00$ & 0 & $7.649 \mathrm{E}-18$ & $\star 8.704 \mathrm{E}+13$ & $5.473 E-23$ & $\star 8.704 \mathrm{E}+13$ \\
\hline$p-237$ & $1.000 \mathrm{E}+00$ & 1050 & $1.866 \mathrm{E}-16$ & $\star 7.047 \mathrm{E}+08$ & 1. $215 \mathrm{E}-17$ & $\star 7.047 \mathrm{E}+08$ \\
\hline$x-238$ & $1.000 \mathrm{E}+00$ & 1050 & $4.450 \mathrm{E}-19$ & $\star 1.712 \mathrm{E}+13$ & $3.924 \mathrm{E}-20$ & $\star 1.712 \mathrm{E}+13$ \\
\hline$x-239$ & $1.000 \mathrm{E}+00$ & 1050 & $7.500 \mathrm{E}-21$ & $\star 6.214 \mathrm{E}+10$ & $3.535 E-22$ & $\star 6.214 \mathrm{E}+10$ \\
\hline$x-240$ & $1.000 \mathrm{E}+00$ & 1050 & $2.711 \mathrm{E}-24$ & $\star 2.278 \mathrm{E}+11$ & $2.966 \mathrm{E}-25$ & $\star 2.278 \mathrm{E}+11$ \\
\hline$=-99$ & $1.000 \mathrm{E}+00$ & 772 & $3.593 \mathrm{E}-02$ & $2.783 E+01$ & $3.593 E-02$ & $2.783 E+01$ \\
\hline $1-228$ & $1.000 \mathrm{E}+00$ & 0 & $8.405 \mathrm{E}-15$ & $1.190 \mathrm{E}+14$ & $0.000 \mathrm{E}+00$ & $\star 8.195 \mathrm{E}+14$ \\
\hline $1-230$ & $1.000 \mathrm{E}+00$ & 1050 & $3.061 \mathrm{E}-13$ & $\star 2.018 \mathrm{E}+10$ & $4.062 \mathrm{E}-14$ & $\star 2.018 \mathrm{E}+10$ \\
\hline $1-232$ & $1.000 \mathrm{E}+00$ & 1050 & $3.379 \mathrm{E}-12$ & $* 1.097 \mathrm{E}+05$ & $7.193 E-13$ & $\star 1.097 \mathrm{E}+05$ \\
\hline-234 & $1.000 \mathrm{E}+00$ & 1050 & $1.553 \mathrm{E}-15$ & $\star 6.247 \mathrm{E}+09$ & $1.488 \mathrm{E}-16$ & $* 6.247 \mathrm{E}+09$ \\
\hline 235 & $1.000 \mathrm{E}+00$ & 1050 & $6.404 \mathrm{E}-17$ & $\star 2.161 \mathrm{E}+06$ & $4.426 \mathrm{E}-18$ & $\star 2.161 \mathrm{E}+06$ \\
\hline 238 & $1.000 \mathrm{E}+00$ & 1050 & $1.945 \mathrm{E}-15$ & $\star 3.361 \mathrm{E}+05$ & $2.516 \mathrm{E}-16$ & $\star 3.361 \mathrm{E}+05$ \\
\hline
\end{tabular}

*At specific activity limit 
RESRAD-OFFSITE, Version 2.

Parent Dose Report

Title : Offsite Resident Farmer Deterministic Run

File : RF FINAL v2.ROF

Individual Nuclide Dose Summed Over All Pathways

Parent Nuclide and Thread Fraction Indicated

Nuclide Parent THF(i) DOSE $(j, t)$, mrem/yr

\begin{tabular}{|c|c|c|}
\hline (j) & (i) & \\
\hline$n-241$ & $A m-241$ & $1.000 \mathrm{E}+00$ \\
\hline-237 & $A m-241$ & $1.000 \mathrm{E}+00$ \\
\hline-237 & $\mathrm{~Np}-237$ & $1.000 \mathrm{E}+00$ \\
\hline 237 & $\sum \operatorname{DOSE}($ & : \\
\hline
\end{tabular}

$\mathrm{U}-233 \quad \mathrm{Am}-241 \quad 1.000 \mathrm{E}+00$

$\mathrm{U}-233 \quad \mathrm{~Np}-237 \quad 1.000 \mathrm{E}+00$

U-233 $\operatorname{DOSE}(j):$

Th-229 Am-241 $1.000 \mathrm{E}+00$

Th-229 Np-237 $1.000 \mathrm{E}+00$

Th-229 $\operatorname{LDOSE}(j):$

Cs-137 Cs $-137 \quad 1.000 \mathrm{E}+00$

$\mathrm{Pu}-238$

$\mathrm{Pu}-238$

$\mathrm{Pu}-238$

$\mathrm{U}-234$

$\mathrm{U}-234$

$\mathrm{U}-234$

$\mathrm{U}-234$

Th -230

Th -230

Th -230

Th -230

Th-230

$\mathrm{Ra}-226$

$\mathrm{Ra}-226$

$\mathrm{Ra}-226$

$\mathrm{Ra}-226$

$\mathrm{Ra}-226$

$\mathrm{Pb}-210 \mathrm{Pu}-238 \quad 1.000 \mathrm{E}+00$

$\mathrm{Pb}-210 \mathrm{Th}-230 \quad 1.000 \mathrm{E}+00$

$\mathrm{Pb}-210 \quad \mathrm{U}-234 \quad 1.000 \mathrm{E}+00$

$\mathrm{Pb}-210 \quad \mathrm{U}-238 \quad 9.999 \mathrm{E}-01$

$\mathrm{Pb}-210 \quad \sum \operatorname{DOSE}(j):$

Pu-239 Pu-239 $1.000 E+00$ $\mathrm{t}=0.000 \mathrm{E}+00 \quad 1.000 \mathrm{E}+00 \quad 5.000 \mathrm{E}+01 \quad 1.000 \mathrm{E}+02 \quad 5.000 \mathrm{E}+02 \quad 7.720 \mathrm{E}+02 \quad 1.026 \mathrm{E}+03$

$\begin{array}{llllllll}1.173 \mathrm{E}-41 & 1.202 \mathrm{E}-41 & 3.982 \mathrm{E}-41 & 1.352 \mathrm{E}-40 & 2.391 \mathrm{E}-36 & 1.849 \mathrm{E}-33 & 9.208 \mathrm{E}-31\end{array}$

$9.379 \mathrm{E}-28 \quad 2.835 \mathrm{E}-27 \quad 1.490 \mathrm{E}-25 \quad 4.678 \mathrm{E}-25 \quad 9.095 \mathrm{E}-23 \quad 1.726 \mathrm{E}-21 \quad 2.417 \mathrm{E}-20$

$\begin{array}{lllllll}5.780 \mathrm{E}-21 & 5.837 \mathrm{E}-21 & 9.466 \mathrm{E}-21 & 1.550 \mathrm{E}-20 & 8.026 \mathrm{E}-19 & 1.175 \mathrm{E}-17 & 1.440 \mathrm{E}-16\end{array}$

$\begin{array}{lllllll}5.780 \mathrm{E}-21 & 5.837 \mathrm{E}-21 & 9.467 \mathrm{E}-21 & 1.550 \mathrm{E}-20 & 8.027 \mathrm{E}-19 & 1.175 \mathrm{E}-17 & 1.441 \mathrm{E}-16\end{array}$

$2.412 \mathrm{E}-38 \quad 1.539 \mathrm{E}-37 \quad 2.808 \mathrm{E}-34 \quad 1.927 \mathrm{E}-33 \quad 3.932 \mathrm{E}-30 \quad 1.900 \mathrm{E}-28 \quad 5.618 \mathrm{E}-27$

$\begin{array}{lllllll}1.969 \mathrm{E}-31 & 5.963 \mathrm{E}-31 & 3.524 \mathrm{E}-29 & 1.247 \mathrm{E}-28 & 6.189 \mathrm{E}-26 & 2.184 \mathrm{E}-24 & 5.394 \mathrm{E}-23\end{array}$

$\begin{array}{lllllll}1.969 \mathrm{E}-31 & 5.963 \mathrm{E}-31 & 3.524 \mathrm{E}-29 & 1.247 \mathrm{E}-28 & 6.190 \mathrm{E}-26 & 2.184 \mathrm{E}-24 & 5.394 \mathrm{E}-23\end{array}$

$1.854 \mathrm{E}-34 \quad 2.341 \mathrm{E}-33 \quad 1.009 \mathrm{E}-28 \quad 1.073 \mathrm{E}-27 \quad 1.480 \mathrm{E}-24 \quad 2.852 \mathrm{E}-23 \quad 3.195 \mathrm{E}-22$

$2.038 \mathrm{E}-27 \quad 1.295 \mathrm{E}-26 \quad 1.887 \mathrm{E}-23 \quad 1.028 \mathrm{E}-22 \quad 3.287 \mathrm{E}-20 \quad 4.493 \mathrm{E}-19 \quad 4.103 \mathrm{E}-18$

$2.038 \mathrm{E}-27 \quad 1.295 \mathrm{E}-26 \quad 1.887 \mathrm{E}-23 \quad 1.028 \mathrm{E}-22 \quad 3.287 \mathrm{E}-20 \quad 4.493 \mathrm{E}-19 \quad 4.103 \mathrm{E}-18$

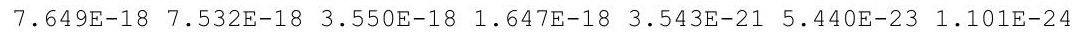

$\begin{array}{lllllll}1.310 \mathrm{E}-41 & 1.321 \mathrm{E}-41 & 1.990 \mathrm{E}-41 & 3.022 \mathrm{E}-41 & 8.560 \mathrm{E}-40 & 8.317 \mathrm{E}-39 & 6.951 \mathrm{E}-38\end{array}$

$\begin{array}{lllllll}7.119 \mathrm{E}-33 & 7.179 \mathrm{E}-33 & 1.081 \mathrm{E}-32 & 1.642 \mathrm{E}-32 & 4.652 \mathrm{E}-31 & 4.520 \mathrm{E}-30 & 3.778 \mathrm{E}-29\end{array}$

$\begin{array}{lllllll}7.119 \mathrm{E}-33 & 7.179 \mathrm{E}-33 & 1.081 \mathrm{E}-32 & 1.642 \mathrm{E}-32 & 4.652 \mathrm{E}-31 & 4.520 \mathrm{E}-30 & 3.778 \mathrm{E}-29\end{array}$

$\begin{array}{lllllll}5.930 \mathrm{E}-38 & 1.798 \mathrm{E}-37 & 1.115 \mathrm{E}-35 & 4.196 \mathrm{E}-35 & 5.105 \mathrm{E}-32 & 4.378 \mathrm{E}-30 & 2.757 \mathrm{E}-28\end{array}$

$\begin{array}{lllllll}4.179 \mathrm{E}-32 & 4.247 \mathrm{E}-32 & 9.442 \mathrm{E}-32 & 2.133 \mathrm{E}-31 & 1.449 \mathrm{E}-28 & 1.222 \mathrm{E}-26 & 7.680 \mathrm{E}-25\end{array}$

$\begin{array}{llllllll}5.948 \mathrm{E}-38 & 1.809 \mathrm{E}-37 & 1.352 \mathrm{E}-35 & 6.079 \mathrm{E}-35 & 2.058 \mathrm{E}-31 & 2.678 \mathrm{E}-29 & 2.238 \mathrm{E}-27\end{array}$

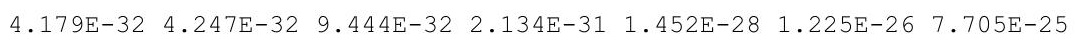

$\begin{array}{lllllll}7.074 \mathrm{E}-42 & 4.520 \mathrm{E}-41 & 9.070 \mathrm{E}-38 & 6.913 \mathrm{E}-37 & 4.079 \mathrm{E}-33 & 4.717 \mathrm{E}-31 & 3.348 \mathrm{E}-29\end{array}$ $\begin{array}{lllllll}1.462 \mathrm{E}-30 & 1.485 \mathrm{E}-30 & 3.170 \mathrm{E}-30 & 6.873 \mathrm{E}-30 & 3.359 \mathrm{E}-27 & 2.263 \mathrm{E}-25 & 1.154 \mathrm{E}-23\end{array}$ $\begin{array}{llllllll}6.605 \mathrm{E}-36 & 2.007 \mathrm{E}-35 & 1.441 \mathrm{E}-33 & 6.216 \mathrm{E}-33 & 1.511 \mathrm{E}-29 & 1.571 \mathrm{E}-27 & 1.064 \mathrm{E}-25\end{array}$ $\begin{array}{lllllll}7.089 \mathrm{E}-42 & 4.540 \mathrm{E}-41 & 1.031 \mathrm{E}-37 & 8.855 \mathrm{E}-37 & 1.072 \mathrm{E}-32 & 1.720 \mathrm{E}-30 & 1.548 \mathrm{E}-28\end{array}$ $\begin{array}{lllllll}1.462 \mathrm{E}-30 & 1.485 \mathrm{E}-30 & 3.171 \mathrm{E}-30 & 6.879 \mathrm{E}-30 & 3.374 \mathrm{E}-27 & 2.279 \mathrm{E}-25 & 1.165 \mathrm{E}-23\end{array}$

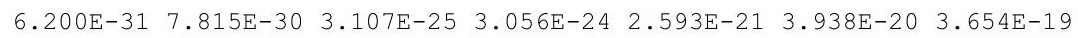
$2.288 \mathrm{E}-19 \quad 6.901 \mathrm{E}-19 \quad 3.138 \mathrm{E}-17 \quad 8.491 \mathrm{E}-17 \quad 4.948 \mathrm{E}-15 \quad 4.074 \mathrm{E}-14 \quad 2.589 \mathrm{E}-13$ $\begin{array}{lllllll}7.794 \mathrm{E}-25 & 4.953 \mathrm{E}-24 & 7.158 \mathrm{E}-21 & 3.868 \mathrm{E}-20 & 1.154 \mathrm{E}-17 & 1.493 \mathrm{E}-16 & 1.282 \mathrm{E}-15\end{array}$ $\begin{array}{lllllll}5.589 \mathrm{E}-31 & 7.732 \mathrm{E}-30 & 3.423 \mathrm{E}-25 & 3.687 \mathrm{E}-24 & 5.554 \mathrm{E}-21 & 1.120 \mathrm{E}-19 & 1.288 \mathrm{E}-18\end{array}$ $\begin{array}{lllllll}2.288 \mathrm{E}-19 & 6.901 \mathrm{E}-19 & 3.139 \mathrm{E}-17 & 8.495 \mathrm{E}-17 & 4.960 \mathrm{E}-15 & 4.089 \mathrm{E}-14 & 2.601 \mathrm{E}-13\end{array}$

$2.070 \mathrm{E}-39 \quad 4.917 \mathrm{E}-38 \quad 4.570 \mathrm{E}-32 \quad 7.489 \mathrm{E}-31 \quad 1.633 \mathrm{E}-27 \quad 3.395 \mathrm{E}-26 \quad 4.208 \mathrm{E}-25$ $\begin{array}{lllllll}1.250 \mathrm{E}-27 & 7.883 \mathrm{E}-27 & 7.635 \mathrm{E}-24 & 3.029 \mathrm{E}-23 & 3.412 \mathrm{E}-21 & 3.713 \mathrm{E}-20 & 3.104 \mathrm{E}-19\end{array}$ $3.169 \mathrm{E}-33 \quad 3.978 \mathrm{E}-32 \quad 1.294 \mathrm{E}-27 \quad 1.103 \mathrm{E}-26 \quad 7.464 \mathrm{E}-24 \quad 1.304 \mathrm{E}-22 \quad 1.487 \mathrm{E}-21$ $\begin{array}{llllllll}7.472 \mathrm{E}-39 & 3.324 \mathrm{E}-38 & 4.957 \mathrm{E}-32 & 8.813 \mathrm{E}-31 & 3.387 \mathrm{E}-27 & 9.392 \mathrm{E}-26 & 1.449 \mathrm{E}-24\end{array}$ $\begin{array}{lllllll}1.250 \mathrm{E}-27 & 7.883 \mathrm{E}-27 & 7.636 \mathrm{E}-24 & 3.030 \mathrm{E}-23 & 3.420 \mathrm{E}-21 & 3.726 \mathrm{E}-20 & 3.119 \mathrm{E}-19\end{array}$

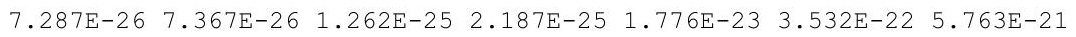


RESRAD-OFFSITE, Version 2.

Parent Dose Report

Title : Offsite Resident Farmer Deterministic Run

File : RF FINAL v2.ROF

Individual Nuclide Dose Summed Over All Pathways

Parent Nuclide and Thread Fraction Indicated

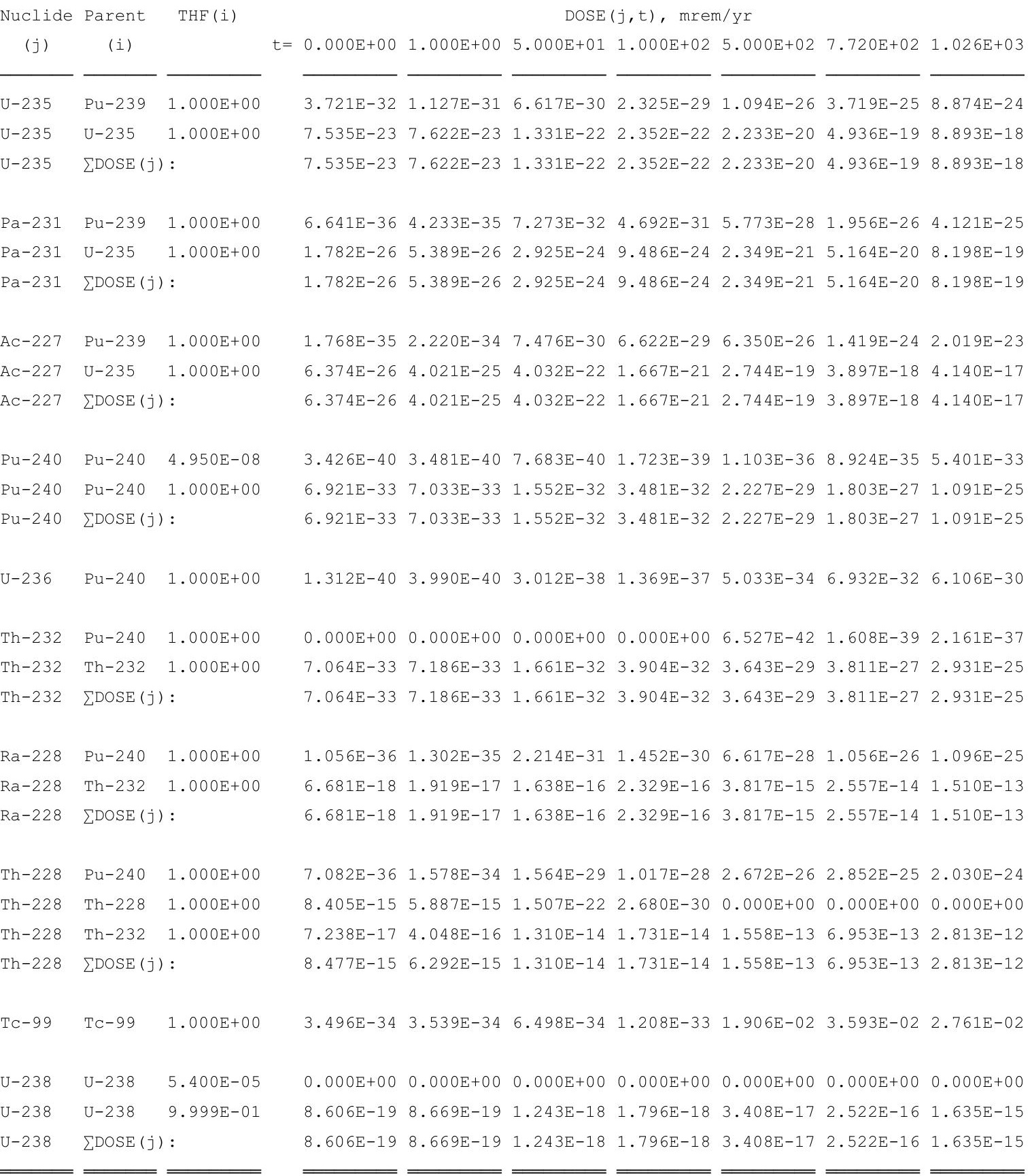

THF(i) is the thread fraction of the parent nuclide. 
RESRAD-OFFSITE, Version 2.

Parent Dose Report

Title : Offsite Resident Farmer Deterministic Run

File : RF FINAL v2.ROF

Individual Nuclide Soil Concentration

Parent Nuclide and Thread Fraction Indicated

Nuclide Parent THF(

\section{(j)}

(i)

$A m-241$

Np-237

Np-237

Np-237

$\mathrm{U}-233$

$\mathrm{U}-233$

$\mathrm{U}-233$

Th-229

Th -229

Th-229

Cs-137

$\mathrm{Pu}-238$

$\mathrm{Pu}-238$

$\mathrm{Pu}-238$

$\mathrm{U}-234$

$\mathrm{U}-234$

$\mathrm{U}-234$

$\mathrm{U}-234$

Th -230

Th-230

Th -230

Th -230

Th-230

$\mathrm{Ra}-226$

$\mathrm{Ra}-226$

$\mathrm{Ra}-226$

$\mathrm{Ra}-226$

Ra-226

$\mathrm{Pb}-210$

$\mathrm{Pb}-210$

$\mathrm{Pb}-210$

$\mathrm{Pb}-210$

$\mathrm{Pb}-210$

Pu-239 Pu-239 1.000E+00
$\mathrm{S}(\mathrm{j}, \mathrm{t}), \mathrm{pCi} / \mathrm{g}$

$t=0.000 \mathrm{E}+00 \quad 1.000 \mathrm{E}+00 \quad 5.000 \mathrm{E}+01 \quad 1.000 \mathrm{E}+02 \quad 5.000 \mathrm{E}+02 \quad 7.720 \mathrm{E}+02 \quad 1.026 \mathrm{E}+03$

$\begin{array}{llllllllllllllll}1.000 \mathrm{E}+00 & 9.984 \mathrm{E}-01 & 9.228 \mathrm{E}-01 & 8.516 \mathrm{E}-01 & 4.478 \mathrm{E}-01 & 2.893 \mathrm{E}-01 & 1.924 \mathrm{E}-01\end{array}$

$\begin{array}{lllllll}0.000 \mathrm{E}+00 & 3.236 \mathrm{E}-07 & 1.553 \mathrm{E}-05 & 2.980 \mathrm{E}-05 & 1.089 \mathrm{E}-04 & 1.382 \mathrm{E}-04 & 1.548 \mathrm{E}-04\end{array}$

$\begin{array}{llllllll}1.000 \mathrm{E}+00 & 9.999 \mathrm{E}-01 & 9.961 \mathrm{E}-01 & 9.922 \mathrm{E}-01 & 9.614 \mathrm{E}-01 & 9.410 \mathrm{E}-01 & 9.224 \mathrm{E}-01\end{array}$

$\begin{array}{llllllll}1.000 \mathrm{E}+00 & 9.999 \mathrm{E}-01 & 9.961 \mathrm{E}-01 & 9.922 \mathrm{E}-01 & 9.615 \mathrm{E}-01 & 9.412 \mathrm{E}-01 & 9.225 \mathrm{E}-01\end{array}$

$0.000 \mathrm{E}+00 \quad 7.166 \mathrm{E}-13 \quad 1.721 \mathrm{E}-09 \quad 6.696 \mathrm{E}-09 \quad 1.355 \mathrm{E}-07 \quad 2.829 \mathrm{E}-07 \quad 4.447 \mathrm{E}-07$

$\begin{array}{lllllll}0.000 \mathrm{E}+00 & 4.373 \mathrm{E}-06 & 2.181 \mathrm{E}-04 & 4.352 \mathrm{E}-04 & 2.135 \mathrm{E}-03 & 3.253 \mathrm{E}-03 & 4.271 \mathrm{E}-03\end{array}$

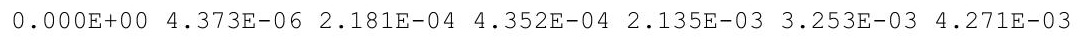

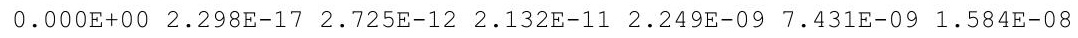

$\begin{array}{lllllll}0.000 \mathrm{E}+00 & 2.090 \mathrm{E}-10 & 5.146 \mathrm{E}-07 & 2.052 \mathrm{E}-06 & 4.999 \mathrm{E}-05 & 1.171 \mathrm{E}-04 & 2.035 \mathrm{E}-04\end{array}$

$\begin{array}{lllllll}0.000 \mathrm{E}+00 & 2.090 \mathrm{E}-10 & 5.146 \mathrm{E}-07 & 2.052 \mathrm{E}-06 & 4.999 \mathrm{E}-05 & 1.171 \mathrm{E}-04 & 2.036 \mathrm{E}-04\end{array}$

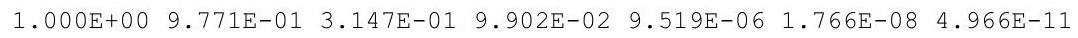

$\begin{array}{lllllll}1.840 \mathrm{E}-09 & 1.826 \mathrm{E}-09 & 1.239 \mathrm{E}-09 & 8.342 \mathrm{E}-10 & 3.525 \mathrm{E}-11 & 4.100 \mathrm{E}-12 & 5.498 \mathrm{E}-13\end{array}$

$\begin{array}{lllllll}1.000 \mathrm{E}+00 & 9.921 \mathrm{E}-01 & 6.733 \mathrm{E}-01 & 4.534 \mathrm{E}-01 & 1.916 \mathrm{E}-02 & 2.228 \mathrm{E}-03 & 2.988 \mathrm{E}-04\end{array}$

$\begin{array}{lllllll}1.000 \mathrm{E}+00 & 9.921 \mathrm{E}-01 & 6.733 \mathrm{E}-01 & 4.534 \mathrm{E}-01 & 1.916 \mathrm{E}-02 & 2.228 \mathrm{E}-03 & 2.988 \mathrm{E}-04\end{array}$

$\begin{array}{lllllll}0.000 \mathrm{E}+00 & 2.824 \mathrm{E}-06 & 1.170 \mathrm{E}-04 & 1.957 \mathrm{E}-04 & 3.494 \mathrm{E}-04 & 3.539 \mathrm{E}-04 & 3.531 \mathrm{E}-04\end{array}$

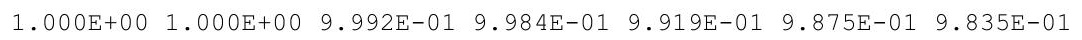

$\begin{array}{lllllll}0.000 \mathrm{E}+00 & 2.835 \mathrm{E}-06 & 1.416 \mathrm{E}-04 & 2.831 \mathrm{E}-04 & 1.407 \mathrm{E}-03 & 2.164 \mathrm{E}-03 & 2.865 \mathrm{E}-03\end{array}$

$\begin{array}{lllllllll}1.000 \mathrm{E}+00 & 1.000 \mathrm{E}+00 & 9.994 \mathrm{E}-01 & 9.989 \mathrm{E}-01 & 9.937 \mathrm{E}-01 & 9.901 \mathrm{E}-01 & 9.867 \mathrm{E}-01\end{array}$

$\begin{array}{lllllll}0.000 \mathrm{E}+00 & 1.288 \mathrm{E}-11 & 2.807 \mathrm{E}-0 & 9.959 \mathrm{E}-08 & 1.206 \mathrm{E}-06 & 2.065 \mathrm{E}-06 & 2.867 \mathrm{E}-06\end{array}$ $\begin{array}{llllllll}1.000 \mathrm{E}+00 & 1.000 \mathrm{E}+00 & 9.995 \mathrm{E}-01 & 9.989 \mathrm{E}-01 & 9.947 \mathrm{E}-01 & 9.918 \mathrm{E}-01 & 9.891 \mathrm{E}-01\end{array}$ $\begin{array}{lllllll}0.000 \mathrm{E}+00 & 9.002 \mathrm{E}-06 & 4.498 \mathrm{E}-04 & 8.990 \mathrm{E}-04 & 4.471 \mathrm{E}-03 & 6.878 \mathrm{E}-03 & 9.109 \mathrm{E}-03\end{array}$ $\begin{array}{lllllll}0.000 \mathrm{E}+00 & 1.292 \mathrm{E}-11 & 3.188 \mathrm{E}-08 & 1.274 \mathrm{E}-07 & 3.168 \mathrm{E}-06 & 7.526 \mathrm{E}-06 & 1.325 \mathrm{E}-05\end{array}$ $\begin{array}{llllllll}1.000 \mathrm{E}+00 & 1.000 \mathrm{E}+00 & 9.999 \mathrm{E}-01 & 9.998 \mathrm{E}-01 & 9.991 \mathrm{E}-01 & 9.986 \mathrm{E}-01 & 9.982 \mathrm{E}-01\end{array}$

$0.000 \mathrm{E}+00 \quad 1.896 \mathrm{E}-15 \quad 2.080 \mathrm{E}-10 \quad 1.511 \mathrm{E}-09 \quad 1.013 \mathrm{E}-07 \quad 2.723 \mathrm{E}-07 \quad 5.006 \mathrm{E}-07$ $\begin{array}{llllllll}0.000 \mathrm{E}+00 & 4.331 \mathrm{E}-04 & 2.142 \mathrm{E}-02 & 4.235 \mathrm{E}-02 & 1.937 \mathrm{E}-01 & 2.819 \mathrm{E}-01 & 3.549 \mathrm{E}-01\end{array}$ $\begin{array}{lllllll}0.000 \mathrm{E}+00 & 1.974 \mathrm{E}-09 & 4.837 \mathrm{E}-06 & 1.920 \mathrm{E}-05 & 4.512 \mathrm{E}-04 & 1.033 \mathrm{E}-03 & 1.756 \mathrm{E}-03\end{array}$ $\begin{array}{llllllll}0.000 \mathrm{E}+00 & 1.940 \mathrm{E}-15 & 2.289 \mathrm{E}-10 & 1.820 \mathrm{E}-09 & 2.170 \mathrm{E}-07 & 7.736 \mathrm{E}-07 & 1.764 \mathrm{E}-06\end{array}$ $\begin{array}{lllllll}0.000 \mathrm{E}+00 & 4.331 \mathrm{E}-04 & 2.142 \mathrm{E}-02 & 4.237 \mathrm{E}-02 & 1.942 \mathrm{E}-01 & 2.829 \mathrm{E}-01 & 3.566 \mathrm{E}-01\end{array}$

$\begin{array}{lllllll}0.000 \mathrm{E}+00 & 1.501 \mathrm{E}-17 & 6.201 \mathrm{E}-11 & 7.209 \mathrm{E}-10 & 8.712 \mathrm{E}-08 & 2.483 \mathrm{E}-07 & 4.685 \mathrm{E}-07\end{array}$ $\begin{array}{llllllll}0.000 \mathrm{E}+00 & 6.744 \mathrm{E}-06 & 1.058 \mathrm{E}-02 & 2.946 \mathrm{E}-02 & 1.823 \mathrm{E}-01 & 2.718 \mathrm{E}-01 & 3.458 \mathrm{E}-01\end{array}$ $\begin{array}{lllllll}0.000 \mathrm{E}+00 & 2.067 \mathrm{E}-11 & 1.773 \mathrm{E}-06 & 1.066 \mathrm{E}-05 & 3.984 \mathrm{E}-04 & 9.537 \mathrm{E}-04 & 1.656 \mathrm{E}-03\end{array}$ $\begin{array}{llllllll}0.000 \mathrm{E}+00 & 6.181 \mathrm{E}-17 & 6.720 \mathrm{E}-11 & 8.476 \mathrm{E}-10 & 1.806 \mathrm{E}-07 & 6.865 \mathrm{E}-07 & 1.612 \mathrm{E}-06\end{array}$ $\begin{array}{lllllllll}0.000 \mathrm{E}+00 & 6.744 \mathrm{E}-06 & 1.058 \mathrm{E}-02 & 2.947 \mathrm{E}-02 & 1.827 \mathrm{E}-01 & 2.727 \mathrm{E}-01 & 3.475 \mathrm{E}-01\end{array}$

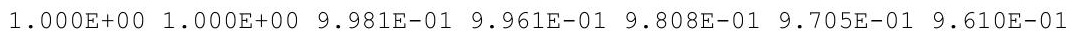


RESRAD-OFFSITE, Version 2.

Parent Dose Report

Title : Offsite Resident Farmer Deterministic Run

File : RF FINAL v2.ROF

Individual Nuclide Soil Concentration

Parent Nuclide and Thread Fraction Indicated

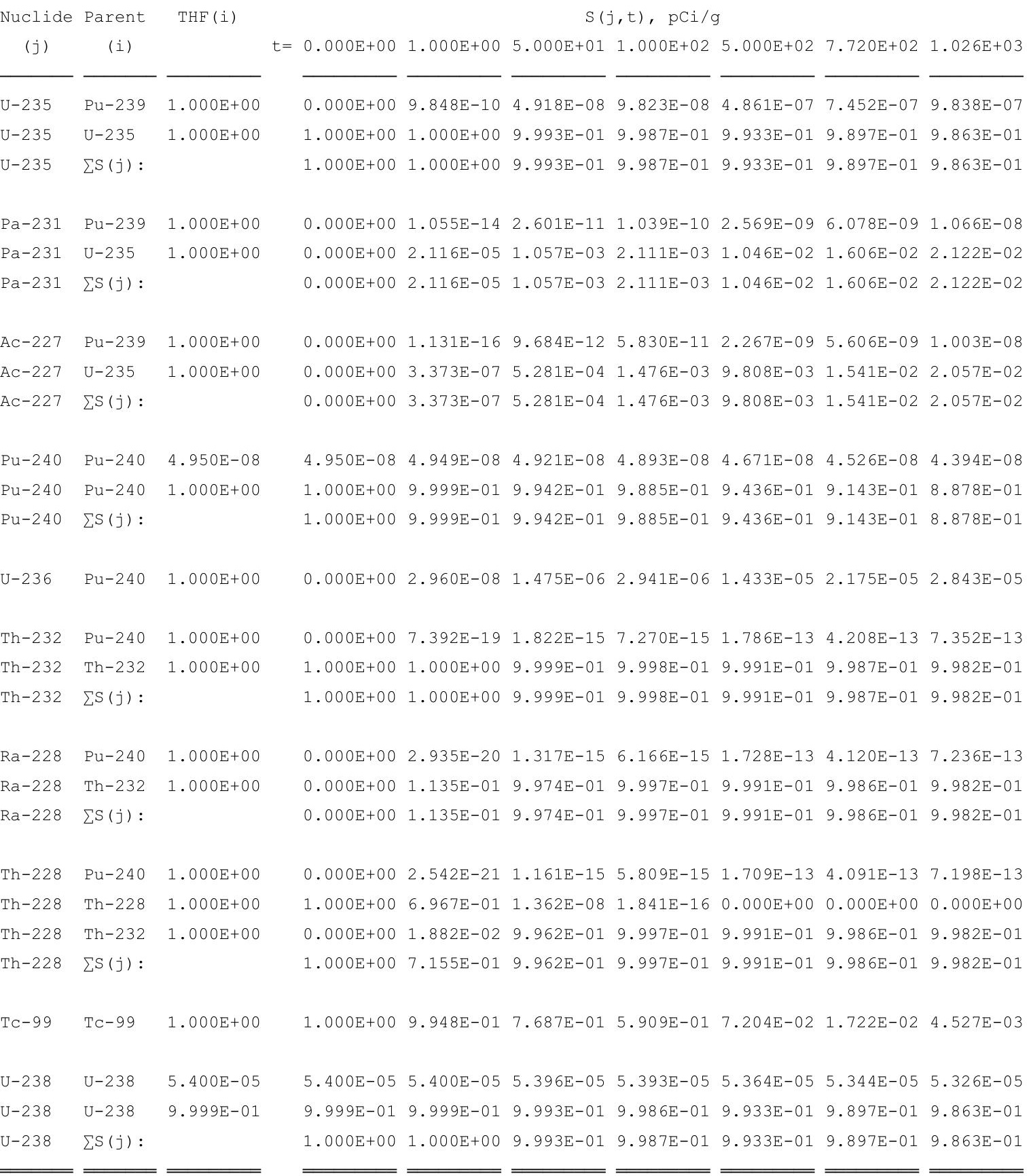

THF (i) is the thread fraction of the parent nuclide. 
RESRAD-OFFSITE, Version $2.5 \quad \mathrm{~T}^{1} \frac{1}{2}$ Limit $=180$ days

Parent Dose Report

Title : Offsite Resident Farmer Deterministic Run

File : RF FINAL v2.ROF

Run Time Information

ResOCalc.EXE execution began at 15:18 on 05/02/2011

ResOCalc.EXE execution ended at 15:20 on 05/02/2011

ResoCalc.EXE execution time 1 minutes 32 seconds

DCN 5090-TR-01-6 


\section{Offsite Resident Farmer}

\section{The following summary report includes the peak dose from cumulative radionuclide inventory.}


THIS PAGE INTENTIONALLY LEFT BLANK 
RESRAD-OFFSITE, Version $2.5, \quad \mathrm{~T}^{1 / 2}$ Limit $=180$ days

Parent Dose Report

Title : Offsite Resident Farmer Deterministic Run

File : RF SG FWD-FINAL v2.ROF

Dose Conversion Factor (and Related) Parameter Summary

Current Library: ICRP 60

Default Library: ICRP 60

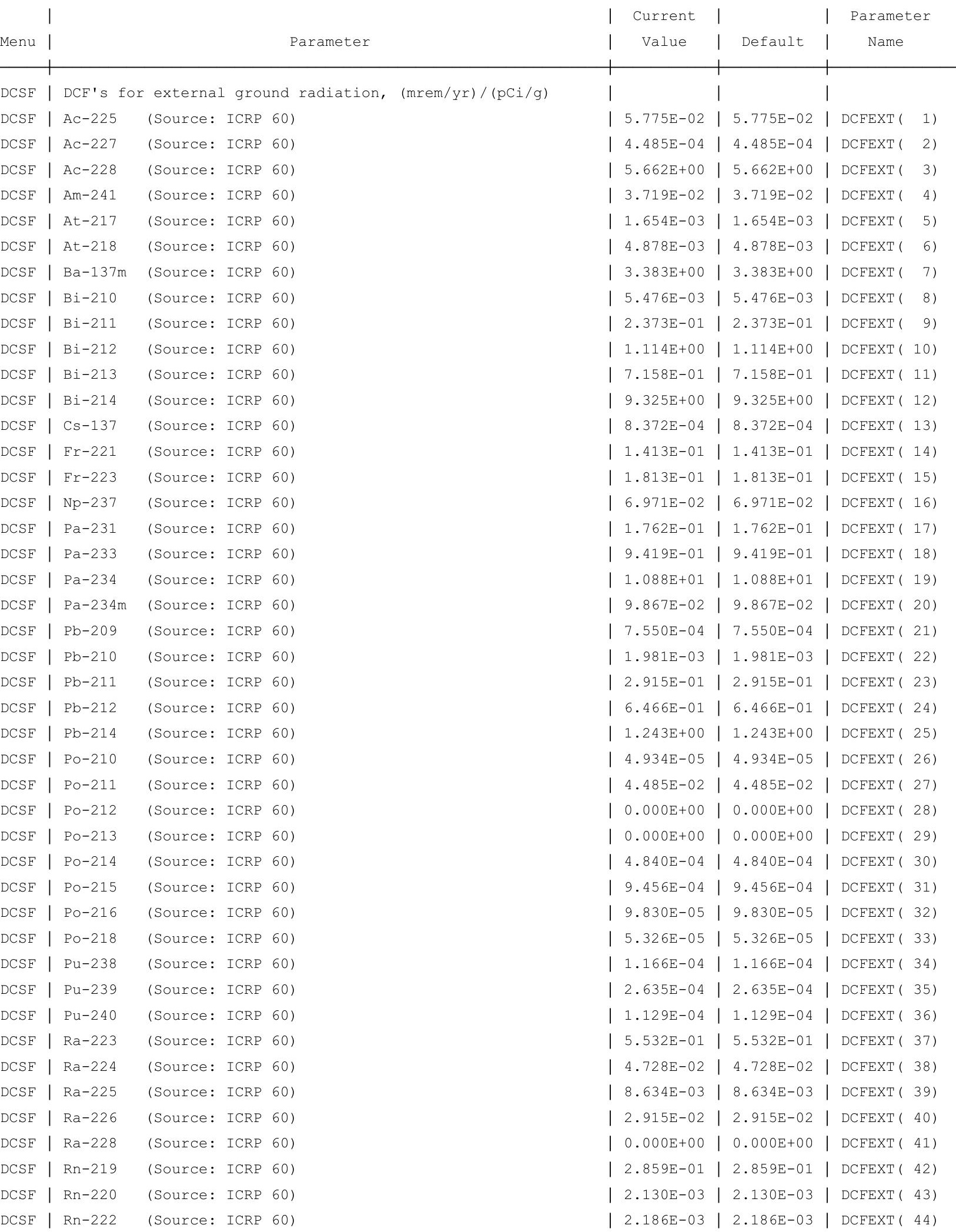


RESRAD-OFFSITE, Version $2.5 \quad \mathrm{~T}^{1 / 2}$ Limit $=180$ days

Parent Dose Report

Title : Offsite Resident Farmer Deterministic Run

File : RF SG FWD-FINAL v2.ROF

Dose Conversion Factor (and Related) Parameter Summary (continued)

Current Library: ICRP 60

Default Library: ICRP 60

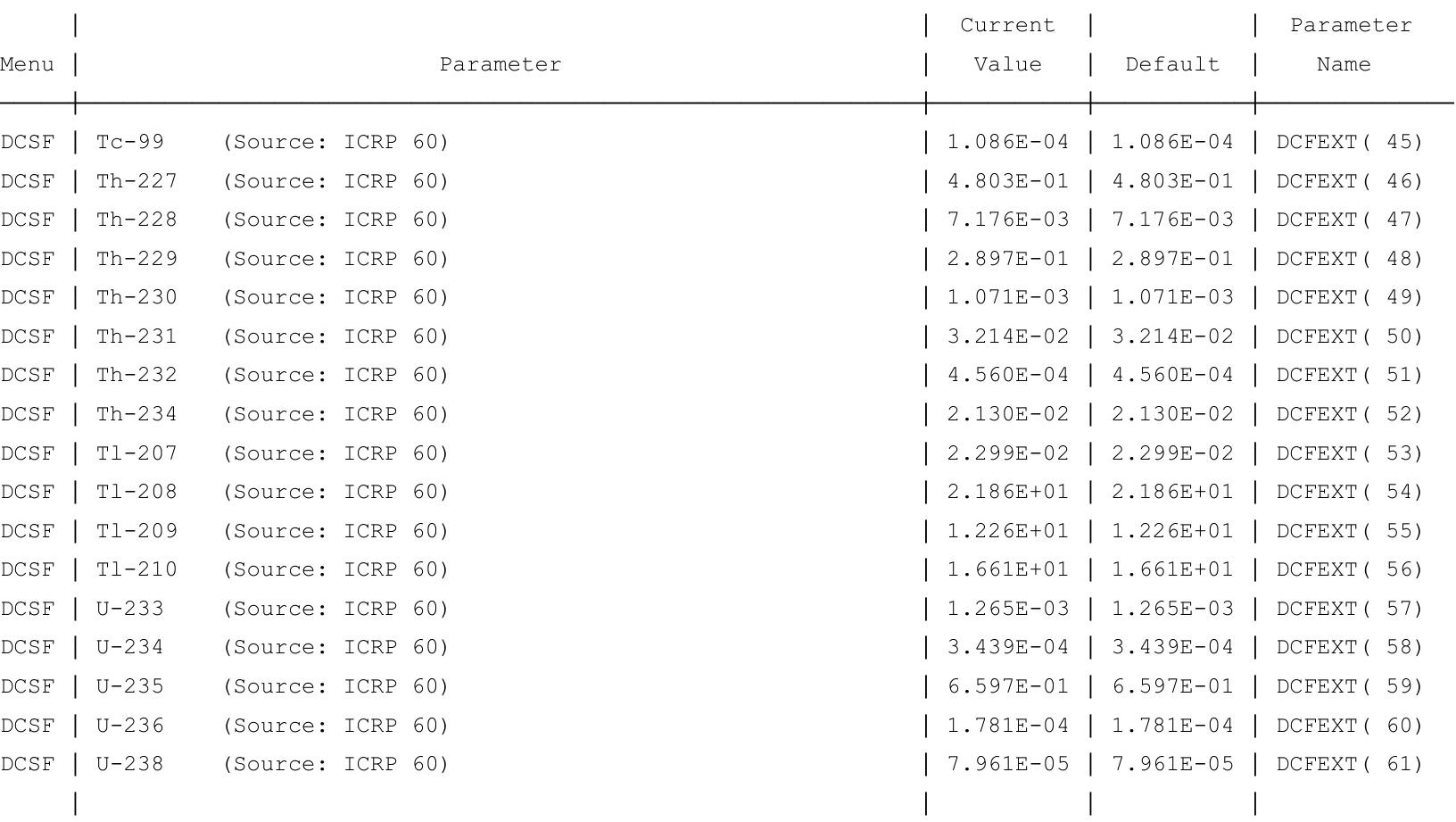

Current Library: ICRP 72 (Adult)

Default Library: ICRP 72 (Adult)

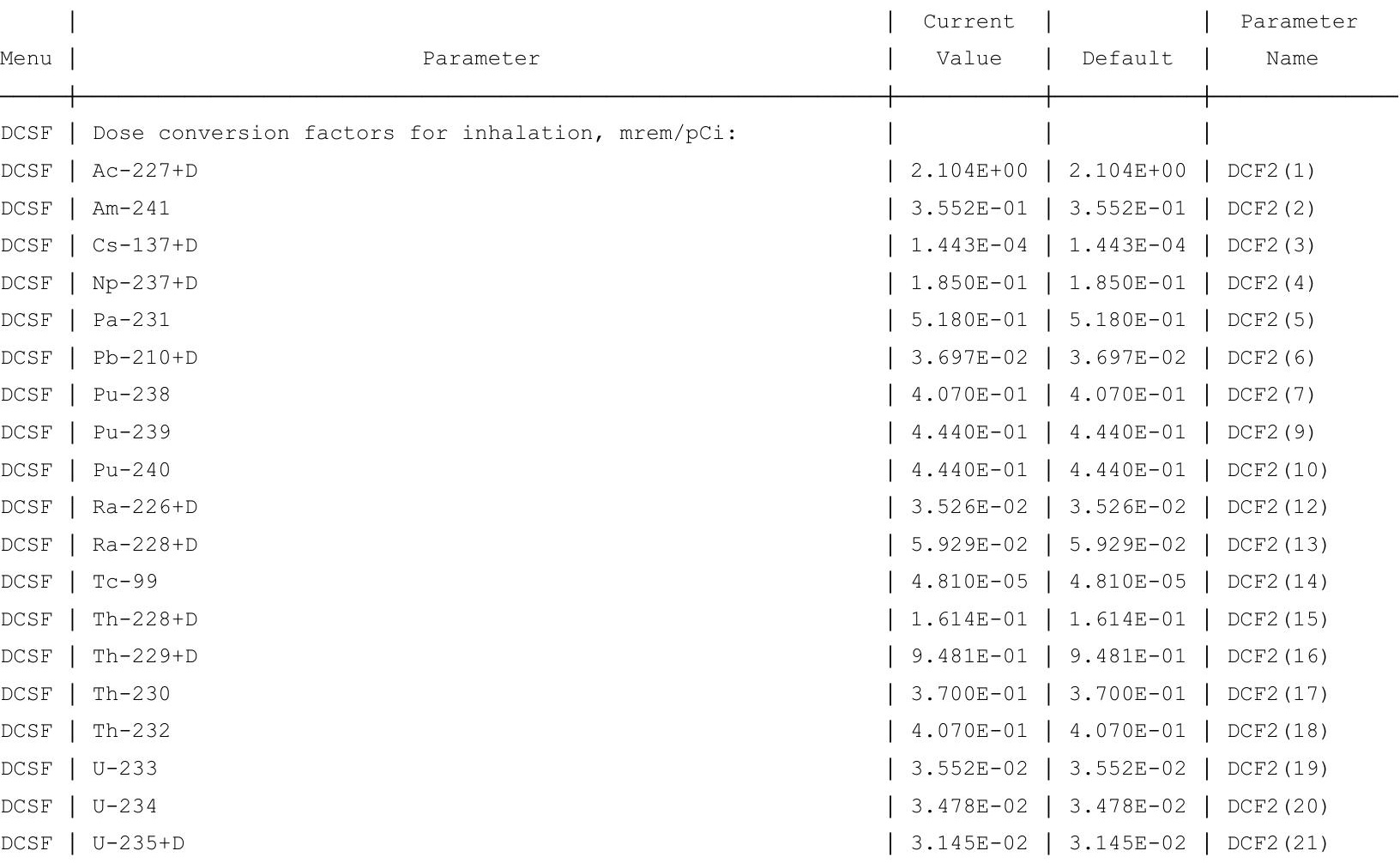


RESRAD-OFFSITE, Version 2.5

Parent Dose Report

Title : Offsite Resident Farmer Deterministic Run

File : RF SG FWD-FINAL v2.ROF

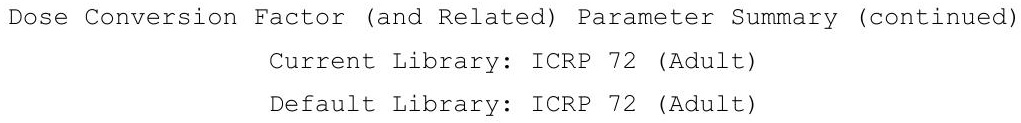

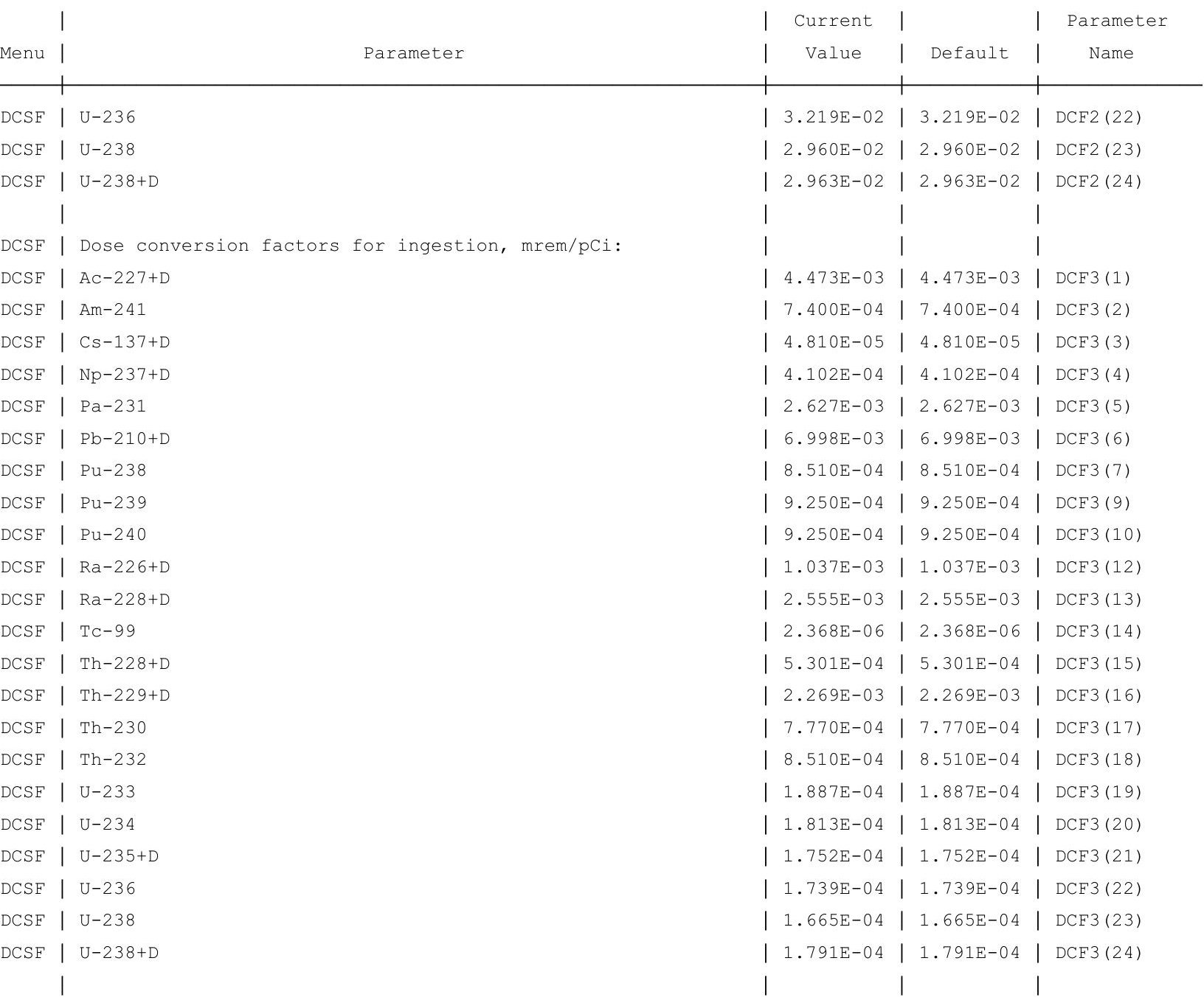


RESRAD-OFFSITE, Version 2.5

Title : Offsite Resident Farmer Deterministic Run

File : RF SG FWD-FINAL v2.ROF

Dose Conversion Factor (and Related) Parameter Summary (continued) Current Library: RESRAD Default Transfer factors Default Library: RESRAD Default Transfer factors

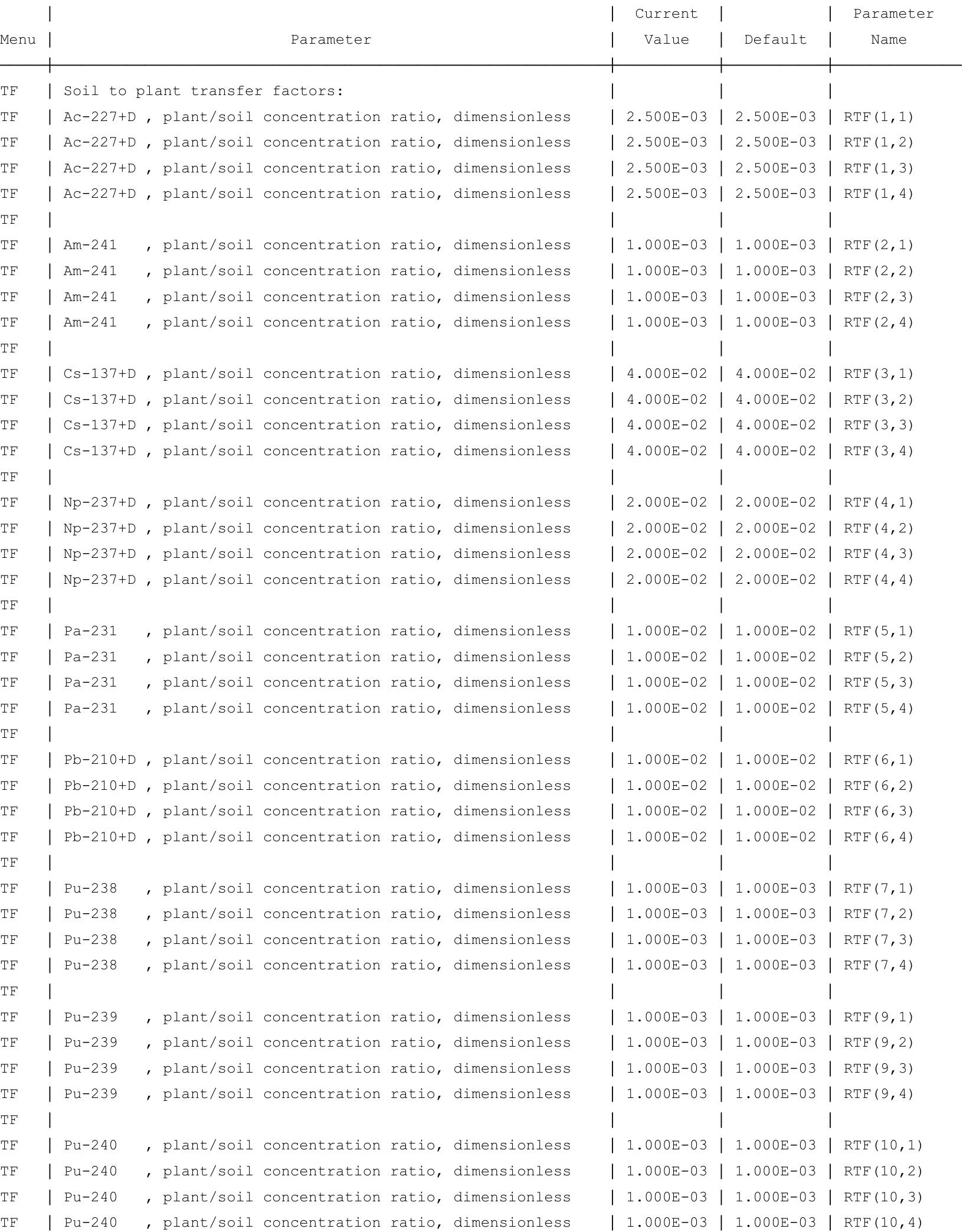


RESRAD-OFFSITE, Version 2.5

Parent Dose Report

Title : Offsite Resident Farmer Deterministic Run

File : RF SG FWD-FINAL v2.ROF

Dose Conversion Factor (and Related) Parameter Summary (continued)

Current Library: RESRAD Default Transfer factors

Default Library: RESRAD Default Transfer factors

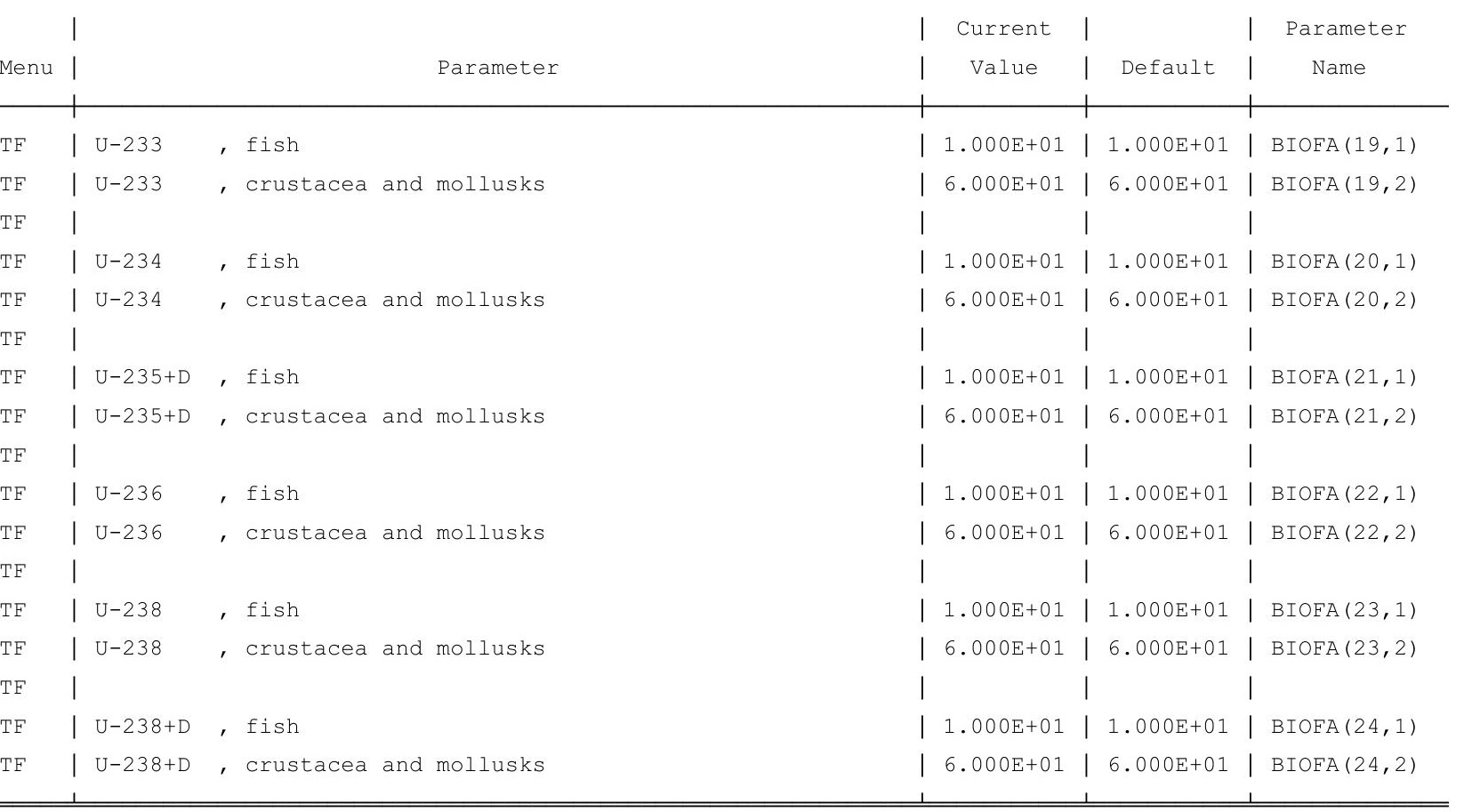


RESRAD-OFFSITE, Version $2.5 \quad \mathrm{~T}^{1 / 2}$ Limit $=180$ days

Parent Dose Report

Title : Offsite Resident Farmer Deterministic Run

File : RF SG FWD-FINAL v2.ROF

Site-Specific Parameter Summary

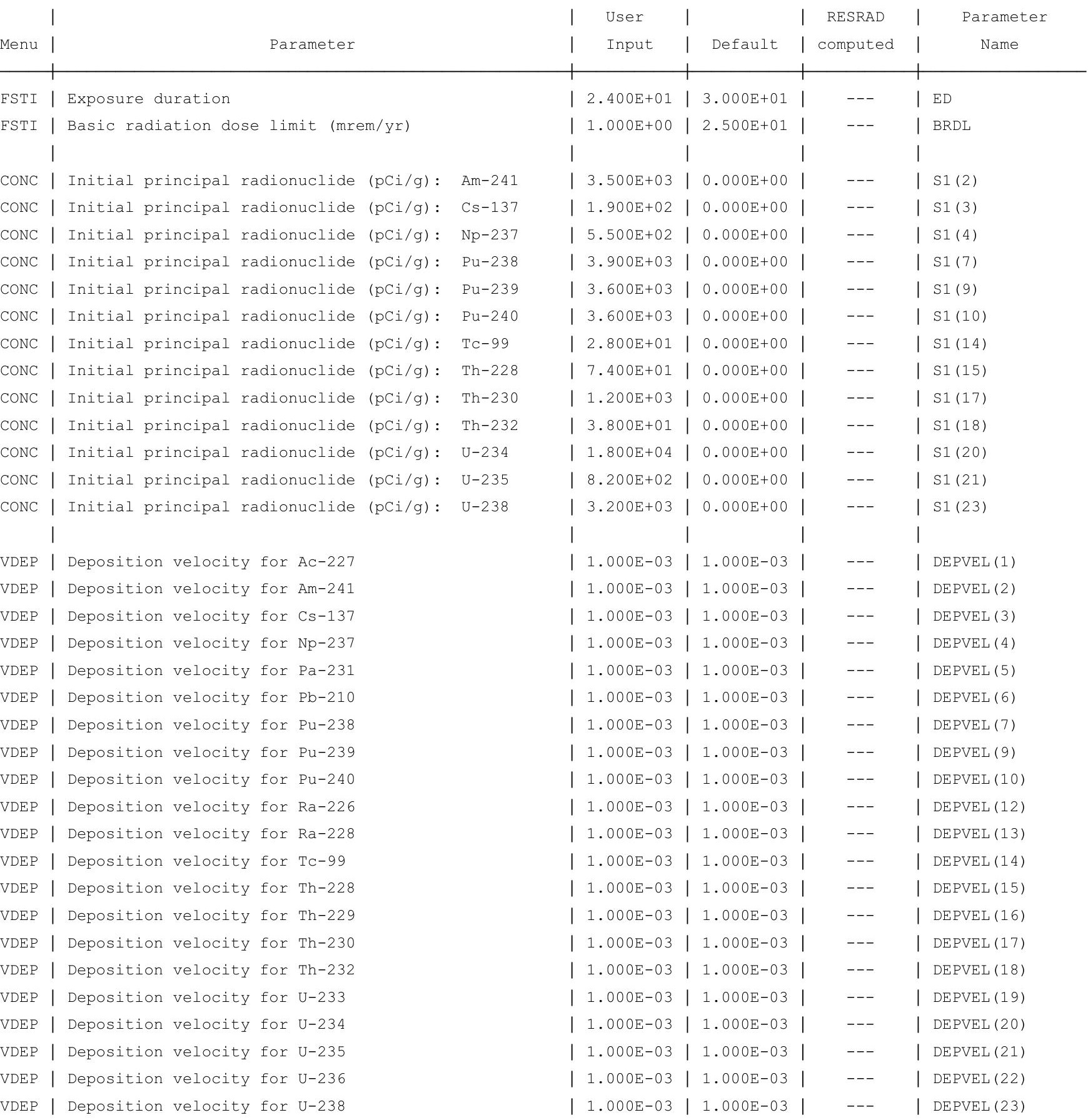


RESRAD-OFFSITE, Version $2.5 \quad \mathrm{~T}^{1 / 2}$ Limit $=180$ days

Parent Dose Report

Title : Offsite Resident Farmer Deterministic Run

File : RF SG FWD-FINAL v2.ROF

Site-Specific Parameter Summary (continued)

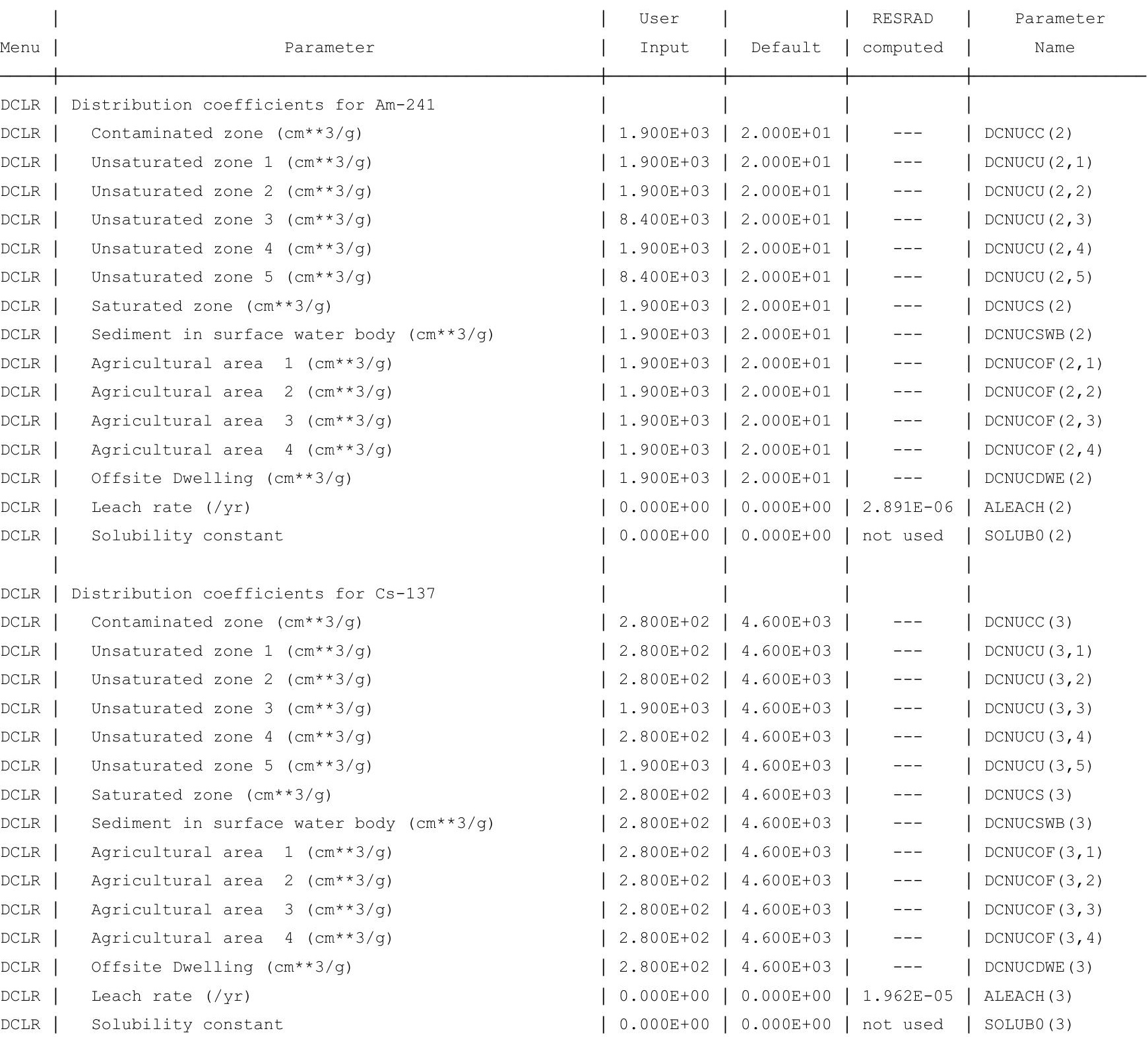


RESRAD-OFFSITE, Version $2.5 \quad \mathrm{~T}^{1 / 2}$ Limit $=180$ days

Parent Dose Report

Title : Offsite Resident Farmer Deterministic Run

File : RF SG FWD-FINAL v2.ROF

Site-Specific Parameter Summary (continued)

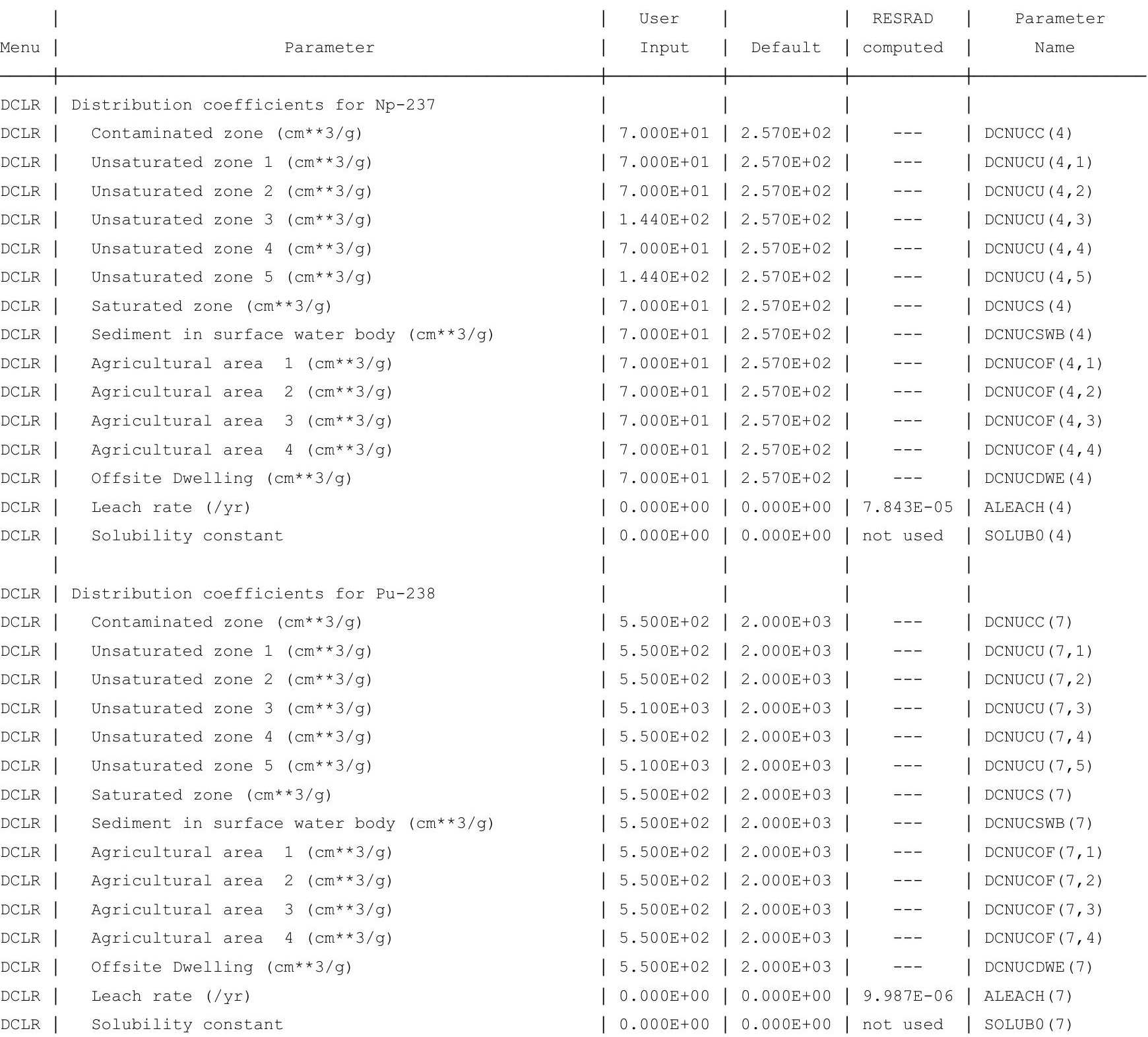


RESRAD-OFFSITE, Version $2.5 \quad \mathrm{~T}^{1 / 2}$ Limit $=180$ days

Parent Dose Report

Title : Offsite Resident Farmer Deterministic Run

File : RF SG FWD-FINAL v2.ROF

Site-Specific Parameter Summary (continued)

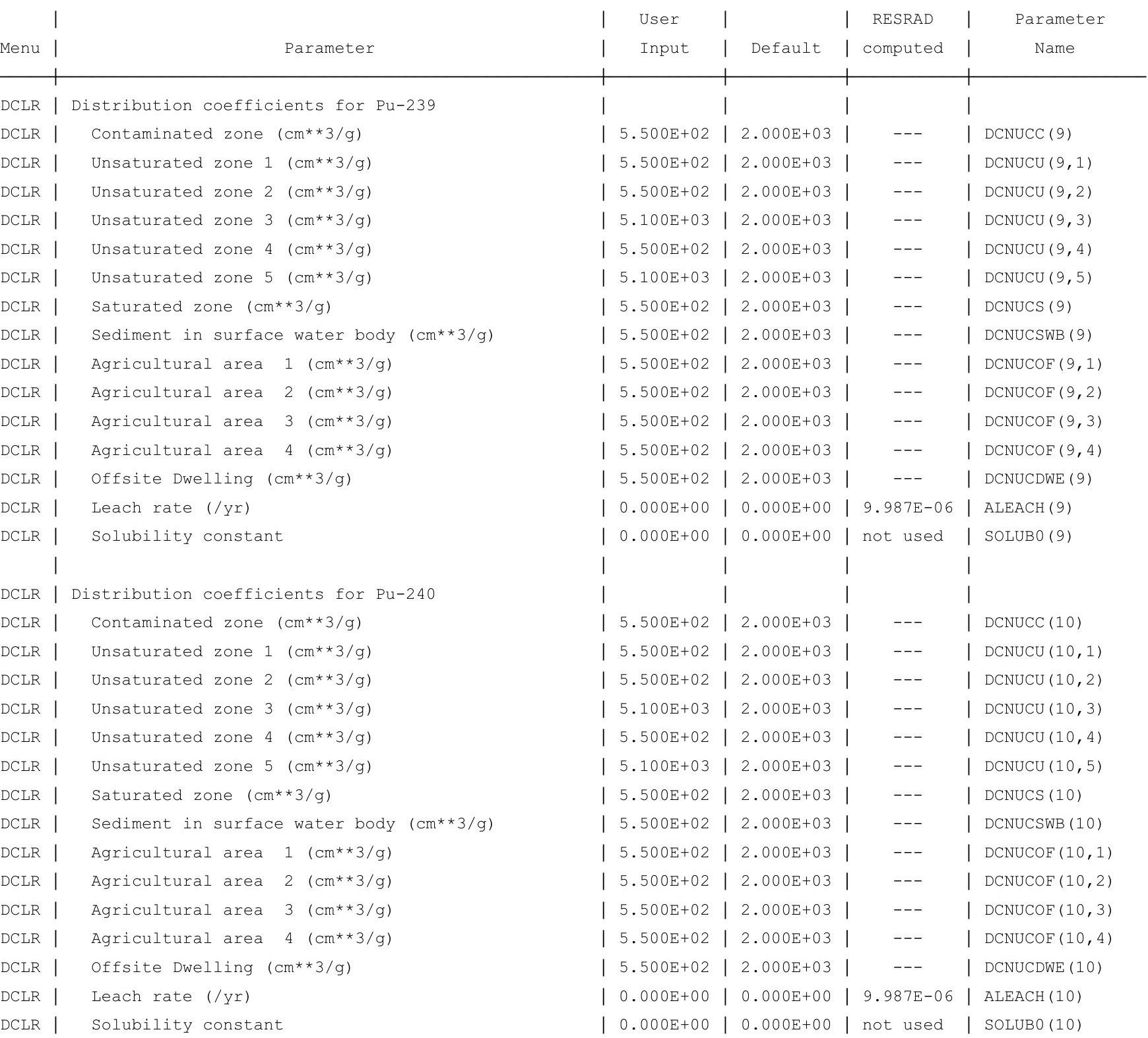


RESRAD-OFFSITE, Version $2.5 \quad \mathrm{~T}^{1 / 2}$ Limit $=180$ days

Parent Dose Report

Title : Offsite Resident Farmer Deterministic Run

File : RF SG FWD-FINAL v2.ROF

Site-Specific Parameter Summary (continued)

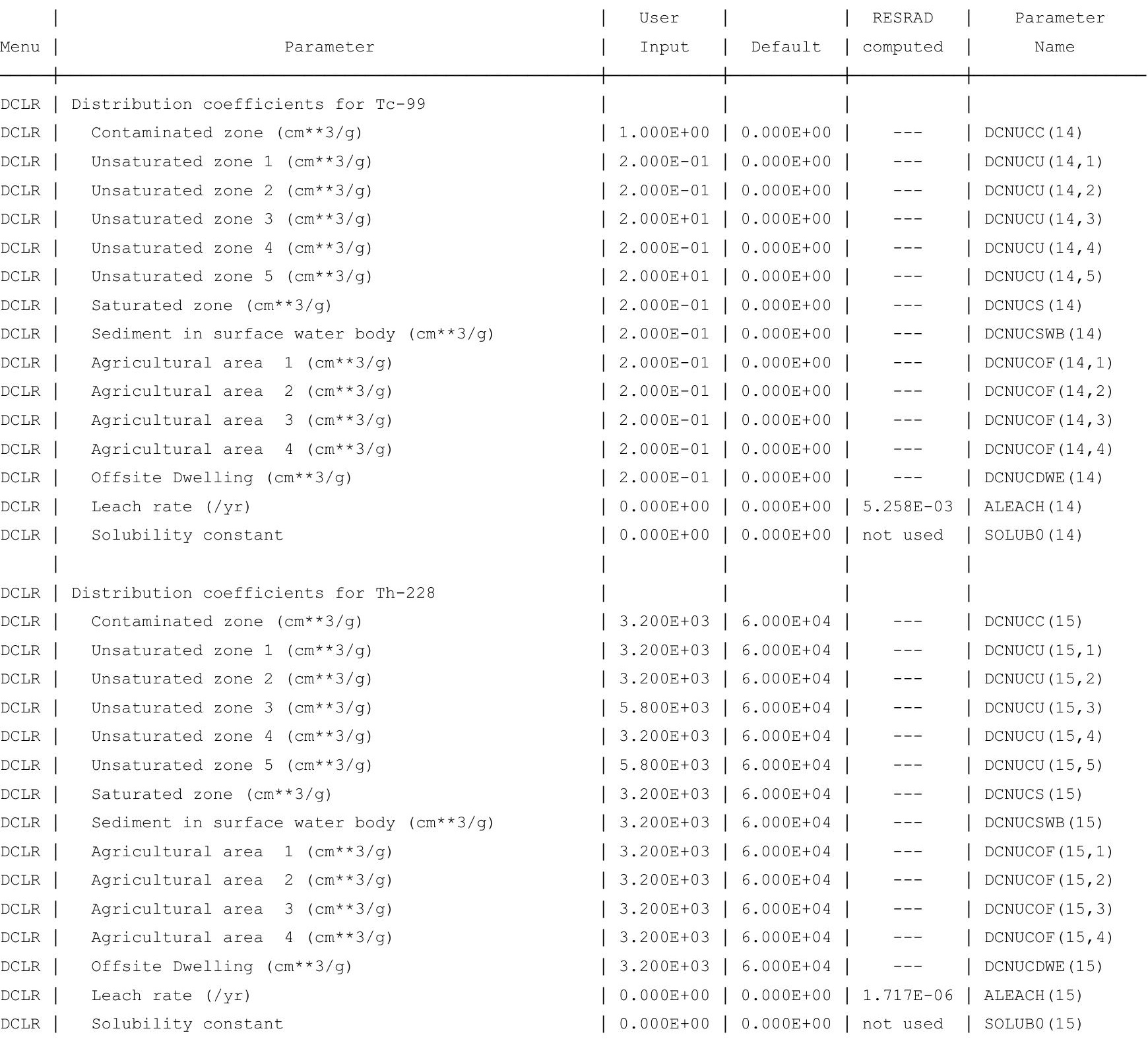


RESRAD-OFFSITE, Version $2.5 \quad \mathrm{~T}^{1 / 2}$ Limit $=180$ days

Parent Dose Report

Title : Offsite Resident Farmer Deterministic Run

File : RF SG FWD-FINAL v2.ROF

Site-Specific Parameter Summary (continued)

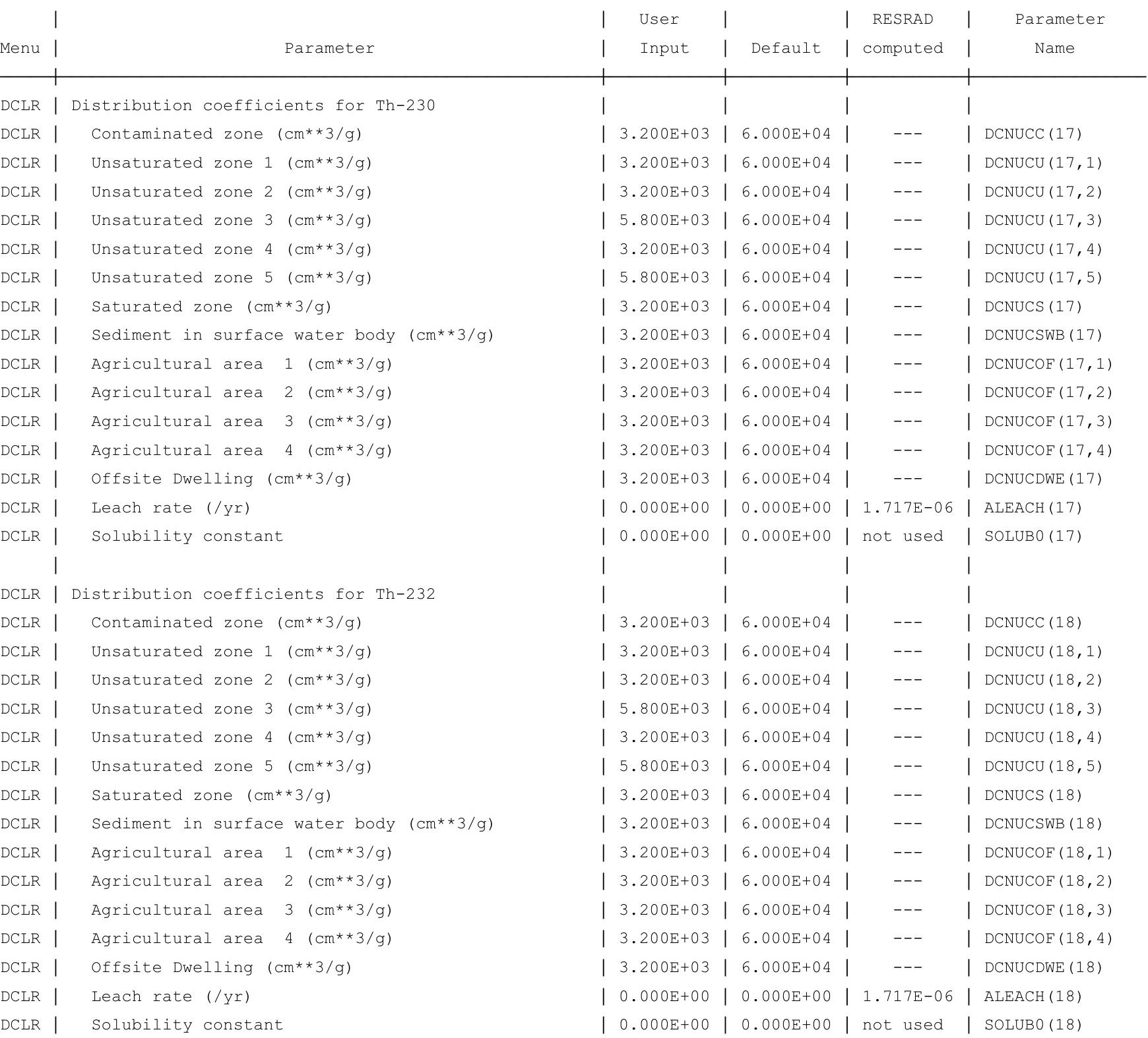


RESRAD-OFFSITE, Version $2.5 \quad \mathrm{~T}^{1 / 2}$ Limit $=180$ days

Parent Dose Report

Title : Offsite Resident Farmer Deterministic Run

File : RF SG FWD-FINAL v2.ROF

Site-Specific Parameter Summary (continued)

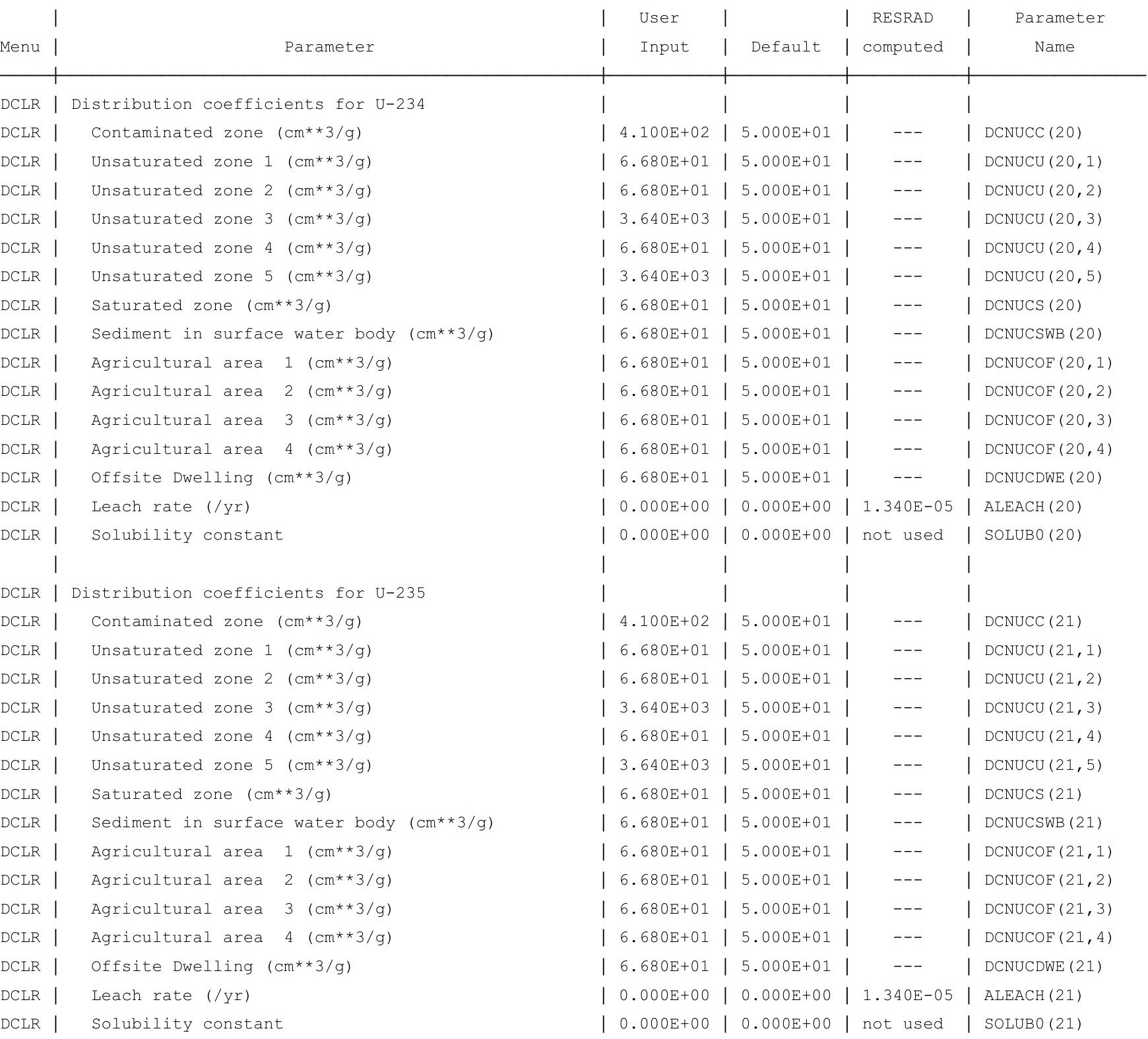


RESRAD-OFFSITE, Version $2.5 \quad \mathrm{~T}^{1 / 2}$ Limit $=180$ days

Parent Dose Report

Title : Offsite Resident Farmer Deterministic Run

File : RF SG FWD-FINAL v2.ROF

Site-Specific Parameter Summary (continued)

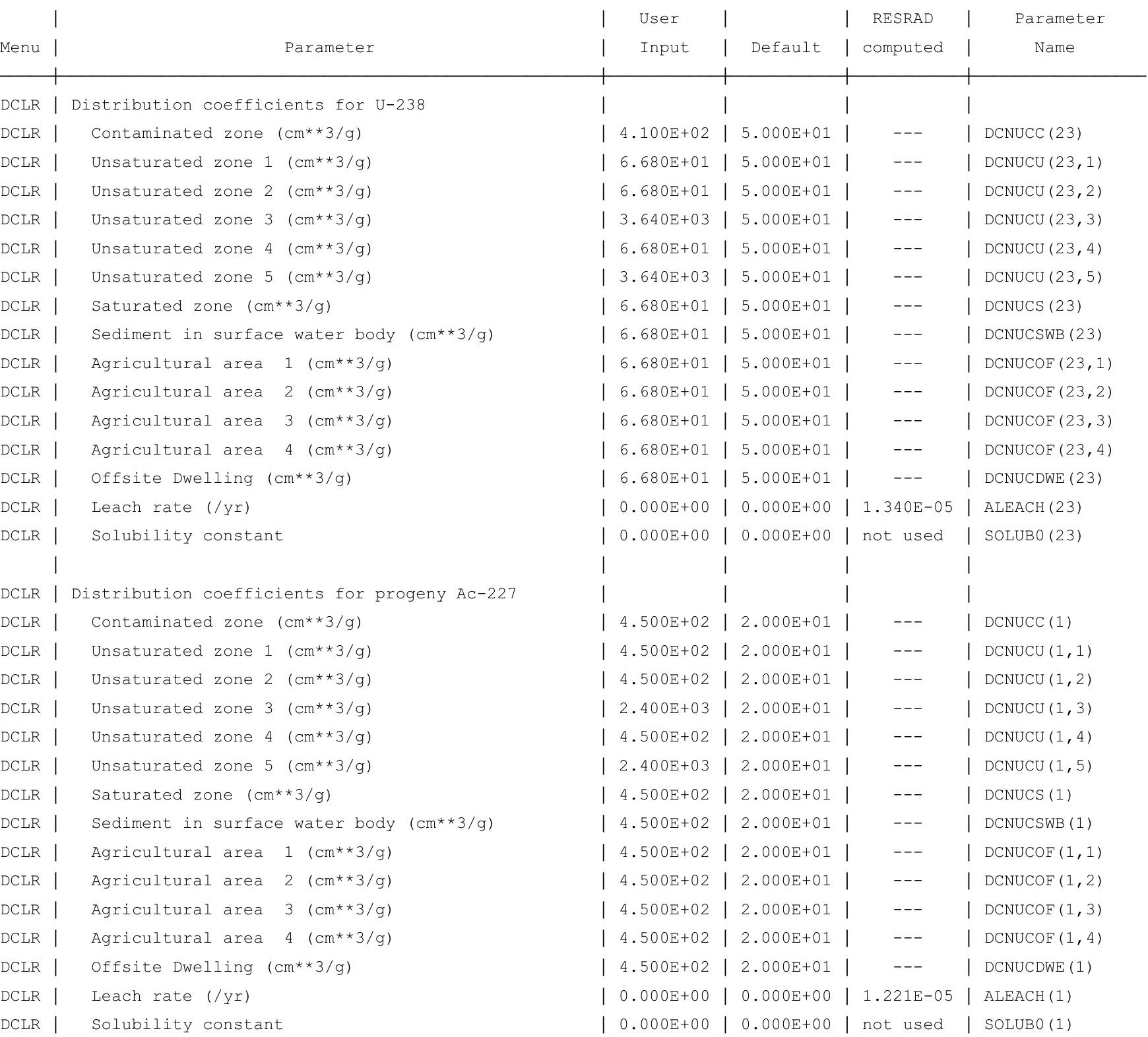


RESRAD-OFFSITE, Version $2.5 \quad \mathrm{~T}^{1 / 2}$ Limit $=180$ days

Parent Dose Report

Title : Offsite Resident Farmer Deterministic Run

File : RF SG FWD-FINAL v2.ROF

Site-Specific Parameter Summary (continued)

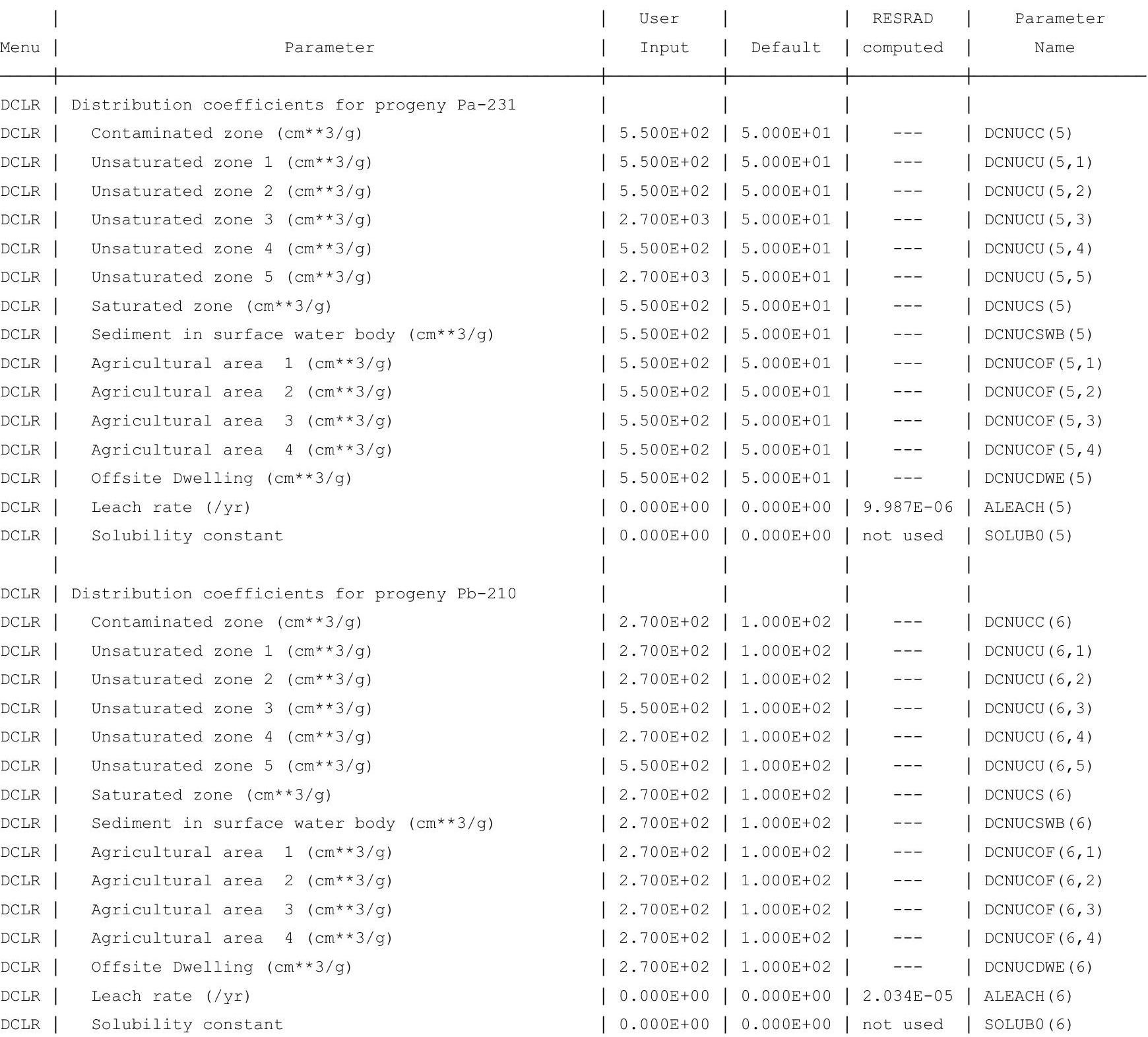


RESRAD-OFFSITE, Version $2.5 \quad \mathrm{~T}^{1 / 2}$ Limit $=180$ days

Parent Dose Report

Title : Offsite Resident Farmer Deterministic Run

File : RF SG FWD-FINAL v2.ROF

Site-Specific Parameter Summary (continued)

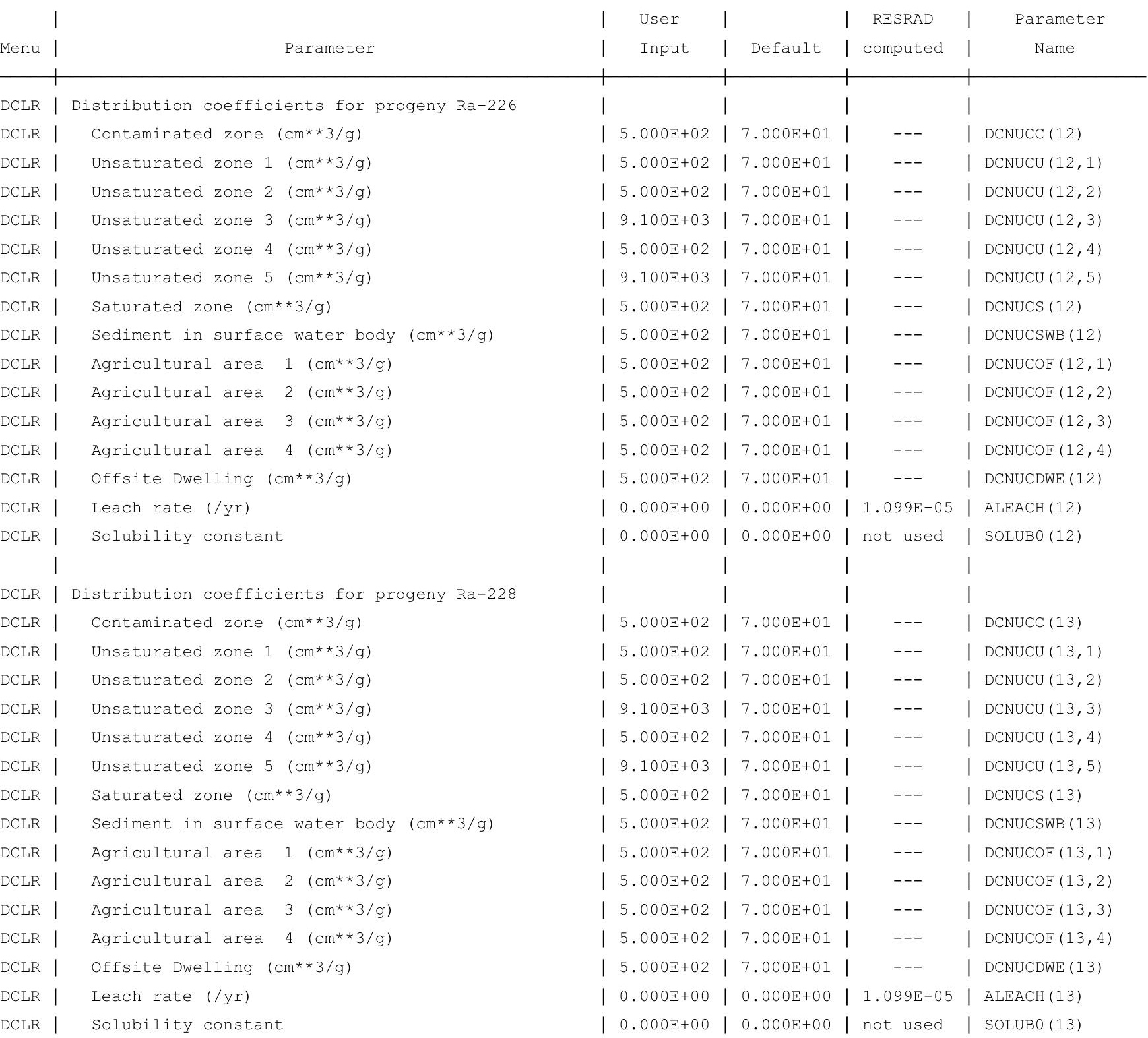


RESRAD-OFFSITE, Version $2.5 \quad \mathrm{~T}^{1 / 2}$ Limit $=180$ days

Parent Dose Report

Title : Offsite Resident Farmer Deterministic Run

File : RF SG FWD-FINAL v2.ROF

Site-Specific Parameter Summary (continued)

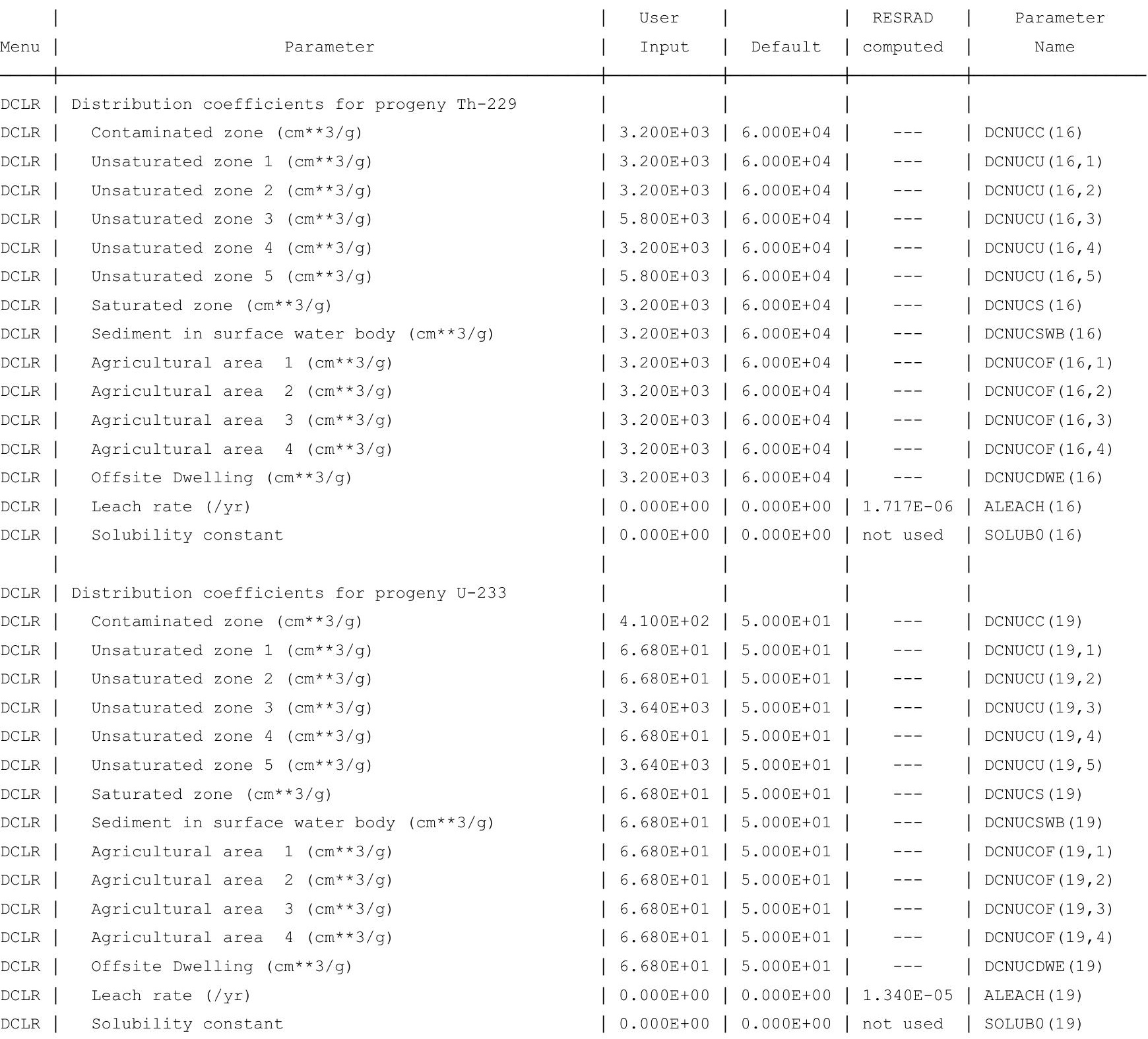


RESRAD-OFFSITE, Version 2.5

Parent Dose Report

Title : Offsite Resident Farmer Deterministic Run

File : RF SG FWD-FINAL v2.ROF

Site-Specific Parameter Summary (continued)

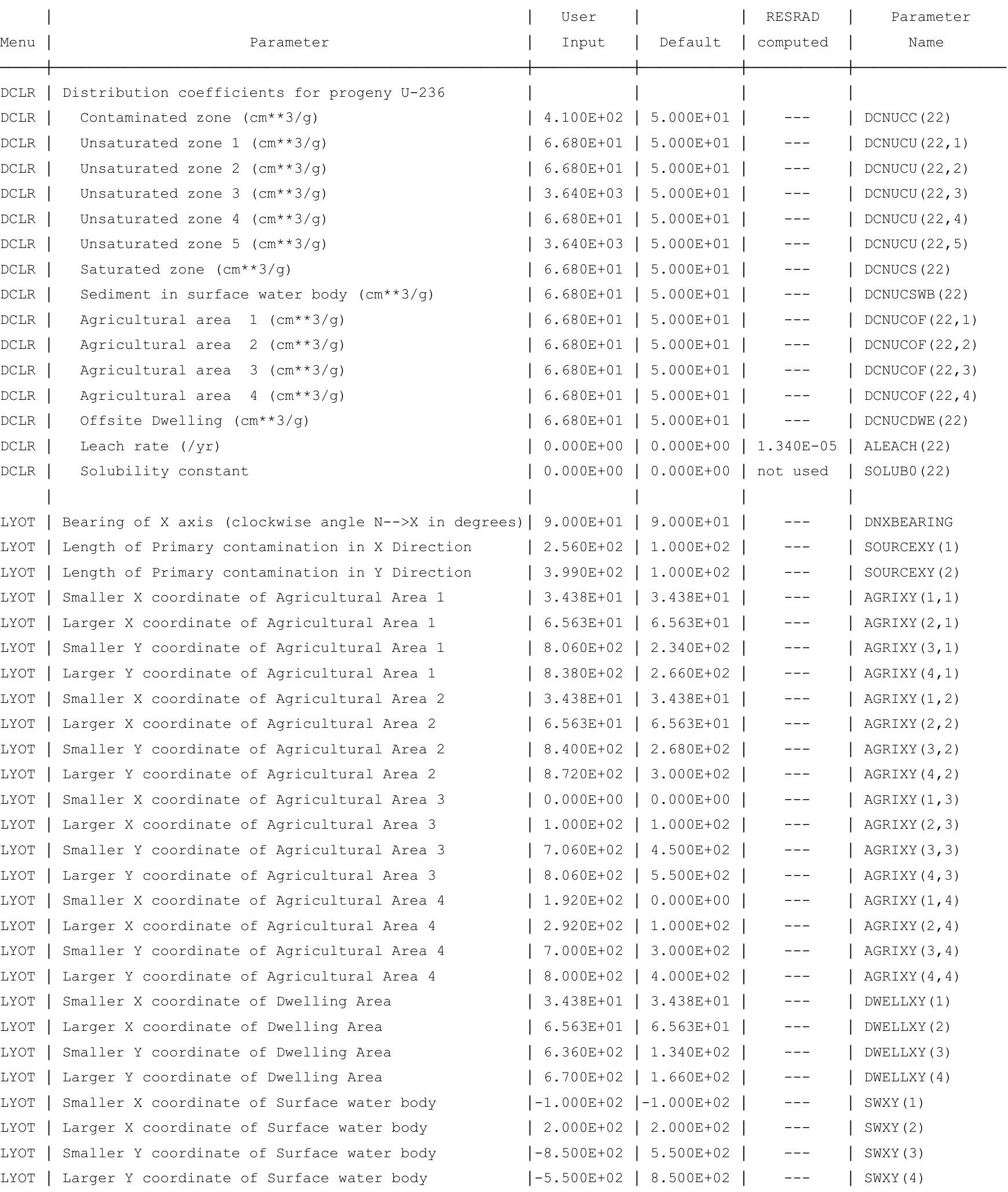


RESRAD-OFFSITE, Version 2.5

Parent Dose Report

Title : Offsite Resident Farmer Deterministic Run

File : RF SG FWD-FINAL v2.ROF

Site-Specific Parameter Summary (continued)

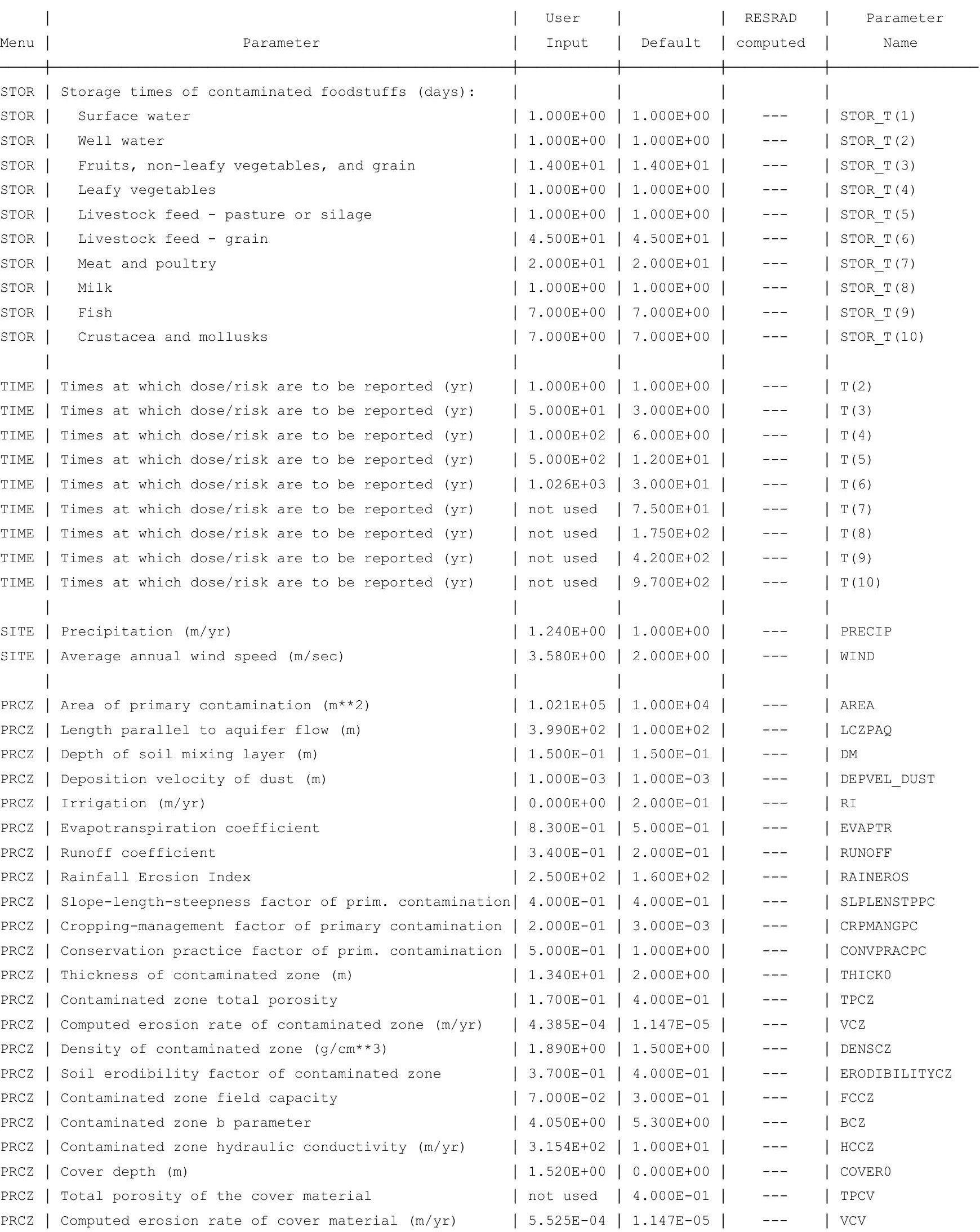


RESRAD-OFFSITE, Version 2.5

Parent Dose Report

Title : Offsite Resident Farmer Deterministic Run

File : RF SG FWD-FINAL v2.ROF

Site-Specific Parameter Summary (continued)

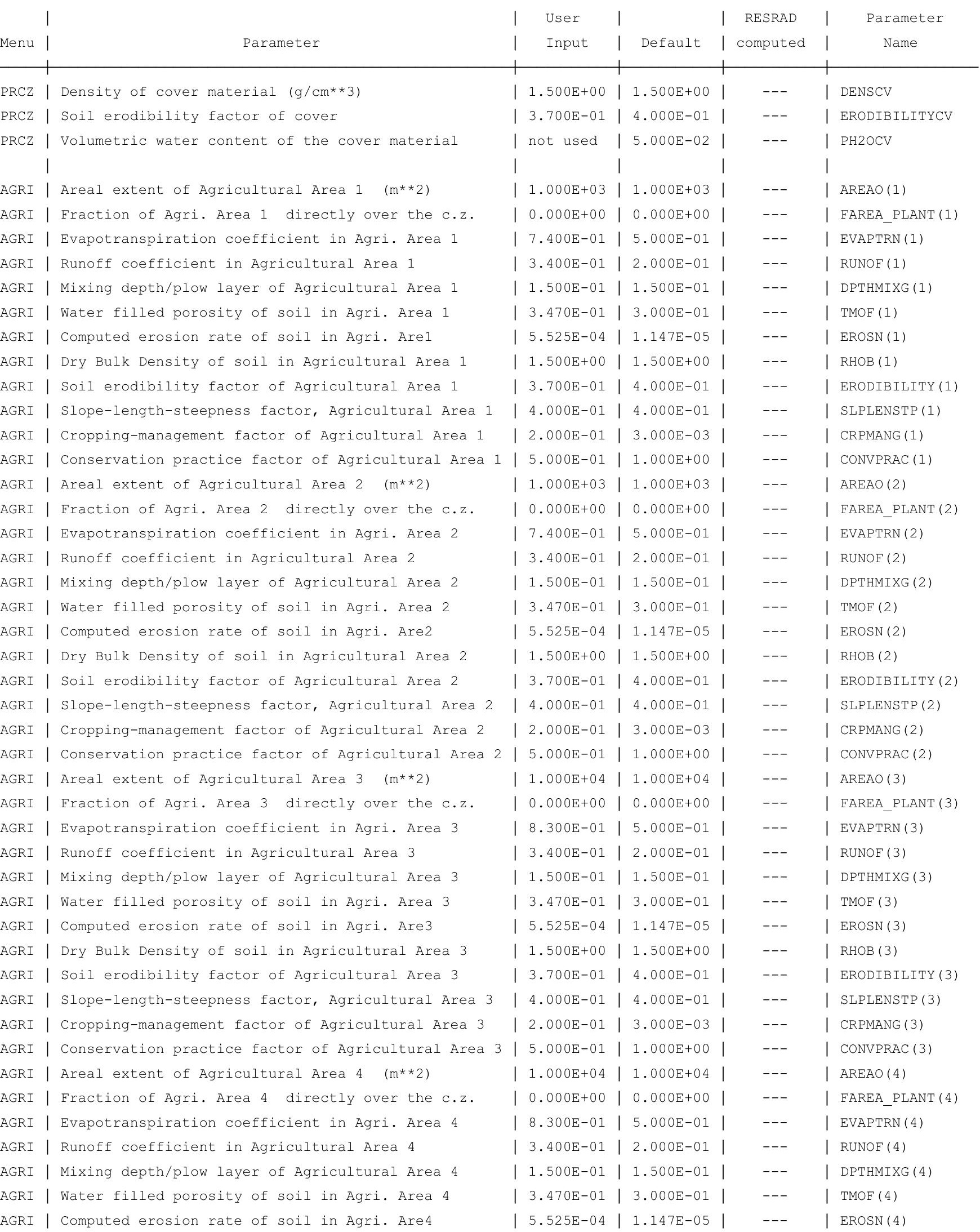


RESRAD-OFFSITE, Version 2.5

Parent Dose Report

Title : Offsite Resident Farmer Deterministic Run

File : RF SG FWD-FINAL v2.ROF

Site-Specific Parameter Summary (continued)

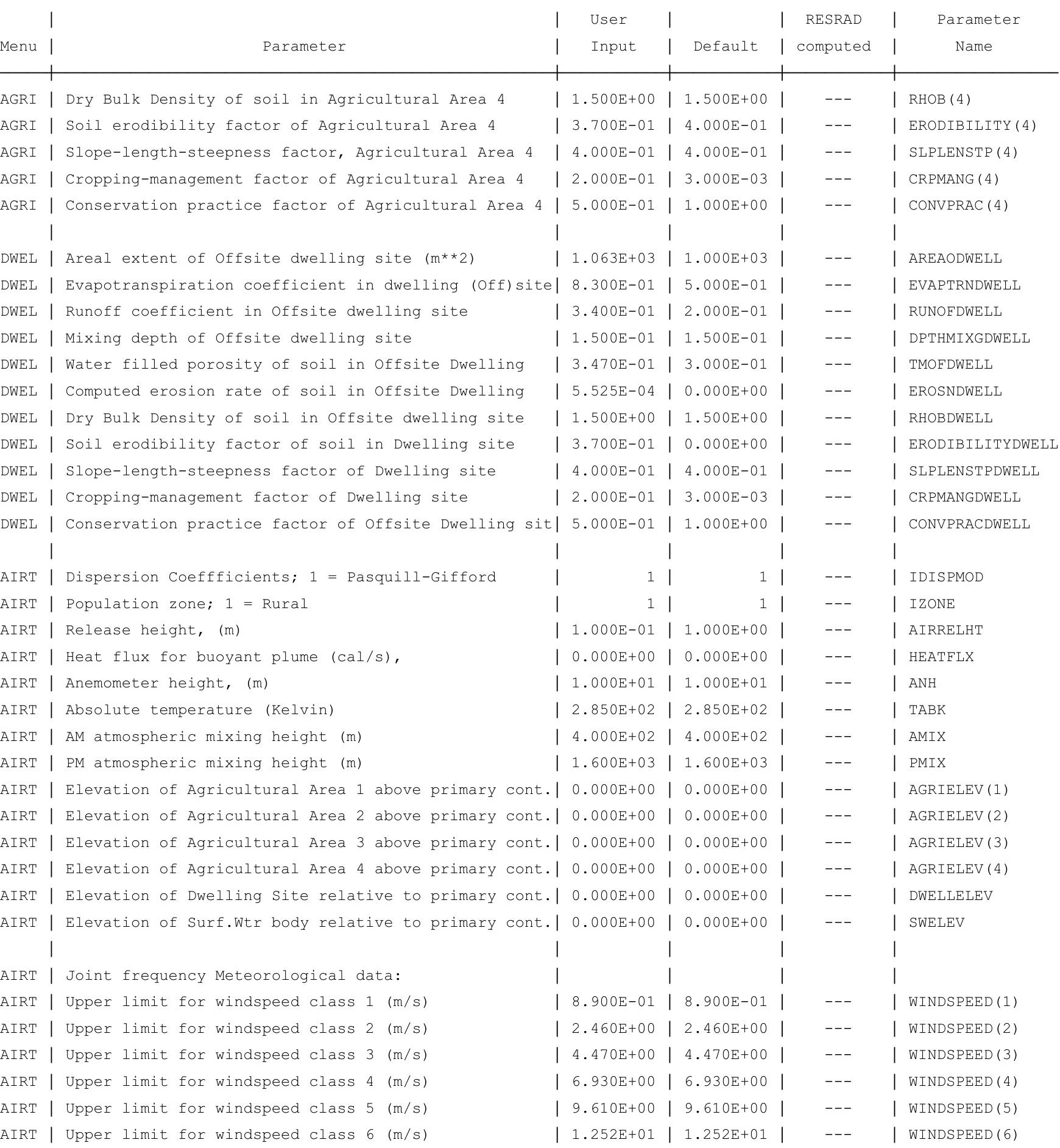


RESRAD-OFFSITE, Version 2.5

$\mathrm{T}^{1 / 2}$ Limit $=180$ days

Parent Dose Report

Title : Offsite Resident Farmer Deterministic Run

File : RF SG FWD-FINAL v2.ROF

Site-Specific Parameter Summary (continued)

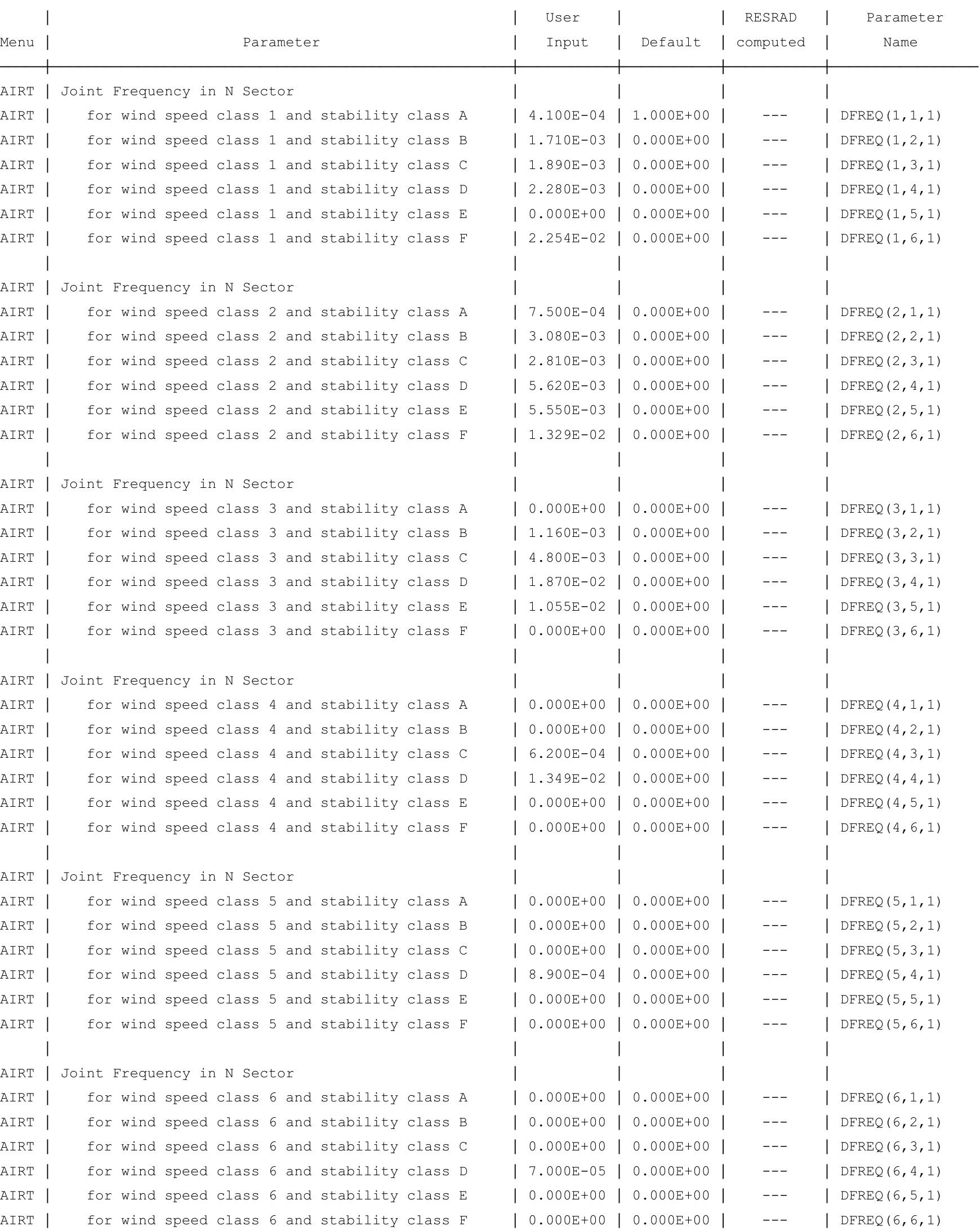


RESRAD-OFFSITE, Version 2.5

$\mathrm{T}^{1 / 2}$ Limit $=180$ days 
RESRAD-OFFSITE, Version 2.5

$\mathrm{T}^{1 / 2}$ Limit $=180$ days

Parent Dose Report

Title : Offsite Resident Farmer Deterministic Run

File : RF SG FWD-FINAL v2.ROF

Site-Specific Parameter Summary (continued)

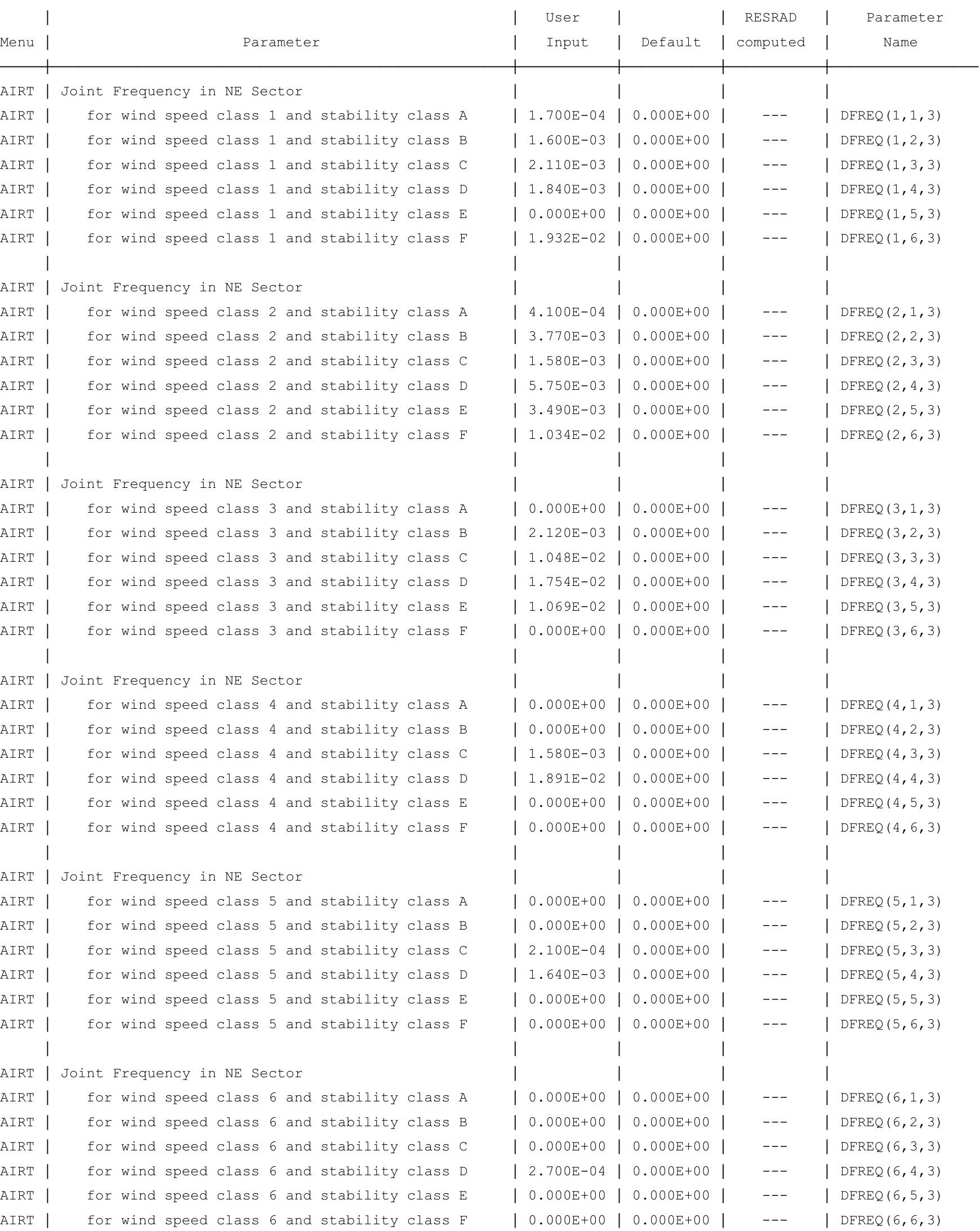


RESRAD-OFFSITE, Version 2.5

$\mathrm{T}^{1 / 2}$ Limit $=180$ days 
RESRAD-OFFSITE, Version 2.5

$\mathrm{T}^{1 / 2}$ Limit $=180$ days 
RESRAD-OFFSITE, Version 2.5

arent Dose Report

Title : Offsite Resident Farmer Deterministic Run

File : RF SG FWD-FINAL v2.ROF

Site-Specific Parameter Summary (continued)

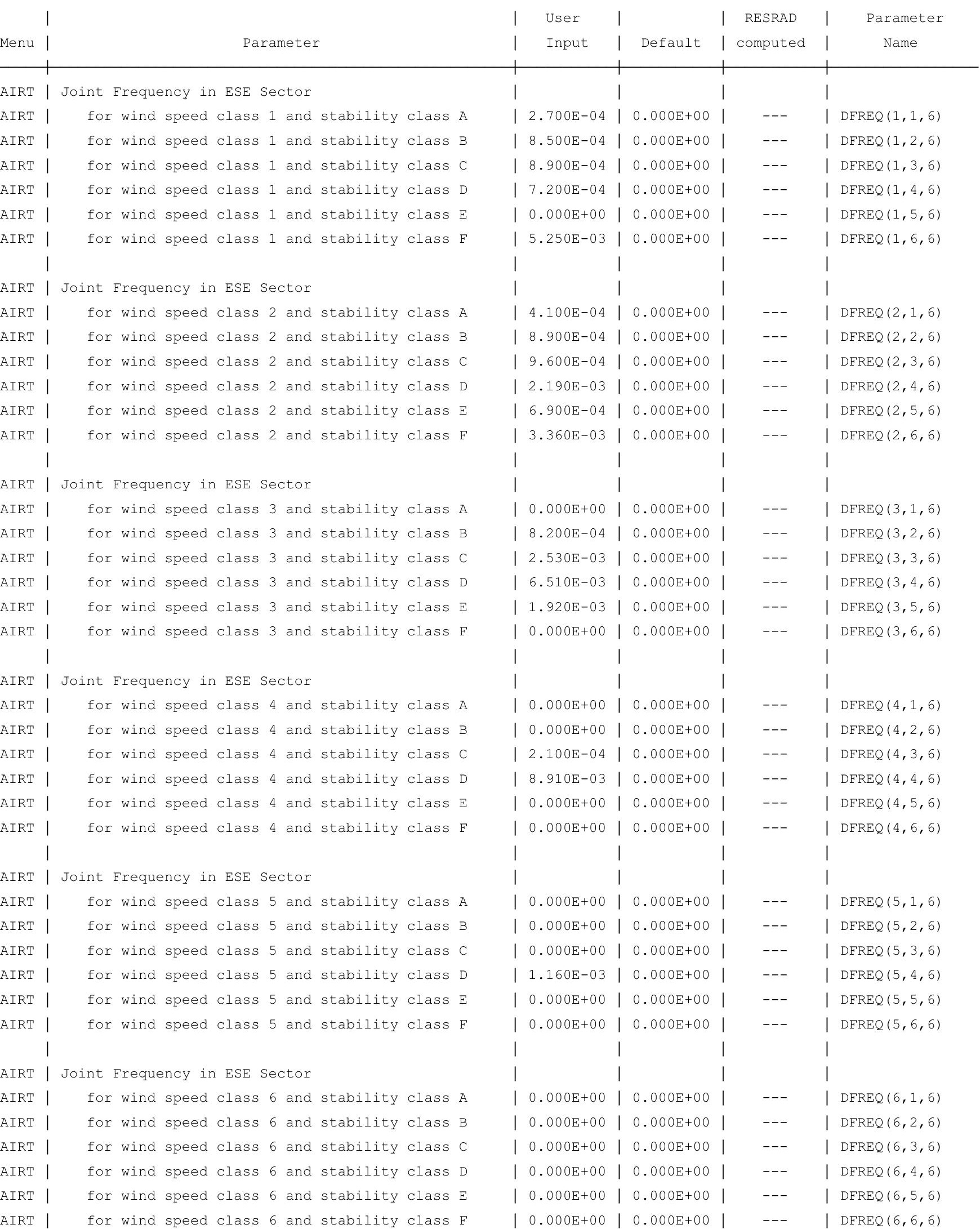


RESRAD-OFFSITE, Version 2.5

$\mathrm{T}^{1 / 2}$ Limit $=180$ days 
RESRAD-OFFSITE, Version 2.5

$\mathrm{T}^{1 / 2}$ Limit $=180$ days 
RESRAD-OFFSITE, Version 2.5

$\mathrm{T}^{1 / 2}$ Limit $=180$ days 
RESRAD-OFFSITE, Version 2.5

$\mathrm{T}^{1 / 2}$ Limit $=180$ days 
RESRAD-OFFSITE, Version 2.5

$\mathrm{T}^{1 / 2}$ Limit $=180$ days 
RESRAD-OFFSITE, Version 2.5

$\mathrm{T}^{1 / 2}$ Limit $=180$ days 
RESRAD-OFFSITE, Version 2.5

$\mathrm{T}^{1 / 2}$ Limit $=180$ days 
RESRAD-OFFSITE, Version 2.5

$\mathrm{T}^{1 / 2}$ Limit $=180$ days 
RESRAD-OFFSITE, Version 2.5

$\mathrm{T}^{1 / 2}$ Limit $=180$ days 
RESRAD-OFFSITE, Version 2.5

$\mathrm{T}^{1 / 2}$ Limit $=180$ days

arent Dose Report

Title : Offsite Resident Farmer Deterministic Run

File : RF SG FWD-FINAL v2.ROF

Site-Specific Parameter Summary (continued)

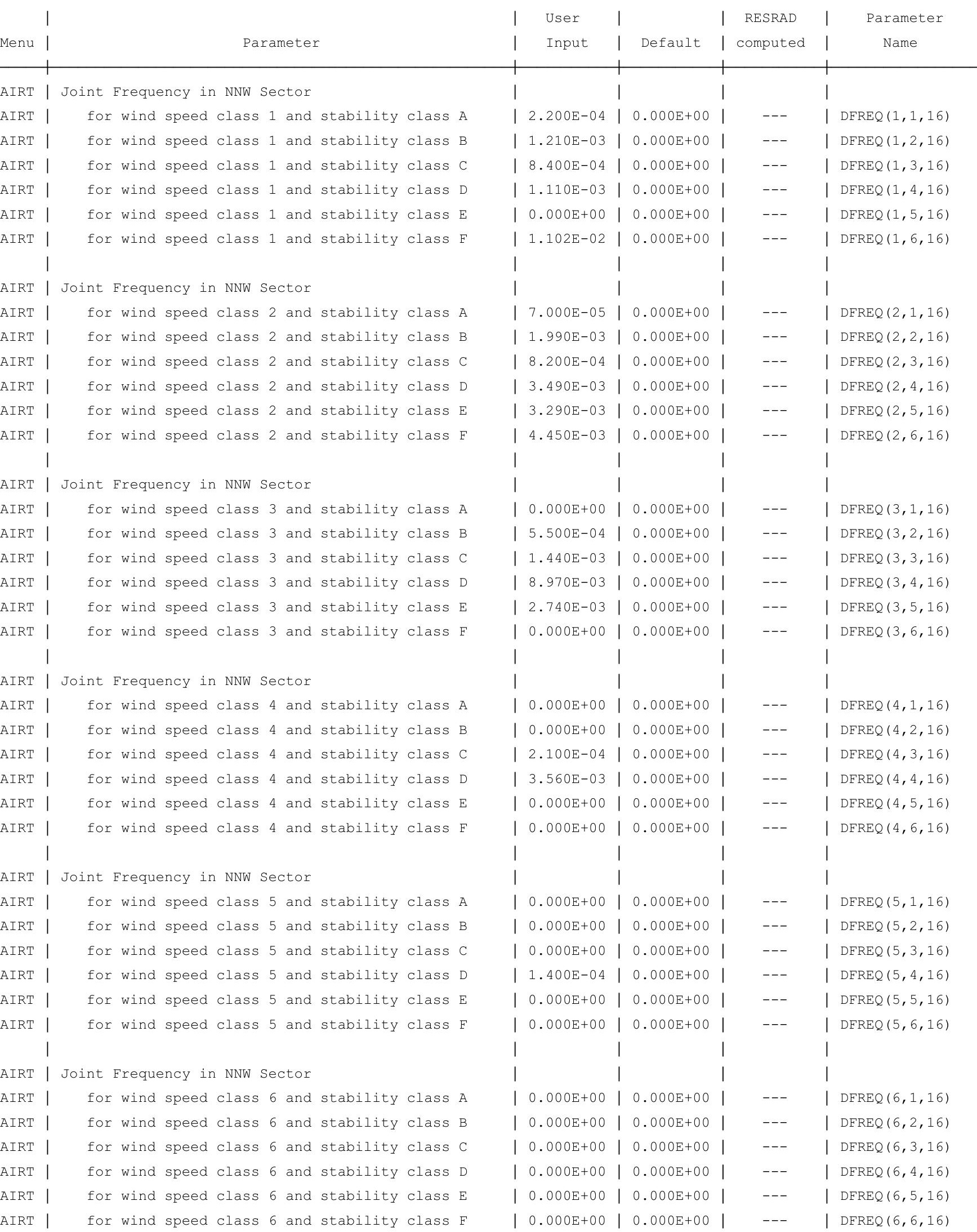


RESRAD-OFFSITE, Version 2.5

Parent Dose Report

Title : Offsite Resident Farmer Deterministic Run

File : RF SG FWD-FINAL v2.ROF

Site-Specific Parameter Summary (continued)

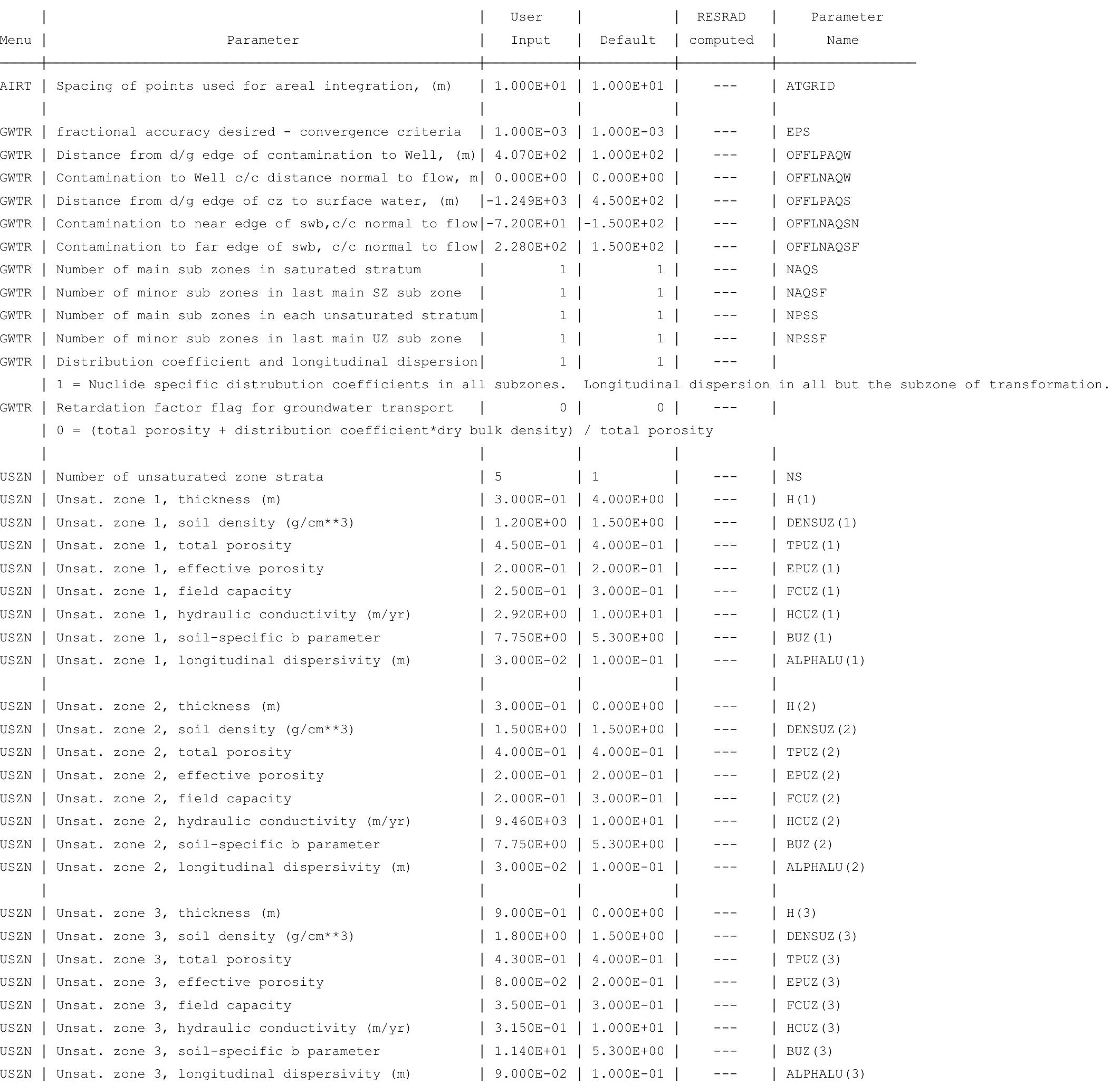


RESRAD-OFFSITE, Version 2.5

$\mathrm{T}^{1 / 2}$ Limit $=180$ days 
RESRAD-OFFSITE, Version 2.5

Parent Dose Report

Title : Offsite Resident Farmer Deterministic Run

File : RF SG FWD-FINAL v2.ROF

Site-Specific Parameter Summary (continued)

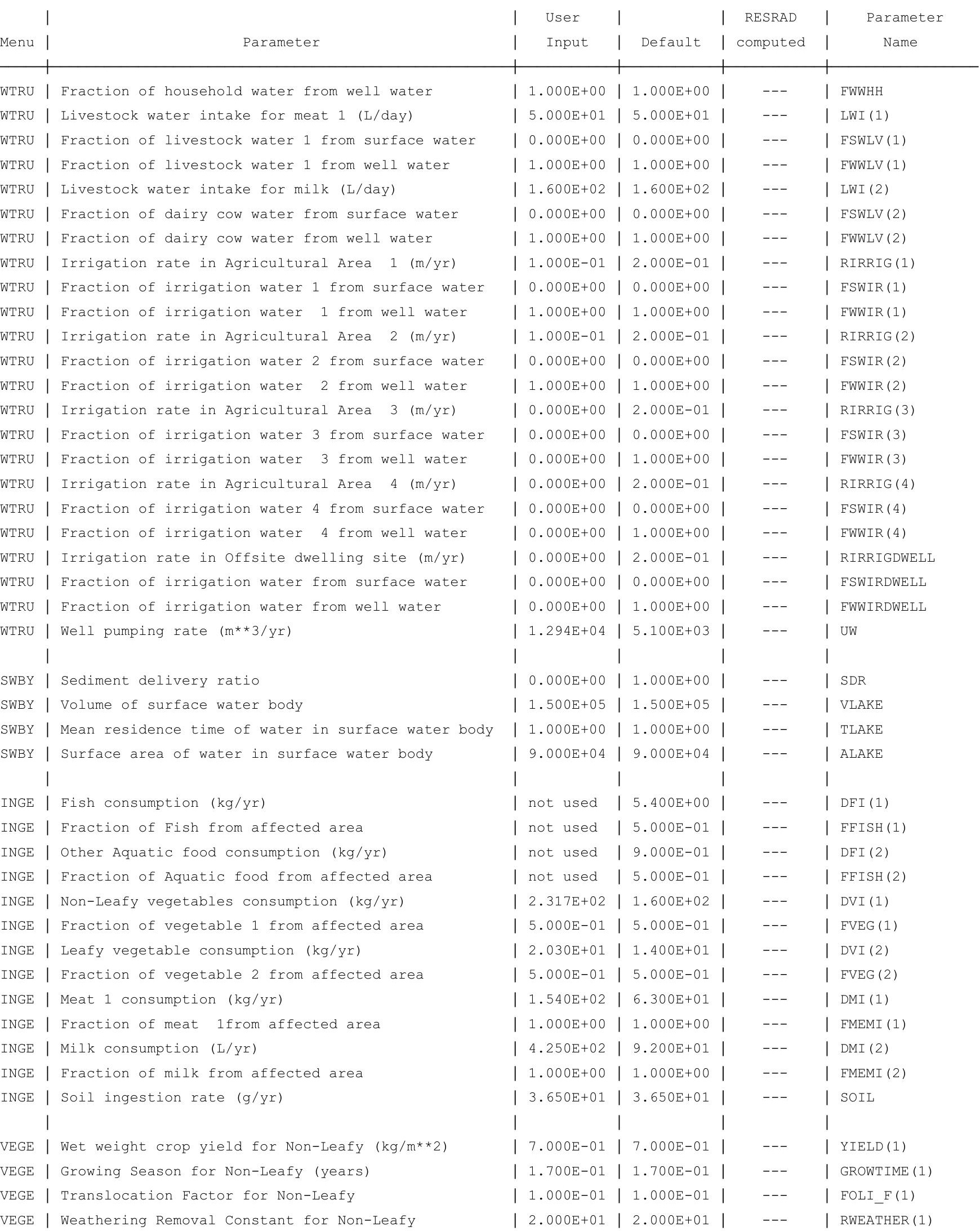


RESRAD-OFFSITE, Version 2.5

$\mathrm{T}^{1} / 2$ Limit $=180$ days

Parent Dose Report

Title : Offsite Resident Farmer Deterministic Run

File : RF SG FWD-FINAL v2.ROF

Site-Specific Parameter Summary (continued)

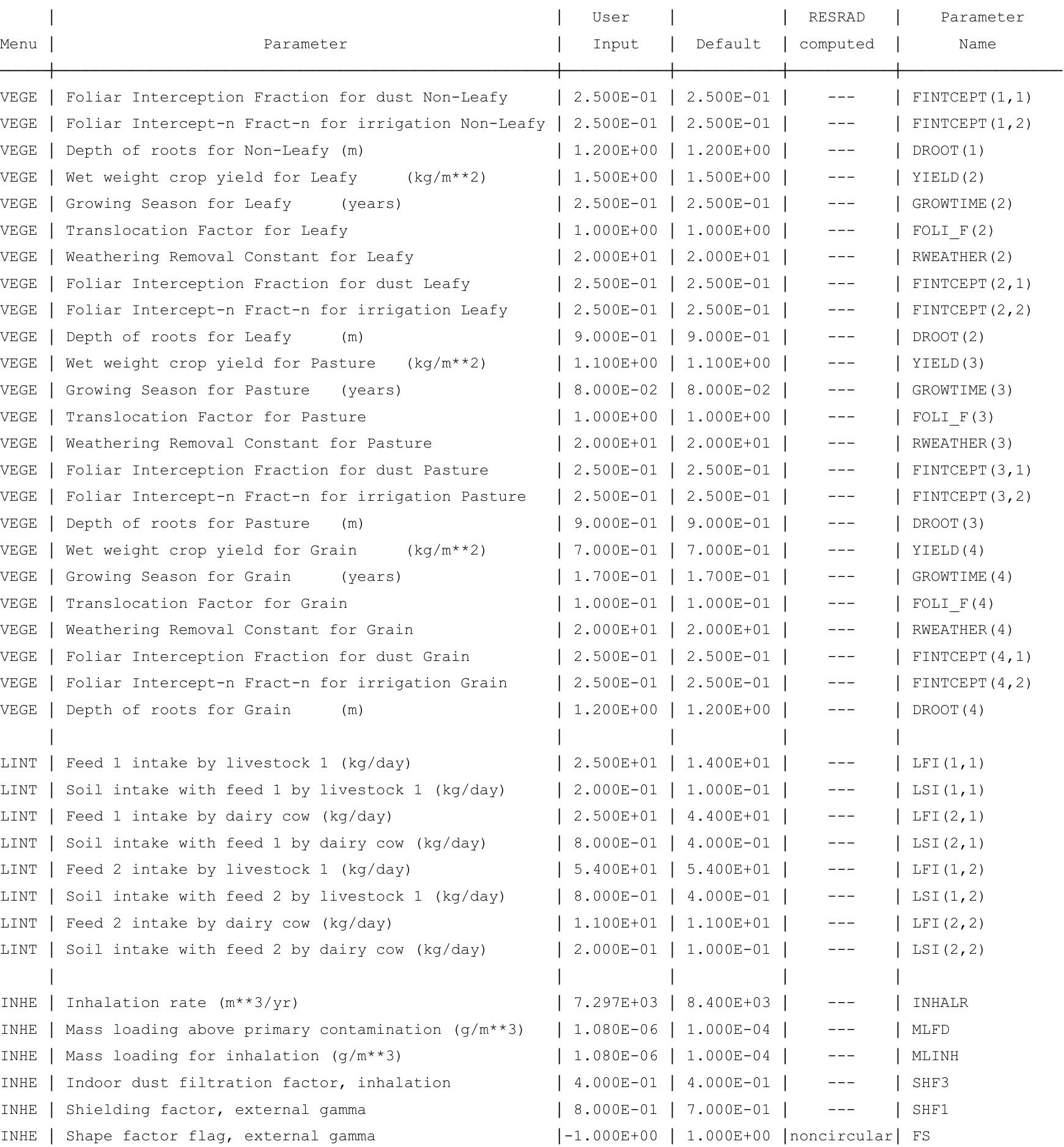


RESRAD-OFFSITE, Version $2.5 \quad \mathrm{~T}^{1 / 2}$ Limit $=180$ days

Parent Dose Report

Title : Offsite Resident Farmer Deterministic Run

File : RF SG FWD-FINAL v2.ROF

Site-Specific Parameter Summary (continued)

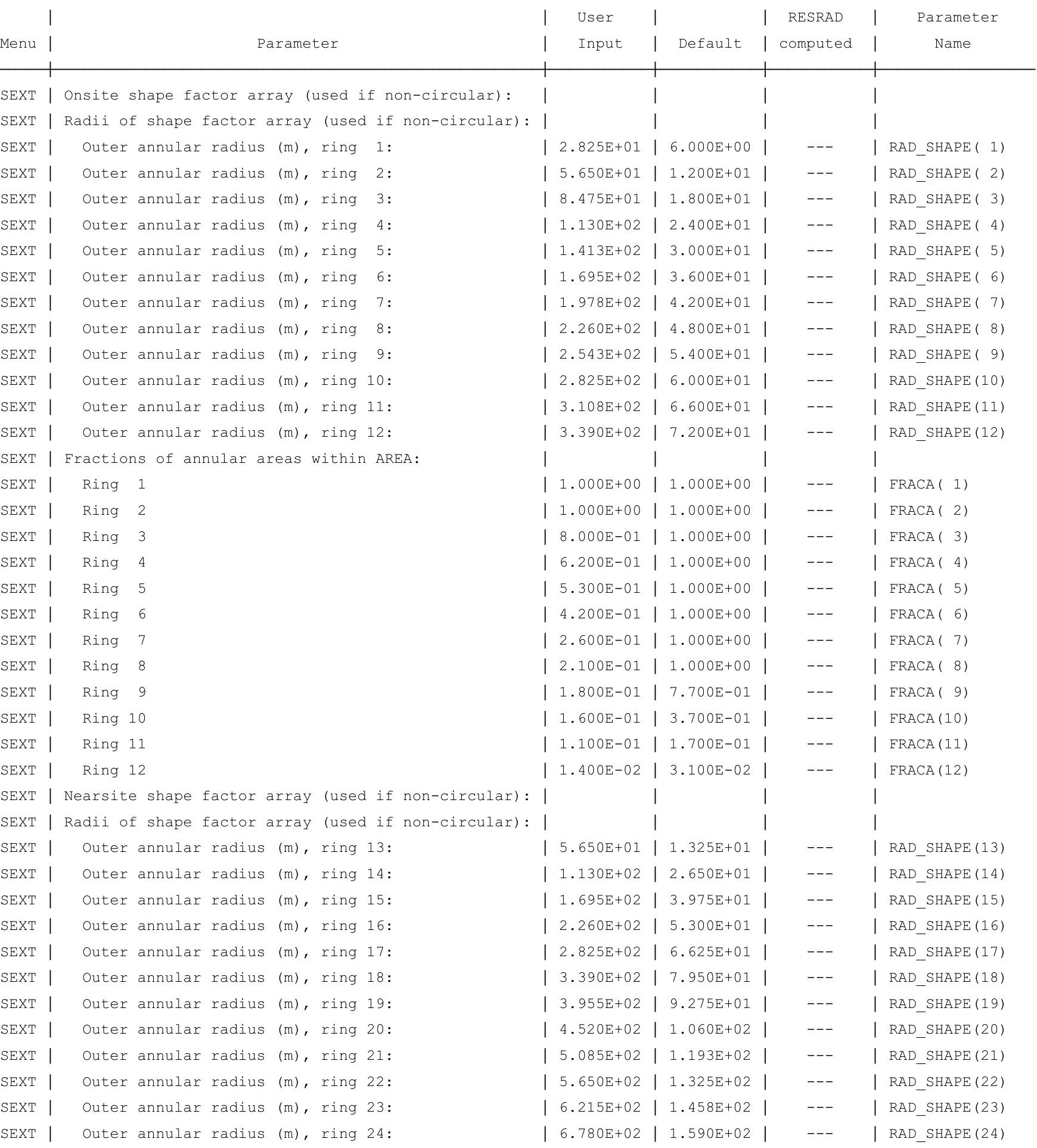


RESRAD-OFFSITE, Version 2.5

$\mathrm{T}^{1 / 2}$ Limit $=180$ days

Parent Dose Report

Title : Offsite Resident Farmer Deterministic Run

File : RF SG FWD-FINAL v2.ROF

Site-Specific Parameter Summary (continued)

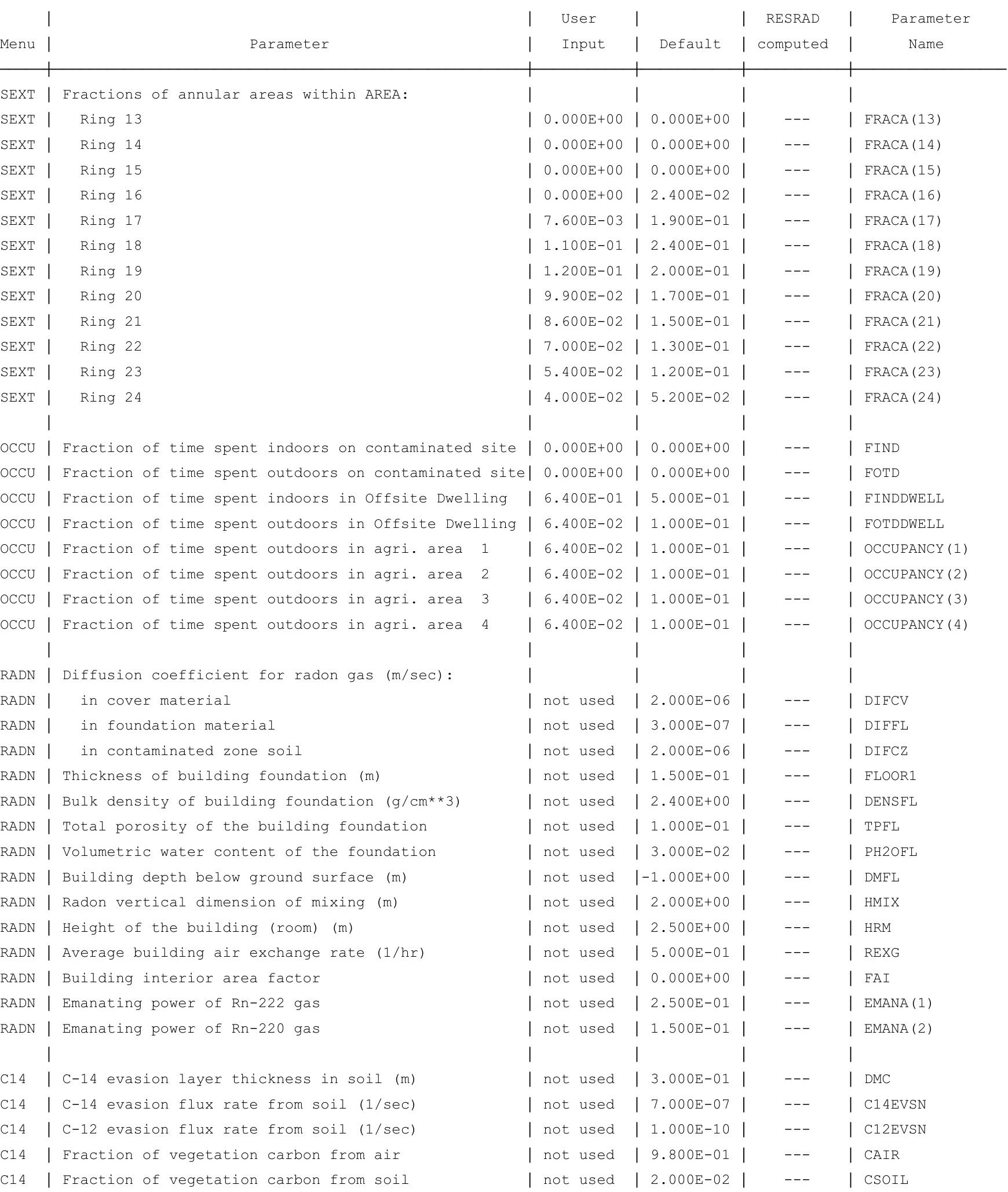


RESRAD-OFFSITE, Version 2.5

Parent Dose Report

Title : Offsite Resident Farmer Deterministic Run

File : RF SG FWD-FINAL v2.ROF

Site-Specific Parameter Summary (continued)

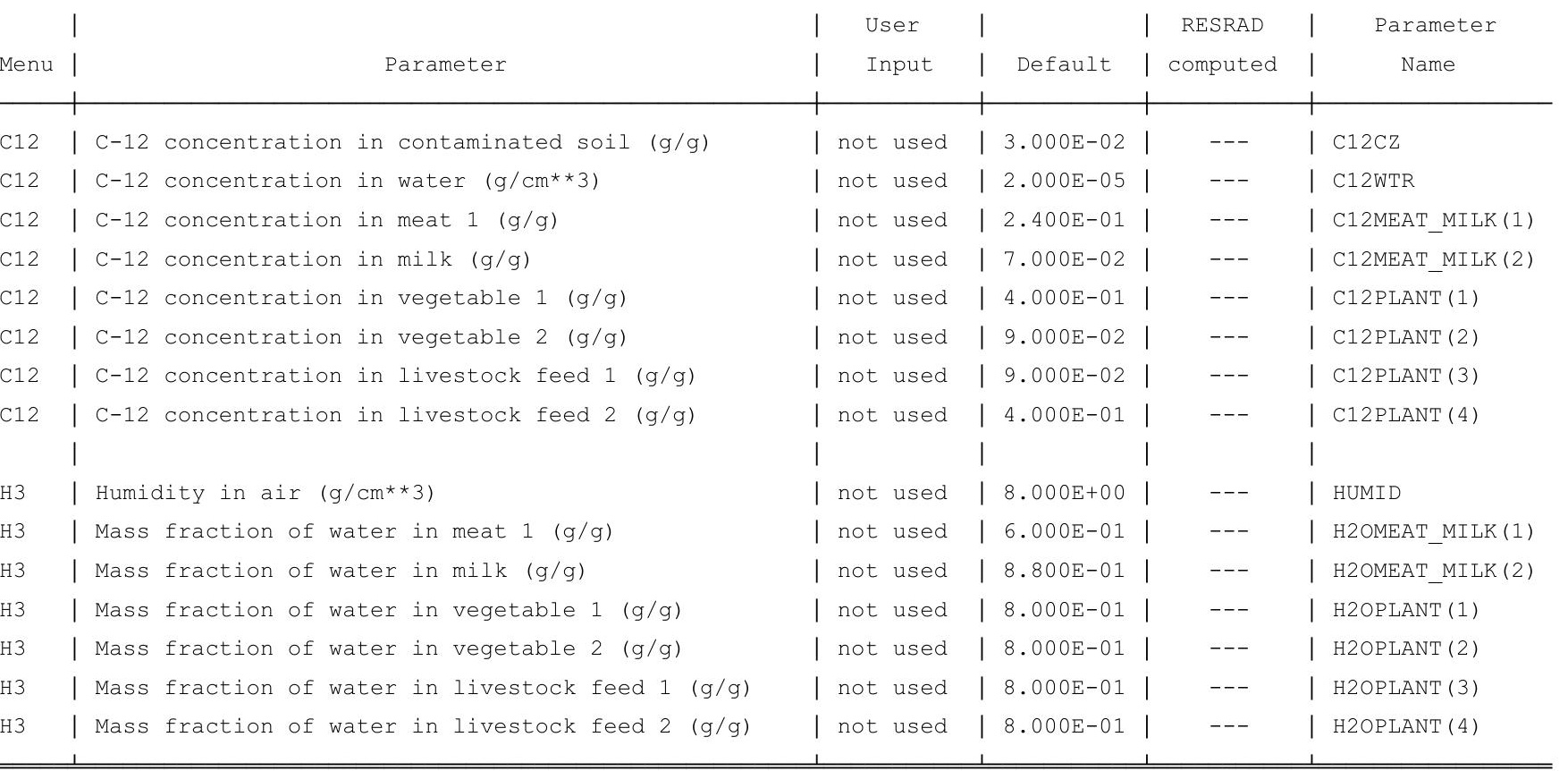

Summary of Pathway Selections

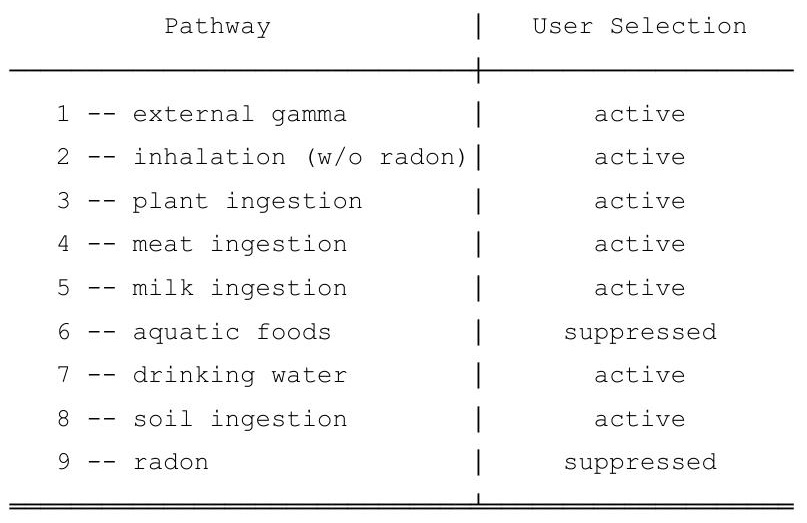


RESRAD-OFFSITE, Version $2.5 \quad \mathrm{~T}^{1 / 2}$ Limit $=180$ days

Parent Dose Report

Title : Offsite Resident Farmer Deterministic Run

File : RF SG FWD-FINAL v2.ROF

Contaminated Zone Dimensions

Area: 102144.00 square meters

Thickness:

Cover Depth:
Initial Soil Concentrations, pCi/g

$\begin{array}{ll}\mathrm{Am}-241 & 3.500 \mathrm{E}+03 \\ \mathrm{Cs}-137 & 1.900 \mathrm{E}+02 \\ \mathrm{~Np}-237 & 5.500 \mathrm{E}+02 \\ \mathrm{Pu}-238 & 3.900 \mathrm{E}+03 \\ \mathrm{Pu}-239 & 3.600 \mathrm{E}+03 \\ \mathrm{Pu}-240 & 3.600 \mathrm{E}+03 \\ \mathrm{TC}-99 & 2.800 \mathrm{E}+01 \\ \mathrm{Th}-228 & 7.400 \mathrm{E}+01 \\ \mathrm{Th}-230 & 1.200 \mathrm{E}+03 \\ \mathrm{Th}-232 & 3.800 \mathrm{E}+01 \\ \mathrm{U}-234 & 1.800 \mathrm{E}+04 \\ \mathrm{U}-235 & 8.200 \mathrm{E}+02 \\ \mathrm{U}-238 & 3.200 \mathrm{E}+03\end{array}$

Total Dose TDOSE(t), mrem/yr

Basic Radiation Dose Limit $=1.000 \mathrm{E}+00 \mathrm{mrem} / \mathrm{yr}$

Total Mixture Sum $M(t)$ = Fraction of Basic Dose Limit Received at Time (t)

$\begin{array}{rllllll}t \text { (years) }: & 0.000 \mathrm{E}+00 & 1.000 \mathrm{E}+00 & 5.000 \mathrm{E}+01 & 1.000 \mathrm{E}+02 & 5.000 \mathrm{E}+02 & 1.026 \mathrm{E}+03 \\ \text { TDOSE }(t): & 6.294 \mathrm{E}-13 & 4.568 \mathrm{E}-13 & 5.466 \mathrm{E}-13 & 7.751 \mathrm{E}-13 & 5.336 \mathrm{E}-01 & 7.732 \mathrm{E}-01 \\ \mathrm{M}(\mathrm{t}): & 6.294 \mathrm{E}-13 & 4.568 \mathrm{E}-13 & 5.466 \mathrm{E}-13 & 7.751 \mathrm{E}-13 & 5.336 \mathrm{E}-01 & 7.732 \mathrm{E}-01\end{array}$

Maximum TDOSE $(t): 1.006 \mathrm{E}+00 \mathrm{mrem} / \mathrm{yr}$ at $t=772$ years 
RESRAD-OFFSITE, Version 2 .

Parent Dose Report

Title : Offsite Resident Farmer Deterministic Run

File : RF SG FWD-FINAL V2.ROF

Total Dose Contributions TDOSE (i,p,t) for Individual Radionuclides (i) and Pathways (p) in mrem/yr and as a Percentage of Total Dose at $t=0$ years

From releases to ground water and to surface water

\begin{tabular}{|c|c|c|c|c|c|c|c|c|c|c|c|c|c|c|c|c|}
\hline & \multicolumn{2}{|c|}{ Ground } & \multicolumn{2}{|l|}{ Fish } & \multicolumn{2}{|c|}{ Radon } & \multicolumn{2}{|c|}{ Plant } & \multicolumn{2}{|l|}{ Meat } & \multicolumn{2}{|l|}{ Milk } & \multicolumn{2}{|l|}{ Soil } & \multicolumn{2}{|c|}{ Water } \\
\hline ide & Dose & $\%$ & Dose & $\%$ & Dose & 응 & Dose & $\frac{\circ}{0}$ & Dose & 응 & Dose & 응 & Dose & $\%$ & Dose & $\%$ \\
\hline-241 & $0.00 \mathrm{E}+00$ & 0 & $0.00 E+00$ & 0 & $0.00 \mathrm{E}+00$ & 0 & $0.00 \mathrm{E}+00$ & 0 & $0.00 \mathrm{E}+00$ & 0 & $0.00 \mathrm{E}+00$ & 0 & $0.00 \mathrm{E}+00$ & 0 & $0.00 \mathrm{E}+00$ & 0 \\
\hline-137 & $0.00 \mathrm{E}+00$ & 0 & $0.00 \mathrm{E}+00$ & 0 & $0.00 \mathrm{E}+00$ & 0 & $0.00 \mathrm{E}+00$ & 0 & $0.00 \mathrm{E}+00$ & 0 & $0.00 \mathrm{E}+00$ & 0 & $0.00 \mathrm{E}+00$ & 0 & $0.00 \mathrm{E}+00$ & 0 \\
\hline-237 & $0.00 \mathrm{E}+00$ & 0 & $0.00 \mathrm{E}+00$ & 0 & $0.00 \mathrm{E}+00$ & 0 & $0.00 \mathrm{E}+00$ & 0 & $0.00 \mathrm{E}+00$ & 0 & $0.00 \mathrm{E}+00$ & 0 & $0.00 \mathrm{E}+00$ & 0 & $0.00 \mathrm{E}+00$ & 0 \\
\hline-238 & $0.00 \mathrm{E}+00$ & 0 & $0.00 \mathrm{E}+00$ & 0 & $0.00 E+00$ & 0 & $0.00 \mathrm{E}+00$ & 0 & $0.00 \mathrm{E}+00$ & 0 & $0.00 E+00$ & 0 & $0.00 \mathrm{E}+00$ & 0 & $0.00 \mathrm{E}+00$ & 0 \\
\hline-239 & $0.00 \mathrm{E}+00$ & 0 & $0.00 \mathrm{E}+00$ & 0 & $0.00 \mathrm{E}+00$ & 0 & $0.00 \mathrm{E}+00$ & 0 & $0.00 \mathrm{E}+00$ & 0 & $0.00 \mathrm{E}+00$ & 0 & $0.00 \mathrm{E}+00$ & 0 & $0.00 \mathrm{E}+00$ & 0 \\
\hline-240 & $0.00 \mathrm{E}+00$ & 0 & $0.00 \mathrm{E}+00$ & 0 & $0.00 \mathrm{E}+00$ & 0 & $0.00 \mathrm{E}+00$ & 0 & $0.00 \mathrm{E}+00$ & 0 & $0.00 \mathrm{E}+00$ & 0 & $0.00 \mathrm{E}+00$ & 0 & $0.00 \mathrm{E}+00$ & 0 \\
\hline-99 & $0.00 \mathrm{E}+00$ & 0 & $0.00 \mathrm{E}+00$ & 0 & $0.00 \mathrm{E}+00$ & 0 & $0.00 \mathrm{E}+00$ & 0 & $0.00 \mathrm{E}+00$ & 0 & $0.00 E+00$ & 0 & $0.00 \mathrm{E}+00$ & 0 & $0.00 \mathrm{E}+00$ & 0 \\
\hline-228 & $0.00 \mathrm{E}+00$ & 0 & $0.00 \mathrm{E}+00$ & 0 & $0.00 \mathrm{E}+00$ & 0 & $0.00 \mathrm{E}+00$ & 0 & $0.00 \mathrm{E}+00$ & 0 & $0.00 \mathrm{E}+00$ & 0 & $0.00 \mathrm{E}+00$ & 0 & $0.00 \mathrm{E}+00$ & 0 \\
\hline-230 & $0.00 \mathrm{E}+00$ & 0 & $0.00 \mathrm{E}+00$ & 0 & $0.00 \mathrm{E}+00$ & 0 & $0.00 \mathrm{E}+00$ & 0 & $0.00 \mathrm{E}+00$ & 0 & $0.00 \mathrm{E}+00$ & 0 & $0.00 \mathrm{E}+00$ & 0 & $0.00 \mathrm{E}+00$ & 0 \\
\hline-232 & $0.00 \mathrm{E}+00$ & 0 & $0.00 \mathrm{E}+00$ & 0 & $0.00 \mathrm{E}+00$ & 0 & $0.00 \mathrm{E}+00$ & 0 & $0.00 \mathrm{E}+00$ & 0 & $0.00 \mathrm{E}+00$ & 0 & $0.00 \mathrm{E}+00$ & 0 & $0.00 \mathrm{E}+00$ & 0 \\
\hline 34 & $0.00 \mathrm{E}+00$ & 0 & $0.00 \mathrm{E}+00$ & 0 & $0.00 \mathrm{E}+00$ & 0 & $0.00 \mathrm{E}+00$ & 0 & $0.00 \mathrm{E}+00$ & 0 & $0.00 \mathrm{E}+00$ & 0 & $0.00 \mathrm{E}+00$ & 0 & $0.00 \mathrm{E}+00$ & 0 \\
\hline 35 & $0.00 \mathrm{E}+00$ & 0 & $0.00 \mathrm{E}+00$ & 0 & $0.00 \mathrm{E}+00$ & 0 & $0.00 \mathrm{E}+00$ & 0 & $0.00 \mathrm{E}+00$ & 0 & $0.00 \mathrm{E}+00$ & 0 & $0.00 \mathrm{E}+00$ & 0 & $0.00 \mathrm{E}+00$ & 0 \\
\hline 38 & $0.00 \mathrm{E}+00$ & 0 & $0.00 \mathrm{E}+00$ & 0 & $0.00 E+00$ & 0 & $0.00 \mathrm{E}+00$ & 0 & $0.00 \mathrm{E}+00$ & 0 & $0.00 E+00$ & 0 & $0.00 \mathrm{E}+00$ & 0 & $0.00 \mathrm{E}+00$ & 0 \\
\hline & $0.00 \mathrm{E}+00$ & 0 & $0.00 E+00$ & 0 & $0.00 \mathrm{E}+00$ & 0 & $0.00 \mathrm{E}+00$ & 0 & $0.00 \mathrm{E}+00$ & 0 & $0.00 \mathrm{E}+00$ & 0 & $0.00 \mathrm{E}+00$ & 0 & $0.00 \mathrm{E}+00$ & 0 \\
\hline
\end{tabular}

Total Dose Contributions TDOSE(i,p,t) for Individual Radionuclides (i) and Pathways (p)

in mrem/yr and as a Percentage of Total Dose at $t=0$ years

Directly from primary contamination and from release to atmosphere (Inhalation excludes radon)

Radio-

Ground

Inhalation

Radon
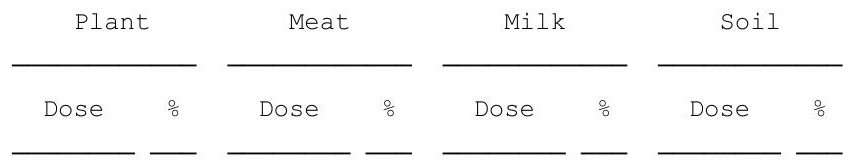

All Pathways*
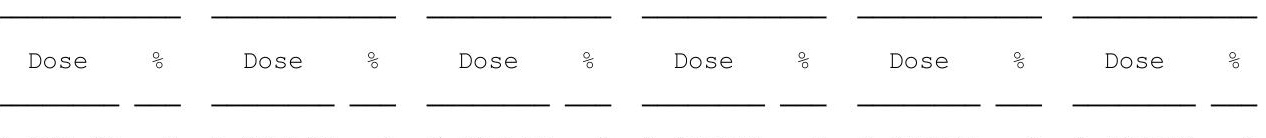

$3.28 \mathrm{E}-240.00 \mathrm{E}+00$

$0.00 \mathrm{E}+00$

$0.00 \mathrm{E}+00$

$0.00 \mathrm{E}+00$

.

1. $45 \mathrm{E}-150.00 \mathrm{E}+00$

$0.00 \mathrm{E}+00$

$0.00 \mathrm{E}+00$

$0.00 \mathrm{E}+00$

00

$3.18 \mathrm{E}-18 \quad 0 \quad 0.00 \mathrm{E}+00$

$0.00 \mathrm{E}+00$

$0.00 \mathrm{E}+00$

$0.00 \mathrm{E}+00$

$0.00 \mathrm{E}+00$

0

$\begin{array}{lllll}2.45 \mathrm{E}-27 & 0 & 0.00 \mathrm{E}+00 & 0 & 0.00 \mathrm{E}+00\end{array}$

$0.00 \mathrm{E}+00$

$0.00 \mathrm{E}+00$

$0.00 \mathrm{E}+00$

0

2. $62 \mathrm{E}-22 \quad 0 \quad 0.00 \mathrm{E}+00$

$0.00 \mathrm{E}+00$

$0.00 \mathrm{E}+00$

$0.00 \mathrm{E}+00$

$0.00 \mathrm{E}+00$

0

$2.49 \mathrm{E}-29000 \mathrm{E}+00$

$0.00 \mathrm{E}+00$

$0.00 \mathrm{E}+00$

$0.00 \mathrm{E}+00$

$0.00 \mathrm{E}+00$

$0.00 \mathrm{E}+00$

$0.00 \mathrm{E}+00$

0

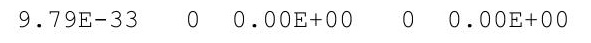

$0.00 \mathrm{E}+00$

$0.00 \mathrm{E}+00$

$0.00 \mathrm{E}+00$

$0.00 \mathrm{E}+00$

$0.00 \mathrm{E}+00$

$0.00 \mathrm{E}+00$

$0.00 \mathrm{E}+00$

$0.00 \mathrm{E}+00$

$0.00 \mathrm{E}+00$

$0.00 \mathrm{E}+00$

$0.00 \mathrm{E}+00$

$0.00 \mathrm{E}+00$

$0.00 \mathrm{E}+00$

00

$0.00 \mathrm{E}+00$

00 .

$0.00 \mathrm{E}+00$

$0.00 \mathrm{E}+00$

$0.00 \mathrm{E}+00$

$0.00 \mathrm{E}+00$

$0.00 \mathrm{E}+00$

$0.00 E+00$

$0.00 \mathrm{E}+00=$

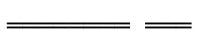

$0.00 \mathrm{E}+00$

$06.29 \mathrm{E}-13 \quad 100$

* Sum of dose from all releases and from primary contamination. 
RESRAD-OFFSITE, Version 2 .

Parent Dose Report

Title : Offsite Resident Farmer Deterministic Run

File : RF SG FWD-FINAL V2.ROF

Total Dose Contributions TDOSE (i,p,t) for Individual Radionuclides (i) and Pathways (p) in mrem/yr and as a Percentage of Total Dose at $t=1$ years

From releases to ground water and to surface water

\begin{tabular}{|c|c|c|c|c|c|c|c|c|c|c|c|c|c|c|c|c|}
\hline & \multicolumn{2}{|c|}{ Ground } & \multicolumn{2}{|l|}{ Fish } & \multicolumn{2}{|c|}{ Radon } & \multicolumn{2}{|c|}{ Plant } & \multicolumn{2}{|l|}{ Meat } & \multicolumn{2}{|l|}{ Milk } & \multicolumn{2}{|l|}{ Soil } & \multicolumn{2}{|c|}{ Water } \\
\hline ide & Dose & $\%$ & Dose & $\%$ & Dose & 응 & Dose & $\frac{\circ}{0}$ & Dose & 응 & Dose & 응 & Dose & $\%$ & Dose & $\%$ \\
\hline-241 & $0.00 \mathrm{E}+00$ & 0 & $0.00 E+00$ & 0 & $0.00 \mathrm{E}+00$ & 0 & $0.00 \mathrm{E}+00$ & 0 & $0.00 \mathrm{E}+00$ & 0 & $0.00 \mathrm{E}+00$ & 0 & $0.00 \mathrm{E}+00$ & 0 & $0.00 \mathrm{E}+00$ & 0 \\
\hline-137 & $0.00 \mathrm{E}+00$ & 0 & $0.00 \mathrm{E}+00$ & 0 & $0.00 \mathrm{E}+00$ & 0 & $0.00 \mathrm{E}+00$ & 0 & $0.00 \mathrm{E}+00$ & 0 & $0.00 \mathrm{E}+00$ & 0 & $0.00 \mathrm{E}+00$ & 0 & $0.00 \mathrm{E}+00$ & 0 \\
\hline-237 & $0.00 \mathrm{E}+00$ & 0 & $0.00 \mathrm{E}+00$ & 0 & $0.00 \mathrm{E}+00$ & 0 & $0.00 \mathrm{E}+00$ & 0 & $0.00 \mathrm{E}+00$ & 0 & $0.00 \mathrm{E}+00$ & 0 & $0.00 \mathrm{E}+00$ & 0 & $0.00 \mathrm{E}+00$ & 0 \\
\hline-238 & $0.00 \mathrm{E}+00$ & 0 & $0.00 \mathrm{E}+00$ & 0 & $0.00 E+00$ & 0 & $0.00 \mathrm{E}+00$ & 0 & $0.00 \mathrm{E}+00$ & 0 & $0.00 E+00$ & 0 & $0.00 \mathrm{E}+00$ & 0 & $0.00 \mathrm{E}+00$ & 0 \\
\hline-239 & $0.00 \mathrm{E}+00$ & 0 & $0.00 \mathrm{E}+00$ & 0 & $0.00 \mathrm{E}+00$ & 0 & $0.00 \mathrm{E}+00$ & 0 & $0.00 \mathrm{E}+00$ & 0 & $0.00 \mathrm{E}+00$ & 0 & $0.00 \mathrm{E}+00$ & 0 & $0.00 \mathrm{E}+00$ & 0 \\
\hline-240 & $0.00 \mathrm{E}+00$ & 0 & $0.00 \mathrm{E}+00$ & 0 & $0.00 \mathrm{E}+00$ & 0 & $0.00 \mathrm{E}+00$ & 0 & $0.00 \mathrm{E}+00$ & 0 & $0.00 \mathrm{E}+00$ & 0 & $0.00 \mathrm{E}+00$ & 0 & $0.00 \mathrm{E}+00$ & 0 \\
\hline-99 & $0.00 \mathrm{E}+00$ & 0 & $0.00 \mathrm{E}+00$ & 0 & $0.00 \mathrm{E}+00$ & 0 & $0.00 \mathrm{E}+00$ & 0 & $0.00 \mathrm{E}+00$ & 0 & $0.00 E+00$ & 0 & $0.00 \mathrm{E}+00$ & 0 & $0.00 \mathrm{E}+00$ & 0 \\
\hline-228 & $0.00 \mathrm{E}+00$ & 0 & $0.00 \mathrm{E}+00$ & 0 & $0.00 \mathrm{E}+00$ & 0 & $0.00 \mathrm{E}+00$ & 0 & $0.00 \mathrm{E}+00$ & 0 & $0.00 \mathrm{E}+00$ & 0 & $0.00 \mathrm{E}+00$ & 0 & $0.00 \mathrm{E}+00$ & 0 \\
\hline-230 & $0.00 \mathrm{E}+00$ & 0 & $0.00 \mathrm{E}+00$ & 0 & $0.00 \mathrm{E}+00$ & 0 & $0.00 \mathrm{E}+00$ & 0 & $0.00 \mathrm{E}+00$ & 0 & $0.00 \mathrm{E}+00$ & 0 & $0.00 \mathrm{E}+00$ & 0 & $0.00 \mathrm{E}+00$ & 0 \\
\hline-232 & $0.00 \mathrm{E}+00$ & 0 & $0.00 \mathrm{E}+00$ & 0 & $0.00 \mathrm{E}+00$ & 0 & $0.00 \mathrm{E}+00$ & 0 & $0.00 \mathrm{E}+00$ & 0 & $0.00 \mathrm{E}+00$ & 0 & $0.00 \mathrm{E}+00$ & 0 & $0.00 \mathrm{E}+00$ & 0 \\
\hline 34 & $0.00 \mathrm{E}+00$ & 0 & $0.00 \mathrm{E}+00$ & 0 & $0.00 \mathrm{E}+00$ & 0 & $0.00 \mathrm{E}+00$ & 0 & $0.00 \mathrm{E}+00$ & 0 & $0.00 \mathrm{E}+00$ & 0 & $0.00 \mathrm{E}+00$ & 0 & $0.00 \mathrm{E}+00$ & 0 \\
\hline 35 & $0.00 \mathrm{E}+00$ & 0 & $0.00 \mathrm{E}+00$ & 0 & $0.00 \mathrm{E}+00$ & 0 & $0.00 \mathrm{E}+00$ & 0 & $0.00 \mathrm{E}+00$ & 0 & $0.00 \mathrm{E}+00$ & 0 & $0.00 \mathrm{E}+00$ & 0 & $0.00 \mathrm{E}+00$ & 0 \\
\hline 38 & $0.00 \mathrm{E}+00$ & 0 & $0.00 \mathrm{E}+00$ & 0 & $0.00 E+00$ & 0 & $0.00 \mathrm{E}+00$ & 0 & $0.00 \mathrm{E}+00$ & 0 & $0.00 E+00$ & 0 & $0.00 \mathrm{E}+00$ & 0 & $0.00 \mathrm{E}+00$ & 0 \\
\hline & $0.00 \mathrm{E}+00$ & 0 & $0.00 E+00$ & 0 & $0.00 \mathrm{E}+00$ & 0 & $0.00 \mathrm{E}+00$ & 0 & $0.00 \mathrm{E}+00$ & 0 & $0.00 \mathrm{E}+00$ & 0 & $0.00 \mathrm{E}+00$ & 0 & $0.00 \mathrm{E}+00$ & 0 \\
\hline
\end{tabular}

Total Dose Contributions TDOSE(i,p,t) for Individual Radionuclides (i) and Pathways (p)

in mrem/yr and as a Percentage of Total Dose at $t=1$ years

Directly from primary contamination and from release to atmosphere (Inhalation excludes radon)

Radio-

Inhalation
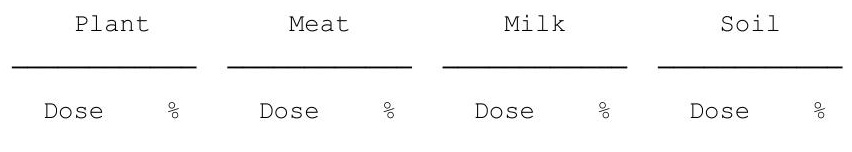

All Pathways*
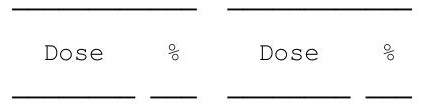

$9.92 \mathrm{E}-24$
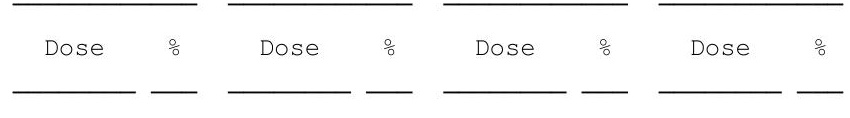

1. $43 \mathrm{E}-15 \quad 0 \quad 0.00 \mathrm{E}+00$

$0.00 \mathrm{E}+00$

$0.00 \mathrm{E}+00$

$0.00 \mathrm{E}+00$

0

$0.00 \mathrm{E}+00$

00

3.21E-18 $0 \quad 0.00 \mathrm{E}+00$

$0.00 \mathrm{E}+00$

$0.00 \mathrm{E}+00$

$0.00 \mathrm{E}+00$

$0.00 \mathrm{E}+00$

$0.00 \mathrm{E}+00$

$0.00 \mathrm{E}+00$

$0.00 \mathrm{E}+00$

$0.00 \mathrm{E}+00$

$0.00 \mathrm{E}+00$

$0.00 \mathrm{E}+00$

$0.00 \mathrm{E}+00$

$0.00 \mathrm{E}+00$

$0.00 \mathrm{E}+00$

$0.00 \mathrm{E}+00$

$0.00 \mathrm{E}+00$

$0.00 \mathrm{E}+00$

$0.00 \mathrm{E}+00$

$0.00 \mathrm{E}+00$
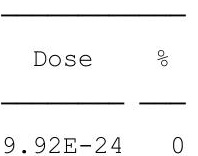

0 1.43E-15 0

$3.05 E-2600.00 E+00$

$2.59 \mathrm{E}-2900.00 \mathrm{E}+00$

4.36E-13 $95 \quad 0.00 \mathrm{E}+00$

$0.00 \mathrm{E}+00$

$0.00 \mathrm{E}+00$

$0.00 \mathrm{E}+00$

$0.00 \mathrm{E}+00$

$0.00 \mathrm{E}+00$

$0.00 \mathrm{E}+00$

$0.00 \mathrm{E}+00$

$\underline{0.00 \mathrm{E}+00 \quad 0}$

$0.00 \mathrm{E}+00$

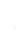

$=$

$\begin{array}{llllllll}4.57 \mathrm{E}-13 & 100 & 0.00 \mathrm{E}+00 & 0 & 0.00 \mathrm{E}+00 & 0 & 0.00 \mathrm{E}+00 & 0\end{array}$

$0.00 \mathrm{E}+00$

$0.00 \mathrm{E}+00$

$0.00 \mathrm{E}+0$

$0 \quad 4.57 \mathrm{E}-13 \quad 100$

* Sum of dose from all releases and from primary contamination. 
RESRAD-OFFSITE, Version 2 .

Parent Dose Report

Title : Offsite Resident Farmer Deterministic Run

File : RF SG FWD-FINAL V2.ROF

Total Dose Contributions TDOSE (i,p,t) for Individual Radionuclides (i) and Pathways (p) in mrem/yr and as a Percentage of Total Dose at $t=50$ years

From releases to ground water and to surface water

\begin{tabular}{|c|c|c|c|c|c|c|c|c|c|c|c|c|c|c|c|c|}
\hline & \multicolumn{2}{|c|}{ Ground } & \multicolumn{2}{|l|}{ Fish } & \multicolumn{2}{|c|}{ Radon } & \multicolumn{2}{|c|}{ Plant } & \multicolumn{2}{|l|}{ Meat } & \multicolumn{2}{|l|}{ Milk } & \multicolumn{2}{|l|}{ Soil } & \multicolumn{2}{|c|}{ Water } \\
\hline ide & Dose & $\%$ & Dose & $\%$ & Dose & 응 & Dose & $\frac{\circ}{0}$ & Dose & 응 & Dose & 응 & Dose & $\%$ & Dose & $\%$ \\
\hline-241 & $0.00 \mathrm{E}+00$ & 0 & $0.00 E+00$ & 0 & $0.00 \mathrm{E}+00$ & 0 & $0.00 \mathrm{E}+00$ & 0 & $0.00 \mathrm{E}+00$ & 0 & $0.00 \mathrm{E}+00$ & 0 & $0.00 \mathrm{E}+00$ & 0 & $0.00 \mathrm{E}+00$ & 0 \\
\hline-137 & $0.00 \mathrm{E}+00$ & 0 & $0.00 \mathrm{E}+00$ & 0 & $0.00 \mathrm{E}+00$ & 0 & $0.00 \mathrm{E}+00$ & 0 & $0.00 \mathrm{E}+00$ & 0 & $0.00 \mathrm{E}+00$ & 0 & $0.00 \mathrm{E}+00$ & 0 & $0.00 \mathrm{E}+00$ & 0 \\
\hline-237 & $0.00 \mathrm{E}+00$ & 0 & $0.00 \mathrm{E}+00$ & 0 & $0.00 \mathrm{E}+00$ & 0 & $0.00 \mathrm{E}+00$ & 0 & $0.00 \mathrm{E}+00$ & 0 & $0.00 \mathrm{E}+00$ & 0 & $0.00 \mathrm{E}+00$ & 0 & $0.00 \mathrm{E}+00$ & 0 \\
\hline-238 & $0.00 \mathrm{E}+00$ & 0 & $0.00 \mathrm{E}+00$ & 0 & $0.00 E+00$ & 0 & $0.00 \mathrm{E}+00$ & 0 & $0.00 \mathrm{E}+00$ & 0 & $0.00 E+00$ & 0 & $0.00 \mathrm{E}+00$ & 0 & $0.00 \mathrm{E}+00$ & 0 \\
\hline-239 & $0.00 \mathrm{E}+00$ & 0 & $0.00 \mathrm{E}+00$ & 0 & $0.00 \mathrm{E}+00$ & 0 & $0.00 \mathrm{E}+00$ & 0 & $0.00 \mathrm{E}+00$ & 0 & $0.00 \mathrm{E}+00$ & 0 & $0.00 \mathrm{E}+00$ & 0 & $0.00 \mathrm{E}+00$ & 0 \\
\hline-240 & $0.00 \mathrm{E}+00$ & 0 & $0.00 \mathrm{E}+00$ & 0 & $0.00 \mathrm{E}+00$ & 0 & $0.00 \mathrm{E}+00$ & 0 & $0.00 \mathrm{E}+00$ & 0 & $0.00 \mathrm{E}+00$ & 0 & $0.00 \mathrm{E}+00$ & 0 & $0.00 \mathrm{E}+00$ & 0 \\
\hline-99 & $0.00 \mathrm{E}+00$ & 0 & $0.00 \mathrm{E}+00$ & 0 & $0.00 \mathrm{E}+00$ & 0 & $0.00 \mathrm{E}+00$ & 0 & $0.00 \mathrm{E}+00$ & 0 & $0.00 E+00$ & 0 & $0.00 \mathrm{E}+00$ & 0 & $0.00 \mathrm{E}+00$ & 0 \\
\hline-228 & $0.00 \mathrm{E}+00$ & 0 & $0.00 \mathrm{E}+00$ & 0 & $0.00 \mathrm{E}+00$ & 0 & $0.00 \mathrm{E}+00$ & 0 & $0.00 \mathrm{E}+00$ & 0 & $0.00 \mathrm{E}+00$ & 0 & $0.00 \mathrm{E}+00$ & 0 & $0.00 \mathrm{E}+00$ & 0 \\
\hline-230 & $0.00 \mathrm{E}+00$ & 0 & $0.00 \mathrm{E}+00$ & 0 & $0.00 \mathrm{E}+00$ & 0 & $0.00 \mathrm{E}+00$ & 0 & $0.00 \mathrm{E}+00$ & 0 & $0.00 \mathrm{E}+00$ & 0 & $0.00 \mathrm{E}+00$ & 0 & $0.00 \mathrm{E}+00$ & 0 \\
\hline-232 & $0.00 \mathrm{E}+00$ & 0 & $0.00 \mathrm{E}+00$ & 0 & $0.00 \mathrm{E}+00$ & 0 & $0.00 \mathrm{E}+00$ & 0 & $0.00 \mathrm{E}+00$ & 0 & $0.00 \mathrm{E}+00$ & 0 & $0.00 \mathrm{E}+00$ & 0 & $0.00 \mathrm{E}+00$ & 0 \\
\hline 34 & $0.00 \mathrm{E}+00$ & 0 & $0.00 \mathrm{E}+00$ & 0 & $0.00 \mathrm{E}+00$ & 0 & $0.00 \mathrm{E}+00$ & 0 & $0.00 \mathrm{E}+00$ & 0 & $0.00 \mathrm{E}+00$ & 0 & $0.00 \mathrm{E}+00$ & 0 & $0.00 \mathrm{E}+00$ & 0 \\
\hline 35 & $0.00 \mathrm{E}+00$ & 0 & $0.00 \mathrm{E}+00$ & 0 & $0.00 \mathrm{E}+00$ & 0 & $0.00 \mathrm{E}+00$ & 0 & $0.00 \mathrm{E}+00$ & 0 & $0.00 \mathrm{E}+00$ & 0 & $0.00 \mathrm{E}+00$ & 0 & $0.00 \mathrm{E}+00$ & 0 \\
\hline 38 & $0.00 \mathrm{E}+00$ & 0 & $0.00 \mathrm{E}+00$ & 0 & $0.00 E+00$ & 0 & $0.00 \mathrm{E}+00$ & 0 & $0.00 \mathrm{E}+00$ & 0 & $0.00 E+00$ & 0 & $0.00 \mathrm{E}+00$ & 0 & $0.00 \mathrm{E}+00$ & 0 \\
\hline & $0.00 \mathrm{E}+00$ & 0 & $0.00 E+00$ & 0 & $0.00 \mathrm{E}+00$ & 0 & $0.00 \mathrm{E}+00$ & 0 & $0.00 \mathrm{E}+00$ & 0 & $0.00 \mathrm{E}+00$ & 0 & $0.00 \mathrm{E}+00$ & 0 & $0.00 \mathrm{E}+00$ & 0 \\
\hline
\end{tabular}

Total Dose Contributions TDOSE(i,p,t) for Individual Radionuclides (i) and Pathways (p) in mrem/yr and as a Percentage of Total Dose at $t=50$ years

Directly from primary contamination and from release to atmosphere (Inhalation excludes radon)

\begin{tabular}{|c|c|c|c|c|c|c|c|c|c|c|c|c|c|c|c|c|}
\hline & \multicolumn{2}{|c|}{ Ground } & \multicolumn{2}{|c|}{ Inhalation } & \multicolumn{2}{|c|}{ Radon } & \multicolumn{2}{|c|}{ Plant } & \multicolumn{2}{|l|}{ Meat } & \multicolumn{2}{|l|}{ Milk } & \multicolumn{2}{|l|}{ Soil } & \multicolumn{2}{|c|}{ All Pathways* } \\
\hline clide & Dose & $\%$ & Dose & \% & Dose & $\%$ & Dose & 음 & Dose & $\%$ & Dose & 음 & Dose & $\%$ & Dose & $\%$ \\
\hline-241 & $5.22 \mathrm{E}-22$ & 0 & $0.00 \mathrm{E}+00$ & 0 & $0.00 \mathrm{E}+00$ & 0 & $0.00 \mathrm{E}+00$ & 0 & $0.00 \mathrm{E}+00$ & 0 & $0.00 \mathrm{E}+00$ & 0 & $0.00 \mathrm{E}+00$ & 0 & 5. $22 \mathrm{E}-22$ & 0 \\
\hline-137 & $6.74 E-16$ & 0 & $0.00 E+00$ & 0 & $0.00 E+00$ & 0 & $0.00 \mathrm{E}+00$ & 0 & $0.00 \mathrm{E}+00$ & 0 & $0.00 E+00$ & 0 & $0.00 \mathrm{E}+00$ & 0 & $6.74 \mathrm{E}-16$ & 0 \\
\hline-237 & $5.22 E-18$ & 0 & $0.00 \mathrm{E}+00$ & 0 & $0.00 E+00$ & 0 & $0.00 \mathrm{E}+00$ & 0 & $0.00 \mathrm{E}+00$ & 0 & $0.00 E+00$ & 0 & $0.00 \mathrm{E}+00$ & 0 & $5.22 \mathrm{E}-18$ & 0 \\
\hline-238 & 1. $21 E-21$ & 0 & $0.00 \mathrm{E}+00$ & 0 & $0.00 \mathrm{E}+00$ & 0 & $0.00 \mathrm{E}+00$ & 0 & $0.00 \mathrm{E}+00$ & 0 & $0.00 \mathrm{E}+00$ & 0 & $0.00 \mathrm{E}+00$ & 0 & 1. $21 \mathrm{E}-21$ & 0 \\
\hline-239 & 4. $55 \mathrm{E}-22$ & 0 & $0.00 \mathrm{E}+00$ & 0 & $0.00 \mathrm{E}+00$ & 0 & $0.00 \mathrm{E}+00$ & 0 & $0.00 \mathrm{E}+00$ & 0 & $0.00 \mathrm{E}+00$ & 0 & $0.00 \mathrm{E}+00$ & 0 & $4.55 E-22$ & 0 \\
\hline-240 & $5.72 E-26$ & 0 & $0.00 \mathrm{E}+00$ & 0 & $0.00 \mathrm{E}+00$ & 0 & $0.00 \mathrm{E}+00$ & 0 & $0.00 \mathrm{E}+00$ & 0 & $0.00 E+00$ & 0 & $0.00 \mathrm{E}+00$ & 0 & $5.72 \mathrm{E}-26$ & 0 \\
\hline-99 & $1.82 E-32$ & 0 & $0.00 \mathrm{E}+00$ & 0 & $0.00 \mathrm{E}+00$ & 0 & $0.00 \mathrm{E}+00$ & 0 & $0.00 \mathrm{E}+00$ & 0 & $0.00 E+00$ & 0 & $0.00 \mathrm{E}+00$ & 0 & 1. $82 \mathrm{E}-32$ & 0 \\
\hline-228 & $1.11 \mathrm{E}-20$ & 0 & $0.00 \mathrm{E}+00$ & 0 & $0.00 \mathrm{E}+00$ & 0 & $0.00 \mathrm{E}+00$ & 0 & $0.00 \mathrm{E}+00$ & 0 & $0.00 \mathrm{E}+00$ & 0 & $0.00 \mathrm{E}+00$ & 0 & 1. $11 \mathrm{E}-20$ & 0 \\
\hline-230 & $3.77 E-14$ & 7 & $0.00 E+00$ & 0 & $0.00 \mathrm{E}+00$ & 0 & $0.00 \mathrm{E}+00$ & 0 & $0.00 \mathrm{E}+00$ & 0 & $0.00 E+00$ & 0 & $0.00 \mathrm{E}+00$ & 0 & $3.77 E-14$ & 7 \\
\hline-232 & $5.04 E-13$ & 92 & $0.00 \mathrm{E}+00$ & 0 & $0.00 E+00$ & 0 & $0.00 \mathrm{E}+00$ & 0 & $0.00 \mathrm{E}+00$ & 0 & $0.00 E+00$ & 0 & $0.00 \mathrm{E}+00$ & 0 & $5.04 \mathrm{E}-13$ & 92 \\
\hline 34 & 1. $29 \mathrm{E}-16$ & 0 & $0.00 \mathrm{E}+00$ & 0 & $0.00 \mathrm{E}+00$ & 0 & $0.00 \mathrm{E}+00$ & 0 & $0.00 \mathrm{E}+00$ & 0 & $0.00 \mathrm{E}+00$ & 0 & $0.00 \mathrm{E}+00$ & 0 & 1. $29 \mathrm{E}-16$ & 0 \\
\hline 35 & 4. $42 \mathrm{E}-19$ & 0 & $0.00 \mathrm{E}+00$ & 0 & $0.00 \mathrm{E}+00$ & 0 & $0.00 \mathrm{E}+00$ & 0 & $0.00 \mathrm{E}+00$ & 0 & $0.00 \mathrm{E}+00$ & 0 & $0.00 \mathrm{E}+00$ & 0 & $4.42 \mathrm{E}-19$ & 0 \\
\hline 38 & $3.98 E-15$ & 1 & $0.00 \mathrm{E}+00$ & 0 & $0.00 \mathrm{E}+00$ & 0 & $0.00 \mathrm{E}+00$ & 0 & $0.00 \mathrm{E}+00$ & 0 & $0.00 E+00$ & 0 & $0.00 \mathrm{E}+00$ & 0 & $3.98 E-15$ & 1 \\
\hline & $5.47 E-13$ & 100 & $0.00 \mathrm{E}+00$ & 0 & $0.00 \mathrm{E}+00$ & 0 & $0.00 \mathrm{E}+00$ & 0 & $0.00 \mathrm{E}+00$ & 0 & $0.00 \mathrm{E}+00$ & 0 & $0.00 \mathrm{E}+00$ & 0 & $5.47 \mathrm{E}-13$ & 100 \\
\hline
\end{tabular}

* Sum of dose from all releases and from primary contamination. 
RESRAD-OFFSITE, Version 2 .

Parent Dose Report

Title : Offsite Resident Farmer Deterministic Run

File : RF SG FWD-FINAL V2.ROF

Total Dose Contributions TDOSE (i,p,t) for Individual Radionuclides (i) and Pathways (p) in mrem/yr and as a Percentage of Total Dose at $t=100$ years

From releases to ground water and to surface water

\begin{tabular}{|c|c|c|c|c|c|c|c|c|c|c|c|c|c|c|c|c|}
\hline & \multicolumn{2}{|c|}{ Ground } & \multicolumn{2}{|l|}{ Fish } & \multicolumn{2}{|c|}{ Radon } & \multicolumn{2}{|c|}{ Plant } & \multicolumn{2}{|l|}{ Meat } & \multicolumn{2}{|l|}{ Milk } & \multicolumn{2}{|l|}{ Soil } & \multicolumn{2}{|c|}{ Water } \\
\hline ide & Dose & $\%$ & Dose & $\%$ & Dose & 응 & Dose & $\frac{\circ}{0}$ & Dose & 응 & Dose & 응 & Dose & $\%$ & Dose & $\%$ \\
\hline-241 & $0.00 \mathrm{E}+00$ & 0 & $0.00 E+00$ & 0 & $0.00 \mathrm{E}+00$ & 0 & $0.00 \mathrm{E}+00$ & 0 & $0.00 \mathrm{E}+00$ & 0 & $0.00 \mathrm{E}+00$ & 0 & $0.00 \mathrm{E}+00$ & 0 & $0.00 \mathrm{E}+00$ & 0 \\
\hline-137 & $0.00 \mathrm{E}+00$ & 0 & $0.00 \mathrm{E}+00$ & 0 & $0.00 \mathrm{E}+00$ & 0 & $0.00 \mathrm{E}+00$ & 0 & $0.00 \mathrm{E}+00$ & 0 & $0.00 \mathrm{E}+00$ & 0 & $0.00 \mathrm{E}+00$ & 0 & $0.00 \mathrm{E}+00$ & 0 \\
\hline-237 & $0.00 \mathrm{E}+00$ & 0 & $0.00 \mathrm{E}+00$ & 0 & $0.00 \mathrm{E}+00$ & 0 & $0.00 \mathrm{E}+00$ & 0 & $0.00 \mathrm{E}+00$ & 0 & $0.00 \mathrm{E}+00$ & 0 & $0.00 \mathrm{E}+00$ & 0 & $0.00 \mathrm{E}+00$ & 0 \\
\hline-238 & $0.00 \mathrm{E}+00$ & 0 & $0.00 \mathrm{E}+00$ & 0 & $0.00 E+00$ & 0 & $0.00 \mathrm{E}+00$ & 0 & $0.00 \mathrm{E}+00$ & 0 & $0.00 E+00$ & 0 & $0.00 \mathrm{E}+00$ & 0 & $0.00 \mathrm{E}+00$ & 0 \\
\hline-239 & $0.00 \mathrm{E}+00$ & 0 & $0.00 \mathrm{E}+00$ & 0 & $0.00 \mathrm{E}+00$ & 0 & $0.00 \mathrm{E}+00$ & 0 & $0.00 \mathrm{E}+00$ & 0 & $0.00 \mathrm{E}+00$ & 0 & $0.00 \mathrm{E}+00$ & 0 & $0.00 \mathrm{E}+00$ & 0 \\
\hline-240 & $0.00 \mathrm{E}+00$ & 0 & $0.00 \mathrm{E}+00$ & 0 & $0.00 \mathrm{E}+00$ & 0 & $0.00 \mathrm{E}+00$ & 0 & $0.00 \mathrm{E}+00$ & 0 & $0.00 \mathrm{E}+00$ & 0 & $0.00 \mathrm{E}+00$ & 0 & $0.00 \mathrm{E}+00$ & 0 \\
\hline-99 & $0.00 \mathrm{E}+00$ & 0 & $0.00 \mathrm{E}+00$ & 0 & $0.00 \mathrm{E}+00$ & 0 & $0.00 \mathrm{E}+00$ & 0 & $0.00 \mathrm{E}+00$ & 0 & $0.00 E+00$ & 0 & $0.00 \mathrm{E}+00$ & 0 & $0.00 \mathrm{E}+00$ & 0 \\
\hline-228 & $0.00 \mathrm{E}+00$ & 0 & $0.00 \mathrm{E}+00$ & 0 & $0.00 \mathrm{E}+00$ & 0 & $0.00 \mathrm{E}+00$ & 0 & $0.00 \mathrm{E}+00$ & 0 & $0.00 \mathrm{E}+00$ & 0 & $0.00 \mathrm{E}+00$ & 0 & $0.00 \mathrm{E}+00$ & 0 \\
\hline-230 & $0.00 \mathrm{E}+00$ & 0 & $0.00 \mathrm{E}+00$ & 0 & $0.00 \mathrm{E}+00$ & 0 & $0.00 \mathrm{E}+00$ & 0 & $0.00 \mathrm{E}+00$ & 0 & $0.00 \mathrm{E}+00$ & 0 & $0.00 \mathrm{E}+00$ & 0 & $0.00 \mathrm{E}+00$ & 0 \\
\hline-232 & $0.00 \mathrm{E}+00$ & 0 & $0.00 \mathrm{E}+00$ & 0 & $0.00 \mathrm{E}+00$ & 0 & $0.00 \mathrm{E}+00$ & 0 & $0.00 \mathrm{E}+00$ & 0 & $0.00 \mathrm{E}+00$ & 0 & $0.00 \mathrm{E}+00$ & 0 & $0.00 \mathrm{E}+00$ & 0 \\
\hline 34 & $0.00 \mathrm{E}+00$ & 0 & $0.00 \mathrm{E}+00$ & 0 & $0.00 \mathrm{E}+00$ & 0 & $0.00 \mathrm{E}+00$ & 0 & $0.00 \mathrm{E}+00$ & 0 & $0.00 \mathrm{E}+00$ & 0 & $0.00 \mathrm{E}+00$ & 0 & $0.00 \mathrm{E}+00$ & 0 \\
\hline 35 & $0.00 \mathrm{E}+00$ & 0 & $0.00 \mathrm{E}+00$ & 0 & $0.00 \mathrm{E}+00$ & 0 & $0.00 \mathrm{E}+00$ & 0 & $0.00 \mathrm{E}+00$ & 0 & $0.00 \mathrm{E}+00$ & 0 & $0.00 \mathrm{E}+00$ & 0 & $0.00 \mathrm{E}+00$ & 0 \\
\hline 38 & $0.00 \mathrm{E}+00$ & 0 & $0.00 \mathrm{E}+00$ & 0 & $0.00 E+00$ & 0 & $0.00 \mathrm{E}+00$ & 0 & $0.00 \mathrm{E}+00$ & 0 & $0.00 E+00$ & 0 & $0.00 \mathrm{E}+00$ & 0 & $0.00 \mathrm{E}+00$ & 0 \\
\hline & $0.00 \mathrm{E}+00$ & 0 & $0.00 E+00$ & 0 & $0.00 \mathrm{E}+00$ & 0 & $0.00 \mathrm{E}+00$ & 0 & $0.00 \mathrm{E}+00$ & 0 & $0.00 \mathrm{E}+00$ & 0 & $0.00 \mathrm{E}+00$ & 0 & $0.00 \mathrm{E}+00$ & 0 \\
\hline
\end{tabular}

Total Dose Contributions TDOSE(i,p,t) for Individual Radionuclides (i) and Pathways (p) in mrem/yr and as a Percentage of Total Dose at $t=100$ years

Directly from primary contamination and from release to atmosphere (Inhalation excludes radon)

\begin{tabular}{|c|c|c|c|c|c|c|c|c|c|c|c|c|c|c|c|c|}
\hline & \multicolumn{2}{|c|}{ Ground } & \multicolumn{2}{|c|}{ Inhalation } & \multicolumn{2}{|c|}{ Radon } & \multicolumn{2}{|c|}{ Plant } & \multicolumn{2}{|l|}{ Meat } & \multicolumn{2}{|l|}{ Milk } & \multicolumn{2}{|l|}{ Soil } & \multicolumn{2}{|c|}{ All Pathways* } \\
\hline clide & Dose & $\%$ & Dose & $\%$ & Dose & $\%$ & Dose & 음 & Dose & $\%$ & Dose & \% & Dose & $\%$ & Dose & \% \\
\hline-241 & 1. $64 \mathrm{E}-21$ & 0 & $0.00 \mathrm{E}+00$ & 0 & $0.00 \mathrm{E}+00$ & 0 & $0.00 E+00$ & 0 & $0.00 \mathrm{E}+00$ & 0 & $0.00 \mathrm{E}+00$ & 0 & $0.00 E+00$ & 0 & $1.64 \mathrm{E}-21$ & 0 \\
\hline-137 & $3.13 E-16$ & 0 & $0.00 E+00$ & 0 & $0.00 \mathrm{E}+00$ & 0 & $0.00 \mathrm{E}+00$ & 0 & $0.00 E+00$ & 0 & $0.00 \mathrm{E}+00$ & 0 & $0.00 \mathrm{E}+00$ & 0 & $3.13 E-16$ & 0 \\
\hline-237 & $8.58 E-18$ & 0 & $0.00 \mathrm{E}+00$ & 0 & $0.00 \mathrm{E}+00$ & 0 & $0.00 \mathrm{E}+00$ & 0 & $0.00 E+00$ & 0 & $0.00 \mathrm{E}+00$ & 0 & $0.00 \mathrm{E}+00$ & 0 & $8.58 E-18$ & 0 \\
\hline-238 & $1.19 \mathrm{E}-20$ & 0 & $0.00 \mathrm{E}+00$ & 0 & $0.00 \mathrm{E}+00$ & 0 & $0.00 \mathrm{E}+00$ & 0 & $0.00 \mathrm{E}+00$ & 0 & $0.00 \mathrm{E}+00$ & 0 & $0.00 \mathrm{E}+00$ & 0 & $1.19 \mathrm{E}-20$ & 0 \\
\hline-239 & $7.88 \mathrm{E}-22$ & 0 & $0.00 \mathrm{E}+00$ & 0 & $0.00 \mathrm{E}+00$ & 0 & $0.00 \mathrm{E}+00$ & 0 & $0.00 \mathrm{E}+00$ & 0 & $0.00 \mathrm{E}+00$ & 0 & $0.00 \mathrm{E}+00$ & 0 & $7.88 E-22$ & 0 \\
\hline-240 & $3.71 \mathrm{E}-25$ & 0 & $0.00 \mathrm{E}+00$ & 0 & $0.00 \mathrm{E}+00$ & 0 & $0.00 \mathrm{E}+00$ & 0 & $0.00 \mathrm{E}+00$ & 0 & $0.00 \mathrm{E}+00$ & 0 & $0.00 \mathrm{E}+00$ & 0 & $3.71 \mathrm{E}-25$ & 0 \\
\hline-99 & $3.38 E-32$ & 0 & $0.00 \mathrm{E}+00$ & 0 & $0.00 \mathrm{E}+00$ & 0 & $0.00 \mathrm{E}+00$ & 0 & $0.00 \mathrm{E}+00$ & 0 & $0.00 \mathrm{E}+00$ & 0 & $0.00 \mathrm{E}+00$ & 0 & $3 \cdot 38 E-32$ & 0 \\
\hline-228 & 1. $98 \mathrm{E}-28$ & 0 & $0.00 \mathrm{E}+00$ & 0 & $0.00 \mathrm{E}+00$ & 0 & $0.00 \mathrm{E}+00$ & 0 & $0.00 \mathrm{E}+00$ & 0 & $0.00 \mathrm{E}+00$ & 0 & $0.00 \mathrm{E}+00$ & 0 & $1.98 \mathrm{E}-28$ & 0 \\
\hline-230 & $1.02 \mathrm{E}-13$ & 13 & $0.00 \mathrm{E}+00$ & 0 & $0.00 \mathrm{E}+00$ & 0 & $0.00 \mathrm{E}+00$ & 0 & $0.00 \mathrm{E}+00$ & 0 & $0.00 \mathrm{E}+00$ & 0 & $0.00 \mathrm{E}+00$ & 0 & $1.02 \mathrm{E}-13$ & 13 \\
\hline-232 & $6.66 \mathrm{E}-13$ & 86 & $0.00 \mathrm{E}+00$ & 0 & $0.00 \mathrm{E}+00$ & 0 & $0.00 \mathrm{E}+00$ & 0 & $0.00 E+00$ & 0 & $0.00 \mathrm{E}+00$ & 0 & $0.00 \mathrm{E}+00$ & 0 & $6.66 \mathrm{E}-13$ & 86 \\
\hline 234 & $6.96 \mathrm{E}-16$ & 0 & $0.00 \mathrm{E}+00$ & 0 & $0.00 \mathrm{E}+00$ & 0 & $0.00 \mathrm{E}+00$ & 0 & $0.00 \mathrm{E}+00$ & 0 & $0.00 \mathrm{E}+00$ & 0 & $0.00 \mathrm{E}+00$ & 0 & $6.96 \mathrm{E}-16$ & 0 \\
\hline 35 & $1.57 \mathrm{E}-18$ & 0 & $0.00 \mathrm{E}+00$ & 0 & $0.00 \mathrm{E}+00$ & 0 & $0.00 \mathrm{E}+00$ & 0 & $0.00 \mathrm{E}+00$ & 0 & $0.00 \mathrm{E}+00$ & 0 & $0.00 \mathrm{E}+00$ & 0 & $1.57 \mathrm{E}-18$ & 0 \\
\hline 38 & $5.75 E-15$ & 1 & $0.00 \mathrm{E}+00$ & 0 & $0.00 \mathrm{E}+00$ & 0 & $0.00 \mathrm{E}+00$ & 0 & $0.00 E+00$ & 0 & $0.00 \mathrm{E}+00$ & 0 & $0.00 \mathrm{E}+00$ & 0 & $5.75 E-15$ & 1 \\
\hline & $7.75 \mathrm{E}-13$ & 100 & $0.00 \mathrm{E}+00$ & 0 & $0.00 \mathrm{E}+00$ & 0 & $0.00 \mathrm{E}+00$ & 0 & $0.00 \mathrm{E}+00$ & 0 & $0.00 \mathrm{E}+00$ & 0 & $0.00 \mathrm{E}+00$ & 0 & $7.75 \mathrm{E}-13$ & 100 \\
\hline
\end{tabular}

* Sum of dose from all releases and from primary contamination. 
RESRAD-OFFSITE, Version 2 .

Parent Dose Report

Title : Offsite Resident Farmer Deterministic Run

File : RF SG FWD-FINAL V2.ROF

Total Dose Contributions TDOSE (i,p,t) for Individual Radionuclides (i) and Pathways (p) in mrem/yr and as a Percentage of Total Dose at $t=500$ years

From releases to ground water and to surface water

\begin{tabular}{|c|c|c|c|c|c|c|c|c|c|c|c|c|c|c|c|c|}
\hline & \multicolumn{2}{|c|}{ Ground } & \multicolumn{2}{|l|}{ Fish } & \multicolumn{2}{|c|}{ Radon } & \multicolumn{2}{|c|}{ Plant } & \multicolumn{2}{|l|}{ Meat } & \multicolumn{2}{|l|}{ Milk } & \multicolumn{2}{|l|}{ Soil } & \multicolumn{2}{|c|}{ Water } \\
\hline clide & Dose & \% & Dose & $\%$ & Dose & \% & Dose & \% & Dose & \% & Dose & \% & Dose & \% & Dose & $\%$ \\
\hline-241 & $0.00 \mathrm{E}+00$ & 0 & $0.00 \mathrm{E}+00$ & 0 & $0.00 \mathrm{E}+00$ & 0 & $0.00 \mathrm{E}+00$ & 0 & $0.00 E+00$ & 0 & $0.00 \mathrm{E}+00$ & 0 & $0.00 \mathrm{E}+00$ & 0 & $0.00 \mathrm{E}+00$ & 0 \\
\hline-137 & $0.00 \mathrm{E}+00$ & 0 & $0.00 \mathrm{E}+00$ & 0 & $0.00 \mathrm{E}+00$ & 0 & $0.00 \mathrm{E}+00$ & 0 & $0.00 \mathrm{E}+00$ & 0 & $0.00 \mathrm{E}+00$ & 0 & $0.00 \mathrm{E}+00$ & 0 & $0.00 \mathrm{E}+00$ & 0 \\
\hline-237 & $0.00 \mathrm{E}+00$ & 0 & $0.00 \mathrm{E}+00$ & 0 & $0.00 \mathrm{E}+00$ & 0 & $0.00 \mathrm{E}+00$ & 0 & $0.00 \mathrm{E}+00$ & 0 & $0.00 \mathrm{E}+00$ & 0 & $0.00 \mathrm{E}+00$ & 0 & $0.00 \mathrm{E}+00$ & 0 \\
\hline-238 & $0.00 \mathrm{E}+00$ & 0 & $0.00 \mathrm{E}+00$ & 0 & $0.00 \mathrm{E}+00$ & 0 & $0.00 \mathrm{E}+00$ & 0 & $0.00 E+00$ & 0 & $0.00 \mathrm{E}+00$ & 0 & $0.00 \mathrm{E}+00$ & 0 & $0.00 \mathrm{E}+00$ & 0 \\
\hline-239 & $0.00 \mathrm{E}+00$ & 0 & $0.00 \mathrm{E}+00$ & 0 & $0.00 \mathrm{E}+00$ & 0 & $0.00 \mathrm{E}+00$ & 0 & $0.00 \mathrm{E}+00$ & 0 & $0.00 E+00$ & 0 & $0.00 \mathrm{E}+00$ & 0 & $0.00 \mathrm{E}+00$ & 0 \\
\hline-240 & $0.00 \mathrm{E}+00$ & 0 & $0.00 \mathrm{E}+00$ & 0 & $0.00 \mathrm{E}+00$ & 0 & $0.00 \mathrm{E}+00$ & 0 & $0.00 \mathrm{E}+00$ & 0 & $0.00 \mathrm{E}+00$ & 0 & $0.00 \mathrm{E}+00$ & 0 & $0.00 \mathrm{E}+00$ & 0 \\
\hline-99 & $4.87 \mathrm{E}-07$ & 0 & $0.00 \mathrm{E}+00$ & 0 & $0.00 \mathrm{E}+00$ & 0 & $1.34 \mathrm{E}-01$ & 25 & $4.01 E-04$ & 0 & $3.54 \mathrm{E}-02$ & 7 & $4.11 \mathrm{E}-07$ & 0 & $3.64 \mathrm{E}-01$ & 68 \\
\hline-228 & $0.00 \mathrm{E}+00$ & 0 & $0.00 \mathrm{E}+00$ & 0 & $0.00 \mathrm{E}+00$ & 0 & $0.00 \mathrm{E}+00$ & 0 & $0.00 \mathrm{E}+00$ & 0 & $0.00 \mathrm{E}+00$ & 0 & $0.00 \mathrm{E}+00$ & 0 & $0.00 \mathrm{E}+00$ & 0 \\
\hline-230 & $0.00 \mathrm{E}+00$ & 0 & $0.00 \mathrm{E}+00$ & 0 & $0.00 \mathrm{E}+00$ & 0 & $0.00 \mathrm{E}+00$ & 0 & $0.00 \mathrm{E}+00$ & 0 & $0.00 \mathrm{E}+00$ & 0 & $0.00 \mathrm{E}+00$ & 0 & $0.00 \mathrm{E}+00$ & 0 \\
\hline-232 & $0.00 \mathrm{E}+00$ & 0 & $0.00 \mathrm{E}+00$ & 0 & $0.00 \mathrm{E}+00$ & 0 & $0.00 \mathrm{E}+00$ & 0 & $0.00 \mathrm{E}+00$ & 0 & $0.00 \mathrm{E}+00$ & 0 & $0.00 \mathrm{E}+00$ & 0 & $0.00 \mathrm{E}+00$ & 0 \\
\hline 234 & $0.00 \mathrm{E}+00$ & 0 & $0.00 \mathrm{E}+00$ & 0 & $0.00 \mathrm{E}+00$ & 0 & $0.00 \mathrm{E}+00$ & 0 & $0.00 \mathrm{E}+00$ & 0 & $0.00 \mathrm{E}+00$ & 0 & $0.00 \mathrm{E}+00$ & 0 & $0.00 \mathrm{E}+00$ & 0 \\
\hline 235 & $0.00 \mathrm{E}+00$ & 0 & $0.00 \mathrm{E}+00$ & 0 & $0.00 \mathrm{E}+00$ & 0 & $0.00 \mathrm{E}+00$ & 0 & $0.00 \mathrm{E}+00$ & 0 & $0.00 E+00$ & 0 & $0.00 \mathrm{E}+00$ & 0 & $0.00 \mathrm{E}+00$ & 0 \\
\hline 38 & $0.00 \mathrm{E}+00$ & 0 & $0.00 \mathrm{E}+00$ & 0 & $0.00 \mathrm{E}+00$ & 0 & $0.00 \mathrm{E}+00$ & 0 & $0.00 \mathrm{E}+00$ & 0 & $0.00 \mathrm{E}+00$ & 0 & $0.00 \mathrm{E}+00$ & 0 & $0.00 \mathrm{E}+00$ & 0 \\
\hline & $4.87 \mathrm{E}-07$ & 0 & $0.00 \mathrm{E}+00$ & 0 & $0.00 \mathrm{E}+00$ & 0 & 1. $34 \mathrm{E}-01$ & 25 & $4.01 \mathrm{E}-04$ & 0 & $3.54 \mathrm{E}-02$ & 7 & $4.11 \mathrm{E}-07$ & 0 & $3.64 \mathrm{E}-01$ & 68 \\
\hline
\end{tabular}

Total Dose Contributions TDOSE(i,p,t) for Individual Radionuclides (i) and Pathways (p) in mrem/yr and as a Percentage of Total Dose at $t=500$ years

Directly from primary contamination and from release to atmosphere (Inhalation excludes radon)

\begin{tabular}{|c|c|c|c|c|c|c|c|c|c|c|c|c|c|c|c|c|}
\hline & \multicolumn{2}{|c|}{ Ground } & \multicolumn{2}{|c|}{ Inhalation } & \multicolumn{2}{|c|}{ Radon } & \multicolumn{2}{|c|}{ Plant } & \multicolumn{2}{|l|}{ Meat } & \multicolumn{2}{|l|}{ Milk } & \multicolumn{2}{|l|}{ Soil } & \multicolumn{2}{|c|}{ All Pathways* } \\
\hline clide & Dose & $\%$ & Dose & $\%$ & Dose & $\%$ & Dose & 음 & Dose & $\%$ & Dose & 음 & Dose & $\%$ & Dose & $\%$ \\
\hline-241 & $3.23 E-19$ & 0 & $0.00 \mathrm{E}+00$ & 0 & $0.00 \mathrm{E}+00$ & 0 & $0.00 \mathrm{E}+00$ & 0 & $0.00 \mathrm{E}+00$ & 0 & $0.00 \mathrm{E}+00$ & 0 & $0.00 \mathrm{E}+00$ & 0 & 3. $23 E-19$ & 0 \\
\hline-137 & $6.73 E-19$ & 0 & $0.00 E+00$ & 0 & $0.00 E+00$ & 0 & $0.00 \mathrm{E}+00$ & 0 & $0.00 \mathrm{E}+00$ & 0 & $0.00 E+00$ & 0 & $0.00 \mathrm{E}+00$ & 0 & $6.73 E-19$ & 0 \\
\hline-237 & $4.59 E-16$ & 0 & $0.00 E+00$ & 0 & $0.00 E+00$ & 0 & $0.00 \mathrm{E}+00$ & 0 & $0.00 \mathrm{E}+00$ & 0 & $0.00 E+00$ & 0 & $0.00 \mathrm{E}+00$ & 0 & $4.59 \mathrm{E}-16$ & 0 \\
\hline-238 & $1.01 \mathrm{E}-17$ & 0 & $0.00 E+00$ & 0 & $0.00 \mathrm{E}+00$ & 0 & $0.00 \mathrm{E}+00$ & 0 & $0.00 \mathrm{E}+00$ & 0 & $0.00 \mathrm{E}+00$ & 0 & $0.00 \mathrm{E}+00$ & 0 & $1.01 \mathrm{E}-17$ & 0 \\
\hline-239 & $6.42 \mathrm{E}-20$ & 0 & $0.00 \mathrm{E}+00$ & 0 & $0.00 \mathrm{E}+00$ & 0 & $0.00 \mathrm{E}+00$ & 0 & $0.00 \mathrm{E}+00$ & 0 & $0.00 \mathrm{E}+00$ & 0 & $0.00 \mathrm{E}+00$ & 0 & $6.42 \mathrm{E}-20$ & 0 \\
\hline-240 & $9.86 \mathrm{E}-23$ & 0 & $0.00 \mathrm{E}+00$ & 0 & $0.00 \mathrm{E}+00$ & 0 & $0.00 \mathrm{E}+00$ & 0 & $0.00 \mathrm{E}+00$ & 0 & $0.00 \mathrm{E}+00$ & 0 & $0.00 \mathrm{E}+00$ & 0 & $9.86 \mathrm{E}-23$ & 0 \\
\hline-99 & $4.82 E-30$ & 0 & $0.00 E+00$ & 0 & $0.00 \mathrm{E}+00$ & 0 & $0.00 \mathrm{E}+00$ & 0 & $0.00 \mathrm{E}+00$ & 0 & $0.00 E+00$ & 0 & $0.00 \mathrm{E}+00$ & 0 & $5.34 \mathrm{E}-01$ & 100 \\
\hline-228 & $0.00 \mathrm{E}+00$ & 0 & $0.00 \mathrm{E}+00$ & 0 & $0.00 \mathrm{E}+00$ & 0 & $0.00 \mathrm{E}+00$ & 0 & $0.00 \mathrm{E}+00$ & 0 & $0.00 \mathrm{E}+00$ & 0 & $0.00 \mathrm{E}+00$ & 0 & $0.00 \mathrm{E}+00$ & 0 \\
\hline-230 & $5.94 E-12$ & 0 & $0.00 E+00$ & 0 & $0.00 \mathrm{E}+00$ & 0 & $0.00 \mathrm{E}+00$ & 0 & $0.00 \mathrm{E}+00$ & 0 & $0.00 E+00$ & 0 & $0.00 \mathrm{E}+00$ & 0 & $5.94 \mathrm{E}-12$ & 0 \\
\hline-232 & $6.07 E-12$ & 0 & $0.00 E+00$ & 0 & $0.00 E+00$ & 0 & $0.00 \mathrm{E}+00$ & 0 & $0.00 \mathrm{E}+00$ & 0 & $0.00 E+00$ & 0 & $0.00 \mathrm{E}+00$ & 0 & $6.07 E-12$ & 0 \\
\hline 34 & $2.08 E-13$ & 0 & $0.00 \mathrm{E}+00$ & 0 & $0.00 \mathrm{E}+00$ & 0 & $0.00 \mathrm{E}+00$ & 0 & $0.00 \mathrm{E}+00$ & 0 & $0.00 \mathrm{E}+00$ & 0 & $0.00 \mathrm{E}+00$ & 0 & $2.08 E-13$ & 0 \\
\hline 35 & $2.45 \mathrm{E}-16$ & 0 & $0.00 \mathrm{E}+00$ & 0 & $0.00 \mathrm{E}+00$ & 0 & $0.00 \mathrm{E}+00$ & 0 & $0.00 \mathrm{E}+00$ & 0 & $0.00 \mathrm{E}+00$ & 0 & $0.00 \mathrm{E}+00$ & 0 & $2.45 E-16$ & 0 \\
\hline 38 & 1. $09 \mathrm{E}-13$ & 0 & $0.00 E+00$ & 0 & $0.00 \mathrm{E}+00$ & 0 & $0.00 \mathrm{E}+00$ & 0 & $0.00 \mathrm{E}+00$ & 0 & $0.00 E+00$ & 0 & $0.00 \mathrm{E}+00$ & 0 & 1. $09 \mathrm{E}-13$ & 0 \\
\hline & $1.23 \mathrm{E}-11$ & 0 & $0.00 \mathrm{E}+00$ & 0 & $0.00 \mathrm{E}+00$ & 0 & $0.00 \mathrm{E}+00$ & 0 & $0.00 \mathrm{E}+00$ & 0 & $0.00 \mathrm{E}+00$ & 0 & $0.00 \mathrm{E}+00$ & 0 & $5.34 \mathrm{E}-01$ & 100 \\
\hline
\end{tabular}

* Sum of dose from all releases and from primary contamination. 
RESRAD-OFFSITE, Version 2 .

Parent Dose Report

Title : Offsite Resident Farmer Deterministic Run

File : RF SG FWD-FINAL V2.ROF

Total Dose Contributions TDOSE (i,p,t) for Individual Radionuclides (i) and Pathways (p) in mrem/yr and as a Percentage of Total Dose at $t=1026$ years

From releases to ground water and to surface water

\begin{tabular}{|c|c|c|c|c|c|c|c|c|c|c|c|c|c|c|c|c|}
\hline & \multicolumn{2}{|c|}{ Ground } & \multicolumn{2}{|l|}{ Fish } & \multicolumn{2}{|c|}{ Radon } & \multicolumn{2}{|c|}{ Plant } & \multicolumn{2}{|l|}{ Meat } & \multicolumn{2}{|l|}{ Milk } & \multicolumn{2}{|l|}{ Soil } & \multicolumn{2}{|c|}{ Water } \\
\hline clide & Dose & \% & Dose & $\%$ & Dose & \% & Dose & \% & Dose & \% & Dose & \% & Dose & \% & Dose & $\%$ \\
\hline-241 & $0.00 \mathrm{E}+00$ & 0 & $0.00 \mathrm{E}+00$ & 0 & $0.00 \mathrm{E}+00$ & 0 & $0.00 \mathrm{E}+00$ & 0 & $0.00 E+00$ & 0 & $0.00 \mathrm{E}+00$ & 0 & $0.00 \mathrm{E}+00$ & 0 & $0.00 \mathrm{E}+00$ & 0 \\
\hline-137 & $0.00 \mathrm{E}+00$ & 0 & $0.00 \mathrm{E}+00$ & 0 & $0.00 \mathrm{E}+00$ & 0 & $0.00 \mathrm{E}+00$ & 0 & $0.00 \mathrm{E}+00$ & 0 & $0.00 \mathrm{E}+00$ & 0 & $0.00 \mathrm{E}+00$ & 0 & $0.00 \mathrm{E}+00$ & 0 \\
\hline-237 & $0.00 \mathrm{E}+00$ & 0 & $0.00 \mathrm{E}+00$ & 0 & $0.00 \mathrm{E}+00$ & 0 & $0.00 \mathrm{E}+00$ & 0 & $0.00 \mathrm{E}+00$ & 0 & $0.00 \mathrm{E}+00$ & 0 & $0.00 \mathrm{E}+00$ & 0 & $0.00 \mathrm{E}+00$ & 0 \\
\hline-238 & $0.00 \mathrm{E}+00$ & 0 & $0.00 \mathrm{E}+00$ & 0 & $0.00 \mathrm{E}+00$ & 0 & $0.00 \mathrm{E}+00$ & 0 & $0.00 E+00$ & 0 & $0.00 \mathrm{E}+00$ & 0 & $0.00 \mathrm{E}+00$ & 0 & $0.00 \mathrm{E}+00$ & 0 \\
\hline-239 & $0.00 \mathrm{E}+00$ & 0 & $0.00 \mathrm{E}+00$ & 0 & $0.00 \mathrm{E}+00$ & 0 & $0.00 \mathrm{E}+00$ & 0 & $0.00 \mathrm{E}+00$ & 0 & $0.00 E+00$ & 0 & $0.00 \mathrm{E}+00$ & 0 & $0.00 \mathrm{E}+00$ & 0 \\
\hline-240 & $0.00 \mathrm{E}+00$ & 0 & $0.00 \mathrm{E}+00$ & 0 & $0.00 \mathrm{E}+00$ & 0 & $0.00 \mathrm{E}+00$ & 0 & $0.00 \mathrm{E}+00$ & 0 & $0.00 \mathrm{E}+00$ & 0 & $0.00 \mathrm{E}+00$ & 0 & $0.00 \mathrm{E}+00$ & 0 \\
\hline-99 & $7.07 \mathrm{E}-07$ & 0 & $0.00 \mathrm{E}+00$ & 0 & $0.00 \mathrm{E}+00$ & 0 & $1.94 \mathrm{E}-01$ & 25 & $5.80 E-04$ & 0 & $5.13 E-02$ & 7 & $5.97 \mathrm{E}-07$ & 0 & $5.28 \mathrm{E}-01$ & 68 \\
\hline-228 & $0.00 \mathrm{E}+00$ & 0 & $0.00 \mathrm{E}+00$ & 0 & $0.00 \mathrm{E}+00$ & 0 & $0.00 \mathrm{E}+00$ & 0 & $0.00 \mathrm{E}+00$ & 0 & $0.00 \mathrm{E}+00$ & 0 & $0.00 \mathrm{E}+00$ & 0 & $0.00 \mathrm{E}+00$ & 0 \\
\hline-230 & $0.00 \mathrm{E}+00$ & 0 & $0.00 \mathrm{E}+00$ & 0 & $0.00 \mathrm{E}+00$ & 0 & $0.00 \mathrm{E}+00$ & 0 & $0.00 \mathrm{E}+00$ & 0 & $0.00 \mathrm{E}+00$ & 0 & $0.00 \mathrm{E}+00$ & 0 & $0.00 \mathrm{E}+00$ & 0 \\
\hline-232 & $0.00 \mathrm{E}+00$ & 0 & $0.00 \mathrm{E}+00$ & 0 & $0.00 \mathrm{E}+00$ & 0 & $0.00 \mathrm{E}+00$ & 0 & $0.00 \mathrm{E}+00$ & 0 & $0.00 \mathrm{E}+00$ & 0 & $0.00 \mathrm{E}+00$ & 0 & $0.00 \mathrm{E}+00$ & 0 \\
\hline 234 & $0.00 \mathrm{E}+00$ & 0 & $0.00 \mathrm{E}+00$ & 0 & $0.00 \mathrm{E}+00$ & 0 & $0.00 \mathrm{E}+00$ & 0 & $0.00 \mathrm{E}+00$ & 0 & $0.00 \mathrm{E}+00$ & 0 & $0.00 \mathrm{E}+00$ & 0 & $0.00 \mathrm{E}+00$ & 0 \\
\hline 235 & $0.00 \mathrm{E}+00$ & 0 & $0.00 \mathrm{E}+00$ & 0 & $0.00 \mathrm{E}+00$ & 0 & $0.00 \mathrm{E}+00$ & 0 & $0.00 \mathrm{E}+00$ & 0 & $0.00 E+00$ & 0 & $0.00 \mathrm{E}+00$ & 0 & $0.00 \mathrm{E}+00$ & 0 \\
\hline 38 & $0.00 \mathrm{E}+00$ & 0 & $0.00 \mathrm{E}+00$ & 0 & $0.00 \mathrm{E}+00$ & 0 & $0.00 \mathrm{E}+00$ & 0 & $0.00 \mathrm{E}+00$ & 0 & $0.00 \mathrm{E}+00$ & 0 & $0.00 \mathrm{E}+00$ & 0 & $0.00 \mathrm{E}+00$ & 0 \\
\hline & $7.07 \mathrm{E}-07$ & 0 & $0.00 \mathrm{E}+00$ & 0 & $0.00 \mathrm{E}+00$ & 0 & $1.94 \mathrm{E}-01$ & 25 & $5.80 \mathrm{E}-04$ & 0 & $5.13 \mathrm{E}-02$ & 7 & $5.97 \mathrm{E}-07$ & 0 & $5.28 \mathrm{E}-01$ & 68 \\
\hline
\end{tabular}

Total Dose Contributions TDOSE(i,p,t) for Individual Radionuclides (i) and Pathways (p) in mrem/yr and as a Percentage of Total Dose at $t=1026$ years

Directly from primary contamination and from release to atmosphere (Inhalation excludes radon)

\begin{tabular}{|c|c|c|c|c|c|c|c|c|c|c|c|c|c|c|c|c|}
\hline & \multicolumn{2}{|c|}{ Ground } & \multicolumn{2}{|c|}{ Inhalation } & \multicolumn{2}{|c|}{ Radon } & \multicolumn{2}{|c|}{ Plant } & \multicolumn{2}{|l|}{ Meat } & \multicolumn{2}{|l|}{ Milk } & \multicolumn{2}{|l|}{ Soil } & \multicolumn{2}{|c|}{ All Pathways* } \\
\hline ide & Dose & $\%$ & Dose & $\%$ & Dose & $\%$ & Dose & 음 & Dose & $\%$ & Dose & 음 & Dose & $\%$ & Dose & $\%$ \\
\hline-241 & $8.57 E-17$ & 0 & $0.00 E+00$ & 0 & $0.00 E+00$ & 0 & $0.00 \mathrm{E}+00$ & 0 & $0.00 \mathrm{E}+00$ & 0 & $0.00 \mathrm{E}+00$ & 0 & $0.00 \mathrm{E}+00$ & 0 & $8.57 \mathrm{E}-17$ & 0 \\
\hline-137 & $2.09 E-22$ & 0 & $0.00 E+00$ & 0 & $0.00 E+00$ & 0 & $0.00 \mathrm{E}+00$ & 0 & $0.00 \mathrm{E}+00$ & 0 & $0.00 E+00$ & 0 & $0.00 \mathrm{E}+00$ & 0 & $2.09 E-22$ & 0 \\
\hline-237 & $8.15 E-14$ & 0 & $0.00 E+00$ & 0 & $0.00 E+00$ & 0 & $0.00 \mathrm{E}+00$ & 0 & $0.00 \mathrm{E}+00$ & 0 & $0.00 E+00$ & 0 & $0.00 \mathrm{E}+00$ & 0 & $8.15 E-14$ & 0 \\
\hline-238 & 1. $43 \mathrm{E}-15$ & 0 & $0.00 E+00$ & 0 & $0.00 \mathrm{E}+00$ & 0 & $0.00 \mathrm{E}+00$ & 0 & $0.00 \mathrm{E}+00$ & 0 & $0.00 \mathrm{E}+00$ & 0 & $0.00 \mathrm{E}+00$ & 0 & $1.43 E-15$ & 0 \\
\hline-239 & $2.09 E-17$ & 0 & $0.00 \mathrm{E}+00$ & 0 & $0.00 \mathrm{E}+00$ & 0 & $0.00 \mathrm{E}+00$ & 0 & $0.00 \mathrm{E}+00$ & 0 & $0.00 \mathrm{E}+00$ & 0 & $0.00 \mathrm{E}+00$ & 0 & $2.09 \mathrm{E}-17$ & 0 \\
\hline-240 & $8.10 \mathrm{E}-21$ & 0 & $0.00 E+00$ & 0 & $0.00 \mathrm{E}+00$ & 0 & $0.00 \mathrm{E}+00$ & 0 & $0.00 \mathrm{E}+00$ & 0 & $0.00 E+00$ & 0 & $0.00 \mathrm{E}+00$ & 0 & $8.10 \mathrm{E}-21$ & 0 \\
\hline-99 & $3.28 E-27$ & 0 & $0.00 E+00$ & 0 & $0.00 \mathrm{E}+00$ & 0 & $0.00 \mathrm{E}+00$ & 0 & $0.00 \mathrm{E}+00$ & 0 & $0.00 E+00$ & 0 & $0.00 \mathrm{E}+00$ & 0 & $7.73 E-01$ & 100 \\
\hline-228 & $0.00 \mathrm{E}+00$ & 0 & $0.00 \mathrm{E}+00$ & 0 & $0.00 \mathrm{E}+00$ & 0 & $0.00 \mathrm{E}+00$ & 0 & $0.00 \mathrm{E}+00$ & 0 & $0.00 \mathrm{E}+00$ & 0 & $0.00 \mathrm{E}+00$ & 0 & $0.00 \mathrm{E}+00$ & 0 \\
\hline-230 & $3.11 \mathrm{E}-10$ & 0 & $0.00 E+00$ & 0 & $0.00 \mathrm{E}+00$ & 0 & $0.00 \mathrm{E}+00$ & 0 & $0.00 \mathrm{E}+00$ & 0 & $0.00 E+00$ & 0 & $0.00 \mathrm{E}+00$ & 0 & $3.11 \mathrm{E}-10$ & 0 \\
\hline-232 & $1.13 \mathrm{E}-10$ & 0 & $0.00 E+00$ & 0 & $0.00 \mathrm{E}+00$ & 0 & $0.00 \mathrm{E}+00$ & 0 & $0.00 \mathrm{E}+00$ & 0 & $0.00 \mathrm{E}+00$ & 0 & $0.00 \mathrm{E}+00$ & 0 & $1.13 \mathrm{E}-10$ & 0 \\
\hline 34 & $2.31 E-11$ & 0 & $0.00 \mathrm{E}+00$ & 0 & $0.00 \mathrm{E}+00$ & 0 & $0.00 \mathrm{E}+00$ & 0 & $0.00 \mathrm{E}+00$ & 0 & $0.00 \mathrm{E}+00$ & 0 & $0.00 \mathrm{E}+00$ & 0 & $2.31 \mathrm{E}-11$ & 0 \\
\hline 35 & $4.19 E-14$ & 0 & $0.00 \mathrm{E}+00$ & 0 & $0.00 \mathrm{E}+00$ & 0 & $0.00 \mathrm{E}+00$ & 0 & $0.00 \mathrm{E}+00$ & 0 & $0.00 \mathrm{E}+00$ & 0 & $0.00 \mathrm{E}+00$ & 0 & $4.19 \mathrm{E}-14$ & 0 \\
\hline 38 & $5.24 E-12$ & 0 & $0.00 E+00$ & 0 & $0.00 \mathrm{E}+00$ & 0 & $0.00 \mathrm{E}+00$ & 0 & $0.00 \mathrm{E}+00$ & 0 & $0.00 E+00$ & 0 & $0.00 \mathrm{E}+00$ & 0 & $5.24 \mathrm{E}-12$ & 0 \\
\hline & $4.52 \mathrm{E}-10$ & 0 & $0.00 E+00$ & 0 & $0.00 E+00$ & 0 & $0.00 \mathrm{E}+00$ & 0 & $0.00 \mathrm{E}+00$ & 0 & $0.00 E+00$ & 0 & $0.00 \mathrm{E}+00$ & 0 & $7.73 E-01$ & 100 \\
\hline
\end{tabular}

* Sum of dose from all releases and from primary contamination. 
RESRAD-OFFSITE, Version 2.

Parent Dose Report

Title : Offsite Resident Farmer Deterministic Run File : RF SG FWD-FINAL v2.ROF

Dose/Source Ratios Summed Over All Pathways

Parent and Progeny Principal Radionuclide Contributions Indicated

Parent Product Thread DSR $(j, \mathrm{t}) \quad(\mathrm{mrem} / \mathrm{yr}) /(\mathrm{pCi} / \mathrm{g})$

(i)

Am-241

Am-241

Am-241

Am-241

Am-241

Cs $-137+D$

$\mathrm{Np}-237+\mathrm{D}$

$\mathrm{Np}-237+\mathrm{D}$

$\mathrm{Np}-237+\mathrm{D}$

Np-237

Pu-238

$\mathrm{Pu}-238$

$\mathrm{Pu}-238$

$\mathrm{Pu}-238$

$\mathrm{Pu}-238$

$\mathrm{Pu}-238$

$\mathrm{Pu}-238$

$\mathrm{Pu}-239$

$\mathrm{Pu}-239$

$\mathrm{Pu}-239$

$\mathrm{Pu}-239$

$\mathrm{Pu}-239$

$\mathrm{Pu}-24 \mathrm{C}$

$\mathrm{Pu}-240$

$\mathrm{Pu}-240$

$\mathrm{Pu}-240$

$\mathrm{Pu}-240$

$\mathrm{Pu}-240$

$\mathrm{Pu}-24 \mathrm{C}$

TC-9s

Th-228+D (j) Fraction

$\begin{array}{ll}\mathrm{Am}-241 & 1.000 \mathrm{E}+00 \\ \mathrm{~Np}-237+\mathrm{D} & 1.000 \mathrm{E}+00 \\ \mathrm{U}-233 & 1.000 \mathrm{E}+00 \\ \operatorname{Th}-229+\mathrm{D} & 1.000 \mathrm{E}+00 \\ \operatorname{\sum DSR}(j) & \end{array}$

Cs-137+D

$\mathrm{Np}-237+\mathrm{D}$

$\mathrm{U}-233$

Th-229+D

$\sum \operatorname{DSR}(j)$

$\mathrm{Pu}-238$

$\mathrm{Pu}-238$

$\mathrm{U}-234$

Th -230

Ra-226+D

$\mathrm{Pb}-210+\mathrm{D}$

$\sum \operatorname{DSR}(j)$

$\mathrm{Pu}-239$

U-235+D

$\mathrm{Pa}-231$

$A C-227+D$

$\operatorname{\sum DSR}(j)$

$\mathrm{Pu}-240$

$\mathrm{Pu}-240$

$\mathrm{U}-236$

Th-232

$\mathrm{Ra}-228+\mathrm{D}$

Th-228+D

$\sum \operatorname{DSR}(j)$

TC-99

$\mathrm{Th}-228+\mathrm{D}$

1. $000 \mathrm{E}+00$

$1.000 \mathrm{E}+00$

$1.000 \mathrm{E}+00$

$1.000 \mathrm{E}+00$
$0.000 \mathrm{E}+00 \quad 1.000 \mathrm{E}+00 \quad 5.000 \mathrm{E}+01 \quad 1.000 \mathrm{E}+02 \quad 5.000 \mathrm{E}+02 \quad 1.026 \mathrm{E}+03$

$\begin{array}{llllll}1.173 \mathrm{E}-41 & 1.202 \mathrm{E}-41 & 3.983 \mathrm{E}-41 & 1.352 \mathrm{E}-40 & 2.391 \mathrm{E}-36 & 9.208 \mathrm{E}-31\end{array}$

$\begin{array}{llllll}9.379 \mathrm{E}-28 & 2.835 \mathrm{E}-27 & 1.490 \mathrm{E}-25 & 4.678 \mathrm{E}-25 & 9.095 \mathrm{E}-23 & 2.417 \mathrm{E}-20\end{array}$

$2.412 \mathrm{E}-38 \quad 1.539 \mathrm{E}-37 \quad 2.808 \mathrm{E}-34 \quad 1.927 \mathrm{E}-33 \quad 3.932 \mathrm{E}-30 \quad 5.618 \mathrm{E}-27$

$1.854 \mathrm{E}-34 \quad 2.341 \mathrm{E}-33 \quad 1.009 \mathrm{E}-28 \quad 1.073 \mathrm{E}-27 \quad 1.480 \mathrm{E}-24 \quad 3.195 \mathrm{E}-22$ $\begin{array}{llllll}9.379 \mathrm{E}-28 & 2.835 \mathrm{E}-27 & 1.491 \mathrm{E}-25 & 4.689 \mathrm{E}-25 & 9.243 \mathrm{E}-23 & 2.449 \mathrm{E}-20\end{array}$

$\begin{array}{llllll}.649 \mathrm{E}-18 & 7.532 \mathrm{E}-18 & 3.550 \mathrm{E}-18 & 1.647 \mathrm{E}-18 & 3.543 \mathrm{E}-21 & 1.101 \mathrm{E}-24\end{array}$

$\begin{array}{lllllll}5.780 \mathrm{E}-21 & 5.837 \mathrm{E}-21 & 9.466 \mathrm{E}-21 & 1.550 \mathrm{E}-20 & 8.026 \mathrm{E}-19 & 1.440 \mathrm{E}-16\end{array}$

$\begin{array}{llllll}1.969 \mathrm{E}-31 & 5.963 \mathrm{E}-31 & 3.524 \mathrm{E}-29 & 1.247 \mathrm{E}-28 & 6.189 \mathrm{E}-26 & 5.394 \mathrm{E}-23\end{array}$

$2.038 \mathrm{E}-27 \quad 1.295 \mathrm{E}-26 \quad 1.887 \mathrm{E}-23 \quad 1.028 \mathrm{E}-22 \quad 3.287 \mathrm{E}-20 \quad 4.103 \mathrm{E}-18$

$\begin{array}{llllll}5.780 \mathrm{E}-21 & 5.837 \mathrm{E}-21 & 9.485 \mathrm{E}-21 & 1.561 \mathrm{E}-20 & 8.354 \mathrm{E}-19 & 1.481 \mathrm{E}-16\end{array}$

$\begin{array}{lllllll}1.840 \mathrm{E}-09 & 1.310 \mathrm{E}-41 & 1.321 \mathrm{E}-41 & 1.990 \mathrm{E}-41 & 3.022 \mathrm{E}-41 & 8.560 \mathrm{E}-40 & 6.951 \mathrm{E}-38\end{array}$

$\begin{array}{lllllll}1.000 \mathrm{E}+00 & 7.119 \mathrm{E}-33 & 7.179 \mathrm{E}-33 & 1.081 \mathrm{E}-32 & 1.642 \mathrm{E}-32 & 4.652 \mathrm{E}-31 & 3.778 \mathrm{E}-29\end{array}$

$\begin{array}{lllllll}1.000 \mathrm{E}+00 & 5.930 \mathrm{E}-38 & 1.798 \mathrm{E}-37 & 1.115 \mathrm{E}-35 & 4.196 \mathrm{E}-35 & 5.105 \mathrm{E}-32 & 2.757 \mathrm{E}-28\end{array}$

$\begin{array}{llllllll}1.000 \mathrm{E}+00 & 7.074 \mathrm{E}-42 & 4.520 \mathrm{E}-41 & 9.070 \mathrm{E}-38 & 6.913 \mathrm{E}-37 & 4.079 \mathrm{E}-33 & 3.348 \mathrm{E}-29\end{array}$

$\begin{array}{lllllll}1.000 \mathrm{E}+00 & 6.200 \mathrm{E}-31 & 7.815 \mathrm{E}-30 & 3.107 \mathrm{E}-25 & 3.056 \mathrm{E}-24 & 2.593 \mathrm{E}-21 & 3.654 \mathrm{E}-19\end{array}$

$\begin{array}{llllllll}1.000 \mathrm{E}+00 & 2.070 \mathrm{E}-39 & 4.917 \mathrm{E}-38 & 4.570 \mathrm{E}-32 & 7.489 \mathrm{E}-31 & 1.633 \mathrm{E}-27 & 4.208 \mathrm{E}-25\end{array}$

$\begin{array}{llllll}6.271 \mathrm{E}-31 & 7.822 \mathrm{E}-30 & 3.107 \mathrm{E}-25 & 3.056 \mathrm{E}-24 & 2.593 \mathrm{E}-21 & 3.654 \mathrm{E}-19\end{array}$

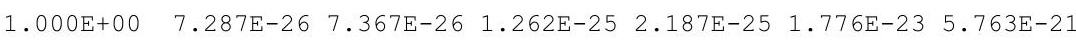

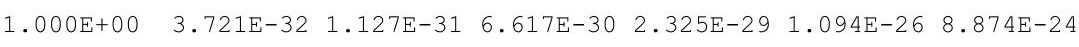

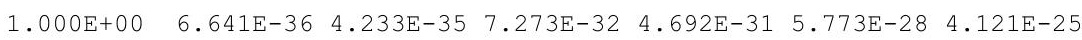

$\begin{array}{lllllll}1.000 \mathrm{E}+00 & 1.768 \mathrm{E}-35 & 2.220 \mathrm{E}-34 & 7.476 \mathrm{E}-30 & 6.622 \mathrm{E}-29 & 6.350 \mathrm{E}-26 & 2.019 \mathrm{E}-23\end{array}$

$\begin{array}{llllll}7.287 \mathrm{E}-26 & 7.367 \mathrm{E}-26 & 1.263 \mathrm{E}-25 & 2.188 \mathrm{E}-25 & 1.784 \mathrm{E}-23 & 5.792 \mathrm{E}-21\end{array}$

$\begin{array}{lllllll}4.950 E-08 & 3.426 E-40 & 3.481 E-40 & 7.683 E-40 & 1.723 E-39 & 1.103 E-36 & 5.401 E-33\end{array}$

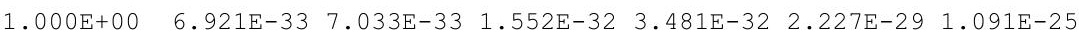

$\begin{array}{lllllll}1.000 \mathrm{E}+00 & 1.312 \mathrm{E}-40 & 3.990 \mathrm{E}-40 & 3.012 \mathrm{E}-38 & 1.369 \mathrm{E}-37 & 5.033 \mathrm{E}-34 & 6.106 \mathrm{E}-30\end{array}$

$\begin{array}{llllllll}1.000 \mathrm{E}+00 & 0.000 \mathrm{E}+00 & 0.000 \mathrm{E}+00 & 0.000 \mathrm{E}+00 & 0.000 \mathrm{E}+00 & 6.526 \mathrm{E}-42 & 2.161 \mathrm{E}-37\end{array}$

$\begin{array}{lllllll}1.000 \mathrm{E}+00 & 1.056 \mathrm{E}-36 & 1.302 \mathrm{E}-35 & 2.214 \mathrm{E}-31 & 1.452 \mathrm{E}-30 & 6.617 \mathrm{E}-28 & 1.096 \mathrm{E}-25\end{array}$

$\begin{array}{llllllll}1.000 \mathrm{E}+00 & 7.082 \mathrm{E}-36 & 1.578 \mathrm{E}-34 & 1.564 \mathrm{E}-29 & 1.017 \mathrm{E}-28 & 2.672 \mathrm{E}-26 & 2.030 \mathrm{E}-24\end{array}$

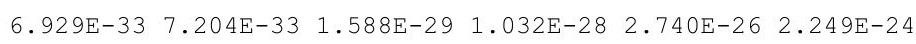

$\begin{array}{lllllll}1.000 E+00 & 3.496 \mathrm{E}-34 & 3.539 \mathrm{E}-34 & 6.498 \mathrm{E}-34 & 1.208 \mathrm{E}-33 & 1.906 \mathrm{E}-02 & 2.761 \mathrm{E}-02\end{array}$

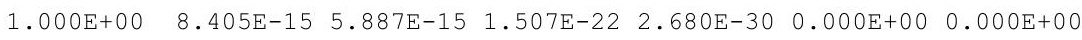


RESRAD-OFFSITE, Version 2.5

Parent Dose Report

Title : Offsite Resident Farmer Deterministic Run

File : RF SG FWD-FINAL v2.ROF

Dose/Source Ratios Summed Over All Pathways

Parent and Progeny Principal Radionuclide Contributions Indicated

\begin{tabular}{|c|c|c|c|c|c|c|c|c|}
\hline Parent & Product & Thread & & $\operatorname{DSR}(j$, & t) $\quad(\mathrm{mrem} / \mathrm{y}$ & $/(\mathrm{pCi} / \mathrm{g})$ & & \\
\hline (i) & $(j)$ & Fraction & $0.000 \mathrm{E}+00$ & $1.000 \mathrm{E}+00$ & $5.000 \mathrm{E}+01$ & $1.000 \mathrm{E}+02$ & $5.000 \mathrm{E}+02$ & $1.026 \mathrm{E}+03$ \\
\hline-230 & $T h-230$ & $1.000 \mathrm{E}+00$ & $1.462 \mathrm{E}-30$ & $1.485 \mathrm{E}-30$ & $3.170 \mathrm{E}-30$ & $6.873 E-30$ & $3.359 \mathrm{E}-27$ & $1.154 \mathrm{E}-23$ \\
\hline-230 & $\mathrm{Ra}-226+\mathrm{D}$ & $1.000 \mathrm{E}+00$ & $2.288 E-19$ & $6.901 E-19$ & $3.138 \mathrm{E}-17$ & $8.491 \mathrm{E}-17$ & $4.948 E-15$ & $2.589 \mathrm{E}-13$ \\
\hline-230 & $\mathrm{~Pb}-210+\mathrm{D}$ & $1.000 \mathrm{E}+00$ & $1.250 \mathrm{E}-27$ & $7.883 \mathrm{E}-27$ & $7.635 \mathrm{E}-24$ & $3.029 \mathrm{E}-23$ & 3. $412 \mathrm{E}-21$ & $3.104 \mathrm{E}-19$ \\
\hline-230 & $\sum \operatorname{DSR}(j)$ & & $2.288 E-19$ & $6.901 \mathrm{E}-19$ & $3.138 \mathrm{E}-17$ & $8.491 \mathrm{E}-17$ & $4.948 E-15$ & $2.589 \mathrm{E}-13$ \\
\hline-232 & Th-232 & $1.000 \mathrm{E}+00$ & $7.064 \mathrm{E}-33$ & $7.186 \mathrm{E}-33$ & 1. $661 \mathrm{E}-32$ & $3.904 \mathrm{E}-32$ & 3. $643 \mathrm{E}-29$ & $2.931 \mathrm{E}-25$ \\
\hline-232 & $\mathrm{Ra}-228+\mathrm{D}$ & $1.000 \mathrm{E}+00$ & $6.681 \mathrm{E}-18$ & 1.919E-17 & $1.638 \mathrm{E}-16$ & $2.329 \mathrm{E}-16$ & $3.817 \mathrm{E}-15$ & 1. $510 \mathrm{E}-13$ \\
\hline-232 & $\mathrm{Th}-228+\mathrm{D}$ & $1.000 \mathrm{E}+00$ & $7.238 \mathrm{E}-17$ & $4.048 \mathrm{E}-16$ & $1.310 \mathrm{E}-14$ & $1.731 \mathrm{E}-14$ & $1.558 \mathrm{E}-13$ & $2.813 \mathrm{E}-12$ \\
\hline-232 & $\sum \operatorname{DSR}(j)$ & & $7.906 \mathrm{E}-17$ & $4.240 \mathrm{E}-16$ & $1.327 \mathrm{E}-14$ & $1.754 \mathrm{E}-14$ & $1.597 \mathrm{E}-13$ & $2.964 \mathrm{E}-12$ \\
\hline 234 & $\mathrm{U}-234$ & $1.000 \mathrm{E}+00$ & $4.179 E-32$ & $4.247 E-32$ & $9.442 \mathrm{E}-32$ & $2.133 E-31$ & 1. $449 \mathrm{E}-28$ & $7.680 \mathrm{E}-25$ \\
\hline-234 & $T h-230$ & $1.000 \mathrm{E}+00$ & $6.605 E-36$ & $2.007 E-35$ & $1.441 E-33$ & $6.216 E-33$ & $1.511 \mathrm{E}-29$ & $1.064 \mathrm{E}-25$ \\
\hline-234 & $\mathrm{Ra}-226+\mathrm{D}$ & $1.000 \mathrm{E}+00$ & $7.794 \mathrm{E}-25$ & $4.953 E-24$ & $7.158 \mathrm{E}-21$ & $3.868 \mathrm{E}-20$ & $1.154 \mathrm{E}-17$ & $1.282 \mathrm{E}-15$ \\
\hline-234 & $\mathrm{~Pb}-210+\mathrm{D}$ & $1.000 \mathrm{E}+00$ & $3.169 E-33$ & $3.978 E-32$ & $1.294 \mathrm{E}-27$ & $1.103 E-26$ & $7.464 \mathrm{E}-24$ & $1.487 \mathrm{E}-21$ \\
\hline-234 & $\sum \operatorname{DSR}(j)$ & & $7.794 E-25$ & $4.953 E-24$ & $7.158 \mathrm{E}-21$ & $3.868 E-20$ & $1.154 \mathrm{E}-17$ & $1.282 \mathrm{E}-15$ \\
\hline$-235+D$ & $\mathrm{U}-235+\mathrm{D}$ & $1.000 \mathrm{E}+00$ & $7.535 E-23$ & 7. $622 \mathrm{E}-23$ & $1.331 \mathrm{E}-22$ & $2.352 E-22$ & $2.233 E-20$ & $8.893 \mathrm{E}-18$ \\
\hline$-235+D$ & $\mathrm{~Pa}-231$ & $1.000 \mathrm{E}+00$ & 1. $782 \mathrm{E}-26$ & $5.389 \mathrm{E}-26$ & $2.925 E-24$ & $9.486 \mathrm{E}-24$ & 2. $349 \mathrm{E}-21$ & $8.198 \mathrm{E}-19$ \\
\hline$-235+D$ & $A c-227+D$ & $1.000 \mathrm{E}+00$ & $6.374 \mathrm{E}-26$ & $4.021 E-25$ & $4.032 E-22$ & $1.667 \mathrm{E}-21$ & $2.744 \mathrm{E}-19$ & $4.140 \mathrm{E}-17$ \\
\hline-235 & $\sum \operatorname{DSR}(j)$ & & $7.544 \mathrm{E}-23$ & 7. $667 \mathrm{E}-23$ & $5.393 E-22$ & $1.912 \mathrm{E}-21$ & $2.991 \mathrm{E}-19$ & $5.111 \mathrm{E}-17$ \\
\hline-238 & $\mathrm{U}-238$ & $5.400 \mathrm{E}-05$ & $0.000 \mathrm{E}+00$ & $0.000 \mathrm{E}+00$ & $0.000 \mathrm{E}+00$ & $0.000 \mathrm{E}+00$ & $0.000 \mathrm{E}+00$ & $0.000 \mathrm{E}+00$ \\
\hline$-238+D$ & $\mathrm{U}-238+\mathrm{D}$ & $9.999 \mathrm{E}-01$ & $8.606 \mathrm{E}-19$ & $8.669 \mathrm{E}-19$ & 1. $243 \mathrm{E}-18$ & $1.796 \mathrm{E}-18$ & $3.408 E-17$ & $1.635 E-15$ \\
\hline$-238+D$ & $U-234$ & $9.999 \mathrm{E}-01$ & $5.948 E-38$ & $1.809 E-37$ & $1.352 E-35$ & $6.079 E-35$ & $2.058 E-31$ & $2.238 E-27$ \\
\hline$-238+D$ & $\mathrm{Th}-230$ & $9.999 \mathrm{E}-01$ & $7.089 E-42$ & $4.540 \mathrm{E}-41$ & $1.031 \mathrm{E}-37$ & $8.855 E-37$ & $1.072 \mathrm{E}-32$ & $1.548 \mathrm{E}-28$ \\
\hline$-238+D$ & $\mathrm{Ra}-226+\mathrm{D}$ & $9.999 \mathrm{E}-01$ & $5.589 E-31$ & $7.732 \mathrm{E}-30$ & $3.423 E-25$ & $3.687 \mathrm{E}-24$ & $5.554 \mathrm{E}-21$ & 1. $288 \mathrm{E}-18$ \\
\hline$-238+D$ & $\mathrm{~Pb}-210+\mathrm{D}$ & $9.999 \mathrm{E}-01$ & $7.472 E-39$ & $3.324 E-38$ & $4.957 E-32$ & $8.813 E-31$ & $3.387 E-27$ & 1. $449 E-24$ \\
\hline-238 & $\sum \operatorname{DSR}(j)$ & & $8.606 \mathrm{E}-19$ & $8.669 \mathrm{E}-19$ & $1.243 \mathrm{E}-18$ & 1. $796 \mathrm{E}-18$ & $3.408 \mathrm{E}-17$ & $1.636 \mathrm{E}-15$ \\
\hline
\end{tabular}

The DSR includes contributions from associated (half-life $\leq 180$ days) daughters. 
RESRAD-OFFSITE, Version 2.5

Parent Dose Report

Title : Offsite Resident Farmer Deterministic Run

File : RF SG FWD-FINAL v2.ROF

Single Radionuclide Soil Guidelines G(i,t) in pCi/g

Basic Radiation Dose Limit $=1.000 \mathrm{E}+00 \mathrm{mrem} / \mathrm{yr}$

\begin{tabular}{|c|c|c|c|c|c|c|}
\hline (i) & $t=0.000 E+00$ & $1.000 \mathrm{E}+00$ & $5.000 \mathrm{E}+01$ & $1.000 \mathrm{E}+02$ & $5.000 \mathrm{E}+02$ & $1.026 \mathrm{E}+03$ \\
\hline & $\star 3.431 \mathrm{E}+12$ & $\star 3.431 \mathrm{E}+12$ & $\star 3.431 \mathrm{E}+12$ & $\star 3.431 \mathrm{E}+12$ & $\star 3.431 \mathrm{E}+12$ & $\star 3.431 \mathrm{E}+12$ \\
\hline-37 & $\star 8.704 \mathrm{E}+13$ & $\star 8.704 \mathrm{E}+13$ & $\star 8.704 \mathrm{E}+13$ & $\star 8.704 \mathrm{E}+13$ & $\star 8.704 \mathrm{E}+13$ & $\star 8.704 \mathrm{E}+1$ \\
\hline 237 & $* 7.047 \mathrm{E}+08$ & $\star 7.047 \mathrm{E}+08$ & $\star 7.047 \mathrm{E}+08$ & $\star 7.047 \mathrm{E}+08$ & $* 7.047 \mathrm{E}+08$ & $\star 7.047 \mathrm{E}+0$ \\
\hline & $\star 1.712 \mathrm{E}+13$ & $* 1.712 \mathrm{E}+13$ & $\star 1.712 \mathrm{E}+13$ & $* 1.712 \mathrm{E}+13$ & $* 1.712 \mathrm{E}+13$ & $* 1.712 \mathrm{E}+1$ \\
\hline 239 & $* 6.214 \mathrm{E}+10$ & $* 6.214 \mathrm{E}+10$ & $* 6.214 \mathrm{E}+10$ & $\star 6.214 \mathrm{E}+10$ & $* 6.214 \mathrm{E}+10$ & $* 6.214 \mathrm{E}+10$ \\
\hline 0 & $* 2.278 \mathrm{E}+11$ & $* 2.278 \mathrm{E}+11$ & $\star 2.278 \mathrm{E}+11$ & $\star 2.278 \mathrm{E}+11$ & $\star 2.278 \mathrm{E}+11$ & $\star 2.278 \mathrm{E}+11$ \\
\hline & $* 1.697 \mathrm{E}+10$ & $\star 1.697 \mathrm{E}+10$ & $* 1.697 \mathrm{E}+10$ & $* 1.697 \mathrm{E}+10$ & $5.247 \mathrm{E}+01$ & $3.621 E+01$ \\
\hline 8 & $1.190 \mathrm{E}+14$ & $1.699 \mathrm{E}+14$ & $\star 8.195 \mathrm{E}+14$ & $\star 8.195 \mathrm{E}+14$ & $\star 8.195 \mathrm{E}+14$ & $\star 8.195 \mathrm{E}+14$ \\
\hline 30 & $* 2.018 \mathrm{E}+10$ & $* 2.018 \mathrm{E}+10$ & $\star 2.018 \mathrm{E}+10$ & $\star 2.018 \mathrm{E}+10$ & $* 2.018 \mathrm{E}+10$ & $\star 2.018 \mathrm{E}+10$ \\
\hline 32 & $* 1.097 \mathrm{E}+05$ & $* 1.097 \mathrm{E}+05$ & $\star 1.097 \mathrm{E}+05$ & $\star 1.097 \mathrm{E}+05$ & $* 1.097 \mathrm{E}+05$ & $\star 1.097 \mathrm{E}+05$ \\
\hline & $\star 6.247 \mathrm{E}+09$ & $\star 6.247 \mathrm{E}+09$ & $* 6.247 \mathrm{E}+09$ & $* 6.247 \mathrm{E}+09$ & $\star 6.247 \mathrm{E}+09$ & $* 6.247 \mathrm{E}+09$ \\
\hline & $\star 2.161 \mathrm{E}+06$ & $\star 2.161 \mathrm{E}+06$ & $\star 2.161 \mathrm{E}+06$ & $\star 2.161 \mathrm{E}+06$ & $\star 2.161 \mathrm{E}+06$ & $\star 2.161 \mathrm{E}+06$ \\
\hline & $* 3.361 \mathrm{E}+05$ & $* 3.361 \mathrm{E}+05$ & $* 3.361 \mathrm{E}+05$ & $* 3.361 \mathrm{E}+05$ & $* 3.361 \mathrm{E}+05$ & $* 3.361 \mathrm{E}+05$ \\
\hline
\end{tabular}

*At specific activity limit

Summed Dose/Source Ratios DSR(i,t) in (mrem/yr)/(pCi/g)

and Single Radionuclide Soil Guidelines $G(i, t)$ in $\mathrm{pCi} / \mathrm{g}$

at $\operatorname{tmin}=$ time of minimum single radionuclide soil guideline

and at tmax $=$ time of maximum total dose $=772$ years

\begin{tabular}{|c|c|c|c|c|c|c|}
\hline $\begin{array}{l}\text { Tuclide } \\
\text { (i) }\end{array}$ & $\begin{array}{l}\text { Initial } \\
(\mathrm{pCi} / \mathrm{g})\end{array}$ & $\begin{array}{c}\text { tmin } \\
\text { (years) }\end{array}$ & $\operatorname{DSR}(i, \operatorname{tmin})$ & $\begin{array}{c}\mathrm{G}(\mathrm{i}, \mathrm{tmin}) \\
(\mathrm{pCi} / \mathrm{g})\end{array}$ & $\operatorname{DSR}(i, \operatorname{tmax})$ & $\begin{array}{l}G(i, t \max ) \\
(\mathrm{pCi} / \mathrm{g})\end{array}$ \\
\hline-241 & $3.500 \mathrm{E}+03$ & 1050 & $3.116 \mathrm{E}-20$ & $3.210 E+19$ & $1.747 \mathrm{E}-21$ & $\star 3.431 \mathrm{E}+12$ \\
\hline-137 & $1.900 \mathrm{E}+02$ & 0 & $7.649 \mathrm{E}-18$ & $1.307 \mathrm{E}+17$ & $5.473 \mathrm{E}-23$ & $\star 8.704 \mathrm{E}+13$ \\
\hline-237 & $5.500 \mathrm{E}+02$ & 1050 & $1.866 \mathrm{E}-16$ & $\star 7.047 \mathrm{E}+08$ & $1.215 \mathrm{E}-17$ & $\star 7.047 \mathrm{E}+08$ \\
\hline-238 & $3.900 \mathrm{E}+03$ & 1050 & $4.450 \mathrm{E}-19$ & $2.247 E+18$ & $3.924 \mathrm{E}-20$ & $\star 1.712 \mathrm{E}+13$ \\
\hline-239 & $3.600 \mathrm{E}+03$ & 1050 & $7.500 \mathrm{E}-21$ & $\star 6.214 \mathrm{E}+10$ & $3.535 E-22$ & $\star 6.214 \mathrm{E}+10$ \\
\hline-240 & $3.600 \mathrm{E}+03$ & 1050 & $2.711 \mathrm{E}-24$ & $\star 2.278 \mathrm{E}+11$ & $2.966 \mathrm{E}-25$ & $\star 2.278 \mathrm{E}+11$ \\
\hline-99 & $2.800 \mathrm{E}+01$ & 772 & $3.593 \mathrm{E}-02$ & $2.783 \mathrm{E}+01$ & $3.593 \mathrm{E}-02$ & $2.783 \mathrm{E}+01$ \\
\hline Th-228 & $7.400 \mathrm{E}+01$ & 0 & $8.405 \mathrm{E}-15$ & $1.190 \mathrm{E}+14$ & $0.000 \mathrm{E}+00$ & $\star 8.195 \mathrm{E}+14$ \\
\hline Th -230 & $1.200 \mathrm{E}+03$ & 1050 & $3.061 \mathrm{E}-13$ & $3.267 \mathrm{E}+12$ & $4.062 \mathrm{E}-14$ & $\star 2.018 \mathrm{E}+10$ \\
\hline-232 & $3.800 \mathrm{E}+01$ & 1050 & $3.379 \mathrm{E}-12$ & $* 1.097 \mathrm{E}+05$ & $7.193 \mathrm{E}-13$ & $* 1.097 \mathrm{E}+05$ \\
\hline 234 & $1.800 \mathrm{E}+04$ & 1050 & $1.553 \mathrm{E}-15$ & $6.440 \mathrm{E}+14$ & $1.488 \mathrm{E}-16$ & $* 6.247 \mathrm{E}+09$ \\
\hline 35 & $8.200 \mathrm{E}+02$ & 1050 & $6.404 \mathrm{E}-17$ & $\star 2.161 \mathrm{E}+06$ & $4.426 \mathrm{E}-18$ & $\star 2.161 \mathrm{E}+06$ \\
\hline 238 & $3.200 E+03$ & 1050 & $1.945 \mathrm{E}-15$ & $\star 3.361 \mathrm{E}+05$ & $2.516 \mathrm{E}-16$ & $\star 3.361 \mathrm{E}+05$ \\
\hline
\end{tabular}

${ }^{*}$ At specific activity limit 
RESRAD-OFFSITE, Version 2.

Parent Dose Report

Title : Offsite Resident Farmer Deterministic Run

File : RF SG FWD-FINAL v2.ROF

Individual Nuclide Dose Summed Over All Pathways

Parent Nuclide and Thread Fraction Indicated

Nuclide Parent THF(i) DOSE $(j, t), \mathrm{mrem} / \mathrm{yr}$

\begin{tabular}{|c|c|c|}
\hline (j) & (i) & \\
\hline$m-241$ & $A m-241$ & $1.000 \mathrm{E}+00$ \\
\hline-237 & $A m-241$ & $1.000 \mathrm{E}+00$ \\
\hline $\mathrm{Jp}-237$ & $\mathrm{~Np}-237$ & $1.000 \mathrm{E}+00$ \\
\hline-237 & $\sum$ DOSE & ): \\
\hline
\end{tabular}

$\mathrm{U}-233 \quad \mathrm{Am}-241 \quad 1.000 \mathrm{E}+00$

$\mathrm{U}-233 \quad \mathrm{~Np}-237 \quad 1.000 \mathrm{E}+00$

U-233 $\operatorname{DOSE}(j)$ :

Th-229 Am-241 $1.000 \mathrm{E}+00$

Th-229 Np-237 $1.000 \mathrm{E}+00$

Th-229 $\operatorname{LDOSE}(j)$ :

Cs-137 Cs $-137 \quad 1.000 \mathrm{E}+00$

$\mathrm{Pu}-238$

$\mathrm{Pu}-238$

$\mathrm{Pu}-238$

$\mathrm{U}-234$

$\mathrm{U}-234$

$\mathrm{U}-234$

$\mathrm{U}-234$

Th -230

Th -230

Th -230

Th-230

Th-230

$\mathrm{Ra}-226$

$\mathrm{Ra}-226$

$\mathrm{Ra}-226$

$\mathrm{Ra}-226$

$\mathrm{Ra}-226$

$\mathrm{Pb}-210$

$\mathrm{Pb}-210$

$\mathrm{Pb}-210$

$\mathrm{Pb}-210$

$\mathrm{Pb}-210$

Pu-239 Pu-239 $1.000 E+00$ $\mathrm{t}=0.000 \mathrm{E}+00 \quad 1.000 \mathrm{E}+00 \quad 5.000 \mathrm{E}+01 \quad 1.000 \mathrm{E}+02 \quad 5.000 \mathrm{E}+02 \quad 1.026 \mathrm{E}+03$

$\begin{array}{llllll}4.105 E-38 & 4.206 E-38 & 1.394 E-37 & 4.733 E-37 & 8.370 E-33 & 3.223 E-27\end{array}$

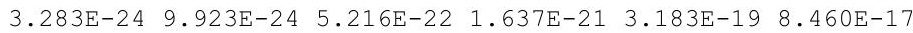

$\begin{array}{llllll}3.179 \mathrm{E}-18 & 3.211 \mathrm{E}-18 & 5.207 \mathrm{E}-18 & 8.527 \mathrm{E}-18 & 4.414 \mathrm{E}-16 & 7.922 \mathrm{E}-14\end{array}$

$\begin{array}{llllll}3.179 \mathrm{E}-18 & 3.211 \mathrm{E}-18 & 5.207 \mathrm{E}-18 & 8.529 \mathrm{E}-18 & 4.417 \mathrm{E}-16 & 7.930 \mathrm{E}-14\end{array}$

$\begin{array}{llllll}8.442 \mathrm{E}-35 & 5.387 \mathrm{E}-34 & 9.829 \mathrm{E}-31 & 6.745 \mathrm{E}-30 & 1.376 \mathrm{E}-26 & 1.966 \mathrm{E}-23\end{array}$

$\begin{array}{llllll}1.083 \mathrm{E}-28 & 3.280 \mathrm{E}-28 & 1.938 \mathrm{E}-26 & 6.856 \mathrm{E}-26 & 3.404 \mathrm{E}-23 & 2.967 \mathrm{E}-20\end{array}$

$\begin{array}{llllll}1.083 \mathrm{E}-28 & 3.280 \mathrm{E}-28 & 1.938 \mathrm{E}-26 & 6.857 \mathrm{E}-26 & 3.406 \mathrm{E}-23 & 2.969 \mathrm{E}-20\end{array}$

$\begin{array}{llllll}6.490 \mathrm{E}-31 & 8.194 \mathrm{E}-30 & 3.532 \mathrm{E}-25 & 3.757 \mathrm{E}-24 & 5.180 \mathrm{E}-21 & 1.118 \mathrm{E}-18\end{array}$

$\begin{array}{llllll}1.121 \mathrm{E}-24 & 7.124 \mathrm{E}-24 & 1.038 \mathrm{E}-20 & 5.653 \mathrm{E}-20 & 1.808 \mathrm{E}-17 & 2.257 \mathrm{E}-15\end{array}$

$\begin{array}{llllll}1.121 \mathrm{E}-24 & 7.124 \mathrm{E}-24 & 1.038 \mathrm{E}-20 & 5.654 \mathrm{E}-20 & 1.808 \mathrm{E}-17 & 2.258 \mathrm{E}-15\end{array}$

$\begin{array}{llllll}1.453 \mathrm{E}-15 & 1.431 \mathrm{E}-15 & 6.744 \mathrm{E}-16 & 3.130 \mathrm{E}-16 & 6.732 \mathrm{E}-19 & 2.092 \mathrm{E}-22\end{array}$

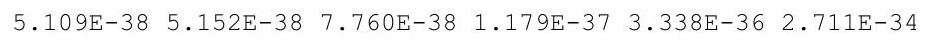

$2.777 \mathrm{E}-29 \quad 2.800 \mathrm{E}-29 \quad 4.217 \mathrm{E}-29 \quad 6.405 \mathrm{E}-29 \quad 1.814 \mathrm{E}-27 \quad 1.473 \mathrm{E}-25$

$2.777 \mathrm{E}-29 \quad 2.800 \mathrm{E}-29 \quad 4.217 \mathrm{E}-29 \quad 6.405 \mathrm{E}-29 \quad 1.814 \mathrm{E}-27 \quad 1.473 \mathrm{E}-25$

$2.313 \mathrm{E}-34 \quad 7.011 \mathrm{E}-34 \quad 4.348 \mathrm{E}-32 \quad 1.636 \mathrm{E}-31 \quad 1.991 \mathrm{E}-28 \quad 1.075 \mathrm{E}-24$

$\begin{array}{llllll}7.522 \mathrm{E}-28 & 7.645 \mathrm{E}-28 & 1.700 \mathrm{E}-27 & 3.840 \mathrm{E}-27 & 2.609 \mathrm{E}-24 & 1.382 \mathrm{E}-20\end{array}$

$\begin{array}{llllll}1.903 \mathrm{E}-34 & 5.788 \mathrm{E}-34 & 4.326 \mathrm{E}-32 & 1.945 \mathrm{E}-31 & 6.585 \mathrm{E}-28 & 7.162 \mathrm{E}-24\end{array}$

$\begin{array}{llllll}7.522 \mathrm{E}-28 & 7.645 \mathrm{E}-28 & 1.700 \mathrm{E}-27 & 3.840 \mathrm{E}-27 & 2.610 \mathrm{E}-24 & 1.383 \mathrm{E}-20\end{array}$

$2.759 \mathrm{E}-38 \quad 1.763 \mathrm{E}-37 \quad 3.537 \mathrm{E}-34 \quad 2.696 \mathrm{E}-33 \quad 1.591 \mathrm{E}-29 \quad 1.306 \mathrm{E}-25$

$\begin{array}{llllll}1.754 \mathrm{E}-27 & 1.781 \mathrm{E}-27 & 3.803 \mathrm{E}-27 & 8.247 \mathrm{E}-27 & 4.031 \mathrm{E}-24 & 1.385 \mathrm{E}-20\end{array}$

$\begin{array}{llllll}1.189 \mathrm{E}-31 & 3.613 \mathrm{E}-31 & 2.593 \mathrm{E}-29 & 1.119 \mathrm{E}-28 & 2.720 \mathrm{E}-25 & 1.915 \mathrm{E}-21\end{array}$

$\begin{array}{lllllll}2.268 \mathrm{E}-38 & 1.453 \mathrm{E}-37 & 3.301 \mathrm{E}-34 & 2.834 \mathrm{E}-33 & 3.431 \mathrm{E}-29 & 4.952 \mathrm{E}-25\end{array}$

$\begin{array}{llllll}1.754 \mathrm{E}-27 & 1.782 \mathrm{E}-27 & 3.829 \mathrm{E}-27 & 8.359 \mathrm{E}-27 & 4.303 \mathrm{E}-24 & 1.577 \mathrm{E}-20\end{array}$

$2.418 \mathrm{E}-27 \quad 3.048 \mathrm{E}-26 \quad 1.212 \mathrm{E}-21 \quad 1.192 \mathrm{E}-20 \quad 1.011 \mathrm{E}-17 \quad 1.425 \mathrm{E}-15$ $2.746 \mathrm{E}-16 \quad 8.281 \mathrm{E}-16 \quad 3.765 \mathrm{E}-14 \quad 1.019 \mathrm{E}-13 \quad 5.938 \mathrm{E}-12 \quad 3.106 \mathrm{E}-10$ $\begin{array}{llllll}1.403 \mathrm{E}-20 & 8.915 \mathrm{E}-20 & 1.288 \mathrm{E}-16 & 6.962 \mathrm{E}-16 & 2.077 \mathrm{E}-13 & 2.307 \mathrm{E}-11\end{array}$ $\begin{array}{llllll}1.788 \mathrm{E}-27 & 2.474 \mathrm{E}-26 & 1.095 \mathrm{E}-21 & 1.180 \mathrm{E}-20 & 1.777 \mathrm{E}-17 & 4.121 \mathrm{E}-15\end{array}$ $\begin{array}{llllll}2.746 \mathrm{E}-16 & 8.282 \mathrm{E}-16 & 3.778 \mathrm{E}-14 & 1.026 \mathrm{E}-13 & 6.146 \mathrm{E}-12 & 3.337 \mathrm{E}-10\end{array}$

$\begin{array}{llllll}8.071 \mathrm{E}-36 & 1.918 \mathrm{E}-34 & 1.782 \mathrm{E}-28 & 2.921 \mathrm{E}-27 & 6.369 \mathrm{E}-24 & 1.641 \mathrm{E}-21\end{array}$ $\begin{array}{lllllll}1.500 \mathrm{E}-24 & 9.460 \mathrm{E}-24 & 9.162 \mathrm{E}-21 & 3.634 \mathrm{E}-20 & 4.095 \mathrm{E}-18 & 3.725 \mathrm{E}-16\end{array}$ $\begin{array}{llllll}5.704 \mathrm{E}-29 & 7.161 \mathrm{E}-28 & 2.330 \mathrm{E}-23 & 1.985 \mathrm{E}-22 & 1.343 \mathrm{E}-19 & 2.677 \mathrm{E}-17\end{array}$ $\begin{array}{llllll}2.391 \mathrm{E}-35 & 1.064 \mathrm{E}-34 & 1.586 \mathrm{E}-28 & 2.820 \mathrm{E}-27 & 1.084 \mathrm{E}-23 & 4.636 \mathrm{E}-21\end{array}$ $\begin{array}{llllll}1.500 \mathrm{E}-24 & 9.461 \mathrm{E}-24 & 9.185 \mathrm{E}-21 & 3.654 \mathrm{E}-20 & 4.229 \mathrm{E}-18 & 3.992 \mathrm{E}-16\end{array}$

$\begin{array}{llllll}2.623 E-22 & 2.652 E-22 & 4.545 E-22 & 7.875 E-22 & 6.395 E-20 & 2.075 E-17\end{array}$ 
RESRAD-OFFSITE, Version 2.

Parent Dose Report

Title : Offsite Resident Farmer Deterministic Run

File : RF SG FWD-FINAL V2.ROF

Individual Nuclide Dose Summed Over All Pathways

Parent Nuclide and Thread Fraction Indicated

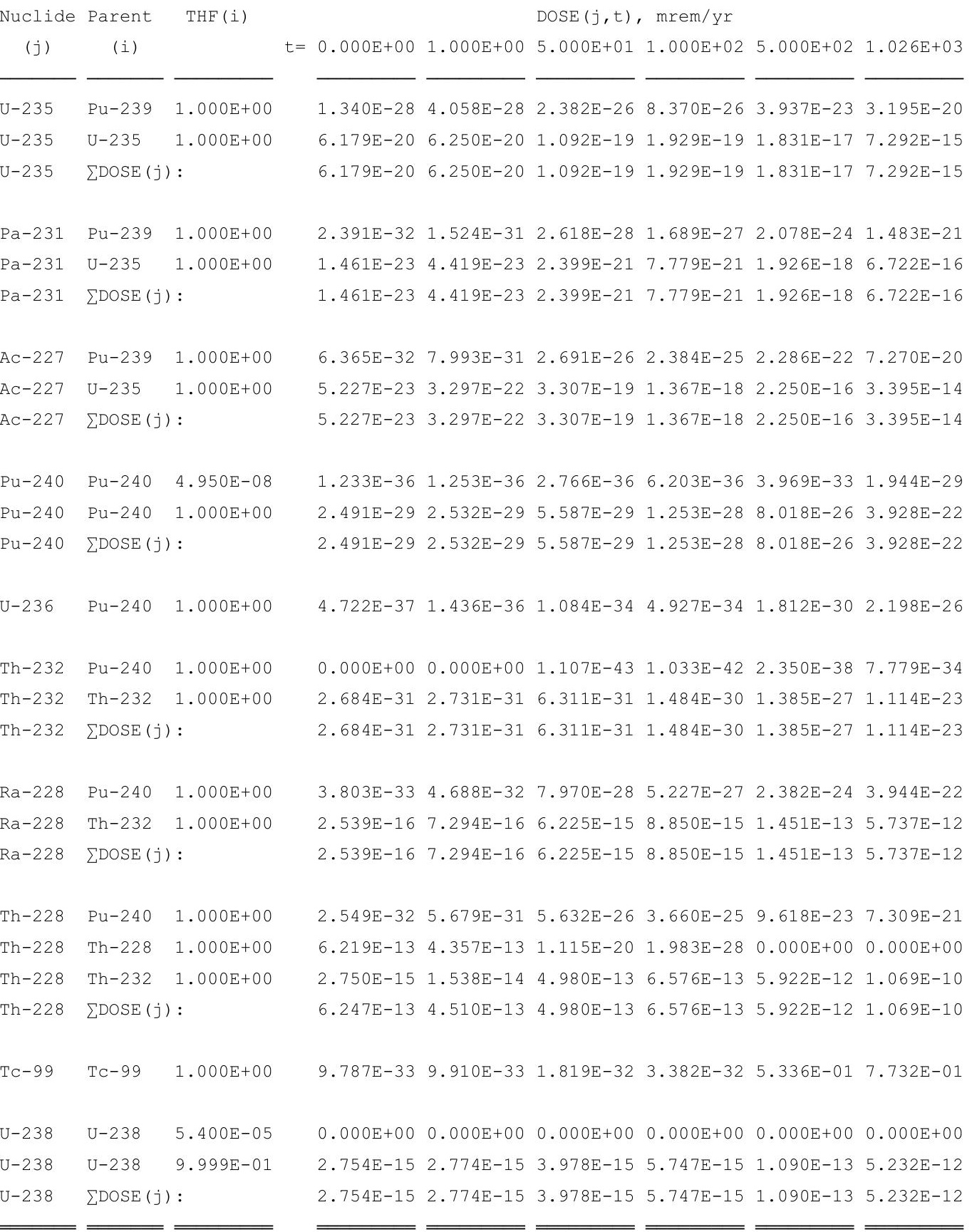

THF(i) is the thread fraction of the parent nuclide. 
RESRAD-OFFSITE, Version 2.

Parent Dose Report

Title : Offsite Resident Farmer Deterministic Run

File : RF SG FWD-FINAL V2.ROF

Individual Nuclide Soil Concentration

Parent Nuclide and Thread Fraction Indicated

\begin{tabular}{|c|c|c|c|c|c|c|c|c|c|}
\hline $\begin{array}{l}\text { aclide } \\
\text { (j) }\end{array}$ & $\begin{array}{c}\text { Parent } \\
\text { (i) }\end{array}$ & $\mathrm{THF}(i)$ & $t=$ & $0.000 \mathrm{E}+00$ & $1.000 \mathrm{E}+00$ & $\begin{array}{r}S(j, t), \\
5.000 E+01\end{array}$ & $\begin{array}{l}\mathrm{pCi} / \mathrm{g} \\
1.000 \mathrm{E}+02\end{array}$ & $5.000 \mathrm{E}+02$ & $1.026 \mathrm{E}+03$ \\
\hline $1-241$ & $A m-241$ & $1.000 \mathrm{E}+00$ & & $3.500 \mathrm{E}+03$ & $3.494 \mathrm{E}+03$ & $3.230 \mathrm{E}+03$ & $2.981 E+03$ & $1.567 \mathrm{E}+03$ & $6.732 \mathrm{E}+02$ \\
\hline-237 & $A m-241$ & $1.000 \mathrm{E}+00$ & & $0.000 \mathrm{E}+00$ & $1.133 \mathrm{E}-03$ & $5.436 \mathrm{E}-02$ & $1.043 \mathrm{E}-01$ & $3.810 \mathrm{E}-01$ & $5.417 \mathrm{E}-01$ \\
\hline-237 & $N p-237$ & $1.000 \mathrm{E}+00$ & & $5.500 \mathrm{E}+02$ & $5.500 \mathrm{E}+02$ & $5.478 E+02$ & $5.457 \mathrm{E}+02$ & $5.288 \mathrm{E}+02$ & $5.073 E+02$ \\
\hline-237 & $\sum S(j):$ & & & $5.500 \mathrm{E}+02$ & $5.500 \mathrm{E}+02$ & $5.479 \mathrm{E}+02$ & $5.458 \mathrm{E}+02$ & $5.291 \mathrm{E}+02$ & $5.078 \mathrm{E}+02$ \\
\hline-233 & $A m-241$ & $1.000 \mathrm{E}+00$ & & $0.000 \mathrm{E}+00$ & $2.508 \mathrm{E}-09$ & $6.025 E-06$ & $2.344 \mathrm{E}-05$ & $4.742 \mathrm{E}-04$ & $1.556 \mathrm{E}-03$ \\
\hline 233 & $\mathrm{~Np}-237$ & $1.000 \mathrm{E}+00$ & & $0.000 \mathrm{E}+00$ & $2.405 E-03$ & 1.200E-01 & $2.394 \mathrm{E}-01$ & $1.174 \mathrm{E}+00$ & $2.349 \mathrm{E}+00$ \\
\hline 233 & $\sum S(j):$ & & & $0.000 \mathrm{E}+00$ & $2.405 E-03$ & $1.200 \mathrm{E}-01$ & $2.394 \mathrm{E}-01$ & $1.174 \mathrm{E}+00$ & $2.350 \mathrm{E}+00$ \\
\hline-229 & $A m-241$ & $1.000 \mathrm{E}+00$ & & $0.000 \mathrm{E}+00$ & $8.043 \mathrm{E}-14$ & $9.538 \mathrm{E}-09$ & 7. $463 \mathrm{E}-08$ & $7.873 E-06$ & $5.545 E-05$ \\
\hline-229 & $\mathrm{~Np}-237$ & $1.000 \mathrm{E}+00$ & & $0.000 \mathrm{E}+00$ & $1.150 \mathrm{E}-07$ & $2.830 \mathrm{E}-04$ & $1.128 \mathrm{E}-03$ & $2.750 \mathrm{E}-02$ & $1.119 \mathrm{E}-01$ \\
\hline-229 & $\sum S(j):$ & & & $0.000 \mathrm{E}+00$ & $1.150 \mathrm{E}-07$ & $2.830 E-04$ & $1.128 E-03$ & $2.750 \mathrm{E}-02$ & $1.120 \mathrm{E}-01$ \\
\hline-137 & $\mathrm{Cs}-137$ & $1.000 \mathrm{E}+00$ & & $1.900 \mathrm{E}+02$ & $1.857 \mathrm{E}+02$ & $5.979 \mathrm{E}+01$ & $1.881 E+01$ & $1.809 \mathrm{E}-03$ & $9.436 \mathrm{E}-09$ \\
\hline-238 & $\mathrm{Pu}-238$ & $1.840 \mathrm{E}-09$ & & $7.176 \mathrm{E}-06$ & $7.119 \mathrm{E}-06$ & $4.832 E-06$ & $3.254 E-06$ & $1.375 E-07$ & $2.144 E-09$ \\
\hline-238 & $\mathrm{Pu}-238$ & $1.000 \mathrm{E}+00$ & & $3.900 \mathrm{E}+03$ & $3.869 \mathrm{E}+03$ & $2.626 \mathrm{E}+03$ & $1.768 \mathrm{E}+03$ & 7. $472 \mathrm{E}+01$ & $1.165 \mathrm{E}+00$ \\
\hline-238 & $\sum S(j):$ & & & $3.900 \mathrm{E}+03$ & $3.869 E+03$ & $2.626 E+03$ & $1.768 \mathrm{E}+03$ & $7.472 \mathrm{E}+01$ & $1.165 \mathrm{E}+00$ \\
\hline 34 & $\mathrm{Pu}-238$ & $1.000 \mathrm{E}+00$ & & $0.000 \mathrm{E}+00$ & $1.101 \mathrm{E}-02$ & $4.564 \mathrm{E}-01$ & 7. $633 \mathrm{E}-01$ & $1.362 \mathrm{E}+00$ & $1.377 \mathrm{E}+00$ \\
\hline 234 & $\mathrm{U}-234$ & $1.000 \mathrm{E}+00$ & & $1.800 \mathrm{E}+04$ & $1.800 \mathrm{E}+04$ & $1.799 \mathrm{E}+04$ & $1.797 \mathrm{E}+04$ & $1.785 \mathrm{E}+04$ & $1.770 \mathrm{E}+04$ \\
\hline 234 & $\mathrm{U}-238$ & $9.999 \mathrm{E}-01$ & & $0.000 \mathrm{E}+00$ & $9.071 \mathrm{E}-03$ & $4.532 \mathrm{E}-01$ & $9.058 \mathrm{E}-01$ & $4.502 \mathrm{E}+00$ & $9.167 \mathrm{E}+00$ \\
\hline & $\sum S(j):$ & & & $1.800 \mathrm{E}+04$ & $1.800 \mathrm{E}+04$ & $1.799 \mathrm{E}+04$ & $1.797 \mathrm{E}+04$ & $1.786 \mathrm{E}+04$ & $1.771 \mathrm{E}+04$ \\
\hline
\end{tabular}

$\mathrm{Th}-230 \mathrm{Pu}-238 \quad 1.000 \mathrm{E}+00$

Th-230 Th-230 1.000E+00

$\mathrm{Th}-230 \mathrm{U}-234 \quad 1.000 \mathrm{E}+00$

Th-230 U-238 9.999E-01

Th-230 $\sum S(j):$

$0.000 \mathrm{E}+00 \quad 5.024 \mathrm{E}-08 \quad 1.095 \mathrm{E}-04 \quad 3.884 \mathrm{E}-04 \quad 4.705 \mathrm{E}-03 \quad 1.118 \mathrm{E}-02$

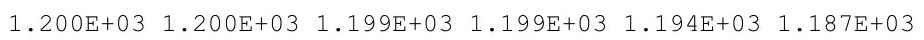
$\begin{array}{lllllll}0.000 \mathrm{E}+00 & 1.620 \mathrm{E}-01 & 8.096 \mathrm{E}+00 & 1.618 \mathrm{E}+01 & 8.047 \mathrm{E}+01 & 1.640 \mathrm{E}+02\end{array}$ $0.000 \mathrm{E}+00 \quad 4.133 \mathrm{E}-08 \quad 1.020 \mathrm{E}-04 \quad 4.078 \mathrm{E}-04 \quad 1.014 \mathrm{E}-02 \quad 4.239 \mathrm{E}-02$

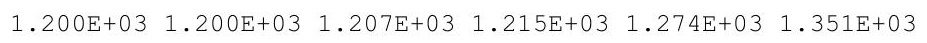

$0.000 \mathrm{E}+00 \quad 7.396 \mathrm{E}-12 \quad 8.112 \mathrm{E}-07 \quad 5.891 \mathrm{E}-06 \quad 3.952 \mathrm{E}-04 \quad 1.952 \mathrm{E}-03$ $\begin{array}{lllllllll}0.000 \mathrm{E}+00 & 5.197 \mathrm{E}-01 & 2.570 \mathrm{E}+01 & 5.082 \mathrm{E}+01 & 2.324 \mathrm{E}+02 & 4.258 \mathrm{E}+02\end{array}$ $0.000 \mathrm{E}+00 \quad 3.553 \mathrm{E}-05 \quad 8.706 \mathrm{E}-02 \quad 3.455 \mathrm{E}-01 \quad 8.122 \mathrm{E}+00 \quad 3.162 \mathrm{E}+01$ $0.000 \mathrm{E}+00 \quad 6.207 \mathrm{E}-12 \quad 7.326 \mathrm{E}-07 \quad 5.825 \mathrm{E}-06 \quad 6.943 \mathrm{E}-04 \quad 5.644 \mathrm{E}-03$ $\begin{array}{llllll}0.000 \mathrm{E}+00 \quad 5.198 \mathrm{E}-01 & 2.579 \mathrm{E}+01 \quad 5.117 \mathrm{E}+01 & 2.406 \mathrm{E}+02 \quad 4.575 \mathrm{E}+02\end{array}$

$0.000 \mathrm{E}+00 \quad 5.853 \mathrm{E}-14 \quad 2.418 \mathrm{E}-07 \quad 2.812 \mathrm{E}-06 \quad 3.398 \mathrm{E}-04 \quad 1.827 \mathrm{E}-03$ $\begin{array}{lllllll}0.000 \mathrm{E}+00 & 8.092 \mathrm{E}-03 & 1.269 \mathrm{E}+01 & 3.535 \mathrm{E}+01 & 2.188 \mathrm{E}+02 \quad 4.150 \mathrm{E}+02\end{array}$ $\begin{array}{lllllll}0.000 \mathrm{E}+00 & 3.721 \mathrm{E}-07 & 3.192 \mathrm{E}-02 & 1.920 \mathrm{E}-01 & 7.171 \mathrm{E}+00 & 2.981 \mathrm{E}+01\end{array}$ $\begin{array}{llllll}0.000 \mathrm{E}+00 & 1.978 \mathrm{E}-13 & 2.150 \mathrm{E}-07 & 2.712 \mathrm{E}-06 & 5.779 \mathrm{E}-04 & 5.159 \mathrm{E}-03\end{array}$ $\begin{array}{lllllll}0.000 \mathrm{E}+00 & 8.093 \mathrm{E}-03 & 1.272 \mathrm{E}+01 & 3.554 \mathrm{E}+01 & 2.260 \mathrm{E}+02 \quad 4.448 \mathrm{E}+02\end{array}$

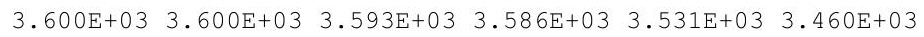


RESRAD-OFFSITE, Version 2.

Parent Dose Report

Title : Offsite Resident Farmer Deterministic Run

File : RF SG FWD-FINAL V2.ROF

Individual Nuclide Soil Concentration

Parent Nuclide and Thread Fraction Indicated

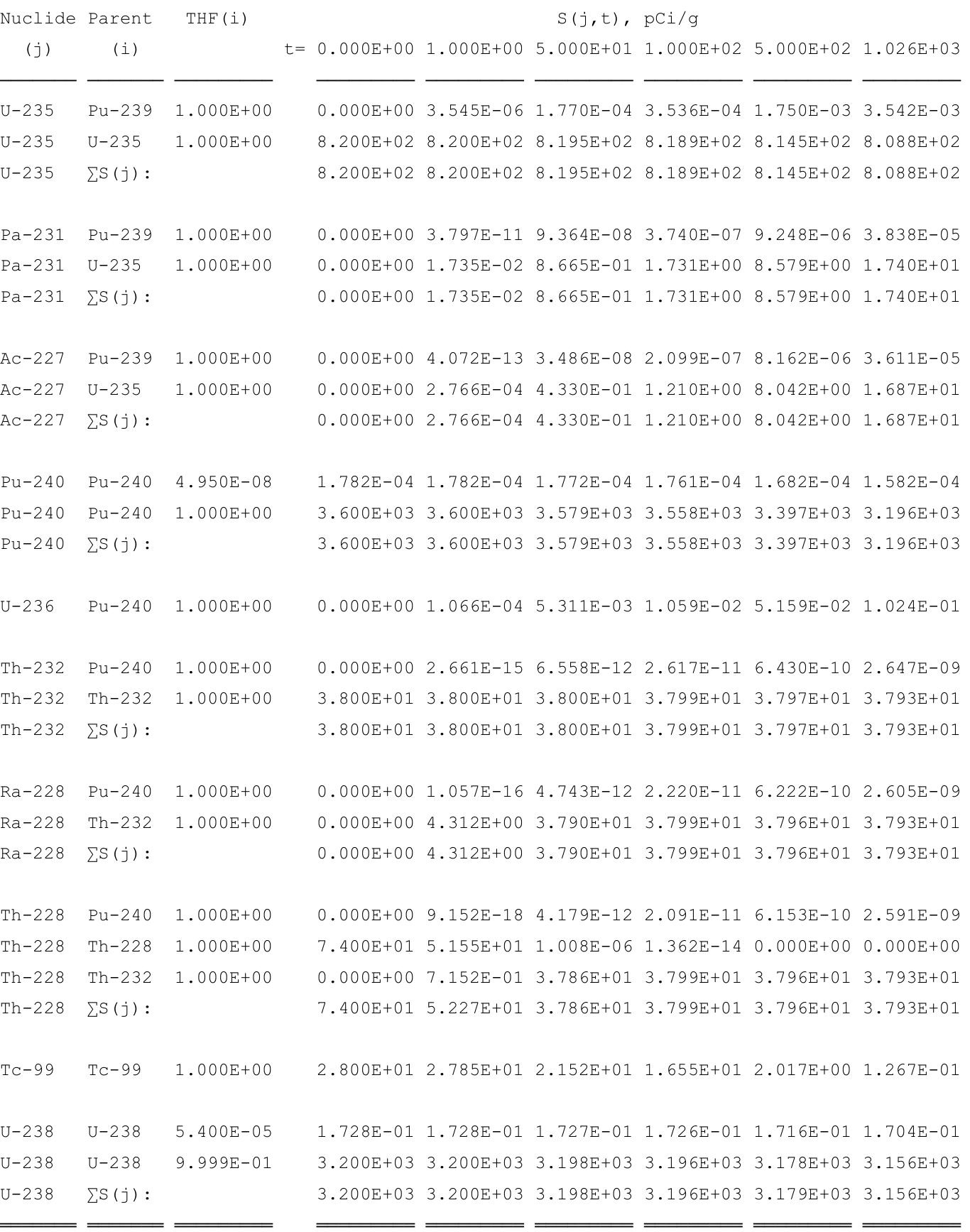

THF(i) is the thread fraction of the parent nuclide. 
RESRAD-OFFSITE, Version $2.5 \quad \mathrm{~T}^{1 / 2}$ Limit $=180$ days

Parent Dose Report

Title : Offsite Resident Farmer Deterministic Run

File : RF SG FWD-FINAL v2.ROF

Run Time Information

ResOCalc.EXE execution began at 15:24 on 05/02/2011

ResOCalc.EXE execution ended at 15:25 on 05/02/2011

ResOCalc.EXE execution time 30.844 seconds

DCN 5090-TR-01-6

D-133 
DOSE MODELING EVALUATIONS AND TECHNICAL SUPPORT DOCUMENT FOR THE AUTHORIZED LIMITS REQUEST FOR THE C-746-U LANDFILL AT THE PADUCAH GASEOUS DIFFUSION PLANT

Appendix E: Additional Documentation 


\section{Table of Contents}

Peak Dose Assessment for Proposed DOE-PPPO Authorized Limits .......................E-1

Evaluation of the Potential for Pooled Leachate to Rise above Ground Surface at

$U$-Landfill as a Result of Synthetic Liner Failure. E-2

Probabilistic Risk Assessment Analysis for Establishing the Technetium-99 Single Radionuclide Soil Guideline from the Drinking Water Pathway for the Offsite Resident Farmer for the C-746-U Landfill at the Paducah Gaseous Diffusion Plant, Paducah Kentucky E-3

Quality Control (QC) for Dose Modeling Evaluations and Technical Support Document for the Authorized Limits Request for the C-746-U Landfill at the Paducah Gaseous Diffusion Plant, Paducah, Kentucky (Oak Ridge Institute for Science and Education, May 2011) .................................................................................. E-4

Quality Control (QC) for the Peak Dose Assessment for Proposed DOE-PPPO Authorized Limits (Oak Ridge Institute for Science and Education, July 2011)......... E-5 


\title{
Peak Dose Assessment for Proposed DOE-PPPO Authorized Limits
}

\author{
By
}

D. G. Maldonado, M.S.

Independent Environmental Assessment and Verification Program

Oak Ridge Institute for Science and Education

Oak Ridge, TN 
THIS PAGE INTENTIONALLY LEFT BLANK 


\section{ORISE}

OAK RIDGE INSTITUTE FOR SCIENCE AND EDUCATION

\section{Peak Dose Assessment for Proposed DOE-PPPD Autharized Limits}

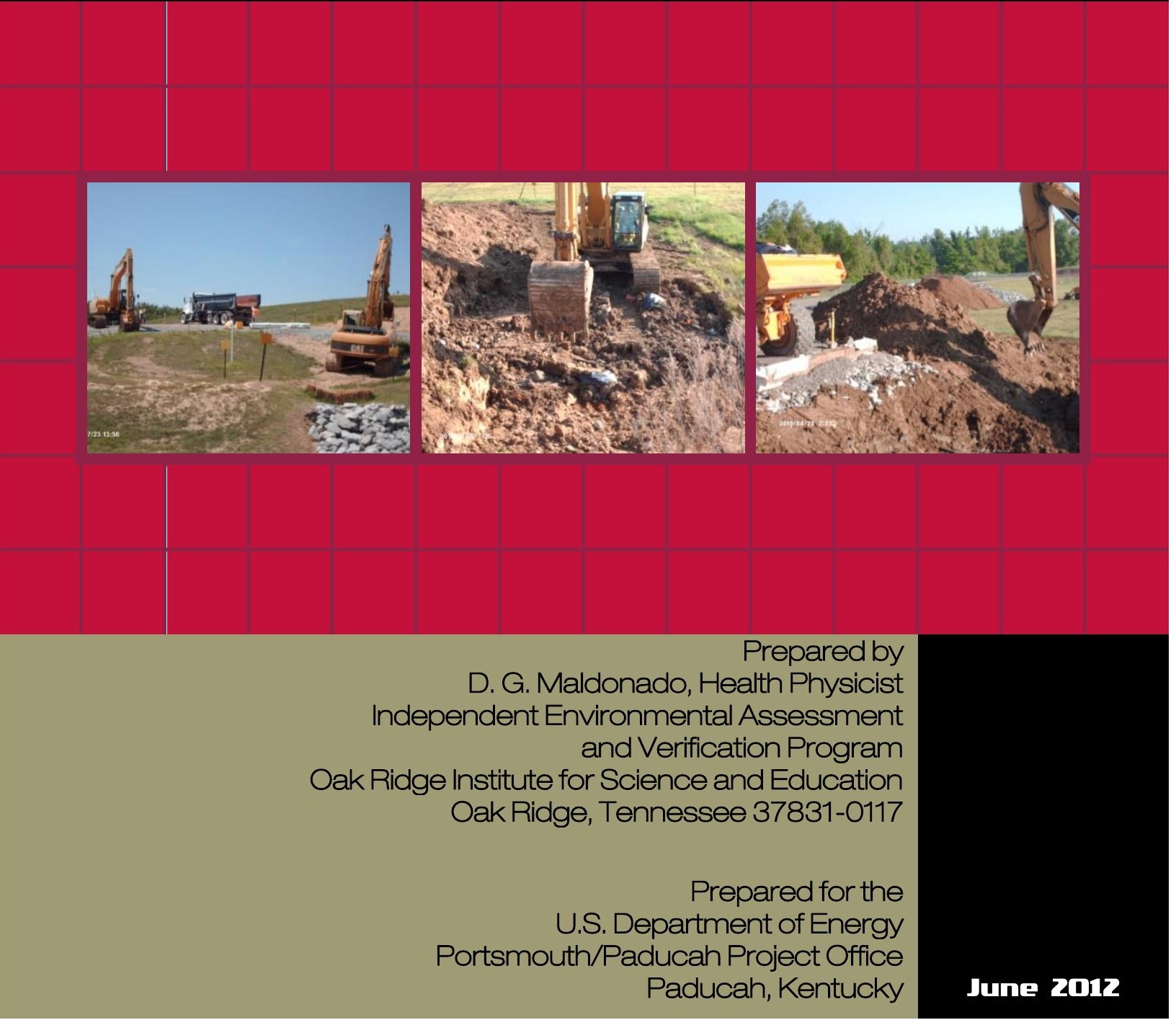

Disclaimer-The dose modeling software codes utilized in this report, RESRAD and RESRAD-OFFSITE, have undergone verification and validation (V\&V) testing by the Argonne National Laboratory Environmental Science Division (ANL/ESD). The RESRAD codes have been approved and used by the U.S. Department of Energy, Nuclear Regulatory Commission, and other regulatory agencies; however, ORISE takes no responsibility for the underlying accuracy of these codes.

Approved for public release; further dissemination unlimited. 
The Oak Ridge Institute for Science and Education (ORISE) is a U.S. Department of Energy institute focusing on scientific initiatives to research health risks from occupational hazards, assess environmental cleanup, respond to radiation medical emergencies, support national security and emergency preparedness, and educate the next generation of scientists. ORISE is managed by Oak Ridge Associated Universities.

\section{NOTICES}

The opinions expressed herein do not necessarily reflect the opinions of the sponsoring institutions of Oak Ridge Associated Universities.

This report was prepared as an account of work sponsored by the United States Government. Neither the United States Government nor the U.S. Department of Energy, nor any of their employees, makes any warranty, expressed or implied, or assumes any legal liability or responsibility for the accuracy, completeness, or usefulness of any information, apparatus, product, or process disclosed, or represents that its use would not infringe on privately owned rights. Reference herein to any specific commercial product, process, or service by trade name, mark, manufacturer, or otherwise, does not necessarily constitute or imply its endorsement or recommendation, or favor by the U.S. Government or any agency thereof. The views and opinions of authors expressed herein do not necessarily state or reflect those of the U.S. Government or any agency thereof. 
Peak Dose Assessment for Proposed DOE-PPPO Authorized Limits

Prepared by

D. G. Maldonado, M.S.

\section{Independent Environmental Assessment and Verification Program}

Oak Ridge Institute for Science and Education

Oak Ridge, Tennessee 37831-0117

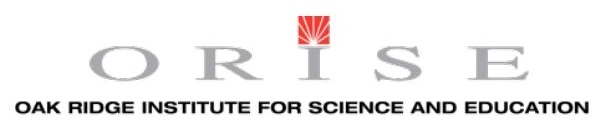

Prepared for the

U.S. Department of Energy

Portsmouth/Paducah Project Office

Paducah, Kentucky

FINAL REPORT

June 2012 
The Oak Ridge Institute for Science and Education (ORISE) appreciated the opportunity to provide technical support to the U.S. Department of Energy Portsmouth/Paducah Project Office (DOE-PPPO) at the Paducah Gaseous Diffusion Plant (PGDP), Paducah, Kentucky. ORISE conducted a peak dose assessment in support of the Authorized Limits Request for Solid Waste Disposal at Landfill C-746-U at the Paducah Gaseous Diffusion Plant.

The author gratefully acknowledges the following individuals for their contributions and assistance with this project:

\section{TECHNICAL SUPPORT}

Dr. Richard Bonczek and Mr. Donald Dihel of DOE-PPPO

Dr. John A. Volpe of Performance Results Corporation (PRC)

Mr. Tom Hansen, CHP, PMP of Ameriphysics, LLC

Dr. Charley Yu, CHP and Dr. Emmanuel Gnanapragasam, PE of

Argonne National Laboratory (ANL)

TECHNICAL REVIEW

Mr. Alex Boerner, CHP of ORISE

ADMINISTRATIVE SUPPORT

Ms. Becky Johnson and Ms. Fleur Riva of ORISE

\section{FINANCIAL ACCOUNTABILITY}

Ms. LaTosha Barton of ORISE 
Table of Contents

Abstract _ 1

1.0: Introduction _ _ 2

2.0: Materials and Methods___ 3

2.1 Radionuclide Concentrations___ 4

2.2 Computer Codes___ 4

2.2.1 RESRAD 4

2.2.2 RESRAD-OFFSITE _L 5

2.3 Peak Dose Assessment Methodology____ 5

2.3.1 Deterministic Analyses to Calculate Peak Doses for all Receptors ___ 6

2.3.1.1 Peak Dose Assessment for Receptors Modeled During the Operational Period_ 6

2.3.1.2 Peak Dose Assessment for Receptors Modeled During the Post-Institutional

Control Period

2.3.2 Probabilistic Analysis to Calculate Peak of the Mean Doses for the Offsite Resident

Farmer

2.3.2.1 Peak of the Mean Dose Assessment for the Offsite Resident Farmer

3.0: Results and Discussion

3.1 Deterministic Peak Dose Assessment for Receptors Modeled During the Operational Period

$\begin{array}{lll}\text { 3.1.1 } & \text { First Assessment } & 10 \\ \text { 3.1.2 Second Assessment___ } & 14\end{array}$

3.2 Deterministic Peak Dose Assessment for Receptors Modeled During the PostInstitutional Control Period.

3.2.1 First Assessment 18

3.2.2 Second Assessment___ 31

3.2.3 Third Assessment _ـ 42

3.3 Probabilistic Peak of the Mean Dose Assessment for the Offsite Resident Farmer

3.3.1 First Run

3.3 .2 Second Run 55

3.3.3 ThirdRun — 56

3.4 Summary of Results __ 58

4.0: References __ 59

Attachment A: RESRAD Summary Reports __A

Attachment B: RESRAD-OFFSITE Parent Dose Reports ___ $B$

Attachment C: RESRAD-OFFSITE Parent Dose Reports and Uncertainty Analysis Reports for the Tc-99Runs. 
Table 2-1. DOE-PPPO Proposed Radionuclide Concentrations for the C-746-U Landfil _ 4 Table 3-1. Peak Dose from DOE-PPPO Proposed Single Radionuclide Soil Guidelines_ 10 Table 3-2. Peak Dose from DOE-PPPO Proposed AL Volumetric Concentrations __ 14 Table 3-3. Peak Doses from DOE-PPPO Proposed Single Radionuclide Soil Guidelines _ 19 Table 3-4. Exposure Pathways and Doses Contributing to the Tc-99 Dose for the Offsite Resident Farmer 30

Table 3-5. Peak Doses from DOE-PPPO Proposed Single Radionuclide Soil Guidelines _ 31 Table 3-6. Peak Doses from DOE-PPPO Proposed Single Radionuclide Soil Guidelines _42 Table 3-7. Peak of the Mean Doses for the First Probabilistic Run Using the DOE-PPPO Proposed Single Radionuclide Soil Guideline for Tc-99 55

Table 3-8. Peak of the Mean Doses for the Second Probabilistic Run Using the DOE-PPPO Proposed Single Radionuclide Soil Guideline for Tc-99 55

Table 3-9. Peak of the Mean Doses for the First and Second Probabilistic Run Using the DOE-PPPO Proposed Single Radionuclide Soil Guideline for Tc-99 56

Table 3-10. Peak of the Mean Doses for the Third Probabilistic Run Using the DOE-PPPO Proposed Single Radionuclide Soil Guideline for Tc-99

Table 3-11. Summary of Deterministic Results for Projected Highest Doses for all Receptors Among all Time Horizons 


\section{List of Figures}

Figure 1-1. C-746-U Landfill Cross-Section (Excerpted from DOE 2003) 3

Figure 3-1. Dose to the Landfill Worker from all Selected Targeted Radionuclides and Pathways 11

Figure 3-2. Dose to the Landfill Worker by Exposure Pathways 12 Figure 3-3. Dose to the Trespasser from all Selected Targeted Radionuclides and Pathways 13

Figure 3-4. Dose to the Trespasser by Exposure Pathways 14 Figure 3-5. Dose to the Landfill Worker from all Selected Targeted Radionuclides and Pathways 15

Figure 3-6. Dose to the Landfill Worker by Exposure Pathways 16 Figure 3-7. Dose to the Trespasser from all Selected Targeted Radionuclides and Pathways 17

Figure 3-8. Dose to the Trespasser by Exposure Pathways 18 Figure 3-9. Dose to the Resident Farmer (onsite) from all Selected Targeted Radionuclides and Pathways 20

Figure 3-10. Dose to the Resident Farmer (onsite) by Exposure Pathways 21 Figure 3-11. Dose to the Resident Gardener from all Selected Targeted Radionuclides and Pathways 22

Figure 3-12. Dose to the Resident Gardener by Exposure Pathways 23

Figure 3-13. Dose to the Recreational User from all Selected Targeted Radionuclides and Pathways

Figure 3-14. Dose to the Recreational User by Exposure Pathways 25

Figure 3-15. Dose to the Outdoor Worker from all Selected Targeted Radionuclides and Pathways

Figure 3-16. Dose to the Outdoor Worker by Exposure Pathways

Figure 3-17. Dose to the Offsite Resident Farmer from all Selected Targeted Radionuclides and Pathways 28

Figure 3-18. Dose to the Offsite Resident Farmer by Exposure Pathways 29

Figure 3-19. Tc-99 Dose by Contributing Exposure Pathway 30

Figure 3-20. Dose to the Resident Farmer (onsite) from all Selected Targeted Radionuclides and Pathways 32

Figure 3-21. Dose to the Resident Farmer (onsite) by Exposure Pathways 33 Figure 3-22. Dose to the Resident Gardener from all Selected Targeted Radionuclides and Pathways 34

Figure 3-23. Dose to the Resident Gardener by Exposure Pathways 35 


\section{List of Figures}

Figure 3-24. Dose to the Recreational User from all Selected Targeted Radionuclides and Pathways

Figure 3-25. Dose to the Recreational User by Exposure Pathways 37

Figure 3-26. Dose to the Outdoor Worker from all Selected Targeted Radionuclides and Pathways 38

Figure 3-27. Dose to the Outdoor Worker by Exposure Pathways 39

Figure 3-28. Dose to the Offsite Resident Farmer from all Selected Targeted Radionuclides and Pathways 41

Figure 3-29. Dose to the Offsite Resident Farmer by Exposure Pathways 42

Figure 3-30. Dose to the Resident Farmer (onsite) from all Selected Targeted Radionuclides and Pathways 44

Figure 3-31. Dose to the Resident Farmer (onsite) by Exposure Pathways 45 Figure 3-32. Dose to the Resident Gardener from all Selected Targeted Radionuclides and Pathways 46

Figure 3-33. Dose to the Resident Gardener by Exposure Pathways 47

Figure 3-34. Dose to the Recreational User from all Selected Targeted Radionuclides and Pathways 48

Figure 3-35. Dose to the Recreational User by Exposure Pathways 49

Figure 3-36. Dose to the Outdoor Worker from all Selected Targeted Radionuclides and Pathways 50

Figure 3-37. Dose to the Outdoor Worker by Exposure Pathways 51

Figure 3-38. Dose to the Offsite Resident Farmer from all Selected Targeted Radionuclides and Pathways 52

Figure 3-39. Dose to the Offsite Resident Farmer by Exposure Pathways 53 
Terms, Acronyms, and Abbreviations

\begin{tabular}{|c|c|}
\hline $\mathrm{ACL}$ & Administrative Control Level \\
\hline AL & Authorized Limit(s) \\
\hline Am-241 & americium-241 \\
\hline ANL & Argonne National Laboratory \\
\hline $\mathrm{Ci}$ & curies \\
\hline Cs-137 & cesium-137 \\
\hline CSM & Conceptual Site Model \\
\hline DOE & U.S. Department of Energy \\
\hline DOE-PPPO & DOE Portsmouth/Paducah Project Office \\
\hline EPA & U.S. Environmental Protection Agency \\
\hline KAR & Kentucky Administrative Regulations \\
\hline KDWM & Kentucky Division of Waste Management \\
\hline MCL & Maximum Contaminant Level \\
\hline mrem & millirem \\
\hline $\mathrm{mrem} / \mathrm{yr}$ & millirem per year \\
\hline Np-237 & neptunium-237 \\
\hline ORAU & Oak Ridge Associated Universities \\
\hline ORISE & Oak Ridge Institute for Science and Education \\
\hline ORO & Oak Ridge Office \\
\hline РCB & Polychlorinated Biphenyl \\
\hline $\mathrm{pCi} / \mathrm{g}$ & picocuries per gram \\
\hline PGDP & Paducah Gaseous Diffusion Plant \\
\hline PRS & Paducah Remediation Services \\
\hline Pu-238 & plutonium-238 \\
\hline Pu-239 & plutonium-239 \\
\hline Pu-240 & plutonium-240 \\
\hline Pu-241 & plutonium-241 \\
\hline RCRA & Resource Conservation and Recovery Act \\
\hline Tc-99 & technetium-99 \\
\hline Th-228 & thorium-228 \\
\hline Th-230 & thorium-230 \\
\hline Th-232 & thorium-232 \\
\hline TSCA & Toxic Substances Control Act \\
\hline U-234 & uranium-234 \\
\hline U-235 & uranium-235 \\
\hline U-238 & uranium-238 \\
\hline yr & year(s) \\
\hline
\end{tabular}




\section{ABSTRACT}

The Oak Ridge Institute for Science and Education (ORISE), a U.S. Department of Energy (DOE) prime contractor, was contracted by the DOE Portsmouth/Paducah Project Office (DOE-PPPO) to conduct a peak dose assessment in support of the Authorized Limits Request for Solid Waste Disposal at Landfill C-746-U at the Paducah Gaseous Diffusion Plant (DOE-PPPO 2011a). The peak doses were calculated based on the DOE-PPPO Proposed Single Radionuclides Soil Guidelines and the DOE-PPPO Proposed Authorized Limits (AL) Volumetric Concentrations available in DOE-PPPO 2011a. This work is provided as an appendix to the Dose Modeling Evaluations and Technical Support Document for the Authorized Limits Request for the C-746-U Landfill at the Paducah Gaseous Diffusion Plant, Paducah, Kentucky (ORISE 2012).

The receptors evaluated in ORISE 2012 were selected by the DOE-PPPO for the additional peak dose evaluations. These receptors included a Landfill Worker, Trespasser, Resident Farmer (onsite), Resident Gardener, Recreational User, Outdoor Worker and an Offsite Resident Farmer. The RESRAD (Version 6.5) and RESRAD-OFFSITE (Version 2.5) computer codes were used for the peak dose assessments. Deterministic peak dose assessments were performed for all the receptors and a probabilistic dose assessment was performed only for the Offsite Resident Farmer at the request of the DOE-PPPO. In a deterministic analysis, a single input value results in a single output value. In other words, a deterministic analysis uses single parameter values for every variable in the code. By contrast, a probabilistic approach assigns parameter ranges to certain variables, and the code randomly selects the values for each variable from the parameter range each time it calculates the dose (NRC 2006). The receptor scenarios, computer codes and parameter input files were previously used in ORISE 2012. A few modifications were made to the parameter input files as appropriate for this effort. Some of these changes included increasing the time horizon beyond 1,050 years (yr), and using the radionuclide concentrations provided by the DOE-PPPO as inputs into the codes. The deterministic peak doses were evaluated within time horizons of $70 \mathrm{yr}$ (for the Landfill Worker and Trespasser), 1,050 yr, 10,000 yr and 100,000 yr (for the Resident Farmer [onsite], Resident Gardener, Recreational User, Outdoor Worker and Offsite Resident Farmer) at the request of the DOE-PPPO. The time horizons of 10,000 $\mathrm{yr}$ and 100,000 yr were used at the request of the DOE-PPPO for informational purposes only. The probabilistic peak of the mean dose assessment was performed for the Offsite Resident Farmer using Technetium-99 (Tc-99) and a time horizon of $1,050 \mathrm{yr}$.

The results of the deterministic analyses indicate that among all receptors and time horizons evaluated, the highest projected dose, 2,700 mrem/yr, occurred for the Resident Farmer (onsite) at $12,773 \mathrm{yr}$. The exposure pathways contributing to the peak dose are ingestion of plants, external gamma, and ingestion of milk, meat and soil. However, this receptor is considered an implausible receptor. The only receptors considered plausible are the Landfill Worker, Recreational User, Outdoor Worker and the Offsite Resident Farmer. The maximum projected dose among the 
plausible receptors is $220 \mathrm{mrem} / \mathrm{yr}$ for the Outdoor Worker and it occurs at 19,045 $\mathrm{yr}$. The exposure pathways contributing to the dose for this receptor are external gamma and soil ingestion.

The results of the probabilistic peak of the mean dose analysis for the Offsite Resident Farmer indicate that the average (arithmetic mean) of the peak of the mean doses for this receptor is $0.98 \mathrm{mrem} / \mathrm{yr}$ and it occurs at 1,050 yr. This dose corresponds to Tc-99 within the time horizon of $1,050 \mathrm{yr}$.

\section{O: INTRODUCTION}

The C-746-U Landfill at the Paducah Gaseous Diffusion Plant (PGDP) was constructed from 1995 to 1997 by DOE for disposal of solid wastes that are not regulated as hazardous waste under the Resource Conservation and Recovery Act (RCRA) Subtitle C or as waste containing Polychlorinated Biphenyls (PCBs) under the Toxic Substances Control Act (TSCA). Construction of the Landfill was needed to continue onsite disposal of certain wastes generated at the PGDP after an older landfill at the PDGP was filled to capacity and closed in accordance with Kentucky requirements.

The C-746-U Landfill is located north of the PGDP and is permitted by the Kentucky Energy and Environment Cabinet, Department for Environmental Protection, Division of Waste Management (KDWM) in accordance with the requirements of its solid waste regulations-401 Kentucky Administrative Regulations (KAR) 48, Standards for Solid Waste Facilities—and Subtitle D of RCRA. A cross-section of the Landfill is provided in Figure 1-1. C-746-U Landfill design features described here were excerpted from DOE 2003. Additional details regarding the Landfill design features, current and planned controls for the Landfill, conceptual site model (CSM) and other assumptions which directly influenced the ORISE modeling analyses, are provided in the main ORISE report Dose Modeling Evaluations and Technical Support Document for the Authorized Limits Request for the C-746-U Landfill at the Paducah Gaseous Diffusion Plant, Paducah, Kentucky (ORISE 2012). 


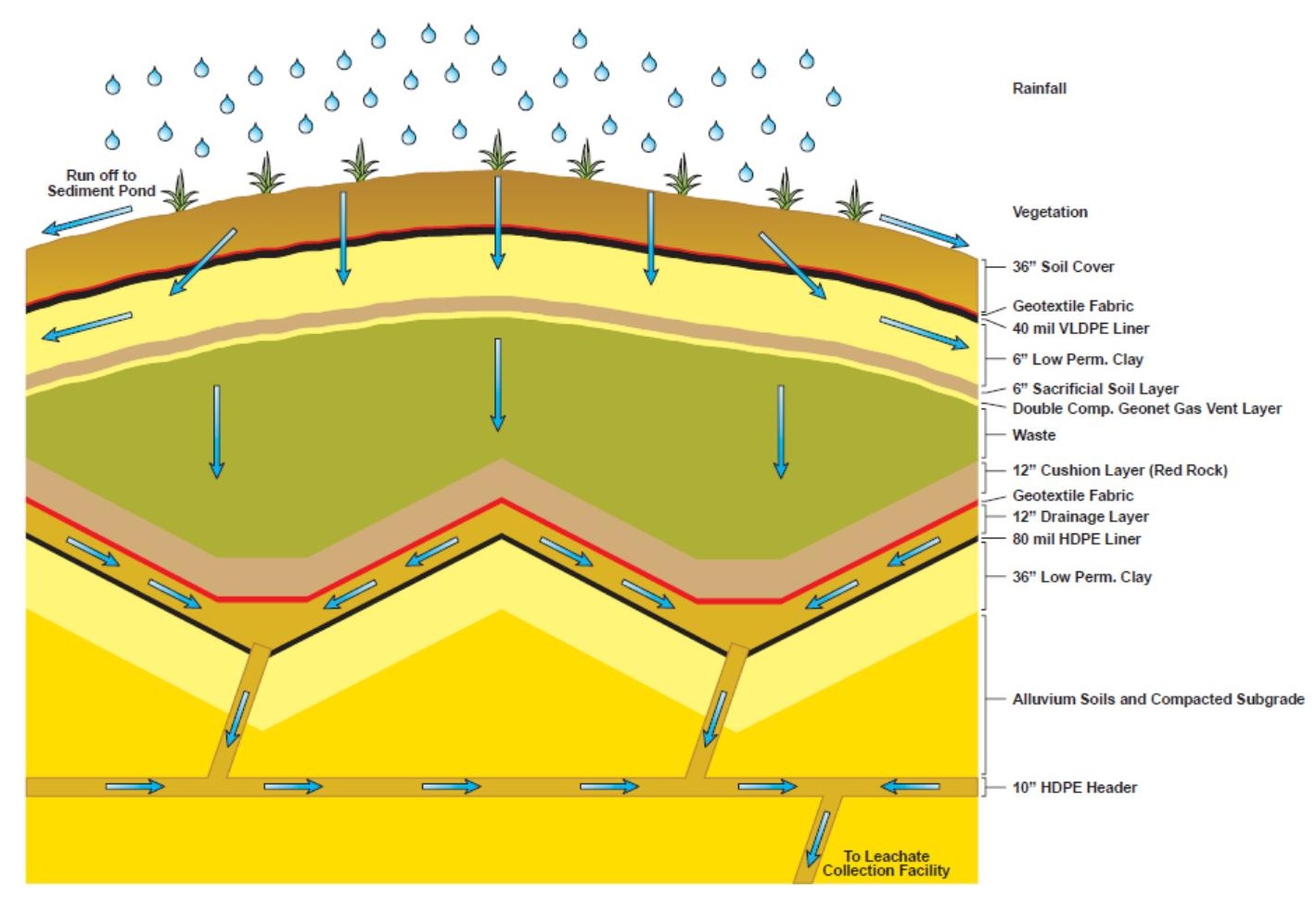

Figure 1-1. C-746-U Landfill Cross-Section (Excerpted from DOE 2003)

The purpose of the analyses presented in this report is to provide deterministic peak dose assessments for seven receptors based on the DOE-PPPO Proposed Single Radionuclide Soil Guidelines and the DOE-PPPO Proposed Authorized Limits as applicable. In addition, a probabilistic peak of the mean dose assessment is provided for only one receptor using the DOE-PPPO Proposed Single Radionuclide Soil Guideline for Tc-99 as selected by the DOE-PPPO. These assessments are conducted in support of the DOE-PPPO Authorized Limits Request for Solid Waste Disposal at Landfill C-746-U at the Paducab Gaseous Diffusion Plant (DOE-PPPO 2011a). The RESRAD (Version 6.5) and RESRAD-OFFSITE (Version 2.5) computer codes are used for the analyses. Furthermore, these analyses included a comparison to the $1 \mathrm{mrem} / \mathrm{yr}$ (above background) dose constraint and the $100 \mathrm{mrem} / \mathrm{yr}$ primary public dose limit (above background) as applicable to each receptor. The $1 \mathrm{mrem} / \mathrm{yr}$ (above background) dose constraint is referred to as a "walk-away" dose (Volpe 2001). This target dose constraint is both a DOE field element and a Commonwealth of Kentucky Radiation Health Branch constraint. The $100 \mathrm{mrem} / \mathrm{yr}$ is the primary public dose limit (above background) cited in DOE Order 458.1, Radiation Protection of the Public and the Environment (DOE 2011).

\section{O: MATERIALS AND METHODS}

The radionuclide concentrations, receptors and their pertinent assumptions for the analyses presented in this report are included in this section. A detailed description of the targeted radionuclides used, target doses and receptor scenarios is included in ORISE 2012. 
The specific radioactive material quantities in picocuries per gram (pCi/g) associated with individual radionuclides were provided by DOE-PPPO to ORISE. These concentrations $(\mathrm{pCi} / \mathrm{g}$ ) for the individual radionuclides were required as inputs to the modeling codes. Table 2-1 lists the radionuclide concentrations $(\mathrm{pCi} / \mathrm{g}$ ) provided by DOE-PPPO. The concentrations represent the DOE-PPPO Proposed Single Radionuclide Soil Guidelines and DOE-PPPO Proposed Authorized Limits (AL) Volumetric Concentrations for the C-746-U Landfill. Details on the derivation of these DOE-PPPO proposed concentrations are provided in the Authorized Limits Request for Solid Waste Disposal at Landfill C-746-U at the Paducah Gaseous Diffusion Plant (DOE-PPPO 2011a).

Table 2-1. DOE-PPPO Proposed Radionuclide Concentrations for the C-746-U Landfill

\begin{tabular}{|c|c|c|}
\hline Radionuclide & $\begin{array}{l}\text { PPPO Proposed } \\
\text { Single Radionuclide } \\
\text { Soil Guidelines } \\
\text { (pCi/g) }\end{array}$ & $\begin{array}{l}\text { PPPO Proposed } \\
\text { Authorized Limits } \\
\text { Volumetric } \\
\text { Concentrations } \\
\text { (pCi/g) }\end{array}$ \\
\hline${ }^{241} \mathrm{Am}$ & 35 & 70 \\
\hline${ }^{137} \mathrm{Cs}$ & 19 & 38 \\
\hline${ }^{237} \mathrm{~Np}$ & 5.5 & 11 \\
\hline${ }^{238} \mathrm{Pu}$ & 39 & 78 \\
\hline${ }^{239} \mathrm{Pu}$ & 36 & 72 \\
\hline${ }^{240} \mathrm{Pu}$ & 36 & 72 \\
\hline${ }^{99} \mathrm{TC}$ & 52 & 104 \\
\hline 228Th & 4 & 8 \\
\hline${ }^{230} \mathrm{Th}$ & 100 & 200 \\
\hline 232Th & 4 & 8 \\
\hline $234 \mathrm{U}$ & 160 & 320 \\
\hline $235 \mathrm{U}$ & 6.5 & 13 \\
\hline $238 \mathrm{U}$ & 160 & 320 \\
\hline
\end{tabular}

Two validated and verified computer codes, developed by Argonne National Laboratory (ANL), were used for the analyses presented in this report.

\subsubsection{RESRAD}

The RESRAD code was developed by ANL over 20 yr ago and has been updated several times since its introduction. RESRAD is a computer model used to evaluate radiation doses and excess cancer risks to an individual exposed from residual radioactive materials in soil (Yu et al. 2001). The code is recognized by the DOE (e.g., in DOE Order 458.1) for use in dose modeling evaluations.

The RESRAD code was used in this project to model six receptors. These include a Landfill Worker, Trespasser, Resident Farmer (onsite), Resident Gardener, Recreational User and an 
Outdoor Worker. The Landfill Worker and the Trespasser were modeled under current (C-746-U Landfill operational period) use scenarios and the other receptors were modeled under future use scenarios (C-746-U Landfill institutional and post-institutional control periods) as modeled in ORISE 2012.

2.2.2 RESRAD-OFFSITE

The RESRAD-OFFSITE dose modeling code was developed much more recently by ANL. RESRAD-OFFSITE is considered by ANL an evolution of RESRAD and is expected to replace RESRAD in the future. RESRAD-OFFSITE uses new models such as a three-dimensional dispersion groundwater flow and radionuclide transport model, a Gaussian plume model for atmospheric dispersion, and a deposition model used to estimate the accumulation of radionuclides in offsite locations and in foods (Yu et al. 2007).

The RESRAD-OFFSITE code evaluates the radiological dose and excess cancer risk to an individual who is exposed while located within or outside the area of initial (primary) contamination. The primary contamination, which is the source of all the releases modeled by the code, is assumed to be a layer of soil. The releases of contaminants from the primary contamination to the atmosphere, to surface runoff, and to groundwater are considered. Unlike RESRAD, RESRAD-OFFSITE can model both onsite and offsite receptors.

The RESRAD-OFFSITE code was used to model the Offsite Resident Farmer under a future use scenario (institutional and post-institutional control periods). Under this scenario, the Offsite Resident Farmer places a well 407 m north from the downgradient edge of the contaminated zone and builds a house, grows crops, and raises livestock near the DOE property boundary. This particular location was selected for consistency with a previously modeled offsite well (DOE 2003).

Several peak dose assessments were performed as requested by the DOE-PPPO. The peak doses appearing within the time periods of $70 \mathrm{yr}, 1,050 \mathrm{yr}, 10,000 \mathrm{yr}$ and 100,000 $\mathrm{yr}$ were determined. The codes' input files used for the peak dose assessment are the same input parameter files used for the development of ORISE 2012. The receptors' files were used, and edited as necessary.

The peak doses for all receptors were assessed by deterministic analyses. However, only the Offsite Resident Farmer's dose was assessed by probabilistic analysis to obtain the peak of the mean doses. The Offsite Resident Farmer was the receptor selected by the DOE-PPPO for the probabilistic analysis. The receptor scenario, computer code, and parameter input file previously used by ORISE for the Offsite Resident Farmer's deterministic analysis in ORISE 2012, are used for the probabilistic analysis. Modifications to the input file were made as needed. Although ORISE's deterministic analysis included 13 radionuclides, Tc-99 contributed $100 \%$ of the peak dose within 
the time frame of 1,050 $\mathrm{yr}$ and DOE-PPPO requested that the probabilistic analysis be performed using Tc-99 only.

The following approaches were used to evaluate the peak doses for all the receptors by using deterministic analyses.

2.3.1 DETERMINISTIC ANALYSES TO CALCULATEPEAKDOSES FORALL RECEPTORS

A deterministic analysis uses a single value for each parameter, resulting in a single dose value (Kamboj et al. 2000). The model computations are performed once using a single set of inputs to produce a single set of deterministic outputs (Yu et al. 2007). The deterministic analyses in this report were conducted to calculate the peak doses for all the receptors.

\subsubsection{Peak Dose Assessment for Receptors Modeled During the Operational Period}

Two peak dose evaluations were performed for the Landfill Worker and the Trespasser using a time horizon of $70 \mathrm{yr}$. The first evaluation involved using DOE-PPPO Proposed Single Radionuclide Soil Guidelines for each targeted radionuclide as inputs into the codes. The second evaluation involved using DOE-PPPO Proposed AL Volumetric Concentrations for each targeted radionuclide as inputs into the codes (See Table 2-1).

The $70 \mathrm{yr}$ time horizon represents the $20 \mathrm{yr}$ for the Landfill's operational period and an additional $50 \mathrm{yr}$ to begin the analysis as of the year 1960. Selection of 1960 represents a reasonable starting point for the analysis and allows for radioactive ingrowth and decay from that time forward. A time period beyond $70 \mathrm{yr}$ is not applicable for the Landfill Worker or the Trespasser, since these receptors are only modeled while the Landfill is operational. Details on the Landfill's operational period are included in ORISE 2012. The Landfill Worker is considered a plausible receptor and the Trespasser is considered an implausible receptor as indicated in ORISE 2012.

\subsubsection{Peak Dose Assessment for Receptors Modeled During the Post- Institutional Control Period}

Three separate peak dose evaluations were performed for the Resident Farmer (onsite), Resident Gardener, Recreational User, Outdoor Worker and Offsite Resident Farmer using time horizons of 1,050 yr, 10,000 yr and 100,000 yr. These evaluations involved using DOE-PPPO Proposed Single Radionuclide Soil Guidelines for each targeted radionuclide as inputs into the codes (see Table 2-1).

The 1,050 yr time horizon represents the conventional period used in the analyses for soil guideline determinations $(1,000 \mathrm{yr})$ and an additional $50 \mathrm{yr}$ to begin the analysis as of the year 1960 . The time frame of 1,050 $\mathrm{yr}$ and beyond is applicable to the receptors modeled during the Landfill's 
post-institutional control period. ORISE did not model the Landfill's institutional control period separately. ORISE did the modeling using the assumptions from the post-institutional control period for the institutional control period and the post-institutional control period. Therefore these two periods were combined into one (the post-institutional control period) as performed in ORISE 2012. Details on these two Landfill control periods are included in ORISE 2012. The Resident Farmer (onsite), and the Resident Gardener are the only two implausible receptors modeled during the post-institutional control period, the other three receptors modeled during this period are considered plausible as indicated in ORISE 2012.

The time horizons of 10,000 $\mathrm{yr}$ and 100,000 $\mathrm{yr}$ (maximum allowed by the codes) were used at the request of the DOE-PPPO for informational purposes to determine the magnitude of the dose during these time periods.

When increasing the time horizon beyond 1,000 yrs in the RESRAD-OFFSITE code, it is important to have a sufficient number of intermediate time points in the code to capture the variation in the computed fluxes and concentrations. The number of intermediate time points specifies the number of graphic points, affects the precision of the computed results and the smoothness of the output graphic curves (Yu et al. 2007). Therefore, ORISE increased the number of points to 16,384 from 2,048 points (code default number of points). Difficulties with the graphics viewer in RESRAD-OFFSITE were encountered when using 22,000 points - the maximum number of points available in the code. Specifically, it was not possible to view the graphics with 22,000 points. According to an ORISE personal communication with ANL, there may be a limit on the number of points in the graphics program used in RESRAD-OFFSITE.

\subsubsection{PROBABILISTIC ANAL YSIS TO CALCULATEPEAKOFTHEMEAN} DOSES FOR THE OFFSITE RESIDENT FARMER

NUREG/CR-6676 (Kamboj et al. 2000) states: "the probabilistic approach uses systematic uncertainty analysis to quantify the uncertainty in dose estimates due to uncertainty in the input parameters. In the probabilistic analysis, a probability distribution is specified for each model input parameter of uncertain value." The probabilistic analysis in this report was conducted to calculate the peak of the mean dose.

\subsubsection{Peak of the Mean Dose Assessment for the Offsite Resident Farmer}

The Offsite Resident Farmer, modeled using the RESRAD-OFFSITE code, was the receptor selected by DOE-PPPO for the probabilistic analysis. The probabilistic dose assessment was performed to determine the peak of the mean doses based on Tc-99 exclusively and demonstrate that the Tc-99 dose meets the constraint of $1 \mathrm{mrem} / \mathrm{yr}$ (above background). As requested by DOE-PPPO, ORISE used the following information for the Tc-99 probabilistic analysis:

The DOE-PPPO Proposed Single Radionuclide Soil Guideline for Tc-99 (i.e., 52 pCi/g) as the input radionuclide concentration. 
The probabilistic inputs and related information were obtained from the DOE-PPPO document entitled: Probabilistic Risk. Assessment Analysis for Establishing the Technetium-99 Single Radionuclide Soil Guideline from the Drinking Water Pathway for the Offsite Resident Farmer for the C-746-U Landfill at the Paducah Gaseous Diffusion Plant, Paducah Kentucky (DOE-PPPO 2011b). For additional details on the DOE-PPPO probabilistic analysis, refer to DOE-PPPO 2011b. Below is the information obtained from DOE-PPPO 2011b:

- Parameters, type of distribution and values selected for Probabilistic Analysis.

\begin{tabular}{|c|c|c|c|c|}
\hline Parameter & $\begin{array}{c}\text { Type of } \\
\text { Distribution }\end{array}$ & $\begin{array}{c}\text { Minimum } \\
\text { Value }\end{array}$ & Mode & $\begin{array}{c}\text { Maximum } \\
\text { Value }\end{array}$ \\
\hline Saturated Zone Hydraulic Conductivity $(\mathrm{m} / \mathrm{yr})$ & Triangular & 27034 & 38938 & 67642 \\
\hline Total Porosity of Saturated Zone & Triangular & 0.27 & 0.39 & 0.54 \\
\hline Effective Porosity of Saturated Zone & Triangular & 0.22 & 0.3 & 0.35 \\
\hline Distribution Coefficient $\left(K_{d}\right)$ of Contaminated Zone $\left(\mathrm{cm}^{3} / \mathrm{g}\right)$ & Triangular & 0.1 & 1 & 10 \\
\hline Dry Bulk Density of Contaminated Zone $\left(\mathrm{g} / \mathrm{cm}^{3}\right)$ & Triangular & 1.5 & 1.85 & 2.5 \\
\hline Unsaturated Zone (5) Effective Porosity & Triangular & 0.1 & 0.25 & 0.4 \\
\hline
\end{tabular}

- The rank correlation coefficient used for the total and effective porosities of the saturated zones was 0.9 .

- The number of observations used was 2,000 and the number of repetitions was 3 .

As mentioned previously, the probabilistic dose assessment was performed to determine the peak of the mean doses based on the DOE-PPPO Proposed Single Soil Guideline of $52 \mathrm{pCi} / \mathrm{g}$ for Tc-99 and to demonstrate compliance with the $1 \mathrm{mrem} / \mathrm{yr}$ (above background). During this probabilistic analysis, ORISE encountered difficulties with the RESRAD-OFFSITE code due to insufficient computer memory available for the code to perform the computations. The initial probabilistic run attempted by ORISE was not successfully completed by the code; it provided an output file indicating the errors. The run included all the exposure pathways as identified in ORISE 2012 (i.e., external gamma, inhalation of dust, drinking water, plant, meat, milk, and soil ingestion) and the probabilistic parameters as described previously in this section. The RESRAD-OFFSITE input files used for this initial run, the probabilistic parameters and the error output file generated by the code were submitted to Argonne National Laboratory (ANL) via the "resrad" email address for assistance.

Due to the fact that a standard computer with limited memory was available to run this code at its full potential, ORISE and DOE-PPPO decided that separate probabilistic runs should be performed to prevent computer memory issues. The rationale of doing these separate probabilistic runs was to incorporate changes in each one in order to minimize the number of calculations executed by the 
code for it to successfully complete the run and still obtain acceptable results. ORISE and DOE-PPPO agreed on maintaining the probabilistic input parameters intact (unchanged). Three probabilistic runs were performed. The first two runs were executed as agreed to with DOE-PPPO. The third run was executed as a confirmatory run as agreed between ORISE and a DOE-PPPO technical consultant. The modifications made for the runs are explained in the points below.

1. For the first probabilistic run, only the exposure pathways by which Tc-99 contributes to the dose were activated. These pathways are drinking water, plant, milk, and meat ingestion as shown by the deterministic analysis within the time frame of 1,050 $\mathrm{yr}$. The external gamma, inhalation of dust, and soil ingestion pathways were deactivated. The deterministic input parameters and probabilistic parameters remained unchanged.

2. For the second probabilistic run, only the pathways by which Tc-99 did not contribute to the dose were activated. These pathways are external gamma, inhalation of dust, and soil ingestion pathways. The drinking water, plant, milk, and meat ingestion pathways were deactivated. The deterministic input parameters and probabilistic parameters remained unchanged.

The purpose for the first and second runs was to add the results of the peak of the mean doses and determine the dose from all seven pathways.

3. For the third probabilistic run all the pathways (i.e., external gamma, inhalation of dust, drinking water, plant, meat, milk, and soil ingestion) remained activated; however, a deterministic parameter called the "grid spacing for areal integration" in the atmospheric transport model was changed from its default value of 10 meters to a maximum of 500 meters. None of the other deterministic inputs parameters or probabilistic parameters were modified.

ANL provides a report in Yu et al. 2007 describing the processes and code options that affect the execution time when performing probabilistic analysis using the RESRAD-OFFSITE code. The information provided by ANL helps the user to select the conditions and code options that will produce all the desired outputs in the shortest time (Yu et al. 2007). According to Yu et al. 2007, the grid spacing for areal integration parameter is one of a number of parameters used in RESRAD-OFFSITE to improve the accuracy of the calculations and hence influence the computational time. The smaller the value for this parameter the greater the amount of time it takes the code to execute the calculations. From the parameters that could have been modified to reduce the execution time as recommended by ANL, the grid spacing for areal integration was selected, because in this run using only Tc-99, the exposure pathways contributing to the dose are not impacted by the atmospheric transport model. In addition, the presence of the Landfill cap/cover during the time frame of 1,050 yr minimizes or prevents resuspension and subsequent air transport to a location 
off the Landfill. A sensitivity analysis was performed on this parameter and as expected it demonstrated that the grid spacing for areal integration parameter does not influence the dose.

By increasing the number of meters in the grid spacing for areal integration, the number of calculations performed by the code and hence its execution time was tremendously reduced. This third run can be used as confirmatory run for the first two runs.

\section{0: RESULTSANDDISCUSSION}

The output results and graphical representations of the peak dose assessments are included in this section. The resultant peak doses were rounded to two significant figures for all receptors unless otherwise noted.

3.1

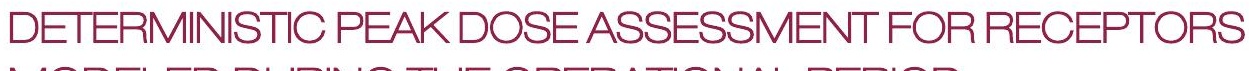
MODELED DURING THE OPERATIONAL PERIOD

The first peak dose assessment involved using the DOE-PPPO Proposed Single Radionuclide Soil Guidelines as input into the codes. The second peak dose assessment involved the use of the DOE-PPPO Proposed AL Volumetric Concentrations as input into the codes and was performed for the Landfill Worker and the Trespasser only.

\subsubsection{FIRST ASSESSMENT}

The output peak doses for this first evaluation are summarized in Table 3-1. This evaluation involved the use of the DOE-PPPO Proposed Single Radionuclide Soil Guidelines and a time horizon of $70 \mathrm{yr}$.

Table 3-1. Peak Dose from DOE-PPPO Proposed Single Radionuclide Soil Guidelines

\begin{tabular}{|ccc|}
\hline Receptor & Landffll Worker & Trespasser \\
\hline Target Dose (mrem/yr) & 100 & 100 \\
\hline Peak Dose (mrem/yr) & 32 & 2.1 \\
\hline Time (yr) & 70 & 70 \\
\hline
\end{tabular}

The code generated results that do not approach the DOE's 2,000 mrem/yr Administrative Control level (ACL) for the Landfill Worker or the DOE's $100 \mathrm{mrem} / \mathrm{yr}$ public dose limit (above background) for the Trespasser. The peak dose for the Landfill Worker and the Trespasser occurs at $70 \mathrm{yr}$, which is also the time horizon used for these receptors. Most of the peak dose for these two receptors is attributed to Th-232, Th-230, U-238 and Cs-137. An analysis of additional RESRAD graphics and data shows that the dose attributed to Th-232 and Th-230 is also due to 
their ingrowth progeny. The exposure pathways contributing to the dose for these receptors are mainly external gamma and soil ingestion.

The following RESRAD graphics were obtained for the Landfill Worker and the Trespasser from the evaluation of the DOE-PPPO Proposed Single Radionuclide Soil Guidelines. Figures 3-1 and 3-3 illustrate the contribution to dose from all targeted radionuclides and pathways. Figures 3-2 and 3-4 illustrate the contribution to the dose from the different component exposure pathways evaluated for these receptors.

\section{LANDFILL WORKER}

\section{DOSE: All Nuclides Summed, All Pathways Summed}

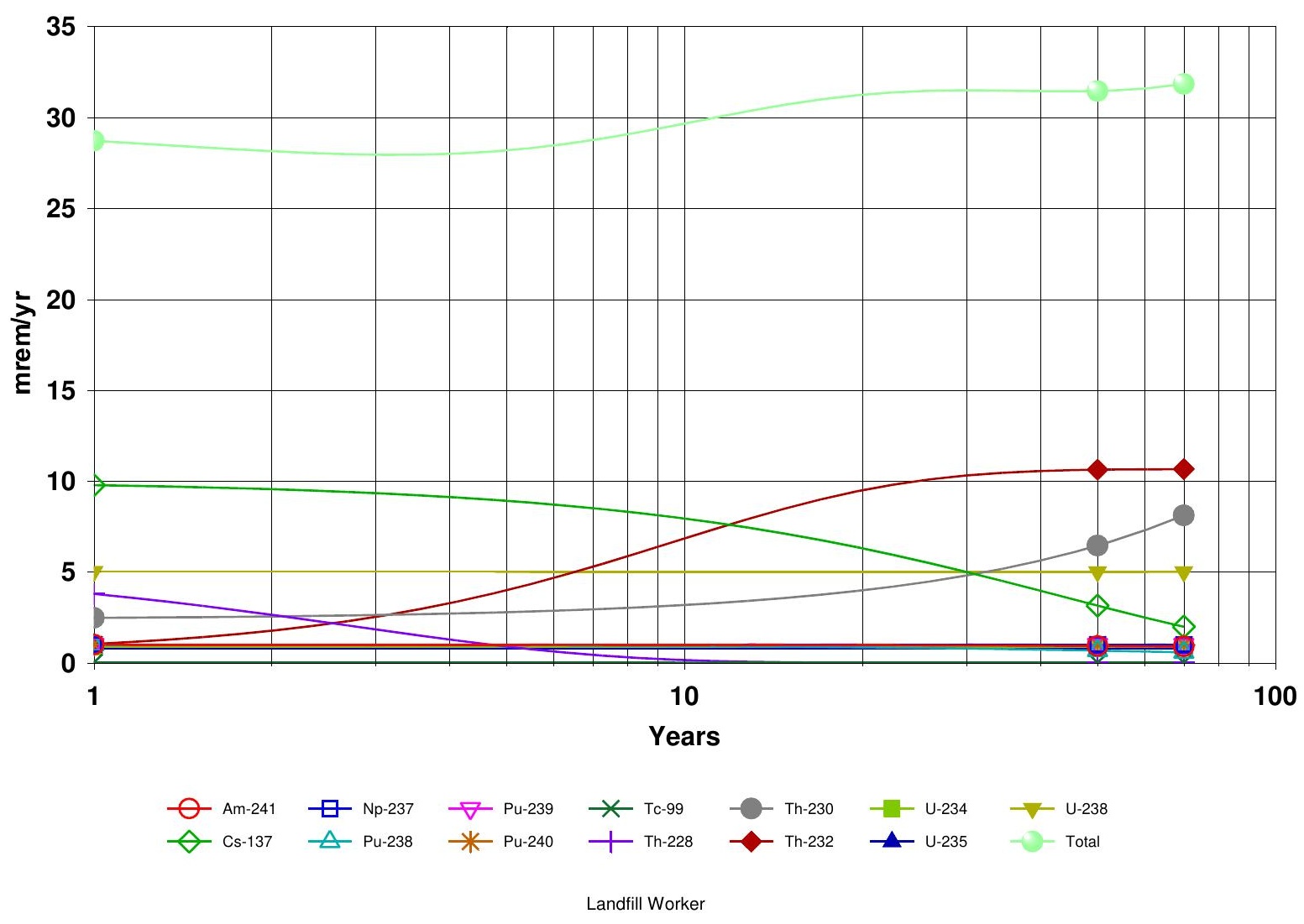

Figure 3-1. Dose to the Landfill Worker from all Selected Targeted Radionuclides and Pathways 
DOSE: All Nuclides Summed, Component Pathways

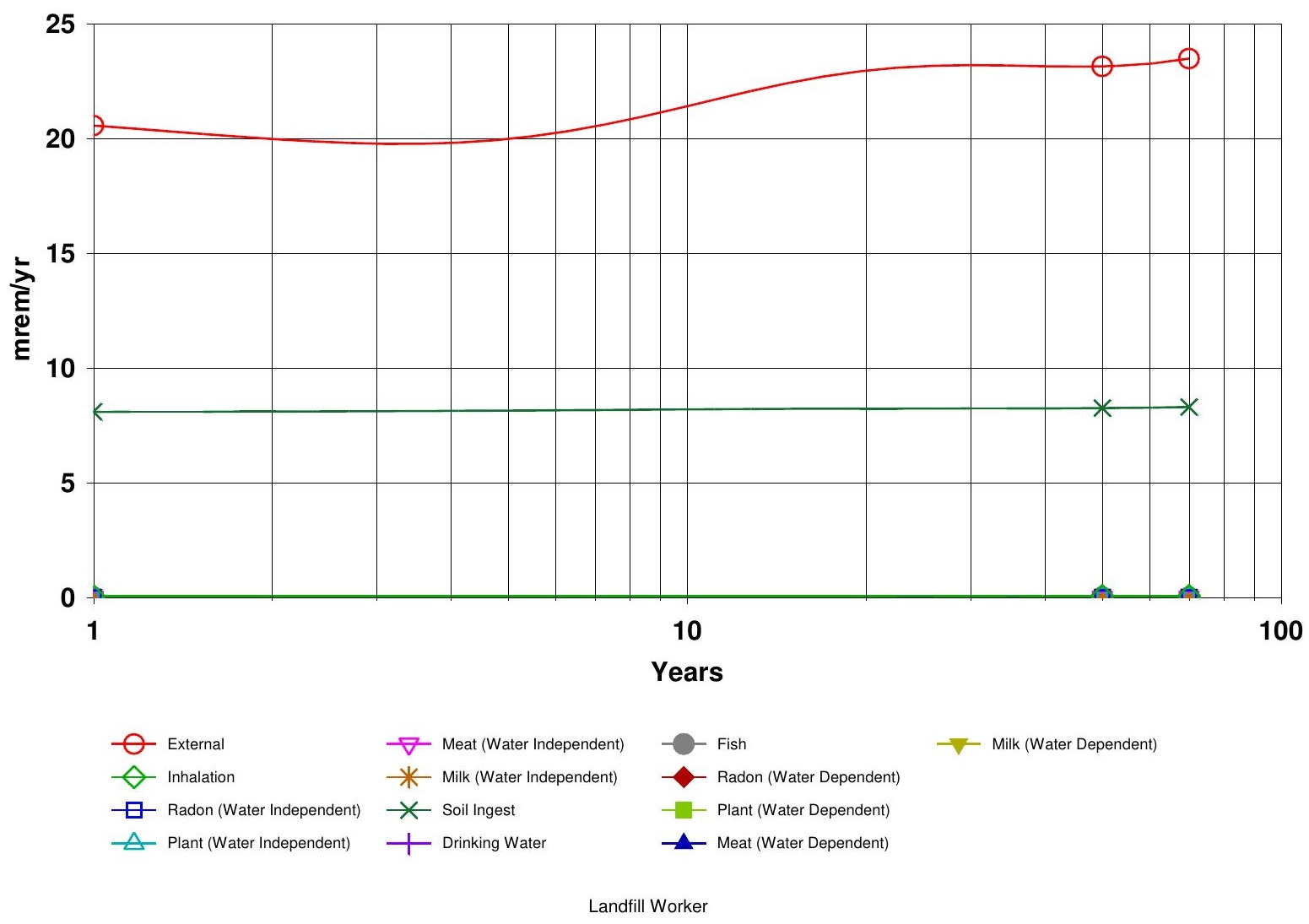

Figure 3-2. Dose to the Landfill Worker by Exposure Pathways 


\section{TRESPASSER}

DOSE: All Nuclides Summed, All Pathways Summed

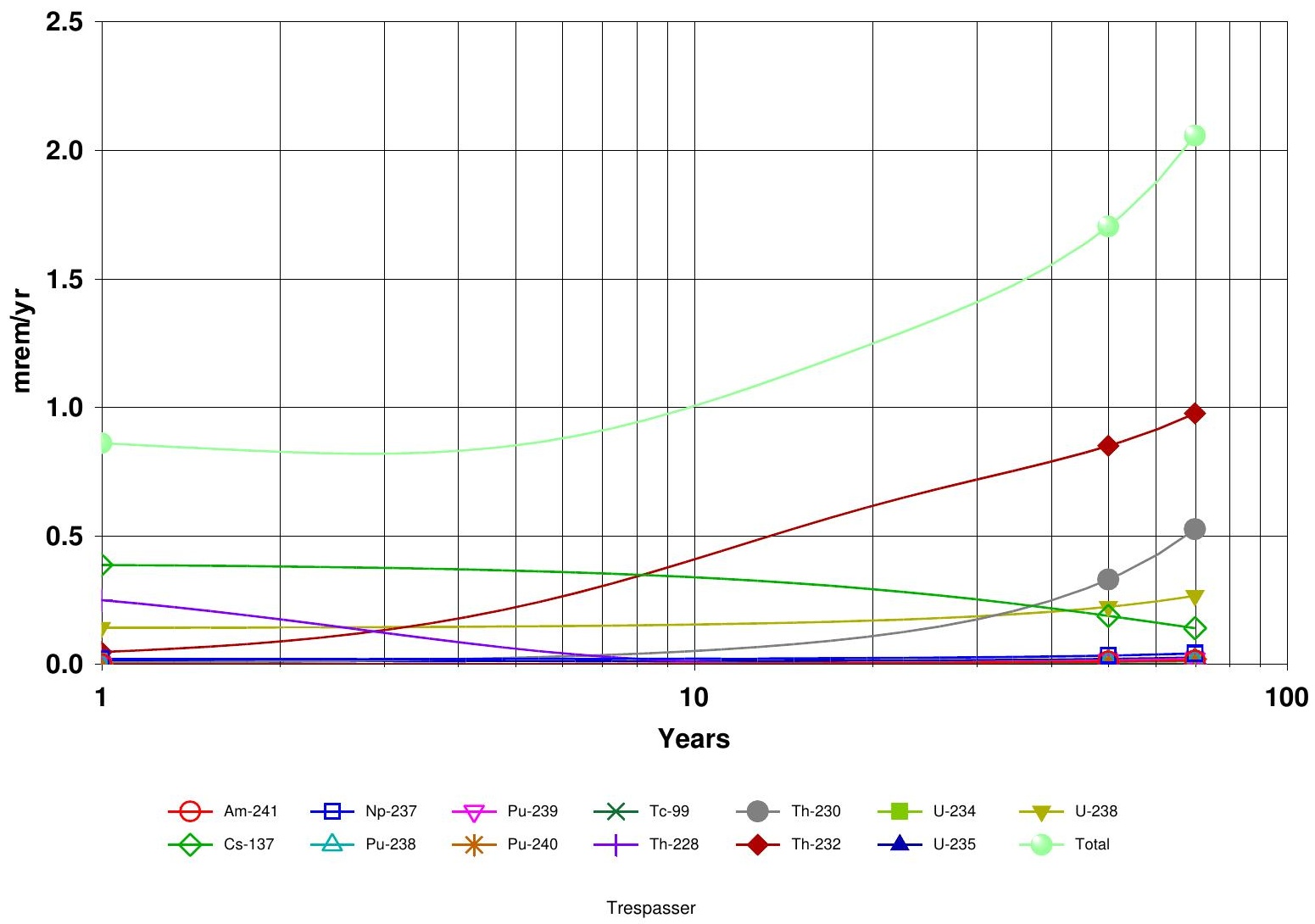

Figure 3-3. Dose to the Trespasser from all Selected Targeted Radionuclides and Pathways 
DOSE: All Nuclides Summed, Component Pathways

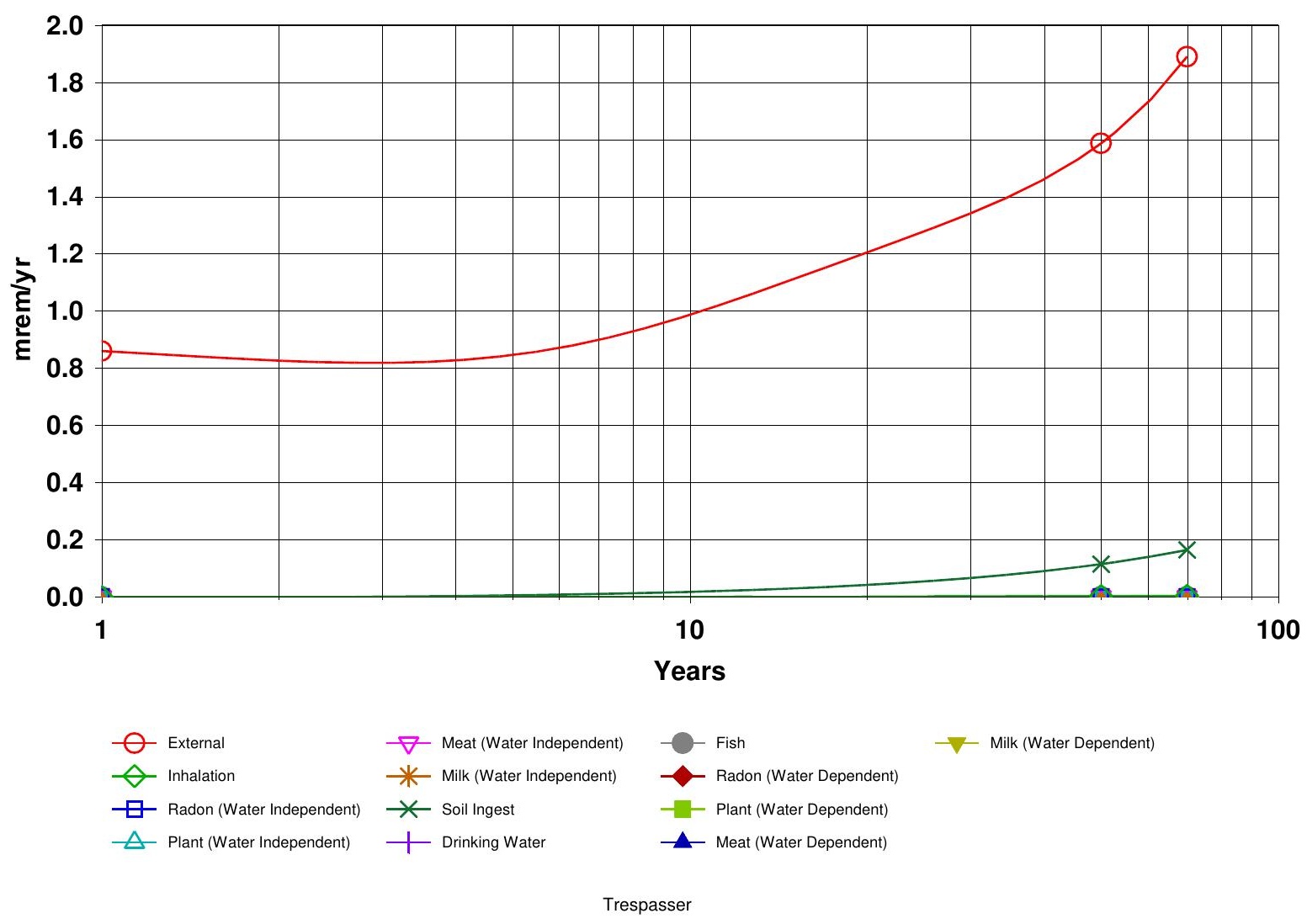

Figure 3-4. Dose to the Trespasser by Exposure Pathways

\subsubsection{SECOND ASSESSMENT}

The output peak doses for the second evaluation for the Landfill Worker and the Trespasser are provided in Table 3-2. This evaluation involved the use of the DOE-PPPO Proposed AL Volumetric Concentrations and a time horizon of $70 \mathrm{yr}$.

Table 3-2. Peak Dose from DOE-PPPO Proposed AL Volumetric Concentrations

\begin{tabular}{|ccc|}
\hline Receptor & Landfill Worker & Trespasser \\
\hline Target Dose (mrem/yr) & 100 & 100 \\
\hline Peak Dose (mrem/yr) & 64 & 4.1 \\
\hline Time (yr) & 70 & 70 \\
\hline
\end{tabular}


In this case, the Landfill Worker's dose remains considerably below the DOE's 2,000 mrem/yr ACL and the Trespasser's dose is still noticeably below the DOE's $100 \mathrm{mrem} / \mathrm{yr}$ public dose limit (above background). The exposure pathways and radionuclides contributing to these receptors' second evaluation of the peak dose were identical to the ones contributing to the dose in the first evaluation. Figures 3-5 through 3-8 were obtained for the Landfill Worker and the Trespasser from the evaluation of the DOE-PPPO Proposed AL Volumetric Concentrations.

\section{LANDFILL WORKER}

\section{DOSE: All Nuclides Summed, All Pathways Summed}

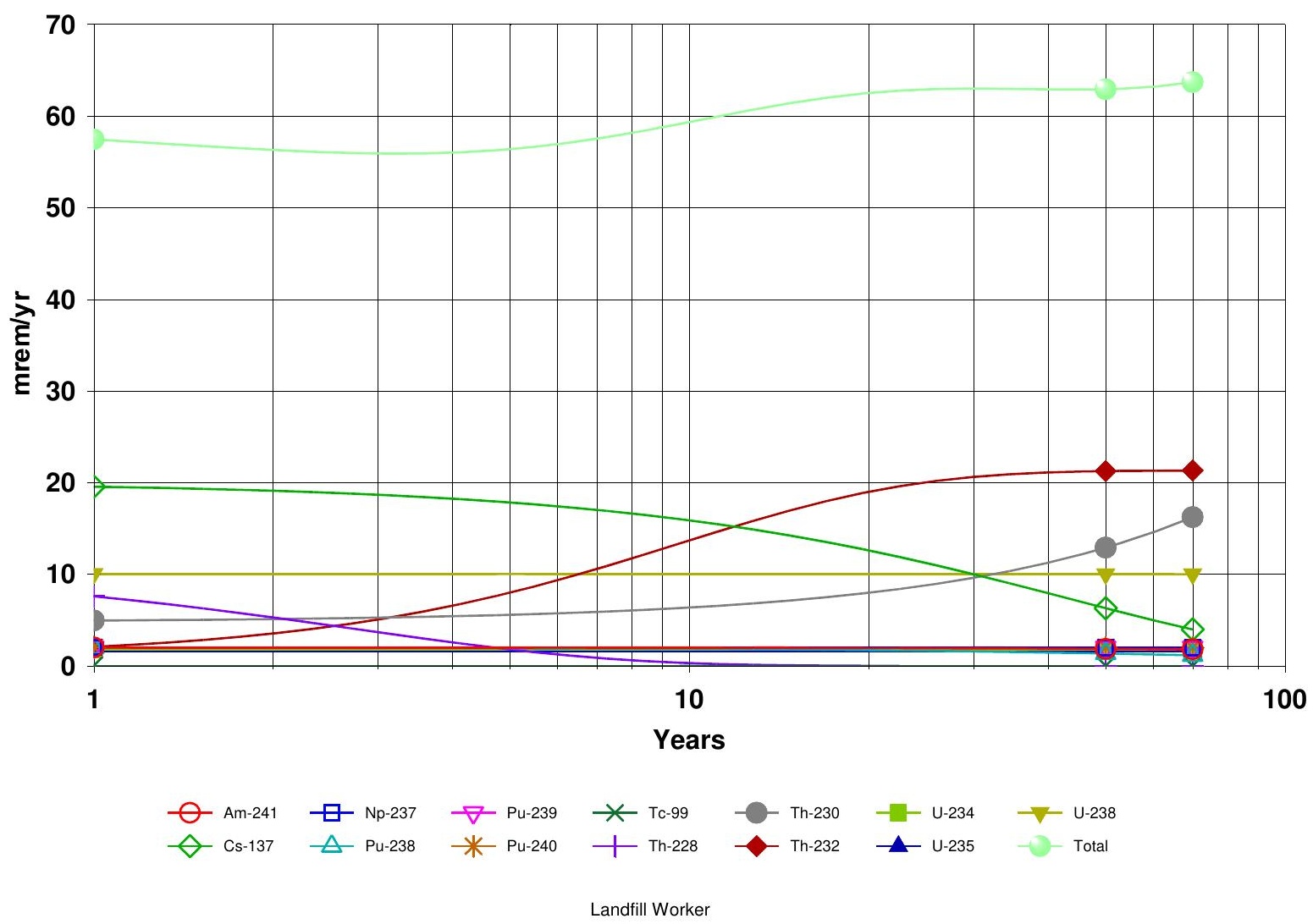

Figure 3-5. Dose to the Landfill Worker from all Selected Targeted Radionuclides and Pathways 


\section{DOSE: All Nuclides Summed, Component Pathways}

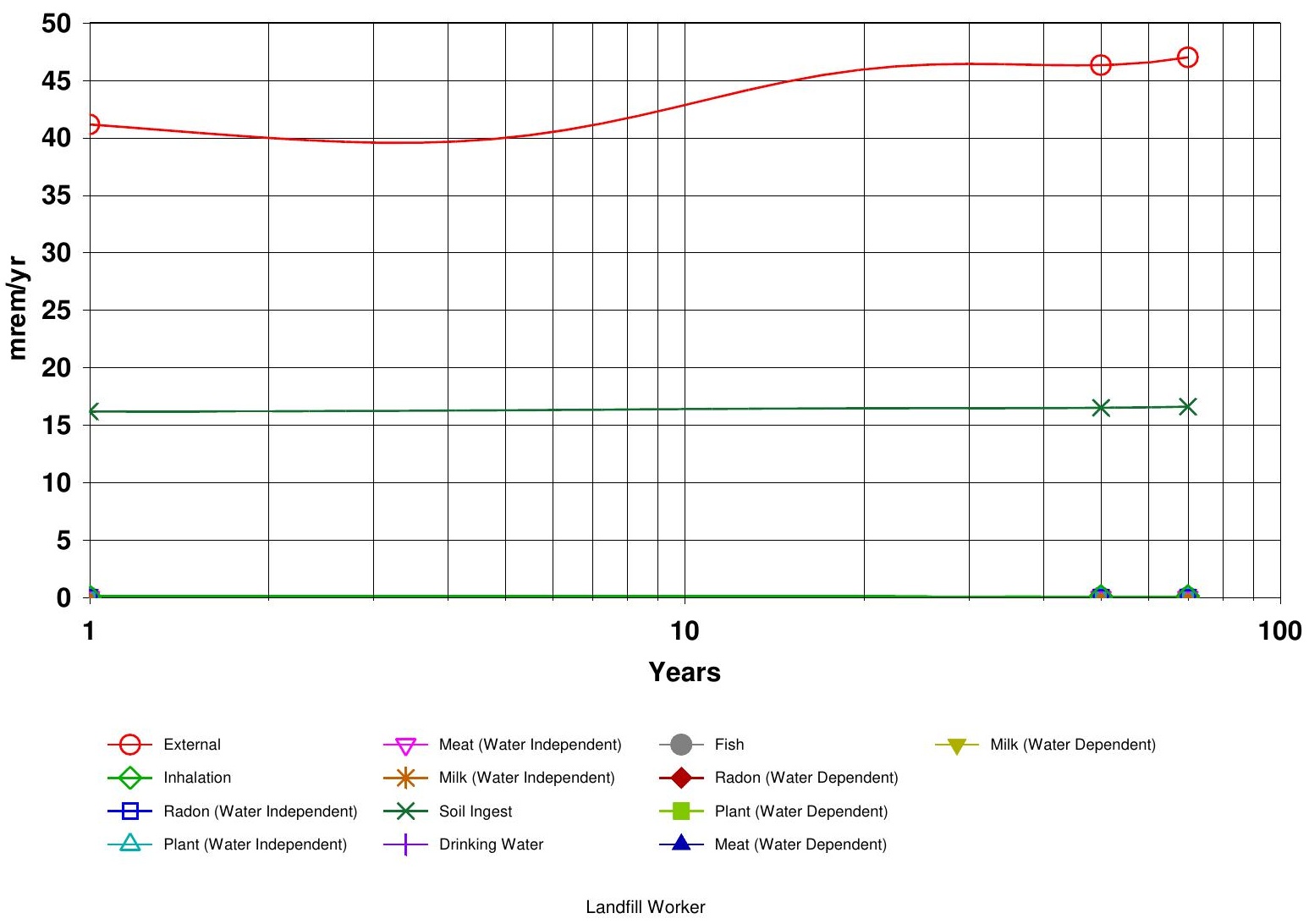

Figure 3-6. Dose to the Landfill Worker by Exposure Pathways 


\section{TRESPASSER}

DOSE: All Nuclides Summed, All Pathways Summed

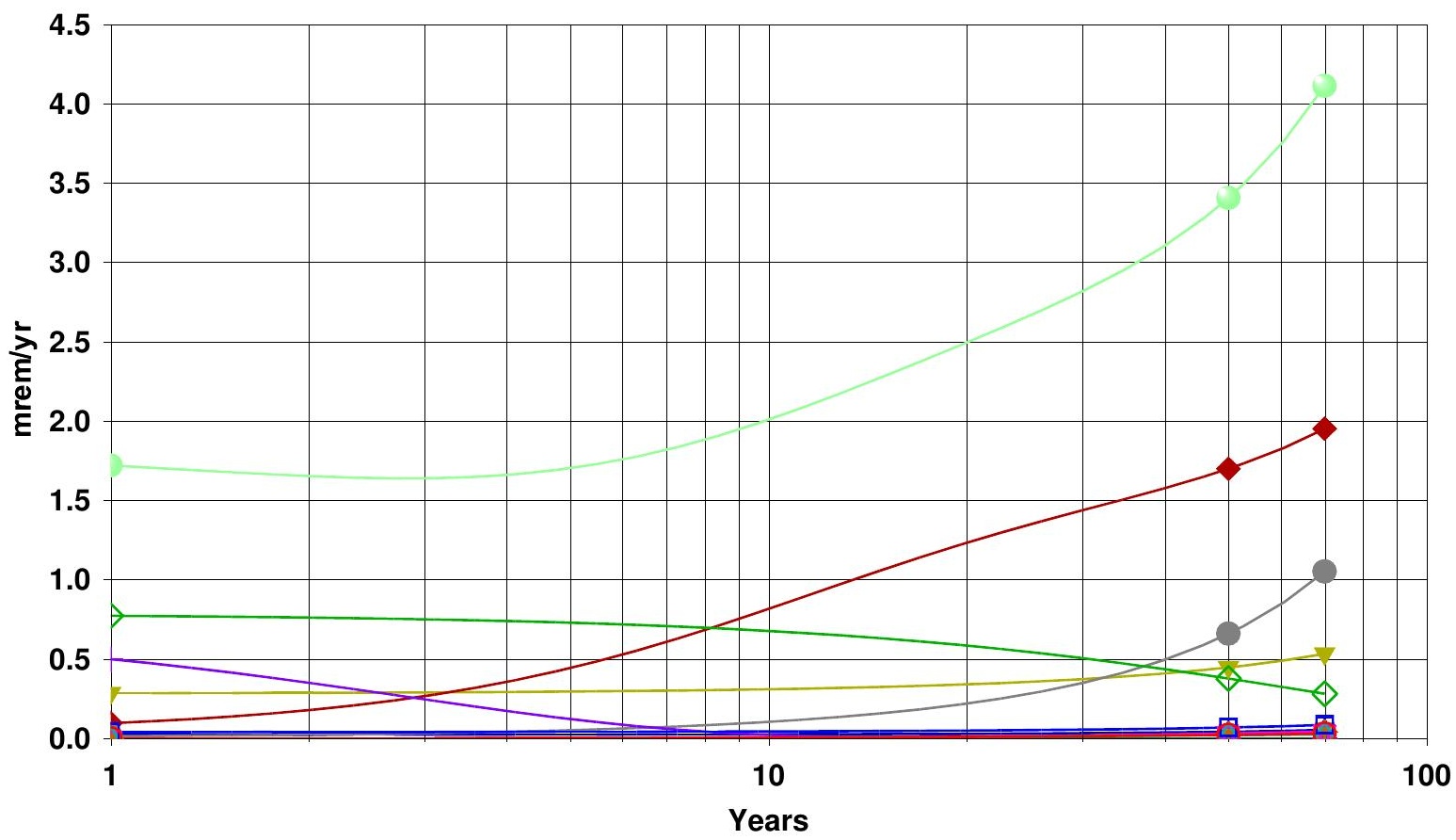

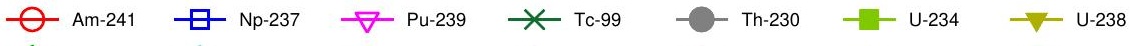

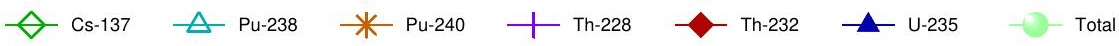

$$
\begin{aligned}
& \text { Trespasser }
\end{aligned}
$$

Figure 3-7. Dose to the Trespasser from all Selected Targeted Radionuclides and Pathways 
DOSE: All Nuclides Summed, Component Pathways

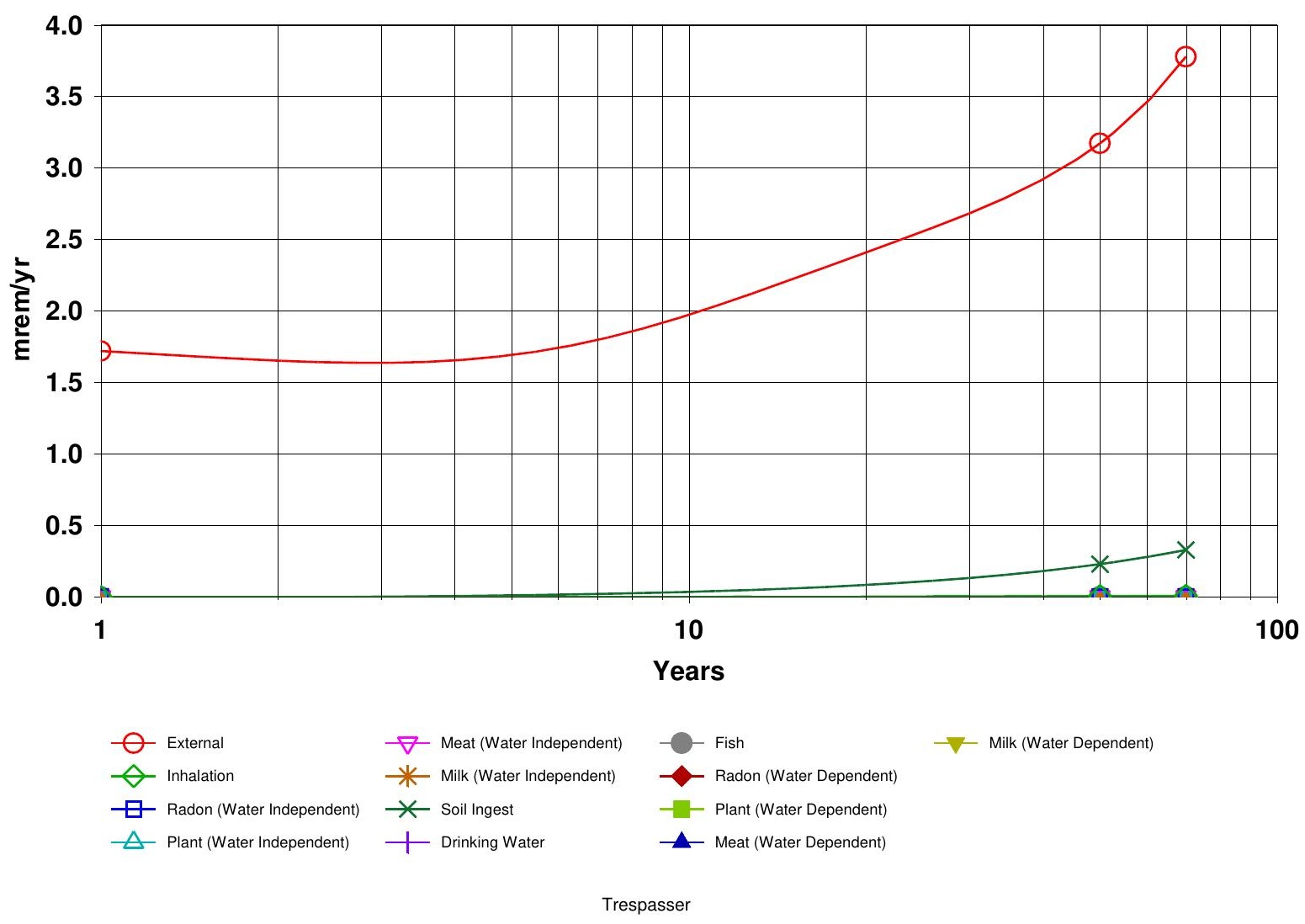

Figure 3-8. Dose to the Trespasser by Exposure Pathways

Three separate peak dose evaluations were performed for the Resident Farmer (onsite), Resident Gardener, Recreational User, Outdoor Worker and Offsite Resident Farmer using the DOE-PPPO Proposed Single Radionuclide Soil Guidelines and time horizons of 1,050 yr, 10,000 yr and $100,000 \mathrm{yr}$. It is important to emphasize that the time horizons of 10,000 yr and 100,000 $\mathrm{yr}$ (maximum allowed by the codes) were used at the request of the DOE-PPPO for informational purposes to determine the magnitude of the dose during these time periods.

\subsubsection{FIRST ASSESSMENT}

The results for the first evaluation using a time horizon of 1,050 $\mathrm{yr}$ are summarized in Table 3-3. 
Table 3-3. Peak Doses from DOE-PPPO Proposed Single Radionuclide Soil Guidelines

\begin{tabular}{|cccccc}
\hline Receptor & $\begin{array}{c}\text { Resident } \\
\text { Farmer } \\
\text { (onsite) }\end{array}$ & $\begin{array}{c}\text { Resident } \\
\text { Gardener }\end{array}$ & $\begin{array}{c}\text { Recreational } \\
\text { User }\end{array}$ & $\begin{array}{c}\text { Outdoor } \\
\text { Worker }\end{array}$ & $\begin{array}{c}\text { Offsite } \\
\text { Resident } \\
\text { Farmer }\end{array}$ \\
\hline Target Dose (mrem/yr) & 100 & 100 & 1 & 1 & 1 \\
\hline Peak Dose (mrem/yr) & 21 & 7 & 0.001 & 0.003 & 1.9 \\
\hline Time (yr) & $425.2 \pm 0.9$ & 1,050 & 1,050 & 1,050 & 772 \\
\hline
\end{tabular}

The codes generated results that do not exceed the DOE's $100 \mathrm{mrem} / \mathrm{yr}$ primary public dose limit (above background) for the Resident Farmer (onsite), Resident Gardener, Recreational User, and Outdoor Worker. However, the result obtained for the Offsite Resident Farmer exceeds the DOE field element and Commonwealth of Kentucky Radiation Health Branch "walk away" dose constraint of $1 \mathrm{mrem} / \mathrm{yr}$ (above background).

\section{RESIDENT FARMER (ONSITE)}

The peak dose for the Resident Farmer (onsite) occurs at $425.2 \pm 0.9 \mathrm{yr}$ when using a time horizon of 1,050 yr. As depicted in Figures 3-9 and 3-10, this receptor's dose is due to Tc-99 through the drinking water, milk and plant ingestion pathways with the maximum dose occurring at $425.2 \pm 0.9 \mathrm{yr}$. The meat ingestion pathway also contributes to the dose; however, the dose contribution is less than $1 \%$. This receptor is considered an implausible receptor as indicated in ORISE 2012.

The following RESRAD graphics correspond to the Resident Farmer (onsite) using a time horizon of $1,050 \mathrm{yr}$. 
DOSE: All Nuclides Summed, All Pathways Summed

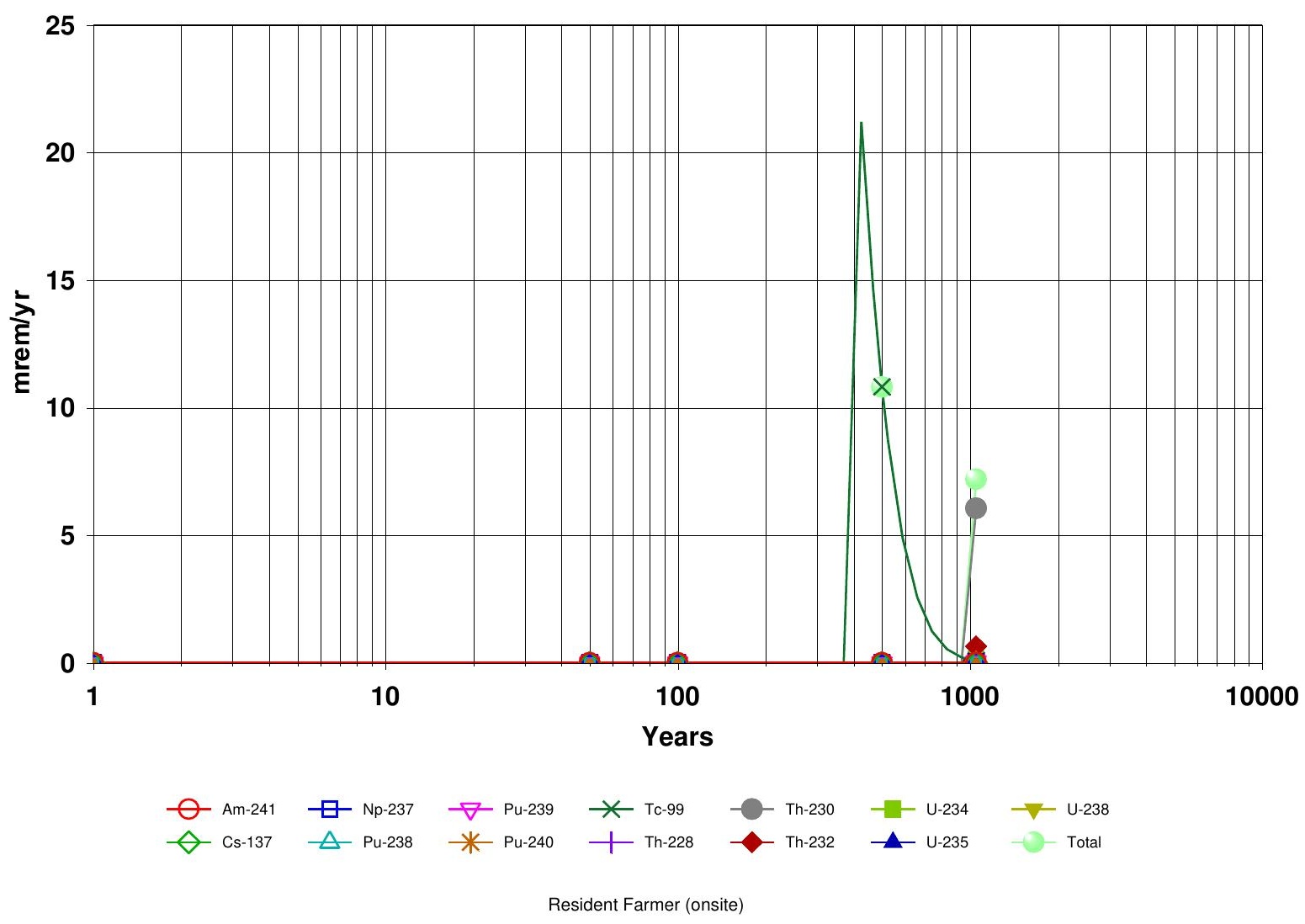

Figure 3-9. Dose to the Resident Farmer (onsite) from all Selected Targeted Radionuclides and Pathways

The sharp peak for Tc-99 may be caused by an artifact in the code; however, the reason why this occurred is not clearly understood. Further investigation and assistance by the developers of the RESRAD code are required to explain the rapid increase and decrease of this peak. 


\section{DOSE: All Nuclides Summed, Component Pathways}

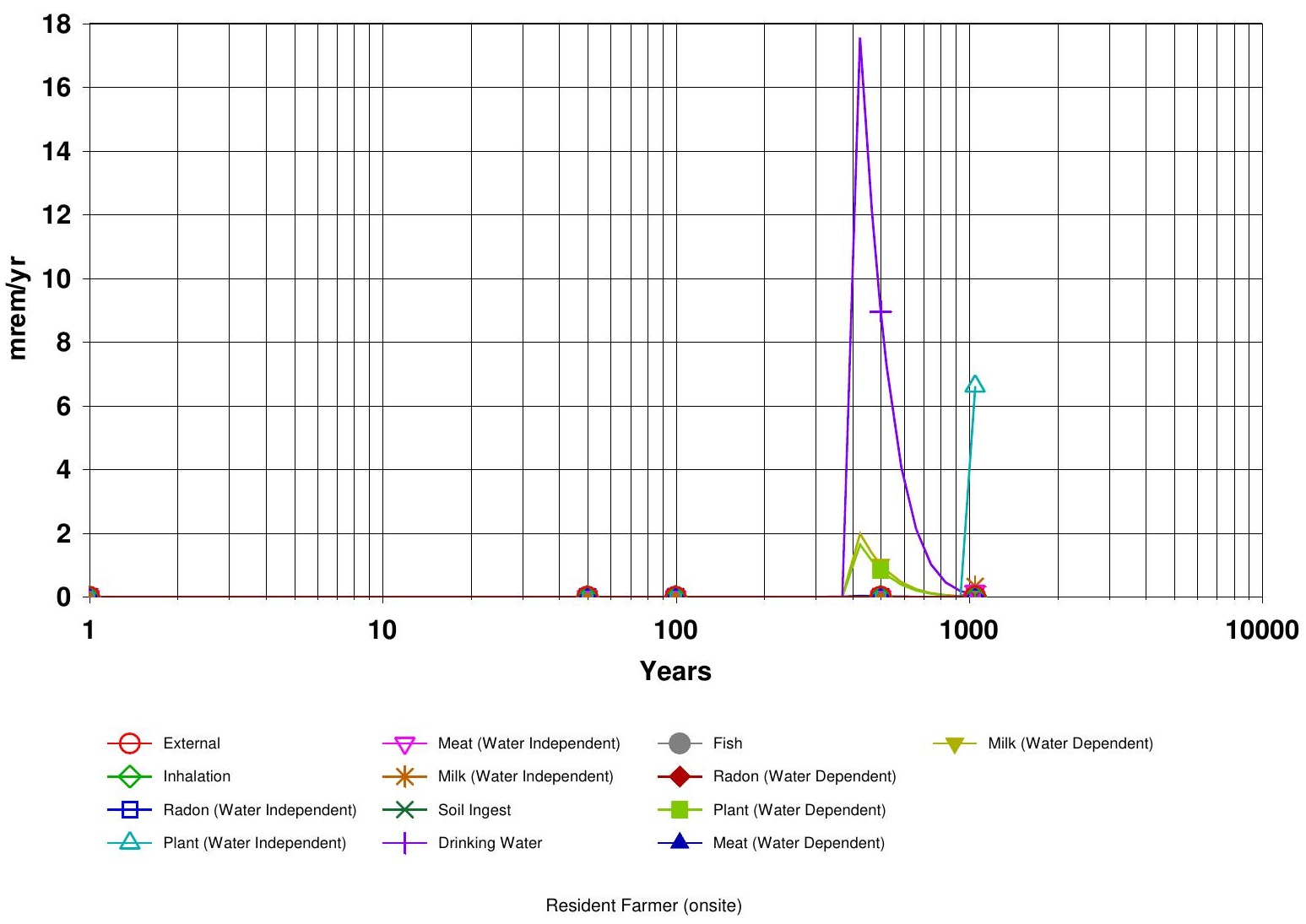

Figure 3-10. Dose to the Resident Farmer (onsite) by Exposure Pathways 


\section{RESIDENT GARDENER}

The peak dose for the Resident Gardener occurs at 1,050 yr which is same as the time horizon used in this evaluation. As depicted in Figures 3-11 and 3-12, this receptor's dose is due to Th-230 and Th-232 through the plant ingestion pathway. This receptor is considered an implausible receptor as indicated in ORISE 2012.

The following RESRAD graphics correspond to the Resident Gardener using a time horizon of $1,050 \mathrm{yr}$.

DOSE: All Nuclides Summed, All Pathways Summed

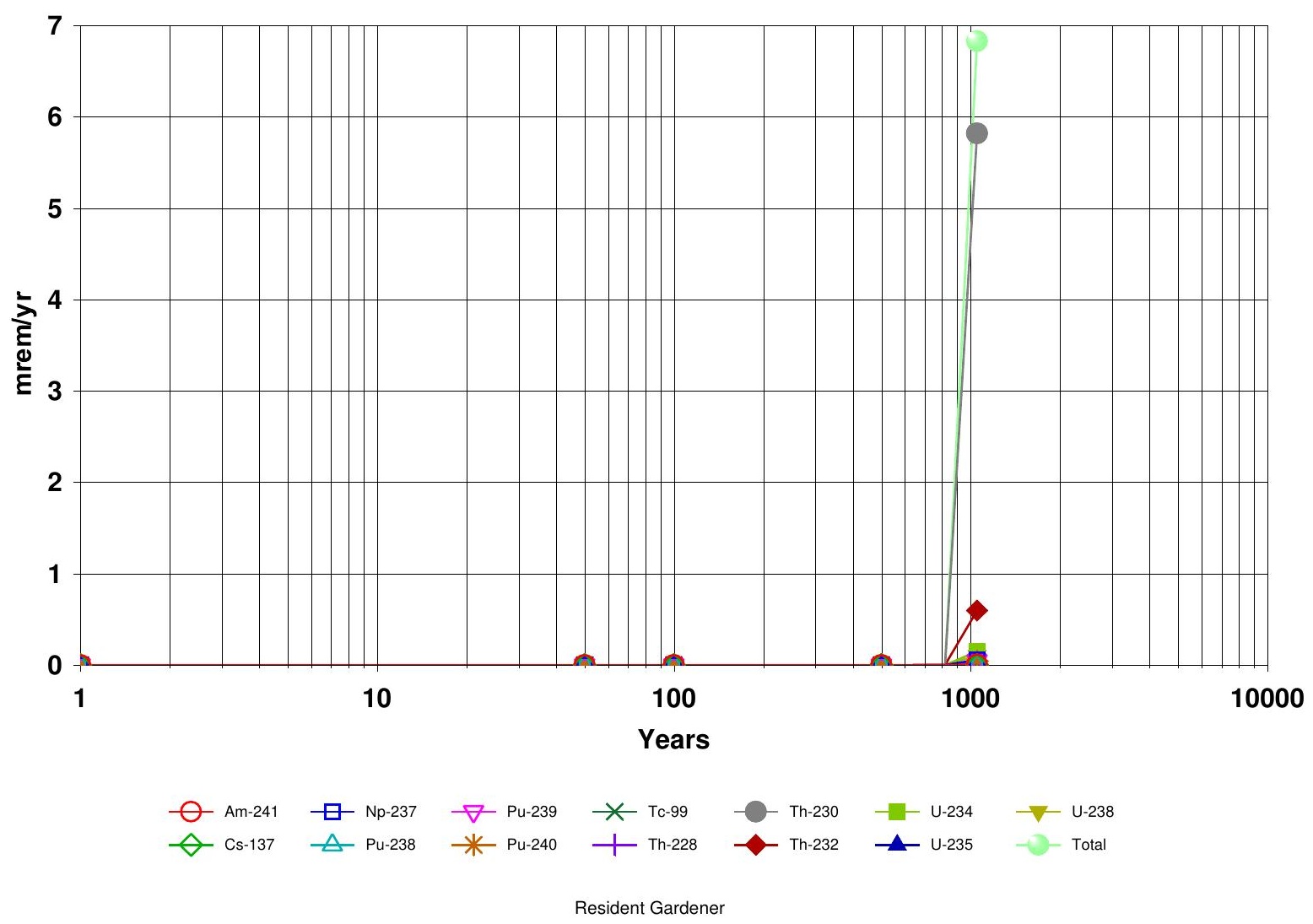

Figure 3-11. Dose to the Resident Gardener from all Selected Targeted Radionuclides and Pathways 


\section{DOSE: All Nuclides Summed, Component Pathways}

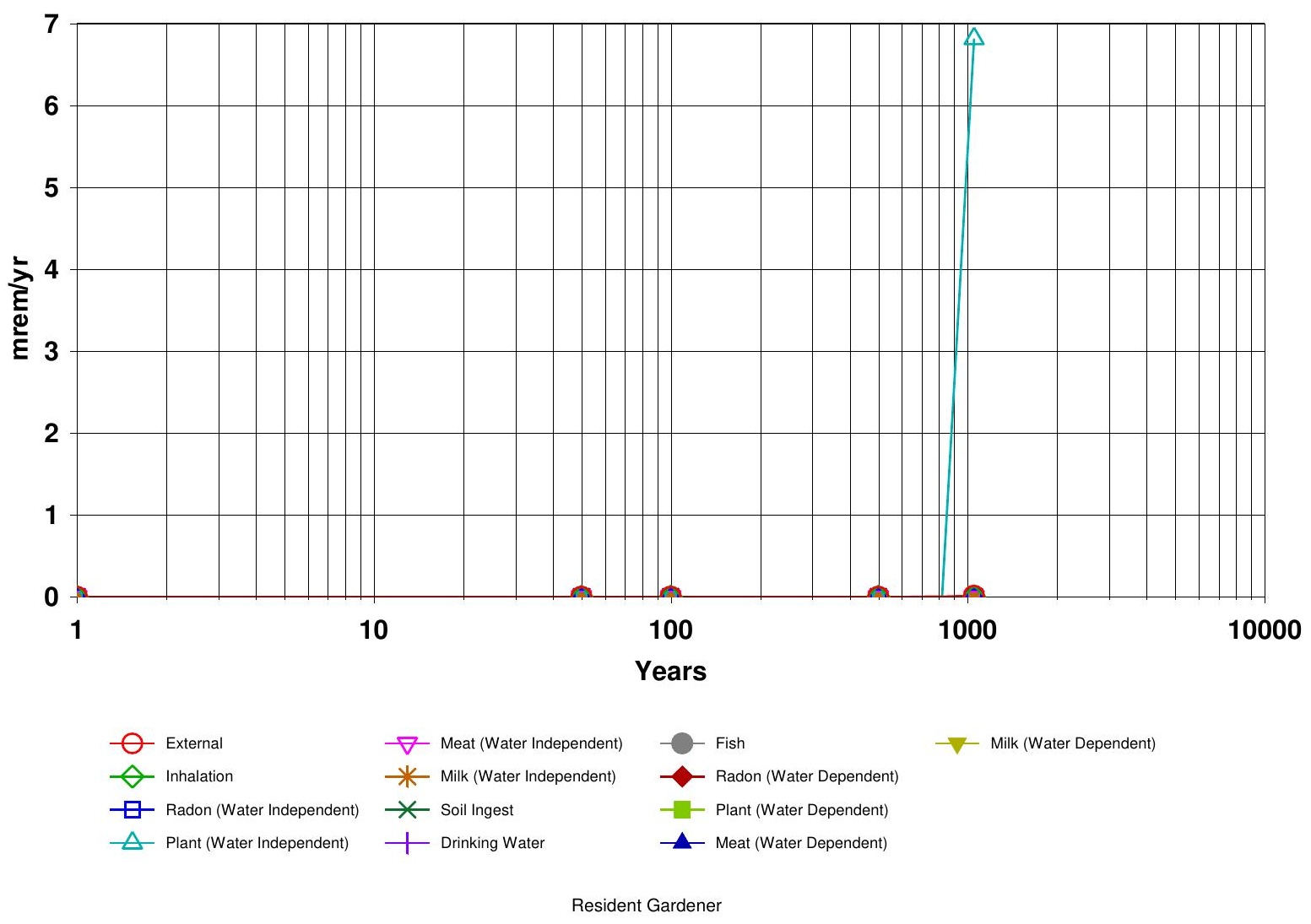

Figure 3-12. Dose to the Resident Gardener by Exposure Pathways 


\section{RECREATIONAL USER}

The peak dose for the Recreational User occurs at 1,050 yr which is same as the time horizon used in this evaluation. As depicted in Figures 3-13 and 3-14, this receptor's dose is due to Th-230 and Th-232 through the external gamma pathway. This receptor is considered a plausible receptor as indicated in ORISE 2012.

The following RESRAD graphics correspond to the Recreational User using a time horizon of $1,050 \mathrm{yr}$.

DOSE: All Nuclides Summed, All Pathways Summed

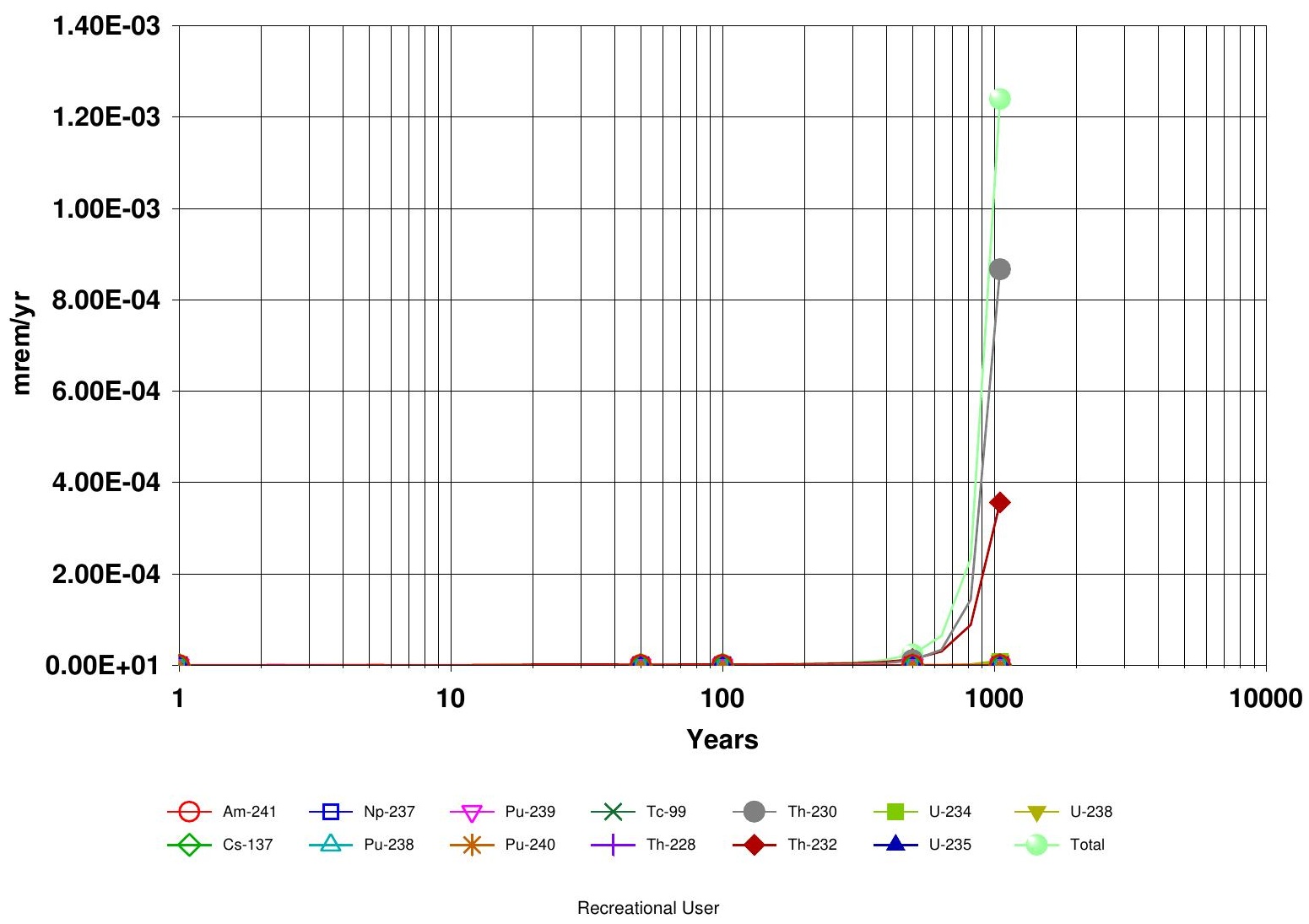

Figure 3-13. Dose to the Recreational User from all Selected Targeted Radionuclides and Pathways 
DOSE: All Nuclides Summed, Component Pathways

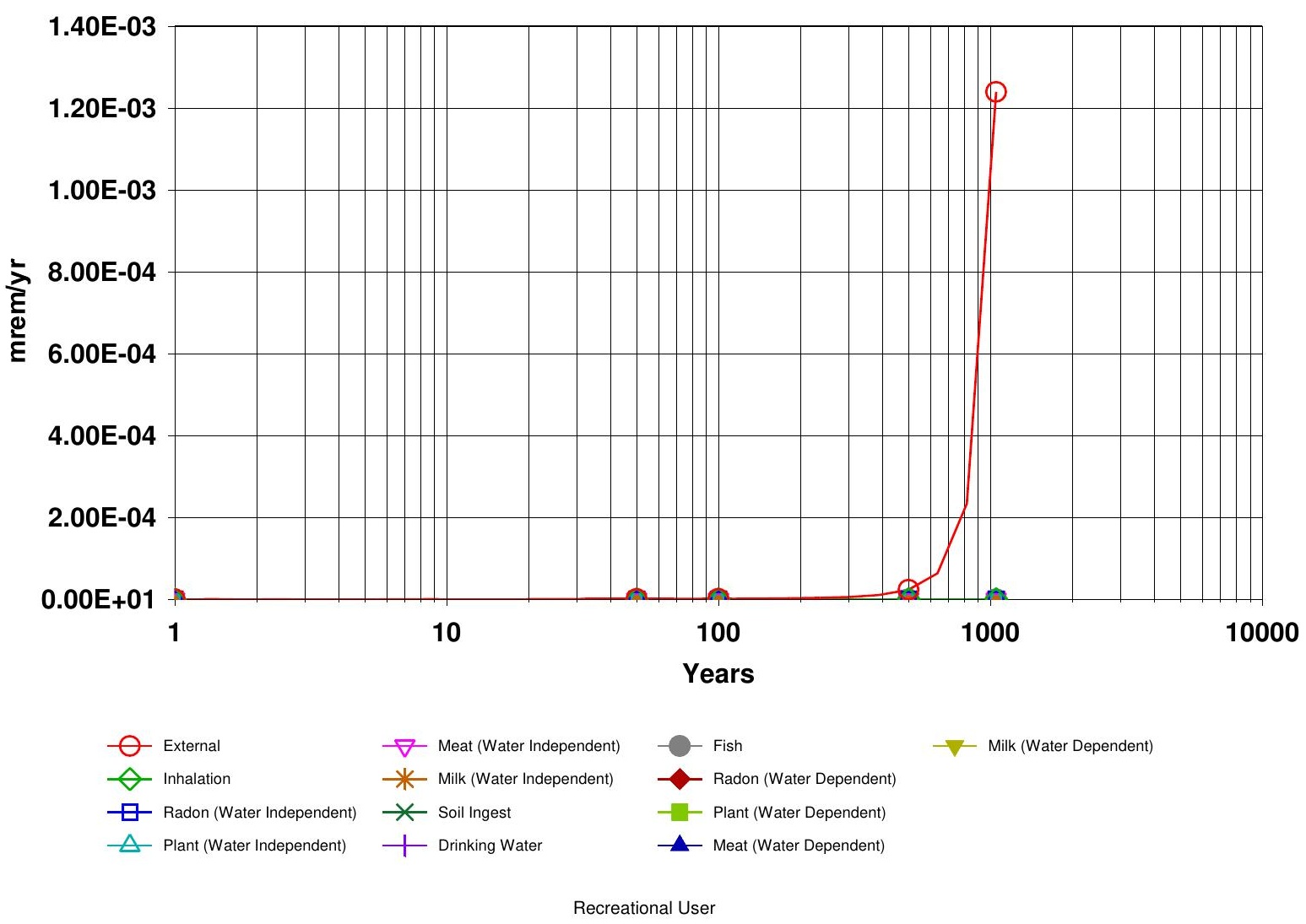

Figure 3-14. Dose to the Recreational User by Exposure Pathways 


\section{OUTDOOR WORKER}

The peak dose for the Outdoor Worker occurs at 1,050 $\mathrm{yr}$ which is same as the time horizon used in this evaluation. As depicted in Figures 3-15 and 3-16, this receptor's dose is due to Th-230 and Th-232 through the external gamma pathway. This receptor is considered an implausible receptor as indicated in ORISE 2012.

The following RESRAD graphics correspond to the Outdoor Worker using a time horizon of $1,050 \mathrm{yr}$.

\section{DOSE: All Nuclides Summed, All Pathways Summed}

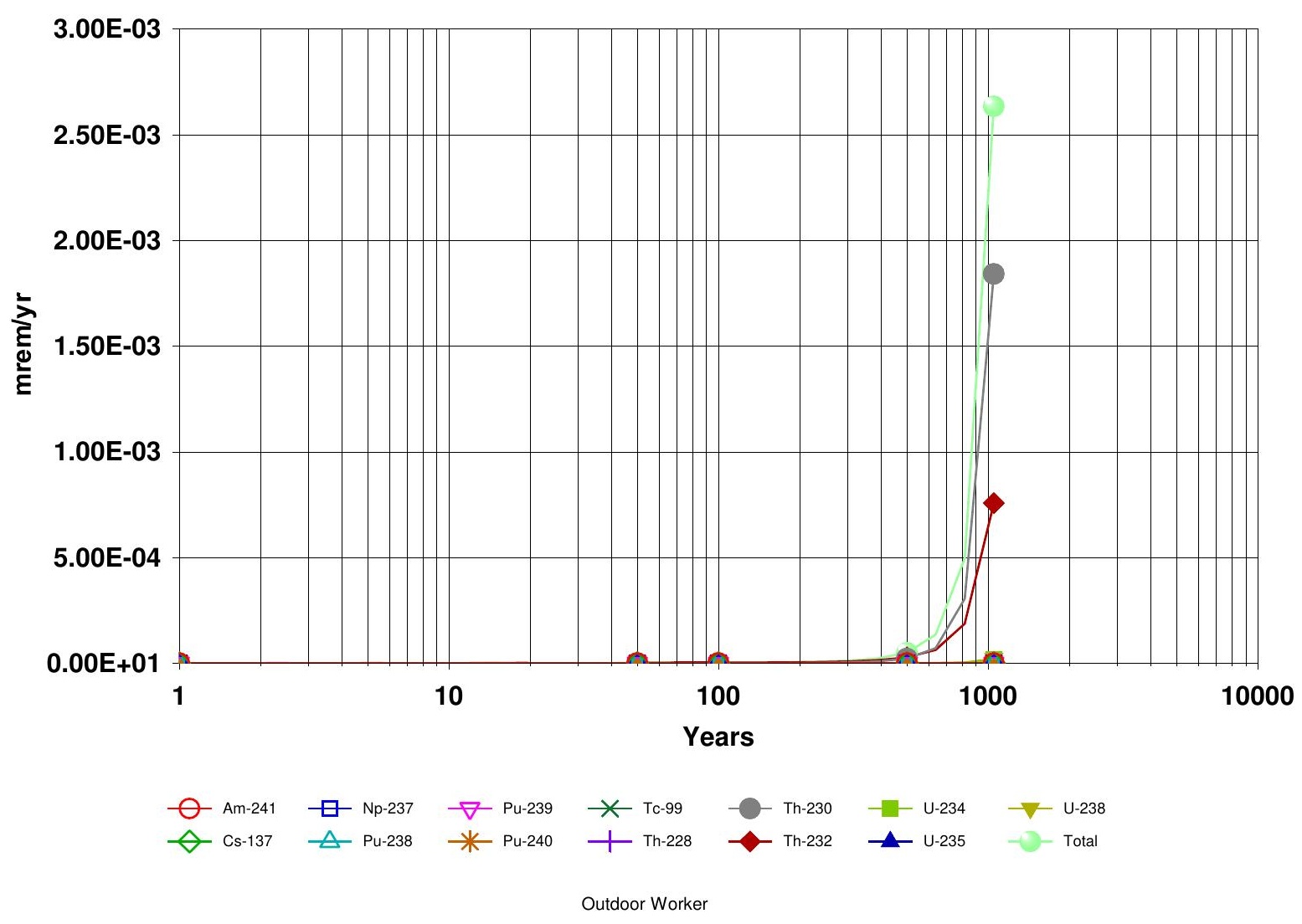

Figure 3-15. Dose to the Outdoor Worker from all Selected Targeted Radionuclides and Pathways 
DOSE: All Nuclides Summed, Component Pathways

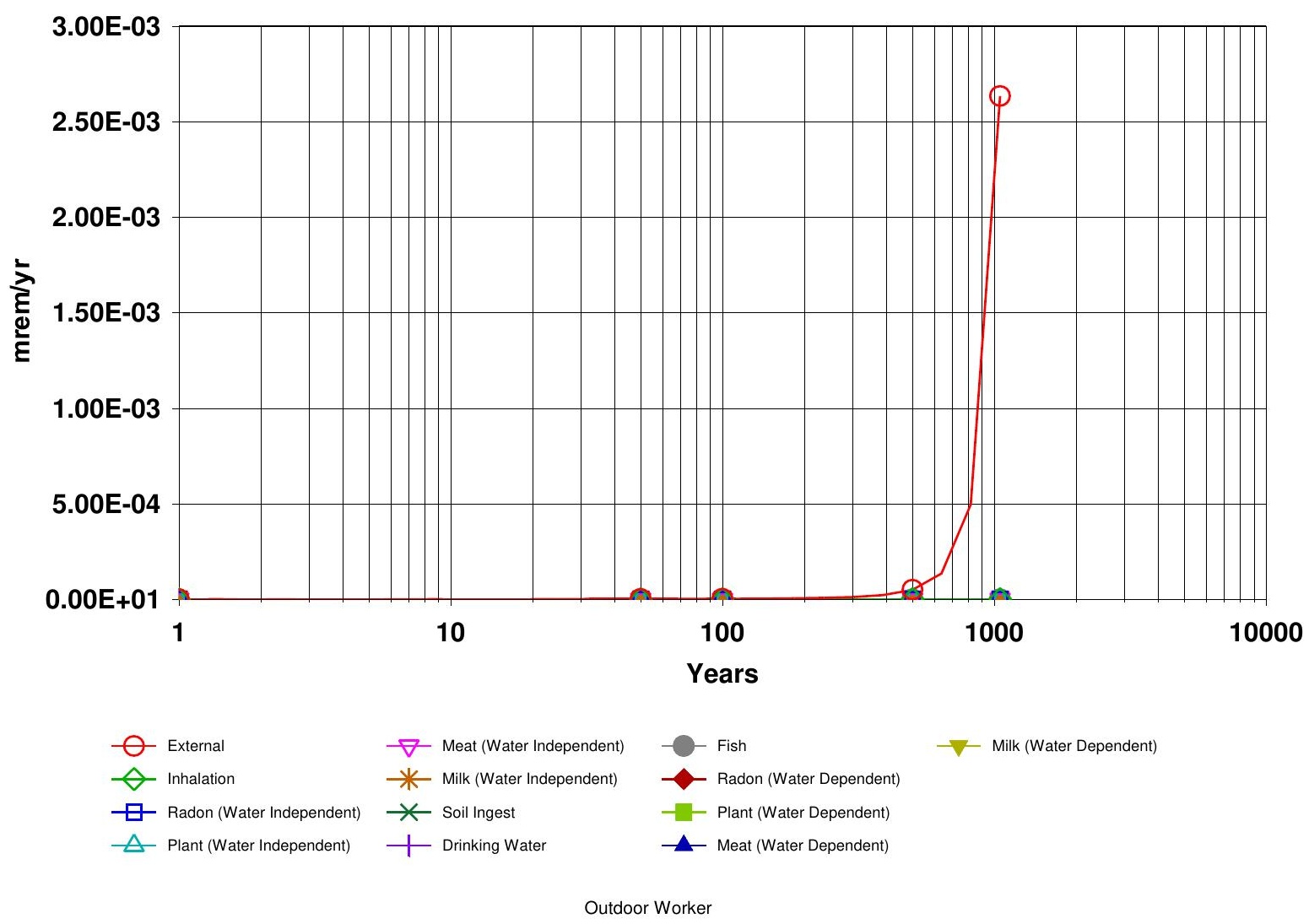

Figure 3-16. Dose to the Outdoor Worker by Exposure Pathways 


\section{OFFSITE RESIDENT FARMER}

The peak dose for the Offsite Resident Farmer occurs at $772 \mathrm{yr}$ when using a time horizon of 1,050 yr. As depicted in Figures 3-17 and 3-18, this receptor's dose is also due entirely to Tc-99 through the drinking water, plant and milk ingestion pathways. The meat ingestion pathway also contributes to the maximum dose; however, the contribution from this pathway is $0.1 \%$. However, it could be assumed that the dose derives from drinking water, plant, and milk ingestion pathways due to the fact that the meat ingestion pathway contribution is miniscule.

The following RESRAD-OFFSITE graphics correspond to the Offsite Resident Farmer using a time horizon of $1,050 \mathrm{yr}$.

DOSE: All Nuclides Summed, All Pathways Summed

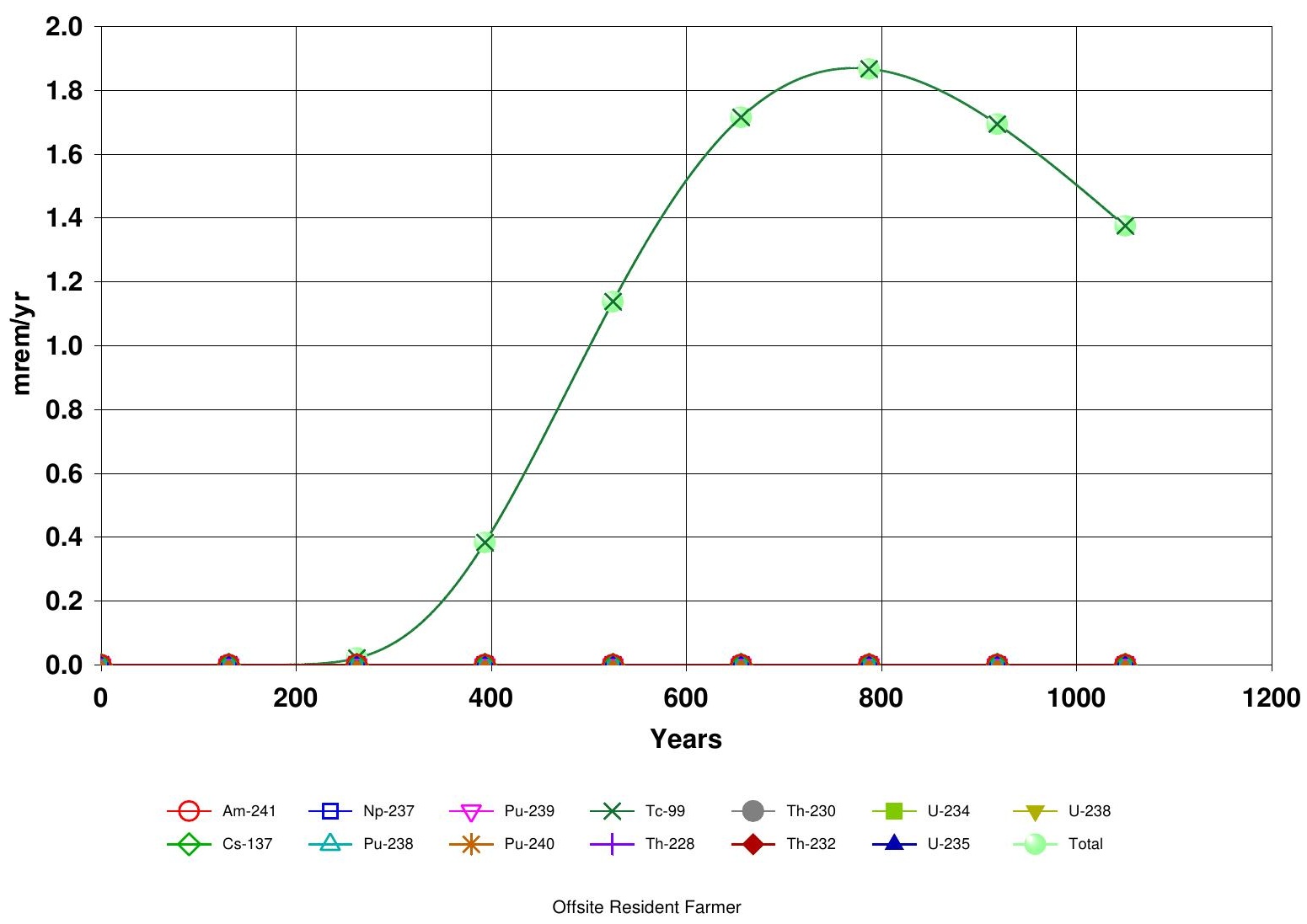

Figure 3-17. Dose to the Offsite Resident Farmer from all Selected Targeted Radionuclides and Pathways 


\section{DOSE: All Nuclides Summed, Component Pathways}

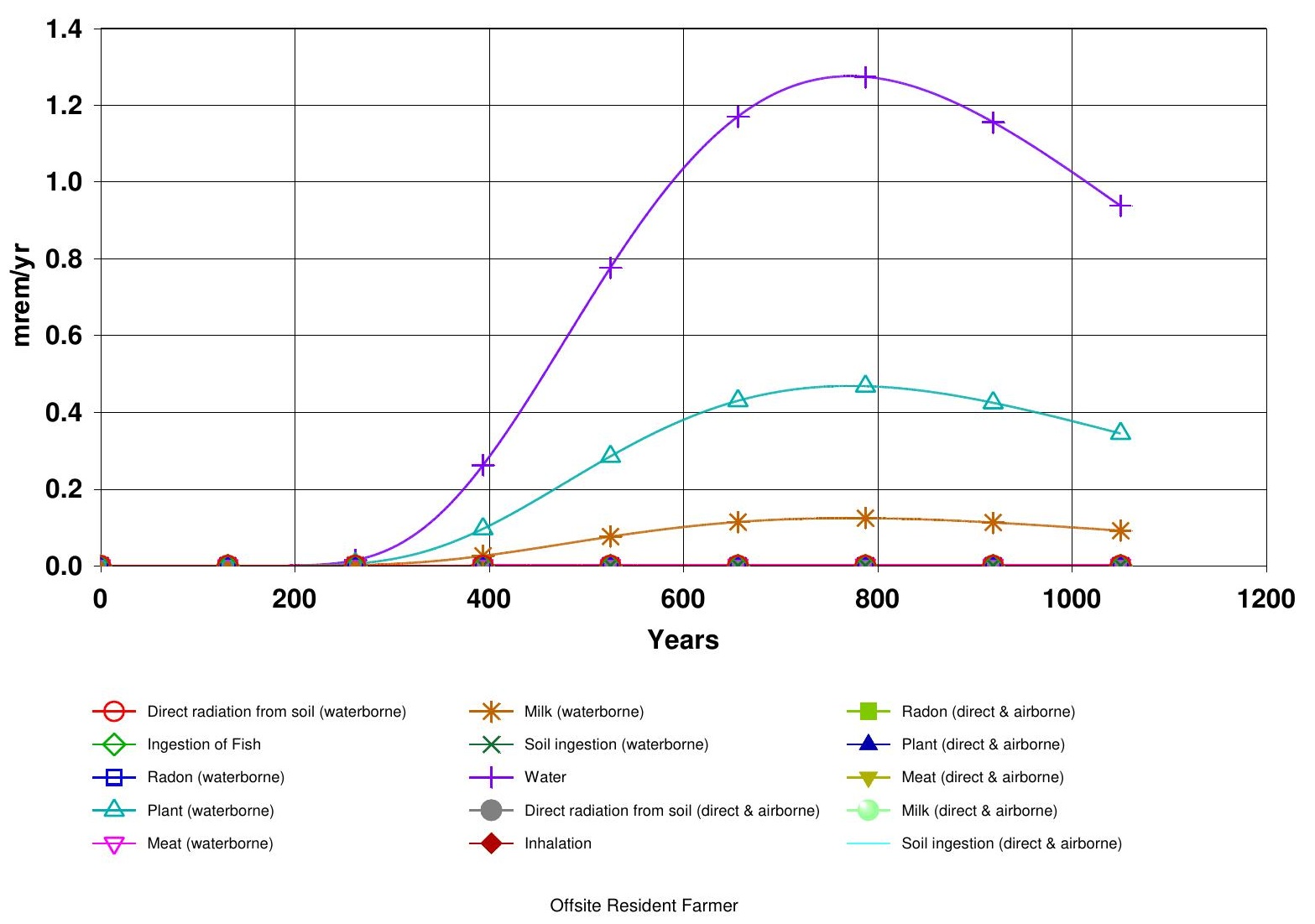

Figure 3-18. Dose to the Offsite Resident Farmer by Exposure Pathways

This receptor is considered plausible in ORISE 2012. The Tc-99 dose to this receptor is worthy of further discussions. Table 3-4 includes a breakdown of the $1.9 \mathrm{mrem} / \mathrm{yr}$ total dose for this receptor from Tc-99. Figure 3-19 is also included to exclusively show the contribution of each pathway to the total Tc-99 dose as a function of time. 
Table 3-4. Exposure Pathways and Doses Contributing to the Tc-99 Dose for the Offsite Resident Farmer

\begin{tabular}{|ccc|}
\hline Exposure Pathway & Dose (mrem/yr)* & $\begin{array}{c}\text { Percentage contributing } \\
\text { to the total dose }\end{array}$ \\
\hline Drinking water & 1.275 & $68 \%$ \\
\hline Ingestion of Plants & 0.4681 & $25 \%$ \\
\hline Ingestion of Milk & 0.1239 & $6.6 \%$ \\
\hline Ingestion of Meat & 0.001403 & $0.1 \%$ \\
\hline
\end{tabular}

*Note: These dose results are not rounded to two significant figures in order to show a more accurate dose contribution by each pathway.

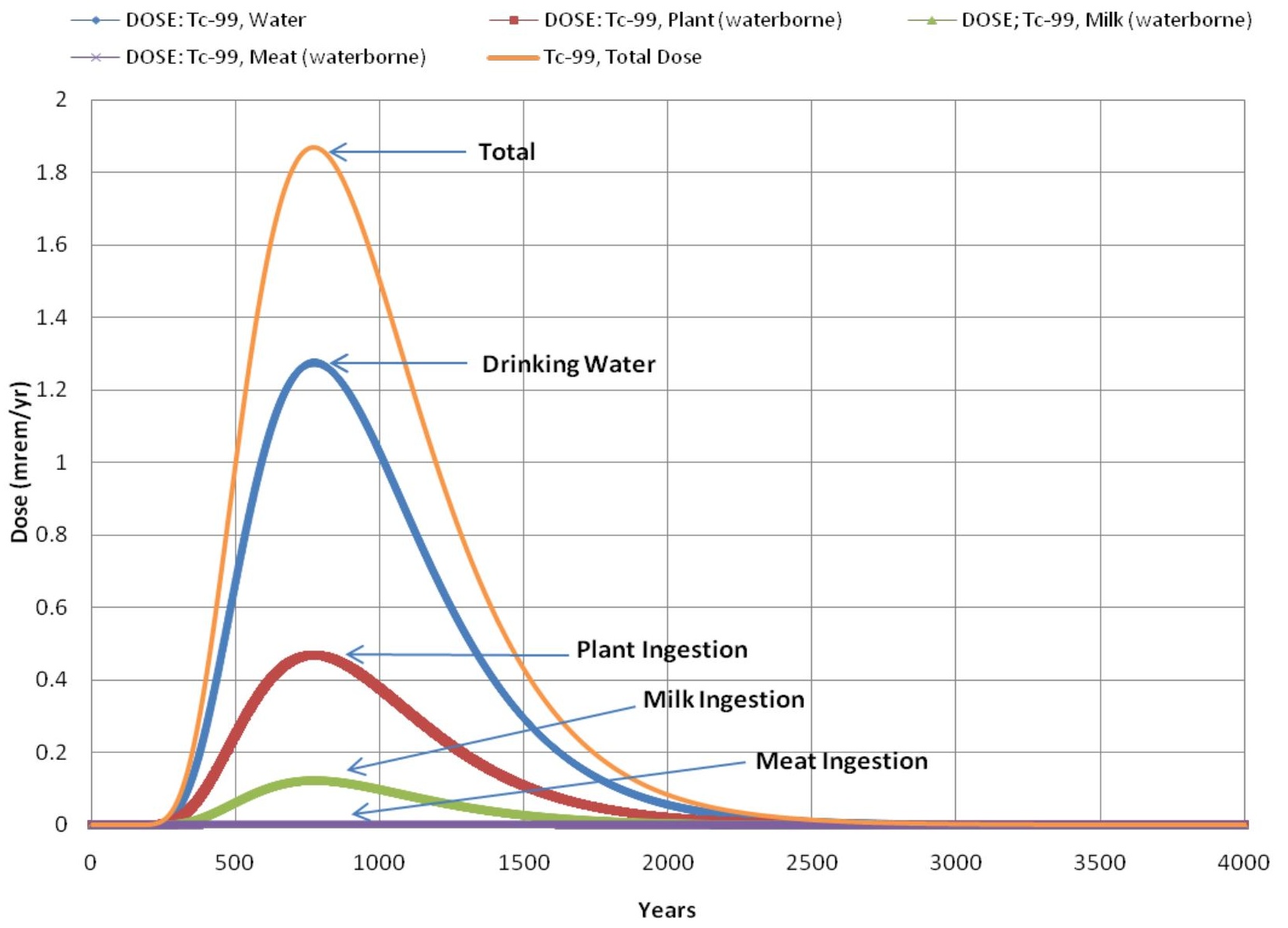

Offsite Resident Farmer

Figure 3-19. Tc-99 Dose by Contributing Exposure Pathway 
The dose from drinking water predicted by the deterministic analysis is above the $1 \mathrm{mrem} / \mathrm{yr}$ (above background) dose constraint, but it is less than the EPA's $4 \mathrm{mrem} / \mathrm{yr}$ MCL for beta particle and photon radioactivity from man-made radionuclides, such as Tc-99, in public drinking water supplies (40 CFR 141.66 (d) and 401 KAR 8:550 Section 1). Contributions to total dose from the other pathways modeled (e.g., plant, milk and meat consumption), were negligible and peaked at $0.59 \mathrm{mrem} / \mathrm{yr}$.

\subsubsection{SECOND ASSESSMENT}

The results for the second evaluation using a time horizon of 10,000 yr are summarized in Table 3-5.

Table 3-5. Peak Doses from DOE-PPPO Proposed Single Radionuclide Soil Guidelines

\begin{tabular}{|cccccc|}
\hline Receptor & $\begin{array}{c}\text { Resident } \\
\text { Farmer } \\
\text { (onsite) }\end{array}$ & $\begin{array}{c}\text { Resident } \\
\text { Gardener }\end{array}$ & $\begin{array}{c}\text { Recreational } \\
\text { User }\end{array}$ & $\begin{array}{c}\text { Outdoor } \\
\text { Worker }\end{array}$ & $\begin{array}{c}\text { Offsite } \\
\text { Resident } \\
\text { Farmer }\end{array}$ \\
\hline Target Dose (mrem/yr) & 100 & 100 & 1 & 1 & 1 \\
\hline Peak Dose (mrem/yr) & 2,700 & 2,400 & 95 & 220 & 2.2 \\
\hline Time (yr) & 10,000 & 10,000 & 10,000 & 10,000 & 10,000 \\
\hline
\end{tabular}

The peak doses for all the receptors exceed the $1 \mathrm{mrem} / \mathrm{yr}$ dose constraint (above background) and the $100 \mathrm{mrem} / \mathrm{yr}$ primary public dose limit (above background). In addition, these peak doses occur at $10,000 \mathrm{yr}$ which is also the time horizon used in these analyses.

\section{RESIDENT FARMER (ONSITE)}

The main radionuclides contributing to the peak dose for the Resident Farmer (onsite) (in descending order) are Th-230, U-234, Th-232, U-238, U-235, Np-237, Pu-239 and Pu-240. As depicted in Figure 3-20 the majority of the dose derives from Th-230. The ingrowth progeny of Th-230, specifically Ra-226 and Pb-210, are the actual contributors to most of the peak dose. The exposure pathways contributing to the peak dose are ingestion of plants, external gamma, and ingestion of milk, meat and soil. These pathways are depicted in Figure 3-21.

The following RESRAD graphics correspond to the Resident Farmer (onsite) using a time horizon of $10,000 \mathrm{yr}$. 
DOSE: All Nuclides Summed, All Pathways Summed

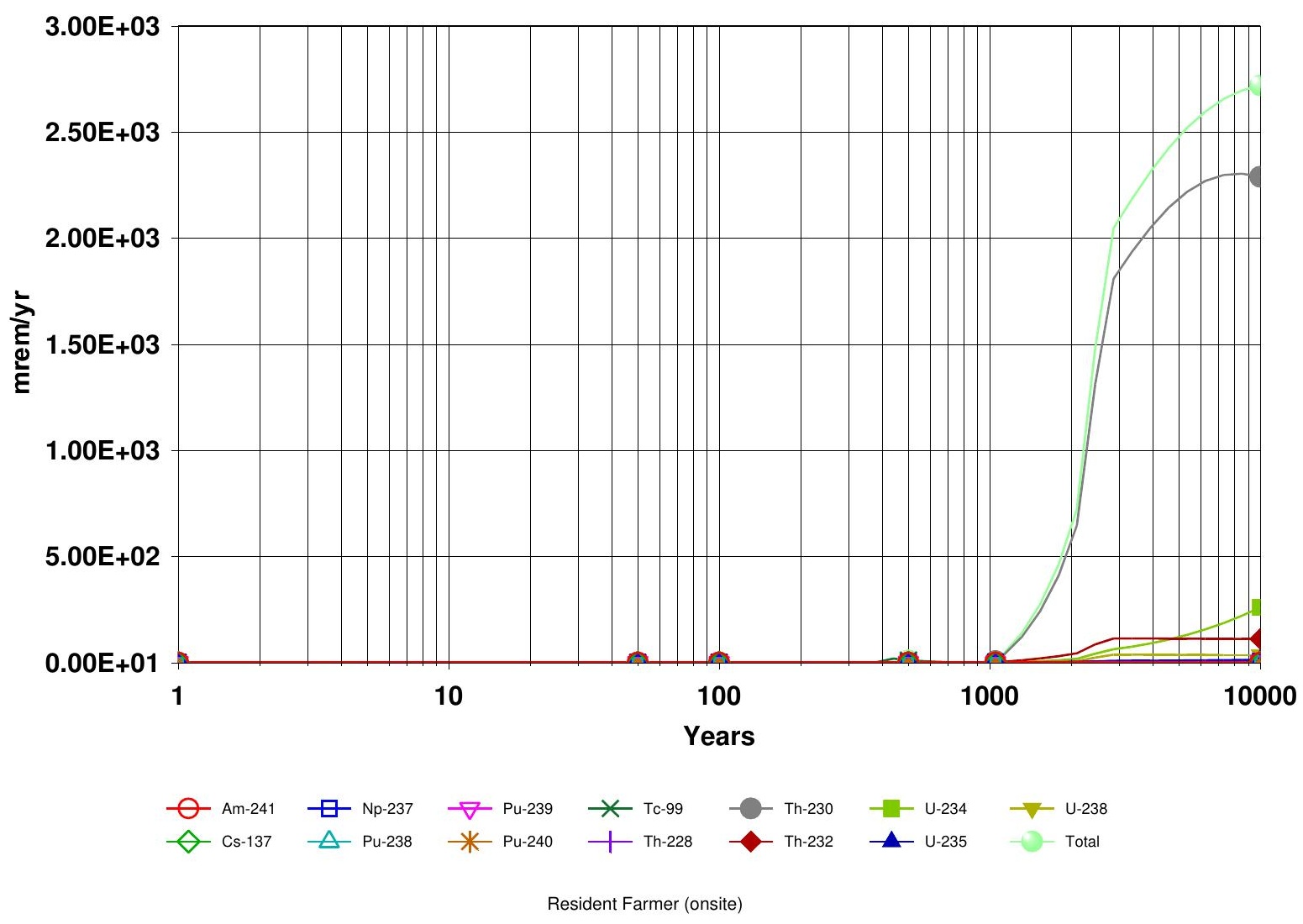

Figure 3-20. Dose to the Resident Farmer (onsite) from all Selected Targeted Radionuclides and Pathways 


\section{DOSE: All Nuclides Summed, Component Pathways}

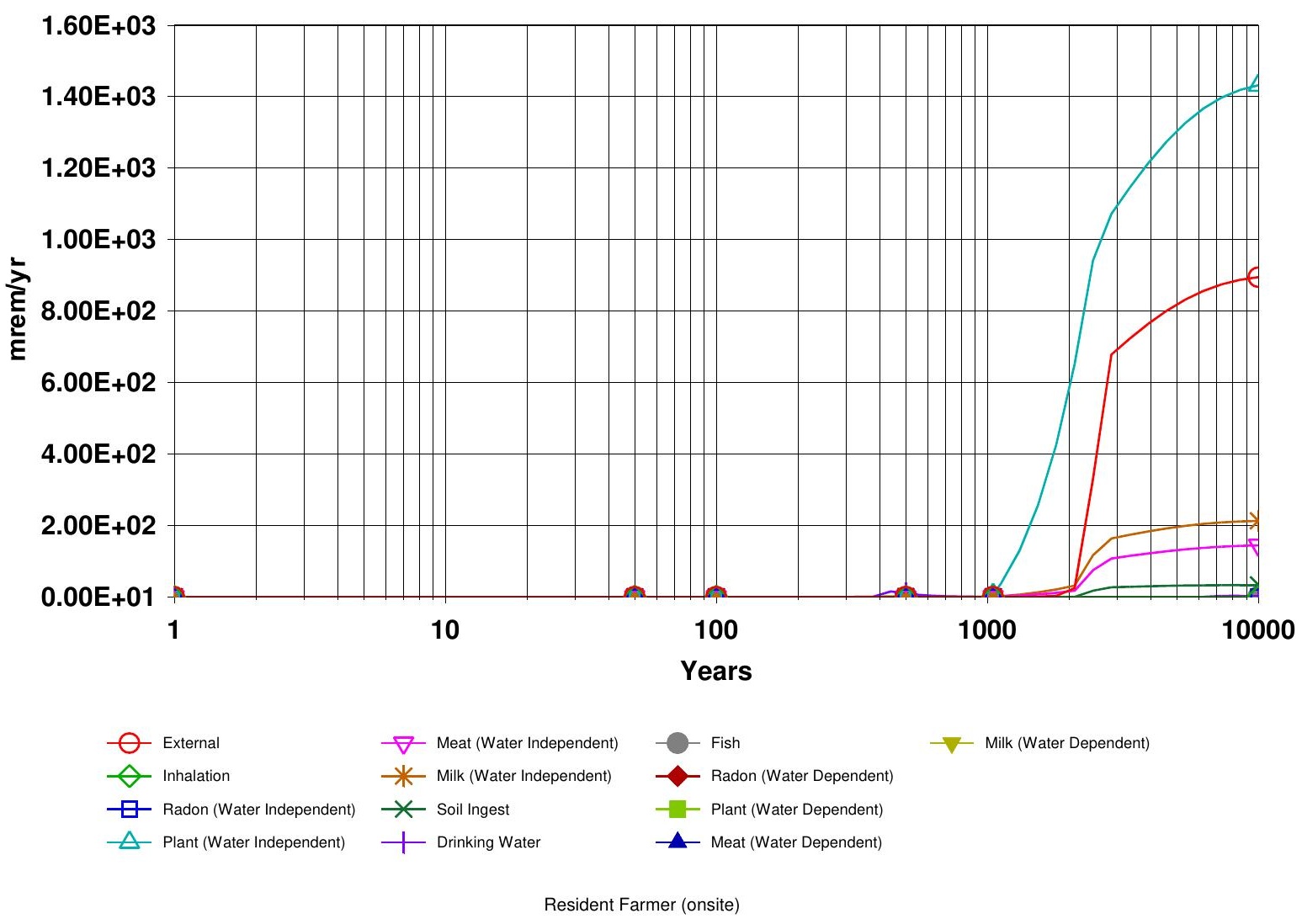

Figure 3-21. Dose to the Resident Farmer (onsite) by Exposure Pathways 


\section{RESIDENT GARDENER}

The principal radionuclides contributing to the peak dose for the Resident Gardener (in descending order) are Th-230, U-234, Th-232, U-238, U-235, Pu-239, Np-237 and Pu-240. As depicted in Figure 3-22 the majority of the dose derives from Th-230. The ingrowth progeny of Th-230, specifically $\mathrm{Ra}-226$ and $\mathrm{Pb}-210$, are the actual contributors to most of the peak dose. The exposure pathways contributing to the peak dose are ingestion of plants, external gamma, and ingestion of soil. These pathways are depicted in Figure 3-23.

The following RESRAD graphics correspond to the Resident Farmer (onsite) using a time horizon of $10,000 \mathrm{yr}$.

DOSE: All Nuclides Summed, All Pathways Summed

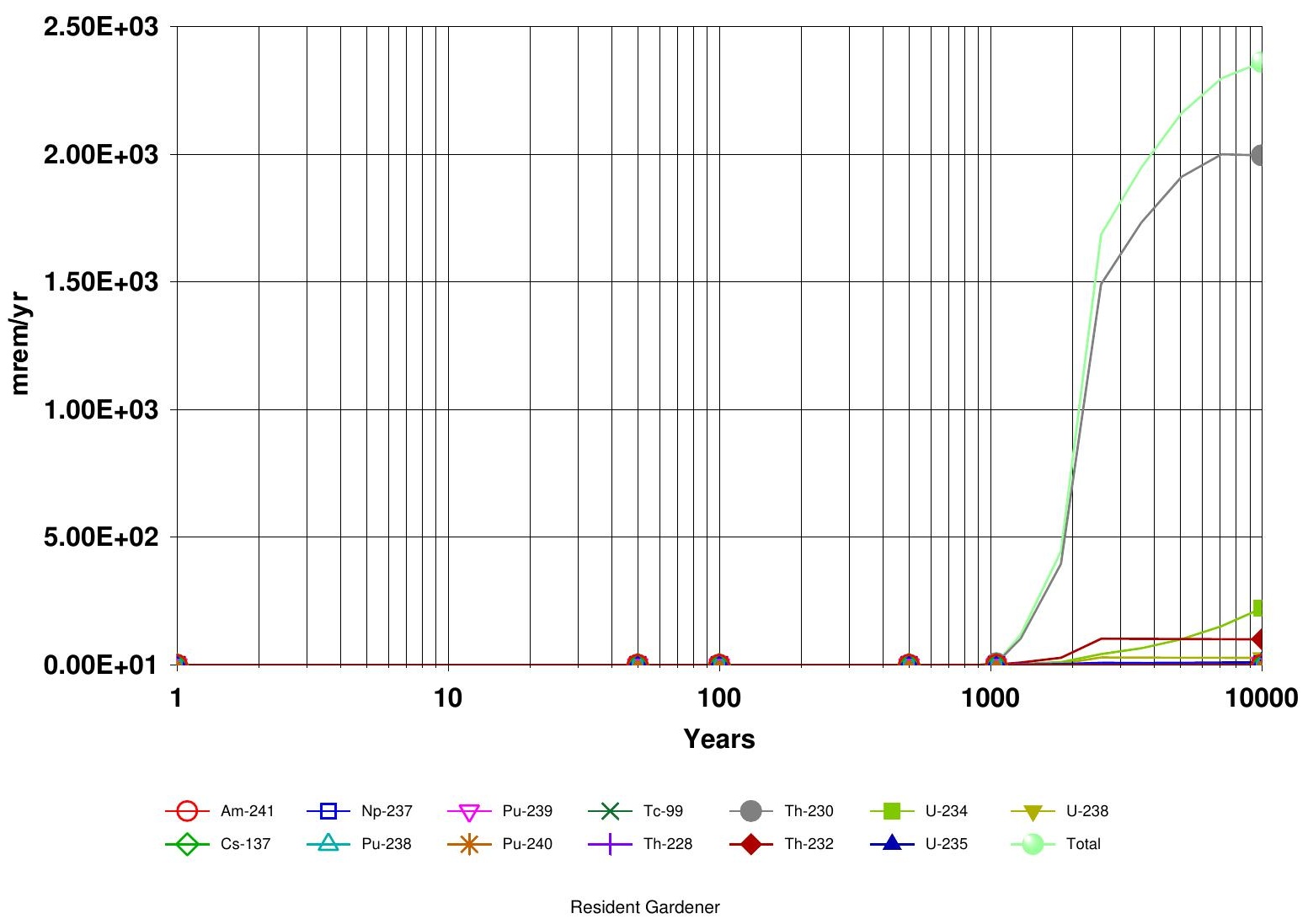

Figure 3-22. Dose to the Resident Gardener from all Selected Targeted Radionuclides and Pathways 


\section{DOSE: All Nuclides Summed, Component Pathways}

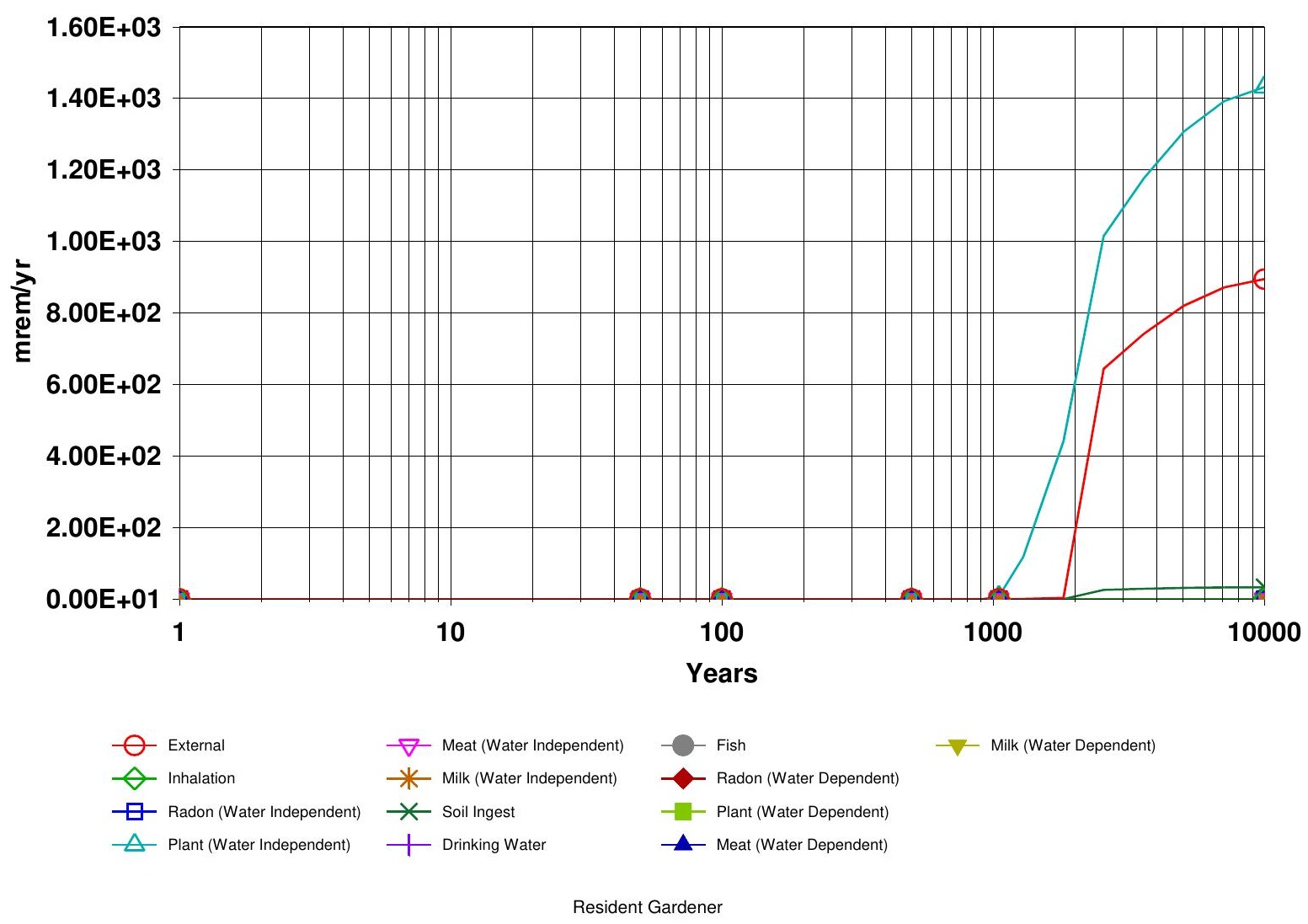

Figure 3-23. Dose to the Resident Gardener by Exposure Pathways 


\section{RECREATIONAL USER}

The peak dose for the Recreational User derives (in descending order) from Th-230, U-234, Th-232, U-238, U-235, Np-237, Pu-239 and Pu-240 through the external gamma and soil ingestion pathways as depicted in Figures 3-24 and 3-25.

The following RESRAD graphics correspond to the Recreational User using a time horizon of $10,000 \mathrm{yr}$.

\section{DOSE: All Nuclides Summed, All Pathways Summed}

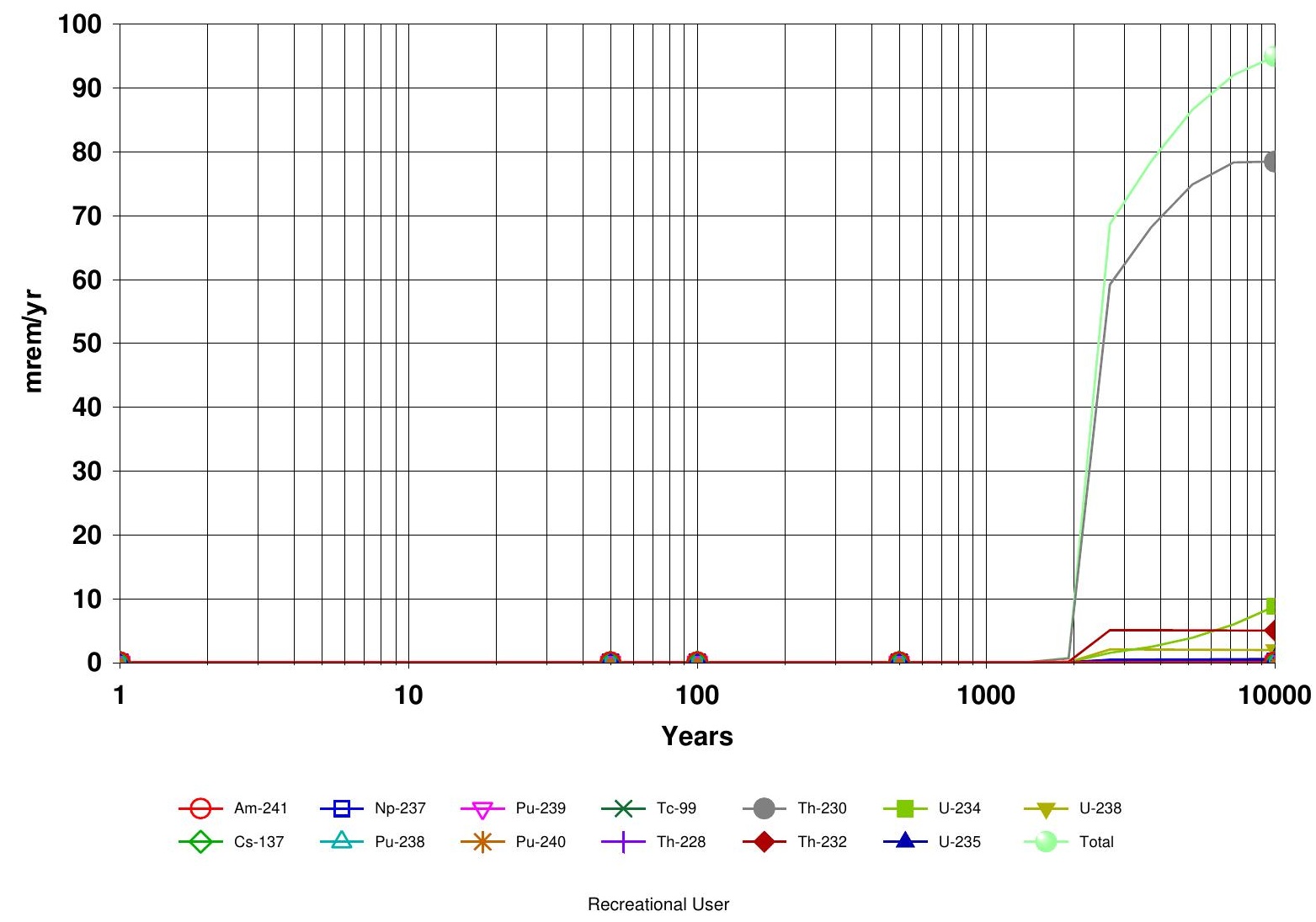

Figure 3-24. Dose to the Recreational User from all Selected Targeted Radionuclides and Pathways 


\section{DOSE: All Nuclides Summed, Component Pathways}

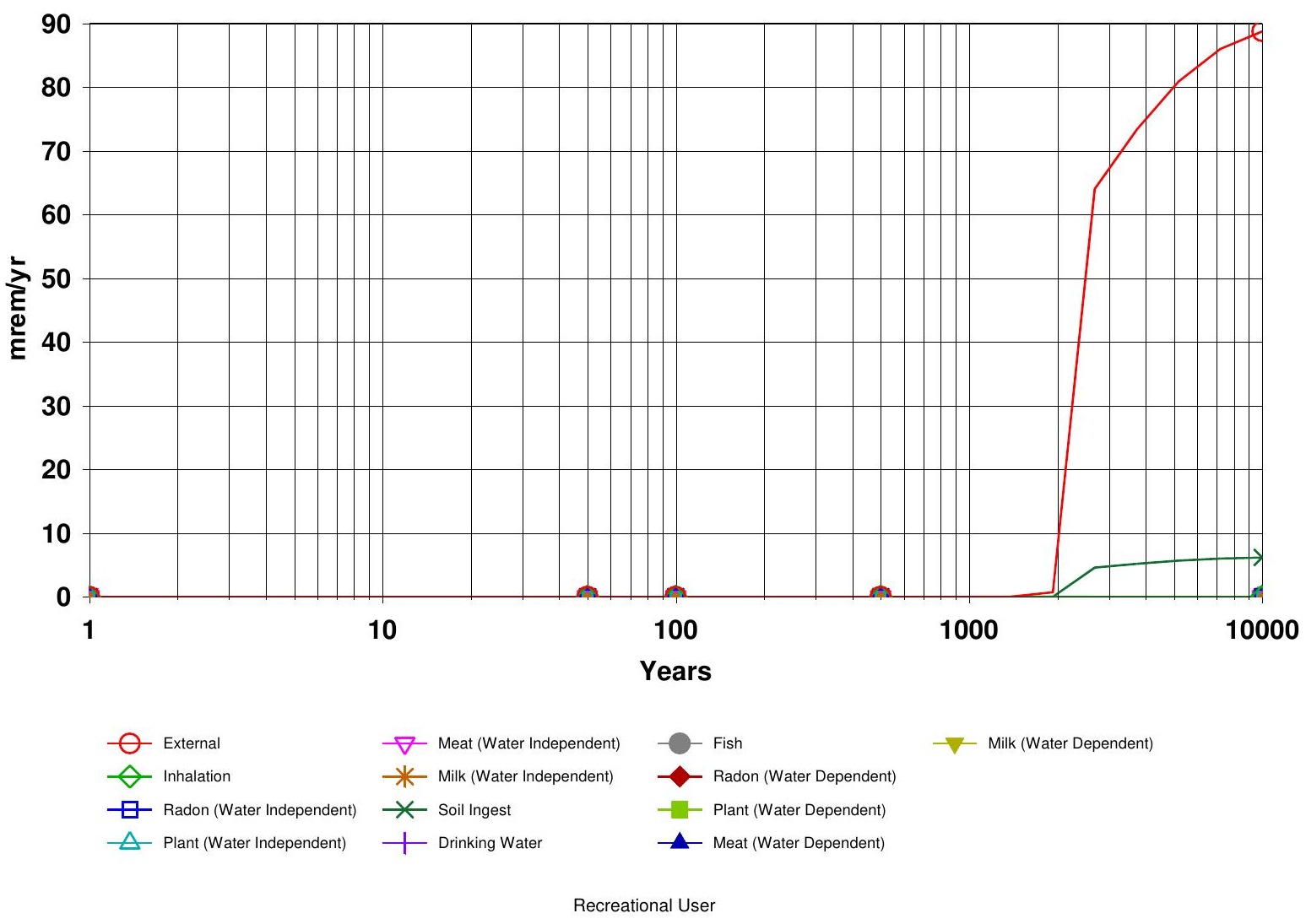

Figure 3-25. Dose to the Recreational User by Exposure Pathways 


\section{OUTDOOR WORKER}

The radionuclides contributing to the peak dose of the Outdoor Worker (in descending order) are Th-230, U-234, Th-232, U-238, U-235, Pu-239, Np-237, and Pu-240. The majority of the dose derives from Th-230 as depicted in Figure 3-26. The ingrowth progeny of Th-230, specifically $\mathrm{Ra}-226$ and $\mathrm{Pb}-210$, are the actual contributors to most of the peak dose. The exposure pathways contributing to the peak dose are external gamma and soil ingestion as depicted in Figures 3-27.

The following RESRAD graphics correspond to the Outdoor Worker using a time horizon of $10,000 \mathrm{yr}$.

DOSE: All Nuclides Summed, All Pathways Summed

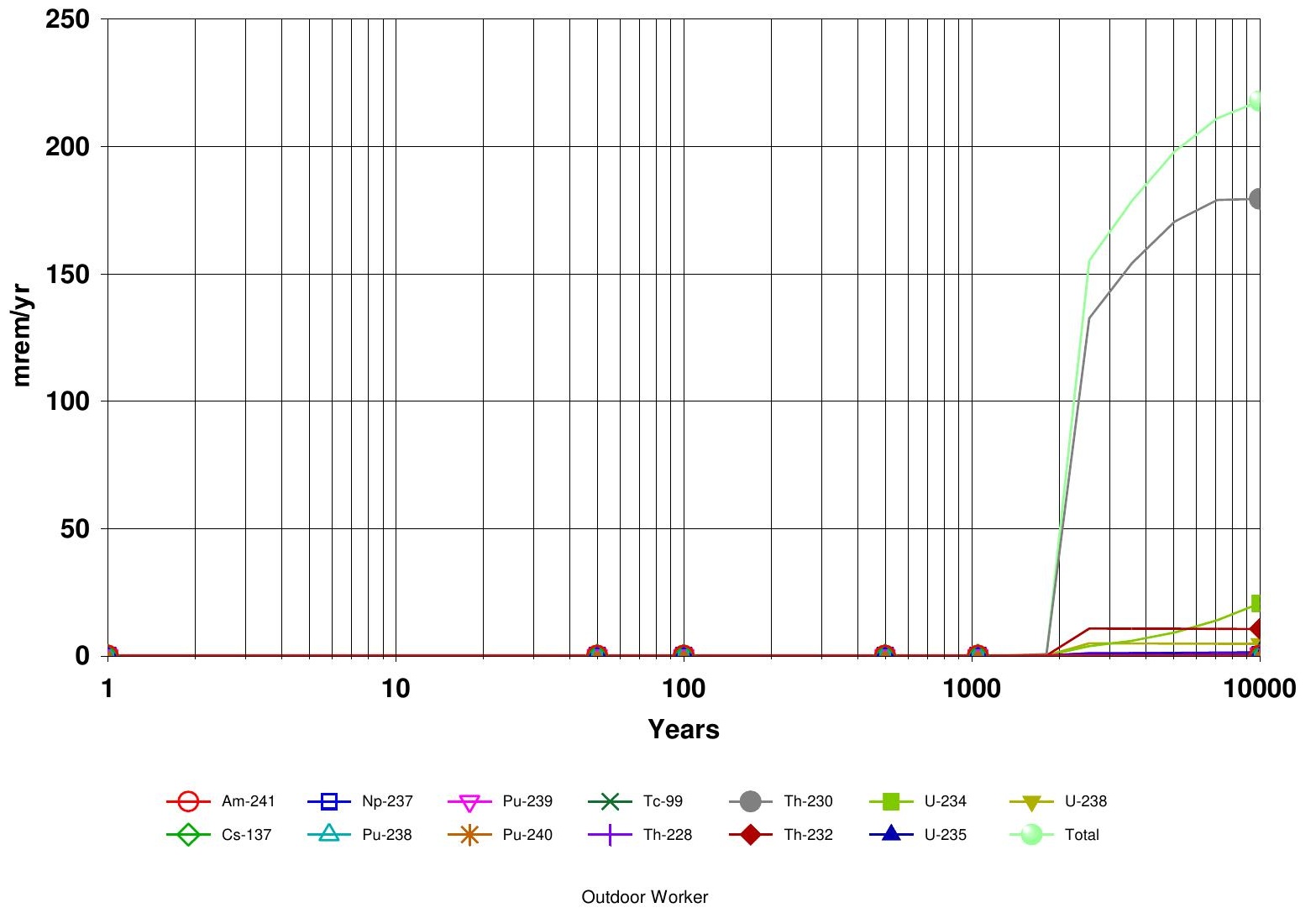

Figure 3-26. Dose to the Outdoor Worker from all Selected Targeted Radionuclides and Pathways 


\section{DOSE: All Nuclides Summed, Component Pathways}

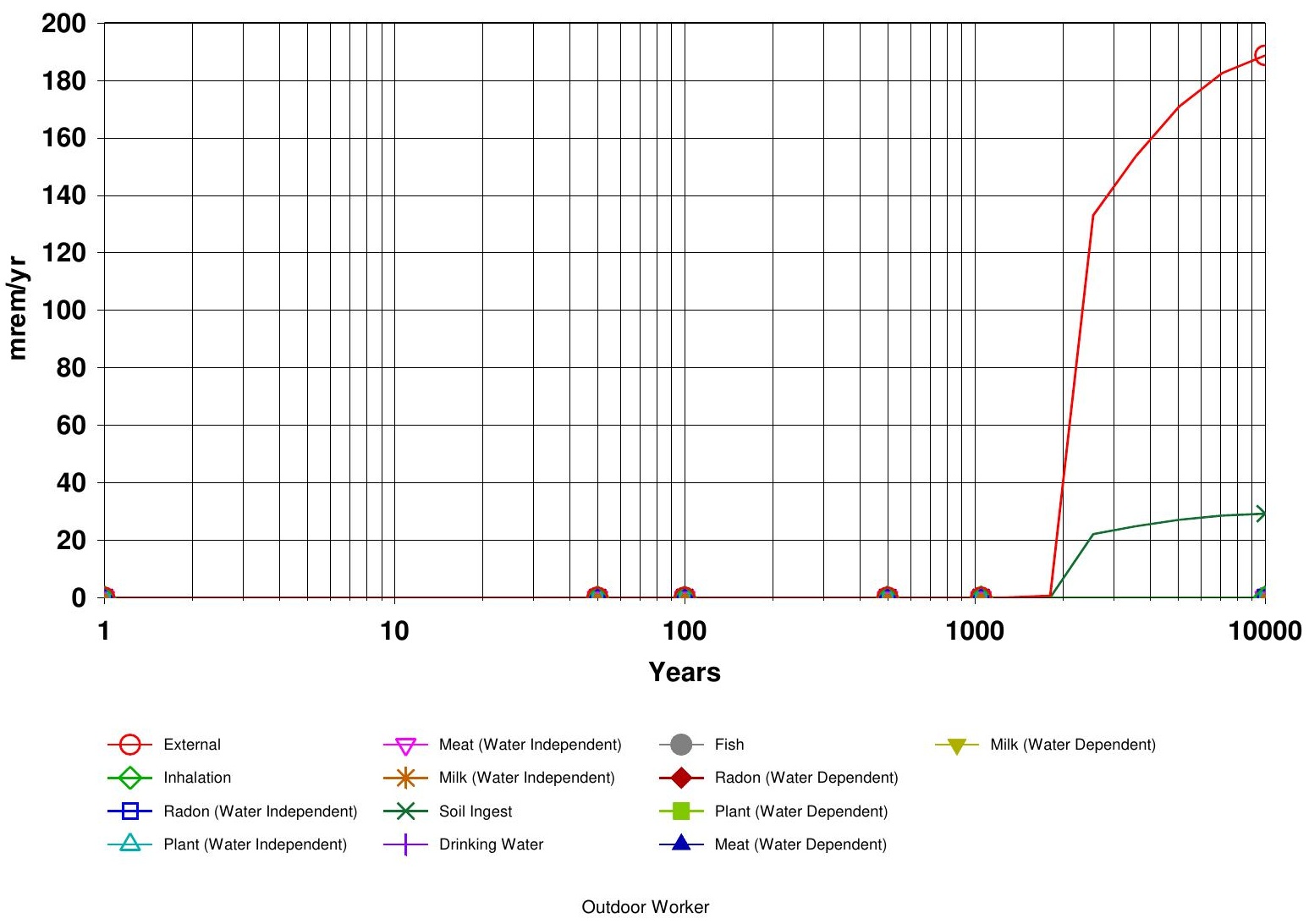

Figure 3-27. Dose to the Outdoor Worker by Exposure Pathways 


\section{OFFSITE RESIDENT FARMER}

For this second assessment, when using a time horizon of 10,000 yr, the peak dose result for the Offsite Resident Farmer is no longer attributed to Tc-99. In this second assessment, the dose from Tc-99 starts disappearing at approximately 2,500 yr as demonstrated in Figure 3-28. However, the highest dose registered by the code is $2.2 \mathrm{mrem} / \mathrm{yr}$ and it occurs at $10,000 \mathrm{yr}$. The dose contribution derives from Np-237, the ingrowth progeny of Th-230 (i.e., Ra-226), U-234 (i.e., Ra-226), Th-232 (i.e., Th-228 and Ra-228) and the parent U-238 with a small contribution from its ingrowth progeny (i.e., Ra-226). The ingrowth progeny are not depicted in Figure 3-28, this figure only depicts the parent radionuclides as the contributors to the dose. However, a review of additional RESRAD-OFFSITE graphics and data indicates that the contribution to the dose from Th-230, U-234 and Th-232 originates from their ingrowth progeny. The principal exposure pathways by which these radionuclides contribute to the dose are drinking water external gamma and plant ingestion. A considerable portion of this dose, about $1.29 \mathrm{mrem} / \mathrm{yr}$, results from $\mathrm{Np}-237$ through the drinking water and plant ingestion pathways. The remaining dose is attributed to the ingrowth progeny of Th-230, U-234, Th-232 and the parent U-238 through the external gamma pathway. Figure 3-29 shows the exposure pathways by which the dose is created.

It is of interest to DOE-PPPO to know how this offsite receptor receives dose through the external gamma pathway indicated by the "direct radiation from soil (direct $\&$ airborne)" curve as illustrated in Figure 3-29. The dose initially appears at approximately 2,750 yrs. By this time the model has eroded the Landfill cover to the extent that the primary contamination is uncovered and it is emitting direct radiation to the receptor. The primary contamination area in the model $\left(91,000 \mathrm{~m}^{2}\right)$ is considerably large; therefore, this receptor is receiving radiation dose at the dwelling area, agricultural areas, and pastures directly from the Landfill. In addition, this receptor spends $1 / 3$ of the time outside. The direct gamma radiation dose predicted by the code is less than $1 \mathrm{mrem} / \mathrm{yr}$.

The following RESRAD graphics correspond to the Offsite Resident Farmer using a time horizon of $10,000 \mathrm{yr}$. 


\section{DOSE: All Nuclides Summed, All Pathways Summed}

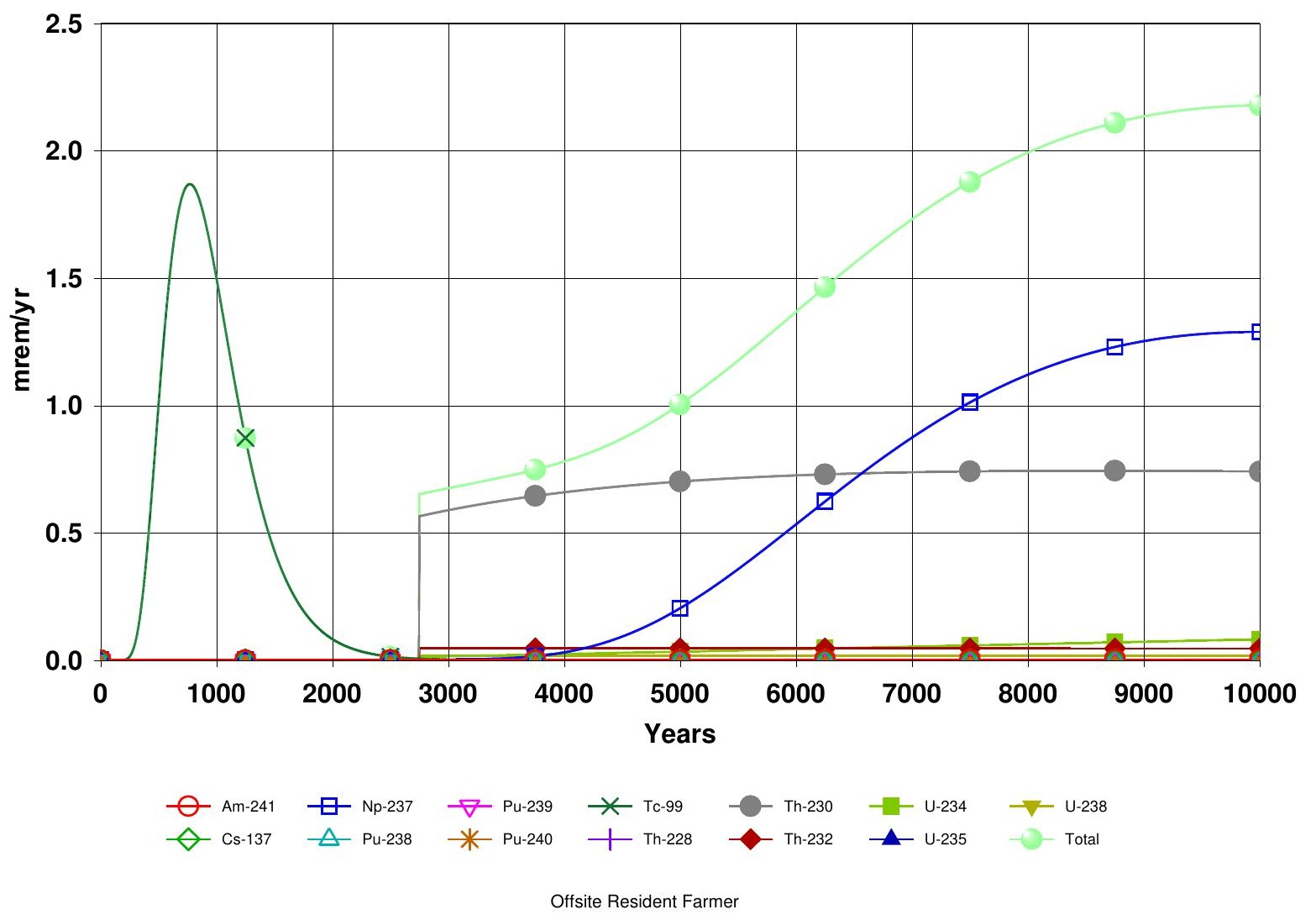

Figure 3-28. Dose to the Offsite Resident Farmer from all Selected Targeted Radionuclides and Pathways

A step increase for Th-230 can be identified in Figure 3-28 which may have been caused by an artifact in the code, however, the reason why this occurred was not clearly understood. While this step increase did not impact the results of the ORISE evaluation, ORISE recommends that further investigation and assistance by the developers of RESRAD-OFFSITE be provided to DOE to resolve this nuance in the code's graphical results. 
DOSE: All Nuclides Summed, Component Pathways

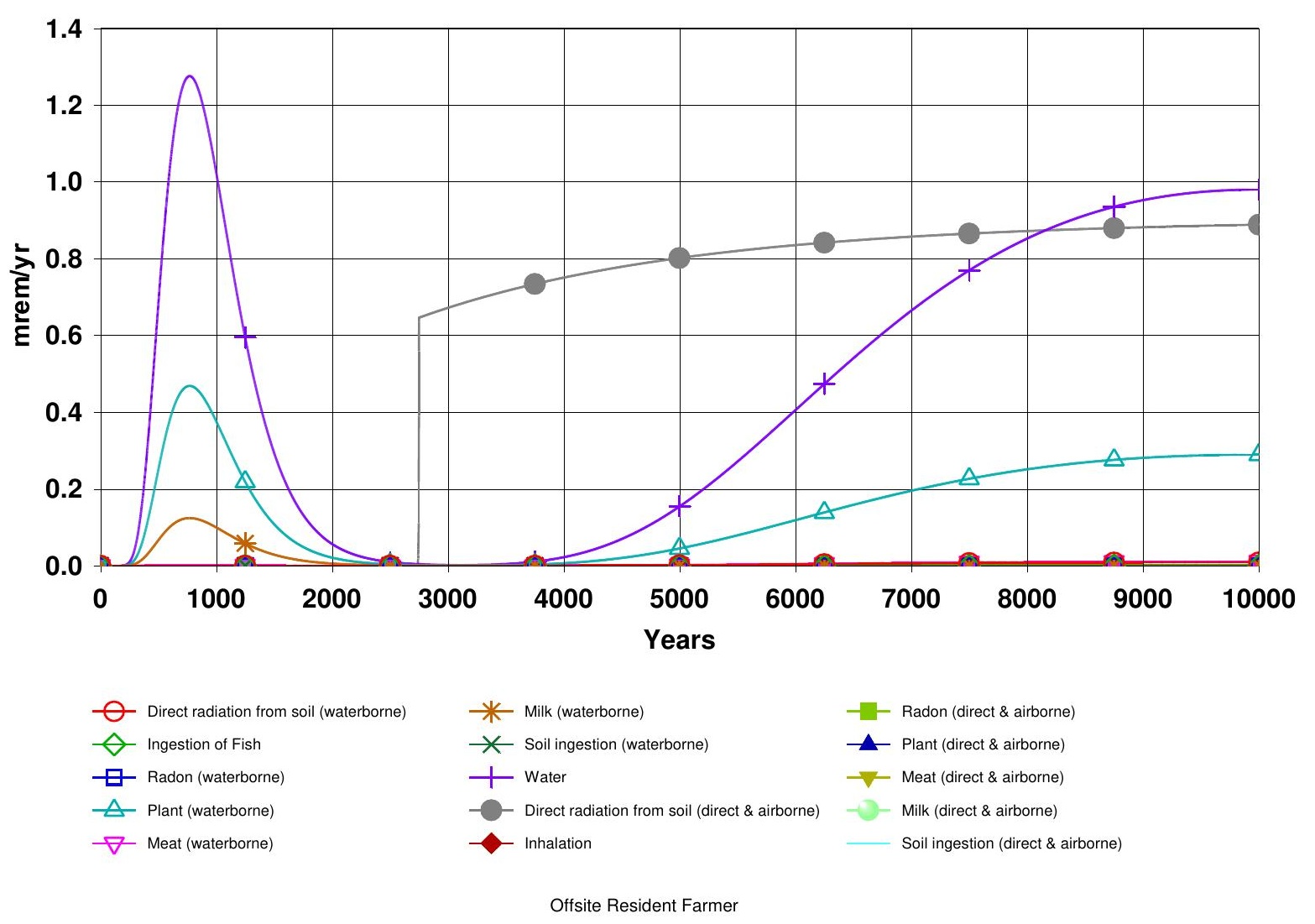

Figure 3-29. Dose to the Offsite Resident Farmer by Exposure Pathways

\subsubsection{THIRD ASSESSMENT}

The results for the third and last deterministic peak dose evaluation using a time horizon of $100,000 \mathrm{yr}$ (maximum allowed by the code) are included in Table 3-6.

Table 3-6. Peak Doses from DOE-PPPO Proposed Single Radionuclide Soil Guidelines

\begin{tabular}{|cccccc|}
\hline Receptor & $\begin{array}{c}\text { Resident } \\
\text { Farmer } \\
\text { (onsite) }\end{array}$ & $\begin{array}{c}\text { Resident } \\
\text { Gardener }\end{array}$ & $\begin{array}{c}\text { Recreational } \\
\text { User }\end{array}$ & $\begin{array}{c}\text { Outdoor } \\
\text { Worker }\end{array}$ & $\begin{array}{c}\text { Offsite } \\
\text { Resident } \\
\text { Farmer }\end{array}$ \\
\hline Target Dose (mrem/yr) & 100 & 100 & 1 & 1 & 1 \\
\hline Peak Dose (mrem/yr) & 2,700 & 2,400 & 96 & 220 & 2.2 \\
\hline Time (yr) & 12,773 & 12,931 & 19,739 & 19,045 & 10,065 \\
\hline
\end{tabular}


In this third assessment, the highest projected doses among all the time frames evaluated were obtained by extending the time frame to $100,000 \mathrm{yr}$. Similar to the second assessment, the results exceed the $1 \mathrm{mrem} / \mathrm{yr}$ constraint (above background) and the $100 \mathrm{mrem} / \mathrm{yr}$ public dose limit (above background). In addition, the radionuclides and pathways contributing to each receptor's peak doses are the same as those identified in the second peak dose assessments.

\section{RESIDENT FARMER (ONSITE)}

The maximum dose for the Resident Farmer (onsite) occurs at 12,773 $\mathrm{yr}$ and the dose is mostly due to Th-230, Th-232, U-234, U-235 and U-238 as depicted in Figure 3-30. A considerable fraction of the maximum dose derives from Th-230 and this third evaluation shows the complete peak for Th-230 in Figure 3-30. A review of additional RESRAD graphics and data reveals that the ingrowth progeny of Th-230, specifically $\mathrm{Ra}-226$ and $\mathrm{Pb}-210$, are the actual contributors to most of the peak dose. The exposure pathways contributing to the peak dose are ingestion of plants, external gamma, and ingestion of milk, meat and soil. These pathways are depicted in Figure 3-31.

The following RESRAD graphics correspond to the Resident Farmer (onsite) using a time horizon of $100,000 \mathrm{yr}$. 
DOSE: All Nuclides Summed, All Pathways Summed

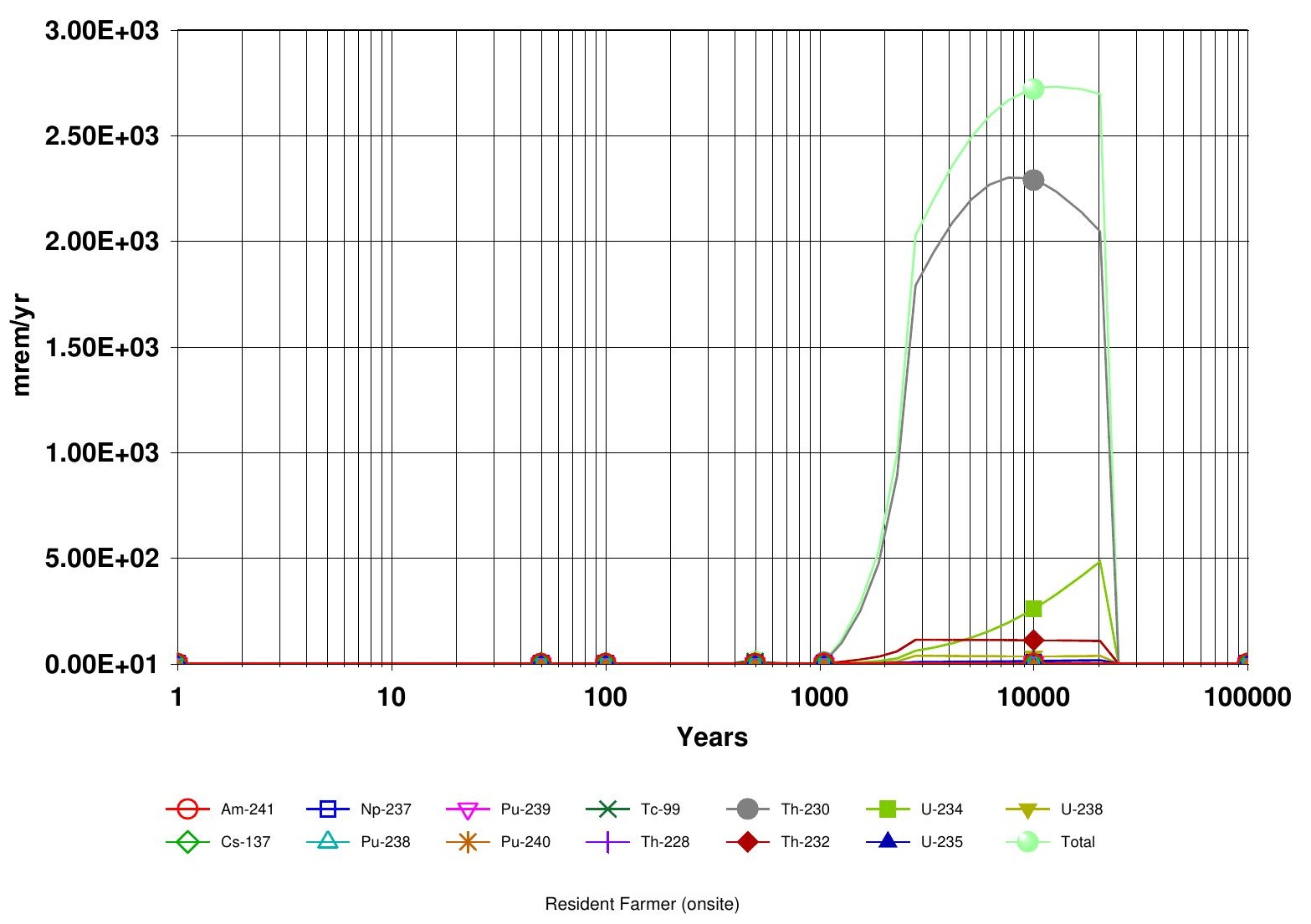

Figure 3-30. Dose to the Resident Farmer (onsite) from all Selected Targeted Radionuclides and Pathways 


\section{DOSE: All Nuclides Summed, Component Pathways}

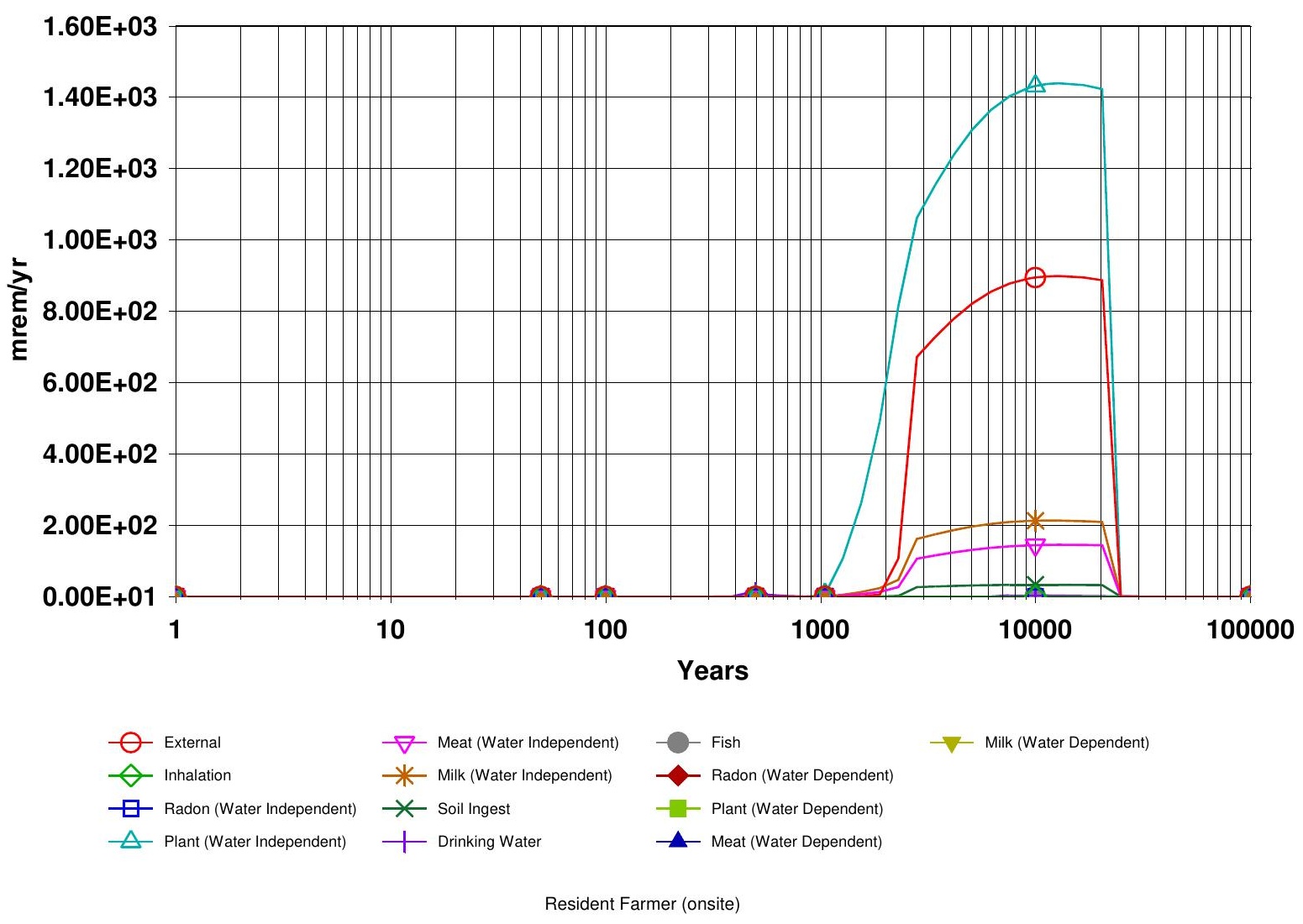

Figure 3-31. Dose to the Resident Farmer (onsite) by Exposure Pathways 


\section{RESIDENT GARDENER}

As in the second assessment, the third peak dose for the Resident Gardener results mainly from Th-230, U-234, Th-232, U-238, U-235, Pu-239, Np-237 and Pu-240. Figure 3-32 illustrates that almost all of the dose derives from Th-230. The ingrowth progeny of Th-230, particularly Ra-226 and $\mathrm{Pb}-210$, are the actual contributors to the majority of the peak dose. The exposure pathways contributing to the peak dose are ingestion of plants, external gamma, and ingestion of soil. These pathways are depicted in Figure 3-33.

The following RESRAD graphics correspond to the Resident Gardener using a time horizon of $100,000 \mathrm{yr}$.

DOSE: All Nuclides Summed, All Pathways Summed

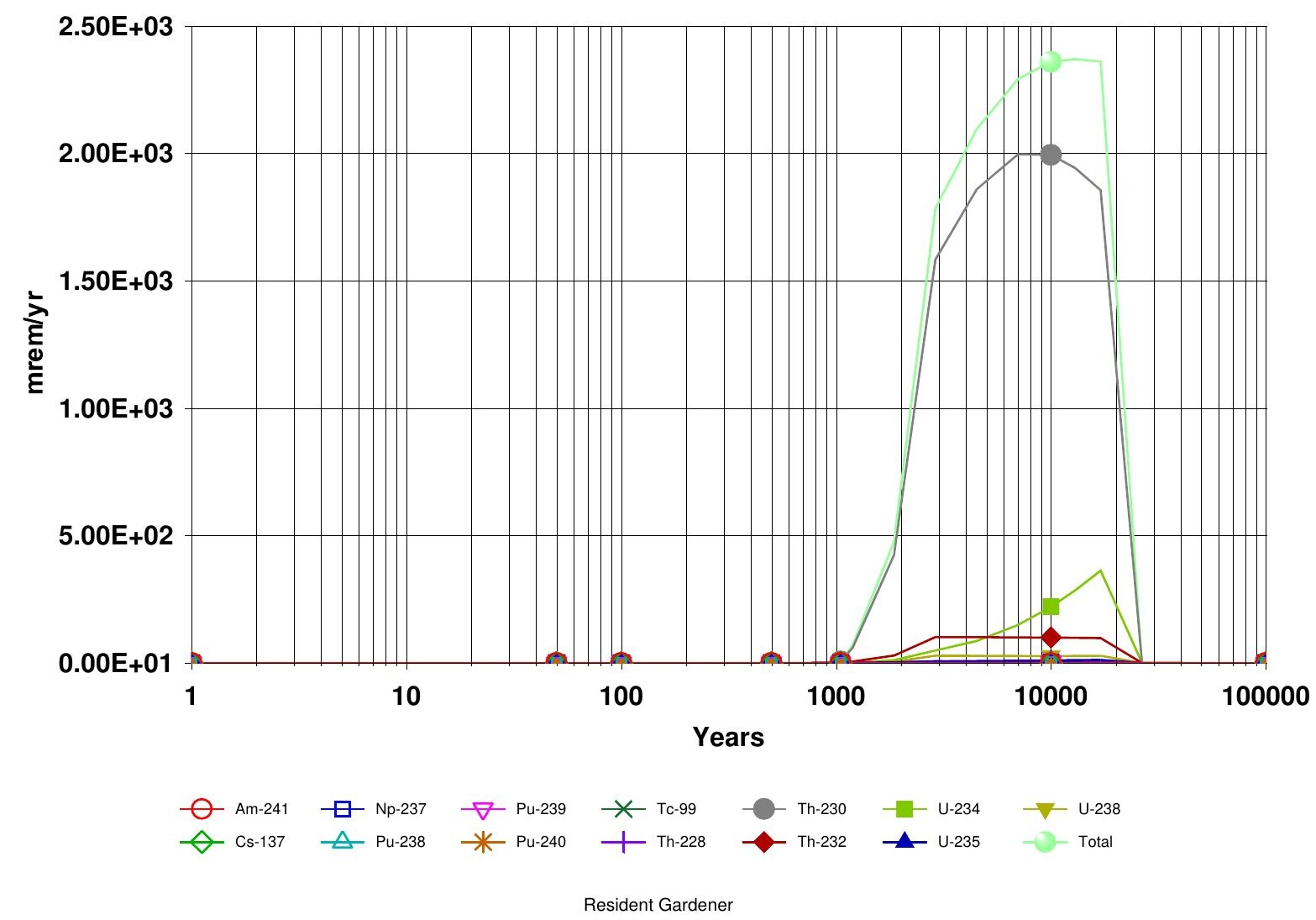

Figure 3-32. Dose to the Resident Gardener from all Selected Targeted Radionuclides and Pathways 
DOSE: All Nuclides Summed, Component Pathways

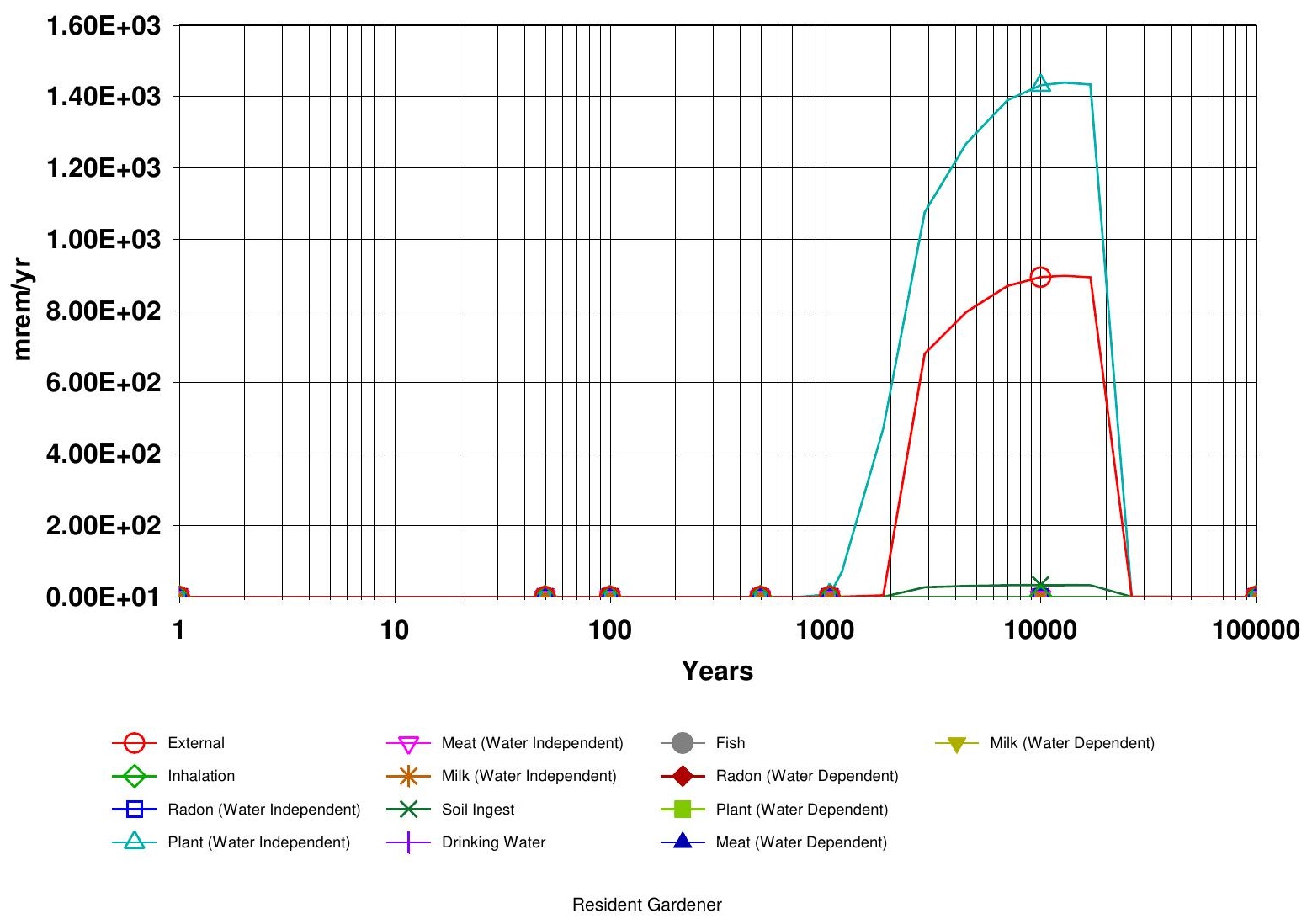

Figure 3-33. Dose to the Resident Gardener by Exposure Pathways 


\section{RECREATIONAL USER}

This third peak dose assessment shows that the dose for the Recreational User results once again from Th-230, U-234, Th-232, U-238, U-235, Np-237, Pu-239 and Pu-240. Similar to the Resident Farmer (onsite) and the Resident Gardener, the principal contributor to this receptor's dose in this assessment is Th-230 as shown in Figure 3-34. The dose is attributed to the external gamma and soil ingestion pathways as depicted in Figure 3-35.

The following RESRAD graphics correspond to the Recreational User using a time horizon of $100,000 \mathrm{yr}$.

DOSE: All Nuclides Summed, All Pathways Summed

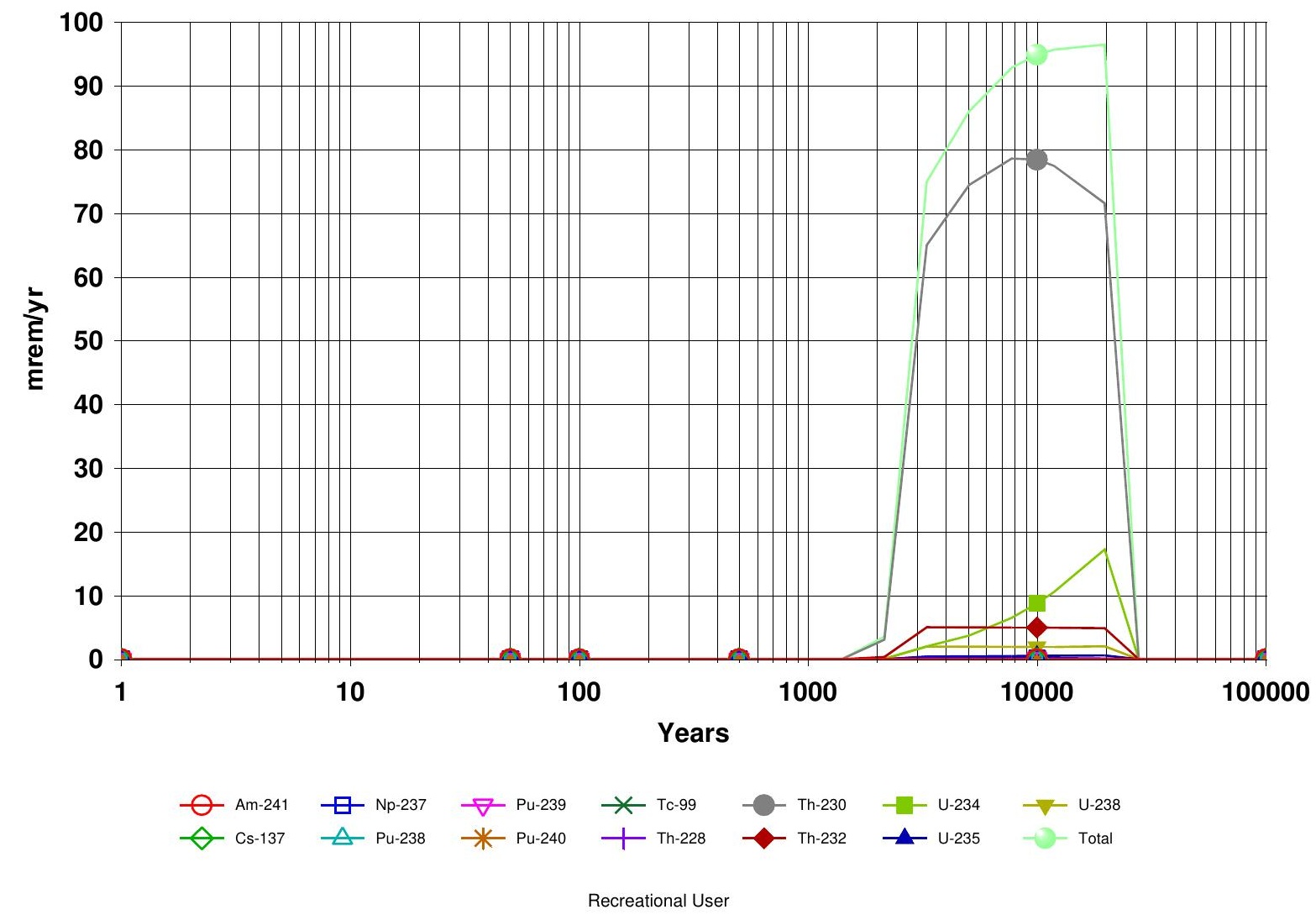

Figure 3-34. Dose to the Recreational User from all Selected Targeted Radionuclides and Pathways 


\section{DOSE: All Nuclides Summed, Component Pathways}

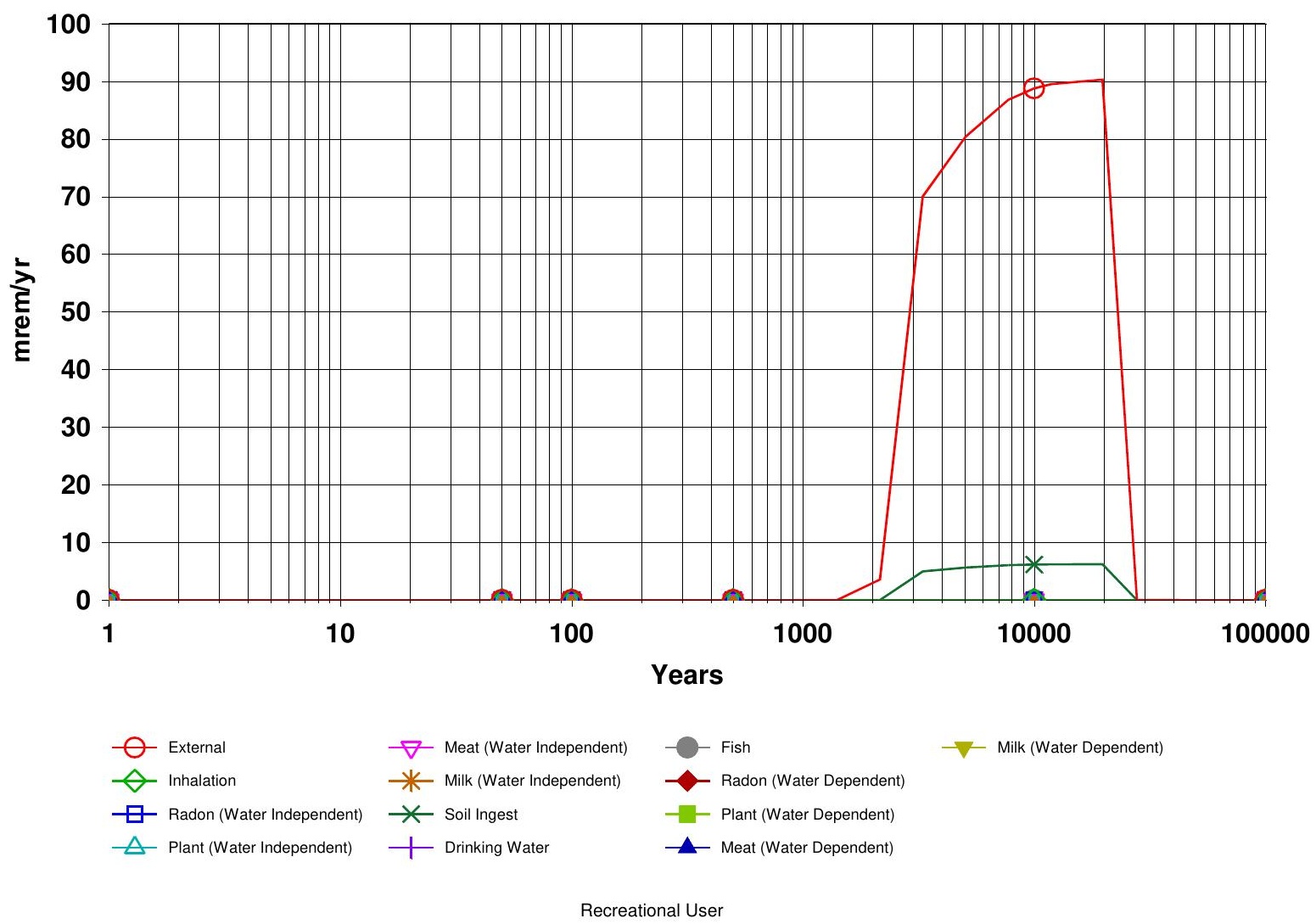

Figure 3-35. Dose to the Recreational User by Exposure Pathways 


\section{OUTDOOR WORKER}

The peak dose calculated for the Outdoor Worker in this third evaluation results from Th-230, U-234, Th-232, U-238, U-235, Pu-239, Np-237, and Pu-240. The dose primarily derives from Th-230 as depicted in Figure 3-36. The ingrowth progeny of Th-230, in particular Ra-226 and $\mathrm{Pb}-210$, are the actual contributors to most of the peak dose. The exposure pathways contributing to the peak dose are external gamma and soil ingestion as depicted in Figures 3-37.

The following RESRAD graphics correspond to the Outdoor Worker using a time horizon of $100,000 \mathrm{yr}$.

DOSE: All Nuclides Summed, All Pathways Summed

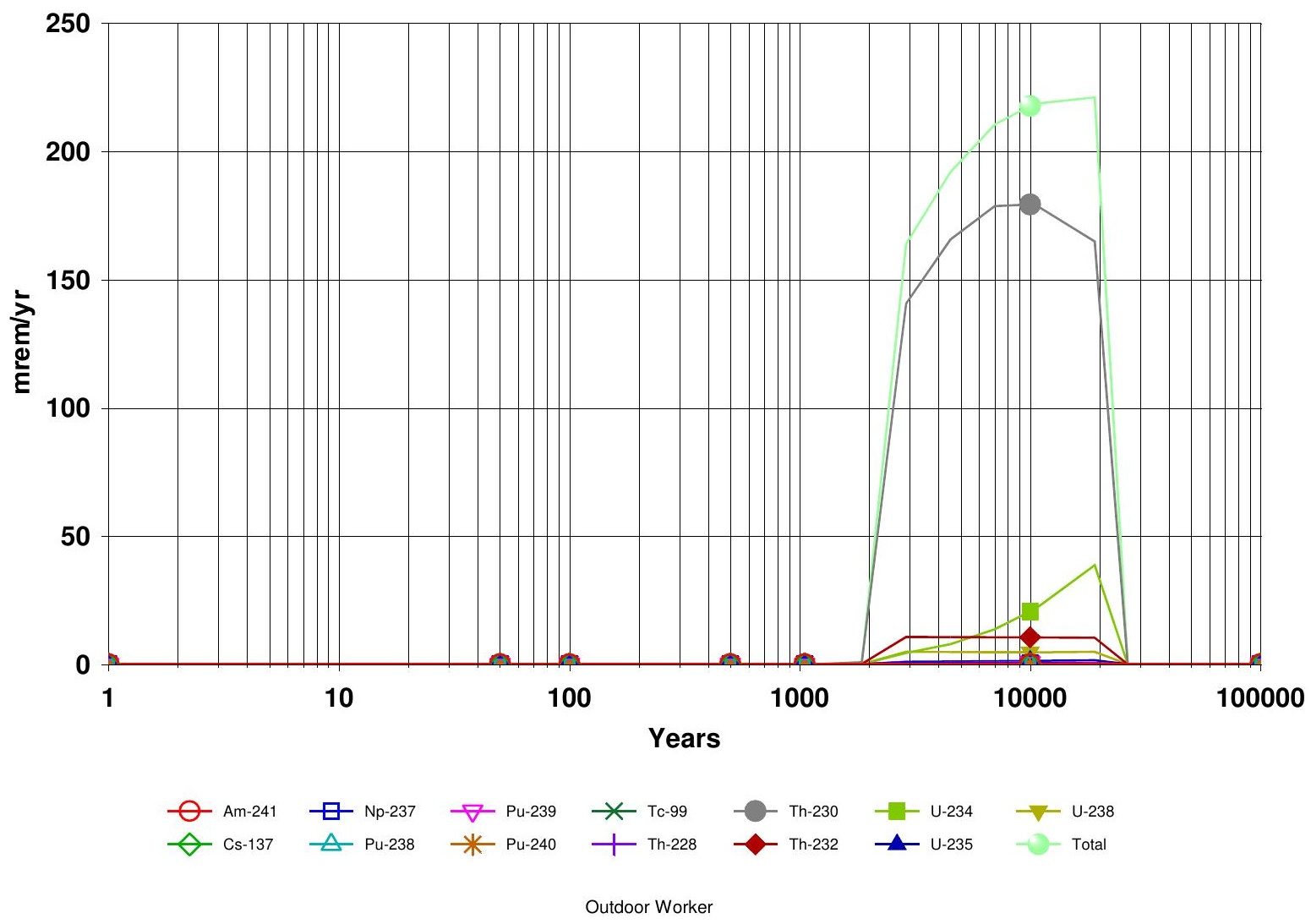

Figure 3-36. Dose to the Outdoor Worker from all Selected Targeted Radionuclides and Pathways 


\section{DOSE: All Nuclides Summed, Component Pathways}

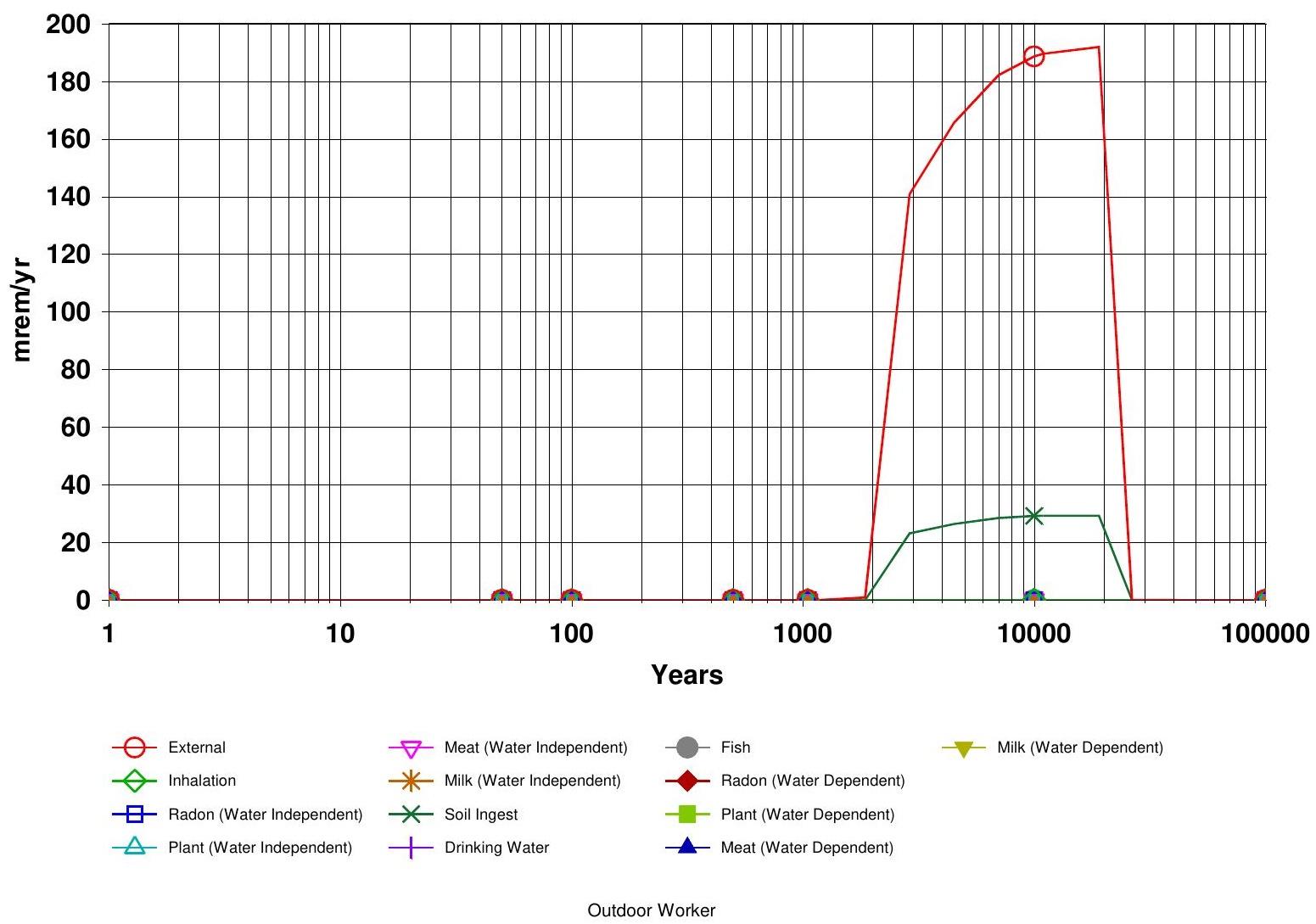

Figure 3-37. Dose to the Outdoor Worker by Exposure Pathways 


\section{OFFSITE RESIDENT FARMER}

The maximum dose for the Offsite Resident Farmer occurs at 10,065 $\mathrm{yr}$ for the maximum time horizon evaluated (i.e., 100,000 yr). The peak dose captured by the code in this third assessment is $2.2 \mathrm{mrem} / \mathrm{yr}$ and is attributed to Np-237, the ingrowth progeny of Th-230 (i.e., Ra-226), U-234 (i.e., Ra-226), Th-232 (i.e., Th-228 and Ra-228), and the parent U-238. The Tc-99 dose is not captured by the RESRAD-OFFSITE code when using 16,384 points for a time horizon of $100,000 \mathrm{yr}$. Therefore, it is not shown in Figures 3-38 or 3-39.

The receptor received the dose through the same radionuclides and exposure pathways as explained earlier in the second assessment. Figure 3-38 and 3-39 illustrate the dose by radionuclides and the dose by exposure pathways, respectively.

The following RESRAD-OFFSITE graphics correspond to the Offsite Resident Farmer using a time horizon of 100,000 yr.

DOSE: All Nuclides Summed, All Pathways Summed

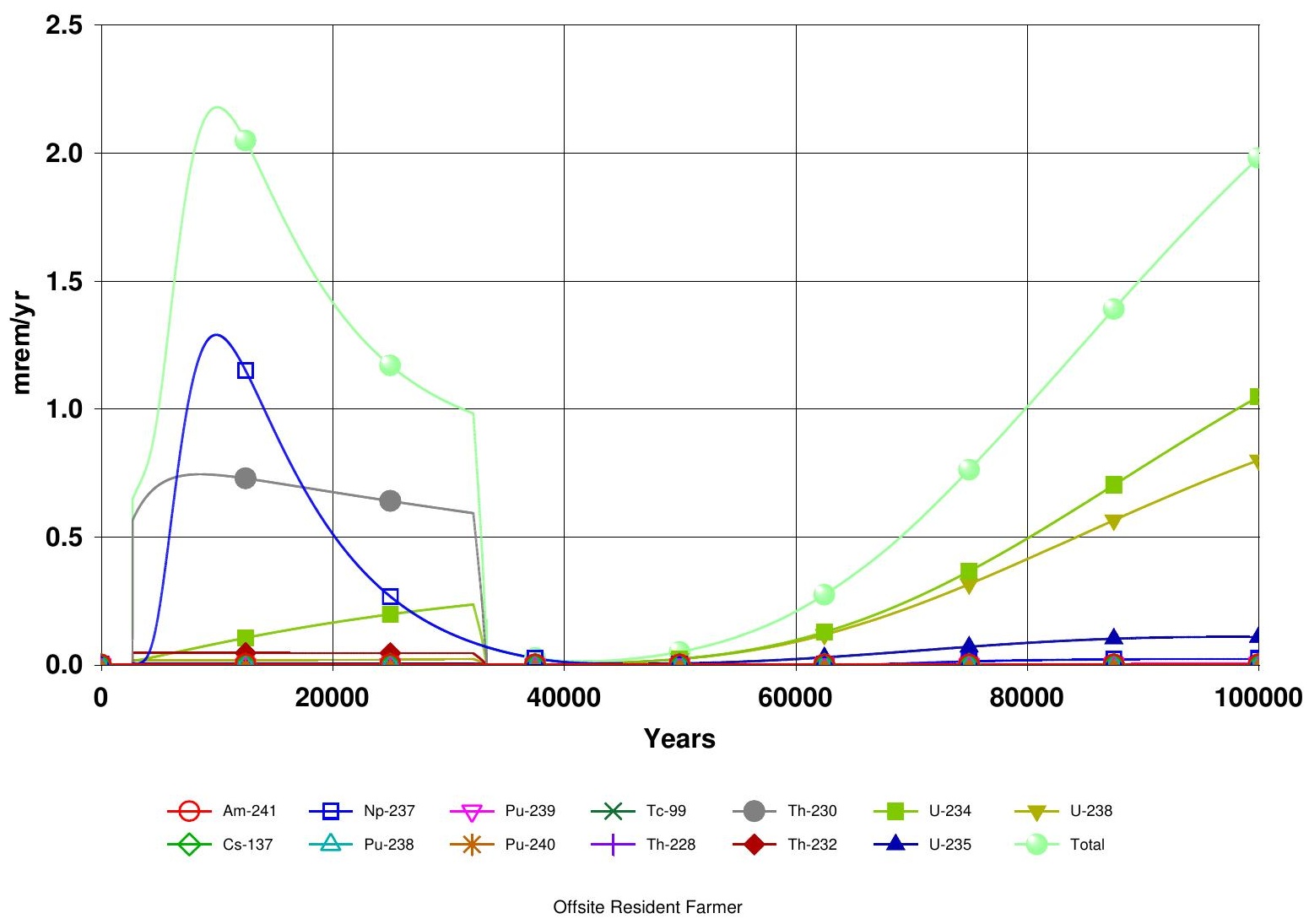

Figure 3-38. Dose to the Offsite Resident Farmer from all Selected Targeted Radionuclides and Pathways 
DOSE: All Nuclides Summed, Component Pathways

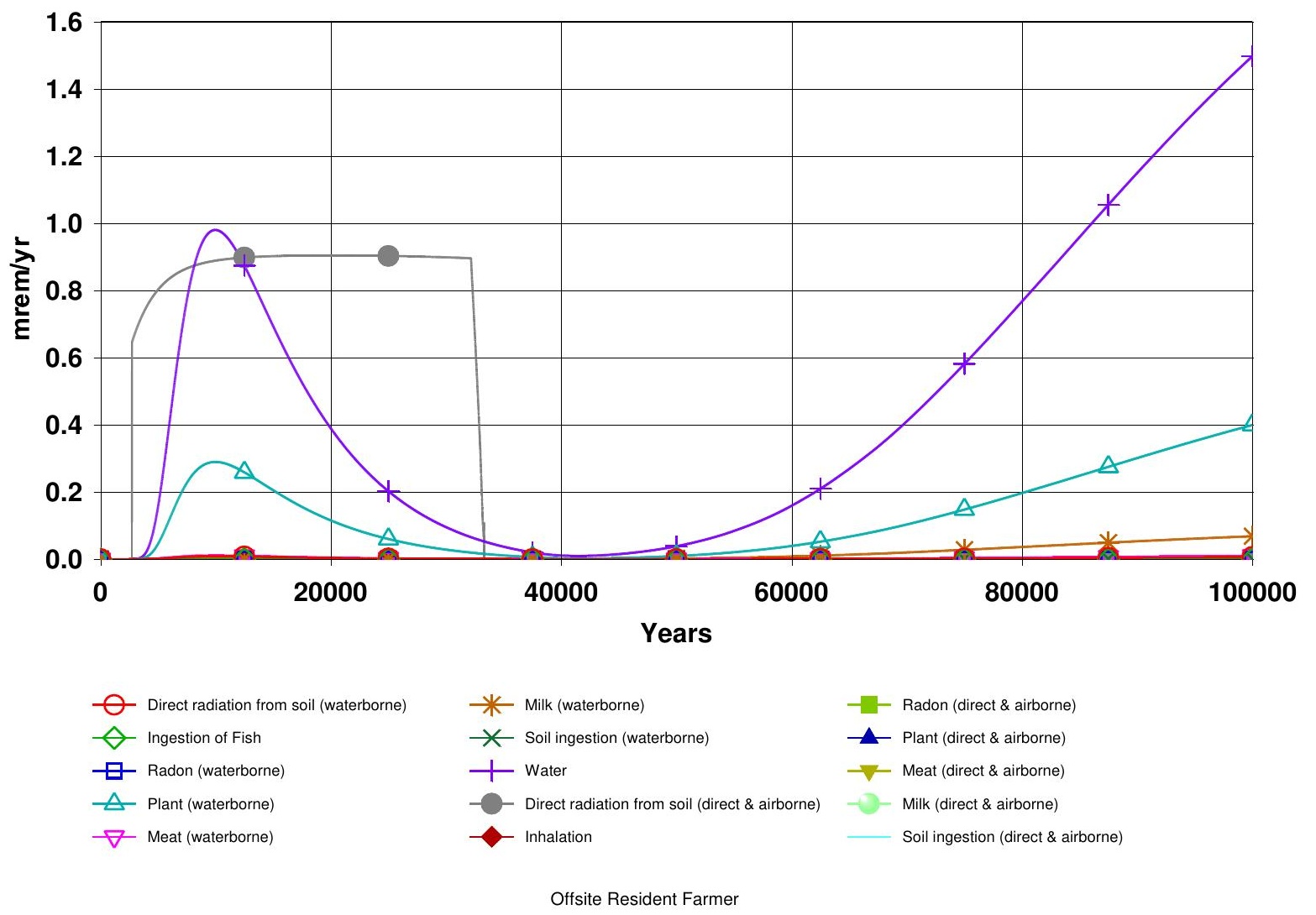

Figure 3-39. Dose to the Offsite Resident Farmer by Exposure Pathways

In summary, the maximum dose predicted among all receptors and time horizons corresponds to the Resident Farmer (onsite), 2,700 mrem/yr, although this receptor is considered implausible due to future planned controls for the C-746-U Landfill. The highest dose projected among the plausible receptors is $220 \mathrm{mrem} / \mathrm{yr}$ and it corresponds to the Outdoor Worker. Section 3.4 includes a summary of the results.

Appendices A and B include the reports generated by the codes called "Summary Reports" (RESRAD) and "Parent Dose Reports" (RESRAD-OFFSITE). 


\subsection{PROBABILISTIC PEAK OF THE MEAN DOSE ASSESSMENT FOR THE OFFSTIE RESIDENT FARMER}

As requested by the DOE-PPPO, a probabilistic analysis was performed only for the Offsite Resident Farmer using Tc-99 in order to determine the peak of the mean doses and demonstrate compliance with the dose constraint of $1 \mathrm{mrem} / \mathrm{yr}$ (above background). The analysis was performed using Tc-99 exclusively and a time horizon of 1,050 yr. The decision was made by DOE-PPPO to include the Tc-99 radionuclide for probabilistic analysis and exclude the other 12 radionuclides, since $100 \%$ of the peak dose within the time frame of 1,050 yr derives from Tc-99 as demonstrated in the deterministic run. Additional probabilistic analyses using a time horizon of 10,000 yr or 100,000 yr were not performed. Since the Tc-99 was the only radionuclide modeled, and the deterministic analysis revealed that the peak dose for Tc-99 occurs at $772 \mathrm{yr}$ and the dose from Tc-99 is almost gone at approximately 2,500 yr, additional analyses using time horizons beyond $1,050 \mathrm{yr}$ were not necessary.

Prior to discussing the probabilistic analysis results, it is of interest to state that the Tc-99 peak dose result via deterministic analysis within the time frame of $1,050 \mathrm{yr}$ was $1.9 \mathrm{mrem} / \mathrm{yr}$ (as shown in Table 3-1). However, 68\% (1.275 mrem/yr) of this peak dose results from the drinking water pathway. The dose from this pathway is above the $1 \mathrm{mrem} / \mathrm{yr}$ (above background) constraint, but it is well below the $4 \mathrm{mrem} / \mathrm{yr}$ Maximum Contaminant Level (MCL) ${ }^{1,2}$ for beta particle and photon radioactivity established for public drinking water by the Environmental Protection Agency (EPA) in 40 CFR 141.66, National Primary Drinking Water Regulations. In addition, the probabilistic dose assessment demonstrates that the dose over all the pathways considered meets the $1 \mathrm{mrem} / \mathrm{yr}$ (above background) and consequently the EPA's 4 mrem/yr MCL.

ORISE used information provided by the DOE-PPPO as described in Section 2.3.2.1 for the Tc-99 probabilistic dose analysis provided as part of this effort. Details on the DOE-PPPO Tc-99 probabilistic analysis are provided in DOE-PPPO 2011b. The results for the three probabilistic runs described in Section 2.3.2.1 of this document are presented as follows.

\subsubsection{FIRSTRUN}

The first probabilistic run was performed with only four exposure pathways (i.e., drinking water, plant, milk, and meat ingestion pathways) activated out of a total of seven pathways as identified in ORISE 2012. The other three pathways (i.e., external gamma, inhalation of dust, and soil ingestion) were deactivated. No other modifications were made. Table 3-7 summarizes the results.

\footnotetext{
140 CFR 141.66 (d) MCL for beta particle and photon radioactivity. (1) The average annual concentration of beta particle and photon radioactivity from man-made radionuclides in drinking water must not produce an annual dose equivalent to the total body or any internal organ greater than 4 millirem/year (mrem/year).

2401 KAR 8:550. Radionuclides. Section 1. A community water system shall meet the requirements for radionuclides in accordance with 40 C.F.R. 141.25, 141.26, 141.55, and 141.66.
} 
Table 3-7. Peak of the Mean Doses for the First Probabilistic Run Using the DOE-PPPO Proposed Single Radionuclide Soil Guideline for Tc-99

\begin{tabular}{|c|c|c|c|c|}
\hline Receptor & \multicolumn{5}{c|}{ Offsite Resident Farmer } \\
\hline Pathways Activated & \multicolumn{4}{|c|}{ Drinking Water, Plant, Milk, and Meat Ingestion } \\
\hline Target Dose (mrem/yr) & \multicolumn{3}{|c|}{ Repetition } & $\begin{array}{c}\text { Average (Arithmetic Mean) of the } \\
\text { Peak of the Mean Doses (mrem/yr) }\end{array}$ \\
\hline \multirow{2}{*}{ Peak of the Mean Dose (mrem/yr) } & 0.9793 & 0.9773 & 0.9772 & \\
\cline { 2 - 4 } & 1 & 2 & 3 & \multirow{2}{*}{$0.98^{\mathrm{b}}$} \\
\hline Time of Peak of the Mean Dose (yr) & 1,050 & 1,050 & 1,050 & \\
\hline
\end{tabular}

a. The peak of the mean dose results are not rounded to two significant figures to show the actual code output.

b. The average (arithmetic mean) of the peak of the mean doses is rounded to two significant figures.

The peak of the mean doses obtained through the drinking water, plant, milk, and meat ingestion pathways meet the target dose constraint of $1 \mathrm{mrem} / \mathrm{yr}$ (above background). The average (arithmetic mean) of the peak of the mean doses calculated by ORISE was $0.98 \mathrm{mrem} / \mathrm{yr}$.

The second probabilistic run was the reverse of the first run. It was performed with only three exposure pathways (i.e., external gamma, inhalation of dust, and soil ingestion) activated out of a total of seven pathways. The other four pathways (i.e., drinking water, plant, milk, and meat ingestion) were deactivated. No other modifications were made. Table 3-8 summarizes the results.

Table 3-8. Peak of the Mean Doses for the Second Probabilistic Run Using the DOE-PPPO Proposed Single Radionuclide Soil Guideline for Tc-99

\begin{tabular}{|c|c|c|c|c|}
\hline Receptor & \multicolumn{4}{|c|}{ Offsite Resident Farmer } \\
\hline Pathways Activated & \multicolumn{4}{|c|}{ External Gamma, Inhalation of Dust, and Soil Ingestion } \\
\hline Target Dose (mrem/yr) & \multicolumn{4}{|c|}{1} \\
\hline \multirow[b]{3}{*}{ Peak of the Mean Dose $(\mathrm{mrem} / \mathrm{yr})^{\mathrm{a}}$} & \multicolumn{3}{|c|}{ Repetition } & $\begin{array}{l}\text { Average (Arithmetic Mean) of the } \\
\text { Peak of the Mean Doses (mrem/yr) }\end{array}$ \\
\hline & 1 & 2 & 3 & \multirow{3}{*}{$0.00^{\mathrm{b}}$} \\
\hline & 1.651E-06 & $1.648 \mathrm{E}-06$ & 1.647E-06 & \\
\hline Time of Peak of the Mean Dose (yr) & 1,050 & 1,050 & 1,050 & \\
\hline
\end{tabular}

a. The peak of the mean dose results are not rounded to two significant figures to show the actual code output.

b. The average (arithmetic mean) of the peak of the mean doses is rounded to two significant figures.

The peak of the mean doses obtained via the external gamma, inhalation of dust, and soil ingestion pathways are practically $0 \mathrm{mrem} / \mathrm{yr}$. There is no noticeable contribution from these pathways to the Tc-99 dose. 
By adding the first and second probabilistic runs, it can be demonstrated that the peak of the mean doses from all seven pathways evaluated meet the $1 \mathrm{mrem} / \mathrm{yr}$ dose constraint (above background). Table 3-9 includes the combined results for these two runs.

Table 3-9. Peak of the Mean Doses for the First and Second Probabilistic Run Using the DOE-PPPO Proposed Single Radionuclide Soil Guideline for Tc-99

\begin{tabular}{|c|c|c|c|c|}
\hline \multirow{2}{*}{ Receptor } & \multicolumn{4}{|c|}{ Offsite Resident Farmer } \\
\hline & \multicolumn{3}{|c|}{ Repetition } & $\begin{array}{c}\text { Average (Arithmetic Mean) of the } \\
\text { Peak of the Mean Doses (mrem/yr) }\end{array}$ \\
\cline { 2 - 4 } & 1 & 2 & 3 & \\
\cline { 2 - 4 } Peak of the Mean Dose (mrem/yr) & 0.9793 & 0.9773 & 0.9772 & \multirow{2}{*}{$0.98^{\mathrm{b}}$} \\
\hline Time of Peak of the Mean Dose (yr) & 1,050 & 1,050 & 1,050 & \\
\hline
\end{tabular}

a. The peak of the mean dose results are not rounded to two significant figures to show the actual code output.

b. The average (arithmetic mean) of the peak of the mean doses is rounded to two significant figures.

These results show that peak of the mean doses obtained in the first run are not impacted by the second run. Therefore, the peak of the mean doses and their average (arithmetic mean) meet the dose constraint of $1 \mathrm{mrem} / \mathrm{yr}$.

\subsubsection{THIRDRUN}

The third probabilistic run was performed with all seven exposure pathways (i.e., external gamma, inhalation of dust, drinking water, plant, milk, meat and soil ingestion) activated. The only other modification made was increasing the size of the grid spacing for areal integration from 10 to 500 meters as described in Section 2.3.2.1. Table 3-10 summarizes the results. 
Table 3-10. Peak of the Mean Doses for the Third Probabilistic Run Using the DOE-PPPO Proposed Single Radionuclide Soil Guideline for Tc-99

\begin{tabular}{|c|c|c|c|c|c|}
\hline Receptor & \multicolumn{5}{|c|}{ Offsite Resident Farmer } \\
\hline Pathways Activated & \multicolumn{5}{|c|}{$\begin{array}{c}\text { External Gamma, Inhalation of Dust, Drinking Water, Plant, Milk, Meat and } \\
\text { Soil Ingestion, }\end{array}$} \\
\hline $\begin{array}{l}\text { Grid spacing for } \\
\text { areal integration }\end{array}$ & \multicolumn{5}{|c|}{500 meters } \\
\hline \multicolumn{2}{|c|}{ Target Dose (mrem/yr) } & \multicolumn{4}{|r|}{1} \\
\hline \multirow{3}{*}{\multicolumn{2}{|c|}{ Peak of the Mean Dose (mrem/yr) ${ }^{a}$}} & \multicolumn{3}{|c|}{ Repetition } & $\begin{array}{l}\text { Average (Arithmetic Mean) of the } \\
\text { Peak of the Mean Doses (mrem/yr) }\end{array}$ \\
\hline & & 1 & 2 & 3 & \multirow{3}{*}{$0.98^{b}$} \\
\hline & & 0.9794 & 0.9773 & 0.9772 & \\
\hline \multicolumn{2}{|c|}{ Time of Peak of the Mean Dose (yr) } & 1,050 & 1,050 & 1,050 & \\
\hline
\end{tabular}

a. The peak of the mean dose results are not rounded to two significant figures to show the actual code output.

b. The average (arithmetic mean) of the peak of the mean doses is rounded to two significant figures.

The results of this run are almost identical to those obtained in the first run. The only negligible difference is the peak of the mean dose result for repetition 1 . The result for repetition 1 in the first run was $0.9793 \mathrm{mrem} / \mathrm{yr}$ and in the third run was $0.9794 \mathrm{mrem} / \mathrm{yr}$. However, when rounded to two significant figures (i.e., $0.98 \mathrm{mrem} / \mathrm{yr}$ ) they are essentially the same number. This third run confirms that the approach used for the first two runs is acceptable by providing comparable results.

Appendix C contains the code's deterministic ("Parent Dose Reports") and uncertainty analyses output reports for the three runs. 
This section includes a summary of the projected highest doses obtained via deterministic and probabilistic analyses. Table 3-11 summarizes the highest doses projected by the RESRAD codes through deterministic analyses for all receptors and among all time horizons (i.e., $70 \mathrm{yr}, 1,050 \mathrm{yr}$, $10,000 \mathrm{yr}$ and 100,000 yr). The peak dose results in Table 3-11 are rounded to two significant figures.

Table 3-11. Summary of Deterministic Results for Projected Highest Doses for all Receptors Among all Time Horizons

\begin{tabular}{|c|c|c|c|c|c|c|c|}
\hline \multirow[b]{2}{*}{ Receptors } & \multicolumn{3}{|c|}{ Implausible } & \multicolumn{4}{|c|}{ Plausible } \\
\hline & Trespasser & $\begin{array}{l}\text { Resident } \\
\text { Farmer } \\
\text { (onsite) }\end{array}$ & $\begin{array}{l}\text { Resident } \\
\text { Gardener }\end{array}$ & $\begin{array}{l}\text { Recreational } \\
\text { User }\end{array}$ & $\begin{array}{l}\text { Outdoor } \\
\text { Worker }\end{array}$ & $\begin{array}{l}\text { Offsite } \\
\text { Resident } \\
\text { Farmer }\end{array}$ & $\begin{array}{l}\text { Landffill } \\
\text { Worker }\end{array}$ \\
\hline Target Dose & \multicolumn{3}{|c|}{$100 \mathrm{mrem} / \mathrm{yr}$} & \multicolumn{3}{|c|}{$1 \mathrm{mrem} / \mathrm{yr}$} & $100 \mathrm{mrem} / \mathrm{yr}$ \\
\hline Peak Dose (mrem/yr) & $4.1^{\mathrm{a}}$ & $2,700^{b}$ & $2,400^{b}$ & $96^{b}$ & $220^{b}$ & $2.2^{\mathrm{b}}$ & $64^{a}$ \\
\hline Time (yr) & 70 & 12,773 & 12,931 & 19,739 & 19,045 & 10,065 & 70 \\
\hline $\begin{array}{l}\text { Exposure Pathways } \\
\text { Contributing to each } \\
\text { Receptor's Dose (in } \\
\text { descending order of } \\
\text { contribution to dose if } \\
\text { more than one is } \\
\text { listed) }\end{array}$ & $\begin{array}{c}\text { External } \\
\text { gamma, and } \\
\text { soil ingestion }\end{array}$ & $\begin{array}{l}\text { Plant ingestion, } \\
\text { external } \\
\text { gamma, milk, } \\
\text { meat and soil } \\
\text { ingestion }\end{array}$ & $\begin{array}{c}\text { Plant ingestion, } \\
\text { external } \\
\text { gamma, and } \\
\text { soil ingestion }\end{array}$ & $\begin{array}{c}\text { External } \\
\text { gamma, and } \\
\text { soil ingestion }\end{array}$ & $\begin{array}{c}\text { External } \\
\text { gamma, and } \\
\text { soil ingestion }\end{array}$ & $\begin{array}{l}\text { Drinking water, } \\
\text { plant and milk } \\
\text { ingestion }\end{array}$ & $\begin{array}{c}\text { External } \\
\text { gamma, and } \\
\text { soil ingestion }\end{array}$ \\
\hline
\end{tabular}

a. The peak dose was calculated based on the DOE-PPPO Proposed AL Volumetric Concentrations and a 70 yr time frame.

b. The peak dose was calculated based on the DOE-PPPO Proposed Single Radionuclide Soil Guidelines and a 100,000 yr time frame.

The highest projected deterministic dose for the Landfill Worker and the Trespasser are attributed to Th-232, Th-230 and their ingrowth progeny.

The highest projected deterministic doses for the Resident Farmer (onsite), Resident Gardener, Recreational User and the Outdoor Worker resulted primarily from the ingrowth progeny of Th-230 (i.e., Ra-226 and $\mathrm{Pb}-210)$. On the other hand, the maximum projected deterministic dose for the Offsite Resident Farmer resulted mainly from Np-237 and the ingrowth progeny of Th-230 (i.e., Ra-226).

Finally, for the probabilistic analysis the average (arithmetic mean) of the peak of the mean doses obtained was $0.98 \mathrm{mrem} / \mathrm{yr}$ at 1,050 yr from Tc-99 for the Offsite Resident Farmer. 


\section{O: REFERENCES}

40 CFR 141. National Primary Drinking Water Regulations, Code of Federal Regulations (CFR), Title 40, Protection of Environment, Part 141, U. S. Environmental Protection Agency, Washington, DC.

401 KAR 8 (Kentucky Administrative Regulations, Title 401, Energy and Environment Cabinet Department for Environmental Protection, Chapter 8), Drinking Water Regulations.

401 KAR 48 (Kentucky Administrative Regulations, Title 401, Energy and Environment Cabinet Department for Environmental Protection, Chapter 48), Standards for Solid W aste Facilities.

DOE 2003. Risk and Performance Evaluation of the C-746-U Landfill at the Paducah Gaseous Diffusion Plant, Paducah, Kentucky, DOE/OR/07-2041\&D2R1, U. S. Department of Energy, Paducah, KY, September.

DOE 2011. Radiation Protection of the Public and the Environment, DOE Order 458.1, U. S. Department of Energy, Washington, DC, February.

DOE-PPPO 2011a. Authorized Limits Request for Solid Waste Disposal at Landfill C-746-U at the Paducah Gaseous Diffusion Plant, U.S. Department of Energy, Portsmouth/Paducah Project Office, July.

DOE-PPPO 2011b. Probabilistic Risk Assessment Analysis for Establishing the Technetium-99 Single Radionuclide Soil Guideline from the Drinking Water Pathway for the Offsite Resident Farmer for the C-746-U Landfill at the Paducah Gaseous Diffusion Plant, Paducah Kentucky, U.S. Department of Energy, Portsmouth/Paducah Project Office, July.

Kamboj, S., D. LePoire, E. Gnanapragasam, B. M. Biwer, J. Cheng, J. Arnish, C. Yu, and S. Y. Chen. 2000. Probabilistic Dose Analysis Using Parameter Distributions Developed for RESRAD and for RESRAD-BUILD Codes, NUREG/CR-6676 (ANL/EAD/TM-89), U.S. Nuclear Regulatory Commission, Washington, DC, May.

NRC 2006. Consolidated Decommissioning Guidance Characterization, Survey, and Determination of Radiological Criteria, NUREG-1757 Vol. 2, Rev. 1, U.S. Nuclear Regulatory Commission, Washington, DC, September.

ORISE 2012. Dose Modeling Evaluations and Technical Support Document for the Authorized Limits Request for the C-746-U Landfill at the Paducah Gaseous Diffusion Plant, Paducah, Kentucky,

DCN 5090-TR-01-6, Oak Ridge Institute for Science and Education, Oak Ridge, TN, June.

Volpe, J. 2001. Risk versus Dose Cleanup Levels (Memorandum), Kentucky Radiation Health and Toxic Agents Branch (currently the Kentucky Radiation Health Branch), March. 
Yu, C., A. J. Zielen, J. J. Cheng, D. J. LePoire, E. Gnanapragasam, S. Kamboj, J. Arnish, A. Wallo, III, W. A. Williams, and H. Peterson 2001. User's Manual for RESRAD Version 6, ANL/EAD-4, Argonne National Laboratory, Environmental Assessment Division, Argonne, IL, July.

Yu, C., E. Gnanapragasam, B. M. Biwer, S. Kamboj, J. J. Cheng, T. Klett, D. LePoire, A. J. Zielen, S. Y. Chen, W. A. Williams, A. Wallo, S. Domotor, T. Mo, and A. Schwartzman 2007. User's Manual for RESRAD-OFFSITE Version 2, ANL/EVS/TM/07-1 (DOE/HS-0005, NUREG/CR-6937), Argonne National Laboratory, Environmental Science Division, Argonne, IL, June. 


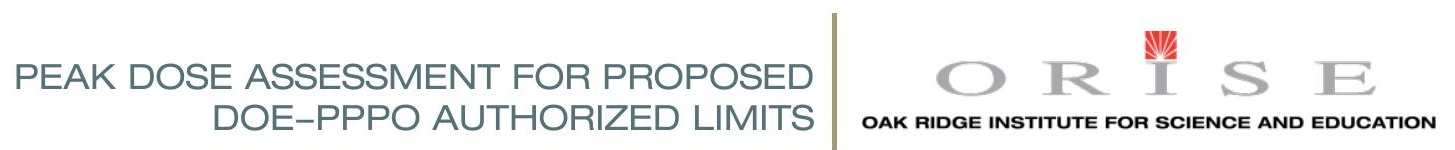

ATTACHMENT A: RESRAD SUMMARYREPORTS 


\section{Table of Contents}

Landfill Worker Summary Report (Deterministic Analysis Report) First Peak Dose

Assessment: Time Horizon 70 yr

Landfill Worker Summary Report (Deterministic Analysis Report) Second Peak

Dose Assessment: Time Horizon 70 yr A-35

Trespasser Summary Report (Deterministic Analysis Report) First Peak Dose Assessment: Time Horizon $70 \mathrm{yr}$.

Trespasser Summary Report (Deterministic Analysis Report) Second Peak Dose Assessment: Time Horizon $70 \mathrm{yr}$

Resident Farmer (onsite) Summary Report (Deterministic Analysis Report) First

Peak Dose Assessment: Time Horizon 1,050 yr. A-131

Resident Farmer (onsite) Summary Report (Deterministic Analysis Report) Second Peak Dose Assessment: Time Horizon 10,000 yr A-166

Resident Farmer (onsite) Summary Report (Deterministic Analysis Report) Third Peak Dose Assessment: Time Horizon 100,000 yr ..... A-201

Resident Gardener Summary Report (Deterministic Analysis Report) First Peak Dose Assessment: Time Horizon 1,050 yr. A-238

Resident Gardener Summary Report (Deterministic Analysis Report) Second Peak Dose Assessment: Time Horizon 10,000 yr . A-272

Resident Gardener Summary Report (Deterministic Analysis Report) Third Peak Dose Assessment: Time Horizon 100,000 yr . A-307

Recreational User Summary Report (Deterministic Analysis Report) First Peak Dose Assessment: Time Horizon 1,050 yr . A-344

Recreational User Summary Report (Deterministic Analysis Report) Second Peak Dose Assessment: Time Horizon 10,000 yr. A-378

Recreational User Summary Report (Deterministic Analysis Report) Third Peak Dose Assessment: Time Horizon 100,000 yr . A-412

Outdoor Worker Summary Report (Deterministic Analysis Report) First Peak Dose Assessment: Time Horizon 1,050 yr A-448

Outdoor Worker Summary Report (Deterministic Analysis Report) Second Peak Dose Assessment: Time Horizon 10,000 yr. A-482 Outdoor Worker Summary Report (Deterministic Analysis Report) Third Peak Dose Assessment: Time Horizon 100,000 yr . A-517 


\section{Landfill Worker}

\section{Summary Report \\ (Deterministic Analysis Report)}

First Peak Dose Assessment

Time Horizon: 70 yr 
THIS PAGE INTENTIONALLY LEFT BLANK 


\section{RESRAD, Version $6.5 \quad \mathrm{~T}^{1 / 2}$ Limit $=180$ days}

Summary : C746U Landfill Worker Deterministic Run

File : $\mathrm{X}: \backslash F I N A L$ V2 $\backslash$ DOE FWD RUNS $\backslash C 746 \mathrm{U}$ LW DOE SG FWD-FV2-70YR.RAD

Table of Contents

Part I: Mixture Sums and Single Radionuclide Guidelines

Dose Conversion Factor (and Related) Parameter Summary ... 2

Site-Specific Parameter Summary $\ldots \ldots \ldots \ldots \ldots \ldots \ldots \ldots \ldots$

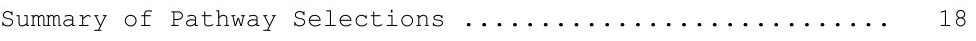

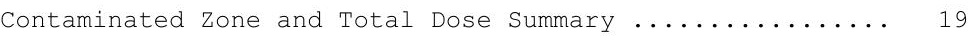

Total Dose Components

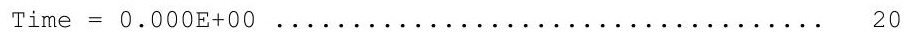

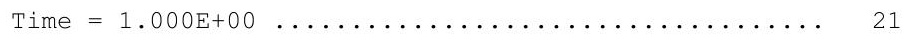

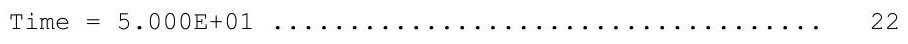

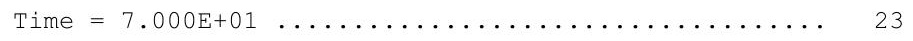

Dose/Source Ratios summed Over All Pathways ............ 24

Single Radionuclide Soil Guidelines ............... 26

Dose Per Nuclide Summed Over All Pathways ............ 27

Soil Concentration Per Nuclide .................. 29 
RESRAD, Version $6.5 \quad \mathrm{~T}^{1 / 2}$ Limit $=180$ days

Summary : C746U Landfill Worker Deterministic Run

File : $\mathrm{X}: \backslash F I N A L$ V2 $\backslash$ DOE FWD RUNS $\backslash$ C746U LW DOE SG FWD-FV2-70YR.RAD

Dose Conversion Factor (and Related) Parameter Summary

Dose Library: ICRP 60 \& ICRP 72 (Adult)

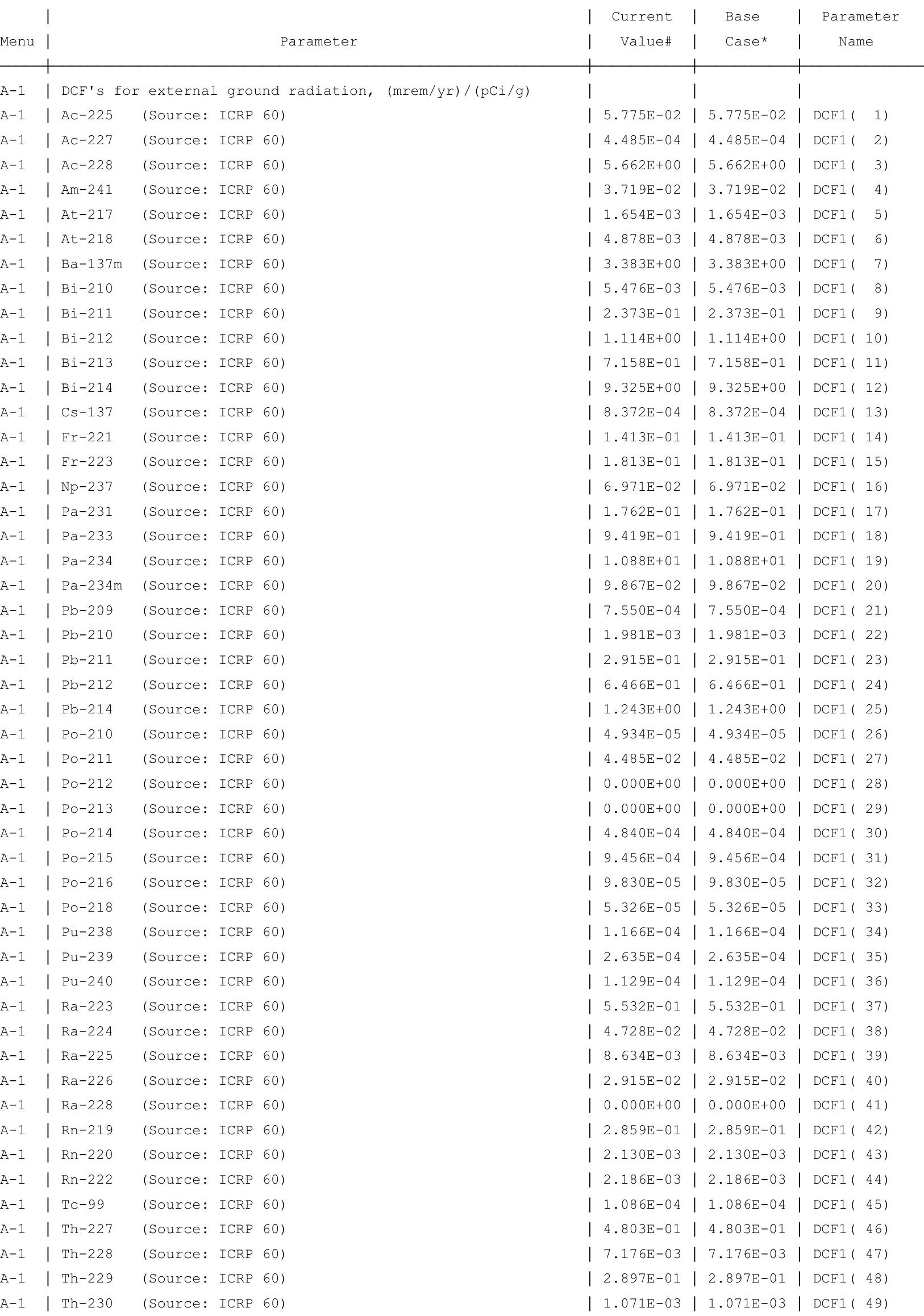


RESRAD, Version $6.5 \quad \mathrm{~T}^{1 / 2}$ Limit $=180$ days

ummary : C746U Landfill Worker Deterministic Run

File : $\mathrm{X}: \backslash F I N A L$ V2 $\backslash$ DOE FWD RUNS $\backslash$ C746U LW DOE SG FWD-FV2-70YR.RAD

Dose Conversion Factor (and Related) Parameter Summary (continued)

Dose Library: ICRP 60 \& ICRP 72 (Adult)

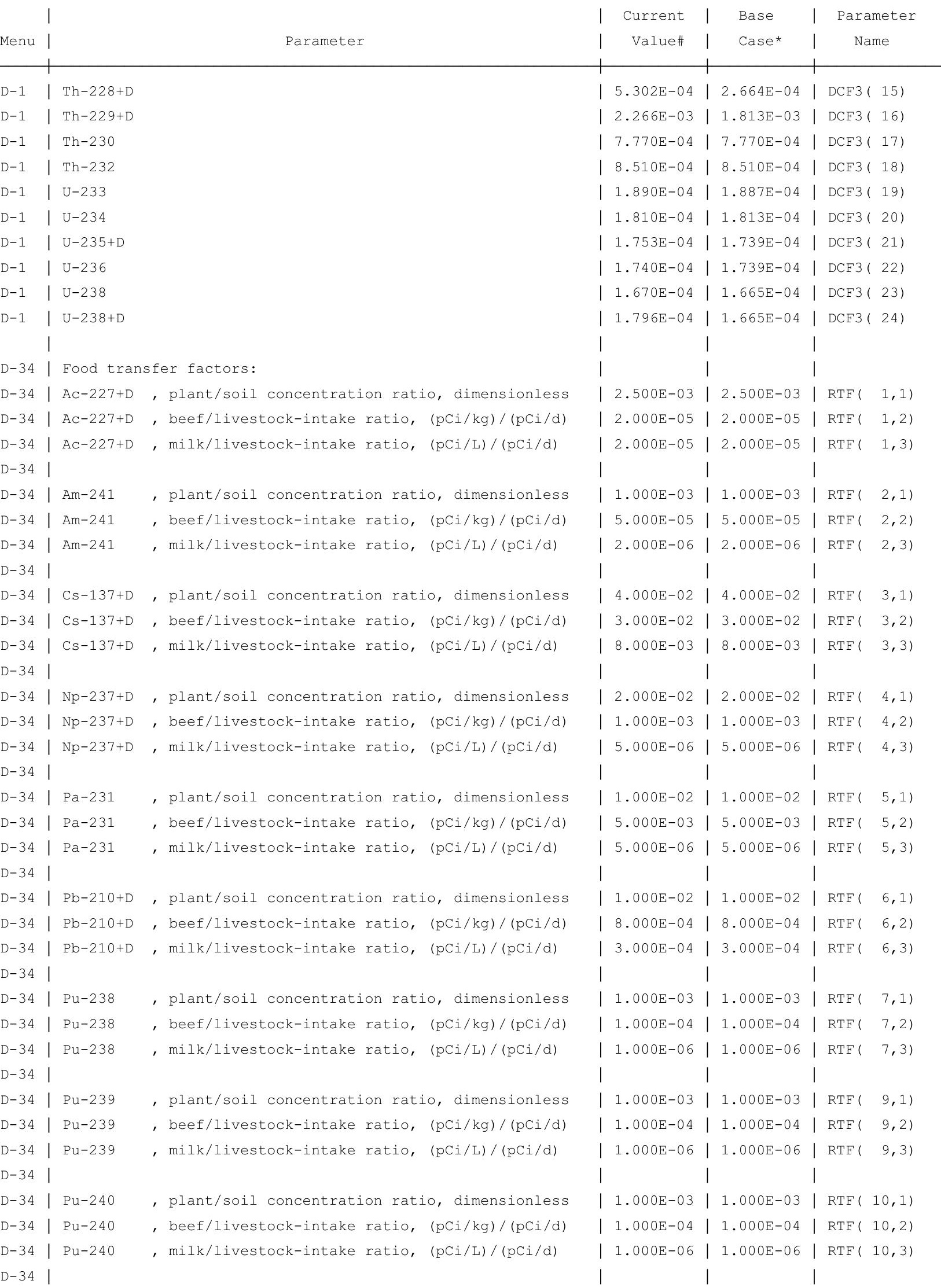


RESRAD, Version $6.5 \quad T^{1 / 2}$ Limit $=180$ days

Summary : C746U Landfill Worker Deterministic Run

File : $X: \backslash F I N A L$ V2 \DOE FWD RUNS \C746U LW DOE SG FWD-FV2-70YR.RAD

Dose Conversion Factor (and Related) Parameter Summary (continued)

Dose Library: ICRP 60 \& ICRP 72 (Adult)

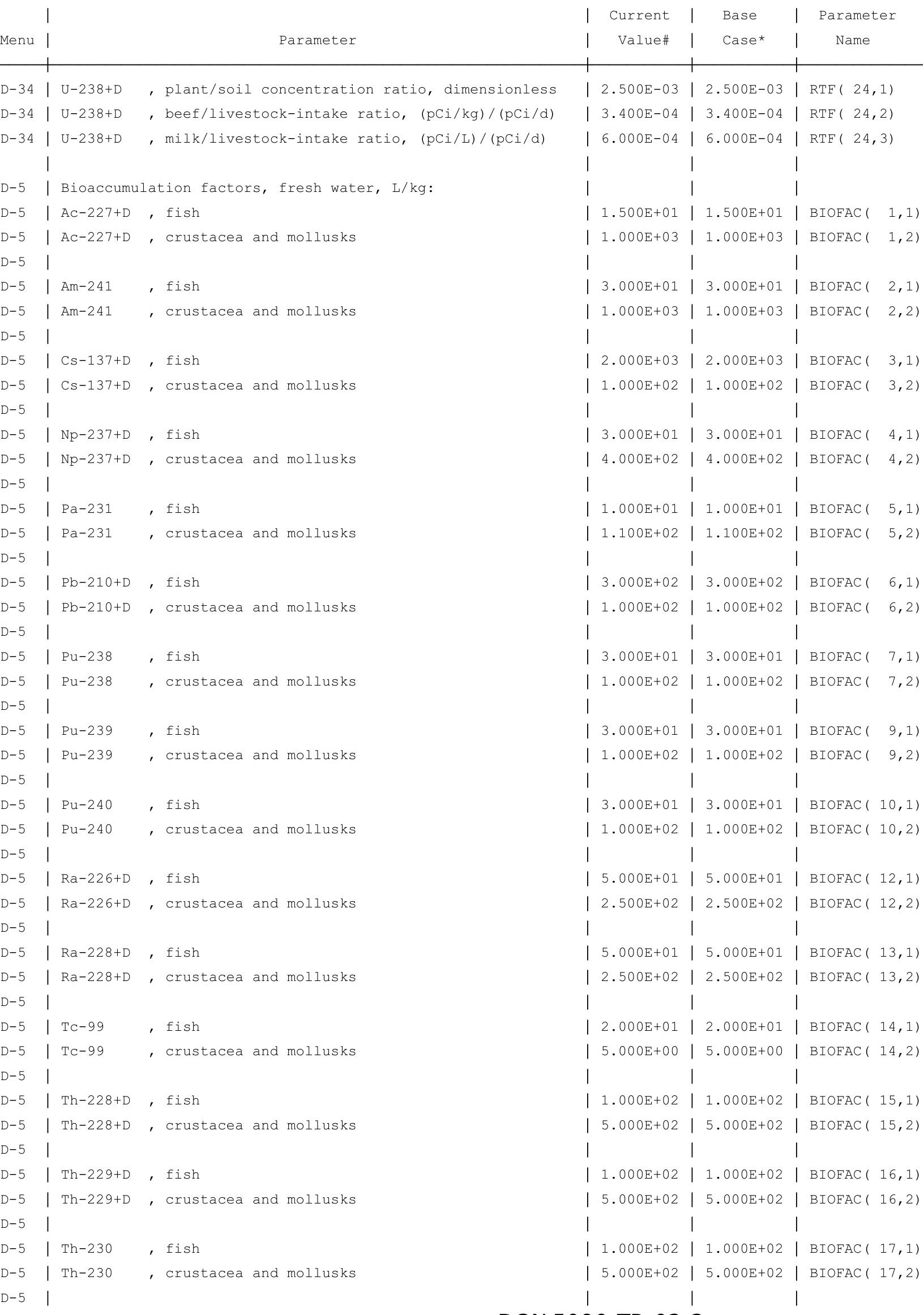


RESRAD, Version $6.5 \quad \mathrm{~T}^{1 / 2}$ Limit $=180$ days

07/15/2011 11:46 Page

ummary : C746U Landfill Worker Deterministic Run

File : $\mathrm{X}: \backslash F I N A L$ V2\DOE FWD RUNS \C746U LW DOE SG FWD-FV2-70YR.RAD

Dose Conversion Factor (and Related) Parameter Summary (continued)

Dose Library: ICRP 60 \& ICRP 72 (Adult)

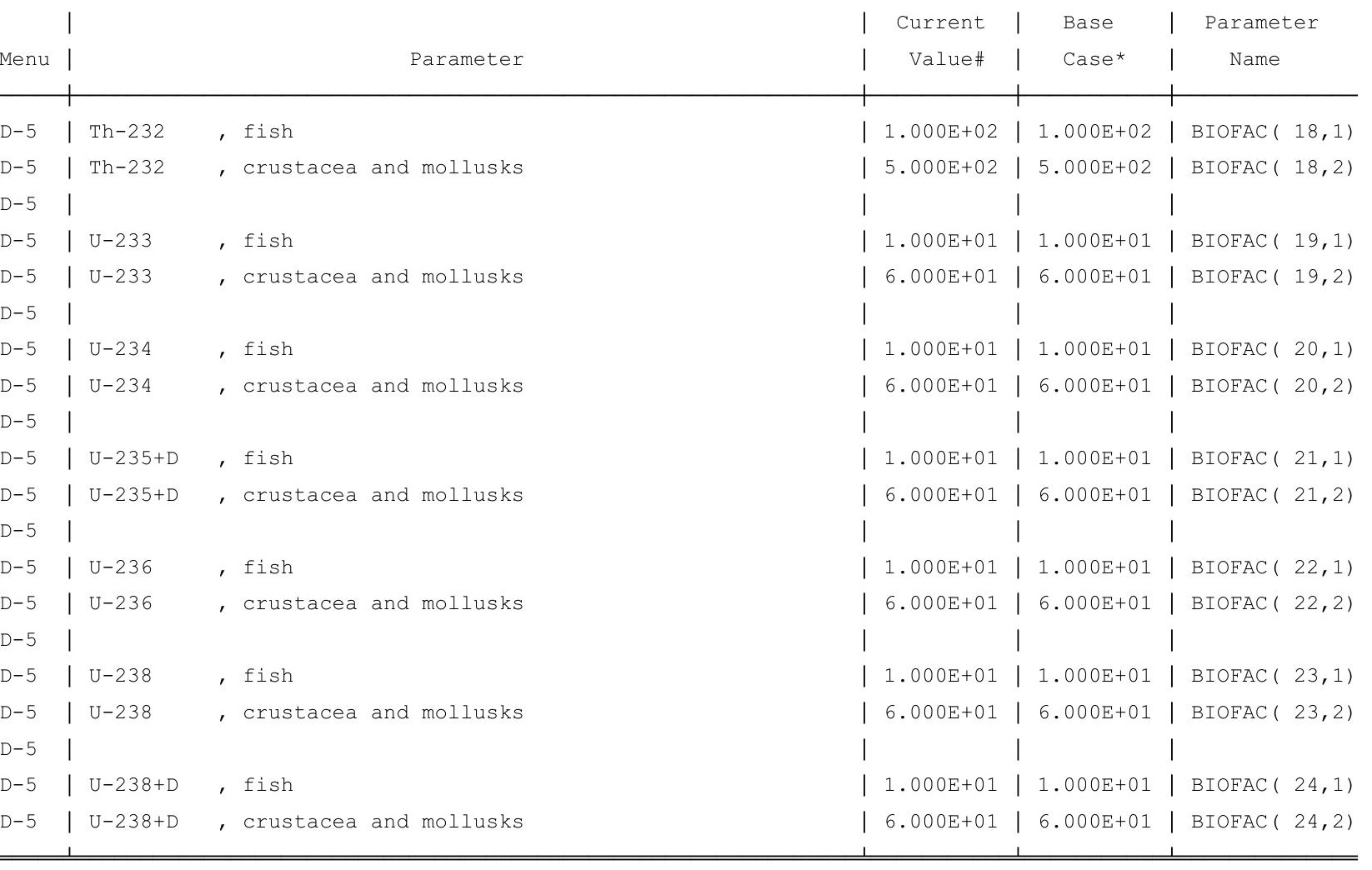

\#For DCF1(xxx) only, factors are for infinite depth \& area. See ETFG table in Ground Pathway of Detailed Report. *Base Case means Default.Lib w/o Associate Nuclide contributions. 
RESRAD, Version $6.5 \quad T^{1 / 2}$ Limit $=180$ days

07/15/2011 11:46 Page

Summary : C746U Landfill Worker Deterministic Run

File : $X: \backslash F I N A L$ V2 \DOE FWD RUNS \C746U LW DOE SG FWD-FV2-70YR.RAD

Site-Specific Parameter Summary (continued)

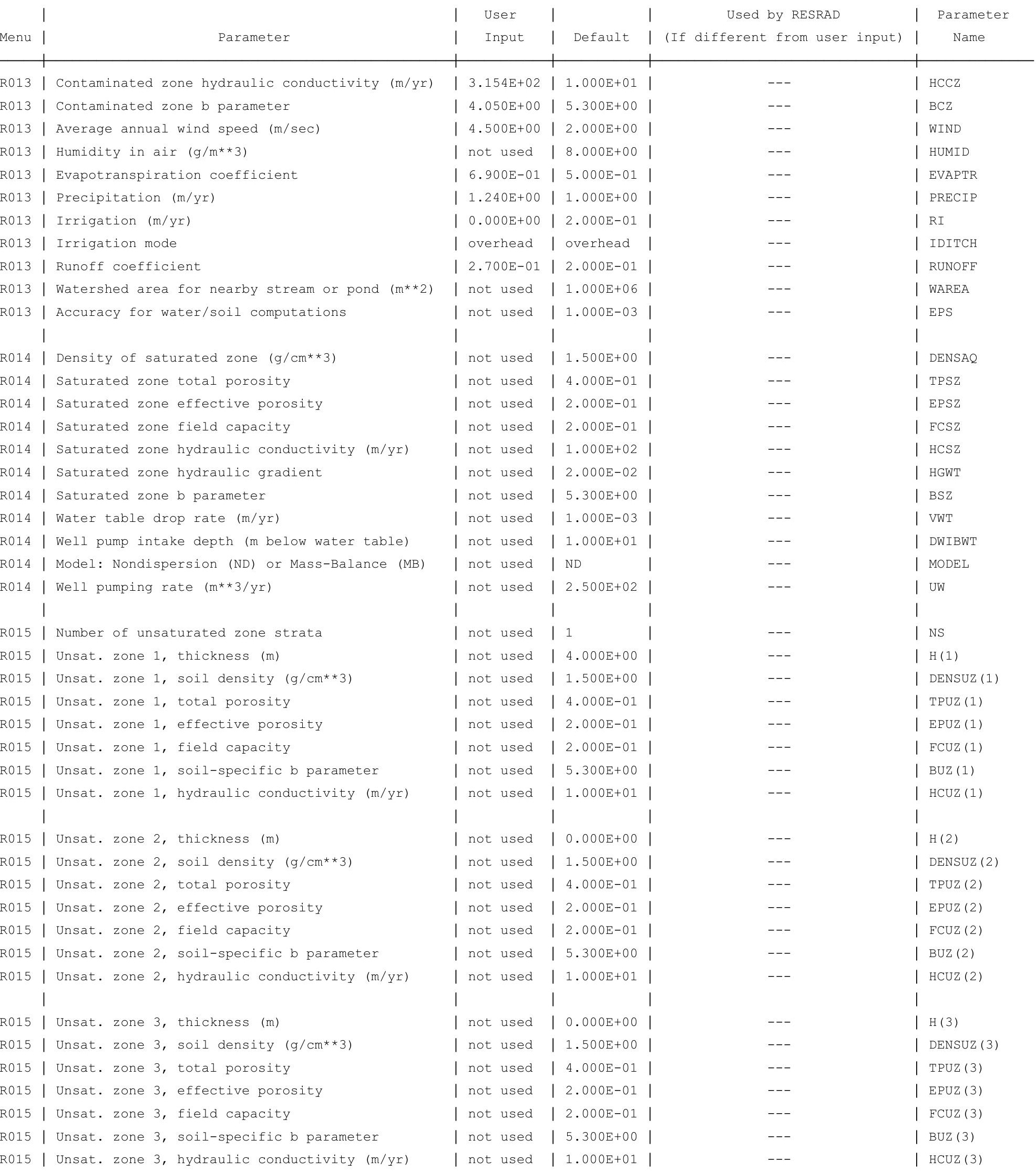


RESRAD, Version $6.5 \quad \mathrm{~T}^{1 / 2}$ Limit $=180$ days

Summary : C746U Landfill Worker Deterministic Run

File : $\mathrm{X}: \backslash F I N A L$ V2 $\backslash$ DOE FWD RUNS $\backslash$ C746U LW DOE SG FWD-FV2-70YR.RAD

Site-Specific Parameter Summary (continued)

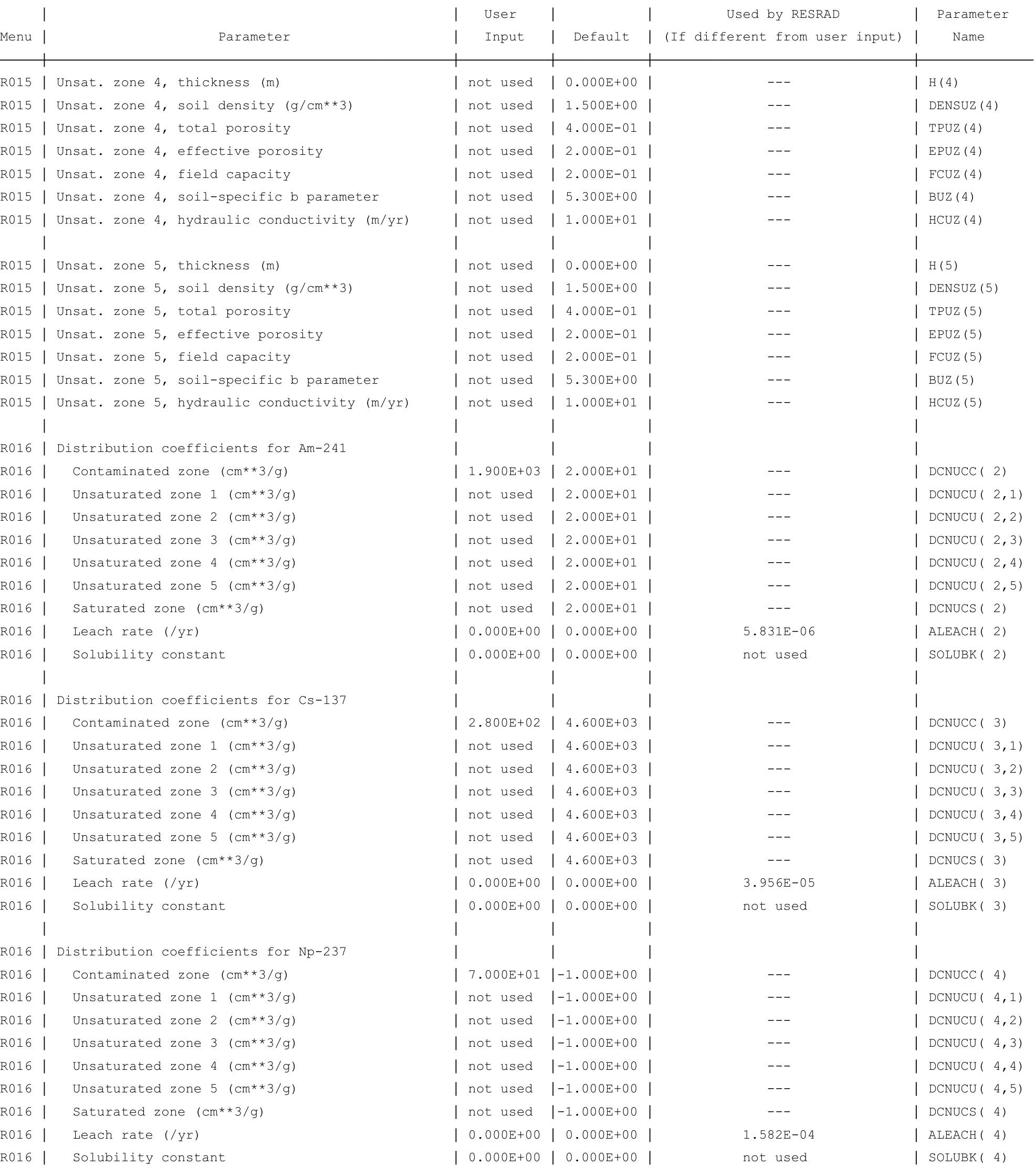


RESRAD, Version $6.5 \quad \mathrm{~T}^{1 / 2}$ Limit $=180$ days

Summary : C746U Landfill Worker Deterministic Run
File : X: $\backslash F I N A L$ V2 $\backslash$ DOE FWD RUNS $\backslash C 746 U$ LW DOE SG FWD-FV2-70YR.RAD

Site-Specific Parameter Summary (continued)

\begin{tabular}{|c|c|c|c|c|c|c|}
\hline & | & User & । & । & Used by RESRAD & I Parameter \\
\hline nu $\mid$ & Parameter & Input & I Default & | (If & different from user input) & Name \\
\hline & | Distribution coefficients for Pu-238 & l & | & | & & | \\
\hline & Contaminated zone $(\mathrm{cm} * * 3 / \mathrm{g})$ & $5.500 \mathrm{E}+02$ & $2.000 \mathrm{E}+03$ & | & --- & | $\operatorname{DCNUCC}(7)$ \\
\hline & Unsaturated zone $1(\mathrm{~cm} * * 3 / \mathrm{g})$ & I not used & $2.000 \mathrm{E}+03$ & | & --- & DCNUCU $(7,1$ \\
\hline & Unsaturated zone $2(\mathrm{~cm} * * 3 / \mathrm{g})$ & I not used & | $2.000 \mathrm{E}+03$ & | & --- & I DCNUCU $(7,2$ \\
\hline 161 & Unsaturated zone $3(\mathrm{~cm} * * 3 / \mathrm{g})$ & I not used & | $2.000 \mathrm{E}+03$ & | & --- & DCNUCU $(7,3$ \\
\hline 161 & Unsaturated zone $4\left(\mathrm{~cm}^{\star \star} 3 / \mathrm{g}\right)$ & I not used & $2.000 \mathrm{E}+03$ & l & --- & I $\operatorname{DCNUCU}(7,4$ \\
\hline $16 \mid$ & Unsaturated zone $5\left(\mathrm{~cm}^{* * 3 / \mathrm{g})}\right.$ & I not used & $2.000 \mathrm{E}+03$ & | & --- & DCNUCU $(7,5$ \\
\hline 161 & Saturated zone $(\mathrm{cm} * * 3 / \mathrm{g})$ & I not used & $2.000 \mathrm{E}+03$ & | & --- & | DCNUCS ( 7) \\
\hline & Leach rate (/yr) & $10.000 \mathrm{E}+00$ & $10.000 \mathrm{E}+00$ & | & $2.014 \mathrm{E}-05$ & | ALEACH ( 7) \\
\hline & Solubility constant & $10.000 \mathrm{E}+00$ & $0.000 \mathrm{E}+00$ & । & not used & | SOLUBK ( 7) \\
\hline & I & । & । & । & & । \\
\hline & | Distribution coefficients for Pu-239 & | & | & | & & | \\
\hline & Contaminated zone $(\mathrm{cm} * * 3 / \mathrm{g})$ & $5.500 \mathrm{E}+02$ & $2.000 \mathrm{E}+03$ & | & --- & | $\operatorname{DCNUCC}(9)$ \\
\hline & Unsaturated zone $1(\mathrm{~cm} * \star 3 / \mathrm{g})$ & I not used & | $2.000 \mathrm{E}+03$ & | & --- & I DCNUCU $(9,1$ \\
\hline & Unsaturated zone $2(\mathrm{~cm} * \star 3 / \mathrm{g})$ & I not used & $2.000 \mathrm{E}+03$ & | & --- & I DCNUCU $(9,2$ \\
\hline & Unsaturated zone $3\left(\mathrm{~cm}^{* * 3 / \mathrm{g})}\right.$ & I not used & $2.000 \mathrm{E}+03$ & | & --- & I DCNUCU ( 9,3 \\
\hline 161 & Unsaturated zone $4(\mathrm{~cm} * \star 3 / \mathrm{g})$ & I not used & | $2.000 \mathrm{E}+03$ & | & --- & I DCNUCU $(9,4$ \\
\hline & Unsaturated zone $5(\mathrm{~cm} * * 3 / \mathrm{g})$ & I not used & | $2.000 \mathrm{E}+03$ & । & --- & I DCNUCU ( 9,5 \\
\hline & Saturated zone $(\mathrm{cm} * * 3 / \mathrm{g})$ & I not used & $2.000 \mathrm{E}+03$ & । & --- & | DCNUCS ( 9) \\
\hline & Leach rate (/yr) & $10.000 \mathrm{E}+00$ & $0.000 \mathrm{E}+00$ & | & $2.014 \mathrm{E}-05$ & | $\operatorname{ALEACH}(9)$ \\
\hline & Solubility constant & $10.000 \mathrm{E}+00$ & $10.000 \mathrm{E}+00$ & | & not used & | SOLUBK (9) \\
\hline & | & l & । & | & & | \\
\hline 161 & | Distribution coefficients for Pu-240 & l & । & | & & I \\
\hline & Contaminated zone $\left(\mathrm{cm}^{* * 3 / \mathrm{g})}\right.$ & $5.500 \mathrm{E}+02$ & $2.000 \mathrm{E}+03$ & | & --- & I DCNUCC (10) \\
\hline & Unsaturated zone $1(\mathrm{~cm} * \star 3 / \mathrm{g})$ & I not used & $2.000 \mathrm{E}+03$ & | & --- & I $\operatorname{DCNUCU}(10,1$ \\
\hline & Unsaturated zone $2(\mathrm{~cm} * * 3 / \mathrm{g})$ & I not used & $2.000 \mathrm{E}+03$ & | & --- & I $\operatorname{DCNUCU}(10,2$ \\
\hline & Unsaturated zone $3(\mathrm{~cm} * \star 3 / \mathrm{g})$ & I not used & | $2.000 \mathrm{E}+03$ & । & --- & I $\operatorname{DCNUCU}(10,3$ \\
\hline & Unsaturated zone $4(\mathrm{~cm} * \star 3 / \mathrm{g})$ & I not used & $2.000 \mathrm{E}+03$ & l & --- & I DCNUCU $(10,4$ \\
\hline & Unsaturated zone $5(\mathrm{~cm} * * 3 / \mathrm{g})$ & I not used & $2.000 \mathrm{E}+03$ & | & --- & I $\operatorname{DCNUCU}(10,5$ \\
\hline & Saturated zone $(\mathrm{cm} * * 3 / \mathrm{g})$ & I not used & $2.000 \mathrm{E}+03$ & | & --- & | DCNUCS (10) \\
\hline & Leach rate (/yr) & $10.000 \mathrm{E}+00$ & $10.000 \mathrm{E}+00$ & | & $2.014 \mathrm{E}-05$ & | ALEACH (10) \\
\hline & Solubility constant & $10.000 \mathrm{E}+00$ & $10.000 \mathrm{E}+00$ & | & not used & I SOLUBK (10) \\
\hline & | & l & | & | & & I \\
\hline & | Distribution coefficients for TC-99 & | & | & | & & I \\
\hline & Contaminated zone $\left(\mathrm{cm}^{* * 3 / \mathrm{g})}\right.$ & $1.000 \mathrm{E}+00$ & $10.000 \mathrm{E}+00$ & I & --- & I DCNUCC (14) \\
\hline & Unsaturated zone $1(\mathrm{~cm} * * 3 / \mathrm{g})$ & I not used & $0.000 \mathrm{E}+00$ & । & --- & I DCNUCU $(14,1$ \\
\hline & Unsaturated zone $2(\mathrm{~cm} * \star 3 / \mathrm{g})$ & I not used & $10.000 \mathrm{E}+00$ & | & --- & | $\operatorname{DCNUCU}(14,2$ \\
\hline & Unsaturated zone $3\left(\mathrm{~cm}^{* *} 3 / \mathrm{g}\right)$ & I not used & $10.000 \mathrm{E}+00$ & | & --- & I DCNUCU $(14,3$ \\
\hline & Unsaturated zone $4\left(\mathrm{~cm}^{* * 3 / \mathrm{g})}\right.$ & I not used & $10.000 \mathrm{E}+00$ & | & --- & I $\operatorname{DCNUCU}(14,4$ \\
\hline & Unsaturated zone $5(\mathrm{~cm} * \star 3 / \mathrm{g})$ & I not used & $0.000 \mathrm{E}+00$ & । & --- & I DCNUCU $(14,5$ \\
\hline & Saturated zone $(\mathrm{cm} * \star 3 / \mathrm{g})$ & I not used & $10.000 \mathrm{E}+00$ & | & --- & I DCNUCS (14) \\
\hline & Leach rate $(/ y r)$ & $10.000 \mathrm{E}+00$ & $10.000 \mathrm{E}+00$ & I & $1.057 \mathrm{E}-02$ & I ALEACH (14) \\
\hline & Solubility constant & $10.000 \mathrm{E}+00$ & $10.000 \mathrm{E}+00$ & & not used & I SOLUBK (14) \\
\hline
\end{tabular}


RESRAD, Version $6.5 \quad \mathrm{~T}^{1 / 2}$ Limit $=180$ days

Summary : C746U Landfill Worker Deterministic Run

File : $\mathrm{X}: \backslash F I N A L$ V2 $\backslash$ DOE FWD RUNS $\backslash$ C746U LW DOE SG FWD-FV2-70YR.RAD

Site-Specific Parameter Summary (continued)

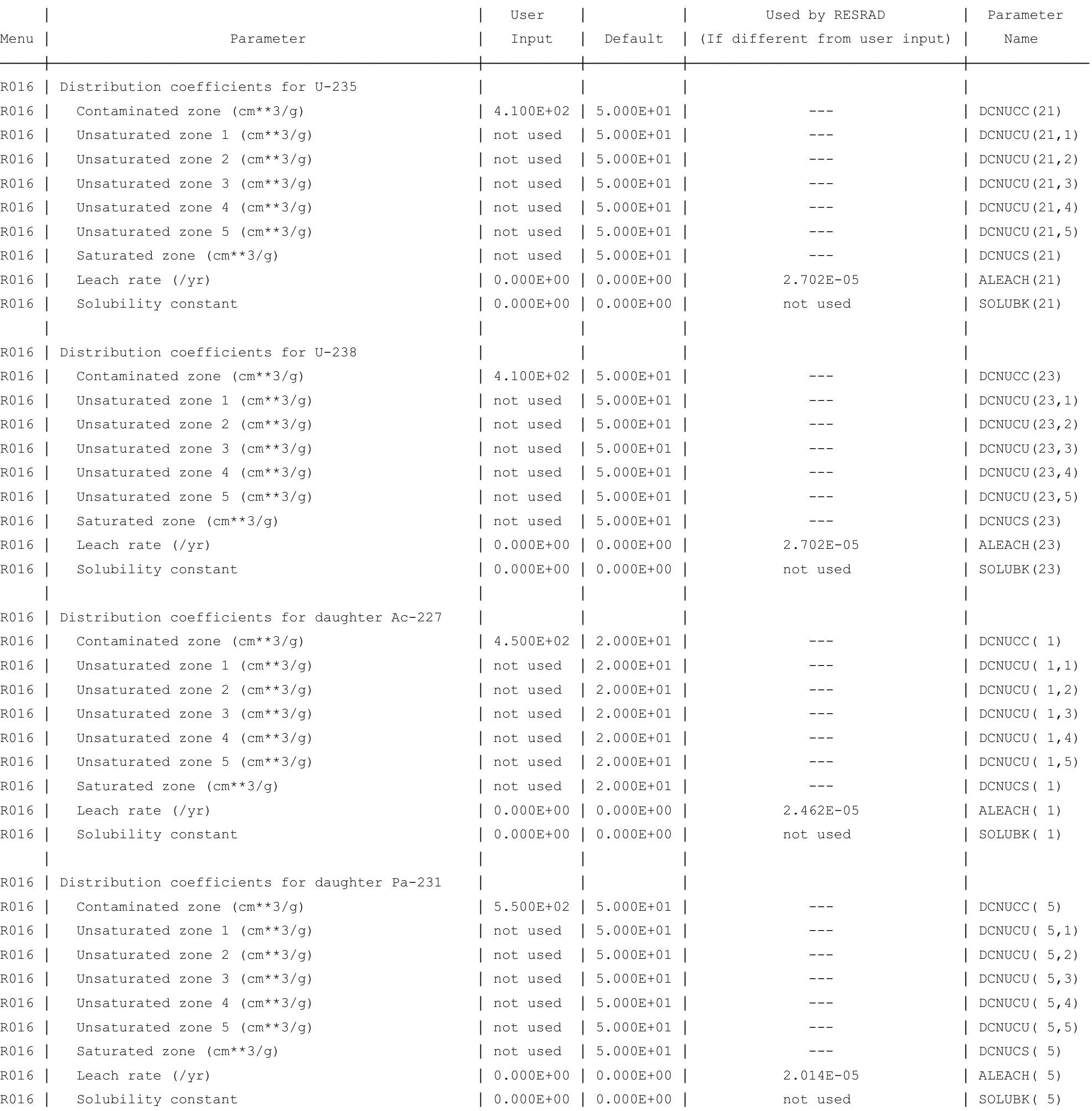


RESRAD, Version $6.5 \quad \mathrm{~T}^{1 / 2}$ Limit $=180$ days

Summary : C746U Landfill Worker Deterministic Run

File : $X: \backslash F I N A L$ V2 \DOE FWD RUNS \C746U LW DOE SG FWD-FV2-70YR.RAD

Site-Specific Parameter Summary (continued)

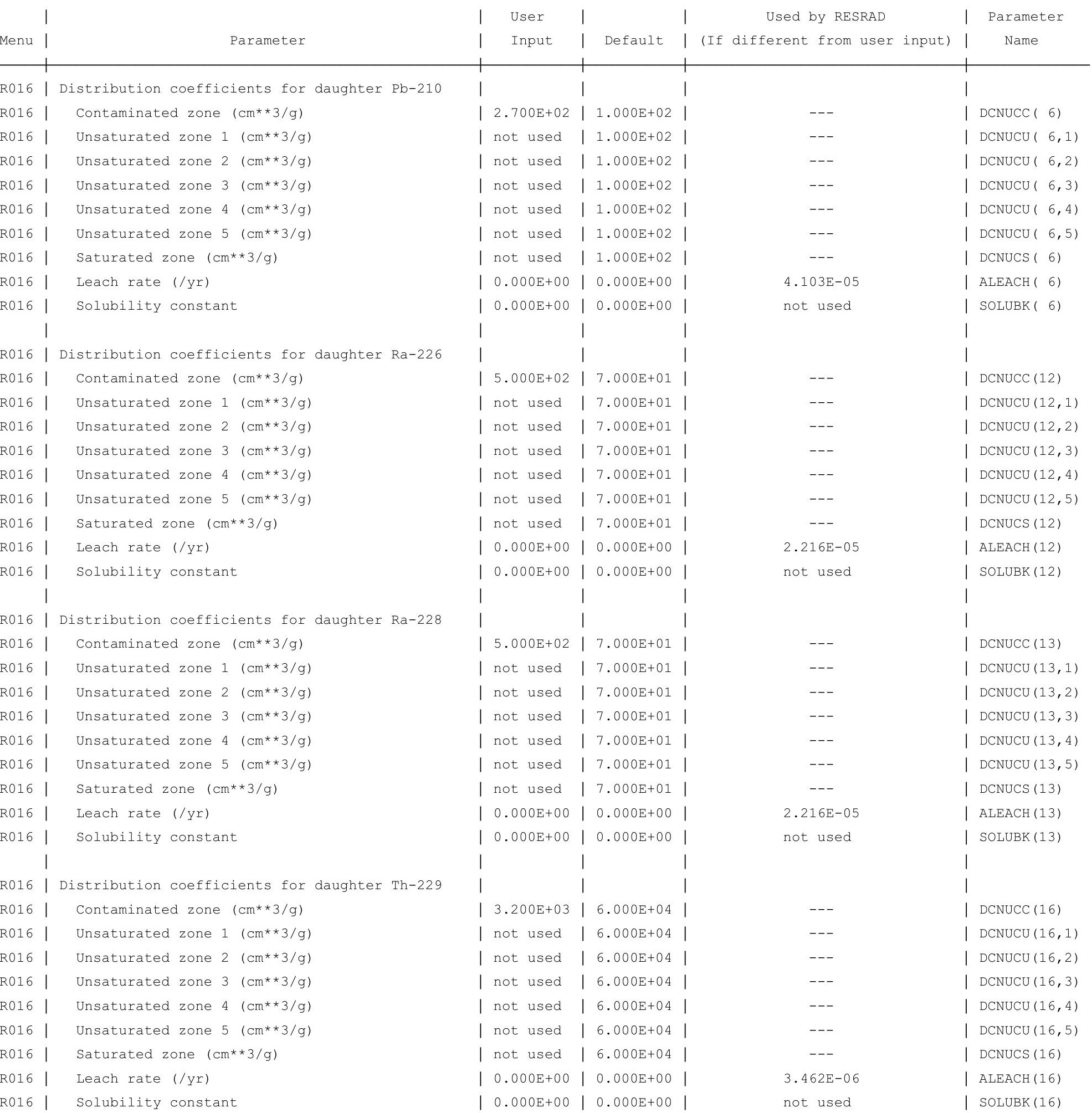


RESRAD, Version $6.5 \quad T^{1 / 2}$ Limit $=180$ days

Summary : C746U Landfill Worker Deterministic Run

File : $X: \backslash F I N A L$ V2 \DOE FWD RUNS \C746U LW DOE SG FWD-FV2-70YR.RAD

Site-Specific Parameter Summary (continued)

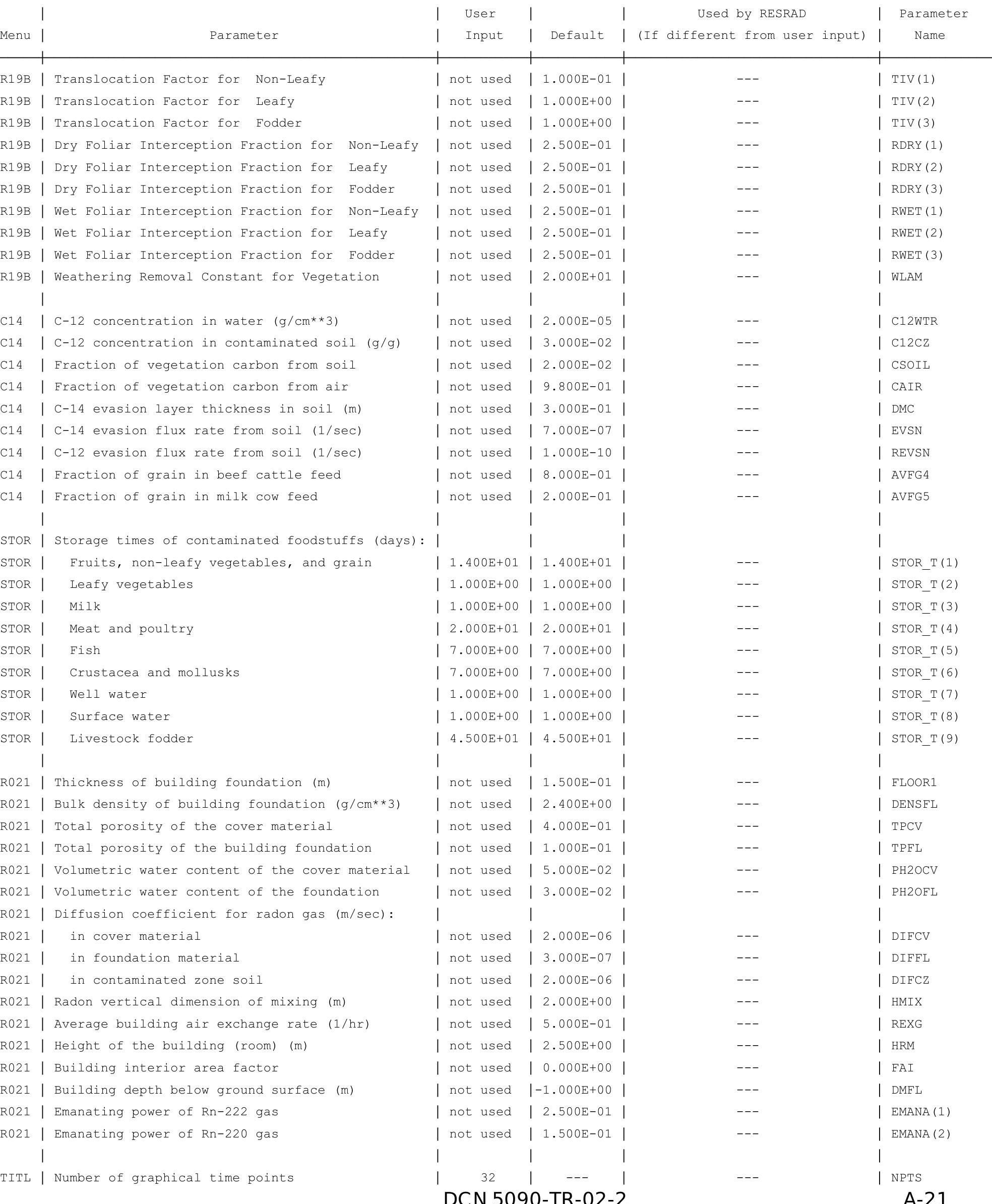


RESRAD, Version $6.5 \quad T^{11 / 2}$ Limit $=180$ days

Summary : C746U Landfill Worker Deterministic Run

File : $X: \backslash F I N A L$ V2 $\backslash$ DOE FWD RUNS $\backslash C 746 U$ LW DOE SG FWD-FV2-70YR.RAD

Contaminated Zone Dimensions

Area: 89436.00 square meters

Thickness:

Cover Depth:
Initial Soil Concentrations, pCi/g

$\begin{array}{ll}\mathrm{Am}-241 & 3.500 \mathrm{E}+01 \\ \mathrm{Cs}-137 & 1.900 \mathrm{E}+01 \\ \mathrm{~Np}-237 & 5.500 \mathrm{E}+00 \\ \mathrm{Pu}-238 & 3.900 \mathrm{E}+01 \\ \mathrm{Pu}-239 & 3.600 \mathrm{E}+01 \\ \mathrm{Pu}-240 & 3.600 \mathrm{E}+01 \\ \mathrm{TC}-99 & 5.200 \mathrm{E}+01 \\ \mathrm{Th}-228 & 4.000 \mathrm{E}+00 \\ \mathrm{Th}-230 & 1.000 \mathrm{E}+02 \\ \mathrm{Th}-232 & 4.000 \mathrm{E}+00 \\ \mathrm{U}-234 & 1.600 \mathrm{E}+02 \\ \mathrm{U}-235 & 6.500 \mathrm{E}+00 \\ \mathrm{U}-238 & 1.600 \mathrm{E}+02\end{array}$

Total Dose TDOSE(t), mrem/yr

Basic Radiation Dose Limit $=1.000 \mathrm{E}+02 \mathrm{mrem} / \mathrm{yr}$

Total Mixture Sum $M(t)$ = Fraction of Basic Dose Limit Received at Time (t)

$\begin{array}{rllll}t \quad \text { years }): & 0.000 \mathrm{E}+00 & 1.000 \mathrm{E}+00 & 5.000 \mathrm{E}+01 & 7.000 \mathrm{E}+01 \\ \text { TDOSE }(t): & 2.988 \mathrm{E}+01 & 2.871 \mathrm{E}+01 & 3.145 \mathrm{E}+01 & 3.184 \mathrm{E}+01 \\ \mathrm{M}(\mathrm{t}): & 2.988 \mathrm{E}-01 & 2.871 \mathrm{E}-01 & 3.145 \mathrm{E}-01 & 3.184 \mathrm{E}-01\end{array}$

Maximum TDOSE $(\mathrm{t}): \quad 3.184 \mathrm{E}+01 \mathrm{mrem} / \mathrm{yr}$ at $t=7.000 \mathrm{E}+01$ years 
RESRAD, Version 6.5

$\mathrm{T}^{1 / 2}$ Limit $=180$ days

07/15/2011 $11: 46$ Page 20

Summary : C746U Landfill Worker Deterministic Run
File : X: $\backslash F I N A L$ V2 $\backslash$ DOE FWD RUNS $\backslash C 746 U$ LW DOE SG FWD-FV2-70YR.RAD

Total Dose Contributions TDOSE (i,p,t) for Individual Radionuclides (i) and Pathways (p) As mrem/yr and Fraction of Total Dose At $t=0.000 \mathrm{E}+00$ years

Water Independent Pathways (Inhalation excludes radon)

\begin{tabular}{|c|c|c|}
\hline clide & mrem/yr & fract. \\
\hline 241 & $2.204 E-01$ & 0.0074 \\
\hline-137 & $9.972 \mathrm{E}+00$ & 0.3338 \\
\hline-237 & $9.311 \mathrm{E}-01$ & 0.0312 \\
\hline-238 & $7.691 \mathrm{E}-04$ & 0.0000 \\
\hline-239 & $1.592 \mathrm{E}-03$ & 0.0001 \\
\hline-240 & $6.888 \mathrm{E}-04$ & 0.0000 \\
\hline-99 & $9.464 \mathrm{E}-04$ & 0.0000 \\
\hline-228 & $5.388 \mathrm{E}+00$ & 0.1804 \\
\hline-230 & $5.615 \mathrm{E}-02$ & 0.0019 \\
\hline-232 & $2.597 \mathrm{E}-01$ & 0.0087 \\
\hline 34 & $9.290 E-03$ & 0.0003 \\
\hline 235 & $7.547 \mathrm{E}-01$ & 0.0253 \\
\hline 38 & $4.148 \mathrm{E}+00$ & 0.1388 \\
\hline & 2. & 0.1218 \\
\hline
\end{tabular}

\begin{abstract}
Inhalation
\end{abstract}

mrem/yr fract.

$\longrightarrow$

$6.316 \mathrm{E}-03 \quad 0.0002$

$1.376 \mathrm{E}-060.0000$

$5.176 \mathrm{E}-04 \quad 0.0000$

$8.043 E-030.0003$

$8.131 \mathrm{E}-030.0003$

$8.131 \mathrm{E}-030.0003$

$1.266 \mathrm{E}-060.0000$

$2.755 E-040.0000$

$1.882 \mathrm{E}-020.0006$

$8.373 E-040.0000$

$2.833 E-030.0001$

$1.042 \mathrm{E}-04 \quad 0.0000$

$2.412 \mathrm{E}-03 \quad 0.0001$

$\overline{\overline{5.643 \mathrm{E}-02}} \overline{\overline{0.0019}}$

Radon
mrem/yr fract. $\overline{0.000 \mathrm{E}+00} \overline{0.0000}$ $0.000 E+00 \quad 0.0000$ $0.000 E+00 \quad 0.0000$ $0.000 \mathrm{E}+00 \quad 0.0000$ $0.000 \mathrm{E}+00 \quad 0.0000$ $0.000 E+00 \quad 0.0000$ $0.000 E+00 \quad 0.0000$ $0.000 E+00 \quad 0.0000$ $0.000 \mathrm{E}+00 \quad 0.0000$ $0.000 \mathrm{E}+00 \quad 0.0000$ $0.000 \mathrm{E}+00 \quad 0.0000$ $0.000 \mathrm{E}+00 \quad 0.0000$ $0.000 \mathrm{E}+00 \quad 0.0000$

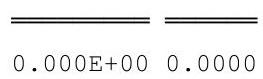

\begin{tabular}{|c|c|c|c|}
\hline \multicolumn{2}{|c|}{ Plant } & \multicolumn{2}{|c|}{ Meat } \\
\hline mrem/yr & fract. & mrem/yr & fract. \\
\hline $0.000 \mathrm{E}+00$ & 0.0000 & $0.000 \mathrm{E}+00$ & 0.0000 \\
\hline $0.000 \mathrm{E}+00$ & 0.0000 & $0.000 \mathrm{E}+00$ & 0.0000 \\
\hline $0.000 \mathrm{E}+00$ & 0.0000 & $0.000 \mathrm{E}+00$ & 0.0000 \\
\hline $0.000 \mathrm{E}+00$ & 0.0000 & $0.000 \mathrm{E}+00$ & 0.0000 \\
\hline $0.000 \mathrm{E}+00$ & 0.0000 & $0.000 \mathrm{E}+00$ & 0.0000 \\
\hline $0.000 \mathrm{E}+00$ & 0.0000 & $0.000 \mathrm{E}+00$ & 0.0000 \\
\hline $0.000 \mathrm{E}+00$ & 0.0000 & $0.000 \mathrm{E}+00$ & 0.0000 \\
\hline $0.000 \mathrm{E}+00$ & 0.0000 & $0.000 \mathrm{E}+00$ & 0.0000 \\
\hline $0.000 \mathrm{E}+00$ & 0.0000 & $0.000 \mathrm{E}+00$ & 0.0000 \\
\hline $0.000 \mathrm{E}+00$ & 0.0000 & $0.000 \mathrm{E}+00$ & 0.0000 \\
\hline $0.000 \mathrm{E}+00$ & 0.0000 & $0.000 \mathrm{E}+00$ & 0.0000 \\
\hline $0.000 \mathrm{E}+00$ & 0.0000 & $0.000 \mathrm{E}+00$ & 0.0000 \\
\hline $0.000 \mathrm{E}+00$ & 0.0000 & $0.000 \mathrm{E}+00$ & 0.0000 \\
\hline & & 0.00 & \\
\hline
\end{tabular}

\begin{tabular}{cc} 
Milk \\
\cline { 1 - 2 } mrem/yr fract. & \\
\cline { 1 - 2 } $0.000 \mathrm{E}+00$ & 0.0000 \\
$0.000 \mathrm{E}+00$ & 0.0000 \\
$0.000 \mathrm{E}+00$ & 0.0000 \\
$0.000 \mathrm{E}+00$ & 0.0000 \\
$0.000 \mathrm{E}+00$ & 0.0000 \\
$0.000 \mathrm{E}+00$ & 0.0000 \\
$0.000 \mathrm{E}+00$ & 0.0000 \\
$0.000 \mathrm{E}+00$ & 0.0000 \\
$0.000 \mathrm{E}+00$ & 0.0000 \\
$0.000 \mathrm{E}+00$ & 0.0000 \\
$0.000 \mathrm{E}+00$ & 0.0000 \\
$0.000 \mathrm{E}+00$ & 0.0000 \\
$0.000 \mathrm{E}+00$ & 0.0000 \\
\hline \hline $0.000 \mathrm{E}+00$ & 0.0000
\end{tabular}

Soil mrem/yr fract. $7.708 \mathrm{E}-010.0258$ 2.691E-02 0.0009 $6.719 \mathrm{E}-02 \quad 0.0022$ $9.846 \mathrm{E}-010.0330$ $9.918 \mathrm{E}-010.0332$ $9.917 \mathrm{E}-010.0332$ $3.651 \mathrm{E}-03 \quad 0.0001$ $5.298 \mathrm{E}-020.0018$ $2.315 \mathrm{E}+00 \quad 0.0775$ $1.194 \mathrm{E}-010.0040$ $8.625 \mathrm{E}-010.0289$ $3.393 \mathrm{E}-020.0011$ $8.559 \mathrm{E}-010.0286$ $8.076 \mathrm{E}+00 \quad 0.2703$

Total Dose Contributions TDOSE (i,p,t) for Individual Radionuclides (i) and Pathways (p) As mrem/yr and Fraction of Total Dose At $t=0.000 \mathrm{E}+00$ years

Water Dependent Pathways

\begin{tabular}{|c|c|c|c|c|c|c|}
\hline & \multicolumn{2}{|c|}{ Water } & \multicolumn{2}{|c|}{ Fish } & \multicolumn{2}{|c|}{ Radon } \\
\hline clide & mrem/yr & fract. & mrem/yr & fract. & mrem/yr & fract. \\
\hline 241 & $0.000 \mathrm{E}+00$ & 0.0000 & $0.000 \mathrm{E}+00$ & 0.0000 & $0.000 \mathrm{E}+00$ & 0.0000 \\
\hline-137 & $0.000 \mathrm{E}+00$ & 0.0000 & $0.000 \mathrm{E}+00$ & 0.0000 & $0.000 \mathrm{E}+00$ & 0.0000 \\
\hline-237 & $0.000 \mathrm{E}+00$ & 0.0000 & $0.000 \mathrm{E}+00$ & 0.0000 & $0.000 \mathrm{E}+00$ & 0.0000 \\
\hline-238 & $0.000 \mathrm{E}+00$ & 0.0000 & $0.000 \mathrm{E}+00$ & 0.0000 & $0.000 \mathrm{E}+00$ & 0.0000 \\
\hline-239 & $0.000 \mathrm{E}+00$ & 0.0000 & $0.000 \mathrm{E}+00$ & 0.0000 & $0.000 \mathrm{E}+00$ & 0.0000 \\
\hline-240 & $0.000 \mathrm{E}+00$ & 0.0000 & $0.000 \mathrm{E}+00$ & 0.0000 & $0.000 \mathrm{E}+00$ & 0.0000 \\
\hline-99 & $0.000 \mathrm{E}+00$ & 0.0000 & $0.000 \mathrm{E}+00$ & 0.0000 & $0.000 \mathrm{E}+00$ & 0.0000 \\
\hline-228 & $0.000 \mathrm{E}+00$ & 0.0000 & $0.000 \mathrm{E}+00$ & 0.0000 & $0.000 \mathrm{E}+00$ & 0.0000 \\
\hline-230 & $0.000 \mathrm{E}+00$ & 0.0000 & $0.000 \mathrm{E}+00$ & 0.0000 & $0.000 \mathrm{E}+00$ & 0.0000 \\
\hline-232 & $0.000 \mathrm{E}+00$ & 0.0000 & $0.000 \mathrm{E}+00$ & 0.0000 & $0.000 \mathrm{E}+00$ & 0.0000 \\
\hline 234 & $0.000 \mathrm{E}+00$ & 0.0000 & $0.000 \mathrm{E}+00$ & 0.0000 & $0.000 \mathrm{E}+00$ & 0.0000 \\
\hline 235 & $0.000 \mathrm{E}+00$ & 0.0000 & $0.000 \mathrm{E}+00$ & 0.0000 & $0.000 \mathrm{E}+00$ & 0.0000 \\
\hline 38 & $0.000 \mathrm{E}+00$ & 0.0000 & $0.000 \mathrm{E}+00$ & 0.0000 & $0.000 \mathrm{E}+00$ & 0.0000 \\
\hline & $0.000 \mathrm{E}+00$ & 0.0000 & $0.000 \mathrm{E}+00$ & 0.0000 & $0.000 \mathrm{E}+00$ & 0.0000 \\
\hline
\end{tabular}

\begin{tabular}{|c|c|}
\hline mrem/yr & fract. \\
\hline $0.000 \mathrm{E}+00$ & 0.0000 \\
\hline $0.000 \mathrm{E}+00$ & 0.0000 \\
\hline $0.000 \mathrm{E}+00$ & 0.0000 \\
\hline $0.000 \mathrm{E}+00$ & 0.0000 \\
\hline $0.000 \mathrm{E}+00$ & 0.0000 \\
\hline $0.000 \mathrm{E}+00$ & 0.0000 \\
\hline $0.000 \mathrm{E}+00$ & 0.0000 \\
\hline $0.000 \mathrm{E}+00$ & 0.0000 \\
\hline $0.000 \mathrm{E}+00$ & 0.0000 \\
\hline $0.000 \mathrm{E}+00$ & 0.0000 \\
\hline $0.000 \mathrm{E}+00$ & 0.0000 \\
\hline $0.000 \mathrm{E}+00$ & 0.0000 \\
\hline $0.000 \mathrm{E}+00$ & 0.0000 \\
\hline
\end{tabular}

$0.000 \mathrm{E}+00 \quad 0.0000$

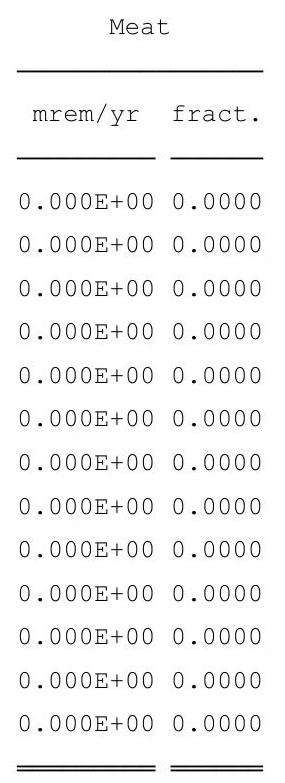

$0.000 \mathrm{E}+00 \quad 0.0000$

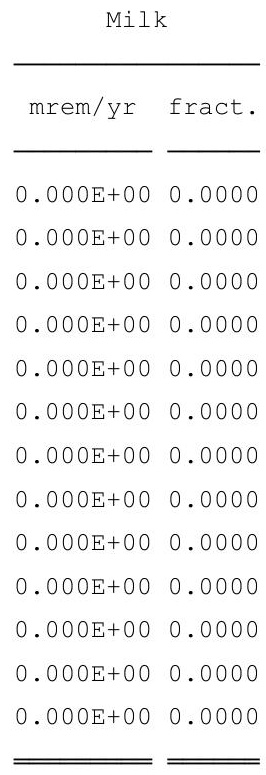

$0.000 \mathrm{E}+00 \quad 0.0000$
All Pathways * mrem/yr fract. 9.975E-01 0.0334 $9.998 \mathrm{E}+00 \quad 0.3347$ $9.988 \mathrm{E}-01 \quad 0.0334$ $9.934 \mathrm{E}-010.0333$ $1.002 \mathrm{E}+00 \quad 0.0335$ $1.001 \mathrm{E}+00 \quad 0.0335$ $4.599 \mathrm{E}-03 \quad 0.0002$ $5.442 \mathrm{E}+00 \quad 0.1821$ $2.390 \mathrm{E}+00 \quad 0.0800$ $3.800 \mathrm{E}-010.0127$ $8.747 \mathrm{E}-010.0293$ $7.888 \mathrm{E}-01 \quad 0.0264$ $5.007 \mathrm{E}+00 \quad 0.1676$ $2.988 E+011.0000$

* Sum of all water independent and dependent pathways. 
RESRAD, Version 6.5

$\mathrm{T}^{1 / 2}$ Limit $=180$ days

07/15/2011 $11: 46 \quad$ Page 21

Summary : C746U Landfill Worker Deterministic Run
File : X: $\backslash F I N A L$ V2 $\backslash$ DOE FWD RUNS $\backslash C 746 U$ LW DOE SG FWD-FV2-70YR.RAD

Total Dose Contributions TDOSE (i,p,t) for Individual Radionuclides (i) and Pathways (p) As mrem/yr and Fraction of Total Dose At $t=1.000 \mathrm{E}+00$ years

Water Independent Pathways (Inhalation excludes radon)

\begin{tabular}{|c|c|c|c|c|c|c|c|c|c|c|c|c|c|c|}
\hline \multirow{2}{*}{ Nuclide } & \multicolumn{2}{|c|}{ Ground } & \multicolumn{2}{|c|}{ Inhalation } & \multicolumn{2}{|c|}{ Radon } & \multicolumn{2}{|c|}{ Plant } & \multicolumn{2}{|c|}{ Meat } & \multicolumn{2}{|c|}{ Milk } & \multicolumn{2}{|c|}{ Soil } \\
\hline & mrem/yr & fract. & mrem/yr & fract. & mrem/yr & fract. & mrem/yr & fract. & mrem/yr & fract. & mrem/yr & fract. & mrem/yr & fract. \\
\hline-241 & $2.200 \mathrm{E}-01$ & 0.0077 & $6.306 \mathrm{E}-03$ & 0.0002 & $0.000 \mathrm{E}+00$ & 0.0000 & $0.000 \mathrm{E}+00$ & 0.0000 & $0.000 \mathrm{E}+00$ & 0.0000 & $0.000 \mathrm{E}+00$ & 0.0000 & 7. $695 \mathrm{E}-01$ & 0.0268 \\
\hline-137 & $9.743 E+00$ & 0.3394 & $1.344 \mathrm{E}-06$ & 0.0000 & $0.000 \mathrm{E}+00$ & 0.0000 & $0.000 \mathrm{E}+00$ & 0.0000 & $0.000 \mathrm{E}+00$ & 0.0000 & $0.000 \mathrm{E}+00$ & 0.0000 & $2.629 \mathrm{E}-02$ & 0.0009 \\
\hline-237 & $9.309 E-01$ & 0.0324 & $5.175 \mathrm{E}-04$ & 0.0000 & $0.000 \mathrm{E}+00$ & 0.0000 & $0.000 \mathrm{E}+00$ & 0.0000 & $0.000 \mathrm{E}+00$ & 0.0000 & $0.000 \mathrm{E}+00$ & 0.0000 & $6.718 \mathrm{E}-02$ & 0.0023 \\
\hline-238 & $7.630 \mathrm{E}-04$ & 0.0000 & 7. $980 \mathrm{E}-03$ & 0.0003 & $0.000 \mathrm{E}+00$ & 0.0000 & $0.000 \mathrm{E}+00$ & 0.0000 & $0.000 \mathrm{E}+00$ & 0.0000 & $0.000 \mathrm{E}+00$ & 0.0000 & $9.768 \mathrm{E}-01$ & 0.0340 \\
\hline-239 & $1.592 \mathrm{E}-03$ & 0.0001 & $8.131 \mathrm{E}-03$ & 0.0003 & $0.000 \mathrm{E}+00$ & 0.0000 & $0.000 \mathrm{E}+00$ & 0.0000 & $0.000 \mathrm{E}+00$ & 0.0000 & $0.000 \mathrm{E}+00$ & 0.0000 & $9.917 \mathrm{E}-01$ & 0.0345 \\
\hline-240 & $6.888 \mathrm{E}-04$ & 0.0000 & $8.130 \mathrm{E}-03$ & 0.0003 & $0.000 \mathrm{E}+00$ & 0.0000 & $0.000 \mathrm{E}+00$ & 0.0000 & $0.000 \mathrm{E}+00$ & 0.0000 & $0.000 \mathrm{E}+00$ & 0.0000 & $9.916 \mathrm{E}-01$ & 0.0345 \\
\hline-99 & $9.365 E-04$ & 0.0000 & $1.252 \mathrm{E}-06$ & 0.0000 & $0.000 \mathrm{E}+00$ & 0.0000 & $0.000 \mathrm{E}+00$ & 0.0000 & $0.000 \mathrm{E}+00$ & 0.0000 & $0.000 \mathrm{E}+00$ & 0.0000 & $3.613 E-03$ & 0.0001 \\
\hline-228 & $3.751 \mathrm{E}+00$ & 0.1306 & $1.918 \mathrm{E}-04$ & 0.0000 & $0.000 \mathrm{E}+00$ & 0.0000 & $0.000 \mathrm{E}+00$ & 0.0000 & $0.000 \mathrm{E}+00$ & 0.0000 & $0.000 \mathrm{E}+00$ & 0.0000 & $3.688 \mathrm{E}-02$ & 0.0013 \\
\hline-230 & $1.323 E-01$ & 0.0046 & $1.882 \mathrm{E}-02$ & 0.0007 & $0.000 \mathrm{E}+00$ & 0.0000 & $0.000 \mathrm{E}+00$ & 0.0000 & $0.000 \mathrm{E}+00$ & 0.0000 & $0.000 \mathrm{E}+00$ & 0.0000 & $2.317 \mathrm{E}+00$ & 0.0807 \\
\hline-232 & $8.754 \mathrm{E}-01$ & 0.0305 & $8.611 \mathrm{E}-04$ & 0.0000 & $0.000 \mathrm{E}+00$ & 0.0000 & $0.000 \mathrm{E}+00$ & 0.0000 & $0.000 \mathrm{E}+00$ & 0.0000 & $0.000 \mathrm{E}+00$ & 0.0000 & $1.540 \mathrm{E}-01$ & 0.0054 \\
\hline 34 & $9.292 \mathrm{E}-03$ & 0.0003 & $2.833 E-03$ & 0.0001 & $0.000 \mathrm{E}+00$ & 0.0000 & $0.000 \mathrm{E}+00$ & 0.0000 & $0.000 \mathrm{E}+00$ & 0.0000 & $0.000 \mathrm{E}+00$ & 0.0000 & $8.626 \mathrm{E}-01$ & 0.0300 \\
\hline 35 & $7.547 \mathrm{E}-01$ & 0.0263 & $1.042 \mathrm{E}-04$ & 0.0000 & $0.000 \mathrm{E}+00$ & 0.0000 & $0.000 \mathrm{E}+00$ & 0.0000 & $0.000 \mathrm{E}+00$ & 0.0000 & $0.000 \mathrm{E}+00$ & 0.0000 & $3.395 \mathrm{E}-02$ & 0.0012 \\
\hline 38 & $4.148 \mathrm{E}+00$ & 0.1445 & $2.412 \mathrm{E}-03$ & 0.0001 & $0.000 \mathrm{E}+00$ & 0.0000 & $0.000 \mathrm{E}+00$ & 0.0000 & $0.000 \mathrm{E}+00$ & 0.0000 & $0.000 \mathrm{E}+00$ & 0.0000 & $8.559 \mathrm{E}-01$ & 0.0298 \\
\hline & $2.057 \mathrm{E}+01$ & 0.7164 & 5. $629 \mathrm{E}-02$ & 0.0020 & $0.000 \mathrm{E}+00$ & 0.0000 & $0.000 \mathrm{E}+00$ & 0.0000 & $0.000 \mathrm{E}+00$ & 0.0000 & $0.000 \mathrm{E}+00$ & 0.0000 & $8.087 \mathrm{E}+00$ & 0.2816 \\
\hline
\end{tabular}

Total Dose Contributions TDOSE(i,p,t) for Individual Radionuclides (i) and Pathways (p) As mrem/yr and Fraction of Total Dose At $t=1.000 \mathrm{E}+00$ years

Water Dependent Pathways

\begin{tabular}{|c|c|c|c|c|c|c|c|c|c|c|c|c|c|c|}
\hline & \multicolumn{2}{|c|}{ Water } & \multicolumn{2}{|c|}{ Fish } & \multicolumn{2}{|c|}{ Radon } & \multicolumn{2}{|c|}{ Plant } & \multicolumn{2}{|c|}{ Meat } & \multicolumn{2}{|c|}{ Milk } & \multicolumn{2}{|c|}{ All Pathways* } \\
\hline clide & mrem/yr & fract. & mrem/yr & fract. & mrem/yr & fract. & mrem/yr & fract. & mrem/yr & fract. & mrem/yr & fract. & mrem/yr & fract. \\
\hline 241 & $0.000 \mathrm{E}+00$ & 0.0000 & $0.000 \mathrm{E}+00$ & 0.0000 & $0.000 \mathrm{E}+00$ & 0.0000 & $0.000 \mathrm{E}+00$ & 0.0000 & $0.000 \mathrm{E}+00$ & 0.0000 & $0.000 \mathrm{E}+00$ & 0.0000 & $9.959 \mathrm{E}-01$ & 0.0347 \\
\hline-137 & $0.000 \mathrm{E}+00$ & 0.0000 & $0.000 \mathrm{E}+00$ & 0.0000 & $0.000 \mathrm{E}+00$ & 0.0000 & $0.000 \mathrm{E}+00$ & 0.0000 & $0.000 \mathrm{E}+00$ & 0.0000 & $0.000 \mathrm{E}+00$ & 0.0000 & $9.770 \mathrm{E}+00$ & 0.3403 \\
\hline-237 & $0.000 \mathrm{E}+00$ & 0.0000 & $0.000 \mathrm{E}+00$ & 0.0000 & $0.000 \mathrm{E}+00$ & 0.0000 & $0.000 \mathrm{E}+00$ & 0.0000 & $0.000 \mathrm{E}+00$ & 0.0000 & $0.000 \mathrm{E}+00$ & 0.0000 & $9.986 \mathrm{E}-01$ & 0.0348 \\
\hline-238 & $0.000 \mathrm{E}+00$ & 0.0000 & $0.000 \mathrm{E}+00$ & 0.0000 & $0.000 \mathrm{E}+00$ & 0.0000 & $0.000 \mathrm{E}+00$ & 0.0000 & $0.000 \mathrm{E}+00$ & 0.0000 & $0.000 \mathrm{E}+00$ & 0.0000 & $9.856 \mathrm{E}-01$ & 0.0343 \\
\hline-239 & $0.000 \mathrm{E}+00$ & 0.0000 & $0.000 \mathrm{E}+00$ & 0.0000 & $0.000 \mathrm{E}+00$ & 0.0000 & $0.000 \mathrm{E}+00$ & 0.0000 & $0.000 \mathrm{E}+00$ & 0.0000 & $0.000 E+00$ & 0.0000 & $1.001 \mathrm{E}+00$ & 0.0349 \\
\hline-240 & $0.000 \mathrm{E}+00$ & 0.0000 & $0.000 \mathrm{E}+00$ & 0.0000 & $0.000 \mathrm{E}+00$ & 0.0000 & $0.000 \mathrm{E}+00$ & 0.0000 & $0.000 \mathrm{E}+00$ & 0.0000 & $0.000 E+00$ & 0.0000 & $1.000 \mathrm{E}+00$ & 0.0348 \\
\hline-99 & $0.000 \mathrm{E}+00$ & 0.0000 & $0.000 \mathrm{E}+00$ & 0.0000 & $0.000 \mathrm{E}+00$ & 0.0000 & $0.000 \mathrm{E}+00$ & 0.0000 & $0.000 \mathrm{E}+00$ & 0.0000 & $0.000 \mathrm{E}+00$ & 0.0000 & $4.551 \mathrm{E}-03$ & 0.0002 \\
\hline-228 & $0.000 \mathrm{E}+00$ & 0.0000 & $0.000 \mathrm{E}+00$ & 0.0000 & $0.000 \mathrm{E}+00$ & 0.0000 & $0.000 \mathrm{E}+00$ & 0.0000 & $0.000 \mathrm{E}+00$ & 0.0000 & $0.000 \mathrm{E}+00$ & 0.0000 & $3.788 \mathrm{E}+00$ & 0.1319 \\
\hline-230 & $0.000 \mathrm{E}+00$ & 0.0000 & $0.000 \mathrm{E}+00$ & 0.0000 & $0.000 \mathrm{E}+00$ & 0.0000 & $0.000 \mathrm{E}+00$ & 0.0000 & $0.000 \mathrm{E}+00$ & 0.0000 & $0.000 E+00$ & 0.0000 & $2.468 \mathrm{E}+00$ & 0.0859 \\
\hline-232 & $0.000 \mathrm{E}+00$ & 0.0000 & $0.000 \mathrm{E}+00$ & 0.0000 & $0.000 \mathrm{E}+00$ & 0.0000 & $0.000 \mathrm{E}+00$ & 0.0000 & $0.000 \mathrm{E}+00$ & 0.0000 & $0.000 \mathrm{E}+00$ & 0.0000 & $1.030 \mathrm{E}+00$ & 0.0359 \\
\hline 34 & $0.000 \mathrm{E}+00$ & 0.0000 & $0.000 \mathrm{E}+00$ & 0.0000 & $0.000 \mathrm{E}+00$ & 0.0000 & $0.000 \mathrm{E}+00$ & 0.0000 & $0.000 \mathrm{E}+00$ & 0.0000 & $0.000 \mathrm{E}+00$ & 0.0000 & $8.747 \mathrm{E}-01$ & 0.0305 \\
\hline 35 & $0.000 \mathrm{E}+00$ & 0.0000 & $0.000 \mathrm{E}+00$ & 0.0000 & $0.000 \mathrm{E}+00$ & 0.0000 & $0.000 \mathrm{E}+00$ & 0.0000 & $0.000 \mathrm{E}+00$ & 0.0000 & $0.000 \mathrm{E}+00$ & 0.0000 & $7.887 \mathrm{E}-01$ & 0.0275 \\
\hline 38 & $0.000 \mathrm{E}+00$ & 0.0000 & $0.000 \mathrm{E}+00$ & 0.0000 & $0.000 \mathrm{E}+00$ & 0.0000 & $0.000 \mathrm{E}+00$ & 0.0000 & $0.000 \mathrm{E}+00$ & 0.0000 & $0.000 \mathrm{E}+00$ & 0.0000 & $5.006 \mathrm{E}+00$ & 0.1744 \\
\hline & $0.000 \mathrm{E}+00$ & 0.0000 & $0.000 \mathrm{E}+00$ & 0.0000 & $0.000 \mathrm{E}+00$ & 0.0000 & $0.000 \mathrm{E}+00$ & 0.0000 & $0.000 \mathrm{E}+00$ & 0.0000 & $0.000 \mathrm{E}+00$ & 0.0000 & $71 E+01$ & 1. \\
\hline
\end{tabular}

* Sum of all water independent and dependent pathways. 
RESRAD, Version 6.5

$\mathrm{T}^{1 / 2}$ Limit $=180$ days

07/15/2011 $11: 46 \quad$ Page 22

Summary : C746U Landfill Worker Deterministic Run
File : X: $\backslash F I N A L$ V2 $\backslash$ DOE FWD RUNS $\backslash C 746 U$ LW DOE SG FWD-FV2-70YR.RAD

Total Dose Contributions TDOSE(i,p,t) for Individual Radionuclides (i) and Pathways (p) As mrem/yr and Fraction of Total Dose At $t=5.000 \mathrm{E}+01$ years

Water Independent Pathways (Inhalation excludes radon)

\begin{tabular}{|c|c|c|}
\hline clide & mrem/yr & fract. \\
\hline 241 & $2.034 E-01$ & 0.0065 \\
\hline-137 & $3.135 E+00$ & 0.0997 \\
\hline-237 & $9.237 \mathrm{E}-01$ & 0.0294 \\
\hline-238 & $5.179 \mathrm{E}-04$ & 0.0000 \\
\hline-239 & $1.588 \mathrm{E}-03$ & 0.0001 \\
\hline-240 & $6.845 \mathrm{E}-04$ & 0.0000 \\
\hline-99 & $5.577 \mathrm{E}-04$ & 0.0000 \\
\hline-228 & $7.308 \mathrm{E}-08$ & 0.0000 \\
\hline-230 & $3.824 E+00$ & 0.1216 \\
\hline-232 & $1.015 \mathrm{E}+01$ & 0.3228 \\
\hline 234 & $1.068 \mathrm{E}-02$ & 0.0003 \\
\hline 235 & $7.550 \mathrm{E}-01$ & 0.0240 \\
\hline 238 & $4.143 E+00$ & 0.1317 \\
\hline & $2.3 \perp J E+U \perp$ & 0.7360 \\
\hline
\end{tabular}

\begin{abstract}
Inhalation
\end{abstract}

mrem/yr fract.

$\longrightarrow$

$5.827 \mathrm{E}-03 \quad 0.0002$

$4.325 \mathrm{E}-07 \quad 0.0000$

$5.136 \mathrm{E}-04 \quad 0.0000$

$5.413 E-030.0002$

$8.111 \mathrm{E}-030.0003$

$8.080 \mathrm{E}-030.0003$

$7.458 \mathrm{E}-07 \quad 0.0000$

$3.737 \mathrm{E}-12 \quad 0.0000$

$1.887 \mathrm{E}-020.0006$

$1.276 \mathrm{E}-030.0000$

$2.842 E-030.0001$

$1.096 \mathrm{E}-040.0000$

$2.409 \mathrm{E}-03 \quad 0.0001$

$\overline{\overline{5.345 \mathrm{E}-02}} \overline{\overline{0.0017}}$

Radon
mrem/yr fract. $\overline{0.000 \mathrm{E}+00} \overline{0.0000}$ $0.000 \mathrm{E}+00 \quad 0.0000$ $0.000 E+00 \quad 0.0000$ $0.000 \mathrm{E}+00 \quad 0.0000$ $0.000 \mathrm{E}+00 \quad 0.0000$ $0.000 E+00 \quad 0.0000$ $0.000 \mathrm{E}+00 \quad 0.0000$ $0.000 E+00 \quad 0.0000$ $0.000 \mathrm{E}+00 \quad 0.0000$ $0.000 \mathrm{E}+00 \quad 0.0000$ $0.000 \mathrm{E}+00 \quad 0.0000$ $0.000 \mathrm{E}+00 \quad 0.0000$ $0.000 \mathrm{E}+00 \quad 0.0000$

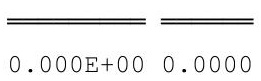

\begin{tabular}{|c|c|c|c|}
\hline \multicolumn{2}{|c|}{ Plant } & \multicolumn{2}{|c|}{ Meat } \\
\hline mrem/yr & fract. & mrem/yr & fract. \\
\hline $.000 \mathrm{E}+00$ & 0.0000 & $0.000 \mathrm{E}+00$ & 0.0000 \\
\hline $0.000 \mathrm{E}+00$ & 0.0000 & $0.000 \mathrm{E}+00$ & 0.0000 \\
\hline $0.000 \mathrm{E}+00$ & 0.0000 & $0.000 \mathrm{E}+00$ & 0.0000 \\
\hline $0.000 \mathrm{E}+00$ & 0.0000 & $0.000 \mathrm{E}+00$ & 0.0000 \\
\hline $0.000 \mathrm{E}+00$ & 0.0000 & $0.000 \mathrm{E}+00$ & 0.0000 \\
\hline $0.000 \mathrm{E}+00$ & 0.0000 & $0.000 \mathrm{E}+00$ & 0.0000 \\
\hline $0.000 \mathrm{E}+00$ & 0.0000 & $0.000 \mathrm{E}+00$ & 0.0000 \\
\hline $0.000 \mathrm{E}+00$ & 0.0000 & $0.000 \mathrm{E}+00$ & 0.0000 \\
\hline $0.000 \mathrm{E}+00$ & 0.0000 & $0.000 \mathrm{E}+00$ & 0.0000 \\
\hline $0.000 \mathrm{E}+00$ & 0.0000 & $0.000 \mathrm{E}+00$ & 0.0000 \\
\hline $0.000 \mathrm{E}+00$ & 0.0000 & $0.000 \mathrm{E}+00$ & 0.0000 \\
\hline $0.000 \mathrm{E}+00$ & 0.0000 & $0.000 \mathrm{E}+00$ & 0.0000 \\
\hline $0.000 \mathrm{E}+00$ & 0.0000 & $0.000 \mathrm{E}+00$ & 0.0000 \\
\hline & & 0.00 & . \\
\hline
\end{tabular}

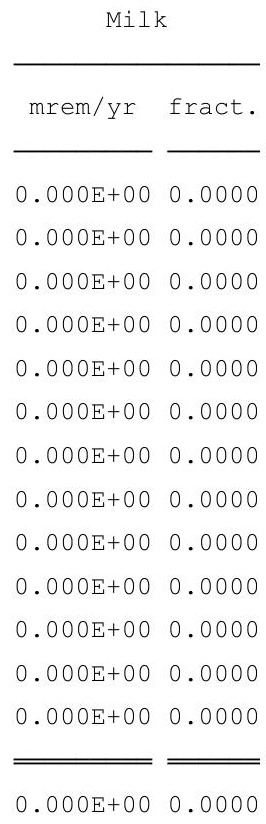

Soil mrem/yr fract. $7.112 \mathrm{E}-010.0226$ $8.458 \mathrm{E}-030.0003$ $6.667 \mathrm{E}-02 \quad 0.0021$ $6.627 \mathrm{E}-010.0211$ $9.894 \mathrm{E}-010.0315$ $9.855 \mathrm{E}-010.0313$ $2.151 \mathrm{E}-03 \quad 0.0001$ $7.186 \mathrm{E}-10 \quad 0.0000$ $2.604 \mathrm{E}+00 \quad 0.0828$ $4.675 \mathrm{E}-010.0149$ $8.630 \mathrm{E}-010.0274$ $3.489 \mathrm{E}-020.0011$ $8.549 \mathrm{E}-01 \quad 0.0272$ $8.250 \mathrm{E}+00 \quad 0.2623$

Total Dose Contributions TDOSE(i,p,t) for Individual Radionuclides (i) and Pathways (p) As mrem/yr and Fraction of Total Dose At $t=5.000 \mathrm{E}+01$ years

Water Dependent Pathways

\begin{tabular}{|c|c|c|c|c|c|c|}
\hline & \multicolumn{2}{|c|}{ Water } & \multicolumn{2}{|c|}{ Fish } & \multicolumn{2}{|c|}{ Radon } \\
\hline clide & mrem/yr & fract. & mrem/yr & fract. & mrem/yr & fract. \\
\hline 41 & $0.000 \mathrm{E}+00$ & 0.0000 & $0.000 \mathrm{E}+00$ & 0.0000 & $0.000 \mathrm{E}+00$ & 0.0000 \\
\hline-137 & $0.000 \mathrm{E}+00$ & 0.0000 & $0.000 \mathrm{E}+00$ & 0.0000 & $0.000 \mathrm{E}+00$ & 0.0000 \\
\hline-237 & $0.000 \mathrm{E}+00$ & 0.0000 & $0.000 \mathrm{E}+00$ & 0.0000 & $0.000 \mathrm{E}+00$ & 0.0000 \\
\hline-238 & $0.000 \mathrm{E}+00$ & 0.0000 & $0.000 \mathrm{E}+00$ & 0.0000 & $0.000 \mathrm{E}+00$ & 0.0000 \\
\hline-239 & $0.000 \mathrm{E}+00$ & 0.0000 & $0.000 \mathrm{E}+00$ & 0.0000 & $0.000 \mathrm{E}+00$ & 0.0000 \\
\hline-240 & $0.000 \mathrm{E}+00$ & 0.0000 & $0.000 \mathrm{E}+00$ & 0.0000 & $0.000 \mathrm{E}+00$ & 0.0000 \\
\hline-99 & $0.000 \mathrm{E}+00$ & 0.0000 & $0.000 \mathrm{E}+00$ & 0.0000 & $0.000 \mathrm{E}+00$ & 0.0000 \\
\hline-228 & $0.000 \mathrm{E}+00$ & 0.0000 & $0.000 \mathrm{E}+00$ & 0.0000 & $0.000 \mathrm{E}+00$ & 0.0000 \\
\hline-230 & $0.000 \mathrm{E}+00$ & 0.0000 & $0.000 \mathrm{E}+00$ & 0.0000 & $0.000 \mathrm{E}+00$ & 0.0000 \\
\hline-232 & $0.000 \mathrm{E}+00$ & 0.0000 & $0.000 \mathrm{E}+00$ & 0.0000 & $0.000 \mathrm{E}+00$ & 0.0000 \\
\hline 234 & $0.000 \mathrm{E}+00$ & 0.0000 & $0.000 \mathrm{E}+00$ & 0.0000 & $0.000 \mathrm{E}+00$ & 0.0000 \\
\hline 35 & $0.000 \mathrm{E}+00$ & 0.0000 & $0.000 \mathrm{E}+00$ & 0.0000 & $0.000 \mathrm{E}+00$ & 0.0000 \\
\hline 38 & $0.000 \mathrm{E}+00$ & 0.0000 & $0.000 \mathrm{E}+00$ & 0.0000 & $0.000 \mathrm{E}+00$ & 0.0000 \\
\hline & $0.000 \mathrm{E}+00$ & 0.0000 & $0.000 \mathrm{E}+00$ & 0.0000 & $0.000 \mathrm{E}+00$ & 0.0000 \\
\hline
\end{tabular}

\begin{tabular}{|c|c|c|c|}
\hline \multicolumn{2}{|c|}{ Plant } & \multicolumn{2}{|c|}{ Meat } \\
\hline $\mathrm{mrem} / \mathrm{yr}$ & fract. & $\mathrm{mrem} / \mathrm{yr}$ & fract. \\
\hline $0.000 \mathrm{E}+00$ & 0.0000 & $0.000 \mathrm{E}+00$ & 0.0000 \\
\hline $0.000 \mathrm{E}+00$ & 0.0000 & $0.000 \mathrm{E}+00$ & 0.0000 \\
\hline $0.000 \mathrm{E}+00$ & 0.0000 & $0.000 \mathrm{E}+00$ & 0.0000 \\
\hline $0.000 \mathrm{E}+00$ & 0.0000 & $0.000 \mathrm{E}+00$ & 0.0000 \\
\hline $0.000 \mathrm{E}+00$ & 0.0000 & $0.000 \mathrm{E}+00$ & 0.0000 \\
\hline $0.000 \mathrm{E}+00$ & 0.0000 & $0.000 \mathrm{E}+00$ & 0.0000 \\
\hline $0.000 \mathrm{E}+00$ & 0.0000 & $0.000 \mathrm{E}+00$ & 0.0000 \\
\hline $0.000 \mathrm{E}+00$ & 0.0000 & $0.000 \mathrm{E}+00$ & 0.0000 \\
\hline $0.000 \mathrm{E}+00$ & 0.0000 & $0.000 \mathrm{E}+00$ & 0.0000 \\
\hline $0.000 \mathrm{E}+00$ & 0.0000 & $0.000 \mathrm{E}+00$ & 0.0000 \\
\hline $0.000 \mathrm{E}+00$ & 0.0000 & $0.000 \mathrm{E}+00$ & 0.0000 \\
\hline $0.000 \mathrm{E}+00$ & 0.0000 & $0.000 \mathrm{E}+00$ & 0.0000 \\
\hline $0.000 \mathrm{E}+00$ & 0.0000 & $0.000 \mathrm{E}+00$ & 0.0000 \\
\hline
\end{tabular}

$0.000 E+00 \quad 0.0000$

$0.000 \mathrm{E}+00 \quad 0.0000$

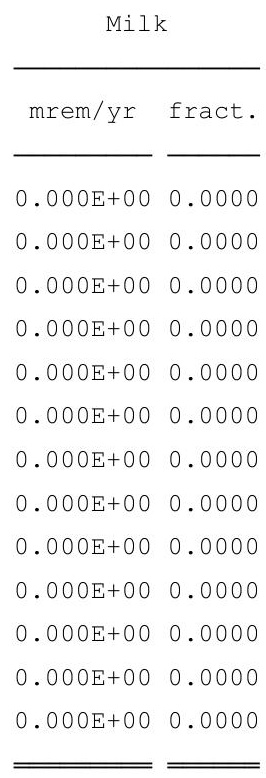

$0.000 \mathrm{E}+00 \quad 0.0000$
All Pathways* mrem/yr fract. 9.205E-01 0.0293 $3.143 \mathrm{E}+00 \quad 0.0999$ 9.909E-01 0.0315 $6.686 \mathrm{E}-010.0213$ $9.991 \mathrm{E}-010.0318$ 9.943E-01 0.0316 $2.710 \mathrm{E}-03 \quad 0.0001$ $7.380 \mathrm{E}-08 \quad 0.0000$ $6.446 \mathrm{E}+00 \quad 0.2050$ $1.062 \mathrm{E}+010.3377$ $8.765 \mathrm{E}-010.0279$ $7.900 \mathrm{E}-010.0251$ $5.000 \mathrm{E}+00 \quad 0.1590$ $3.145 \mathrm{E}+01 \quad 1.0000$

* Sum of all water independent and dependent pathways. 
RESRAD, Version 6.5

$\mathrm{T}^{1 / 2}$ Limit $=180$ days

07/15/2011 $11: 46$ Page 23

Summary : C746U Landfill Worker Deterministic Run
File : X: $\backslash F I N A L$ V2 $\backslash$ DOE FWD RUNS $\backslash C 746 U$ LW DOE SG FWD-FV2-70YR.RAD

Total Dose Contributions TDOSE (i,p,t) for Individual Radionuclides (i) and Pathways (p) As mrem/yr and Fraction of Total Dose At $t=7.000 \mathrm{E}+01$ years

Water Independent Pathways (Inhalation excludes radon)

\begin{tabular}{|c|c|c|c|c|c|c|c|c|c|c|c|c|c|c|}
\hline \multirow{2}{*}{ Nuclide } & \multicolumn{2}{|c|}{ Ground } & \multicolumn{2}{|c|}{ Inhalation } & \multicolumn{2}{|c|}{ Radon } & \multicolumn{2}{|c|}{ Plant } & \multicolumn{2}{|c|}{ Meat } & \multicolumn{2}{|c|}{ Milk } & \multicolumn{2}{|c|}{ Soil } \\
\hline & mrem/yr & fract. & mrem/yr & fract. & mrem/yr & fract. & mrem/yr & fract. & mrem/yr & fract. & mrem/yr & fract. & mrem/yr & fract. \\
\hline-241 & $1.970 \mathrm{E}-01$ & 0.0062 & $5.643 E-03$ & 0.0002 & $0.000 \mathrm{E}+00$ & 0.0000 & $0.000 \mathrm{E}+00$ & 0.0000 & $0.000 \mathrm{E}+00$ & 0.0000 & $0.000 \mathrm{E}+00$ & 0.0000 & $6.887 \mathrm{E}-01$ & 0.0216 \\
\hline-137 & $1.973 \mathrm{E}+00$ & 0.0620 & $2.723 \mathrm{E}-07$ & 0.0000 & $0.000 \mathrm{E}+00$ & 0.0000 & $0.000 \mathrm{E}+00$ & 0.0000 & $0.000 \mathrm{E}+00$ & 0.0000 & $0.000 \mathrm{E}+00$ & 0.0000 & $5.324 \mathrm{E}-03$ & 0.0002 \\
\hline-237 & $9.208 \mathrm{E}-01$ & 0.0289 & $5.119 \mathrm{E}-04$ & 0.0000 & $0.000 \mathrm{E}+00$ & 0.0000 & $0.000 \mathrm{E}+00$ & 0.0000 & $0.000 \mathrm{E}+00$ & 0.0000 & $0.000 \mathrm{E}+00$ & 0.0000 & $6.646 \mathrm{E}-02$ & 0.0021 \\
\hline-238 & $4.422 \mathrm{E}-04$ & 0.0000 & 4. $620 \mathrm{E}-03$ & 0.0001 & $0.000 \mathrm{E}+00$ & 0.0000 & $0.000 \mathrm{E}+00$ & 0.0000 & $0.000 \mathrm{E}+00$ & 0.0000 & $0.000 \mathrm{E}+00$ & 0.0000 & $5.656 \mathrm{E}-01$ & 0.0178 \\
\hline-239 & $1.587 \mathrm{E}-03$ & 0.0000 & $8.103 E-03$ & 0.0003 & $0.000 \mathrm{E}+00$ & 0.0000 & $0.000 \mathrm{E}+00$ & 0.0000 & $0.000 \mathrm{E}+00$ & 0.0000 & $0.000 \mathrm{E}+00$ & 0.0000 & $9.884 \mathrm{E}-01$ & 0.0310 \\
\hline-240 & $6.828 \mathrm{E}-04$ & 0.0000 & $8.059 \mathrm{E}-03$ & 0.0003 & $0.000 \mathrm{E}+00$ & 0.0000 & $0.000 \mathrm{E}+00$ & 0.0000 & $0.000 \mathrm{E}+00$ & 0.0000 & $0.000 \mathrm{E}+00$ & 0.0000 & $9.830 \mathrm{E}-01$ & 0.0309 \\
\hline-99 & $4.513 E-04$ & 0.0000 & $6.036 \mathrm{E}-07$ & 0.0000 & $0.000 \mathrm{E}+00$ & 0.0000 & $0.000 \mathrm{E}+00$ & 0.0000 & $0.000 \mathrm{E}+00$ & 0.0000 & $0.000 \mathrm{E}+00$ & 0.0000 & $1.741 \mathrm{E}-03$ & 0.0001 \\
\hline-228 & $5.209 \mathrm{E}-11$ & 0.0000 & $2.663 \mathrm{E}-15$ & 0.0000 & $0.000 \mathrm{E}+00$ & 0.0000 & $0.000 \mathrm{E}+00$ & 0.0000 & $0.000 \mathrm{E}+00$ & 0.0000 & $0.000 \mathrm{E}+00$ & 0.0000 & $5.122 \mathrm{E}-13$ & 0.0000 \\
\hline-230 & $5.307 \mathrm{E}+00$ & 0.1667 & $1.889 \mathrm{E}-02$ & 0.0006 & $0.000 \mathrm{E}+00$ & 0.0000 & $0.000 \mathrm{E}+00$ & 0.0000 & $0.000 \mathrm{E}+00$ & 0.0000 & $0.000 \mathrm{E}+00$ & 0.0000 & $2.779 \mathrm{E}+00$ & 0.0873 \\
\hline-232 & $1.018 \mathrm{E}+01$ & 0.3197 & $1.277 \mathrm{E}-03$ & 0.0000 & $0.000 \mathrm{E}+00$ & 0.0000 & $0.000 \mathrm{E}+00$ & 0.0000 & $0.000 \mathrm{E}+00$ & 0.0000 & $0.000 \mathrm{E}+00$ & 0.0000 & $4.683 \mathrm{E}-01$ & 0.0147 \\
\hline 34 & $1.199 E-02$ & 0.0004 & $2.846 E-03$ & 0.0001 & $0.000 \mathrm{E}+00$ & 0.0000 & $0.000 \mathrm{E}+00$ & 0.0000 & $0.000 \mathrm{E}+00$ & 0.0000 & $0.000 \mathrm{E}+00$ & 0.0000 & $8.633 E-01$ & 0.0271 \\
\hline 35 & $7.554 \mathrm{E}-01$ & 0.0237 & $1.128 \mathrm{E}-04$ & 0.0000 & $0.000 \mathrm{E}+00$ & 0.0000 & $0.000 \mathrm{E}+00$ & 0.0000 & $0.000 \mathrm{E}+00$ & 0.0000 & $0.000 \mathrm{E}+00$ & 0.0000 & $3.540 \mathrm{E}-02$ & 0.0011 \\
\hline 38 & $4.140 \mathrm{E}+00$ & 0.1300 & $2.408 E-03$ & 0.0001 & $0.000 \mathrm{E}+00$ & 0.0000 & $0.000 \mathrm{E}+00$ & 0.0000 & $0.000 \mathrm{E}+00$ & 0.0000 & $0.000 \mathrm{E}+00$ & 0.0000 & $8.544 \mathrm{E}-01$ & 0.0268 \\
\hline & $2.349 \mathrm{E}+01$ & 0.7377 & $5.248 \mathrm{E}-02$ & 0.0016 & $0.000 \mathrm{E}+00$ & 0.0000 & $0.000 \mathrm{E}+00$ & 0.0000 & $0.000 \mathrm{E}+00$ & 0.0000 & $0.000 \mathrm{E}+00$ & 0.0000 & 3. $299 \mathrm{E}+00$ & 0.2607 \\
\hline
\end{tabular}

Total Dose Contributions TDOSE(i,p,t) for Individual Radionuclides (i) and Pathways (p) As mrem/yr and Fraction of Total Dose At $t=7.000 \mathrm{E}+01$ years

Water Dependent Pathways

\begin{tabular}{|c|c|c|c|c|c|c|c|c|c|c|c|c|c|c|}
\hline & \multicolumn{2}{|c|}{ Water } & \multicolumn{2}{|c|}{ Fish } & \multicolumn{2}{|c|}{ Radon } & \multicolumn{2}{|c|}{ Plant } & \multicolumn{2}{|c|}{ Meat } & \multicolumn{2}{|c|}{ Milk } & \multicolumn{2}{|c|}{ All Pathways* } \\
\hline clide & mrem/yr & fract. & mrem/yr & fract. & mrem/yr & fract. & mrem/yr & fract. & mrem/yr & fract. & mrem/yr & fract. & mrem/yr & fract. \\
\hline 241 & $0.000 \mathrm{E}+00$ & 0.0000 & $0.000 \mathrm{E}+00$ & 0.0000 & $0.000 \mathrm{E}+00$ & 0.0000 & $0.000 \mathrm{E}+00$ & 0.0000 & $0.000 \mathrm{E}+00$ & 0.0000 & $0.000 \mathrm{E}+00$ & 0.0000 & $8.913 \mathrm{E}-01$ & 0.0280 \\
\hline-137 & $0.000 \mathrm{E}+00$ & 0.0000 & $0.000 \mathrm{E}+00$ & 0.0000 & $0.000 \mathrm{E}+00$ & 0.0000 & $0.000 \mathrm{E}+00$ & 0.0000 & $0.000 \mathrm{E}+00$ & 0.0000 & $0.000 \mathrm{E}+00$ & 0.0000 & $1.978 \mathrm{E}+00$ & 0.0621 \\
\hline-237 & $0.000 \mathrm{E}+00$ & 0.0000 & $0.000 \mathrm{E}+00$ & 0.0000 & $0.000 \mathrm{E}+00$ & 0.0000 & $0.000 \mathrm{E}+00$ & 0.0000 & $0.000 \mathrm{E}+00$ & 0.0000 & $0.000 \mathrm{E}+00$ & 0.0000 & $9.878 E-01$ & 0.0310 \\
\hline-238 & $0.000 \mathrm{E}+00$ & 0.0000 & $0.000 \mathrm{E}+00$ & 0.0000 & $0.000 \mathrm{E}+00$ & 0.0000 & $0.000 \mathrm{E}+00$ & 0.0000 & $0.000 \mathrm{E}+00$ & 0.0000 & $0.000 \mathrm{E}+00$ & 0.0000 & $5.707 \mathrm{E}-01$ & 0.0179 \\
\hline-239 & $0.000 \mathrm{E}+00$ & 0.0000 & $0.000 \mathrm{E}+00$ & 0.0000 & $0.000 \mathrm{E}+00$ & 0.0000 & $0.000 \mathrm{E}+00$ & 0.0000 & $0.000 \mathrm{E}+00$ & 0.0000 & $0.000 E+00$ & 0.0000 & $9.981 \mathrm{E}-01$ & 0.0313 \\
\hline-240 & $0.000 \mathrm{E}+00$ & 0.0000 & $0.000 \mathrm{E}+00$ & 0.0000 & $0.000 \mathrm{E}+00$ & 0.0000 & $0.000 \mathrm{E}+00$ & 0.0000 & $0.000 \mathrm{E}+00$ & 0.0000 & $0.000 E+00$ & 0.0000 & $9.918 \mathrm{E}-01$ & 0.0311 \\
\hline-99 & $0.000 \mathrm{E}+00$ & 0.0000 & $0.000 \mathrm{E}+00$ & 0.0000 & $0.000 \mathrm{E}+00$ & 0.0000 & $0.000 \mathrm{E}+00$ & 0.0000 & $0.000 \mathrm{E}+00$ & 0.0000 & $0.000 \mathrm{E}+00$ & 0.0000 & $2.193 E-03$ & 0.0001 \\
\hline-228 & $0.000 \mathrm{E}+00$ & 0.0000 & $0.000 \mathrm{E}+00$ & 0.0000 & $0.000 \mathrm{E}+00$ & 0.0000 & $0.000 \mathrm{E}+00$ & 0.0000 & $0.000 \mathrm{E}+00$ & 0.0000 & $0.000 \mathrm{E}+00$ & 0.0000 & $5.260 \mathrm{E}-11$ & 0.0000 \\
\hline-230 & $0.000 \mathrm{E}+00$ & 0.0000 & $0.000 \mathrm{E}+00$ & 0.0000 & $0.000 \mathrm{E}+00$ & 0.0000 & $0.000 \mathrm{E}+00$ & 0.0000 & $0.000 \mathrm{E}+00$ & 0.0000 & $0.000 E+00$ & 0.0000 & $8.104 \mathrm{E}+00$ & 0.2545 \\
\hline-232 & $0.000 \mathrm{E}+00$ & 0.0000 & $0.000 \mathrm{E}+00$ & 0.0000 & $0.000 \mathrm{E}+00$ & 0.0000 & $0.000 \mathrm{E}+00$ & 0.0000 & $0.000 \mathrm{E}+00$ & 0.0000 & $0.000 \mathrm{E}+00$ & 0.0000 & $1.065 \mathrm{E}+01$ & 0.3344 \\
\hline 34 & $0.000 \mathrm{E}+00$ & 0.0000 & $0.000 \mathrm{E}+00$ & 0.0000 & $0.000 \mathrm{E}+00$ & 0.0000 & $0.000 \mathrm{E}+00$ & 0.0000 & $0.000 \mathrm{E}+00$ & 0.0000 & $0.000 \mathrm{E}+00$ & 0.0000 & $8.781 \mathrm{E}-01$ & 0.0276 \\
\hline 35 & $0.000 \mathrm{E}+00$ & 0.0000 & $0.000 \mathrm{E}+00$ & 0.0000 & $0.000 \mathrm{E}+00$ & 0.0000 & $0.000 \mathrm{E}+00$ & 0.0000 & $0.000 \mathrm{E}+00$ & 0.0000 & $0.000 \mathrm{E}+00$ & 0.0000 & 7. $909 \mathrm{E}-01$ & 0.0248 \\
\hline 38 & $0.000 \mathrm{E}+00$ & 0.0000 & $0.000 \mathrm{E}+00$ & 0.0000 & $0.000 \mathrm{E}+00$ & 0.0000 & $0.000 \mathrm{E}+00$ & 0.0000 & $0.000 \mathrm{E}+00$ & 0.0000 & $0.000 \mathrm{E}+00$ & 0.0000 & $4.997 \mathrm{E}+00$ & 0.1570 \\
\hline & $0.000 \mathrm{E}+00$ & 0.0000 & $0.000 \mathrm{E}+00$ & 0.0000 & $0.000 \mathrm{E}+00$ & 0.0000 & $0.000 \mathrm{E}+00$ & 0.0000 & $0.000 \mathrm{E}+00$ & 0.0000 & $0.000 \mathrm{E}+00$ & 0.0000 & $3.184 \mathrm{E}+01$ & 1. \\
\hline
\end{tabular}

* Sum of all water independent and dependent pathways. 
RESRAD, Version $6.5 \quad \mathrm{~T}^{1 / 2}$ Limit $=180$ days

Summary : C746U Landfill Worker Deterministic Run
File : X: $\backslash$ FINAL V2 $\backslash$ DOE FWD RUNS \C746U LW DOE SG FWD-FV2-70YR.RAD

Dose/Source Ratios Summed Over All Pathways

Parent and Progeny Principal Radionuclide Contributions Indicated

Parent Product Thread DSR $(j, t)$ At Time in Years (mrem/yr)/(pCi/g)

(i) (j) Fraction $0.000 \mathrm{E}+001.000 \mathrm{E}+00 \quad 5.000 \mathrm{E}+017.000 \mathrm{E}+01$

Am-241

Am-241

Am-241

Am-241

Am-241

$C s-137+D$

$\mathrm{Np}-237+\mathrm{D}$

$\mathrm{Np}-237+\mathrm{D}$

$\mathrm{Np}-237+\mathrm{D}$

$\mathrm{Np}-237+\mathrm{D}$

$\mathrm{Pu}-238$

$\mathrm{Pu}-238$

1. $840 E-09$

$\begin{array}{llllll}\text { Am-241 } & 1.000 \mathrm{E}+00 & 2.850 \mathrm{E}-02 & 2.845 \mathrm{E}-02 & 2.630 \mathrm{E}-02 & 2.546 \mathrm{E}-02\end{array}$

$\begin{array}{lllllll}\mathrm{Np}-237+\mathrm{D} & 1.000 \mathrm{E}+00 & 2.940 \mathrm{E}-08 & 8.812 \mathrm{E}-08 & 2.842 \mathrm{E}-06 & 3.898 \mathrm{E}-06\end{array}$

$\begin{array}{lllllll}\mathrm{U}-233 & 1.000 \mathrm{E}+00 & 1.383 \mathrm{E}-15 & 9.674 \mathrm{E}-15 & 1.027 \mathrm{E}-11 & 1.978 \mathrm{E}-11\end{array}$

$\begin{array}{llllllll}\mathrm{Th}-229+\mathrm{D} & 1.000 \mathrm{E}+00 & 1.756 \mathrm{E}-18 & 2.633 \mathrm{E}-17 & 8.837 \mathrm{E}-13 & 2.382 \mathrm{E}-12\end{array}$

$\sum \operatorname{DSR}(j)$

$\begin{array}{llll}2.850 \mathrm{E}-02 & 2.845 \mathrm{E}-02 & 2.630 \mathrm{E}-02 & 2.547 \mathrm{E}-02\end{array}$

$\mathrm{Cs}-137+\mathrm{D} \quad 1.000 \mathrm{E}+00 \quad 5.262 \mathrm{E}-01 \quad 5.142 \mathrm{E}-01 \quad 1.654 \mathrm{E}-01 \quad 1.041 \mathrm{E}-01$

$\mathrm{Np}-237+\mathrm{D} \quad 1.000 \mathrm{E}+00 \quad 1.816 \mathrm{E}-01 \quad 1.816 \mathrm{E}-01 \quad 1.802 \mathrm{E}-01 \quad 1.796 \mathrm{E}-01$

U-233 1.000E+00 1.281E-08 3.843E-08 $1.288 \mathrm{E}-06 \quad 1.795 \mathrm{E}-06$

$\begin{array}{llllllll}\mathrm{Th}-229+\mathrm{D} \quad 1.000 \mathrm{E}+00 \quad 2.169 \mathrm{E}-11 & 1.518 \mathrm{E}-10 & 1.652 \mathrm{E}-07 & 3.213 \mathrm{E}-07\end{array}$

$\operatorname{\sum DSR}(j) \quad 1.816 \mathrm{E}-01 \quad 1.816 \mathrm{E}-01 \quad 1.802 \mathrm{E}-01 \quad 1.796 \mathrm{E}-01$

$\mathrm{Pu}-238$

$\begin{array}{lllllll}\mathrm{Pu}-238 & 1.000 \mathrm{E}+00 & 2.547 \mathrm{E}-02 & 2.527 \mathrm{E}-02 & 1.714 \mathrm{E}-02 & 1.463 \mathrm{E}-02\end{array}$

$\begin{array}{lllllll}\mathrm{U}-234 & 1.000 \mathrm{E}+00 & 7.728 \mathrm{E}-09 & 2.310 \mathrm{E}-08 & 6.445 \mathrm{E}-07 & 8.363 \mathrm{E}-07\end{array}$

$\begin{array}{llllll}\mathrm{Th}-230 & 1.000 \mathrm{E}+00 & 9.980 \mathrm{E}-14 & 6.970 \mathrm{E}-13 & 6.720 \mathrm{E}-10 & 1.247 \mathrm{E}-09\end{array}$

$\mathrm{Ra}-226+\mathrm{D} \quad 1.000 \mathrm{E}+00 \quad 8.234 \mathrm{E}-16 \quad 1.233 \mathrm{E}-14 \quad 3.832 \mathrm{E}-10 \quad 1.002 \mathrm{E}-09$

$\mathrm{Pb}-210+\mathrm{D} \quad 1.000 \mathrm{E}+00 \quad 5.964 \mathrm{E}-19 \quad 1.836 \mathrm{E}-17 \quad 1.347 \mathrm{E}-11 \quad 4.480 \mathrm{E}-11$

$\operatorname{LDSR}(j) \quad 2.547 \mathrm{E}-02 \quad 2.527 \mathrm{E}-02 \quad 1.714 \mathrm{E}-02 \quad 1.463 \mathrm{E}-02$

$\begin{array}{llllll}\mathrm{Pu}-239 & 1.000 \mathrm{E}+00 & 2.782 \mathrm{E}-02 & 2.782 \mathrm{E}-02 & 2.775 \mathrm{E}-02 & 2.772 \mathrm{E}-02\end{array}$

$\begin{array}{lllllll}\mathrm{U}-235+\mathrm{D} & 1.000 \mathrm{E}+00 & 5.975 \mathrm{E}-11 & 1.793 \mathrm{E}-10 & 6.024 \mathrm{E}-09 & 8.403 \mathrm{E}-09\end{array}$

$\begin{array}{lllllll}\mathrm{Pa}-231 & 1.000 \mathrm{E}+00 & 3.752 \mathrm{E}-16 & 2.626 \mathrm{E}-15 & 2.865 \mathrm{E}-12 & 5.580 \mathrm{E}-12\end{array}$

$\mathrm{AC}-227+\mathrm{D} \quad 1.000 \mathrm{E}+00 \quad 1.227 \mathrm{E}-17 \quad 1.828 \mathrm{E}-16 \quad 4.441 \mathrm{E}-12 \quad 1.071 \mathrm{E}-11$

$\begin{array}{llllll}\operatorname{LDSR}(j) & 2.782 \mathrm{E}-02 & 2.782 \mathrm{E}-02 & 2.775 \mathrm{E}-02 & 2.772 \mathrm{E}-02\end{array}$

Pu-240 4.950E-08 1.376E-09 $1.376 E-09 \quad 1.367 E-09 \quad 1.364 E-09$

$\begin{array}{llllll}\mathrm{Pu}-240 \quad 1.000 \mathrm{E}+00 & 2.779 \mathrm{E}-02 & 2.779 \mathrm{E}-02 & 2.762 \mathrm{E}-02 & 2.755 \mathrm{E}-02\end{array}$

$\begin{array}{lllllll}\mathrm{U}-236 & 1.000 \mathrm{E}+00 & 7.739 \mathrm{E}-11 & 2.322 \mathrm{E}-10 & 7.787 \mathrm{E}-09 & 1.085 \mathrm{E}-08\end{array}$

$\begin{array}{llllll}\mathrm{Th}-232 & 1.000 \mathrm{E}+00 & 6.238 \mathrm{E}-21 & 4.367 \mathrm{E}-20 & 4.761 \mathrm{E}-17 & 9.268 \mathrm{E}-17\end{array}$

$\mathrm{Ra}-228+\mathrm{D} \quad 1.000 \mathrm{E}+00 \quad 7.279 \mathrm{E}-21 \quad 1.065 \mathrm{E}-19 \quad 1.370 \mathrm{E}-15 \quad 2.913 \mathrm{E}-15$

$\begin{array}{lllllll}\mathrm{Th}-228+\mathrm{D} & 1.000 \mathrm{E}+00 & 7.965 \mathrm{E}-22 & 2.280 \mathrm{E}-20 & 1.928 \mathrm{E}-15 & 4.261 \mathrm{E}-15\end{array}$

$\begin{array}{llllll}\operatorname{DDSR}(j) & 2.779 \mathrm{E}-02 & 2.779 \mathrm{E}-02 & 2.762 \mathrm{E}-02 & 2.755 \mathrm{E}-02\end{array}$

TC-99 1.000E+00 8.844E-05 8.751E-05 5.211E-05 4.218E-05

Th-228+D $1.000 \mathrm{E}+00 \quad 1.360 \mathrm{E}+00 \quad 9.469 \mathrm{E}-01 \quad 1.845 \mathrm{E}-08 \quad 1.315 \mathrm{E}-11$

$\begin{array}{llllll}\mathrm{Th}-230 & 1.000 \mathrm{E}+00 & 2.351 \mathrm{E}-02 & 2.351 \mathrm{E}-02 & 2.350 \mathrm{E}-02 & 2.349 \mathrm{E}-02\end{array}$

$\mathrm{Ra}-226+\mathrm{D} \quad 1.000 \mathrm{E}+00 \quad 3.878 \mathrm{E}-04 \quad 1.163 \mathrm{E}-03 \quad 3.871 \mathrm{E}-02 \quad 5.379 \mathrm{E}-02$

$\mathrm{Pb}-210+\mathrm{D} \quad 1.000 \mathrm{E}+00 \quad 4.667 \mathrm{E}-07 \quad 3.238 \mathrm{E}-06 \quad 2.251 \mathrm{E}-03 \quad 3.757 \mathrm{E}-03$

$\operatorname{LDSR}(j) \quad 2.390 \mathrm{E}-02 \quad 2.468 \mathrm{E}-02 \quad 6.446 \mathrm{E}-02 \quad 8.104 \mathrm{E}-02$ 


\section{RESRAD, Version $6.5 \quad \mathrm{~T}^{1 / 2}$ Limit $=180$ days}

Summary : C746U Landfill Worker Deterministic Run

File : $X: \backslash F I N A L$ V2 $\backslash$ DOE FWD RUNS $\backslash C 746 U$ LW DOE SG FWD-FV2-70YR.RAD

Dose/Source Ratios Summed Over All Pathways

Parent and Progeny Principal Radionuclide Contributions Indicated

\begin{tabular}{|c|c|c|c|c|c|c|}
\hline Parent & Product & Thread & $R(j, t) \quad A t$ & Time in $Y$ & (mre & $\mathrm{em} / \mathrm{yr}) /(\mathrm{pCi}$ \\
\hline (i) & $(j)$ & Fraction & $0.000 \mathrm{E}+00$ & $1.000 \mathrm{E}+00$ & $5.000 \mathrm{E}+01$ & $7.000 \mathrm{E}+01$ \\
\hline-232 & Th-232 & $1.000 \mathrm{E}+00$ & $2.563 E-02$ & $2.563 E-02$ & $2.563 E-02$ & $2.562 \mathrm{E}-02$ \\
\hline-232 & $\mathrm{Ra}-228+\mathrm{D}$ & $1.000 \mathrm{E}+00$ & $5.887 \mathrm{E}-02$ & $1.676 \mathrm{E}-01$ & $1.014 \mathrm{E}+00$ & $1.016 \mathrm{E}+00$ \\
\hline-232 & $\mathrm{Th}-228+\mathrm{D}$ & $1.000 \mathrm{E}+00$ & $1.049 \mathrm{E}-02$ & $6.433 E-02$ & $1.616 \mathrm{E}+00$ & $1.621 \mathrm{E}+00$ \\
\hline-232 & $\sum \operatorname{DSR}(j)$ & & $9.499 \mathrm{E}-02$ & $2.576 \mathrm{E}-01$ & $2.655 \mathrm{E}+00$ & $2.662 \mathrm{E}+00$ \\
\hline-234 & $\mathrm{U}-234$ & $1.000 \mathrm{E}+00$ & $5.467 \mathrm{E}-03$ & $5.466 \mathrm{E}-03$ & $5.458 \mathrm{E}-03$ & $5.455 \mathrm{E}-03$ \\
\hline-234 & Th-230 & $1.000 \mathrm{E}+00$ & $1.058 \mathrm{E}-07$ & $3.175 E-07$ & $1.068 \mathrm{E}-05$ & $1.490 \mathrm{E}-05$ \\
\hline-234 & $\mathrm{Ra}-226+\mathrm{D}$ & $1.000 \mathrm{E}+00$ & $1.164 \mathrm{E}-09$ & $8.144 \mathrm{E}-09$ & $8.830 \mathrm{E}-06$ & $1.715 \mathrm{E}-05$ \\
\hline-234 & $\mathrm{~Pb}-210+\mathrm{D}$ & $1.000 \mathrm{E}+00$ & 1. 052E-12 & 1. $567 \mathrm{E}-11$ & $3.816 \mathrm{E}-07$ & $9.196 \mathrm{E}-07$ \\
\hline-234 & $\sum \operatorname{DSR}(j)$ & & $5.467 \mathrm{E}-03$ & $5.467 \mathrm{E}-03$ & $5.478 E-03$ & $5.488 E-03$ \\
\hline$-235+D$ & $\mathrm{U}-235+\mathrm{D}$ & $1.000 \mathrm{E}+00$ & $1.213 \mathrm{E}-01$ & 1. $213 \mathrm{E}-01$ & 1. $212 \mathrm{E}-01$ & 1. $211 \mathrm{E}-01$ \\
\hline$-235+D$ & $\mathrm{~Pa}-231$ & $1.000 \mathrm{E}+00$ & $1.143 E-06$ & $3.429 \mathrm{E}-06$ & $1.152 \mathrm{E}-04$ & $1.608 \mathrm{E}-04$ \\
\hline$-235+D$ & $A c-227+D$ & $1.000 \mathrm{E}+00$ & $4.976 \mathrm{E}-08$ & $3.452 \mathrm{E}-07$ & $2.396 \mathrm{E}-04$ & $4.001 \mathrm{E}-04$ \\
\hline$-235+D$ & $\sum \operatorname{DSR}(j)$ & & $1.213 \mathrm{E}-01$ & 1. $213 E-01$ & $1.215 \mathrm{E}-01$ & $1.217 \mathrm{E}-01$ \\
\hline-238 & $\mathrm{U}-238$ & $5.400 E-05$ & $2.701 \mathrm{E}-07$ & $2.701 E-07$ & $2.698 E-07$ & $2.696 \mathrm{E}-07$ \\
\hline$-238+D$ & $\mathrm{U}-238+\mathrm{D}$ & $9.999 \mathrm{E}-01$ & $3.129 \mathrm{E}-02$ & $3.129 \mathrm{E}-02$ & $3.125 \mathrm{E}-02$ & $3.123 \mathrm{E}-02$ \\
\hline$J-238+D$ & $\mathrm{U}-234$ & $9.999 \mathrm{E}-01$ & $7.748 E-09$ & $2.324 \mathrm{E}-08$ & $7.815 \mathrm{E}-07$ & $1.090 \mathrm{E}-06$ \\
\hline$J-238+D$ & $T h-230$ & $9.999 \mathrm{E}-01$ & $9.999 \mathrm{E}-14$ & $6.999 \mathrm{E}-13$ & $7.642 \mathrm{E}-10$ & $1.489 \mathrm{E}-09$ \\
\hline$-238+D$ & $\mathrm{Ra}-226+\mathrm{D}$ & $9.999 \mathrm{E}-01$ & $8.247 \mathrm{E}-16$ & 1. $237 \mathrm{E}-14$ & $4.221 \mathrm{E}-10$ & $1.145 \mathrm{E}-09$ \\
\hline$-238+D$ & $\mathrm{~Pb}-210+\mathrm{D}$ & $9.999 \mathrm{E}-01$ & $5.972 \mathrm{E}-19$ & $1.841 \mathrm{E}-17$ & $1.461 \mathrm{E}-11$ & $5.020 \mathrm{E}-11$ \\
\hline$-238+D$ & $\sum \operatorname{DSR}(j)$ & & $3.129 \mathrm{E}-02$ & $3.129 \mathrm{E}-02$ & $3.125 \mathrm{E}-02$ & $3.123 E-02$ \\
\hline
\end{tabular}

The DSR includes contributions from associated (half-life $\leq 180$ days) daughters. 
RESRAD, Version $6.5 \quad \mathrm{~T}^{1 / 2}$ Limit $=180$ days

Summary : C746U Landfill Worker Deterministic Run

File : $\mathrm{X}: \backslash F I N A L$ V2 $\backslash$ DOE FWD RUNS $\backslash C 746 \mathrm{U}$ LW DOE SG FWD-FV2-70YR.RAD

Single Radionuclide Soil Guidelines G(i,t) in pCi/g

Basic Radiation Dose Limit $=1.000 \mathrm{E}+02 \mathrm{mrem} / \mathrm{yr}$

Nuclide

\begin{tabular}{cccccc} 
(i) & $\mathrm{t}=$ & $0.000 \mathrm{E}+00$ & $1.000 \mathrm{E}+00$ & $5.000 \mathrm{E}+01$ & $7.000 \mathrm{E}+01$ \\
\cline { 1 - 1 } $\mathrm{Am}-241$ & & $3.509 \mathrm{E}+03$ & $3.514 \mathrm{E}+03$ & $3.802 \mathrm{E}+03$ & $3.927 \mathrm{E}+03$ \\
$\mathrm{Cs}-137$ & & $1.900 \mathrm{E}+02$ & $1.945 \mathrm{E}+02$ & $6.045 \mathrm{E}+02$ & $9.603 \mathrm{E}+02$ \\
$\mathrm{~Np}-237$ & $5.507 \mathrm{E}+02$ & $5.507 \mathrm{E}+02$ & $5.550 \mathrm{E}+02$ & $5.568 \mathrm{E}+02$ \\
$\mathrm{Pu}-238$ & $3.926 \mathrm{E}+03$ & $3.957 \mathrm{E}+03$ & $5.833 \mathrm{E}+03$ & $6.834 \mathrm{E}+03$ \\
$\mathrm{Pu}-239$ & $3.595 \mathrm{E}+03$ & $3.595 \mathrm{E}+03$ & $3.603 \mathrm{E}+03$ & $3.607 \mathrm{E}+03$ \\
$\mathrm{Pu}-240$ & $3.598 \mathrm{E}+03$ & $3.598 \mathrm{E}+03$ & $3.621 \mathrm{E}+03$ & $3.630 \mathrm{E}+03$ \\
$\mathrm{TC}-99$ & & $1.131 \mathrm{E}+06$ & $1.143 \mathrm{E}+06$ & $1.919 \mathrm{E}+06$ & $2.371 \mathrm{E}+06$ \\
$\mathrm{Th}-228$ & $7.351 \mathrm{E}+01$ & $1.056 \mathrm{E}+02$ & $5.420 \mathrm{E}+09$ & $7.604 \mathrm{E}+12$ \\
$\mathrm{Th}-230$ & $4.184 \mathrm{E}+03$ & $4.052 \mathrm{E}+03$ & $1.551 \mathrm{E}+03$ & $1.234 \mathrm{E}+03$ \\
$\mathrm{Th}-232$ & $1.053 \mathrm{E}+03$ & $3.882 \mathrm{E}+02$ & $3.766 \mathrm{E}+01$ & $3.757 \mathrm{E}+01$ \\
$\mathrm{U}-234$ & $1.829 \mathrm{E}+04$ & $1.829 \mathrm{E}+04$ & $1.825 \mathrm{E}+04$ & $1.822 \mathrm{E}+04$ \\
$\mathrm{U}-235$ & $8.241 \mathrm{E}+02$ & $8.241 \mathrm{E}+02$ & $8.228 \mathrm{E}+02$ & $8.218 \mathrm{E}+02$ \\
$\mathrm{U}-238$ & $3.196 \mathrm{E}+03$ & $3.196 \mathrm{E}+03$ & $3.200 \mathrm{E}+03$ & $3.202 \mathrm{E}+03$ \\
\hline \hline
\end{tabular}

Summed Dose/Source Ratios DSR(i,t) in (mrem/yr)/(pCi/g) and Single Radionuclide Soil Guidelines $G(i, t)$ in pCi/g at tmin = time of minimum single radionuclide soil guideline and at $\operatorname{tmax}=$ time of maximum total dose $=7.000 \mathrm{E}+01$ years

\begin{tabular}{|c|c|c|c|c|c|c|}
\hline $\begin{array}{l}\text { uclide } \\
\text { (i) }\end{array}$ & $\begin{array}{l}\text { Initial } \\
(\mathrm{pCi} / \mathrm{g})\end{array}$ & $\begin{array}{c}\text { tmin } \\
\text { (years) }\end{array}$ & $\operatorname{DSR}(i, \operatorname{tmin})$ & $\begin{array}{c}\mathrm{G}(\mathrm{i}, \mathrm{tmin}) \\
(\mathrm{pCi} / \mathrm{g})\end{array}$ & $\operatorname{DSR}(i, t \max )$ & $\begin{array}{c}G(i, t \max ) \\
(\mathrm{pCi} / \mathrm{g})\end{array}$ \\
\hline$n-241$ & $3.500 \mathrm{E}+01$ & $0.000 \mathrm{E}+00$ & $2.850 \mathrm{E}-02$ & $3.509 \mathrm{E}+03$ & $2.547 \mathrm{E}-02$ & $3.927 E+03$ \\
\hline-137 & $1.900 \mathrm{E}+01$ & $0.000 \mathrm{E}+00$ & $5.262 \mathrm{E}-01$ & $1.900 \mathrm{E}+02$ & $1.041 \mathrm{E}-01$ & $9.603 \mathrm{E}+02$ \\
\hline-237 & $5.500 \mathrm{E}+00$ & $0.000 \mathrm{E}+00$ & $1.816 \mathrm{E}-01$ & $5.507 \mathrm{E}+02$ & $1.796 E-01$ & $5.568 \mathrm{E}+02$ \\
\hline-238 & $3.900 \mathrm{E}+01$ & $0.000 \mathrm{E}+00$ & $2.547 \mathrm{E}-02$ & $3.926 \mathrm{E}+03$ & $1.463 E-02$ & $6.834 \mathrm{E}+03$ \\
\hline-239 & $3.600 \mathrm{E}+01$ & $0.000 \mathrm{E}+00$ & $2.782 \mathrm{E}-02$ & $3.595 E+03$ & $2.772 \mathrm{E}-02$ & $3.607 \mathrm{E}+03$ \\
\hline$x-240$ & $3.600 \mathrm{E}+01$ & $0.000 \mathrm{E}+00$ & $2.779 \mathrm{E}-02$ & $3.598 \mathrm{E}+03$ & $2.755 E-02$ & $3.630 \mathrm{E}+03$ \\
\hline-99 & $5.200 \mathrm{E}+01$ & $0.000 \mathrm{E}+00$ & $8.844 \mathrm{E}-05$ & $1.131 \mathrm{E}+06$ & $4.218 E-05$ & $2.371 \mathrm{E}+06$ \\
\hline-228 & $4.000 \mathrm{E}+00$ & $0.000 \mathrm{E}+00$ & $1.360 \mathrm{E}+00$ & 7. $351 E+01$ & 1. $315 \mathrm{E}-11$ & $7.604 \mathrm{E}+12$ \\
\hline-230 & $1.000 \mathrm{E}+02$ & $7.000 \mathrm{E}+01$ & $8.104 \mathrm{E}-02$ & $1.234 \mathrm{E}+03$ & $8.104 \mathrm{E}-02$ & $1.234 \mathrm{E}+03$ \\
\hline-232 & $4.000 E+00$ & $7.000 E+01$ & $2.662 \mathrm{E}+00$ & $3.757 \mathrm{E}+01$ & $2.662 E+00$ & $3.757 \mathrm{E}+01$ \\
\hline-234 & $1.600 \mathrm{E}+02$ & $7.000 \mathrm{E}+01$ & $5.488 \mathrm{E}-03$ & $1.822 \mathrm{E}+04$ & $5.488 E-03$ & $1.822 \mathrm{E}+04$ \\
\hline 235 & $6.500 \mathrm{E}+00$ & $7.000 \mathrm{E}+01$ & $1.217 \mathrm{E}-01$ & $8.218 \mathrm{E}+02$ & 1. $217 \mathrm{E}-01$ & $8.218 E+02$ \\
\hline 238 & $1.600 \mathrm{E}+02$ & $0.000 \mathrm{E}+00$ & $3.129 \mathrm{E}-02$ & $3.196 \mathrm{E}+03$ & $3.123 \mathrm{E}-02$ & $3.202 E+03$ \\
\hline
\end{tabular}


RESRAD, Version $6.5 \quad \mathrm{~T}^{1 / 2}$ Limit $=180$ days

Summary : C746U Landfill Worker Deterministic Run

File : $X: \backslash F I N A L$ V2 \DOE FWD RUNS \C746U LW DOE SG FWD-FV2-70YR.RAD

Individual Nuclide Dose Summed Over All Pathways

Parent Nuclide and Branch Fraction Indicated

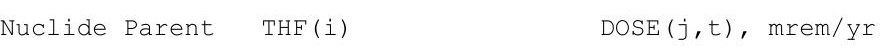




\section{RESRAD, Version $6.5 \quad \mathrm{~T}^{1 / 2}$ Limit $=180$ days}

Summary : C746U Landfill Worker Deterministic Run

File : $\mathrm{X}: \backslash F I N A L$ V2 $\backslash$ DOE FWD RUNS $\backslash \mathrm{C746U}$ LW DOE SG FWD-FV2-70YR.RAD

Individual Nuclide Dose Summed Over All Pathways

Parent Nuclide and Branch Fraction Indicated

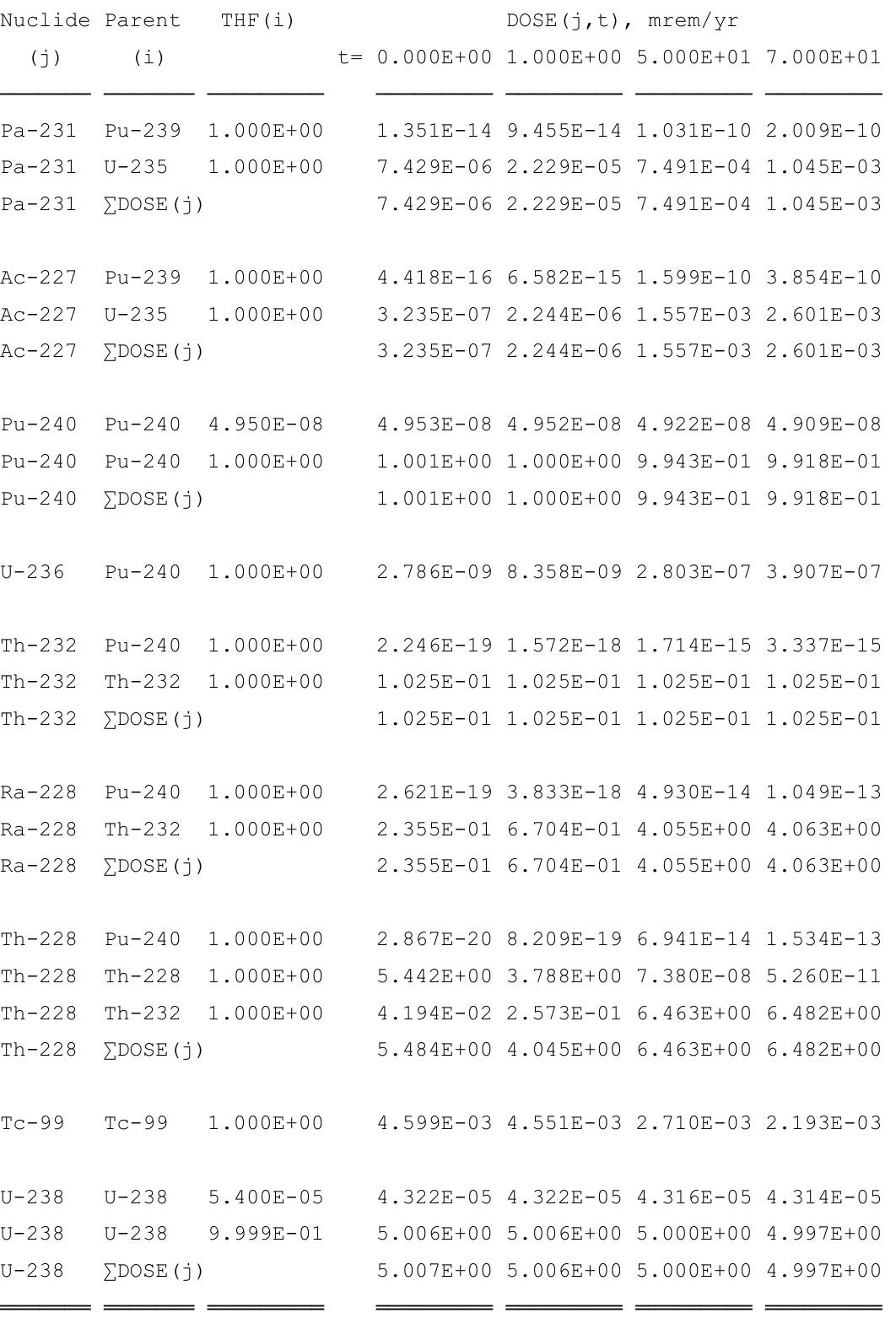

THF(i) is the thread fraction of the parent nuclide. 
RESRAD, Version $6.5 \quad \mathrm{~T}^{1 / 2}$ Limit $=180$ days

Summary : C746U Landfill Worker Deterministic Run
File : X: $\backslash$ FINAL V2 $\backslash$ DOE FWD RUNS $\backslash C 746 U$ LW DOE SG FWD-FV2-70YR.RAD

Individual Nuclide Soil Concentration

Parent Nuclide and Branch Fraction Indicated

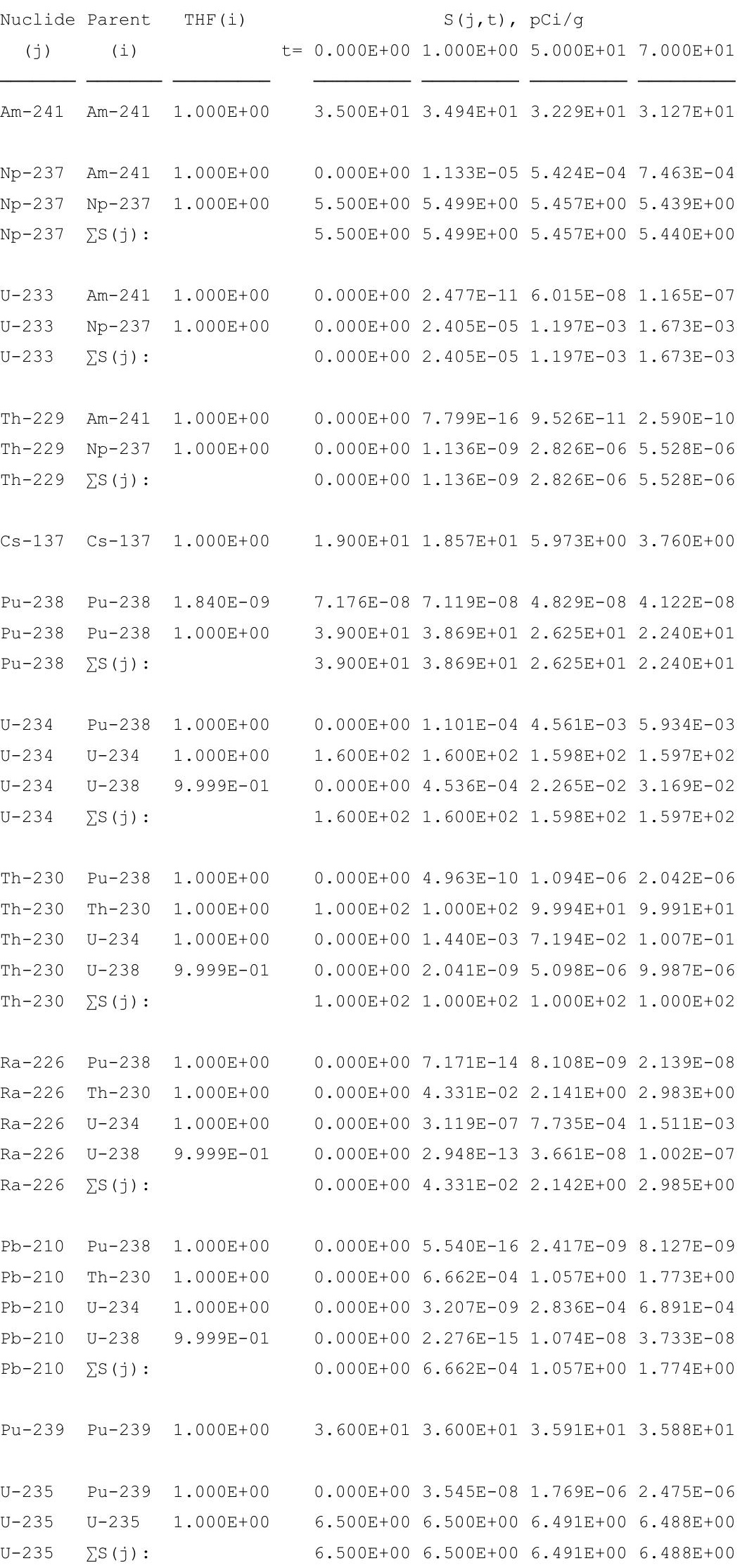




\section{RESRAD, Version $6.5 \quad \mathrm{~T}^{1 / 2}$ Limit $=180$ days}

Summary : C746U Landfill Worker Deterministic Run

File : $X: \backslash F I N A L$ V2 \DOE FWD RUNS \C746U LW DOE SG FWD-FV2-70YR.RAD

Individual Nuclide Soil Concentration

Parent Nuclide and Branch Fraction Indicated

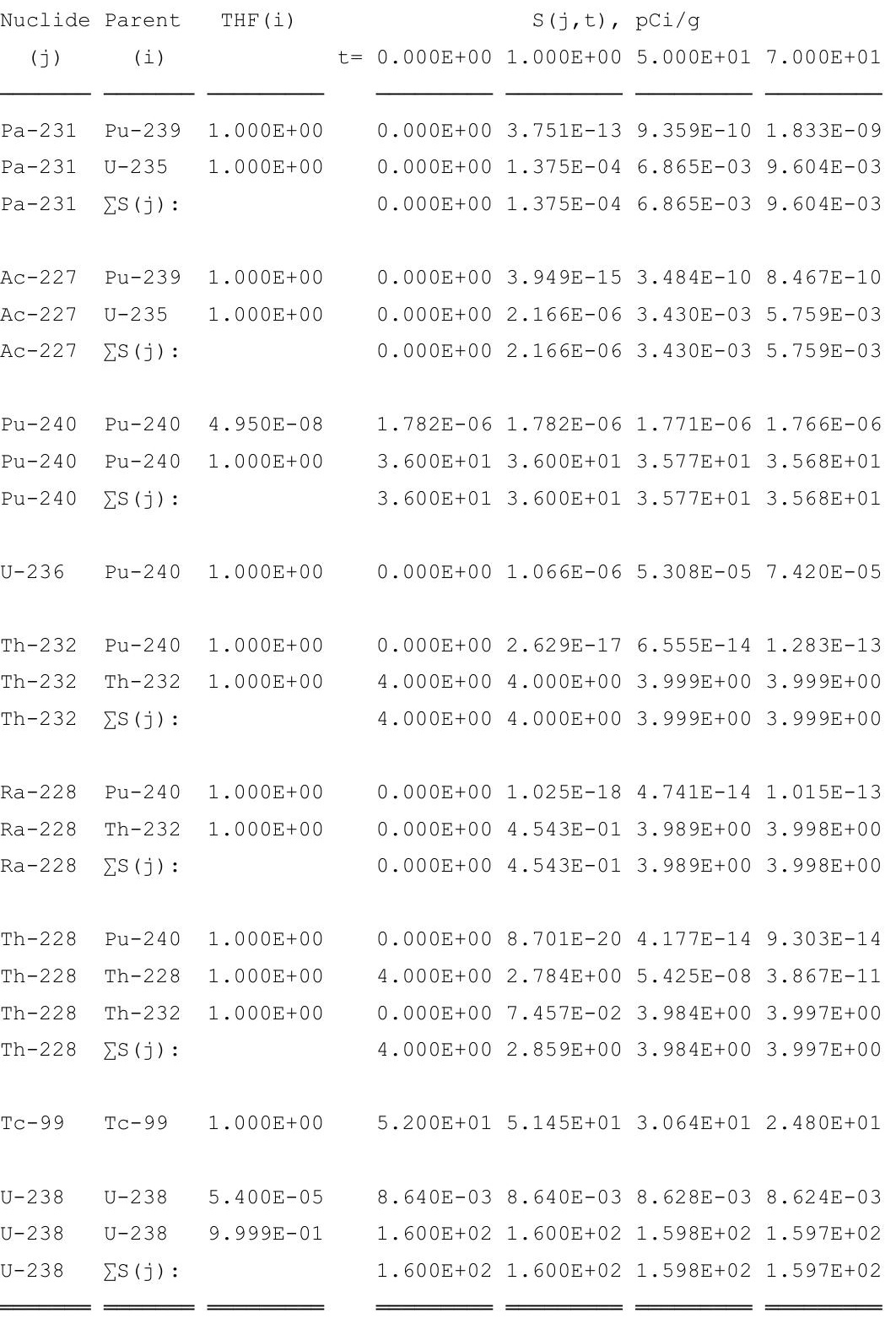

THF(i) is the thread fraction of the parent nuclide.

RESCALC.EXE execution time $=5.42$ seconds 


\section{Landfill Worker}

\section{Summary Report \\ (Deterministic Analysis Report)}

Second Peak Dose Assessment

Time Horizon: $70 \mathrm{yr}$ 
THIS PAGE INTENTIONALLY LEFT BLANK 


\section{RESRAD, Version $6.5 \quad \mathrm{~T}^{1 / 2}$ Limit $=180$ days}

Summary : C746U Landfill Worker Deterministic Run

File : $\mathrm{X}: \backslash F I N A L$ V2 $\backslash$ DOE FWD RUNS $\backslash C 746 \mathrm{U}$ LW DOE AL FWD-FV2-70YR. RAD

Table of Contents

Part I: Mixture Sums and Single Radionuclide Guidelines

Dose Conversion Factor (and Related) Parameter Summary ... 2

Site-Specific Parameter Summary $\ldots \ldots \ldots \ldots \ldots \ldots \ldots \ldots$

Summary of Pathway Selections ................... 18

Contaminated Zone and Total Dose Summary ............. 19

Total Dose Components

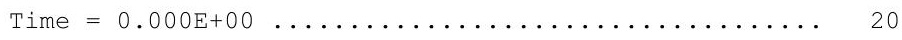

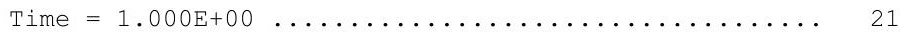

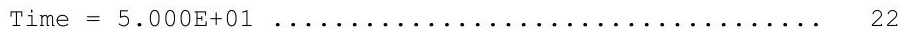

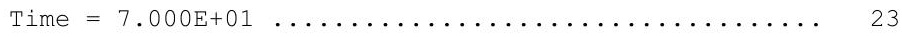

Dose/Source Ratios Summed Over All Pathways ............. 24

Single Radionuclide soil Guidelines ............... 26

Dose Per Nuclide Summed Over All Pathways ............ 27

Soil Concentration Per Nuclide .................... 29 
RESRAD, Version $6.5 \quad \mathrm{~T}^{1 / 2}$ Limit $=180$ days

Summary : C746U Landfill Worker Deterministic Run

File : $\mathrm{X}: \backslash F I N A L$ V2 $\backslash$ DOE FWD RUNS $\backslash$ C746U LW DOE AL FWD-FV2-70YR.RAD

Dose Conversion Factor (and Related) Parameter Summary

Dose Library: ICRP 60 \& ICRP 72 (Adult)

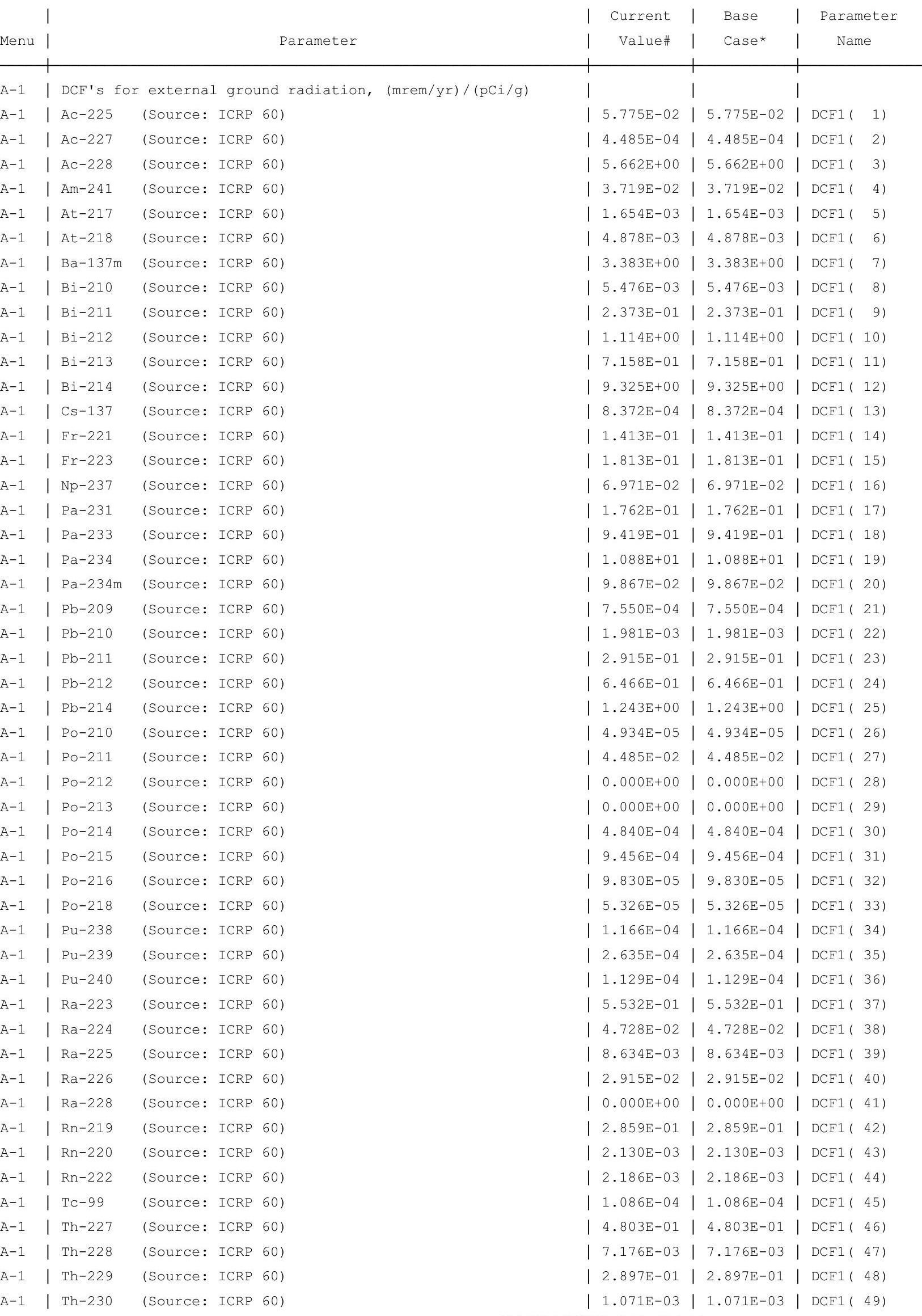


RESRAD, Version $6.5 \quad \mathrm{~T}^{1 / 2}$ Limit $=180$ days

Summary : C746U Landfill Worker Deterministic Run
File : X: $\backslash$ FINAL V2 \DOE FWD RUNS \C746U LW DOE AL FWD-FV2-70YR.RAD

Dose Conversion Factor (and Related) Parameter Summary (continued) Dose Library: ICRP 60 \& ICRP 72 (Adult)

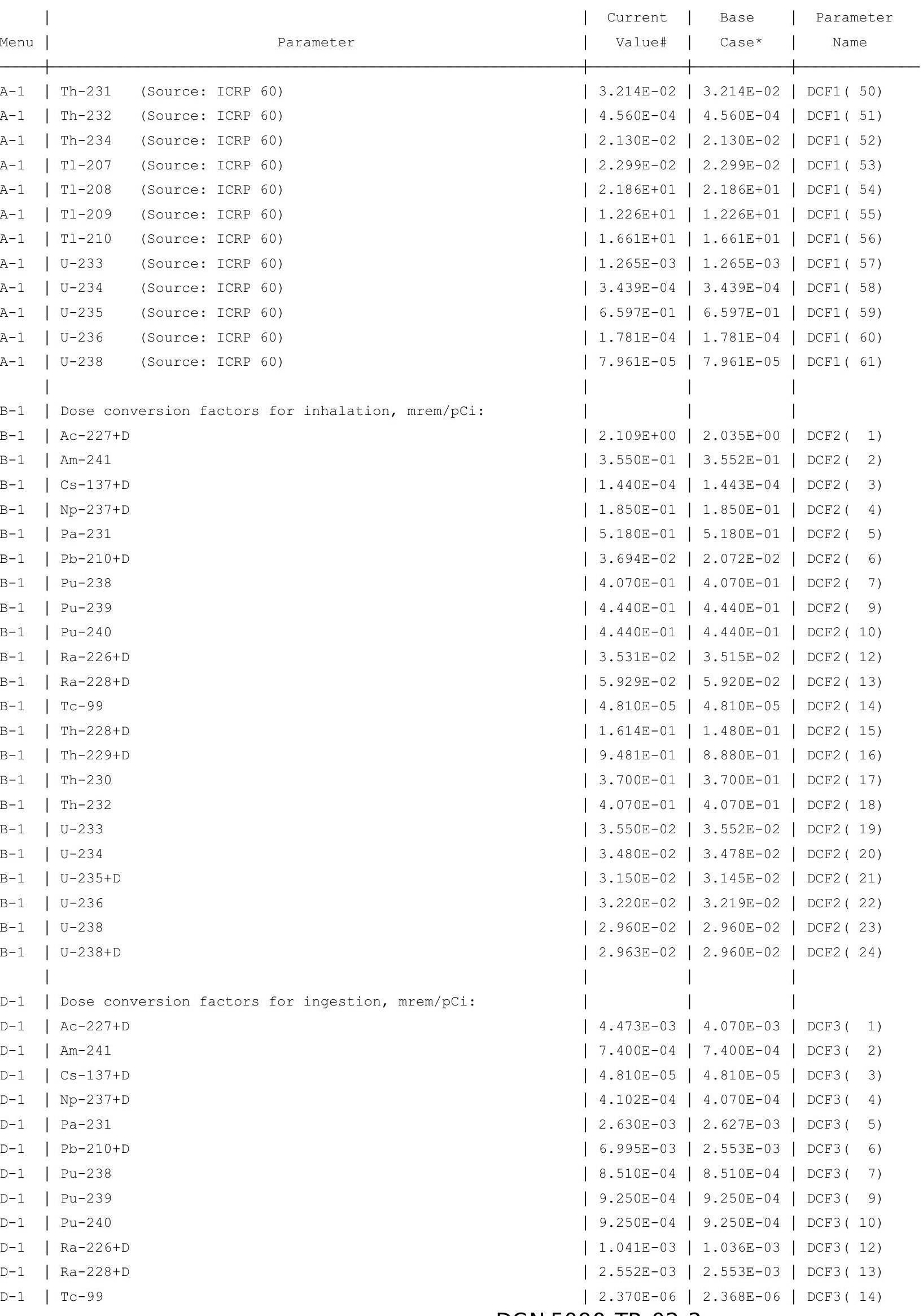


RESRAD, Version $6.5 \quad \mathrm{~T}^{1 / 2}$ Limit $=180$ days

umary : C746U Landfill Worker Deterministic Run

File : $\mathrm{X}: \backslash F I N A L$ V2 $\backslash$ DOE FWD RUNS $\backslash$ C746U LW DOE AL FWD-FV2-70YR.RAD

Dose Conversion Factor (and Related) Parameter Summary (continued)

Dose Library: ICRP 60 \& ICRP 72 (Adult)

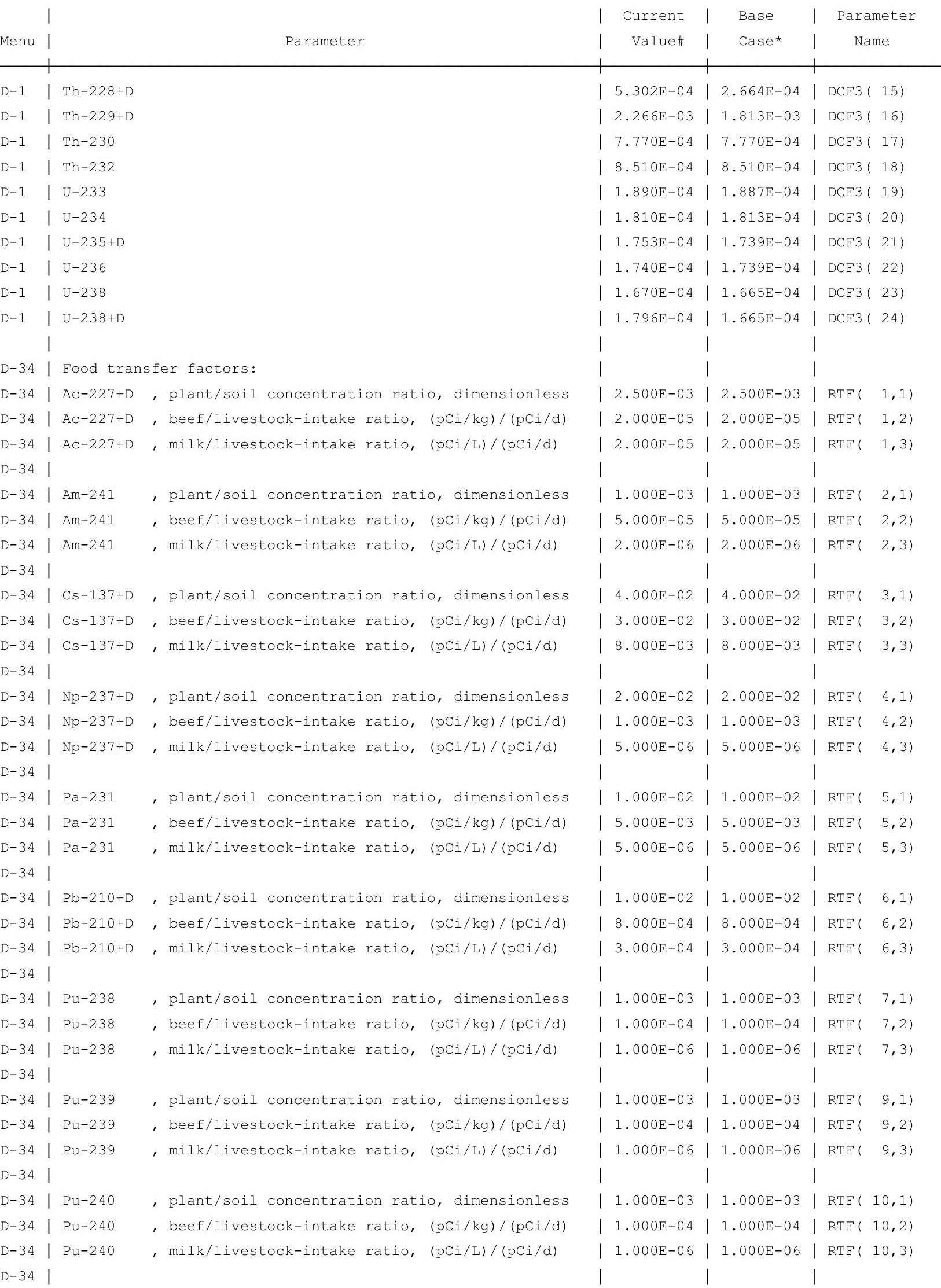


RESRAD, Version $6.5 \quad \mathrm{~T}^{1} \frac{1}{2}$ Limit $=180$ days

ummary : C746U Landfill Worker Deterministic Run

File : $X: \backslash F I N A L$ V2 \DOE FWD RUNS \C746U LW DOE AL FWD-FV2-70YR.RAD

Dose Conversion Factor (and Related) Parameter Summary (continued)

Dose Library: ICRP 60 \& ICRP 72 (Adult)

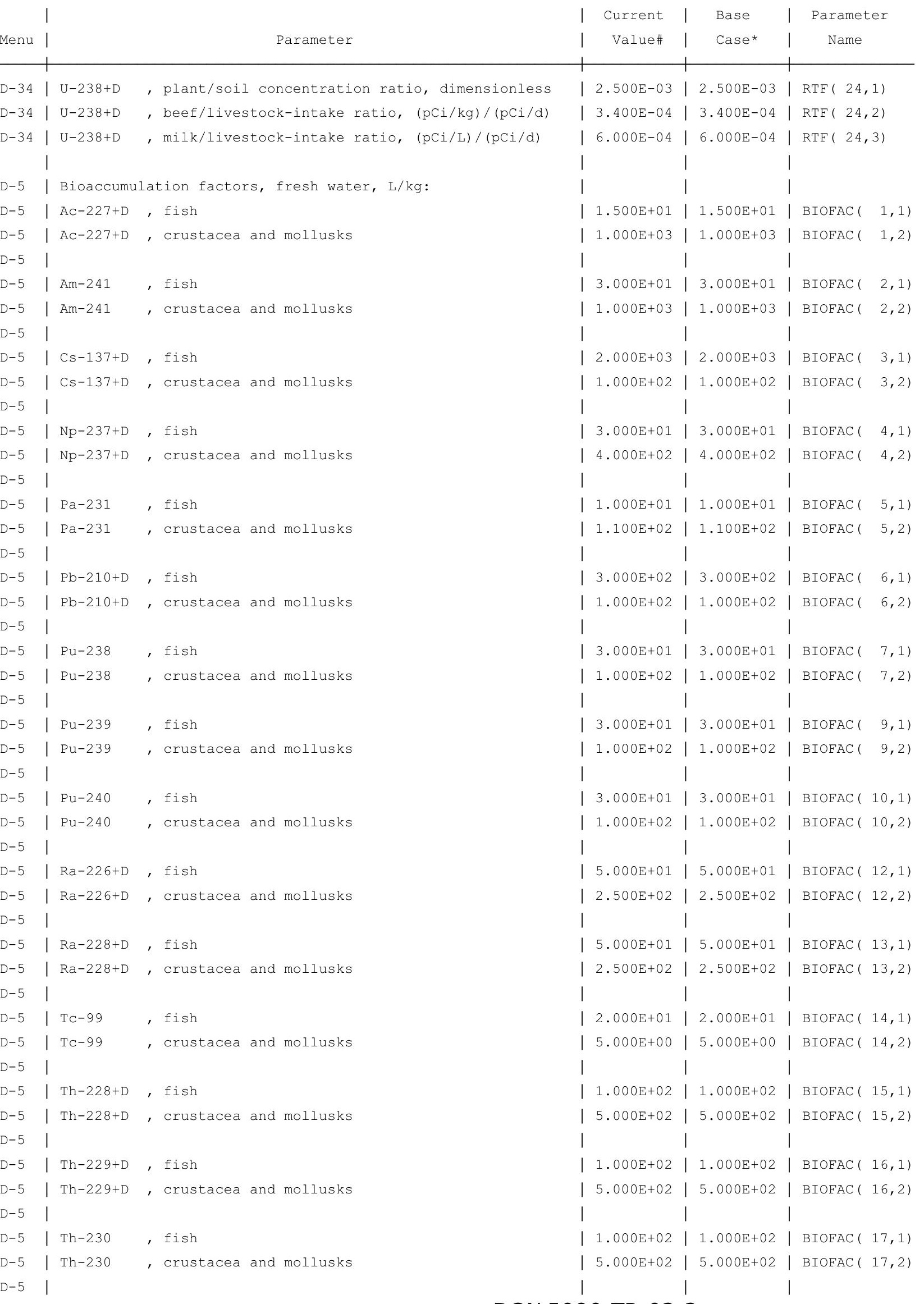


RESRAD, Version $6.5 \quad T^{1 / 2}$ Limit $=180$ days

07/15/2011 11:56 Page

Summary : C746U Landfill Worker Deterministic Run

File : $X: \backslash F I N A L$ V2 \DOE FWD RUNS \C746U LW DOE AL FWD-FV2-70YR.RAD

Site-Specific Parameter Summary (continued)

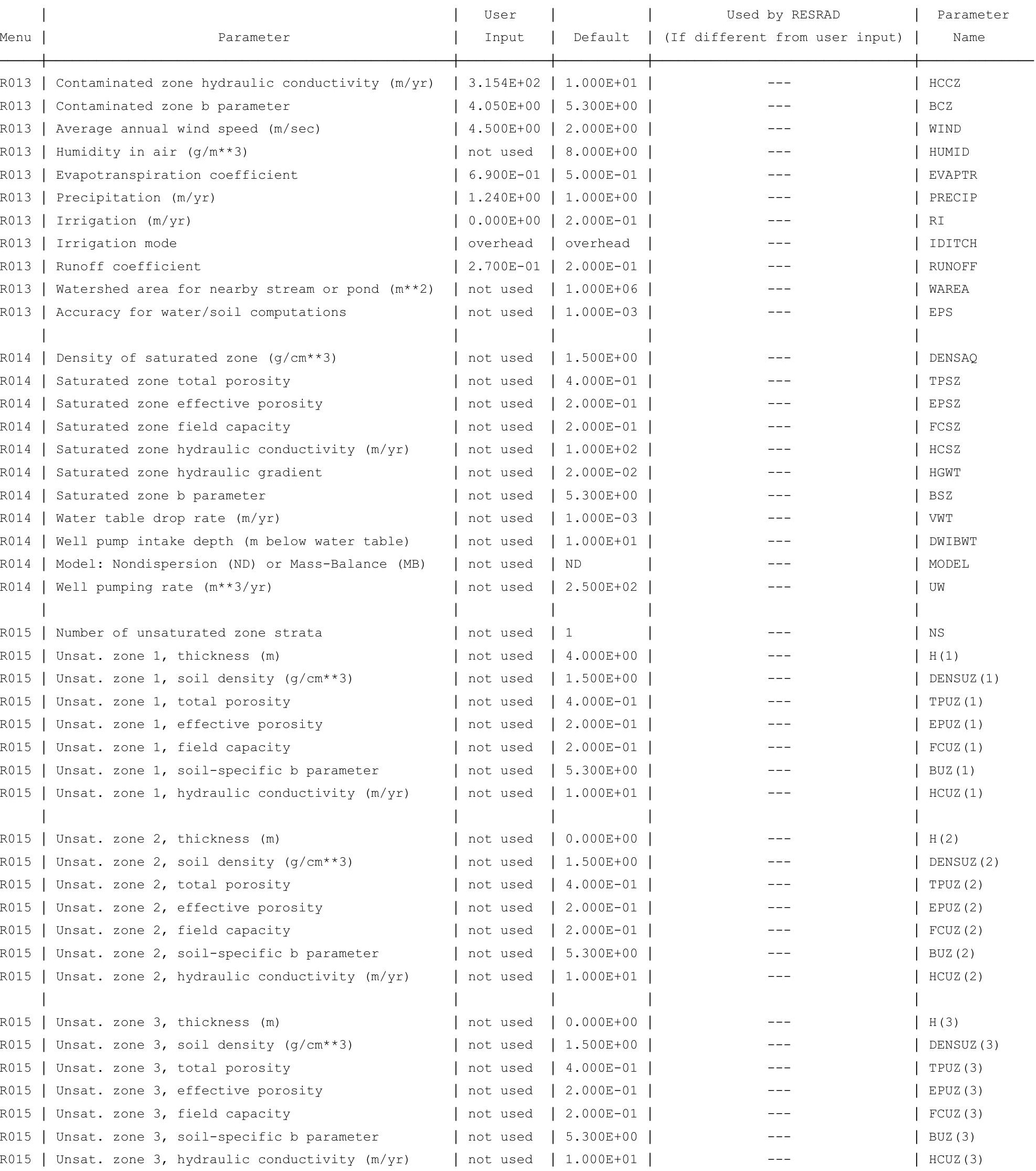


RESRAD, Version $6.5 \quad \mathrm{~T}^{1 / 2}$ Limit $=180$ days

Summary : C746U Landfill Worker Deterministic Run

File : $\mathrm{X}: \backslash F I N A L$ V2 $\backslash$ DOE FWD RUNS $\backslash$ C746U LW DOE AL FWD-FV2-70YR.RAD

Site-Specific Parameter Summary (continued)

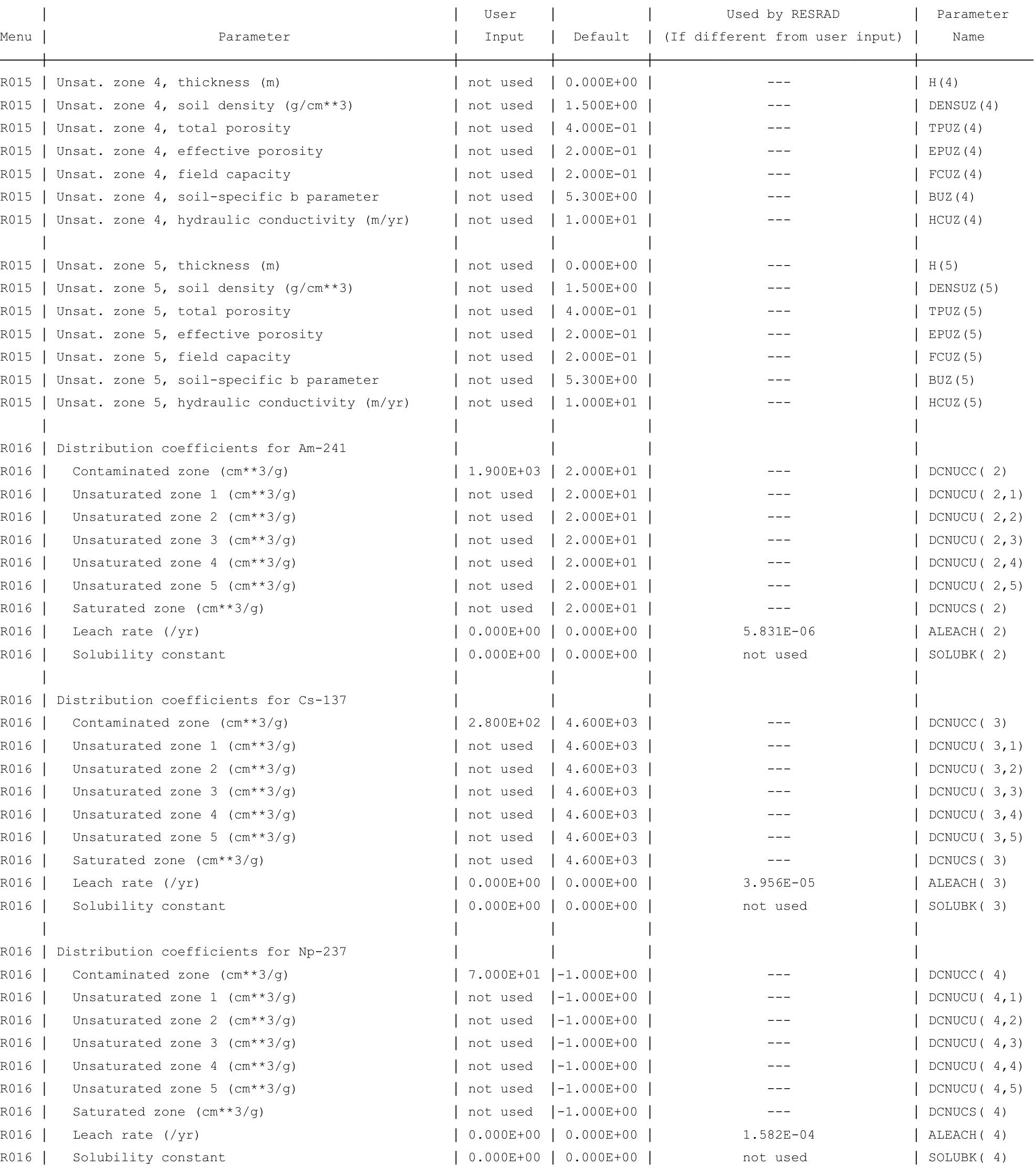


RESRAD, Version $6.5 \quad \mathrm{~T}^{1 / 2}$ Limit $=180$ days

07/15/2011 11:56 Page

Summary : C746U Landfill Worker Deterministic Run

File : $X: \backslash F I N A L$ V2 \DOE FWD RUNS \C746U LW DOE AL FWD-FV2-70YR.RAD

Site-Specific Parameter Summary (continued)

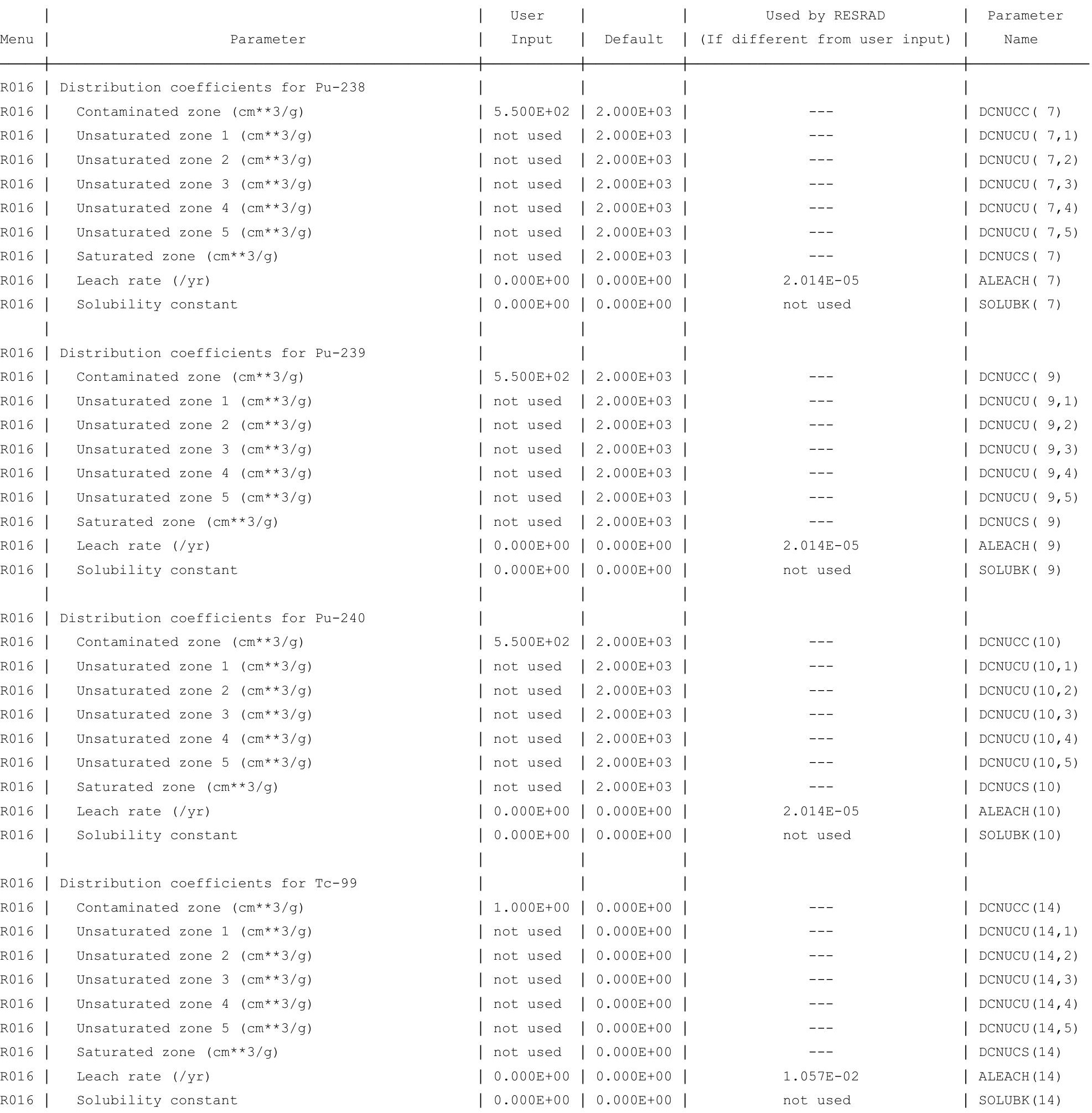


RESRAD, Version $6.5 \quad \mathrm{~T}^{1 / 2}$ Limit $=180$ days

Summary : C746U Landfill Worker Deterministic Run

File : $X: \backslash F I N A L$ V2 \DOE FWD RUNS \C746U LW DOE AL FWD-FV2-70YR.RAD

Site-Specific Parameter Summary (continued)

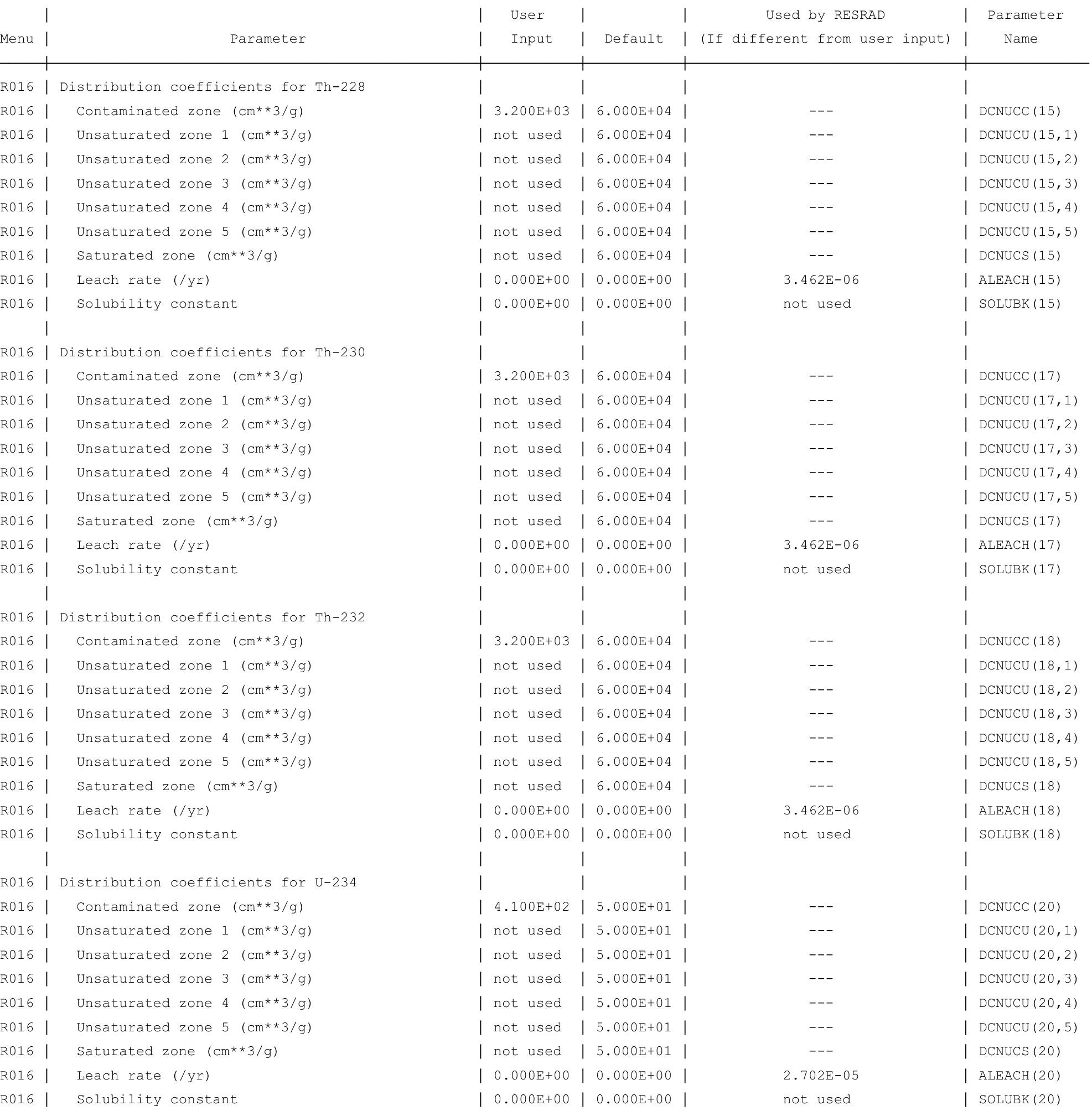


RESRAD, Version $6.5 \quad \mathrm{~T}^{1 / 2}$ Limit $=180$ days

Summary : C746U Landfill Worker Deterministic Run

File : $X: \backslash F I N A L$ V2 \DOE FWD RUNS \C746U LW DOE AL FWD-FV2-70YR.RAD

Site-Specific Parameter Summary (continued)

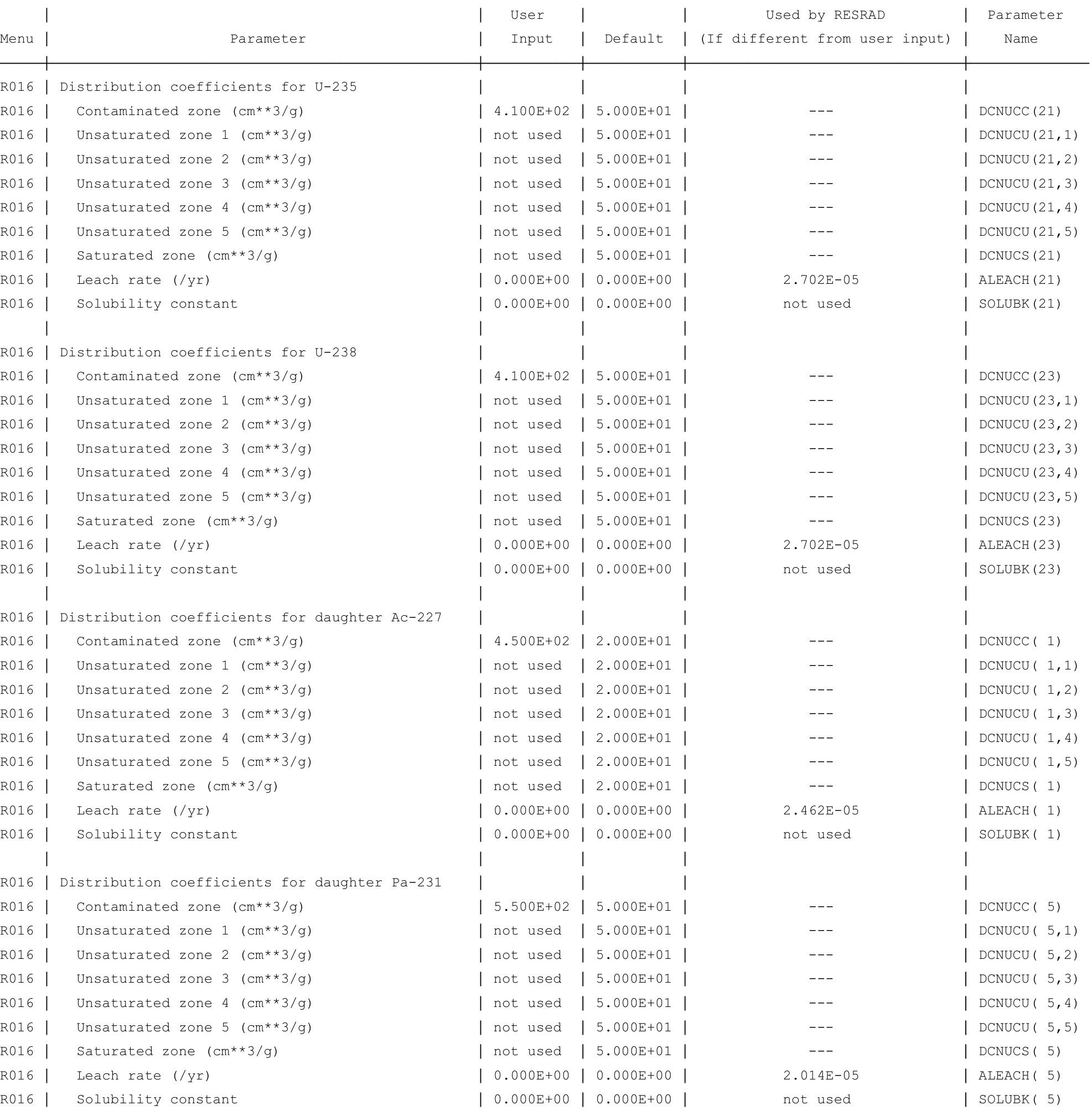


RESRAD, Version $6.5 \quad \mathrm{~T}^{1 / 2}$ Limit $=180$ days

Summary : C746U Landfill Worker Deterministic Run

File : $X: \backslash F I N A L$ V2 \DOE FWD RUNS \C746U LW DOE AL FWD-FV2-70YR.RAD

Site-Specific Parameter Summary (continued)

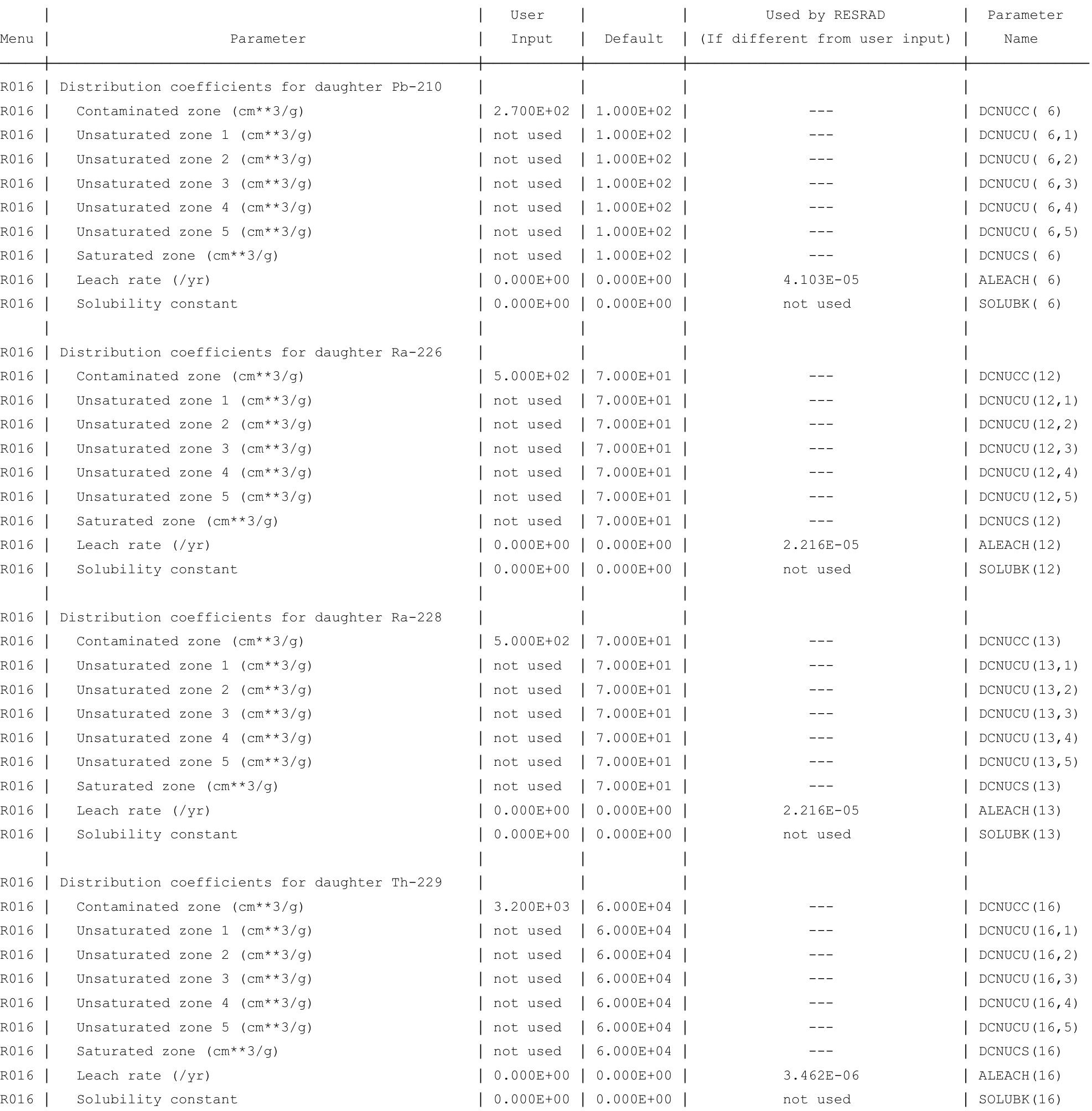


RESRAD, Version $6.5 \quad T^{1 / 2}$ Limit $=180$ days

Summary : C746U Landfill Worker Deterministic Run

File : $X: \backslash F I N A L$ V2 \DOE FWD RUNS \C746U LW DOE AL FWD-FV2-70YR.RAD

Site-Specific Parameter Summary (continued)

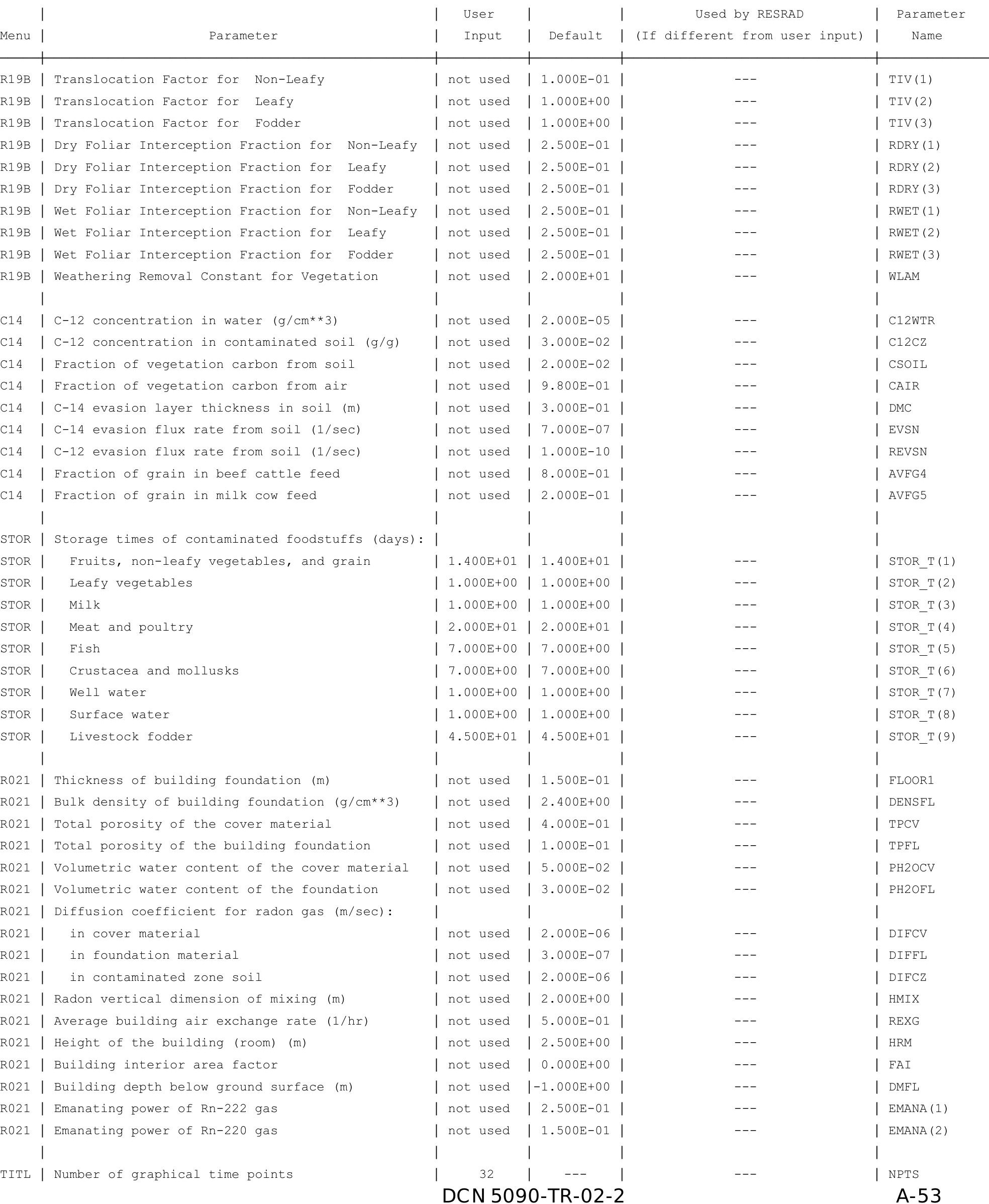


RESRAD, Version $6.5 \quad T^{11 / 2}$ Limit $=180$ days

Summary : C746U Landfill Worker Deterministic Run

File : X: \FINAL V2 \DOE FWD RUNS $\backslash$ C746U LW DOE AL FWD-FV2-70YR.RAD

Contaminated Zone Dimensions

Area: 89436.00 square meters

Thickness:

Cover Depth:

\begin{abstract}
13.40 meters
0.00 meters
\end{abstract}

Initial Soil Concentrations, pCi/g

$\begin{array}{ll}\mathrm{Am}-241 & 7.000 \mathrm{E}+01 \\ \mathrm{Cs}-137 & 3.800 \mathrm{E}+01 \\ \mathrm{~Np}-237 & 1.100 \mathrm{E}+01 \\ \mathrm{Pu}-238 & 7.800 \mathrm{E}+01 \\ \mathrm{Pu}-239 & 7.200 \mathrm{E}+01 \\ \mathrm{Pu}-240 & 7.200 \mathrm{E}+01 \\ \mathrm{TC}-99 & 1.040 \mathrm{E}+02 \\ \mathrm{Th}-228 & 8.000 \mathrm{E}+00 \\ \mathrm{Th}-230 & 2.000 \mathrm{E}+02 \\ \mathrm{Th}-232 & 8.000 \mathrm{E}+00 \\ \mathrm{U}-234 & 3.200 \mathrm{E}+02 \\ \mathrm{U}-235 & 1.300 \mathrm{E}+01 \\ \mathrm{U}-238 & 3.200 \mathrm{E}+02\end{array}$

Total Dose TDOSE(t), mrem/yr

Basic Radiation Dose Limit $=1.000 \mathrm{E}+02 \mathrm{mrem} / \mathrm{yr}$

Total Mixture Sum $M(t)$ = Fraction of Basic Dose Limit Received at Time (t)

$\begin{array}{rllll}t \text { (years): } & 0.000 \mathrm{E}+00 & 1.000 \mathrm{E}+00 & 5.000 \mathrm{E}+01 & 7.000 \mathrm{E}+01 \\ \text { TDOSE }(t): & 5.975 \mathrm{E}+01 & 5.742 \mathrm{E}+01 & 6.290 \mathrm{E}+01 & 6.368 \mathrm{E}+01 \\ \mathrm{M}(t): & 5.975 \mathrm{E}-01 & 5.742 \mathrm{E}-01 & 6.290 \mathrm{E}-01 & 6.368 \mathrm{E}-01\end{array}$

Maximum TDOSE $(t): 6.368 \mathrm{E}+01 \mathrm{mrem} / \mathrm{yr}$ at $t=7.000 \mathrm{E}+01$ years 
RESRAD, Version 6.5

$\mathrm{T}^{1 / 2}$ Limit = 180 days

07/15/2011 11:56 Page 20

Summary : C746U Landfill Worker Deterministic Run
File : X: $\backslash F I N A L$ V2 $\backslash$ DOE FWD RUNS $\backslash C 746 U$ LW DOE AL FWD-FV2-70YR.RAD

Total Dose Contributions TDOSE (i,p,t) for Individual Radionuclides (i) and Pathways (p) As mrem/yr and Fraction of Total Dose At $t=0.000 \mathrm{E}+00$ years

Water Independent Pathways (Inhalation excludes radon)

\begin{tabular}{|c|c|c|c|c|c|c|c|c|c|c|c|c|c|c|}
\hline \multirow{2}{*}{ Nuclide } & \multicolumn{2}{|c|}{ Ground } & \multicolumn{2}{|c|}{ Inhalation } & \multicolumn{2}{|c|}{ Radon } & \multicolumn{2}{|c|}{ Plant } & \multicolumn{2}{|c|}{ Meat } & \multicolumn{2}{|c|}{ Milk } & \multicolumn{2}{|c|}{ Soil } \\
\hline & mrem/yr & fract. & mrem/yr & fract. & mrem/yr & fract. & mrem/yr & fract. & mrem/yr & fract. & mrem/yr & fract. & mrem/yr & fract. \\
\hline-241 & $4.408 E-01$ & 0.0074 & $1.263 \mathrm{E}-02$ & 0.0002 & $0.000 \mathrm{E}+00$ & 0.0000 & $0.000 \mathrm{E}+00$ & 0.0000 & $0.000 \mathrm{E}+00$ & 0.0000 & $0.000 \mathrm{E}+00$ & 0.0000 & $1.542 \mathrm{E}+00$ & 0.0258 \\
\hline-137 & $1.994 \mathrm{E}+01$ & 0.3338 & $2.752 \mathrm{E}-06$ & 0.0000 & $0.000 \mathrm{E}+00$ & 0.0000 & $0.000 \mathrm{E}+00$ & 0.0000 & $0.000 \mathrm{E}+00$ & 0.0000 & $0.000 \mathrm{E}+00$ & 0.0000 & $5.381 \mathrm{E}-02$ & 0.0009 \\
\hline-237 & $1.862 \mathrm{E}+00$ & 0.0312 & $1.035 \mathrm{E}-03$ & 0.0000 & $0.000 \mathrm{E}+00$ & 0.0000 & $0.000 \mathrm{E}+00$ & 0.0000 & $0.000 \mathrm{E}+00$ & 0.0000 & $0.000 \mathrm{E}+00$ & 0.0000 & $1.344 \mathrm{E}-01$ & 0.0022 \\
\hline-238 & $1.538 \mathrm{E}-03$ & 0.0000 & $1.609 \mathrm{E}-02$ & 0.0003 & $0.000 \mathrm{E}+00$ & 0.0000 & $0.000 \mathrm{E}+00$ & 0.0000 & $0.000 \mathrm{E}+00$ & 0.0000 & $0.000 \mathrm{E}+00$ & 0.0000 & $1.969 \mathrm{E}+00$ & 0.0330 \\
\hline-239 & $3.184 \mathrm{E}-03$ & 0.0001 & 1. $626 \mathrm{E}-02$ & 0.0003 & $0.000 \mathrm{E}+00$ & 0.0000 & $0.000 \mathrm{E}+00$ & 0.0000 & $0.000 \mathrm{E}+00$ & 0.0000 & $0.000 \mathrm{E}+00$ & 0.0000 & $1.984 \mathrm{E}+00$ & 0.0332 \\
\hline-240 & $1.378 \mathrm{E}-03$ & 0.0000 & $1.626 \mathrm{E}-02$ & 0.0003 & $0.000 \mathrm{E}+00$ & 0.0000 & $0.000 \mathrm{E}+00$ & 0.0000 & $0.000 \mathrm{E}+00$ & 0.0000 & $0.000 \mathrm{E}+00$ & 0.0000 & $1.983 \mathrm{E}+00$ & 0.0332 \\
\hline-99 & $1.893 E-03$ & 0.0000 & $2.531 \mathrm{E}-06$ & 0.0000 & $0.000 \mathrm{E}+00$ & 0.0000 & $0.000 \mathrm{E}+00$ & 0.0000 & $0.000 \mathrm{E}+00$ & 0.0000 & $0.000 \mathrm{E}+00$ & 0.0000 & 7. $302 \mathrm{E}-03$ & 0.0001 \\
\hline-228 & $1.078 \mathrm{E}+01$ & 0.1804 & $5.511 \mathrm{E}-04$ & 0.0000 & $0.000 \mathrm{E}+00$ & 0.0000 & $0.000 \mathrm{E}+00$ & 0.0000 & $0.000 \mathrm{E}+00$ & 0.0000 & $0.000 \mathrm{E}+00$ & 0.0000 & $1.060 \mathrm{E}-01$ & 0.0018 \\
\hline-230 & $1.123 \mathrm{E}-01$ & 0.0019 & $3.765 \mathrm{E}-02$ & 0.0006 & $0.000 \mathrm{E}+00$ & 0.0000 & $0.000 \mathrm{E}+00$ & 0.0000 & $0.000 \mathrm{E}+00$ & 0.0000 & $0.000 \mathrm{E}+00$ & 0.0000 & $4.630 \mathrm{E}+00$ & 0.0775 \\
\hline-232 & $5.194 \mathrm{E}-01$ & 0.0087 & $1.675 \mathrm{E}-03$ & 0.0000 & $0.000 \mathrm{E}+00$ & 0.0000 & $0.000 \mathrm{E}+00$ & 0.0000 & $0.000 \mathrm{E}+00$ & 0.0000 & $0.000 \mathrm{E}+00$ & 0.0000 & $2.388 \mathrm{E}-01$ & 0.0040 \\
\hline 34 & $1.858 \mathrm{E}-02$ & 0.0003 & $5.665 \mathrm{E}-03$ & 0.0001 & $0.000 \mathrm{E}+00$ & 0.0000 & $0.000 \mathrm{E}+00$ & 0.0000 & $0.000 \mathrm{E}+00$ & 0.0000 & $0.000 \mathrm{E}+00$ & 0.0000 & $1.725 \mathrm{E}+00$ & 0.0289 \\
\hline 35 & $1.509 \mathrm{E}+00$ & 0.0253 & $2.084 \mathrm{E}-04$ & 0.0000 & $0.000 \mathrm{E}+00$ & 0.0000 & $0.000 \mathrm{E}+00$ & 0.0000 & $0.000 \mathrm{E}+00$ & 0.0000 & $0.000 \mathrm{E}+00$ & 0.0000 & $6.787 \mathrm{E}-02$ & 0.0011 \\
\hline 38 & $8.296 \mathrm{E}+00$ & 0.1388 & $4.823 E-03$ & 0.0001 & $0.000 \mathrm{E}+00$ & 0.0000 & $0.000 \mathrm{E}+00$ & 0.0000 & $0.000 \mathrm{E}+00$ & 0.0000 & $0.000 \mathrm{E}+00$ & 0.0000 & $1.712 \mathrm{E}+00$ & 0.0286 \\
\hline & $4.349 \mathrm{E}+01$ & 0.7278 & 1.129E-01 & 0.0019 & $0.000 \mathrm{E}+00$ & 0.0000 & $0.000 \mathrm{E}+00$ & 0.0000 & $0.000 \mathrm{E}+00$ & 0.0000 & $0.000 \mathrm{E}+00$ & 0.0000 & 1. $615 \mathrm{E}+01$ & 0.2100 \\
\hline
\end{tabular}

Total Dose Contributions TDOSE(i,p,t) for Individual Radionuclides (i) and Pathways (p) As mrem/yr and Fraction of Total Dose At $t=0.000 \mathrm{E}+00$ years

Water Dependent Pathways

\begin{tabular}{|c|c|c|c|c|c|c|c|c|c|c|c|c|c|c|}
\hline & \multicolumn{2}{|c|}{ Water } & \multicolumn{2}{|c|}{ Fish } & \multicolumn{2}{|c|}{ Radon } & \multicolumn{2}{|c|}{ Plant } & \multicolumn{2}{|c|}{ Meat } & \multicolumn{2}{|c|}{ Milk } & \multicolumn{2}{|c|}{ All Pathways* } \\
\hline clide & mrem/yr & fract. & mrem/yr & fract. & mrem/yr & fract. & mrem/yr & fract. & mrem/yr & fract. & mrem/yr & fract. & mrem/yr & fract. \\
\hline-241 & $0.000 \mathrm{E}+00$ & 0.0000 & $0.000 \mathrm{E}+00$ & 0.0000 & $0.000 \mathrm{E}+00$ & 0.0000 & $0.000 \mathrm{E}+00$ & 0.0000 & $0.000 \mathrm{E}+00$ & 0.0000 & $0.000 \mathrm{E}+00$ & 0.0000 & $1.995 \mathrm{E}+00$ & 0.0334 \\
\hline-137 & $0.000 \mathrm{E}+00$ & 0.0000 & $0.000 \mathrm{E}+00$ & 0.0000 & $0.000 \mathrm{E}+00$ & 0.0000 & $0.000 \mathrm{E}+00$ & 0.0000 & $0.000 \mathrm{E}+00$ & 0.0000 & $0.000 \mathrm{E}+00$ & 0.0000 & $2.000 \mathrm{E}+01$ & 0.3347 \\
\hline-237 & $0.000 \mathrm{E}+00$ & 0.0000 & $0.000 \mathrm{E}+00$ & 0.0000 & $0.000 \mathrm{E}+00$ & 0.0000 & $0.000 \mathrm{E}+00$ & 0.0000 & $0.000 E+00$ & 0.0000 & $0.000 \mathrm{E}+00$ & 0.0000 & $1.998 \mathrm{E}+00$ & 0.0334 \\
\hline-238 & $0.000 \mathrm{E}+00$ & 0.0000 & $0.000 \mathrm{E}+00$ & 0.0000 & $0.000 \mathrm{E}+00$ & 0.0000 & $0.000 \mathrm{E}+00$ & 0.0000 & $0.000 \mathrm{E}+00$ & 0.0000 & $0.000 \mathrm{E}+00$ & 0.0000 & $1.987 \mathrm{E}+00$ & 0.0333 \\
\hline-239 & $0.000 \mathrm{E}+00$ & 0.0000 & $0.000 \mathrm{E}+00$ & 0.0000 & $0.000 \mathrm{E}+00$ & 0.0000 & $0.000 \mathrm{E}+00$ & 0.0000 & $0.000 \mathrm{E}+00$ & 0.0000 & $0.000 \mathrm{E}+00$ & 0.0000 & $2.003 E+00$ & 0.0335 \\
\hline 240 & $0.000 \mathrm{E}+00$ & 0.0000 & $0.000 \mathrm{E}+00$ & 0.0000 & $0.000 \mathrm{E}+00$ & 0.0000 & $0.000 \mathrm{E}+00$ & 0.0000 & $0.000 \mathrm{E}+00$ & 0.0000 & $0.000 \mathrm{E}+00$ & 0.0000 & $2.001 \mathrm{E}+00$ & 0.0335 \\
\hline 99 & $0.000 \mathrm{E}+00$ & 0.0000 & $0.000 \mathrm{E}+00$ & 0.0000 & $0.000 \mathrm{E}+00$ & 0.0000 & $0.000 \mathrm{E}+00$ & 0.0000 & $0.000 \mathrm{E}+00$ & 0.0000 & $0.000 \mathrm{E}+00$ & 0.0000 & $9.198 \mathrm{E}-03$ & 0.0002 \\
\hline-228 & $0.000 \mathrm{E}+00$ & 0.0000 & $0.000 \mathrm{E}+00$ & 0.0000 & $0.000 \mathrm{E}+00$ & 0.0000 & $0.000 \mathrm{E}+00$ & 0.0000 & $0.000 \mathrm{E}+00$ & 0.0000 & $0.000 \mathrm{E}+00$ & 0.0000 & $1.088 \mathrm{E}+01$ & 0.1821 \\
\hline 230 & $0.000 \mathrm{E}+00$ & 0.0000 & $0.000 \mathrm{E}+00$ & 0.0000 & $0.000 \mathrm{E}+00$ & 0.0000 & $0.000 \mathrm{E}+00$ & 0.0000 & $0.000 \mathrm{E}+00$ & 0.0000 & $0.000 \mathrm{E}+00$ & 0.0000 & $4.780 \mathrm{E}+00$ & 0.0800 \\
\hline 232 & $0.000 \mathrm{E}+00$ & 0.0000 & $0.000 \mathrm{E}+00$ & 0.0000 & $0.000 \mathrm{E}+00$ & 0.0000 & $0.000 \mathrm{E}+00$ & 0.0000 & $0.000 \mathrm{E}+00$ & 0.0000 & $0.000 \mathrm{E}+00$ & 0.0000 & $7.599 \mathrm{E}-01$ & 0.0127 \\
\hline & $0.000 \mathrm{E}+00$ & 0.0000 & $0.000 \mathrm{E}+00$ & 0.0000 & $0.000 \mathrm{E}+00$ & 0.0000 & $0.000 \mathrm{E}+00$ & 0.0000 & $0.000 \mathrm{E}+00$ & 0.0000 & $0.000 \mathrm{E}+00$ & 0.0000 & $1.749 \mathrm{E}+00$ & 0.0293 \\
\hline 35 & $0.000 \mathrm{E}+00$ & 0.0000 & $0.000 \mathrm{E}+00$ & 0.0000 & $0.000 \mathrm{E}+00$ & 0.0000 & $0.000 \mathrm{E}+00$ & 0.0000 & $0.000 \mathrm{E}+00$ & 0.0000 & $0.000 \mathrm{E}+00$ & 0.0000 & $1.578 \mathrm{E}+00$ & 0.0264 \\
\hline 38 & $0.000 \mathrm{E}+00$ & 0.0000 & $0.000 \mathrm{E}+00$ & 0.0000 & $0.000 \mathrm{E}+00$ & 0.0000 & $0.000 \mathrm{E}+00$ & 0.0000 & $0.000 \mathrm{E}+00$ & 0.0000 & $0.000 \mathrm{E}+00$ & 0.0000 & $1.001 \mathrm{E}+01$ & 0.1676 \\
\hline & $0.000 \mathrm{E}+00$ & 0.0000 & $0.000 \mathrm{E}+00$ & 0.0000 & $0.000 \mathrm{E}+00$ & 0.0000 & $0.000 \mathrm{E}+00$ & 0.0000 & $0.000 \mathrm{E}+00$ & 0.0000 & $0.000 \mathrm{E}+00$ & 000 & +01 & 000 \\
\hline
\end{tabular}

* Sum of all water independent and dependent pathways. 
RESRAD, Version 6.5

$\mathrm{T}^{1 / 2}$ Limit $=180$ days

07/15/2011 11:56 Page 21

Summary : C746U Landfill Worker Deterministic Run
File : X: $\backslash F I N A L$ V2 $\backslash$ DOE FWD RUNS $\backslash C 746 U$ LW DOE AL FWD-FV2-70YR.RAD

Total Dose Contributions TDOSE (i,p,t) for Individual Radionuclides (i) and Pathways (p) As mrem/yr and Fraction of Total Dose At $t=1.000 \mathrm{E}+00$ years

Water Independent Pathways (Inhalation excludes radon)

\begin{tabular}{|c|c|c|c|c|c|c|c|c|c|c|c|c|c|c|}
\hline \multirow{2}{*}{ Nuclide } & \multicolumn{2}{|c|}{ Ground } & \multicolumn{2}{|c|}{ Inhalation } & \multicolumn{2}{|c|}{ Radon } & \multicolumn{2}{|c|}{ Plant } & \multicolumn{2}{|c|}{ Meat } & \multicolumn{2}{|c|}{ Milk } & \multicolumn{2}{|c|}{ Soil } \\
\hline & mrem/yr & fract. & mrem/yr & fract. & mrem/yr & fract. & mrem/yr & fract. & mrem/yr & fract. & mrem/yr & fract. & mrem/yr & fract. \\
\hline-241 & $4.401 \mathrm{E}-01$ & 0.0077 & $1.261 \mathrm{E}-02$ & 0.0002 & $0.000 \mathrm{E}+00$ & 0.0000 & $0.000 \mathrm{E}+00$ & 0.0000 & $0.000 \mathrm{E}+00$ & 0.0000 & $0.000 \mathrm{E}+00$ & 0.0000 & $1.539 \mathrm{E}+00$ & 0.0268 \\
\hline-137 & $1.949 \mathrm{E}+01$ & 0.3394 & $2.689 \mathrm{E}-06$ & 0.0000 & $0.000 \mathrm{E}+00$ & 0.0000 & $0.000 \mathrm{E}+00$ & 0.0000 & $0.000 \mathrm{E}+00$ & 0.0000 & $0.000 \mathrm{E}+00$ & 0.0000 & $5.258 \mathrm{E}-02$ & 0.0009 \\
\hline-237 & $1.862 \mathrm{E}+00$ & 0.0324 & $1.035 \mathrm{E}-03$ & 0.0000 & $0.000 \mathrm{E}+00$ & 0.0000 & $0.000 \mathrm{E}+00$ & 0.0000 & $0.000 \mathrm{E}+00$ & 0.0000 & $0.000 \mathrm{E}+00$ & 0.0000 & $1.344 \mathrm{E}-01$ & 0.0023 \\
\hline-238 & 1. $526 \mathrm{E}-03$ & 0.0000 & $1.596 \mathrm{E}-02$ & 0.0003 & $0.000 \mathrm{E}+00$ & 0.0000 & $0.000 \mathrm{E}+00$ & 0.0000 & $0.000 \mathrm{E}+00$ & 0.0000 & $0.000 \mathrm{E}+00$ & 0.0000 & $1.954 \mathrm{E}+00$ & 0.0340 \\
\hline-239 & $3.184 \mathrm{E}-03$ & 0.0001 & 1. $626 \mathrm{E}-02$ & 0.0003 & $0.000 \mathrm{E}+00$ & 0.0000 & $0.000 \mathrm{E}+00$ & 0.0000 & $0.000 \mathrm{E}+00$ & 0.0000 & $0.000 \mathrm{E}+00$ & 0.0000 & $1.983 \mathrm{E}+00$ & 0.0345 \\
\hline-240 & $1.378 \mathrm{E}-03$ & 0.0000 & $1.626 \mathrm{E}-02$ & 0.0003 & $0.000 \mathrm{E}+00$ & 0.0000 & $0.000 \mathrm{E}+00$ & 0.0000 & $0.000 \mathrm{E}+00$ & 0.0000 & $0.000 \mathrm{E}+00$ & 0.0000 & $1.983 \mathrm{E}+00$ & 0.0345 \\
\hline-99 & $1.873 E-03$ & 0.0000 & $2.505 E-06$ & 0.0000 & $0.000 \mathrm{E}+00$ & 0.0000 & $0.000 \mathrm{E}+00$ & 0.0000 & $0.000 \mathrm{E}+00$ & 0.0000 & $0.000 \mathrm{E}+00$ & 0.0000 & 7. 226E-03 & 0.0001 \\
\hline-228 & $7.501 \mathrm{E}+00$ & 0.1306 & $3.836 \mathrm{E}-04$ & 0.0000 & $0.000 \mathrm{E}+00$ & 0.0000 & $0.000 \mathrm{E}+00$ & 0.0000 & $0.000 \mathrm{E}+00$ & 0.0000 & $0.000 \mathrm{E}+00$ & 0.0000 & $7.376 \mathrm{E}-02$ & 0.0013 \\
\hline-230 & $2.647 \mathrm{E}-01$ & 0.0046 & $3.765 \mathrm{E}-02$ & 0.0007 & $0.000 \mathrm{E}+00$ & 0.0000 & $0.000 \mathrm{E}+00$ & 0.0000 & $0.000 \mathrm{E}+00$ & 0.0000 & $0.000 \mathrm{E}+00$ & 0.0000 & $4.633 E+00$ & 0.0807 \\
\hline-232 & $1.751 \mathrm{E}+00$ & 0.0305 & $1.722 \mathrm{E}-03$ & 0.0000 & $0.000 \mathrm{E}+00$ & 0.0000 & $0.000 \mathrm{E}+00$ & 0.0000 & $0.000 \mathrm{E}+00$ & 0.0000 & $0.000 \mathrm{E}+00$ & 0.0000 & $3.080 \mathrm{E}-01$ & 0.0054 \\
\hline 34 & $1.858 \mathrm{E}-02$ & 0.0003 & $5.666 \mathrm{E}-03$ & 0.0001 & $0.000 \mathrm{E}+00$ & 0.0000 & $0.000 \mathrm{E}+00$ & 0.0000 & $0.000 \mathrm{E}+00$ & 0.0000 & $0.000 \mathrm{E}+00$ & 0.0000 & $1.725 \mathrm{E}+00$ & 0.0300 \\
\hline 35 & $1.509 \mathrm{E}+00$ & 0.0263 & $2.084 \mathrm{E}-04$ & 0.0000 & $0.000 \mathrm{E}+00$ & 0.0000 & $0.000 \mathrm{E}+00$ & 0.0000 & $0.000 \mathrm{E}+00$ & 0.0000 & $0.000 \mathrm{E}+00$ & 0.0000 & $6.789 \mathrm{E}-02$ & 0.0012 \\
\hline 38 & $8.296 \mathrm{E}+00$ & 0.1445 & $4.823 E-03$ & 0.0001 & $0.000 \mathrm{E}+00$ & 0.0000 & $0.000 \mathrm{E}+00$ & 0.0000 & $0.000 \mathrm{E}+00$ & 0.0000 & $0.000 \mathrm{E}+00$ & 0.0000 & $1.712 \mathrm{E}+00$ & 0.0298 \\
\hline & $4.114 \mathrm{E}+01$ & 0.7164 & $1.126 \mathrm{E}-01$ & 0.0020 & $0.000 \mathrm{E}+00$ & 0.0000 & $0.000 \mathrm{E}+00$ & 0.0000 & $0.000 \mathrm{E}+00$ & 0.0000 & $0.000 \mathrm{E}+00$ & 0.0000 & 1. $617 \mathrm{E}+01$ & 0.2816 \\
\hline
\end{tabular}

Total Dose Contributions TDOSE(i,p,t) for Individual Radionuclides (i) and Pathways (p) As mrem/yr and Fraction of Total Dose At $t=1.000 \mathrm{E}+00$ years

Water Dependent Pathways

\begin{tabular}{|c|c|c|c|c|c|c|c|c|c|c|c|c|c|c|}
\hline & \multicolumn{2}{|c|}{ Water } & \multicolumn{2}{|c|}{ Fish } & \multicolumn{2}{|c|}{ Radon } & \multicolumn{2}{|c|}{ Plant } & \multicolumn{2}{|c|}{ Meat } & \multicolumn{2}{|c|}{ Milk } & \multicolumn{2}{|c|}{ All Pathways* } \\
\hline clide & mrem/yr & fract. & mrem/yr & fract. & mrem/yr & fract. & mrem/yr & fract. & mrem/yr & fract. & mrem/yr & fract. & mrem/yr & fract. \\
\hline-241 & $0.000 \mathrm{E}+00$ & 0.0000 & $0.000 \mathrm{E}+00$ & 0.0000 & $0.000 \mathrm{E}+00$ & 0.0000 & $0.000 \mathrm{E}+00$ & 0.0000 & $0.000 \mathrm{E}+00$ & 0.0000 & $0.000 \mathrm{E}+00$ & 0.0000 & $1.992 \mathrm{E}+00$ & 0.0347 \\
\hline-137 & $0.000 \mathrm{E}+00$ & 0.0000 & $0.000 \mathrm{E}+00$ & 0.0000 & $0.000 \mathrm{E}+00$ & 0.0000 & $0.000 \mathrm{E}+00$ & 0.0000 & $0.000 \mathrm{E}+00$ & 0.0000 & $0.000 \mathrm{E}+00$ & 0.0000 & $1.954 \mathrm{E}+01$ & 0.3403 \\
\hline-237 & $0.000 \mathrm{E}+00$ & 0.0000 & $0.000 \mathrm{E}+00$ & 0.0000 & $0.000 \mathrm{E}+00$ & 0.0000 & $0.000 \mathrm{E}+00$ & 0.0000 & $0.000 \mathrm{E}+00$ & 0.0000 & $0.000 \mathrm{E}+00$ & 0.0000 & $1.997 \mathrm{E}+00$ & 0.0348 \\
\hline 238 & $0.000 \mathrm{E}+00$ & 0.0000 & $0.000 \mathrm{E}+00$ & 0.0000 & $0.000 \mathrm{E}+00$ & 0.0000 & $0.000 \mathrm{E}+00$ & 0.0000 & $0.000 \mathrm{E}+00$ & 0.0000 & $0.000 \mathrm{E}+00$ & 0.0000 & $1.971 \mathrm{E}+00$ & 0.0343 \\
\hline 239 & $0.000 \mathrm{E}+00$ & 0.0000 & $0.000 \mathrm{E}+00$ & 0.0000 & $0.000 \mathrm{E}+00$ & 0.0000 & $0.000 \mathrm{E}+00$ & 0.0000 & $0.000 \mathrm{E}+00$ & 0.0000 & $0.000 \mathrm{E}+00$ & 0.0000 & $2.003 E+00$ & 0.0349 \\
\hline 240 & $0.000 \mathrm{E}+00$ & 0.0000 & $0.000 \mathrm{E}+00$ & 0.0000 & $0.000 \mathrm{E}+00$ & 0.0000 & $0.000 \mathrm{E}+00$ & 0.0000 & $0.000 \mathrm{E}+00$ & 0.0000 & $0.000 \mathrm{E}+00$ & 0.0000 & $2.001 E+00$ & 0.0348 \\
\hline 99 & $0.000 \mathrm{E}+00$ & 0.0000 & $0.000 \mathrm{E}+00$ & 0.0000 & $0.000 \mathrm{E}+00$ & 0.0000 & $0.000 \mathrm{E}+00$ & 0.0000 & $0.000 \mathrm{E}+00$ & 0.0000 & $0.000 \mathrm{E}+00$ & 0.0000 & $9.101 \mathrm{E}-03$ & 0.0002 \\
\hline 228 & $0.000 \mathrm{E}+00$ & 0.0000 & $0.000 \mathrm{E}+00$ & 0.0000 & $0.000 \mathrm{E}+00$ & 0.0000 & $0.000 \mathrm{E}+00$ & 0.0000 & $0.000 \mathrm{E}+00$ & 0.0000 & $0.000 \mathrm{E}+00$ & 0.0000 & $7.575 \mathrm{E}+00$ & 0.1319 \\
\hline 230 & $0.000 \mathrm{E}+00$ & 0.0000 & $0.000 \mathrm{E}+00$ & 0.0000 & $0.000 \mathrm{E}+00$ & 0.0000 & $0.000 \mathrm{E}+00$ & 0.0000 & $0.000 \mathrm{E}+00$ & 0.0000 & $0.000 \mathrm{E}+00$ & 0.0000 & $4.935 E+00$ & 0.0859 \\
\hline 232 & $0.000 \mathrm{E}+00$ & 0.0000 & $0.000 \mathrm{E}+00$ & 0.0000 & $0.000 \mathrm{E}+00$ & 0.0000 & $0.000 \mathrm{E}+00$ & 0.0000 & $0.000 \mathrm{E}+00$ & 0.0000 & $0.000 \mathrm{E}+00$ & 0.0000 & $2.061 \mathrm{E}+00$ & 0.0359 \\
\hline 34 & $0.000 \mathrm{E}+00$ & 0.0000 & $0.000 \mathrm{E}+00$ & 0.0000 & $0.000 \mathrm{E}+00$ & 0.0000 & $0.000 \mathrm{E}+00$ & 0.0000 & $0.000 \mathrm{E}+00$ & 0.0000 & $0.000 \mathrm{E}+00$ & 0.0000 & $1.749 \mathrm{E}+00$ & 0.0305 \\
\hline 35 & $0.000 \mathrm{E}+00$ & 0.0000 & $0.000 \mathrm{E}+00$ & 0.0000 & $0.000 \mathrm{E}+00$ & 0.0000 & $0.000 \mathrm{E}+00$ & 0.0000 & $0.000 \mathrm{E}+00$ & 0.0000 & $0.000 \mathrm{E}+00$ & 0.0000 & $1.577 \mathrm{E}+00$ & 0.0275 \\
\hline 38 & $0.000 \mathrm{E}+00$ & 0.0000 & $0.000 \mathrm{E}+00$ & 0.0000 & $0.000 \mathrm{E}+00$ & 0.0000 & $0.000 \mathrm{E}+00$ & 0.0000 & $0.000 \mathrm{E}+00$ & 0.0000 & $0.000 \mathrm{E}+00$ & 0.0000 & $1.001 \mathrm{E}+01$ & 0.1744 \\
\hline & $0.000 \mathrm{E}+00$ & 0.0000 & $0.000 \mathrm{E}+00$ & 0.0000 & $0.000 \mathrm{E}+00$ & 0.0000 & $0.000 \mathrm{E}+00$ & 0.0000 & $0.000 \mathrm{E}+00$ & 0.0000 & $0.000 \mathrm{E}+00$ & 000 & -01 & 1.0000 \\
\hline
\end{tabular}

* Sum of all water independent and dependent pathways. 
RESRAD, Version 6.5

$\mathrm{T}^{1 / 2}$ Limit $=180$ days

07/15/2011 $11: 56 \quad$ Page 22

Summary : C746U Landfill Worker Deterministic Run
File : X: $\backslash F I N A L$ V2 $\backslash$ DOE FWD RUNS $\backslash C 746 U$ LW DOE AL FWD-FV2-70YR.RAD

Total Dose Contributions TDOSE(i,p,t) for Individual Radionuclides (i) and Pathways (p) As mrem/yr and Fraction of Total Dose At $t=5.000 \mathrm{E}+01$ years

Water Independent Pathways (Inhalation excludes radon)

\begin{tabular}{|c|c|c|c|c|c|c|c|c|c|c|c|c|c|c|}
\hline \multirow{2}{*}{ Nuclide } & \multicolumn{2}{|c|}{ Ground } & \multicolumn{2}{|c|}{ Inhalation } & \multicolumn{2}{|c|}{ Radon } & \multicolumn{2}{|c|}{ Plant } & \multicolumn{2}{|c|}{ Meat } & \multicolumn{2}{|c|}{ Milk } & \multicolumn{2}{|c|}{ Soil } \\
\hline & mrem/yr & fract. & mrem/yr & fract. & mrem/yr & fract. & mrem/yr & fract. & mrem/yr & fract. & mrem/yr & fract. & mrem/yr & fract. \\
\hline-241 & $4.069 \mathrm{E}-01$ & 0.0065 & $1.165 \mathrm{E}-02$ & 0.0002 & $0.000 \mathrm{E}+00$ & 0.0000 & $0.000 \mathrm{E}+00$ & 0.0000 & $0.000 \mathrm{E}+00$ & 0.0000 & $0.000 \mathrm{E}+00$ & 0.0000 & 1. $422 \mathrm{E}+00$ & 0.0226 \\
\hline-137 & $6.269 \mathrm{E}+00$ & 0.0997 & $8.650 \mathrm{E}-07$ & 0.0000 & $0.000 \mathrm{E}+00$ & 0.0000 & $0.000 \mathrm{E}+00$ & 0.0000 & $0.000 \mathrm{E}+00$ & 0.0000 & $0.000 \mathrm{E}+00$ & 0.0000 & $1.692 \mathrm{E}-02$ & 0.0003 \\
\hline-237 & $1.847 \mathrm{E}+00$ & 0.0294 & $1.027 \mathrm{E}-03$ & 0.0000 & $0.000 \mathrm{E}+00$ & 0.0000 & $0.000 \mathrm{E}+00$ & 0.0000 & $0.000 \mathrm{E}+00$ & 0.0000 & $0.000 \mathrm{E}+00$ & 0.0000 & $1.333 E-01$ & 0.0021 \\
\hline-238 & $1.036 \mathrm{E}-03$ & 0.0000 & $1.083 \mathrm{E}-02$ & 0.0002 & $0.000 \mathrm{E}+00$ & 0.0000 & $0.000 \mathrm{E}+00$ & 0.0000 & $0.000 \mathrm{E}+00$ & 0.0000 & $0.000 \mathrm{E}+00$ & 0.0000 & $1.325 \mathrm{E}+00$ & 0.0211 \\
\hline-239 & $3.176 \mathrm{E}-03$ & 0.0001 & 1. $622 \mathrm{E}-02$ & 0.0003 & $0.000 \mathrm{E}+00$ & 0.0000 & $0.000 \mathrm{E}+00$ & 0.0000 & $0.000 \mathrm{E}+00$ & 0.0000 & $0.000 \mathrm{E}+00$ & 0.0000 & $1.979 \mathrm{E}+00$ & 0.0315 \\
\hline-240 & $1.369 \mathrm{E}-03$ & 0.0000 & $1.616 \mathrm{E}-02$ & 0.0003 & $0.000 \mathrm{E}+00$ & 0.0000 & $0.000 \mathrm{E}+00$ & 0.0000 & $0.000 \mathrm{E}+00$ & 0.0000 & $0.000 \mathrm{E}+00$ & 0.0000 & $1.971 \mathrm{E}+00$ & 0.0313 \\
\hline-99 & $1.115 \mathrm{E}-03$ & 0.0000 & $1.492 \mathrm{E}-06$ & 0.0000 & $0.000 \mathrm{E}+00$ & 0.0000 & $0.000 \mathrm{E}+00$ & 0.0000 & $0.000 \mathrm{E}+00$ & 0.0000 & $0.000 \mathrm{E}+00$ & 0.0000 & $4.303 E-03$ & 0.0001 \\
\hline-228 & $1.462 \mathrm{E}-07$ & 0.0000 & $7.474 \mathrm{E}-12$ & 0.0000 & $0.000 \mathrm{E}+00$ & 0.0000 & $0.000 \mathrm{E}+00$ & 0.0000 & $0.000 \mathrm{E}+00$ & 0.0000 & $0.000 \mathrm{E}+00$ & 0.0000 & $1.437 \mathrm{E}-09$ & 0.0000 \\
\hline-230 & $7.647 \mathrm{E}+00$ & 0.1216 & $3.774 \mathrm{E}-02$ & 0.0006 & $0.000 \mathrm{E}+00$ & 0.0000 & $0.000 \mathrm{E}+00$ & 0.0000 & $0.000 \mathrm{E}+00$ & 0.0000 & $0.000 \mathrm{E}+00$ & 0.0000 & $5.207 \mathrm{E}+00$ & 0.0828 \\
\hline-232 & $2.030 E+01$ & 0.3228 & $2.551 \mathrm{E}-03$ & 0.0000 & $0.000 \mathrm{E}+00$ & 0.0000 & $0.000 \mathrm{E}+00$ & 0.0000 & $0.000 \mathrm{E}+00$ & 0.0000 & $0.000 \mathrm{E}+00$ & 0.0000 & $9.350 \mathrm{E}-01$ & 0.0149 \\
\hline 34 & $2.136 \mathrm{E}-02$ & 0.0003 & $5.684 \mathrm{E}-03$ & 0.0001 & $0.000 \mathrm{E}+00$ & 0.0000 & $0.000 \mathrm{E}+00$ & 0.0000 & $0.000 \mathrm{E}+00$ & 0.0000 & $0.000 \mathrm{E}+00$ & 0.0000 & $1.726 \mathrm{E}+00$ & 0.0274 \\
\hline 35 & $1.510 \mathrm{E}+00$ & 0.0240 & $2.192 \mathrm{E}-04$ & 0.0000 & $0.000 \mathrm{E}+00$ & 0.0000 & $0.000 \mathrm{E}+00$ & 0.0000 & $0.000 \mathrm{E}+00$ & 0.0000 & $0.000 \mathrm{E}+00$ & 0.0000 & $6.978 \mathrm{E}-02$ & 0.0011 \\
\hline 38 & $8.285 E+00$ & 0.1317 & $4.818 E-03$ & 0.0001 & $0.000 \mathrm{E}+00$ & 0.0000 & $0.000 \mathrm{E}+00$ & 0.0000 & $0.000 \mathrm{E}+00$ & 0.0000 & $0.000 \mathrm{E}+00$ & 0.0000 & $1.710 \mathrm{E}+00$ & 0.0272 \\
\hline & $4.630 \mathrm{E}+01$ & 0.7360 & $1.069 \mathrm{E}-01$ & 0.0017 & $0.000 \mathrm{E}+00$ & 0.0000 & $0.000 \mathrm{E}+00$ & 0.0000 & $0.000 \mathrm{E}+00$ & 0.0000 & $0.000 \mathrm{E}+00$ & 0.0000 & 1. $650 \mathrm{E}+01$ & 0.2623 \\
\hline
\end{tabular}

Total Dose Contributions TDOSE(i,p,t) for Individual Radionuclides (i) and Pathways (p) As mrem/yr and Fraction of Total Dose At $t=5.000 \mathrm{E}+01$ years

Water Dependent Pathways

\begin{tabular}{|c|c|c|c|c|c|c|c|c|c|c|c|c|c|c|}
\hline & \multicolumn{2}{|c|}{ Water } & \multicolumn{2}{|c|}{ Fish } & \multicolumn{2}{|c|}{ Radon } & \multicolumn{2}{|c|}{ Plant } & \multicolumn{2}{|c|}{ Meat } & \multicolumn{2}{|c|}{ Milk } & \multicolumn{2}{|c|}{ All Pathways* } \\
\hline clide & mrem/yr & fract. & mrem/yr & fract. & mrem/yr & fract. & mrem/yr & fract. & mrem/yr & fract. & mrem/yr & fract. & mrem/yr & fract. \\
\hline-241 & $0.000 \mathrm{E}+00$ & 0.0000 & $0.000 \mathrm{E}+00$ & 0.0000 & $0.000 \mathrm{E}+00$ & 0.0000 & $0.000 \mathrm{E}+00$ & 0.0000 & $0.000 \mathrm{E}+00$ & 0.0000 & $0.000 \mathrm{E}+00$ & 0.0000 & $1.841 \mathrm{E}+00$ & 0.0293 \\
\hline-137 & $0.000 \mathrm{E}+00$ & 0.0000 & $0.000 \mathrm{E}+00$ & 0.0000 & $0.000 \mathrm{E}+00$ & 0.0000 & $0.000 \mathrm{E}+00$ & 0.0000 & $0.000 \mathrm{E}+00$ & 0.0000 & $0.000 \mathrm{E}+00$ & 0.0000 & $6.286 \mathrm{E}+00$ & 0.0999 \\
\hline-237 & $0.000 \mathrm{E}+00$ & 0.0000 & $0.000 \mathrm{E}+00$ & 0.0000 & $0.000 \mathrm{E}+00$ & 0.0000 & $0.000 \mathrm{E}+00$ & 0.0000 & $0.000 \mathrm{E}+00$ & 0.0000 & $0.000 \mathrm{E}+00$ & 0.0000 & $1.982 \mathrm{E}+00$ & 0.0315 \\
\hline-238 & $0.000 \mathrm{E}+00$ & 0.0000 & $0.000 \mathrm{E}+00$ & 0.0000 & $0.000 \mathrm{E}+00$ & 0.0000 & $0.000 \mathrm{E}+00$ & 0.0000 & $0.000 \mathrm{E}+00$ & 0.0000 & $0.000 \mathrm{E}+00$ & 0.0000 & $1.337 \mathrm{E}+00$ & 0.0213 \\
\hline-239 & $0.000 \mathrm{E}+00$ & 0.0000 & $0.000 \mathrm{E}+00$ & 0.0000 & $0.000 \mathrm{E}+00$ & 0.0000 & $0.000 \mathrm{E}+00$ & 0.0000 & $0.000 \mathrm{E}+00$ & 0.0000 & $0.000 E+00$ & 0.0000 & $1.998 \mathrm{E}+00$ & 0.0318 \\
\hline-240 & $0.000 \mathrm{E}+00$ & 0.0000 & $0.000 \mathrm{E}+00$ & 0.0000 & $0.000 \mathrm{E}+00$ & 0.0000 & $0.000 \mathrm{E}+00$ & 0.0000 & $0.000 \mathrm{E}+00$ & 0.0000 & $0.000 E+00$ & 0.0000 & $1.989 \mathrm{E}+00$ & 0.0316 \\
\hline-99 & $0.000 \mathrm{E}+00$ & 0.0000 & $0.000 \mathrm{E}+00$ & 0.0000 & $0.000 \mathrm{E}+00$ & 0.0000 & $0.000 \mathrm{E}+00$ & 0.0000 & $0.000 \mathrm{E}+00$ & 0.0000 & $0.000 \mathrm{E}+00$ & 0.0000 & $5.420 \mathrm{E}-03$ & 0.0001 \\
\hline-228 & $0.000 \mathrm{E}+00$ & 0.0000 & $0.000 \mathrm{E}+00$ & 0.0000 & $0.000 \mathrm{E}+00$ & 0.0000 & $0.000 \mathrm{E}+00$ & 0.0000 & $0.000 \mathrm{E}+00$ & 0.0000 & $0.000 \mathrm{E}+00$ & 0.0000 & $1.476 \mathrm{E}-07$ & 0.0000 \\
\hline-230 & $0.000 \mathrm{E}+00$ & 0.0000 & $0.000 \mathrm{E}+00$ & 0.0000 & $0.000 \mathrm{E}+00$ & 0.0000 & $0.000 \mathrm{E}+00$ & 0.0000 & $0.000 \mathrm{E}+00$ & 0.0000 & $0.000 E+00$ & 0.0000 & $1.289 \mathrm{E}+01$ & 0.2050 \\
\hline 232 & $0.000 \mathrm{E}+00$ & 0.0000 & $0.000 \mathrm{E}+00$ & 0.0000 & $0.000 \mathrm{E}+00$ & 0.0000 & $0.000 \mathrm{E}+00$ & 0.0000 & $0.000 \mathrm{E}+00$ & 0.0000 & $0.000 \mathrm{E}+00$ & 0.0000 & $2.124 \mathrm{E}+01$ & 0.3377 \\
\hline 34 & $0.000 \mathrm{E}+00$ & 0.0000 & $0.000 \mathrm{E}+00$ & 0.0000 & $0.000 \mathrm{E}+00$ & 0.0000 & $0.000 \mathrm{E}+00$ & 0.0000 & $0.000 \mathrm{E}+00$ & 0.0000 & $0.000 \mathrm{E}+00$ & 0.0000 & $1.753 \mathrm{E}+00$ & 0.0279 \\
\hline 35 & $0.000 \mathrm{E}+00$ & 0.0000 & $0.000 \mathrm{E}+00$ & 0.0000 & $0.000 \mathrm{E}+00$ & 0.0000 & $0.000 \mathrm{E}+00$ & 0.0000 & $0.000 \mathrm{E}+00$ & 0.0000 & $0.000 E+00$ & 0.0000 & $1.580 \mathrm{E}+00$ & 0.0251 \\
\hline 38 & $0.000 \mathrm{E}+00$ & 0.0000 & $0.000 \mathrm{E}+00$ & 0.0000 & $0.000 \mathrm{E}+00$ & 0.0000 & $0.000 \mathrm{E}+00$ & 0.0000 & $0.000 \mathrm{E}+00$ & 0.0000 & $0.000 \mathrm{E}+00$ & 0.0000 & $1.000 \mathrm{E}+01$ & 0.1590 \\
\hline & $0.000 \mathrm{E}+00$ & 0.0000 & $0.000 \mathrm{E}+00$ & 0.0000 & $0.000 \mathrm{E}+00$ & 0.0000 & $0.000 \mathrm{E}+00$ & 0.0000 & $0.000 \mathrm{E}+00$ & 0.0000 & $0.000 \mathrm{E}+00$ & 0.0000 & $E+01$ & 1. \\
\hline
\end{tabular}

* Sum of all water independent and dependent pathways. 
RESRAD, Version 6.5

$\mathrm{T}^{1 / 2}$ Limit $=180$ days

File : C746U Landfill Worker Deterministic Run
File $\backslash$ FINAL V2 $\backslash$ DOE FWD RUNS \C746U LW DOE AL FWD-FV2-70YR.RAD

Total Dose Contributions TDOSE(i,p,t) for Individual Radionuclides (i) and Pathways (p) As mrem/yr and Fraction of Total Dose At $t=7.000 \mathrm{E}+01$ years

Water Independent Pathways (Inhalation excludes radon)

\begin{tabular}{|c|c|c|c|c|c|c|c|c|c|c|c|c|c|c|}
\hline \multirow{2}{*}{ Nuclide } & \multicolumn{2}{|c|}{ Ground } & \multicolumn{2}{|c|}{ Inhalation } & \multicolumn{2}{|c|}{ Radon } & \multicolumn{2}{|c|}{ Plant } & \multicolumn{2}{|c|}{ Meat } & \multicolumn{2}{|c|}{ Milk } & \multicolumn{2}{|c|}{ Soil } \\
\hline & mrem/yr & fract. & mrem/yr & fract. & mrem/yr & fract. & mrem/yr & fract. & mrem/yr & fract. & mrem/yr & fract. & mrem/yr & fract. \\
\hline-241 & $3.941 \mathrm{E}-01$ & 0.0062 & $1.129 \mathrm{E}-02$ & 0.0002 & $0.000 \mathrm{E}+00$ & 0.0000 & $0.000 \mathrm{E}+00$ & 0.0000 & $0.000 \mathrm{E}+00$ & 0.0000 & $0.000 \mathrm{E}+00$ & 0.0000 & $1.377 \mathrm{E}+00$ & 0.0216 \\
\hline-137 & $3.946 \mathrm{E}+00$ & 0.0620 & $5.445 \mathrm{E}-07$ & 0.0000 & $0.000 \mathrm{E}+00$ & 0.0000 & $0.000 \mathrm{E}+00$ & 0.0000 & $0.000 \mathrm{E}+00$ & 0.0000 & $0.000 \mathrm{E}+00$ & 0.0000 & $1.065 \mathrm{E}-02$ & 0.0002 \\
\hline-237 & $1.842 \mathrm{E}+00$ & 0.0289 & $1.024 \mathrm{E}-03$ & 0.0000 & $0.000 \mathrm{E}+00$ & 0.0000 & $0.000 \mathrm{E}+00$ & 0.0000 & $0.000 \mathrm{E}+00$ & 0.0000 & $0.000 \mathrm{E}+00$ & 0.0000 & $1.329 \mathrm{E}-01$ & 0.0021 \\
\hline-238 & $8.843 E-04$ & 0.0000 & $9.240 \mathrm{E}-03$ & 0.0001 & $0.000 \mathrm{E}+00$ & 0.0000 & $0.000 \mathrm{E}+00$ & 0.0000 & $0.000 \mathrm{E}+00$ & 0.0000 & $0.000 \mathrm{E}+00$ & 0.0000 & $1.131 \mathrm{E}+00$ & 0.0178 \\
\hline-239 & $3.174 \mathrm{E}-03$ & 0.0000 & 1. $621 \mathrm{E}-02$ & 0.0003 & $0.000 \mathrm{E}+00$ & 0.0000 & $0.000 \mathrm{E}+00$ & 0.0000 & $0.000 \mathrm{E}+00$ & 0.0000 & $0.000 \mathrm{E}+00$ & 0.0000 & $1.977 \mathrm{E}+00$ & 0.0310 \\
\hline-240 & $1.366 \mathrm{E}-03$ & 0.0000 & 1. $612 \mathrm{E}-02$ & 0.0003 & $0.000 \mathrm{E}+00$ & 0.0000 & $0.000 \mathrm{E}+00$ & 0.0000 & $0.000 \mathrm{E}+00$ & 0.0000 & $0.000 \mathrm{E}+00$ & 0.0000 & $1.966 \mathrm{E}+00$ & 0.0309 \\
\hline-99 & $9.027 E-04$ & 0.0000 & $1.207 \mathrm{E}-06$ & 0.0000 & $0.000 \mathrm{E}+00$ & 0.0000 & $0.000 \mathrm{E}+00$ & 0.0000 & $0.000 \mathrm{E}+00$ & 0.0000 & $0.000 \mathrm{E}+00$ & 0.0000 & $3.482 \mathrm{E}-03$ & 0.0001 \\
\hline-228 & $1.042 \mathrm{E}-10$ & 0.0000 & $5.327 \mathrm{E}-15$ & 0.0000 & $0.000 \mathrm{E}+00$ & 0.0000 & $0.000 \mathrm{E}+00$ & 0.0000 & $0.000 \mathrm{E}+00$ & 0.0000 & $0.000 \mathrm{E}+00$ & 0.0000 & $1.024 \mathrm{E}-12$ & 0.0000 \\
\hline-230 & $1.061 \mathrm{E}+01$ & 0.1667 & $3.779 \mathrm{E}-02$ & 0.0006 & $0.000 \mathrm{E}+00$ & 0.0000 & $0.000 \mathrm{E}+00$ & 0.0000 & $0.000 \mathrm{E}+00$ & 0.0000 & $0.000 \mathrm{E}+00$ & 0.0000 & $5.557 \mathrm{E}+00$ & 0.0873 \\
\hline-232 & $2.036 \mathrm{E}+01$ & 0.3197 & $2.554 \mathrm{E}-03$ & 0.0000 & $0.000 \mathrm{E}+00$ & 0.0000 & $0.000 \mathrm{E}+00$ & 0.0000 & $0.000 \mathrm{E}+00$ & 0.0000 & $0.000 \mathrm{E}+00$ & 0.0000 & $9.366 \mathrm{E}-01$ & 0.0147 \\
\hline 34 & $2.397 E-02$ & 0.0004 & $5.692 \mathrm{E}-03$ & 0.0001 & $0.000 \mathrm{E}+00$ & 0.0000 & $0.000 \mathrm{E}+00$ & 0.0000 & $0.000 \mathrm{E}+00$ & 0.0000 & $0.000 \mathrm{E}+00$ & 0.0000 & $1.727 \mathrm{E}+00$ & 0.0271 \\
\hline 35 & $1.511 \mathrm{E}+00$ & 0.0237 & $2.255 \mathrm{E}-04$ & 0.0000 & $0.000 \mathrm{E}+00$ & 0.0000 & $0.000 \mathrm{E}+00$ & 0.0000 & $0.000 \mathrm{E}+00$ & 0.0000 & $0.000 \mathrm{E}+00$ & 0.0000 & $7.080 \mathrm{E}-02$ & 0.0011 \\
\hline 38 & $8.281 E+00$ & 0.1300 & $4.815 E-03$ & 0.0001 & $0.000 \mathrm{E}+00$ & 0.0000 & $0.000 \mathrm{E}+00$ & 0.0000 & $0.000 \mathrm{E}+00$ & 0.0000 & $0.000 \mathrm{E}+00$ & 0.0000 & $1.709 \mathrm{E}+00$ & 0.0268 \\
\hline & $4.697 \mathrm{E}+01$ & 0.7377 & $1.050 \mathrm{E}-01$ & 0.0016 & $0.000 \mathrm{E}+00$ & 0.0000 & $0.000 \mathrm{E}+00$ & 0.0000 & $0.000 \mathrm{E}+00$ & 0.0000 & $0.000 \mathrm{E}+00$ & 0.0000 & 1. $660 \mathrm{E}+01$ & 0.2607 \\
\hline
\end{tabular}

Total Dose Contributions TDOSE(i,p,t) for Individual Radionuclides (i) and Pathways (p) As mrem/yr and Fraction of Total Dose At $t=7.000 \mathrm{E}+01$ years

Water Dependent Pathways

\begin{tabular}{|c|c|c|c|c|c|c|c|c|c|c|c|c|c|c|}
\hline & \multicolumn{2}{|c|}{ Water } & \multicolumn{2}{|c|}{ Fish } & \multicolumn{2}{|c|}{ Radon } & \multicolumn{2}{|c|}{ Plant } & \multicolumn{2}{|c|}{ Meat } & \multicolumn{2}{|c|}{ Milk } & \multicolumn{2}{|c|}{ All Pathways* } \\
\hline clide & mrem/yr & fract. & mrem/yr & fract. & mrem/yr & fract. & mrem/yr & fract. & mrem/yr & fract. & mrem/yr & fract. & mrem/yr & fract. \\
\hline 241 & $0.000 \mathrm{E}+00$ & 0.0000 & $0.000 \mathrm{E}+00$ & 0.0000 & $0.000 \mathrm{E}+00$ & 0.0000 & $0.000 \mathrm{E}+00$ & 0.0000 & $0.000 \mathrm{E}+00$ & 0.0000 & $0.000 \mathrm{E}+00$ & 0.0000 & $1.783 \mathrm{E}+00$ & 0.0280 \\
\hline-137 & $0.000 \mathrm{E}+00$ & 0.0000 & $0.000 \mathrm{E}+00$ & 0.0000 & $0.000 \mathrm{E}+00$ & 0.0000 & $0.000 \mathrm{E}+00$ & 0.0000 & $0.000 \mathrm{E}+00$ & 0.0000 & $0.000 \mathrm{E}+00$ & 0.0000 & $3.957 \mathrm{E}+00$ & 0.0621 \\
\hline-237 & $0.000 \mathrm{E}+00$ & 0.0000 & $0.000 \mathrm{E}+00$ & 0.0000 & $0.000 \mathrm{E}+00$ & 0.0000 & $0.000 \mathrm{E}+00$ & 0.0000 & $0.000 \mathrm{E}+00$ & 0.0000 & $0.000 \mathrm{E}+00$ & 0.0000 & $1.976 \mathrm{E}+00$ & 0.0310 \\
\hline-238 & $0.000 \mathrm{E}+00$ & 0.0000 & $0.000 \mathrm{E}+00$ & 0.0000 & $0.000 \mathrm{E}+00$ & 0.0000 & $0.000 \mathrm{E}+00$ & 0.0000 & $0.000 \mathrm{E}+00$ & 0.0000 & $0.000 \mathrm{E}+00$ & 0.0000 & $1.141 \mathrm{E}+00$ & 0.0179 \\
\hline-239 & $0.000 \mathrm{E}+00$ & 0.0000 & $0.000 \mathrm{E}+00$ & 0.0000 & $0.000 \mathrm{E}+00$ & 0.0000 & $0.000 \mathrm{E}+00$ & 0.0000 & $0.000 \mathrm{E}+00$ & 0.0000 & $0.000 E+00$ & 0.0000 & $1.996 \mathrm{E}+00$ & 0.0313 \\
\hline-240 & $0.000 \mathrm{E}+00$ & 0.0000 & $0.000 \mathrm{E}+00$ & 0.0000 & $0.000 \mathrm{E}+00$ & 0.0000 & $0.000 \mathrm{E}+00$ & 0.0000 & $0.000 \mathrm{E}+00$ & 0.0000 & $0.000 E+00$ & 0.0000 & $1.984 \mathrm{E}+00$ & 0.0311 \\
\hline-99 & $0.000 \mathrm{E}+00$ & 0.0000 & $0.000 \mathrm{E}+00$ & 0.0000 & $0.000 \mathrm{E}+00$ & 0.0000 & $0.000 \mathrm{E}+00$ & 0.0000 & $0.000 \mathrm{E}+00$ & 0.0000 & $0.000 \mathrm{E}+00$ & 0.0000 & $4.386 \mathrm{E}-03$ & 0.0001 \\
\hline-228 & $0.000 \mathrm{E}+00$ & 0.0000 & $0.000 \mathrm{E}+00$ & 0.0000 & $0.000 \mathrm{E}+00$ & 0.0000 & $0.000 \mathrm{E}+00$ & 0.0000 & $0.000 \mathrm{E}+00$ & 0.0000 & $0.000 \mathrm{E}+00$ & 0.0000 & $1.052 \mathrm{E}-10$ & 0.0000 \\
\hline-230 & $0.000 \mathrm{E}+00$ & 0.0000 & $0.000 \mathrm{E}+00$ & 0.0000 & $0.000 \mathrm{E}+00$ & 0.0000 & $0.000 \mathrm{E}+00$ & 0.0000 & $0.000 \mathrm{E}+00$ & 0.0000 & $0.000 E+00$ & 0.0000 & $1.621 \mathrm{E}+01$ & 0.2545 \\
\hline-232 & $0.000 \mathrm{E}+00$ & 0.0000 & $0.000 \mathrm{E}+00$ & 0.0000 & $0.000 \mathrm{E}+00$ & 0.0000 & $0.000 \mathrm{E}+00$ & 0.0000 & $0.000 \mathrm{E}+00$ & 0.0000 & $0.000 \mathrm{E}+00$ & 0.0000 & $2.130 \mathrm{E}+01$ & 0.3344 \\
\hline 34 & $0.000 \mathrm{E}+00$ & 0.0000 & $0.000 \mathrm{E}+00$ & 0.0000 & $0.000 \mathrm{E}+00$ & 0.0000 & $0.000 \mathrm{E}+00$ & 0.0000 & $0.000 \mathrm{E}+00$ & 0.0000 & $0.000 \mathrm{E}+00$ & 0.0000 & $1.756 \mathrm{E}+00$ & 0.0276 \\
\hline 35 & $0.000 \mathrm{E}+00$ & 0.0000 & $0.000 \mathrm{E}+00$ & 0.0000 & $0.000 \mathrm{E}+00$ & 0.0000 & $0.000 \mathrm{E}+00$ & 0.0000 & $0.000 \mathrm{E}+00$ & 0.0000 & $0.000 \mathrm{E}+00$ & 0.0000 & $1.582 \mathrm{E}+00$ & 0.0248 \\
\hline 38 & $0.000 \mathrm{E}+00$ & 0.0000 & $0.000 \mathrm{E}+00$ & 0.0000 & $0.000 \mathrm{E}+00$ & 0.0000 & $0.000 \mathrm{E}+00$ & 0.0000 & $0.000 \mathrm{E}+00$ & 0.0000 & $0.000 \mathrm{E}+00$ & 0.0000 & $9.995 \mathrm{E}+00$ & 0.1570 \\
\hline & $0.000 \mathrm{E}+00$ & 0.0000 & $0.000 \mathrm{E}+00$ & 0.0000 & $0.000 \mathrm{E}+00$ & 0.0000 & $0.000 \mathrm{E}+00$ & 0.0000 & $0.000 \mathrm{E}+00$ & 0.0000 & $0.000 \mathrm{E}+00$ & 0.0000 & $3 E+01$ & 1. \\
\hline
\end{tabular}

* Sum of all water independent and dependent pathways. 
RESRAD, Version $6.5 \quad \mathrm{~T}^{1 / 2}$ Limit $=180$ days

Summary : C746U Landfill Worker Deterministic Run
File : X: $\backslash$ FINAL V2 $\backslash$ DOE FWD RUNS \C746U LW DOE AL FWD-FV2-70YR.RAD

Dose/Source Ratios Summed Over All Pathways

Parent and Progeny Principal Radionuclide Contributions Indicated

Parent Product Thread DSR $(j, t)$ At Time in Years (mrem/yr)/(pCi/g)

(i) (j) Fraction $0.000 \mathrm{E}+001.000 \mathrm{E}+00 \quad 5.000 \mathrm{E}+017.000 \mathrm{E}+01$

Am-241

Am-241

Am-241

Am-241

Am-241

$\mathrm{Cs}-137+\mathrm{D}$

$\mathrm{Np}-237+\mathrm{D}$

$\mathrm{Np}-237+\mathrm{D}$

$\mathrm{Np}-237+\mathrm{D}$

$\mathrm{Np}-237+\mathrm{D}$

$\mathrm{Pu}-238$

$\mathrm{Pu}-238$

1. $840 E-09$

$\begin{array}{llllll}\text { Am-241 } & 1.000 \mathrm{E}+00 & 2.850 \mathrm{E}-02 & 2.845 \mathrm{E}-02 & 2.630 \mathrm{E}-02 & 2.546 \mathrm{E}-02\end{array}$

$\begin{array}{lllllll}\mathrm{Np}-237+\mathrm{D} & 1.000 \mathrm{E}+00 & 2.940 \mathrm{E}-08 & 8.812 \mathrm{E}-08 & 2.842 \mathrm{E}-06 & 3.898 \mathrm{E}-06\end{array}$

$\begin{array}{llllll}\mathrm{U}-233 & 1.000 \mathrm{E}+00 & 1.383 \mathrm{E}-15 & 9.674 \mathrm{E}-15 & 1.027 \mathrm{E}-11 & 1.978 \mathrm{E}-11\end{array}$

$\begin{array}{llllllll}\mathrm{Th}-229+\mathrm{D} & 1.000 \mathrm{E}+00 & 1.756 \mathrm{E}-18 & 2.633 \mathrm{E}-17 & 8.837 \mathrm{E}-13 & 2.382 \mathrm{E}-12\end{array}$

$\operatorname{LDSR}(j) \quad 2.850 \mathrm{E}-02 \quad 2.845 \mathrm{E}-02 \quad 2.630 \mathrm{E}-02 \quad 2.547 \mathrm{E}-02$

$\mathrm{Cs}-137+\mathrm{D} \quad 1.000 \mathrm{E}+00 \quad 5.262 \mathrm{E}-01 \quad 5.142 \mathrm{E}-01 \quad 1.654 \mathrm{E}-01 \quad 1.041 \mathrm{E}-01$

$\mathrm{Np}-237+\mathrm{D} \quad 1.000 \mathrm{E}+00 \quad 1.816 \mathrm{E}-01 \quad 1.816 \mathrm{E}-01 \quad 1.802 \mathrm{E}-01 \quad 1.796 \mathrm{E}-01$

U-233 1.000E+00 1.281E-08 3.843E-08 $1.288 \mathrm{E}-06 \quad 1.795 \mathrm{E}-06$

$\begin{array}{lllllll}\mathrm{Th}-229+\mathrm{D} & 1.000 \mathrm{E}+00 & 2.169 \mathrm{E}-11 & 1.518 \mathrm{E}-10 & 1.652 \mathrm{E}-07 & 3.213 \mathrm{E}-07\end{array}$

$\operatorname{\sum DSR}(j) \quad 1.816 \mathrm{E}-01 \quad 1.816 \mathrm{E}-01 \quad 1.802 \mathrm{E}-01 \quad 1.796 \mathrm{E}-01$

$\mathrm{Pu}-238$

$\begin{array}{lllllll}\mathrm{Pu}-238 & 1.000 \mathrm{E}+00 & 2.547 \mathrm{E}-02 & 2.527 \mathrm{E}-02 & 1.714 \mathrm{E}-02 & 1.463 \mathrm{E}-02\end{array}$

$\begin{array}{lllllll}\mathrm{U}-234 & 1.000 \mathrm{E}+00 & 7.728 \mathrm{E}-09 & 2.310 \mathrm{E}-08 & 6.445 \mathrm{E}-07 & 8.363 \mathrm{E}-07\end{array}$

$\begin{array}{llllll}\mathrm{Th}-230 & 1.000 \mathrm{E}+00 & 9.980 \mathrm{E}-14 & 6.970 \mathrm{E}-13 & 6.720 \mathrm{E}-10 & 1.247 \mathrm{E}-09\end{array}$

$\mathrm{Ra}-226+\mathrm{D} \quad 1.000 \mathrm{E}+00 \quad 8.234 \mathrm{E}-16 \quad 1.233 \mathrm{E}-14 \quad 3.832 \mathrm{E}-10 \quad 1.002 \mathrm{E}-09$

$\mathrm{Pb}-210+\mathrm{D} \quad 1.000 \mathrm{E}+00 \quad 5.964 \mathrm{E}-19 \quad 1.836 \mathrm{E}-17 \quad 1.347 \mathrm{E}-11 \quad 4.480 \mathrm{E}-11$

$\operatorname{LDSR}(j) \quad 2.547 \mathrm{E}-02 \quad 2.527 \mathrm{E}-02 \quad 1.714 \mathrm{E}-02 \quad 1.463 \mathrm{E}-02$

$\begin{array}{llllll}\mathrm{Pu}-239 & 1.000 \mathrm{E}+00 & 2.782 \mathrm{E}-02 & 2.782 \mathrm{E}-02 & 2.775 \mathrm{E}-02 & 2.772 \mathrm{E}-02\end{array}$

$\begin{array}{lllllll}\mathrm{U}-235+\mathrm{D} & 1.000 \mathrm{E}+00 & 5.975 \mathrm{E}-11 & 1.793 \mathrm{E}-10 & 6.024 \mathrm{E}-09 & 8.403 \mathrm{E}-09\end{array}$

$\begin{array}{lllllll}\mathrm{Pa}-231 & 1.000 \mathrm{E}+00 & 3.752 \mathrm{E}-16 & 2.626 \mathrm{E}-15 & 2.865 \mathrm{E}-12 & 5.580 \mathrm{E}-12\end{array}$

$\mathrm{AC}-227+\mathrm{D} \quad 1.000 \mathrm{E}+00 \quad 1.227 \mathrm{E}-17 \quad 1.828 \mathrm{E}-16 \quad 4.441 \mathrm{E}-12 \quad 1.071 \mathrm{E}-11$

$\operatorname{\sum DSR}(j) \quad 2.782 \mathrm{E}-02 \quad 2.782 \mathrm{E}-02 \quad 2.775 \mathrm{E}-02 \quad 2.772 \mathrm{E}-02$

Pu-240 4.950E-08 1.376E-09 $1.376 E-09 \quad 1.367 E-09 \quad 1.364 E-09$

$\begin{array}{llllll}\mathrm{Pu}-240 \quad 1.000 \mathrm{E}+00 & 2.779 \mathrm{E}-02 & 2.779 \mathrm{E}-02 & 2.762 \mathrm{E}-02 & 2.755 \mathrm{E}-02\end{array}$

$\begin{array}{lllllll}\mathrm{U}-236 & 1.000 \mathrm{E}+00 & 7.739 \mathrm{E}-11 & 2.322 \mathrm{E}-10 & 7.787 \mathrm{E}-09 & 1.085 \mathrm{E}-08\end{array}$

$\begin{array}{llllll}\mathrm{Th}-232 & 1.000 \mathrm{E}+00 & 6.238 \mathrm{E}-21 & 4.367 \mathrm{E}-20 & 4.761 \mathrm{E}-17 & 9.268 \mathrm{E}-17\end{array}$

$\begin{array}{llllll}\mathrm{Ra}-228+\mathrm{D} & 1.000 \mathrm{E}+00 & 7.279 \mathrm{E}-21 & 1.065 \mathrm{E}-19 & 1.370 \mathrm{E}-15 & 2.913 \mathrm{E}-15\end{array}$

Th-228+D 1.000E+00 7.965E-22 $2.280 \mathrm{E}-20 \quad 1.928 \mathrm{E}-15 \quad 4.261 \mathrm{E}-15$

$\begin{array}{llllll}\operatorname{DDSR}(j) & 2.779 \mathrm{E}-02 & 2.779 \mathrm{E}-02 & 2.762 \mathrm{E}-02 & 2.755 \mathrm{E}-02\end{array}$

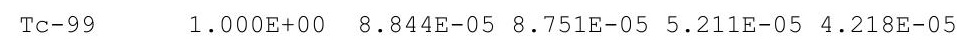

Th-228+D 1.000E+00 1.360E+00 9.469E-01 $1.845 \mathrm{E}-08 \quad 1.315 \mathrm{E}-11$

$\begin{array}{llllll}\mathrm{Th}-230 & 1.000 \mathrm{E}+00 & 2.351 \mathrm{E}-02 & 2.351 \mathrm{E}-02 & 2.350 \mathrm{E}-02 & 2.349 \mathrm{E}-02\end{array}$

$\mathrm{Ra}-226+\mathrm{D} \quad 1.000 \mathrm{E}+00 \quad 3.878 \mathrm{E}-04 \quad 1.163 \mathrm{E}-03 \quad 3.871 \mathrm{E}-02 \quad 5.379 \mathrm{E}-02$

$\mathrm{Pb}-210+\mathrm{D} \quad 1.000 \mathrm{E}+00 \quad 4.667 \mathrm{E}-07 \quad 3.238 \mathrm{E}-06 \quad 2.251 \mathrm{E}-03 \quad 3.757 \mathrm{E}-03$

$\operatorname{LDSR}(j) \quad 2.390 \mathrm{E}-02 \quad 2.468 \mathrm{E}-02 \quad 6.446 \mathrm{E}-02 \quad 8.104 \mathrm{E}-02$ 


\section{RESRAD, Version $6.5 \quad T^{1 / 2}$ Limit $=180$ days}

Summary : C746U Landfill Worker Deterministic Run

File : $X: \backslash F I N A L$ V2 $\backslash$ DOE FWD RUNS $\backslash C 746 U$ LW DOE AL FWD-FV2-70YR. RAD

Dose/Source Ratios Summed Over All Pathways

Parent and Progeny Principal Radionuclide Contributions Indicated

\begin{tabular}{|c|c|c|c|c|c|c|}
\hline Parent & Product & Thread & $R(j, t) \quad A t$ & Time in $Y$ & (mre & $\mathrm{em} / \mathrm{yr}) /(\mathrm{pCi}$ \\
\hline (i) & $(j)$ & Fraction & $0.000 \mathrm{E}+00$ & $1.000 \mathrm{E}+00$ & $5.000 \mathrm{E}+01$ & $7.000 \mathrm{E}+01$ \\
\hline-232 & Th-232 & $1.000 \mathrm{E}+00$ & $2.563 E-02$ & $2.563 E-02$ & $2.563 E-02$ & $2.562 \mathrm{E}-02$ \\
\hline-232 & $\mathrm{Ra}-228+\mathrm{D}$ & $1.000 \mathrm{E}+00$ & $5.887 \mathrm{E}-02$ & $1.676 \mathrm{E}-01$ & $1.014 \mathrm{E}+00$ & $1.016 \mathrm{E}+00$ \\
\hline-232 & $\mathrm{Th}-228+\mathrm{D}$ & $1.000 \mathrm{E}+00$ & $1.049 \mathrm{E}-02$ & $6.433 E-02$ & $1.616 \mathrm{E}+00$ & $1.621 \mathrm{E}+00$ \\
\hline-232 & $\sum \operatorname{DSR}(j)$ & & $9.499 \mathrm{E}-02$ & $2.576 \mathrm{E}-01$ & $2.655 \mathrm{E}+00$ & $2.662 \mathrm{E}+00$ \\
\hline-234 & $\mathrm{U}-234$ & $1.000 \mathrm{E}+00$ & $5.467 \mathrm{E}-03$ & $5.466 \mathrm{E}-03$ & $5.458 \mathrm{E}-03$ & $5.455 \mathrm{E}-03$ \\
\hline-234 & Th-230 & $1.000 \mathrm{E}+00$ & $1.058 \mathrm{E}-07$ & $3.175 E-07$ & $1.068 \mathrm{E}-05$ & $1.490 \mathrm{E}-05$ \\
\hline-234 & $\mathrm{Ra}-226+\mathrm{D}$ & $1.000 \mathrm{E}+00$ & $1.164 \mathrm{E}-09$ & $8.144 \mathrm{E}-09$ & $8.830 \mathrm{E}-06$ & $1.715 \mathrm{E}-05$ \\
\hline-234 & $\mathrm{~Pb}-210+\mathrm{D}$ & $1.000 \mathrm{E}+00$ & 1. 052E-12 & 1. $567 \mathrm{E}-11$ & $3.816 \mathrm{E}-07$ & $9.196 \mathrm{E}-07$ \\
\hline-234 & $\sum \operatorname{DSR}(j)$ & & $5.467 \mathrm{E}-03$ & $5.467 \mathrm{E}-03$ & $5.478 E-03$ & $5.488 E-03$ \\
\hline$-235+D$ & $\mathrm{U}-235+\mathrm{D}$ & $1.000 \mathrm{E}+00$ & $1.213 \mathrm{E}-01$ & 1. $213 \mathrm{E}-01$ & 1. $212 \mathrm{E}-01$ & 1. $211 \mathrm{E}-01$ \\
\hline$-235+D$ & $\mathrm{~Pa}-231$ & $1.000 \mathrm{E}+00$ & $1.143 E-06$ & $3.429 \mathrm{E}-06$ & $1.152 \mathrm{E}-04$ & $1.608 \mathrm{E}-04$ \\
\hline$-235+D$ & $A c-227+D$ & $1.000 \mathrm{E}+00$ & $4.976 \mathrm{E}-08$ & $3.452 \mathrm{E}-07$ & $2.396 \mathrm{E}-04$ & $4.001 \mathrm{E}-04$ \\
\hline$-235+D$ & $\sum \operatorname{DSR}(j)$ & & $1.213 \mathrm{E}-01$ & 1. $213 E-01$ & $1.215 \mathrm{E}-01$ & $1.217 \mathrm{E}-01$ \\
\hline-238 & $\mathrm{U}-238$ & $5.400 E-05$ & $2.701 \mathrm{E}-07$ & $2.701 E-07$ & $2.698 E-07$ & $2.696 \mathrm{E}-07$ \\
\hline$-238+D$ & $\mathrm{U}-238+\mathrm{D}$ & $9.999 \mathrm{E}-01$ & $3.129 \mathrm{E}-02$ & $3.129 \mathrm{E}-02$ & $3.125 \mathrm{E}-02$ & $3.123 \mathrm{E}-02$ \\
\hline$J-238+D$ & $\mathrm{U}-234$ & $9.999 \mathrm{E}-01$ & $7.748 E-09$ & $2.324 \mathrm{E}-08$ & $7.815 \mathrm{E}-07$ & $1.090 \mathrm{E}-06$ \\
\hline$J-238+D$ & $T h-230$ & $9.999 \mathrm{E}-01$ & $9.999 \mathrm{E}-14$ & $6.999 \mathrm{E}-13$ & $7.642 \mathrm{E}-10$ & $1.489 \mathrm{E}-09$ \\
\hline$-238+D$ & $\mathrm{Ra}-226+\mathrm{D}$ & $9.999 \mathrm{E}-01$ & $8.247 \mathrm{E}-16$ & 1. $237 \mathrm{E}-14$ & $4.221 \mathrm{E}-10$ & $1.145 \mathrm{E}-09$ \\
\hline$-238+D$ & $\mathrm{~Pb}-210+\mathrm{D}$ & $9.999 \mathrm{E}-01$ & $5.972 \mathrm{E}-19$ & $1.841 \mathrm{E}-17$ & $1.461 \mathrm{E}-11$ & $5.020 \mathrm{E}-11$ \\
\hline$-238+D$ & $\sum \operatorname{DSR}(j)$ & & $3.129 \mathrm{E}-02$ & $3.129 \mathrm{E}-02$ & $3.125 \mathrm{E}-02$ & $3.123 E-02$ \\
\hline
\end{tabular}

The DSR includes contributions from associated (half-life $\leq 180$ days) daughters. 
RESRAD, Version $6.5 \quad \mathrm{~T}^{1 / 2}$ Limit $=180$ days

Summary : C746U Landfill Worker Deterministic Run

File : $\mathrm{X}: \backslash F I N A L$ V2 $\backslash$ DOE FWD RUNS $\backslash$ C746U LW DOE AL FWD-FV2-70YR.RAD

Single Radionuclide Soil Guidelines G(i,t) in pCi/g

Basic Radiation Dose Limit $=1.000 \mathrm{E}+02 \mathrm{mrem} / \mathrm{yr}$

Nuclide

\begin{tabular}{cccccc} 
(i) & $\mathrm{t}=$ & $0.000 \mathrm{E}+00$ & $1.000 \mathrm{E}+00$ & $5.000 \mathrm{E}+01$ & $7.000 \mathrm{E}+01$ \\
\cline { 1 - 1 } $\mathrm{Am}-241$ & & $3.509 \mathrm{E}+03$ & $3.514 \mathrm{E}+03$ & $3.802 \mathrm{E}+03$ & $3.927 \mathrm{E}+03$ \\
$\mathrm{Cs}-137$ & & $1.900 \mathrm{E}+02$ & $1.945 \mathrm{E}+02$ & $6.045 \mathrm{E}+02$ & $9.603 \mathrm{E}+02$ \\
$\mathrm{~Np}-237$ & $5.507 \mathrm{E}+02$ & $5.507 \mathrm{E}+02$ & $5.550 \mathrm{E}+02$ & $5.568 \mathrm{E}+02$ \\
$\mathrm{Pu}-238$ & $3.926 \mathrm{E}+03$ & $3.957 \mathrm{E}+03$ & $5.833 \mathrm{E}+03$ & $6.834 \mathrm{E}+03$ \\
$\mathrm{Pu}-239$ & $3.595 \mathrm{E}+03$ & $3.595 \mathrm{E}+03$ & $3.603 \mathrm{E}+03$ & $3.607 \mathrm{E}+03$ \\
$\mathrm{Pu}-240$ & $3.598 \mathrm{E}+03$ & $3.598 \mathrm{E}+03$ & $3.621 \mathrm{E}+03$ & $3.630 \mathrm{E}+03$ \\
$\mathrm{TC}-99$ & & $1.131 \mathrm{E}+06$ & $1.143 \mathrm{E}+06$ & $1.919 \mathrm{E}+06$ & $2.371 \mathrm{E}+06$ \\
$\mathrm{Th}-228$ & $7.351 \mathrm{E}+01$ & $1.056 \mathrm{E}+02$ & $5.420 \mathrm{E}+09$ & $7.604 \mathrm{E}+12$ \\
$\mathrm{Th}-230$ & $4.184 \mathrm{E}+03$ & $4.052 \mathrm{E}+03$ & $1.551 \mathrm{E}+03$ & $1.234 \mathrm{E}+03$ \\
$\mathrm{Th}-232$ & $1.053 \mathrm{E}+03$ & $3.882 \mathrm{E}+02$ & $3.766 \mathrm{E}+01$ & $3.757 \mathrm{E}+01$ \\
$\mathrm{U}-234$ & $1.829 \mathrm{E}+04$ & $1.829 \mathrm{E}+04$ & $1.825 \mathrm{E}+04$ & $1.822 \mathrm{E}+04$ \\
$\mathrm{U}-235$ & $8.241 \mathrm{E}+02$ & $8.241 \mathrm{E}+02$ & $8.228 \mathrm{E}+02$ & $8.218 \mathrm{E}+02$ \\
$\mathrm{U}-238$ & $3.196 \mathrm{E}+03$ & $3.196 \mathrm{E}+03$ & $3.200 \mathrm{E}+03$ & $3.202 \mathrm{E}+03$ \\
\hline \hline
\end{tabular}

Summed Dose/Source Ratios DSR(i,t) in (mrem/yr)/(pCi/g) and Single Radionuclide Soil Guidelines $G(i, t)$ in pCi/g at tmin = time of minimum single radionuclide soil guideline and at $\operatorname{tmax}=$ time of maximum total dose $=7.000 \mathrm{E}+01$ years

\begin{tabular}{|c|c|c|c|c|c|c|}
\hline $\begin{array}{l}\text { Nuclide } \\
\text { (i) }\end{array}$ & $\begin{array}{l}\text { Initial } \\
(\mathrm{pCi} / \mathrm{g})\end{array}$ & $\begin{array}{c}\text { tmin } \\
\text { (years) }\end{array}$ & $\operatorname{DSR}(i, \operatorname{tmin})$ & $\begin{array}{c}\mathrm{G}(\mathrm{i}, \mathrm{tmin}) \\
(\mathrm{pCi} / \mathrm{g})\end{array}$ & $\operatorname{DSR}(i, t \max )$ & $\begin{array}{c}G(i, \operatorname{tmax}) \\
(\mathrm{pCi} / \mathrm{g})\end{array}$ \\
\hline-241 & $7.000 E+01$ & $0.000 \mathrm{E}+00$ & $2.850 \mathrm{E}-02$ & $3.509 E+03$ & $2.547 E-02$ & $3.927 \mathrm{E}+03$ \\
\hline-137 & $3.800 \mathrm{E}+01$ & $0.000 \mathrm{E}+00$ & $5.262 E-01$ & $1.900 \mathrm{E}+02$ & $1.041 \mathrm{E}-01$ & $9.603 \mathrm{E}+02$ \\
\hline-237 & $1.100 \mathrm{E}+01$ & $0.000 \mathrm{E}+00$ & $1.816 \mathrm{E}-01$ & $5.507 \mathrm{E}+02$ & $1.796 \mathrm{E}-01$ & $5.568 \mathrm{E}+02$ \\
\hline-238 & $7.800 \mathrm{E}+01$ & $0.000 \mathrm{E}+00$ & $2.547 \mathrm{E}-02$ & $3.926 \mathrm{E}+03$ & $1.463 \mathrm{E}-02$ & $6.834 \mathrm{E}+03$ \\
\hline-239 & $7.200 \mathrm{E}+01$ & $0.000 \mathrm{E}+00$ & $2.782 \mathrm{E}-02$ & $3.595 E+03$ & $2.772 E-02$ & $3.607 \mathrm{E}+03$ \\
\hline-240 & $7.200 \mathrm{E}+01$ & $0.000 \mathrm{E}+00$ & $2.779 \mathrm{E}-02$ & $3.598 E+03$ & $2.755 E-02$ & $3.630 \mathrm{E}+03$ \\
\hline-99 & $1.040 E+02$ & $0.000 \mathrm{E}+00$ & $8.844 \mathrm{E}-05$ & $1.131 \mathrm{E}+06$ & $4.218 E-05$ & $2.371 \mathrm{E}+06$ \\
\hline-228 & $8.000 \mathrm{E}+00$ & $0.000 \mathrm{E}+00$ & $1.360 \mathrm{E}+00$ & 7. $351 E+01$ & 1. $315 \mathrm{E}-11$ & $7.604 \mathrm{E}+12$ \\
\hline-230 & $2.000 \mathrm{E}+02$ & $7.000 \mathrm{E}+01$ & $8.104 \mathrm{E}-02$ & $1.234 \mathrm{E}+03$ & $8.104 \mathrm{E}-02$ & $1.234 \mathrm{E}+03$ \\
\hline-232 & $8.000 \mathrm{E}+00$ & $7.000 \mathrm{E}+01$ & $2.662 \mathrm{E}+00$ & $3.757 \mathrm{E}+01$ & $2.662 \mathrm{E}+00$ & $3.757 \mathrm{E}+01$ \\
\hline 234 & $3.200 E+02$ & $7.000 \mathrm{E}+01$ & $5.488 E-03$ & $1.822 \mathrm{E}+04$ & $5.488 E-03$ & $1.822 \mathrm{E}+04$ \\
\hline 235 & $1.300 \mathrm{E}+01$ & $7.000 \mathrm{E}+01$ & $1.217 \mathrm{E}-01$ & $8.218 E+02$ & $1.217 \mathrm{E}-01$ & $8.218 \mathrm{E}+02$ \\
\hline 38 & $3.200 \mathrm{E}+02$ & $0.000 \mathrm{E}+00$ & $3.129 \mathrm{E}-02$ & $3.196 \mathrm{E}+03$ & $3.123 E-02$ & $3.202 E+03$ \\
\hline
\end{tabular}


RESRAD, Version $6.5 \quad \mathrm{~T}^{1 / 2}$ Limit $=180$ days

Summary : C746U Landfill Worker Deterministic Run

File : $X: \backslash F I N A L$ V2 \DOE FWD RUNS \C746U LW DOE AL FWD-FV2-70YR.RAD

Individual Nuclide Dose Summed Over All Pathways

Parent Nuclide and Branch Fraction Indicated

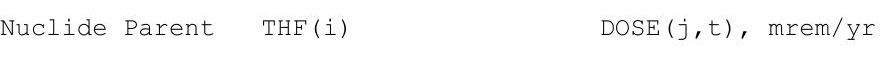




\section{RESRAD, Version $6.5 \quad \mathrm{~T}^{1 / 2}$ Limit $=180$ days}

Summary : C746U Landfill Worker Deterministic Run

File : $X: \backslash F I N A L$ V2 \DOE FWD RUNS \C746U LW DOE AL FWD-FV2-70YR.RAD

Individual Nuclide Dose Summed Over All Pathways

Parent Nuclide and Branch Fraction Indicated

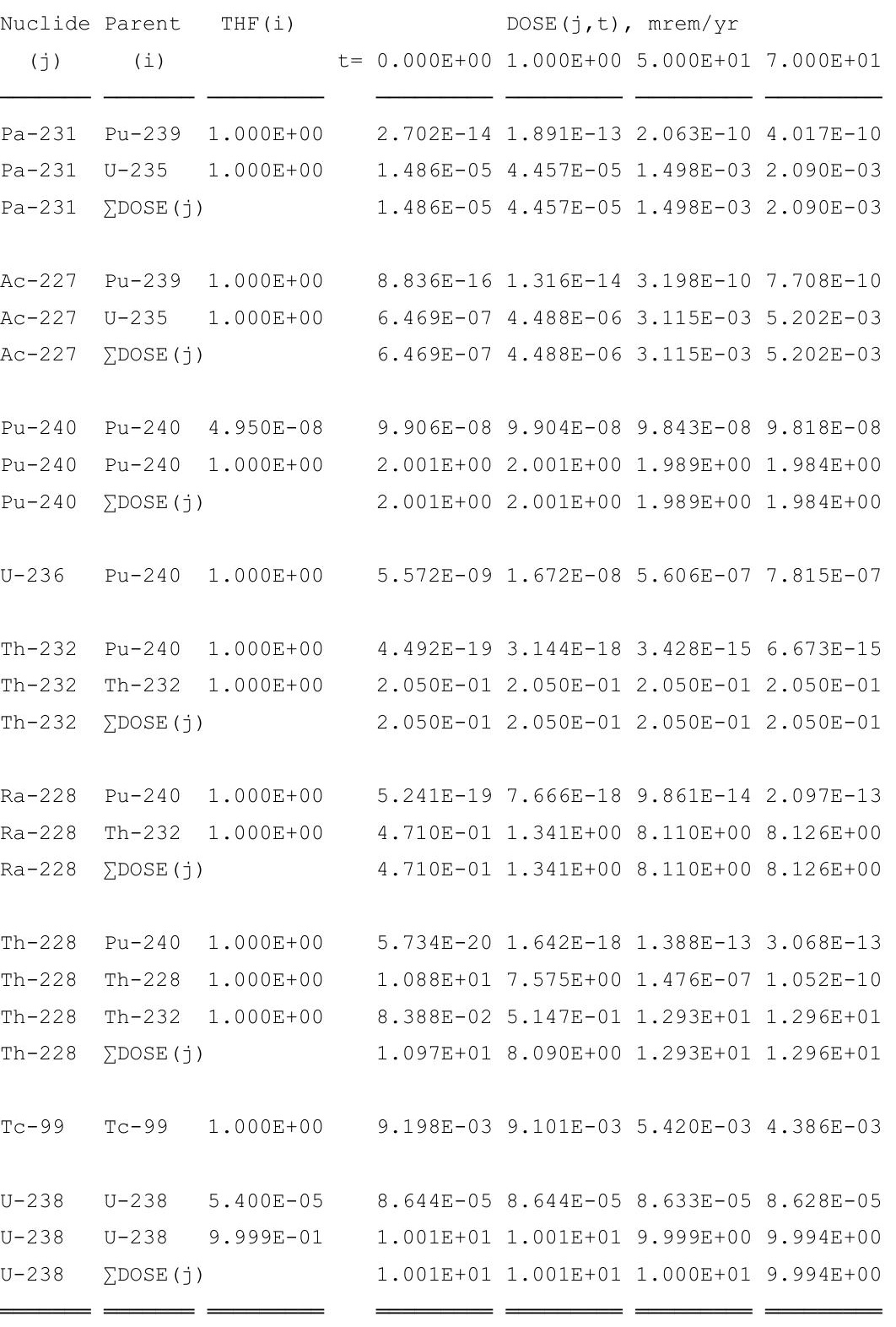

THF(i) is the thread fraction of the parent nuclide. 
RESRAD, Version $6.5 \quad \mathrm{~T}^{1 / 2}$ Limit $=180$ days

Summary : C746U Landfill Worker Deterministic Run
File : X: $\backslash$ FINAL V2 $\backslash$ DOE FWD RUNS $\backslash C 746 U$ LW DOE AL FWD-FV2-70YR.RAD

Individual Nuclide Soil Concentration

Parent Nuclide and Branch Fraction Indicated

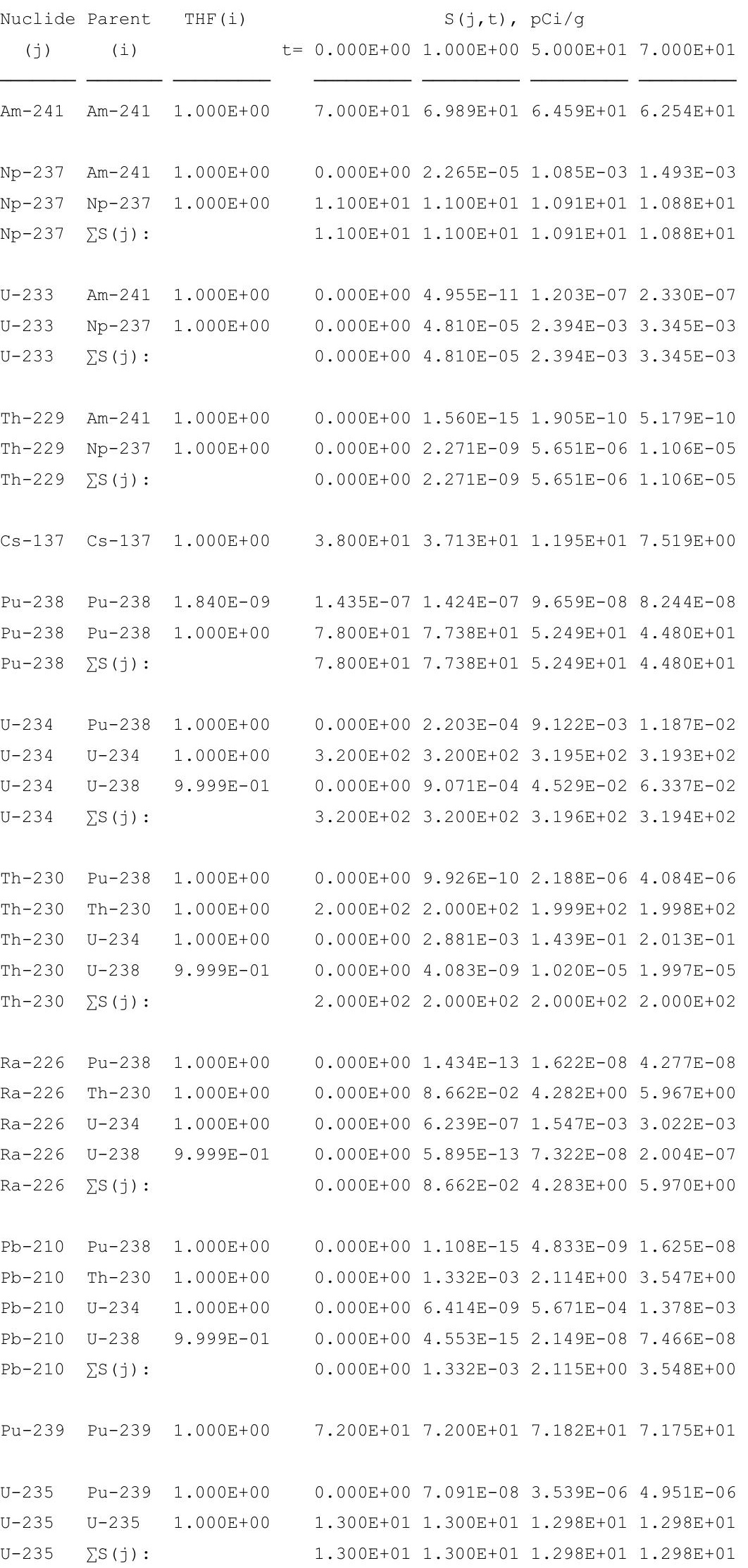




\section{RESRAD, Version $6.5 \quad T^{1 / 2}$ Limit $=180$ days}

Summary : C746U Landfill Worker Deterministic Run

File : $X: \backslash F I N A L$ V2 \DOE FWD RUNS \C746U LW DOE AL FWD-FV2-70YR.RAD

Individual Nuclide Soil Concentration

Parent Nuclide and Branch Fraction Indicated

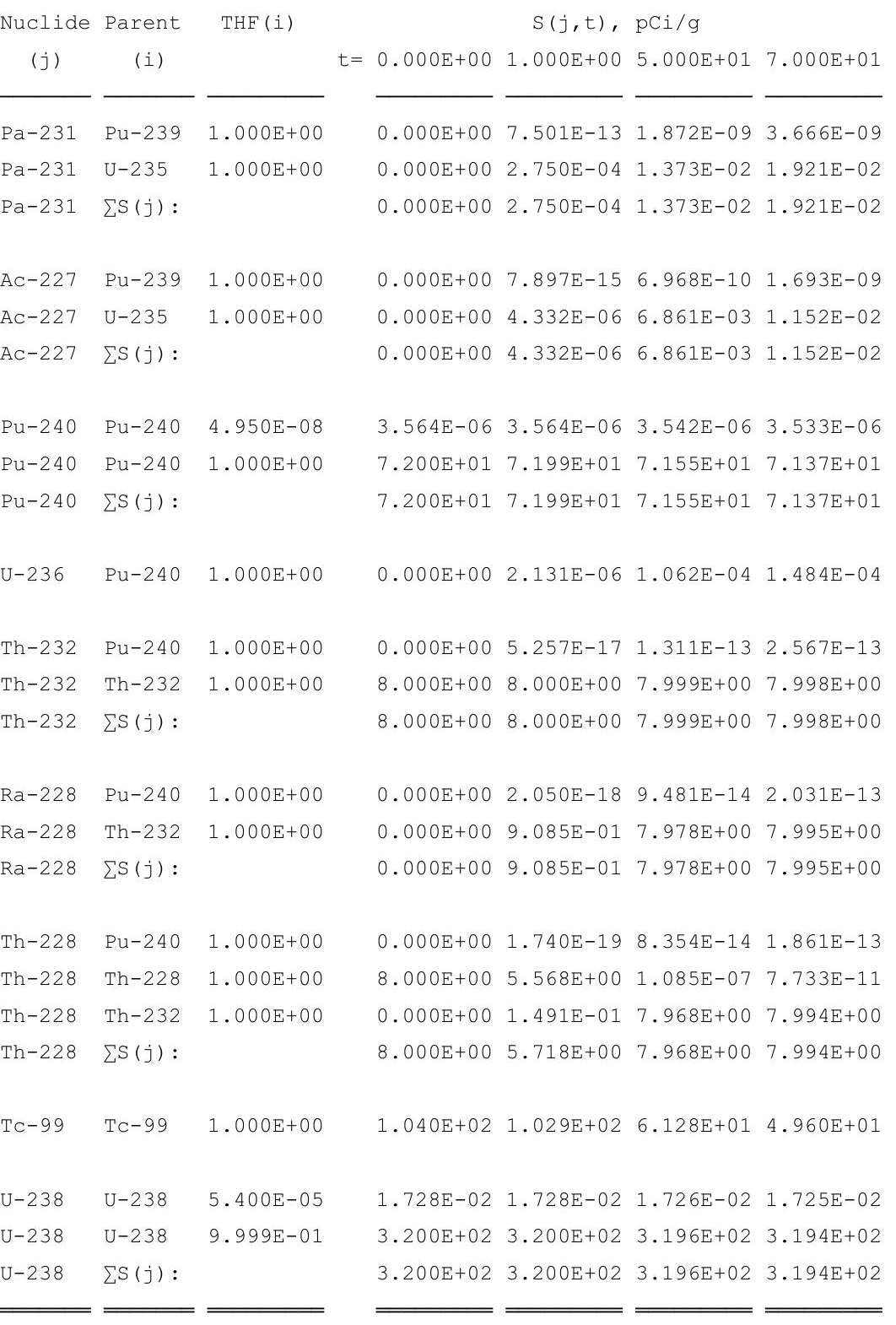

THF(i) is the thread fraction of the parent nuclide.

RESCALC.EXE execution time $=2.70$ seconds 


\section{Trespasser}

\section{Summary Report \\ (Deterministic Analysis Report)}

First Peak Dose Assessment

Time Horizon: 70 yr 
THIS PAGE INTENTIONALLY LEFT BLANK 
RESRAD, Version $6.5 \quad T^{1 / 2}$ Limit $=180$ days

Summary : C746U Trespasser Deterministic Run

File : $\mathrm{X}: \backslash$ FINAL V2 \DOE FWD RUNS \C746U T SG DOE FWD-FV2-70YR. RAD

Table of Contents

Part I: Mixture Sums and Single Radionuclide Guidelines

Dose Conversion Factor (and Related) Parameter Summary ... 2

Site-Specific Parameter Summary $\ldots \ldots \ldots \ldots \ldots \ldots \ldots \ldots \ldots$

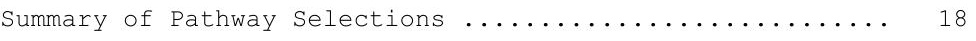

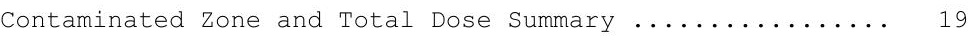

Total Dose Components

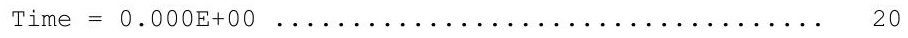

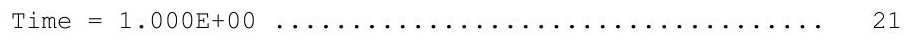

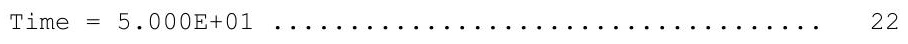

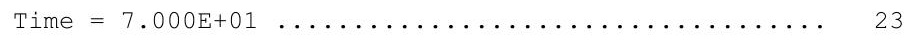

Dose/Source Ratios summed Over All Pathways ............ 24

Single Radionuclide Soil Guidelines ............... 26

Dose Per Nuclide Summed Over All Pathways ............ 27

Soil Concentration Per Nuclide .................. 29 
RESRAD, Version $6.5 \quad \mathrm{~T}^{1 / 2}$ Limit $=180$ days

Summary : C746U Trespasser Deterministic Run

File : $\mathrm{X}: \backslash$ FINAL V2 $\backslash$ DOE FWD RUNS $\backslash C 746 U$ T SG DOE FWD-FV2-70YR.RAD

Dose Conversion Factor (and Related) Parameter Summary

Dose Library: ICRP 60 \& ICRP 72 (Adult)

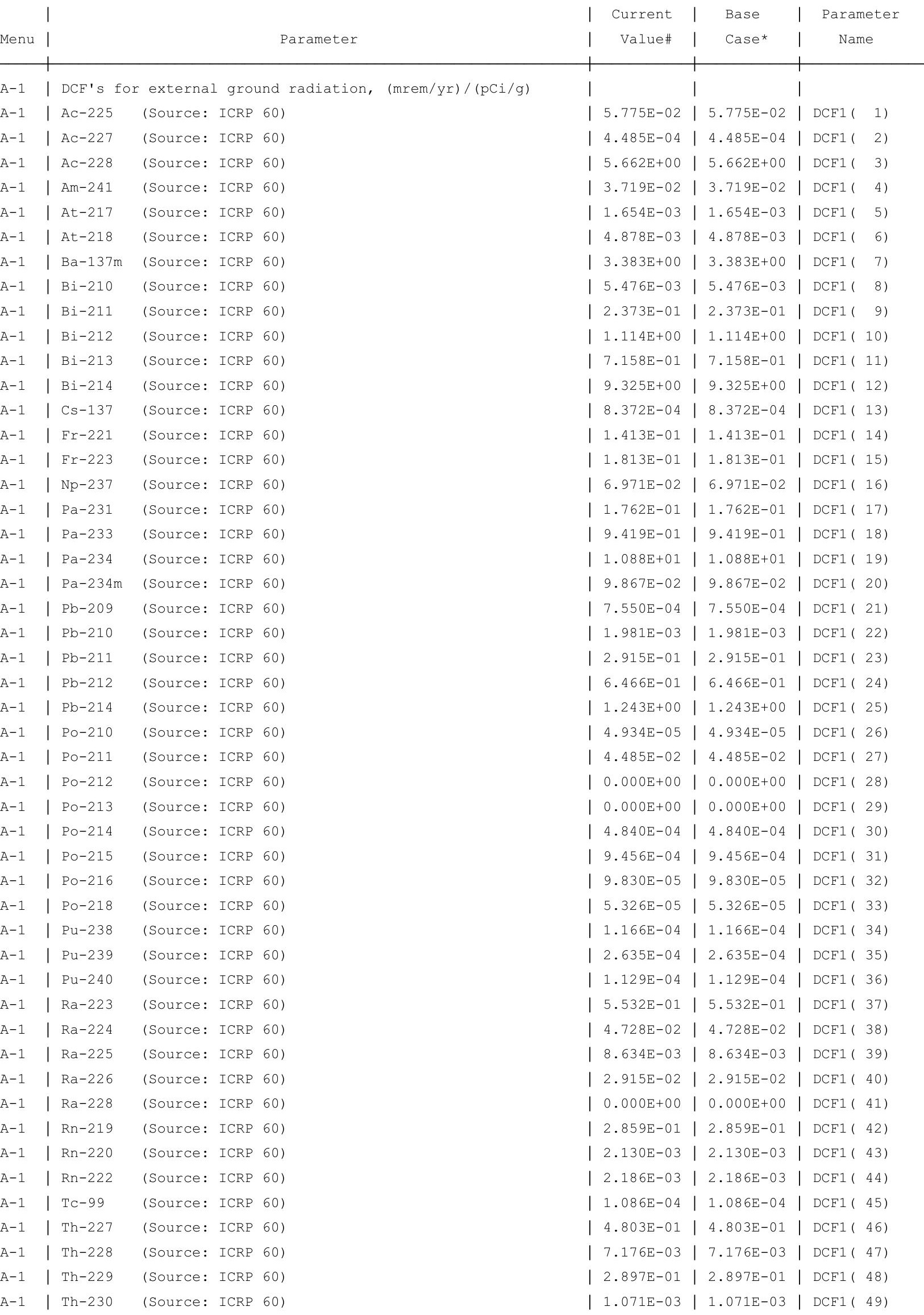


RESRAD, Version $6.5 \quad \mathrm{~T}^{1 / 2}$ Limit $=180$ days

Summary : C746U Trespasser Deterministic Run

File : $\mathrm{X}: \backslash F I N A L$ V2 $\backslash$ DOE FWD RUNS \C746U T SG DOE FWD-FV2-70YR.RAD

Dose Conversion Factor (and Related) Parameter Summary (continued)

Dose Library: ICRP 60 \& ICRP 72 (Adult)

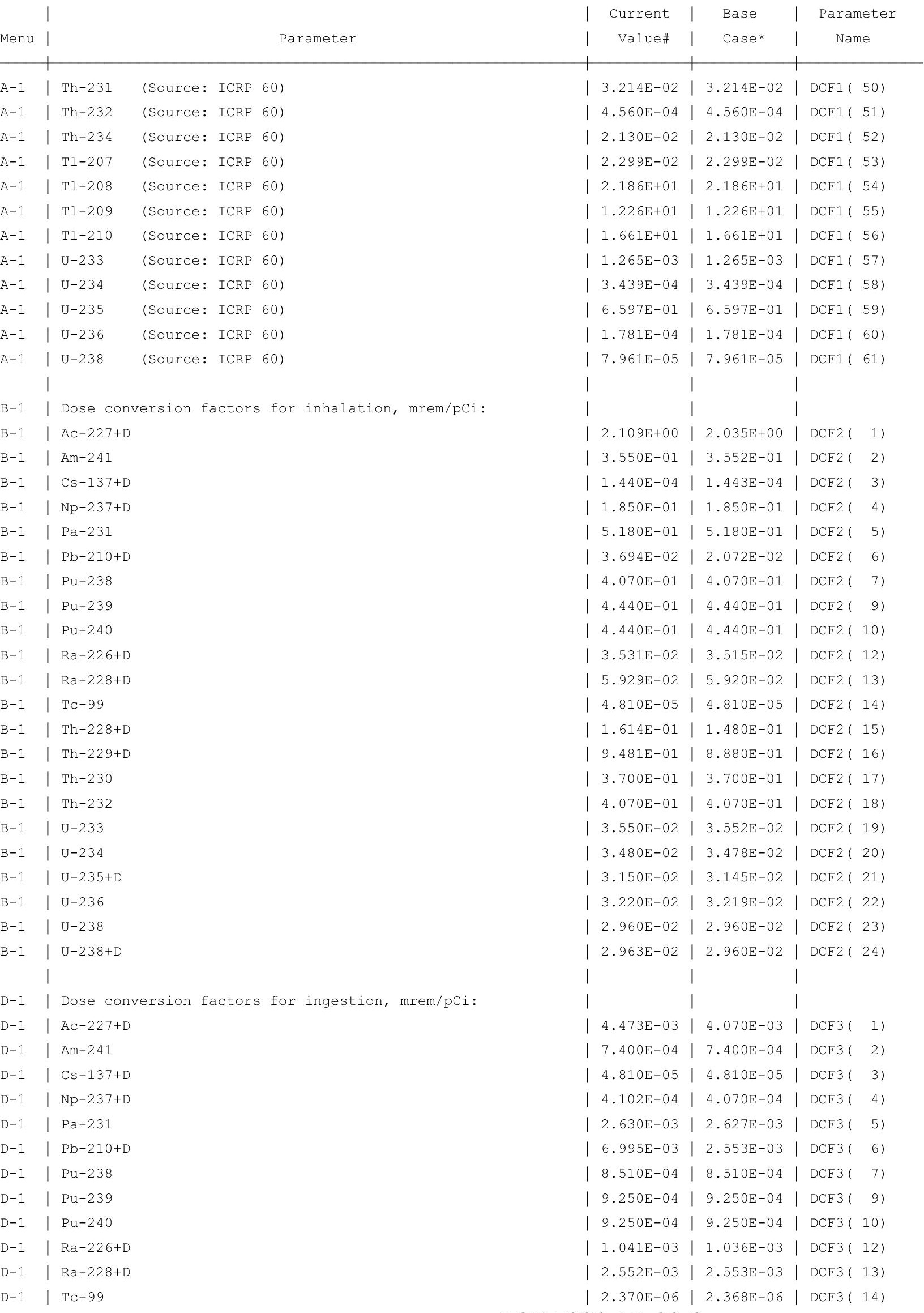


RESRAD, Version $6.5 \quad \mathrm{~T}^{1 / 2}$ Limit $=180$ days

ummary : C746U Trespasser Deterministic Run

File : $\mathrm{X}: \backslash$ FINAL V2 \DOE FWD RUNS \C746U T SG DOE FWD-FV2-70YR. RAD

Dose Conversion Factor (and Related) Parameter Summary (continued)

Dose Library: ICRP 60 \& ICRP 72 (Adult)

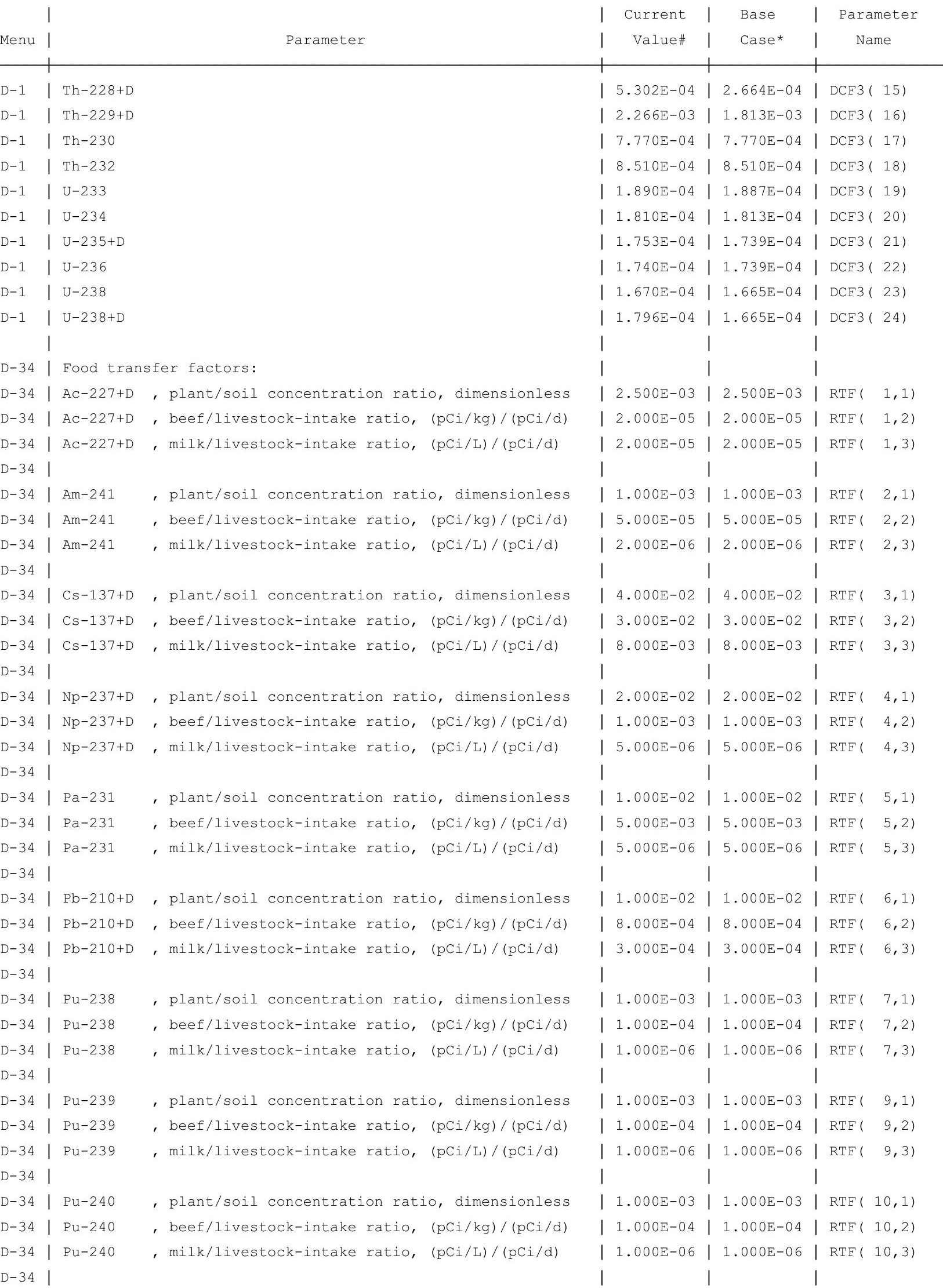


RESRAD, Version $6.5 \quad \mathrm{~T}^{1 / 2}$ Limit $=180$ days

Summary : C746U Trespasser Deterministic Run

File : $\mathrm{X}: \backslash F I N A L$ V2 $\backslash$ DOE FWD RUNS $\backslash C 746 U$ T SG DOE FWD-FV2-70YR.RAD

Dose Conversion Factor (and Related) Parameter Summary (continued)

Dose Library: ICRP 60 \& ICRP 72 (Adult)

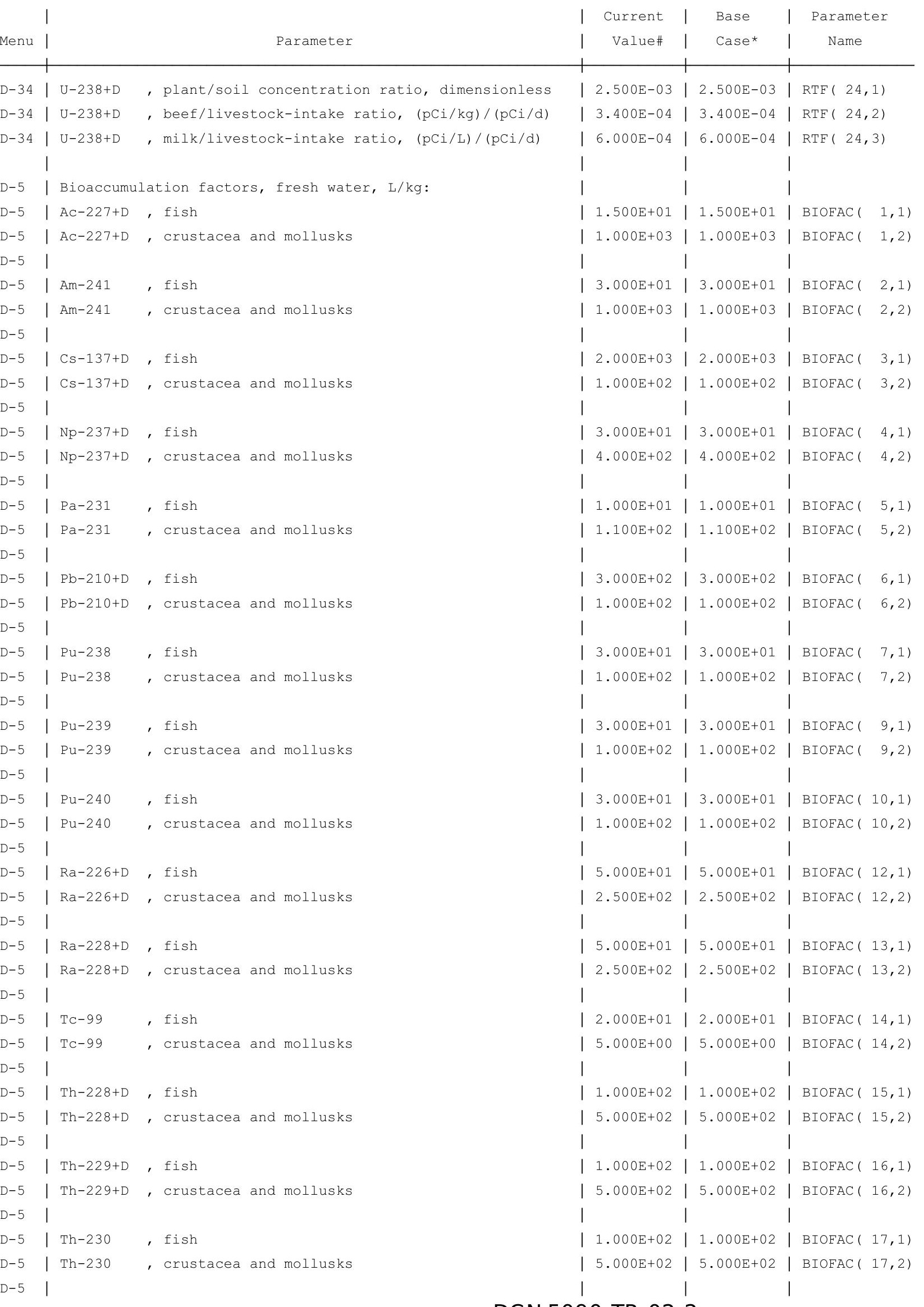


RESRAD, Version $6.5 \quad \mathrm{~T}^{1 / 2}$ Limit $=180$ days

Summary : C746U Trespasser Deterministic Run

File : $X: \backslash F I N A L$ V2 \DOE FWD RUNS \C746U T SG DOE FWD-FV2-70YR.RAD

Dose Conversion Factor (and Related) Parameter Summary (continued)

Dose Library: ICRP 60 \& ICRP 72 (Adult)

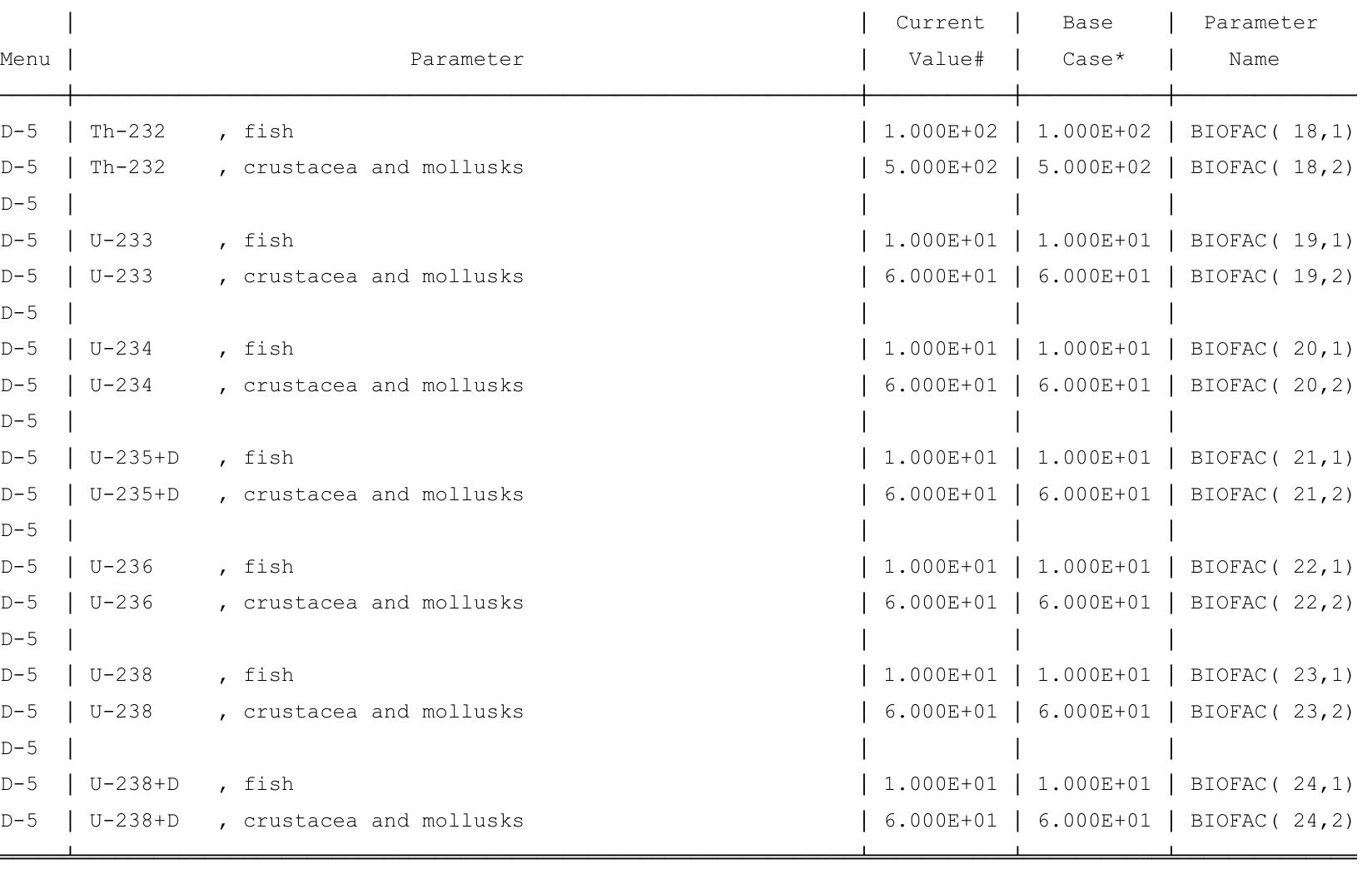

\#For DCFl(xxx) only, factors are for infinite depth \& area. See ETFG table in Ground Pathway of Detailed Report. *Base Case means Default.Lib w/o Associate Nuclide contributions. 
RESRAD, Version $6.5 \quad \mathrm{~T}^{1 / 2}$ Limit $=180$ days

Summary : C746U Trespasser Deterministic Run

File : $\mathrm{X}: \backslash F I N A L$ V2 $\backslash$ DOE FWD RUNS $\backslash C 746 U$ T SG DOE FWD-FV2-70YR.RAD

Site-Specific Parameter Summary (continued)

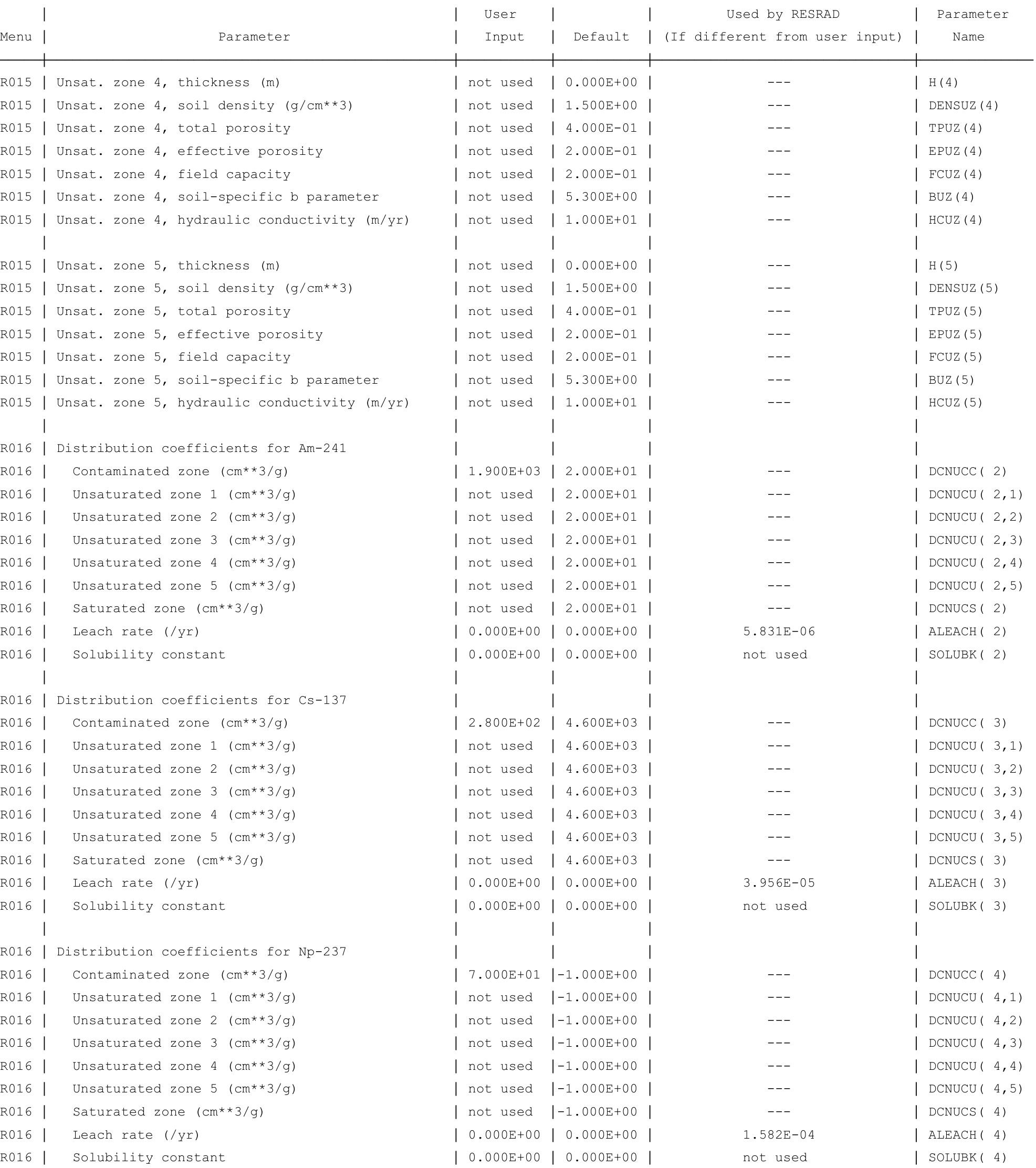


RESRAD, Version $6.5 \quad \mathrm{~T}^{1 / 2}$ Limit $=180$ days

Summary : C746U Trespasser Deterministic Run

File : $\mathrm{X}: \backslash F I N A L$ V2 $\backslash$ DOE FWD RUNS $\backslash C 746 U$ T SG DOE FWD-FV2-70YR.RAD

Site-Specific Parameter Summary (continued)

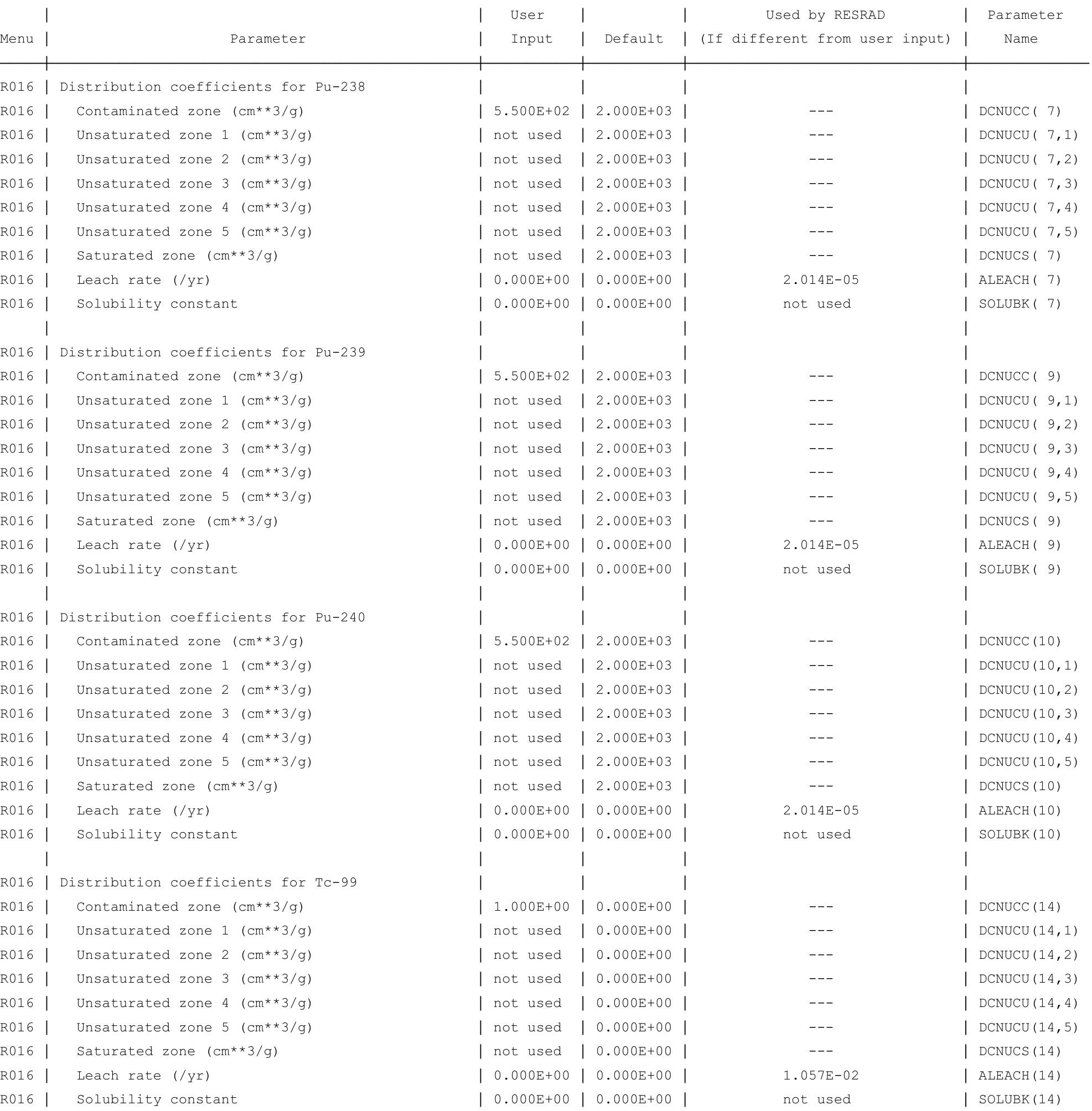


RESRAD, Version $6.5 \quad \mathrm{~T}^{1 / 2}$ Limit $=180$ days

Summary : C746U Trespasser Deterministic Run

File : $\mathrm{X}: \backslash$ FINAL V2 $\backslash$ DOE FWD RUNS \C746U T SG DOE FWD-FV2-70YR.RAD

Site-Specific Parameter Summary (continued)

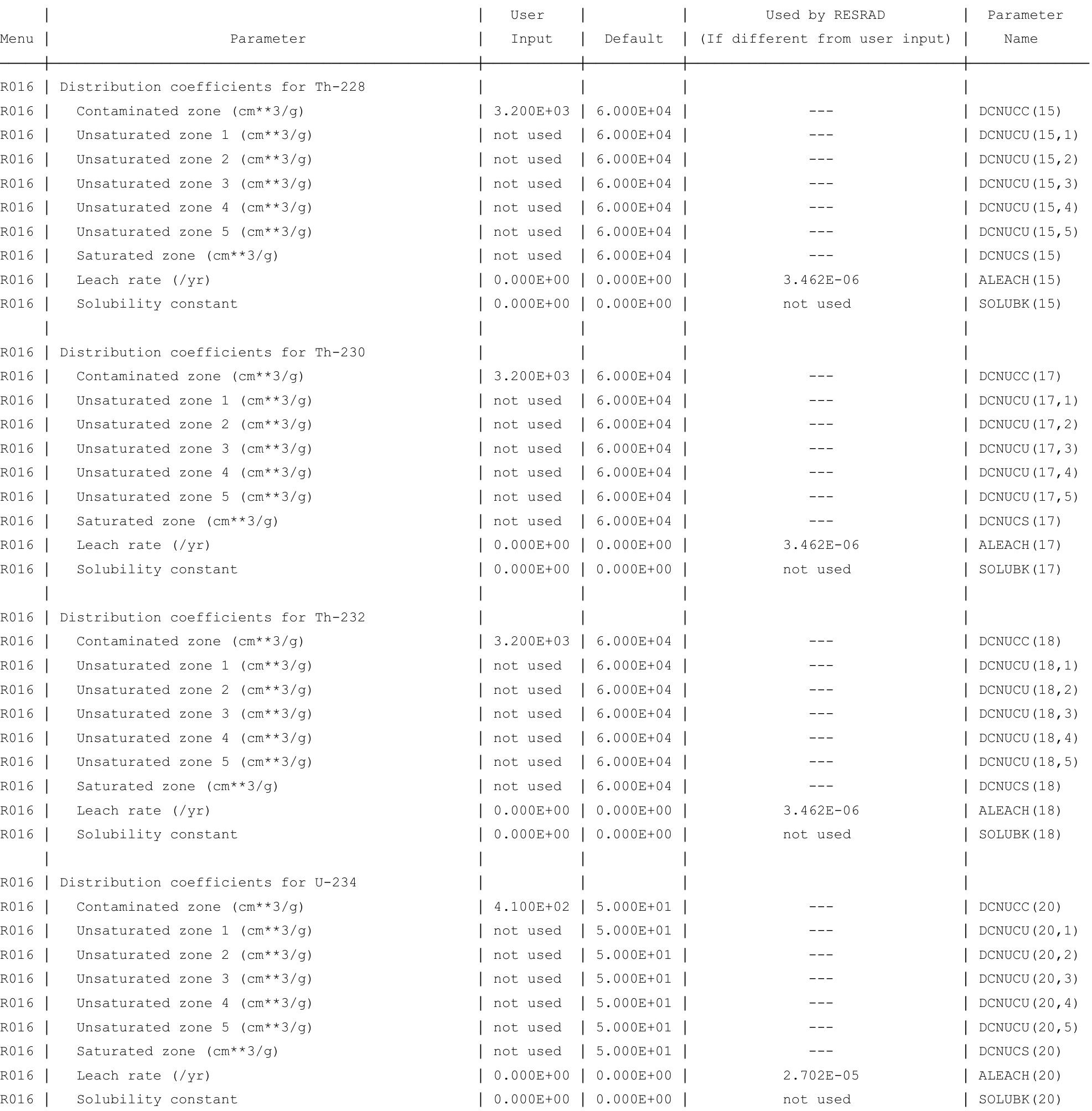


RESRAD, Version $6.5 \quad \mathrm{~T}^{1 / 2}$ Limit $=180$ days

Summary : C746U Trespasser Deterministic Run

File : $X: \backslash F I N A L$ V2 $\backslash$ DOE FWD RUNS \C746U T SG DOE FWD-FV2-70YR.RAD

Site-Specific Parameter Summary (continued)

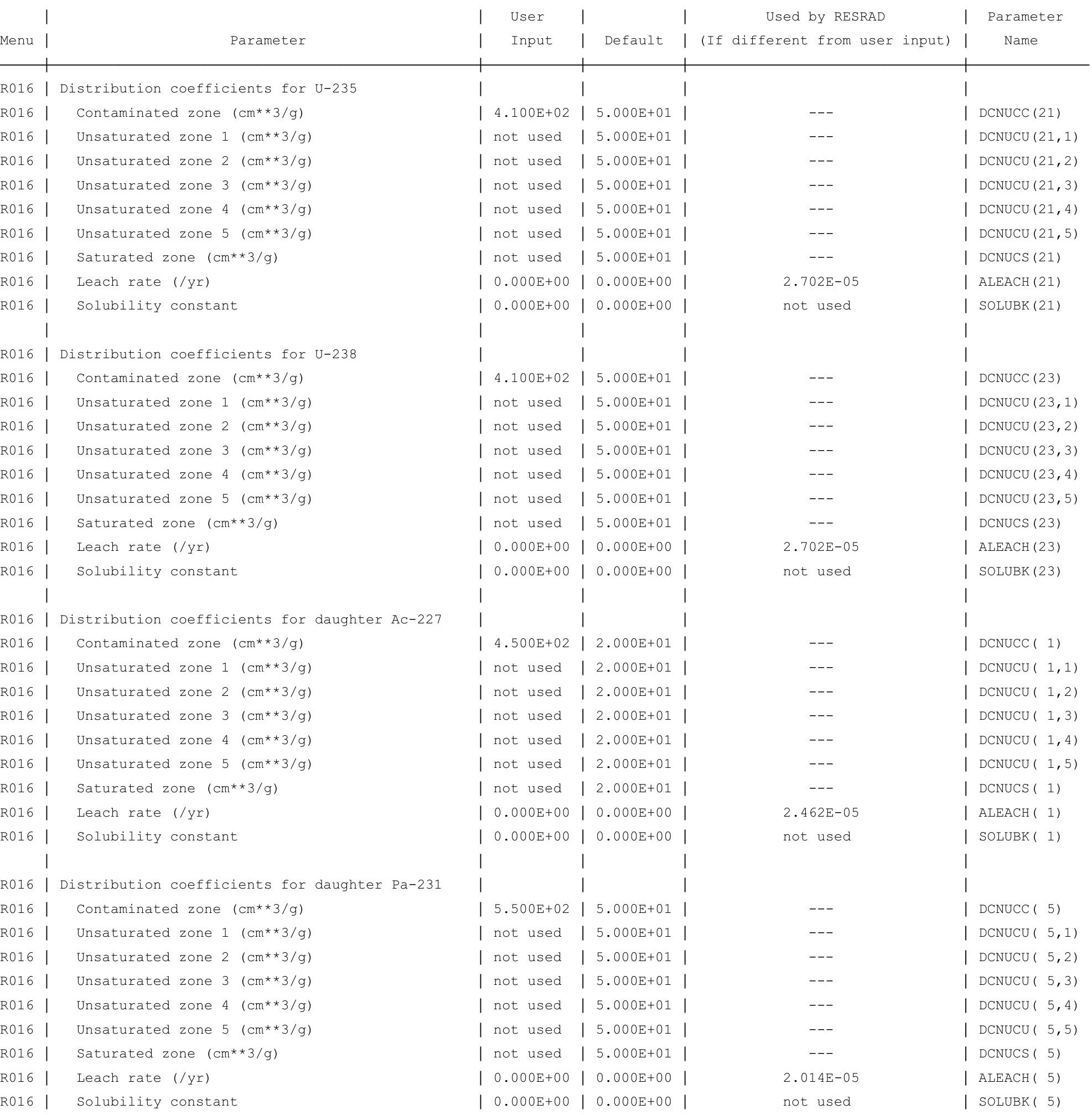


RESRAD, Version $6.5 \quad \mathrm{~T}^{1 / 2}$ Limit $=180$ days

ummary : C746U Trespasser Deterministic Run

File : X: $\backslash$ FINAL V2 $\backslash$ DOE FWD RUNS \C746U T SG DOE FWD-FV2-70YR.RAD

Site-Specific Parameter Summary (continued)

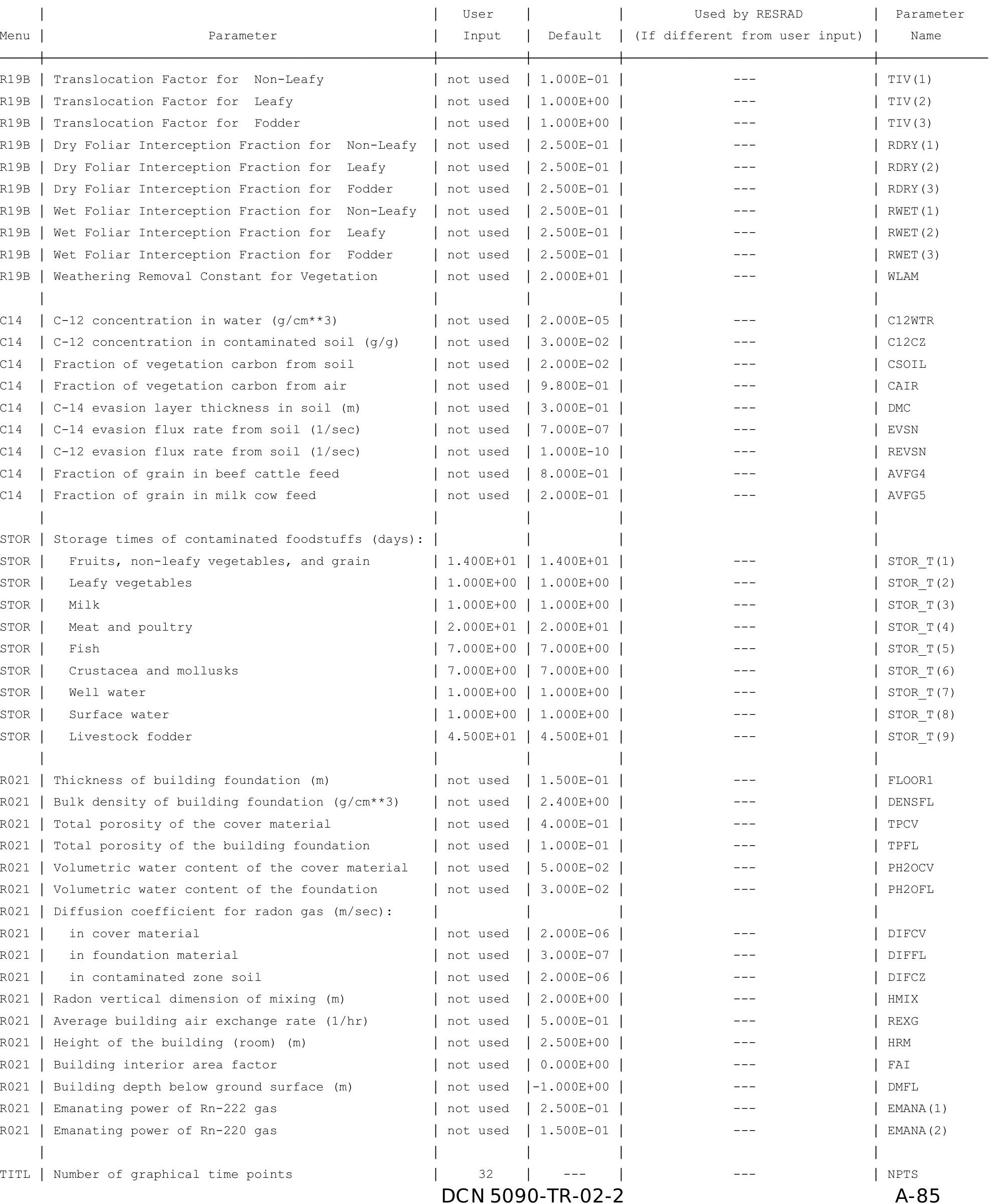


RESRAD, Version $6.5 \quad \mathrm{~T}^{1 / 2}$ Limit $=180$ days

Summary : C746U Trespasser Deterministic Run

File : $\mathrm{X}: \backslash F I N A L$ V2 $\backslash$ DOE FWD RUNS \C746U T SG DOE FWD-FV2-70YR.RAD

Contaminated Zone Dimensions

Area: $\quad 89436.00$ square meters

Thickness:

Cover Depth:

\begin{abstract}
13.40 meters
0.15 meters
\end{abstract}

Initial Soil Concentrations, pCi/g

$\begin{array}{ll}\mathrm{Am}-241 & 3.500 \mathrm{E}+01 \\ \mathrm{Cs}-137 & 1.900 \mathrm{E}+01 \\ \mathrm{~Np}-237 & 5.500 \mathrm{E}+00 \\ \mathrm{Pu}-238 & 3.900 \mathrm{E}+01 \\ \mathrm{Pu}-239 & 3.600 \mathrm{E}+01 \\ \mathrm{Pu}-240 & 3.600 \mathrm{E}+01 \\ \mathrm{TC}-99 & 5.200 \mathrm{E}+01 \\ \mathrm{Th}-228 & 4.000 \mathrm{E}+00 \\ \mathrm{Th}-230 & 1.000 \mathrm{E}+02 \\ \mathrm{Th}-232 & 4.000 \mathrm{E}+00 \\ \mathrm{U}-234 & 1.600 \mathrm{E}+02 \\ \mathrm{U}-235 & 6.500 \mathrm{E}+00 \\ \mathrm{U}-238 & 1.600 \mathrm{E}+02\end{array}$

Total Dose TDOSE(t), mrem/yr

Basic Radiation Dose Limit $=1.000 \mathrm{E}+02 \mathrm{mrem} / \mathrm{yr}$

Total Mixture Sum $M(t)$ = Fraction of Basic Dose Limit Received at Time (t)

$\begin{array}{rllll}t \quad \text { years }): & 0.000 \mathrm{E}+00 & 1.000 \mathrm{E}+00 & 5.000 \mathrm{E}+01 & 7.000 \mathrm{E}+01 \\ \text { TDOSE }(t): & 9.324 \mathrm{E}-01 & 8.597 \mathrm{E}-01 & 1.703 \mathrm{E}+00 & 2.056 \mathrm{E}+00 \\ \mathrm{M}(\mathrm{t}): & 9.324 \mathrm{E}-03 & 8.597 \mathrm{E}-03 & 1.703 \mathrm{E}-02 & 2.056 \mathrm{E}-02\end{array}$

Maximum TDOSE $(t): 2.056 \mathrm{E}+00 \mathrm{mrem} / \mathrm{yr}$ at $t=7.000 \mathrm{E}+01$ years 
RESRAD, Version $6.5 \quad \mathrm{~T}^{1 / 2}$ Limit $=180$ days

Summary : C746U Trespasser Deterministic Run

File : X: \FINAL V2 \DOE FWD RUNS \C746U T SG DOE FWD-FV2-70YR.RAD

Total Dose Contributions TDOSE(i,p,t) for Individual Radionuclides (i) and Pathways (p) As mrem/yr and Fraction of Total Dose At $t=0.000 \mathrm{E}+00$ years

Water Independent Pathways (Inhalation excludes radon)

\begin{tabular}{|c|c|c|c|c|c|c|c|c|c|c|c|c|c|c|}
\hline \multirow{2}{*}{ Nuclide } & \multicolumn{2}{|c|}{ Ground } & \multicolumn{2}{|c|}{ Inhalation } & \multicolumn{2}{|c|}{ Radon } & \multicolumn{2}{|c|}{ Plant } & \multicolumn{2}{|c|}{ Meat } & \multicolumn{2}{|c|}{ Milk } & \multicolumn{2}{|c|}{ Soil } \\
\hline & mrem/yr & fract. & mrem/yr & fract. & mrem/yr & fract. & mrem/yr & fract. & mrem/yr & fract. & mrem/yr & fract. & mrem/yr & fract. \\
\hline-241 & $5.101 \mathrm{E}-05$ & 0.0001 & $0.000 \mathrm{E}+00$ & 0.0000 & $0.000 \mathrm{E}+00$ & 0.0000 & $0.000 \mathrm{E}+00$ & 0.0000 & $0.000 \mathrm{E}+00$ & 0.0000 & $0.000 \mathrm{E}+00$ & 0.0000 & $0.000 \mathrm{E}+00$ & 0.0000 \\
\hline-137 & $3.913 E-01$ & 0.4197 & $0.000 \mathrm{E}+00$ & 0.0000 & $0.000 \mathrm{E}+00$ & 0.0000 & $0.000 \mathrm{E}+00$ & 0.0000 & $0.000 \mathrm{E}+00$ & 0.0000 & $0.000 \mathrm{E}+00$ & 0.0000 & $0.000 \mathrm{E}+00$ & 0.0000 \\
\hline-237 & $1.899 \mathrm{E}-02$ & 0.0204 & $0.000 \mathrm{E}+00$ & 0.0000 & $0.000 \mathrm{E}+00$ & 0.0000 & $0.000 \mathrm{E}+00$ & 0.0000 & $0.000 \mathrm{E}+00$ & 0.0000 & $0.000 \mathrm{E}+00$ & 0.0000 & $0.000 \mathrm{E}+00$ & 0.0000 \\
\hline-238 & $1.030 \mathrm{E}-06$ & 0.0000 & $0.000 \mathrm{E}+00$ & 0.0000 & $0.000 \mathrm{E}+00$ & 0.0000 & $0.000 \mathrm{E}+00$ & 0.0000 & $0.000 \mathrm{E}+00$ & 0.0000 & $0.000 \mathrm{E}+00$ & 0.0000 & $0.000 \mathrm{E}+00$ & 0.0000 \\
\hline-239 & $2.269 \mathrm{E}-05$ & 0.0000 & $0.000 \mathrm{E}+00$ & 0.0000 & $0.000 \mathrm{E}+00$ & 0.0000 & $0.000 \mathrm{E}+00$ & 0.0000 & $0.000 \mathrm{E}+00$ & 0.0000 & $0.000 \mathrm{E}+00$ & 0.0000 & $0.000 \mathrm{E}+00$ & 0.0000 \\
\hline-240 & $9.241 \mathrm{E}-07$ & 0.0000 & $0.000 \mathrm{E}+00$ & 0.0000 & $0.000 \mathrm{E}+00$ & 0.0000 & $0.000 \mathrm{E}+00$ & 0.0000 & $0.000 \mathrm{E}+00$ & 0.0000 & $0.000 \mathrm{E}+00$ & 0.0000 & $0.000 \mathrm{E}+00$ & 0.0000 \\
\hline 99 & $2.113 E-06$ & 0.0000 & $0.000 \mathrm{E}+00$ & 0.0000 & $0.000 \mathrm{E}+00$ & 0.0000 & $0.000 \mathrm{E}+00$ & 0.0000 & $0.000 \mathrm{E}+00$ & 0.0000 & $0.000 \mathrm{E}+00$ & 0.0000 & $0.000 \mathrm{E}+00$ & 0.0000 \\
\hline-228 & $3.555 \mathrm{E}-01$ & 0.3813 & $0.000 \mathrm{E}+00$ & 0.0000 & $0.000 \mathrm{E}+00$ & 0.0000 & $0.000 \mathrm{E}+00$ & 0.0000 & $0.000 \mathrm{E}+00$ & 0.0000 & $0.000 \mathrm{E}+00$ & 0.0000 & $0.000 \mathrm{E}+00$ & 0.0000 \\
\hline-230 & $2.131 \mathrm{E}-03$ & 0.0023 & $0.000 \mathrm{E}+00$ & 0.0000 & $0.000 \mathrm{E}+00$ & 0.0000 & $0.000 \mathrm{E}+00$ & 0.0000 & $0.000 \mathrm{E}+00$ & 0.0000 & $0.000 \mathrm{E}+00$ & 0.0000 & $0.000 \mathrm{E}+00$ & 0.0000 \\
\hline-232 & $1.332 \mathrm{E}-02$ & 0.0143 & $0.000 \mathrm{E}+00$ & 0.0000 & $0.000 \mathrm{E}+00$ & 0.0000 & $0.000 \mathrm{E}+00$ & 0.0000 & $0.000 \mathrm{E}+00$ & 0.0000 & $0.000 \mathrm{E}+00$ & 0.0000 & $0.000 \mathrm{E}+00$ & 0.0000 \\
\hline 234 & $2.806 \mathrm{E}-05$ & 0.0000 & $0.000 \mathrm{E}+00$ & 0.0000 & $0.000 \mathrm{E}+00$ & 0.0000 & $0.000 \mathrm{E}+00$ & 0.0000 & $0.000 \mathrm{E}+00$ & 0.0000 & $0.000 \mathrm{E}+00$ & 0.0000 & $0.000 \mathrm{E}+00$ & 0.0000 \\
\hline 235 & $1.058 \mathrm{E}-02$ & 0.0113 & $0.000 \mathrm{E}+00$ & 0.0000 & $0.000 \mathrm{E}+00$ & 0.0000 & $0.000 \mathrm{E}+00$ & 0.0000 & $0.000 \mathrm{E}+00$ & 0.0000 & $0.000 \mathrm{E}+00$ & 0.0000 & $0.000 \mathrm{E}+00$ & 0.0000 \\
\hline 38 & $1.404 \mathrm{E}-01$ & 0.1506 & $0.000 \mathrm{E}+00$ & 0.0000 & $0.000 \mathrm{E}+00$ & 0.0000 & $0.000 \mathrm{E}+00$ & 0.0000 & $0.000 \mathrm{E}+00$ & 0.0000 & $0.000 \mathrm{E}+00$ & 0.0000 & $0.000 \mathrm{E}+00$ & 0.0000 \\
\hline & $9.324 \mathrm{E}-01$ & 1.0000 & $0.000 \mathrm{E}+00$ & 0.0000 & $0.000 \mathrm{E}+00$ & 0.0000 & $0.000 \mathrm{E}+00$ & 0.0000 & $0.000 \mathrm{E}+00$ & 0.0000 & $0.000 \mathrm{E}+00$ & 0.0000 & $.000 \mathrm{E}+00$ & 0.0000 \\
\hline
\end{tabular}

Total Dose Contributions TDOSE (i,p,t) for Individual Radionuclides (i) and Pathways (p) As mrem/yr and Fraction of Total Dose At $t=0.000 \mathrm{E}+00$ years

Water Dependent Pathways

\begin{tabular}{|c|c|c|c|c|c|c|c|c|c|c|c|c|c|c|}
\hline & \multicolumn{2}{|c|}{ Water } & \multicolumn{2}{|c|}{ Fish } & \multicolumn{2}{|c|}{ Radon } & \multicolumn{2}{|c|}{ Plant } & \multicolumn{2}{|c|}{ Meat } & \multicolumn{2}{|c|}{ Milk } & \multicolumn{2}{|c|}{ All Pathways* } \\
\hline clide & mrem/yr & fract. & mrem/yr & fract. & mrem/yr & fract. & mrem/yr & fract. & mrem/yr & fract. & mrem/yr & fract. & mrem/yr & fract. \\
\hline-241 & $0.000 \mathrm{E}+00$ & 0.0000 & $0.000 \mathrm{E}+00$ & 0.0000 & $0.000 \mathrm{E}+00$ & 0.0000 & $0.000 \mathrm{E}+00$ & 0.0000 & $0.000 \mathrm{E}+00$ & 0.0000 & $0.000 \mathrm{E}+00$ & 0.0000 & $5.101 \mathrm{E}-05$ & 0.0001 \\
\hline-137 & $0.000 \mathrm{E}+00$ & 0.0000 & $0.000 \mathrm{E}+00$ & 0.0000 & $0.000 \mathrm{E}+00$ & 0.0000 & $0.000 \mathrm{E}+00$ & 0.0000 & $0.000 \mathrm{E}+00$ & 0.0000 & $0.000 \mathrm{E}+00$ & 0.0000 & $3.913 \mathrm{E}-01$ & 0.4197 \\
\hline-237 & $0.000 \mathrm{E}+00$ & 0.0000 & $0.000 \mathrm{E}+00$ & 0.0000 & $0.000 \mathrm{E}+00$ & 0.0000 & $0.000 \mathrm{E}+00$ & 0.0000 & $0.000 \mathrm{E}+00$ & 0.0000 & $0.000 \mathrm{E}+00$ & 0.0000 & $1.899 \mathrm{E}-02$ & 0.0204 \\
\hline 238 & $0.000 \mathrm{E}+00$ & 0.0000 & $0.000 \mathrm{E}+00$ & 0.0000 & $0.000 \mathrm{E}+00$ & 0.0000 & $0.000 \mathrm{E}+00$ & 0.0000 & $0.000 \mathrm{E}+00$ & 0.0000 & $0.000 \mathrm{E}+00$ & 0.0000 & $1.030 \mathrm{E}-06$ & 0.0000 \\
\hline 239 & $0.000 \mathrm{E}+00$ & 0.0000 & $0.000 \mathrm{E}+00$ & 0.0000 & $0.000 \mathrm{E}+00$ & 0.0000 & $0.000 \mathrm{E}+00$ & 0.0000 & $0.000 \mathrm{E}+00$ & 0.0000 & $0.000 \mathrm{E}+00$ & 0.0000 & $2.269 \mathrm{E}-05$ & 0.0000 \\
\hline 240 & $0.000 \mathrm{E}+00$ & 0.0000 & $0.000 \mathrm{E}+00$ & 0.0000 & $0.000 \mathrm{E}+00$ & 0.0000 & $0.000 \mathrm{E}+00$ & 0.0000 & $0.000 \mathrm{E}+00$ & 0.0000 & $0.000 \mathrm{E}+00$ & 0.0000 & $9.241 \mathrm{E}-07$ & 0.0000 \\
\hline 99 & $0.000 \mathrm{E}+00$ & 0.0000 & $0.000 \mathrm{E}+00$ & 0.0000 & $0.000 \mathrm{E}+00$ & 0.0000 & $0.000 \mathrm{E}+00$ & 0.0000 & $0.000 \mathrm{E}+00$ & 0.0000 & $0.000 \mathrm{E}+00$ & 0.0000 & $2.113 \mathrm{E}-06$ & 0.0000 \\
\hline 228 & $0.000 \mathrm{E}+00$ & 0.0000 & $0.000 \mathrm{E}+00$ & 0.0000 & $0.000 \mathrm{E}+00$ & 0.0000 & $0.000 \mathrm{E}+00$ & 0.0000 & $0.000 \mathrm{E}+00$ & 0.0000 & $0.000 \mathrm{E}+00$ & 0.0000 & $3.555 \mathrm{E}-01$ & 0.3813 \\
\hline 230 & $0.000 \mathrm{E}+00$ & 0.0000 & $0.000 \mathrm{E}+00$ & 0.0000 & $0.000 \mathrm{E}+00$ & 0.0000 & $0.000 \mathrm{E}+00$ & 0.0000 & $0.000 \mathrm{E}+00$ & 0.0000 & $0.000 \mathrm{E}+00$ & 0.0000 & $2.131 \mathrm{E}-03$ & 0.0023 \\
\hline 232 & $0.000 \mathrm{E}+00$ & 0.0000 & $0.000 \mathrm{E}+00$ & 0.0000 & $0.000 \mathrm{E}+00$ & 0.0000 & $0.000 \mathrm{E}+00$ & 0.0000 & $0.000 \mathrm{E}+00$ & 0.0000 & $0.000 \mathrm{E}+00$ & 0.0000 & $1.332 \mathrm{E}-02$ & 0.0143 \\
\hline 34 & $0.000 \mathrm{E}+00$ & 0.0000 & $0.000 \mathrm{E}+00$ & 0.0000 & $0.000 \mathrm{E}+00$ & 0.0000 & $0.000 \mathrm{E}+00$ & 0.0000 & $0.000 \mathrm{E}+00$ & 0.0000 & $0.000 \mathrm{E}+00$ & 0.0000 & $2.806 \mathrm{E}-05$ & 0.0000 \\
\hline 35 & $0.000 \mathrm{E}+00$ & 0.0000 & $0.000 \mathrm{E}+00$ & 0.0000 & $0.000 \mathrm{E}+00$ & 0.0000 & $0.000 \mathrm{E}+00$ & 0.0000 & $0.000 \mathrm{E}+00$ & 0.0000 & $0.000 \mathrm{E}+00$ & 0.0000 & $1.058 \mathrm{E}-02$ & 0.0113 \\
\hline 38 & $0.000 \mathrm{E}+00$ & 0.0000 & $0.000 \mathrm{E}+00$ & 0.0000 & $0.000 \mathrm{E}+00$ & 0.0000 & $0.000 \mathrm{E}+00$ & 0.0000 & $0.000 \mathrm{E}+00$ & 0.0000 & $0.000 \mathrm{E}+00$ & 0.0000 & $1.404 \mathrm{E}-01$ & 0.1506 \\
\hline & $0.000 \mathrm{E}+00$ & 0.0000 & $0.000 \mathrm{E}+00$ & 0.0000 & $0.000 \mathrm{E}+00$ & 0.0000 & $0.000 \mathrm{E}+00$ & 0.0000 & $0.000 \mathrm{E}+00$ & 0.0000 & $.000 \mathrm{E}+00$ & 000 & -01 & 1.0000 \\
\hline
\end{tabular}

* Sum of all water independent and dependent pathways. 
RESRAD, Version $6.5 \quad \mathrm{~T}^{1 / 2}$ Limit $=180$ days

ummary : C746U Trespasser Deterministic Run

File : $\mathrm{X}: \backslash F I N A L$ V2 $\backslash$ DOE FWD RUNS $\backslash$ C746U T SG DOE FWD-FV2-70YR.RAD

Total Dose Contributions TDOSE(i,p,t) for Individual Radionuclides (i) and Pathways (p) As mrem/yr and Fraction of Total Dose At $t=1.000 \mathrm{E}+00$ years

Water Independent Pathways (Inhalation excludes radon)

\begin{tabular}{|c|c|c|c|c|c|c|c|c|c|c|c|c|c|c|}
\hline \multirow{2}{*}{ Nuclide } & \multicolumn{2}{|c|}{ Ground } & \multicolumn{2}{|c|}{ Inhalation } & \multicolumn{2}{|c|}{ Radon } & \multicolumn{2}{|c|}{ Plant } & \multicolumn{2}{|c|}{ Meat } & \multicolumn{2}{|c|}{ Milk } & \multicolumn{2}{|c|}{ Soil } \\
\hline & mrem/yr & fract. & mrem/yr & fract. & mrem/yr & fract. & mrem/yr & fract. & mrem/yr & fract. & mrem/yr & fract. & mrem/yr & fract. \\
\hline-241 & $5.243 E-05$ & 0.0001 & $0.000 \mathrm{E}+00$ & 0.0000 & $0.000 \mathrm{E}+00$ & 0.0000 & $0.000 \mathrm{E}+00$ & 0.0000 & $0.000 \mathrm{E}+00$ & 0.0000 & $0.000 \mathrm{E}+00$ & 0.0000 & $0.000 \mathrm{E}+00$ & 0.0000 \\
\hline-137 & $3.856 \mathrm{E}-01$ & 0.4485 & $0.000 \mathrm{E}+00$ & 0.0000 & $0.000 \mathrm{E}+00$ & 0.0000 & $0.000 \mathrm{E}+00$ & 0.0000 & $0.000 \mathrm{E}+00$ & 0.0000 & $0.000 \mathrm{E}+00$ & 0.0000 & $0.000 \mathrm{E}+00$ & 0.0000 \\
\hline-237 & $1.919 \mathrm{E}-02$ & 0.0223 & $0.000 \mathrm{E}+00$ & 0.0000 & $0.000 \mathrm{E}+00$ & 0.0000 & $0.000 \mathrm{E}+00$ & 0.0000 & $0.000 \mathrm{E}+00$ & 0.0000 & $0.000 \mathrm{E}+00$ & 0.0000 & $0.000 \mathrm{E}+00$ & 0.0000 \\
\hline-238 & $1.040 \mathrm{E}-06$ & 0.0000 & $0.000 \mathrm{E}+00$ & 0.0000 & $0.000 \mathrm{E}+00$ & 0.0000 & $0.000 \mathrm{E}+00$ & 0.0000 & $0.000 \mathrm{E}+00$ & 0.0000 & $0.000 \mathrm{E}+00$ & 0.0000 & $0.000 \mathrm{E}+00$ & 0.0000 \\
\hline-239 & $2.296 \mathrm{E}-05$ & 0.0000 & $0.000 \mathrm{E}+00$ & 0.0000 & $0.000 \mathrm{E}+00$ & 0.0000 & $0.000 \mathrm{E}+00$ & 0.0000 & $0.000 \mathrm{E}+00$ & 0.0000 & $0.000 \mathrm{E}+00$ & 0.0000 & $0.000 \mathrm{E}+00$ & 0.0000 \\
\hline-240 & $9.405 \mathrm{E}-07$ & 0.0000 & $0.000 \mathrm{E}+00$ & 0.0000 & $0.000 \mathrm{E}+00$ & 0.0000 & $0.000 \mathrm{E}+00$ & 0.0000 & $0.000 \mathrm{E}+00$ & 0.0000 & $0.000 \mathrm{E}+00$ & 0.0000 & $0.000 \mathrm{E}+00$ & 0.0000 \\
\hline 99 & $2.131 E-06$ & 0.0000 & $0.000 \mathrm{E}+00$ & 0.0000 & $0.000 \mathrm{E}+00$ & 0.0000 & $0.000 \mathrm{E}+00$ & 0.0000 & $0.000 \mathrm{E}+00$ & 0.0000 & $0.000 \mathrm{E}+00$ & 0.0000 & $0.000 \mathrm{E}+00$ & 0.0000 \\
\hline-228 & $2.490 \mathrm{E}-01$ & 0.2897 & $0.000 \mathrm{E}+00$ & 0.0000 & $0.000 \mathrm{E}+00$ & 0.0000 & $0.000 \mathrm{E}+00$ & 0.0000 & $0.000 \mathrm{E}+00$ & 0.0000 & $0.000 \mathrm{E}+00$ & 0.0000 & $0.000 \mathrm{E}+00$ & 0.0000 \\
\hline-230 & $6.276 \mathrm{E}-03$ & 0.0073 & $0.000 \mathrm{E}+00$ & 0.0000 & $0.000 \mathrm{E}+00$ & 0.0000 & $0.000 \mathrm{E}+00$ & 0.0000 & $0.000 \mathrm{E}+00$ & 0.0000 & $0.000 \mathrm{E}+00$ & 0.0000 & $0.000 \mathrm{E}+00$ & 0.0000 \\
\hline-232 & $4.723 E-02$ & 0.0549 & $0.000 \mathrm{E}+00$ & 0.0000 & $0.000 \mathrm{E}+00$ & 0.0000 & $0.000 \mathrm{E}+00$ & 0.0000 & $0.000 \mathrm{E}+00$ & 0.0000 & $0.000 \mathrm{E}+00$ & 0.0000 & $0.000 \mathrm{E}+00$ & 0.0000 \\
\hline 234 & $2.862 E-05$ & 0.0000 & $0.000 \mathrm{E}+00$ & 0.0000 & $0.000 \mathrm{E}+00$ & 0.0000 & $0.000 \mathrm{E}+00$ & 0.0000 & $0.000 \mathrm{E}+00$ & 0.0000 & $0.000 \mathrm{E}+00$ & 0.0000 & $0.000 \mathrm{E}+00$ & 0.0000 \\
\hline 235 & $1.071 \mathrm{E}-02$ & 0.0125 & $0.000 \mathrm{E}+00$ & 0.0000 & $0.000 \mathrm{E}+00$ & 0.0000 & $0.000 \mathrm{E}+00$ & 0.0000 & $0.000 \mathrm{E}+00$ & 0.0000 & $0.000 \mathrm{E}+00$ & 0.0000 & $0.000 \mathrm{E}+00$ & 0.0000 \\
\hline 38 & $1.415 E-01$ & 0.1646 & $0.000 \mathrm{E}+00$ & 0.0000 & $0.000 \mathrm{E}+00$ & 0.0000 & $0.000 \mathrm{E}+00$ & 0.0000 & $0.000 \mathrm{E}+00$ & 0.0000 & $0.000 \mathrm{E}+00$ & 0.0000 & $0.000 \mathrm{E}+00$ & 0.0000 \\
\hline & $8.597 \mathrm{E}-01$ & 1.0000 & $0.000 \mathrm{E}+00$ & 0.0000 & $0.000 \mathrm{E}+00$ & 0.0000 & $0.000 \mathrm{E}+00$ & 0.0000 & $0.000 \mathrm{E}+00$ & 0.0000 & $0.000 \mathrm{E}+00$ & 0.0000 & $.000 \mathrm{E}+00$ & 0.0000 \\
\hline
\end{tabular}

Total Dose Contributions TDOSE (i,p,t) for Individual Radionuclides (i) and Pathways (p) As mrem/yr and Fraction of Total Dose At $t=1.000 \mathrm{E}+00$ years

Water Dependent Pathways

\begin{tabular}{|c|c|c|c|c|c|c|c|c|c|c|c|c|c|c|}
\hline & \multicolumn{2}{|c|}{ Water } & \multicolumn{2}{|c|}{ Fish } & \multicolumn{2}{|c|}{ Radon } & \multicolumn{2}{|c|}{ Plant } & \multicolumn{2}{|c|}{ Meat } & \multicolumn{2}{|c|}{ Milk } & \multicolumn{2}{|c|}{ All Pathways* } \\
\hline clide & mrem/yr & fract. & mrem/yr & fract. & mrem/yr & fract. & mrem/yr & fract. & mrem/yr & fract. & mrem/yr & fract. & mrem/yr & fract. \\
\hline-241 & $0.000 \mathrm{E}+00$ & 0.0000 & $0.000 \mathrm{E}+00$ & 0.0000 & $0.000 \mathrm{E}+00$ & 0.0000 & $0.000 \mathrm{E}+00$ & 0.0000 & $0.000 \mathrm{E}+00$ & 0.0000 & $0.000 E+00$ & 0.0000 & $5.243 E-05$ & 0.0001 \\
\hline-137 & $0.000 \mathrm{E}+00$ & 0.0000 & $0.000 \mathrm{E}+00$ & 0.0000 & $0.000 \mathrm{E}+00$ & 0.0000 & $0.000 \mathrm{E}+00$ & 0.0000 & $0.000 \mathrm{E}+00$ & 0.0000 & $0.000 \mathrm{E}+00$ & 0.0000 & $3.856 \mathrm{E}-01$ & 0.4485 \\
\hline-237 & $0.000 \mathrm{E}+00$ & 0.0000 & $0.000 \mathrm{E}+00$ & 0.0000 & $0.000 \mathrm{E}+00$ & 0.0000 & $0.000 \mathrm{E}+00$ & 0.0000 & $0.000 \mathrm{E}+00$ & 0.0000 & $0.000 \mathrm{E}+00$ & 0.0000 & $1.919 \mathrm{E}-02$ & 0.0223 \\
\hline 238 & $0.000 \mathrm{E}+00$ & 0.0000 & $0.000 \mathrm{E}+00$ & 0.0000 & $0.000 \mathrm{E}+00$ & 0.0000 & $0.000 \mathrm{E}+00$ & 0.0000 & $0.000 \mathrm{E}+00$ & 0.0000 & $0.000 \mathrm{E}+00$ & 0.0000 & $1.040 \mathrm{E}-06$ & 0.0000 \\
\hline 239 & $0.000 \mathrm{E}+00$ & 0.0000 & $0.000 \mathrm{E}+00$ & 0.0000 & $0.000 \mathrm{E}+00$ & 0.0000 & $0.000 \mathrm{E}+00$ & 0.0000 & $0.000 \mathrm{E}+00$ & 0.0000 & $0.000 \mathrm{E}+00$ & 0.0000 & $2.296 \mathrm{E}-05$ & 0.0000 \\
\hline 240 & $0.000 \mathrm{E}+00$ & 0.0000 & $0.000 \mathrm{E}+00$ & 0.0000 & $0.000 \mathrm{E}+00$ & 0.0000 & $0.000 \mathrm{E}+00$ & 0.0000 & $0.000 \mathrm{E}+00$ & 0.0000 & $0.000 \mathrm{E}+00$ & 0.0000 & $9.405 \mathrm{E}-07$ & 0.0000 \\
\hline 99 & $0.000 \mathrm{E}+00$ & 0.0000 & $0.000 \mathrm{E}+00$ & 0.0000 & $0.000 \mathrm{E}+00$ & 0.0000 & $0.000 \mathrm{E}+00$ & 0.0000 & $0.000 \mathrm{E}+00$ & 0.0000 & $0.000 \mathrm{E}+00$ & 0.0000 & $2.131 \mathrm{E}-06$ & 0.0000 \\
\hline 228 & $0.000 \mathrm{E}+00$ & 0.0000 & $0.000 \mathrm{E}+00$ & 0.0000 & $0.000 \mathrm{E}+00$ & 0.0000 & $0.000 \mathrm{E}+00$ & 0.0000 & $0.000 \mathrm{E}+00$ & 0.0000 & $0.000 \mathrm{E}+00$ & 0.0000 & $2.490 \mathrm{E}-01$ & 0.2897 \\
\hline 230 & $0.000 \mathrm{E}+00$ & 0.0000 & $0.000 \mathrm{E}+00$ & 0.0000 & $0.000 \mathrm{E}+00$ & 0.0000 & $0.000 \mathrm{E}+00$ & 0.0000 & $0.000 \mathrm{E}+00$ & 0.0000 & $0.000 \mathrm{E}+00$ & 0.0000 & $6.276 \mathrm{E}-03$ & 0.0073 \\
\hline 232 & $0.000 \mathrm{E}+00$ & 0.0000 & $0.000 \mathrm{E}+00$ & 0.0000 & $0.000 \mathrm{E}+00$ & 0.0000 & $0.000 \mathrm{E}+00$ & 0.0000 & $0.000 \mathrm{E}+00$ & 0.0000 & $0.000 \mathrm{E}+00$ & 0.0000 & $4.723 E-02$ & 0.0549 \\
\hline 34 & $0.000 \mathrm{E}+00$ & 0.0000 & $0.000 \mathrm{E}+00$ & 0.0000 & $0.000 \mathrm{E}+00$ & 0.0000 & $0.000 \mathrm{E}+00$ & 0.0000 & $0.000 \mathrm{E}+00$ & 0.0000 & $0.000 \mathrm{E}+00$ & 0.0000 & $2.862 \mathrm{E}-05$ & 0.0000 \\
\hline 35 & $0.000 \mathrm{E}+00$ & 0.0000 & $0.000 \mathrm{E}+00$ & 0.0000 & $0.000 \mathrm{E}+00$ & 0.0000 & $0.000 \mathrm{E}+00$ & 0.0000 & $0.000 \mathrm{E}+00$ & 0.0000 & $0.000 \mathrm{E}+00$ & 0.0000 & $1.071 \mathrm{E}-02$ & 0.0125 \\
\hline 38 & $0.000 \mathrm{E}+00$ & 0.0000 & $0.000 \mathrm{E}+00$ & 0.0000 & $0.000 \mathrm{E}+00$ & 0.0000 & $0.000 \mathrm{E}+00$ & 0.0000 & $0.000 \mathrm{E}+00$ & 0.0000 & $0.000 \mathrm{E}+00$ & 0.0000 & $1.415 \mathrm{E}-01$ & 0.1646 \\
\hline & $0.000 \mathrm{E}+00$ & 0.0000 & $0.000 \mathrm{E}+00$ & 0.0000 & $0.000 \mathrm{E}+00$ & 0.0000 & $0.000 \mathrm{E}+00$ & 0.0000 & $0.000 \mathrm{E}+00$ & 0.0000 & $0.000 \mathrm{E}+00$ & 000 & -01 & 1.0000 \\
\hline
\end{tabular}

* Sum of all water independent and dependent pathways. 
RESRAD, Version $6.5 \quad \mathrm{~T}^{1 / 2}$ Limit $=180$ days

Summary : C746U Trespasser Deterministic Run

File : X: \FINAL V2 \DOE FWD RUNS \C746U T SG DOE FWD-FV2-70YR.RAD

Total Dose Contributions TDOSE (i,p,t) for Individual Radionuclides (i) and Pathways (p) As mrem/yr and Fraction of Total Dose At $t=5.000 \mathrm{E}+01$ years

Water Independent Pathways (Inhalation excludes radon)

\begin{tabular}{|c|c|c|c|c|c|c|c|c|c|c|c|c|c|c|}
\hline \multirow{2}{*}{ Nuclide } & \multicolumn{2}{|c|}{ Ground } & \multicolumn{2}{|c|}{ Inhalation } & \multicolumn{2}{|c|}{ Radon } & \multicolumn{2}{|c|}{ Plant } & \multicolumn{2}{|c|}{ Meat } & \multicolumn{2}{|c|}{ Milk } & \multicolumn{2}{|c|}{ Soil } \\
\hline & mrem/yr & fract. & mrem/yr & fract. & mrem/yr & fract. & mrem/yr & fract. & mrem/yr & fract. & mrem/yr & fract. & mrem/yr & fract. \\
\hline-241 & $1.969 \mathrm{E}-04$ & 0.0001 & 2. $603 \mathrm{E}-04$ & 0.0002 & $0.000 \mathrm{E}+00$ & 0.0000 & $0.000 \mathrm{E}+00$ & 0.0000 & $0.000 \mathrm{E}+00$ & 0.0000 & $0.000 \mathrm{E}+00$ & 0.0000 & $9.866 \mathrm{E}-03$ & 0.0058 \\
\hline-137 & $1.876 \mathrm{E}-01$ & 0.1102 & $1.932 \mathrm{E}-08$ & 0.0000 & $0.000 \mathrm{E}+00$ & 0.0000 & $0.000 \mathrm{E}+00$ & 0.0000 & $0.000 \mathrm{E}+00$ & 0.0000 & $0.000 \mathrm{E}+00$ & 0.0000 & $1.173 \mathrm{E}-04$ & 0.0001 \\
\hline-237 & $3.250 \mathrm{E}-02$ & 0.0191 & $2.294 \mathrm{E}-05$ & 0.0000 & $0.000 \mathrm{E}+00$ & 0.0000 & $0.000 \mathrm{E}+00$ & 0.0000 & $0.000 \mathrm{E}+00$ & 0.0000 & $0.000 \mathrm{E}+00$ & 0.0000 & $9.249 \mathrm{E}-04$ & 0.0005 \\
\hline-238 & $1.680 \mathrm{E}-06$ & 0.0000 & $2.418 E-04$ & 0.0001 & $0.000 \mathrm{E}+00$ & 0.0000 & $0.000 \mathrm{E}+00$ & 0.0000 & $0.000 \mathrm{E}+00$ & 0.0000 & $0.000 \mathrm{E}+00$ & 0.0000 & $9.193 \mathrm{E}-03$ & 0.0054 \\
\hline-239 & $4.120 \mathrm{E}-05$ & 0.0000 & $3.623 E-04$ & 0.0002 & $0.000 \mathrm{E}+00$ & 0.0000 & $0.000 \mathrm{E}+00$ & 0.0000 & $0.000 \mathrm{E}+00$ & 0.0000 & $0.000 \mathrm{E}+00$ & 0.0000 & $1.372 E-02$ & 0.0081 \\
\hline-240 & $2.221 E-06$ & 0.0000 & $3.609 \mathrm{E}-04$ & 0.0002 & $0.000 \mathrm{E}+00$ & 0.0000 & $0.000 \mathrm{E}+00$ & 0.0000 & $0.000 \mathrm{E}+00$ & 0.0000 & $0.000 \mathrm{E}+00$ & 0.0000 & $1.367 \mathrm{E}-02$ & 0.0080 \\
\hline 99 & $3.248 E-06$ & 0.0000 & $3.331 E-08$ & 0.0000 & $0.000 \mathrm{E}+00$ & 0.0000 & $0.000 \mathrm{E}+00$ & 0.0000 & $0.000 \mathrm{E}+00$ & 0.0000 & $0.000 \mathrm{E}+00$ & 0.0000 & $2.985 E-05$ & 0.0000 \\
\hline-228 & $6.585 E-09$ & 0.0000 & $1.668 \mathrm{E}-13$ & 0.0000 & $0.000 \mathrm{E}+00$ & 0.0000 & $0.000 \mathrm{E}+00$ & 0.0000 & $0.000 \mathrm{E}+00$ & 0.0000 & $0.000 \mathrm{E}+00$ & 0.0000 & $9.962 \mathrm{E}-12$ & 0.0000 \\
\hline-230 & $2.923 E-01$ & 0.1717 & $8.429 \mathrm{E}-04$ & 0.0005 & $0.000 \mathrm{E}+00$ & 0.0000 & $0.000 \mathrm{E}+00$ & 0.0000 & $0.000 \mathrm{E}+00$ & 0.0000 & $0.000 \mathrm{E}+00$ & 0.0000 & $3.612 \mathrm{E}-02$ & 0.0212 \\
\hline-232 & $8.425 E-01$ & 0.4948 & $5.698 E-05$ & 0.0000 & $0.000 \mathrm{E}+00$ & 0.0000 & $0.000 \mathrm{E}+00$ & 0.0000 & $0.000 \mathrm{E}+00$ & 0.0000 & $0.000 \mathrm{E}+00$ & 0.0000 & $6.485 \mathrm{E}-03$ & 0.0038 \\
\hline 234 & $1.747 \mathrm{E}-04$ & 0.0001 & $1.269 \mathrm{E}-04$ & 0.0001 & $0.000 \mathrm{E}+00$ & 0.0000 & $0.000 \mathrm{E}+00$ & 0.0000 & $0.000 \mathrm{E}+00$ & 0.0000 & $0.000 \mathrm{E}+00$ & 0.0000 & $1.197 \mathrm{E}-02$ & 0.0070 \\
\hline 235 & $1.973 E-02$ & 0.0116 & $4.895 \mathrm{E}-06$ & 0.0000 & $0.000 \mathrm{E}+00$ & 0.0000 & $0.000 \mathrm{E}+00$ & 0.0000 & $0.000 \mathrm{E}+00$ & 0.0000 & $0.000 \mathrm{E}+00$ & 0.0000 & $4.840 \mathrm{E}-04$ & 0.0003 \\
\hline 38 & $2.109 E-01$ & 0.1239 & $1.076 \mathrm{E}-04$ & 0.0001 & $0.000 \mathrm{E}+00$ & 0.0000 & $0.000 \mathrm{E}+00$ & 0.0000 & $0.000 \mathrm{E}+00$ & 0.0000 & $0.000 \mathrm{E}+00$ & 0.0000 & $1.186 \mathrm{E}-02$ & 0.0070 \\
\hline & $1.586 \mathrm{E}+00$ & 0.9314 & $2.388 E-03$ & 0.0014 & $0.000 \mathrm{E}+00$ & 0.0000 & $0.000 \mathrm{E}+00$ & 0.0000 & $0.000 \mathrm{E}+00$ & 0.0000 & $0.000 \mathrm{E}+00$ & 0.0000 & $1.144 \mathrm{E}-01$ & 0.0672 \\
\hline
\end{tabular}

Total Dose Contributions TDOSE(i,p,t) for Individual Radionuclides (i) and Pathways (p) As mrem/yr and Fraction of Total Dose At $t=5.000 \mathrm{E}+01$ years

Water Dependent Pathways

\begin{tabular}{|c|c|c|c|c|c|c|c|c|c|c|c|c|c|c|}
\hline & \multicolumn{2}{|c|}{ Water } & \multicolumn{2}{|c|}{ Fish } & \multicolumn{2}{|c|}{ Radon } & \multicolumn{2}{|c|}{ Plant } & \multicolumn{2}{|c|}{ Meat } & \multicolumn{2}{|c|}{ Milk } & \multicolumn{2}{|c|}{ All Pathways* } \\
\hline clide & mrem/yr & fract. & mrem/yr & fract. & mrem/yr & fract. & mrem/yr & fract. & mrem/yr & fract. & mrem/yr & fract. & mrem/yr & fract. \\
\hline 241 & $0.000 \mathrm{E}+00$ & 0.0000 & $0.000 \mathrm{E}+00$ & 0.0000 & $0.000 \mathrm{E}+00$ & 0.0000 & $0.000 \mathrm{E}+00$ & 0.0000 & $0.000 \mathrm{E}+00$ & 0.0000 & $0.000 \mathrm{E}+00$ & 0.0000 & $1.032 \mathrm{E}-02$ & 0.0061 \\
\hline-137 & $0.000 \mathrm{E}+00$ & 0.0000 & $0.000 \mathrm{E}+00$ & 0.0000 & $0.000 \mathrm{E}+00$ & 0.0000 & $0.000 \mathrm{E}+00$ & 0.0000 & $0.000 \mathrm{E}+00$ & 0.0000 & $0.000 \mathrm{E}+00$ & 0.0000 & $1.877 \mathrm{E}-01$ & 0.1102 \\
\hline-237 & $0.000 \mathrm{E}+00$ & 0.0000 & $0.000 \mathrm{E}+00$ & 0.0000 & $0.000 \mathrm{E}+00$ & 0.0000 & $0.000 \mathrm{E}+00$ & 0.0000 & $0.000 \mathrm{E}+00$ & 0.0000 & $0.000 \mathrm{E}+00$ & 0.0000 & $3.345 E-02$ & 0.0196 \\
\hline-238 & $0.000 \mathrm{E}+00$ & 0.0000 & $0.000 \mathrm{E}+00$ & 0.0000 & $0.000 \mathrm{E}+00$ & 0.0000 & $0.000 \mathrm{E}+00$ & 0.0000 & $0.000 \mathrm{E}+00$ & 0.0000 & $0.000 \mathrm{E}+00$ & 0.0000 & $9.436 \mathrm{E}-03$ & 0.0055 \\
\hline-239 & $0.000 \mathrm{E}+00$ & 0.0000 & $0.000 \mathrm{E}+00$ & 0.0000 & $0.000 \mathrm{E}+00$ & 0.0000 & $0.000 \mathrm{E}+00$ & 0.0000 & $0.000 \mathrm{E}+00$ & 0.0000 & $0.000 E+00$ & 0.0000 & 1. $413 \mathrm{E}-02$ & 0.0083 \\
\hline-240 & $0.000 \mathrm{E}+00$ & 0.0000 & $0.000 \mathrm{E}+00$ & 0.0000 & $0.000 \mathrm{E}+00$ & 0.0000 & $0.000 \mathrm{E}+00$ & 0.0000 & $0.000 \mathrm{E}+00$ & 0.0000 & $0.000 E+00$ & 0.0000 & $1.403 \mathrm{E}-02$ & 0.0082 \\
\hline-99 & $0.000 \mathrm{E}+00$ & 0.0000 & $0.000 \mathrm{E}+00$ & 0.0000 & $0.000 \mathrm{E}+00$ & 0.0000 & $0.000 \mathrm{E}+00$ & 0.0000 & $0.000 \mathrm{E}+00$ & 0.0000 & $0.000 \mathrm{E}+00$ & 0.0000 & $3.313 E-05$ & 0.0000 \\
\hline-228 & $0.000 \mathrm{E}+00$ & 0.0000 & $0.000 \mathrm{E}+00$ & 0.0000 & $0.000 \mathrm{E}+00$ & 0.0000 & $0.000 \mathrm{E}+00$ & 0.0000 & $0.000 \mathrm{E}+00$ & 0.0000 & $0.000 \mathrm{E}+00$ & 0.0000 & $6.595 E-09$ & 0.0000 \\
\hline-230 & $0.000 \mathrm{E}+00$ & 0.0000 & $0.000 \mathrm{E}+00$ & 0.0000 & $0.000 \mathrm{E}+00$ & 0.0000 & $0.000 \mathrm{E}+00$ & 0.0000 & $0.000 \mathrm{E}+00$ & 0.0000 & $0.000 E+00$ & 0.0000 & $3.293 \mathrm{E}-01$ & 0.1934 \\
\hline-232 & $0.000 \mathrm{E}+00$ & 0.0000 & $0.000 \mathrm{E}+00$ & 0.0000 & $0.000 \mathrm{E}+00$ & 0.0000 & $0.000 \mathrm{E}+00$ & 0.0000 & $0.000 \mathrm{E}+00$ & 0.0000 & $0.000 \mathrm{E}+00$ & 0.0000 & $8.490 \mathrm{E}-01$ & 0.4986 \\
\hline 34 & $0.000 \mathrm{E}+00$ & 0.0000 & $0.000 \mathrm{E}+00$ & 0.0000 & $0.000 \mathrm{E}+00$ & 0.0000 & $0.000 \mathrm{E}+00$ & 0.0000 & $0.000 \mathrm{E}+00$ & 0.0000 & $0.000 \mathrm{E}+00$ & 0.0000 & $1.227 \mathrm{E}-02$ & 0.0072 \\
\hline 35 & $0.000 \mathrm{E}+00$ & 0.0000 & $0.000 \mathrm{E}+00$ & 0.0000 & $0.000 \mathrm{E}+00$ & 0.0000 & $0.000 \mathrm{E}+00$ & 0.0000 & $0.000 \mathrm{E}+00$ & 0.0000 & $0.000 \mathrm{E}+00$ & 0.0000 & $2.022 \mathrm{E}-02$ & 0.0119 \\
\hline 38 & $0.000 \mathrm{E}+00$ & 0.0000 & $0.000 \mathrm{E}+00$ & 0.0000 & $0.000 \mathrm{E}+00$ & 0.0000 & $0.000 \mathrm{E}+00$ & 0.0000 & $0.000 \mathrm{E}+00$ & 0.0000 & $0.000 \mathrm{E}+00$ & 0.0000 & $2.229 \mathrm{E}-01$ & 0.1309 \\
\hline & $0.000 \mathrm{E}+00$ & 0.0000 & $0.000 \mathrm{E}+00$ & 0.0000 & $0.000 \mathrm{E}+00$ & 0.0000 & $0.000 \mathrm{E}+00$ & 0.0000 & $0.000 \mathrm{E}+00$ & 0.0000 & $0.000 \mathrm{E}+00$ & 0.0000 & $1.703 E+00$ & 1. \\
\hline
\end{tabular}

* Sum of all water independent and dependent pathways. 
RESRAD, Version $6.5 \quad \mathrm{~T}^{1 / 2}$ Limit $=180$ days

ummary : C746U Trespasser Deterministic Run

File : X: \FINAL V2 \DOE FWD RUNS \C746U T SG DOE FWD-FV2-70YR.RAD

Total Dose Contributions TDOSE(i,p,t) for Individual Radionuclides (i) and Pathways (p) As mrem/yr and Fraction of Total Dose At $t=7.000 \mathrm{E}+01$ years

Water Independent Pathways (Inhalation excludes radon)

\begin{tabular}{|c|c|c|c|c|c|c|c|c|c|c|c|c|c|c|}
\hline \multirow{2}{*}{ Nuclide } & \multicolumn{2}{|c|}{ Ground } & \multicolumn{2}{|c|}{ Inhalation } & \multicolumn{2}{|c|}{ Radon } & \multicolumn{2}{|c|}{ Plant } & \multicolumn{2}{|c|}{ Meat } & \multicolumn{2}{|c|}{ Milk } & \multicolumn{2}{|c|}{ Soil } \\
\hline & mrem/yr & fract. & mrem/yr & fract. & mrem/yr & fract. & mrem/yr & fract. & mrem/yr & fract. & mrem/yr & fract. & mrem/yr & fract. \\
\hline-241 & $3.358 E-04$ & 0.0002 & $3.589 \mathrm{E}-04$ & 0.0002 & $0.000 \mathrm{E}+00$ & 0.0000 & $0.000 \mathrm{E}+00$ & 0.0000 & $0.000 \mathrm{E}+00$ & 0.0000 & $0.000 \mathrm{E}+00$ & 0.0000 & $1.360 \mathrm{E}-02$ & 0.0066 \\
\hline-137 & $1.398 E-01$ & 0.0680 & $1.732 \mathrm{E}-08$ & 0.0000 & $0.000 \mathrm{E}+00$ & 0.0000 & $0.000 \mathrm{E}+00$ & 0.0000 & $0.000 \mathrm{E}+00$ & 0.0000 & $0.000 \mathrm{E}+00$ & 0.0000 & $1.052 \mathrm{E}-04$ & 0.0001 \\
\hline-237 & $4.032 \mathrm{E}-02$ & 0.0196 & $3.256 \mathrm{E}-05$ & 0.0000 & $0.000 \mathrm{E}+00$ & 0.0000 & $0.000 \mathrm{E}+00$ & 0.0000 & $0.000 \mathrm{E}+00$ & 0.0000 & $0.000 \mathrm{E}+00$ & 0.0000 & $1.313 \mathrm{E}-03$ & 0.0006 \\
\hline-238 & $2.045 E-06$ & 0.0000 & $2.939 E-04$ & 0.0001 & $0.000 \mathrm{E}+00$ & 0.0000 & $0.000 \mathrm{E}+00$ & 0.0000 & $0.000 \mathrm{E}+00$ & 0.0000 & $0.000 \mathrm{E}+00$ & 0.0000 & $1.117 \mathrm{E}-02$ & 0.0054 \\
\hline-239 & $5.231 \mathrm{E}-05$ & 0.0000 & $5.154 \mathrm{E}-04$ & 0.0003 & $0.000 \mathrm{E}+00$ & 0.0000 & $0.000 \mathrm{E}+00$ & 0.0000 & $0.000 \mathrm{E}+00$ & 0.0000 & $0.000 \mathrm{E}+00$ & 0.0000 & 1.953E-02 & 0.0095 \\
\hline-240 & $3.155 \mathrm{E}-06$ & 0.0000 & $5.126 \mathrm{E}-04$ & 0.0002 & $0.000 \mathrm{E}+00$ & 0.0000 & $0.000 \mathrm{E}+00$ & 0.0000 & $0.000 \mathrm{E}+00$ & 0.0000 & $0.000 \mathrm{E}+00$ & 0.0000 & $1.942 \mathrm{E}-02$ & 0.0094 \\
\hline 99 & $3.858 E-06$ & 0.0000 & $3.839 E-08$ & 0.0000 & $0.000 \mathrm{E}+00$ & 0.0000 & $0.000 \mathrm{E}+00$ & 0.0000 & $0.000 \mathrm{E}+00$ & 0.0000 & $0.000 \mathrm{E}+00$ & 0.0000 & $3.440 \mathrm{E}-05$ & 0.0000 \\
\hline-228 & $5.320 \mathrm{E}-12$ & 0.0000 & $1.693 \mathrm{E}-16$ & 0.0000 & $0.000 \mathrm{E}+00$ & 0.0000 & $0.000 \mathrm{E}+00$ & 0.0000 & $0.000 \mathrm{E}+00$ & 0.0000 & $0.000 \mathrm{E}+00$ & 0.0000 & $1.011 \mathrm{E}-14$ & 0.0000 \\
\hline-230 & $4.685 E-01$ & 0.2278 & $1.202 \mathrm{E}-03$ & 0.0006 & $0.000 \mathrm{E}+00$ & 0.0000 & $0.000 \mathrm{E}+00$ & 0.0000 & $0.000 \mathrm{E}+00$ & 0.0000 & $0.000 \mathrm{E}+00$ & 0.0000 & $5.489 \mathrm{E}-02$ & 0.0267 \\
\hline-232 & $9.657 \mathrm{E}-01$ & 0.4696 & $8.122 \mathrm{E}-05$ & 0.0000 & $0.000 \mathrm{E}+00$ & 0.0000 & $0.000 \mathrm{E}+00$ & 0.0000 & $0.000 \mathrm{E}+00$ & 0.0000 & $0.000 \mathrm{E}+00$ & 0.0000 & $9.251 \mathrm{E}-03$ & 0.0045 \\
\hline 234 & $3.359 \mathrm{E}-04$ & 0.0002 & $1.810 \mathrm{E}-04$ & 0.0001 & $0.000 \mathrm{E}+00$ & 0.0000 & $0.000 \mathrm{E}+00$ & 0.0000 & $0.000 \mathrm{E}+00$ & 0.0000 & $0.000 \mathrm{E}+00$ & 0.0000 & $1.705 \mathrm{E}-02$ & 0.0083 \\
\hline 235 & $2.534 \mathrm{E}-02$ & 0.0123 & $7.173 \mathrm{E}-06$ & 0.0000 & $0.000 \mathrm{E}+00$ & 0.0000 & $0.000 \mathrm{E}+00$ & 0.0000 & $0.000 \mathrm{E}+00$ & 0.0000 & $0.000 \mathrm{E}+00$ & 0.0000 & $6.993 E-04$ & 0.0003 \\
\hline 38 & $2.486 \mathrm{E}-01$ & 0.1209 & $1.531 \mathrm{E}-04$ & 0.0001 & $0.000 \mathrm{E}+00$ & 0.0000 & $0.000 \mathrm{E}+00$ & 0.0000 & $0.000 \mathrm{E}+00$ & 0.0000 & $0.000 \mathrm{E}+00$ & 0.0000 & $1.688 \mathrm{E}-02$ & 0.0082 \\
\hline & $1.889 \mathrm{E}+00$ & 0.9186 & $3.338 E-03$ & 0.0016 & $0.000 \mathrm{E}+00$ & 0.0000 & $0.000 \mathrm{E}+00$ & 0.0000 & $0.000 \mathrm{E}+00$ & 0.0000 & $0.000 \mathrm{E}+00$ & 0.0000 & $1.640 \mathrm{E}-01$ & 0.0797 \\
\hline
\end{tabular}

Total Dose Contributions TDOSE (i,p,t) for Individual Radionuclides (i) and Pathways (p) As mrem/yr and Fraction of Total Dose At $t=7.000 \mathrm{E}+01$ years

Water Dependent Pathways

\begin{tabular}{|c|c|c|c|c|c|c|c|c|c|c|c|c|c|c|}
\hline & \multicolumn{2}{|c|}{ Water } & \multicolumn{2}{|c|}{ Fish } & \multicolumn{2}{|c|}{ Radon } & \multicolumn{2}{|c|}{ Plant } & \multicolumn{2}{|c|}{ Meat } & \multicolumn{2}{|c|}{ Milk } & \multicolumn{2}{|c|}{ All Pathways* } \\
\hline clide & mrem/yr & fract. & mrem/yr & fract. & mrem/yr & fract. & mrem/yr & fract. & mrem/yr & fract. & mrem/yr & fract. & mrem/yr & fract. \\
\hline-241 & $0.000 \mathrm{E}+00$ & 0.0000 & $0.000 \mathrm{E}+00$ & 0.0000 & $0.000 \mathrm{E}+00$ & 0.0000 & $0.000 \mathrm{E}+00$ & 0.0000 & $0.000 \mathrm{E}+00$ & 0.0000 & $0.000 \mathrm{E}+00$ & 0.0000 & $1.430 \mathrm{E}-02$ & 0.0070 \\
\hline-137 & $0.000 \mathrm{E}+00$ & 0.0000 & $0.000 \mathrm{E}+00$ & 0.0000 & $0.000 \mathrm{E}+00$ & 0.0000 & $0.000 \mathrm{E}+00$ & 0.0000 & $0.000 \mathrm{E}+00$ & 0.0000 & $0.000 \mathrm{E}+00$ & 0.0000 & $1.399 \mathrm{E}-01$ & 0.0680 \\
\hline-237 & $0.000 \mathrm{E}+00$ & 0.0000 & $0.000 \mathrm{E}+00$ & 0.0000 & $0.000 \mathrm{E}+00$ & 0.0000 & $0.000 \mathrm{E}+00$ & 0.0000 & $0.000 \mathrm{E}+00$ & 0.0000 & $0.000 \mathrm{E}+00$ & 0.0000 & $4.166 \mathrm{E}-02$ & 0.0203 \\
\hline-238 & $0.000 \mathrm{E}+00$ & 0.0000 & $0.000 \mathrm{E}+00$ & 0.0000 & $0.000 \mathrm{E}+00$ & 0.0000 & $0.000 \mathrm{E}+00$ & 0.0000 & $0.000 \mathrm{E}+00$ & 0.0000 & $0.000 \mathrm{E}+00$ & 0.0000 & $1.147 \mathrm{E}-02$ & 0.0056 \\
\hline-239 & $0.000 \mathrm{E}+00$ & 0.0000 & $0.000 \mathrm{E}+00$ & 0.0000 & $0.000 \mathrm{E}+00$ & 0.0000 & $0.000 \mathrm{E}+00$ & 0.0000 & $0.000 \mathrm{E}+00$ & 0.0000 & $0.000 E+00$ & 0.0000 & $2.009 E-02$ & 0.0098 \\
\hline-240 & $0.000 \mathrm{E}+00$ & 0.0000 & $0.000 \mathrm{E}+00$ & 0.0000 & $0.000 \mathrm{E}+00$ & 0.0000 & $0.000 \mathrm{E}+00$ & 0.0000 & $0.000 \mathrm{E}+00$ & 0.0000 & $0.000 E+00$ & 0.0000 & $1.994 \mathrm{E}-02$ & 0.0097 \\
\hline-99 & $0.000 \mathrm{E}+00$ & 0.0000 & $0.000 \mathrm{E}+00$ & 0.0000 & $0.000 \mathrm{E}+00$ & 0.0000 & $0.000 \mathrm{E}+00$ & 0.0000 & $0.000 \mathrm{E}+00$ & 0.0000 & $0.000 \mathrm{E}+00$ & 0.0000 & $3.829 E-05$ & 0.0000 \\
\hline-228 & $0.000 \mathrm{E}+00$ & 0.0000 & $0.000 \mathrm{E}+00$ & 0.0000 & $0.000 \mathrm{E}+00$ & 0.0000 & $0.000 \mathrm{E}+00$ & 0.0000 & $0.000 \mathrm{E}+00$ & 0.0000 & $0.000 \mathrm{E}+00$ & 0.0000 & $5.330 \mathrm{E}-12$ & 0.0000 \\
\hline-230 & $0.000 \mathrm{E}+00$ & 0.0000 & $0.000 \mathrm{E}+00$ & 0.0000 & $0.000 \mathrm{E}+00$ & 0.0000 & $0.000 \mathrm{E}+00$ & 0.0000 & $0.000 \mathrm{E}+00$ & 0.0000 & $0.000 E+00$ & 0.0000 & $5.246 \mathrm{E}-01$ & 0.2551 \\
\hline-232 & $0.000 \mathrm{E}+00$ & 0.0000 & $0.000 \mathrm{E}+00$ & 0.0000 & $0.000 \mathrm{E}+00$ & 0.0000 & $0.000 \mathrm{E}+00$ & 0.0000 & $0.000 \mathrm{E}+00$ & 0.0000 & $0.000 \mathrm{E}+00$ & 0.0000 & $9.750 \mathrm{E}-01$ & 0.4742 \\
\hline 34 & $0.000 \mathrm{E}+00$ & 0.0000 & $0.000 \mathrm{E}+00$ & 0.0000 & $0.000 \mathrm{E}+00$ & 0.0000 & $0.000 \mathrm{E}+00$ & 0.0000 & $0.000 \mathrm{E}+00$ & 0.0000 & $0.000 \mathrm{E}+00$ & 0.0000 & $1.757 \mathrm{E}-02$ & 0.0085 \\
\hline 35 & $0.000 \mathrm{E}+00$ & 0.0000 & $0.000 \mathrm{E}+00$ & 0.0000 & $0.000 \mathrm{E}+00$ & 0.0000 & $0.000 \mathrm{E}+00$ & 0.0000 & $0.000 \mathrm{E}+00$ & 0.0000 & $0.000 E+00$ & 0.0000 & $2.605 E-02$ & 0.0127 \\
\hline 38 & $0.000 \mathrm{E}+00$ & 0.0000 & $0.000 \mathrm{E}+00$ & 0.0000 & $0.000 \mathrm{E}+00$ & 0.0000 & $0.000 \mathrm{E}+00$ & 0.0000 & $0.000 \mathrm{E}+00$ & 0.0000 & $0.000 \mathrm{E}+00$ & 0.0000 & $2.656 \mathrm{E}-01$ & 0.1292 \\
\hline & $0.000 \mathrm{E}+00$ & 0.0000 & $0.000 \mathrm{E}+00$ & 0.0000 & $0.000 \mathrm{E}+00$ & 0.0000 & $0.000 \mathrm{E}+00$ & 0.0000 & $0.000 \mathrm{E}+00$ & 0.0000 & $0.000 \mathrm{E}+00$ & 0.0000 & $.056 \mathrm{E}+00$ & 1. \\
\hline
\end{tabular}

* Sum of all water independent and dependent pathways. 
RESRAD, Version $6.5 \quad \mathrm{~T}^{1 / 2}$ Limit $=180$ days

Summary : C746U Trespasser Deterministic Run

File : $\mathrm{X}: \backslash F I N A L$ V2 $\backslash$ DOE FWD RUNS \C746U T SG DOE FWD-FV2-70YR.RAD

Dose/Source Ratios Summed Over All Pathways

Parent and Progeny Principal Radionuclide Contributions Indicated

Parent Product Thread DSR $(j, t)$ At Time in Years (mrem/yr) $/(\mathrm{pCi} / \mathrm{g})$

(i) (j) Fraction $0.000 \mathrm{E}+001.000 \mathrm{E}+005.000 \mathrm{E}+017.000 \mathrm{E}+01$

Am-241

Am-241

Am-241

Am-241

Am-241

$C s-137+D$

$\mathrm{Np}-237+\mathrm{D}$

$\mathrm{Np}-237+\mathrm{D}$

$\mathrm{Np}-237+\mathrm{D}$

$\mathrm{NP}-237+\mathrm{D}$

$\mathrm{Pu}-238$

$\mathrm{Pu}-238$

1. $840 E-09$

$\begin{array}{llllll}\mathrm{Am}-241 & 1.000 \mathrm{E}+00 & & & & \\ 1.457 \mathrm{E}-06 & 1.496 \mathrm{E}-06 & 2.949 \mathrm{E}-04 & 4.084 \mathrm{E}-04\end{array}$

$\begin{array}{lllllll}\mathrm{Np}-237+\mathrm{D} & 1.000 \mathrm{E}+00 & 5.599 \mathrm{E}-10 & 1.695 \mathrm{E}-09 & 9.593 \mathrm{E}-08 & 1.644 \mathrm{E}-07\end{array}$

$\begin{array}{lllllll}\mathrm{U}-233 & 1.000 \mathrm{E}+00 & 6.695 \mathrm{E}-19 & 4.735 \mathrm{E}-18 & 1.476 \mathrm{E}-13 & 4.022 \mathrm{E}-13\end{array}$

$\begin{array}{lllllll}\mathrm{Th}-229+\mathrm{D} & 1.000 \mathrm{E}+00 & 3.971 \mathrm{E}-20 & 5.999 \mathrm{E}-19 & 3.406 \mathrm{E}-14 & 1.120 \mathrm{E}-13\end{array}$

$\operatorname{LDSR}(j) \quad 1.457 \mathrm{E}-06 \quad 1.498 \mathrm{E}-06 \quad 2.949 \mathrm{E}-04 \quad 4.085 \mathrm{E}-04$

$\mathrm{Cs}-137+\mathrm{D} \quad 1.000 \mathrm{E}+00 \quad 2.060 \mathrm{E}-02 \quad 2.029 \mathrm{E}-02 \quad 9.878 \mathrm{E}-03 \quad 7.362 \mathrm{E}-03$

$\mathrm{Np}-237+\mathrm{D} \quad 1.000 \mathrm{E}+00 \quad 3.453 \mathrm{E}-03 \quad 3.490 \mathrm{E}-03 \quad 6.082 \mathrm{E}-03 \quad 7.575 \mathrm{E}-03$

$\begin{array}{llllll}\mathrm{U}-233 & 1.000 \mathrm{E}+00 & 6.197 \mathrm{E}-12 & 1.880 \mathrm{E}-11 & 1.851 \mathrm{E}-08 & 3.649 \mathrm{E}-08\end{array}$

$\begin{array}{llllllll}\mathrm{Th}-229+\mathrm{D} & 1.000 \mathrm{E}+00 \quad 4.903 \mathrm{E}-13 & 3.458 \mathrm{E}-12 & 6.365 \mathrm{E}-09 & 1.511 \mathrm{E}-08\end{array}$

$\operatorname{SDSR}(j) \quad 3.453 \mathrm{E}-03 \quad 3.490 \mathrm{E}-03 \quad 6.082 \mathrm{E}-03 \quad 7.575 \mathrm{E}-03$

$\mathrm{Pu}-238$

$\begin{array}{lllllll}\mathrm{Pu}-238 & 1.000 \mathrm{E}+00 & 2.641 \mathrm{E}-08 & 2.667 \mathrm{E}-08 & 2.419 \mathrm{E}-04 & 2.941 \mathrm{E}-04\end{array}$

$\begin{array}{lllllll}\mathrm{U}-234 & 1.000 \mathrm{E}+00 & 2.486 \mathrm{E}-13 & 7.549 \mathrm{E}-13 & 8.961 \mathrm{E}-09 & 1.656 \mathrm{E}-08\end{array}$

$\begin{array}{llllll}\mathrm{Th}-230 & 1.000 \mathrm{E}+00 & 3.358 \mathrm{E}-18 & 2.380 \mathrm{E}-17 & 9.470 \mathrm{E}-12 & 2.502 \mathrm{E}-11\end{array}$

$\begin{array}{llllllll}\mathrm{Ra}-226+\mathrm{D} & 1.000 \mathrm{E}+00 \quad 4.363 \mathrm{E}-17 & 6.572 \mathrm{E}-16 & 2.901 \mathrm{E}-11 & 8.757 \mathrm{E}-11\end{array}$

$\mathrm{Pb}-210+\mathrm{D} \quad 1.000 \mathrm{E}+00 \quad 2.379 \mathrm{E}-23 \quad 7.401 \mathrm{E}-22 \quad 1.868 \mathrm{E}-13 \quad 8.841 \mathrm{E}-13$

$\operatorname{LDSR}(j) \quad 2.641 \mathrm{E}-08 \quad 2.667 \mathrm{E}-08 \quad 2.420 \mathrm{E}-04 \quad 2.941 \mathrm{E}-04$

$\begin{array}{llllll}\mathrm{Pu}-239 & 1.000 \mathrm{E}+00 & 6.302 \mathrm{E}-07 & 6.378 \mathrm{E}-07 & 3.925 \mathrm{E}-04 & 5.581 \mathrm{E}-04\end{array}$

$\begin{array}{llllll}\mathrm{U}-235+\mathrm{D} & 1.000 \mathrm{E}+00 & 8.030 \mathrm{E}-13 & 2.436 \mathrm{E}-12 & 1.542 \mathrm{E}-10 & 2.766 \mathrm{E}-10\end{array}$

$\begin{array}{lllllll}\mathrm{Pa}-231 & 1.000 \mathrm{E}+00 & 2.330 \mathrm{E}-18 & 1.646 \mathrm{E}-17 & 5.933 \mathrm{E}-14 & 1.535 \mathrm{E}-13\end{array}$

$\mathrm{AC}-227+\mathrm{D} \quad 1.000 \mathrm{E}+00 \quad 2.010 \mathrm{E}-19 \quad 3.022 \mathrm{E}-18 \quad 1.404 \mathrm{E}-13 \quad 4.252 \mathrm{E}-13$

$\operatorname{\sum DSR}(j) \quad 6.302 \mathrm{E}-07 \quad 6.378 \mathrm{E}-07 \quad 3.925 \mathrm{E}-04 \quad 5.581 \mathrm{E}-04$

Pu-240 4.950E-08 1.271E-15 $1.293 \mathrm{E}-15 \quad 1.930 \mathrm{E}-11 \quad 2.741 \mathrm{E}-11$

$\begin{array}{llllll}\mathrm{Pu}-240 \quad 1.000 \mathrm{E}+00 & 2.567 \mathrm{E}-08 & 2.612 \mathrm{E}-08 & 3.899 \mathrm{E}-04 & 5.538 \mathrm{E}-04\end{array}$

$\begin{array}{llllll}\mathrm{U}-236 & 1.000 \mathrm{E}+00 & 1.038 \mathrm{E}-15 & 3.165 \mathrm{E}-15 & 1.084 \mathrm{E}-10 & 2.152 \mathrm{E}-10\end{array}$

$\begin{array}{llllll}\mathrm{Th}-232 & 1.000 \mathrm{E}+00 & 4.987 \mathrm{E}-26 & 3.547 \mathrm{E}-25 & 6.713 \mathrm{E}-19 & 1.861 \mathrm{E}-18\end{array}$

$\begin{array}{llllll}\mathrm{Ra}-228+\mathrm{D} & 1.000 \mathrm{E}+00 \quad 3.271 \mathrm{E}-22 & 4.816 \mathrm{E}-21 & 9.118 \mathrm{E}-17 & 2.265 \mathrm{E}-16\end{array}$

$\begin{array}{lllllll}\mathrm{Th}-228+\mathrm{D} & 1.000 \mathrm{E}+00 & 5.216 \mathrm{E}-23 & 1.501 \mathrm{E}-21 & 1.723 \mathrm{E}-16 & 4.318 \mathrm{E}-16\end{array}$

$\begin{array}{lllll}\operatorname{LDSR}(j) & 2.567 \mathrm{E}-08 & 2.612 \mathrm{E}-08 & 3.899 \mathrm{E}-04 & 5.538 \mathrm{E}-04\end{array}$

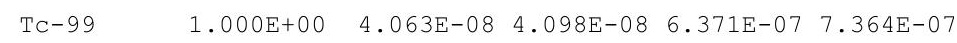

$\begin{array}{lllllll}\mathrm{Th}-228+\mathrm{D} & 1.000 \mathrm{E}+00 \quad 8.889 \mathrm{E}-02 & 6.226 \mathrm{E}-02 & 1.649 \mathrm{E}-09 & 1.333 \mathrm{E}-12\end{array}$

Th-230 1.000E+00 7.878E-07 8.012E-07 $\quad 3.311 \mathrm{E}-04 \quad 4.713 \mathrm{E}-04$

$\mathrm{Ra}-226+\mathrm{D} \quad 1.000 \mathrm{E}+00 \quad 2.053 \mathrm{E}-05 \quad 6.196 \mathrm{E}-05 \quad 2.931 \mathrm{E}-03 \quad 4.701 \mathrm{E}-03$

$\mathrm{Pb}-210+\mathrm{D} \quad 1.000 \mathrm{E}+00 \quad 1.860 \mathrm{E}-11 \quad 1.304 \mathrm{E}-10 \quad 3.121 \mathrm{E}-05 \quad 7.413 \mathrm{E}-05$

$\operatorname{LDSR}(j) \quad 2.131 \mathrm{E}-05 \quad 6.276 \mathrm{E}-05 \quad 3.293 \mathrm{E}-03 \quad 5.246 \mathrm{E}-03$ 
RESRAD, Version $6.5 \quad T^{1 / 2}$ Limit $=180$ days

Summary : C746U Trespasser Deterministic Run

File : $X: \backslash F I N A L$ V2 \DOE FWD RUNS \C746U T SG DOE FWD-FV2-70YR.RAD

Dose/Source Ratios Summed Over All Pathways

Parent and Progeny Principal Radionuclide Contributions Indicated

\begin{tabular}{|c|c|c|c|c|c|c|}
\hline $\begin{array}{l}\text { Parent } \\
\text { (i) }\end{array}$ & $\begin{array}{c}\text { Product } \\
(j)\end{array}$ & $\begin{array}{c}\text { Thread } \\
\text { Fraction }\end{array}$ & $\begin{array}{l}\mathrm{SR}(j, t) \text { At } \\
0.000 \mathrm{E}+00\end{array}$ & $\begin{array}{l}\text { Time in Ye } \\
1.000 \mathrm{E}+00\end{array}$ & $\begin{array}{l}\text { ears (mre } \\
5.000 \mathrm{E}+01\end{array}$ & $\begin{array}{l}\mathrm{em} / \mathrm{yr}) /(\mathrm{pC} \\
7.000 \mathrm{E}+01\end{array}$ \\
\hline$h-232$ & Th-232 & $1.000 \mathrm{E}+00$ & $2.040 \mathrm{E}-07$ & $2.078 \mathrm{E}-07$ & $3.613 \mathrm{E}-04$ & $5.145 \mathrm{E}-04$ \\
\hline Th-232 & $\mathrm{Ra}-228+\mathrm{D}$ & $1.000 \mathrm{E}+00$ & $2.643 \mathrm{E}-03$ & $7.575 \mathrm{E}-03$ & $6.750 \mathrm{E}-02$ & $7.900 \mathrm{E}-02$ \\
\hline Th-232 & Th $-228+D$ & $1.000 \mathrm{E}+00$ & $6.862 \mathrm{E}-04$ & $4.233 \mathrm{E}-03$ & $1.444 \mathrm{E}-01$ & $1.642 \mathrm{E}-01$ \\
\hline Th-232 & $\sum \operatorname{DSR}(j)$ & & $3.329 \mathrm{E}-03$ & $1.181 \mathrm{E}-02$ & $2.123 \mathrm{E}-01$ & $2.438 \mathrm{E}-01$ \\
\hline $\mathrm{J}-234$ & $\mathrm{U}-234$ & $1.000 \mathrm{E}+00$ & $1.753 \mathrm{E}-07$ & $1.784 \mathrm{E}-07$ & $7.589 \mathrm{E}-05$ & $1.080 \mathrm{E}-04$ \\
\hline $\mathrm{U}-234$ & Th-230 & $1.000 \mathrm{E}+00$ & $3.556 \mathrm{E}-12$ & $1.083 \mathrm{E}-11$ & $1.504 \mathrm{E}-07$ & $2.989 \mathrm{E}-07$ \\
\hline-234 & $\mathrm{Ra}-226+\mathrm{D}$ & $1.000 \mathrm{E}+00$ & $6.163 \mathrm{E}-11$ & $4.340 \mathrm{E}-10$ & $6.685 \mathrm{E}-07$ & $1.499 \mathrm{E}-06$ \\
\hline $\mathrm{U}-234$ & $\mathrm{~Pb}-210+\mathrm{D}$ & $1.000 \mathrm{E}+00$ & $4.195 \mathrm{E}-17$ & $6.314 \mathrm{E}-16$ & $5.291 \mathrm{E}-09$ & $1.815 \mathrm{E}-08$ \\
\hline $\mathrm{U}-234$ & $\sum \operatorname{DSR}(j)$ & & $1.754 \mathrm{E}-07$ & $1.789 \mathrm{E}-07$ & $7.671 \mathrm{E}-05$ & $1.098 \mathrm{E}-04$ \\
\hline$U-235+D$ & $\mathrm{U}-235+\mathrm{D}$ & $1.000 \mathrm{E}+00$ & $1.627 \mathrm{E}-03$ & $1.648 \mathrm{E}-03$ & $3.101 \mathrm{E}-03$ & $3.987 \mathrm{E}-03$ \\
\hline$U-235+D$ & $\mathrm{~Pa}-231$ & $1.000 \mathrm{E}+00$ & $7.092 \mathrm{E}-09$ & $2.148 \mathrm{E}-08$ & $2.386 \mathrm{E}-06$ & $4.423 \mathrm{E}-06$ \\
\hline$U-235+D$ & $A c-227+D$ & $1.000 \mathrm{E}+00$ & $8.148 \mathrm{E}-10$ & $5.702 \mathrm{E}-09$ & $7.572 \mathrm{E}-06$ & $1.589 \mathrm{E}-05$ \\
\hline$U-235+D$ & $\sum \operatorname{DSR}(j)$ & & $1.627 \mathrm{E}-03$ & $1.648 \mathrm{E}-03$ & $3.111 \mathrm{E}-03$ & $4.007 \mathrm{E}-03$ \\
\hline $\mathrm{U}-238$ & $\mathrm{U}-238$ & $5.400 \mathrm{E}-05$ & $1.359 \mathrm{E}-15$ & $1.421 \mathrm{E}-15$ & $3.757 \mathrm{E}-09$ & $5.348 \mathrm{E}-09$ \\
\hline$U-238+D$ & $\mathrm{U}-238+\mathrm{D}$ & $9.999 \mathrm{E}-01$ & $8.774 \mathrm{E}-04$ & $8.846 \mathrm{E}-04$ & $1.393 \mathrm{E}-03$ & $1.660 \mathrm{E}-03$ \\
\hline$U-238+D$ & $\mathrm{U}-234$ & $9.999 \mathrm{E}-01$ & $2.492 \mathrm{E}-13$ & $7.595 \mathrm{E}-13$ & $1.086 \mathrm{E}-08$ & $2.159 \mathrm{E}-08$ \\
\hline$U-238+D$ & Th-230 & $9.999 \mathrm{E}-01$ & 3. $365 \mathrm{E}-18$ & $2.390 \mathrm{E}-17$ & $1.077 \mathrm{E}-11$ & $2.987 \mathrm{E}-11$ \\
\hline $\mathrm{U}-238+\mathrm{D}$ & $\mathrm{Ra}-226+\mathrm{D}$ & $9.999 \mathrm{E}-01$ & $4.369 \mathrm{E}-17$ & $6.593 \mathrm{E}-16$ & $3.196 \mathrm{E}-11$ & $1.001 \mathrm{E}-10$ \\
\hline $\mathrm{U}-238+\mathrm{D}$ & $\mathrm{Pb}-210+\mathrm{D}$ & $9.999 \mathrm{E}-01$ & $2.382 \mathrm{E}-23$ & $7.420 \mathrm{E}-22$ & $2.026 \mathrm{E}-13$ & $9.906 \mathrm{E}-13$ \\
\hline$U-238+D$ & $\sum \operatorname{DSR}(j)$ & & $8.774 \mathrm{E}-04$ & $8.846 \mathrm{E}-04$ & $1.393 \mathrm{E}-03$ & $1.660 \mathrm{E}-03$ \\
\hline
\end{tabular}

The DSR includes contributions from associated (half-life $\leq 180$ days) daughters. 
RESRAD, Version $6.5 \quad \mathrm{~T}^{1 / 2}$ Limit $=180$ days

Summary : C746U Trespasser Deterministic Run

File : $\mathrm{X}: \backslash$ FINAL V2 \DOE FWD RUNS \C746U T SG DOE FWD-FV2-70YR. RAD

Single Radionuclide Soil Guidelines $G(i, t)$ in $\mathrm{pCi} / \mathrm{g}$

Basic Radiation Dose Limit $=1.000 \mathrm{E}+02 \mathrm{mrem} / \mathrm{yr}$

Nuclide

\begin{tabular}{|c|c|c|c|c|}
\hline (i) & $t=0.000 E+00$ & $1.000 \mathrm{E}+00$ & $5.000 \mathrm{E}+01$ & $7.000 \mathrm{E}+01$ \\
\hline$n-241$ & $6.861 \mathrm{E}+07$ & $6.676 \mathrm{E}+07$ & $3.390 E+05$ & $2.448 E+05$ \\
\hline$s-137$ & $4.856 \mathrm{E}+03$ & $4.927 \mathrm{E}+03$ & $1.012 \mathrm{E}+04$ & $1.358 \mathrm{E}+04$ \\
\hline$p-237$ & $2.896 \mathrm{E}+04$ & $2.866 \mathrm{E}+04$ & $1.644 \mathrm{E}+04$ & $1.320 \mathrm{E}+04$ \\
\hline$u-238$ & $3.787 \mathrm{E}+09$ & $3.750 \mathrm{E}+09$ & $4.133 E+05$ & $3.400 \mathrm{E}+05$ \\
\hline$u-239$ & $1.587 \mathrm{E}+08$ & $1.568 \mathrm{E}+08$ & $2.548 E+05$ & $1.792 \mathrm{E}+05$ \\
\hline$u-240$ & $3.896 \mathrm{E}+09$ & $3.828 \mathrm{E}+09$ & $2.565 E+05$ & $1.806 \mathrm{E}+05$ \\
\hline$c-99$ & $2.461 \mathrm{E}+09$ & $2.440 \mathrm{E}+09$ & $1.570 \mathrm{E}+08$ & $1.358 \mathrm{E}+08$ \\
\hline Th-228 & $1.125 \mathrm{E}+03$ & $1.606 \mathrm{E}+03$ & $6.065 E+10$ & $7.505 E+13$ \\
\hline Th -230 & $4.692 \mathrm{E}+06$ & $1.593 \mathrm{E}+06$ & $3.037 E+04$ & $1.906 \mathrm{E}+04$ \\
\hline Th-232 & $3.004 \mathrm{E}+04$ & $8.469 \mathrm{E}+03$ & $4.711 \mathrm{E}+02$ & $4.102 \mathrm{E}+02$ \\
\hline$J-234$ & $5.702 \mathrm{E}+08$ & $5.590 \mathrm{E}+08$ & $1.304 \mathrm{E}+06$ & $9.106 \mathrm{E}+05$ \\
\hline 35 & $6.145 \mathrm{E}+04$ & $6.069 \mathrm{E}+04$ & $3.214 \mathrm{E}+04$ & $2.495 \mathrm{E}+04$ \\
\hline 238 & $1.140 \mathrm{E}+05$ & $1.131 \mathrm{E}+05$ & $7.179 \mathrm{E}+04$ & $6.024 \mathrm{E}+04$ \\
\hline
\end{tabular}

Summed Dose/Source Ratios DSR(i,t) in (mrem/yr)/(pCi/g) and Single Radionuclide Soil Guidelines $\mathrm{G}(i, t)$ in $\mathrm{pCi} / \mathrm{g}$ at $\operatorname{tmin}=$ time of minimum single radionuclide soil guideline and at $\operatorname{tmax}=$ time of maximum total dose $=7.000 \mathrm{E}+01$ years

\begin{tabular}{|c|c|c|c|c|c|c|}
\hline $\begin{array}{l}\text { uclide } \\
\text { (i) }\end{array}$ & $\begin{array}{l}\text { Initial } \\
(\mathrm{pCi} / \mathrm{g})\end{array}$ & $\begin{array}{c}\text { tmin } \\
\text { (years) }\end{array}$ & $\operatorname{DSR}(i, \operatorname{tmin})$ & $\begin{array}{c}\mathrm{G}(\mathrm{i}, \mathrm{tmin}) \\
(\mathrm{pCi} / \mathrm{g})\end{array}$ & $\operatorname{DSR}(i, \operatorname{tmax})$ & $\begin{array}{c}G(i, t \max ) \\
(\mathrm{pCi} / \mathrm{g})\end{array}$ \\
\hline-241 & $3.500 \mathrm{E}+01$ & $7.000 \mathrm{E}+01$ & $4.085 \mathrm{E}-04$ & $2.448 \mathrm{E}+05$ & $4.085 \mathrm{E}-04$ & $2.448 E+05$ \\
\hline-137 & $1.900 \mathrm{E}+01$ & $0.000 \mathrm{E}+00$ & $2.060 \mathrm{E}-02$ & $4.856 \mathrm{E}+03$ & $7.362 E-03$ & $1.358 \mathrm{E}+04$ \\
\hline-237 & $5.500 \mathrm{E}+00$ & $7.000 \mathrm{E}+01$ & $7.575 \mathrm{E}-03$ & $1.320 \mathrm{E}+04$ & $7.575 E-03$ & $1.320 \mathrm{E}+04$ \\
\hline-238 & $3.900 \mathrm{E}+01$ & $7.000 \mathrm{E}+01$ & $2.941 \mathrm{E}-04$ & $3.400 \mathrm{E}+05$ & $2.941 E-04$ & $3.400 \mathrm{E}+05$ \\
\hline-239 & $3.600 \mathrm{E}+01$ & $7.000 \mathrm{E}+01$ & $5.581 \mathrm{E}-04$ & $1.792 \mathrm{E}+05$ & $5.581 \mathrm{E}-04$ & $1.792 \mathrm{E}+05$ \\
\hline $1-240$ & $3.600 \mathrm{E}+01$ & $7.000 \mathrm{E}+01$ & $5.538 \mathrm{E}-04$ & $1.806 \mathrm{E}+05$ & $5.538 \mathrm{E}-04$ & $1.806 \mathrm{E}+05$ \\
\hline TC-99 & $5.200 \mathrm{E}+01$ & $7.000 \mathrm{E}+01$ & $7.364 \mathrm{E}-07$ & $1.358 \mathrm{E}+08$ & $7.364 \mathrm{E}-07$ & $1.358 \mathrm{E}+08$ \\
\hline-228 & $4.000 \mathrm{E}+00$ & $0.000 \mathrm{E}+00$ & $8.889 \mathrm{E}-02$ & $1.125 \mathrm{E}+03$ & $1.333 \mathrm{E}-12$ & $7.505 E+13$ \\
\hline-230 & $1.000 \mathrm{E}+02$ & $7.000 \mathrm{E}+01$ & $5.246 \mathrm{E}-03$ & $1.906 \mathrm{E}+04$ & $5.246 \mathrm{E}-03$ & $1.906 \mathrm{E}+04$ \\
\hline 232 & $4.000 \mathrm{E}+00$ & $7.000 \mathrm{E}+01$ & $2.438 \mathrm{E}-01$ & $4.102 \mathrm{E}+02$ & $2.438 \mathrm{E}-01$ & $4.102 \mathrm{E}+02$ \\
\hline 34 & $1.600 \mathrm{E}+02$ & $7.000 E+01$ & $1.098 \mathrm{E}-04$ & $9.106 \mathrm{E}+05$ & $1.098 \mathrm{E}-04$ & $9.106 \mathrm{E}+05$ \\
\hline 35 & $6.500 \mathrm{E}+00$ & $7.000 \mathrm{E}+01$ & $4.007 \mathrm{E}-03$ & $2.495 E+04$ & $4.007 E-03$ & $2.495 \mathrm{E}+04$ \\
\hline 238 & $1.600 \mathrm{E}+02$ & $7.000 \mathrm{E}+01$ & $1.660 \mathrm{E}-03$ & $6.024 \mathrm{E}+04$ & $1.660 \mathrm{E}-03$ & $6.024 \mathrm{E}+04$ \\
\hline
\end{tabular}


RESRAD, Version $6.5 \quad \mathrm{~T}^{1 / 2}$ Limit $=180$ days

Summary : C746U Trespasser Deterministic Run

File : $\mathrm{X}: \backslash F I N A L$ V2 $\backslash$ DOE FWD RUNS \C746U T SG DOE FWD-FV2-70YR.RAD

Individual Nuclide Dose Summed Over All Pathways

Parent Nuclide and Branch Fraction Indicated

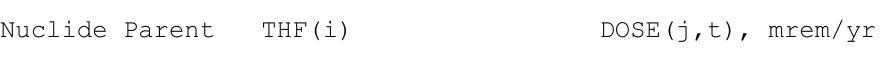


RESRAD, Version $6.5 \quad \mathrm{~T}^{1 / 2}$ Limit $=180$ days

Summary : C746U Trespasser Deterministic Run

File : $\mathrm{X}: \backslash$ FINAL V2 \DOE FWD RUNS \C746U T SG DOE FWD-FV2-70YR. RAD

Individual Nuclide Dose Summed Over All Pathways

Parent Nuclide and Branch Fraction Indicated

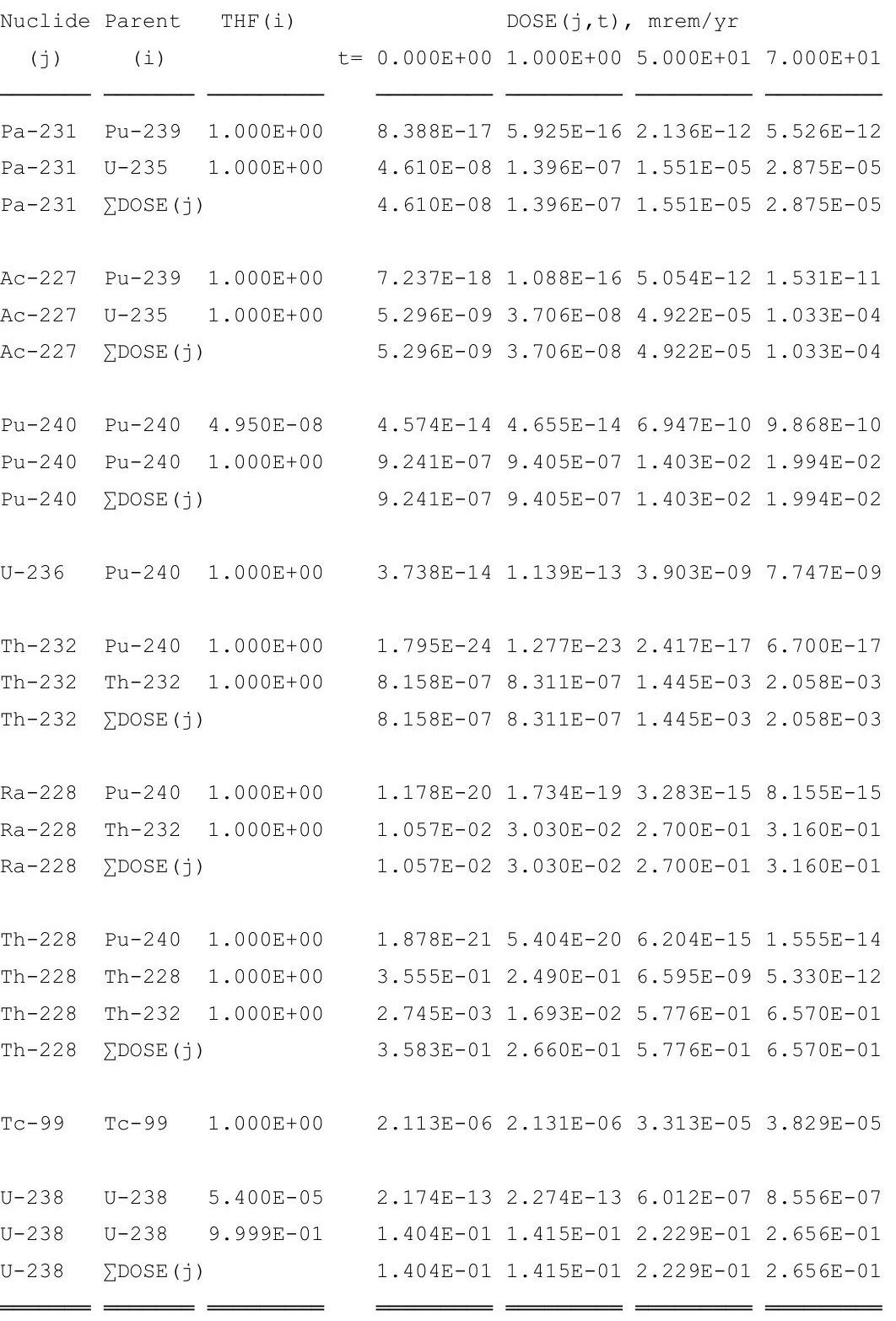

THF(i) is the thread fraction of the parent nuclide. 
RESRAD, Version $6.5 \quad T^{1 / 2}$ Limit $=180$ days

Summary : C746U Trespasser Deterministic Run

File : $\mathrm{X}: \backslash$ FINAL V2 \DOE FWD RUNS \C746U T SG DOE FWD-FV2-70YR.RAD

Individual Nuclide Soil Concentration

Parent Nuclide and Branch Fraction Indicated

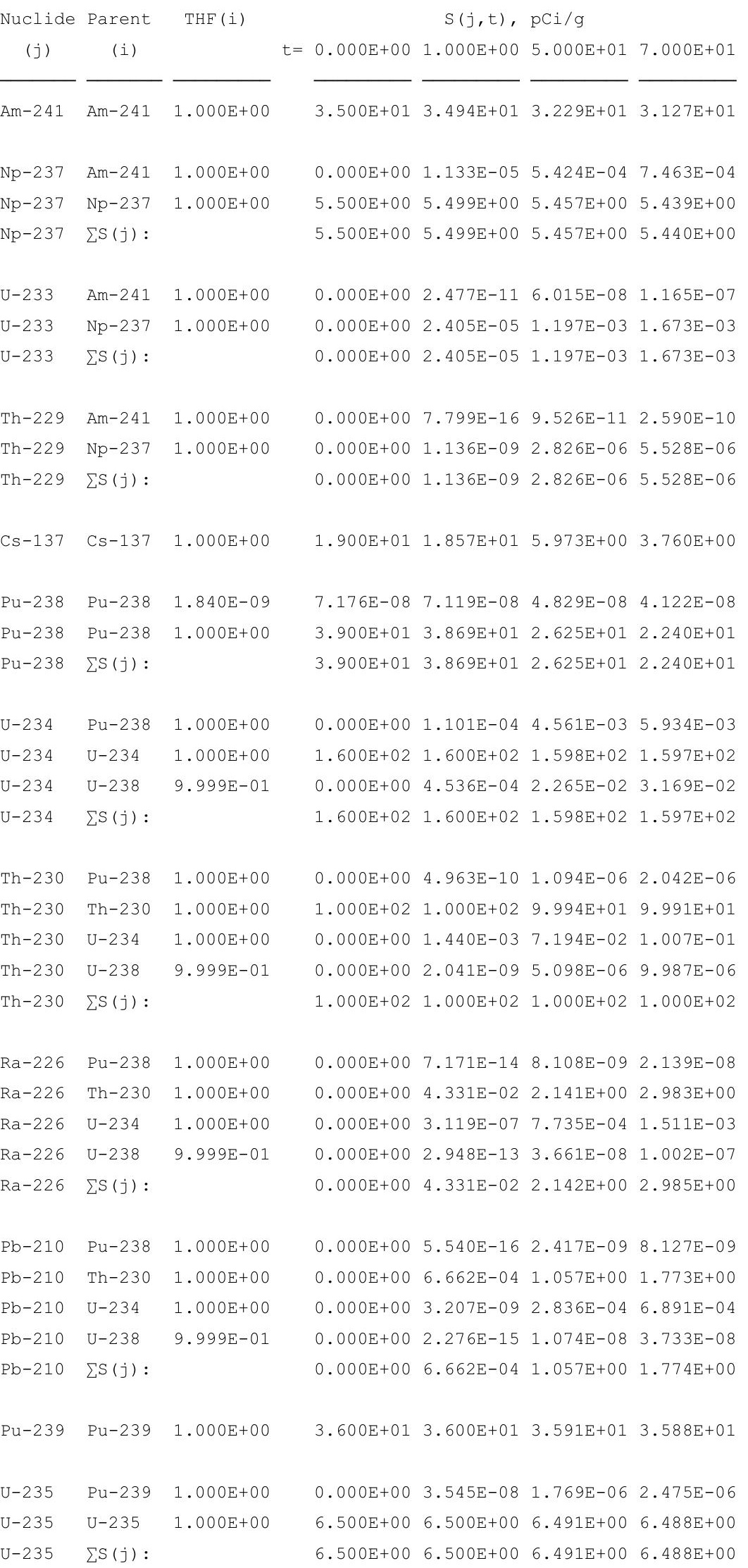


RESRAD, Version $6.5 \quad T^{1 / 2}$ Limit $=180$ days

Summary : C746U Trespasser Deterministic Run

File : $\mathrm{X}: \backslash$ FINAL V2 $\backslash$ DOE FWD RUNS $\backslash C 746 \mathrm{U}$ T SG DOE FWD-FV2-70YR. RAD

Individual Nuclide Soil Concentration

Parent Nuclide and Branch Fraction Indicated

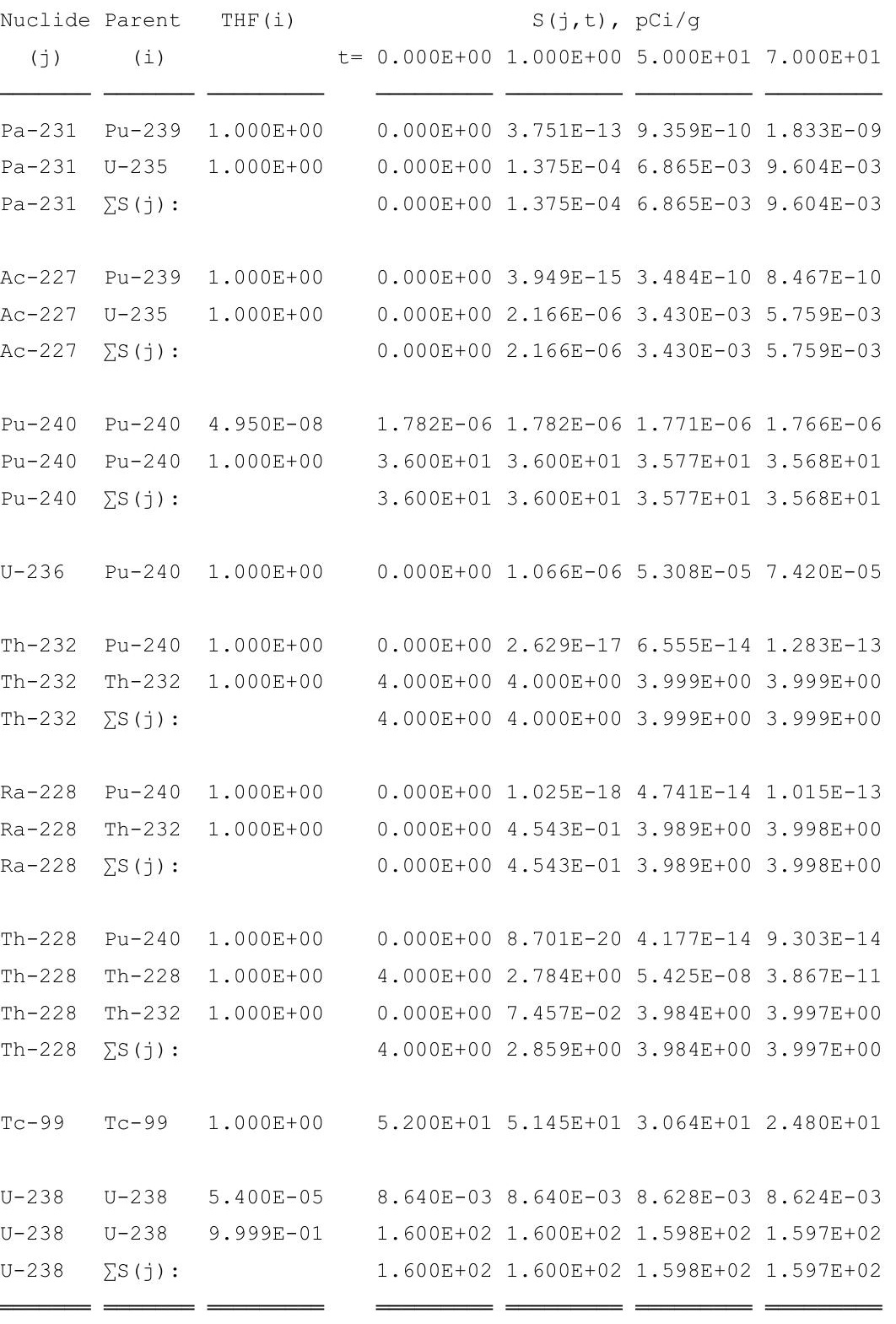

THF(i) is the thread fraction of the parent nuclide.

RESCALC.EXE execution time = 4.03 seconds 


\section{Trespasser}

\section{Summary Report \\ (Deterministic Analysis Report)}

Second Peak Dose Assessment

Time Horizon: $70 \mathrm{yr}$ 
THIS PAGE INTENTIONALLY LEFT BLANK 
RESRAD, Version $6.5 \quad T^{1 / 2}$ Limit $=180$ days

Summary : C746U Trespasser Deterministic Run

File : X: \FINAL V2 $\backslash$ DOE FWD RUNS \C746U T AL DOE FWD-FV2-70YR. RAD

Table of Contents

Part I: Mixture Sums and Single Radionuclide Guidelines

Dose Conversion Factor (and Related) Parameter Summary ... 2

Site-Specific Parameter Summary $\ldots \ldots \ldots \ldots \ldots \ldots \ldots \ldots \ldots$

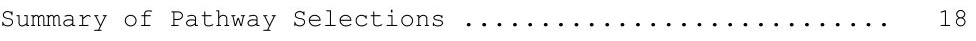

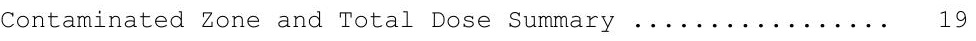

Total Dose Components

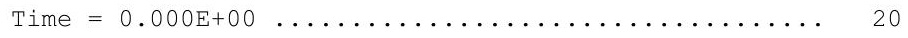

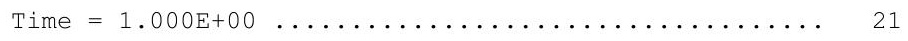

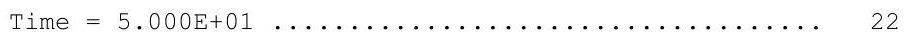

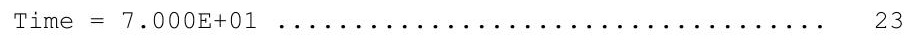

Dose/Source Ratios summed Over All Pathways ............ 24

Single Radionuclide Soil Guidelines ............... 26

Dose Per Nuclide Summed Over All Pathways ............ 27

Soil Concentration Per Nuclide .................. 29 
RESRAD, Version $6.5 \quad \mathrm{~T}^{1 / 2}$ Limit $=180$ days

Summary : C746U Trespasser Deterministic Run

File : $\mathrm{X}: \backslash F I N A L$ V2 $\backslash$ DOE FWD RUNS $\backslash \mathrm{C} 746 \mathrm{U}$ T AL DOE FWD-FV2-70YR.RAD

Dose Conversion Factor (and Related) Parameter Summary

Dose Library: ICRP 60 \& ICRP 72 (Adult)

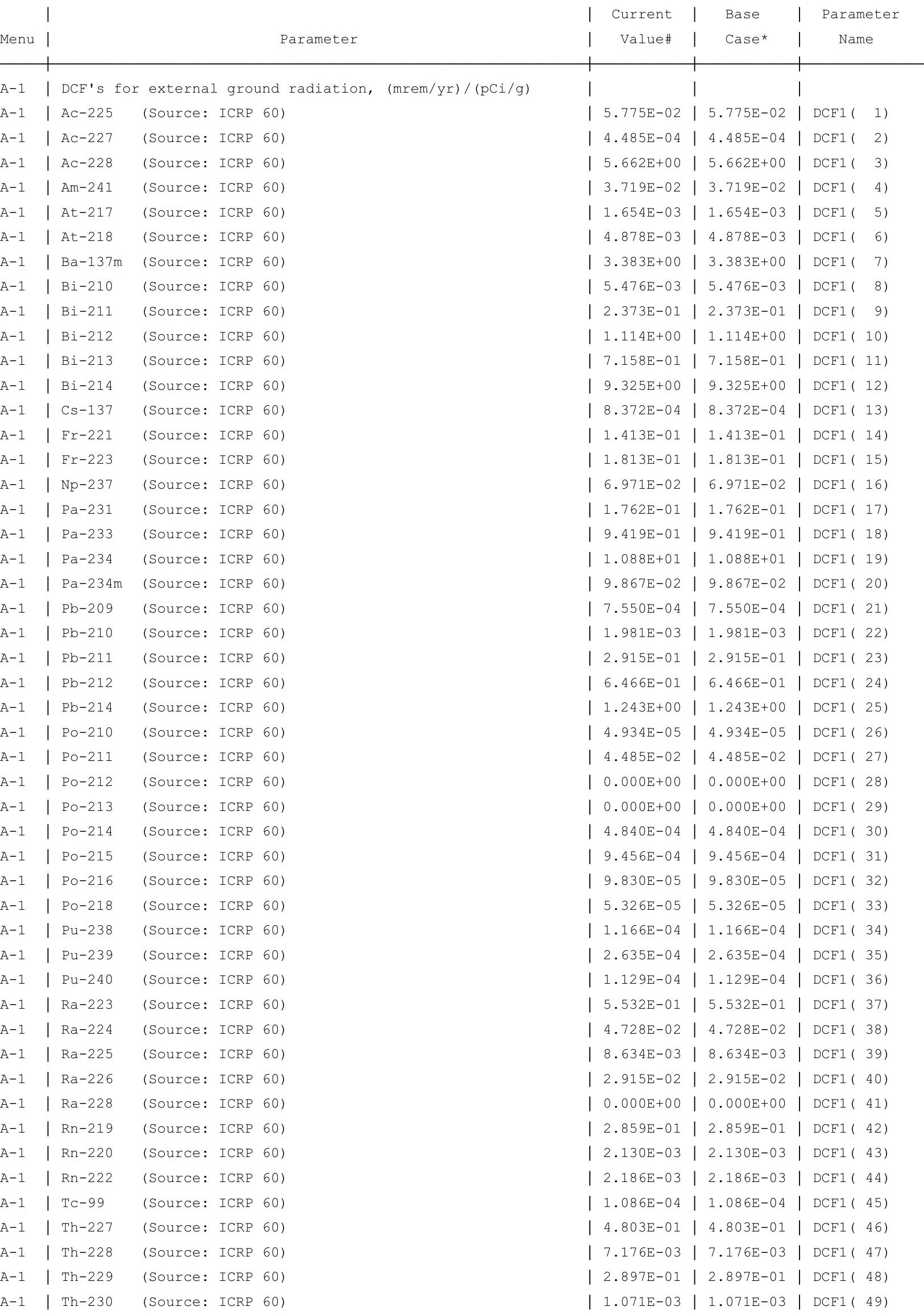


RESRAD, Version $6.5 \quad \mathrm{~T}^{1 / 2}$ Limit $=180$ days

Summary : C746U Trespasser Deterministic Run

File : $\mathrm{X}: \backslash F I N A L$ V2 $\backslash$ DOE FWD RUNS $\backslash C 746 U$ T AL DOE FWD-FV2-70YR.RAD

Dose Conversion Factor (and Related) Parameter Summary (continued)

Dose Library: ICRP 60 \& ICRP 72 (Adult)

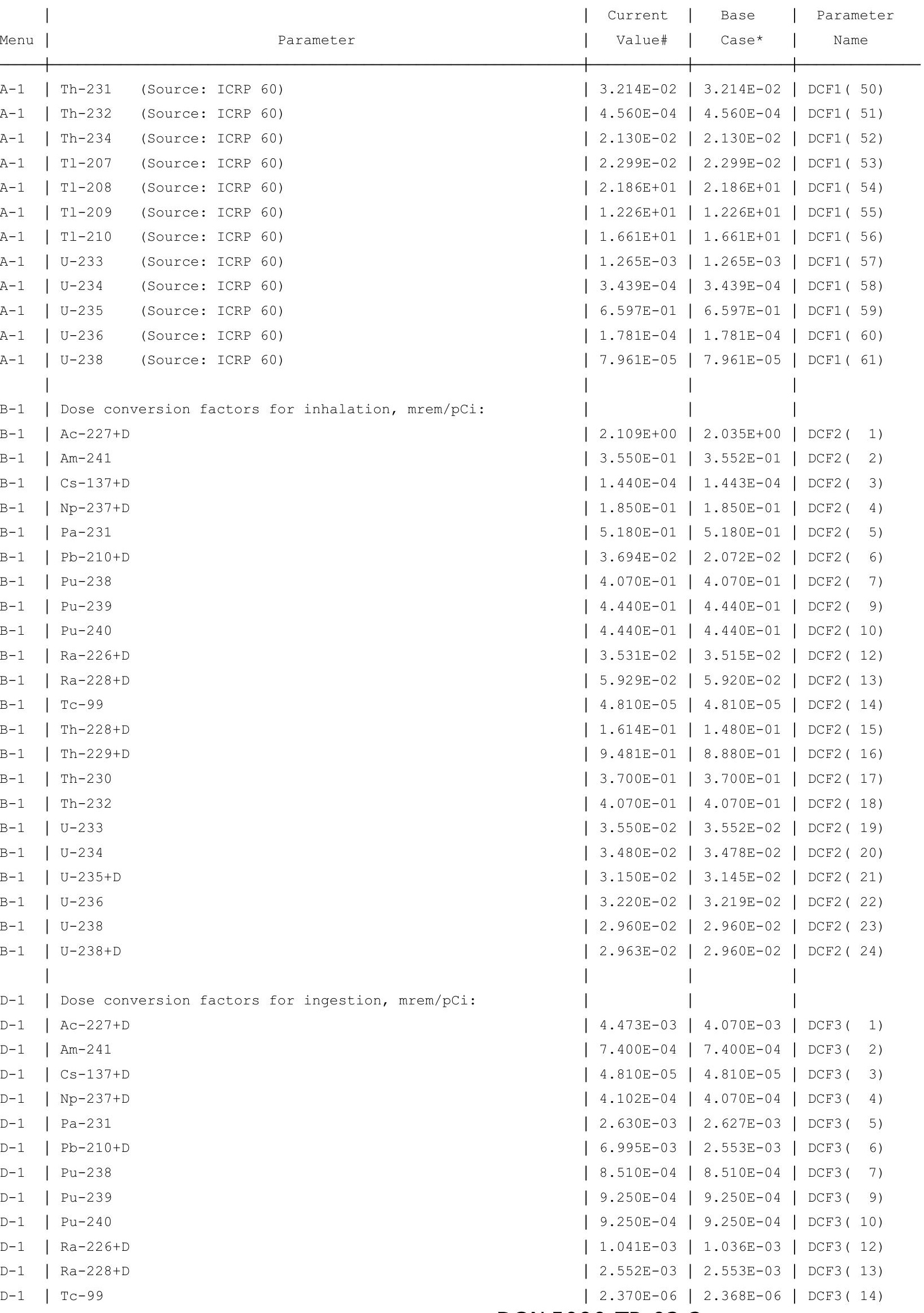


RESRAD, Version $6.5 \quad T^{1 / 2}$ Limit $=180$ days

Summary : C746U Trespasser Deterministic Run

File : $\mathrm{X}: \backslash$ FINAL V2 $\backslash$ DOE FWD RUNS $\backslash C 746 \mathrm{U} T$ AL DOE FWD-FV2-70YR.RAD

Dose Conversion Factor (and Related) Parameter Summary (continued)

Dose Library: ICRP 60 \& ICRP 72 (Adult)

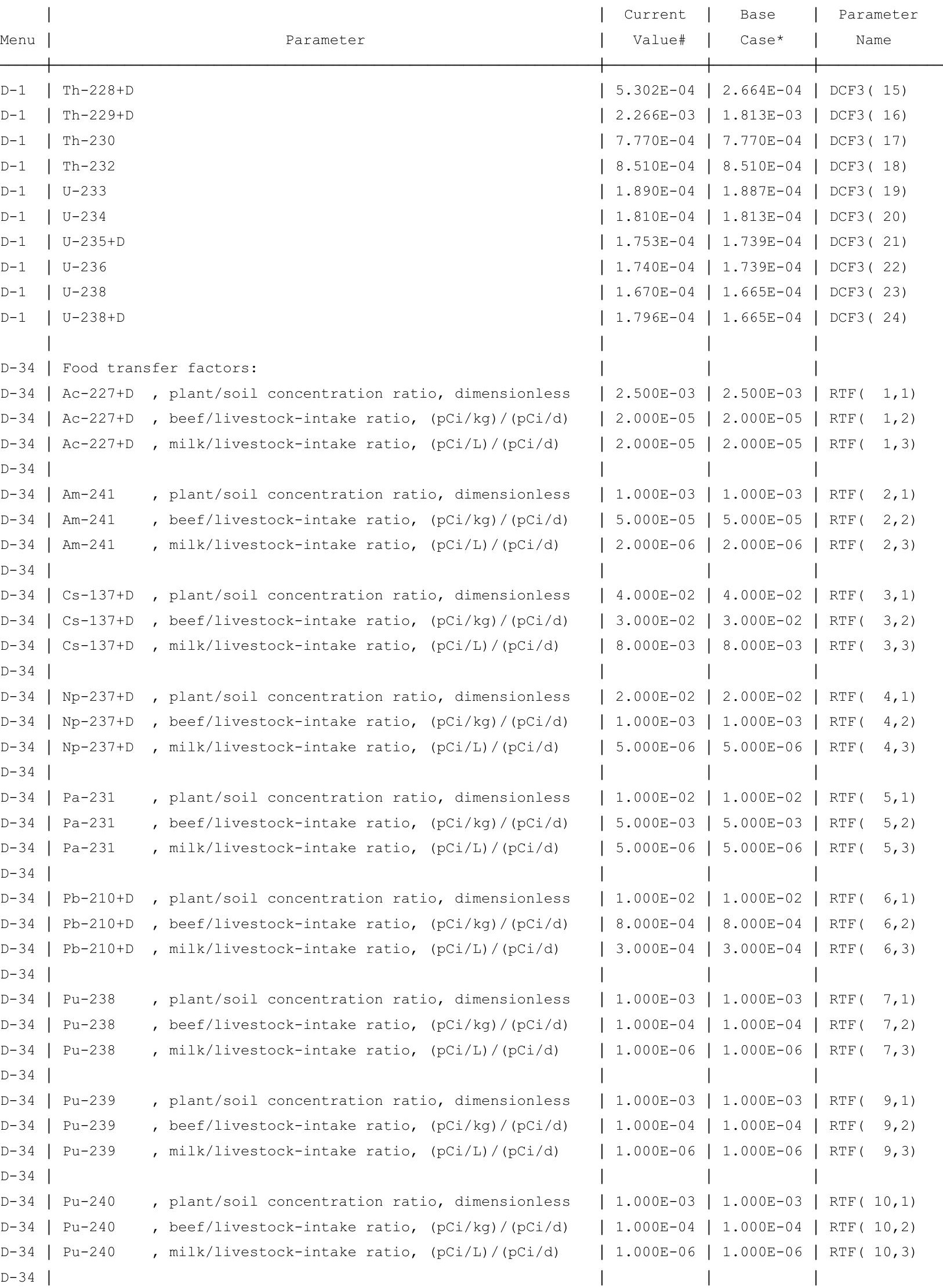


RESRAD, Version $6.5 \quad \mathrm{~T}^{1 / 2}$ Limit $=180$ days

Summary : C746U Trespasser Deterministic Run

File : $\mathrm{X}: \backslash F I N A L$ V2 $\backslash$ DOE FWD RUNS $\backslash C 746 U$ T AL DOE FWD-FV2-70YR.RAD

Dose Conversion Factor (and Related) Parameter Summary (continued)

Dose Library: ICRP 60 \& ICRP 72 (Adult)

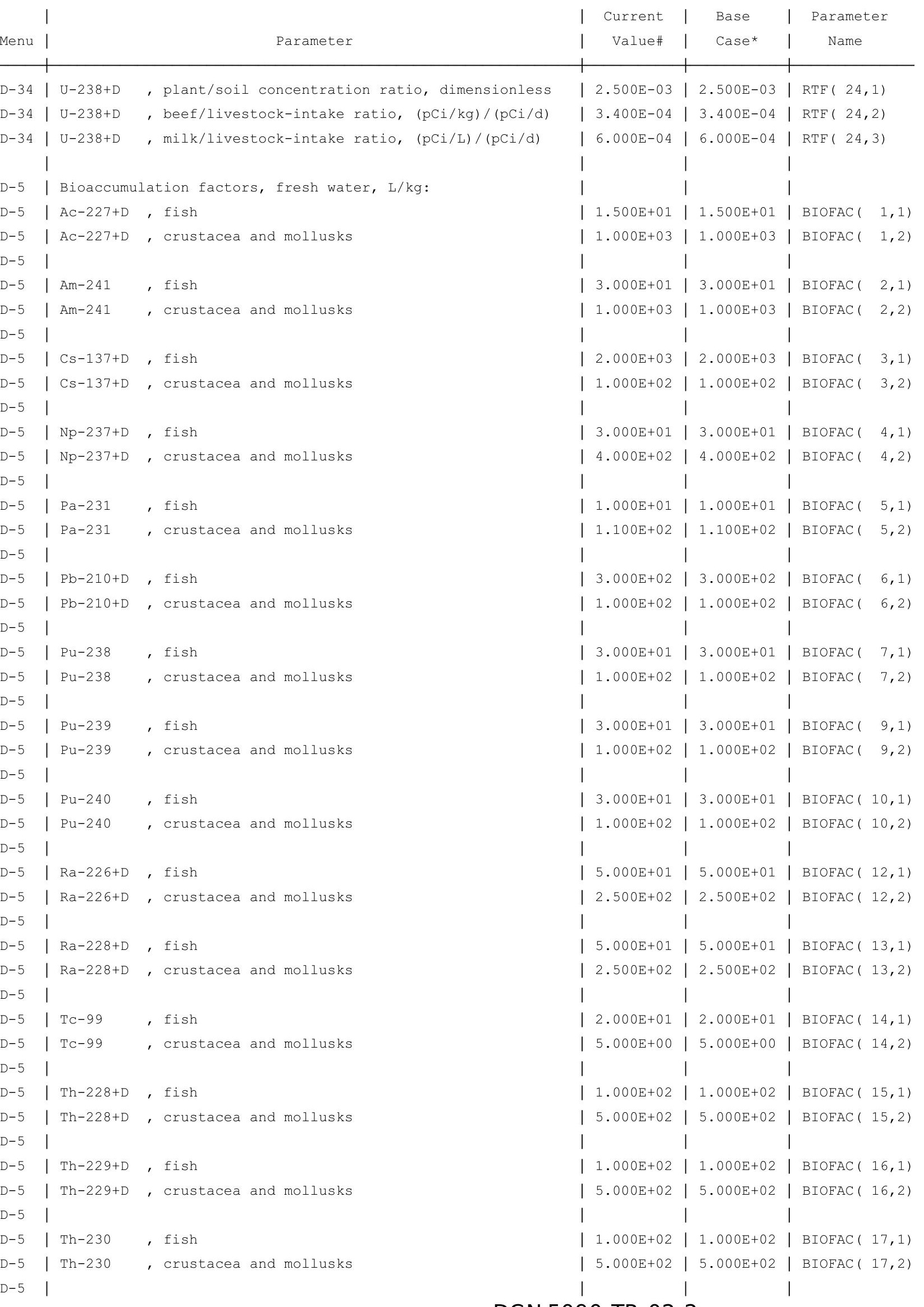


RESRAD, Version $6.5 \quad \mathrm{~T}^{1 / 2}$ Limit $=180$ days

Summary : C746U Trespasser Deterministic Run

File : $\mathrm{X}: \backslash$ FINAL V2 $\backslash$ DOE FWD RUNS \C746U T AL DOE FWD-FV2-70YR.RAD

Dose Conversion Factor (and Related) Parameter Summary (continued)

Dose Library: ICRP 60 \& ICRP 72 (Adult)

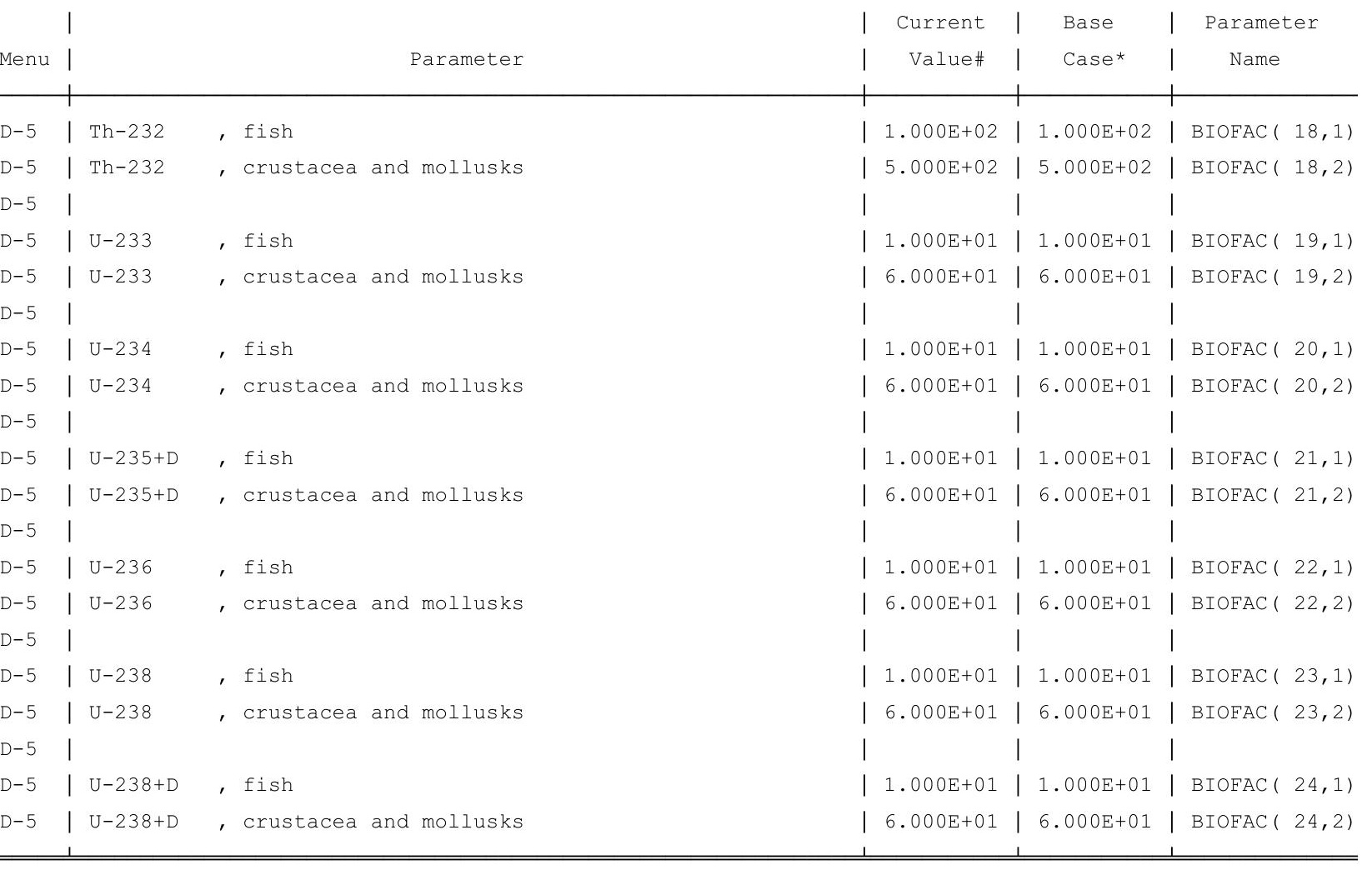

\#For DCFl(xxx) only, factors are for infinite depth \& area. See ETFG table in Ground Pathway of Detailed Report. *Base Case means Default.Lib w/o Associate Nuclide contributions. 
RESRAD, Version $6.5 \quad \mathrm{~T}^{1 / 2}$ Limit $=180$ days

Summary : C746U Trespasser Deterministic Run

File : $X: \backslash F I N A L$ V2 $\backslash$ DOE FWD RUNS $\backslash C 746 U$ T AL DOE FWD-FV2-70YR.RAD

Site-Specific Parameter Summary (continued)

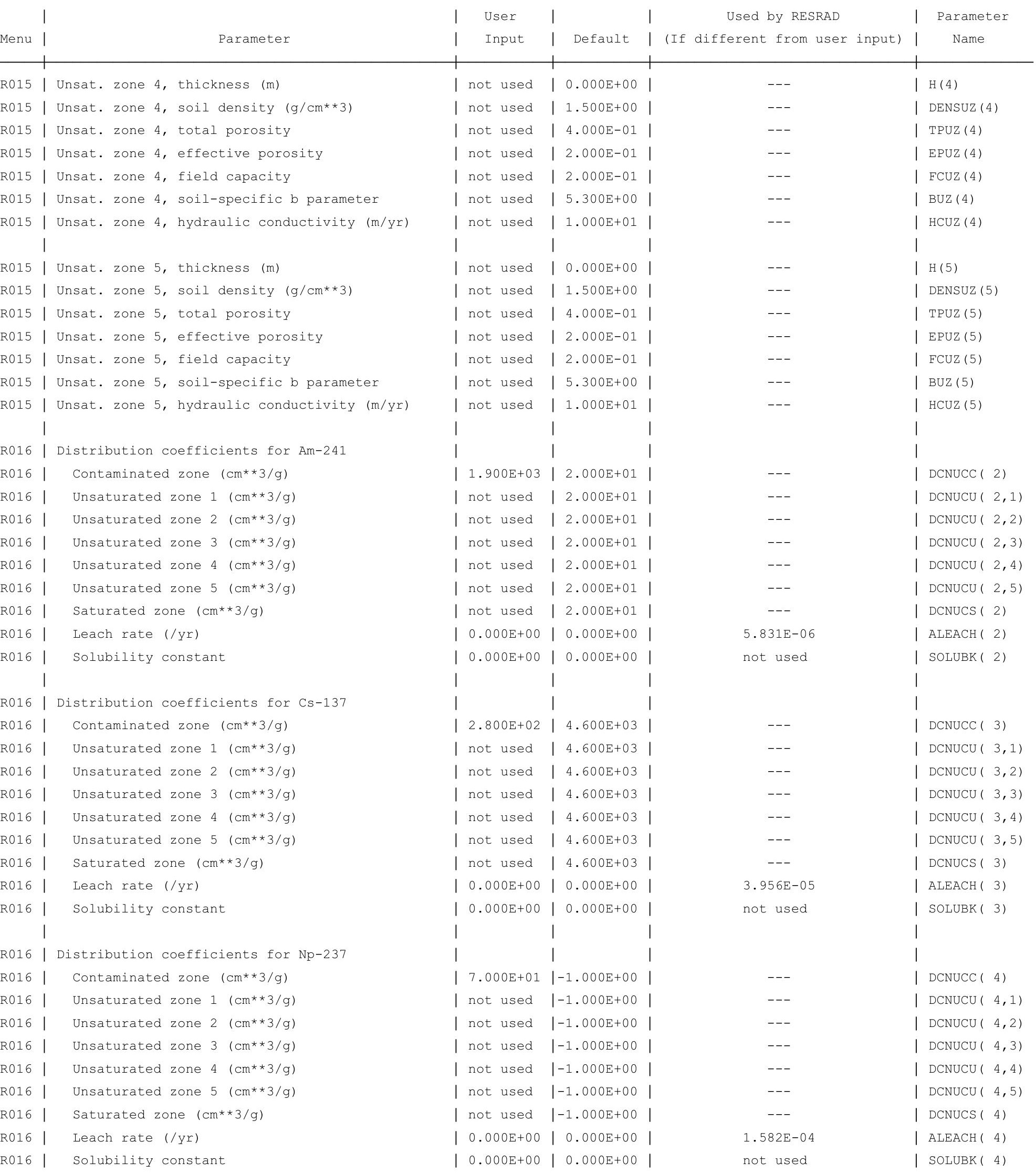


RESRAD, Version $6.5 \quad \mathrm{~T}^{1 / 2}$ Limit $=180$ days

Summary : C746U Trespasser Deterministic Run

File : $\mathrm{X}: \backslash F I N A L$ V2 $\backslash$ DOE FWD RUNS $\backslash C 746 U$ T AL DOE FWD-FV2-70YR.RAD

Site-Specific Parameter Summary (continued)

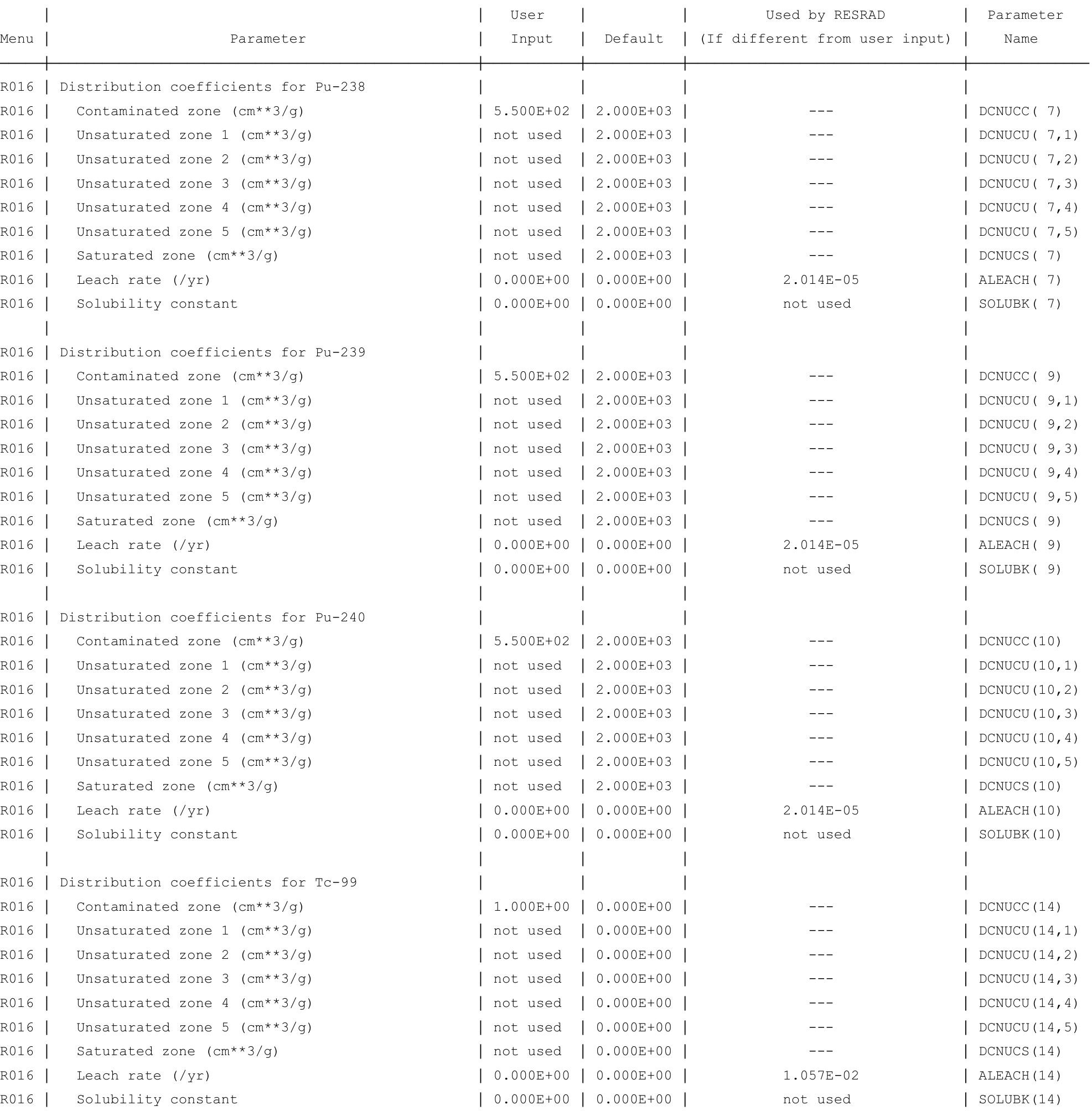


RESRAD, Version $6.5 \quad \mathrm{~T}^{1 / 2}$ Limit $=180$ days

Summary : C746U Trespasser Deterministic Run

File : $\mathrm{X}: \backslash F I N A L$ V2 $\backslash$ DOE FWD RUNS $\backslash C 746 U$ T AL DOE FWD-FV2-70YR.RAD

Site-Specific Parameter Summary (continued)

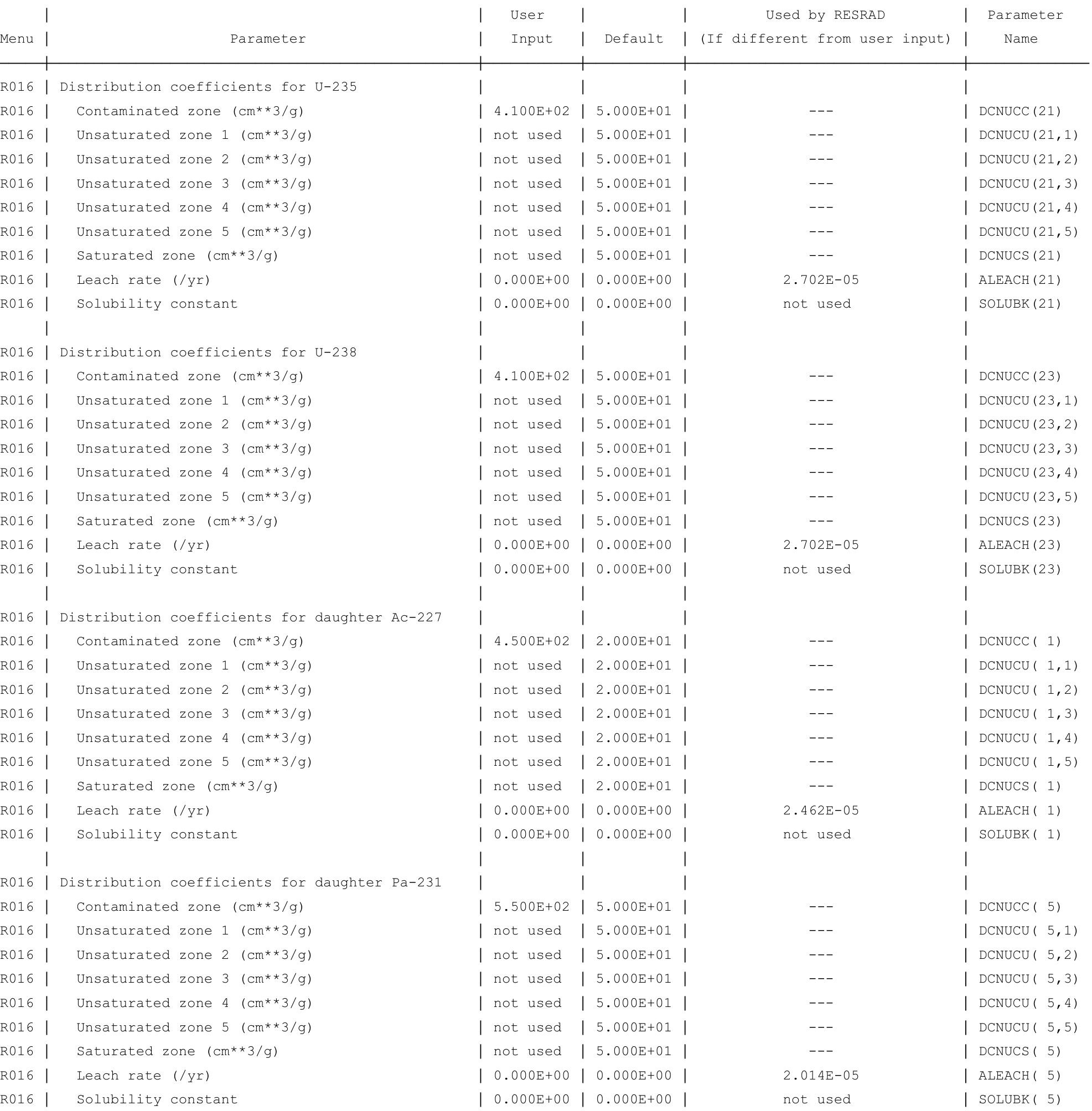


RESRAD, Version $6.5 \quad \mathrm{~T}^{1 / 2}$ Limit $=180$ days

ummary : C746U Trespasser Deterministic Run

File : X: $\backslash F I N A L$ V2 $\backslash$ DOE FWD RUNS $\backslash C 746 U$ T AL DOE FWD-FV2-70YR.RAD

Site-Specific Parameter Summary (continued)

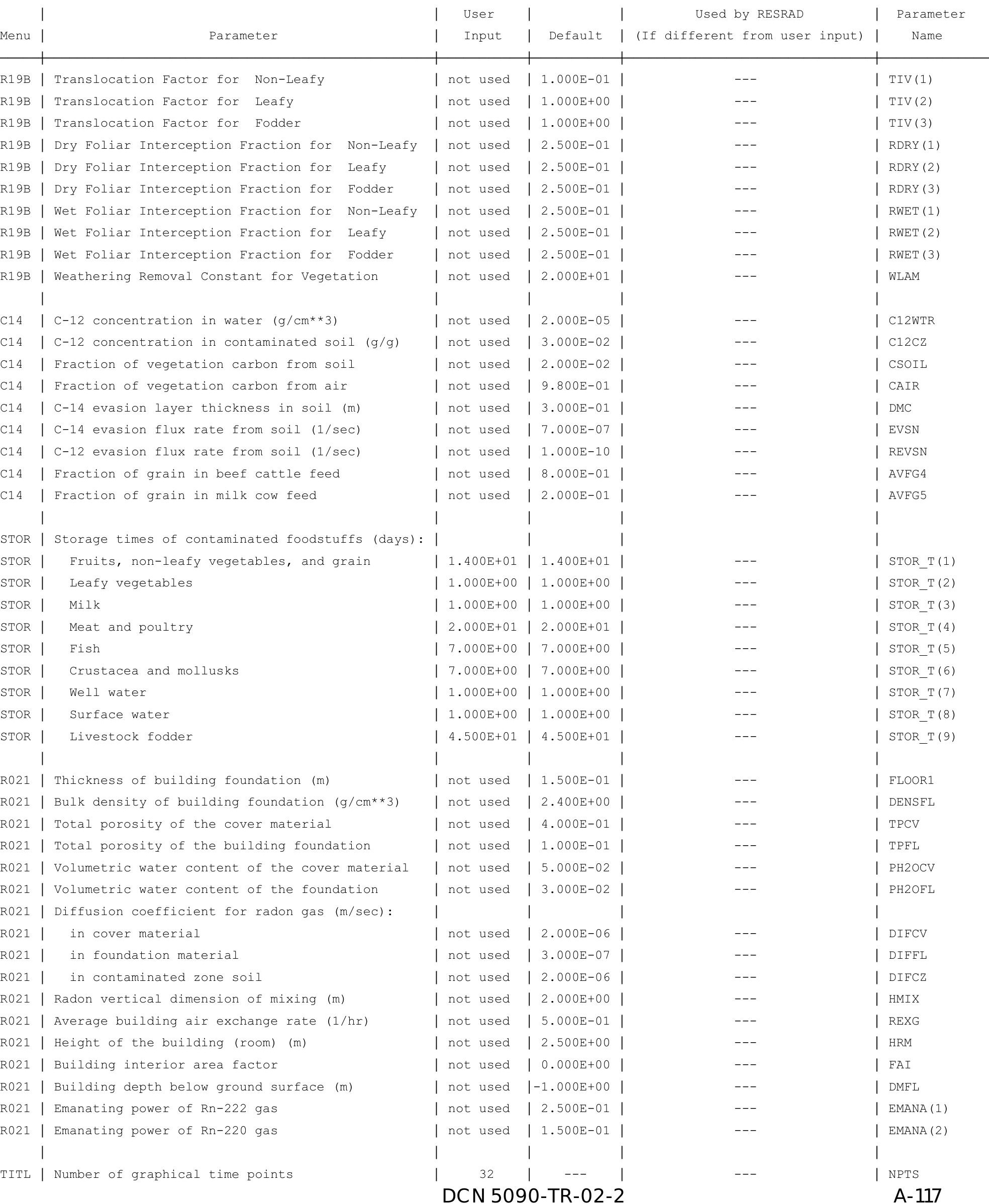


RESRAD, Version $6.5 \quad \mathrm{~T}^{1 / 2}$ Limit $=180$ days

Summary : C746U Trespasser Deterministic Run

File : $\mathrm{X}: \backslash F I N A L$ V2 $\backslash$ DOE FWD RUNS \C746U T AL DOE FWD-FV2-70YR.RAD

Contaminated Zone Dimensions

Area: $\quad 89436.00$ square meters

Thickness:

Cover Depth:

\begin{abstract}
13.40 meters
\end{abstract}
0.15 meters
Initial Soil Concentrations, pCi/g

$\begin{array}{ll}\mathrm{Am}-241 & 7.000 \mathrm{E}+01 \\ \mathrm{Cs}-137 & 3.800 \mathrm{E}+01 \\ \mathrm{~Np}-237 & 1.100 \mathrm{E}+01 \\ \mathrm{Pu}-238 & 7.800 \mathrm{E}+01 \\ \mathrm{Pu}-239 & 7.200 \mathrm{E}+01 \\ \mathrm{Pu}-240 & 7.200 \mathrm{E}+01 \\ \mathrm{TC}-99 & 1.040 \mathrm{E}+02 \\ \mathrm{Th}-228 & 8.000 \mathrm{E}+00 \\ \mathrm{Th}-230 & 2.000 \mathrm{E}+02 \\ \mathrm{Th}-232 & 8.000 \mathrm{E}+00 \\ \mathrm{U}-234 & 3.200 \mathrm{E}+02 \\ \mathrm{U}-235 & 1.300 \mathrm{E}+01 \\ \mathrm{U}-238 & 3.200 \mathrm{E}+02\end{array}$

Total Dose TDOSE(t), mrem/yr

Basic Radiation Dose Limit $=1.000 \mathrm{E}+02 \mathrm{mrem} / \mathrm{yr}$

Total Mixture Sum $M(t)$ = Fraction of Basic Dose Limit Received at Time (t)

$\begin{array}{rllll}t \text { (years): } & 0.000 \mathrm{E}+00 & 1.000 \mathrm{E}+00 & 5.000 \mathrm{E}+01 & 7.000 \mathrm{E}+01 \\ \mathrm{TDOSE}(\mathrm{t}): & 1.865 \mathrm{E}+00 & 1.719 \mathrm{E}+00 & 3.406 \mathrm{E}+00 & 4.112 \mathrm{E}+00 \\ \mathrm{M}(\mathrm{t}): & 1.865 \mathrm{E}-02 & 1.719 \mathrm{E}-02 & 3.406 \mathrm{E}-02 & 4.112 \mathrm{E}-02\end{array}$

Maximum TDOSE $(t): 4.112 \mathrm{E}+00 \mathrm{mrem} / \mathrm{yr}$ at $t=7.000 \mathrm{E}+01$ years 
RESRAD, Version $6.5 \quad \mathrm{~T}^{1 / 2}$ Limit $=180$ days

Summary : C746U Trespasser Deterministic Run
File $\mathrm{X}: \backslash$ FINAL V2 \DOE FWD RUNS \C746U T AL DOE FWD-FV2-70YR.RAD

Total Dose Contributions TDOSE(i,p,t) for Individual Radionuclides (i) and Pathways (p) As mrem/yr and Fraction of Total Dose At $t=0.000 \mathrm{E}+00$ years

Water Independent Pathways (Inhalation excludes radon)

\begin{tabular}{|c|c|c|c|c|c|c|c|c|c|c|c|c|c|c|}
\hline \multirow{2}{*}{ Nuclide } & \multicolumn{2}{|c|}{ Ground } & \multicolumn{2}{|c|}{ Inhalation } & \multicolumn{2}{|c|}{ Radon } & \multicolumn{2}{|c|}{ Plant } & \multicolumn{2}{|c|}{ Meat } & \multicolumn{2}{|c|}{ Milk } & \multicolumn{2}{|c|}{ Soil } \\
\hline & mrem/yr & fract. & mrem/yr & fract. & mrem/yr & fract. & mrem/yr & fract. & mrem/yr & fract. & mrem/yr & fract. & mrem/yr & fract. \\
\hline-241 & $1.020 \mathrm{E}-04$ & 0.0001 & $0.000 \mathrm{E}+00$ & 0.0000 & $0.000 \mathrm{E}+00$ & 0.0000 & $0.000 \mathrm{E}+00$ & 0.0000 & $0.000 \mathrm{E}+00$ & 0.0000 & $0.000 \mathrm{E}+00$ & 0.0000 & $0.000 \mathrm{E}+00$ & 0.0000 \\
\hline-137 & $7.826 \mathrm{E}-01$ & 0.4197 & $0.000 \mathrm{E}+00$ & 0.0000 & $0.000 \mathrm{E}+00$ & 0.0000 & $0.000 \mathrm{E}+00$ & 0.0000 & $0.000 \mathrm{E}+00$ & 0.0000 & $0.000 \mathrm{E}+00$ & 0.0000 & $0.000 \mathrm{E}+00$ & 0.0000 \\
\hline-237 & $3.798 E-02$ & 0.0204 & $0.000 \mathrm{E}+00$ & 0.0000 & $0.000 \mathrm{E}+00$ & 0.0000 & $0.000 \mathrm{E}+00$ & 0.0000 & $0.000 \mathrm{E}+00$ & 0.0000 & $0.000 \mathrm{E}+00$ & 0.0000 & $0.000 \mathrm{E}+00$ & 0.0000 \\
\hline-238 & $2.060 E-06$ & 0.0000 & $0.000 \mathrm{E}+00$ & 0.0000 & $0.000 \mathrm{E}+00$ & 0.0000 & $0.000 \mathrm{E}+00$ & 0.0000 & $0.000 \mathrm{E}+00$ & 0.0000 & $0.000 \mathrm{E}+00$ & 0.0000 & $0.000 \mathrm{E}+00$ & 0.0000 \\
\hline-239 & $4.538 \mathrm{E}-05$ & 0.0000 & $0.000 \mathrm{E}+00$ & 0.0000 & $0.000 \mathrm{E}+00$ & 0.0000 & $0.000 \mathrm{E}+00$ & 0.0000 & $0.000 \mathrm{E}+00$ & 0.0000 & $0.000 \mathrm{E}+00$ & 0.0000 & $0.000 \mathrm{E}+00$ & 0.0000 \\
\hline-240 & $1.848 E-06$ & 0.0000 & $0.000 \mathrm{E}+00$ & 0.0000 & $0.000 \mathrm{E}+00$ & 0.0000 & $0.000 \mathrm{E}+00$ & 0.0000 & $0.000 \mathrm{E}+00$ & 0.0000 & $0.000 \mathrm{E}+00$ & 0.0000 & $0.000 \mathrm{E}+00$ & 0.0000 \\
\hline 99 & $4.225 E-06$ & 0.0000 & $0.000 \mathrm{E}+00$ & 0.0000 & $0.000 \mathrm{E}+00$ & 0.0000 & $0.000 \mathrm{E}+00$ & 0.0000 & $0.000 \mathrm{E}+00$ & 0.0000 & $0.000 \mathrm{E}+00$ & 0.0000 & $0.000 \mathrm{E}+00$ & 0.0000 \\
\hline-228 & 7. $111 \mathrm{E}-01$ & 0.3813 & $0.000 \mathrm{E}+00$ & 0.0000 & $0.000 \mathrm{E}+00$ & 0.0000 & $0.000 \mathrm{E}+00$ & 0.0000 & $0.000 \mathrm{E}+00$ & 0.0000 & $0.000 \mathrm{E}+00$ & 0.0000 & $0.000 \mathrm{E}+00$ & 0.0000 \\
\hline-230 & $4.263 E-03$ & 0.0023 & $0.000 \mathrm{E}+00$ & 0.0000 & $0.000 \mathrm{E}+00$ & 0.0000 & $0.000 \mathrm{E}+00$ & 0.0000 & $0.000 \mathrm{E}+00$ & 0.0000 & $0.000 \mathrm{E}+00$ & 0.0000 & $0.000 \mathrm{E}+00$ & 0.0000 \\
\hline-232 & $2.663 E-02$ & 0.0143 & $0.000 \mathrm{E}+00$ & 0.0000 & $0.000 \mathrm{E}+00$ & 0.0000 & $0.000 \mathrm{E}+00$ & 0.0000 & $0.000 \mathrm{E}+00$ & 0.0000 & $0.000 \mathrm{E}+00$ & 0.0000 & $0.000 \mathrm{E}+00$ & 0.0000 \\
\hline 234 & $5.612 \mathrm{E}-05$ & 0.0000 & $0.000 \mathrm{E}+00$ & 0.0000 & $0.000 \mathrm{E}+00$ & 0.0000 & $0.000 \mathrm{E}+00$ & 0.0000 & $0.000 \mathrm{E}+00$ & 0.0000 & $0.000 \mathrm{E}+00$ & 0.0000 & $0.000 \mathrm{E}+00$ & 0.0000 \\
\hline 235 & $2.116 \mathrm{E}-02$ & 0.0113 & $0.000 \mathrm{E}+00$ & 0.0000 & $0.000 \mathrm{E}+00$ & 0.0000 & $0.000 \mathrm{E}+00$ & 0.0000 & $0.000 \mathrm{E}+00$ & 0.0000 & $0.000 \mathrm{E}+00$ & 0.0000 & $0.000 \mathrm{E}+00$ & 0.0000 \\
\hline 38 & $2.808 E-01$ & 0.1506 & $0.000 \mathrm{E}+00$ & 0.0000 & $0.000 \mathrm{E}+00$ & 0.0000 & $0.000 \mathrm{E}+00$ & 0.0000 & $0.000 \mathrm{E}+00$ & 0.0000 & $0.000 \mathrm{E}+00$ & 0.0000 & $0.000 \mathrm{E}+00$ & 0.0000 \\
\hline & $1.865 E+00$ & 1.0000 & $0.000 \mathrm{E}+00$ & 0.0000 & $0.000 \mathrm{E}+00$ & 0.0000 & $0.000 \mathrm{E}+00$ & 0.0000 & $0.000 \mathrm{E}+00$ & 0.0000 & $0.000 \mathrm{E}+00$ & 0.0000 & $.000 \mathrm{E}+00$ & 0.0000 \\
\hline
\end{tabular}

Total Dose Contributions TDOSE (i,p,t) for Individual Radionuclides (i) and Pathways (p) As mrem/yr and Fraction of Total Dose At $t=0.000 \mathrm{E}+00$ years

Water Dependent Pathways

\begin{tabular}{|c|c|c|c|c|c|c|c|c|c|c|c|c|c|c|}
\hline & \multicolumn{2}{|c|}{ Water } & \multicolumn{2}{|c|}{ Fish } & \multicolumn{2}{|c|}{ Radon } & \multicolumn{2}{|c|}{ Plant } & \multicolumn{2}{|c|}{ Meat } & \multicolumn{2}{|c|}{ Milk } & \multicolumn{2}{|c|}{ All Pathways* } \\
\hline clide & mrem/yr & fract. & mrem/yr & fract. & mrem/yr & fract. & mrem/yr & fract. & mrem/yr & fract. & mrem/yr & fract. & mrem/yr & fract. \\
\hline 241 & $0.000 \mathrm{E}+00$ & 0.0000 & $0.000 \mathrm{E}+00$ & 0.0000 & $0.000 \mathrm{E}+00$ & 0.0000 & $0.000 \mathrm{E}+00$ & 0.0000 & $0.000 \mathrm{E}+00$ & 0.0000 & $0.000 \mathrm{E}+00$ & 0.0000 & $1.020 \mathrm{E}-04$ & 0.0001 \\
\hline-137 & $0.000 \mathrm{E}+00$ & 0.0000 & $0.000 \mathrm{E}+00$ & 0.0000 & $0.000 \mathrm{E}+00$ & 0.0000 & $0.000 \mathrm{E}+00$ & 0.0000 & $0.000 \mathrm{E}+00$ & 0.0000 & $0.000 \mathrm{E}+00$ & 0.0000 & $7.826 \mathrm{E}-01$ & 0.4197 \\
\hline-237 & $0.000 \mathrm{E}+00$ & 0.0000 & $0.000 \mathrm{E}+00$ & 0.0000 & $0.000 \mathrm{E}+00$ & 0.0000 & $0.000 \mathrm{E}+00$ & 0.0000 & $0.000 \mathrm{E}+00$ & 0.0000 & $0.000 \mathrm{E}+00$ & 0.0000 & $3.798 E-02$ & 0.0204 \\
\hline-238 & $0.000 \mathrm{E}+00$ & 0.0000 & $0.000 \mathrm{E}+00$ & 0.0000 & $0.000 \mathrm{E}+00$ & 0.0000 & $0.000 \mathrm{E}+00$ & 0.0000 & $0.000 \mathrm{E}+00$ & 0.0000 & $0.000 \mathrm{E}+00$ & 0.0000 & $2.060 \mathrm{E}-06$ & 0.0000 \\
\hline-239 & $0.000 \mathrm{E}+00$ & 0.0000 & $0.000 \mathrm{E}+00$ & 0.0000 & $0.000 \mathrm{E}+00$ & 0.0000 & $0.000 \mathrm{E}+00$ & 0.0000 & $0.000 \mathrm{E}+00$ & 0.0000 & $0.000 E+00$ & 0.0000 & $4.538 E-05$ & 0.0000 \\
\hline-240 & $0.000 \mathrm{E}+00$ & 0.0000 & $0.000 \mathrm{E}+00$ & 0.0000 & $0.000 \mathrm{E}+00$ & 0.0000 & $0.000 \mathrm{E}+00$ & 0.0000 & $0.000 \mathrm{E}+00$ & 0.0000 & $0.000 E+00$ & 0.0000 & $1.848 \mathrm{E}-06$ & 0.0000 \\
\hline-99 & $0.000 \mathrm{E}+00$ & 0.0000 & $0.000 \mathrm{E}+00$ & 0.0000 & $0.000 \mathrm{E}+00$ & 0.0000 & $0.000 \mathrm{E}+00$ & 0.0000 & $0.000 \mathrm{E}+00$ & 0.0000 & $0.000 \mathrm{E}+00$ & 0.0000 & $4.225 E-06$ & 0.0000 \\
\hline-228 & $0.000 \mathrm{E}+00$ & 0.0000 & $0.000 \mathrm{E}+00$ & 0.0000 & $0.000 \mathrm{E}+00$ & 0.0000 & $0.000 \mathrm{E}+00$ & 0.0000 & $0.000 \mathrm{E}+00$ & 0.0000 & $0.000 \mathrm{E}+00$ & 0.0000 & $7.111 \mathrm{E}-01$ & 0.3813 \\
\hline-230 & $0.000 \mathrm{E}+00$ & 0.0000 & $0.000 \mathrm{E}+00$ & 0.0000 & $0.000 \mathrm{E}+00$ & 0.0000 & $0.000 \mathrm{E}+00$ & 0.0000 & $0.000 \mathrm{E}+00$ & 0.0000 & $0.000 E+00$ & 0.0000 & $4.263 E-03$ & 0.0023 \\
\hline-232 & $0.000 \mathrm{E}+00$ & 0.0000 & $0.000 \mathrm{E}+00$ & 0.0000 & $0.000 \mathrm{E}+00$ & 0.0000 & $0.000 \mathrm{E}+00$ & 0.0000 & $0.000 \mathrm{E}+00$ & 0.0000 & $0.000 \mathrm{E}+00$ & 0.0000 & $2.663 E-02$ & 0.0143 \\
\hline 34 & $0.000 \mathrm{E}+00$ & 0.0000 & $0.000 \mathrm{E}+00$ & 0.0000 & $0.000 \mathrm{E}+00$ & 0.0000 & $0.000 \mathrm{E}+00$ & 0.0000 & $0.000 \mathrm{E}+00$ & 0.0000 & $0.000 \mathrm{E}+00$ & 0.0000 & $5.612 \mathrm{E}-05$ & 0.0000 \\
\hline 35 & $0.000 \mathrm{E}+00$ & 0.0000 & $0.000 \mathrm{E}+00$ & 0.0000 & $0.000 \mathrm{E}+00$ & 0.0000 & $0.000 \mathrm{E}+00$ & 0.0000 & $0.000 \mathrm{E}+00$ & 0.0000 & $0.000 E+00$ & 0.0000 & $2.116 \mathrm{E}-02$ & 0.0113 \\
\hline 38 & $0.000 \mathrm{E}+00$ & 0.0000 & $0.000 \mathrm{E}+00$ & 0.0000 & $0.000 \mathrm{E}+00$ & 0.0000 & $0.000 \mathrm{E}+00$ & 0.0000 & $0.000 \mathrm{E}+00$ & 0.0000 & $0.000 \mathrm{E}+00$ & 0.0000 & $2.808 \mathrm{E}-01$ & 0.1506 \\
\hline & $0.000 \mathrm{E}+00$ & 0.0000 & $0.000 \mathrm{E}+00$ & 0.0000 & $0.000 \mathrm{E}+00$ & 0.0000 & $0.000 \mathrm{E}+00$ & 0.0000 & $0.000 \mathrm{E}+00$ & 0.0000 & $0.000 \mathrm{E}+00$ & 0.0000 & $5 E+00$ & 1. \\
\hline
\end{tabular}

* Sum of all water independent and dependent pathways. 
RESRAD, Version $6.5 \quad \mathrm{~T}^{1 / 2}$ Limit $=180$ days

Summary : C746U Trespasser Deterministic Run
File : X: $\backslash$ FINAL V2 $\backslash$ DOE FWD RUNS $\backslash C 746 U$ T AL DOE FWD-FV2-70YR.RAD

Total Dose Contributions TDOSE (i,p,t) for Individual Radionuclides (i) and Pathways (p) As mrem/yr and Fraction of Total Dose At $t=1.000 \mathrm{E}+00$ years

Water Independent Pathways (Inhalation excludes radon)

\begin{tabular}{|c|c|c|c|c|c|c|c|c|c|c|c|c|c|c|}
\hline \multirow{2}{*}{ Nuclide } & \multicolumn{2}{|c|}{ Ground } & \multicolumn{2}{|c|}{ Inhalation } & \multicolumn{2}{|c|}{ Radon } & \multicolumn{2}{|c|}{ Plant } & \multicolumn{2}{|c|}{ Meat } & \multicolumn{2}{|c|}{ Milk } & \multicolumn{2}{|c|}{ Soil } \\
\hline & mrem/yr & fract. & mrem/yr & fract. & mrem/yr & fract. & mrem/yr & fract. & mrem/yr & fract. & mrem/yr & fract. & mrem/yr & fract. \\
\hline-241 & $1.049 \mathrm{E}-04$ & 0.0001 & $0.000 \mathrm{E}+00$ & 0.0000 & $0.000 \mathrm{E}+00$ & 0.0000 & $0.000 \mathrm{E}+00$ & 0.0000 & $0.000 \mathrm{E}+00$ & 0.0000 & $0.000 \mathrm{E}+00$ & 0.0000 & $0.000 \mathrm{E}+00$ & 0.0000 \\
\hline-137 & 7. $712 \mathrm{E}-01$ & 0.4485 & $0.000 \mathrm{E}+00$ & 0.0000 & $0.000 \mathrm{E}+00$ & 0.0000 & $0.000 \mathrm{E}+00$ & 0.0000 & $0.000 \mathrm{E}+00$ & 0.0000 & $0.000 \mathrm{E}+00$ & 0.0000 & $0.000 \mathrm{E}+00$ & 0.0000 \\
\hline-237 & $3.839 \mathrm{E}-02$ & 0.0223 & $0.000 \mathrm{E}+00$ & 0.0000 & $0.000 \mathrm{E}+00$ & 0.0000 & $0.000 \mathrm{E}+00$ & 0.0000 & $0.000 \mathrm{E}+00$ & 0.0000 & $0.000 \mathrm{E}+00$ & 0.0000 & $0.000 \mathrm{E}+00$ & 0.0000 \\
\hline-238 & $2.080 E-06$ & 0.0000 & $0.000 \mathrm{E}+00$ & 0.0000 & $0.000 \mathrm{E}+00$ & 0.0000 & $0.000 \mathrm{E}+00$ & 0.0000 & $0.000 \mathrm{E}+00$ & 0.0000 & $0.000 \mathrm{E}+00$ & 0.0000 & $0.000 \mathrm{E}+00$ & 0.0000 \\
\hline-239 & $4.592 E-05$ & 0.0000 & $0.000 \mathrm{E}+00$ & 0.0000 & $0.000 \mathrm{E}+00$ & 0.0000 & $0.000 \mathrm{E}+00$ & 0.0000 & $0.000 \mathrm{E}+00$ & 0.0000 & $0.000 \mathrm{E}+00$ & 0.0000 & $0.000 \mathrm{E}+00$ & 0.0000 \\
\hline-240 & $1.881 \mathrm{E}-06$ & 0.0000 & $0.000 \mathrm{E}+00$ & 0.0000 & $0.000 \mathrm{E}+00$ & 0.0000 & $0.000 \mathrm{E}+00$ & 0.0000 & $0.000 \mathrm{E}+00$ & 0.0000 & $0.000 \mathrm{E}+00$ & 0.0000 & $0.000 \mathrm{E}+00$ & 0.0000 \\
\hline 99 & $4.262 \mathrm{E}-06$ & 0.0000 & $0.000 \mathrm{E}+00$ & 0.0000 & $0.000 \mathrm{E}+00$ & 0.0000 & $0.000 \mathrm{E}+00$ & 0.0000 & $0.000 \mathrm{E}+00$ & 0.0000 & $0.000 \mathrm{E}+00$ & 0.0000 & $0.000 \mathrm{E}+00$ & 0.0000 \\
\hline-228 & $4.980 \mathrm{E}-01$ & 0.2897 & $0.000 \mathrm{E}+00$ & 0.0000 & $0.000 \mathrm{E}+00$ & 0.0000 & $0.000 \mathrm{E}+00$ & 0.0000 & $0.000 \mathrm{E}+00$ & 0.0000 & $0.000 \mathrm{E}+00$ & 0.0000 & $0.000 \mathrm{E}+00$ & 0.0000 \\
\hline-230 & $1.255 \mathrm{E}-02$ & 0.0073 & $0.000 \mathrm{E}+00$ & 0.0000 & $0.000 \mathrm{E}+00$ & 0.0000 & $0.000 \mathrm{E}+00$ & 0.0000 & $0.000 \mathrm{E}+00$ & 0.0000 & $0.000 \mathrm{E}+00$ & 0.0000 & $0.000 \mathrm{E}+00$ & 0.0000 \\
\hline-232 & $9.446 E-02$ & 0.0549 & $0.000 \mathrm{E}+00$ & 0.0000 & $0.000 \mathrm{E}+00$ & 0.0000 & $0.000 \mathrm{E}+00$ & 0.0000 & $0.000 \mathrm{E}+00$ & 0.0000 & $0.000 \mathrm{E}+00$ & 0.0000 & $0.000 \mathrm{E}+00$ & 0.0000 \\
\hline 234 & $5.724 \mathrm{E}-05$ & 0.0000 & $0.000 \mathrm{E}+00$ & 0.0000 & $0.000 \mathrm{E}+00$ & 0.0000 & $0.000 \mathrm{E}+00$ & 0.0000 & $0.000 \mathrm{E}+00$ & 0.0000 & $0.000 \mathrm{E}+00$ & 0.0000 & $0.000 \mathrm{E}+00$ & 0.0000 \\
\hline 235 & $2.142 \mathrm{E}-02$ & 0.0125 & $0.000 \mathrm{E}+00$ & 0.0000 & $0.000 \mathrm{E}+00$ & 0.0000 & $0.000 \mathrm{E}+00$ & 0.0000 & $0.000 \mathrm{E}+00$ & 0.0000 & $0.000 \mathrm{E}+00$ & 0.0000 & $0.000 \mathrm{E}+00$ & 0.0000 \\
\hline 38 & $2.831 E-01$ & 0.1646 & $0.000 \mathrm{E}+00$ & 0.0000 & $0.000 \mathrm{E}+00$ & 0.0000 & $0.000 \mathrm{E}+00$ & 0.0000 & $0.000 \mathrm{E}+00$ & 0.0000 & $0.000 \mathrm{E}+00$ & 0.0000 & $0.000 \mathrm{E}+00$ & 0.0000 \\
\hline & $1.719 \mathrm{E}+00$ & 1.0000 & $0.000 \mathrm{E}+00$ & 0.0000 & $0.000 \mathrm{E}+00$ & 0.0000 & $0.000 \mathrm{E}+00$ & 0.0000 & $0.000 \mathrm{E}+00$ & 0.0000 & $0.000 \mathrm{E}+00$ & 0.0000 & $.000 \mathrm{E}+00$ & 0.0000 \\
\hline
\end{tabular}

Total Dose Contributions TDOSE(i,p,t) for Individual Radionuclides (i) and Pathways (p) As mrem/yr and Fraction of Total Dose At $t=1.000 \mathrm{E}+00$ years

Water Dependent Pathways

\begin{tabular}{|c|c|c|c|c|c|c|c|c|c|c|c|c|c|c|}
\hline \multirow{2}{*}{ Nuclide } & \multicolumn{2}{|c|}{ Water } & \multicolumn{2}{|c|}{ Fish } & \multicolumn{2}{|c|}{ Radon } & \multicolumn{2}{|c|}{ Plant } & \multicolumn{2}{|c|}{ Meat } & \multicolumn{2}{|c|}{ Milk } & \multicolumn{2}{|c|}{ All Pathways* } \\
\hline & mrem/yr & fract. & mrem/yr & fract. & mrem/yr & fract. & mrem/yr & fract. & mrem/yr & fract. & mrem/yr & fract. & mrem/yr & fract. \\
\hline-241 & $0.000 \mathrm{E}+00$ & 0.0000 & $0.000 \mathrm{E}+00$ & 0.0000 & $0.000 \mathrm{E}+00$ & 0.0000 & $0.000 \mathrm{E}+00$ & 0.0000 & $0.000 \mathrm{E}+00$ & 0.0000 & $0.000 \mathrm{E}+00$ & 0.0000 & $1.049 \mathrm{E}-04$ & 0.0001 \\
\hline-137 & $0.000 \mathrm{E}+00$ & 0.0000 & $0.000 \mathrm{E}+00$ & 0.0000 & $0.000 \mathrm{E}+00$ & 0.0000 & $0.000 \mathrm{E}+00$ & 0.0000 & $0.000 \mathrm{E}+00$ & 0.0000 & $0.000 \mathrm{E}+00$ & 0.0000 & 7. $712 \mathrm{E}-01$ & 0.4485 \\
\hline-237 & $0.000 \mathrm{E}+00$ & 0.0000 & $0.000 \mathrm{E}+00$ & 0.0000 & $0.000 \mathrm{E}+00$ & 0.0000 & $0.000 \mathrm{E}+00$ & 0.0000 & $0.000 \mathrm{E}+00$ & 0.0000 & $0.000 \mathrm{E}+00$ & 0.0000 & $3.839 \mathrm{E}-02$ & 0.0223 \\
\hline-238 & $0.000 \mathrm{E}+00$ & 0.0000 & $0.000 \mathrm{E}+00$ & 0.0000 & $0.000 \mathrm{E}+00$ & 0.0000 & $0.000 \mathrm{E}+00$ & 0.0000 & $0.000 \mathrm{E}+00$ & 0.0000 & $0.000 \mathrm{E}+00$ & 0.0000 & $2.080 \mathrm{E}-06$ & 0.0000 \\
\hline-239 & $0.000 \mathrm{E}+00$ & 0.0000 & $0.000 \mathrm{E}+00$ & 0.0000 & $0.000 \mathrm{E}+00$ & 0.0000 & $0.000 \mathrm{E}+00$ & 0.0000 & $0.000 \mathrm{E}+00$ & 0.0000 & $0.000 \mathrm{E}+00$ & 0.0000 & $4.592 \mathrm{E}-05$ & 0.0000 \\
\hline-240 & $0.000 \mathrm{E}+00$ & 0.0000 & $0.000 \mathrm{E}+00$ & 0.0000 & $0.000 \mathrm{E}+00$ & 0.0000 & $0.000 \mathrm{E}+00$ & 0.0000 & $0.000 \mathrm{E}+00$ & 0.0000 & $0.000 \mathrm{E}+00$ & 0.0000 & $1.881 \mathrm{E}-06$ & 0.0000 \\
\hline-99 & $0.000 \mathrm{E}+00$ & 0.0000 & $0.000 \mathrm{E}+00$ & 0.0000 & $0.000 \mathrm{E}+00$ & 0.0000 & $0.000 \mathrm{E}+00$ & 0.0000 & $0.000 \mathrm{E}+00$ & 0.0000 & $0.000 \mathrm{E}+00$ & 0.0000 & $4.262 \mathrm{E}-06$ & 0.0000 \\
\hline-228 & $0.000 \mathrm{E}+00$ & 0.0000 & $0.000 \mathrm{E}+00$ & 0.0000 & $0.000 \mathrm{E}+00$ & 0.0000 & $0.000 \mathrm{E}+00$ & 0.0000 & $0.000 \mathrm{E}+00$ & 0.0000 & $0.000 \mathrm{E}+00$ & 0.0000 & $4.980 \mathrm{E}-01$ & 0.2897 \\
\hline 230 & $0.000 \mathrm{E}+00$ & 0.0000 & $0.000 \mathrm{E}+00$ & 0.0000 & $0.000 \mathrm{E}+00$ & 0.0000 & $0.000 \mathrm{E}+00$ & 0.0000 & $0.000 \mathrm{E}+00$ & 0.0000 & $0.000 \mathrm{E}+00$ & 0.0000 & $1.255 \mathrm{E}-02$ & 0.0073 \\
\hline 232 & $0.000 \mathrm{E}+00$ & 0.0000 & $0.000 \mathrm{E}+00$ & 0.0000 & $0.000 \mathrm{E}+00$ & 0.0000 & $0.000 \mathrm{E}+00$ & 0.0000 & $0.000 \mathrm{E}+00$ & 0.0000 & $0.000 \mathrm{E}+00$ & 0.0000 & $9.446 \mathrm{E}-02$ & 0.0549 \\
\hline 34 & $0.000 \mathrm{E}+00$ & 0.0000 & $0.000 \mathrm{E}+00$ & 0.0000 & $0.000 \mathrm{E}+00$ & 0.0000 & $0.000 \mathrm{E}+00$ & 0.0000 & $0.000 \mathrm{E}+00$ & 0.0000 & $0.000 \mathrm{E}+00$ & 0.0000 & $5.724 \mathrm{E}-05$ & 0.0000 \\
\hline 35 & $0.000 \mathrm{E}+00$ & 0.0000 & $0.000 \mathrm{E}+00$ & 0.0000 & $0.000 \mathrm{E}+00$ & 0.0000 & $0.000 \mathrm{E}+00$ & 0.0000 & $0.000 \mathrm{E}+00$ & 0.0000 & $0.000 \mathrm{E}+00$ & 0.0000 & $2.142 \mathrm{E}-02$ & 0.0125 \\
\hline 38 & $0.000 \mathrm{E}+00$ & 0.0000 & $0.000 \mathrm{E}+00$ & 0.0000 & $0.000 \mathrm{E}+00$ & 0.0000 & $0.000 \mathrm{E}+00$ & 0.0000 & $0.000 \mathrm{E}+00$ & 0.0000 & $0.000 \mathrm{E}+00$ & 0.0000 & $2.831 \mathrm{E}-01$ & 0.1646 \\
\hline & $0.000 \mathrm{E}+00$ & 0.0000 & $0.000 \mathrm{E}+00$ & 0.0000 & $0.000 \mathrm{E}+00$ & 0.0000 & $0.000 \mathrm{E}+00$ & 0.0000 & $0.000 \mathrm{E}+00$ & 0.0000 & $0.000 \mathrm{E}+00$ & 0.0000 & $9 \mathrm{E}+00$ & 1.0000 \\
\hline
\end{tabular}

* Sum of all water independent and dependent pathways. 
RESRAD, Version $6.5 \quad \mathrm{~T}^{1 / 2}$ Limit $=180$ days

Summary : C746U Trespasser Deterministic Run
File $\mathrm{X}: \backslash$ FINAL V2 \DOE FWD RUNS \C746U T AL DOE FWD-FV2-70YR.RAD

Total Dose Contributions TDOSE(i,p,t) for Individual Radionuclides (i) and Pathways (p) As mrem/yr and Fraction of Total Dose At $t=5.000 \mathrm{E}+01$ years

Water Independent Pathways (Inhalation excludes radon)

\begin{tabular}{|c|c|c|c|c|c|c|c|c|c|c|c|c|c|c|}
\hline \multirow{2}{*}{ Nuclide } & \multicolumn{2}{|c|}{ Ground } & \multicolumn{2}{|c|}{ Inhalation } & \multicolumn{2}{|c|}{ Radon } & \multicolumn{2}{|c|}{ Plant } & \multicolumn{2}{|c|}{ Meat } & \multicolumn{2}{|c|}{ Milk } & \multicolumn{2}{|c|}{ Soil } \\
\hline & mrem/yr & fract. & mrem/yr & fract. & mrem/yr & fract. & mrem/yr & fract. & mrem/yr & fract. & mrem/yr & fract. & mrem/yr & fract. \\
\hline $1-241$ & $3.938 \mathrm{E}-04$ & 0.0001 & $5.206 \mathrm{E}-04$ & 0.0002 & $0.000 \mathrm{E}+00$ & 0.0000 & $0.000 \mathrm{E}+00$ & 0.0000 & $0.000 \mathrm{E}+00$ & 0.0000 & $0.000 \mathrm{E}+00$ & 0.0000 & $1.973 \mathrm{E}-02$ & 0.0058 \\
\hline-137 & $3.751 \mathrm{E}-01$ & 0.1102 & $3.864 \mathrm{E}-08$ & 0.0000 & $0.000 \mathrm{E}+00$ & 0.0000 & $0.000 \mathrm{E}+00$ & 0.0000 & $0.000 \mathrm{E}+00$ & 0.0000 & $0.000 \mathrm{E}+00$ & 0.0000 & $2.347 \mathrm{E}-04$ & 0.0001 \\
\hline-237 & $6.501 \mathrm{E}-02$ & 0.0191 & $4.588 \mathrm{E}-05$ & 0.0000 & $0.000 \mathrm{E}+00$ & 0.0000 & $0.000 \mathrm{E}+00$ & 0.0000 & $0.000 \mathrm{E}+00$ & 0.0000 & $0.000 \mathrm{E}+00$ & 0.0000 & $1.850 \mathrm{E}-03$ & 0.0005 \\
\hline-238 & $3.360 \mathrm{E}-06$ & 0.0000 & $4.836 \mathrm{E}-04$ & 0.0001 & $0.000 \mathrm{E}+00$ & 0.0000 & $0.000 \mathrm{E}+00$ & 0.0000 & $0.000 \mathrm{E}+00$ & 0.0000 & $0.000 \mathrm{E}+00$ & 0.0000 & $1.839 \mathrm{E}-02$ & 0.0054 \\
\hline-239 & $8.241 E-05$ & 0.0000 & $7.246 \mathrm{E}-04$ & 0.0002 & $0.000 \mathrm{E}+00$ & 0.0000 & $0.000 \mathrm{E}+00$ & 0.0000 & $0.000 \mathrm{E}+00$ & 0.0000 & $0.000 \mathrm{E}+00$ & 0.0000 & $2.745 \mathrm{E}-02$ & 0.0081 \\
\hline-240 & $4.443 E-06$ & 0.0000 & $7.218 \mathrm{E}-04$ & 0.0002 & $0.000 \mathrm{E}+00$ & 0.0000 & $0.000 \mathrm{E}+00$ & 0.0000 & $0.000 \mathrm{E}+00$ & 0.0000 & $0.000 \mathrm{E}+00$ & 0.0000 & $2.734 \mathrm{E}-02$ & 0.0080 \\
\hline-99 & $6.496 \mathrm{E}-06$ & 0.0000 & $6.663 E-08$ & 0.0000 & $0.000 \mathrm{E}+00$ & 0.0000 & $0.000 \mathrm{E}+00$ & 0.0000 & $0.000 \mathrm{E}+00$ & 0.0000 & $0.000 \mathrm{E}+00$ & 0.0000 & $5.969 \mathrm{E}-05$ & 0.0000 \\
\hline-228 & $1.317 \mathrm{E}-08$ & 0.0000 & $3.336 \mathrm{E}-13$ & 0.0000 & $0.000 \mathrm{E}+00$ & 0.0000 & $0.000 \mathrm{E}+00$ & 0.0000 & $0.000 \mathrm{E}+00$ & 0.0000 & $0.000 \mathrm{E}+00$ & 0.0000 & $1.992 \mathrm{E}-11$ & 0.0000 \\
\hline-230 & $5.847 \mathrm{E}-01$ & 0.1717 & $1.686 \mathrm{E}-03$ & 0.0005 & $0.000 \mathrm{E}+00$ & 0.0000 & $0.000 \mathrm{E}+00$ & 0.0000 & $0.000 \mathrm{E}+00$ & 0.0000 & $0.000 \mathrm{E}+00$ & 0.0000 & $7.224 \mathrm{E}-02$ & 0.0212 \\
\hline-232 & $1.685 \mathrm{E}+00$ & 0.4948 & $1.140 \mathrm{E}-04$ & 0.0000 & $0.000 \mathrm{E}+00$ & 0.0000 & $0.000 \mathrm{E}+00$ & 0.0000 & $0.000 E+00$ & 0.0000 & $0.000 \mathrm{E}+00$ & 0.0000 & $1.297 \mathrm{E}-02$ & 0.0038 \\
\hline 234 & $3.494 \mathrm{E}-04$ & 0.0001 & $2.539 E-04$ & 0.0001 & $0.000 E+00$ & 0.0000 & $0.000 \mathrm{E}+00$ & 0.0000 & $0.000 \mathrm{E}+00$ & 0.0000 & $0.000 \mathrm{E}+00$ & 0.0000 & $2.394 \mathrm{E}-02$ & 0.0070 \\
\hline 235 & $3.947 \mathrm{E}-02$ & 0.0116 & $9.790 \mathrm{E}-06$ & 0.0000 & $0.000 \mathrm{E}+00$ & 0.0000 & $0.000 \mathrm{E}+00$ & 0.0000 & $0.000 \mathrm{E}+00$ & 0.0000 & $0.000 \mathrm{E}+00$ & 0.0000 & $9.680 \mathrm{E}-04$ & 0.0003 \\
\hline 38 & $4.218 E-01$ & 0.1239 & $2.152 \mathrm{E}-04$ & 0.0001 & $0.000 \mathrm{E}+00$ & 0.0000 & $0.000 \mathrm{E}+00$ & 0.0000 & $0.000 E+00$ & 0.0000 & $0.000 \mathrm{E}+00$ & 0.0000 & $2.372 \mathrm{E}-02$ & 0.0070 \\
\hline & $3.172 \mathrm{E}+00$ & 0.9314 & $4.775 E-03$ & 0.0014 & $0.000 \mathrm{E}+00$ & 0.0000 & $0.000 \mathrm{E}+00$ & 0.0000 & $0.000 \mathrm{E}+00$ & 0.0000 & $0.000 \mathrm{E}+00$ & 0.0000 & $2.289 \mathrm{E}-01$ & 0.0672 \\
\hline
\end{tabular}

Total Dose Contributions TDOSE (i,p,t) for Individual Radionuclides (i) and Pathways (p) As mrem/yr and Fraction of Total Dose At $t=5.000 \mathrm{E}+01$ years

Water Dependent Pathways

\begin{tabular}{|c|c|c|c|c|c|c|c|c|c|c|c|c|c|c|}
\hline & \multicolumn{2}{|c|}{ Water } & \multicolumn{2}{|c|}{ Fish } & \multicolumn{2}{|c|}{ Radon } & \multicolumn{2}{|c|}{ Plant } & \multicolumn{2}{|c|}{ Meat } & \multicolumn{2}{|c|}{ Milk } & \multicolumn{2}{|c|}{ All Pathways* } \\
\hline clide & mrem/yr & fract. & mrem/yr & fract. & mrem/yr & fract. & mrem/yr & fract. & mrem/yr & fract. & mrem/yr & fract. & mrem/yr & fract. \\
\hline 241 & $0.000 \mathrm{E}+00$ & 0.0000 & $0.000 \mathrm{E}+00$ & 0.0000 & $0.000 \mathrm{E}+00$ & 0.0000 & $0.000 \mathrm{E}+00$ & 0.0000 & $0.000 \mathrm{E}+00$ & 0.0000 & $0.000 \mathrm{E}+00$ & 0.0000 & $2.065 E-02$ & 0.0061 \\
\hline-137 & $0.000 \mathrm{E}+00$ & 0.0000 & $0.000 \mathrm{E}+00$ & 0.0000 & $0.000 \mathrm{E}+00$ & 0.0000 & $0.000 \mathrm{E}+00$ & 0.0000 & $0.000 \mathrm{E}+00$ & 0.0000 & $0.000 \mathrm{E}+00$ & 0.0000 & $3.754 \mathrm{E}-01$ & 0.1102 \\
\hline-237 & $0.000 \mathrm{E}+00$ & 0.0000 & $0.000 \mathrm{E}+00$ & 0.0000 & $0.000 \mathrm{E}+00$ & 0.0000 & $0.000 \mathrm{E}+00$ & 0.0000 & $0.000 \mathrm{E}+00$ & 0.0000 & $0.000 \mathrm{E}+00$ & 0.0000 & $6.690 \mathrm{E}-02$ & 0.0196 \\
\hline-238 & $0.000 \mathrm{E}+00$ & 0.0000 & $0.000 \mathrm{E}+00$ & 0.0000 & $0.000 \mathrm{E}+00$ & 0.0000 & $0.000 \mathrm{E}+00$ & 0.0000 & $0.000 \mathrm{E}+00$ & 0.0000 & $0.000 \mathrm{E}+00$ & 0.0000 & $1.887 \mathrm{E}-02$ & 0.0055 \\
\hline-239 & $0.000 \mathrm{E}+00$ & 0.0000 & $0.000 \mathrm{E}+00$ & 0.0000 & $0.000 \mathrm{E}+00$ & 0.0000 & $0.000 \mathrm{E}+00$ & 0.0000 & $0.000 \mathrm{E}+00$ & 0.0000 & $0.000 E+00$ & 0.0000 & $2.826 \mathrm{E}-02$ & 0.0083 \\
\hline-240 & $0.000 \mathrm{E}+00$ & 0.0000 & $0.000 \mathrm{E}+00$ & 0.0000 & $0.000 \mathrm{E}+00$ & 0.0000 & $0.000 \mathrm{E}+00$ & 0.0000 & $0.000 \mathrm{E}+00$ & 0.0000 & $0.000 E+00$ & 0.0000 & $2.807 \mathrm{E}-02$ & 0.0082 \\
\hline-99 & $0.000 \mathrm{E}+00$ & 0.0000 & $0.000 \mathrm{E}+00$ & 0.0000 & $0.000 \mathrm{E}+00$ & 0.0000 & $0.000 \mathrm{E}+00$ & 0.0000 & $0.000 \mathrm{E}+00$ & 0.0000 & $0.000 \mathrm{E}+00$ & 0.0000 & $6.625 \mathrm{E}-05$ & 0.0000 \\
\hline-228 & $0.000 \mathrm{E}+00$ & 0.0000 & $0.000 \mathrm{E}+00$ & 0.0000 & $0.000 \mathrm{E}+00$ & 0.0000 & $0.000 \mathrm{E}+00$ & 0.0000 & $0.000 \mathrm{E}+00$ & 0.0000 & $0.000 \mathrm{E}+00$ & 0.0000 & $1.319 \mathrm{E}-08$ & 0.0000 \\
\hline-230 & $0.000 \mathrm{E}+00$ & 0.0000 & $0.000 \mathrm{E}+00$ & 0.0000 & $0.000 \mathrm{E}+00$ & 0.0000 & $0.000 \mathrm{E}+00$ & 0.0000 & $0.000 \mathrm{E}+00$ & 0.0000 & $0.000 E+00$ & 0.0000 & $6.586 \mathrm{E}-01$ & 0.1934 \\
\hline-232 & $0.000 \mathrm{E}+00$ & 0.0000 & $0.000 \mathrm{E}+00$ & 0.0000 & $0.000 \mathrm{E}+00$ & 0.0000 & $0.000 \mathrm{E}+00$ & 0.0000 & $0.000 \mathrm{E}+00$ & 0.0000 & $0.000 \mathrm{E}+00$ & 0.0000 & $1.698 \mathrm{E}+00$ & 0.4986 \\
\hline 34 & $0.000 \mathrm{E}+00$ & 0.0000 & $0.000 \mathrm{E}+00$ & 0.0000 & $0.000 \mathrm{E}+00$ & 0.0000 & $0.000 \mathrm{E}+00$ & 0.0000 & $0.000 \mathrm{E}+00$ & 0.0000 & $0.000 \mathrm{E}+00$ & 0.0000 & $2.455 E-02$ & 0.0072 \\
\hline 35 & $0.000 \mathrm{E}+00$ & 0.0000 & $0.000 \mathrm{E}+00$ & 0.0000 & $0.000 \mathrm{E}+00$ & 0.0000 & $0.000 \mathrm{E}+00$ & 0.0000 & $0.000 \mathrm{E}+00$ & 0.0000 & $0.000 \mathrm{E}+00$ & 0.0000 & $4.044 \mathrm{E}-02$ & 0.0119 \\
\hline 38 & $0.000 \mathrm{E}+00$ & 0.0000 & $0.000 \mathrm{E}+00$ & 0.0000 & $0.000 \mathrm{E}+00$ & 0.0000 & $0.000 \mathrm{E}+00$ & 0.0000 & $0.000 \mathrm{E}+00$ & 0.0000 & $0.000 \mathrm{E}+00$ & 0.0000 & $4.458 \mathrm{E}-01$ & 0.1309 \\
\hline & $0.000 \mathrm{E}+00$ & 0.0000 & $0.000 \mathrm{E}+00$ & 0.0000 & $0.000 \mathrm{E}+00$ & 0.0000 & $0.000 \mathrm{E}+00$ & 0.0000 & $0.000 \mathrm{E}+00$ & 0.0000 & $0.000 \mathrm{E}+00$ & 0.0000 & $3.406 \mathrm{E}+00$ & 1. \\
\hline
\end{tabular}

* Sum of all water independent and dependent pathways. 
RESRAD, Version $6.5 \quad \mathrm{~T}^{1 / 2}$ Limit $=180$ days

Summary : C746U Trespasser Deterministic Run
File $\mathrm{X}: \backslash$ FINAL V2 \DOE FWD RUNS \C746U T AL DOE FWD-FV2-70YR.RAD

Total Dose Contributions TDOSE(i,p,t) for Individual Radionuclides (i) and Pathways (p) As mrem/yr and Fraction of Total Dose At $t=7.000 \mathrm{E}+01$ years

Water Independent Pathways (Inhalation excludes radon)

\begin{tabular}{|c|c|c|c|c|c|c|c|c|c|c|c|c|c|c|}
\hline \multirow{2}{*}{ Nuclide } & \multicolumn{2}{|c|}{ Ground } & \multicolumn{2}{|c|}{ Inhalation } & \multicolumn{2}{|c|}{ Radon } & \multicolumn{2}{|c|}{ Plant } & \multicolumn{2}{|c|}{ Meat } & \multicolumn{2}{|c|}{ Milk } & \multicolumn{2}{|c|}{ Soil } \\
\hline & mrem/yr & fract. & mrem/yr & fract. & mrem/yr & fract. & mrem/yr & fract. & mrem/yr & fract. & mrem/yr & fract. & mrem/yr & fract. \\
\hline-241 & $6.715 E-04$ & 0.0002 & $7.179 \mathrm{E}-04$ & 0.0002 & $0.000 \mathrm{E}+00$ & 0.0000 & $0.000 \mathrm{E}+00$ & 0.0000 & $0.000 \mathrm{E}+00$ & 0.0000 & $0.000 \mathrm{E}+00$ & 0.0000 & $2.721 \mathrm{E}-02$ & 0.0066 \\
\hline-137 & $2.795 E-01$ & 0.0680 & $3.463 \mathrm{E}-08$ & 0.0000 & $0.000 \mathrm{E}+00$ & 0.0000 & $0.000 \mathrm{E}+00$ & 0.0000 & $0.000 \mathrm{E}+00$ & 0.0000 & $0.000 \mathrm{E}+00$ & 0.0000 & $2.104 \mathrm{E}-04$ & 0.0001 \\
\hline-237 & $8.064 \mathrm{E}-02$ & 0.0196 & $6.513 E-05$ & 0.0000 & $0.000 \mathrm{E}+00$ & 0.0000 & $0.000 \mathrm{E}+00$ & 0.0000 & $0.000 \mathrm{E}+00$ & 0.0000 & $0.000 \mathrm{E}+00$ & 0.0000 & $2.626 \mathrm{E}-03$ & 0.0006 \\
\hline-238 & $4.089 E-06$ & 0.0000 & $5.878 E-04$ & 0.0001 & $0.000 \mathrm{E}+00$ & 0.0000 & $0.000 \mathrm{E}+00$ & 0.0000 & $0.000 \mathrm{E}+00$ & 0.0000 & $0.000 \mathrm{E}+00$ & 0.0000 & $2.235 \mathrm{E}-02$ & 0.0054 \\
\hline-239 & $1.046 \mathrm{E}-04$ & 0.0000 & $1.031 \mathrm{E}-03$ & 0.0003 & $0.000 \mathrm{E}+00$ & 0.0000 & $0.000 \mathrm{E}+00$ & 0.0000 & $0.000 \mathrm{E}+00$ & 0.0000 & $0.000 \mathrm{E}+00$ & 0.0000 & $3.905 E-02$ & 0.0095 \\
\hline-240 & $6.310 \mathrm{E}-06$ & 0.0000 & $1.025 \mathrm{E}-03$ & 0.0002 & $0.000 \mathrm{E}+00$ & 0.0000 & $0.000 \mathrm{E}+00$ & 0.0000 & $0.000 \mathrm{E}+00$ & 0.0000 & $0.000 \mathrm{E}+00$ & 0.0000 & $3.884 \mathrm{E}-02$ & 0.0094 \\
\hline 99 & $7.715 E-06$ & 0.0000 & $7.679 \mathrm{E}-08$ & 0.0000 & $0.000 \mathrm{E}+00$ & 0.0000 & $0.000 \mathrm{E}+00$ & 0.0000 & $0.000 \mathrm{E}+00$ & 0.0000 & $0.000 \mathrm{E}+00$ & 0.0000 & $6.880 \mathrm{E}-05$ & 0.0000 \\
\hline-228 & $1.064 \mathrm{E}-11$ & 0.0000 & $3.387 \mathrm{E}-16$ & 0.0000 & $0.000 \mathrm{E}+00$ & 0.0000 & $0.000 \mathrm{E}+00$ & 0.0000 & $0.000 \mathrm{E}+00$ & 0.0000 & $0.000 \mathrm{E}+00$ & 0.0000 & $2.023 E-14$ & 0.0000 \\
\hline-230 & $9.370 \mathrm{E}-01$ & 0.2278 & $2.404 \mathrm{E}-03$ & 0.0006 & $0.000 \mathrm{E}+00$ & 0.0000 & $0.000 \mathrm{E}+00$ & 0.0000 & $0.000 \mathrm{E}+00$ & 0.0000 & $0.000 \mathrm{E}+00$ & 0.0000 & $1.098 \mathrm{E}-01$ & 0.0267 \\
\hline-232 & $1.931 \mathrm{E}+00$ & 0.4696 & $1.624 \mathrm{E}-04$ & 0.0000 & $0.000 \mathrm{E}+00$ & 0.0000 & $0.000 \mathrm{E}+00$ & 0.0000 & $0.000 \mathrm{E}+00$ & 0.0000 & $0.000 \mathrm{E}+00$ & 0.0000 & $1.850 \mathrm{E}-02$ & 0.0045 \\
\hline 234 & $6.718 \mathrm{E}-04$ & 0.0002 & $3.620 \mathrm{E}-04$ & 0.0001 & $0.000 \mathrm{E}+00$ & 0.0000 & $0.000 \mathrm{E}+00$ & 0.0000 & $0.000 \mathrm{E}+00$ & 0.0000 & $0.000 \mathrm{E}+00$ & 0.0000 & $3.411 \mathrm{E}-02$ & 0.0083 \\
\hline 235 & $5.068 \mathrm{E}-02$ & 0.0123 & $1.435 \mathrm{E}-05$ & 0.0000 & $0.000 \mathrm{E}+00$ & 0.0000 & $0.000 \mathrm{E}+00$ & 0.0000 & $0.000 \mathrm{E}+00$ & 0.0000 & $0.000 \mathrm{E}+00$ & 0.0000 & $1.399 \mathrm{E}-03$ & 0.0003 \\
\hline 38 & $4.971 E-01$ & 0.1209 & $3.063 E-04$ & 0.0001 & $0.000 \mathrm{E}+00$ & 0.0000 & $0.000 \mathrm{E}+00$ & 0.0000 & $0.000 \mathrm{E}+00$ & 0.0000 & $0.000 \mathrm{E}+00$ & 0.0000 & $3.376 \mathrm{E}-02$ & 0.0082 \\
\hline & $3.778 E+00$ & 0.9186 & $6.676 \mathrm{E}-03$ & 0.0016 & $0.000 \mathrm{E}+00$ & 0.0000 & $0.000 \mathrm{E}+00$ & 0.0000 & $0.000 \mathrm{E}+00$ & 0.0000 & $0.000 \mathrm{E}+00$ & 0.0000 & 3.279E-01 & 0.0797 \\
\hline
\end{tabular}

Total Dose Contributions TDOSE (i,p,t) for Individual Radionuclides (i) and Pathways (p) As mrem/yr and Fraction of Total Dose At $t=7.000 \mathrm{E}+01$ years

Water Dependent Pathways

\begin{tabular}{|c|c|c|c|c|c|c|c|c|c|c|c|c|c|c|}
\hline & \multicolumn{2}{|c|}{ Water } & \multicolumn{2}{|c|}{ Fish } & \multicolumn{2}{|c|}{ Radon } & \multicolumn{2}{|c|}{ Plant } & \multicolumn{2}{|c|}{ Meat } & \multicolumn{2}{|c|}{ Milk } & \multicolumn{2}{|c|}{ All Pathways* } \\
\hline clide & mrem/yr & fract. & mrem/yr & fract. & mrem/yr & fract. & mrem/yr & fract. & mrem/yr & fract. & mrem/yr & fract. & mrem/yr & fract. \\
\hline-241 & $0.000 \mathrm{E}+00$ & 0.0000 & $0.000 \mathrm{E}+00$ & 0.0000 & $0.000 \mathrm{E}+00$ & 0.0000 & $0.000 \mathrm{E}+00$ & 0.0000 & $0.000 \mathrm{E}+00$ & 0.0000 & $0.000 \mathrm{E}+00$ & 0.0000 & $2.860 \mathrm{E}-02$ & 0.0070 \\
\hline-137 & $0.000 \mathrm{E}+00$ & 0.0000 & $0.000 \mathrm{E}+00$ & 0.0000 & $0.000 \mathrm{E}+00$ & 0.0000 & $0.000 \mathrm{E}+00$ & 0.0000 & $0.000 \mathrm{E}+00$ & 0.0000 & $0.000 \mathrm{E}+00$ & 0.0000 & $2.798 \mathrm{E}-01$ & 0.0680 \\
\hline-237 & $0.000 \mathrm{E}+00$ & 0.0000 & $0.000 \mathrm{E}+00$ & 0.0000 & $0.000 \mathrm{E}+00$ & 0.0000 & $0.000 \mathrm{E}+00$ & 0.0000 & $0.000 \mathrm{E}+00$ & 0.0000 & $0.000 \mathrm{E}+00$ & 0.0000 & $8.333 E-02$ & 0.0203 \\
\hline 238 & $0.000 \mathrm{E}+00$ & 0.0000 & $0.000 \mathrm{E}+00$ & 0.0000 & $0.000 \mathrm{E}+00$ & 0.0000 & $0.000 \mathrm{E}+00$ & 0.0000 & $0.000 \mathrm{E}+00$ & 0.0000 & $0.000 \mathrm{E}+00$ & 0.0000 & $2.294 \mathrm{E}-02$ & 0.0056 \\
\hline 239 & $0.000 \mathrm{E}+00$ & 0.0000 & $0.000 \mathrm{E}+00$ & 0.0000 & $0.000 \mathrm{E}+00$ & 0.0000 & $0.000 \mathrm{E}+00$ & 0.0000 & $0.000 \mathrm{E}+00$ & 0.0000 & $0.000 \mathrm{E}+00$ & 0.0000 & $4.019 \mathrm{E}-02$ & 0.0098 \\
\hline 240 & $0.000 \mathrm{E}+00$ & 0.0000 & $0.000 \mathrm{E}+00$ & 0.0000 & $0.000 \mathrm{E}+00$ & 0.0000 & $0.000 \mathrm{E}+00$ & 0.0000 & $0.000 \mathrm{E}+00$ & 0.0000 & $0.000 \mathrm{E}+00$ & 0.0000 & $3.987 \mathrm{E}-02$ & 0.0097 \\
\hline 99 & $0.000 \mathrm{E}+00$ & 0.0000 & $0.000 \mathrm{E}+00$ & 0.0000 & $0.000 \mathrm{E}+00$ & 0.0000 & $0.000 \mathrm{E}+00$ & 0.0000 & $0.000 \mathrm{E}+00$ & 0.0000 & $0.000 \mathrm{E}+00$ & 0.0000 & $7.659 \mathrm{E}-05$ & 0.0000 \\
\hline 228 & $0.000 \mathrm{E}+00$ & 0.0000 & $0.000 \mathrm{E}+00$ & 0.0000 & $0.000 \mathrm{E}+00$ & 0.0000 & $0.000 \mathrm{E}+00$ & 0.0000 & $0.000 \mathrm{E}+00$ & 0.0000 & $0.000 \mathrm{E}+00$ & 0.0000 & $1.066 \mathrm{E}-11$ & 0.0000 \\
\hline 230 & $0.000 \mathrm{E}+00$ & 0.0000 & $0.000 \mathrm{E}+00$ & 0.0000 & $0.000 \mathrm{E}+00$ & 0.0000 & $0.000 \mathrm{E}+00$ & 0.0000 & $0.000 \mathrm{E}+00$ & 0.0000 & $0.000 \mathrm{E}+00$ & 0.0000 & $1.049 \mathrm{E}+00$ & 0.2551 \\
\hline 232 & $0.000 \mathrm{E}+00$ & 0.0000 & $0.000 \mathrm{E}+00$ & 0.0000 & $0.000 \mathrm{E}+00$ & 0.0000 & $0.000 \mathrm{E}+00$ & 0.0000 & $0.000 \mathrm{E}+00$ & 0.0000 & $0.000 \mathrm{E}+00$ & 0.0000 & $1.950 \mathrm{E}+00$ & 0.4742 \\
\hline 34 & $0.000 \mathrm{E}+00$ & 0.0000 & $0.000 \mathrm{E}+00$ & 0.0000 & $0.000 \mathrm{E}+00$ & 0.0000 & $0.000 \mathrm{E}+00$ & 0.0000 & $0.000 \mathrm{E}+00$ & 0.0000 & $0.000 \mathrm{E}+00$ & 0.0000 & $3.514 \mathrm{E}-02$ & 0.0085 \\
\hline 35 & $0.000 \mathrm{E}+00$ & 0.0000 & $0.000 \mathrm{E}+00$ & 0.0000 & $0.000 \mathrm{E}+00$ & 0.0000 & $0.000 \mathrm{E}+00$ & 0.0000 & $0.000 \mathrm{E}+00$ & 0.0000 & $0.000 \mathrm{E}+00$ & 0.0000 & $5.210 \mathrm{E}-02$ & 0.0127 \\
\hline 38 & $0.000 \mathrm{E}+00$ & 0.0000 & $0.000 \mathrm{E}+00$ & 0.0000 & $0.000 \mathrm{E}+00$ & 0.0000 & $0.000 \mathrm{E}+00$ & 0.0000 & $0.000 \mathrm{E}+00$ & 0.0000 & $0.000 \mathrm{E}+00$ & 0.0000 & $5.312 \mathrm{E}-01$ & 0.1292 \\
\hline & $0.000 \mathrm{E}+00$ & 0.0000 & $0.000 \mathrm{E}+00$ & 0.0000 & $0.000 \mathrm{E}+00$ & 0.0000 & $0.000 \mathrm{E}+00$ & 0.0000 & $0.000 \mathrm{E}+00$ & 0.0000 & $0.000 \mathrm{E}+00$ & 000 & +00 & 1.0000 \\
\hline
\end{tabular}

* Sum of all water independent and dependent pathways. 
RESRAD, Version $6.5 \quad \mathrm{~T}^{1 / 2}$ Limit $=180$ days

Summary : C746U Trespasser Deterministic Run

File : $\mathrm{X}: \backslash F I N A L$ V2 $\backslash$ DOE FWD RUNS \C746U T AL DOE FWD-FV2-70YR.RAD

Dose/Source Ratios Summed Over All Pathways

Parent and Progeny Principal Radionuclide Contributions Indicated

Parent Product Thread DSR $(j, t)$ At Time in Years (mrem/yr) $/(\mathrm{pCi} / \mathrm{g})$

(i) (j) Fraction $0.000 \mathrm{E}+001.000 \mathrm{E}+00 \quad 5.000 \mathrm{E}+01 \quad 7.000 \mathrm{E}+01$

Am-241

Am-241

Am-241

Am-241

Am-241

$C s-137+D$

$\mathrm{Np}-237+\mathrm{D}$

$\mathrm{Np}-237+\mathrm{D}$

$\mathrm{Np}-237+\mathrm{D}$

$\mathrm{Np}-237+\mathrm{D}$

$\mathrm{Pu}-238$

$\mathrm{Pu}-238$

1. $840 E-09$

$\begin{array}{llllll}\mathrm{Am}-241 & 1.000 \mathrm{E}+00 & & & & \\ 1.457 \mathrm{E}-06 & 1.496 \mathrm{E}-06 & 2.949 \mathrm{E}-04 & 4.084 \mathrm{E}-04\end{array}$

$\begin{array}{lllllll}\mathrm{Np}-237+\mathrm{D} & 1.000 \mathrm{E}+00 & 5.599 \mathrm{E}-10 & 1.695 \mathrm{E}-09 & 9.593 \mathrm{E}-08 & 1.644 \mathrm{E}-07\end{array}$

$\begin{array}{lllllll}\mathrm{U}-233 & 1.000 \mathrm{E}+00 & 6.695 \mathrm{E}-19 & 4.735 \mathrm{E}-18 & 1.476 \mathrm{E}-13 & 4.022 \mathrm{E}-13\end{array}$

$\begin{array}{lllllll}\mathrm{Th}-229+\mathrm{D} & 1.000 \mathrm{E}+00 & 3.971 \mathrm{E}-20 & 5.999 \mathrm{E}-19 & 3.406 \mathrm{E}-14 & 1.120 \mathrm{E}-13\end{array}$

$\operatorname{LDSR}(j) \quad 1.457 \mathrm{E}-06 \quad 1.498 \mathrm{E}-06 \quad 2.949 \mathrm{E}-04 \quad 4.085 \mathrm{E}-04$

$\mathrm{Cs}-137+\mathrm{D} \quad 1.000 \mathrm{E}+00 \quad 2.060 \mathrm{E}-02 \quad 2.029 \mathrm{E}-02 \quad 9.878 \mathrm{E}-03 \quad 7.362 \mathrm{E}-03$

$\mathrm{Np}-237+\mathrm{D} \quad 1.000 \mathrm{E}+00 \quad 3.453 \mathrm{E}-03 \quad 3.490 \mathrm{E}-03 \quad 6.082 \mathrm{E}-03 \quad 7.575 \mathrm{E}-03$

$\begin{array}{llllll}\mathrm{U}-233 & 1.000 \mathrm{E}+00 & 6.197 \mathrm{E}-12 & 1.880 \mathrm{E}-11 & 1.851 \mathrm{E}-08 & 3.649 \mathrm{E}-08\end{array}$

$\begin{array}{lllllll}\mathrm{Th}-229+\mathrm{D} \quad 1.000 \mathrm{E}+00 \quad 4.903 \mathrm{E}-13 & 3.458 \mathrm{E}-12 & 6.365 \mathrm{E}-09 & 1.511 \mathrm{E}-08\end{array}$

$\operatorname{SDSR}(j) \quad 3.453 \mathrm{E}-03 \quad 3.490 \mathrm{E}-03 \quad 6.082 \mathrm{E}-03 \quad 7.575 \mathrm{E}-03$

$\mathrm{Pu}-238$

$\begin{array}{lllllll}\mathrm{Pu}-238 & 1.000 \mathrm{E}+00 & 2.641 \mathrm{E}-08 & 2.667 \mathrm{E}-08 & 2.419 \mathrm{E}-04 & 2.941 \mathrm{E}-04\end{array}$

$\begin{array}{lllllll}\mathrm{U}-234 & 1.000 \mathrm{E}+00 & 2.486 \mathrm{E}-13 & 7.549 \mathrm{E}-13 & 8.961 \mathrm{E}-09 & 1.656 \mathrm{E}-08\end{array}$

$\begin{array}{llllll}\mathrm{Th}-230 & 1.000 \mathrm{E}+00 & 3.358 \mathrm{E}-18 & 2.380 \mathrm{E}-17 & 9.470 \mathrm{E}-12 & 2.502 \mathrm{E}-11\end{array}$

$\begin{array}{llllllll}\mathrm{Ra}-226+\mathrm{D} & 1.000 \mathrm{E}+00 \quad 4.363 \mathrm{E}-17 & 6.572 \mathrm{E}-16 & 2.901 \mathrm{E}-11 & 8.757 \mathrm{E}-11\end{array}$

$\mathrm{Pb}-210+\mathrm{D} \quad 1.000 \mathrm{E}+00 \quad 2.379 \mathrm{E}-23 \quad 7.401 \mathrm{E}-22 \quad 1.868 \mathrm{E}-13 \quad 8.841 \mathrm{E}-13$

$\operatorname{LDSR}(j) \quad 2.641 \mathrm{E}-08 \quad 2.667 \mathrm{E}-08 \quad 2.420 \mathrm{E}-04 \quad 2.941 \mathrm{E}-04$

$\begin{array}{llllll}\mathrm{Pu}-239 & 1.000 \mathrm{E}+00 & 6.302 \mathrm{E}-07 & 6.378 \mathrm{E}-07 & 3.925 \mathrm{E}-04 & 5.581 \mathrm{E}-04\end{array}$

$\begin{array}{llllll}\mathrm{U}-235+\mathrm{D} & 1.000 \mathrm{E}+00 & 8.030 \mathrm{E}-13 & 2.436 \mathrm{E}-12 & 1.542 \mathrm{E}-10 & 2.766 \mathrm{E}-10\end{array}$

$\begin{array}{lllllll}\mathrm{Pa}-231 & 1.000 \mathrm{E}+00 & 2.330 \mathrm{E}-18 & 1.646 \mathrm{E}-17 & 5.933 \mathrm{E}-14 & 1.535 \mathrm{E}-13\end{array}$

$\mathrm{AC}-227+\mathrm{D} \quad 1.000 \mathrm{E}+00 \quad 2.010 \mathrm{E}-19 \quad 3.022 \mathrm{E}-18 \quad 1.404 \mathrm{E}-13 \quad 4.252 \mathrm{E}-13$

$\operatorname{\sum DSR}(j) \quad 6.302 \mathrm{E}-07 \quad 6.378 \mathrm{E}-07 \quad 3.925 \mathrm{E}-04 \quad 5.581 \mathrm{E}-04$

Pu-240 4.950E-08 1.271E-15 $1.293 \mathrm{E}-15 \quad 1.930 \mathrm{E}-11 \quad 2.741 \mathrm{E}-11$

$\begin{array}{llllll}\mathrm{Pu}-240 \quad 1.000 \mathrm{E}+00 & 2.567 \mathrm{E}-08 & 2.612 \mathrm{E}-08 & 3.899 \mathrm{E}-04 & 5.538 \mathrm{E}-04\end{array}$

$\begin{array}{llllll}\mathrm{U}-236 & 1.000 \mathrm{E}+00 & 1.038 \mathrm{E}-15 & 3.165 \mathrm{E}-15 & 1.084 \mathrm{E}-10 & 2.152 \mathrm{E}-10\end{array}$

$\begin{array}{llllll}\mathrm{Th}-232 & 1.000 \mathrm{E}+00 & 4.987 \mathrm{E}-26 & 3.547 \mathrm{E}-25 & 6.713 \mathrm{E}-19 & 1.861 \mathrm{E}-18\end{array}$

$\begin{array}{llllll}\mathrm{Ra}-228+\mathrm{D} & 1.000 \mathrm{E}+00 \quad 3.271 \mathrm{E}-22 & 4.816 \mathrm{E}-21 & 9.118 \mathrm{E}-17 & 2.265 \mathrm{E}-16\end{array}$

$\begin{array}{lllllll}\mathrm{Th}-228+\mathrm{D} & 1.000 \mathrm{E}+00 & 5.216 \mathrm{E}-23 & 1.501 \mathrm{E}-21 & 1.723 \mathrm{E}-16 & 4.318 \mathrm{E}-16\end{array}$

$\begin{array}{lllll}\operatorname{LDSR}(j) & 2.567 \mathrm{E}-08 & 2.612 \mathrm{E}-08 & 3.899 \mathrm{E}-04 & 5.538 \mathrm{E}-04\end{array}$

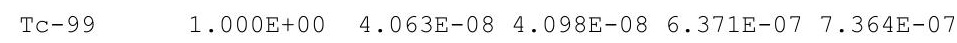

$\begin{array}{lllllll}\mathrm{Th}-228+\mathrm{D} & 1.000 \mathrm{E}+00 \quad 8.889 \mathrm{E}-02 & 6.226 \mathrm{E}-02 & 1.649 \mathrm{E}-09 & 1.333 \mathrm{E}-12\end{array}$

Th-230 1.000E+00 7.878E-07 8.012E-07 $\quad 3.311 \mathrm{E}-04 \quad 4.713 \mathrm{E}-04$

$\mathrm{Ra}-226+\mathrm{D} \quad 1.000 \mathrm{E}+00 \quad 2.053 \mathrm{E}-05 \quad 6.196 \mathrm{E}-05 \quad 2.931 \mathrm{E}-03 \quad 4.701 \mathrm{E}-03$

$\mathrm{Pb}-210+\mathrm{D} \quad 1.000 \mathrm{E}+00 \quad 1.860 \mathrm{E}-11 \quad 1.304 \mathrm{E}-10 \quad 3.121 \mathrm{E}-05 \quad 7.413 \mathrm{E}-05$

$\operatorname{LDSR}(j) \quad 2.131 \mathrm{E}-05 \quad 6.276 \mathrm{E}-05 \quad 3.293 \mathrm{E}-03 \quad 5.246 \mathrm{E}-03$ 
RESRAD, Version $6.5 \quad T^{13 / 2}$ Limit $=180$ days

Summary : C746U Trespasser Deterministic Run

File : $X: \backslash F I N A L$ V2 \DOE FWD RUNS \C746U T AL DOE FWD-FV2-70YR.RAD

Dose/Source Ratios Summed Over All Pathways

Parent and Progeny Principal Radionuclide Contributions Indicated

\begin{tabular}{|c|c|c|c|c|c|c|}
\hline $\begin{array}{l}\text { Parent } \\
\text { (i) }\end{array}$ & $\begin{array}{c}\text { Product } \\
(j)\end{array}$ & $\begin{array}{c}\text { Thread } \\
\text { Fraction }\end{array}$ & $\begin{array}{l}\mathrm{SR}(j, t) \text { At } \\
0.000 \mathrm{E}+00\end{array}$ & $\begin{array}{l}\text { Time in Ye } \\
1.000 \mathrm{E}+00\end{array}$ & $\begin{array}{l}\text { ears (mre } \\
5.000 \mathrm{E}+01\end{array}$ & $\begin{array}{l}\mathrm{em} / \mathrm{yr}) /(\mathrm{pC} \\
7.000 \mathrm{E}+01\end{array}$ \\
\hline$h-232$ & Th-232 & $1.000 \mathrm{E}+00$ & $2.040 \mathrm{E}-07$ & $2.078 \mathrm{E}-07$ & $3.613 \mathrm{E}-04$ & $5.145 \mathrm{E}-04$ \\
\hline Th-232 & $\mathrm{Ra}-228+\mathrm{D}$ & $1.000 \mathrm{E}+00$ & $2.643 \mathrm{E}-03$ & $7.575 \mathrm{E}-03$ & $6.750 \mathrm{E}-02$ & $7.900 \mathrm{E}-02$ \\
\hline Th-232 & Th $-228+D$ & $1.000 \mathrm{E}+00$ & $6.862 \mathrm{E}-04$ & $4.233 \mathrm{E}-03$ & $1.444 \mathrm{E}-01$ & $1.642 \mathrm{E}-01$ \\
\hline Th-232 & $\sum \operatorname{DSR}(j)$ & & $3.329 \mathrm{E}-03$ & $1.181 \mathrm{E}-02$ & $2.123 \mathrm{E}-01$ & $2.438 \mathrm{E}-01$ \\
\hline $\mathrm{J}-234$ & $\mathrm{U}-234$ & $1.000 \mathrm{E}+00$ & $1.753 \mathrm{E}-07$ & $1.784 \mathrm{E}-07$ & $7.589 \mathrm{E}-05$ & $1.080 \mathrm{E}-04$ \\
\hline $\mathrm{U}-234$ & Th-230 & $1.000 \mathrm{E}+00$ & $3.556 \mathrm{E}-12$ & $1.083 \mathrm{E}-11$ & $1.504 \mathrm{E}-07$ & $2.989 \mathrm{E}-07$ \\
\hline-234 & $\mathrm{Ra}-226+\mathrm{D}$ & $1.000 \mathrm{E}+00$ & $6.163 \mathrm{E}-11$ & $4.340 \mathrm{E}-10$ & $6.685 \mathrm{E}-07$ & $1.499 \mathrm{E}-06$ \\
\hline $\mathrm{U}-234$ & $\mathrm{~Pb}-210+\mathrm{D}$ & $1.000 \mathrm{E}+00$ & $4.195 \mathrm{E}-17$ & $6.314 \mathrm{E}-16$ & $5.291 \mathrm{E}-09$ & $1.815 \mathrm{E}-08$ \\
\hline $\mathrm{U}-234$ & $\sum \operatorname{DSR}(j)$ & & $1.754 \mathrm{E}-07$ & $1.789 \mathrm{E}-07$ & $7.671 \mathrm{E}-05$ & $1.098 \mathrm{E}-04$ \\
\hline$U-235+D$ & $\mathrm{U}-235+\mathrm{D}$ & $1.000 \mathrm{E}+00$ & $1.627 \mathrm{E}-03$ & $1.648 \mathrm{E}-03$ & $3.101 \mathrm{E}-03$ & $3.987 \mathrm{E}-03$ \\
\hline$U-235+D$ & $\mathrm{~Pa}-231$ & $1.000 \mathrm{E}+00$ & $7.092 \mathrm{E}-09$ & $2.148 \mathrm{E}-08$ & $2.386 \mathrm{E}-06$ & $4.423 \mathrm{E}-06$ \\
\hline$U-235+D$ & $A c-227+D$ & $1.000 \mathrm{E}+00$ & $8.148 \mathrm{E}-10$ & $5.702 \mathrm{E}-09$ & $7.572 \mathrm{E}-06$ & $1.589 \mathrm{E}-05$ \\
\hline$U-235+D$ & $\sum \operatorname{DSR}(j)$ & & $1.627 \mathrm{E}-03$ & $1.648 \mathrm{E}-03$ & $3.111 \mathrm{E}-03$ & $4.007 \mathrm{E}-03$ \\
\hline $\mathrm{U}-238$ & $\mathrm{U}-238$ & $5.400 \mathrm{E}-05$ & $1.359 \mathrm{E}-15$ & $1.421 \mathrm{E}-15$ & $3.757 \mathrm{E}-09$ & $5.348 \mathrm{E}-09$ \\
\hline$U-238+D$ & $\mathrm{U}-238+\mathrm{D}$ & $9.999 \mathrm{E}-01$ & $8.774 \mathrm{E}-04$ & $8.846 \mathrm{E}-04$ & $1.393 \mathrm{E}-03$ & $1.660 \mathrm{E}-03$ \\
\hline$U-238+D$ & $\mathrm{U}-234$ & $9.999 \mathrm{E}-01$ & $2.492 \mathrm{E}-13$ & $7.595 \mathrm{E}-13$ & $1.086 \mathrm{E}-08$ & $2.159 \mathrm{E}-08$ \\
\hline$U-238+D$ & Th-230 & $9.999 \mathrm{E}-01$ & 3. $365 \mathrm{E}-18$ & $2.390 \mathrm{E}-17$ & $1.077 \mathrm{E}-11$ & $2.987 \mathrm{E}-11$ \\
\hline $\mathrm{U}-238+\mathrm{D}$ & $\mathrm{Ra}-226+\mathrm{D}$ & $9.999 \mathrm{E}-01$ & $4.369 \mathrm{E}-17$ & $6.593 \mathrm{E}-16$ & $3.196 \mathrm{E}-11$ & $1.001 \mathrm{E}-10$ \\
\hline $\mathrm{U}-238+\mathrm{D}$ & $\mathrm{Pb}-210+\mathrm{D}$ & $9.999 \mathrm{E}-01$ & $2.382 \mathrm{E}-23$ & $7.420 \mathrm{E}-22$ & $2.026 \mathrm{E}-13$ & $9.906 \mathrm{E}-13$ \\
\hline$U-238+D$ & $\sum \operatorname{DSR}(j)$ & & $8.774 \mathrm{E}-04$ & $8.846 \mathrm{E}-04$ & $1.393 \mathrm{E}-03$ & $1.660 \mathrm{E}-03$ \\
\hline
\end{tabular}

The DSR includes contributions from associated (half-life $\leq 180$ days) daughters. 
RESRAD, Version $6.5 \quad \mathrm{~T}^{1 / 2}$ Limit $=180$ days

Summary : C746U Trespasser Deterministic Run

File : $X: \backslash F I N A L$ V2 \DOE FWD RUNS \C746U T AL DOE FWD-FV2-70YR. RAD

Single Radionuclide Soil Guidelines $G(i, t)$ in $\mathrm{pCi} / \mathrm{g}$

Basic Radiation Dose Limit $=1.000 \mathrm{E}+02 \mathrm{mrem} / \mathrm{yr}$

Nuclide

\begin{tabular}{cccccc} 
(i) & $\mathrm{t}=$ & $0.000 \mathrm{E}+00$ & $1.000 \mathrm{E}+00$ & $5.000 \mathrm{E}+01$ & $7.000 \mathrm{E}+01$ \\
\cline { 1 - 1 } $\mathrm{Am}-241$ & & $6.861 \mathrm{E}+07$ & $6.676 \mathrm{E}+07$ & $3.390 \mathrm{E}+05$ & $2.448 \mathrm{E}+05$ \\
$\mathrm{Cs}-137$ & & $4.856 \mathrm{E}+03$ & $4.927 \mathrm{E}+03$ & $1.012 \mathrm{E}+04$ & $1.358 \mathrm{E}+04$ \\
$\mathrm{~Np}-237$ & & $2.896 \mathrm{E}+04$ & $2.866 \mathrm{E}+04$ & $1.644 \mathrm{E}+04$ & $1.320 \mathrm{E}+04$ \\
$\mathrm{Pu}-238$ & & $3.787 \mathrm{E}+09$ & $3.750 \mathrm{E}+09$ & $4.133 \mathrm{E}+05$ & $3.400 \mathrm{E}+05$ \\
$\mathrm{Pu}-239$ & & $1.587 \mathrm{E}+08$ & $1.568 \mathrm{E}+08$ & $2.548 \mathrm{E}+05$ & $1.792 \mathrm{E}+05$ \\
$\mathrm{Pu}-240$ & & $3.896 \mathrm{E}+09$ & $3.828 \mathrm{E}+09$ & $2.565 \mathrm{E}+05$ & $1.806 \mathrm{E}+05$ \\
$\mathrm{TC}-99$ & & $2.461 \mathrm{E}+09$ & $2.440 \mathrm{E}+09$ & $1.570 \mathrm{E}+08$ & $1.358 \mathrm{E}+08$ \\
$\mathrm{Th}-228$ & & $1.125 \mathrm{E}+03$ & $1.606 \mathrm{E}+03$ & $6.065 \mathrm{E}+10$ & $7.505 \mathrm{E}+13$ \\
$\mathrm{Th}-230$ & & $4.692 \mathrm{E}+06$ & $1.593 \mathrm{E}+06$ & $3.037 \mathrm{E}+04$ & $1.906 \mathrm{E}+04$ \\
$\mathrm{Th}-232$ & & $3.004 \mathrm{E}+04$ & $8.469 \mathrm{E}+03$ & $4.711 \mathrm{E}+02$ & $4.102 \mathrm{E}+02$ \\
$\mathrm{U}-234$ & $5.702 \mathrm{E}+08$ & $5.590 \mathrm{E}+08$ & $1.304 \mathrm{E}+06$ & $9.106 \mathrm{E}+05$ \\
$\mathrm{U}-235$ & $6.145 \mathrm{E}+04$ & $6.069 \mathrm{E}+04$ & $3.214 \mathrm{E}+04$ & $2.495 \mathrm{E}+04$ \\
$\mathrm{U}-238$ & $1.140 \mathrm{E}+05$ & $1.131 \mathrm{E}+05$ & $7.179 \mathrm{E}+04$ & $6.024 \mathrm{E}+04$ \\
\hline \hline
\end{tabular}

Summed Dose/Source Ratios DSR(i,t) in (mrem/yr)/(pCi/g) and Single Radionuclide Soil Guidelines $\mathrm{G}(i, t)$ in $\mathrm{pCi} / \mathrm{g}$ at $\operatorname{tmin}=$ time of minimum single radionuclide soil guideline and at $\operatorname{tmax}=$ time of maximum total dose $=7.000 \mathrm{E}+01$ years

\begin{tabular}{|c|c|c|c|c|c|c|}
\hline $\begin{array}{l}\text { uclide } \\
\text { (i) }\end{array}$ & $\begin{array}{c}\text { Initial } \\
(\mathrm{pCi} / \mathrm{g})\end{array}$ & $\begin{array}{c}\text { tmin } \\
\text { (years) }\end{array}$ & $\operatorname{DSR}(i, \operatorname{tmin})$ & $\begin{array}{c}\mathrm{G}(i, \mathrm{tmin}) \\
(\mathrm{pCi} / \mathrm{g})\end{array}$ & $\operatorname{DSR}(i, \operatorname{tmax})$ & $\begin{array}{c}G(i, t \max ) \\
(\mathrm{pCi} / \mathrm{g})\end{array}$ \\
\hline-241 & $7.000 \mathrm{E}+01$ & $7.000 \mathrm{E}+01$ & $4.085 \mathrm{E}-04$ & $2.448 E+05$ & $4.085 \mathrm{E}-04$ & $2.448 E+05$ \\
\hline-137 & $3.800 \mathrm{E}+01$ & $0.000 \mathrm{E}+00$ & $2.060 \mathrm{E}-02$ & $4.856 \mathrm{E}+03$ & $7.362 \mathrm{E}-03$ & $1.358 \mathrm{E}+04$ \\
\hline-237 & $1.100 \mathrm{E}+01$ & $7.000 \mathrm{E}+01$ & $7.575 \mathrm{E}-03$ & $1.320 E+04$ & $7.575 \mathrm{E}-03$ & $1.320 \mathrm{E}+04$ \\
\hline-238 & $7.800 \mathrm{E}+01$ & $7.000 \mathrm{E}+01$ & $2.941 \mathrm{E}-04$ & $3.400 \mathrm{E}+05$ & $2.941 \mathrm{E}-04$ & $3.400 \mathrm{E}+05$ \\
\hline-239 & $7.200 \mathrm{E}+01$ & $7.000 \mathrm{E}+01$ & $5.581 \mathrm{E}-04$ & $1.792 \mathrm{E}+05$ & $5.581 \mathrm{E}-04$ & $1.792 \mathrm{E}+05$ \\
\hline-240 & $7.200 \mathrm{E}+01$ & $7.000 \mathrm{E}+01$ & $5.538 \mathrm{E}-04$ & $1.806 \mathrm{E}+05$ & $5.538 \mathrm{E}-04$ & $1.806 \mathrm{E}+05$ \\
\hline-99 & $1.040 \mathrm{E}+02$ & $7.000 \mathrm{E}+01$ & $7.364 \mathrm{E}-07$ & $1.358 \mathrm{E}+08$ & $7.364 \mathrm{E}-07$ & $1.358 \mathrm{E}+08$ \\
\hline$h-228$ & $8.000 \mathrm{E}+00$ & $0.000 \mathrm{E}+00$ & $8.889 \mathrm{E}-02$ & $1.125 \mathrm{E}+03$ & $1.333 \mathrm{E}-12$ & $7.505 \mathrm{E}+13$ \\
\hline$h-230$ & $2.000 \mathrm{E}+02$ & $7.000 \mathrm{E}+01$ & $5.246 \mathrm{E}-03$ & $1.906 \mathrm{E}+04$ & $5.246 \mathrm{E}-03$ & $1.906 \mathrm{E}+04$ \\
\hline$h-232$ & $8.000 \mathrm{E}+00$ & $7.000 \mathrm{E}+01$ & $2.438 \mathrm{E}-01$ & $4.102 E+02$ & $2.438 \mathrm{E}-01$ & $4.102 \mathrm{E}+02$ \\
\hline 34 & $3.200 \mathrm{E}+02$ & $7.000 \mathrm{E}+01$ & $1.098 \mathrm{E}-04$ & $9.106 \mathrm{E}+05$ & $1.098 \mathrm{E}-04$ & $9.106 \mathrm{E}+05$ \\
\hline 35 & $1.300 \mathrm{E}+01$ & $7.000 \mathrm{E}+01$ & $4.007 \mathrm{E}-03$ & $2.495 E+04$ & $4.007 \mathrm{E}-03$ & $2.495 \mathrm{E}+04$ \\
\hline 38 & $3.200 \mathrm{E}+02$ & $7.000 \mathrm{E}+01$ & $1.660 \mathrm{E}-03$ & $6.024 \mathrm{E}+04$ & $1.660 \mathrm{E}-03$ & $6.024 \mathrm{E}+04$ \\
\hline
\end{tabular}


RESRAD, Version $6.5 \quad T^{1 / 2}$ Limit $=180$ days

Summary : C746U Trespasser Deterministic Run

File : $\mathrm{X}: \backslash F I N A L$ V2 $\backslash$ DOE FWD RUNS \C746U T AL DOE FWD-FV2-70YR.RAD

Individual Nuclide Dose Summed Over All Pathways

Parent Nuclide and Branch Fraction Indicated

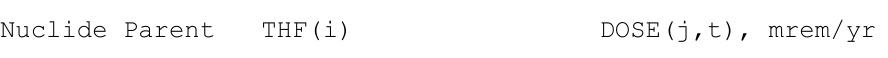


RESRAD, Version $6.5 \quad \mathrm{~T}^{1 / 2}$ Limit $=180$ days

Summary : C746U Trespasser Deterministic Run

File : $\mathrm{X}: \backslash F I N A L$ V2 $\backslash$ DOE FWD RUNS $\backslash C 746 \mathrm{U} T$ AL DOE FWD-FV2-70YR. RAD

Individual Nuclide Dose Summed Over All Pathways

Parent Nuclide and Branch Fraction Indicated

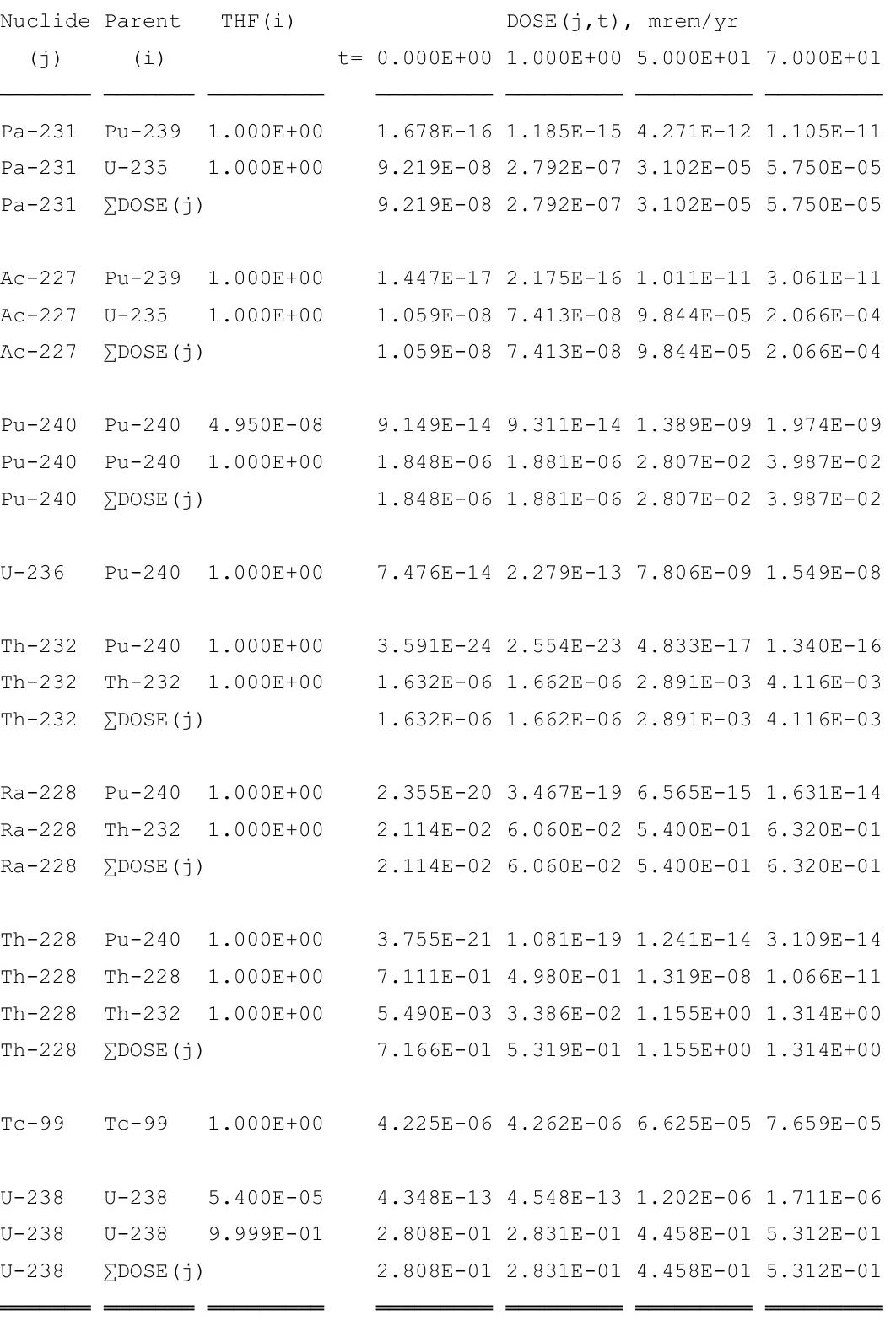

THF(i) is the thread fraction of the parent nuclide. 
RESRAD, Version $6.5 \quad T^{1 / 2}$ Limit $=180$ days

Summary : C746U Trespasser Deterministic Run

File : $\mathrm{X}: \backslash F I N A L$ V2 $\backslash$ DOE FWD RUNS \C746U T AL DOE FWD-FV2-70YR.RAD

Individual Nuclide Soil Concentration

Parent Nuclide and Branch Fraction Indicated

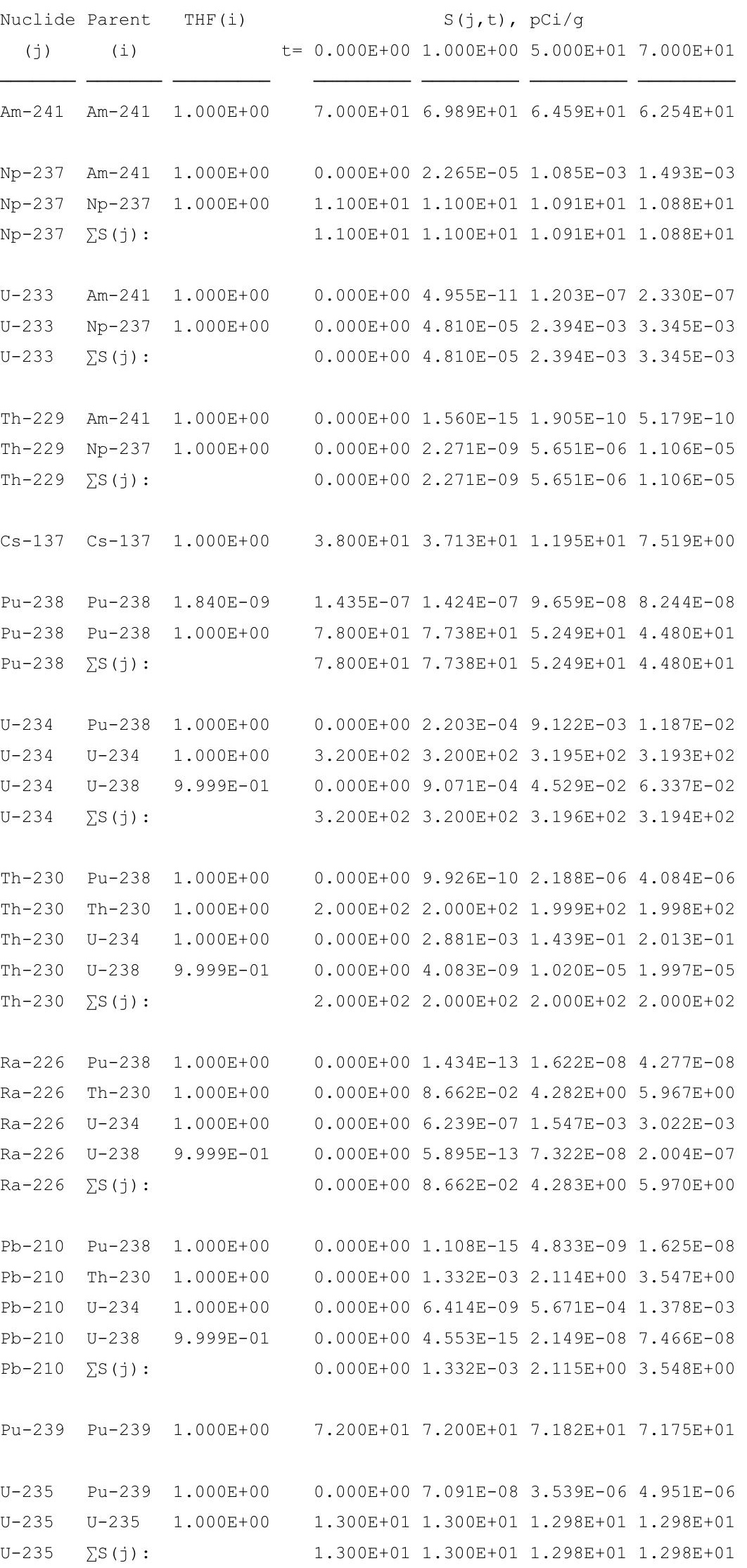


RESRAD, Version $6.5 \quad \mathrm{~T}^{1 / 2}$ Limit $=180$ days

Summary : C746U Trespasser Deterministic Run

File : $\mathrm{X}: \backslash F I N A L$ V2 $\backslash$ DOE FWD RUNS $\backslash C 746 \mathrm{U}$ T AL DOE FWD-FV2-70YR. RAD

Individual Nuclide Soil Concentration

Parent Nuclide and Branch Fraction Indicated

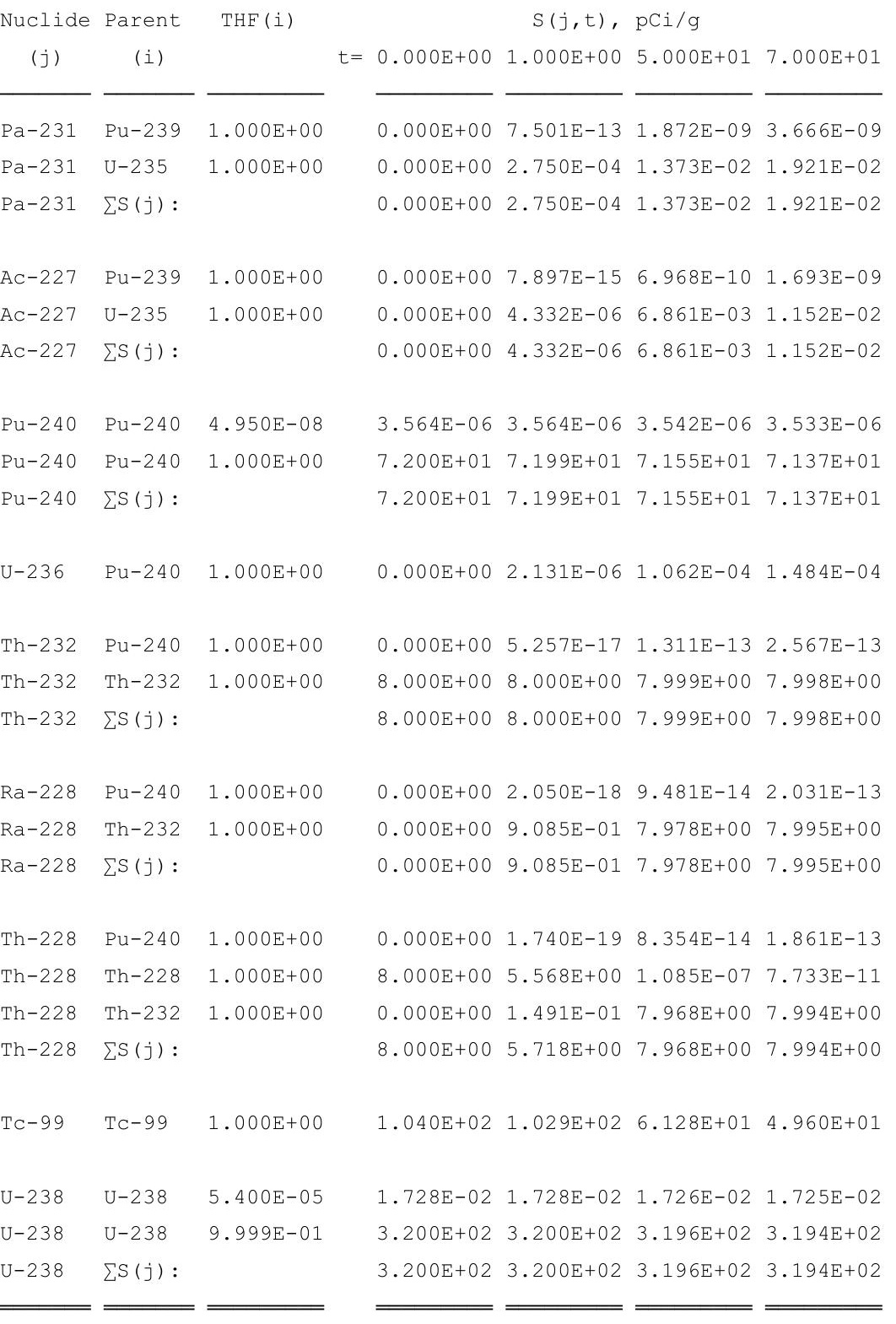

THF(i) is the thread fraction of the parent nuclide.

RESCALC.EXE execution time $=4.80$ seconds 


\section{Resident Farmer (onsite)}

\section{Summary Report \\ (Deterministic Analysis Report)}

First Peak Dose Assessment

Time Horizon: 1,050 yr 
THIS PAGE INTENTIONALLY LEFT BLANK 


\section{RESRAD, Version $6.5 \quad \mathrm{~T}^{1 / 2}$ Limit $=180$ days}

Summary : C746U Resident Farmer Deterministic Run

File : $\mathrm{X}: \backslash F I N A L$ V2 $\backslash$ DOE FWD RUNS $\backslash C 746 U$ RF DOE SG FWD-FV2-1050YR.RAD

Table of Contents

Part I: Mixture Sums and Single Radionuclide Guidelines

Dose Conversion Factor (and Related) Parameter Summary ... 2

Site-Specific Parameter Summary $\ldots \ldots \ldots \ldots \ldots \ldots \ldots \ldots \ldots$

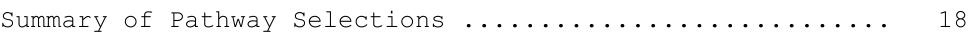

Contaminated Zone and Total Dose Summary ............. 19

Total Dose Components

Time $=0.000 \mathrm{E}+00 \ldots \ldots \ldots \ldots \ldots \ldots \ldots \ldots \ldots \ldots \ldots \ldots \ldots \ldots \ldots \ldots \ldots \ldots$

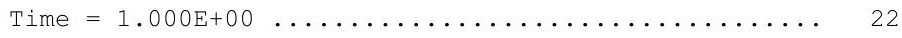

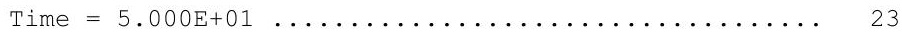

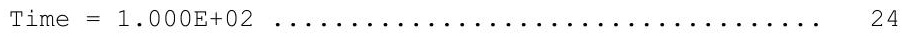

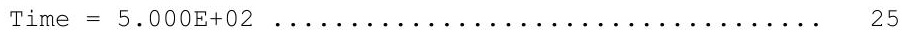

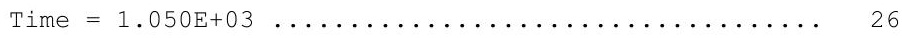

Dose/Source Ratios Summed Over All Pathways .......... 27

Single Radionuclide Soil Guidelines ............... 29

Dose Per Nuclide Summed Over All Pathways ............ 30

Soil Concentration Per Nuclide ................ 32 
RESRAD, Version $6.5 \quad \mathrm{~T}^{1 / 2}$ Limit $=180$ days

Summary : C746U Resident Farmer Deterministic Run

File : X: $\backslash$ FINAL V2 $\backslash$ DOE FWD RUNS $\backslash C 746 U$ RF DOE SG FWD-FV2-1050YR.RAD

Dose Conversion Factor (and Related) Parameter Summary

Dose Library: ICRP 60 \& ICRP 72 (Adult)

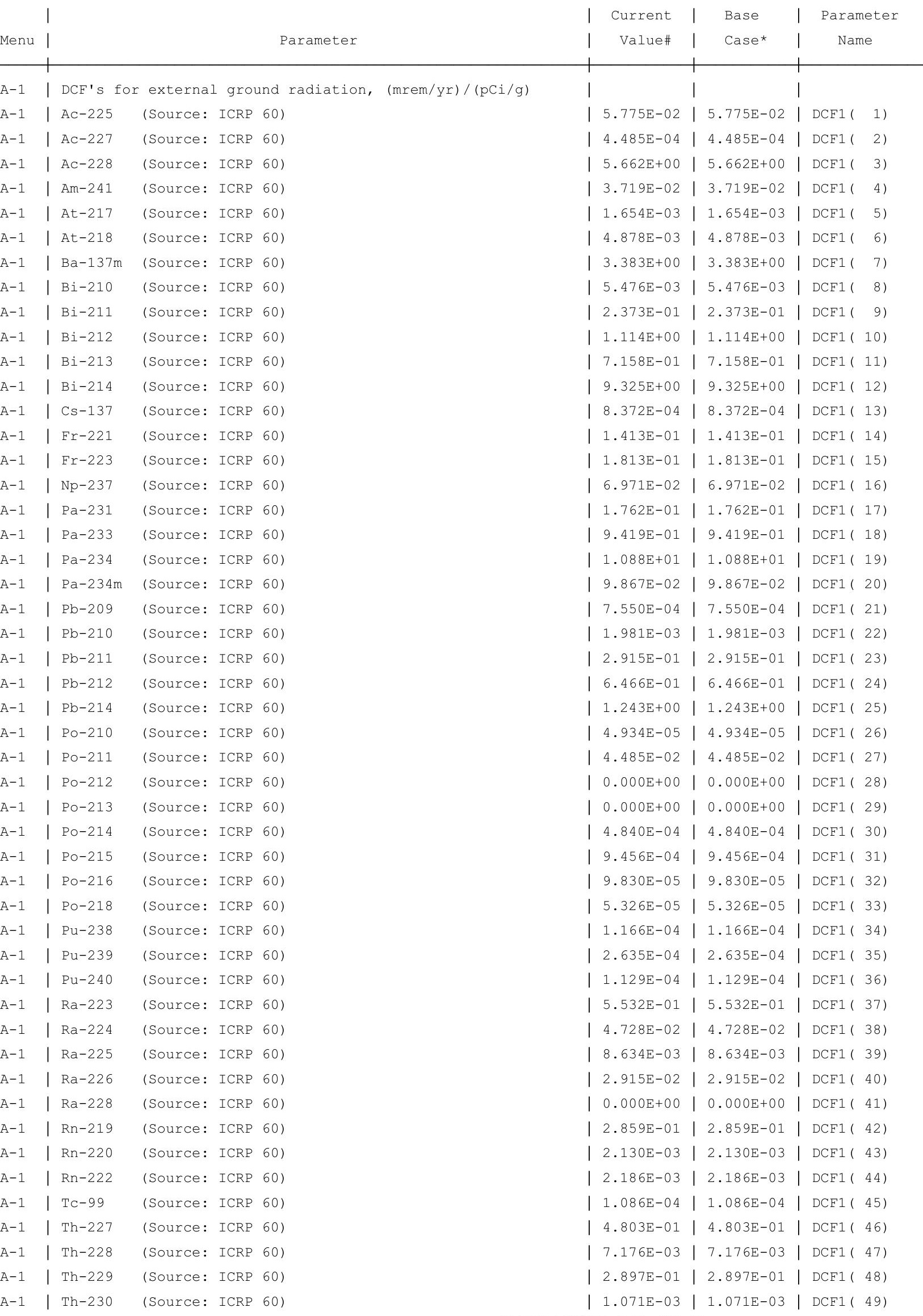


RESRAD, Version $6.5 \quad \mathrm{~T}^{1 / 2}$ Limit $=180$ days

07/15/2011 13:56 Page

Summary : C746U Resident Farmer Deterministic Run

File : X: $\backslash$ FINAL V2 \DOE FWD RUNS \C746U RF DOE SG FWD-FV2-1050YR. RAD

Dose Conversion Factor (and Related) Parameter Summary (continued)

Dose Library: ICRP 60 \& ICRP 72 (Adult)

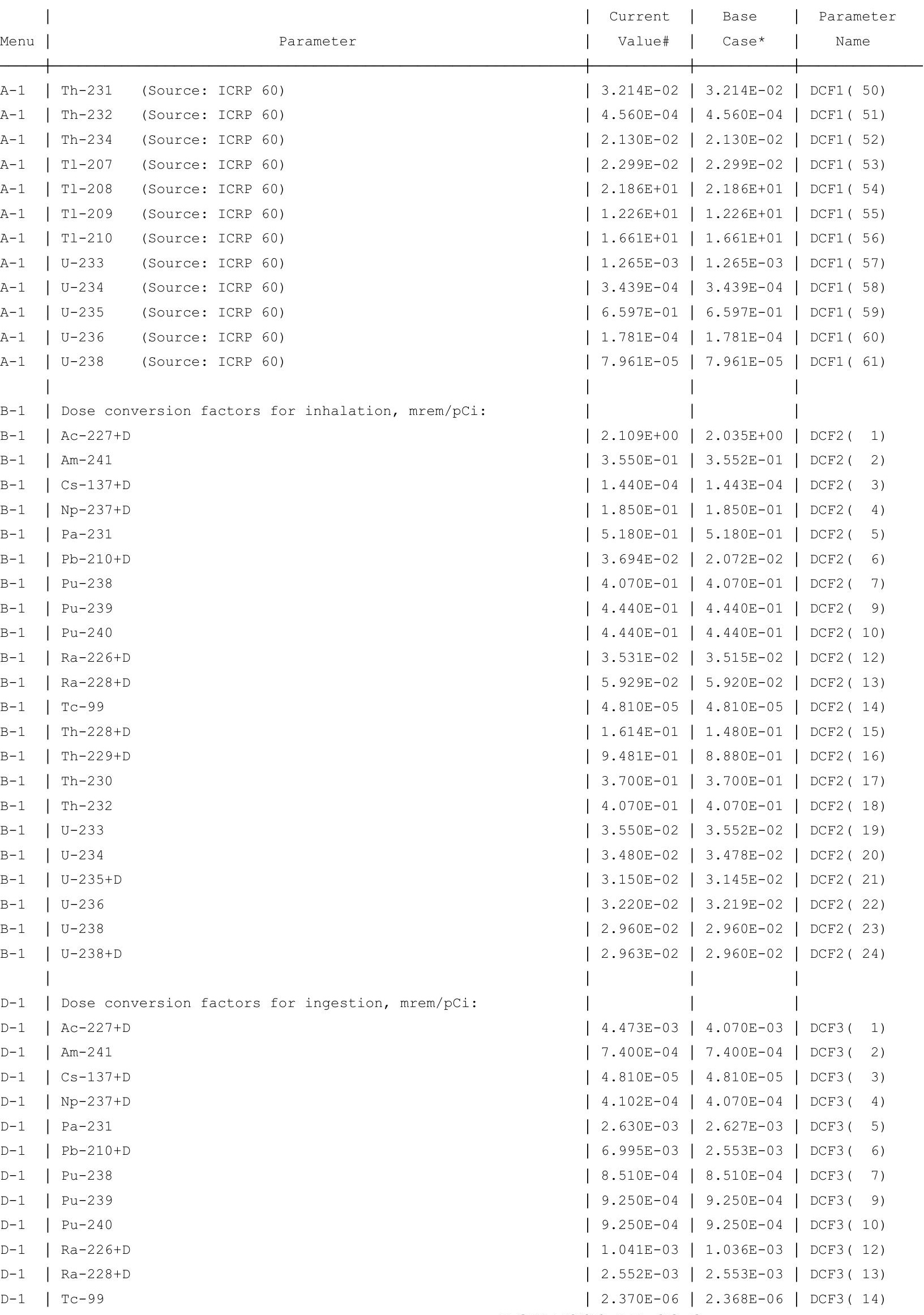


RESRAD, Version $6.5 \quad \mathrm{~T}^{1 / 2}$ Limit $=180$ days

ummary : C746U Resident Farmer Deterministic Run

File : $\mathrm{X}: \backslash F I N A L$ V2 $\backslash$ DOE FWD RUNS \C746U RF DOE SG FWD-FV2-1050YR.RAD

Dose Conversion Factor (and Related) Parameter Summary (continued)

Dose Library: ICRP 60 \& ICRP 72 (Adult)

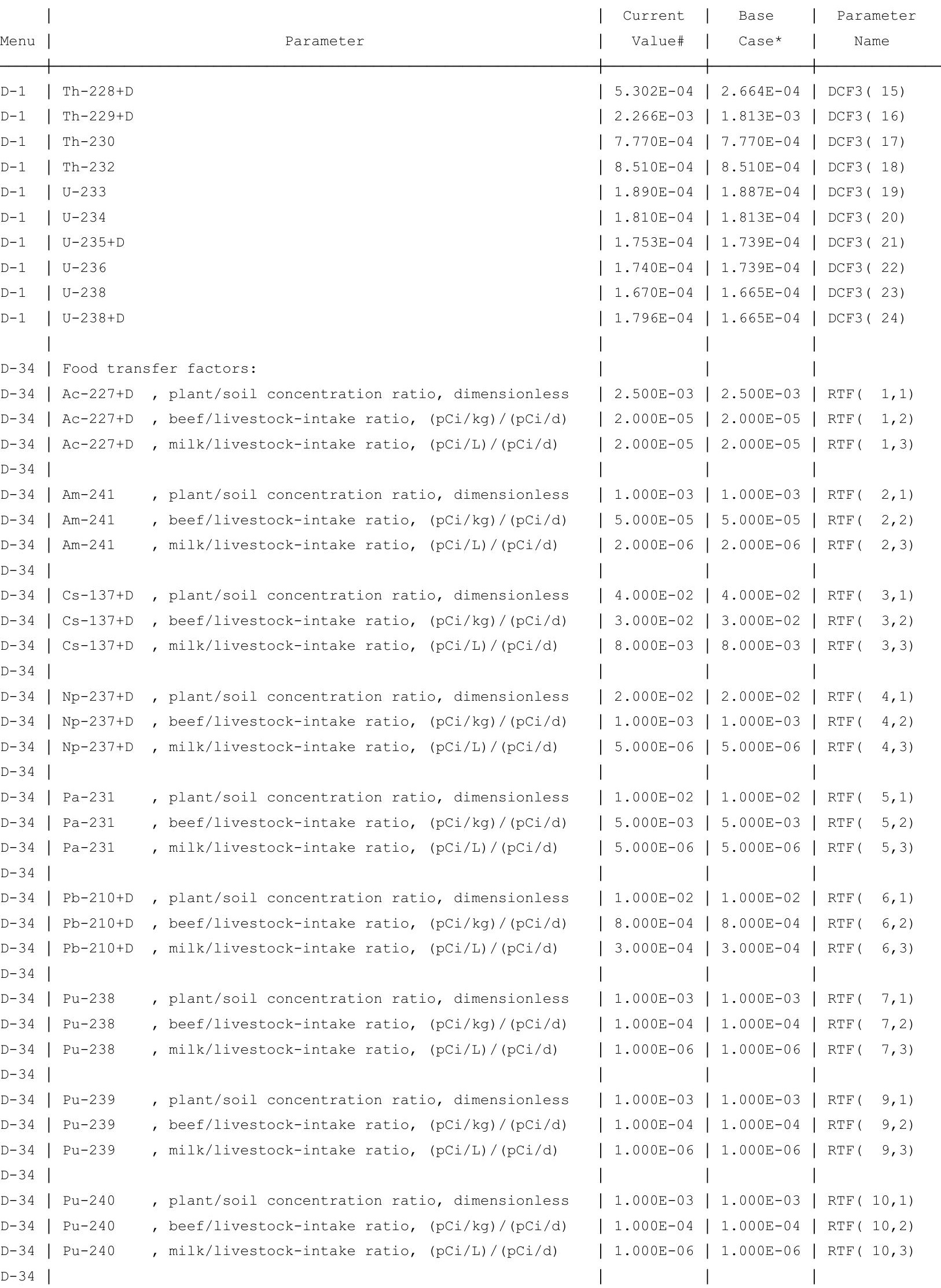


RESRAD, Version $6.5 \quad \mathrm{~T}^{\mathbb{1} 1 / 2}$ Limit $=180$ days

Summary : C746U Resident Farmer Deterministic Run

File : X: $\backslash$ FINAL V2 \DOE FWD RUNS \C746U RF DOE SG FWD-FV2-1050YR. RAD

Dose Conversion Factor (and Related) Parameter Summary (continued)

Dose Library: ICRP 60 \& ICRP 72 (Adult)

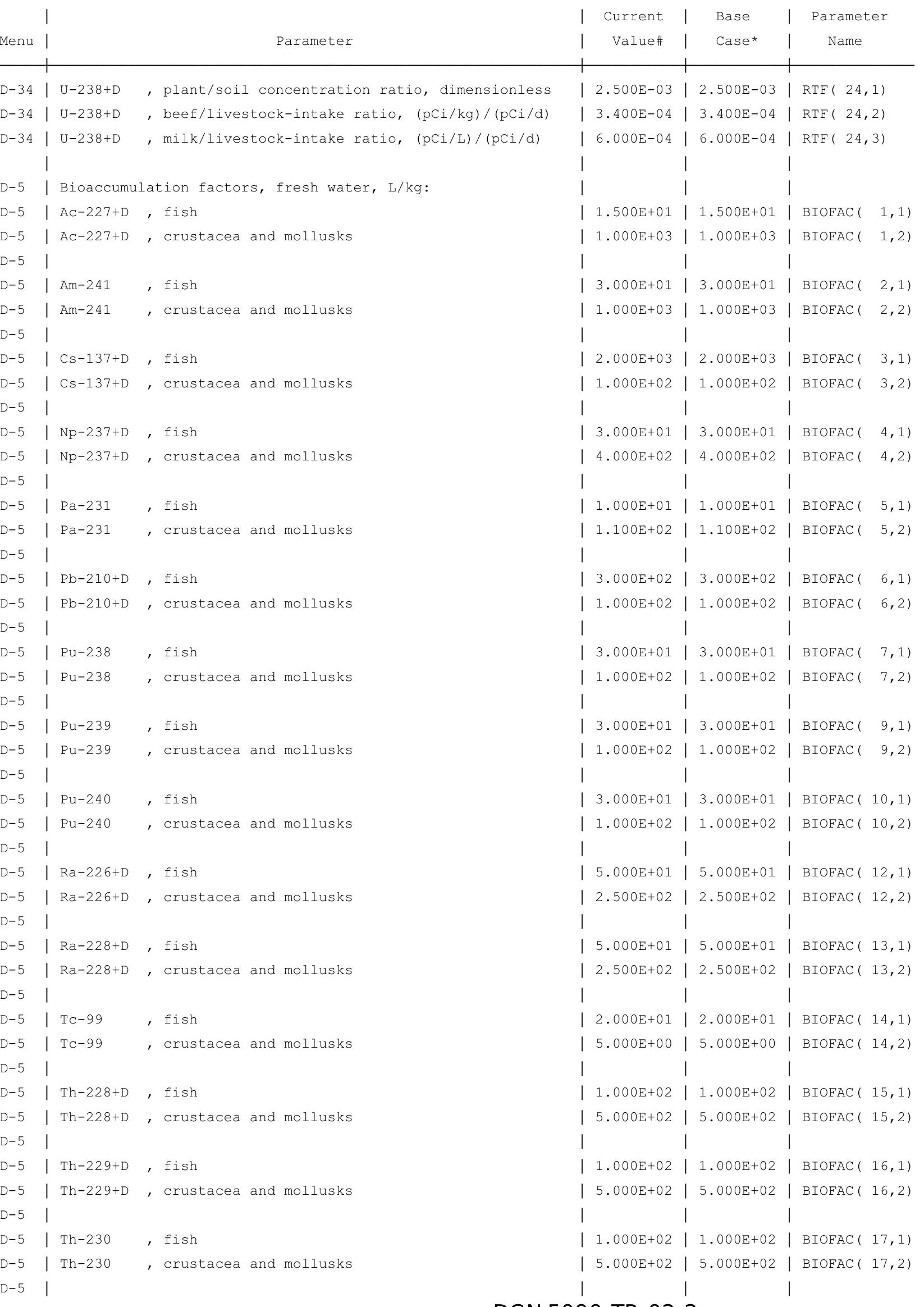


RESRAD, Version $6.5 \quad \mathrm{~T}^{1} \frac{1}{2}$ Limit $=180$ days

07/15/2011 13:56 Page

ummary : C746U Resident Farmer Deterministic Run

File : $\mathrm{X}: \backslash F I N A L$ V2\DOE FWD RUNS \C746U RF DOE SG FWD-FV2-1050YR.RAD

Dose Conversion Factor (and Related) Parameter Summary (continued)

Dose Library: ICRP 60 \& ICRP 72 (Adult)

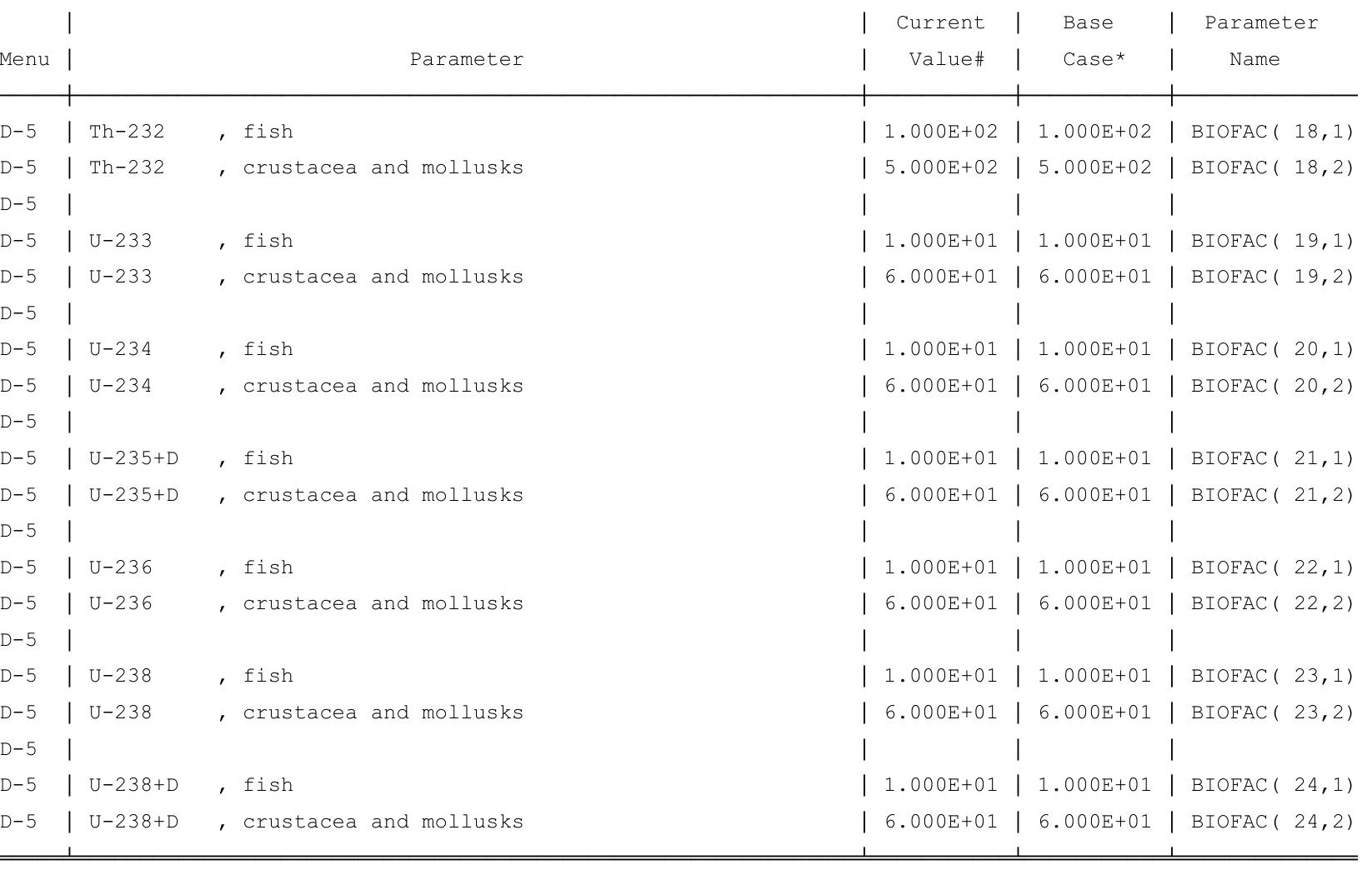

\#For DCFl(xxx) only, factors are for infinite depth \& area. See ETFG table in Ground Pathway of Detailed Report. *Base Case means Default.Lib w/o Associate Nuclide contributions. 
RESRAD, Version $6.5 \quad \mathrm{~T}^{1 / 2}$ Limit $=180$ days

Summary : C746U Resident Farmer Deterministic Run

File : $\mathrm{X}: \backslash F I N A L$ V2 $\backslash$ DOE FWD RUNS \C746U RF DOE SG FWD-FV2-1050YR.RAD

Site-Specific Parameter Summary (continued)

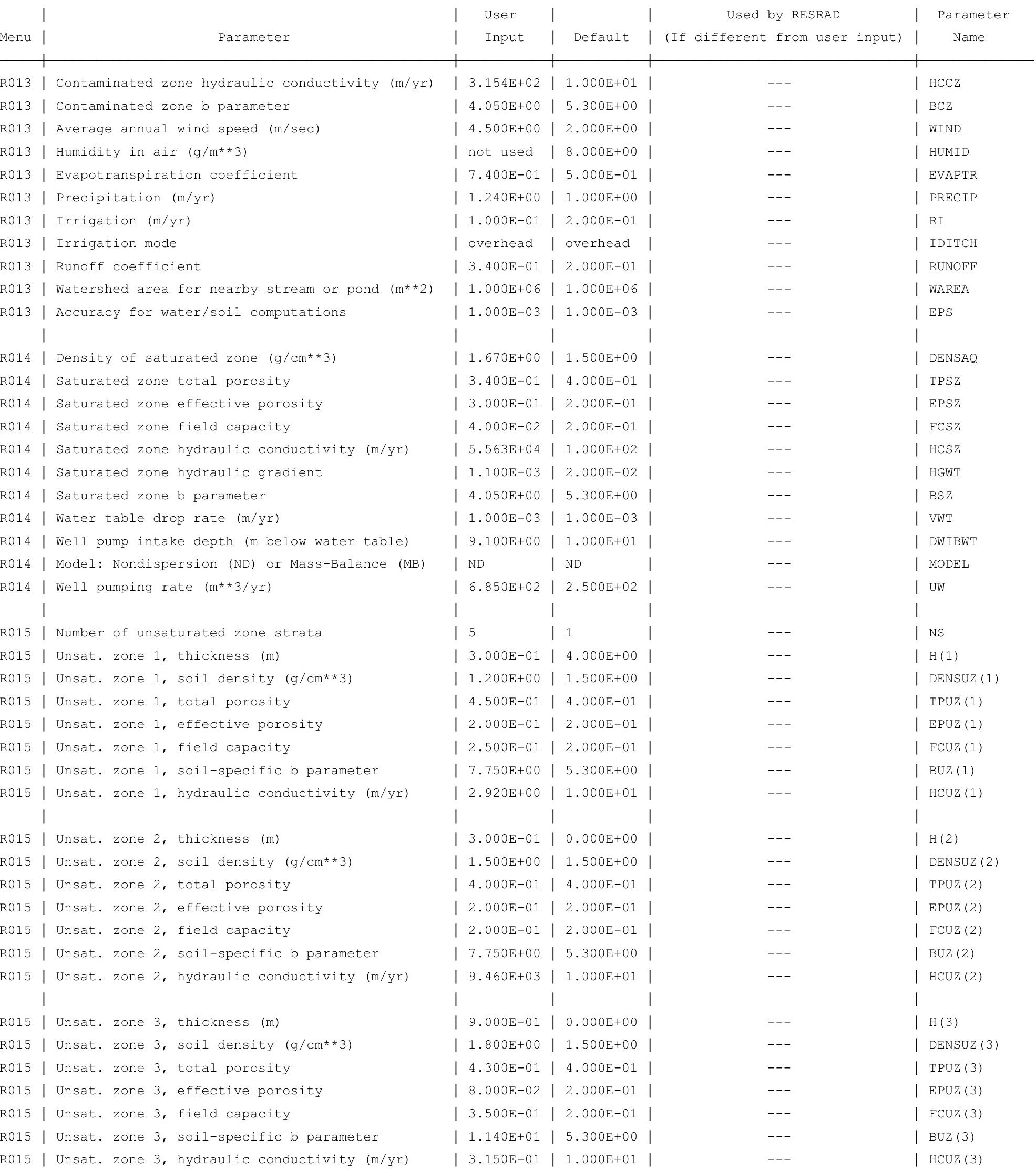


RESRAD, Version $6.5 \quad \mathrm{~T}^{1 / 2}$ Limit $=180$ days

Summary : C746U Resident Farmer Deterministic Run

File : $\mathrm{X}: \backslash F I N A L$ V2 $\backslash$ DOE FWD RUNS \C746U RF DOE SG FWD-FV2-1050YR.RAD

Site-Specific Parameter Summary (continued)

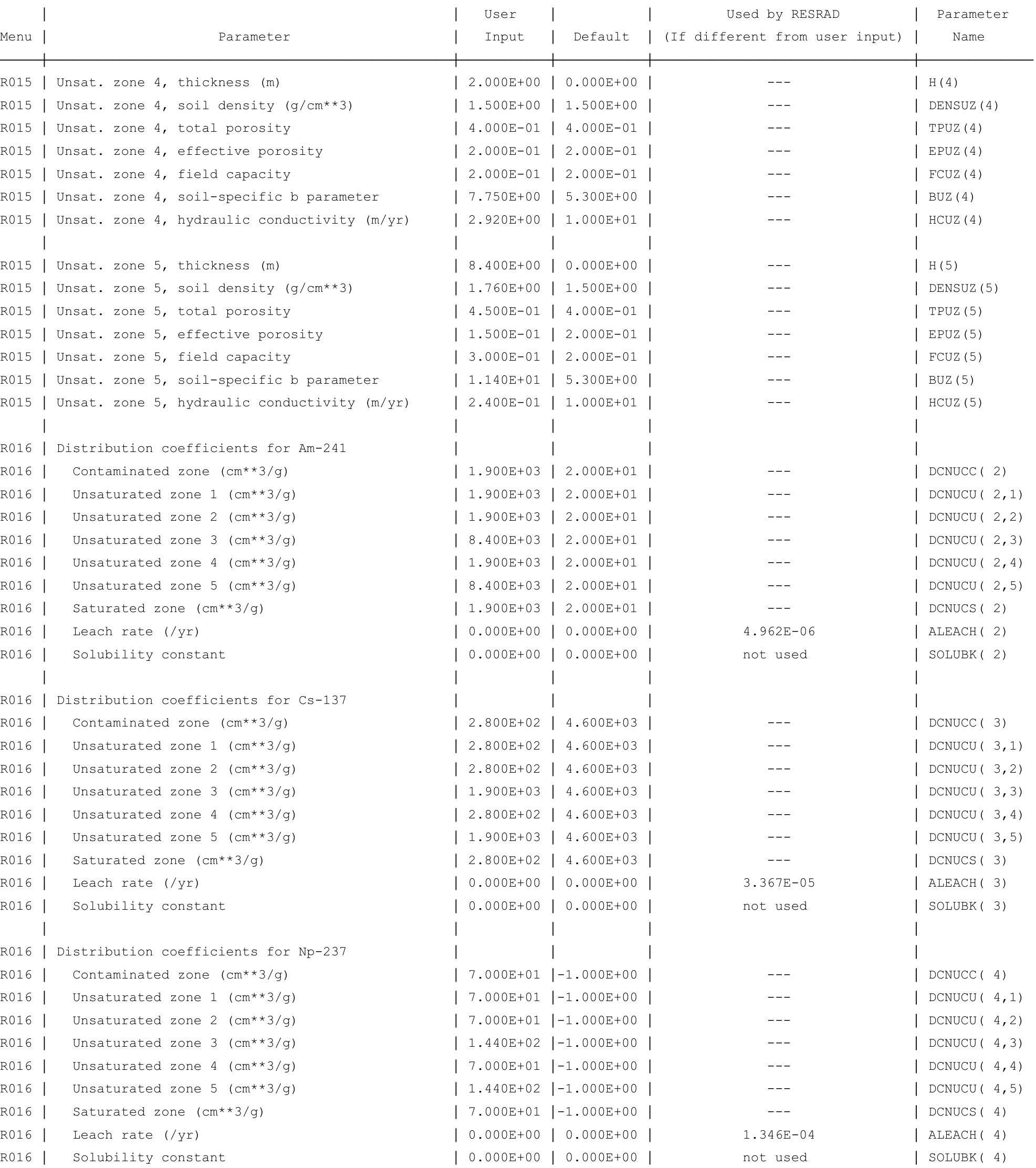


RESRAD, Version $6.5 \quad \mathrm{~T}^{1 / 2}$ Limit $=180$ days

07/15/2011 13:56 Page

Summary : C746U Resident Farmer Deterministic Run

File : $\mathrm{X}: \backslash F I N A L$ V2 $\backslash$ DOE FWD RUNS \C746U RF DOE SG FWD-FV2-1050YR.RAD

Site-Specific Parameter Summary (continued)

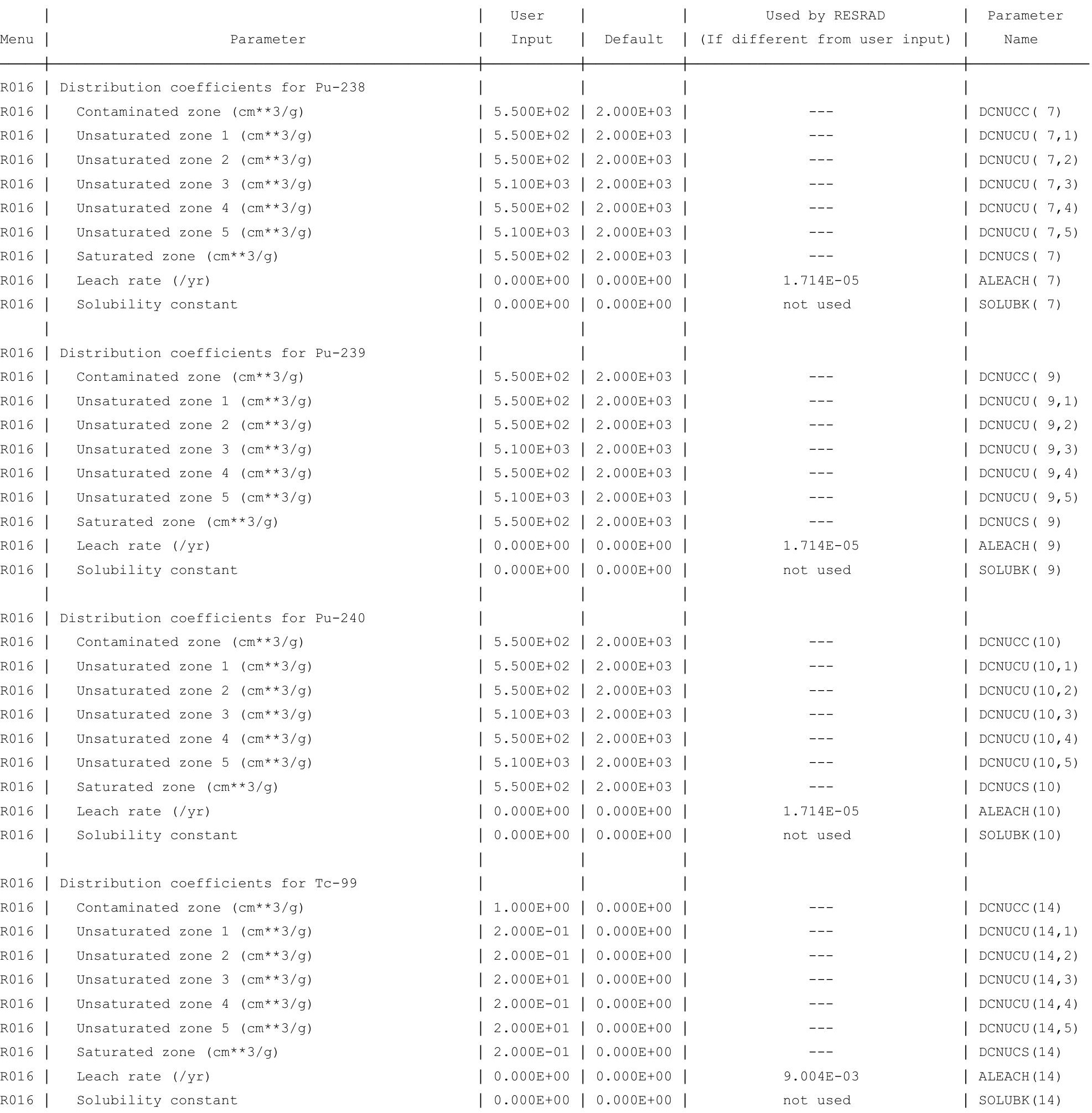


RESRAD, Version $6.5 \quad \mathrm{~T}^{1 / 2}$ Limit $=180$ days

Summary : C746U Resident Farmer Deterministic Run

File : $\mathrm{X}: \backslash F I N A L$ V2 $\backslash$ DOE FWD RUNS \C746U RF DOE SG FWD-FV2-1050YR.RAD

Site-Specific Parameter Summary (continued)

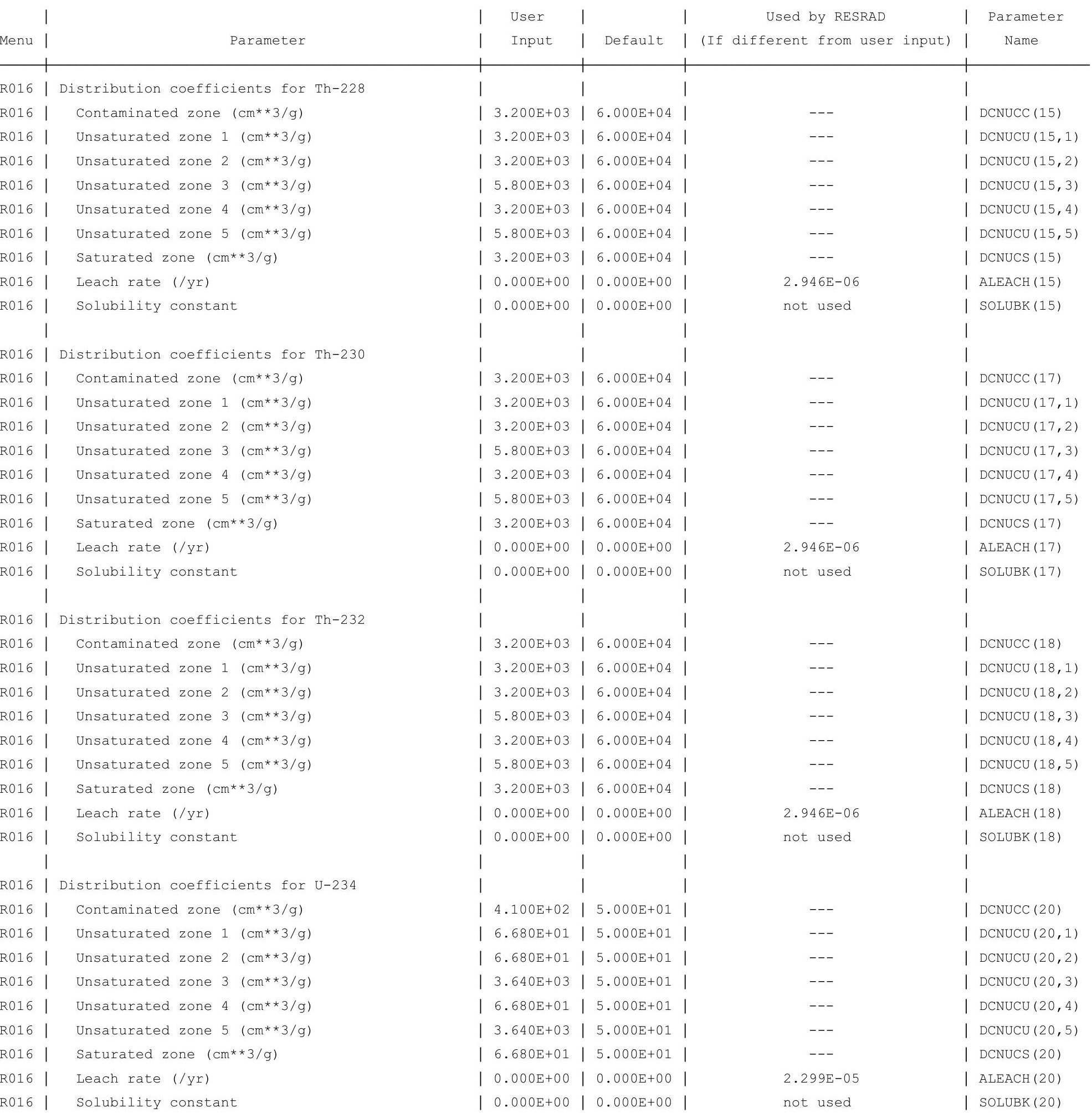


RESRAD, Version $6.5 \quad \mathrm{~T}^{1 / 2}$ Limit $=180$ days

Summary : C746U Resident Farmer Deterministic Run

File : $\mathrm{X}: \backslash F I N A L$ V2 $\backslash$ DOE FWD RUNS $\backslash C 746 \mathrm{U}$ RF DOE SG FWD-FV2-1050YR.RAD

Site-Specific Parameter Summary (continued)

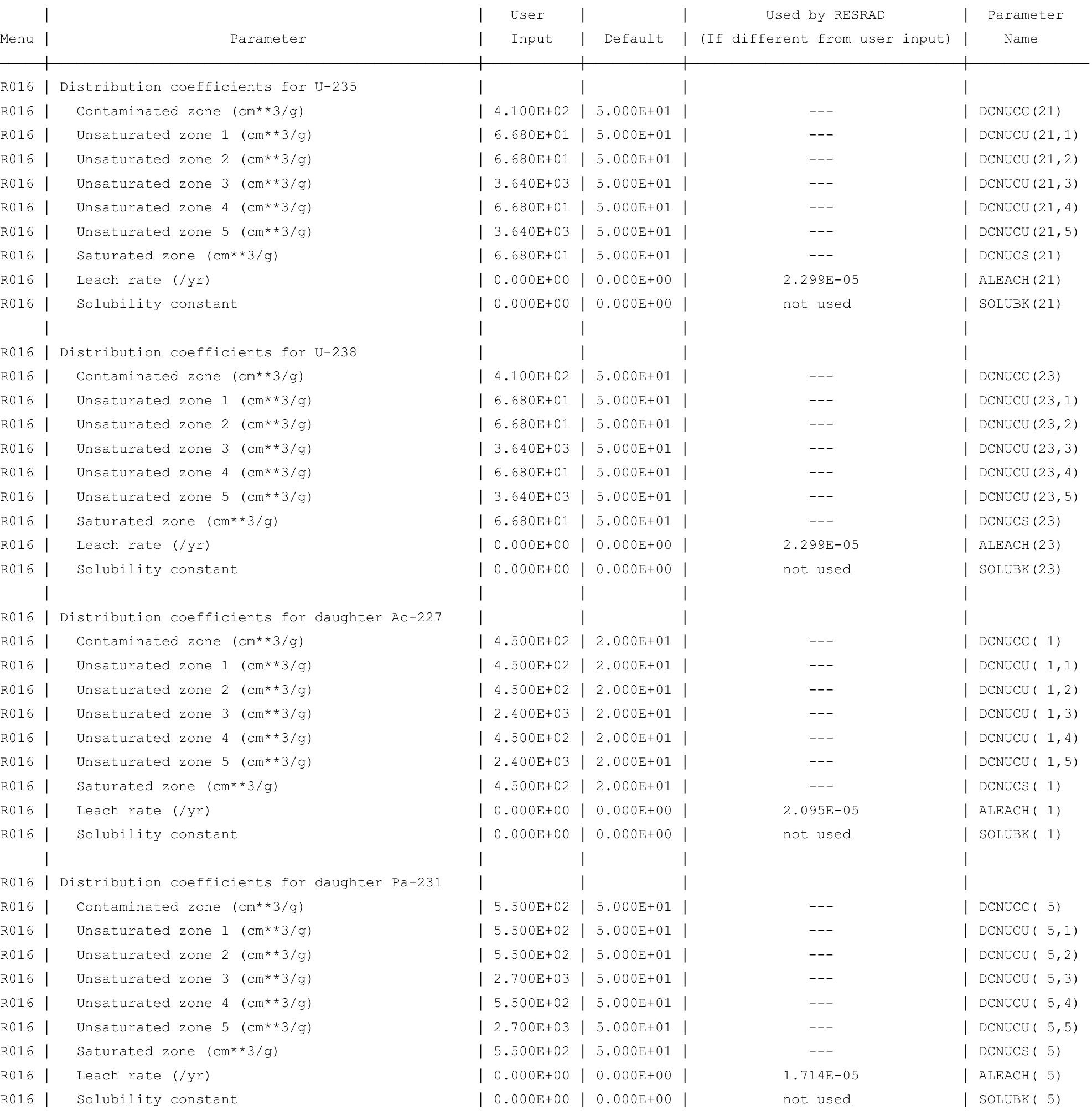


RESRAD, Version $6.5 \quad \mathrm{~T}^{1 / 2}$ Limit $=180$ days

Summary : C746U Resident Farmer Deterministic Run

File : $\mathrm{X}: \backslash F I N A L$ V2 $\backslash$ DOE FWD RUNS $\backslash C 746 U$ RF DOE SG FWD-FV2-1050YR.RAD

Site-Specific Parameter Summary (continued)

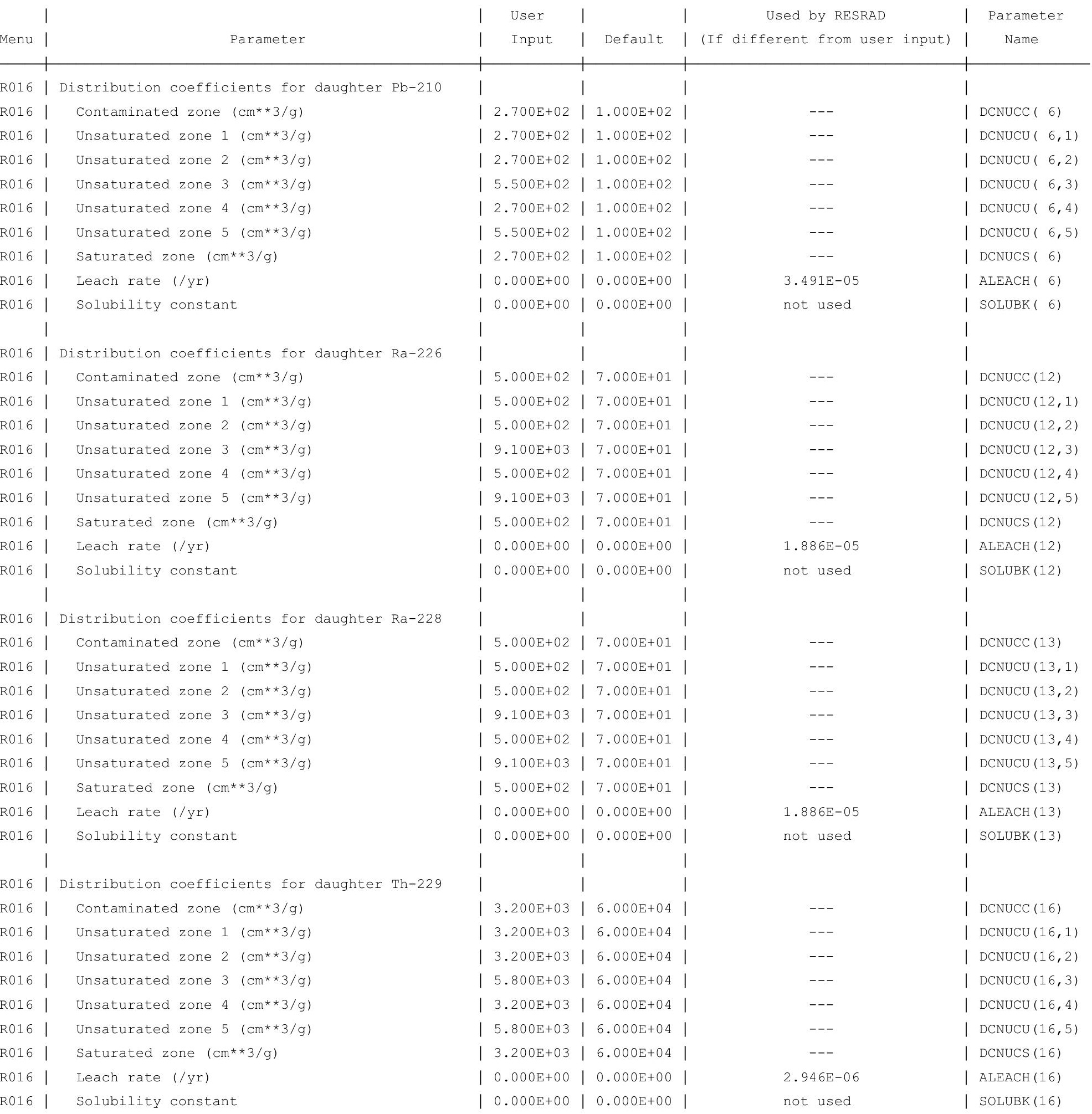


RESRAD, Version $6.5 \quad T^{1 / 2}$ Limit $=180$ days

Summary : C746U Resident Farmer Deterministic Run

File : $\mathrm{X}: \backslash F I N A L$ V2 $\backslash$ DOE FWD RUNS \C746U RF DOE SG FWD-FV2-1050YR.RAD

Site-Specific Parameter Summary (continued)

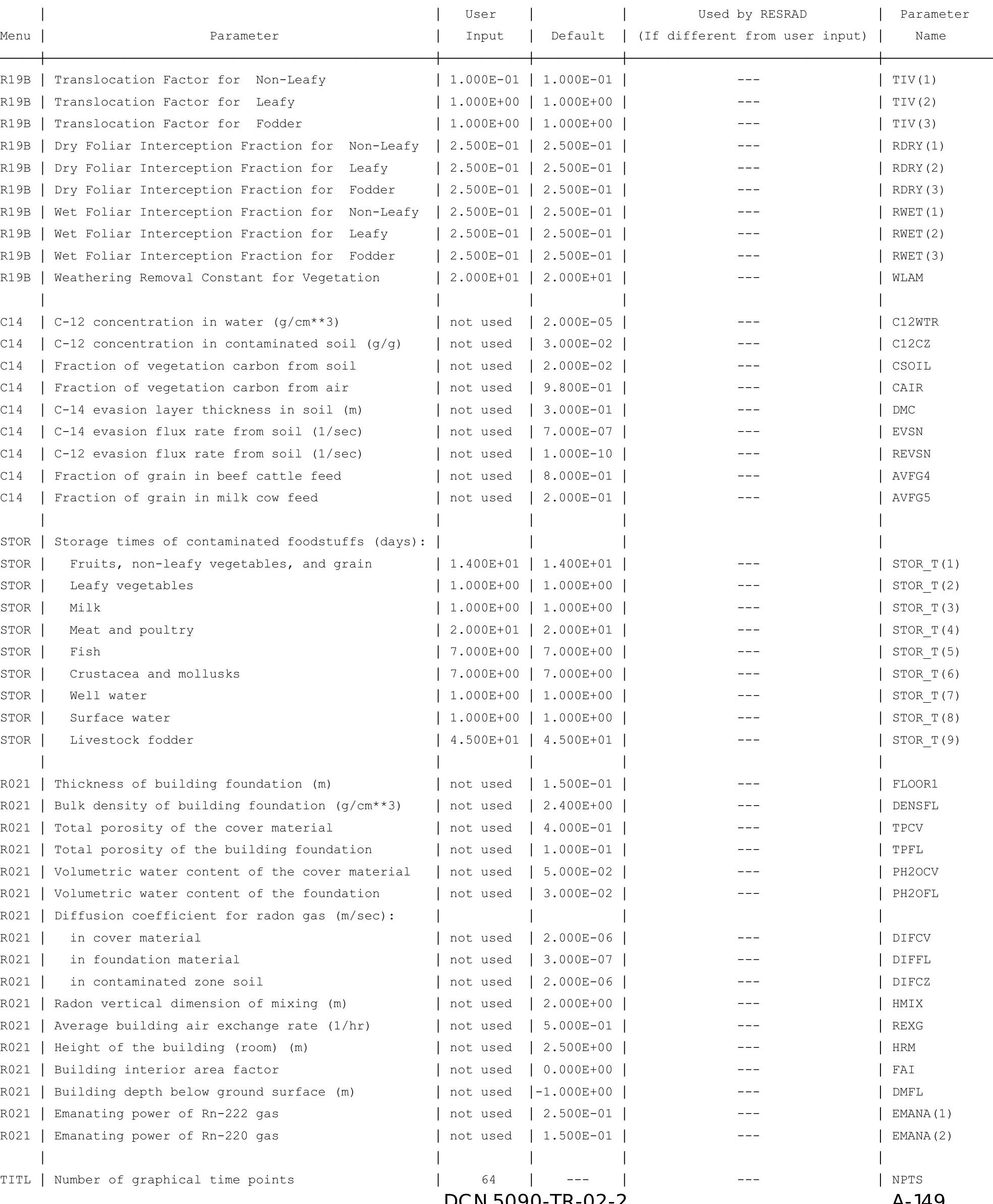


RESRAD, Version $6.5 \quad \mathrm{~T}^{1} \frac{1}{2}$ Limit $=180$ days

Summary : C746U Resident Farmer Deterministic Run

File : $\mathrm{X}: \backslash F I N A L$ V2 $\backslash$ DOE FWD RUNS \C746U RF DOE SG FWD-FV2-1050YR.RAD

Contaminated Zone Dimensions

Area: 89436.00 square meters

Thickness:

Cover Depth:

\begin{abstract}
13.40 meters
1.52 meters
\end{abstract}

Initial Soil Concentrations, pCi/g

$\begin{array}{ll}\text { Am-241 } & 3.500 \mathrm{E}+01 \\ \mathrm{Cs}-137 & 1.900 \mathrm{E}+01 \\ \mathrm{~Np}-237 & 5.500 \mathrm{E}+00 \\ \mathrm{Pu}-238 & 3.900 \mathrm{E}+01 \\ \mathrm{Pu}-239 & 3.600 \mathrm{E}+01 \\ \mathrm{Pu}-240 & 3.600 \mathrm{E}+01 \\ \mathrm{TC}-99 & 5.200 \mathrm{E}+01 \\ \mathrm{Th}-228 & 4.000 \mathrm{E}+00 \\ \mathrm{Th}-230 & 1.000 \mathrm{E}+02 \\ \mathrm{Th}-232 & 4.000 \mathrm{E}+00 \\ \mathrm{U}-234 & 1.600 \mathrm{E}+02 \\ \mathrm{U}-235 & 6.500 \mathrm{E}+00 \\ \mathrm{U}-238 & 1.600 \mathrm{E}+02\end{array}$

Total Dose TDOSE(t), mrem/yr

Basic Radiation Dose Limit $=1.000 \mathrm{E}+02 \mathrm{mrem} / \mathrm{yr}$

Total Mixture Sum $M(t)$ = Fraction of Basic Dose Limit Received at Time (t)

$\begin{array}{rllllll}t \text { (years): } & 0.000 \mathrm{E}+00 & 1.000 \mathrm{E}+00 & 5.000 \mathrm{E}+01 & 1.000 \mathrm{E}+02 & 5.000 \mathrm{E}+02 & 1.050 \mathrm{E}+03 \\ \text { TDOSE }(\mathrm{t}): & 6.620 \mathrm{E}-06 & 4.789 \mathrm{E}-06 & 9.505 \mathrm{E}-06 & 1.362 \mathrm{E}-05 & 1.081 \mathrm{E}+01 & 7.196 \mathrm{E}+00 \\ \mathrm{M}(\mathrm{t}): & 6.620 \mathrm{E}-08 & 4.789 \mathrm{E}-08 & 9.505 \mathrm{E}-08 & 1.362 \mathrm{E}-07 & 1.081 \mathrm{E}-01 & 7.196 \mathrm{E}-02\end{array}$

Maximum TDOSE(t): $2.120 \mathrm{E}+01 \mathrm{mrem} / \mathrm{yr}$ at $t=425.2 \pm 0.9$ years

Total Dose Contributions TDOSE (i,p,t) for Individual Radionuclides (i) and Pathways (p) As mrem/yr and Fraction of Total Dose At $t=4.252 \mathrm{E}+02$ years

Water Independent Pathways (Inhalation excludes radon)

\begin{tabular}{|c|c|c|c|c|c|c|c|c|c|c|c|c|c|c|}
\hline & \multicolumn{2}{|c|}{ Ground } & \multicolumn{2}{|c|}{ Inhalation } & \multicolumn{2}{|c|}{ Radon } & \multicolumn{2}{|c|}{ Plant } & \multicolumn{2}{|c|}{ Meat } & \multicolumn{2}{|c|}{ Milk } & \multicolumn{2}{|c|}{ Soil } \\
\hline clide & mrem/yr & fract. & mrem/yr & fract. & mrem/yr & fract. & mrem/yr & fract. & mrem/yr & fract. & mrem/yr & fract. & mrem/yr & fract. \\
\hline 241 & $3.207 E-13$ & 0.0000 & $0.000 \mathrm{E}+00$ & 0.0000 & $0.000 \mathrm{E}+00$ & 0.0000 & $0.000 \mathrm{E}+00$ & 0.0000 & $0.000 \mathrm{E}+00$ & 0.0000 & $0.000 \mathrm{E}+00$ & 0.0000 & $0.000 \mathrm{E}+00$ & 0.0000 \\
\hline-137 & $4.660 \mathrm{E}-11$ & 0.0000 & $0.000 \mathrm{E}+00$ & 0.0000 & $0.000 \mathrm{E}+00$ & 0.0000 & $0.000 \mathrm{E}+00$ & 0.0000 & $0.000 \mathrm{E}+00$ & 0.0000 & $0.000 \mathrm{E}+00$ & 0.0000 & $0.000 \mathrm{E}+00$ & 0.0000 \\
\hline-237 & $5.027 \mathrm{E}-10$ & 0.0000 & $0.000 \mathrm{E}+00$ & 0.0000 & $0.000 \mathrm{E}+00$ & 0.0000 & $0.000 \mathrm{E}+00$ & 0.0000 & $0.000 \mathrm{E}+00$ & 0.0000 & $0.000 \mathrm{E}+00$ & 0.0000 & $0.000 \mathrm{E}+00$ & 0.0000 \\
\hline-238 & $8.802 E-12$ & 0.0000 & $0.000 \mathrm{E}+00$ & 0.0000 & $0.000 \mathrm{E}+00$ & 0.0000 & $0.000 \mathrm{E}+00$ & 0.0000 & $0.000 \mathrm{E}+00$ & 0.0000 & $0.000 \mathrm{E}+00$ & 0.0000 & $0.000 \mathrm{E}+00$ & 0.0000 \\
\hline-239 & $6.896 \mathrm{E}-14$ & 0.0000 & $0.000 \mathrm{E}+00$ & 0.0000 & $0.000 \mathrm{E}+00$ & 0.0000 & $0.000 \mathrm{E}+00$ & 0.0000 & $0.000 \mathrm{E}+00$ & 0.0000 & $0.000 \mathrm{E}+00$ & 0.0000 & $0.000 \mathrm{E}+00$ & 0.0000 \\
\hline-240 & $9.403 E-17$ & 0.0000 & $0.000 \mathrm{E}+00$ & 0.0000 & $0.000 \mathrm{E}+00$ & 0.0000 & $0.000 \mathrm{E}+00$ & 0.0000 & $0.000 \mathrm{E}+00$ & 0.0000 & $0.000 \mathrm{E}+00$ & 0.0000 & $0.000 \mathrm{E}+00$ & 0.0000 \\
\hline 99 & $2.250 \mathrm{E}-22$ & 0.0000 & $0.000 \mathrm{E}+00$ & 0.0000 & $0.000 \mathrm{E}+00$ & 0.0000 & $0.000 \mathrm{E}+00$ & 0.0000 & $0.000 \mathrm{E}+00$ & 0.0000 & $0.000 \mathrm{E}+00$ & 0.0000 & $0.000 \mathrm{E}+00$ & 0.0000 \\
\hline-228 & $0.000 \mathrm{E}+00$ & 0.0000 & $0.000 \mathrm{E}+00$ & 0.0000 & $0.000 \mathrm{E}+00$ & 0.0000 & $0.000 \mathrm{E}+00$ & 0.0000 & $0.000 \mathrm{E}+00$ & 0.0000 & $0.000 \mathrm{E}+00$ & 0.0000 & $0.000 \mathrm{E}+00$ & 0.0000 \\
\hline-230 & $5.495 E-05$ & 0.0000 & $0.000 \mathrm{E}+00$ & 0.0000 & $0.000 \mathrm{E}+00$ & 0.0000 & $0.000 \mathrm{E}+00$ & 0.0000 & $0.000 \mathrm{E}+00$ & 0.0000 & $0.000 \mathrm{E}+00$ & 0.0000 & $0.000 \mathrm{E}+00$ & 0.0000 \\
\hline-232 & $8.493 E-05$ & 0.0000 & $0.000 \mathrm{E}+00$ & 0.0000 & $0.000 \mathrm{E}+00$ & 0.0000 & $0.000 \mathrm{E}+00$ & 0.0000 & $0.000 \mathrm{E}+00$ & 0.0000 & $0.000 \mathrm{E}+00$ & 0.0000 & $0.000 \mathrm{E}+00$ & 0.0000 \\
\hline 34 & $1.731 E-07$ & 0.0000 & $0.000 \mathrm{E}+00$ & 0.0000 & $0.000 \mathrm{E}+00$ & 0.0000 & $0.000 \mathrm{E}+00$ & 0.0000 & $0.000 \mathrm{E}+00$ & 0.0000 & $0.000 E+00$ & 0.0000 & $0.000 \mathrm{E}+00$ & 0.0000 \\
\hline 35 & $1.970 \mathrm{E}-10$ & 0.0000 & $0.000 \mathrm{E}+00$ & 0.0000 & $0.000 \mathrm{E}+00$ & 0.0000 & $0.000 \mathrm{E}+00$ & 0.0000 & $0.000 \mathrm{E}+00$ & 0.0000 & $0.000 \mathrm{E}+00$ & 0.0000 & $0.000 \mathrm{E}+00$ & 0.0000 \\
\hline 38 & $6.734 \mathrm{E}-07$ & 0.0000 & $0.000 \mathrm{E}+00$ & 0.0000 & $0.000 \mathrm{E}+00$ & 0.0000 & $0.000 \mathrm{E}+00$ & 0.0000 & $0.000 \mathrm{E}+00$ & 0.0000 & $0.000 \mathrm{E}+00$ & 0.0000 & $0.000 \mathrm{E}+00$ & 0.0000 \\
\hline & $7 \mathrm{E}-04$ & 0.0 & $.000 \mathrm{E}+00$ & 0.0000 & $0.000 \mathrm{E}+00$ & 0.0000 & $0.000 \mathrm{E}+00$ & 0.0000 & $0.000 \mathrm{E}+00$ & 0.0000 & $0.000 \mathrm{E}+00$ & 000 & $0 E+00$ & 00 \\
\hline
\end{tabular}


RESRAD, Version $6.5 \quad \mathrm{~T}^{1 / 2}$ Limit $=180$ days

Summary : C746U Resident Farmer Deterministic Run

File : $\mathrm{X}: \backslash F I N A L$ V2 $\backslash$ DOE FWD RUNS \C746U RF DOE SG FWD-FV2-1050YR.RAD

Total Dose Contributions TDOSE(i,p,t) for Individual Radionuclides (i) and Pathways (p) As mrem/yr and Fraction of Total Dose At $t=4.252 \mathrm{E}+02$ years

Water Dependent Pathways

\begin{tabular}{|c|c|c|c|c|c|c|c|c|c|c|c|c|c|c|}
\hline & \multicolumn{2}{|c|}{ Water } & \multicolumn{2}{|c|}{ Fish } & \multicolumn{2}{|c|}{ Radon } & \multicolumn{2}{|c|}{ Plant } & \multicolumn{2}{|c|}{ Meat } & \multicolumn{2}{|c|}{ Milk } & \multicolumn{2}{|c|}{ All Pathways* } \\
\hline clide & mrem/yr & fract. & mrem/yr & fract. & mrem/yr & fract. & mrem/yr & fract. & mrem/yr & fract. & mrem/yr & fract. & mrem/yr & fract. \\
\hline 241 & $0.000 \mathrm{E}+00$ & 0.0000 & $0.000 \mathrm{E}+00$ & 0.0000 & $0.000 \mathrm{E}+00$ & 0.0000 & $0.000 \mathrm{E}+00$ & 0.0000 & $0.000 \mathrm{E}+00$ & 0.0000 & $0.000 \mathrm{E}+00$ & 0.0000 & $3.207 E-13$ & 0.0000 \\
\hline-137 & $0.000 \mathrm{E}+00$ & 0.0000 & $0.000 \mathrm{E}+00$ & 0.0000 & $0.000 \mathrm{E}+00$ & 0.0000 & $0.000 \mathrm{E}+00$ & 0.0000 & $0.000 \mathrm{E}+00$ & 0.0000 & $0.000 \mathrm{E}+00$ & 0.0000 & $4.660 \mathrm{E}-11$ & 0.0000 \\
\hline-237 & $0.000 \mathrm{E}+00$ & 0.0000 & $0.000 \mathrm{E}+00$ & 0.0000 & $0.000 \mathrm{E}+00$ & 0.0000 & $0.000 \mathrm{E}+00$ & 0.0000 & $0.000 \mathrm{E}+00$ & 0.0000 & $0.000 \mathrm{E}+00$ & 0.0000 & $5.027 \mathrm{E}-10$ & 0.0000 \\
\hline-238 & $0.000 \mathrm{E}+00$ & 0.0000 & $0.000 \mathrm{E}+00$ & 0.0000 & $0.000 \mathrm{E}+00$ & 0.0000 & $0.000 \mathrm{E}+00$ & 0.0000 & $0.000 \mathrm{E}+00$ & 0.0000 & $0.000 \mathrm{E}+00$ & 0.0000 & $8.802 \mathrm{E}-12$ & 0.0000 \\
\hline-239 & $0.000 \mathrm{E}+00$ & 0.0000 & $0.000 \mathrm{E}+00$ & 0.0000 & $0.000 \mathrm{E}+00$ & 0.0000 & $0.000 \mathrm{E}+00$ & 0.0000 & $0.000 \mathrm{E}+00$ & 0.0000 & $0.000 \mathrm{E}+00$ & 0.0000 & $6.896 \mathrm{E}-14$ & 0.0000 \\
\hline-240 & $0.000 \mathrm{E}+00$ & 0.0000 & $0.000 \mathrm{E}+00$ & 0.0000 & $0.000 \mathrm{E}+00$ & 0.0000 & $0.000 \mathrm{E}+00$ & 0.0000 & $0.000 \mathrm{E}+00$ & 0.0000 & $0.000 \mathrm{E}+00$ & 0.0000 & $9.403 E-17$ & 0.0000 \\
\hline 99 & $1.754 \mathrm{E}+01$ & 0.8277 & $0.000 \mathrm{E}+00$ & 0.0000 & $0.000 \mathrm{E}+00$ & 0.0000 & $1.640 \mathrm{E}+00$ & 0.0774 & $2.936 \mathrm{E}-02$ & 0.0014 & $1.982 \mathrm{E}+00$ & 0.0935 & $2.120 \mathrm{E}+01$ & 1.0000 \\
\hline 228 & $0.000 \mathrm{E}+00$ & 0.0000 & $0.000 \mathrm{E}+00$ & 0.0000 & $0.000 \mathrm{E}+00$ & 0.0000 & $0.000 \mathrm{E}+00$ & 0.0000 & $0.000 \mathrm{E}+00$ & 0.0000 & $0.000 \mathrm{E}+00$ & 0.0000 & $0.000 \mathrm{E}+00$ & 0.0000 \\
\hline 230 & $0.000 \mathrm{E}+00$ & 0.0000 & $0.000 \mathrm{E}+00$ & 0.0000 & $0.000 \mathrm{E}+00$ & 0.0000 & $0.000 \mathrm{E}+00$ & 0.0000 & $0.000 \mathrm{E}+00$ & 0.0000 & $0.000 \mathrm{E}+00$ & 0.0000 & $5.495 E-05$ & 0.0000 \\
\hline 232 & $0.000 \mathrm{E}+00$ & 0.0000 & $0.000 \mathrm{E}+00$ & 0.0000 & $0.000 \mathrm{E}+00$ & 0.0000 & $0.000 \mathrm{E}+00$ & 0.0000 & $0.000 \mathrm{E}+00$ & 0.0000 & $0.000 \mathrm{E}+00$ & 0.0000 & $8.493 E-05$ & 0.0000 \\
\hline 34 & $0.000 \mathrm{E}+00$ & 0.0000 & $0.000 \mathrm{E}+00$ & 0.0000 & $0.000 \mathrm{E}+00$ & 0.0000 & $0.000 \mathrm{E}+00$ & 0.0000 & $0.000 \mathrm{E}+00$ & 0.0000 & $0.000 \mathrm{E}+00$ & 0.0000 & $1.731 \mathrm{E}-07$ & 0.0000 \\
\hline & $0.000 \mathrm{E}+00$ & 0.0000 & $0.000 \mathrm{E}+00$ & 0.0000 & $0.000 \mathrm{E}+00$ & 0.0000 & $0.000 \mathrm{E}+00$ & 0.0000 & $0.000 \mathrm{E}+00$ & 0.0000 & $0.000 \mathrm{E}+00$ & 0.0000 & $1.970 \mathrm{E}-10$ & 0.0000 \\
\hline & $0.000 \mathrm{E}+00$ & 0.0000 & $0.000 \mathrm{E}+00$ & 0.0000 & $0.000 \mathrm{E}+00$ & 0.0000 & $0.000 \mathrm{E}+00$ & 0.0000 & $0.000 \mathrm{E}+00$ & 0.0000 & $0.000 \mathrm{E}+00$ & 0.0000 & $6.734 \mathrm{E}-07$ & 0.0000 \\
\hline & $1.754 \mathrm{E}+01$ & 0.8277 & $0.000 \mathrm{E}+00$ & 0.0000 & $0.000 \mathrm{E}+00$ & 0.0000 & $1.640 \mathrm{E}+00$ & 0.0774 & $2.936 \mathrm{E}-02$ & 0.0014 & $1.982 \mathrm{E}+00$ & 0.0935 & $0 E+01$ & 1. \\
\hline
\end{tabular}

* Sum of all water independent and dependent pathways. 
RESRAD, Version 6.5

$\mathrm{T}^{1 / 2}$ Limit = 180 days

07/15/2011 13:56 Page 21

ummary : C746U Resident Farmer Deterministic Run

: X: $\backslash F I N A L$ V2 \DOE FWD RUNS \C746U RF DOE SG FWD-FV2-1050YR.RAD

Total Dose Contributions TDOSE (i,p,t) for Individual Radionuclides (i) and Pathways (p) As mrem/yr and Fraction of Total Dose At $t=0.000 \mathrm{E}+00$ years

Water Independent Pathways (Inhalation excludes radon)

\begin{tabular}{|c|c|c|c|c|c|c|c|c|c|c|c|c|c|c|}
\hline \multirow{2}{*}{ Nuclide } & \multicolumn{2}{|c|}{ Ground } & \multicolumn{2}{|c|}{ Inhalation } & \multicolumn{2}{|c|}{ Radon } & \multicolumn{2}{|c|}{ Plant } & \multicolumn{2}{|c|}{ Meat } & \multicolumn{2}{|c|}{ Milk } & \multicolumn{2}{|c|}{ Soil } \\
\hline & mrem/yr & fract. & mrem/yr & fract. & mrem/yr & fract. & mrem/yr & fract. & mrem/yr & fract. & mrem/yr & fract. & mrem/yr & fract. \\
\hline-241 & $0.000 \mathrm{E}+00$ & 0.0000 & $0.000 \mathrm{E}+00$ & 0.0000 & $0.000 \mathrm{E}+00$ & 0.0000 & $0.000 \mathrm{E}+00$ & 0.0000 & $0.000 \mathrm{E}+00$ & 0.0000 & $0.000 \mathrm{E}+00$ & 0.0000 & $0.000 \mathrm{E}+00$ & 0.0000 \\
\hline-137 & $2.415 E-08$ & 0.0036 & $0.000 \mathrm{E}+00$ & 0.0000 & $0.000 \mathrm{E}+00$ & 0.0000 & $0.000 \mathrm{E}+00$ & 0.0000 & $0.000 \mathrm{E}+00$ & 0.0000 & $0.000 \mathrm{E}+00$ & 0.0000 & $0.000 \mathrm{E}+00$ & 0.0000 \\
\hline-237 & $5.217 \mathrm{E}-12$ & 0.0000 & $0.000 \mathrm{E}+00$ & 0.0000 & $0.000 \mathrm{E}+00$ & 0.0000 & $0.000 \mathrm{E}+00$ & 0.0000 & $0.000 \mathrm{E}+00$ & 0.0000 & $0.000 \mathrm{E}+00$ & 0.0000 & $0.000 \mathrm{E}+00$ & 0.0000 \\
\hline-238 & $4.560 E-23$ & 0.0000 & $0.000 \mathrm{E}+00$ & 0.0000 & $0.000 \mathrm{E}+00$ & 0.0000 & $0.000 \mathrm{E}+00$ & 0.0000 & $0.000 \mathrm{E}+00$ & 0.0000 & $0.000 \mathrm{E}+00$ & 0.0000 & $0.000 \mathrm{E}+00$ & 0.0000 \\
\hline-239 & $4.302 E-16$ & 0.0000 & $0.000 \mathrm{E}+00$ & 0.0000 & $0.000 \mathrm{E}+00$ & 0.0000 & $0.000 \mathrm{E}+00$ & 0.0000 & $0.000 \mathrm{E}+00$ & 0.0000 & $0.000 \mathrm{E}+00$ & 0.0000 & $0.000 \mathrm{E}+00$ & 0.0000 \\
\hline-240 & $4.075 E-23$ & 0.0000 & $0.000 \mathrm{E}+00$ & 0.0000 & $0.000 \mathrm{E}+00$ & 0.0000 & $0.000 \mathrm{E}+00$ & 0.0000 & $0.000 \mathrm{E}+00$ & 0.0000 & $0.000 \mathrm{E}+00$ & 0.0000 & $0.000 \mathrm{E}+00$ & 0.0000 \\
\hline 99 & $2.979 E-24$ & 0.0000 & $0.000 \mathrm{E}+00$ & 0.0000 & $0.000 \mathrm{E}+00$ & 0.0000 & $0.000 \mathrm{E}+00$ & 0.0000 & $0.000 \mathrm{E}+00$ & 0.0000 & $0.000 \mathrm{E}+00$ & 0.0000 & $0.000 \mathrm{E}+00$ & 0.0000 \\
\hline-228 & $6.573 E-06$ & 0.9929 & $0.000 \mathrm{E}+00$ & 0.0000 & $0.000 \mathrm{E}+00$ & 0.0000 & $0.000 \mathrm{E}+00$ & 0.0000 & $0.000 \mathrm{E}+00$ & 0.0000 & $0.000 \mathrm{E}+00$ & 0.0000 & $0.000 \mathrm{E}+00$ & 0.0000 \\
\hline-230 & $2.392 \mathrm{E}-20$ & 0.0000 & $0.000 \mathrm{E}+00$ & 0.0000 & $0.000 \mathrm{E}+00$ & 0.0000 & $0.000 \mathrm{E}+00$ & 0.0000 & $0.000 \mathrm{E}+00$ & 0.0000 & $0.000 \mathrm{E}+00$ & 0.0000 & $0.000 \mathrm{E}+00$ & 0.0000 \\
\hline-232 & $4.620 E-24$ & 0.0000 & $0.000 \mathrm{E}+00$ & 0.0000 & $0.000 \mathrm{E}+00$ & 0.0000 & $0.000 \mathrm{E}+00$ & 0.0000 & $0.000 \mathrm{E}+00$ & 0.0000 & $0.000 \mathrm{E}+00$ & 0.0000 & $0.000 \mathrm{E}+00$ & 0.0000 \\
\hline 234 & $1.094 \mathrm{E}-21$ & 0.0000 & $0.000 \mathrm{E}+00$ & 0.0000 & $0.000 \mathrm{E}+00$ & 0.0000 & $0.000 \mathrm{E}+00$ & 0.0000 & $0.000 \mathrm{E}+00$ & 0.0000 & $0.000 \mathrm{E}+00$ & 0.0000 & $0.000 \mathrm{E}+00$ & 0.0000 \\
\hline 235 & $8.032 \mathrm{E}-14$ & 0.0000 & $0.000 \mathrm{E}+00$ & 0.0000 & $0.000 \mathrm{E}+00$ & 0.0000 & $0.000 \mathrm{E}+00$ & 0.0000 & $0.000 \mathrm{E}+00$ & 0.0000 & $0.000 \mathrm{E}+00$ & 0.0000 & $0.000 \mathrm{E}+00$ & 0.0000 \\
\hline 38 & $2.262 E-08$ & 0.0034 & $0.000 \mathrm{E}+00$ & 0.0000 & $0.000 \mathrm{E}+00$ & 0.0000 & $0.000 \mathrm{E}+00$ & 0.0000 & $0.000 \mathrm{E}+00$ & 0.0000 & $0.000 \mathrm{E}+00$ & 0.0000 & $0.000 \mathrm{E}+00$ & 0.0000 \\
\hline & $6.620 \mathrm{E}-06$ & 1.0000 & $0.000 \mathrm{E}+00$ & 0.0000 & $0.000 \mathrm{E}+00$ & 0.0000 & $0.000 \mathrm{E}+00$ & 0.0000 & $0.000 \mathrm{E}+00$ & 0.0000 & $0.000 \mathrm{E}+00$ & 0.0000 & $.000 \mathrm{E}+00$ & 0.0000 \\
\hline
\end{tabular}

Total Dose Contributions TDOSE (i,p,t) for Individual Radionuclides (i) and Pathways (p) As mrem/yr and Fraction of Total Dose At $t=0.000 \mathrm{E}+00$ years

Water Dependent Pathways

\begin{tabular}{|c|c|c|c|c|c|c|c|c|c|c|c|c|c|c|}
\hline & \multicolumn{2}{|c|}{ Water } & \multicolumn{2}{|c|}{ Fish } & \multicolumn{2}{|c|}{ Radon } & \multicolumn{2}{|c|}{ Plant } & \multicolumn{2}{|c|}{ Meat } & \multicolumn{2}{|c|}{ Milk } & \multicolumn{2}{|c|}{ All Pathways* } \\
\hline clide & mrem/yr & fract. & mrem/yr & fract. & mrem/yr & fract. & mrem/yr & fract. & mrem/yr & fract. & mrem/yr & fract. & mrem/yr & fract. \\
\hline-241 & $0.000 \mathrm{E}+00$ & 0.0000 & $0.000 \mathrm{E}+00$ & 0.0000 & $0.000 \mathrm{E}+00$ & 0.0000 & $0.000 \mathrm{E}+00$ & 0.0000 & $0.000 \mathrm{E}+00$ & 0.0000 & $0.000 \mathrm{E}+00$ & 0.0000 & $0.000 \mathrm{E}+00$ & 0.0000 \\
\hline-137 & $0.000 \mathrm{E}+00$ & 0.0000 & $0.000 \mathrm{E}+00$ & 0.0000 & $0.000 \mathrm{E}+00$ & 0.0000 & $0.000 \mathrm{E}+00$ & 0.0000 & $0.000 \mathrm{E}+00$ & 0.0000 & $0.000 \mathrm{E}+00$ & 0.0000 & $2.415 \mathrm{E}-08$ & 0.0036 \\
\hline-237 & $0.000 \mathrm{E}+00$ & 0.0000 & $0.000 \mathrm{E}+00$ & 0.0000 & $0.000 \mathrm{E}+00$ & 0.0000 & $0.000 \mathrm{E}+00$ & 0.0000 & $0.000 \mathrm{E}+00$ & 0.0000 & $0.000 \mathrm{E}+00$ & 0.0000 & $5.217 \mathrm{E}-12$ & 0.0000 \\
\hline-238 & $0.000 \mathrm{E}+00$ & 0.0000 & $0.000 \mathrm{E}+00$ & 0.0000 & $0.000 \mathrm{E}+00$ & 0.0000 & $0.000 \mathrm{E}+00$ & 0.0000 & $0.000 \mathrm{E}+00$ & 0.0000 & $0.000 \mathrm{E}+00$ & 0.0000 & $4.560 \mathrm{E}-23$ & 0.0000 \\
\hline-239 & $0.000 \mathrm{E}+00$ & 0.0000 & $0.000 \mathrm{E}+00$ & 0.0000 & $0.000 \mathrm{E}+00$ & 0.0000 & $0.000 \mathrm{E}+00$ & 0.0000 & $0.000 \mathrm{E}+00$ & 0.0000 & $0.000 E+00$ & 0.0000 & $4.302 \mathrm{E}-16$ & 0.0000 \\
\hline-240 & $0.000 \mathrm{E}+00$ & 0.0000 & $0.000 \mathrm{E}+00$ & 0.0000 & $0.000 \mathrm{E}+00$ & 0.0000 & $0.000 \mathrm{E}+00$ & 0.0000 & $0.000 \mathrm{E}+00$ & 0.0000 & $0.000 E+00$ & 0.0000 & $4.075 E-23$ & 0.0000 \\
\hline-99 & $0.000 \mathrm{E}+00$ & 0.0000 & $0.000 \mathrm{E}+00$ & 0.0000 & $0.000 \mathrm{E}+00$ & 0.0000 & $0.000 \mathrm{E}+00$ & 0.0000 & $0.000 \mathrm{E}+00$ & 0.0000 & $0.000 \mathrm{E}+00$ & 0.0000 & $2.979 E-24$ & 0.0000 \\
\hline-228 & $0.000 \mathrm{E}+00$ & 0.0000 & $0.000 \mathrm{E}+00$ & 0.0000 & $0.000 \mathrm{E}+00$ & 0.0000 & $0.000 \mathrm{E}+00$ & 0.0000 & $0.000 \mathrm{E}+00$ & 0.0000 & $0.000 \mathrm{E}+00$ & 0.0000 & $6.573 E-06$ & 0.9929 \\
\hline-230 & $0.000 \mathrm{E}+00$ & 0.0000 & $0.000 \mathrm{E}+00$ & 0.0000 & $0.000 \mathrm{E}+00$ & 0.0000 & $0.000 \mathrm{E}+00$ & 0.0000 & $0.000 \mathrm{E}+00$ & 0.0000 & $0.000 E+00$ & 0.0000 & $2.392 \mathrm{E}-20$ & 0.0000 \\
\hline 232 & $0.000 \mathrm{E}+00$ & 0.0000 & $0.000 \mathrm{E}+00$ & 0.0000 & $0.000 \mathrm{E}+00$ & 0.0000 & $0.000 \mathrm{E}+00$ & 0.0000 & $0.000 \mathrm{E}+00$ & 0.0000 & $0.000 \mathrm{E}+00$ & 0.0000 & $4.620 \mathrm{E}-24$ & 0.0000 \\
\hline 34 & $0.000 \mathrm{E}+00$ & 0.0000 & $0.000 \mathrm{E}+00$ & 0.0000 & $0.000 \mathrm{E}+00$ & 0.0000 & $0.000 \mathrm{E}+00$ & 0.0000 & $0.000 \mathrm{E}+00$ & 0.0000 & $0.000 \mathrm{E}+00$ & 0.0000 & $1.094 \mathrm{E}-21$ & 0.0000 \\
\hline 35 & $0.000 \mathrm{E}+00$ & 0.0000 & $0.000 \mathrm{E}+00$ & 0.0000 & $0.000 \mathrm{E}+00$ & 0.0000 & $0.000 \mathrm{E}+00$ & 0.0000 & $0.000 \mathrm{E}+00$ & 0.0000 & $0.000 E+00$ & 0.0000 & $8.032 \mathrm{E}-14$ & 0.0000 \\
\hline 38 & $0.000 \mathrm{E}+00$ & 0.0000 & $0.000 \mathrm{E}+00$ & 0.0000 & $0.000 \mathrm{E}+00$ & 0.0000 & $0.000 \mathrm{E}+00$ & 0.0000 & $0.000 \mathrm{E}+00$ & 0.0000 & $0.000 \mathrm{E}+00$ & 0.0000 & $2.262 \mathrm{E}-08$ & 0.0034 \\
\hline & $0.000 \mathrm{E}+00$ & 0.0000 & $0.000 \mathrm{E}+00$ & 0.0000 & $0.000 \mathrm{E}+00$ & 0.0000 & $0.000 \mathrm{E}+00$ & 0.0000 & $0.000 \mathrm{E}+00$ & 0.0000 & $0.000 \mathrm{E}+00$ & 0.0000 & $20 E-06$ & 1. \\
\hline
\end{tabular}

* Sum of all water independent and dependent pathways. 
RESRAD, Version 6.5

$\mathrm{T}^{1 / 2}$ Limit = 180 days

07/15/2011 13:56 Page 22

ummary : C746U Resident Farmer Deterministic Run

: X: $\backslash F I N A L$ V2 \DOE FWD RUNS \C746U RF DOE SG FWD-FV2-1050YR.RAD

Total Dose Contributions TDOSE (i,p,t) for Individual Radionuclides (i) and Pathways (p) As mrem/yr and Fraction of Total Dose At $t=1.000 \mathrm{E}+00$ years

Water Independent Pathways (Inhalation excludes radon)

\begin{tabular}{|c|c|c|c|c|c|c|c|c|c|c|c|c|c|c|}
\hline \multirow{2}{*}{ Nuclide } & \multicolumn{2}{|c|}{ Ground } & \multicolumn{2}{|c|}{ Inhalation } & \multicolumn{2}{|c|}{ Radon } & \multicolumn{2}{|c|}{ Plant } & \multicolumn{2}{|c|}{ Meat } & \multicolumn{2}{|c|}{ Milk } & \multicolumn{2}{|c|}{ Soil } \\
\hline & mrem/yr & fract. & mrem/yr & fract. & mrem/yr & fract. & mrem/yr & fract. & mrem/yr & fract. & mrem/yr & fract. & mrem/yr & fract. \\
\hline-241 & $1.086 \mathrm{E}-17$ & 0.0000 & $0.000 \mathrm{E}+00$ & 0.0000 & $0.000 \mathrm{E}+00$ & 0.0000 & $0.000 \mathrm{E}+00$ & 0.0000 & $0.000 \mathrm{E}+00$ & 0.0000 & $0.000 \mathrm{E}+00$ & 0.0000 & $0.000 \mathrm{E}+00$ & 0.0000 \\
\hline-137 & $2.380 E-08$ & 0.0050 & $0.000 \mathrm{E}+00$ & 0.0000 & $0.000 \mathrm{E}+00$ & 0.0000 & $0.000 \mathrm{E}+00$ & 0.0000 & $0.000 \mathrm{E}+00$ & 0.0000 & $0.000 \mathrm{E}+00$ & 0.0000 & $0.000 \mathrm{E}+00$ & 0.0000 \\
\hline-237 & $5.273 E-12$ & 0.0000 & $0.000 \mathrm{E}+00$ & 0.0000 & $0.000 \mathrm{E}+00$ & 0.0000 & $0.000 \mathrm{E}+00$ & 0.0000 & $0.000 \mathrm{E}+00$ & 0.0000 & $0.000 \mathrm{E}+00$ & 0.0000 & $0.000 \mathrm{E}+00$ & 0.0000 \\
\hline-238 & $1.257 \mathrm{E}-20$ & 0.0000 & $0.000 \mathrm{E}+00$ & 0.0000 & $0.000 \mathrm{E}+00$ & 0.0000 & $0.000 \mathrm{E}+00$ & 0.0000 & $0.000 \mathrm{E}+00$ & 0.0000 & $0.000 \mathrm{E}+00$ & 0.0000 & $0.000 \mathrm{E}+00$ & 0.0000 \\
\hline-239 & $4.354 \mathrm{E}-16$ & 0.0000 & $0.000 \mathrm{E}+00$ & 0.0000 & $0.000 \mathrm{E}+00$ & 0.0000 & $0.000 \mathrm{E}+00$ & 0.0000 & $0.000 \mathrm{E}+00$ & 0.0000 & $0.000 \mathrm{E}+00$ & 0.0000 & $0.000 \mathrm{E}+00$ & 0.0000 \\
\hline-240 & $4.164 \mathrm{E}-23$ & 0.0000 & $0.000 \mathrm{E}+00$ & 0.0000 & $0.000 \mathrm{E}+00$ & 0.0000 & $0.000 \mathrm{E}+00$ & 0.0000 & $0.000 \mathrm{E}+00$ & 0.0000 & $0.000 \mathrm{E}+00$ & 0.0000 & $0.000 \mathrm{E}+00$ & 0.0000 \\
\hline 99 & $3.009 E-24$ & 0.0000 & $0.000 \mathrm{E}+00$ & 0.0000 & $0.000 \mathrm{E}+00$ & 0.0000 & $0.000 \mathrm{E}+00$ & 0.0000 & $0.000 \mathrm{E}+00$ & 0.0000 & $0.000 \mathrm{E}+00$ & 0.0000 & $0.000 \mathrm{E}+00$ & 0.0000 \\
\hline-228 & $4.603 E-06$ & 0.9611 & $0.000 \mathrm{E}+00$ & 0.0000 & $0.000 \mathrm{E}+00$ & 0.0000 & $0.000 \mathrm{E}+00$ & 0.0000 & $0.000 \mathrm{E}+00$ & 0.0000 & $0.000 \mathrm{E}+00$ & 0.0000 & $0.000 \mathrm{E}+00$ & 0.0000 \\
\hline-230 & $7.565 \mathrm{E}-09$ & 0.0016 & $0.000 \mathrm{E}+00$ & 0.0000 & $0.000 \mathrm{E}+00$ & 0.0000 & $0.000 \mathrm{E}+00$ & 0.0000 & $0.000 \mathrm{E}+00$ & 0.0000 & $0.000 \mathrm{E}+00$ & 0.0000 & $0.000 \mathrm{E}+00$ & 0.0000 \\
\hline-232 & $1.320 \mathrm{E}-07$ & 0.0276 & $0.000 \mathrm{E}+00$ & 0.0000 & $0.000 \mathrm{E}+00$ & 0.0000 & $0.000 \mathrm{E}+00$ & 0.0000 & $0.000 \mathrm{E}+00$ & 0.0000 & $0.000 \mathrm{E}+00$ & 0.0000 & $0.000 \mathrm{E}+00$ & 0.0000 \\
\hline 234 & $5.448 \mathrm{E}-14$ & 0.0000 & $0.000 \mathrm{E}+00$ & 0.0000 & $0.000 \mathrm{E}+00$ & 0.0000 & $0.000 \mathrm{E}+00$ & 0.0000 & $0.000 \mathrm{E}+00$ & 0.0000 & $0.000 \mathrm{E}+00$ & 0.0000 & $0.000 \mathrm{E}+00$ & 0.0000 \\
\hline 235 & $8.153 \mathrm{E}-14$ & 0.0000 & $0.000 \mathrm{E}+00$ & 0.0000 & $0.000 \mathrm{E}+00$ & 0.0000 & $0.000 \mathrm{E}+00$ & 0.0000 & $0.000 \mathrm{E}+00$ & 0.0000 & $0.000 \mathrm{E}+00$ & 0.0000 & $0.000 \mathrm{E}+00$ & 0.0000 \\
\hline 38 & $2.280 E-08$ & 0.0048 & $0.000 \mathrm{E}+00$ & 0.0000 & $0.000 \mathrm{E}+00$ & 0.0000 & $0.000 \mathrm{E}+00$ & 0.0000 & $0.000 \mathrm{E}+00$ & 0.0000 & $0.000 \mathrm{E}+00$ & 0.0000 & $0.000 \mathrm{E}+00$ & 0.0000 \\
\hline & $4.789 E-06$ & 1.0000 & $0.000 \mathrm{E}+00$ & 0.0000 & $0.000 \mathrm{E}+00$ & 0.0000 & $0.000 \mathrm{E}+00$ & 0.0000 & $0.000 \mathrm{E}+00$ & 0.0000 & $0.000 \mathrm{E}+00$ & 0.0000 & $.000 \mathrm{E}+00$ & 0.0000 \\
\hline
\end{tabular}

Total Dose Contributions TDOSE (i,p,t) for Individual Radionuclides (i) and Pathways (p) As mrem/yr and Fraction of Total Dose At $t=1.000 \mathrm{E}+00$ years

Water Dependent Pathways

\begin{tabular}{|c|c|c|c|c|c|c|c|c|c|c|c|c|c|c|}
\hline & \multicolumn{2}{|c|}{ Water } & \multicolumn{2}{|c|}{ Fish } & \multicolumn{2}{|c|}{ Radon } & \multicolumn{2}{|c|}{ Plant } & \multicolumn{2}{|c|}{ Meat } & \multicolumn{2}{|c|}{ Milk } & \multicolumn{2}{|c|}{ All Pathways* } \\
\hline clide & mrem/yr & fract. & mrem/yr & fract. & mrem/yr & fract. & mrem/yr & fract. & mrem/yr & fract. & mrem/yr & fract. & mrem/yr & fract. \\
\hline-241 & $0.000 \mathrm{E}+00$ & 0.0000 & $0.000 \mathrm{E}+00$ & 0.0000 & $0.000 \mathrm{E}+00$ & 0.0000 & $0.000 \mathrm{E}+00$ & 0.0000 & $0.000 \mathrm{E}+00$ & 0.0000 & $0.000 \mathrm{E}+00$ & 0.0000 & $1.086 \mathrm{E}-17$ & 0.0000 \\
\hline-137 & $0.000 \mathrm{E}+00$ & 0.0000 & $0.000 \mathrm{E}+00$ & 0.0000 & $0.000 \mathrm{E}+00$ & 0.0000 & $0.000 \mathrm{E}+00$ & 0.0000 & $0.000 \mathrm{E}+00$ & 0.0000 & $0.000 \mathrm{E}+00$ & 0.0000 & $2.380 \mathrm{E}-08$ & 0.0050 \\
\hline-237 & $0.000 \mathrm{E}+00$ & 0.0000 & $0.000 \mathrm{E}+00$ & 0.0000 & $0.000 \mathrm{E}+00$ & 0.0000 & $0.000 \mathrm{E}+00$ & 0.0000 & $0.000 \mathrm{E}+00$ & 0.0000 & $0.000 \mathrm{E}+00$ & 0.0000 & $5.273 E-12$ & 0.0000 \\
\hline-238 & $0.000 \mathrm{E}+00$ & 0.0000 & $0.000 \mathrm{E}+00$ & 0.0000 & $0.000 \mathrm{E}+00$ & 0.0000 & $0.000 \mathrm{E}+00$ & 0.0000 & $0.000 \mathrm{E}+00$ & 0.0000 & $0.000 \mathrm{E}+00$ & 0.0000 & $1.257 \mathrm{E}-20$ & 0.0000 \\
\hline-239 & $0.000 \mathrm{E}+00$ & 0.0000 & $0.000 \mathrm{E}+00$ & 0.0000 & $0.000 \mathrm{E}+00$ & 0.0000 & $0.000 \mathrm{E}+00$ & 0.0000 & $0.000 \mathrm{E}+00$ & 0.0000 & $0.000 E+00$ & 0.0000 & $4.354 \mathrm{E}-16$ & 0.0000 \\
\hline-240 & $0.000 \mathrm{E}+00$ & 0.0000 & $0.000 \mathrm{E}+00$ & 0.0000 & $0.000 \mathrm{E}+00$ & 0.0000 & $0.000 \mathrm{E}+00$ & 0.0000 & $0.000 \mathrm{E}+00$ & 0.0000 & $0.000 E+00$ & 0.0000 & $4.164 \mathrm{E}-23$ & 0.0000 \\
\hline-99 & $0.000 \mathrm{E}+00$ & 0.0000 & $0.000 \mathrm{E}+00$ & 0.0000 & $0.000 \mathrm{E}+00$ & 0.0000 & $0.000 \mathrm{E}+00$ & 0.0000 & $0.000 \mathrm{E}+00$ & 0.0000 & $0.000 \mathrm{E}+00$ & 0.0000 & $3.009 E-24$ & 0.0000 \\
\hline-228 & $0.000 \mathrm{E}+00$ & 0.0000 & $0.000 \mathrm{E}+00$ & 0.0000 & $0.000 \mathrm{E}+00$ & 0.0000 & $0.000 \mathrm{E}+00$ & 0.0000 & $0.000 \mathrm{E}+00$ & 0.0000 & $0.000 \mathrm{E}+00$ & 0.0000 & $4.603 E-06$ & 0.9611 \\
\hline-230 & $0.000 \mathrm{E}+00$ & 0.0000 & $0.000 \mathrm{E}+00$ & 0.0000 & $0.000 \mathrm{E}+00$ & 0.0000 & $0.000 \mathrm{E}+00$ & 0.0000 & $0.000 \mathrm{E}+00$ & 0.0000 & $0.000 E+00$ & 0.0000 & $7.565 \mathrm{E}-09$ & 0.0016 \\
\hline 232 & $0.000 \mathrm{E}+00$ & 0.0000 & $0.000 \mathrm{E}+00$ & 0.0000 & $0.000 \mathrm{E}+00$ & 0.0000 & $0.000 \mathrm{E}+00$ & 0.0000 & $0.000 \mathrm{E}+00$ & 0.0000 & $0.000 \mathrm{E}+00$ & 0.0000 & $1.320 \mathrm{E}-07$ & 0.0276 \\
\hline 34 & $0.000 \mathrm{E}+00$ & 0.0000 & $0.000 \mathrm{E}+00$ & 0.0000 & $0.000 \mathrm{E}+00$ & 0.0000 & $0.000 \mathrm{E}+00$ & 0.0000 & $0.000 \mathrm{E}+00$ & 0.0000 & $0.000 \mathrm{E}+00$ & 0.0000 & $5.448 \mathrm{E}-14$ & 0.0000 \\
\hline 35 & $0.000 \mathrm{E}+00$ & 0.0000 & $0.000 \mathrm{E}+00$ & 0.0000 & $0.000 \mathrm{E}+00$ & 0.0000 & $0.000 \mathrm{E}+00$ & 0.0000 & $0.000 \mathrm{E}+00$ & 0.0000 & $0.000 E+00$ & 0.0000 & $8.153 \mathrm{E}-14$ & 0.0000 \\
\hline 38 & $0.000 \mathrm{E}+00$ & 0.0000 & $0.000 \mathrm{E}+00$ & 0.0000 & $0.000 \mathrm{E}+00$ & 0.0000 & $0.000 \mathrm{E}+00$ & 0.0000 & $0.000 \mathrm{E}+00$ & 0.0000 & $0.000 \mathrm{E}+00$ & 0.0000 & $2.280 \mathrm{E}-08$ & 0.0048 \\
\hline & $0.000 \mathrm{E}+00$ & 0.0000 & $0.000 \mathrm{E}+00$ & 0.0000 & $0.000 \mathrm{E}+00$ & 0.0000 & $0.000 \mathrm{E}+00$ & 0.0000 & $0.000 \mathrm{E}+00$ & 0.0000 & $0.000 \mathrm{E}+00$ & 0.0000 & $39 E-06$ & 1.0000 \\
\hline
\end{tabular}

* Sum of all water independent and dependent pathways. 
RESRAD, Version 6.5

$\mathrm{T}^{1 / 2}$ Limit = 180 days

07/15/2011 13:56 Page 23

ummary : C746U Resident Farmer Deterministic Run

: X: $\backslash F I N A L$ V2 \DOE FWD RUNS \C746U RF DOE SG FWD-FV2-1050YR.RAD

Total Dose Contributions TDOSE (i,p,t) for Individual Radionuclides (i) and Pathways (p) As mrem/yr and Fraction of Total Dose At $t=5.000 \mathrm{E}+01$ years

Water Independent Pathways (Inhalation excludes radon)

\begin{tabular}{|c|c|c|c|c|c|c|c|c|c|c|c|c|c|c|}
\hline \multirow{2}{*}{ Nuclide } & \multicolumn{2}{|c|}{ Ground } & \multicolumn{2}{|c|}{ Inhalation } & \multicolumn{2}{|c|}{ Radon } & \multicolumn{2}{|c|}{ Plant } & \multicolumn{2}{|c|}{ Meat } & \multicolumn{2}{|c|}{ Milk } & \multicolumn{2}{|c|}{ Soil } \\
\hline & mrem/yr & fract. & mrem/yr & fract. & mrem/yr & fract. & mrem/yr & fract. & mrem/yr & fract. & mrem/yr & fract. & mrem/yr & fract. \\
\hline-241 & $8.840 \mathrm{E}-16$ & 0.0000 & $0.000 \mathrm{E}+00$ & 0.0000 & $0.000 \mathrm{E}+00$ & 0.0000 & $0.000 \mathrm{E}+00$ & 0.0000 & $0.000 \mathrm{E}+00$ & 0.0000 & $0.000 \mathrm{E}+00$ & 0.0000 & $0.000 \mathrm{E}+00$ & 0.0000 \\
\hline-137 & $1.158 \mathrm{E}-08$ & 0.0012 & $0.000 \mathrm{E}+00$ & 0.0000 & $0.000 \mathrm{E}+00$ & 0.0000 & $0.000 \mathrm{E}+00$ & 0.0000 & $0.000 \mathrm{E}+00$ & 0.0000 & $0.000 \mathrm{E}+00$ & 0.0000 & $0.000 \mathrm{E}+00$ & 0.0000 \\
\hline-237 & $8.909 \mathrm{E}-12$ & 0.0000 & $0.000 \mathrm{E}+00$ & 0.0000 & $0.000 \mathrm{E}+00$ & 0.0000 & $0.000 \mathrm{E}+00$ & 0.0000 & $0.000 \mathrm{E}+00$ & 0.0000 & $0.000 \mathrm{E}+00$ & 0.0000 & $0.000 \mathrm{E}+00$ & 0.0000 \\
\hline-238 & $1.988 E-15$ & 0.0000 & $0.000 \mathrm{E}+00$ & 0.0000 & $0.000 \mathrm{E}+00$ & 0.0000 & $0.000 \mathrm{E}+00$ & 0.0000 & $0.000 \mathrm{E}+00$ & 0.0000 & $0.000 \mathrm{E}+00$ & 0.0000 & $0.000 \mathrm{E}+00$ & 0.0000 \\
\hline-239 & $7.814 \mathrm{E}-16$ & 0.0000 & $0.000 \mathrm{E}+00$ & 0.0000 & $0.000 \mathrm{E}+00$ & 0.0000 & $0.000 \mathrm{E}+00$ & 0.0000 & $0.000 \mathrm{E}+00$ & 0.0000 & $0.000 \mathrm{E}+00$ & 0.0000 & $0.000 \mathrm{E}+00$ & 0.0000 \\
\hline-240 & $9.393 E-20$ & 0.0000 & $0.000 \mathrm{E}+00$ & 0.0000 & $0.000 \mathrm{E}+00$ & 0.0000 & $0.000 \mathrm{E}+00$ & 0.0000 & $0.000 \mathrm{E}+00$ & 0.0000 & $0.000 \mathrm{E}+00$ & 0.0000 & $0.000 \mathrm{E}+00$ & 0.0000 \\
\hline 99 & $4.954 \mathrm{E}-24$ & 0.0000 & $0.000 \mathrm{E}+00$ & 0.0000 & $0.000 \mathrm{E}+00$ & 0.0000 & $0.000 \mathrm{E}+00$ & 0.0000 & $0.000 \mathrm{E}+00$ & 0.0000 & $0.000 \mathrm{E}+00$ & 0.0000 & $0.000 \mathrm{E}+00$ & 0.0000 \\
\hline-228 & $1.201 \mathrm{E}-13$ & 0.0000 & $0.000 \mathrm{E}+00$ & 0.0000 & $0.000 \mathrm{E}+00$ & 0.0000 & $0.000 \mathrm{E}+00$ & 0.0000 & $0.000 \mathrm{E}+00$ & 0.0000 & $0.000 \mathrm{E}+00$ & 0.0000 & $0.000 \mathrm{E}+00$ & 0.0000 \\
\hline-230 & $5.249 \mathrm{E}-07$ & 0.0552 & $0.000 \mathrm{E}+00$ & 0.0000 & $0.000 \mathrm{E}+00$ & 0.0000 & $0.000 \mathrm{E}+00$ & 0.0000 & $0.000 \mathrm{E}+00$ & 0.0000 & $0.000 \mathrm{E}+00$ & 0.0000 & $0.000 \mathrm{E}+00$ & 0.0000 \\
\hline-232 & $8.935 E-06$ & 0.9400 & $0.000 \mathrm{E}+00$ & 0.0000 & $0.000 \mathrm{E}+00$ & 0.0000 & $0.000 \mathrm{E}+00$ & 0.0000 & $0.000 \mathrm{E}+00$ & 0.0000 & $0.000 \mathrm{E}+00$ & 0.0000 & $0.000 \mathrm{E}+00$ & 0.0000 \\
\hline 234 & $1.897 \mathrm{E}-10$ & 0.0000 & $0.000 \mathrm{E}+00$ & 0.0000 & $0.000 \mathrm{E}+00$ & 0.0000 & $0.000 \mathrm{E}+00$ & 0.0000 & $0.000 \mathrm{E}+00$ & 0.0000 & $0.000 \mathrm{E}+00$ & 0.0000 & $0.000 \mathrm{E}+00$ & 0.0000 \\
\hline 235 & $5.905 E-13$ & 0.0000 & $0.000 \mathrm{E}+00$ & 0.0000 & $0.000 \mathrm{E}+00$ & 0.0000 & $0.000 \mathrm{E}+00$ & 0.0000 & $0.000 \mathrm{E}+00$ & 0.0000 & $0.000 \mathrm{E}+00$ & 0.0000 & $0.000 \mathrm{E}+00$ & 0.0000 \\
\hline 38 & $3.372 E-08$ & 0.0035 & $0.000 \mathrm{E}+00$ & 0.0000 & $0.000 \mathrm{E}+00$ & 0.0000 & $0.000 \mathrm{E}+00$ & 0.0000 & $0.000 \mathrm{E}+00$ & 0.0000 & $0.000 \mathrm{E}+00$ & 0.0000 & $0.000 \mathrm{E}+00$ & 0.0000 \\
\hline & $9.505 E-06$ & 1.0000 & $0.000 \mathrm{E}+00$ & 0.0000 & $0.000 \mathrm{E}+00$ & 0.0000 & $0.000 \mathrm{E}+00$ & 0.0000 & $0.000 \mathrm{E}+00$ & 0.0000 & $0.000 \mathrm{E}+00$ & 0.0000 & $.000 \mathrm{E}+00$ & 0.0000 \\
\hline
\end{tabular}

Total Dose Contributions TDOSE (i,p,t) for Individual Radionuclides (i) and Pathways (p) As mrem/yr and Fraction of Total Dose At $t=5.000 \mathrm{E}+01$ years

Water Dependent Pathways

\begin{tabular}{|c|c|c|c|c|c|c|c|c|c|c|c|c|c|c|}
\hline & \multicolumn{2}{|c|}{ Water } & \multicolumn{2}{|c|}{ Fish } & \multicolumn{2}{|c|}{ Radon } & \multicolumn{2}{|c|}{ Plant } & \multicolumn{2}{|c|}{ Meat } & \multicolumn{2}{|c|}{ Milk } & \multicolumn{2}{|c|}{ All Pathways* } \\
\hline clide & mrem/yr & fract. & mrem/yr & fract. & mrem/yr & fract. & mrem/yr & fract. & mrem/yr & fract. & mrem/yr & fract. & mrem/yr & fract. \\
\hline-241 & $0.000 \mathrm{E}+00$ & 0.0000 & $0.000 \mathrm{E}+00$ & 0.0000 & $0.000 \mathrm{E}+00$ & 0.0000 & $0.000 \mathrm{E}+00$ & 0.0000 & $0.000 \mathrm{E}+00$ & 0.0000 & $0.000 \mathrm{E}+00$ & 0.0000 & $8.840 \mathrm{E}-16$ & 0.0000 \\
\hline-137 & $0.000 \mathrm{E}+00$ & 0.0000 & $0.000 \mathrm{E}+00$ & 0.0000 & $0.000 \mathrm{E}+00$ & 0.0000 & $0.000 \mathrm{E}+00$ & 0.0000 & $0.000 \mathrm{E}+00$ & 0.0000 & $0.000 \mathrm{E}+00$ & 0.0000 & $1.158 \mathrm{E}-08$ & 0.0012 \\
\hline-237 & $0.000 \mathrm{E}+00$ & 0.0000 & $0.000 \mathrm{E}+00$ & 0.0000 & $0.000 \mathrm{E}+00$ & 0.0000 & $0.000 \mathrm{E}+00$ & 0.0000 & $0.000 \mathrm{E}+00$ & 0.0000 & $0.000 \mathrm{E}+00$ & 0.0000 & $8.909 \mathrm{E}-12$ & 0.0000 \\
\hline-238 & $0.000 \mathrm{E}+00$ & 0.0000 & $0.000 \mathrm{E}+00$ & 0.0000 & $0.000 \mathrm{E}+00$ & 0.0000 & $0.000 \mathrm{E}+00$ & 0.0000 & $0.000 \mathrm{E}+00$ & 0.0000 & $0.000 \mathrm{E}+00$ & 0.0000 & $1.988 \mathrm{E}-15$ & 0.0000 \\
\hline-239 & $0.000 \mathrm{E}+00$ & 0.0000 & $0.000 \mathrm{E}+00$ & 0.0000 & $0.000 \mathrm{E}+00$ & 0.0000 & $0.000 \mathrm{E}+00$ & 0.0000 & $0.000 \mathrm{E}+00$ & 0.0000 & $0.000 E+00$ & 0.0000 & $7.814 \mathrm{E}-16$ & 0.0000 \\
\hline-240 & $0.000 \mathrm{E}+00$ & 0.0000 & $0.000 \mathrm{E}+00$ & 0.0000 & $0.000 \mathrm{E}+00$ & 0.0000 & $0.000 \mathrm{E}+00$ & 0.0000 & $0.000 \mathrm{E}+00$ & 0.0000 & $0.000 E+00$ & 0.0000 & $9.393 \mathrm{E}-20$ & 0.0000 \\
\hline-99 & $0.000 \mathrm{E}+00$ & 0.0000 & $0.000 \mathrm{E}+00$ & 0.0000 & $0.000 \mathrm{E}+00$ & 0.0000 & $0.000 \mathrm{E}+00$ & 0.0000 & $0.000 \mathrm{E}+00$ & 0.0000 & $0.000 \mathrm{E}+00$ & 0.0000 & $4.954 \mathrm{E}-24$ & 0.0000 \\
\hline-228 & $0.000 \mathrm{E}+00$ & 0.0000 & $0.000 \mathrm{E}+00$ & 0.0000 & $0.000 \mathrm{E}+00$ & 0.0000 & $0.000 \mathrm{E}+00$ & 0.0000 & $0.000 \mathrm{E}+00$ & 0.0000 & $0.000 \mathrm{E}+00$ & 0.0000 & $1.201 \mathrm{E}-13$ & 0.0000 \\
\hline-230 & $0.000 \mathrm{E}+00$ & 0.0000 & $0.000 \mathrm{E}+00$ & 0.0000 & $0.000 \mathrm{E}+00$ & 0.0000 & $0.000 \mathrm{E}+00$ & 0.0000 & $0.000 \mathrm{E}+00$ & 0.0000 & $0.000 E+00$ & 0.0000 & $5.249 \mathrm{E}-07$ & 0.0552 \\
\hline 232 & $0.000 \mathrm{E}+00$ & 0.0000 & $0.000 \mathrm{E}+00$ & 0.0000 & $0.000 \mathrm{E}+00$ & 0.0000 & $0.000 \mathrm{E}+00$ & 0.0000 & $0.000 \mathrm{E}+00$ & 0.0000 & $0.000 \mathrm{E}+00$ & 0.0000 & $8.935 E-06$ & 0.9400 \\
\hline 34 & $0.000 \mathrm{E}+00$ & 0.0000 & $0.000 \mathrm{E}+00$ & 0.0000 & $0.000 \mathrm{E}+00$ & 0.0000 & $0.000 \mathrm{E}+00$ & 0.0000 & $0.000 \mathrm{E}+00$ & 0.0000 & $0.000 \mathrm{E}+00$ & 0.0000 & $1.897 \mathrm{E}-10$ & 0.0000 \\
\hline 35 & $0.000 \mathrm{E}+00$ & 0.0000 & $0.000 \mathrm{E}+00$ & 0.0000 & $0.000 \mathrm{E}+00$ & 0.0000 & $0.000 \mathrm{E}+00$ & 0.0000 & $0.000 \mathrm{E}+00$ & 0.0000 & $0.000 E+00$ & 0.0000 & $5.905 E-13$ & 0.0000 \\
\hline 38 & $0.000 \mathrm{E}+00$ & 0.0000 & $0.000 \mathrm{E}+00$ & 0.0000 & $0.000 \mathrm{E}+00$ & 0.0000 & $0.000 \mathrm{E}+00$ & 0.0000 & $0.000 \mathrm{E}+00$ & 0.0000 & $0.000 \mathrm{E}+00$ & 0.0000 & $3.372 \mathrm{E}-08$ & 0.0035 \\
\hline & $0.000 \mathrm{E}+00$ & 0.0000 & $0.000 \mathrm{E}+00$ & 0.0000 & $0.000 \mathrm{E}+00$ & 0.0000 & $0.000 \mathrm{E}+00$ & 0.0000 & $0.000 \mathrm{E}+00$ & 0.0000 & $0.000 \mathrm{E}+00$ & 0.0000 & $5 E-06$ & 1. \\
\hline
\end{tabular}

* Sum of all water independent and dependent pathways. 
RESRAD, Version 6.5

$\mathrm{T}^{1 / 2}$ Limit = 180 days

07/15/2011 13:56 Page 24

Summary : C746U Resident Farmer Deterministic Run
File : X: $\backslash$ FINAL V2 $\backslash$ DOE FWD RUNS $\backslash C 746 U$ RF DOE SG FWD-FV2-1050YR.RAD

Total Dose Contributions TDOSE(i,p,t) for Individual Radionuclides (i) and Pathways (p) As mrem/yr and Fraction of Total Dose At $t=1.000 \mathrm{E}+02$ years

Water Independent Pathways (Inhalation excludes radon)

\begin{tabular}{|c|c|c|c|c|c|c|c|c|c|c|c|c|c|c|}
\hline \multirow{2}{*}{ Nuclide } & \multicolumn{2}{|c|}{ Ground } & \multicolumn{2}{|c|}{ Inhalation } & \multicolumn{2}{|c|}{ Radon } & \multicolumn{2}{|c|}{ Plant } & \multicolumn{2}{|c|}{ Meat } & \multicolumn{2}{|c|}{ Milk } & \multicolumn{2}{|c|}{ Soil } \\
\hline & mrem/yr & fract. & mrem/yr & fract. & mrem/yr & fract. & mrem/yr & fract. & mrem/yr & fract. & mrem/yr & fract. & mrem/yr & fract. \\
\hline-241 & $2.911 E-15$ & 0.0000 & $0.000 \mathrm{E}+00$ & 0.0000 & $0.000 \mathrm{E}+00$ & 0.0000 & $0.000 \mathrm{E}+00$ & 0.0000 & $0.000 \mathrm{E}+00$ & 0.0000 & $0.000 \mathrm{E}+00$ & 0.0000 & $0.000 \mathrm{E}+00$ & 0.0000 \\
\hline-137 & $5.552 E-09$ & 0.0004 & $0.000 \mathrm{E}+00$ & 0.0000 & $0.000 \mathrm{E}+00$ & 0.0000 & $0.000 \mathrm{E}+00$ & 0.0000 & $0.000 \mathrm{E}+00$ & 0.0000 & $0.000 \mathrm{E}+00$ & 0.0000 & $0.000 \mathrm{E}+00$ & 0.0000 \\
\hline-237 & 1. $525 \mathrm{E}-11$ & 0.0000 & $0.000 \mathrm{E}+00$ & 0.0000 & $0.000 \mathrm{E}+00$ & 0.0000 & $0.000 \mathrm{E}+00$ & 0.0000 & $0.000 \mathrm{E}+00$ & 0.0000 & $0.000 \mathrm{E}+00$ & 0.0000 & $0.000 \mathrm{E}+00$ & 0.0000 \\
\hline-238 & $2.040 \mathrm{E}-14$ & 0.0000 & $0.000 \mathrm{E}+00$ & 0.0000 & $0.000 \mathrm{E}+00$ & 0.0000 & $0.000 \mathrm{E}+00$ & 0.0000 & $0.000 \mathrm{E}+00$ & 0.0000 & $0.000 \mathrm{E}+00$ & 0.0000 & $0.000 \mathrm{E}+00$ & 0.0000 \\
\hline-239 & $1.419 \mathrm{E}-15$ & 0.0000 & $0.000 \mathrm{E}+00$ & 0.0000 & $0.000 \mathrm{E}+00$ & 0.0000 & $0.000 \mathrm{E}+00$ & 0.0000 & $0.000 \mathrm{E}+00$ & 0.0000 & $0.000 \mathrm{E}+00$ & 0.0000 & $0.000 \mathrm{E}+00$ & 0.0000 \\
\hline-240 & $6.330 \mathrm{E}-19$ & 0.0000 & $0.000 \mathrm{E}+00$ & 0.0000 & $0.000 \mathrm{E}+00$ & 0.0000 & $0.000 \mathrm{E}+00$ & 0.0000 & $0.000 \mathrm{E}+00$ & 0.0000 & $0.000 \mathrm{E}+00$ & 0.0000 & $0.000 \mathrm{E}+00$ & 0.0000 \\
\hline 99 & $8.238 E-24$ & 0.0000 & $0.000 \mathrm{E}+00$ & 0.0000 & $0.000 \mathrm{E}+00$ & 0.0000 & $0.000 \mathrm{E}+00$ & 0.0000 & $0.000 \mathrm{E}+00$ & 0.0000 & $0.000 \mathrm{E}+00$ & 0.0000 & $0.000 \mathrm{E}+00$ & 0.0000 \\
\hline-228 & $2.196 \mathrm{E}-21$ & 0.0000 & $0.000 \mathrm{E}+00$ & 0.0000 & $0.000 \mathrm{E}+00$ & 0.0000 & $0.000 \mathrm{E}+00$ & 0.0000 & $0.000 \mathrm{E}+00$ & 0.0000 & $0.000 \mathrm{E}+00$ & 0.0000 & $0.000 \mathrm{E}+00$ & 0.0000 \\
\hline-230 & $1.467 \mathrm{E}-06$ & 0.1077 & $0.000 \mathrm{E}+00$ & 0.0000 & $0.000 \mathrm{E}+00$ & 0.0000 & $0.000 \mathrm{E}+00$ & 0.0000 & $0.000 \mathrm{E}+00$ & 0.0000 & $0.000 \mathrm{E}+00$ & 0.0000 & $0.000 \mathrm{E}+00$ & 0.0000 \\
\hline-232 & $1.209 E-05$ & 0.8881 & $0.000 \mathrm{E}+00$ & 0.0000 & $0.000 \mathrm{E}+00$ & 0.0000 & $0.000 \mathrm{E}+00$ & 0.0000 & $0.000 \mathrm{E}+00$ & 0.0000 & $0.000 \mathrm{E}+00$ & 0.0000 & $0.000 \mathrm{E}+00$ & 0.0000 \\
\hline 234 & $1.064 \mathrm{E}-09$ & 0.0001 & $0.000 \mathrm{E}+00$ & 0.0000 & $0.000 \mathrm{E}+00$ & 0.0000 & $0.000 \mathrm{E}+00$ & 0.0000 & $0.000 \mathrm{E}+00$ & 0.0000 & $0.000 \mathrm{E}+00$ & 0.0000 & $0.000 \mathrm{E}+00$ & 0.0000 \\
\hline 235 & $2.179 \mathrm{E}-12$ & 0.0000 & $0.000 \mathrm{E}+00$ & 0.0000 & $0.000 \mathrm{E}+00$ & 0.0000 & $0.000 \mathrm{E}+00$ & 0.0000 & $0.000 \mathrm{E}+00$ & 0.0000 & $0.000 \mathrm{E}+00$ & 0.0000 & $0.000 \mathrm{E}+00$ & 0.0000 \\
\hline 38 & $5.025 E-08$ & 0.0037 & $0.000 \mathrm{E}+00$ & 0.0000 & $0.000 \mathrm{E}+00$ & 0.0000 & $0.000 \mathrm{E}+00$ & 0.0000 & $0.000 \mathrm{E}+00$ & 0.0000 & $0.000 \mathrm{E}+00$ & 0.0000 & $0.000 \mathrm{E}+00$ & 0.0000 \\
\hline & $1.362 \mathrm{E}-05$ & 1.0000 & $0.000 \mathrm{E}+00$ & 0.0000 & $0.000 \mathrm{E}+00$ & 0.0000 & $0.000 \mathrm{E}+00$ & 0.0000 & $0.000 \mathrm{E}+00$ & 0.0000 & $0.000 \mathrm{E}+00$ & 0.0000 & $.000 \mathrm{E}+00$ & 0.0000 \\
\hline
\end{tabular}

Total Dose Contributions TDOSE(i,p,t) for Individual Radionuclides (i) and Pathways (p) As mrem/yr and Fraction of Total Dose At $t=1.000 \mathrm{E}+02$ years

Water Dependent Pathways

\begin{tabular}{|c|c|c|c|c|c|c|c|c|c|c|c|c|c|c|}
\hline & \multicolumn{2}{|c|}{ Water } & \multicolumn{2}{|c|}{ Fish } & \multicolumn{2}{|c|}{ Radon } & \multicolumn{2}{|c|}{ Plant } & \multicolumn{2}{|c|}{ Meat } & \multicolumn{2}{|c|}{ Milk } & \multicolumn{2}{|c|}{ All Pathways* } \\
\hline clide & mrem/yr & fract. & mrem/yr & fract. & mrem/yr & fract. & mrem/yr & fract. & mrem/yr & fract. & mrem/yr & fract. & mrem/yr & fract. \\
\hline-241 & $0.000 \mathrm{E}+00$ & 0.0000 & $0.000 \mathrm{E}+00$ & 0.0000 & $0.000 \mathrm{E}+00$ & 0.0000 & $0.000 \mathrm{E}+00$ & 0.0000 & $0.000 \mathrm{E}+00$ & 0.0000 & $0.000 \mathrm{E}+00$ & 0.0000 & $2.911 \mathrm{E}-15$ & 0.0000 \\
\hline-137 & $0.000 \mathrm{E}+00$ & 0.0000 & $0.000 \mathrm{E}+00$ & 0.0000 & $0.000 \mathrm{E}+00$ & 0.0000 & $0.000 \mathrm{E}+00$ & 0.0000 & $0.000 \mathrm{E}+00$ & 0.0000 & $0.000 \mathrm{E}+00$ & 0.0000 & $5.552 \mathrm{E}-09$ & 0.0004 \\
\hline-237 & $0.000 \mathrm{E}+00$ & 0.0000 & $0.000 \mathrm{E}+00$ & 0.0000 & $0.000 \mathrm{E}+00$ & 0.0000 & $0.000 \mathrm{E}+00$ & 0.0000 & $0.000 \mathrm{E}+00$ & 0.0000 & $0.000 \mathrm{E}+00$ & 0.0000 & $1.525 \mathrm{E}-11$ & 0.0000 \\
\hline-238 & $0.000 \mathrm{E}+00$ & 0.0000 & $0.000 \mathrm{E}+00$ & 0.0000 & $0.000 \mathrm{E}+00$ & 0.0000 & $0.000 \mathrm{E}+00$ & 0.0000 & $0.000 \mathrm{E}+00$ & 0.0000 & $0.000 \mathrm{E}+00$ & 0.0000 & $2.040 \mathrm{E}-14$ & 0.0000 \\
\hline-239 & $0.000 \mathrm{E}+00$ & 0.0000 & $0.000 \mathrm{E}+00$ & 0.0000 & $0.000 \mathrm{E}+00$ & 0.0000 & $0.000 \mathrm{E}+00$ & 0.0000 & $0.000 \mathrm{E}+00$ & 0.0000 & $0.000 \mathrm{E}+00$ & 0.0000 & 1. $419 \mathrm{E}-15$ & 0.0000 \\
\hline-240 & $0.000 \mathrm{E}+00$ & 0.0000 & $0.000 \mathrm{E}+00$ & 0.0000 & $0.000 \mathrm{E}+00$ & 0.0000 & $0.000 \mathrm{E}+00$ & 0.0000 & $0.000 \mathrm{E}+00$ & 0.0000 & $0.000 \mathrm{E}+00$ & 0.0000 & $6.330 \mathrm{E}-19$ & 0.0000 \\
\hline 99 & $0.000 \mathrm{E}+00$ & 0.0000 & $0.000 \mathrm{E}+00$ & 0.0000 & $0.000 \mathrm{E}+00$ & 0.0000 & $0.000 \mathrm{E}+00$ & 0.0000 & $0.000 \mathrm{E}+00$ & 0.0000 & $0.000 \mathrm{E}+00$ & 0.0000 & $8.238 E-24$ & 0.0000 \\
\hline-228 & $0.000 \mathrm{E}+00$ & 0.0000 & $0.000 \mathrm{E}+00$ & 0.0000 & $0.000 \mathrm{E}+00$ & 0.0000 & $0.000 \mathrm{E}+00$ & 0.0000 & $0.000 \mathrm{E}+00$ & 0.0000 & $0.000 \mathrm{E}+00$ & 0.0000 & $2.196 \mathrm{E}-21$ & 0.0000 \\
\hline-230 & $0.000 \mathrm{E}+00$ & 0.0000 & $0.000 \mathrm{E}+00$ & 0.0000 & $0.000 \mathrm{E}+00$ & 0.0000 & $0.000 \mathrm{E}+00$ & 0.0000 & $0.000 \mathrm{E}+00$ & 0.0000 & $0.000 \mathrm{E}+00$ & 0.0000 & $1.467 \mathrm{E}-06$ & 0.1077 \\
\hline-232 & $0.000 \mathrm{E}+00$ & 0.0000 & $0.000 \mathrm{E}+00$ & 0.0000 & $0.000 \mathrm{E}+00$ & 0.0000 & $0.000 \mathrm{E}+00$ & 0.0000 & $0.000 \mathrm{E}+00$ & 0.0000 & $0.000 \mathrm{E}+00$ & 0.0000 & $1.209 E-05$ & 0.8881 \\
\hline 234 & $0.000 \mathrm{E}+00$ & 0.0000 & $0.000 \mathrm{E}+00$ & 0.0000 & $0.000 \mathrm{E}+00$ & 0.0000 & $0.000 \mathrm{E}+00$ & 0.0000 & $0.000 \mathrm{E}+00$ & 0.0000 & $0.000 \mathrm{E}+00$ & 0.0000 & $1.064 \mathrm{E}-09$ & 0.0001 \\
\hline 35 & $0.000 \mathrm{E}+00$ & 0.0000 & $0.000 \mathrm{E}+00$ & 0.0000 & $0.000 \mathrm{E}+00$ & 0.0000 & $0.000 \mathrm{E}+00$ & 0.0000 & $0.000 \mathrm{E}+00$ & 0.0000 & $0.000 \mathrm{E}+00$ & 0.0000 & $2.179 \mathrm{E}-12$ & 0.0000 \\
\hline 38 & $0.000 \mathrm{E}+00$ & 0.0000 & $0.000 \mathrm{E}+00$ & 0.0000 & $0.000 \mathrm{E}+00$ & 0.0000 & $0.000 \mathrm{E}+00$ & 0.0000 & $0.000 \mathrm{E}+00$ & 0.0000 & $0.000 \mathrm{E}+00$ & 0.0000 & $5.025 \mathrm{E}-08$ & 0.0037 \\
\hline & $0.000 \mathrm{E}+00$ & 0.0000 & $0.000 \mathrm{E}+00$ & 0.0000 & $0.000 \mathrm{E}+00$ & 0.0000 & $0.000 \mathrm{E}+00$ & 0.0000 & $0.000 \mathrm{E}+00$ & 0.0000 & $0.000 \mathrm{E}+00$ & 0.0000 & $1.362 E-05$ & 1.0000 \\
\hline
\end{tabular}

* Sum of all water independent and dependent pathways. 
RESRAD, Version 6.5

$\mathrm{T}^{1 / 2}$ Limit = 180 days

07/15/2011 13:56 Page 25

Summary : C746U Resident Farmer Deterministic Run
File : X: $\backslash$ FINAL V2 $\backslash$ DOE FWD RUNS $\backslash C 746 U$ RF DOE SG FWD-FV2-1050YR.RAD

Total Dose Contributions TDOSE(i,p,t) for Individual Radionuclides (i) and Pathways (p) As mrem/yr and Fraction of Total Dose At $t=5.000 \mathrm{E}+02$ years

Water Independent Pathways (Inhalation excludes radon)

\begin{tabular}{|c|c|c|}
\hline clide & mrem/yr & fract. \\
\hline-241 & $7.984 \mathrm{E}-13$ & 0.0000 \\
\hline-137 & $1.551 \mathrm{E}-11$ & 0.0000 \\
\hline-237 & $1.118 \mathrm{E}-09$ & 0.0000 \\
\hline-238 & $2.174 \mathrm{E}-11$ & 0.0000 \\
\hline-239 & $1.685 E-13$ & 0.0000 \\
\hline-240 & $2.048 \mathrm{E}-16$ & 0.0000 \\
\hline-99 & $4.816 \mathrm{E}-22$ & 0.0000 \\
\hline-228 & $0.000 \mathrm{E}+00$ & 0.0000 \\
\hline-230 & $1.066 \mathrm{E}-04$ & 0.0000 \\
\hline-232 & $1.331 \mathrm{E}-04$ & 0.0000 \\
\hline 234 & $3.972 E-07$ & 0.0000 \\
\hline 235 & $4.546 \mathrm{E}-10$ & 0.0000 \\
\hline 238 & $1.224 E-06$ & 0.0000 \\
\hline & $2.414 \mathrm{E}-04$ & 0.0000 \\
\hline
\end{tabular}

Radio-

Total

$2.414 \mathrm{E}-04 \quad 0.0000$

\begin{abstract}
Inhalation
\end{abstract}
$\overline{\mathrm{mrem} / \mathrm{yr} \text { fract. }}$

$\overline{0.000 E+00} 0.0000$

$0.000 \mathrm{E}+00 \quad 0.0000$

$0.000 \mathrm{E}+00 \quad 0.0000$

$0.000 \mathrm{E}+00 \quad 0.0000$

$0.000 \mathrm{E}+00 \quad 0.0000$

$0.000 \mathrm{E}+00 \quad 0.0000$

$0.000 E+00 \quad 0.0000$

$0.000 \mathrm{E}+00 \quad 0.0000$

$0.000 \mathrm{E}+00 \quad 0.0000$

$0.000 \mathrm{E}+00 \quad 0.0000$

$0.000 \mathrm{E}+00 \quad 0.0000$

$0.000 E+00 \quad 0.0000$

$0.000 \mathrm{E}+00 \quad 0.0000$

$\overline{0.000 \mathrm{E}+00} \overline{\underline{0.0000}}$

Radon
mrem/yr fract. $\overline{0.000 \mathrm{E}+00} \overline{0.0000}$ $0.000 E+00 \quad 0.0000$ $0.000 E+00 \quad 0.0000$ $0.000 \mathrm{E}+00 \quad 0.0000$ $0.000 \mathrm{E}+00 \quad 0.0000$ $0.000 E+00 \quad 0.0000$ $0.000 \mathrm{E}+00 \quad 0.0000$ $0.000 \mathrm{E}+00 \quad 0.0000$ $0.000 \mathrm{E}+00 \quad 0.0000$ $0.000 \mathrm{E}+00 \quad 0.0000$ $0.000 \mathrm{E}+00 \quad 0.0000$ $0.000 \mathrm{E}+00 \quad 0.0000$ $0.000 \mathrm{E}+00 \quad 0.0000$

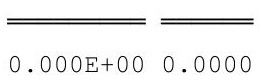

\begin{tabular}{|c|c|c|c|}
\hline \multicolumn{2}{|c|}{ Plant } & \multicolumn{2}{|c|}{ Meat } \\
\hline mrem/yr & fract. & mrem/yr & fract. \\
\hline $.000 \mathrm{E}+00$ & 0.0000 & $0.000 \mathrm{E}+00$ & 0.0000 \\
\hline $0.000 \mathrm{E}+00$ & 0.0000 & $0.000 \mathrm{E}+00$ & 0.0000 \\
\hline $0.000 \mathrm{E}+00$ & 0.0000 & $0.000 \mathrm{E}+00$ & 0.0000 \\
\hline $0.000 \mathrm{E}+00$ & 0.0000 & $0.000 \mathrm{E}+00$ & 0.0000 \\
\hline $0.000 \mathrm{E}+00$ & 0.0000 & $0.000 \mathrm{E}+00$ & 0.0000 \\
\hline $0.000 \mathrm{E}+00$ & 0.0000 & $0.000 \mathrm{E}+00$ & 0.0000 \\
\hline $0.000 \mathrm{E}+00$ & 0.0000 & $0.000 \mathrm{E}+00$ & 0.0000 \\
\hline $0.000 \mathrm{E}+00$ & 0.0000 & $0.000 \mathrm{E}+00$ & 0.0000 \\
\hline $0.000 \mathrm{E}+00$ & 0.0000 & $0.000 \mathrm{E}+00$ & 0.0000 \\
\hline $0.000 \mathrm{E}+00$ & 0.0000 & $0.000 \mathrm{E}+00$ & 0.0000 \\
\hline $0.000 \mathrm{E}+00$ & 0.0000 & $0.000 \mathrm{E}+00$ & 0.0000 \\
\hline $0.000 \mathrm{E}+00$ & 0.0000 & $0.000 \mathrm{E}+00$ & 0.0000 \\
\hline $0.000 \mathrm{E}+00$ & 0.0000 & $0.000 \mathrm{E}+00$ & 0.0000 \\
\hline & & 0.00 & . \\
\hline
\end{tabular}

\begin{tabular}{cc} 
Milk \\
\hline mrem/yr fract. \\
\cline { 1 - 2 } $0.000 \mathrm{E}+00$ & 0.0000 \\
$0.000 \mathrm{E}+00$ & 0.0000 \\
$0.000 \mathrm{E}+00$ & 0.0000 \\
$0.000 \mathrm{E}+00$ & 0.0000 \\
$0.000 \mathrm{E}+00$ & 0.0000 \\
$0.000 \mathrm{E}+00$ & 0.0000 \\
$0.000 \mathrm{E}+00$ & 0.0000 \\
$0.000 \mathrm{E}+00$ & 0.0000 \\
$0.000 \mathrm{E}+00$ & 0.0000 \\
$0.000 \mathrm{E}+00$ & 0.0000 \\
$0.000 \mathrm{E}+00$ & 0.0000 \\
$0.000 \mathrm{E}+00$ & 0.0000 \\
$0.000 \mathrm{E}+00$ & 0.0000 \\
\hline \hline $0.000 \mathrm{E}+00$ & 0.0000
\end{tabular}

Soil mrem/yr fract. $0.000 \mathrm{E}+00 \quad 0.0000$ $0.000 \mathrm{E}+00 \quad 0.0000$ $0.000 \mathrm{E}+00 \quad 0.0000$ $0.000 \mathrm{E}+00 \quad 0.0000$ $0.000 \mathrm{E}+00 \quad 0.0000$ $0.000 \mathrm{E}+00 \quad 0.0000$ $0.000 \mathrm{E}+00 \quad 0.0000$ $0.000 \mathrm{E}+00 \quad 0.0000$ $0.000 \mathrm{E}+00 \quad 0.0000$ $0.000 \mathrm{E}+00 \quad 0.0000$ $0.000 \mathrm{E}+00 \quad 0.0000$ $0.000 \mathrm{E}+00 \quad 0.0000$ $0.000 \mathrm{E}+00 \quad 0.0000$ $0.000 \mathrm{E}+00 \quad 0.0000$

Total Dose Contributions TDOSE(i,p,t) for Individual Radionuclides (i) and Pathways (p) As mrem/yr and Fraction of Total Dose At $t=5.000 \mathrm{E}+02$ years

Water Dependent Pathways

\begin{tabular}{|c|c|c|c|c|c|c|}
\hline & \multicolumn{2}{|c|}{ Water } & \multicolumn{2}{|c|}{ Fish } & \multicolumn{2}{|c|}{ Radon } \\
\hline clide & mrem/yr & fract. & mrem/yr & fract. & mrem/yr & fract. \\
\hline 41 & $0.000 \mathrm{E}+00$ & 0.0000 & $0.000 \mathrm{E}+00$ & 0.0000 & $0.000 \mathrm{E}+00$ & 0.0000 \\
\hline-137 & $0.000 \mathrm{E}+00$ & 0.0000 & $0.000 \mathrm{E}+00$ & 0.0000 & $0.000 \mathrm{E}+00$ & 0.0000 \\
\hline-237 & $0.000 \mathrm{E}+00$ & 0.0000 & $0.000 \mathrm{E}+00$ & 0.0000 & $0.000 \mathrm{E}+00$ & 0.0000 \\
\hline-238 & $0.000 \mathrm{E}+00$ & 0.0000 & $0.000 \mathrm{E}+00$ & 0.0000 & $0.000 \mathrm{E}+00$ & 0.0000 \\
\hline-239 & $0.000 \mathrm{E}+00$ & 0.0000 & $0.000 \mathrm{E}+00$ & 0.0000 & $0.000 \mathrm{E}+00$ & 0.0000 \\
\hline-240 & $0.000 \mathrm{E}+00$ & 0.0000 & $0.000 \mathrm{E}+00$ & 0.0000 & $0.000 \mathrm{E}+00$ & 0.0000 \\
\hline-99 & $8.951 E+00$ & 0.8277 & $0.000 \mathrm{E}+00$ & 0.0000 & $0.000 \mathrm{E}+00$ & 0.0000 \\
\hline-228 & $0.000 \mathrm{E}+00$ & 0.0000 & $0.000 \mathrm{E}+00$ & 0.0000 & $0.000 \mathrm{E}+00$ & 0.0000 \\
\hline-230 & $0.000 \mathrm{E}+00$ & 0.0000 & $0.000 \mathrm{E}+00$ & 0.0000 & $0.000 \mathrm{E}+00$ & 0.0000 \\
\hline-232 & $0.000 \mathrm{E}+00$ & 0.0000 & $0.000 \mathrm{E}+00$ & 0.0000 & $0.000 \mathrm{E}+00$ & 0.0000 \\
\hline 234 & $0.000 \mathrm{E}+00$ & 0.0000 & $0.000 \mathrm{E}+00$ & 0.0000 & $0.000 \mathrm{E}+00$ & 0.0000 \\
\hline 35 & $0.000 \mathrm{E}+00$ & 0.0000 & $0.000 \mathrm{E}+00$ & 0.0000 & $0.000 \mathrm{E}+00$ & 0.0000 \\
\hline 38 & $0.000 \mathrm{E}+00$ & 0.0000 & $0.000 \mathrm{E}+00$ & 0.0000 & $0.000 \mathrm{E}+00$ & 0.0000 \\
\hline & $8.951 E+00$ & 0.8277 & $0.000 \mathrm{E}+00$ & 0.0000 & $0.000 \mathrm{E}+00$ & 0.0000 \\
\hline
\end{tabular}

\begin{tabular}{|c|c|c|c|}
\hline \multicolumn{2}{|c|}{ Plant } & \multicolumn{2}{|c|}{ Meat } \\
\hline mrem/yr & fract. & mrem/yr & fract. \\
\hline $0.000 \mathrm{E}+00$ & 0.0000 & $0.000 \mathrm{E}+00$ & 0.0000 \\
\hline $0.000 \mathrm{E}+00$ & 0.0000 & $0.000 \mathrm{E}+00$ & 0.0000 \\
\hline $0.000 \mathrm{E}+00$ & 0.0000 & $0.000 \mathrm{E}+00$ & 0.0000 \\
\hline $0.000 \mathrm{E}+00$ & 0.0000 & $0.000 \mathrm{E}+00$ & 0.0000 \\
\hline $0.000 \mathrm{E}+00$ & 0.0000 & $0.000 \mathrm{E}+00$ & 0.0000 \\
\hline $0.000 \mathrm{E}+00$ & 0.0000 & $0.000 \mathrm{E}+00$ & 0.0000 \\
\hline $8.368 \mathrm{E}-01$ & 0.0774 & $1.498 \mathrm{E}-02$ & 0.0014 \\
\hline $0.000 \mathrm{E}+00$ & 0.0000 & $0.000 \mathrm{E}+00$ & 0.0000 \\
\hline $0.000 \mathrm{E}+00$ & 0.0000 & $0.000 \mathrm{E}+00$ & 0.0000 \\
\hline $0.000 \mathrm{E}+00$ & 0.0000 & $0.000 \mathrm{E}+00$ & 0.0000 \\
\hline $0.000 \mathrm{E}+00$ & 0.0000 & $0.000 \mathrm{E}+00$ & 0.0000 \\
\hline $0.000 \mathrm{E}+00$ & 0.0000 & $0.000 \mathrm{E}+00$ & 0.0000 \\
\hline $0.000 \mathrm{E}+00$ & 0.0000 & $0.000 \mathrm{E}+00$ & 0.0000 \\
\hline
\end{tabular}

$8.368 \mathrm{E}-010.0774$

$1.498 \mathrm{E}-02 \quad 0.0014$

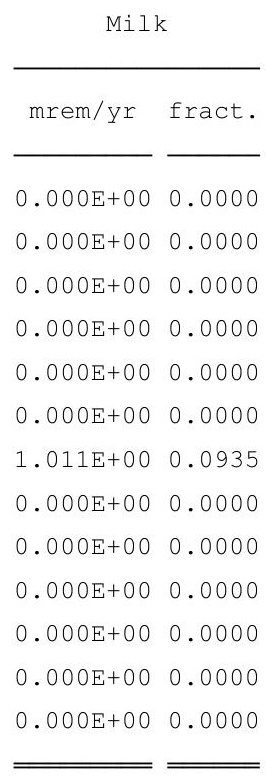

$1.011 \mathrm{E}+00 \quad 0.0935$
All Pathways* mrem/yr fract.

$7.984 \mathrm{E}-13 \quad 0.0000$ $1.551 \mathrm{E}-110.0000$ $1.118 \mathrm{E}-090.0000$ $2.174 \mathrm{E}-110.0000$ $1.685 \mathrm{E}-13 \quad 0.0000$ $2.048 E-160.0000$ $1.081 \mathrm{E}+011.0000$ $0.000 \mathrm{E}+00 \quad 0.0000$ $1.066 \mathrm{E}-04 \quad 0.0000$ $1.331 \mathrm{E}-04 \quad 0.0000$ $3.972 \mathrm{E}-07 \quad 0.0000$ $4.546 \mathrm{E}-10 \quad 0.0000$ $1.224 \mathrm{E}-06 \quad 0.0000$ $1.081 \mathrm{E}+011.0000$

* Sum of all water independent and dependent pathways. 
RESRAD, Version 6.5

$\mathrm{T}^{1 / 2}$ Limit = 180 days

07/15/2011 13:56 Page 26

ummary : C746U Resident Farmer Deterministic Run

: X: $\backslash F I N A L$ V2 \DOE FWD RUNS \C746U RF DOE SG FWD-FV2-1050YR.RAD

Total Dose Contributions TDOSE(i,p,t) for Individual Radionuclides (i) and Pathways (p) As mrem/yr and Fraction of Total Dose At $t=1.050 \mathrm{E}+03$ years

Water Independent Pathways (Inhalation excludes radon)

\begin{tabular}{|c|c|c|c|c|c|c|c|c|c|c|c|c|c|c|}
\hline \multirow{2}{*}{ Nuclide } & \multicolumn{2}{|c|}{ Ground } & \multicolumn{2}{|c|}{ Inhalation } & \multicolumn{2}{|c|}{ Radon } & \multicolumn{2}{|c|}{ Plant } & \multicolumn{2}{|c|}{ Meat } & \multicolumn{2}{|c|}{ Milk } & \multicolumn{2}{|c|}{ Soil } \\
\hline & mrem/yr & fract. & mrem/yr & fract. & mrem/yr & fract. & mrem/yr & fract. & mrem/yr & fract. & mrem/yr & fract. & mrem/yr & fract. \\
\hline-241 & $4.234 \mathrm{E}-10$ & 0.0000 & $0.000 \mathrm{E}+00$ & 0.0000 & $0.000 \mathrm{E}+00$ & 0.0000 & $6.742 \mathrm{E}-03$ & 0.0009 & $1.195 \mathrm{E}-05$ & 0.0000 & $1.147 \mathrm{E}-06$ & 0.0000 & $0.000 \mathrm{E}+00$ & 0.0000 \\
\hline-137 & $4.776 E-15$ & 0.0000 & $0.000 \mathrm{E}+00$ & 0.0000 & $0.000 \mathrm{E}+00$ & 0.0000 & $1.435 \mathrm{E}-12$ & 0.0000 & $1.304 \mathrm{E}-12$ & 0.0000 & $9.626 \mathrm{E}-13$ & 0.0000 & $0.000 \mathrm{E}+00$ & 0.0000 \\
\hline-237 & $3.889 \mathrm{E}-07$ & 0.0000 & $0.000 \mathrm{E}+00$ & 0.0000 & $0.000 \mathrm{E}+00$ & 0.0000 & $5.473 E-02$ & 0.0076 & $1.658 \mathrm{E}-03$ & 0.0002 & $2.372 E-05$ & 0.0000 & $0.000 \mathrm{E}+00$ & 0.0000 \\
\hline-238 & $5.054 \mathrm{E}-09$ & 0.0000 & $0.000 \mathrm{E}+00$ & 0.0000 & $0.000 \mathrm{E}+00$ & 0.0000 & $2.317 E-05$ & 0.0000 & $2.055 E-07$ & 0.0000 & $5.814 \mathrm{E}-07$ & 0.0000 & $0.000 \mathrm{E}+00$ & 0.0000 \\
\hline-239 & $1.194 \mathrm{E}-10$ & 0.0000 & $0.000 \mathrm{E}+00$ & 0.0000 & $0.000 \mathrm{E}+00$ & 0.0000 & $4.433 E-02$ & 0.0062 & $1.343 \mathrm{E}-04$ & 0.0000 & $3.719 \mathrm{E}-06$ & 0.0000 & $0.000 \mathrm{E}+00$ & 0.0000 \\
\hline-240 & $2.901 \mathrm{E}-14$ & 0.0000 & $0.000 \mathrm{E}+00$ & 0.0000 & $0.000 \mathrm{E}+00$ & 0.0000 & $4.088 \mathrm{E}-02$ & 0.0057 & $1.238 \mathrm{E}-04$ & 0.0000 & $3.460 \mathrm{E}-06$ & 0.0000 & $0.000 \mathrm{E}+00$ & 0.0000 \\
\hline 99 & $1.295 E-19$ & 0.0000 & $0.000 \mathrm{E}+00$ & 0.0000 & $0.000 \mathrm{E}+00$ & 0.0000 & $6.721 \mathrm{E}-05$ & 0.0000 & $2.039 \mathrm{E}-07$ & 0.0000 & $5.641 \mathrm{E}-06$ & 0.0000 & $0.000 \mathrm{E}+00$ & 0.0000 \\
\hline-228 & $0.000 \mathrm{E}+00$ & 0.0000 & $0.000 \mathrm{E}+00$ & 0.0000 & $0.000 \mathrm{E}+00$ & 0.0000 & $0.000 \mathrm{E}+00$ & 0.0000 & $0.000 \mathrm{E}+00$ & 0.0000 & $0.000 \mathrm{E}+00$ & 0.0000 & $0.000 \mathrm{E}+00$ & 0.0000 \\
\hline-230 & $8.932 \mathrm{E}-03$ & 0.0012 & $0.000 \mathrm{E}+00$ & 0.0000 & $0.000 \mathrm{E}+00$ & 0.0000 & $5.638 \mathrm{E}+00$ & 0.7834 & $1.483 \mathrm{E}-01$ & 0.0206 & $2.628 \mathrm{E}-01$ & 0.0365 & $0.000 \mathrm{E}+00$ & 0.0000 \\
\hline-232 & $3.686 E-03$ & 0.0005 & $0.000 \mathrm{E}+00$ & 0.0000 & $0.000 \mathrm{E}+00$ & 0.0000 & $5.753 \mathrm{E}-01$ & 0.0799 & $1.697 \mathrm{E}-02$ & 0.0024 & $4.699 \mathrm{E}-02$ & 0.0065 & $0.000 \mathrm{E}+00$ & 0.0000 \\
\hline 234 & $7.236 \mathrm{E}-05$ & 0.0000 & $0.000 \mathrm{E}+00$ & 0.0000 & $0.000 \mathrm{E}+00$ & 0.0000 & $1.440 \mathrm{E}-01$ & 0.0200 & $2.196 \mathrm{E}-03$ & 0.0003 & $7.061 \mathrm{E}-03$ & 0.0010 & $0.000 \mathrm{E}+00$ & 0.0000 \\
\hline 235 & $1.519 \mathrm{E}-07$ & 0.0000 & $0.000 \mathrm{E}+00$ & 0.0000 & $0.000 \mathrm{E}+00$ & 0.0000 & $1.115 \mathrm{E}-02$ & 0.0015 & $8.217 \mathrm{E}-04$ & 0.0001 & $2.012 \mathrm{E}-04$ & 0.0000 & $0.000 \mathrm{E}+00$ & 0.0000 \\
\hline 38 & $9.880 \mathrm{E}-05$ & 0.0000 & $0.000 \mathrm{E}+00$ & 0.0000 & $0.000 \mathrm{E}+00$ & 0.0000 & $9.831 \mathrm{E}-02$ & 0.0137 & $1.013 E-03$ & 0.0001 & $4.947 \mathrm{E}-03$ & 0.0007 & $0.000 \mathrm{E}+00$ & 0.0000 \\
\hline & 1.279E-02 & 0.0018 & $0.000 \mathrm{E}+00$ & 0.0000 & $0.000 \mathrm{E}+00$ & 0.0000 & $6.613 E+00$ & 0.9190 & $1.712 \mathrm{E}-01$ & 0.0238 & $3.221 \mathrm{E}-01$ & 0.0448 & $.000 \mathrm{E}+00$ & 0.0000 \\
\hline
\end{tabular}

Total Dose Contributions TDOSE (i,p,t) for Individual Radionuclides (i) and Pathways (p) As mrem/yr and Fraction of Total Dose At $t=1.050 \mathrm{E}+03$ years

Water Dependent Pathways

\begin{tabular}{|c|c|c|c|c|c|c|c|c|c|c|c|c|c|c|}
\hline \multirow{2}{*}{ Nuclide } & \multicolumn{2}{|c|}{ Water } & \multicolumn{2}{|c|}{ Fish } & \multicolumn{2}{|c|}{ Radon } & \multicolumn{2}{|c|}{ Plant } & \multicolumn{2}{|c|}{ Meat } & \multicolumn{2}{|c|}{ Milk } & \multicolumn{2}{|c|}{ All Pathways* } \\
\hline & mrem/yr & fract. & mrem/yr & fract. & mrem/yr & fract. & mrem/yr & fract. & mrem/yr & fract. & mrem/yr & fract. & mrem/yr & fract. \\
\hline-241 & $0.000 \mathrm{E}+00$ & 0.0000 & $0.000 \mathrm{E}+00$ & 0.0000 & $0.000 \mathrm{E}+00$ & 0.0000 & $0.000 \mathrm{E}+00$ & 0.0000 & $0.000 \mathrm{E}+00$ & 0.0000 & $0.000 \mathrm{E}+00$ & 0.0000 & $6.755 E-03$ & 0.0009 \\
\hline-137 & $0.000 \mathrm{E}+00$ & 0.0000 & $0.000 \mathrm{E}+00$ & 0.0000 & $0.000 \mathrm{E}+00$ & 0.0000 & $0.000 \mathrm{E}+00$ & 0.0000 & $0.000 \mathrm{E}+00$ & 0.0000 & $0.000 \mathrm{E}+00$ & 0.0000 & $3.706 \mathrm{E}-12$ & 0.0000 \\
\hline-237 & $0.000 \mathrm{E}+00$ & 0.0000 & $0.000 \mathrm{E}+00$ & 0.0000 & $0.000 \mathrm{E}+00$ & 0.0000 & $0.000 \mathrm{E}+00$ & 0.0000 & $0.000 \mathrm{E}+00$ & 0.0000 & $0.000 \mathrm{E}+00$ & 0.0000 & $5.641 \mathrm{E}-02$ & 0.0078 \\
\hline-238 & $0.000 \mathrm{E}+00$ & 0.0000 & $0.000 \mathrm{E}+00$ & 0.0000 & $0.000 \mathrm{E}+00$ & 0.0000 & $0.000 \mathrm{E}+00$ & 0.0000 & $0.000 \mathrm{E}+00$ & 0.0000 & $0.000 \mathrm{E}+00$ & 0.0000 & $2.396 \mathrm{E}-05$ & 0.0000 \\
\hline-239 & $0.000 \mathrm{E}+00$ & 0.0000 & $0.000 \mathrm{E}+00$ & 0.0000 & $0.000 \mathrm{E}+00$ & 0.0000 & $0.000 \mathrm{E}+00$ & 0.0000 & $0.000 \mathrm{E}+00$ & 0.0000 & $0.000 \mathrm{E}+00$ & 0.0000 & $4.447 \mathrm{E}-02$ & 0.0062 \\
\hline-240 & $0.000 \mathrm{E}+00$ & 0.0000 & $0.000 \mathrm{E}+00$ & 0.0000 & $0.000 \mathrm{E}+00$ & 0.0000 & $0.000 \mathrm{E}+00$ & 0.0000 & $0.000 \mathrm{E}+00$ & 0.0000 & $0.000 \mathrm{E}+00$ & 0.0000 & $4.101 \mathrm{E}-02$ & 0.0057 \\
\hline-99 & $6.365 \mathrm{E}-02$ & 0.0088 & $0.000 \mathrm{E}+00$ & 0.0000 & $0.000 \mathrm{E}+00$ & 0.0000 & $5.951 \mathrm{E}-03$ & 0.0008 & $1.065 \mathrm{E}-04$ & 0.0000 & $7.190 \mathrm{E}-03$ & 0.0010 & 7. $697 \mathrm{E}-02$ & 0.0107 \\
\hline-228 & $0.000 \mathrm{E}+00$ & 0.0000 & $0.000 \mathrm{E}+00$ & 0.0000 & $0.000 \mathrm{E}+00$ & 0.0000 & $0.000 \mathrm{E}+00$ & 0.0000 & $0.000 \mathrm{E}+00$ & 0.0000 & $0.000 \mathrm{E}+00$ & 0.0000 & $0.000 \mathrm{E}+00$ & 0.0000 \\
\hline 230 & $0.000 \mathrm{E}+00$ & 0.0000 & $0.000 \mathrm{E}+00$ & 0.0000 & $0.000 \mathrm{E}+00$ & 0.0000 & $0.000 \mathrm{E}+00$ & 0.0000 & $0.000 \mathrm{E}+00$ & 0.0000 & $0.000 \mathrm{E}+00$ & 0.0000 & $6.058 \mathrm{E}+00$ & 0.8418 \\
\hline 232 & $0.000 \mathrm{E}+00$ & 0.0000 & $0.000 \mathrm{E}+00$ & 0.0000 & $0.000 \mathrm{E}+00$ & 0.0000 & $0.000 \mathrm{E}+00$ & 0.0000 & $0.000 \mathrm{E}+00$ & 0.0000 & $0.000 \mathrm{E}+00$ & 0.0000 & $6.430 \mathrm{E}-01$ & 0.0893 \\
\hline 34 & $0.000 \mathrm{E}+00$ & 0.0000 & $0.000 \mathrm{E}+00$ & 0.0000 & $0.000 \mathrm{E}+00$ & 0.0000 & $0.000 \mathrm{E}+00$ & 0.0000 & $0.000 \mathrm{E}+00$ & 0.0000 & $0.000 \mathrm{E}+00$ & 0.0000 & $1.533 \mathrm{E}-01$ & 0.0213 \\
\hline 35 & $0.000 \mathrm{E}+00$ & 0.0000 & $0.000 \mathrm{E}+00$ & 0.0000 & $0.000 \mathrm{E}+00$ & 0.0000 & $0.000 \mathrm{E}+00$ & 0.0000 & $0.000 \mathrm{E}+00$ & 0.0000 & $0.000 \mathrm{E}+00$ & 0.0000 & $1.217 \mathrm{E}-02$ & 0.0017 \\
\hline 38 & $0.000 \mathrm{E}+00$ & 0.0000 & $0.000 \mathrm{E}+00$ & 0.0000 & $0.000 \mathrm{E}+00$ & 0.0000 & $0.000 \mathrm{E}+00$ & 0.0000 & $0.000 \mathrm{E}+00$ & 0.0000 & $0.000 \mathrm{E}+00$ & 0.0000 & $1.044 \mathrm{E}-01$ & 0.0145 \\
\hline & $6.365 E-02$ & 0.0088 & $0.000 \mathrm{E}+00$ & 0.0000 & $0.000 \mathrm{E}+00$ & 0.0000 & $5.951 E-03$ & 0.0008 & $1.065 \mathrm{E}-04$ & 0.0000 & $7.190 \mathrm{E}-03$ & 0.0010 & $6 \mathrm{E}+00$ & 1.0000 \\
\hline
\end{tabular}

* Sum of all water independent and dependent pathways. 
RESRAD, Version $6.5 \quad \mathrm{~T}^{1} \frac{1}{2}$ Limit $=180$ days

Summary : C746U Resident Farmer Deterministic Run
File : X: $\backslash$ FINAL V2 $\backslash$ DOE FWD RUNS \C746U RF DOE SG FWD-FV2-1050YR.RAD

Dose/Source Ratios Summed Over All Pathways

Parent and Progeny Principal Radionuclide Contributions Indicated

Parent Product Thread DSR $(j, t)$ At Time in Years (mrem/yr)/(pCi/g)

(i) (j) Fraction $0.000 \mathrm{E}+001.000 \mathrm{E}+005.000 \mathrm{E}+011.000 \mathrm{E}+025.000 \mathrm{E}+021.050 \mathrm{E}+03$

Am-241

$\overline{A m-241} \overline{1.000 E+00}$

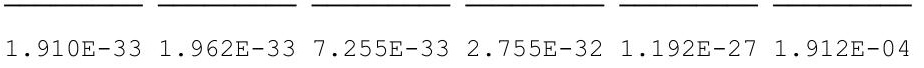

$\begin{array}{lllllllll}\mathrm{Np}-237+\mathrm{D} & 1.000 \mathrm{E}+00 & 0.000 \mathrm{E}+00 & 3.103 \mathrm{E}-19 & 2.524 \mathrm{E}-17 & 8.299 \mathrm{E}-17 & 2.249 \mathrm{E}-14 & 1.774 \mathrm{E}-06\end{array}$

$\begin{array}{llllllll}\mathrm{U}-233 & 1.000 \mathrm{E}+00 & 0.000 \mathrm{E}+00 & 1.055 \mathrm{E}-29 & 4.739 \mathrm{E}-26 & 3.448 \mathrm{E}-25 & 1.045 \mathrm{E}-21 & 3.144 \mathrm{E}-10\end{array}$

$\begin{array}{llllllll}\mathrm{Th}-229+\mathrm{D} & 1.000 \mathrm{E}+00 & 0.000 \mathrm{E}+00 & 9.607 \mathrm{E}-26 & 1.654 \mathrm{E}-20 & 1.834 \mathrm{E}-19 & 3.175 \mathrm{E}-16 & 5.257 \mathrm{E}-11\end{array}$

$\operatorname{LDSR}(j) \quad \begin{array}{llllll}1.910 \mathrm{E}-33 & 3.103 \mathrm{E}-19 & 2.526 \mathrm{E}-17 & 8.317 \mathrm{E}-17 & 2.281 \mathrm{E}-14 & 1.930 \mathrm{E}-04\end{array}$

$\mathrm{Cs}-137+\mathrm{D} \quad 1.000 \mathrm{E}+00 \quad 1.271 \mathrm{E}-09 \quad 1.253 \mathrm{E}-09 \quad 6.094 \mathrm{E}-10 \quad 2.922 \mathrm{E}-10 \quad 8.163 \mathrm{E}-13 \quad 1.950 \mathrm{E}-13$

$\mathrm{Np}-237+\mathrm{D} \quad 1.000 \mathrm{E}+00 \quad 9.485 \mathrm{E}-13 \quad 9.587 \mathrm{E}-13 \quad 1.617 \mathrm{E}-12 \quad 2.756 \mathrm{E}-12 \quad 1.963 \mathrm{E}-10 \quad 1.025 \mathrm{E}-02$

$\begin{array}{llllllll}\mathrm{U}-233 & 1.000 \mathrm{E}+00 & 0.000 \mathrm{E}+00 & 6.517 \mathrm{E}-23 & 6.002 \mathrm{E}-21 & 2.239 \mathrm{E}-20 & 1.638 \mathrm{E}-17 & 2.955 \mathrm{E}-06\end{array}$

$\begin{array}{llllllllll}\mathrm{Th}-229+\mathrm{D} & 1.000 \mathrm{E}+00 & 0.000 \mathrm{E}+00 & 8.902 \mathrm{E}-19 & 3.122 \mathrm{E}-15 & 1.764 \mathrm{E}-14 & 7.041 \mathrm{E}-12 & 6.620 \mathrm{E}-07\end{array}$

$\operatorname{\sum DSR}(j) \quad 9.485 \mathrm{E}-13 \quad 9.587 \mathrm{E}-13 \quad 1.620 \mathrm{E}-12 \quad 2.773 \mathrm{E}-12 \quad 2.033 \mathrm{E}-10 \quad 1.026 \mathrm{E}-02$

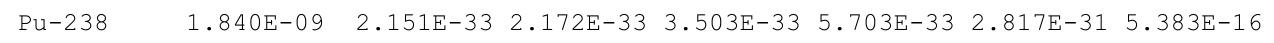

$\begin{array}{llllllll}\mathrm{Pu}-238 & 1.000 \mathrm{E}+00 & 1.169 \mathrm{E}-24 & 1.181 \mathrm{E}-24 & 1.904 \mathrm{E}-24 & 3.100 \mathrm{E}-24 & 1.531 \mathrm{E}-22 & 2.925 \mathrm{E}-07\end{array}$

$\begin{array}{lllllllll}\mathrm{U}-234 & 1.000 \mathrm{E}+00 & 0.000 \mathrm{E}+00 & 1.965 \mathrm{E}-29 & 1.939 \mathrm{E}-27 & 7.864 \mathrm{E}-27 & 1.675 \mathrm{E}-23 & 2.344 \mathrm{E}-07\end{array}$

$\begin{array}{lllllllll}\mathrm{Th}-230 & 1.000 \mathrm{E}+00 & 0.000 \mathrm{E}+00 & 3.096 \mathrm{E}-33 & 1.556 \mathrm{E}-29 & 1.280 \mathrm{E}-28 & 1.293 \mathrm{E}-24 & 3.186 \mathrm{E}-09\end{array}$

$\begin{array}{lllllllll}\mathrm{Ra}-226+\mathrm{D} \quad 1.000 \mathrm{E}+00 \quad 0.000 \mathrm{E}+00 & 3.212 \mathrm{E}-22 & 5.098 \mathrm{E}-17 & 5.231 \mathrm{E}-16 & 5.574 \mathrm{E}-13 & 3.395 \mathrm{E}-08\end{array}$

$\mathrm{Pb}-210+\mathrm{D} \quad 1.000 \mathrm{E}+00 \quad 0.000 \mathrm{E}+00 \quad 1.163 \mathrm{E}-30 \quad 7.464 \mathrm{E}-24 \quad 1.287 \mathrm{E}-22 \quad 3.648 \mathrm{E}-19 \quad 5.037 \mathrm{E}-08$

$\operatorname{LDSR}(j) \quad 1.169 \mathrm{E}-24 \quad 3.223 \mathrm{E}-22 \quad 5.098 \mathrm{E}-17 \quad 5.231 \mathrm{E}-16 \quad 5.574 \mathrm{E}-13 \quad 6.144 \mathrm{E}-07$

$\begin{array}{llllllllll}\mathrm{Pu}-239 & 1.000 \mathrm{E}+00 & 1.195 \mathrm{E}-17 & 1.209 \mathrm{E}-17 & 2.170 \mathrm{E}-17 & 3.941 \mathrm{E}-17 & 4.662 \mathrm{E}-15 & 1.235 \mathrm{E}-03\end{array}$

$\begin{array}{llllllll}\mathrm{U}-235+\mathrm{D} & 1.000 \mathrm{E}+00 & 0.000 \mathrm{E}+00 & 1.232 \mathrm{E}-23 & 1.128 \mathrm{E}-21 & 4.180 \mathrm{E}-21 & 2.910 \mathrm{E}-18 & 6.475 \mathrm{E}-10\end{array}$

$\begin{array}{llllllll}\mathrm{Pa}-231 & 1.000 \mathrm{E}+00 & 0.000 \mathrm{E}+00 & 2.903 \mathrm{E}-27 & 1.220 \mathrm{E}-23 & 8.286 \mathrm{E}-23 & 1.434 \mathrm{E}-19 & 4.682 \mathrm{E}-10\end{array}$

$\begin{array}{lllllllll}\mathrm{AC}-227+\mathrm{D} & 1.000 \mathrm{E}+00 & 0.000 \mathrm{E}+00 & 9.153 \mathrm{E}-27 & 1.237 \mathrm{E}-21 & 1.150 \mathrm{E}-20 & 1.466 \mathrm{E}-17 & 1.640 \mathrm{E}-10\end{array}$

$\operatorname{\sum DSR}(j) \quad 1.195 \mathrm{E}-17 \quad 1.209 \mathrm{E}-17 \quad 2.170 \mathrm{E}-17 \quad 3.943 \mathrm{E}-17 \quad 4.680 \mathrm{E}-15 \quad 1.235 \mathrm{E}-03$

$\begin{array}{llllllll}\mathrm{Pu}-240 \quad 4.950 \mathrm{E}-08 & 5.604 \mathrm{E}-32 & 5.703 \mathrm{E}-32 & 1.347 \mathrm{E}-31 & 3.239 \mathrm{E}-31 & 3.615 \mathrm{E}-28 & 5.638 \mathrm{E}-11\end{array}$

$\begin{array}{llllllllll}\mathrm{Pu}-240 & 1.000 \mathrm{E}+00 & 1.132 \mathrm{E}-24 & 1.152 \mathrm{E}-24 & 2.722 \mathrm{E}-24 & 6.543 \mathrm{E}-24 & 7.302 \mathrm{E}-21 & 1.139 \mathrm{E}-03\end{array}$

$\begin{array}{llllllll}\mathrm{U}-236 & 1.000 \mathrm{E}+00 & 0.000 \mathrm{E}+00 & 4.350 \mathrm{E}-32 & 5.235 \mathrm{E}-30 & 2.566 \mathrm{E}-29 & 1.669 \mathrm{E}-25 & 1.856 \mathrm{E}-08\end{array}$

$\begin{array}{llllllll}\mathrm{Th}-232 & 1.000 \mathrm{E}+00 & 0.000 \mathrm{E}+00 & 8.590 \mathrm{E}-43 & 5.322 \mathrm{E}-39 & 5.373 \mathrm{E}-38 & 2.213 \mathrm{E}-33 & 9.120 \mathrm{E}-16\end{array}$

$\begin{array}{lllllllll}\mathrm{Ra}-228+\mathrm{D} & 1.000 \mathrm{E}+00 & 0.000 \mathrm{E}+00 & 5.459 \mathrm{E}-28 & 3.662 \mathrm{E}-23 & 2.505 \mathrm{E}-22 & 1.461 \mathrm{E}-19 & 1.189 \mathrm{E}-13\end{array}$

$\begin{array}{lllllllll}\mathrm{Th}-228+\mathrm{D} & 1.000 \mathrm{E}+00 & 0.000 \mathrm{E}+00 & 3.996 \mathrm{E}-27 & 2.570 \mathrm{E}-21 & 1.733 \mathrm{E}-20 & 5.536 \mathrm{E}-18 & 1.502 \mathrm{E}-15\end{array}$

$\begin{array}{lllllll}\operatorname{DDSR}(j) & 1.132 \mathrm{E}-24 & 1.157 \mathrm{E}-24 & 2.609 \mathrm{E}-21 & 1.758 \mathrm{E}-20 & 5.690 \mathrm{E}-18 & 1.139 \mathrm{E}-03\end{array}$

TC-99 1.000E+00 5.729E-26 5.787E-26 $9.526 \mathrm{E}-26 \quad 1.584 \mathrm{E}-25 \quad 2.080 \mathrm{E}-01 \quad 1.480 \mathrm{E}-03$

Th-228+D 1.000E+00 1.643E-06 1.151E-06 3.003E-14 5.489E-22 $0.000 \mathrm{E}+00 \quad 0.000 \mathrm{E}+00$

$\begin{array}{lllllllll}\mathrm{Th}-230 & 1.000 \mathrm{E}+00 & 2.392 \mathrm{E}-22 & 2.432 \mathrm{E}-22 & 5.543 \mathrm{E}-22 & 1.285 \mathrm{E}-21 & 1.069 \mathrm{E}-18 & 1.076 \mathrm{E}-03\end{array}$

$\begin{array}{lllllllll}\mathrm{Ra}-226+\mathrm{D} & 1.000 \mathrm{E}+00 & 0.000 \mathrm{E}+00 & 7.565 \mathrm{E}-11 & 5.249 \mathrm{E}-09 & 1.467 \mathrm{E}-08 & 1.066 \mathrm{E}-06 & 2.340 \mathrm{E}-02\end{array}$

$\mathrm{Pb}-210+\mathrm{D} \quad 1.000 \mathrm{E}+00 \quad 0.000 \mathrm{E}+00 \quad 5.454 \mathrm{E}-19 \quad 1.273 \mathrm{E}-15 \quad 5.257 \mathrm{E}-15 \quad 7.641 \mathrm{E}-13 \quad 3.610 \mathrm{E}-02$

$\operatorname{LDSR}(j) \quad 2.392 \mathrm{E}-22 \quad 7.565 \mathrm{E}-11 \quad 5.249 \mathrm{E}-09 \quad 1.467 \mathrm{E}-08 \quad 1.066 \mathrm{E}-06 \quad 6.058 \mathrm{E}-02$ 


\section{RESRAD, Version $6.5 \quad T^{1 / 2}$ Limit $=180$ days}

Summary : C746U Resident Farmer Deterministic Run

File : $\mathrm{X}: \backslash F I N A L$ V2 $\backslash$ DOE FWD RUNS \C746U RF DOE SG FWD-FV2-1050YR.RAD

Dose/Source Ratios Summed Over All Pathways

Parent and Progeny Principal Radionuclide Contributions Indicated

\begin{tabular}{|c|c|c|c|c|c|c|c|c|}
\hline $\begin{array}{c}\text { Parent } \\
\text { (i) }\end{array}$ & $\begin{array}{l}\text { Product } \\
(j)\end{array}$ & $\begin{array}{l}\text { Thread } \\
\text { Fraction }\end{array}$ & $\begin{array}{r}\text { DSR } \\
0.000 \mathrm{E}+00\end{array}$ & $\begin{array}{l}(j, t) \text { At } T \\
1.000 \mathrm{E}+00\end{array}$ & $\begin{array}{l}\text { ime in Yea } \\
5.000 \mathrm{E}+01\end{array}$ & $\begin{array}{l}\text { rs (mrem } \\
1.000 \mathrm{E}+02\end{array}$ & $\begin{array}{l}/ \mathrm{yr}) /(\mathrm{pCi} / \mathrm{g} \\
5.000 \mathrm{E}+02\end{array}$ & $\begin{array}{l}\text { g) } \\
1.050 \mathrm{E}+03\end{array}$ \\
\hline-232 & $\mathrm{Th}-232$ & $1.000 \mathrm{E}+00$ & $1.155 \mathrm{E}-24$ & $1.177 \mathrm{E}-24$ & $2.922 E-24$ & $7.393 E-24$ & $1.241 \mathrm{E}-20$ & $1.189 \mathrm{E}-03$ \\
\hline-232 & $\mathrm{Ra}-228+\mathrm{D}$ & $1.000 \mathrm{E}+00$ & $0.000 \mathrm{E}+00$ & $2.177 \mathrm{E}-09$ & $2.773 \mathrm{E}-08$ & $4.064 \mathrm{E}-08$ & $8.465 E-07$ & $1.576 \mathrm{E}-01$ \\
\hline $1-232$ & $T h-228+D$ & $1.000 \mathrm{E}+00$ & $0.000 \mathrm{E}+00$ & $3.082 \mathrm{E}-08$ & $2.206 \mathrm{E}-06$ & $2.983 E-06$ & $3.244 E-05$ & $1.998 \mathrm{E}-03$ \\
\hline-232 & $\sum \operatorname{DSR}(j)$ & & $1.155 \mathrm{E}-24$ & $3.300 \mathrm{E}-08$ & $2.234 \mathrm{E}-06$ & $3.024 \mathrm{E}-06$ & $3.328 E-05$ & $1.607 \mathrm{E}-01$ \\
\hline-234 & $\mathrm{U}-234$ & $1.000 \mathrm{E}+00$ & $6.835 E-24$ & $6.957 \mathrm{E}-24$ & $1.656 \mathrm{E}-23$ & $4.011 \mathrm{E}-23$ & $4.756 \mathrm{E}-20$ & $6.525 E-04$ \\
\hline-234 & Th-230 & $1.000 \mathrm{E}+00$ & $0.000 \mathrm{E}+00$ & $2.190 \mathrm{E}-27$ & $2.494 \mathrm{E}-25$ & $1.156 \mathrm{E}-24$ & $4.793 E-21$ & $1.009 \mathrm{E}-05$ \\
\hline-234 & $\mathrm{Ra}-226+\mathrm{D}$ & $1.000 \mathrm{E}+00$ & $0.000 \mathrm{E}+00$ & $3.405 \mathrm{E}-16$ & $1.185 \mathrm{E}-12$ & $6.647 \mathrm{E}-12$ & $2.482 E-09$ & $1.185 \mathrm{E}-04$ \\
\hline-234 & $\mathrm{~Pb}-210+\mathrm{D}$ & $1.000 \mathrm{E}+00$ & $0.000 \mathrm{E}+00$ & $1.641 \mathrm{E}-24$ & $2.135 \mathrm{E}-19$ & $1.903 \mathrm{E}-18$ & $1.668 \mathrm{E}-15$ & $1.770 \mathrm{E}-04$ \\
\hline-234 & $\sum \operatorname{DSR}(j)$ & & $6.835 E-24$ & $3.405 \mathrm{E}-16$ & $1.185 \mathrm{E}-12$ & $6.647 \mathrm{E}-12$ & $2.482 E-09$ & $9.581 \mathrm{E}-04$ \\
\hline$-235+D$ & $U-235+D$ & $1.000 \mathrm{E}+00$ & $1.236 \mathrm{E}-14$ & $1.251 \mathrm{E}-14$ & $2.291 \mathrm{E}-14$ & $4.249 \mathrm{E}-14$ & $5.944 \mathrm{E}-12$ & $6.337 \mathrm{E}-04$ \\
\hline$-235+D$ & $\mathrm{~Pa}-231$ & $1.000 \mathrm{E}+00$ & $0.000 \mathrm{E}+00$ & $5.896 \mathrm{E}-18$ & 4. $955 \mathrm{E}-16$ & $1.684 \mathrm{E}-15$ & $5.839 \mathrm{E}-13$ & $9.104 \mathrm{E}-04$ \\
\hline$-235+D$ & $A C-227+D$ & $1.000 \mathrm{E}+00$ & $0.000 \mathrm{E}+00$ & $2.781 \mathrm{E}-17$ & $6.744 \mathrm{E}-14$ & $2.910 \mathrm{E}-13$ & $6.341 \mathrm{E}-11$ & $3.284 \mathrm{E}-04$ \\
\hline$-235+D$ & $\sum \operatorname{DSR}(j)$ & & $1.236 \mathrm{E}-14$ & $1.254 \mathrm{E}-14$ & $9.085 \mathrm{E}-14$ & 3. $352 \mathrm{E}-13$ & $6.994 \mathrm{E}-11$ & $1.873 \mathrm{E}-03$ \\
\hline-238 & $U-238$ & $5.400 E-05$ & $0.000 \mathrm{E}+00$ & $0.000 \mathrm{E}+00$ & $0.000 \mathrm{E}+00$ & $0.000 \mathrm{E}+00$ & $0.000 \mathrm{E}+00$ & $3.261 \mathrm{E}-08$ \\
\hline$-238+D$ & $\mathrm{U}-238+\mathrm{D}$ & $9.999 \mathrm{E}-01$ & $1.414 \mathrm{E}-10$ & 1. $425 \mathrm{E}-10$ & $2.107 \mathrm{E}-10$ & $3.141 \mathrm{E}-10$ & $7.648 \mathrm{E}-09$ & $6.500 \mathrm{E}-04$ \\
\hline$-238+D$ & $\mathrm{U}-234$ & $9.999 \mathrm{E}-01$ & $0.000 \mathrm{E}+00$ & $1.972 \mathrm{E}-29$ & $2.347 \mathrm{E}-27$ & $1.137 \mathrm{E}-26$ & $6.745 E-23$ & $1.945 \mathrm{E}-06$ \\
\hline$-238+D$ & $\mathrm{Th}-230$ & $9.999 E-01$ & $0.000 \mathrm{E}+00$ & $3.104 \mathrm{E}-33$ & $1.767 \mathrm{E}-29$ & $1.638 \mathrm{E}-28$ & $3.394 \mathrm{E}-24$ & $1.500 \mathrm{E}-08$ \\
\hline$-238+D$ & $\mathrm{Ra}-226+\mathrm{D}$ & $9.999 \mathrm{E}-01$ & $0.000 \mathrm{E}+00$ & $3.218 E-22$ & $5.610 \mathrm{E}-17$ & $6.303 E-16$ & $1.193 \mathrm{E}-12$ & $1.217 \mathrm{E}-07$ \\
\hline$-238+D$ & $\mathrm{~Pb}-210+\mathrm{D}$ & $9.999 \mathrm{E}-01$ & $0.000 \mathrm{E}+00$ & $1.165 \mathrm{E}-30$ & $8.088 \mathrm{E}-24$ & 1. $513 \mathrm{E}-22$ & $7.559 \mathrm{E}-19$ & $1.765 \mathrm{E}-07$ \\
\hline$-238+D$ & $\sum \operatorname{DSR}(j)$ & & 1. $414 \mathrm{E}-10$ & 1. $425 \mathrm{E}-10$ & $2.107 \mathrm{E}-10$ & $3.141 \mathrm{E}-10$ & $7.649 \mathrm{E}-09$ & $6.523 \mathrm{E}-04$ \\
\hline
\end{tabular}

The DSR includes contributions from associated (half-life $\leq 180$ days) daughters. 
RESRAD, Version $6.5 \quad \mathrm{~T}^{1} \frac{1}{2}$ Limit $=180$ days

mmary : C746U Resident Farmer Deterministic Run

File : $\mathrm{X}: \backslash F I N A L$ V2 $\backslash$ DOE FWD RUNS \C746U RF DOE SG FWD-FV2-1050YR.RAD

Single Radionuclide Soil Guidelines $G(i, t)$ in $\mathrm{pCi} / \mathrm{g}$

Basic Radiation Dose Limit $=1.000 \mathrm{E}+02 \mathrm{mrem} / \mathrm{yr}$

Nuclide

\begin{tabular}{|c|c|c|c|c|c|c|}
\hline (i) & $t=0.000 E+00$ & $1.000 \mathrm{E}+00$ & $5.000 \mathrm{E}+01$ & $1.000 \mathrm{E}+02$ & $5.000 \mathrm{E}+02$ & $1.050 \mathrm{E}+03$ \\
\hline$n-241$ & $\star 3.431 \mathrm{E}+12$ & $\star 3.431 \mathrm{E}+12$ & $\star 3.431 \mathrm{E}+12$ & $\star 3.431 \mathrm{E}+12$ & $\star 3.431 \mathrm{E}+12$ & $5.181 \mathrm{E}+05$ \\
\hline$s-137$ & $7.867 \mathrm{E}+10$ & $7.984 \mathrm{E}+10$ & $1.641 \mathrm{E}+11$ & $3.422 \mathrm{E}+11$ & $\star 8.704 \mathrm{E}+13$ & $\star 8.704 \mathrm{E}+13$ \\
\hline $0-237$ & $\star 7.047 \mathrm{E}+08$ & $\star 7.047 \mathrm{E}+08$ & $\star 7.047 \mathrm{E}+08$ & $\star 7.047 \mathrm{E}+08$ & $\star 7.047 \mathrm{E}+08$ & $9.749 E+03$ \\
\hline$u-238$ & $\star 1.712 \mathrm{E}+13$ & $\star 1.712 \mathrm{E}+13$ & $\star 1.712 \mathrm{E}+13$ & $\star 1.712 \mathrm{E}+13$ & $* 1.712 \mathrm{E}+13$ & $1.628 \mathrm{E}+08$ \\
\hline$u-239$ & $\star 6.214 \mathrm{E}+10$ & $\star 6.214 \mathrm{E}+10$ & $* 6.214 \mathrm{E}+10$ & $\star 6.214 \mathrm{E}+10$ & $\star 6.214 \mathrm{E}+10$ & $8.096 \mathrm{E}+04$ \\
\hline$u-240$ & $\star 2.278 \mathrm{E}+11$ & $\star 2.278 \mathrm{E}+11$ & $\star 2.278 \mathrm{E}+11$ & $\star 2.278 \mathrm{E}+11$ & $\star 2.278 \mathrm{E}+11$ & $8.779 \mathrm{E}+04$ \\
\hline$c-99$ & $\star 1.697 \mathrm{E}+10$ & $\star 1.697 \mathrm{E}+10$ & $\star 1.697 \mathrm{E}+10$ & $* 1.697 \mathrm{E}+10$ & $4.808 E+02$ & $6.756 \mathrm{E}+04$ \\
\hline Th-228 & $6.085 E+07$ & $8.690 \mathrm{E}+07$ & $\star 8.195 \mathrm{E}+14$ & $\star 8.195 \mathrm{E}+14$ & $\star 8.195 \mathrm{E}+14$ & $* 8.195 \mathrm{E}+14$ \\
\hline Th -230 & $\star 2.018 \mathrm{E}+10$ & $\star 2.018 \mathrm{E}+10$ & $1.905 \mathrm{E}+10$ & $6.818 \mathrm{E}+09$ & $9.377 \mathrm{E}+07$ & $1.651 \mathrm{E}+03$ \\
\hline Th-232 & $* 1.097 \mathrm{E}+05$ & $* 1.097 \mathrm{E}+05$ & $* 1.097 \mathrm{E}+05$ & $\star 1.097 \mathrm{E}+05$ & $* 1.097 \mathrm{E}+05$ & $6.221 \mathrm{E}+02$ \\
\hline $\mathrm{U}-234$ & $\star 6.247 \mathrm{E}+09$ & $\star 6.247 \mathrm{E}+09$ & $\star 6.247 \mathrm{E}+09$ & $* 6.247 \mathrm{E}+09$ & $* 6.247 \mathrm{E}+09$ & $1.044 \mathrm{E}+05$ \\
\hline-235 & $\star 2.161 \mathrm{E}+06$ & $\star 2.161 \mathrm{E}+06$ & $\star 2.161 \mathrm{E}+06$ & $\star 2.161 \mathrm{E}+06$ & $\star 2.161 \mathrm{E}+06$ & $5.340 \mathrm{E}+04$ \\
\hline 238 & $\star 3.361 \mathrm{E}+05$ & $\star 3.361 \mathrm{E}+05$ & $\star 3.361 \mathrm{E}+05$ & $\star 3.361 \mathrm{E}+05$ & $\star 3.361 \mathrm{E}+05$ & $1.533 \mathrm{E}+05$ \\
\hline
\end{tabular}

*At specific activity limit

Summed Dose/Source Ratios DSR (i,t) in (mrem/yr)/(pCi/g) and Single Radionuclide Soil Guidelines G(i,t) in pCi/g

at $\operatorname{tmin}=$ time of minimum single radionuclide soil guideline and at $\operatorname{tmax}=$ time of maximum total dose $=425.2 \pm 0.9$ years

\begin{tabular}{|c|c|c|c|c|c|c|}
\hline $\begin{array}{l}\text { uclide } \\
\text { (i) }\end{array}$ & $\begin{array}{l}\text { Initial } \\
(\mathrm{pCi} / \mathrm{g})\end{array}$ & $\begin{array}{c}\text { tmin } \\
\text { (years) }\end{array}$ & $\operatorname{DSR}(i, \operatorname{tmin})$ & $\begin{array}{c}\mathrm{G}(\mathrm{i}, \mathrm{tmin}) \\
(\mathrm{pCi} / \mathrm{g})\end{array}$ & $\operatorname{DSR}(i, t \max )$ & $\begin{array}{c}G(i, \text { tmax }) \\
(\mathrm{pCi} / \mathrm{g})\end{array}$ \\
\hline-241 & $3.500 \mathrm{E}+01$ & $1.050 \mathrm{E}+03$ & $1.930 \mathrm{E}-04$ & $5.181 E+05$ & $9.162 \mathrm{E}-15$ & $\star 3.431 \mathrm{E}+12$ \\
\hline-137 & $1.900 \mathrm{E}+01$ & $0.000 \mathrm{E}+00$ & $1.271 E-09$ & $7.867 \mathrm{E}+10$ & $2.453 \mathrm{E}-12$ & $4.077 \mathrm{E}+13$ \\
\hline-237 & $5.500 \mathrm{E}+00$ & $1.050 \mathrm{E}+03$ & $1.026 \mathrm{E}-02$ & $9.749 \mathrm{E}+03$ & $9.140 \mathrm{E}-11$ & $\star 7.047 \mathrm{E}+08$ \\
\hline-238 & $3.900 E+01$ & $1.050 \mathrm{E}+03$ & $6.144 \mathrm{E}-07$ & $1.628 \mathrm{E}+08$ & $2.257 \mathrm{E}-13$ & $\star 1.712 \mathrm{E}+13$ \\
\hline-239 & $3.600 \mathrm{E}+01$ & $1.050 \mathrm{E}+03$ & $1.235 E-03$ & $8.096 \mathrm{E}+04$ & 1. $915 \mathrm{E}-15$ & $\star 6.214 \mathrm{E}+10$ \\
\hline-240 & $3.600 \mathrm{E}+01$ & $1.050 \mathrm{E}+03$ & $1.139 \mathrm{E}-03$ & $8.779 \mathrm{E}+04$ & $2.612 \mathrm{E}-18$ & $\star 2.278 \mathrm{E}+11$ \\
\hline-99 & $5.200 \mathrm{E}+01$ & $425.2 \pm 0.9$ & $4.076 \mathrm{E}-01$ & $2.453 E+02$ & $4.076 \mathrm{E}-01$ & $2.453 E+02$ \\
\hline-228 & $4.000 \mathrm{E}+00$ & $0.000 \mathrm{E}+00$ & $1.643 \mathrm{E}-06$ & $6.085 E+07$ & $0.000 \mathrm{E}+00$ & $\star 8.195 \mathrm{E}+14$ \\
\hline-230 & $1.000 \mathrm{E}+02$ & $1.050 \mathrm{E}+03$ & $6.058 \mathrm{E}-02$ & $1.651 \mathrm{E}+03$ & $5.495 \mathrm{E}-07$ & $1.820 \mathrm{E}+08$ \\
\hline-232 & $4.000 \mathrm{E}+00$ & $1.050 \mathrm{E}+03$ & $1.607 \mathrm{E}-01$ & $6.221 E+02$ & $2.123 E-05$ & $\star 1.097 \mathrm{E}+05$ \\
\hline 234 & $1.600 \mathrm{E}+02$ & $1.050 \mathrm{E}+03$ & $9.581 \mathrm{E}-04$ & $1.044 \mathrm{E}+05$ & $1.082 E-09$ & $* 6.247 \mathrm{E}+09$ \\
\hline 35 & $6.500 \mathrm{E}+00$ & $1.050 \mathrm{E}+03$ & $1.873 \mathrm{E}-03$ & $5.340 \mathrm{E}+04$ & $3.031 \mathrm{E}-11$ & $\star 2.161 \mathrm{E}+06$ \\
\hline 38 & $1.600 \mathrm{E}+02$ & $1.050 E+03$ & $6.523 E-04$ & $1.533 E+05$ & $4.209 \mathrm{E}-09$ & $* 3.361 \mathrm{E}+05$ \\
\hline
\end{tabular}

*At specific activity limit 
RESRAD, Version 6.5

$\mathrm{T}^{1 / 2}$ Limit $=180$ days

07/15/2011 13:56 Page 30

ummary : C746U Resident Farmer Deterministic Run

File : $\mathrm{X}: \backslash F I N A L$ V2 $\backslash$ DOE FWD RUNS $\backslash C 746 U$ RF DOE SG FWD-FV2-1050YR.RAD

Individual Nuclide Dose Summed Over All Pathways

Parent Nuclide and Branch Fraction Indicated

Nuclide Parent THF(i) DOSE $(j, t)$, mrem/yr

\begin{tabular}{|c|c|c|}
\hline$(j)$ & (i) & \\
\hline$n-241$ & $A m-241$ & $1.000 \mathrm{E}+00$ \\
\hline-237 & $A m-241$ & $1.000 \mathrm{E}+00$ \\
\hline $\mathrm{Np}-237$ & $\mathrm{~Np}-237$ & $1.000 \mathrm{E}+00$ \\
\hline $\mathrm{Np}-237$ & $\sum \operatorname{DOSE}(j$ & \\
\hline
\end{tabular}

$\mathrm{U}-233 \quad \mathrm{Am}-241 \quad 1.000 \mathrm{E}+00$

$\mathrm{U}-233 \quad \mathrm{~Np}-237 \quad 1.000 \mathrm{E}+00$

U-233 $\quad$ DOSE $(j)$

Th-229

Th-229

Th-229

Cs -137

$\mathrm{Pu}-238$

$\mathrm{Pu}-238$

$\mathrm{Pu}-238$

$\mathrm{U}-234$

$\mathrm{U}-234$

$\mathrm{U}-234$

$\mathrm{U}-234$

Th-230

$\mathrm{Th}-230$

Th -230

Th -230

$\mathrm{Th}-230$

$\mathrm{Ra}-226$

$\mathrm{Ra}-226$

$\mathrm{Ra}-226$

$\mathrm{Ra}-226$

$\operatorname{Ra}-226$

$\mathrm{Pb}-210$

$\mathrm{Pb}-210$

$\mathrm{Pb}-210$

$\mathrm{Pb}-210$

$\mathrm{Pb}-210$

$\mathrm{Pu}-239$

Pu-239 1.000E+00 U-235 $1.000 \mathrm{E}+00$

¿DOSE (j) $t=0.000 \mathrm{E}+00 \quad 1.000 \mathrm{E}+00 \quad 5.000 \mathrm{E}+01 \quad 1.000 \mathrm{E}+02 \quad 5.000 \mathrm{E}+02 \quad 1.050 \mathrm{E}+03$

$0.000 \mathrm{E}+00 \quad 0.000 \mathrm{E}+00 \quad 0.000 \mathrm{E}+00 \quad 0.000 \mathrm{E}+00 \quad 4.171 \mathrm{E}-26 \quad 6.693 \mathrm{E}-03$

$0.000 \mathrm{E}+00 \quad 1.086 \mathrm{E}-17 \quad 8.834 \mathrm{E}-16 \quad 2.905 \mathrm{E}-15 \quad 7.873 \mathrm{E}-13 \quad 6.209 \mathrm{E}-05$

$5.217 \mathrm{E}-12 \quad 5.273 \mathrm{E}-12 \quad 8.892 \mathrm{E}-12 \quad 1.516 \mathrm{E}-11 \quad 1.080 \mathrm{E}-09 \quad 5.639 \mathrm{E}-02$

$5.217 \mathrm{E}-12 \quad 5.273 \mathrm{E}-12 \quad 8.893 \mathrm{E}-12 \quad 1.516 \mathrm{E}-11 \quad 1.080 \mathrm{E}-09 \quad 5.646 \mathrm{E}-02$

$0.000 \mathrm{E}+00 \quad 3.692 \mathrm{E}-28 \quad 1.659 \mathrm{E}-24 \quad 1.207 \mathrm{E}-23 \quad 3.656 \mathrm{E}-20 \quad 1.100 \mathrm{E}-08$

$0.000 \mathrm{E}+00 \quad 3.584 \mathrm{E}-22 \quad 3.301 \mathrm{E}-20 \quad 1.231 \mathrm{E}-19 \quad 9.010 \mathrm{E}-17 \quad 1.625 \mathrm{E}-05$

$0.000 \mathrm{E}+00 \quad 3.584 \mathrm{E}-22 \quad 3.301 \mathrm{E}-20 \quad 1.231 \mathrm{E}-19 \quad 9.014 \mathrm{E}-17 \quad 1.626 \mathrm{E}-05$

$0.000 \mathrm{E}+00 \quad 3.363 \mathrm{E}-24 \quad 5.788 \mathrm{E}-19 \quad 6.420 \mathrm{E}-18 \quad 1.111 \mathrm{E}-14 \quad 1.840 \mathrm{E}-09$

$0.000 \mathrm{E}+00 \quad 4.896 \mathrm{E}-18 \quad 1.717 \mathrm{E}-14 \quad 9.703 \mathrm{E}-14 \quad 3.873 \mathrm{E}-11 \quad 3.641 \mathrm{E}-06$

$0.000 \mathrm{E}+00 \quad 4.896 \mathrm{E}-18 \quad 1.717 \mathrm{E}-14 \quad 9.703 \mathrm{E}-14 \quad 3.874 \mathrm{E}-11 \quad 3.643 \mathrm{E}-06$

$2.415 \mathrm{E}-08 \quad 2.380 \mathrm{E}-08 \quad 1.158 \mathrm{E}-08 \quad 5.552 \mathrm{E}-09 \quad 1.551 \mathrm{E}-11 \quad 3.706 \mathrm{E}-12$

$\begin{array}{lllllll}0.000 \mathrm{E}+00 & 0.000 \mathrm{E}+00 & 0.000 \mathrm{E}+00 & 0.000 \mathrm{E}+00 & 0.000 \mathrm{E}+00 & 2.099 \mathrm{E}-14\end{array}$

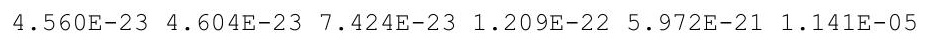

$4.560 \mathrm{E}-23 \quad 4.604 \mathrm{E}-23 \quad 7.424 \mathrm{E}-23 \quad 1.209 \mathrm{E}-22 \quad 5.972 \mathrm{E}-21 \quad 1.141 \mathrm{E}-05$

$0.000 \mathrm{E}+00 \quad 7.662 \mathrm{E}-28 \quad 7.563 \mathrm{E}-26 \quad 3.067 \mathrm{E}-25 \quad 6.534 \mathrm{E}-22 \quad 9.140 \mathrm{E}-06$

$\begin{array}{llllllll}1.094 \mathrm{E}-21 & 1.113 \mathrm{E}-21 & 2.649 \mathrm{E}-21 & 6.417 \mathrm{E}-21 & 7.609 \mathrm{E}-18 & 1.044 \mathrm{E}-01\end{array}$

$0.000 \mathrm{E}+00 \quad 3.156 \mathrm{E}-27 \quad 3.755 \mathrm{E}-25 \quad 1.819 \mathrm{E}-24 \quad 1.079 \mathrm{E}-20 \quad 3.112 \mathrm{E}-04$

$\begin{array}{lllllll}1.094 \mathrm{E}-21 & 1.113 \mathrm{E}-21 & 2.650 \mathrm{E}-21 & 6.420 \mathrm{E}-21 & 7.620 \mathrm{E}-18 & 1.047 \mathrm{E}-01\end{array}$

$0.000 \mathrm{E}+00 \quad 0.000 \mathrm{E}+00 \quad 6.069 \mathrm{E}-28 \quad 4.992 \mathrm{E}-27 \quad 5.043 \mathrm{E}-23 \quad 1.243 \mathrm{E}-07$

$\begin{array}{lllllll}2.392 \mathrm{E}-20 & 2.432 \mathrm{E}-20 & 5.543 \mathrm{E}-20 & 1.285 \mathrm{E}-19 & 1.069 \mathrm{E}-16 & 1.076 \mathrm{E}-01\end{array}$

$0.000 \mathrm{E}+00 \quad 3.503 \mathrm{E}-25 \quad 3.990 \mathrm{E}-23 \quad 1.849 \mathrm{E}-22 \quad 7.668 \mathrm{E}-19 \quad 1.615 \mathrm{E}-03$

$0.000 \mathrm{E}+00 \quad 0.000 \mathrm{E}+00 \quad 2.828 \mathrm{E}-27 \quad 2.620 \mathrm{E}-26 \quad 5.431 \mathrm{E}-22 \quad 2.400 \mathrm{E}-06$

$\begin{array}{llllll}2.392 \mathrm{E}-20 & 2.432 \mathrm{E}-20 & 5.547 \mathrm{E}-20 & 1.286 \mathrm{E}-19 & 1.076 \mathrm{E}-16 & 1.092 \mathrm{E}-01\end{array}$

$0.000 \mathrm{E}+00 \quad 1.253 \mathrm{E}-20 \quad 1.988 \mathrm{E}-15 \quad 2.040 \mathrm{E}-14 \quad 2.174 \mathrm{E}-11 \quad 1.324 \mathrm{E}-06$ $\begin{array}{lllllll}0.000 \mathrm{E}+00 & 7.565 \mathrm{E}-09 & 5.249 \mathrm{E}-07 & 1.467 \mathrm{E}-06 & 1.066 \mathrm{E}-04 & 2.340 \mathrm{E}+00\end{array}$ $\begin{array}{lllllll}0.000 \mathrm{E}+00 & 5.448 \mathrm{E}-14 & 1.897 \mathrm{E}-10 & 1.064 \mathrm{E}-09 & 3.972 \mathrm{E}-07 & 1.896 \mathrm{E}-02\end{array}$ $0.000 \mathrm{E}+00 \quad 5.149 \mathrm{E}-20 \quad 8.977 \mathrm{E}-15 \quad 1.009 \mathrm{E}-13 \quad 1.909 \mathrm{E}-10 \quad 1.948 \mathrm{E}-05$ $\begin{array}{lllllll}0.000 \mathrm{E}+00 & 7.565 \mathrm{E}-09 & 5.251 \mathrm{E}-07 & 1.468 \mathrm{E}-06 & 1.070 \mathrm{E}-04 & 2.359 \mathrm{E}+00\end{array}$

$0.000 \mathrm{E}+00 \quad 4.535 \mathrm{E}-29 \quad 2.911 \mathrm{E}-22 \quad 5.018 \mathrm{E}-21 \quad 1.423 \mathrm{E}-17 \quad 1.964 \mathrm{E}-06$ $\begin{array}{llllll}0.000 \mathrm{E}+00 & 5.454 \mathrm{E}-17 & 1.273 \mathrm{E}-13 & 5.257 \mathrm{E}-13 & 7.641 \mathrm{E}-11 & 3.610 \mathrm{E}+00\end{array}$ $\begin{array}{lllllll}0.000 \mathrm{E}+00 & 2.625 \mathrm{E}-22 & 3.416 \mathrm{E}-17 & 3.045 \mathrm{E}-16 & 2.669 \mathrm{E}-13 & 2.832 \mathrm{E}-02\end{array}$ $\begin{array}{lllllll}0.000 \mathrm{E}+00 & 1.863 \mathrm{E}-28 & 1.294 \mathrm{E}-21 & 2.420 \mathrm{E}-20 & 1.209 \mathrm{E}-16 & 2.824 \mathrm{E}-05\end{array}$ $\begin{array}{llllll}0.000 \mathrm{E}+00 & 5.454 \mathrm{E}-17 & 1.274 \mathrm{E}-13 & 5.260 \mathrm{E}-13 & 7.667 \mathrm{E}-11 & 3.639 \mathrm{E}+00\end{array}$

$4.302 \mathrm{E}-16 \quad 4.354 \mathrm{E}-16 \quad 7.813 \mathrm{E}-16 \quad 1.419 \mathrm{E}-15 \quad 1.678 \mathrm{E}-13 \quad 4.447 \mathrm{E}-02$

$0.000 \mathrm{E}+00 \quad 4.435 \mathrm{E}-22 \quad 4.060 \mathrm{E}-20 \quad 1.505 \mathrm{E}-19 \quad 1.048 \mathrm{E}-16 \quad 2.331 \mathrm{E}-08$ $\begin{array}{lllllll}8.032 \mathrm{E}-14 & 8.131 \mathrm{E}-14 & 1.489 \mathrm{E}-13 & 2.762 \mathrm{E}-13 & 3.864 \mathrm{E}-11 & 4.119 \mathrm{E}-03\end{array}$ $\begin{array}{lllllll}8.032 \mathrm{E}-14 & 8.131 \mathrm{E}-14 & 1.489 \mathrm{E}-13 & 2.762 \mathrm{E}-13 & 3.864 \mathrm{E}-11 & 4.119 \mathrm{E}-03\end{array}$ 


\section{RESRAD, Version $6.5 \quad \mathrm{~T}^{1 / 2}$ Limit $=180$ days}

ummary : C746U Resident Farmer Deterministic Run

File : $\mathrm{X}: \backslash F I N A L$ V2 $\backslash$ DOE FWD RUNS \C746U RF DOE SG FWD-FV2-1050YR.RAD

Individual Nuclide Dose Summed Over All Pathways

Parent Nuclide and Branch Fraction Indicated

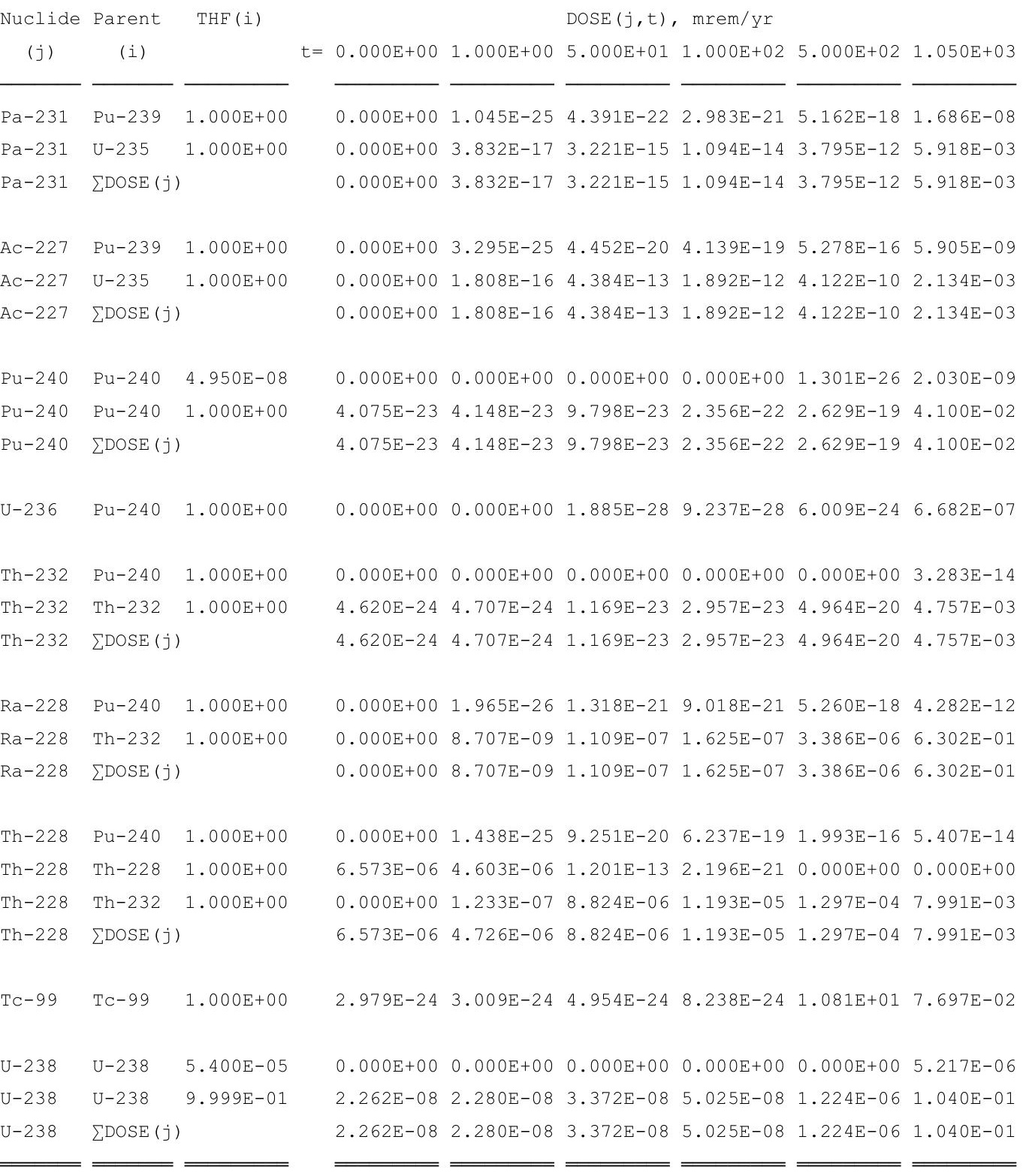

THF(i) is the thread fraction of the parent nuclide. 


\section{RESRAD, Version $6.5 \quad T^{1 / 2}$ Limit $=180$ days}

Summary : C746U Resident Farmer Deterministic Run

File : X: \FINAL V2 \DOE FWD RUNS \C746U RF DOE SG FWD-FV2-1050YR.RAD

Individual Nuclide Soil Concentration

Parent Nuclide and Branch Fraction Indicated

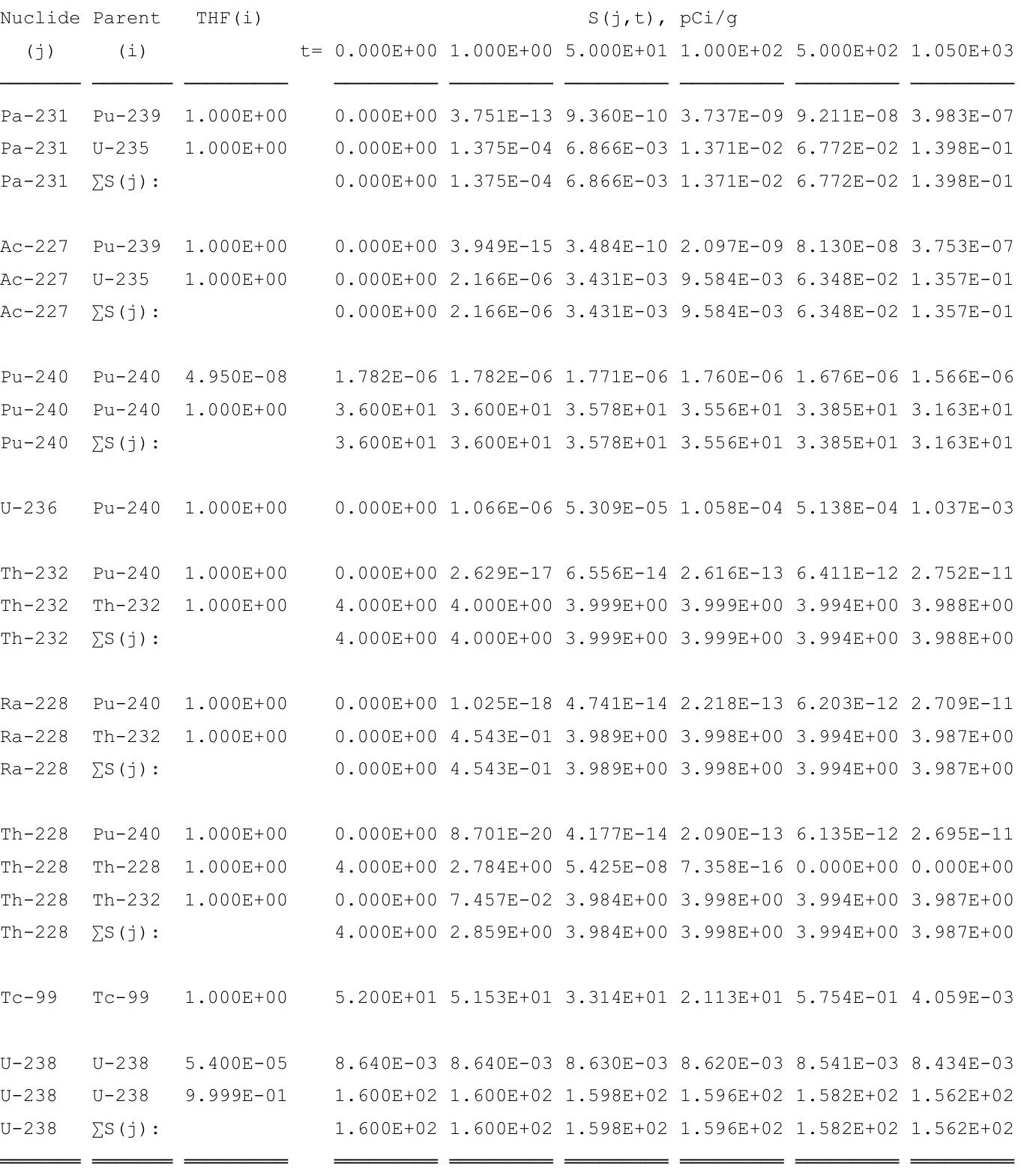

THF(i) is the thread fraction of the parent nuclide.

RESCALC.EXE execution time $=\quad 8.59$ seconds 


\title{
Resident Farmer (onsite)
}

\author{
Summary Report \\ (Deterministic Analysis Report)
}

Second Peak Dose Assessment

Time Horizon: 10,000 yr 
THIS PAGE INTENTIONALLY LEFT BLANK 


\section{RESRAD, Version $6.5 \quad \mathrm{~T}^{1 / 2}$ Limit $=180$ days}

Summary : C746U Resident Farmer Deterministic Run

File : $\mathrm{X}: \backslash F I N A L$ V2 \DOE FWD RUNS \C746U RF DOE SG FWD-FV2-10000YR.RAD

Table of Contents

Part I: Mixture Sums and Single Radionuclide Guidelines

Dose Conversion Factor (and Related) Parameter Summary ... 2

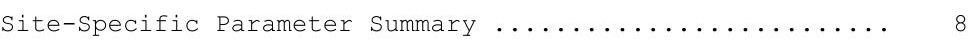

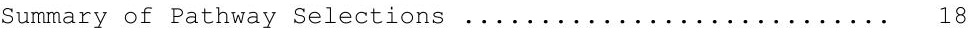

Contaminated Zone and Total Dose Summary ............. 19

Total Dose Components

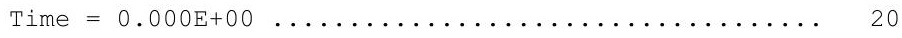

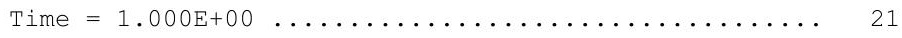

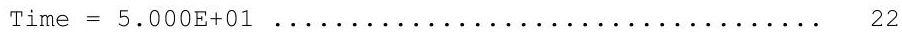

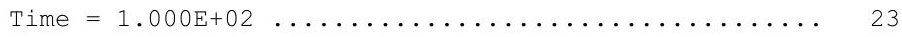

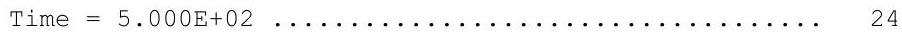

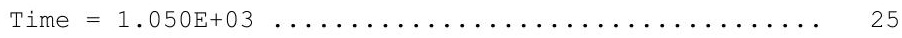

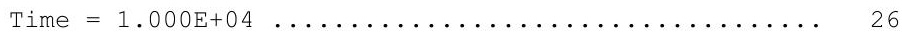

Dose/Source Ratios Summed Over All Pathways .......... 27

Single Radionuclide Soil Guidelines ............... 29

Dose Per Nuclide Summed Over All Pathways ............ 30

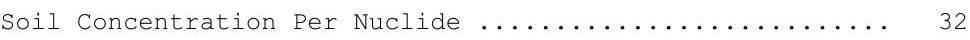


RESRAD, Version $6.5 \quad \mathrm{~T}^{1 / 2}$ Limit $=180$ days

Summary : C746U Resident Farmer Deterministic Run

File : $\mathrm{X}: \backslash F I N A L$ V2 \DOE FWD RUNS \C746U RF DOE SG FWD-FV2-10000YR.RAD

Dose Conversion Factor (and Related) Parameter Summary

Dose Library: ICRP 60 \& ICRP 72 (Adult)

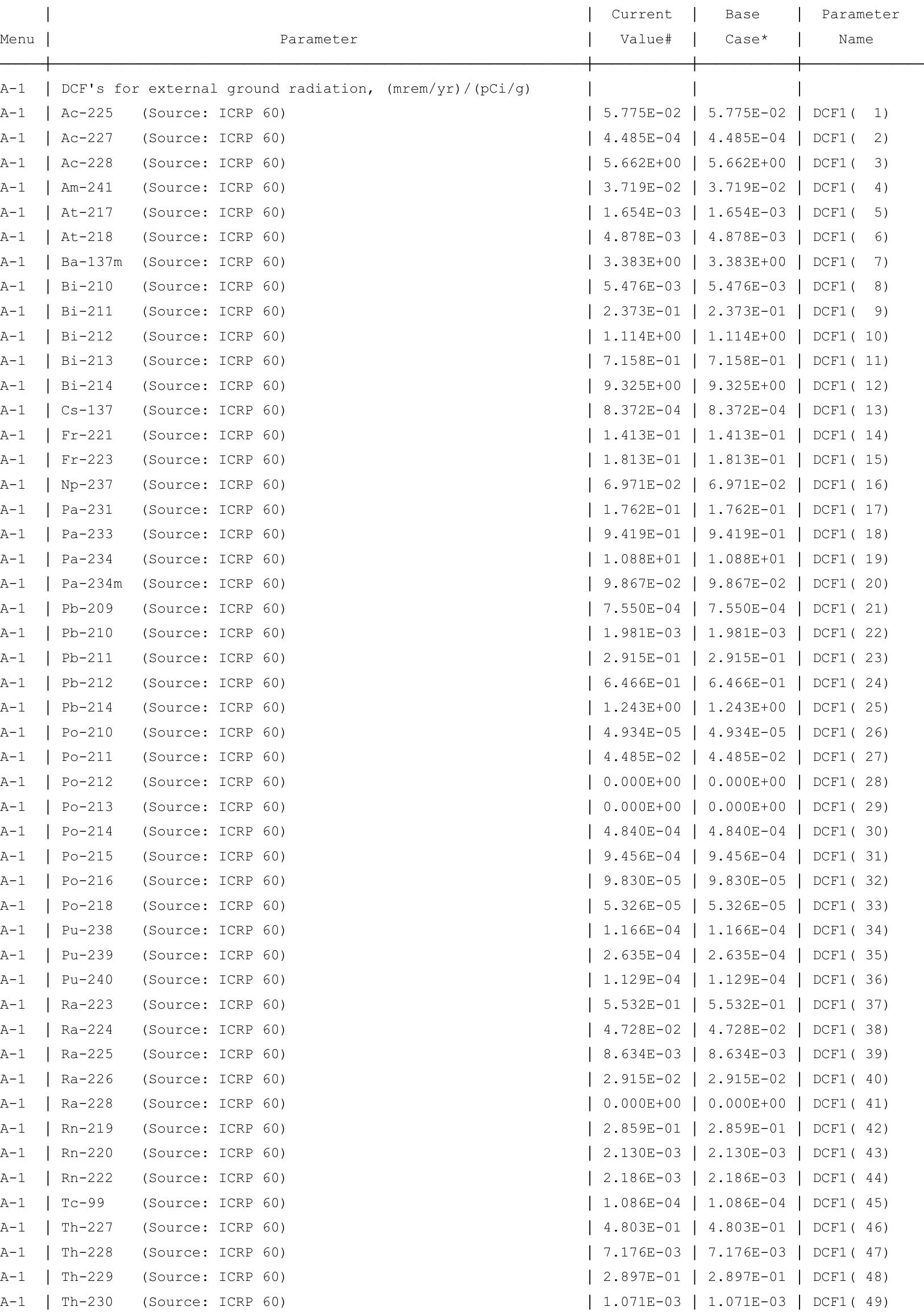


RESRAD, Version $6.5 \quad \mathrm{~T}^{1 / 2}$ Limit $=180$ days

07/18/2011 14:15 Page

Summary : C746U Resident Farmer Deterministic Run

File : $\mathrm{X}: \backslash F I N A L$ V2 \DOE FWD RUNS \C746U RF DOE SG FWD-FV2-10000YR. RAD

Dose Conversion Factor (and Related) Parameter Summary (continued)

Dose Library: ICRP 60 \& ICRP 72 (Adult)

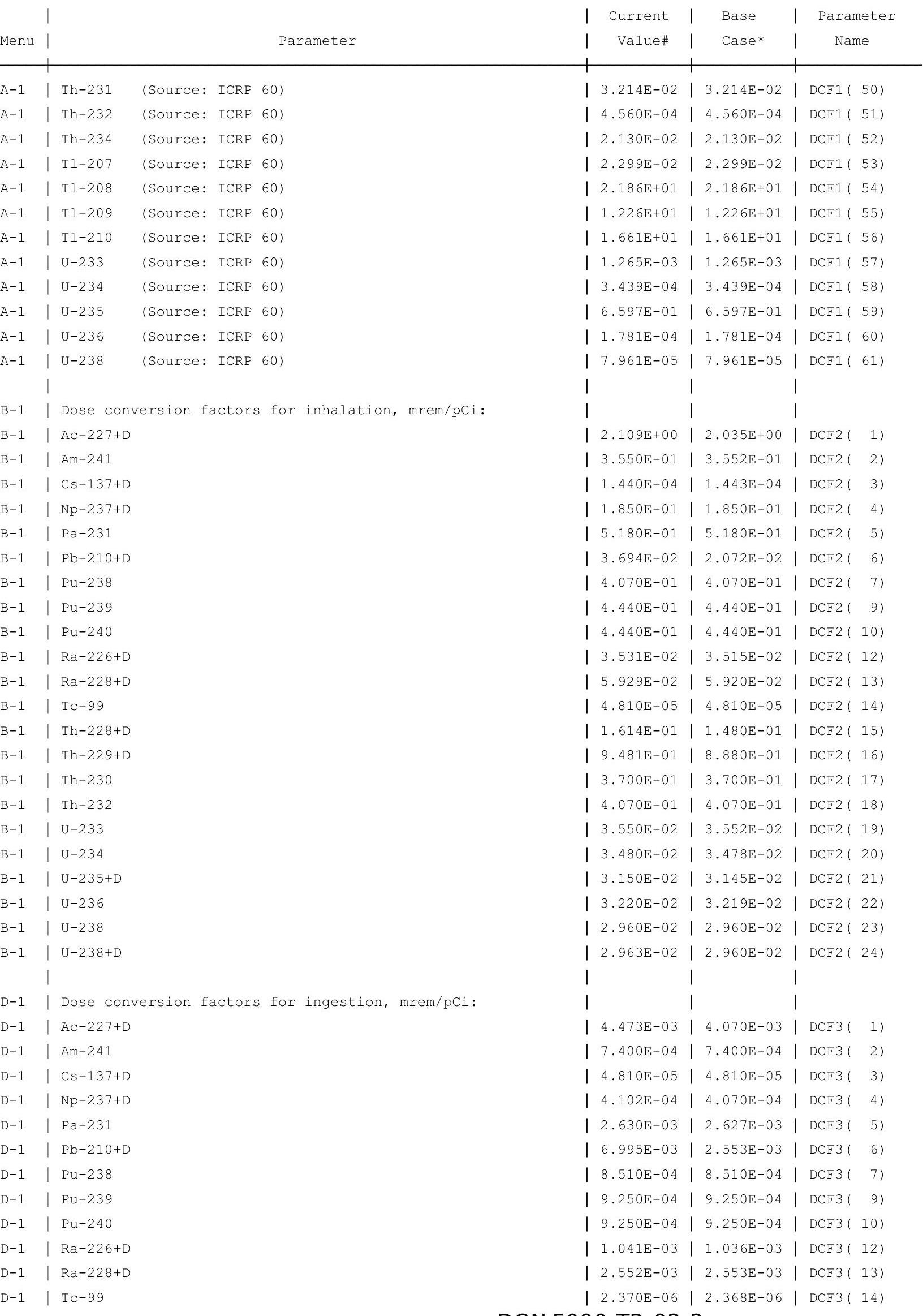


RESRAD, Version $6.5 \quad \mathrm{~T}^{1 / 2}$ Limit $=180$ days

ummary : C746U Resident Farmer Deterministic Run

File : $X: \backslash F I N A L$ V2 \DOE FWD RUNS \C746U RF DOE SG FWD-FV2-10000YR.RAD

Dose Conversion Factor (and Related) Parameter Summary (continued)

Dose Library: ICRP 60 \& ICRP 72 (Adult)

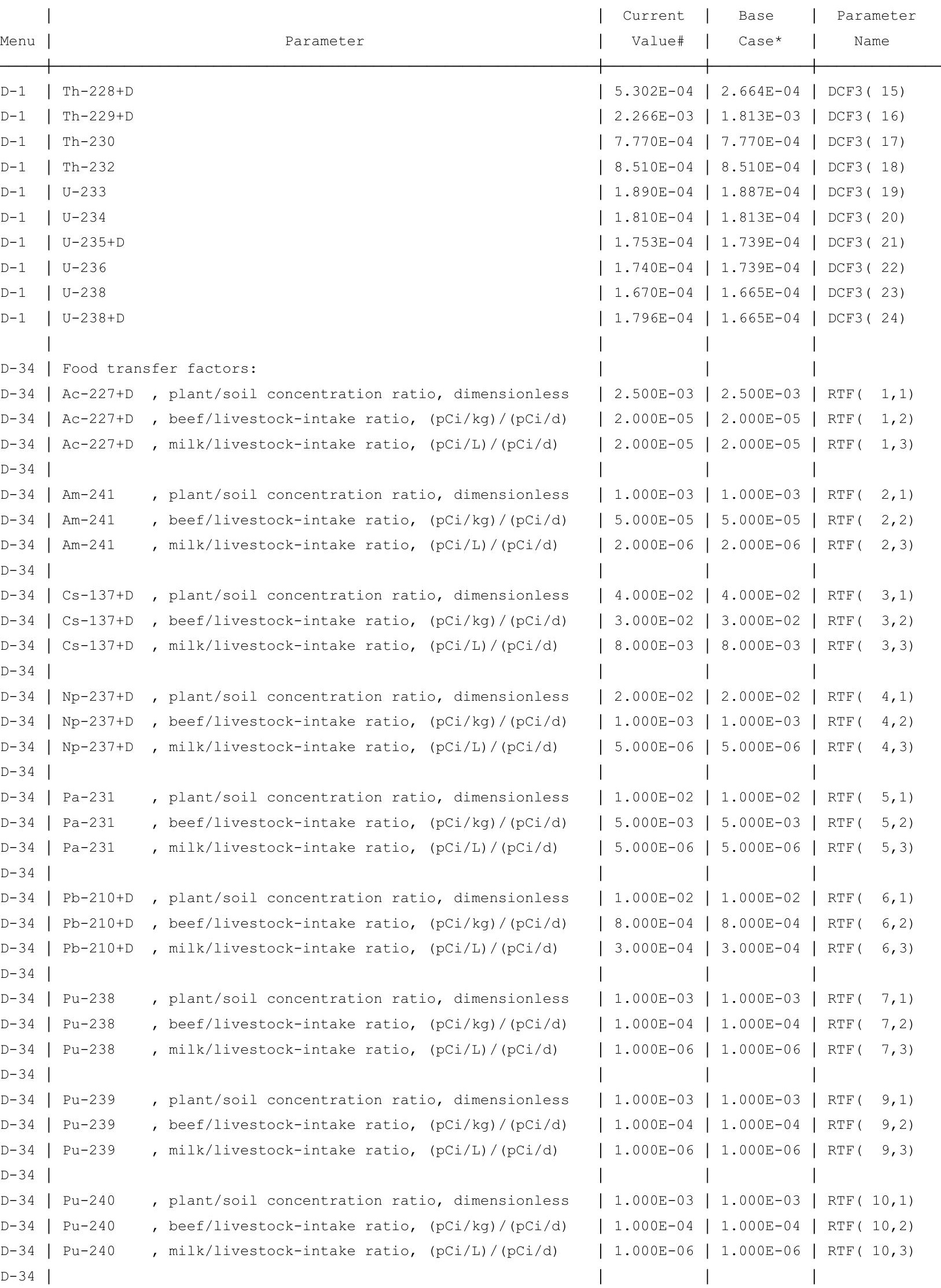


RESRAD, Version $6.5 \quad \mathrm{~T}^{1} \frac{1}{2}$ Limit $=180$ days

umary : C746U Resident Farmer Deterministic Run

File : $X: \backslash F I N A L$ V2 \DOE FWD RUNS \C746U RF DOE SG FWD-FV2-10000YR. RAD

Dose Conversion Factor (and Related) Parameter Summary (continued)

Dose Library: ICRP 60 \& ICRP 72 (Adult)

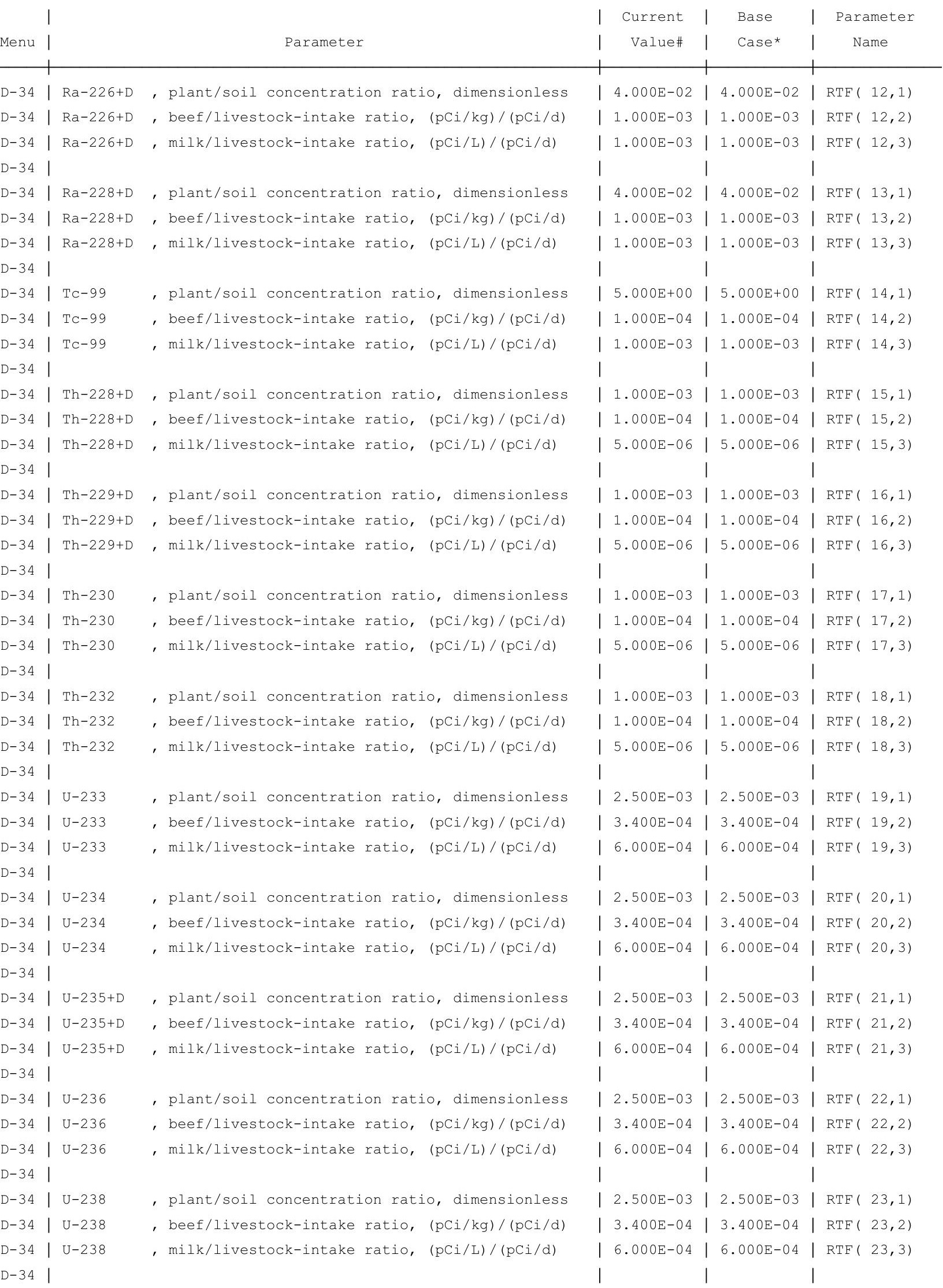


RESRAD, Version $6.5 \quad T^{1 / 2}$ Limit $=180$ days

Summary : C746U Resident Farmer Deterministic Run

File : $X: \backslash F I N A L$ V2 \DOE FWD RUNS \C746U RF DOE SG FWD-FV2-10000YR.RAD

Dose Conversion Factor (and Related) Parameter Summary (continued)

Dose Library: ICRP 60 \& ICRP 72 (Adult)

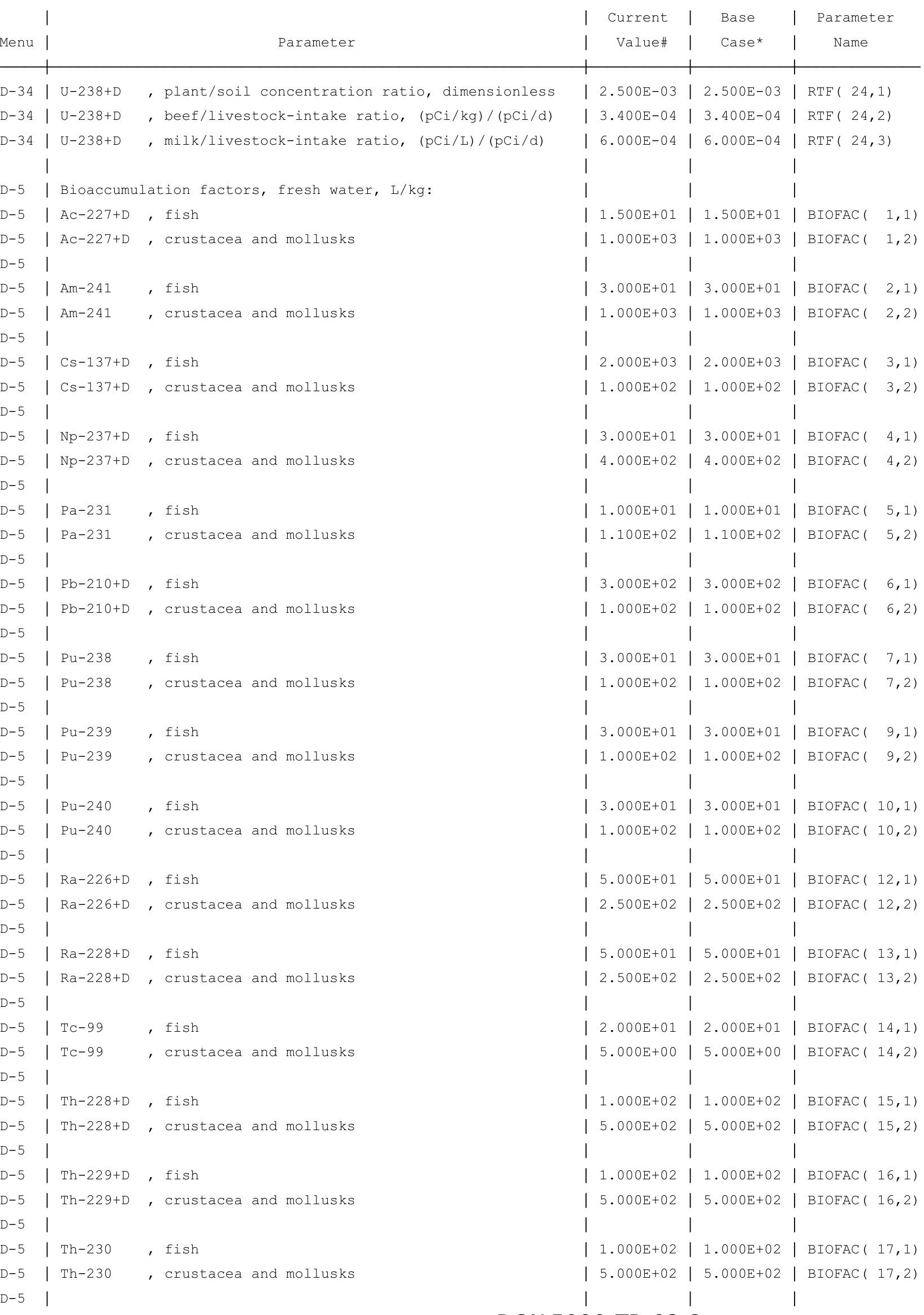


RESRAD, Version $6.5 \quad \mathrm{~T}^{1 / 2}$ Limit $=180$ days

07/18/2011 14:15 Page

ummary : C746U Resident Farmer Deterministic Run

File : $\mathrm{X}: \backslash F I N A L$ V2\DOE FWD RUNS \C746U RF DOE SG FWD-FV2-10000YR.RAD

Dose Conversion Factor (and Related) Parameter Summary (continued)

Dose Library: ICRP 60 \& ICRP 72 (Adult)

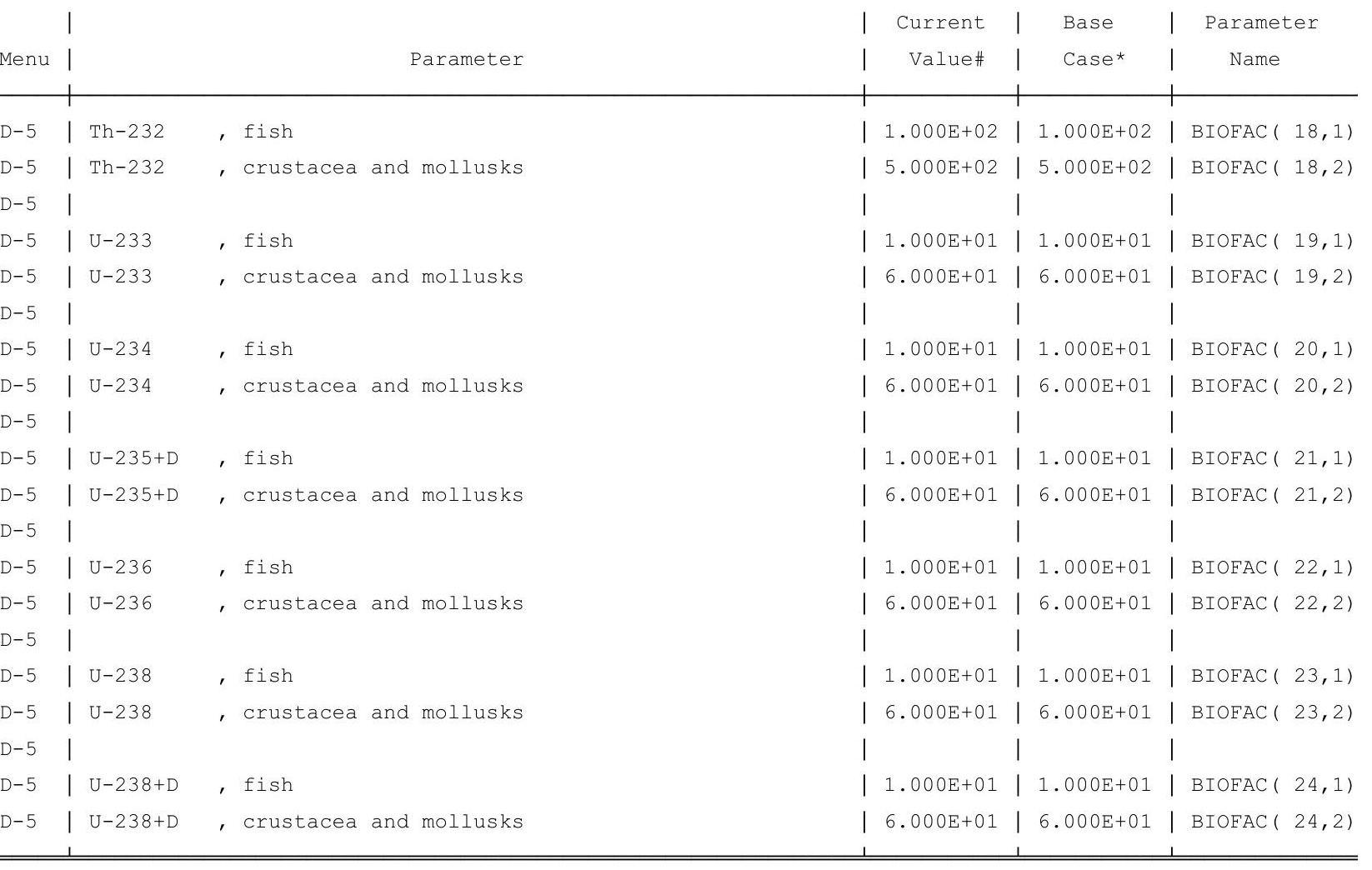

\#For DCFl(xxx) only, factors are for infinite depth \& area. See ETFG table in Ground Pathway of Detailed Report. *Base Case means Default.Lib w/o Associate Nuclide contributions. 
RESRAD, Version $6.5 \quad \mathrm{~T}^{1 / 2}$ Limit $=180$ days

07/18/2011 14:15 Page

Summary : C746U Resident Farmer Deterministic Run

File : $X: \backslash F I N A L$ V2 \DOE FWD RUNS \C746U RF DOE SG FWD-FV2-10000YR.RAD

Site-Specific Parameter Summary (continued)

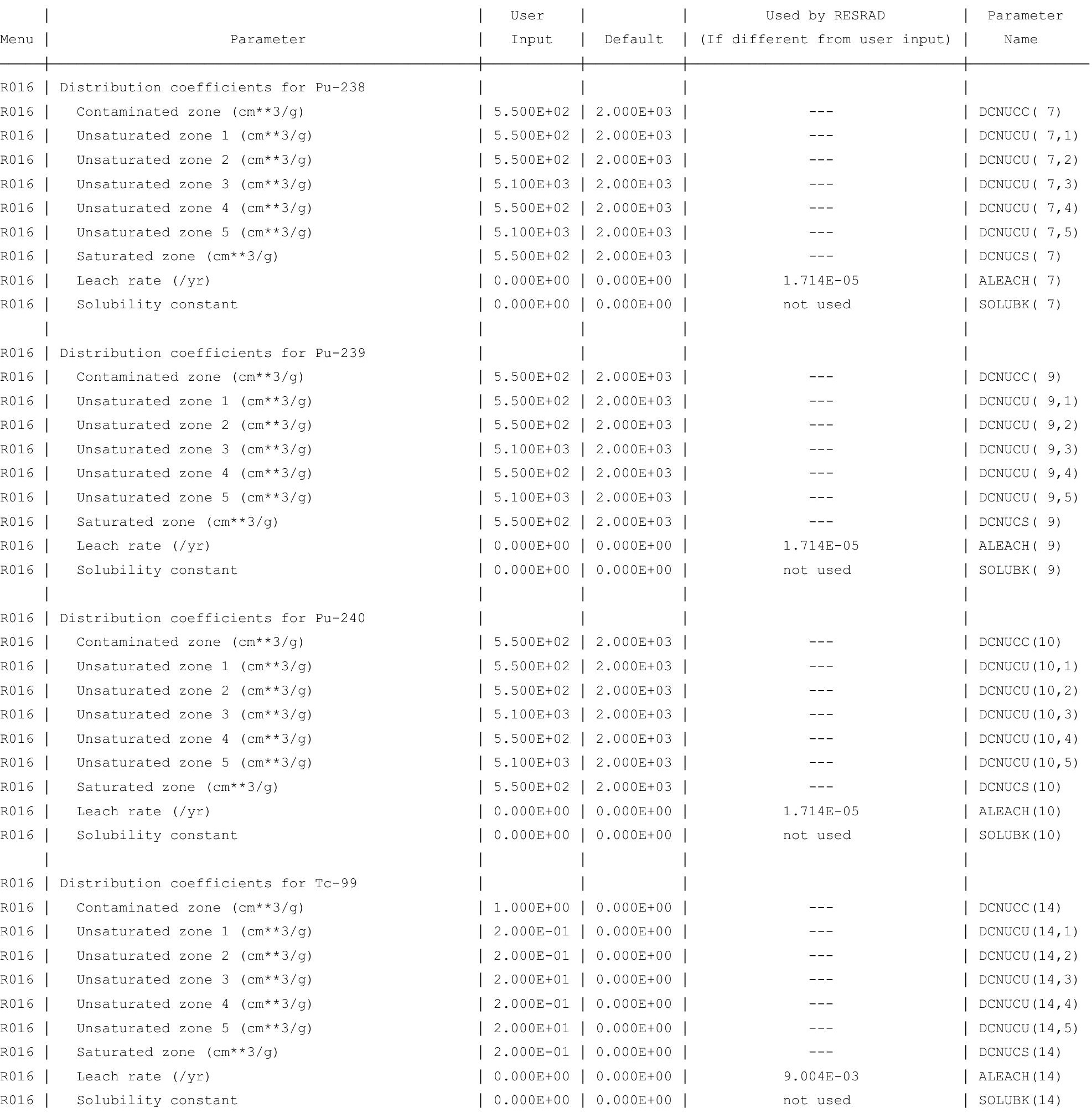


RESRAD, Version $6.5 \quad \mathrm{~T}^{1 / 2}$ Limit $=180$ days

07/18/2011 14:15 Page 12

ummary : C746U Resident Farmer Deterministic Run

File : $X: \backslash F I N A L$ V2 \DOE FWD RUNS \C746U RF DOE SG FWD-FV2-10000YR.RAD

Site-Specific Parameter Summary (continued)

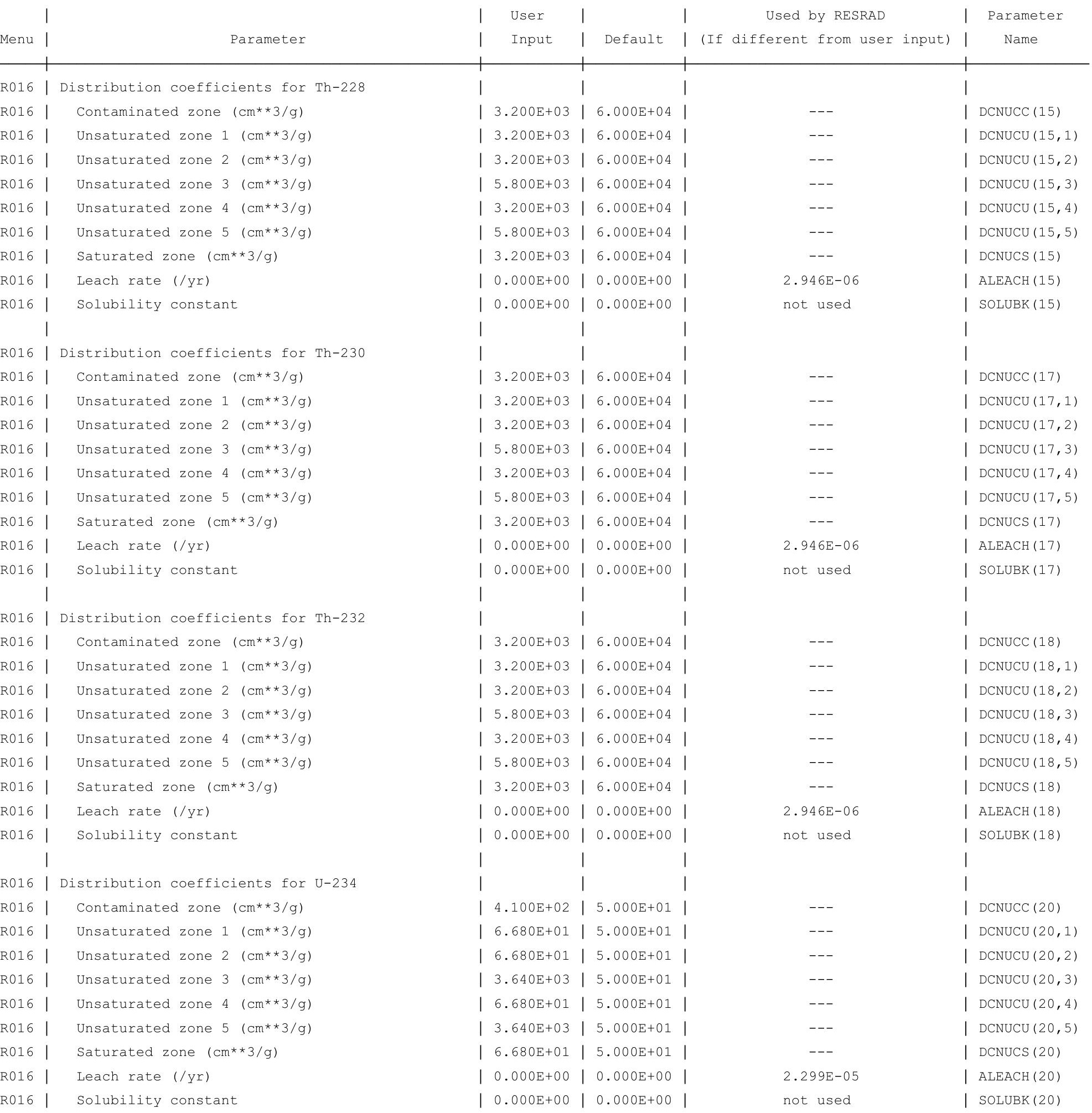


RESRAD, Version $6.5 \quad \mathrm{~T}^{1 / 2}$ Limit $=180$ days

Summary : C746U Resident Farmer Deterministic Run

File : $X: \backslash F I N A L$ V2 \DOE FWD RUNS \C746U RF DOE SG FWD-FV2-10000YR.RAD

Site-Specific Parameter Summary (continued)

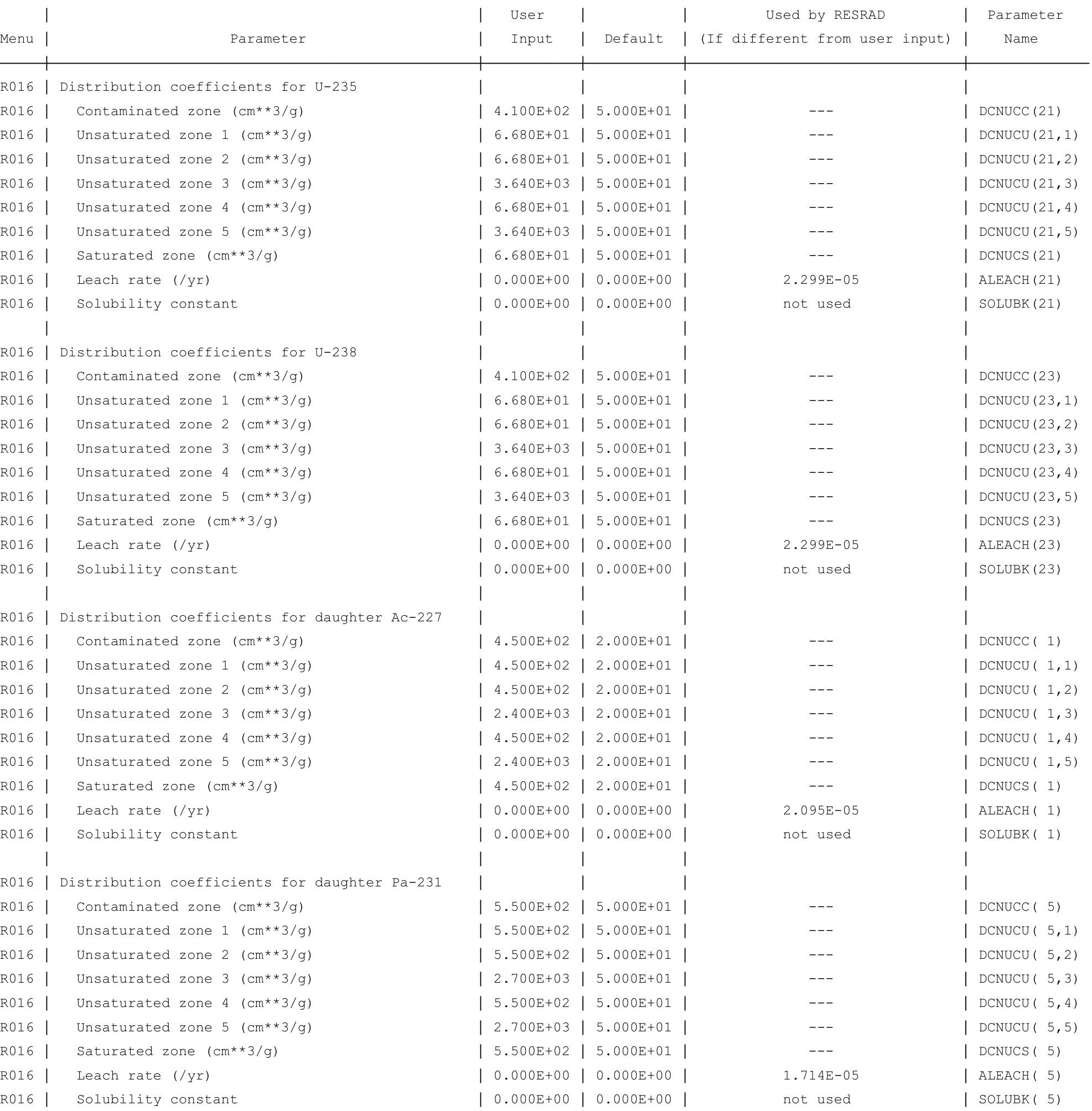


RESRAD, Version $6.5 \quad \mathrm{~T}^{1 / 2}$ Limit $=180$ days

Summary : C746U Resident Farmer Deterministic Run

File : $X: \backslash F I N A L$ V2 \DOE FWD RUNS \C746U RF DOE SG FWD-FV2-10000YR.RAD

Site-Specific Parameter Summary (continued)

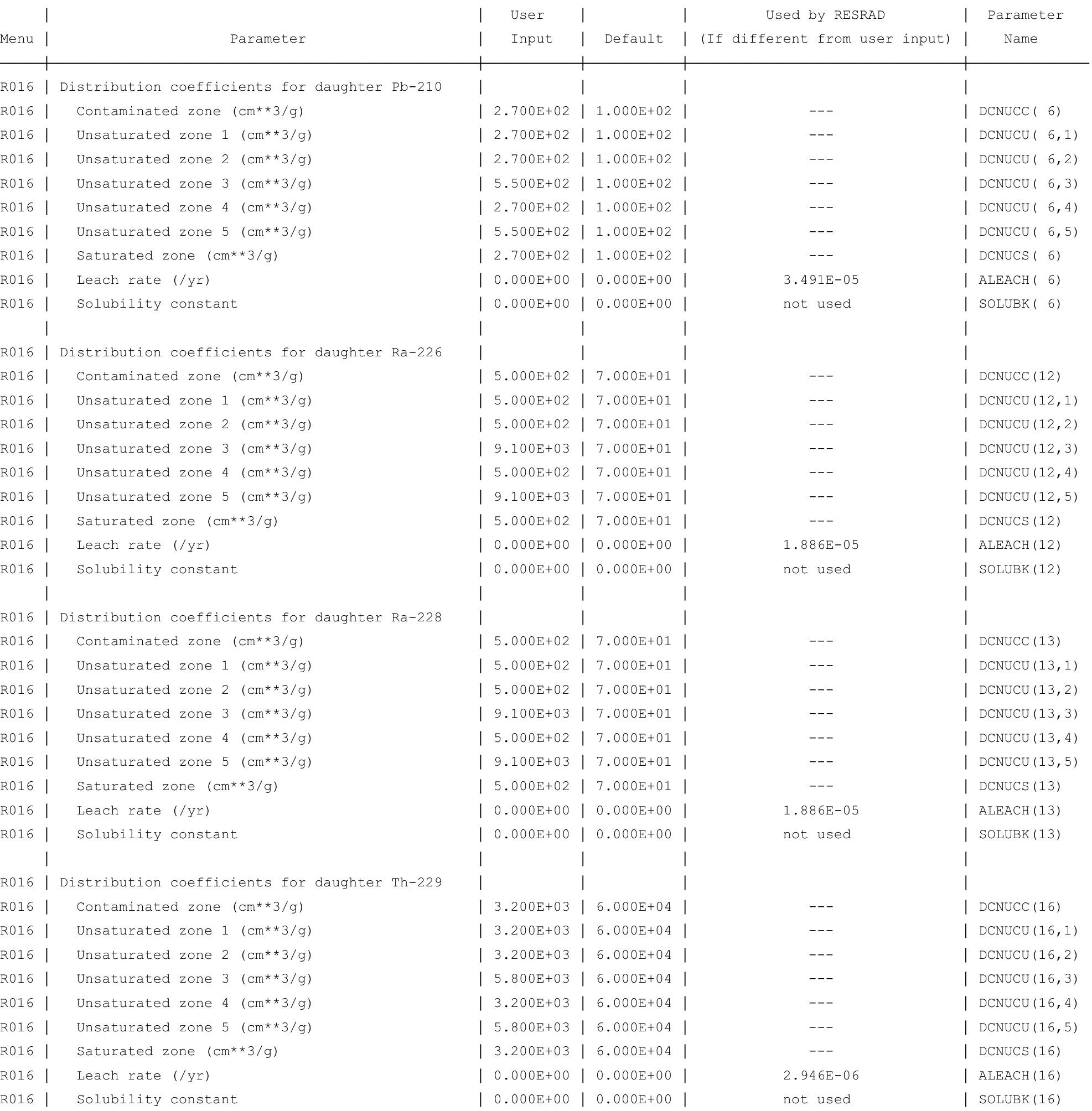


RESRAD, Version $6.5 \quad \mathrm{~T}^{1 / 2}$ Limit $=180$ days

Summary : C746U Resident Farmer Deterministic Run

File : $X: \backslash F I N A L$ V2 \DOE FWD RUNS \C746U RF DOE SG FWD-FV2-10000YR.RAD

Site-Specific Parameter Summary (continued)

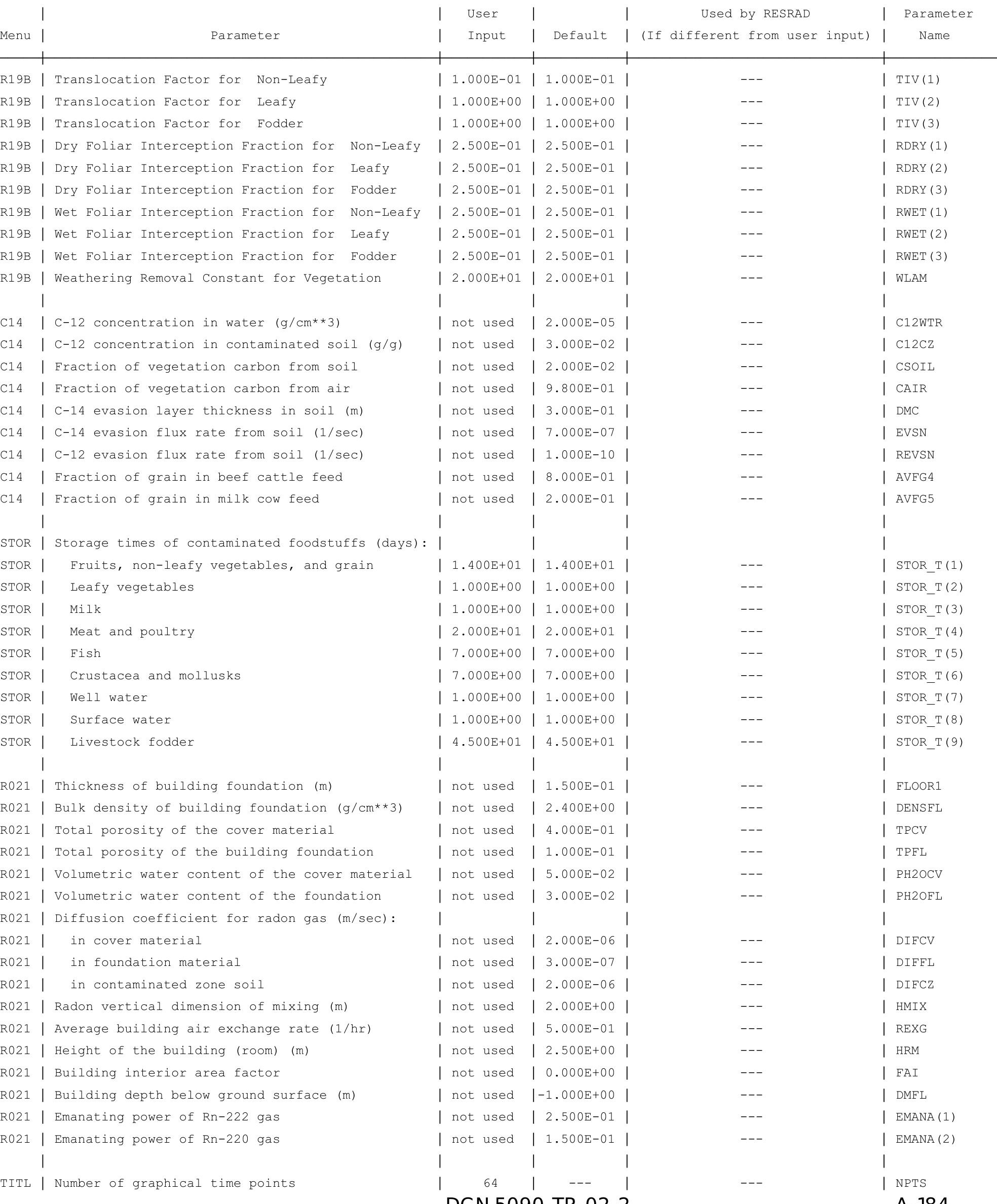


RESRAD, Version $6.5 \quad \mathrm{~T}^{1 / 2}$ Limit $=180$ days

Summary : C746U Resident Farmer Deterministic Run

File : $\mathrm{X}: \backslash F I N A L$ V2 $\backslash$ DOE FWD RUNS $\backslash C 746 \mathrm{U}$ RF DOE SG FWD-FV2-10000YR. RAD

Contaminated Zone Dimensions

Area: 89436.00 square meters

Thickness:

Cover Depth:

\begin{abstract}
13.40 meters
1.52 meters
\end{abstract}

Initial Soil Concentrations, pCi/g

$\begin{array}{ll}\text { Am-241 } & 3.500 \mathrm{E}+01 \\ \mathrm{Cs}-137 & 1.900 \mathrm{E}+01 \\ \mathrm{~Np}-237 & 5.500 \mathrm{E}+00 \\ \mathrm{Pu}-238 & 3.900 \mathrm{E}+01 \\ \mathrm{Pu}-239 & 3.600 \mathrm{E}+01 \\ \mathrm{Pu}-240 & 3.600 \mathrm{E}+01 \\ \mathrm{TC}-99 & 5.200 \mathrm{E}+01 \\ \mathrm{Th}-228 & 4.000 \mathrm{E}+00 \\ \mathrm{Th}-230 & 1.000 \mathrm{E}+02 \\ \mathrm{Th}-232 & 4.000 \mathrm{E}+00 \\ \mathrm{U}-234 & 1.600 \mathrm{E}+02 \\ \mathrm{U}-235 & 6.500 \mathrm{E}+00 \\ \mathrm{U}-238 & 1.600 \mathrm{E}+02\end{array}$

Total Dose TDOSE(t), mrem/yr

Basic Radiation Dose Limit $=1.000 \mathrm{E}+02 \mathrm{mrem} / \mathrm{yr}$

Total Mixture Sum $M(t)$ = Fraction of Basic Dose Limit Received at Time (t)

$\begin{array}{rlllllll}t \text { (years) }: & 0.000 \mathrm{E}+00 & 1.000 \mathrm{E}+00 & 5.000 \mathrm{E}+01 & 1.000 \mathrm{E}+02 & 5.000 \mathrm{E}+02 & 1.050 \mathrm{E}+03 & 1.000 \mathrm{E}+04 \\ \mathrm{TDOSE}(\mathrm{t}): & 6.620 \mathrm{E}-06 & 4.789 \mathrm{E}-06 & 9.505 \mathrm{E}-06 & 1.362 \mathrm{E}-05 & 1.081 \mathrm{E}+01 & 7.196 \mathrm{E}+00 & 2.719 \mathrm{E}+03 \\ \mathrm{M}(\mathrm{t}): & 6.620 \mathrm{E}-08 & 4.789 \mathrm{E}-08 & 9.505 \mathrm{E}-08 & 1.362 \mathrm{E}-07 & 1.081 \mathrm{E}-01 & 7.196 \mathrm{E}-02 & 2.719 \mathrm{E}+01\end{array}$

Maximum TDOSE $(\mathrm{t}): 2.719 \mathrm{E}+03 \mathrm{mrem} / \mathrm{yr}$ at $t=1.000 \mathrm{E}+04$ years 
RESRAD, Version 6.5

$\mathrm{T}^{1 / 2}$ Limit = 180 days

ummary : C746U Resident Farmer Deterministic Run

: $\mathrm{X}: \backslash F I N A L$ V2 $\backslash$ DOE FWD RUNS $\backslash C 746 \mathrm{U}$ RF DOE SG FWD-FV2-10000YR.RAD

Total Dose Contributions TDOSE(i,p,t) for Individual Radionuclides (i) and Pathways (p) As mrem/yr and Fraction of Total Dose At $t=0.000 \mathrm{E}+00$ years

Water Independent Pathways (Inhalation excludes radon)

\begin{tabular}{|c|c|c|c|c|c|c|c|c|c|c|c|c|c|c|}
\hline \multirow{2}{*}{ Nuclide } & \multicolumn{2}{|c|}{ Ground } & \multicolumn{2}{|c|}{ Inhalation } & \multicolumn{2}{|c|}{ Radon } & \multicolumn{2}{|c|}{ Plant } & \multicolumn{2}{|c|}{ Meat } & \multicolumn{2}{|c|}{ Milk } & \multicolumn{2}{|c|}{ Soil } \\
\hline & mrem/yr & fract. & mrem/yr & fract. & mrem/yr & fract. & mrem/yr & fract. & mrem/yr & fract. & mrem/yr & fract. & mrem/yr & fract. \\
\hline-241 & $0.000 \mathrm{E}+00$ & 0.0000 & $0.000 \mathrm{E}+00$ & 0.0000 & $0.000 \mathrm{E}+00$ & 0.0000 & $0.000 \mathrm{E}+00$ & 0.0000 & $0.000 \mathrm{E}+00$ & 0.0000 & $0.000 \mathrm{E}+00$ & 0.0000 & $0.000 \mathrm{E}+00$ & 0.0000 \\
\hline-137 & $2.415 E-08$ & 0.0036 & $0.000 \mathrm{E}+00$ & 0.0000 & $0.000 \mathrm{E}+00$ & 0.0000 & $0.000 \mathrm{E}+00$ & 0.0000 & $0.000 \mathrm{E}+00$ & 0.0000 & $0.000 \mathrm{E}+00$ & 0.0000 & $0.000 \mathrm{E}+00$ & 0.0000 \\
\hline-237 & $5.217 \mathrm{E}-12$ & 0.0000 & $0.000 \mathrm{E}+00$ & 0.0000 & $0.000 \mathrm{E}+00$ & 0.0000 & $0.000 \mathrm{E}+00$ & 0.0000 & $0.000 \mathrm{E}+00$ & 0.0000 & $0.000 \mathrm{E}+00$ & 0.0000 & $0.000 \mathrm{E}+00$ & 0.0000 \\
\hline-238 & $4.560 E-23$ & 0.0000 & $0.000 \mathrm{E}+00$ & 0.0000 & $0.000 \mathrm{E}+00$ & 0.0000 & $0.000 \mathrm{E}+00$ & 0.0000 & $0.000 \mathrm{E}+00$ & 0.0000 & $0.000 \mathrm{E}+00$ & 0.0000 & $0.000 \mathrm{E}+00$ & 0.0000 \\
\hline-239 & $4.302 E-16$ & 0.0000 & $0.000 \mathrm{E}+00$ & 0.0000 & $0.000 \mathrm{E}+00$ & 0.0000 & $0.000 \mathrm{E}+00$ & 0.0000 & $0.000 \mathrm{E}+00$ & 0.0000 & $0.000 \mathrm{E}+00$ & 0.0000 & $0.000 \mathrm{E}+00$ & 0.0000 \\
\hline-240 & $4.075 E-23$ & 0.0000 & $0.000 \mathrm{E}+00$ & 0.0000 & $0.000 \mathrm{E}+00$ & 0.0000 & $0.000 \mathrm{E}+00$ & 0.0000 & $0.000 \mathrm{E}+00$ & 0.0000 & $0.000 \mathrm{E}+00$ & 0.0000 & $0.000 \mathrm{E}+00$ & 0.0000 \\
\hline 99 & $2.979 E-24$ & 0.0000 & $0.000 \mathrm{E}+00$ & 0.0000 & $0.000 \mathrm{E}+00$ & 0.0000 & $0.000 \mathrm{E}+00$ & 0.0000 & $0.000 \mathrm{E}+00$ & 0.0000 & $0.000 \mathrm{E}+00$ & 0.0000 & $0.000 \mathrm{E}+00$ & 0.0000 \\
\hline-228 & $6.573 E-06$ & 0.9929 & $0.000 \mathrm{E}+00$ & 0.0000 & $0.000 \mathrm{E}+00$ & 0.0000 & $0.000 \mathrm{E}+00$ & 0.0000 & $0.000 \mathrm{E}+00$ & 0.0000 & $0.000 \mathrm{E}+00$ & 0.0000 & $0.000 \mathrm{E}+00$ & 0.0000 \\
\hline-230 & $2.392 \mathrm{E}-20$ & 0.0000 & $0.000 \mathrm{E}+00$ & 0.0000 & $0.000 \mathrm{E}+00$ & 0.0000 & $0.000 \mathrm{E}+00$ & 0.0000 & $0.000 \mathrm{E}+00$ & 0.0000 & $0.000 \mathrm{E}+00$ & 0.0000 & $0.000 \mathrm{E}+00$ & 0.0000 \\
\hline-232 & $4.620 E-24$ & 0.0000 & $0.000 \mathrm{E}+00$ & 0.0000 & $0.000 \mathrm{E}+00$ & 0.0000 & $0.000 \mathrm{E}+00$ & 0.0000 & $0.000 \mathrm{E}+00$ & 0.0000 & $0.000 \mathrm{E}+00$ & 0.0000 & $0.000 \mathrm{E}+00$ & 0.0000 \\
\hline 234 & $1.094 \mathrm{E}-21$ & 0.0000 & $0.000 \mathrm{E}+00$ & 0.0000 & $0.000 \mathrm{E}+00$ & 0.0000 & $0.000 \mathrm{E}+00$ & 0.0000 & $0.000 \mathrm{E}+00$ & 0.0000 & $0.000 \mathrm{E}+00$ & 0.0000 & $0.000 \mathrm{E}+00$ & 0.0000 \\
\hline 235 & $8.032 \mathrm{E}-14$ & 0.0000 & $0.000 \mathrm{E}+00$ & 0.0000 & $0.000 \mathrm{E}+00$ & 0.0000 & $0.000 \mathrm{E}+00$ & 0.0000 & $0.000 \mathrm{E}+00$ & 0.0000 & $0.000 \mathrm{E}+00$ & 0.0000 & $0.000 \mathrm{E}+00$ & 0.0000 \\
\hline 38 & $2.262 E-08$ & 0.0034 & $0.000 \mathrm{E}+00$ & 0.0000 & $0.000 \mathrm{E}+00$ & 0.0000 & $0.000 \mathrm{E}+00$ & 0.0000 & $0.000 \mathrm{E}+00$ & 0.0000 & $0.000 \mathrm{E}+00$ & 0.0000 & $0.000 \mathrm{E}+00$ & 0.0000 \\
\hline & $6.620 \mathrm{E}-06$ & 1.0000 & $0.000 \mathrm{E}+00$ & 0.0000 & $0.000 \mathrm{E}+00$ & 0.0000 & $0.000 \mathrm{E}+00$ & 0.0000 & $0.000 \mathrm{E}+00$ & 0.0000 & $0.000 \mathrm{E}+00$ & 0.0000 & $.000 \mathrm{E}+00$ & 0.0000 \\
\hline
\end{tabular}

Total Dose Contributions TDOSE (i,p,t) for Individual Radionuclides (i) and Pathways (p) As mrem/yr and Fraction of Total Dose At $t=0.000 \mathrm{E}+00$ years

Water Dependent Pathways

\begin{tabular}{|c|c|c|c|c|c|c|c|c|c|c|c|c|c|c|}
\hline & \multicolumn{2}{|c|}{ Water } & \multicolumn{2}{|c|}{ Fish } & \multicolumn{2}{|c|}{ Radon } & \multicolumn{2}{|c|}{ Plant } & \multicolumn{2}{|c|}{ Meat } & \multicolumn{2}{|c|}{ Milk } & \multicolumn{2}{|c|}{ All Pathways* } \\
\hline clide & mrem/yr & fract. & mrem/yr & fract. & mrem/yr & fract. & mrem/yr & fract. & mrem/yr & fract. & mrem/yr & fract. & mrem/yr & fract. \\
\hline-241 & $0.000 \mathrm{E}+00$ & 0.0000 & $0.000 \mathrm{E}+00$ & 0.0000 & $0.000 \mathrm{E}+00$ & 0.0000 & $0.000 \mathrm{E}+00$ & 0.0000 & $0.000 \mathrm{E}+00$ & 0.0000 & $0.000 \mathrm{E}+00$ & 0.0000 & $0.000 \mathrm{E}+00$ & 0.0000 \\
\hline-137 & $0.000 \mathrm{E}+00$ & 0.0000 & $0.000 \mathrm{E}+00$ & 0.0000 & $0.000 \mathrm{E}+00$ & 0.0000 & $0.000 \mathrm{E}+00$ & 0.0000 & $0.000 \mathrm{E}+00$ & 0.0000 & $0.000 \mathrm{E}+00$ & 0.0000 & $2.415 \mathrm{E}-08$ & 0.0036 \\
\hline-237 & $0.000 \mathrm{E}+00$ & 0.0000 & $0.000 \mathrm{E}+00$ & 0.0000 & $0.000 \mathrm{E}+00$ & 0.0000 & $0.000 \mathrm{E}+00$ & 0.0000 & $0.000 \mathrm{E}+00$ & 0.0000 & $0.000 \mathrm{E}+00$ & 0.0000 & $5.217 \mathrm{E}-12$ & 0.0000 \\
\hline 238 & $0.000 \mathrm{E}+00$ & 0.0000 & $0.000 \mathrm{E}+00$ & 0.0000 & $0.000 \mathrm{E}+00$ & 0.0000 & $0.000 \mathrm{E}+00$ & 0.0000 & $0.000 \mathrm{E}+00$ & 0.0000 & $0.000 \mathrm{E}+00$ & 0.0000 & $4.560 \mathrm{E}-23$ & 0.0000 \\
\hline 239 & $0.000 \mathrm{E}+00$ & 0.0000 & $0.000 \mathrm{E}+00$ & 0.0000 & $0.000 \mathrm{E}+00$ & 0.0000 & $0.000 \mathrm{E}+00$ & 0.0000 & $0.000 \mathrm{E}+00$ & 0.0000 & $0.000 \mathrm{E}+00$ & 0.0000 & $4.302 \mathrm{E}-16$ & 0.0000 \\
\hline 240 & $0.000 \mathrm{E}+00$ & 0.0000 & $0.000 \mathrm{E}+00$ & 0.0000 & $0.000 \mathrm{E}+00$ & 0.0000 & $0.000 \mathrm{E}+00$ & 0.0000 & $0.000 \mathrm{E}+00$ & 0.0000 & $0.000 \mathrm{E}+00$ & 0.0000 & $4.075 E-23$ & 0.0000 \\
\hline 99 & $0.000 \mathrm{E}+00$ & 0.0000 & $0.000 \mathrm{E}+00$ & 0.0000 & $0.000 \mathrm{E}+00$ & 0.0000 & $0.000 \mathrm{E}+00$ & 0.0000 & $0.000 \mathrm{E}+00$ & 0.0000 & $0.000 \mathrm{E}+00$ & 0.0000 & $2.979 E-24$ & 0.0000 \\
\hline 228 & $0.000 \mathrm{E}+00$ & 0.0000 & $0.000 \mathrm{E}+00$ & 0.0000 & $0.000 \mathrm{E}+00$ & 0.0000 & $0.000 \mathrm{E}+00$ & 0.0000 & $0.000 \mathrm{E}+00$ & 0.0000 & $0.000 \mathrm{E}+00$ & 0.0000 & $6.573 E-06$ & 0.9929 \\
\hline 230 & $0.000 \mathrm{E}+00$ & 0.0000 & $0.000 \mathrm{E}+00$ & 0.0000 & $0.000 \mathrm{E}+00$ & 0.0000 & $0.000 \mathrm{E}+00$ & 0.0000 & $0.000 \mathrm{E}+00$ & 0.0000 & $0.000 \mathrm{E}+00$ & 0.0000 & $2.392 \mathrm{E}-20$ & 0.0000 \\
\hline 232 & $0.000 \mathrm{E}+00$ & 0.0000 & $0.000 \mathrm{E}+00$ & 0.0000 & $0.000 \mathrm{E}+00$ & 0.0000 & $0.000 \mathrm{E}+00$ & 0.0000 & $0.000 \mathrm{E}+00$ & 0.0000 & $0.000 \mathrm{E}+00$ & 0.0000 & $4.620 \mathrm{E}-24$ & 0.0000 \\
\hline 34 & $0.000 \mathrm{E}+00$ & 0.0000 & $0.000 \mathrm{E}+00$ & 0.0000 & $0.000 \mathrm{E}+00$ & 0.0000 & $0.000 \mathrm{E}+00$ & 0.0000 & $0.000 \mathrm{E}+00$ & 0.0000 & $0.000 \mathrm{E}+00$ & 0.0000 & $1.094 \mathrm{E}-21$ & 0.0000 \\
\hline 35 & $0.000 \mathrm{E}+00$ & 0.0000 & $0.000 \mathrm{E}+00$ & 0.0000 & $0.000 \mathrm{E}+00$ & 0.0000 & $0.000 \mathrm{E}+00$ & 0.0000 & $0.000 \mathrm{E}+00$ & 0.0000 & $0.000 \mathrm{E}+00$ & 0.0000 & $8.032 \mathrm{E}-14$ & 0.0000 \\
\hline 38 & $0.000 \mathrm{E}+00$ & 0.0000 & $0.000 \mathrm{E}+00$ & 0.0000 & $0.000 \mathrm{E}+00$ & 0.0000 & $0.000 \mathrm{E}+00$ & 0.0000 & $0.000 \mathrm{E}+00$ & 0.0000 & $0.000 \mathrm{E}+00$ & 0.0000 & $2.262 \mathrm{E}-08$ & 0.0034 \\
\hline & $0.000 \mathrm{E}+00$ & 0.0000 & $0.000 \mathrm{E}+00$ & 0.0000 & $0.000 \mathrm{E}+00$ & 0.0000 & $0.000 \mathrm{E}+00$ & 0.0000 & $0.000 \mathrm{E}+00$ & 0.0000 & $0.000 \mathrm{E}+00$ & 000 & -06 & 1.0000 \\
\hline
\end{tabular}

* Sum of all water independent and dependent pathways. 
RESRAD, Version 6.5

$\mathrm{T}^{1 / 2}$ Limit = 180 days

07/18/2011 14:15 Page 21

ummary : C746U Resident Farmer Deterministic Run

: $\mathrm{X}: \backslash F I N A L$ V2\DOE FWD RUNS \C746U RF DOE SG FWD-FV2-10000YR.RAD

Total Dose Contributions TDOSE (i,p,t) for Individual Radionuclides (i) and Pathways (p) As mrem/yr and Fraction of Total Dose At $t=1.000 \mathrm{E}+00$ years

Water Independent Pathways (Inhalation excludes radon)

\begin{tabular}{|c|c|c|c|c|c|c|c|c|c|c|c|c|c|c|}
\hline \multirow{2}{*}{ Nuclide } & \multicolumn{2}{|c|}{ Ground } & \multicolumn{2}{|c|}{ Inhalation } & \multicolumn{2}{|c|}{ Radon } & \multicolumn{2}{|c|}{ Plant } & \multicolumn{2}{|c|}{ Meat } & \multicolumn{2}{|c|}{ Milk } & \multicolumn{2}{|c|}{ Soil } \\
\hline & mrem/yr & fract. & mrem/yr & fract. & mrem/yr & fract. & mrem/yr & fract. & mrem/yr & fract. & mrem/yr & fract. & mrem/yr & fract. \\
\hline-241 & $1.086 \mathrm{E}-17$ & 0.0000 & $0.000 \mathrm{E}+00$ & 0.0000 & $0.000 \mathrm{E}+00$ & 0.0000 & $0.000 \mathrm{E}+00$ & 0.0000 & $0.000 \mathrm{E}+00$ & 0.0000 & $0.000 \mathrm{E}+00$ & 0.0000 & $0.000 \mathrm{E}+00$ & 0.0000 \\
\hline-137 & $2.380 E-08$ & 0.0050 & $0.000 \mathrm{E}+00$ & 0.0000 & $0.000 \mathrm{E}+00$ & 0.0000 & $0.000 \mathrm{E}+00$ & 0.0000 & $0.000 \mathrm{E}+00$ & 0.0000 & $0.000 \mathrm{E}+00$ & 0.0000 & $0.000 \mathrm{E}+00$ & 0.0000 \\
\hline-237 & $5.273 E-12$ & 0.0000 & $0.000 \mathrm{E}+00$ & 0.0000 & $0.000 \mathrm{E}+00$ & 0.0000 & $0.000 \mathrm{E}+00$ & 0.0000 & $0.000 \mathrm{E}+00$ & 0.0000 & $0.000 \mathrm{E}+00$ & 0.0000 & $0.000 \mathrm{E}+00$ & 0.0000 \\
\hline-238 & $1.257 \mathrm{E}-20$ & 0.0000 & $0.000 \mathrm{E}+00$ & 0.0000 & $0.000 \mathrm{E}+00$ & 0.0000 & $0.000 \mathrm{E}+00$ & 0.0000 & $0.000 \mathrm{E}+00$ & 0.0000 & $0.000 \mathrm{E}+00$ & 0.0000 & $0.000 \mathrm{E}+00$ & 0.0000 \\
\hline-239 & $4.354 \mathrm{E}-16$ & 0.0000 & $0.000 \mathrm{E}+00$ & 0.0000 & $0.000 \mathrm{E}+00$ & 0.0000 & $0.000 \mathrm{E}+00$ & 0.0000 & $0.000 \mathrm{E}+00$ & 0.0000 & $0.000 \mathrm{E}+00$ & 0.0000 & $0.000 \mathrm{E}+00$ & 0.0000 \\
\hline-240 & $4.164 \mathrm{E}-23$ & 0.0000 & $0.000 \mathrm{E}+00$ & 0.0000 & $0.000 \mathrm{E}+00$ & 0.0000 & $0.000 \mathrm{E}+00$ & 0.0000 & $0.000 \mathrm{E}+00$ & 0.0000 & $0.000 \mathrm{E}+00$ & 0.0000 & $0.000 \mathrm{E}+00$ & 0.0000 \\
\hline 99 & $3.009 E-24$ & 0.0000 & $0.000 \mathrm{E}+00$ & 0.0000 & $0.000 \mathrm{E}+00$ & 0.0000 & $0.000 \mathrm{E}+00$ & 0.0000 & $0.000 \mathrm{E}+00$ & 0.0000 & $0.000 \mathrm{E}+00$ & 0.0000 & $0.000 \mathrm{E}+00$ & 0.0000 \\
\hline-228 & $4.603 E-06$ & 0.9611 & $0.000 \mathrm{E}+00$ & 0.0000 & $0.000 \mathrm{E}+00$ & 0.0000 & $0.000 \mathrm{E}+00$ & 0.0000 & $0.000 \mathrm{E}+00$ & 0.0000 & $0.000 \mathrm{E}+00$ & 0.0000 & $0.000 \mathrm{E}+00$ & 0.0000 \\
\hline-230 & $7.565 \mathrm{E}-09$ & 0.0016 & $0.000 \mathrm{E}+00$ & 0.0000 & $0.000 \mathrm{E}+00$ & 0.0000 & $0.000 \mathrm{E}+00$ & 0.0000 & $0.000 \mathrm{E}+00$ & 0.0000 & $0.000 \mathrm{E}+00$ & 0.0000 & $0.000 \mathrm{E}+00$ & 0.0000 \\
\hline-232 & $1.320 \mathrm{E}-07$ & 0.0276 & $0.000 \mathrm{E}+00$ & 0.0000 & $0.000 \mathrm{E}+00$ & 0.0000 & $0.000 \mathrm{E}+00$ & 0.0000 & $0.000 \mathrm{E}+00$ & 0.0000 & $0.000 \mathrm{E}+00$ & 0.0000 & $0.000 \mathrm{E}+00$ & 0.0000 \\
\hline 234 & $5.448 \mathrm{E}-14$ & 0.0000 & $0.000 \mathrm{E}+00$ & 0.0000 & $0.000 \mathrm{E}+00$ & 0.0000 & $0.000 \mathrm{E}+00$ & 0.0000 & $0.000 \mathrm{E}+00$ & 0.0000 & $0.000 \mathrm{E}+00$ & 0.0000 & $0.000 \mathrm{E}+00$ & 0.0000 \\
\hline 235 & $8.153 \mathrm{E}-14$ & 0.0000 & $0.000 \mathrm{E}+00$ & 0.0000 & $0.000 \mathrm{E}+00$ & 0.0000 & $0.000 \mathrm{E}+00$ & 0.0000 & $0.000 \mathrm{E}+00$ & 0.0000 & $0.000 \mathrm{E}+00$ & 0.0000 & $0.000 \mathrm{E}+00$ & 0.0000 \\
\hline 38 & $2.280 E-08$ & 0.0048 & $0.000 \mathrm{E}+00$ & 0.0000 & $0.000 \mathrm{E}+00$ & 0.0000 & $0.000 \mathrm{E}+00$ & 0.0000 & $0.000 \mathrm{E}+00$ & 0.0000 & $0.000 \mathrm{E}+00$ & 0.0000 & $0.000 \mathrm{E}+00$ & 0.0000 \\
\hline & $4.789 E-06$ & 1.0000 & $0.000 \mathrm{E}+00$ & 0.0000 & $0.000 \mathrm{E}+00$ & 0.0000 & $0.000 \mathrm{E}+00$ & 0.0000 & $0.000 \mathrm{E}+00$ & 0.0000 & $0.000 \mathrm{E}+00$ & 0.0000 & $.000 \mathrm{E}+00$ & 0.0000 \\
\hline
\end{tabular}

Total Dose Contributions TDOSE (i,p,t) for Individual Radionuclides (i) and Pathways (p) As mrem/yr and Fraction of Total Dose At $t=1.000 \mathrm{E}+00$ years

Water Dependent Pathways

\begin{tabular}{|c|c|c|c|c|c|c|c|c|c|c|c|c|c|c|}
\hline & \multicolumn{2}{|c|}{ Water } & \multicolumn{2}{|c|}{ Fish } & \multicolumn{2}{|c|}{ Radon } & \multicolumn{2}{|c|}{ Plant } & \multicolumn{2}{|c|}{ Meat } & \multicolumn{2}{|c|}{ Milk } & \multicolumn{2}{|c|}{ All Pathways* } \\
\hline clide & mrem/yr & fract. & mrem/yr & fract. & mrem/yr & fract. & mrem/yr & fract. & mrem/yr & fract. & mrem/yr & fract. & mrem/yr & fract. \\
\hline-241 & $0.000 \mathrm{E}+00$ & 0.0000 & $0.000 \mathrm{E}+00$ & 0.0000 & $0.000 \mathrm{E}+00$ & 0.0000 & $0.000 \mathrm{E}+00$ & 0.0000 & $0.000 \mathrm{E}+00$ & 0.0000 & $0.000 \mathrm{E}+00$ & 0.0000 & $1.086 \mathrm{E}-17$ & 0.0000 \\
\hline-137 & $0.000 \mathrm{E}+00$ & 0.0000 & $0.000 \mathrm{E}+00$ & 0.0000 & $0.000 \mathrm{E}+00$ & 0.0000 & $0.000 \mathrm{E}+00$ & 0.0000 & $0.000 \mathrm{E}+00$ & 0.0000 & $0.000 \mathrm{E}+00$ & 0.0000 & $2.380 \mathrm{E}-08$ & 0.0050 \\
\hline-237 & $0.000 \mathrm{E}+00$ & 0.0000 & $0.000 \mathrm{E}+00$ & 0.0000 & $0.000 \mathrm{E}+00$ & 0.0000 & $0.000 \mathrm{E}+00$ & 0.0000 & $0.000 \mathrm{E}+00$ & 0.0000 & $0.000 \mathrm{E}+00$ & 0.0000 & $5.273 E-12$ & 0.0000 \\
\hline-238 & $0.000 \mathrm{E}+00$ & 0.0000 & $0.000 \mathrm{E}+00$ & 0.0000 & $0.000 \mathrm{E}+00$ & 0.0000 & $0.000 \mathrm{E}+00$ & 0.0000 & $0.000 \mathrm{E}+00$ & 0.0000 & $0.000 \mathrm{E}+00$ & 0.0000 & $1.257 \mathrm{E}-20$ & 0.0000 \\
\hline-239 & $0.000 \mathrm{E}+00$ & 0.0000 & $0.000 \mathrm{E}+00$ & 0.0000 & $0.000 \mathrm{E}+00$ & 0.0000 & $0.000 \mathrm{E}+00$ & 0.0000 & $0.000 \mathrm{E}+00$ & 0.0000 & $0.000 E+00$ & 0.0000 & $4.354 \mathrm{E}-16$ & 0.0000 \\
\hline-240 & $0.000 \mathrm{E}+00$ & 0.0000 & $0.000 \mathrm{E}+00$ & 0.0000 & $0.000 \mathrm{E}+00$ & 0.0000 & $0.000 \mathrm{E}+00$ & 0.0000 & $0.000 \mathrm{E}+00$ & 0.0000 & $0.000 E+00$ & 0.0000 & $4.164 \mathrm{E}-23$ & 0.0000 \\
\hline-99 & $0.000 \mathrm{E}+00$ & 0.0000 & $0.000 \mathrm{E}+00$ & 0.0000 & $0.000 \mathrm{E}+00$ & 0.0000 & $0.000 \mathrm{E}+00$ & 0.0000 & $0.000 \mathrm{E}+00$ & 0.0000 & $0.000 \mathrm{E}+00$ & 0.0000 & $3.009 E-24$ & 0.0000 \\
\hline-228 & $0.000 \mathrm{E}+00$ & 0.0000 & $0.000 \mathrm{E}+00$ & 0.0000 & $0.000 \mathrm{E}+00$ & 0.0000 & $0.000 \mathrm{E}+00$ & 0.0000 & $0.000 \mathrm{E}+00$ & 0.0000 & $0.000 \mathrm{E}+00$ & 0.0000 & $4.603 E-06$ & 0.9611 \\
\hline-230 & $0.000 \mathrm{E}+00$ & 0.0000 & $0.000 \mathrm{E}+00$ & 0.0000 & $0.000 \mathrm{E}+00$ & 0.0000 & $0.000 \mathrm{E}+00$ & 0.0000 & $0.000 \mathrm{E}+00$ & 0.0000 & $0.000 E+00$ & 0.0000 & $7.565 \mathrm{E}-09$ & 0.0016 \\
\hline 232 & $0.000 \mathrm{E}+00$ & 0.0000 & $0.000 \mathrm{E}+00$ & 0.0000 & $0.000 \mathrm{E}+00$ & 0.0000 & $0.000 \mathrm{E}+00$ & 0.0000 & $0.000 \mathrm{E}+00$ & 0.0000 & $0.000 \mathrm{E}+00$ & 0.0000 & $1.320 \mathrm{E}-07$ & 0.0276 \\
\hline 34 & $0.000 \mathrm{E}+00$ & 0.0000 & $0.000 \mathrm{E}+00$ & 0.0000 & $0.000 \mathrm{E}+00$ & 0.0000 & $0.000 \mathrm{E}+00$ & 0.0000 & $0.000 \mathrm{E}+00$ & 0.0000 & $0.000 \mathrm{E}+00$ & 0.0000 & $5.448 \mathrm{E}-14$ & 0.0000 \\
\hline 35 & $0.000 \mathrm{E}+00$ & 0.0000 & $0.000 \mathrm{E}+00$ & 0.0000 & $0.000 \mathrm{E}+00$ & 0.0000 & $0.000 \mathrm{E}+00$ & 0.0000 & $0.000 \mathrm{E}+00$ & 0.0000 & $0.000 E+00$ & 0.0000 & $8.153 \mathrm{E}-14$ & 0.0000 \\
\hline 38 & $0.000 \mathrm{E}+00$ & 0.0000 & $0.000 \mathrm{E}+00$ & 0.0000 & $0.000 \mathrm{E}+00$ & 0.0000 & $0.000 \mathrm{E}+00$ & 0.0000 & $0.000 \mathrm{E}+00$ & 0.0000 & $0.000 \mathrm{E}+00$ & 0.0000 & $2.280 \mathrm{E}-08$ & 0.0048 \\
\hline & $0.000 \mathrm{E}+00$ & 0.0000 & $0.000 \mathrm{E}+00$ & 0.0000 & $0.000 \mathrm{E}+00$ & 0.0000 & $0.000 \mathrm{E}+00$ & 0.0000 & $0.000 \mathrm{E}+00$ & 0.0000 & $0.000 \mathrm{E}+00$ & 0.0000 & $39 E-06$ & 1.0000 \\
\hline
\end{tabular}

* Sum of all water independent and dependent pathways. 
RESRAD, Version 6.5

$\mathrm{T}^{1 / 2}$ Limit = 180 days

07/18/2011 14:15 Page 22

ummary : C746U Resident Farmer Deterministic Run

: $\mathrm{X}: \backslash F I N A L$ V2 $\backslash$ DOE FWD RUNS $\backslash C 746 \mathrm{U}$ RF DOE SG FWD-FV2-10000YR.RAD

Total Dose Contributions TDOSE(i,p,t) for Individual Radionuclides (i) and Pathways (p) As mrem/yr and Fraction of Total Dose At $t=5.000 \mathrm{E}+01$ years

Water Independent Pathways (Inhalation excludes radon)

\begin{tabular}{|c|c|c|c|c|c|c|c|c|c|c|c|c|c|c|}
\hline \multirow{2}{*}{ Nuclide } & \multicolumn{2}{|c|}{ Ground } & \multicolumn{2}{|c|}{ Inhalation } & \multicolumn{2}{|c|}{ Radon } & \multicolumn{2}{|c|}{ Plant } & \multicolumn{2}{|c|}{ Meat } & \multicolumn{2}{|c|}{ Milk } & \multicolumn{2}{|c|}{ Soil } \\
\hline & mrem/yr & fract. & mrem/yr & fract. & mrem/yr & fract. & mrem/yr & fract. & mrem/yr & fract. & mrem/yr & fract. & mrem/yr & fract. \\
\hline-241 & $8.840 \mathrm{E}-16$ & 0.0000 & $0.000 \mathrm{E}+00$ & 0.0000 & $0.000 \mathrm{E}+00$ & 0.0000 & $0.000 \mathrm{E}+00$ & 0.0000 & $0.000 \mathrm{E}+00$ & 0.0000 & $0.000 \mathrm{E}+00$ & 0.0000 & $0.000 \mathrm{E}+00$ & 0.0000 \\
\hline-137 & $1.158 \mathrm{E}-08$ & 0.0012 & $0.000 \mathrm{E}+00$ & 0.0000 & $0.000 \mathrm{E}+00$ & 0.0000 & $0.000 \mathrm{E}+00$ & 0.0000 & $0.000 \mathrm{E}+00$ & 0.0000 & $0.000 \mathrm{E}+00$ & 0.0000 & $0.000 \mathrm{E}+00$ & 0.0000 \\
\hline-237 & $8.909 \mathrm{E}-12$ & 0.0000 & $0.000 \mathrm{E}+00$ & 0.0000 & $0.000 \mathrm{E}+00$ & 0.0000 & $0.000 \mathrm{E}+00$ & 0.0000 & $0.000 \mathrm{E}+00$ & 0.0000 & $0.000 \mathrm{E}+00$ & 0.0000 & $0.000 \mathrm{E}+00$ & 0.0000 \\
\hline-238 & $1.988 E-15$ & 0.0000 & $0.000 \mathrm{E}+00$ & 0.0000 & $0.000 \mathrm{E}+00$ & 0.0000 & $0.000 \mathrm{E}+00$ & 0.0000 & $0.000 \mathrm{E}+00$ & 0.0000 & $0.000 \mathrm{E}+00$ & 0.0000 & $0.000 \mathrm{E}+00$ & 0.0000 \\
\hline-239 & $7.814 \mathrm{E}-16$ & 0.0000 & $0.000 \mathrm{E}+00$ & 0.0000 & $0.000 \mathrm{E}+00$ & 0.0000 & $0.000 \mathrm{E}+00$ & 0.0000 & $0.000 \mathrm{E}+00$ & 0.0000 & $0.000 \mathrm{E}+00$ & 0.0000 & $0.000 \mathrm{E}+00$ & 0.0000 \\
\hline-240 & $9.393 E-20$ & 0.0000 & $0.000 \mathrm{E}+00$ & 0.0000 & $0.000 \mathrm{E}+00$ & 0.0000 & $0.000 \mathrm{E}+00$ & 0.0000 & $0.000 \mathrm{E}+00$ & 0.0000 & $0.000 \mathrm{E}+00$ & 0.0000 & $0.000 \mathrm{E}+00$ & 0.0000 \\
\hline 99 & $4.954 \mathrm{E}-24$ & 0.0000 & $0.000 \mathrm{E}+00$ & 0.0000 & $0.000 \mathrm{E}+00$ & 0.0000 & $0.000 \mathrm{E}+00$ & 0.0000 & $0.000 \mathrm{E}+00$ & 0.0000 & $0.000 \mathrm{E}+00$ & 0.0000 & $0.000 \mathrm{E}+00$ & 0.0000 \\
\hline-228 & $1.201 \mathrm{E}-13$ & 0.0000 & $0.000 \mathrm{E}+00$ & 0.0000 & $0.000 \mathrm{E}+00$ & 0.0000 & $0.000 \mathrm{E}+00$ & 0.0000 & $0.000 \mathrm{E}+00$ & 0.0000 & $0.000 \mathrm{E}+00$ & 0.0000 & $0.000 \mathrm{E}+00$ & 0.0000 \\
\hline-230 & $5.249 \mathrm{E}-07$ & 0.0552 & $0.000 \mathrm{E}+00$ & 0.0000 & $0.000 \mathrm{E}+00$ & 0.0000 & $0.000 \mathrm{E}+00$ & 0.0000 & $0.000 \mathrm{E}+00$ & 0.0000 & $0.000 \mathrm{E}+00$ & 0.0000 & $0.000 \mathrm{E}+00$ & 0.0000 \\
\hline-232 & $8.935 E-06$ & 0.9400 & $0.000 \mathrm{E}+00$ & 0.0000 & $0.000 \mathrm{E}+00$ & 0.0000 & $0.000 \mathrm{E}+00$ & 0.0000 & $0.000 \mathrm{E}+00$ & 0.0000 & $0.000 \mathrm{E}+00$ & 0.0000 & $0.000 \mathrm{E}+00$ & 0.0000 \\
\hline 234 & $1.897 \mathrm{E}-10$ & 0.0000 & $0.000 \mathrm{E}+00$ & 0.0000 & $0.000 \mathrm{E}+00$ & 0.0000 & $0.000 \mathrm{E}+00$ & 0.0000 & $0.000 \mathrm{E}+00$ & 0.0000 & $0.000 \mathrm{E}+00$ & 0.0000 & $0.000 \mathrm{E}+00$ & 0.0000 \\
\hline 235 & $5.905 E-13$ & 0.0000 & $0.000 \mathrm{E}+00$ & 0.0000 & $0.000 \mathrm{E}+00$ & 0.0000 & $0.000 \mathrm{E}+00$ & 0.0000 & $0.000 \mathrm{E}+00$ & 0.0000 & $0.000 \mathrm{E}+00$ & 0.0000 & $0.000 \mathrm{E}+00$ & 0.0000 \\
\hline 38 & $3.372 E-08$ & 0.0035 & $0.000 \mathrm{E}+00$ & 0.0000 & $0.000 \mathrm{E}+00$ & 0.0000 & $0.000 \mathrm{E}+00$ & 0.0000 & $0.000 \mathrm{E}+00$ & 0.0000 & $0.000 \mathrm{E}+00$ & 0.0000 & $0.000 \mathrm{E}+00$ & 0.0000 \\
\hline & $9.505 E-06$ & 1.0000 & $0.000 \mathrm{E}+00$ & 0.0000 & $0.000 \mathrm{E}+00$ & 0.0000 & $0.000 \mathrm{E}+00$ & 0.0000 & $0.000 \mathrm{E}+00$ & 0.0000 & $0.000 \mathrm{E}+00$ & 0.0000 & $.000 \mathrm{E}+00$ & 0.0000 \\
\hline
\end{tabular}

Total Dose Contributions TDOSE (i,p,t) for Individual Radionuclides (i) and Pathways (p) As mrem/yr and Fraction of Total Dose At $t=5.000 \mathrm{E}+01$ years

Water Dependent Pathways

\begin{tabular}{|c|c|c|c|c|c|c|c|c|c|c|c|c|c|c|}
\hline & \multicolumn{2}{|c|}{ Water } & \multicolumn{2}{|c|}{ Fish } & \multicolumn{2}{|c|}{ Radon } & \multicolumn{2}{|c|}{ Plant } & \multicolumn{2}{|c|}{ Meat } & \multicolumn{2}{|c|}{ Milk } & \multicolumn{2}{|c|}{ All Pathways* } \\
\hline clide & mrem/yr & fract. & mrem/yr & fract. & mrem/yr & fract. & mrem/yr & fract. & mrem/yr & fract. & mrem/yr & fract. & mrem/yr & fract. \\
\hline-241 & $0.000 \mathrm{E}+00$ & 0.0000 & $0.000 \mathrm{E}+00$ & 0.0000 & $0.000 \mathrm{E}+00$ & 0.0000 & $0.000 \mathrm{E}+00$ & 0.0000 & $0.000 \mathrm{E}+00$ & 0.0000 & $0.000 \mathrm{E}+00$ & 0.0000 & $8.840 \mathrm{E}-16$ & 0.0000 \\
\hline-137 & $0.000 \mathrm{E}+00$ & 0.0000 & $0.000 \mathrm{E}+00$ & 0.0000 & $0.000 \mathrm{E}+00$ & 0.0000 & $0.000 \mathrm{E}+00$ & 0.0000 & $0.000 \mathrm{E}+00$ & 0.0000 & $0.000 \mathrm{E}+00$ & 0.0000 & $1.158 \mathrm{E}-08$ & 0.0012 \\
\hline-237 & $0.000 \mathrm{E}+00$ & 0.0000 & $0.000 \mathrm{E}+00$ & 0.0000 & $0.000 \mathrm{E}+00$ & 0.0000 & $0.000 \mathrm{E}+00$ & 0.0000 & $0.000 \mathrm{E}+00$ & 0.0000 & $0.000 \mathrm{E}+00$ & 0.0000 & $8.909 \mathrm{E}-12$ & 0.0000 \\
\hline-238 & $0.000 \mathrm{E}+00$ & 0.0000 & $0.000 \mathrm{E}+00$ & 0.0000 & $0.000 \mathrm{E}+00$ & 0.0000 & $0.000 \mathrm{E}+00$ & 0.0000 & $0.000 \mathrm{E}+00$ & 0.0000 & $0.000 \mathrm{E}+00$ & 0.0000 & $1.988 \mathrm{E}-15$ & 0.0000 \\
\hline-239 & $0.000 \mathrm{E}+00$ & 0.0000 & $0.000 \mathrm{E}+00$ & 0.0000 & $0.000 \mathrm{E}+00$ & 0.0000 & $0.000 \mathrm{E}+00$ & 0.0000 & $0.000 \mathrm{E}+00$ & 0.0000 & $0.000 E+00$ & 0.0000 & $7.814 \mathrm{E}-16$ & 0.0000 \\
\hline-240 & $0.000 \mathrm{E}+00$ & 0.0000 & $0.000 \mathrm{E}+00$ & 0.0000 & $0.000 \mathrm{E}+00$ & 0.0000 & $0.000 \mathrm{E}+00$ & 0.0000 & $0.000 \mathrm{E}+00$ & 0.0000 & $0.000 E+00$ & 0.0000 & $9.393 \mathrm{E}-20$ & 0.0000 \\
\hline-99 & $0.000 \mathrm{E}+00$ & 0.0000 & $0.000 \mathrm{E}+00$ & 0.0000 & $0.000 \mathrm{E}+00$ & 0.0000 & $0.000 \mathrm{E}+00$ & 0.0000 & $0.000 \mathrm{E}+00$ & 0.0000 & $0.000 \mathrm{E}+00$ & 0.0000 & $4.954 \mathrm{E}-24$ & 0.0000 \\
\hline-228 & $0.000 \mathrm{E}+00$ & 0.0000 & $0.000 \mathrm{E}+00$ & 0.0000 & $0.000 \mathrm{E}+00$ & 0.0000 & $0.000 \mathrm{E}+00$ & 0.0000 & $0.000 \mathrm{E}+00$ & 0.0000 & $0.000 \mathrm{E}+00$ & 0.0000 & $1.201 \mathrm{E}-13$ & 0.0000 \\
\hline-230 & $0.000 \mathrm{E}+00$ & 0.0000 & $0.000 \mathrm{E}+00$ & 0.0000 & $0.000 \mathrm{E}+00$ & 0.0000 & $0.000 \mathrm{E}+00$ & 0.0000 & $0.000 \mathrm{E}+00$ & 0.0000 & $0.000 E+00$ & 0.0000 & $5.249 \mathrm{E}-07$ & 0.0552 \\
\hline 232 & $0.000 \mathrm{E}+00$ & 0.0000 & $0.000 \mathrm{E}+00$ & 0.0000 & $0.000 \mathrm{E}+00$ & 0.0000 & $0.000 \mathrm{E}+00$ & 0.0000 & $0.000 \mathrm{E}+00$ & 0.0000 & $0.000 \mathrm{E}+00$ & 0.0000 & $8.935 E-06$ & 0.9400 \\
\hline 34 & $0.000 \mathrm{E}+00$ & 0.0000 & $0.000 \mathrm{E}+00$ & 0.0000 & $0.000 \mathrm{E}+00$ & 0.0000 & $0.000 \mathrm{E}+00$ & 0.0000 & $0.000 \mathrm{E}+00$ & 0.0000 & $0.000 \mathrm{E}+00$ & 0.0000 & $1.897 \mathrm{E}-10$ & 0.0000 \\
\hline 35 & $0.000 \mathrm{E}+00$ & 0.0000 & $0.000 \mathrm{E}+00$ & 0.0000 & $0.000 \mathrm{E}+00$ & 0.0000 & $0.000 \mathrm{E}+00$ & 0.0000 & $0.000 \mathrm{E}+00$ & 0.0000 & $0.000 E+00$ & 0.0000 & $5.905 E-13$ & 0.0000 \\
\hline 38 & $0.000 \mathrm{E}+00$ & 0.0000 & $0.000 \mathrm{E}+00$ & 0.0000 & $0.000 \mathrm{E}+00$ & 0.0000 & $0.000 \mathrm{E}+00$ & 0.0000 & $0.000 \mathrm{E}+00$ & 0.0000 & $0.000 \mathrm{E}+00$ & 0.0000 & $3.372 \mathrm{E}-08$ & 0.0035 \\
\hline & $0.000 \mathrm{E}+00$ & 0.0000 & $0.000 \mathrm{E}+00$ & 0.0000 & $0.000 \mathrm{E}+00$ & 0.0000 & $0.000 \mathrm{E}+00$ & 0.0000 & $0.000 \mathrm{E}+00$ & 0.0000 & $0.000 \mathrm{E}+00$ & 0.0000 & $5 E-06$ & 1. \\
\hline
\end{tabular}

* Sum of all water independent and dependent pathways. 
RESRAD, Version 6.5

$\mathrm{T}^{1 / 2}$ Limit = 180 days

ummary : C746U Resident Farmer Deterministic Run

: X: $\backslash$ FINAL V2 \DOE FWD RUNS \C746U RF DOE SG FWD-FV2-10000YR.RAD

Total Dose Contributions TDOSE(i,p,t) for Individual Radionuclides (i) and Pathways (p) As mrem/yr and Fraction of Total Dose At $t=1.000 \mathrm{E}+02$ years

Water Independent Pathways (Inhalation excludes radon)

\begin{tabular}{|c|c|c|c|c|c|c|c|c|c|c|c|c|c|c|}
\hline \multirow{2}{*}{ Nuclide } & \multicolumn{2}{|c|}{ Ground } & \multicolumn{2}{|c|}{ Inhalation } & \multicolumn{2}{|c|}{ Radon } & \multicolumn{2}{|c|}{ Plant } & \multicolumn{2}{|c|}{ Meat } & \multicolumn{2}{|c|}{ Milk } & \multicolumn{2}{|c|}{ Soil } \\
\hline & mrem/yr & fract. & mrem/yr & fract. & mrem/yr & fract. & mrem/yr & fract. & mrem/yr & fract. & mrem/yr & fract. & mrem/yr & fract. \\
\hline-241 & $2.911 E-15$ & 0.0000 & $0.000 \mathrm{E}+00$ & 0.0000 & $0.000 \mathrm{E}+00$ & 0.0000 & $0.000 \mathrm{E}+00$ & 0.0000 & $0.000 \mathrm{E}+00$ & 0.0000 & $0.000 \mathrm{E}+00$ & 0.0000 & $0.000 \mathrm{E}+00$ & 0.0000 \\
\hline-137 & $5.552 E-09$ & 0.0004 & $0.000 \mathrm{E}+00$ & 0.0000 & $0.000 \mathrm{E}+00$ & 0.0000 & $0.000 \mathrm{E}+00$ & 0.0000 & $0.000 \mathrm{E}+00$ & 0.0000 & $0.000 \mathrm{E}+00$ & 0.0000 & $0.000 \mathrm{E}+00$ & 0.0000 \\
\hline-237 & 1. $525 \mathrm{E}-11$ & 0.0000 & $0.000 \mathrm{E}+00$ & 0.0000 & $0.000 \mathrm{E}+00$ & 0.0000 & $0.000 \mathrm{E}+00$ & 0.0000 & $0.000 \mathrm{E}+00$ & 0.0000 & $0.000 \mathrm{E}+00$ & 0.0000 & $0.000 \mathrm{E}+00$ & 0.0000 \\
\hline-238 & $2.040 \mathrm{E}-14$ & 0.0000 & $0.000 \mathrm{E}+00$ & 0.0000 & $0.000 \mathrm{E}+00$ & 0.0000 & $0.000 \mathrm{E}+00$ & 0.0000 & $0.000 \mathrm{E}+00$ & 0.0000 & $0.000 \mathrm{E}+00$ & 0.0000 & $0.000 \mathrm{E}+00$ & 0.0000 \\
\hline-239 & $1.419 \mathrm{E}-15$ & 0.0000 & $0.000 \mathrm{E}+00$ & 0.0000 & $0.000 \mathrm{E}+00$ & 0.0000 & $0.000 \mathrm{E}+00$ & 0.0000 & $0.000 \mathrm{E}+00$ & 0.0000 & $0.000 \mathrm{E}+00$ & 0.0000 & $0.000 \mathrm{E}+00$ & 0.0000 \\
\hline-240 & $6.330 \mathrm{E}-19$ & 0.0000 & $0.000 \mathrm{E}+00$ & 0.0000 & $0.000 \mathrm{E}+00$ & 0.0000 & $0.000 \mathrm{E}+00$ & 0.0000 & $0.000 \mathrm{E}+00$ & 0.0000 & $0.000 \mathrm{E}+00$ & 0.0000 & $0.000 \mathrm{E}+00$ & 0.0000 \\
\hline 99 & $8.238 E-24$ & 0.0000 & $0.000 \mathrm{E}+00$ & 0.0000 & $0.000 \mathrm{E}+00$ & 0.0000 & $0.000 \mathrm{E}+00$ & 0.0000 & $0.000 \mathrm{E}+00$ & 0.0000 & $0.000 \mathrm{E}+00$ & 0.0000 & $0.000 \mathrm{E}+00$ & 0.0000 \\
\hline-228 & $2.196 \mathrm{E}-21$ & 0.0000 & $0.000 \mathrm{E}+00$ & 0.0000 & $0.000 \mathrm{E}+00$ & 0.0000 & $0.000 \mathrm{E}+00$ & 0.0000 & $0.000 \mathrm{E}+00$ & 0.0000 & $0.000 \mathrm{E}+00$ & 0.0000 & $0.000 \mathrm{E}+00$ & 0.0000 \\
\hline-230 & $1.467 \mathrm{E}-06$ & 0.1077 & $0.000 \mathrm{E}+00$ & 0.0000 & $0.000 \mathrm{E}+00$ & 0.0000 & $0.000 \mathrm{E}+00$ & 0.0000 & $0.000 \mathrm{E}+00$ & 0.0000 & $0.000 \mathrm{E}+00$ & 0.0000 & $0.000 \mathrm{E}+00$ & 0.0000 \\
\hline-232 & $1.209 E-05$ & 0.8881 & $0.000 \mathrm{E}+00$ & 0.0000 & $0.000 \mathrm{E}+00$ & 0.0000 & $0.000 \mathrm{E}+00$ & 0.0000 & $0.000 \mathrm{E}+00$ & 0.0000 & $0.000 \mathrm{E}+00$ & 0.0000 & $0.000 \mathrm{E}+00$ & 0.0000 \\
\hline 234 & $1.064 \mathrm{E}-09$ & 0.0001 & $0.000 \mathrm{E}+00$ & 0.0000 & $0.000 \mathrm{E}+00$ & 0.0000 & $0.000 \mathrm{E}+00$ & 0.0000 & $0.000 \mathrm{E}+00$ & 0.0000 & $0.000 \mathrm{E}+00$ & 0.0000 & $0.000 \mathrm{E}+00$ & 0.0000 \\
\hline 235 & $2.179 \mathrm{E}-12$ & 0.0000 & $0.000 \mathrm{E}+00$ & 0.0000 & $0.000 \mathrm{E}+00$ & 0.0000 & $0.000 \mathrm{E}+00$ & 0.0000 & $0.000 \mathrm{E}+00$ & 0.0000 & $0.000 \mathrm{E}+00$ & 0.0000 & $0.000 \mathrm{E}+00$ & 0.0000 \\
\hline 38 & $5.025 E-08$ & 0.0037 & $0.000 \mathrm{E}+00$ & 0.0000 & $0.000 \mathrm{E}+00$ & 0.0000 & $0.000 \mathrm{E}+00$ & 0.0000 & $0.000 \mathrm{E}+00$ & 0.0000 & $0.000 \mathrm{E}+00$ & 0.0000 & $0.000 \mathrm{E}+00$ & 0.0000 \\
\hline & $1.362 \mathrm{E}-05$ & 1.0000 & $0.000 \mathrm{E}+00$ & 0.0000 & $0.000 \mathrm{E}+00$ & 0.0000 & $0.000 \mathrm{E}+00$ & 0.0000 & $0.000 \mathrm{E}+00$ & 0.0000 & $0.000 \mathrm{E}+00$ & 0.0000 & $.000 \mathrm{E}+00$ & 0.0000 \\
\hline
\end{tabular}

Total Dose Contributions TDOSE (i,p,t) for Individual Radionuclides (i) and Pathways (p) As mrem/yr and Fraction of Total Dose At $t=1.000 \mathrm{E}+02$ years

Water Dependent Pathways

\begin{tabular}{|c|c|c|c|c|c|c|c|c|c|c|c|c|c|c|}
\hline & \multicolumn{2}{|c|}{ Water } & \multicolumn{2}{|c|}{ Fish } & \multicolumn{2}{|c|}{ Radon } & \multicolumn{2}{|c|}{ Plant } & \multicolumn{2}{|c|}{ Meat } & \multicolumn{2}{|c|}{ Milk } & \multicolumn{2}{|c|}{ All Pathways* } \\
\hline clide & mrem/yr & fract. & mrem/yr & fract. & mrem/yr & fract. & mrem/yr & fract. & mrem/yr & fract. & mrem/yr & fract. & mrem/yr & fract. \\
\hline 241 & $0.000 \mathrm{E}+00$ & 0.0000 & $0.000 \mathrm{E}+00$ & 0.0000 & $0.000 \mathrm{E}+00$ & 0.0000 & $0.000 \mathrm{E}+00$ & 0.0000 & $0.000 \mathrm{E}+00$ & 0.0000 & $0.000 \mathrm{E}+00$ & 0.0000 & $2.911 E-15$ & 0.0000 \\
\hline-137 & $0.000 \mathrm{E}+00$ & 0.0000 & $0.000 \mathrm{E}+00$ & 0.0000 & $0.000 \mathrm{E}+00$ & 0.0000 & $0.000 \mathrm{E}+00$ & 0.0000 & $0.000 \mathrm{E}+00$ & 0.0000 & $0.000 \mathrm{E}+00$ & 0.0000 & $5.552 \mathrm{E}-09$ & 0.0004 \\
\hline-237 & $0.000 \mathrm{E}+00$ & 0.0000 & $0.000 \mathrm{E}+00$ & 0.0000 & $0.000 \mathrm{E}+00$ & 0.0000 & $0.000 \mathrm{E}+00$ & 0.0000 & $0.000 \mathrm{E}+00$ & 0.0000 & $0.000 \mathrm{E}+00$ & 0.0000 & $1.525 \mathrm{E}-11$ & 0.0000 \\
\hline-238 & $0.000 \mathrm{E}+00$ & 0.0000 & $0.000 \mathrm{E}+00$ & 0.0000 & $0.000 \mathrm{E}+00$ & 0.0000 & $0.000 \mathrm{E}+00$ & 0.0000 & $0.000 \mathrm{E}+00$ & 0.0000 & $0.000 \mathrm{E}+00$ & 0.0000 & $2.040 \mathrm{E}-14$ & 0.0000 \\
\hline-239 & $0.000 \mathrm{E}+00$ & 0.0000 & $0.000 \mathrm{E}+00$ & 0.0000 & $0.000 \mathrm{E}+00$ & 0.0000 & $0.000 \mathrm{E}+00$ & 0.0000 & $0.000 \mathrm{E}+00$ & 0.0000 & $0.000 E+00$ & 0.0000 & 1. $419 \mathrm{E}-15$ & 0.0000 \\
\hline-240 & $0.000 \mathrm{E}+00$ & 0.0000 & $0.000 \mathrm{E}+00$ & 0.0000 & $0.000 \mathrm{E}+00$ & 0.0000 & $0.000 \mathrm{E}+00$ & 0.0000 & $0.000 \mathrm{E}+00$ & 0.0000 & $0.000 E+00$ & 0.0000 & $6.330 \mathrm{E}-19$ & 0.0000 \\
\hline-99 & $0.000 \mathrm{E}+00$ & 0.0000 & $0.000 \mathrm{E}+00$ & 0.0000 & $0.000 \mathrm{E}+00$ & 0.0000 & $0.000 \mathrm{E}+00$ & 0.0000 & $0.000 \mathrm{E}+00$ & 0.0000 & $0.000 \mathrm{E}+00$ & 0.0000 & $8.238 E-24$ & 0.0000 \\
\hline-228 & $0.000 \mathrm{E}+00$ & 0.0000 & $0.000 \mathrm{E}+00$ & 0.0000 & $0.000 \mathrm{E}+00$ & 0.0000 & $0.000 \mathrm{E}+00$ & 0.0000 & $0.000 \mathrm{E}+00$ & 0.0000 & $0.000 \mathrm{E}+00$ & 0.0000 & $2.196 \mathrm{E}-21$ & 0.0000 \\
\hline-230 & $0.000 \mathrm{E}+00$ & 0.0000 & $0.000 \mathrm{E}+00$ & 0.0000 & $0.000 \mathrm{E}+00$ & 0.0000 & $0.000 \mathrm{E}+00$ & 0.0000 & $0.000 \mathrm{E}+00$ & 0.0000 & $0.000 E+00$ & 0.0000 & $1.467 \mathrm{E}-06$ & 0.1077 \\
\hline 232 & $0.000 \mathrm{E}+00$ & 0.0000 & $0.000 \mathrm{E}+00$ & 0.0000 & $0.000 \mathrm{E}+00$ & 0.0000 & $0.000 \mathrm{E}+00$ & 0.0000 & $0.000 \mathrm{E}+00$ & 0.0000 & $0.000 \mathrm{E}+00$ & 0.0000 & $1.209 E-05$ & 0.8881 \\
\hline 34 & $0.000 \mathrm{E}+00$ & 0.0000 & $0.000 \mathrm{E}+00$ & 0.0000 & $0.000 \mathrm{E}+00$ & 0.0000 & $0.000 \mathrm{E}+00$ & 0.0000 & $0.000 \mathrm{E}+00$ & 0.0000 & $0.000 \mathrm{E}+00$ & 0.0000 & $1.064 \mathrm{E}-09$ & 0.0001 \\
\hline 35 & $0.000 \mathrm{E}+00$ & 0.0000 & $0.000 \mathrm{E}+00$ & 0.0000 & $0.000 \mathrm{E}+00$ & 0.0000 & $0.000 \mathrm{E}+00$ & 0.0000 & $0.000 \mathrm{E}+00$ & 0.0000 & $0.000 E+00$ & 0.0000 & $2.179 \mathrm{E}-12$ & 0.0000 \\
\hline 38 & $0.000 \mathrm{E}+00$ & 0.0000 & $0.000 \mathrm{E}+00$ & 0.0000 & $0.000 \mathrm{E}+00$ & 0.0000 & $0.000 \mathrm{E}+00$ & 0.0000 & $0.000 \mathrm{E}+00$ & 0.0000 & $0.000 \mathrm{E}+00$ & 0.0000 & $5.025 \mathrm{E}-08$ & 0.0037 \\
\hline & $0.000 \mathrm{E}+00$ & 0.0000 & $0.000 \mathrm{E}+00$ & 0.0000 & $0.000 \mathrm{E}+00$ & 0.0000 & $0.000 \mathrm{E}+00$ & 0.0000 & $0.000 \mathrm{E}+00$ & 0.0000 & $0.000 \mathrm{E}+00$ & 0.0000 & $2 E-05$ & 1.0000 \\
\hline
\end{tabular}

* Sum of all water independent and dependent pathways. 
RESRAD, Version 6.5

$\mathrm{T}^{1 / 2}$ Limit = 180 days

07/18/2011 14:15 Page 24

ummary : C746U Resident Farmer Deterministic Run

: $\mathrm{X}: \backslash \mathrm{FINAL}$ V2 $\backslash$ DOE FWD RUNS $\backslash C 746 \mathrm{U}$ RF DOE SG FWD-FV2-10000YR.RAD

Total Dose Contributions TDOSE (i,p,t) for Individual Radionuclides (i) and Pathways (p) As mrem/yr and Fraction of Total Dose At $t=5.000 \mathrm{E}+02$ years

Water Independent Pathways (Inhalation excludes radon)

\begin{tabular}{|c|c|c|c|c|c|c|c|c|c|c|c|c|c|c|}
\hline \multirow{2}{*}{ Nuclide } & \multicolumn{2}{|c|}{ Ground } & \multicolumn{2}{|c|}{ Inhalation } & \multicolumn{2}{|c|}{ Radon } & \multicolumn{2}{|c|}{ Plant } & \multicolumn{2}{|c|}{ Meat } & \multicolumn{2}{|c|}{ Milk } & \multicolumn{2}{|c|}{ Soil } \\
\hline & mrem/yr & fract. & mrem/yr & fract. & mrem/yr & fract. & mrem/yr & fract. & mrem/yr & fract. & mrem/yr & fract. & mrem/yr & fract. \\
\hline-241 & $7.984 \mathrm{E}-13$ & 0.0000 & $0.000 \mathrm{E}+00$ & 0.0000 & $0.000 \mathrm{E}+00$ & 0.0000 & $0.000 \mathrm{E}+00$ & 0.0000 & $0.000 \mathrm{E}+00$ & 0.0000 & $0.000 \mathrm{E}+00$ & 0.0000 & $0.000 \mathrm{E}+00$ & 0.0000 \\
\hline-137 & $1.551 \mathrm{E}-11$ & 0.0000 & $0.000 \mathrm{E}+00$ & 0.0000 & $0.000 \mathrm{E}+00$ & 0.0000 & $0.000 \mathrm{E}+00$ & 0.0000 & $0.000 \mathrm{E}+00$ & 0.0000 & $0.000 \mathrm{E}+00$ & 0.0000 & $0.000 \mathrm{E}+00$ & 0.0000 \\
\hline-237 & $1.118 \mathrm{E}-09$ & 0.0000 & $0.000 \mathrm{E}+00$ & 0.0000 & $0.000 \mathrm{E}+00$ & 0.0000 & $0.000 \mathrm{E}+00$ & 0.0000 & $0.000 \mathrm{E}+00$ & 0.0000 & $0.000 \mathrm{E}+00$ & 0.0000 & $0.000 \mathrm{E}+00$ & 0.0000 \\
\hline-238 & $2.174 \mathrm{E}-11$ & 0.0000 & $0.000 \mathrm{E}+00$ & 0.0000 & $0.000 \mathrm{E}+00$ & 0.0000 & $0.000 \mathrm{E}+00$ & 0.0000 & $0.000 \mathrm{E}+00$ & 0.0000 & $0.000 \mathrm{E}+00$ & 0.0000 & $0.000 \mathrm{E}+00$ & 0.0000 \\
\hline-239 & 1. $685 \mathrm{E}-13$ & 0.0000 & $0.000 \mathrm{E}+00$ & 0.0000 & $0.000 \mathrm{E}+00$ & 0.0000 & $0.000 \mathrm{E}+00$ & 0.0000 & $0.000 \mathrm{E}+00$ & 0.0000 & $0.000 \mathrm{E}+00$ & 0.0000 & $0.000 \mathrm{E}+00$ & 0.0000 \\
\hline-240 & $2.048 E-16$ & 0.0000 & $0.000 \mathrm{E}+00$ & 0.0000 & $0.000 \mathrm{E}+00$ & 0.0000 & $0.000 \mathrm{E}+00$ & 0.0000 & $0.000 \mathrm{E}+00$ & 0.0000 & $0.000 \mathrm{E}+00$ & 0.0000 & $0.000 \mathrm{E}+00$ & 0.0000 \\
\hline 99 & $4.816 E-22$ & 0.0000 & $0.000 \mathrm{E}+00$ & 0.0000 & $0.000 \mathrm{E}+00$ & 0.0000 & $0.000 \mathrm{E}+00$ & 0.0000 & $0.000 \mathrm{E}+00$ & 0.0000 & $0.000 \mathrm{E}+00$ & 0.0000 & $0.000 \mathrm{E}+00$ & 0.0000 \\
\hline-228 & $0.000 \mathrm{E}+00$ & 0.0000 & $0.000 \mathrm{E}+00$ & 0.0000 & $0.000 \mathrm{E}+00$ & 0.0000 & $0.000 \mathrm{E}+00$ & 0.0000 & $0.000 \mathrm{E}+00$ & 0.0000 & $0.000 \mathrm{E}+00$ & 0.0000 & $0.000 \mathrm{E}+00$ & 0.0000 \\
\hline-230 & $1.066 \mathrm{E}-04$ & 0.0000 & $0.000 \mathrm{E}+00$ & 0.0000 & $0.000 \mathrm{E}+00$ & 0.0000 & $0.000 \mathrm{E}+00$ & 0.0000 & $0.000 \mathrm{E}+00$ & 0.0000 & $0.000 \mathrm{E}+00$ & 0.0000 & $0.000 \mathrm{E}+00$ & 0.0000 \\
\hline-232 & $1.331 E-04$ & 0.0000 & $0.000 \mathrm{E}+00$ & 0.0000 & $0.000 \mathrm{E}+00$ & 0.0000 & $0.000 \mathrm{E}+00$ & 0.0000 & $0.000 \mathrm{E}+00$ & 0.0000 & $0.000 \mathrm{E}+00$ & 0.0000 & $0.000 \mathrm{E}+00$ & 0.0000 \\
\hline 234 & $3.972 \mathrm{E}-07$ & 0.0000 & $0.000 \mathrm{E}+00$ & 0.0000 & $0.000 \mathrm{E}+00$ & 0.0000 & $0.000 \mathrm{E}+00$ & 0.0000 & $0.000 \mathrm{E}+00$ & 0.0000 & $0.000 \mathrm{E}+00$ & 0.0000 & $0.000 \mathrm{E}+00$ & 0.0000 \\
\hline 235 & $4.546 \mathrm{E}-10$ & 0.0000 & $0.000 \mathrm{E}+00$ & 0.0000 & $0.000 \mathrm{E}+00$ & 0.0000 & $0.000 \mathrm{E}+00$ & 0.0000 & $0.000 \mathrm{E}+00$ & 0.0000 & $0.000 \mathrm{E}+00$ & 0.0000 & $0.000 \mathrm{E}+00$ & 0.0000 \\
\hline 38 & $1.224 E-06$ & 0.0000 & $0.000 \mathrm{E}+00$ & 0.0000 & $0.000 \mathrm{E}+00$ & 0.0000 & $0.000 \mathrm{E}+00$ & 0.0000 & $0.000 \mathrm{E}+00$ & 0.0000 & $0.000 \mathrm{E}+00$ & 0.0000 & $0.000 \mathrm{E}+00$ & 0.0000 \\
\hline & $2.414 \mathrm{E}-04$ & 0.0000 & $0.000 \mathrm{E}+00$ & 0.0000 & $0.000 \mathrm{E}+00$ & 0.0000 & $0.000 \mathrm{E}+00$ & 0.0000 & $0.000 \mathrm{E}+00$ & 0.0000 & $0.000 \mathrm{E}+00$ & 0.0000 & $.000 \mathrm{E}+00$ & 0.0000 \\
\hline
\end{tabular}

Total Dose Contributions TDOSE (i,p,t) for Individual Radionuclides (i) and Pathways (p) As mrem/yr and Fraction of Total Dose At $t=5.000 \mathrm{E}+02$ years

Water Dependent Pathways

\begin{tabular}{|c|c|c|c|c|c|c|c|c|c|c|c|c|c|c|}
\hline & \multicolumn{2}{|c|}{ Water } & \multicolumn{2}{|c|}{ Fish } & \multicolumn{2}{|c|}{ Radon } & \multicolumn{2}{|c|}{ Plant } & \multicolumn{2}{|c|}{ Meat } & \multicolumn{2}{|c|}{ Milk } & \multicolumn{2}{|c|}{ All Pathways* } \\
\hline clide & mrem/yr & fract. & mrem/yr & fract. & mrem/yr & fract. & mrem/yr & fract. & mrem/yr & fract. & mrem/yr & fract. & mrem/yr & fract. \\
\hline 241 & $0.000 \mathrm{E}+00$ & 0.0000 & $0.000 \mathrm{E}+00$ & 0.0000 & $0.000 \mathrm{E}+00$ & 0.0000 & $0.000 \mathrm{E}+00$ & 0.0000 & $0.000 \mathrm{E}+00$ & 0.0000 & $0.000 \mathrm{E}+00$ & 0.0000 & $7.984 \mathrm{E}-13$ & 0.0000 \\
\hline-137 & $0.000 \mathrm{E}+00$ & 0.0000 & $0.000 \mathrm{E}+00$ & 0.0000 & $0.000 \mathrm{E}+00$ & 0.0000 & $0.000 \mathrm{E}+00$ & 0.0000 & $0.000 \mathrm{E}+00$ & 0.0000 & $0.000 \mathrm{E}+00$ & 0.0000 & $1.551 \mathrm{E}-11$ & 0.0000 \\
\hline-237 & $0.000 \mathrm{E}+00$ & 0.0000 & $0.000 \mathrm{E}+00$ & 0.0000 & $0.000 \mathrm{E}+00$ & 0.0000 & $0.000 \mathrm{E}+00$ & 0.0000 & $0.000 \mathrm{E}+00$ & 0.0000 & $0.000 \mathrm{E}+00$ & 0.0000 & $1.118 \mathrm{E}-09$ & 0.0000 \\
\hline-238 & $0.000 \mathrm{E}+00$ & 0.0000 & $0.000 \mathrm{E}+00$ & 0.0000 & $0.000 \mathrm{E}+00$ & 0.0000 & $0.000 \mathrm{E}+00$ & 0.0000 & $0.000 \mathrm{E}+00$ & 0.0000 & $0.000 \mathrm{E}+00$ & 0.0000 & $2.174 \mathrm{E}-11$ & 0.0000 \\
\hline-239 & $0.000 \mathrm{E}+00$ & 0.0000 & $0.000 \mathrm{E}+00$ & 0.0000 & $0.000 \mathrm{E}+00$ & 0.0000 & $0.000 \mathrm{E}+00$ & 0.0000 & $0.000 \mathrm{E}+00$ & 0.0000 & $0.000 E+00$ & 0.0000 & $1.685 \mathrm{E}-13$ & 0.0000 \\
\hline-240 & $0.000 \mathrm{E}+00$ & 0.0000 & $0.000 \mathrm{E}+00$ & 0.0000 & $0.000 \mathrm{E}+00$ & 0.0000 & $0.000 \mathrm{E}+00$ & 0.0000 & $0.000 \mathrm{E}+00$ & 0.0000 & $0.000 E+00$ & 0.0000 & $2.048 E-16$ & 0.0000 \\
\hline-99 & $8.951 E+00$ & 0.8277 & $0.000 \mathrm{E}+00$ & 0.0000 & $0.000 \mathrm{E}+00$ & 0.0000 & $8.368 E-01$ & 0.0774 & $1.498 \mathrm{E}-02$ & 0.0014 & $1.011 \mathrm{E}+00$ & 0.0935 & $1.081 \mathrm{E}+01$ & 1.0000 \\
\hline-228 & $0.000 \mathrm{E}+00$ & 0.0000 & $0.000 \mathrm{E}+00$ & 0.0000 & $0.000 \mathrm{E}+00$ & 0.0000 & $0.000 \mathrm{E}+00$ & 0.0000 & $0.000 \mathrm{E}+00$ & 0.0000 & $0.000 \mathrm{E}+00$ & 0.0000 & $0.000 \mathrm{E}+00$ & 0.0000 \\
\hline-230 & $0.000 \mathrm{E}+00$ & 0.0000 & $0.000 \mathrm{E}+00$ & 0.0000 & $0.000 \mathrm{E}+00$ & 0.0000 & $0.000 \mathrm{E}+00$ & 0.0000 & $0.000 \mathrm{E}+00$ & 0.0000 & $0.000 E+00$ & 0.0000 & $1.066 \mathrm{E}-04$ & 0.0000 \\
\hline-232 & $0.000 \mathrm{E}+00$ & 0.0000 & $0.000 \mathrm{E}+00$ & 0.0000 & $0.000 \mathrm{E}+00$ & 0.0000 & $0.000 \mathrm{E}+00$ & 0.0000 & $0.000 \mathrm{E}+00$ & 0.0000 & $0.000 \mathrm{E}+00$ & 0.0000 & $1.331 \mathrm{E}-04$ & 0.0000 \\
\hline 34 & $0.000 \mathrm{E}+00$ & 0.0000 & $0.000 \mathrm{E}+00$ & 0.0000 & $0.000 \mathrm{E}+00$ & 0.0000 & $0.000 \mathrm{E}+00$ & 0.0000 & $0.000 \mathrm{E}+00$ & 0.0000 & $0.000 \mathrm{E}+00$ & 0.0000 & $3.972 \mathrm{E}-07$ & 0.0000 \\
\hline 35 & $0.000 \mathrm{E}+00$ & 0.0000 & $0.000 \mathrm{E}+00$ & 0.0000 & $0.000 \mathrm{E}+00$ & 0.0000 & $0.000 \mathrm{E}+00$ & 0.0000 & $0.000 \mathrm{E}+00$ & 0.0000 & $0.000 \mathrm{E}+00$ & 0.0000 & $4.546 \mathrm{E}-10$ & 0.0000 \\
\hline 38 & $0.000 \mathrm{E}+00$ & 0.0000 & $0.000 \mathrm{E}+00$ & 0.0000 & $0.000 \mathrm{E}+00$ & 0.0000 & $0.000 \mathrm{E}+00$ & 0.0000 & $0.000 \mathrm{E}+00$ & 0.0000 & $0.000 \mathrm{E}+00$ & 0.0000 & $1.224 \mathrm{E}-06$ & 0.0000 \\
\hline & $8.951 \mathrm{E}+00$ & 0.8277 & $0.000 \mathrm{E}+00$ & 0.0000 & $0.000 \mathrm{E}+00$ & 0.0000 & $8.368 \mathrm{E}-01$ & 0.0774 & $1.498 \mathrm{E}-02$ & 0.0014 & $1.011 \mathrm{E}+00$ & 0.0935 & $1.081 \mathrm{E}+01$ & 1.0000 \\
\hline
\end{tabular}

* Sum of all water independent and dependent pathways. 
RESRAD, Version 6.5

$\mathrm{T}^{1 / 2}$ Limit = 180 days

07/18/2011 14:15 Page 25

ummary : C746U Resident Farmer Deterministic Run

: $\mathrm{X}: \backslash F I N A L$ V2\DOE FWD RUNS \C746U RF DOE SG FWD-FV2-10000YR.RAD

Total Dose Contributions TDOSE (i,p,t) for Individual Radionuclides (i) and Pathways (p) As mrem/yr and Fraction of Total Dose At $t=1.050 \mathrm{E}+03$ years

Water Independent Pathways (Inhalation excludes radon)

\begin{tabular}{|c|c|c|c|c|c|c|c|c|c|c|c|c|c|c|}
\hline \multirow{2}{*}{ Nuclide } & \multicolumn{2}{|c|}{ Ground } & \multicolumn{2}{|c|}{ Inhalation } & \multicolumn{2}{|c|}{ Radon } & \multicolumn{2}{|c|}{ Plant } & \multicolumn{2}{|c|}{ Meat } & \multicolumn{2}{|c|}{ Milk } & \multicolumn{2}{|c|}{ Soil } \\
\hline & mrem/yr & fract. & mrem/yr & fract. & mrem/yr & fract. & mrem/yr & fract. & mrem/yr & fract. & mrem/yr & fract. & mrem/yr & fract. \\
\hline-241 & $4.234 \mathrm{E}-10$ & 0.0000 & $0.000 \mathrm{E}+00$ & 0.0000 & $0.000 \mathrm{E}+00$ & 0.0000 & $6.742 \mathrm{E}-03$ & 0.0009 & $1.195 \mathrm{E}-05$ & 0.0000 & $1.147 \mathrm{E}-06$ & 0.0000 & $0.000 \mathrm{E}+00$ & 0.0000 \\
\hline-137 & $4.776 E-15$ & 0.0000 & $0.000 \mathrm{E}+00$ & 0.0000 & $0.000 \mathrm{E}+00$ & 0.0000 & $1.435 \mathrm{E}-12$ & 0.0000 & $1.304 \mathrm{E}-12$ & 0.0000 & $9.626 \mathrm{E}-13$ & 0.0000 & $0.000 \mathrm{E}+00$ & 0.0000 \\
\hline-237 & $3.889 \mathrm{E}-07$ & 0.0000 & $0.000 \mathrm{E}+00$ & 0.0000 & $0.000 \mathrm{E}+00$ & 0.0000 & $5.473 E-02$ & 0.0076 & $1.658 \mathrm{E}-03$ & 0.0002 & $2.372 E-05$ & 0.0000 & $0.000 \mathrm{E}+00$ & 0.0000 \\
\hline-238 & $5.054 \mathrm{E}-09$ & 0.0000 & $0.000 \mathrm{E}+00$ & 0.0000 & $0.000 \mathrm{E}+00$ & 0.0000 & $2.317 E-05$ & 0.0000 & $2.055 E-07$ & 0.0000 & $5.814 \mathrm{E}-07$ & 0.0000 & $0.000 \mathrm{E}+00$ & 0.0000 \\
\hline-239 & $1.194 \mathrm{E}-10$ & 0.0000 & $0.000 \mathrm{E}+00$ & 0.0000 & $0.000 \mathrm{E}+00$ & 0.0000 & $4.433 E-02$ & 0.0062 & $1.343 \mathrm{E}-04$ & 0.0000 & $3.719 \mathrm{E}-06$ & 0.0000 & $0.000 \mathrm{E}+00$ & 0.0000 \\
\hline-240 & $2.901 \mathrm{E}-14$ & 0.0000 & $0.000 \mathrm{E}+00$ & 0.0000 & $0.000 \mathrm{E}+00$ & 0.0000 & $4.088 \mathrm{E}-02$ & 0.0057 & $1.238 \mathrm{E}-04$ & 0.0000 & $3.460 \mathrm{E}-06$ & 0.0000 & $0.000 \mathrm{E}+00$ & 0.0000 \\
\hline 99 & $1.295 E-19$ & 0.0000 & $0.000 \mathrm{E}+00$ & 0.0000 & $0.000 \mathrm{E}+00$ & 0.0000 & $6.721 \mathrm{E}-05$ & 0.0000 & $2.039 \mathrm{E}-07$ & 0.0000 & $5.641 \mathrm{E}-06$ & 0.0000 & $0.000 \mathrm{E}+00$ & 0.0000 \\
\hline-228 & $0.000 \mathrm{E}+00$ & 0.0000 & $0.000 \mathrm{E}+00$ & 0.0000 & $0.000 \mathrm{E}+00$ & 0.0000 & $0.000 \mathrm{E}+00$ & 0.0000 & $0.000 \mathrm{E}+00$ & 0.0000 & $0.000 \mathrm{E}+00$ & 0.0000 & $0.000 \mathrm{E}+00$ & 0.0000 \\
\hline-230 & $8.932 \mathrm{E}-03$ & 0.0012 & $0.000 \mathrm{E}+00$ & 0.0000 & $0.000 \mathrm{E}+00$ & 0.0000 & $5.638 \mathrm{E}+00$ & 0.7834 & $1.483 \mathrm{E}-01$ & 0.0206 & $2.628 \mathrm{E}-01$ & 0.0365 & $0.000 \mathrm{E}+00$ & 0.0000 \\
\hline-232 & $3.686 E-03$ & 0.0005 & $0.000 \mathrm{E}+00$ & 0.0000 & $0.000 \mathrm{E}+00$ & 0.0000 & $5.753 \mathrm{E}-01$ & 0.0799 & $1.697 \mathrm{E}-02$ & 0.0024 & $4.699 \mathrm{E}-02$ & 0.0065 & $0.000 \mathrm{E}+00$ & 0.0000 \\
\hline 234 & $7.236 \mathrm{E}-05$ & 0.0000 & $0.000 \mathrm{E}+00$ & 0.0000 & $0.000 \mathrm{E}+00$ & 0.0000 & $1.440 \mathrm{E}-01$ & 0.0200 & $2.196 \mathrm{E}-03$ & 0.0003 & $7.061 \mathrm{E}-03$ & 0.0010 & $0.000 \mathrm{E}+00$ & 0.0000 \\
\hline 235 & $1.519 \mathrm{E}-07$ & 0.0000 & $0.000 \mathrm{E}+00$ & 0.0000 & $0.000 \mathrm{E}+00$ & 0.0000 & $1.115 \mathrm{E}-02$ & 0.0015 & $8.217 \mathrm{E}-04$ & 0.0001 & $2.012 \mathrm{E}-04$ & 0.0000 & $0.000 \mathrm{E}+00$ & 0.0000 \\
\hline 38 & $9.880 \mathrm{E}-05$ & 0.0000 & $0.000 \mathrm{E}+00$ & 0.0000 & $0.000 \mathrm{E}+00$ & 0.0000 & $9.831 \mathrm{E}-02$ & 0.0137 & $1.013 E-03$ & 0.0001 & $4.947 \mathrm{E}-03$ & 0.0007 & $0.000 \mathrm{E}+00$ & 0.0000 \\
\hline & 1.279E-02 & 0.0018 & $0.000 \mathrm{E}+00$ & 0.0000 & $0.000 \mathrm{E}+00$ & 0.0000 & $6.613 E+00$ & 0.9190 & $1.712 \mathrm{E}-01$ & 0.0238 & $3.221 \mathrm{E}-01$ & 0.0448 & $.000 \mathrm{E}+00$ & 0.0000 \\
\hline
\end{tabular}

Total Dose Contributions TDOSE (i,p,t) for Individual Radionuclides (i) and Pathways (p) As mrem/yr and Fraction of Total Dose At $t=1.050 \mathrm{E}+03$ years

Water Dependent Pathways

\begin{tabular}{|c|c|c|c|c|c|c|c|c|c|c|c|c|c|c|}
\hline & \multicolumn{2}{|c|}{ Water } & \multicolumn{2}{|c|}{ Fish } & \multicolumn{2}{|c|}{ Radon } & \multicolumn{2}{|c|}{ Plant } & \multicolumn{2}{|c|}{ Meat } & \multicolumn{2}{|c|}{ Milk } & \multicolumn{2}{|c|}{ All Pathways* } \\
\hline clide & mrem/yr & fract. & mrem/yr & fract. & mrem/yr & fract. & mrem/yr & fract. & mrem/yr & fract. & mrem/yr & fract. & mrem/yr & fract. \\
\hline 241 & $0.000 \mathrm{E}+00$ & 0.0000 & $0.000 \mathrm{E}+00$ & 0.0000 & $0.000 \mathrm{E}+00$ & 0.0000 & $0.000 \mathrm{E}+00$ & 0.0000 & $0.000 \mathrm{E}+00$ & 0.0000 & $0.000 \mathrm{E}+00$ & 0.0000 & $6.755 E-03$ & 0.0009 \\
\hline-137 & $0.000 \mathrm{E}+00$ & 0.0000 & $0.000 \mathrm{E}+00$ & 0.0000 & $0.000 \mathrm{E}+00$ & 0.0000 & $0.000 \mathrm{E}+00$ & 0.0000 & $0.000 \mathrm{E}+00$ & 0.0000 & $0.000 \mathrm{E}+00$ & 0.0000 & $3.706 \mathrm{E}-12$ & 0.0000 \\
\hline-237 & $0.000 \mathrm{E}+00$ & 0.0000 & $0.000 \mathrm{E}+00$ & 0.0000 & $0.000 \mathrm{E}+00$ & 0.0000 & $0.000 \mathrm{E}+00$ & 0.0000 & $0.000 \mathrm{E}+00$ & 0.0000 & $0.000 \mathrm{E}+00$ & 0.0000 & $5.641 \mathrm{E}-02$ & 0.0078 \\
\hline-238 & $0.000 \mathrm{E}+00$ & 0.0000 & $0.000 \mathrm{E}+00$ & 0.0000 & $0.000 \mathrm{E}+00$ & 0.0000 & $0.000 \mathrm{E}+00$ & 0.0000 & $0.000 \mathrm{E}+00$ & 0.0000 & $0.000 \mathrm{E}+00$ & 0.0000 & $2.396 \mathrm{E}-05$ & 0.0000 \\
\hline-239 & $0.000 \mathrm{E}+00$ & 0.0000 & $0.000 \mathrm{E}+00$ & 0.0000 & $0.000 \mathrm{E}+00$ & 0.0000 & $0.000 \mathrm{E}+00$ & 0.0000 & $0.000 \mathrm{E}+00$ & 0.0000 & $0.000 E+00$ & 0.0000 & $4.447 \mathrm{E}-02$ & 0.0062 \\
\hline-240 & $0.000 \mathrm{E}+00$ & 0.0000 & $0.000 \mathrm{E}+00$ & 0.0000 & $0.000 \mathrm{E}+00$ & 0.0000 & $0.000 \mathrm{E}+00$ & 0.0000 & $0.000 \mathrm{E}+00$ & 0.0000 & $0.000 E+00$ & 0.0000 & $4.101 \mathrm{E}-02$ & 0.0057 \\
\hline-99 & $6.365 E-02$ & 0.0088 & $0.000 \mathrm{E}+00$ & 0.0000 & $0.000 \mathrm{E}+00$ & 0.0000 & $5.951 \mathrm{E}-03$ & 0.0008 & $1.065 E-04$ & 0.0000 & $7.190 \mathrm{E}-03$ & 0.0010 & $7.697 \mathrm{E}-02$ & 0.0107 \\
\hline-228 & $0.000 \mathrm{E}+00$ & 0.0000 & $0.000 \mathrm{E}+00$ & 0.0000 & $0.000 \mathrm{E}+00$ & 0.0000 & $0.000 \mathrm{E}+00$ & 0.0000 & $0.000 \mathrm{E}+00$ & 0.0000 & $0.000 \mathrm{E}+00$ & 0.0000 & $0.000 \mathrm{E}+00$ & 0.0000 \\
\hline-230 & $0.000 \mathrm{E}+00$ & 0.0000 & $0.000 \mathrm{E}+00$ & 0.0000 & $0.000 \mathrm{E}+00$ & 0.0000 & $0.000 \mathrm{E}+00$ & 0.0000 & $0.000 \mathrm{E}+00$ & 0.0000 & $0.000 E+00$ & 0.0000 & $6.058 \mathrm{E}+00$ & 0.8418 \\
\hline-232 & $0.000 \mathrm{E}+00$ & 0.0000 & $0.000 \mathrm{E}+00$ & 0.0000 & $0.000 \mathrm{E}+00$ & 0.0000 & $0.000 \mathrm{E}+00$ & 0.0000 & $0.000 \mathrm{E}+00$ & 0.0000 & $0.000 \mathrm{E}+00$ & 0.0000 & $6.430 \mathrm{E}-01$ & 0.0893 \\
\hline 34 & $0.000 \mathrm{E}+00$ & 0.0000 & $0.000 \mathrm{E}+00$ & 0.0000 & $0.000 \mathrm{E}+00$ & 0.0000 & $0.000 \mathrm{E}+00$ & 0.0000 & $0.000 \mathrm{E}+00$ & 0.0000 & $0.000 \mathrm{E}+00$ & 0.0000 & $1.533 \mathrm{E}-01$ & 0.0213 \\
\hline 35 & $0.000 \mathrm{E}+00$ & 0.0000 & $0.000 \mathrm{E}+00$ & 0.0000 & $0.000 \mathrm{E}+00$ & 0.0000 & $0.000 \mathrm{E}+00$ & 0.0000 & $0.000 \mathrm{E}+00$ & 0.0000 & $0.000 \mathrm{E}+00$ & 0.0000 & $1.217 \mathrm{E}-02$ & 0.0017 \\
\hline 38 & $0.000 \mathrm{E}+00$ & 0.0000 & $0.000 \mathrm{E}+00$ & 0.0000 & $0.000 \mathrm{E}+00$ & 0.0000 & $0.000 \mathrm{E}+00$ & 0.0000 & $0.000 \mathrm{E}+00$ & 0.0000 & $0.000 \mathrm{E}+00$ & 0.0000 & $1.044 \mathrm{E}-01$ & 0.0145 \\
\hline & $6.365 \mathrm{E}-02$ & 0.0088 & $0.000 \mathrm{E}+00$ & 0.0000 & $0.000 \mathrm{E}+00$ & 0.0000 & $5.951 \mathrm{E}-03$ & 0.0008 & $1.065 E-04$ & 0.0000 & $7.190 \mathrm{E}-03$ & 0.0010 & $7.196 \mathrm{E}+00$ & 1. \\
\hline
\end{tabular}

* Sum of all water independent and dependent pathways. 
RESRAD, Version 6.5

$\mathrm{T}^{1 / 2}$ Limit = 180 days

ummary : C746U Resident Farmer Deterministic Run

: X: $\backslash$ FINAL V2 \DOE FWD RUNS \C746U RF DOE SG FWD-FV2-10000YR.RAD

Total Dose Contributions TDOSE(i,p,t) for Individual Radionuclides (i) and Pathways (p) As mrem/yr and Fraction of Total Dose At $t=1.000 \mathrm{E}+04$ years

Water Independent Pathways (Inhalation excludes radon)

\begin{tabular}{|c|c|c|c|c|c|c|c|c|c|c|c|c|c|c|}
\hline \multirow{2}{*}{ Nuclide } & \multicolumn{2}{|c|}{ Ground } & \multicolumn{2}{|c|}{ Inhalation } & \multicolumn{2}{|c|}{ Radon } & \multicolumn{2}{|c|}{ Plant } & \multicolumn{2}{|c|}{ Meat } & \multicolumn{2}{|c|}{ Milk } & \multicolumn{2}{|c|}{ Soil } \\
\hline & mrem/yr & fract. & mrem/yr & fract. & mrem/yr & fract. & mrem/yr & fract. & mrem/yr & fract. & mrem/yr & fract. & mrem/yr & fract. \\
\hline-241 & $1.724 \mathrm{E}-03$ & 0.0000 & $1.816 \mathrm{E}-07$ & 0.0000 & $0.000 \mathrm{E}+00$ & 0.0000 & $2.088 E-03$ & 0.0000 & $1.927 \mathrm{E}-04$ & 0.0000 & $1.010 \mathrm{E}-05$ & 0.0000 & $3.432 \mathrm{E}-05$ & 0.0000 \\
\hline-137 & $0.000 \mathrm{E}+00$ & 0.0000 & $0.000 \mathrm{E}+00$ & 0.0000 & $0.000 \mathrm{E}+00$ & 0.0000 & $0.000 \mathrm{E}+00$ & 0.0000 & $0.000 \mathrm{E}+00$ & 0.0000 & $0.000 \mathrm{E}+00$ & 0.0000 & $0.000 \mathrm{E}+00$ & 0.0000 \\
\hline-237 & $1.242 \mathrm{E}+00$ & 0.0005 & $1.327 \mathrm{E}-04$ & 0.0000 & $0.000 \mathrm{E}+00$ & 0.0000 & $1.496 \mathrm{E}+00$ & 0.0006 & $1.382 \mathrm{E}-01$ & 0.0001 & $7.847 E-03$ & 0.0000 & $2.514 \mathrm{E}-02$ & 0.0000 \\
\hline-238 & $6.838 E-03$ & 0.0000 & $3.439 E-07$ & 0.0000 & $0.000 \mathrm{E}+00$ & 0.0000 & $1.186 \mathrm{E}-02$ & 0.0000 & $1.230 \mathrm{E}-03$ & 0.0000 & $2.116 \mathrm{E}-03$ & 0.0000 & $3.191 \mathrm{E}-04$ & 0.0000 \\
\hline-239 & $5.108 E-03$ & 0.0000 & $4.259 \mathrm{E}-03$ & 0.0000 & $0.000 \mathrm{E}+00$ & 0.0000 & $2.652 \mathrm{E}+00$ & 0.0010 & $3.321 \mathrm{E}-01$ & 0.0001 & $9.176 \mathrm{E}-03$ & 0.0000 & $7.370 \mathrm{E}-01$ & 0.0003 \\
\hline-240 & $9.845 \mathrm{E}-04$ & 0.0000 & $1.968 \mathrm{E}-03$ & 0.0000 & $0.000 \mathrm{E}+00$ & 0.0000 & $1.225 \mathrm{E}+00$ & 0.0005 & $1.534 \mathrm{E}-01$ & 0.0001 & $4.485 E-03$ & 0.0000 & $3.405 E-01$ & 0.0001 \\
\hline 99 & $0.000 \mathrm{E}+00$ & 0.0000 & $0.000 \mathrm{E}+00$ & 0.0000 & $0.000 \mathrm{E}+00$ & 0.0000 & $0.000 \mathrm{E}+00$ & 0.0000 & $0.000 \mathrm{E}+00$ & 0.0000 & $0.000 \mathrm{E}+00$ & 0.0000 & $0.000 \mathrm{E}+00$ & 0.0000 \\
\hline-228 & $0.000 \mathrm{E}+00$ & 0.0000 & $0.000 \mathrm{E}+00$ & 0.0000 & $0.000 \mathrm{E}+00$ & 0.0000 & $0.000 \mathrm{E}+00$ & 0.0000 & $0.000 \mathrm{E}+00$ & 0.0000 & $0.000 \mathrm{E}+00$ & 0.0000 & $0.000 \mathrm{E}+00$ & 0.0000 \\
\hline-230 & $7.436 \mathrm{E}+02$ & 0.2735 & $1.648 \mathrm{E}-02$ & 0.0000 & $0.000 \mathrm{E}+00$ & 0.0000 & $1.224 \mathrm{E}+03$ & 0.4501 & 1. $220 \mathrm{E}+02$ & 0.0449 & $1.728 \mathrm{E}+02$ & 0.0636 & $2.669 \mathrm{E}+01$ & 0.0098 \\
\hline-232 & $4.839 E+01$ & 0.0178 & $1.028 E-03$ & 0.0000 & $0.000 \mathrm{E}+00$ & 0.0000 & $5.054 \mathrm{E}+01$ & 0.0186 & $3.109 \mathrm{E}+00$ & 0.0011 & $8.373 E+00$ & 0.0031 & $5.352 \mathrm{E}-01$ & 0.0002 \\
\hline 234 & $7.944 \mathrm{E}+01$ & 0.0292 & $3.957 \mathrm{E}-03$ & 0.0000 & $0.000 \mathrm{E}+00$ & 0.0000 & $1.377 \mathrm{E}+02$ & 0.0506 & $1.426 \mathrm{E}+01$ & 0.0052 & $2.448 E+01$ & 0.0090 & $3.693 \mathrm{E}+00$ & 0.0014 \\
\hline 235 & $4.626 \mathrm{E}+00$ & 0.0017 & $1.189 \mathrm{E}-03$ & 0.0000 & $0.000 \mathrm{E}+00$ & 0.0000 & $5.072 \mathrm{E}+00$ & 0.0019 & $2.638 \mathrm{E}+00$ & 0.0010 & $2.932 \mathrm{E}-01$ & 0.0001 & $2.835 \mathrm{E}-01$ & 0.0001 \\
\hline 38 & $1.706 \mathrm{E}+01$ & 0.0063 & $1.671 E-03$ & 0.0000 & $0.000 \mathrm{E}+00$ & 0.0000 & $8.921 \mathrm{E}+00$ & 0.0033 & $1.458 \mathrm{E}+00$ & 0.0005 & $6.576 \mathrm{E}+00$ & 0.0024 & $8.572 \mathrm{E}-01$ & 0.0003 \\
\hline & $8.943 E+02$ & 0.3290 & $3.068 E-02$ & 0.0000 & $0.000 \mathrm{E}+00$ & 0.0000 & $1.431 \mathrm{E}+03$ & 0.5264 & $1.441 \mathrm{E}+02$ & 0.0530 & $2.126 \mathrm{E}+02$ & 0.0782 & $3.316 \mathrm{E}+01$ & 0.0122 \\
\hline
\end{tabular}

Total Dose Contributions TDOSE (i,p,t) for Individual Radionuclides (i) and Pathways (p) As mrem/yr and Fraction of Total Dose At $t=1.000 \mathrm{E}+04$ years

Water Dependent Pathways

\begin{tabular}{|c|c|c|c|c|c|c|c|c|c|c|c|c|c|c|}
\hline & \multicolumn{2}{|c|}{ Water } & \multicolumn{2}{|c|}{ Fish } & \multicolumn{2}{|c|}{ Radon } & \multicolumn{2}{|c|}{ Plant } & \multicolumn{2}{|c|}{ Meat } & \multicolumn{2}{|c|}{ Milk } & \multicolumn{2}{|c|}{ All Pathways* } \\
\hline clide & mrem/yr & fract. & mrem/yr & fract. & mrem/yr & fract. & mrem/yr & fract. & mrem/yr & fract. & mrem/yr & fract. & mrem/yr & fract. \\
\hline 241 & $4.122 \mathrm{E}-03$ & 0.0000 & $0.000 \mathrm{E}+00$ & 0.0000 & $0.000 \mathrm{E}+00$ & 0.0000 & $1.681 \mathrm{E}-04$ & 0.0000 & $6.589 E-05$ & 0.0000 & $2.364 E-06$ & 0.0000 & $8.407 \mathrm{E}-03$ & 0.0000 \\
\hline-137 & $0.000 \mathrm{E}+00$ & 0.0000 & $0.000 \mathrm{E}+00$ & 0.0000 & $0.000 \mathrm{E}+00$ & 0.0000 & $0.000 \mathrm{E}+00$ & 0.0000 & $0.000 \mathrm{E}+00$ & 0.0000 & $0.000 \mathrm{E}+00$ & 0.0000 & $0.000 \mathrm{E}+00$ & 0.0000 \\
\hline-237 & $3.092 \mathrm{E}+00$ & 0.0011 & $0.000 \mathrm{E}+00$ & 0.0000 & $0.000 \mathrm{E}+00$ & 0.0000 & $1.261 \mathrm{E}-01$ & 0.0000 & $4.943 E-02$ & 0.0000 & $1.801 E-03$ & 0.0000 & $6.178 \mathrm{E}+00$ & 0.0023 \\
\hline-238 & $0.000 \mathrm{E}+00$ & 0.0000 & $0.000 \mathrm{E}+00$ & 0.0000 & $0.000 \mathrm{E}+00$ & 0.0000 & $0.000 \mathrm{E}+00$ & 0.0000 & $0.000 \mathrm{E}+00$ & 0.0000 & $0.000 \mathrm{E}+00$ & 0.0000 & $2.236 \mathrm{E}-02$ & 0.0000 \\
\hline-239 & $0.000 \mathrm{E}+00$ & 0.0000 & $0.000 \mathrm{E}+00$ & 0.0000 & $0.000 \mathrm{E}+00$ & 0.0000 & $0.000 \mathrm{E}+00$ & 0.0000 & $0.000 \mathrm{E}+00$ & 0.0000 & $0.000 E+00$ & 0.0000 & $3.740 \mathrm{E}+00$ & 0.0014 \\
\hline-240 & $0.000 \mathrm{E}+00$ & 0.0000 & $0.000 \mathrm{E}+00$ & 0.0000 & $0.000 \mathrm{E}+00$ & 0.0000 & $0.000 \mathrm{E}+00$ & 0.0000 & $0.000 \mathrm{E}+00$ & 0.0000 & $0.000 E+00$ & 0.0000 & $1.727 \mathrm{E}+00$ & 0.0006 \\
\hline-99 & $0.000 \mathrm{E}+00$ & 0.0000 & $0.000 \mathrm{E}+00$ & 0.0000 & $0.000 \mathrm{E}+00$ & 0.0000 & $0.000 \mathrm{E}+00$ & 0.0000 & $0.000 \mathrm{E}+00$ & 0.0000 & $0.000 \mathrm{E}+00$ & 0.0000 & $0.000 \mathrm{E}+00$ & 0.0000 \\
\hline-228 & $0.000 \mathrm{E}+00$ & 0.0000 & $0.000 \mathrm{E}+00$ & 0.0000 & $0.000 \mathrm{E}+00$ & 0.0000 & $0.000 \mathrm{E}+00$ & 0.0000 & $0.000 \mathrm{E}+00$ & 0.0000 & $0.000 \mathrm{E}+00$ & 0.0000 & $0.000 \mathrm{E}+00$ & 0.0000 \\
\hline-230 & $0.000 \mathrm{E}+00$ & 0.0000 & $0.000 \mathrm{E}+00$ & 0.0000 & $0.000 \mathrm{E}+00$ & 0.0000 & $0.000 \mathrm{E}+00$ & 0.0000 & $0.000 \mathrm{E}+00$ & 0.0000 & $0.000 E+00$ & 0.0000 & $2.289 \mathrm{E}+03$ & 0.8418 \\
\hline-232 & $0.000 \mathrm{E}+00$ & 0.0000 & $0.000 \mathrm{E}+00$ & 0.0000 & $0.000 \mathrm{E}+00$ & 0.0000 & $0.000 \mathrm{E}+00$ & 0.0000 & $0.000 \mathrm{E}+00$ & 0.0000 & $0.000 \mathrm{E}+00$ & 0.0000 & 1.110E+02 & 0.0408 \\
\hline 34 & $0.000 \mathrm{E}+00$ & 0.0000 & $0.000 \mathrm{E}+00$ & 0.0000 & $0.000 \mathrm{E}+00$ & 0.0000 & $0.000 \mathrm{E}+00$ & 0.0000 & $0.000 \mathrm{E}+00$ & 0.0000 & $0.000 \mathrm{E}+00$ & 0.0000 & $2.595 E+02$ & 0.0955 \\
\hline 35 & $0.000 \mathrm{E}+00$ & 0.0000 & $0.000 \mathrm{E}+00$ & 0.0000 & $0.000 \mathrm{E}+00$ & 0.0000 & $0.000 \mathrm{E}+00$ & 0.0000 & $0.000 \mathrm{E}+00$ & 0.0000 & $0.000 \mathrm{E}+00$ & 0.0000 & $1.291 \mathrm{E}+01$ & 0.0048 \\
\hline 38 & $0.000 \mathrm{E}+00$ & 0.0000 & $0.000 \mathrm{E}+00$ & 0.0000 & $0.000 \mathrm{E}+00$ & 0.0000 & $0.000 \mathrm{E}+00$ & 0.0000 & $0.000 \mathrm{E}+00$ & 0.0000 & $0.000 \mathrm{E}+00$ & 0.0000 & $3.487 \mathrm{E}+01$ & 0.0128 \\
\hline & $3.096 \mathrm{E}+00$ & 0.0011 & $0.000 \mathrm{E}+00$ & 0.0000 & $0.000 \mathrm{E}+00$ & 0.0000 & $1.263 \mathrm{E}-01$ & 0.0000 & $4.950 \mathrm{E}-02$ & 0.0000 & $1.804 \mathrm{E}-03$ & 0.0000 & $.719 E+03$ & 1. \\
\hline
\end{tabular}

* Sum of all water independent and dependent pathways. 
RESRAD, Version 6.5

$\mathrm{T}^{1 / 2}$ Limit $=180$ days

07/18/2011 14:15 Page 27

ummary : C746U Resident Farmer Deterministic Run

File : $\mathrm{X}: \backslash F I N A L$ V2 \DOE FWD RUNS \C746U RF DOE SG FWD-FV2-10000YR.RAD

Dose/Source Ratios Summed Over All Pathways

Parent and Progeny Principal Radionuclide Contributions Indicated

\begin{tabular}{|c|c|c|c|c|c|c|c|c|c|}
\hline $\begin{array}{l}\text { Parent } \\
\text { (i) }\end{array}$ & $\begin{array}{l}\text { Product } \\
(j)\end{array}$ & $\begin{array}{l}\text { Thread } \\
\text { Fraction }\end{array}$ & $0.000 \mathrm{E}+00$ & $\begin{array}{r}\operatorname{DSR}(j, t) \\
1.000 \mathrm{E}+00\end{array}$ & $\begin{array}{l}\text { At Time ir } \\
5.000 \mathrm{E}+01\end{array}$ & $\begin{array}{l}\text { Years } \\
1.000 \mathrm{E}+02\end{array}$ & $\begin{array}{l}(\text { mrem/yr) } / \\
5.000 \mathrm{E}+02\end{array}$ & $\begin{array}{l}(\mathrm{pCi} / \mathrm{g}) \\
1.050 \mathrm{E}+03\end{array}$ & $1.000 \mathrm{E}+04$ \\
\hline-241 & $A m-241$ & $1.000 \mathrm{E}+00$ & $1.910 E-33$ & $1.962 E-33$ & $7.255 E-33$ & $2.755 E-32$ & $1.192 \mathrm{E}-27$ & $1.912 \mathrm{E}-04$ & $1.616 \mathrm{E}-08$ \\
\hline-241 & $N p-237+D$ & $1.000 \mathrm{E}+00$ & $0.000 \mathrm{E}+00$ & $3.103 \mathrm{E}-19$ & $2.524 \mathrm{E}-17$ & $8.299 \mathrm{E}-17$ & $2.249 \mathrm{E}-14$ & $1.774 \mathrm{E}-06$ & $2.370 \mathrm{E}-04$ \\
\hline-241 & $\mathrm{U}-233$ & $1.000 \mathrm{E}+00$ & $0.000 \mathrm{E}+00$ & $1.055 \mathrm{E}-29$ & $4.739 E-26$ & $3.448 E-25$ & $1.045 \mathrm{E}-21$ & $3.144 \mathrm{E}-10$ & $5.555 E-07$ \\
\hline-241 & $\mathrm{Th}-229+\mathrm{D}$ & $1.000 \mathrm{E}+00$ & $0.000 \mathrm{E}+00$ & $9.607 \mathrm{E}-26$ & $1.654 \mathrm{E}-20$ & $1.834 \mathrm{E}-19$ & $3.175 \mathrm{E}-16$ & $5.257 \mathrm{E}-11$ & $2.687 \mathrm{E}-06$ \\
\hline-241 & $\sum \operatorname{DSR}(j)$ & & $1.910 \mathrm{E}-33$ & $3.103 \mathrm{E}-19$ & $2.526 \mathrm{E}-17$ & $8.317 \mathrm{E}-17$ & $2.281 \mathrm{E}-14$ & $1.930 \mathrm{E}-04$ & $2.402 \mathrm{E}-04$ \\
\hline$-137+D$ & $\mathrm{Cs}-137+\mathrm{D}$ & $1.000 \mathrm{E}+00$ & $1.271 \mathrm{E}-09$ & $1.253 \mathrm{E}-09$ & $6.094 \mathrm{E}-10$ & $2.922 \mathrm{E}-10$ & $8.163 \mathrm{E}-13$ & $1.950 \mathrm{E}-13$ & $0.000 \mathrm{E}+00$ \\
\hline$-237+D$ & $N p-237+D$ & $1.000 \mathrm{E}+00$ & $9.485 \mathrm{E}-13$ & $9.587 \mathrm{E}-13$ & $1.617 \mathrm{E}-12$ & $2.756 \mathrm{E}-12$ & 1. $963 \mathrm{E}-10$ & $1.025 E-02$ & $1.106 \mathrm{E}+00$ \\
\hline$-237+D$ & $\mathrm{U}-233$ & $1.000 \mathrm{E}+00$ & $0.000 \mathrm{E}+00$ & $6.517 \mathrm{E}-23$ & $6.002 \mathrm{E}-21$ & $2.239 \mathrm{E}-20$ & $1.638 \mathrm{E}-17$ & $2.955 E-06$ & $2.892 E-03$ \\
\hline$-237+D$ & $\mathrm{Th}-229+\mathrm{D}$ & $1.000 \mathrm{E}+00$ & $0.000 \mathrm{E}+00$ & $8.902 \mathrm{E}-19$ & $3.122 \mathrm{E}-15$ & $1.764 \mathrm{E}-14$ & $7.041 \mathrm{E}-12$ & $6.620 \mathrm{E}-07$ & $1.446 \mathrm{E}-02$ \\
\hline$-237+D$ & $\sum \operatorname{DSR}(j)$ & & $9.485 E-13$ & $9.587 \mathrm{E}-13$ & $1.620 \mathrm{E}-12$ & $2.773 \mathrm{E}-12$ & $2.033 E-10$ & $1.026 \mathrm{E}-02$ & $1.123 \mathrm{E}+00$ \\
\hline-238 & $\mathrm{Pu}-238$ & $1.840 \mathrm{E}-09$ & $2.151 \mathrm{E}-33$ & $2.172 \mathrm{E}-33$ & $3.503 E-33$ & $5.703 E-33$ & $2.817 \mathrm{E}-31$ & $5.383 E-16$ & $2.803 E-45$ \\
\hline-238 & $\mathrm{Pu}-238$ & $1.000 \mathrm{E}+00$ & $1.169 \mathrm{E}-24$ & $1.181 \mathrm{E}-24$ & $1.904 \mathrm{E}-24$ & $3.100 \mathrm{E}-24$ & $1.531 \mathrm{E}-22$ & $2.925 E-07$ & $6.248 E-36$ \\
\hline-238 & $\mathrm{U}-234$ & $1.000 \mathrm{E}+00$ & $0.000 \mathrm{E}+00$ & $1.965 \mathrm{E}-29$ & $1.939 \mathrm{E}-27$ & $7.864 \mathrm{E}-27$ & $1.675 E-23$ & $2.344 E-07$ & $3.407 E-05$ \\
\hline-238 & $T h-230$ & $1.000 \mathrm{E}+00$ & $0.000 \mathrm{E}+00$ & $3.096 \mathrm{E}-33$ & $1.556 \mathrm{E}-29$ & $1.280 \mathrm{E}-28$ & $1.293 \mathrm{E}-24$ & $3.186 \mathrm{E}-09$ & $3.705 \mathrm{E}-06$ \\
\hline-238 & $\mathrm{Ra}-226+\mathrm{D}$ & $1.000 \mathrm{E}+00$ & $0.000 \mathrm{E}+00$ & $3.212 \mathrm{E}-22$ & $5.098 \mathrm{E}-17$ & $5.231 \mathrm{E}-16$ & $5.574 \mathrm{E}-13$ & $3.395 E-08$ & $3.070 \mathrm{E}-04$ \\
\hline-238 & $\mathrm{~Pb}-210+\mathrm{D}$ & $1.000 \mathrm{E}+00$ & $0.000 \mathrm{E}+00$ & $1.163 \mathrm{E}-30$ & $7.464 \mathrm{E}-24$ & $1.287 \mathrm{E}-22$ & $3.648 \mathrm{E}-19$ & $5.037 \mathrm{E}-08$ & $2.286 \mathrm{E}-04$ \\
\hline-238 & $\sum \operatorname{DSR}(j)$ & & $1.169 \mathrm{E}-24$ & $3.223 E-22$ & $5.098 \mathrm{E}-17$ & $5.231 \mathrm{E}-16$ & $5.574 \mathrm{E}-13$ & $6.144 \mathrm{E}-07$ & $5.734 \mathrm{E}-04$ \\
\hline-239 & $\mathrm{Pu}-239$ & $1.000 \mathrm{E}+00$ & $1.195 \mathrm{E}-17$ & $1.209 \mathrm{E}-17$ & $2.170 \mathrm{E}-17$ & $3.941 \mathrm{E}-17$ & 4. $662 \mathrm{E}-15$ & $1.235 E-03$ & $1.039 \mathrm{E}-01$ \\
\hline-239 & $\mathrm{U}-235+\mathrm{D}$ & $1.000 \mathrm{E}+00$ & $0.000 \mathrm{E}+00$ & $1.232 \mathrm{E}-23$ & $1.128 \mathrm{E}-21$ & $4.180 \mathrm{E}-21$ & $2.910 \mathrm{E}-18$ & $6.475 \mathrm{E}-10$ & $4.803 E-06$ \\
\hline-239 & $\mathrm{~Pa}-231$ & $1.000 \mathrm{E}+00$ & $0.000 \mathrm{E}+00$ & $2.903 E-27$ & $1.220 \mathrm{E}-23$ & $8.286 \mathrm{E}-23$ & $1.434 \mathrm{E}-19$ & 4. $682 \mathrm{E}-10$ & $4.442 \mathrm{E}-06$ \\
\hline-239 & $A C-227+D$ & $1.000 \mathrm{E}+00$ & $0.000 \mathrm{E}+00$ & $9.153 E-27$ & $1.237 \mathrm{E}-21$ & $1.150 \mathrm{E}-20$ & $1.466 \mathrm{E}-17$ & $1.640 \mathrm{E}-10$ & $2.295 E-06$ \\
\hline-239 & $\sum \operatorname{DSR}(j)$ & & $1.195 \mathrm{E}-17$ & $1.209 \mathrm{E}-17$ & $2.170 \mathrm{E}-17$ & $3.943 \mathrm{E}-17$ & $4.680 \mathrm{E}-15$ & $1.235 E-03$ & $1.039 \mathrm{E}-01$ \\
\hline-240 & $\mathrm{Pu}-240$ & $4.950 E-08$ & $5.604 \mathrm{E}-32$ & $5.703 E-32$ & $1.347 E-31$ & $3.239 E-31$ & $3.615 E-28$ & $5.638 E-11$ & $2.373 E-09$ \\
\hline-240 & $\mathrm{Pu}-240$ & $1.000 \mathrm{E}+00$ & $1.132 \mathrm{E}-24$ & $1.152 \mathrm{E}-24$ & $2.722 \mathrm{E}-24$ & $6.543 E-24$ & $7.302 \mathrm{E}-21$ & $1.139 \mathrm{E}-03$ & $4.795 E-02$ \\
\hline-240 & $U-236$ & $1.000 \mathrm{E}+00$ & $0.000 \mathrm{E}+00$ & $4.350 E-32$ & $5.235 E-30$ & $2.566 \mathrm{E}-29$ & $1.669 \mathrm{E}-25$ & $1.856 \mathrm{E}-08$ & $1.752 \mathrm{E}-05$ \\
\hline-240 & Th-232 & $1.000 \mathrm{E}+00$ & $0.000 \mathrm{E}+00$ & $8.590 E-43$ & $5.322 E-39$ & $5.373 E-38$ & $2.213 E-33$ & $9.120 \mathrm{E}-16$ & $7.021 \mathrm{E}-12$ \\
\hline-240 & $\mathrm{Ra}-228+\mathrm{D}$ & $1.000 \mathrm{E}+00$ & $0.000 \mathrm{E}+00$ & $5.459 \mathrm{E}-28$ & $3.662 E-23$ & $2.505 E-22$ & $1.461 \mathrm{E}-19$ & $1.189 \mathrm{E}-13$ & $9.363 E-10$ \\
\hline-240 & $T h-228+D$ & $1.000 \mathrm{E}+00$ & $0.000 \mathrm{E}+00$ & $3.996 \mathrm{E}-27$ & $2.570 \mathrm{E}-21$ & $1.733 \mathrm{E}-20$ & $5.536 \mathrm{E}-18$ & $1.502 \mathrm{E}-15$ & $3.661 \mathrm{E}-10$ \\
\hline-240 & $\sum \operatorname{DSR}(j)$ & & $1.132 \mathrm{E}-24$ & $1.157 \mathrm{E}-24$ & $2.609 \mathrm{E}-21$ & $1.758 \mathrm{E}-20$ & $5.690 \mathrm{E}-18$ & $1.139 \mathrm{E}-03$ & $4.796 \mathrm{E}-02$ \\
\hline-99 & TC-99 & $1.000 \mathrm{E}+00$ & $5.729 E-26$ & $5.787 \mathrm{E}-26$ & $9.526 \mathrm{E}-26$ & $1.584 \mathrm{E}-25$ & $2.080 \mathrm{E}-01$ & $1.480 \mathrm{E}-03$ & $1.248 E-38$ \\
\hline$-228+D$ & $T h-228+D$ & $1.000 \mathrm{E}+00$ & $1.643 E-06$ & $1.151 \mathrm{E}-06$ & $3.003 \mathrm{E}-14$ & $5.489 \mathrm{E}-22$ & $0.000 \mathrm{E}+00$ & $0.000 \mathrm{E}+00$ & $0.000 \mathrm{E}+00$ \\
\hline 230 & $T h-230$ & $1.000 \mathrm{E}+00$ & $2.392 E-22$ & $2.432 \mathrm{E}-22$ & $5.543 E-22$ & $1.285 \mathrm{E}-21$ & $1.069 \mathrm{E}-18$ & $1.076 \mathrm{E}-03$ & $1.244 \mathrm{E}-01$ \\
\hline 230 & $\mathrm{Ra}-226+\mathrm{D}$ & $1.000 \mathrm{E}+00$ & $0.000 \mathrm{E}+00$ & $7.565 \mathrm{E}-11$ & $5.249 \mathrm{E}-09$ & $1.467 \mathrm{E}-08$ & $1.066 \mathrm{E}-06$ & $2.340 E-02$ & $1.303 \mathrm{E}+01$ \\
\hline 230 & $\mathrm{~Pb}-210+\mathrm{D}$ & $1.000 \mathrm{E}+00$ & $0.000 \mathrm{E}+00$ & $5.454 \mathrm{E}-19$ & $1.273 E-15$ & $5.257 E-15$ & $7.641 \mathrm{E}-13$ & $3.610 \mathrm{E}-02$ & $9.735 \mathrm{E}+00$ \\
\hline 230 & $\sum \operatorname{DSR}(j)$ & & 2. $392 \mathrm{E}-22$ & $7.565 \mathrm{E}-11$ & $5.249 \mathrm{E}-09$ & $1.467 \mathrm{E}-08$ & $1.066 \mathrm{E}-06$ & $6.058 \mathrm{E}-02$ & $2.289 \mathrm{E}+01$ \\
\hline
\end{tabular}


RESRAD, Version 6.5

$\mathrm{T}^{1 / 2}$ Limit $=180$ days

Summary : C746U Resident Farmer Deterministic Run

File : $X: \backslash F I N A L$ V2 \DOE FWD RUNS \C746U RF DOE SG FWD-FV2-10000YR.RAD

Dose/Source Ratios Summed Over All Pathways

Parent and Progeny Principal Radionuclide Contributions Indicated

\begin{tabular}{|c|c|c|c|c|c|c|c|c|c|}
\hline Parent & Product & Thread & & $\operatorname{DSR}(j, t)$ & At Time ir & n Years & (mrem/yr) / & $(\mathrm{pCi} / \mathrm{g})$ & \\
\hline (i) & $(j)$ & Fraction & $0.000 \mathrm{E}+00$ & $1.000 \mathrm{E}+00$ & $5.000 \mathrm{E}+01$ & $1.000 \mathrm{E}+02$ & $5.000 \mathrm{E}+02$ & $1.050 \mathrm{E}+03$ & $1.000 \mathrm{E}+04$ \\
\hline 232 & $T h-232$ & $1.000 \mathrm{E}+00$ & $1.155 \mathrm{E}-24$ & $1.177 \mathrm{E}-24$ & $2.922 \mathrm{E}-24$ & $7.393 E-24$ & $1.241 \mathrm{E}-20$ & $1.189 \mathrm{E}-03$ & 1. $485 \mathrm{E}-01$ \\
\hline-232 & $\mathrm{Ra}-228+\mathrm{D}$ & $1.000 \mathrm{E}+00$ & $0.000 \mathrm{E}+00$ & $2.177 \mathrm{E}-09$ & $2.773 \mathrm{E}-08$ & $4.064 \mathrm{E}-08$ & $8.465 E-07$ & $1.576 \mathrm{E}-01$ & 1. $983 \mathrm{E}+01$ \\
\hline-232 & $\mathrm{Th}-228+\mathrm{D}$ & $1.000 \mathrm{E}+00$ & $0.000 \mathrm{E}+00$ & $3.082 \mathrm{E}-08$ & $2.206 \mathrm{E}-06$ & $2.983 \mathrm{E}-06$ & $3.244 \mathrm{E}-05$ & $1.998 \mathrm{E}-03$ & $7.758 \mathrm{E}+00$ \\
\hline-232 & $\sum \operatorname{DSR}(j)$ & & $1.155 \mathrm{E}-24$ & $3.300 \mathrm{E}-08$ & $2.234 \mathrm{E}-06$ & $3.024 \mathrm{E}-06$ & $3.328 E-05$ & $1.607 \mathrm{E}-01$ & $2.774 \mathrm{E}+01$ \\
\hline 234 & $U-234$ & $1.000 \mathrm{E}+00$ & $6.835 E-24$ & $6.957 \mathrm{E}-24$ & $1.656 \mathrm{E}-23$ & $4.011 \mathrm{E}-23$ & $4.756 \mathrm{E}-20$ & $6.525 E-04$ & $9.484 \mathrm{E}-02$ \\
\hline 234 & Th-230 & $1.000 \mathrm{E}+00$ & $0.000 \mathrm{E}+00$ & $2.190 \mathrm{E}-27$ & $2.494 E-25$ & $1.156 \mathrm{E}-24$ & $4.793 E-21$ & $1.009 E-05$ & $1.046 E-02$ \\
\hline-234 & $\mathrm{Ra}-226+\mathrm{D}$ & $1.000 \mathrm{E}+00$ & $0.000 \mathrm{E}+00$ & $3.405 E-16$ & $1.185 \mathrm{E}-12$ & $6.647 \mathrm{E}-12$ & $2.482 \mathrm{E}-09$ & $1.185 \mathrm{E}-04$ & $8.695 E-01$ \\
\hline-234 & $\mathrm{~Pb}-210+\mathrm{D}$ & $1.000 \mathrm{E}+00$ & $0.000 \mathrm{E}+00$ & 1. $641 \mathrm{E}-24$ & $2.135 \mathrm{E}-19$ & $1.903 \mathrm{E}-18$ & 1. $668 \mathrm{E}-15$ & $1.770 \mathrm{E}-04$ & $6.474 \mathrm{E}-01$ \\
\hline 234 & $\sum \operatorname{DSR}(j)$ & & $6.835 E-24$ & $3.405 E-16$ & $1.185 \mathrm{E}-12$ & $6.647 \mathrm{E}-12$ & $2.482 E-09$ & $9.581 \mathrm{E}-04$ & $1.622 \mathrm{E}+00$ \\
\hline$-235+D$ & $\mathrm{U}-235+\mathrm{D}$ & $1.000 \mathrm{E}+00$ & $1.236 \mathrm{E}-14$ & 1. $251 \mathrm{E}-14$ & $2.291 \mathrm{E}-14$ & $4.249 \mathrm{E}-14$ & $5.944 \mathrm{E}-12$ & $6.337 \mathrm{E}-04$ & $5.458 \mathrm{E}-01$ \\
\hline$-235+D$ & $\mathrm{~Pa}-231$ & $1.000 \mathrm{E}+00$ & $0.000 \mathrm{E}+00$ & $5.896 \mathrm{E}-18$ & $4.955 E-16$ & $1.684 \mathrm{E}-15$ & $5.839 E-13$ & $9.104 \mathrm{E}-04$ & $9.492 \mathrm{E}-01$ \\
\hline$-235+D$ & $A C-227+D$ & $1.000 \mathrm{E}+00$ & $0.000 \mathrm{E}+00$ & $2.781 \mathrm{E}-17$ & $6.744 \mathrm{E}-14$ & $2.910 \mathrm{E}-13$ & $6.341 \mathrm{E}-11$ & $3.284 E-04$ & $4.918 E-01$ \\
\hline$-235+D$ & $\sum \operatorname{DSR}(j)$ & & $1.236 \mathrm{E}-14$ & $1.254 \mathrm{E}-14$ & $9.085 \mathrm{E}-14$ & $3.352 E-13$ & $6.994 \mathrm{E}-11$ & $1.873 E-03$ & $1.987 \mathrm{E}+00$ \\
\hline-238 & $\mathrm{U}-238$ & $5.400 \mathrm{E}-05$ & $0.000 \mathrm{E}+00$ & $0.000 \mathrm{E}+00$ & $0.000 \mathrm{E}+00$ & $0.000 \mathrm{E}+00$ & $0.000 \mathrm{E}+00$ & $3.261 \mathrm{E}-08$ & $4.852 E-06$ \\
\hline $38+D$ & $\mathrm{U}-238+\mathrm{D}$ & $9.999 \mathrm{E}-01$ & $1.414 \mathrm{E}-10$ & $1.425 \mathrm{E}-10$ & $2.107 \mathrm{E}-10$ & $3.141 \mathrm{E}-10$ & $7.648 \mathrm{E}-09$ & $6.500 \mathrm{E}-04$ & $1.974 \mathrm{E}-01$ \\
\hline$-238+D$ & $\mathrm{U}-234$ & $9.999 \mathrm{E}-01$ & $0.000 \mathrm{E}+00$ & $1.972 \mathrm{E}-29$ & $2.347 E-27$ & $1.137 \mathrm{E}-26$ & $6.745 E-23$ & $1.945 E-06$ & $2.727 E-03$ \\
\hline$-238+D$ & $\mathrm{Th}-230$ & $9.999 \mathrm{E}-01$ & $0.000 \mathrm{E}+00$ & $3.104 \mathrm{E}-33$ & $1.767 \mathrm{E}-29$ & $1.638 \mathrm{E}-28$ & $3.394 \mathrm{E}-24$ & $1.500 \mathrm{E}-08$ & $1.461 \mathrm{E}-04$ \\
\hline$-238+D$ & $\mathrm{Ra}-226+\mathrm{D}$ & $9.999 \mathrm{E}-01$ & $0.000 \mathrm{E}+00$ & $3.218 E-22$ & $5.610 \mathrm{E}-17$ & $6.303 E-16$ & $1.193 \mathrm{E}-12$ & $1.217 \mathrm{E}-07$ & $1.015 E-02$ \\
\hline$-238+D$ & $\mathrm{~Pb}-210+\mathrm{D}$ & $9.999 \mathrm{E}-01$ & $0.000 \mathrm{E}+00$ & $1.165 \mathrm{E}-30$ & $8.088 E-24$ & $1.513 \mathrm{E}-22$ & $7.559 \mathrm{E}-19$ & $1.765 E-07$ & $7.528 E-03$ \\
\hline$-238+D$ & $\sum \operatorname{DSR}(j)$ & & $1.414 \mathrm{E}-10$ & $1.425 \mathrm{E}-10$ & $2.107 \mathrm{E}-10$ & $3.141 \mathrm{E}-10$ & $7.649 E-09$ & $6.523 E-04$ & $2.180 E-01$ \\
\hline
\end{tabular}

The DSR includes contributions from associated (half-life $\leq 180$ days) daughters. 
RESRAD, Version $6.5 \quad \mathrm{~T}^{1} \frac{1}{2}$ Limit $=180$ days

Summary : C746U Resident Farmer Deterministic Run
File : X: $\backslash$ FINAL V2 $\backslash$ DOE FWD RUNS \C746U RF DOE SG FWD-FV2-10000YR.RAD

Single Radionuclide Soil Guidelines G(i,t) in pCi/g

Basic Radiation Dose Limit $=1.000 \mathrm{E}+02 \mathrm{mrem} / \mathrm{yr}$

Nuclide

\begin{tabular}{|c|c|c|c|c|c|c|c|}
\hline (i) & $\mathrm{t}=0.000 \mathrm{E}+00$ & $1.000 \mathrm{E}+00$ & $5.000 \mathrm{E}+01$ & $1.000 \mathrm{E}+02$ & $5.000 \mathrm{E}+02$ & $1.050 \mathrm{E}+03$ & $1.000 \mathrm{E}+0$ \\
\hline-241 & $\star 3.431 \mathrm{E}+12$ & $\star 3.431 \mathrm{E}+12$ & $\star 3.431 \mathrm{E}+12$ & $\star 3.431 \mathrm{E}+12$ & $\star 3.431 \mathrm{E}+12$ & $5.181 \mathrm{E}+05$ & $4.163 \mathrm{E}+05$ \\
\hline-137 & $7.867 \mathrm{E}+10$ & $7.984 \mathrm{E}+10$ & $1.641 \mathrm{E}+11$ & $3.422 E+11$ & $\star 8.704 \mathrm{E}+13$ & $\star 8.704 \mathrm{E}+13$ & $\star 8.704 \mathrm{E}+13$ \\
\hline-237 & $\star 7.047 \mathrm{E}+08$ & $\star 7.047 \mathrm{E}+08$ & $\star 7.047 \mathrm{E}+08$ & $\star 7.047 \mathrm{E}+08$ & $\star 7.047 \mathrm{E}+08$ & $9.749 \mathrm{E}+03$ & $8.902 E+01$ \\
\hline$x-238$ & $\star 1.712 \mathrm{E}+13$ & $\star 1.712 \mathrm{E}+13$ & $\star 1.712 \mathrm{E}+13$ & $\star 1.712 \mathrm{E}+13$ & $\star 1.712 \mathrm{E}+13$ & $1.628 \mathrm{E}+08$ & $1.744 \mathrm{E}+05$ \\
\hline-239 & $* 6.214 \mathrm{E}+10$ & $* 6.214 \mathrm{E}+10$ & $* 6.214 \mathrm{E}+10$ & $* 6.214 \mathrm{E}+10$ & $* 6.214 \mathrm{E}+10$ & $8.096 \mathrm{E}+04$ & $9.626 \mathrm{E}+02$ \\
\hline-240 & $\star 2.278 \mathrm{E}+11$ & $\star 2.278 \mathrm{E}+11$ & $\star 2.278 \mathrm{E}+11$ & $\star 2.278 \mathrm{E}+11$ & $\star 2.278 \mathrm{E}+11$ & $8.779 \mathrm{E}+04$ & $2.085 \mathrm{E}+03$ \\
\hline-99 & $* 1.697 \mathrm{E}+10$ & $* 1.697 \mathrm{E}+10$ & $\star 1.697 \mathrm{E}+10$ & $\star 1.697 \mathrm{E}+10$ & $4.808 E+02$ & $6.756 \mathrm{E}+04$ & $* 1.697 \mathrm{E}+10$ \\
\hline$h-228$ & $6.085 E+07$ & $8.690 \mathrm{E}+07$ & $\star 8.195 \mathrm{E}+14$ & $\star 8.195 \mathrm{E}+14$ & $\star 8.195 \mathrm{E}+14$ & $\star 8.195 \mathrm{E}+14$ & $\star 8.195 \mathrm{E}+14$ \\
\hline$h-230$ & $\star 2.018 \mathrm{E}+10$ & $\star 2.018 \mathrm{E}+10$ & $1.905 \mathrm{E}+10$ & $6.818 \mathrm{E}+09$ & $9.377 \mathrm{E}+07$ & $1.651 \mathrm{E}+03$ & $4.369 \mathrm{E}+0$ \\
\hline Th-232 & $* 1.097 \mathrm{E}+05$ & $* 1.097 \mathrm{E}+05$ & $* 1.097 \mathrm{E}+05$ & $* 1.097 \mathrm{E}+05$ & $* 1.097 \mathrm{E}+05$ & $6.221 \mathrm{E}+02$ & $3.605 \mathrm{E}+00$ \\
\hline$J-234$ & $\star 6.247 \mathrm{E}+09$ & $\star 6.247 \mathrm{E}+09$ & $\star 6.247 \mathrm{E}+09$ & $\star 6.247 \mathrm{E}+09$ & $* 6.247 \mathrm{E}+09$ & $1.044 \mathrm{E}+05$ & $6.165 \mathrm{E}+0$ \\
\hline 35 & $\star 2.161 \mathrm{E}+06$ & $\star 2.161 \mathrm{E}+06$ & $\star 2.161 \mathrm{E}+06$ & $\star 2.161 \mathrm{E}+06$ & $\star 2.161 \mathrm{E}+06$ & $5.340 \mathrm{E}+04$ & $5.033 E+0$ \\
\hline 238 & $\star 3.361 \mathrm{E}+05$ & $\star 3.361 \mathrm{E}+05$ & $\star 3.361 \mathrm{E}+05$ & $\star 3.361 \mathrm{E}+05$ & $\star 3.361 \mathrm{E}+05$ & $1.533 \mathrm{E}+05$ & $4.588 \mathrm{E}+02$ \\
\hline
\end{tabular}

*At specific activity limit

Summed Dose/Source Ratios DSR (i,t) in (mrem/yr)/(pCi/g)

and Single Radionuclide Soil Guidelines G(i,t) in pCi/g

at tmin = time of minimum single radionuclide soil guideline and at $\operatorname{tmax}=$ time of maximum total dose $=1.000 \mathrm{E}+04$ years

\begin{tabular}{|c|c|c|c|c|c|c|}
\hline $\begin{array}{l}\text { uclide } \\
\text { (i) }\end{array}$ & $\begin{array}{l}\text { Initial } \\
(\mathrm{pCi} / \mathrm{g})\end{array}$ & $\begin{array}{c}\text { tmin } \\
\text { (years) }\end{array}$ & $\operatorname{DSR}(i, \operatorname{tmin})$ & $\begin{array}{c}G(i, \text { tmin }) \\
(p C i / g)\end{array}$ & $\operatorname{DSR}(i, \operatorname{tmax})$ & $\begin{array}{c}\mathrm{G}(\mathrm{i}, \mathrm{tmax}) \\
(\mathrm{pci} / \mathrm{g})\end{array}$ \\
\hline $1-241$ & $3.500 \mathrm{E}+01$ & $1672 \pm 3$ & $2.773 E-03$ & $3.607 E+04$ & $2.402 E-04$ & $4.163 E+05$ \\
\hline-137 & 1. $900 \mathrm{E}+01$ & $0.000 \mathrm{E}+00$ & $1.271 \mathrm{E}-09$ & $7.867 \mathrm{E}+10$ & $0.000 \mathrm{E}+00$ & $\star 8.704 \mathrm{E}+13$ \\
\hline-237 & $5.500 \mathrm{E}+00$ & $2534 \pm 5$ & $1.404 \mathrm{E}+00$ & $7.120 \mathrm{E}+01$ & $1.123 E+00$ & $8.902 E+01$ \\
\hline-238 & $3.900 \mathrm{E}+01$ & $1.000 \mathrm{E}+04$ & $5.734 \mathrm{E}-04$ & $1.744 \mathrm{E}+05$ & $5.734 \mathrm{E}-04$ & $1.744 \mathrm{E}+05$ \\
\hline-239 & $3.600 \mathrm{E}+01$ & $2534 \pm 5$ & $1.464 \mathrm{E}-01$ & $6.832 E+02$ & $1.039 E-01$ & $9.626 \mathrm{E}+02$ \\
\hline-240 & $3.600 \mathrm{E}+01$ & $2534 \pm 5$ & $1.203 E-01$ & $8.314 E+02$ & $4.796 E-02$ & $2.085 E+03$ \\
\hline-99 & $5.200 \mathrm{E}+01$ & $425.1 \pm 0.9$ & $4.080 \mathrm{E}-01$ & $2.451 E+02$ & $0.000 \mathrm{E}+00$ & $\star 1.697 \mathrm{E}+10$ \\
\hline-228 & $4.000 \mathrm{E}+00$ & $0.000 \mathrm{E}+00$ & $1.643 E-06$ & $6.085 E+07$ & $0.000 \mathrm{E}+00$ & $\star 8.195 \mathrm{E}+14$ \\
\hline-230 & $1.000 \mathrm{E}+02$ & $8261 \pm *$ & $2.303 E+01$ & $4.342 E+00$ & $2.289 \mathrm{E}+01$ & $4.369 E+00$ \\
\hline-232 & $4.000 \mathrm{E}+00$ & $2534 \pm 5$ & $2.835 E+01$ & $3.527 \mathrm{E}+00$ & $2.774 \mathrm{E}+01$ & $3.605 E+00$ \\
\hline 234 & $1.600 \mathrm{E}+02$ & $1.000 \mathrm{E}+04$ & $1.622 \mathrm{E}+00$ & $6.165 \mathrm{E}+01$ & $1.622 \mathrm{E}+00$ & $6.165 E+01$ \\
\hline 235 & $6.500 \mathrm{E}+00$ & $1.000 \mathrm{E}+04$ & $1.987 \mathrm{E}+00$ & $5.033 E+01$ & $1.987 \mathrm{E}+00$ & $5.033 E+01$ \\
\hline-238 & $1.600 \mathrm{E}+02$ & $2534 \pm 5$ & $2.358 \mathrm{E}-01$ & $4.241 E+02$ & $2.180 \mathrm{E}-01$ & $4.588 E+02$ \\
\hline
\end{tabular}

*At specific activity limit 
RESRAD, Version 6.5

$\mathrm{T}^{1 / 2}$ Limit = 180 days

07/18/2011 14:15 Page 30

ummary : C746U Resident Farmer Deterministic Run

File : $\mathrm{X}: \backslash F I N A L$ V2 \DOE FWD RUNS \C746U RF DOE SG FWD-FV2-10000YR. RAD

Individual Nuclide Dose Summed Over All Pathways

Parent Nuclide and Branch Fraction Indicated

Nuclide Parent THF(i) DOSE $(j, t), \mathrm{mrem} / \mathrm{yr}$

\begin{tabular}{|c|c|c|}
\hline$(j)$ & (i) & \\
\hline $\mathrm{Am}-241$ & $A m-241$ & $1.000 \mathrm{E}+00$ \\
\hline$p-237$ & Am-241 & $1.000 \mathrm{E}+00$ \\
\hline-237 & $N p-237$ & $1.000 \mathrm{E}+00$ \\
\hline 237 & $\sum$ DOSE & \\
\hline
\end{tabular}

$\mathrm{U}-233 \mathrm{Am}-241 \quad 1.000 \mathrm{E}+00$

$\mathrm{U}-233 \quad \mathrm{~Np}-237 \quad 1.000 \mathrm{E}+00$

U-233 $\sum \operatorname{DOSE}(j)$

Th-229

$\mathrm{Th}-229$

$\mathrm{Th}-229$

Cs -137

$\mathrm{Pu}-238$

$\mathrm{Pu}-238$

$\mathrm{Pu}-238$

$\mathrm{U}-234$

$\mathrm{U}-234$

$\mathrm{U}-234$

$\mathrm{U}-234$

$\mathrm{Th}-230$

$\mathrm{Th}-230$

$\mathrm{Th}-230$

$\mathrm{Th}-230$

$\mathrm{Th}-230$

$\mathrm{Ra}-226$

$\mathrm{Ra}-226$

$\mathrm{Ra}-226$

$\mathrm{Ra}-226$

$\mathrm{Ra}-226$

$\mathrm{Pb}-210$

$\mathrm{Pb}-210$

$\mathrm{Pb}-210$

$\mathrm{Pb}-210$

$\mathrm{Pb}-210$

Pu-239

Am-241 1.000E+00

$\mathrm{Np}-237 \quad 1.000 \mathrm{E}+00$

$\sum \operatorname{DOSE}(j)$

Cs-137 1.000E+00

$\mathrm{Pu}-238$ 1.840E-09

$\mathrm{Pu}-238 \quad 1.000 \mathrm{E}+00$

$\sum \operatorname{DOSE}(j)$

$\mathrm{Pu}-238 \quad 1.000 \mathrm{E}+00$

$\mathrm{U}-234 \quad 1.000 \mathrm{E}+00$

U-238 9.999E-01

$\sum \operatorname{DOSE}(j)$

$\mathrm{Pu}-238 \quad 1.000 \mathrm{E}+00$

Th-230 1.000E+00

$\mathrm{U}-234 \quad 1.000 \mathrm{E}+00$

U-238 9.999E-01

$\sum \operatorname{DOSE}(j)$

$\mathrm{Pu}-238 \quad 1.000 \mathrm{E}+00$

Th-230 1.000E+00

U-234 $1.000 \mathrm{E}+00$

U-238 9.999E-01

$\sum \operatorname{DOSE}(j)$

$\mathrm{Pu}-238 \quad 1.000 \mathrm{E}+00$

Th-230 1.000E+00

$\mathrm{U}-234 \quad 1.000 \mathrm{E}+00$

U-238 9.999E-01

$\sum \operatorname{DOSE}(j)$

$\mathrm{Pu}-239 \quad 1.000 \mathrm{E}+00$

$\mathrm{Pu}-239 \quad 1.000 \mathrm{E}+00$

$\mathrm{U}-2351.000 \mathrm{E}+00$

$\sum \operatorname{DOSE}(j)$
$\mathrm{E}=0.000 \mathrm{E}+00 \quad 1.000 \mathrm{E}+00 \quad 5.000 \mathrm{E}+01 \quad 1.000 \mathrm{E}+02 \quad 5.000 \mathrm{E}+02 \quad 1.050 \mathrm{E}+03 \quad 1.000 \mathrm{E}+04$

$0.000 \mathrm{E}+00 \quad 0.000 \mathrm{E}+00 \quad 0.000 \mathrm{E}+00 \quad 0.000 \mathrm{E}+00 \quad 4.171 \mathrm{E}-26 \quad 6.693 \mathrm{E}-03 \quad 5.656 \mathrm{E}-07$

$0.000 \mathrm{E}+00 \quad 1.086 \mathrm{E}-17 \quad 8.834 \mathrm{E}-16 \quad 2.905 \mathrm{E}-15 \quad 7.873 \mathrm{E}-13 \quad 6.209 \mathrm{E}-05 \quad 8.293 \mathrm{E}-03$

$5.217 \mathrm{E}-12 \quad 5.273 \mathrm{E}-12 \quad 8.892 \mathrm{E}-12 \quad 1.516 \mathrm{E}-11 \quad 1.080 \mathrm{E}-09 \quad 5.639 \mathrm{E}-02 \quad 6.083 \mathrm{E}+00$

$5.217 \mathrm{E}-12 \quad 5.273 \mathrm{E}-12 \quad 8.893 \mathrm{E}-12 \quad 1.516 \mathrm{E}-11 \quad 1.080 \mathrm{E}-09 \quad 5.646 \mathrm{E}-02 \quad 6.091 \mathrm{E}+00$

$0.000 \mathrm{E}+00 \quad 3.692 \mathrm{E}-28 \quad 1.659 \mathrm{E}-24 \quad 1.207 \mathrm{E}-23 \quad 3.656 \mathrm{E}-20 \quad 1.100 \mathrm{E}-08 \quad 1.944 \mathrm{E}-05$

$0.000 \mathrm{E}+00 \quad 3.584 \mathrm{E}-22 \quad 3.301 \mathrm{E}-20 \quad 1.231 \mathrm{E}-19 \quad 9.010 \mathrm{E}-17 \quad 1.625 \mathrm{E}-05 \quad 1.591 \mathrm{E}-02$

$0.000 \mathrm{E}+00 \quad 3.584 \mathrm{E}-22 \quad 3.301 \mathrm{E}-20 \quad 1.231 \mathrm{E}-19 \quad 9.014 \mathrm{E}-17 \quad 1.626 \mathrm{E}-05 \quad 1.593 \mathrm{E}-02$

$0.000 \mathrm{E}+00 \quad 3.363 \mathrm{E}-24 \quad 5.788 \mathrm{E}-19 \quad 6.420 \mathrm{E}-18 \quad 1.111 \mathrm{E}-14 \quad 1.840 \mathrm{E}-09 \quad 9.405 \mathrm{E}-05$

$0.000 \mathrm{E}+00 \quad 4.896 \mathrm{E}-18 \quad 1.717 \mathrm{E}-14 \quad 9.703 \mathrm{E}-14 \quad 3.873 \mathrm{E}-11 \quad 3.641 \mathrm{E}-06 \quad 7.950 \mathrm{E}-02$

$0.000 \mathrm{E}+00 \quad 4.896 \mathrm{E}-18 \quad 1.717 \mathrm{E}-14 \quad 9.703 \mathrm{E}-14 \quad 3.874 \mathrm{E}-11 \quad 3.643 \mathrm{E}-06 \quad 7.960 \mathrm{E}-02$

$2.415 \mathrm{E}-08 \quad 2.380 \mathrm{E}-08 \quad 1.158 \mathrm{E}-08 \quad 5.552 \mathrm{E}-09 \quad 1.551 \mathrm{E}-11 \quad 3.706 \mathrm{E}-12 \quad 0.000 \mathrm{E}+00$

$\begin{array}{lllllll}0.000 \mathrm{E}+00 & 0.000 \mathrm{E}+00 & 0.000 \mathrm{E}+00 & 0.000 \mathrm{E}+00 & 0.000 \mathrm{E}+00 & 2.099 \mathrm{E}-14 & 0.000 \mathrm{E}+00\end{array}$

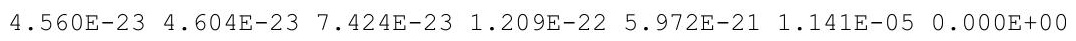

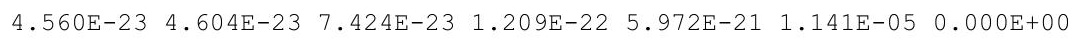

$0.000 \mathrm{E}+00 \quad 7.662 \mathrm{E}-28 \quad 7.563 \mathrm{E}-26 \quad 3.067 \mathrm{E}-25 \quad 6.534 \mathrm{E}-22 \quad 9.140 \mathrm{E}-06 \quad 1.329 \mathrm{E}-03$

$\begin{array}{llllllllll}1.094 \mathrm{E}-21 & 1.113 \mathrm{E}-21 & 2.649 \mathrm{E}-21 & 6.417 \mathrm{E}-21 & 7.609 \mathrm{E}-18 & 1.044 \mathrm{E}-01 & 1.517 \mathrm{E}+01\end{array}$

$\begin{array}{llllllll}0.000 E+00 & 3.156 E-27 & 3.755 E-25 & 1.819 E-24 & 1.079 E-20 & 3.112 E-04 & 4.363 E-01\end{array}$

$\begin{array}{llllllll}1.094 \mathrm{E}-21 & 1.113 \mathrm{E}-21 & 2.650 \mathrm{E}-21 & 6.420 \mathrm{E}-21 & 7.620 \mathrm{E}-18 & 1.047 \mathrm{E}-01 & 1.561 \mathrm{E}+01\end{array}$

$0.000 \mathrm{E}+00 \quad 0.000 \mathrm{E}+00 \quad 6.069 \mathrm{E}-28 \quad 4.992 \mathrm{E}-27 \quad 5.043 \mathrm{E}-23 \quad 1.243 \mathrm{E}-07 \quad 1.445 \mathrm{E}-04$ $\begin{array}{lllllllll}2.392 \mathrm{E}-20 & 2.432 \mathrm{E}-20 & 5.543 \mathrm{E}-20 & 1.285 \mathrm{E}-19 & 1.069 \mathrm{E}-16 & 1.076 \mathrm{E}-01 & 1.244 \mathrm{E}+01\end{array}$ $0.000 \mathrm{E}+00 \quad 3.503 \mathrm{E}-25 \quad 3.990 \mathrm{E}-23 \quad 1.849 \mathrm{E}-22 \quad 7.668 \mathrm{E}-19 \quad 1.615 \mathrm{E}-03 \quad 1.673 \mathrm{E}+00$ $\begin{array}{lllllll}0.000 \mathrm{E}+00 & 0.000 \mathrm{E}+00 & 2.828 \mathrm{E}-27 & 2.620 \mathrm{E}-26 & 5.431 \mathrm{E}-22 & 2.400 \mathrm{E}-06 & 2.338 \mathrm{E}-02\end{array}$ $\begin{array}{llllllll}2.392 \mathrm{E}-20 & 2.432 \mathrm{E}-20 & 5.547 \mathrm{E}-20 & 1.286 \mathrm{E}-19 & 1.076 \mathrm{E}-16 & 1.092 \mathrm{E}-01 & 1.414 \mathrm{E}+01\end{array}$

$\begin{array}{llllllllll}0.000 \mathrm{E}+00 & 1.253 \mathrm{E}-20 & 1.988 \mathrm{E}-15 & 2.040 \mathrm{E}-14 & 2.174 \mathrm{E}-11 & 1.324 \mathrm{E}-06 & 1.197 \mathrm{E}-02\end{array}$ $\begin{array}{llllllll}0.000 \mathrm{E}+00 & 7.565 \mathrm{E}-09 & 5.249 \mathrm{E}-07 & 1.467 \mathrm{E}-06 & 1.066 \mathrm{E}-04 & 2.340 \mathrm{E}+00 & 1.303 \mathrm{E}+03\end{array}$ $\begin{array}{lllllll}0.000 \mathrm{E}+00 & 5.448 \mathrm{E}-14 & 1.897 \mathrm{E}-10 & 1.064 \mathrm{E}-09 & 3.972 \mathrm{E}-07 & 1.896 \mathrm{E}-02 & 1.391 \mathrm{E}+02\end{array}$ $0.000 \mathrm{E}+00 \quad 5.149 \mathrm{E}-20 \quad 8.977 \mathrm{E}-15 \quad 1.009 \mathrm{E}-13 \quad 1.909 \mathrm{E}-10 \quad 1.948 \mathrm{E}-05 \quad 1.624 \mathrm{E}+00$ $\begin{array}{llllllll}0.000 \mathrm{E}+00 & 7.565 \mathrm{E}-09 & 5.251 \mathrm{E}-07 & 1.468 \mathrm{E}-06 & 1.070 \mathrm{E}-04 & 2.359 \mathrm{E}+00 & 1.443 \mathrm{E}+03\end{array}$

$0.000 \mathrm{E}+00 \quad 4.535 \mathrm{E}-29 \quad 2.911 \mathrm{E}-22 \quad 5.018 \mathrm{E}-21 \quad 1.423 \mathrm{E}-17 \quad 1.964 \mathrm{E}-06 \quad 8.915 \mathrm{E}-03$ $\begin{array}{lllllll}0.000 \mathrm{E}+00 & 5.454 \mathrm{E}-17 & 1.273 \mathrm{E}-13 & 5.257 \mathrm{E}-13 & 7.641 \mathrm{E}-11 & 3.610 \mathrm{E}+00 & 9.735 \mathrm{E}+02\end{array}$ $\begin{array}{llllllll}0.000 \mathrm{E}+00 & 2.625 \mathrm{E}-22 & 3.416 \mathrm{E}-17 & 3.045 \mathrm{E}-16 & 2.669 \mathrm{E}-13 & 2.832 \mathrm{E}-02 & 1.036 \mathrm{E}+02\end{array}$ $\begin{array}{lllllll}0.000 \mathrm{E}+00 & 1.863 \mathrm{E}-28 & 1.294 \mathrm{E}-21 & 2.420 \mathrm{E}-20 & 1.209 \mathrm{E}-16 & 2.824 \mathrm{E}-05 & 1.205 \mathrm{E}+00\end{array}$ $\begin{array}{lllllll}0.000 \mathrm{E}+00 & 5.454 \mathrm{E}-17 & 1.274 \mathrm{E}-13 & 5.260 \mathrm{E}-13 & 7.667 \mathrm{E}-11 & 3.639 \mathrm{E}+00 & 1.078 \mathrm{E}+03\end{array}$

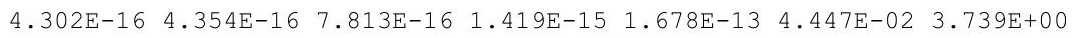

$0.000 \mathrm{E}+00 \quad 4.435 \mathrm{E}-22 \quad 4.060 \mathrm{E}-20 \quad 1.505 \mathrm{E}-19 \quad 1.048 \mathrm{E}-16 \quad 2.331 \mathrm{E}-08 \quad 1.729 \mathrm{E}-04$ $\begin{array}{llllllll}8.032 \mathrm{E}-14 & 8.131 \mathrm{E}-14 & 1.489 \mathrm{E}-13 & 2.762 \mathrm{E}-13 & 3.864 \mathrm{E}-11 & 4.119 \mathrm{E}-03 & 3.548 \mathrm{E}+00\end{array}$ $\begin{array}{llllllll}8.032 \mathrm{E}-14 & 8.131 \mathrm{E}-14 & 1.489 \mathrm{E}-13 & 2.762 \mathrm{E}-13 & 3.864 \mathrm{E}-11 & 4.119 \mathrm{E}-03 & 3.548 \mathrm{E}+00\end{array}$ 
RESRAD, Version 6.5

Summary : C746U Resident Farmer Deterministic Run

File : $X: \backslash F I N A L$ V2 \DOE FWD RUNS \C746U RF DOE SG FWD-FV2-10000YR.RAD

Individual Nuclide Dose Summed Over All Pathways

Parent Nuclide and Branch Fraction Indicated

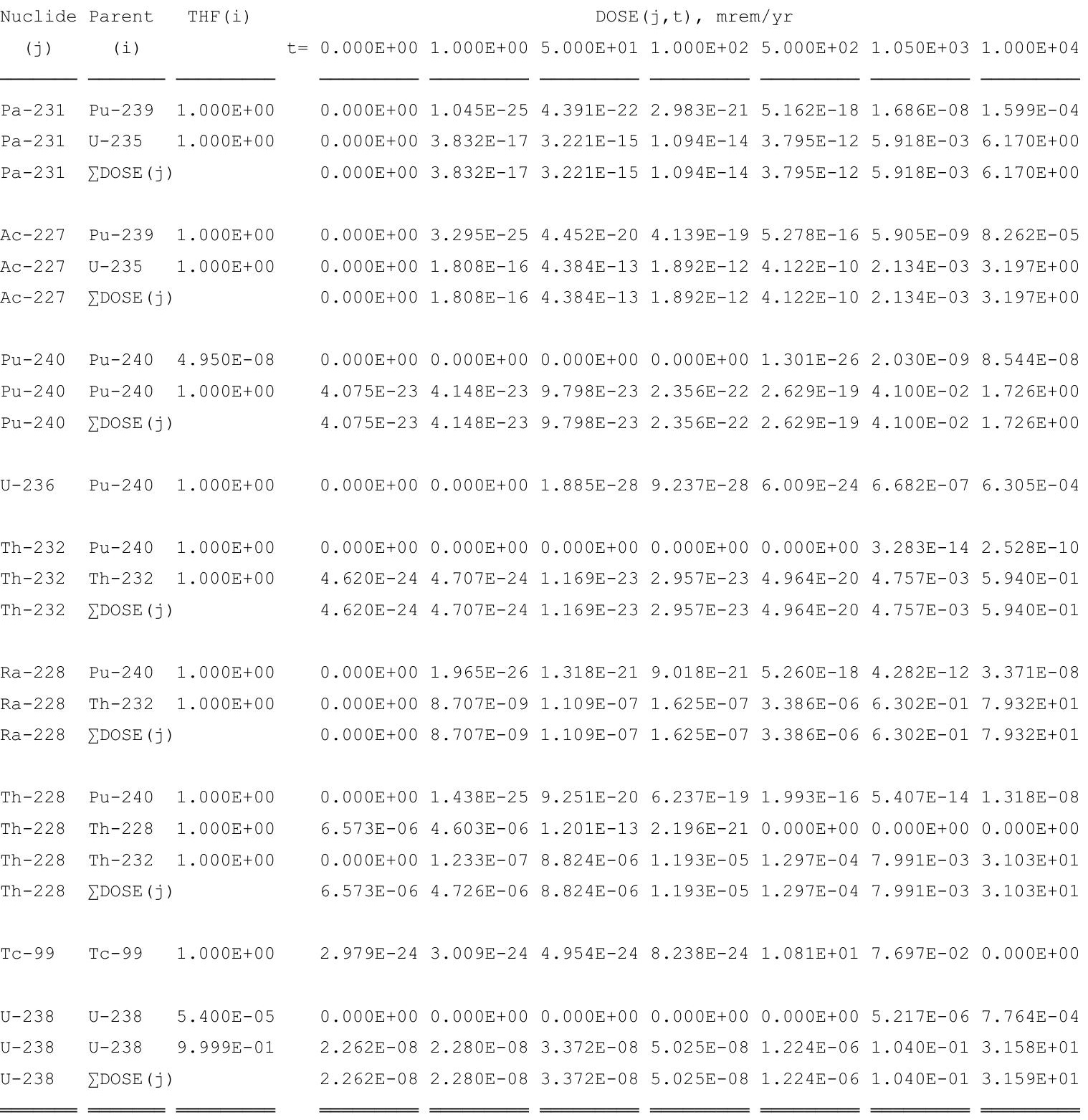

THF(i) is the thread fraction of the parent nuclide. 
RESRAD, Version 6.5

ummary : C746U Resident Farmer Deterministic Run

File : $\mathrm{X}: \backslash F I N A L$ V2 \DOE FWD RUNS \C746U RF DOE SG FWD-FV2-10000YR.RAD

Individual Nuclide Soil Concentration

Parent Nuclide and Branch Fraction Indicated

Nuclide Parent THF(

(j)

Am-241

(i)

$\overline{\mathrm{Am}-241} \overline{1.000 \mathrm{E}+00}$

Np-237 Am-241 $1.000 E+00$

$\mathrm{Np}-237 \quad \mathrm{~Np}-237 \quad 1.000 \mathrm{E}+00$

Np-237 $\sum S(j):$

$\mathrm{U}-233 \quad \mathrm{Am}-241 \quad 1.000 \mathrm{E}+00$

$\mathrm{U}-233 \quad \mathrm{~Np}-237 \quad 1.000 \mathrm{E}+00$

$\mathrm{U}-233 \sum \mathrm{S}(\mathrm{j}):$

Th -229

Th-229

Th-229

Cs -137

$\mathrm{Pu}-238$

$\mathrm{Pu}-238$

$\mathrm{Pu}-238$

$\mathrm{U}-234$

$\mathrm{U}-234$

$\mathrm{U}-234$

$\mathrm{U}-234$

Th-230

$\mathrm{Th}-230$

Th -230

Th -230

Th -230

$\mathrm{Ra}-226$

$\mathrm{Ra}-226$

$\mathrm{Ra}-226$

$\mathrm{Ra}-226$

$\operatorname{Ra}-226$

$\mathrm{Pb}-210$

$\mathrm{Pb}-210$

$\mathrm{Pb}-210$

$\mathrm{Pb}-210$

$\mathrm{Pb}-210$

$\mathrm{Pu}-239$
Np-237 1.000E+00

$\sum S(j):$

Cs $-137 \quad 1.000 E+00$

Pu-238 1.840E-09

Pu-238 1.000E+00

$\sum S(j):$

Pu-238 1.000E+00

$\mathrm{U}-234 \quad 1.000 \mathrm{E}+00$

U-238 $9.999 \mathrm{E}-01$

$\sum S(j):$

$\mathrm{Pu}-238 \quad 1.000 \mathrm{E}+00$

Th-230 1.000E+00

$\mathrm{U}-234 \quad 1.000 \mathrm{E}+00$

U-238 $9.999 \mathrm{E}-01$

$\sum S(j):$

$\mathrm{Pu}-238 \quad 1.000 \mathrm{E}+00$

Th-230 1.000E+00

$\mathrm{U}-234 \quad 1.000 \mathrm{E}+00$

$\mathrm{U}-238 \quad 9.999 \mathrm{E}-01$

$\sum S(j):$

$\mathrm{Pu}-238 \quad 1.000 \mathrm{E}+00$

Th-230 1.000E+00

$\mathrm{U}-2341.000 \mathrm{E}+00$

$\mathrm{U}-238 \quad 9.999 \mathrm{E}-01$

$\sum S(j):$

$\mathrm{Pu}-239 \quad 1.000 \mathrm{E}+00$

$\mathrm{Pu}-239 \quad 1.000 \mathrm{E}+00$

$\mathrm{U}-2351.000 \mathrm{E}+00$

$\sum S(j):$
$\mathrm{Am}-241 \quad 1.000 \mathrm{E}+00$
$\mathrm{S}(j, \mathrm{t}), \mathrm{pCi} / \mathrm{g}$

$\mathrm{t}=0.000 \mathrm{E}+00 \quad 1.000 \mathrm{E}+00 \quad 5.000 \mathrm{E}+01 \quad 1.000 \mathrm{E}+02 \quad 5.000 \mathrm{E}+02 \quad 1.050 \mathrm{E}+03 \quad 1.000 \mathrm{E}+04$

$\begin{array}{llllllllll}3.500 \mathrm{E}+01 & 3.494 \mathrm{E}+01 & 3.229 \mathrm{E}+01 & 2.980 \mathrm{E}+01 & 1.566 \mathrm{E}+01 & 6.464 \mathrm{E}+00 & 3.610 \mathrm{E}-06\end{array}$

$0.000 \mathrm{E}+00 \quad 1.133 \mathrm{E}-05 \quad 5.428 \mathrm{E}-04 \quad 1.040 \mathrm{E}-03 \quad 3.749 \mathrm{E}-03 \quad 5.255 \mathrm{E}-03 \quad 1.996 \mathrm{E}-03$

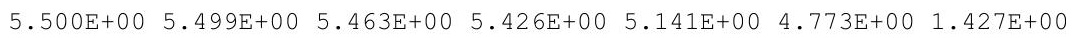

$\begin{array}{lllllll}5.500 \mathrm{E}+00 & 5.499 \mathrm{E}+00 & 5.464 \mathrm{E}+00 & 5.427 \mathrm{E}+00 & 5.145 \mathrm{E}+00 & 4.779 \mathrm{E}+00 & 1.429 \mathrm{E}+00\end{array}$

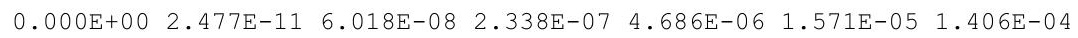

$\begin{array}{lllllll}0.000 \mathrm{E}+00 & 2.405 \mathrm{E}-05 & 1.198 \mathrm{E}-03 & 2.386 \mathrm{E}-03 & 1.155 \mathrm{E}-02 & 2.320 \mathrm{E}-02 & 1.121 \mathrm{E}-01\end{array}$

$\begin{array}{lllllll}0.000 \mathrm{E}+00 & 2.405 \mathrm{E}-05 & 1.198 \mathrm{E}-03 & 2.386 \mathrm{E}-03 & 1.155 \mathrm{E}-02 & 2.322 \mathrm{E}-02 & 1.122 \mathrm{E}-01\end{array}$

$0.000 \mathrm{E}+00 \quad 7.799 \mathrm{E}-16 \quad 9.529 \mathrm{E}-11 \quad 7.450 \mathrm{E}-10 \quad 7.803 \mathrm{E}-08 \quad 5.780 \mathrm{E}-07 \quad 5.806 \mathrm{E}-05$

$0.000 \mathrm{E}+00 \quad 1.136 \mathrm{E}-09 \quad 2.827 \mathrm{E}-06 \quad 1.126 \mathrm{E}-05 \quad 2.719 \mathrm{E}-04 \quad 1.144 \mathrm{E}-03 \quad 4.901 \mathrm{E}-02$

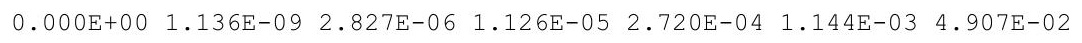

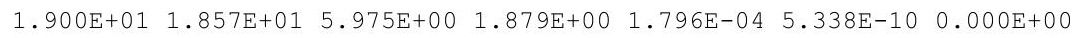

$\begin{array}{lllllll}7.176 \mathrm{E}-08 & 7.119 \mathrm{E}-08 & 4.830 \mathrm{E}-08 & 3.251 \mathrm{E}-08 & 1.370 \mathrm{E}-09 & 1.760 \mathrm{E}-11 & 2.951 \mathrm{E}-42\end{array}$

$\begin{array}{llllllll}3.900 \mathrm{E}+01 & 3.869 \mathrm{E}+01 & 2.625 \mathrm{E}+01 & 1.767 \mathrm{E}+01 & 7.445 \mathrm{E}-01 & 9.567 \mathrm{E}-03 & 1.612 \mathrm{E}-33\end{array}$

$\begin{array}{lllllllll}3.900 \mathrm{E}+01 & 3.869 \mathrm{E}+01 & 2.625 \mathrm{E}+01 & 1.767 \mathrm{E}+01 & 7.445 \mathrm{E}-01 & 9.567 \mathrm{E}-03 & 1.612 \mathrm{E}-33\end{array}$

$0.000 \mathrm{E}+00 \quad 1.101 \mathrm{E}-04 \quad 4.562 \mathrm{E}-03 \quad 7.627 \mathrm{E}-03 \quad 1.356 \mathrm{E}-02 \quad 1.363 \mathrm{E}-02 \quad 1.082 \mathrm{E}-02$

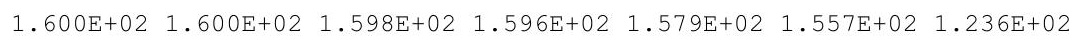

$\begin{array}{llllllll}0.000 \mathrm{E}+00 & 4.536 \mathrm{E}-04 & 2.265 \mathrm{E}-02 & 4.525 \mathrm{E}-02 & 2.240 \mathrm{E}-01 & 4.642 \mathrm{E}-01 & 3.553 \mathrm{E}+00\end{array}$

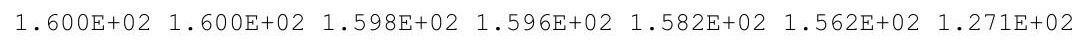

$0.000 \mathrm{E}+00 \quad 4.963 \mathrm{E}-10 \quad 1.094 \mathrm{E}-06 \quad 3.882 \mathrm{E}-06 \quad 4.691 \mathrm{E}-05 \quad 1.141 \mathrm{E}-04 \quad 1.031 \mathrm{E}-03$ $\begin{array}{lllllllll}1.000 \mathrm{E}+02 & 1.000 \mathrm{E}+02 & 9.994 \mathrm{E}+01 & 9.988 \mathrm{E}+01 & 9.940 \mathrm{E}+01 & 9.875 \mathrm{E}+01 & 8.874 \mathrm{E}+01\end{array}$ $0.000 \mathrm{E}+00 \quad 1.440 \mathrm{E}-03 \quad 7.195 \mathrm{E}-02 \quad 1.438 \mathrm{E}-01 \quad 7.134 \mathrm{E}-01 \quad 1.483 \mathrm{E}+00 \quad 1.193 \mathrm{E}+01$ $\begin{array}{lllllll}0.000 \mathrm{E}+00 & 2.041 \mathrm{E}-09 & 5.099 \mathrm{E}-06 & 2.037 \mathrm{E}-05 & 5.052 \mathrm{E}-04 & 2.203 \mathrm{E}-03 & 1.668 \mathrm{E}-01\end{array}$

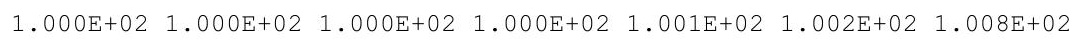

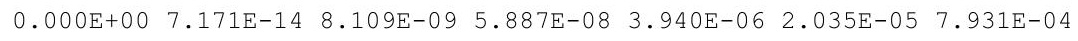
$\begin{array}{llllllll}0.000 \mathrm{E}+00 & 4.331 \mathrm{E}-02 & 2.141 \mathrm{E}+00 & 4.233 \mathrm{E}+00 & 1.933 \mathrm{E}+01 & 3.597 \mathrm{E}+01 & 8.627 \mathrm{E}+01\end{array}$ $\begin{array}{lllllll}0.000 \mathrm{E}+00 & 3.119 \mathrm{E}-07 & 7.736 \mathrm{E}-04 & 3.069 \mathrm{E}-03 & 7.197 \mathrm{E}-02 & 2.914 \mathrm{E}-01 & 9.214 \mathrm{E}+00\end{array}$ $\begin{array}{lllllll}0.000 \mathrm{E}+00 & 2.948 \mathrm{E}-13 & 3.662 \mathrm{E}-08 & 2.911 \mathrm{E}-07 & 3.459 \mathrm{E}-05 & 2.994 \mathrm{E}-04 & 1.075 \mathrm{E}-01\end{array}$ $\begin{array}{lllllll}0.000 \mathrm{E}+00 & 4.331 \mathrm{E}-02 & 2.142 \mathrm{E}+00 & 4.236 \mathrm{E}+00 & 1.940 \mathrm{E}+01 & 3.626 \mathrm{E}+01 & 9.560 \mathrm{E}+01\end{array}$

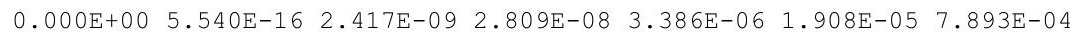
$\begin{array}{llllllll}0.000 \mathrm{E}+00 & 6.662 \mathrm{E}-04 & 1.057 \mathrm{E}+00 & 2.944 \mathrm{E}+00 & 1.819 \mathrm{E}+01 & 3.507 \mathrm{E}+01 & 8.620 \mathrm{E}+01\end{array}$ $\begin{array}{lllllll}0.000 \mathrm{E}+00 & 3.207 \mathrm{E}-09 & 2.836 \mathrm{E}-04 & 1.705 \mathrm{E}-03 & 6.353 \mathrm{E}-02 & 2.751 \mathrm{E}-01 & 9.171 \mathrm{E}+00\end{array}$ $\begin{array}{lllllll}0.000 \mathrm{E}+00 & 2.276 \mathrm{E}-15 & 1.075 \mathrm{E}-08 & 1.355 \mathrm{E}-07 & 2.879 \mathrm{E}-05 & 2.742 \mathrm{E}-04 & 1.066 \mathrm{E}-01\end{array}$ $\begin{array}{lllllll}0.000 \mathrm{E}+00 & 6.663 \mathrm{E}-04 & 1.058 \mathrm{E}+00 & 2.945 \mathrm{E}+00 & 1.825 \mathrm{E}+01 & 3.534 \mathrm{E}+01 & 9.547 \mathrm{E}+01\end{array}$

$\begin{array}{lllllllll}3.600 \mathrm{E}+01 & 3.600 \mathrm{E}+01 & 3.592 \mathrm{E}+01 & 3.583 \mathrm{E}+01 & 3.518 \mathrm{E}+01 & 3.430 \mathrm{E}+01 & 2.274 \mathrm{E}+01\end{array}$

$0.000 \mathrm{E}+00 \quad 3.545 \mathrm{E}-08 \quad 1.770 \mathrm{E}-06 \quad 3.533 \mathrm{E}-06 \quad 1.742 \mathrm{E}-05 \quad 3.591 \mathrm{E}-05 \quad 2.517 \mathrm{E}-04$ $\begin{array}{lllllll}6.500 \mathrm{E}+00 & 6.500 \mathrm{E}+00 & 6.493 \mathrm{E}+00 & 6.485 \mathrm{E}+00 & 6.426 \mathrm{E}+00 & 6.345 \mathrm{E}+00 & 5.165 \mathrm{E}+00\end{array}$

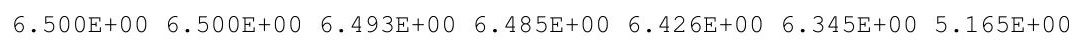


RESRAD, Version 6.5

Summary : C746U Resident Farmer Deterministic Run

File : $X: \backslash F I N A L$ V2 \DOE FWD RUNS \C746U RF DOE SG FWD-FV2-10000YR.RAD

Individual Nuclide Soil Concentration

Parent Nuclide and Branch Fraction Indicated

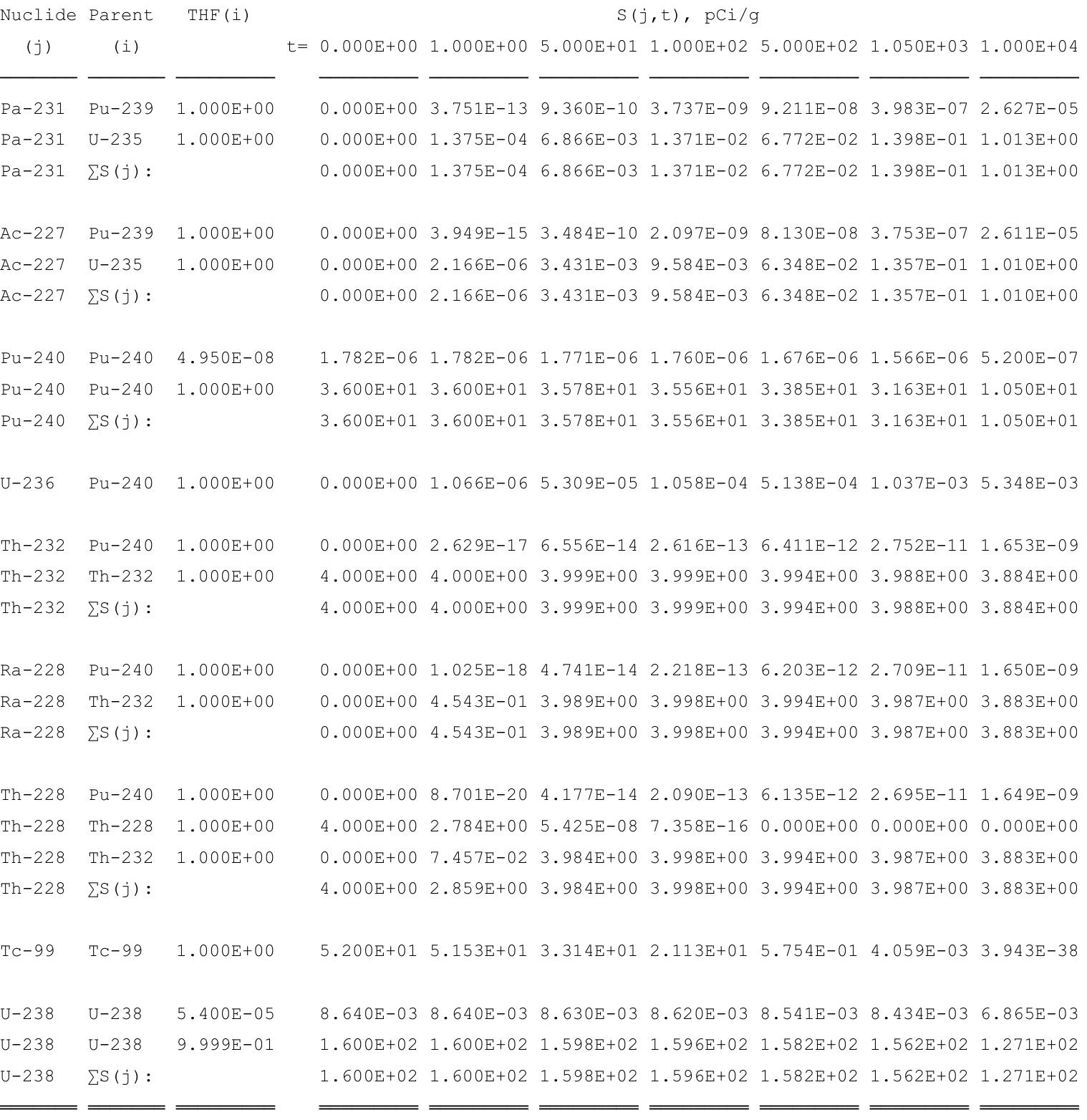

THF(i) is the thread fraction of the parent nuclide.

RESCALC.EXE execution time $=5.14$ seconds 


\title{
Resident Farmer (onsite)
}

\author{
Summary Report \\ (Deterministic Analysis Report)
}

Third Peak Dose Assessment

Time Horizon: 100,000 yr 
THIS PAGE INTENTIONALLY LEFT BLANK 


\section{RESRAD, Version $6.5 \quad \mathrm{~T}^{1 / 2}$ Limit $=180$ days}

Summary : C746U Resident Farmer Deterministic Run

File : $\mathrm{X}: \backslash F I N A L$ V2 $\backslash$ DOE FWD RUNS \C746U RF DOE SG FWD-FV2-100000YR.RAD

\section{Table of Contents}

Part I: Mixture Sums and Single Radionuclide Guidelines

Dose Conversion Factor (and Related) Parameter Summary ... 2

Site-Specific Parameter Summary ................ 8

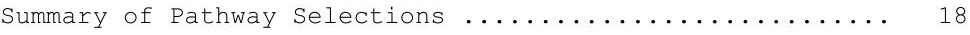

Contaminated Zone and Total Dose Summary ............. 19

Total Dose Components

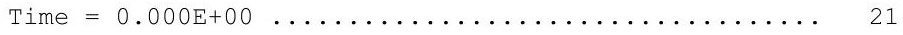

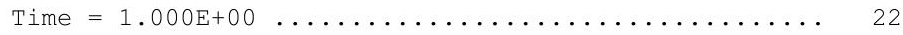

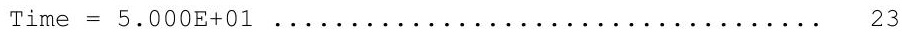

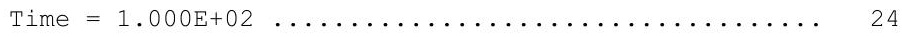

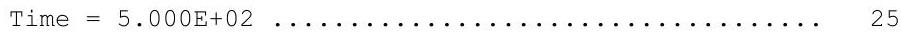

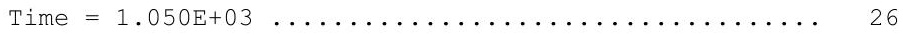

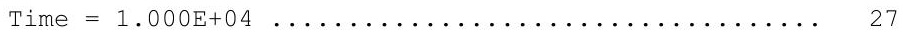

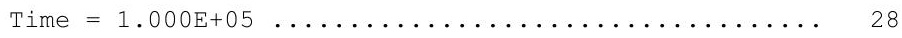

Dose/Source Ratios Summed Over All Pathways ........... 29

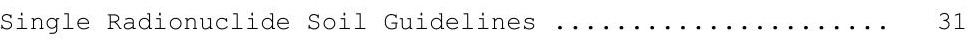

Dose Per Nuclide Summed Over All Pathways ............ 32

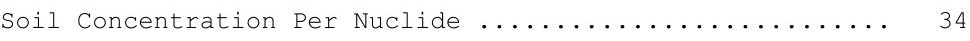


Summary : C746U Resident Farmer Deterministic Run

File : $\mathrm{X}: \backslash F I N A L$ V2 $\backslash$ DOE FWD RUNS \C746U RF DOE SG FWD-FV2-100000YR. RAD

Dose Conversion Factor (and Related) Parameter Summary

Dose Library: ICRP 60 \& ICRP 72 (Adult)

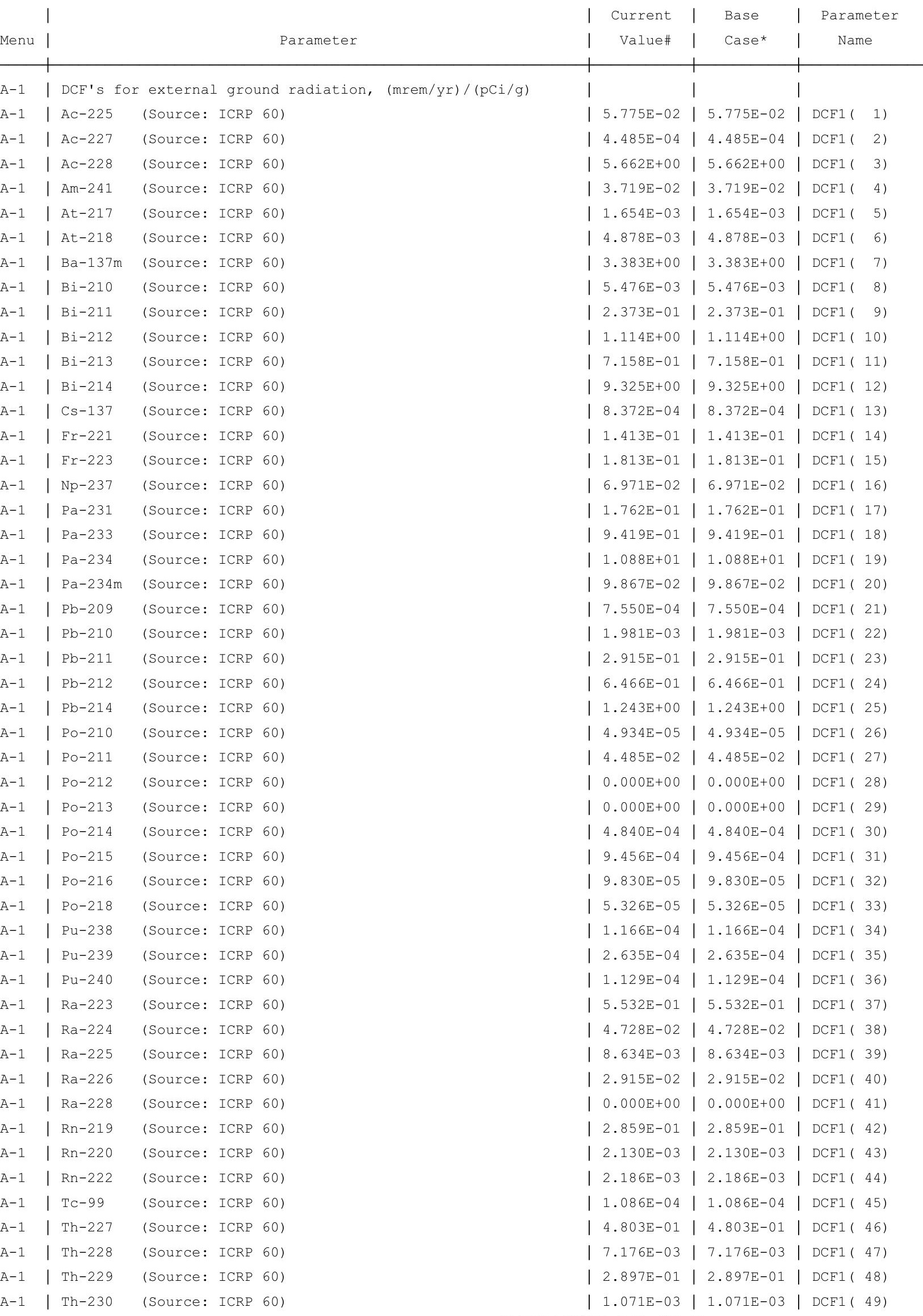


RESRAD, Version $6.5 \quad \mathrm{~T}^{1 / 2}$ Limit $=180$ days

07/18/2011 14:42 Page

Summary : C746U Resident Farmer Deterministic Run

File : $\mathrm{X}: \backslash F I N A L$ V2 $\backslash$ DOE FWD RUNS \C746U RF DOE SG FWD-FV2-100000YR.RAD

Dose Conversion Factor (and Related) Parameter Summary (continued)

Dose Library: ICRP 60 \& ICRP 72 (Adult)

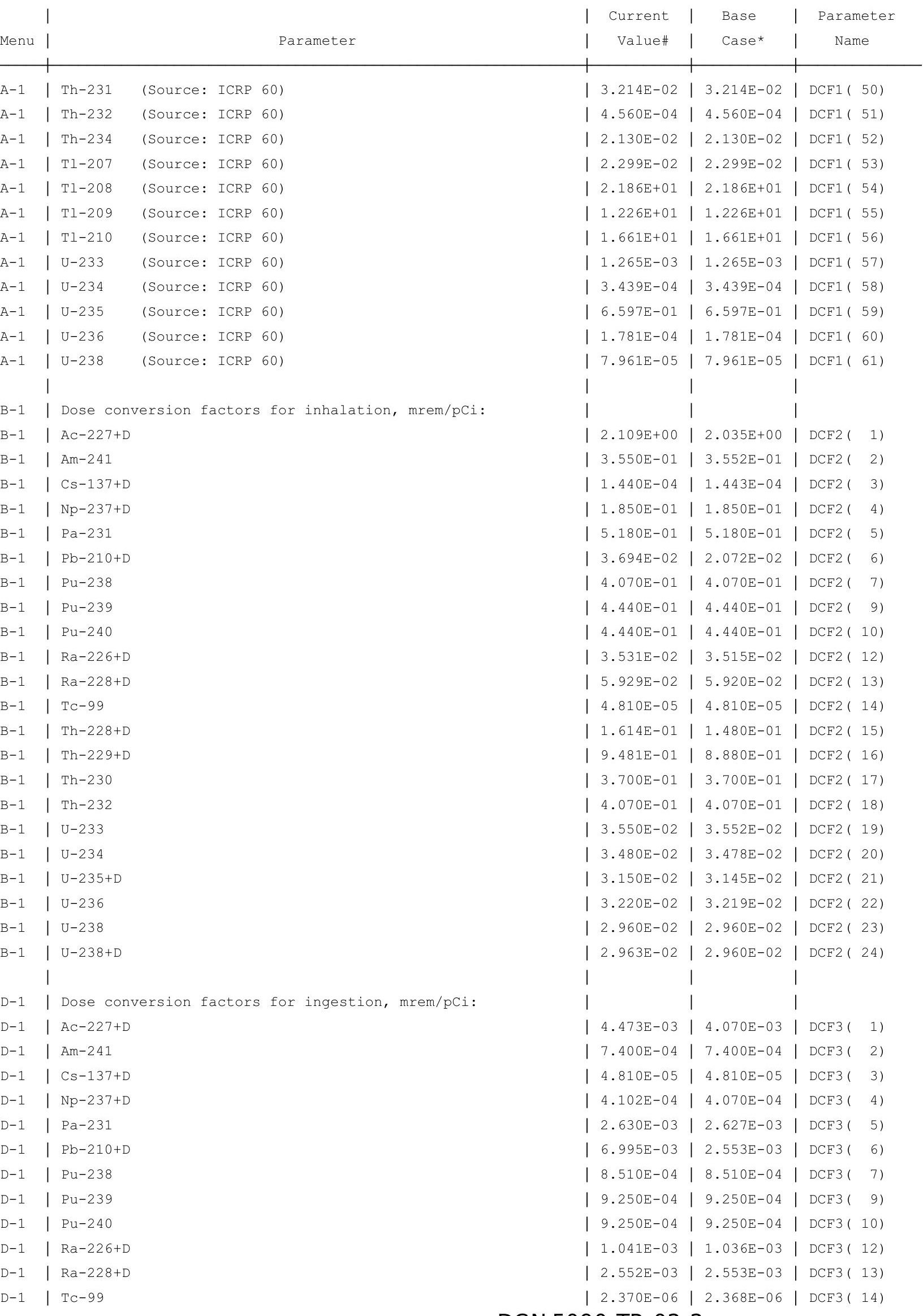


RESRAD, Version $6.5 \quad \mathrm{~T}^{\mathbb{1} 1 / 2}$ Limit $=180$ days

ummary : C746U Resident Farmer Deterministic Run

File : X: $\backslash F I N A L$ V2 $\backslash$ DOE FWD RUNS \C746U RF DOE SG FWD-FV2-100000YR.RAD

Dose Conversion Factor (and Related) Parameter Summary (continued)

Dose Library: ICRP 60 \& ICRP 72 (Adult)

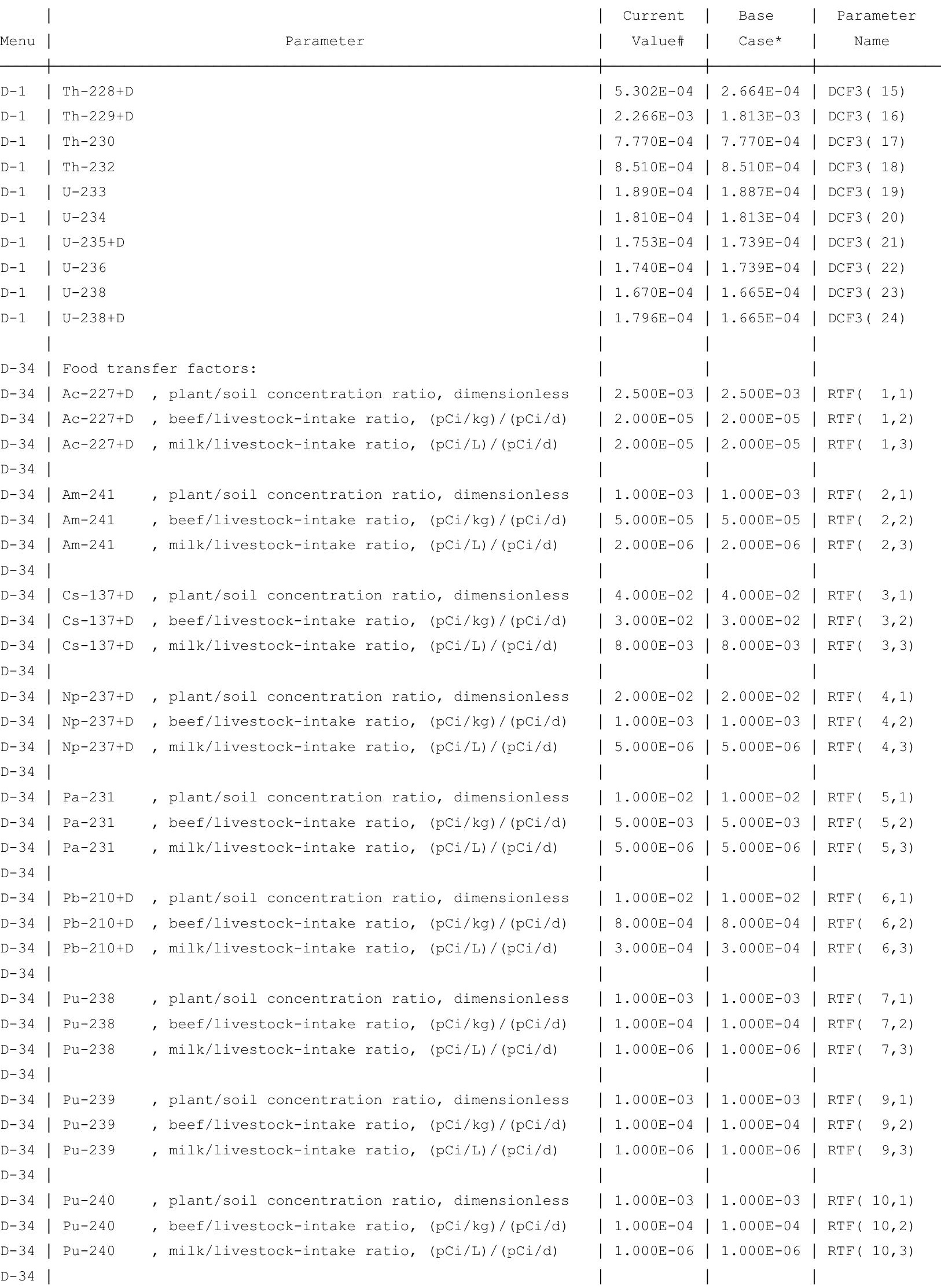


RESRAD, Version $6.5 \quad T^{1 / 2}$ Limit $=180$ days

ummary : C746U Resident Farmer Deterministic Run

File : $\mathrm{X}: \backslash F I N A L$ V2 $\backslash$ DOE FWD RUNS \C746U RF DOE SG FWD-FV2-100000YR.RAD

Dose Conversion Factor (and Related) Parameter Summary (continued)

Dose Library: ICRP 60 \& ICRP 72 (Adult)

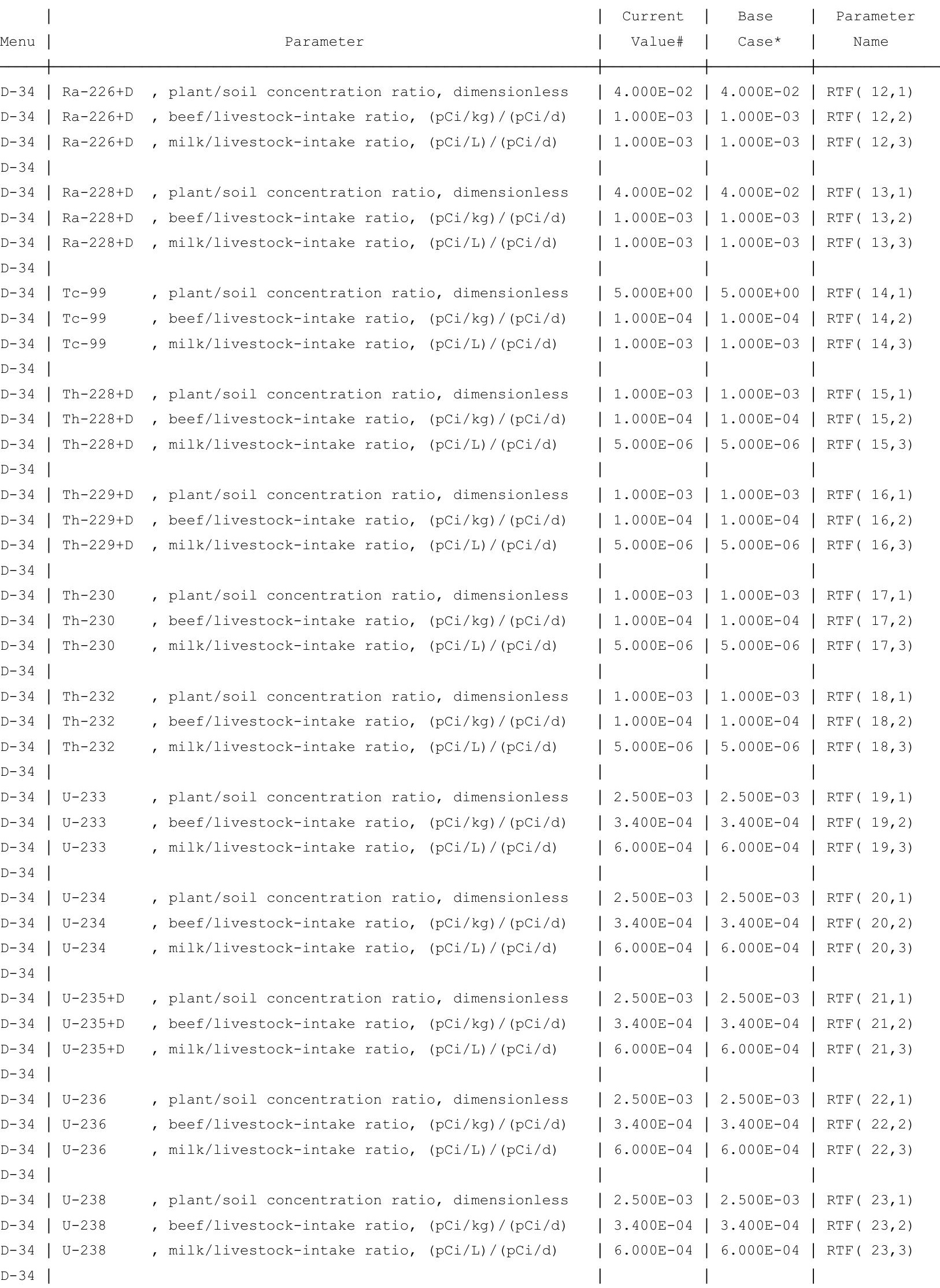


RESRAD, Version $6.5 \quad \mathrm{~T}^{1 / 2}$ Limit $=180$ days

Summary : C746U Resident Farmer Deterministic Run

File : $\mathrm{X}: \backslash F I N A L$ V2 $\backslash$ DOE FWD RUNS \C746U RF DOE SG FWD-FV2-100000YR. RAD

Dose Conversion Factor (and Related) Parameter Summary (continued)

Dose Library: ICRP 60 \& ICRP 72 (Adult)

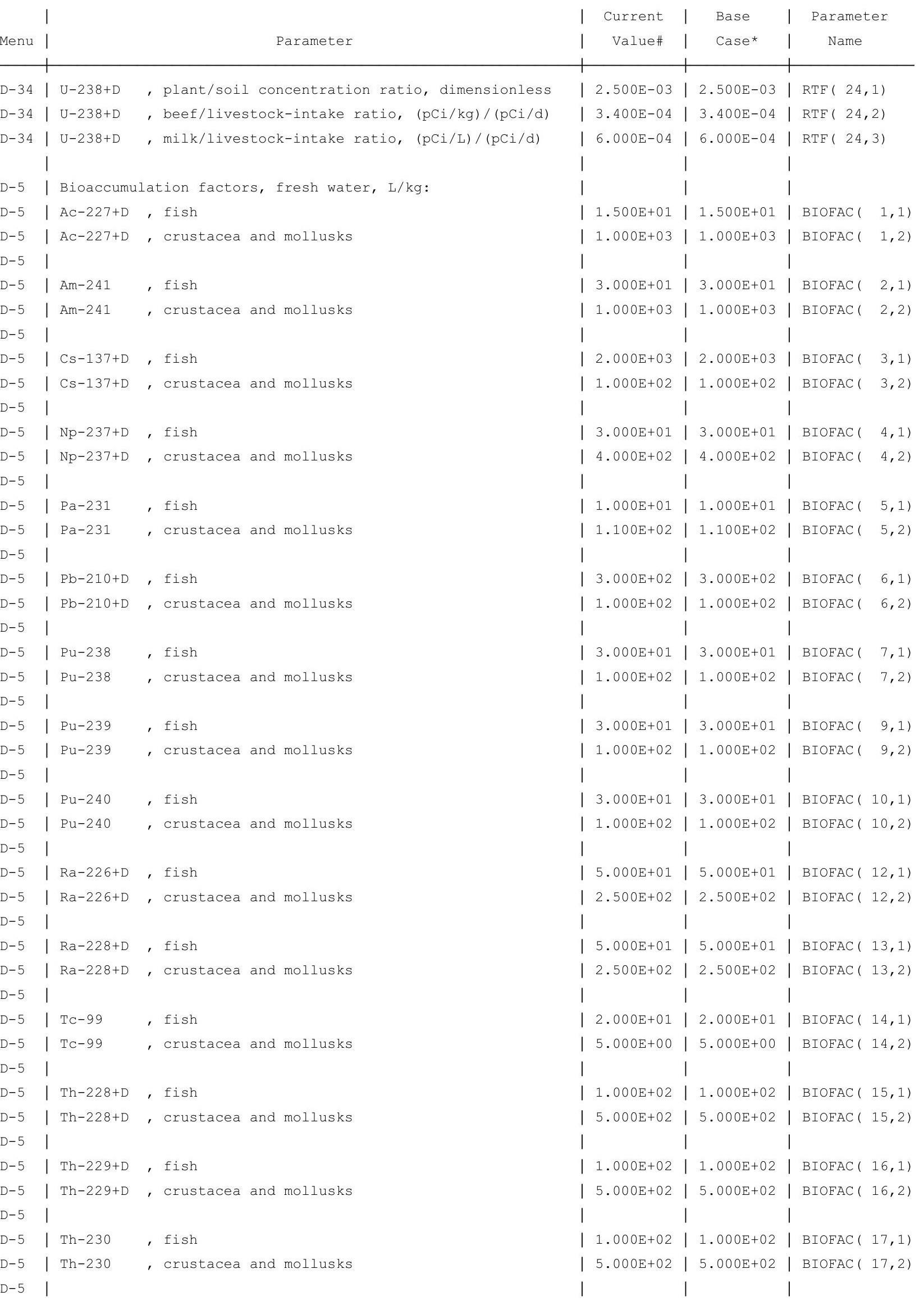


RESRAD, Version $6.5 \quad \mathrm{~T}^{1 / 2}$ Limit $=180$ days

07/18/2011 14:42 Page

ummary : C746U Resident Farmer Deterministic Run

File : $X: \backslash F I N A L$ V2 \DOE FWD RUNS \C746U RF DOE SG FWD-FV2-100000YR.RAD

Dose Conversion Factor (and Related) Parameter Summary (continued)

Dose Library: ICRP 60 \& ICRP 72 (Adult)

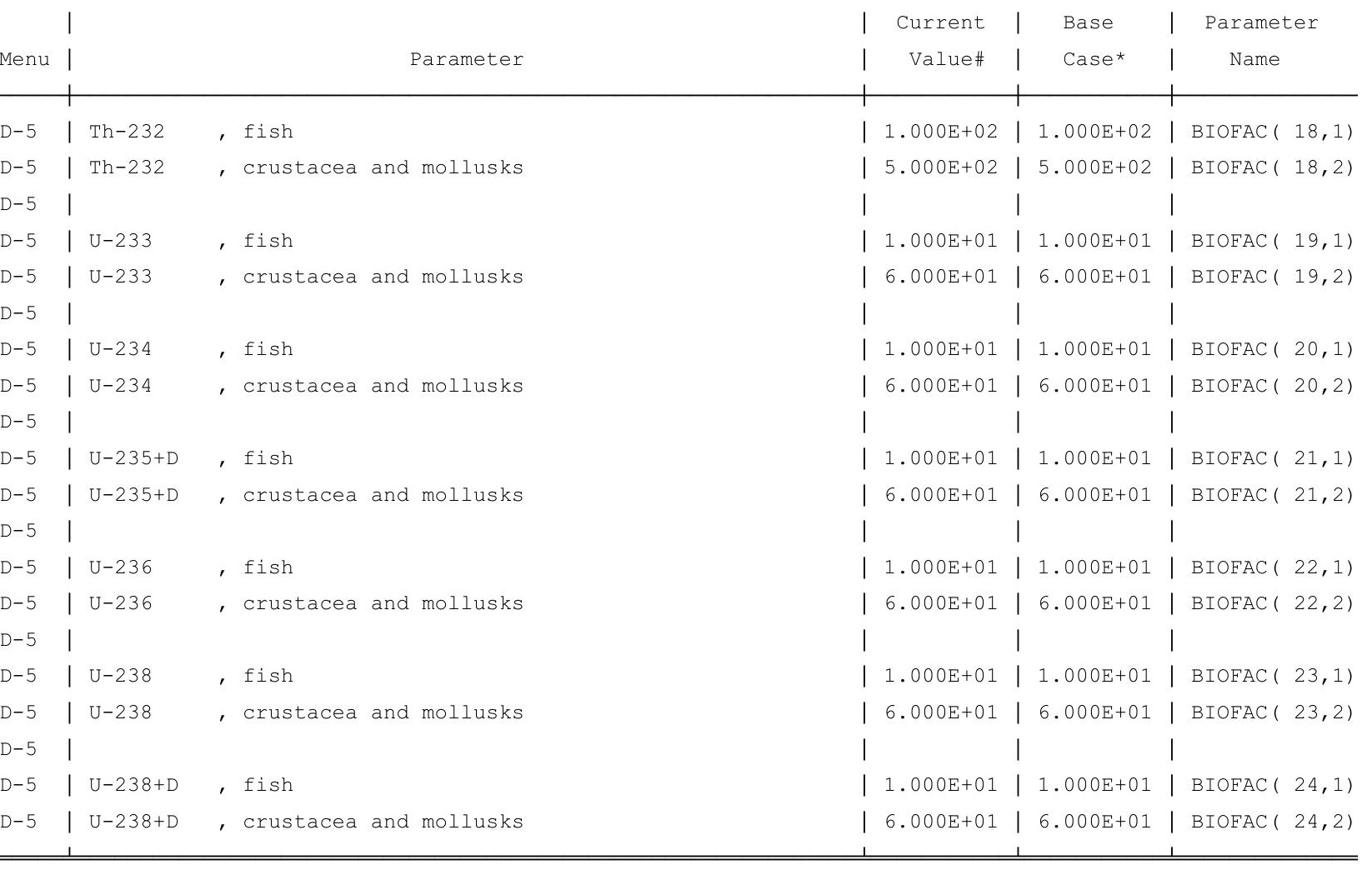

\#For DCFl(xxx) only, factors are for infinite depth \& area. See ETFG table in Ground Pathway of Detailed Report. *Base Case means Default.Lib w/o Associate Nuclide contributions. 
RESRAD, Version $6.5 \quad \mathrm{~T}^{1 / 2}$ Limit $=180$ days

Summary : C746U Resident Farmer Deterministic Run

File : X: $\backslash F I N A L$ V2 $\backslash$ DOE FWD RUNS \C746U RF DOE SG FWD-FV2-100000YR.RAD

Site-Specific Parameter Summary (continued)

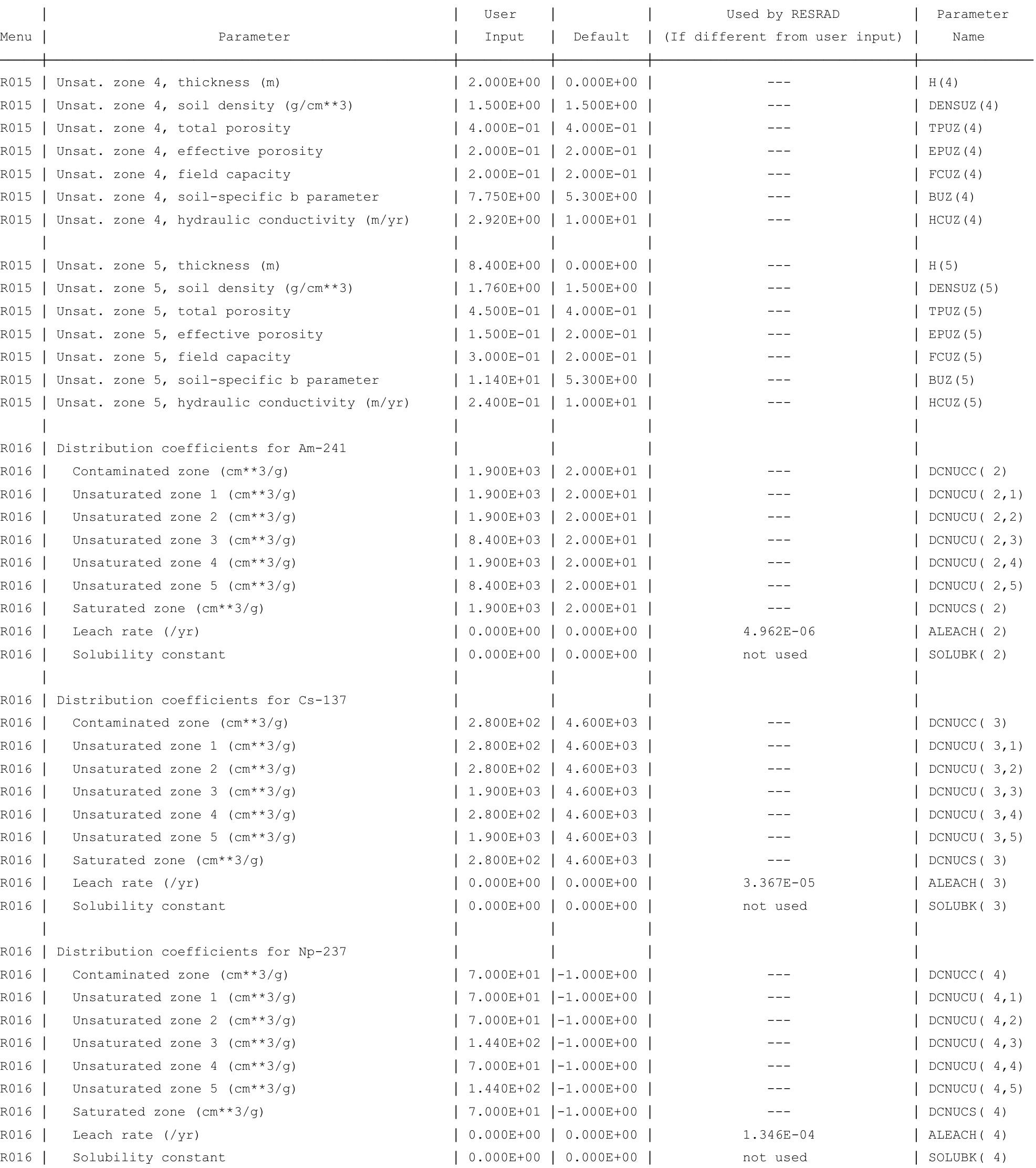


RESRAD, Version $6.5 \quad \mathrm{~T}^{1 / 2}$ Limit $=180$ days

Summary : C746U Resident Farmer Deterministic Run

File : X: $\backslash F I N A L$ V2 $\backslash$ DOE FWD RUNS \C746U RF DOE SG FWD-FV2-100000YR.RAD

Site-Specific Parameter Summary (continued)

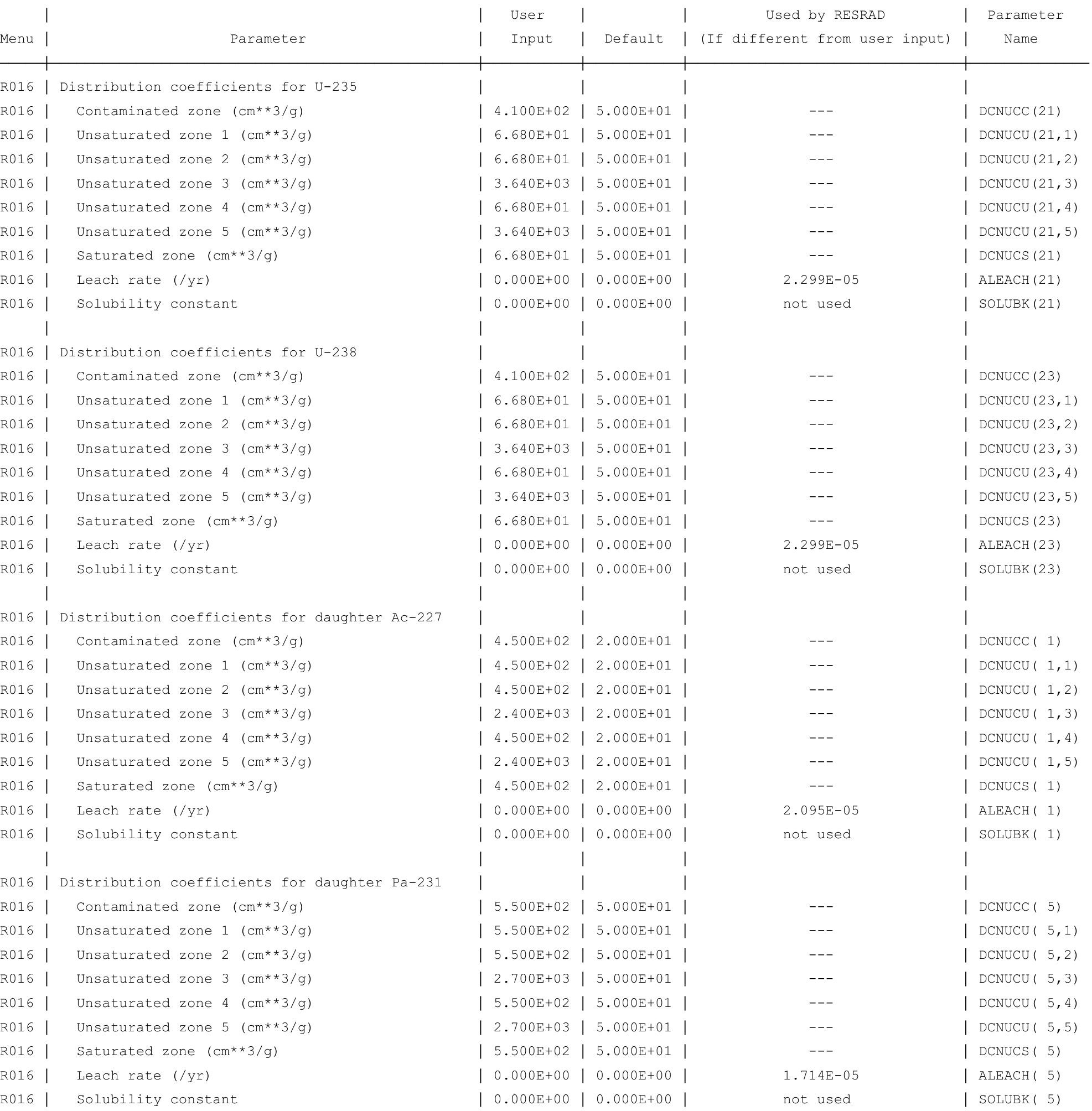


RESRAD, Version $6.5 \quad \mathrm{~T}^{1 / 2}$ Limit $=180$ days

Summary : C746U Resident Farmer Deterministic Run

File : X: $\backslash F I N A L$ V2 $\backslash$ DOE FWD RUNS \C746U RF DOE SG FWD-FV2-100000YR.RAD

Site-Specific Parameter Summary (continued)

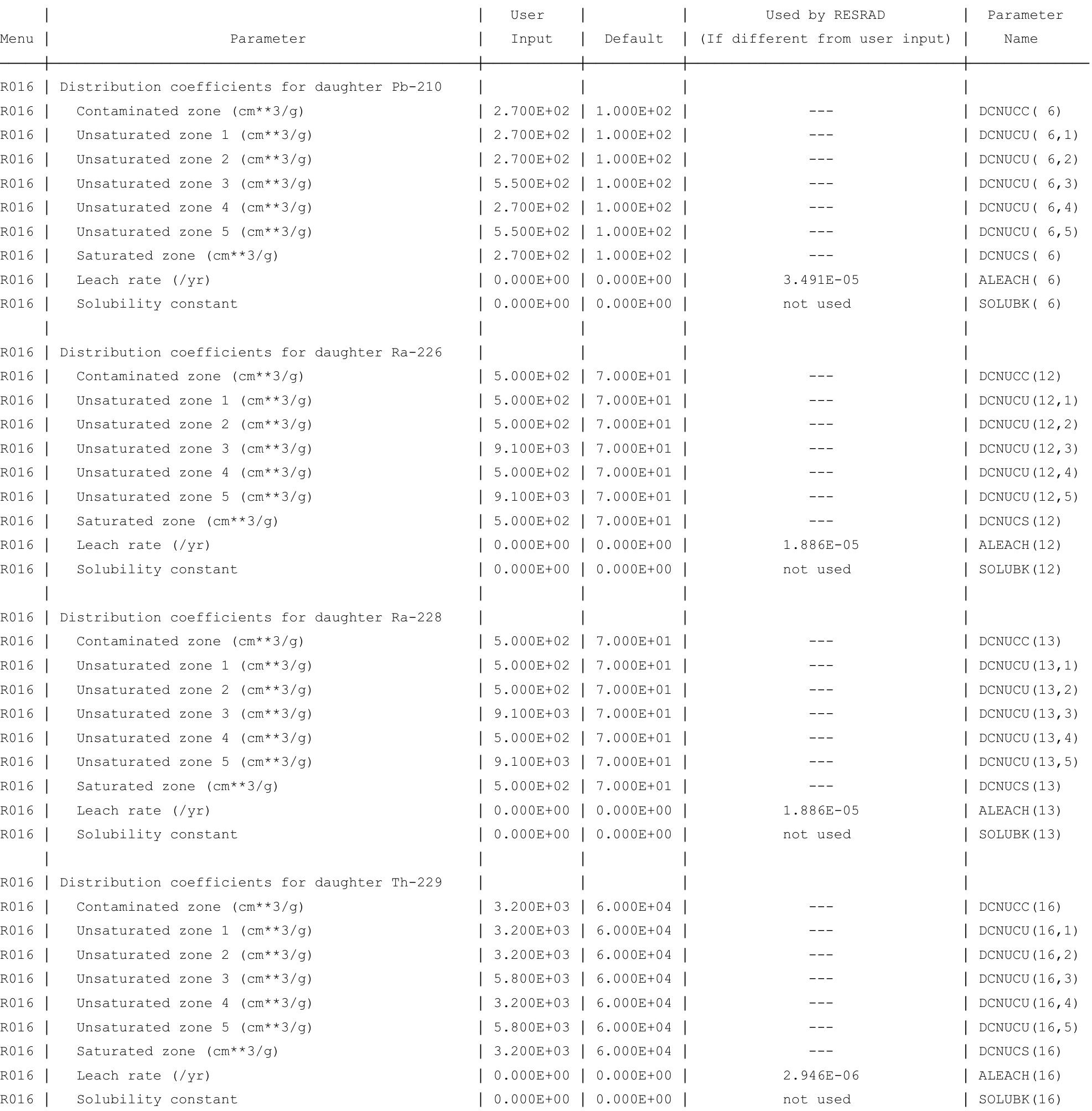


RESRAD, Version $6.5 \quad \mathrm{~T}^{1 / 2}$ Limit $=180$ days

Summary : C746U Resident Farmer Deterministic Run
File : X: $\backslash$ FINAL V2 $\backslash$ DOE FWD RUNS \C746U RF DOE SG FWD-FV2-100000YR.RAD

Site-Specific Parameter Summary (continued)

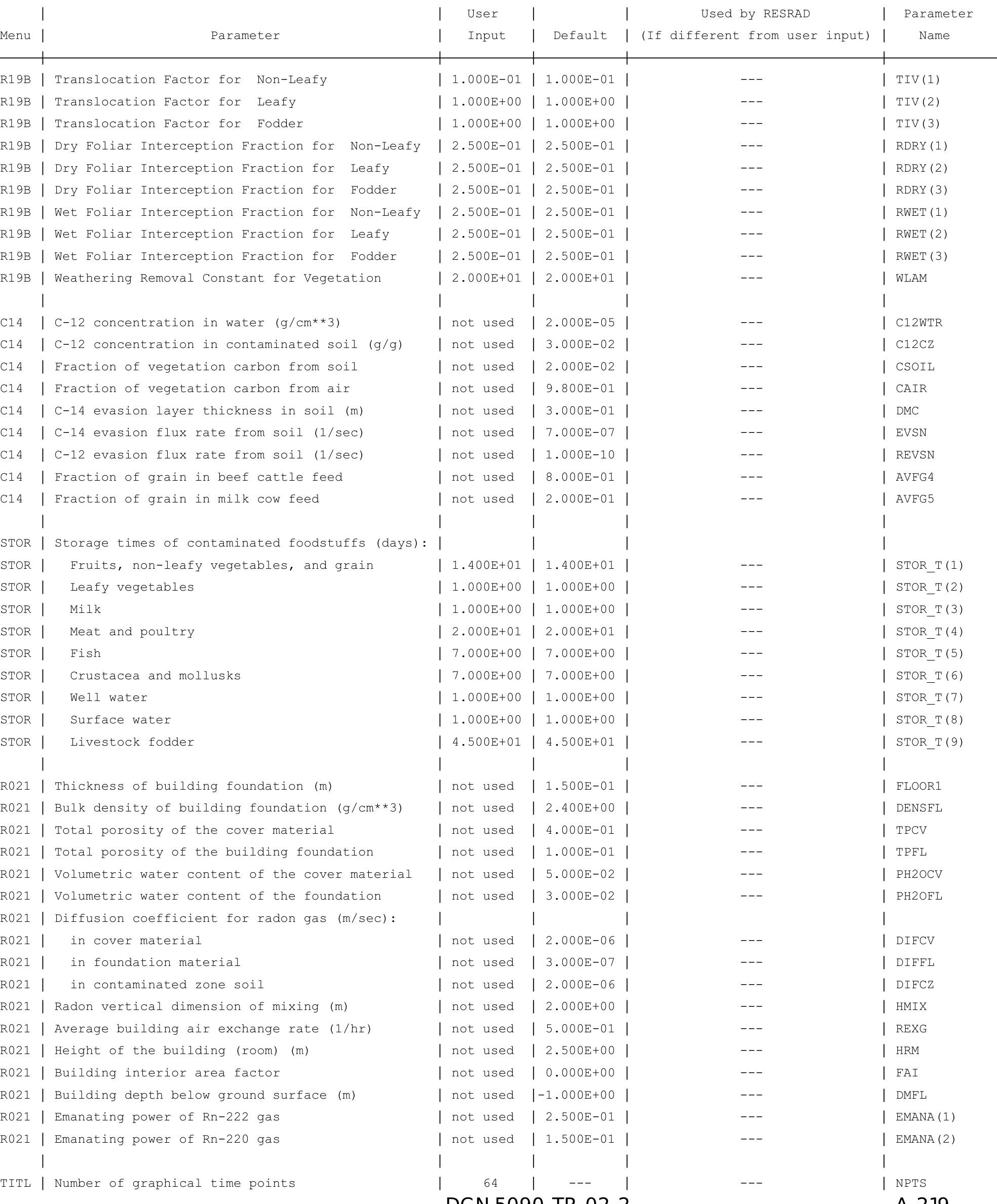


RESRAD, Version $6.5 \quad T^{1 / 2}$ Limit $=180$ days

Summary : C746U Resident Farmer Deterministic Run

File : X: $\backslash F I N A L$ V2 $\backslash$ DOE FWD RUNS \C746U RF DOE SG FWD-FV2-100000YR.RAD

Contaminated Zone Dimensions

Area: 89436.00 square meters

Thickness:

Cover Depth:

$$
\begin{array}{r}
13.40 \text { meters } \\
1.52 \text { meters }
\end{array}
$$

Initial Soil Concentrations, pCi/g

$\begin{array}{ll}\text { Am-241 } & 3.500 \mathrm{E}+01 \\ \mathrm{Cs}-137 & 1.900 \mathrm{E}+01 \\ \mathrm{~Np}-237 & 5.500 \mathrm{E}+00 \\ \mathrm{Pu}-238 & 3.900 \mathrm{E}+01 \\ \mathrm{Pu}-239 & 3.600 \mathrm{E}+01 \\ \mathrm{Pu}-240 & 3.600 \mathrm{E}+01 \\ \mathrm{Tc}-99 & 5.200 \mathrm{E}+01 \\ \mathrm{Th}-228 & 4.000 \mathrm{E}+00 \\ \mathrm{Th}-230 & 1.000 \mathrm{E}+02 \\ \mathrm{Th}-232 & 4.000 \mathrm{E}+00 \\ \mathrm{U}-234 & 1.600 \mathrm{E}+02 \\ \mathrm{U}-235 & 6.500 \mathrm{E}+00 \\ \mathrm{U}-238 & 1.600 \mathrm{E}+02\end{array}$

Total Dose TDOSE(t), mrem/yr

Basic Radiation Dose Limit $=1.000 \mathrm{E}+02 \mathrm{mrem} / \mathrm{yr}$

Total Mixture Sum $M(t)$ = Fraction of Basic Dose Limit Received at Time (t)

$\begin{array}{rlllllllll}t \text { (years) }: & 0.000 \mathrm{E}+00 & 1.000 \mathrm{E}+00 & 5.000 \mathrm{E}+01 & 1.000 \mathrm{E}+02 & 5.000 \mathrm{E}+02 & 1.050 \mathrm{E}+03 & 1.000 \mathrm{E}+04 & 1.000 \mathrm{E}+05 \\ \text { TDOSE }(\mathrm{t}): & 6.620 \mathrm{E}-06 & 4.789 \mathrm{E}-06 & 9.505 \mathrm{E}-06 & 1.362 \mathrm{E}-05 & 1.081 \mathrm{E}+01 & 7.196 \mathrm{E}+00 & 2.719 \mathrm{E}+03 & 3.773 \mathrm{E}-02 \\ \mathrm{M}(\mathrm{t}): & 6.620 \mathrm{E}-08 & 4.789 \mathrm{E}-08 & 9.505 \mathrm{E}-08 & 1.362 \mathrm{E}-07 & 1.081 \mathrm{E}-01 & 7.196 \mathrm{E}-02 & 2.719 \mathrm{E}+01 & 3.773 \mathrm{E}-04\end{array}$

Maximum TDOSE $(t): 2.731 \mathrm{E}+03 \mathrm{mrem} / \mathrm{yr}$ at $t=12773 \pm$ * years

Total Dose Contributions TDOSE (i,p,t) for Individual Radionuclides (i) and Pathways (p) As mrem/yr and Fraction of Total Dose At $t=1.277 \mathrm{E}+04$ years

\begin{tabular}{|c|c|c|c|c|c|c|c|c|c|c|c|c|c|c|}
\hline & \multicolumn{2}{|c|}{ Ground } & \multicolumn{2}{|c|}{ Inhalation } & \multicolumn{2}{|c|}{ Radon } & \multicolumn{2}{|c|}{ Plant } & \multicolumn{2}{|c|}{ Meat } & \multicolumn{2}{|c|}{ Milk } & \multicolumn{2}{|c|}{ Soil } \\
\hline clide & mrem/yr & fract. & mrem/yr & fract. & mrem/yr & fract. & mrem/yr & fract. & mrem/yr & fract. & mrem/yr & fract. & mrem/yr & fract. \\
\hline 241 & $1.232 \mathrm{E}-03$ & 0.0000 & $1.405 \mathrm{E}-07$ & 0.0000 & $0.000 \mathrm{E}+00$ & 0.0000 & $1.450 \mathrm{E}-03$ & 0.0000 & $1.345 E-04$ & 0.0000 & $9.844 \mathrm{E}-06$ & 0.0000 & $2.690 \mathrm{E}-05$ & 0.0000 \\
\hline-137 & $0.000 \mathrm{E}+00$ & 0.0000 & $0.000 \mathrm{E}+00$ & 0.0000 & $0.000 \mathrm{E}+00$ & 0.0000 & $0.000 \mathrm{E}+00$ & 0.0000 & $0.000 \mathrm{E}+00$ & 0.0000 & $0.000 \mathrm{E}+00$ & 0.0000 & $0.000 \mathrm{E}+00$ & 0.0000 \\
\hline-237 & $8.908 E-01$ & 0.0003 & $1.039 \mathrm{E}-04$ & 0.0000 & $0.000 \mathrm{E}+00$ & 0.0000 & $1.040 \mathrm{E}+00$ & 0.0004 & $9.654 \mathrm{E}-02$ & 0.0000 & $7.629 \mathrm{E}-03$ & 0.0000 & $1.996 \mathrm{E}-02$ & 0.0000 \\
\hline-238 & $8.841 E-03$ & 0.0000 & $3.748 \mathrm{E}-07$ & 0.0000 & $0.000 \mathrm{E}+00$ & 0.0000 & $1.511 \mathrm{E}-02$ & 0.0000 & $1.551 \mathrm{E}-03$ & 0.0000 & $2.546 \mathrm{E}-03$ & 0.0000 & $3.859 \mathrm{E}-04$ & 0.0000 \\
\hline-239 & $4.564 \mathrm{E}-03$ & 0.0000 & $3.750 \mathrm{E}-03$ & 0.0000 & $0.000 \mathrm{E}+00$ & 0.0000 & $2.335 \mathrm{E}+00$ & 0.0009 & $2.924 \mathrm{E}-01$ & 0.0001 & $8.083 E-03$ & 0.0000 & $6.489 \mathrm{E}-01$ & 0.0002 \\
\hline-240 & $7.000 \mathrm{E}-04$ & 0.0000 & $1.398 E-03$ & 0.0000 & $0.000 \mathrm{E}+00$ & 0.0000 & $8.709 \mathrm{E}-01$ & 0.0003 & $1.091 \mathrm{E}-01$ & 0.0000 & $3.278 E-03$ & 0.0000 & $2.420 \mathrm{E}-01$ & 0.0001 \\
\hline 99 & $0.000 \mathrm{E}+00$ & 0.0000 & $0.000 \mathrm{E}+00$ & 0.0000 & $0.000 \mathrm{E}+00$ & 0.0000 & $0.000 \mathrm{E}+00$ & 0.0000 & $0.000 \mathrm{E}+00$ & 0.0000 & $0.000 \mathrm{E}+00$ & 0.0000 & $0.000 \mathrm{E}+00$ & 0.0000 \\
\hline-228 & $0.000 \mathrm{E}+00$ & 0.0000 & $0.000 \mathrm{E}+00$ & 0.0000 & $0.000 \mathrm{E}+00$ & 0.0000 & $0.000 \mathrm{E}+00$ & 0.0000 & $0.000 \mathrm{E}+00$ & 0.0000 & $0.000 \mathrm{E}+00$ & 0.0000 & $0.000 \mathrm{E}+00$ & 0.0000 \\
\hline-230 & $7.256 \mathrm{E}+02$ & 0.2657 & $1.596 \mathrm{E}-02$ & 0.0000 & $0.000 \mathrm{E}+00$ & 0.0000 & $1.194 \mathrm{E}+03$ & 0.4373 & $1.190 \mathrm{E}+02$ & 0.0436 & $1.687 \mathrm{E}+02$ & 0.0618 & $2.603 E+01$ & 0.0095 \\
\hline 232 & $4.800 E+01$ & 0.0176 & $1.020 \mathrm{E}-03$ & 0.0000 & $0.000 \mathrm{E}+00$ & 0.0000 & $5.013 E+01$ & 0.0184 & $3.084 \mathrm{E}+00$ & 0.0011 & $8.305 E+00$ & 0.0030 & $5.308 \mathrm{E}-01$ & 0.0002 \\
\hline 34 & $1.023 E+02$ & 0.0375 & $4.309 E-03$ & 0.0000 & $0.000 \mathrm{E}+00$ & 0.0000 & $1.748 \mathrm{E}+02$ & 0.0640 & $1.793 \mathrm{E}+01$ & 0.0066 & $2.938 E+01$ & 0.0108 & $4.454 \mathrm{E}+00$ & 0.0016 \\
\hline 35 & $4.741 E+00$ & 0.0017 & $1.380 \mathrm{E}-03$ & 0.0000 & $0.000 \mathrm{E}+00$ & 0.0000 & $5.888 \mathrm{E}+00$ & 0.0022 & $3.085 \mathrm{E}+00$ & 0.0011 & $2.864 \mathrm{E}-01$ & 0.0001 & $3.254 \mathrm{E}-01$ & 0.0001 \\
\hline 38 & $1.670 \mathrm{E}+01$ & 0.0061 & $1.599 \mathrm{E}-03$ & 0.0000 & $0.000 \mathrm{E}+00$ & 0.0000 & $9.563 \mathrm{E}+00$ & 0.0035 & $1.491 \mathrm{E}+00$ & 0.0005 & $6.375 \mathrm{E}+00$ & 0.0023 & $8.354 \mathrm{E}-01$ & 0.0003 \\
\hline & $8.983 E+02$ & 0.3289 & $.953 E-02$ & 0.0000 & $0.000 \mathrm{E}+00$ & 0.0000 & $1.439 \mathrm{E}+03$ & 0.5268 & $1.451 \mathrm{E}+02$ & 531 & $2.130 \mathrm{E}+02$ & 780 & +01 & 121 \\
\hline
\end{tabular}

Water Independent Pathways (Inhalation excludes radon) 
RESRAD, Version $6.5 \quad \mathrm{~T}^{1 / 2}$ Limit $=180$ days

Summary : C746U Resident Farmer Deterministic Run

File : $\mathrm{X}: \backslash F I N A L$ V2 $\backslash$ DOE FWD RUNS \C746U RF DOE SG FWD-FV2-100000YR.RAD

Total Dose Contributions TDOSE(i,p,t) for Individual Radionuclides (i) and Pathways (p) As mrem/yr and Fraction of Total Dose At $t=1.277 \mathrm{E}+04$ years

Water Dependent Pathways

\begin{tabular}{|c|c|c|c|c|c|c|c|c|c|c|c|c|c|c|}
\hline & \multicolumn{2}{|c|}{ Water } & \multicolumn{2}{|c|}{ Fish } & \multicolumn{2}{|c|}{ Radon } & \multicolumn{2}{|c|}{ Plant } & \multicolumn{2}{|c|}{ Meat } & \multicolumn{2}{|c|}{ Milk } & \multicolumn{2}{|c|}{ All Pathways* } \\
\hline lide & mrem/yr & fract. & mrem/yr & fract. & mrem/yr & fract. & mrem/yr & fract. & mrem/yr & fract. & mrem/yr & fract. & mrem/yr & fract. \\
\hline-241 & $3.501 \mathrm{E}-03$ & 0.0000 & $0.000 \mathrm{E}+00$ & 0.0000 & $0.000 \mathrm{E}+00$ & 0.0000 & $1.428 \mathrm{E}-04$ & 0.0000 & $5.595 \mathrm{E}-05$ & 0.0000 & $2.136 \mathrm{E}-06$ & 0.0000 & $6.556 \mathrm{E}-03$ & 0.0000 \\
\hline-137 & $0.000 \mathrm{E}+00$ & 0.0000 & $0.000 \mathrm{E}+00$ & 0.0000 & $0.000 \mathrm{E}+00$ & 0.0000 & $0.000 \mathrm{E}+00$ & 0.0000 & $0.000 \mathrm{E}+00$ & 0.0000 & $0.000 \mathrm{E}+00$ & 0.0000 & $0.000 \mathrm{E}+00$ & 0.0000 \\
\hline-237 & $2.425 E+00$ & 0.0009 & $0.000 \mathrm{E}+00$ & 0.0000 & $0.000 \mathrm{E}+00$ & 0.0000 & $9.890 \mathrm{E}-02$ & 0.0000 & $3.874 \mathrm{E}-02$ & 0.0000 & $1.518 \mathrm{E}-03$ & 0.0000 & $4.619 \mathrm{E}+00$ & 0.0017 \\
\hline-238 & $0.000 \mathrm{E}+00$ & 0.0000 & $0.000 \mathrm{E}+00$ & 0.0000 & $0.000 \mathrm{E}+00$ & 0.0000 & $0.000 \mathrm{E}+00$ & 0.0000 & $0.000 \mathrm{E}+00$ & 0.0000 & $0.000 \mathrm{E}+00$ & 0.0000 & $2.844 \mathrm{E}-02$ & 0.0000 \\
\hline-239 & $0.000 \mathrm{E}+00$ & 0.0000 & $0.000 \mathrm{E}+00$ & 0.0000 & $0.000 \mathrm{E}+00$ & 0.0000 & $0.000 \mathrm{E}+00$ & 0.0000 & $0.000 \mathrm{E}+00$ & 0.0000 & $0.000 \mathrm{E}+00$ & 0.0000 & $3.293 \mathrm{E}+00$ & 0.0012 \\
\hline-240 & $0.000 \mathrm{E}+00$ & 0.0000 & $0.000 \mathrm{E}+00$ & 0.0000 & $0.000 \mathrm{E}+00$ & 0.0000 & $0.000 \mathrm{E}+00$ & 0.0000 & $0.000 \mathrm{E}+00$ & 0.0000 & $0.000 \mathrm{E}+00$ & 0.0000 & $1.227 \mathrm{E}+00$ & 0.0004 \\
\hline-99 & $0.000 \mathrm{E}+00$ & 0.0000 & $0.000 \mathrm{E}+00$ & 0.0000 & $0.000 \mathrm{E}+00$ & 0.0000 & $0.000 \mathrm{E}+00$ & 0.0000 & $0.000 \mathrm{E}+00$ & 0.0000 & $0.000 \mathrm{E}+00$ & 0.0000 & $0.000 \mathrm{E}+00$ & 0.0000 \\
\hline-228 & $0.000 \mathrm{E}+00$ & 0.0000 & $0.000 \mathrm{E}+00$ & 0.0000 & $0.000 \mathrm{E}+00$ & 0.0000 & $0.000 \mathrm{E}+00$ & 0.0000 & $0.000 \mathrm{E}+00$ & 0.0000 & $0.000 \mathrm{E}+00$ & 0.0000 & $0.000 \mathrm{E}+00$ & 0.0000 \\
\hline-230 & $0.000 \mathrm{E}+00$ & 0.0000 & $0.000 \mathrm{E}+00$ & 0.0000 & $0.000 \mathrm{E}+00$ & 0.0000 & $0.000 \mathrm{E}+00$ & 0.0000 & $0.000 \mathrm{E}+00$ & 0.0000 & $0.000 \mathrm{E}+00$ & 0.0000 & $2.233 E+03$ & 0.8179 \\
\hline-232 & $0.000 \mathrm{E}+00$ & 0.0000 & $0.000 \mathrm{E}+00$ & 0.0000 & $0.000 \mathrm{E}+00$ & 0.0000 & $0.000 \mathrm{E}+00$ & 0.0000 & $0.000 \mathrm{E}+00$ & 0.0000 & $0.000 \mathrm{E}+00$ & 0.0000 & $1.100 \mathrm{E}+02$ & 0.0403 \\
\hline 34 & $0.000 \mathrm{E}+00$ & 0.0000 & $0.000 \mathrm{E}+00$ & 0.0000 & $0.000 \mathrm{E}+00$ & 0.0000 & $0.000 \mathrm{E}+00$ & 0.0000 & $0.000 \mathrm{E}+00$ & 0.0000 & $0.000 \mathrm{E}+00$ & 0.0000 & $3.288 \mathrm{E}+02$ & 0.1204 \\
\hline 35 & $0.000 \mathrm{E}+00$ & 0.0000 & $0.000 \mathrm{E}+00$ & 0.0000 & $0.000 \mathrm{E}+00$ & 0.0000 & $0.000 \mathrm{E}+00$ & 0.0000 & $0.000 \mathrm{E}+00$ & 0.0000 & $0.000 \mathrm{E}+00$ & 0.0000 & $1.433 \mathrm{E}+01$ & 0.0052 \\
\hline 38 & $0.000 \mathrm{E}+00$ & 0.0000 & $0.000 \mathrm{E}+00$ & 0.0000 & $0.000 \mathrm{E}+00$ & 0.0000 & $0.000 \mathrm{E}+00$ & 0.0000 & $0.000 \mathrm{E}+00$ & 0.0000 & $0.000 \mathrm{E}+00$ & 0.0000 & $3.497 \mathrm{E}+01$ & 0.0128 \\
\hline & $2.429 \mathrm{E}+00$ & 0.0009 & $0.000 \mathrm{E}+00$ & 0.0000 & $0.000 \mathrm{E}+00$ & 0.0000 & $9.904 \mathrm{E}-02$ & 0.0000 & $3.879 \mathrm{E}-02$ & 0.0000 & $1.520 \mathrm{E}-03$ & 0.0000 & $.731 E+03$ & 1.0000 \\
\hline
\end{tabular}

* Sum of all water independent and dependent pathways. 
RESRAD, Version 6.5

$\mathrm{T}^{1 / 2}$ Limit = 180 days

07/18/2011 14:42 Page 21

ummary : C746U Resident Farmer Deterministic Run

: X: $\backslash$ FINAL V2 \DOE FWD RUNS \C746U RF DOE SG FWD-FV2-100000YR.RAD

Total Dose Contributions TDOSE (i,p,t) for Individual Radionuclides (i) and Pathways (p) As mrem/yr and Fraction of Total Dose At $t=0.000 \mathrm{E}+00$ years

Water Independent Pathways (Inhalation excludes radon)

\begin{tabular}{|c|c|c|c|c|c|c|c|c|c|c|c|c|c|c|}
\hline \multirow{2}{*}{ Nuclide } & \multicolumn{2}{|c|}{ Ground } & \multicolumn{2}{|c|}{ Inhalation } & \multicolumn{2}{|c|}{ Radon } & \multicolumn{2}{|c|}{ Plant } & \multicolumn{2}{|c|}{ Meat } & \multicolumn{2}{|c|}{ Milk } & \multicolumn{2}{|c|}{ Soil } \\
\hline & mrem/yr & fract. & mrem/yr & fract. & mrem/yr & fract. & mrem/yr & fract. & mrem/yr & fract. & mrem/yr & fract. & mrem/yr & fract. \\
\hline-241 & $0.000 \mathrm{E}+00$ & 0.0000 & $0.000 \mathrm{E}+00$ & 0.0000 & $0.000 \mathrm{E}+00$ & 0.0000 & $0.000 \mathrm{E}+00$ & 0.0000 & $0.000 \mathrm{E}+00$ & 0.0000 & $0.000 \mathrm{E}+00$ & 0.0000 & $0.000 \mathrm{E}+00$ & 0.0000 \\
\hline-137 & $2.415 E-08$ & 0.0036 & $0.000 \mathrm{E}+00$ & 0.0000 & $0.000 \mathrm{E}+00$ & 0.0000 & $0.000 \mathrm{E}+00$ & 0.0000 & $0.000 \mathrm{E}+00$ & 0.0000 & $0.000 \mathrm{E}+00$ & 0.0000 & $0.000 \mathrm{E}+00$ & 0.0000 \\
\hline-237 & $5.217 \mathrm{E}-12$ & 0.0000 & $0.000 \mathrm{E}+00$ & 0.0000 & $0.000 \mathrm{E}+00$ & 0.0000 & $0.000 \mathrm{E}+00$ & 0.0000 & $0.000 \mathrm{E}+00$ & 0.0000 & $0.000 \mathrm{E}+00$ & 0.0000 & $0.000 \mathrm{E}+00$ & 0.0000 \\
\hline-238 & $4.560 E-23$ & 0.0000 & $0.000 \mathrm{E}+00$ & 0.0000 & $0.000 \mathrm{E}+00$ & 0.0000 & $0.000 \mathrm{E}+00$ & 0.0000 & $0.000 \mathrm{E}+00$ & 0.0000 & $0.000 \mathrm{E}+00$ & 0.0000 & $0.000 \mathrm{E}+00$ & 0.0000 \\
\hline-239 & $4.302 E-16$ & 0.0000 & $0.000 \mathrm{E}+00$ & 0.0000 & $0.000 \mathrm{E}+00$ & 0.0000 & $0.000 \mathrm{E}+00$ & 0.0000 & $0.000 \mathrm{E}+00$ & 0.0000 & $0.000 \mathrm{E}+00$ & 0.0000 & $0.000 \mathrm{E}+00$ & 0.0000 \\
\hline-240 & $4.075 E-23$ & 0.0000 & $0.000 \mathrm{E}+00$ & 0.0000 & $0.000 \mathrm{E}+00$ & 0.0000 & $0.000 \mathrm{E}+00$ & 0.0000 & $0.000 \mathrm{E}+00$ & 0.0000 & $0.000 \mathrm{E}+00$ & 0.0000 & $0.000 \mathrm{E}+00$ & 0.0000 \\
\hline 99 & $2.979 E-24$ & 0.0000 & $0.000 \mathrm{E}+00$ & 0.0000 & $0.000 \mathrm{E}+00$ & 0.0000 & $0.000 \mathrm{E}+00$ & 0.0000 & $0.000 \mathrm{E}+00$ & 0.0000 & $0.000 \mathrm{E}+00$ & 0.0000 & $0.000 \mathrm{E}+00$ & 0.0000 \\
\hline-228 & $6.573 E-06$ & 0.9929 & $0.000 \mathrm{E}+00$ & 0.0000 & $0.000 \mathrm{E}+00$ & 0.0000 & $0.000 \mathrm{E}+00$ & 0.0000 & $0.000 \mathrm{E}+00$ & 0.0000 & $0.000 \mathrm{E}+00$ & 0.0000 & $0.000 \mathrm{E}+00$ & 0.0000 \\
\hline-230 & $2.392 \mathrm{E}-20$ & 0.0000 & $0.000 \mathrm{E}+00$ & 0.0000 & $0.000 \mathrm{E}+00$ & 0.0000 & $0.000 \mathrm{E}+00$ & 0.0000 & $0.000 \mathrm{E}+00$ & 0.0000 & $0.000 \mathrm{E}+00$ & 0.0000 & $0.000 \mathrm{E}+00$ & 0.0000 \\
\hline-232 & $4.620 E-24$ & 0.0000 & $0.000 \mathrm{E}+00$ & 0.0000 & $0.000 \mathrm{E}+00$ & 0.0000 & $0.000 \mathrm{E}+00$ & 0.0000 & $0.000 \mathrm{E}+00$ & 0.0000 & $0.000 \mathrm{E}+00$ & 0.0000 & $0.000 \mathrm{E}+00$ & 0.0000 \\
\hline 234 & $1.094 \mathrm{E}-21$ & 0.0000 & $0.000 \mathrm{E}+00$ & 0.0000 & $0.000 \mathrm{E}+00$ & 0.0000 & $0.000 \mathrm{E}+00$ & 0.0000 & $0.000 \mathrm{E}+00$ & 0.0000 & $0.000 \mathrm{E}+00$ & 0.0000 & $0.000 \mathrm{E}+00$ & 0.0000 \\
\hline 235 & $8.032 \mathrm{E}-14$ & 0.0000 & $0.000 \mathrm{E}+00$ & 0.0000 & $0.000 \mathrm{E}+00$ & 0.0000 & $0.000 \mathrm{E}+00$ & 0.0000 & $0.000 \mathrm{E}+00$ & 0.0000 & $0.000 \mathrm{E}+00$ & 0.0000 & $0.000 \mathrm{E}+00$ & 0.0000 \\
\hline 38 & $2.262 E-08$ & 0.0034 & $0.000 \mathrm{E}+00$ & 0.0000 & $0.000 \mathrm{E}+00$ & 0.0000 & $0.000 \mathrm{E}+00$ & 0.0000 & $0.000 \mathrm{E}+00$ & 0.0000 & $0.000 \mathrm{E}+00$ & 0.0000 & $0.000 \mathrm{E}+00$ & 0.0000 \\
\hline & $6.620 \mathrm{E}-06$ & 1.0000 & $0.000 \mathrm{E}+00$ & 0.0000 & $0.000 \mathrm{E}+00$ & 0.0000 & $0.000 \mathrm{E}+00$ & 0.0000 & $0.000 \mathrm{E}+00$ & 0.0000 & $0.000 \mathrm{E}+00$ & 0.0000 & $.000 \mathrm{E}+00$ & 0.0000 \\
\hline
\end{tabular}

Total Dose Contributions TDOSE (i,p,t) for Individual Radionuclides (i) and Pathways (p) As mrem/yr and Fraction of Total Dose At $t=0.000 \mathrm{E}+00$ years

Water Dependent Pathways

\begin{tabular}{|c|c|c|c|c|c|c|c|c|c|c|c|c|c|c|}
\hline & \multicolumn{2}{|c|}{ Water } & \multicolumn{2}{|c|}{ Fish } & \multicolumn{2}{|c|}{ Radon } & \multicolumn{2}{|c|}{ Plant } & \multicolumn{2}{|c|}{ Meat } & \multicolumn{2}{|c|}{ Milk } & \multicolumn{2}{|c|}{ All Pathways* } \\
\hline clide & mrem/yr & fract. & mrem/yr & fract. & mrem/yr & fract. & mrem/yr & fract. & mrem/yr & fract. & mrem/yr & fract. & mrem/yr & fract. \\
\hline-241 & $0.000 \mathrm{E}+00$ & 0.0000 & $0.000 \mathrm{E}+00$ & 0.0000 & $0.000 \mathrm{E}+00$ & 0.0000 & $0.000 \mathrm{E}+00$ & 0.0000 & $0.000 \mathrm{E}+00$ & 0.0000 & $0.000 \mathrm{E}+00$ & 0.0000 & $0.000 \mathrm{E}+00$ & 0.0000 \\
\hline-137 & $0.000 \mathrm{E}+00$ & 0.0000 & $0.000 \mathrm{E}+00$ & 0.0000 & $0.000 \mathrm{E}+00$ & 0.0000 & $0.000 \mathrm{E}+00$ & 0.0000 & $0.000 \mathrm{E}+00$ & 0.0000 & $0.000 \mathrm{E}+00$ & 0.0000 & $2.415 \mathrm{E}-08$ & 0.0036 \\
\hline-237 & $0.000 \mathrm{E}+00$ & 0.0000 & $0.000 \mathrm{E}+00$ & 0.0000 & $0.000 \mathrm{E}+00$ & 0.0000 & $0.000 \mathrm{E}+00$ & 0.0000 & $0.000 \mathrm{E}+00$ & 0.0000 & $0.000 \mathrm{E}+00$ & 0.0000 & $5.217 \mathrm{E}-12$ & 0.0000 \\
\hline-238 & $0.000 \mathrm{E}+00$ & 0.0000 & $0.000 \mathrm{E}+00$ & 0.0000 & $0.000 \mathrm{E}+00$ & 0.0000 & $0.000 \mathrm{E}+00$ & 0.0000 & $0.000 \mathrm{E}+00$ & 0.0000 & $0.000 \mathrm{E}+00$ & 0.0000 & $4.560 \mathrm{E}-23$ & 0.0000 \\
\hline-239 & $0.000 \mathrm{E}+00$ & 0.0000 & $0.000 \mathrm{E}+00$ & 0.0000 & $0.000 \mathrm{E}+00$ & 0.0000 & $0.000 \mathrm{E}+00$ & 0.0000 & $0.000 \mathrm{E}+00$ & 0.0000 & $0.000 E+00$ & 0.0000 & $4.302 \mathrm{E}-16$ & 0.0000 \\
\hline-240 & $0.000 \mathrm{E}+00$ & 0.0000 & $0.000 \mathrm{E}+00$ & 0.0000 & $0.000 \mathrm{E}+00$ & 0.0000 & $0.000 \mathrm{E}+00$ & 0.0000 & $0.000 \mathrm{E}+00$ & 0.0000 & $0.000 E+00$ & 0.0000 & $4.075 E-23$ & 0.0000 \\
\hline-99 & $0.000 \mathrm{E}+00$ & 0.0000 & $0.000 \mathrm{E}+00$ & 0.0000 & $0.000 \mathrm{E}+00$ & 0.0000 & $0.000 \mathrm{E}+00$ & 0.0000 & $0.000 \mathrm{E}+00$ & 0.0000 & $0.000 \mathrm{E}+00$ & 0.0000 & $2.979 E-24$ & 0.0000 \\
\hline-228 & $0.000 \mathrm{E}+00$ & 0.0000 & $0.000 \mathrm{E}+00$ & 0.0000 & $0.000 \mathrm{E}+00$ & 0.0000 & $0.000 \mathrm{E}+00$ & 0.0000 & $0.000 \mathrm{E}+00$ & 0.0000 & $0.000 \mathrm{E}+00$ & 0.0000 & $6.573 E-06$ & 0.9929 \\
\hline-230 & $0.000 \mathrm{E}+00$ & 0.0000 & $0.000 \mathrm{E}+00$ & 0.0000 & $0.000 \mathrm{E}+00$ & 0.0000 & $0.000 \mathrm{E}+00$ & 0.0000 & $0.000 \mathrm{E}+00$ & 0.0000 & $0.000 E+00$ & 0.0000 & $2.392 \mathrm{E}-20$ & 0.0000 \\
\hline 232 & $0.000 \mathrm{E}+00$ & 0.0000 & $0.000 \mathrm{E}+00$ & 0.0000 & $0.000 \mathrm{E}+00$ & 0.0000 & $0.000 \mathrm{E}+00$ & 0.0000 & $0.000 \mathrm{E}+00$ & 0.0000 & $0.000 \mathrm{E}+00$ & 0.0000 & $4.620 \mathrm{E}-24$ & 0.0000 \\
\hline 34 & $0.000 \mathrm{E}+00$ & 0.0000 & $0.000 \mathrm{E}+00$ & 0.0000 & $0.000 \mathrm{E}+00$ & 0.0000 & $0.000 \mathrm{E}+00$ & 0.0000 & $0.000 \mathrm{E}+00$ & 0.0000 & $0.000 \mathrm{E}+00$ & 0.0000 & $1.094 \mathrm{E}-21$ & 0.0000 \\
\hline 35 & $0.000 \mathrm{E}+00$ & 0.0000 & $0.000 \mathrm{E}+00$ & 0.0000 & $0.000 \mathrm{E}+00$ & 0.0000 & $0.000 \mathrm{E}+00$ & 0.0000 & $0.000 \mathrm{E}+00$ & 0.0000 & $0.000 E+00$ & 0.0000 & $8.032 \mathrm{E}-14$ & 0.0000 \\
\hline 38 & $0.000 \mathrm{E}+00$ & 0.0000 & $0.000 \mathrm{E}+00$ & 0.0000 & $0.000 \mathrm{E}+00$ & 0.0000 & $0.000 \mathrm{E}+00$ & 0.0000 & $0.000 \mathrm{E}+00$ & 0.0000 & $0.000 \mathrm{E}+00$ & 0.0000 & $2.262 \mathrm{E}-08$ & 0.0034 \\
\hline & $0.000 \mathrm{E}+00$ & 0.0000 & $0.000 \mathrm{E}+00$ & 0.0000 & $0.000 \mathrm{E}+00$ & 0.0000 & $0.000 \mathrm{E}+00$ & 0.0000 & $0.000 \mathrm{E}+00$ & 0.0000 & $0.000 \mathrm{E}+00$ & 0.0000 & $20 E-06$ & 1. \\
\hline
\end{tabular}

* Sum of all water independent and dependent pathways. 
RESRAD, Version 6.5

$\mathrm{T}^{1 / 2}$ Limit = 180 days

07/18/2011 $14: 42 \quad$ Page 22

ummary : C746U Resident Farmer Deterministic Run

: X: $\backslash$ FINAL V2 \DOE FWD RUNS \C746U RF DOE SG FWD-FV2-100000YR.RAD

Total Dose Contributions TDOSE(i,p,t) for Individual Radionuclides (i) and Pathways (p) As mrem/yr and Fraction of Total Dose At $t=1.000 \mathrm{E}+00$ years

Water Independent Pathways (Inhalation excludes radon)

\begin{tabular}{|c|c|c|c|c|c|c|c|c|c|c|c|c|c|c|}
\hline \multirow{2}{*}{ Nuclide } & \multicolumn{2}{|c|}{ Ground } & \multicolumn{2}{|c|}{ Inhalation } & \multicolumn{2}{|c|}{ Radon } & \multicolumn{2}{|c|}{ Plant } & \multicolumn{2}{|c|}{ Meat } & \multicolumn{2}{|c|}{ Milk } & \multicolumn{2}{|c|}{ Soil } \\
\hline & mrem/yr & fract. & mrem/yr & fract. & mrem/yr & fract. & mrem/yr & fract. & mrem/yr & fract. & mrem/yr & fract. & mrem/yr & fract. \\
\hline-241 & $1.086 \mathrm{E}-17$ & 0.0000 & $0.000 \mathrm{E}+00$ & 0.0000 & $0.000 \mathrm{E}+00$ & 0.0000 & $0.000 \mathrm{E}+00$ & 0.0000 & $0.000 \mathrm{E}+00$ & 0.0000 & $0.000 \mathrm{E}+00$ & 0.0000 & $0.000 \mathrm{E}+00$ & 0.0000 \\
\hline-137 & $2.380 E-08$ & 0.0050 & $0.000 \mathrm{E}+00$ & 0.0000 & $0.000 \mathrm{E}+00$ & 0.0000 & $0.000 \mathrm{E}+00$ & 0.0000 & $0.000 \mathrm{E}+00$ & 0.0000 & $0.000 \mathrm{E}+00$ & 0.0000 & $0.000 \mathrm{E}+00$ & 0.0000 \\
\hline-237 & $5.273 E-12$ & 0.0000 & $0.000 \mathrm{E}+00$ & 0.0000 & $0.000 \mathrm{E}+00$ & 0.0000 & $0.000 \mathrm{E}+00$ & 0.0000 & $0.000 \mathrm{E}+00$ & 0.0000 & $0.000 \mathrm{E}+00$ & 0.0000 & $0.000 \mathrm{E}+00$ & 0.0000 \\
\hline-238 & $1.257 \mathrm{E}-20$ & 0.0000 & $0.000 \mathrm{E}+00$ & 0.0000 & $0.000 \mathrm{E}+00$ & 0.0000 & $0.000 \mathrm{E}+00$ & 0.0000 & $0.000 \mathrm{E}+00$ & 0.0000 & $0.000 \mathrm{E}+00$ & 0.0000 & $0.000 \mathrm{E}+00$ & 0.0000 \\
\hline-239 & $4.354 \mathrm{E}-16$ & 0.0000 & $0.000 \mathrm{E}+00$ & 0.0000 & $0.000 \mathrm{E}+00$ & 0.0000 & $0.000 \mathrm{E}+00$ & 0.0000 & $0.000 \mathrm{E}+00$ & 0.0000 & $0.000 \mathrm{E}+00$ & 0.0000 & $0.000 \mathrm{E}+00$ & 0.0000 \\
\hline-240 & $4.164 \mathrm{E}-23$ & 0.0000 & $0.000 \mathrm{E}+00$ & 0.0000 & $0.000 \mathrm{E}+00$ & 0.0000 & $0.000 \mathrm{E}+00$ & 0.0000 & $0.000 \mathrm{E}+00$ & 0.0000 & $0.000 \mathrm{E}+00$ & 0.0000 & $0.000 \mathrm{E}+00$ & 0.0000 \\
\hline 99 & $3.009 E-24$ & 0.0000 & $0.000 \mathrm{E}+00$ & 0.0000 & $0.000 \mathrm{E}+00$ & 0.0000 & $0.000 \mathrm{E}+00$ & 0.0000 & $0.000 \mathrm{E}+00$ & 0.0000 & $0.000 \mathrm{E}+00$ & 0.0000 & $0.000 \mathrm{E}+00$ & 0.0000 \\
\hline-228 & $4.603 E-06$ & 0.9611 & $0.000 \mathrm{E}+00$ & 0.0000 & $0.000 \mathrm{E}+00$ & 0.0000 & $0.000 \mathrm{E}+00$ & 0.0000 & $0.000 \mathrm{E}+00$ & 0.0000 & $0.000 \mathrm{E}+00$ & 0.0000 & $0.000 \mathrm{E}+00$ & 0.0000 \\
\hline-230 & $7.565 \mathrm{E}-09$ & 0.0016 & $0.000 \mathrm{E}+00$ & 0.0000 & $0.000 \mathrm{E}+00$ & 0.0000 & $0.000 \mathrm{E}+00$ & 0.0000 & $0.000 \mathrm{E}+00$ & 0.0000 & $0.000 \mathrm{E}+00$ & 0.0000 & $0.000 \mathrm{E}+00$ & 0.0000 \\
\hline-232 & $1.320 \mathrm{E}-07$ & 0.0276 & $0.000 \mathrm{E}+00$ & 0.0000 & $0.000 \mathrm{E}+00$ & 0.0000 & $0.000 \mathrm{E}+00$ & 0.0000 & $0.000 \mathrm{E}+00$ & 0.0000 & $0.000 \mathrm{E}+00$ & 0.0000 & $0.000 \mathrm{E}+00$ & 0.0000 \\
\hline 234 & $5.448 \mathrm{E}-14$ & 0.0000 & $0.000 \mathrm{E}+00$ & 0.0000 & $0.000 \mathrm{E}+00$ & 0.0000 & $0.000 \mathrm{E}+00$ & 0.0000 & $0.000 \mathrm{E}+00$ & 0.0000 & $0.000 \mathrm{E}+00$ & 0.0000 & $0.000 \mathrm{E}+00$ & 0.0000 \\
\hline 235 & $8.153 \mathrm{E}-14$ & 0.0000 & $0.000 \mathrm{E}+00$ & 0.0000 & $0.000 \mathrm{E}+00$ & 0.0000 & $0.000 \mathrm{E}+00$ & 0.0000 & $0.000 \mathrm{E}+00$ & 0.0000 & $0.000 \mathrm{E}+00$ & 0.0000 & $0.000 \mathrm{E}+00$ & 0.0000 \\
\hline 38 & $2.280 E-08$ & 0.0048 & $0.000 \mathrm{E}+00$ & 0.0000 & $0.000 \mathrm{E}+00$ & 0.0000 & $0.000 \mathrm{E}+00$ & 0.0000 & $0.000 \mathrm{E}+00$ & 0.0000 & $0.000 \mathrm{E}+00$ & 0.0000 & $0.000 \mathrm{E}+00$ & 0.0000 \\
\hline & $4.789 E-06$ & 1.0000 & $0.000 \mathrm{E}+00$ & 0.0000 & $0.000 \mathrm{E}+00$ & 0.0000 & $0.000 \mathrm{E}+00$ & 0.0000 & $0.000 \mathrm{E}+00$ & 0.0000 & $0.000 \mathrm{E}+00$ & 0.0000 & $.000 \mathrm{E}+00$ & 0.0000 \\
\hline
\end{tabular}

Total Dose Contributions TDOSE (i,p,t) for Individual Radionuclides (i) and Pathways (p) As mrem/yr and Fraction of Total Dose At $t=1.000 \mathrm{E}+00$ years

Water Dependent Pathways

\begin{tabular}{|c|c|c|c|c|c|c|c|c|c|c|c|c|c|c|}
\hline & \multicolumn{2}{|c|}{ Water } & \multicolumn{2}{|c|}{ Fish } & \multicolumn{2}{|c|}{ Radon } & \multicolumn{2}{|c|}{ Plant } & \multicolumn{2}{|c|}{ Meat } & \multicolumn{2}{|c|}{ Milk } & \multicolumn{2}{|c|}{ All Pathways* } \\
\hline clide & mrem/yr & fract. & mrem/yr & fract. & mrem/yr & fract. & mrem/yr & fract. & mrem/yr & fract. & mrem/yr & fract. & mrem/yr & fract. \\
\hline-241 & $0.000 \mathrm{E}+00$ & 0.0000 & $0.000 \mathrm{E}+00$ & 0.0000 & $0.000 \mathrm{E}+00$ & 0.0000 & $0.000 \mathrm{E}+00$ & 0.0000 & $0.000 \mathrm{E}+00$ & 0.0000 & $0.000 \mathrm{E}+00$ & 0.0000 & $1.086 \mathrm{E}-17$ & 0.0000 \\
\hline-137 & $0.000 \mathrm{E}+00$ & 0.0000 & $0.000 \mathrm{E}+00$ & 0.0000 & $0.000 \mathrm{E}+00$ & 0.0000 & $0.000 \mathrm{E}+00$ & 0.0000 & $0.000 \mathrm{E}+00$ & 0.0000 & $0.000 \mathrm{E}+00$ & 0.0000 & $2.380 \mathrm{E}-08$ & 0.0050 \\
\hline-237 & $0.000 \mathrm{E}+00$ & 0.0000 & $0.000 \mathrm{E}+00$ & 0.0000 & $0.000 \mathrm{E}+00$ & 0.0000 & $0.000 \mathrm{E}+00$ & 0.0000 & $0.000 \mathrm{E}+00$ & 0.0000 & $0.000 \mathrm{E}+00$ & 0.0000 & $5.273 E-12$ & 0.0000 \\
\hline-238 & $0.000 \mathrm{E}+00$ & 0.0000 & $0.000 \mathrm{E}+00$ & 0.0000 & $0.000 \mathrm{E}+00$ & 0.0000 & $0.000 \mathrm{E}+00$ & 0.0000 & $0.000 \mathrm{E}+00$ & 0.0000 & $0.000 \mathrm{E}+00$ & 0.0000 & $1.257 \mathrm{E}-20$ & 0.0000 \\
\hline-239 & $0.000 \mathrm{E}+00$ & 0.0000 & $0.000 \mathrm{E}+00$ & 0.0000 & $0.000 \mathrm{E}+00$ & 0.0000 & $0.000 \mathrm{E}+00$ & 0.0000 & $0.000 \mathrm{E}+00$ & 0.0000 & $0.000 E+00$ & 0.0000 & $4.354 \mathrm{E}-16$ & 0.0000 \\
\hline-240 & $0.000 \mathrm{E}+00$ & 0.0000 & $0.000 \mathrm{E}+00$ & 0.0000 & $0.000 \mathrm{E}+00$ & 0.0000 & $0.000 \mathrm{E}+00$ & 0.0000 & $0.000 \mathrm{E}+00$ & 0.0000 & $0.000 E+00$ & 0.0000 & $4.164 \mathrm{E}-23$ & 0.0000 \\
\hline-99 & $0.000 \mathrm{E}+00$ & 0.0000 & $0.000 \mathrm{E}+00$ & 0.0000 & $0.000 \mathrm{E}+00$ & 0.0000 & $0.000 \mathrm{E}+00$ & 0.0000 & $0.000 \mathrm{E}+00$ & 0.0000 & $0.000 \mathrm{E}+00$ & 0.0000 & $3.009 E-24$ & 0.0000 \\
\hline-228 & $0.000 \mathrm{E}+00$ & 0.0000 & $0.000 \mathrm{E}+00$ & 0.0000 & $0.000 \mathrm{E}+00$ & 0.0000 & $0.000 \mathrm{E}+00$ & 0.0000 & $0.000 \mathrm{E}+00$ & 0.0000 & $0.000 \mathrm{E}+00$ & 0.0000 & $4.603 E-06$ & 0.9611 \\
\hline-230 & $0.000 \mathrm{E}+00$ & 0.0000 & $0.000 \mathrm{E}+00$ & 0.0000 & $0.000 \mathrm{E}+00$ & 0.0000 & $0.000 \mathrm{E}+00$ & 0.0000 & $0.000 \mathrm{E}+00$ & 0.0000 & $0.000 E+00$ & 0.0000 & $7.565 \mathrm{E}-09$ & 0.0016 \\
\hline 232 & $0.000 \mathrm{E}+00$ & 0.0000 & $0.000 \mathrm{E}+00$ & 0.0000 & $0.000 \mathrm{E}+00$ & 0.0000 & $0.000 \mathrm{E}+00$ & 0.0000 & $0.000 \mathrm{E}+00$ & 0.0000 & $0.000 \mathrm{E}+00$ & 0.0000 & $1.320 \mathrm{E}-07$ & 0.0276 \\
\hline 34 & $0.000 \mathrm{E}+00$ & 0.0000 & $0.000 \mathrm{E}+00$ & 0.0000 & $0.000 \mathrm{E}+00$ & 0.0000 & $0.000 \mathrm{E}+00$ & 0.0000 & $0.000 \mathrm{E}+00$ & 0.0000 & $0.000 \mathrm{E}+00$ & 0.0000 & $5.448 \mathrm{E}-14$ & 0.0000 \\
\hline 35 & $0.000 \mathrm{E}+00$ & 0.0000 & $0.000 \mathrm{E}+00$ & 0.0000 & $0.000 \mathrm{E}+00$ & 0.0000 & $0.000 \mathrm{E}+00$ & 0.0000 & $0.000 \mathrm{E}+00$ & 0.0000 & $0.000 E+00$ & 0.0000 & $8.153 \mathrm{E}-14$ & 0.0000 \\
\hline 38 & $0.000 \mathrm{E}+00$ & 0.0000 & $0.000 \mathrm{E}+00$ & 0.0000 & $0.000 \mathrm{E}+00$ & 0.0000 & $0.000 \mathrm{E}+00$ & 0.0000 & $0.000 \mathrm{E}+00$ & 0.0000 & $0.000 \mathrm{E}+00$ & 0.0000 & $2.280 \mathrm{E}-08$ & 0.0048 \\
\hline & $0.000 \mathrm{E}+00$ & 0.0000 & $0.000 \mathrm{E}+00$ & 0.0000 & $0.000 \mathrm{E}+00$ & 0.0000 & $0.000 \mathrm{E}+00$ & 0.0000 & $0.000 \mathrm{E}+00$ & 0.0000 & $0.000 \mathrm{E}+00$ & 0.0000 & $39 E-06$ & 1.0000 \\
\hline
\end{tabular}

* Sum of all water independent and dependent pathways. 
RESRAD, Version 6.5

$\mathrm{T}^{1 / 2}$ Limit = 180 days

07/18/2011 14:42 Page 23

ummary : C746U Resident Farmer Deterministic Run

: X: $\backslash$ FINAL V2 \DOE FWD RUNS \C746U RF DOE SG FWD-FV2-100000YR.RAD

Total Dose Contributions TDOSE (i,p,t) for Individual Radionuclides (i) and Pathways (p) As mrem/yr and Fraction of Total Dose At $t=5.000 \mathrm{E}+01$ years

Water Independent Pathways (Inhalation excludes radon)

\begin{tabular}{|c|c|c|c|c|c|c|c|c|c|c|c|c|c|c|}
\hline \multirow{2}{*}{ Nuclide } & \multicolumn{2}{|c|}{ Ground } & \multicolumn{2}{|c|}{ Inhalation } & \multicolumn{2}{|c|}{ Radon } & \multicolumn{2}{|c|}{ Plant } & \multicolumn{2}{|c|}{ Meat } & \multicolumn{2}{|c|}{ Milk } & \multicolumn{2}{|c|}{ Soil } \\
\hline & mrem/yr & fract. & mrem/yr & fract. & mrem/yr & fract. & mrem/yr & fract. & mrem/yr & fract. & mrem/yr & fract. & mrem/yr & fract. \\
\hline-241 & $8.840 \mathrm{E}-16$ & 0.0000 & $0.000 \mathrm{E}+00$ & 0.0000 & $0.000 \mathrm{E}+00$ & 0.0000 & $0.000 \mathrm{E}+00$ & 0.0000 & $0.000 \mathrm{E}+00$ & 0.0000 & $0.000 \mathrm{E}+00$ & 0.0000 & $0.000 \mathrm{E}+00$ & 0.0000 \\
\hline-137 & $1.158 \mathrm{E}-08$ & 0.0012 & $0.000 \mathrm{E}+00$ & 0.0000 & $0.000 \mathrm{E}+00$ & 0.0000 & $0.000 \mathrm{E}+00$ & 0.0000 & $0.000 \mathrm{E}+00$ & 0.0000 & $0.000 \mathrm{E}+00$ & 0.0000 & $0.000 \mathrm{E}+00$ & 0.0000 \\
\hline-237 & $8.909 \mathrm{E}-12$ & 0.0000 & $0.000 \mathrm{E}+00$ & 0.0000 & $0.000 \mathrm{E}+00$ & 0.0000 & $0.000 \mathrm{E}+00$ & 0.0000 & $0.000 \mathrm{E}+00$ & 0.0000 & $0.000 \mathrm{E}+00$ & 0.0000 & $0.000 \mathrm{E}+00$ & 0.0000 \\
\hline-238 & $1.988 E-15$ & 0.0000 & $0.000 \mathrm{E}+00$ & 0.0000 & $0.000 \mathrm{E}+00$ & 0.0000 & $0.000 \mathrm{E}+00$ & 0.0000 & $0.000 \mathrm{E}+00$ & 0.0000 & $0.000 \mathrm{E}+00$ & 0.0000 & $0.000 \mathrm{E}+00$ & 0.0000 \\
\hline-239 & $7.814 \mathrm{E}-16$ & 0.0000 & $0.000 \mathrm{E}+00$ & 0.0000 & $0.000 \mathrm{E}+00$ & 0.0000 & $0.000 \mathrm{E}+00$ & 0.0000 & $0.000 \mathrm{E}+00$ & 0.0000 & $0.000 \mathrm{E}+00$ & 0.0000 & $0.000 \mathrm{E}+00$ & 0.0000 \\
\hline-240 & $9.393 E-20$ & 0.0000 & $0.000 \mathrm{E}+00$ & 0.0000 & $0.000 \mathrm{E}+00$ & 0.0000 & $0.000 \mathrm{E}+00$ & 0.0000 & $0.000 \mathrm{E}+00$ & 0.0000 & $0.000 \mathrm{E}+00$ & 0.0000 & $0.000 \mathrm{E}+00$ & 0.0000 \\
\hline 99 & $4.954 \mathrm{E}-24$ & 0.0000 & $0.000 \mathrm{E}+00$ & 0.0000 & $0.000 \mathrm{E}+00$ & 0.0000 & $0.000 \mathrm{E}+00$ & 0.0000 & $0.000 \mathrm{E}+00$ & 0.0000 & $0.000 \mathrm{E}+00$ & 0.0000 & $0.000 \mathrm{E}+00$ & 0.0000 \\
\hline-228 & $1.201 \mathrm{E}-13$ & 0.0000 & $0.000 \mathrm{E}+00$ & 0.0000 & $0.000 \mathrm{E}+00$ & 0.0000 & $0.000 \mathrm{E}+00$ & 0.0000 & $0.000 \mathrm{E}+00$ & 0.0000 & $0.000 \mathrm{E}+00$ & 0.0000 & $0.000 \mathrm{E}+00$ & 0.0000 \\
\hline-230 & $5.249 \mathrm{E}-07$ & 0.0552 & $0.000 \mathrm{E}+00$ & 0.0000 & $0.000 \mathrm{E}+00$ & 0.0000 & $0.000 \mathrm{E}+00$ & 0.0000 & $0.000 \mathrm{E}+00$ & 0.0000 & $0.000 \mathrm{E}+00$ & 0.0000 & $0.000 \mathrm{E}+00$ & 0.0000 \\
\hline-232 & $8.935 E-06$ & 0.9400 & $0.000 \mathrm{E}+00$ & 0.0000 & $0.000 \mathrm{E}+00$ & 0.0000 & $0.000 \mathrm{E}+00$ & 0.0000 & $0.000 \mathrm{E}+00$ & 0.0000 & $0.000 \mathrm{E}+00$ & 0.0000 & $0.000 \mathrm{E}+00$ & 0.0000 \\
\hline 234 & $1.897 \mathrm{E}-10$ & 0.0000 & $0.000 \mathrm{E}+00$ & 0.0000 & $0.000 \mathrm{E}+00$ & 0.0000 & $0.000 \mathrm{E}+00$ & 0.0000 & $0.000 \mathrm{E}+00$ & 0.0000 & $0.000 \mathrm{E}+00$ & 0.0000 & $0.000 \mathrm{E}+00$ & 0.0000 \\
\hline 235 & $5.905 E-13$ & 0.0000 & $0.000 \mathrm{E}+00$ & 0.0000 & $0.000 \mathrm{E}+00$ & 0.0000 & $0.000 \mathrm{E}+00$ & 0.0000 & $0.000 \mathrm{E}+00$ & 0.0000 & $0.000 \mathrm{E}+00$ & 0.0000 & $0.000 \mathrm{E}+00$ & 0.0000 \\
\hline 38 & $3.372 E-08$ & 0.0035 & $0.000 \mathrm{E}+00$ & 0.0000 & $0.000 \mathrm{E}+00$ & 0.0000 & $0.000 \mathrm{E}+00$ & 0.0000 & $0.000 \mathrm{E}+00$ & 0.0000 & $0.000 \mathrm{E}+00$ & 0.0000 & $0.000 \mathrm{E}+00$ & 0.0000 \\
\hline & $9.505 E-06$ & 1.0000 & $0.000 \mathrm{E}+00$ & 0.0000 & $0.000 \mathrm{E}+00$ & 0.0000 & $0.000 \mathrm{E}+00$ & 0.0000 & $0.000 \mathrm{E}+00$ & 0.0000 & $0.000 \mathrm{E}+00$ & 0.0000 & $.000 \mathrm{E}+00$ & 0.0000 \\
\hline
\end{tabular}

Total Dose Contributions TDOSE (i,p,t) for Individual Radionuclides (i) and Pathways (p) As mrem/yr and Fraction of Total Dose At $t=5.000 \mathrm{E}+01$ years

Water Dependent Pathways

\begin{tabular}{|c|c|c|c|c|c|c|c|c|c|c|c|c|c|c|}
\hline & \multicolumn{2}{|c|}{ Water } & \multicolumn{2}{|c|}{ Fish } & \multicolumn{2}{|c|}{ Radon } & \multicolumn{2}{|c|}{ Plant } & \multicolumn{2}{|c|}{ Meat } & \multicolumn{2}{|c|}{ Milk } & \multicolumn{2}{|c|}{ All Pathways* } \\
\hline clide & mrem/yr & fract. & mrem/yr & fract. & mrem/yr & fract. & mrem/yr & fract. & mrem/yr & fract. & mrem/yr & fract. & mrem/yr & fract. \\
\hline-241 & $0.000 \mathrm{E}+00$ & 0.0000 & $0.000 \mathrm{E}+00$ & 0.0000 & $0.000 \mathrm{E}+00$ & 0.0000 & $0.000 \mathrm{E}+00$ & 0.0000 & $0.000 \mathrm{E}+00$ & 0.0000 & $0.000 \mathrm{E}+00$ & 0.0000 & $8.840 \mathrm{E}-16$ & 0.0000 \\
\hline-137 & $0.000 \mathrm{E}+00$ & 0.0000 & $0.000 \mathrm{E}+00$ & 0.0000 & $0.000 \mathrm{E}+00$ & 0.0000 & $0.000 \mathrm{E}+00$ & 0.0000 & $0.000 \mathrm{E}+00$ & 0.0000 & $0.000 \mathrm{E}+00$ & 0.0000 & $1.158 \mathrm{E}-08$ & 0.0012 \\
\hline-237 & $0.000 \mathrm{E}+00$ & 0.0000 & $0.000 \mathrm{E}+00$ & 0.0000 & $0.000 \mathrm{E}+00$ & 0.0000 & $0.000 \mathrm{E}+00$ & 0.0000 & $0.000 \mathrm{E}+00$ & 0.0000 & $0.000 \mathrm{E}+00$ & 0.0000 & $8.909 \mathrm{E}-12$ & 0.0000 \\
\hline 238 & $0.000 \mathrm{E}+00$ & 0.0000 & $0.000 \mathrm{E}+00$ & 0.0000 & $0.000 \mathrm{E}+00$ & 0.0000 & $0.000 \mathrm{E}+00$ & 0.0000 & $0.000 \mathrm{E}+00$ & 0.0000 & $0.000 \mathrm{E}+00$ & 0.0000 & $1.988 \mathrm{E}-15$ & 0.0000 \\
\hline 239 & $0.000 \mathrm{E}+00$ & 0.0000 & $0.000 \mathrm{E}+00$ & 0.0000 & $0.000 \mathrm{E}+00$ & 0.0000 & $0.000 \mathrm{E}+00$ & 0.0000 & $0.000 \mathrm{E}+00$ & 0.0000 & $0.000 \mathrm{E}+00$ & 0.0000 & $7.814 \mathrm{E}-16$ & 0.0000 \\
\hline 240 & $0.000 \mathrm{E}+00$ & 0.0000 & $0.000 \mathrm{E}+00$ & 0.0000 & $0.000 \mathrm{E}+00$ & 0.0000 & $0.000 \mathrm{E}+00$ & 0.0000 & $0.000 \mathrm{E}+00$ & 0.0000 & $0.000 \mathrm{E}+00$ & 0.0000 & $9.393 E-20$ & 0.0000 \\
\hline 99 & $0.000 \mathrm{E}+00$ & 0.0000 & $0.000 \mathrm{E}+00$ & 0.0000 & $0.000 \mathrm{E}+00$ & 0.0000 & $0.000 \mathrm{E}+00$ & 0.0000 & $0.000 \mathrm{E}+00$ & 0.0000 & $0.000 \mathrm{E}+00$ & 0.0000 & $4.954 \mathrm{E}-24$ & 0.0000 \\
\hline 228 & $0.000 \mathrm{E}+00$ & 0.0000 & $0.000 \mathrm{E}+00$ & 0.0000 & $0.000 \mathrm{E}+00$ & 0.0000 & $0.000 \mathrm{E}+00$ & 0.0000 & $0.000 \mathrm{E}+00$ & 0.0000 & $0.000 \mathrm{E}+00$ & 0.0000 & $1.201 \mathrm{E}-13$ & 0.0000 \\
\hline 230 & $0.000 \mathrm{E}+00$ & 0.0000 & $0.000 \mathrm{E}+00$ & 0.0000 & $0.000 \mathrm{E}+00$ & 0.0000 & $0.000 \mathrm{E}+00$ & 0.0000 & $0.000 \mathrm{E}+00$ & 0.0000 & $0.000 \mathrm{E}+00$ & 0.0000 & $5.249 \mathrm{E}-07$ & 0.0552 \\
\hline 232 & $0.000 \mathrm{E}+00$ & 0.0000 & $0.000 \mathrm{E}+00$ & 0.0000 & $0.000 \mathrm{E}+00$ & 0.0000 & $0.000 \mathrm{E}+00$ & 0.0000 & $0.000 \mathrm{E}+00$ & 0.0000 & $0.000 \mathrm{E}+00$ & 0.0000 & $8.935 E-06$ & 0.9400 \\
\hline 34 & $0.000 \mathrm{E}+00$ & 0.0000 & $0.000 \mathrm{E}+00$ & 0.0000 & $0.000 \mathrm{E}+00$ & 0.0000 & $0.000 \mathrm{E}+00$ & 0.0000 & $0.000 \mathrm{E}+00$ & 0.0000 & $0.000 \mathrm{E}+00$ & 0.0000 & $1.897 \mathrm{E}-10$ & 0.0000 \\
\hline 35 & $0.000 \mathrm{E}+00$ & 0.0000 & $0.000 \mathrm{E}+00$ & 0.0000 & $0.000 \mathrm{E}+00$ & 0.0000 & $0.000 \mathrm{E}+00$ & 0.0000 & $0.000 \mathrm{E}+00$ & 0.0000 & $0.000 \mathrm{E}+00$ & 0.0000 & $5.905 E-13$ & 0.0000 \\
\hline 38 & $0.000 \mathrm{E}+00$ & 0.0000 & $0.000 \mathrm{E}+00$ & 0.0000 & $0.000 \mathrm{E}+00$ & 0.0000 & $0.000 \mathrm{E}+00$ & 0.0000 & $0.000 \mathrm{E}+00$ & 0.0000 & $0.000 \mathrm{E}+00$ & 0.0000 & $3.372 \mathrm{E}-08$ & 0.0035 \\
\hline & $0.000 \mathrm{E}+00$ & 0.0000 & $0.000 \mathrm{E}+00$ & 0.0000 & $0.000 \mathrm{E}+00$ & 0.0000 & $0.000 \mathrm{E}+00$ & 0.0000 & $0.000 \mathrm{E}+00$ & 0.0000 & $0.000 \mathrm{E}+00$ & 000 & -06 & 1.0000 \\
\hline
\end{tabular}

* Sum of all water independent and dependent pathways. 
RESRAD, Version 6.5

$\mathrm{T}^{1 / 2}$ Limit = 180 days

07/18/2011 14:42 Page 24

ummary : C746U Resident Farmer Deterministic Run

: X: $\backslash$ FINAL V2 \DOE FWD RUNS \C746U RF DOE SG FWD-FV2-100000YR.RAD

Total Dose Contributions TDOSE(i,p,t) for Individual Radionuclides (i) and Pathways (p) As mrem/yr and Fraction of Total Dose At $t=1.000 \mathrm{E}+02$ years

Water Independent Pathways (Inhalation excludes radon)

\begin{tabular}{|c|c|c|c|c|c|c|c|c|c|c|c|c|c|c|}
\hline \multirow{2}{*}{ Nuclide } & \multicolumn{2}{|c|}{ Ground } & \multicolumn{2}{|c|}{ Inhalation } & \multicolumn{2}{|c|}{ Radon } & \multicolumn{2}{|c|}{ Plant } & \multicolumn{2}{|c|}{ Meat } & \multicolumn{2}{|c|}{ Milk } & \multicolumn{2}{|c|}{ Soil } \\
\hline & mrem/yr & fract. & mrem/yr & fract. & mrem/yr & fract. & mrem/yr & fract. & mrem/yr & fract. & mrem/yr & fract. & mrem/yr & fract. \\
\hline-241 & $2.911 E-15$ & 0.0000 & $0.000 \mathrm{E}+00$ & 0.0000 & $0.000 \mathrm{E}+00$ & 0.0000 & $0.000 \mathrm{E}+00$ & 0.0000 & $0.000 \mathrm{E}+00$ & 0.0000 & $0.000 \mathrm{E}+00$ & 0.0000 & $0.000 \mathrm{E}+00$ & 0.0000 \\
\hline-137 & $5.552 E-09$ & 0.0004 & $0.000 \mathrm{E}+00$ & 0.0000 & $0.000 \mathrm{E}+00$ & 0.0000 & $0.000 \mathrm{E}+00$ & 0.0000 & $0.000 \mathrm{E}+00$ & 0.0000 & $0.000 \mathrm{E}+00$ & 0.0000 & $0.000 \mathrm{E}+00$ & 0.0000 \\
\hline-237 & 1. $525 \mathrm{E}-11$ & 0.0000 & $0.000 \mathrm{E}+00$ & 0.0000 & $0.000 \mathrm{E}+00$ & 0.0000 & $0.000 \mathrm{E}+00$ & 0.0000 & $0.000 \mathrm{E}+00$ & 0.0000 & $0.000 \mathrm{E}+00$ & 0.0000 & $0.000 \mathrm{E}+00$ & 0.0000 \\
\hline-238 & $2.040 \mathrm{E}-14$ & 0.0000 & $0.000 \mathrm{E}+00$ & 0.0000 & $0.000 \mathrm{E}+00$ & 0.0000 & $0.000 \mathrm{E}+00$ & 0.0000 & $0.000 \mathrm{E}+00$ & 0.0000 & $0.000 \mathrm{E}+00$ & 0.0000 & $0.000 \mathrm{E}+00$ & 0.0000 \\
\hline-239 & $1.419 \mathrm{E}-15$ & 0.0000 & $0.000 \mathrm{E}+00$ & 0.0000 & $0.000 \mathrm{E}+00$ & 0.0000 & $0.000 \mathrm{E}+00$ & 0.0000 & $0.000 \mathrm{E}+00$ & 0.0000 & $0.000 \mathrm{E}+00$ & 0.0000 & $0.000 \mathrm{E}+00$ & 0.0000 \\
\hline-240 & $6.330 \mathrm{E}-19$ & 0.0000 & $0.000 \mathrm{E}+00$ & 0.0000 & $0.000 \mathrm{E}+00$ & 0.0000 & $0.000 \mathrm{E}+00$ & 0.0000 & $0.000 \mathrm{E}+00$ & 0.0000 & $0.000 \mathrm{E}+00$ & 0.0000 & $0.000 \mathrm{E}+00$ & 0.0000 \\
\hline 99 & $8.238 E-24$ & 0.0000 & $0.000 \mathrm{E}+00$ & 0.0000 & $0.000 \mathrm{E}+00$ & 0.0000 & $0.000 \mathrm{E}+00$ & 0.0000 & $0.000 \mathrm{E}+00$ & 0.0000 & $0.000 \mathrm{E}+00$ & 0.0000 & $0.000 \mathrm{E}+00$ & 0.0000 \\
\hline-228 & $2.196 \mathrm{E}-21$ & 0.0000 & $0.000 \mathrm{E}+00$ & 0.0000 & $0.000 \mathrm{E}+00$ & 0.0000 & $0.000 \mathrm{E}+00$ & 0.0000 & $0.000 \mathrm{E}+00$ & 0.0000 & $0.000 \mathrm{E}+00$ & 0.0000 & $0.000 \mathrm{E}+00$ & 0.0000 \\
\hline-230 & $1.467 \mathrm{E}-06$ & 0.1077 & $0.000 \mathrm{E}+00$ & 0.0000 & $0.000 \mathrm{E}+00$ & 0.0000 & $0.000 \mathrm{E}+00$ & 0.0000 & $0.000 \mathrm{E}+00$ & 0.0000 & $0.000 \mathrm{E}+00$ & 0.0000 & $0.000 \mathrm{E}+00$ & 0.0000 \\
\hline-232 & $1.209 E-05$ & 0.8881 & $0.000 \mathrm{E}+00$ & 0.0000 & $0.000 \mathrm{E}+00$ & 0.0000 & $0.000 \mathrm{E}+00$ & 0.0000 & $0.000 \mathrm{E}+00$ & 0.0000 & $0.000 \mathrm{E}+00$ & 0.0000 & $0.000 \mathrm{E}+00$ & 0.0000 \\
\hline 234 & $1.064 \mathrm{E}-09$ & 0.0001 & $0.000 \mathrm{E}+00$ & 0.0000 & $0.000 \mathrm{E}+00$ & 0.0000 & $0.000 \mathrm{E}+00$ & 0.0000 & $0.000 \mathrm{E}+00$ & 0.0000 & $0.000 \mathrm{E}+00$ & 0.0000 & $0.000 \mathrm{E}+00$ & 0.0000 \\
\hline 235 & $2.179 \mathrm{E}-12$ & 0.0000 & $0.000 \mathrm{E}+00$ & 0.0000 & $0.000 \mathrm{E}+00$ & 0.0000 & $0.000 \mathrm{E}+00$ & 0.0000 & $0.000 \mathrm{E}+00$ & 0.0000 & $0.000 \mathrm{E}+00$ & 0.0000 & $0.000 \mathrm{E}+00$ & 0.0000 \\
\hline 38 & $5.025 E-08$ & 0.0037 & $0.000 \mathrm{E}+00$ & 0.0000 & $0.000 \mathrm{E}+00$ & 0.0000 & $0.000 \mathrm{E}+00$ & 0.0000 & $0.000 \mathrm{E}+00$ & 0.0000 & $0.000 \mathrm{E}+00$ & 0.0000 & $0.000 \mathrm{E}+00$ & 0.0000 \\
\hline & $1.362 \mathrm{E}-05$ & 1.0000 & $0.000 \mathrm{E}+00$ & 0.0000 & $0.000 \mathrm{E}+00$ & 0.0000 & $0.000 \mathrm{E}+00$ & 0.0000 & $0.000 \mathrm{E}+00$ & 0.0000 & $0.000 \mathrm{E}+00$ & 0.0000 & $.000 \mathrm{E}+00$ & 0.0000 \\
\hline
\end{tabular}

Total Dose Contributions TDOSE (i,p,t) for Individual Radionuclides (i) and Pathways (p) As mrem/yr and Fraction of Total Dose At $t=1.000 \mathrm{E}+02$ years

Water Dependent Pathways

\begin{tabular}{|c|c|c|c|c|c|c|c|c|c|c|c|c|c|c|}
\hline & \multicolumn{2}{|c|}{ Water } & \multicolumn{2}{|c|}{ Fish } & \multicolumn{2}{|c|}{ Radon } & \multicolumn{2}{|c|}{ Plant } & \multicolumn{2}{|c|}{ Meat } & \multicolumn{2}{|c|}{ Milk } & \multicolumn{2}{|c|}{ All Pathways* } \\
\hline clide & mrem/yr & fract. & mrem/yr & fract. & mrem/yr & fract. & mrem/yr & fract. & mrem/yr & fract. & mrem/yr & fract. & mrem/yr & fract. \\
\hline-241 & $0.000 \mathrm{E}+00$ & 0.0000 & $0.000 \mathrm{E}+00$ & 0.0000 & $0.000 \mathrm{E}+00$ & 0.0000 & $0.000 \mathrm{E}+00$ & 0.0000 & $0.000 \mathrm{E}+00$ & 0.0000 & $0.000 \mathrm{E}+00$ & 0.0000 & $2.911 E-15$ & 0.0000 \\
\hline-137 & $0.000 \mathrm{E}+00$ & 0.0000 & $0.000 \mathrm{E}+00$ & 0.0000 & $0.000 \mathrm{E}+00$ & 0.0000 & $0.000 \mathrm{E}+00$ & 0.0000 & $0.000 \mathrm{E}+00$ & 0.0000 & $0.000 \mathrm{E}+00$ & 0.0000 & $5.552 \mathrm{E}-09$ & 0.0004 \\
\hline-237 & $0.000 \mathrm{E}+00$ & 0.0000 & $0.000 \mathrm{E}+00$ & 0.0000 & $0.000 \mathrm{E}+00$ & 0.0000 & $0.000 \mathrm{E}+00$ & 0.0000 & $0.000 \mathrm{E}+00$ & 0.0000 & $0.000 \mathrm{E}+00$ & 0.0000 & $1.525 \mathrm{E}-11$ & 0.0000 \\
\hline 238 & $0.000 \mathrm{E}+00$ & 0.0000 & $0.000 \mathrm{E}+00$ & 0.0000 & $0.000 \mathrm{E}+00$ & 0.0000 & $0.000 \mathrm{E}+00$ & 0.0000 & $0.000 \mathrm{E}+00$ & 0.0000 & $0.000 \mathrm{E}+00$ & 0.0000 & $2.040 \mathrm{E}-14$ & 0.0000 \\
\hline 239 & $0.000 \mathrm{E}+00$ & 0.0000 & $0.000 \mathrm{E}+00$ & 0.0000 & $0.000 \mathrm{E}+00$ & 0.0000 & $0.000 \mathrm{E}+00$ & 0.0000 & $0.000 \mathrm{E}+00$ & 0.0000 & $0.000 \mathrm{E}+00$ & 0.0000 & $1.419 \mathrm{E}-15$ & 0.0000 \\
\hline 240 & $0.000 \mathrm{E}+00$ & 0.0000 & $0.000 \mathrm{E}+00$ & 0.0000 & $0.000 \mathrm{E}+00$ & 0.0000 & $0.000 \mathrm{E}+00$ & 0.0000 & $0.000 \mathrm{E}+00$ & 0.0000 & $0.000 \mathrm{E}+00$ & 0.0000 & $6.330 \mathrm{E}-19$ & 0.0000 \\
\hline 99 & $0.000 \mathrm{E}+00$ & 0.0000 & $0.000 \mathrm{E}+00$ & 0.0000 & $0.000 \mathrm{E}+00$ & 0.0000 & $0.000 \mathrm{E}+00$ & 0.0000 & $0.000 \mathrm{E}+00$ & 0.0000 & $0.000 \mathrm{E}+00$ & 0.0000 & $8.238 E-24$ & 0.0000 \\
\hline 228 & $0.000 \mathrm{E}+00$ & 0.0000 & $0.000 \mathrm{E}+00$ & 0.0000 & $0.000 \mathrm{E}+00$ & 0.0000 & $0.000 \mathrm{E}+00$ & 0.0000 & $0.000 \mathrm{E}+00$ & 0.0000 & $0.000 \mathrm{E}+00$ & 0.0000 & $2.196 \mathrm{E}-21$ & 0.0000 \\
\hline 230 & $0.000 \mathrm{E}+00$ & 0.0000 & $0.000 \mathrm{E}+00$ & 0.0000 & $0.000 \mathrm{E}+00$ & 0.0000 & $0.000 \mathrm{E}+00$ & 0.0000 & $0.000 \mathrm{E}+00$ & 0.0000 & $0.000 \mathrm{E}+00$ & 0.0000 & $1.467 \mathrm{E}-06$ & 0.1077 \\
\hline 232 & $0.000 \mathrm{E}+00$ & 0.0000 & $0.000 \mathrm{E}+00$ & 0.0000 & $0.000 \mathrm{E}+00$ & 0.0000 & $0.000 \mathrm{E}+00$ & 0.0000 & $0.000 \mathrm{E}+00$ & 0.0000 & $0.000 \mathrm{E}+00$ & 0.0000 & $1.209 \mathrm{E}-05$ & 0.8881 \\
\hline 34 & $0.000 \mathrm{E}+00$ & 0.0000 & $0.000 \mathrm{E}+00$ & 0.0000 & $0.000 \mathrm{E}+00$ & 0.0000 & $0.000 \mathrm{E}+00$ & 0.0000 & $0.000 \mathrm{E}+00$ & 0.0000 & $0.000 \mathrm{E}+00$ & 0.0000 & $1.064 \mathrm{E}-09$ & 0.0001 \\
\hline 35 & $0.000 \mathrm{E}+00$ & 0.0000 & $0.000 \mathrm{E}+00$ & 0.0000 & $0.000 \mathrm{E}+00$ & 0.0000 & $0.000 \mathrm{E}+00$ & 0.0000 & $0.000 \mathrm{E}+00$ & 0.0000 & $0.000 \mathrm{E}+00$ & 0.0000 & $2.179 \mathrm{E}-12$ & 0.0000 \\
\hline 38 & $0.000 \mathrm{E}+00$ & 0.0000 & $0.000 \mathrm{E}+00$ & 0.0000 & $0.000 \mathrm{E}+00$ & 0.0000 & $0.000 \mathrm{E}+00$ & 0.0000 & $0.000 \mathrm{E}+00$ & 0.0000 & $0.000 \mathrm{E}+00$ & 0.0000 & $5.025 \mathrm{E}-08$ & 0.0037 \\
\hline & $0.000 \mathrm{E}+00$ & 0.0000 & $0.000 \mathrm{E}+00$ & 0.0000 & $0.000 \mathrm{E}+00$ & 0.0000 & $0.000 \mathrm{E}+00$ & 0.0000 & $0.000 \mathrm{E}+00$ & 0.0000 & $0.000 \mathrm{E}+00$ & 000 & -05 & 1.0000 \\
\hline
\end{tabular}

* Sum of all water independent and dependent pathways. 
RESRAD, Version 6.5

$\mathrm{T}^{1 / 2}$ Limit = 180 days

07/18/2011 $14: 42 \quad$ Page 25

ummary : C746U Resident Farmer Deterministic Run

: X: $\backslash$ FINAL V2 \DOE FWD RUNS \C746U RF DOE SG FWD-FV2-100000YR.RAD

Total Dose Contributions TDOSE (i,p,t) for Individual Radionuclides (i) and Pathways (p) As mrem/yr and Fraction of Total Dose At $t=5.000 \mathrm{E}+02$ years

Water Independent Pathways (Inhalation excludes radon)

\begin{tabular}{|c|c|c|c|c|c|c|c|c|c|c|c|c|c|c|}
\hline \multirow{2}{*}{ Nuclide } & \multicolumn{2}{|c|}{ Ground } & \multicolumn{2}{|c|}{ Inhalation } & \multicolumn{2}{|c|}{ Radon } & \multicolumn{2}{|c|}{ Plant } & \multicolumn{2}{|c|}{ Meat } & \multicolumn{2}{|c|}{ Milk } & \multicolumn{2}{|c|}{ Soil } \\
\hline & mrem/yr & fract. & mrem/yr & fract. & mrem/yr & fract. & mrem/yr & fract. & mrem/yr & fract. & mrem/yr & fract. & mrem/yr & fract. \\
\hline-241 & $7.984 \mathrm{E}-13$ & 0.0000 & $0.000 \mathrm{E}+00$ & 0.0000 & $0.000 \mathrm{E}+00$ & 0.0000 & $0.000 \mathrm{E}+00$ & 0.0000 & $0.000 \mathrm{E}+00$ & 0.0000 & $0.000 \mathrm{E}+00$ & 0.0000 & $0.000 \mathrm{E}+00$ & 0.0000 \\
\hline-137 & $1.551 \mathrm{E}-11$ & 0.0000 & $0.000 \mathrm{E}+00$ & 0.0000 & $0.000 \mathrm{E}+00$ & 0.0000 & $0.000 \mathrm{E}+00$ & 0.0000 & $0.000 \mathrm{E}+00$ & 0.0000 & $0.000 \mathrm{E}+00$ & 0.0000 & $0.000 \mathrm{E}+00$ & 0.0000 \\
\hline-237 & $1.118 \mathrm{E}-09$ & 0.0000 & $0.000 \mathrm{E}+00$ & 0.0000 & $0.000 \mathrm{E}+00$ & 0.0000 & $0.000 \mathrm{E}+00$ & 0.0000 & $0.000 \mathrm{E}+00$ & 0.0000 & $0.000 \mathrm{E}+00$ & 0.0000 & $0.000 \mathrm{E}+00$ & 0.0000 \\
\hline-238 & $2.174 \mathrm{E}-11$ & 0.0000 & $0.000 \mathrm{E}+00$ & 0.0000 & $0.000 \mathrm{E}+00$ & 0.0000 & $0.000 \mathrm{E}+00$ & 0.0000 & $0.000 \mathrm{E}+00$ & 0.0000 & $0.000 \mathrm{E}+00$ & 0.0000 & $0.000 \mathrm{E}+00$ & 0.0000 \\
\hline-239 & 1. $685 \mathrm{E}-13$ & 0.0000 & $0.000 \mathrm{E}+00$ & 0.0000 & $0.000 \mathrm{E}+00$ & 0.0000 & $0.000 \mathrm{E}+00$ & 0.0000 & $0.000 \mathrm{E}+00$ & 0.0000 & $0.000 \mathrm{E}+00$ & 0.0000 & $0.000 \mathrm{E}+00$ & 0.0000 \\
\hline-240 & $2.048 E-16$ & 0.0000 & $0.000 \mathrm{E}+00$ & 0.0000 & $0.000 \mathrm{E}+00$ & 0.0000 & $0.000 \mathrm{E}+00$ & 0.0000 & $0.000 \mathrm{E}+00$ & 0.0000 & $0.000 \mathrm{E}+00$ & 0.0000 & $0.000 \mathrm{E}+00$ & 0.0000 \\
\hline 99 & $4.816 E-22$ & 0.0000 & $0.000 \mathrm{E}+00$ & 0.0000 & $0.000 \mathrm{E}+00$ & 0.0000 & $0.000 \mathrm{E}+00$ & 0.0000 & $0.000 \mathrm{E}+00$ & 0.0000 & $0.000 \mathrm{E}+00$ & 0.0000 & $0.000 \mathrm{E}+00$ & 0.0000 \\
\hline-228 & $0.000 \mathrm{E}+00$ & 0.0000 & $0.000 \mathrm{E}+00$ & 0.0000 & $0.000 \mathrm{E}+00$ & 0.0000 & $0.000 \mathrm{E}+00$ & 0.0000 & $0.000 \mathrm{E}+00$ & 0.0000 & $0.000 \mathrm{E}+00$ & 0.0000 & $0.000 \mathrm{E}+00$ & 0.0000 \\
\hline-230 & $1.066 \mathrm{E}-04$ & 0.0000 & $0.000 \mathrm{E}+00$ & 0.0000 & $0.000 \mathrm{E}+00$ & 0.0000 & $0.000 \mathrm{E}+00$ & 0.0000 & $0.000 \mathrm{E}+00$ & 0.0000 & $0.000 \mathrm{E}+00$ & 0.0000 & $0.000 \mathrm{E}+00$ & 0.0000 \\
\hline-232 & $1.331 E-04$ & 0.0000 & $0.000 \mathrm{E}+00$ & 0.0000 & $0.000 \mathrm{E}+00$ & 0.0000 & $0.000 \mathrm{E}+00$ & 0.0000 & $0.000 \mathrm{E}+00$ & 0.0000 & $0.000 \mathrm{E}+00$ & 0.0000 & $0.000 \mathrm{E}+00$ & 0.0000 \\
\hline 234 & $3.972 \mathrm{E}-07$ & 0.0000 & $0.000 \mathrm{E}+00$ & 0.0000 & $0.000 \mathrm{E}+00$ & 0.0000 & $0.000 \mathrm{E}+00$ & 0.0000 & $0.000 \mathrm{E}+00$ & 0.0000 & $0.000 \mathrm{E}+00$ & 0.0000 & $0.000 \mathrm{E}+00$ & 0.0000 \\
\hline 235 & $4.546 \mathrm{E}-10$ & 0.0000 & $0.000 \mathrm{E}+00$ & 0.0000 & $0.000 \mathrm{E}+00$ & 0.0000 & $0.000 \mathrm{E}+00$ & 0.0000 & $0.000 \mathrm{E}+00$ & 0.0000 & $0.000 \mathrm{E}+00$ & 0.0000 & $0.000 \mathrm{E}+00$ & 0.0000 \\
\hline 38 & $1.224 E-06$ & 0.0000 & $0.000 \mathrm{E}+00$ & 0.0000 & $0.000 \mathrm{E}+00$ & 0.0000 & $0.000 \mathrm{E}+00$ & 0.0000 & $0.000 \mathrm{E}+00$ & 0.0000 & $0.000 \mathrm{E}+00$ & 0.0000 & $0.000 \mathrm{E}+00$ & 0.0000 \\
\hline & $2.414 \mathrm{E}-04$ & 0.0000 & $0.000 \mathrm{E}+00$ & 0.0000 & $0.000 \mathrm{E}+00$ & 0.0000 & $0.000 \mathrm{E}+00$ & 0.0000 & $0.000 \mathrm{E}+00$ & 0.0000 & $0.000 \mathrm{E}+00$ & 0.0000 & $.000 \mathrm{E}+00$ & 0.0000 \\
\hline
\end{tabular}

Total Dose Contributions TDOSE (i,p,t) for Individual Radionuclides (i) and Pathways (p) As mrem/yr and Fraction of Total Dose At $t=5.000 \mathrm{E}+02$ years

Water Dependent Pathways

\begin{tabular}{|c|c|c|c|c|c|c|c|c|c|c|c|c|c|c|}
\hline & \multicolumn{2}{|c|}{ Water } & \multicolumn{2}{|c|}{ Fish } & \multicolumn{2}{|c|}{ Radon } & \multicolumn{2}{|c|}{ Plant } & \multicolumn{2}{|c|}{ Meat } & \multicolumn{2}{|c|}{ Milk } & \multicolumn{2}{|c|}{ All Pathways* } \\
\hline clide & mrem/yr & fract. & mrem/yr & fract. & mrem/yr & fract. & mrem/yr & fract. & mrem/yr & fract. & mrem/yr & fract. & mrem/yr & fract. \\
\hline 241 & $0.000 \mathrm{E}+00$ & 0.0000 & $0.000 \mathrm{E}+00$ & 0.0000 & $0.000 \mathrm{E}+00$ & 0.0000 & $0.000 \mathrm{E}+00$ & 0.0000 & $0.000 \mathrm{E}+00$ & 0.0000 & $0.000 \mathrm{E}+00$ & 0.0000 & $7.984 \mathrm{E}-13$ & 0.0000 \\
\hline-137 & $0.000 \mathrm{E}+00$ & 0.0000 & $0.000 \mathrm{E}+00$ & 0.0000 & $0.000 \mathrm{E}+00$ & 0.0000 & $0.000 \mathrm{E}+00$ & 0.0000 & $0.000 \mathrm{E}+00$ & 0.0000 & $0.000 \mathrm{E}+00$ & 0.0000 & $1.551 \mathrm{E}-11$ & 0.0000 \\
\hline-237 & $0.000 \mathrm{E}+00$ & 0.0000 & $0.000 \mathrm{E}+00$ & 0.0000 & $0.000 \mathrm{E}+00$ & 0.0000 & $0.000 \mathrm{E}+00$ & 0.0000 & $0.000 \mathrm{E}+00$ & 0.0000 & $0.000 \mathrm{E}+00$ & 0.0000 & $1.118 \mathrm{E}-09$ & 0.0000 \\
\hline-238 & $0.000 \mathrm{E}+00$ & 0.0000 & $0.000 \mathrm{E}+00$ & 0.0000 & $0.000 \mathrm{E}+00$ & 0.0000 & $0.000 \mathrm{E}+00$ & 0.0000 & $0.000 \mathrm{E}+00$ & 0.0000 & $0.000 \mathrm{E}+00$ & 0.0000 & $2.174 \mathrm{E}-11$ & 0.0000 \\
\hline-239 & $0.000 \mathrm{E}+00$ & 0.0000 & $0.000 \mathrm{E}+00$ & 0.0000 & $0.000 \mathrm{E}+00$ & 0.0000 & $0.000 \mathrm{E}+00$ & 0.0000 & $0.000 \mathrm{E}+00$ & 0.0000 & $0.000 E+00$ & 0.0000 & $1.685 \mathrm{E}-13$ & 0.0000 \\
\hline-240 & $0.000 \mathrm{E}+00$ & 0.0000 & $0.000 \mathrm{E}+00$ & 0.0000 & $0.000 \mathrm{E}+00$ & 0.0000 & $0.000 \mathrm{E}+00$ & 0.0000 & $0.000 \mathrm{E}+00$ & 0.0000 & $0.000 E+00$ & 0.0000 & $2.048 E-16$ & 0.0000 \\
\hline-99 & $8.951 E+00$ & 0.8277 & $0.000 \mathrm{E}+00$ & 0.0000 & $0.000 \mathrm{E}+00$ & 0.0000 & $8.368 E-01$ & 0.0774 & $1.498 \mathrm{E}-02$ & 0.0014 & $1.011 \mathrm{E}+00$ & 0.0935 & $1.081 \mathrm{E}+01$ & 1.0000 \\
\hline-228 & $0.000 \mathrm{E}+00$ & 0.0000 & $0.000 \mathrm{E}+00$ & 0.0000 & $0.000 \mathrm{E}+00$ & 0.0000 & $0.000 \mathrm{E}+00$ & 0.0000 & $0.000 \mathrm{E}+00$ & 0.0000 & $0.000 \mathrm{E}+00$ & 0.0000 & $0.000 \mathrm{E}+00$ & 0.0000 \\
\hline-230 & $0.000 \mathrm{E}+00$ & 0.0000 & $0.000 \mathrm{E}+00$ & 0.0000 & $0.000 \mathrm{E}+00$ & 0.0000 & $0.000 \mathrm{E}+00$ & 0.0000 & $0.000 \mathrm{E}+00$ & 0.0000 & $0.000 E+00$ & 0.0000 & $1.066 \mathrm{E}-04$ & 0.0000 \\
\hline-232 & $0.000 \mathrm{E}+00$ & 0.0000 & $0.000 \mathrm{E}+00$ & 0.0000 & $0.000 \mathrm{E}+00$ & 0.0000 & $0.000 \mathrm{E}+00$ & 0.0000 & $0.000 \mathrm{E}+00$ & 0.0000 & $0.000 \mathrm{E}+00$ & 0.0000 & $1.331 \mathrm{E}-04$ & 0.0000 \\
\hline 34 & $0.000 \mathrm{E}+00$ & 0.0000 & $0.000 \mathrm{E}+00$ & 0.0000 & $0.000 \mathrm{E}+00$ & 0.0000 & $0.000 \mathrm{E}+00$ & 0.0000 & $0.000 \mathrm{E}+00$ & 0.0000 & $0.000 \mathrm{E}+00$ & 0.0000 & $3.972 \mathrm{E}-07$ & 0.0000 \\
\hline 35 & $0.000 \mathrm{E}+00$ & 0.0000 & $0.000 \mathrm{E}+00$ & 0.0000 & $0.000 \mathrm{E}+00$ & 0.0000 & $0.000 \mathrm{E}+00$ & 0.0000 & $0.000 \mathrm{E}+00$ & 0.0000 & $0.000 \mathrm{E}+00$ & 0.0000 & $4.546 \mathrm{E}-10$ & 0.0000 \\
\hline 38 & $0.000 \mathrm{E}+00$ & 0.0000 & $0.000 \mathrm{E}+00$ & 0.0000 & $0.000 \mathrm{E}+00$ & 0.0000 & $0.000 \mathrm{E}+00$ & 0.0000 & $0.000 \mathrm{E}+00$ & 0.0000 & $0.000 \mathrm{E}+00$ & 0.0000 & $1.224 \mathrm{E}-06$ & 0.0000 \\
\hline & $8.951 \mathrm{E}+00$ & 0.8277 & $0.000 \mathrm{E}+00$ & 0.0000 & $0.000 \mathrm{E}+00$ & 0.0000 & $8.368 \mathrm{E}-01$ & 0.0774 & $1.498 \mathrm{E}-02$ & 0.0014 & $1.011 \mathrm{E}+00$ & 0.0935 & $1.081 \mathrm{E}+01$ & 1.0000 \\
\hline
\end{tabular}

* Sum of all water independent and dependent pathways. 
RESRAD, Version 6.5

$\mathrm{T}^{1 / 2}$ Limit = 180 days

ummary : C746U Resident Farmer Deterministic Run

: $\mathrm{X}: \backslash F I N A L$ V2 $\backslash$ DOE FWD RUNS $\backslash C 746 U$ RF DOE SG FWD-FV2-100000YR.RAD

Total Dose Contributions TDOSE (i,p,t) for Individual Radionuclides (i) and Pathways (p) As mrem/yr and Fraction of Total Dose At $t=1.050 \mathrm{E}+03$ years

Water Independent Pathways (Inhalation excludes radon)

\begin{tabular}{|c|c|c|c|c|c|c|c|c|c|c|c|c|c|c|}
\hline \multirow{2}{*}{ Nuclide } & \multicolumn{2}{|c|}{ Ground } & \multicolumn{2}{|c|}{ Inhalation } & \multicolumn{2}{|c|}{ Radon } & \multicolumn{2}{|c|}{ Plant } & \multicolumn{2}{|c|}{ Meat } & \multicolumn{2}{|c|}{ Milk } & \multicolumn{2}{|c|}{ Soil } \\
\hline & mrem/yr & fract. & mrem/yr & fract. & mrem/yr & fract. & mrem/yr & fract. & mrem/yr & fract. & mrem/yr & fract. & mrem/yr & fract. \\
\hline-241 & $4.234 \mathrm{E}-10$ & 0.0000 & $0.000 \mathrm{E}+00$ & 0.0000 & $0.000 \mathrm{E}+00$ & 0.0000 & $6.742 \mathrm{E}-03$ & 0.0009 & $1.195 \mathrm{E}-05$ & 0.0000 & $1.147 \mathrm{E}-06$ & 0.0000 & $0.000 \mathrm{E}+00$ & 0.0000 \\
\hline-137 & $4.776 E-15$ & 0.0000 & $0.000 \mathrm{E}+00$ & 0.0000 & $0.000 \mathrm{E}+00$ & 0.0000 & $1.435 \mathrm{E}-12$ & 0.0000 & $1.304 \mathrm{E}-12$ & 0.0000 & $9.626 \mathrm{E}-13$ & 0.0000 & $0.000 \mathrm{E}+00$ & 0.0000 \\
\hline-237 & $3.889 \mathrm{E}-07$ & 0.0000 & $0.000 \mathrm{E}+00$ & 0.0000 & $0.000 \mathrm{E}+00$ & 0.0000 & $5.473 E-02$ & 0.0076 & $1.658 \mathrm{E}-03$ & 0.0002 & $2.372 E-05$ & 0.0000 & $0.000 \mathrm{E}+00$ & 0.0000 \\
\hline-238 & $5.054 \mathrm{E}-09$ & 0.0000 & $0.000 \mathrm{E}+00$ & 0.0000 & $0.000 \mathrm{E}+00$ & 0.0000 & $2.317 E-05$ & 0.0000 & $2.055 E-07$ & 0.0000 & $5.814 \mathrm{E}-07$ & 0.0000 & $0.000 \mathrm{E}+00$ & 0.0000 \\
\hline-239 & $1.194 \mathrm{E}-10$ & 0.0000 & $0.000 \mathrm{E}+00$ & 0.0000 & $0.000 \mathrm{E}+00$ & 0.0000 & $4.433 E-02$ & 0.0062 & $1.343 \mathrm{E}-04$ & 0.0000 & $3.719 \mathrm{E}-06$ & 0.0000 & $0.000 \mathrm{E}+00$ & 0.0000 \\
\hline-240 & $2.901 \mathrm{E}-14$ & 0.0000 & $0.000 \mathrm{E}+00$ & 0.0000 & $0.000 \mathrm{E}+00$ & 0.0000 & $4.088 \mathrm{E}-02$ & 0.0057 & $1.238 \mathrm{E}-04$ & 0.0000 & $3.460 \mathrm{E}-06$ & 0.0000 & $0.000 \mathrm{E}+00$ & 0.0000 \\
\hline 99 & $1.295 E-19$ & 0.0000 & $0.000 \mathrm{E}+00$ & 0.0000 & $0.000 \mathrm{E}+00$ & 0.0000 & $6.721 \mathrm{E}-05$ & 0.0000 & $2.039 \mathrm{E}-07$ & 0.0000 & $5.641 \mathrm{E}-06$ & 0.0000 & $0.000 \mathrm{E}+00$ & 0.0000 \\
\hline-228 & $0.000 \mathrm{E}+00$ & 0.0000 & $0.000 \mathrm{E}+00$ & 0.0000 & $0.000 \mathrm{E}+00$ & 0.0000 & $0.000 \mathrm{E}+00$ & 0.0000 & $0.000 \mathrm{E}+00$ & 0.0000 & $0.000 \mathrm{E}+00$ & 0.0000 & $0.000 \mathrm{E}+00$ & 0.0000 \\
\hline-230 & $8.932 \mathrm{E}-03$ & 0.0012 & $0.000 \mathrm{E}+00$ & 0.0000 & $0.000 \mathrm{E}+00$ & 0.0000 & $5.638 \mathrm{E}+00$ & 0.7834 & $1.483 \mathrm{E}-01$ & 0.0206 & $2.628 \mathrm{E}-01$ & 0.0365 & $0.000 \mathrm{E}+00$ & 0.0000 \\
\hline-232 & $3.686 E-03$ & 0.0005 & $0.000 \mathrm{E}+00$ & 0.0000 & $0.000 \mathrm{E}+00$ & 0.0000 & $5.753 \mathrm{E}-01$ & 0.0799 & $1.697 \mathrm{E}-02$ & 0.0024 & $4.699 \mathrm{E}-02$ & 0.0065 & $0.000 \mathrm{E}+00$ & 0.0000 \\
\hline 234 & $7.236 \mathrm{E}-05$ & 0.0000 & $0.000 \mathrm{E}+00$ & 0.0000 & $0.000 \mathrm{E}+00$ & 0.0000 & $1.440 \mathrm{E}-01$ & 0.0200 & $2.196 \mathrm{E}-03$ & 0.0003 & $7.061 \mathrm{E}-03$ & 0.0010 & $0.000 \mathrm{E}+00$ & 0.0000 \\
\hline 235 & $1.519 \mathrm{E}-07$ & 0.0000 & $0.000 \mathrm{E}+00$ & 0.0000 & $0.000 \mathrm{E}+00$ & 0.0000 & $1.115 \mathrm{E}-02$ & 0.0015 & $8.217 \mathrm{E}-04$ & 0.0001 & $2.012 \mathrm{E}-04$ & 0.0000 & $0.000 \mathrm{E}+00$ & 0.0000 \\
\hline 38 & $9.880 \mathrm{E}-05$ & 0.0000 & $0.000 \mathrm{E}+00$ & 0.0000 & $0.000 \mathrm{E}+00$ & 0.0000 & $9.831 \mathrm{E}-02$ & 0.0137 & $1.013 E-03$ & 0.0001 & $4.947 \mathrm{E}-03$ & 0.0007 & $0.000 \mathrm{E}+00$ & 0.0000 \\
\hline & 1.279E-02 & 0.0018 & $0.000 \mathrm{E}+00$ & 0.0000 & $0.000 \mathrm{E}+00$ & 0.0000 & $6.613 E+00$ & 0.9190 & $1.712 \mathrm{E}-01$ & 0.0238 & $3.221 \mathrm{E}-01$ & 0.0448 & $.000 \mathrm{E}+00$ & 0.0000 \\
\hline
\end{tabular}

Total Dose Contributions TDOSE (i,p,t) for Individual Radionuclides (i) and Pathways (p) As mrem/yr and Fraction of Total Dose At $t=1.050 \mathrm{E}+03$ years

Water Dependent Pathways

\begin{tabular}{|c|c|c|c|c|c|c|c|c|c|c|c|c|c|c|}
\hline & \multicolumn{2}{|c|}{ Water } & \multicolumn{2}{|c|}{ Fish } & \multicolumn{2}{|c|}{ Radon } & \multicolumn{2}{|c|}{ Plant } & \multicolumn{2}{|c|}{ Meat } & \multicolumn{2}{|c|}{ Milk } & \multicolumn{2}{|c|}{ All Pathways* } \\
\hline clide & mrem/yr & fract. & mrem/yr & fract. & mrem/yr & fract. & mrem/yr & fract. & mrem/yr & fract. & mrem/yr & fract. & mrem/yr & fract. \\
\hline-241 & $0.000 \mathrm{E}+00$ & 0.0000 & $0.000 \mathrm{E}+00$ & 0.0000 & $0.000 \mathrm{E}+00$ & 0.0000 & $0.000 \mathrm{E}+00$ & 0.0000 & $0.000 \mathrm{E}+00$ & 0.0000 & $0.000 E+00$ & 0.0000 & $6.755 E-03$ & 0.0009 \\
\hline-137 & $0.000 \mathrm{E}+00$ & 0.0000 & $0.000 \mathrm{E}+00$ & 0.0000 & $0.000 \mathrm{E}+00$ & 0.0000 & $0.000 \mathrm{E}+00$ & 0.0000 & $0.000 \mathrm{E}+00$ & 0.0000 & $0.000 \mathrm{E}+00$ & 0.0000 & $3.706 \mathrm{E}-12$ & 0.0000 \\
\hline-237 & $0.000 \mathrm{E}+00$ & 0.0000 & $0.000 \mathrm{E}+00$ & 0.0000 & $0.000 \mathrm{E}+00$ & 0.0000 & $0.000 \mathrm{E}+00$ & 0.0000 & $0.000 \mathrm{E}+00$ & 0.0000 & $0.000 \mathrm{E}+00$ & 0.0000 & $5.641 \mathrm{E}-02$ & 0.0078 \\
\hline 238 & $0.000 \mathrm{E}+00$ & 0.0000 & $0.000 \mathrm{E}+00$ & 0.0000 & $0.000 \mathrm{E}+00$ & 0.0000 & $0.000 \mathrm{E}+00$ & 0.0000 & $0.000 \mathrm{E}+00$ & 0.0000 & $0.000 \mathrm{E}+00$ & 0.0000 & $2.396 \mathrm{E}-05$ & 0.0000 \\
\hline 239 & $0.000 \mathrm{E}+00$ & 0.0000 & $0.000 \mathrm{E}+00$ & 0.0000 & $0.000 \mathrm{E}+00$ & 0.0000 & $0.000 \mathrm{E}+00$ & 0.0000 & $0.000 \mathrm{E}+00$ & 0.0000 & $0.000 \mathrm{E}+00$ & 0.0000 & $4.447 \mathrm{E}-02$ & 0.0062 \\
\hline 240 & $0.000 \mathrm{E}+00$ & 0.0000 & $0.000 \mathrm{E}+00$ & 0.0000 & $0.000 \mathrm{E}+00$ & 0.0000 & $0.000 \mathrm{E}+00$ & 0.0000 & $0.000 \mathrm{E}+00$ & 0.0000 & $0.000 \mathrm{E}+00$ & 0.0000 & $4.101 \mathrm{E}-02$ & 0.0057 \\
\hline 99 & $6.365 E-02$ & 0.0088 & $0.000 \mathrm{E}+00$ & 0.0000 & $0.000 \mathrm{E}+00$ & 0.0000 & $5.951 \mathrm{E}-03$ & 0.0008 & $1.065 E-04$ & 0.0000 & $7.190 \mathrm{E}-03$ & 0.0010 & $7.697 \mathrm{E}-02$ & 0.0107 \\
\hline 228 & $0.000 \mathrm{E}+00$ & 0.0000 & $0.000 \mathrm{E}+00$ & 0.0000 & $0.000 \mathrm{E}+00$ & 0.0000 & $0.000 \mathrm{E}+00$ & 0.0000 & $0.000 \mathrm{E}+00$ & 0.0000 & $0.000 \mathrm{E}+00$ & 0.0000 & $0.000 \mathrm{E}+00$ & 0.0000 \\
\hline 230 & $0.000 \mathrm{E}+00$ & 0.0000 & $0.000 \mathrm{E}+00$ & 0.0000 & $0.000 \mathrm{E}+00$ & 0.0000 & $0.000 \mathrm{E}+00$ & 0.0000 & $0.000 \mathrm{E}+00$ & 0.0000 & $0.000 \mathrm{E}+00$ & 0.0000 & $6.058 \mathrm{E}+00$ & 0.8418 \\
\hline 232 & $0.000 \mathrm{E}+00$ & 0.0000 & $0.000 \mathrm{E}+00$ & 0.0000 & $0.000 \mathrm{E}+00$ & 0.0000 & $0.000 \mathrm{E}+00$ & 0.0000 & $0.000 \mathrm{E}+00$ & 0.0000 & $0.000 \mathrm{E}+00$ & 0.0000 & $6.430 \mathrm{E}-01$ & 0.0893 \\
\hline 34 & $0.000 \mathrm{E}+00$ & 0.0000 & $0.000 \mathrm{E}+00$ & 0.0000 & $0.000 \mathrm{E}+00$ & 0.0000 & $0.000 \mathrm{E}+00$ & 0.0000 & $0.000 \mathrm{E}+00$ & 0.0000 & $0.000 \mathrm{E}+00$ & 0.0000 & $1.533 \mathrm{E}-01$ & 0.0213 \\
\hline 35 & $0.000 \mathrm{E}+00$ & 0.0000 & $0.000 \mathrm{E}+00$ & 0.0000 & $0.000 \mathrm{E}+00$ & 0.0000 & $0.000 \mathrm{E}+00$ & 0.0000 & $0.000 \mathrm{E}+00$ & 0.0000 & $0.000 \mathrm{E}+00$ & 0.0000 & $1.217 \mathrm{E}-02$ & 0.0017 \\
\hline 38 & $0.000 \mathrm{E}+00$ & 0.0000 & $0.000 \mathrm{E}+00$ & 0.0000 & $0.000 \mathrm{E}+00$ & 0.0000 & $0.000 \mathrm{E}+00$ & 0.0000 & $0.000 \mathrm{E}+00$ & 0.0000 & $0.000 \mathrm{E}+00$ & 0.0000 & $1.044 \mathrm{E}-01$ & 0.0145 \\
\hline & $6.365 E-02$ & 0.0088 & $0.000 \mathrm{E}+00$ & 0.0000 & $0.000 \mathrm{E}+00$ & 0.0000 & $5.951 \mathrm{E}-03$ & 0.0008 & $1.065 \mathrm{E}-04$ & 0.0000 & $7.190 \mathrm{E}-03$ & 010 & +00 & 1.0000 \\
\hline
\end{tabular}

* Sum of all water independent and dependent pathways. 
RESRAD, Version 6.5

$\mathrm{T}^{1 / 2}$ Limit = 180 days

07/18/2011 14:42 Page 27

ummary : C746U Resident Farmer Deterministic Run

: X: $\backslash$ FINAL V2 \DOE FWD RUNS \C746U RF DOE SG FWD-FV2-100000YR.RAD

Total Dose Contributions TDOSE(i,p,t) for Individual Radionuclides (i) and Pathways (p) As mrem/yr and Fraction of Total Dose At $t=1.000 \mathrm{E}+04$ years

Water Independent Pathways (Inhalation excludes radon)

\begin{tabular}{|c|c|c|c|c|c|c|c|c|c|c|c|c|c|c|}
\hline \multirow{2}{*}{ Nuclide } & \multicolumn{2}{|c|}{ Ground } & \multicolumn{2}{|c|}{ Inhalation } & \multicolumn{2}{|c|}{ Radon } & \multicolumn{2}{|c|}{ Plant } & \multicolumn{2}{|c|}{ Meat } & \multicolumn{2}{|c|}{ Milk } & \multicolumn{2}{|c|}{ Soil } \\
\hline & mrem/yr & fract. & mrem/yr & fract. & mrem/yr & fract. & mrem/yr & fract. & mrem/yr & fract. & mrem/yr & fract. & mrem/yr & fract. \\
\hline-241 & $1.724 \mathrm{E}-03$ & 0.0000 & $1.816 \mathrm{E}-07$ & 0.0000 & $0.000 \mathrm{E}+00$ & 0.0000 & $2.088 E-03$ & 0.0000 & $1.927 \mathrm{E}-04$ & 0.0000 & $1.010 \mathrm{E}-05$ & 0.0000 & $3.432 \mathrm{E}-05$ & 0.0000 \\
\hline-137 & $0.000 \mathrm{E}+00$ & 0.0000 & $0.000 \mathrm{E}+00$ & 0.0000 & $0.000 \mathrm{E}+00$ & 0.0000 & $0.000 \mathrm{E}+00$ & 0.0000 & $0.000 \mathrm{E}+00$ & 0.0000 & $0.000 \mathrm{E}+00$ & 0.0000 & $0.000 \mathrm{E}+00$ & 0.0000 \\
\hline-237 & $1.242 \mathrm{E}+00$ & 0.0005 & $1.327 \mathrm{E}-04$ & 0.0000 & $0.000 \mathrm{E}+00$ & 0.0000 & $1.496 \mathrm{E}+00$ & 0.0006 & $1.382 \mathrm{E}-01$ & 0.0001 & $7.847 E-03$ & 0.0000 & $2.514 \mathrm{E}-02$ & 0.0000 \\
\hline-238 & $6.838 E-03$ & 0.0000 & $3.439 E-07$ & 0.0000 & $0.000 \mathrm{E}+00$ & 0.0000 & $1.186 \mathrm{E}-02$ & 0.0000 & $1.230 \mathrm{E}-03$ & 0.0000 & $2.116 \mathrm{E}-03$ & 0.0000 & $3.191 \mathrm{E}-04$ & 0.0000 \\
\hline-239 & $5.108 E-03$ & 0.0000 & $4.259 \mathrm{E}-03$ & 0.0000 & $0.000 \mathrm{E}+00$ & 0.0000 & $2.652 \mathrm{E}+00$ & 0.0010 & $3.321 \mathrm{E}-01$ & 0.0001 & $9.176 \mathrm{E}-03$ & 0.0000 & $7.370 \mathrm{E}-01$ & 0.0003 \\
\hline-240 & $9.845 \mathrm{E}-04$ & 0.0000 & $1.968 \mathrm{E}-03$ & 0.0000 & $0.000 \mathrm{E}+00$ & 0.0000 & $1.225 \mathrm{E}+00$ & 0.0005 & $1.534 \mathrm{E}-01$ & 0.0001 & $4.485 E-03$ & 0.0000 & $3.405 E-01$ & 0.0001 \\
\hline 99 & $0.000 \mathrm{E}+00$ & 0.0000 & $0.000 \mathrm{E}+00$ & 0.0000 & $0.000 \mathrm{E}+00$ & 0.0000 & $0.000 \mathrm{E}+00$ & 0.0000 & $0.000 \mathrm{E}+00$ & 0.0000 & $0.000 \mathrm{E}+00$ & 0.0000 & $0.000 \mathrm{E}+00$ & 0.0000 \\
\hline-228 & $0.000 \mathrm{E}+00$ & 0.0000 & $0.000 \mathrm{E}+00$ & 0.0000 & $0.000 \mathrm{E}+00$ & 0.0000 & $0.000 \mathrm{E}+00$ & 0.0000 & $0.000 \mathrm{E}+00$ & 0.0000 & $0.000 \mathrm{E}+00$ & 0.0000 & $0.000 \mathrm{E}+00$ & 0.0000 \\
\hline-230 & $7.436 \mathrm{E}+02$ & 0.2735 & $1.648 \mathrm{E}-02$ & 0.0000 & $0.000 \mathrm{E}+00$ & 0.0000 & $1.224 \mathrm{E}+03$ & 0.4501 & 1. $220 \mathrm{E}+02$ & 0.0449 & $1.728 \mathrm{E}+02$ & 0.0636 & $2.669 \mathrm{E}+01$ & 0.0098 \\
\hline-232 & $4.839 E+01$ & 0.0178 & $1.028 E-03$ & 0.0000 & $0.000 \mathrm{E}+00$ & 0.0000 & $5.054 \mathrm{E}+01$ & 0.0186 & $3.109 \mathrm{E}+00$ & 0.0011 & $8.373 E+00$ & 0.0031 & $5.352 \mathrm{E}-01$ & 0.0002 \\
\hline 234 & $7.944 \mathrm{E}+01$ & 0.0292 & $3.957 \mathrm{E}-03$ & 0.0000 & $0.000 \mathrm{E}+00$ & 0.0000 & $1.377 \mathrm{E}+02$ & 0.0506 & $1.426 \mathrm{E}+01$ & 0.0052 & $2.448 E+01$ & 0.0090 & $3.693 \mathrm{E}+00$ & 0.0014 \\
\hline 235 & $4.626 \mathrm{E}+00$ & 0.0017 & $1.189 \mathrm{E}-03$ & 0.0000 & $0.000 \mathrm{E}+00$ & 0.0000 & $5.072 \mathrm{E}+00$ & 0.0019 & $2.638 \mathrm{E}+00$ & 0.0010 & $2.932 \mathrm{E}-01$ & 0.0001 & $2.835 \mathrm{E}-01$ & 0.0001 \\
\hline 38 & $1.706 \mathrm{E}+01$ & 0.0063 & $1.671 E-03$ & 0.0000 & $0.000 \mathrm{E}+00$ & 0.0000 & $8.921 \mathrm{E}+00$ & 0.0033 & $1.458 \mathrm{E}+00$ & 0.0005 & $6.576 \mathrm{E}+00$ & 0.0024 & $8.572 \mathrm{E}-01$ & 0.0003 \\
\hline & $8.943 E+02$ & 0.3290 & $3.068 E-02$ & 0.0000 & $0.000 \mathrm{E}+00$ & 0.0000 & $1.431 \mathrm{E}+03$ & 0.5264 & $1.441 \mathrm{E}+02$ & 0.0530 & $2.126 \mathrm{E}+02$ & 0.0782 & $3.316 \mathrm{E}+01$ & 0.0122 \\
\hline
\end{tabular}

Total Dose Contributions TDOSE (i,p,t) for Individual Radionuclides (i) and Pathways (p) As mrem/yr and Fraction of Total Dose At $t=1.000 \mathrm{E}+04$ years

Water Dependent Pathways

\begin{tabular}{|c|c|c|c|c|c|c|c|c|c|c|c|c|c|c|}
\hline & \multicolumn{2}{|c|}{ Water } & \multicolumn{2}{|c|}{ Fish } & \multicolumn{2}{|c|}{ Radon } & \multicolumn{2}{|c|}{ Plant } & \multicolumn{2}{|c|}{ Meat } & \multicolumn{2}{|c|}{ Milk } & \multicolumn{2}{|c|}{ All Pathways* } \\
\hline clide & mrem/yr & fract. & mrem/yr & fract. & mrem/yr & fract. & mrem/yr & fract. & mrem/yr & fract. & mrem/yr & fract. & mrem/yr & fract. \\
\hline 241 & $4.122 \mathrm{E}-03$ & 0.0000 & $0.000 \mathrm{E}+00$ & 0.0000 & $0.000 \mathrm{E}+00$ & 0.0000 & $1.681 \mathrm{E}-04$ & 0.0000 & $6.589 E-05$ & 0.0000 & $2.364 E-06$ & 0.0000 & $8.407 \mathrm{E}-03$ & 0.0000 \\
\hline-137 & $0.000 \mathrm{E}+00$ & 0.0000 & $0.000 \mathrm{E}+00$ & 0.0000 & $0.000 \mathrm{E}+00$ & 0.0000 & $0.000 \mathrm{E}+00$ & 0.0000 & $0.000 \mathrm{E}+00$ & 0.0000 & $0.000 \mathrm{E}+00$ & 0.0000 & $0.000 \mathrm{E}+00$ & 0.0000 \\
\hline-237 & $3.092 \mathrm{E}+00$ & 0.0011 & $0.000 \mathrm{E}+00$ & 0.0000 & $0.000 \mathrm{E}+00$ & 0.0000 & $1.261 \mathrm{E}-01$ & 0.0000 & $4.943 E-02$ & 0.0000 & $1.801 E-03$ & 0.0000 & $6.178 \mathrm{E}+00$ & 0.0023 \\
\hline-238 & $0.000 \mathrm{E}+00$ & 0.0000 & $0.000 \mathrm{E}+00$ & 0.0000 & $0.000 \mathrm{E}+00$ & 0.0000 & $0.000 \mathrm{E}+00$ & 0.0000 & $0.000 \mathrm{E}+00$ & 0.0000 & $0.000 \mathrm{E}+00$ & 0.0000 & $2.236 \mathrm{E}-02$ & 0.0000 \\
\hline-239 & $0.000 \mathrm{E}+00$ & 0.0000 & $0.000 \mathrm{E}+00$ & 0.0000 & $0.000 \mathrm{E}+00$ & 0.0000 & $0.000 \mathrm{E}+00$ & 0.0000 & $0.000 \mathrm{E}+00$ & 0.0000 & $0.000 E+00$ & 0.0000 & $3.740 \mathrm{E}+00$ & 0.0014 \\
\hline-240 & $0.000 \mathrm{E}+00$ & 0.0000 & $0.000 \mathrm{E}+00$ & 0.0000 & $0.000 \mathrm{E}+00$ & 0.0000 & $0.000 \mathrm{E}+00$ & 0.0000 & $0.000 \mathrm{E}+00$ & 0.0000 & $0.000 E+00$ & 0.0000 & $1.727 \mathrm{E}+00$ & 0.0006 \\
\hline-99 & $0.000 \mathrm{E}+00$ & 0.0000 & $0.000 \mathrm{E}+00$ & 0.0000 & $0.000 \mathrm{E}+00$ & 0.0000 & $0.000 \mathrm{E}+00$ & 0.0000 & $0.000 \mathrm{E}+00$ & 0.0000 & $0.000 \mathrm{E}+00$ & 0.0000 & $0.000 \mathrm{E}+00$ & 0.0000 \\
\hline-228 & $0.000 \mathrm{E}+00$ & 0.0000 & $0.000 \mathrm{E}+00$ & 0.0000 & $0.000 \mathrm{E}+00$ & 0.0000 & $0.000 \mathrm{E}+00$ & 0.0000 & $0.000 \mathrm{E}+00$ & 0.0000 & $0.000 \mathrm{E}+00$ & 0.0000 & $0.000 \mathrm{E}+00$ & 0.0000 \\
\hline-230 & $0.000 \mathrm{E}+00$ & 0.0000 & $0.000 \mathrm{E}+00$ & 0.0000 & $0.000 \mathrm{E}+00$ & 0.0000 & $0.000 \mathrm{E}+00$ & 0.0000 & $0.000 \mathrm{E}+00$ & 0.0000 & $0.000 E+00$ & 0.0000 & $2.289 \mathrm{E}+03$ & 0.8418 \\
\hline-232 & $0.000 \mathrm{E}+00$ & 0.0000 & $0.000 \mathrm{E}+00$ & 0.0000 & $0.000 \mathrm{E}+00$ & 0.0000 & $0.000 \mathrm{E}+00$ & 0.0000 & $0.000 \mathrm{E}+00$ & 0.0000 & $0.000 \mathrm{E}+00$ & 0.0000 & 1.110E+02 & 0.0408 \\
\hline 34 & $0.000 \mathrm{E}+00$ & 0.0000 & $0.000 \mathrm{E}+00$ & 0.0000 & $0.000 \mathrm{E}+00$ & 0.0000 & $0.000 \mathrm{E}+00$ & 0.0000 & $0.000 \mathrm{E}+00$ & 0.0000 & $0.000 \mathrm{E}+00$ & 0.0000 & $2.595 E+02$ & 0.0955 \\
\hline 35 & $0.000 \mathrm{E}+00$ & 0.0000 & $0.000 \mathrm{E}+00$ & 0.0000 & $0.000 \mathrm{E}+00$ & 0.0000 & $0.000 \mathrm{E}+00$ & 0.0000 & $0.000 \mathrm{E}+00$ & 0.0000 & $0.000 \mathrm{E}+00$ & 0.0000 & $1.291 \mathrm{E}+01$ & 0.0048 \\
\hline 38 & $0.000 \mathrm{E}+00$ & 0.0000 & $0.000 \mathrm{E}+00$ & 0.0000 & $0.000 \mathrm{E}+00$ & 0.0000 & $0.000 \mathrm{E}+00$ & 0.0000 & $0.000 \mathrm{E}+00$ & 0.0000 & $0.000 \mathrm{E}+00$ & 0.0000 & $3.487 \mathrm{E}+01$ & 0.0128 \\
\hline & $3.096 \mathrm{E}+00$ & 0.0011 & $0.000 \mathrm{E}+00$ & 0.0000 & $0.000 \mathrm{E}+00$ & 0.0000 & $1.263 \mathrm{E}-01$ & 0.0000 & $4.950 \mathrm{E}-02$ & 0.0000 & $1.804 \mathrm{E}-03$ & 0.0000 & $.719 E+03$ & 1. \\
\hline
\end{tabular}

* Sum of all water independent and dependent pathways. 
RESRAD, Version 6.5

$\mathrm{T}^{1 / 2}$ Limit = 180 days

07/18/2011 $14: 42 \quad$ Page 28

ummary : C746U Resident Farmer Deterministic Run

: $\mathrm{X}: \backslash F I N A L$ V2 $\backslash$ DOE FWD RUNS $\backslash C 746 U$ RF DOE SG FWD-FV2-100000YR.RAD

Total Dose Contributions TDOSE (i,p,t) for Individual Radionuclides (i) and Pathways (p) As mrem/yr and Fraction of Total Dose At $t=1.000 \mathrm{E}+05$ years

Water Independent Pathways (Inhalation excludes radon)

\begin{tabular}{|c|c|c|c|c|c|c|c|c|c|c|c|c|c|c|}
\hline \multirow{2}{*}{ Nuclide } & \multicolumn{2}{|c|}{ Ground } & \multicolumn{2}{|c|}{ Inhalation } & \multicolumn{2}{|c|}{ Radon } & \multicolumn{2}{|c|}{ Plant } & \multicolumn{2}{|c|}{ Meat } & \multicolumn{2}{|c|}{ Milk } & \multicolumn{2}{|c|}{ Soil } \\
\hline & mrem/yr & fract. & mrem/yr & fract. & mrem/yr & fract. & mrem/yr & fract. & mrem/yr & fract. & mrem/yr & fract. & mrem/yr & fract. \\
\hline-241 & $0.000 \mathrm{E}+00$ & 0.0000 & $0.000 \mathrm{E}+00$ & 0.0000 & $0.000 \mathrm{E}+00$ & 0.0000 & $0.000 \mathrm{E}+00$ & 0.0000 & $0.000 \mathrm{E}+00$ & 0.0000 & $0.000 \mathrm{E}+00$ & 0.0000 & $0.000 \mathrm{E}+00$ & 0.0000 \\
\hline-137 & $0.000 \mathrm{E}+00$ & 0.0000 & $0.000 \mathrm{E}+00$ & 0.0000 & $0.000 \mathrm{E}+00$ & 0.0000 & $0.000 \mathrm{E}+00$ & 0.0000 & $0.000 \mathrm{E}+00$ & 0.0000 & $0.000 \mathrm{E}+00$ & 0.0000 & $0.000 \mathrm{E}+00$ & 0.0000 \\
\hline-237 & $0.000 \mathrm{E}+00$ & 0.0000 & $0.000 \mathrm{E}+00$ & 0.0000 & $0.000 \mathrm{E}+00$ & 0.0000 & $0.000 \mathrm{E}+00$ & 0.0000 & $0.000 \mathrm{E}+00$ & 0.0000 & $0.000 \mathrm{E}+00$ & 0.0000 & $0.000 \mathrm{E}+00$ & 0.0000 \\
\hline-238 & $0.000 \mathrm{E}+00$ & 0.0000 & $0.000 \mathrm{E}+00$ & 0.0000 & $0.000 \mathrm{E}+00$ & 0.0000 & $0.000 \mathrm{E}+00$ & 0.0000 & $0.000 \mathrm{E}+00$ & 0.0000 & $0.000 \mathrm{E}+00$ & 0.0000 & $0.000 \mathrm{E}+00$ & 0.0000 \\
\hline-239 & $0.000 \mathrm{E}+00$ & 0.0000 & $0.000 \mathrm{E}+00$ & 0.0000 & $0.000 \mathrm{E}+00$ & 0.0000 & $0.000 \mathrm{E}+00$ & 0.0000 & $0.000 \mathrm{E}+00$ & 0.0000 & $0.000 \mathrm{E}+00$ & 0.0000 & $0.000 \mathrm{E}+00$ & 0.0000 \\
\hline-240 & $0.000 \mathrm{E}+00$ & 0.0000 & $0.000 \mathrm{E}+00$ & 0.0000 & $0.000 \mathrm{E}+00$ & 0.0000 & $0.000 \mathrm{E}+00$ & 0.0000 & $0.000 \mathrm{E}+00$ & 0.0000 & $0.000 \mathrm{E}+00$ & 0.0000 & $0.000 \mathrm{E}+00$ & 0.0000 \\
\hline 99 & $0.000 \mathrm{E}+00$ & 0.0000 & $0.000 \mathrm{E}+00$ & 0.0000 & $0.000 \mathrm{E}+00$ & 0.0000 & $0.000 \mathrm{E}+00$ & 0.0000 & $0.000 \mathrm{E}+00$ & 0.0000 & $0.000 \mathrm{E}+00$ & 0.0000 & $0.000 \mathrm{E}+00$ & 0.0000 \\
\hline-228 & $0.000 \mathrm{E}+00$ & 0.0000 & $0.000 \mathrm{E}+00$ & 0.0000 & $0.000 \mathrm{E}+00$ & 0.0000 & $0.000 \mathrm{E}+00$ & 0.0000 & $0.000 \mathrm{E}+00$ & 0.0000 & $0.000 \mathrm{E}+00$ & 0.0000 & $0.000 \mathrm{E}+00$ & 0.0000 \\
\hline-230 & $0.000 \mathrm{E}+00$ & 0.0000 & $0.000 \mathrm{E}+00$ & 0.0000 & $0.000 \mathrm{E}+00$ & 0.0000 & $0.000 \mathrm{E}+00$ & 0.0000 & $0.000 \mathrm{E}+00$ & 0.0000 & $0.000 \mathrm{E}+00$ & 0.0000 & $0.000 \mathrm{E}+00$ & 0.0000 \\
\hline-232 & $0.000 \mathrm{E}+00$ & 0.0000 & $0.000 \mathrm{E}+00$ & 0.0000 & $0.000 \mathrm{E}+00$ & 0.0000 & $0.000 \mathrm{E}+00$ & 0.0000 & $0.000 \mathrm{E}+00$ & 0.0000 & $0.000 \mathrm{E}+00$ & 0.0000 & $0.000 \mathrm{E}+00$ & 0.0000 \\
\hline 234 & $0.000 \mathrm{E}+00$ & 0.0000 & $0.000 \mathrm{E}+00$ & 0.0000 & $0.000 \mathrm{E}+00$ & 0.0000 & $0.000 \mathrm{E}+00$ & 0.0000 & $0.000 \mathrm{E}+00$ & 0.0000 & $0.000 \mathrm{E}+00$ & 0.0000 & $0.000 \mathrm{E}+00$ & 0.0000 \\
\hline 235 & $0.000 \mathrm{E}+00$ & 0.0000 & $0.000 \mathrm{E}+00$ & 0.0000 & $0.000 \mathrm{E}+00$ & 0.0000 & $0.000 \mathrm{E}+00$ & 0.0000 & $0.000 \mathrm{E}+00$ & 0.0000 & $0.000 \mathrm{E}+00$ & 0.0000 & $0.000 \mathrm{E}+00$ & 0.0000 \\
\hline 38 & $0.000 \mathrm{E}+00$ & 0.0000 & $0.000 \mathrm{E}+00$ & 0.0000 & $0.000 \mathrm{E}+00$ & 0.0000 & $0.000 \mathrm{E}+00$ & 0.0000 & $0.000 \mathrm{E}+00$ & 0.0000 & $0.000 \mathrm{E}+00$ & 0.0000 & $0.000 \mathrm{E}+00$ & 0.0000 \\
\hline & $0.000 \mathrm{E}+00$ & 0.0000 & $0.000 \mathrm{E}+00$ & 0.0000 & $0.000 \mathrm{E}+00$ & 0.0000 & $0.000 \mathrm{E}+00$ & 0.0000 & $0.000 \mathrm{E}+00$ & 0.0000 & $0.000 \mathrm{E}+00$ & 0.0000 & $0.000 \mathrm{E}+00$ & 0.0000 \\
\hline
\end{tabular}

Total Dose Contributions TDOSE (i,p,t) for Individual Radionuclides (i) and Pathways (p) As mrem/yr and Fraction of Total Dose At $t=1.000 \mathrm{E}+05$ years

Water Dependent Pathways

\begin{tabular}{|c|c|c|c|c|c|c|c|c|c|c|c|c|c|c|}
\hline & \multicolumn{2}{|c|}{ Water } & \multicolumn{2}{|c|}{ Fish } & \multicolumn{2}{|c|}{ Radon } & \multicolumn{2}{|c|}{ Plant } & \multicolumn{2}{|c|}{ Meat } & \multicolumn{2}{|c|}{ Milk } & \multicolumn{2}{|c|}{ All Pathways* } \\
\hline clide & mrem/yr & fract. & mrem/yr & fract. & mrem/yr & fract. & mrem/yr & fract. & mrem/yr & fract. & mrem/yr & fract. & mrem/yr & fract. \\
\hline-241 & $4.511 E-05$ & 0.0012 & $0.000 \mathrm{E}+00$ & 0.0000 & $0.000 \mathrm{E}+00$ & 0.0000 & $1.831 \mathrm{E}-06$ & 0.0000 & $1.728 \mathrm{E}-07$ & 0.0000 & $1.756 \mathrm{E}-06$ & 0.0000 & $4.887 \mathrm{E}-05$ & 0.0013 \\
\hline-137 & $0.000 \mathrm{E}+00$ & 0.0000 & $0.000 \mathrm{E}+00$ & 0.0000 & $0.000 \mathrm{E}+00$ & 0.0000 & $0.000 \mathrm{E}+00$ & 0.0000 & $0.000 \mathrm{E}+00$ & 0.0000 & $0.000 \mathrm{E}+00$ & 0.0000 & $0.000 \mathrm{E}+00$ & 0.0000 \\
\hline-237 & $3.478 E-02$ & 0.9219 & $0.000 \mathrm{E}+00$ & 0.0000 & $0.000 \mathrm{E}+00$ & 0.0000 & $1.412 \mathrm{E}-03$ & 0.0374 & $1.332 \mathrm{E}-04$ & 0.0035 & $1.354 \mathrm{E}-03$ & 0.0359 & $3.768 E-02$ & 0.9987 \\
\hline-238 & $0.000 \mathrm{E}+00$ & 0.0000 & $0.000 \mathrm{E}+00$ & 0.0000 & $0.000 \mathrm{E}+00$ & 0.0000 & $0.000 \mathrm{E}+00$ & 0.0000 & $0.000 \mathrm{E}+00$ & 0.0000 & $0.000 \mathrm{E}+00$ & 0.0000 & $0.000 \mathrm{E}+00$ & 0.0000 \\
\hline-239 & $0.000 \mathrm{E}+00$ & 0.0000 & $0.000 \mathrm{E}+00$ & 0.0000 & $0.000 \mathrm{E}+00$ & 0.0000 & $0.000 \mathrm{E}+00$ & 0.0000 & $0.000 \mathrm{E}+00$ & 0.0000 & $0.000 E+00$ & 0.0000 & $0.000 \mathrm{E}+00$ & 0.0000 \\
\hline-240 & $0.000 \mathrm{E}+00$ & 0.0000 & $0.000 \mathrm{E}+00$ & 0.0000 & $0.000 \mathrm{E}+00$ & 0.0000 & $0.000 \mathrm{E}+00$ & 0.0000 & $0.000 \mathrm{E}+00$ & 0.0000 & $0.000 E+00$ & 0.0000 & $0.000 \mathrm{E}+00$ & 0.0000 \\
\hline-99 & $0.000 \mathrm{E}+00$ & 0.0000 & $0.000 \mathrm{E}+00$ & 0.0000 & $0.000 \mathrm{E}+00$ & 0.0000 & $0.000 \mathrm{E}+00$ & 0.0000 & $0.000 \mathrm{E}+00$ & 0.0000 & $0.000 \mathrm{E}+00$ & 0.0000 & $0.000 \mathrm{E}+00$ & 0.0000 \\
\hline-228 & $0.000 \mathrm{E}+00$ & 0.0000 & $0.000 \mathrm{E}+00$ & 0.0000 & $0.000 \mathrm{E}+00$ & 0.0000 & $0.000 \mathrm{E}+00$ & 0.0000 & $0.000 \mathrm{E}+00$ & 0.0000 & $0.000 \mathrm{E}+00$ & 0.0000 & $0.000 \mathrm{E}+00$ & 0.0000 \\
\hline-230 & $0.000 \mathrm{E}+00$ & 0.0000 & $0.000 \mathrm{E}+00$ & 0.0000 & $0.000 \mathrm{E}+00$ & 0.0000 & $0.000 \mathrm{E}+00$ & 0.0000 & $0.000 \mathrm{E}+00$ & 0.0000 & $0.000 E+00$ & 0.0000 & $0.000 \mathrm{E}+00$ & 0.0000 \\
\hline-232 & $0.000 \mathrm{E}+00$ & 0.0000 & $0.000 \mathrm{E}+00$ & 0.0000 & $0.000 \mathrm{E}+00$ & 0.0000 & $0.000 \mathrm{E}+00$ & 0.0000 & $0.000 \mathrm{E}+00$ & 0.0000 & $0.000 \mathrm{E}+00$ & 0.0000 & $0.000 \mathrm{E}+00$ & 0.0000 \\
\hline 34 & $0.000 \mathrm{E}+00$ & 0.0000 & $0.000 \mathrm{E}+00$ & 0.0000 & $0.000 \mathrm{E}+00$ & 0.0000 & $0.000 \mathrm{E}+00$ & 0.0000 & $0.000 \mathrm{E}+00$ & 0.0000 & $0.000 \mathrm{E}+00$ & 0.0000 & $0.000 \mathrm{E}+00$ & 0.0000 \\
\hline 35 & $0.000 \mathrm{E}+00$ & 0.0000 & $0.000 \mathrm{E}+00$ & 0.0000 & $0.000 \mathrm{E}+00$ & 0.0000 & $0.000 \mathrm{E}+00$ & 0.0000 & $0.000 \mathrm{E}+00$ & 0.0000 & $0.000 \mathrm{E}+00$ & 0.0000 & $0.000 \mathrm{E}+00$ & 0.0000 \\
\hline 38 & $0.000 \mathrm{E}+00$ & 0.0000 & $0.000 \mathrm{E}+00$ & 0.0000 & $0.000 \mathrm{E}+00$ & 0.0000 & $0.000 \mathrm{E}+00$ & 0.0000 & $0.000 \mathrm{E}+00$ & 0.0000 & $0.000 \mathrm{E}+00$ & 0.0000 & $0.000 \mathrm{E}+00$ & 0.0000 \\
\hline & $3.483 E-02$ & 0.9231 & $0.000 \mathrm{E}+00$ & 0.0000 & $0.000 \mathrm{E}+00$ & 0.0000 & $1.414 \mathrm{E}-03$ & 0.0375 & $1.334 \mathrm{E}-04$ & 0.0035 & $1.355 \mathrm{E}-03$ & 0.0359 & $3 E-02$ & 1.0000 \\
\hline
\end{tabular}

* Sum of all water independent and dependent pathways. 
RESRAD, Version 6.5

ummary : C746U Resident Farmer Deterministic Run

File : $\mathrm{X}: \backslash F I N A L$ V2 $\backslash$ DOE FWD RUNS $\backslash C 746 \mathrm{U}$ RF DOE SG FWD-FV2-100000YR.RAD

Dose/Source Ratios Summed Over All Pathways

Parent and Progeny Principal Radionuclide Contributions Indicated

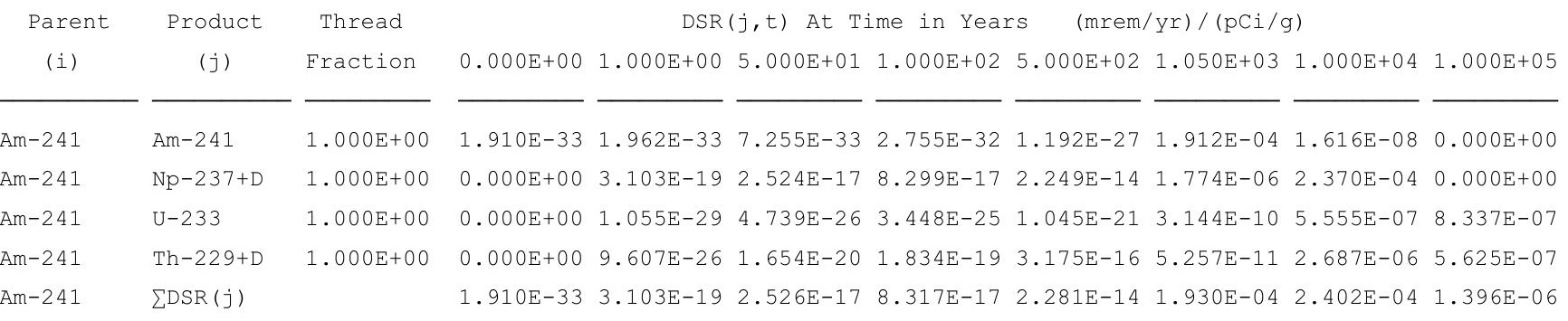

Cs $-137+\mathrm{D} \quad \mathrm{Cs}-137+\mathrm{D}$

$\begin{array}{lllllllll}1.000 \mathrm{E}+00 & 1.271 \mathrm{E}-09 & 1.253 \mathrm{E}-09 & 6.094 \mathrm{E}-10 & 2.922 \mathrm{E}-10 & 8.163 \mathrm{E}-13 & 1.950 \mathrm{E}-13 & 0.000 \mathrm{E}+00 & 0.000 \mathrm{E}+00\end{array}$

$\mathrm{Np}-237+\mathrm{D}$

$\mathrm{Np}-237+\mathrm{D}$

$\mathrm{Np}-237+\mathrm{D}$

$\mathrm{Np}-237+\mathrm{D}$

$\mathrm{Pu}-238$

$\mathrm{Pu}-238$

$\mathrm{Pu}-238$

$\mathrm{Pu}-238$

$\mathrm{Pu}-238$

$\mathrm{Pu}-238$

$\mathrm{Pu}-238$

$\mathrm{Pu}-239$

$\mathrm{Pu}-239$

$\mathrm{Pu}-239$

$\mathrm{Pu}-239$

$\mathrm{Pu}-239$

Pu-240

$\mathrm{Pu}-240$

$\mathrm{Pu}-240$

$\mathrm{Pu}-240$

$\mathrm{Pu}-240$

$\mathrm{Pu}-240$

$\mathrm{Pu}-240$

TC-99

Th $-228+D$

Th -230

Th-230

$\mathrm{Th}-230$

Th-230
$\mathrm{Np}-237+\mathrm{D}$

$\mathrm{U}-233$

Th-229+D

$\sum \operatorname{DSR}(j)$

$\mathrm{Pu}-238$

$\mathrm{Pu}-238$

$\mathrm{U}-234$

Th-230

$\mathrm{Ra}-226+\mathrm{D}$

$\mathrm{Pb}-210+\mathrm{D}$

$\sum \operatorname{DSR}(j)$

$\mathrm{Pu}-239$

$\mathrm{U}-235+\mathrm{D}$

$\mathrm{Pa}-231$

AC $-227+D$

$\sum \operatorname{DSR}(j)$

$\mathrm{Pu}-240$

$\mathrm{Pu}-240$

$\mathrm{U}-236$

Th-232

$\mathrm{Ra}-228+\mathrm{D}$

Th-228+D

$\sum \operatorname{DSR}(j)$

TC-99

Th-228+D

Th-230

Ra-226+D

$\mathrm{Pb}-210+\mathrm{D}$

$\sum \operatorname{DSR}(j)$
1. $000 \mathrm{E}+00$

$1.000 \mathrm{E}+00$

$1.000 \mathrm{E}+00$

$1.840 \mathrm{E}-0$

$1.000 \mathrm{E}+00$

$1.000 \mathrm{E}+00$

1. $000 \mathrm{E}+00$

1. $000 \mathrm{E}+00$

1. $000 \mathrm{E}+00$

$1.000 \mathrm{E}+00$

1. $000 \mathrm{E}+00$

1. $000 \mathrm{E}+00$

1. $000 \mathrm{E}+00$

4. $950 \mathrm{E}-0$

1. $000 \mathrm{E}+00$

1. $000 \mathrm{E}+00$

1. $000 \mathrm{E}+00$

1. $000 \mathrm{E}+00$

1. $000 \mathrm{E}+00$

1. $000 \mathrm{E}+00$

1. $000 \mathrm{E}+00$

1. $000 \mathrm{E}+00$

1. $000 \mathrm{E}+00$

1. $000 \mathrm{E}+00$

(0)

$\begin{array}{llllllll}0.000 \mathrm{E}+00 & 5.454 \mathrm{E}-19 & 1.273 \mathrm{E}-15 & 5.257 \mathrm{E}-15 & 7.641 \mathrm{E}-13 & 3.610 \mathrm{E}-02 & 9.735 \mathrm{E}+00 & 0.000 \mathrm{E}+00\end{array}$

$\begin{array}{llllllll}2.392 \mathrm{E}-22 & 7.565 \mathrm{E}-11 & 5.249 \mathrm{E}-09 & 1.467 \mathrm{E}-08 & 1.066 \mathrm{E}-06 & 6.058 \mathrm{E}-02 & 2.289 \mathrm{E}+01 & 0.000 \mathrm{E}+00\end{array}$ 
RESRAD, Version 6.5

$\mathrm{T}^{1 / 2}$ Limit $=180$ days

ummary : C746U Resident Farmer Deterministic Run

File : $\mathrm{X}: \backslash F I N A L$ V2 $\backslash$ DOE FWD RUNS \C746U RF DOE SG FWD-FV2-100000YR.RAD

Dose/Source Ratios Summed Over All Pathways

Parent and Progeny Principal Radionuclide Contributions Indicated

\begin{tabular}{|c|c|c|c|c|c|c|c|c|c|c|}
\hline Parent & Product & Thread & & $\mathrm{DS}$ & $(j, t) \quad A t$ & ime in Yea & (mren & $/ \mathrm{yr}) /(\mathrm{pCi} / \mathrm{g}$ & & \\
\hline (i) & $(j)$ & Fraction & $0.000 \mathrm{E}+00$ & $1.000 \mathrm{E}+00$ & $5.000 \mathrm{E}+01$ & $1.000 \mathrm{E}+02$ & $5.000 \mathrm{E}+02$ & $1.050 \mathrm{E}+03$ & $1.000 \mathrm{E}+04$ & $1.000 \mathrm{E}+05$ \\
\hline 232 & $T h-232$ & $1.000 \mathrm{E}+00$ & $1.155 \mathrm{E}-24$ & $1.177 \mathrm{E}-24$ & $2.922 \mathrm{E}-24$ & $7.393 E-24$ & $1.241 \mathrm{E}-20$ & $1.189 \mathrm{E}-03$ & $1.485 \mathrm{E}-01$ & $0.000 \mathrm{E}+00$ \\
\hline 232 & $\mathrm{Ra}-228+\mathrm{D}$ & $1.000 \mathrm{E}+00$ & $0.000 \mathrm{E}+00$ & $2.177 \mathrm{E}-09$ & $2.773 \mathrm{E}-08$ & $4.064 \mathrm{E}-08$ & $8.465 E-07$ & $1.576 \mathrm{E}-01$ & 1. $983 \mathrm{E}+01$ & $0.000 \mathrm{E}+00$ \\
\hline-232 & $\mathrm{Th}-228+\mathrm{D}$ & $1.000 \mathrm{E}+00$ & $0.000 \mathrm{E}+00$ & $3.082 \mathrm{E}-08$ & $2.206 \mathrm{E}-06$ & $2.983 \mathrm{E}-06$ & $3.244 \mathrm{E}-05$ & $1.998 \mathrm{E}-03$ & $7.758 \mathrm{E}+00$ & $0.000 \mathrm{E}+00$ \\
\hline-232 & $\sum \operatorname{DSR}(j)$ & & $1.155 \mathrm{E}-24$ & $3.300 \mathrm{E}-08$ & $2.234 \mathrm{E}-06$ & $3.024 \mathrm{E}-06$ & $3.328 \mathrm{E}-05$ & $1.607 \mathrm{E}-01$ & $2.774 \mathrm{E}+01$ & $0.000 \mathrm{E}+00$ \\
\hline 234 & $U-234$ & $1.000 \mathrm{E}+00$ & $6.835 E-24$ & $6.957 \mathrm{E}-24$ & $1.656 \mathrm{E}-23$ & $4.011 \mathrm{E}-23$ & $4.756 \mathrm{E}-20$ & $6.525 E-04$ & $9.484 \mathrm{E}-02$ & $0.000 \mathrm{E}+00$ \\
\hline-234 & $\mathrm{Th}-230$ & $1.000 \mathrm{E}+00$ & $0.000 \mathrm{E}+00$ & $2.190 \mathrm{E}-27$ & $2.494 \mathrm{E}-25$ & $1.156 \mathrm{E}-24$ & 4. $793 E-21$ & $1.009 E-05$ & $1.046 \mathrm{E}-02$ & $0.000 \mathrm{E}+00$ \\
\hline 234 & $\mathrm{Ra}-226+\mathrm{D}$ & $1.000 \mathrm{E}+00$ & $0.000 \mathrm{E}+00$ & $3.405 E-16$ & $1.185 \mathrm{E}-12$ & $6.647 \mathrm{E}-12$ & $2.482 E-09$ & $1.185 E-04$ & $8.695 E-01$ & $0.000 \mathrm{E}+00$ \\
\hline 234 & $\mathrm{~Pb}-210+\mathrm{D}$ & $1.000 \mathrm{E}+00$ & $0.000 \mathrm{E}+00$ & $1.641 \mathrm{E}-24$ & $2.135 \mathrm{E}-19$ & 1. $903 \mathrm{E}-18$ & $1.668 \mathrm{E}-15$ & $1.770 \mathrm{E}-04$ & $6.474 \mathrm{E}-01$ & $0.000 \mathrm{E}+00$ \\
\hline 234 & $\sum \operatorname{DSR}(j)$ & & $6.835 E-24$ & $3.405 E-16$ & $1.185 \mathrm{E}-12$ & $6.647 \mathrm{E}-12$ & $2.482 E-09$ & $9.581 E-04$ & $1.622 \mathrm{E}+00$ & $0.000 \mathrm{E}+00$ \\
\hline$-235+D$ & $\mathrm{U}-235+\mathrm{D}$ & $1.000 \mathrm{E}+00$ & $1.236 \mathrm{E}-14$ & 1. $251 \mathrm{E}-14$ & $2.291 \mathrm{E}-14$ & $4.249 \mathrm{E}-14$ & $5.944 \mathrm{E}-12$ & $6.337 \mathrm{E}-04$ & $5.458 \mathrm{E}-01$ & $0.000 \mathrm{E}+00$ \\
\hline$-235+D$ & $\mathrm{~Pa}-231$ & $1.000 \mathrm{E}+00$ & $0.000 \mathrm{E}+00$ & $5.896 \mathrm{E}-18$ & $4.955 E-16$ & $1.684 \mathrm{E}-15$ & $5.839 E-13$ & $9.104 \mathrm{E}-04$ & $9.492 \mathrm{E}-01$ & $0.000 \mathrm{E}+00$ \\
\hline$-235+D$ & $A C-227+D$ & $1.000 \mathrm{E}+00$ & $0.000 \mathrm{E}+00$ & $2.781 \mathrm{E}-17$ & $6.744 \mathrm{E}-14$ & $2.910 \mathrm{E}-13$ & $6.341 \mathrm{E}-11$ & $3.284 \mathrm{E}-04$ & $4.918 E-01$ & $0.000 \mathrm{E}+00$ \\
\hline$-235+D$ & $\sum \operatorname{DSR}(j)$ & & $1.236 \mathrm{E}-14$ & $1.254 \mathrm{E}-14$ & $9.085 \mathrm{E}-14$ & $3.352 \mathrm{E}-13$ & $6.994 \mathrm{E}-11$ & $1.873 E-03$ & $1.987 \mathrm{E}+00$ & $0.000 \mathrm{E}+00$ \\
\hline-238 & $\mathrm{U}-238$ & $5.400 \mathrm{E}-05$ & $0.000 \mathrm{E}+00$ & $0.000 \mathrm{E}+00$ & $0.000 \mathrm{E}+00$ & $0.000 \mathrm{E}+00$ & $0.000 \mathrm{E}+00$ & $3.261 \mathrm{E}-08$ & $4.852 E-06$ & $0.000 \mathrm{E}+00$ \\
\hline $38+D$ & $\mathrm{U}-238+\mathrm{D}$ & $9.999 \mathrm{E}-01$ & $1.414 \mathrm{E}-10$ & $1.425 \mathrm{E}-10$ & $2.107 \mathrm{E}-10$ & $3.141 \mathrm{E}-10$ & $7.648 \mathrm{E}-09$ & $6.500 \mathrm{E}-04$ & $1.974 \mathrm{E}-01$ & $0.000 \mathrm{E}+00$ \\
\hline$-238+D$ & $\mathrm{U}-234$ & $9.999 \mathrm{E}-01$ & $0.000 \mathrm{E}+00$ & $1.972 \mathrm{E}-29$ & $2.347 E-27$ & $1.137 \mathrm{E}-26$ & $6.745 E-23$ & $1.945 E-06$ & $2.727 \mathrm{E}-03$ & $0.000 \mathrm{E}+00$ \\
\hline$-238+D$ & $T h-230$ & $9.999 \mathrm{E}-01$ & $0.000 \mathrm{E}+00$ & $3.104 \mathrm{E}-33$ & $1.767 \mathrm{E}-29$ & $1.638 E-28$ & $3.394 E-24$ & $1.500 E-08$ & $1.461 \mathrm{E}-04$ & $0.000 \mathrm{E}+00$ \\
\hline$-238+D$ & $\mathrm{Ra}-226+\mathrm{D}$ & $9.999 \mathrm{E}-01$ & $0.000 \mathrm{E}+00$ & $3.218 E-22$ & $5.610 \mathrm{E}-17$ & $6.303 E-16$ & $1.193 \mathrm{E}-12$ & $1.217 \mathrm{E}-07$ & $1.015 E-02$ & $0.000 \mathrm{E}+00$ \\
\hline$-238+D$ & $\mathrm{~Pb}-210+\mathrm{D}$ & $9.999 \mathrm{E}-01$ & $0.000 \mathrm{E}+00$ & $1.165 \mathrm{E}-30$ & $8.088 E-24$ & $1.513 \mathrm{E}-22$ & $7.559 \mathrm{E}-19$ & $1.765 E-07$ & $7.528 E-03$ & $0.000 \mathrm{E}+00$ \\
\hline$-238+D$ & $\sum \operatorname{DSR}(j)$ & & $1.414 \mathrm{E}-10$ & $1.425 \mathrm{E}-10$ & $2.107 \mathrm{E}-10$ & $3.141 \mathrm{E}-10$ & $7.649 E-09$ & $6.523 E-04$ & $2.180 E-01$ & $0.000 \mathrm{E}+00$ \\
\hline
\end{tabular}

The DSR includes contributions from associated (half-life $\leq 180$ days) daughters. 
RESRAD, Version $6.5 \quad \mathrm{~T}^{1} \frac{1}{2}$ Limit $=180$ days

07/18/2011 14:42 Page 31

ummary : C746U Resident Farmer Deterministic Run

File : X: $\backslash F I N A L$ V2 $\backslash$ DOE FWD RUNS \C746U RF DOE SG FWD-FV2-100000YR.RAD

Single Radionuclide Soil Guidelines G(i,t) in pCi/g

Basic Radiation Dose Limit $=1.000 \mathrm{E}+02 \mathrm{mrem} / \mathrm{yr}$

Nuclide

\begin{tabular}{|c|c|c|c|c|c|c|c|c|}
\hline (i) & $t=0.000 E+00$ & $1.000 \mathrm{E}+00$ & $5.000 E+01$ & $1.000 \mathrm{E}+02$ & $5.000 \mathrm{E}+02$ & $1.050 \mathrm{E}+03$ & $1.000 \mathrm{E}+04$ & $1.000 \mathrm{E}+05$ \\
\hline-241 & $\star 3.431 \mathrm{E}+12$ & $\star 3.431 \mathrm{E}+12$ & $\star 3.431 \mathrm{E}+12$ & $\star 3.431 \mathrm{E}+12$ & $\star 3.431 \mathrm{E}+12$ & $5.181 \mathrm{E}+05$ & $4.163 \mathrm{E}+05$ & $7.162 \mathrm{E}+07$ \\
\hline-137 & $7.867 \mathrm{E}+10$ & $7.984 \mathrm{E}+10$ & $1.641 \mathrm{E}+11$ & $3.422 \mathrm{E}+11$ & $\star 8.704 \mathrm{E}+13$ & $\star 8.704 \mathrm{E}+13$ & $\star 8.704 \mathrm{E}+13$ & $\star 8.704 \mathrm{E}+13$ \\
\hline-237 & $\star 7.047 \mathrm{E}+08$ & $\star 7.047 \mathrm{E}+08$ & $\star 7.047 \mathrm{E}+08$ & $\star 7.047 \mathrm{E}+08$ & $\star 7.047 \mathrm{E}+08$ & $9.749 \mathrm{E}+03$ & $8.902 \mathrm{E}+01$ & $1.460 \mathrm{E}+04$ \\
\hline$u-238$ & $\star 1.712 \mathrm{E}+13$ & $\star 1.712 \mathrm{E}+13$ & $\star 1.712 \mathrm{E}+13$ & $\star 1.712 \mathrm{E}+13$ & $\star 1.712 \mathrm{E}+13$ & $1.628 \mathrm{E}+08$ & $1.744 \mathrm{E}+05$ & $\star 1.712 \mathrm{E}+13$ \\
\hline$x-239$ & $* 6.214 \mathrm{E}+10$ & $* 6.214 \mathrm{E}+10$ & $* 6.214 \mathrm{E}+10$ & $\star 6.214 \mathrm{E}+10$ & $\star 6.214 \mathrm{E}+10$ & $8.096 \mathrm{E}+04$ & $9.626 \mathrm{E}+02$ & $\star 6.214 \mathrm{E}+10$ \\
\hline$u-240$ & $\star 2.278 \mathrm{E}+11$ & $\star 2.278 \mathrm{E}+11$ & $\star 2.278 \mathrm{E}+11$ & $\star 2.278 \mathrm{E}+11$ & $\star 2.278 \mathrm{E}+11$ & $8.779 \mathrm{E}+04$ & $2.085 E+03$ & $\star 2.278 \mathrm{E}+11$ \\
\hline$c-99$ & $* 1.697 \mathrm{E}+10$ & $* 1.697 \mathrm{E}+10$ & $\star 1.697 \mathrm{E}+10$ & $\star 1.697 \mathrm{E}+10$ & $4.808 E+02$ & $6.756 \mathrm{E}+04$ & $\star 1.697 \mathrm{E}+10$ & $\star 1.697 \mathrm{E}+10$ \\
\hline$h-228$ & $6.085 E+07$ & $8.690 \mathrm{E}+07$ & $\star 8.195 \mathrm{E}+14$ & $\star 8.195 \mathrm{E}+14$ & $\star 8.195 \mathrm{E}+14$ & $\star 8.195 \mathrm{E}+14$ & $\star 8.195 \mathrm{E}+14$ & $\star 8.195 \mathrm{E}+14$ \\
\hline Th -230 & $\star 2.018 \mathrm{E}+10$ & $\star 2.018 \mathrm{E}+10$ & $1.905 \mathrm{E}+10$ & $6.818 \mathrm{E}+09$ & $9.377 \mathrm{E}+07$ & $1.651 \mathrm{E}+03$ & $4.369 \mathrm{E}+00$ & $\star 2.018 \mathrm{E}+10$ \\
\hline Th-232 & $* 1.097 \mathrm{E}+05$ & $* 1.097 \mathrm{E}+05$ & $* 1.097 \mathrm{E}+05$ & *1.097E+05 & $* 1.097 \mathrm{E}+05$ & $6.221 \mathrm{E}+02$ & $3.605 \mathrm{E}+00$ & $\star 1.097 \mathrm{E}+05$ \\
\hline$J-234$ & $\star 6.247 \mathrm{E}+09$ & $\star 6.247 \mathrm{E}+09$ & $\star 6.247 \mathrm{E}+09$ & $\star 6.247 \mathrm{E}+09$ & $* 6.247 \mathrm{E}+09$ & $1.044 \mathrm{E}+05$ & $6.165 \mathrm{E}+01$ & $\star 6.247 \mathrm{E}+09$ \\
\hline 35 & $\star 2.161 \mathrm{E}+06$ & $\star 2.161 \mathrm{E}+06$ & $\star 2.161 \mathrm{E}+06$ & $\star 2.161 \mathrm{E}+06$ & $\star 2.161 \mathrm{E}+06$ & $5.340 \mathrm{E}+04$ & $5.033 \mathrm{E}+01$ & $\star 2.161 \mathrm{E}+06$ \\
\hline 238 & $\star 3.361 \mathrm{E}+05$ & $\star 3.361 \mathrm{E}+05$ & $\star 3.361 \mathrm{E}+05$ & $\star 3.361 \mathrm{E}+05$ & $\star 3.361 \mathrm{E}+05$ & $1.533 \mathrm{E}+05$ & $4.588 \mathrm{E}+02$ & $\star 3.361 \mathrm{E}+05$ \\
\hline
\end{tabular}

*At specific activity limit

Summed Dose/Source Ratios DSR (i,t) in (mrem/yr)/(pCi/g)

and Single Radionuclide Soil Guidelines G(i,t) in pCi/g

at tmin = time of minimum single radionuclide soil guideline and at $\operatorname{tmax}=$ time of maximum total dose $=12773 \pm *$ years

\begin{tabular}{|c|c|c|c|c|c|c|}
\hline $\begin{array}{l}\text { uclide } \\
\text { (i) }\end{array}$ & $\begin{array}{l}\text { Initial } \\
(\mathrm{pCi} / \mathrm{g})\end{array}$ & $\begin{array}{c}\text { tmin } \\
\text { (years) }\end{array}$ & $\operatorname{DSR}(i, \operatorname{tmin})$ & $\begin{array}{c}\mathrm{G}(\mathrm{i}, \mathrm{tmin}) \\
(\mathrm{pCi} / \mathrm{g})\end{array}$ & $\operatorname{DSR}(i, t \max )$ & $\begin{array}{c}G(i, \operatorname{tmax}) \\
(\mathrm{pC} i / \mathrm{g})\end{array}$ \\
\hline-241 & $3.500 \mathrm{E}+01$ & $1672 \pm 3$ & $2.773 E-03$ & $3.607 E+04$ & $1.873 \mathrm{E}-04$ & $5.339 \mathrm{E}+05$ \\
\hline-137 & $1.900 \mathrm{E}+01$ & $0.000 \mathrm{E}+00$ & $1.271 \mathrm{E}-09$ & $7.867 \mathrm{E}+10$ & $0.000 \mathrm{E}+00$ & $\star 8.704 \mathrm{E}+13$ \\
\hline-237 & $5.500 \mathrm{E}+00$ & $7683 \pm *$ & 1. $422 \mathrm{E}+00$ & $7.032 E+01$ & $8.399 E-01$ & 1. $191 \mathrm{E}+02$ \\
\hline-238 & $3.900 \mathrm{E}+01$ & $23361 \pm *$ & $1.182 \mathrm{E}-03$ & $8.460 \mathrm{E}+04$ & $7.291 E-04$ & $1.371 \mathrm{E}+05$ \\
\hline-239 & $3.600 \mathrm{E}+01$ & $2534 \pm 5$ & $1.464 \mathrm{E}-01$ & $6.832 E+02$ & $9.146 \mathrm{E}-02$ & $1.093 E+03$ \\
\hline-240 & $3.600 \mathrm{E}+01$ & $2534 \pm 5$ & $1.203 \mathrm{E}-01$ & $8.314 \mathrm{E}+02$ & $3.409 \mathrm{E}-02$ & $2.933 E+03$ \\
\hline-99 & $5.200 \mathrm{E}+01$ & $425.2 \pm 0.9$ & $4.075 E-01$ & $2.454 \mathrm{E}+02$ & $0.000 \mathrm{E}+00$ & $\star 1.697 \mathrm{E}+10$ \\
\hline-228 & $4.000 \mathrm{E}+00$ & $0.000 \mathrm{E}+00$ & $1.643 \mathrm{E}-06$ & $6.085 E+07$ & $0.000 \mathrm{E}+00$ & $\star 8.195 \mathrm{E}+14$ \\
\hline-230 & $1.000 \mathrm{E}+02$ & $8255 \pm *$ & $2.303 E+01$ & $4.342 E+00$ & $2.233 E+01$ & $4.477 \mathrm{E}+00$ \\
\hline-232 & $4.000 \mathrm{E}+00$ & $2534 \pm 5$ & $2.835 E+01$ & $3.527 \mathrm{E}+00$ & $2.751 \mathrm{E}+01$ & $3.635 \mathrm{E}+00$ \\
\hline 34 & $1.600 \mathrm{E}+02$ & $23361 \pm *$ & $3.313 \mathrm{E}+00$ & $3.019 \mathrm{E}+01$ & $2.055 E+00$ & $4.866 \mathrm{E}+01$ \\
\hline 5 & $6.500 \mathrm{E}+00$ & $23361 \pm *$ & $2.648 \mathrm{E}+00$ & $3.777 \mathrm{E}+01$ & $2.204 \mathrm{E}+00$ & $4.537 \mathrm{E}+01$ \\
\hline 38 & $1.600 \mathrm{E}+02$ & $23361 \pm *$ & $2.448 E-01$ & $4.085 E+02$ & $2.185 \mathrm{E}-01$ & $4.576 \mathrm{E}+02$ \\
\hline
\end{tabular}

*At specific activity limit 
RESRAD, Version 6.5

Summary : C746U Resident Farmer Deterministic Run

File : $X: \backslash F I N A L$ V2 \DOE FWD RUNS \C746U RF DOE SG FWD-FV2-100000YR.RAD

Individual Nuclide Dose Summed Over All Pathways

Parent Nuclide and Branch Fraction Indicated

Nuclide Parent THF(i) DOSE $(j, t), \mathrm{mrem} / \mathrm{yr}$

\begin{tabular}{llll}
\multicolumn{1}{c}{$(j)$} & & $(i)$ & \\
\cline { 1 - 1 }$A m-241$ & $A m-241$ & $1.000 E+00$ \\
Np-237 & Am-241 & $1.000 E+00$ \\
Np-237 & Np-237 & $1.000 E+00$ \\
$N p-237$ & $\sum \operatorname{DOSE}(j)$
\end{tabular}

$\mathrm{U}-233 \quad \mathrm{Am}-241 \quad 1.000 \mathrm{E}+00$

$\mathrm{U}-233 \quad \mathrm{~Np}-237 \quad 1.000 \mathrm{E}+00$

U-233 $\quad$ DOSE $(j)$

Th-229 Am-241 $1.000 \mathrm{E}+00$

Th-229 Np-237 $1.000 \mathrm{E}+00$

Th-229 $\sum \operatorname{DOSE}(j)$

Cs -137 Cs $-137 \quad 1.000 E+00$

$\mathrm{Pu}-238$

$\mathrm{Pu}-238$

$\mathrm{Pu}-238$

$\mathrm{U}-234$

$\mathrm{U}-234$

$\mathrm{U}-234$

$\mathrm{U}-234$

Th-230

Th -230

Th -230

Th-230

Th -230

$\mathrm{Ra}-226$

$\mathrm{Ra}-226$

$\mathrm{Ra}-226$

$\mathrm{Ra}-226$

$\mathrm{Ra}-226$

$\mathrm{Pb}-210$

$\mathrm{Pb}-210$

$\mathrm{Pb}-210$

$\mathrm{Pb}-210$

$\mathrm{Pb}-210$

$\mathrm{Pu}-239$

Pu-239 $1.000 \mathrm{E}+00$ $\mathrm{U}-2351.000 \mathrm{E}+00$ $\sum \operatorname{DOSE}(j)$ $\mathrm{t}=0.000 \mathrm{E}+00 \quad 1.000 \mathrm{E}+00 \quad 5.000 \mathrm{E}+01 \quad 1.000 \mathrm{E}+02 \quad 5.000 \mathrm{E}+02 \quad 1.050 \mathrm{E}+03 \quad 1.000 \mathrm{E}+04 \quad 1.000 \mathrm{E}+05$

$\begin{array}{llllllllll}0.000 \mathrm{E}+00 & 0.000 \mathrm{E}+00 & 0.000 \mathrm{E}+00 & 0.000 \mathrm{E}+00 & 4.171 \mathrm{E}-26 & 6.693 \mathrm{E}-03 & 5.656 \mathrm{E}-07 & 0.000 \mathrm{E}+00\end{array}$

$0.000 \mathrm{E}+00 \quad 1.086 \mathrm{E}-17 \quad 8.834 \mathrm{E}-16 \quad 2.905 \mathrm{E}-15 \quad 7.873 \mathrm{E}-13 \quad 6.209 \mathrm{E}-05 \quad 8.293 \mathrm{E}-03 \quad 0.000 \mathrm{E}+00$

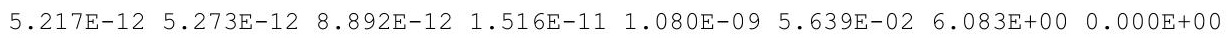

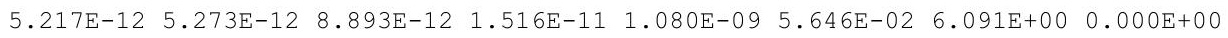

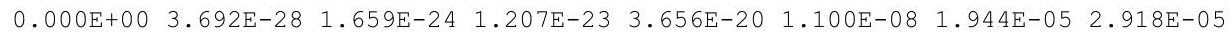
$\begin{array}{llllllll}0.000 \mathrm{E}+00 & 3.584 \mathrm{E}-22 & 3.301 \mathrm{E}-20 & 1.231 \mathrm{E}-19 & 9.010 \mathrm{E}-17 & 1.625 \mathrm{E}-05 & 1.591 \mathrm{E}-02 & 2.249 \mathrm{E}-02\end{array}$

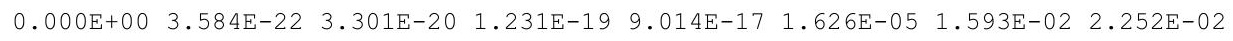

$0.000 \mathrm{E}+00 \quad 3.363 \mathrm{E}-24 \quad 5.788 \mathrm{E}-19 \quad 6.420 \mathrm{E}-18 \quad 1.111 \mathrm{E}-14 \quad 1.840 \mathrm{E}-09 \quad 9.405 \mathrm{E}-05 \quad 1.969 \mathrm{E}-05$ $\begin{array}{llllllll}0.000 \mathrm{E}+00 & 4.896 \mathrm{E}-18 & 1.717 \mathrm{E}-14 & 9.703 \mathrm{E}-14 & 3.873 \mathrm{E}-11 & 3.641 \mathrm{E}-06 & 7.950 \mathrm{E}-02 & 1.519 \mathrm{E}-02\end{array}$ $\begin{array}{llllllll}0.000 \mathrm{E}+00 & 4.896 \mathrm{E}-18 & 1.717 \mathrm{E}-14 & 9.703 \mathrm{E}-14 & 3.874 \mathrm{E}-11 & 3.643 \mathrm{E}-06 & 7.960 \mathrm{E}-02 & 1.521 \mathrm{E}-02\end{array}$

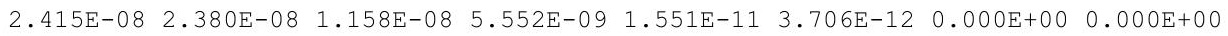

$\begin{array}{lllllllll}0.000 \mathrm{E}+00 & 0.000 \mathrm{E}+00 & 0.000 \mathrm{E}+00 & 0.000 \mathrm{E}+00 & 0.000 \mathrm{E}+00 & 2.099 \mathrm{E}-14 & 0.000 \mathrm{E}+00 & 0.000 \mathrm{E}+00\end{array}$ $\begin{array}{llllllll}4.560 \mathrm{E}-23 & 4.604 \mathrm{E}-23 & 7.424 \mathrm{E}-23 & 1.209 \mathrm{E}-22 & 5.972 \mathrm{E}-21 & 1.141 \mathrm{E}-05 & 0.000 \mathrm{E}+00 & 0.000 \mathrm{E}+00\end{array}$

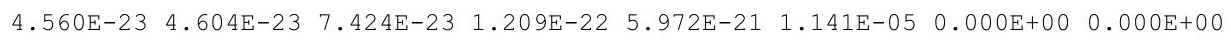

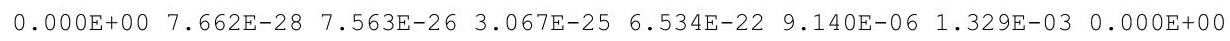
$\begin{array}{llllllllllll}1.094 \mathrm{E}-21 & 1.113 \mathrm{E}-21 & 2.649 \mathrm{E}-21 & 6.417 \mathrm{E}-21 & 7.609 \mathrm{E}-18 & 1.044 \mathrm{E}-01 & 1.517 \mathrm{E}+01 & 0.000 \mathrm{E}+00\end{array}$ $\begin{array}{llllllll}0.000 \mathrm{E}+00 & 3.156 \mathrm{E}-27 & 3.755 \mathrm{E}-25 & 1.819 \mathrm{E}-24 & 1.079 \mathrm{E}-20 & 3.112 \mathrm{E}-04 & 4.363 \mathrm{E}-01 & 0.000 \mathrm{E}+00\end{array}$ $\begin{array}{llllllllll}1.094 \mathrm{E}-21 & 1.113 \mathrm{E}-21 & 2.650 \mathrm{E}-21 & 6.420 \mathrm{E}-21 & 7.620 \mathrm{E}-18 & 1.047 \mathrm{E}-01 & 1.561 \mathrm{E}+01 & 0.000 \mathrm{E}+00\end{array}$

$\begin{array}{llllllll}0.000 \mathrm{E}+00 & 0.000 \mathrm{E}+00 & 6.069 \mathrm{E}-28 & 4.992 \mathrm{E}-27 & 5.043 \mathrm{E}-23 & 1.243 \mathrm{E}-07 & 1.445 \mathrm{E}-04 & 0.000 \mathrm{E}+00\end{array}$ $\begin{array}{llllllll}2.392 \mathrm{E}-20 & 2.432 \mathrm{E}-20 & 5.543 \mathrm{E}-20 & 1.285 \mathrm{E}-19 & 1.069 \mathrm{E}-16 & 1.076 \mathrm{E}-01 & 1.244 \mathrm{E}+01 & 0.000 \mathrm{E}+00\end{array}$ $\begin{array}{llllllll}0.000 \mathrm{E}+00 & 3.503 \mathrm{E}-25 & 3.990 \mathrm{E}-23 & 1.849 \mathrm{E}-22 & 7.668 \mathrm{E}-19 & 1.615 \mathrm{E}-03 & 1.673 \mathrm{E}+00 & 0.000 \mathrm{E}+00\end{array}$ $\begin{array}{llllllll}0.000 \mathrm{E}+00 & 0.000 \mathrm{E}+00 & 2.828 \mathrm{E}-27 & 2.620 \mathrm{E}-26 & 5.431 \mathrm{E}-22 & 2.400 \mathrm{E}-06 & 2.338 \mathrm{E}-02 & 0.000 \mathrm{E}+00\end{array}$

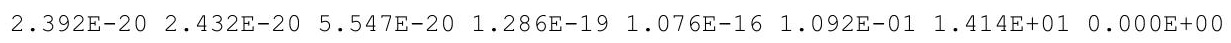

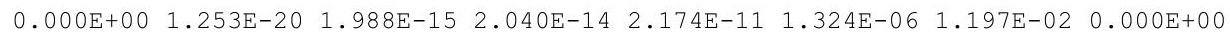
$\begin{array}{llllllll}0.000 \mathrm{E}+00 & 7.565 \mathrm{E}-09 & 5.249 \mathrm{E}-07 & 1.467 \mathrm{E}-06 & 1.066 \mathrm{E}-04 & 2.340 \mathrm{E}+00 & 1.303 \mathrm{E}+03 & 0.000 \mathrm{E}+00\end{array}$ $\begin{array}{llllllll}0.000 \mathrm{E}+00 & 5.448 \mathrm{E}-14 & 1.897 \mathrm{E}-10 & 1.064 \mathrm{E}-09 & 3.972 \mathrm{E}-07 & 1.896 \mathrm{E}-02 & 1.391 \mathrm{E}+02 & 0.000 \mathrm{E}+00\end{array}$

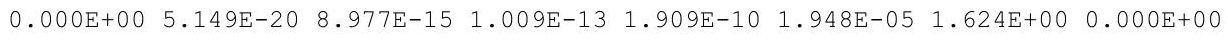

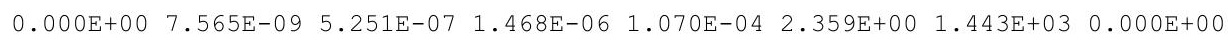

$\begin{array}{llllllll}0.000 \mathrm{E}+00 & 4.535 \mathrm{E}-29 & 2.911 \mathrm{E}-22 & 5.018 \mathrm{E}-21 & 1.423 \mathrm{E}-17 & 1.964 \mathrm{E}-06 & 8.915 \mathrm{E}-03 & 0.000 \mathrm{E}+00\end{array}$ $\begin{array}{lllllllll}0.000 \mathrm{E}+00 & 5.454 \mathrm{E}-17 & 1.273 \mathrm{E}-13 & 5.257 \mathrm{E}-13 & 7.641 \mathrm{E}-11 & 3.610 \mathrm{E}+00 & 9.735 \mathrm{E}+02 & 0.000 \mathrm{E}+00\end{array}$ $\begin{array}{lllllllll}0.000 \mathrm{E}+00 & 2.625 \mathrm{E}-22 & 3.416 \mathrm{E}-17 & 3.045 \mathrm{E}-16 & 2.669 \mathrm{E}-13 & 2.832 \mathrm{E}-02 & 1.036 \mathrm{E}+02 & 0.000 \mathrm{E}+00\end{array}$

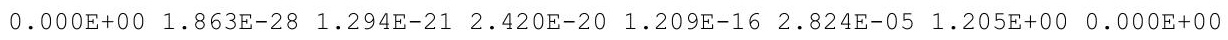
$\begin{array}{llllllll}0.000 \mathrm{E}+00 & 5.454 \mathrm{E}-17 & 1.274 \mathrm{E}-13 & 5.260 \mathrm{E}-13 & 7.667 \mathrm{E}-11 & 3.639 \mathrm{E}+00 & 1.078 \mathrm{E}+03 & 0.000 \mathrm{E}+00\end{array}$

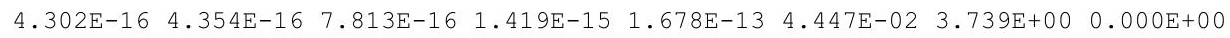

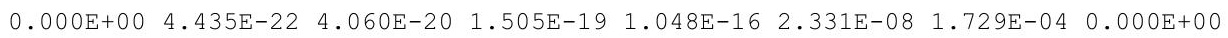
$\begin{array}{llllllllll}8.032 \mathrm{E}-14 & 8.131 \mathrm{E}-14 & 1.489 \mathrm{E}-13 & 2.762 \mathrm{E}-13 & 3.864 \mathrm{E}-11 & 4.119 \mathrm{E}-03 & 3.548 \mathrm{E}+00 & 0.000 \mathrm{E}+00\end{array}$ $\begin{array}{lllllllll}8.032 \mathrm{E}-14 & 8.131 \mathrm{E}-14 & 1.489 \mathrm{E}-13 & 2.762 \mathrm{E}-13 & 3.864 \mathrm{E}-11 & 4.119 \mathrm{E}-03 & 3.548 \mathrm{E}+00 & 0.000 \mathrm{E}+00\end{array}$ 
RESRAD, Version 6.5

Summary : C746U Resident Farmer Deterministic Run

File : $\mathrm{X}: \backslash F I N A L$ V2 $\backslash$ DOE FWD RUNS \C746U RF DOE SG FWD-FV2-100000YR.RAD

Individual Nuclide Soil Concentration

Parent Nuclide and Branch Fraction Indicated

Nuclide Parent THF(

(j)

$\overline{A m-241}$

(i)

$\overline{A m-241} \overline{1.000 \mathrm{E}+00}$

Np-237 Am-241 1.000E+00

$\mathrm{Np}-237 \quad \mathrm{~Np}-237 \quad 1.000 \mathrm{E}+00$

Np-237 $\sum S(j):$

$\mathrm{U}-233 \quad \mathrm{Am}-241 \quad 1.000 \mathrm{E}+00$

$\mathrm{U}-233 \quad \mathrm{~Np}-237 \quad 1.000 \mathrm{E}+00$

$\mathrm{U}-233 \sum \mathrm{S}(\mathrm{j}):$

$\mathrm{Am}-241 \quad 1.000 \mathrm{E}+00$ Np-237 1.000E+00 $\sum S(j):$

Cs-137 1.000E+00

Pu-238 1.840E-09 Pu-238 1.000E+00 $\sum S(j):$

Pu-238 1.000E+00 $\mathrm{U}-234 \quad 1.000 \mathrm{E}+00$ U-238 $9.999 \mathrm{E}-01$ $\sum S(j):$

$\mathrm{Pu}-238 \quad 1.000 \mathrm{E}+00$ Th-230 1.000E+00 $\mathrm{U}-234 \quad 1.000 \mathrm{E}+00$ U-238 $9.999 \mathrm{E}-01$ $\sum S(j):$

$\mathrm{Pu}-238 \quad 1.000 \mathrm{E}+00$ Th-230 1.000E+00 $\mathrm{U}-234 \quad 1.000 \mathrm{E}+00$ $\mathrm{U}-238 \quad 9.999 \mathrm{E}-01$ $\sum S(j):$

$\mathrm{Pu}-238 \quad 1.000 \mathrm{E}+00$ Th-230 1.000E+00 U-234 $1.000 \mathrm{E}+00$ $\mathrm{U}-238 \quad 9.999 \mathrm{E}-01$ $\sum S(j):$

$\mathrm{Pu}-239 \quad 1.000 \mathrm{E}+00$

Pu-239 1.000E+00 $\mathrm{U}-235 \quad 1.000 \mathrm{E}+00$ $\sum S(j):$
$\mathrm{S}(j, t), \mathrm{pCi} / \mathrm{g}$

$\mathrm{t}=0.000 \mathrm{E}+00 \quad 1.000 \mathrm{E}+00 \quad 5.000 \mathrm{E}+01 \quad 1.000 \mathrm{E}+02 \quad 5.000 \mathrm{E}+02 \quad 1.050 \mathrm{E}+03 \quad 1.000 \mathrm{E}+04 \quad 1.000 \mathrm{E}+05$

$\begin{array}{lllllllllll}3.500 \mathrm{E}+01 & 3.494 \mathrm{E}+01 & 3.229 \mathrm{E}+01 & 2.980 \mathrm{E}+01 & 1.566 \mathrm{E}+01 & 6.464 \mathrm{E}+00 & 3.610 \mathrm{E}-06 & 0.000 \mathrm{E}+00\end{array}$

$0.000 \mathrm{E}+00 \quad 1.133 \mathrm{E}-05 \quad 5.428 \mathrm{E}-04 \quad 1.040 \mathrm{E}-03 \quad 3.749 \mathrm{E}-03 \quad 5.255 \mathrm{E}-03 \quad 1.996 \mathrm{E}-03 \quad 1.062 \mathrm{E}-08$

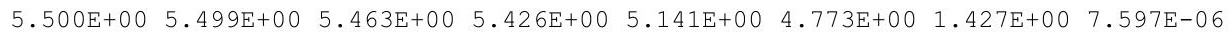
$\begin{array}{llllllll}5.500 \mathrm{E}+00 & 5.499 \mathrm{E}+00 & 5.464 \mathrm{E}+00 & 5.427 \mathrm{E}+00 & 5.145 \mathrm{E}+00 & 4.779 \mathrm{E}+00 & 1.429 \mathrm{E}+00 & 7.608 \mathrm{E}-06\end{array}$

$\begin{array}{llllllll}0.000 \mathrm{E}+00 & 2.477 \mathrm{E}-11 & 6.018 \mathrm{E}-08 & 2.338 \mathrm{E}-07 & 4.686 \mathrm{E}-06 & 1.571 \mathrm{E}-05 & 1.406 \mathrm{E}-04 & 1.888 \mathrm{E}-05\end{array}$ $\begin{array}{llllllll}0.000 \mathrm{E}+00 & 2.405 \mathrm{E}-05 & 1.198 \mathrm{E}-03 & 2.386 \mathrm{E}-03 & 1.155 \mathrm{E}-02 & 2.320 \mathrm{E}-02 & 1.121 \mathrm{E}-01 & 1.449 \mathrm{E}-02\end{array}$

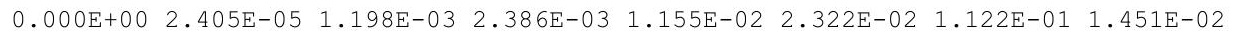

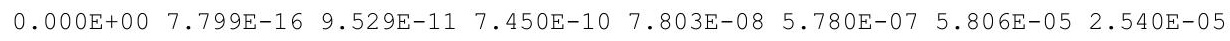

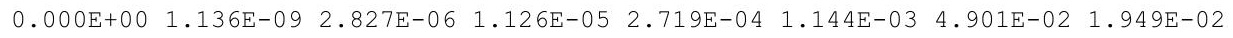

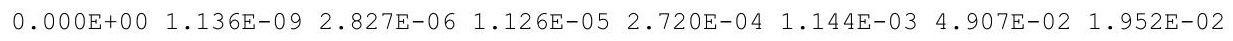

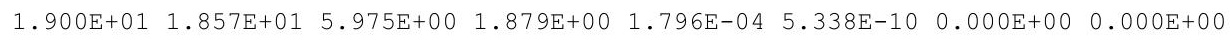

$\begin{array}{llllllll}7.176 \mathrm{E}-08 & 7.119 \mathrm{E}-08 & 4.830 \mathrm{E}-08 & 3.251 \mathrm{E}-08 & 1.370 \mathrm{E}-09 & 1.760 \mathrm{E}-11 & 2.951 \mathrm{E}-42 & 0.000 \mathrm{E}+00\end{array}$ $\begin{array}{llllllllll}3.900 \mathrm{E}+01 & 3.869 \mathrm{E}+01 & 2.625 \mathrm{E}+01 & 1.767 \mathrm{E}+01 & 7.445 \mathrm{E}-01 & 9.567 \mathrm{E}-03 & 1.612 \mathrm{E}-33 & 0.000 \mathrm{E}+00\end{array}$ $\begin{array}{llllllllll}3.900 \mathrm{E}+01 & 3.869 \mathrm{E}+01 & 2.625 \mathrm{E}+01 & 1.767 \mathrm{E}+01 & 7.445 \mathrm{E}-01 & 9.567 \mathrm{E}-03 & 1.612 \mathrm{E}-33 & 0.000 \mathrm{E}+00\end{array}$

$0.000 \mathrm{E}+00 \quad 1.101 \mathrm{E}-04 \quad 4.562 \mathrm{E}-03 \quad 7.627 \mathrm{E}-03 \quad 1.356 \mathrm{E}-02 \quad 1.363 \mathrm{E}-02 \quad 1.082 \mathrm{E}-02 \quad 1.059 \mathrm{E}-03$ $\begin{array}{lllllllll}1.600 \mathrm{E}+02 & 1.600 \mathrm{E}+02 & 1.598 \mathrm{E}+02 & 1.596 \mathrm{E}+02 & 1.579 \mathrm{E}+02 & 1.557 \mathrm{E}+02 & 1.236 \mathrm{E}+02 & 1.209 \mathrm{E}+01\end{array}$ $\begin{array}{llllllll}0.000 \mathrm{E}+00 & 4.536 \mathrm{E}-04 & 2.265 \mathrm{E}-02 & 4.525 \mathrm{E}-02 & 2.240 \mathrm{E}-01 & 4.642 \mathrm{E}-01 & 3.553 \mathrm{E}+00 & 3.962 \mathrm{E}+00\end{array}$ $\begin{array}{llllllll}1.600 \mathrm{E}+02 & 1.600 \mathrm{E}+02 & 1.598 \mathrm{E}+02 & 1.596 \mathrm{E}+02 & 1.582 \mathrm{E}+02 & 1.562 \mathrm{E}+02 & 1.271 \mathrm{E}+02 & 1.605 \mathrm{E}+01\end{array}$

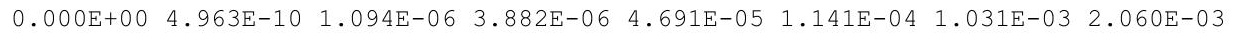
$\begin{array}{llllllllllll}1.000 \mathrm{E}+02 & 1.000 \mathrm{E}+02 & 9.994 \mathrm{E}+01 & 9.988 \mathrm{E}+01 & 9.940 \mathrm{E}+01 & 9.875 \mathrm{E}+01 & 8.874 \mathrm{E}+01 & 3.028 \mathrm{E}+01\end{array}$ $\begin{array}{lllllllllll}0.000 \mathrm{E}+00 & 1.440 \mathrm{E}-03 & 7.195 \mathrm{E}-02 & 1.438 \mathrm{E}-01 & 7.134 \mathrm{E}-01 & 1.483 \mathrm{E}+00 & 1.193 \mathrm{E}+01 & 2.358 \mathrm{E}+01\end{array}$ $\begin{array}{lllllllll}0.000 \mathrm{E}+00 & 2.041 \mathrm{E}-09 & 5.099 \mathrm{E}-06 & 2.037 \mathrm{E}-05 & 5.052 \mathrm{E}-04 & 2.203 \mathrm{E}-03 & 1.668 \mathrm{E}-01 & 2.822 \mathrm{E}+00\end{array}$

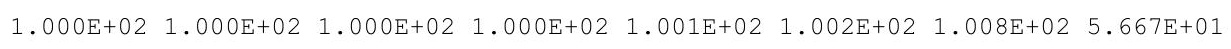

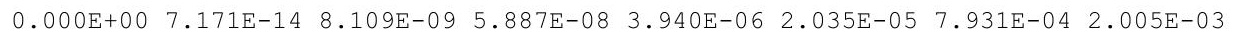
$\begin{array}{llllllllll}0.000 \mathrm{E}+00 & 4.331 \mathrm{E}-02 & 2.141 \mathrm{E}+00 & 4.233 \mathrm{E}+00 & 1.933 \mathrm{E}+01 & 3.597 \mathrm{E}+01 & 8.627 \mathrm{E}+01 & 2.980 \mathrm{E}+01\end{array}$ $\begin{array}{llllllll}0.000 \mathrm{E}+00 & 3.119 \mathrm{E}-07 & 7.736 \mathrm{E}-04 & 3.069 \mathrm{E}-03 & 7.197 \mathrm{E}-02 & 2.914 \mathrm{E}-01 & 9.214 \mathrm{E}+00 & 2.295 \mathrm{E}+01\end{array}$ $\begin{array}{lllllllll}0.000 \mathrm{E}+00 & 2.948 \mathrm{E}-13 & 3.662 \mathrm{E}-08 & 2.911 \mathrm{E}-07 & 3.459 \mathrm{E}-05 & 2.994 \mathrm{E}-04 & 1.075 \mathrm{E}-01 & 2.697 \mathrm{E}+00\end{array}$ $\begin{array}{lllllllll}0.000 \mathrm{E}+00 & 4.331 \mathrm{E}-02 & 2.142 \mathrm{E}+00 & 4.236 \mathrm{E}+00 & 1.940 \mathrm{E}+01 & 3.626 \mathrm{E}+01 & 9.560 \mathrm{E}+01 & 5.545 \mathrm{E}+01\end{array}$

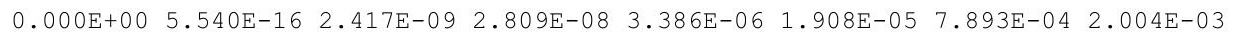
$\begin{array}{llllllllll}0.000 \mathrm{E}+00 & 6.662 \mathrm{E}-04 & 1.057 \mathrm{E}+0 & 2.944 \mathrm{E}+00 & 1.819 \mathrm{E}+01 & 3.507 \mathrm{E}+01 & 8.620 \mathrm{E}+01 & 2.978 \mathrm{E}+01\end{array}$ $\begin{array}{lllllllll}0.000 \mathrm{E}+00 & 3.207 \mathrm{E}-09 & 2.836 \mathrm{E}-04 & 1.705 \mathrm{E}-03 & 6.353 \mathrm{E}-02 & 2.751 \mathrm{E}-01 & 9.171 \mathrm{E}+00 & 2.293 \mathrm{E}+01\end{array}$ $\begin{array}{lllllllll}0.000 \mathrm{E}+00 & 2.276 \mathrm{E}-15 & 1.075 \mathrm{E}-0 & 1.355 \mathrm{E}-07 & 2.879 \mathrm{E}-05 & 2.742 \mathrm{E}-04 & 1.066 \mathrm{E}-01 & 2.694 \mathrm{E}+00\end{array}$ $\begin{array}{lllllllll}0.000 \mathrm{E}+00 & 6.663 \mathrm{E}-04 & 1.058 \mathrm{E}+00 & 2.945 \mathrm{E}+00 & 1.825 \mathrm{E}+01 & 3.534 \mathrm{E}+01 & 9.547 \mathrm{E}+01 & 5.541 \mathrm{E}+01\end{array}$

$\begin{array}{llllllll}3.600 \mathrm{E}+01 & 3.600 \mathrm{E}+01 & 3.592 \mathrm{E}+01 & 3.583 \mathrm{E}+01 & 3.518 \mathrm{E}+01 & 3.430 \mathrm{E}+01 & 2.274 \mathrm{E}+01 & 3.639 \mathrm{E}-01\end{array}$

$0.000 \mathrm{E}+00 \quad 3.545 \mathrm{E}-08 \quad 1.770 \mathrm{E}-06 \quad 3.533 \mathrm{E}-06 \quad 1.742 \mathrm{E}-05 \quad 3.591 \mathrm{E}-05 \quad 2.517 \mathrm{E}-04 \quad 1.394 \mathrm{E}-04$

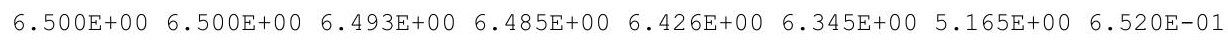

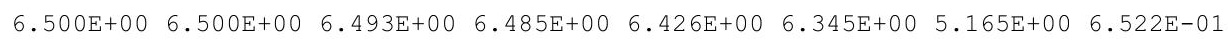




\section{Resident Gardener}

\section{Summary Report \\ (Deterministic Analysis Report)}

First Peak Dose Assessment

Time Horizon: 1,050 yr 
THIS PAGE INTENTIONALLY LEFT BLANK 
RESRAD, Version $6.5 \quad \mathrm{~T}^{1 / 2}$ Limit $=180$ days

Summary : C746U Resident Gardener Deterministic Run

File : $\mathrm{X}: \backslash F I N A L$ V2 $\backslash$ DOE FWD RUNS \C746U RG DOE SG FWD-FV2-1050YR.RAD

Table of Contents

Part I: Mixture Sums and Single Radionuclide Guidelines

Dose Conversion Factor (and Related) Parameter Summary ... 2

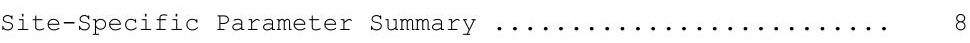

Summary of Pathway Selections ..................... 18

Contaminated Zone and Total Dose Summary ............. 19

Total Dose Components

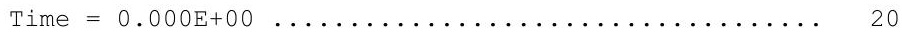

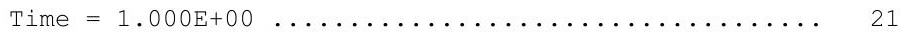

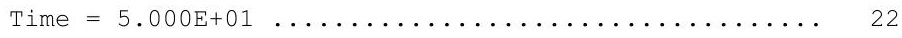

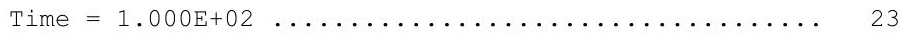

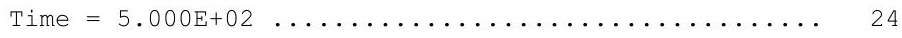

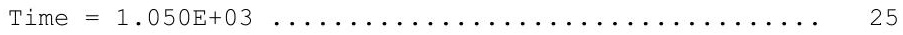

Dose/Source Ratios Summed Over All Pathways .......... 26

Single Radionuclide Soil Guidelines ............... 28

Dose Per Nuclide Summed Over All Pathways ............. 29

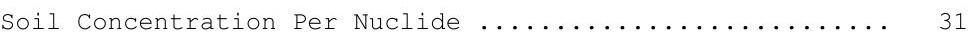


RESRAD, Version $6.5 \quad \mathrm{~T}^{1 / 2}$ Limit $=180$ days

Summary : C746U Resident Gardener Deterministic Run

File : $\mathrm{X}: \backslash F I N A L$ V2 $\backslash$ DOE FWD RUNS \C746U RG DOE SG FWD-FV2-1050YR.RAD

Dose Conversion Factor (and Related) Parameter Summary

Dose Library: ICRP 60 \& ICRP 72 (Adult)

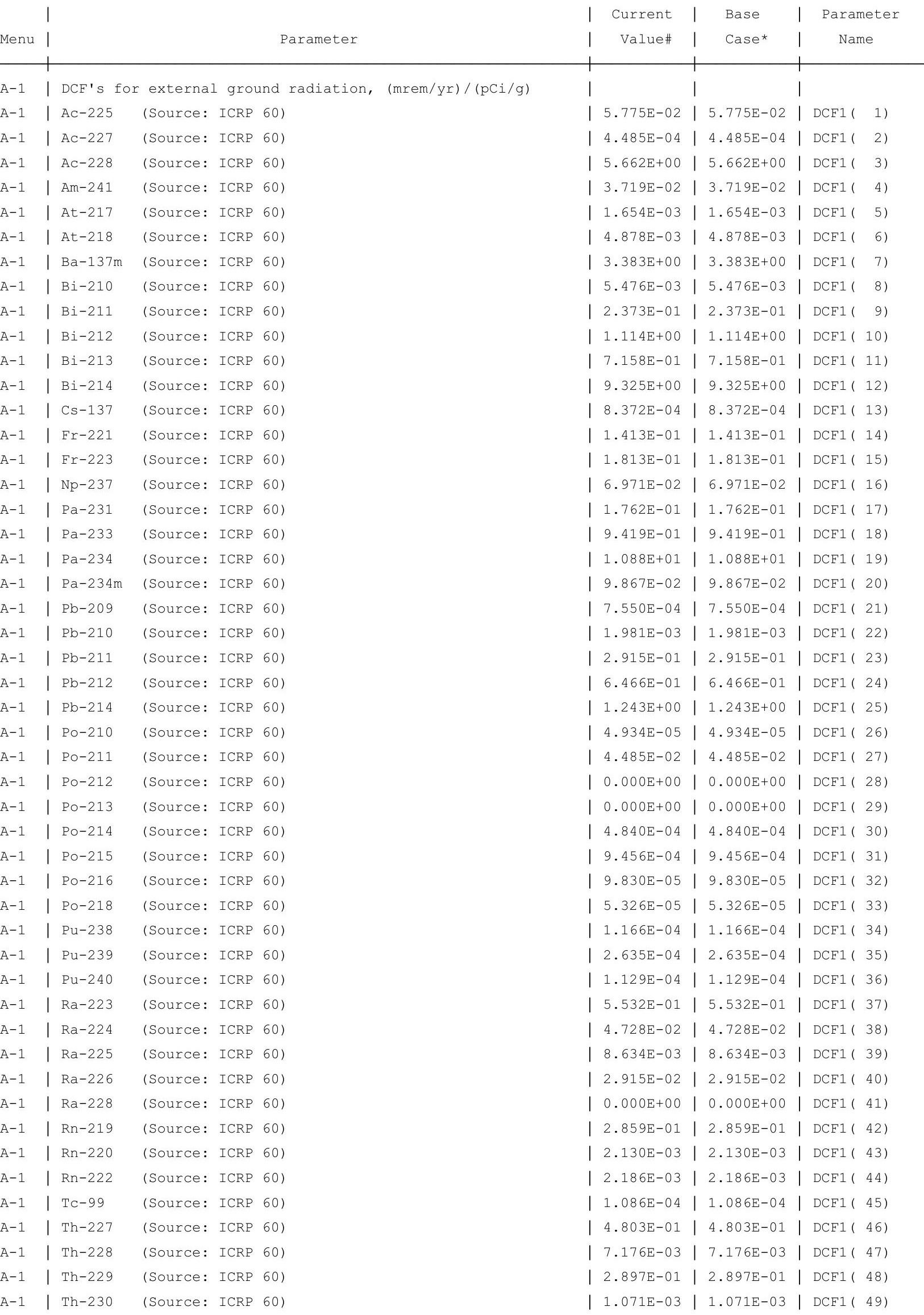


RESRAD, Version $6.5 \quad T^{1 / 2}$ Limit $=180$ days

Summary : C746U Resident Gardener Deterministic Run

File : $\mathrm{X}: \backslash F I N A L$ V2 $\backslash$ DOE FWD RUNS $\backslash C 746 U$ RG DOE SG FWD-FV2-1050YR. RAD

Dose Conversion Factor (and Related) Parameter Summary (continued)

Dose Library: ICRP 60 \& ICRP 72 (Adult)

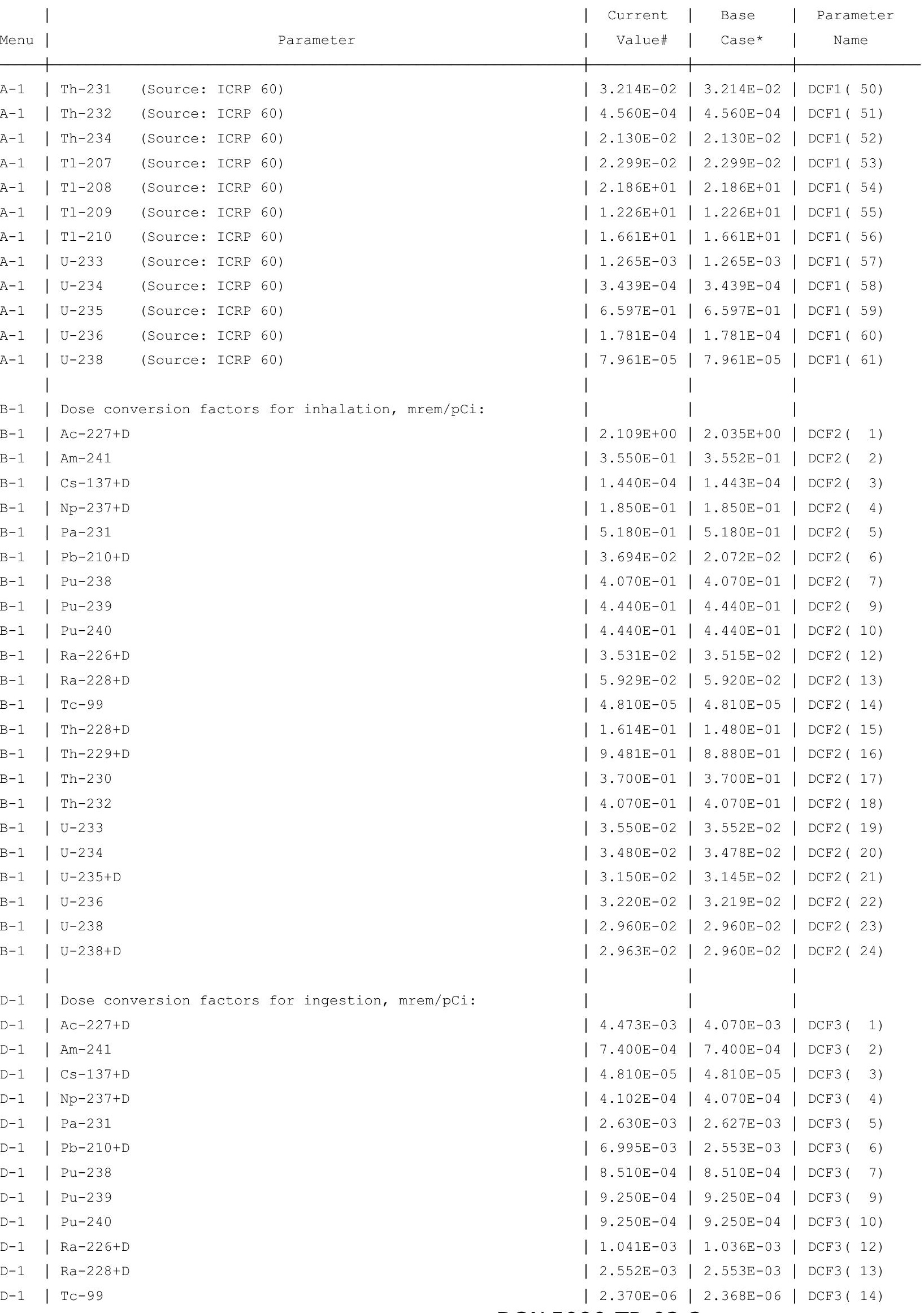


RESRAD, Version $6.5 \quad T^{1 / 2}$ Limit $=180$ days

Summary : C746U Resident Gardener Deterministic Run

File : $\mathrm{X}: \backslash F I N A L$ V2 $\backslash$ DOE FWD RUNS \C746U RG DOE SG FWD-FV2-1050YR.RAD

Dose Conversion Factor (and Related) Parameter Summary (continued)

Dose Library: ICRP 60 \& ICRP 72 (Adult)

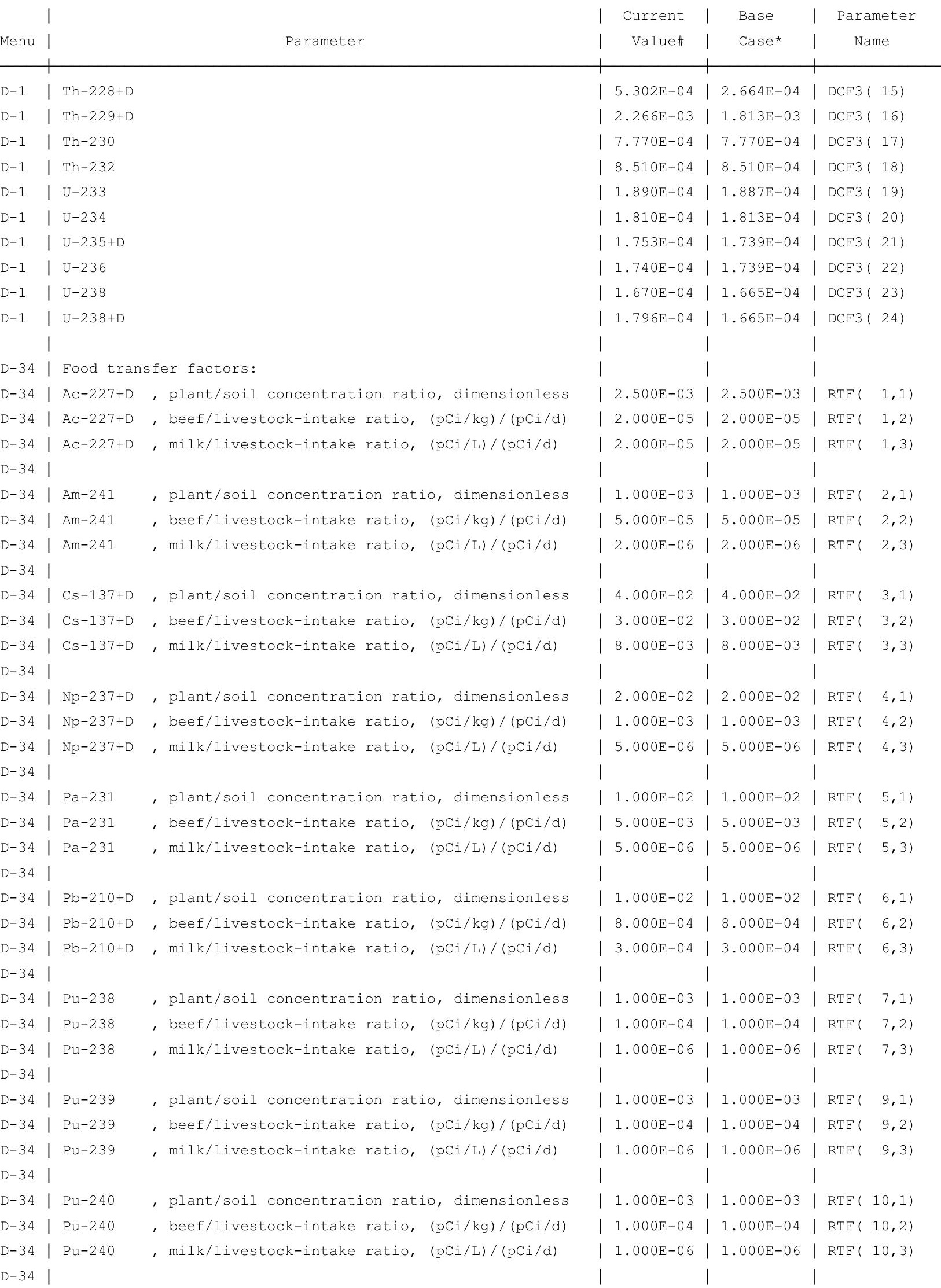


RESRAD, Version $6.5 \quad \mathrm{~T}^{\mathbb{1} 1 / 2}$ Limit $=180$ days

Summary : C746U Resident Gardener Deterministic Run

File : $\mathrm{X}: \backslash F I N A L$ V2 $\backslash$ DOE FWD RUNS $\backslash C 746 U$ RG DOE SG FWD-FV2-1050YR.RAD

Dose Conversion Factor (and Related) Parameter Summary (continued)

Dose Library: ICRP 60 \& ICRP 72 (Adult)

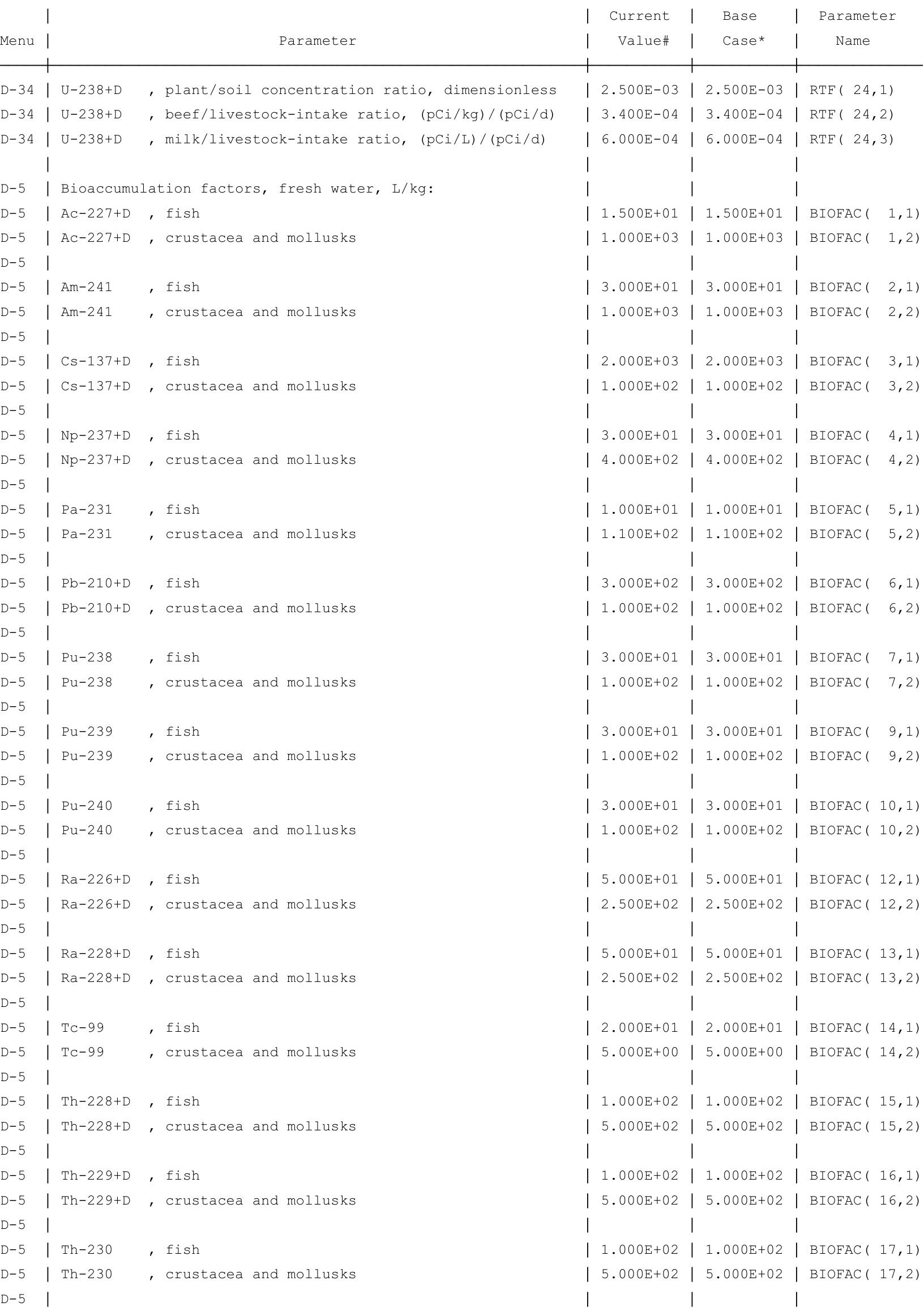


RESRAD, Version $6.5 \quad \mathrm{~T}^{1 / 2}$ Limit $=180$ days

Summary : C746U Resident Gardener Deterministic Run

File : $\mathrm{X}: \backslash F I N A L$ V2 $\backslash$ DOE FWD RUNS $\backslash C 746 U$ RG DOE SG FWD-FV2-1050YR.RAD

Site-Specific Parameter Summary (continued)

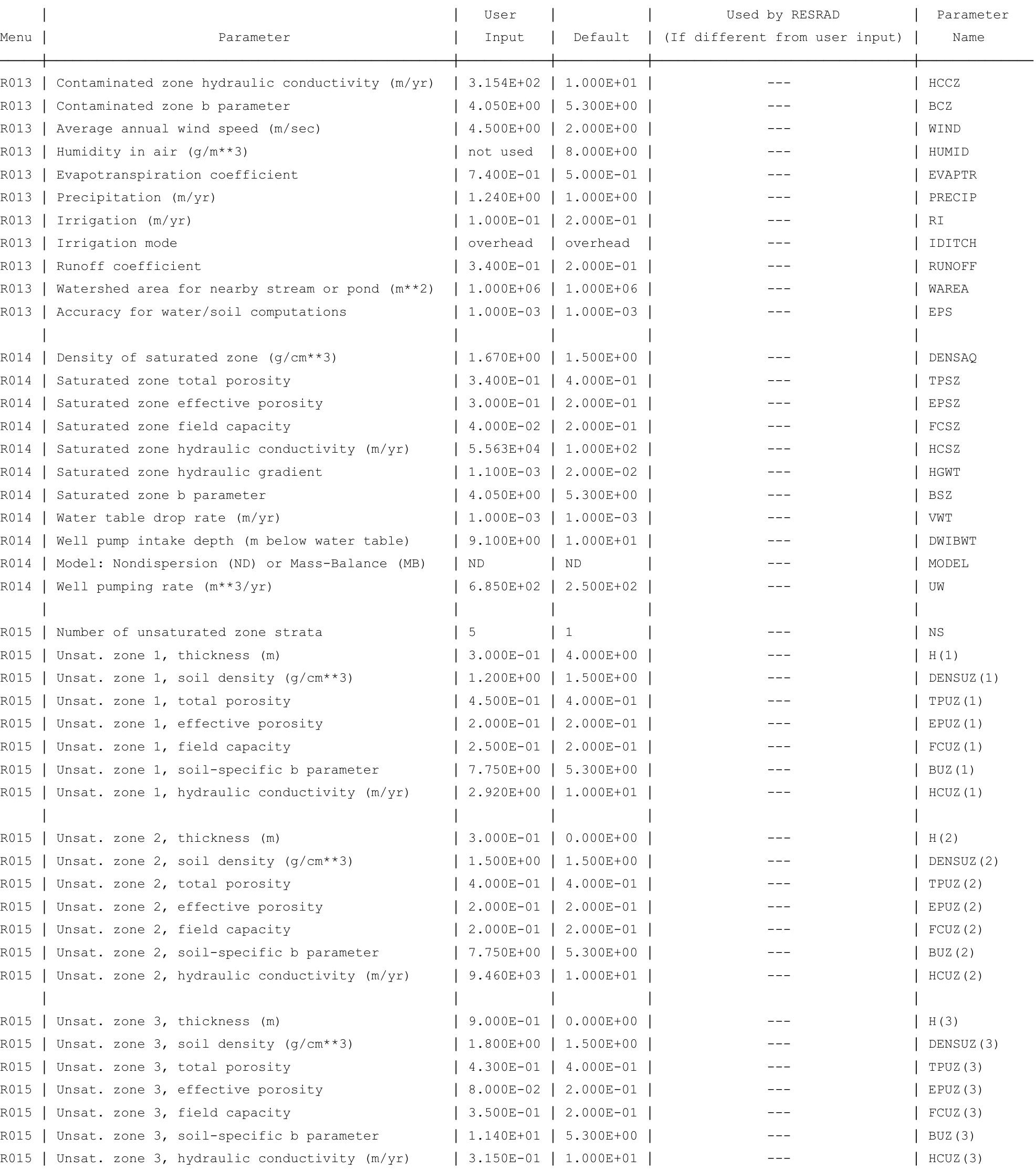


RESRAD, Version $6.5 \quad \mathrm{~T}^{1} \frac{1}{2}$ Limit $=180$ days

Summary : C746U Resident Gardener Deterministic Run

File : $\mathrm{X}: \backslash F I N A L$ V2 $\backslash$ DOE FWD RUNS \C746U RG DOE SG FWD-FV2-1050YR.RAD

Site-Specific Parameter Summary (continued)

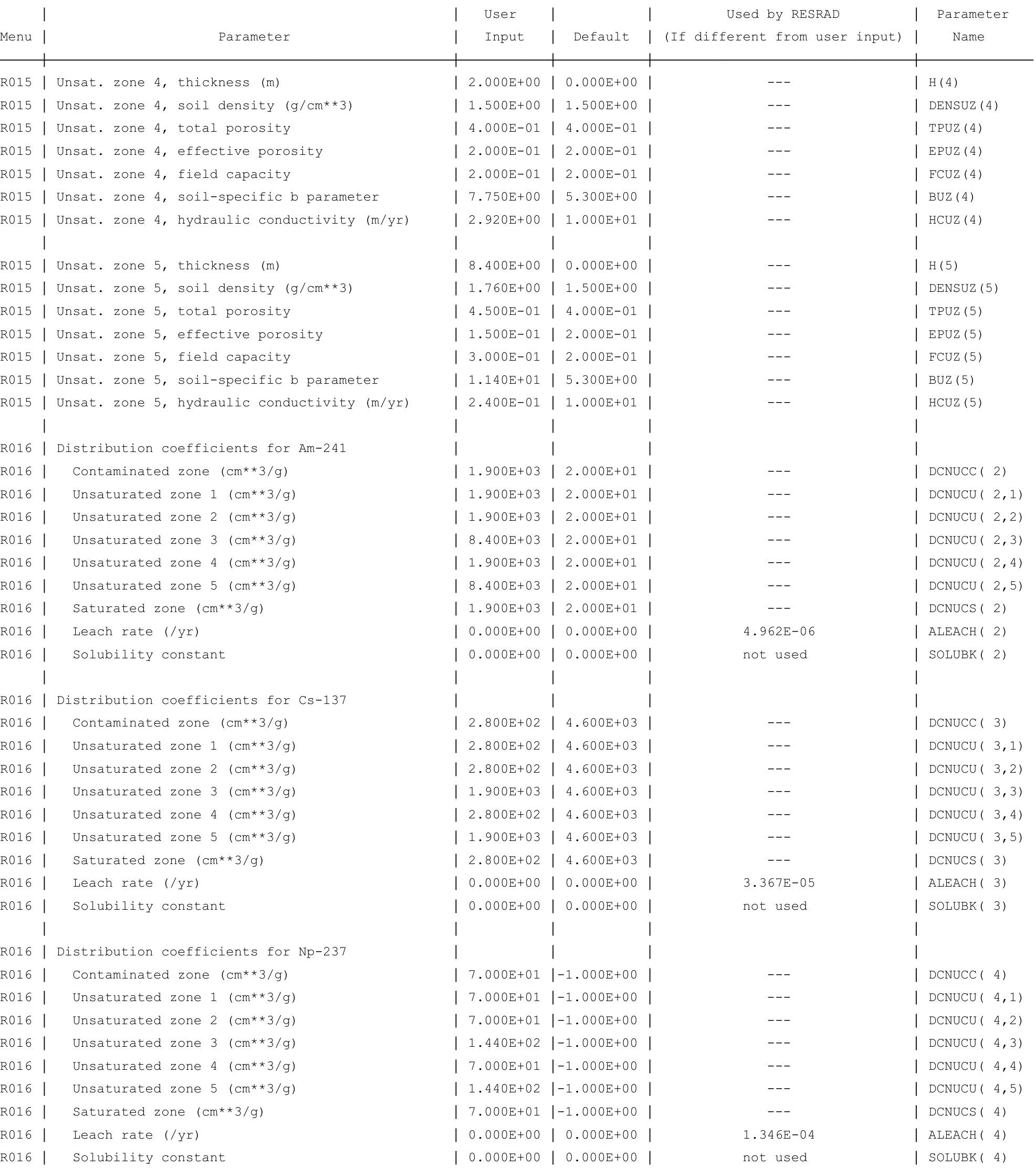


RESRAD, Version $6.5 \quad T^{1 / 2}$ Limit $=180$ days

Summary : C746U Resident Gardener Deterministic Run

File : $\mathrm{X}: \backslash F I N A L$ V2 $\backslash$ DOE FWD RUNS \C746U RG DOE SG FWD-FV2-1050YR.RAD

Site-Specific Parameter Summary (continued)

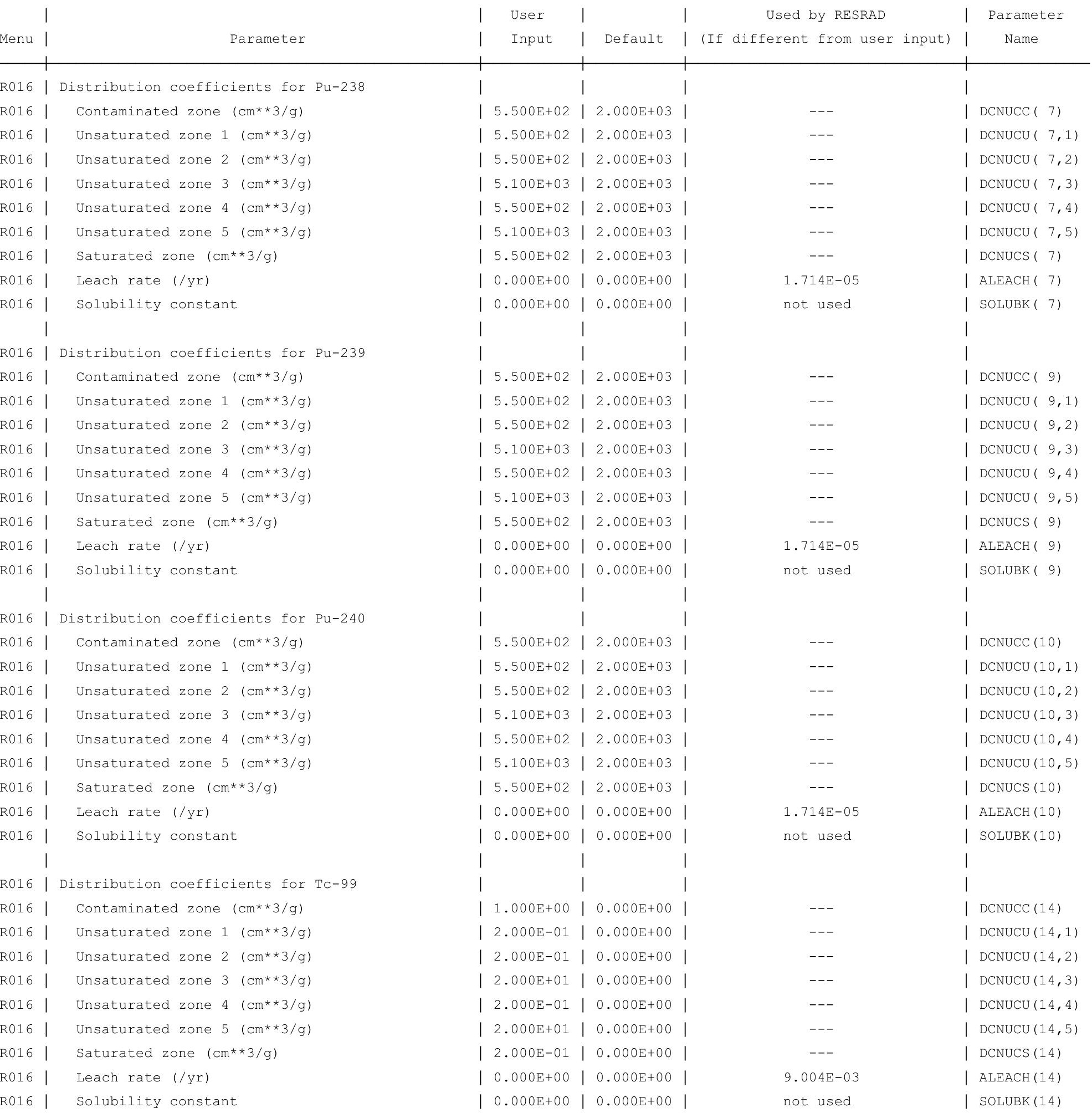


RESRAD, Version $6.5 \quad T^{1 / 2}$ Limit $=180$ days

Summary : C746U Resident Gardener Deterministic Run

File : $\mathrm{X}: \backslash F I N A L$ V2 $\backslash$ DOE FWD RUNS \C746U RG DOE SG FWD-FV2-1050YR.RAD

Site-Specific Parameter Summary (continued)

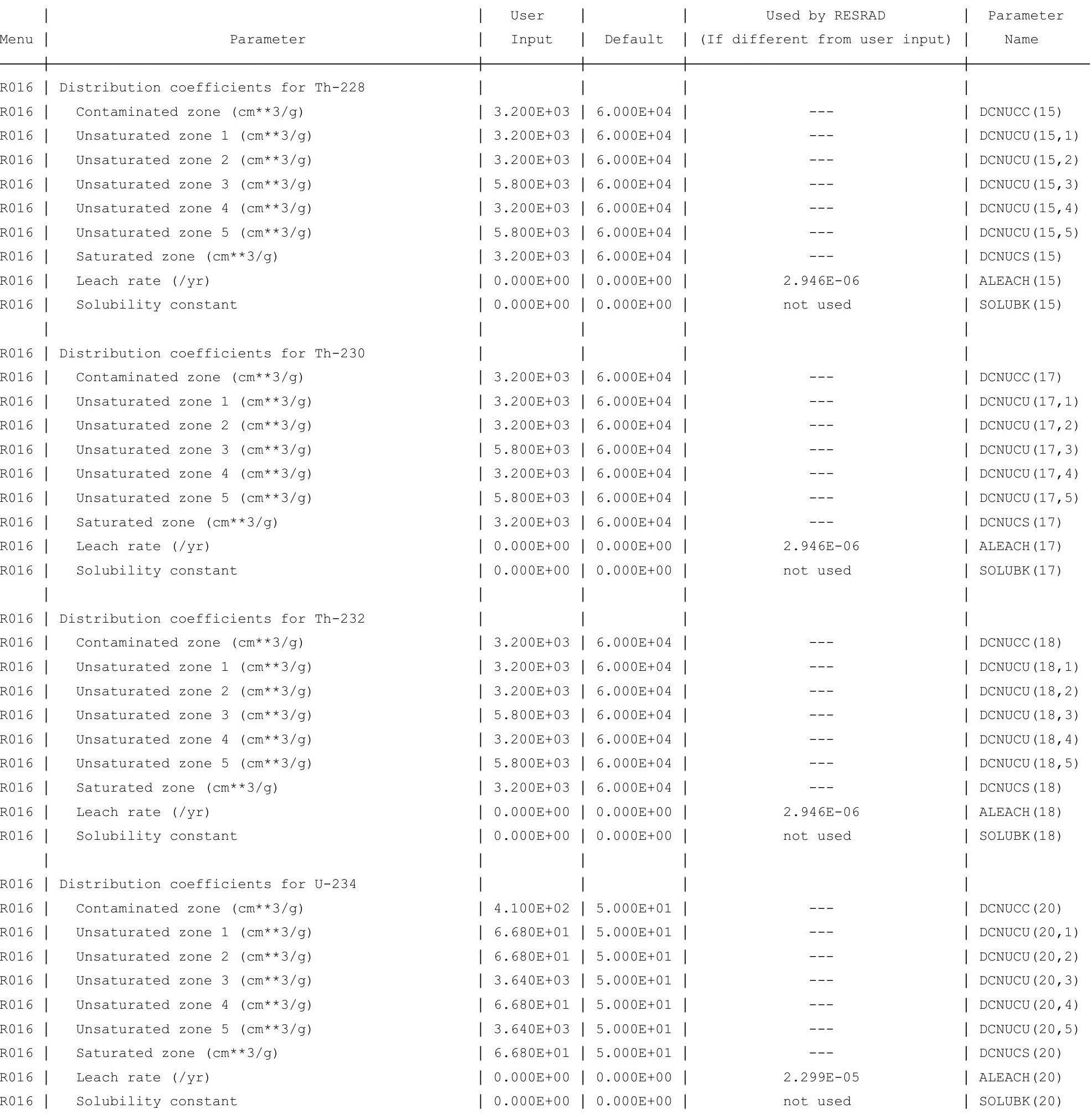


RESRAD, Version $6.5 \quad T^{1 / 2}$ Limit $=180$ days

Summary : C746U Resident Gardener Deterministic Run

File : $\mathrm{X}: \backslash F I N A L$ V2 $\backslash$ DOE FWD RUNS $\backslash C 746 U$ RG DOE SG FWD-FV2-1050YR. RAD

Site-Specific Parameter Summary (continued)

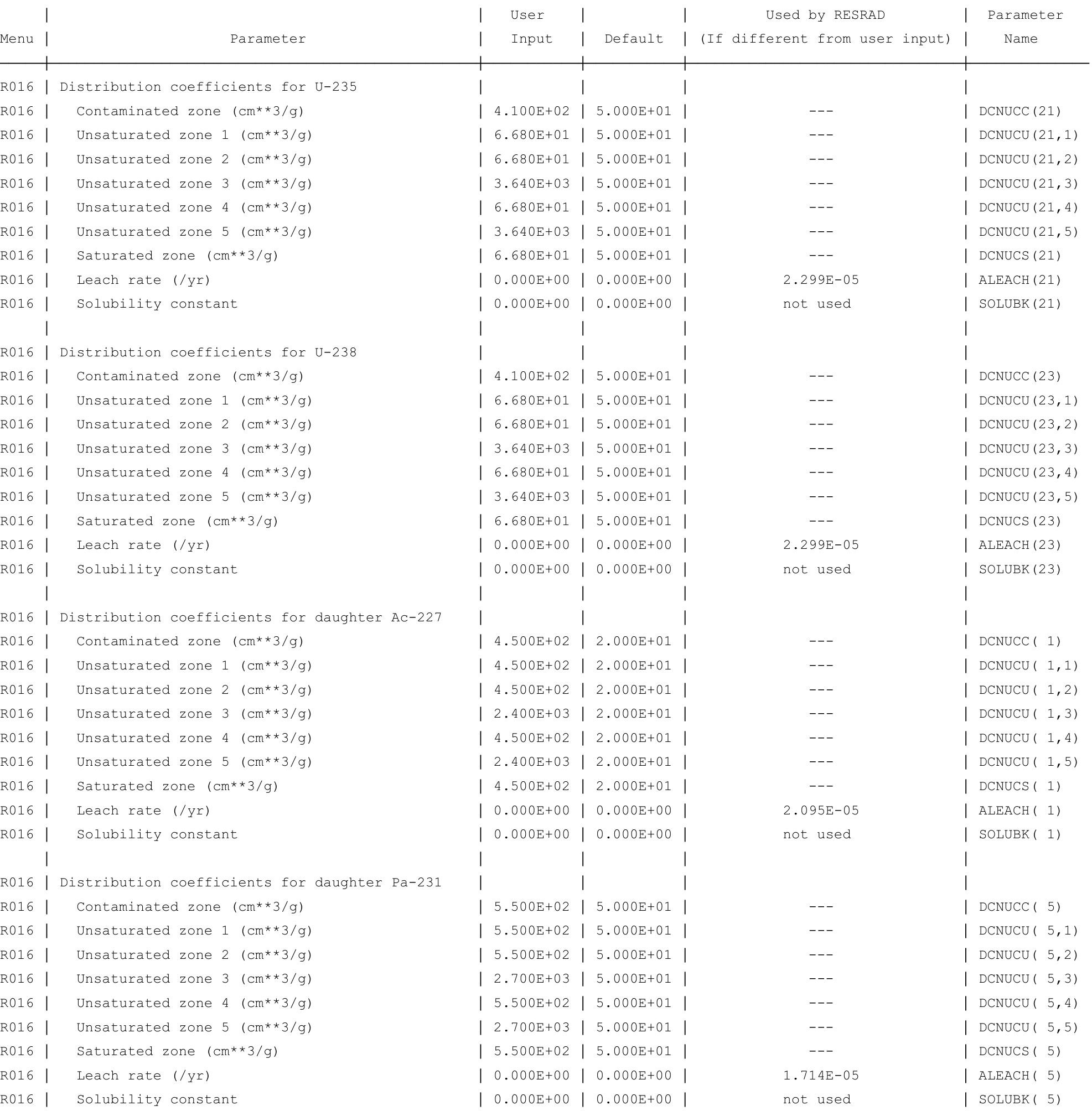


RESRAD, Version $6.5 \quad T^{1 / 2}$ Limit $=180$ days

Summary : C746U Resident Gardener Deterministic Run

File : $\mathrm{X}: \backslash F I N A L$ V2 $\backslash$ DOE FWD RUNS $\backslash C 746 U$ RG DOE SG FWD-FV2-1050YR. RAD

Site-Specific Parameter Summary (continued)

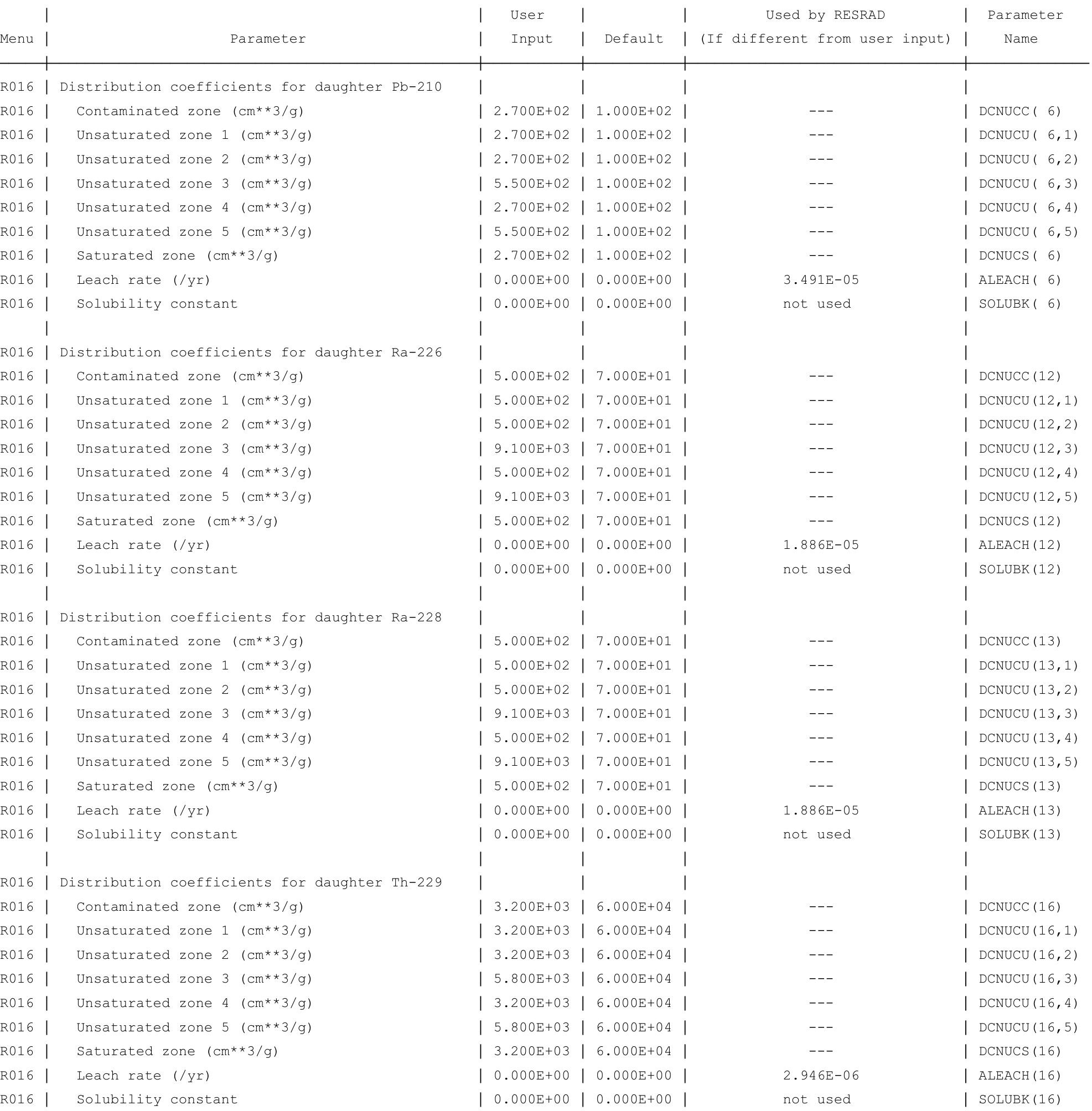


RESRAD, Version $6.5 \quad T^{1 / 2}$ Limit $=180$ days

Summary : C746U Resident Gardener Deterministic Run

File : $\mathrm{X}: \backslash F I N A L$ V2 $\backslash$ DOE FWD RUNS \C746U RG DOE SG FWD-FV2-1050YR.RAD

Site-Specific Parameter Summary (continued)

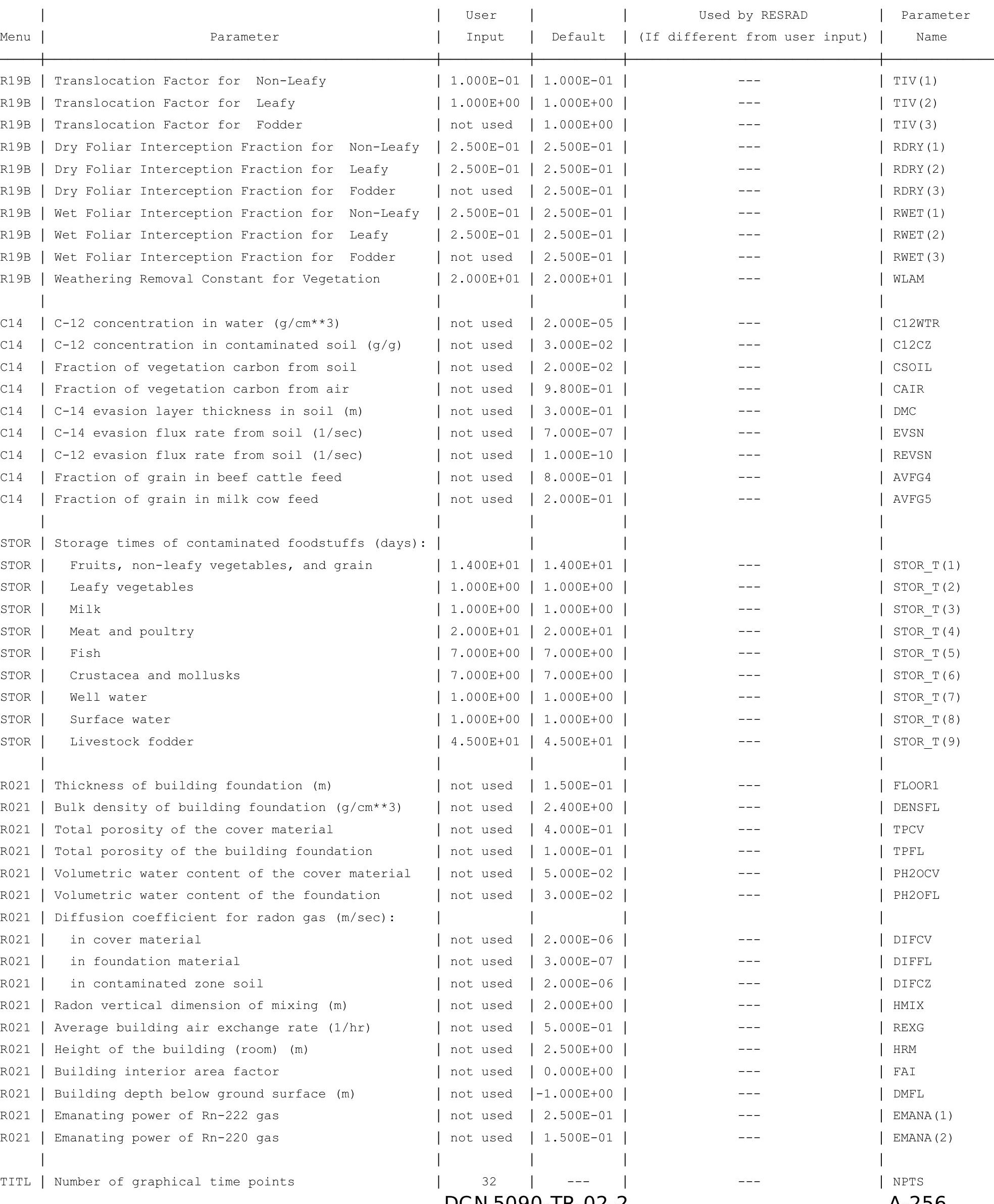


RESRAD, Version $6.5 \quad \mathrm{~T}^{1 / 2}$ Limit $=180$ days

Summary : C746U Resident Gardener Deterministic Run

File : $\mathrm{X}: \backslash F I N A L$ V2 $\backslash$ DOE FWD RUNS \C746U RG DOE SG FWD-FV2-1050YR.RAD

Contaminated Zone Dimensions

Area: 89436.00 square meters

Thickness:

Cover Depth:

Initial Soil Concentrations, pci/g

$\begin{array}{ll}\mathrm{Am}-241 & 3.500 \mathrm{E}+01 \\ \mathrm{Cs}-137 & 1.900 \mathrm{E}+01 \\ \mathrm{~Np}-237 & 5.500 \mathrm{E}+00 \\ \mathrm{Pu}-238 & 3.900 \mathrm{E}+01 \\ \mathrm{Pu}-239 & 3.600 \mathrm{E}+01 \\ \mathrm{Pu}-240 & 3.600 \mathrm{E}+01 \\ \mathrm{TC}-99 & 5.200 \mathrm{E}+01 \\ \mathrm{Th}-228 & 4.000 \mathrm{E}+00 \\ \mathrm{Th}-230 & 1.000 \mathrm{E}+02 \\ \mathrm{Th}-232 & 4.000 \mathrm{E}+00 \\ \mathrm{U}-234 & 1.600 \mathrm{E}+02 \\ \mathrm{U}-235 & 6.500 \mathrm{E}+00 \\ \mathrm{U}-238 & 1.600 \mathrm{E}+02\end{array}$

Total Dose TDOSE(t), mrem/yr

Basic Radiation Dose Limit $=1.000 \mathrm{E}+02 \mathrm{mrem} / \mathrm{yr}$

Total Mixture Sum $M(t)$ = Fraction of Basic Dose Limit Received at Time (t)

Maximum TDOSE $(\mathrm{t}): 6.827 \mathrm{E}+00 \mathrm{mrem} / \mathrm{yr}$ at $t=1.050 \mathrm{E}+03$ years 
RESRAD, Version 6.5

ummary : C746U Resident Gardener Deterministic Run

File : $\mathrm{X}: \backslash F I N A L$ V2 $\backslash$ DOE FWD RUNS \C746U RG DOE SG FWD-FV2-1050YR.RAD

Total Dose Contributions TDOSE(i,p,t) for Individual Radionuclides (i) and Pathways (p) As mrem/yr and Fraction of Total Dose At $t=0.000 \mathrm{E}+00$ years

Water Independent Pathways (Inhalation excludes radon)

\begin{tabular}{|c|c|c|c|c|c|c|c|c|c|c|c|c|c|c|}
\hline \multirow{2}{*}{ Nuclide } & \multicolumn{2}{|c|}{ Ground } & \multicolumn{2}{|c|}{ Inhalation } & \multicolumn{2}{|c|}{ Radon } & \multicolumn{2}{|c|}{ Plant } & \multicolumn{2}{|c|}{ Meat } & \multicolumn{2}{|c|}{ Milk } & \multicolumn{2}{|c|}{ Soil } \\
\hline & mrem/yr & fract. & mrem/yr & fract. & mrem/yr & fract. & mrem/yr & fract. & mrem/yr & fract. & mrem/yr & fract. & mrem/yr & fract. \\
\hline-241 & $5.412 \mathrm{E}-18$ & 0.0000 & $0.000 \mathrm{E}+00$ & 0.0000 & $0.000 \mathrm{E}+00$ & 0.0000 & $0.000 \mathrm{E}+00$ & 0.0000 & $0.000 \mathrm{E}+00$ & 0.0000 & $0.000 \mathrm{E}+00$ & 0.0000 & $0.000 \mathrm{E}+00$ & 0.0000 \\
\hline-137 & $2.397 E-08$ & 0.0043 & $0.000 \mathrm{E}+00$ & 0.0000 & $0.000 \mathrm{E}+00$ & 0.0000 & $0.000 \mathrm{E}+00$ & 0.0000 & $0.000 \mathrm{E}+00$ & 0.0000 & $0.000 \mathrm{E}+00$ & 0.0000 & $0.000 \mathrm{E}+00$ & 0.0000 \\
\hline-237 & $5.245 E-12$ & 0.0000 & $0.000 \mathrm{E}+00$ & 0.0000 & $0.000 \mathrm{E}+00$ & 0.0000 & $0.000 \mathrm{E}+00$ & 0.0000 & $0.000 \mathrm{E}+00$ & 0.0000 & $0.000 \mathrm{E}+00$ & 0.0000 & $0.000 \mathrm{E}+00$ & 0.0000 \\
\hline-238 & $3.174 \mathrm{E}-21$ & 0.0000 & $0.000 \mathrm{E}+00$ & 0.0000 & $0.000 \mathrm{E}+00$ & 0.0000 & $0.000 \mathrm{E}+00$ & 0.0000 & $0.000 \mathrm{E}+00$ & 0.0000 & $0.000 \mathrm{E}+00$ & 0.0000 & $0.000 \mathrm{E}+00$ & 0.0000 \\
\hline-239 & $4.328 E-16$ & 0.0000 & $0.000 \mathrm{E}+00$ & 0.0000 & $0.000 \mathrm{E}+00$ & 0.0000 & $0.000 \mathrm{E}+00$ & 0.0000 & $0.000 \mathrm{E}+00$ & 0.0000 & $0.000 \mathrm{E}+00$ & 0.0000 & $0.000 \mathrm{E}+00$ & 0.0000 \\
\hline-240 & $4.115 \mathrm{E}-23$ & 0.0000 & $0.000 \mathrm{E}+00$ & 0.0000 & $0.000 \mathrm{E}+00$ & 0.0000 & $0.000 \mathrm{E}+00$ & 0.0000 & $0.000 \mathrm{E}+00$ & 0.0000 & $0.000 \mathrm{E}+00$ & 0.0000 & $0.000 \mathrm{E}+00$ & 0.0000 \\
\hline 99 & $2.994 E-24$ & 0.0000 & $0.000 \mathrm{E}+00$ & 0.0000 & $0.000 \mathrm{E}+00$ & 0.0000 & $0.000 \mathrm{E}+00$ & 0.0000 & $0.000 \mathrm{E}+00$ & 0.0000 & $0.000 \mathrm{E}+00$ & 0.0000 & $0.000 \mathrm{E}+00$ & 0.0000 \\
\hline-228 & $5.530 \mathrm{E}-06$ & 0.9827 & $0.000 \mathrm{E}+00$ & 0.0000 & $0.000 \mathrm{E}+00$ & 0.0000 & $0.000 \mathrm{E}+00$ & 0.0000 & $0.000 \mathrm{E}+00$ & 0.0000 & $0.000 \mathrm{E}+00$ & 0.0000 & $0.000 \mathrm{E}+00$ & 0.0000 \\
\hline-230 & $3.774 \mathrm{E}-09$ & 0.0007 & $0.000 \mathrm{E}+00$ & 0.0000 & $0.000 \mathrm{E}+00$ & 0.0000 & $0.000 \mathrm{E}+00$ & 0.0000 & $0.000 \mathrm{E}+00$ & 0.0000 & $0.000 \mathrm{E}+00$ & 0.0000 & $0.000 \mathrm{E}+00$ & 0.0000 \\
\hline-232 & $4.712 \mathrm{E}-08$ & 0.0084 & $0.000 \mathrm{E}+00$ & 0.0000 & $0.000 \mathrm{E}+00$ & 0.0000 & $0.000 \mathrm{E}+00$ & 0.0000 & $0.000 \mathrm{E}+00$ & 0.0000 & $0.000 \mathrm{E}+00$ & 0.0000 & $0.000 \mathrm{E}+00$ & 0.0000 \\
\hline 234 & $1.813 \mathrm{E}-14$ & 0.0000 & $0.000 \mathrm{E}+00$ & 0.0000 & $0.000 \mathrm{E}+00$ & 0.0000 & $0.000 \mathrm{E}+00$ & 0.0000 & $0.000 \mathrm{E}+00$ & 0.0000 & $0.000 \mathrm{E}+00$ & 0.0000 & $0.000 \mathrm{E}+00$ & 0.0000 \\
\hline 235 & $8.089 \mathrm{E}-14$ & 0.0000 & $0.000 \mathrm{E}+00$ & 0.0000 & $0.000 \mathrm{E}+00$ & 0.0000 & $0.000 \mathrm{E}+00$ & 0.0000 & $0.000 \mathrm{E}+00$ & 0.0000 & $0.000 \mathrm{E}+00$ & 0.0000 & $0.000 \mathrm{E}+00$ & 0.0000 \\
\hline 238 & $2.271 E-08$ & 0.0040 & $0.000 \mathrm{E}+00$ & 0.0000 & $0.000 \mathrm{E}+00$ & 0.0000 & $0.000 \mathrm{E}+00$ & 0.0000 & $0.000 \mathrm{E}+00$ & 0.0000 & $0.000 \mathrm{E}+00$ & 0.0000 & $0.000 \mathrm{E}+00$ & 0.0000 \\
\hline & $5.627 \mathrm{E}-06$ & 1.0000 & $0.000 \mathrm{E}+00$ & 0.0000 & $0.000 \mathrm{E}+00$ & 0.0000 & $0.000 \mathrm{E}+00$ & 0.0000 & $0.000 \mathrm{E}+00$ & 0.0000 & $0.000 \mathrm{E}+00$ & 0.0000 & $.000 \mathrm{E}+00$ & 0.0000 \\
\hline
\end{tabular}

Total Dose Contributions TDOSE (i,p,t) for Individual Radionuclides (i) and Pathways (p) As mrem/yr and Fraction of Total Dose At $t=0.000 \mathrm{E}+00$ years

Water Dependent Pathways

\begin{tabular}{|c|c|c|c|c|c|c|c|c|c|c|c|c|c|c|}
\hline & \multicolumn{2}{|c|}{ Water } & \multicolumn{2}{|c|}{ Fish } & \multicolumn{2}{|c|}{ Radon } & \multicolumn{2}{|c|}{ Plant } & \multicolumn{2}{|c|}{ Meat } & \multicolumn{2}{|c|}{ Milk } & \multicolumn{2}{|c|}{ All Pathways* } \\
\hline clide & mrem/yr & fract. & mrem/yr & fract. & mrem/yr & fract. & mrem/yr & fract. & mrem/yr & fract. & mrem/yr & fract. & mrem/yr & fract. \\
\hline-241 & $0.000 \mathrm{E}+00$ & 0.0000 & $0.000 \mathrm{E}+00$ & 0.0000 & $0.000 \mathrm{E}+00$ & 0.0000 & $0.000 \mathrm{E}+00$ & 0.0000 & $0.000 \mathrm{E}+00$ & 0.0000 & $0.000 \mathrm{E}+00$ & 0.0000 & $5.412 \mathrm{E}-18$ & 0.0000 \\
\hline-137 & $0.000 \mathrm{E}+00$ & 0.0000 & $0.000 \mathrm{E}+00$ & 0.0000 & $0.000 \mathrm{E}+00$ & 0.0000 & $0.000 \mathrm{E}+00$ & 0.0000 & $0.000 \mathrm{E}+00$ & 0.0000 & $0.000 \mathrm{E}+00$ & 0.0000 & $2.397 \mathrm{E}-08$ & 0.0043 \\
\hline-237 & $0.000 \mathrm{E}+00$ & 0.0000 & $0.000 \mathrm{E}+00$ & 0.0000 & $0.000 \mathrm{E}+00$ & 0.0000 & $0.000 \mathrm{E}+00$ & 0.0000 & $0.000 \mathrm{E}+00$ & 0.0000 & $0.000 \mathrm{E}+00$ & 0.0000 & $5.245 E-12$ & 0.0000 \\
\hline-238 & $0.000 \mathrm{E}+00$ & 0.0000 & $0.000 \mathrm{E}+00$ & 0.0000 & $0.000 \mathrm{E}+00$ & 0.0000 & $0.000 \mathrm{E}+00$ & 0.0000 & $0.000 \mathrm{E}+00$ & 0.0000 & $0.000 \mathrm{E}+00$ & 0.0000 & $3.174 \mathrm{E}-21$ & 0.0000 \\
\hline-239 & $0.000 \mathrm{E}+00$ & 0.0000 & $0.000 \mathrm{E}+00$ & 0.0000 & $0.000 \mathrm{E}+00$ & 0.0000 & $0.000 \mathrm{E}+00$ & 0.0000 & $0.000 \mathrm{E}+00$ & 0.0000 & $0.000 E+00$ & 0.0000 & $4.328 E-16$ & 0.0000 \\
\hline-240 & $0.000 \mathrm{E}+00$ & 0.0000 & $0.000 \mathrm{E}+00$ & 0.0000 & $0.000 \mathrm{E}+00$ & 0.0000 & $0.000 \mathrm{E}+00$ & 0.0000 & $0.000 \mathrm{E}+00$ & 0.0000 & $0.000 E+00$ & 0.0000 & $4.115 \mathrm{E}-23$ & 0.0000 \\
\hline-99 & $0.000 \mathrm{E}+00$ & 0.0000 & $0.000 \mathrm{E}+00$ & 0.0000 & $0.000 \mathrm{E}+00$ & 0.0000 & $0.000 \mathrm{E}+00$ & 0.0000 & $0.000 \mathrm{E}+00$ & 0.0000 & $0.000 \mathrm{E}+00$ & 0.0000 & $2.994 \mathrm{E}-24$ & 0.0000 \\
\hline-228 & $0.000 \mathrm{E}+00$ & 0.0000 & $0.000 \mathrm{E}+00$ & 0.0000 & $0.000 \mathrm{E}+00$ & 0.0000 & $0.000 \mathrm{E}+00$ & 0.0000 & $0.000 \mathrm{E}+00$ & 0.0000 & $0.000 \mathrm{E}+00$ & 0.0000 & $5.530 \mathrm{E}-06$ & 0.9827 \\
\hline-230 & $0.000 \mathrm{E}+00$ & 0.0000 & $0.000 \mathrm{E}+00$ & 0.0000 & $0.000 \mathrm{E}+00$ & 0.0000 & $0.000 \mathrm{E}+00$ & 0.0000 & $0.000 \mathrm{E}+00$ & 0.0000 & $0.000 E+00$ & 0.0000 & $3.774 \mathrm{E}-09$ & 0.0007 \\
\hline 232 & $0.000 \mathrm{E}+00$ & 0.0000 & $0.000 \mathrm{E}+00$ & 0.0000 & $0.000 \mathrm{E}+00$ & 0.0000 & $0.000 \mathrm{E}+00$ & 0.0000 & $0.000 \mathrm{E}+00$ & 0.0000 & $0.000 \mathrm{E}+00$ & 0.0000 & $4.712 \mathrm{E}-08$ & 0.0084 \\
\hline 34 & $0.000 \mathrm{E}+00$ & 0.0000 & $0.000 \mathrm{E}+00$ & 0.0000 & $0.000 \mathrm{E}+00$ & 0.0000 & $0.000 \mathrm{E}+00$ & 0.0000 & $0.000 \mathrm{E}+00$ & 0.0000 & $0.000 \mathrm{E}+00$ & 0.0000 & $1.813 \mathrm{E}-14$ & 0.0000 \\
\hline 35 & $0.000 \mathrm{E}+00$ & 0.0000 & $0.000 \mathrm{E}+00$ & 0.0000 & $0.000 \mathrm{E}+00$ & 0.0000 & $0.000 \mathrm{E}+00$ & 0.0000 & $0.000 \mathrm{E}+00$ & 0.0000 & $0.000 E+00$ & 0.0000 & $8.089 \mathrm{E}-14$ & 0.0000 \\
\hline 38 & $0.000 \mathrm{E}+00$ & 0.0000 & $0.000 \mathrm{E}+00$ & 0.0000 & $0.000 \mathrm{E}+00$ & 0.0000 & $0.000 \mathrm{E}+00$ & 0.0000 & $0.000 \mathrm{E}+00$ & 0.0000 & $0.000 \mathrm{E}+00$ & 0.0000 & $2.271 E-08$ & 0.0040 \\
\hline & $0.000 \mathrm{E}+00$ & 0.0000 & $0.000 \mathrm{E}+00$ & 0.0000 & $0.000 \mathrm{E}+00$ & 0.0000 & $0.000 \mathrm{E}+00$ & 0.0000 & $0.000 \mathrm{E}+00$ & 0.0000 & $0.000 \mathrm{E}+00$ & 0.0000 & $7 E-06$ & 1. \\
\hline
\end{tabular}

* Sum of all water independent and dependent pathways. 
RESRAD, Version 6.5

ummary : C746U Resident Gardener Deterministic Run

File : $\mathrm{X}: \backslash F I N A L$ V2 $\backslash$ DOE FWD RUNS \C746U RG DOE SG FWD-FV2-1050YR.RAD

Total Dose Contributions TDOSE(i,p,t) for Individual Radionuclides (i) and Pathways (p) As mrem/yr and Fraction of Total Dose At $t=1.000 \mathrm{E}+00$ years

Water Independent Pathways (Inhalation excludes radon)

\begin{tabular}{|c|c|c|}
\hline clide & mrem/yr & fract. \\
\hline-241 & $1.638 \mathrm{E}-17$ & 0.0000 \\
\hline-137 & $2.362 E-08$ & 0.0056 \\
\hline-237 & $5.301 \mathrm{E}-12$ & 0.0000 \\
\hline-238 & $4.717 E-20$ & 0.0000 \\
\hline-239 & $4.380 \mathrm{E}-16$ & 0.0000 \\
\hline-240 & $4.275 E-23$ & 0.0000 \\
\hline-99 & $3.025 E-24$ & 0.0000 \\
\hline-228 & $3.872 \mathrm{E}-06$ & 0.9206 \\
\hline-230 & $1.139 \mathrm{E}-08$ & 0.0027 \\
\hline 232 & $2.759 \mathrm{E}-07$ & 0.0656 \\
\hline 34 & $1.277 E-13$ & 0.0000 \\
\hline 35 & $8.230 \mathrm{E}-14$ & 0.0000 \\
\hline 238 & $2.290 \mathrm{E}-08$ & 0.0054 \\
\hline & $4.206 \mathrm{E}-06$ & 1.0000 \\
\hline
\end{tabular}

Radio-

Total

$4.206 \mathrm{E}-06 \quad 1.0000$

Inhalation

\section{mrem/yr fract.}

$\overline{0.000 \mathrm{E}+00} \overline{0.0000}$

$0.000 \mathrm{E}+00 \quad 0.0000$

$0.000 \mathrm{E}+00 \quad 0.0000$

$0.000 \mathrm{E}+00 \quad 0.0000$

$0.000 \mathrm{E}+00 \quad 0.0000$

$0.000 \mathrm{E}+00 \quad 0.0000$

$0.000 E+00 \quad 0.0000$

$0.000 \mathrm{E}+00 \quad 0.0000$

$0.000 \mathrm{E}+00 \quad 0.0000$

$0.000 E+00 \quad 0.0000$

$0.000 \mathrm{E}+00 \quad 0.0000$

$0.000 E+00 \quad 0.0000$

$0.000 \mathrm{E}+00 \quad 0.0000$

$\overline{\overline{0.000 \mathrm{E}+00}} \overline{\overline{0.0000}}$

Radon
mrem/yr fract. $\overline{0.000 E+00} 0.0000$ $0.000 E+00 \quad 0.0000$ $0.000 E+00 \quad 0.0000$ $0.000 E+00 \quad 0.0000$ $0.000 \mathrm{E}+00 \quad 0.0000$ $0.000 E+00 \quad 0.0000$ $0.000 \mathrm{E}+00 \quad 0.0000$ $0.000 \mathrm{E}+00 \quad 0.0000$ $0.000 \mathrm{E}+00 \quad 0.0000$ $0.000 \mathrm{E}+00 \quad 0.0000$ $0.000 \mathrm{E}+00 \quad 0.0000$ $0.000 \mathrm{E}+00 \quad 0.0000$ $0.000 \mathrm{E}+00 \quad 0.0000$

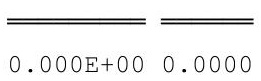

\begin{tabular}{|c|c|c|c|}
\hline \multicolumn{2}{|c|}{ Plant } & \multicolumn{2}{|c|}{ Meat } \\
\hline mrem/yr & fract. & mrem/yr & fract. \\
\hline $.000 \mathrm{E}+00$ & 0.0000 & $0.000 \mathrm{E}+00$ & 0.0000 \\
\hline $0.000 \mathrm{E}+00$ & 0.0000 & $0.000 \mathrm{E}+00$ & 0.0000 \\
\hline $0.000 \mathrm{E}+00$ & 0.0000 & $0.000 \mathrm{E}+00$ & 0.0000 \\
\hline $0.000 \mathrm{E}+00$ & 0.0000 & $0.000 \mathrm{E}+00$ & 0.0000 \\
\hline $0.000 \mathrm{E}+00$ & 0.0000 & $0.000 \mathrm{E}+00$ & 0.0000 \\
\hline $0.000 \mathrm{E}+00$ & 0.0000 & $0.000 \mathrm{E}+00$ & 0.0000 \\
\hline $0.000 \mathrm{E}+00$ & 0.0000 & $0.000 \mathrm{E}+00$ & 0.0000 \\
\hline $0.000 \mathrm{E}+00$ & 0.0000 & $0.000 \mathrm{E}+00$ & 0.0000 \\
\hline $0.000 \mathrm{E}+00$ & 0.0000 & $0.000 \mathrm{E}+00$ & 0.0000 \\
\hline $0.000 \mathrm{E}+00$ & 0.0000 & $0.000 \mathrm{E}+00$ & 0.0000 \\
\hline $0.000 \mathrm{E}+00$ & 0.0000 & $0.000 \mathrm{E}+00$ & 0.0000 \\
\hline $0.000 \mathrm{E}+00$ & 0.0000 & $0.000 \mathrm{E}+00$ & 0.0000 \\
\hline $0.000 \mathrm{E}+00$ & 0.0000 & $0.000 \mathrm{E}+00$ & 0.0000 \\
\hline & & 0.00 & . \\
\hline
\end{tabular}

\begin{tabular}{cc} 
Milk \\
\hline mrem/yr fract. \\
\cline { 1 - 2 } $0.000 \mathrm{E}+00$ & 0.0000 \\
$0.000 \mathrm{E}+00$ & 0.0000 \\
$0.000 \mathrm{E}+00$ & 0.0000 \\
$0.000 \mathrm{E}+00$ & 0.0000 \\
$0.000 \mathrm{E}+00$ & 0.0000 \\
$0.000 \mathrm{E}+00$ & 0.0000 \\
$0.000 \mathrm{E}+00$ & 0.0000 \\
$0.000 \mathrm{E}+00$ & 0.0000 \\
$0.000 \mathrm{E}+00$ & 0.0000 \\
$0.000 \mathrm{E}+00$ & 0.0000 \\
$0.000 \mathrm{E}+00$ & 0.0000 \\
$0.000 \mathrm{E}+00$ & 0.0000 \\
$0.000 \mathrm{E}+00$ & 0.0000 \\
\hline \hline $0.000 \mathrm{E}+00$ & 0.0000
\end{tabular}

Soil mrem/yr fract. $0.000 \mathrm{E}+00 \quad 0.0000$ $0.000 \mathrm{E}+00 \quad 0.0000$ $0.000 \mathrm{E}+00 \quad 0.0000$ $0.000 \mathrm{E}+00 \quad 0.0000$ $0.000 \mathrm{E}+00 \quad 0.0000$ $0.000 \mathrm{E}+00 \quad 0.0000$ $0.000 \mathrm{E}+00 \quad 0.0000$ $0.000 \mathrm{E}+00 \quad 0.0000$ $0.000 \mathrm{E}+00 \quad 0.0000$ $0.000 \mathrm{E}+00 \quad 0.0000$ $0.000 \mathrm{E}+00 \quad 0.0000$ $0.000 \mathrm{E}+00 \quad 0.0000$ $0.000 \mathrm{E}+00 \quad 0.0000$ $0.000 \mathrm{E}+00 \quad 0.0000$

Total Dose Contributions TDOSE (i,p,t) for Individual Radionuclides (i) and Pathways (p) As mrem/yr and Fraction of Total Dose At $t=1.000 \mathrm{E}+00$ years

Water Dependent Pathways

\begin{tabular}{|c|c|c|c|c|c|c|}
\hline & \multicolumn{2}{|c|}{ Water } & \multicolumn{2}{|c|}{ Fish } & \multicolumn{2}{|c|}{ Radon } \\
\hline clide & mrem/yr & fract. & mrem/yr & fract. & mrem/yr & fract. \\
\hline-241 & $0.000 \mathrm{E}+00$ & 0.0000 & $0.000 \mathrm{E}+00$ & 0.0000 & $0.000 \mathrm{E}+00$ & 0.0000 \\
\hline-137 & $0.000 \mathrm{E}+00$ & 0.0000 & $0.000 \mathrm{E}+00$ & 0.0000 & $0.000 \mathrm{E}+00$ & 0.0000 \\
\hline-237 & $0.000 \mathrm{E}+00$ & 0.0000 & $0.000 \mathrm{E}+00$ & 0.0000 & $0.000 \mathrm{E}+00$ & 0.0000 \\
\hline-238 & $0.000 \mathrm{E}+00$ & 0.0000 & $0.000 \mathrm{E}+00$ & 0.0000 & $0.000 \mathrm{E}+00$ & 0.0000 \\
\hline-239 & $0.000 \mathrm{E}+00$ & 0.0000 & $0.000 \mathrm{E}+00$ & 0.0000 & $0.000 \mathrm{E}+00$ & 0.0000 \\
\hline-240 & $0.000 \mathrm{E}+00$ & 0.0000 & $0.000 \mathrm{E}+00$ & 0.0000 & $0.000 \mathrm{E}+00$ & 0.0000 \\
\hline 99 & $0.000 \mathrm{E}+00$ & 0.0000 & $0.000 \mathrm{E}+00$ & 0.0000 & $0.000 \mathrm{E}+00$ & 0.0000 \\
\hline-228 & $0.000 \mathrm{E}+00$ & 0.0000 & $0.000 \mathrm{E}+00$ & 0.0000 & $0.000 \mathrm{E}+00$ & 0.0000 \\
\hline-230 & $0.000 \mathrm{E}+00$ & 0.0000 & $0.000 \mathrm{E}+00$ & 0.0000 & $0.000 \mathrm{E}+00$ & 0.0000 \\
\hline 232 & $0.000 \mathrm{E}+00$ & 0.0000 & $0.000 \mathrm{E}+00$ & 0.0000 & $0.000 \mathrm{E}+00$ & 0.0000 \\
\hline 234 & $0.000 \mathrm{E}+00$ & 0.0000 & $0.000 \mathrm{E}+00$ & 0.0000 & $0.000 \mathrm{E}+00$ & 0.0000 \\
\hline 235 & $0.000 \mathrm{E}+00$ & 0.0000 & $0.000 \mathrm{E}+00$ & 0.0000 & $0.000 \mathrm{E}+00$ & 0.0000 \\
\hline 238 & $0.000 \mathrm{E}+00$ & 0.0000 & $0.000 \mathrm{E}+00$ & 0.0000 & $0.000 \mathrm{E}+00$ & 0.0000 \\
\hline & $0.000 \mathrm{E}+00$ & 0.0000 & $0.000 \mathrm{E}+00$ & 0.0000 & $0.000 \mathrm{E}+00$ & 0.0000 \\
\hline
\end{tabular}

\begin{tabular}{|c|c|c|c|}
\hline \multicolumn{2}{|c|}{ Plant } & \multicolumn{2}{|c|}{ Meat } \\
\hline mrem/yr & fract. & mrem/yr & fract. \\
\hline $0.000 \mathrm{E}+00$ & 0.0000 & $0.000 \mathrm{E}+00$ & 0.0000 \\
\hline $0.000 \mathrm{E}+00$ & 0.0000 & $0.000 \mathrm{E}+00$ & 0.0000 \\
\hline $0.000 \mathrm{E}+00$ & 0.0000 & $0.000 \mathrm{E}+00$ & 0.0000 \\
\hline $0.000 \mathrm{E}+00$ & 0.0000 & $0.000 \mathrm{E}+00$ & 0.0000 \\
\hline $0.000 \mathrm{E}+00$ & 0.0000 & $0.000 \mathrm{E}+00$ & 0.0000 \\
\hline $0.000 \mathrm{E}+00$ & 0.0000 & $0.000 \mathrm{E}+00$ & 0.0000 \\
\hline $0.000 \mathrm{E}+00$ & 0.0000 & $0.000 \mathrm{E}+00$ & 0.0000 \\
\hline $0.000 \mathrm{E}+00$ & 0.0000 & $0.000 \mathrm{E}+00$ & 0.0000 \\
\hline $0.000 \mathrm{E}+00$ & 0.0000 & $0.000 \mathrm{E}+00$ & 0.0000 \\
\hline $0.000 \mathrm{E}+00$ & 0.0000 & $0.000 \mathrm{E}+00$ & 0.0000 \\
\hline $0.000 \mathrm{E}+00$ & 0.0000 & $0.000 \mathrm{E}+00$ & 0.0000 \\
\hline $0.000 \mathrm{E}+00$ & 0.0000 & $0.000 \mathrm{E}+00$ & 0.0000 \\
\hline $0.000 \mathrm{E}+00$ & 0.0000 & $0.000 \mathrm{E}+00$ & 0.0000 \\
\hline
\end{tabular}

$0.000 \mathrm{E}+00 \quad 0.0000$

$0.000 \mathrm{E}+00 \quad 0.0000$

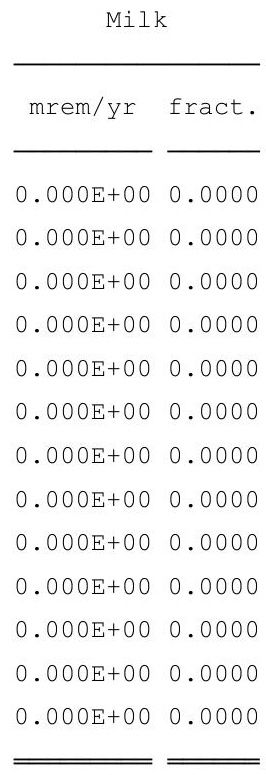

$0.000 \mathrm{E}+00 \quad 0.0000$
All Pathways* mrem/yr fract. $1.638 \mathrm{E}-170.0000$ $2.362 \mathrm{E}-08 \quad 0.0056$ $5.301 \mathrm{E}-12 \quad 0.0000$ $4.717 \mathrm{E}-20 \quad 0.0000$ $4.380 \mathrm{E}-160.0000$ $4.275 \mathrm{E}-23 \quad 0.0000$ $3.025 \mathrm{E}-240.0000$ $3.872 \mathrm{E}-06 \quad 0.9206$ $1.139 \mathrm{E}-08 \quad 0.0027$ $2.759 \mathrm{E}-070.0656$ $1.277 \mathrm{E}-130.0000$ $8.230 \mathrm{E}-14 \quad 0.0000$ $2.290 \mathrm{E}-08 \quad 0.0054$ $4.206 \mathrm{E}-061.0000$

* Sum of all water independent and dependent pathways. 
RESRAD, Version 6.5

Summary : C746U Resident Gardener Deterministic Run
File : X: $\backslash$ FINAL V2 $\backslash$ DOE FWD RUNS $\backslash C 746 U$ RG DOE SG FWD-FV2-1050YR.RAD

Total Dose Contributions TDOSE (i,p,t) for Individual Radionuclides (i) and Pathways (p) As mrem/yr and Fraction of Total Dose At $t=5.000 \mathrm{E}+01$ years

Water Independent Pathways (Inhalation excludes radon)

\begin{tabular}{|c|c|c|}
\hline clide & mrem/yr & fract. \\
\hline-241 & $8.973 E-16$ & 0.0000 \\
\hline-137 & $1.149 \mathrm{E}-08$ & 0.0012 \\
\hline-237 & $8.957 \mathrm{E}-12$ & 0.0000 \\
\hline-238 & $2.054 \mathrm{E}-15$ & 0.0000 \\
\hline-239 & $7.861 \mathrm{E}-16$ & 0.0000 \\
\hline-240 & $9.653 \mathrm{E}-20$ & 0.0000 \\
\hline-99 & $4.979 \mathrm{E}-24$ & 0.0000 \\
\hline-228 & $1.011 \mathrm{E}-13$ & 0.0000 \\
\hline-230 & $5.320 \mathrm{E}-07$ & 0.0558 \\
\hline 232 & $8.963 E-06$ & 0.9395 \\
\hline 234 & $1.941 \mathrm{E}-10$ & 0.0000 \\
\hline 235 & $6.005 \mathrm{E}-13$ & 0.0000 \\
\hline 238 & $3.385 E-08$ & 0.0035 \\
\hline & $9.541 \mathrm{E}-06$ & 1 \\
\hline
\end{tabular}

Radio-

Total

9.541E-06 1.0000

Inhalation

\section{mrem/yr fract.}

$\overline{0.000 \mathrm{E}+00} \overline{0.0000}$

$0.000 \mathrm{E}+00 \quad 0.0000$

$0.000 \mathrm{E}+00 \quad 0.0000$

$0.000 \mathrm{E}+00 \quad 0.0000$

$0.000 \mathrm{E}+00 \quad 0.0000$

$0.000 \mathrm{E}+00 \quad 0.0000$

$0.000 E+00 \quad 0.0000$

$0.000 \mathrm{E}+00 \quad 0.0000$

$0.000 \mathrm{E}+00 \quad 0.0000$

$0.000 E+00 \quad 0.0000$

$0.000 \mathrm{E}+00 \quad 0.0000$

$0.000 E+00 \quad 0.0000$

$0.000 \mathrm{E}+00 \quad 0.0000$

$\overline{\overline{0.000 \mathrm{E}+00}} \overline{\overline{0.0000}}$

Radon
mrem/yr fract. $\overline{0.000 \mathrm{E}+00} \overline{0.0000}$ $0.000 \mathrm{E}+00 \quad 0.0000$ $0.000 E+00 \quad 0.0000$ $0.000 E+00 \quad 0.0000$ $0.000 \mathrm{E}+00 \quad 0.0000$ $0.000 E+00 \quad 0.0000$ $0.000 \mathrm{E}+00 \quad 0.0000$ $0.000 \mathrm{E}+00 \quad 0.0000$ $0.000 \mathrm{E}+00 \quad 0.0000$ $0.000 \mathrm{E}+00 \quad 0.0000$ $0.000 \mathrm{E}+00 \quad 0.0000$ $0.000 \mathrm{E}+00 \quad 0.0000$ $0.000 \mathrm{E}+00 \quad 0.0000$

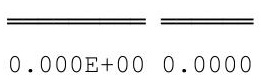

\begin{tabular}{|c|c|c|c|}
\hline \multicolumn{2}{|c|}{ Plant } & \multicolumn{2}{|c|}{ Meat } \\
\hline mrem/yr & fract. & mrem/yr & fract. \\
\hline $0.000 \mathrm{E}+00$ & 0.0000 & $0.000 \mathrm{E}+00$ & 0.0000 \\
\hline $0.000 \mathrm{E}+00$ & 0.0000 & $0.000 \mathrm{E}+00$ & 0.0000 \\
\hline $0.000 \mathrm{E}+00$ & 0.0000 & $0.000 \mathrm{E}+00$ & 0.0000 \\
\hline $0.000 \mathrm{E}+00$ & 0.0000 & $0.000 \mathrm{E}+00$ & 0.0000 \\
\hline $0.000 \mathrm{E}+00$ & 0.0000 & $0.000 \mathrm{E}+00$ & 0.0000 \\
\hline $0.000 \mathrm{E}+00$ & 0.0000 & $0.000 \mathrm{E}+00$ & 0.0000 \\
\hline $0.000 \mathrm{E}+00$ & 0.0000 & $0.000 \mathrm{E}+00$ & 0.0000 \\
\hline $0.000 \mathrm{E}+00$ & 0.0000 & $0.000 \mathrm{E}+00$ & 0.0000 \\
\hline $0.000 \mathrm{E}+00$ & 0.0000 & $0.000 \mathrm{E}+00$ & 0.0000 \\
\hline $0.000 \mathrm{E}+00$ & 0.0000 & $0.000 \mathrm{E}+00$ & 0.0000 \\
\hline $0.000 \mathrm{E}+00$ & 0.0000 & $0.000 \mathrm{E}+00$ & 0.0000 \\
\hline $0.000 \mathrm{E}+00$ & 0.0000 & $0.000 \mathrm{E}+00$ & 0.0000 \\
\hline $0.000 \mathrm{E}+00$ & 0.0000 & $0.000 \mathrm{E}+00$ & 0.0000 \\
\hline & & 0.00 & \\
\hline
\end{tabular}

\begin{tabular}{cc} 
Milk \\
\hline mrem/yr fract. \\
\cline { 1 - 2 } 0.000E+00 & 0.0000 \\
$0.000 \mathrm{E}+00$ & 0.0000 \\
$0.000 \mathrm{E}+00$ & 0.0000 \\
$0.000 \mathrm{E}+00$ & 0.0000 \\
$0.000 \mathrm{E}+00$ & 0.0000 \\
$0.000 \mathrm{E}+00$ & 0.0000 \\
$0.000 \mathrm{E}+00$ & 0.0000 \\
$0.000 \mathrm{E}+00$ & 0.0000 \\
$0.000 \mathrm{E}+00$ & 0.0000 \\
$0.000 \mathrm{E}+00$ & 0.0000 \\
$0.000 \mathrm{E}+00$ & 0.0000 \\
$0.000 \mathrm{E}+00$ & 0.0000 \\
$0.000 \mathrm{E}+00$ & 0.0000 \\
\hline \hline $0.000 \mathrm{E}+00$ & 0.0000
\end{tabular}

Soil mrem/yr fract. $0.000 \mathrm{E}+00 \quad 0.0000$ $0.000 \mathrm{E}+00 \quad 0.0000$ $0.000 \mathrm{E}+00 \quad 0.0000$ $0.000 \mathrm{E}+00 \quad 0.0000$ $0.000 \mathrm{E}+00 \quad 0.0000$ $0.000 \mathrm{E}+00 \quad 0.0000$ $0.000 \mathrm{E}+00 \quad 0.0000$ $0.000 \mathrm{E}+00 \quad 0.0000$ $0.000 \mathrm{E}+00 \quad 0.0000$ $0.000 \mathrm{E}+00 \quad 0.0000$ $0.000 \mathrm{E}+00 \quad 0.0000$ $0.000 \mathrm{E}+00 \quad 0.0000$ $0.000 \mathrm{E}+00 \quad 0.0000$ $0.000 \mathrm{E}+00 \quad 0.0000$

Total Dose Contributions TDOSE (i,p,t) for Individual Radionuclides (i) and Pathways (p) As mrem/yr and Fraction of Total Dose At $t=5.000 \mathrm{E}+01$ years

Water Dependent Pathways

\begin{tabular}{|c|c|c|c|c|c|c|}
\hline & \multicolumn{2}{|c|}{ Water } & \multicolumn{2}{|c|}{ Fish } & \multicolumn{2}{|c|}{ Radon } \\
\hline clide & mrem/yr & fract. & mrem/yr & fract. & mrem/yr & fract. \\
\hline 41 & $0.000 \mathrm{E}+00$ & 0.0000 & $0.000 \mathrm{E}+00$ & 0.0000 & $0.000 \mathrm{E}+00$ & 0.0000 \\
\hline-137 & $0.000 \mathrm{E}+00$ & 0.0000 & $0.000 \mathrm{E}+00$ & 0.0000 & $0.000 \mathrm{E}+00$ & 0.0000 \\
\hline-237 & $0.000 \mathrm{E}+00$ & 0.0000 & $0.000 \mathrm{E}+00$ & 0.0000 & $0.000 \mathrm{E}+00$ & 0.0000 \\
\hline-238 & $0.000 \mathrm{E}+00$ & 0.0000 & $0.000 \mathrm{E}+00$ & 0.0000 & $0.000 \mathrm{E}+00$ & 0.0000 \\
\hline-239 & $0.000 \mathrm{E}+00$ & 0.0000 & $0.000 \mathrm{E}+00$ & 0.0000 & $0.000 \mathrm{E}+00$ & 0.0000 \\
\hline-240 & $0.000 \mathrm{E}+00$ & 0.0000 & $0.000 \mathrm{E}+00$ & 0.0000 & $0.000 \mathrm{E}+00$ & 0.0000 \\
\hline-99 & $0.000 \mathrm{E}+00$ & 0.0000 & $0.000 \mathrm{E}+00$ & 0.0000 & $0.000 \mathrm{E}+00$ & 0.0000 \\
\hline-228 & $0.000 \mathrm{E}+00$ & 0.0000 & $0.000 \mathrm{E}+00$ & 0.0000 & $0.000 \mathrm{E}+00$ & 0.0000 \\
\hline-230 & $0.000 \mathrm{E}+00$ & 0.0000 & $0.000 \mathrm{E}+00$ & 0.0000 & $0.000 \mathrm{E}+00$ & 0.0000 \\
\hline-232 & $0.000 \mathrm{E}+00$ & 0.0000 & $0.000 \mathrm{E}+00$ & 0.0000 & $0.000 \mathrm{E}+00$ & 0.0000 \\
\hline 234 & $0.000 \mathrm{E}+00$ & 0.0000 & $0.000 \mathrm{E}+00$ & 0.0000 & $0.000 \mathrm{E}+00$ & 0.0000 \\
\hline 35 & $0.000 \mathrm{E}+00$ & 0.0000 & $0.000 \mathrm{E}+00$ & 0.0000 & $0.000 \mathrm{E}+00$ & 0.0000 \\
\hline 38 & $0.000 \mathrm{E}+00$ & 0.0000 & $0.000 \mathrm{E}+00$ & 0.0000 & $0.000 \mathrm{E}+00$ & 0.0000 \\
\hline & $0.000 \mathrm{E}+00$ & 0.0000 & $0.000 \mathrm{E}+00$ & 0.0000 & $0.000 \mathrm{E}+00$ & 0.0000 \\
\hline
\end{tabular}

\begin{tabular}{|c|c|c|c|}
\hline \multicolumn{2}{|c|}{ Plant } & \multicolumn{2}{|c|}{ Meat } \\
\hline mrem/yr & fract. & mrem/yr & fract. \\
\hline $0.000 \mathrm{E}+00$ & 0.0000 & $0.000 \mathrm{E}+00$ & 0.0000 \\
\hline $0.000 \mathrm{E}+00$ & 0.0000 & $0.000 \mathrm{E}+00$ & 0.0000 \\
\hline $0.000 \mathrm{E}+00$ & 0.0000 & $0.000 \mathrm{E}+00$ & 0.0000 \\
\hline $0.000 \mathrm{E}+00$ & 0.0000 & $0.000 \mathrm{E}+00$ & 0.0000 \\
\hline $0.000 \mathrm{E}+00$ & 0.0000 & $0.000 \mathrm{E}+00$ & 0.0000 \\
\hline $0.000 \mathrm{E}+00$ & 0.0000 & $0.000 \mathrm{E}+00$ & 0.0000 \\
\hline $0.000 \mathrm{E}+00$ & 0.0000 & $0.000 \mathrm{E}+00$ & 0.0000 \\
\hline $0.000 \mathrm{E}+00$ & 0.0000 & $0.000 \mathrm{E}+00$ & 0.0000 \\
\hline $0.000 \mathrm{E}+00$ & 0.0000 & $0.000 \mathrm{E}+00$ & 0.0000 \\
\hline $0.000 \mathrm{E}+00$ & 0.0000 & $0.000 \mathrm{E}+00$ & 0.0000 \\
\hline $0.000 \mathrm{E}+00$ & 0.0000 & $0.000 \mathrm{E}+00$ & 0.0000 \\
\hline $0.000 \mathrm{E}+00$ & 0.0000 & $0.000 \mathrm{E}+00$ & 0.0000 \\
\hline $0.000 \mathrm{E}+00$ & 0.0000 & $0.000 \mathrm{E}+00$ & 0.0000 \\
\hline
\end{tabular}

$0.000 \mathrm{E}+00 \quad 0.0000$

$0.000 \mathrm{E}+00 \quad 0.0000$

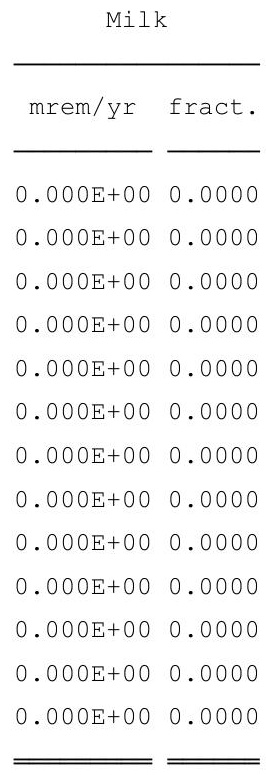

$0.000 \mathrm{E}+00 \quad 0.0000$
All Pathways* mrem/yr fract. $8.973 E-160.0000$ $1.149 \mathrm{E}-08 \quad 0.0012$ $8.957 \mathrm{E}-120.0000$ $2.054 \mathrm{E}-150.0000$ $7.861 \mathrm{E}-16 \quad 0.0000$ $9.653 \mathrm{E}-20 \quad 0.0000$ $4.979 \mathrm{E}-24 \quad 0.0000$ $1.011 \mathrm{E}-13 \quad 0.0000$ $5.320 \mathrm{E}-070.0558$ $8.963 \mathrm{E}-06 \quad 0.9395$ $1.941 \mathrm{E}-10 \quad 0.0000$ $6.005 \mathrm{E}-130.0000$ $3.385 \mathrm{E}-08 \quad 0.0035$ $9.541 \mathrm{E}-06 \quad 1.0000$

* Sum of all water independent and dependent pathways. 
RESRAD, Version 6.5

Summary : C746U Resident Gardener Deterministic Run
File : X: $\backslash$ FINAL V2 $\backslash$ DOE FWD RUNS $\backslash C 746 U$ RG DOE SG FWD-FV2-1050YR.RAD

Total Dose Contributions TDOSE (i,p,t) for Individual Radionuclides (i) and Pathways (p) As mrem/yr and Fraction of Total Dose At $t=1.000 \mathrm{E}+02$ years

Water Independent Pathways (Inhalation excludes radon)

\begin{tabular}{|c|c|c|c|c|c|c|c|c|c|c|c|c|c|c|}
\hline \multirow{2}{*}{ Nuclide } & \multicolumn{2}{|c|}{ Ground } & \multicolumn{2}{|c|}{ Inhalation } & \multicolumn{2}{|c|}{ Radon } & \multicolumn{2}{|c|}{ Plant } & \multicolumn{2}{|c|}{ Meat } & \multicolumn{2}{|c|}{ Milk } & \multicolumn{2}{|c|}{ Soil } \\
\hline & mrem/yr & fract. & mrem/yr & fract. & mrem/yr & fract. & mrem/yr & fract. & mrem/yr & fract. & mrem/yr & fract. & mrem/yr & fract. \\
\hline-241 & $2.940 \mathrm{E}-15$ & 0.0000 & $0.000 \mathrm{E}+00$ & 0.0000 & $0.000 \mathrm{E}+00$ & 0.0000 & $0.000 \mathrm{E}+00$ & 0.0000 & $0.000 \mathrm{E}+00$ & 0.0000 & $0.000 \mathrm{E}+00$ & 0.0000 & $0.000 \mathrm{E}+00$ & 0.0000 \\
\hline-137 & $5.512 \mathrm{E}-09$ & 0.0004 & $0.000 \mathrm{E}+00$ & 0.0000 & $0.000 \mathrm{E}+00$ & 0.0000 & $0.000 \mathrm{E}+00$ & 0.0000 & $0.000 \mathrm{E}+00$ & 0.0000 & $0.000 \mathrm{E}+00$ & 0.0000 & $0.000 \mathrm{E}+00$ & 0.0000 \\
\hline-237 & $1.534 \mathrm{E}-11$ & 0.0000 & $0.000 \mathrm{E}+00$ & 0.0000 & $0.000 \mathrm{E}+00$ & 0.0000 & $0.000 \mathrm{E}+00$ & 0.0000 & $0.000 \mathrm{E}+00$ & 0.0000 & $0.000 \mathrm{E}+00$ & 0.0000 & $0.000 \mathrm{E}+00$ & 0.0000 \\
\hline-238 & $2.076 \mathrm{E}-14$ & 0.0000 & $0.000 \mathrm{E}+00$ & 0.0000 & $0.000 \mathrm{E}+00$ & 0.0000 & $0.000 \mathrm{E}+00$ & 0.0000 & $0.000 \mathrm{E}+00$ & 0.0000 & $0.000 \mathrm{E}+00$ & 0.0000 & $0.000 \mathrm{E}+00$ & 0.0000 \\
\hline-239 & $1.428 \mathrm{E}-15$ & 0.0000 & $0.000 \mathrm{E}+00$ & 0.0000 & $0.000 \mathrm{E}+00$ & 0.0000 & $0.000 \mathrm{E}+00$ & 0.0000 & $0.000 \mathrm{E}+00$ & 0.0000 & $0.000 \mathrm{E}+00$ & 0.0000 & $0.000 \mathrm{E}+00$ & 0.0000 \\
\hline-240 & $6.420 \mathrm{E}-19$ & 0.0000 & $0.000 \mathrm{E}+00$ & 0.0000 & $0.000 \mathrm{E}+00$ & 0.0000 & $0.000 \mathrm{E}+00$ & 0.0000 & $0.000 \mathrm{E}+00$ & 0.0000 & $0.000 \mathrm{E}+00$ & 0.0000 & $0.000 \mathrm{E}+00$ & 0.0000 \\
\hline-99 & $8.280 E-24$ & 0.0000 & $0.000 \mathrm{E}+00$ & 0.0000 & $0.000 \mathrm{E}+00$ & 0.0000 & $0.000 \mathrm{E}+00$ & 0.0000 & $0.000 \mathrm{E}+00$ & 0.0000 & $0.000 \mathrm{E}+00$ & 0.0000 & $0.000 \mathrm{E}+00$ & 0.0000 \\
\hline-228 & $1.847 \mathrm{E}-21$ & 0.0000 & $0.000 \mathrm{E}+00$ & 0.0000 & $0.000 \mathrm{E}+00$ & 0.0000 & $0.000 \mathrm{E}+00$ & 0.0000 & $0.000 \mathrm{E}+00$ & 0.0000 & $0.000 \mathrm{E}+00$ & 0.0000 & $0.000 \mathrm{E}+00$ & 0.0000 \\
\hline-230 & $1.479 \mathrm{E}-06$ & 0.1082 & $0.000 \mathrm{E}+00$ & 0.0000 & $0.000 \mathrm{E}+00$ & 0.0000 & $0.000 \mathrm{E}+00$ & 0.0000 & $0.000 \mathrm{E}+00$ & 0.0000 & $0.000 \mathrm{E}+00$ & 0.0000 & $0.000 \mathrm{E}+00$ & 0.0000 \\
\hline-232 & $1.213 E-05$ & 0.8876 & $0.000 \mathrm{E}+00$ & 0.0000 & $0.000 \mathrm{E}+00$ & 0.0000 & $0.000 \mathrm{E}+00$ & 0.0000 & $0.000 \mathrm{E}+00$ & 0.0000 & $0.000 \mathrm{E}+00$ & 0.0000 & $0.000 \mathrm{E}+00$ & 0.0000 \\
\hline 34 & $1.078 \mathrm{E}-09$ & 0.0001 & $0.000 \mathrm{E}+00$ & 0.0000 & $0.000 \mathrm{E}+00$ & 0.0000 & $0.000 \mathrm{E}+00$ & 0.0000 & $0.000 \mathrm{E}+00$ & 0.0000 & $0.000 \mathrm{E}+00$ & 0.0000 & $0.000 \mathrm{E}+00$ & 0.0000 \\
\hline 35 & $2.202 \mathrm{E}-12$ & 0.0000 & $0.000 \mathrm{E}+00$ & 0.0000 & $0.000 \mathrm{E}+00$ & 0.0000 & $0.000 \mathrm{E}+00$ & 0.0000 & $0.000 \mathrm{E}+00$ & 0.0000 & $0.000 \mathrm{E}+00$ & 0.0000 & $0.000 \mathrm{E}+00$ & 0.0000 \\
\hline 38 & $5.045 E-08$ & 0.0037 & $0.000 \mathrm{E}+00$ & 0.0000 & $0.000 \mathrm{E}+00$ & 0.0000 & $0.000 \mathrm{E}+00$ & 0.0000 & $0.000 \mathrm{E}+00$ & 0.0000 & $0.000 \mathrm{E}+00$ & 0.0000 & $0.000 \mathrm{E}+00$ & 0.0000 \\
\hline & $1.367 \mathrm{E}-05$ & 1.0000 & $0.000 \mathrm{E}+00$ & 0.0000 & $0.000 \mathrm{E}+00$ & 0.0000 & $0.000 \mathrm{E}+00$ & 0.0000 & $0.000 \mathrm{E}+00$ & 0.0000 & $0.000 \mathrm{E}+00$ & 0.0000 & $0.000 \mathrm{E}+00$ & 0.0000 \\
\hline
\end{tabular}

Total Dose Contributions TDOSE(i,p,t) for Individual Radionuclides (i) and Pathways (p) As mrem/yr and Fraction of Total Dose At $t=1.000 \mathrm{E}+02$ years

Water Dependent Pathways

\begin{tabular}{|c|c|c|c|c|c|c|c|c|c|c|c|c|c|c|}
\hline & \multicolumn{2}{|c|}{ Water } & \multicolumn{2}{|c|}{ Fish } & \multicolumn{2}{|c|}{ Radon } & \multicolumn{2}{|c|}{ Plant } & \multicolumn{2}{|c|}{ Meat } & \multicolumn{2}{|c|}{ Milk } & \multicolumn{2}{|c|}{ All Pathways* } \\
\hline clide & mrem/yr & fract. & mrem/yr & fract. & mrem/yr & fract. & mrem/yr & fract. & mrem/yr & fract. & mrem/yr & fract. & mrem/yr & fract. \\
\hline 241 & $0.000 \mathrm{E}+00$ & 0.0000 & $0.000 \mathrm{E}+00$ & 0.0000 & $0.000 \mathrm{E}+00$ & 0.0000 & $0.000 \mathrm{E}+00$ & 0.0000 & $0.000 \mathrm{E}+00$ & 0.0000 & $0.000 \mathrm{E}+00$ & 0.0000 & $2.940 \mathrm{E}-15$ & 0.0000 \\
\hline-137 & $0.000 \mathrm{E}+00$ & 0.0000 & $0.000 \mathrm{E}+00$ & 0.0000 & $0.000 \mathrm{E}+00$ & 0.0000 & $0.000 \mathrm{E}+00$ & 0.0000 & $0.000 \mathrm{E}+00$ & 0.0000 & $0.000 \mathrm{E}+00$ & 0.0000 & $5.512 \mathrm{E}-09$ & 0.0004 \\
\hline-237 & $0.000 \mathrm{E}+00$ & 0.0000 & $0.000 \mathrm{E}+00$ & 0.0000 & $0.000 \mathrm{E}+00$ & 0.0000 & $0.000 \mathrm{E}+00$ & 0.0000 & $0.000 \mathrm{E}+00$ & 0.0000 & $0.000 \mathrm{E}+00$ & 0.0000 & $1.534 \mathrm{E}-11$ & 0.0000 \\
\hline-238 & $0.000 \mathrm{E}+00$ & 0.0000 & $0.000 \mathrm{E}+00$ & 0.0000 & $0.000 \mathrm{E}+00$ & 0.0000 & $0.000 \mathrm{E}+00$ & 0.0000 & $0.000 \mathrm{E}+00$ & 0.0000 & $0.000 \mathrm{E}+00$ & 0.0000 & $2.076 \mathrm{E}-14$ & 0.0000 \\
\hline-239 & $0.000 \mathrm{E}+00$ & 0.0000 & $0.000 \mathrm{E}+00$ & 0.0000 & $0.000 \mathrm{E}+00$ & 0.0000 & $0.000 \mathrm{E}+00$ & 0.0000 & $0.000 \mathrm{E}+00$ & 0.0000 & $0.000 E+00$ & 0.0000 & 1. $428 \mathrm{E}-15$ & 0.0000 \\
\hline-240 & $0.000 \mathrm{E}+00$ & 0.0000 & $0.000 \mathrm{E}+00$ & 0.0000 & $0.000 \mathrm{E}+00$ & 0.0000 & $0.000 \mathrm{E}+00$ & 0.0000 & $0.000 \mathrm{E}+00$ & 0.0000 & $0.000 E+00$ & 0.0000 & $6.420 \mathrm{E}-19$ & 0.0000 \\
\hline-99 & $0.000 \mathrm{E}+00$ & 0.0000 & $0.000 \mathrm{E}+00$ & 0.0000 & $0.000 \mathrm{E}+00$ & 0.0000 & $0.000 \mathrm{E}+00$ & 0.0000 & $0.000 \mathrm{E}+00$ & 0.0000 & $0.000 \mathrm{E}+00$ & 0.0000 & $8.280 \mathrm{E}-24$ & 0.0000 \\
\hline-228 & $0.000 \mathrm{E}+00$ & 0.0000 & $0.000 \mathrm{E}+00$ & 0.0000 & $0.000 \mathrm{E}+00$ & 0.0000 & $0.000 \mathrm{E}+00$ & 0.0000 & $0.000 \mathrm{E}+00$ & 0.0000 & $0.000 \mathrm{E}+00$ & 0.0000 & $1.847 \mathrm{E}-21$ & 0.0000 \\
\hline-230 & $0.000 \mathrm{E}+00$ & 0.0000 & $0.000 \mathrm{E}+00$ & 0.0000 & $0.000 \mathrm{E}+00$ & 0.0000 & $0.000 \mathrm{E}+00$ & 0.0000 & $0.000 \mathrm{E}+00$ & 0.0000 & $0.000 E+00$ & 0.0000 & $1.479 \mathrm{E}-06$ & 0.1082 \\
\hline-232 & $0.000 \mathrm{E}+00$ & 0.0000 & $0.000 \mathrm{E}+00$ & 0.0000 & $0.000 \mathrm{E}+00$ & 0.0000 & $0.000 \mathrm{E}+00$ & 0.0000 & $0.000 \mathrm{E}+00$ & 0.0000 & $0.000 \mathrm{E}+00$ & 0.0000 & $1.213 E-05$ & 0.8876 \\
\hline 34 & $0.000 \mathrm{E}+00$ & 0.0000 & $0.000 \mathrm{E}+00$ & 0.0000 & $0.000 \mathrm{E}+00$ & 0.0000 & $0.000 \mathrm{E}+00$ & 0.0000 & $0.000 \mathrm{E}+00$ & 0.0000 & $0.000 \mathrm{E}+00$ & 0.0000 & $1.078 \mathrm{E}-09$ & 0.0001 \\
\hline 35 & $0.000 \mathrm{E}+00$ & 0.0000 & $0.000 \mathrm{E}+00$ & 0.0000 & $0.000 \mathrm{E}+00$ & 0.0000 & $0.000 \mathrm{E}+00$ & 0.0000 & $0.000 \mathrm{E}+00$ & 0.0000 & $0.000 \mathrm{E}+00$ & 0.0000 & 2. $202 \mathrm{E}-12$ & 0.0000 \\
\hline 38 & $0.000 \mathrm{E}+00$ & 0.0000 & $0.000 \mathrm{E}+00$ & 0.0000 & $0.000 \mathrm{E}+00$ & 0.0000 & $0.000 \mathrm{E}+00$ & 0.0000 & $0.000 \mathrm{E}+00$ & 0.0000 & $0.000 \mathrm{E}+00$ & 0.0000 & $5.045 E-08$ & 0.0037 \\
\hline & $0.000 \mathrm{E}+00$ & 0.0000 & $0.000 \mathrm{E}+00$ & 0.0000 & $0.000 \mathrm{E}+00$ & 0.0000 & $0.000 \mathrm{E}+00$ & 0.0000 & $0.000 \mathrm{E}+00$ & 0.0000 & $0.000 \mathrm{E}+00$ & 0.0000 & $7 E-05$ & 1.0000 \\
\hline
\end{tabular}

* Sum of all water independent and dependent pathways. 
RESRAD, Version 6.5

Summary : C746U Resident Gardener Deterministic Run
File : X: $\backslash$ FINAL V2 $\backslash$ DOE FWD RUNS $\backslash C 746 U$ RG DOE SG FWD-FV2-1050YR.RAD

Total Dose Contributions TDOSE (i,p,t) for Individual Radionuclides (i) and Pathways (p) As mrem/yr and Fraction of Total Dose At $t=5.000 \mathrm{E}+02$ years

Water Independent Pathways (Inhalation excludes radon)

\begin{tabular}{|c|c|c|}
\hline clide & mrem/yr & fract. \\
\hline-241 & $8.032 \mathrm{E}-13$ & 0.0000 \\
\hline-137 & $1.540 \mathrm{E}-11$ & 0.0000 \\
\hline-237 & $1.124 \mathrm{E}-09$ & 0.0000 \\
\hline-238 & $2.187 \mathrm{E}-11$ & 0.0000 \\
\hline-239 & $1.695 \mathrm{E}-13$ & 0.0000 \\
\hline-240 & $2.059 \mathrm{E}-16$ & 0.0000 \\
\hline-99 & $4.841 \mathrm{E}-22$ & 0.0000 \\
\hline-228 & $0.000 \mathrm{E}+00$ & 0.0000 \\
\hline-230 & $1.071 \mathrm{E}-04$ & 0.4421 \\
\hline-232 & $1.335 \mathrm{E}-04$ & 0.5512 \\
\hline 234 & $3.993 E-07$ & 0.0016 \\
\hline 235 & $4.571 E-10$ & 0.0000 \\
\hline 238 & $1.229 \mathrm{E}-06$ & 0.0051 \\
\hline & $2.423 E-04$ & 1.0000 \\
\hline
\end{tabular}

\begin{abstract}
Inhalation
\end{abstract}

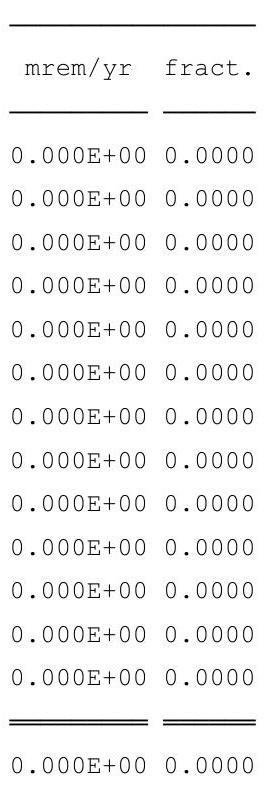

Radon
mrem/yr fract. $\overline{0.000 \mathrm{E}+00} \overline{0.0000}$ $0.000 \mathrm{E}+00 \quad 0.0000$ $0.000 \mathrm{E}+00 \quad 0.0000$ $0.000 \mathrm{E}+00 \quad 0.0000$ $0.000 \mathrm{E}+00 \quad 0.0000$ $0.000 E+00 \quad 0.0000$ $0.000 \mathrm{E}+00 \quad 0.0000$ $0.000 \mathrm{E}+00 \quad 0.0000$ $0.000 \mathrm{E}+00 \quad 0.0000$ $0.000 \mathrm{E}+00 \quad 0.0000$ $0.000 \mathrm{E}+00 \quad 0.0000$ $0.000 \mathrm{E}+00 \quad 0.0000$ $0.000 \mathrm{E}+00 \quad 0.0000$

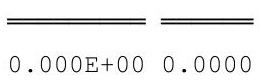

\begin{tabular}{ccccc} 
Plant & & Meat \\
\cline { 1 - 1 } mrem/yr fract. & & mrem/yr fract. & & \\
\cline { 1 - 1 } $0.000 \mathrm{E}+00$ & 0.0000 & & $0.000 \mathrm{E}+00$ & 0.0000 \\
$0.000 \mathrm{E}+00$ & 0.0000 & $0.000 \mathrm{E}+00$ & 0.0000 \\
$0.000 \mathrm{E}+00$ & 0.0000 & $0.000 \mathrm{E}+00$ & 0.0000 \\
$0.000 \mathrm{E}+00$ & 0.0000 & $0.000 \mathrm{E}+00$ & 0.0000 \\
$0.000 \mathrm{E}+00$ & 0.0000 & & $0.000 \mathrm{E}+00$ & 0.0000 \\
$0.000 \mathrm{E}+00$ & 0.0000 & $0.000 \mathrm{E}+00$ & 0.0000 \\
$0.000 \mathrm{E}+00$ & 0.0000 & $0.000 \mathrm{E}+00$ & 0.0000 \\
$0.000 \mathrm{E}+00$ & 0.0000 & $0.000 \mathrm{E}+00$ & 0.0000 \\
$0.000 \mathrm{E}+00$ & 0.0000 & $0.000 \mathrm{E}+00$ & 0.0000 \\
$0.000 \mathrm{E}+00$ & 0.0000 & $0.000 \mathrm{E}+00$ & 0.0000 \\
$0.000 \mathrm{E}+00$ & 0.0000 & $0.000 \mathrm{E}+00$ & 0.0000 \\
$0.000 \mathrm{E}+00$ & 0.0000 & $0.000 \mathrm{E}+00$ & 0.0000 \\
$0.000 \mathrm{E}+00$ & 0.0000 & $0.000 \mathrm{E}+00$ & 0.0000 \\
\hline \hline $0.000 \mathrm{E}+00$ & 0.0000 & $0.000 \mathrm{E}+00$ & 0.0000
\end{tabular}

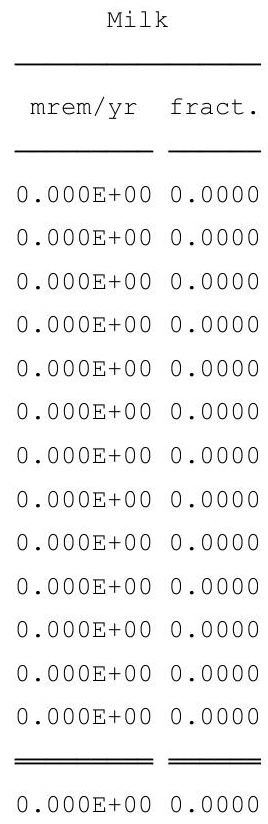

Soil mrem/yr fract. $0.000 \mathrm{E}+00 \quad 0.0000$ $0.000 \mathrm{E}+00 \quad 0.0000$ $0.000 \mathrm{E}+00 \quad 0.0000$ $0.000 \mathrm{E}+00 \quad 0.0000$ $0.000 \mathrm{E}+00 \quad 0.0000$ $0.000 \mathrm{E}+00 \quad 0.0000$ $0.000 \mathrm{E}+00 \quad 0.0000$ $0.000 \mathrm{E}+00 \quad 0.0000$ $0.000 \mathrm{E}+00 \quad 0.0000$ $0.000 \mathrm{E}+00 \quad 0.0000$ $0.000 \mathrm{E}+00 \quad 0.0000$ $0.000 \mathrm{E}+00 \quad 0.0000$ $0.000 \mathrm{E}+00 \quad 0.0000$ $0.000 \mathrm{E}+00 \quad 0.0000$

Total Dose Contributions TDOSE (i,p,t) for Individual Radionuclides (i) and Pathways (p) As mrem/yr and Fraction of Total Dose At $t=5.000 \mathrm{E}+02$ years

Water Dependent Pathways

\begin{tabular}{|c|c|c|c|c|c|c|}
\hline \multirow{2}{*}{ Nuclide } & \multicolumn{2}{|c|}{ Water } & \multicolumn{2}{|c|}{ Fish } & \multicolumn{2}{|c|}{ Radon } \\
\hline & $\mathrm{mrem} / \mathrm{yr}$ & fract. & mrem/yr & fract. & mrem/yr & fract. \\
\hline-241 & $0.000 \mathrm{E}+00$ & 0.0000 & $0.000 \mathrm{E}+00$ & 0.0000 & $0.000 \mathrm{E}+00$ & 0.0000 \\
\hline-137 & $0.000 \mathrm{E}+00$ & 0.0000 & $0.000 \mathrm{E}+00$ & 0.0000 & $0.000 \mathrm{E}+00$ & 0.0000 \\
\hline-237 & $0.000 \mathrm{E}+00$ & 0.0000 & $0.000 \mathrm{E}+00$ & 0.0000 & $0.000 \mathrm{E}+00$ & 0.0000 \\
\hline-238 & $0.000 \mathrm{E}+00$ & 0.0000 & $0.000 \mathrm{E}+00$ & 0.0000 & $0.000 \mathrm{E}+00$ & 0.0000 \\
\hline 239 & $0.000 \mathrm{E}+00$ & 0.0000 & $0.000 \mathrm{E}+00$ & 0.0000 & $0.000 \mathrm{E}+00$ & 0.0000 \\
\hline 240 & $0.000 \mathrm{E}+00$ & 0.0000 & $0.000 \mathrm{E}+00$ & 0.0000 & $0.000 \mathrm{E}+00$ & 0.0000 \\
\hline 99 & $0.000 \mathrm{E}+00$ & 0.0000 & $0.000 \mathrm{E}+00$ & 0.0000 & $0.000 \mathrm{E}+00$ & 0.0000 \\
\hline 228 & $0.000 \mathrm{E}+00$ & 0.0000 & $0.000 \mathrm{E}+00$ & 0.0000 & $0.000 \mathrm{E}+00$ & 0.0000 \\
\hline 230 & $0.000 \mathrm{E}+00$ & 0.0000 & $0.000 \mathrm{E}+00$ & 0.0000 & $0.000 \mathrm{E}+00$ & 0.0000 \\
\hline 232 & $0.000 \mathrm{E}+00$ & 0.0000 & $0.000 \mathrm{E}+00$ & 0.0000 & $0.000 \mathrm{E}+00$ & 0.0000 \\
\hline & $0.000 \mathrm{E}+00$ & 0.0000 & $0.000 \mathrm{E}+00$ & 0.0000 & $0.000 \mathrm{E}+00$ & 0.0000 \\
\hline 35 & $0.000 \mathrm{E}+00$ & 0.0000 & $0.000 \mathrm{E}+00$ & 0.0000 & $0.000 \mathrm{E}+00$ & 0.0000 \\
\hline & $0.000 \mathrm{E}+00$ & 0.0000 & $0.000 \mathrm{E}+00$ & 0.0000 & $0.000 \mathrm{E}+00$ & 0.0000 \\
\hline & D & .0000 & .0 & 0 & 0 & 0 \\
\hline
\end{tabular}

\begin{tabular}{ll} 
Plant \\
\hline mrem/yr fract. \\
\hline $0.000 \mathrm{E}+00$ & 0.0000 \\
$0.000 \mathrm{E}+00$ & 0.0000 \\
$0.000 \mathrm{E}+00$ & 0.0000 \\
$0.000 \mathrm{E}+00$ & 0.0000 \\
$0.000 \mathrm{E}+00$ & 0.0000 \\
$0.000 \mathrm{E}+00$ & 0.0000 \\
$0.000 \mathrm{E}+00$ & 0.0000 \\
$0.000 \mathrm{E}+00$ & 0.0000 \\
$0.000 \mathrm{E}+00$ & 0.0000 \\
$0.000 \mathrm{E}+00$ & 0.0000 \\
$0.000 \mathrm{E}+00$ & 0.0000 \\
$0.000 \mathrm{E}+00$ & 0.0000 \\
$0.000 \mathrm{E}+00$ & 0.0000 \\
\hline \hline
\end{tabular}

$0.000 \mathrm{E}+00 \quad 0.0000$

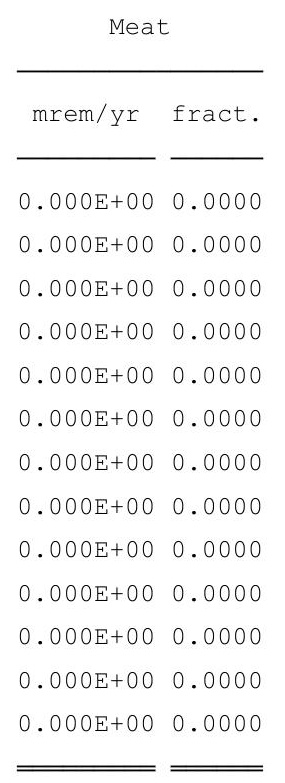

$0.000 \mathrm{E}+00 \quad 0.0000$

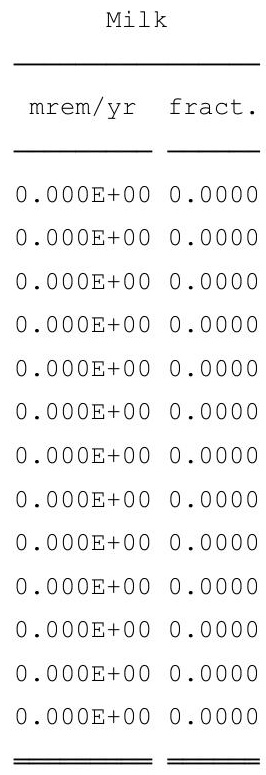

$0.000 \mathrm{E}+00 \quad 0.0000$
All Pathways* mrem/yr fract. $8.032 \mathrm{E}-13 \quad 0.0000$ $1.540 \mathrm{E}-110.0000$ $1.124 \mathrm{E}-09 \quad 0.0000$ $2.187 \mathrm{E}-11 \quad 0.0000$ $1.695 \mathrm{E}-13 \quad 0.0000$ $2.059 \mathrm{E}-16 \quad 0.0000$ $4.841 \mathrm{E}-22 \quad 0.0000$ $0.000 \mathrm{E}+00 \quad 0.0000$ $1.071 \mathrm{E}-04 \quad 0.4421$ $1.335 \mathrm{E}-04 \quad 0.5512$ $3.993 \mathrm{E}-07 \quad 0.0016$ $4.571 \mathrm{E}-10 \quad 0.0000$ $1.229 \mathrm{E}-06 \quad 0.0051$

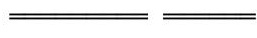

$2.423 E-04 \quad 1.0000$

*Sum of all water independent and dependent pathways. 
RESRAD, Version 6.5

Summary : C746U Resident Gardener Deterministic Run
File : X: $\backslash$ FINAL V2 $\backslash$ DOE FWD RUNS $\backslash C 746 U$ RG DOE SG FWD-FV2-1050YR.RAD

Total Dose Contributions TDOSE (i,p,t) for Individual Radionuclides (i) and Pathways (p) As mrem/yr and Fraction of Total Dose At $t=1.050 \mathrm{E}+03$ years

Water Independent Pathways (Inhalation excludes radon)

\begin{tabular}{|c|c|c|}
\hline clide & mrem/yr & fract. \\
\hline-241 & $4.257 E-10$ & 0.0000 \\
\hline-137 & $4.741 \mathrm{E}-15$ & 0.0000 \\
\hline-237 & $3.910 \mathrm{E}-07$ & 0.0000 \\
\hline-238 & $5.077 \mathrm{E}-09$ & 0.0000 \\
\hline-239 & 1.202E-10 & 0.0000 \\
\hline-240 & $2.914 \mathrm{E}-14$ & 0.0000 \\
\hline-99 & 1. 302E-19 & 0.0000 \\
\hline-228 & $0.000 \mathrm{E}+00$ & 0.0000 \\
\hline-230 & $8.967 \mathrm{E}-03$ & 0.0013 \\
\hline-232 & $3.698 \mathrm{E}-03$ & 0.0005 \\
\hline 234 & 7. $268 \mathrm{E}-05$ & 0.0000 \\
\hline 235 & $1.527 \mathrm{E}-07$ & 0.0000 \\
\hline 38 & $9.919 \mathrm{E}-05$ & 0.0000 \\
\hline & $1.204 \mathrm{E}-0$ & 0.0 \\
\hline
\end{tabular}

\begin{abstract}
Inhalation
\end{abstract}
$\longrightarrow$

mrem/yr fract.

$0.000 \mathrm{E}+00 \quad 0.0000$

$0.000 \mathrm{E}+00 \quad 0.0000$

$0.000 \mathrm{E}+00 \quad 0.0000$

$0.000 \mathrm{E}+00 \quad 0.0000$

$0.000 \mathrm{E}+00 \quad 0.0000$

$0.000 \mathrm{E}+00 \quad 0.0000$

$0.000 E+00 \quad 0.0000$

$0.000 \mathrm{E}+00 \quad 0.0000$

$0.000 \mathrm{E}+00 \quad 0.0000$

$0.000 \mathrm{E}+00 \quad 0.0000$

$0.000 \mathrm{E}+00 \quad 0.0000$

$0.000 E+00 \quad 0.0000$

$0.000 \mathrm{E}+00 \quad 0.0000$

$\overline{\overline{0.000 E+00}} \overline{0.0000}$

Radon
mrem/yr fract. $\overline{0.000 E+00} 0.0000$ $0.000 E+00 \quad 0.0000$ $0.000 E+00 \quad 0.0000$ $0.000 E+00 \quad 0.0000$ $0.000 E+00 \quad 0.0000$ $0.000 E+00 \quad 0.0000$ $0.000 \mathrm{E}+00 \quad 0.0000$ $0.000 E+00 \quad 0.0000$ $0.000 \mathrm{E}+00 \quad 0.0000$ $0.000 \mathrm{E}+00 \quad 0.0000$ $0.000 \mathrm{E}+00 \quad 0.0000$ $0.000 \mathrm{E}+00 \quad 0.0000$ $0.000 \mathrm{E}+00 \quad 0.0000$

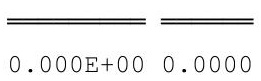

\begin{tabular}{|c|c|c|c|}
\hline \multicolumn{2}{|c|}{ Plant } & \multicolumn{2}{|c|}{ Meat } \\
\hline mrem/yr & fract. & mrem/yr & fract. \\
\hline $5.939 E-03$ & 0.0010 & $0.000 \mathrm{E}+00$ & 0.0000 \\
\hline 1. $461 \mathrm{E}-12$ & 0.0000 & $0.000 \mathrm{E}+00$ & 0.0000 \\
\hline $5.637 \mathrm{E}-02$ & 0.0083 & $0.000 \mathrm{E}+00$ & 0.0000 \\
\hline $2.382 E-05$ & 0.0000 & $0.000 \mathrm{E}+00$ & 0.0000 \\
\hline $4.566 \mathrm{E}-02$ & 0.0067 & $0.000 \mathrm{E}+00$ & 0.0000 \\
\hline $4.210 \mathrm{E}-02$ & 0.0062 & $0.000 \mathrm{E}+00$ & 0.0000 \\
\hline $6.892 \mathrm{E}-05$ & 0.0000 & $0.000 \mathrm{E}+00$ & 0.0000 \\
\hline $0.000 \mathrm{E}+00$ & 0.0000 & $0.000 \mathrm{E}+00$ & 0.0000 \\
\hline $5.809 \mathrm{E}+00$ & 0.8509 & $0.000 \mathrm{E}+00$ & 0.0000 \\
\hline $5.926 \mathrm{E}-01$ & 0.0868 & $0.000 \mathrm{E}+00$ & 0.0000 \\
\hline 1. $483 \mathrm{E}-01$ & 0.0217 & $0.000 \mathrm{E}+00$ & 0.0000 \\
\hline $1.149 \mathrm{E}-02$ & 0.0017 & $0.000 \mathrm{E}+00$ & 0.0000 \\
\hline $1.013 E-01$ & 0.0148 & $0.000 \mathrm{E}+00$ & 0.0000 \\
\hline & & 0.06 & . \\
\hline
\end{tabular}

\begin{tabular}{cc} 
Milk \\
\hline mrem/yr fract. \\
\cline { 1 - 2 } $0.000 \mathrm{E}+00$ & 0.0000 \\
$0.000 \mathrm{E}+00$ & 0.0000 \\
$0.000 \mathrm{E}+00$ & 0.0000 \\
$0.000 \mathrm{E}+00$ & 0.0000 \\
$0.000 \mathrm{E}+00$ & 0.0000 \\
$0.000 \mathrm{E}+00$ & 0.0000 \\
$0.000 \mathrm{E}+00$ & 0.0000 \\
$0.000 \mathrm{E}+00$ & 0.0000 \\
$0.000 \mathrm{E}+00$ & 0.0000 \\
$0.000 \mathrm{E}+00$ & 0.0000 \\
$0.000 \mathrm{E}+00$ & 0.0000 \\
$0.000 \mathrm{E}+00$ & 0.0000 \\
$0.000 \mathrm{E}+00$ & 0.0000 \\
\hline \hline $0.000 \mathrm{E}+00$ & 0.0000
\end{tabular}

Soil mrem/yr fract. $0.000 \mathrm{E}+00 \quad 0.0000$ $0.000 \mathrm{E}+00 \quad 0.0000$ $0.000 \mathrm{E}+00 \quad 0.0000$ $0.000 \mathrm{E}+00 \quad 0.0000$ $0.000 \mathrm{E}+00 \quad 0.0000$ $0.000 \mathrm{E}+00 \quad 0.0000$ $0.000 \mathrm{E}+00 \quad 0.0000$ $0.000 \mathrm{E}+00 \quad 0.0000$ $0.000 \mathrm{E}+00 \quad 0.0000$ $0.000 \mathrm{E}+00 \quad 0.0000$ $0.000 \mathrm{E}+00 \quad 0.0000$ $0.000 \mathrm{E}+00 \quad 0.0000$ $0.000 \mathrm{E}+00 \quad 0.0000$ $0.000 \mathrm{E}+00 \quad 0.0000$

Total Dose Contributions TDOSE (i,p,t) for Individual Radionuclides (i) and Pathways (p) As mrem/yr and Fraction of Total Dose At $t=1.050 \mathrm{E}+03$ years

Water Dependent Pathways

\begin{tabular}{|c|c|c|c|c|c|c|}
\hline & \multicolumn{2}{|c|}{ Water } & \multicolumn{2}{|c|}{ Fish } & \multicolumn{2}{|c|}{ Radon } \\
\hline clide & mrem/yr & fract. & mrem/yr & fract. & mrem/yr & fract. \\
\hline 41 & $0.000 \mathrm{E}+00$ & 0.0000 & $0.000 \mathrm{E}+00$ & 0.0000 & $0.000 \mathrm{E}+00$ & 0.0000 \\
\hline-137 & $0.000 \mathrm{E}+00$ & 0.0000 & $0.000 \mathrm{E}+00$ & 0.0000 & $0.000 \mathrm{E}+00$ & 0.0000 \\
\hline-237 & $0.000 \mathrm{E}+00$ & 0.0000 & $0.000 \mathrm{E}+00$ & 0.0000 & $0.000 \mathrm{E}+00$ & 0.0000 \\
\hline-238 & $0.000 \mathrm{E}+00$ & 0.0000 & $0.000 \mathrm{E}+00$ & 0.0000 & $0.000 \mathrm{E}+00$ & 0.0000 \\
\hline-239 & $0.000 \mathrm{E}+00$ & 0.0000 & $0.000 \mathrm{E}+00$ & 0.0000 & $0.000 \mathrm{E}+00$ & 0.0000 \\
\hline-240 & $0.000 \mathrm{E}+00$ & 0.0000 & $0.000 \mathrm{E}+00$ & 0.0000 & $0.000 \mathrm{E}+00$ & 0.0000 \\
\hline-99 & $0.000 \mathrm{E}+00$ & 0.0000 & $0.000 \mathrm{E}+00$ & 0.0000 & $0.000 \mathrm{E}+00$ & 0.0000 \\
\hline-228 & $0.000 \mathrm{E}+00$ & 0.0000 & $0.000 \mathrm{E}+00$ & 0.0000 & $0.000 \mathrm{E}+00$ & 0.0000 \\
\hline-230 & $0.000 \mathrm{E}+00$ & 0.0000 & $0.000 \mathrm{E}+00$ & 0.0000 & $0.000 \mathrm{E}+00$ & 0.0000 \\
\hline-232 & $0.000 \mathrm{E}+00$ & 0.0000 & $0.000 \mathrm{E}+00$ & 0.0000 & $0.000 \mathrm{E}+00$ & 0.0000 \\
\hline 234 & $0.000 \mathrm{E}+00$ & 0.0000 & $0.000 \mathrm{E}+00$ & 0.0000 & $0.000 \mathrm{E}+00$ & 0.0000 \\
\hline 35 & $0.000 \mathrm{E}+00$ & 0.0000 & $0.000 \mathrm{E}+00$ & 0.0000 & $0.000 \mathrm{E}+00$ & 0.0000 \\
\hline 38 & $0.000 \mathrm{E}+00$ & 0.0000 & $0.000 \mathrm{E}+00$ & 0.0000 & $0.000 \mathrm{E}+00$ & 0.0000 \\
\hline & $0.000 \mathrm{E}+00$ & 0.0000 & $0.000 \mathrm{E}+00$ & 0.0000 & $0.000 \mathrm{E}+00$ & 0.0000 \\
\hline
\end{tabular}

\begin{tabular}{|c|c|c|c|}
\hline \multicolumn{2}{|c|}{ Plant } & \multicolumn{2}{|c|}{ Meat } \\
\hline mrem/yr & fract. & mrem/yr & fract. \\
\hline $0.000 \mathrm{E}+00$ & 0.0000 & $0.000 \mathrm{E}+00$ & 0.0000 \\
\hline $0.000 \mathrm{E}+00$ & 0.0000 & $0.000 \mathrm{E}+00$ & 0.0000 \\
\hline $0.000 \mathrm{E}+00$ & 0.0000 & $0.000 \mathrm{E}+00$ & 0.0000 \\
\hline $0.000 \mathrm{E}+00$ & 0.0000 & $0.000 \mathrm{E}+00$ & 0.0000 \\
\hline $0.000 \mathrm{E}+00$ & 0.0000 & $0.000 \mathrm{E}+00$ & 0.0000 \\
\hline $0.000 \mathrm{E}+00$ & 0.0000 & $0.000 \mathrm{E}+00$ & 0.0000 \\
\hline $0.000 \mathrm{E}+00$ & 0.0000 & $0.000 \mathrm{E}+00$ & 0.0000 \\
\hline $0.000 \mathrm{E}+00$ & 0.0000 & $0.000 \mathrm{E}+00$ & 0.0000 \\
\hline $0.000 \mathrm{E}+00$ & 0.0000 & $0.000 \mathrm{E}+00$ & 0.0000 \\
\hline $0.000 \mathrm{E}+00$ & 0.0000 & $0.000 \mathrm{E}+00$ & 0.0000 \\
\hline $0.000 \mathrm{E}+00$ & 0.0000 & $0.000 \mathrm{E}+00$ & 0.0000 \\
\hline $0.000 \mathrm{E}+00$ & 0.0000 & $0.000 \mathrm{E}+00$ & 0.0000 \\
\hline $0.000 \mathrm{E}+00$ & 0.0000 & $0.000 \mathrm{E}+00$ & 0.0000 \\
\hline
\end{tabular}

$0.000 \mathrm{E}+00 \quad 0.0000$

$0.000 \mathrm{E}+00 \quad 0.0000$

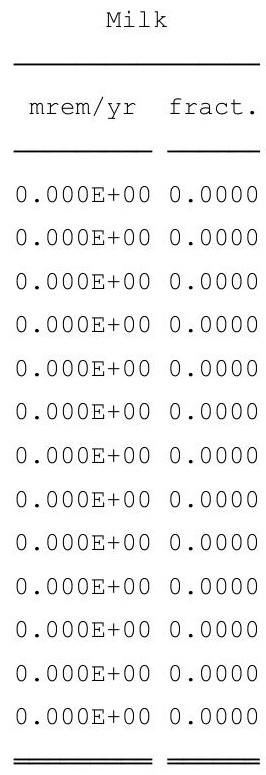

$0.000 \mathrm{E}+00 \quad 0.0000$
All Pathways * mrem/yr fract. $6.939 \mathrm{E}-03 \quad 0.0010$ $1.465 \mathrm{E}-120.0000$ $5.637 \mathrm{E}-02 \quad 0.0083$ $2.383 E-050.0000$ $4.566 \mathrm{E}-02 \quad 0.0067$ $4.210 \mathrm{E}-02 \quad 0.0062$ $6.892 \mathrm{E}-050.0000$ $0.000 \mathrm{E}+00 \quad 0.0000$ $5.818 \mathrm{E}+00 \quad 0.8522$ $5.963 \mathrm{E}-010.0873$ $1.484 \mathrm{E}-010.0217$ $1.149 \mathrm{E}-02 \quad 0.0017$ $1.014 \mathrm{E}-010.0148$

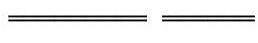
$6.827 \mathrm{E}+001.0000$

* Sum of all water independent and dependent pathways. 
RESRAD, Version 6.5

Summary : C746U Resident Gardener Deterministic Run

File : $\mathrm{X}: \backslash F I N A L$ V2 $\backslash$ DOE FWD RUNS \C746U RG DOE SG FWD-FV2-1050YR.RAD

Dose/Source Ratios Summed Over All Pathways

Parent and Progeny Principal Radionuclide Contributions Indicated

Parent Product Thread DSR $(j, t)$ At Time in Years (mrem/yr)/(pCi/g)

(i)

Am-241

Am-241

Am-241

Am-241

Am-241

$C s-137+D$

$\mathrm{Np}-237+\mathrm{D}$

$\mathrm{Np}-237+\mathrm{D}$

$\mathrm{Np}-237+\mathrm{D}$

$\mathrm{Np}-237+\mathrm{D}$

$\mathrm{Pu}-238$

$\mathrm{Pu}-238$

$\mathrm{Pu}-238$

$\mathrm{Pu}-238$

$\mathrm{Pu}-238$

$\mathrm{Pu}-238$

$\mathrm{Pu}-238$

$\mathrm{Pu}-239$

$\mathrm{Pu}-239$

$\mathrm{Pu}-239$

$\mathrm{Pu}-239$

Pu-239

$\mathrm{Pu}-240$

$\mathrm{Pu}-240$

$\mathrm{Pu}-240$

$\mathrm{Pu}-240$

$\mathrm{Pu}-240$

$\mathrm{Pu}-240$

$\mathrm{Pu}-240$

TC-99

Th $-228+D$

$\mathrm{Th}-230$

$\mathrm{Th}-230$

$\mathrm{Th}-230$

$\mathrm{Th}-230$

(j) Fraction

$\begin{array}{ll}\mathrm{Am}-241 & 1.000 \mathrm{E}+00 \\ \mathrm{~Np}-237+\mathrm{D} & 1.000 \mathrm{E}+00 \\ \mathrm{U}-233 & 1.000 \mathrm{E}+00 \\ \mathrm{Th}-229+\mathrm{D} & 1.000 \mathrm{E}+00 \\ \operatorname{\sum DSR}(j) & \end{array}$

Cs $-137+D$

$\mathrm{Np}-237+\mathrm{D}$

$\mathrm{U}-233$

Th-229+D

$\sum \operatorname{DSR}(j)$

$\mathrm{Pu}-238$

$\mathrm{Pu}-238$

$\mathrm{U}-234$

Th-230

$\mathrm{Ra}-226+\mathrm{D}$

$\mathrm{Pb}-210+\mathrm{D}$

$\sum \operatorname{DSR}(j)$

$\mathrm{Pu}-239$

$\mathrm{U}-235+\mathrm{D}$

$\mathrm{Pa}-231$

$\mathrm{Ac}-227+\mathrm{D}$

$\sum \operatorname{DSR}(j)$

$\mathrm{Pu}-240$

$\mathrm{Pu}-240$

$\mathrm{U}-236$

Th-232

$\mathrm{Ra}-228+\mathrm{D}$

Th-228+D

$\sum \mathrm{DSR}(j)$

TC-99

Th $-228+\mathrm{D}$

Th-230

Ra-226+D

$\mathrm{Pb}-210+\mathrm{D}$

$\sum \mathrm{DSR}(\mathrm{j})$ $\begin{array}{llllllll}1.000 \mathrm{E}+00 & 1.262 \mathrm{E}-09 & 1.243 \mathrm{E}-09 & 6.050 \mathrm{E}-10 & 2.901 \mathrm{E}-10 & 8.104 \mathrm{E}-13 & 7.713 \mathrm{E}-14\end{array}$

$\begin{array}{lllllllll}1.000 \mathrm{E}+00 & 9.536 \mathrm{E}-13 & 9.638 \mathrm{E}-13 & 1.625 \mathrm{E}-12 & 2.770 \mathrm{E}-12 & 1.974 \mathrm{E}-10 & 1.025 \mathrm{E}-02\end{array}$

$\begin{array}{llllllll}1.000 \mathrm{E}+00 & 3.245 \mathrm{E}-23 & 9.844 \mathrm{E}-23 & 6.100 \mathrm{E}-21 & 2.264 \mathrm{E}-20 & 1.650 \mathrm{E}-17 & 2.871 \mathrm{E}-06\end{array}$

$\begin{array}{lllllll}1.000 \mathrm{E}+00 & 2.962 \mathrm{E}-19 & 2.086 \mathrm{E}-18 & 3.196 \mathrm{E}-15 & 1.788 \mathrm{E}-14 & 7.080 \mathrm{E}-12 & 6.801 \mathrm{E}-07\end{array}$

$9.536 \mathrm{E}-13 \quad 9.638 \mathrm{E}-13 \quad 1.629 \mathrm{E}-12 \quad 2.788 \mathrm{E}-12 \quad 2.044 \mathrm{E}-10 \quad 1.025 \mathrm{E}-02$

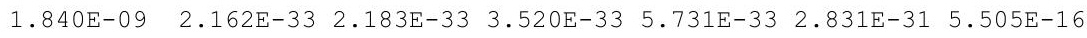

$\begin{array}{llllllll}1.000 \mathrm{E}+00 & 1.175 \mathrm{E}-24 & 1.186 \mathrm{E}-24 & 1.913 \mathrm{E}-24 & 3.115 \mathrm{E}-24 & 1.539 \mathrm{E}-22 & 2.992 \mathrm{E}-07\end{array}$

$\begin{array}{llllllll}1.000 \mathrm{E}+00 & 9.778 \mathrm{E}-30 & 2.969 \mathrm{E}-29 & 1.973 \mathrm{E}-27 & 7.960 \mathrm{E}-27 & 1.690 \mathrm{E}-23 & 2.276 \mathrm{E}-07\end{array}$

$\begin{array}{lllllll}1.000 \mathrm{E}+00 & 1.028 \mathrm{E}-33 & 7.286 \mathrm{E}-33 & 1.599 \mathrm{E}-29 & 1.302 \mathrm{E}-28 & 1.306 \mathrm{E}-24 & 3.273 \mathrm{E}-09\end{array}$

$\begin{array}{lllllll}1.000 \mathrm{E}+00 \quad 8.021 \mathrm{E}-23 & 1.208 \mathrm{E}-21 & 5.266 \mathrm{E}-17 & 5.323 \mathrm{E}-16 & 5.607 \mathrm{E}-13 & 3.143 \mathrm{E}-08\end{array}$

$\begin{array}{llllllll}1.000 \mathrm{E}+00 \quad 2.326 \mathrm{E}-31 & 7.210 \mathrm{E}-30 & 7.772 \mathrm{E}-24 & 1.314 \mathrm{E}-22 & 3.671 \mathrm{E}-19 & 4.946 \mathrm{E}-08\end{array}$ $\begin{array}{llllll}8.139 \mathrm{E}-23 & 1.209 \mathrm{E}-21 & 5.266 \mathrm{E}-17 & 5.323 \mathrm{E}-16 & 5.607 \mathrm{E}-13 & 6.110 \mathrm{E}-07\end{array}$

$\begin{array}{lllllllll}1.000 \mathrm{E}+00 & 1.202 \mathrm{E}-17 & 1.217 \mathrm{E}-17 & 2.183 \mathrm{E}-17 & 3.965 \mathrm{E}-17 & 4.690 \mathrm{E}-15 & 1.268 \mathrm{E}-03\end{array}$

$\begin{array}{llllllll}1.000 \mathrm{E}+00 & 6.135 \mathrm{E}-24 & 1.861 \mathrm{E}-23 & 1.146 \mathrm{E}-21 & 4.227 \mathrm{E}-21 & 2.931 \mathrm{E}-18 & 6.291 \mathrm{E}-10\end{array}$

$\begin{array}{lllllll}1.000 \mathrm{E}+00 & 9.652 \mathrm{E}-28 & 6.818 \mathrm{E}-27 & 1.251 \mathrm{E}-23 & 8.414 \mathrm{E}-23 & 1.444 \mathrm{E}-19 & 4.191 \mathrm{E}-10\end{array}$

$\begin{array}{llllllll}1.000 \mathrm{E}+00 & 2.288 \mathrm{E}-27 & 3.434 \mathrm{E}-26 & 1.276 \mathrm{E}-21 & 1.169 \mathrm{E}-20 & 1.476 \mathrm{E}-17 & 1.686 \mathrm{E}-10\end{array}$

$\begin{array}{llllll}1.202 \mathrm{E}-17 & 1.217 \mathrm{E}-17 & 2.183 \mathrm{E}-17 & 3.966 \mathrm{E}-17 & 4.708 \mathrm{E}-15 & 1.268 \mathrm{E}-03\end{array}$

$\begin{array}{lllllll}4.950 E-08 & 5.653 E-32 & 5.753 E-32 & 1.359 E-31 & 3.267 E-31 & 3.647 E-28 & 5.789 E-11\end{array}$

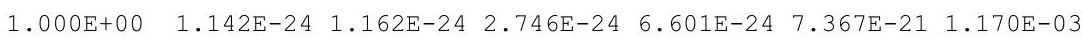

$\begin{array}{llllllll}1.000 \mathrm{E}+00 & 2.162 \mathrm{E}-32 & 6.590 \mathrm{E}-32 & 5.335 \mathrm{E}-30 & 2.602 \mathrm{E}-29 & 1.686 \mathrm{E}-25 & 1.804 \mathrm{E}-08\end{array}$

$\begin{array}{lllllll}1.000 \mathrm{E}+00 & 2.845 \mathrm{E}-43 & 2.028 \mathrm{E}-42 & 5.480 \mathrm{E}-39 & 5.478 \mathrm{E}-38 & 2.238 \mathrm{E}-33 & 9.371 \mathrm{E}-16\end{array}$

$\begin{array}{llllllll}1.000 \mathrm{E}+00 & 1.371 \mathrm{E}-28 & 2.018 \mathrm{E}-27 & 3.762 \mathrm{E}-23 & 2.542 \mathrm{E}-22 & 1.470 \mathrm{E}-19 & 1.102 \mathrm{E}-13\end{array}$

$\begin{array}{llllllll}1.000 \mathrm{E}+00 & 8.111 \mathrm{E}-28 & 2.334 \mathrm{E}-26 & 2.641 \mathrm{E}-21 & 1.757 \mathrm{E}-20 & 5.564 \mathrm{E}-18 & 1.510 \mathrm{E}-15\end{array}$

$\begin{array}{llllll}1.143 \mathrm{E}-24 & 1.188 \mathrm{E}-24 & 2.681 \mathrm{E}-21 & 1.783 \mathrm{E}-20 & 5.719 \mathrm{E}-18 & 1.170 \mathrm{E}-03\end{array}$

$\begin{array}{lllllll}1.000 \mathrm{E}+00 \quad 5.758 \mathrm{E}-26 & 5.817 \mathrm{E}-26 & 9.575 \mathrm{E}-26 & 1.592 \mathrm{E}-25 & 9.310 \mathrm{E}-24 & 1.325 \mathrm{E}-06\end{array}$

$\begin{array}{llllll}1.000 \mathrm{E}+00 \quad 1.382 \mathrm{E}-06 & 9.680 \mathrm{E}-07 & 2.527 \mathrm{E}-14 & 4.618 \mathrm{E}-22 & 0.000 \mathrm{E}+00 \quad 0.000 \mathrm{E}+00\end{array}$

$\begin{array}{lllllll}1.000 \mathrm{E}+00 & 2.412 \mathrm{E}-22 & 2.453 \mathrm{E}-22 & 5.590 \mathrm{E}-22 & 1.295 \mathrm{E}-21 & 1.078 \mathrm{E}-18 & 1.104 \mathrm{E}-03\end{array}$

$\begin{array}{llllllll}1.000 \mathrm{E}+00 & 3.774 \mathrm{E}-11 & 1.139 \mathrm{E}-10 & 5.320 \mathrm{E}-09 & 1.479 \mathrm{E}-08 & 1.071 \mathrm{E}-06 & 2.165 \mathrm{E}-02\end{array}$

$\begin{array}{llllllll}1.000 \mathrm{E}+00 & 1.819 \mathrm{E}-19 & 1.271 \mathrm{E}-18 & 1.299 \mathrm{E}-15 & 5.314 \mathrm{E}-15 & 7.678 \mathrm{E}-13 & 3.543 \mathrm{E}-02\end{array}$

$\begin{array}{llllll}3.774 \mathrm{E}-11 & 1.139 \mathrm{E}-10 & 5.320 \mathrm{E}-09 & 1.479 \mathrm{E}-08 & 1.071 \mathrm{E}-06 & 5.818 \mathrm{E}-02\end{array}$ 
RESRAD, Version 6.5

Summary : C746U Resident Gardener Deterministic Run

File : $\mathrm{X}: \backslash F I N A L$ V2 $\backslash$ DOE FWD RUNS \C746U RG DOE SG FWD-FV2-1050YR.RAD

Dose/Source Ratios Summed Over All Pathways

Parent and Progeny Principal Radionuclide Contributions Indicated

\begin{tabular}{|c|c|c|c|c|c|c|c|c|}
\hline $\begin{array}{c}\text { Parent } \\
\text { (i) }\end{array}$ & $\begin{array}{c}\text { Product } \\
(j)\end{array}$ & $\begin{array}{l}\text { Thread } \\
\text { Fraction }\end{array}$ & $\begin{array}{r}\text { DSR } \\
0.000 \mathrm{E}+00\end{array}$ & $\begin{array}{l}(j, t) \text { At } T \\
1.000 \mathrm{E}+00\end{array}$ & $\begin{array}{l}\text { ime in Yea } \\
5.000 \mathrm{E}+01\end{array}$ & $\begin{array}{l}\text { Es (mrem/ } \\
1.000 \mathrm{E}+02\end{array}$ & $\begin{array}{l}/ \mathrm{yr}) /(\mathrm{pCi} / \\
5.000 \mathrm{E}+02\end{array}$ & $\begin{array}{l}\text { g) } \\
1.050 \mathrm{E}+03\end{array}$ \\
\hline-232 & $\mathrm{Th}-232$ & $1.000 \mathrm{E}+00$ & $1.166 \mathrm{E}-24$ & $1.188 \mathrm{E}-24$ & $2.949 E-24$ & $7.462 \mathrm{E}-24$ & 1. $252 \mathrm{E}-20$ & $1.221 \mathrm{E}-03$ \\
\hline-232 & $\mathrm{Ra}-228+\mathrm{D}$ & $1.000 \mathrm{E}+00$ & $1.107 \mathrm{E}-09$ & $3.174 \mathrm{E}-09$ & $2.784 \mathrm{E}-08$ & $4.079 \mathrm{E}-08$ & $8.497 \mathrm{E}-07$ & $1.458 \mathrm{E}-01$ \\
\hline $1-232$ & $\mathrm{Th}-228+\mathrm{D}$ & $1.000 \mathrm{E}+00$ & $1.067 \mathrm{E}-08$ & $6.581 \mathrm{E}-08$ & $2.213 E-06$ & $2.992 E-06$ & $3.253 E-05$ & $2.007 E-03$ \\
\hline-232 & $\sum \operatorname{DSR}(j)$ & & $1.178 \mathrm{E}-08$ & $6.899 \mathrm{E}-08$ & $2.241 \mathrm{E}-06$ & $3.033 E-06$ & $3.338 E-05$ & 1. $491 \mathrm{E}-01$ \\
\hline-234 & $\mathrm{U}-234$ & $1.000 \mathrm{E}+00$ & $6.896 \mathrm{E}-24$ & $7.019 \mathrm{E}-24$ & $1.670 \mathrm{E}-23$ & $4.047 E-23$ & $4.798 E-20$ & $6.337 E-04$ \\
\hline-234 & Th-230 & $1.000 \mathrm{E}+00$ & $1.089 \mathrm{E}-27$ & $3.315 E-27$ & $2.540 \mathrm{E}-25$ & $1.171 \mathrm{E}-24$ & $4.838 E-21$ & $1.037 \mathrm{E}-05$ \\
\hline-234 & $\mathrm{Ra}-226+\mathrm{D}$ & $1.000 \mathrm{E}+00$ & $1.133 \mathrm{E}-16$ & $7.978 E-16$ & $1.213 \mathrm{E}-12$ & $6.737 \mathrm{E}-12$ & $2.496 \mathrm{E}-09$ & $1.097 \mathrm{E}-04$ \\
\hline-234 & $\mathrm{~Pb}-210+\mathrm{D}$ & $1.000 \mathrm{E}+00$ & $4.102 E-25$ & $6.153 E-24$ & $2.201 \mathrm{E}-19$ & $1.935 \mathrm{E}-18$ & 1. $678 \mathrm{E}-15$ & $1.738 \mathrm{E}-04$ \\
\hline-234 & $\sum \operatorname{DSR}(j)$ & & $1.133 \mathrm{E}-16$ & $7.978 \mathrm{E}-16$ & 1. $213 \mathrm{E}-12$ & $6.737 \mathrm{E}-12$ & $2.496 \mathrm{E}-09$ & $9.276 \mathrm{E}-04$ \\
\hline$-235+D$ & $U-235+D$ & $1.000 \mathrm{E}+00$ & $1.243 \mathrm{E}-14$ & $1.259 \mathrm{E}-14$ & $2.306 \mathrm{E}-14$ & $4.276 \mathrm{E}-14$ & $5.981 \mathrm{E}-12$ & $6.155 \mathrm{E}-04$ \\
\hline$-235+D$ & $\mathrm{~Pa}-231$ & $1.000 \mathrm{E}+00$ & $2.937 \mathrm{E}-18$ & $8.896 \mathrm{E}-18$ & $5.031 \mathrm{E}-16$ & $1.701 \mathrm{E}-15$ & $5.876 \mathrm{E}-13$ & $8.145 E-04$ \\
\hline$-235+D$ & $A C-227+D$ & $1.000 \mathrm{E}+00$ & $9.274 \mathrm{E}-18$ & $6.481 \mathrm{E}-17$ & $6.882 \mathrm{E}-14$ & $2.943 \mathrm{E}-13$ & $6.376 \mathrm{E}-11$ & $3.373 \mathrm{E}-04$ \\
\hline$-235+D$ & $\sum \operatorname{DSR}(j)$ & & $1.245 \mathrm{E}-14$ & $1.266 \mathrm{E}-14$ & $9.238 \mathrm{E}-14$ & $3.388 \mathrm{E}-13$ & $7.033 E-11$ & $1.767 \mathrm{E}-03$ \\
\hline-238 & $U-238$ & $5.400 E-05$ & $0.000 \mathrm{E}+00$ & $0.000 \mathrm{E}+00$ & $0.000 \mathrm{E}+00$ & $0.000 \mathrm{E}+00$ & $0.000 \mathrm{E}+00$ & $3.167 \mathrm{E}-08$ \\
\hline$-238+D$ & $\mathrm{U}-238+\mathrm{D}$ & $9.999 \mathrm{E}-01$ & $1.420 \mathrm{E}-10$ & $1.431 \mathrm{E}-10$ & $2.116 \mathrm{E}-10$ & $3.153 E-10$ & $7.678 \mathrm{E}-09$ & $6.313 E-04$ \\
\hline$-238+D$ & $\mathrm{U}-234$ & $9.999 \mathrm{E}-01$ & $9.803 E-30$ & $2.988 E-29$ & $2.392 E-27$ & $1.153 \mathrm{E}-26$ & $6.812 \mathrm{E}-23$ & $1.890 \mathrm{E}-06$ \\
\hline$-238+D$ & Th-230 & $9.999 \mathrm{E}-01$ & $1.030 \mathrm{E}-33$ & $7.316 \mathrm{E}-33$ & $1.818 \mathrm{E}-29$ & $1.668 \mathrm{E}-28$ & $3.430 \mathrm{E}-24$ & $1.541 \mathrm{E}-08$ \\
\hline$-238+D$ & $\mathrm{Ra}-226+\mathrm{D}$ & $9.999 \mathrm{E}-01$ & $8.034 \mathrm{E}-23$ & 1. $212 \mathrm{E}-21$ & $5.801 \mathrm{E}-17$ & $6.420 \mathrm{E}-16$ & $1.201 \mathrm{E}-12$ & $1.127 E-07$ \\
\hline$-238+D$ & $\mathrm{~Pb}-210+\mathrm{D}$ & $9.999 \mathrm{E}-01$ & $2.329 E-31$ & $7.229 \mathrm{E}-30$ & $8.430 E-24$ & $1.546 \mathrm{E}-22$ & 7. $612 \mathrm{E}-19$ & $1.734 \mathrm{E}-07$ \\
\hline$-238+D$ & $\sum \operatorname{DSR}(j)$ & & 1. $420 \mathrm{E}-10$ & $1.431 \mathrm{E}-10$ & $2.116 \mathrm{E}-10$ & $3.153 \mathrm{E}-10$ & $7.680 \mathrm{E}-09$ & $6.335 \mathrm{E}-04$ \\
\hline
\end{tabular}

The DSR includes contributions from associated (half-life $\leq 180$ days) daughters. 
RESRAD, Version $6.5 \quad \mathrm{~T}^{\mathbb{1} 1 / 2}$ Limit $=180$ days

Summary : C746U Resident Gardener Deterministic Run

File : $\mathrm{X}: \backslash F I N A L$ V2 $\backslash$ DOE FWD RUNS \C746U RG DOE SG FWD-FV2-1050YR.RAD

Single Radionuclide Soil Guidelines $G(i, t)$ in $\mathrm{pCi} / \mathrm{g}$

Basic Radiation Dose Limit $=1.000 \mathrm{E}+02 \mathrm{mrem} / \mathrm{yr}$

Nuclide

\begin{tabular}{|c|c|c|c|c|c|c|}
\hline (i) & $t=0.000 E+00$ & $1.000 \mathrm{E}+00$ & $5.000 \mathrm{E}+01$ & $1.000 \mathrm{E}+02$ & $5.000 \mathrm{E}+02$ & $1.050 \mathrm{E}+03$ \\
\hline-241 & $\star 3.431 \mathrm{E}+12$ & $\star 3.431 \mathrm{E}+12$ & $\star 3.431 \mathrm{E}+12$ & $\star 3.431 \mathrm{E}+12$ & $\star 3.431 \mathrm{E}+12$ & $5.044 \mathrm{E}+05$ \\
\hline$s-137$ & $7.925 \mathrm{E}+10$ & $8.043 \mathrm{E}+10$ & $1.653 \mathrm{E}+11$ & $3.447 \mathrm{E}+11$ & $\star 8.704 \mathrm{E}+13$ & $\star 8.704 \mathrm{E}+13$ \\
\hline$p-237$ & $\star 7.047 \mathrm{E}+08$ & $\star 7.047 \mathrm{E}+08$ & $\star 7.047 \mathrm{E}+08$ & $\star 7.047 \mathrm{E}+08$ & $\star 7.047 \mathrm{E}+08$ & $9.756 \mathrm{E}+03$ \\
\hline$u-238$ & $\star 1.712 \mathrm{E}+13$ & $\star 1.712 \mathrm{E}+13$ & $\star 1.712 \mathrm{E}+13$ & $\star 1.712 \mathrm{E}+13$ & $\star 1.712 \mathrm{E}+13$ & $1.637 \mathrm{E}+08$ \\
\hline$u-239$ & $* 6.214 \mathrm{E}+10$ & $* 6.214 \mathrm{E}+10$ & $* 6.214 \mathrm{E}+10$ & $\star 6.214 \mathrm{E}+10$ & $\star 6.214 \mathrm{E}+10$ & $7.884 \mathrm{E}+04$ \\
\hline$u-240$ & $\star 2.278 \mathrm{E}+11$ & $\star 2.278 \mathrm{E}+11$ & $\star 2.278 \mathrm{E}+11$ & $\star 2.278 \mathrm{E}+11$ & $\star 2.278 \mathrm{E}+11$ & $8.550 \mathrm{E}+04$ \\
\hline$c-99$ & $* 1.697 \mathrm{E}+10$ & $\star 1.697 \mathrm{E}+10$ & $\star 1.697 \mathrm{E}+10$ & $\star 1.697 \mathrm{E}+10$ & $\star 1.697 \mathrm{E}+10$ & $7.545 \mathrm{E}+07$ \\
\hline Th-228 & $7.234 \mathrm{E}+07$ & $1.033 \mathrm{E}+08$ & $\star 8.195 \mathrm{E}+14$ & $\star 8.195 \mathrm{E}+14$ & $\star 8.195 \mathrm{E}+14$ & $\star 8.195 \mathrm{E}+14$ \\
\hline Th -230 & $\star 2.018 \mathrm{E}+10$ & $\star 2.018 \mathrm{E}+10$ & $1.880 \mathrm{E}+10$ & $6.761 \mathrm{E}+09$ & $9.336 \mathrm{E}+07$ & $1.719 \mathrm{E}+03$ \\
\hline Th-232 & $* 1.097 \mathrm{E}+05$ & $\star 1.097 \mathrm{E}+05$ & $* 1.097 \mathrm{E}+05$ & *1.097E+05 & $* 1.097 \mathrm{E}+05$ & $6.708 \mathrm{E}+02$ \\
\hline $\mathrm{U}-234$ & $* 6.247 \mathrm{E}+09$ & $\star 6.247 \mathrm{E}+09$ & $\star 6.247 \mathrm{E}+09$ & $\star 6.247 \mathrm{E}+09$ & $\star 6.247 \mathrm{E}+09$ & $1.078 \mathrm{E}+05$ \\
\hline-235 & $\star 2.161 \mathrm{E}+06$ & $\star 2.161 \mathrm{E}+06$ & $\star 2.161 \mathrm{E}+06$ & $\star 2.161 \mathrm{E}+06$ & $\star 2.161 \mathrm{E}+06$ & $5.658 \mathrm{E}+04$ \\
\hline 238 & $\star 3.361 \mathrm{E}+05$ & $\star 3.361 \mathrm{E}+05$ & $\star 3.361 \mathrm{E}+05$ & $\star 3.361 \mathrm{E}+05$ & $\star 3.361 \mathrm{E}+05$ & $1.578 \mathrm{E}+05$ \\
\hline
\end{tabular}

*At specific activity limit

Summed Dose/Source Ratios DSR (i,t) in (mrem/yr)/(pCi/g)

and Single Radionuclide Soil Guidelines G(i,t) in pCi/g

at tmin = time of minimum single radionuclide soil guideline and at $\operatorname{tmax}=$ time of maximum total dose $=1.050 \mathrm{E}+03$ years

\begin{tabular}{|c|c|c|c|c|c|c|}
\hline $\begin{array}{l}\text { uclide } \\
\text { (i) }\end{array}$ & $\begin{array}{l}\text { Initial } \\
(\mathrm{pCi} / \mathrm{g})\end{array}$ & $\begin{array}{c}\text { tmin } \\
\text { (years) }\end{array}$ & $\operatorname{DSR}(i, \operatorname{tmin})$ & $\begin{array}{c}\mathrm{G}(\mathrm{i}, \mathrm{tmin}) \\
(\mathrm{pCi} / \mathrm{g})\end{array}$ & $\operatorname{DSR}(i, t \max )$ & $\begin{array}{c}G(i, \operatorname{tmax}) \\
(\mathrm{pC} i / g)\end{array}$ \\
\hline$n-241$ & $3.500 \mathrm{E}+01$ & $1.050 \mathrm{E}+03$ & $1.983 \mathrm{E}-04$ & $5.044 \mathrm{E}+05$ & 1. $983 \mathrm{E}-04$ & $5.044 \mathrm{E}+05$ \\
\hline-137 & $1.900 \mathrm{E}+01$ & $0.000 \mathrm{E}+00$ & $1.262 \mathrm{E}-09$ & $7.925 E+10$ & $7.713 \mathrm{E}-14$ & $\star 8.704 \mathrm{E}+13$ \\
\hline-237 & $5.500 \mathrm{E}+00$ & $1.050 \mathrm{E}+03$ & $1.025 E-02$ & $9.756 \mathrm{E}+03$ & $1.025 E-02$ & $9.756 \mathrm{E}+03$ \\
\hline-238 & $3.900 \mathrm{E}+01$ & $1.050 E+03$ & $6.110 E-07$ & $1.637 \mathrm{E}+08$ & $6.110 \mathrm{E}-07$ & $1.637 \mathrm{E}+08$ \\
\hline-239 & $3.600 \mathrm{E}+01$ & $1.050 \mathrm{E}+03$ & $1.268 \mathrm{E}-03$ & $7.884 \mathrm{E}+04$ & $1.268 \mathrm{E}-03$ & $7.884 \mathrm{E}+04$ \\
\hline-240 & $3.600 \mathrm{E}+01$ & $1.050 \mathrm{E}+03$ & $1.170 \mathrm{E}-03$ & $8.550 \mathrm{E}+04$ & $1.170 \mathrm{E}-03$ & $8.550 \mathrm{E}+04$ \\
\hline-99 & $5.200 \mathrm{E}+01$ & $1.050 \mathrm{E}+03$ & 1. $325 E-06$ & $7.545 \mathrm{E}+07$ & 1. $325 E-06$ & $7.545 \mathrm{E}+07$ \\
\hline-228 & $4.000 \mathrm{E}+00$ & $0.000 \mathrm{E}+00$ & 1. $382 \mathrm{E}-06$ & $7.234 \mathrm{E}+07$ & $0.000 \mathrm{E}+00$ & $\star 8.195 \mathrm{E}+14$ \\
\hline-230 & $1.000 \mathrm{E}+02$ & $1.050 \mathrm{E}+03$ & $5.818 \mathrm{E}-02$ & $1.719 \mathrm{E}+03$ & $5.818 E-02$ & 1. $719 \mathrm{E}+03$ \\
\hline-232 & $4.000 \mathrm{E}+00$ & $1.050 \mathrm{E}+03$ & $1.491 \mathrm{E}-01$ & $6.708 E+02$ & $1.491 \mathrm{E}-01$ & $6.708 \mathrm{E}+02$ \\
\hline 234 & $1.600 \mathrm{E}+02$ & $1.050 \mathrm{E}+03$ & $9.276 \mathrm{E}-04$ & $1.078 \mathrm{E}+05$ & $9.276 \mathrm{E}-04$ & $1.078 \mathrm{E}+05$ \\
\hline 235 & $6.500 \mathrm{E}+00$ & $1.050 \mathrm{E}+03$ & $1.767 \mathrm{E}-03$ & $5.658 \mathrm{E}+04$ & $1.767 \mathrm{E}-03$ & $5.658 \mathrm{E}+04$ \\
\hline 238 & $1.600 \mathrm{E}+02$ & $1.050 E+03$ & $6.335 E-04$ & $1.578 \mathrm{E}+05$ & $6.335 E-04$ & $1.578 \mathrm{E}+05$ \\
\hline
\end{tabular}

*At specific activity limit 
RESRAD, Version $6.5 \quad \mathrm{~T}^{1 / 2}$ Limit $=180$ days

mmary : C746U Resident Gardener Deterministic Run

File : $X: \backslash F I N A L$ V2 $\backslash$ DOE FWD RUNS \C746U RG DOE SG FWD-FV2-1050YR.RAD

Individual Nuclide Dose Summed Over All Pathways

Parent Nuclide and Branch Fraction Indicated

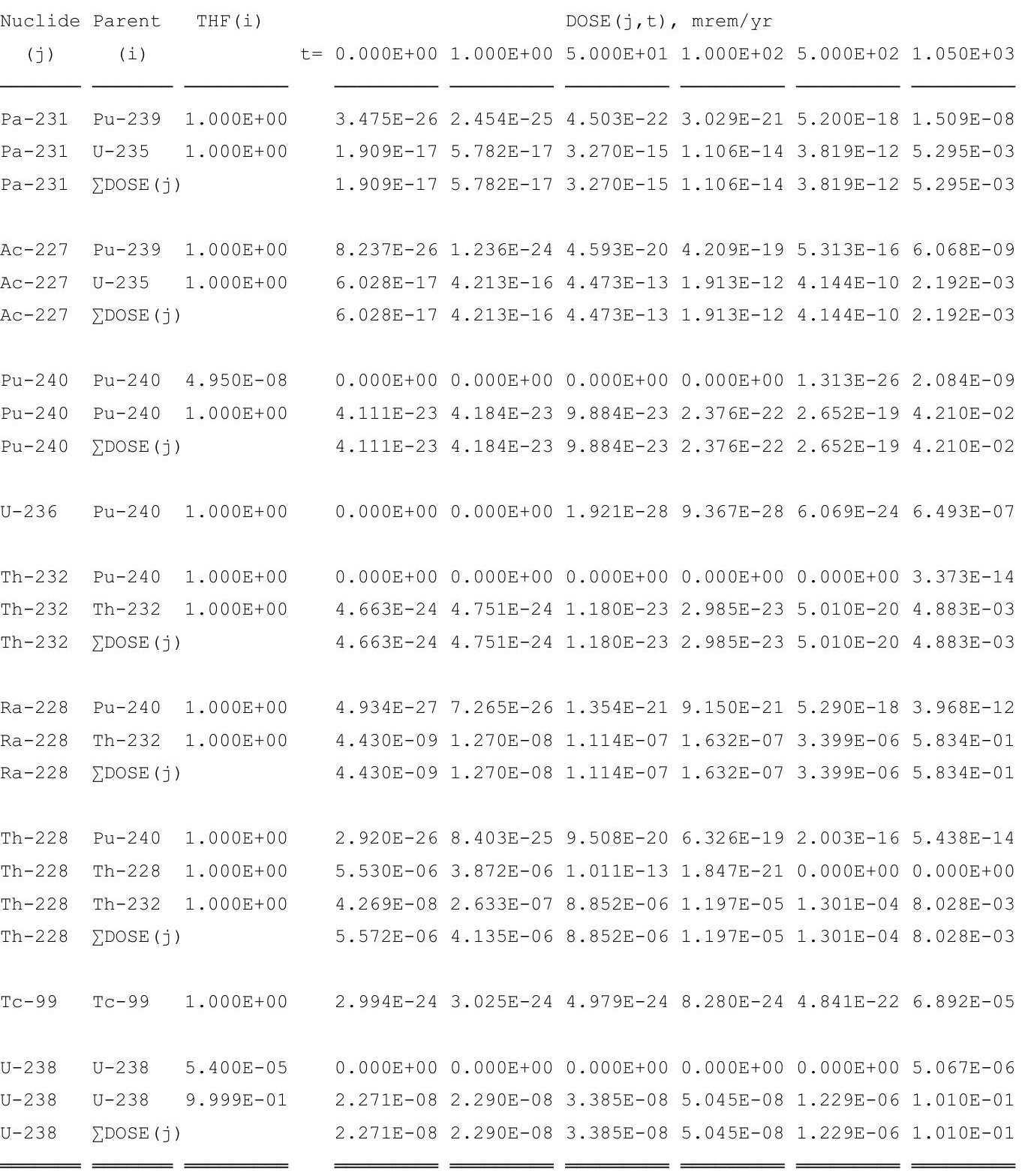

THF(i) is the thread fraction of the parent nuclide. 
RESRAD, Version 6.5

Summary : C746U Resident Gardener Deterministic Run

File : $\mathrm{X}: \backslash F I N A L$ V2 $\backslash$ DOE FWD RUNS \C746U RG DOE SG FWD-FV2-1050YR.RAD

Individual Nuclide Soil Concentration

Parent Nuclide and Branch Fraction Indicated

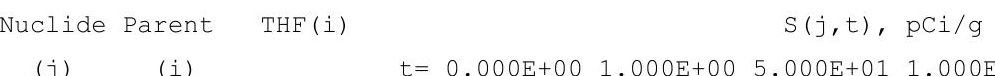

\section{(j)}

(i)

Am-241 Am-241 1.000E+00

$\mathrm{Np}-237 \mathrm{Am}-241 \quad 1.000 \mathrm{E}+00$

$\mathrm{Np}-237 \quad \mathrm{~Np}-237 \quad 1.000 \mathrm{E}+00$

Np-237 $\sum S(j):$

$\mathrm{U}-233 \quad \mathrm{Am}-241 \quad 1.000 \mathrm{E}+00$

$\mathrm{U}-233 \mathrm{~Np}-237 \quad 1.000 \mathrm{E}+00$

$\mathrm{U}-233 \sum \mathrm{S}(j):$

$\mathrm{Th}-229$

$\mathrm{Th}-229$

$\mathrm{Th}-229$

Cs -137

$\mathrm{Pu}-238$

$\mathrm{Pu}-238$

$\mathrm{Pu}-238$

$\mathrm{U}-234$

$\mathrm{U}-234$

$\mathrm{U}-234$

$\mathrm{U}-234$

Th-230

Th-230

Th-230

$\mathrm{Th}-230$

$\mathrm{Th}-230$

$\mathrm{Ra}-226$

$\mathrm{Ra}-226$

$\mathrm{Ra}-226$

$\mathrm{Ra}-226$

$\mathrm{Ra}-226$

$\mathrm{Pb}-210$

$\mathrm{Pb}-210$

$\mathrm{Pb}-210$

$\mathrm{Pb}-210$

$\mathrm{Pb}-210$

$\mathrm{Pu}-239$

Am-241 1.000E+00

$\mathrm{Np}-237 \quad 1.000 \mathrm{E}+00$

$\sum S(j):$

Cs-137 1.000E+00

$\mathrm{Pu}-238$ 1.840E-09

$\mathrm{Pu}-238 \quad 1.000 \mathrm{E}+00$

$\sum S(j):$

$\mathrm{Pu}-238 \quad 1.000 \mathrm{E}+00$

$\mathrm{U}-234 \quad 1.000 \mathrm{E}+00$

U-238 9.999E-01

$\sum S(j):$

$\mathrm{Pu}-238 \quad 1.000 \mathrm{E}+00$

Th-230 1.000E+00

U-234 $1.000 \mathrm{E}+00$

U-238 9.999E-01

$\sum S(j):$

$\mathrm{Pu}-238 \quad 1.000 \mathrm{E}+00$

Th-230 1.000E+00

$\mathrm{U}-2341.000 \mathrm{E}+00$

U-238 9.999E-01

$\sum S(j):$

$\mathrm{Pu}-238 \quad 1.000 \mathrm{E}+00$

Th-230 1.000E+00

$\mathrm{U}-234 \quad 1.000 \mathrm{E}+00$

U-238 9.999E-01

$\sum S(j):$

Pu-239 1.000E+00

$\mathrm{Pu}-2391.000 \mathrm{E}+00$

$\mathrm{U}-2351.000 \mathrm{E}+00$

$\sum S(j):$
$=0.000 \mathrm{E}+00 \quad 1.000 \mathrm{E}+00 \quad 5.000 \mathrm{E}+01 \quad 1.000 \mathrm{E}+02 \quad 5.000 \mathrm{E}+02 \quad 1.050 \mathrm{E}+03$

$\begin{array}{lllllll}3.500 \mathrm{E}+01 & 3.494 \mathrm{E}+01 & 3.229 \mathrm{E}+01 & 2.980 \mathrm{E}+01 & 1.566 \mathrm{E}+01 & 6.464 \mathrm{E}+00\end{array}$

0.000E+00 1.133E-05 5.428E-04 1.040E-03 3.749E-03 5.255E-03

$\begin{array}{llllll}5.500 \mathrm{E}+00 & 5.499 \mathrm{E}+00 & 5.463 \mathrm{E}+00 & 5.426 \mathrm{E}+00 & 5.141 \mathrm{E}+00 & 4.773 \mathrm{E}+00\end{array}$

$\begin{array}{llll}5.500 \mathrm{E}+00 & 5.499 \mathrm{E}+00 \quad 5.464 \mathrm{E}+00 \quad 5.427 \mathrm{E}+00 \quad 5.145 \mathrm{E}+00 \quad 4.779 \mathrm{E}+00\end{array}$

$0.000 E+00 \quad 2.477 E-11 \quad 6.018 E-08 \quad 2.338 E-07 \quad 4.686 E-06 \quad 1.571 E-05$

$\begin{array}{lllllll}0.000 \mathrm{E}+00 & 2.405 \mathrm{E}-05 & 1.198 \mathrm{E}-03 & 2.386 \mathrm{E}-03 & 1.155 \mathrm{E}-02 & 2.320 \mathrm{E}-02\end{array}$

$0.000 \mathrm{E}+00 \quad 2.405 \mathrm{E}-05 \quad 1.198 \mathrm{E}-03 \quad 2.386 \mathrm{E}-03 \quad 1.155 \mathrm{E}-02 \quad 2.322 \mathrm{E}-02$

$0.000 \mathrm{E}+00 \quad 7.799 \mathrm{E}-16 \quad 9.529 \mathrm{E}-11 \quad 7.450 \mathrm{E}-10 \quad 7.803 \mathrm{E}-08 \quad 5.780 \mathrm{E}-07$

$0.000 \mathrm{E}+00 \quad 1.136 \mathrm{E}-09 \quad 2.827 \mathrm{E}-06 \quad 1.126 \mathrm{E}-05 \quad 2.719 \mathrm{E}-04 \quad 1.144 \mathrm{E}-03$

$\begin{array}{llllll}0.000 \mathrm{E}+00 & 1.136 \mathrm{E}-09 & 2.827 \mathrm{E}-06 & 1.126 \mathrm{E}-05 & 2.720 \mathrm{E}-04 & 1.144 \mathrm{E}-03\end{array}$

$\begin{array}{llllll}1.900 \mathrm{E}+01 & 1.857 \mathrm{E}+01 & 5.975 \mathrm{E}+00 & 1.879 \mathrm{E}+00 & 1.796 \mathrm{E}-04 & 5.338 \mathrm{E}-10\end{array}$

$\begin{array}{lllllll}7.176 \mathrm{E}-08 & 7.119 \mathrm{E}-08 & 4.830 \mathrm{E}-08 & 3.251 \mathrm{E}-08 & 1.370 \mathrm{E}-09 & 1.760 \mathrm{E}-11\end{array}$

$\begin{array}{llllllll}3.900 \mathrm{E}+01 & 3.869 \mathrm{E}+01 & 2.625 \mathrm{E}+01 & 1.767 \mathrm{E}+01 & 7.445 \mathrm{E}-01 & 9.567 \mathrm{E}-03\end{array}$

$\begin{array}{lllllll}3.900 \mathrm{E}+01 & 3.869 \mathrm{E}+01 & 2.625 \mathrm{E}+01 & 1.767 \mathrm{E}+01 & 7.445 \mathrm{E}-01 & 9.567 \mathrm{E}-03\end{array}$

$0.000 \mathrm{E}+00 \quad 1.101 \mathrm{E}-04 \quad 4.562 \mathrm{E}-03 \quad 7.627 \mathrm{E}-03 \quad 1.356 \mathrm{E}-02 \quad 1.363 \mathrm{E}-02$

$\begin{array}{lllll}1.600 \mathrm{E}+02 & 1.600 \mathrm{E}+02 & 1.598 \mathrm{E}+02 & 1.596 \mathrm{E}+02 & 1.579 \mathrm{E}+02 \quad 1.557 \mathrm{E}+02\end{array}$

$\begin{array}{lllllll}0.000 \mathrm{E}+00 & 4.536 \mathrm{E}-04 & 2.265 \mathrm{E}-02 & 4.525 \mathrm{E}-02 & 2.240 \mathrm{E}-01 & 4.642 \mathrm{E}-01\end{array}$

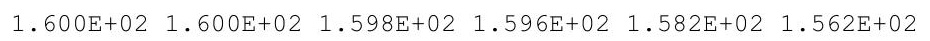

$0.000 \mathrm{E}+00 \quad 4.963 \mathrm{E}-10 \quad 1.094 \mathrm{E}-06 \quad 3.882 \mathrm{E}-06 \quad 4.691 \mathrm{E}-05 \quad 1.141 \mathrm{E}-04$ $\begin{array}{lllllll}1.000 \mathrm{E}+02 & 1.000 \mathrm{E}+02 & 9.994 \mathrm{E}+01 & 9.988 \mathrm{E}+01 & 9.940 \mathrm{E}+01 & 9.875 \mathrm{E}+01\end{array}$ $0.000 \mathrm{E}+00 \quad 1.440 \mathrm{E}-03 \quad 7.195 \mathrm{E}-02 \quad 1.438 \mathrm{E}-01 \quad 7.134 \mathrm{E}-01 \quad 1.483 \mathrm{E}+00$ $0.000 \mathrm{E}+00 \quad 2.041 \mathrm{E}-09 \quad 5.099 \mathrm{E}-06 \quad 2.037 \mathrm{E}-05 \quad 5.052 \mathrm{E}-04 \quad 2.203 \mathrm{E}-03$

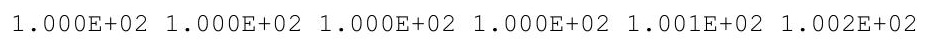

$0.000 \mathrm{E}+00 \quad 7.171 \mathrm{E}-14 \quad 8.109 \mathrm{E}-09 \quad 5.887 \mathrm{E}-08 \quad 3.940 \mathrm{E}-06 \quad 2.035 \mathrm{E}-05$ $\begin{array}{lllllll}0.000 \mathrm{E}+00 & 4.331 \mathrm{E}-02 & 2.141 \mathrm{E}+00 & 4.233 \mathrm{E}+00 & 1.933 \mathrm{E}+01 & 3.597 \mathrm{E}+01\end{array}$ $\begin{array}{llllll}0.000 \mathrm{E}+00 & 3.119 \mathrm{E}-07 & 7.736 \mathrm{E}-04 & 3.069 \mathrm{E}-03 & 7.197 \mathrm{E}-02 & 2.914 \mathrm{E}-01\end{array}$ $\begin{array}{llllll}0.000 \mathrm{E}+00 & 2.948 \mathrm{E}-13 & 3.662 \mathrm{E}-08 & 2.911 \mathrm{E}-07 & 3.459 \mathrm{E}-05 & 2.994 \mathrm{E}-04\end{array}$ $0.000 \mathrm{E}+00 \quad 4.331 \mathrm{E}-02 \quad 2.142 \mathrm{E}+00 \quad 4.236 \mathrm{E}+00 \quad 1.940 \mathrm{E}+01 \quad 3.626 \mathrm{E}+01$

$0.000 \mathrm{E}+00 \quad 5.540 \mathrm{E}-16 \quad 2.417 \mathrm{E}-09 \quad 2.809 \mathrm{E}-08 \quad 3.386 \mathrm{E}-06 \quad 1.908 \mathrm{E}-05$ $\begin{array}{lllllll}0.000 \mathrm{E}+00 & 6.662 \mathrm{E}-04 & 1.057 \mathrm{E}+00 & 2.944 \mathrm{E}+00 & 1.819 \mathrm{E}+01 \quad 3.507 \mathrm{E}+01\end{array}$ $0.000 \mathrm{E}+00 \quad 3.207 \mathrm{E}-09 \quad 2.836 \mathrm{E}-04 \quad 1.705 \mathrm{E}-03 \quad 6.353 \mathrm{E}-02 \quad 2.751 \mathrm{E}-01$ $\begin{array}{llllll}0.000 \mathrm{E}+00 & 2.276 \mathrm{E}-15 & 1.075 \mathrm{E}-08 & 1.355 \mathrm{E}-07 & 2.879 \mathrm{E}-05 & 2.742 \mathrm{E}-04\end{array}$ $\begin{array}{lllllll}0.000 \mathrm{E}+00 & 6.663 \mathrm{E}-04 & 1.058 \mathrm{E}+00 & 2.945 \mathrm{E}+00 & 1.825 \mathrm{E}+01 & 3.534 \mathrm{E}+01\end{array}$ $\begin{array}{llllll}3.600 \mathrm{E}+01 & 3.600 \mathrm{E}+01 & 3.592 \mathrm{E}+01 & 3.583 \mathrm{E}+01 & 3.518 \mathrm{E}+01 & 3.430 \mathrm{E}+01\end{array}$ $0.000 \mathrm{E}+00 \quad 3.545 \mathrm{E}-08 \quad 1.770 \mathrm{E}-06 \quad 3.533 \mathrm{E}-06 \quad 1.742 \mathrm{E}-05 \quad 3.591 \mathrm{E}-05$

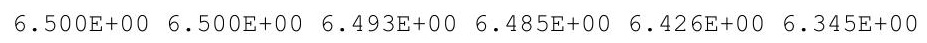

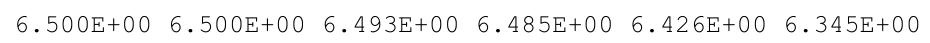


RESRAD, Version $6.5 \quad \mathrm{~T}^{1 / 2}$ Limit $=180$ days

Summary : C746U Resident Gardener Deterministic Run

File : $X: \backslash F I N A L$ V2 $\backslash$ DOE FWD RUNS \C746U RG DOE SG FWD-FV2-1050YR. RAD

Individual Nuclide Soil Concentration

Parent Nuclide and Branch Fraction Indicated

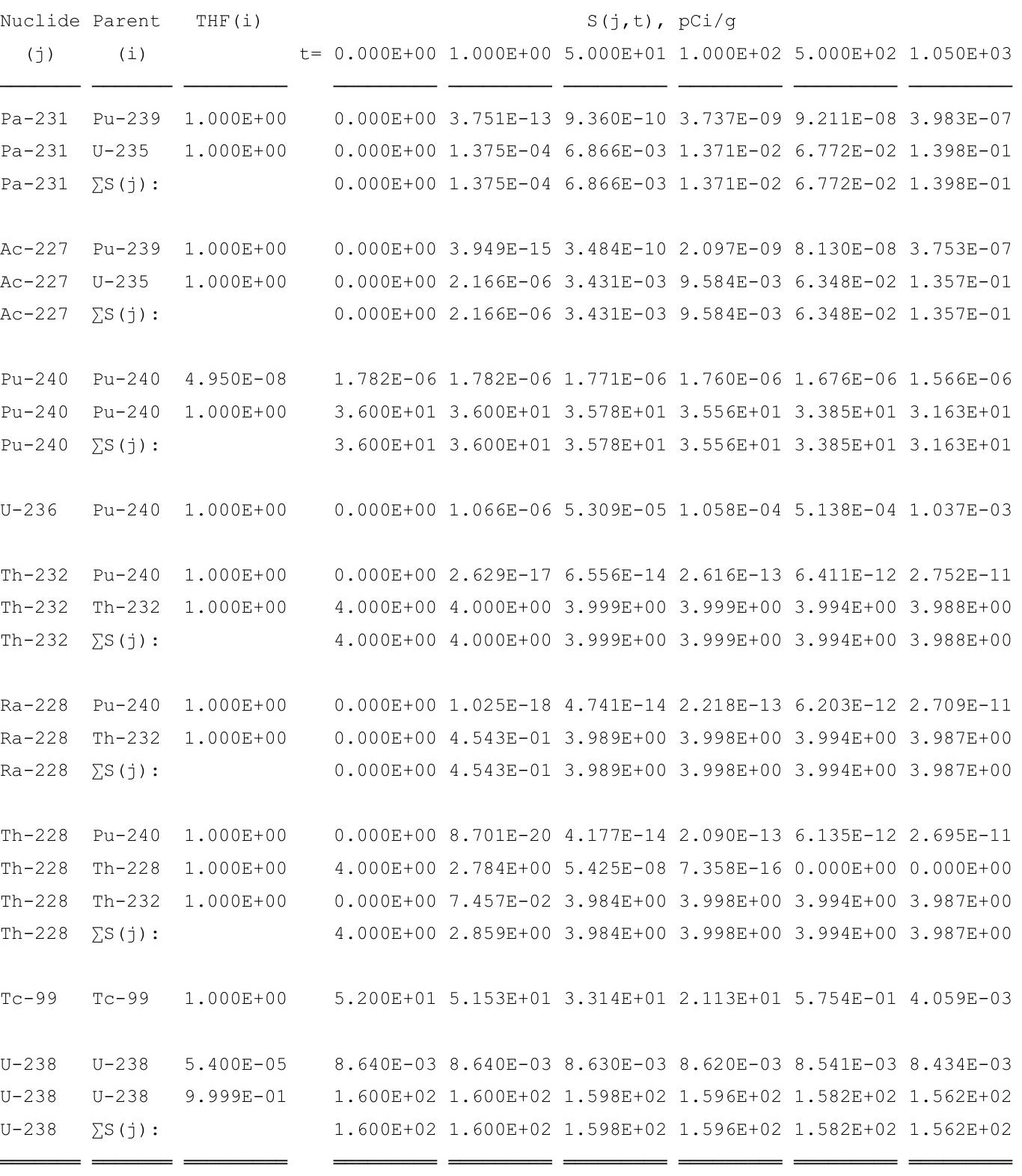

THF(i) is the thread fraction of the parent nuclide.

RESCALC.EXE execution time $=4.93$ seconds 


\title{
Resident Gardener
}

\author{
Summary Report \\ (Deterministic Analysis Report) \\ Second Peak Dose Assessment \\ Time Horizon: 10,000 yr
}


THIS PAGE INTENTIONALLY LEFT BLANK 
RESRAD, Version $6.5 \quad \mathrm{~T}^{1 / 2}$ Limit $=180$ days

Summary : C746U Resident Gardener Deterministic Run

File : $\mathrm{X}: \backslash F I N A L$ V2 \DOE FWD RUNS \C746U RG DOE SG FWD-FV2-10000YR.RAD

Table of Contents

Part I: Mixture Sums and Single Radionuclide Guidelines

Dose Conversion Factor (and Related) Parameter Summary ... 2

Site-Specific Parameter Summary ................... 8

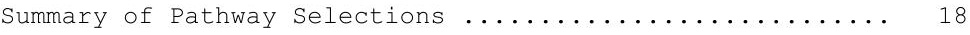

Contaminated Zone and Total Dose Summary ............. 19

Total Dose Components

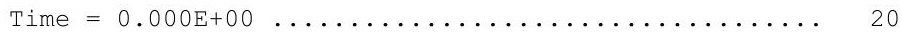

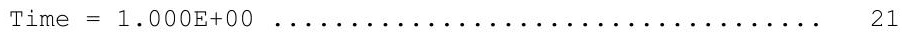

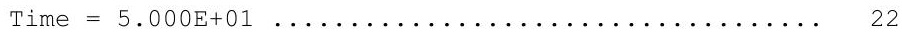

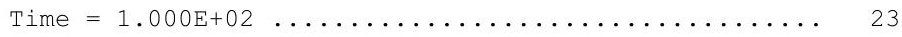

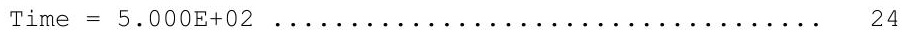

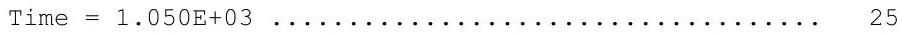

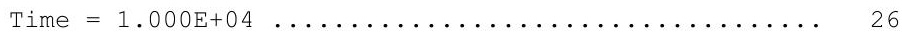

Dose/Source Ratios Summed Over All Pathways .......... 27

Single Radionuclide Soil Guidelines ............... 29

Dose Per Nuclide Summed Over All Pathways ............ 30

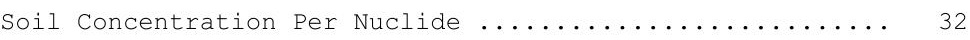


RESRAD, Version $6.5 \quad T^{1 / 2}$ Limit $=180$ days

Summary : C746U Resident Gardener Deterministic Run

File : $X: \backslash F I N A L$ V2\DOE FWD RUNS \C746U RG DOE SG FWD-FV2-10000YR.RAD

Dose Conversion Factor (and Related) Parameter Summary

Dose Library: ICRP 60 \& ICRP 72 (Adult)

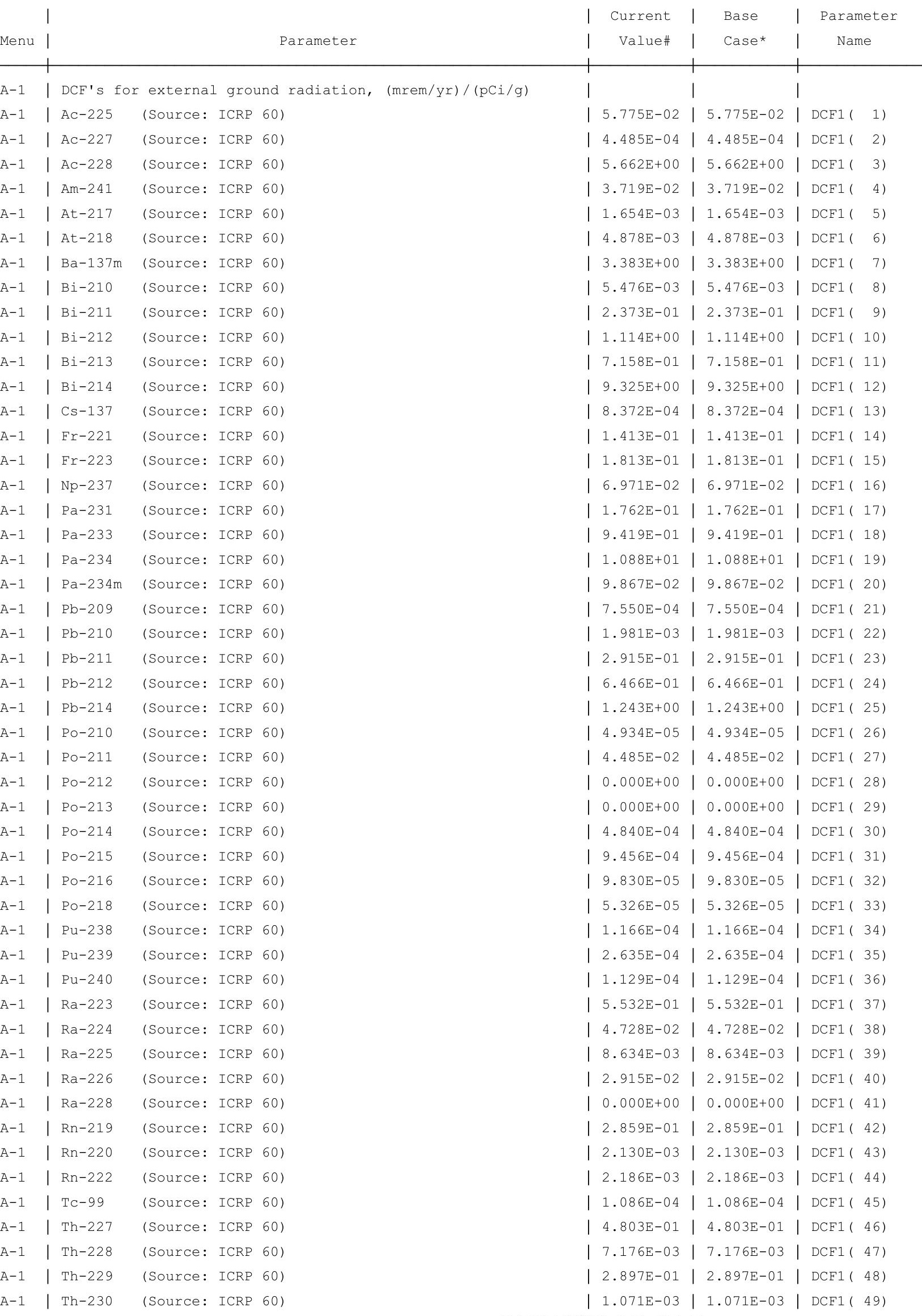


RESRAD, Version $6.5 \quad T^{1 / 2}$ Limit $=180$ days

Summary : C746U Resident Gardener Deterministic Run

File : $X: \backslash F I N A L$ V2 \DOE FWD RUNS \C746U RG DOE SG FWD-FV2-10000YR.RAD

Dose Conversion Factor (and Related) Parameter Summary (continued)

Dose Library: ICRP 60 \& ICRP 72 (Adult)

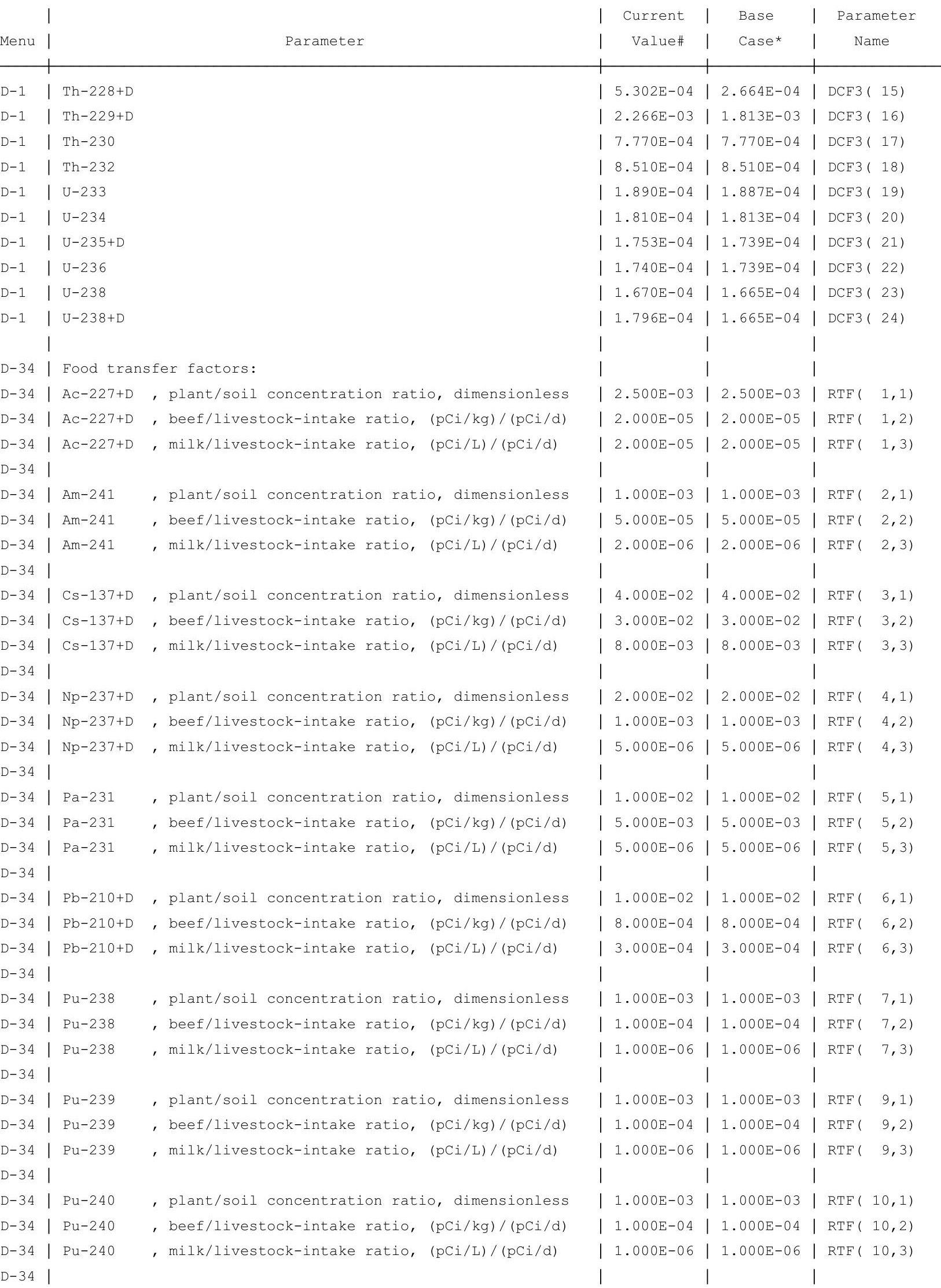


RESRAD, Version $6.5 \quad \mathrm{~T}^{1 / 2}$ Limit $=180$ days

Summary : C746U Resident Gardener Deterministic Run

File : $\mathrm{X}: \backslash F I N A L$ V2 \DOE FWD RUNS \C746U RG DOE SG FWD-FV2-10000YR.RAD

Dose Conversion Factor (and Related) Parameter Summary (continued)

Dose Library: ICRP 60 \& ICRP 72 (Adult)

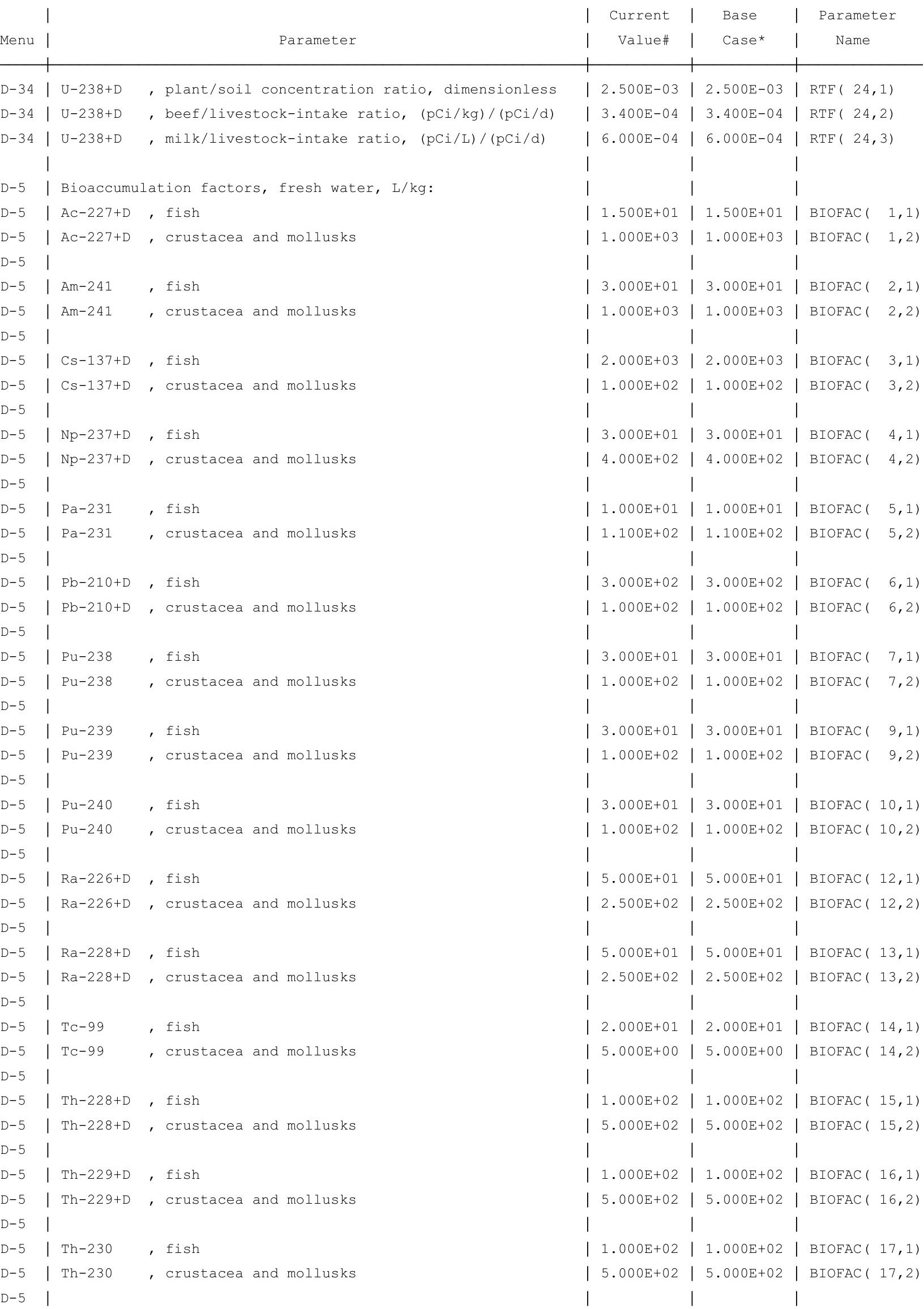


RESRAD, Version $6.5 \quad \mathrm{~T}^{1} \frac{1}{2}$ Limit $=180$ days

Summary : C746U Resident Gardener Deterministic Run

File : $\mathrm{X}: \backslash F I N A L$ V2 \DOE FWD RUNS \C746U RG DOE SG FWD-FV2-10000YR.RAD

Site-Specific Parameter Summary (continued)

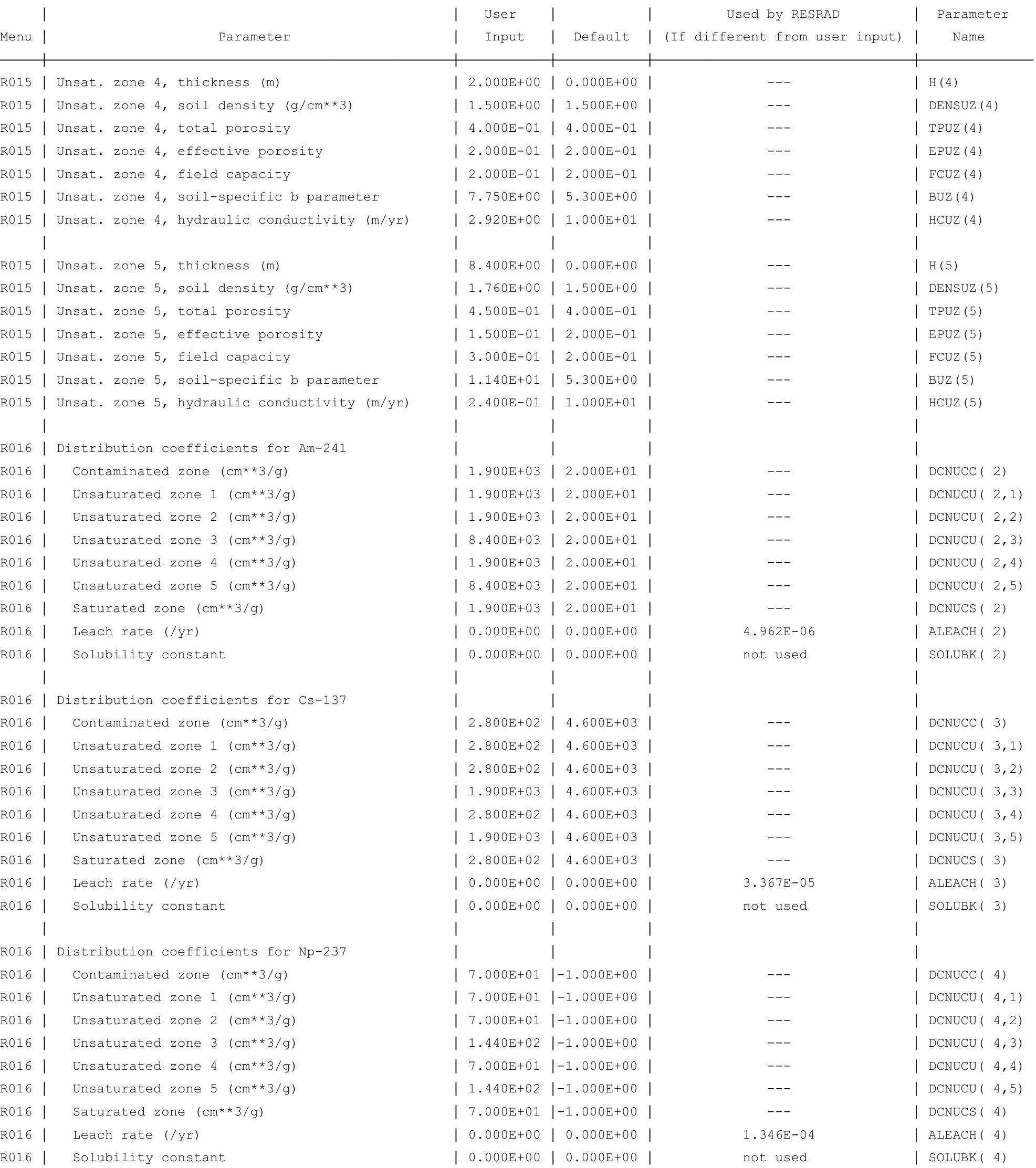


RESRAD, Version $6.5 \quad T^{1 / 2}$ Limit $=180$ days

Summary : C746U Resident Gardener Deterministic Run

File : $X: \backslash F I N A L$ V2 \DOE FWD RUNS \C746U RG DOE SG FWD-FV2-10000YR. RAD

Site-Specific Parameter Summary (continued)

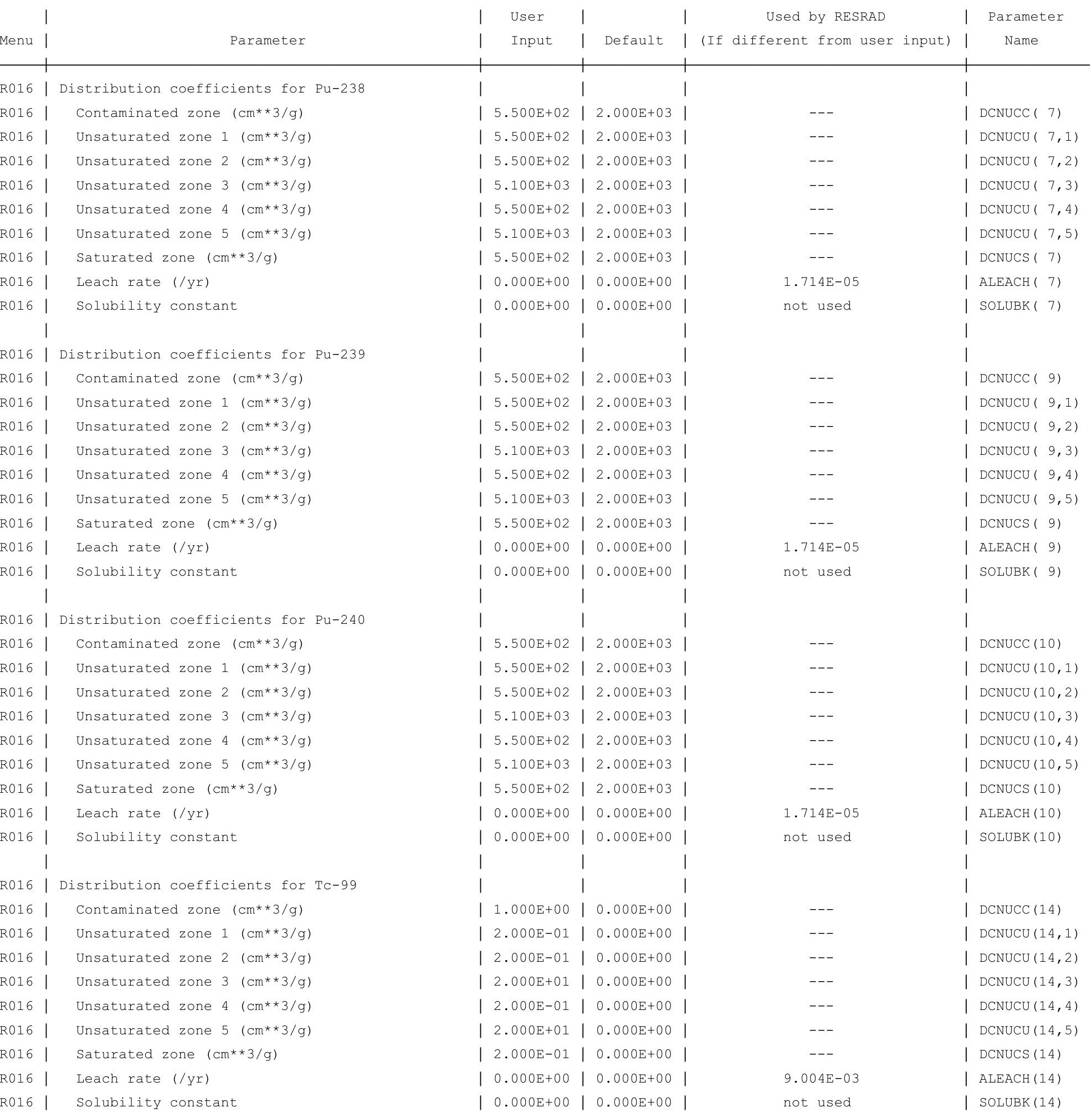


RESRAD, Version $6.5 \quad T^{1 / 2}$ Limit $=180$ days

Summary : C746U Resident Gardener Deterministic Run

File : $X: \backslash F I N A L$ V2\DOE FWD RUNS \C746U RG DOE SG FWD-FV2-10000YR.RAD

Site-Specific Parameter Summary (continued)

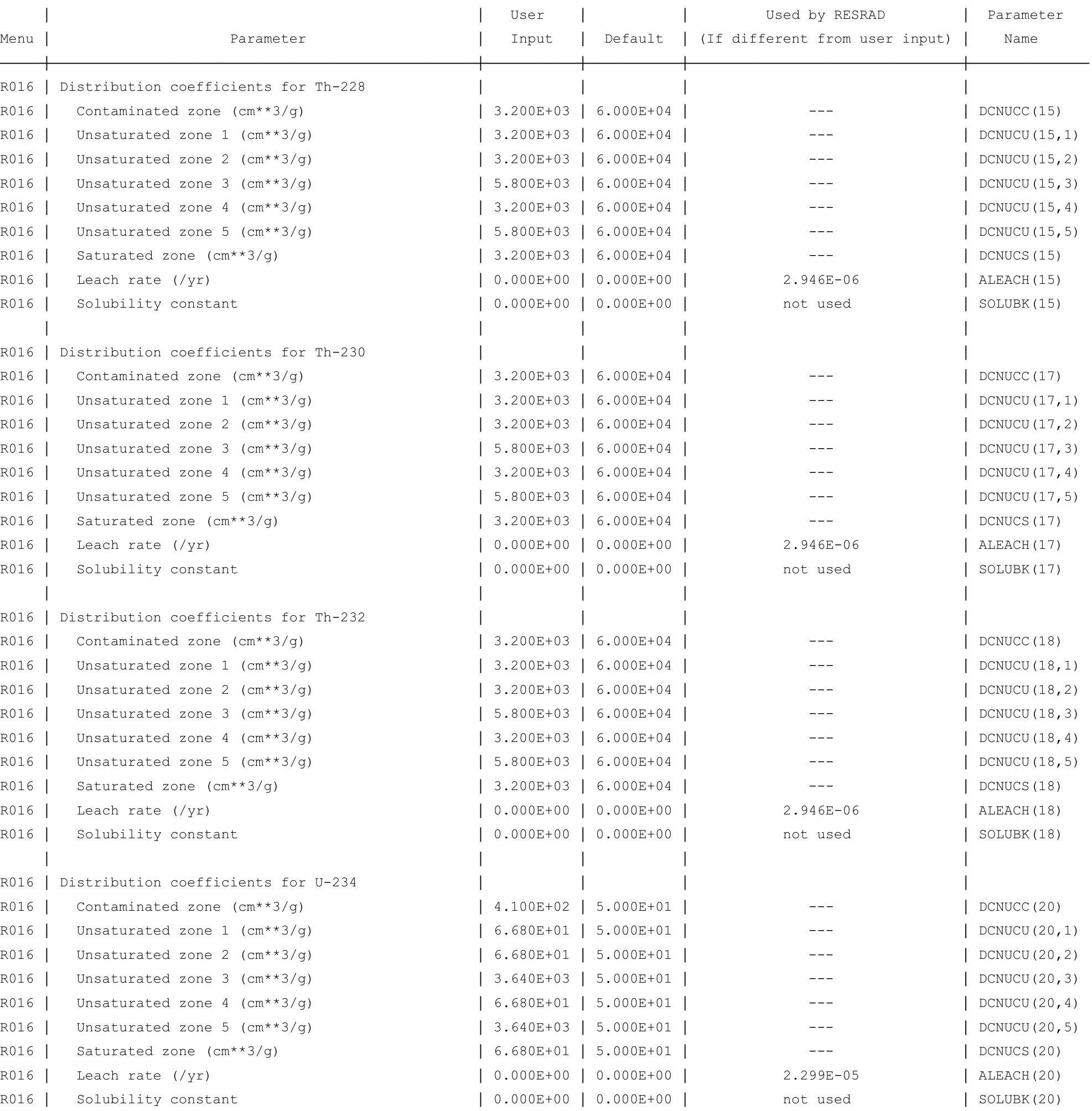


RESRAD, Version $6.5 \quad T^{1 / 2}$ Limit $=180$ days

Summary : C746U Resident Gardener Deterministic Run

File : $X: \backslash F I N A L$ V2\DOE FWD RUNS \C746U RG DOE SG FWD-FV2-10000YR.RAD

Site-Specific Parameter Summary (continued)

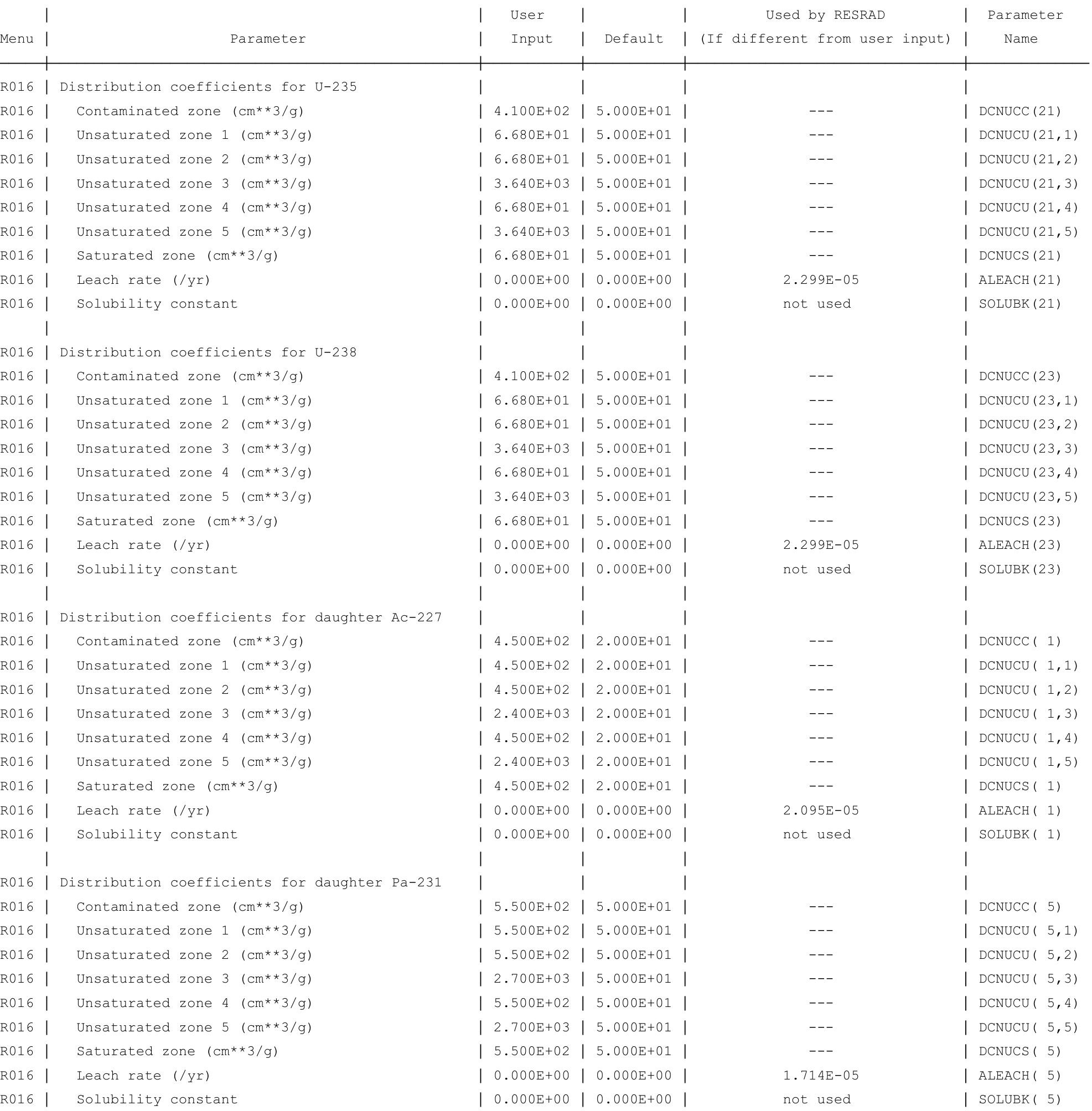


RESRAD, Version $6.5 \quad T^{1 / 2}$ Limit $=180$ days

Summary : C746U Resident Gardener Deterministic Run

File : $X: \backslash F I N A L$ V2\DOE FWD RUNS \C746U RG DOE SG FWD-FV2-10000YR.RAD

Site-Specific Parameter Summary (continued)

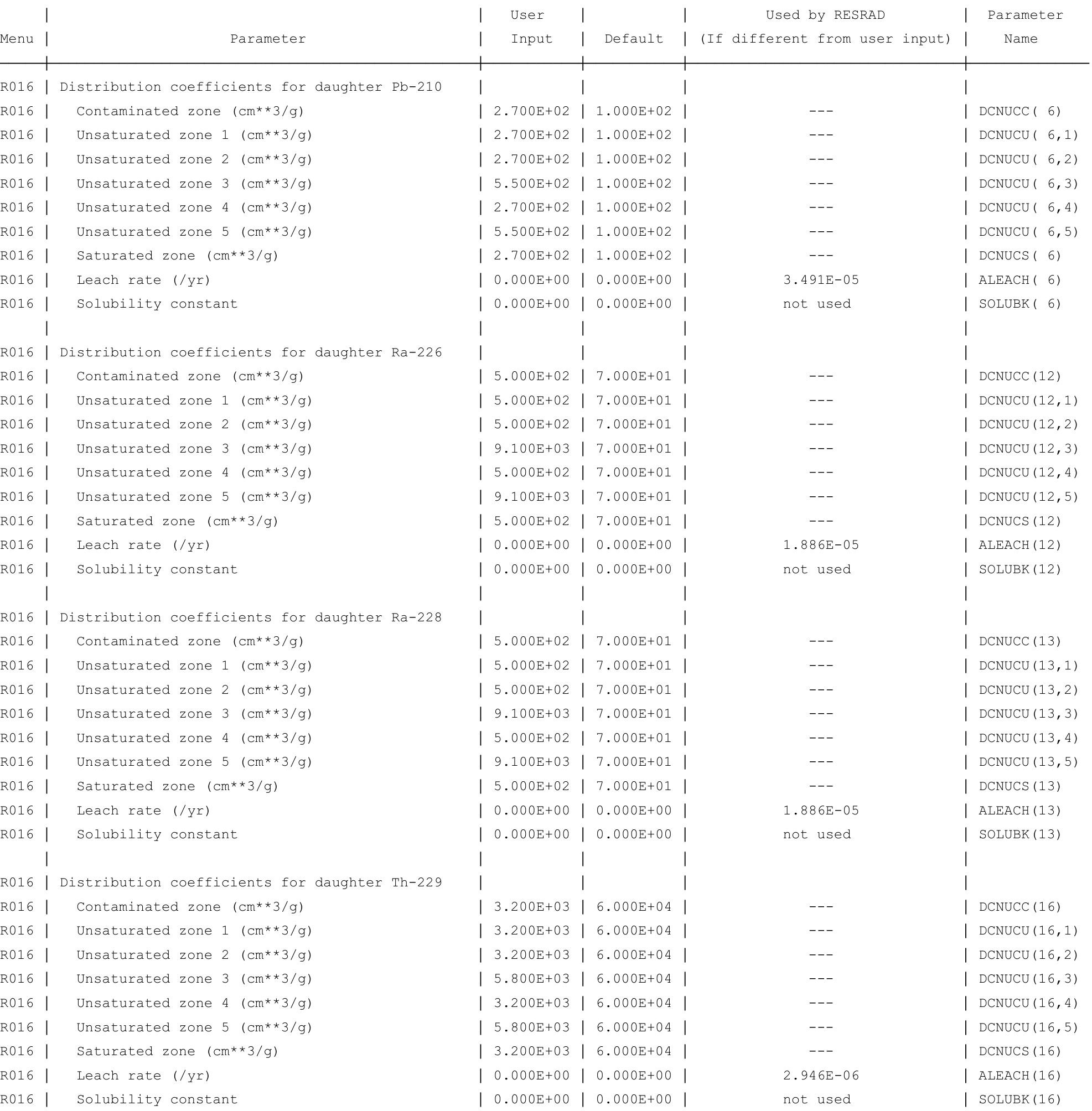


RESRAD, Version $6.5 \quad T^{1 / 2}$ Limit $=180$ days

Summary : C746U Resident Gardener Deterministic Run

File : $X: \backslash F I N A L$ V2\DOE FWD RUNS \C746U RG DOE SG FWD-FV2-10000YR.RAD

Site-Specific Parameter Summary (continued)

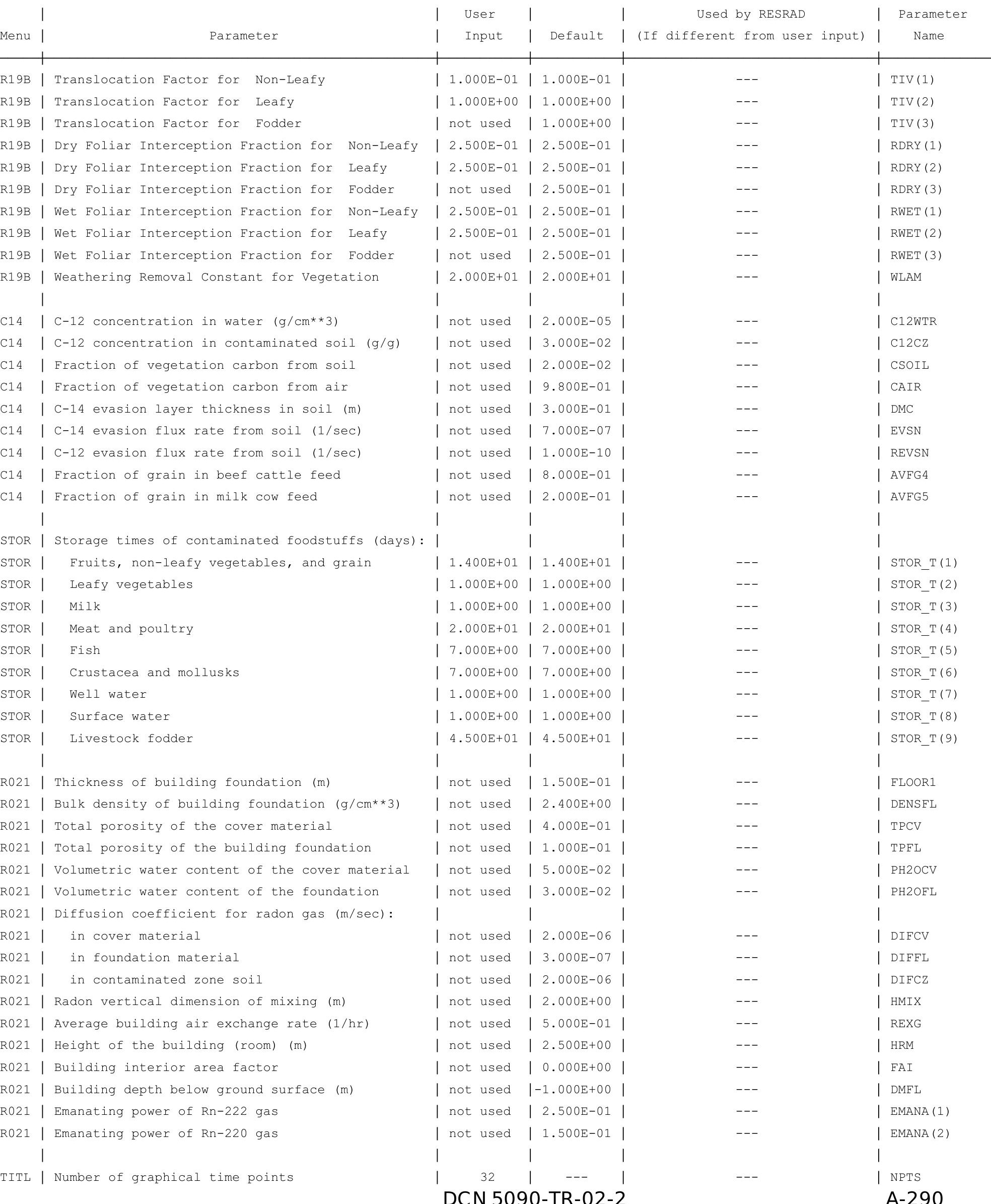


RESRAD, Version $6.5 \quad \mathrm{~T}^{1 / 2}$ Limit $=180$ days

Summary : C746U Resident Gardener Deterministic Run

File : $\mathrm{X}: \backslash F I N A L$ V2 \DOE FWD RUNS \C746U RG DOE SG FWD-FV2-10000YR. RAD

Contaminated Zone Dimensions

Area: $\quad 89436.00$ square meters

Thickness:

Cover Depth:

\begin{abstract}
13.40 meters
\end{abstract}
1.52 meters
Initial Soil Concentrations, pci/g

$\begin{array}{ll}\text { Am-241 } & 3.500 \mathrm{E}+01 \\ \mathrm{Cs}-137 & 1.900 \mathrm{E}+01 \\ \mathrm{~Np}-237 & 5.500 \mathrm{E}+00 \\ \mathrm{Pu}-238 & 3.900 \mathrm{E}+01 \\ \mathrm{Pu}-239 & 3.600 \mathrm{E}+01 \\ \mathrm{Pu}-240 & 3.600 \mathrm{E}+01 \\ \mathrm{TC}-99 & 5.200 \mathrm{E}+01 \\ \mathrm{Th}-228 & 4.000 \mathrm{E}+00 \\ \mathrm{Th}-230 & 1.000 \mathrm{E}+02 \\ \mathrm{Th}-232 & 4.000 \mathrm{E}+00 \\ \mathrm{U}-234 & 1.600 \mathrm{E}+02 \\ \mathrm{U}-235 & 6.500 \mathrm{E}+00 \\ \mathrm{U}-238 & 1.600 \mathrm{E}+02\end{array}$

Total Dose TDOSE(t), mrem/yr

Basic Radiation Dose Limit $=1.000 \mathrm{E}+02 \mathrm{mrem} / \mathrm{yr}$

Total Mixture Sum $M(t)$ = Fraction of Basic Dose Limit Received at Time (t)

$\begin{array}{rlllllll}t \text { (years) }: & 0.000 \mathrm{E}+00 & 1.000 \mathrm{E}+00 & 5.000 \mathrm{E}+01 & 1.000 \mathrm{E}+02 & 5.000 \mathrm{E}+02 & 1.050 \mathrm{E}+03 & 1.000 \mathrm{E}+04 \\ \mathrm{TDOSE}(\mathrm{t}): & 5.627 \mathrm{E}-06 & 4.206 \mathrm{E}-06 & 9.541 \mathrm{E}-06 & 1.367 \mathrm{E}-05 & 2.423 \mathrm{E}-04 & 6.827 \mathrm{E}+00 & 2.359 \mathrm{E}+03 \\ \mathrm{M}(\mathrm{t}): & 5.627 \mathrm{E}-08 & 4.206 \mathrm{E}-08 & 9.541 \mathrm{E}-08 & 1.367 \mathrm{E}-07 & 2.423 \mathrm{E}-06 & 6.827 \mathrm{E}-02 & 2.359 \mathrm{E}+01\end{array}$

Maximum TDOSE $(t): 2.359 \mathrm{E}+03 \mathrm{mrem} / \mathrm{yr}$ at $t=1.000 \mathrm{E}+04$ years 
RESRAD, Version 6.5

ummary : C746U Resident Gardener Deterministic Run

File : X: \FINAL V2 \DOE FWD RUNS \C746U RG DOE SG FWD-FV2-10000YR.RAD

Total Dose Contributions TDOSE(i,p,t) for Individual Radionuclides (i) and Pathways (p) As mrem/yr and Fraction of Total Dose At $t=0.000 \mathrm{E}+00$ years

Water Independent Pathways (Inhalation excludes radon)

\begin{tabular}{|c|c|c|c|c|c|c|c|c|c|c|c|c|c|c|}
\hline \multirow[b]{2}{*}{ clide } & \multicolumn{2}{|c|}{ Ground } & \multicolumn{2}{|c|}{ Inhalation } & \multicolumn{2}{|c|}{ Radon } & \multicolumn{2}{|c|}{ Plant } & \multicolumn{2}{|c|}{ Meat } & \multicolumn{2}{|c|}{ Milk } & \multicolumn{2}{|c|}{ Soil } \\
\hline & mrem/yr & fract. & mrem/yr & fract. & mrem/yr & fract. & mrem/yr & fract. & mrem/yr & fract. & mrem/yr & fract. & mrem/yr & fract. \\
\hline 41 & $5.412 \mathrm{E}-18$ & 0.0000 & $0.000 \mathrm{E}+00$ & 0.0000 & $0.000 \mathrm{E}+00$ & 0.0000 & $0.000 \mathrm{E}+00$ & 0.0000 & $0.000 \mathrm{E}+00$ & 0.0000 & $0.000 \mathrm{E}+00$ & 0.0000 & $0.000 \mathrm{E}+00$ & 0.0000 \\
\hline 37 & $2.397 \mathrm{E}-08$ & 0.0043 & $0.000 \mathrm{E}+00$ & 0.0000 & $0.000 \mathrm{E}+00$ & 0.0000 & $0.000 \mathrm{E}+00$ & 0.0000 & $0.000 \mathrm{E}+00$ & 0.0000 & $0.000 \mathrm{E}+00$ & 0.0000 & $0.000 \mathrm{E}+00$ & 0.0000 \\
\hline 37 & $5.245 \mathrm{E}-12$ & 0.0000 & $0.000 \mathrm{E}+00$ & 0.0000 & $0.000 \mathrm{E}+00$ & 0.0000 & $0.000 \mathrm{E}+00$ & 0.0000 & $0.000 \mathrm{E}+00$ & 0.0000 & $0.000 \mathrm{E}+00$ & 0.0000 & $0.000 \mathrm{E}+00$ & 0.0000 \\
\hline 238 & $3.174 \mathrm{E}-21$ & 0.0000 & $0.000 \mathrm{E}+00$ & 0.0000 & $0.000 \mathrm{E}+00$ & 0.0000 & $0.000 \mathrm{E}+00$ & 0.0000 & $0.000 \mathrm{E}+00$ & 0.0000 & $0.000 \mathrm{E}+00$ & 0.0000 & $0.000 \mathrm{E}+00$ & 0.0000 \\
\hline 239 & $4.328 \mathrm{E}-16$ & 0.0000 & $0.000 \mathrm{E}+00$ & 0.0000 & $0.000 \mathrm{E}+00$ & 0.0000 & $0.000 \mathrm{E}+00$ & 0.0000 & $0.000 \mathrm{E}+00$ & 0.0000 & $0.000 \mathrm{E}+00$ & 0.0000 & $0.000 \mathrm{E}+00$ & 0.0000 \\
\hline & $4.115 \mathrm{E}-23$ & 0 & $0.000 \mathrm{E}$ & 0 & $0.000 \mathrm{E}+00$ & 0 & $0.000 \mathrm{E}+00$ & 0 & $0.000 \mathrm{E}+00$ & 0 & $0.000 \mathrm{E}+00$ & 0 & $0.000 \mathrm{E}+00$ & 0000 \\
\hline 99 & $2.994 \mathrm{E}-24$ & 0.0000 & $0.000 \mathrm{E}+00$ & 0.0000 & $0.000 \mathrm{E}+00$ & 0.0000 & $0.000 \mathrm{E}+00$ & 0.00 & $0.000 \mathrm{E}+00$ & 0.00 & $0.000 \mathrm{E}+00$ & 0.0000 & $0.000 \mathrm{E}+00$ & 0.0000 \\
\hline 20 & $5.530 \mathrm{E}-06$ & 0.9827 & $0.000 \mathrm{E}+00$ & 0.0000 & $0.000 \mathrm{E}+00$ & 0.0000 & $0.000 \mathrm{E}+00$ & 0.0000 & $0.000 \mathrm{E}+00$ & 0.0000 & $0.000 \mathrm{E}+00$ & 0.0000 & $0.000 \mathrm{E}+00$ & 0.0000 \\
\hline 230 & $3.774 \mathrm{E}-09$ & 0.0007 & $0.000 \mathrm{E}+00$ & 0.0000 & $0.000 \mathrm{E}+00$ & 0.0000 & $0.000 \mathrm{E}+00$ & 0.0000 & $0.000 \mathrm{E}+00$ & 0.0000 & $0.000 \mathrm{E}+00$ & 0.0000 & $0.000 \mathrm{E}+00$ & 0.0000 \\
\hline & $4.712 \mathrm{E}-08$ & 0.0084 & $0.000 \mathrm{E}+00$ & 0.0000 & $0.000 \mathrm{E}+00$ & 0.0000 & $0.000 \mathrm{E}+00$ & 0.0000 & $0.000 \mathrm{E}+00$ & 0.0000 & $0.000 \mathrm{E}+00$ & 0.0000 & $0.000 \mathrm{E}+00$ & 0.0000 \\
\hline & $1.813 \mathrm{E}-14$ & 0.0000 & $0.000 \mathrm{E}+00$ & 0.0000 & $0.000 \mathrm{E}+00$ & 0.0000 & $0.000 \mathrm{E}+00$ & 0.0000 & $0.000 \mathrm{E}+00$ & 0.0000 & $0.000 \mathrm{E}+00$ & 0.0000 & $0.000 \mathrm{E}+00$ & 0.0000 \\
\hline & $8.089 \mathrm{E}-14$ & 0.0000 & $0.000 \mathrm{E}+00$ & 0.0000 & $0.000 \mathrm{E}+00$ & 0.0000 & $0.000 \mathrm{E}+00$ & 0.0000 & $0.000 \mathrm{E}+00$ & 0.0000 & $0.000 \mathrm{E}+00$ & 0.0000 & $0.000 \mathrm{E}+00$ & 0.0000 \\
\hline & $2.271 \mathrm{E}-08$ & 0.0040 & $0.000 \mathrm{E}+00$ & 0.0000 & $0.000 \mathrm{E}+00$ & 0.0000 & $0.000 \mathrm{E}+00$ & 0.0000 & $0.000 \mathrm{E}+00$ & 0.0000 & $0.000 \mathrm{E}+00$ & 0.0000 & $0.000 \mathrm{E}+00$ & 0.0000 \\
\hline & & & $0.000 \mathrm{E}+00$ & 0.0000 & $0.000 \mathrm{E}+00$ & 0.0000 & $0.000 \mathrm{E}+00$ & 0.0000 & $0.000 \mathrm{E}+00$ & 0.0000 & $0.000 \mathrm{E}+0$ & 0.0000 & $E+00$ & .0 \\
\hline
\end{tabular}

Total Dose Contributions TDOSE (i,p,t) for Individual Radionuclides (i) and Pathways (p) As mrem/yr and Fraction of Total Dose At $t=0.000 \mathrm{E}+00$ years

Water Dependent Pathways

\begin{tabular}{|c|c|c|c|c|c|c|c|c|c|c|c|c|c|c|}
\hline \multirow[b]{2}{*}{ Nuclide } & \multicolumn{2}{|c|}{ Water } & \multicolumn{2}{|c|}{ Fish } & \multicolumn{2}{|c|}{ Radon } & \multicolumn{2}{|c|}{ Plant } & \multicolumn{2}{|c|}{ Meat } & \multicolumn{2}{|c|}{ Milk } & \multicolumn{2}{|c|}{ All Pathways* } \\
\hline & mrem/yr & fract. & $\mathrm{mrem} / \mathrm{yr}$ & fract. & $\mathrm{mrem} / \mathrm{yr}$ & fract. & mrem/yr & fract. & mrem/yr & fract. & $\mathrm{mrem} / \mathrm{yr}$ & fract. & $\mathrm{mrem} / \mathrm{yr}$ & fract. \\
\hline-241 & $0.000 \mathrm{E}+00$ & 0.0000 & $0.000 \mathrm{E}+00$ & 0.0000 & $0.000 \mathrm{E}+00$ & 0.0000 & $0.000 \mathrm{E}+00$ & 0.0000 & $0.000 \mathrm{E}+00$ & 0.0000 & $0.000 \mathrm{E}+00$ & 0.0000 & $5.412 \mathrm{E}-18$ & 0.0000 \\
\hline 37 & $0.000 \mathrm{E}+00$ & 0.0000 & $0.000 \mathrm{E}+00$ & 0.0000 & $0.000 \mathrm{E}+00$ & 0.0000 & $0.000 \mathrm{E}+00$ & 0.0000 & $0.000 \mathrm{E}+00$ & 0.0000 & $0.000 \mathrm{E}+00$ & 0.0000 & $2.397 \mathrm{E}-08$ & 0.0043 \\
\hline 37 & $0.000 \mathrm{E}+00$ & 0.0000 & $0.000 \mathrm{E}+00$ & 0.0000 & $0.000 \mathrm{E}+00$ & 0.0000 & $0.000 \mathrm{E}+00$ & 0.0000 & $0.000 \mathrm{E}+00$ & 0.0000 & $0.000 \mathrm{E}+00$ & 0.0000 & $5.245 \mathrm{E}-12$ & 0.0000 \\
\hline 238 & $0.000 \mathrm{E}+00$ & 0.0000 & $0.000 \mathrm{E}+00$ & 0.0000 & $0.000 \mathrm{E}+00$ & 0.0000 & $0.000 \mathrm{E}+00$ & 0.0000 & $0.000 \mathrm{E}+00$ & 0.0000 & $0.000 \mathrm{E}+00$ & 0.0000 & $3.174 \mathrm{E}-21$ & 0.0000 \\
\hline 239 & $0.000 \mathrm{E}+00$ & 0.0000 & $0.000 \mathrm{E}+00$ & 0.0000 & $0.000 \mathrm{E}+00$ & 0.0000 & $0.000 \mathrm{E}+00$ & 0.0000 & $0.000 \mathrm{E}+00$ & 0.0000 & $0.000 \mathrm{E}+00$ & 0.0000 & $4.328 \mathrm{E}-16$ & 0.0000 \\
\hline 240 & $0.000 \mathrm{E}+00$ & 0.0 & $0.000 \mathrm{E}+00$ & 0 & $0.000 \mathrm{E}+00$ & 0. & $0.000 \mathrm{E}+00$ & 0 & 0 & 0 & $0.000 \mathrm{E}+00$ & 0 & $115 E-23$ & 0000 \\
\hline 年 & $0.000 \mathrm{E}+00$ & 0 & $0.000 \mathrm{E}+00$ & 0 & $0.000 \mathrm{E}+00$ & 0 & $0.000 \mathrm{E}+00$ & 0.00 & $0.000 \mathrm{E}+00$ & 00 & $0.000 \mathrm{E}+00$ & 0 & $2.994 \mathrm{E}-24$ & 0.0000 \\
\hline-228 & $0.000 \mathrm{E}+00$ & 0.0000 & $0.000 \mathrm{E}+00$ & 0.0000 & $0.000 \mathrm{E}+00$ & 0.0000 & $0.000 \mathrm{E}+00$ & 0.0000 & $0.000 \mathrm{E}+00$ & 0.0000 & $0.000 \mathrm{E}+00$ & 0.0000 & $5.530 \mathrm{E}-06$ & 0.9827 \\
\hline 230 & $0.000 \mathrm{E}+00$ & 0.0000 & $0.000 \mathrm{E}+00$ & 0.0000 & $0.000 \mathrm{E}+00$ & 0.0000 & $0.000 \mathrm{E}+00$ & 0.0000 & $0.000 \mathrm{E}+00$ & 0.0000 & $0.000 \mathrm{E}+00$ & 0.0000 & $3.774 \mathrm{E}-09$ & 0.0007 \\
\hline 232 & $0.000 \mathrm{E}+00$ & 0.0000 & $0.000 \mathrm{E}+00$ & 0.0000 & $0.000 \mathrm{E}+00$ & 0.0000 & $0.000 \mathrm{E}+00$ & 0.0000 & $0.000 \mathrm{E}+00$ & 0.0000 & $0.000 \mathrm{E}+00$ & 0.0000 & $4.712 \mathrm{E}-08$ & 0.0084 \\
\hline & $0.000 \mathrm{E}+00$ & 0.0000 & $0.000 \mathrm{E}+00$ & 0.0000 & $0.000 \mathrm{E}+00$ & 0.0000 & $0.000 \mathrm{E}+00$ & 0.0000 & $0.000 \mathrm{E}+00$ & 0.0000 & $0.000 \mathrm{E}+00$ & 0.0000 & $1.813 \mathrm{E}-14$ & 0.0000 \\
\hline & $0.000 \mathrm{E}+00$ & 0.0000 & $0.000 \mathrm{E}+00$ & 0.0000 & $0.000 \mathrm{E}+00$ & 0.0000 & $0.000 \mathrm{E}+00$ & 0.0000 & $0.000 \mathrm{E}+00$ & 0.0000 & $0.000 \mathrm{E}+00$ & 0.0000 & $8.089 \mathrm{E}-14$ & 0.0000 \\
\hline 38 & $0.000 \mathrm{E}+00$ & 0.0000 & $0.000 \mathrm{E}+00$ & 0.0000 & $0.000 \mathrm{E}+00$ & 0.0000 & $0.000 \mathrm{E}+00$ & 0.0000 & $0.000 \mathrm{E}+00$ & 0.0000 & $0.000 \mathrm{E}+00$ & 0.0000 & $2.271 \mathrm{E}-08$ & 0.0040 \\
\hline & & .0000 & $.000 \mathrm{E}+00$ & 000 & $E+00$ & 0.0000 & $.000 \mathrm{E}+00$ & .0000 & $.000 \mathrm{E}+00$ & 0 & $8+0$ & & . & \\
\hline
\end{tabular}

*Sum of all water independent and dependent pathways. 
RESRAD, Version 6.5

ummary : C746U Resident Gardener Deterministic Run

File : X: \FINAL V2 \DOE FWD RUNS \C746U RG DOE SG FWD-FV2-10000YR.RAD

Total Dose Contributions TDOSE(i,p,t) for Individual Radionuclides (i) and Pathways (p) As mrem/yr and Fraction of Total Dose At $t=1.000 \mathrm{E}+00$ years

Water Independent Pathways (Inhalation excludes radon)

\begin{tabular}{|c|c|c|c|c|c|c|c|c|c|c|c|c|c|c|}
\hline \multirow[b]{2}{*}{ clide } & \multicolumn{2}{|c|}{ Ground } & \multicolumn{2}{|c|}{ Inhalation } & \multicolumn{2}{|c|}{ Radon } & \multicolumn{2}{|c|}{ Plant } & \multicolumn{2}{|c|}{ Meat } & \multicolumn{2}{|c|}{ Milk } & \multicolumn{2}{|l|}{ Soil } \\
\hline & mrem/yr & fract. & mrem/yr & fract. & mrem/yr & fract. & mrem/yr & fract. & mrem/yr & fract. & mrem/yr & fract. & mrem/yr & fract. \\
\hline 41 & $1.638 \mathrm{E}-17$ & 0.0000 & $0.000 \mathrm{E}+00$ & 0.0000 & $0.000 \mathrm{E}+00$ & 0.0000 & $0.000 \mathrm{E}+00$ & 0.0000 & $0.000 \mathrm{E}+00$ & 0.0000 & $0.000 \mathrm{E}+00$ & 0.0000 & $0.000 \mathrm{E}+00$ & 0.0000 \\
\hline 37 & $2.362 \mathrm{E}-08$ & 0.0056 & $0.000 \mathrm{E}+00$ & 0.0000 & $0.000 \mathrm{E}+00$ & 0.0000 & $0.000 \mathrm{E}+00$ & 0.0000 & $0.000 \mathrm{E}+00$ & 0.0000 & $0.000 \mathrm{E}+00$ & 0.0000 & $0.000 \mathrm{E}+00$ & 0.0000 \\
\hline 237 & $5.301 \mathrm{E}-12$ & 0.0000 & $0.000 \mathrm{E}+00$ & 0.0000 & $0.000 \mathrm{E}+00$ & 0.0000 & $0.000 \mathrm{E}+00$ & 0.0000 & $0.000 \mathrm{E}+00$ & 0.0000 & $0.000 \mathrm{E}+00$ & 0.0000 & $0.000 \mathrm{E}+00$ & 0.0000 \\
\hline 238 & $4.717 \mathrm{E}-20$ & 0.0000 & $0.000 \mathrm{E}+00$ & 0.0000 & $0.000 \mathrm{E}+00$ & 0.0000 & $0.000 \mathrm{E}+00$ & 0.0000 & $0.000 \mathrm{E}+00$ & 0.0000 & $0.000 \mathrm{E}+00$ & 0.0000 & $0.000 \mathrm{E}+00$ & 0.0000 \\
\hline 239 & $4.380 \mathrm{E}-16$ & 0.0000 & $0.000 \mathrm{E}+00$ & 0.0000 & $0.000 \mathrm{E}+00$ & 0.0000 & $0.000 \mathrm{E}+00$ & 0.0000 & $0.000 \mathrm{E}+00$ & 0.0000 & $0.000 \mathrm{E}+00$ & 0.0000 & $0.000 \mathrm{E}+00$ & 000 \\
\hline 2 & $4.275 \mathrm{E}-23$ & 0 & $0.000 \mathrm{E}$ & 0 & $0.000 \mathrm{E}+00$ & 0 & $0.000 \mathrm{E}+00$ & 0 & $0.000 \mathrm{E}+00$ & 0 & $0.000 \mathrm{E}+00$ & 0 & $0.000 \mathrm{E}+00$ & 0000 \\
\hline 99 & $3.025 \mathrm{E}-24$ & 0.0000 & $0.000 \mathrm{E}+00$ & 0.0000 & $0.000 \mathrm{E}+00$ & 0.0000 & $0.000 \mathrm{E}+00$ & 0.0000 & $0.000 \mathrm{E}+00$ & 0.0000 & $0.000 \mathrm{E}+00$ & 0.0000 & $0.000 \mathrm{E}+00$ & 0.0000 \\
\hline 20 & $3.872 E-06$ & 0.9206 & $0.000 \mathrm{E}+00$ & 0.0000 & $0.000 \mathrm{E}+00$ & 0.0000 & $0.000 \mathrm{E}+00$ & 0.0000 & $0.000 \mathrm{E}+00$ & 0.0000 & $0.000 \mathrm{E}+00$ & 0.0000 & $0.000 \mathrm{E}+00$ & 0.0000 \\
\hline 230 & $1.139 \mathrm{E}-08$ & 0.0027 & $0.000 \mathrm{E}+00$ & 0.0000 & $0.000 \mathrm{E}+00$ & 0.0000 & $0.000 \mathrm{E}+00$ & 0.0000 & $0.000 \mathrm{E}+00$ & 0.0000 & $0.000 \mathrm{E}+00$ & 0.0000 & $0.000 \mathrm{E}+00$ & 0.0000 \\
\hline & $2.759 \mathrm{E}-07$ & 0.0656 & $0.000 \mathrm{E}+00$ & 0.0000 & $0.000 \mathrm{E}+00$ & 0.0000 & $0.000 \mathrm{E}+00$ & 0.0000 & $0.000 \mathrm{E}+00$ & 0.0000 & $0.000 \mathrm{E}+00$ & 0.0000 & $0.000 \mathrm{E}+00$ & 0.0000 \\
\hline & $1.277 \mathrm{E}-13$ & 0.0000 & $0.000 \mathrm{E}+00$ & 0.0000 & $0.000 \mathrm{E}+00$ & 0.0000 & $0.000 \mathrm{E}+00$ & 0.0000 & $0.000 \mathrm{E}+00$ & 0.0000 & $0.000 \mathrm{E}+00$ & 0.0000 & $0.000 \mathrm{E}+00$ & 0.0000 \\
\hline & $8.230 \mathrm{E}-14$ & 0.0000 & $0.000 \mathrm{E}+00$ & 0.0000 & $0.000 \mathrm{E}+00$ & 0.0000 & $0.000 \mathrm{E}+00$ & 0.0000 & $0.000 \mathrm{E}+00$ & 0.0000 & $0.000 \mathrm{E}+00$ & 0.0000 & $0.000 \mathrm{E}+00$ & 0.0000 \\
\hline & $2.290 \mathrm{E}-08$ & 0.0054 & $0.000 \mathrm{E}+00$ & 0.0000 & $0.000 \mathrm{E}+00$ & 0.0000 & $0.000 \mathrm{E}+00$ & 0.0000 & $0.000 \mathrm{E}+00$ & 0.0000 & $0.000 \mathrm{E}+00$ & 0.0000 & $0.000 \mathrm{E}+00$ & 0.0000 \\
\hline & & & $0.000 \mathrm{E}+00$ & 0.0000 & $0.000 \mathrm{E}+00$ & 0.0000 & $0.000 \mathrm{E}+00$ & 0.0000 & $0.000 \mathrm{E}+00$ & 0. & $0.000 \mathrm{E}+0$ & & $E+00$ & 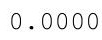 \\
\hline
\end{tabular}

Total Dose Contributions TDOSE (i,p,t) for Individual Radionuclides (i) and Pathways (p) As mrem/yr and Fraction of Total Dose At $t=1.000 \mathrm{E}+00$ years

Water Dependent Pathways

\begin{tabular}{|c|c|c|c|c|c|c|c|c|c|c|c|c|c|c|}
\hline \multirow[b]{2}{*}{ clide } & \multicolumn{2}{|c|}{ Water } & \multicolumn{2}{|c|}{ Fish } & \multicolumn{2}{|c|}{ Radon } & \multicolumn{2}{|c|}{ Plant } & \multicolumn{2}{|c|}{ Meat } & \multicolumn{2}{|c|}{ Milk } & \multicolumn{2}{|c|}{ All Pathways* } \\
\hline & mrem/yr & fract. & mrem/yr & fract. & mrem/yr & fract. & mrem/yr & fract. & mrem/yr & fract. & mrem/yr & fract. & mrem/yr & fract. \\
\hline-241 & $0.000 \mathrm{E}+00$ & 0.0000 & $0.000 \mathrm{E}+00$ & 0.0000 & $0.000 \mathrm{E}+00$ & 0.0000 & $0.000 \mathrm{E}+00$ & 0.0000 & $0.000 \mathrm{E}+00$ & 0.0000 & $0.000 \mathrm{E}+00$ & 0.0000 & $1.638 \mathrm{E}-17$ & 0.0000 \\
\hline . & $0.000 \mathrm{E}+00$ & 0.0000 & $0.000 \mathrm{E}+00$ & 0.0000 & $0.000 \mathrm{E}+00$ & 0.0000 & $0.000 \mathrm{E}+00$ & 0.0000 & $0.000 \mathrm{E}+00$ & 0.0000 & $0.000 \mathrm{E}+00$ & 0.0000 & $.362 E-08$ & 0.0056 \\
\hline 237 & $0.000 \mathrm{E}+00$ & 0.0 & $0.000 \mathrm{E}+00$ & 0 & $0.000 \mathrm{E}+00$ & 0 & $0.000 \mathrm{E}+00$ & 0 & $0.000 \mathrm{E}+00$ & 0 & $0.000 \mathrm{E}+00$ & 0 & $.301 \mathrm{E}-12$ & 00 \\
\hline & $0.000 \mathrm{E}+00$ & 0 & $0.000 \mathrm{E}+00$ & 0 & $0.000 \mathrm{E}+00$ & 0 & $0.000 \mathrm{E}+00$ & 0 & $0.000 \mathrm{E}+00$ & 00 & $0.000 \mathrm{E}+00$ & 0 & $.717 \mathrm{E}-20$ & 000 \\
\hline 239 & $0.000 \mathrm{E}+00$ & 0.0000 & $0.000 \mathrm{E}+00$ & 0.0000 & $0.000 \mathrm{E}+00$ & 0.0000 & $0.000 \mathrm{E}+00$ & 0.0000 & $0.000 \mathrm{E}+00$ & 0.0000 & $0.000 \mathrm{E}+00$ & 0.0000 & $4.380 \mathrm{E}-16$ & 0.0000 \\
\hline 240 & $0.000 \mathrm{E}+00$ & 0.0000 & $0.000 \mathrm{E}+00$ & 0.0000 & $0.000 \mathrm{E}+00$ & 0.0000 & $0.000 \mathrm{E}+00$ & 0.0000 & $0.000 \mathrm{E}+00$ & 0.0000 & $0.000 \mathrm{E}+00$ & 0.0000 & $4.275 E-23$ & 0.0000 \\
\hline & $0.000 \mathrm{E}+00$ & 0.0000 & $0.000 \mathrm{E}+00$ & 0.0000 & $0.000 \mathrm{E}+00$ & 0.0000 & $0.000 \mathrm{E}+00$ & 0.0000 & $0.000 \mathrm{E}+00$ & 0.0000 & $0.000 \mathrm{E}+00$ & 0.0000 & $3.025 \mathrm{E}-24$ & 0.0000 \\
\hline & $0.000 \mathrm{E}+00$ & 0.0000 & $0.000 \mathrm{E}+00$ & 0.0000 & $0.000 \mathrm{E}+00$ & 0.0000 & $0.000 \mathrm{E}+00$ & 0.0000 & $0.000 \mathrm{E}+00$ & 0.0000 & $0.000 \mathrm{E}+00$ & 0.0000 & $3.872 \mathrm{E}-06$ & 0.9206 \\
\hline & $0.000 \mathrm{E}+00$ & 0.0000 & $0.000 \mathrm{E}+00$ & 0.0000 & $0.000 \mathrm{E}+00$ & 0.0000 & $0.000 \mathrm{E}+00$ & 0.0000 & $0.000 \mathrm{E}+00$ & 0.0000 & $0.000 \mathrm{E}+00$ & 0.0000 & $1.139 \mathrm{E}-08$ & 0.0027 \\
\hline & $0.000 \mathrm{E}+00$ & 0.0000 & $0.000 \mathrm{E}+00$ & 0.0000 & $0.000 \mathrm{E}+00$ & 0.0000 & $0.000 \mathrm{E}+00$ & 0.0000 & $0.000 \mathrm{E}+00$ & 0.0000 & $0.000 \mathrm{E}+00$ & 0.0000 & $2.759 \mathrm{E}-07$ & 0.0656 \\
\hline & $0.000 \mathrm{E}+00$ & 0.0000 & $0.000 \mathrm{E}+00$ & 0.0000 & $0.000 \mathrm{E}+00$ & 0.0000 & $0.000 \mathrm{E}+00$ & 0.0000 & $0.000 \mathrm{E}+00$ & 0.0000 & $0.000 \mathrm{E}+00$ & 0.0000 & $1.277 \mathrm{E}-13$ & 0.0000 \\
\hline & $0.000 \mathrm{E}+00$ & 0.0000 & $0.000 \mathrm{E}+00$ & 0.0000 & $0.000 \mathrm{E}+00$ & 0.0000 & $0.000 \mathrm{E}+00$ & 0.0000 & $0.000 \mathrm{E}+00$ & 0.0000 & $0.000 \mathrm{E}+00$ & 0.0000 & $8.230 \mathrm{E}-14$ & 0.0000 \\
\hline & $0.000 \mathrm{E}+00$ & 0.0000 & $0.000 \mathrm{E}+00$ & 0.0000 & $0.000 \mathrm{E}+00$ & 0.0000 & $0.000 \mathrm{E}+00$ & 0.0000 & $0.000 \mathrm{E}+00$ & 0.0000 & $0.000 \mathrm{E}+00$ & 0.0000 & $2.290 \mathrm{E}-08$ & 0.0054 \\
\hline & . & 0000 & $.000 \mathrm{E}+00$ & 0.0000 & $0.000 \mathrm{E}+00$ & 0.0000 & $0.000 \mathrm{E}+00$ & 0.0000 & $.000 \mathrm{E}+00$ & 0.0000 & $0.000 \mathrm{E}+00$ & 0.0000 & $4.206 \mathrm{E}-06$ & 1.0000 \\
\hline
\end{tabular}

*Sum of all water independent and dependent pathways. 
RESRAD, Version 6.5

Summary : C746U Resident Gardener Deterministic Run
File : X: \FINAL V2 \DOE FWD RUNS \C746U RG DOE SG FWD-FV2-10000YR.RAD

Total Dose Contributions TDOSE (i,p,t) for Individual Radionuclides (i) and Pathways (p) As mrem/yr and Fraction of Total Dose At $t=5.000 \mathrm{E}+01$ years

Water Independent Pathways (Inhalation excludes radon)

\begin{tabular}{|c|c|c|c|c|c|c|c|c|c|c|c|c|c|c|}
\hline \multirow{2}{*}{ Nuclide } & \multicolumn{2}{|c|}{ Ground } & \multicolumn{2}{|c|}{ Inhalation } & \multicolumn{2}{|c|}{ Radon } & \multicolumn{2}{|c|}{ Plant } & \multicolumn{2}{|c|}{ Meat } & \multicolumn{2}{|c|}{ Milk } & \multicolumn{2}{|c|}{ Soil } \\
\hline & mrem/yr & fract. & mrem/yr & fract. & mrem/yr & fract. & mrem/yr & fract. & mrem/yr & fract. & mrem/yr & fract. & mrem/yr & fract. \\
\hline-241 & $8.973 E-16$ & 0.0000 & $0.000 \mathrm{E}+00$ & 0.0000 & $0.000 \mathrm{E}+00$ & 0.0000 & $0.000 \mathrm{E}+00$ & 0.0000 & $0.000 \mathrm{E}+00$ & 0.0000 & $0.000 \mathrm{E}+00$ & 0.0000 & $0.000 \mathrm{E}+00$ & 0.0000 \\
\hline-137 & $1.149 \mathrm{E}-08$ & 0.0012 & $0.000 \mathrm{E}+00$ & 0.0000 & $0.000 \mathrm{E}+00$ & 0.0000 & $0.000 \mathrm{E}+00$ & 0.0000 & $0.000 \mathrm{E}+00$ & 0.0000 & $0.000 \mathrm{E}+00$ & 0.0000 & $0.000 \mathrm{E}+00$ & 0.0000 \\
\hline-237 & $8.957 \mathrm{E}-12$ & 0.0000 & $0.000 \mathrm{E}+00$ & 0.0000 & $0.000 \mathrm{E}+00$ & 0.0000 & $0.000 \mathrm{E}+00$ & 0.0000 & $0.000 \mathrm{E}+00$ & 0.0000 & $0.000 \mathrm{E}+00$ & 0.0000 & $0.000 \mathrm{E}+00$ & 0.0000 \\
\hline-238 & $2.054 \mathrm{E}-15$ & 0.0000 & $0.000 \mathrm{E}+00$ & 0.0000 & $0.000 \mathrm{E}+00$ & 0.0000 & $0.000 \mathrm{E}+00$ & 0.0000 & $0.000 \mathrm{E}+00$ & 0.0000 & $0.000 \mathrm{E}+00$ & 0.0000 & $0.000 \mathrm{E}+00$ & 0.0000 \\
\hline-239 & $7.861 E-16$ & 0.0000 & $0.000 \mathrm{E}+00$ & 0.0000 & $0.000 \mathrm{E}+00$ & 0.0000 & $0.000 \mathrm{E}+00$ & 0.0000 & $0.000 \mathrm{E}+00$ & 0.0000 & $0.000 \mathrm{E}+00$ & 0.0000 & $0.000 \mathrm{E}+00$ & 0.0000 \\
\hline-240 & $9.653 \mathrm{E}-20$ & 0.0000 & $0.000 \mathrm{E}+00$ & 0.0000 & $0.000 \mathrm{E}+00$ & 0.0000 & $0.000 \mathrm{E}+00$ & 0.0000 & $0.000 \mathrm{E}+00$ & 0.0000 & $0.000 \mathrm{E}+00$ & 0.0000 & $0.000 \mathrm{E}+00$ & 0.0000 \\
\hline 99 & $4.979 E-24$ & 0.0000 & $0.000 \mathrm{E}+00$ & 0.0000 & $0.000 \mathrm{E}+00$ & 0.0000 & $0.000 \mathrm{E}+00$ & 0.0000 & $0.000 \mathrm{E}+00$ & 0.0000 & $0.000 \mathrm{E}+00$ & 0.0000 & $0.000 \mathrm{E}+00$ & 0.0000 \\
\hline-228 & 1.011E-13 & 0.0000 & $0.000 \mathrm{E}+00$ & 0.0000 & $0.000 \mathrm{E}+00$ & 0.0000 & $0.000 \mathrm{E}+00$ & 0.0000 & $0.000 \mathrm{E}+00$ & 0.0000 & $0.000 \mathrm{E}+00$ & 0.0000 & $0.000 \mathrm{E}+00$ & 0.0000 \\
\hline-230 & $5.320 \mathrm{E}-07$ & 0.0558 & $0.000 \mathrm{E}+00$ & 0.0000 & $0.000 \mathrm{E}+00$ & 0.0000 & $0.000 \mathrm{E}+00$ & 0.0000 & $0.000 \mathrm{E}+00$ & 0.0000 & $0.000 \mathrm{E}+00$ & 0.0000 & $0.000 \mathrm{E}+00$ & 0.0000 \\
\hline-232 & $8.963 E-06$ & 0.9395 & $0.000 \mathrm{E}+00$ & 0.0000 & $0.000 \mathrm{E}+00$ & 0.0000 & $0.000 \mathrm{E}+00$ & 0.0000 & $0.000 \mathrm{E}+00$ & 0.0000 & $0.000 \mathrm{E}+00$ & 0.0000 & $0.000 \mathrm{E}+00$ & 0.0000 \\
\hline 234 & $1.941 \mathrm{E}-10$ & 0.0000 & $0.000 \mathrm{E}+00$ & 0.0000 & $0.000 \mathrm{E}+00$ & 0.0000 & $0.000 \mathrm{E}+00$ & 0.0000 & $0.000 \mathrm{E}+00$ & 0.0000 & $0.000 \mathrm{E}+00$ & 0.0000 & $0.000 \mathrm{E}+00$ & 0.0000 \\
\hline 235 & $6.005 E-13$ & 0.0000 & $0.000 \mathrm{E}+00$ & 0.0000 & $0.000 \mathrm{E}+00$ & 0.0000 & $0.000 \mathrm{E}+00$ & 0.0000 & $0.000 \mathrm{E}+00$ & 0.0000 & $0.000 \mathrm{E}+00$ & 0.0000 & $0.000 \mathrm{E}+00$ & 0.0000 \\
\hline 38 & $3.385 E-08$ & 0.0035 & $0.000 \mathrm{E}+00$ & 0.0000 & $0.000 \mathrm{E}+00$ & 0.0000 & $0.000 \mathrm{E}+00$ & 0.0000 & $0.000 \mathrm{E}+00$ & 0.0000 & $0.000 \mathrm{E}+00$ & 0.0000 & $0.000 \mathrm{E}+00$ & 0.0000 \\
\hline & $9.541 \mathrm{E}-06$ & 1.0000 & $0.000 \mathrm{E}+00$ & 0.0000 & $0.000 \mathrm{E}+00$ & 0.0000 & $0.000 \mathrm{E}+00$ & 0.0000 & $0.000 \mathrm{E}+00$ & 0.0000 & $0.000 \mathrm{E}+00$ & 0.0000 & $.000 \mathrm{E}+00$ & 0.0000 \\
\hline
\end{tabular}

Total Dose Contributions TDOSE (i,p,t) for Individual Radionuclides (i) and Pathways (p) As mrem/yr and Fraction of Total Dose At $t=5.000 \mathrm{E}+01$ years

Water Dependent Pathways

\begin{tabular}{|c|c|c|c|c|c|c|c|c|c|c|c|c|c|c|}
\hline & \multicolumn{2}{|c|}{ Water } & \multicolumn{2}{|c|}{ Fish } & \multicolumn{2}{|c|}{ Radon } & \multicolumn{2}{|c|}{ Plant } & \multicolumn{2}{|c|}{ Meat } & \multicolumn{2}{|c|}{ Milk } & \multicolumn{2}{|c|}{ All Pathways* } \\
\hline clide & mrem/yr & fract. & mrem/yr & fract. & mrem/yr & fract. & mrem/yr & fract. & mrem/yr & fract. & mrem/yr & fract. & mrem/yr & fract. \\
\hline-241 & $0.000 \mathrm{E}+00$ & 0.0000 & $0.000 \mathrm{E}+00$ & 0.0000 & $0.000 \mathrm{E}+00$ & 0.0000 & $0.000 \mathrm{E}+00$ & 0.0000 & $0.000 \mathrm{E}+00$ & 0.0000 & $0.000 \mathrm{E}+00$ & 0.0000 & $8.973 E-16$ & 0.0000 \\
\hline-137 & $0.000 \mathrm{E}+00$ & 0.0000 & $0.000 \mathrm{E}+00$ & 0.0000 & $0.000 \mathrm{E}+00$ & 0.0000 & $0.000 \mathrm{E}+00$ & 0.0000 & $0.000 \mathrm{E}+00$ & 0.0000 & $0.000 \mathrm{E}+00$ & 0.0000 & $1.149 \mathrm{E}-08$ & 0.0012 \\
\hline-237 & $0.000 \mathrm{E}+00$ & 0.0000 & $0.000 \mathrm{E}+00$ & 0.0000 & $0.000 \mathrm{E}+00$ & 0.0000 & $0.000 \mathrm{E}+00$ & 0.0000 & $0.000 \mathrm{E}+00$ & 0.0000 & $0.000 \mathrm{E}+00$ & 0.0000 & $8.957 \mathrm{E}-12$ & 0.0000 \\
\hline 238 & $0.000 \mathrm{E}+00$ & 0.0000 & $0.000 \mathrm{E}+00$ & 0.0000 & $0.000 \mathrm{E}+00$ & 0.0000 & $0.000 \mathrm{E}+00$ & 0.0000 & $0.000 \mathrm{E}+00$ & 0.0000 & $0.000 \mathrm{E}+00$ & 0.0000 & $2.054 \mathrm{E}-15$ & 0.0000 \\
\hline 239 & $0.000 \mathrm{E}+00$ & 0.0000 & $0.000 \mathrm{E}+00$ & 0.0000 & $0.000 \mathrm{E}+00$ & 0.0000 & $0.000 \mathrm{E}+00$ & 0.0000 & $0.000 \mathrm{E}+00$ & 0.0000 & $0.000 \mathrm{E}+00$ & 0.0000 & $7.861 \mathrm{E}-16$ & 0.0000 \\
\hline 240 & $0.000 \mathrm{E}+00$ & 0.0000 & $0.000 \mathrm{E}+00$ & 0.0000 & $0.000 \mathrm{E}+00$ & 0.0000 & $0.000 \mathrm{E}+00$ & 0.0000 & $0.000 \mathrm{E}+00$ & 0.0000 & $0.000 \mathrm{E}+00$ & 0.0000 & $9.653 \mathrm{E}-20$ & 0.0000 \\
\hline 99 & $0.000 \mathrm{E}+00$ & 0.0000 & $0.000 \mathrm{E}+00$ & 0.0000 & $0.000 \mathrm{E}+00$ & 0.0000 & $0.000 \mathrm{E}+00$ & 0.0000 & $0.000 \mathrm{E}+00$ & 0.0000 & $0.000 \mathrm{E}+00$ & 0.0000 & $4.979 E-24$ & 0.0000 \\
\hline 228 & $0.000 \mathrm{E}+00$ & 0.0000 & $0.000 \mathrm{E}+00$ & 0.0000 & $0.000 \mathrm{E}+00$ & 0.0000 & $0.000 \mathrm{E}+00$ & 0.0000 & $0.000 \mathrm{E}+00$ & 0.0000 & $0.000 \mathrm{E}+00$ & 0.0000 & $1.011 \mathrm{E}-13$ & 0.0000 \\
\hline 230 & $0.000 \mathrm{E}+00$ & 0.0000 & $0.000 \mathrm{E}+00$ & 0.0000 & $0.000 \mathrm{E}+00$ & 0.0000 & $0.000 \mathrm{E}+00$ & 0.0000 & $0.000 \mathrm{E}+00$ & 0.0000 & $0.000 \mathrm{E}+00$ & 0.0000 & $5.320 \mathrm{E}-07$ & 0.0558 \\
\hline 232 & $0.000 \mathrm{E}+00$ & 0.0000 & $0.000 \mathrm{E}+00$ & 0.0000 & $0.000 \mathrm{E}+00$ & 0.0000 & $0.000 \mathrm{E}+00$ & 0.0000 & $0.000 \mathrm{E}+00$ & 0.0000 & $0.000 \mathrm{E}+00$ & 0.0000 & $8.963 E-06$ & 0.9395 \\
\hline 34 & $0.000 \mathrm{E}+00$ & 0.0000 & $0.000 \mathrm{E}+00$ & 0.0000 & $0.000 \mathrm{E}+00$ & 0.0000 & $0.000 \mathrm{E}+00$ & 0.0000 & $0.000 \mathrm{E}+00$ & 0.0000 & $0.000 \mathrm{E}+00$ & 0.0000 & $1.941 \mathrm{E}-10$ & 0.0000 \\
\hline 35 & $0.000 \mathrm{E}+00$ & 0.0000 & $0.000 \mathrm{E}+00$ & 0.0000 & $0.000 \mathrm{E}+00$ & 0.0000 & $0.000 \mathrm{E}+00$ & 0.0000 & $0.000 \mathrm{E}+00$ & 0.0000 & $0.000 \mathrm{E}+00$ & 0.0000 & $6.005 E-13$ & 0.0000 \\
\hline 38 & $0.000 \mathrm{E}+00$ & 0.0000 & $0.000 \mathrm{E}+00$ & 0.0000 & $0.000 \mathrm{E}+00$ & 0.0000 & $0.000 \mathrm{E}+00$ & 0.0000 & $0.000 \mathrm{E}+00$ & 0.0000 & $0.000 \mathrm{E}+00$ & 0.0000 & $3.385 \mathrm{E}-08$ & 0.0035 \\
\hline & $0.000 \mathrm{E}+00$ & 0.0000 & $0.000 \mathrm{E}+00$ & 0.0000 & $0.000 \mathrm{E}+00$ & 0.0000 & $0.000 \mathrm{E}+00$ & 0.0000 & $0.000 \mathrm{E}+00$ & 0.0000 & $0.000 \mathrm{E}+00$ & 000 & -06 & 1.0000 \\
\hline
\end{tabular}

* Sum of all water independent and dependent pathways. 
RESRAD, Version 6.5

ummary : C746U Resident Gardener Deterministic Run

File : $\mathrm{X}: \backslash F I N A L$ V2 $\backslash$ DOE FWD RUNS \C746U RG DOE SG FWD-FV2-10000YR.RAD

Total Dose Contributions TDOSE (i,p,t) for Individual Radionuclides (i) and Pathways (p) As mrem/yr and Fraction of Total Dose At $t=1.000 \mathrm{E}+02$ years

Water Independent Pathways (Inhalation excludes radon)

\begin{tabular}{|c|c|c|c|c|c|c|c|c|c|c|c|c|c|c|}
\hline \multirow[b]{2}{*}{ clide } & \multicolumn{2}{|c|}{ Ground } & \multicolumn{2}{|c|}{ Inhalation } & \multicolumn{2}{|c|}{ Radon } & \multicolumn{2}{|c|}{ Plant } & \multicolumn{2}{|c|}{ Meat } & \multicolumn{2}{|c|}{ Milk } & \multicolumn{2}{|c|}{ Soil } \\
\hline & mrem/yr & fract. & mrem/yr & fract. & mrem/yr & fract. & mrem/yr & fract. & mrem/yr & fract. & mrem/yr & fract. & mrem/yr & fract. \\
\hline 41 & $2.940 \mathrm{E}-15$ & 0.0000 & $0.000 \mathrm{E}+00$ & 0.0000 & $0.000 \mathrm{E}+00$ & 0.0000 & $0.000 \mathrm{E}+00$ & 0.0000 & $0.000 \mathrm{E}+00$ & 0.0000 & $0.000 \mathrm{E}+00$ & 0.0000 & $0.000 \mathrm{E}+00$ & 0.0000 \\
\hline 37 & $5.512 \mathrm{E}-09$ & 0.0004 & $0.000 \mathrm{E}+00$ & 0.0000 & $0.000 \mathrm{E}+00$ & 0.0000 & $0.000 \mathrm{E}+00$ & 0.0000 & $0.000 \mathrm{E}+00$ & 0.0000 & $0.000 \mathrm{E}+00$ & 0.0000 & $0.000 \mathrm{E}+00$ & 0.0000 \\
\hline 237 & $1.534 \mathrm{E}-11$ & 0.0000 & $0.000 \mathrm{E}+00$ & 0.0000 & $0.000 \mathrm{E}+00$ & 0.0000 & $0.000 \mathrm{E}+00$ & 0.0000 & $0.000 \mathrm{E}+00$ & 0.0000 & $0.000 \mathrm{E}+00$ & 0.0000 & $0.000 \mathrm{E}+00$ & 0.0000 \\
\hline 238 & $2.076 \mathrm{E}-14$ & 0.0000 & $0.000 \mathrm{E}+00$ & 0.0000 & $0.000 \mathrm{E}+00$ & 0.0000 & $0.000 \mathrm{E}+00$ & 0.0000 & $0.000 \mathrm{E}+00$ & 0.0000 & $0.000 \mathrm{E}+00$ & 0.0000 & $0.000 \mathrm{E}+00$ & 0.0000 \\
\hline 239 & $1.428 \mathrm{E}-15$ & 0.0000 & $0.000 \mathrm{E}+00$ & 0.0000 & $0.000 \mathrm{E}+00$ & 0.0000 & $0.000 \mathrm{E}+00$ & 0.0000 & $0.000 \mathrm{E}+00$ & 0.0000 & $0.000 \mathrm{E}+00$ & 0.0000 & $0.000 \mathrm{E}+00$ & 000 \\
\hline 2 & $6.420 \mathrm{E}-19$ & 0 & $0.000 \mathrm{E}$ & 0 & $0.000 \mathrm{E}+00$ & 0 & $0.000 \mathrm{E}+00$ & 0 & $0.000 \mathrm{E}+00$ & 0 & $0.000 \mathrm{E}+00$ & 0 & $0.000 \mathrm{E}+00$ & 0000 \\
\hline 99 & $8.280 \mathrm{E}-24$ & 0.0000 & $0.000 \mathrm{E}+00$ & 0.0000 & $0.000 \mathrm{E}+00$ & 0.0000 & $0.000 \mathrm{E}+00$ & 0.0000 & $0.000 \mathrm{E}+00$ & 0.0000 & $0.000 \mathrm{E}+00$ & 0.0000 & $0.000 \mathrm{E}+00$ & 0.0000 \\
\hline 20 & $1.847 \mathrm{E}-21$ & 0.0000 & $0.000 \mathrm{E}+00$ & 0.0000 & $0.000 \mathrm{E}+00$ & 0.0000 & $0.000 \mathrm{E}+00$ & 0.0000 & $0.000 \mathrm{E}+00$ & 0.0000 & $0.000 \mathrm{E}+00$ & 0.0000 & $0.000 \mathrm{E}+00$ & 0.0000 \\
\hline 230 & $1.479 \mathrm{E}-06$ & 0.1082 & $0.000 \mathrm{E}+00$ & 0.0000 & $0.000 \mathrm{E}+00$ & 0.0000 & $0.000 \mathrm{E}+00$ & 0.0000 & $0.000 \mathrm{E}+00$ & 0.0000 & $0.000 \mathrm{E}+00$ & 0.0000 & $0.000 \mathrm{E}+00$ & 0.0000 \\
\hline & $1.213 \mathrm{E}-05$ & 0.8876 & $0.000 \mathrm{E}+00$ & 0.0000 & $0.000 \mathrm{E}+00$ & 0.0000 & $0.000 \mathrm{E}+00$ & 0.0000 & $0.000 \mathrm{E}+00$ & 0.0000 & $0.000 \mathrm{E}+00$ & 0.0000 & $0.000 \mathrm{E}+00$ & 0.0000 \\
\hline & $1.078 \mathrm{E}-09$ & 0.0001 & $0.000 \mathrm{E}+00$ & 0.0000 & $0.000 \mathrm{E}+00$ & 0.0000 & $0.000 \mathrm{E}+00$ & 0.0000 & $0.000 \mathrm{E}+00$ & 0.0000 & $0.000 \mathrm{E}+00$ & 0.0000 & $0.000 \mathrm{E}+00$ & 0.0000 \\
\hline & $2.202 E-12$ & 0.0000 & $0.000 \mathrm{E}+00$ & 0.0000 & $0.000 \mathrm{E}+00$ & 0.0000 & $0.000 \mathrm{E}+00$ & 0.0000 & $0.000 \mathrm{E}+00$ & 0.0000 & $0.000 \mathrm{E}+00$ & 0.0000 & $0.000 \mathrm{E}+00$ & 0.0000 \\
\hline & $5.045 \mathrm{E}-08$ & 0.0037 & $0.000 \mathrm{E}+00$ & 0.0000 & $0.000 \mathrm{E}+00$ & 0.0000 & $0.000 \mathrm{E}+00$ & 0.0000 & $0.000 \mathrm{E}+00$ & 0.0000 & $0.000 \mathrm{E}+00$ & 0.0000 & $0.000 \mathrm{E}+00$ & 0.0000 \\
\hline & & & $0.000 \mathrm{E}+00$ & 0.0000 & +00 & 0.0000 & $0.000 \mathrm{E}+00$ & 0.0000 & $0.000 \mathrm{E}+00$ & 0 . & $0.000 \mathrm{E}+0$ & & $E+00$ & 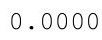 \\
\hline
\end{tabular}

Total Dose Contributions TDOSE (i,p,t) for Individual Radionuclides (i) and Pathways (p) As mrem/yr and Fraction of Total Dose At $t=1.000 \mathrm{E}+02$ years

Water Dependent Pathways

\begin{tabular}{|c|c|c|c|c|c|c|c|c|c|c|c|c|c|c|}
\hline \multirow[b]{2}{*}{ Nuclide } & \multicolumn{2}{|c|}{ Water } & \multicolumn{2}{|c|}{ Fish } & \multicolumn{2}{|c|}{ Radon } & \multicolumn{2}{|c|}{ Plant } & \multicolumn{2}{|c|}{ Meat } & \multicolumn{2}{|c|}{ Milk } & \multicolumn{2}{|c|}{ All Pathways* } \\
\hline & mrem/yr & fract. & $\mathrm{mrem} / \mathrm{yr}$ & fract. & $\mathrm{mrem} / \mathrm{yr}$ & fract. & mrem/yr & fract. & mrem/yr & fract. & $\mathrm{mrem} / \mathrm{yr}$ & fract. & $\mathrm{mrem} / \mathrm{yr}$ & fract. \\
\hline-241 & $0.000 \mathrm{E}+00$ & 0.0000 & $0.000 \mathrm{E}+00$ & 0.0000 & $0.000 \mathrm{E}+00$ & 0.0000 & $0.000 \mathrm{E}+00$ & 0.0000 & $0.000 \mathrm{E}+00$ & 0.0000 & $0.000 \mathrm{E}+00$ & 0.0000 & $2.940 \mathrm{E}-15$ & 0.0000 \\
\hline 137 & $0.000 \mathrm{E}+00$ & 0.0000 & $0.000 \mathrm{E}+00$ & 0.0000 & $0.000 \mathrm{E}+00$ & 0.0000 & $0.000 \mathrm{E}+00$ & 0.0000 & $0.000 \mathrm{E}+00$ & 0.0000 & $0.000 \mathrm{E}+00$ & 0.0000 & $5.512 \mathrm{E}-09$ & 0.0004 \\
\hline 37 & $0.000 \mathrm{E}+00$ & 0.0000 & $0.000 \mathrm{E}+00$ & 0.0000 & $0.000 \mathrm{E}+00$ & 0.0000 & $0.000 \mathrm{E}+00$ & 0.0000 & $0.000 \mathrm{E}+00$ & 0.0000 & $0.000 \mathrm{E}+00$ & 0.0000 & $1.534 \mathrm{E}-11$ & 0.0000 \\
\hline 238 & $0.000 \mathrm{E}+00$ & 0.0000 & $0.000 \mathrm{E}+00$ & 0.0000 & $0.000 \mathrm{E}+00$ & 0.0000 & $0.000 \mathrm{E}+00$ & 0.0000 & $0.000 \mathrm{E}+00$ & 0.0000 & $0.000 \mathrm{E}+00$ & 0.0000 & $2.076 \mathrm{E}-14$ & 0.0000 \\
\hline 239 & $0.000 \mathrm{E}+00$ & 0.0000 & $0.000 \mathrm{E}+00$ & 0.0000 & $0.000 \mathrm{E}+00$ & 0.0000 & $0.000 \mathrm{E}+00$ & 0.0000 & $0.000 \mathrm{E}+00$ & 0.0000 & $0.000 \mathrm{E}+00$ & 0.0000 & $1.428 \mathrm{E}-15$ & 0.0000 \\
\hline 240 & $0.000 \mathrm{E}+00$ & 0.0 & $0.000 \mathrm{E}+00$ & 0 & $0.000 \mathrm{E}+00$ & 0. & $0.000 \mathrm{E}+00$ & 0 & 0 & 0 & $0.000 \mathrm{E}+00$ & 0 & $420 \mathrm{E}-19$ & 0000 \\
\hline 年 & $0.000 \mathrm{E}+00$ & 0 & $0.000 \mathrm{E}+00$ & 0 & $0.000 \mathrm{E}+00$ & 0 & $0.000 \mathrm{E}+00$ & 0.00 & $0.000 \mathrm{E}+00$ & 00 & $0.000 \mathrm{E}+00$ & 0 & $.280 \mathrm{E}-24$ & 0.0000 \\
\hline-228 & $0.000 \mathrm{E}+00$ & 0.0000 & $0.000 \mathrm{E}+00$ & 0.0000 & $0.000 \mathrm{E}+00$ & 0.0000 & $0.000 \mathrm{E}+00$ & 0.0000 & $0.000 \mathrm{E}+00$ & 0.0000 & $0.000 \mathrm{E}+00$ & 0.0000 & $1.847 \mathrm{E}-21$ & 0.0000 \\
\hline 230 & $0.000 \mathrm{E}+00$ & 0.0000 & $0.000 \mathrm{E}+00$ & 0.0000 & $0.000 \mathrm{E}+00$ & 0.0000 & $0.000 \mathrm{E}+00$ & 0.0000 & $0.000 \mathrm{E}+00$ & 0.0000 & $0.000 \mathrm{E}+00$ & 0.0000 & $1.479 \mathrm{E}-06$ & 0.1082 \\
\hline 232 & $0.000 \mathrm{E}+00$ & 0.0000 & $0.000 \mathrm{E}+00$ & 0.0000 & $0.000 \mathrm{E}+00$ & 0.0000 & $0.000 \mathrm{E}+00$ & 0.0000 & $0.000 \mathrm{E}+00$ & 0.0000 & $0.000 \mathrm{E}+00$ & 0.0000 & $1.213 \mathrm{E}-05$ & 0.8876 \\
\hline & $0.000 \mathrm{E}+00$ & 0.0000 & $0.000 \mathrm{E}+00$ & 0.0000 & $0.000 \mathrm{E}+00$ & 0.0000 & $0.000 \mathrm{E}+00$ & 0.0000 & $0.000 \mathrm{E}+00$ & 0.0000 & $0.000 \mathrm{E}+00$ & 0.0000 & $1.078 \mathrm{E}-09$ & 0.0001 \\
\hline & $0.000 \mathrm{E}+00$ & 0.0000 & $0.000 \mathrm{E}+00$ & 0.0000 & $0.000 \mathrm{E}+00$ & 0.0000 & $0.000 \mathrm{E}+00$ & 0.0000 & $0.000 \mathrm{E}+00$ & 0.0000 & $0.000 \mathrm{E}+00$ & 0.0000 & $2.202 \mathrm{E}-12$ & 0.0000 \\
\hline 38 & $0.000 \mathrm{E}+00$ & 0.0000 & $0.000 \mathrm{E}+00$ & 0.0000 & $0.000 \mathrm{E}+00$ & 0.0000 & $0.000 \mathrm{E}+00$ & 0.0000 & $0.000 \mathrm{E}+00$ & 0.0000 & $0.000 \mathrm{E}+00$ & 0.0000 & $5.045 \mathrm{E}-08$ & 0.0037 \\
\hline & & 0 & $.000 \mathrm{E}+00$ & 000 & $E+00$ & 0.0000 & $.000 \mathrm{E}+00$ & .0000 & $.000 \mathrm{E}+00$ & 0 & $8+0$ & & 1. & \\
\hline
\end{tabular}

*Sum of all water independent and dependent pathways. 
RESRAD, Version 6.5

Summary : C746U Resident Gardener Deterministic Run
File : X: $\backslash$ FINAL V2 $\backslash$ DOE FWD RUNS $\backslash C 746 U$ RG DOE SG FWD-FV2-10000YR.RAD

Total Dose Contributions TDOSE(i,p,t) for Individual Radionuclides (i) and Pathways (p) As mrem/yr and Fraction of Total Dose At $t=5.000 \mathrm{E}+02$ years

Water Independent Pathways (Inhalation excludes radon)

\begin{tabular}{|c|c|c|c|c|c|c|c|c|c|c|c|c|c|c|}
\hline \multirow{2}{*}{ Nuclide } & \multicolumn{2}{|c|}{ Ground } & \multicolumn{2}{|c|}{ Inhalation } & \multicolumn{2}{|c|}{ Radon } & \multicolumn{2}{|c|}{ Plant } & \multicolumn{2}{|c|}{ Meat } & \multicolumn{2}{|c|}{ Milk } & \multicolumn{2}{|c|}{ Soil } \\
\hline & mrem/yr & fract. & mrem/yr & fract. & mrem/yr & fract. & mrem/yr & fract. & mrem/yr & fract. & mrem/yr & fract. & mrem/yr & fract. \\
\hline-241 & $8.032 \mathrm{E}-13$ & 0.0000 & $0.000 \mathrm{E}+00$ & 0.0000 & $0.000 \mathrm{E}+00$ & 0.0000 & $0.000 \mathrm{E}+00$ & 0.0000 & $0.000 \mathrm{E}+00$ & 0.0000 & $0.000 \mathrm{E}+00$ & 0.0000 & $0.000 \mathrm{E}+00$ & 0.0000 \\
\hline-137 & $1.540 \mathrm{E}-11$ & 0.0000 & $0.000 \mathrm{E}+00$ & 0.0000 & $0.000 \mathrm{E}+00$ & 0.0000 & $0.000 \mathrm{E}+00$ & 0.0000 & $0.000 \mathrm{E}+00$ & 0.0000 & $0.000 \mathrm{E}+00$ & 0.0000 & $0.000 \mathrm{E}+00$ & 0.0000 \\
\hline-237 & $1.124 \mathrm{E}-09$ & 0.0000 & $0.000 \mathrm{E}+00$ & 0.0000 & $0.000 \mathrm{E}+00$ & 0.0000 & $0.000 \mathrm{E}+00$ & 0.0000 & $0.000 \mathrm{E}+00$ & 0.0000 & $0.000 \mathrm{E}+00$ & 0.0000 & $0.000 \mathrm{E}+00$ & 0.0000 \\
\hline-238 & $2.187 \mathrm{E}-11$ & 0.0000 & $0.000 \mathrm{E}+00$ & 0.0000 & $0.000 \mathrm{E}+00$ & 0.0000 & $0.000 \mathrm{E}+00$ & 0.0000 & $0.000 \mathrm{E}+00$ & 0.0000 & $0.000 \mathrm{E}+00$ & 0.0000 & $0.000 \mathrm{E}+00$ & 0.0000 \\
\hline-239 & 1. $695 \mathrm{E}-13$ & 0.0000 & $0.000 \mathrm{E}+00$ & 0.0000 & $0.000 \mathrm{E}+00$ & 0.0000 & $0.000 \mathrm{E}+00$ & 0.0000 & $0.000 \mathrm{E}+00$ & 0.0000 & $0.000 \mathrm{E}+00$ & 0.0000 & $0.000 \mathrm{E}+00$ & 0.0000 \\
\hline-240 & $2.059 \mathrm{E}-16$ & 0.0000 & $0.000 \mathrm{E}+00$ & 0.0000 & $0.000 \mathrm{E}+00$ & 0.0000 & $0.000 \mathrm{E}+00$ & 0.0000 & $0.000 \mathrm{E}+00$ & 0.0000 & $0.000 \mathrm{E}+00$ & 0.0000 & $0.000 \mathrm{E}+00$ & 0.0000 \\
\hline 99 & $4.841 E-22$ & 0.0000 & $0.000 \mathrm{E}+00$ & 0.0000 & $0.000 \mathrm{E}+00$ & 0.0000 & $0.000 \mathrm{E}+00$ & 0.0000 & $0.000 \mathrm{E}+00$ & 0.0000 & $0.000 \mathrm{E}+00$ & 0.0000 & $0.000 \mathrm{E}+00$ & 0.0000 \\
\hline-228 & $0.000 \mathrm{E}+00$ & 0.0000 & $0.000 \mathrm{E}+00$ & 0.0000 & $0.000 \mathrm{E}+00$ & 0.0000 & $0.000 \mathrm{E}+00$ & 0.0000 & $0.000 \mathrm{E}+00$ & 0.0000 & $0.000 \mathrm{E}+00$ & 0.0000 & $0.000 \mathrm{E}+00$ & 0.0000 \\
\hline-230 & $1.071 \mathrm{E}-04$ & 0.4421 & $0.000 \mathrm{E}+00$ & 0.0000 & $0.000 \mathrm{E}+00$ & 0.0000 & $0.000 \mathrm{E}+00$ & 0.0000 & $0.000 \mathrm{E}+00$ & 0.0000 & $0.000 \mathrm{E}+00$ & 0.0000 & $0.000 \mathrm{E}+00$ & 0.0000 \\
\hline-232 & $1.335 E-04$ & 0.5512 & $0.000 \mathrm{E}+00$ & 0.0000 & $0.000 \mathrm{E}+00$ & 0.0000 & $0.000 \mathrm{E}+00$ & 0.0000 & $0.000 \mathrm{E}+00$ & 0.0000 & $0.000 \mathrm{E}+00$ & 0.0000 & $0.000 \mathrm{E}+00$ & 0.0000 \\
\hline 234 & $3.993 E-07$ & 0.0016 & $0.000 \mathrm{E}+00$ & 0.0000 & $0.000 \mathrm{E}+00$ & 0.0000 & $0.000 \mathrm{E}+00$ & 0.0000 & $0.000 \mathrm{E}+00$ & 0.0000 & $0.000 \mathrm{E}+00$ & 0.0000 & $0.000 \mathrm{E}+00$ & 0.0000 \\
\hline 235 & $4.571 \mathrm{E}-10$ & 0.0000 & $0.000 \mathrm{E}+00$ & 0.0000 & $0.000 \mathrm{E}+00$ & 0.0000 & $0.000 \mathrm{E}+00$ & 0.0000 & $0.000 \mathrm{E}+00$ & 0.0000 & $0.000 \mathrm{E}+00$ & 0.0000 & $0.000 \mathrm{E}+00$ & 0.0000 \\
\hline 38 & $1.229 E-06$ & 0.0051 & $0.000 \mathrm{E}+00$ & 0.0000 & $0.000 \mathrm{E}+00$ & 0.0000 & $0.000 \mathrm{E}+00$ & 0.0000 & $0.000 \mathrm{E}+00$ & 0.0000 & $0.000 \mathrm{E}+00$ & 0.0000 & $0.000 \mathrm{E}+00$ & 0.0000 \\
\hline & $2.423 E-04$ & 1.0000 & $0.000 \mathrm{E}+00$ & 0.0000 & $0.000 \mathrm{E}+00$ & 0.0000 & $0.000 \mathrm{E}+00$ & 0.0000 & $0.000 \mathrm{E}+00$ & 0.0000 & $0.000 \mathrm{E}+00$ & 0.0000 & $.000 \mathrm{E}+00$ & 0.0000 \\
\hline
\end{tabular}

Total Dose Contributions TDOSE (i,p,t) for Individual Radionuclides (i) and Pathways (p) As mrem/yr and Fraction of Total Dose At $t=5.000 \mathrm{E}+02$ years

Water Dependent Pathways

\begin{tabular}{|c|c|c|c|c|c|c|c|c|c|c|c|c|c|c|}
\hline & \multicolumn{2}{|c|}{ Water } & \multicolumn{2}{|c|}{ Fish } & \multicolumn{2}{|c|}{ Radon } & \multicolumn{2}{|c|}{ Plant } & \multicolumn{2}{|c|}{ Meat } & \multicolumn{2}{|c|}{ Milk } & \multicolumn{2}{|c|}{ All Pathways* } \\
\hline clide & mrem/yr & fract. & mrem/yr & fract. & mrem/yr & fract. & mrem/yr & fract. & mrem/yr & fract. & mrem/yr & fract. & mrem/yr & fract. \\
\hline-241 & $0.000 \mathrm{E}+00$ & 0.0000 & $0.000 \mathrm{E}+00$ & 0.0000 & $0.000 \mathrm{E}+00$ & 0.0000 & $0.000 \mathrm{E}+00$ & 0.0000 & $0.000 \mathrm{E}+00$ & 0.0000 & $0.000 \mathrm{E}+00$ & 0.0000 & $8.032 \mathrm{E}-13$ & 0.0000 \\
\hline-137 & $0.000 \mathrm{E}+00$ & 0.0000 & $0.000 \mathrm{E}+00$ & 0.0000 & $0.000 \mathrm{E}+00$ & 0.0000 & $0.000 \mathrm{E}+00$ & 0.0000 & $0.000 \mathrm{E}+00$ & 0.0000 & $0.000 \mathrm{E}+00$ & 0.0000 & $1.540 \mathrm{E}-11$ & 0.0000 \\
\hline-237 & $0.000 \mathrm{E}+00$ & 0.0000 & $0.000 \mathrm{E}+00$ & 0.0000 & $0.000 \mathrm{E}+00$ & 0.0000 & $0.000 \mathrm{E}+00$ & 0.0000 & $0.000 \mathrm{E}+00$ & 0.0000 & $0.000 \mathrm{E}+00$ & 0.0000 & $1.124 \mathrm{E}-09$ & 0.0000 \\
\hline 238 & $0.000 \mathrm{E}+00$ & 0.0000 & $0.000 \mathrm{E}+00$ & 0.0000 & $0.000 \mathrm{E}+00$ & 0.0000 & $0.000 \mathrm{E}+00$ & 0.0000 & $0.000 \mathrm{E}+00$ & 0.0000 & $0.000 \mathrm{E}+00$ & 0.0000 & $2.187 \mathrm{E}-11$ & 0.0000 \\
\hline 239 & $0.000 \mathrm{E}+00$ & 0.0000 & $0.000 \mathrm{E}+00$ & 0.0000 & $0.000 \mathrm{E}+00$ & 0.0000 & $0.000 \mathrm{E}+00$ & 0.0000 & $0.000 \mathrm{E}+00$ & 0.0000 & $0.000 \mathrm{E}+00$ & 0.0000 & $1.695 \mathrm{E}-13$ & 0.0000 \\
\hline 240 & $0.000 \mathrm{E}+00$ & 0.0000 & $0.000 \mathrm{E}+00$ & 0.0000 & $0.000 \mathrm{E}+00$ & 0.0000 & $0.000 \mathrm{E}+00$ & 0.0000 & $0.000 \mathrm{E}+00$ & 0.0000 & $0.000 \mathrm{E}+00$ & 0.0000 & $2.059 \mathrm{E}-16$ & 0.0000 \\
\hline 99 & $0.000 \mathrm{E}+00$ & 0.0000 & $0.000 \mathrm{E}+00$ & 0.0000 & $0.000 \mathrm{E}+00$ & 0.0000 & $0.000 \mathrm{E}+00$ & 0.0000 & $0.000 \mathrm{E}+00$ & 0.0000 & $0.000 \mathrm{E}+00$ & 0.0000 & $4.841 \mathrm{E}-22$ & 0.0000 \\
\hline 228 & $0.000 \mathrm{E}+00$ & 0.0000 & $0.000 \mathrm{E}+00$ & 0.0000 & $0.000 \mathrm{E}+00$ & 0.0000 & $0.000 \mathrm{E}+00$ & 0.0000 & $0.000 \mathrm{E}+00$ & 0.0000 & $0.000 \mathrm{E}+00$ & 0.0000 & $0.000 \mathrm{E}+00$ & 0.0000 \\
\hline 230 & $0.000 \mathrm{E}+00$ & 0.0000 & $0.000 \mathrm{E}+00$ & 0.0000 & $0.000 \mathrm{E}+00$ & 0.0000 & $0.000 \mathrm{E}+00$ & 0.0000 & $0.000 \mathrm{E}+00$ & 0.0000 & $0.000 \mathrm{E}+00$ & 0.0000 & $1.071 \mathrm{E}-04$ & 0.4421 \\
\hline 232 & $0.000 \mathrm{E}+00$ & 0.0000 & $0.000 \mathrm{E}+00$ & 0.0000 & $0.000 \mathrm{E}+00$ & 0.0000 & $0.000 \mathrm{E}+00$ & 0.0000 & $0.000 \mathrm{E}+00$ & 0.0000 & $0.000 \mathrm{E}+00$ & 0.0000 & $1.335 \mathrm{E}-04$ & 0.5512 \\
\hline 34 & $0.000 \mathrm{E}+00$ & 0.0000 & $0.000 \mathrm{E}+00$ & 0.0000 & $0.000 \mathrm{E}+00$ & 0.0000 & $0.000 \mathrm{E}+00$ & 0.0000 & $0.000 \mathrm{E}+00$ & 0.0000 & $0.000 \mathrm{E}+00$ & 0.0000 & $3.993 E-07$ & 0.0016 \\
\hline 35 & $0.000 \mathrm{E}+00$ & 0.0000 & $0.000 \mathrm{E}+00$ & 0.0000 & $0.000 \mathrm{E}+00$ & 0.0000 & $0.000 \mathrm{E}+00$ & 0.0000 & $0.000 \mathrm{E}+00$ & 0.0000 & $0.000 \mathrm{E}+00$ & 0.0000 & $4.571 \mathrm{E}-10$ & 0.0000 \\
\hline 38 & $0.000 \mathrm{E}+00$ & 0.0000 & $0.000 \mathrm{E}+00$ & 0.0000 & $0.000 \mathrm{E}+00$ & 0.0000 & $0.000 \mathrm{E}+00$ & 0.0000 & $0.000 \mathrm{E}+00$ & 0.0000 & $0.000 \mathrm{E}+00$ & 0.0000 & $1.229 \mathrm{E}-06$ & 0.0051 \\
\hline & $0.000 \mathrm{E}+00$ & 0.0000 & $0.000 \mathrm{E}+00$ & 0.0000 & $0.000 \mathrm{E}+00$ & 0.0000 & $0.000 \mathrm{E}+00$ & 0.0000 & $0.000 \mathrm{E}+00$ & 0.0000 & $0.000 \mathrm{E}+00$ & 000 & -04 & 1.0000 \\
\hline
\end{tabular}

* Sum of all water independent and dependent pathways. 
RESRAD, Version 6.5

Summary : C746U Resident Gardener Deterministic Run
File : X: $\backslash$ FINAL V2 $\backslash$ DOE FWD RUNS $\backslash C 746 U$ RG DOE SG FWD-FV2-10000YR.RAD

Total Dose Contributions TDOSE(i,p,t) for Individual Radionuclides (i) and Pathways (p) As mrem/yr and Fraction of Total Dose At $t=1.050 \mathrm{E}+03$ years

Water Independent Pathways (Inhalation excludes radon)

\begin{tabular}{|c|c|c|c|c|c|c|c|c|c|c|c|c|c|c|}
\hline \multirow[b]{2}{*}{ Iuclide } & \multicolumn{2}{|c|}{ Ground } & \multicolumn{2}{|c|}{ Inhalation } & \multicolumn{2}{|c|}{ Radon } & \multicolumn{2}{|c|}{ Plant } & \multicolumn{2}{|c|}{ Meat } & \multicolumn{2}{|c|}{ Milk } & \multicolumn{2}{|c|}{ Soil } \\
\hline & mrem/yr & fract. & mrem/yr & fract. & mrem/yr & fract. & mrem/yr & fract. & mrem/yr & fract. & mrem/yr & fract. & mrem/yr & fract. \\
\hline-241 & 4. $257 \mathrm{E}-10$ & 0.0000 & $0.000 \mathrm{E}+00$ & 0.0000 & $0.000 \mathrm{E}+00$ & 0.0000 & $6.939 \mathrm{E}-03$ & 0.0010 & $0.000 \mathrm{E}+00$ & 0.0000 & $0.000 \mathrm{E}+00$ & 0.0000 & $0.000 \mathrm{E}+00$ & 0.0000 \\
\hline-137 & $4.741 E-15$ & 0.0000 & $0.000 \mathrm{E}+00$ & 0.0000 & $0.000 \mathrm{E}+00$ & 0.0000 & $1.461 \mathrm{E}-12$ & 0.0000 & $0.000 \mathrm{E}+00$ & 0.0000 & $0.000 \mathrm{E}+00$ & 0.0000 & $0.000 \mathrm{E}+00$ & 0.0000 \\
\hline-237 & $3.910 \mathrm{E}-07$ & 0.0000 & $0.000 \mathrm{E}+00$ & 0.0000 & $0.000 \mathrm{E}+00$ & 0.0000 & $5.637 \mathrm{E}-02$ & 0.0083 & $0.000 \mathrm{E}+00$ & 0.0000 & $0.000 \mathrm{E}+00$ & 0.0000 & $0.000 \mathrm{E}+00$ & 0.0000 \\
\hline 238 & $5.077 \mathrm{E}-09$ & 0.0000 & $0.000 \mathrm{E}+00$ & 0.0000 & $0.000 \mathrm{E}+00$ & 0.0000 & $2.382 E-05$ & 0.0000 & $0.000 \mathrm{E}+00$ & 0.0000 & $0.000 \mathrm{E}+00$ & 0.0000 & $0.000 \mathrm{E}+00$ & 0.0000 \\
\hline 239 & $1.202 \mathrm{E}-10$ & 0.0000 & $0.000 \mathrm{E}+00$ & 0.0000 & $0.000 \mathrm{E}+00$ & 0.0000 & $4.566 \mathrm{E}-02$ & 0.0067 & $0.000 \mathrm{E}+00$ & 0.0000 & $0.000 \mathrm{E}+00$ & 0.0000 & $0.000 \mathrm{E}+00$ & 0.0000 \\
\hline-240 & $2.914 \mathrm{E}-14$ & 0.0000 & $0.000 \mathrm{E}+00$ & 0.0000 & $0.000 \mathrm{E}+00$ & 0.0000 & $4.210 \mathrm{E}-02$ & 0.0062 & $0.000 \mathrm{E}+00$ & 0.0000 & $0.000 \mathrm{E}+00$ & 0.0000 & $0.000 \mathrm{E}+00$ & 0.0000 \\
\hline-99 & 1. $302 \mathrm{E}-19$ & 0.0000 & $0.000 \mathrm{E}+00$ & 0.0000 & $0.000 \mathrm{E}+00$ & 0.0000 & $6.892 E-05$ & 0.0000 & $0.000 \mathrm{E}+00$ & 0.0000 & $0.000 \mathrm{E}+00$ & 0.0000 & $0.000 \mathrm{E}+00$ & 0.0000 \\
\hline 228 & $0.000 \mathrm{E}+00$ & 0.0000 & $0.000 \mathrm{E}+00$ & 0.0000 & $0.000 \mathrm{E}+00$ & 0.0000 & $0.000 \mathrm{E}+00$ & 0.0000 & $0.000 \mathrm{E}+00$ & 0.0000 & $0.000 \mathrm{E}+00$ & 0.0000 & $0.000 \mathrm{E}+00$ & 0.0000 \\
\hline 230 & $8.967 \mathrm{E}-03$ & 0.0013 & $0.000 \mathrm{E}+00$ & 0.0000 & $0.000 \mathrm{E}+00$ & 0.0000 & $5.809 \mathrm{E}+00$ & 0.8509 & $0.000 \mathrm{E}+00$ & 0.0000 & $0.000 \mathrm{E}+00$ & 0.0000 & $0.000 \mathrm{E}+00$ & 0.0000 \\
\hline-232 & $3.698 E-03$ & 0.0005 & $0.000 \mathrm{E}+00$ & 0.0000 & $0.000 \mathrm{E}+00$ & 0.0000 & $5.926 \mathrm{E}-01$ & 0.0868 & $0.000 \mathrm{E}+00$ & 0.0000 & $0.000 \mathrm{E}+00$ & 0.0000 & $0.000 \mathrm{E}+00$ & 0.0000 \\
\hline 34 & $7.268 E-05$ & 0.0000 & $0.000 \mathrm{E}+00$ & 0.0000 & $0.000 \mathrm{E}+00$ & 0.0000 & $1.483 \mathrm{E}-01$ & 0.0217 & $0.000 \mathrm{E}+00$ & 0.0000 & $0.000 \mathrm{E}+00$ & 0.0000 & $0.000 \mathrm{E}+00$ & 0.0000 \\
\hline 235 & $1.527 \mathrm{E}-07$ & 0.0000 & $0.000 \mathrm{E}+00$ & 0.0000 & $0.000 \mathrm{E}+00$ & 0.0000 & $1.149 \mathrm{E}-02$ & 0.0017 & $0.000 \mathrm{E}+00$ & 0.0000 & $0.000 \mathrm{E}+00$ & 0.0000 & $0.000 \mathrm{E}+00$ & 0.0000 \\
\hline 38 & $9.919 \mathrm{E}-05$ & 0.0000 & $0.000 \mathrm{E}+00$ & 0.0000 & $0.000 \mathrm{E}+00$ & 0.0000 & $1.013 \mathrm{E}-01$ & 0.0148 & $0.000 \mathrm{E}+00$ & 0.0000 & $0.000 \mathrm{E}+00$ & 0.0000 & $0.000 \mathrm{E}+00$ & 0.0000 \\
\hline & $1.284 \mathrm{E}-02$ & 0.0019 & $0.000 \mathrm{E}+00$ & 0.0000 & $0.000 \mathrm{E}+00$ & 0.0000 & $6.814 \mathrm{E}+00$ & 0.9981 & $0.000 \mathrm{E}+00$ & 0.0000 & $0.000 \mathrm{E}+00$ & 0.0000 & $0.000 \mathrm{E}+00$ & 0.0000 \\
\hline
\end{tabular}

Total Dose Contributions TDOSE (i,p,t) for Individual Radionuclides (i) and Pathways (p) As mrem/yr and Fraction of Total Dose At $t=1.050 \mathrm{E}+03$ years

Water Dependent Pathways

\begin{tabular}{|c|c|c|c|c|c|c|c|c|c|c|c|c|c|c|}
\hline & \multicolumn{2}{|c|}{ Water } & \multicolumn{2}{|c|}{ Fish } & \multicolumn{2}{|c|}{ Radon } & \multicolumn{2}{|c|}{ Plant } & \multicolumn{2}{|c|}{ Meat } & \multicolumn{2}{|c|}{ Milk } & \multicolumn{2}{|c|}{ All Pathways* } \\
\hline clide & mrem/yr & fract. & mrem/yr & fract. & mrem/yr & fract. & mrem/yr & fract. & mrem/yr & fract. & mrem/yr & fract. & mrem/yr & fract. \\
\hline 241 & $0.000 \mathrm{E}+00$ & 0.0000 & $0.000 \mathrm{E}+00$ & 0.0000 & $0.000 \mathrm{E}+00$ & 0.0000 & $0.000 \mathrm{E}+00$ & 0.0000 & $0.000 \mathrm{E}+00$ & 0.0000 & $0.000 \mathrm{E}+00$ & 0.0000 & $6.939 E-03$ & 0.0010 \\
\hline-137 & $0.000 \mathrm{E}+00$ & 0.0000 & $0.000 \mathrm{E}+00$ & 0.0000 & $0.000 \mathrm{E}+00$ & 0.0000 & $0.000 \mathrm{E}+00$ & 0.0000 & $0.000 \mathrm{E}+00$ & 0.0000 & $0.000 \mathrm{E}+00$ & 0.0000 & 1. $465 \mathrm{E}-12$ & 0.0000 \\
\hline-237 & $0.000 \mathrm{E}+00$ & 0.0000 & $0.000 \mathrm{E}+00$ & 0.0000 & $0.000 \mathrm{E}+00$ & 0.0000 & $0.000 \mathrm{E}+00$ & 0.0000 & $0.000 \mathrm{E}+00$ & 0.0000 & $0.000 \mathrm{E}+00$ & 0.0000 & $5.637 \mathrm{E}-02$ & 0.0083 \\
\hline-238 & $0.000 \mathrm{E}+00$ & 0.0000 & $0.000 \mathrm{E}+00$ & 0.0000 & $0.000 \mathrm{E}+00$ & 0.0000 & $0.000 \mathrm{E}+00$ & 0.0000 & $0.000 \mathrm{E}+00$ & 0.0000 & $0.000 \mathrm{E}+00$ & 0.0000 & $2.383 E-05$ & 0.0000 \\
\hline-239 & $0.000 \mathrm{E}+00$ & 0.0000 & $0.000 \mathrm{E}+00$ & 0.0000 & $0.000 \mathrm{E}+00$ & 0.0000 & $0.000 \mathrm{E}+00$ & 0.0000 & $0.000 \mathrm{E}+00$ & 0.0000 & $0.000 E+00$ & 0.0000 & $4.566 \mathrm{E}-02$ & 0.0067 \\
\hline-240 & $0.000 \mathrm{E}+00$ & 0.0000 & $0.000 \mathrm{E}+00$ & 0.0000 & $0.000 \mathrm{E}+00$ & 0.0000 & $0.000 \mathrm{E}+00$ & 0.0000 & $0.000 \mathrm{E}+00$ & 0.0000 & $0.000 E+00$ & 0.0000 & $4.210 \mathrm{E}-02$ & 0.0062 \\
\hline-99 & $0.000 \mathrm{E}+00$ & 0.0000 & $0.000 \mathrm{E}+00$ & 0.0000 & $0.000 \mathrm{E}+00$ & 0.0000 & $0.000 \mathrm{E}+00$ & 0.0000 & $0.000 \mathrm{E}+00$ & 0.0000 & $0.000 \mathrm{E}+00$ & 0.0000 & $6.892 \mathrm{E}-05$ & 0.0000 \\
\hline-228 & $0.000 \mathrm{E}+00$ & 0.0000 & $0.000 \mathrm{E}+00$ & 0.0000 & $0.000 \mathrm{E}+00$ & 0.0000 & $0.000 \mathrm{E}+00$ & 0.0000 & $0.000 \mathrm{E}+00$ & 0.0000 & $0.000 \mathrm{E}+00$ & 0.0000 & $0.000 \mathrm{E}+00$ & 0.0000 \\
\hline-230 & $0.000 \mathrm{E}+00$ & 0.0000 & $0.000 \mathrm{E}+00$ & 0.0000 & $0.000 \mathrm{E}+00$ & 0.0000 & $0.000 \mathrm{E}+00$ & 0.0000 & $0.000 \mathrm{E}+00$ & 0.0000 & $0.000 E+00$ & 0.0000 & $5.818 \mathrm{E}+00$ & 0.8522 \\
\hline 232 & $0.000 \mathrm{E}+00$ & 0.0000 & $0.000 \mathrm{E}+00$ & 0.0000 & $0.000 \mathrm{E}+00$ & 0.0000 & $0.000 \mathrm{E}+00$ & 0.0000 & $0.000 \mathrm{E}+00$ & 0.0000 & $0.000 \mathrm{E}+00$ & 0.0000 & $5.963 \mathrm{E}-01$ & 0.0873 \\
\hline 34 & $0.000 \mathrm{E}+00$ & 0.0000 & $0.000 \mathrm{E}+00$ & 0.0000 & $0.000 \mathrm{E}+00$ & 0.0000 & $0.000 \mathrm{E}+00$ & 0.0000 & $0.000 \mathrm{E}+00$ & 0.0000 & $0.000 \mathrm{E}+00$ & 0.0000 & 1. $484 \mathrm{E}-01$ & 0.0217 \\
\hline 35 & $0.000 \mathrm{E}+00$ & 0.0000 & $0.000 \mathrm{E}+00$ & 0.0000 & $0.000 \mathrm{E}+00$ & 0.0000 & $0.000 \mathrm{E}+00$ & 0.0000 & $0.000 \mathrm{E}+00$ & 0.0000 & $0.000 E+00$ & 0.0000 & $1.149 \mathrm{E}-02$ & 0.0017 \\
\hline 38 & $0.000 \mathrm{E}+00$ & 0.0000 & $0.000 \mathrm{E}+00$ & 0.0000 & $0.000 \mathrm{E}+00$ & 0.0000 & $0.000 \mathrm{E}+00$ & 0.0000 & $0.000 \mathrm{E}+00$ & 0.0000 & $0.000 \mathrm{E}+00$ & 0.0000 & $1.014 \mathrm{E}-01$ & 0.0148 \\
\hline & $0.000 \mathrm{E}+00$ & 0.0000 & $0.000 \mathrm{E}+00$ & 0.0000 & $0.000 \mathrm{E}+00$ & 0.0000 & $0.000 \mathrm{E}+00$ & 0.0000 & $0.000 \mathrm{E}+00$ & 0.0000 & $0.000 \mathrm{E}+00$ & 0.0000 & $6.827 \mathrm{E}+00$ & 1. \\
\hline
\end{tabular}

* Sum of all water independent and dependent pathways. 
RESRAD, Version 6.5

Summary : C746U Resident Gardener Deterministic Run
File : X: $\backslash$ FINAL V2 $\backslash$ DOE FWD RUNS $\backslash C 746 U$ RG DOE SG FWD-FV2-10000YR.RAD

Total Dose Contributions TDOSE(i,p,t) for Individual Radionuclides (i) and Pathways (p) As mrem/yr and Fraction of Total Dose At $t=1.000 \mathrm{E}+04$ years

Water Independent Pathways (Inhalation excludes radon)

\begin{tabular}{|c|c|c|c|c|c|c|c|c|c|c|c|c|c|c|}
\hline \multirow{2}{*}{ Nuclide } & \multicolumn{2}{|c|}{ Ground } & \multicolumn{2}{|c|}{ Inhalation } & \multicolumn{2}{|c|}{ Radon } & \multicolumn{2}{|c|}{ Plant } & \multicolumn{2}{|c|}{ Meat } & \multicolumn{2}{|c|}{ Milk } & \multicolumn{2}{|c|}{ Soil } \\
\hline & mrem/yr & fract. & mrem/yr & fract. & mrem/yr & fract. & mrem/yr & fract. & mrem/yr & fract. & mrem/yr & fract. & mrem/yr & fract. \\
\hline-241 & $1.724 \mathrm{E}-03$ & 0.0000 & $1.816 \mathrm{E}-07$ & 0.0000 & $0.000 \mathrm{E}+00$ & 0.0000 & $2.088 E-03$ & 0.0000 & $0.000 \mathrm{E}+00$ & 0.0000 & $0.000 \mathrm{E}+00$ & 0.0000 & $3.432 \mathrm{E}-05$ & 0.0000 \\
\hline-137 & $0.000 \mathrm{E}+00$ & 0.0000 & $0.000 \mathrm{E}+00$ & 0.0000 & $0.000 \mathrm{E}+00$ & 0.0000 & $0.000 \mathrm{E}+00$ & 0.0000 & $0.000 \mathrm{E}+00$ & 0.0000 & $0.000 \mathrm{E}+00$ & 0.0000 & $0.000 \mathrm{E}+00$ & 0.0000 \\
\hline-237 & $1.242 \mathrm{E}+00$ & 0.0005 & $1.326 E-04$ & 0.0000 & $0.000 \mathrm{E}+00$ & 0.0000 & $1.496 \mathrm{E}+00$ & 0.0006 & $0.000 \mathrm{E}+00$ & 0.0000 & $0.000 \mathrm{E}+00$ & 0.0000 & $2.514 \mathrm{E}-02$ & 0.0000 \\
\hline-238 & $6.839 E-03$ & 0.0000 & $3.439 E-07$ & 0.0000 & $0.000 \mathrm{E}+00$ & 0.0000 & $1.186 \mathrm{E}-02$ & 0.0000 & $0.000 \mathrm{E}+00$ & 0.0000 & $0.000 \mathrm{E}+00$ & 0.0000 & $3.191 \mathrm{E}-04$ & 0.0000 \\
\hline-239 & $5.108 E-03$ & 0.0000 & $4.259 E-03$ & 0.0000 & $0.000 \mathrm{E}+00$ & 0.0000 & $2.652 \mathrm{E}+00$ & 0.0011 & $0.000 \mathrm{E}+00$ & 0.0000 & $0.000 \mathrm{E}+00$ & 0.0000 & $7.370 \mathrm{E}-01$ & 0.0003 \\
\hline-240 & $9.845 \mathrm{E}-04$ & 0.0000 & $1.967 \mathrm{E}-03$ & 0.0000 & $0.000 \mathrm{E}+00$ & 0.0000 & $1.225 \mathrm{E}+00$ & 0.0005 & $0.000 \mathrm{E}+00$ & 0.0000 & $0.000 \mathrm{E}+00$ & 0.0000 & $3.405 \mathrm{E}-01$ & 0.0001 \\
\hline-99 & $0.000 \mathrm{E}+00$ & 0.0000 & $0.000 \mathrm{E}+00$ & 0.0000 & $0.000 \mathrm{E}+00$ & 0.0000 & $0.000 \mathrm{E}+00$ & 0.0000 & $0.000 \mathrm{E}+00$ & 0.0000 & $0.000 \mathrm{E}+00$ & 0.0000 & $0.000 \mathrm{E}+00$ & 0.0000 \\
\hline 228 & $0.000 \mathrm{E}+00$ & 0.0000 & $0.000 \mathrm{E}+00$ & 0.0000 & $0.000 \mathrm{E}+00$ & 0.0000 & $0.000 \mathrm{E}+00$ & 0.0000 & $0.000 \mathrm{E}+00$ & 0.0000 & $0.000 \mathrm{E}+00$ & 0.0000 & $0.000 \mathrm{E}+00$ & 0.0000 \\
\hline 230 & $7.436 \mathrm{E}+02$ & 0.3152 & $1.648 \mathrm{E}-02$ & 0.0000 & $0.000 \mathrm{E}+00$ & 0.0000 & $1.224 \mathrm{E}+03$ & 0.5187 & $0.000 \mathrm{E}+00$ & 0.0000 & $0.000 \mathrm{E}+00$ & 0.0000 & $2.669 \mathrm{E}+01$ & 0.0113 \\
\hline 232 & $4.839 E+01$ & 0.0205 & $1.028 E-03$ & 0.0000 & $0.000 \mathrm{E}+00$ & 0.0000 & $5.054 \mathrm{E}+01$ & 0.0214 & $0.000 \mathrm{E}+00$ & 0.0000 & $0.000 \mathrm{E}+00$ & 0.0000 & $5.352 \mathrm{E}-01$ & 0.0002 \\
\hline 34 & $7.945 E+01$ & 0.0337 & $3.957 \mathrm{E}-03$ & 0.0000 & $0.000 \mathrm{E}+00$ & 0.0000 & $1.377 \mathrm{E}+02$ & 0.0584 & $0.000 \mathrm{E}+00$ & 0.0000 & $0.000 \mathrm{E}+00$ & 0.0000 & $3.693 \mathrm{E}+00$ & 0.0016 \\
\hline 35 & $4.626 \mathrm{E}+00$ & 0.0020 & $1.189 \mathrm{E}-03$ & 0.0000 & $0.000 \mathrm{E}+00$ & 0.0000 & $5.072 \mathrm{E}+00$ & 0.0022 & $0.000 \mathrm{E}+00$ & 0.0000 & $0.000 \mathrm{E}+00$ & 0.0000 & $2.835 \mathrm{E}-01$ & 0.0001 \\
\hline 238 & $1.706 \mathrm{E}+01$ & 0.0072 & $1.671 \mathrm{E}-03$ & 0.0000 & $0.000 \mathrm{E}+00$ & 0.0000 & $8.921 \mathrm{E}+00$ & 0.0038 & $0.000 \mathrm{E}+00$ & 0.0000 & $0.000 \mathrm{E}+00$ & 0.0000 & $8.572 \mathrm{E}-01$ & 0.0004 \\
\hline & $3 E+02$ & 0. & $3.068 \mathrm{E}-02$ & 0.0 & $0.000 \mathrm{E}+00$ & 00 & $1.431 \mathrm{E}+03$ & 0.6068 & $0.000 \mathrm{E}+00$ & 00 & $E+00$ & 00 & +01 & 14 \\
\hline
\end{tabular}

Total Dose Contributions TDOSE (i,p,t) for Individual Radionuclides (i) and Pathways (p) As mrem/yr and Fraction of Total Dose At $t=1.000 \mathrm{E}+04$ years

Water Dependent Pathways

\begin{tabular}{|c|c|c|c|c|c|c|c|c|c|c|c|c|c|c|}
\hline & \multicolumn{2}{|c|}{ Water } & \multicolumn{2}{|c|}{ Fish } & \multicolumn{2}{|c|}{ Radon } & \multicolumn{2}{|c|}{ Plant } & \multicolumn{2}{|c|}{ Meat } & \multicolumn{2}{|c|}{ Milk } & \multicolumn{2}{|c|}{ All Pathways* } \\
\hline clide & mrem/yr & fract. & mrem/yr & fract. & mrem/yr & fract. & mrem/yr & fract. & mrem/yr & fract. & mrem/yr & fract. & mrem/yr & fract. \\
\hline 241 & $0.000 \mathrm{E}+00$ & 0.0000 & $0.000 \mathrm{E}+00$ & 0.0000 & $0.000 \mathrm{E}+00$ & 0.0000 & $0.000 \mathrm{E}+00$ & 0.0000 & $0.000 \mathrm{E}+00$ & 0.0000 & $0.000 \mathrm{E}+00$ & 0.0000 & $3.847 \mathrm{E}-03$ & 0.0000 \\
\hline-137 & $0.000 \mathrm{E}+00$ & 0.0000 & $0.000 \mathrm{E}+00$ & 0.0000 & $0.000 \mathrm{E}+00$ & 0.0000 & $0.000 \mathrm{E}+00$ & 0.0000 & $0.000 \mathrm{E}+00$ & 0.0000 & $0.000 \mathrm{E}+00$ & 0.0000 & $0.000 \mathrm{E}+00$ & 0.0000 \\
\hline-237 & $0.000 \mathrm{E}+00$ & 0.0000 & $0.000 \mathrm{E}+00$ & 0.0000 & $0.000 \mathrm{E}+00$ & 0.0000 & $0.000 \mathrm{E}+00$ & 0.0000 & $0.000 \mathrm{E}+00$ & 0.0000 & $0.000 \mathrm{E}+00$ & 0.0000 & $2.763 E+00$ & 0.0012 \\
\hline-238 & $0.000 \mathrm{E}+00$ & 0.0000 & $0.000 \mathrm{E}+00$ & 0.0000 & $0.000 \mathrm{E}+00$ & 0.0000 & $0.000 \mathrm{E}+00$ & 0.0000 & $0.000 \mathrm{E}+00$ & 0.0000 & $0.000 \mathrm{E}+00$ & 0.0000 & $1.902 \mathrm{E}-02$ & 0.0000 \\
\hline-239 & $0.000 \mathrm{E}+00$ & 0.0000 & $0.000 \mathrm{E}+00$ & 0.0000 & $0.000 \mathrm{E}+00$ & 0.0000 & $0.000 \mathrm{E}+00$ & 0.0000 & $0.000 \mathrm{E}+00$ & 0.0000 & $0.000 E+00$ & 0.0000 & $3.398 \mathrm{E}+00$ & 0.0014 \\
\hline-240 & $0.000 \mathrm{E}+00$ & 0.0000 & $0.000 \mathrm{E}+00$ & 0.0000 & $0.000 \mathrm{E}+00$ & 0.0000 & $0.000 \mathrm{E}+00$ & 0.0000 & $0.000 \mathrm{E}+00$ & 0.0000 & $0.000 E+00$ & 0.0000 & $1.569 \mathrm{E}+00$ & 0.0007 \\
\hline-99 & $0.000 \mathrm{E}+00$ & 0.0000 & $0.000 \mathrm{E}+00$ & 0.0000 & $0.000 \mathrm{E}+00$ & 0.0000 & $0.000 \mathrm{E}+00$ & 0.0000 & $0.000 \mathrm{E}+00$ & 0.0000 & $0.000 \mathrm{E}+00$ & 0.0000 & $0.000 \mathrm{E}+00$ & 0.0000 \\
\hline-228 & $0.000 \mathrm{E}+00$ & 0.0000 & $0.000 \mathrm{E}+00$ & 0.0000 & $0.000 \mathrm{E}+00$ & 0.0000 & $0.000 \mathrm{E}+00$ & 0.0000 & $0.000 \mathrm{E}+00$ & 0.0000 & $0.000 \mathrm{E}+00$ & 0.0000 & $0.000 \mathrm{E}+00$ & 0.0000 \\
\hline-230 & $0.000 \mathrm{E}+00$ & 0.0000 & $0.000 \mathrm{E}+00$ & 0.0000 & $0.000 \mathrm{E}+00$ & 0.0000 & $0.000 \mathrm{E}+00$ & 0.0000 & $0.000 \mathrm{E}+00$ & 0.0000 & $0.000 E+00$ & 0.0000 & $1.994 \mathrm{E}+03$ & 0.8453 \\
\hline-232 & $0.000 \mathrm{E}+00$ & 0.0000 & $0.000 \mathrm{E}+00$ & 0.0000 & $0.000 \mathrm{E}+00$ & 0.0000 & $0.000 \mathrm{E}+00$ & 0.0000 & $0.000 \mathrm{E}+00$ & 0.0000 & $0.000 \mathrm{E}+00$ & 0.0000 & $9.947 \mathrm{E}+01$ & 0.0422 \\
\hline 34 & $0.000 \mathrm{E}+00$ & 0.0000 & $0.000 \mathrm{E}+00$ & 0.0000 & $0.000 \mathrm{E}+00$ & 0.0000 & $0.000 \mathrm{E}+00$ & 0.0000 & $0.000 \mathrm{E}+00$ & 0.0000 & $0.000 \mathrm{E}+00$ & 0.0000 & $2.208 E+02$ & 0.0936 \\
\hline 35 & $0.000 \mathrm{E}+00$ & 0.0000 & $0.000 \mathrm{E}+00$ & 0.0000 & $0.000 \mathrm{E}+00$ & 0.0000 & $0.000 \mathrm{E}+00$ & 0.0000 & $0.000 \mathrm{E}+00$ & 0.0000 & $0.000 \mathrm{E}+00$ & 0.0000 & $9.983 E+00$ & 0.0042 \\
\hline 38 & $0.000 \mathrm{E}+00$ & 0.0000 & $0.000 \mathrm{E}+00$ & 0.0000 & $0.000 \mathrm{E}+00$ & 0.0000 & $0.000 \mathrm{E}+00$ & 0.0000 & $0.000 \mathrm{E}+00$ & 0.0000 & $0.000 \mathrm{E}+00$ & 0.0000 & $2.684 \mathrm{E}+01$ & 0.0114 \\
\hline & $0.000 \mathrm{E}+00$ & 0.0000 & $0.000 \mathrm{E}+00$ & 0.0000 & $0.000 \mathrm{E}+00$ & 0.0000 & $0.000 \mathrm{E}+00$ & 0.0000 & $0.000 \mathrm{E}+00$ & 0.0000 & $0.000 \mathrm{E}+00$ & 0.0000 & $.359 \mathrm{E}+03$ & 1. \\
\hline
\end{tabular}

* Sum of all water independent and dependent pathways. 
RESRAD, Version 6.5

$\mathrm{T}^{1 / 2}$ Limit $=180$ days

Summary : C746U Resident Gardener Deterministic Run

File : $\mathrm{X}: \backslash F I N A L$ V2 \DOE FWD RUNS \C746U RG DOE SG FWD-FV2-10000YR.RAD

Dose/Source Ratios Summed Over All Pathways

Parent and Progeny Principal Radionuclide Contributions Indicated

\begin{tabular}{|c|c|c|c|c|c|c|c|c|c|}
\hline $\begin{array}{l}\text { Parent } \\
\text { (i) }\end{array}$ & $\begin{array}{l}\text { Product } \\
(j)\end{array}$ & $\begin{array}{l}\text { Thread } \\
\text { Fraction }\end{array}$ & $0.000 \mathrm{E}+00$ & $\begin{array}{r}\operatorname{DSR}(j, t) \\
1.000 \mathrm{E}+00\end{array}$ & $\begin{array}{l}\text { At Time ir } \\
5.000 \mathrm{E}+01\end{array}$ & $\begin{array}{l}\text { Years } \\
1.000 \mathrm{E}+02\end{array}$ & $\begin{array}{l}(\text { mrem/yr) } / \\
5.000 \mathrm{E}+02\end{array}$ & $\begin{array}{l}(\mathrm{pCi} / \mathrm{g}) \\
1.050 \mathrm{E}+03\end{array}$ & $1.000 \mathrm{E}+04$ \\
\hline-241 & $A m-241$ & $1.000 \mathrm{E}+00$ & $1.936 E-33$ & $1.989 \mathrm{E}-33$ & $7.353 E-33$ & $2.792 E-32$ & $1.208 E-27$ & $1.965 E-04$ & $1.548 E-08$ \\
\hline-241 & $N p-237+D$ & $1.000 \mathrm{E}+00$ & $1.546 \mathrm{E}-19$ & 4. $680 \mathrm{E}-19$ & $2.562 \mathrm{E}-17$ & $8.382 \mathrm{E}-17$ & $2.263 E-14$ & $1.773 \mathrm{E}-06$ & $1.070 \mathrm{E}-04$ \\
\hline-241 & $\mathrm{U}-233$ & $1.000 \mathrm{E}+00$ & $3.506 \mathrm{E}-30$ & $2.479 E-29$ & $4.863 E-26$ & $3.503 E-25$ & $1.053 \mathrm{E}-21$ & $3.056 \mathrm{E}-10$ & $2.700 \mathrm{E}-07$ \\
\hline-241 & $\mathrm{Th}-229+\mathrm{D}$ & $1.000 \mathrm{E}+00$ & $2.399 E-26$ & $3.618 \mathrm{E}-25$ & $1.710 \mathrm{E}-20$ & $1.868 \mathrm{E}-19$ & $3.195 \mathrm{E}-16$ & $5.403 E-11$ & $2.614 \mathrm{E}-06$ \\
\hline-241 & $\sum \operatorname{DSR}(j)$ & & $1.546 \mathrm{E}-19$ & 4. $680 \mathrm{E}-19$ & $2.564 \mathrm{E}-17$ & $8.401 \mathrm{E}-17$ & $2.295 E-14$ & 1. $983 \mathrm{E}-04$ & $1.099 \mathrm{E}-04$ \\
\hline$-137+D$ & $\mathrm{Cs}-137+\mathrm{D}$ & $1.000 \mathrm{E}+00$ & $1.262 \mathrm{E}-09$ & $1.243 \mathrm{E}-09$ & $6.050 \mathrm{E}-10$ & $2.901 \mathrm{E}-10$ & $8.104 \mathrm{E}-13$ & $7.713 \mathrm{E}-14$ & $0.000 \mathrm{E}+00$ \\
\hline$-237+D$ & $N p-237+D$ & $1.000 \mathrm{E}+00$ & $9.536 \mathrm{E}-13$ & $9.638 \mathrm{E}-13$ & $1.625 \mathrm{E}-12$ & $2.770 \mathrm{E}-12$ & $1.974 \mathrm{E}-10$ & $1.025 E-02$ & $4.869 \mathrm{E}-01$ \\
\hline$-237+D$ & $\mathrm{U}-233$ & $1.000 \mathrm{E}+00$ & $3.245 \mathrm{E}-23$ & $9.844 \mathrm{E}-23$ & $6.100 \mathrm{E}-21$ & $2.264 \mathrm{E}-20$ & $1.650 \mathrm{E}-17$ & $2.871 E-06$ & $1.370 \mathrm{E}-03$ \\
\hline$-237+D$ & $\mathrm{Th}-229+\mathrm{D}$ & $1.000 \mathrm{E}+00$ & $2.962 \mathrm{E}-19$ & $2.086 \mathrm{E}-18$ & $3.196 \mathrm{E}-15$ & 1. $788 \mathrm{E}-14$ & $7.080 \mathrm{E}-12$ & $6.801 \mathrm{E}-07$ & 1. $404 \mathrm{E}-02$ \\
\hline$-237+D$ & $\sum \operatorname{DSR}(j)$ & & $9.536 \mathrm{E}-13$ & $9.638 \mathrm{E}-13$ & 1. $629 \mathrm{E}-12$ & $2.788 E-12$ & $2.044 \mathrm{E}-10$ & $1.025 E-02$ & $5.023 E-01$ \\
\hline-238 & $\mathrm{Pu}-238$ & $1.840 \mathrm{E}-09$ & $2.162 \mathrm{E}-33$ & $2.183 E-33$ & $3.520 \mathrm{E}-33$ & $5.731 \mathrm{E}-33$ & $2.831 \mathrm{E}-31$ & $5.505 \mathrm{E}-16$ & $2.803 E-45$ \\
\hline 238 & $\mathrm{Pu}-238$ & $1.000 \mathrm{E}+00$ & $1.175 \mathrm{E}-24$ & $1.186 \mathrm{E}-24$ & $1.913 \mathrm{E}-24$ & $3.115 \mathrm{E}-24$ & $1.539 \mathrm{E}-22$ & $2.992 E-07$ & $5.655 \mathrm{E}-36$ \\
\hline-238 & $\mathrm{U}-234$ & $1.000 \mathrm{E}+00$ & $9.778 E-30$ & $2.969 \mathrm{E}-29$ & $1.973 \mathrm{E}-27$ & $7.960 \mathrm{E}-27$ & $1.690 \mathrm{E}-23$ & $2.276 \mathrm{E}-07$ & $1.767 \mathrm{E}-05$ \\
\hline-238 & $T h-230$ & $1.000 \mathrm{E}+00$ & $1.028 E-33$ & 7. $286 \mathrm{E}-33$ & $1.599 \mathrm{E}-29$ & 1. $302 \mathrm{E}-28$ & 1. $306 \mathrm{E}-24$ & $3.273 E-09$ & $3.337 \mathrm{E}-06$ \\
\hline-238 & $\mathrm{Ra}-226+\mathrm{D}$ & $1.000 \mathrm{E}+00$ & $8.021 \mathrm{E}-23$ & $1.208 \mathrm{E}-21$ & $5.266 \mathrm{E}-17$ & $5.323 E-16$ & $5.607 \mathrm{E}-13$ & $3.143 E-08$ & $2.825 E-04$ \\
\hline-238 & $\mathrm{~Pb}-210+\mathrm{D}$ & $1.000 \mathrm{E}+00$ & $2.326 \mathrm{E}-31$ & $7.210 \mathrm{E}-30$ & $7.772 \mathrm{E}-24$ & $1.314 \mathrm{E}-22$ & $3.671 \mathrm{E}-19$ & $4.946 \mathrm{E}-08$ & $1.841 \mathrm{E}-04$ \\
\hline-238 & $\sum \operatorname{DSR}(j)$ & & $8.139 E-23$ & $1.209 \mathrm{E}-21$ & $5.266 \mathrm{E}-17$ & $5.323 E-16$ & $5.607 \mathrm{E}-13$ & $6.110 \mathrm{E}-07$ & $4.876 E-04$ \\
\hline-239 & $\mathrm{Pu}-239$ & $1.000 \mathrm{E}+00$ & $1.202 \mathrm{E}-17$ & $1.217 \mathrm{E}-17$ & $2.183 \mathrm{E}-17$ & $3.965 \mathrm{E}-17$ & 4. $690 \mathrm{E}-15$ & $1.268 E-03$ & $9.439 \mathrm{E}-02$ \\
\hline-239 & $\mathrm{U}-235+\mathrm{D}$ & $1.000 \mathrm{E}+00$ & $6.135 \mathrm{E}-24$ & $1.861 \mathrm{E}-23$ & $1.146 \mathrm{E}-21$ & $4.227 E-21$ & $2.931 \mathrm{E}-18$ & $6.291 \mathrm{E}-10$ & $4.403 E-06$ \\
\hline-239 & $\mathrm{~Pa}-231$ & $1.000 \mathrm{E}+00$ & $9.652 \mathrm{E}-28$ & $6.818 \mathrm{E}-27$ & $1.251 \mathrm{E}-23$ & $8.414 \mathrm{E}-23$ & $1.444 \mathrm{E}-19$ & $4.191 \mathrm{E}-10$ & $2.591 \mathrm{E}-06$ \\
\hline-239 & $A C-227+D$ & $1.000 \mathrm{E}+00$ & $2.288 E-27$ & $3.434 \mathrm{E}-26$ & $1.276 \mathrm{E}-21$ & $1.169 \mathrm{E}-20$ & $1.476 \mathrm{E}-17$ & $1.686 \mathrm{E}-10$ & $2.250 \mathrm{E}-06$ \\
\hline$x-239$ & $\sum \operatorname{DSR}(j)$ & & $1.202 \mathrm{E}-17$ & $1.217 \mathrm{E}-17$ & $2.183 \mathrm{E}-17$ & $3.966 \mathrm{E}-17$ & $4.708 E-15$ & $1.268 \mathrm{E}-03$ & $9.440 \mathrm{E}-02$ \\
\hline-240 & $\mathrm{Pu}-240$ & $4.950 E-08$ & $5.653 E-32$ & $5.753 E-32$ & $1.359 \mathrm{E}-31$ & $3.267 E-31$ & $3.647 E-28$ & $5.789 E-11$ & $2.157 \mathrm{E}-09$ \\
\hline-240 & $\mathrm{Pu}-240$ & $1.000 \mathrm{E}+00$ & $1.142 \mathrm{E}-24$ & $1.162 \mathrm{E}-24$ & $2.746 \mathrm{E}-24$ & $6.601 \mathrm{E}-24$ & $7.367 \mathrm{E}-21$ & $1.170 \mathrm{E}-03$ & $4.357 \mathrm{E}-02$ \\
\hline-240 & $\mathrm{U}-236$ & $1.000 \mathrm{E}+00$ & $2.162 E-32$ & $6.590 \mathrm{E}-32$ & $5.335 E-30$ & $2.602 E-29$ & $1.686 \mathrm{E}-25$ & $1.804 \mathrm{E}-08$ & $9.074 \mathrm{E}-06$ \\
\hline-240 & Th-232 & $1.000 \mathrm{E}+00$ & $2.845 E-43$ & $2.028 E-42$ & $5.480 E-39$ & $5.478 E-38$ & $2.238 E-33$ & $9.371 \mathrm{E}-16$ & $6.320 \mathrm{E}-12$ \\
\hline-240 & $\mathrm{Ra}-228+\mathrm{D}$ & $1.000 \mathrm{E}+00$ & $1.371 \mathrm{E}-28$ & $2.018 E-27$ & $3.762 E-23$ & $2.542 E-22$ & $1.470 \mathrm{E}-19$ & $1.102 \mathrm{E}-13$ & $8.021 E-10$ \\
\hline-240 & $\mathrm{Th}-228+\mathrm{D}$ & $1.000 \mathrm{E}+00$ & $8.111 \mathrm{E}-28$ & $2.334 \mathrm{E}-26$ & $2.641 \mathrm{E}-21$ & $1.757 \mathrm{E}-20$ & $5.564 \mathrm{E}-18$ & $1.510 \mathrm{E}-15$ & $3.655 \mathrm{E}-10$ \\
\hline-240 & $\sum \operatorname{DSR}(j)$ & & $1.143 E-24$ & $1.188 \mathrm{E}-24$ & $2.681 \mathrm{E}-21$ & $1.783 \mathrm{E}-20$ & $5.719 \mathrm{E}-18$ & $1.170 \mathrm{E}-03$ & $4.358 \mathrm{E}-02$ \\
\hline-99 & TC-99 & $1.000 \mathrm{E}+00$ & $5.758 \mathrm{E}-26$ & $5.817 \mathrm{E}-26$ & $9.575 E-26$ & $1.592 \mathrm{E}-25$ & $9.310 \mathrm{E}-24$ & $1.325 E-06$ & $1.128 \mathrm{E}-39$ \\
\hline$-228+D$ & $\mathrm{Th}-228+\mathrm{D}$ & $1.000 \mathrm{E}+00$ & $1.382 \mathrm{E}-06$ & $9.680 \mathrm{E}-07$ & $2.527 E-14$ & $4.618 E-22$ & $0.000 \mathrm{E}+00$ & $0.000 \mathrm{E}+00$ & $0.000 \mathrm{E}+00$ \\
\hline 230 & $\mathrm{Th}-230$ & $1.000 \mathrm{E}+00$ & $2.412 E-22$ & $2.453 \mathrm{E}-22$ & $5.590 \mathrm{E}-22$ & $1.295 \mathrm{E}-21$ & $1.078 \mathrm{E}-18$ & $1.104 \mathrm{E}-03$ & $1.120 \mathrm{E}-01$ \\
\hline 230 & $\mathrm{Ra}-226+\mathrm{D}$ & $1.000 \mathrm{E}+00$ & $3.774 \mathrm{E}-11$ & $1.139 \mathrm{E}-10$ & $5.320 \mathrm{E}-09$ & $1.479 \mathrm{E}-08$ & $1.071 \mathrm{E}-06$ & $2.165 E-02$ & $1.199 \mathrm{E}+01$ \\
\hline 230 & $\mathrm{~Pb}-210+\mathrm{D}$ & $1.000 \mathrm{E}+00$ & $1.819 \mathrm{E}-19$ & $1.271 \mathrm{E}-18$ & $1.299 \mathrm{E}-15$ & $5.314 \mathrm{E}-15$ & $7.678 E-13$ & $3.543 E-02$ & $7.839 \mathrm{E}+00$ \\
\hline 230 & $\sum \operatorname{DSR}(j)$ & & $3.774 \mathrm{E}-11$ & $1.139 \mathrm{E}-10$ & $5.320 \mathrm{E}-09$ & $1.479 \mathrm{E}-08$ & $1.071 \mathrm{E}-06$ & $5.818 \mathrm{E}-02$ & $1.994 \mathrm{E}+0$ \\
\hline
\end{tabular}


RESRAD, Version 6.5

$\mathrm{T}^{1 / 2}$ Limit $=180$ days

07/18/2011 14:54 Page 28

Summary : C746U Resident Gardener Deterministic Run

File : $X: \backslash F I N A L$ V2 \DOE FWD RUNS \C746U RG DOE SG FWD-FV2-10000YR.RAD

Dose/Source Ratios Summed Over All Pathways

Parent and Progeny Principal Radionuclide Contributions Indicated

\begin{tabular}{|c|c|c|c|c|c|c|c|c|c|}
\hline Parent & Product & Thread & & $\operatorname{DSR}(j, t)$ & At Time ir & n Years & (mrem/yr) / & $(\mathrm{pCi} / \mathrm{g})$ & \\
\hline (i) & $(j)$ & Fraction & $0.000 \mathrm{E}+00$ & $1.000 \mathrm{E}+00$ & $5.000 \mathrm{E}+01$ & $1.000 \mathrm{E}+02$ & $5.000 \mathrm{E}+02$ & $1.050 \mathrm{E}+03$ & $1.000 \mathrm{E}+04$ \\
\hline 232 & $T h-232$ & $1.000 \mathrm{E}+00$ & $1.166 \mathrm{E}-24$ & $1.188 \mathrm{E}-24$ & $2.949 \mathrm{E}-24$ & $7.462 \mathrm{E}-24$ & $1.252 \mathrm{E}-20$ & $1.221 \mathrm{E}-03$ & $1.337 \mathrm{E}-01$ \\
\hline 232 & $\mathrm{Ra}-228+\mathrm{D}$ & $1.000 \mathrm{E}+00$ & $1.107 \mathrm{E}-09$ & $3.174 \mathrm{E}-09$ & $2.784 \mathrm{E}-08$ & $4.079 \mathrm{E}-08$ & $8.497 E-07$ & 1. $458 \mathrm{E}-01$ & $1.699 \mathrm{E}+01$ \\
\hline-232 & $\mathrm{Th}-228+\mathrm{D}$ & $1.000 \mathrm{E}+00$ & $1.067 \mathrm{E}-08$ & $6.581 \mathrm{E}-08$ & $2.213 \mathrm{E}-06$ & $2.992 \mathrm{E}-06$ & $3.253 E-05$ & $2.007 \mathrm{E}-03$ & $7.745 \mathrm{E}+00$ \\
\hline-232 & $\sum \operatorname{DSR}(j)$ & & $1.178 \mathrm{E}-08$ & $6.899 \mathrm{E}-08$ & $2.241 \mathrm{E}-06$ & $3.033 \mathrm{E}-06$ & $3.338 E-05$ & 1. $491 \mathrm{E}-01$ & $2.487 \mathrm{E}+01$ \\
\hline 234 & $U-234$ & $1.000 \mathrm{E}+00$ & $6.896 \mathrm{E}-24$ & $7.019 \mathrm{E}-24$ & $1.670 \mathrm{E}-23$ & $4.047 \mathrm{E}-23$ & $4.798 E-20$ & $6.337 \mathrm{E}-04$ & $4.918 \mathrm{E}-02$ \\
\hline 234 & Th-230 & $1.000 \mathrm{E}+00$ & $1.089 \mathrm{E}-27$ & $3.315 E-27$ & $2.540 \mathrm{E}-25$ & $1.171 \mathrm{E}-24$ & $4.838 E-21$ & $1.037 E-05$ & $9.415 E-03$ \\
\hline-234 & $\mathrm{Ra}-226+\mathrm{D}$ & $1.000 \mathrm{E}+00$ & $1.133 \mathrm{E}-16$ & $7.978 E-16$ & 1. $213 \mathrm{E}-12$ & $6.737 \mathrm{E}-12$ & $2.496 \mathrm{E}-09$ & $1.097 \mathrm{E}-04$ & $8.001 \mathrm{E}-01$ \\
\hline-234 & $\mathrm{~Pb}-210+\mathrm{D}$ & $1.000 \mathrm{E}+00$ & $4.102 \mathrm{E}-25$ & $6.153 \mathrm{E}-24$ & $2.201 \mathrm{E}-19$ & 1. $935 \mathrm{E}-18$ & $1.678 \mathrm{E}-15$ & $1.738 \mathrm{E}-04$ & $5.213 E-01$ \\
\hline 234 & $\sum \operatorname{DSR}(j)$ & & $1.133 E-16$ & $7.978 E-16$ & 1. $213 \mathrm{E}-12$ & $6.737 \mathrm{E}-12$ & $2.496 \mathrm{E}-09$ & $9.276 E-04$ & $1.380 \mathrm{E}+00$ \\
\hline$-235+D$ & $\mathrm{U}-235+\mathrm{D}$ & $1.000 \mathrm{E}+00$ & 1. $243 \mathrm{E}-14$ & 1. $259 \mathrm{E}-14$ & $2.306 \mathrm{E}-14$ & $4.276 \mathrm{E}-14$ & $5.981 \mathrm{E}-12$ & $6.155 \mathrm{E}-04$ & $5.003 E-01$ \\
\hline$-235+D$ & $\mathrm{~Pa}-231$ & $1.000 \mathrm{E}+00$ & $2.937 E-18$ & $8.896 \mathrm{E}-18$ & $5.031 \mathrm{E}-16$ & $1.701 \mathrm{E}-15$ & $5.876 \mathrm{E}-13$ & $8.145 E-04$ & $5.535 E-01$ \\
\hline$-235+D$ & $A C-227+D$ & $1.000 \mathrm{E}+00$ & $9.274 \mathrm{E}-18$ & $6.481 \mathrm{E}-17$ & $6.882 E-14$ & $2.943 E-13$ & $6.376 \mathrm{E}-11$ & $3.373 E-04$ & $4.821 \mathrm{E}-01$ \\
\hline$-235+D$ & $\sum \operatorname{DSR}(j)$ & & $1.245 \mathrm{E}-14$ & $1.266 \mathrm{E}-14$ & $9.238 \mathrm{E}-14$ & $3.388 E-13$ & $7.033 E-11$ & $1.767 \mathrm{E}-03$ & $1.536 \mathrm{E}+00$ \\
\hline-238 & $\mathrm{U}-238$ & $5.400 \mathrm{E}-05$ & $0.000 \mathrm{E}+00$ & $0.000 \mathrm{E}+00$ & $0.000 \mathrm{E}+00$ & $0.000 \mathrm{E}+00$ & $0.000 \mathrm{E}+00$ & $3.167 \mathrm{E}-08$ & $2.512 \mathrm{E}-06$ \\
\hline$-238+D$ & $\mathrm{U}-238+\mathrm{D}$ & $9.999 \mathrm{E}-01$ & $1.420 \mathrm{E}-10$ & $1.431 \mathrm{E}-10$ & $2.116 \mathrm{E}-10$ & $3.153 \mathrm{E}-10$ & $7.678 \mathrm{E}-09$ & $6.313 E-04$ & $1.508 \mathrm{E}-01$ \\
\hline$-238+D$ & $\mathrm{U}-234$ & $9.999 \mathrm{E}-01$ & $9.803 E-30$ & $2.988 E-29$ & $2.392 E-27$ & $1.153 \mathrm{E}-26$ & $6.812 E-23$ & $1.890 \mathrm{E}-06$ & $1.414 \mathrm{E}-03$ \\
\hline$-238+D$ & $T h-230$ & $9.999 \mathrm{E}-01$ & $1.030 \mathrm{E}-33$ & $7.316 E-33$ & $1.818 \mathrm{E}-29$ & $1.668 \mathrm{E}-28$ & $3.430 E-24$ & $1.541 \mathrm{E}-08$ & $1.316 \mathrm{E}-04$ \\
\hline$-238+D$ & $\mathrm{Ra}-226+\mathrm{D}$ & $9.999 \mathrm{E}-01$ & $8.034 E-23$ & 1. $212 \mathrm{E}-21$ & $5.801 \mathrm{E}-17$ & $6.420 \mathrm{E}-16$ & $1.201 \mathrm{E}-12$ & $1.127 \mathrm{E}-07$ & $9.339 E-03$ \\
\hline$-238+D$ & $\mathrm{~Pb}-210+\mathrm{D}$ & $9.999 \mathrm{E}-01$ & $2.329 E-31$ & $7.229 E-30$ & $8.430 E-24$ & $1.546 \mathrm{E}-22$ & 7. $612 \mathrm{E}-19$ & $1.734 \mathrm{E}-07$ & $6.063 E-03$ \\
\hline$-238+D$ & $\sum \operatorname{DSR}(j)$ & & $1.420 \mathrm{E}-10$ & $1.431 \mathrm{E}-10$ & $2.116 \mathrm{E}-10$ & $3.153 \mathrm{E}-10$ & $7.680 \mathrm{E}-09$ & $6.335 E-04$ & $1.677 \mathrm{E}-01$ \\
\hline
\end{tabular}

The DSR includes contributions from associated (half-life $\leq 180$ days) daughters. 
RESRAD, Version $6.5 \quad T^{1 / 2}$ Limit $=180$ days

ummary : C746U Resident Gardener Deterministic Run

File : $\mathrm{X}: \backslash F I N A L$ V2 \DOE FWD RUNS \C746U RG DOE SG FWD-FV2-10000YR.RAD

Single Radionuclide Soil Guidelines G(i,t) in pCi/g

Basic Radiation Dose Limit $=1.000 \mathrm{E}+02 \mathrm{mrem} / \mathrm{yr}$

Nuclide

\begin{tabular}{|c|c|c|c|c|c|c|c|}
\hline (i) & $t=0.000 E+00$ & $1.000 \mathrm{E}+00$ & $5.000 \mathrm{E}+01$ & $1.000 \mathrm{E}+02$ & $5.000 \mathrm{E}+02$ & $1.050 \mathrm{E}+03$ & $1.000 \mathrm{E}+0$ \\
\hline-241 & $\star 3.431 \mathrm{E}+12$ & $\star 3.431 \mathrm{E}+12$ & $\star 3.431 \mathrm{E}+12$ & $\star 3.431 \mathrm{E}+12$ & $\star 3.431 \mathrm{E}+12$ & $5.044 \mathrm{E}+05$ & $9.099 \mathrm{E}+05$ \\
\hline-137 & $7.925 E+10$ & $8.043 E+10$ & $1.653 E+11$ & $3.447 E+11$ & $\star 8.704 \mathrm{E}+13$ & $\star 8.704 \mathrm{E}+13$ & $\star 8.704 \mathrm{E}+13$ \\
\hline-237 & $\star 7.047 \mathrm{E}+08$ & $\star 7.047 \mathrm{E}+08$ & $\star 7.047 \mathrm{E}+08$ & $\star 7.047 \mathrm{E}+08$ & $\star 7.047 \mathrm{E}+08$ & $9.756 \mathrm{E}+03$ & $1.991 \mathrm{E}+02$ \\
\hline$x-238$ & $* 1.712 \mathrm{E}+13$ & $\star 1.712 \mathrm{E}+13$ & $\star 1.712 \mathrm{E}+13$ & $\star 1.712 \mathrm{E}+13$ & $\star 1.712 \mathrm{E}+13$ & $1.637 \mathrm{E}+08$ & $2.051 \mathrm{E}+05$ \\
\hline-239 & $* 6.214 \mathrm{E}+10$ & $* 6.214 \mathrm{E}+10$ & $* 6.214 \mathrm{E}+10$ & $* 6.214 \mathrm{E}+10$ & $* 6.214 \mathrm{E}+10$ & $7.884 \mathrm{E}+04$ & $1.059 \mathrm{E}+03$ \\
\hline-240 & $\star 2.278 \mathrm{E}+11$ & $\star 2.278 \mathrm{E}+11$ & $\star 2.278 \mathrm{E}+11$ & $\star 2.278 \mathrm{E}+11$ & $\star 2.278 \mathrm{E}+11$ & $8.550 \mathrm{E}+04$ & $2.295 \mathrm{E}+03$ \\
\hline-99 & $\star 1.697 \mathrm{E}+10$ & $* 1.697 \mathrm{E}+10$ & $\star 1.697 \mathrm{E}+10$ & $\star 1.697 \mathrm{E}+10$ & $* 1.697 \mathrm{E}+10$ & $7.545 \mathrm{E}+07$ & $* 1.697 \mathrm{E}+10$ \\
\hline$h-228$ & $7.234 \mathrm{E}+07$ & $1.033 \mathrm{E}+08$ & $\star 8.195 \mathrm{E}+14$ & $\star 8.195 \mathrm{E}+14$ & $\star 8.195 \mathrm{E}+14$ & $* 8.195 \mathrm{E}+14$ & $* 8.195 \mathrm{E}+14$ \\
\hline Th -230 & $\star 2.018 \mathrm{E}+10$ & $\star 2.018 \mathrm{E}+10$ & $1.880 \mathrm{E}+10$ & $6.761 E+09$ & $9.336 \mathrm{E}+07$ & $1.719 \mathrm{E}+03$ & $5.016 \mathrm{E}+0$ \\
\hline Th-232 & $\star 1.097 \mathrm{E}+05$ & $* 1.097 \mathrm{E}+05$ & $* 1.097 \mathrm{E}+05$ & $\star 1.097 \mathrm{E}+05$ & $\star 1.097 \mathrm{E}+05$ & $6.708 \mathrm{E}+02$ & $4.021 \mathrm{E}+0 \mathrm{C}$ \\
\hline-234 & $* 6.247 \mathrm{E}+09$ & $\star 6.247 \mathrm{E}+09$ & $\star 6.247 \mathrm{E}+09$ & $* 6.247 \mathrm{E}+09$ & $* 6.247 \mathrm{E}+09$ & $1.078 \mathrm{E}+05$ & $7.246 \mathrm{E}+0$ \\
\hline 35 & $\star 2.161 \mathrm{E}+06$ & $\star 2.161 \mathrm{E}+06$ & $\star 2.161 \mathrm{E}+06$ & $\star 2.161 \mathrm{E}+06$ & $\star 2.161 \mathrm{E}+06$ & $5.658 \mathrm{E}+04$ & $6.511 \mathrm{E}+0$ \\
\hline 238 & $\star 3.361 \mathrm{E}+05$ & $\star 3.361 \mathrm{E}+05$ & $\star 3.361 \mathrm{E}+05$ & $\star 3.361 \mathrm{E}+05$ & $\star 3.361 \mathrm{E}+05$ & $1.578 \mathrm{E}+05$ & $5.961 \mathrm{E}+02$ \\
\hline
\end{tabular}

*At specific activity limit

Summed Dose/Source Ratios DSR(i,t) in (mrem/yr)/(pCi/g) and Single Radionuclide Soil Guidelines $G(i, t)$ in pCi/g

at $\operatorname{tmin}=$ time of minimum single radionuclide soil guideline and at $\operatorname{tmax}=$ time of maximum total dose $=1.000 \mathrm{E}+04$ years

\begin{tabular}{|c|c|c|c|c|c|c|}
\hline $\begin{array}{l}\text { uclide } \\
\text { (i) }\end{array}$ & $\begin{array}{l}\text { Initial } \\
(\mathrm{pCi} / \mathrm{g})\end{array}$ & $\begin{array}{c}\text { tmin } \\
\text { (years) }\end{array}$ & $\operatorname{DSR}(i, \operatorname{tmin})$ & $\begin{array}{c}\mathrm{G}(\mathrm{i}, \mathrm{tmin}) \\
(\mathrm{pCi} / \mathrm{g})\end{array}$ & $\operatorname{DSR}(i, t \max )$ & $\begin{array}{c}G(i, t \max ) \\
(\mathrm{pci} / \mathrm{g})\end{array}$ \\
\hline$n-241$ & $3.500 \mathrm{E}+01$ & $2536 \pm 5$ & $2.825 E-03$ & $3.540 \mathrm{E}+04$ & $1.099 E-04$ & $9.099 \mathrm{E}+05$ \\
\hline-137 & $1.900 \mathrm{E}+01$ & $0.000 \mathrm{E}+00$ & $1.262 E-09$ & 7. $925 \mathrm{E}+10$ & $0.000 \mathrm{E}+00$ & $\star 8.704 \mathrm{E}+13$ \\
\hline-237 & $5.500 \mathrm{E}+00$ & $2533 \pm 5$ & $1.336 \mathrm{E}+00$ & $7.488 \mathrm{E}+01$ & $5.023 E-01$ & $1.991 \mathrm{E}+02$ \\
\hline$x-238$ & $3.900 \mathrm{E}+01$ & $1.000 \mathrm{E}+04$ & $4.876 \mathrm{E}-04$ & $2.051 E+05$ & $4.876 \mathrm{E}-04$ & $2.051 E+05$ \\
\hline-239 & $3.600 \mathrm{E}+01$ & $2533 \pm 5$ & $1.330 \mathrm{E}-01$ & $7.518 \mathrm{E}+02$ & $9.440 \mathrm{E}-02$ & $1.059 \mathrm{E}+03$ \\
\hline-240 & $3.600 \mathrm{E}+01$ & $2533 \pm 5$ & $1.093 E-01$ & $9.150 \mathrm{E}+02$ & $4.358 E-02$ & $2.295 E+03$ \\
\hline-99 & $5.200 \mathrm{E}+01$ & $1144 \pm 2$ & $3.687 \mathrm{E}-06$ & $2.712 \mathrm{E}+07$ & $0.000 \mathrm{E}+00$ & $\star 1.697 \mathrm{E}+10$ \\
\hline-228 & $4.000 \mathrm{E}+00$ & $0.000 \mathrm{E}+00$ & $1.382 E-06$ & $7.234 \mathrm{E}+07$ & $0.000 \mathrm{E}+00$ & $\star 8.195 \mathrm{E}+14$ \\
\hline-230 & $1.000 \mathrm{E}+02$ & $8251 \pm *$ & $2.007 \mathrm{E}+01$ & $4.984 \mathrm{E}+00$ & $1.994 \mathrm{E}+01$ & $5.016 \mathrm{E}+00$ \\
\hline-232 & $4.000 \mathrm{E}+00$ & $2536 \pm 5$ & $2.542 E+01$ & $3.934 \mathrm{E}+00$ & $2.487 E+01$ & $4.021 E+00$ \\
\hline-234 & $1.600 \mathrm{E}+02$ & $1.000 \mathrm{E}+04$ & $1.380 \mathrm{E}+00$ & $7.246 \mathrm{E}+01$ & 1. $380 \mathrm{E}+00$ & $7.246 \mathrm{E}+01$ \\
\hline 235 & $6.500 \mathrm{E}+00$ & $1.000 \mathrm{E}+04$ & $1.536 \mathrm{E}+00$ & $6.511 \mathrm{E}+01$ & $1.536 \mathrm{E}+00$ & $6.511 \mathrm{E}+01$ \\
\hline-238 & $1.600 \mathrm{E}+02$ & $2536 \pm 5$ & $1.800 \mathrm{E}-01$ & $5.556 \mathrm{E}+02$ & $1.677 \mathrm{E}-01$ & $5.961 E+02$ \\
\hline
\end{tabular}

*At specific activity limit 
RESRAD, Version 6.5

ummary : C746U Resident Gardener Deterministic Run

File : $\mathrm{X}: \backslash F I N A L$ V2 \DOE FWD RUNS \C746U RG DOE SG FWD-FV2-10000YR.RAD

Individual Nuclide Dose Summed Over All Pathways

Parent Nuclide and Branch Fraction Indicated

Nuclide Parent THF(i) DOSE $(j, t), \mathrm{mrem} / \mathrm{yr}$

\begin{tabular}{|c|c|c|}
\hline$(j)$ & (i) & \\
\hline $\mathrm{Am}-241$ & $A m-241$ & $1.000 \mathrm{E}+00$ \\
\hline$p-237$ & Am-241 & $1.000 \mathrm{E}+00$ \\
\hline-237 & $N p-237$ & $1.000 \mathrm{E}+00$ \\
\hline 237 & $\sum$ DOSE & \\
\hline
\end{tabular}

$\mathrm{U}-233 \mathrm{Am}-241 \quad 1.000 \mathrm{E}+00$

$\mathrm{U}-233 \quad \mathrm{~Np}-237 \quad 1.000 \mathrm{E}+00$

U-233 $\sum \operatorname{DOSE}(j)$

Th-229

$\mathrm{Th}-229$

$\mathrm{Th}-229$

$\mathrm{Cs}-137$

$\mathrm{Pu}-238$

$\mathrm{Pu}-238$

$\mathrm{Pu}-238$

$\mathrm{U}-234$

$\mathrm{U}-234$

$\mathrm{U}-234$

$\mathrm{U}-234$

$\mathrm{Th}-230$

$\mathrm{Th}-230$

$\mathrm{Th}-230$

$\mathrm{Th}-230$

$\mathrm{Th}-230$

$\mathrm{Ra}-226$

$\mathrm{Ra}-226$

$\mathrm{Ra}-226$

$\mathrm{Ra}-226$

$\mathrm{Ra}-226$

$\mathrm{Pb}-210$

$\mathrm{Pb}-210$

$\mathrm{Pb}-210$

$\mathrm{Pb}-210$

$\mathrm{Pb}-210$

Pu-239

Am-241 1.000E+00

$\mathrm{Np}-237 \quad 1.000 \mathrm{E}+00$

$\sum \operatorname{DOSE}(j)$

Cs-137 1.000E+00

$\mathrm{Pu}-238$ 1.840E-09

$\mathrm{Pu}-238 \quad 1.000 \mathrm{E}+00$

$\sum \operatorname{DOSE}(j)$

$\mathrm{Pu}-238 \quad 1.000 \mathrm{E}+00$

$\mathrm{U}-234 \quad 1.000 \mathrm{E}+00$

U-238 9.999E-01

$\sum \operatorname{DOSE}(j)$

$\mathrm{Pu}-238 \quad 1.000 \mathrm{E}+00$

Th-230 1.000E+00

$\mathrm{U}-234 \quad 1.000 \mathrm{E}+00$

U-238 9.999E-01

$\sum \operatorname{DOSE}(j)$

$\mathrm{Pu}-238 \quad 1.000 \mathrm{E}+00$

Th-230 1.000E+00

U-234 $1.000 \mathrm{E}+00$

U-238 9.999E-01

$\sum \operatorname{DOSE}(j)$

$\mathrm{Pu}-238 \quad 1.000 \mathrm{E}+00$

Th-230 1.000E+00

$\mathrm{U}-234 \quad 1.000 \mathrm{E}+00$

U-238 9.999E-01

$\sum \operatorname{DOSE}(j)$

$\mathrm{Pu}-239 \quad 1.000 \mathrm{E}+00$

$\mathrm{Pu}-239 \quad 1.000 \mathrm{E}+00$

$\mathrm{U}-2351.000 \mathrm{E}+00$

¿DOSE $(j)$
$\mathrm{E}=0.000 \mathrm{E}+001.000 \mathrm{E}+00 \quad 5.000 \mathrm{E}+01 \quad 1.000 \mathrm{E}+02 \quad 5.000 \mathrm{E}+02 \quad 1.050 \mathrm{E}+03 \quad 1.000 \mathrm{E}+04$

$0.000 \mathrm{E}+00 \quad 0.000 \mathrm{E}+00 \quad 0.000 \mathrm{E}+00 \quad 0.000 \mathrm{E}+00 \quad 4.227 \mathrm{E}-26 \quad 6.877 \mathrm{E}-03 \quad 5.418 \mathrm{E}-07$

$\begin{array}{llllllll}5.412 \mathrm{E}-18 & 1.638 \mathrm{E}-17 & 8.967 \mathrm{E}-16 & 2.934 \mathrm{E}-15 & 7.921 \mathrm{E}-13 & 6.206 \mathrm{E}-05 & 3.745 \mathrm{E}-03\end{array}$

$5.245 \mathrm{E}-12 \quad 5.301 \mathrm{E}-12 \quad 8.939 \mathrm{E}-12 \quad 1.524 \mathrm{E}-11 \quad 1.085 \mathrm{E}-09 \quad 5.635 \mathrm{E}-02 \quad 2.678 \mathrm{E}+00$

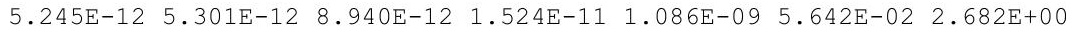

$\begin{array}{lllllll}1.227 \mathrm{E}-28 & 8.678 \mathrm{E}-28 & 1.702 \mathrm{E}-24 & 1.226 \mathrm{E}-23 & 3.685 \mathrm{E}-20 & 1.069 \mathrm{E}-08 & 9.450 \mathrm{E}-06\end{array}$

$\begin{array}{lllllll}1.785 \mathrm{E}-22 & 5.414 \mathrm{E}-22 & 3.355 \mathrm{E}-20 & 1.245 \mathrm{E}-19 & 9.076 \mathrm{E}-17 & 1.579 \mathrm{E}-05 & 7.534 \mathrm{E}-03\end{array}$

$\begin{array}{lllllll}1.785 \mathrm{E}-22 & 5.414 \mathrm{E}-22 & 3.355 \mathrm{E}-20 & 1.245 \mathrm{E}-19 & 9.079 \mathrm{E}-17 & 1.580 \mathrm{E}-05 & 7.544 \mathrm{E}-03\end{array}$

8.395E-25 1.266E-23 5.984E-19 $\quad 6.539 \mathrm{E}-18 \quad 1.118 \mathrm{E}-14 \quad 1.891 \mathrm{E}-09 \quad 9.148 \mathrm{E}-05$

$\begin{array}{lllllll}1.629 \mathrm{E}-18 & 1.147 \mathrm{E}-17 & 1.758 \mathrm{E}-14 & 9.834 \mathrm{E}-14 & 3.894 \mathrm{E}-11 & 3.741 \mathrm{E}-06 & 7.722 \mathrm{E}-02\end{array}$

$\begin{array}{lllllll}1.629 \mathrm{E}-18 & 1.147 \mathrm{E}-17 & 1.758 \mathrm{E}-14 & 9.835 \mathrm{E}-14 & 3.895 \mathrm{E}-11 & 3.743 \mathrm{E}-06 & 7.731 \mathrm{E}-02\end{array}$

$\begin{array}{llllllll}2.397 \mathrm{E}-08 & 2.362 \mathrm{E}-08 & 1.149 \mathrm{E}-08 & 5.512 \mathrm{E}-09 & 1.540 \mathrm{E}-11 & 1.465 \mathrm{E}-12 & 0.000 \mathrm{E}+00\end{array}$

$\begin{array}{lllllll}0.000 \mathrm{E}+00 & 0.000 \mathrm{E}+00 & 0.000 \mathrm{E}+00 & 0.000 \mathrm{E}+00 & 0.000 \mathrm{E}+00 & 2.147 \mathrm{E}-14 & 0.000 \mathrm{E}+00\end{array}$

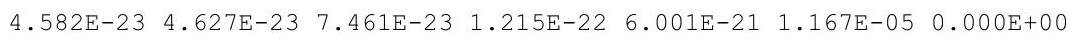

$4.582 \mathrm{E}-23 \quad 4.627 \mathrm{E}-23 \quad 7.461 \mathrm{E}-23 \quad 1.215 \mathrm{E}-22 \quad 6.001 \mathrm{E}-21 \quad 1.167 \mathrm{E}-05 \quad 0.000 \mathrm{E}+00$

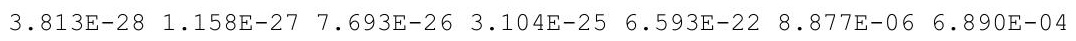
$\begin{array}{llllllll}1.103 E-21 & 1.123 \mathrm{E}-21 & 2.673 \mathrm{E}-21 & 6.475 \mathrm{E}-21 & 7.677 \mathrm{E}-18 & 1.014 \mathrm{E}-01 & 7.868 \mathrm{E}+00\end{array}$ $\begin{array}{llllllll}1.569 \mathrm{E}-27 & 4.780 \mathrm{E}-27 & 3.827 \mathrm{E}-25 & 1.845 \mathrm{E}-24 & 1.090 \mathrm{E}-20 & 3.024 \mathrm{E}-04 & 2.263 \mathrm{E}-01\end{array}$ $\begin{array}{llllllll}1.103 E-21 & 1.123 E-21 & 2.673 E-21 & 6.477 E-21 & 7.688 E-18 & 1.017 E-01 & 8.095 E+00\end{array}$

$0.000 \mathrm{E}+00 \quad 0.000 \mathrm{E}+00 \quad 6.236 \mathrm{E}-28 \quad 5.079 \mathrm{E}-27 \quad 5.092 \mathrm{E}-23 \quad 1.276 \mathrm{E}-07 \quad 1.301 \mathrm{E}-04$ $2.412 \mathrm{E}-20 \quad 2.453 \mathrm{E}-20 \quad 5.590 \mathrm{E}-20 \quad 1.295 \mathrm{E}-19 \quad 1.078 \mathrm{E}-16 \quad 1.104 \mathrm{E}-01 \quad 1.120 \mathrm{E}+01$ $\begin{array}{llllllll}1.742 \mathrm{E}-25 & 5.304 \mathrm{E}-25 & 4.065 \mathrm{E}-23 & 1.874 \mathrm{E}-22 & 7.741 \mathrm{E}-19 & 1.659 \mathrm{E}-03 & 1.506 \mathrm{E}+00\end{array}$ $\begin{array}{lllllll}0.000 \mathrm{E}+00 & 0.000 \mathrm{E}+00 & 2.909 \mathrm{E}-27 & 2.669 \mathrm{E}-26 & 5.488 \mathrm{E}-22 & 2.466 \mathrm{E}-06 & 2.106 \mathrm{E}-02\end{array}$ $2.412 \mathrm{E}-20 \quad 2.453 \mathrm{E}-20 \quad 5.594 \mathrm{E}-20 \quad 1.297 \mathrm{E}-19 \quad 1.085 \mathrm{E}-16 \quad 1.121 \mathrm{E}-01 \quad 1.273 \mathrm{E}+01$

$\begin{array}{lllllll}3.128 \mathrm{E}-21 & 4.712 \mathrm{E}-20 & 2.054 \mathrm{E}-15 & 2.076 \mathrm{E}-14 & 2.187 \mathrm{E}-11 & 1.226 \mathrm{E}-06 & 1.102 \mathrm{E}-02\end{array}$ $\begin{array}{llllllll}3.774 \mathrm{E}-09 & 1.139 \mathrm{E}-08 & 5.320 \mathrm{E}-07 & 1.479 \mathrm{E}-06 & 1.071 \mathrm{E}-04 & 2.165 \mathrm{E}+00 & 1.199 \mathrm{E}+03\end{array}$ $\begin{array}{llllllll}1.813 \mathrm{E}-14 & 1.277 \mathrm{E}-13 & 1.941 \mathrm{E}-10 & 1.078 \mathrm{E}-09 & 3.993 \mathrm{E}-07 & 1.755 \mathrm{E}-02 & 1.280 \mathrm{E}+02\end{array}$ $\begin{array}{lllllll}1.285 \mathrm{E}-20 & 1.939 \mathrm{E}-19 & 9.281 \mathrm{E}-15 & 1.027 \mathrm{E}-13 & 1.921 \mathrm{E}-10 & 1.804 \mathrm{E}-05 & 1.494 \mathrm{E}+00\end{array}$ $\begin{array}{llllllll}3.774 \mathrm{E}-09 & 1.139 \mathrm{E}-08 & 5.322 \mathrm{E}-07 & 1.480 \mathrm{E}-06 & 1.075 \mathrm{E}-04 & 2.183 \mathrm{E}+00 & 1.328 \mathrm{E}+03\end{array}$

$0.000 \mathrm{E}+00 \quad 2.812 \mathrm{E}-28 \quad 3.031 \mathrm{E}-22 \quad 5.124 \mathrm{E}-21 \quad 1.432 \mathrm{E}-17 \quad 1.929 \mathrm{E}-06 \quad 7.179 \mathrm{E}-03$ $\begin{array}{lllllll}1.819 \mathrm{E}-17 & 1.271 \mathrm{E}-16 & 1.299 \mathrm{E}-13 & 5.314 \mathrm{E}-13 & 7.678 \mathrm{E}-11 & 3.543 \mathrm{E}+00 & 7.839 \mathrm{E}+02\end{array}$ $\begin{array}{llllllll}6.563 \mathrm{E}-23 & 9.844 \mathrm{E}-22 & 3.522 \mathrm{E}-17 & 3.095 \mathrm{E}-16 & 2.685 \mathrm{E}-13 & 2.781 \mathrm{E}-02 & 8.341 \mathrm{E}+01\end{array}$ $\begin{array}{llllllll}0.000 \mathrm{E}+00 & 1.157 \mathrm{E}-27 & 1.349 \mathrm{E}-21 & 2.474 \mathrm{E}-20 & 1.218 \mathrm{E}-16 & 2.774 \mathrm{E}-05 & 9.701 \mathrm{E}-01\end{array}$ $\begin{array}{lllllll}1.819 \mathrm{E}-17 & 1.271 \mathrm{E}-16 & 1.299 \mathrm{E}-13 & 5.317 \mathrm{E}-13 & 7.705 \mathrm{E}-11 & 3.571 \mathrm{E}+00 & 8.683 \mathrm{E}+02\end{array}$

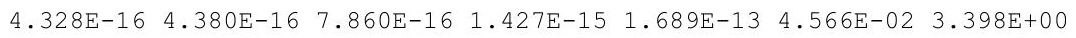

$2.209 \mathrm{E}-22 \quad 6.699 \mathrm{E}-22 \quad 4.126 \mathrm{E}-20 \quad 1.522 \mathrm{E}-19 \quad 1.055 \mathrm{E}-16 \quad 2.265 \mathrm{E}-08 \quad 1.585 \mathrm{E}-04$ $\begin{array}{lllllll}8.081 \mathrm{E}-14 & 8.182 \mathrm{E}-14 & 1.499 \mathrm{E}-13 & 2.779 \mathrm{E}-13 & 3.888 \mathrm{E}-11 & 4.001 \mathrm{E}-03 & 3.252 \mathrm{E}+00\end{array}$ $\begin{array}{lllllll}8.081 \mathrm{E}-14 & 8.182 \mathrm{E}-14 & 1.499 \mathrm{E}-13 & 2.779 \mathrm{E}-13 & 3.888 \mathrm{E}-11 & 4.001 \mathrm{E}-03 & 3.252 \mathrm{E}+00\end{array}$ 
RESRAD, Version 6.5

Summary : C746U Resident Gardener Deterministic Run

File : $X: \backslash F I N A L$ V2 $\backslash$ DOE FWD RUNS \C746U RG DOE SG FWD-FV2-10000YR.RAD

Individual Nuclide Dose Summed Over All Pathways

Parent Nuclide and Branch Fraction Indicated

Nuclide Parent THF(i) DOSE $(j, t), \mathrm{mrem} / \mathrm{yr}$

\begin{tabular}{|c|c|c|c|c|c|c|c|c|c|c|}
\hline (j) & (i) & & $t=$ & $0.000 \mathrm{E}+00$ & $1.000 \mathrm{E}+00$ & $5.000 \mathrm{E}+01$ & $1.000 \mathrm{E}+02$ & $5.000 \mathrm{E}+02$ & $1.050 \mathrm{E}+03$ & $1.000 \mathrm{E}+04$ \\
\hline-231 & $\mathrm{Pu}-239$ & $1.000 \mathrm{E}+00$ & & $3.475 \mathrm{E}-26$ & $2.454 \mathrm{E}-25$ & $4.503 E-22$ & $3.029 \mathrm{E}-21$ & $5.200 \mathrm{E}-18$ & $1.509 \mathrm{E}-08$ & $9.326 \mathrm{E}-05$ \\
\hline-231 & $\mathrm{U}-235$ & $1.000 \mathrm{E}+00$ & & $1.909 \mathrm{E}-17$ & $5.782 \mathrm{E}-17$ & $3.270 \mathrm{E}-15$ & $1.106 \mathrm{E}-14$ & $3.819 \mathrm{E}-12$ & $5.295 \mathrm{E}-03$ & $3.598 \mathrm{E}+00$ \\
\hline-231 & $\sum \operatorname{DOSE}(j)$ & & & $1.909 \mathrm{E}-17$ & $5.782 \mathrm{E}-17$ & $3.270 \mathrm{E}-15$ & $1.106 \mathrm{E}-14$ & $3.819 \mathrm{E}-12$ & $5.295 \mathrm{E}-03$ & $3.598 \mathrm{E}+00$ \\
\hline-227 & $\mathrm{Pu}-239$ & $1.000 \mathrm{E}+00$ & & $8.237 \mathrm{E}-26$ & $1.236 \mathrm{E}-24$ & $4.593 \mathrm{E}-20$ & $4.209 \mathrm{E}-19$ & $5.313 \mathrm{E}-16$ & $6.068 \mathrm{E}-09$ & $8.099 \mathrm{E}-05$ \\
\hline-227 & $\mathrm{U}-235$ & $1.000 \mathrm{E}+00$ & & $6.028 \mathrm{E}-17$ & $4.213 \mathrm{E}-16$ & $4.473 E-13$ & $1.913 \mathrm{E}-12$ & $4.144 \mathrm{E}-10$ & $2.192 \mathrm{E}-03$ & $3.134 \mathrm{E}+00$ \\
\hline-227 & $\sum \operatorname{DOSE}(j)$ & & & $6.028 \mathrm{E}-17$ & $4.213 \mathrm{E}-16$ & $4.473 \mathrm{E}-13$ & $1.913 \mathrm{E}-12$ & $4.144 \mathrm{E}-10$ & $2.192 \mathrm{E}-03$ & $3.134 \mathrm{E}+00$ \\
\hline-240 & $\mathrm{Pu}-240$ & $4.950 \mathrm{E}-08$ & & $0.000 \mathrm{E}+00$ & $0.000 \mathrm{E}+00$ & $0.000 \mathrm{E}+00$ & $0.000 \mathrm{E}+00$ & $1.313 \mathrm{E}-26$ & $2.084 \mathrm{E}-09$ & $7.763 \mathrm{E}-08$ \\
\hline-240 & $\mathrm{Pu}-240$ & $1.000 \mathrm{E}+00$ & & $4.111 \mathrm{E}-23$ & $4.184 \mathrm{E}-23$ & $9.884 \mathrm{E}-23$ & $2.376 \mathrm{E}-22$ & $2.652 \mathrm{E}-19$ & $4.210 \mathrm{E}-02$ & $1.568 \mathrm{E}+00$ \\
\hline $1-240$ & $\sum \operatorname{DOSE}(j)$ & & & $4.111 \mathrm{E}-23$ & $4.184 \mathrm{E}-23$ & $9.884 \mathrm{E}-23$ & $2.376 \mathrm{E}-22$ & $2.652 \mathrm{E}-19$ & $4.210 \mathrm{E}-02$ & $1.568 \mathrm{E}+00$ \\
\hline 236 & $\mathrm{Pu}-240$ & $1.000 \mathrm{E}+00$ & & $0.000 \mathrm{E}+00$ & $0.000 \mathrm{E}+00$ & $1.921 E-28$ & $9.367 \mathrm{E}-28$ & $6.069 \mathrm{E}-24$ & $6.493 \mathrm{E}-07$ & $3.267 \mathrm{E}-04$ \\
\hline$h-232$ & $\mathrm{Pu}-240$ & $1.000 \mathrm{E}+00$ & & $0.000 \mathrm{E}+00$ & $0.000 \mathrm{E}+00$ & $0.000 \mathrm{E}+00$ & $0.000 \mathrm{E}+00$ & $0.000 \mathrm{E}+00$ & $3.373 \mathrm{E}-14$ & $2.275 \mathrm{E}-10$ \\
\hline$h-232$ & Th-232 & $1.000 \mathrm{E}+00$ & & $4.663 \mathrm{E}-24$ & $4.751 \mathrm{E}-24$ & $1.180 \mathrm{E}-23$ & $2.985 \mathrm{E}-23$ & $5.010 \mathrm{E}-20$ & $4.883 \mathrm{E}-03$ & $5.347 \mathrm{E}-01$ \\
\hline$h-232$ & $\sum \operatorname{DOSE}(j)$ & & & $4.663 \mathrm{E}-24$ & $4.751 \mathrm{E}-24$ & $1.180 \mathrm{E}-23$ & $2.985 \mathrm{E}-23$ & $5.010 \mathrm{E}-20$ & $4.883 \mathrm{E}-03$ & $5.347 \mathrm{E}-01$ \\
\hline-228 & $\mathrm{Pu}-240$ & $1.000 \mathrm{E}+00$ & & $4.934 \mathrm{E}-27$ & $7.265 \mathrm{E}-26$ & $1.354 \mathrm{E}-21$ & $9.150 \mathrm{E}-21$ & $5.290 \mathrm{E}-18$ & $3.968 \mathrm{E}-12$ & $2.888 \mathrm{E}-08$ \\
\hline $\mathrm{R} a-228$ & $T h-232$ & $1.000 \mathrm{E}+00$ & & $4.430 \mathrm{E}-09$ & $1.270 \mathrm{E}-08$ & $1.114 \mathrm{E}-07$ & $1.632 \mathrm{E}-07$ & $3.399 \mathrm{E}-06$ & $5.834 \mathrm{E}-01$ & $6.795 \mathrm{E}+01$ \\
\hline $\mathrm{Ra}-228$ & $\sum \operatorname{DOSE}(j)$ & & & $4.430 \mathrm{E}-09$ & $1.270 \mathrm{E}-08$ & $1.114 \mathrm{E}-07$ & $1.632 \mathrm{E}-07$ & $3.399 \mathrm{E}-06$ & $5.834 \mathrm{E}-01$ & $6.795 \mathrm{E}+01$ \\
\hline$T h-228$ & $\mathrm{Pu}-240$ & $1.000 \mathrm{E}+00$ & & $2.920 \mathrm{E}-26$ & $8.403 E-25$ & $9.508 \mathrm{E}-20$ & $6.326 \mathrm{E}-19$ & $2.003 E-16$ & $5.438 \mathrm{E}-14$ & $1.316 \mathrm{E}-08$ \\
\hline$T h-228$ & Th-228 & $1.000 \mathrm{E}+00$ & & $5.530 \mathrm{E}-06$ & $3.872 \mathrm{E}-06$ & $1.011 \mathrm{E}-13$ & $1.847 \mathrm{E}-21$ & $0.000 \mathrm{E}+00$ & $0.000 \mathrm{E}+00$ & $0.000 \mathrm{E}+00$ \\
\hline-228 & Th-232 & $1.000 \mathrm{E}+00$ & & $4.269 \mathrm{E}-08$ & $2.633 \mathrm{E}-07$ & $8.852 \mathrm{E}-06$ & $1.197 \mathrm{E}-05$ & $1.301 \mathrm{E}-04$ & $8.028 \mathrm{E}-03$ & $3.098 \mathrm{E}+01$ \\
\hline-228 & $\sum \operatorname{DOSE}(j)$ & & & $5.572 \mathrm{E}-06$ & $4.135 \mathrm{E}-06$ & $8.852 E-06$ & $1.197 \mathrm{E}-05$ & $1.301 \mathrm{E}-04$ & $8.028 \mathrm{E}-03$ & $3.098 \mathrm{E}+01$ \\
\hline-99 & TC-99 & $1.000 \mathrm{E}+00$ & & $2.994 \mathrm{E}-24$ & $3.025 \mathrm{E}-24$ & $4.979 \mathrm{E}-24$ & $8.280 \mathrm{E}-24$ & $4.841 \mathrm{E}-22$ & $6.892 \mathrm{E}-05$ & $0.000 \mathrm{E}+00$ \\
\hline $\mathrm{U}-238$ & $\mathrm{U}-238$ & $5.400 \mathrm{E}-05$ & & $0.000 \mathrm{E}+00$ & $0.000 \mathrm{E}+00$ & $0.000 \mathrm{E}+00$ & $0.000 \mathrm{E}+00$ & $0.000 \mathrm{E}+00$ & $5.067 \mathrm{E}-06$ & $4.019 \mathrm{E}-04$ \\
\hline $\mathrm{U}-238$ & $\mathrm{U}-238$ & $9.999 \mathrm{E}-01$ & & $2.271 \mathrm{E}-08$ & $2.290 \mathrm{E}-08$ & $3.385 E-08$ & $5.045 \mathrm{E}-08$ & $1.229 \mathrm{E}-06$ & $1.010 \mathrm{E}-01$ & $2.413 \mathrm{E}+01$ \\
\hline-238 & $\sum \operatorname{DOSE}(j)$ & & & $2.271 \mathrm{E}-08$ & $2.290 \mathrm{E}-08$ & $3.385 E-08$ & $5.045 \mathrm{E}-08$ & $1.229 \mathrm{E}-06$ & $1.010 \mathrm{E}-01$ & $2.413 E+01$ \\
\hline
\end{tabular}

THF(i) is the thread fraction of the parent nuclide. 
RESRAD, Version 6.5

Summary : C746U Resident Gardener Deterministic Run

File : $\mathrm{X}: \backslash F I N A L$ V2 \DOE FWD RUNS \C746U RG DOE SG FWD-FV2-10000YR.RAD

Individual Nuclide Soil Concentration

Parent Nuclide and Branch Fraction Indicated

Nuclide Parent THF(

(j)

$\operatorname{Am}-241$

(i)

$\overline{\mathrm{Am}-241} \overline{1.000 \mathrm{E}+00}$

Np-237 Am-241 $1.000 E+00$

$\mathrm{Np}-237 \quad \mathrm{~Np}-237 \quad 1.000 \mathrm{E}+00$

Np-237 $\sum S(j):$

$\mathrm{U}-233 \quad \mathrm{Am}-241 \quad 1.000 \mathrm{E}+00$

$\mathrm{U}-233 \quad \mathrm{~Np}-237 \quad 1.000 \mathrm{E}+00$

$\mathrm{U}-233 \sum \mathrm{S}(\mathrm{j}):$

Th -229

Th-229

Th-229

Cs-137

$\mathrm{Pu}-238$

$\mathrm{Pu}-238$

$\mathrm{Pu}-238$

$\mathrm{U}-234$

$\mathrm{U}-234$

$\mathrm{U}-234$

$\mathrm{U}-234$

Th-230

Th-230

Th -230

Th -230

Th -230

$\mathrm{Ra}-226$

$\mathrm{Ra}-226$

$\mathrm{Ra}-226$

$\mathrm{Ra}-226$

$\operatorname{Ra}-226$

$\mathrm{Pb}-210$

$\mathrm{Pb}-210$

$\mathrm{Pb}-210$

$\mathrm{Pb}-210$

$\mathrm{Pb}-210$

$\mathrm{Pu}-239$
Am-241 $1.000 \mathrm{E}+00$

Np-237 1.000E+00

$\sum S(j):$

Cs $-137 \quad 1.000 E+00$

Pu-238 1.840E-09

$\sum S(j):$

$\mathrm{Pu}-238 \quad 1.000 \mathrm{E}+00$

$\mathrm{U}-234 \quad 1.000 \mathrm{E}+00$

$\sum S(j):$

$\mathrm{Pu}-238 \quad 1.000 \mathrm{E}+00$

Th-230 1.000E+00

U-234 $1.000 \mathrm{E}+00$

U-238 $9.999 \mathrm{E}-01$

$\sum S(j):$

Th-230 1.000E+00

$\mathrm{U}-234 \quad 1.000 \mathrm{E}+00$

$\mathrm{U}-238 \quad 9.999 \mathrm{E}-01$

$\sum S(j):$

$\mathrm{Pu}-238 \quad 1.000 \mathrm{E}+00$

Th-230 1.000E+00

$\mathrm{U}-2341.000 \mathrm{E}+00$

U-238 9.999E-01

$\sum S(j):$

$\mathrm{Pu}-239 \quad 1.000 \mathrm{E}+00$

$\mathrm{Pu}-239 \quad 1.000 \mathrm{E}+00$

$\mathrm{U}-2351.000 \mathrm{E}+00$

$\sum S(j):$
$\mathrm{Pu}-238 \quad 1.000 \mathrm{E}+00$

$\mathrm{U}-238 \quad 9.999 \mathrm{E}-01$

$\mathrm{Pu}-238 \quad 1.000 \mathrm{E}+00$
$\mathrm{S}(j, \mathrm{t}), \mathrm{pCi} / \mathrm{g}$

$\mathrm{t}=0.000 \mathrm{E}+00 \quad 1.000 \mathrm{E}+00 \quad 5.000 \mathrm{E}+01 \quad 1.000 \mathrm{E}+02 \quad 5.000 \mathrm{E}+02 \quad 1.050 \mathrm{E}+03 \quad 1.000 \mathrm{E}+04$

$\begin{array}{llllllllll}3.500 \mathrm{E}+01 & 3.494 \mathrm{E}+01 & 3.229 \mathrm{E}+01 & 2.980 \mathrm{E}+01 & 1.566 \mathrm{E}+01 & 6.464 \mathrm{E}+00 & 3.610 \mathrm{E}-06\end{array}$

$0.000 \mathrm{E}+00 \quad 1.133 \mathrm{E}-05 \quad 5.428 \mathrm{E}-04 \quad 1.040 \mathrm{E}-03 \quad 3.749 \mathrm{E}-03 \quad 5.255 \mathrm{E}-03 \quad 1.996 \mathrm{E}-03$

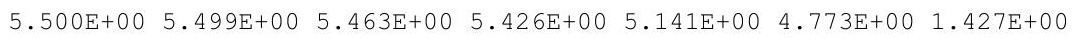

$\begin{array}{lllllll}5.500 \mathrm{E}+00 & 5.499 \mathrm{E}+00 & 5.464 \mathrm{E}+00 & 5.427 \mathrm{E}+00 & 5.145 \mathrm{E}+00 & 4.779 \mathrm{E}+00 & 1.429 \mathrm{E}+00\end{array}$

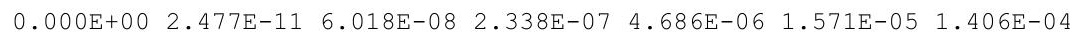

$\begin{array}{lllllll}0.000 \mathrm{E}+00 & 2.405 \mathrm{E}-05 & 1.198 \mathrm{E}-03 & 2.386 \mathrm{E}-03 & 1.155 \mathrm{E}-02 & 2.320 \mathrm{E}-02 & 1.121 \mathrm{E}-01\end{array}$

$\begin{array}{lllllll}0.000 \mathrm{E}+00 & 2.405 \mathrm{E}-05 & 1.198 \mathrm{E}-03 & 2.386 \mathrm{E}-03 & 1.155 \mathrm{E}-02 & 2.322 \mathrm{E}-02 & 1.122 \mathrm{E}-01\end{array}$

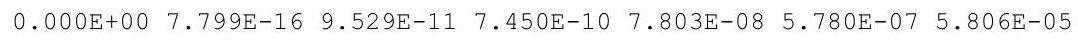

$0.000 \mathrm{E}+00 \quad 1.136 \mathrm{E}-09 \quad 2.827 \mathrm{E}-06 \quad 1.126 \mathrm{E}-05 \quad 2.719 \mathrm{E}-04 \quad 1.144 \mathrm{E}-03 \quad 4.901 \mathrm{E}-02$

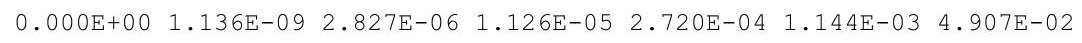

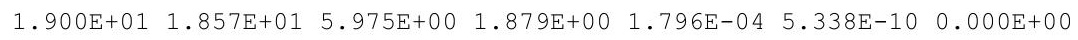

$\begin{array}{lllllll}7.176 \mathrm{E}-08 & 7.119 \mathrm{E}-08 & 4.830 \mathrm{E}-08 & 3.251 \mathrm{E}-08 & 1.370 \mathrm{E}-09 & 1.760 \mathrm{E}-11 & 2.951 \mathrm{E}-42\end{array}$

$\begin{array}{llllllll}3.900 \mathrm{E}+01 & 3.869 \mathrm{E}+01 & 2.625 \mathrm{E}+01 & 1.767 \mathrm{E}+01 & 7.445 \mathrm{E}-01 & 9.567 \mathrm{E}-03 & 1.612 \mathrm{E}-33\end{array}$

$\begin{array}{lllllllll}3.900 \mathrm{E}+01 & 3.869 \mathrm{E}+01 & 2.625 \mathrm{E}+01 & 1.767 \mathrm{E}+01 & 7.445 \mathrm{E}-01 & 9.567 \mathrm{E}-03 & 1.612 \mathrm{E}-33\end{array}$

$0.000 \mathrm{E}+00 \quad 1.101 \mathrm{E}-04 \quad 4.562 \mathrm{E}-03 \quad 7.627 \mathrm{E}-03 \quad 1.356 \mathrm{E}-02 \quad 1.363 \mathrm{E}-02 \quad 1.082 \mathrm{E}-02$

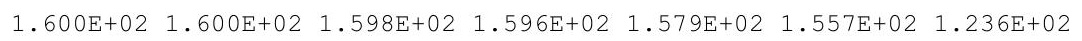

$\begin{array}{llllllll}0.000 \mathrm{E}+00 & 4.536 \mathrm{E}-04 & 2.265 \mathrm{E}-02 & 4.525 \mathrm{E}-02 & 2.240 \mathrm{E}-01 & 4.642 \mathrm{E}-01 & 3.553 \mathrm{E}+00\end{array}$

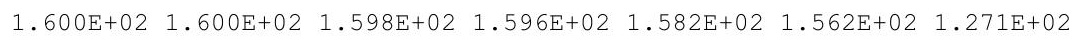

$0.000 \mathrm{E}+00 \quad 4.963 \mathrm{E}-10 \quad 1.094 \mathrm{E}-06 \quad 3.882 \mathrm{E}-06 \quad 4.691 \mathrm{E}-05 \quad 1.141 \mathrm{E}-04 \quad 1.031 \mathrm{E}-03$ $\begin{array}{lllllllll}1.000 \mathrm{E}+02 & 1.000 \mathrm{E}+02 & 9.994 \mathrm{E}+01 & 9.988 \mathrm{E}+01 & 9.940 \mathrm{E}+01 & 9.875 \mathrm{E}+01 & 8.874 \mathrm{E}+01\end{array}$ $0.000 \mathrm{E}+00 \quad 1.440 \mathrm{E}-03 \quad 7.195 \mathrm{E}-02 \quad 1.438 \mathrm{E}-01 \quad 7.134 \mathrm{E}-01 \quad 1.483 \mathrm{E}+00 \quad 1.193 \mathrm{E}+01$ $\begin{array}{lllllll}0.000 \mathrm{E}+00 & 2.041 \mathrm{E}-09 & 5.099 \mathrm{E}-06 & 2.037 \mathrm{E}-05 & 5.052 \mathrm{E}-04 & 2.203 \mathrm{E}-03 & 1.668 \mathrm{E}-01\end{array}$

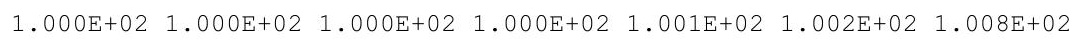

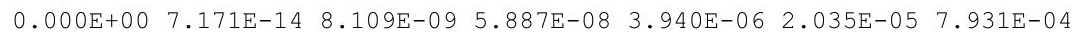
$\begin{array}{llllllll}0.000 \mathrm{E}+00 & 4.331 \mathrm{E}-02 & 2.141 \mathrm{E}+00 & 4.233 \mathrm{E}+00 & 1.933 \mathrm{E}+01 & 3.597 \mathrm{E}+01 & 8.627 \mathrm{E}+01\end{array}$ $\begin{array}{lllllll}0.000 \mathrm{E}+00 & 3.119 \mathrm{E}-07 & 7.736 \mathrm{E}-04 & 3.069 \mathrm{E}-03 & 7.197 \mathrm{E}-02 & 2.914 \mathrm{E}-01 & 9.214 \mathrm{E}+00\end{array}$ $\begin{array}{lllllll}0.000 \mathrm{E}+00 & 2.948 \mathrm{E}-13 & 3.662 \mathrm{E}-08 & 2.911 \mathrm{E}-07 & 3.459 \mathrm{E}-05 & 2.994 \mathrm{E}-04 & 1.075 \mathrm{E}-01\end{array}$ $\begin{array}{lllllll}0.000 \mathrm{E}+00 & 4.331 \mathrm{E}-02 & 2.142 \mathrm{E}+00 & 4.236 \mathrm{E}+00 & 1.940 \mathrm{E}+01 & 3.626 \mathrm{E}+01 & 9.560 \mathrm{E}+01\end{array}$

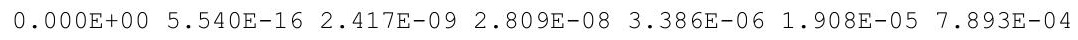
$\begin{array}{llllllll}0.000 \mathrm{E}+00 & 6.662 \mathrm{E}-04 & 1.057 \mathrm{E}+00 & 2.944 \mathrm{E}+00 & 1.819 \mathrm{E}+01 & 3.507 \mathrm{E}+01 & 8.620 \mathrm{E}+01\end{array}$ $\begin{array}{lllllll}0.000 \mathrm{E}+00 & 3.207 \mathrm{E}-09 & 2.836 \mathrm{E}-04 & 1.705 \mathrm{E}-03 & 6.353 \mathrm{E}-02 & 2.751 \mathrm{E}-01 & 9.171 \mathrm{E}+00\end{array}$ $\begin{array}{lllllll}0.000 \mathrm{E}+00 & 2.276 \mathrm{E}-15 & 1.075 \mathrm{E}-08 & 1.355 \mathrm{E}-07 & 2.879 \mathrm{E}-05 & 2.742 \mathrm{E}-04 & 1.066 \mathrm{E}-01\end{array}$ $\begin{array}{llllllll}0.000 \mathrm{E}+00 & 6.663 \mathrm{E}-04 & 1.058 \mathrm{E}+00 & 2.945 \mathrm{E}+00 & 1.825 \mathrm{E}+01 & 3.534 \mathrm{E}+01 & 9.547 \mathrm{E}+01\end{array}$

$\begin{array}{lllllllll}3.600 \mathrm{E}+01 & 3.600 \mathrm{E}+01 & 3.592 \mathrm{E}+01 & 3.583 \mathrm{E}+01 & 3.518 \mathrm{E}+01 & 3.430 \mathrm{E}+01 & 2.274 \mathrm{E}+01\end{array}$

$0.000 \mathrm{E}+00 \quad 3.545 \mathrm{E}-08 \quad 1.770 \mathrm{E}-06 \quad 3.533 \mathrm{E}-06 \quad 1.742 \mathrm{E}-05 \quad 3.591 \mathrm{E}-05 \quad 2.517 \mathrm{E}-04$ $\begin{array}{lllllll}6.500 \mathrm{E}+00 & 6.500 \mathrm{E}+00 & 6.493 \mathrm{E}+00 & 6.485 \mathrm{E}+00 & 6.426 \mathrm{E}+00 & 6.345 \mathrm{E}+00 & 5.165 \mathrm{E}+00\end{array}$

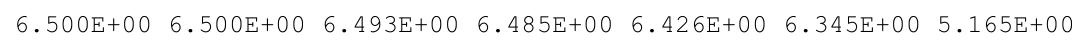


RESRAD, Version 6.5

Summary : C746U Resident Gardener Deterministic Run

File : $X: \backslash F I N A L$ V2 \DOE FWD RUNS \C746U RG DOE SG FWD-FV2-10000YR.RAD

Individual Nuclide Soil Concentration

Parent Nuclide and Branch Fraction Indicated

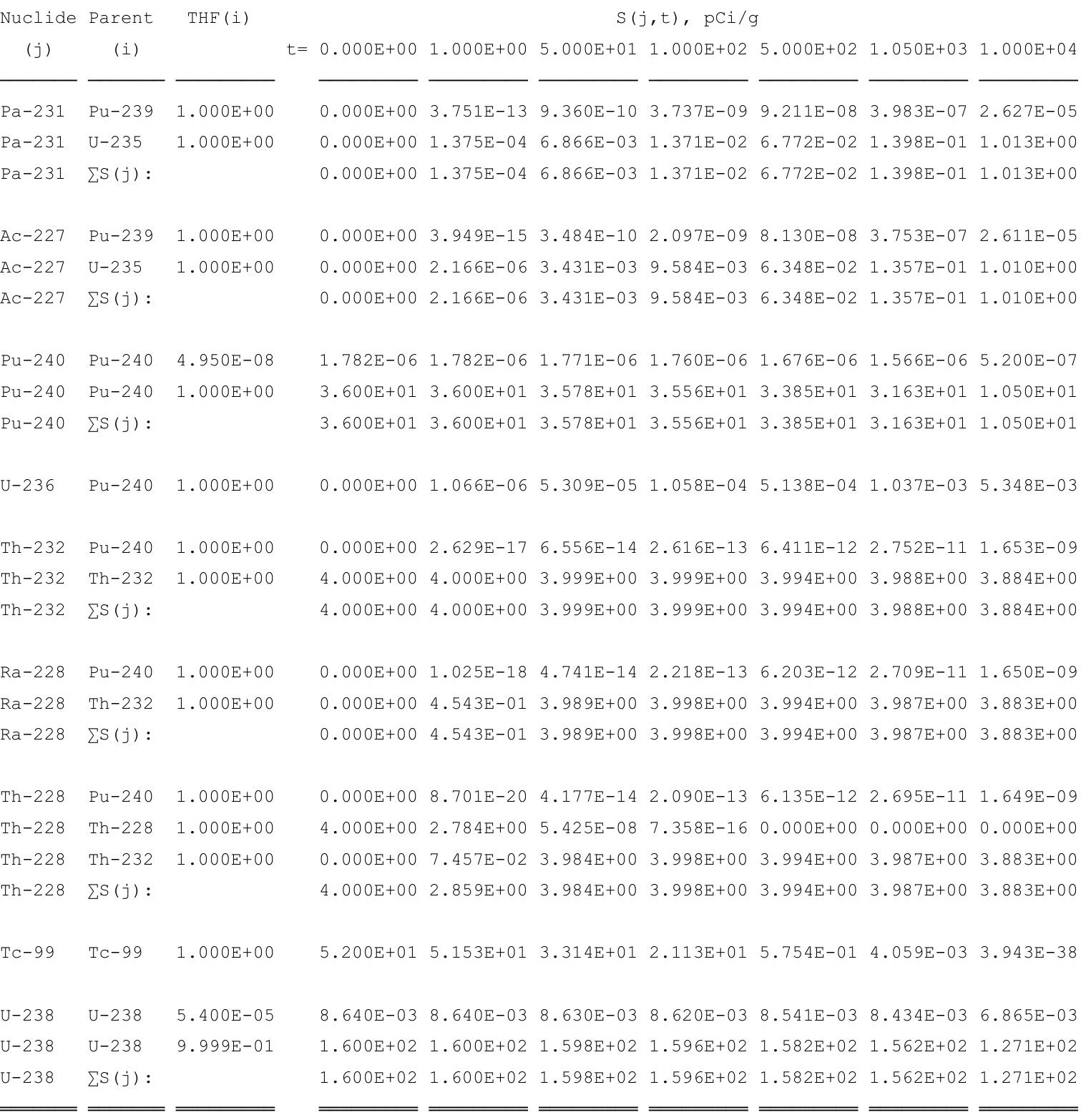

THF(i) is the thread fraction of the parent nuclide.

RESCALC.EXE execution time $=4.36$ seconds 


\section{Resident Gardener}

\section{Summary Report \\ (Deterministic Analysis Report)}

Third Peak Dose Assessment

Time Horizon: 100,000 yr 
THIS PAGE INTENTIONALLY LEFT BLANK 
RESRAD, Version $6.5 \quad T^{1 / 2}$ Limit $=180$ days

Summary : C746U Resident Gardener Deterministic Run

File : $\mathrm{X}: \backslash F I N A L$ V2 $\backslash$ DOE FWD RUNS \C746U RG DOE SG FWD-FV2-100000YR.RAD

Table of Contents

Part I: Mixture Sums and Single Radionuclide Guidelines

Dose Conversion Factor (and Related) Parameter Summary ... 2

Site-Specific Parameter Summary ................ 8

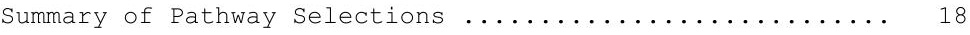

Contaminated Zone and Total Dose Summary ............. 19

Total Dose Components

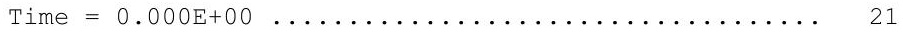

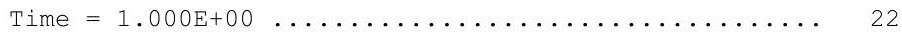

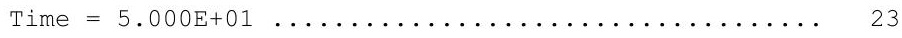

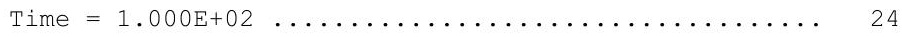

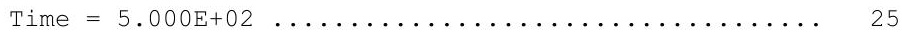

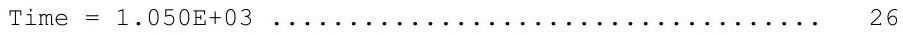

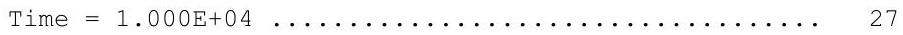

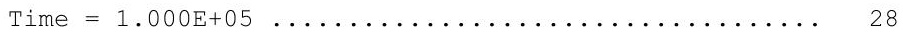

Dose/Source Ratios Summed Over All Pathways ........... 29

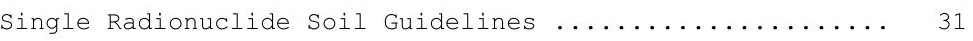

Dose Per Nuclide Summed Over All Pathways ............ 32

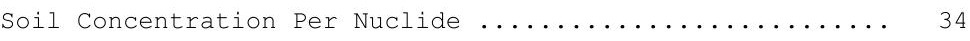


Summary : C746U Resident Gardener Deterministic Run

File : X: $\backslash F I N A L$ V2 $\backslash$ DOE FWD RUNS \C746U RG DOE SG FWD-FV2-100000YR.RAD

Dose Conversion Factor (and Related) Parameter Summary

Dose Library: ICRP 60 \& ICRP 72 (Adult)

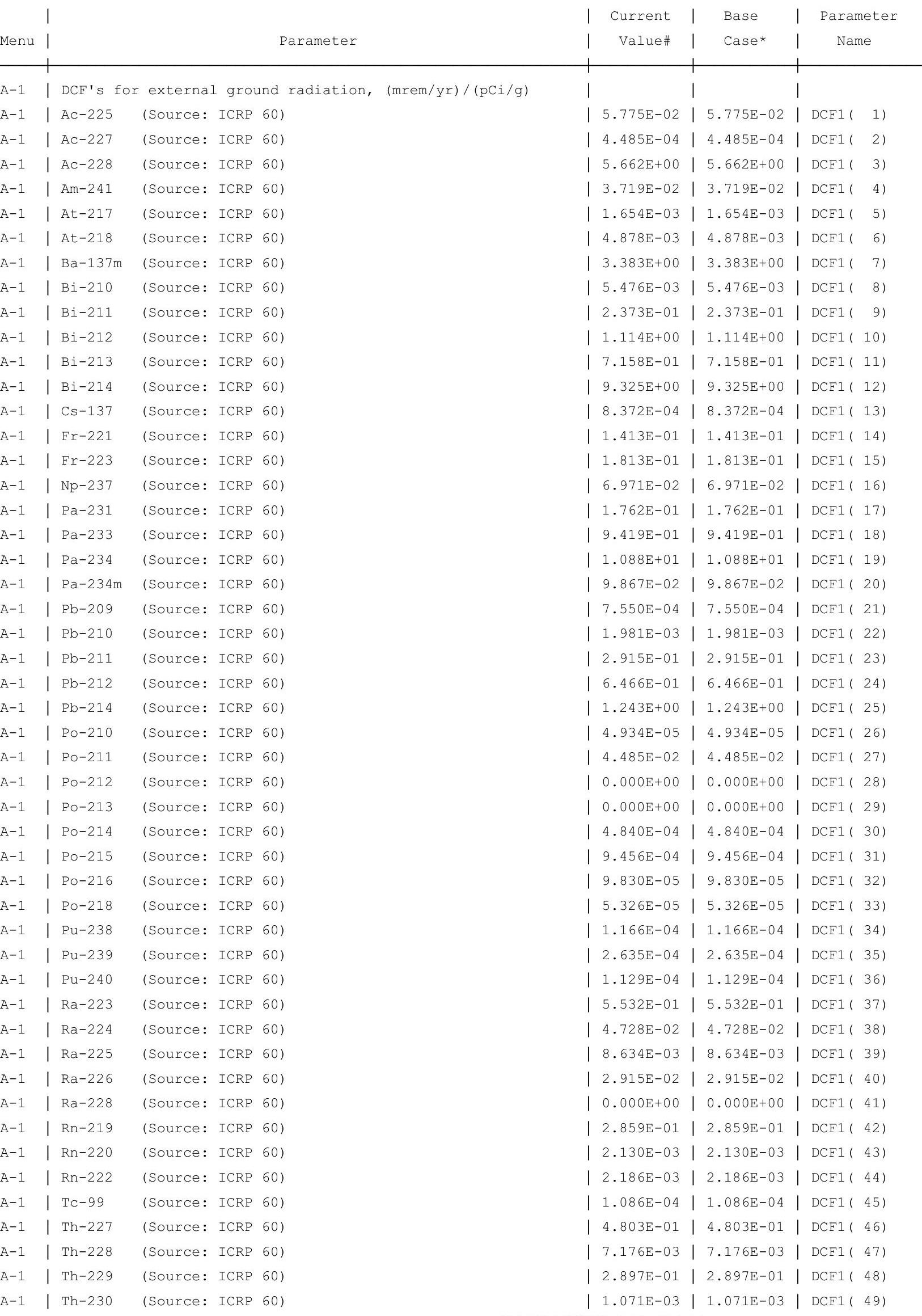


RESRAD, Version $6.5 \quad \mathrm{~T}^{\mathbb{1} 1 / 2}$ Limit $=180$ days

Summary : C746U Resident Gardener Deterministic Run

File : X: $\backslash F I N A L$ V2 $\backslash$ DOE FWD RUNS \C746U RG DOE SG FWD-FV2-100000YR.RAD

Dose Conversion Factor (and Related) Parameter Summary (continued)

Dose Library: ICRP 60 \& ICRP 72 (Adult)

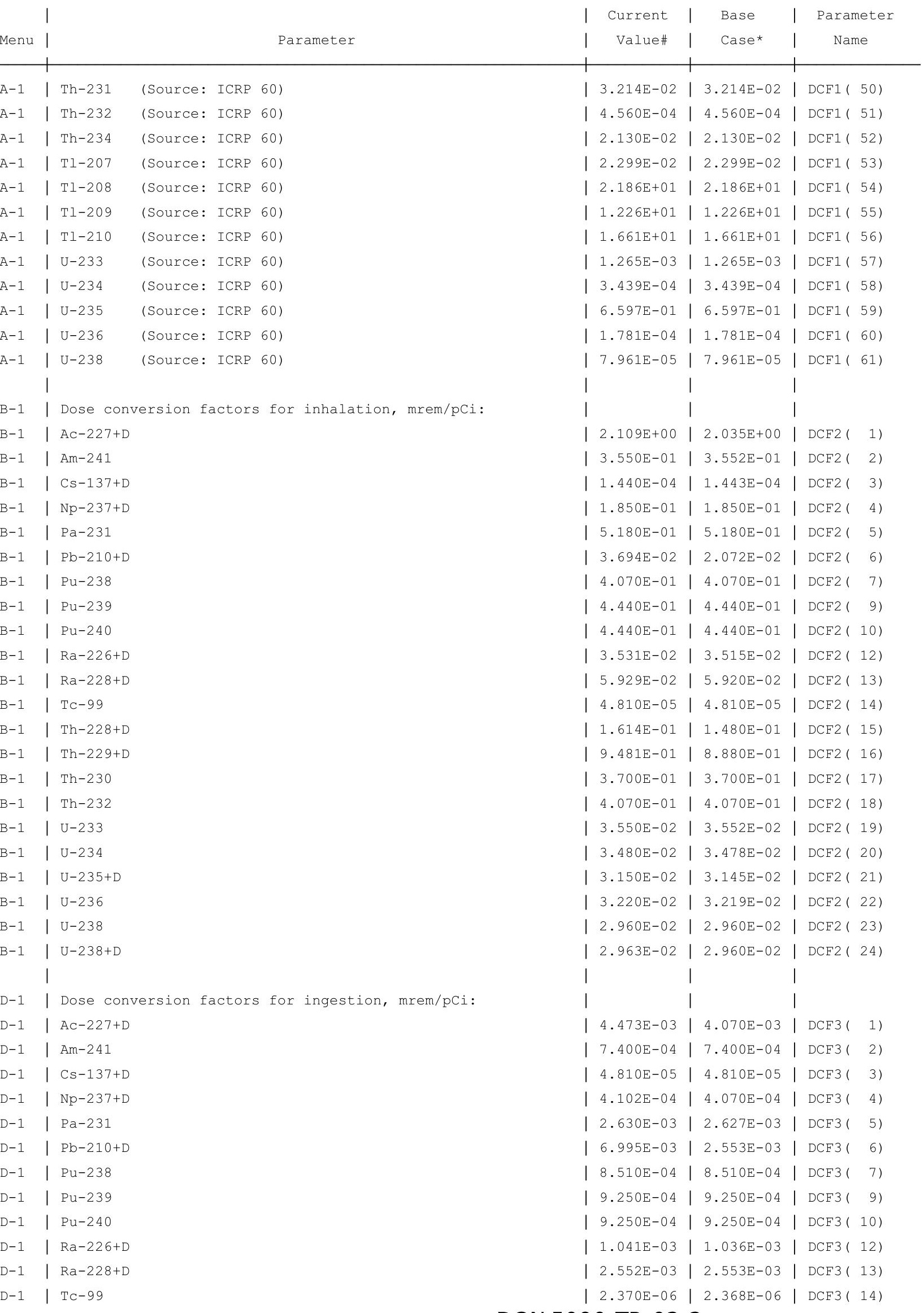


RESRAD, Version $6.5 \quad T^{1 / 2}$ Limit $=180$ days

Summary : C746U Resident Gardener Deterministic Run

File : X: $\backslash F I N A L$ V2 $\backslash$ DOE FWD RUNS \C746U RG DOE SG FWD-FV2-100000YR.RAD

Dose Conversion Factor (and Related) Parameter Summary (continued)

Dose Library: ICRP 60 \& ICRP 72 (Adult)

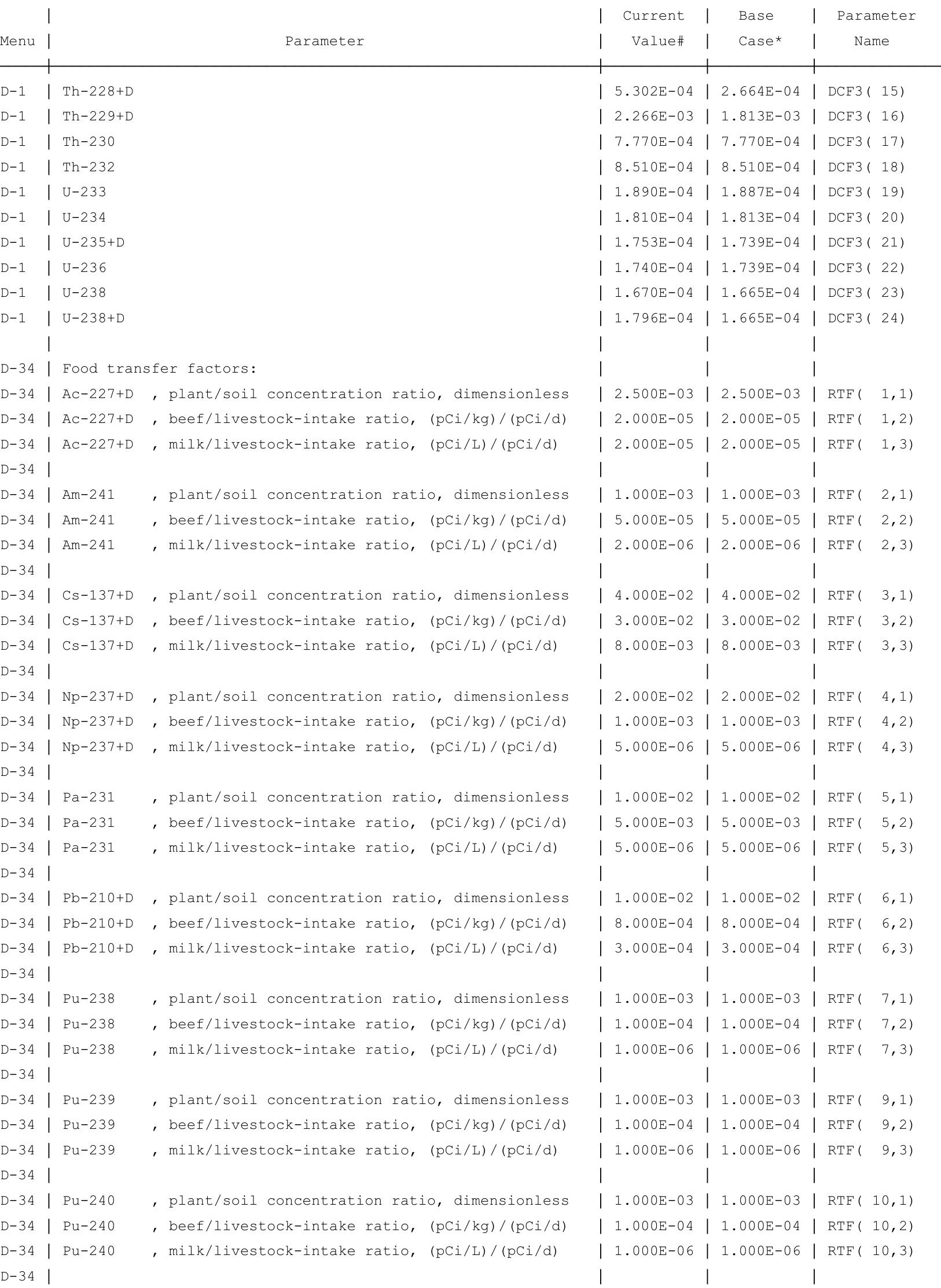


RESRAD, Version $6.5 \quad T^{1 / 2}$ Limit $=180$ days

Summary : C746U Resident Gardener Deterministic Run

File : $\mathrm{X}: \backslash F I N A L$ V2 $\backslash$ DOE FWD RUNS \C746U RG DOE SG FWD-FV2-100000YR. RAD

Dose Conversion Factor (and Related) Parameter Summary (continued)

Dose Library: ICRP 60 \& ICRP 72 (Adult)

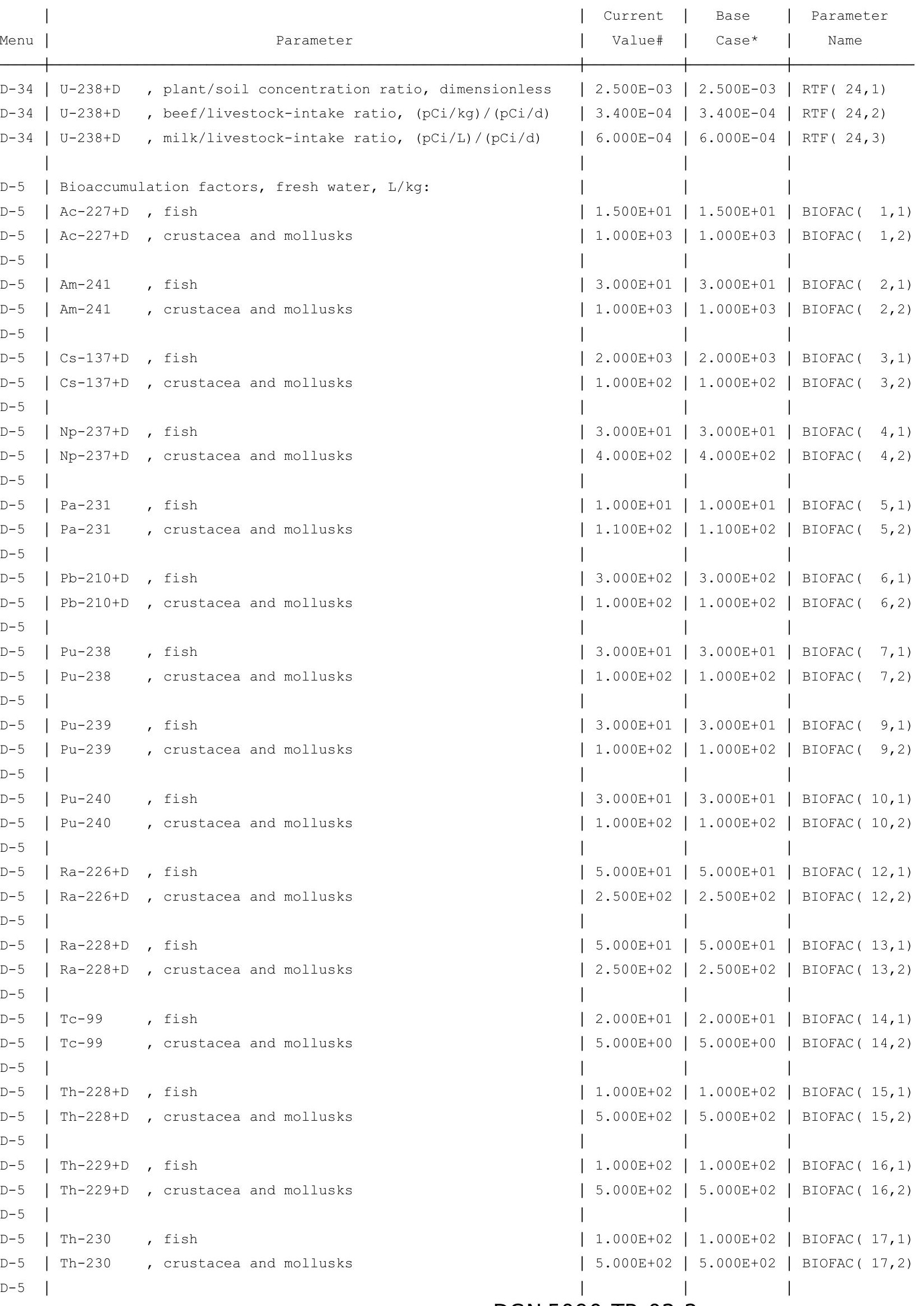


RESRAD, Version $6.5 \quad \mathrm{~T}^{1 / 2}$ Limit $=180$ days

Summary : C746U Resident Gardener Deterministic Run

File : $\mathrm{X}: \backslash F I N A L$ V2 $\backslash$ DOE FWD RUNS \C746U RG DOE SG FWD-FV2-100000YR.RAD

Dose Conversion Factor (and Related) Parameter Summary (continued)

Dose Library: ICRP 60 \& ICRP 72 (Adult)

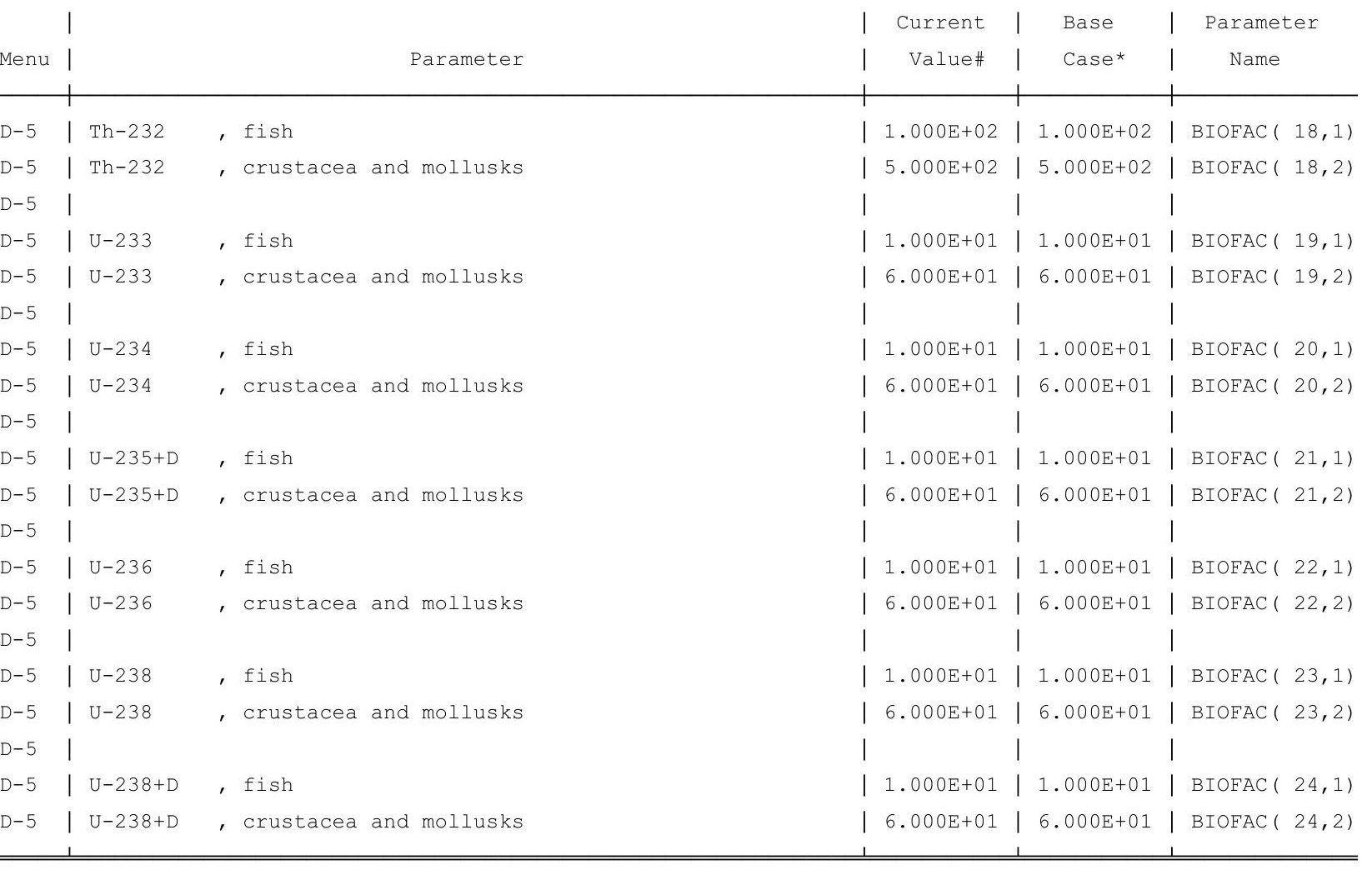

\#For DCF1(xxx) only, factors are for infinite depth \& area. See ETFG table in Ground Pathway of Detailed Report. *Base Case means Default.Lib w/o Associate Nuclide contributions. 
RESRAD, Version $6.5 \quad T^{1 / 2}$ Limit $=180$ days

Summary : C746U Resident Gardener Deterministic Run

File : $\mathrm{X}: \backslash F I N A L$ V2 $\backslash$ DOE FWD RUNS $\backslash C 746 U$ RG DOE SG FWD-FV2-100000YR.RAD

Site-Specific Parameter Summary (continued)

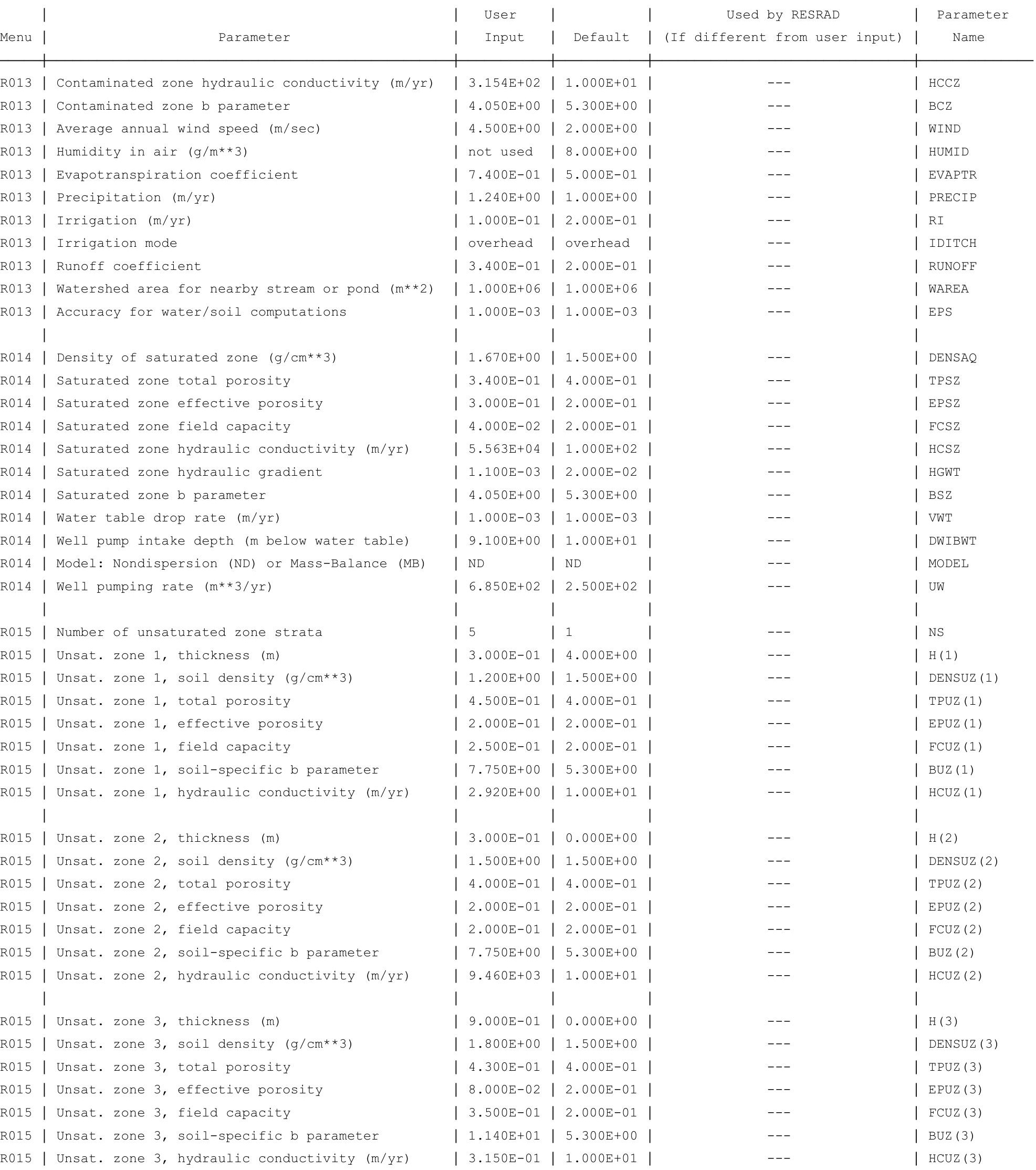


RESRAD, Version $6.5 \quad \mathrm{~T}^{1} \frac{1}{2}$ Limit $=180$ days

Summary : C746U Resident Gardener Deterministic Run

File : $\mathrm{X}: \backslash F I N A L$ V2 $\backslash$ DOE FWD RUNS \C746U RG DOE SG FWD-FV2-100000YR.RAD

Site-Specific Parameter Summary (continued)

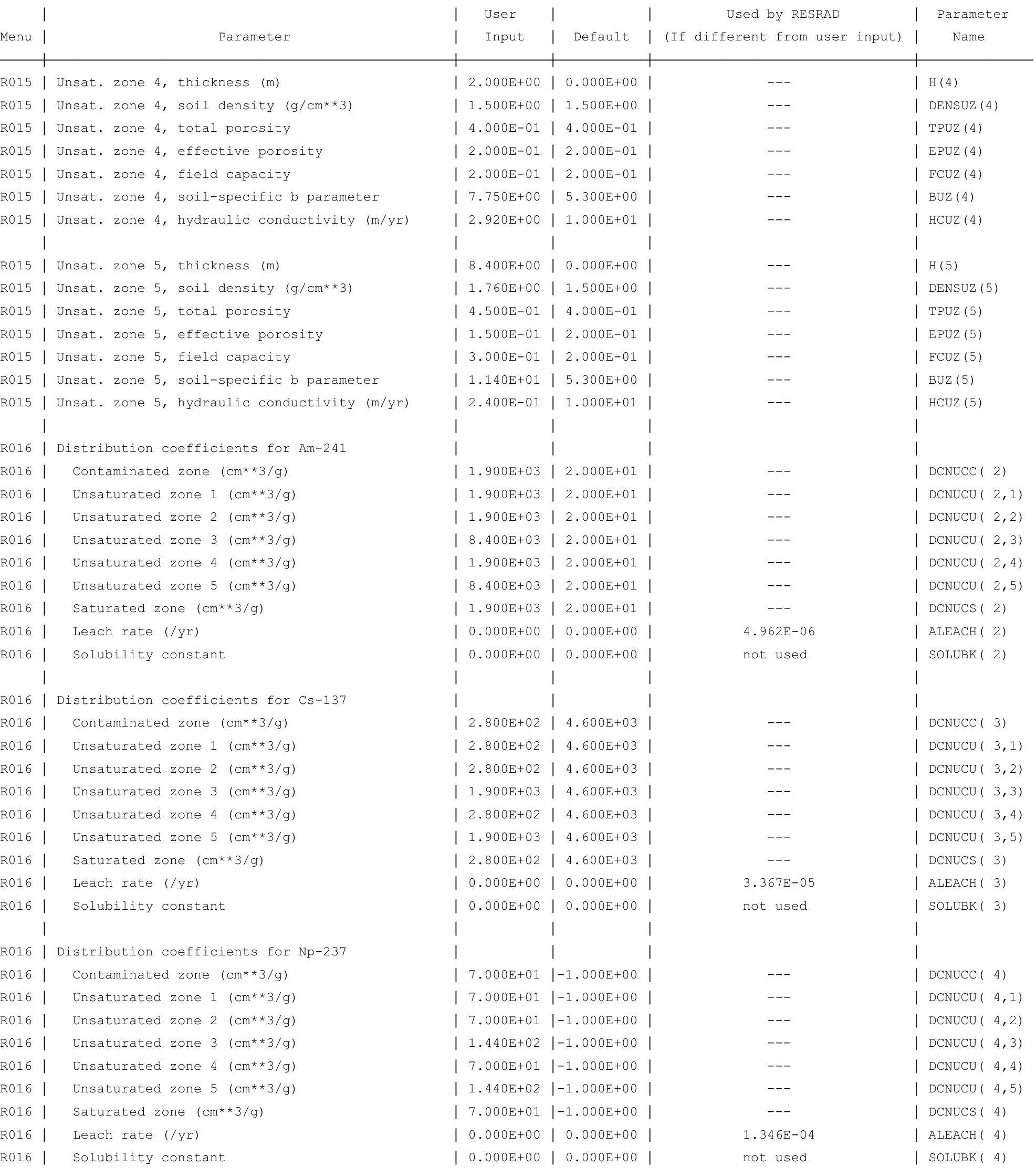


RESRAD, Version $6.5 \quad T^{1 / 2}$ Limit $=180$ days

Summary : C746U Resident Gardener Deterministic Run

File : X: $\backslash F I N A L$ V2 $\backslash$ DOE FWD RUNS \C746U RG DOE SG FWD-FV2-100000YR.RAD

Site-Specific Parameter Summary (continued)

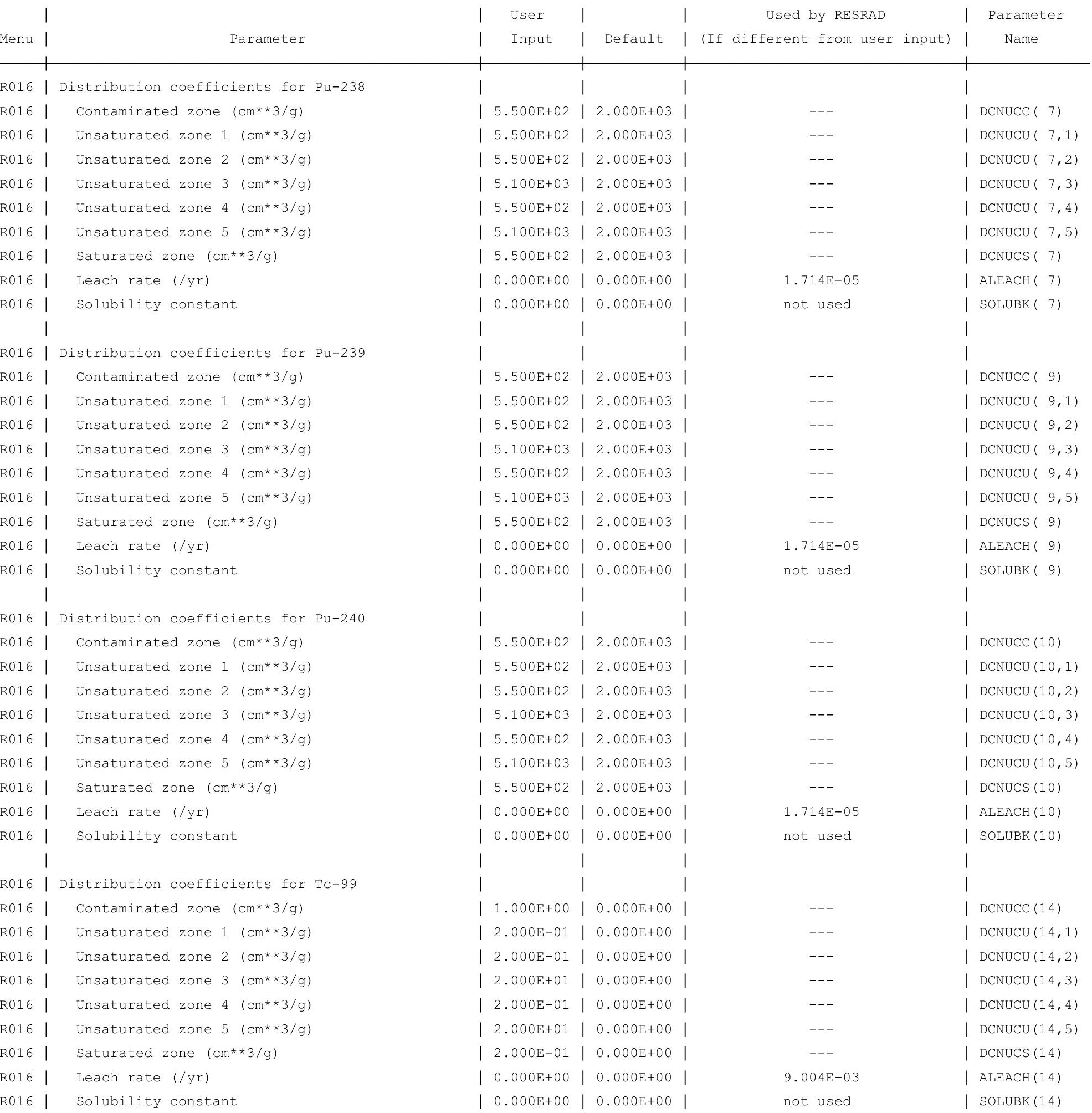


RESRAD, Version $6.5 \quad T^{1 / 2}$ Limit $=180$ days

Summary : C746U Resident Gardener Deterministic Run

File : X: $\backslash F I N A L$ V2 $\backslash$ DOE FWD RUNS \C746U RG DOE SG FWD-FV2-100000YR.RAD

Site-Specific Parameter Summary (continued)

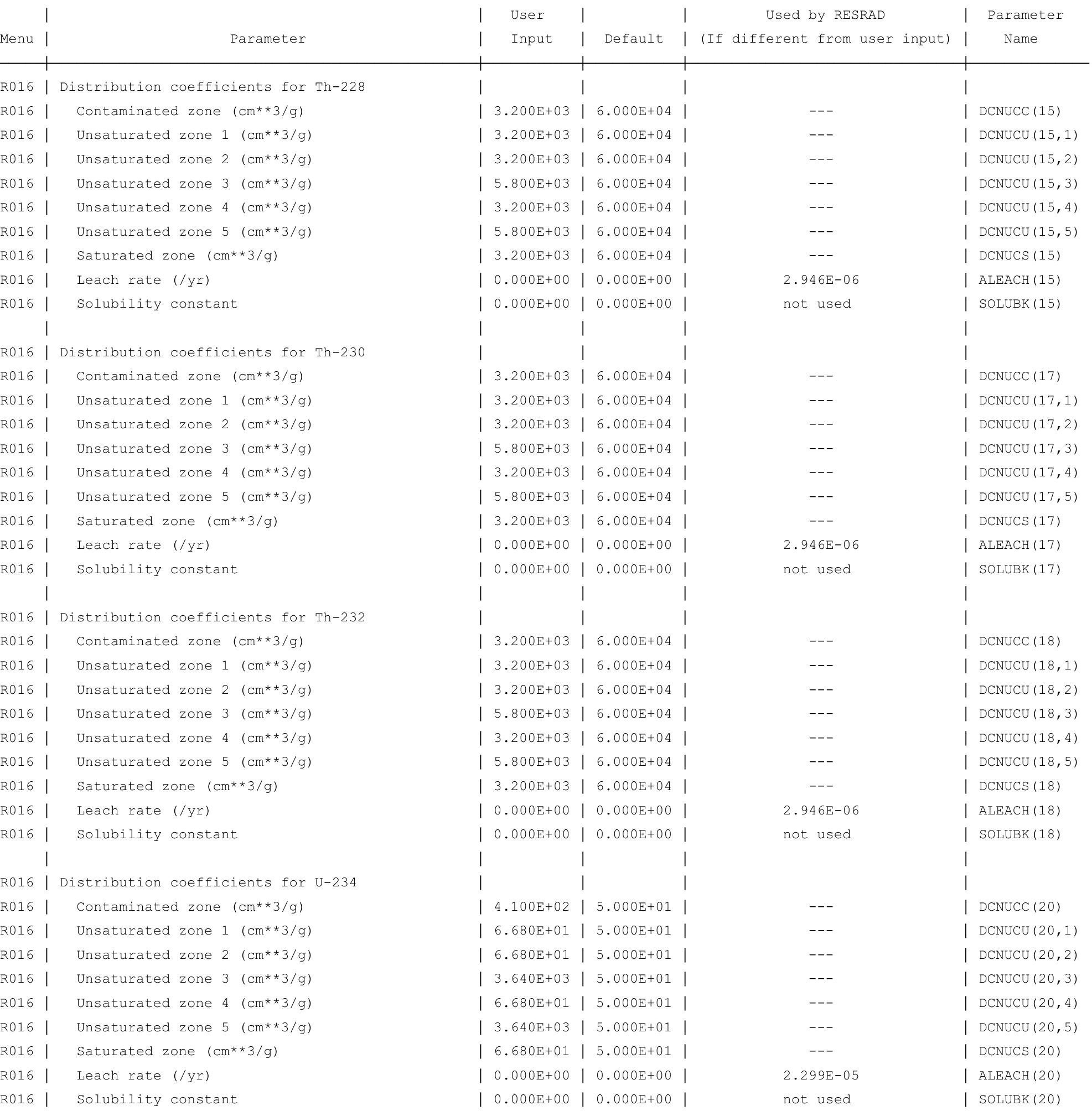


RESRAD, Version $6.5 \quad T^{1 / 2}$ Limit $=180$ days

Summary : C746U Resident Gardener Deterministic Run

File : X: $\backslash F I N A L$ V2 $\backslash$ DOE FWD RUNS \C746U RG DOE SG FWD-FV2-100000YR.RAD

Site-Specific Parameter Summary (continued)

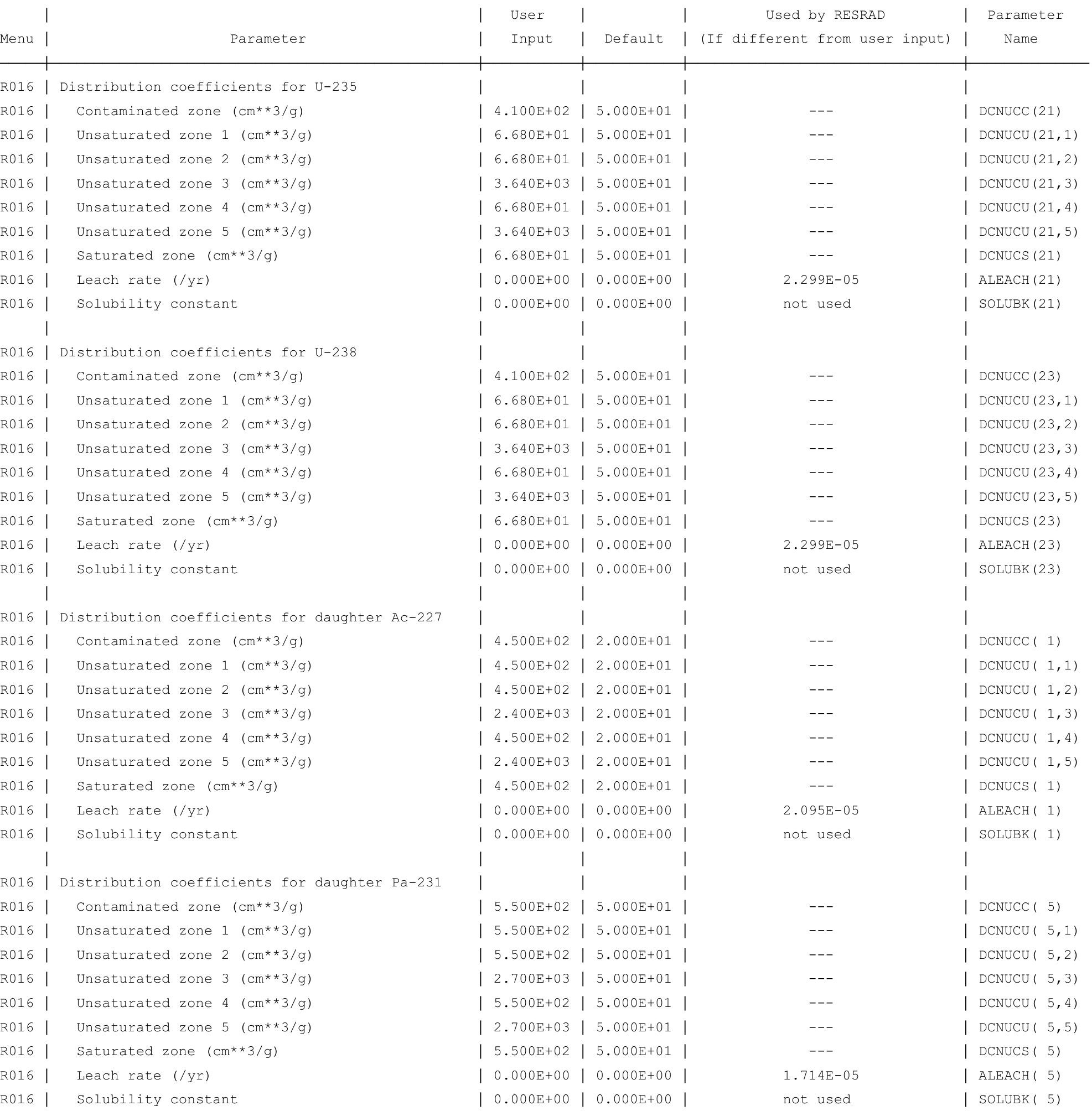


RESRAD, Version $6.5 \quad T^{1 / 2}$ Limit $=180$ days

Summary : C746U Resident Gardener Deterministic Run

File : X: $\backslash F I N A L$ V2 $\backslash$ DOE FWD RUNS \C746U RG DOE SG FWD-FV2-100000YR.RAD

Site-Specific Parameter Summary (continued)

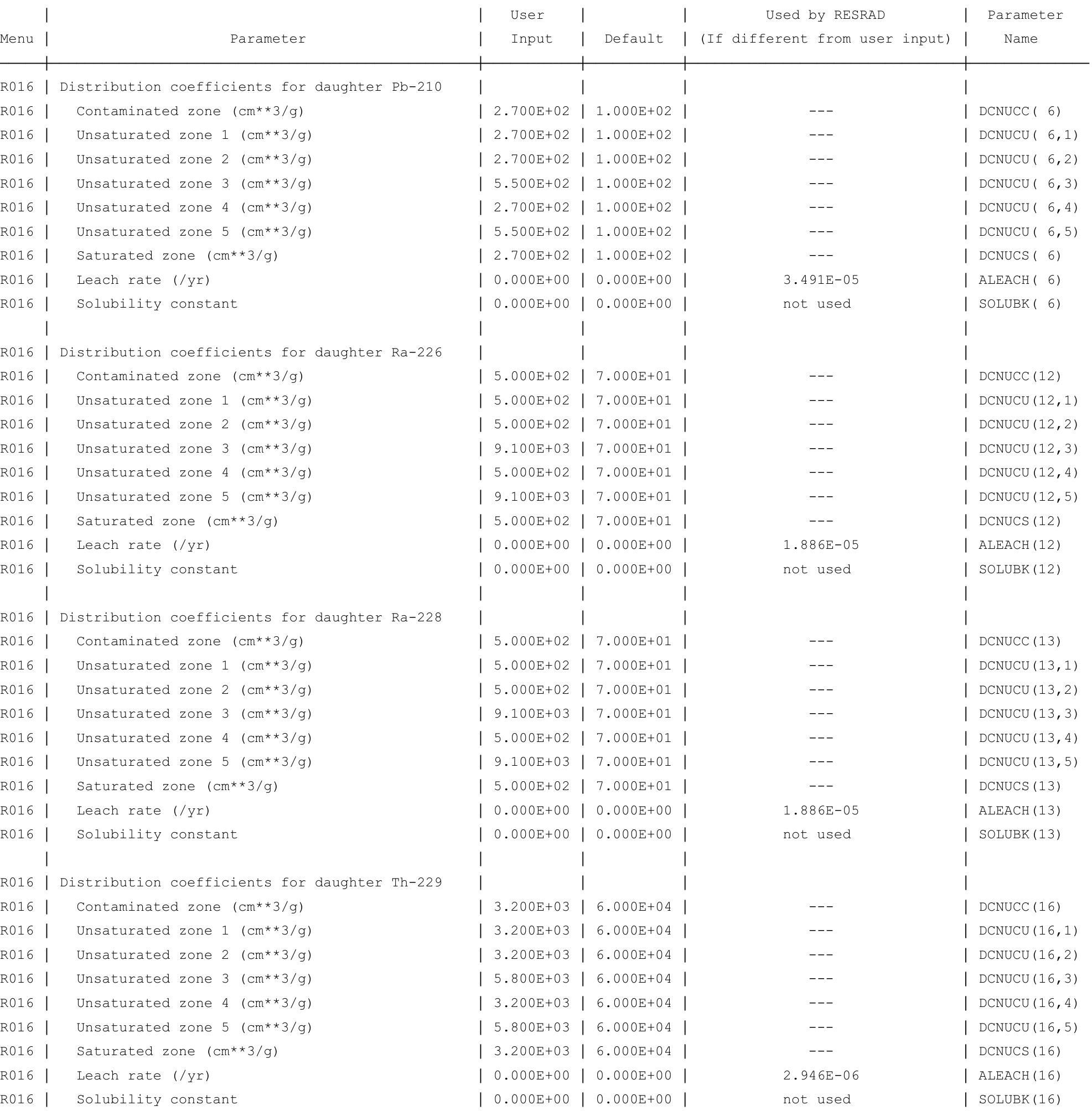


RESRAD, Version $6.5 \quad T^{1 / 2}$ Limit $=180$ days

Summary : C746U Resident Gardener Deterministic Run

File : X: $\backslash F I N A L$ V2 $\backslash$ DOE FWD RUNS \C746U RG DOE SG FWD-FV2-100000YR.RAD

Site-Specific Parameter Summary (continued)

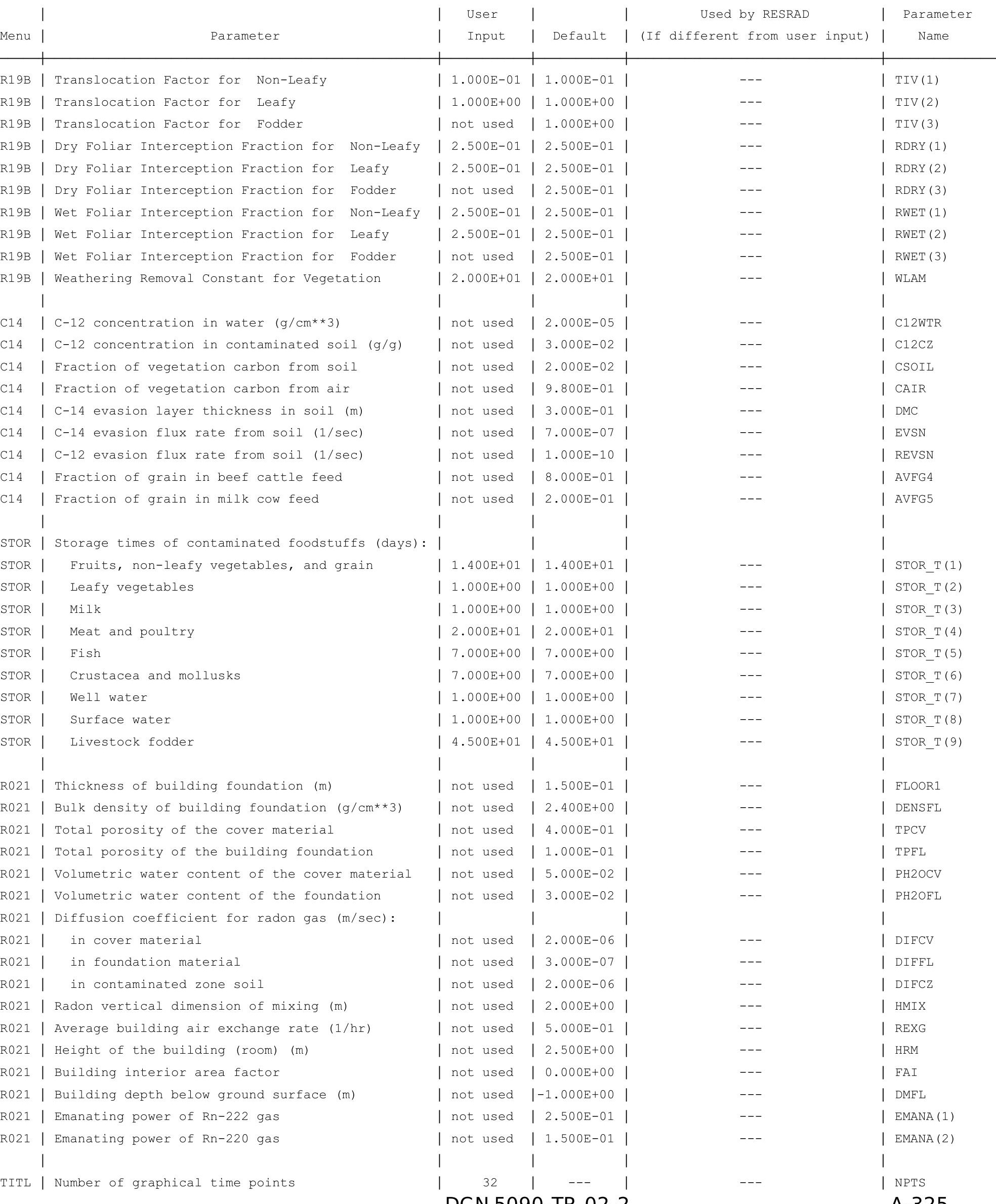


RESRAD, Version $6.5 \quad \mathrm{~T}^{1 / 2}$ Limit $=180$ days

Summary : C746U Resident Gardener Deterministic Run

File : $\mathrm{X}: \backslash F I N A L$ V2 $\backslash$ DOE FWD RUNS $\backslash C 746 \mathrm{U}$ RG DOE SG FWD-FV2-100000YR.RAD

Contaminated Zone Dimensions

Area: 89436.00 square meters

Thickness:

Cover Depth:

$$
\begin{array}{r}
13.40 \text { meters } \\
1.52 \text { meters }
\end{array}
$$

Initial Soil Concentrations, pCi/g

$\begin{array}{ll}\mathrm{Am}-241 & 3.500 \mathrm{E}+01 \\ \mathrm{Cs}-137 & 1.900 \mathrm{E}+01 \\ \mathrm{~Np}-237 & 5.500 \mathrm{E}+00 \\ \mathrm{Pu}-238 & 3.900 \mathrm{E}+01 \\ \mathrm{Pu}-239 & 3.600 \mathrm{E}+01 \\ \mathrm{Pu}-240 & 3.600 \mathrm{E}+01 \\ \mathrm{TC}-99 & 5.200 \mathrm{E}+01 \\ \mathrm{Th}-228 & 4.000 \mathrm{E}+00 \\ \mathrm{Th}-230 & 1.000 \mathrm{E}+02 \\ \mathrm{Th}-232 & 4.000 \mathrm{E}+00 \\ \mathrm{U}-234 & 1.600 \mathrm{E}+02 \\ \mathrm{U}-235 & 6.500 \mathrm{E}+00 \\ \mathrm{U}-238 & 1.600 \mathrm{E}+02\end{array}$

Total Dose TDOSE(t), mrem/yr

Basic Radiation Dose Limit $=1.000 \mathrm{E}+02 \mathrm{mrem} / \mathrm{yr}$

Total Mixture Sum $M(t)$ = Fraction of Basic Dose Limit Received at Time (t)

$\begin{array}{rlllllllll}t \text { (years) : } & 0.000 \mathrm{E}+00 & 1.000 \mathrm{E}+00 & 5.000 \mathrm{E}+01 & 1.000 \mathrm{E}+02 & 5.000 \mathrm{E}+02 & 1.050 \mathrm{E}+03 & 1.000 \mathrm{E}+04 & 1.000 \mathrm{E}+05 \\ \mathrm{TDOSE}(\mathrm{t}): & 5.627 \mathrm{E}-06 & 4.206 \mathrm{E}-06 & 9.541 \mathrm{E}-06 & 1.367 \mathrm{E}-05 & 2.423 \mathrm{E}-04 & 6.827 \mathrm{E}+00 & 2.359 \mathrm{E}+03 & 0.000 \mathrm{E}+00 \\ \mathrm{M}(\mathrm{t}): & 5.627 \mathrm{E}-08 & 4.206 \mathrm{E}-08 & 9.541 \mathrm{E}-08 & 1.367 \mathrm{E}-07 & 2.423 \mathrm{E}-06 & 6.827 \mathrm{E}-02 & 2.359 \mathrm{E}+01 & 0.000 \mathrm{E}+00\end{array}$

Maximum TDOSE $(t): 2.370 \mathrm{E}+03 \mathrm{mrem} / \mathrm{yr}$ at $t=12931 \pm$ * years

Total Dose Contributions TDOSE (i,p,t) for Individual Radionuclides (i) and Pathways (p) As mrem/yr and Fraction of Total Dose At $t=1.293 \mathrm{E}+04$ years

\begin{tabular}{|c|c|c|c|c|c|c|c|c|c|c|c|c|c|c|}
\hline & \multicolumn{2}{|c|}{ Ground } & \multicolumn{2}{|c|}{ Inhalation } & \multicolumn{2}{|c|}{ Radon } & \multicolumn{2}{|c|}{ Plant } & \multicolumn{2}{|c|}{ Meat } & \multicolumn{2}{|c|}{ Milk } & \multicolumn{2}{|c|}{ Soil } \\
\hline clide & mrem/yr & fract. & mrem/yr & fract. & mrem/yr & fract. & mrem/yr & fract. & mrem/yr & fract. & mrem/yr & fract. & mrem/yr & fract. \\
\hline 241 & $1.209 E-03$ & 0.0000 & $1.387 \mathrm{E}-07$ & 0.0000 & $0.000 \mathrm{E}+00$ & 0.0000 & $1.420 \mathrm{E}-03$ & 0.0000 & $0.000 \mathrm{E}+00$ & 0.0000 & $0.000 \mathrm{E}+00$ & 0.0000 & $2.657 \mathrm{E}-05$ & 0.0000 \\
\hline-137 & $0.000 \mathrm{E}+00$ & 0.0000 & $0.000 \mathrm{E}+00$ & 0.0000 & $0.000 \mathrm{E}+00$ & 0.0000 & $0.000 \mathrm{E}+00$ & 0.0000 & $0.000 \mathrm{E}+00$ & 0.0000 & $0.000 \mathrm{E}+00$ & 0.0000 & $0.000 \mathrm{E}+00$ & 0.0000 \\
\hline-237 & $8.744 E-01$ & 0.0004 & $1.026 \mathrm{E}-04$ & 0.0000 & $0.000 \mathrm{E}+00$ & 0.0000 & $1.019 \mathrm{E}+00$ & 0.0004 & $0.000 \mathrm{E}+00$ & 0.0000 & $0.000 \mathrm{E}+00$ & 0.0000 & $1.973 E-02$ & 0.0000 \\
\hline-238 & $8.950 E-03$ & 0.0000 & $3.764 \mathrm{E}-07$ & 0.0000 & $0.000 \mathrm{E}+00$ & 0.0000 & $1.529 \mathrm{E}-02$ & 0.0000 & $0.000 \mathrm{E}+00$ & 0.0000 & $0.000 \mathrm{E}+00$ & 0.0000 & $3.895 \mathrm{E}-04$ & 0.0000 \\
\hline-239 & $4.534 \mathrm{E}-03$ & 0.0000 & $3.722 \mathrm{E}-03$ & 0.0000 & $0.000 \mathrm{E}+00$ & 0.0000 & $2.318 \mathrm{E}+00$ & 0.0010 & $0.000 \mathrm{E}+00$ & 0.0000 & $0.000 \mathrm{E}+00$ & 0.0000 & $6.441 \mathrm{E}-01$ & 0.0003 \\
\hline-240 & $6.864 \mathrm{E}-04$ & 0.0000 & $1.371 \mathrm{E}-03$ & 0.0000 & $0.000 \mathrm{E}+00$ & 0.0000 & $8.540 \mathrm{E}-01$ & 0.0004 & $0.000 \mathrm{E}+00$ & 0.0000 & $0.000 \mathrm{E}+00$ & 0.0000 & $2.373 E-01$ & 0.0001 \\
\hline 99 & $0.000 \mathrm{E}+00$ & 0.0000 & $0.000 \mathrm{E}+00$ & 0.0000 & $0.000 \mathrm{E}+00$ & 0.0000 & $0.000 \mathrm{E}+00$ & 0.0000 & $0.000 \mathrm{E}+00$ & 0.0000 & $0.000 \mathrm{E}+00$ & 0.0000 & $0.000 \mathrm{E}+00$ & 0.0000 \\
\hline-228 & $0.000 \mathrm{E}+00$ & 0.0000 & $0.000 \mathrm{E}+00$ & 0.0000 & $0.000 \mathrm{E}+00$ & 0.0000 & $0.000 \mathrm{E}+00$ & 0.0000 & $0.000 \mathrm{E}+00$ & 0.0000 & $0.000 \mathrm{E}+00$ & 0.0000 & $0.000 \mathrm{E}+00$ & 0.0000 \\
\hline-230 & $7.244 \mathrm{E}+02$ & 0.3057 & $1.594 \mathrm{E}-02$ & 0.0000 & $0.000 \mathrm{E}+00$ & 0.0000 & $1.192 \mathrm{E}+03$ & 0.5030 & $0.000 \mathrm{E}+00$ & 0.0000 & $0.000 \mathrm{E}+00$ & 0.0000 & $2.598 \mathrm{E}+01$ & 0.0110 \\
\hline-232 & $4.798 E+01$ & 0.0202 & $1.020 \mathrm{E}-03$ & 0.0000 & $0.000 \mathrm{E}+00$ & 0.0000 & $5.010 \mathrm{E}+01$ & 0.0211 & $0.000 \mathrm{E}+00$ & 0.0000 & $0.000 \mathrm{E}+00$ & 0.0000 & $5.306 \mathrm{E}-01$ & 0.0002 \\
\hline 34 & $1.035 E+02$ & 0.0437 & $4.328 E-03$ & 0.0000 & $0.000 \mathrm{E}+00$ & 0.0000 & $1.768 \mathrm{E}+02$ & 0.0746 & $0.000 \mathrm{E}+00$ & 0.0000 & $0.000 E+00$ & 0.0000 & $4.495 \mathrm{E}+00$ & 0.0019 \\
\hline 35 & $4.746 \mathrm{E}+00$ & 0.0020 & $1.390 \mathrm{E}-03$ & 0.0000 & $0.000 \mathrm{E}+00$ & 0.0000 & $5.930 \mathrm{E}+00$ & 0.0025 & $0.000 \mathrm{E}+00$ & 0.0000 & $0.000 \mathrm{E}+00$ & 0.0000 & $3.275 E-01$ & 0.0001 \\
\hline 38 & $1.669 \mathrm{E}+01$ & 0.0070 & $1.595 \mathrm{E}-03$ & 0.0000 & $0.000 \mathrm{E}+00$ & 0.0000 & $9.607 \mathrm{E}+00$ & 0.0041 & $0.000 \mathrm{E}+00$ & 0.0000 & $0.000 \mathrm{E}+00$ & 0.0000 & $8.344 \mathrm{E}-01$ & 0.0004 \\
\hline & $8.982 \mathrm{E}+02$ & 0.3 & $.946 \mathrm{E}-02$ & 0.0000 & $0.000 \mathrm{E}+00$ & 0.0000 & $1.439 \mathrm{E}+03$ & 070 & $0.000 \mathrm{E}+00$ & 000 & $0.000 \mathrm{E}+00$ & 000 & +01 & 140 \\
\hline
\end{tabular}

Water Independent Pathways (Inhalation excludes radon) 
RESRAD, Version $6.5 \quad \mathrm{~T}^{1 / 2}$ Limit $=180$ days

Summary : C746U Resident Gardener Deterministic Run

File : $\mathrm{X}: \backslash F I N A L$ V2 \DOE FWD RUNS \C746U RG DOE SG FWD-FV2-100000YR.RAD

Total Dose Contributions TDOSE(i,p,t) for Individual Radionuclides (i) and Pathways (p)

As mrem/yr and Fraction of Total Dose At $t=1.293 \mathrm{E}+04$ years

Water Dependent Pathways

\begin{tabular}{|c|c|c|c|c|c|c|c|c|c|c|c|c|c|c|}
\hline & \multicolumn{2}{|c|}{ Water } & \multicolumn{2}{|c|}{ Fish } & \multicolumn{2}{|c|}{ Radon } & \multicolumn{2}{|c|}{ Plant } & \multicolumn{2}{|c|}{ Meat } & \multicolumn{2}{|c|}{ Milk } & \multicolumn{2}{|c|}{ All Pathways* } \\
\hline ide & mrem/yr & fract. & mrem/yr & fract. & mrem/yr & fract. & mrem/yr & fract. & mrem/yr & fract. & mrem/yr & fract. & mrem/yr & fract. \\
\hline-241 & $0.000 \mathrm{E}+00$ & 0.0000 & $0.000 \mathrm{E}+00$ & 0.0000 & $0.000 \mathrm{E}+00$ & 0.0000 & $0.000 \mathrm{E}+00$ & 0.0000 & $0.000 \mathrm{E}+00$ & 0.0000 & $0.000 \mathrm{E}+00$ & 0.0000 & $2.656 \mathrm{E}-03$ & 0.0000 \\
\hline-137 & $0.000 \mathrm{E}+00$ & 0.0000 & $0.000 \mathrm{E}+00$ & 0.0000 & $0.000 \mathrm{E}+00$ & 0.0000 & $0.000 \mathrm{E}+00$ & 0.0000 & $0.000 \mathrm{E}+00$ & 0.0000 & $0.000 \mathrm{E}+00$ & 0.0000 & $0.000 \mathrm{E}+00$ & 0.0000 \\
\hline-237 & $0.000 \mathrm{E}+00$ & 0.0000 & $0.000 \mathrm{E}+00$ & 0.0000 & $0.000 \mathrm{E}+00$ & 0.0000 & $0.000 \mathrm{E}+00$ & 0.0000 & $0.000 \mathrm{E}+00$ & 0.0000 & $0.000 \mathrm{E}+00$ & 0.0000 & $1.913 \mathrm{E}+00$ & 0.0008 \\
\hline-238 & $0.000 \mathrm{E}+00$ & 0.0000 & $0.000 \mathrm{E}+00$ & 0.0000 & $0.000 \mathrm{E}+00$ & 0.0000 & $0.000 \mathrm{E}+00$ & 0.0000 & $0.000 \mathrm{E}+00$ & 0.0000 & $0.000 \mathrm{E}+00$ & 0.0000 & $2.463 E-02$ & 0.0000 \\
\hline-239 & $0.000 \mathrm{E}+00$ & 0.0000 & $0.000 \mathrm{E}+00$ & 0.0000 & $0.000 \mathrm{E}+00$ & 0.0000 & $0.000 \mathrm{E}+00$ & 0.0000 & $0.000 \mathrm{E}+00$ & 0.0000 & $0.000 \mathrm{E}+00$ & 0.0000 & $2.970 \mathrm{E}+00$ & 0.0013 \\
\hline-240 & $0.000 \mathrm{E}+00$ & 0.0000 & $0.000 \mathrm{E}+00$ & 0.0000 & $0.000 \mathrm{E}+00$ & 0.0000 & $0.000 \mathrm{E}+00$ & 0.0000 & $0.000 \mathrm{E}+00$ & 0.0000 & $0.000 \mathrm{E}+00$ & 0.0000 & $1.093 \mathrm{E}+00$ & 0.0005 \\
\hline 99 & $0.000 \mathrm{E}+00$ & 0.0000 & $0.000 \mathrm{E}+00$ & 0.0000 & $0.000 \mathrm{E}+00$ & 0.0000 & $0.000 \mathrm{E}+00$ & 0.0000 & $0.000 \mathrm{E}+00$ & 0.0000 & $0.000 \mathrm{E}+00$ & 0.0000 & $0.000 \mathrm{E}+00$ & 0.0000 \\
\hline-228 & $0.000 \mathrm{E}+00$ & 0.0000 & $0.000 \mathrm{E}+00$ & 0.0000 & $0.000 \mathrm{E}+00$ & 0.0000 & $0.000 \mathrm{E}+00$ & 0.0000 & $0.000 \mathrm{E}+00$ & 0.0000 & $0.000 \mathrm{E}+00$ & 0.0000 & $0.000 \mathrm{E}+00$ & 0.0000 \\
\hline-230 & $0.000 \mathrm{E}+00$ & 0.0000 & $0.000 \mathrm{E}+00$ & 0.0000 & $0.000 \mathrm{E}+00$ & 0.0000 & $0.000 \mathrm{E}+00$ & 0.0000 & $0.000 \mathrm{E}+00$ & 0.0000 & $0.000 \mathrm{E}+00$ & 0.0000 & $1.943 \mathrm{E}+03$ & 0.8196 \\
\hline 232 & $0.000 \mathrm{E}+00$ & 0.0000 & $0.000 \mathrm{E}+00$ & 0.0000 & $0.000 \mathrm{E}+00$ & 0.0000 & $0.000 \mathrm{E}+00$ & 0.0000 & $0.000 \mathrm{E}+00$ & 0.0000 & $0.000 \mathrm{E}+00$ & 0.0000 & $9.861 \mathrm{E}+01$ & 0.0416 \\
\hline & $0.000 \mathrm{E}+00$ & 0.0000 & $0.000 \mathrm{E}+00$ & 0.0000 & $0.000 \mathrm{E}+00$ & 0.0000 & $0.000 \mathrm{E}+00$ & 0.0000 & $0.000 \mathrm{E}+00$ & 0.0000 & $0.000 \mathrm{E}+00$ & 0.0000 & $2.848 E+02$ & 0.1202 \\
\hline 35 & $0.000 \mathrm{E}+00$ & 0.0000 & $0.000 \mathrm{E}+00$ & 0.0000 & $0.000 \mathrm{E}+00$ & 0.0000 & $0.000 \mathrm{E}+00$ & 0.0000 & $0.000 \mathrm{E}+00$ & 0.0000 & $0.000 \mathrm{E}+00$ & 0.0000 & $1.100 \mathrm{E}+01$ & 0.0046 \\
\hline 38 & $0.000 \mathrm{E}+00$ & 0.0000 & $0.000 \mathrm{E}+00$ & 0.0000 & $0.000 \mathrm{E}+00$ & 0.0000 & $0.000 \mathrm{E}+00$ & 0.0000 & $0.000 \mathrm{E}+00$ & 0.0000 & $0.000 \mathrm{E}+00$ & 0.0000 & $2.713 \mathrm{E}+01$ & 0.0114 \\
\hline & $0.000 \mathrm{E}+00$ & 0.0000 & $.000 E+00$ & 0.0000 & $0.000 \mathrm{E}+00$ & 0.0000 & $0.000 \mathrm{E}+00$ & 0.0000 & $0.000 \mathrm{E}+00$ & 0.0000 & $0.000 \mathrm{E}+00$ & 0000 & +03 & 00 \\
\hline
\end{tabular}

* Sum of all water independent and dependent pathways.

DCN 5090-TR-02-2

A-328 
RESRAD, Version 6.5

ummary : C746U Resident Gardener Deterministic Run

File : $\mathrm{X}: \backslash F I N A L$ V2 $\backslash$ DOE FWD RUNS \C746U RG DOE SG FWD-FV2-100000YR.RAD

Total Dose Contributions TDOSE(i,p,t) for Individual Radionuclides (i) and Pathways (p) As mrem/yr and Fraction of Total Dose At $t=0.000 \mathrm{E}+00$ years

Water Independent Pathways (Inhalation excludes radon)

\begin{tabular}{|c|c|c|c|c|c|c|c|c|c|c|c|c|c|c|}
\hline \multirow{2}{*}{ Nuclide } & \multicolumn{2}{|c|}{ Ground } & \multicolumn{2}{|c|}{ Inhalation } & \multicolumn{2}{|c|}{ Radon } & \multicolumn{2}{|c|}{ Plant } & \multicolumn{2}{|c|}{ Meat } & \multicolumn{2}{|c|}{ Milk } & \multicolumn{2}{|c|}{ Soil } \\
\hline & mrem/yr & fract. & mrem/yr & fract. & mrem/yr & fract. & mrem/yr & fract. & mrem/yr & fract. & mrem/yr & fract. & mrem/yr & fract. \\
\hline-241 & $5.412 \mathrm{E}-18$ & 0.0000 & $0.000 \mathrm{E}+00$ & 0.0000 & $0.000 \mathrm{E}+00$ & 0.0000 & $0.000 \mathrm{E}+00$ & 0.0000 & $0.000 \mathrm{E}+00$ & 0.0000 & $0.000 \mathrm{E}+00$ & 0.0000 & $0.000 \mathrm{E}+00$ & 0.0000 \\
\hline-137 & $2.397 E-08$ & 0.0043 & $0.000 \mathrm{E}+00$ & 0.0000 & $0.000 \mathrm{E}+00$ & 0.0000 & $0.000 \mathrm{E}+00$ & 0.0000 & $0.000 \mathrm{E}+00$ & 0.0000 & $0.000 \mathrm{E}+00$ & 0.0000 & $0.000 \mathrm{E}+00$ & 0.0000 \\
\hline-237 & $5.245 E-12$ & 0.0000 & $0.000 \mathrm{E}+00$ & 0.0000 & $0.000 \mathrm{E}+00$ & 0.0000 & $0.000 \mathrm{E}+00$ & 0.0000 & $0.000 \mathrm{E}+00$ & 0.0000 & $0.000 \mathrm{E}+00$ & 0.0000 & $0.000 \mathrm{E}+00$ & 0.0000 \\
\hline-238 & $3.174 \mathrm{E}-21$ & 0.0000 & $0.000 \mathrm{E}+00$ & 0.0000 & $0.000 \mathrm{E}+00$ & 0.0000 & $0.000 \mathrm{E}+00$ & 0.0000 & $0.000 \mathrm{E}+00$ & 0.0000 & $0.000 \mathrm{E}+00$ & 0.0000 & $0.000 \mathrm{E}+00$ & 0.0000 \\
\hline-239 & $4.328 E-16$ & 0.0000 & $0.000 \mathrm{E}+00$ & 0.0000 & $0.000 \mathrm{E}+00$ & 0.0000 & $0.000 \mathrm{E}+00$ & 0.0000 & $0.000 \mathrm{E}+00$ & 0.0000 & $0.000 \mathrm{E}+00$ & 0.0000 & $0.000 \mathrm{E}+00$ & 0.0000 \\
\hline-240 & $4.115 \mathrm{E}-23$ & 0.0000 & $0.000 \mathrm{E}+00$ & 0.0000 & $0.000 \mathrm{E}+00$ & 0.0000 & $0.000 \mathrm{E}+00$ & 0.0000 & $0.000 \mathrm{E}+00$ & 0.0000 & $0.000 \mathrm{E}+00$ & 0.0000 & $0.000 \mathrm{E}+00$ & 0.0000 \\
\hline 99 & $2.994 E-24$ & 0.0000 & $0.000 \mathrm{E}+00$ & 0.0000 & $0.000 \mathrm{E}+00$ & 0.0000 & $0.000 \mathrm{E}+00$ & 0.0000 & $0.000 \mathrm{E}+00$ & 0.0000 & $0.000 \mathrm{E}+00$ & 0.0000 & $0.000 \mathrm{E}+00$ & 0.0000 \\
\hline-228 & $5.530 \mathrm{E}-06$ & 0.9827 & $0.000 \mathrm{E}+00$ & 0.0000 & $0.000 \mathrm{E}+00$ & 0.0000 & $0.000 \mathrm{E}+00$ & 0.0000 & $0.000 \mathrm{E}+00$ & 0.0000 & $0.000 \mathrm{E}+00$ & 0.0000 & $0.000 \mathrm{E}+00$ & 0.0000 \\
\hline-230 & $3.774 \mathrm{E}-09$ & 0.0007 & $0.000 \mathrm{E}+00$ & 0.0000 & $0.000 \mathrm{E}+00$ & 0.0000 & $0.000 \mathrm{E}+00$ & 0.0000 & $0.000 \mathrm{E}+00$ & 0.0000 & $0.000 \mathrm{E}+00$ & 0.0000 & $0.000 \mathrm{E}+00$ & 0.0000 \\
\hline-232 & $4.712 \mathrm{E}-08$ & 0.0084 & $0.000 \mathrm{E}+00$ & 0.0000 & $0.000 \mathrm{E}+00$ & 0.0000 & $0.000 \mathrm{E}+00$ & 0.0000 & $0.000 \mathrm{E}+00$ & 0.0000 & $0.000 \mathrm{E}+00$ & 0.0000 & $0.000 \mathrm{E}+00$ & 0.0000 \\
\hline 234 & $1.813 \mathrm{E}-14$ & 0.0000 & $0.000 \mathrm{E}+00$ & 0.0000 & $0.000 \mathrm{E}+00$ & 0.0000 & $0.000 \mathrm{E}+00$ & 0.0000 & $0.000 \mathrm{E}+00$ & 0.0000 & $0.000 \mathrm{E}+00$ & 0.0000 & $0.000 \mathrm{E}+00$ & 0.0000 \\
\hline 235 & $8.089 \mathrm{E}-14$ & 0.0000 & $0.000 \mathrm{E}+00$ & 0.0000 & $0.000 \mathrm{E}+00$ & 0.0000 & $0.000 \mathrm{E}+00$ & 0.0000 & $0.000 \mathrm{E}+00$ & 0.0000 & $0.000 \mathrm{E}+00$ & 0.0000 & $0.000 \mathrm{E}+00$ & 0.0000 \\
\hline 238 & $2.271 E-08$ & 0.0040 & $0.000 \mathrm{E}+00$ & 0.0000 & $0.000 \mathrm{E}+00$ & 0.0000 & $0.000 \mathrm{E}+00$ & 0.0000 & $0.000 \mathrm{E}+00$ & 0.0000 & $0.000 \mathrm{E}+00$ & 0.0000 & $0.000 \mathrm{E}+00$ & 0.0000 \\
\hline & $5.627 \mathrm{E}-06$ & 1.0000 & $0.000 \mathrm{E}+00$ & 0.0000 & $0.000 \mathrm{E}+00$ & 0.0000 & $0.000 \mathrm{E}+00$ & 0.0000 & $0.000 \mathrm{E}+00$ & 0.0000 & $0.000 \mathrm{E}+00$ & 0.0000 & $.000 \mathrm{E}+00$ & 0.0000 \\
\hline
\end{tabular}

Total Dose Contributions TDOSE (i,p,t) for Individual Radionuclides (i) and Pathways (p) As mrem/yr and Fraction of Total Dose At $t=0.000 \mathrm{E}+00$ years

Water Dependent Pathways

\begin{tabular}{|c|c|c|c|c|c|c|c|c|c|c|c|c|c|c|}
\hline & \multicolumn{2}{|c|}{ Water } & \multicolumn{2}{|c|}{ Fish } & \multicolumn{2}{|c|}{ Radon } & \multicolumn{2}{|c|}{ Plant } & \multicolumn{2}{|c|}{ Meat } & \multicolumn{2}{|c|}{ Milk } & \multicolumn{2}{|c|}{ All Pathways* } \\
\hline clide & mrem/yr & fract. & mrem/yr & fract. & mrem/yr & fract. & mrem/yr & fract. & mrem/yr & fract. & mrem/yr & fract. & mrem/yr & fract. \\
\hline-241 & $0.000 \mathrm{E}+00$ & 0.0000 & $0.000 \mathrm{E}+00$ & 0.0000 & $0.000 \mathrm{E}+00$ & 0.0000 & $0.000 \mathrm{E}+00$ & 0.0000 & $0.000 \mathrm{E}+00$ & 0.0000 & $0.000 \mathrm{E}+00$ & 0.0000 & $5.412 \mathrm{E}-18$ & 0.0000 \\
\hline-137 & $0.000 \mathrm{E}+00$ & 0.0000 & $0.000 \mathrm{E}+00$ & 0.0000 & $0.000 \mathrm{E}+00$ & 0.0000 & $0.000 \mathrm{E}+00$ & 0.0000 & $0.000 \mathrm{E}+00$ & 0.0000 & $0.000 \mathrm{E}+00$ & 0.0000 & $2.397 \mathrm{E}-08$ & 0.0043 \\
\hline-237 & $0.000 \mathrm{E}+00$ & 0.0000 & $0.000 \mathrm{E}+00$ & 0.0000 & $0.000 \mathrm{E}+00$ & 0.0000 & $0.000 \mathrm{E}+00$ & 0.0000 & $0.000 \mathrm{E}+00$ & 0.0000 & $0.000 \mathrm{E}+00$ & 0.0000 & $5.245 E-12$ & 0.0000 \\
\hline 238 & $0.000 \mathrm{E}+00$ & 0.0000 & $0.000 \mathrm{E}+00$ & 0.0000 & $0.000 \mathrm{E}+00$ & 0.0000 & $0.000 \mathrm{E}+00$ & 0.0000 & $0.000 \mathrm{E}+00$ & 0.0000 & $0.000 \mathrm{E}+00$ & 0.0000 & $3.174 \mathrm{E}-21$ & 0.0000 \\
\hline 239 & $0.000 \mathrm{E}+00$ & 0.0000 & $0.000 \mathrm{E}+00$ & 0.0000 & $0.000 \mathrm{E}+00$ & 0.0000 & $0.000 \mathrm{E}+00$ & 0.0000 & $0.000 \mathrm{E}+00$ & 0.0000 & $0.000 \mathrm{E}+00$ & 0.0000 & $4.328 \mathrm{E}-16$ & 0.0000 \\
\hline 240 & $0.000 \mathrm{E}+00$ & 0.0000 & $0.000 \mathrm{E}+00$ & 0.0000 & $0.000 \mathrm{E}+00$ & 0.0000 & $0.000 \mathrm{E}+00$ & 0.0000 & $0.000 \mathrm{E}+00$ & 0.0000 & $0.000 \mathrm{E}+00$ & 0.0000 & $4.115 E-23$ & 0.0000 \\
\hline 99 & $0.000 \mathrm{E}+00$ & 0.0000 & $0.000 \mathrm{E}+00$ & 0.0000 & $0.000 \mathrm{E}+00$ & 0.0000 & $0.000 \mathrm{E}+00$ & 0.0000 & $0.000 \mathrm{E}+00$ & 0.0000 & $0.000 \mathrm{E}+00$ & 0.0000 & $2.994 \mathrm{E}-24$ & 0.0000 \\
\hline 228 & $0.000 \mathrm{E}+00$ & 0.0000 & $0.000 \mathrm{E}+00$ & 0.0000 & $0.000 \mathrm{E}+00$ & 0.0000 & $0.000 \mathrm{E}+00$ & 0.0000 & $0.000 \mathrm{E}+00$ & 0.0000 & $0.000 \mathrm{E}+00$ & 0.0000 & $5.530 \mathrm{E}-06$ & 0.9827 \\
\hline 230 & $0.000 \mathrm{E}+00$ & 0.0000 & $0.000 \mathrm{E}+00$ & 0.0000 & $0.000 \mathrm{E}+00$ & 0.0000 & $0.000 \mathrm{E}+00$ & 0.0000 & $0.000 \mathrm{E}+00$ & 0.0000 & $0.000 \mathrm{E}+00$ & 0.0000 & $3.774 \mathrm{E}-09$ & 0.0007 \\
\hline 232 & $0.000 \mathrm{E}+00$ & 0.0000 & $0.000 \mathrm{E}+00$ & 0.0000 & $0.000 \mathrm{E}+00$ & 0.0000 & $0.000 \mathrm{E}+00$ & 0.0000 & $0.000 \mathrm{E}+00$ & 0.0000 & $0.000 \mathrm{E}+00$ & 0.0000 & $4.712 \mathrm{E}-08$ & 0.0084 \\
\hline 34 & $0.000 \mathrm{E}+00$ & 0.0000 & $0.000 \mathrm{E}+00$ & 0.0000 & $0.000 \mathrm{E}+00$ & 0.0000 & $0.000 \mathrm{E}+00$ & 0.0000 & $0.000 \mathrm{E}+00$ & 0.0000 & $0.000 \mathrm{E}+00$ & 0.0000 & $1.813 \mathrm{E}-14$ & 0.0000 \\
\hline 35 & $0.000 \mathrm{E}+00$ & 0.0000 & $0.000 \mathrm{E}+00$ & 0.0000 & $0.000 \mathrm{E}+00$ & 0.0000 & $0.000 \mathrm{E}+00$ & 0.0000 & $0.000 \mathrm{E}+00$ & 0.0000 & $0.000 \mathrm{E}+00$ & 0.0000 & $8.089 \mathrm{E}-14$ & 0.0000 \\
\hline 38 & $0.000 \mathrm{E}+00$ & 0.0000 & $0.000 \mathrm{E}+00$ & 0.0000 & $0.000 \mathrm{E}+00$ & 0.0000 & $0.000 \mathrm{E}+00$ & 0.0000 & $0.000 \mathrm{E}+00$ & 0.0000 & $0.000 \mathrm{E}+00$ & 0.0000 & $2.271 \mathrm{E}-08$ & 0.0040 \\
\hline & $0.000 \mathrm{E}+00$ & 0.0000 & $0.000 \mathrm{E}+00$ & 0.0000 & $0.000 \mathrm{E}+00$ & 0.0000 & $0.000 \mathrm{E}+00$ & 0.0000 & $0.000 \mathrm{E}+00$ & 0.0000 & $0.000 \mathrm{E}+00$ & 000 & -06 & 1.0000 \\
\hline
\end{tabular}

* Sum of all water independent and dependent pathways. 
RESRAD, Version 6.5

ummary : C746U Resident Gardener Deterministic Run

File : $\mathrm{X}: \backslash F I N A L$ V2 $\backslash$ DOE FWD RUNS \C746U RG DOE SG FWD-FV2-100000YR.RAD

Total Dose Contributions TDOSE(i,p,t) for Individual Radionuclides (i) and Pathways (p) As mrem/yr and Fraction of Total Dose At $t=1.000 \mathrm{E}+00$ years

Water Independent Pathways (Inhalation excludes radon)

\begin{tabular}{|c|c|c|c|c|c|c|c|c|c|c|c|c|c|c|}
\hline \multirow{2}{*}{ Nuclide } & \multicolumn{2}{|c|}{ Ground } & \multicolumn{2}{|c|}{ Inhalation } & \multicolumn{2}{|c|}{ Radon } & \multicolumn{2}{|c|}{ Plant } & \multicolumn{2}{|c|}{ Meat } & \multicolumn{2}{|c|}{ Milk } & \multicolumn{2}{|c|}{ Soil } \\
\hline & mrem/yr & fract. & mrem/yr & fract. & mrem/yr & fract. & mrem/yr & fract. & mrem/yr & fract. & mrem/yr & fract. & mrem/yr & fract. \\
\hline-241 & $1.638 \mathrm{E}-17$ & 0.0000 & $0.000 \mathrm{E}+00$ & 0.0000 & $0.000 \mathrm{E}+00$ & 0.0000 & $0.000 \mathrm{E}+00$ & 0.0000 & $0.000 \mathrm{E}+00$ & 0.0000 & $0.000 \mathrm{E}+00$ & 0.0000 & $0.000 \mathrm{E}+00$ & 0.0000 \\
\hline-137 & $2.362 E-08$ & 0.0056 & $0.000 \mathrm{E}+00$ & 0.0000 & $0.000 \mathrm{E}+00$ & 0.0000 & $0.000 \mathrm{E}+00$ & 0.0000 & $0.000 \mathrm{E}+00$ & 0.0000 & $0.000 \mathrm{E}+00$ & 0.0000 & $0.000 \mathrm{E}+00$ & 0.0000 \\
\hline-237 & $5.301 \mathrm{E}-12$ & 0.0000 & $0.000 \mathrm{E}+00$ & 0.0000 & $0.000 \mathrm{E}+00$ & 0.0000 & $0.000 \mathrm{E}+00$ & 0.0000 & $0.000 \mathrm{E}+00$ & 0.0000 & $0.000 \mathrm{E}+00$ & 0.0000 & $0.000 \mathrm{E}+00$ & 0.0000 \\
\hline-238 & $4.717 \mathrm{E}-20$ & 0.0000 & $0.000 \mathrm{E}+00$ & 0.0000 & $0.000 \mathrm{E}+00$ & 0.0000 & $0.000 \mathrm{E}+00$ & 0.0000 & $0.000 \mathrm{E}+00$ & 0.0000 & $0.000 \mathrm{E}+00$ & 0.0000 & $0.000 \mathrm{E}+00$ & 0.0000 \\
\hline-239 & $4.380 E-16$ & 0.0000 & $0.000 \mathrm{E}+00$ & 0.0000 & $0.000 \mathrm{E}+00$ & 0.0000 & $0.000 \mathrm{E}+00$ & 0.0000 & $0.000 \mathrm{E}+00$ & 0.0000 & $0.000 \mathrm{E}+00$ & 0.0000 & $0.000 \mathrm{E}+00$ & 0.0000 \\
\hline-240 & $4.275 E-23$ & 0.0000 & $0.000 \mathrm{E}+00$ & 0.0000 & $0.000 \mathrm{E}+00$ & 0.0000 & $0.000 \mathrm{E}+00$ & 0.0000 & $0.000 \mathrm{E}+00$ & 0.0000 & $0.000 \mathrm{E}+00$ & 0.0000 & $0.000 \mathrm{E}+00$ & 0.0000 \\
\hline 99 & $3.025 E-24$ & 0.0000 & $0.000 \mathrm{E}+00$ & 0.0000 & $0.000 \mathrm{E}+00$ & 0.0000 & $0.000 \mathrm{E}+00$ & 0.0000 & $0.000 \mathrm{E}+00$ & 0.0000 & $0.000 \mathrm{E}+00$ & 0.0000 & $0.000 \mathrm{E}+00$ & 0.0000 \\
\hline-228 & $3.872 E-06$ & 0.9206 & $0.000 \mathrm{E}+00$ & 0.0000 & $0.000 \mathrm{E}+00$ & 0.0000 & $0.000 \mathrm{E}+00$ & 0.0000 & $0.000 \mathrm{E}+00$ & 0.0000 & $0.000 \mathrm{E}+00$ & 0.0000 & $0.000 \mathrm{E}+00$ & 0.0000 \\
\hline-230 & $1.139 \mathrm{E}-08$ & 0.0027 & $0.000 \mathrm{E}+00$ & 0.0000 & $0.000 \mathrm{E}+00$ & 0.0000 & $0.000 \mathrm{E}+00$ & 0.0000 & $0.000 \mathrm{E}+00$ & 0.0000 & $0.000 \mathrm{E}+00$ & 0.0000 & $0.000 \mathrm{E}+00$ & 0.0000 \\
\hline-232 & $2.759 \mathrm{E}-07$ & 0.0656 & $0.000 \mathrm{E}+00$ & 0.0000 & $0.000 \mathrm{E}+00$ & 0.0000 & $0.000 \mathrm{E}+00$ & 0.0000 & $0.000 \mathrm{E}+00$ & 0.0000 & $0.000 \mathrm{E}+00$ & 0.0000 & $0.000 \mathrm{E}+00$ & 0.0000 \\
\hline 234 & $1.277 \mathrm{E}-13$ & 0.0000 & $0.000 \mathrm{E}+00$ & 0.0000 & $0.000 \mathrm{E}+00$ & 0.0000 & $0.000 \mathrm{E}+00$ & 0.0000 & $0.000 \mathrm{E}+00$ & 0.0000 & $0.000 \mathrm{E}+00$ & 0.0000 & $0.000 \mathrm{E}+00$ & 0.0000 \\
\hline 235 & $8.230 \mathrm{E}-14$ & 0.0000 & $0.000 \mathrm{E}+00$ & 0.0000 & $0.000 \mathrm{E}+00$ & 0.0000 & $0.000 \mathrm{E}+00$ & 0.0000 & $0.000 \mathrm{E}+00$ & 0.0000 & $0.000 \mathrm{E}+00$ & 0.0000 & $0.000 \mathrm{E}+00$ & 0.0000 \\
\hline 238 & $2.290 E-08$ & 0.0054 & $0.000 \mathrm{E}+00$ & 0.0000 & $0.000 \mathrm{E}+00$ & 0.0000 & $0.000 \mathrm{E}+00$ & 0.0000 & $0.000 \mathrm{E}+00$ & 0.0000 & $0.000 \mathrm{E}+00$ & 0.0000 & $0.000 \mathrm{E}+00$ & 0.0000 \\
\hline & $4.206 E-06$ & 1.0000 & $0.000 \mathrm{E}+00$ & 0.0000 & $0.000 \mathrm{E}+00$ & 0.0000 & $0.000 \mathrm{E}+00$ & 0.0000 & $0.000 \mathrm{E}+00$ & 0.0000 & $0.000 \mathrm{E}+00$ & 0.0000 & $.000 \mathrm{E}+00$ & 0.0000 \\
\hline
\end{tabular}

Total Dose Contributions TDOSE (i,p,t) for Individual Radionuclides (i) and Pathways (p) As mrem/yr and Fraction of Total Dose At $t=1.000 \mathrm{E}+00$ years

Water Dependent Pathways

\begin{tabular}{|c|c|c|c|c|c|c|c|c|c|c|c|c|c|c|}
\hline & \multicolumn{2}{|c|}{ Water } & \multicolumn{2}{|c|}{ Fish } & \multicolumn{2}{|c|}{ Radon } & \multicolumn{2}{|c|}{ Plant } & \multicolumn{2}{|c|}{ Meat } & \multicolumn{2}{|c|}{ Milk } & \multicolumn{2}{|c|}{ All Pathways* } \\
\hline clide & mrem/yr & fract. & mrem/yr & fract. & mrem/yr & fract. & mrem/yr & fract. & mrem/yr & fract. & mrem/yr & fract. & mrem/yr & fract. \\
\hline-241 & $0.000 \mathrm{E}+00$ & 0.0000 & $0.000 \mathrm{E}+00$ & 0.0000 & $0.000 \mathrm{E}+00$ & 0.0000 & $0.000 \mathrm{E}+00$ & 0.0000 & $0.000 \mathrm{E}+00$ & 0.0000 & $0.000 \mathrm{E}+00$ & 0.0000 & $1.638 \mathrm{E}-17$ & 0.0000 \\
\hline-137 & $0.000 \mathrm{E}+00$ & 0.0000 & $0.000 \mathrm{E}+00$ & 0.0000 & $0.000 \mathrm{E}+00$ & 0.0000 & $0.000 \mathrm{E}+00$ & 0.0000 & $0.000 \mathrm{E}+00$ & 0.0000 & $0.000 \mathrm{E}+00$ & 0.0000 & $2.362 \mathrm{E}-08$ & 0.0056 \\
\hline-237 & $0.000 \mathrm{E}+00$ & 0.0000 & $0.000 \mathrm{E}+00$ & 0.0000 & $0.000 \mathrm{E}+00$ & 0.0000 & $0.000 \mathrm{E}+00$ & 0.0000 & $0.000 \mathrm{E}+00$ & 0.0000 & $0.000 \mathrm{E}+00$ & 0.0000 & $5.301 \mathrm{E}-12$ & 0.0000 \\
\hline 238 & $0.000 \mathrm{E}+00$ & 0.0000 & $0.000 \mathrm{E}+00$ & 0.0000 & $0.000 \mathrm{E}+00$ & 0.0000 & $0.000 \mathrm{E}+00$ & 0.0000 & $0.000 \mathrm{E}+00$ & 0.0000 & $0.000 \mathrm{E}+00$ & 0.0000 & $4.717 \mathrm{E}-20$ & 0.0000 \\
\hline 239 & $0.000 \mathrm{E}+00$ & 0.0000 & $0.000 \mathrm{E}+00$ & 0.0000 & $0.000 \mathrm{E}+00$ & 0.0000 & $0.000 \mathrm{E}+00$ & 0.0000 & $0.000 \mathrm{E}+00$ & 0.0000 & $0.000 \mathrm{E}+00$ & 0.0000 & $4.380 \mathrm{E}-16$ & 0.0000 \\
\hline 240 & $0.000 \mathrm{E}+00$ & 0.0000 & $0.000 \mathrm{E}+00$ & 0.0000 & $0.000 \mathrm{E}+00$ & 0.0000 & $0.000 \mathrm{E}+00$ & 0.0000 & $0.000 \mathrm{E}+00$ & 0.0000 & $0.000 \mathrm{E}+00$ & 0.0000 & $4.275 E-23$ & 0.0000 \\
\hline 99 & $0.000 \mathrm{E}+00$ & 0.0000 & $0.000 \mathrm{E}+00$ & 0.0000 & $0.000 \mathrm{E}+00$ & 0.0000 & $0.000 \mathrm{E}+00$ & 0.0000 & $0.000 \mathrm{E}+00$ & 0.0000 & $0.000 \mathrm{E}+00$ & 0.0000 & $3.025 \mathrm{E}-24$ & 0.0000 \\
\hline 228 & $0.000 \mathrm{E}+00$ & 0.0000 & $0.000 \mathrm{E}+00$ & 0.0000 & $0.000 \mathrm{E}+00$ & 0.0000 & $0.000 \mathrm{E}+00$ & 0.0000 & $0.000 \mathrm{E}+00$ & 0.0000 & $0.000 \mathrm{E}+00$ & 0.0000 & $3.872 \mathrm{E}-06$ & 0.9206 \\
\hline 230 & $0.000 \mathrm{E}+00$ & 0.0000 & $0.000 \mathrm{E}+00$ & 0.0000 & $0.000 \mathrm{E}+00$ & 0.0000 & $0.000 \mathrm{E}+00$ & 0.0000 & $0.000 \mathrm{E}+00$ & 0.0000 & $0.000 \mathrm{E}+00$ & 0.0000 & $1.139 \mathrm{E}-08$ & 0.0027 \\
\hline 232 & $0.000 \mathrm{E}+00$ & 0.0000 & $0.000 \mathrm{E}+00$ & 0.0000 & $0.000 \mathrm{E}+00$ & 0.0000 & $0.000 \mathrm{E}+00$ & 0.0000 & $0.000 \mathrm{E}+00$ & 0.0000 & $0.000 \mathrm{E}+00$ & 0.0000 & $2.759 \mathrm{E}-07$ & 0.0656 \\
\hline 34 & $0.000 \mathrm{E}+00$ & 0.0000 & $0.000 \mathrm{E}+00$ & 0.0000 & $0.000 \mathrm{E}+00$ & 0.0000 & $0.000 \mathrm{E}+00$ & 0.0000 & $0.000 \mathrm{E}+00$ & 0.0000 & $0.000 \mathrm{E}+00$ & 0.0000 & $1.277 \mathrm{E}-13$ & 0.0000 \\
\hline 35 & $0.000 \mathrm{E}+00$ & 0.0000 & $0.000 \mathrm{E}+00$ & 0.0000 & $0.000 \mathrm{E}+00$ & 0.0000 & $0.000 \mathrm{E}+00$ & 0.0000 & $0.000 \mathrm{E}+00$ & 0.0000 & $0.000 \mathrm{E}+00$ & 0.0000 & $8.230 \mathrm{E}-14$ & 0.0000 \\
\hline 38 & $0.000 \mathrm{E}+00$ & 0.0000 & $0.000 \mathrm{E}+00$ & 0.0000 & $0.000 \mathrm{E}+00$ & 0.0000 & $0.000 \mathrm{E}+00$ & 0.0000 & $0.000 \mathrm{E}+00$ & 0.0000 & $0.000 \mathrm{E}+00$ & 0.0000 & $2.290 \mathrm{E}-08$ & 0.0054 \\
\hline & $0.000 \mathrm{E}+00$ & 0.0000 & $0.000 \mathrm{E}+00$ & 0.0000 & $0.000 \mathrm{E}+00$ & 0.0000 & $0.000 \mathrm{E}+00$ & 0.0000 & $0.000 \mathrm{E}+00$ & 0.0000 & $0.000 \mathrm{E}+00$ & 000 & -06 & 1.0000 \\
\hline
\end{tabular}

* Sum of all water independent and dependent pathways. 
RESRAD, Version 6.5

ummary : C746U Resident Gardener Deterministic Run

File : $\mathrm{X}: \backslash F I N A L$ V2 \DOE FWD RUNS $\backslash$ C746U RG DOE SG FWD-FV2-100000YR.RAD

Total Dose Contributions TDOSE(i,p,t) for Individual Radionuclides (i) and Pathways (p) As mrem/yr and Fraction of Total Dose At $t=5.000 \mathrm{E}+01$ years

Water Independent Pathways (Inhalation excludes radon)

\begin{tabular}{|c|c|c|c|c|c|c|c|c|c|c|c|c|c|c|}
\hline \multirow{2}{*}{ Nuclide } & \multicolumn{2}{|c|}{ Ground } & \multicolumn{2}{|c|}{ Inhalation } & \multicolumn{2}{|c|}{ Radon } & \multicolumn{2}{|c|}{ Plant } & \multicolumn{2}{|c|}{ Meat } & \multicolumn{2}{|c|}{ Milk } & \multicolumn{2}{|c|}{ Soil } \\
\hline & mrem/yr & fract. & mrem/yr & fract. & mrem/yr & fract. & mrem/yr & fract. & mrem/yr & fract. & mrem/yr & fract. & mrem/yr & fract. \\
\hline-241 & $8.973 E-16$ & 0.0000 & $0.000 \mathrm{E}+00$ & 0.0000 & $0.000 \mathrm{E}+00$ & 0.0000 & $0.000 \mathrm{E}+00$ & 0.0000 & $0.000 \mathrm{E}+00$ & 0.0000 & $0.000 \mathrm{E}+00$ & 0.0000 & $0.000 \mathrm{E}+00$ & 0.0000 \\
\hline-137 & $1.149 \mathrm{E}-08$ & 0.0012 & $0.000 \mathrm{E}+00$ & 0.0000 & $0.000 \mathrm{E}+00$ & 0.0000 & $0.000 \mathrm{E}+00$ & 0.0000 & $0.000 \mathrm{E}+00$ & 0.0000 & $0.000 \mathrm{E}+00$ & 0.0000 & $0.000 \mathrm{E}+00$ & 0.0000 \\
\hline-237 & $8.957 \mathrm{E}-12$ & 0.0000 & $0.000 \mathrm{E}+00$ & 0.0000 & $0.000 \mathrm{E}+00$ & 0.0000 & $0.000 \mathrm{E}+00$ & 0.0000 & $0.000 \mathrm{E}+00$ & 0.0000 & $0.000 \mathrm{E}+00$ & 0.0000 & $0.000 \mathrm{E}+00$ & 0.0000 \\
\hline-238 & $2.054 \mathrm{E}-15$ & 0.0000 & $0.000 \mathrm{E}+00$ & 0.0000 & $0.000 \mathrm{E}+00$ & 0.0000 & $0.000 \mathrm{E}+00$ & 0.0000 & $0.000 \mathrm{E}+00$ & 0.0000 & $0.000 \mathrm{E}+00$ & 0.0000 & $0.000 \mathrm{E}+00$ & 0.0000 \\
\hline-239 & $7.861 E-16$ & 0.0000 & $0.000 \mathrm{E}+00$ & 0.0000 & $0.000 \mathrm{E}+00$ & 0.0000 & $0.000 \mathrm{E}+00$ & 0.0000 & $0.000 \mathrm{E}+00$ & 0.0000 & $0.000 \mathrm{E}+00$ & 0.0000 & $0.000 \mathrm{E}+00$ & 0.0000 \\
\hline-240 & $9.653 \mathrm{E}-20$ & 0.0000 & $0.000 \mathrm{E}+00$ & 0.0000 & $0.000 \mathrm{E}+00$ & 0.0000 & $0.000 \mathrm{E}+00$ & 0.0000 & $0.000 \mathrm{E}+00$ & 0.0000 & $0.000 \mathrm{E}+00$ & 0.0000 & $0.000 \mathrm{E}+00$ & 0.0000 \\
\hline 99 & $4.979 E-24$ & 0.0000 & $0.000 \mathrm{E}+00$ & 0.0000 & $0.000 \mathrm{E}+00$ & 0.0000 & $0.000 \mathrm{E}+00$ & 0.0000 & $0.000 \mathrm{E}+00$ & 0.0000 & $0.000 \mathrm{E}+00$ & 0.0000 & $0.000 \mathrm{E}+00$ & 0.0000 \\
\hline-228 & 1.011E-13 & 0.0000 & $0.000 \mathrm{E}+00$ & 0.0000 & $0.000 \mathrm{E}+00$ & 0.0000 & $0.000 \mathrm{E}+00$ & 0.0000 & $0.000 \mathrm{E}+00$ & 0.0000 & $0.000 \mathrm{E}+00$ & 0.0000 & $0.000 \mathrm{E}+00$ & 0.0000 \\
\hline-230 & $5.320 \mathrm{E}-07$ & 0.0558 & $0.000 \mathrm{E}+00$ & 0.0000 & $0.000 \mathrm{E}+00$ & 0.0000 & $0.000 \mathrm{E}+00$ & 0.0000 & $0.000 \mathrm{E}+00$ & 0.0000 & $0.000 \mathrm{E}+00$ & 0.0000 & $0.000 \mathrm{E}+00$ & 0.0000 \\
\hline-232 & $8.963 E-06$ & 0.9395 & $0.000 \mathrm{E}+00$ & 0.0000 & $0.000 \mathrm{E}+00$ & 0.0000 & $0.000 \mathrm{E}+00$ & 0.0000 & $0.000 \mathrm{E}+00$ & 0.0000 & $0.000 \mathrm{E}+00$ & 0.0000 & $0.000 \mathrm{E}+00$ & 0.0000 \\
\hline 234 & $1.941 \mathrm{E}-10$ & 0.0000 & $0.000 \mathrm{E}+00$ & 0.0000 & $0.000 \mathrm{E}+00$ & 0.0000 & $0.000 \mathrm{E}+00$ & 0.0000 & $0.000 \mathrm{E}+00$ & 0.0000 & $0.000 \mathrm{E}+00$ & 0.0000 & $0.000 \mathrm{E}+00$ & 0.0000 \\
\hline 235 & $6.005 E-13$ & 0.0000 & $0.000 \mathrm{E}+00$ & 0.0000 & $0.000 \mathrm{E}+00$ & 0.0000 & $0.000 \mathrm{E}+00$ & 0.0000 & $0.000 \mathrm{E}+00$ & 0.0000 & $0.000 \mathrm{E}+00$ & 0.0000 & $0.000 \mathrm{E}+00$ & 0.0000 \\
\hline 38 & $3.385 E-08$ & 0.0035 & $0.000 \mathrm{E}+00$ & 0.0000 & $0.000 \mathrm{E}+00$ & 0.0000 & $0.000 \mathrm{E}+00$ & 0.0000 & $0.000 \mathrm{E}+00$ & 0.0000 & $0.000 \mathrm{E}+00$ & 0.0000 & $0.000 \mathrm{E}+00$ & 0.0000 \\
\hline & $9.541 \mathrm{E}-06$ & 1.0000 & $0.000 \mathrm{E}+00$ & 0.0000 & $0.000 \mathrm{E}+00$ & 0.0000 & $0.000 \mathrm{E}+00$ & 0.0000 & $0.000 \mathrm{E}+00$ & 0.0000 & $0.000 \mathrm{E}+00$ & 0.0000 & $.000 \mathrm{E}+00$ & 0.0000 \\
\hline
\end{tabular}

Total Dose Contributions TDOSE (i,p,t) for Individual Radionuclides (i) and Pathways (p) As mrem/yr and Fraction of Total Dose At $t=5.000 \mathrm{E}+01$ years

Water Dependent Pathways

\begin{tabular}{|c|c|c|c|c|c|c|c|c|c|c|c|c|c|c|}
\hline & \multicolumn{2}{|c|}{ Water } & \multicolumn{2}{|c|}{ Fish } & \multicolumn{2}{|c|}{ Radon } & \multicolumn{2}{|c|}{ Plant } & \multicolumn{2}{|c|}{ Meat } & \multicolumn{2}{|c|}{ Milk } & \multicolumn{2}{|c|}{ All Pathways* } \\
\hline clide & mrem/yr & fract. & mrem/yr & fract. & mrem/yr & fract. & mrem/yr & fract. & mrem/yr & fract. & mrem/yr & fract. & mrem/yr & fract. \\
\hline-241 & $0.000 \mathrm{E}+00$ & 0.0000 & $0.000 \mathrm{E}+00$ & 0.0000 & $0.000 \mathrm{E}+00$ & 0.0000 & $0.000 \mathrm{E}+00$ & 0.0000 & $0.000 \mathrm{E}+00$ & 0.0000 & $0.000 \mathrm{E}+00$ & 0.0000 & $8.973 E-16$ & 0.0000 \\
\hline-137 & $0.000 \mathrm{E}+00$ & 0.0000 & $0.000 \mathrm{E}+00$ & 0.0000 & $0.000 \mathrm{E}+00$ & 0.0000 & $0.000 \mathrm{E}+00$ & 0.0000 & $0.000 \mathrm{E}+00$ & 0.0000 & $0.000 \mathrm{E}+00$ & 0.0000 & $1.149 \mathrm{E}-08$ & 0.0012 \\
\hline-237 & $0.000 \mathrm{E}+00$ & 0.0000 & $0.000 \mathrm{E}+00$ & 0.0000 & $0.000 \mathrm{E}+00$ & 0.0000 & $0.000 \mathrm{E}+00$ & 0.0000 & $0.000 \mathrm{E}+00$ & 0.0000 & $0.000 \mathrm{E}+00$ & 0.0000 & $8.957 \mathrm{E}-12$ & 0.0000 \\
\hline 238 & $0.000 \mathrm{E}+00$ & 0.0000 & $0.000 \mathrm{E}+00$ & 0.0000 & $0.000 \mathrm{E}+00$ & 0.0000 & $0.000 \mathrm{E}+00$ & 0.0000 & $0.000 \mathrm{E}+00$ & 0.0000 & $0.000 \mathrm{E}+00$ & 0.0000 & $2.054 \mathrm{E}-15$ & 0.0000 \\
\hline 239 & $0.000 \mathrm{E}+00$ & 0.0000 & $0.000 \mathrm{E}+00$ & 0.0000 & $0.000 \mathrm{E}+00$ & 0.0000 & $0.000 \mathrm{E}+00$ & 0.0000 & $0.000 \mathrm{E}+00$ & 0.0000 & $0.000 \mathrm{E}+00$ & 0.0000 & $7.861 \mathrm{E}-16$ & 0.0000 \\
\hline 240 & $0.000 \mathrm{E}+00$ & 0.0000 & $0.000 \mathrm{E}+00$ & 0.0000 & $0.000 \mathrm{E}+00$ & 0.0000 & $0.000 \mathrm{E}+00$ & 0.0000 & $0.000 \mathrm{E}+00$ & 0.0000 & $0.000 \mathrm{E}+00$ & 0.0000 & $9.653 \mathrm{E}-20$ & 0.0000 \\
\hline 99 & $0.000 \mathrm{E}+00$ & 0.0000 & $0.000 \mathrm{E}+00$ & 0.0000 & $0.000 \mathrm{E}+00$ & 0.0000 & $0.000 \mathrm{E}+00$ & 0.0000 & $0.000 \mathrm{E}+00$ & 0.0000 & $0.000 \mathrm{E}+00$ & 0.0000 & $4.979 E-24$ & 0.0000 \\
\hline 228 & $0.000 \mathrm{E}+00$ & 0.0000 & $0.000 \mathrm{E}+00$ & 0.0000 & $0.000 \mathrm{E}+00$ & 0.0000 & $0.000 \mathrm{E}+00$ & 0.0000 & $0.000 \mathrm{E}+00$ & 0.0000 & $0.000 \mathrm{E}+00$ & 0.0000 & $1.011 \mathrm{E}-13$ & 0.0000 \\
\hline 230 & $0.000 \mathrm{E}+00$ & 0.0000 & $0.000 \mathrm{E}+00$ & 0.0000 & $0.000 \mathrm{E}+00$ & 0.0000 & $0.000 \mathrm{E}+00$ & 0.0000 & $0.000 \mathrm{E}+00$ & 0.0000 & $0.000 \mathrm{E}+00$ & 0.0000 & $5.320 \mathrm{E}-07$ & 0.0558 \\
\hline 232 & $0.000 \mathrm{E}+00$ & 0.0000 & $0.000 \mathrm{E}+00$ & 0.0000 & $0.000 \mathrm{E}+00$ & 0.0000 & $0.000 \mathrm{E}+00$ & 0.0000 & $0.000 \mathrm{E}+00$ & 0.0000 & $0.000 \mathrm{E}+00$ & 0.0000 & $8.963 E-06$ & 0.9395 \\
\hline 34 & $0.000 \mathrm{E}+00$ & 0.0000 & $0.000 \mathrm{E}+00$ & 0.0000 & $0.000 \mathrm{E}+00$ & 0.0000 & $0.000 \mathrm{E}+00$ & 0.0000 & $0.000 \mathrm{E}+00$ & 0.0000 & $0.000 \mathrm{E}+00$ & 0.0000 & $1.941 \mathrm{E}-10$ & 0.0000 \\
\hline 35 & $0.000 \mathrm{E}+00$ & 0.0000 & $0.000 \mathrm{E}+00$ & 0.0000 & $0.000 \mathrm{E}+00$ & 0.0000 & $0.000 \mathrm{E}+00$ & 0.0000 & $0.000 \mathrm{E}+00$ & 0.0000 & $0.000 \mathrm{E}+00$ & 0.0000 & $6.005 E-13$ & 0.0000 \\
\hline 38 & $0.000 \mathrm{E}+00$ & 0.0000 & $0.000 \mathrm{E}+00$ & 0.0000 & $0.000 \mathrm{E}+00$ & 0.0000 & $0.000 \mathrm{E}+00$ & 0.0000 & $0.000 \mathrm{E}+00$ & 0.0000 & $0.000 \mathrm{E}+00$ & 0.0000 & $3.385 \mathrm{E}-08$ & 0.0035 \\
\hline & $0.000 \mathrm{E}+00$ & 0.0000 & $0.000 \mathrm{E}+00$ & 0.0000 & $0.000 \mathrm{E}+00$ & 0.0000 & $0.000 \mathrm{E}+00$ & 0.0000 & $0.000 \mathrm{E}+00$ & 0.0000 & $0.000 \mathrm{E}+00$ & 000 & -06 & 1.0000 \\
\hline
\end{tabular}

* Sum of all water independent and dependent pathways. 
RESRAD, Version 6.5

ummary : C746U Resident Gardener Deterministic Run

File : $\mathrm{X}: \backslash F I N A L$ V2 \DOE FWD RUNS $\backslash$ C746U RG DOE SG FWD-FV2-100000YR.RAD

Total Dose Contributions TDOSE(i,p,t) for Individual Radionuclides (i) and Pathways (p) As mrem/yr and Fraction of Total Dose At $t=1.000 \mathrm{E}+02$ years

Water Independent Pathways (Inhalation excludes radon)

\begin{tabular}{|c|c|c|c|c|c|c|c|c|c|c|c|c|c|c|}
\hline \multirow{2}{*}{ Nuclide } & \multicolumn{2}{|c|}{ Ground } & \multicolumn{2}{|c|}{ Inhalation } & \multicolumn{2}{|c|}{ Radon } & \multicolumn{2}{|c|}{ Plant } & \multicolumn{2}{|c|}{ Meat } & \multicolumn{2}{|c|}{ Milk } & \multicolumn{2}{|c|}{ Soil } \\
\hline & mrem/yr & fract. & mrem/yr & fract. & mrem/yr & fract. & mrem/yr & fract. & mrem/yr & fract. & mrem/yr & fract. & mrem/yr & fract. \\
\hline-241 & $2.940 \mathrm{E}-15$ & 0.0000 & $0.000 \mathrm{E}+00$ & 0.0000 & $0.000 \mathrm{E}+00$ & 0.0000 & $0.000 \mathrm{E}+00$ & 0.0000 & $0.000 \mathrm{E}+00$ & 0.0000 & $0.000 \mathrm{E}+00$ & 0.0000 & $0.000 \mathrm{E}+00$ & 0.0000 \\
\hline-137 & $5.512 E-09$ & 0.0004 & $0.000 \mathrm{E}+00$ & 0.0000 & $0.000 \mathrm{E}+00$ & 0.0000 & $0.000 \mathrm{E}+00$ & 0.0000 & $0.000 \mathrm{E}+00$ & 0.0000 & $0.000 \mathrm{E}+00$ & 0.0000 & $0.000 \mathrm{E}+00$ & 0.0000 \\
\hline-237 & $1.534 \mathrm{E}-11$ & 0.0000 & $0.000 \mathrm{E}+00$ & 0.0000 & $0.000 \mathrm{E}+00$ & 0.0000 & $0.000 \mathrm{E}+00$ & 0.0000 & $0.000 \mathrm{E}+00$ & 0.0000 & $0.000 \mathrm{E}+00$ & 0.0000 & $0.000 \mathrm{E}+00$ & 0.0000 \\
\hline-238 & $2.076 \mathrm{E}-14$ & 0.0000 & $0.000 \mathrm{E}+00$ & 0.0000 & $0.000 \mathrm{E}+00$ & 0.0000 & $0.000 \mathrm{E}+00$ & 0.0000 & $0.000 \mathrm{E}+00$ & 0.0000 & $0.000 \mathrm{E}+00$ & 0.0000 & $0.000 \mathrm{E}+00$ & 0.0000 \\
\hline-239 & 1. $428 \mathrm{E}-15$ & 0.0000 & $0.000 \mathrm{E}+00$ & 0.0000 & $0.000 \mathrm{E}+00$ & 0.0000 & $0.000 \mathrm{E}+00$ & 0.0000 & $0.000 \mathrm{E}+00$ & 0.0000 & $0.000 \mathrm{E}+00$ & 0.0000 & $0.000 \mathrm{E}+00$ & 0.0000 \\
\hline-240 & $6.420 \mathrm{E}-19$ & 0.0000 & $0.000 \mathrm{E}+00$ & 0.0000 & $0.000 \mathrm{E}+00$ & 0.0000 & $0.000 \mathrm{E}+00$ & 0.0000 & $0.000 \mathrm{E}+00$ & 0.0000 & $0.000 \mathrm{E}+00$ & 0.0000 & $0.000 \mathrm{E}+00$ & 0.0000 \\
\hline 99 & $8.280 E-24$ & 0.0000 & $0.000 \mathrm{E}+00$ & 0.0000 & $0.000 \mathrm{E}+00$ & 0.0000 & $0.000 \mathrm{E}+00$ & 0.0000 & $0.000 \mathrm{E}+00$ & 0.0000 & $0.000 \mathrm{E}+00$ & 0.0000 & $0.000 \mathrm{E}+00$ & 0.0000 \\
\hline-228 & $1.847 \mathrm{E}-21$ & 0.0000 & $0.000 \mathrm{E}+00$ & 0.0000 & $0.000 \mathrm{E}+00$ & 0.0000 & $0.000 \mathrm{E}+00$ & 0.0000 & $0.000 \mathrm{E}+00$ & 0.0000 & $0.000 \mathrm{E}+00$ & 0.0000 & $0.000 \mathrm{E}+00$ & 0.0000 \\
\hline-230 & $1.479 \mathrm{E}-06$ & 0.1082 & $0.000 \mathrm{E}+00$ & 0.0000 & $0.000 \mathrm{E}+00$ & 0.0000 & $0.000 \mathrm{E}+00$ & 0.0000 & $0.000 \mathrm{E}+00$ & 0.0000 & $0.000 \mathrm{E}+00$ & 0.0000 & $0.000 \mathrm{E}+00$ & 0.0000 \\
\hline-232 & $1.213 E-05$ & 0.8876 & $0.000 \mathrm{E}+00$ & 0.0000 & $0.000 \mathrm{E}+00$ & 0.0000 & $0.000 \mathrm{E}+00$ & 0.0000 & $0.000 \mathrm{E}+00$ & 0.0000 & $0.000 \mathrm{E}+00$ & 0.0000 & $0.000 \mathrm{E}+00$ & 0.0000 \\
\hline 234 & $1.078 \mathrm{E}-09$ & 0.0001 & $0.000 \mathrm{E}+00$ & 0.0000 & $0.000 \mathrm{E}+00$ & 0.0000 & $0.000 \mathrm{E}+00$ & 0.0000 & $0.000 \mathrm{E}+00$ & 0.0000 & $0.000 \mathrm{E}+00$ & 0.0000 & $0.000 \mathrm{E}+00$ & 0.0000 \\
\hline 235 & $2.202 \mathrm{E}-12$ & 0.0000 & $0.000 \mathrm{E}+00$ & 0.0000 & $0.000 \mathrm{E}+00$ & 0.0000 & $0.000 \mathrm{E}+00$ & 0.0000 & $0.000 \mathrm{E}+00$ & 0.0000 & $0.000 \mathrm{E}+00$ & 0.0000 & $0.000 \mathrm{E}+00$ & 0.0000 \\
\hline 38 & $5.045 E-08$ & 0.0037 & $0.000 \mathrm{E}+00$ & 0.0000 & $0.000 \mathrm{E}+00$ & 0.0000 & $0.000 \mathrm{E}+00$ & 0.0000 & $0.000 \mathrm{E}+00$ & 0.0000 & $0.000 \mathrm{E}+00$ & 0.0000 & $0.000 \mathrm{E}+00$ & 0.0000 \\
\hline & $1.367 \mathrm{E}-05$ & 1.0000 & $0.000 \mathrm{E}+00$ & 0.0000 & $0.000 \mathrm{E}+00$ & 0.0000 & $0.000 \mathrm{E}+00$ & 0.0000 & $0.000 \mathrm{E}+00$ & 0.0000 & $0.000 \mathrm{E}+00$ & 0.0000 & $.000 \mathrm{E}+00$ & 0.0000 \\
\hline
\end{tabular}

Total Dose Contributions TDOSE (i,p,t) for Individual Radionuclides (i) and Pathways (p) As mrem/yr and Fraction of Total Dose At $t=1.000 \mathrm{E}+02$ years

Water Dependent Pathways

\begin{tabular}{|c|c|c|c|c|c|c|c|c|c|c|c|c|c|c|}
\hline & \multicolumn{2}{|c|}{ Water } & \multicolumn{2}{|c|}{ Fish } & \multicolumn{2}{|c|}{ Radon } & \multicolumn{2}{|c|}{ Plant } & \multicolumn{2}{|c|}{ Meat } & \multicolumn{2}{|c|}{ Milk } & \multicolumn{2}{|c|}{ All Pathways* } \\
\hline clide & mrem/yr & fract. & mrem/yr & fract. & mrem/yr & fract. & mrem/yr & fract. & mrem/yr & fract. & mrem/yr & fract. & mrem/yr & fract. \\
\hline-241 & $0.000 \mathrm{E}+00$ & 0.0000 & $0.000 \mathrm{E}+00$ & 0.0000 & $0.000 \mathrm{E}+00$ & 0.0000 & $0.000 \mathrm{E}+00$ & 0.0000 & $0.000 \mathrm{E}+00$ & 0.0000 & $0.000 \mathrm{E}+00$ & 0.0000 & $2.940 \mathrm{E}-15$ & 0.0000 \\
\hline-137 & $0.000 \mathrm{E}+00$ & 0.0000 & $0.000 \mathrm{E}+00$ & 0.0000 & $0.000 \mathrm{E}+00$ & 0.0000 & $0.000 \mathrm{E}+00$ & 0.0000 & $0.000 \mathrm{E}+00$ & 0.0000 & $0.000 \mathrm{E}+00$ & 0.0000 & $5.512 \mathrm{E}-09$ & 0.0004 \\
\hline-237 & $0.000 \mathrm{E}+00$ & 0.0000 & $0.000 \mathrm{E}+00$ & 0.0000 & $0.000 \mathrm{E}+00$ & 0.0000 & $0.000 \mathrm{E}+00$ & 0.0000 & $0.000 \mathrm{E}+00$ & 0.0000 & $0.000 \mathrm{E}+00$ & 0.0000 & $1.534 \mathrm{E}-11$ & 0.0000 \\
\hline 238 & $0.000 \mathrm{E}+00$ & 0.0000 & $0.000 \mathrm{E}+00$ & 0.0000 & $0.000 \mathrm{E}+00$ & 0.0000 & $0.000 \mathrm{E}+00$ & 0.0000 & $0.000 \mathrm{E}+00$ & 0.0000 & $0.000 \mathrm{E}+00$ & 0.0000 & $2.076 \mathrm{E}-14$ & 0.0000 \\
\hline 239 & $0.000 \mathrm{E}+00$ & 0.0000 & $0.000 \mathrm{E}+00$ & 0.0000 & $0.000 \mathrm{E}+00$ & 0.0000 & $0.000 \mathrm{E}+00$ & 0.0000 & $0.000 \mathrm{E}+00$ & 0.0000 & $0.000 \mathrm{E}+00$ & 0.0000 & $1.428 \mathrm{E}-15$ & 0.0000 \\
\hline 240 & $0.000 \mathrm{E}+00$ & 0.0000 & $0.000 \mathrm{E}+00$ & 0.0000 & $0.000 \mathrm{E}+00$ & 0.0000 & $0.000 \mathrm{E}+00$ & 0.0000 & $0.000 \mathrm{E}+00$ & 0.0000 & $0.000 \mathrm{E}+00$ & 0.0000 & $6.420 \mathrm{E}-19$ & 0.0000 \\
\hline 99 & $0.000 \mathrm{E}+00$ & 0.0000 & $0.000 \mathrm{E}+00$ & 0.0000 & $0.000 \mathrm{E}+00$ & 0.0000 & $0.000 \mathrm{E}+00$ & 0.0000 & $0.000 \mathrm{E}+00$ & 0.0000 & $0.000 \mathrm{E}+00$ & 0.0000 & $8.280 \mathrm{E}-24$ & 0.0000 \\
\hline 228 & $0.000 \mathrm{E}+00$ & 0.0000 & $0.000 \mathrm{E}+00$ & 0.0000 & $0.000 \mathrm{E}+00$ & 0.0000 & $0.000 \mathrm{E}+00$ & 0.0000 & $0.000 \mathrm{E}+00$ & 0.0000 & $0.000 \mathrm{E}+00$ & 0.0000 & $1.847 \mathrm{E}-21$ & 0.0000 \\
\hline 230 & $0.000 \mathrm{E}+00$ & 0.0000 & $0.000 \mathrm{E}+00$ & 0.0000 & $0.000 \mathrm{E}+00$ & 0.0000 & $0.000 \mathrm{E}+00$ & 0.0000 & $0.000 \mathrm{E}+00$ & 0.0000 & $0.000 \mathrm{E}+00$ & 0.0000 & $1.479 \mathrm{E}-06$ & 0.1082 \\
\hline 232 & $0.000 \mathrm{E}+00$ & 0.0000 & $0.000 \mathrm{E}+00$ & 0.0000 & $0.000 \mathrm{E}+00$ & 0.0000 & $0.000 \mathrm{E}+00$ & 0.0000 & $0.000 \mathrm{E}+00$ & 0.0000 & $0.000 \mathrm{E}+00$ & 0.0000 & $1.213 E-05$ & 0.8876 \\
\hline 34 & $0.000 \mathrm{E}+00$ & 0.0000 & $0.000 \mathrm{E}+00$ & 0.0000 & $0.000 \mathrm{E}+00$ & 0.0000 & $0.000 \mathrm{E}+00$ & 0.0000 & $0.000 \mathrm{E}+00$ & 0.0000 & $0.000 \mathrm{E}+00$ & 0.0000 & $1.078 \mathrm{E}-09$ & 0.0001 \\
\hline 35 & $0.000 \mathrm{E}+00$ & 0.0000 & $0.000 \mathrm{E}+00$ & 0.0000 & $0.000 \mathrm{E}+00$ & 0.0000 & $0.000 \mathrm{E}+00$ & 0.0000 & $0.000 \mathrm{E}+00$ & 0.0000 & $0.000 \mathrm{E}+00$ & 0.0000 & $2.202 \mathrm{E}-12$ & 0.0000 \\
\hline 38 & $0.000 \mathrm{E}+00$ & 0.0000 & $0.000 \mathrm{E}+00$ & 0.0000 & $0.000 \mathrm{E}+00$ & 0.0000 & $0.000 \mathrm{E}+00$ & 0.0000 & $0.000 \mathrm{E}+00$ & 0.0000 & $0.000 \mathrm{E}+00$ & 0.0000 & $5.045 \mathrm{E}-08$ & 0.0037 \\
\hline & $0.000 \mathrm{E}+00$ & 0.0000 & $0.000 \mathrm{E}+00$ & 0.0000 & $0.000 \mathrm{E}+00$ & 0.0000 & $0.000 \mathrm{E}+00$ & 0.0000 & $0.000 \mathrm{E}+00$ & 0.0000 & $0.000 \mathrm{E}+00$ & 000 & -05 & 1.0000 \\
\hline
\end{tabular}

* Sum of all water independent and dependent pathways. 
RESRAD, Version 6.5

Summary : C746U Resident Gardener Deterministic Run
File : X: $\backslash$ FINAL V2 \DOE FWD RUNS \C746U RG DOE SG FWD-FV2-100000YR.RAD

Total Dose Contributions TDOSE (i,p,t) for Individual Radionuclides (i) and Pathways (p) As mrem/yr and Fraction of Total Dose At $t=5.000 \mathrm{E}+02$ years

Water Independent Pathways (Inhalation excludes radon)

\begin{tabular}{|c|c|c|}
\hline clide & mrem/yr & fract. \\
\hline-241 & $8.032 \mathrm{E}-13$ & 0.0000 \\
\hline-137 & $1.540 \mathrm{E}-11$ & 0.0000 \\
\hline-237 & $1.124 \mathrm{E}-09$ & 0.0000 \\
\hline-238 & $2.187 \mathrm{E}-11$ & 0.0000 \\
\hline-239 & $1.695 \mathrm{E}-13$ & 0.0000 \\
\hline-240 & $2.059 \mathrm{E}-16$ & 0.0000 \\
\hline-99 & $4.841 \mathrm{E}-22$ & 0.0000 \\
\hline-228 & $0.000 \mathrm{E}+00$ & 0.0000 \\
\hline-230 & $1.071 \mathrm{E}-04$ & 0.4421 \\
\hline-232 & $1.335 \mathrm{E}-04$ & 0.5512 \\
\hline 234 & $3.993 E-07$ & 0.0016 \\
\hline 235 & $4.571 E-10$ & 0.0000 \\
\hline 238 & $1.229 \mathrm{E}-06$ & 0.0051 \\
\hline & $2.423 E-04$ & 1.0000 \\
\hline
\end{tabular}

\begin{abstract}
Inhalation
\end{abstract}

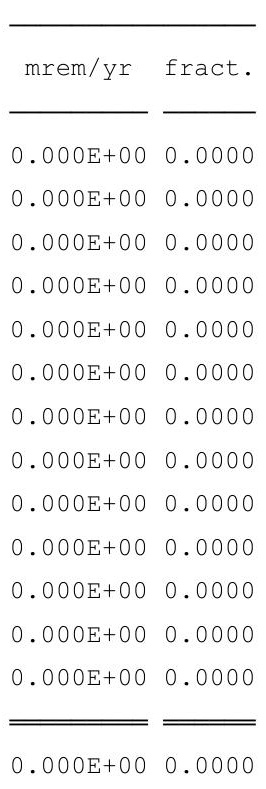

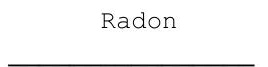

mrem/yr fract.

$\overline{0.000 E+00} \overline{0.0000}$

$0.000 \mathrm{E}+00 \quad 0.0000$

$0.000 E+00 \quad 0.0000$

$0.000 E+00 \quad 0.0000$

$0.000 E+00 \quad 0.0000$

$0.000 E+00 \quad 0.0000$

$0.000 E+00 \quad 0.0000$

$0.000 E+00 \quad 0.0000$

$0.000 \mathrm{E}+00 \quad 0.0000$

$0.000 \mathrm{E}+00 \quad 0.0000$

$0.000 \mathrm{E}+00 \quad 0.0000$

$0.000 E+00 \quad 0.0000$

$0.000 \mathrm{E}+00 \quad 0.0000$

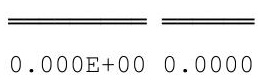

\begin{tabular}{|c|c|c|c|}
\hline \multicolumn{2}{|c|}{ Plant } & \multicolumn{2}{|c|}{ Meat } \\
\hline mrem/yr & fract. & mrem/yr & fract. \\
\hline $0.000 \mathrm{E}+00$ & 0.0000 & $0.000 \mathrm{E}+00$ & 0.0000 \\
\hline $0.000 \mathrm{E}+00$ & 0.0000 & $0.000 \mathrm{E}+00$ & 0.0000 \\
\hline $0.000 \mathrm{E}+00$ & 0.0000 & $0.000 \mathrm{E}+00$ & 0.0000 \\
\hline $0.000 \mathrm{E}+00$ & 0.0000 & $0.000 \mathrm{E}+00$ & 0.0000 \\
\hline $0.000 \mathrm{E}+00$ & 0.0000 & $0.000 \mathrm{E}+00$ & 0.0000 \\
\hline $0.000 \mathrm{E}+00$ & 0.0000 & $0.000 \mathrm{E}+00$ & 0.0000 \\
\hline $0.000 \mathrm{E}+00$ & 0.0000 & $0.000 \mathrm{E}+00$ & 0.0000 \\
\hline $0.000 \mathrm{E}+00$ & 0.0000 & $0.000 \mathrm{E}+00$ & 0.0000 \\
\hline $0.000 \mathrm{E}+00$ & 0.0000 & $0.000 \mathrm{E}+00$ & 0.0000 \\
\hline $0.000 \mathrm{E}+00$ & 0.0000 & $0.000 \mathrm{E}+00$ & 0.0000 \\
\hline $0.000 \mathrm{E}+00$ & 0.0000 & $0.000 \mathrm{E}+00$ & 0.0000 \\
\hline $0.000 \mathrm{E}+00$ & 0.0000 & $0.000 \mathrm{E}+00$ & 0.0000 \\
\hline $0.000 \mathrm{E}+00$ & 0.0000 & $0.000 \mathrm{E}+00$ & 0.0000 \\
\hline $.000 E+00$ & 0.0000 & $0.000 \mathrm{E}+00$ & 0.0000 \\
\hline
\end{tabular}

\begin{tabular}{cc} 
Milk \\
\hline mrem/yr fract. \\
\cline { 1 - 2 } $0.000 \mathrm{E}+00$ & 0.0000 \\
$0.000 \mathrm{E}+00$ & 0.0000 \\
$0.000 \mathrm{E}+00$ & 0.0000 \\
$0.000 \mathrm{E}+00$ & 0.0000 \\
$0.000 \mathrm{E}+00$ & 0.0000 \\
$0.000 \mathrm{E}+00$ & 0.0000 \\
$0.000 \mathrm{E}+00$ & 0.0000 \\
$0.000 \mathrm{E}+00$ & 0.0000 \\
$0.000 \mathrm{E}+00$ & 0.0000 \\
$0.000 \mathrm{E}+00$ & 0.0000 \\
$0.000 \mathrm{E}+00$ & 0.0000 \\
$0.000 \mathrm{E}+00$ & 0.0000 \\
$0.000 \mathrm{E}+00$ & 0.0000 \\
\hline \hline $0.000 \mathrm{E}+00$ & 0.0000
\end{tabular}

Soil mrem/yr fract. $0.000 \mathrm{E}+00 \quad 0.0000$ $0.000 \mathrm{E}+00 \quad 0.0000$ $0.000 \mathrm{E}+00 \quad 0.0000$ $0.000 \mathrm{E}+00 \quad 0.0000$ $0.000 \mathrm{E}+00 \quad 0.0000$ $0.000 \mathrm{E}+00 \quad 0.0000$ $0.000 \mathrm{E}+00 \quad 0.0000$ $0.000 \mathrm{E}+00 \quad 0.0000$ $0.000 \mathrm{E}+00 \quad 0.0000$ $0.000 \mathrm{E}+00 \quad 0.0000$ $0.000 \mathrm{E}+00 \quad 0.0000$ $0.000 \mathrm{E}+00 \quad 0.0000$ $0.000 \mathrm{E}+00 \quad 0.0000$ $0.000 \mathrm{E}+00 \quad 0.0000$

Total Dose Contributions TDOSE (i,p,t) for Individual Radionuclides (i) and Pathways (p) As mrem/yr and Fraction of Total Dose At $t=5.000 \mathrm{E}+02$ years

Water Dependent Pathways

\begin{tabular}{|c|c|c|c|c|c|c|}
\hline & \multicolumn{2}{|c|}{ Water } & \multicolumn{2}{|c|}{ Fish } & \multicolumn{2}{|c|}{ Radon } \\
\hline clide & mrem/yr & fract. & mrem/yr & fract. & mrem/yr & fract. \\
\hline 41 & $0.000 \mathrm{E}+00$ & 0.0000 & $0.000 \mathrm{E}+00$ & 0.0000 & $0.000 \mathrm{E}+00$ & 0.0000 \\
\hline-137 & $0.000 \mathrm{E}+00$ & 0.0000 & $0.000 \mathrm{E}+00$ & 0.0000 & $0.000 \mathrm{E}+00$ & 0.0000 \\
\hline-237 & $0.000 \mathrm{E}+00$ & 0.0000 & $0.000 \mathrm{E}+00$ & 0.0000 & $0.000 \mathrm{E}+00$ & 0.0000 \\
\hline-238 & $0.000 \mathrm{E}+00$ & 0.0000 & $0.000 \mathrm{E}+00$ & 0.0000 & $0.000 \mathrm{E}+00$ & 0.0000 \\
\hline-239 & $0.000 \mathrm{E}+00$ & 0.0000 & $0.000 \mathrm{E}+00$ & 0.0000 & $0.000 \mathrm{E}+00$ & 0.0000 \\
\hline-240 & $0.000 \mathrm{E}+00$ & 0.0000 & $0.000 \mathrm{E}+00$ & 0.0000 & $0.000 \mathrm{E}+00$ & 0.0000 \\
\hline-99 & $0.000 \mathrm{E}+00$ & 0.0000 & $0.000 \mathrm{E}+00$ & 0.0000 & $0.000 \mathrm{E}+00$ & 0.0000 \\
\hline-228 & $0.000 \mathrm{E}+00$ & 0.0000 & $0.000 \mathrm{E}+00$ & 0.0000 & $0.000 \mathrm{E}+00$ & 0.0000 \\
\hline-230 & $0.000 \mathrm{E}+00$ & 0.0000 & $0.000 \mathrm{E}+00$ & 0.0000 & $0.000 \mathrm{E}+00$ & 0.0000 \\
\hline-232 & $0.000 \mathrm{E}+00$ & 0.0000 & $0.000 \mathrm{E}+00$ & 0.0000 & $0.000 \mathrm{E}+00$ & 0.0000 \\
\hline 234 & $0.000 \mathrm{E}+00$ & 0.0000 & $0.000 \mathrm{E}+00$ & 0.0000 & $0.000 \mathrm{E}+00$ & 0.0000 \\
\hline 35 & $0.000 \mathrm{E}+00$ & 0.0000 & $0.000 \mathrm{E}+00$ & 0.0000 & $0.000 \mathrm{E}+00$ & 0.0000 \\
\hline 38 & $0.000 \mathrm{E}+00$ & 0.0000 & $0.000 \mathrm{E}+00$ & 0.0000 & $0.000 \mathrm{E}+00$ & 0.0000 \\
\hline & $0.000 \mathrm{E}+00$ & 0.0000 & $0.000 \mathrm{E}+00$ & 0.0000 & $0.000 \mathrm{E}+00$ & 0.0000 \\
\hline
\end{tabular}

\begin{tabular}{|c|c|c|c|}
\hline \multicolumn{2}{|c|}{ Plant } & \multicolumn{2}{|c|}{ Meat } \\
\hline mrem/yr & fract. & mrem/yr & fract. \\
\hline $0.000 \mathrm{E}+00$ & 0.0000 & $0.000 \mathrm{E}+00$ & 0.0000 \\
\hline $0.000 \mathrm{E}+00$ & 0.0000 & $0.000 \mathrm{E}+00$ & 0.0000 \\
\hline $0.000 \mathrm{E}+00$ & 0.0000 & $0.000 \mathrm{E}+00$ & 0.0000 \\
\hline $0.000 \mathrm{E}+00$ & 0.0000 & $0.000 \mathrm{E}+00$ & 0.0000 \\
\hline $0.000 \mathrm{E}+00$ & 0.0000 & $0.000 \mathrm{E}+00$ & 0.0000 \\
\hline $0.000 \mathrm{E}+00$ & 0.0000 & $0.000 \mathrm{E}+00$ & 0.0000 \\
\hline $0.000 \mathrm{E}+00$ & 0.0000 & $0.000 \mathrm{E}+00$ & 0.0000 \\
\hline $0.000 \mathrm{E}+00$ & 0.0000 & $0.000 \mathrm{E}+00$ & 0.0000 \\
\hline $0.000 \mathrm{E}+00$ & 0.0000 & $0.000 \mathrm{E}+00$ & 0.0000 \\
\hline $0.000 \mathrm{E}+00$ & 0.0000 & $0.000 \mathrm{E}+00$ & 0.0000 \\
\hline $0.000 \mathrm{E}+00$ & 0.0000 & $0.000 \mathrm{E}+00$ & 0.0000 \\
\hline $0.000 \mathrm{E}+00$ & 0.0000 & $0.000 \mathrm{E}+00$ & 0.0000 \\
\hline $0.000 \mathrm{E}+00$ & 0.0000 & $0.000 \mathrm{E}+00$ & 0.0000 \\
\hline
\end{tabular}

$0.000 \mathrm{E}+00 \quad 0.0000$

$0.000 \mathrm{E}+00 \quad 0.0000$

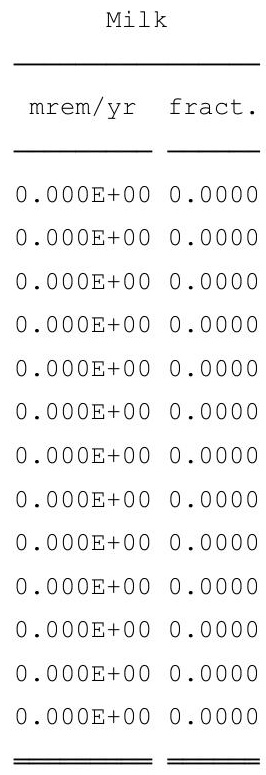

$0.000 \mathrm{E}+00 \quad 0.0000$
All Pathways * mrem/yr fract. $8.032 \mathrm{E}-13 \quad 0.0000$ $1.540 \mathrm{E}-110.0000$ $1.124 \mathrm{E}-090.0000$ $2.187 \mathrm{E}-110.0000$ $1.695 \mathrm{E}-13 \quad 0.0000$ $2.059 \mathrm{E}-160.0000$ $4.841 \mathrm{E}-22 \quad 0.0000$ $0.000 \mathrm{E}+00 \quad 0.0000$ $1.071 \mathrm{E}-04 \quad 0.4421$ $1.335 \mathrm{E}-04 \quad 0.5512$ $3.993 \mathrm{E}-070.0016$ $4.571 \mathrm{E}-10 \quad 0.0000$ $1.229 \mathrm{E}-06 \quad 0.0051$ $2.423 E-04 \quad 1.0000$

* Sum of all water independent and dependent pathways. 
RESRAD, Version 6.5

Summary : C746U Resident Gardener Deterministic Run
File : X: $\backslash$ FINAL V2 \DOE FWD RUNS \C746U RG DOE SG FWD-FV2-100000YR.RAD

Total Dose Contributions TDOSE (i,p,t) for Individual Radionuclides (i) and Pathways (p) As mrem/yr and Fraction of Total Dose At $t=1.050 \mathrm{E}+03$ years

Water Independent Pathways (Inhalation excludes radon)

\begin{tabular}{|c|c|c|}
\hline clide & mrem/yr & fract. \\
\hline-241 & $4.257 E-10$ & 0.0000 \\
\hline-137 & $4.741 \mathrm{E}-15$ & 0.0000 \\
\hline-237 & $3.910 \mathrm{E}-07$ & 0.0000 \\
\hline-238 & $5.077 \mathrm{E}-09$ & 0.0000 \\
\hline-239 & 1.202E-10 & 0.0000 \\
\hline-240 & $2.914 \mathrm{E}-14$ & 0.0000 \\
\hline-99 & 1. 302E-19 & 0.0000 \\
\hline-228 & $0.000 \mathrm{E}+00$ & 0.0000 \\
\hline-230 & $8.967 \mathrm{E}-03$ & 0.0013 \\
\hline-232 & $3.698 \mathrm{E}-03$ & 0.0005 \\
\hline 234 & 7. $268 \mathrm{E}-05$ & 0.0000 \\
\hline 235 & $1.527 \mathrm{E}-07$ & 0.0000 \\
\hline 38 & $9.919 \mathrm{E}-05$ & 0.0000 \\
\hline & $1.204 \mathrm{E}-0$ & 0.0 \\
\hline
\end{tabular}

Inhalation

\begin{tabular}{ll}
\hline mrem/yr fract. & fru \\
\hline $0.000 \mathrm{E}+00$ & 0.0000 \\
$0.000 \mathrm{E}+00$ & 0.0000 \\
$0.000 \mathrm{E}+00$ & 0.0000 \\
$0.000 \mathrm{E}+00$ & 0.0000 \\
$0.000 \mathrm{E}+00$ & 0.0000 \\
$0.000 \mathrm{E}+00$ & 0.0000 \\
$0.000 \mathrm{E}+00$ & 0.0000 \\
$0.000 \mathrm{E}+00$ & 0.0000 \\
$0.000 \mathrm{E}+00$ & 0.0000 \\
$0.000 \mathrm{E}+00$ & 0.0000 \\
$0.000 \mathrm{E}+00$ & 0.0000 \\
$0.000 \mathrm{E}+00$ & 0.0000 \\
$0.000 \mathrm{E}+00$ & 0.0000 \\
\hline \hline $0.000 \mathrm{E}+00$ & 0.0000 \\
\hline \hline
\end{tabular}

Radon
mrem/yr fract. $\overline{0.000 E+00} 0.0000$ $0.000 E+00 \quad 0.0000$ $0.000 E+00 \quad 0.0000$ $0.000 E+00 \quad 0.0000$ $0.000 \mathrm{E}+00 \quad 0.0000$ $0.000 E+00 \quad 0.0000$ $0.000 \mathrm{E}+00 \quad 0.0000$ $0.000 E+00 \quad 0.0000$ $0.000 \mathrm{E}+00 \quad 0.0000$ $0.000 \mathrm{E}+00 \quad 0.0000$ $0.000 \mathrm{E}+00 \quad 0.0000$ $0.000 \mathrm{E}+00 \quad 0.0000$ $0.000 \mathrm{E}+00 \quad 0.0000$

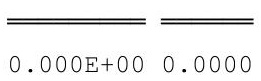

\begin{tabular}{|c|c|c|c|}
\hline \multicolumn{2}{|c|}{ Plant } & \multicolumn{2}{|c|}{ Meat } \\
\hline mrem/yr & fract. & mrem/yr & fract. \\
\hline $6.939 E-03$ & 0.0010 & $0.000 \mathrm{E}+00$ & 0.0000 \\
\hline $1.461 \mathrm{E}-12$ & 0.0000 & $0.000 \mathrm{E}+00$ & 0.0000 \\
\hline $5.637 \mathrm{E}-02$ & 0.0083 & $0.000 \mathrm{E}+00$ & 0.0000 \\
\hline $2.382 \mathrm{E}-05$ & 0.0000 & $0.000 \mathrm{E}+00$ & 0.0000 \\
\hline $4.566 \mathrm{E}-02$ & 0.0067 & $0.000 \mathrm{E}+00$ & 0.0000 \\
\hline $4.210 \mathrm{E}-02$ & 0.0062 & $0.000 \mathrm{E}+00$ & 0.0000 \\
\hline $6.892 \mathrm{E}-05$ & 0.0000 & $0.000 \mathrm{E}+00$ & 0.0000 \\
\hline $0.000 \mathrm{E}+00$ & 0.0000 & $0.000 \mathrm{E}+00$ & 0.0000 \\
\hline $5.809 \mathrm{E}+00$ & 0.8509 & $0.000 \mathrm{E}+00$ & 0.0000 \\
\hline $5.926 \mathrm{E}-01$ & 0.0868 & $0.000 \mathrm{E}+00$ & 0.0000 \\
\hline 1. $483 \mathrm{E}-01$ & 0.0217 & $0.000 \mathrm{E}+00$ & 0.0000 \\
\hline $1.149 \mathrm{E}-02$ & 0.0017 & $0.000 \mathrm{E}+00$ & 0.0000 \\
\hline 1.013E-01 & 0.0148 & $0.000 \mathrm{E}+00$ & 0.0000 \\
\hline & & 0.00 & 0. \\
\hline
\end{tabular}

\begin{tabular}{cc} 
Milk \\
\hline mrem/yr fract. \\
\cline { 1 - 2 } 0.000E+00 & 0.0000 \\
$0.000 \mathrm{E}+00$ & 0.0000 \\
$0.000 \mathrm{E}+00$ & 0.0000 \\
$0.000 \mathrm{E}+00$ & 0.0000 \\
$0.000 \mathrm{E}+00$ & 0.0000 \\
$0.000 \mathrm{E}+00$ & 0.0000 \\
$0.000 \mathrm{E}+00$ & 0.0000 \\
$0.000 \mathrm{E}+00$ & 0.0000 \\
$0.000 \mathrm{E}+00$ & 0.0000 \\
$0.000 \mathrm{E}+00$ & 0.0000 \\
$0.000 \mathrm{E}+00$ & 0.0000 \\
$0.000 \mathrm{E}+00$ & 0.0000 \\
$0.000 \mathrm{E}+00$ & 0.0000 \\
\hline \hline $0.000 \mathrm{E}+00$ & 0.0000
\end{tabular}

\begin{tabular}{cc} 
Soil \\
\cline { 1 - 2 } mrem/yr fract. & \multicolumn{1}{c}{ fran } \\
\cline { 1 - 2 } $0.000 \mathrm{E}+00$ & 0.0000 \\
$0.000 \mathrm{E}+00$ & 0.0000 \\
$0.000 \mathrm{E}+00$ & 0.0000 \\
$0.000 \mathrm{E}+00$ & 0.0000 \\
$0.000 \mathrm{E}+00$ & 0.0000 \\
$0.000 \mathrm{E}+00$ & 0.0000 \\
$0.000 \mathrm{E}+00$ & 0.0000 \\
$0.000 \mathrm{E}+00$ & 0.0000 \\
$0.000 \mathrm{E}+00$ & 0.0000 \\
$0.000 \mathrm{E}+00$ & 0.0000 \\
$0.000 \mathrm{E}+00$ & 0.0000 \\
$0.000 \mathrm{E}+00$ & 0.0000 \\
$0.000 \mathrm{E}+00$ & 0.0000 \\
\hline \hline $0.000 \mathrm{E}+00$ & 0.0000
\end{tabular}

Total Dose Contributions TDOSE (i,p,t) for Individual Radionuclides (i) and Pathways (p) As mrem/yr and Fraction of Total Dose At $t=1.050 \mathrm{E}+03$ years

Water Dependent Pathways

\begin{tabular}{|c|c|c|c|c|c|c|}
\hline & \multicolumn{2}{|c|}{ Water } & \multicolumn{2}{|c|}{ Fish } & \multicolumn{2}{|c|}{ Radon } \\
\hline clide & mrem/yr & fract. & mrem/yr & fract. & mrem/yr & fract. \\
\hline-241 & $0.000 \mathrm{E}+00$ & 0.0000 & $0.000 \mathrm{E}+00$ & 0.0000 & $0.000 \mathrm{E}+00$ & 0.0000 \\
\hline-137 & $0.000 \mathrm{E}+00$ & 0.0000 & $0.000 \mathrm{E}+00$ & 0.0000 & $0.000 \mathrm{E}+00$ & 0.0000 \\
\hline-237 & $0.000 \mathrm{E}+00$ & 0.0000 & $0.000 \mathrm{E}+00$ & 0.0000 & $0.000 \mathrm{E}+00$ & 0.0000 \\
\hline-238 & $0.000 \mathrm{E}+00$ & 0.0000 & $0.000 \mathrm{E}+00$ & 0.0000 & $0.000 \mathrm{E}+00$ & 0.0000 \\
\hline-239 & $0.000 \mathrm{E}+00$ & 0.0000 & $0.000 \mathrm{E}+00$ & 0.0000 & $0.000 \mathrm{E}+00$ & 0.0000 \\
\hline-240 & $0.000 \mathrm{E}+00$ & 0.0000 & $0.000 \mathrm{E}+00$ & 0.0000 & $0.000 \mathrm{E}+00$ & 0.0000 \\
\hline-99 & $0.000 \mathrm{E}+00$ & 0.0000 & $0.000 \mathrm{E}+00$ & 0.0000 & $0.000 \mathrm{E}+00$ & 0.0000 \\
\hline-228 & $0.000 \mathrm{E}+00$ & 0.0000 & $0.000 \mathrm{E}+00$ & 0.0000 & $0.000 \mathrm{E}+00$ & 0.0000 \\
\hline-230 & $0.000 \mathrm{E}+00$ & 0.0000 & $0.000 \mathrm{E}+00$ & 0.0000 & $0.000 \mathrm{E}+00$ & 0.0000 \\
\hline 232 & $0.000 \mathrm{E}+00$ & 0.0000 & $0.000 \mathrm{E}+00$ & 0.0000 & $0.000 \mathrm{E}+00$ & 0.0000 \\
\hline 34 & $0.000 \mathrm{E}+00$ & 0.0000 & $0.000 \mathrm{E}+00$ & 0.0000 & $0.000 \mathrm{E}+00$ & 0.0000 \\
\hline 35 & $0.000 \mathrm{E}+00$ & 0.0000 & $0.000 \mathrm{E}+00$ & 0.0000 & $0.000 \mathrm{E}+00$ & 0.0000 \\
\hline 238 & $0.000 \mathrm{E}+00$ & 0.0000 & $0.000 \mathrm{E}+00$ & 0.0000 & $0.000 \mathrm{E}+00$ & 0.0000 \\
\hline & $0.000 \mathrm{E}+00$ & 0.0000 & $0.000 \mathrm{E}+00$ & 0.0000 & $0.000 \mathrm{E}+00$ & 0.0000 \\
\hline
\end{tabular}

\begin{tabular}{|c|c|c|c|}
\hline \multicolumn{2}{|c|}{ Plant } & \multicolumn{2}{|c|}{ Meat } \\
\hline mrem/yr & fract. & mrem/yr & fract. \\
\hline $0.000 \mathrm{E}+00$ & 0.0000 & $0.000 \mathrm{E}+00$ & 0.0000 \\
\hline $0.000 \mathrm{E}+00$ & 0.0000 & $0.000 \mathrm{E}+00$ & 0.0000 \\
\hline $0.000 \mathrm{E}+00$ & 0.0000 & $0.000 \mathrm{E}+00$ & 0.0000 \\
\hline $0.000 \mathrm{E}+00$ & 0.0000 & $0.000 \mathrm{E}+00$ & 0.0000 \\
\hline $0.000 \mathrm{E}+00$ & 0.0000 & $0.000 \mathrm{E}+00$ & 0.0000 \\
\hline $0.000 \mathrm{E}+00$ & 0.0000 & $0.000 \mathrm{E}+00$ & 0.0000 \\
\hline $0.000 \mathrm{E}+00$ & 0.0000 & $0.000 \mathrm{E}+00$ & 0.0000 \\
\hline $0.000 \mathrm{E}+00$ & 0.0000 & $0.000 \mathrm{E}+00$ & 0.0000 \\
\hline $0.000 \mathrm{E}+00$ & 0.0000 & $0.000 \mathrm{E}+00$ & 0.0000 \\
\hline $0.000 \mathrm{E}+00$ & 0.0000 & $0.000 \mathrm{E}+00$ & 0.0000 \\
\hline $0.000 \mathrm{E}+00$ & 0.0000 & $0.000 \mathrm{E}+00$ & 0.0000 \\
\hline $0.000 \mathrm{E}+00$ & 0.0000 & $0.000 \mathrm{E}+00$ & 0.0000 \\
\hline $0.000 \mathrm{E}+00$ & 0.0000 & $0.000 \mathrm{E}+00$ & 0.0000 \\
\hline
\end{tabular}

$0.000 \mathrm{E}+00 \quad 0.0000$

$0.000 \mathrm{E}+00 \quad 0.0000$

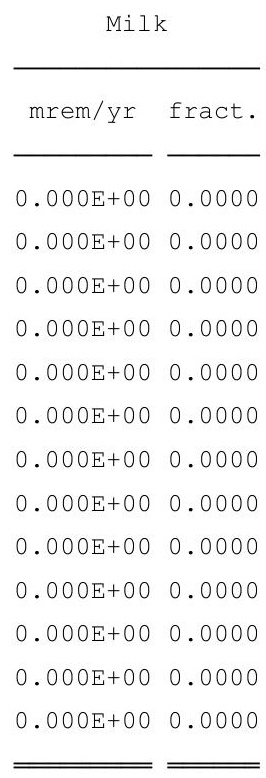

$0.000 \mathrm{E}+00 \quad 0.0000$
All Pathways* mrem/yr fract. $6.939 \mathrm{E}-03 \quad 0.0010$ $1.465 \mathrm{E}-120.0000$ $5.637 \mathrm{E}-02 \quad 0.0083$ $2.383 E-050.0000$ $4.566 \mathrm{E}-02 \quad 0.0067$ $4.210 \mathrm{E}-02 \quad 0.0062$ $6.892 \mathrm{E}-050.0000$ $0.000 \mathrm{E}+00 \quad 0.0000$ $5.818 \mathrm{E}+00 \quad 0.8522$ $5.963 \mathrm{E}-010.0873$ $1.484 \mathrm{E}-010.0217$ $1.149 \mathrm{E}-02 \quad 0.0017$ $1.014 \mathrm{E}-010.0148$

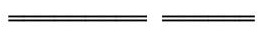
$6.827 \mathrm{E}+00 \quad 1.0000$

* Sum of all water independent and dependent pathways. 
RESRAD, Version 6.5

ummary : C746U Resident Gardener Deterministic Run

File : $\mathrm{X}: \backslash F I N A L$ V2 \DOE FWD RUNS \C746U RG DOE SG FWD-FV2-100000YR.RAD

Total Dose Contributions TDOSE(i,p,t) for Individual Radionuclides (i) and Pathways (p) As mrem/yr and Fraction of Total Dose At $t=1.000 \mathrm{E}+04$ years

Water Independent Pathways (Inhalation excludes radon)

\begin{tabular}{|c|c|c|c|c|c|c|c|c|c|c|c|c|c|c|}
\hline \multirow{2}{*}{ Nuclide } & \multicolumn{2}{|c|}{ Ground } & \multicolumn{2}{|c|}{ Inhalation } & \multicolumn{2}{|c|}{ Radon } & \multicolumn{2}{|c|}{ Plant } & \multicolumn{2}{|c|}{ Meat } & \multicolumn{2}{|c|}{ Milk } & \multicolumn{2}{|c|}{ Soil } \\
\hline & mrem/yr & fract. & mrem/yr & fract. & mrem/yr & fract. & mrem/yr & fract. & mrem/yr & fract. & mrem/yr & fract. & mrem/yr & fract. \\
\hline-241 & $1.724 \mathrm{E}-03$ & 0.0000 & $1.816 \mathrm{E}-07$ & 0.0000 & $0.000 \mathrm{E}+00$ & 0.0000 & $2.088 E-03$ & 0.0000 & $0.000 \mathrm{E}+00$ & 0.0000 & $0.000 \mathrm{E}+00$ & 0.0000 & $3.432 \mathrm{E}-05$ & 0.0000 \\
\hline-137 & $0.000 \mathrm{E}+00$ & 0.0000 & $0.000 \mathrm{E}+00$ & 0.0000 & $0.000 \mathrm{E}+00$ & 0.0000 & $0.000 \mathrm{E}+00$ & 0.0000 & $0.000 \mathrm{E}+00$ & 0.0000 & $0.000 \mathrm{E}+00$ & 0.0000 & $0.000 \mathrm{E}+00$ & 0.0000 \\
\hline-237 & $1.242 \mathrm{E}+00$ & 0.0005 & $1.326 E-04$ & 0.0000 & $0.000 \mathrm{E}+00$ & 0.0000 & $1.496 \mathrm{E}+00$ & 0.0006 & $0.000 \mathrm{E}+00$ & 0.0000 & $0.000 \mathrm{E}+00$ & 0.0000 & $2.514 \mathrm{E}-02$ & 0.0000 \\
\hline-238 & $6.839 E-03$ & 0.0000 & $3.439 E-07$ & 0.0000 & $0.000 \mathrm{E}+00$ & 0.0000 & $1.186 \mathrm{E}-02$ & 0.0000 & $0.000 \mathrm{E}+00$ & 0.0000 & $0.000 \mathrm{E}+00$ & 0.0000 & $3.191 \mathrm{E}-04$ & 0.0000 \\
\hline-239 & $5.108 E-03$ & 0.0000 & $4.259 E-03$ & 0.0000 & $0.000 \mathrm{E}+00$ & 0.0000 & $2.652 \mathrm{E}+00$ & 0.0011 & $0.000 \mathrm{E}+00$ & 0.0000 & $0.000 \mathrm{E}+00$ & 0.0000 & $7.370 \mathrm{E}-01$ & 0.0003 \\
\hline-240 & $9.845 \mathrm{E}-04$ & 0.0000 & $1.967 \mathrm{E}-03$ & 0.0000 & $0.000 \mathrm{E}+00$ & 0.0000 & $1.225 \mathrm{E}+00$ & 0.0005 & $0.000 \mathrm{E}+00$ & 0.0000 & $0.000 \mathrm{E}+00$ & 0.0000 & $3.405 \mathrm{E}-01$ & 0.0001 \\
\hline-99 & $0.000 \mathrm{E}+00$ & 0.0000 & $0.000 \mathrm{E}+00$ & 0.0000 & $0.000 \mathrm{E}+00$ & 0.0000 & $0.000 \mathrm{E}+00$ & 0.0000 & $0.000 \mathrm{E}+00$ & 0.0000 & $0.000 \mathrm{E}+00$ & 0.0000 & $0.000 \mathrm{E}+00$ & 0.0000 \\
\hline 228 & $0.000 \mathrm{E}+00$ & 0.0000 & $0.000 \mathrm{E}+00$ & 0.0000 & $0.000 \mathrm{E}+00$ & 0.0000 & $0.000 \mathrm{E}+00$ & 0.0000 & $0.000 \mathrm{E}+00$ & 0.0000 & $0.000 \mathrm{E}+00$ & 0.0000 & $0.000 \mathrm{E}+00$ & 0.0000 \\
\hline 230 & $7.436 \mathrm{E}+02$ & 0.3152 & $1.648 \mathrm{E}-02$ & 0.0000 & $0.000 \mathrm{E}+00$ & 0.0000 & $1.224 \mathrm{E}+03$ & 0.5187 & $0.000 \mathrm{E}+00$ & 0.0000 & $0.000 \mathrm{E}+00$ & 0.0000 & $2.669 \mathrm{E}+01$ & 0.0113 \\
\hline 232 & $4.839 E+01$ & 0.0205 & $1.028 E-03$ & 0.0000 & $0.000 \mathrm{E}+00$ & 0.0000 & $5.054 \mathrm{E}+01$ & 0.0214 & $0.000 \mathrm{E}+00$ & 0.0000 & $0.000 \mathrm{E}+00$ & 0.0000 & $5.352 \mathrm{E}-01$ & 0.0002 \\
\hline 34 & $7.945 E+01$ & 0.0337 & $3.957 \mathrm{E}-03$ & 0.0000 & $0.000 \mathrm{E}+00$ & 0.0000 & $1.377 \mathrm{E}+02$ & 0.0584 & $0.000 \mathrm{E}+00$ & 0.0000 & $0.000 \mathrm{E}+00$ & 0.0000 & $3.693 \mathrm{E}+00$ & 0.0016 \\
\hline 35 & $4.626 \mathrm{E}+00$ & 0.0020 & $1.189 \mathrm{E}-03$ & 0.0000 & $0.000 \mathrm{E}+00$ & 0.0000 & $5.072 \mathrm{E}+00$ & 0.0022 & $0.000 \mathrm{E}+00$ & 0.0000 & $0.000 \mathrm{E}+00$ & 0.0000 & $2.835 \mathrm{E}-01$ & 0.0001 \\
\hline 238 & $1.706 \mathrm{E}+01$ & 0.0072 & $1.671 \mathrm{E}-03$ & 0.0000 & $0.000 \mathrm{E}+00$ & 0.0000 & $8.921 \mathrm{E}+00$ & 0.0038 & $0.000 \mathrm{E}+00$ & 0.0000 & $0.000 \mathrm{E}+00$ & 0.0000 & $8.572 \mathrm{E}-01$ & 0.0004 \\
\hline & $3 E+02$ & 0. & $3.068 \mathrm{E}-02$ & 0.0 & $0.000 \mathrm{E}+00$ & 00 & $1.431 \mathrm{E}+03$ & 0.6068 & $0.000 \mathrm{E}+00$ & 00 & $E+00$ & 00 & +01 & 14 \\
\hline
\end{tabular}

Total Dose Contributions TDOSE (i,p,t) for Individual Radionuclides (i) and Pathways (p) As mrem/yr and Fraction of Total Dose At $t=1.000 \mathrm{E}+04$ years

Water Dependent Pathways

\begin{tabular}{|c|c|c|c|c|c|c|c|c|c|c|c|c|c|c|}
\hline & \multicolumn{2}{|c|}{ Water } & \multicolumn{2}{|c|}{ Fish } & \multicolumn{2}{|c|}{ Radon } & \multicolumn{2}{|c|}{ Plant } & \multicolumn{2}{|c|}{ Meat } & \multicolumn{2}{|c|}{ Milk } & \multicolumn{2}{|c|}{ All Pathways* } \\
\hline clide & mrem/yr & fract. & mrem/yr & fract. & mrem/yr & fract. & mrem/yr & fract. & mrem/yr & fract. & mrem/yr & fract. & mrem/yr & fract. \\
\hline 241 & $0.000 \mathrm{E}+00$ & 0.0000 & $0.000 \mathrm{E}+00$ & 0.0000 & $0.000 \mathrm{E}+00$ & 0.0000 & $0.000 \mathrm{E}+00$ & 0.0000 & $0.000 \mathrm{E}+00$ & 0.0000 & $0.000 \mathrm{E}+00$ & 0.0000 & $3.847 \mathrm{E}-03$ & 0.0000 \\
\hline-137 & $0.000 \mathrm{E}+00$ & 0.0000 & $0.000 \mathrm{E}+00$ & 0.0000 & $0.000 \mathrm{E}+00$ & 0.0000 & $0.000 \mathrm{E}+00$ & 0.0000 & $0.000 \mathrm{E}+00$ & 0.0000 & $0.000 \mathrm{E}+00$ & 0.0000 & $0.000 \mathrm{E}+00$ & 0.0000 \\
\hline-237 & $0.000 \mathrm{E}+00$ & 0.0000 & $0.000 \mathrm{E}+00$ & 0.0000 & $0.000 \mathrm{E}+00$ & 0.0000 & $0.000 \mathrm{E}+00$ & 0.0000 & $0.000 \mathrm{E}+00$ & 0.0000 & $0.000 \mathrm{E}+00$ & 0.0000 & $2.763 E+00$ & 0.0012 \\
\hline-238 & $0.000 \mathrm{E}+00$ & 0.0000 & $0.000 \mathrm{E}+00$ & 0.0000 & $0.000 \mathrm{E}+00$ & 0.0000 & $0.000 \mathrm{E}+00$ & 0.0000 & $0.000 \mathrm{E}+00$ & 0.0000 & $0.000 \mathrm{E}+00$ & 0.0000 & $1.902 \mathrm{E}-02$ & 0.0000 \\
\hline-239 & $0.000 \mathrm{E}+00$ & 0.0000 & $0.000 \mathrm{E}+00$ & 0.0000 & $0.000 \mathrm{E}+00$ & 0.0000 & $0.000 \mathrm{E}+00$ & 0.0000 & $0.000 \mathrm{E}+00$ & 0.0000 & $0.000 E+00$ & 0.0000 & $3.398 \mathrm{E}+00$ & 0.0014 \\
\hline-240 & $0.000 \mathrm{E}+00$ & 0.0000 & $0.000 \mathrm{E}+00$ & 0.0000 & $0.000 \mathrm{E}+00$ & 0.0000 & $0.000 \mathrm{E}+00$ & 0.0000 & $0.000 \mathrm{E}+00$ & 0.0000 & $0.000 E+00$ & 0.0000 & $1.569 \mathrm{E}+00$ & 0.0007 \\
\hline-99 & $0.000 \mathrm{E}+00$ & 0.0000 & $0.000 \mathrm{E}+00$ & 0.0000 & $0.000 \mathrm{E}+00$ & 0.0000 & $0.000 \mathrm{E}+00$ & 0.0000 & $0.000 \mathrm{E}+00$ & 0.0000 & $0.000 \mathrm{E}+00$ & 0.0000 & $0.000 \mathrm{E}+00$ & 0.0000 \\
\hline-228 & $0.000 \mathrm{E}+00$ & 0.0000 & $0.000 \mathrm{E}+00$ & 0.0000 & $0.000 \mathrm{E}+00$ & 0.0000 & $0.000 \mathrm{E}+00$ & 0.0000 & $0.000 \mathrm{E}+00$ & 0.0000 & $0.000 \mathrm{E}+00$ & 0.0000 & $0.000 \mathrm{E}+00$ & 0.0000 \\
\hline-230 & $0.000 \mathrm{E}+00$ & 0.0000 & $0.000 \mathrm{E}+00$ & 0.0000 & $0.000 \mathrm{E}+00$ & 0.0000 & $0.000 \mathrm{E}+00$ & 0.0000 & $0.000 \mathrm{E}+00$ & 0.0000 & $0.000 E+00$ & 0.0000 & $1.994 \mathrm{E}+03$ & 0.8453 \\
\hline-232 & $0.000 \mathrm{E}+00$ & 0.0000 & $0.000 \mathrm{E}+00$ & 0.0000 & $0.000 \mathrm{E}+00$ & 0.0000 & $0.000 \mathrm{E}+00$ & 0.0000 & $0.000 \mathrm{E}+00$ & 0.0000 & $0.000 \mathrm{E}+00$ & 0.0000 & $9.947 \mathrm{E}+01$ & 0.0422 \\
\hline 34 & $0.000 \mathrm{E}+00$ & 0.0000 & $0.000 \mathrm{E}+00$ & 0.0000 & $0.000 \mathrm{E}+00$ & 0.0000 & $0.000 \mathrm{E}+00$ & 0.0000 & $0.000 \mathrm{E}+00$ & 0.0000 & $0.000 \mathrm{E}+00$ & 0.0000 & $2.208 E+02$ & 0.0936 \\
\hline 35 & $0.000 \mathrm{E}+00$ & 0.0000 & $0.000 \mathrm{E}+00$ & 0.0000 & $0.000 \mathrm{E}+00$ & 0.0000 & $0.000 \mathrm{E}+00$ & 0.0000 & $0.000 \mathrm{E}+00$ & 0.0000 & $0.000 \mathrm{E}+00$ & 0.0000 & $9.983 E+00$ & 0.0042 \\
\hline 38 & $0.000 \mathrm{E}+00$ & 0.0000 & $0.000 \mathrm{E}+00$ & 0.0000 & $0.000 \mathrm{E}+00$ & 0.0000 & $0.000 \mathrm{E}+00$ & 0.0000 & $0.000 \mathrm{E}+00$ & 0.0000 & $0.000 \mathrm{E}+00$ & 0.0000 & $2.684 \mathrm{E}+01$ & 0.0114 \\
\hline & $0.000 \mathrm{E}+00$ & 0.0000 & $0.000 \mathrm{E}+00$ & 0.0000 & $0.000 \mathrm{E}+00$ & 0.0000 & $0.000 \mathrm{E}+00$ & 0.0000 & $0.000 \mathrm{E}+00$ & 0.0000 & $0.000 \mathrm{E}+00$ & 0.0000 & $.359 \mathrm{E}+03$ & 1. \\
\hline
\end{tabular}

* Sum of all water independent and dependent pathways. 
RESRAD, Version 6.5

ummary : C746U Resident Gardener Deterministic Run

File : $\mathrm{X}: \backslash F I N A L$ V2 \DOE FWD RUNS $\backslash$ C746U RG DOE SG FWD-FV2-100000YR.RAD

Total Dose Contributions TDOSE(i,p,t) for Individual Radionuclides (i) and Pathways (p) As mrem/yr and Fraction of Total Dose At $t=1.000 \mathrm{E}+05$ years

Water Independent Pathways (Inhalation excludes radon)

\begin{tabular}{|c|c|c|c|c|c|c|c|c|c|c|c|c|c|c|}
\hline \multirow{2}{*}{ Nuclide } & \multicolumn{2}{|c|}{ Ground } & \multicolumn{2}{|c|}{ Inhalation } & \multicolumn{2}{|c|}{ Radon } & \multicolumn{2}{|c|}{ Plant } & \multicolumn{2}{|c|}{ Meat } & \multicolumn{2}{|c|}{ Milk } & \multicolumn{2}{|c|}{ Soil } \\
\hline & mrem/yr & fract. & mrem/yr & fract. & mrem/yr & fract. & mrem/yr & fract. & mrem/yr & fract. & mrem/yr & fract. & mrem/yr & fract. \\
\hline-241 & $0.000 \mathrm{E}+00$ & 0.0000 & $0.000 \mathrm{E}+00$ & 0.0000 & $0.000 \mathrm{E}+00$ & 0.0000 & $0.000 \mathrm{E}+00$ & 0.0000 & $0.000 \mathrm{E}+00$ & 0.0000 & $0.000 \mathrm{E}+00$ & 0.0000 & $0.000 \mathrm{E}+00$ & 0.0000 \\
\hline-137 & $0.000 \mathrm{E}+00$ & 0.0000 & $0.000 \mathrm{E}+00$ & 0.0000 & $0.000 \mathrm{E}+00$ & 0.0000 & $0.000 \mathrm{E}+00$ & 0.0000 & $0.000 \mathrm{E}+00$ & 0.0000 & $0.000 \mathrm{E}+00$ & 0.0000 & $0.000 \mathrm{E}+00$ & 0.0000 \\
\hline-237 & $0.000 \mathrm{E}+00$ & 0.0000 & $0.000 \mathrm{E}+00$ & 0.0000 & $0.000 \mathrm{E}+00$ & 0.0000 & $0.000 \mathrm{E}+00$ & 0.0000 & $0.000 \mathrm{E}+00$ & 0.0000 & $0.000 \mathrm{E}+00$ & 0.0000 & $0.000 \mathrm{E}+00$ & 0.0000 \\
\hline-238 & $0.000 \mathrm{E}+00$ & 0.0000 & $0.000 \mathrm{E}+00$ & 0.0000 & $0.000 \mathrm{E}+00$ & 0.0000 & $0.000 \mathrm{E}+00$ & 0.0000 & $0.000 \mathrm{E}+00$ & 0.0000 & $0.000 \mathrm{E}+00$ & 0.0000 & $0.000 \mathrm{E}+00$ & 0.0000 \\
\hline-239 & $0.000 \mathrm{E}+00$ & 0.0000 & $0.000 \mathrm{E}+00$ & 0.0000 & $0.000 \mathrm{E}+00$ & 0.0000 & $0.000 \mathrm{E}+00$ & 0.0000 & $0.000 \mathrm{E}+00$ & 0.0000 & $0.000 \mathrm{E}+00$ & 0.0000 & $0.000 \mathrm{E}+00$ & 0.0000 \\
\hline-240 & $0.000 \mathrm{E}+00$ & 0.0000 & $0.000 \mathrm{E}+00$ & 0.0000 & $0.000 \mathrm{E}+00$ & 0.0000 & $0.000 \mathrm{E}+00$ & 0.0000 & $0.000 \mathrm{E}+00$ & 0.0000 & $0.000 \mathrm{E}+00$ & 0.0000 & $0.000 \mathrm{E}+00$ & 0.0000 \\
\hline 99 & $0.000 \mathrm{E}+00$ & 0.0000 & $0.000 \mathrm{E}+00$ & 0.0000 & $0.000 \mathrm{E}+00$ & 0.0000 & $0.000 \mathrm{E}+00$ & 0.0000 & $0.000 \mathrm{E}+00$ & 0.0000 & $0.000 \mathrm{E}+00$ & 0.0000 & $0.000 \mathrm{E}+00$ & 0.0000 \\
\hline-228 & $0.000 \mathrm{E}+00$ & 0.0000 & $0.000 \mathrm{E}+00$ & 0.0000 & $0.000 \mathrm{E}+00$ & 0.0000 & $0.000 \mathrm{E}+00$ & 0.0000 & $0.000 \mathrm{E}+00$ & 0.0000 & $0.000 \mathrm{E}+00$ & 0.0000 & $0.000 \mathrm{E}+00$ & 0.0000 \\
\hline-230 & $0.000 \mathrm{E}+00$ & 0.0000 & $0.000 \mathrm{E}+00$ & 0.0000 & $0.000 \mathrm{E}+00$ & 0.0000 & $0.000 \mathrm{E}+00$ & 0.0000 & $0.000 \mathrm{E}+00$ & 0.0000 & $0.000 \mathrm{E}+00$ & 0.0000 & $0.000 \mathrm{E}+00$ & 0.0000 \\
\hline-232 & $0.000 \mathrm{E}+00$ & 0.0000 & $0.000 \mathrm{E}+00$ & 0.0000 & $0.000 \mathrm{E}+00$ & 0.0000 & $0.000 \mathrm{E}+00$ & 0.0000 & $0.000 \mathrm{E}+00$ & 0.0000 & $0.000 \mathrm{E}+00$ & 0.0000 & $0.000 \mathrm{E}+00$ & 0.0000 \\
\hline 234 & $0.000 \mathrm{E}+00$ & 0.0000 & $0.000 \mathrm{E}+00$ & 0.0000 & $0.000 \mathrm{E}+00$ & 0.0000 & $0.000 \mathrm{E}+00$ & 0.0000 & $0.000 \mathrm{E}+00$ & 0.0000 & $0.000 \mathrm{E}+00$ & 0.0000 & $0.000 \mathrm{E}+00$ & 0.0000 \\
\hline 235 & $0.000 \mathrm{E}+00$ & 0.0000 & $0.000 \mathrm{E}+00$ & 0.0000 & $0.000 \mathrm{E}+00$ & 0.0000 & $0.000 \mathrm{E}+00$ & 0.0000 & $0.000 \mathrm{E}+00$ & 0.0000 & $0.000 \mathrm{E}+00$ & 0.0000 & $0.000 \mathrm{E}+00$ & 0.0000 \\
\hline 38 & $0.000 \mathrm{E}+00$ & 0.0000 & $0.000 \mathrm{E}+00$ & 0.0000 & $0.000 \mathrm{E}+00$ & 0.0000 & $0.000 \mathrm{E}+00$ & 0.0000 & $0.000 \mathrm{E}+00$ & 0.0000 & $0.000 \mathrm{E}+00$ & 0.0000 & $0.000 \mathrm{E}+00$ & 0.0000 \\
\hline & $0.000 \mathrm{E}+00$ & 0.0000 & $0.000 \mathrm{E}+00$ & 0.0000 & $0.000 \mathrm{E}+00$ & 0.0000 & $0.000 \mathrm{E}+00$ & 0.0000 & $0.000 \mathrm{E}+00$ & 0.0000 & $0.000 \mathrm{E}+00$ & 0.0000 & $.000 \mathrm{E}+00$ & 0.0000 \\
\hline
\end{tabular}

Total Dose Contributions TDOSE (i,p,t) for Individual Radionuclides (i) and Pathways (p) As mrem/yr and Fraction of Total Dose At $t=1.000 \mathrm{E}+05$ years

Water Dependent Pathways

\begin{tabular}{|c|c|c|c|c|c|c|c|c|c|c|c|c|c|c|}
\hline & \multicolumn{2}{|c|}{ Water } & \multicolumn{2}{|c|}{ Fish } & \multicolumn{2}{|c|}{ Radon } & \multicolumn{2}{|c|}{ Plant } & \multicolumn{2}{|c|}{ Meat } & \multicolumn{2}{|c|}{ Milk } & \multicolumn{2}{|c|}{ All Pathways* } \\
\hline clide & mrem/yr & fract. & mrem/yr & fract. & mrem/yr & fract. & mrem/yr & fract. & mrem/yr & fract. & mrem/yr & fract. & mrem/yr & fract. \\
\hline 241 & $0.000 \mathrm{E}+00$ & 0.0000 & $0.000 \mathrm{E}+00$ & 0.0000 & $0.000 \mathrm{E}+00$ & 0.0000 & $0.000 \mathrm{E}+00$ & 0.0000 & $0.000 \mathrm{E}+00$ & 0.0000 & $0.000 \mathrm{E}+00$ & 0.0000 & $0.000 \mathrm{E}+00$ & 0.0000 \\
\hline-137 & $0.000 \mathrm{E}+00$ & 0.0000 & $0.000 \mathrm{E}+00$ & 0.0000 & $0.000 \mathrm{E}+00$ & 0.0000 & $0.000 \mathrm{E}+00$ & 0.0000 & $0.000 \mathrm{E}+00$ & 0.0000 & $0.000 \mathrm{E}+00$ & 0.0000 & $0.000 \mathrm{E}+00$ & 0.0000 \\
\hline-237 & $0.000 \mathrm{E}+00$ & 0.0000 & $0.000 \mathrm{E}+00$ & 0.0000 & $0.000 \mathrm{E}+00$ & 0.0000 & $0.000 \mathrm{E}+00$ & 0.0000 & $0.000 \mathrm{E}+00$ & 0.0000 & $0.000 \mathrm{E}+00$ & 0.0000 & $0.000 \mathrm{E}+00$ & 0.0000 \\
\hline-238 & $0.000 \mathrm{E}+00$ & 0.0000 & $0.000 \mathrm{E}+00$ & 0.0000 & $0.000 \mathrm{E}+00$ & 0.0000 & $0.000 \mathrm{E}+00$ & 0.0000 & $0.000 \mathrm{E}+00$ & 0.0000 & $0.000 \mathrm{E}+00$ & 0.0000 & $0.000 \mathrm{E}+00$ & 0.0000 \\
\hline-239 & $0.000 \mathrm{E}+00$ & 0.0000 & $0.000 \mathrm{E}+00$ & 0.0000 & $0.000 \mathrm{E}+00$ & 0.0000 & $0.000 \mathrm{E}+00$ & 0.0000 & $0.000 \mathrm{E}+00$ & 0.0000 & $0.000 E+00$ & 0.0000 & $0.000 \mathrm{E}+00$ & 0.0000 \\
\hline-240 & $0.000 \mathrm{E}+00$ & 0.0000 & $0.000 \mathrm{E}+00$ & 0.0000 & $0.000 \mathrm{E}+00$ & 0.0000 & $0.000 \mathrm{E}+00$ & 0.0000 & $0.000 \mathrm{E}+00$ & 0.0000 & $0.000 E+00$ & 0.0000 & $0.000 \mathrm{E}+00$ & 0.0000 \\
\hline-99 & $0.000 \mathrm{E}+00$ & 0.0000 & $0.000 \mathrm{E}+00$ & 0.0000 & $0.000 \mathrm{E}+00$ & 0.0000 & $0.000 \mathrm{E}+00$ & 0.0000 & $0.000 \mathrm{E}+00$ & 0.0000 & $0.000 \mathrm{E}+00$ & 0.0000 & $0.000 \mathrm{E}+00$ & 0.0000 \\
\hline-228 & $0.000 \mathrm{E}+00$ & 0.0000 & $0.000 \mathrm{E}+00$ & 0.0000 & $0.000 \mathrm{E}+00$ & 0.0000 & $0.000 \mathrm{E}+00$ & 0.0000 & $0.000 \mathrm{E}+00$ & 0.0000 & $0.000 \mathrm{E}+00$ & 0.0000 & $0.000 \mathrm{E}+00$ & 0.0000 \\
\hline-230 & $0.000 \mathrm{E}+00$ & 0.0000 & $0.000 \mathrm{E}+00$ & 0.0000 & $0.000 \mathrm{E}+00$ & 0.0000 & $0.000 \mathrm{E}+00$ & 0.0000 & $0.000 \mathrm{E}+00$ & 0.0000 & $0.000 E+00$ & 0.0000 & $0.000 \mathrm{E}+00$ & 0.0000 \\
\hline-232 & $0.000 \mathrm{E}+00$ & 0.0000 & $0.000 \mathrm{E}+00$ & 0.0000 & $0.000 \mathrm{E}+00$ & 0.0000 & $0.000 \mathrm{E}+00$ & 0.0000 & $0.000 \mathrm{E}+00$ & 0.0000 & $0.000 \mathrm{E}+00$ & 0.0000 & $0.000 \mathrm{E}+00$ & 0.0000 \\
\hline 34 & $0.000 \mathrm{E}+00$ & 0.0000 & $0.000 \mathrm{E}+00$ & 0.0000 & $0.000 \mathrm{E}+00$ & 0.0000 & $0.000 \mathrm{E}+00$ & 0.0000 & $0.000 \mathrm{E}+00$ & 0.0000 & $0.000 \mathrm{E}+00$ & 0.0000 & $0.000 \mathrm{E}+00$ & 0.0000 \\
\hline 35 & $0.000 \mathrm{E}+00$ & 0.0000 & $0.000 \mathrm{E}+00$ & 0.0000 & $0.000 \mathrm{E}+00$ & 0.0000 & $0.000 \mathrm{E}+00$ & 0.0000 & $0.000 \mathrm{E}+00$ & 0.0000 & $0.000 E+00$ & 0.0000 & $0.000 \mathrm{E}+00$ & 0.0000 \\
\hline 38 & $0.000 \mathrm{E}+00$ & 0.0000 & $0.000 \mathrm{E}+00$ & 0.0000 & $0.000 \mathrm{E}+00$ & 0.0000 & $0.000 \mathrm{E}+00$ & 0.0000 & $0.000 \mathrm{E}+00$ & 0.0000 & $0.000 \mathrm{E}+00$ & 0.0000 & $0.000 \mathrm{E}+00$ & 0.0000 \\
\hline & $0.000 \mathrm{E}+00$ & 0.0000 & $0.000 \mathrm{E}+00$ & 0.0000 & $0.000 \mathrm{E}+00$ & 0.0000 & $0.000 \mathrm{E}+00$ & 0.0000 & $0.000 \mathrm{E}+00$ & 0.0000 & $0.000 \mathrm{E}+00$ & 0.0000 & $0.000 \mathrm{E}+00$ & 0.0000 \\
\hline
\end{tabular}

* Sum of all water independent and dependent pathways. 
RESRAD, Version 6.5

ummary : C746U Resident Gardener Deterministic Run

File : $\mathrm{X}: \backslash F I N A L$ V2 $\backslash$ DOE FWD RUNS $\backslash$ C746U RG DOE SG FWD-FV2-100000YR.RAD

Dose/Source Ratios Summed Over All Pathways

Parent and Progeny Principal Radionuclide Contributions Indicated

$\begin{array}{ccccc}\text { Parent Product } & \text { Thread } & \text { DSR }(j, t) \text { At Time in Years (mrem/yr)/(pCi/g) } \\ \text { (i) } & \text { (j) } & \text { Fraction } 0.000 \mathrm{E}+001.000 \mathrm{E}+005.000 \mathrm{E}+011.000 \mathrm{E}+025.000 \mathrm{E}+021.050 \mathrm{E}+031 .\end{array}$

(i)

Am-241

Am-241

Am-241

Am-241

Am-241

Cs $-137+D$

$\mathrm{Np}-237+\mathrm{D}$

$\mathrm{Np}-237+\mathrm{D}$

$\mathrm{Np}-237+\mathrm{D}$

$\mathrm{Np}-237+\mathrm{D}$

$\mathrm{Pu}-238$

$\mathrm{Pu}-238$

$\mathrm{Pu}-238$

$\mathrm{Pu}-238$

$\mathrm{Pu}-238$

$\mathrm{Pu}-238$

$\mathrm{Pu}-238$

$\mathrm{Pu}-239$

$\mathrm{Pu}-239$

$\mathrm{Pu}-239$

$\mathrm{Pu}-239$

Pu-239

$\mathrm{Pu}-240$

$\mathrm{Pu}-240$

$\mathrm{Pu}-240$

$\mathrm{Pu}-240$

$\mathrm{Pu}-240$

$\mathrm{Pu}-240$

$\mathrm{Pu}-240$

TC-99

Th $-228+\mathrm{D}$

Th-230

Th-230

$\mathrm{Th}-230$

$\mathrm{Th}-230$ (j)

\section{Am-241}

$\mathrm{Np}-237+\mathrm{D}$

$\mathrm{U}-233$

Th-229+D

$\sum \operatorname{DSR}(j)$

Cs $-137+D$

$\mathrm{Np}-237+\mathrm{D}$

$\mathrm{U}-233$

Th-229+D

$\sum \operatorname{DSR}(j)$

$\mathrm{Pu}-238$

$\mathrm{Pu}-238$

$\mathrm{U}-234$

Th-230

Ra $-226+\mathrm{D}$

$\mathrm{Pb}-210+\mathrm{D}$

$\sum \operatorname{DSR}(j)$

$\mathrm{Pu}-239$

$\mathrm{U}-235+\mathrm{D}$

$\mathrm{Pa}-231$

Ac $-227+D$

$\sum \operatorname{DSR}(j)$

Pu-240

$\mathrm{Pu}-240$

$\mathrm{U}-236$

Th-232

$\mathrm{Ra}-228+\mathrm{D}$

Th-228+D

$\sum \operatorname{DSR}(j)$

Tc-99

Th-228+D

Th-230

Ra-226+D

$\mathrm{Pb}-210+\mathrm{D}$

$\operatorname{CDSR}(j)$
$0.000 \mathrm{E}+00 \quad 1.000 \mathrm{E}+00 \quad 5.000 \mathrm{E}+01 \quad 1.000 \mathrm{E}+02 \quad 5.000 \mathrm{E}+02 \quad 1.050 \mathrm{E}+03 \quad 1.000 \mathrm{E}+04 \quad 1.000 \mathrm{E}+05$

$1.000 \mathrm{E}+00$

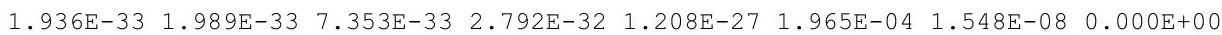

$1.000 \mathrm{E}+00$

$\begin{array}{llllllll}1.546 \mathrm{E}-19 & 4.680 \mathrm{E}-19 & 2.562 \mathrm{E}-17 & 8.382 \mathrm{E}-17 & 2.263 \mathrm{E}-14 & 1.773 \mathrm{E}-06 & 1.070 \mathrm{E}-04 & 0.000 \mathrm{E}+00\end{array}$

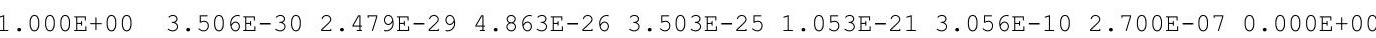

$1.000 \mathrm{E}+00$

$2.399 \mathrm{E}-26 \quad 3.618 \mathrm{E}-25 \quad 1.710 \mathrm{E}-20 \quad 1.868 \mathrm{E}-19 \quad 3.195 \mathrm{E}-16 \quad 5.403 \mathrm{E}-11 \quad 2.614 \mathrm{E}-06 \quad 0.000 \mathrm{E}+00$

$\begin{array}{llllllll}1.546 \mathrm{E}-19 & 4.680 \mathrm{E}-19 & 2.564 \mathrm{E}-17 & 8.401 \mathrm{E}-17 & 2.295 \mathrm{E}-14 & 1.983 \mathrm{E}-04 & 1.099 \mathrm{E}-04 & 0.000 \mathrm{E}+00\end{array}$

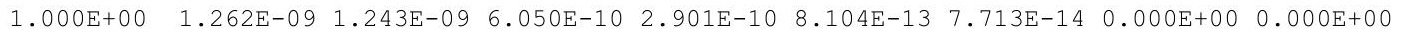

$1.000 \mathrm{E}+00$

$1.000 \mathrm{E}+00$

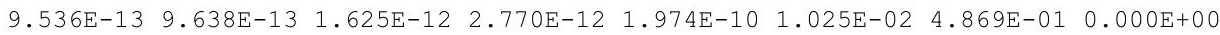

$.000 \mathrm{E}+00$

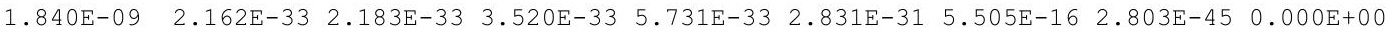

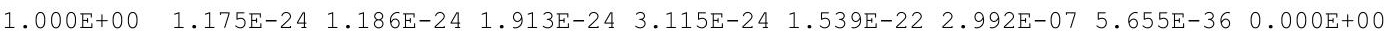

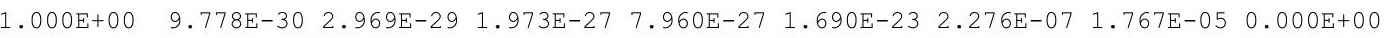

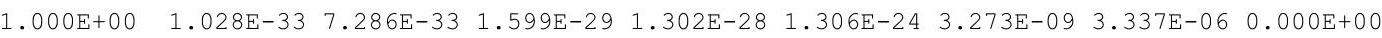

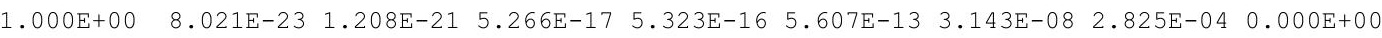

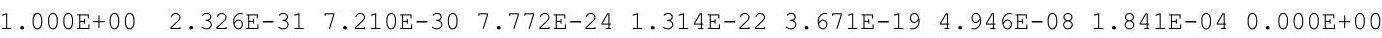
$\begin{array}{llllllll}8.139 \mathrm{E}-23 & 1.209 \mathrm{E}-21 & 5.266 \mathrm{E}-17 & 5.323 \mathrm{E}-16 & 5.607 \mathrm{E}-13 & 6.110 \mathrm{E}-07 & 4.876 \mathrm{E}-04 & 0.000 \mathrm{E}+00\end{array}$

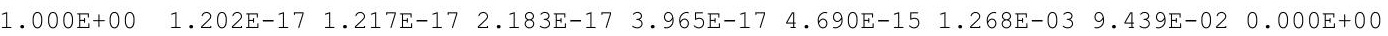
$\begin{array}{llllllllll}1.000 \mathrm{E}+00 & 6.135 \mathrm{E}-24 & 1.861 \mathrm{E}-23 & 1.146 \mathrm{E}-21 & 4.227 \mathrm{E}-21 & 2.931 \mathrm{E}-18 & 6.291 \mathrm{E}-10 & 4.403 \mathrm{E}-06 & 0.000 \mathrm{E}+00\end{array}$ $\begin{array}{lllllllll}1.000 \mathrm{E}+00 & 9.652 \mathrm{E}-28 & 6.818 \mathrm{E}-27 & 1.251 \mathrm{E}-23 & 8.414 \mathrm{E}-23 & 1.444 \mathrm{E}-19 & 4.191 \mathrm{E}-10 & 2.591 \mathrm{E}-06 & 0.000 \mathrm{E}+00\end{array}$ $1.000 \mathrm{E}+00$

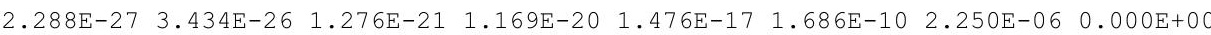

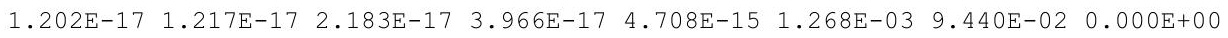

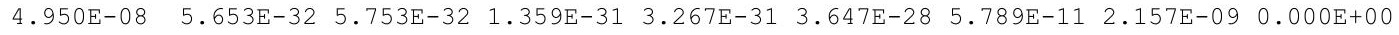

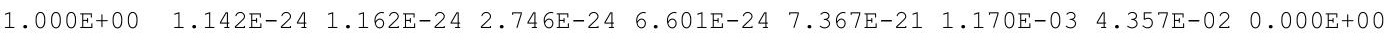
$\begin{array}{lllllllll}1.000 \mathrm{E}+00 & 2.162 \mathrm{E}-32 & 6.590 \mathrm{E}-32 & 5.335 \mathrm{E}-30 & 2.602 \mathrm{E}-29 & 1.686 \mathrm{E}-25 & 1.804 \mathrm{E}-08 & 9.074 \mathrm{E}-06 & 0.000 \mathrm{E}+00\end{array}$ $\begin{array}{lllllllll}1.000 \mathrm{E}+00 & 2.845 \mathrm{E}-43 & 2.028 \mathrm{E}-42 & 5.480 \mathrm{E}-39 & 5.478 \mathrm{E}-38 & 2.238 \mathrm{E}-33 & 9.371 \mathrm{E}-16 & 6.320 \mathrm{E}-12 & 0.000 \mathrm{E}+00\end{array}$ $\begin{array}{llllllllll}1.000 \mathrm{E}+00 & 1.371 \mathrm{E}-28 & 2.018 \mathrm{E}-27 & 3.762 \mathrm{E}-23 & 2.542 \mathrm{E}-22 & 1.470 \mathrm{E}-19 & 1.102 \mathrm{E}-13 & 8.021 \mathrm{E}-10 & 0.000 \mathrm{E}+00\end{array}$ $\begin{array}{lllllllll}1.000 \mathrm{E}+00 & 8.111 \mathrm{E}-28 & 2.334 \mathrm{E}-26 & 2.641 \mathrm{E}-21 & 1.757 \mathrm{E}-20 & 5.564 \mathrm{E}-18 & 1.510 \mathrm{E}-15 & 3.655 \mathrm{E}-10 & 0.000 \mathrm{E}+00\end{array}$ $\begin{array}{llllllll}1.143 \mathrm{E}-24 & 1.188 \mathrm{E}-24 & 2.681 \mathrm{E}-21 & 1.783 \mathrm{E}-20 & 5.719 \mathrm{E}-18 & 1.170 \mathrm{E}-03 & 4.358 \mathrm{E}-02 & 0.000 \mathrm{E}+00\end{array}$

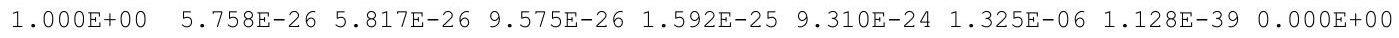

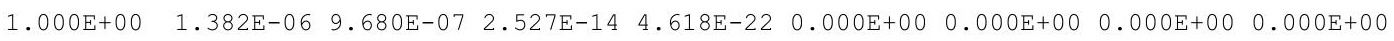

$\begin{array}{lllllllll}1.000 \mathrm{E}+00 & 2.412 \mathrm{E}-22 & 2.453 \mathrm{E}-22 & 5.590 \mathrm{E}-22 & 1.295 \mathrm{E}-21 & 1.078 \mathrm{E}-18 & 1.104 \mathrm{E}-03 & 1.120 \mathrm{E}-01 & 0.000 \mathrm{E}+00\end{array}$ $\begin{array}{lllllllll}1.000 \mathrm{E}+00 & 3.774 \mathrm{E}-11 & 1.139 \mathrm{E}-10 & 5.320 \mathrm{E}-09 & 1.479 \mathrm{E}-08 & 1.071 \mathrm{E}-06 & 2.165 \mathrm{E}-02 & 1.199 \mathrm{E}+01 & 0.000 \mathrm{E}+00\end{array}$ $\begin{array}{lllllllll}1.000 \mathrm{E}+00 & 1.819 \mathrm{E}-19 & 1.271 \mathrm{E}-18 & 1.299 \mathrm{E}-15 & 5.314 \mathrm{E}-15 & 7.678 \mathrm{E}-13 & 3.543 \mathrm{E}-02 & 7.839 \mathrm{E}+00 & 0.000 \mathrm{E}+00\end{array}$ $\begin{array}{lllllll}3.774 \mathrm{E}-11 & 1.139 \mathrm{E}-10 & 5.320 \mathrm{E}-09 & 1.479 \mathrm{E}-08 & 1.071 \mathrm{E}-06 & 5.818 \mathrm{E}-02 & 1.994 \mathrm{E}+01 \quad 0.000 \mathrm{E}+00\end{array}$ 
RESRAD, Version 6.5

$\mathrm{T}^{1 / 2}$ Limit $=180$ days

07/18/2011 15:11 Page 30

ummary : C746U Resident Gardener Deterministic Run

File : X: $\backslash F I N A L$ V2 \DOE FWD RUNS \C746U RG DOE SG FWD-FV2-100000YR.RAD

Dose/Source Ratios Summed Over All Pathways

Parent and Progeny Principal Radionuclide Contributions Indicated

\begin{tabular}{|c|c|c|c|c|c|c|c|c|c|c|}
\hline Parent & Product & Thread & & DSR & $(j, t)$ At & me in Yea & (mrem) & (yr)/(pCi/ & & \\
\hline (i) & $(j)$ & Fraction & $0.000 \mathrm{E}+00$ & $1.000 \mathrm{E}+00$ & $5.000 \mathrm{E}+01$ & $1.000 \mathrm{E}+02$ & $5.000 \mathrm{E}+02$ & $1.050 \mathrm{E}+03$ & $1.000 \mathrm{E}+04$ & $1.000 \mathrm{E}+05$ \\
\hline-232 & $\mathrm{Th}-232$ & $1.000 \mathrm{E}+00$ & $1.166 \mathrm{E}-24$ & $1.188 \mathrm{E}-24$ & $2.949 \mathrm{E}-24$ & $7.462 \mathrm{E}-24$ & $1.252 \mathrm{E}-20$ & $1.221 \mathrm{E}-03$ & $1.337 \mathrm{E}-01$ & $0.000 \mathrm{E}+00$ \\
\hline$h-232$ & $\mathrm{Ra}-228+\mathrm{D}$ & $1.000 \mathrm{E}+00$ & $1.107 \mathrm{E}-09$ & $3.174 \mathrm{E}-09$ & $2.784 \mathrm{E}-08$ & $4.079 E-08$ & $8.497 E-07$ & $1.458 \mathrm{E}-01$ & $1.699 \mathrm{E}+01$ & $0.000 \mathrm{E}+00$ \\
\hline$h-232$ & $\mathrm{Th}-228+\mathrm{D}$ & $1.000 \mathrm{E}+00$ & $1.067 \mathrm{E}-08$ & $6.581 \mathrm{E}-08$ & $2.213 \mathrm{E}-06$ & $2.992 E-06$ & $3.253 E-05$ & $2.007 \mathrm{E}-03$ & $7.745 \mathrm{E}+00$ & $0.000 \mathrm{E}+00$ \\
\hline$h-232$ & $\sum \operatorname{DSR}(j)$ & & $1.178 \mathrm{E}-08$ & $6.899 \mathrm{E}-08$ & $2.241 \mathrm{E}-06$ & $3.033 E-06$ & $3.338 E-05$ & 1. $491 \mathrm{E}-01$ & $2.487 \mathrm{E}+01$ & $0.000 \mathrm{E}+00$ \\
\hline-234 & $\mathrm{U}-234$ & $1.000 \mathrm{E}+00$ & $6.896 \mathrm{E}-24$ & $7.019 \mathrm{E}-24$ & $1.670 \mathrm{E}-23$ & $4.047 \mathrm{E}-23$ & $4.798 E-20$ & $6.337 \mathrm{E}-04$ & $4.918 E-02$ & $0.000 \mathrm{E}+00$ \\
\hline-234 & $\mathrm{Th}-230$ & $1.000 \mathrm{E}+00$ & $1.089 \mathrm{E}-27$ & $3.315 E-27$ & $2.540 \mathrm{E}-25$ & $1.171 \mathrm{E}-24$ & $4.838 E-21$ & $1.037 \mathrm{E}-05$ & $9.415 E-03$ & $0.000 \mathrm{E}+00$ \\
\hline-234 & $\mathrm{Ra}-226+\mathrm{D}$ & $1.000 \mathrm{E}+00$ & $1.133 \mathrm{E}-16$ & $7.978 E-16$ & $1.213 \mathrm{E}-12$ & $6.737 \mathrm{E}-12$ & $2.496 \mathrm{E}-09$ & $1.097 \mathrm{E}-04$ & $8.001 E-01$ & $0.000 \mathrm{E}+00$ \\
\hline-234 & $\mathrm{~Pb}-210+\mathrm{D}$ & $1.000 \mathrm{E}+00$ & $4.102 \mathrm{E}-25$ & $6.153 \mathrm{E}-24$ & $2.201 \mathrm{E}-19$ & $1.935 \mathrm{E}-18$ & 1. $678 \mathrm{E}-15$ & $1.738 \mathrm{E}-04$ & $5.213 E-01$ & $0.000 \mathrm{E}+00$ \\
\hline-234 & $\sum \operatorname{DSR}(j)$ & & $1.133 E-16$ & $7.978 E-16$ & 1. $213 \mathrm{E}-12$ & $6.737 E-12$ & $2.496 E-09$ & $9.276 \mathrm{E}-04$ & $1.380 E+00$ & $0.000 \mathrm{E}+00$ \\
\hline$-235+D$ & $\mathrm{U}-235+\mathrm{D}$ & $1.000 \mathrm{E}+00$ & 1. $243 \mathrm{E}-14$ & 1. $259 \mathrm{E}-14$ & $2.306 \mathrm{E}-14$ & $4.276 \mathrm{E}-14$ & $5.981 \mathrm{E}-12$ & $6.155 \mathrm{E}-04$ & $5.003 E-01$ & $0.000 \mathrm{E}+00$ \\
\hline$-235+D$ & $\mathrm{~Pa}-231$ & $1.000 \mathrm{E}+00$ & $2.937 E-18$ & $8.896 \mathrm{E}-18$ & $5.031 \mathrm{E}-16$ & $1.701 \mathrm{E}-15$ & $5.876 E-13$ & $8.145 \mathrm{E}-04$ & $5.535 E-01$ & $0.000 \mathrm{E}+00$ \\
\hline$-235+D$ & $A C-227+D$ & $1.000 \mathrm{E}+00$ & $9.274 \mathrm{E}-18$ & $6.481 \mathrm{E}-17$ & $6.882 E-14$ & $2.943 E-13$ & $6.376 \mathrm{E}-11$ & $3.373 E-04$ & $4.821 E-01$ & $0.000 \mathrm{E}+00$ \\
\hline$-235+D$ & $\sum \operatorname{DSR}(j)$ & & $1.245 \mathrm{E}-14$ & $1.266 \mathrm{E}-14$ & $9.238 \mathrm{E}-14$ & $3.388 E-13$ & $7.033 \mathrm{E}-11$ & $1.767 \mathrm{E}-03$ & $1.536 \mathrm{E}+00$ & $0.000 \mathrm{E}+00$ \\
\hline-238 & $\mathrm{U}-238$ & $5.400 E-05$ & $0.000 \mathrm{E}+00$ & $0.000 \mathrm{E}+00$ & $0.000 \mathrm{E}+00$ & $0.000 \mathrm{E}+00$ & $0.000 \mathrm{E}+00$ & $3.167 \mathrm{E}-08$ & $2.512 E-06$ & $0.000 \mathrm{E}+00$ \\
\hline$J-238+D$ & $\mathrm{U}-238+\mathrm{D}$ & $9.999 \mathrm{E}-01$ & $1.420 \mathrm{E}-10$ & $1.431 \mathrm{E}-10$ & $2.116 \mathrm{E}-10$ & $3.153 \mathrm{E}-10$ & $7.678 \mathrm{E}-09$ & $6.313 E-04$ & $1.508 \mathrm{E}-01$ & $0.000 \mathrm{E}+00$ \\
\hline$J-238+D$ & $\mathrm{U}-234$ & $9.999 \mathrm{E}-01$ & $9.803 E-30$ & $2.988 E-29$ & $2.392 E-27$ & $1.153 \mathrm{E}-26$ & $6.812 E-23$ & $1.890 \mathrm{E}-06$ & $1.414 \mathrm{E}-03$ & $0.000 \mathrm{E}+00$ \\
\hline$J-238+D$ & $T h-230$ & $9.999 \mathrm{E}-01$ & $1.030 \mathrm{E}-33$ & $7.316 E-33$ & $1.818 \mathrm{E}-29$ & $1.668 \mathrm{E}-28$ & $3.430 E-24$ & $1.541 \mathrm{E}-08$ & $1.316 \mathrm{E}-04$ & $0.000 \mathrm{E}+00$ \\
\hline$J-238+D$ & $\mathrm{Ra}-226+\mathrm{D}$ & $9.999 \mathrm{E}-01$ & $8.034 \mathrm{E}-23$ & 1. $212 \mathrm{E}-21$ & $5.801 \mathrm{E}-17$ & $6.420 \mathrm{E}-16$ & 1. $201 \mathrm{E}-12$ & $1.127 \mathrm{E}-07$ & $9.339 E-03$ & $0.000 \mathrm{E}+00$ \\
\hline$J-238+D$ & $\mathrm{~Pb}-210+\mathrm{D}$ & $9.999 \mathrm{E}-01$ & $2.329 E-31$ & $7.229 E-30$ & $8.430 E-24$ & $1.546 \mathrm{E}-22$ & $7.612 E-19$ & $1.734 \mathrm{E}-07$ & $6.063 E-03$ & $0.000 \mathrm{E}+00$ \\
\hline$J-238+D$ & $\sum \operatorname{DSR}(j)$ & & $1.420 \mathrm{E}-10$ & $1.431 \mathrm{E}-10$ & $2.116 \mathrm{E}-10$ & $3.153 \mathrm{E}-10$ & $7.680 E-09$ & $6.335 E-04$ & $1.677 \mathrm{E}-01$ & $0.000 \mathrm{E}+00$ \\
\hline
\end{tabular}

The DSR includes contributions from associated (half-life $\leq 180$ days) daughters. 
RESRAD, Version 6.5

07/18/2011 15:11 Page

ummary : C746U Resident Gardener Deterministic Run

File : $\mathrm{X}: \backslash F I N A L$ V2 $\backslash$ DOE FWD RUNS \C746U RG DOE SG FWD-FV2-100000YR.RAD

Single Radionuclide Soil Guidelines G(i,t) in pCi/g

Basic Radiation Dose Limit $=1.000 \mathrm{E}+02 \mathrm{mrem} / \mathrm{yr}$

Nuclide

\begin{tabular}{|c|c|c|c|c|c|c|c|c|}
\hline (i) & $t=0.000 \mathrm{E}+00$ & $1.000 \mathrm{E}+00$ & $5.000 \mathrm{E}+01$ & $1.000 \mathrm{E}+02$ & $5.000 \mathrm{E}+02$ & $1.050 \mathrm{E}+03$ & $1.000 \mathrm{E}+04$ & $1.000 \mathrm{E}+05$ \\
\hline $1-241$ & $\star 3.431 \mathrm{E}+12$ & $\star 3.431 \mathrm{E}+12$ & $\star 3.431 \mathrm{E}+12$ & $\star 3.431 \mathrm{E}+12$ & $\star 3.431 \mathrm{E}+12$ & $5.044 \mathrm{E}+05$ & $9.099 \mathrm{E}+05$ & $\star 3.431 \mathrm{E}+12$ \\
\hline-137 & $7.925 E+10$ & $8.043 E+10$ & $1.653 \mathrm{E}+11$ & $3.447 \mathrm{E}+11$ & $\star 8.704 \mathrm{E}+13$ & $\star 8.704 \mathrm{E}+13$ & $\star 8.704 \mathrm{E}+13$ & $\star 8.704 \mathrm{E}+13$ \\
\hline-237 & $\star 7.047 \mathrm{E}+08$ & $\star 7.047 \mathrm{E}+08$ & $\star 7.047 \mathrm{E}+08$ & $\star 7.047 \mathrm{E}+08$ & $\star 7.047 \mathrm{E}+08$ & $9.756 \mathrm{E}+03$ & $1.991 \mathrm{E}+02$ & $\star 7.047 \mathrm{E}+08$ \\
\hline-238 & $\star 1.712 \mathrm{E}+13$ & $\star 1.712 \mathrm{E}+13$ & $\star 1.712 \mathrm{E}+13$ & $\star 1.712 \mathrm{E}+13$ & $* 1.712 \mathrm{E}+13$ & $1.637 \mathrm{E}+08$ & $2.051 \mathrm{E}+05$ & $* 1.712 \mathrm{E}+13$ \\
\hline-239 & $\star 6.214 \mathrm{E}+10$ & $* 6.214 \mathrm{E}+10$ & $* 6.214 \mathrm{E}+10$ & $\star 6.214 \mathrm{E}+10$ & $\star 6.214 \mathrm{E}+10$ & $7.884 \mathrm{E}+04$ & $1.059 \mathrm{E}+03$ & $* 6.214 \mathrm{E}+10$ \\
\hline$u-240$ & $\star 2.278 \mathrm{E}+11$ & $\star 2.278 \mathrm{E}+11$ & $\star 2.278 \mathrm{E}+11$ & $\star 2.278 \mathrm{E}+11$ & $\star 2.278 \mathrm{E}+11$ & $8.550 \mathrm{E}+04$ & $2.295 E+03$ & $\star 2.278 \mathrm{E}+11$ \\
\hline$c-99$ & $\star 1.697 \mathrm{E}+10$ & $* 1.697 \mathrm{E}+10$ & $\star 1.697 \mathrm{E}+10$ & $* 1.697 \mathrm{E}+10$ & $* 1.697 \mathrm{E}+10$ & $7.545 \mathrm{E}+07$ & $\star 1.697 \mathrm{E}+10$ & $* 1.697 \mathrm{E}+10$ \\
\hline$h-228$ & $7.234 \mathrm{E}+07$ & $1.033 E+08$ & $\star 8.195 \mathrm{E}+14$ & $\star 8.195 \mathrm{E}+14$ & $\star 8.195 \mathrm{E}+14$ & $* 8.195 \mathrm{E}+14$ & $\star 8.195 \mathrm{E}+14$ & $\star 8.195 \mathrm{E}+14$ \\
\hline Th -230 & $\star 2.018 \mathrm{E}+10$ & $\star 2.018 \mathrm{E}+10$ & $1.880 \mathrm{E}+10$ & $6.761 \mathrm{E}+09$ & $9.336 \mathrm{E}+07$ & $1.719 \mathrm{E}+03$ & $5.016 \mathrm{E}+00$ & $* 2.018 \mathrm{E}+10$ \\
\hline Th-232 & $* 1.097 \mathrm{E}+05$ & $\star 1.097 \mathrm{E}+05$ & $\star 1.097 \mathrm{E}+05$ & $\star 1.097 \mathrm{E}+05$ & $* 1.097 \mathrm{E}+05$ & $6.708 \mathrm{E}+02$ & $4.021 \mathrm{E}+00$ & $* 1.097 \mathrm{E}+05$ \\
\hline$J-234$ & $* 6.247 \mathrm{E}+09$ & $\star 6.247 \mathrm{E}+09$ & $\star 6.247 \mathrm{E}+09$ & $\star 6.247 \mathrm{E}+09$ & $\star 6.247 \mathrm{E}+09$ & $1.078 \mathrm{E}+05$ & $7.246 \mathrm{E}+01$ & $* 6.247 \mathrm{E}+09$ \\
\hline 235 & $\star 2.161 \mathrm{E}+06$ & $\star 2.161 \mathrm{E}+06$ & $\star 2.161 \mathrm{E}+06$ & $\star 2.161 \mathrm{E}+06$ & $\star 2.161 \mathrm{E}+06$ & $5.658 \mathrm{E}+04$ & $6.511 \mathrm{E}+01$ & $\star 2.161 \mathrm{E}+06$ \\
\hline 38 & $\star 3.361 \mathrm{E}+05$ & $\star 3.361 \mathrm{E}+05$ & $\star 3.361 \mathrm{E}+05$ & $\star 3.361 \mathrm{E}+05$ & $\star 3.361 \mathrm{E}+05$ & $1.578 \mathrm{E}+05$ & $5.961 \mathrm{E}+02$ & $\star 3.361 E+05$ \\
\hline
\end{tabular}

*At specific activity limit

Summed Dose/Source Ratios DSR(i,t) in (mrem/yr)/(pCi/g)

and Single Radionuclide Soil Guidelines $G(i, t)$ in $\mathrm{pCi} / \mathrm{g}$

at $\operatorname{tmin}=$ time of minimum single radionuclide soil guideline and at $\operatorname{tmax}=$ time of maximum total dose $=12931 \pm *$ years

\begin{tabular}{|c|c|c|c|c|c|c|}
\hline $\begin{array}{l}\text { uclide } \\
\text { (i) }\end{array}$ & $\begin{array}{l}\text { Initial } \\
\text { (pCi/g) }\end{array}$ & $\begin{array}{c}\text { tmin } \\
\text { (years) }\end{array}$ & $\operatorname{DSR}(i, \operatorname{tmin})$ & $\begin{array}{c}\mathrm{G}(i, \mathrm{tmin}) \\
(\mathrm{pCi} / \mathrm{g})\end{array}$ & $\operatorname{DSR}(i, t \max )$ & $\begin{array}{c}\mathrm{G}(i, \mathrm{tmax}) \\
(\mathrm{pCi} / \mathrm{g})\end{array}$ \\
\hline $1-241$ & $3.500 \mathrm{E}+01$ & $1670 \pm 3$ & $2.766 \mathrm{E}-03$ & $3.615 E+04$ & $7.589 \mathrm{E}-05$ & 1. $318 \mathrm{E}+06$ \\
\hline-137 & $1.900 \mathrm{E}+01$ & $0.000 \mathrm{E}+00$ & $1.262 E-09$ & $7.925 E+10$ & $0.000 \mathrm{E}+00$ & $\star 8.704 \mathrm{E}+13$ \\
\hline-237 & $5.500 \mathrm{E}+00$ & $2534 \pm 5$ & $1.335 \mathrm{E}+00$ & $7.488 \mathrm{E}+01$ & $3.478 \mathrm{E}-01$ & $2.875 E+02$ \\
\hline-238 & $3.900 \mathrm{E}+01$ & $23363 \pm *$ & $1.021 \mathrm{E}-03$ & $9.790 \mathrm{E}+04$ & $6.315 E-04$ & $1.584 \mathrm{E}+05$ \\
\hline-239 & $3.600 \mathrm{E}+01$ & $2537 \pm 5$ & $1.330 E-01$ & $7.519 \mathrm{E}+02$ & $8.251 E-02$ & 1. $212 \mathrm{E}+03$ \\
\hline-240 & $3.600 \mathrm{E}+01$ & $2535 \pm 5$ & $1.093 E-01$ & $9.151 \mathrm{E}+02$ & $3.037 \mathrm{E}-02$ & $3.293 E+03$ \\
\hline-99 & $5.200 \mathrm{E}+01$ & $1144 \pm 2$ & $3.687 E-06$ & $2.712 E+07$ & $0.000 \mathrm{E}+00$ & $* 1.697 \mathrm{E}+10$ \\
\hline-228 & $4.000 \mathrm{E}+00$ & $0.000 \mathrm{E}+00$ & $1.382 E-06$ & $7.234 E+07$ & $0.000 \mathrm{E}+00$ & $\star 8.195 \mathrm{E}+14$ \\
\hline-230 & $1.000 \mathrm{E}+02$ & $8258 \pm *$ & $2.007 \mathrm{E}+01$ & $4.984 \mathrm{E}+00$ & $1.943 \mathrm{E}+01$ & $5.148 \mathrm{E}+00$ \\
\hline-232 & $4.000 \mathrm{E}+00$ & $2534 \pm 5$ & $2.542 E+01$ & $3.934 E+00$ & $2.465 E+01$ & $4.056 \mathrm{E}+00$ \\
\hline 234 & $1.600 \mathrm{E}+02$ & $23360 \pm *$ & $2.863 \mathrm{E}+00$ & $3.493 \mathrm{E}+01$ & $1.780 \mathrm{E}+00$ & $5.618 \mathrm{E}+01$ \\
\hline 235 & $6.500 \mathrm{E}+00$ & $23350 \pm \star *$ & $1.982 \mathrm{E}+00$ & $5.044 \mathrm{E}+01$ & $1.693 E+00$ & $5.907 \mathrm{E}+01$ \\
\hline 238 & $1.600 \mathrm{E}+02$ & $2534 \pm 5$ & $1.800 \mathrm{E}-01$ & $5.556 \mathrm{E}+02$ & $1.696 \mathrm{E}-01$ & $5.898 E+02$ \\
\hline
\end{tabular}

*At specific activity limit 
RESRAD, Version 6.5

ummary : C746U Resident Gardener Deterministic Run

File : $\mathrm{X}: \backslash F I N A L$ V2 $\backslash$ DOE FWD RUNS $\backslash C 746 \mathrm{U}$ RG DOE SG FWD-FV2-100000YR.RAD

Individual Nuclide Dose Summed Over All Pathways

Parent Nuclide and Branch Fraction Indicated

Nuclide Parent THF(i) DOSE (j,t), mrem/yr

\begin{tabular}{|c|c|c|}
\hline (j) & (i) & \\
\hline-241 & $A m-241$ & $1.000 \mathrm{E}+00$ \\
\hline-237 & $A m-241$ & $1.000 \mathrm{E}+00$ \\
\hline-237 & $\mathrm{~Np}-237$ & $1.000 \mathrm{E}+00$ \\
\hline 237 & $\sum \operatorname{DOSE}(j$ & \\
\hline
\end{tabular}

$\mathrm{U}-233 \quad \mathrm{Am}-241 \quad 1.000 \mathrm{E}+00$

$\mathrm{U}-233 \quad \mathrm{~Np}-237 \quad 1.000 \mathrm{E}+00$

U-233 $\quad$ DOSE $(j)$

Th-229

Th-229

Th-229

Cs-137

$\mathrm{Pu}-238$

$\mathrm{Pu}-238$

$\mathrm{Pu}-238$

$\mathrm{U}-234$

$\mathrm{U}-234$

$\mathrm{U}-234$

$\mathrm{U}-234$

Th-230

Th -230

Th -230

Th-230

Th -230

$\mathrm{Ra}-226$

$\mathrm{Ra}-226$

$\mathrm{Ra}-226$

$\mathrm{Ra}-226$

Ra-226

$\mathrm{Pb}-210$

$\mathrm{Pb}-210$

$\mathrm{Pb}-210$

$\mathrm{Pb}-210$

$\mathrm{Pb}-210$

$\mathrm{Pu}-239$

$\mathrm{Pu}-239 \quad 1.000 \mathrm{E}+00$ $\mathrm{U}-2351.000 \mathrm{E}+00$ ¿DOSE $(j)$ $t=0.000 \mathrm{E}+00 \quad 1.000 \mathrm{E}+00 \quad 5.000 \mathrm{E}+01 \quad 1.000 \mathrm{E}+02 \quad 5.000 \mathrm{E}+02 \quad 1.050 \mathrm{E}+03 \quad 1.000 \mathrm{E}+04 \quad 1.000 \mathrm{E}+05$

$\begin{array}{llllllll}0.000 \mathrm{E}+00 & 0.000 \mathrm{E}+00 & 0.000 \mathrm{E}+00 & 0.000 \mathrm{E}+00 & 4.227 \mathrm{E}-26 & 6.877 \mathrm{E}-03 & 5.418 \mathrm{E}-07 & 0.000 \mathrm{E}+0\end{array}$

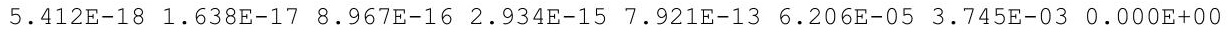

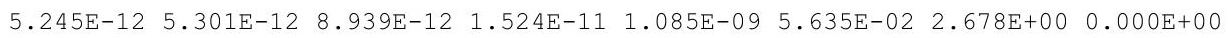

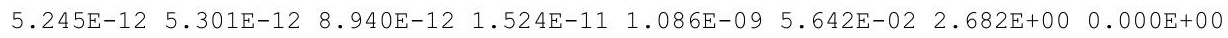

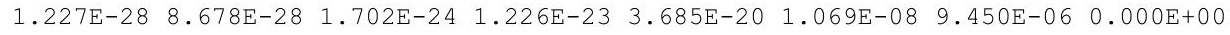
$\begin{array}{llllllll}1.785 \mathrm{E}-22 & 5.414 \mathrm{E}-22 & 3.355 \mathrm{E}-20 & 1.245 \mathrm{E}-19 & 9.076 \mathrm{E}-17 & 1.579 \mathrm{E}-05 & 7.534 \mathrm{E}-03 & 0.000 \mathrm{E}+00\end{array}$ $\begin{array}{llllllll}1.785 \mathrm{E}-22 & 5.414 \mathrm{E}-22 & 3.355 \mathrm{E}-20 & 1.245 \mathrm{E}-19 & 9.079 \mathrm{E}-17 & 1.580 \mathrm{E}-05 & 7.544 \mathrm{E}-03 & 0.000 \mathrm{E}+00\end{array}$

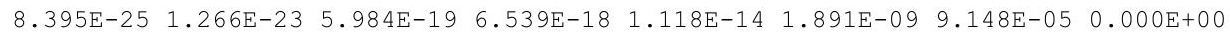
$\begin{array}{llllllll}1.629 \mathrm{E}-18 & 1.147 \mathrm{E}-17 & 1.758 \mathrm{E}-14 & 9.834 \mathrm{E}-14 & 3.894 \mathrm{E}-11 & 3.741 \mathrm{E}-06 & 7.722 \mathrm{E}-02 & 0.000 \mathrm{E}+00\end{array}$ $\begin{array}{lllllllll}1.629 \mathrm{E}-18 & 1.147 \mathrm{E}-17 & 1.758 \mathrm{E}-14 & 9.835 \mathrm{E}-14 & 3.895 \mathrm{E}-11 & 3.743 \mathrm{E}-06 & 7.731 \mathrm{E}-02 & 0.000 \mathrm{E}+00\end{array}$

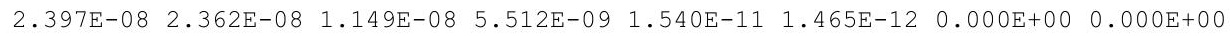

$\begin{array}{lllllllll}0.000 \mathrm{E}+00 & 0.000 \mathrm{E}+00 & 0.000 \mathrm{E}+00 & 0.000 \mathrm{E}+00 & 0.000 \mathrm{E}+00 & 2.147 \mathrm{E}-14 & 0.000 \mathrm{E}+00 & 0.000 \mathrm{E}+00\end{array}$ $\begin{array}{llllllll}4.582 \mathrm{E}-23 & 4.627 \mathrm{E}-23 & 7.461 \mathrm{E}-23 & 1.215 \mathrm{E}-22 & 6.001 \mathrm{E}-21 & 1.167 \mathrm{E}-05 & 0.000 \mathrm{E}+00 & 0.000 \mathrm{E}+00\end{array}$

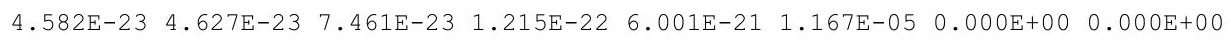

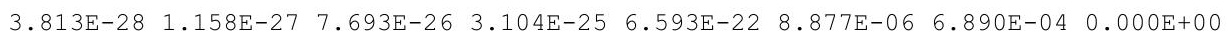
$\begin{array}{llllllllll}1.103 \mathrm{E}-21 & 1.123 \mathrm{E}-21 & 2.673 \mathrm{E}-21 & 6.475 \mathrm{E}-21 & 7.677 \mathrm{E}-18 & 1.014 \mathrm{E}-01 & 7.868 \mathrm{E}+00 & 0.000 \mathrm{E}+00\end{array}$ $\begin{array}{llllllll}1.569 \mathrm{E}-27 & 4.780 \mathrm{E}-27 & 3.827 \mathrm{E}-25 & 1.845 \mathrm{E}-24 & 1.090 \mathrm{E}-20 & 3.024 \mathrm{E}-04 & 2.263 \mathrm{E}-01 & 0.000 \mathrm{E}+00\end{array}$ $\begin{array}{lllllllll}1.103 \mathrm{E}-21 & 1.123 \mathrm{E}-21 & 2.673 \mathrm{E}-21 & 6.477 \mathrm{E}-21 & 7.688 \mathrm{E}-18 & 1.017 \mathrm{E}-01 & 8.095 \mathrm{E}+00 & 0.000 \mathrm{E}+00\end{array}$

$\begin{array}{llllllll}0.000 \mathrm{E}+00 & 0.000 \mathrm{E}+00 & 6.236 \mathrm{E}-28 & 5.079 \mathrm{E}-27 & 5.092 \mathrm{E}-23 & 1.276 \mathrm{E}-07 & 1.301 \mathrm{E}-04 & 0.000 \mathrm{E}+00\end{array}$ $\begin{array}{llllllll}2.412 \mathrm{E}-20 & 2.453 \mathrm{E}-20 & 5.590 \mathrm{E}-20 & 1.295 \mathrm{E}-19 & 1.078 \mathrm{E}-16 & 1.104 \mathrm{E}-01 & 1.120 \mathrm{E}+01 & 0.000 \mathrm{E}+00\end{array}$ $\begin{array}{llllllll}1.742 \mathrm{E}-25 & 5.304 \mathrm{E}-25 & 4.065 \mathrm{E}-23 & 1.874 \mathrm{E}-22 & 7.741 \mathrm{E}-19 & 1.659 \mathrm{E}-03 & 1.506 \mathrm{E}+00 & 0.000 \mathrm{E}+00\end{array}$ $\begin{array}{lllllllll}0.000 \mathrm{E}+00 & 0.000 \mathrm{E}+00 & 2.909 \mathrm{E}-27 & 2.669 \mathrm{E}-26 & 5.488 \mathrm{E}-22 & 2.466 \mathrm{E}-06 & 2.106 \mathrm{E}-02 & 0.000 \mathrm{E}+00\end{array}$

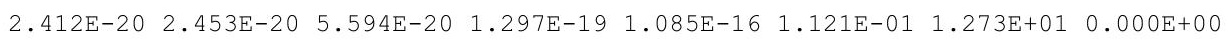

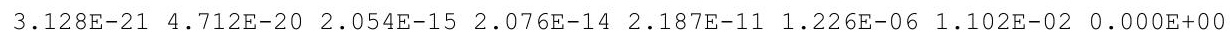

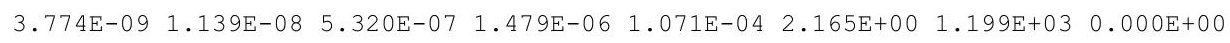
$\begin{array}{llllllll}1.813 \mathrm{E}-14 & 1.277 \mathrm{E}-13 & 1.941 \mathrm{E}-10 & 1.078 \mathrm{E}-09 & 3.993 \mathrm{E}-07 & 1.755 \mathrm{E}-02 & 1.280 \mathrm{E}+02 & 0.000 \mathrm{E}+00\end{array}$

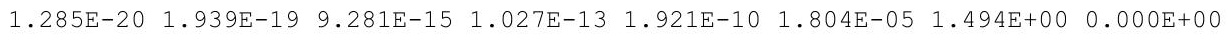

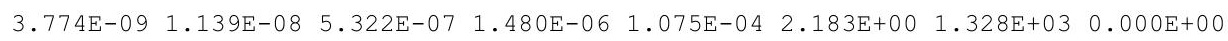

$\begin{array}{llllllll}0.000 \mathrm{E}+00 & 2.812 \mathrm{E}-28 & 3.031 \mathrm{E}-22 & 5.124 \mathrm{E}-21 & 1.432 \mathrm{E}-17 & 1.929 \mathrm{E}-06 & 7.179 \mathrm{E}-03 & 0.000 \mathrm{E}+00\end{array}$ $\begin{array}{lllllllll}1.819 \mathrm{E}-17 & 1.271 \mathrm{E}-16 & 1.299 \mathrm{E}-13 & 5.314 \mathrm{E}-13 & 7.678 \mathrm{E}-11 & 3.543 \mathrm{E}+00 & 7.839 \mathrm{E}+02 & 0.000 \mathrm{E}+00\end{array}$ $\begin{array}{lllllllll}6.563 \mathrm{E}-23 & 9.844 \mathrm{E}-22 & 3.522 \mathrm{E}-17 & 3.095 \mathrm{E}-16 & 2.685 \mathrm{E}-13 & 2.781 \mathrm{E}-02 & 8.341 \mathrm{E}+01 & 0.000 \mathrm{E}+00\end{array}$ $0.000 \mathrm{E}+00 \quad 1.157 \mathrm{E}-27 \quad 1.349 \mathrm{E}-21 \quad 2.474 \mathrm{E}-20 \quad 1.218 \mathrm{E}-16 \quad 2.774 \mathrm{E}-05 \quad 9.701 \mathrm{E}-01 \quad 0.000 \mathrm{E}+00$ $\begin{array}{llllllll}1.819 \mathrm{E}-17 & 1.271 \mathrm{E}-16 & 1.299 \mathrm{E}-13 & 5.317 \mathrm{E}-13 & 7.705 \mathrm{E}-11 & 3.571 \mathrm{E}+00 & 8.683 \mathrm{E}+02 & 0.000 \mathrm{E}+00\end{array}$

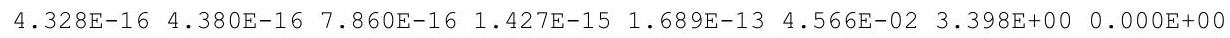

$2.209 \mathrm{E}-22 \quad 6.699 \mathrm{E}-22 \quad 4.126 \mathrm{E}-20 \quad 1.522 \mathrm{E}-19 \quad 1.055 \mathrm{E}-16 \quad 2.265 \mathrm{E}-08 \quad 1.585 \mathrm{E}-04 \quad 0.000 \mathrm{E}+00$ 8.081E-14 8.182E-14 1.499E-13 2.779E-13 3.888E-11 4.001E-03 3.252E+00 $0.000 \mathrm{E}+00$ $\begin{array}{llllllll}8.081 \mathrm{E}-14 & 8.182 \mathrm{E}-14 & 1.499 \mathrm{E}-13 & 2.779 \mathrm{E}-13 & 3.888 \mathrm{E}-11 & 4.001 \mathrm{E}-03 & 3.252 \mathrm{E}+00 & 0.000 \mathrm{E}+00\end{array}$ 
RESRAD, Version 6.5

ummary : C746U Resident Gardener Deterministic Run

File : $\mathrm{X}: \backslash F I N A L$ V2 $\backslash$ DOE FWD RUNS $\backslash C 746 \mathrm{U}$ RG DOE SG FWD-FV2-100000YR.RAD

Individual Nuclide Soil Concentration

Parent Nuclide and Branch Fraction Indicated

Nuclide Parent THF(

(j)

\section{Am-241}

(i)

$\overline{A m-241} \overline{1.000 \mathrm{E}+00}$

Np-237 Am-241 $1.000 \mathrm{E}+00$

$\mathrm{Np}-237 \quad \mathrm{~Np}-237 \quad 1.000 \mathrm{E}+00$

Np-237 $\sum S(j):$

$\mathrm{U}-233 \quad \mathrm{Am}-241 \quad 1.000 \mathrm{E}+00$

$\mathrm{U}-233 \quad \mathrm{~Np}-237 \quad 1.000 \mathrm{E}+00$

$\mathrm{U}-233 \sum \mathrm{S}(\mathrm{j}):$

$\mathrm{Am}-241 \quad 1.000 \mathrm{E}+00$ Np-237 1.000E+00 $\sum S(j):$

Cs-137 1.000E+00

Pu-238 1.840E-09 Pu-238 1.000E+00 $\sum S(j):$

$\mathrm{Pu}-238 \quad 1.000 \mathrm{E}+00$ $\mathrm{U}-234 \quad 1.000 \mathrm{E}+00$ U-238 $9.999 \mathrm{E}-01$ $\sum S(j):$

$\mathrm{Pu}-238 \quad 1.000 \mathrm{E}+00$ Th-230 1.000E+00 $\mathrm{U}-234 \quad 1.000 \mathrm{E}+00$ U-238 $9.999 \mathrm{E}-01$ $\sum S(j):$

$\mathrm{Pu}-238 \quad 1.000 \mathrm{E}+00$ Th-230 1.000E+00 $\mathrm{U}-234 \quad 1.000 \mathrm{E}+00$ $\mathrm{U}-238 \quad 9.999 \mathrm{E}-01$ $\sum S(j):$

$\mathrm{Pu}-238 \quad 1.000 \mathrm{E}+00$ Th-230 1.000E+00 $\mathrm{U}-2341.000 \mathrm{E}+00$ U-238 9.999E-01 $\sum S(j):$

$\mathrm{Pu}-239 \quad 1.000 \mathrm{E}+00$

$\mathrm{Pu}-239 \quad 1.000 \mathrm{E}+00$ $\mathrm{U}-235 \quad 1.000 \mathrm{E}+00$ $\sum S(j):$
$\mathrm{S}(j, t), \mathrm{pCi} / \mathrm{g}$

$t=0.000 \mathrm{E}+00 \quad 1.000 \mathrm{E}+00 \quad 5.000 \mathrm{E}+01 \quad 1.000 \mathrm{E}+02 \quad 5.000 \mathrm{E}+02 \quad 1.050 \mathrm{E}+03 \quad 1.000 \mathrm{E}+04 \quad 1.000 \mathrm{E}+05$

$\begin{array}{lllllllllll}3.500 \mathrm{E}+01 & 3.494 \mathrm{E}+01 & 3.229 \mathrm{E}+01 & 2.980 \mathrm{E}+01 & 1.566 \mathrm{E}+01 & 6.464 \mathrm{E}+00 & 3.610 \mathrm{E}-06 & 0.000 \mathrm{E}+00\end{array}$

$0.000 \mathrm{E}+00 \quad 1.133 \mathrm{E}-05 \quad 5.428 \mathrm{E}-04 \quad 1.040 \mathrm{E}-03 \quad 3.749 \mathrm{E}-03 \quad 5.255 \mathrm{E}-03 \quad 1.996 \mathrm{E}-03 \quad 1.062 \mathrm{E}-08$

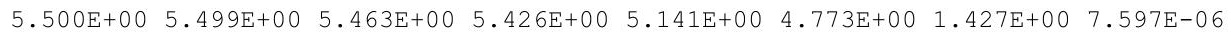
$\begin{array}{llllllll}5.500 \mathrm{E}+00 & 5.499 \mathrm{E}+00 & 5.464 \mathrm{E}+00 & 5.427 \mathrm{E}+00 & 5.145 \mathrm{E}+00 & 4.779 \mathrm{E}+00 & 1.429 \mathrm{E}+00 & 7.608 \mathrm{E}-06\end{array}$

$\begin{array}{llllllll}0.000 \mathrm{E}+00 & 2.477 \mathrm{E}-11 & 6.018 \mathrm{E}-08 & 2.338 \mathrm{E}-07 & 4.686 \mathrm{E}-06 & 1.571 \mathrm{E}-05 & 1.406 \mathrm{E}-04 & 1.888 \mathrm{E}-05\end{array}$ $\begin{array}{llllllll}0.000 \mathrm{E}+00 & 2.405 \mathrm{E}-05 & 1.198 \mathrm{E}-03 & 2.386 \mathrm{E}-03 & 1.155 \mathrm{E}-02 & 2.320 \mathrm{E}-02 & 1.121 \mathrm{E}-01 & 1.449 \mathrm{E}-02\end{array}$

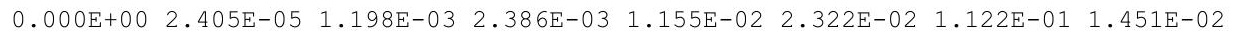

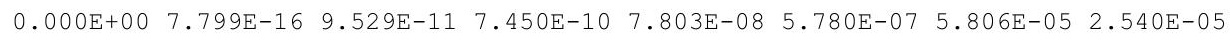

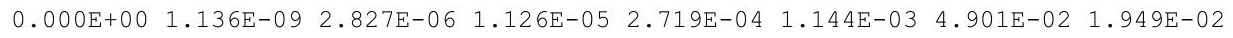

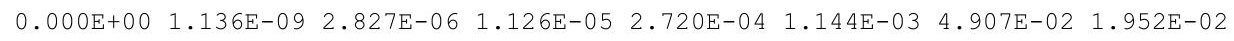

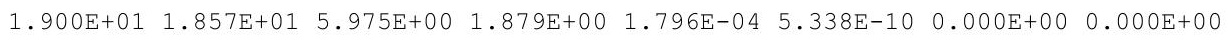

$\begin{array}{llllllll}7.176 \mathrm{E}-08 & 7.119 \mathrm{E}-08 & 4.830 \mathrm{E}-08 & 3.251 \mathrm{E}-08 & 1.370 \mathrm{E}-09 & 1.760 \mathrm{E}-11 & 2.951 \mathrm{E}-42 & 0.000 \mathrm{E}+00\end{array}$ $\begin{array}{llllllllll}3.900 \mathrm{E}+01 & 3.869 \mathrm{E}+01 & 2.625 \mathrm{E}+01 & 1.767 \mathrm{E}+01 & 7.445 \mathrm{E}-01 & 9.567 \mathrm{E}-03 & 1.612 \mathrm{E}-33 & 0.000 \mathrm{E}+00\end{array}$ $\begin{array}{llllllllll}3.900 \mathrm{E}+01 & 3.869 \mathrm{E}+01 & 2.625 \mathrm{E}+01 & 1.767 \mathrm{E}+01 & 7.445 \mathrm{E}-01 & 9.567 \mathrm{E}-03 & 1.612 \mathrm{E}-33 & 0.000 \mathrm{E}+00\end{array}$

$0.000 \mathrm{E}+00 \quad 1.101 \mathrm{E}-04 \quad 4.562 \mathrm{E}-03 \quad 7.627 \mathrm{E}-03 \quad 1.356 \mathrm{E}-02 \quad 1.363 \mathrm{E}-02 \quad 1.082 \mathrm{E}-02 \quad 1.059 \mathrm{E}-03$ $\begin{array}{lllllllll}1.600 \mathrm{E}+02 & 1.600 \mathrm{E}+02 & 1.598 \mathrm{E}+02 & 1.596 \mathrm{E}+02 & 1.579 \mathrm{E}+02 & 1.557 \mathrm{E}+02 & 1.236 \mathrm{E}+02 & 1.209 \mathrm{E}+01\end{array}$ $\begin{array}{llllllll}0.000 \mathrm{E}+00 & 4.536 \mathrm{E}-04 & 2.265 \mathrm{E}-02 & 4.525 \mathrm{E}-02 & 2.240 \mathrm{E}-01 & 4.642 \mathrm{E}-01 & 3.553 \mathrm{E}+00 & 3.962 \mathrm{E}+00\end{array}$ $\begin{array}{llllllll}1.600 \mathrm{E}+02 & 1.600 \mathrm{E}+02 & 1.598 \mathrm{E}+02 & 1.596 \mathrm{E}+02 & 1.582 \mathrm{E}+02 & 1.562 \mathrm{E}+02 & 1.271 \mathrm{E}+02 & 1.605 \mathrm{E}+01\end{array}$

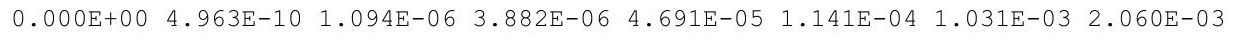
$\begin{array}{llllllllllll}1.000 \mathrm{E}+02 & 1.000 \mathrm{E}+02 & 9.994 \mathrm{E}+01 & 9.988 \mathrm{E}+01 & 9.940 \mathrm{E}+01 & 9.875 \mathrm{E}+01 & 8.874 \mathrm{E}+01 & 3.028 \mathrm{E}+01\end{array}$ $\begin{array}{lllllllllll}0.000 \mathrm{E}+00 & 1.440 \mathrm{E}-03 & 7.195 \mathrm{E}-02 & 1.438 \mathrm{E}-01 & 7.134 \mathrm{E}-01 & 1.483 \mathrm{E}+00 & 1.193 \mathrm{E}+01 & 2.358 \mathrm{E}+01\end{array}$ $\begin{array}{llllllllll}0.000 \mathrm{E}+00 & 2.041 \mathrm{E}-09 & 5.099 \mathrm{E}-06 & 2.037 \mathrm{E}-0 & 5.052 \mathrm{E}-04 & 2.203 \mathrm{E}-03 & 1.668 \mathrm{E}-01 & 2.822 \mathrm{E}+00\end{array}$

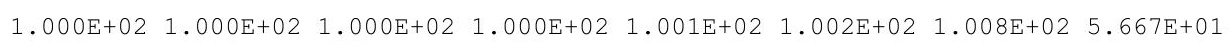

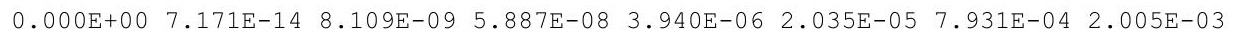
$\begin{array}{lllllllll}0.000 \mathrm{E}+00 & 4.331 \mathrm{E}-02 & 2.141 \mathrm{E}+00 & 4.233 \mathrm{E}+00 & 1.933 \mathrm{E}+01 & 3.597 \mathrm{E}+01 & 8.627 \mathrm{E}+01 & 2.980 \mathrm{E}+01\end{array}$ $\begin{array}{lllllllll}0.000 \mathrm{E}+00 & 3.119 \mathrm{E}-07 & 7.736 \mathrm{E}-04 & 3.069 \mathrm{E}-03 & 7.197 \mathrm{E}-02 & 2.914 \mathrm{E}-01 & 9.214 \mathrm{E}+00 & 2.295 \mathrm{E}+01\end{array}$ $\begin{array}{lllllllll}0.000 \mathrm{E}+00 & 2.948 \mathrm{E}-13 & 3.662 \mathrm{E}-08 & 2.911 \mathrm{E}-07 & 3.459 \mathrm{E}-05 & 2.994 \mathrm{E}-04 & 1.075 \mathrm{E}-01 & 2.697 \mathrm{E}+00\end{array}$ $\begin{array}{lllllllll}0.000 \mathrm{E}+00 & 4.331 \mathrm{E}-02 & 2.142 \mathrm{E}+00 & 4.236 \mathrm{E}+00 & 1.940 \mathrm{E}+01 & 3.626 \mathrm{E}+01 & 9.560 \mathrm{E}+01 & 5.545 \mathrm{E}+01\end{array}$

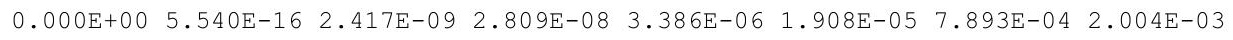
$\begin{array}{llllllllll}0.000 \mathrm{E}+00 & 6.662 \mathrm{E}-04 & 1.057 \mathrm{E}+0 & 2.944 \mathrm{E}+00 & 1.819 \mathrm{E}+01 & 3.507 \mathrm{E}+01 & 8.620 \mathrm{E}+01 & 2.978 \mathrm{E}+01\end{array}$ $\begin{array}{lllllllll}0.000 \mathrm{E}+00 & 3.207 \mathrm{E}-09 & 2.836 \mathrm{E}-04 & 1.705 \mathrm{E}-03 & 6.353 \mathrm{E}-02 & 2.751 \mathrm{E}-01 & 9.171 \mathrm{E}+00 & 2.293 \mathrm{E}+01\end{array}$ $0.000 \mathrm{E}+00 \quad 2.276 \mathrm{E}-15 \quad 1.075 \mathrm{E}-08 \quad 1.355 \mathrm{E}-07 \quad 2.879 \mathrm{E}-05 \quad 2.742 \mathrm{E}-04 \quad 1.066 \mathrm{E}-01 \quad 2.694 \mathrm{E}+00$ $\begin{array}{lllllllll}0.000 \mathrm{E}+00 & 6.663 \mathrm{E}-04 & 1.058 \mathrm{E}+00 & 2.945 \mathrm{E}+00 & 1.825 \mathrm{E}+01 & 3.534 \mathrm{E}+01 & 9.547 \mathrm{E}+01 & 5.541 \mathrm{E}+01\end{array}$

$\begin{array}{llllllll}3.600 \mathrm{E}+01 & 3.600 \mathrm{E}+01 & 3.592 \mathrm{E}+01 & 3.583 \mathrm{E}+01 & 3.518 \mathrm{E}+01 & 3.430 \mathrm{E}+01 & 2.274 \mathrm{E}+01 & 3.639 \mathrm{E}-01\end{array}$

$0.000 \mathrm{E}+00 \quad 3.545 \mathrm{E}-08 \quad 1.770 \mathrm{E}-06 \quad 3.533 \mathrm{E}-06 \quad 1.742 \mathrm{E}-05 \quad 3.591 \mathrm{E}-05 \quad 2.517 \mathrm{E}-04 \quad 1.394 \mathrm{E}-04$

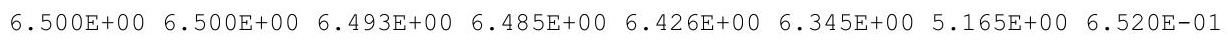

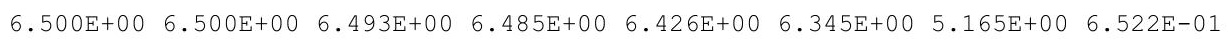




\section{Recreational User}

\section{Summary Report \\ (Deterministic Analysis Report)}

First Peak Dose Assessment

Time Horizon: 1,050 yr 
THIS PAGE INTENTIONALLY LEFT BLANK 
RESRAD, Version $6.5 \quad T^{1 / 2}$ Limit $=180$ days

Summary : C746U Recreational User Deterministic Run

File : $\mathrm{X}: \backslash F I N A L$ V2 $\backslash$ DOE FWD RUNS \C746U RU DOE SG FWD-FV2-1050YR.RAD

Table of Contents

Part I: Mixture Sums and Single Radionuclide Guidelines

Dose Conversion Factor (and Related) Parameter Summary ... 2

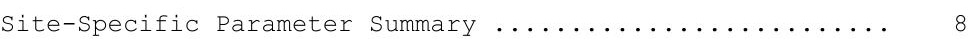

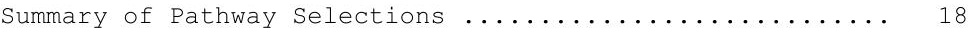

Contaminated Zone and Total Dose Summary ............. 19

Total Dose Components

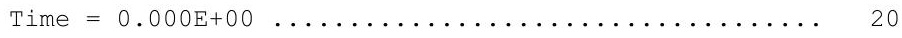

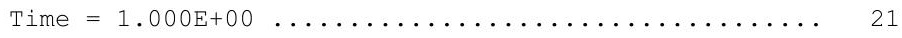

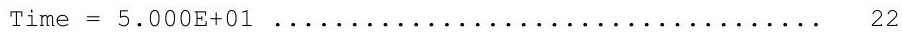

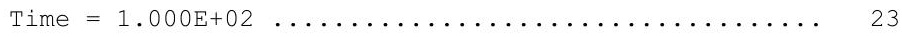

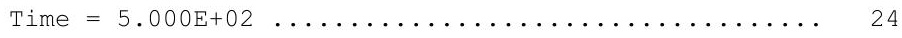

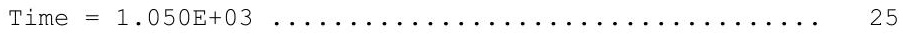

Dose/Source Ratios Summed Over All Pathways .......... 26

Single Radionuclide Soil Guidelines ............... 28

Dose Per Nuclide Summed Over All Pathways ............. 29

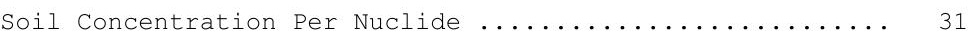


RESRAD, Version $6.5 \quad \mathrm{~T}^{1 / 2}$ Limit $=180$ days

Summary : C746U Recreational User Deterministic Run

File : $\mathrm{X}: \backslash F I N A L$ V2 $\backslash$ DOE FWD RUNS \C746U RU DOE SG FWD-FV2-1050YR.RAD

Dose Conversion Factor (and Related) Parameter Summary

Dose Library: Teen Recreational User Plus ICRP 60 \& ICRP 72 (Age 15)

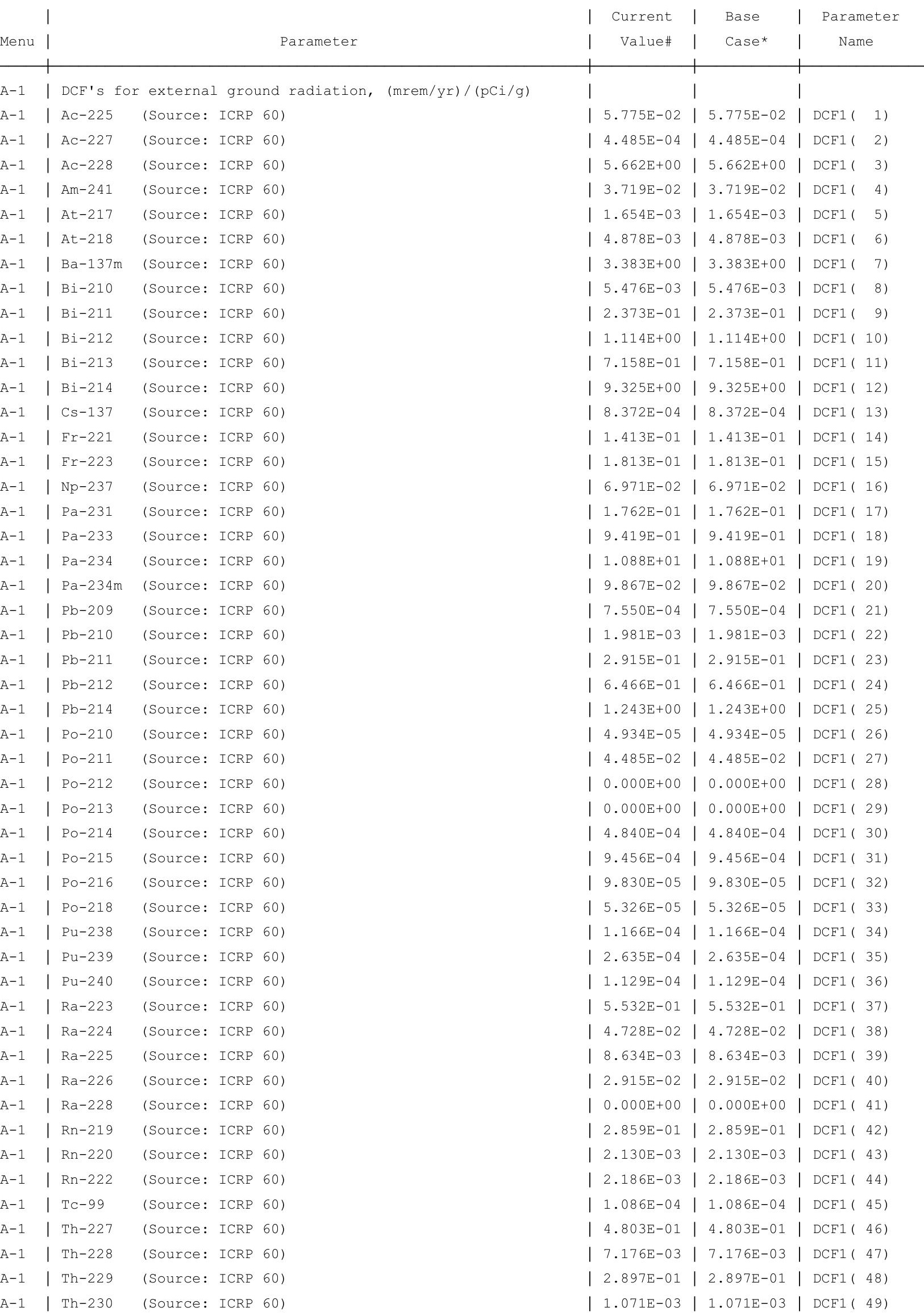


RESRAD, Version $6.5 \quad T^{1 / 2}$ Limit $=180$ days

Summary : C746U Recreational User Deterministic Run

File : $\mathrm{X}: \backslash F I N A L$ V2 $\backslash$ DOE FWD RUNS $\backslash C 746 U$ RU DOE SG FWD-FV2-1050YR. RAD

Dose Conversion Factor (and Related) Parameter Summary (continued)

Dose Library: Teen Recreational User Plus ICRP 60 \& ICRP 72 (Age 15)

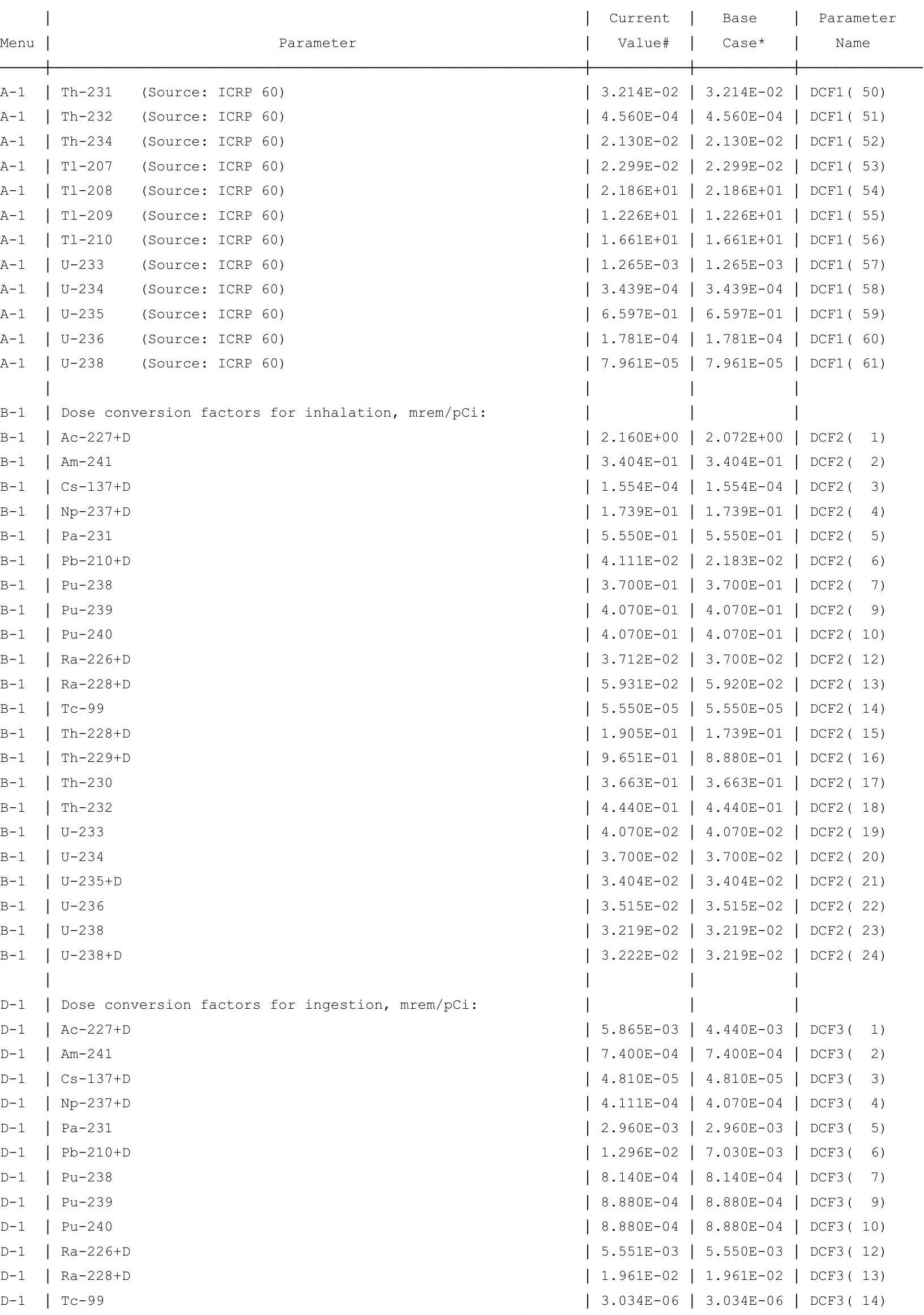


RESRAD, Version $6.5 \quad \mathrm{~T}^{1 / 2}$ Limit $=180$ days

Summary : C746U Recreational User Deterministic Run

File : $\mathrm{X}: \backslash F I N A L$ V2 $\backslash$ DOE FWD RUNS \C746U RU DOE SG FWD-FV2-1050YR. RAD

Dose Conversion Factor (and Related) Parameter Summary (continued)

Dose Library: Teen Recreational User Plus ICRP 60 \& ICRP 72 (Age 15)

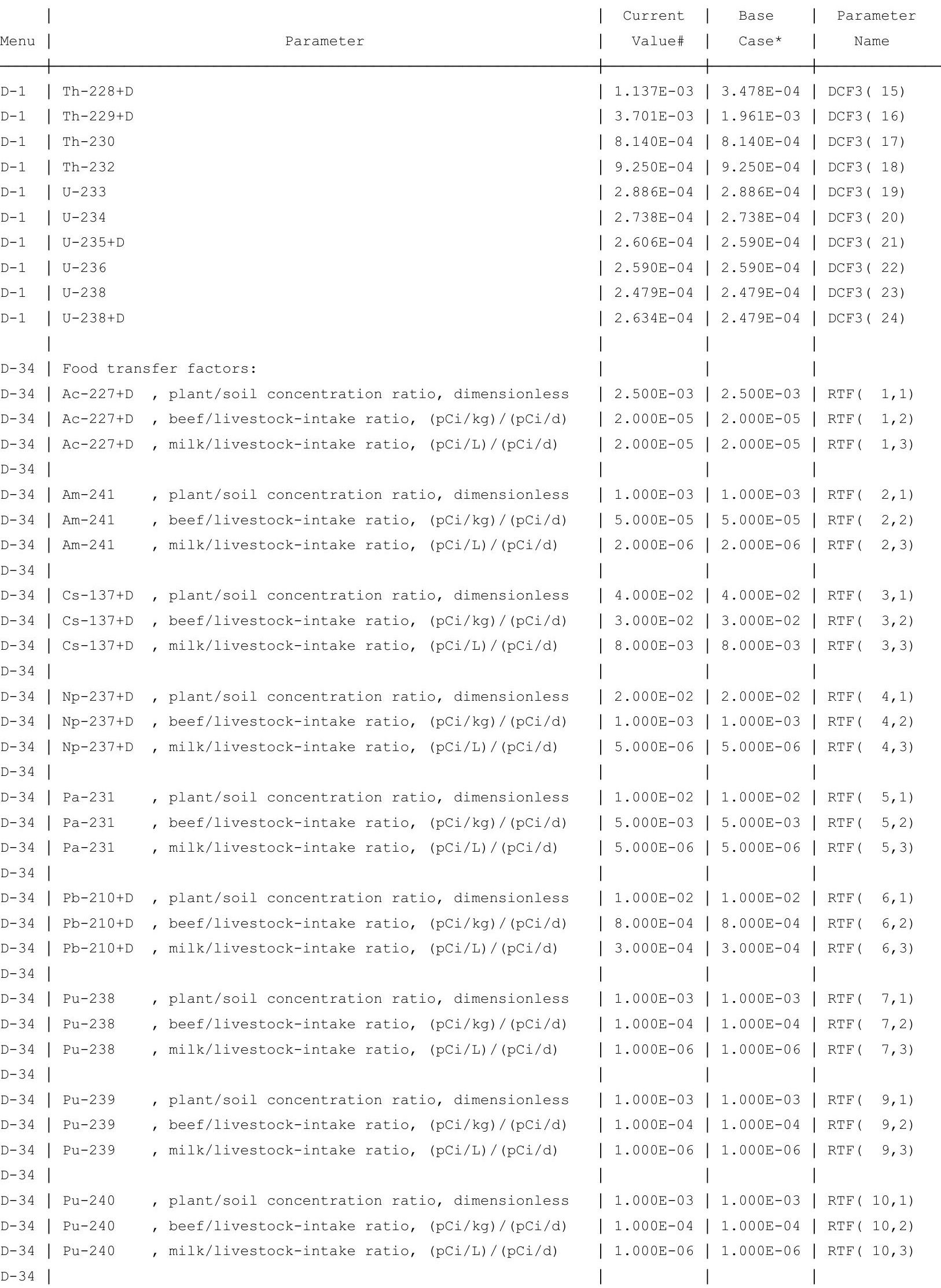


RESRAD, Version $6.5 \quad \mathrm{~T}^{\mathbb{1} 1 / 2}$ Limit $=180$ days

Summary : C746U Recreational User Deterministic Run

File : $\mathrm{X}: \backslash F I N A L$ V2 $\backslash$ DOE FWD RUNS \C746U RU DOE SG FWD-FV2-1050YR. RAD

Dose Conversion Factor (and Related) Parameter Summary (continued)

Dose Library: Teen Recreational User Plus ICRP 60 \& ICRP 72 (Age 15)

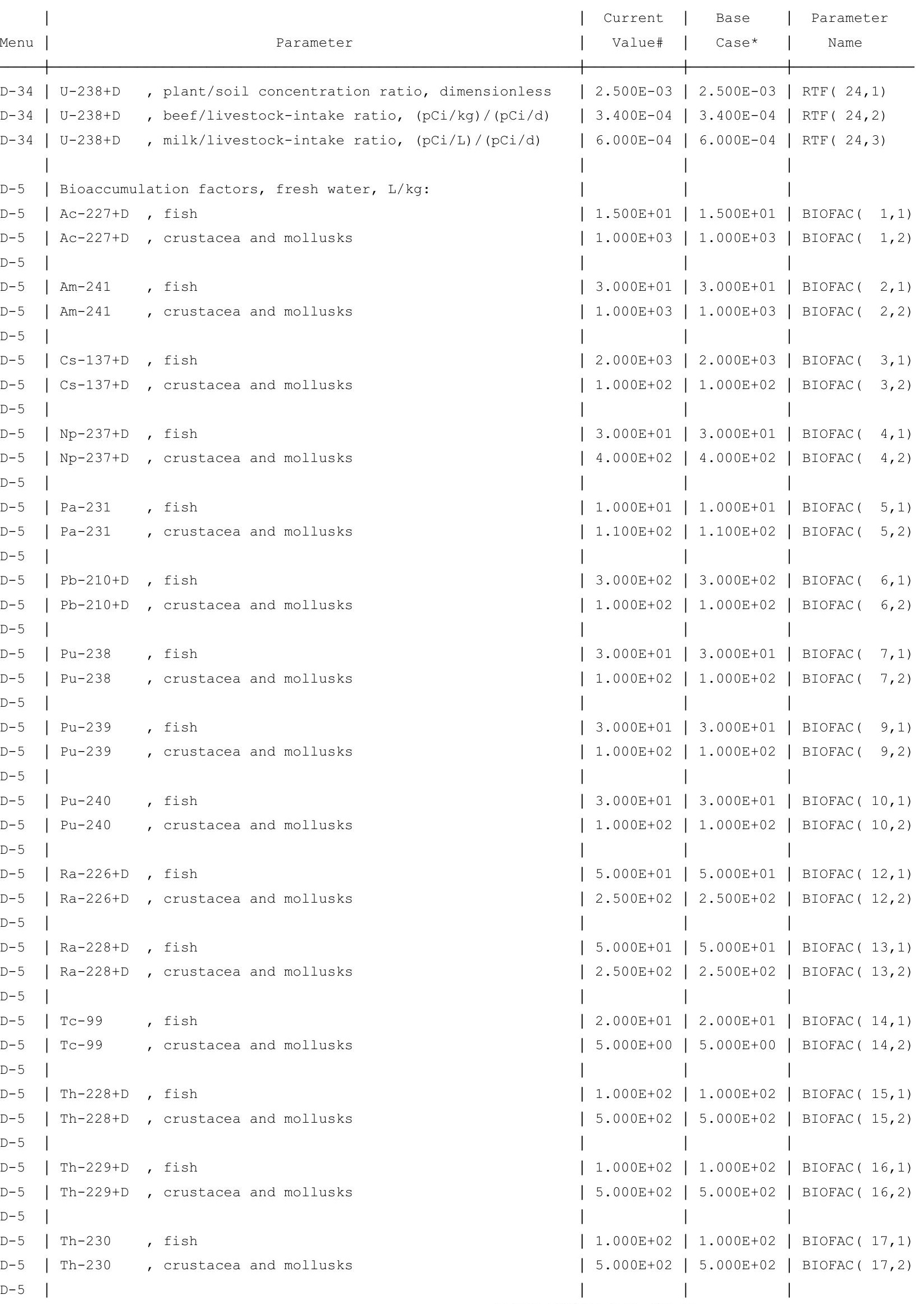


RESRAD, Version $6.5 \quad T^{1 / 2}$ Limit $=180$ days

Summary : C746U Recreational User Deterministic Run

File : $X: \backslash F I N A L$ V2 $\backslash$ DOE FWD RUNS \C746U RU DOE SG FWD-FV2-1050YR. RAD

Dose Conversion Factor (and Related) Parameter Summary (continued)

Dose Library: Teen Recreational User Plus ICRP 60 \& ICRP 72 (Age 15)

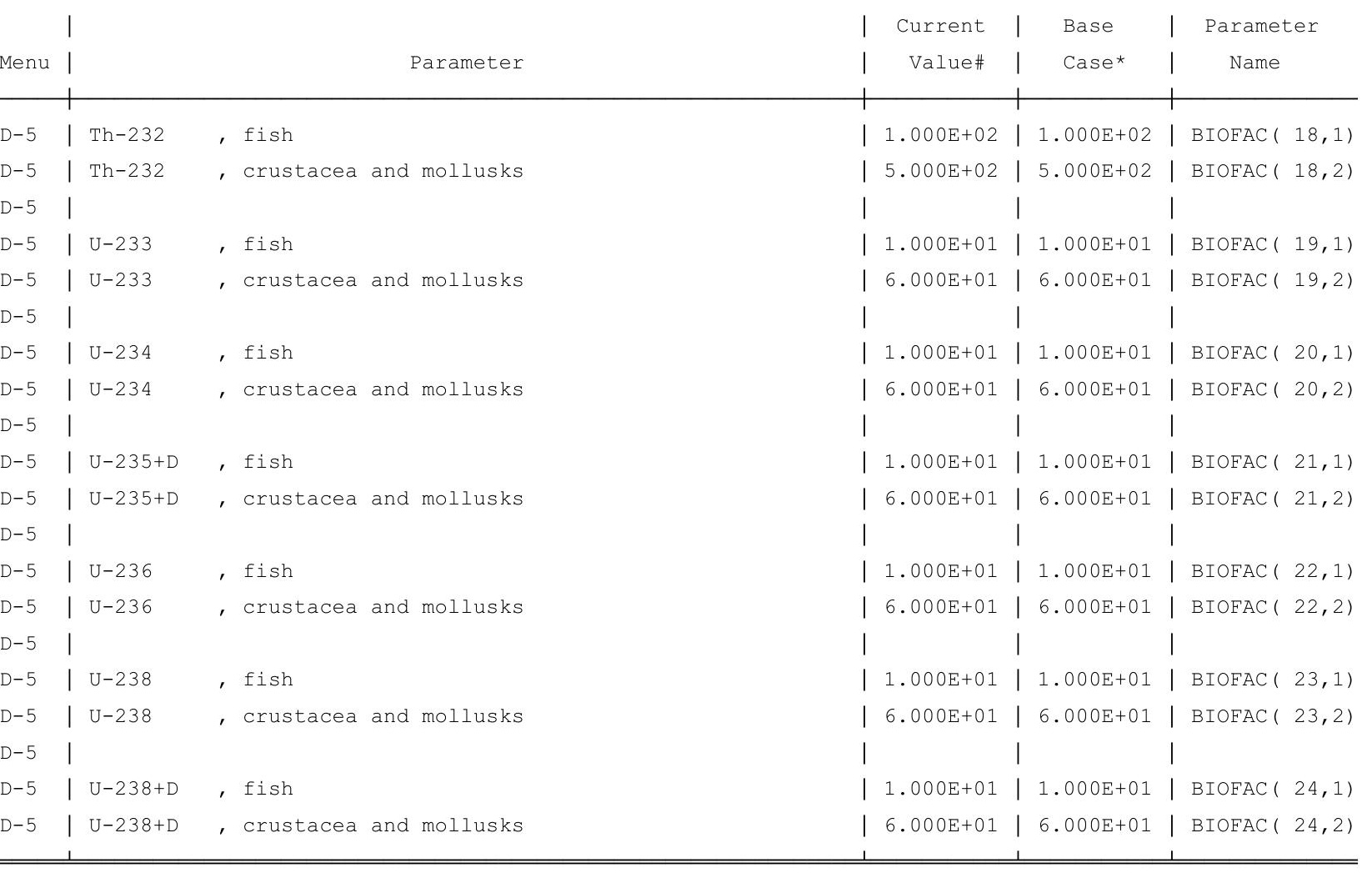

\#For DCFl(xxx) only, factors are for infinite depth \& area. See ETFG table in Ground Pathway of Detailed Report. *Base Case means Default.Lib w/o Associate Nuclide contributions. 
RESRAD, Version $6.5 \quad T^{1 / 2}$ Limit $=180$ days

Summary : C746U Recreational User Deterministic Run

File : $\mathrm{X}: \backslash F I N A L$ V2 $\backslash$ DOE FWD RUNS $\backslash C 746 U$ RU DOE SG FWD-FV2-1050YR.RAD

Site-Specific Parameter Summary (continued)

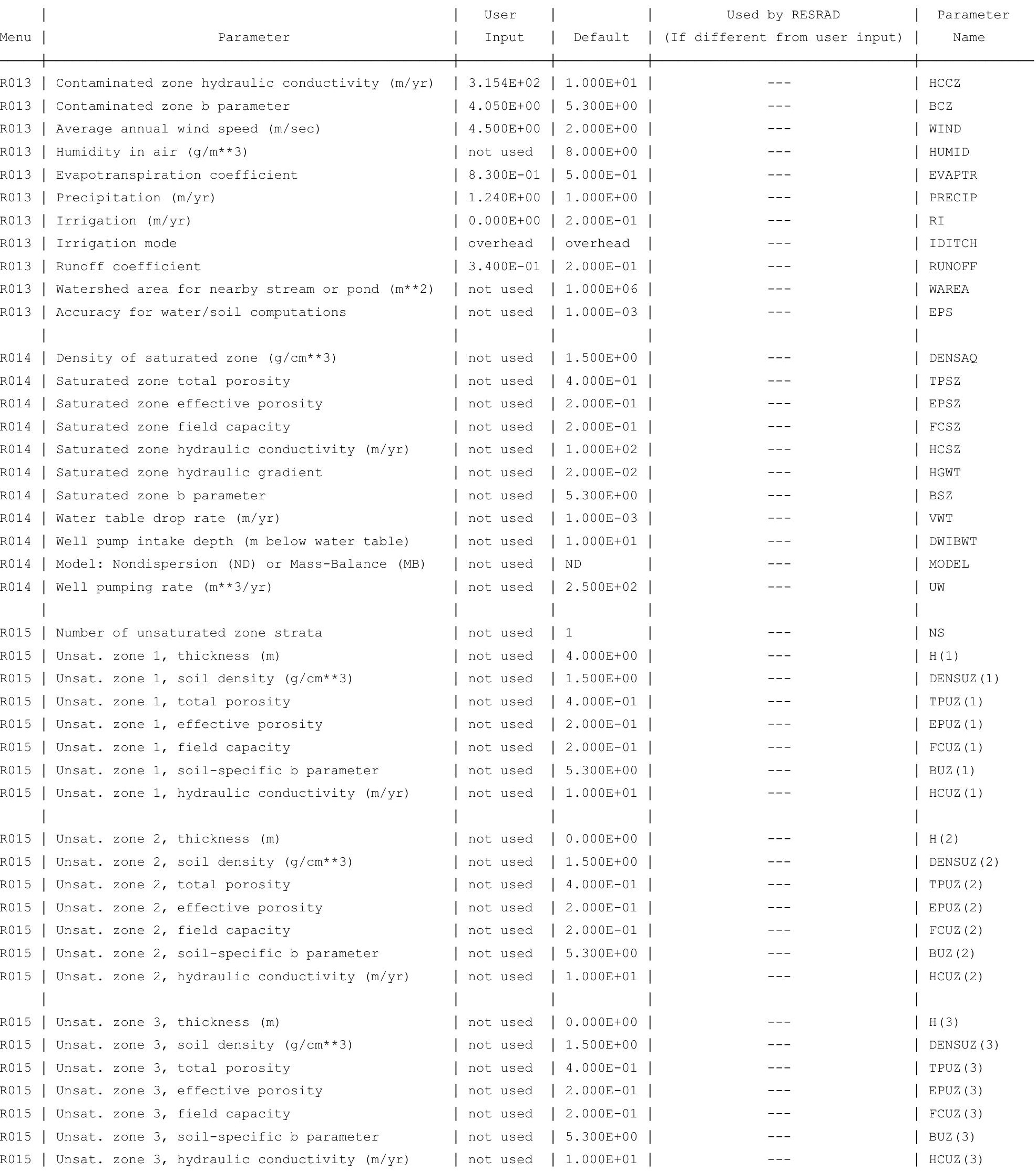


RESRAD, Version $6.5 \quad T^{1 / 2}$ Limit $=180$ days

Summary : C746U Recreational User Deterministic Run

File : $\mathrm{X}: \backslash F I N A L$ V2 $\backslash$ DOE FWD RUNS \C746U RU DOE SG FWD-FV2-1050YR.RAD

Site-Specific Parameter Summary (continued)

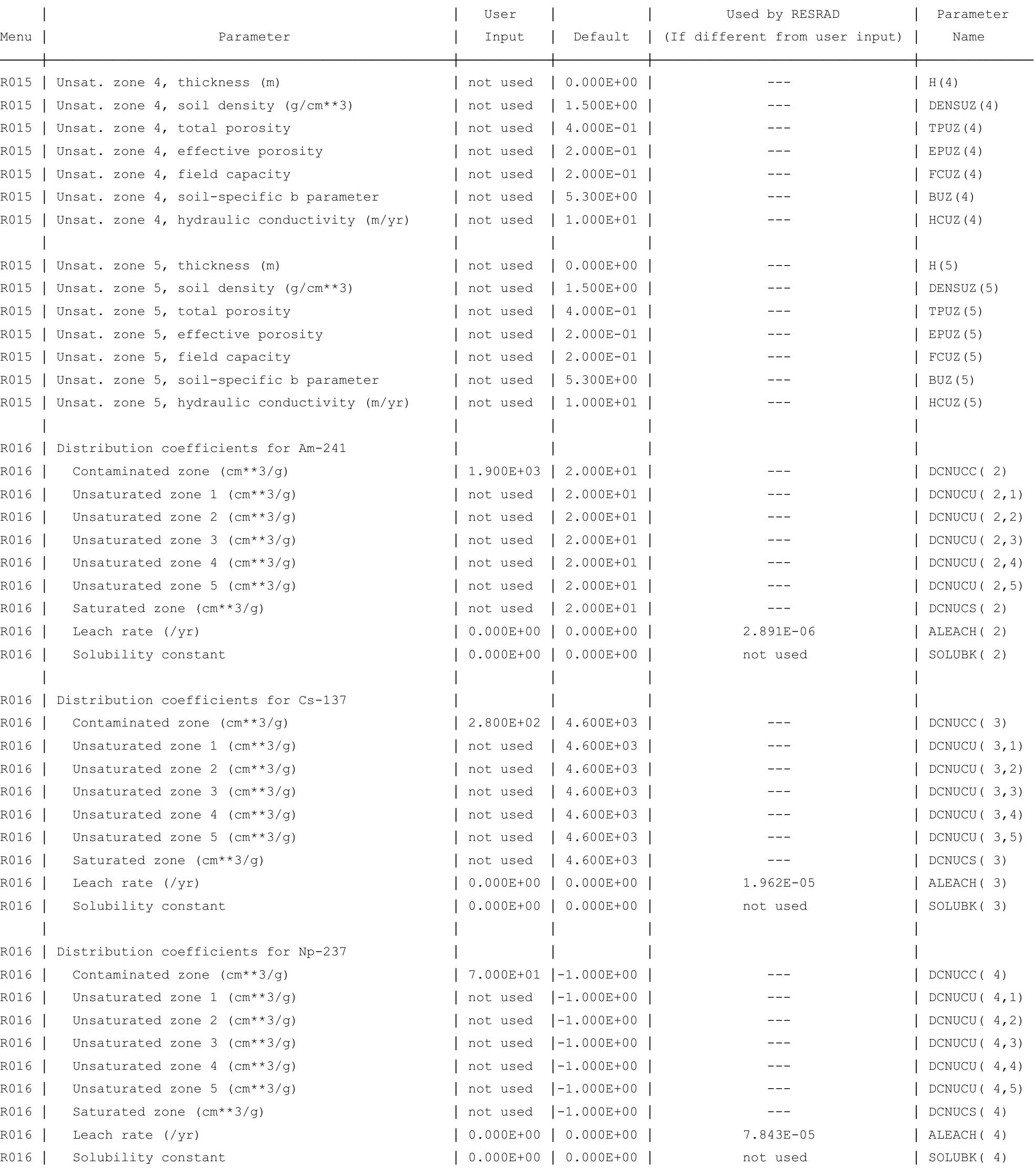


RESRAD, Version $6.5 \quad T^{1 / 2}$ Limit $=180$ days

Summary : C746U Recreational User Deterministic Run

File : $\mathrm{X}: \backslash F I N A L$ V2 $\backslash$ DOE FWD RUNS \C746U RU DOE SG FWD-FV2-1050YR.RAD

Site-Specific Parameter Summary (continued)

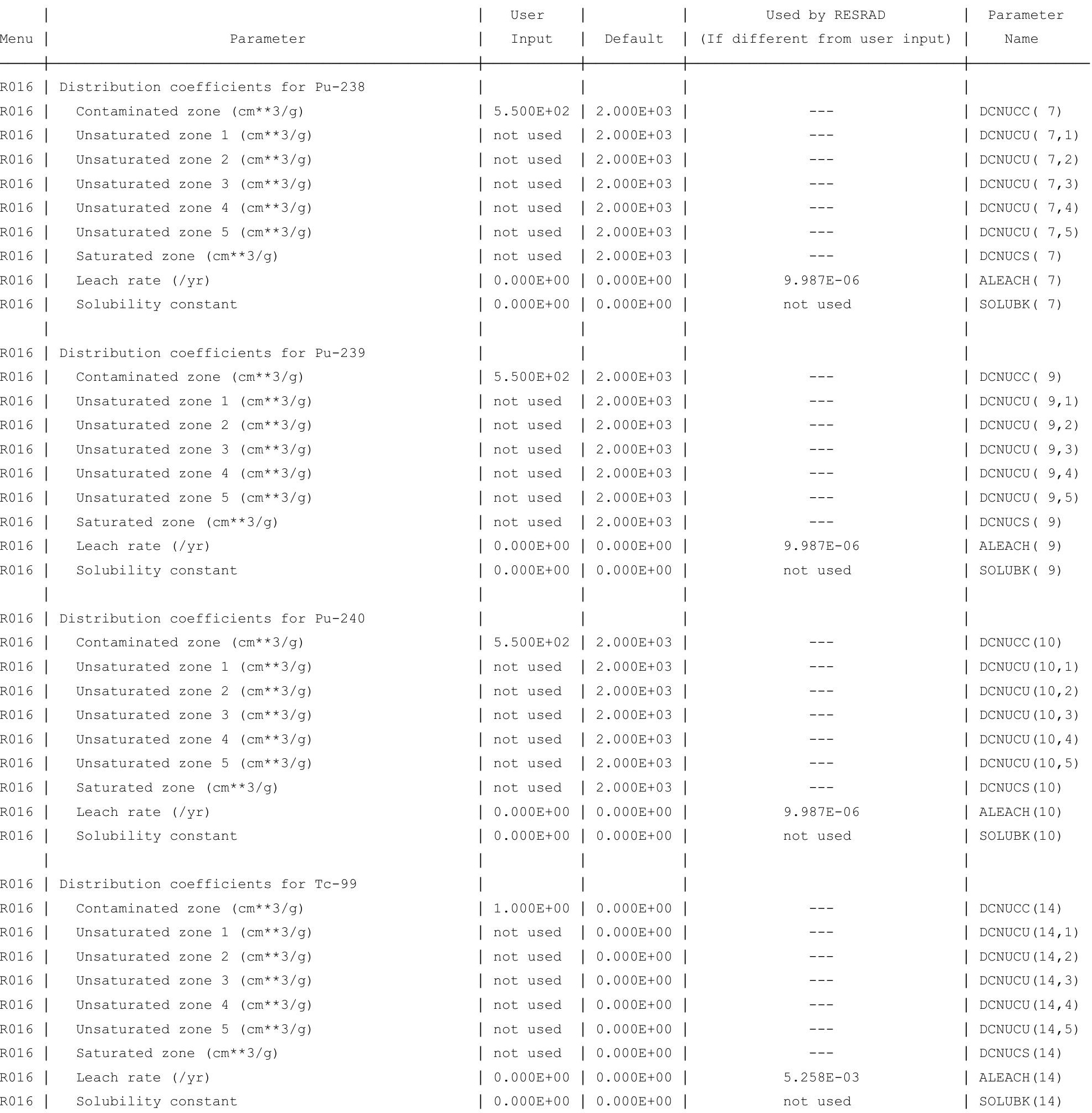


RESRAD, Version $6.5 \quad T^{1 / 2}$ Limit $=180$ days

Summary : C746U Recreational User Deterministic Run

File : $\mathrm{X}: \backslash F I N A L$ V2 $\backslash$ DOE FWD RUNS $\backslash C 746 U$ RU DOE SG FWD-FV2-1050YR. RAD

Site-Specific Parameter Summary (continued)

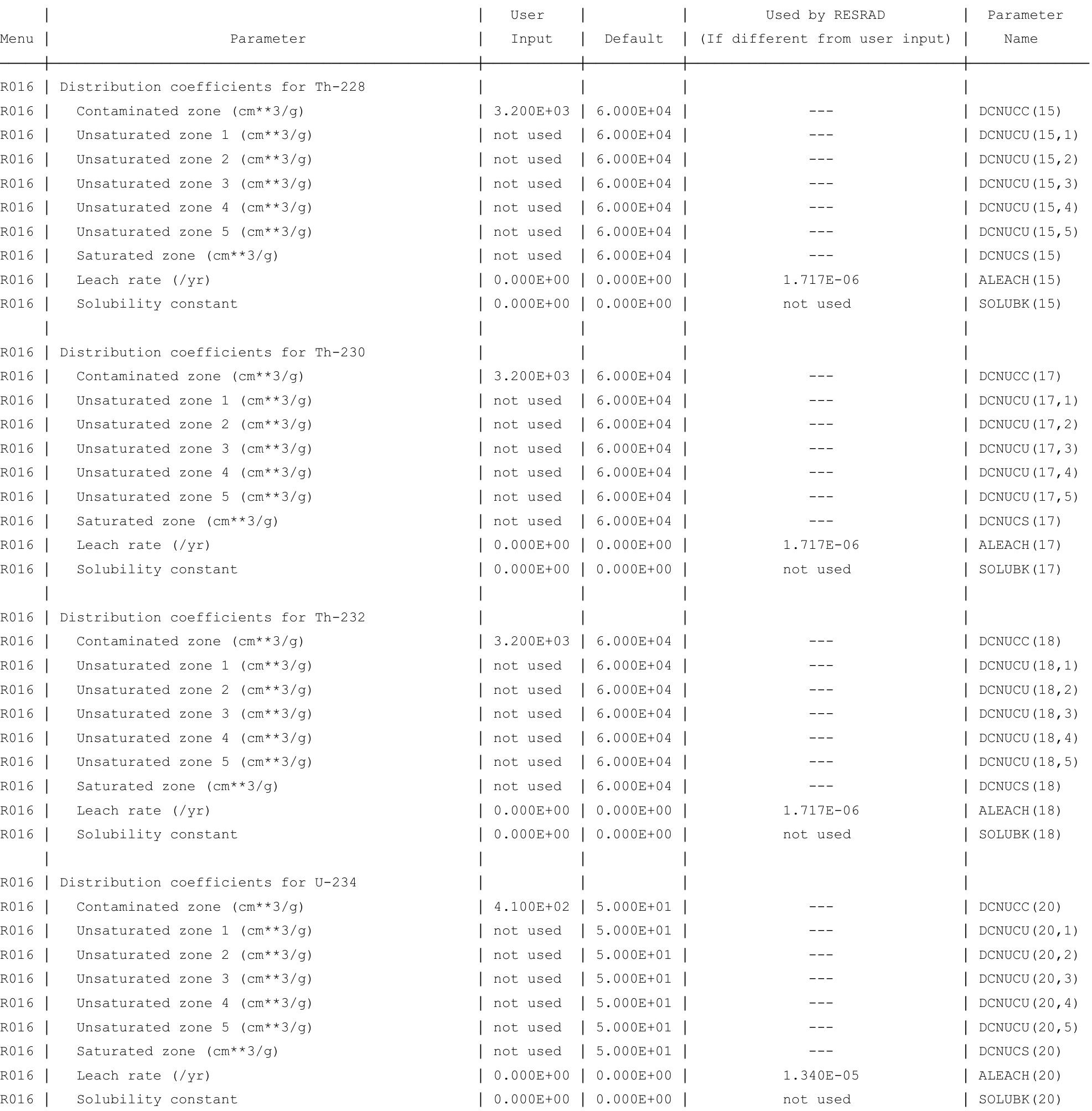


RESRAD, Version $6.5 \quad T^{1 / 2}$ Limit $=180$ days

Summary : C746U Recreational User Deterministic Run

File : $\mathrm{X}: \backslash F I N A L$ V2 $\backslash$ DOE FWD RUNS $\backslash C 746 U$ RU DOE SG FWD-FV2-1050YR. RAD

Site-Specific Parameter Summary (continued)

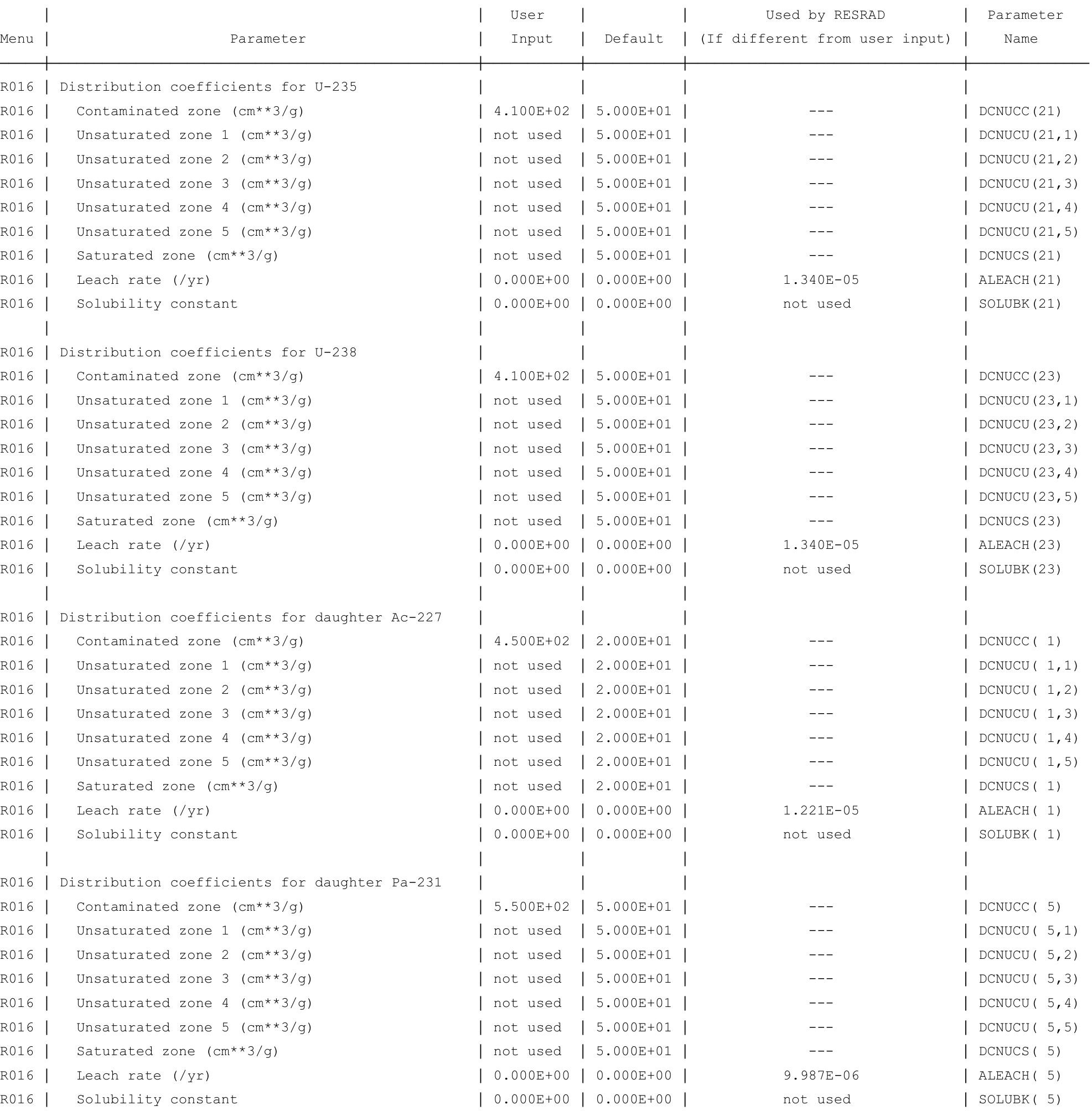


RESRAD, Version $6.5 \quad T^{1 / 2}$ Limit $=180$ days

Summary : C746U Recreational User Deterministic Run

File : $\mathrm{X}: \backslash F I N A L$ V2 $\backslash$ DOE FWD RUNS $\backslash C 746 U$ RU DOE SG FWD-FV2-1050YR. RAD

Site-Specific Parameter Summary (continued)

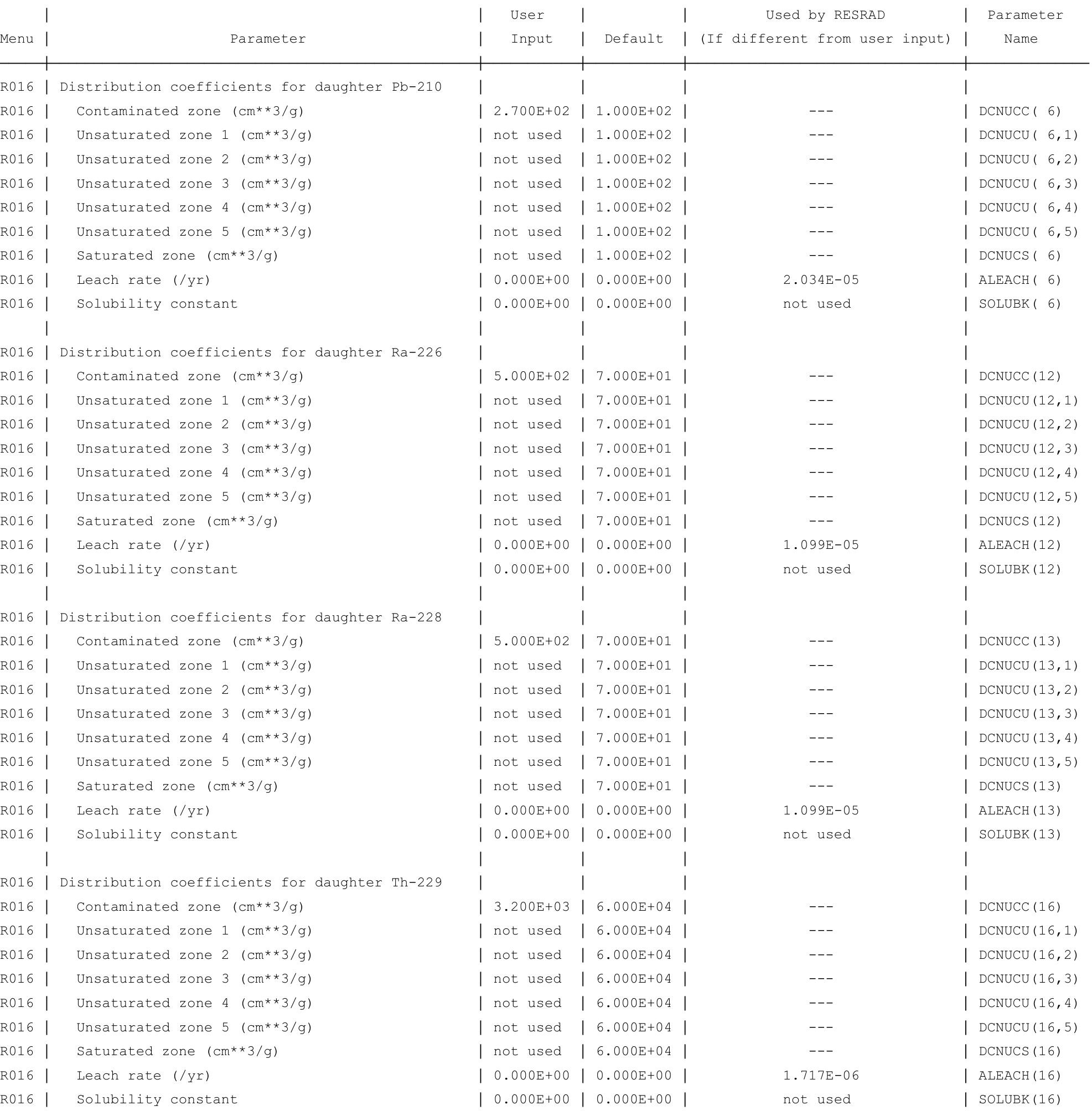


RESRAD, Version $6.5 \quad T^{1 / 2}$ Limit $=180$ days

Summary : C746U Recreational User Deterministic Run

File : $\mathrm{X}: \backslash F I N A L$ V2 $\backslash$ DOE FWD RUNS $\backslash C 746 U$ RU DOE SG FWD-FV2-1050YR. RAD

Site-Specific Parameter Summary (continued)

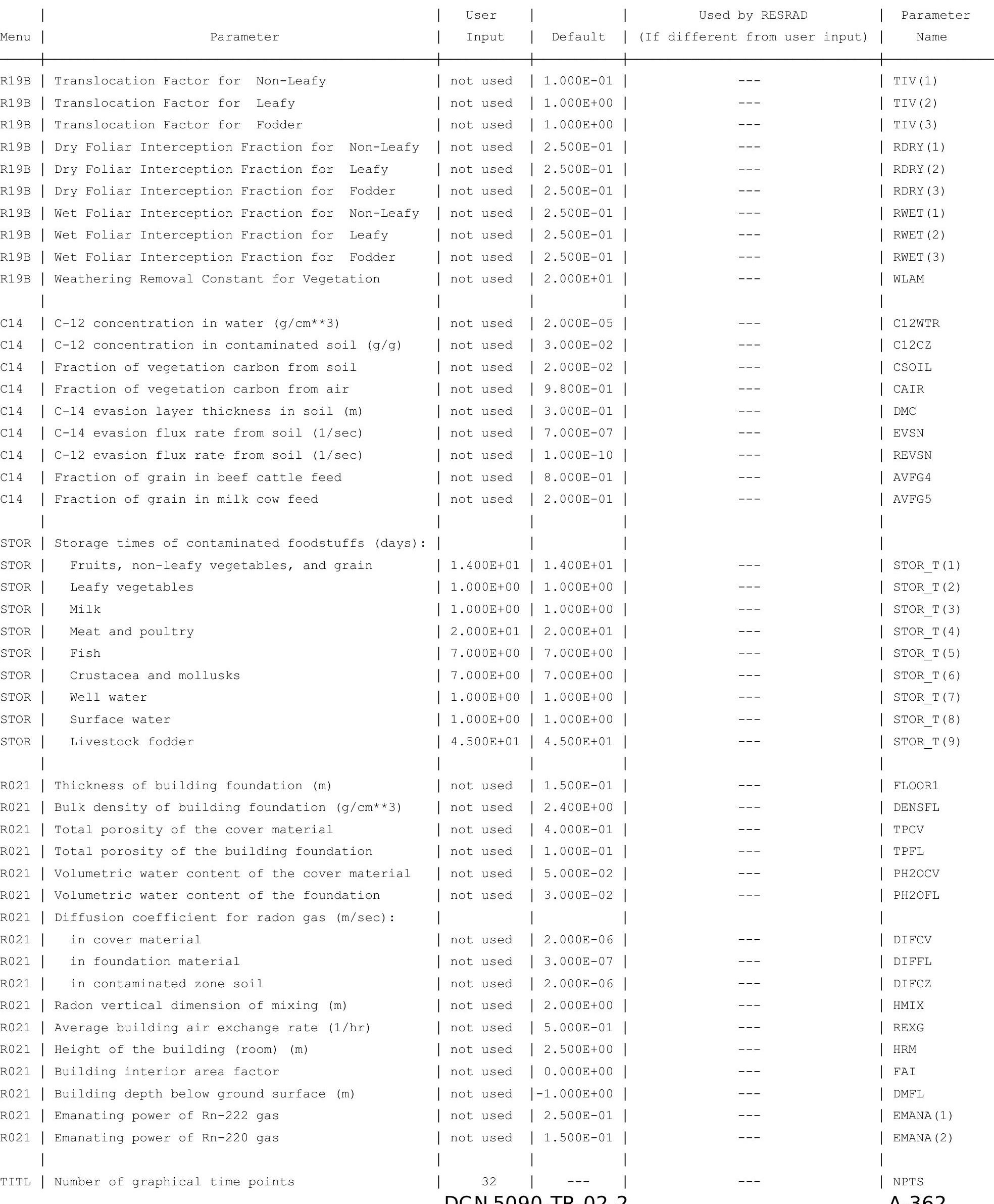


RESRAD, Version $6.5 \quad \mathrm{~T}^{1 / 2}$ Limit $=180$ days

Summary : C746U Recreational User Deterministic Run

File : $\mathrm{X}: \backslash F I N A L$ V2 $\backslash$ DOE FWD RUNS \C746U RU DOE SG FWD-FV2-1050YR.RAD

Contaminated Zone Dimensions

Area: $\quad 89436.00$ square meters

Thickness:

Cover Depth:
Initial Soil Concentrations, pci/g

$\begin{array}{ll}\mathrm{Am}-241 & 3.500 \mathrm{E}+01 \\ \mathrm{Cs}-137 & 1.900 \mathrm{E}+01 \\ \mathrm{~Np}-237 & 5.500 \mathrm{E}+00 \\ \mathrm{Pu}-238 & 3.900 \mathrm{E}+01 \\ \mathrm{Pu}-239 & 3.600 \mathrm{E}+01 \\ \mathrm{Pu}-240 & 3.600 \mathrm{E}+01 \\ \mathrm{TC}-99 & 5.200 \mathrm{E}+01 \\ \mathrm{Th}-228 & 4.000 \mathrm{E}+00 \\ \mathrm{Th}-230 & 1.000 \mathrm{E}+02 \\ \mathrm{Th}-232 & 4.000 \mathrm{E}+00 \\ \mathrm{U}-234 & 1.600 \mathrm{E}+02 \\ \mathrm{U}-235 & 6.500 \mathrm{E}+00 \\ \mathrm{U}-238 & 1.600 \mathrm{E}+02\end{array}$

Total Dose TDOSE(t), mrem/yr

Basic Radiation Dose Limit $=1.000 \mathrm{E}+00 \mathrm{mrem} / \mathrm{yr}$

Total Mixture Sum $M(t)=$ Fraction of Basic Dose Limit Received at Time (t)

$\begin{array}{rllllll}t \text { (years): } & 0.000 \mathrm{E}+00 & 1.000 \mathrm{E}+00 & 5.000 \mathrm{E}+01 & 1.000 \mathrm{E}+02 & 5.000 \mathrm{E}+02 & 1.050 \mathrm{E}+03 \\ \text { TDOSE }(t): & 5.411 \mathrm{E}-07 & 4.044 \mathrm{E}-07 & 9.175 \mathrm{E}-07 & 1.314 \mathrm{E}-06 & 2.333 \mathrm{E}-05 & 1.239 \mathrm{E}-03 \\ \mathrm{M}(\mathrm{t}): & 5.411 \mathrm{E}-07 & 4.044 \mathrm{E}-07 & 9.175 \mathrm{E}-07 & 1.314 \mathrm{E}-06 & 2.333 \mathrm{E}-05 & 1.239 \mathrm{E}-03\end{array}$

Maximum TDOSE $(t): 1.239 \mathrm{E}-03 \mathrm{mrem} / \mathrm{yr}$ at $t=1.050 \mathrm{E}+03$ years 
RESRAD, Version 6.5

$\mathrm{T}^{1 / 2}$ Limit $=180$ days

ummary : C746U Recreational User Deterministic Run

: X: $\backslash F I N A L$ V2 \DOE FWD RUNS \C746U RU DOE SG FWD-FV2-1050YR.RAD

Total Dose Contributions TDOSE (i,p,t) for Individual Radionuclides (i) and Pathways (p) As mrem/yr and Fraction of Total Dose At $t=0.000 \mathrm{E}+00$ years

Water Independent Pathways (Inhalation excludes radon)

\begin{tabular}{|c|c|c|c|c|c|c|c|c|c|c|c|c|c|c|}
\hline \multirow{2}{*}{ Nuclide } & \multicolumn{2}{|c|}{ Ground } & \multicolumn{2}{|c|}{ Inhalation } & \multicolumn{2}{|c|}{ Radon } & \multicolumn{2}{|c|}{ Plant } & \multicolumn{2}{|c|}{ Meat } & \multicolumn{2}{|c|}{ Milk } & \multicolumn{2}{|c|}{ Soil } \\
\hline & mrem/yr & fract. & mrem/yr & fract. & mrem/yr & fract. & mrem/yr & fract. & mrem/yr & fract. & mrem/yr & fract. & mrem/yr & fract. \\
\hline-241 & $5.204 \mathrm{E}-19$ & 0.0000 & $0.000 \mathrm{E}+00$ & 0.0000 & $0.000 \mathrm{E}+00$ & 0.0000 & $0.000 \mathrm{E}+00$ & 0.0000 & $0.000 \mathrm{E}+00$ & 0.0000 & $0.000 \mathrm{E}+00$ & 0.0000 & $0.000 \mathrm{E}+00$ & 0.0000 \\
\hline-137 & $2.305 E-09$ & 0.0043 & $0.000 \mathrm{E}+00$ & 0.0000 & $0.000 \mathrm{E}+00$ & 0.0000 & $0.000 \mathrm{E}+00$ & 0.0000 & $0.000 \mathrm{E}+00$ & 0.0000 & $0.000 \mathrm{E}+00$ & 0.0000 & $0.000 \mathrm{E}+00$ & 0.0000 \\
\hline-237 & $5.043 E-13$ & 0.0000 & $0.000 \mathrm{E}+00$ & 0.0000 & $0.000 \mathrm{E}+00$ & 0.0000 & $0.000 \mathrm{E}+00$ & 0.0000 & $0.000 \mathrm{E}+00$ & 0.0000 & $0.000 \mathrm{E}+00$ & 0.0000 & $0.000 \mathrm{E}+00$ & 0.0000 \\
\hline-238 & $3.052 \mathrm{E}-22$ & 0.0000 & $0.000 \mathrm{E}+00$ & 0.0000 & $0.000 \mathrm{E}+00$ & 0.0000 & $0.000 \mathrm{E}+00$ & 0.0000 & $0.000 \mathrm{E}+00$ & 0.0000 & $0.000 \mathrm{E}+00$ & 0.0000 & $0.000 \mathrm{E}+00$ & 0.0000 \\
\hline-239 & $4.161 \mathrm{E}-17$ & 0.0000 & $0.000 \mathrm{E}+00$ & 0.0000 & $0.000 \mathrm{E}+00$ & 0.0000 & $0.000 \mathrm{E}+00$ & 0.0000 & $0.000 \mathrm{E}+00$ & 0.0000 & $0.000 \mathrm{E}+00$ & 0.0000 & $0.000 \mathrm{E}+00$ & 0.0000 \\
\hline-240 & $3.957 \mathrm{E}-24$ & 0.0000 & $0.000 \mathrm{E}+00$ & 0.0000 & $0.000 \mathrm{E}+00$ & 0.0000 & $0.000 \mathrm{E}+00$ & 0.0000 & $0.000 \mathrm{E}+00$ & 0.0000 & $0.000 \mathrm{E}+00$ & 0.0000 & $0.000 \mathrm{E}+00$ & 0.0000 \\
\hline 99 & $2.884 E-25$ & 0.0000 & $0.000 \mathrm{E}+00$ & 0.0000 & $0.000 \mathrm{E}+00$ & 0.0000 & $0.000 \mathrm{E}+00$ & 0.0000 & $0.000 \mathrm{E}+00$ & 0.0000 & $0.000 \mathrm{E}+00$ & 0.0000 & $0.000 \mathrm{E}+00$ & 0.0000 \\
\hline-228 & $5.317 \mathrm{E}-07$ & 0.9827 & $0.000 \mathrm{E}+00$ & 0.0000 & $0.000 \mathrm{E}+00$ & 0.0000 & $0.000 \mathrm{E}+00$ & 0.0000 & $0.000 \mathrm{E}+00$ & 0.0000 & $0.000 \mathrm{E}+00$ & 0.0000 & $0.000 \mathrm{E}+00$ & 0.0000 \\
\hline-230 & $3.629 \mathrm{E}-10$ & 0.0007 & $0.000 \mathrm{E}+00$ & 0.0000 & $0.000 \mathrm{E}+00$ & 0.0000 & $0.000 \mathrm{E}+00$ & 0.0000 & $0.000 \mathrm{E}+00$ & 0.0000 & $0.000 \mathrm{E}+00$ & 0.0000 & $0.000 \mathrm{E}+00$ & 0.0000 \\
\hline-232 & $4.531 E-09$ & 0.0084 & $0.000 \mathrm{E}+00$ & 0.0000 & $0.000 \mathrm{E}+00$ & 0.0000 & $0.000 \mathrm{E}+00$ & 0.0000 & $0.000 \mathrm{E}+00$ & 0.0000 & $0.000 \mathrm{E}+00$ & 0.0000 & $0.000 \mathrm{E}+00$ & 0.0000 \\
\hline 234 & 1. $743 \mathrm{E}-15$ & 0.0000 & $0.000 \mathrm{E}+00$ & 0.0000 & $0.000 \mathrm{E}+00$ & 0.0000 & $0.000 \mathrm{E}+00$ & 0.0000 & $0.000 \mathrm{E}+00$ & 0.0000 & $0.000 \mathrm{E}+00$ & 0.0000 & $0.000 \mathrm{E}+00$ & 0.0000 \\
\hline 235 & $7.778 \mathrm{E}-15$ & 0.0000 & $0.000 \mathrm{E}+00$ & 0.0000 & $0.000 \mathrm{E}+00$ & 0.0000 & $0.000 \mathrm{E}+00$ & 0.0000 & $0.000 \mathrm{E}+00$ & 0.0000 & $0.000 \mathrm{E}+00$ & 0.0000 & $0.000 \mathrm{E}+00$ & 0.0000 \\
\hline 38 & $2.184 E-09$ & 0.0040 & $0.000 \mathrm{E}+00$ & 0.0000 & $0.000 \mathrm{E}+00$ & 0.0000 & $0.000 \mathrm{E}+00$ & 0.0000 & $0.000 \mathrm{E}+00$ & 0.0000 & $0.000 \mathrm{E}+00$ & 0.0000 & $0.000 \mathrm{E}+00$ & 0.0000 \\
\hline & $5.411 \mathrm{E}-07$ & 1.0000 & $0.000 \mathrm{E}+00$ & 0.0000 & $0.000 \mathrm{E}+00$ & 0.0000 & $0.000 \mathrm{E}+00$ & 0.0000 & $0.000 \mathrm{E}+00$ & 0.0000 & $0.000 \mathrm{E}+00$ & 0.0000 & $.000 \mathrm{E}+00$ & 0.0000 \\
\hline
\end{tabular}

Total Dose Contributions TDOSE (i,p,t) for Individual Radionuclides (i) and Pathways (p) As mrem/yr and Fraction of Total Dose At $t=0.000 \mathrm{E}+00$ years

Water Dependent Pathways

\begin{tabular}{|c|c|c|c|c|c|c|c|c|c|c|c|c|c|c|}
\hline & \multicolumn{2}{|c|}{ Water } & \multicolumn{2}{|c|}{ Fish } & \multicolumn{2}{|c|}{ Radon } & \multicolumn{2}{|c|}{ Plant } & \multicolumn{2}{|c|}{ Meat } & \multicolumn{2}{|c|}{ Milk } & \multicolumn{2}{|c|}{ All Pathways* } \\
\hline clide & mrem/yr & fract. & mrem/yr & fract. & mrem/yr & fract. & mrem/yr & fract. & mrem/yr & fract. & mrem/yr & fract. & mrem/yr & fract. \\
\hline 241 & $0.000 \mathrm{E}+00$ & 0.0000 & $0.000 \mathrm{E}+00$ & 0.0000 & $0.000 \mathrm{E}+00$ & 0.0000 & $0.000 \mathrm{E}+00$ & 0.0000 & $0.000 \mathrm{E}+00$ & 0.0000 & $0.000 \mathrm{E}+00$ & 0.0000 & $5.204 \mathrm{E}-19$ & 0.0000 \\
\hline-137 & $0.000 \mathrm{E}+00$ & 0.0000 & $0.000 \mathrm{E}+00$ & 0.0000 & $0.000 \mathrm{E}+00$ & 0.0000 & $0.000 \mathrm{E}+00$ & 0.0000 & $0.000 \mathrm{E}+00$ & 0.0000 & $0.000 \mathrm{E}+00$ & 0.0000 & $2.305 E-09$ & 0.0043 \\
\hline-237 & $0.000 \mathrm{E}+00$ & 0.0000 & $0.000 \mathrm{E}+00$ & 0.0000 & $0.000 \mathrm{E}+00$ & 0.0000 & $0.000 \mathrm{E}+00$ & 0.0000 & $0.000 \mathrm{E}+00$ & 0.0000 & $0.000 \mathrm{E}+00$ & 0.0000 & $5.043 E-13$ & 0.0000 \\
\hline-238 & $0.000 \mathrm{E}+00$ & 0.0000 & $0.000 \mathrm{E}+00$ & 0.0000 & $0.000 \mathrm{E}+00$ & 0.0000 & $0.000 \mathrm{E}+00$ & 0.0000 & $0.000 \mathrm{E}+00$ & 0.0000 & $0.000 \mathrm{E}+00$ & 0.0000 & $3.052 \mathrm{E}-22$ & 0.0000 \\
\hline-239 & $0.000 \mathrm{E}+00$ & 0.0000 & $0.000 \mathrm{E}+00$ & 0.0000 & $0.000 \mathrm{E}+00$ & 0.0000 & $0.000 \mathrm{E}+00$ & 0.0000 & $0.000 \mathrm{E}+00$ & 0.0000 & $0.000 E+00$ & 0.0000 & $4.161 \mathrm{E}-17$ & 0.0000 \\
\hline-240 & $0.000 \mathrm{E}+00$ & 0.0000 & $0.000 \mathrm{E}+00$ & 0.0000 & $0.000 \mathrm{E}+00$ & 0.0000 & $0.000 \mathrm{E}+00$ & 0.0000 & $0.000 \mathrm{E}+00$ & 0.0000 & $0.000 E+00$ & 0.0000 & $3.957 \mathrm{E}-24$ & 0.0000 \\
\hline-99 & $0.000 \mathrm{E}+00$ & 0.0000 & $0.000 \mathrm{E}+00$ & 0.0000 & $0.000 \mathrm{E}+00$ & 0.0000 & $0.000 \mathrm{E}+00$ & 0.0000 & $0.000 \mathrm{E}+00$ & 0.0000 & $0.000 \mathrm{E}+00$ & 0.0000 & $2.884 \mathrm{E}-25$ & 0.0000 \\
\hline-228 & $0.000 \mathrm{E}+00$ & 0.0000 & $0.000 \mathrm{E}+00$ & 0.0000 & $0.000 \mathrm{E}+00$ & 0.0000 & $0.000 \mathrm{E}+00$ & 0.0000 & $0.000 \mathrm{E}+00$ & 0.0000 & $0.000 \mathrm{E}+00$ & 0.0000 & $5.317 \mathrm{E}-07$ & 0.9827 \\
\hline-230 & $0.000 \mathrm{E}+00$ & 0.0000 & $0.000 \mathrm{E}+00$ & 0.0000 & $0.000 \mathrm{E}+00$ & 0.0000 & $0.000 \mathrm{E}+00$ & 0.0000 & $0.000 \mathrm{E}+00$ & 0.0000 & $0.000 E+00$ & 0.0000 & $3.629 \mathrm{E}-10$ & 0.0007 \\
\hline-232 & $0.000 \mathrm{E}+00$ & 0.0000 & $0.000 \mathrm{E}+00$ & 0.0000 & $0.000 \mathrm{E}+00$ & 0.0000 & $0.000 \mathrm{E}+00$ & 0.0000 & $0.000 \mathrm{E}+00$ & 0.0000 & $0.000 \mathrm{E}+00$ & 0.0000 & $4.531 E-09$ & 0.0084 \\
\hline 34 & $0.000 \mathrm{E}+00$ & 0.0000 & $0.000 \mathrm{E}+00$ & 0.0000 & $0.000 \mathrm{E}+00$ & 0.0000 & $0.000 \mathrm{E}+00$ & 0.0000 & $0.000 \mathrm{E}+00$ & 0.0000 & $0.000 \mathrm{E}+00$ & 0.0000 & $1.743 \mathrm{E}-15$ & 0.0000 \\
\hline 35 & $0.000 \mathrm{E}+00$ & 0.0000 & $0.000 \mathrm{E}+00$ & 0.0000 & $0.000 \mathrm{E}+00$ & 0.0000 & $0.000 \mathrm{E}+00$ & 0.0000 & $0.000 \mathrm{E}+00$ & 0.0000 & $0.000 \mathrm{E}+00$ & 0.0000 & 7. $778 \mathrm{E}-15$ & 0.0000 \\
\hline 38 & $0.000 \mathrm{E}+00$ & 0.0000 & $0.000 \mathrm{E}+00$ & 0.0000 & $0.000 \mathrm{E}+00$ & 0.0000 & $0.000 \mathrm{E}+00$ & 0.0000 & $0.000 \mathrm{E}+00$ & 0.0000 & $0.000 \mathrm{E}+00$ & 0.0000 & $2.184 \mathrm{E}-09$ & 0.0040 \\
\hline & $0.000 \mathrm{E}+00$ & 0.0000 & $0.000 \mathrm{E}+00$ & 0.0000 & $0.000 \mathrm{E}+00$ & 0.0000 & $0.000 \mathrm{E}+00$ & 0.0000 & $0.000 \mathrm{E}+00$ & 0.0000 & $0.000 \mathrm{E}+00$ & 0.0000 & $11 \mathrm{E}-07$ & 1.0000 \\
\hline
\end{tabular}

* Sum of all water independent and dependent pathways. 
RESRAD, Version 6.5

$\mathrm{T}^{1 / 2}$ Limit $=180$ days

ummary : C746U Recreational User Deterministic Run

: $\mathrm{X}: \backslash F I N A L$ V2 $\backslash$ DOE FWD RUNS \C746U RU DOE SG FWD-FV2-1050YR.RAD

Total Dose Contributions TDOSE (i,p,t) for Individual Radionuclides (i) and Pathways (p) As mrem/yr and Fraction of Total Dose At $t=1.000 \mathrm{E}+00$ years

Water Independent Pathways (Inhalation excludes radon)

\begin{tabular}{|c|c|c|c|c|c|c|c|c|c|c|c|c|c|c|}
\hline \multirow{2}{*}{ Nuclide } & \multicolumn{2}{|c|}{ Ground } & \multicolumn{2}{|c|}{ Inhalation } & \multicolumn{2}{|c|}{ Radon } & \multicolumn{2}{|c|}{ Plant } & \multicolumn{2}{|c|}{ Meat } & \multicolumn{2}{|c|}{ Milk } & \multicolumn{2}{|c|}{ Soil } \\
\hline & mrem/yr & fract. & mrem/yr & fract. & mrem/yr & fract. & mrem/yr & fract. & mrem/yr & fract. & mrem/yr & fract. & mrem/yr & fract. \\
\hline-241 & $1.575 \mathrm{E}-18$ & 0.0000 & $0.000 \mathrm{E}+00$ & 0.0000 & $0.000 \mathrm{E}+00$ & 0.0000 & $0.000 \mathrm{E}+00$ & 0.0000 & $0.000 \mathrm{E}+00$ & 0.0000 & $0.000 \mathrm{E}+00$ & 0.0000 & $0.000 \mathrm{E}+00$ & 0.0000 \\
\hline-137 & $2.272 E-09$ & 0.0056 & $0.000 \mathrm{E}+00$ & 0.0000 & $0.000 \mathrm{E}+00$ & 0.0000 & $0.000 \mathrm{E}+00$ & 0.0000 & $0.000 \mathrm{E}+00$ & 0.0000 & $0.000 \mathrm{E}+00$ & 0.0000 & $0.000 \mathrm{E}+00$ & 0.0000 \\
\hline-237 & $5.097 \mathrm{E}-13$ & 0.0000 & $0.000 \mathrm{E}+00$ & 0.0000 & $0.000 \mathrm{E}+00$ & 0.0000 & $0.000 \mathrm{E}+00$ & 0.0000 & $0.000 \mathrm{E}+00$ & 0.0000 & $0.000 \mathrm{E}+00$ & 0.0000 & $0.000 \mathrm{E}+00$ & 0.0000 \\
\hline-238 & $4.535 E-21$ & 0.0000 & $0.000 \mathrm{E}+00$ & 0.0000 & $0.000 \mathrm{E}+00$ & 0.0000 & $0.000 \mathrm{E}+00$ & 0.0000 & $0.000 \mathrm{E}+00$ & 0.0000 & $0.000 \mathrm{E}+00$ & 0.0000 & $0.000 \mathrm{E}+00$ & 0.0000 \\
\hline-239 & $4.211 \mathrm{E}-17$ & 0.0000 & $0.000 \mathrm{E}+00$ & 0.0000 & $0.000 \mathrm{E}+00$ & 0.0000 & $0.000 \mathrm{E}+00$ & 0.0000 & $0.000 \mathrm{E}+00$ & 0.0000 & $0.000 \mathrm{E}+00$ & 0.0000 & $0.000 \mathrm{E}+00$ & 0.0000 \\
\hline-240 & $4.111 \mathrm{E}-24$ & 0.0000 & $0.000 \mathrm{E}+00$ & 0.0000 & $0.000 \mathrm{E}+00$ & 0.0000 & $0.000 \mathrm{E}+00$ & 0.0000 & $0.000 \mathrm{E}+00$ & 0.0000 & $0.000 \mathrm{E}+00$ & 0.0000 & $0.000 \mathrm{E}+00$ & 0.0000 \\
\hline 99 & $2.925 E-25$ & 0.0000 & $0.000 \mathrm{E}+00$ & 0.0000 & $0.000 \mathrm{E}+00$ & 0.0000 & $0.000 \mathrm{E}+00$ & 0.0000 & $0.000 \mathrm{E}+00$ & 0.0000 & $0.000 \mathrm{E}+00$ & 0.0000 & $0.000 \mathrm{E}+00$ & 0.0000 \\
\hline-228 & $3.723 E-07$ & 0.9206 & $0.000 \mathrm{E}+00$ & 0.0000 & $0.000 \mathrm{E}+00$ & 0.0000 & $0.000 \mathrm{E}+00$ & 0.0000 & $0.000 \mathrm{E}+00$ & 0.0000 & $0.000 \mathrm{E}+00$ & 0.0000 & $0.000 \mathrm{E}+00$ & 0.0000 \\
\hline-230 & $1.095 E-09$ & 0.0027 & $0.000 \mathrm{E}+00$ & 0.0000 & $0.000 \mathrm{E}+00$ & 0.0000 & $0.000 \mathrm{E}+00$ & 0.0000 & $0.000 \mathrm{E}+00$ & 0.0000 & $0.000 \mathrm{E}+00$ & 0.0000 & $0.000 \mathrm{E}+00$ & 0.0000 \\
\hline-232 & $2.653 E-08$ & 0.0656 & $0.000 \mathrm{E}+00$ & 0.0000 & $0.000 \mathrm{E}+00$ & 0.0000 & $0.000 \mathrm{E}+00$ & 0.0000 & $0.000 \mathrm{E}+00$ & 0.0000 & $0.000 \mathrm{E}+00$ & 0.0000 & $0.000 \mathrm{E}+00$ & 0.0000 \\
\hline 234 & $1.227 \mathrm{E}-14$ & 0.0000 & $0.000 \mathrm{E}+00$ & 0.0000 & $0.000 \mathrm{E}+00$ & 0.0000 & $0.000 \mathrm{E}+00$ & 0.0000 & $0.000 \mathrm{E}+00$ & 0.0000 & $0.000 \mathrm{E}+00$ & 0.0000 & $0.000 \mathrm{E}+00$ & 0.0000 \\
\hline 235 & 7. $913 \mathrm{E}-15$ & 0.0000 & $0.000 \mathrm{E}+00$ & 0.0000 & $0.000 \mathrm{E}+00$ & 0.0000 & $0.000 \mathrm{E}+00$ & 0.0000 & $0.000 \mathrm{E}+00$ & 0.0000 & $0.000 \mathrm{E}+00$ & 0.0000 & $0.000 \mathrm{E}+00$ & 0.0000 \\
\hline 38 & $2.202 E-09$ & 0.0054 & $0.000 \mathrm{E}+00$ & 0.0000 & $0.000 \mathrm{E}+00$ & 0.0000 & $0.000 \mathrm{E}+00$ & 0.0000 & $0.000 \mathrm{E}+00$ & 0.0000 & $0.000 \mathrm{E}+00$ & 0.0000 & $0.000 \mathrm{E}+00$ & 0.0000 \\
\hline & $4.044 \mathrm{E}-07$ & 1.0000 & $0.000 \mathrm{E}+00$ & 0.0000 & $0.000 \mathrm{E}+00$ & 0.0000 & $0.000 \mathrm{E}+00$ & 0.0000 & $0.000 \mathrm{E}+00$ & 0.0000 & $0.000 \mathrm{E}+00$ & 0.0000 & $.000 \mathrm{E}+00$ & 0.0000 \\
\hline
\end{tabular}

Total Dose Contributions TDOSE (i,p,t) for Individual Radionuclides (i) and Pathways (p) As mrem/yr and Fraction of Total Dose At $t=1.000 \mathrm{E}+00$ years

Water Dependent Pathways

\begin{tabular}{|c|c|c|c|c|c|c|c|c|c|c|c|c|c|c|}
\hline & \multicolumn{2}{|c|}{ Water } & \multicolumn{2}{|c|}{ Fish } & \multicolumn{2}{|c|}{ Radon } & \multicolumn{2}{|c|}{ Plant } & \multicolumn{2}{|c|}{ Meat } & \multicolumn{2}{|c|}{ Milk } & \multicolumn{2}{|c|}{ All Pathways* } \\
\hline clide & mrem/yr & fract. & mrem/yr & fract. & mrem/yr & fract. & mrem/yr & fract. & mrem/yr & fract. & mrem/yr & fract. & mrem/yr & fract. \\
\hline-241 & $0.000 \mathrm{E}+00$ & 0.0000 & $0.000 \mathrm{E}+00$ & 0.0000 & $0.000 \mathrm{E}+00$ & 0.0000 & $0.000 \mathrm{E}+00$ & 0.0000 & $0.000 \mathrm{E}+00$ & 0.0000 & $0.000 \mathrm{E}+00$ & 0.0000 & $1.575 \mathrm{E}-18$ & 0.0000 \\
\hline-137 & $0.000 \mathrm{E}+00$ & 0.0000 & $0.000 \mathrm{E}+00$ & 0.0000 & $0.000 \mathrm{E}+00$ & 0.0000 & $0.000 \mathrm{E}+00$ & 0.0000 & $0.000 \mathrm{E}+00$ & 0.0000 & $0.000 \mathrm{E}+00$ & 0.0000 & $2.272 \mathrm{E}-09$ & 0.0056 \\
\hline-237 & $0.000 \mathrm{E}+00$ & 0.0000 & $0.000 \mathrm{E}+00$ & 0.0000 & $0.000 \mathrm{E}+00$ & 0.0000 & $0.000 \mathrm{E}+00$ & 0.0000 & $0.000 \mathrm{E}+00$ & 0.0000 & $0.000 \mathrm{E}+00$ & 0.0000 & $5.097 \mathrm{E}-13$ & 0.0000 \\
\hline-238 & $0.000 \mathrm{E}+00$ & 0.0000 & $0.000 \mathrm{E}+00$ & 0.0000 & $0.000 \mathrm{E}+00$ & 0.0000 & $0.000 \mathrm{E}+00$ & 0.0000 & $0.000 \mathrm{E}+00$ & 0.0000 & $0.000 \mathrm{E}+00$ & 0.0000 & $4.535 \mathrm{E}-21$ & 0.0000 \\
\hline-239 & $0.000 \mathrm{E}+00$ & 0.0000 & $0.000 \mathrm{E}+00$ & 0.0000 & $0.000 \mathrm{E}+00$ & 0.0000 & $0.000 \mathrm{E}+00$ & 0.0000 & $0.000 \mathrm{E}+00$ & 0.0000 & $0.000 E+00$ & 0.0000 & $4.211 \mathrm{E}-17$ & 0.0000 \\
\hline-240 & $0.000 \mathrm{E}+00$ & 0.0000 & $0.000 \mathrm{E}+00$ & 0.0000 & $0.000 \mathrm{E}+00$ & 0.0000 & $0.000 \mathrm{E}+00$ & 0.0000 & $0.000 \mathrm{E}+00$ & 0.0000 & $0.000 E+00$ & 0.0000 & $4.111 \mathrm{E}-24$ & 0.0000 \\
\hline-99 & $0.000 \mathrm{E}+00$ & 0.0000 & $0.000 \mathrm{E}+00$ & 0.0000 & $0.000 \mathrm{E}+00$ & 0.0000 & $0.000 \mathrm{E}+00$ & 0.0000 & $0.000 \mathrm{E}+00$ & 0.0000 & $0.000 \mathrm{E}+00$ & 0.0000 & $2.925 E-25$ & 0.0000 \\
\hline-228 & $0.000 \mathrm{E}+00$ & 0.0000 & $0.000 \mathrm{E}+00$ & 0.0000 & $0.000 \mathrm{E}+00$ & 0.0000 & $0.000 \mathrm{E}+00$ & 0.0000 & $0.000 \mathrm{E}+00$ & 0.0000 & $0.000 \mathrm{E}+00$ & 0.0000 & $3.723 E-07$ & 0.9206 \\
\hline-230 & $0.000 \mathrm{E}+00$ & 0.0000 & $0.000 \mathrm{E}+00$ & 0.0000 & $0.000 \mathrm{E}+00$ & 0.0000 & $0.000 \mathrm{E}+00$ & 0.0000 & $0.000 \mathrm{E}+00$ & 0.0000 & $0.000 E+00$ & 0.0000 & $1.095 \mathrm{E}-09$ & 0.0027 \\
\hline 232 & $0.000 \mathrm{E}+00$ & 0.0000 & $0.000 \mathrm{E}+00$ & 0.0000 & $0.000 \mathrm{E}+00$ & 0.0000 & $0.000 \mathrm{E}+00$ & 0.0000 & $0.000 \mathrm{E}+00$ & 0.0000 & $0.000 \mathrm{E}+00$ & 0.0000 & $2.653 E-08$ & 0.0656 \\
\hline 34 & $0.000 \mathrm{E}+00$ & 0.0000 & $0.000 \mathrm{E}+00$ & 0.0000 & $0.000 \mathrm{E}+00$ & 0.0000 & $0.000 \mathrm{E}+00$ & 0.0000 & $0.000 \mathrm{E}+00$ & 0.0000 & $0.000 \mathrm{E}+00$ & 0.0000 & 1. $227 \mathrm{E}-14$ & 0.0000 \\
\hline 35 & $0.000 \mathrm{E}+00$ & 0.0000 & $0.000 \mathrm{E}+00$ & 0.0000 & $0.000 \mathrm{E}+00$ & 0.0000 & $0.000 \mathrm{E}+00$ & 0.0000 & $0.000 \mathrm{E}+00$ & 0.0000 & $0.000 E+00$ & 0.0000 & $7.913 \mathrm{E}-15$ & 0.0000 \\
\hline 38 & $0.000 \mathrm{E}+00$ & 0.0000 & $0.000 \mathrm{E}+00$ & 0.0000 & $0.000 \mathrm{E}+00$ & 0.0000 & $0.000 \mathrm{E}+00$ & 0.0000 & $0.000 \mathrm{E}+00$ & 0.0000 & $0.000 \mathrm{E}+00$ & 0.0000 & $2.202 \mathrm{E}-09$ & 0.0054 \\
\hline & $0.000 \mathrm{E}+00$ & 0.0000 & $0.000 \mathrm{E}+00$ & 0.0000 & $0.000 \mathrm{E}+00$ & 0.0000 & $0.000 \mathrm{E}+00$ & 0.0000 & $0.000 \mathrm{E}+00$ & 0.0000 & $0.000 \mathrm{E}+00$ & 0.0000 & $44 \mathrm{E}-07$ & 1.0000 \\
\hline
\end{tabular}

* Sum of all water independent and dependent pathways. 
RESRAD, Version 6.5

$\mathrm{T}^{1 / 2}$ Limit $=180$ days

ummary : C746U Recreational User Deterministic Run

: X: $\backslash F I N A L$ V2 \DOE FWD RUNS \C746U RU DOE SG FWD-FV2-1050YR.RAD

Total Dose Contributions TDOSE (i,p,t) for Individual Radionuclides (i) and Pathways (p) As mrem/yr and Fraction of Total Dose At $t=5.000 \mathrm{E}+01$ years

Water Independent Pathways (Inhalation excludes radon)

\begin{tabular}{|c|c|c|c|c|c|c|c|c|c|c|c|c|c|c|}
\hline \multirow{2}{*}{ Nuclide } & \multicolumn{2}{|c|}{ Ground } & \multicolumn{2}{|c|}{ Inhalation } & \multicolumn{2}{|c|}{ Radon } & \multicolumn{2}{|c|}{ Plant } & \multicolumn{2}{|c|}{ Meat } & \multicolumn{2}{|c|}{ Milk } & \multicolumn{2}{|c|}{ Soil } \\
\hline & mrem/yr & fract. & mrem/yr & fract. & mrem/yr & fract. & mrem/yr & fract. & mrem/yr & fract. & mrem/yr & fract. & mrem/yr & fract. \\
\hline-241 & $8.641 \mathrm{E}-17$ & 0.0000 & $0.000 \mathrm{E}+00$ & 0.0000 & $0.000 \mathrm{E}+00$ & 0.0000 & $0.000 \mathrm{E}+00$ & 0.0000 & $0.000 \mathrm{E}+00$ & 0.0000 & $0.000 \mathrm{E}+00$ & 0.0000 & $0.000 \mathrm{E}+00$ & 0.0000 \\
\hline-137 & $1.106 \mathrm{E}-09$ & 0.0012 & $0.000 \mathrm{E}+00$ & 0.0000 & $0.000 \mathrm{E}+00$ & 0.0000 & $0.000 \mathrm{E}+00$ & 0.0000 & $0.000 \mathrm{E}+00$ & 0.0000 & $0.000 \mathrm{E}+00$ & 0.0000 & $0.000 \mathrm{E}+00$ & 0.0000 \\
\hline-237 & $8.637 E-13$ & 0.0000 & $0.000 \mathrm{E}+00$ & 0.0000 & $0.000 \mathrm{E}+00$ & 0.0000 & $0.000 \mathrm{E}+00$ & 0.0000 & $0.000 \mathrm{E}+00$ & 0.0000 & $0.000 \mathrm{E}+00$ & 0.0000 & $0.000 \mathrm{E}+00$ & 0.0000 \\
\hline-238 & $1.975 E-16$ & 0.0000 & $0.000 \mathrm{E}+00$ & 0.0000 & $0.000 \mathrm{E}+00$ & 0.0000 & $0.000 \mathrm{E}+00$ & 0.0000 & $0.000 \mathrm{E}+00$ & 0.0000 & $0.000 \mathrm{E}+00$ & 0.0000 & $0.000 \mathrm{E}+00$ & 0.0000 \\
\hline-239 & 7. $561 \mathrm{E}-17$ & 0.0000 & $0.000 \mathrm{E}+00$ & 0.0000 & $0.000 \mathrm{E}+00$ & 0.0000 & $0.000 \mathrm{E}+00$ & 0.0000 & $0.000 \mathrm{E}+00$ & 0.0000 & $0.000 \mathrm{E}+00$ & 0.0000 & $0.000 \mathrm{E}+00$ & 0.0000 \\
\hline-240 & $9.285 \mathrm{E}-21$ & 0.0000 & $0.000 \mathrm{E}+00$ & 0.0000 & $0.000 \mathrm{E}+00$ & 0.0000 & $0.000 \mathrm{E}+00$ & 0.0000 & $0.000 \mathrm{E}+00$ & 0.0000 & $0.000 \mathrm{E}+00$ & 0.0000 & $0.000 \mathrm{E}+00$ & 0.0000 \\
\hline 99 & $5.785 E-25$ & 0.0000 & $0.000 \mathrm{E}+00$ & 0.0000 & $0.000 \mathrm{E}+00$ & 0.0000 & $0.000 \mathrm{E}+00$ & 0.0000 & $0.000 \mathrm{E}+00$ & 0.0000 & $0.000 \mathrm{E}+00$ & 0.0000 & $0.000 \mathrm{E}+00$ & 0.0000 \\
\hline-228 & $9.718 \mathrm{E}-15$ & 0.0000 & $0.000 \mathrm{E}+00$ & 0.0000 & $0.000 \mathrm{E}+00$ & 0.0000 & $0.000 \mathrm{E}+00$ & 0.0000 & $0.000 \mathrm{E}+00$ & 0.0000 & $0.000 \mathrm{E}+00$ & 0.0000 & $0.000 \mathrm{E}+00$ & 0.0000 \\
\hline-230 & $5.116 \mathrm{E}-08$ & 0.0558 & $0.000 \mathrm{E}+00$ & 0.0000 & $0.000 \mathrm{E}+00$ & 0.0000 & $0.000 \mathrm{E}+00$ & 0.0000 & $0.000 \mathrm{E}+00$ & 0.0000 & $0.000 \mathrm{E}+00$ & 0.0000 & $0.000 \mathrm{E}+00$ & 0.0000 \\
\hline-232 & $8.620 E-07$ & 0.9395 & $0.000 \mathrm{E}+00$ & 0.0000 & $0.000 \mathrm{E}+00$ & 0.0000 & $0.000 \mathrm{E}+00$ & 0.0000 & $0.000 \mathrm{E}+00$ & 0.0000 & $0.000 \mathrm{E}+00$ & 0.0000 & $0.000 \mathrm{E}+00$ & 0.0000 \\
\hline 234 & $1.867 \mathrm{E}-11$ & 0.0000 & $0.000 \mathrm{E}+00$ & 0.0000 & $0.000 \mathrm{E}+00$ & 0.0000 & $0.000 \mathrm{E}+00$ & 0.0000 & $0.000 \mathrm{E}+00$ & 0.0000 & $0.000 \mathrm{E}+00$ & 0.0000 & $0.000 \mathrm{E}+00$ & 0.0000 \\
\hline 235 & $5.776 \mathrm{E}-14$ & 0.0000 & $0.000 \mathrm{E}+00$ & 0.0000 & $0.000 \mathrm{E}+00$ & 0.0000 & $0.000 \mathrm{E}+00$ & 0.0000 & $0.000 \mathrm{E}+00$ & 0.0000 & $0.000 \mathrm{E}+00$ & 0.0000 & $0.000 \mathrm{E}+00$ & 0.0000 \\
\hline 38 & $3.257 E-09$ & 0.0035 & $0.000 \mathrm{E}+00$ & 0.0000 & $0.000 \mathrm{E}+00$ & 0.0000 & $0.000 \mathrm{E}+00$ & 0.0000 & $0.000 \mathrm{E}+00$ & 0.0000 & $0.000 \mathrm{E}+00$ & 0.0000 & $0.000 \mathrm{E}+00$ & 0.0000 \\
\hline & $9.175 E-07$ & 1.0000 & $0.000 \mathrm{E}+00$ & 0.0000 & $0.000 \mathrm{E}+00$ & 0.0000 & $0.000 \mathrm{E}+00$ & 0.0000 & $0.000 \mathrm{E}+00$ & 0.0000 & $0.000 \mathrm{E}+00$ & 0.0000 & $.000 \mathrm{E}+00$ & 0.0000 \\
\hline
\end{tabular}

Total Dose Contributions TDOSE (i,p,t) for Individual Radionuclides (i) and Pathways (p) As mrem/yr and Fraction of Total Dose At $t=5.000 \mathrm{E}+01$ years

Water Dependent Pathways

\begin{tabular}{|c|c|c|c|c|c|c|c|c|c|c|c|c|c|c|}
\hline & \multicolumn{2}{|c|}{ Water } & \multicolumn{2}{|c|}{ Fish } & \multicolumn{2}{|c|}{ Radon } & \multicolumn{2}{|c|}{ Plant } & \multicolumn{2}{|c|}{ Meat } & \multicolumn{2}{|c|}{ Milk } & \multicolumn{2}{|c|}{ All Pathways* } \\
\hline clide & mrem/yr & fract. & mrem/yr & fract. & mrem/yr & fract. & mrem/yr & fract. & mrem/yr & fract. & mrem/yr & fract. & mrem/yr & fract. \\
\hline-241 & $0.000 \mathrm{E}+00$ & 0.0000 & $0.000 \mathrm{E}+00$ & 0.0000 & $0.000 \mathrm{E}+00$ & 0.0000 & $0.000 \mathrm{E}+00$ & 0.0000 & $0.000 \mathrm{E}+00$ & 0.0000 & $0.000 \mathrm{E}+00$ & 0.0000 & $8.641 \mathrm{E}-17$ & 0.0000 \\
\hline-137 & $0.000 \mathrm{E}+00$ & 0.0000 & $0.000 \mathrm{E}+00$ & 0.0000 & $0.000 \mathrm{E}+00$ & 0.0000 & $0.000 \mathrm{E}+00$ & 0.0000 & $0.000 \mathrm{E}+00$ & 0.0000 & $0.000 \mathrm{E}+00$ & 0.0000 & $1.106 \mathrm{E}-09$ & 0.0012 \\
\hline-237 & $0.000 \mathrm{E}+00$ & 0.0000 & $0.000 \mathrm{E}+00$ & 0.0000 & $0.000 \mathrm{E}+00$ & 0.0000 & $0.000 \mathrm{E}+00$ & 0.0000 & $0.000 \mathrm{E}+00$ & 0.0000 & $0.000 \mathrm{E}+00$ & 0.0000 & $8.637 \mathrm{E}-13$ & 0.0000 \\
\hline-238 & $0.000 \mathrm{E}+00$ & 0.0000 & $0.000 \mathrm{E}+00$ & 0.0000 & $0.000 \mathrm{E}+00$ & 0.0000 & $0.000 \mathrm{E}+00$ & 0.0000 & $0.000 \mathrm{E}+00$ & 0.0000 & $0.000 \mathrm{E}+00$ & 0.0000 & $1.975 \mathrm{E}-16$ & 0.0000 \\
\hline-239 & $0.000 \mathrm{E}+00$ & 0.0000 & $0.000 \mathrm{E}+00$ & 0.0000 & $0.000 \mathrm{E}+00$ & 0.0000 & $0.000 \mathrm{E}+00$ & 0.0000 & $0.000 \mathrm{E}+00$ & 0.0000 & $0.000 E+00$ & 0.0000 & $7.561 \mathrm{E}-17$ & 0.0000 \\
\hline-240 & $0.000 \mathrm{E}+00$ & 0.0000 & $0.000 \mathrm{E}+00$ & 0.0000 & $0.000 \mathrm{E}+00$ & 0.0000 & $0.000 \mathrm{E}+00$ & 0.0000 & $0.000 \mathrm{E}+00$ & 0.0000 & $0.000 E+00$ & 0.0000 & $9.285 \mathrm{E}-21$ & 0.0000 \\
\hline-99 & $0.000 \mathrm{E}+00$ & 0.0000 & $0.000 \mathrm{E}+00$ & 0.0000 & $0.000 \mathrm{E}+00$ & 0.0000 & $0.000 \mathrm{E}+00$ & 0.0000 & $0.000 \mathrm{E}+00$ & 0.0000 & $0.000 \mathrm{E}+00$ & 0.0000 & $5.785 \mathrm{E}-25$ & 0.0000 \\
\hline-228 & $0.000 \mathrm{E}+00$ & 0.0000 & $0.000 \mathrm{E}+00$ & 0.0000 & $0.000 \mathrm{E}+00$ & 0.0000 & $0.000 \mathrm{E}+00$ & 0.0000 & $0.000 \mathrm{E}+00$ & 0.0000 & $0.000 \mathrm{E}+00$ & 0.0000 & $9.718 \mathrm{E}-15$ & 0.0000 \\
\hline-230 & $0.000 \mathrm{E}+00$ & 0.0000 & $0.000 \mathrm{E}+00$ & 0.0000 & $0.000 \mathrm{E}+00$ & 0.0000 & $0.000 \mathrm{E}+00$ & 0.0000 & $0.000 \mathrm{E}+00$ & 0.0000 & $0.000 E+00$ & 0.0000 & $5.116 \mathrm{E}-08$ & 0.0558 \\
\hline 232 & $0.000 \mathrm{E}+00$ & 0.0000 & $0.000 \mathrm{E}+00$ & 0.0000 & $0.000 \mathrm{E}+00$ & 0.0000 & $0.000 \mathrm{E}+00$ & 0.0000 & $0.000 \mathrm{E}+00$ & 0.0000 & $0.000 \mathrm{E}+00$ & 0.0000 & $8.620 \mathrm{E}-07$ & 0.9395 \\
\hline 34 & $0.000 \mathrm{E}+00$ & 0.0000 & $0.000 \mathrm{E}+00$ & 0.0000 & $0.000 \mathrm{E}+00$ & 0.0000 & $0.000 \mathrm{E}+00$ & 0.0000 & $0.000 \mathrm{E}+00$ & 0.0000 & $0.000 \mathrm{E}+00$ & 0.0000 & $1.867 \mathrm{E}-11$ & 0.0000 \\
\hline 35 & $0.000 \mathrm{E}+00$ & 0.0000 & $0.000 \mathrm{E}+00$ & 0.0000 & $0.000 \mathrm{E}+00$ & 0.0000 & $0.000 \mathrm{E}+00$ & 0.0000 & $0.000 \mathrm{E}+00$ & 0.0000 & $0.000 E+00$ & 0.0000 & $5.776 \mathrm{E}-14$ & 0.0000 \\
\hline 38 & $0.000 \mathrm{E}+00$ & 0.0000 & $0.000 \mathrm{E}+00$ & 0.0000 & $0.000 \mathrm{E}+00$ & 0.0000 & $0.000 \mathrm{E}+00$ & 0.0000 & $0.000 \mathrm{E}+00$ & 0.0000 & $0.000 \mathrm{E}+00$ & 0.0000 & $3.257 \mathrm{E}-09$ & 0.0035 \\
\hline & $0.000 \mathrm{E}+00$ & 0.0000 & $0.000 \mathrm{E}+00$ & 0.0000 & $0.000 \mathrm{E}+00$ & 0.0000 & $0.000 \mathrm{E}+00$ & 0.0000 & $0.000 \mathrm{E}+00$ & 0.0000 & $0.000 \mathrm{E}+00$ & 0.0000 & $9.175 \mathrm{E}-07$ & 1.0000 \\
\hline
\end{tabular}

* Sum of all water independent and dependent pathways. 
RESRAD, Version 6.5

$\mathrm{T}^{1 / 2}$ Limit $=180$ days

ummary : C746U Recreational User Deterministic Run

: $\mathrm{X}: \backslash F I N A L$ V2 $\backslash$ DOE FWD RUNS \C746U RU DOE SG FWD-FV2-1050YR.RAD

Total Dose Contributions TDOSE (i,p,t) for Individual Radionuclides (i) and Pathways (p) As mrem/yr and Fraction of Total Dose At $t=1.000 \mathrm{E}+02$ years

Water Independent Pathways (Inhalation excludes radon)

\begin{tabular}{|c|c|c|c|c|c|c|c|c|c|c|c|c|c|c|}
\hline \multirow{2}{*}{ Nuclide } & \multicolumn{2}{|c|}{ Ground } & \multicolumn{2}{|c|}{ Inhalation } & \multicolumn{2}{|c|}{ Radon } & \multicolumn{2}{|c|}{ Plant } & \multicolumn{2}{|c|}{ Meat } & \multicolumn{2}{|c|}{ Milk } & \multicolumn{2}{|c|}{ Soil } \\
\hline & mrem/yr & fract. & mrem/yr & fract. & mrem/yr & fract. & mrem/yr & fract. & mrem/yr & fract. & mrem/yr & fract. & mrem/yr & fract. \\
\hline-241 & $2.836 \mathrm{E}-16$ & 0.0000 & $0.000 \mathrm{E}+00$ & 0.0000 & $0.000 \mathrm{E}+00$ & 0.0000 & $0.000 \mathrm{E}+00$ & 0.0000 & $0.000 \mathrm{E}+00$ & 0.0000 & $0.000 \mathrm{E}+00$ & 0.0000 & $0.000 \mathrm{E}+00$ & 0.0000 \\
\hline-137 & $5.307 E-10$ & 0.0004 & $0.000 \mathrm{E}+00$ & 0.0000 & $0.000 \mathrm{E}+00$ & 0.0000 & $0.000 \mathrm{E}+00$ & 0.0000 & $0.000 \mathrm{E}+00$ & 0.0000 & $0.000 \mathrm{E}+00$ & 0.0000 & $0.000 \mathrm{E}+00$ & 0.0000 \\
\hline-237 & $1.483 \mathrm{E}-12$ & 0.0000 & $0.000 \mathrm{E}+00$ & 0.0000 & $0.000 \mathrm{E}+00$ & 0.0000 & $0.000 \mathrm{E}+00$ & 0.0000 & $0.000 \mathrm{E}+00$ & 0.0000 & $0.000 \mathrm{E}+00$ & 0.0000 & $0.000 \mathrm{E}+00$ & 0.0000 \\
\hline-238 & $1.997 \mathrm{E}-15$ & 0.0000 & $0.000 \mathrm{E}+00$ & 0.0000 & $0.000 \mathrm{E}+00$ & 0.0000 & $0.000 \mathrm{E}+00$ & 0.0000 & $0.000 \mathrm{E}+00$ & 0.0000 & $0.000 \mathrm{E}+00$ & 0.0000 & $0.000 \mathrm{E}+00$ & 0.0000 \\
\hline-239 & $1.374 \mathrm{E}-16$ & 0.0000 & $0.000 \mathrm{E}+00$ & 0.0000 & $0.000 \mathrm{E}+00$ & 0.0000 & $0.000 \mathrm{E}+00$ & 0.0000 & $0.000 \mathrm{E}+00$ & 0.0000 & $0.000 \mathrm{E}+00$ & 0.0000 & $0.000 \mathrm{E}+00$ & 0.0000 \\
\hline-240 & $6.177 \mathrm{E}-20$ & 0.0000 & $0.000 \mathrm{E}+00$ & 0.0000 & $0.000 \mathrm{E}+00$ & 0.0000 & $0.000 \mathrm{E}+00$ & 0.0000 & $0.000 \mathrm{E}+00$ & 0.0000 & $0.000 \mathrm{E}+00$ & 0.0000 & $0.000 \mathrm{E}+00$ & 0.0000 \\
\hline 99 & $1.160 \mathrm{E}-24$ & 0.0000 & $0.000 \mathrm{E}+00$ & 0.0000 & $0.000 \mathrm{E}+00$ & 0.0000 & $0.000 \mathrm{E}+00$ & 0.0000 & $0.000 \mathrm{E}+00$ & 0.0000 & $0.000 \mathrm{E}+00$ & 0.0000 & $0.000 \mathrm{E}+00$ & 0.0000 \\
\hline-228 & $1.776 \mathrm{E}-22$ & 0.0000 & $0.000 \mathrm{E}+00$ & 0.0000 & $0.000 \mathrm{E}+00$ & 0.0000 & $0.000 \mathrm{E}+00$ & 0.0000 & $0.000 \mathrm{E}+00$ & 0.0000 & $0.000 \mathrm{E}+00$ & 0.0000 & $0.000 \mathrm{E}+00$ & 0.0000 \\
\hline-230 & $1.423 E-07$ & 0.1082 & $0.000 \mathrm{E}+00$ & 0.0000 & $0.000 \mathrm{E}+00$ & 0.0000 & $0.000 \mathrm{E}+00$ & 0.0000 & $0.000 \mathrm{E}+00$ & 0.0000 & $0.000 \mathrm{E}+00$ & 0.0000 & $0.000 \mathrm{E}+00$ & 0.0000 \\
\hline-232 & $1.167 \mathrm{E}-06$ & 0.8876 & $0.000 \mathrm{E}+00$ & 0.0000 & $0.000 \mathrm{E}+00$ & 0.0000 & $0.000 \mathrm{E}+00$ & 0.0000 & $0.000 \mathrm{E}+00$ & 0.0000 & $0.000 \mathrm{E}+00$ & 0.0000 & $0.000 \mathrm{E}+00$ & 0.0000 \\
\hline 234 & $1.037 \mathrm{E}-10$ & 0.0001 & $0.000 \mathrm{E}+00$ & 0.0000 & $0.000 \mathrm{E}+00$ & 0.0000 & $0.000 \mathrm{E}+00$ & 0.0000 & $0.000 \mathrm{E}+00$ & 0.0000 & $0.000 \mathrm{E}+00$ & 0.0000 & $0.000 \mathrm{E}+00$ & 0.0000 \\
\hline 235 & $2.119 \mathrm{E}-13$ & 0.0000 & $0.000 \mathrm{E}+00$ & 0.0000 & $0.000 \mathrm{E}+00$ & 0.0000 & $0.000 \mathrm{E}+00$ & 0.0000 & $0.000 \mathrm{E}+00$ & 0.0000 & $0.000 \mathrm{E}+00$ & 0.0000 & $0.000 \mathrm{E}+00$ & 0.0000 \\
\hline 38 & $4.856 E-09$ & 0.0037 & $0.000 \mathrm{E}+00$ & 0.0000 & $0.000 \mathrm{E}+00$ & 0.0000 & $0.000 \mathrm{E}+00$ & 0.0000 & $0.000 \mathrm{E}+00$ & 0.0000 & $0.000 \mathrm{E}+00$ & 0.0000 & $0.000 \mathrm{E}+00$ & 0.0000 \\
\hline & $1.314 \mathrm{E}-06$ & 1.0000 & $0.000 \mathrm{E}+00$ & 0.0000 & $0.000 \mathrm{E}+00$ & 0.0000 & $0.000 \mathrm{E}+00$ & 0.0000 & $0.000 \mathrm{E}+00$ & 0.0000 & $0.000 \mathrm{E}+00$ & 0.0000 & $.000 \mathrm{E}+00$ & 0.0000 \\
\hline
\end{tabular}

Total Dose Contributions TDOSE (i,p,t) for Individual Radionuclides (i) and Pathways (p) As mrem/yr and Fraction of Total Dose At $t=1.000 \mathrm{E}+02$ years

Water Dependent Pathways

\begin{tabular}{|c|c|c|c|c|c|c|c|c|c|c|c|c|c|c|}
\hline & \multicolumn{2}{|c|}{ Water } & \multicolumn{2}{|c|}{ Fish } & \multicolumn{2}{|c|}{ Radon } & \multicolumn{2}{|c|}{ Plant } & \multicolumn{2}{|c|}{ Meat } & \multicolumn{2}{|c|}{ Milk } & \multicolumn{2}{|c|}{ All Pathways* } \\
\hline clide & mrem/yr & fract. & mrem/yr & fract. & mrem/yr & fract. & mrem/yr & fract. & mrem/yr & fract. & mrem/yr & fract. & mrem/yr & fract. \\
\hline 241 & $0.000 \mathrm{E}+00$ & 0.0000 & $0.000 \mathrm{E}+00$ & 0.0000 & $0.000 \mathrm{E}+00$ & 0.0000 & $0.000 \mathrm{E}+00$ & 0.0000 & $0.000 \mathrm{E}+00$ & 0.0000 & $0.000 \mathrm{E}+00$ & 0.0000 & $2.836 \mathrm{E}-16$ & 0.0000 \\
\hline-137 & $0.000 \mathrm{E}+00$ & 0.0000 & $0.000 \mathrm{E}+00$ & 0.0000 & $0.000 \mathrm{E}+00$ & 0.0000 & $0.000 \mathrm{E}+00$ & 0.0000 & $0.000 \mathrm{E}+00$ & 0.0000 & $0.000 \mathrm{E}+00$ & 0.0000 & $5.307 \mathrm{E}-10$ & 0.0004 \\
\hline-237 & $0.000 \mathrm{E}+00$ & 0.0000 & $0.000 \mathrm{E}+00$ & 0.0000 & $0.000 \mathrm{E}+00$ & 0.0000 & $0.000 \mathrm{E}+00$ & 0.0000 & $0.000 \mathrm{E}+00$ & 0.0000 & $0.000 \mathrm{E}+00$ & 0.0000 & $1.483 \mathrm{E}-12$ & 0.0000 \\
\hline-238 & $0.000 \mathrm{E}+00$ & 0.0000 & $0.000 \mathrm{E}+00$ & 0.0000 & $0.000 \mathrm{E}+00$ & 0.0000 & $0.000 \mathrm{E}+00$ & 0.0000 & $0.000 \mathrm{E}+00$ & 0.0000 & $0.000 \mathrm{E}+00$ & 0.0000 & $1.997 \mathrm{E}-15$ & 0.0000 \\
\hline-239 & $0.000 \mathrm{E}+00$ & 0.0000 & $0.000 \mathrm{E}+00$ & 0.0000 & $0.000 \mathrm{E}+00$ & 0.0000 & $0.000 \mathrm{E}+00$ & 0.0000 & $0.000 \mathrm{E}+00$ & 0.0000 & $0.000 E+00$ & 0.0000 & $1.374 \mathrm{E}-16$ & 0.0000 \\
\hline-240 & $0.000 \mathrm{E}+00$ & 0.0000 & $0.000 \mathrm{E}+00$ & 0.0000 & $0.000 \mathrm{E}+00$ & 0.0000 & $0.000 \mathrm{E}+00$ & 0.0000 & $0.000 \mathrm{E}+00$ & 0.0000 & $0.000 E+00$ & 0.0000 & $6.177 \mathrm{E}-20$ & 0.0000 \\
\hline-99 & $0.000 \mathrm{E}+00$ & 0.0000 & $0.000 \mathrm{E}+00$ & 0.0000 & $0.000 \mathrm{E}+00$ & 0.0000 & $0.000 \mathrm{E}+00$ & 0.0000 & $0.000 \mathrm{E}+00$ & 0.0000 & $0.000 \mathrm{E}+00$ & 0.0000 & $1.160 \mathrm{E}-24$ & 0.0000 \\
\hline-228 & $0.000 \mathrm{E}+00$ & 0.0000 & $0.000 \mathrm{E}+00$ & 0.0000 & $0.000 \mathrm{E}+00$ & 0.0000 & $0.000 \mathrm{E}+00$ & 0.0000 & $0.000 \mathrm{E}+00$ & 0.0000 & $0.000 \mathrm{E}+00$ & 0.0000 & $1.776 \mathrm{E}-22$ & 0.0000 \\
\hline-230 & $0.000 \mathrm{E}+00$ & 0.0000 & $0.000 \mathrm{E}+00$ & 0.0000 & $0.000 \mathrm{E}+00$ & 0.0000 & $0.000 \mathrm{E}+00$ & 0.0000 & $0.000 \mathrm{E}+00$ & 0.0000 & $0.000 E+00$ & 0.0000 & $1.423 \mathrm{E}-07$ & 0.1082 \\
\hline 232 & $0.000 \mathrm{E}+00$ & 0.0000 & $0.000 \mathrm{E}+00$ & 0.0000 & $0.000 \mathrm{E}+00$ & 0.0000 & $0.000 \mathrm{E}+00$ & 0.0000 & $0.000 \mathrm{E}+00$ & 0.0000 & $0.000 \mathrm{E}+00$ & 0.0000 & $1.167 \mathrm{E}-06$ & 0.8876 \\
\hline 34 & $0.000 \mathrm{E}+00$ & 0.0000 & $0.000 \mathrm{E}+00$ & 0.0000 & $0.000 \mathrm{E}+00$ & 0.0000 & $0.000 \mathrm{E}+00$ & 0.0000 & $0.000 \mathrm{E}+00$ & 0.0000 & $0.000 \mathrm{E}+00$ & 0.0000 & $1.037 \mathrm{E}-10$ & 0.0001 \\
\hline 35 & $0.000 \mathrm{E}+00$ & 0.0000 & $0.000 \mathrm{E}+00$ & 0.0000 & $0.000 \mathrm{E}+00$ & 0.0000 & $0.000 \mathrm{E}+00$ & 0.0000 & $0.000 \mathrm{E}+00$ & 0.0000 & $0.000 E+00$ & 0.0000 & $2.119 \mathrm{E}-13$ & 0.0000 \\
\hline 38 & $0.000 \mathrm{E}+00$ & 0.0000 & $0.000 \mathrm{E}+00$ & 0.0000 & $0.000 \mathrm{E}+00$ & 0.0000 & $0.000 \mathrm{E}+00$ & 0.0000 & $0.000 \mathrm{E}+00$ & 0.0000 & $0.000 \mathrm{E}+00$ & 0.0000 & $4.856 \mathrm{E}-09$ & 0.0037 \\
\hline & $0.000 \mathrm{E}+00$ & 0.0000 & $0.000 \mathrm{E}+00$ & 0.0000 & $0.000 \mathrm{E}+00$ & 0.0000 & $0.000 \mathrm{E}+00$ & 0.0000 & $0.000 \mathrm{E}+00$ & 0.0000 & $0.000 \mathrm{E}+00$ & 0.0000 & $4 \mathrm{E}-06$ & 1. \\
\hline
\end{tabular}

* Sum of all water independent and dependent pathways. 
RESRAD, Version 6.5

$\mathrm{T}^{1 / 2}$ Limit $=180$ days

ummary : C746U Recreational User Deterministic Run

: $\mathrm{X}: \backslash F I N A L$ V2 $\backslash$ DOE FWD RUNS \C746U RU DOE SG FWD-FV2-1050YR.RAD

Total Dose Contributions TDOSE (i,p,t) for Individual Radionuclides (i) and Pathways (p) As mrem/yr and Fraction of Total Dose At $t=5.000 \mathrm{E}+02$ years

Water Independent Pathways (Inhalation excludes radon)

\begin{tabular}{|c|c|c|c|c|c|c|c|c|c|c|c|c|c|c|}
\hline \multirow{2}{*}{ Nuclide } & \multicolumn{2}{|c|}{ Ground } & \multicolumn{2}{|c|}{ Inhalation } & \multicolumn{2}{|c|}{ Radon } & \multicolumn{2}{|c|}{ Plant } & \multicolumn{2}{|c|}{ Meat } & \multicolumn{2}{|c|}{ Milk } & \multicolumn{2}{|c|}{ Soil } \\
\hline & mrem/yr & fract. & mrem/yr & fract. & mrem/yr & fract. & mrem/yr & fract. & mrem/yr & fract. & mrem/yr & fract. & mrem/yr & fract. \\
\hline-241 & $7.849 \mathrm{E}-14$ & 0.0000 & $0.000 \mathrm{E}+00$ & 0.0000 & $0.000 \mathrm{E}+00$ & 0.0000 & $0.000 \mathrm{E}+00$ & 0.0000 & $0.000 \mathrm{E}+00$ & 0.0000 & $0.000 \mathrm{E}+00$ & 0.0000 & $0.000 \mathrm{E}+00$ & 0.0000 \\
\hline-137 & $1.491 \mathrm{E}-12$ & 0.0000 & $0.000 \mathrm{E}+00$ & 0.0000 & $0.000 \mathrm{E}+00$ & 0.0000 & $0.000 \mathrm{E}+00$ & 0.0000 & $0.000 \mathrm{E}+00$ & 0.0000 & $0.000 \mathrm{E}+00$ & 0.0000 & $0.000 \mathrm{E}+00$ & 0.0000 \\
\hline-237 & $1.111 \mathrm{E}-10$ & 0.0000 & $0.000 \mathrm{E}+00$ & 0.0000 & $0.000 \mathrm{E}+00$ & 0.0000 & $0.000 \mathrm{E}+00$ & 0.0000 & $0.000 \mathrm{E}+00$ & 0.0000 & $0.000 \mathrm{E}+00$ & 0.0000 & $0.000 \mathrm{E}+00$ & 0.0000 \\
\hline-238 & $2.109 \mathrm{E}-12$ & 0.0000 & $0.000 \mathrm{E}+00$ & 0.0000 & $0.000 \mathrm{E}+00$ & 0.0000 & $0.000 \mathrm{E}+00$ & 0.0000 & $0.000 \mathrm{E}+00$ & 0.0000 & $0.000 \mathrm{E}+00$ & 0.0000 & $0.000 \mathrm{E}+00$ & 0.0000 \\
\hline-239 & $1.636 \mathrm{E}-14$ & 0.0000 & $0.000 \mathrm{E}+00$ & 0.0000 & $0.000 \mathrm{E}+00$ & 0.0000 & $0.000 \mathrm{E}+00$ & 0.0000 & $0.000 \mathrm{E}+00$ & 0.0000 & $0.000 \mathrm{E}+00$ & 0.0000 & $0.000 \mathrm{E}+00$ & 0.0000 \\
\hline-240 & $1.985 \mathrm{E}-17$ & 0.0000 & $0.000 \mathrm{E}+00$ & 0.0000 & $0.000 \mathrm{E}+00$ & 0.0000 & $0.000 \mathrm{E}+00$ & 0.0000 & $0.000 \mathrm{E}+00$ & 0.0000 & $0.000 \mathrm{E}+00$ & 0.0000 & $0.000 \mathrm{E}+00$ & 0.0000 \\
\hline 99 & $3.036 E-22$ & 0.0000 & $0.000 \mathrm{E}+00$ & 0.0000 & $0.000 \mathrm{E}+00$ & 0.0000 & $0.000 \mathrm{E}+00$ & 0.0000 & $0.000 \mathrm{E}+00$ & 0.0000 & $0.000 \mathrm{E}+00$ & 0.0000 & $0.000 \mathrm{E}+00$ & 0.0000 \\
\hline-228 & $0.000 \mathrm{E}+00$ & 0.0000 & $0.000 \mathrm{E}+00$ & 0.0000 & $0.000 \mathrm{E}+00$ & 0.0000 & $0.000 \mathrm{E}+00$ & 0.0000 & $0.000 \mathrm{E}+00$ & 0.0000 & $0.000 \mathrm{E}+00$ & 0.0000 & $0.000 \mathrm{E}+00$ & 0.0000 \\
\hline-230 & $1.032 \mathrm{E}-05$ & 0.4425 & $0.000 \mathrm{E}+00$ & 0.0000 & $0.000 \mathrm{E}+00$ & 0.0000 & $0.000 \mathrm{E}+00$ & 0.0000 & $0.000 \mathrm{E}+00$ & 0.0000 & $0.000 \mathrm{E}+00$ & 0.0000 & $0.000 \mathrm{E}+00$ & 0.0000 \\
\hline-232 & $1.285 E-05$ & 0.5508 & $0.000 \mathrm{E}+00$ & 0.0000 & $0.000 \mathrm{E}+00$ & 0.0000 & $0.000 \mathrm{E}+00$ & 0.0000 & $0.000 \mathrm{E}+00$ & 0.0000 & $0.000 \mathrm{E}+00$ & 0.0000 & $0.000 \mathrm{E}+00$ & 0.0000 \\
\hline 234 & $3.851 \mathrm{E}-08$ & 0.0017 & $0.000 \mathrm{E}+00$ & 0.0000 & $0.000 \mathrm{E}+00$ & 0.0000 & $0.000 \mathrm{E}+00$ & 0.0000 & $0.000 \mathrm{E}+00$ & 0.0000 & $0.000 \mathrm{E}+00$ & 0.0000 & $0.000 \mathrm{E}+00$ & 0.0000 \\
\hline 235 & $4.414 \mathrm{E}-11$ & 0.0000 & $0.000 \mathrm{E}+00$ & 0.0000 & $0.000 \mathrm{E}+00$ & 0.0000 & $0.000 \mathrm{E}+00$ & 0.0000 & $0.000 \mathrm{E}+00$ & 0.0000 & $0.000 \mathrm{E}+00$ & 0.0000 & $0.000 \mathrm{E}+00$ & 0.0000 \\
\hline 38 & $1.187 \mathrm{E}-07$ & 0.0051 & $0.000 \mathrm{E}+00$ & 0.0000 & $0.000 \mathrm{E}+00$ & 0.0000 & $0.000 \mathrm{E}+00$ & 0.0000 & $0.000 \mathrm{E}+00$ & 0.0000 & $0.000 \mathrm{E}+00$ & 0.0000 & $0.000 \mathrm{E}+00$ & 0.0000 \\
\hline & $2.333 E-05$ & 1.0000 & $0.000 \mathrm{E}+00$ & 0.0000 & $0.000 \mathrm{E}+00$ & 0.0000 & $0.000 \mathrm{E}+00$ & 0.0000 & $0.000 \mathrm{E}+00$ & 0.0000 & $0.000 \mathrm{E}+00$ & 0.0000 & $.000 \mathrm{E}+00$ & 0.0000 \\
\hline
\end{tabular}

Total Dose Contributions TDOSE (i,p,t) for Individual Radionuclides (i) and Pathways (p) As mrem/yr and Fraction of Total Dose At $t=5.000 \mathrm{E}+02$ years

Water Dependent Pathways

\begin{tabular}{|c|c|c|c|c|c|c|c|c|c|c|c|c|c|c|}
\hline & \multicolumn{2}{|c|}{ Water } & \multicolumn{2}{|c|}{ Fish } & \multicolumn{2}{|c|}{ Radon } & \multicolumn{2}{|c|}{ Plant } & \multicolumn{2}{|c|}{ Meat } & \multicolumn{2}{|c|}{ Milk } & \multicolumn{2}{|c|}{ All Pathways* } \\
\hline clide & mrem/yr & fract. & mrem/yr & fract. & mrem/yr & fract. & mrem/yr & fract. & mrem/yr & fract. & mrem/yr & fract. & mrem/yr & fract. \\
\hline 241 & $0.000 \mathrm{E}+00$ & 0.0000 & $0.000 \mathrm{E}+00$ & 0.0000 & $0.000 \mathrm{E}+00$ & 0.0000 & $0.000 \mathrm{E}+00$ & 0.0000 & $0.000 \mathrm{E}+00$ & 0.0000 & $0.000 \mathrm{E}+00$ & 0.0000 & $7.849 \mathrm{E}-14$ & 0.0000 \\
\hline-137 & $0.000 \mathrm{E}+00$ & 0.0000 & $0.000 \mathrm{E}+00$ & 0.0000 & $0.000 \mathrm{E}+00$ & 0.0000 & $0.000 \mathrm{E}+00$ & 0.0000 & $0.000 \mathrm{E}+00$ & 0.0000 & $0.000 \mathrm{E}+00$ & 0.0000 & 1. $491 \mathrm{E}-12$ & 0.0000 \\
\hline-237 & $0.000 \mathrm{E}+00$ & 0.0000 & $0.000 \mathrm{E}+00$ & 0.0000 & $0.000 \mathrm{E}+00$ & 0.0000 & $0.000 \mathrm{E}+00$ & 0.0000 & $0.000 \mathrm{E}+00$ & 0.0000 & $0.000 \mathrm{E}+00$ & 0.0000 & $1.111 \mathrm{E}-10$ & 0.0000 \\
\hline-238 & $0.000 \mathrm{E}+00$ & 0.0000 & $0.000 \mathrm{E}+00$ & 0.0000 & $0.000 \mathrm{E}+00$ & 0.0000 & $0.000 \mathrm{E}+00$ & 0.0000 & $0.000 \mathrm{E}+00$ & 0.0000 & $0.000 \mathrm{E}+00$ & 0.0000 & $2.109 \mathrm{E}-12$ & 0.0000 \\
\hline-239 & $0.000 \mathrm{E}+00$ & 0.0000 & $0.000 \mathrm{E}+00$ & 0.0000 & $0.000 \mathrm{E}+00$ & 0.0000 & $0.000 \mathrm{E}+00$ & 0.0000 & $0.000 \mathrm{E}+00$ & 0.0000 & $0.000 E+00$ & 0.0000 & $1.636 \mathrm{E}-14$ & 0.0000 \\
\hline-240 & $0.000 \mathrm{E}+00$ & 0.0000 & $0.000 \mathrm{E}+00$ & 0.0000 & $0.000 \mathrm{E}+00$ & 0.0000 & $0.000 \mathrm{E}+00$ & 0.0000 & $0.000 \mathrm{E}+00$ & 0.0000 & $0.000 E+00$ & 0.0000 & $1.985 \mathrm{E}-17$ & 0.0000 \\
\hline-99 & $0.000 \mathrm{E}+00$ & 0.0000 & $0.000 \mathrm{E}+00$ & 0.0000 & $0.000 \mathrm{E}+00$ & 0.0000 & $0.000 \mathrm{E}+00$ & 0.0000 & $0.000 \mathrm{E}+00$ & 0.0000 & $0.000 \mathrm{E}+00$ & 0.0000 & $3.036 \mathrm{E}-22$ & 0.0000 \\
\hline-228 & $0.000 \mathrm{E}+00$ & 0.0000 & $0.000 \mathrm{E}+00$ & 0.0000 & $0.000 \mathrm{E}+00$ & 0.0000 & $0.000 \mathrm{E}+00$ & 0.0000 & $0.000 \mathrm{E}+00$ & 0.0000 & $0.000 \mathrm{E}+00$ & 0.0000 & $0.000 \mathrm{E}+00$ & 0.0000 \\
\hline-230 & $0.000 \mathrm{E}+00$ & 0.0000 & $0.000 \mathrm{E}+00$ & 0.0000 & $0.000 \mathrm{E}+00$ & 0.0000 & $0.000 \mathrm{E}+00$ & 0.0000 & $0.000 \mathrm{E}+00$ & 0.0000 & $0.000 E+00$ & 0.0000 & $1.032 \mathrm{E}-05$ & 0.4425 \\
\hline-232 & $0.000 \mathrm{E}+00$ & 0.0000 & $0.000 \mathrm{E}+00$ & 0.0000 & $0.000 \mathrm{E}+00$ & 0.0000 & $0.000 \mathrm{E}+00$ & 0.0000 & $0.000 \mathrm{E}+00$ & 0.0000 & $0.000 \mathrm{E}+00$ & 0.0000 & 1. $285 \mathrm{E}-05$ & 0.5508 \\
\hline 34 & $0.000 \mathrm{E}+00$ & 0.0000 & $0.000 \mathrm{E}+00$ & 0.0000 & $0.000 \mathrm{E}+00$ & 0.0000 & $0.000 \mathrm{E}+00$ & 0.0000 & $0.000 \mathrm{E}+00$ & 0.0000 & $0.000 \mathrm{E}+00$ & 0.0000 & $3.851 \mathrm{E}-08$ & 0.0017 \\
\hline 35 & $0.000 \mathrm{E}+00$ & 0.0000 & $0.000 \mathrm{E}+00$ & 0.0000 & $0.000 \mathrm{E}+00$ & 0.0000 & $0.000 \mathrm{E}+00$ & 0.0000 & $0.000 \mathrm{E}+00$ & 0.0000 & $0.000 \mathrm{E}+00$ & 0.0000 & $4.414 \mathrm{E}-11$ & 0.0000 \\
\hline 38 & $0.000 \mathrm{E}+00$ & 0.0000 & $0.000 \mathrm{E}+00$ & 0.0000 & $0.000 \mathrm{E}+00$ & 0.0000 & $0.000 \mathrm{E}+00$ & 0.0000 & $0.000 \mathrm{E}+00$ & 0.0000 & $0.000 \mathrm{E}+00$ & 0.0000 & $1.187 \mathrm{E}-07$ & 0.0051 \\
\hline & $0.000 \mathrm{E}+00$ & 0.0000 & $0.000 \mathrm{E}+00$ & 0.0000 & $0.000 \mathrm{E}+00$ & 0.0000 & $0.000 \mathrm{E}+00$ & 0.0000 & $0.000 \mathrm{E}+00$ & 0.0000 & $0.000 \mathrm{E}+00$ & 0.0000 & $3 E-05$ & 1.0000 \\
\hline
\end{tabular}

* Sum of all water independent and dependent pathways. 
RESRAD, Version 6.5

$\mathrm{T}^{1 / 2}$ Limit $=180$ days

ummary : C746U Recreational User Deterministic Run

: $\mathrm{X}: \backslash F I N A L$ V2 $\backslash$ DOE FWD RUNS \C746U RU DOE SG FWD-FV2-1050YR.RAD

Total Dose Contributions TDOSE (i,p,t) for Individual Radionuclides (i) and Pathways (p) As mrem/yr and Fraction of Total Dose At $t=1.050 \mathrm{E}+03$ years

Water Independent Pathways (Inhalation excludes radon)

\begin{tabular}{|c|c|c|c|c|c|c|c|c|c|c|c|c|c|c|}
\hline \multirow{2}{*}{ Nuclide } & \multicolumn{2}{|c|}{ Ground } & \multicolumn{2}{|c|}{ Inhalation } & \multicolumn{2}{|c|}{ Radon } & \multicolumn{2}{|c|}{ Plant } & \multicolumn{2}{|c|}{ Meat } & \multicolumn{2}{|c|}{ Milk } & \multicolumn{2}{|c|}{ Soil } \\
\hline & mrem/yr & fract. & mrem/yr & fract. & mrem/yr & fract. & mrem/yr & fract. & mrem/yr & fract. & mrem/yr & fract. & mrem/yr & fract. \\
\hline-241 & $4.250 \mathrm{E}-11$ & 0.0000 & $0.000 \mathrm{E}+00$ & 0.0000 & $0.000 \mathrm{E}+00$ & 0.0000 & $0.000 \mathrm{E}+00$ & 0.0000 & $0.000 \mathrm{E}+00$ & 0.0000 & $0.000 \mathrm{E}+00$ & 0.0000 & $0.000 \mathrm{E}+00$ & 0.0000 \\
\hline-137 & $4.627 E-16$ & 0.0000 & $0.000 \mathrm{E}+00$ & 0.0000 & $0.000 \mathrm{E}+00$ & 0.0000 & $0.000 \mathrm{E}+00$ & 0.0000 & $0.000 \mathrm{E}+00$ & 0.0000 & $0.000 \mathrm{E}+00$ & 0.0000 & $0.000 \mathrm{E}+00$ & 0.0000 \\
\hline-237 & $3.985 E-08$ & 0.0000 & $0.000 \mathrm{E}+00$ & 0.0000 & $0.000 \mathrm{E}+00$ & 0.0000 & $0.000 \mathrm{E}+00$ & 0.0000 & $0.000 \mathrm{E}+00$ & 0.0000 & $0.000 \mathrm{E}+00$ & 0.0000 & $0.000 \mathrm{E}+00$ & 0.0000 \\
\hline-238 & $4.914 \mathrm{E}-10$ & 0.0000 & $0.000 \mathrm{E}+00$ & 0.0000 & $0.000 \mathrm{E}+00$ & 0.0000 & $0.000 \mathrm{E}+00$ & 0.0000 & $0.000 \mathrm{E}+00$ & 0.0000 & $0.000 \mathrm{E}+00$ & 0.0000 & $0.000 \mathrm{E}+00$ & 0.0000 \\
\hline-239 & $1.164 \mathrm{E}-11$ & 0.0000 & $0.000 \mathrm{E}+00$ & 0.0000 & $0.000 \mathrm{E}+00$ & 0.0000 & $0.000 \mathrm{E}+00$ & 0.0000 & $0.000 \mathrm{E}+00$ & 0.0000 & $0.000 \mathrm{E}+00$ & 0.0000 & $0.000 \mathrm{E}+00$ & 0.0000 \\
\hline-240 & $2.820 \mathrm{E}-15$ & 0.0000 & $0.000 \mathrm{E}+00$ & 0.0000 & $0.000 \mathrm{E}+00$ & 0.0000 & $0.000 \mathrm{E}+00$ & 0.0000 & $0.000 \mathrm{E}+00$ & 0.0000 & $0.000 \mathrm{E}+00$ & 0.0000 & $0.000 \mathrm{E}+00$ & 0.0000 \\
\hline 99 & $6.409 \mathrm{E}-19$ & 0.0000 & $0.000 \mathrm{E}+00$ & 0.0000 & $0.000 \mathrm{E}+00$ & 0.0000 & $0.000 \mathrm{E}+00$ & 0.0000 & $0.000 \mathrm{E}+00$ & 0.0000 & $0.000 \mathrm{E}+00$ & 0.0000 & $0.000 \mathrm{E}+00$ & 0.0000 \\
\hline-228 & $0.000 \mathrm{E}+00$ & 0.0000 & $0.000 \mathrm{E}+00$ & 0.0000 & $0.000 \mathrm{E}+00$ & 0.0000 & $0.000 \mathrm{E}+00$ & 0.0000 & $0.000 \mathrm{E}+00$ & 0.0000 & $0.000 \mathrm{E}+00$ & 0.0000 & $0.000 \mathrm{E}+00$ & 0.0000 \\
\hline-230 & $8.661 \mathrm{E}-04$ & 0.6991 & $0.000 \mathrm{E}+00$ & 0.0000 & $0.000 \mathrm{E}+00$ & 0.0000 & $0.000 \mathrm{E}+00$ & 0.0000 & $0.000 \mathrm{E}+00$ & 0.0000 & $0.000 \mathrm{E}+00$ & 0.0000 & $0.000 \mathrm{E}+00$ & 0.0000 \\
\hline-232 & $3.560 E-04$ & 0.2874 & $0.000 \mathrm{E}+00$ & 0.0000 & $0.000 \mathrm{E}+00$ & 0.0000 & $0.000 \mathrm{E}+00$ & 0.0000 & $0.000 \mathrm{E}+00$ & 0.0000 & $0.000 \mathrm{E}+00$ & 0.0000 & $0.000 \mathrm{E}+00$ & 0.0000 \\
\hline 234 & $7.034 \mathrm{E}-06$ & 0.0057 & $0.000 \mathrm{E}+00$ & 0.0000 & $0.000 \mathrm{E}+00$ & 0.0000 & $0.000 \mathrm{E}+00$ & 0.0000 & $0.000 \mathrm{E}+00$ & 0.0000 & $0.000 \mathrm{E}+00$ & 0.0000 & $0.000 \mathrm{E}+00$ & 0.0000 \\
\hline 235 & $1.481 \mathrm{E}-08$ & 0.0000 & $0.000 \mathrm{E}+00$ & 0.0000 & $0.000 \mathrm{E}+00$ & 0.0000 & $0.000 \mathrm{E}+00$ & 0.0000 & $0.000 \mathrm{E}+00$ & 0.0000 & $0.000 \mathrm{E}+00$ & 0.0000 & $0.000 \mathrm{E}+00$ & 0.0000 \\
\hline 38 & $9.634 \mathrm{E}-06$ & 0.0078 & $0.000 \mathrm{E}+00$ & 0.0000 & $0.000 \mathrm{E}+00$ & 0.0000 & $0.000 \mathrm{E}+00$ & 0.0000 & $0.000 \mathrm{E}+00$ & 0.0000 & $0.000 \mathrm{E}+00$ & 0.0000 & $0.000 \mathrm{E}+00$ & 0.0000 \\
\hline & $1.239 \mathrm{E}-03$ & 1.0000 & $0.000 \mathrm{E}+00$ & 0.0000 & $0.000 \mathrm{E}+00$ & 0.0000 & $0.000 \mathrm{E}+00$ & 0.0000 & $0.000 \mathrm{E}+00$ & 0.0000 & $0.000 \mathrm{E}+00$ & 0.0000 & $.000 \mathrm{E}+00$ & 0.0000 \\
\hline
\end{tabular}

Total Dose Contributions TDOSE (i,p,t) for Individual Radionuclides (i) and Pathways (p) As mrem/yr and Fraction of Total Dose At $t=1.050 \mathrm{E}+03$ years

Water Dependent Pathways

\begin{tabular}{|c|c|c|c|c|c|c|c|c|c|c|c|c|c|c|}
\hline & \multicolumn{2}{|c|}{ Water } & \multicolumn{2}{|c|}{ Fish } & \multicolumn{2}{|c|}{ Radon } & \multicolumn{2}{|c|}{ Plant } & \multicolumn{2}{|c|}{ Meat } & \multicolumn{2}{|c|}{ Milk } & \multicolumn{2}{|c|}{ All Pathways* } \\
\hline clide & mrem/yr & fract. & mrem/yr & fract. & mrem/yr & fract. & mrem/yr & fract. & mrem/yr & fract. & mrem/yr & fract. & mrem/yr & fract. \\
\hline-241 & $0.000 \mathrm{E}+00$ & 0.0000 & $0.000 \mathrm{E}+00$ & 0.0000 & $0.000 \mathrm{E}+00$ & 0.0000 & $0.000 \mathrm{E}+00$ & 0.0000 & $0.000 \mathrm{E}+00$ & 0.0000 & $0.000 \mathrm{E}+00$ & 0.0000 & $4.250 \mathrm{E}-11$ & 0.0000 \\
\hline-137 & $0.000 \mathrm{E}+00$ & 0.0000 & $0.000 \mathrm{E}+00$ & 0.0000 & $0.000 \mathrm{E}+00$ & 0.0000 & $0.000 \mathrm{E}+00$ & 0.0000 & $0.000 \mathrm{E}+00$ & 0.0000 & $0.000 \mathrm{E}+00$ & 0.0000 & $4.627 \mathrm{E}-16$ & 0.0000 \\
\hline-237 & $0.000 \mathrm{E}+00$ & 0.0000 & $0.000 \mathrm{E}+00$ & 0.0000 & $0.000 \mathrm{E}+00$ & 0.0000 & $0.000 \mathrm{E}+00$ & 0.0000 & $0.000 \mathrm{E}+00$ & 0.0000 & $0.000 \mathrm{E}+00$ & 0.0000 & $3.985 E-08$ & 0.0000 \\
\hline 238 & $0.000 \mathrm{E}+00$ & 0.0000 & $0.000 \mathrm{E}+00$ & 0.0000 & $0.000 \mathrm{E}+00$ & 0.0000 & $0.000 \mathrm{E}+00$ & 0.0000 & $0.000 \mathrm{E}+00$ & 0.0000 & $0.000 \mathrm{E}+00$ & 0.0000 & $4.914 \mathrm{E}-10$ & 0.0000 \\
\hline 239 & $0.000 \mathrm{E}+00$ & 0.0000 & $0.000 \mathrm{E}+00$ & 0.0000 & $0.000 \mathrm{E}+00$ & 0.0000 & $0.000 \mathrm{E}+00$ & 0.0000 & $0.000 \mathrm{E}+00$ & 0.0000 & $0.000 \mathrm{E}+00$ & 0.0000 & $1.164 \mathrm{E}-11$ & 0.0000 \\
\hline 240 & $0.000 \mathrm{E}+00$ & 0.0000 & $0.000 \mathrm{E}+00$ & 0.0000 & $0.000 \mathrm{E}+00$ & 0.0000 & $0.000 \mathrm{E}+00$ & 0.0000 & $0.000 \mathrm{E}+00$ & 0.0000 & $0.000 \mathrm{E}+00$ & 0.0000 & $2.820 \mathrm{E}-15$ & 0.0000 \\
\hline 99 & $0.000 \mathrm{E}+00$ & 0.0000 & $0.000 \mathrm{E}+00$ & 0.0000 & $0.000 \mathrm{E}+00$ & 0.0000 & $0.000 \mathrm{E}+00$ & 0.0000 & $0.000 \mathrm{E}+00$ & 0.0000 & $0.000 \mathrm{E}+00$ & 0.0000 & $6.409 \mathrm{E}-19$ & 0.0000 \\
\hline 228 & $0.000 \mathrm{E}+00$ & 0.0000 & $0.000 \mathrm{E}+00$ & 0.0000 & $0.000 \mathrm{E}+00$ & 0.0000 & $0.000 \mathrm{E}+00$ & 0.0000 & $0.000 \mathrm{E}+00$ & 0.0000 & $0.000 \mathrm{E}+00$ & 0.0000 & $0.000 \mathrm{E}+00$ & 0.0000 \\
\hline 230 & $0.000 \mathrm{E}+00$ & 0.0000 & $0.000 \mathrm{E}+00$ & 0.0000 & $0.000 \mathrm{E}+00$ & 0.0000 & $0.000 \mathrm{E}+00$ & 0.0000 & $0.000 \mathrm{E}+00$ & 0.0000 & $0.000 \mathrm{E}+00$ & 0.0000 & $8.661 E-04$ & 0.6991 \\
\hline 232 & $0.000 \mathrm{E}+00$ & 0.0000 & $0.000 \mathrm{E}+00$ & 0.0000 & $0.000 \mathrm{E}+00$ & 0.0000 & $0.000 \mathrm{E}+00$ & 0.0000 & $0.000 \mathrm{E}+00$ & 0.0000 & $0.000 \mathrm{E}+00$ & 0.0000 & $3.560 \mathrm{E}-04$ & 0.2874 \\
\hline 34 & $0.000 \mathrm{E}+00$ & 0.0000 & $0.000 \mathrm{E}+00$ & 0.0000 & $0.000 \mathrm{E}+00$ & 0.0000 & $0.000 \mathrm{E}+00$ & 0.0000 & $0.000 \mathrm{E}+00$ & 0.0000 & $0.000 \mathrm{E}+00$ & 0.0000 & $7.034 \mathrm{E}-06$ & 0.0057 \\
\hline 35 & $0.000 \mathrm{E}+00$ & 0.0000 & $0.000 \mathrm{E}+00$ & 0.0000 & $0.000 \mathrm{E}+00$ & 0.0000 & $0.000 \mathrm{E}+00$ & 0.0000 & $0.000 \mathrm{E}+00$ & 0.0000 & $0.000 \mathrm{E}+00$ & 0.0000 & $1.481 \mathrm{E}-08$ & 0.0000 \\
\hline 38 & $0.000 \mathrm{E}+00$ & 0.0000 & $0.000 \mathrm{E}+00$ & 0.0000 & $0.000 \mathrm{E}+00$ & 0.0000 & $0.000 \mathrm{E}+00$ & 0.0000 & $0.000 \mathrm{E}+00$ & 0.0000 & $0.000 \mathrm{E}+00$ & 0.0000 & $9.634 \mathrm{E}-06$ & 0.0078 \\
\hline & $0.000 \mathrm{E}+00$ & 0.0000 & $0.000 \mathrm{E}+00$ & 0.0000 & $0.000 \mathrm{E}+00$ & 0.0000 & $0.000 \mathrm{E}+00$ & 0.0000 & $0.000 \mathrm{E}+00$ & 0.0000 & $0.000 \mathrm{E}+00$ & 000 & -03 & 1.0000 \\
\hline
\end{tabular}

* Sum of all water independent and dependent pathways. 
RESRAD, Version $6.5 \quad \mathrm{~T}^{1 / 2}$ Limit $=180$ days

Summary : C746U Recreational User Deterministic Run

File : $\mathrm{X}: \backslash F I N A L$ V2 $\backslash$ DOE FWD RUNS \C746U RU DOE SG FWD-FV2-1050YR.RAD

Dose/Source Ratios Summed Over All Pathways

Parent and Progeny Principal Radionuclide Contributions Indicated

Parent Product Thread DSR $(j, t)$ At Time in Years (mrem/yr)/(pCi/g)

(i)

(j)

$\begin{array}{ll}\mathrm{Am}-241 & 1.000 \mathrm{E}+00 \\ \mathrm{~Np}-237+\mathrm{D} & 1.000 \mathrm{E}+00 \\ \mathrm{U}-233 & 1.000 \mathrm{E}+00 \\ \mathrm{Th}-229+\mathrm{D} & 1.000 \mathrm{E}+00 \\ \operatorname{\sum DSR}(j) & \end{array}$

Cs $-137+D$

$\mathrm{Np}-237+\mathrm{D}$

U-233

Th-229+D

$\sum \operatorname{DSR}(j)$

$\mathrm{Pu}-238$

$\mathrm{Pu}-238$

U-234

Th-230

Ra-226+D

$\mathrm{Pb}-210+\mathrm{D}$

$\sum \operatorname{DSR}(j)$

$\mathrm{Pu}-239$

U-235+D

$\mathrm{Pa}-231$

$\mathrm{AC}-227+\mathrm{D}$

$\sum \operatorname{DSR}(j)$

$\mathrm{Pu}-240$

Pu-240

U-236

Th-232

$\mathrm{Ra}-228+\mathrm{D}$

Th-228+D

$\sum \operatorname{DSR}(j)$

TC-99

Th-228+D

Th-230

Ra-226+D

$\mathrm{Pb}-210+\mathrm{D}$

$\sum \operatorname{DSR}(j)$ $\begin{array}{lllllllll}1.000 \mathrm{E}+00 & 1.213 \mathrm{E}-10 & 1.196 \mathrm{E}-10 & 5.821 \mathrm{E}-11 & 2.793 \mathrm{E}-11 & 7.847 \mathrm{E}-14 & 2.435 \mathrm{E}-17\end{array}$

$\begin{array}{lllllll}1.000 \mathrm{E}+00 & 9.169 \mathrm{E}-14 & 9.268 \mathrm{E}-14 & 1.567 \mathrm{E}-13 & 2.679 \mathrm{E}-13 & 1.952 \mathrm{E}-11 & 7.101 \mathrm{E}-09\end{array}$

$\begin{array}{lllllll}1.000 \mathrm{E}+00 \quad 3.120 \mathrm{E}-24 & 9.466 \mathrm{E}-24 & 5.875 \mathrm{E}-22 & 2.184 \mathrm{E}-21 & 1.613 \mathrm{E}-18 & 3.273 \mathrm{E}-15\end{array}$

$\begin{array}{lllllll}1.000 \mathrm{E}+00 & 2.848 \mathrm{E}-20 & 2.006 \mathrm{E}-19 & 3.076 \mathrm{E}-16 & 1.723 \mathrm{E}-15 & 6.884 \mathrm{E}-13 & 1.443 \mathrm{E}-10\end{array}$ $\begin{array}{lllllll}9.169 \mathrm{E}-14 & 9.268 \mathrm{E}-14 & 1.570 \mathrm{E}-13 & 2.696 \mathrm{E}-13 & 2.021 \mathrm{E}-11 & 7.245 \mathrm{E}-09\end{array}$

$\begin{array}{lllllll}1.840 E-09 & 2.079 E-34 & 2.099 E-34 & 3.386 E-34 & 5.515 E-34 & 2.732 E-32 & 5.849 E-30\end{array}$

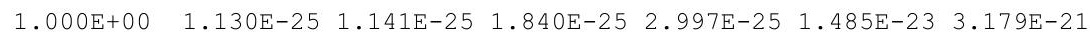

$\begin{array}{llllllll}1.000 \mathrm{E}+00 & 9.402 \mathrm{E}-31 & 2.855 \mathrm{E}-30 & 1.897 \mathrm{E}-28 & 7.660 \mathrm{E}-28 & 1.633 \mathrm{E}-24 & 2.820 \mathrm{E}-20\end{array}$

$\begin{array}{lllllll}1.000 \mathrm{E}+00 & 9.887 \mathrm{E}-35 & 7.005 \mathrm{E}-34 & 1.538 \mathrm{E}-30 & 1.253 \mathrm{E}-29 & 1.259 \mathrm{E}-25 & 3.198 \mathrm{E}-21\end{array}$

$\begin{array}{llllllll}1.000 \mathrm{E}+00 & 7.713 \mathrm{E}-24 & 1.162 \mathrm{E}-22 & 5.065 \mathrm{E}-18 & 5.122 \mathrm{E}-17 & 5.408 \mathrm{E}-14 & 1.260 \mathrm{E}-11\end{array}$

$\begin{array}{lllllll}1.000 \mathrm{E}+00 & 2.237 \mathrm{E}-32 & 6.933 \mathrm{E}-31 & 7.476 \mathrm{E}-25 & 1.264 \mathrm{E}-23 & 3.542 \mathrm{E}-20 & 1.664 \mathrm{E}-17\end{array}$

$\begin{array}{lllllll}7.826 \mathrm{E}-24 & 1.163 \mathrm{E}-22 & 5.065 \mathrm{E}-18 & 5.122 \mathrm{E}-17 & 5.408 \mathrm{E}-14 & 1.260 \mathrm{E}-11\end{array}$

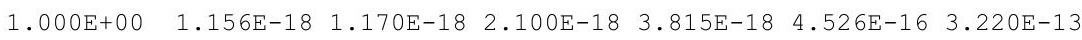

$\begin{array}{llllll}1.000 \mathrm{E}+00 \quad 5.899 \mathrm{E}-25 & 1.789 \mathrm{E}-24 & 1.102 \mathrm{E}-22 & 4.068 \mathrm{E}-22 & 2.830 \mathrm{E}-19 & 5.291 \mathrm{E}-16\end{array}$

$\begin{array}{llllllll}1.000 \mathrm{E}+00 & 9.281 \mathrm{E}-29 & 6.556 \mathrm{E}-28 & 1.203 \mathrm{E}-24 & 8.097 \mathrm{E}-24 & 1.394 \mathrm{E}-20 & 2.092 \mathrm{E}-17\end{array}$

$\begin{array}{lllllll}1.000 \mathrm{E}+00 & 2.200 \mathrm{E}-28 & 3.302 \mathrm{E}-27 & 1.227 \mathrm{E}-22 & 1.125 \mathrm{E}-21 & 1.425 \mathrm{E}-18 & 8.591 \mathrm{E}-16\end{array}$

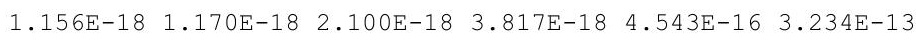

4.950E-08 5.436E-33 5.532E-33 1.307E-32 3.144E-32 3.519E-29 5.479E-25

1.000E+00 1.098E-25 1.118E-25 2.641E-25 6.352E-25 $\quad 7.109 \mathrm{E}-22 \quad 1.107 \mathrm{E}-17$

$\begin{array}{llllllll}1.000 E+00 & 2.079 E-33 & 6.337 E-33 & 5.132 E-31 & 2.504 E-30 & 1.628 E-26 & 6.574 E-22\end{array}$

$\begin{array}{llllllll}1.000 E+00 & 2.803 E-44 & 1.948 E-43 & 5.271 E-40 & 5.270 E-39 & 2.159 E-34 & 2.528 E-29\end{array}$

$\begin{array}{lllllll}1.000 \mathrm{E}+00 & 1.318 \mathrm{E}-29 & 1.940 \mathrm{E}-28 & 3.618 \mathrm{E}-24 & 2.445 \mathrm{E}-23 & 1.417 \mathrm{E}-20 & 4.042 \mathrm{E}-18\end{array}$

$\begin{array}{llllllll}1.000 \mathrm{E}+00 & 7.799 \mathrm{E}-29 & 2.244 \mathrm{E}-27 & 2.540 \mathrm{E}-22 & 1.691 \mathrm{E}-21 & 5.366 \mathrm{E}-19 & 6.323 \mathrm{E}-17\end{array}$

$\begin{array}{lllllll}1.099 \mathrm{E}-25 & 1.142 \mathrm{E}-25 & 2.579 \mathrm{E}-22 & 1.716 \mathrm{E}-21 & 5.515 \mathrm{E}-19 & 7.834 \mathrm{E}-17\end{array}$

$\begin{array}{lllllll}1.000 \mathrm{E}+00 & 5.547 \mathrm{E}-27 & 5.625 \mathrm{E}-27 & 1.112 \mathrm{E}-26 & 2.231 \mathrm{E}-26 & 5.839 \mathrm{E}-24 & 1.233 \mathrm{E}-20\end{array}$

$\begin{array}{lllllll}1.000 \mathrm{E}+00 & 1.329 \mathrm{E}-07 & 9.308 \mathrm{E}-08 & 2.430 \mathrm{E}-15 & 4.441 \mathrm{E}-23 & 0.000 \mathrm{E}+00 \quad 0.000 \mathrm{E}+00\end{array}$

$\begin{array}{llllllll}1.000 \mathrm{E}+00 & 2.319 \mathrm{E}-23 & 2.359 \mathrm{E}-23 & 5.375 \mathrm{E}-23 & 1.246 \mathrm{E}-22 & 1.037 \mathrm{E}-19 & 1.074 \mathrm{E}-15\end{array}$

$\begin{array}{llllllll}1.000 \mathrm{E}+00 & 3.629 \mathrm{E}-12 & 1.095 \mathrm{E}-11 & 5.116 \mathrm{E}-10 & 1.423 \mathrm{E}-09 & 1.032 \mathrm{E}-07 & 8.661 \mathrm{E}-06\end{array}$

$1.000 \mathrm{E}+00 \quad 1.749 \mathrm{E}-20 \quad 1.222 \mathrm{E}-19 \quad 1.249 \mathrm{E}-16 \quad 5.113 \mathrm{E}-16 \quad 7.402 \mathrm{E}-14 \quad 1.190 \mathrm{E}-11$

$3.629 \mathrm{E}-12$ 1.095E-11 $5.116 \mathrm{E}-10 \quad 1.423 \mathrm{E}-09 \quad 1.032 \mathrm{E}-07 \quad 8.661 \mathrm{E}-06$ 
RESRAD, Version $6.5 \quad \mathrm{~T}^{1 / 2}$ Limit $=180$ days

Summary : C746U Recreational User Deterministic Run

File : $X: \backslash F I N A L$ V2 $\backslash$ DOE FWD RUNS \C746U RU DOE SG FWD-FV2-1050YR. RAD

Dose/Source Ratios Summed Over All Pathways

Parent and Progeny Principal Radionuclide Contributions Indicated

\begin{tabular}{|c|c|c|c|c|c|c|c|c|}
\hline $\begin{array}{l}\text { Parent } \\
\text { (i) }\end{array}$ & $\begin{array}{l}\text { Product } \\
\text { (j) }\end{array}$ & $\begin{array}{l}\text { Thread } \\
\text { Fraction }\end{array}$ & $\begin{array}{r}\text { DSR } \\
0.000 \mathrm{E}+00\end{array}$ & $\begin{array}{l}(j, t) \text { At } T \\
1.000 E+00\end{array}$ & $\begin{array}{l}\text { ime in Yea } \\
5.000 \mathrm{E}+01\end{array}$ & $\begin{array}{l}\text { rs (mrem, } \\
1.000 \mathrm{E}+02\end{array}$ & $\begin{array}{l}(\mathrm{yr}) /(\mathrm{pCi} / \mathrm{g} \\
5.000 \mathrm{E}+02\end{array}$ & $\begin{array}{l}\text { g) } \\
1.050 \mathrm{E}+03\end{array}$ \\
\hline-232 & $\mathrm{Th}-232$ & $1.000 \mathrm{E}+00$ & $1.121 \mathrm{E}-25$ & $1.142 \mathrm{E}-25$ & $2.836 \mathrm{E}-25$ & $7.176 \mathrm{E}-25$ & 1. $205 E-21$ & $3.277 \mathrm{E}-17$ \\
\hline-232 & $\mathrm{Ra}-228+\mathrm{D}$ & $1.000 \mathrm{E}+00$ & $1.065 \mathrm{E}-10$ & $3.052 \mathrm{E}-10$ & $2.678 \mathrm{E}-09$ & $3.923 \mathrm{E}-09$ & $8.176 \mathrm{E}-08$ & $5.322 \mathrm{E}-06$ \\
\hline $1-232$ & $T h-228+D$ & $1.000 \mathrm{E}+00$ & $1.026 \mathrm{E}-09$ & $6.328 E-09$ & $2.128 \mathrm{E}-07$ & $2.877 \mathrm{E}-07$ & $3.130 \mathrm{E}-06$ & $8.368 E-05$ \\
\hline-232 & $\sum \operatorname{DSR}(j)$ & & $1.133 E-09$ & $6.633 E-09$ & $2.155 \mathrm{E}-07$ & $2.917 \mathrm{E}-07$ & $3.212 \mathrm{E}-06$ & $8.900 \mathrm{E}-05$ \\
\hline-234 & $\mathrm{U}-234$ & $1.000 \mathrm{E}+00$ & $6.631 E-25$ & $6.749 \mathrm{E}-25$ & 1. $607 \mathrm{E}-24$ & $3.895 E-24$ & $4.636 \mathrm{E}-21$ & $7.854 \mathrm{E}-17$ \\
\hline-234 & Th-230 & $1.000 \mathrm{E}+00$ & $1.047 \mathrm{E}-28$ & $3.188 \mathrm{E}-28$ & $2.443 E-26$ & $1.127 \mathrm{E}-25$ & $4.665 E-22$ & $1.013 \mathrm{E}-17$ \\
\hline-234 & $\mathrm{Ra}-226+\mathrm{D}$ & $1.000 \mathrm{E}+00$ & $1.090 \mathrm{E}-17$ & $7.671 \mathrm{E}-17$ & $1.167 \mathrm{E}-13$ & $6.482 \mathrm{E}-13$ & $2.407 \mathrm{E}-10$ & 4. 396E-08 \\
\hline-234 & $\mathrm{~Pb}-210+\mathrm{D}$ & $1.000 \mathrm{E}+00$ & $3.944 \mathrm{E}-26$ & $5.916 \mathrm{E}-25$ & $2.118 \mathrm{E}-20$ & $1.862 \mathrm{E}-19$ & $1.619 \mathrm{E}-16$ & $5.847 \mathrm{E}-14$ \\
\hline-234 & $\sum \operatorname{DSR}(j)$ & & $1.090 \mathrm{E}-17$ & $7.671 \mathrm{E}-17$ & $1.167 \mathrm{E}-13$ & $6.482 \mathrm{E}-13$ & $2.407 \mathrm{E}-10$ & $4.396 \mathrm{E}-08$ \\
\hline$-235+D$ & $\mathrm{U}-235+\mathrm{D}$ & $1.000 \mathrm{E}+00$ & $1.195 \mathrm{E}-15$ & $1.210 \mathrm{E}-15$ & $2.218 E-15$ & $4.115 \mathrm{E}-15$ & $5.779 \mathrm{E}-13$ & $5.183 \mathrm{E}-10$ \\
\hline$-235+D$ & $\mathrm{~Pa}-231$ & $1.000 \mathrm{E}+00$ & $2.825 E-19$ & $8.554 \mathrm{E}-19$ & $4.840 \mathrm{E}-17$ & $1.637 \mathrm{E}-16$ & $5.673 \mathrm{E}-14$ & $4.068 \mathrm{E}-11$ \\
\hline$-235+D$ & $A C-227+D$ & $1.000 \mathrm{E}+00$ & $8.917 \mathrm{E}-19$ & $6.232 \mathrm{E}-18$ & $6.620 \mathrm{E}-15$ & $2.832 \mathrm{E}-14$ & $6.156 \mathrm{E}-12$ & $1.720 \mathrm{E}-09$ \\
\hline$-235+D$ & $\sum \operatorname{DSR}(j)$ & & $1.197 \mathrm{E}-15$ & $1.217 \mathrm{E}-15$ & $8.886 \mathrm{E}-15$ & $3.260 \mathrm{E}-14$ & $6.791 \mathrm{E}-12$ & $2.279 \mathrm{E}-09$ \\
\hline-238 & $U-238$ & $5.400 E-05$ & $0.000 \mathrm{E}+00$ & $0.000 \mathrm{E}+00$ & $0.000 \mathrm{E}+00$ & $0.000 \mathrm{E}+00$ & $0.000 \mathrm{E}+00$ & $1.636 \mathrm{E}-39$ \\
\hline$-238+D$ & $\mathrm{U}-238+\mathrm{D}$ & $9.999 \mathrm{E}-01$ & 1. $365 \mathrm{E}-11$ & 1. $376 \mathrm{E}-11$ & $2.035 \mathrm{E}-11$ & $3.035 \mathrm{E}-11$ & 7. $419 \mathrm{E}-10$ & $6.017 \mathrm{E}-08$ \\
\hline$-238+D$ & $\mathrm{U}-234$ & $9.999 \mathrm{E}-01$ & $9.426 \mathrm{E}-31$ & $2.873 E-30$ & $2.301 \mathrm{E}-28$ & $1.110 \mathrm{E}-27$ & $6.582 \mathrm{E}-24$ & $2.342 \mathrm{E}-19$ \\
\hline$-238+D$ & $\mathrm{Th}-230$ & $9.999 E-01$ & $9.906 \mathrm{E}-35$ & $7.035 \mathrm{E}-34$ & $1.749 \mathrm{E}-30$ & $1.605 \mathrm{E}-29$ & $3.309 \mathrm{E}-25$ & $1.508 \mathrm{E}-20$ \\
\hline$-238+D$ & $\mathrm{Ra}-226+\mathrm{D}$ & $9.999 \mathrm{E}-01$ & $7.725 E-24$ & $1.165 E-22$ & $5.580 \mathrm{E}-18$ & $6.178 \mathrm{E}-17$ & $1.159 \mathrm{E}-13$ & $4.523 E-11$ \\
\hline$-238+D$ & $\mathrm{~Pb}-210+\mathrm{D}$ & $9.999 \mathrm{E}-01$ & $2.239 \mathrm{E}-32$ & $6.951 \mathrm{E}-31$ & $8.109 \mathrm{E}-25$ & $1.488 \mathrm{E}-23$ & 7. $347 \mathrm{E}-20$ & $5.837 \mathrm{E}-17$ \\
\hline$-238+D$ & $\sum \operatorname{DSR}(j)$ & & $1.365 \mathrm{E}-11$ & 1. $376 \mathrm{E}-11$ & $2.035 \mathrm{E}-11$ & $3.035 \mathrm{E}-11$ & $7.420 \mathrm{E}-10$ & $6.021 \mathrm{E}-08$ \\
\hline
\end{tabular}

The DSR includes contributions from associated (half-life $\leq 180$ days) daughters. 
RESRAD, Version $6.5 \quad \mathrm{~T}^{1 / 2}$ Limit $=180$ days

ummary : C746U Recreational User Deterministic Run

File : $\mathrm{X}: \backslash F I N A L$ V2 $\backslash$ DOE FWD RUNS $\backslash C 746 U$ RU DOE SG FWD-FV2-1050YR. RAD

Single Radionuclide Soil Guidelines G(i,t) in pCi/g

Basic Radiation Dose Limit $=1.000 \mathrm{E}+00 \mathrm{mrem} / \mathrm{yr}$

Nuclide

\begin{tabular}{|c|c|c|c|c|c|c|}
\hline (i) & $t=0.000 \mathrm{E}+00$ & $1.000 \mathrm{E}+00$ & $5.000 E+01$ & $1.000 \mathrm{E}+02$ & $5.000 \mathrm{E}+02$ & $1.050 \mathrm{E}+03$ \\
\hline$n-241$ & $\star 3.431 \mathrm{E}+12$ & $\star 3.431 \mathrm{E}+12$ & $\star 3.431 \mathrm{E}+12$ & $\star 3.431 \mathrm{E}+12$ & $* 3.431 \mathrm{E}+12$ & $8.235 \mathrm{E}+11$ \\
\hline$s-137$ & $8.242 E+09$ & $8.364 \mathrm{E}+09$ & $1.718 \mathrm{E}+10$ & $3.580 \mathrm{E}+10$ & $1.274 \mathrm{E}+13$ & $\star 8.704 \mathrm{E}+13$ \\
\hline$p-237$ & $\star 7.047 \mathrm{E}+08$ & $\star 7.047 \mathrm{E}+08$ & $\star 7.047 \mathrm{E}+08$ & $\star 7.047 \mathrm{E}+08$ & $\star 7.047 \mathrm{E}+08$ & $1.380 \mathrm{E}+08$ \\
\hline$u-238$ & $\star 1.712 \mathrm{E}+13$ & $\star 1.712 \mathrm{E}+13$ & $\star 1.712 \mathrm{E}+13$ & $* 1.712 \mathrm{E}+13$ & $* 1.712 \mathrm{E}+13$ & $7.937 \mathrm{E}+1 \mathrm{C}$ \\
\hline$u-239$ & $\star 6.214 \mathrm{E}+10$ & $* 6.214 \mathrm{E}+10$ & $* 6.214 \mathrm{E}+10$ & $* 6.214 \mathrm{E}+10$ & $\star 6.214 \mathrm{E}+10$ & $* 6.214 \mathrm{E}+1 \mathrm{C}$ \\
\hline $\mathrm{Pu}-240$ & $\star 2.278 \mathrm{E}+11$ & $\star 2.278 \mathrm{E}+11$ & $\star 2.278 \mathrm{E}+11$ & $\star 2.278 \mathrm{E}+11$ & $\star 2.278 \mathrm{E}+11$ & $\star 2.278 \mathrm{E}+11$ \\
\hline TC-99 & $\star 1.697 \mathrm{E}+10$ & $* 1.697 \mathrm{E}+10$ & $\star 1.697 \mathrm{E}+10$ & $* 1.697 \mathrm{E}+10$ & $\star 1.697 \mathrm{E}+10$ & $\star 1.697 \mathrm{E}+1 \mathrm{C}$ \\
\hline$T h-228$ & $7.523 E+06$ & $1.074 \mathrm{E}+07$ & $4.116 \mathrm{E}+14$ & $\star 8.195 \mathrm{E}+14$ & $\star 8.195 \mathrm{E}+14$ & $* 8.195 \mathrm{E}+1 \mathrm{C}$ \\
\hline$T h-230$ & $\star 2.018 \mathrm{E}+10$ & $\star 2.018 \mathrm{E}+10$ & $1.955 \mathrm{E}+09$ & $7.028 \mathrm{E}+08$ & $9.688 \mathrm{E}+06$ & $1.155 \mathrm{E}+05$ \\
\hline$T h-232$ & $* 1.097 \mathrm{E}+05$ & $\star 1.097 \mathrm{E}+05$ & $\star 1.097 \mathrm{E}+05$ & $\star 1.097 \mathrm{E}+05$ & $* 1.097 \mathrm{E}+05$ & $1.124 \mathrm{E}+04$ \\
\hline$U-234$ & $\star 6.247 \mathrm{E}+09$ & $\star 6.247 \mathrm{E}+09$ & $* 6.247 \mathrm{E}+09$ & $\star 6.247 \mathrm{E}+09$ & $4.154 \mathrm{E}+09$ & $2.275 \mathrm{E}+0$ \\
\hline 235 & $\star 2.161 \mathrm{E}+06$ & $\star 2.161 \mathrm{E}+06$ & $\star 2.161 \mathrm{E}+06$ & $\star 2.161 \mathrm{E}+06$ & $\star 2.161 \mathrm{E}+06$ & $\star 2.161 \mathrm{E}+0 \mathrm{E}$ \\
\hline 238 & $\star 3.361 \mathrm{E}+05$ & $\star 3.361 \mathrm{E}+05$ & $\star 3.361 \mathrm{E}+05$ & $\star 3.361 E+05$ & $\star 3.361 \mathrm{E}+05$ & $* 3.361 \mathrm{E}+05$ \\
\hline
\end{tabular}

*At specific activity limit

Summed Dose/Source Ratios DSR (i,t) in (mrem/yr)/(pCi/g)

and Single Radionuclide Soil Guidelines G(i,t) in pCi/g

at $\operatorname{tmin}=$ time of minimum single radionuclide soil guideline

and at $\operatorname{tmax}=$ time of maximum total dose $=1.050 \mathrm{E}+03$ years

\begin{tabular}{|c|c|c|c|c|c|c|}
\hline $\begin{array}{l}\text { uclide } \\
\text { (i) }\end{array}$ & $\begin{array}{l}\text { Initial } \\
(\mathrm{pCi} / \mathrm{g})\end{array}$ & $\begin{array}{c}\text { tmin } \\
\text { (years) }\end{array}$ & $\operatorname{DSR}(i, \operatorname{tmin})$ & $\begin{array}{c}G(i, \operatorname{tmin}) \\
(\mathrm{pCi} / \mathrm{g})\end{array}$ & $\operatorname{DSR}(i, t \max )$ & $\begin{array}{c}G(i, t \max ) \\
(\mathrm{pCi} / \mathrm{g})\end{array}$ \\
\hline $1-241$ & $3.500 \mathrm{E}+01$ & $1.050 \mathrm{E}+03$ & 1. $214 \mathrm{E}-12$ & $8.235 E+11$ & 1. $214 \mathrm{E}-12$ & $8.235 E+11$ \\
\hline-137 & $1.900 \mathrm{E}+01$ & $0.000 \mathrm{E}+00$ & $1.213 \mathrm{E}-10$ & $8.242 E+09$ & $2.435 E-17$ & $\star 8.704 \mathrm{E}+13$ \\
\hline-237 & $5.500 \mathrm{E}+00$ & $1.050 \mathrm{E}+03$ & $7.245 \mathrm{E}-09$ & $1.380 \mathrm{E}+08$ & $7.245 \mathrm{E}-09$ & $1.380 \mathrm{E}+08$ \\
\hline-238 & $3.900 \mathrm{E}+01$ & $1.050 \mathrm{E}+03$ & $1.260 \mathrm{E}-11$ & $7.937 \mathrm{E}+10$ & 1. $260 \mathrm{E}-11$ & $7.937 \mathrm{E}+10$ \\
\hline-239 & $3.600 \mathrm{E}+01$ & $1.050 \mathrm{E}+03$ & $3.234 \mathrm{E}-13$ & $\star 6.214 \mathrm{E}+10$ & $3.234 \mathrm{E}-13$ & $* 6.214 \mathrm{E}+10$ \\
\hline-240 & $3.600 \mathrm{E}+01$ & $1.050 \mathrm{E}+03$ & $7.834 \mathrm{E}-17$ & $\star 2.278 \mathrm{E}+11$ & $7.834 \mathrm{E}-17$ & $\star 2.278 \mathrm{E}+11$ \\
\hline-99 & $5.200 \mathrm{E}+01$ & $1.050 \mathrm{E}+03$ & $1.233 E-20$ & $\star 1.697 \mathrm{E}+10$ & $1.233 \mathrm{E}-20$ & $* 1.697 \mathrm{E}+10$ \\
\hline 228 & $4.000 \mathrm{E}+00$ & $0.000 \mathrm{E}+00$ & $1.329 \mathrm{E}-07$ & $7.523 E+06$ & $0.000 \mathrm{E}+00$ & $\star 8.195 \mathrm{E}+14$ \\
\hline-230 & $1.000 \mathrm{E}+02$ & $1.050 \mathrm{E}+03$ & $8.661 \mathrm{E}-06$ & $1.155 \mathrm{E}+05$ & $8.661 \mathrm{E}-06$ & $1.155 \mathrm{E}+05$ \\
\hline-232 & $4.000 \mathrm{E}+00$ & $1.050 \mathrm{E}+03$ & $8.900 \mathrm{E}-05$ & $1.124 \mathrm{E}+04$ & $8.900 E-05$ & $1.124 \mathrm{E}+04$ \\
\hline 234 & $1.600 \mathrm{E}+02$ & $1.050 \mathrm{E}+03$ & $4.396 \mathrm{E}-08$ & $2.275 E+07$ & $4.396 E-08$ & $2.275 E+07$ \\
\hline 235 & $6.500 \mathrm{E}+00$ & $1.050 \mathrm{E}+03$ & $2.279 \mathrm{E}-09$ & $\star 2.161 \mathrm{E}+06$ & $2.279 \mathrm{E}-09$ & $\star 2.161 \mathrm{E}+06$ \\
\hline 238 & $1.600 \mathrm{E}+02$ & $1.050 \mathrm{E}+03$ & $6.021 \mathrm{E}-08$ & $\star 3.361 \mathrm{E}+05$ & $6.021 E-08$ & $\star 3.361 \mathrm{E}+05$ \\
\hline
\end{tabular}

*At specific activity limit 
RESRAD, Version 6.5

Summary : C746U Recreational User Deterministic Run

File : $\mathrm{X}: \backslash F I N A L$ V2 $\backslash$ DOE FWD RUNS $\backslash C 746 U$ RU DOE SG FWD-FV2-1050YR.RAD

Individual Nuclide Dose Summed Over All Pathways

Parent Nuclide and Branch Fraction Indicated

Nuclide Parent THF(i) DOSE $(j, t)$, mrem/yr

\begin{tabular}{|c|c|c|}
\hline$(j)$ & (i) & \\
\hline-241 & $A m-241$ & $1.000 \mathrm{E}+00$ \\
\hline$p-237$ & $A m-241$ & $1.000 \mathrm{E}+00$ \\
\hline $\mathrm{Np}-237$ & $\mathrm{~Np}-237$ & $1.000 \mathrm{E}+00$ \\
\hline Np-237 & $\sum \operatorname{DOSE}(j$ & \\
\hline
\end{tabular}

$\mathrm{U}-233 \quad \mathrm{Am}-241 \quad 1.000 \mathrm{E}+00$

$\mathrm{U}-233 \quad \mathrm{~Np}-237 \quad 1.000 \mathrm{E}+00$

U-233 $\quad$ DOSE $(j)$

Th-229

Th-229

Th-229

Cs -137

$\mathrm{Pu}-238$

$\mathrm{Pu}-238$

$\mathrm{Pu}-238$

$\mathrm{U}-234$

$\mathrm{U}-234$

$\mathrm{U}-234$

$\mathrm{U}-234$

Th-230

$\mathrm{Th}-230$

Th -230

Th -230

$\mathrm{Th}-230$

$\mathrm{Ra}-226$

$\mathrm{Ra}-226$

$\mathrm{Ra}-226$

$\mathrm{Ra}-226$

$\operatorname{Ra}-226$

$\mathrm{Pb}-210$

$\mathrm{Pb}-210$

$\mathrm{Pb}-210$

$\mathrm{Pb}-210$

$\mathrm{Pb}-210$

$\mathrm{Pu}-239$

$\mathrm{U}-235$

$\mathrm{U}-235$

$\mathrm{U}-235$
$\mathrm{Np}-237 \quad 1.000 \mathrm{E}+00$

$\sum \operatorname{DOSE}(j)$

Cs-137 1.000E+00

$\mathrm{Pu}-238 \quad 1.000 \mathrm{E}+00$

$\sum \operatorname{DOSE}(j)$

Pu-238 1.000E+00

$\mathrm{U}-234 \quad 1.000 \mathrm{E}+00$

U-238 9.999E-01

$\operatorname{LDOSE}(j)$

$\mathrm{Pu}-238 \quad 1.000 \mathrm{E}+00$

Th-230 1.000E+00

$\mathrm{U}-234 \quad 1.000 \mathrm{E}+00$

$\sum \operatorname{DOSE}(j)$

$\mathrm{Pu}-238 \quad 1.000 \mathrm{E}+00$

Th-230 1.000E+00

$\mathrm{U}-238 \quad 9.999 \mathrm{E}-01$

$\sum \operatorname{DOSE}(j)$

$\mathrm{Pu}-238 \quad 1.000 \mathrm{E}+00$

Th-230 $1.000 \mathrm{E}+00$

U-234 $1.000 \mathrm{E}+00$

U-238 $9.999 \mathrm{E}-01$

$\operatorname{LDOSE}(j)$

$\mathrm{Pu}-239 \quad 1.000 \mathrm{E}+00$

$\mathrm{Pu}-239 \quad 1.000 \mathrm{E}+00$

¿DOSE (j)
$A m-241 \quad 1.000 \mathrm{E}+00$

Pu-238 1.840E-09

$\mathrm{U}-238 \quad 9.999 \mathrm{E}-01$

$\mathrm{U}-234 \quad 1.000 \mathrm{E}+00$

U-235 $1.000 \mathrm{E}+00$ $\mathrm{t}=0.000 \mathrm{E}+00 \quad 1.000 \mathrm{E}+00 \quad 5.000 \mathrm{E}+01 \quad 1.000 \mathrm{E}+02 \quad 5.000 \mathrm{E}+02 \quad 1.050 \mathrm{E}+03$

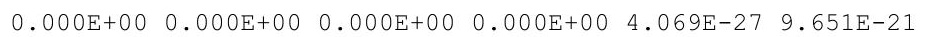

$\begin{array}{llllll}5.204 \mathrm{E}-19 & 1.575 \mathrm{E}-18 & 8.635 \mathrm{E}-17 & 2.829 \mathrm{E}-16 & 7.741 \mathrm{E}-14 & 4.210 \mathrm{E}-11\end{array}$

$5.043 \mathrm{E}-13 \quad 5.097 \mathrm{E}-13 \quad 8.620 \mathrm{E}-13 \quad 1.473 \mathrm{E}-12 \quad 1.073 \mathrm{E}-10 \quad 3.906 \mathrm{E}-08$

$\begin{array}{llllll}5.043 \mathrm{E}-13 & 5.097 \mathrm{E}-13 & 8.621 \mathrm{E}-13 & 1.474 \mathrm{E}-12 & 1.074 \mathrm{E}-10 & 3.910 \mathrm{E}-08\end{array}$

$\begin{array}{llllll}0.000 \mathrm{E}+00 & 8.344 \mathrm{E}-29 & 1.639 \mathrm{E}-25 & 1.182 \mathrm{E}-24 & 3.586 \mathrm{E}-21 & 1.209 \mathrm{E}-17\end{array}$

$\begin{array}{llllll}1.716 \mathrm{E}-23 & 5.206 \mathrm{E}-23 & 3.231 \mathrm{E}-21 & 1.201 \mathrm{E}-20 & 8.871 \mathrm{E}-18 & 1.800 \mathrm{E}-14\end{array}$

$\begin{array}{llllll}1.716 \mathrm{E}-23 & 5.206 \mathrm{E}-23 & 3.231 \mathrm{E}-21 & 1.201 \mathrm{E}-20 & 8.874 \mathrm{E}-18 & 1.801 \mathrm{E}-14\end{array}$

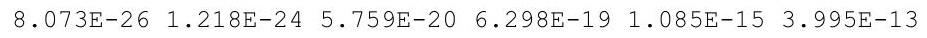

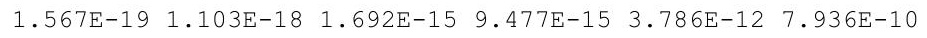

$\begin{array}{llllll}1.567 \mathrm{E}-19 & 1.103 \mathrm{E}-18 & 1.692 \mathrm{E}-15 & 9.478 \mathrm{E}-15 & 3.787 \mathrm{E}-12 & 7.940 \mathrm{E}-10\end{array}$

$2.305 \mathrm{E}-09 \quad 2.272 \mathrm{E}-09 \quad 1.106 \mathrm{E}-09 \quad 5.307 \mathrm{E}-10 \quad 1.491 \mathrm{E}-12 \quad 4.627 \mathrm{E}-16$

$\begin{array}{llllll}0.000 \mathrm{E}+00 & 0.000 \mathrm{E}+00 & 0.000 \mathrm{E}+00 & 0.000 \mathrm{E}+00 & 0.000 \mathrm{E}+00 & 2.281 \mathrm{E}-28\end{array}$

$\begin{array}{llllll}4.406 \mathrm{E}-24 & 4.449 \mathrm{E}-24 & 7.176 \mathrm{E}-24 & 1.169 \mathrm{E}-23 & 5.791 \mathrm{E}-22 & 1.240 \mathrm{E}-19\end{array}$

$\begin{array}{llllll}4.406 \mathrm{E}-24 & 4.449 \mathrm{E}-24 & 7.176 \mathrm{E}-24 & 1.169 \mathrm{E}-23 & 5.791 \mathrm{E}-22 & 1.240 \mathrm{E}-19\end{array}$

$\begin{array}{llllll}0.000 \mathrm{E}+00 & 1.114 \mathrm{E}-28 & 7.400 \mathrm{E}-27 & 2.988 \mathrm{E}-26 & 6.368 \mathrm{E}-23 & 1.100 \mathrm{E}-18\end{array}$

$\begin{array}{llllll}1.061 \mathrm{E}-22 & 1.080 \mathrm{E}-22 & 2.571 \mathrm{E}-22 & 6.232 \mathrm{E}-22 & 7.417 \mathrm{E}-19 & 1.257 \mathrm{E}-14\end{array}$

$0.000 \mathrm{E}+00 \quad 4.596 \mathrm{E}-28 \quad 3.681 \mathrm{E}-26 \quad 1.776 \mathrm{E}-25 \quad 1.053 \mathrm{E}-21 \quad 3.748 \mathrm{E}-17$

$\begin{array}{llllll}1.061 \mathrm{E}-22 & 1.080 \mathrm{E}-22 & 2.572 \mathrm{E}-22 & 6.234 \mathrm{E}-22 & 7.428 \mathrm{E}-19 & 1.261 \mathrm{E}-14\end{array}$

$\begin{array}{llllll}0.000 \mathrm{E}+00 & 0.000 \mathrm{E}+00 & 5.998 \mathrm{E}-29 & 4.887 \mathrm{E}-28 & 4.910 \mathrm{E}-24 & 1.247 \mathrm{E}-19\end{array}$

$\begin{array}{lllllll}2.319 \mathrm{E}-21 & 2.359 \mathrm{E}-21 & 5.375 \mathrm{E}-21 & 1.246 \mathrm{E}-20 & 1.037 \mathrm{E}-17 & 1.074 \mathrm{E}-13\end{array}$

$\begin{array}{llllll}1.675 \mathrm{E}-26 & 5.101 \mathrm{E}-26 & 3.909 \mathrm{E}-24 & 1.803 \mathrm{E}-23 & 7.463 \mathrm{E}-20 & 1.620 \mathrm{E}-15\end{array}$

$\begin{array}{lllllll}0.000 \mathrm{E}+00 & 0.000 \mathrm{E}+00 & 2.798 \mathrm{E}-28 & 2.568 \mathrm{E}-27 & 5.295 \mathrm{E}-23 & 2.413 \mathrm{E}-18\end{array}$

$\begin{array}{llllll}2.319 \mathrm{E}-21 & 2.359 \mathrm{E}-21 & 5.379 \mathrm{E}-21 & 1.248 \mathrm{E}-20 & 1.044 \mathrm{E}-17 & 1.090 \mathrm{E}-13\end{array}$

$3.008 \mathrm{E}-22 \quad 4.531 \mathrm{E}-21 \quad 1.975 \mathrm{E}-16 \quad 1.997 \mathrm{E}-15 \quad 2.109 \mathrm{E}-12 \quad 4.914 \mathrm{E}-10$ $\begin{array}{llllll}3.629 \mathrm{E}-10 & 1.095 \mathrm{E}-09 & 5.116 \mathrm{E}-08 & 1.423 \mathrm{E}-07 & 1.032 \mathrm{E}-05 & 8.661 \mathrm{E}-04\end{array}$ $\begin{array}{lllllll}1.743 \mathrm{E}-15 & 1.227 \mathrm{E}-14 & 1.867 \mathrm{E}-11 & 1.037 \mathrm{E}-10 & 3.851 \mathrm{E}-08 & 7.034 \mathrm{E}-06\end{array}$ $\begin{array}{llllll}1.236 \mathrm{E}-21 & 1.865 \mathrm{E}-20 & 8.928 \mathrm{E}-16 & 9.885 \mathrm{E}-15 & 1.854 \mathrm{E}-11 & 7.237 \mathrm{E}-09\end{array}$

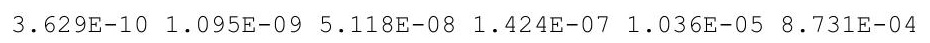

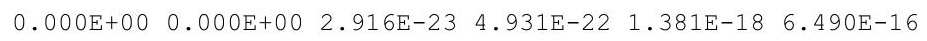
$\begin{array}{lllllll}1.749 \mathrm{E}-18 & 1.222 \mathrm{E}-17 & 1.249 \mathrm{E}-14 & 5.113 \mathrm{E}-14 & 7.402 \mathrm{E}-12 & 1.190 \mathrm{E}-0\end{array}$ $\begin{array}{llllll}6.310 \mathrm{E}-24 & 9.466 \mathrm{E}-23 & 3.388 \mathrm{E}-18 & 2.979 \mathrm{E}-17 & 2.590 \mathrm{E}-14 & 9.356 \mathrm{E}-12\end{array}$ $\begin{array}{llllll}0.000 \mathrm{E}+00 & 0.000 \mathrm{E}+00 & 1.297 \mathrm{E}-22 & 2.380 \mathrm{E}-21 & 1.176 \mathrm{E}-17 & 9.340 \mathrm{E}-15\end{array}$ $\begin{array}{llllll}1.749 \mathrm{E}-18 & 1.222 \mathrm{E}-17 & 1.250 \mathrm{E}-14 & 5.116 \mathrm{E}-14 & 7.428 \mathrm{E}-12 & 1.199 \mathrm{E}-09\end{array}$

$\begin{array}{llllll}4.161 \mathrm{E}-17 & 4.211 \mathrm{E}-17 & 7.560 \mathrm{E}-17 & 1.373 \mathrm{E}-16 & 1.629 \mathrm{E}-14 & 1.159 \mathrm{E}-11\end{array}$

$2.124 \mathrm{E}-23 \quad 6.441 \mathrm{E}-23 \quad 3.969 \mathrm{E}-21 \quad 1.465 \mathrm{E}-20 \quad 1.019 \mathrm{E}-17 \quad 1.905 \mathrm{E}-14$

$\begin{array}{lllllll}7.771 \mathrm{E}-15 & 7.867 \mathrm{E}-15 & 1.442 \mathrm{E}-14 & 2.675 \mathrm{E}-14 & 3.756 \mathrm{E}-12 & 3.369 \mathrm{E}-09\end{array}$

$\begin{array}{llllll}7.771 \mathrm{E}-15 & 7.867 \mathrm{E}-15 & 1.442 \mathrm{E}-14 & 2.675 \mathrm{E}-14 & 3.756 \mathrm{E}-12 & 3.369 \mathrm{E}-09\end{array}$ 
RESRAD, Version $6.5 \quad \mathrm{~T}^{1 / 2}$ Limit $=180$ days

Summary : C746U Recreational User Deterministic Run

File : $X: \backslash F I N A L$ V2 $\backslash$ DOE FWD RUNS \C746U RU DOE SG FWD-FV2-1050YR. RAD

Individual Nuclide Dose Summed Over All Pathways

Parent Nuclide and Branch Fraction Indicated

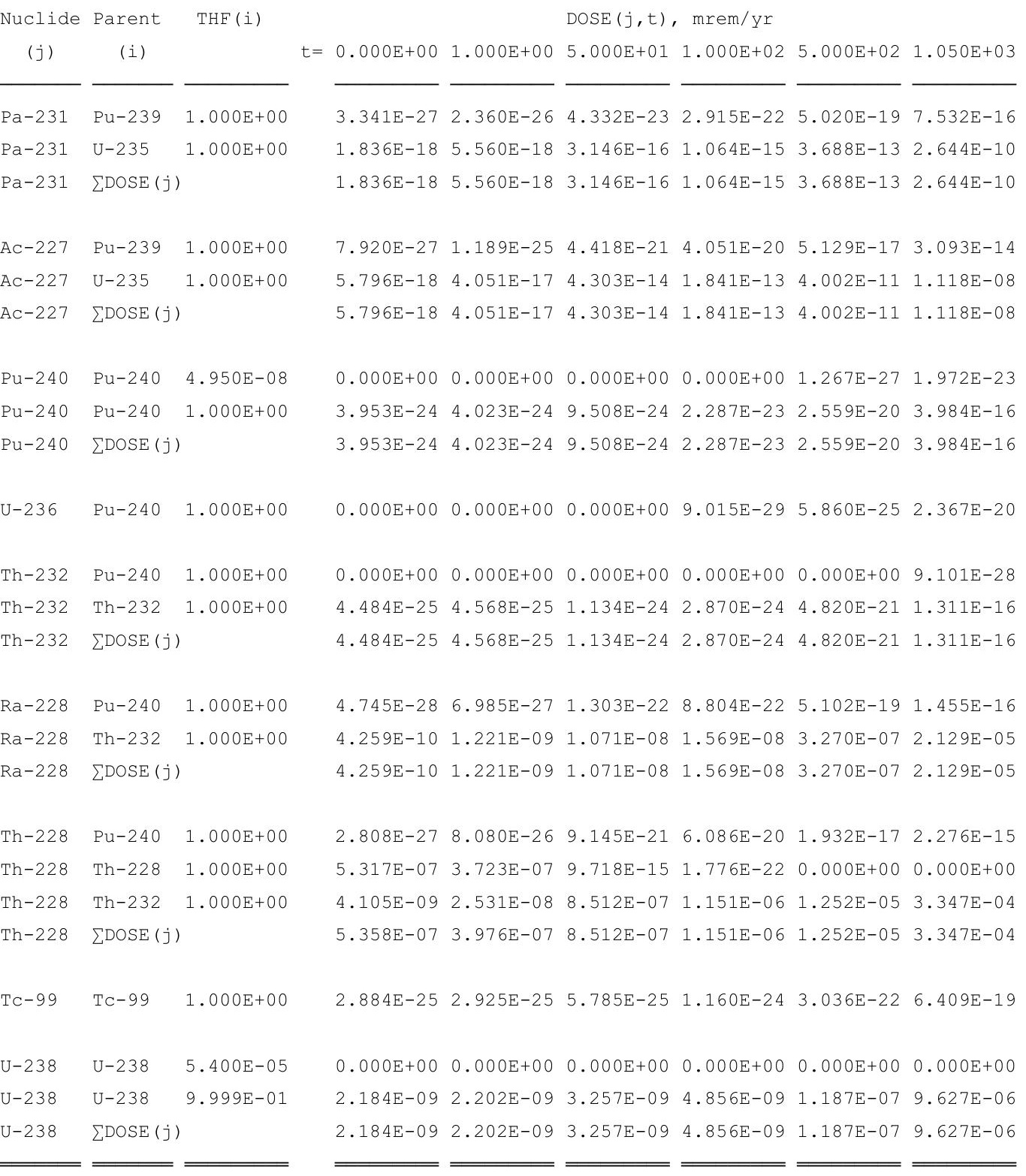

THF(i) is the thread fraction of the parent nuclide. 
RESRAD, Version 6.5

Summary : C746U Recreational User Deterministic Run

File : $\mathrm{X}: \backslash F I N A L$ V2 $\backslash$ DOE FWD RUNS $\backslash$ C746U RU DOE SG FWD-FV2-1050YR.RAD

Individual Nuclide Soil Concentration

Parent Nuclide and Branch Fraction Indicated

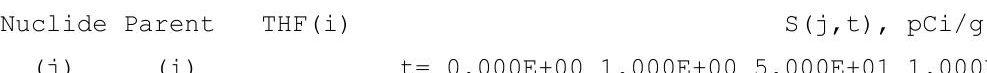

\section{(j)}

Am-241 Am-241 1.000E+00

$\mathrm{Np}-237 \mathrm{Am}-241 \quad 1.000 \mathrm{E}+00$

$\mathrm{Np}-237 \quad \mathrm{~Np}-237 \quad 1.000 \mathrm{E}+00$

Np-237 $\sum S(j):$

U-233 Am-241 1.000E+00

$\mathrm{U}-233 \mathrm{~Np}-237 \quad 1.000 \mathrm{E}+00$

$\mathrm{U}-233 \sum \mathrm{S}(j)$ :

Th-229

$\mathrm{Th}-229$

$\mathrm{Th}-229$

$\mathrm{Cs}-137$

$\mathrm{Pu}-238$

$\mathrm{Pu}-238$

$\mathrm{Pu}-238$

$\mathrm{U}-234$

$\mathrm{U}-234$

$\mathrm{U}-234$

$\mathrm{U}-234$

Th -230

$\mathrm{Th}-230$

$\mathrm{Th}-230$

$\mathrm{Th}-230$

$\mathrm{Th}-230$

$\mathrm{Ra}-226$

$\mathrm{Ra}-226$

$\mathrm{Ra}-226$

$\mathrm{Ra}-226$

$\mathrm{Ra}-226$

$\mathrm{Pb}-210$

$\mathrm{Pb}-210$

$\mathrm{Pb}-210$

$\mathrm{Pb}-210$

$\mathrm{Pb}-210$

Pu-239

Am-241 1.000E+00

$\mathrm{Np}-237 \quad 1.000 \mathrm{E}+00$

$\sum S(j):$

Cs-137 1.000E+00

Pu-238 1.840E-09

$\mathrm{Pu}-238 \quad 1.000 \mathrm{E}+00$

$\sum S(j):$

$\mathrm{Pu}-238 \quad 1.000 \mathrm{E}+00$

$\mathrm{U}-234 \quad 1.000 \mathrm{E}+00$

U-238 9.999E-01

$\sum S(j):$

$\mathrm{Pu}-238 \quad 1.000 \mathrm{E}+00$

Th-230 1.000E+00

U-234 $1.000 \mathrm{E}+00$

U-238 9.999E-01

$\sum S(j):$

$\mathrm{Pu}-238 \quad 1.000 \mathrm{E}+00$

Th-230 1.000E+00

$\mathrm{U}-234 \quad 1.000 \mathrm{E}+00$

U-238 9.999E-01

$\sum S(j):$

$\mathrm{Pu}-238 \quad 1.000 \mathrm{E}+00$

Th-230 1.000E+00

$\mathrm{U}-234 \quad 1.000 \mathrm{E}+00$

U-238 9.999E-01

$\sum S(j):$

Pu-239 1.000E+00

Pu-239 1.000E+00

$\mathrm{U}-235 \quad 1.000 \mathrm{E}+00$

$\sum S(j):$
$=0.000 \mathrm{E}+001.000 \mathrm{E}+00 \quad 5.000 \mathrm{E}+01 \quad 1.000 \mathrm{E}+02 \quad 5.000 \mathrm{E}+02 \quad 1.050 \mathrm{E}+03$

$\begin{array}{llllll}3.500 \mathrm{E}+01 & 3.494 \mathrm{E}+01 & 3.230 \mathrm{E}+01 & 2.981 \mathrm{E}+01 & 1.567 \mathrm{E}+01 & 6.478 \mathrm{E}+00\end{array}$

$0.000 \mathrm{E}+00 \quad 1.133 \mathrm{E}-05 \quad 5.436 \mathrm{E}-04 \quad 1.043 \mathrm{E}-03 \quad 3.810 \mathrm{E}-03 \quad 5.458 \mathrm{E}-03$

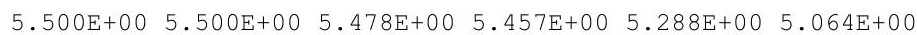

$\begin{array}{lllll}5.500 \mathrm{E}+00 & 5.500 \mathrm{E}+00 \quad 5.479 \mathrm{E}+00 \quad 5.458 \mathrm{E}+00 & 5.291 \mathrm{E}+00 \quad 5.069 \mathrm{E}+00\end{array}$

$\begin{array}{llllllll}0.000 E+00 & 2.477 E-11 & 6.025 E-08 & 2.344 E-07 \quad 4.742 E-06 & 1.613 E-05\end{array}$

$0.000 \mathrm{E}+00 \quad 2.405 \mathrm{E}-05 \quad 1.200 \mathrm{E}-03 \quad 2.394 \mathrm{E}-03 \quad 1.174 \mathrm{E}-02 \quad 2.401 \mathrm{E}-02$

$0.000 \mathrm{E}+00 \quad 2.405 \mathrm{E}-05 \quad 1.200 \mathrm{E}-03 \quad 2.394 \mathrm{E}-03 \quad 1.174 \mathrm{E}-02 \quad 2.403 \mathrm{E}-02$

$0.000 \mathrm{E}+00 \quad 7.799 \mathrm{E}-16 \quad 9.538 \mathrm{E}-11 \quad 7.463 \mathrm{E}-10 \quad 7.873 \mathrm{E}-08 \quad 5.891 \mathrm{E}-07$

$0.000 \mathrm{E}+00 \quad 1.136 \mathrm{E}-09 \quad 2.830 \mathrm{E}-06 \quad 1.128 \mathrm{E}-05 \quad 2.750 \mathrm{E}-04 \quad 1.171 \mathrm{E}-03$

$0.000 \mathrm{E}+00 \quad 1.136 \mathrm{E}-09 \quad 2.830 \mathrm{E}-06 \quad 1.128 \mathrm{E}-05 \quad 2.750 \mathrm{E}-04 \quad 1.171 \mathrm{E}-03$

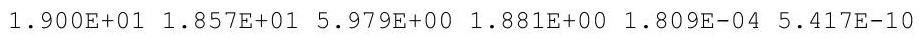

$\begin{array}{lllllll}7.176 \mathrm{E}-08 & 7.119 \mathrm{E}-08 & 4.832 \mathrm{E}-08 & 3.254 \mathrm{E}-08 & 1.375 \mathrm{E}-09 & 1.774 \mathrm{E}-11\end{array}$

$\begin{array}{lllllll}3.900 \mathrm{E}+01 & 3.869 \mathrm{E}+01 & 2.626 \mathrm{E}+01 & 1.768 \mathrm{E}+01 & 7.472 \mathrm{E}-01 & 9.639 \mathrm{E}-03\end{array}$

$\begin{array}{lllllll}3.900 \mathrm{E}+01 & 3.869 \mathrm{E}+01 & 2.626 \mathrm{E}+01 & 1.768 \mathrm{E}+01 & 7.472 \mathrm{E}-01 & 9.639 \mathrm{E}-03\end{array}$

$0.000 \mathrm{E}+00 \quad 1.101 \mathrm{E}-04 \quad 4.564 \mathrm{E}-03 \quad 7.633 \mathrm{E}-03 \quad 1.362 \mathrm{E}-02 \quad 1.377 \mathrm{E}-02$

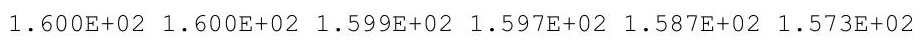

$\begin{array}{lllllll}0.000 \mathrm{E}+00 & 4.536 \mathrm{E}-04 & 2.266 \mathrm{E}-02 & 4.529 \mathrm{E}-02 & 2.251 \mathrm{E}-01 & 4.689 \mathrm{E}-01\end{array}$

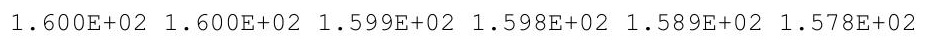

$0.000 \mathrm{E}+00 \quad 4.963 \mathrm{E}-10 \quad 1.095 \mathrm{E}-06 \quad 3.884 \mathrm{E}-06 \quad 4.705 \mathrm{E}-05 \quad 1.147 \mathrm{E}-04$ $\begin{array}{llllllll}1.000 \mathrm{E}+02 & 1.000 \mathrm{E}+02 & 9.995 \mathrm{E}+01 & 9.989 \mathrm{E}+01 & 9.947 \mathrm{E}+01 & 9.888 \mathrm{E}+01\end{array}$ $0.000 \mathrm{E}+00 \quad 1.440 \mathrm{E}-03 \quad 7.197 \mathrm{E}-02 \quad 1.438 \mathrm{E}-01 \quad 7.153 \mathrm{E}-01 \quad 1.491 \mathrm{E}+00$

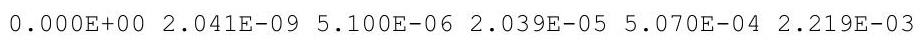
$1.000 \mathrm{E}+02 \quad 1.000 \mathrm{E}+02 \quad 1.000 \mathrm{E}+02 \quad 1.000 \mathrm{E}+02 \quad 1.002 \mathrm{E}+02 \quad 1.004 \mathrm{E}+02$

$0.000 \mathrm{E}+00 \quad 7.171 \mathrm{E}-14 \quad 8.112 \mathrm{E}-09 \quad 5.891 \mathrm{E}-08 \quad 3.952 \mathrm{E}-06 \quad 2.049 \mathrm{E}-05$ $0.000 \mathrm{E}+00 \quad 4.331 \mathrm{E}-02 \quad 2.142 \mathrm{E}+00 \quad 4.235 \mathrm{E}+00 \quad 1.937 \mathrm{E}+01 \quad 3.613 \mathrm{E}+01$ $0.000 \mathrm{E}+00 \quad 3.119 \mathrm{E}-07 \quad 7.739 \mathrm{E}-04 \quad 3.071 \mathrm{E}-03 \quad 7.220 \mathrm{E}-02 \quad 2.933 \mathrm{E}-01$ $0.000 \mathrm{E}+00 \quad 2.948 \mathrm{E}-13 \quad 3.663 \mathrm{E}-08 \quad 2.913 \mathrm{E}-07 \quad 3.471 \mathrm{E}-05 \quad 3.016 \mathrm{E}-04$ $0.000 \mathrm{E}+00 \quad 4.331 \mathrm{E}-02 \quad 2.142 \mathrm{E}+00 \quad 4.238 \mathrm{E}+00 \quad 1.944 \mathrm{E}+01 \quad 3.643 \mathrm{E}+01$

$0.000 \mathrm{E}+00 \quad 5.540 \mathrm{E}-16 \quad 2.418 \mathrm{E}-09 \quad 2.812 \mathrm{E}-08 \quad 3.398 \mathrm{E}-06 \quad 1.921 \mathrm{E}-05$ $\begin{array}{lllllll}0.000 \mathrm{E}+00 & 6.663 \mathrm{E}-04 & 1.058 \mathrm{E}+00 & 2.946 \mathrm{E}+00 & 1.823 \mathrm{E}+01 & 3.524 \mathrm{E}+01\end{array}$ $\begin{array}{llllll}0.000 \mathrm{E}+00 & 3.207 \mathrm{E}-09 & 2.837 \mathrm{E}-04 & 1.706 \mathrm{E}-03 & 6.374 \mathrm{E}-02 & 2.769 \mathrm{E}-01\end{array}$ $\begin{array}{llllll}0.000 \mathrm{E}+00 & 2.276 \mathrm{E}-15 & 1.075 \mathrm{E}-08 & 1.356 \mathrm{E}-07 & 2.889 \mathrm{E}-05 & 2.763 \mathrm{E}-04\end{array}$ $\begin{array}{lllllll}0.000 \mathrm{E}+00 & 6.663 \mathrm{E}-04 & 1.058 \mathrm{E}+00 & 2.947 \mathrm{E}+00 & 1.830 \mathrm{E}+01 & 3.551 \mathrm{E}+01\end{array}$ $\begin{array}{llllll}3.600 \mathrm{E}+01 & 3.600 \mathrm{E}+01 & 3.593 \mathrm{E}+01 & 3.586 \mathrm{E}+01 & 3.531 \mathrm{E}+01 & 3.456 \mathrm{E}+01\end{array}$ $0.000 \mathrm{E}+00 \quad 3.545 \mathrm{E}-08 \quad 1.770 \mathrm{E}-06 \quad 3.536 \mathrm{E}-06 \quad 1.750 \mathrm{E}-05 \quad 3.622 \mathrm{E}-05$

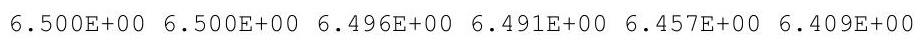

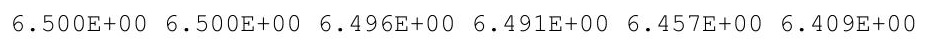


RESRAD, Version $6.5 \quad \mathrm{~T}^{1 / 2}$ Limit $=180$ days

Summary : C746U Recreational User Deterministic Run

File : X: \FINAL V2 \DOE FWD RUNS \C746U RU DOE SG FWD-FV2-1050YR.RAD

Individual Nuclide Soil Concentration

Parent Nuclide and Branch Fraction Indicated

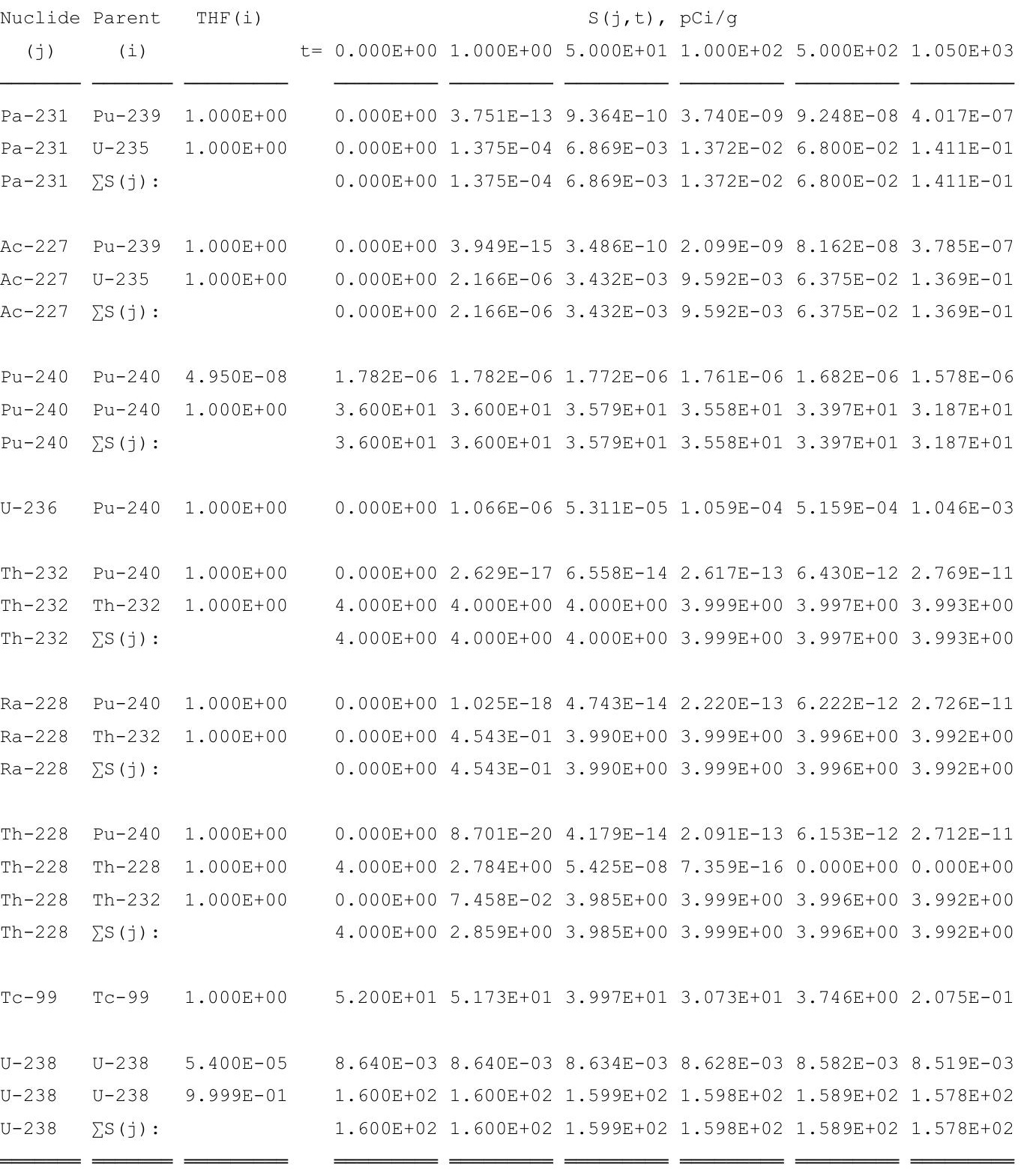

THF(i) is the thread fraction of the parent nuclide.

RESCALC.EXE execution time $=7.66$ seconds 


\title{
Recreational User
}

\author{
Summary Report \\ (Deterministic Analysis Report)
}

Second Peak Dose Assessment

Time Horizon: 10,000 yr 
THIS PAGE INTENTIONALLY LEFT BLANK 
RESRAD, Version $6.5 \quad \mathrm{~T}^{1 / 2}$ Limit $=180$ days

Summary : C746U Recreational User Deterministic Run

File : $\mathrm{X}: \backslash F I N A L$ V2 \DOE FWD RUNS \C746U RU DOE SG FWD-FV2-10000YR.RAD

Table of Contents

Part I: Mixture Sums and Single Radionuclide Guidelines

Dose Conversion Factor (and Related) Parameter Summary ... 2

Site-Specific Parameter Summary ................ 8

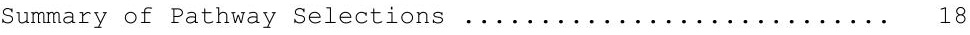

Contaminated Zone and Total Dose Summary ............. 19

Total Dose Components

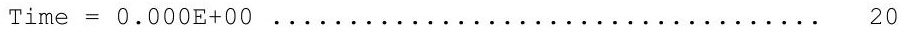

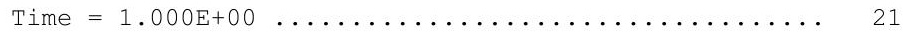

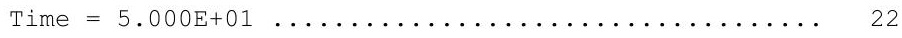

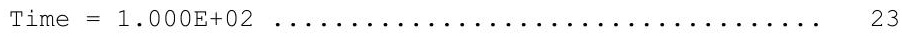

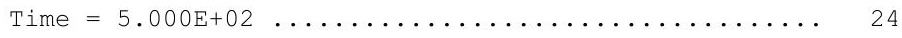

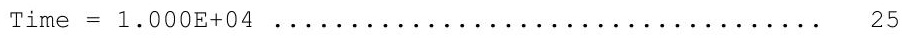

Dose/Source Ratios Summed Over All Pathways .......... 26

Single Radionuclide Soil Guidelines ............... 28

Dose Per Nuclide Summed Over All Pathways ............ 29

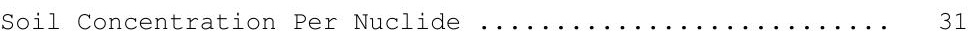


RESRAD, Version $6.5 \quad T^{1 / 2}$ Limit $=180$ days

Summary : C746U Recreational User Deterministic Run

File : $X: \backslash F I N A L$ V2 \DOE FWD RUNS \C746U RU DOE SG FWD-FV2-10000YR. RAD

Dose Conversion Factor (and Related) Parameter Summary (continued)

Dose Library: Teen Recreational User Plus ICRP 60 \& ICRP 72 (Age 15)

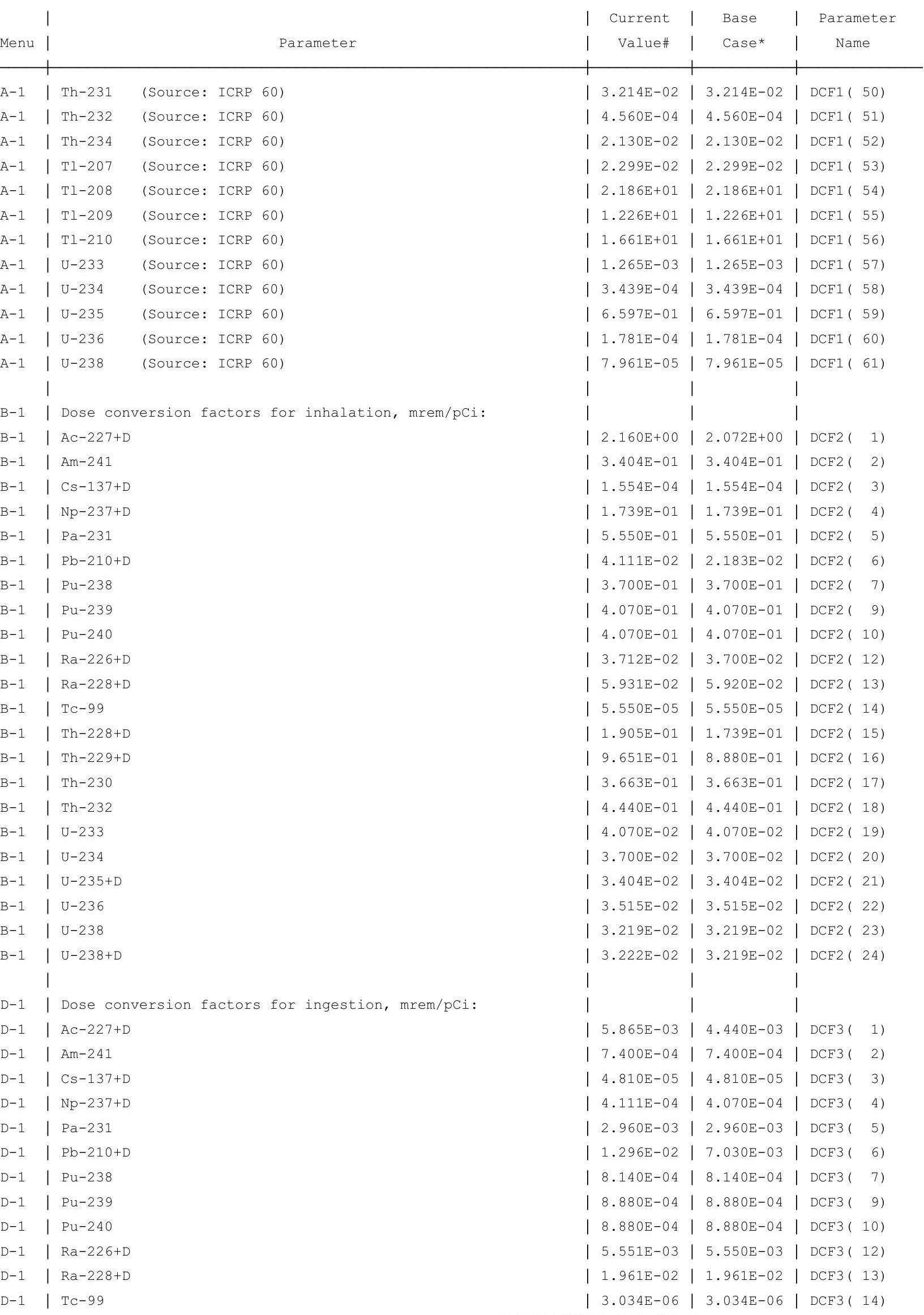


RESRAD, Version $6.5 \quad \mathrm{~T}^{1 / 2}$ Limit $=180$ days

Summary : C746U Recreational User Deterministic Run

File : $\mathrm{X}: \backslash F I N A L$ V2 \DOE FWD RUNS \C746U RU DOE SG FWD-FV2-10000YR.RAD

Dose Conversion Factor (and Related) Parameter Summary (continued)

Dose Library: Teen Recreational User Plus ICRP 60 \& ICRP 72 (Age 15)

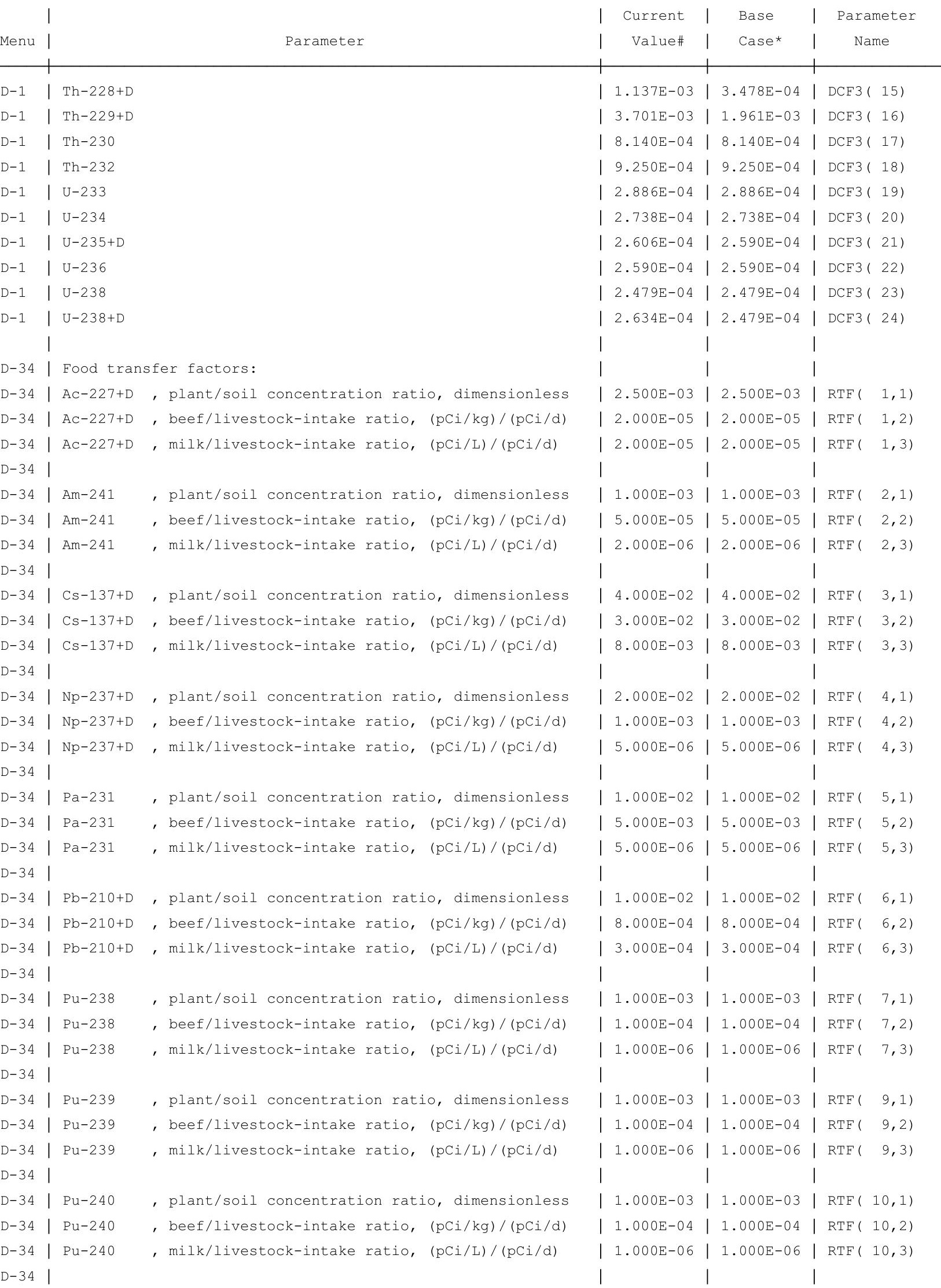


RESRAD, Version $6.5 \quad \mathrm{~T}^{1 / 2}$ Limit $=180$ days

Summary : C746U Recreational User Deterministic Run

File : $X: \backslash F I N A L$ V2\DOE FWD RUNS \C746U RU DOE SG FWD-FV2-10000YR.RAD

Dose Conversion Factor (and Related) Parameter Summary (continued)

Dose Library: Teen Recreational User Plus ICRP 60 \& ICRP 72 (Age 15)

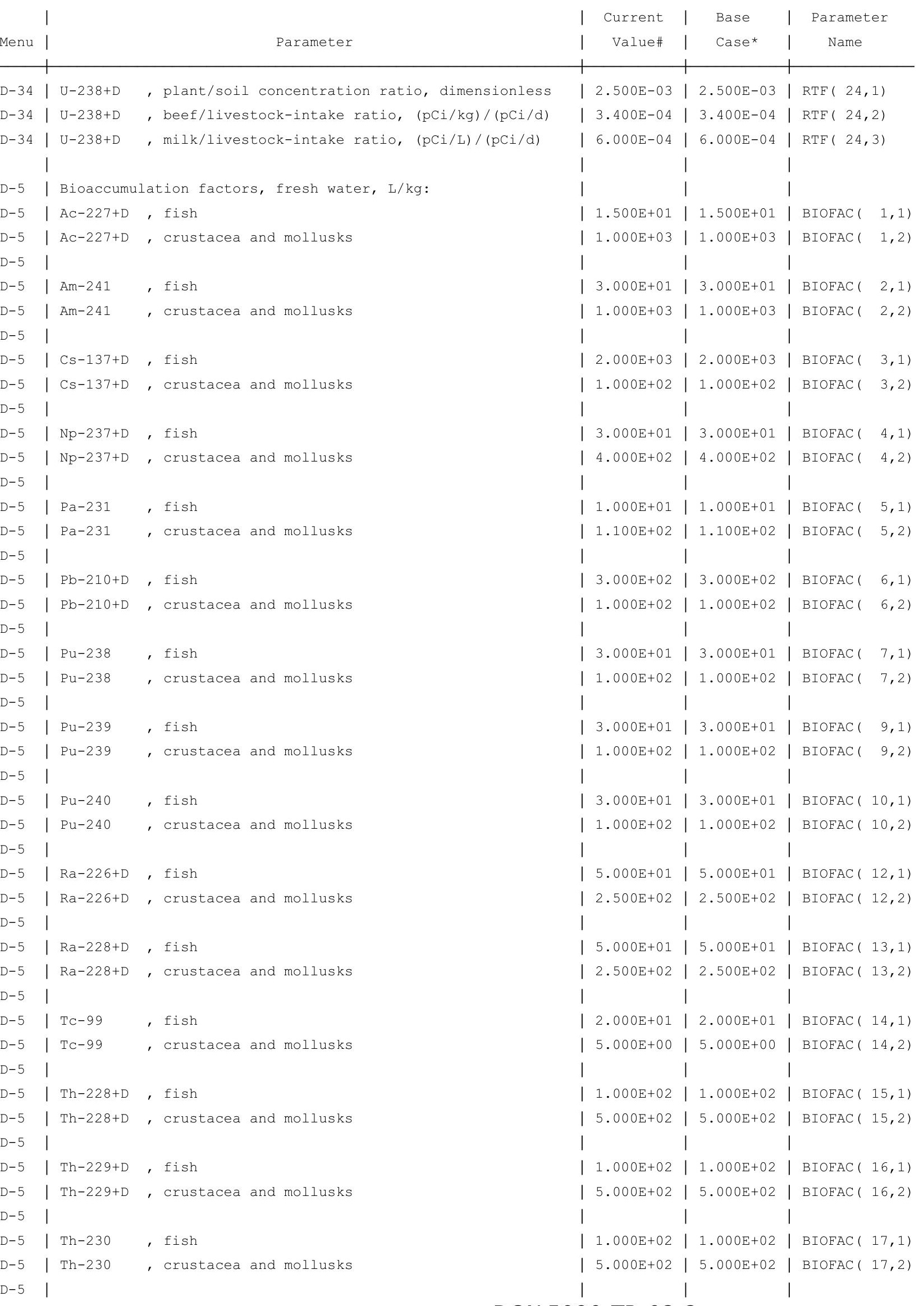


RESRAD, Version $6.5 \quad T^{1 / 2}$ Limit $=180$ days

Summary : C746U Recreational User Deterministic Run

File : $\mathrm{X}: \backslash F I N A L$ V2 \DOE FWD RUNS \C746U RU DOE SG FWD-FV2-10000YR.RAD

Site-Specific Parameter Summary (continued)

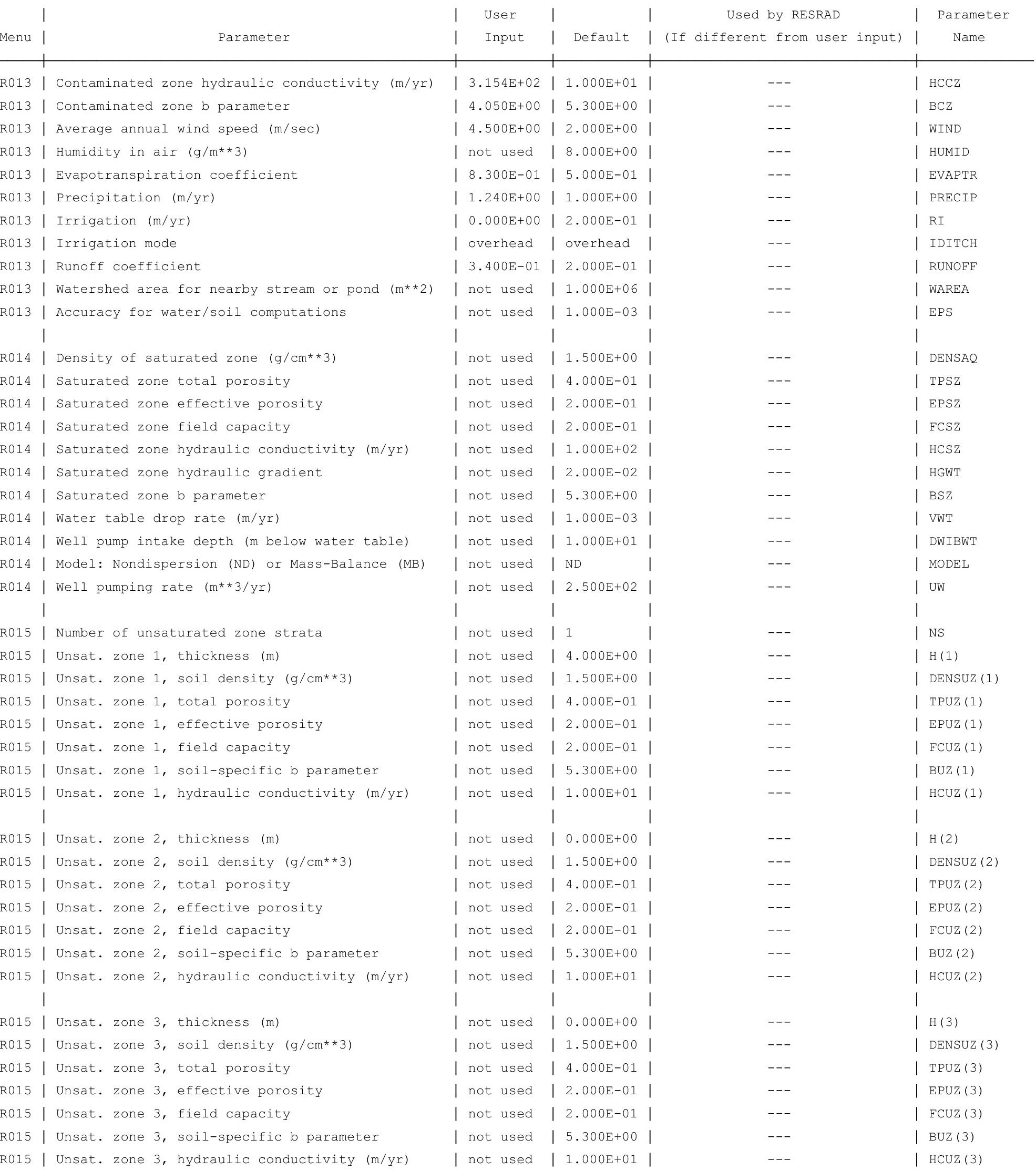


RESRAD, Version $6.5 \quad T^{1 / 2}$ Limit $=180$ days

Summary : C746U Recreational User Deterministic Run

File : $X: \backslash F I N A L$ V2 \DOE FWD RUNS \C746U RU DOE SG FWD-FV2-10000YR. RAD

Site-Specific Parameter Summary (continued)

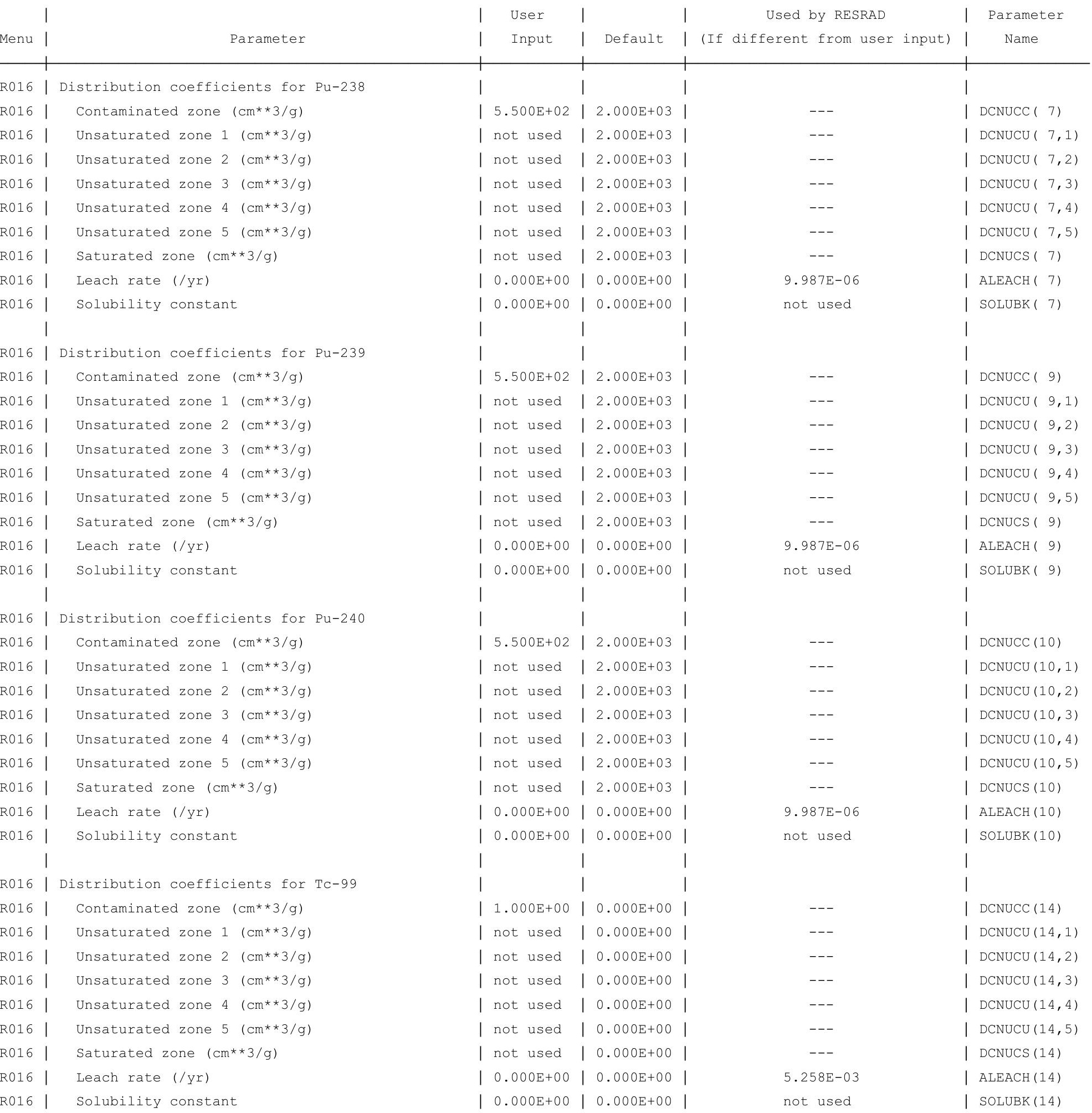


RESRAD, Version $6.5 \quad T^{1 / 2}$ Limit $=180$ days

Summary : C746U Recreational User Deterministic Run

File : $X: \backslash F I N A L$ V2 \DOE FWD RUNS \C746U RU DOE SG FWD-FV2-10000YR. RAD

Site-Specific Parameter Summary (continued)

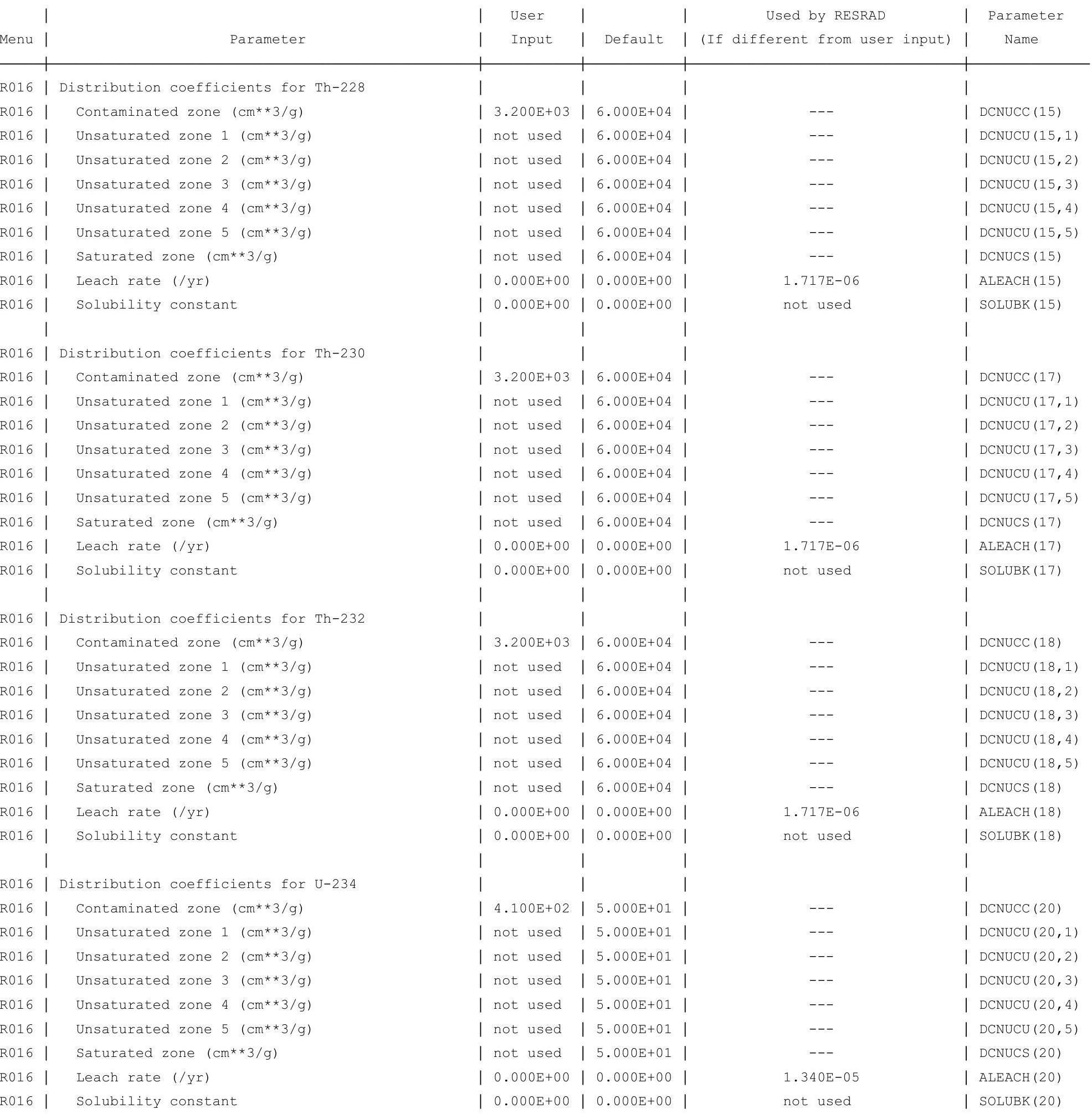


RESRAD, Version $6.5 \quad \mathrm{~T}^{1} \frac{1}{2}$ Limit $=180$ days

Summary : C746U Recreational User Deterministic Run

File : $X: \backslash F I N A L$ V2\DOE FWD RUNS \C746U RU DOE SG FWD-FV2-10000YR.RAD

Site-Specific Parameter Summary (continued)

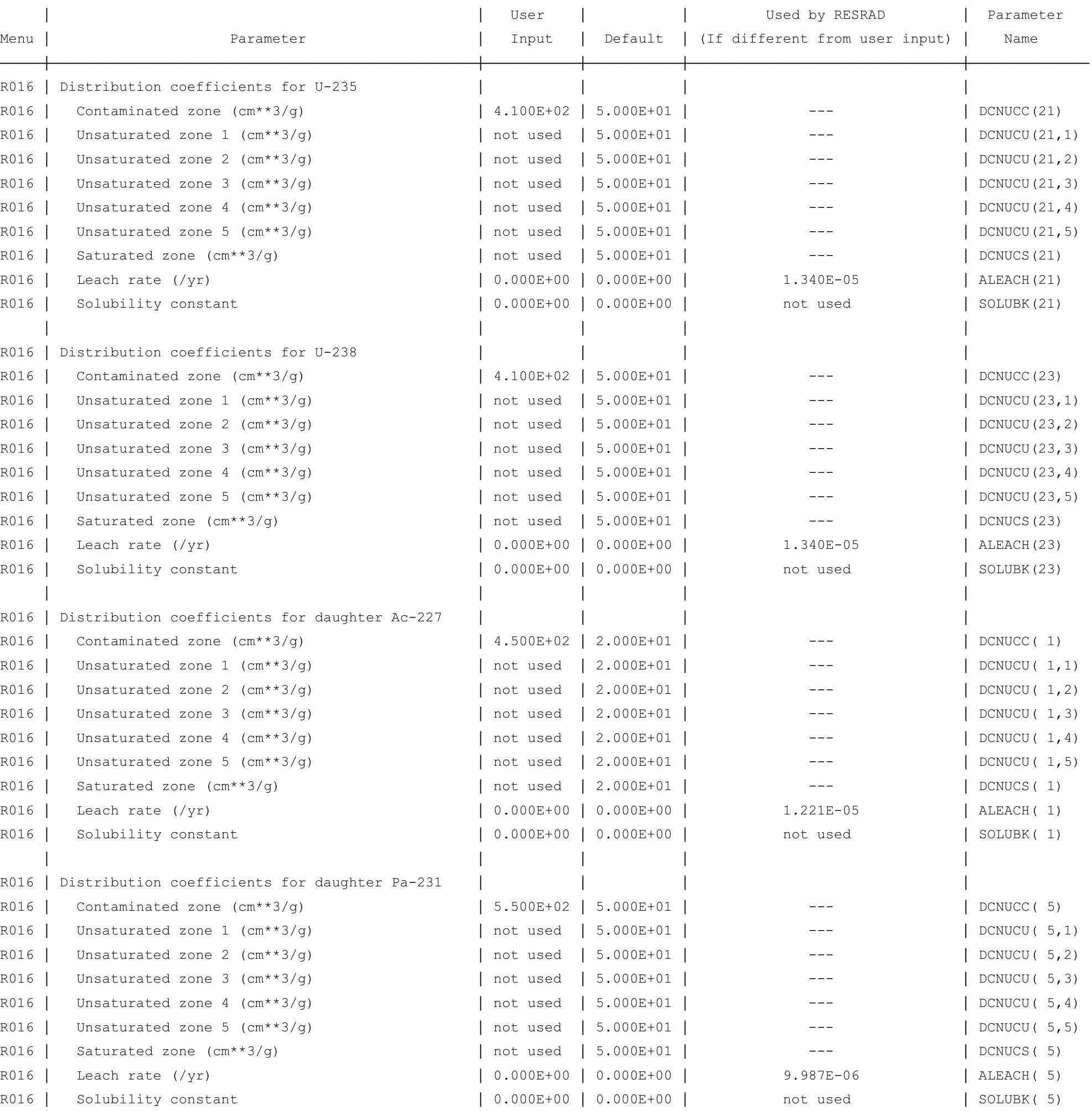


RESRAD, Version $6.5 \quad T^{1 / 2}$ Limit $=180$ days

Summary : C746U Recreational User Deterministic Run

File : $X: \backslash F I N A L$ V2 \DOE FWD RUNS \C746U RU DOE SG FWD-FV2-10000YR.RAD

Site-Specific Parameter Summary (continued)

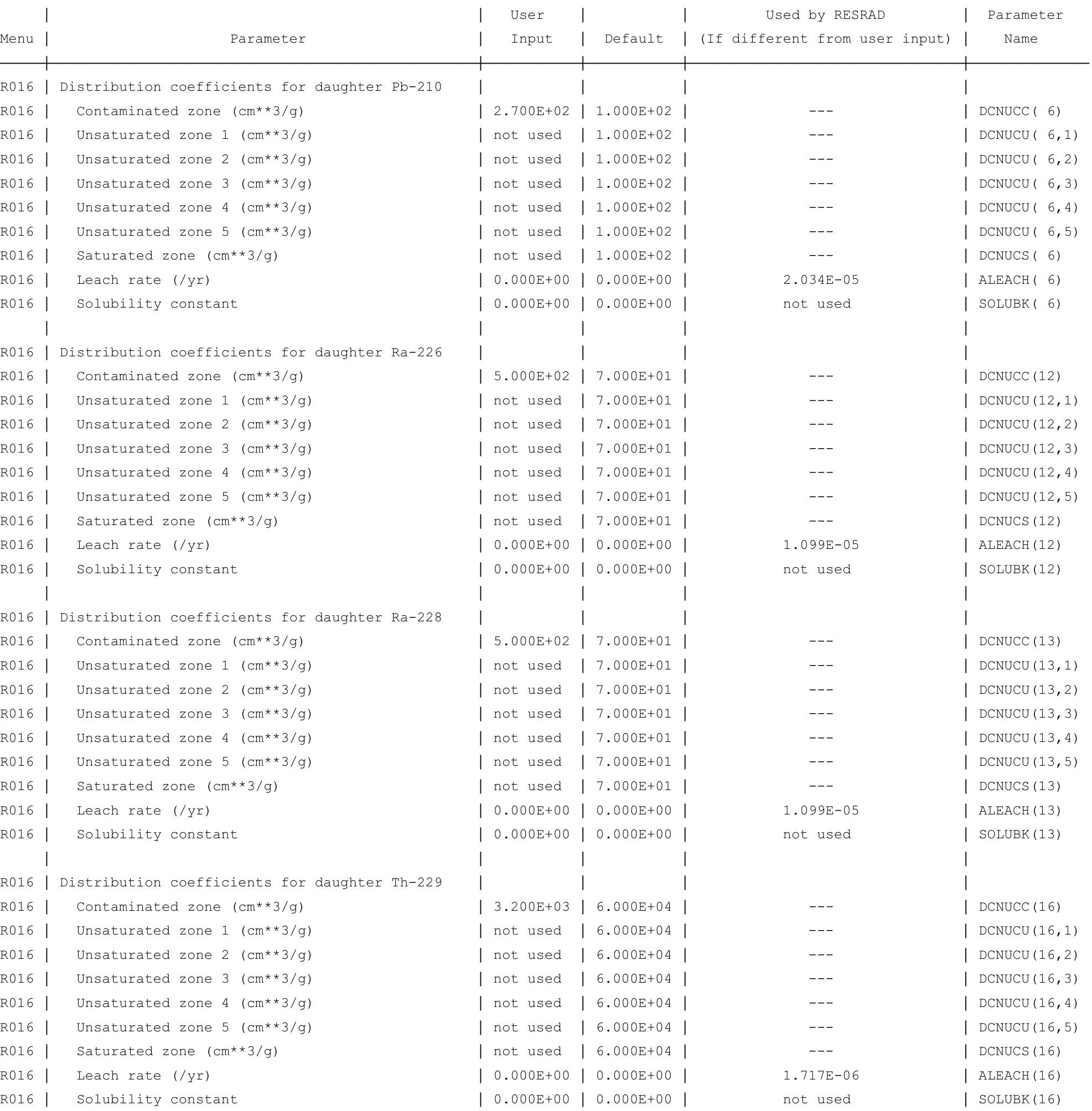


RESRAD, Version $6.5 \quad T^{1 / 2}$ Limit $=180$ days

Summary : C746U Recreational User Deterministic Run

File : $X: \backslash F I N A L$ V2 \DOE FWD RUNS \C746U RU DOE SG FWD-FV2-10000YR. RAD

Site-Specific Parameter Summary (continued)

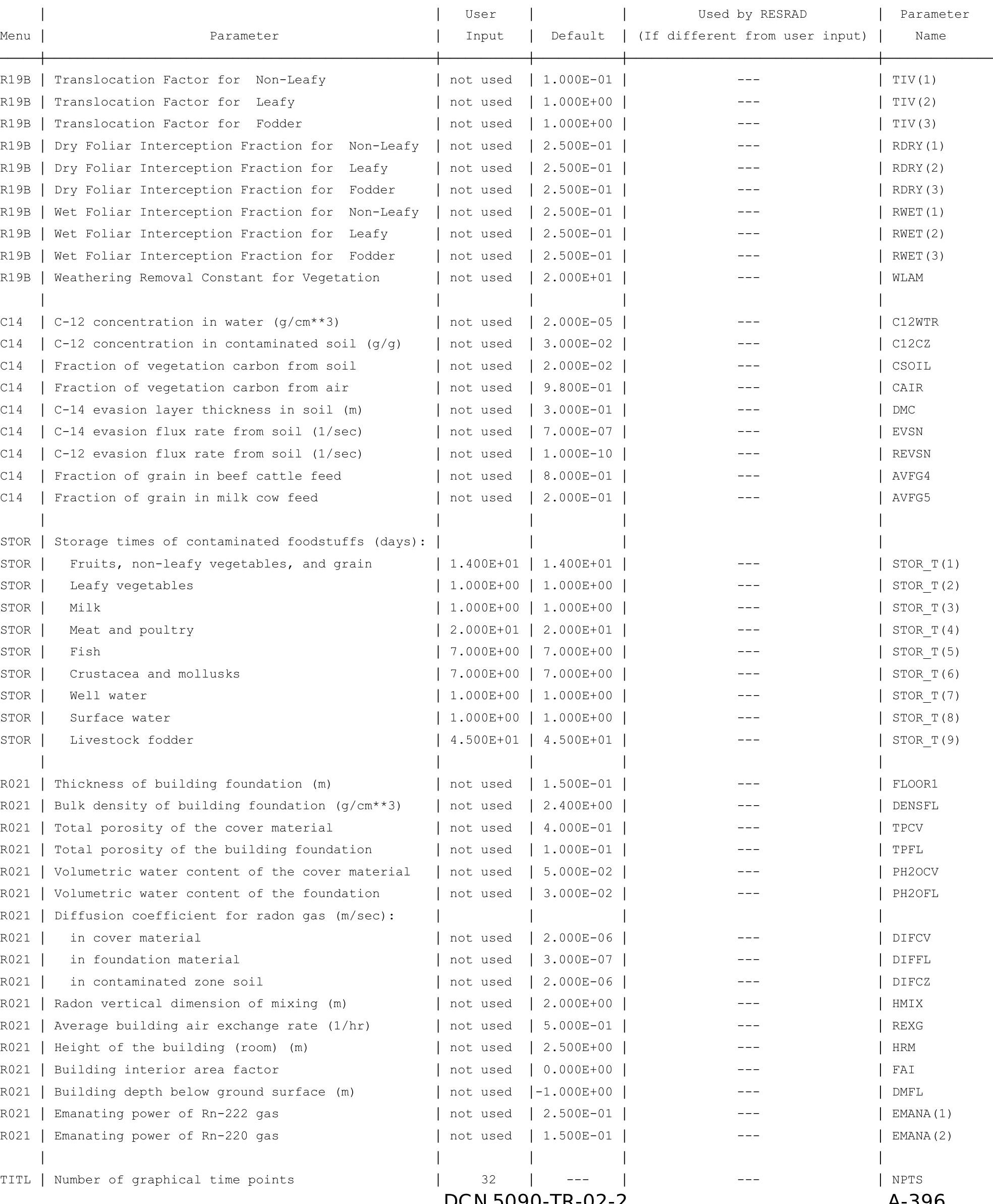


RESRAD, Version $6.5 \quad \mathrm{~T}^{1 / 2}$ Limit $=180$ days

Summary : C746U Recreational User Deterministic Run

File : $X: \backslash F I N A L$ V2 \DOE FWD RUNS CC746U RU DOE SG FWD-FV2-10000YR. RAD

Contaminated Zone Dimensions

Area: $\quad 89436.00$ square meters

Thickness:

Cover Depth:

\begin{abstract}
13.40 meters
1.52 meters
\end{abstract}

Initial Soil Concentrations, pCi/g

$\begin{array}{ll}\text { Am-241 } & 3.500 \mathrm{E}+01 \\ \mathrm{Cs}-137 & 1.900 \mathrm{E}+01 \\ \mathrm{~Np}-237 & 5.500 \mathrm{E}+00 \\ \mathrm{Pu}-238 & 3.900 \mathrm{E}+01 \\ \mathrm{Pu}-239 & 3.600 \mathrm{E}+01 \\ \mathrm{Pu}-240 & 3.600 \mathrm{E}+01 \\ \mathrm{TC}-99 & 5.200 \mathrm{E}+01 \\ \mathrm{Th}-228 & 4.000 \mathrm{E}+00 \\ \mathrm{Th}-230 & 1.000 \mathrm{E}+02 \\ \mathrm{Th}-232 & 4.000 \mathrm{E}+00 \\ \mathrm{U}-234 & 1.600 \mathrm{E}+02 \\ \mathrm{U}-235 & 6.500 \mathrm{E}+00 \\ \mathrm{U}-238 & 1.600 \mathrm{E}+02\end{array}$

Total Dose TDOSE(t), mrem/yr

Basic Radiation Dose Limit $=1.000 \mathrm{E}+00 \mathrm{mrem} / \mathrm{yr}$

Total Mixture Sum $M(t)$ = Fraction of Basic Dose Limit Received at Time (t)

$\begin{array}{rllllll}t \text { (years) }: & 0.000 \mathrm{E}+00 & 1.000 \mathrm{E}+00 & 5.000 \mathrm{E}+01 & 1.000 \mathrm{E}+02 & 5.000 \mathrm{E}+02 & 1.000 \mathrm{E}+04 \\ \mathrm{TDOSE}(\mathrm{t}): & 5.411 \mathrm{E}-07 & 4.044 \mathrm{E}-07 & 9.175 \mathrm{E}-07 & 1.314 \mathrm{E}-06 & 2.333 \mathrm{E}-05 & 9.490 \mathrm{E}+01 \\ \mathrm{M}(\mathrm{t}): & 5.411 \mathrm{E}-07 & 4.044 \mathrm{E}-07 & 9.175 \mathrm{E}-07 & 1.314 \mathrm{E}-06 & 2.333 \mathrm{E}-05 & 9.490 \mathrm{E}+01\end{array}$

Maximum TDOSE $(\mathrm{t}): 9.490 \mathrm{E}+01 \mathrm{mrem} / \mathrm{yr}$ at $\mathrm{t}=1.000 \mathrm{E}+04$ years 
RESRAD, Version 6.5

$\mathrm{T}^{1 / 2}$ Limit $=180$ days

ummary : C746U Recreational User Deterministic Run

: $\mathrm{X}: \backslash F I N A L$ V2 $\backslash$ DOE FWD RUNS $\backslash C 746 U$ RU DOE SG FWD-FV2-10000YR.RAD

Total Dose Contributions TDOSE (i,p,t) for Individual Radionuclides (i) and Pathways (p) As mrem/yr and Fraction of Total Dose At $t=0.000 \mathrm{E}+00$ years

Water Independent Pathways (Inhalation excludes radon)

\begin{tabular}{|c|c|c|c|c|c|c|c|c|c|c|c|c|c|c|}
\hline \multirow{2}{*}{ Nuclide } & \multicolumn{2}{|c|}{ Ground } & \multicolumn{2}{|c|}{ Inhalation } & \multicolumn{2}{|c|}{ Radon } & \multicolumn{2}{|c|}{ Plant } & \multicolumn{2}{|c|}{ Meat } & \multicolumn{2}{|c|}{ Milk } & \multicolumn{2}{|c|}{ Soil } \\
\hline & mrem/yr & fract. & mrem/yr & fract. & mrem/yr & fract. & mrem/yr & fract. & mrem/yr & fract. & mrem/yr & fract. & mrem/yr & fract. \\
\hline-241 & $5.204 \mathrm{E}-19$ & 0.0000 & $0.000 \mathrm{E}+00$ & 0.0000 & $0.000 \mathrm{E}+00$ & 0.0000 & $0.000 \mathrm{E}+00$ & 0.0000 & $0.000 \mathrm{E}+00$ & 0.0000 & $0.000 \mathrm{E}+00$ & 0.0000 & $0.000 \mathrm{E}+00$ & 0.0000 \\
\hline-137 & $2.305 E-09$ & 0.0043 & $0.000 \mathrm{E}+00$ & 0.0000 & $0.000 \mathrm{E}+00$ & 0.0000 & $0.000 \mathrm{E}+00$ & 0.0000 & $0.000 \mathrm{E}+00$ & 0.0000 & $0.000 \mathrm{E}+00$ & 0.0000 & $0.000 \mathrm{E}+00$ & 0.0000 \\
\hline-237 & $5.043 E-13$ & 0.0000 & $0.000 \mathrm{E}+00$ & 0.0000 & $0.000 \mathrm{E}+00$ & 0.0000 & $0.000 \mathrm{E}+00$ & 0.0000 & $0.000 \mathrm{E}+00$ & 0.0000 & $0.000 \mathrm{E}+00$ & 0.0000 & $0.000 \mathrm{E}+00$ & 0.0000 \\
\hline-238 & $3.052 \mathrm{E}-22$ & 0.0000 & $0.000 \mathrm{E}+00$ & 0.0000 & $0.000 \mathrm{E}+00$ & 0.0000 & $0.000 \mathrm{E}+00$ & 0.0000 & $0.000 \mathrm{E}+00$ & 0.0000 & $0.000 \mathrm{E}+00$ & 0.0000 & $0.000 \mathrm{E}+00$ & 0.0000 \\
\hline-239 & $4.161 \mathrm{E}-17$ & 0.0000 & $0.000 \mathrm{E}+00$ & 0.0000 & $0.000 \mathrm{E}+00$ & 0.0000 & $0.000 \mathrm{E}+00$ & 0.0000 & $0.000 \mathrm{E}+00$ & 0.0000 & $0.000 \mathrm{E}+00$ & 0.0000 & $0.000 \mathrm{E}+00$ & 0.0000 \\
\hline-240 & $3.957 \mathrm{E}-24$ & 0.0000 & $0.000 \mathrm{E}+00$ & 0.0000 & $0.000 \mathrm{E}+00$ & 0.0000 & $0.000 \mathrm{E}+00$ & 0.0000 & $0.000 \mathrm{E}+00$ & 0.0000 & $0.000 \mathrm{E}+00$ & 0.0000 & $0.000 \mathrm{E}+00$ & 0.0000 \\
\hline 99 & $2.884 E-25$ & 0.0000 & $0.000 \mathrm{E}+00$ & 0.0000 & $0.000 \mathrm{E}+00$ & 0.0000 & $0.000 \mathrm{E}+00$ & 0.0000 & $0.000 \mathrm{E}+00$ & 0.0000 & $0.000 \mathrm{E}+00$ & 0.0000 & $0.000 \mathrm{E}+00$ & 0.0000 \\
\hline-228 & $5.317 \mathrm{E}-07$ & 0.9827 & $0.000 \mathrm{E}+00$ & 0.0000 & $0.000 \mathrm{E}+00$ & 0.0000 & $0.000 \mathrm{E}+00$ & 0.0000 & $0.000 \mathrm{E}+00$ & 0.0000 & $0.000 \mathrm{E}+00$ & 0.0000 & $0.000 \mathrm{E}+00$ & 0.0000 \\
\hline-230 & $3.629 \mathrm{E}-10$ & 0.0007 & $0.000 \mathrm{E}+00$ & 0.0000 & $0.000 \mathrm{E}+00$ & 0.0000 & $0.000 \mathrm{E}+00$ & 0.0000 & $0.000 \mathrm{E}+00$ & 0.0000 & $0.000 \mathrm{E}+00$ & 0.0000 & $0.000 \mathrm{E}+00$ & 0.0000 \\
\hline-232 & $4.531 E-09$ & 0.0084 & $0.000 \mathrm{E}+00$ & 0.0000 & $0.000 \mathrm{E}+00$ & 0.0000 & $0.000 \mathrm{E}+00$ & 0.0000 & $0.000 \mathrm{E}+00$ & 0.0000 & $0.000 \mathrm{E}+00$ & 0.0000 & $0.000 \mathrm{E}+00$ & 0.0000 \\
\hline 234 & 1. $743 \mathrm{E}-15$ & 0.0000 & $0.000 \mathrm{E}+00$ & 0.0000 & $0.000 \mathrm{E}+00$ & 0.0000 & $0.000 \mathrm{E}+00$ & 0.0000 & $0.000 \mathrm{E}+00$ & 0.0000 & $0.000 \mathrm{E}+00$ & 0.0000 & $0.000 \mathrm{E}+00$ & 0.0000 \\
\hline 235 & $7.778 \mathrm{E}-15$ & 0.0000 & $0.000 \mathrm{E}+00$ & 0.0000 & $0.000 \mathrm{E}+00$ & 0.0000 & $0.000 \mathrm{E}+00$ & 0.0000 & $0.000 \mathrm{E}+00$ & 0.0000 & $0.000 \mathrm{E}+00$ & 0.0000 & $0.000 \mathrm{E}+00$ & 0.0000 \\
\hline 38 & $2.184 E-09$ & 0.0040 & $0.000 \mathrm{E}+00$ & 0.0000 & $0.000 \mathrm{E}+00$ & 0.0000 & $0.000 \mathrm{E}+00$ & 0.0000 & $0.000 \mathrm{E}+00$ & 0.0000 & $0.000 \mathrm{E}+00$ & 0.0000 & $0.000 \mathrm{E}+00$ & 0.0000 \\
\hline & $5.411 \mathrm{E}-07$ & 1.0000 & $0.000 \mathrm{E}+00$ & 0.0000 & $0.000 \mathrm{E}+00$ & 0.0000 & $0.000 \mathrm{E}+00$ & 0.0000 & $0.000 \mathrm{E}+00$ & 0.0000 & $0.000 \mathrm{E}+00$ & 0.0000 & $.000 \mathrm{E}+00$ & 0.0000 \\
\hline
\end{tabular}

Total Dose Contributions TDOSE (i,p,t) for Individual Radionuclides (i) and Pathways (p) As mrem/yr and Fraction of Total Dose At $t=0.000 \mathrm{E}+00$ years

Water Dependent Pathways

\begin{tabular}{|c|c|c|c|c|c|c|c|c|c|c|c|c|c|c|}
\hline & \multicolumn{2}{|c|}{ Water } & \multicolumn{2}{|c|}{ Fish } & \multicolumn{2}{|c|}{ Radon } & \multicolumn{2}{|c|}{ Plant } & \multicolumn{2}{|c|}{ Meat } & \multicolumn{2}{|c|}{ Milk } & \multicolumn{2}{|c|}{ All Pathways* } \\
\hline clide & mrem/yr & fract. & mrem/yr & fract. & mrem/yr & fract. & mrem/yr & fract. & mrem/yr & fract. & mrem/yr & fract. & mrem/yr & fract. \\
\hline 241 & $0.000 \mathrm{E}+00$ & 0.0000 & $0.000 \mathrm{E}+00$ & 0.0000 & $0.000 \mathrm{E}+00$ & 0.0000 & $0.000 \mathrm{E}+00$ & 0.0000 & $0.000 \mathrm{E}+00$ & 0.0000 & $0.000 \mathrm{E}+00$ & 0.0000 & $5.204 \mathrm{E}-19$ & 0.0000 \\
\hline-137 & $0.000 \mathrm{E}+00$ & 0.0000 & $0.000 \mathrm{E}+00$ & 0.0000 & $0.000 \mathrm{E}+00$ & 0.0000 & $0.000 \mathrm{E}+00$ & 0.0000 & $0.000 \mathrm{E}+00$ & 0.0000 & $0.000 \mathrm{E}+00$ & 0.0000 & $2.305 E-09$ & 0.0043 \\
\hline-237 & $0.000 \mathrm{E}+00$ & 0.0000 & $0.000 \mathrm{E}+00$ & 0.0000 & $0.000 \mathrm{E}+00$ & 0.0000 & $0.000 \mathrm{E}+00$ & 0.0000 & $0.000 \mathrm{E}+00$ & 0.0000 & $0.000 \mathrm{E}+00$ & 0.0000 & $5.043 E-13$ & 0.0000 \\
\hline-238 & $0.000 \mathrm{E}+00$ & 0.0000 & $0.000 \mathrm{E}+00$ & 0.0000 & $0.000 \mathrm{E}+00$ & 0.0000 & $0.000 \mathrm{E}+00$ & 0.0000 & $0.000 \mathrm{E}+00$ & 0.0000 & $0.000 \mathrm{E}+00$ & 0.0000 & $3.052 \mathrm{E}-22$ & 0.0000 \\
\hline-239 & $0.000 \mathrm{E}+00$ & 0.0000 & $0.000 \mathrm{E}+00$ & 0.0000 & $0.000 \mathrm{E}+00$ & 0.0000 & $0.000 \mathrm{E}+00$ & 0.0000 & $0.000 \mathrm{E}+00$ & 0.0000 & $0.000 E+00$ & 0.0000 & $4.161 \mathrm{E}-17$ & 0.0000 \\
\hline-240 & $0.000 \mathrm{E}+00$ & 0.0000 & $0.000 \mathrm{E}+00$ & 0.0000 & $0.000 \mathrm{E}+00$ & 0.0000 & $0.000 \mathrm{E}+00$ & 0.0000 & $0.000 \mathrm{E}+00$ & 0.0000 & $0.000 E+00$ & 0.0000 & $3.957 \mathrm{E}-24$ & 0.0000 \\
\hline-99 & $0.000 \mathrm{E}+00$ & 0.0000 & $0.000 \mathrm{E}+00$ & 0.0000 & $0.000 \mathrm{E}+00$ & 0.0000 & $0.000 \mathrm{E}+00$ & 0.0000 & $0.000 \mathrm{E}+00$ & 0.0000 & $0.000 \mathrm{E}+00$ & 0.0000 & $2.884 \mathrm{E}-25$ & 0.0000 \\
\hline-228 & $0.000 \mathrm{E}+00$ & 0.0000 & $0.000 \mathrm{E}+00$ & 0.0000 & $0.000 \mathrm{E}+00$ & 0.0000 & $0.000 \mathrm{E}+00$ & 0.0000 & $0.000 \mathrm{E}+00$ & 0.0000 & $0.000 \mathrm{E}+00$ & 0.0000 & $5.317 \mathrm{E}-07$ & 0.9827 \\
\hline-230 & $0.000 \mathrm{E}+00$ & 0.0000 & $0.000 \mathrm{E}+00$ & 0.0000 & $0.000 \mathrm{E}+00$ & 0.0000 & $0.000 \mathrm{E}+00$ & 0.0000 & $0.000 \mathrm{E}+00$ & 0.0000 & $0.000 E+00$ & 0.0000 & $3.629 \mathrm{E}-10$ & 0.0007 \\
\hline-232 & $0.000 \mathrm{E}+00$ & 0.0000 & $0.000 \mathrm{E}+00$ & 0.0000 & $0.000 \mathrm{E}+00$ & 0.0000 & $0.000 \mathrm{E}+00$ & 0.0000 & $0.000 \mathrm{E}+00$ & 0.0000 & $0.000 \mathrm{E}+00$ & 0.0000 & $4.531 E-09$ & 0.0084 \\
\hline 34 & $0.000 \mathrm{E}+00$ & 0.0000 & $0.000 \mathrm{E}+00$ & 0.0000 & $0.000 \mathrm{E}+00$ & 0.0000 & $0.000 \mathrm{E}+00$ & 0.0000 & $0.000 \mathrm{E}+00$ & 0.0000 & $0.000 \mathrm{E}+00$ & 0.0000 & $1.743 \mathrm{E}-15$ & 0.0000 \\
\hline 35 & $0.000 \mathrm{E}+00$ & 0.0000 & $0.000 \mathrm{E}+00$ & 0.0000 & $0.000 \mathrm{E}+00$ & 0.0000 & $0.000 \mathrm{E}+00$ & 0.0000 & $0.000 \mathrm{E}+00$ & 0.0000 & $0.000 \mathrm{E}+00$ & 0.0000 & 7. $778 \mathrm{E}-15$ & 0.0000 \\
\hline 38 & $0.000 \mathrm{E}+00$ & 0.0000 & $0.000 \mathrm{E}+00$ & 0.0000 & $0.000 \mathrm{E}+00$ & 0.0000 & $0.000 \mathrm{E}+00$ & 0.0000 & $0.000 \mathrm{E}+00$ & 0.0000 & $0.000 \mathrm{E}+00$ & 0.0000 & $2.184 \mathrm{E}-09$ & 0.0040 \\
\hline & $0.000 \mathrm{E}+00$ & 0.0000 & $0.000 \mathrm{E}+00$ & 0.0000 & $0.000 \mathrm{E}+00$ & 0.0000 & $0.000 \mathrm{E}+00$ & 0.0000 & $0.000 \mathrm{E}+00$ & 0.0000 & $0.000 \mathrm{E}+00$ & 0.0000 & $11 \mathrm{E}-07$ & 1.0000 \\
\hline
\end{tabular}

* Sum of all water independent and dependent pathways. 
RESRAD, Version 6.5

$\mathrm{T}^{1 / 2}$ Limit $=180$ days

ummary : C746U Recreational User Deterministic Run

: $\mathrm{X}: \backslash F I N A L$ V2 $\backslash$ DOE FWD RUNS $\backslash C 746 U$ RU DOE SG FWD-FV2-10000YR.RAD

Total Dose Contributions TDOSE (i,p,t) for Individual Radionuclides (i) and Pathways (p) As mrem/yr and Fraction of Total Dose At $t=1.000 \mathrm{E}+00$ years

Water Independent Pathways (Inhalation excludes radon)

\begin{tabular}{|c|c|c|c|c|c|c|c|c|c|c|c|c|c|c|}
\hline \multirow{2}{*}{ Nuclide } & \multicolumn{2}{|c|}{ Ground } & \multicolumn{2}{|c|}{ Inhalation } & \multicolumn{2}{|c|}{ Radon } & \multicolumn{2}{|c|}{ Plant } & \multicolumn{2}{|c|}{ Meat } & \multicolumn{2}{|c|}{ Milk } & \multicolumn{2}{|c|}{ Soil } \\
\hline & mrem/yr & fract. & mrem/yr & fract. & mrem/yr & fract. & mrem/yr & fract. & mrem/yr & fract. & mrem/yr & fract. & mrem/yr & fract. \\
\hline-241 & $1.575 \mathrm{E}-18$ & 0.0000 & $0.000 \mathrm{E}+00$ & 0.0000 & $0.000 \mathrm{E}+00$ & 0.0000 & $0.000 \mathrm{E}+00$ & 0.0000 & $0.000 \mathrm{E}+00$ & 0.0000 & $0.000 \mathrm{E}+00$ & 0.0000 & $0.000 \mathrm{E}+00$ & 0.0000 \\
\hline-137 & $2.272 E-09$ & 0.0056 & $0.000 \mathrm{E}+00$ & 0.0000 & $0.000 \mathrm{E}+00$ & 0.0000 & $0.000 \mathrm{E}+00$ & 0.0000 & $0.000 \mathrm{E}+00$ & 0.0000 & $0.000 \mathrm{E}+00$ & 0.0000 & $0.000 \mathrm{E}+00$ & 0.0000 \\
\hline-237 & $5.097 \mathrm{E}-13$ & 0.0000 & $0.000 \mathrm{E}+00$ & 0.0000 & $0.000 \mathrm{E}+00$ & 0.0000 & $0.000 \mathrm{E}+00$ & 0.0000 & $0.000 \mathrm{E}+00$ & 0.0000 & $0.000 \mathrm{E}+00$ & 0.0000 & $0.000 \mathrm{E}+00$ & 0.0000 \\
\hline-238 & $4.535 E-21$ & 0.0000 & $0.000 \mathrm{E}+00$ & 0.0000 & $0.000 \mathrm{E}+00$ & 0.0000 & $0.000 \mathrm{E}+00$ & 0.0000 & $0.000 \mathrm{E}+00$ & 0.0000 & $0.000 \mathrm{E}+00$ & 0.0000 & $0.000 \mathrm{E}+00$ & 0.0000 \\
\hline-239 & $4.211 \mathrm{E}-17$ & 0.0000 & $0.000 \mathrm{E}+00$ & 0.0000 & $0.000 \mathrm{E}+00$ & 0.0000 & $0.000 \mathrm{E}+00$ & 0.0000 & $0.000 \mathrm{E}+00$ & 0.0000 & $0.000 \mathrm{E}+00$ & 0.0000 & $0.000 \mathrm{E}+00$ & 0.0000 \\
\hline-240 & $4.111 \mathrm{E}-24$ & 0.0000 & $0.000 \mathrm{E}+00$ & 0.0000 & $0.000 \mathrm{E}+00$ & 0.0000 & $0.000 \mathrm{E}+00$ & 0.0000 & $0.000 \mathrm{E}+00$ & 0.0000 & $0.000 \mathrm{E}+00$ & 0.0000 & $0.000 \mathrm{E}+00$ & 0.0000 \\
\hline 99 & $2.925 E-25$ & 0.0000 & $0.000 \mathrm{E}+00$ & 0.0000 & $0.000 \mathrm{E}+00$ & 0.0000 & $0.000 \mathrm{E}+00$ & 0.0000 & $0.000 \mathrm{E}+00$ & 0.0000 & $0.000 \mathrm{E}+00$ & 0.0000 & $0.000 \mathrm{E}+00$ & 0.0000 \\
\hline-228 & $3.723 E-07$ & 0.9206 & $0.000 \mathrm{E}+00$ & 0.0000 & $0.000 \mathrm{E}+00$ & 0.0000 & $0.000 \mathrm{E}+00$ & 0.0000 & $0.000 \mathrm{E}+00$ & 0.0000 & $0.000 \mathrm{E}+00$ & 0.0000 & $0.000 \mathrm{E}+00$ & 0.0000 \\
\hline-230 & $1.095 E-09$ & 0.0027 & $0.000 \mathrm{E}+00$ & 0.0000 & $0.000 \mathrm{E}+00$ & 0.0000 & $0.000 \mathrm{E}+00$ & 0.0000 & $0.000 \mathrm{E}+00$ & 0.0000 & $0.000 \mathrm{E}+00$ & 0.0000 & $0.000 \mathrm{E}+00$ & 0.0000 \\
\hline-232 & $2.653 E-08$ & 0.0656 & $0.000 \mathrm{E}+00$ & 0.0000 & $0.000 \mathrm{E}+00$ & 0.0000 & $0.000 \mathrm{E}+00$ & 0.0000 & $0.000 \mathrm{E}+00$ & 0.0000 & $0.000 \mathrm{E}+00$ & 0.0000 & $0.000 \mathrm{E}+00$ & 0.0000 \\
\hline 234 & $1.227 \mathrm{E}-14$ & 0.0000 & $0.000 \mathrm{E}+00$ & 0.0000 & $0.000 \mathrm{E}+00$ & 0.0000 & $0.000 \mathrm{E}+00$ & 0.0000 & $0.000 \mathrm{E}+00$ & 0.0000 & $0.000 \mathrm{E}+00$ & 0.0000 & $0.000 \mathrm{E}+00$ & 0.0000 \\
\hline 235 & 7. $913 \mathrm{E}-15$ & 0.0000 & $0.000 \mathrm{E}+00$ & 0.0000 & $0.000 \mathrm{E}+00$ & 0.0000 & $0.000 \mathrm{E}+00$ & 0.0000 & $0.000 \mathrm{E}+00$ & 0.0000 & $0.000 \mathrm{E}+00$ & 0.0000 & $0.000 \mathrm{E}+00$ & 0.0000 \\
\hline 38 & $2.202 E-09$ & 0.0054 & $0.000 \mathrm{E}+00$ & 0.0000 & $0.000 \mathrm{E}+00$ & 0.0000 & $0.000 \mathrm{E}+00$ & 0.0000 & $0.000 \mathrm{E}+00$ & 0.0000 & $0.000 \mathrm{E}+00$ & 0.0000 & $0.000 \mathrm{E}+00$ & 0.0000 \\
\hline & $4.044 \mathrm{E}-07$ & 1.0000 & $0.000 \mathrm{E}+00$ & 0.0000 & $0.000 \mathrm{E}+00$ & 0.0000 & $0.000 \mathrm{E}+00$ & 0.0000 & $0.000 \mathrm{E}+00$ & 0.0000 & $0.000 \mathrm{E}+00$ & 0.0000 & $.000 \mathrm{E}+00$ & 0.0000 \\
\hline
\end{tabular}

Total Dose Contributions TDOSE (i,p,t) for Individual Radionuclides (i) and Pathways (p) As mrem/yr and Fraction of Total Dose At $t=1.000 \mathrm{E}+00$ years

Water Dependent Pathways

\begin{tabular}{|c|c|c|c|c|c|c|c|c|c|c|c|c|c|c|}
\hline & \multicolumn{2}{|c|}{ Water } & \multicolumn{2}{|c|}{ Fish } & \multicolumn{2}{|c|}{ Radon } & \multicolumn{2}{|c|}{ Plant } & \multicolumn{2}{|c|}{ Meat } & \multicolumn{2}{|c|}{ Milk } & \multicolumn{2}{|c|}{ All Pathways* } \\
\hline clide & mrem/yr & fract. & mrem/yr & fract. & mrem/yr & fract. & mrem/yr & fract. & mrem/yr & fract. & mrem/yr & fract. & mrem/yr & fract. \\
\hline-241 & $0.000 \mathrm{E}+00$ & 0.0000 & $0.000 \mathrm{E}+00$ & 0.0000 & $0.000 \mathrm{E}+00$ & 0.0000 & $0.000 \mathrm{E}+00$ & 0.0000 & $0.000 \mathrm{E}+00$ & 0.0000 & $0.000 \mathrm{E}+00$ & 0.0000 & $1.575 \mathrm{E}-18$ & 0.0000 \\
\hline-137 & $0.000 \mathrm{E}+00$ & 0.0000 & $0.000 \mathrm{E}+00$ & 0.0000 & $0.000 \mathrm{E}+00$ & 0.0000 & $0.000 \mathrm{E}+00$ & 0.0000 & $0.000 \mathrm{E}+00$ & 0.0000 & $0.000 \mathrm{E}+00$ & 0.0000 & $2.272 \mathrm{E}-09$ & 0.0056 \\
\hline-237 & $0.000 \mathrm{E}+00$ & 0.0000 & $0.000 \mathrm{E}+00$ & 0.0000 & $0.000 \mathrm{E}+00$ & 0.0000 & $0.000 \mathrm{E}+00$ & 0.0000 & $0.000 \mathrm{E}+00$ & 0.0000 & $0.000 \mathrm{E}+00$ & 0.0000 & $5.097 \mathrm{E}-13$ & 0.0000 \\
\hline-238 & $0.000 \mathrm{E}+00$ & 0.0000 & $0.000 \mathrm{E}+00$ & 0.0000 & $0.000 \mathrm{E}+00$ & 0.0000 & $0.000 \mathrm{E}+00$ & 0.0000 & $0.000 \mathrm{E}+00$ & 0.0000 & $0.000 \mathrm{E}+00$ & 0.0000 & $4.535 \mathrm{E}-21$ & 0.0000 \\
\hline-239 & $0.000 \mathrm{E}+00$ & 0.0000 & $0.000 \mathrm{E}+00$ & 0.0000 & $0.000 \mathrm{E}+00$ & 0.0000 & $0.000 \mathrm{E}+00$ & 0.0000 & $0.000 \mathrm{E}+00$ & 0.0000 & $0.000 E+00$ & 0.0000 & $4.211 \mathrm{E}-17$ & 0.0000 \\
\hline-240 & $0.000 \mathrm{E}+00$ & 0.0000 & $0.000 \mathrm{E}+00$ & 0.0000 & $0.000 \mathrm{E}+00$ & 0.0000 & $0.000 \mathrm{E}+00$ & 0.0000 & $0.000 \mathrm{E}+00$ & 0.0000 & $0.000 E+00$ & 0.0000 & $4.111 \mathrm{E}-24$ & 0.0000 \\
\hline-99 & $0.000 \mathrm{E}+00$ & 0.0000 & $0.000 \mathrm{E}+00$ & 0.0000 & $0.000 \mathrm{E}+00$ & 0.0000 & $0.000 \mathrm{E}+00$ & 0.0000 & $0.000 \mathrm{E}+00$ & 0.0000 & $0.000 \mathrm{E}+00$ & 0.0000 & $2.925 E-25$ & 0.0000 \\
\hline-228 & $0.000 \mathrm{E}+00$ & 0.0000 & $0.000 \mathrm{E}+00$ & 0.0000 & $0.000 \mathrm{E}+00$ & 0.0000 & $0.000 \mathrm{E}+00$ & 0.0000 & $0.000 \mathrm{E}+00$ & 0.0000 & $0.000 \mathrm{E}+00$ & 0.0000 & $3.723 E-07$ & 0.9206 \\
\hline-230 & $0.000 \mathrm{E}+00$ & 0.0000 & $0.000 \mathrm{E}+00$ & 0.0000 & $0.000 \mathrm{E}+00$ & 0.0000 & $0.000 \mathrm{E}+00$ & 0.0000 & $0.000 \mathrm{E}+00$ & 0.0000 & $0.000 E+00$ & 0.0000 & $1.095 \mathrm{E}-09$ & 0.0027 \\
\hline 232 & $0.000 \mathrm{E}+00$ & 0.0000 & $0.000 \mathrm{E}+00$ & 0.0000 & $0.000 \mathrm{E}+00$ & 0.0000 & $0.000 \mathrm{E}+00$ & 0.0000 & $0.000 \mathrm{E}+00$ & 0.0000 & $0.000 \mathrm{E}+00$ & 0.0000 & $2.653 E-08$ & 0.0656 \\
\hline 34 & $0.000 \mathrm{E}+00$ & 0.0000 & $0.000 \mathrm{E}+00$ & 0.0000 & $0.000 \mathrm{E}+00$ & 0.0000 & $0.000 \mathrm{E}+00$ & 0.0000 & $0.000 \mathrm{E}+00$ & 0.0000 & $0.000 \mathrm{E}+00$ & 0.0000 & 1. $227 \mathrm{E}-14$ & 0.0000 \\
\hline 35 & $0.000 \mathrm{E}+00$ & 0.0000 & $0.000 \mathrm{E}+00$ & 0.0000 & $0.000 \mathrm{E}+00$ & 0.0000 & $0.000 \mathrm{E}+00$ & 0.0000 & $0.000 \mathrm{E}+00$ & 0.0000 & $0.000 E+00$ & 0.0000 & $7.913 \mathrm{E}-15$ & 0.0000 \\
\hline 38 & $0.000 \mathrm{E}+00$ & 0.0000 & $0.000 \mathrm{E}+00$ & 0.0000 & $0.000 \mathrm{E}+00$ & 0.0000 & $0.000 \mathrm{E}+00$ & 0.0000 & $0.000 \mathrm{E}+00$ & 0.0000 & $0.000 \mathrm{E}+00$ & 0.0000 & $2.202 \mathrm{E}-09$ & 0.0054 \\
\hline & $0.000 \mathrm{E}+00$ & 0.0000 & $0.000 \mathrm{E}+00$ & 0.0000 & $0.000 \mathrm{E}+00$ & 0.0000 & $0.000 \mathrm{E}+00$ & 0.0000 & $0.000 \mathrm{E}+00$ & 0.0000 & $0.000 \mathrm{E}+00$ & 0.0000 & $44 \mathrm{E}-07$ & 1.0000 \\
\hline
\end{tabular}

* Sum of all water independent and dependent pathways. 
RESRAD, Version 6.5

$\mathrm{T}^{1 / 2}$ Limit $=180$ days

ummary : C746U Recreational User Deterministic Run

: $\mathrm{X}: \backslash F I N A L$ V2 $\backslash$ DOE FWD RUNS $\backslash C 746 U$ RU DOE SG FWD-FV2-10000YR.RAD

Total Dose Contributions TDOSE (i,p,t) for Individual Radionuclides (i) and Pathways (p) As mrem/yr and Fraction of Total Dose At $t=5.000 \mathrm{E}+01$ years

Water Independent Pathways (Inhalation excludes radon)

\begin{tabular}{|c|c|c|c|c|c|c|c|c|c|c|c|c|c|c|}
\hline \multirow{2}{*}{ Nuclide } & \multicolumn{2}{|c|}{ Ground } & \multicolumn{2}{|c|}{ Inhalation } & \multicolumn{2}{|c|}{ Radon } & \multicolumn{2}{|c|}{ Plant } & \multicolumn{2}{|c|}{ Meat } & \multicolumn{2}{|c|}{ Milk } & \multicolumn{2}{|c|}{ Soil } \\
\hline & mrem/yr & fract. & mrem/yr & fract. & mrem/yr & fract. & mrem/yr & fract. & mrem/yr & fract. & mrem/yr & fract. & mrem/yr & fract. \\
\hline-241 & $8.641 \mathrm{E}-17$ & 0.0000 & $0.000 \mathrm{E}+00$ & 0.0000 & $0.000 \mathrm{E}+00$ & 0.0000 & $0.000 \mathrm{E}+00$ & 0.0000 & $0.000 \mathrm{E}+00$ & 0.0000 & $0.000 \mathrm{E}+00$ & 0.0000 & $0.000 \mathrm{E}+00$ & 0.0000 \\
\hline-137 & $1.106 \mathrm{E}-09$ & 0.0012 & $0.000 \mathrm{E}+00$ & 0.0000 & $0.000 \mathrm{E}+00$ & 0.0000 & $0.000 \mathrm{E}+00$ & 0.0000 & $0.000 \mathrm{E}+00$ & 0.0000 & $0.000 \mathrm{E}+00$ & 0.0000 & $0.000 \mathrm{E}+00$ & 0.0000 \\
\hline-237 & $8.637 E-13$ & 0.0000 & $0.000 \mathrm{E}+00$ & 0.0000 & $0.000 \mathrm{E}+00$ & 0.0000 & $0.000 \mathrm{E}+00$ & 0.0000 & $0.000 \mathrm{E}+00$ & 0.0000 & $0.000 \mathrm{E}+00$ & 0.0000 & $0.000 \mathrm{E}+00$ & 0.0000 \\
\hline-238 & $1.975 E-16$ & 0.0000 & $0.000 \mathrm{E}+00$ & 0.0000 & $0.000 \mathrm{E}+00$ & 0.0000 & $0.000 \mathrm{E}+00$ & 0.0000 & $0.000 \mathrm{E}+00$ & 0.0000 & $0.000 \mathrm{E}+00$ & 0.0000 & $0.000 \mathrm{E}+00$ & 0.0000 \\
\hline-239 & 7. $561 \mathrm{E}-17$ & 0.0000 & $0.000 \mathrm{E}+00$ & 0.0000 & $0.000 \mathrm{E}+00$ & 0.0000 & $0.000 \mathrm{E}+00$ & 0.0000 & $0.000 \mathrm{E}+00$ & 0.0000 & $0.000 \mathrm{E}+00$ & 0.0000 & $0.000 \mathrm{E}+00$ & 0.0000 \\
\hline-240 & $9.285 \mathrm{E}-21$ & 0.0000 & $0.000 \mathrm{E}+00$ & 0.0000 & $0.000 \mathrm{E}+00$ & 0.0000 & $0.000 \mathrm{E}+00$ & 0.0000 & $0.000 \mathrm{E}+00$ & 0.0000 & $0.000 \mathrm{E}+00$ & 0.0000 & $0.000 \mathrm{E}+00$ & 0.0000 \\
\hline 99 & $5.785 E-25$ & 0.0000 & $0.000 \mathrm{E}+00$ & 0.0000 & $0.000 \mathrm{E}+00$ & 0.0000 & $0.000 \mathrm{E}+00$ & 0.0000 & $0.000 \mathrm{E}+00$ & 0.0000 & $0.000 \mathrm{E}+00$ & 0.0000 & $0.000 \mathrm{E}+00$ & 0.0000 \\
\hline-228 & $9.718 \mathrm{E}-15$ & 0.0000 & $0.000 \mathrm{E}+00$ & 0.0000 & $0.000 \mathrm{E}+00$ & 0.0000 & $0.000 \mathrm{E}+00$ & 0.0000 & $0.000 \mathrm{E}+00$ & 0.0000 & $0.000 \mathrm{E}+00$ & 0.0000 & $0.000 \mathrm{E}+00$ & 0.0000 \\
\hline-230 & $5.116 \mathrm{E}-08$ & 0.0558 & $0.000 \mathrm{E}+00$ & 0.0000 & $0.000 \mathrm{E}+00$ & 0.0000 & $0.000 \mathrm{E}+00$ & 0.0000 & $0.000 \mathrm{E}+00$ & 0.0000 & $0.000 \mathrm{E}+00$ & 0.0000 & $0.000 \mathrm{E}+00$ & 0.0000 \\
\hline-232 & $8.620 E-07$ & 0.9395 & $0.000 \mathrm{E}+00$ & 0.0000 & $0.000 \mathrm{E}+00$ & 0.0000 & $0.000 \mathrm{E}+00$ & 0.0000 & $0.000 \mathrm{E}+00$ & 0.0000 & $0.000 \mathrm{E}+00$ & 0.0000 & $0.000 \mathrm{E}+00$ & 0.0000 \\
\hline 234 & $1.867 \mathrm{E}-11$ & 0.0000 & $0.000 \mathrm{E}+00$ & 0.0000 & $0.000 \mathrm{E}+00$ & 0.0000 & $0.000 \mathrm{E}+00$ & 0.0000 & $0.000 \mathrm{E}+00$ & 0.0000 & $0.000 \mathrm{E}+00$ & 0.0000 & $0.000 \mathrm{E}+00$ & 0.0000 \\
\hline 235 & $5.776 \mathrm{E}-14$ & 0.0000 & $0.000 \mathrm{E}+00$ & 0.0000 & $0.000 \mathrm{E}+00$ & 0.0000 & $0.000 \mathrm{E}+00$ & 0.0000 & $0.000 \mathrm{E}+00$ & 0.0000 & $0.000 \mathrm{E}+00$ & 0.0000 & $0.000 \mathrm{E}+00$ & 0.0000 \\
\hline 38 & $3.257 E-09$ & 0.0035 & $0.000 \mathrm{E}+00$ & 0.0000 & $0.000 \mathrm{E}+00$ & 0.0000 & $0.000 \mathrm{E}+00$ & 0.0000 & $0.000 \mathrm{E}+00$ & 0.0000 & $0.000 \mathrm{E}+00$ & 0.0000 & $0.000 \mathrm{E}+00$ & 0.0000 \\
\hline & $9.175 E-07$ & 1.0000 & $0.000 \mathrm{E}+00$ & 0.0000 & $0.000 \mathrm{E}+00$ & 0.0000 & $0.000 \mathrm{E}+00$ & 0.0000 & $0.000 \mathrm{E}+00$ & 0.0000 & $0.000 \mathrm{E}+00$ & 0.0000 & $.000 \mathrm{E}+00$ & 0.0000 \\
\hline
\end{tabular}

Total Dose Contributions TDOSE (i,p,t) for Individual Radionuclides (i) and Pathways (p) As mrem/yr and Fraction of Total Dose At $t=5.000 \mathrm{E}+01$ years

Water Dependent Pathways

\begin{tabular}{|c|c|c|c|c|c|c|c|c|c|c|c|c|c|c|}
\hline & \multicolumn{2}{|c|}{ Water } & \multicolumn{2}{|c|}{ Fish } & \multicolumn{2}{|c|}{ Radon } & \multicolumn{2}{|c|}{ Plant } & \multicolumn{2}{|c|}{ Meat } & \multicolumn{2}{|c|}{ Milk } & \multicolumn{2}{|c|}{ All Pathways* } \\
\hline clide & mrem/yr & fract. & mrem/yr & fract. & mrem/yr & fract. & mrem/yr & fract. & mrem/yr & fract. & mrem/yr & fract. & mrem/yr & fract. \\
\hline-241 & $0.000 \mathrm{E}+00$ & 0.0000 & $0.000 \mathrm{E}+00$ & 0.0000 & $0.000 \mathrm{E}+00$ & 0.0000 & $0.000 \mathrm{E}+00$ & 0.0000 & $0.000 \mathrm{E}+00$ & 0.0000 & $0.000 \mathrm{E}+00$ & 0.0000 & $8.641 \mathrm{E}-17$ & 0.0000 \\
\hline-137 & $0.000 \mathrm{E}+00$ & 0.0000 & $0.000 \mathrm{E}+00$ & 0.0000 & $0.000 \mathrm{E}+00$ & 0.0000 & $0.000 \mathrm{E}+00$ & 0.0000 & $0.000 \mathrm{E}+00$ & 0.0000 & $0.000 \mathrm{E}+00$ & 0.0000 & $1.106 \mathrm{E}-09$ & 0.0012 \\
\hline-237 & $0.000 \mathrm{E}+00$ & 0.0000 & $0.000 \mathrm{E}+00$ & 0.0000 & $0.000 \mathrm{E}+00$ & 0.0000 & $0.000 \mathrm{E}+00$ & 0.0000 & $0.000 \mathrm{E}+00$ & 0.0000 & $0.000 \mathrm{E}+00$ & 0.0000 & $8.637 \mathrm{E}-13$ & 0.0000 \\
\hline-238 & $0.000 \mathrm{E}+00$ & 0.0000 & $0.000 \mathrm{E}+00$ & 0.0000 & $0.000 \mathrm{E}+00$ & 0.0000 & $0.000 \mathrm{E}+00$ & 0.0000 & $0.000 \mathrm{E}+00$ & 0.0000 & $0.000 \mathrm{E}+00$ & 0.0000 & $1.975 \mathrm{E}-16$ & 0.0000 \\
\hline-239 & $0.000 \mathrm{E}+00$ & 0.0000 & $0.000 \mathrm{E}+00$ & 0.0000 & $0.000 \mathrm{E}+00$ & 0.0000 & $0.000 \mathrm{E}+00$ & 0.0000 & $0.000 \mathrm{E}+00$ & 0.0000 & $0.000 E+00$ & 0.0000 & $7.561 \mathrm{E}-17$ & 0.0000 \\
\hline-240 & $0.000 \mathrm{E}+00$ & 0.0000 & $0.000 \mathrm{E}+00$ & 0.0000 & $0.000 \mathrm{E}+00$ & 0.0000 & $0.000 \mathrm{E}+00$ & 0.0000 & $0.000 \mathrm{E}+00$ & 0.0000 & $0.000 E+00$ & 0.0000 & $9.285 \mathrm{E}-21$ & 0.0000 \\
\hline-99 & $0.000 \mathrm{E}+00$ & 0.0000 & $0.000 \mathrm{E}+00$ & 0.0000 & $0.000 \mathrm{E}+00$ & 0.0000 & $0.000 \mathrm{E}+00$ & 0.0000 & $0.000 \mathrm{E}+00$ & 0.0000 & $0.000 \mathrm{E}+00$ & 0.0000 & $5.785 \mathrm{E}-25$ & 0.0000 \\
\hline-228 & $0.000 \mathrm{E}+00$ & 0.0000 & $0.000 \mathrm{E}+00$ & 0.0000 & $0.000 \mathrm{E}+00$ & 0.0000 & $0.000 \mathrm{E}+00$ & 0.0000 & $0.000 \mathrm{E}+00$ & 0.0000 & $0.000 \mathrm{E}+00$ & 0.0000 & $9.718 \mathrm{E}-15$ & 0.0000 \\
\hline-230 & $0.000 \mathrm{E}+00$ & 0.0000 & $0.000 \mathrm{E}+00$ & 0.0000 & $0.000 \mathrm{E}+00$ & 0.0000 & $0.000 \mathrm{E}+00$ & 0.0000 & $0.000 \mathrm{E}+00$ & 0.0000 & $0.000 E+00$ & 0.0000 & $5.116 \mathrm{E}-08$ & 0.0558 \\
\hline 232 & $0.000 \mathrm{E}+00$ & 0.0000 & $0.000 \mathrm{E}+00$ & 0.0000 & $0.000 \mathrm{E}+00$ & 0.0000 & $0.000 \mathrm{E}+00$ & 0.0000 & $0.000 \mathrm{E}+00$ & 0.0000 & $0.000 \mathrm{E}+00$ & 0.0000 & $8.620 \mathrm{E}-07$ & 0.9395 \\
\hline 34 & $0.000 \mathrm{E}+00$ & 0.0000 & $0.000 \mathrm{E}+00$ & 0.0000 & $0.000 \mathrm{E}+00$ & 0.0000 & $0.000 \mathrm{E}+00$ & 0.0000 & $0.000 \mathrm{E}+00$ & 0.0000 & $0.000 \mathrm{E}+00$ & 0.0000 & $1.867 \mathrm{E}-11$ & 0.0000 \\
\hline 35 & $0.000 \mathrm{E}+00$ & 0.0000 & $0.000 \mathrm{E}+00$ & 0.0000 & $0.000 \mathrm{E}+00$ & 0.0000 & $0.000 \mathrm{E}+00$ & 0.0000 & $0.000 \mathrm{E}+00$ & 0.0000 & $0.000 E+00$ & 0.0000 & $5.776 \mathrm{E}-14$ & 0.0000 \\
\hline 38 & $0.000 \mathrm{E}+00$ & 0.0000 & $0.000 \mathrm{E}+00$ & 0.0000 & $0.000 \mathrm{E}+00$ & 0.0000 & $0.000 \mathrm{E}+00$ & 0.0000 & $0.000 \mathrm{E}+00$ & 0.0000 & $0.000 \mathrm{E}+00$ & 0.0000 & $3.257 \mathrm{E}-09$ & 0.0035 \\
\hline & $0.000 \mathrm{E}+00$ & 0.0000 & $0.000 \mathrm{E}+00$ & 0.0000 & $0.000 \mathrm{E}+00$ & 0.0000 & $0.000 \mathrm{E}+00$ & 0.0000 & $0.000 \mathrm{E}+00$ & 0.0000 & $0.000 \mathrm{E}+00$ & 0.0000 & $9.175 \mathrm{E}-07$ & 1.0000 \\
\hline
\end{tabular}

* Sum of all water independent and dependent pathways. 
RESRAD, Version 6.5

$\mathrm{T}^{1 / 2}$ Limit $=180$ days

ummary : C746U Recreational User Deterministic Run

: $\mathrm{X}: \backslash F I N A L$ V2 $\backslash$ DOE FWD RUNS $\backslash C 746 U$ RU DOE SG FWD-FV2-10000YR.RAD

Total Dose Contributions TDOSE (i,p,t) for Individual Radionuclides (i) and Pathways (p) As mrem/yr and Fraction of Total Dose At $t=1.000 \mathrm{E}+02$ years

Water Independent Pathways (Inhalation excludes radon)

\begin{tabular}{|c|c|c|c|c|c|c|c|c|c|c|c|c|c|c|}
\hline \multirow{2}{*}{ Nuclide } & \multicolumn{2}{|c|}{ Ground } & \multicolumn{2}{|c|}{ Inhalation } & \multicolumn{2}{|c|}{ Radon } & \multicolumn{2}{|c|}{ Plant } & \multicolumn{2}{|c|}{ Meat } & \multicolumn{2}{|c|}{ Milk } & \multicolumn{2}{|c|}{ Soil } \\
\hline & mrem/yr & fract. & mrem/yr & fract. & mrem/yr & fract. & mrem/yr & fract. & mrem/yr & fract. & mrem/yr & fract. & mrem/yr & fract. \\
\hline-241 & $2.836 \mathrm{E}-16$ & 0.0000 & $0.000 \mathrm{E}+00$ & 0.0000 & $0.000 \mathrm{E}+00$ & 0.0000 & $0.000 \mathrm{E}+00$ & 0.0000 & $0.000 \mathrm{E}+00$ & 0.0000 & $0.000 \mathrm{E}+00$ & 0.0000 & $0.000 \mathrm{E}+00$ & 0.0000 \\
\hline-137 & $5.307 E-10$ & 0.0004 & $0.000 \mathrm{E}+00$ & 0.0000 & $0.000 \mathrm{E}+00$ & 0.0000 & $0.000 \mathrm{E}+00$ & 0.0000 & $0.000 \mathrm{E}+00$ & 0.0000 & $0.000 \mathrm{E}+00$ & 0.0000 & $0.000 \mathrm{E}+00$ & 0.0000 \\
\hline-237 & $1.483 \mathrm{E}-12$ & 0.0000 & $0.000 \mathrm{E}+00$ & 0.0000 & $0.000 \mathrm{E}+00$ & 0.0000 & $0.000 \mathrm{E}+00$ & 0.0000 & $0.000 \mathrm{E}+00$ & 0.0000 & $0.000 \mathrm{E}+00$ & 0.0000 & $0.000 \mathrm{E}+00$ & 0.0000 \\
\hline-238 & $1.997 \mathrm{E}-15$ & 0.0000 & $0.000 \mathrm{E}+00$ & 0.0000 & $0.000 \mathrm{E}+00$ & 0.0000 & $0.000 \mathrm{E}+00$ & 0.0000 & $0.000 \mathrm{E}+00$ & 0.0000 & $0.000 \mathrm{E}+00$ & 0.0000 & $0.000 \mathrm{E}+00$ & 0.0000 \\
\hline-239 & $1.374 \mathrm{E}-16$ & 0.0000 & $0.000 \mathrm{E}+00$ & 0.0000 & $0.000 \mathrm{E}+00$ & 0.0000 & $0.000 \mathrm{E}+00$ & 0.0000 & $0.000 \mathrm{E}+00$ & 0.0000 & $0.000 \mathrm{E}+00$ & 0.0000 & $0.000 \mathrm{E}+00$ & 0.0000 \\
\hline-240 & $6.177 \mathrm{E}-20$ & 0.0000 & $0.000 \mathrm{E}+00$ & 0.0000 & $0.000 \mathrm{E}+00$ & 0.0000 & $0.000 \mathrm{E}+00$ & 0.0000 & $0.000 \mathrm{E}+00$ & 0.0000 & $0.000 \mathrm{E}+00$ & 0.0000 & $0.000 \mathrm{E}+00$ & 0.0000 \\
\hline 99 & $1.160 \mathrm{E}-24$ & 0.0000 & $0.000 \mathrm{E}+00$ & 0.0000 & $0.000 \mathrm{E}+00$ & 0.0000 & $0.000 \mathrm{E}+00$ & 0.0000 & $0.000 \mathrm{E}+00$ & 0.0000 & $0.000 \mathrm{E}+00$ & 0.0000 & $0.000 \mathrm{E}+00$ & 0.0000 \\
\hline-228 & $1.776 \mathrm{E}-22$ & 0.0000 & $0.000 \mathrm{E}+00$ & 0.0000 & $0.000 \mathrm{E}+00$ & 0.0000 & $0.000 \mathrm{E}+00$ & 0.0000 & $0.000 \mathrm{E}+00$ & 0.0000 & $0.000 \mathrm{E}+00$ & 0.0000 & $0.000 \mathrm{E}+00$ & 0.0000 \\
\hline-230 & $1.423 E-07$ & 0.1082 & $0.000 \mathrm{E}+00$ & 0.0000 & $0.000 \mathrm{E}+00$ & 0.0000 & $0.000 \mathrm{E}+00$ & 0.0000 & $0.000 \mathrm{E}+00$ & 0.0000 & $0.000 \mathrm{E}+00$ & 0.0000 & $0.000 \mathrm{E}+00$ & 0.0000 \\
\hline-232 & $1.167 \mathrm{E}-06$ & 0.8876 & $0.000 \mathrm{E}+00$ & 0.0000 & $0.000 \mathrm{E}+00$ & 0.0000 & $0.000 \mathrm{E}+00$ & 0.0000 & $0.000 \mathrm{E}+00$ & 0.0000 & $0.000 \mathrm{E}+00$ & 0.0000 & $0.000 \mathrm{E}+00$ & 0.0000 \\
\hline 234 & $1.037 \mathrm{E}-10$ & 0.0001 & $0.000 \mathrm{E}+00$ & 0.0000 & $0.000 \mathrm{E}+00$ & 0.0000 & $0.000 \mathrm{E}+00$ & 0.0000 & $0.000 \mathrm{E}+00$ & 0.0000 & $0.000 \mathrm{E}+00$ & 0.0000 & $0.000 \mathrm{E}+00$ & 0.0000 \\
\hline 235 & $2.119 \mathrm{E}-13$ & 0.0000 & $0.000 \mathrm{E}+00$ & 0.0000 & $0.000 \mathrm{E}+00$ & 0.0000 & $0.000 \mathrm{E}+00$ & 0.0000 & $0.000 \mathrm{E}+00$ & 0.0000 & $0.000 \mathrm{E}+00$ & 0.0000 & $0.000 \mathrm{E}+00$ & 0.0000 \\
\hline 38 & $4.856 E-09$ & 0.0037 & $0.000 \mathrm{E}+00$ & 0.0000 & $0.000 \mathrm{E}+00$ & 0.0000 & $0.000 \mathrm{E}+00$ & 0.0000 & $0.000 \mathrm{E}+00$ & 0.0000 & $0.000 \mathrm{E}+00$ & 0.0000 & $0.000 \mathrm{E}+00$ & 0.0000 \\
\hline & $1.314 \mathrm{E}-06$ & 1.0000 & $0.000 \mathrm{E}+00$ & 0.0000 & $0.000 \mathrm{E}+00$ & 0.0000 & $0.000 \mathrm{E}+00$ & 0.0000 & $0.000 \mathrm{E}+00$ & 0.0000 & $0.000 \mathrm{E}+00$ & 0.0000 & $.000 \mathrm{E}+00$ & 0.0000 \\
\hline
\end{tabular}

Total Dose Contributions TDOSE (i,p,t) for Individual Radionuclides (i) and Pathways (p) As mrem/yr and Fraction of Total Dose At $t=1.000 \mathrm{E}+02$ years

Water Dependent Pathways

\begin{tabular}{|c|c|c|c|c|c|c|c|c|c|c|c|c|c|c|}
\hline & \multicolumn{2}{|c|}{ Water } & \multicolumn{2}{|c|}{ Fish } & \multicolumn{2}{|c|}{ Radon } & \multicolumn{2}{|c|}{ Plant } & \multicolumn{2}{|c|}{ Meat } & \multicolumn{2}{|c|}{ Milk } & \multicolumn{2}{|c|}{ All Pathways* } \\
\hline clide & mrem/yr & fract. & mrem/yr & fract. & mrem/yr & fract. & mrem/yr & fract. & mrem/yr & fract. & mrem/yr & fract. & mrem/yr & fract. \\
\hline 241 & $0.000 \mathrm{E}+00$ & 0.0000 & $0.000 \mathrm{E}+00$ & 0.0000 & $0.000 \mathrm{E}+00$ & 0.0000 & $0.000 \mathrm{E}+00$ & 0.0000 & $0.000 \mathrm{E}+00$ & 0.0000 & $0.000 \mathrm{E}+00$ & 0.0000 & $2.836 \mathrm{E}-16$ & 0.0000 \\
\hline-137 & $0.000 \mathrm{E}+00$ & 0.0000 & $0.000 \mathrm{E}+00$ & 0.0000 & $0.000 \mathrm{E}+00$ & 0.0000 & $0.000 \mathrm{E}+00$ & 0.0000 & $0.000 \mathrm{E}+00$ & 0.0000 & $0.000 \mathrm{E}+00$ & 0.0000 & $5.307 \mathrm{E}-10$ & 0.0004 \\
\hline-237 & $0.000 \mathrm{E}+00$ & 0.0000 & $0.000 \mathrm{E}+00$ & 0.0000 & $0.000 \mathrm{E}+00$ & 0.0000 & $0.000 \mathrm{E}+00$ & 0.0000 & $0.000 \mathrm{E}+00$ & 0.0000 & $0.000 \mathrm{E}+00$ & 0.0000 & $1.483 \mathrm{E}-12$ & 0.0000 \\
\hline-238 & $0.000 \mathrm{E}+00$ & 0.0000 & $0.000 \mathrm{E}+00$ & 0.0000 & $0.000 \mathrm{E}+00$ & 0.0000 & $0.000 \mathrm{E}+00$ & 0.0000 & $0.000 \mathrm{E}+00$ & 0.0000 & $0.000 \mathrm{E}+00$ & 0.0000 & $1.997 \mathrm{E}-15$ & 0.0000 \\
\hline-239 & $0.000 \mathrm{E}+00$ & 0.0000 & $0.000 \mathrm{E}+00$ & 0.0000 & $0.000 \mathrm{E}+00$ & 0.0000 & $0.000 \mathrm{E}+00$ & 0.0000 & $0.000 \mathrm{E}+00$ & 0.0000 & $0.000 E+00$ & 0.0000 & $1.374 \mathrm{E}-16$ & 0.0000 \\
\hline-240 & $0.000 \mathrm{E}+00$ & 0.0000 & $0.000 \mathrm{E}+00$ & 0.0000 & $0.000 \mathrm{E}+00$ & 0.0000 & $0.000 \mathrm{E}+00$ & 0.0000 & $0.000 \mathrm{E}+00$ & 0.0000 & $0.000 E+00$ & 0.0000 & $6.177 \mathrm{E}-20$ & 0.0000 \\
\hline-99 & $0.000 \mathrm{E}+00$ & 0.0000 & $0.000 \mathrm{E}+00$ & 0.0000 & $0.000 \mathrm{E}+00$ & 0.0000 & $0.000 \mathrm{E}+00$ & 0.0000 & $0.000 \mathrm{E}+00$ & 0.0000 & $0.000 \mathrm{E}+00$ & 0.0000 & $1.160 \mathrm{E}-24$ & 0.0000 \\
\hline-228 & $0.000 \mathrm{E}+00$ & 0.0000 & $0.000 \mathrm{E}+00$ & 0.0000 & $0.000 \mathrm{E}+00$ & 0.0000 & $0.000 \mathrm{E}+00$ & 0.0000 & $0.000 \mathrm{E}+00$ & 0.0000 & $0.000 \mathrm{E}+00$ & 0.0000 & $1.776 \mathrm{E}-22$ & 0.0000 \\
\hline-230 & $0.000 \mathrm{E}+00$ & 0.0000 & $0.000 \mathrm{E}+00$ & 0.0000 & $0.000 \mathrm{E}+00$ & 0.0000 & $0.000 \mathrm{E}+00$ & 0.0000 & $0.000 \mathrm{E}+00$ & 0.0000 & $0.000 E+00$ & 0.0000 & $1.423 \mathrm{E}-07$ & 0.1082 \\
\hline 232 & $0.000 \mathrm{E}+00$ & 0.0000 & $0.000 \mathrm{E}+00$ & 0.0000 & $0.000 \mathrm{E}+00$ & 0.0000 & $0.000 \mathrm{E}+00$ & 0.0000 & $0.000 \mathrm{E}+00$ & 0.0000 & $0.000 \mathrm{E}+00$ & 0.0000 & $1.167 \mathrm{E}-06$ & 0.8876 \\
\hline 34 & $0.000 \mathrm{E}+00$ & 0.0000 & $0.000 \mathrm{E}+00$ & 0.0000 & $0.000 \mathrm{E}+00$ & 0.0000 & $0.000 \mathrm{E}+00$ & 0.0000 & $0.000 \mathrm{E}+00$ & 0.0000 & $0.000 \mathrm{E}+00$ & 0.0000 & $1.037 \mathrm{E}-10$ & 0.0001 \\
\hline 35 & $0.000 \mathrm{E}+00$ & 0.0000 & $0.000 \mathrm{E}+00$ & 0.0000 & $0.000 \mathrm{E}+00$ & 0.0000 & $0.000 \mathrm{E}+00$ & 0.0000 & $0.000 \mathrm{E}+00$ & 0.0000 & $0.000 E+00$ & 0.0000 & $2.119 \mathrm{E}-13$ & 0.0000 \\
\hline 38 & $0.000 \mathrm{E}+00$ & 0.0000 & $0.000 \mathrm{E}+00$ & 0.0000 & $0.000 \mathrm{E}+00$ & 0.0000 & $0.000 \mathrm{E}+00$ & 0.0000 & $0.000 \mathrm{E}+00$ & 0.0000 & $0.000 \mathrm{E}+00$ & 0.0000 & $4.856 \mathrm{E}-09$ & 0.0037 \\
\hline & $0.000 \mathrm{E}+00$ & 0.0000 & $0.000 \mathrm{E}+00$ & 0.0000 & $0.000 \mathrm{E}+00$ & 0.0000 & $0.000 \mathrm{E}+00$ & 0.0000 & $0.000 \mathrm{E}+00$ & 0.0000 & $0.000 \mathrm{E}+00$ & 0.0000 & $4 \mathrm{E}-06$ & 1. \\
\hline
\end{tabular}

* Sum of all water independent and dependent pathways. 
RESRAD, Version 6.5

$\mathrm{T}^{1 / 2}$ Limit $=180$ days

ummary : C746U Recreational User Deterministic Run

: $\mathrm{X}: \backslash F I N A L$ V2 $\backslash$ DOE FWD RUNS $\backslash C 746 U$ RU DOE SG FWD-FV2-10000YR.RAD

Total Dose Contributions TDOSE (i,p,t) for Individual Radionuclides (i) and Pathways (p) As mrem/yr and Fraction of Total Dose At $t=5.000 \mathrm{E}+02$ years

Water Independent Pathways (Inhalation excludes radon)

\begin{tabular}{|c|c|c|c|c|c|c|c|c|c|c|c|c|c|c|}
\hline \multirow{2}{*}{ Nuclide } & \multicolumn{2}{|c|}{ Ground } & \multicolumn{2}{|c|}{ Inhalation } & \multicolumn{2}{|c|}{ Radon } & \multicolumn{2}{|c|}{ Plant } & \multicolumn{2}{|c|}{ Meat } & \multicolumn{2}{|c|}{ Milk } & \multicolumn{2}{|c|}{ Soil } \\
\hline & mrem/yr & fract. & mrem/yr & fract. & mrem/yr & fract. & mrem/yr & fract. & mrem/yr & fract. & mrem/yr & fract. & mrem/yr & fract. \\
\hline-241 & $7.849 \mathrm{E}-14$ & 0.0000 & $0.000 \mathrm{E}+00$ & 0.0000 & $0.000 \mathrm{E}+00$ & 0.0000 & $0.000 \mathrm{E}+00$ & 0.0000 & $0.000 \mathrm{E}+00$ & 0.0000 & $0.000 \mathrm{E}+00$ & 0.0000 & $0.000 \mathrm{E}+00$ & 0.0000 \\
\hline-137 & $1.491 \mathrm{E}-12$ & 0.0000 & $0.000 \mathrm{E}+00$ & 0.0000 & $0.000 \mathrm{E}+00$ & 0.0000 & $0.000 \mathrm{E}+00$ & 0.0000 & $0.000 \mathrm{E}+00$ & 0.0000 & $0.000 \mathrm{E}+00$ & 0.0000 & $0.000 \mathrm{E}+00$ & 0.0000 \\
\hline-237 & $1.111 \mathrm{E}-10$ & 0.0000 & $0.000 \mathrm{E}+00$ & 0.0000 & $0.000 \mathrm{E}+00$ & 0.0000 & $0.000 \mathrm{E}+00$ & 0.0000 & $0.000 \mathrm{E}+00$ & 0.0000 & $0.000 \mathrm{E}+00$ & 0.0000 & $0.000 \mathrm{E}+00$ & 0.0000 \\
\hline-238 & $2.109 \mathrm{E}-12$ & 0.0000 & $0.000 \mathrm{E}+00$ & 0.0000 & $0.000 \mathrm{E}+00$ & 0.0000 & $0.000 \mathrm{E}+00$ & 0.0000 & $0.000 \mathrm{E}+00$ & 0.0000 & $0.000 \mathrm{E}+00$ & 0.0000 & $0.000 \mathrm{E}+00$ & 0.0000 \\
\hline-239 & $1.636 \mathrm{E}-14$ & 0.0000 & $0.000 \mathrm{E}+00$ & 0.0000 & $0.000 \mathrm{E}+00$ & 0.0000 & $0.000 \mathrm{E}+00$ & 0.0000 & $0.000 \mathrm{E}+00$ & 0.0000 & $0.000 \mathrm{E}+00$ & 0.0000 & $0.000 \mathrm{E}+00$ & 0.0000 \\
\hline-240 & $1.985 \mathrm{E}-17$ & 0.0000 & $0.000 \mathrm{E}+00$ & 0.0000 & $0.000 \mathrm{E}+00$ & 0.0000 & $0.000 \mathrm{E}+00$ & 0.0000 & $0.000 \mathrm{E}+00$ & 0.0000 & $0.000 \mathrm{E}+00$ & 0.0000 & $0.000 \mathrm{E}+00$ & 0.0000 \\
\hline 99 & $3.036 E-22$ & 0.0000 & $0.000 \mathrm{E}+00$ & 0.0000 & $0.000 \mathrm{E}+00$ & 0.0000 & $0.000 \mathrm{E}+00$ & 0.0000 & $0.000 \mathrm{E}+00$ & 0.0000 & $0.000 \mathrm{E}+00$ & 0.0000 & $0.000 \mathrm{E}+00$ & 0.0000 \\
\hline-228 & $0.000 \mathrm{E}+00$ & 0.0000 & $0.000 \mathrm{E}+00$ & 0.0000 & $0.000 \mathrm{E}+00$ & 0.0000 & $0.000 \mathrm{E}+00$ & 0.0000 & $0.000 \mathrm{E}+00$ & 0.0000 & $0.000 \mathrm{E}+00$ & 0.0000 & $0.000 \mathrm{E}+00$ & 0.0000 \\
\hline-230 & $1.032 \mathrm{E}-05$ & 0.4425 & $0.000 \mathrm{E}+00$ & 0.0000 & $0.000 \mathrm{E}+00$ & 0.0000 & $0.000 \mathrm{E}+00$ & 0.0000 & $0.000 \mathrm{E}+00$ & 0.0000 & $0.000 \mathrm{E}+00$ & 0.0000 & $0.000 \mathrm{E}+00$ & 0.0000 \\
\hline-232 & $1.285 E-05$ & 0.5508 & $0.000 \mathrm{E}+00$ & 0.0000 & $0.000 \mathrm{E}+00$ & 0.0000 & $0.000 \mathrm{E}+00$ & 0.0000 & $0.000 \mathrm{E}+00$ & 0.0000 & $0.000 \mathrm{E}+00$ & 0.0000 & $0.000 \mathrm{E}+00$ & 0.0000 \\
\hline 234 & $3.851 \mathrm{E}-08$ & 0.0017 & $0.000 \mathrm{E}+00$ & 0.0000 & $0.000 \mathrm{E}+00$ & 0.0000 & $0.000 \mathrm{E}+00$ & 0.0000 & $0.000 \mathrm{E}+00$ & 0.0000 & $0.000 \mathrm{E}+00$ & 0.0000 & $0.000 \mathrm{E}+00$ & 0.0000 \\
\hline 235 & $4.414 \mathrm{E}-11$ & 0.0000 & $0.000 \mathrm{E}+00$ & 0.0000 & $0.000 \mathrm{E}+00$ & 0.0000 & $0.000 \mathrm{E}+00$ & 0.0000 & $0.000 \mathrm{E}+00$ & 0.0000 & $0.000 \mathrm{E}+00$ & 0.0000 & $0.000 \mathrm{E}+00$ & 0.0000 \\
\hline 38 & $1.187 \mathrm{E}-07$ & 0.0051 & $0.000 \mathrm{E}+00$ & 0.0000 & $0.000 \mathrm{E}+00$ & 0.0000 & $0.000 \mathrm{E}+00$ & 0.0000 & $0.000 \mathrm{E}+00$ & 0.0000 & $0.000 \mathrm{E}+00$ & 0.0000 & $0.000 \mathrm{E}+00$ & 0.0000 \\
\hline & $2.333 E-05$ & 1.0000 & $0.000 \mathrm{E}+00$ & 0.0000 & $0.000 \mathrm{E}+00$ & 0.0000 & $0.000 \mathrm{E}+00$ & 0.0000 & $0.000 \mathrm{E}+00$ & 0.0000 & $0.000 \mathrm{E}+00$ & 0.0000 & $.000 \mathrm{E}+00$ & 0.0000 \\
\hline
\end{tabular}

Total Dose Contributions TDOSE (i,p,t) for Individual Radionuclides (i) and Pathways (p) As mrem/yr and Fraction of Total Dose At $t=5.000 \mathrm{E}+02$ years

Water Dependent Pathways

\begin{tabular}{|c|c|c|c|c|c|c|c|c|c|c|c|c|c|c|}
\hline & \multicolumn{2}{|c|}{ Water } & \multicolumn{2}{|c|}{ Fish } & \multicolumn{2}{|c|}{ Radon } & \multicolumn{2}{|c|}{ Plant } & \multicolumn{2}{|c|}{ Meat } & \multicolumn{2}{|c|}{ Milk } & \multicolumn{2}{|c|}{ All Pathways* } \\
\hline clide & mrem/yr & fract. & mrem/yr & fract. & mrem/yr & fract. & mrem/yr & fract. & mrem/yr & fract. & mrem/yr & fract. & mrem/yr & fract. \\
\hline 241 & $0.000 \mathrm{E}+00$ & 0.0000 & $0.000 \mathrm{E}+00$ & 0.0000 & $0.000 \mathrm{E}+00$ & 0.0000 & $0.000 \mathrm{E}+00$ & 0.0000 & $0.000 \mathrm{E}+00$ & 0.0000 & $0.000 \mathrm{E}+00$ & 0.0000 & $7.849 \mathrm{E}-14$ & 0.0000 \\
\hline-137 & $0.000 \mathrm{E}+00$ & 0.0000 & $0.000 \mathrm{E}+00$ & 0.0000 & $0.000 \mathrm{E}+00$ & 0.0000 & $0.000 \mathrm{E}+00$ & 0.0000 & $0.000 \mathrm{E}+00$ & 0.0000 & $0.000 \mathrm{E}+00$ & 0.0000 & 1. $491 \mathrm{E}-12$ & 0.0000 \\
\hline-237 & $0.000 \mathrm{E}+00$ & 0.0000 & $0.000 \mathrm{E}+00$ & 0.0000 & $0.000 \mathrm{E}+00$ & 0.0000 & $0.000 \mathrm{E}+00$ & 0.0000 & $0.000 \mathrm{E}+00$ & 0.0000 & $0.000 \mathrm{E}+00$ & 0.0000 & $1.111 \mathrm{E}-10$ & 0.0000 \\
\hline-238 & $0.000 \mathrm{E}+00$ & 0.0000 & $0.000 \mathrm{E}+00$ & 0.0000 & $0.000 \mathrm{E}+00$ & 0.0000 & $0.000 \mathrm{E}+00$ & 0.0000 & $0.000 \mathrm{E}+00$ & 0.0000 & $0.000 \mathrm{E}+00$ & 0.0000 & $2.109 \mathrm{E}-12$ & 0.0000 \\
\hline-239 & $0.000 \mathrm{E}+00$ & 0.0000 & $0.000 \mathrm{E}+00$ & 0.0000 & $0.000 \mathrm{E}+00$ & 0.0000 & $0.000 \mathrm{E}+00$ & 0.0000 & $0.000 \mathrm{E}+00$ & 0.0000 & $0.000 E+00$ & 0.0000 & $1.636 \mathrm{E}-14$ & 0.0000 \\
\hline-240 & $0.000 \mathrm{E}+00$ & 0.0000 & $0.000 \mathrm{E}+00$ & 0.0000 & $0.000 \mathrm{E}+00$ & 0.0000 & $0.000 \mathrm{E}+00$ & 0.0000 & $0.000 \mathrm{E}+00$ & 0.0000 & $0.000 E+00$ & 0.0000 & $1.985 \mathrm{E}-17$ & 0.0000 \\
\hline-99 & $0.000 \mathrm{E}+00$ & 0.0000 & $0.000 \mathrm{E}+00$ & 0.0000 & $0.000 \mathrm{E}+00$ & 0.0000 & $0.000 \mathrm{E}+00$ & 0.0000 & $0.000 \mathrm{E}+00$ & 0.0000 & $0.000 \mathrm{E}+00$ & 0.0000 & $3.036 \mathrm{E}-22$ & 0.0000 \\
\hline-228 & $0.000 \mathrm{E}+00$ & 0.0000 & $0.000 \mathrm{E}+00$ & 0.0000 & $0.000 \mathrm{E}+00$ & 0.0000 & $0.000 \mathrm{E}+00$ & 0.0000 & $0.000 \mathrm{E}+00$ & 0.0000 & $0.000 \mathrm{E}+00$ & 0.0000 & $0.000 \mathrm{E}+00$ & 0.0000 \\
\hline-230 & $0.000 \mathrm{E}+00$ & 0.0000 & $0.000 \mathrm{E}+00$ & 0.0000 & $0.000 \mathrm{E}+00$ & 0.0000 & $0.000 \mathrm{E}+00$ & 0.0000 & $0.000 \mathrm{E}+00$ & 0.0000 & $0.000 E+00$ & 0.0000 & $1.032 \mathrm{E}-05$ & 0.4425 \\
\hline-232 & $0.000 \mathrm{E}+00$ & 0.0000 & $0.000 \mathrm{E}+00$ & 0.0000 & $0.000 \mathrm{E}+00$ & 0.0000 & $0.000 \mathrm{E}+00$ & 0.0000 & $0.000 \mathrm{E}+00$ & 0.0000 & $0.000 \mathrm{E}+00$ & 0.0000 & 1. $285 \mathrm{E}-05$ & 0.5508 \\
\hline 34 & $0.000 \mathrm{E}+00$ & 0.0000 & $0.000 \mathrm{E}+00$ & 0.0000 & $0.000 \mathrm{E}+00$ & 0.0000 & $0.000 \mathrm{E}+00$ & 0.0000 & $0.000 \mathrm{E}+00$ & 0.0000 & $0.000 \mathrm{E}+00$ & 0.0000 & $3.851 \mathrm{E}-08$ & 0.0017 \\
\hline 35 & $0.000 \mathrm{E}+00$ & 0.0000 & $0.000 \mathrm{E}+00$ & 0.0000 & $0.000 \mathrm{E}+00$ & 0.0000 & $0.000 \mathrm{E}+00$ & 0.0000 & $0.000 \mathrm{E}+00$ & 0.0000 & $0.000 \mathrm{E}+00$ & 0.0000 & $4.414 \mathrm{E}-11$ & 0.0000 \\
\hline 38 & $0.000 \mathrm{E}+00$ & 0.0000 & $0.000 \mathrm{E}+00$ & 0.0000 & $0.000 \mathrm{E}+00$ & 0.0000 & $0.000 \mathrm{E}+00$ & 0.0000 & $0.000 \mathrm{E}+00$ & 0.0000 & $0.000 \mathrm{E}+00$ & 0.0000 & $1.187 \mathrm{E}-07$ & 0.0051 \\
\hline & $0.000 \mathrm{E}+00$ & 0.0000 & $0.000 \mathrm{E}+00$ & 0.0000 & $0.000 \mathrm{E}+00$ & 0.0000 & $0.000 \mathrm{E}+00$ & 0.0000 & $0.000 \mathrm{E}+00$ & 0.0000 & $0.000 \mathrm{E}+00$ & 0.0000 & $3 E-05$ & 1.0000 \\
\hline
\end{tabular}

* Sum of all water independent and dependent pathways. 
RESRAD, Version 6.5

$\mathrm{T}^{1 / 2}$ Limit $=180$ days

ummary : C746U Recreational User Deterministic Run

: $\mathrm{X}: \backslash F I N A L$ V2 $\backslash$ DOE FWD RUNS $\backslash C 746 U$ RU DOE SG FWD-FV2-10000YR.RAD

Total Dose Contributions TDOSE (i,p,t) for Individual Radionuclides (i) and Pathways (p) As mrem/yr and Fraction of Total Dose At $t=1.000 \mathrm{E}+04$ years

Water Independent Pathways (Inhalation excludes radon)

\begin{tabular}{|c|c|c|c|c|c|c|c|c|c|c|c|c|c|c|}
\hline \multirow{2}{*}{ Nuclide } & \multicolumn{2}{|c|}{ Ground } & \multicolumn{2}{|c|}{ Inhalation } & \multicolumn{2}{|c|}{ Radon } & \multicolumn{2}{|c|}{ Plant } & \multicolumn{2}{|c|}{ Meat } & \multicolumn{2}{|c|}{ Milk } & \multicolumn{2}{|c|}{ Soil } \\
\hline & mrem/yr & fract. & mrem/yr & fract. & mrem/yr & fract. & mrem/yr & fract. & mrem/yr & fract. & mrem/yr & fract. & mrem/yr & fract. \\
\hline-241 & $2.772 \mathrm{E}-04$ & 0.0000 & $1.067 \mathrm{E}-07$ & 0.0000 & $0.000 \mathrm{E}+00$ & 0.0000 & $0.000 \mathrm{E}+00$ & 0.0000 & $0.000 \mathrm{E}+00$ & 0.0000 & $0.000 \mathrm{E}+00$ & 0.0000 & $4.985 \mathrm{E}-06$ & 0.0000 \\
\hline-137 & $0.000 \mathrm{E}+00$ & 0.0000 & $0.000 \mathrm{E}+00$ & 0.0000 & $0.000 \mathrm{E}+00$ & 0.0000 & $0.000 \mathrm{E}+00$ & 0.0000 & $0.000 \mathrm{E}+00$ & 0.0000 & $0.000 \mathrm{E}+00$ & 0.0000 & $0.000 \mathrm{E}+00$ & 0.0000 \\
\hline-237 & $2.064 \mathrm{E}-01$ & 0.0022 & $8.027 \mathrm{E}-05$ & 0.0000 & $0.000 \mathrm{E}+00$ & 0.0000 & $0.000 \mathrm{E}+00$ & 0.0000 & $0.000 \mathrm{E}+00$ & 0.0000 & $0.000 \mathrm{E}+00$ & 0.0000 & $3.786 \mathrm{E}-03$ & 0.0000 \\
\hline-238 & $6.968 E-04$ & 0.0000 & $1.453 E-07$ & 0.0000 & $0.000 \mathrm{E}+00$ & 0.0000 & $0.000 \mathrm{E}+00$ & 0.0000 & $0.000 \mathrm{E}+00$ & 0.0000 & $0.000 \mathrm{E}+00$ & 0.0000 & $5.738 E-05$ & 0.0000 \\
\hline-239 & $5.278 \mathrm{E}-04$ & 0.0000 & $1.596 \mathrm{E}-03$ & 0.0000 & $0.000 \mathrm{E}+00$ & 0.0000 & $0.000 \mathrm{E}+00$ & 0.0000 & $0.000 \mathrm{E}+00$ & 0.0000 & $0.000 \mathrm{E}+00$ & 0.0000 & $6.333 E-02$ & 0.0007 \\
\hline-240 & $1.017 \mathrm{E}-04$ & 0.0000 & $7.375 E-04$ & 0.0000 & $0.000 \mathrm{E}+00$ & 0.0000 & $0.000 \mathrm{E}+00$ & 0.0000 & $0.000 \mathrm{E}+00$ & 0.0000 & $0.000 \mathrm{E}+00$ & 0.0000 & $2.926 \mathrm{E}-02$ & 0.0003 \\
\hline 99 & $6.336 E-27$ & 0.0000 & $0.000 \mathrm{E}+00$ & 0.0000 & $0.000 \mathrm{E}+00$ & 0.0000 & $0.000 \mathrm{E}+00$ & 0.0000 & $0.000 \mathrm{E}+00$ & 0.0000 & $0.000 \mathrm{E}+00$ & 0.0000 & $6.519 \mathrm{E}-27$ & 0.0000 \\
\hline-228 & $0.000 \mathrm{E}+00$ & 0.0000 & $0.000 \mathrm{E}+00$ & 0.0000 & $0.000 \mathrm{E}+00$ & 0.0000 & $0.000 \mathrm{E}+00$ & 0.0000 & $0.000 \mathrm{E}+00$ & 0.0000 & $0.000 \mathrm{E}+00$ & 0.0000 & $0.000 \mathrm{E}+00$ & 0.0000 \\
\hline-230 & 7. $343 \mathrm{E}+01$ & 0.7737 & $6.397 \mathrm{E}-03$ & 0.0001 & $0.000 \mathrm{E}+00$ & 0.0000 & $0.000 \mathrm{E}+00$ & 0.0000 & $0.000 \mathrm{E}+00$ & 0.0000 & $0.000 \mathrm{E}+00$ & 0.0000 & $5.000 \mathrm{E}+00$ & 0.0527 \\
\hline-232 & $4.711 E+00$ & 0.0496 & $4.381 E-04$ & 0.0000 & $0.000 \mathrm{E}+00$ & 0.0000 & $0.000 \mathrm{E}+00$ & 0.0000 & $0.000 \mathrm{E}+00$ & 0.0000 & $0.000 \mathrm{E}+00$ & 0.0000 & $2.488 \mathrm{E}-01$ & 0.0026 \\
\hline 234 & $8.094 \mathrm{E}+00$ & 0.0853 & $1.671 \mathrm{E}-03$ & 0.0000 & $0.000 \mathrm{E}+00$ & 0.0000 & $0.000 \mathrm{E}+00$ & 0.0000 & $0.000 \mathrm{E}+00$ & 0.0000 & $0.000 \mathrm{E}+00$ & 0.0000 & $6.646 \mathrm{E}-01$ & 0.0070 \\
\hline 235 & $4.875 E-01$ & 0.0051 & $5.106 \mathrm{E}-04$ & 0.0000 & $0.000 \mathrm{E}+00$ & 0.0000 & $0.000 \mathrm{E}+00$ & 0.0000 & $0.000 \mathrm{E}+00$ & 0.0000 & $0.000 \mathrm{E}+00$ & 0.0000 & $3.267 \mathrm{E}-02$ & 0.0003 \\
\hline 38 & $1.803 E+00$ & 0.0190 & $7.593 E-04$ & 0.0000 & $0.000 \mathrm{E}+00$ & 0.0000 & $0.000 \mathrm{E}+00$ & 0.0000 & $0.000 \mathrm{E}+00$ & 0.0000 & $0.000 \mathrm{E}+00$ & 0.0000 & $1.174 \mathrm{E}-01$ & 0.0012 \\
\hline & $8.873 E+01$ & 0.9350 & $1.219 \mathrm{E}-02$ & 0.0001 & $0.000 \mathrm{E}+00$ & 0.0000 & $0.000 \mathrm{E}+00$ & 0.0000 & $0.000 \mathrm{E}+00$ & 0.0000 & $0.000 \mathrm{E}+00$ & 0.0000 & $6.160 \mathrm{E}+00$ & 0.0649 \\
\hline
\end{tabular}

Total Dose Contributions TDOSE (i,p,t) for Individual Radionuclides (i) and Pathways (p) As mrem/yr and Fraction of Total Dose At $t=1.000 \mathrm{E}+04$ years

Water Dependent Pathways

\begin{tabular}{|c|c|c|c|c|c|c|c|c|c|c|c|c|c|c|}
\hline & \multicolumn{2}{|c|}{ Water } & \multicolumn{2}{|c|}{ Fish } & \multicolumn{2}{|c|}{ Radon } & \multicolumn{2}{|c|}{ Plant } & \multicolumn{2}{|c|}{ Meat } & \multicolumn{2}{|c|}{ Milk } & \multicolumn{2}{|c|}{ All Pathways* } \\
\hline clide & mrem/yr & fract. & mrem/yr & fract. & mrem/yr & fract. & mrem/yr & fract. & mrem/yr & fract. & mrem/yr & fract. & mrem/yr & fract. \\
\hline 241 & $0.000 \mathrm{E}+00$ & 0.0000 & $0.000 \mathrm{E}+00$ & 0.0000 & $0.000 \mathrm{E}+00$ & 0.0000 & $0.000 \mathrm{E}+00$ & 0.0000 & $0.000 \mathrm{E}+00$ & 0.0000 & $0.000 \mathrm{E}+00$ & 0.0000 & $2.823 E-04$ & 0.0000 \\
\hline-137 & $0.000 \mathrm{E}+00$ & 0.0000 & $0.000 \mathrm{E}+00$ & 0.0000 & $0.000 \mathrm{E}+00$ & 0.0000 & $0.000 \mathrm{E}+00$ & 0.0000 & $0.000 \mathrm{E}+00$ & 0.0000 & $0.000 \mathrm{E}+00$ & 0.0000 & $0.000 \mathrm{E}+00$ & 0.0000 \\
\hline-237 & $0.000 \mathrm{E}+00$ & 0.0000 & $0.000 \mathrm{E}+00$ & 0.0000 & $0.000 \mathrm{E}+00$ & 0.0000 & $0.000 \mathrm{E}+00$ & 0.0000 & $0.000 \mathrm{E}+00$ & 0.0000 & $0.000 \mathrm{E}+00$ & 0.0000 & $2.103 E-01$ & 0.0022 \\
\hline-238 & $0.000 \mathrm{E}+00$ & 0.0000 & $0.000 \mathrm{E}+00$ & 0.0000 & $0.000 \mathrm{E}+00$ & 0.0000 & $0.000 \mathrm{E}+00$ & 0.0000 & $0.000 \mathrm{E}+00$ & 0.0000 & $0.000 \mathrm{E}+00$ & 0.0000 & $7.543 \mathrm{E}-04$ & 0.0000 \\
\hline-239 & $0.000 \mathrm{E}+00$ & 0.0000 & $0.000 \mathrm{E}+00$ & 0.0000 & $0.000 \mathrm{E}+00$ & 0.0000 & $0.000 \mathrm{E}+00$ & 0.0000 & $0.000 \mathrm{E}+00$ & 0.0000 & $0.000 E+00$ & 0.0000 & $6.546 \mathrm{E}-02$ & 0.0007 \\
\hline-240 & $0.000 \mathrm{E}+00$ & 0.0000 & $0.000 \mathrm{E}+00$ & 0.0000 & $0.000 \mathrm{E}+00$ & 0.0000 & $0.000 \mathrm{E}+00$ & 0.0000 & $0.000 \mathrm{E}+00$ & 0.0000 & $0.000 E+00$ & 0.0000 & $3.010 \mathrm{E}-02$ & 0.0003 \\
\hline-99 & $0.000 \mathrm{E}+00$ & 0.0000 & $0.000 \mathrm{E}+00$ & 0.0000 & $0.000 \mathrm{E}+00$ & 0.0000 & $0.000 \mathrm{E}+00$ & 0.0000 & $0.000 \mathrm{E}+00$ & 0.0000 & $0.000 \mathrm{E}+00$ & 0.0000 & 1. $285 \mathrm{E}-26$ & 0.0000 \\
\hline-228 & $0.000 \mathrm{E}+00$ & 0.0000 & $0.000 \mathrm{E}+00$ & 0.0000 & $0.000 \mathrm{E}+00$ & 0.0000 & $0.000 \mathrm{E}+00$ & 0.0000 & $0.000 \mathrm{E}+00$ & 0.0000 & $0.000 \mathrm{E}+00$ & 0.0000 & $0.000 \mathrm{E}+00$ & 0.0000 \\
\hline-230 & $0.000 \mathrm{E}+00$ & 0.0000 & $0.000 \mathrm{E}+00$ & 0.0000 & $0.000 \mathrm{E}+00$ & 0.0000 & $0.000 \mathrm{E}+00$ & 0.0000 & $0.000 \mathrm{E}+00$ & 0.0000 & $0.000 E+00$ & 0.0000 & $7.843 \mathrm{E}+01$ & 0.8265 \\
\hline-232 & $0.000 \mathrm{E}+00$ & 0.0000 & $0.000 \mathrm{E}+00$ & 0.0000 & $0.000 \mathrm{E}+00$ & 0.0000 & $0.000 \mathrm{E}+00$ & 0.0000 & $0.000 \mathrm{E}+00$ & 0.0000 & $0.000 \mathrm{E}+00$ & 0.0000 & $4.960 \mathrm{E}+00$ & 0.0523 \\
\hline 34 & $0.000 \mathrm{E}+00$ & 0.0000 & $0.000 \mathrm{E}+00$ & 0.0000 & $0.000 \mathrm{E}+00$ & 0.0000 & $0.000 \mathrm{E}+00$ & 0.0000 & $0.000 \mathrm{E}+00$ & 0.0000 & $0.000 \mathrm{E}+00$ & 0.0000 & $8.760 \mathrm{E}+00$ & 0.0923 \\
\hline 35 & $0.000 \mathrm{E}+00$ & 0.0000 & $0.000 \mathrm{E}+00$ & 0.0000 & $0.000 \mathrm{E}+00$ & 0.0000 & $0.000 \mathrm{E}+00$ & 0.0000 & $0.000 \mathrm{E}+00$ & 0.0000 & $0.000 E+00$ & 0.0000 & $5.207 \mathrm{E}-01$ & 0.0055 \\
\hline 38 & $0.000 \mathrm{E}+00$ & 0.0000 & $0.000 \mathrm{E}+00$ & 0.0000 & $0.000 \mathrm{E}+00$ & 0.0000 & $0.000 \mathrm{E}+00$ & 0.0000 & $0.000 \mathrm{E}+00$ & 0.0000 & $0.000 \mathrm{E}+00$ & 0.0000 & $1.921 \mathrm{E}+00$ & 0.0202 \\
\hline & $0.000 \mathrm{E}+00$ & 0.0000 & $0.000 \mathrm{E}+00$ & 0.0000 & $0.000 \mathrm{E}+00$ & 0.0000 & $0.000 \mathrm{E}+00$ & 0.0000 & $0.000 \mathrm{E}+00$ & 0.0000 & $0.000 \mathrm{E}+00$ & 0.0000 & $\mathrm{DE}+01$ & 1. \\
\hline
\end{tabular}

* Sum of all water independent and dependent pathways. 
RESRAD, Version $6.5 \quad \mathrm{~T}^{1 / 2}$ Limit $=180$ days

Summary : C746U Recreational User Deterministic Run

File : $\mathrm{X}: \backslash F I N A L$ V2 \DOE FWD RUNS \C746U RU DOE SG FWD-FV2-10000YR.RAD

Dose/Source Ratios Summed Over All Pathways

Parent and Progeny Principal Radionuclide Contributions Indicated

Parent Product Thread DSR $(j, t)$ At Time in Years (mrem/yr)/(pCi/g)

(i)

(j)

$\begin{array}{ll}\mathrm{Am}-241 & 1.000 \mathrm{E}+00 \\ \mathrm{~Np}-237+\mathrm{D} & 1.000 \mathrm{E}+00 \\ \mathrm{U}-233 & 1.000 \mathrm{E}+00 \\ \mathrm{Th}-229+\mathrm{D} & 1.000 \mathrm{E}+00 \\ \operatorname{\sum DSR}(j) & \end{array}$

Cs $-137+D$

$\mathrm{Np}-237+\mathrm{D}$

$\mathrm{U}-233$

Th-229+D

$\sum \operatorname{DSR}(j)$

$\mathrm{Pu}-238$

Pu-238

U-234

Th-230

Ra-226+D

$\mathrm{Pb}-210+\mathrm{D}$

$\sum \operatorname{DSR}(j)$

Pu-239

$\mathrm{U}-235+\mathrm{D}$

$\mathrm{Pa}-231$

AC-227+D

$\sum \operatorname{DSR}(j)$

Pu-2 40

$\mathrm{Pu}-240$

U-236

Th-232

$\mathrm{Ra}-228+\mathrm{D}$

Th-228+D

$\sum \mathrm{DSR}(j)$

TC-99

Th-228+D

1. $000 \mathrm{E}+00$

Th-230

1. $000 \mathrm{E}+00$

Ra-226+D

$1.000 \mathrm{E}+00$

$\mathrm{Pb}-210+\mathrm{D}$

$\sum \operatorname{DSR}(j)$
$0.000 \mathrm{E}+00 \quad 1.000 \mathrm{E}+00 \quad 5.000 \mathrm{E}+01 \quad 1.000 \mathrm{E}+02 \quad 5.000 \mathrm{E}+02 \quad 1.000 \mathrm{E}+04$

$1.862 \mathrm{E}-34 \quad 1.912 \mathrm{E}-34 \quad 7.071 \mathrm{E}-34 \quad 2.685 \mathrm{E}-33 \quad 1.163 \mathrm{E}-28 \quad 5.451 \mathrm{E}-10$

$\begin{array}{lllll}1.487 \mathrm{E}-20 & 4.500 \mathrm{E}-20 & 2.467 \mathrm{E}-18 & 8.084 \mathrm{E}-18 & 2.212 \mathrm{E}-15 \quad 7.802 \mathrm{E}-06\end{array}$

$3.371 \mathrm{E}-31 \quad 2.384 \mathrm{E}-30 \quad 4.682 \mathrm{E}-27 \quad 3.376 \mathrm{E}-26 \quad 1.025 \mathrm{E}-22 \quad 5.052 \mathrm{E}-09$

$2.306 \mathrm{E}-27 \quad 3.479 \mathrm{E}-26 \quad 1.645 \mathrm{E}-21 \quad 1.799 \mathrm{E}-20 \quad 3.100 \mathrm{E}-17 \quad 2.585 \mathrm{E}-07$

$\begin{array}{lllll}1.487 \mathrm{E}-20 & 4.500 \mathrm{E}-20 & 2.469 \mathrm{E}-18 \quad 8.102 \mathrm{E}-18 \quad 2.243 \mathrm{E}-15 \quad 8.067 \mathrm{E}-06\end{array}$

$1.000 \mathrm{E}+00 \quad 1.213 \mathrm{E}-10 \quad 1.196 \mathrm{E}-10 \quad 5.821 \mathrm{E}-11 \quad 2.793 \mathrm{E}-11 \quad 7.847 \mathrm{E}-14 \quad 0.000 \mathrm{E}+00$

$\begin{array}{lllllll}1.000 \mathrm{E}+00 & 9.169 \mathrm{E}-14 & 9.268 \mathrm{E}-14 & 1.567 \mathrm{E}-13 & 2.679 \mathrm{E}-13 & 1.952 \mathrm{E}-11 & 3.681 \mathrm{E}-02\end{array}$

$\begin{array}{llllllll}1.000 \mathrm{E}+00 & 3.120 \mathrm{E}-24 & 9.466 \mathrm{E}-24 & 5.875 \mathrm{E}-22 & 2.184 \mathrm{E}-21 & 1.613 \mathrm{E}-18 & 2.602 \mathrm{E}-05\end{array}$

$\begin{array}{lllllll}1.000 \mathrm{E}+00 & 2.848 \mathrm{E}-20 & 2.006 \mathrm{E}-19 & 3.076 \mathrm{E}-16 & 1.723 \mathrm{E}-15 & 6.884 \mathrm{E}-13 & 1.403 \mathrm{E}-03\end{array}$

$\begin{array}{llllll}9.169 \mathrm{E}-14 & 9.268 \mathrm{E}-14 & 1.570 \mathrm{E}-13 & 2.696 \mathrm{E}-13 & 2.021 \mathrm{E}-11 & 3.824 \mathrm{E}-02\end{array}$

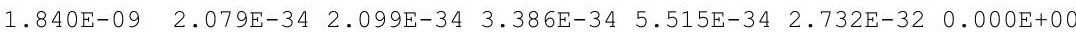

1.000E+00 1.130E-25 $1.141 \mathrm{E}-25 \quad 1.840 \mathrm{E}-25 \quad 2.997 \mathrm{E}-25 \quad 1.485 \mathrm{E}-23 \quad 1.081 \mathrm{E}-37$

$\begin{array}{llllllll}1.000 E+00 & 9.402 E-31 & 2.855 E-30 & 1.897 E-28 & 7.660 E-28 & 1.633 E-24 & 2.543 E-07\end{array}$

$\begin{array}{lllllll}1.000 \mathrm{E}+00 & 9.887 \mathrm{E}-35 & 7.005 \mathrm{E}-34 & 1.538 \mathrm{E}-30 & 1.253 \mathrm{E}-29 & 1.259 \mathrm{E}-25 & 7.030 \mathrm{E}-08\end{array}$

$\begin{array}{llllllll}1.000 \mathrm{E}+00 & 7.713 \mathrm{E}-24 & 1.162 \mathrm{E}-22 & 5.065 \mathrm{E}-18 & 5.122 \mathrm{E}-17 & 5.408 \mathrm{E}-14 & 1.819 \mathrm{E}-05\end{array}$

$\begin{array}{llllllll}1.000 \mathrm{E}+00 & 2.237 \mathrm{E}-32 & 6.933 \mathrm{E}-31 & 7.476 \mathrm{E}-25 & 1.264 \mathrm{E}-23 & 3.542 \mathrm{E}-20 & 8.245 \mathrm{E}-07\end{array}$

$\begin{array}{llllll}7.826 \mathrm{E}-24 & 1.163 \mathrm{E}-22 & 5.065 \mathrm{E}-18 & 5.122 \mathrm{E}-17 & 5.408 \mathrm{E}-14 & 1.934 \mathrm{E}-05\end{array}$

$\begin{array}{lllllll}1.000 \mathrm{E}+00 & 1.156 \mathrm{E}-18 & 1.170 \mathrm{E}-18 & 2.100 \mathrm{E}-18 & 3.815 \mathrm{E}-18 & 4.526 \mathrm{E}-16 & 1.818 \mathrm{E}-03\end{array}$

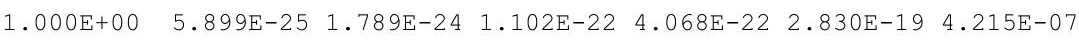

$\begin{array}{llllllll}1.000 \mathrm{E}+00 & 9.281 \mathrm{E}-29 & 6.556 \mathrm{E}-28 & 1.203 \mathrm{E}-24 & 8.097 \mathrm{E}-24 & 1.394 \mathrm{E}-20 & 1.785 \mathrm{E}-08\end{array}$

$\begin{array}{llllllll}1.000 \mathrm{E}+00 & 2.200 \mathrm{E}-28 & 3.302 \mathrm{E}-27 & 1.227 \mathrm{E}-22 & 1.125 \mathrm{E}-21 & 1.425 \mathrm{E}-18 & 1.293 \mathrm{E}-07\end{array}$

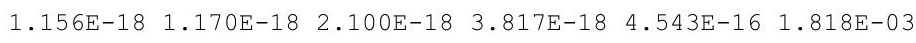

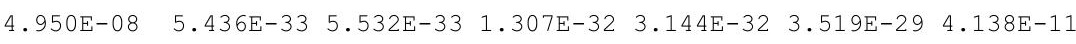

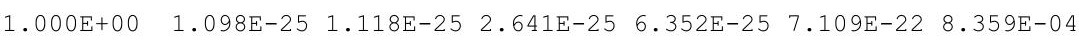

$\begin{array}{llllllll}1.000 \mathrm{E}+00 & 2.079 \mathrm{E}-33 & 6.337 \mathrm{E}-33 & 5.132 \mathrm{E}-31 & 2.504 \mathrm{E}-30 & 1.628 \mathrm{E}-26 & 1.256 \mathrm{E}-07\end{array}$

$\begin{array}{lllllllll}1.000 \mathrm{E}+00 \quad 2.803 \mathrm{E}-44 & 1.948 \mathrm{E}-43 & 5.271 \mathrm{E}-40 & 5.270 \mathrm{E}-39 & 2.159 \mathrm{E}-34 & 1.367 \mathrm{E}-13\end{array}$

$\begin{array}{llllllll}1.000 \mathrm{E}+00 & 1.318 \mathrm{E}-29 & 1.940 \mathrm{E}-28 & 3.618 \mathrm{E}-24 & 2.445 \mathrm{E}-23 & 1.417 \mathrm{E}-20 & 2.429 \mathrm{E}-11\end{array}$

$\begin{array}{lllllll}1.000 \mathrm{E}+00 & 7.799 \mathrm{E}-29 & 2.244 \mathrm{E}-27 & 2.540 \mathrm{E}-22 & 1.691 \mathrm{E}-21 & 5.366 \mathrm{E}-19 & 3.687 \mathrm{E}-11\end{array}$

$\begin{array}{llllll}1.099 \mathrm{E}-25 & 1.142 \mathrm{E}-25 & 2.579 \mathrm{E}-22 & 1.716 \mathrm{E}-21 & 5.515 \mathrm{E}-19 & 8.361 \mathrm{E}-04\end{array}$

$\begin{array}{lllllll}1.000 \mathrm{E}+00 & 5.547 \mathrm{E}-27 & 5.625 \mathrm{E}-27 & 1.112 \mathrm{E}-26 & 2.231 \mathrm{E}-26 & 5.839 \mathrm{E}-24 & 2.473 \mathrm{E}-28\end{array}$

$\begin{array}{llllll}1.749 \mathrm{E}-20 & 1.222 \mathrm{E}-19 & 1.249 \mathrm{E}-16 \quad 5.113 \mathrm{E}-16 \quad 7.402 \mathrm{E}-14 & 3.403 \mathrm{E}-02\end{array}$

$3.629 \mathrm{E}-12 \quad 1.095 \mathrm{E}-11 \quad 5.116 \mathrm{E}-10 \quad 1.423 \mathrm{E}-09 \quad 1.032 \mathrm{E}-07 \quad 7.843 \mathrm{E}-01$ 
RESRAD, Version $6.5 \quad \mathrm{~T}^{1 / 2}$ Limit $=180$ days

Summary : C746U Recreational User Deterministic Run

File : $\mathrm{X}: \backslash F I N A L$ V2\DOE FWD RUNS \C746U RU DOE SG FWD-FV2-10000YR.RAD

Dose/Source Ratios Summed Over All Pathways

Parent and Progeny Principal Radionuclide Contributions Indicated

\begin{tabular}{|c|c|c|c|c|c|c|c|c|}
\hline $\begin{array}{c}\text { Parent } \\
\text { (i) }\end{array}$ & $\begin{array}{c}\text { Product } \\
(j)\end{array}$ & $\begin{array}{l}\text { Thread } \\
\text { Fraction }\end{array}$ & $\begin{array}{r}\text { DSR } \\
0.000 \mathrm{E}+00\end{array}$ & $\begin{array}{l}(j, t) \text { At } T \\
1.000 \mathrm{E}+00\end{array}$ & $\begin{array}{l}\text { ime in Yea } \\
5.000 \mathrm{E}+01\end{array}$ & $\begin{array}{l}\text { rs (mrem } \\
1.000 \mathrm{E}+02\end{array}$ & $\begin{array}{l}/ \mathrm{yr}) /(\mathrm{pCi} / \\
5.000 \mathrm{E}+02\end{array}$ & $\begin{array}{l}\text { g) } \\
1.000 \mathrm{E}+04\end{array}$ \\
\hline-232 & $\mathrm{Th}-232$ & $1.000 \mathrm{E}+00$ & $1.121 \mathrm{E}-25$ & $1.142 \mathrm{E}-25$ & $2.836 \mathrm{E}-25$ & $7.176 \mathrm{E}-25$ & 1. $205 \mathrm{E}-21$ & $2.761 E-03$ \\
\hline-232 & $\mathrm{Ra}-228+\mathrm{D}$ & $1.000 \mathrm{E}+00$ & $1.065 \mathrm{E}-10$ & $3.052 \mathrm{E}-10$ & $2.678 \mathrm{E}-09$ & $3.923 \mathrm{E}-09$ & $8.176 \mathrm{E}-08$ & $4.913 \mathrm{E}-01$ \\
\hline $1-232$ & $\mathrm{Th}-228+\mathrm{D}$ & $1.000 \mathrm{E}+00$ & $1.026 \mathrm{E}-09$ & $6.328 E-09$ & $2.128 \mathrm{E}-07$ & $2.877 \mathrm{E}-07$ & $3.130 \mathrm{E}-06$ & 7. $461 \mathrm{E}-01$ \\
\hline-232 & $\sum \operatorname{DSR}(j)$ & & $1.133 E-09$ & $6.633 E-09$ & $2.155 \mathrm{E}-07$ & $2.917 \mathrm{E}-07$ & $3.212 \mathrm{E}-06$ & $1.240 \mathrm{E}+00$ \\
\hline-234 & $\mathrm{U}-234$ & $1.000 \mathrm{E}+00$ & $6.631 E-25$ & $6.749 \mathrm{E}-25$ & 1. $607 \mathrm{E}-24$ & $3.895 E-24$ & $4.636 E-21$ & $7.080 \mathrm{E}-04$ \\
\hline-234 & Th-230 & $1.000 \mathrm{E}+00$ & $1.047 \mathrm{E}-28$ & $3.188 \mathrm{E}-28$ & $2.443 E-26$ & $1.127 \mathrm{E}-25$ & $4.665 E-22$ & 1. $983 \mathrm{E}-04$ \\
\hline-234 & $\mathrm{Ra}-226+\mathrm{D}$ & $1.000 \mathrm{E}+00$ & $1.090 \mathrm{E}-17$ & $7.671 \mathrm{E}-17$ & $1.167 \mathrm{E}-13$ & $6.482 \mathrm{E}-13$ & $2.407 \mathrm{E}-10$ & $5.151 \mathrm{E}-02$ \\
\hline-234 & $\mathrm{~Pb}-210+\mathrm{D}$ & $1.000 \mathrm{E}+00$ & $3.944 \mathrm{E}-26$ & $5.916 \mathrm{E}-25$ & $2.118 \mathrm{E}-20$ & $1.862 \mathrm{E}-19$ & 1. $619 \mathrm{E}-16$ & $2.335 E-03$ \\
\hline-234 & $\sum \operatorname{DSR}(j)$ & & $1.090 \mathrm{E}-17$ & $7.671 \mathrm{E}-17$ & $1.167 \mathrm{E}-13$ & $6.482 \mathrm{E}-13$ & $2.407 \mathrm{E}-10$ & $5.475 E-02$ \\
\hline$-235+D$ & $\mathrm{U}-235+\mathrm{D}$ & $1.000 \mathrm{E}+00$ & $1.195 \mathrm{E}-15$ & 1. $210 \mathrm{E}-15$ & $2.218 \mathrm{E}-15$ & $4.115 \mathrm{E}-15$ & $5.779 \mathrm{E}-13$ & $4.846 E-02$ \\
\hline$-235+D$ & $\mathrm{~Pa}-231$ & $1.000 \mathrm{E}+00$ & $2.825 E-19$ & $8.554 \mathrm{E}-19$ & $4.840 \mathrm{E}-17$ & $1.637 \mathrm{E}-16$ & $5.673 \mathrm{E}-14$ & $3.830 \mathrm{E}-03$ \\
\hline$-235+D$ & $A C-227+D$ & $1.000 \mathrm{E}+00$ & $8.917 \mathrm{E}-19$ & $6.232 \mathrm{E}-18$ & $6.620 \mathrm{E}-15$ & $2.832 \mathrm{E}-14$ & $6.156 \mathrm{E}-12$ & $2.782 \mathrm{E}-02$ \\
\hline$-235+D$ & $\sum \operatorname{DSR}(j)$ & & $1.197 \mathrm{E}-15$ & $1.217 \mathrm{E}-15$ & $8.886 \mathrm{E}-15$ & $3.260 \mathrm{E}-14$ & $6.791 \mathrm{E}-12$ & $8.011 \mathrm{E}-02$ \\
\hline-238 & $U-238$ & $5.400 E-05$ & $0.000 \mathrm{E}+00$ & $0.000 \mathrm{E}+00$ & $0.000 \mathrm{E}+00$ & $0.000 \mathrm{E}+00$ & $0.000 \mathrm{E}+00$ & $3.473 E-08$ \\
\hline$-238+D$ & $\mathrm{U}-238+\mathrm{D}$ & $9.999 \mathrm{E}-01$ & 1. $365 \mathrm{E}-11$ & 1. $376 \mathrm{E}-11$ & $2.035 \mathrm{E}-11$ & $3.035 \mathrm{E}-11$ & 7. $419 \mathrm{E}-10$ & $1.135 \mathrm{E}-02$ \\
\hline$-238+D$ & $\mathrm{U}-234$ & $9.999 \mathrm{E}-01$ & $9.426 \mathrm{E}-31$ & $2.873 E-30$ & $2.301 \mathrm{E}-28$ & $1.110 \mathrm{E}-27$ & $6.582 \mathrm{E}-24$ & $2.036 \mathrm{E}-05$ \\
\hline$-238+D$ & $\mathrm{Th}-230$ & $9.999 E-01$ & $9.906 \mathrm{E}-35$ & $7.035 \mathrm{E}-34$ & $1.749 \mathrm{E}-30$ & $1.605 \mathrm{E}-29$ & $3.309 E-25$ & $2.812 \mathrm{E}-06$ \\
\hline$-238+D$ & $\mathrm{Ra}-226+\mathrm{D}$ & $9.999 E-01$ & $7.725 \mathrm{E}-24$ & $1.165 \mathrm{E}-22$ & $5.580 \mathrm{E}-18$ & $6.178 \mathrm{E}-17$ & $1.159 \mathrm{E}-13$ & $6.081 \mathrm{E}-04$ \\
\hline$-238+D$ & $\mathrm{~Pb}-210+\mathrm{D}$ & $9.999 \mathrm{E}-01$ & $2.239 \mathrm{E}-32$ & $6.951 \mathrm{E}-31$ & $8.109 \mathrm{E}-25$ & $1.488 \mathrm{E}-23$ & 7. $347 \mathrm{E}-20$ & $2.746 \mathrm{E}-05$ \\
\hline$-238+D$ & $\sum \operatorname{DSR}(j)$ & & $1.365 \mathrm{E}-11$ & 1. $376 \mathrm{E}-11$ & $2.035 \mathrm{E}-11$ & $3.035 \mathrm{E}-11$ & $7.420 \mathrm{E}-10$ & 1.201E-02 \\
\hline
\end{tabular}

The DSR includes contributions from associated (half-life $\leq 180$ days) daughters. 
RESRAD, Version $6.5 \quad T^{1 / 2}$ Limit $=180$ days

Summary : C746U Recreational User Deterministic Run

File : $X: \backslash F I N A L$ V2 \DOE FWD RUNS \C746U RU DOE SG FWD-FV2-10000YR. RAD

Single Radionuclide Soil Guidelines $G(i, t)$ in $\mathrm{pCi} / \mathrm{g}$

Basic Radiation Dose Limit $=1.000 \mathrm{E}+00 \mathrm{mrem} / \mathrm{yr}$

Nuclide

\begin{tabular}{|c|c|c|c|c|c|c|}
\hline (i) & $\mathrm{t}=0.000 \mathrm{E}+00$ & $1.000 \mathrm{E}+00$ & $5.000 \mathrm{E}+01$ & $1.000 \mathrm{E}+02$ & $5.000 \mathrm{E}+02$ & $1.000 \mathrm{E}+04$ \\
\hline-241 & $\star 3.431 \mathrm{E}+12$ & $\star 3.431 \mathrm{E}+12$ & $\star 3.431 \mathrm{E}+12$ & $\star 3.431 \mathrm{E}+12$ & $\star 3.431 \mathrm{E}+12$ & $1.240 \mathrm{E}+05$ \\
\hline$s-137$ & $8.242 \mathrm{E}+09$ & $8.364 \mathrm{E}+09$ & $1.718 \mathrm{E}+10$ & $3.580 \mathrm{E}+10$ & $1.274 \mathrm{E}+13$ & $\star 8.704 \mathrm{E}+13$ \\
\hline$p-237$ & $\star 7.047 \mathrm{E}+08$ & $\star 7.047 \mathrm{E}+08$ & $\star 7.047 \mathrm{E}+08$ & $\star 7.047 \mathrm{E}+08$ & $\star 7.047 \mathrm{E}+08$ & $2.615 \mathrm{E}+01$ \\
\hline$u-238$ & $\star 1.712 \mathrm{E}+13$ & $\star 1.712 \mathrm{E}+13$ & $\star 1.712 \mathrm{E}+13$ & $\star 1.712 \mathrm{E}+13$ & $\star 1.712 \mathrm{E}+13$ & $5.170 \mathrm{E}+04$ \\
\hline$u-239$ & $\star 6.214 \mathrm{E}+10$ & $\star 6.214 \mathrm{E}+10$ & $\star 6.214 \mathrm{E}+10$ & $\star 6.214 \mathrm{E}+10$ & $\star 6.214 \mathrm{E}+10$ & $5.500 \mathrm{E}+02$ \\
\hline$u-240$ & $\star 2.278 \mathrm{E}+11$ & $\star 2.278 \mathrm{E}+11$ & $\star 2.278 \mathrm{E}+11$ & $\star 2.278 \mathrm{E}+11$ & $\star 2.278 \mathrm{E}+11$ & $1.196 \mathrm{E}+03$ \\
\hline$c-99$ & $* 1.697 \mathrm{E}+10$ & $\star 1.697 \mathrm{E}+10$ & $\star 1.697 \mathrm{E}+10$ & $\star 1.697 \mathrm{E}+10$ & $* 1.697 \mathrm{E}+10$ & $* 1.697 \mathrm{E}+10$ \\
\hline Th-228 & $7.523 E+06$ & $1.074 \mathrm{E}+07$ & $4.116 \mathrm{E}+14$ & $\star 8.195 \mathrm{E}+14$ & $\star 8.195 \mathrm{E}+14$ & $* 8.195 \mathrm{E}+14$ \\
\hline Th -230 & $\star 2.018 \mathrm{E}+10$ & $\star 2.018 \mathrm{E}+10$ & $1.955 \mathrm{E}+09$ & $7.028 \mathrm{E}+08$ & $9.688 \mathrm{E}+06$ & $1.275 \mathrm{E}+00$ \\
\hline Th-232 & $* 1.097 \mathrm{E}+05$ & $\star 1.097 \mathrm{E}+05$ & $* 1.097 \mathrm{E}+05$ & *1.097E+05 & $* 1.097 \mathrm{E}+05$ & $8.064 \mathrm{E}-01$ \\
\hline $\mathrm{U}-234$ & $* 6.247 \mathrm{E}+09$ & $\star 6.247 \mathrm{E}+09$ & $\star 6.247 \mathrm{E}+09$ & $\star 6.247 \mathrm{E}+09$ & $4.154 \mathrm{E}+09$ & $1.827 \mathrm{E}+01$ \\
\hline $\mathrm{J}-235$ & $\star 2.161 \mathrm{E}+06$ & $\star 2.161 \mathrm{E}+06$ & $\star 2.161 \mathrm{E}+06$ & $\star 2.161 \mathrm{E}+06$ & $\star 2.161 \mathrm{E}+06$ & $1.248 \mathrm{E}+01$ \\
\hline 238 & $\star 3.361 \mathrm{E}+05$ & $\star 3.361 \mathrm{E}+05$ & $\star 3.361 \mathrm{E}+05$ & $\star 3.361 \mathrm{E}+05$ & $\star 3.361 \mathrm{E}+05$ & $8.328 E+01$ \\
\hline
\end{tabular}

*At specific activity limit

Summed Dose/Source Ratios DSR (i,t) in (mrem/yr)/(pCi/g)

and Single Radionuclide Soil Guidelines G(i,t) in pCi/g

at $\operatorname{tmin}=$ time of minimum single radionuclide soil guideline and at $\operatorname{tmax}=$ time of maximum total dose $=1.000 \mathrm{E}+04$ years

\begin{tabular}{|c|c|c|c|c|c|c|}
\hline $\begin{array}{l}\text { uclide } \\
\text { (i) }\end{array}$ & $\begin{array}{l}\text { Initial } \\
\text { (pCi/g) }\end{array}$ & $\begin{array}{c}\text { tmin } \\
\text { (years) }\end{array}$ & $\operatorname{DSR}(i, \operatorname{tmin})$ & $\begin{array}{c}\mathrm{G}(\mathrm{i}, \mathrm{tmin}) \\
(\mathrm{pCi} / \mathrm{g})\end{array}$ & $\operatorname{DSR}(i, t \max )$ & $\begin{array}{c}G(i, \operatorname{tmax}) \\
(\mathrm{pCi} / \mathrm{g})\end{array}$ \\
\hline $1-241$ & $3.500 \mathrm{E}+01$ & $2534 \pm 5$ & $1.021 \mathrm{E}-04$ & $9.793 E+03$ & $8.067 E-06$ & $1.240 \mathrm{E}+05$ \\
\hline-137 & $1.900 \mathrm{E}+01$ & $0.000 \mathrm{E}+00$ & 1. $213 \mathrm{E}-10$ & $8.242 E+09$ & $0.000 \mathrm{E}+00$ & $\star 8.704 \mathrm{E}+13$ \\
\hline-237 & $5.500 \mathrm{E}+00$ & $2535 \pm 5$ & $6.641 E-02$ & $1.506 \mathrm{E}+01$ & $3.824 \mathrm{E}-02$ & $2.615 E+01$ \\
\hline-238 & $3.900 \mathrm{E}+01$ & $1.000 \mathrm{E}+04$ & $1.934 \mathrm{E}-05$ & $5.170 \mathrm{E}+04$ & $1.934 \mathrm{E}-05$ & $5.170 \mathrm{E}+04$ \\
\hline-239 & $3.600 \mathrm{E}+01$ & $2535 \pm 5$ & $2.428 \mathrm{E}-03$ & $4.118 \mathrm{E}+02$ & $1.818 E-03$ & $5.500 \mathrm{E}+02$ \\
\hline-240 & $3.600 \mathrm{E}+01$ & $2535 \pm 5$ & $1.988 \mathrm{E}-03$ & $5.031 E+02$ & $8.361 E-04$ & $1.196 \mathrm{E}+03$ \\
\hline-99 & $5.200 \mathrm{E}+01$ & $2534 \pm 5$ & $2.827 \mathrm{E}-11$ & $\star 1.697 \mathrm{E}+10$ & $2.472 \mathrm{E}-28$ & $* 1.697 \mathrm{E}+10$ \\
\hline-228 & $4.000 \mathrm{E}+00$ & $0.000 \mathrm{E}+00$ & $1.329 \mathrm{E}-07$ & $7.523 E+06$ & $0.000 \mathrm{E}+00$ & $\star 8.195 \mathrm{E}+14$ \\
\hline-230 & $1.000 \mathrm{E}+02$ & $1.000 \mathrm{E}+04$ & $7.843 \mathrm{E}-01$ & $1.275 \mathrm{E}+00$ & $7.843 E-01$ & $1.275 \mathrm{E}+00$ \\
\hline-232 & $4.000 \mathrm{E}+00$ & $2535 \pm 5$ & $1.256 \mathrm{E}+00$ & $7.961 \mathrm{E}-01$ & $1.240 \mathrm{E}+00$ & $8.064 \mathrm{E}-01$ \\
\hline 234 & $1.600 \mathrm{E}+02$ & $1.000 \mathrm{E}+04$ & $5.475 \mathrm{E}-02$ & $1.827 \mathrm{E}+01$ & $5.475 E-02$ & $1.827 \mathrm{E}+01$ \\
\hline 235 & $6.500 \mathrm{E}+00$ & $1.000 \mathrm{E}+04$ & $8.011 \mathrm{E}-02$ & $1.248 E+01$ & $8.011 E-02$ & $1.248 \mathrm{E}+01$ \\
\hline 238 & $1.600 \mathrm{E}+02$ & $2535 \pm 5$ & $1.257 \mathrm{E}-02$ & $7.957 \mathrm{E}+01$ & $1.201 \mathrm{E}-02$ & $8.328 \mathrm{E}+01$ \\
\hline
\end{tabular}

*At specific activity limit 
RESRAD, Version 6.5

Summary : C746U Recreational User Deterministic Run

File : $\mathrm{X}: \backslash F I N A L$ V2 \DOE FWD RUNS \C746U RU DOE SG FWD-FV2-10000YR.RAD

Individual Nuclide Dose Summed Over All Pathways

Parent Nuclide and Branch Fraction Indicated

Nuclide Parent THF(i) DOSE $(j, t)$, mrem/yr

\begin{tabular}{|c|c|c|}
\hline (j) & (i) & \\
\hline $\mathrm{Am}-241$ & $A m-241$ & $1.000 \mathrm{E}+00$ \\
\hline$p-237$ & $A m-241$ & $1.000 \mathrm{E}+00$ \\
\hline $\mathrm{Jp}-237$ & $\mathrm{~Np}-237$ & $1.000 \mathrm{E}+00$ \\
\hline-237 & $\sum$ DOSE & \\
\hline
\end{tabular}

$\mathrm{U}-233 \mathrm{Am}-241 \quad 1.000 \mathrm{E}+00$

$\mathrm{U}-233 \quad \mathrm{~Np}-237 \quad 1.000 \mathrm{E}+00$

U-233 $\quad$ DDOSE $(j)$

Th-229

$\mathrm{Th}-229$

$\mathrm{Th}-229$

Cs -137

$\mathrm{Pu}-238$

$\mathrm{Pu}-238$

$\mathrm{Pu}-238$

$\mathrm{U}-234$

$\mathrm{U}-234$

$\mathrm{U}-234$

$\mathrm{U}-234$

Th-230

$\mathrm{Th}-230$

Th-230

$\mathrm{Th}-230$

$\mathrm{Th}-230$

$\mathrm{Ra}-226$

$\mathrm{Ra}-226$

$\mathrm{Ra}-226$

$\mathrm{Ra}-226$

$\mathrm{Ra}-226$

$\mathrm{Pb}-210$

$\mathrm{Pb}-210$

$\mathrm{Pb}-210$

$\mathrm{Pb}-210$

$\mathrm{Pb}-210$

Pu-239

Am-241 1.000E+00

$\mathrm{Np}-237 \quad 1.000 \mathrm{E}+00$

$\sum \operatorname{DOSE}(j)$

Cs $-137 \quad 1.000 \mathrm{E}+00$

Pu-238 1.840E-09

$\mathrm{Pu}-238 \quad 1.000 \mathrm{E}+00$

$\sum \operatorname{DOSE}(j)$

$\mathrm{Pu}-238 \quad 1.000 \mathrm{E}+00$

$\mathrm{U}-234 \quad 1.000 \mathrm{E}+00$

U-238 9.999E-01

$\sum \operatorname{DOSE}(j)$

$\mathrm{Pu}-238 \quad 1.000 \mathrm{E}+00$

Th-230 1.000E+00

$\mathrm{U}-234 \quad 1.000 \mathrm{E}+00$

U-238 9.999E-01

$\sum \operatorname{DOSE}(j)$

$\mathrm{Pu}-238 \quad 1.000 \mathrm{E}+00$

Th-230 1.000E+00

$\mathrm{U}-234 \quad 1.000 \mathrm{E}+00$

U-238 9.999E-01

$\sum \operatorname{DOSE}(j)$

$\mathrm{Pu}-238 \quad 1.000 \mathrm{E}+00$

Th-230 1.000E+00

$\mathrm{U}-234 \quad 1.000 \mathrm{E}+00$

U-238 9.999E-01

$\sum \operatorname{DOSE}(j)$

$\mathrm{Pu}-239 \quad 1.000 \mathrm{E}+00$

$\mathrm{Pu}-239 \quad 1.000 \mathrm{E}+00$

U-235 $1.000 \mathrm{E}+00$

$\sum \operatorname{DOSE}(j)$ $t=0.000 \mathrm{E}+001.000 \mathrm{E}+00 \quad 5.000 \mathrm{E}+01 \quad 1.000 \mathrm{E}+02 \quad 5.000 \mathrm{E}+02 \quad 1.000 \mathrm{E}+04$

$0.000 \mathrm{E}+00 \quad 0.000 \mathrm{E}+00 \quad 0.000 \mathrm{E}+00 \quad 0.000 \mathrm{E}+00 \quad 4.069 \mathrm{E}-27 \quad 1.908 \mathrm{E}-08$

$\begin{array}{lllllll}5.204 E-19 & 1.575 E-18 & 8.635 E-17 & 2.829 E-16 & 7.741 E-14 & 2.731 E-04\end{array}$

$\begin{array}{llllll}5.043 \mathrm{E}-13 & 5.097 \mathrm{E}-13 & 8.620 \mathrm{E}-13 & 1.473 \mathrm{E}-12 & 1.073 \mathrm{E}-10 & 2.024 \mathrm{E}-01\end{array}$

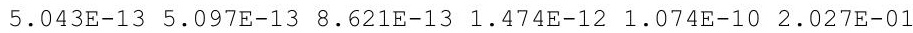

$0.000 \mathrm{E}+00 \quad 8.344 \mathrm{E}-29 \quad 1.639 \mathrm{E}-25 \quad 1.182 \mathrm{E}-24 \quad 3.586 \mathrm{E}-21 \quad 1.768 \mathrm{E}-07$

$1.716 \mathrm{E}-23 \quad 5.206 \mathrm{E}-23 \quad 3.231 \mathrm{E}-21 \quad 1.201 \mathrm{E}-20 \quad 8.871 \mathrm{E}-18 \quad 1.431 \mathrm{E}-04$

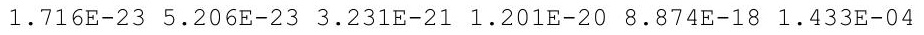

$8.073 \mathrm{E}-26 \quad 1.218 \mathrm{E}-24 \quad 5.759 \mathrm{E}-20 \quad 6.298 \mathrm{E}-19 \quad 1.085 \mathrm{E}-15 \quad 9.049 \mathrm{E}-06$

$1.567 \mathrm{E}-19 \quad 1.103 \mathrm{E}-18 \quad 1.692 \mathrm{E}-15 \quad 9.477 \mathrm{E}-15 \quad 3.786 \mathrm{E}-12 \quad 7.718 \mathrm{E}-03$

$1.567 \mathrm{E}-19 \quad 1.103 \mathrm{E}-18 \quad 1.692 \mathrm{E}-15 \quad 9.478 \mathrm{E}-15 \quad 3.787 \mathrm{E}-12 \quad 7.727 \mathrm{E}-03$

2.305E-09 2.272E-09 1.106E-09 5.307E-10 1.491E-12 0.000E+00

$\begin{array}{llllll}0.000 \mathrm{E}+00 & 0.000 \mathrm{E}+00 & 0.000 \mathrm{E}+00 & 0.000 \mathrm{E}+00 & 0.000 \mathrm{E}+00 & 0.000 \mathrm{E}+00\end{array}$

$\begin{array}{lllllll}4.406 \mathrm{E}-24 & 4.449 \mathrm{E}-24 & 7.176 \mathrm{E}-24 & 1.169 \mathrm{E}-23 & 5.791 \mathrm{E}-22 & 0.000 \mathrm{E}+00\end{array}$

$4.406 \mathrm{E}-24 \quad 4.449 \mathrm{E}-24 \quad 7.176 \mathrm{E}-24 \quad 1.169 \mathrm{E}-23 \quad 5.791 \mathrm{E}-22 \quad 0.000 \mathrm{E}+00$

$0.000 \mathrm{E}+00 \quad 1.114 \mathrm{E}-28 \quad 7.400 \mathrm{E}-27 \quad 2.988 \mathrm{E}-26 \quad 6.368 \mathrm{E}-23 \quad 9.916 \mathrm{E}-06$

$\begin{array}{llllll}1.061 \mathrm{E}-22 & 1.080 \mathrm{E}-22 & 2.571 \mathrm{E}-22 & 6.232 \mathrm{E}-22 & 7.417 \mathrm{E}-19 & 1.133 \mathrm{E}-01\end{array}$

$0.000 \mathrm{E}+00 \quad 4.596 \mathrm{E}-28 \quad 3.681 \mathrm{E}-26 \quad 1.776 \mathrm{E}-25 \quad 1.053 \mathrm{E}-21 \quad 3.257 \mathrm{E}-03$

$\begin{array}{llllll}1.061 \mathrm{E}-22 & 1.080 \mathrm{E}-22 & 2.572 \mathrm{E}-22 & 6.234 \mathrm{E}-22 & 7.428 \mathrm{E}-19 & 1.165 \mathrm{E}-01\end{array}$

$0.000 \mathrm{E}+00 \quad 0.000 \mathrm{E}+00 \quad 5.998 \mathrm{E}-29 \quad 4.887 \mathrm{E}-28 \quad 4.910 \mathrm{E}-24 \quad 2.742 \mathrm{E}-06$

$\begin{array}{lllllll}2.319 \mathrm{E}-21 & 2.359 \mathrm{E}-21 & 5.375 \mathrm{E}-21 & 1.246 \mathrm{E}-20 & 1.037 \mathrm{E}-17 & 2.264 \mathrm{E}-01\end{array}$

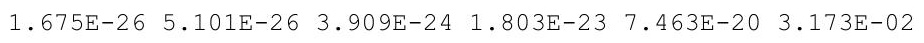

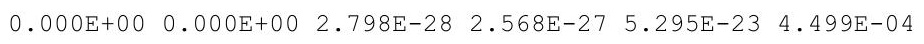

$\begin{array}{lllllll}2.319 \mathrm{E}-21 & 2.359 \mathrm{E}-21 & 5.379 \mathrm{E}-21 & 1.248 \mathrm{E}-20 & 1.044 \mathrm{E}-17 & 2.586 \mathrm{E}-01\end{array}$

$3.008 \mathrm{E}-22 \quad 4.531 \mathrm{E}-21 \quad 1.975 \mathrm{E}-16 \quad 1.997 \mathrm{E}-15 \quad 2.109 \mathrm{E}-12 \quad 7.095 \mathrm{E}-04$ $\begin{array}{llllll}3.629 \mathrm{E}-10 & 1.095 \mathrm{E}-09 & 5.116 \mathrm{E}-08 & 1.423 \mathrm{E}-07 & 1.032 \mathrm{E}-05 & 7.480 \mathrm{E}+01\end{array}$ $\begin{array}{lllllll}1.743 \mathrm{E}-15 & 1.227 \mathrm{E}-14 & 1.867 \mathrm{E}-11 & 1.037 \mathrm{E}-10 & 3.851 \mathrm{E}-08 & 8.241 \mathrm{E}+00\end{array}$ $\begin{array}{lllllll}1.236 \mathrm{E}-21 & 1.865 \mathrm{E}-20 & 8.928 \mathrm{E}-16 & 9.885 \mathrm{E}-15 & 1.854 \mathrm{E}-11 & 9.730 \mathrm{E}-02\end{array}$ $3.629 \mathrm{E}-10 \quad 1.095 \mathrm{E}-09 \quad 5.118 \mathrm{E}-08 \quad 1.424 \mathrm{E}-07 \quad 1.036 \mathrm{E}-05 \quad 8.314 \mathrm{E}+01$

$0.000 \mathrm{E}+00 \quad 0.000 \mathrm{E}+00 \quad 2.916 \mathrm{E}-23 \quad 4.931 \mathrm{E}-22 \quad 1.381 \mathrm{E}-18 \quad 3.216 \mathrm{E}-05$ $\begin{array}{llllll}1.749 \mathrm{E}-18 & 1.222 \mathrm{E}-17 & 1.249 \mathrm{E}-14 & 5.113 \mathrm{E}-14 & 7.402 \mathrm{E}-12 & 3.403 \mathrm{E}+00\end{array}$ $\begin{array}{lllllll}6.310 \mathrm{E}-24 & 9.466 \mathrm{E}-23 & 3.388 \mathrm{E}-18 & 2.979 \mathrm{E}-17 & 2.590 \mathrm{E}-14 & 3.735 \mathrm{E}-01\end{array}$ $0.000 \mathrm{E}+00 \quad 0.000 \mathrm{E}+00 \quad 1.297 \mathrm{E}-22 \quad 2.380 \mathrm{E}-21 \quad 1.176 \mathrm{E}-17 \quad 4.394 \mathrm{E}-03$ $\begin{array}{llllll}1.749 \mathrm{E}-18 & 1.222 \mathrm{E}-17 & 1.250 \mathrm{E}-14 & 5.116 \mathrm{E}-14 & 7.428 \mathrm{E}-12 & 3.781 \mathrm{E}+00\end{array}$

$4.161 \mathrm{E}-17 \quad 4.211 \mathrm{E}-17 \quad 7.560 \mathrm{E}-17 \quad 1.373 \mathrm{E}-16 \quad 1.629 \mathrm{E}-14 \quad 6.544 \mathrm{E}-02$

$2.124 \mathrm{E}-23 \quad 6.441 \mathrm{E}-23 \quad 3.969 \mathrm{E}-21 \quad 1.465 \mathrm{E}-20 \quad 1.019 \mathrm{E}-17 \quad 1.517 \mathrm{E}-05$

$\begin{array}{llllll}7.771 \mathrm{E}-15 & 7.867 \mathrm{E}-15 & 1.442 \mathrm{E}-14 & 2.675 \mathrm{E}-14 & 3.756 \mathrm{E}-12 & 3.150 \mathrm{E}-01\end{array}$

$\begin{array}{lllllll}7.771 \mathrm{E}-15 & 7.867 \mathrm{E}-15 & 1.442 \mathrm{E}-14 & 2.675 \mathrm{E}-14 & 3.756 \mathrm{E}-12 & 3.150 \mathrm{E}-01\end{array}$ 
RESRAD, Version $6.5 \quad \mathrm{~T}^{1 / 2}$ Limit $=180$ days

Summary : C746U Recreational User Deterministic Run

File : $X: \backslash F I N A L$ V2 $\backslash$ DOE FWD RUNS \C746U RU DOE SG FWD-FV2-10000YR.RAD

Individual Nuclide Dose Summed Over All Pathways

Parent Nuclide and Branch Fraction Indicated

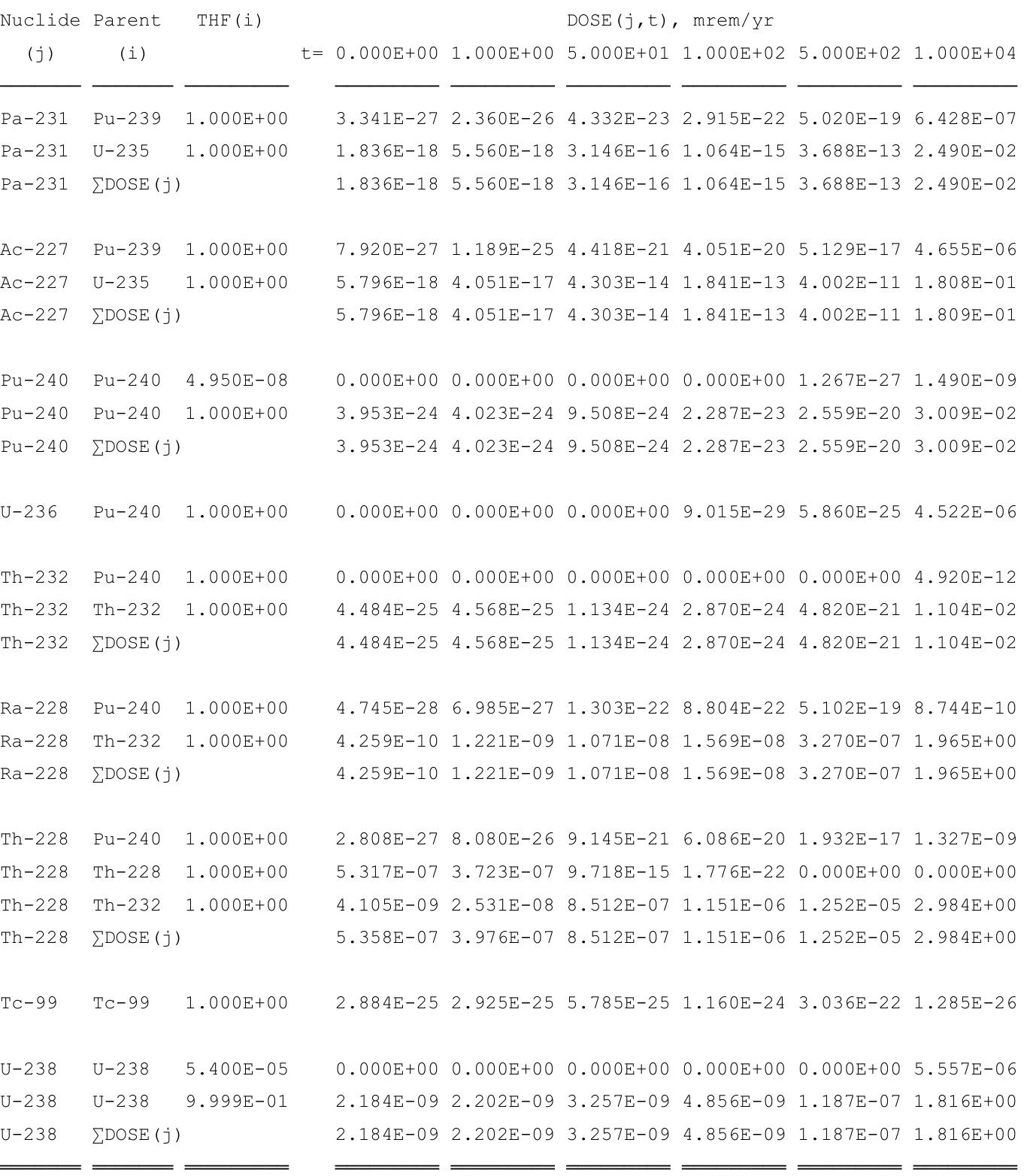

THF(i) is the thread fraction of the parent nuclide. 
RESRAD, Version 6.5

Summary : C746U Recreational User Deterministic Run
File : X: \FINAL V2 \DOE FWD RUNS \C746U RU DOE SG FWD-FV2-10000YR.RAD

Individual Nuclide Soil Concentration

Parent Nuclide and Branch Fraction Indicated

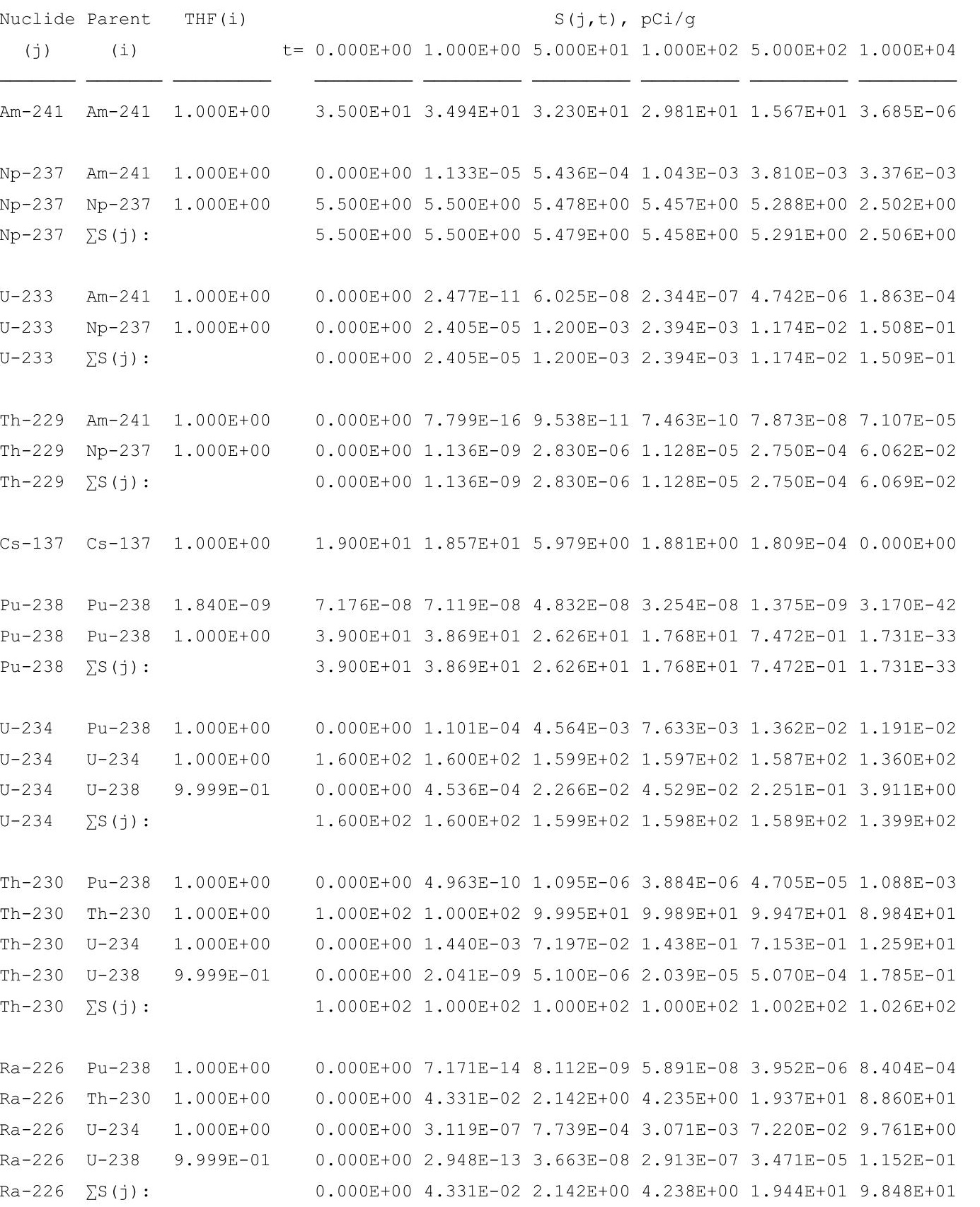

$\mathrm{Pb}-210 \quad \mathrm{Pu}-238 \quad 1.000 \mathrm{E}+00$

$\mathrm{Pb}-210 \mathrm{Th}-230 \quad 1.000 \mathrm{E}+00$

$\mathrm{Pb}-210 \quad \mathrm{U}-234 \quad 1.000 \mathrm{E}+00$

$\mathrm{Pb}-210 \mathrm{U}-238 \quad 9.999 \mathrm{E}-01$

$0.000 \mathrm{E}+00 \quad 5.540 \mathrm{E}-16 \quad 2.418 \mathrm{E}-09 \quad 2.812 \mathrm{E}-08 \quad 3.398 \mathrm{E}-06 \quad 8.367 \mathrm{E}-04$ $\begin{array}{lllllll}0.000 \mathrm{E}+00 & 6.663 \mathrm{E}-04 & 1.058 \mathrm{E}+00 & 2.946 \mathrm{E}+00 & 1.823 \mathrm{E}+01 & 8.856 \mathrm{E}+01\end{array}$ $\begin{array}{llllll}0.000 \mathrm{E}+00 & 3.207 \mathrm{E}-09 & 2.837 \mathrm{E}-04 & 1.706 \mathrm{E}-03 & 6.374 \mathrm{E}-02 & 9.719 \mathrm{E}+00\end{array}$ $0.000 \mathrm{E}+00 \quad 2.276 \mathrm{E}-15 \quad 1.075 \mathrm{E}-08 \quad 1.356 \mathrm{E}-07 \quad 2.889 \mathrm{E}-05 \quad 1.143 \mathrm{E}-01$ $\begin{array}{lllllll}0.000 \mathrm{E}+00 & 6.663 \mathrm{E}-04 & 1.058 \mathrm{E}+00 & 2.947 \mathrm{E}+00 & 1.830 \mathrm{E}+01 & 9.839 \mathrm{E}+01\end{array}$

Pu-239 Pu-239 1.000E+00 $\begin{array}{lllllll}3.600 \mathrm{E}+01 & 3.600 \mathrm{E}+01 & 3.593 \mathrm{E}+01 & 3.586 \mathrm{E}+01 & 3.531 \mathrm{E}+01 & 2.443 \mathrm{E}+01\end{array}$

$\mathrm{Pu}-239 \quad 1.000 \mathrm{E}+00$ $0.000 \mathrm{E}+00 \quad 3.545 \mathrm{E}-08 \quad 1.770 \mathrm{E}-06 \quad 3.536 \mathrm{E}-06 \quad 1.750 \mathrm{E}-05 \quad 2.739 \mathrm{E}-04$ $\mathrm{U}-235 \quad 1.000 \mathrm{E}+00$ $\begin{array}{llllll}6.500 \mathrm{E}+00 & 6.500 \mathrm{E}+00 & 6.496 \mathrm{E}+00 & 6.491 \mathrm{E}+00 & 6.457 \mathrm{E}+00 & 5.685 \mathrm{E}+00\end{array}$

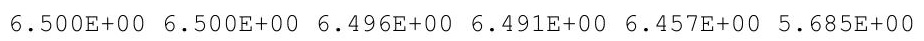


RESRAD, Version $6.5 \quad \mathrm{~T}^{1 / 2}$ Limit $=180$ days

Summary : C746U Recreational User Deterministic Run

File : $\mathrm{X}: \backslash F I N A L$ V2 \DOE FWD RUNS \C746U RU DOE SG FWD-FV2-10000YR.RAD

Individual Nuclide Soil Concentration

Parent Nuclide and Branch Fraction Indicated

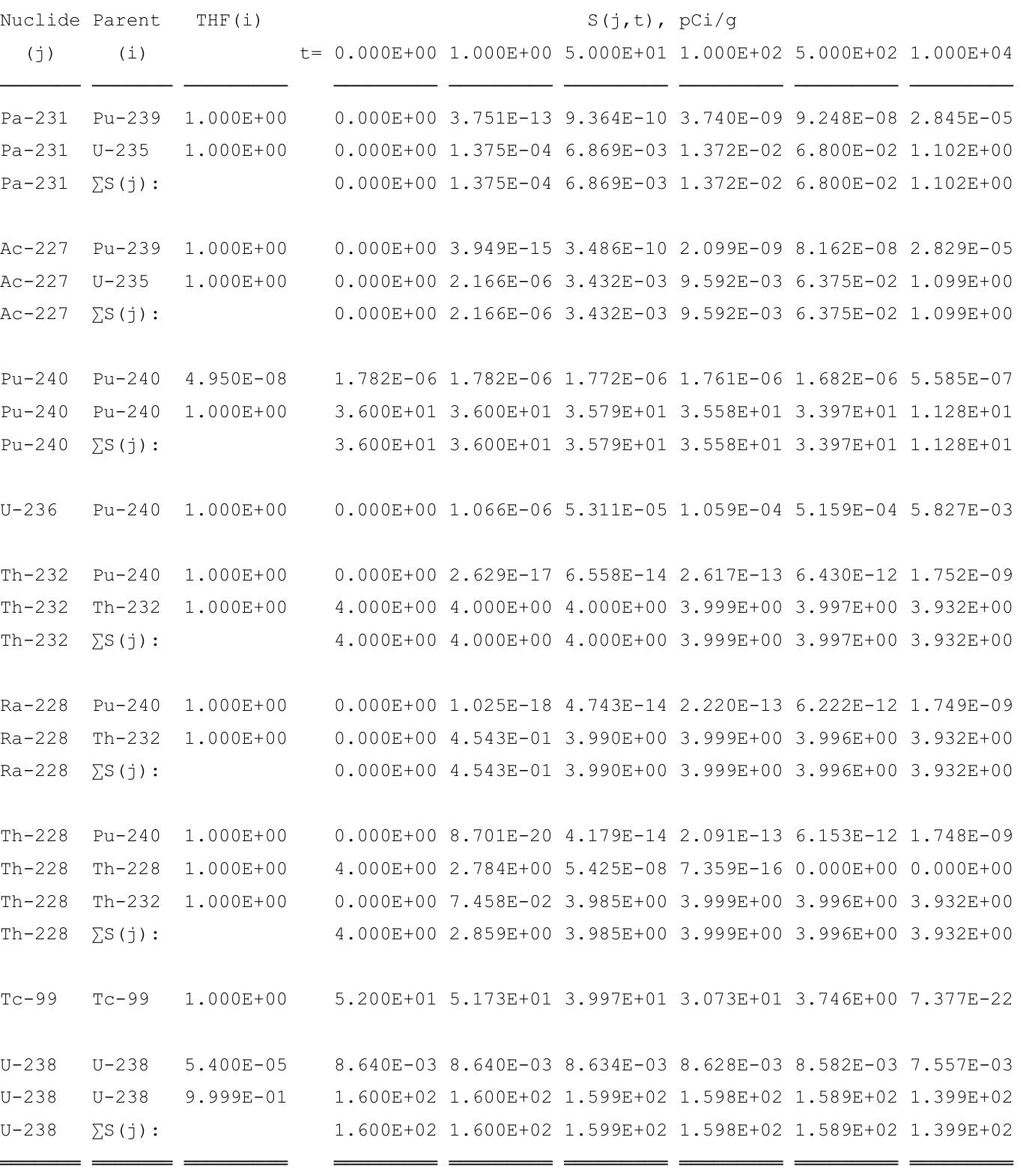

THF(i) is the thread fraction of the parent nuclide.

RESCALC.EXE execution time $=7.78$ seconds 


\section{Recreational User}

\section{Summary Report \\ (Deterministic Analysis Report)}

Third Peak Dose Assessment

Time Horizon: 100,000 yr 
THIS PAGE INTENTIONALLY LEFT BLANK 
RESRAD, Version $6.5 \quad T^{1 / 2}$ Limit $=180$ days

Summary : C746U Recreational User Deterministic Run

File : $\mathrm{X}: \backslash F I N A L$ V2 $\backslash$ DOE FWD RUNS \C746U RU DOE SG FWD-FV2-100000YR.RAD

Table of Contents

Part I: Mixture Sums and Single Radionuclide Guidelines

Dose Conversion Factor (and Related) Parameter Summary ... 2

Site-Specific Parameter Summary ............... 8

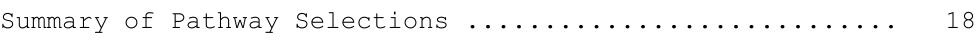

Contaminated zone and Total Dose Summary ............. 19

Total Dose Components

Time $=0.000 \mathrm{E}+00 \ldots \ldots \ldots \ldots \ldots \ldots \ldots \ldots \ldots \ldots \ldots \ldots \ldots \ldots \ldots \ldots \ldots$

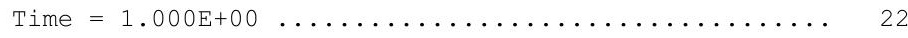

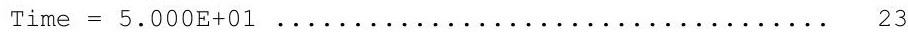

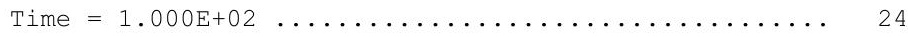

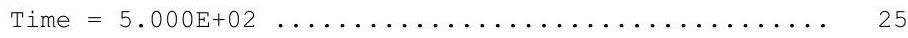

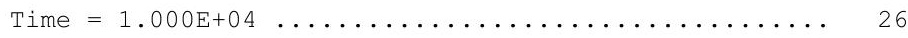

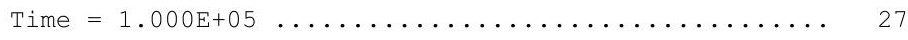

Dose/Source Ratios Summed Over All Pathways ........... 28

Single Radionuclide Soil Guidelines ............... 30

Dose Per Nuclide Summed Over All Pathways ............. 31

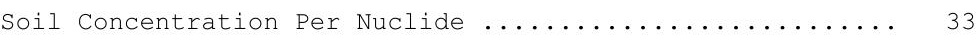


RESRAD, Version $6.5 \quad \mathrm{~T}^{1 / 2}$ Limit $=180$ days

Summary : C746U Recreational User Deterministic Run

File : $\mathrm{X}: \backslash F I N A L$ V2 $\backslash$ DOE FWD RUNS \C746U RU DOE SG FWD-FV2-100000YR.RAD

Dose Conversion Factor (and Related) Parameter Summary (continued)

Dose Library: Teen Recreational User Plus ICRP 60 \& ICRP 72 (Age 15)

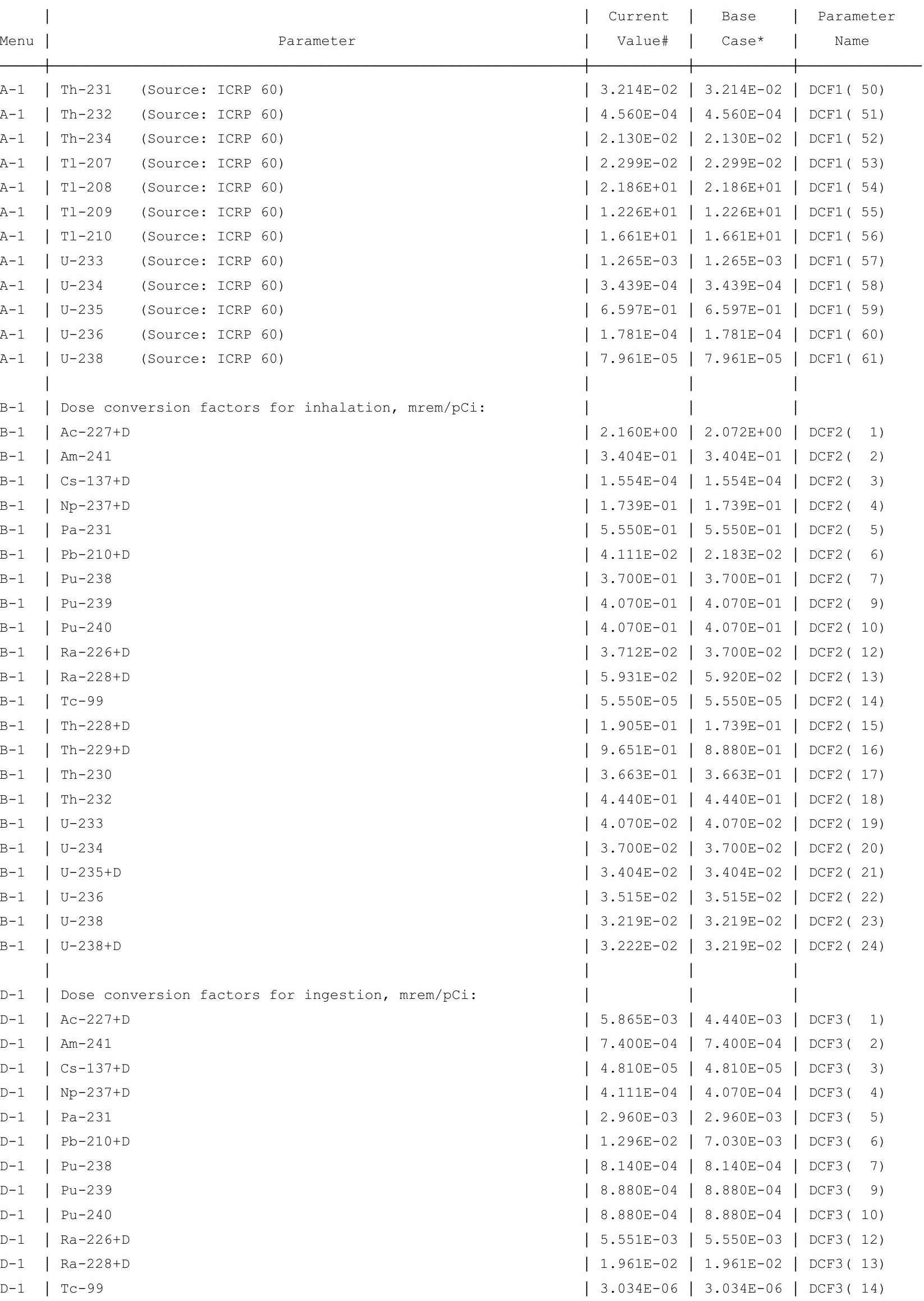


RESRAD, Version $6.5 \quad \mathrm{~T}^{1 / 2}$ Limit $=180$ days

ummary : C746U Recreational User Deterministic Run

File : $\mathrm{X}: \backslash F I N A L$ V2 \DOE FWD RUNS $\backslash$ C746U RU DOE SG FWD-FV2-100000YR.RAD

Dose Conversion Factor (and Related) Parameter Summary (continued)

Dose Library: Teen Recreational User Plus ICRP 60 \& ICRP 72 (Age 15)

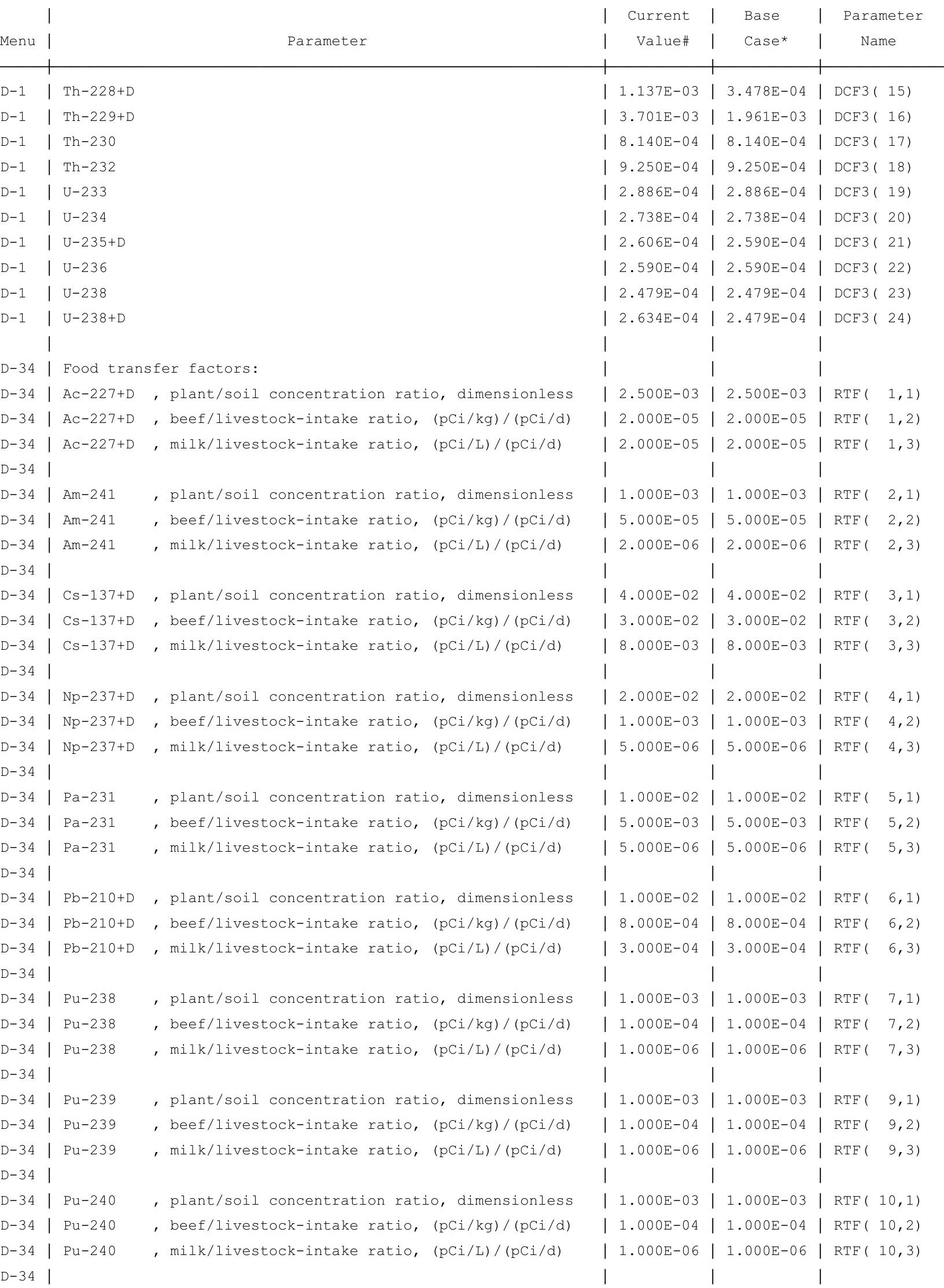


RESRAD, Version $6.5 \quad \mathrm{~T}^{1 / 2}$ Limit $=180$ days

ummary : C746U Recreational User Deterministic Run

File : $\mathrm{X}: \backslash F I N A L$ V2 \DOE FWD RUNS $\backslash$ C746U RU DOE SG FWD-FV2-100000YR.RAD

Dose Conversion Factor (and Related) Parameter Summary (continued)

Dose Library: Teen Recreational User Plus ICRP 60 \& ICRP 72 (Age 15)

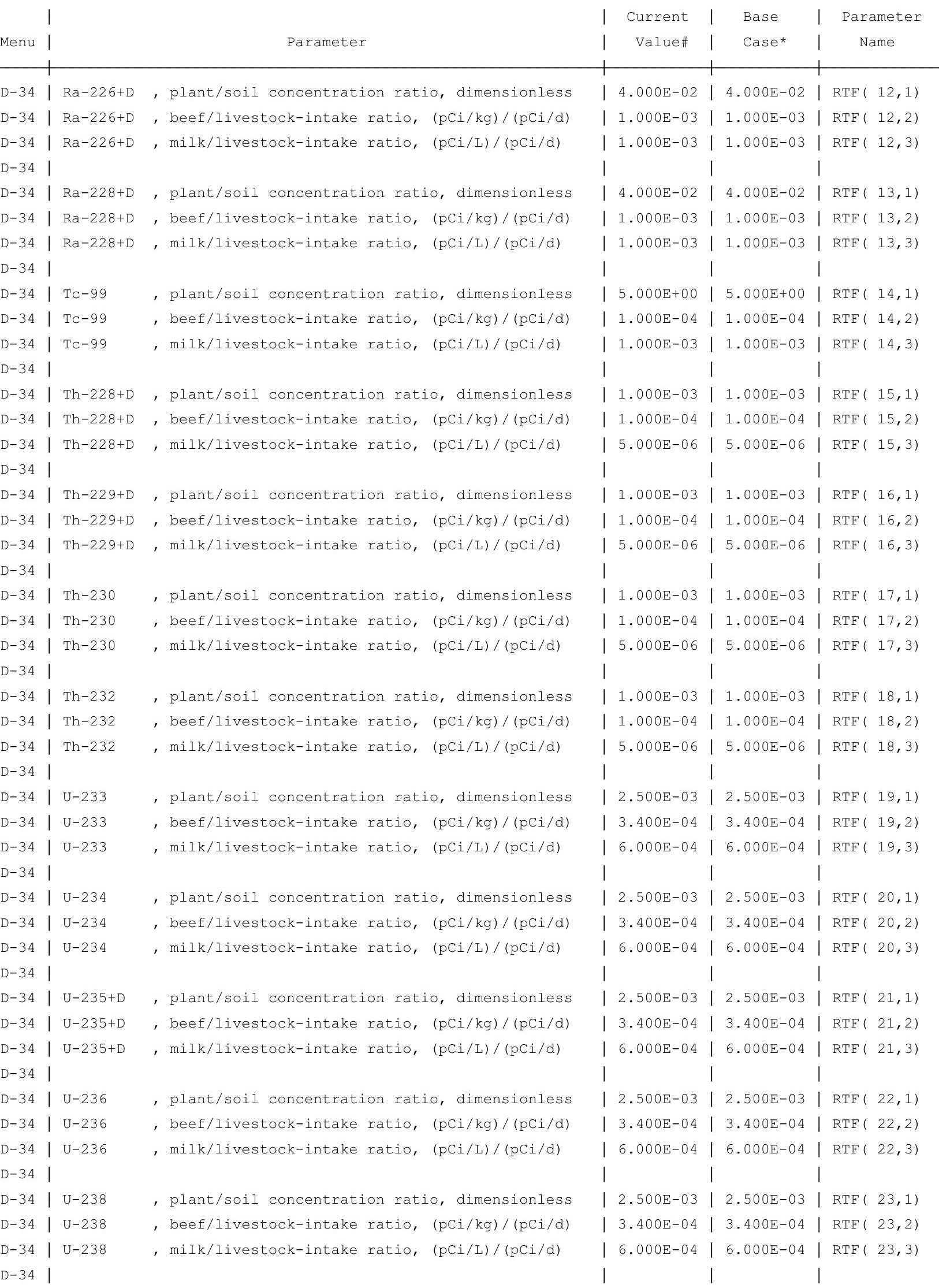


RESRAD, Version $6.5 \quad \mathrm{~T}^{1 / 2}$ Limit $=180$ days

Summary : C746U Recreational User Deterministic Run

File : $\mathrm{X}: \backslash F I N A L$ V2 $\backslash$ DOE FWD RUNS \C746U RU DOE SG FWD-FV2-100000YR.RAD

Dose Conversion Factor (and Related) Parameter Summary (continued) Dose Library: Teen Recreational User Plus ICRP 60 \& ICRP 72 (Age 15)

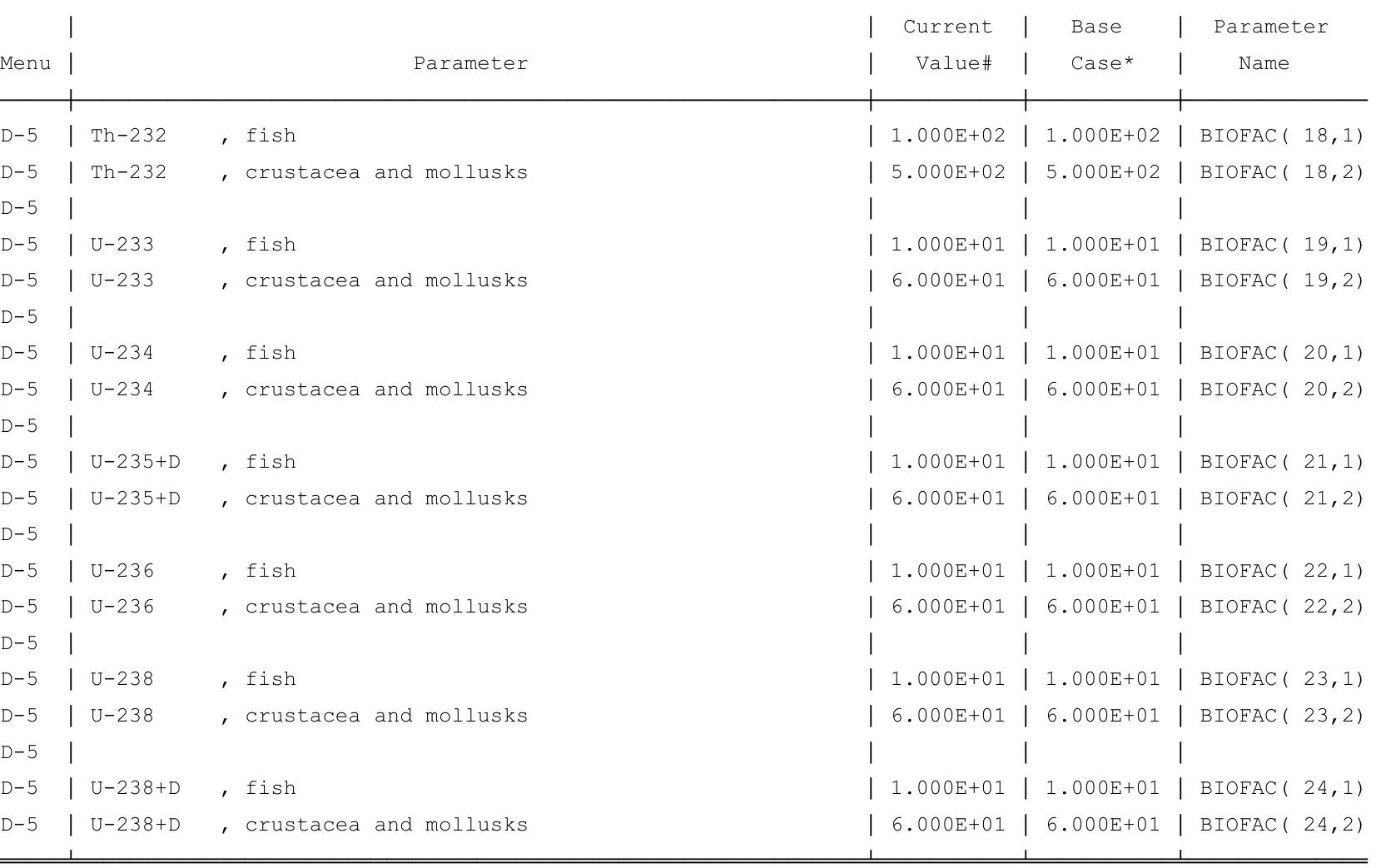

\#For DCF1(xxx) only, factors are for infinite depth \& area. See ETFG table in Ground Pathway of Detailed Report. *Base Case means Default.Lib w/o Associate Nuclide contributions. 
RESRAD, Version $6.5 \quad \mathrm{~T}^{1 / 2}$ Limit $=180$ days

Summary : C746U Recreational User Deterministic Run

File : $X: \backslash F I N A L$ V2 \DOE FWD RUNS \C746U RU DOE SG FWD-FV2-100000YR.RAD

Site-Specific Parameter Summary (continued)

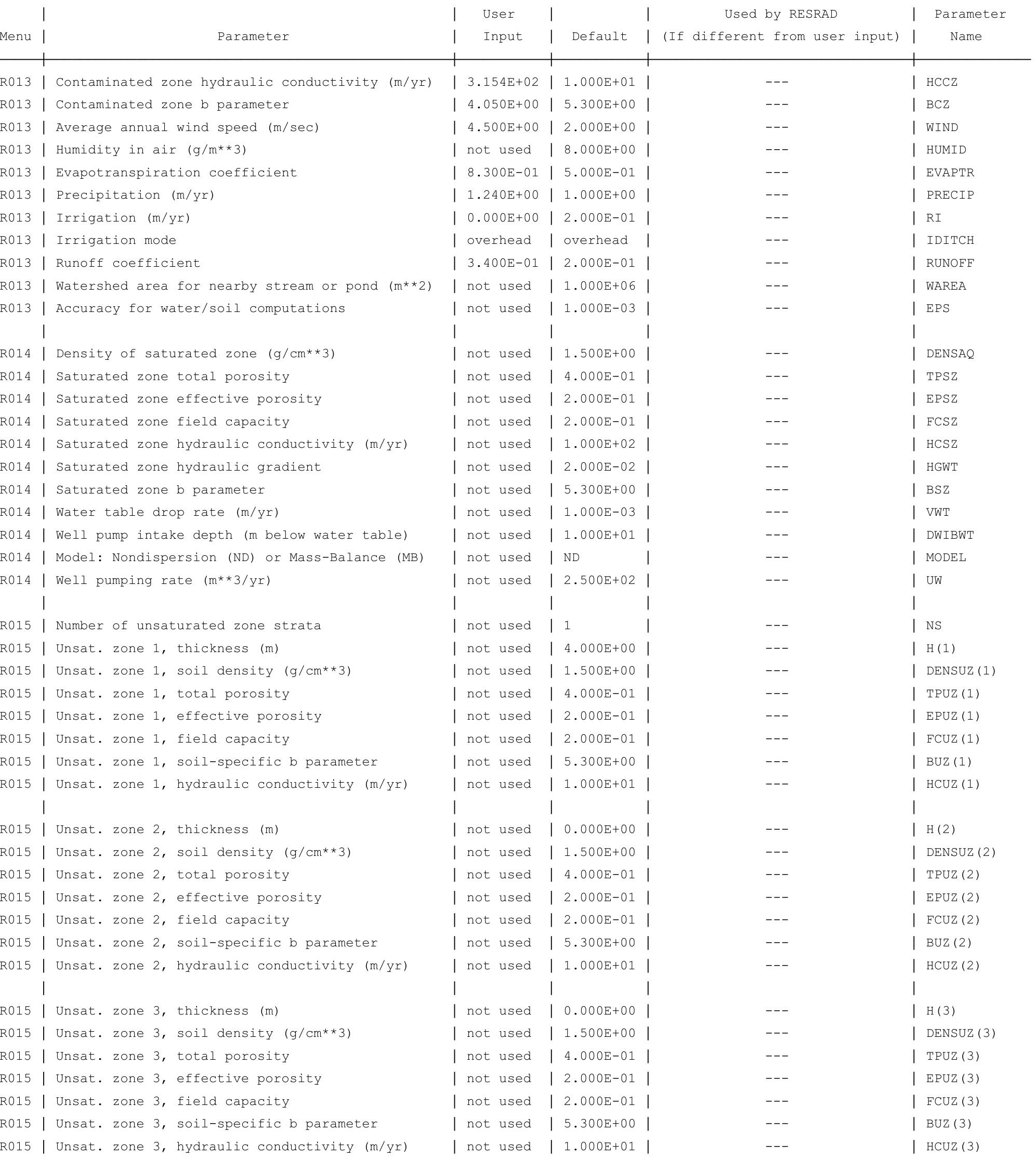


RESRAD, Version $6.5 \quad \mathrm{~T}^{1 / 2}$ Limit $=180$ days

Summary : C746U Recreational User Deterministic Run

File : $X: \backslash F I N A L$ V2 \DOE FWD RUNS \C746U RU DOE SG FWD-FV2-100000YR.RAD

Site-Specific Parameter Summary (continued)

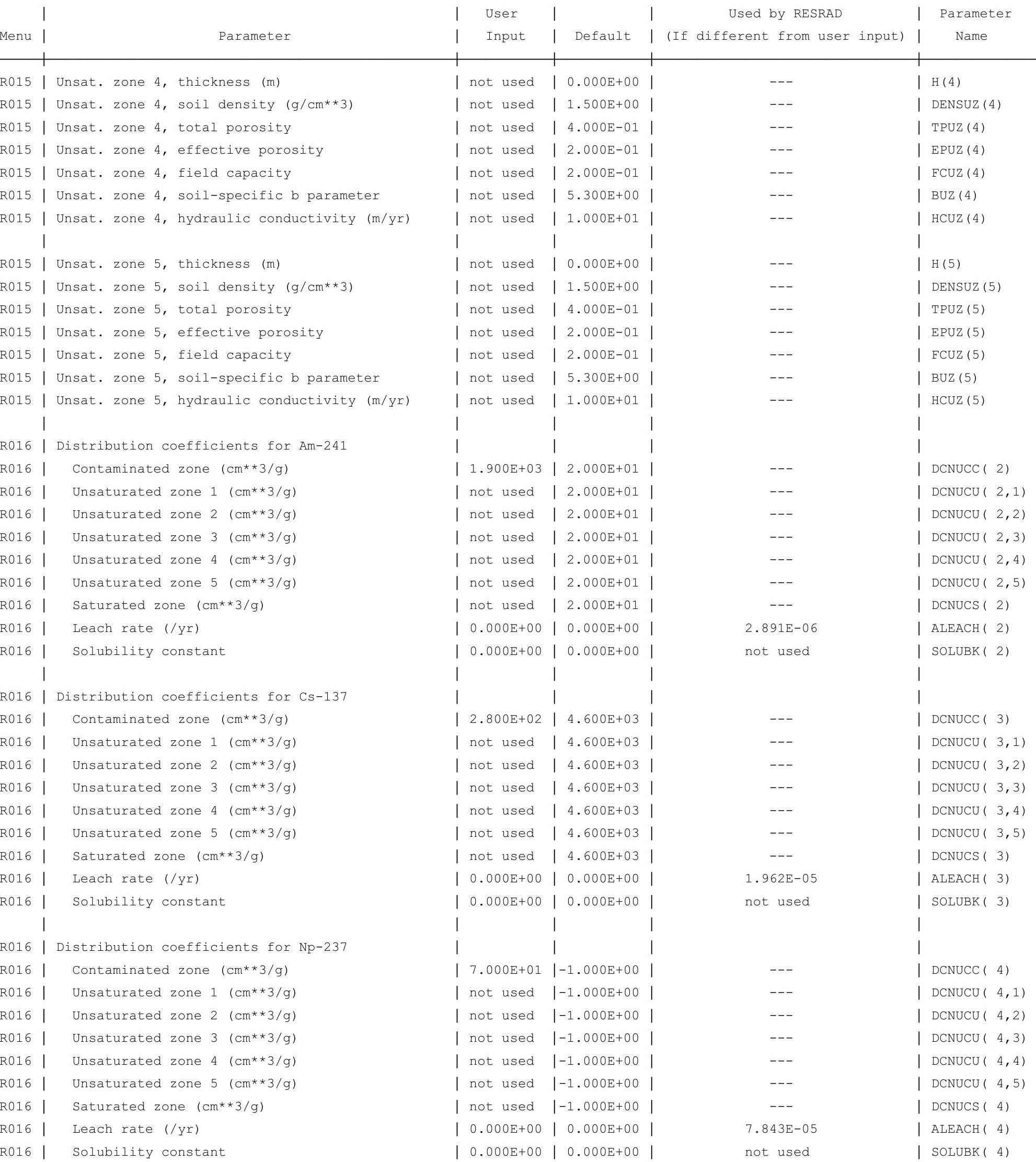


RESRAD, Version $6.5 \quad \mathrm{~T}^{1 / 2}$ Limit $=180$ days

Summary : C746U Recreational User Deterministic Run

File : $X: \backslash F I N A L$ V2 $\backslash$ DOE FWD RUNS \C746U RU DOE SG FWD-FV2-100000YR.RAD

Site-Specific Parameter Summary (continued)

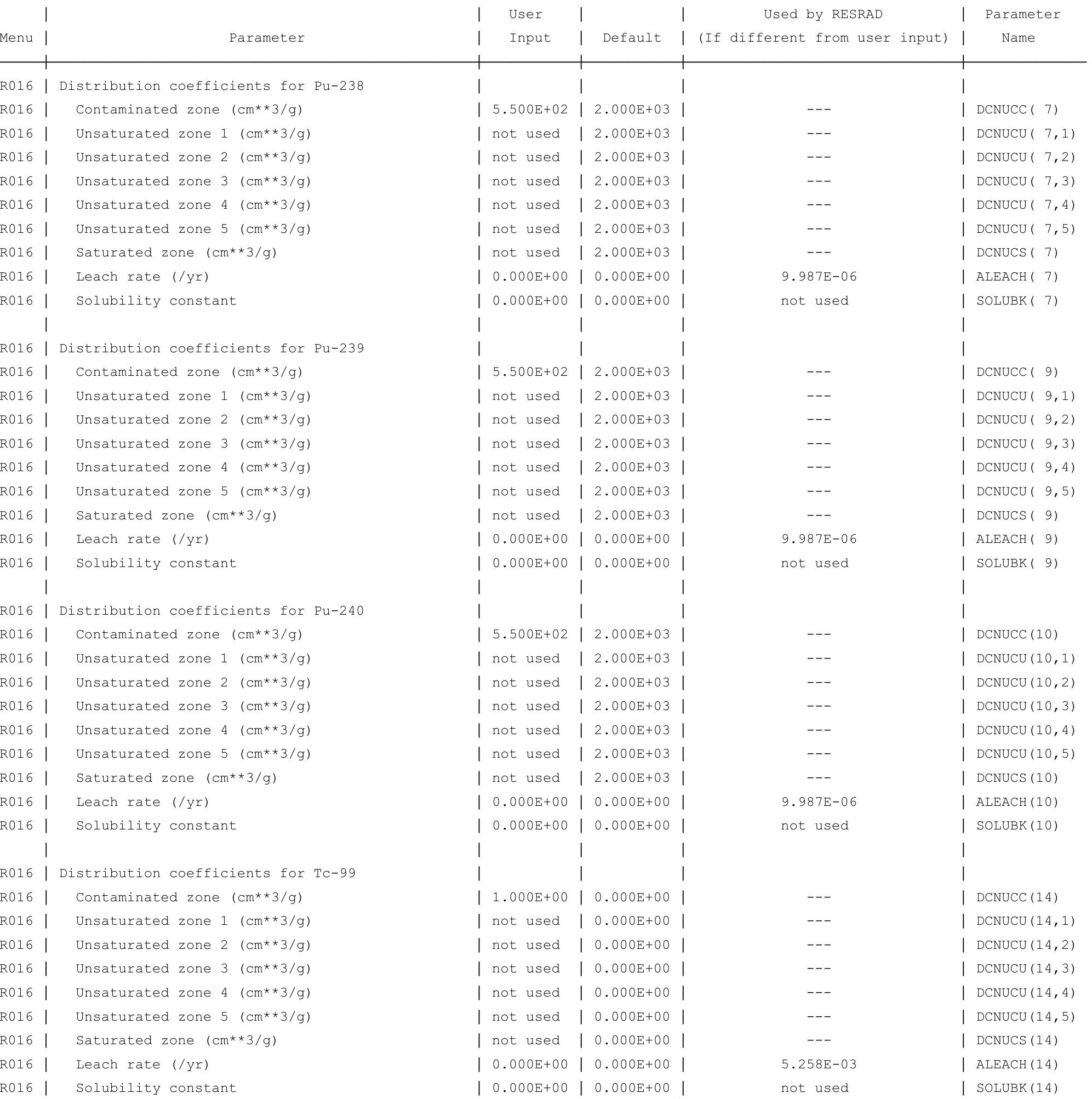


RESRAD, Version $6.5 \quad \mathrm{~T}^{1 / 2}$ Limit $=180$ days

Summary : C746U Recreational User Deterministic Run

File : $X: \backslash F I N A L$ V2 \DOE FWD RUNS \C746U RU DOE SG FWD-FV2-100000YR.RAD

Site-Specific Parameter Summary (continued)

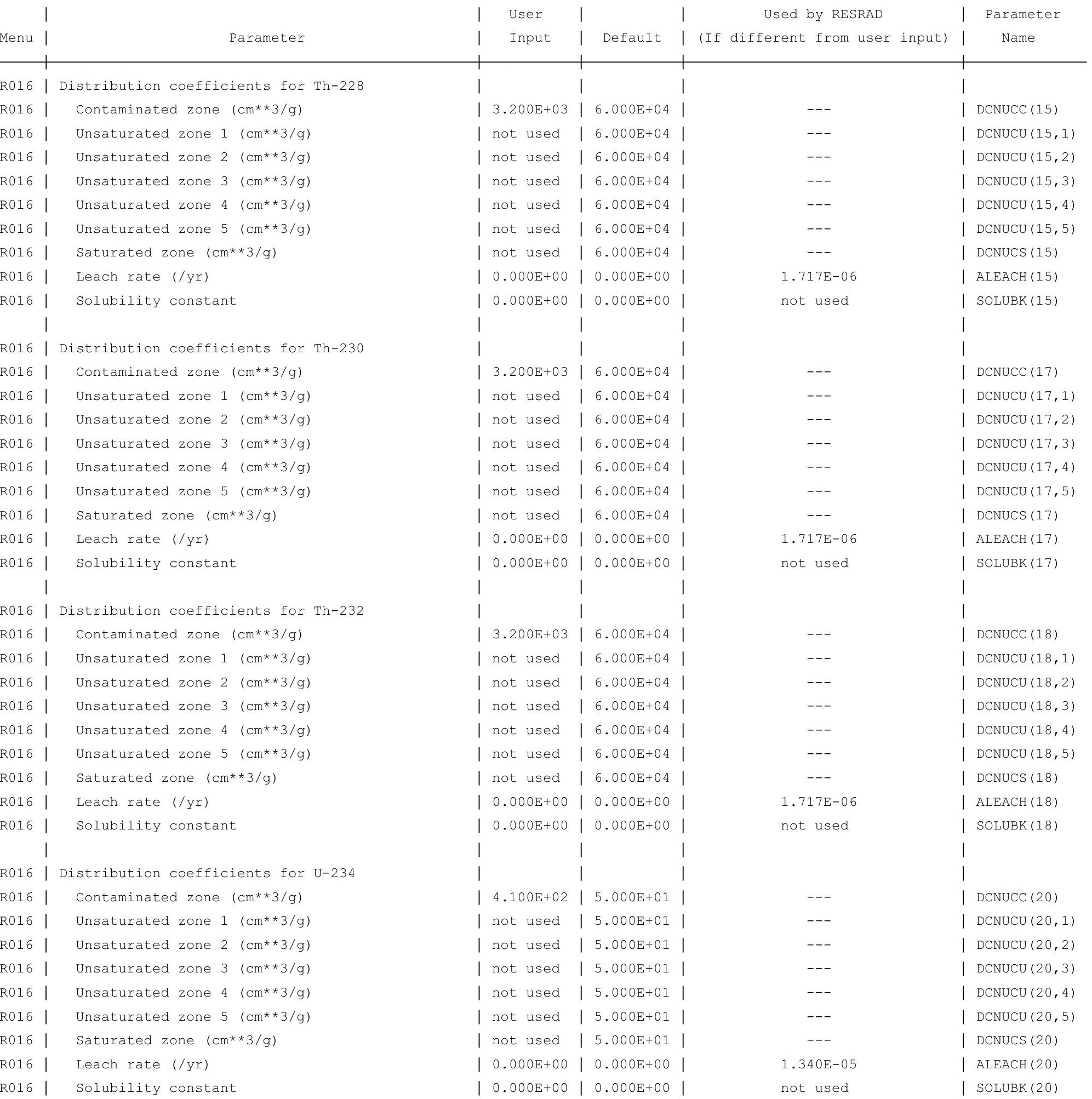


RESRAD, Version $6.5 \quad \mathrm{~T}^{1 / 2}$ Limit $=180$ days

Summary : C746U Recreational User Deterministic Run

File : $\mathrm{X}: \backslash F I N A L$ V2 $\backslash$ DOE FWD RUNS $\backslash C 746 \mathrm{U}$ RU DOE SG FWD-FV2-100000YR.RAD

Site-Specific Parameter Summary (continued)

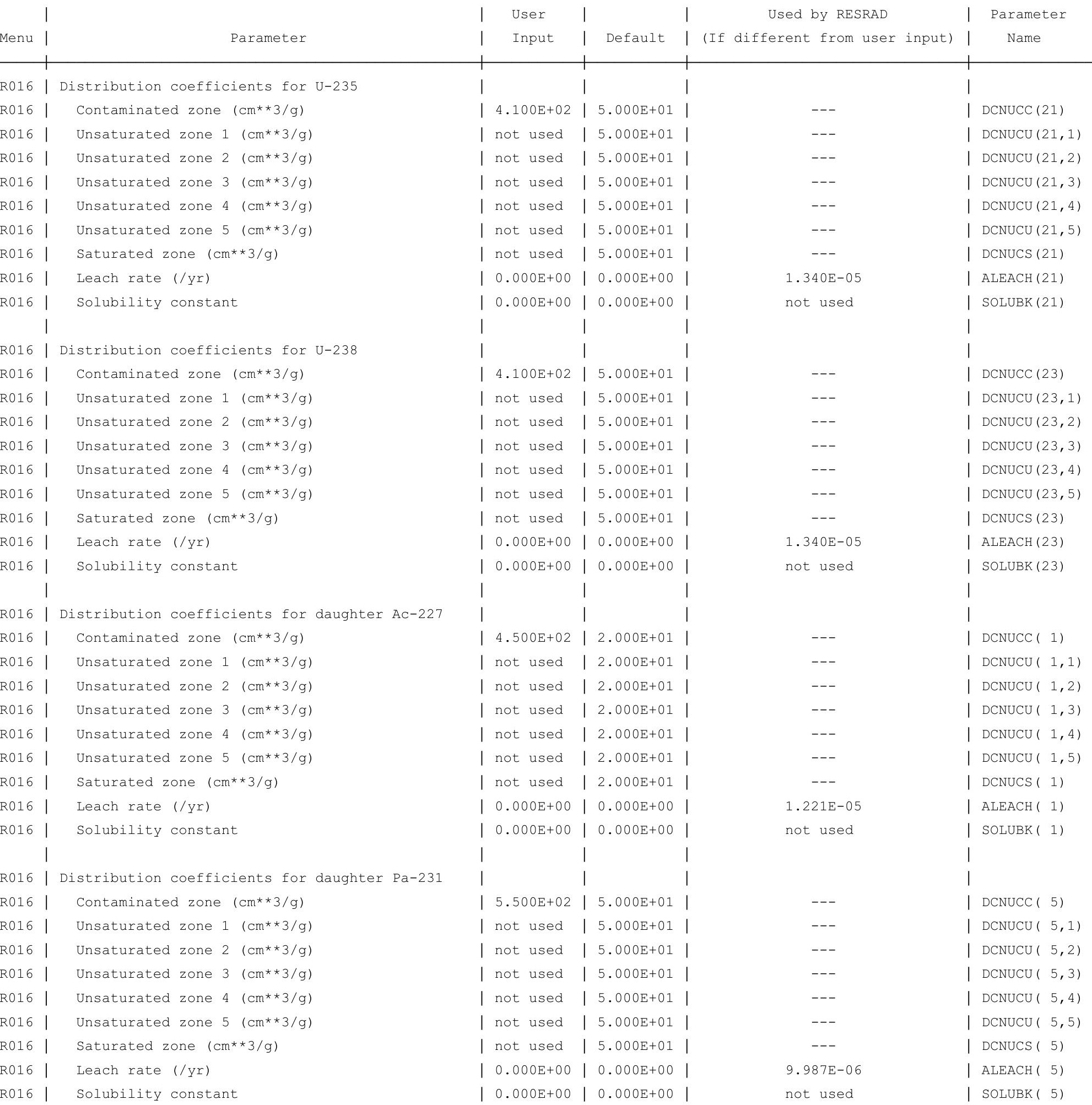


RESRAD, Version $6.5 \quad \mathrm{~T}^{1 / 2}$ Limit $=180$ days

Summary : C746U Recreational User Deterministic Run

File : $\mathrm{X}: \backslash F I N A L$ V2 $\backslash$ DOE FWD RUNS \C746U RU DOE SG FWD-FV2-100000YR.RAD

Site-Specific Parameter Summary (continued)

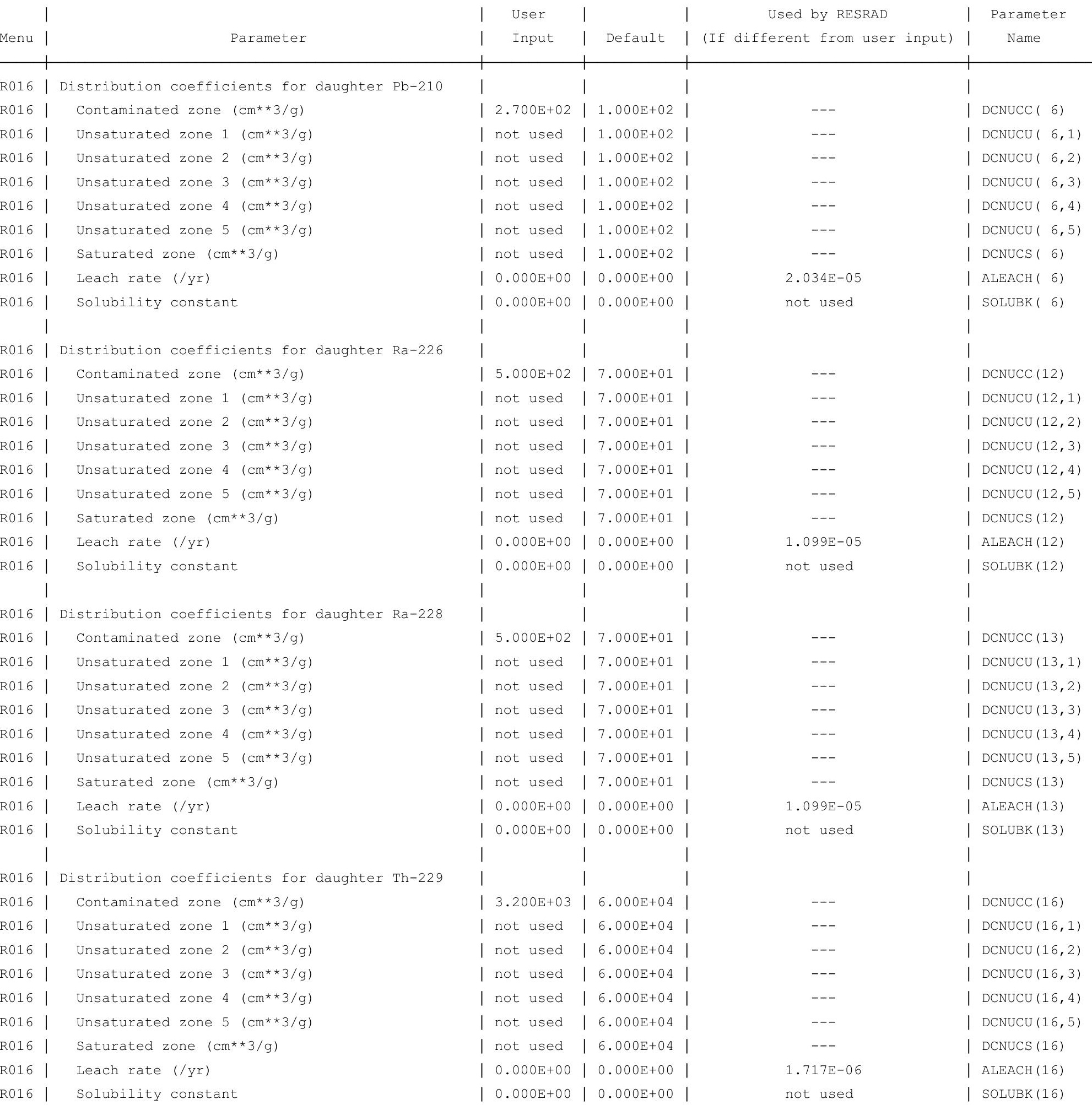


RESRAD, Version $6.5 \quad \mathrm{~T}^{1 / 2}$ Limit $=180$ days

Summary : C746U Recreational User Deterministic Run

File : $\mathrm{X}: \backslash F I N A L$ V2 $\backslash$ DOE FWD RUNS \C746U RU DOE SG FWD-FV2-100000YR.RAD

Site-Specific Parameter Summary (continued)

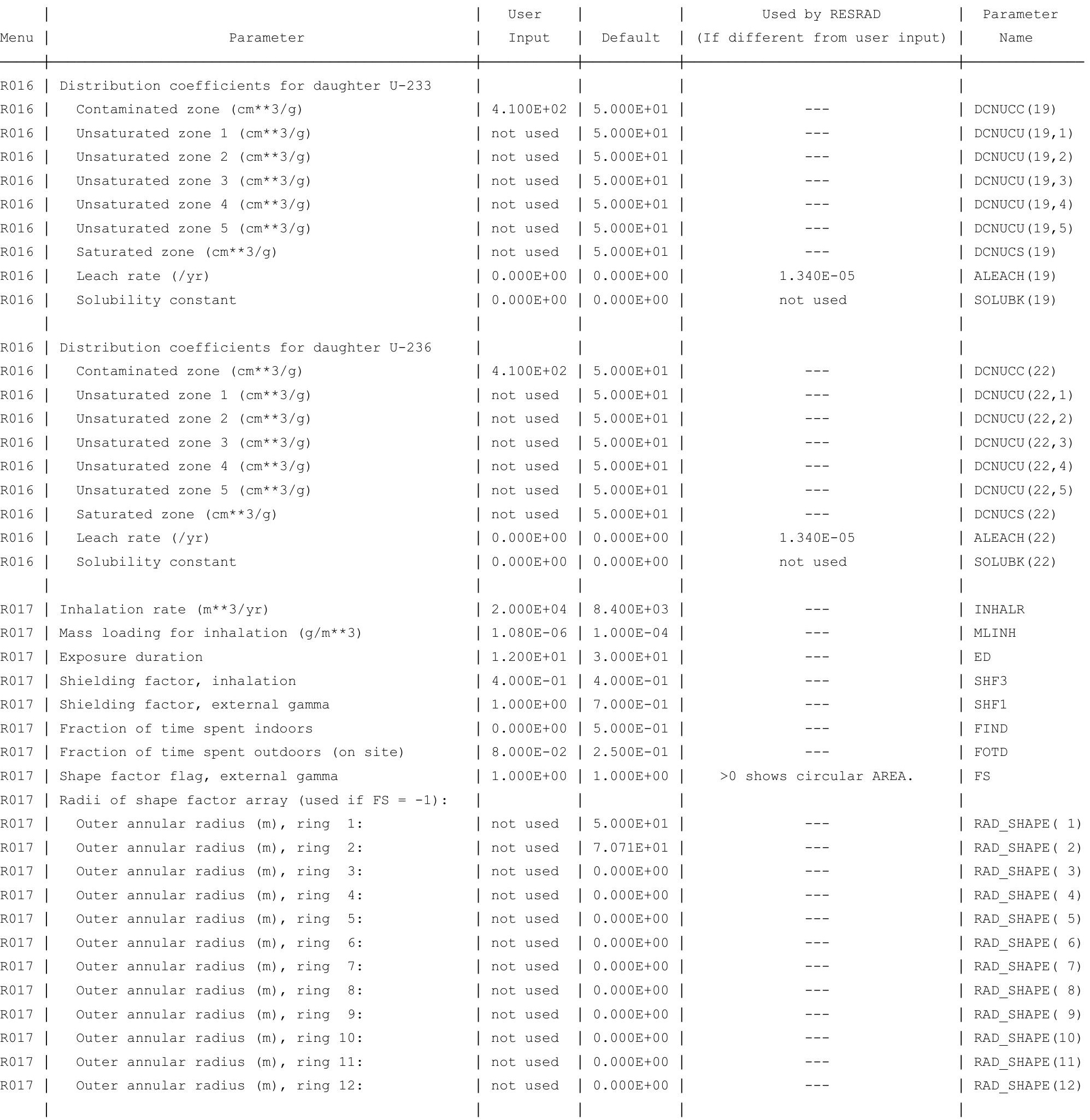


RESRAD, Version $6.5 \quad \mathrm{~T}^{1 / 2}$ Limit $=180$ days

Summary : C746U Recreational User Deterministic Run

File : $\mathrm{X}: \backslash F$ INAL V2 \DOE FWD RUNS \C746U RU DOE SG FWD-FV2-100000YR.RAD

Site-Specific Parameter Summary (continued)

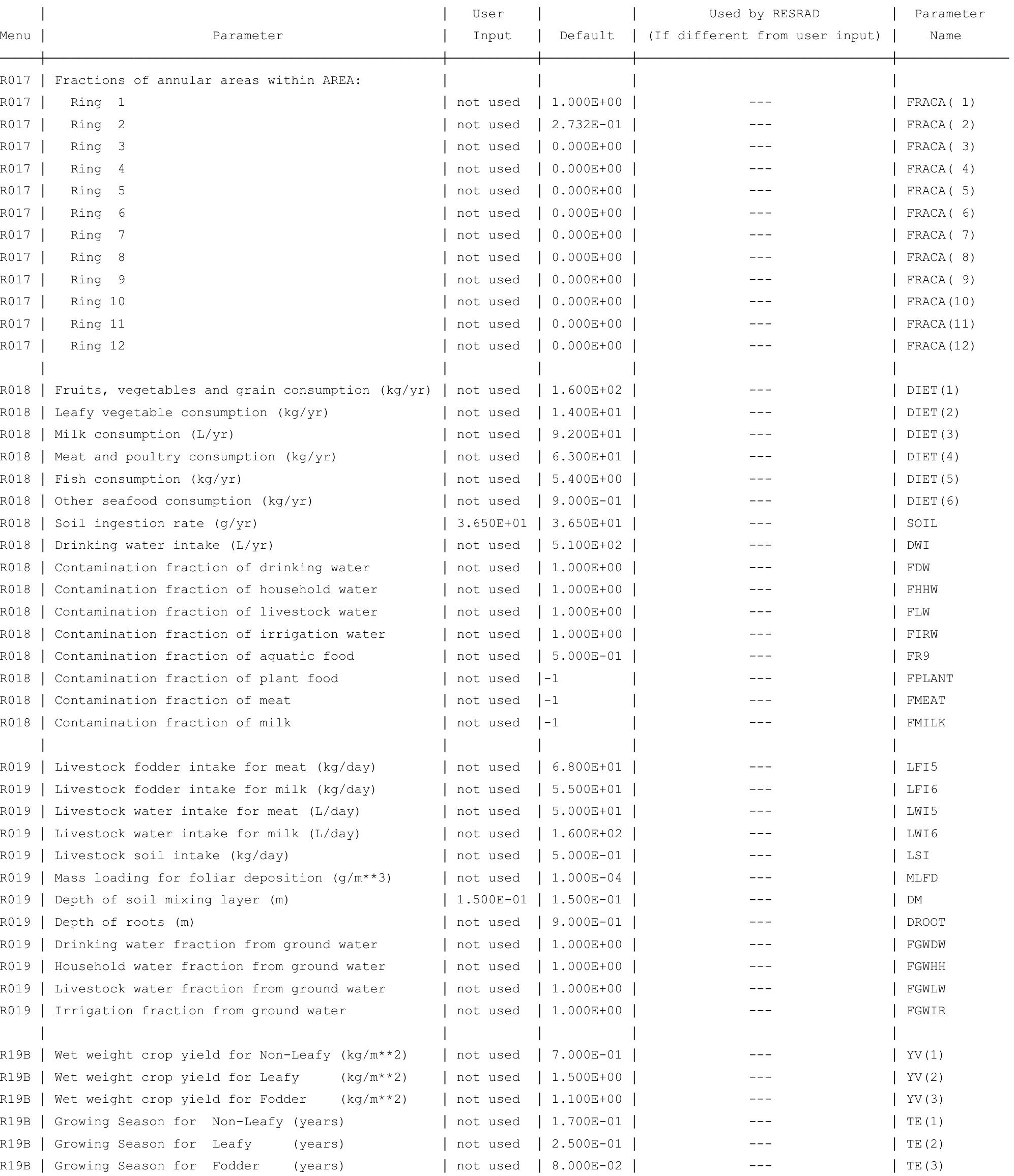


RESRAD, Version $6.5 \quad \mathrm{~T}^{1 / 2}$ Limit $=180$ days

Summary : C746U Recreational User Deterministic Run

File : $X: \backslash F I N A L$ V2 \DOE FWD RUNS \C746U RU DOE SG FWD-FV2-100000YR.RAD

Site-Specific Parameter Summary (continued)

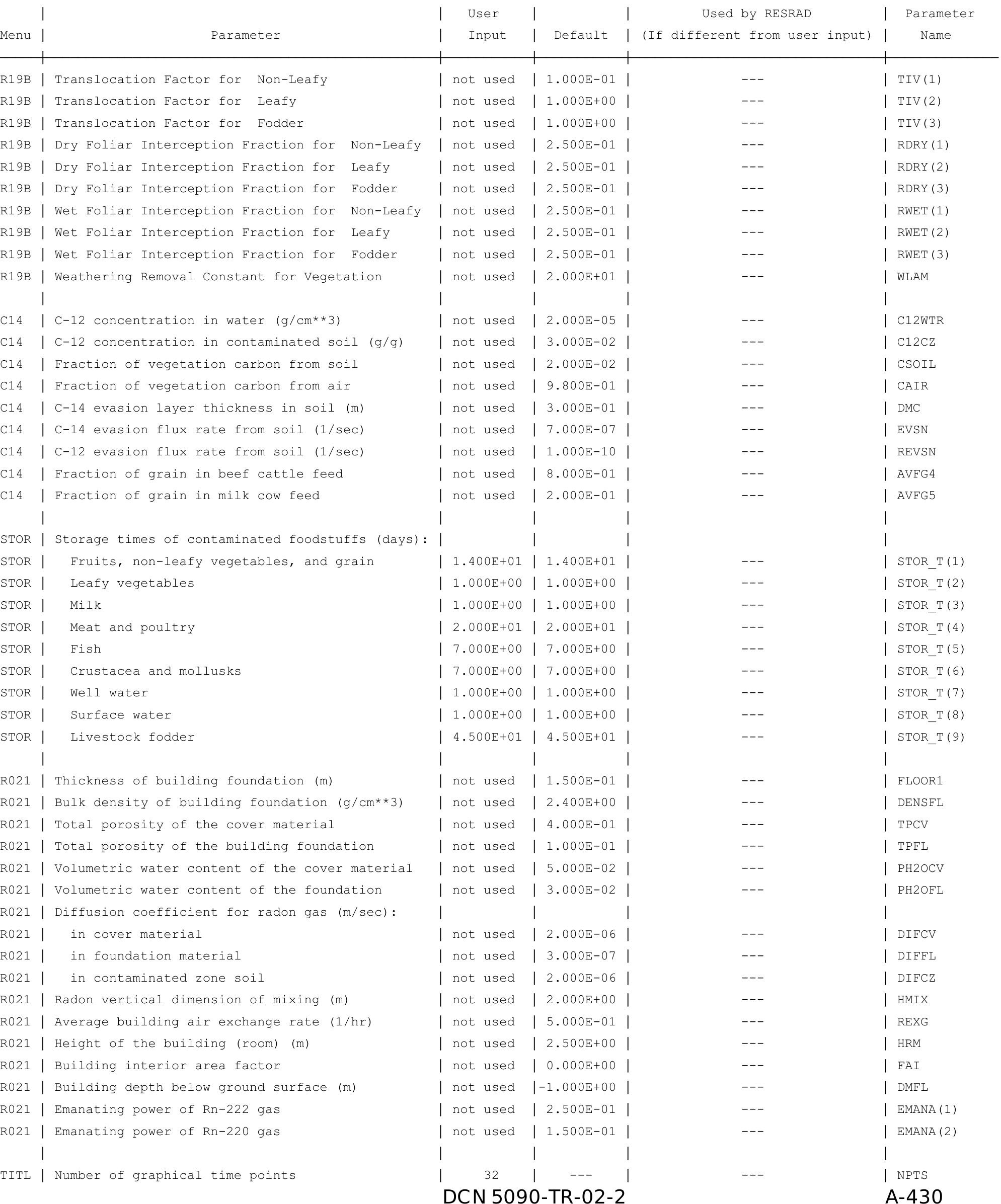


RESRAD, Version $6.5 \quad T^{1 / 2}$ Limit $=180$ days

07/27/2011 $10: 30 \quad$ Page 18

Summary : C746U Recreational User Deterministic Run

File : $\mathrm{X}: \backslash F I N A L$ V2 \DOE FWD RUNS $\backslash$ C746U RU DOE SG FWD-FV2-100000YR.RAD

Site-Specific Parameter Summary (continued)

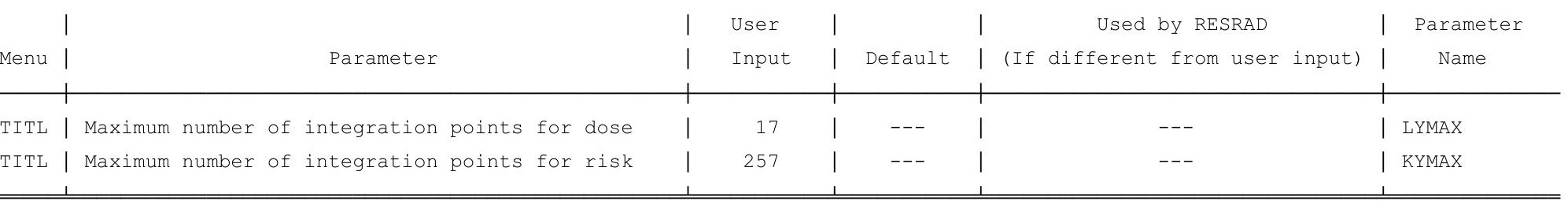

Summary of Pathway selections

\begin{tabular}{|c|c|}
\hline Pathway & User Selection \\
\hline 1 -- external gamma & active \\
\hline 2 -- inhalation (w/o radon) & active \\
\hline $3--$ plant ingestion & suppressed \\
\hline 4 -- meat ingestion & suppressed \\
\hline $5--$ milk ingestion & suppressed \\
\hline 6 -- aquatic foods & suppressed \\
\hline 7 -- drinking water & suppressed \\
\hline 8 -- soil ingestion & active \\
\hline 9 -- radon & suppressed \\
\hline Find peak pathway doses & active \\
\hline
\end{tabular}


RESRAD, Version $6.5 \quad \mathrm{~T}^{1 / 2}$ Limit $=180$ days

ummary : C746U Recreational User Deterministic Run

File : $\mathrm{X}: \backslash F I N A L$ V2 $\backslash$ DOE FWD RUNS $\backslash C 746 U$ RU DOE SG FWD-FV2-100000YR.RAD

Contaminated Zone Dimensions

Area: 89436.00 square meters

Thickness:

Cover Depth:

$$
\begin{array}{r}
13.40 \text { meters } \\
1.52 \text { meters }
\end{array}
$$

Initial Soil Concentrations, pCi/g

Total Dose TDOSE(t), mrem/yr

Basic Radiation Dose Limit $=1.000 \mathrm{E}+00 \mathrm{mrem} / \mathrm{yr}$

Total Mixture Sum $M(t)$ = Fraction of Basic Dose Limit Received at Time (t)

$\begin{array}{rlllllll}t \text { (years) }: & 0.000 \mathrm{E}+00 & 1.000 \mathrm{E}+00 & 5.000 \mathrm{E}+01 & 1.000 \mathrm{E}+02 & 5.000 \mathrm{E}+02 & 1.000 \mathrm{E}+04 & 1.000 \mathrm{E}+05 \\ \mathrm{TDOSE}(\mathrm{t}): & 5.411 \mathrm{E}-07 & 4.044 \mathrm{E}-07 & 9.175 \mathrm{E}-07 & 1.314 \mathrm{E}-06 & 2.333 \mathrm{E}-05 & 9.490 \mathrm{E}+01 & 0.000 \mathrm{E}+00 \\ \mathrm{M}(\mathrm{t}): & 5.411 \mathrm{E}-07 & 4.044 \mathrm{E}-07 & 9.175 \mathrm{E}-07 & 1.314 \mathrm{E}-06 & 2.333 \mathrm{E}-05 & 9.490 \mathrm{E}+01 & 0.000 \mathrm{E}+00\end{array}$

Maximum TDOSE $(t): 9.649 \mathrm{E}+01 \mathrm{mrem} / \mathrm{yr}$ at $t=19739 \pm *$ years

Total Dose Contributions TDOSE(i,p,t) for Individual Radionuclides (i) and Pathways (p)

As mrem/yr and Fraction of Total Dose At $t=1.974 \mathrm{E}+04$ years

\begin{tabular}{|c|c|c|c|c|c|c|c|c|c|c|c|c|c|c|}
\hline & \multicolumn{2}{|c|}{ Ground } & \multicolumn{2}{|c|}{ Inhalation } & \multicolumn{2}{|c|}{ Radon } & \multicolumn{2}{|c|}{ Plant } & \multicolumn{2}{|c|}{ Meat } & \multicolumn{2}{|c|}{ Milk } & \multicolumn{2}{|c|}{ Soil } \\
\hline clide & mrem/yr & fract. & mrem/yr & fract. & mrem/yr & fract. & mrem/yr & fract. & mrem/yr & fract. & mrem/yr & fract. & mrem/yr & fract. \\
\hline 241 & $1.441 \mathrm{E}-04$ & 0.0000 & $7.090 \mathrm{E}-08$ & 0.0000 & $0.000 \mathrm{E}+00$ & 0.0000 & $0.000 \mathrm{E}+00$ & 0.0000 & $0.000 \mathrm{E}+00$ & 0.0000 & $0.000 \mathrm{E}+00$ & 0.0000 & $3.869 E-06$ & 0.0000 \\
\hline-137 & $0.000 \mathrm{E}+00$ & 0.0000 & $0.000 \mathrm{E}+00$ & 0.0000 & $0.000 \mathrm{E}+00$ & 0.0000 & $0.000 \mathrm{E}+00$ & 0.0000 & $0.000 \mathrm{E}+00$ & 0.0000 & $0.000 \mathrm{E}+00$ & 0.0000 & $0.000 \mathrm{E}+00$ & 0.0000 \\
\hline-237 & $1.080 \mathrm{E}-01$ & 0.0011 & $5.417 E-05$ & 0.0000 & $0.000 \mathrm{E}+00$ & 0.0000 & $0.000 \mathrm{E}+00$ & 0.0000 & $0.000 \mathrm{E}+00$ & 0.0000 & $0.000 \mathrm{E}+00$ & 0.0000 & $2.984 \mathrm{E}-03$ & 0.0000 \\
\hline-238 & $1.393 E-03$ & 0.0000 & $1.930 \mathrm{E}-07$ & 0.0000 & $0.000 \mathrm{E}+00$ & 0.0000 & $0.000 \mathrm{E}+00$ & 0.0000 & $0.000 \mathrm{E}+00$ & 0.0000 & $0.000 \mathrm{E}+00$ & 0.0000 & $1.033 \mathrm{E}-04$ & 0.0000 \\
\hline-239 & $3.851 \mathrm{E}-04$ & 0.0000 & $1.094 \mathrm{E}-03$ & 0.0000 & $0.000 \mathrm{E}+00$ & 0.0000 & $0.000 \mathrm{E}+00$ & 0.0000 & $0.000 \mathrm{E}+00$ & 0.0000 & $0.000 \mathrm{E}+00$ & 0.0000 & $4.341 E-02$ & 0.0004 \\
\hline-240 & $3.293 E-05$ & 0.0000 & $2.383 E-04$ & 0.0000 & $0.000 \mathrm{E}+00$ & 0.0000 & $0.000 \mathrm{E}+00$ & 0.0000 & $0.000 \mathrm{E}+00$ & 0.0000 & $0.000 \mathrm{E}+00$ & 0.0000 & $9.456 \mathrm{E}-03$ & 0.0001 \\
\hline 99 & $0.000 \mathrm{E}+00$ & 0.0000 & $0.000 \mathrm{E}+00$ & 0.0000 & $0.000 \mathrm{E}+00$ & 0.0000 & $0.000 \mathrm{E}+00$ & 0.0000 & $0.000 \mathrm{E}+00$ & 0.0000 & $0.000 \mathrm{E}+00$ & 0.0000 & $0.000 \mathrm{E}+00$ & 0.0000 \\
\hline-228 & $0.000 \mathrm{E}+00$ & 0.0000 & $0.000 \mathrm{E}+00$ & 0.0000 & $0.000 \mathrm{E}+00$ & 0.0000 & $0.000 \mathrm{E}+00$ & 0.0000 & $0.000 \mathrm{E}+00$ & 0.0000 & $0.000 \mathrm{E}+00$ & 0.0000 & $0.000 \mathrm{E}+00$ & 0.0000 \\
\hline-230 & $6.701 \mathrm{E}+01$ & 0.6945 & $5.776 \mathrm{E}-03$ & 0.0001 & $0.000 \mathrm{E}+00$ & 0.0000 & $0.000 \mathrm{E}+00$ & 0.0000 & $0.000 \mathrm{E}+00$ & 0.0000 & $0.000 \mathrm{E}+00$ & 0.0000 & $4.561 \mathrm{E}+00$ & 0.0473 \\
\hline-232 & $4.633 \mathrm{E}+00$ & 0.0480 & $4.308 E-04$ & 0.0000 & $0.000 \mathrm{E}+00$ & 0.0000 & $0.000 \mathrm{E}+00$ & 0.0000 & $0.000 \mathrm{E}+00$ & 0.0000 & $0.000 \mathrm{E}+00$ & 0.0000 & $2.447 \mathrm{E}-01$ & 0.0025 \\
\hline 34 & $1.604 \mathrm{E}+01$ & 0.1662 & $2.215 E-03$ & 0.0000 & $0.000 \mathrm{E}+00$ & 0.0000 & $0.000 \mathrm{E}+00$ & 0.0000 & $0.000 \mathrm{E}+00$ & 0.0000 & $0.000 \mathrm{E}+00$ & 0.0000 & $1.189 \mathrm{E}+00$ & 0.0123 \\
\hline 35 & $5.552 \mathrm{E}-01$ & 0.0058 & $7.930 \mathrm{E}-04$ & 0.0000 & $0.000 \mathrm{E}+00$ & 0.0000 & $0.000 \mathrm{E}+00$ & 0.0000 & $0.000 \mathrm{E}+00$ & 0.0000 & $0.000 \mathrm{E}+00$ & 0.0000 & $4.906 \mathrm{E}-02$ & 0.0005 \\
\hline 38 & $1.902 \mathrm{E}+00$ & 0.0197 & $7.173 \mathrm{E}-04$ & 0.0000 & $0.000 \mathrm{E}+00$ & 0.0000 & $0.000 \mathrm{E}+00$ & 0.0000 & $0.000 \mathrm{E}+00$ & 0.0000 & $0.000 \mathrm{E}+00$ & 0.0000 & 1. $275 \mathrm{E}-01$ & 0.0013 \\
\hline & $9.025 \mathrm{E}+01$ & 0 & $1.132 \mathrm{E}-02$ & 0.0001 & $0.000 \mathrm{E}+00$ & 000 & $0.000 \mathrm{E}+00$ & 000 & $0.000 \mathrm{E}+00$ & 00 & $0 \mathrm{E}+00$ & 00 & 00 & 5 \\
\hline
\end{tabular}

Water Independent Pathways (Inhalation excludes radon) 
RESRAD, Version $6.5 \quad \mathrm{~T}^{1 / 2}$ Limit $=180$ days

ummary : C746U Recreational User Deterministic Run

File : $\mathrm{X}: \backslash F I N A L$ V2 $\backslash$ DOE FWD RUNS \C746U RU DOE SG FWD-FV2-100000YR.RAD

Total Dose Contributions TDOSE (i,p,t) for Individual Radionuclides (i) and Pathways (p) As mrem/yr and Fraction of Total Dose At $t=1.974 \mathrm{E}+04$ years

Water Dependent Pathways

\begin{tabular}{|c|c|c|c|c|c|c|c|c|c|c|c|c|c|c|}
\hline & \multicolumn{2}{|c|}{ Water } & \multicolumn{2}{|c|}{ Fish } & \multicolumn{2}{|c|}{ Radon } & \multicolumn{2}{|c|}{ Plant } & \multicolumn{2}{|c|}{ Meat } & \multicolumn{2}{|c|}{ Milk } & \multicolumn{2}{|c|}{ All Pathways* } \\
\hline clide & mrem/yr & fract. & mrem/yr & fract. & mrem/yr & fract. & mrem/yr & fract. & mrem/yr & fract. & mrem/yr & fract. & mrem/yr & fract. \\
\hline-241 & $0.000 \mathrm{E}+00$ & 0.0000 & $0.000 \mathrm{E}+00$ & 0.0000 & $0.000 \mathrm{E}+00$ & 0.0000 & $0.000 \mathrm{E}+00$ & 0.0000 & $0.000 \mathrm{E}+00$ & 0.0000 & $0.000 \mathrm{E}+00$ & 0.0000 & $1.480 \mathrm{E}-04$ & 0.0000 \\
\hline-137 & $0.000 \mathrm{E}+00$ & 0.0000 & $0.000 \mathrm{E}+00$ & 0.0000 & $0.000 \mathrm{E}+00$ & 0.0000 & $0.000 \mathrm{E}+00$ & 0.0000 & $0.000 \mathrm{E}+00$ & 0.0000 & $0.000 \mathrm{E}+00$ & 0.0000 & $0.000 \mathrm{E}+00$ & 0.0000 \\
\hline-237 & $0.000 \mathrm{E}+00$ & 0.0000 & $0.000 \mathrm{E}+00$ & 0.0000 & $0.000 \mathrm{E}+00$ & 0.0000 & $0.000 \mathrm{E}+00$ & 0.0000 & $0.000 \mathrm{E}+00$ & 0.0000 & $0.000 \mathrm{E}+00$ & 0.0000 & $1.110 \mathrm{E}-01$ & 0.0012 \\
\hline-238 & $0.000 \mathrm{E}+00$ & 0.0000 & $0.000 \mathrm{E}+00$ & 0.0000 & $0.000 \mathrm{E}+00$ & 0.0000 & $0.000 \mathrm{E}+00$ & 0.0000 & $0.000 \mathrm{E}+00$ & 0.0000 & $0.000 \mathrm{E}+00$ & 0.0000 & $1.497 \mathrm{E}-03$ & 0.0000 \\
\hline-239 & $0.000 \mathrm{E}+00$ & 0.0000 & $0.000 \mathrm{E}+00$ & 0.0000 & $0.000 \mathrm{E}+00$ & 0.0000 & $0.000 \mathrm{E}+00$ & 0.0000 & $0.000 \mathrm{E}+00$ & 0.0000 & $0.000 \mathrm{E}+00$ & 0.0000 & $4.489 \mathrm{E}-02$ & 0.0005 \\
\hline-240 & $0.000 \mathrm{E}+00$ & 0.0000 & $0.000 \mathrm{E}+00$ & 0.0000 & $0.000 \mathrm{E}+00$ & 0.0000 & $0.000 \mathrm{E}+00$ & 0.0000 & $0.000 \mathrm{E}+00$ & 0.0000 & $0.000 \mathrm{E}+00$ & 0.0000 & $9.727 E-03$ & 0.0001 \\
\hline-99 & $0.000 \mathrm{E}+00$ & 0.0000 & $0.000 \mathrm{E}+00$ & 0.0000 & $0.000 \mathrm{E}+00$ & 0.0000 & $0.000 \mathrm{E}+00$ & 0.0000 & $0.000 \mathrm{E}+00$ & 0.0000 & $0.000 \mathrm{E}+00$ & 0.0000 & $0.000 \mathrm{E}+00$ & 0.0000 \\
\hline-228 & $0.000 \mathrm{E}+00$ & 0.0000 & $0.000 \mathrm{E}+00$ & 0.0000 & $0.000 \mathrm{E}+00$ & 0.0000 & $0.000 \mathrm{E}+00$ & 0.0000 & $0.000 \mathrm{E}+00$ & 0.0000 & $0.000 \mathrm{E}+00$ & 0.0000 & $0.000 \mathrm{E}+00$ & 0.0000 \\
\hline-230 & $0.000 \mathrm{E}+00$ & 0.0000 & $0.000 \mathrm{E}+00$ & 0.0000 & $0.000 \mathrm{E}+00$ & 0.0000 & $0.000 \mathrm{E}+00$ & 0.0000 & $0.000 \mathrm{E}+00$ & 0.0000 & $0.000 \mathrm{E}+00$ & 0.0000 & $7.158 \mathrm{E}+01$ & 0.7419 \\
\hline-232 & $0.000 \mathrm{E}+00$ & 0.0000 & $0.000 \mathrm{E}+00$ & 0.0000 & $0.000 \mathrm{E}+00$ & 0.0000 & $0.000 \mathrm{E}+00$ & 0.0000 & $0.000 \mathrm{E}+00$ & 0.0000 & $0.000 \mathrm{E}+00$ & 0.0000 & $4.878 E+00$ & 0.0506 \\
\hline 234 & $0.000 \mathrm{E}+00$ & 0.0000 & $0.000 \mathrm{E}+00$ & 0.0000 & $0.000 \mathrm{E}+00$ & 0.0000 & $0.000 \mathrm{E}+00$ & 0.0000 & $0.000 \mathrm{E}+00$ & 0.0000 & $0.000 \mathrm{E}+00$ & 0.0000 & 1. $723 \mathrm{E}+01$ & 0.1785 \\
\hline 35 & $0.000 \mathrm{E}+00$ & 0.0000 & $0.000 \mathrm{E}+00$ & 0.0000 & $0.000 \mathrm{E}+00$ & 0.0000 & $0.000 \mathrm{E}+00$ & 0.0000 & $0.000 \mathrm{E}+00$ & 0.0000 & $0.000 \mathrm{E}+00$ & 0.0000 & $6.051 \mathrm{E}-01$ & 0.0063 \\
\hline 38 & $0.000 \mathrm{E}+00$ & 0.0000 & $0.000 \mathrm{E}+00$ & 0.0000 & $0.000 \mathrm{E}+00$ & 0.0000 & $0.000 \mathrm{E}+00$ & 0.0000 & $0.000 \mathrm{E}+00$ & 0.0000 & $0.000 \mathrm{E}+00$ & 0.0000 & $2.030 \mathrm{E}+00$ & 0.0210 \\
\hline & $0.000 \mathrm{E}+00$ & 0.0000 & $0.000 \mathrm{E}+00$ & 0.0000 & $0.000 \mathrm{E}+00$ & 0.0000 & $0.000 \mathrm{E}+00$ & 0.0000 & $0.000 \mathrm{E}+00$ & 0.0000 & $0.000 \mathrm{E}+00$ & 0.0000 & $9 \mathrm{E}+01$ & 1.0000 \\
\hline
\end{tabular}

* Sum of all water independent and dependent pathways. 
RESRAD, Version $6.5 \quad \mathrm{~T}^{1 / 2}$ Limit $=180$ days

mmary : C746U Recreational User Deterministic Run

File : $X: \backslash F I N A L$ V2 \DOE FWD RUNS \C746U RU DOE SG FWD-FV2-100000YR.RAD

Total Dose Contributions TDOSE (i,p,t) for Individual Radionuclides (i) and Pathways (p) As mrem/yr and Fraction of Total Dose At $t=0.000 \mathrm{E}+00$ years

Water Independent Pathways (Inhalation excludes radon)

\begin{tabular}{|c|c|c|c|c|c|c|c|c|c|c|c|c|c|c|}
\hline \multirow[b]{2}{*}{ uclide } & \multicolumn{2}{|c|}{ Ground } & \multicolumn{2}{|c|}{ Inhalation } & \multicolumn{2}{|c|}{ Radon } & \multicolumn{2}{|c|}{ Plant } & \multicolumn{2}{|c|}{ Meat } & \multicolumn{2}{|c|}{ Milk } & \multicolumn{2}{|c|}{ Soil } \\
\hline & mrem/yr & fract. & mrem/yr & fract. & mrem/yr & fract. & mrem/yr & fract. & mrem/yr & fract. & mrem/yr & fract. & mrem/yr & fract. \\
\hline 241 & $5.204 \mathrm{E}-19$ & 0.0000 & $0.000 \mathrm{E}+00$ & 0.0000 & $0.000 \mathrm{E}+00$ & 0.0000 & $0.000 \mathrm{E}+00$ & 0.0000 & $0.000 \mathrm{E}+00$ & 0.0000 & $0.000 \mathrm{E}+00$ & 0.0000 & $0.000 \mathrm{E}+00$ & 0.0000 \\
\hline 137 & $2.305 E-09$ & 0.0043 & $0.000 \mathrm{E}+00$ & 0.0000 & $0.000 \mathrm{E}+00$ & 0.0000 & $0.000 \mathrm{E}+00$ & 0.0000 & $0.000 \mathrm{E}+00$ & 0.0000 & $0.000 \mathrm{E}+00$ & 0.0000 & $0.000 \mathrm{E}+00$ & 0.0000 \\
\hline 237 & $5.043 \mathrm{E}-13$ & 0.0000 & $0.000 \mathrm{E}+00$ & 0.0000 & $0.000 \mathrm{E}+00$ & 0.0000 & $0.000 \mathrm{E}+00$ & 0.0000 & $0.000 \mathrm{E}+00$ & 0.0000 & $0.000 \mathrm{E}+00$ & 0.0000 & $0.000 \mathrm{E}+00$ & 0.0000 \\
\hline 238 & $3.052 \mathrm{E}-22$ & 0.0000 & $0.000 \mathrm{E}+00$ & 0.0000 & $0.000 \mathrm{E}+00$ & 0.0000 & $0.000 \mathrm{E}+00$ & 0.0000 & $0.000 \mathrm{E}+00$ & 0.0000 & $0.000 \mathrm{E}+00$ & 0.0000 & $0.000 \mathrm{E}+00$ & 0.0000 \\
\hline 240 & $3.957 E-24$ & 0.0000 & $0.000 \mathrm{E}+00$ & 0.0000 & $0.000 \mathrm{E}+00$ & 0.0000 & $0.000 \mathrm{E}+00$ & 0.0000 & $0.000 \mathrm{E}+00$ & 0.0000 & $0.000 \mathrm{E}+00$ & 0.0000 & $0.000 \mathrm{E}+00$ & 0.0000 \\
\hline & $2.884 \mathrm{E}-25$ & 0.0000 & $0.000 \mathrm{E}+00$ & 0.0000 & $0.000 \mathrm{E}+00$ & 0.0000 & $0.000 \mathrm{E}+00$ & 0.0000 & $0.000 \mathrm{E}+00$ & 0.0000 & $0.000 \mathrm{E}+00$ & 0.0000 & $0.000 \mathrm{E}+00$ & 0.0000 \\
\hline 228 & $5.317 \mathrm{E}-07$ & 0.9827 & $0.000 \mathrm{E}+00$ & 0.0000 & $0.000 \mathrm{E}+00$ & 0.0000 & $0.000 \mathrm{E}+00$ & 0.0000 & $0.000 \mathrm{E}+00$ & 0.0000 & $0.000 \mathrm{E}+00$ & 0.0000 & $0.000 \mathrm{E}+00$ & 0.0000 \\
\hline 30 & $3.629 \mathrm{E}-10$ & 0.0007 & $0.000 \mathrm{E}+00$ & 0.0000 & $0.000 \mathrm{E}+00$ & 0.0000 & $0.000 \mathrm{E}+00$ & 0.0000 & $0.000 \mathrm{E}+00$ & 0.0000 & $0.000 \mathrm{E}+00$ & 0.0000 & $0.000 \mathrm{E}+00$ & 0.0000 \\
\hline 232 & $4.531 \mathrm{E}-09$ & 0.0084 & $0.000 \mathrm{E}+00$ & 0.0000 & $0.000 \mathrm{E}+00$ & 0.0000 & $0.000 \mathrm{E}+00$ & 0.0000 & $0.000 \mathrm{E}+00$ & 0.0000 & $0.000 \mathrm{E}+00$ & 0.0000 & $0.000 \mathrm{E}+00$ & 0.0000 \\
\hline & $1.743 \mathrm{E}-15$ & 0.0000 & $0.000 \mathrm{E}+00$ & 0.0000 & $0.000 \mathrm{E}+00$ & 0.0000 & $0.000 \mathrm{E}+00$ & 0.0000 & $0.000 \mathrm{E}+00$ & 0.0000 & $0.000 \mathrm{E}+00$ & 0.0000 & $0.000 \mathrm{E}+00$ & 0.0000 \\
\hline & $7.778 \mathrm{E}-15$ & 0.0000 & $0.000 \mathrm{E}+00$ & 0.0000 & $0.000 \mathrm{E}+00$ & 0.0000 & $0.000 \mathrm{E}+00$ & 0.0000 & $0.000 \mathrm{E}+00$ & 0.0000 & $0.000 \mathrm{E}+00$ & 0.0000 & $0.000 \mathrm{E}+00$ & 0.0000 \\
\hline & $5.411 \mathrm{E}-07$ & 1.0000 & $0.000 \mathrm{E}+00$ & 0.0000 & $0.000 \mathrm{E}+00$ & 0.0000 & $0.000 \mathrm{E}+00$ & 0.0000 & $0.000 \mathrm{E}+00$ & 0.0000 & $0.000 \mathrm{E}+00$ & 0.0000 & $0.000 \mathrm{E}+00$ & 0.0000 \\
\hline
\end{tabular}

Total Dose Contributions TDOSE(i,p,t) for Individual Radionuclides (i) and Pathways (p) As mrem/yr and Fraction of Total Dose At $t=0.000 \mathrm{E}+00$ years

Water Dependent Pathways

\begin{tabular}{|c|c|c|c|c|c|c|c|c|c|c|c|c|c|c|}
\hline \multirow[b]{2}{*}{ clide } & \multicolumn{2}{|c|}{ Water } & \multicolumn{2}{|c|}{ Fish } & \multicolumn{2}{|c|}{ Radon } & \multicolumn{2}{|c|}{ Plant } & \multicolumn{2}{|c|}{ Meat } & \multicolumn{2}{|c|}{ Milk } & \multicolumn{2}{|c|}{ All Pathways* } \\
\hline & $\mathrm{mrem} / \mathrm{yr}$ & fract. & $\mathrm{mrem} / \mathrm{yr}$ & fract. & $\mathrm{mrem} / \mathrm{yr}$ & fract. & $\mathrm{rem} / \mathrm{yr}$ & fract. & $\mathrm{rem} / \mathrm{yr}$ & fract. & $\mathrm{rem} / \mathrm{yr}$ & fra & nrem/yr & fract. \\
\hline 81 & $0.000 \mathrm{E}+00$ & 0.0000 & $0.000 \mathrm{E}+00$ & 0.0000 & $0.000 \mathrm{E}+00$ & 0.0000 & $0.000 \mathrm{E}+00$ & 0.0000 & $0.000 \mathrm{E}+00$ & 0.0000 & $0.000 \mathrm{E}+00$ & 0.0000 & $5.204 \mathrm{E}-19$ & 0.0000 \\
\hline & $0.000 \mathrm{E}+00$ & 0.0000 & $0.000 \mathrm{E}+00$ & 0.0000 & $0.000 \mathrm{E}+00$ & 0.0000 & $0.000 \mathrm{E}+00$ & 0.0000 & $0.000 \mathrm{E}+00$ & 0.0000 & $0.000 \mathrm{E}+00$ & 0.0000 & $2.305 \mathrm{E}-09$ & 0.0043 \\
\hline & $0.000 \mathrm{E}+00$ & 0.0000 & $0.000 \mathrm{E}+00$ & 0.0000 & $0.000 \mathrm{E}+00$ & 0.0000 & $0.000 \mathrm{E}+00$ & 0.0000 & $0.000 \mathrm{E}+00$ & 0.0000 & $0.000 \mathrm{E}+00$ & 0.0000 & $5.043 E-13$ & 0.0000 \\
\hline 238 & $0.000 \mathrm{E}+00$ & 0.0000 & $0.000 \mathrm{E}+00$ & 0.0000 & $0.000 \mathrm{E}+00$ & 0.0000 & $0.000 \mathrm{E}+00$ & 0.0000 & $0.000 \mathrm{E}+00$ & 0.0000 & $0.000 \mathrm{E}+00$ & 0.0000 & $3.052 \mathrm{E}-22$ & 0.0000 \\
\hline 239 & $0.000 \mathrm{E}+00$ & 0 & $0.000 \mathrm{E}+00$ & 0 & & 0 & $0.000 \mathrm{E}+00$ & 0 & & 0 & $0.000 \mathrm{E}+00$ & & 17 & 000 \\
\hline & $0.000 \mathrm{E}+00$ & 0.0000 & $0.000 \mathrm{E}+00$ & 0.00 & $0.000 \mathrm{E}+00$ & 0.0 & $0.000 \mathrm{E}+00$ & 0.0 & $0.000 \mathrm{E}+00$ & 0 & $0.000 \mathrm{E}+00$ & 0 & $3.957 \mathrm{E}-24$ & 0.0000 \\
\hline & $0.000 \mathrm{E}+00$ & 0.0 & $0.000 \mathrm{E}+00$ & 0.00 & $0.000 \mathrm{E}+00$ & 0.0 & $0.000 \mathrm{E}+00$ & 0.0 & $0.000 \mathrm{E}+00$ & 0.0 & $0.000 \mathrm{E}+00$ & 0 & 25 & 0000 \\
\hline 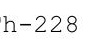 & $0.000 \mathrm{E}+00$ & 0.0000 & $0.000 \mathrm{E}+00$ & 0.0000 & $0.000 \mathrm{E}+00$ & 0.0000 & $0.000 \mathrm{E}+00$ & 0.0000 & $0.000 \mathrm{E}+00$ & 0.0000 & $0.000 \mathrm{E}+00$ & 0.0000 & $5.317 \mathrm{E}-07$ & 0.9827 \\
\hline & $0.000 \mathrm{E}+00$ & 0.0000 & $0.000 \mathrm{E}+00$ & 0.0000 & $0.000 \mathrm{E}+00$ & 0.0000 & $0.000 \mathrm{E}+00$ & 0.0000 & $0.000 \mathrm{E}+00$ & 0.0000 & $0.000 \mathrm{E}+00$ & 0.0000 & $3.629 \mathrm{E}-10$ & 0.0007 \\
\hline & $0.000 \mathrm{E}+00$ & 0.0000 & $0.000 \mathrm{E}+00$ & 0.0000 & $0.000 \mathrm{E}+00$ & 0.0000 & $0.000 \mathrm{E}+00$ & 0.0000 & $0.000 \mathrm{E}+00$ & 0.0000 & $0.000 \mathrm{E}+00$ & 0.0000 & $4.531 \mathrm{E}-09$ & 0.0084 \\
\hline & $0.000 \mathrm{E}+00$ & 0.0000 & $0.000 \mathrm{E}+00$ & 0.0000 & $0.000 \mathrm{E}+00$ & 0.0000 & $0.000 \mathrm{E}+00$ & 0.0000 & $0.000 \mathrm{E}+00$ & 0.0000 & $0.000 \mathrm{E}+00$ & 0.0000 & $1.743 \mathrm{E}-15$ & 0.0000 \\
\hline & $0.000 \mathrm{E}+00$ & 0.0000 & $0.000 \mathrm{E}+00$ & 0.0000 & $0.000 \mathrm{E}+00$ & 0.0000 & $0.000 \mathrm{E}+00$ & 0.0000 & $0.000 \mathrm{E}+00$ & 0.0000 & $0.000 \mathrm{E}+00$ & 0.0000 & $7.778 \mathrm{E}-15$ & 0.0000 \\
\hline & $0.000 \mathrm{E}+00$ & 0.0000 & $0.000 \mathrm{E}+00$ & 0.0000 & $0.000 \mathrm{E}+00$ & 0.0000 & $0.000 \mathrm{E}+00$ & 0.0000 & $0.000 \mathrm{E}+00$ & 0.0000 & $0.000 \mathrm{E}+00$ & 0.0000 & $2.184 \mathrm{E}-09$ & 0.0040 \\
\hline & 0 & 000 & $.000 \mathrm{E}+00$ & 0.0000 & $.000 \mathrm{E}+00$ & 0.0000 & $.000 \mathrm{E}+00$ & 0.0 & +00 & c & $z+00$ & & -07 & \\
\hline
\end{tabular}

*Sum of all water independent and dependent pathways. 
RESRAD, Version $6.5 \quad \mathrm{~T}^{1 / 2}$ Limit $=180$ days

mmary : C746U Recreational User Deterministic Run

File : $\mathrm{X}: \backslash F$ INAL V2 \DOE FWD RUNS \C746U RU DOE SG FWD-FV2-100000YR.RAD

Total Dose Contributions TDOSE (i,p,t) for Individual Radionuclides (i) and Pathways (p) As mrem/yr and Fraction of Total Dose At $t=1.000 \mathrm{E}+00$ years

Water Independent Pathways (Inhalation excludes radon)

\begin{tabular}{|c|c|c|c|c|c|c|c|c|c|c|c|c|c|c|}
\hline \multirow[b]{2}{*}{ clide } & \multicolumn{2}{|c|}{ Ground } & \multicolumn{2}{|c|}{ Inhalation } & \multicolumn{2}{|c|}{ Radon } & \multicolumn{2}{|c|}{ Plant } & \multicolumn{2}{|c|}{ Meat } & \multicolumn{2}{|c|}{ Milk } & \multicolumn{2}{|c|}{ Soil } \\
\hline & mrem/yr & fract. & mrem/yr & fract. & mrem/yr & fract. & mrem/yr & fract. & $\mathrm{mrem} / \mathrm{yr}$ & fract. & mrem/yr & fract. & $\mathrm{mrem} / \mathrm{yr}$ & fract. \\
\hline-241 & $1.575 \mathrm{E}-18$ & 0.0000 & $0.000 \mathrm{E}+00$ & 0.0000 & $0.000 \mathrm{E}+00$ & 0.0000 & $0.000 \mathrm{E}+00$ & 0.0000 & $0.000 \mathrm{E}+00$ & 0.0000 & $0.000 \mathrm{E}+00$ & 0.0000 & $0.000 \mathrm{E}+00$ & 0.0000 \\
\hline 137 & $2.272 \mathrm{E}-09$ & 0.0056 & $0.000 \mathrm{E}+00$ & 0.0000 & $0.000 \mathrm{E}+00$ & 0.0000 & $0.000 \mathrm{E}+00$ & 0.0000 & $0.000 \mathrm{E}+00$ & 0.0000 & $0.000 \mathrm{E}+00$ & 0.0000 & $0.000 \mathrm{E}+00$ & 0.0000 \\
\hline 237 & $5.097 \mathrm{E}-13$ & 0.0000 & $0.000 \mathrm{E}+00$ & 0.0000 & $0.000 \mathrm{E}+00$ & 0.0000 & $0.000 \mathrm{E}+00$ & 0.0000 & $0.000 \mathrm{E}+00$ & 0.0000 & $0.000 \mathrm{E}+00$ & 0.0000 & $0.000 \mathrm{E}+00$ & 0.0000 \\
\hline 238 & $4.535 E-21$ & 0.0000 & $0.000 \mathrm{E}+00$ & 0.0000 & $0.000 \mathrm{E}+00$ & 0.0000 & $0.000 \mathrm{E}+00$ & 0.0000 & $0.000 \mathrm{E}+00$ & 0.0000 & $0.000 \mathrm{E}+00$ & 0.0000 & $0.000 \mathrm{E}+00$ & 0.0000 \\
\hline 240 & $4.111 \mathrm{E}-24$ & 0.0000 & $0.000 \mathrm{E}+00$ & 0.0000 & $0.000 \mathrm{E}+00$ & 0.0000 & $0.000 \mathrm{E}+00$ & 0.0000 & $0.000 \mathrm{E}+00$ & 0.0000 & $0.000 \mathrm{E}+00$ & 0.0000 & $0.000 \mathrm{E}+00$ & 0.0000 \\
\hline & $2.925 \mathrm{E}-25$ & 0.0000 & $0.000 \mathrm{E}+00$ & 0.0000 & $0.000 \mathrm{E}+00$ & 0.0000 & $0.000 \mathrm{E}+00$ & 0.0000 & $0.000 \mathrm{E}+00$ & 0.0000 & $0.000 \mathrm{E}+00$ & 0.0000 & $0.000 \mathrm{E}+00$ & 0.0000 \\
\hline 228 & $3.723 \mathrm{E}-07$ & 0.9206 & $0.000 \mathrm{E}+00$ & 0.0000 & $0.000 \mathrm{E}+00$ & 0.0000 & $0.000 \mathrm{E}+00$ & 0.0000 & $0.000 \mathrm{E}+00$ & 0.0000 & $0.000 \mathrm{E}+00$ & 0.0000 & $0.000 \mathrm{E}+00$ & 0.0000 \\
\hline 230 & $1.095 \mathrm{E}-09$ & 0.0027 & $0.000 \mathrm{E}+00$ & 0.0000 & $0.000 \mathrm{E}+00$ & 0.0000 & $0.000 \mathrm{E}+00$ & 0.0000 & $0.000 \mathrm{E}+00$ & 0.0000 & $0.000 \mathrm{E}+00$ & 0.0000 & $0.000 \mathrm{E}+00$ & 0.0000 \\
\hline 232 & $2.653 E-08$ & 0.0656 & $0.000 \mathrm{E}+00$ & 0.0000 & $0.000 \mathrm{E}+00$ & 0.0000 & $0.000 \mathrm{E}+00$ & 0.0000 & $0.000 \mathrm{E}+00$ & 0.0000 & $0.000 \mathrm{E}+00$ & 0.0000 & $0.000 \mathrm{E}+00$ & 0.0000 \\
\hline & $1.227 \mathrm{E}-14$ & 0.0000 & $0.000 \mathrm{E}+00$ & 0.0000 & $0.000 \mathrm{E}+00$ & 0.0000 & $0.000 \mathrm{E}+00$ & 0.0000 & $0.000 \mathrm{E}+00$ & 0.0000 & $0.000 \mathrm{E}+00$ & 0.0000 & $0.000 \mathrm{E}+00$ & 0.0000 \\
\hline & $7.913 \mathrm{E}-15$ & 0.0000 & $0.000 \mathrm{E}+00$ & 0.0000 & $0.000 \mathrm{E}+00$ & 0.0000 & $0.000 \mathrm{E}+00$ & 0.0000 & $0.000 \mathrm{E}+00$ & 0.0000 & $0.000 \mathrm{E}+00$ & 0.0000 & $0.000 \mathrm{E}+00$ & 0.0000 \\
\hline & $4.044 \mathrm{E}-07$ & 1.0000 & $0.000 \mathrm{E}+00$ & 0.0000 & $0.000 \mathrm{E}+00$ & 0.0000 & $0.000 \mathrm{E}+00$ & 0.0000 & $0.000 \mathrm{E}+00$ & 0.0000 & $0.000 \mathrm{E}+00$ & 0.0000 & $E+00$ & 0 \\
\hline
\end{tabular}

Total Dose Contributions TDOSE(i,p,t) for Individual Radionuclides (i) and Pathways (p) As mrem/yr and Fraction of Total Dose At $t=1.000 \mathrm{E}+00$ years

Water Dependent Pathways

\begin{tabular}{|c|c|c|c|c|c|c|c|c|c|c|c|c|c|c|}
\hline \multirow[b]{2}{*}{ clide } & \multicolumn{2}{|c|}{ Water } & \multicolumn{2}{|c|}{ Fish } & \multicolumn{2}{|c|}{ Radon } & \multicolumn{2}{|c|}{ Plant } & \multicolumn{2}{|c|}{ Meat } & \multicolumn{2}{|c|}{ Milk } & \multicolumn{2}{|c|}{ All Pathways* } \\
\hline & $\mathrm{mrem} / \mathrm{yr}$ & fract. & $\mathrm{mrem} / \mathrm{yr}$ & fract. & $\mathrm{mrem} / \mathrm{yr}$ & fract. & $\mathrm{rem} / \mathrm{yr}$ & fract. & $\mathrm{rem} / \mathrm{yr}$ & fract. & $\mathrm{rem} / \mathrm{yr}$ & fra & nrem/yr & fract \\
\hline 81 & $0.000 \mathrm{E}+00$ & 0.0000 & $0.000 \mathrm{E}+00$ & 0.0000 & $0.000 \mathrm{E}+00$ & 0.0000 & $0.000 \mathrm{E}+00$ & 0.0000 & $0.000 \mathrm{E}+00$ & 0.0000 & $0.000 \mathrm{E}+00$ & 0.0000 & $1.575 \mathrm{E}-18$ & 0.0000 \\
\hline & $0.000 \mathrm{E}+00$ & 0.0000 & $0.000 \mathrm{E}+00$ & 0.0000 & $0.000 \mathrm{E}+00$ & 0.0000 & $0.000 \mathrm{E}+00$ & 0.0000 & $0.000 \mathrm{E}+00$ & 0.0000 & $0.000 \mathrm{E}+00$ & 0.0000 & $2.272 \mathrm{E}-09$ & 0.0056 \\
\hline & $0.000 \mathrm{E}+00$ & 0.0000 & $0.000 \mathrm{E}+00$ & 0.0000 & $0.000 \mathrm{E}+00$ & 0.0000 & $0.000 \mathrm{E}+00$ & 0.0000 & $0.000 \mathrm{E}+00$ & 0.0000 & $0.000 \mathrm{E}+00$ & 0.0000 & $5.097 \mathrm{E}-13$ & 0.0000 \\
\hline 238 & $0.000 \mathrm{E}+00$ & 0.0000 & $0.000 \mathrm{E}+00$ & 0.0000 & $0.000 \mathrm{E}+00$ & 0.0000 & $0.000 \mathrm{E}+00$ & 0.0000 & $0.000 \mathrm{E}+00$ & 0.0000 & $0.000 \mathrm{E}+00$ & 0.0000 & $4.535 \mathrm{E}-21$ & 0.0000 \\
\hline 239 & $0.000 \mathrm{E}+00$ & 0 & $0.000 \mathrm{E}+00$ & & & 0 & $0.000 \mathrm{E}+00$ & 0 & & 0 & $0.000 \mathrm{E}+00$ & & 17 & 000 \\
\hline & $0.000 \mathrm{E}+00$ & 0.0000 & $0.000 \mathrm{E}+00$ & 0.00 & $0.000 \mathrm{E}+00$ & 0.0 & $0.000 \mathrm{E}+00$ & 0 & $0.000 \mathrm{E}+00$ & 0 & $0.000 \mathrm{E}+00$ & 0 & $4.111 \mathrm{E}-24$ & 0.0000 \\
\hline & $0.000 \mathrm{E}+00$ & 0.0 & $0.000 \mathrm{E}+00$ & 0.00 & $0.000 \mathrm{E}+00$ & 0.0 & $0.000 \mathrm{E}+00$ & 0.0 & $0.000 \mathrm{E}+00$ & 0.0 & $0.000 \mathrm{E}+00$ & 0 & $25 E-25$ & 0000 \\
\hline 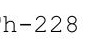 & $0.000 \mathrm{E}+00$ & 0.0000 & $0.000 \mathrm{E}+00$ & 0.0000 & $0.000 \mathrm{E}+00$ & 0.0000 & $0.000 \mathrm{E}+00$ & 0.0000 & $0.000 \mathrm{E}+00$ & 0.0000 & $0.000 \mathrm{E}+00$ & 0.0000 & $3.723 \mathrm{E}-07$ & 0.920 \\
\hline & $0.000 \mathrm{E}+00$ & 0.0000 & $0.000 \mathrm{E}+00$ & 0.0000 & $0.000 \mathrm{E}+00$ & 0.0000 & $0.000 \mathrm{E}+00$ & 0.0000 & $0.000 \mathrm{E}+00$ & 0.0000 & $0.000 \mathrm{E}+00$ & 0.0000 & $1.095 \mathrm{E}-09$ & 0.0027 \\
\hline & $0.000 \mathrm{E}+00$ & 0.0000 & $0.000 \mathrm{E}+00$ & 0.0000 & $0.000 \mathrm{E}+00$ & 0.0000 & $0.000 \mathrm{E}+00$ & 0.0000 & $0.000 \mathrm{E}+00$ & 0.0000 & $0.000 \mathrm{E}+00$ & 0.0000 & $2.653 \mathrm{E}-08$ & 0.0656 \\
\hline & $0.000 \mathrm{E}+00$ & 0.0000 & $0.000 \mathrm{E}+00$ & 0.0000 & $0.000 \mathrm{E}+00$ & 0.0000 & $0.000 \mathrm{E}+00$ & 0.0000 & $0.000 \mathrm{E}+00$ & 0.0000 & $0.000 \mathrm{E}+00$ & 0.0000 & $1.227 \mathrm{E}-14$ & 0.0000 \\
\hline & $0.000 \mathrm{E}+00$ & 0.0000 & $0.000 \mathrm{E}+00$ & 0.0000 & $0.000 \mathrm{E}+00$ & 0.0000 & $0.000 \mathrm{E}+00$ & 0.0000 & $0.000 \mathrm{E}+00$ & 0.0000 & $0.000 \mathrm{E}+00$ & 0.0000 & $7.913 \mathrm{E}-15$ & 0.0000 \\
\hline & $0.000 \mathrm{E}+00$ & 0.0000 & $0.000 \mathrm{E}+00$ & 0.0000 & $0.000 \mathrm{E}+00$ & 0.0000 & $0.000 \mathrm{E}+00$ & 0.0000 & $0.000 \mathrm{E}+00$ & 0.0000 & $0.000 \mathrm{E}+00$ & 0.0000 & $2.202 \mathrm{E}-09$ & 0.0054 \\
\hline & 0 & 000 & $.000 \mathrm{E}+00$ & 0.0000 & $.000 \mathrm{E}+00$ & 0.0000 & $.000 \mathrm{E}+00$ & 0.0 & +00 & c & $z+00$ & & -07 & \\
\hline
\end{tabular}

*Sum of all water independent and dependent pathways. 
RESRAD, Version $6.5 \quad \mathrm{~T}^{1 / 2}$ Limit $=180$ days

mmary : C746U Recreational User Deterministic Run

File : $\mathrm{X}: \backslash F$ INAL V2 \DOE FWD RUNS \C746U RU DOE SG FWD-FV2-100000YR.RAD

Total Dose Contributions TDOSE (i,p,t) for Individual Radionuclides (i) and Pathways (p) As mrem/yr and Fraction of Total Dose At $t=5.000 \mathrm{E}+01$ years

Water Independent Pathways (Inhalation excludes radon)

\begin{tabular}{|c|c|c|c|c|c|c|c|c|c|c|c|c|c|c|}
\hline \multirow[b]{2}{*}{ uclide } & \multicolumn{2}{|c|}{ Ground } & \multicolumn{2}{|c|}{ Inhalation } & \multicolumn{2}{|c|}{ Radon } & \multicolumn{2}{|c|}{ Plant } & \multicolumn{2}{|c|}{ Meat } & \multicolumn{2}{|c|}{ Milk } & \multicolumn{2}{|c|}{ Soil } \\
\hline & mrem/yr & fract. & mrem/yr & fract. & mrem/yr & fract. & mrem/yr & fract. & mrem/yr & fract. & mrem/yr & fract. & mrem/yr & fract. \\
\hline 241 & $8.641 E-17$ & 0.0000 & $0.000 \mathrm{E}+00$ & 0.0000 & $0.000 \mathrm{E}+00$ & 0.0000 & $0.000 \mathrm{E}+00$ & 0.0000 & $0.000 \mathrm{E}+00$ & 0.0000 & $0.000 \mathrm{E}+00$ & 0.0000 & $0.000 \mathrm{E}+00$ & 0.0000 \\
\hline 137 & $1.106 \mathrm{E}-09$ & 0.0012 & $0.000 \mathrm{E}+00$ & 0.0000 & $0.000 \mathrm{E}+00$ & 0.0000 & $0.000 \mathrm{E}+00$ & 0.0000 & $0.000 \mathrm{E}+00$ & 0.0000 & $0.000 \mathrm{E}+00$ & 0.0000 & $0.000 \mathrm{E}+00$ & 0.0000 \\
\hline 237 & $8.637 \mathrm{E}-13$ & 0.0000 & $0.000 \mathrm{E}+00$ & 0.0000 & $0.000 \mathrm{E}+00$ & 0.0000 & $0.000 \mathrm{E}+00$ & 0.0000 & $0.000 \mathrm{E}+00$ & 0.0000 & $0.000 \mathrm{E}+00$ & 0.0000 & $0.000 \mathrm{E}+00$ & 0.0000 \\
\hline 238 & $1.975 \mathrm{E}-16$ & 0.0000 & $0.000 \mathrm{E}+00$ & 0.0000 & $0.000 \mathrm{E}+00$ & 0.0000 & $0.000 \mathrm{E}+00$ & 0.0000 & $0.000 \mathrm{E}+00$ & 0.0000 & $0.000 \mathrm{E}+00$ & 0.0000 & $0.000 \mathrm{E}+00$ & 0.0000 \\
\hline 240 & $9.285 E-21$ & 0.0000 & $0.000 \mathrm{E}+00$ & 0.0000 & $0.000 \mathrm{E}+00$ & 0.0000 & $0.000 \mathrm{E}+00$ & 0.0000 & $0.000 \mathrm{E}+00$ & 0.0000 & $0.000 \mathrm{E}+00$ & 0.0000 & $0.000 \mathrm{E}+00$ & 0.0000 \\
\hline & $5.785 E-25$ & 0.0000 & $0.000 \mathrm{E}+00$ & 0.0000 & $0.000 \mathrm{E}+00$ & 0.0000 & $0.000 \mathrm{E}+00$ & 0.0000 & $0.000 \mathrm{E}+00$ & 0.0000 & $0.000 \mathrm{E}+00$ & 0.0000 & $0.000 \mathrm{E}+00$ & 0.0000 \\
\hline 228 & $9.718 \mathrm{E}-15$ & 0.0000 & $0.000 \mathrm{E}+00$ & 0.0000 & $0.000 \mathrm{E}+00$ & 0.0000 & $0.000 \mathrm{E}+00$ & 0.0000 & $0.000 \mathrm{E}+00$ & 0.0000 & $0.000 \mathrm{E}+00$ & 0.0000 & $0.000 \mathrm{E}+00$ & 0.0000 \\
\hline 30 & $5.116 \mathrm{E}-08$ & 0.0558 & $0.000 \mathrm{E}+00$ & 0.0000 & $0.000 \mathrm{E}+00$ & 0.0000 & $0.000 \mathrm{E}+00$ & 0.0000 & $0.000 \mathrm{E}+00$ & 0.0000 & $0.000 \mathrm{E}+00$ & 0.0000 & $0.000 \mathrm{E}+00$ & 0.0000 \\
\hline 232 & $8.620 \mathrm{E}-07$ & 0.9395 & $0.000 \mathrm{E}+00$ & 0.0000 & $0.000 \mathrm{E}+00$ & 0.0000 & $0.000 \mathrm{E}+00$ & 0.0000 & $0.000 \mathrm{E}+00$ & 0.0000 & $0.000 \mathrm{E}+00$ & 0.0000 & $0.000 \mathrm{E}+00$ & 0.0000 \\
\hline & $1.867 \mathrm{E}-11$ & 0.0000 & $0.000 \mathrm{E}+00$ & 0.0000 & $0.000 \mathrm{E}+00$ & 0.0000 & $0.000 \mathrm{E}+00$ & 0.0000 & $0.000 \mathrm{E}+00$ & 0.0000 & $0.000 \mathrm{E}+00$ & 0.0000 & $0.000 \mathrm{E}+00$ & 0.0000 \\
\hline & $5.776 \mathrm{E}-14$ & 0.0000 & $0.000 \mathrm{E}+00$ & 0.0000 & $0.000 \mathrm{E}+00$ & 0.0000 & $0.000 \mathrm{E}+00$ & 0.0000 & $0.000 \mathrm{E}+00$ & 0.0000 & $0.000 \mathrm{E}+00$ & 0.0000 & $0.000 \mathrm{E}+00$ & 0.0000 \\
\hline & $9.175 \mathrm{E}-07$ & 1.0000 & $0.000 \mathrm{E}+00$ & 0.0000 & $0.000 \mathrm{E}+00$ & 0.0000 & $0.000 \mathrm{E}+00$ & 0.0000 & $0.000 \mathrm{E}+00$ & 0.0000 & $0.000 \mathrm{E}+00$ & 0.0000 & $0.000 \mathrm{E}+00$ & 0.0000 \\
\hline
\end{tabular}

Total Dose Contributions TDOSE(i,p,t) for Individual Radionuclides (i) and Pathways (p) As mrem/yr and Fraction of Total Dose At $t=5.000 \mathrm{E}+01$ years

Water Dependent Pathways

\begin{tabular}{|c|c|c|c|c|c|c|c|c|c|c|c|c|c|c|}
\hline \multirow[b]{2}{*}{ clide } & \multicolumn{2}{|c|}{ Water } & \multicolumn{2}{|c|}{ Fish } & \multicolumn{2}{|c|}{ Radon } & \multicolumn{2}{|c|}{ Plant } & \multicolumn{2}{|c|}{ Meat } & \multicolumn{2}{|c|}{ Milk } & \multicolumn{2}{|c|}{ All Pathways* } \\
\hline & mrem/yr & fract. & mrem/yr & fract. & mrem/yr & fract. & mrem/yr & fract. & $n r e m / y r$ & fract. & nrem/yr & fract. & $\mathrm{mrem} / \mathrm{yr}$ & fract. \\
\hline 11 & $0.000 \mathrm{E}+00$ & 0.0000 & $0.000 \mathrm{E}+00$ & 0.0000 & $0.000 \mathrm{E}+00$ & 0.0000 & $0.000 \mathrm{E}+00$ & 0.0000 & $0.000 \mathrm{E}+00$ & 0.0000 & $0.000 \mathrm{E}+00$ & 0.0000 & $8.641 \mathrm{E}-17$ & 0.0000 \\
\hline & $0.000 \mathrm{E}+00$ & 0.0000 & $0.000 \mathrm{E}+00$ & 0.0000 & $0.000 \mathrm{E}+00$ & 0.0000 & $0.000 \mathrm{E}+00$ & 0.0000 & $0.000 \mathrm{E}+00$ & 0.0000 & $0.000 \mathrm{E}+00$ & 0.0000 & $1.106 \mathrm{E}-09$ & 0.0012 \\
\hline & $0.000 \mathrm{E}+00$ & 0.0000 & $0.000 \mathrm{E}+00$ & 0.0000 & $0.000 \mathrm{E}+00$ & 0.0000 & $0.000 \mathrm{E}+00$ & 0.0000 & $0.000 \mathrm{E}+00$ & 0.0000 & $0.000 \mathrm{E}+00$ & 0.0000 & $8.637 E-13$ & 0.0000 \\
\hline 238 & $0.000 \mathrm{E}+00$ & 0.0000 & $0.000 \mathrm{E}+00$ & 0.0000 & $0.000 \mathrm{E}+00$ & 0.0000 & $0.000 \mathrm{E}+00$ & 0.0000 & $0.000 \mathrm{E}+00$ & 0.0000 & $0.000 \mathrm{E}+00$ & 0.0000 & $1.975 \mathrm{E}-16$ & 0.0000 \\
\hline 239 & $0.000 \mathrm{E}+00$ & 0 & $0.000 \mathrm{E}+00$ & & & & $0.000 \mathrm{E}+00$ & 0 & & 0 & $0.000 \mathrm{E}+00$ & & 17 & 000 \\
\hline & $0.000 \mathrm{E}+00$ & 0.00 & $0.000 \mathrm{E}+00$ & 0.0 & $0.000 \mathrm{E}+00$ & 0 & $0.000 \mathrm{E}+00$ & 0 & $0.000 \mathrm{E}+00$ & 0 & $0.000 \mathrm{E}+00$ & 0 & $9.285 \mathrm{E}-21$ & 0.0000 \\
\hline & $0.000 \mathrm{E}+00$ & 0.0000 & $0.000 \mathrm{E}+00$ & 0.0000 & $0.000 \mathrm{E}+00$ & 0.00 & $0.000 \mathrm{E}+00$ & 0.00 & $0.000 \mathrm{E}+00$ & 0.0 & $0.000 \mathrm{E}+00$ & 0.0 & $5 E-25$ & 0.0000 \\
\hline 0 & $0.000 \mathrm{E}+00$ & 0.0000 & $0.000 \mathrm{E}+00$ & 0.0000 & $0.000 \mathrm{E}+00$ & 0.0000 & $0.000 \mathrm{E}+00$ & 0.0000 & $0.000 \mathrm{E}+00$ & 0.0000 & $0.000 \mathrm{E}+00$ & 0.0000 & $9.718 \mathrm{E}-15$ & 0.0000 \\
\hline & $0.000 \mathrm{E}+00$ & 0.0000 & $0.000 \mathrm{E}+00$ & 0.0000 & $0.000 \mathrm{E}+00$ & 0.0000 & $0.000 \mathrm{E}+00$ & 0.0000 & $0.000 \mathrm{E}+00$ & 0.0000 & $0.000 \mathrm{E}+00$ & 0.0000 & $5.116 \mathrm{E}-08$ & 0.0558 \\
\hline & $0.000 \mathrm{E}+00$ & 0.0000 & $0.000 \mathrm{E}+00$ & 0.0000 & $0.000 \mathrm{E}+00$ & 0.0000 & $0.000 \mathrm{E}+00$ & 0.0000 & $0.000 \mathrm{E}+00$ & 0.0000 & $0.000 \mathrm{E}+00$ & 0.0000 & $8.620 \mathrm{E}-07$ & 0.9395 \\
\hline & $0.000 \mathrm{E}+00$ & 0.0000 & $0.000 \mathrm{E}+00$ & 0.0000 & $0.000 \mathrm{E}+00$ & 0.0000 & $0.000 \mathrm{E}+00$ & 0.0000 & $0.000 \mathrm{E}+00$ & 0.0000 & $0.000 \mathrm{E}+00$ & 0.0000 & $1.867 \mathrm{E}-11$ & 0.0000 \\
\hline & $0.000 \mathrm{E}+00$ & 0.0000 & $0.000 \mathrm{E}+00$ & 0.0000 & $0.000 \mathrm{E}+00$ & 0.0000 & $0.000 \mathrm{E}+00$ & 0.0000 & $0.000 \mathrm{E}+00$ & 0.0000 & $0.000 \mathrm{E}+00$ & 0.0000 & $5.776 \mathrm{E}-14$ & 0.0000 \\
\hline & $0.000 \mathrm{E}+00$ & 0.0000 & $0.000 \mathrm{E}+00$ & 0.0000 & $0.000 \mathrm{E}+00$ & 0.0000 & $0.000 \mathrm{E}+00$ & 0.0000 & $0.000 \mathrm{E}+00$ & 0.0000 & $0.000 \mathrm{E}+00$ & 0.0000 & $3.257 \mathrm{E}-09$ & 0.0035 \\
\hline & 0 & 000 & $.000 \mathrm{E}+00$ & 0.0000 & $.000 \mathrm{E}+00$ & 0.0000 & $.000 \mathrm{E}+00$ & 0 & +00 & 0 & +00 & & -07 & \\
\hline
\end{tabular}

*Sum of all water independent and dependent pathways. 
RESRAD, Version $6.5 \quad \mathrm{~T}^{1 / 2}$ Limit $=180$ days

umary : C746U Recreational User Deterministic Run

File : $X: \backslash F I N A L$ V2 \DOE FWD RUNS \C746U RU DOE SG FWD-FV2-100000YR.RAD

Total Dose Contributions TDOSE (i,p,t) for Individual Radionuclides (i) and Pathways (p) As mrem/yr and Fraction of Total Dose At $t=1.000 \mathrm{E}+02$ years

Water Independent Pathways (Inhalation excludes radon)

\begin{tabular}{|c|c|c|c|c|c|c|c|c|c|c|c|c|c|c|}
\hline \multirow[b]{2}{*}{ clide } & \multicolumn{2}{|c|}{ Ground } & \multicolumn{2}{|c|}{ Inhalation } & \multicolumn{2}{|c|}{ Radon } & \multicolumn{2}{|c|}{ Plant } & \multicolumn{2}{|c|}{ Meat } & \multicolumn{2}{|c|}{ Milk } & \multicolumn{2}{|c|}{ Soil } \\
\hline & mrem/yr & fract. & mrem/yr & fract. & mrem/yr & fract. & mrem/yr & fract. & mrem/yr & fract. & mrem/yr & fract. & mrem/yr & fract. \\
\hline-241 & $2.836 \mathrm{E}-16$ & 0.0000 & $0.000 \mathrm{E}+00$ & 0.0000 & $0.000 \mathrm{E}+00$ & 0.0000 & $0.000 \mathrm{E}+00$ & 0.0000 & $0.000 \mathrm{E}+00$ & 0.0000 & $0.000 \mathrm{E}+00$ & 0.0000 & $0.000 \mathrm{E}+00$ & 0.0000 \\
\hline 137 & $5.307 \mathrm{E}-10$ & 0.0004 & $0.000 \mathrm{E}+00$ & 0.0000 & $0.000 \mathrm{E}+00$ & 0.0000 & $0.000 \mathrm{E}+00$ & 0.0000 & $0.000 \mathrm{E}+00$ & 0.0000 & $0.000 \mathrm{E}+00$ & 0.0000 & $0.000 \mathrm{E}+00$ & 0.0000 \\
\hline-237 & $1.483 \mathrm{E}-12$ & 0.0000 & $0.000 \mathrm{E}+00$ & 0.0000 & $0.000 \mathrm{E}+00$ & 0.0000 & $0.000 \mathrm{E}+00$ & 0.0000 & $0.000 \mathrm{E}+00$ & 0.0000 & $0.000 \mathrm{E}+00$ & 0.0000 & $0.000 \mathrm{E}+00$ & 0.0000 \\
\hline 238 & $1.997 \mathrm{E}-15$ & 0.0000 & $0.000 \mathrm{E}+00$ & 0.0000 & $0.000 \mathrm{E}+00$ & 0.0000 & $0.000 \mathrm{E}+00$ & 0.0000 & $0.000 \mathrm{E}+00$ & 0.0000 & $0.000 \mathrm{E}+00$ & 0.0000 & $0.000 \mathrm{E}+00$ & 0.0000 \\
\hline 240 & $6.177 \mathrm{E}-20$ & 0.0000 & $0.000 \mathrm{E}+00$ & 0.0000 & $0.000 \mathrm{E}+00$ & 0.0000 & $0.000 \mathrm{E}+00$ & 0.0000 & $0.000 \mathrm{E}+00$ & 0.0000 & $0.000 \mathrm{E}+00$ & 0.0000 & $0.000 \mathrm{E}+00$ & 0.0000 \\
\hline & $1.160 \mathrm{E}-24$ & 0.0000 & $0.000 \mathrm{E}+00$ & 0.0000 & $0.000 \mathrm{E}+00$ & 0.0000 & $0.000 \mathrm{E}+00$ & 0.0000 & $0.000 \mathrm{E}+00$ & 0.0000 & $0.000 \mathrm{E}+00$ & 0.0000 & $0.000 \mathrm{E}+00$ & 0.0000 \\
\hline 228 & $1.776 \mathrm{E}-22$ & 0.0000 & $0.000 \mathrm{E}+00$ & 0.0000 & $0.000 \mathrm{E}+00$ & 0.0000 & $0.000 \mathrm{E}+00$ & 0.0000 & $0.000 \mathrm{E}+00$ & 0.0000 & $0.000 \mathrm{E}+00$ & 0.0000 & $0.000 \mathrm{E}+00$ & 0.0000 \\
\hline 230 & $1.423 \mathrm{E}-07$ & 0.1082 & $0.000 \mathrm{E}+00$ & 0.0000 & $0.000 \mathrm{E}+00$ & 0.0000 & $0.000 \mathrm{E}+00$ & 0.0000 & $0.000 \mathrm{E}+00$ & 0.0000 & $0.000 \mathrm{E}+00$ & 0.0000 & $0.000 \mathrm{E}+00$ & 0.0000 \\
\hline 32 & $1.167 \mathrm{E}-06$ & 0.8876 & $0.000 \mathrm{E}+00$ & 0.0000 & $0.000 \mathrm{E}+00$ & 0.0000 & $0.000 \mathrm{E}+00$ & 0.0000 & $0.000 \mathrm{E}+00$ & 0.0000 & $0.000 \mathrm{E}+00$ & 0.0000 & $0.000 \mathrm{E}+00$ & 0.0000 \\
\hline & $1.037 \mathrm{E}-10$ & 0.0001 & $0.000 \mathrm{E}+00$ & 0.0000 & $0.000 \mathrm{E}+00$ & 0.0000 & $0.000 \mathrm{E}+00$ & 0.0000 & $0.000 \mathrm{E}+00$ & 0.0000 & $0.000 \mathrm{E}+00$ & 0.0000 & $0.000 \mathrm{E}+00$ & 0.0000 \\
\hline & $2.119 \mathrm{E}-13$ & 0.0000 & $0.000 \mathrm{E}+00$ & 0.0000 & $0.000 \mathrm{E}+00$ & 0.0000 & $0.000 \mathrm{E}+00$ & 0.0000 & $0.000 \mathrm{E}+00$ & 0.0000 & $0.000 \mathrm{E}+00$ & 0.0000 & $0.000 \mathrm{E}+00$ & 0.0000 \\
\hline & $1.314 \mathrm{E}-00$ & 1.0000 & $0.000 \mathrm{E}+00$ & 0.0000 & $0.000 \mathrm{E}+00$ & 0.0000 & $0.000 E+00$ & 0.0000 & $0.000 \mathrm{E}+00$ & 0.0000 & $0.000 \mathrm{E}+00$ & 0.0000 & $0.000 \mathrm{E}+00$ & 0.0000 \\
\hline
\end{tabular}

Total Dose Contributions TDOSE(i,p,t) for Individual Radionuclides (i) and Pathways (p) As mrem/yr and Fraction of Total Dose At $t=1.000 \mathrm{E}+02$ years

Water Dependent Pathways

\begin{tabular}{|c|c|c|c|c|c|c|c|c|c|c|c|c|c|c|}
\hline \multirow[b]{2}{*}{ clide } & \multicolumn{2}{|c|}{ Water } & \multicolumn{2}{|c|}{ Fish } & \multicolumn{2}{|c|}{ Radon } & \multicolumn{2}{|c|}{ Plant } & \multicolumn{2}{|c|}{ Meat } & \multicolumn{2}{|c|}{ Milk } & \multicolumn{2}{|c|}{ All Pathways* } \\
\hline & $\mathrm{mrem} / \mathrm{yr}$ & fract. & $\mathrm{mrem} / \mathrm{yr}$ & fract. & $\mathrm{mrem} / \mathrm{yr}$ & fract. & $\mathrm{rem} / \mathrm{yr}$ & fract. & $\mathrm{rem} / \mathrm{yr}$ & fract. & $\mathrm{rem} / \mathrm{yr}$ & fra & nrem/yr & fract. \\
\hline 11 & $0.000 \mathrm{E}+00$ & 0.0000 & $0.000 \mathrm{E}+00$ & 0.0000 & $0.000 \mathrm{E}+00$ & 0.0000 & $0.000 \mathrm{E}+00$ & 0.0000 & $0.000 \mathrm{E}+00$ & 0.0000 & $0.000 \mathrm{E}+00$ & 0.0000 & $2.836 \mathrm{E}-16$ & 0.0000 \\
\hline & $0.000 \mathrm{E}+00$ & 0.0000 & $0.000 \mathrm{E}+00$ & 0.0000 & $0.000 \mathrm{E}+00$ & 0.0000 & $0.000 \mathrm{E}+00$ & 0.0000 & $0.000 \mathrm{E}+00$ & 0.0000 & $0.000 \mathrm{E}+00$ & 0.0000 & $5.307 \mathrm{E}-10$ & 0.0004 \\
\hline & $0.000 \mathrm{E}+00$ & 0.0000 & $0.000 \mathrm{E}+00$ & 0.0000 & $0.000 \mathrm{E}+00$ & 0.0000 & $0.000 \mathrm{E}+00$ & 0.0000 & $0.000 \mathrm{E}+00$ & 0.0000 & $0.000 \mathrm{E}+00$ & 0.0000 & $1.483 \mathrm{E}-12$ & 0.0000 \\
\hline 238 & $0.000 \mathrm{E}+00$ & 0.0000 & $0.000 \mathrm{E}+00$ & 0.0000 & $0.000 \mathrm{E}+00$ & 0.0000 & $0.000 \mathrm{E}+00$ & 0.0000 & $0.000 \mathrm{E}+00$ & 0.0000 & $0.000 \mathrm{E}+00$ & 0.0000 & $1.997 \mathrm{E}-15$ & 0.0000 \\
\hline 239 & $0.000 \mathrm{E}+00$ & 0 & $0.000 \mathrm{E}+00$ & & & 0 & $0.000 \mathrm{E}+00$ & 0 & & 0 & $0.000 \mathrm{E}+00$ & & 16 & 000 \\
\hline & $0.000 \mathrm{E}+00$ & 0.00 & $0.000 \mathrm{E}+00$ & 0.00 & $0.000 \mathrm{E}+00$ & 0 & $0.000 \mathrm{E}+00$ & 0 & $0.000 \mathrm{E}+00$ & 0 & $0.000 \mathrm{E}+00$ & 0 & $6.177 \mathrm{E}-20$ & 0.0000 \\
\hline & $0.000 \mathrm{E}+00$ & 0.0000 & $0.000 \mathrm{E}+00$ & 0.00 & $0.000 \mathrm{E}+00$ & 0.0 & $0.000 \mathrm{E}+00$ & 0.0 & $0.000 \mathrm{E}+00$ & 0.0 & $0.000 \mathrm{E}+00$ & 0.0 & $1.160 \mathrm{E}-24$ & 0000 \\
\hline 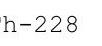 & $0.000 \mathrm{E}+00$ & 0.0000 & $0.000 \mathrm{E}+00$ & 0.0000 & $0.000 \mathrm{E}+00$ & 0.0000 & $0.000 \mathrm{E}+00$ & 0.0000 & $0.000 \mathrm{E}+00$ & 0.0000 & $0.000 \mathrm{E}+00$ & 0.0000 & $1.776 \mathrm{E}-22$ & 0.0000 \\
\hline & $0.000 \mathrm{E}+00$ & 0.0000 & $0.000 \mathrm{E}+00$ & 0.0000 & $0.000 \mathrm{E}+00$ & 0.0000 & $0.000 \mathrm{E}+00$ & 0.0000 & $0.000 \mathrm{E}+00$ & 0.0000 & $0.000 \mathrm{E}+00$ & 0.0000 & $1.423 \mathrm{E}-07$ & 0.1082 \\
\hline & $0.000 \mathrm{E}+00$ & 0.0000 & $0.000 \mathrm{E}+00$ & 0.0000 & $0.000 \mathrm{E}+00$ & 0.0000 & $0.000 \mathrm{E}+00$ & 0.0000 & $0.000 \mathrm{E}+00$ & 0.0000 & $0.000 \mathrm{E}+00$ & 0.0000 & $1.167 \mathrm{E}-06$ & 0.8876 \\
\hline & $0.000 \mathrm{E}+00$ & 0.0000 & $0.000 \mathrm{E}+00$ & 0.0000 & $0.000 \mathrm{E}+00$ & 0.0000 & $0.000 \mathrm{E}+00$ & 0.0000 & $0.000 \mathrm{E}+00$ & 0.0000 & $0.000 \mathrm{E}+00$ & 0.0000 & $1.037 \mathrm{E}-10$ & 0.0001 \\
\hline & $0.000 \mathrm{E}+00$ & 0.0000 & $0.000 \mathrm{E}+00$ & 0.0000 & $0.000 \mathrm{E}+00$ & 0.0000 & $0.000 \mathrm{E}+00$ & 0.0000 & $0.000 \mathrm{E}+00$ & 0.0000 & $0.000 \mathrm{E}+00$ & 0.0000 & $2.119 \mathrm{E}-13$ & 0.0000 \\
\hline & $0.000 \mathrm{E}+00$ & 0.0000 & $0.000 \mathrm{E}+00$ & 0.0000 & $0.000 \mathrm{E}+00$ & 0.0000 & $0.000 \mathrm{E}+00$ & 0.0000 & $0.000 \mathrm{E}+00$ & 0.0000 & $0.000 \mathrm{E}+00$ & 0.0000 & $4.856 \mathrm{E}-09$ & 0.0037 \\
\hline & 0 & 000 & $.000 \mathrm{E}+00$ & 0.0000 & $.000 \mathrm{E}+00$ & 0.0000 & $.000 \mathrm{E}+00$ & 0 & +00 & & +00 & & -06 & \\
\hline
\end{tabular}

*Sum of all water independent and dependent pathways. 
RESRAD, Version $6.5 \quad \mathrm{~T}^{1 / 2}$ Limit $=180$ days

mmary : C746U Recreational User Deterministic Run

File : $\mathrm{X}: \backslash F$ INAL V2 \DOE FWD RUNS \C746U RU DOE SG FWD-FV2-100000YR.RAD

Total Dose Contributions TDOSE (i,p,t) for Individual Radionuclides (i) and Pathways (p) As mrem/yr and Fraction of Total Dose At $t=5.000 \mathrm{E}+02$ years

Water Independent Pathways (Inhalation excludes radon)

\begin{tabular}{|c|c|c|c|c|c|c|c|c|c|c|c|c|c|c|}
\hline \multirow[b]{2}{*}{ uclide } & \multicolumn{2}{|c|}{ Ground } & \multicolumn{2}{|c|}{ Inhalation } & \multicolumn{2}{|c|}{ Radon } & \multicolumn{2}{|c|}{ Plant } & \multicolumn{2}{|c|}{ Meat } & \multicolumn{2}{|c|}{ Milk } & \multicolumn{2}{|c|}{ Soil } \\
\hline & mrem/yr & fract. & mrem/yr & fract. & mrem/yr & fract. & mrem/yr & fract. & mrem/yr & fract. & mrem/yr & fract. & mrem/yr & fract. \\
\hline 241 & $7.849 E-14$ & 0.0000 & $0.000 \mathrm{E}+00$ & 0.0000 & $0.000 \mathrm{E}+00$ & 0.0000 & $0.000 \mathrm{E}+00$ & 0.0000 & $0.000 \mathrm{E}+00$ & 0.0000 & $0.000 \mathrm{E}+00$ & 0.0000 & $0.000 \mathrm{E}+00$ & 0.0000 \\
\hline 137 & $1.491 \mathrm{E}-12$ & 0.0000 & $0.000 \mathrm{E}+00$ & 0.0000 & $0.000 \mathrm{E}+00$ & 0.0000 & $0.000 \mathrm{E}+00$ & 0.0000 & $0.000 \mathrm{E}+00$ & 0.0000 & $0.000 \mathrm{E}+00$ & 0.0000 & $0.000 \mathrm{E}+00$ & 0.0000 \\
\hline 237 & $1.111 \mathrm{E}-10$ & 0.0000 & $0.000 \mathrm{E}+00$ & 0.0000 & $0.000 \mathrm{E}+00$ & 0.0000 & $0.000 \mathrm{E}+00$ & 0.0000 & $0.000 \mathrm{E}+00$ & 0.0000 & $0.000 \mathrm{E}+00$ & 0.0000 & $0.000 \mathrm{E}+00$ & 0.0000 \\
\hline 238 & $2.109 \mathrm{E}-12$ & 0.0000 & $0.000 \mathrm{E}+00$ & 0.0000 & $0.000 \mathrm{E}+00$ & 0.0000 & $0.000 \mathrm{E}+00$ & 0.0000 & $0.000 \mathrm{E}+00$ & 0.0000 & $0.000 \mathrm{E}+00$ & 0.0000 & $0.000 \mathrm{E}+00$ & 0.0000 \\
\hline 240 & $1.985 \mathrm{E}-17$ & 0.0000 & $0.000 \mathrm{E}+00$ & 0.0000 & $0.000 \mathrm{E}+00$ & 0.0000 & $0.000 \mathrm{E}+00$ & 0.0000 & $0.000 \mathrm{E}+00$ & 0.0000 & $0.000 \mathrm{E}+00$ & 0.0000 & $0.000 \mathrm{E}+00$ & 0.0000 \\
\hline & $3.036 \mathrm{E}-22$ & 0.0000 & $0.000 \mathrm{E}+00$ & 0.0000 & $0.000 \mathrm{E}+00$ & 0.0000 & $0.000 \mathrm{E}+00$ & 0.0000 & $0.000 \mathrm{E}+00$ & 0.0000 & $0.000 \mathrm{E}+00$ & 0.0000 & $0.000 \mathrm{E}+00$ & 0.0000 \\
\hline 228 & $0.000 \mathrm{E}+00$ & 0.0000 & $0.000 \mathrm{E}+00$ & 0.0000 & $0.000 \mathrm{E}+00$ & 0.0000 & $0.000 \mathrm{E}+00$ & 0.0000 & $0.000 \mathrm{E}+00$ & 0.0000 & $0.000 \mathrm{E}+00$ & 0.0000 & $0.000 \mathrm{E}+00$ & 0.0000 \\
\hline 30 & $1.032 \mathrm{E}-05$ & 0.4425 & $0.000 \mathrm{E}+00$ & 0.0000 & $0.000 \mathrm{E}+00$ & 0.0000 & $0.000 \mathrm{E}+00$ & 0.0000 & $0.000 \mathrm{E}+00$ & 0.0000 & $0.000 \mathrm{E}+00$ & 0.0000 & $0.000 \mathrm{E}+00$ & 0.0000 \\
\hline 232 & $1.285 \mathrm{E}-05$ & 0.5508 & $0.000 \mathrm{E}+00$ & 0.0000 & $0.000 \mathrm{E}+00$ & 0.0000 & $0.000 \mathrm{E}+00$ & 0.0000 & $0.000 \mathrm{E}+00$ & 0.0000 & $0.000 \mathrm{E}+00$ & 0.0000 & $0.000 \mathrm{E}+00$ & 0.0000 \\
\hline & $3.851 \mathrm{E}-08$ & 0.0017 & $0.000 \mathrm{E}+00$ & 0.0000 & $0.000 \mathrm{E}+00$ & 0.0000 & $0.000 \mathrm{E}+00$ & 0.0000 & $0.000 \mathrm{E}+00$ & 0.0000 & $0.000 \mathrm{E}+00$ & 0.0000 & $0.000 \mathrm{E}+00$ & 0.0000 \\
\hline & $4.414 \mathrm{E}-11$ & 0.0000 & $0.000 \mathrm{E}+00$ & 0.0000 & $0.000 \mathrm{E}+00$ & 0.0000 & $0.000 \mathrm{E}+00$ & 0.0000 & $0.000 \mathrm{E}+00$ & 0.0000 & $0.000 \mathrm{E}+00$ & 0.0000 & $0.000 \mathrm{E}+00$ & 0.0000 \\
\hline & $2.333 \mathrm{E}-05$ & 1.0000 & $0.000 \mathrm{E}+00$ & 0.0000 & $0.000 \mathrm{E}+00$ & 0.0000 & $0.000 \mathrm{E}+00$ & 0.0000 & $0.000 \mathrm{E}+00$ & 0.0000 & $0.000 \mathrm{E}+00$ & 0.0000 & $0.000 \mathrm{E}+00$ & 0.0000 \\
\hline
\end{tabular}

Total Dose Contributions TDOSE(i,p,t) for Individual Radionuclides (i) and Pathways (p) As mrem/yr and Fraction of Total Dose At $t=5.000 \mathrm{E}+02$ years

Water Dependent Pathways

\begin{tabular}{|c|c|c|c|c|c|c|c|c|c|c|c|c|c|c|}
\hline \multirow[b]{2}{*}{ clide } & \multicolumn{2}{|c|}{ Water } & \multicolumn{2}{|c|}{ Fish } & \multicolumn{2}{|c|}{ Radon } & \multicolumn{2}{|c|}{ Plant } & \multicolumn{2}{|c|}{ Meat } & \multicolumn{2}{|c|}{ Milk } & \multicolumn{2}{|c|}{ All Pathways* } \\
\hline & $\mathrm{mrem} / \mathrm{yr}$ & fract. & $\mathrm{mrem} / \mathrm{yr}$ & fract. & $\mathrm{mrem} / \mathrm{yr}$ & fract. & $\mathrm{rem} / \mathrm{yr}$ & fract. & $\mathrm{rem} / \mathrm{yr}$ & fract. & $\mathrm{rem} / \mathrm{yr}$ & fra & nrem/yr & fract. \\
\hline 11 & $0.000 \mathrm{E}+00$ & 0.0000 & $0.000 \mathrm{E}+00$ & 0.0000 & $0.000 \mathrm{E}+00$ & 0.0000 & $0.000 \mathrm{E}+00$ & 0.0000 & $0.000 \mathrm{E}+00$ & 0.0000 & $0.000 \mathrm{E}+00$ & 0.0000 & $7.849 \mathrm{E}-14$ & 0.0000 \\
\hline & $0.000 \mathrm{E}+00$ & 0.0000 & $0.000 \mathrm{E}+00$ & 0.0000 & $0.000 \mathrm{E}+00$ & 0.0000 & $0.000 \mathrm{E}+00$ & 0.0000 & $0.000 \mathrm{E}+00$ & 0.0000 & $0.000 \mathrm{E}+00$ & 0.0000 & $1.491 \mathrm{E}-12$ & 0.0000 \\
\hline & $0.000 \mathrm{E}+00$ & 0.0000 & $0.000 \mathrm{E}+00$ & 0.0000 & $0.000 \mathrm{E}+00$ & 0.0000 & $0.000 \mathrm{E}+00$ & 0.0000 & $0.000 \mathrm{E}+00$ & 0.0000 & $0.000 \mathrm{E}+00$ & 0.0000 & $1.111 \mathrm{E}-10$ & 0.0000 \\
\hline 238 & $0.000 \mathrm{E}+00$ & 0.0000 & $0.000 \mathrm{E}+00$ & 0.0000 & $0.000 \mathrm{E}+00$ & 0.0000 & $0.000 \mathrm{E}+00$ & 0.0000 & $0.000 \mathrm{E}+00$ & 0.0000 & $0.000 \mathrm{E}+00$ & 0.0000 & $2.109 \mathrm{E}-12$ & 0.0000 \\
\hline 239 & $0.000 \mathrm{E}+00$ & 0 & $0.000 \mathrm{E}+00$ & & & 0 & $0.000 \mathrm{E}+00$ & 0 & & 0 & $0.000 \mathrm{E}+00$ & & 14 & 000 \\
\hline & $0.000 \mathrm{E}+00$ & 0.00 & $0.000 \mathrm{E}+00$ & 0.00 & $0.000 \mathrm{E}+00$ & 0 & $0.000 \mathrm{E}+00$ & 0 & $0.000 \mathrm{E}+00$ & 0 & $0.000 \mathrm{E}+00$ & 0 & $1.985 \mathrm{E}-17$ & 0.0000 \\
\hline & $0.000 \mathrm{E}+00$ & 0.0000 & $0.000 \mathrm{E}+00$ & 0.00 & $0.000 \mathrm{E}+00$ & 0.0 & $0.000 \mathrm{E}+00$ & 0.0 & $0.000 \mathrm{E}+00$ & 0.0 & $0.000 \mathrm{E}+00$ & $0 . c$ & $3.036 \mathrm{E}-22$ & 0000 \\
\hline 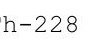 & $0.000 \mathrm{E}+00$ & 0.0000 & $0.000 \mathrm{E}+00$ & 0.0000 & $0.000 \mathrm{E}+00$ & 0.0000 & $0.000 \mathrm{E}+00$ & 0.0000 & $0.000 \mathrm{E}+00$ & 0.0000 & $0.000 \mathrm{E}+00$ & 0.0000 & $0.000 \mathrm{E}+00$ & 0.0000 \\
\hline & $0.000 \mathrm{E}+00$ & 0.0000 & $0.000 \mathrm{E}+00$ & 0.0000 & $0.000 \mathrm{E}+00$ & 0.0000 & $0.000 \mathrm{E}+00$ & 0.0000 & $0.000 \mathrm{E}+00$ & 0.0000 & $0.000 \mathrm{E}+00$ & 0.0000 & $1.032 \mathrm{E}-05$ & 0.4425 \\
\hline & $0.000 \mathrm{E}+00$ & 0.0000 & $0.000 \mathrm{E}+00$ & 0.0000 & $0.000 \mathrm{E}+00$ & 0.0000 & $0.000 \mathrm{E}+00$ & 0.0000 & $0.000 \mathrm{E}+00$ & 0.0000 & $0.000 \mathrm{E}+00$ & 0.0000 & $1.285 \mathrm{E}-05$ & 0.5508 \\
\hline & $0.000 \mathrm{E}+00$ & 0.0000 & $0.000 \mathrm{E}+00$ & 0.0000 & $0.000 \mathrm{E}+00$ & 0.0000 & $0.000 \mathrm{E}+00$ & 0.0000 & $0.000 \mathrm{E}+00$ & 0.0000 & $0.000 \mathrm{E}+00$ & 0.0000 & $3.851 \mathrm{E}-08$ & 0.0017 \\
\hline & $0.000 \mathrm{E}+00$ & 0.0000 & $0.000 \mathrm{E}+00$ & 0.0000 & $0.000 \mathrm{E}+00$ & 0.0000 & $0.000 \mathrm{E}+00$ & 0.0000 & $0.000 \mathrm{E}+00$ & 0.0000 & $0.000 \mathrm{E}+00$ & 0.0000 & $4.414 \mathrm{E}-11$ & 0.0000 \\
\hline & $0.000 \mathrm{E}+00$ & 0.0000 & $0.000 \mathrm{E}+00$ & 0.0000 & $0.000 \mathrm{E}+00$ & 0.0000 & $0.000 \mathrm{E}+00$ & 0.0000 & $0.000 \mathrm{E}+00$ & 0.0000 & $0.000 \mathrm{E}+00$ & 0.0000 & $1.187 \mathrm{E}-07$ & 0.0051 \\
\hline & 0 & 000 & $.000 \mathrm{E}+00$ & 0.0000 & $.000 \mathrm{E}+00$ & 0.0000 & $.000 \mathrm{E}+00$ & 0 & +00 & c & $z+00$ & & -05 & \\
\hline
\end{tabular}

*Sum of all water independent and dependent pathways. 
RESRAD, Version $6.5 \quad \mathrm{~T}^{1 / 2}$ Limit $=180$ days

mmary : C746U Recreational User Deterministic Run

File : $X: \backslash F I N A L$ V2 \DOE FWD RUNS \C746U RU DOE SG FWD-FV2-100000YR.RAD

Total Dose Contributions TDOSE (i,p,t) for Individual Radionuclides (i) and Pathways (p) As mrem/yr and Fraction of Total Dose At $t=1.000 \mathrm{E}+04$ years

Water Independent Pathways (Inhalation excludes radon)

\begin{tabular}{|c|c|c|c|c|c|c|c|c|c|c|c|c|c|c|}
\hline \multirow[b]{2}{*}{ Nuclide } & \multicolumn{2}{|c|}{ Ground } & \multicolumn{2}{|c|}{ Inhalation } & \multicolumn{2}{|c|}{ Radon } & \multicolumn{2}{|c|}{ Plant } & \multicolumn{2}{|c|}{ Meat } & \multicolumn{2}{|c|}{ Milk } & \multicolumn{2}{|c|}{ Soil } \\
\hline & mrem/yr & fract. & mrem/yr & fract. & mrem/yr & fract. & mrem/yr & fract. & mrem/yr & fract. & mrem/yr & fract. & mrem/yr & fract. \\
\hline 241 & $2.772 \mathrm{E}-04$ & 0.0000 & $1.067 \mathrm{E}-07$ & 0.0000 & $0.000 \mathrm{E}+00$ & 0.0000 & $0.000 \mathrm{E}+00$ & 0.0000 & $0.000 \mathrm{E}+00$ & 0.0000 & $0.000 \mathrm{E}+00$ & 0.0000 & $4.985 \mathrm{E}-06$ & 0.0000 \\
\hline 137 & $0.000 \mathrm{E}+00$ & 0.0000 & $0.000 \mathrm{E}+00$ & 0.0000 & $0.000 \mathrm{E}+00$ & 0.0000 & $0.000 \mathrm{E}+00$ & 0.0000 & $0.000 \mathrm{E}+00$ & 0.0000 & $0.000 \mathrm{E}+00$ & 0.0000 & $0.000 \mathrm{E}+00$ & 0.0000 \\
\hline 37 & $2.064 \mathrm{E}-01$ & 0.0022 & $8.027 \mathrm{E}-05$ & 0.0000 & $0.000 \mathrm{E}+00$ & 0.0000 & $0.000 \mathrm{E}+00$ & 0.0000 & $0.000 \mathrm{E}+00$ & 0.0000 & $0.000 \mathrm{E}+00$ & 0.0000 & $3.786 \mathrm{E}-03$ & 0.0000 \\
\hline 238 & $6.968 \mathrm{E}-04$ & 0.0000 & $1.453 \mathrm{E}-07$ & 0.0000 & $0.000 \mathrm{E}+00$ & 0.0000 & $0.000 \mathrm{E}+00$ & 0.0000 & $0.000 \mathrm{E}+00$ & 0.0000 & $0.000 \mathrm{E}+00$ & 0.0000 & $5.738 \mathrm{E}-05$ & 0.0000 \\
\hline 240 & $1.017 \mathrm{E}-04$ & 0.0000 & $7.375 \mathrm{E}-04$ & 0.0000 & $0.000 \mathrm{E}+00$ & 0.0000 & $0.000 \mathrm{E}+00$ & 0.0000 & $0.000 \mathrm{E}+00$ & 0.0000 & $0.000 \mathrm{E}+00$ & 0.0000 & $2.926 \mathrm{E}-02$ & 0.0003 \\
\hline ? & $6.336 \mathrm{E}-27$ & 0.0000 & $0.000 \mathrm{E}+00$ & 0.0000 & $0.000 \mathrm{E}+00$ & 0.0000 & $0.000 \mathrm{E}+00$ & 0.0000 & $0.000 \mathrm{E}+00$ & 0.0000 & $0.000 \mathrm{E}+00$ & 0.0000 & $6.519 \mathrm{E}-27$ & 0.0000 \\
\hline 228 & $0.000 \mathrm{E}+00$ & 0.0000 & $0.000 \mathrm{E}+00$ & 0.0000 & $0.000 \mathrm{E}+00$ & 0.0000 & $0.000 \mathrm{E}+00$ & 0.0000 & $0.000 \mathrm{E}+00$ & 0.0000 & $0.000 \mathrm{E}+00$ & 0.0000 & $0.000 \mathrm{E}+00$ & 0.0000 \\
\hline 230 & $7.343 \mathrm{E}+01$ & 0.7737 & $6.397 \mathrm{E}-03$ & 0.0001 & $0.000 \mathrm{E}+00$ & 0.0000 & $0.000 \mathrm{E}+00$ & 0.0000 & $0.000 \mathrm{E}+00$ & 0.0000 & $0.000 \mathrm{E}+00$ & 0.0000 & $5.000 \mathrm{E}+00$ & 0.0527 \\
\hline 232 & $4.711 \mathrm{E}+00$ & 0.0496 & $4.381 \mathrm{E}-04$ & 0.0000 & $0.000 \mathrm{E}+00$ & 0.0000 & $0.000 \mathrm{E}+00$ & 0.0000 & $0.000 \mathrm{E}+00$ & 0.0000 & $0.000 \mathrm{E}+00$ & 0.0000 & $2.488 \mathrm{E}-01$ & 0.0026 \\
\hline & $8.094 \mathrm{E}+00$ & 0.0853 & $1.671 \mathrm{E}-03$ & 0.0000 & $0.000 \mathrm{E}+00$ & 0.0000 & $0.000 \mathrm{E}+00$ & 0.0000 & $0.000 \mathrm{E}+00$ & 0.0000 & $0.000 \mathrm{E}+00$ & 0.0000 & $6.646 \mathrm{E}-01$ & 0.0070 \\
\hline & $4.875 \mathrm{E}-01$ & 0.0051 & $5.106 \mathrm{E}-04$ & 0.0000 & $0.000 \mathrm{E}+00$ & 0.0000 & $0.000 \mathrm{E}+00$ & 0.0000 & $0.000 \mathrm{E}+00$ & 0.0000 & $0.000 \mathrm{E}+00$ & 0.0000 & $3.267 \mathrm{E}-02$ & 0.0003 \\
\hline & $.873 \mathrm{E}+01$ & 0.9350 & $1.219 \mathrm{E}-02$ & 0.0001 & $0.000 \mathrm{E}+00$ & 0.0000 & $0.000 \mathrm{E}+00$ & 0.0000 & $0.000 \mathrm{E}+00$ & 0.0000 & $0.000 \mathrm{E}+00$ & 0. & $6.160 \mathrm{E}+00$ & 9 \\
\hline
\end{tabular}

Total Dose Contributions TDOSE (i,p,t) for Individual Radionuclides (i) and Pathways (p) As mrem/yr and Fraction of Total Dose At $t=1.000 \mathrm{E}+04$ years

Water Dependent Pathways

\begin{tabular}{|c|c|c|c|c|c|c|c|c|c|c|c|c|c|c|}
\hline \multirow[b]{2}{*}{ clide } & \multicolumn{2}{|c|}{ Water } & \multicolumn{2}{|c|}{ Fish } & \multicolumn{2}{|c|}{ Radon } & \multicolumn{2}{|c|}{ Plant } & \multicolumn{2}{|c|}{ Meat } & \multicolumn{2}{|c|}{ Milk } & \multicolumn{2}{|c|}{ All Pathways* } \\
\hline & $\mathrm{mrem} / \mathrm{yr}$ & fract. & $\mathrm{mrem} / \mathrm{yr}$ & fract. & $\mathrm{mrem} / \mathrm{yr}$ & fract. & $\mathrm{rem} / \mathrm{yr}$ & fract. & $\mathrm{rem} / \mathrm{yr}$ & fract. & $\mathrm{rem} / \mathrm{yr}$ & fra & nrem/yr & fract. \\
\hline 11 & $0.000 \mathrm{E}+00$ & 0.0000 & $0.000 \mathrm{E}+00$ & 0.0000 & $0.000 \mathrm{E}+00$ & 0.0000 & $0.000 \mathrm{E}+00$ & 0.0000 & $0.000 \mathrm{E}+00$ & 0.0000 & $0.000 \mathrm{E}+00$ & 0.0000 & $2.823 \mathrm{E}-04$ & 0.0000 \\
\hline & $0.000 \mathrm{E}+00$ & 0.0000 & $0.000 \mathrm{E}+00$ & 0.0000 & $0.000 \mathrm{E}+00$ & 0.0000 & $0.000 \mathrm{E}+00$ & 0.0000 & $0.000 \mathrm{E}+00$ & 0.0000 & $0.000 \mathrm{E}+00$ & 0.0000 & $0.000 \mathrm{E}+00$ & 0.0000 \\
\hline & $0.000 \mathrm{E}+00$ & 0.0000 & $0.000 \mathrm{E}+00$ & 0.0000 & $0.000 \mathrm{E}+00$ & 0.0000 & $0.000 \mathrm{E}+00$ & 0.0000 & $0.000 \mathrm{E}+00$ & 0.0000 & $0.000 \mathrm{E}+00$ & 0.0000 & $2.103 \mathrm{E}-01$ & 0.0022 \\
\hline 238 & $0.000 \mathrm{E}+00$ & 0.0000 & $0.000 \mathrm{E}+00$ & 0.0000 & $0.000 \mathrm{E}+00$ & 0.0000 & $0.000 \mathrm{E}+00$ & 0.0000 & $0.000 \mathrm{E}+00$ & 0.0000 & $0.000 \mathrm{E}+00$ & 0.0000 & -04 & 0.0000 \\
\hline 239 & $0.000 \mathrm{E}+00$ & 0 & $0.000 \mathrm{E}+00$ & & & & $0.000 \mathrm{E}+00$ & 0 & & 0 & $0.000 \mathrm{E}+00$ & & 02 & 007 \\
\hline & $0.000 \mathrm{E}+00$ & 0.00 & $0.000 \mathrm{E}+00$ & 0.0 & $0.000 \mathrm{E}+00$ & 0 & $0.000 \mathrm{E}+00$ & 0 & $0.000 \mathrm{E}+00$ & 0 & $0.000 \mathrm{E}+00$ & 0 & $3.010 \mathrm{E}-02$ & 0.0003 \\
\hline & $0.000 \mathrm{E}+00$ & 0.0000 & $0.000 \mathrm{E}+00$ & 0.00 & $0.000 \mathrm{E}+00$ & 0.0 & $0.000 \mathrm{E}+00$ & 0.0 & $0.000 \mathrm{E}+00$ & 0.0 & $0.000 \mathrm{E}+00$ & $0 . c$ & $1.285 \mathrm{E}-26$ & 0000 \\
\hline 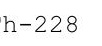 & $0.000 \mathrm{E}+00$ & 0.0000 & $0.000 \mathrm{E}+00$ & 0.0000 & $0.000 \mathrm{E}+00$ & 0.0000 & $0.000 \mathrm{E}+00$ & 0.0000 & $0.000 \mathrm{E}+00$ & 0.0000 & $0.000 \mathrm{E}+00$ & 0.0000 & $0.000 \mathrm{E}+00$ & 0.0000 \\
\hline & $0.000 \mathrm{E}+00$ & 0.0000 & $0.000 \mathrm{E}+00$ & 0.0000 & $0.000 \mathrm{E}+00$ & 0.0000 & $0.000 \mathrm{E}+00$ & 0.0000 & $0.000 \mathrm{E}+00$ & 0.0000 & $0.000 \mathrm{E}+00$ & 0.0000 & $7.843 \mathrm{E}+01$ & 0.8265 \\
\hline & $0.000 \mathrm{E}+00$ & 0.0000 & $0.000 \mathrm{E}+00$ & 0.0000 & $0.000 \mathrm{E}+00$ & 0.0000 & $0.000 \mathrm{E}+00$ & 0.0000 & $0.000 \mathrm{E}+00$ & 0.0000 & $0.000 \mathrm{E}+00$ & 0.0000 & $4.960 \mathrm{E}+00$ & 0.0523 \\
\hline & $0.000 \mathrm{E}+00$ & 0.0000 & $0.000 \mathrm{E}+00$ & 0.0000 & $0.000 \mathrm{E}+00$ & 0.0000 & $0.000 \mathrm{E}+00$ & 0.0000 & $0.000 \mathrm{E}+00$ & 0.0000 & $0.000 \mathrm{E}+00$ & 0.0000 & $8.760 \mathrm{E}+00$ & 0.0923 \\
\hline & $0.000 \mathrm{E}+00$ & 0.0000 & $0.000 \mathrm{E}+00$ & 0.0000 & $0.000 \mathrm{E}+00$ & 0.0000 & $0.000 \mathrm{E}+00$ & 0.0000 & $0.000 \mathrm{E}+00$ & 0.0000 & $0.000 \mathrm{E}+00$ & 0.0000 & $5.207 \mathrm{E}-01$ & 0.0055 \\
\hline & $0.000 \mathrm{E}+00$ & 0.0000 & $0.000 \mathrm{E}+00$ & 0.0000 & $0.000 \mathrm{E}+00$ & 0.0000 & $0.000 \mathrm{E}+00$ & 0.0000 & $0.000 \mathrm{E}+00$ & 0.0000 & $0.000 \mathrm{E}+00$ & 0.0000 & $1.921 \mathrm{E}+00$ & 0.0202 \\
\hline & & 000 & $.000 \mathrm{E}+00$ & 0.0000 & $.000 \mathrm{E}+00$ & 0.0000 & $.000 \mathrm{E}+00$ & 0 & +00 & 0 & $E+00$ & & +01 & \\
\hline
\end{tabular}

*Sum of all water independent and dependent pathways. 
RESRAD, Version $6.5 \quad \mathrm{~T}^{1 / 2}$ Limit $=180$ days

mmary : C746U Recreational User Deterministic Run

File : $X: \backslash F I N A L$ V2 \DOE FWD RUNS \C746U RU DOE SG FWD-FV2-100000YR.RAD

Total Dose Contributions TDOSE (i,p,t) for Individual Radionuclides (i) and Pathways (p) As mrem/yr and Fraction of Total Dose At $t=1.000 \mathrm{E}+05$ years

Water Independent Pathways (Inhalation excludes radon)

\begin{tabular}{|c|c|c|c|c|c|c|c|c|c|c|c|c|c|c|}
\hline \multirow[b]{2}{*}{ uclide } & \multicolumn{2}{|c|}{ Ground } & \multicolumn{2}{|c|}{ Inhalation } & \multicolumn{2}{|c|}{ Radon } & \multicolumn{2}{|c|}{ Plant } & \multicolumn{2}{|c|}{ Meat } & \multicolumn{2}{|c|}{ Milk } & \multicolumn{2}{|c|}{ Soil } \\
\hline & mrem/yr & fract. & mrem/yr & fract. & mrem/yr & fract. & mrem/yr & fract. & $\mathrm{mrem} / \mathrm{yr}$ & fract. & mrem/yr & fract. & $\mathrm{mrem} / \mathrm{yr}$ & fract. \\
\hline 241 & $0.000 \mathrm{E}+00$ & 0.0000 & $0.000 \mathrm{E}+00$ & 0.0000 & $0.000 \mathrm{E}+00$ & 0.0000 & $0.000 \mathrm{E}+00$ & 0.0000 & $0.000 \mathrm{E}+00$ & 0.0000 & $0.000 \mathrm{E}+00$ & 0.0000 & $0.000 \mathrm{E}+00$ & 0.0000 \\
\hline-137 & $0.000 \mathrm{E}+00$ & 0.0000 & $0.000 \mathrm{E}+00$ & 0.0000 & $0.000 \mathrm{E}+00$ & 0.0000 & $0.000 \mathrm{E}+00$ & 0.0000 & $0.000 \mathrm{E}+00$ & 0.0000 & $0.000 \mathrm{E}+00$ & 0.0000 & $0.000 \mathrm{E}+00$ & 0.0000 \\
\hline 237 & $0.000 \mathrm{E}+00$ & 0.0000 & $0.000 \mathrm{E}+00$ & 0.0000 & $0.000 \mathrm{E}+00$ & 0.0000 & $0.000 \mathrm{E}+00$ & 0.0000 & $0.000 \mathrm{E}+00$ & 0.0000 & $0.000 \mathrm{E}+00$ & 0.0000 & $0.000 \mathrm{E}+00$ & 0.0000 \\
\hline 238 & $0.000 \mathrm{E}+00$ & 0.0000 & $0.000 \mathrm{E}+00$ & 0.0000 & $0.000 \mathrm{E}+00$ & 0.0000 & $0.000 \mathrm{E}+00$ & 0.0000 & $0.000 \mathrm{E}+00$ & 0.0000 & $0.000 \mathrm{E}+00$ & 0.0000 & $0.000 \mathrm{E}+00$ & 0.0000 \\
\hline 240 & $0.000 \mathrm{E}+00$ & 0.0000 & $0.000 \mathrm{E}+00$ & 0.0000 & $0.000 \mathrm{E}+00$ & 0.0000 & $0.000 \mathrm{E}+00$ & 0.0000 & $0.000 \mathrm{E}+00$ & 0.0000 & $0.000 \mathrm{E}+00$ & 0.0000 & $0.000 \mathrm{E}+00$ & 0.0000 \\
\hline & $0.000 \mathrm{E}+00$ & 0.0000 & $0.000 \mathrm{E}+00$ & 0.0000 & $0.000 \mathrm{E}+00$ & 0.0000 & $0.000 \mathrm{E}+00$ & 0.0000 & $0.000 \mathrm{E}+00$ & 0.0000 & $0.000 \mathrm{E}+00$ & 0.0000 & $0.000 \mathrm{E}+00$ & 0.0000 \\
\hline 228 & $0.000 \mathrm{E}+00$ & 0.0000 & $0.000 \mathrm{E}+00$ & 0.0000 & $0.000 \mathrm{E}+00$ & 0.0000 & $0.000 \mathrm{E}+00$ & 0.0000 & $0.000 \mathrm{E}+00$ & 0.0000 & $0.000 \mathrm{E}+00$ & 0.0000 & $0.000 \mathrm{E}+00$ & 0.0000 \\
\hline 30 & $0.000 \mathrm{E}+00$ & 0.0000 & $0.000 \mathrm{E}+00$ & 0.0000 & $0.000 \mathrm{E}+00$ & 0.0000 & $0.000 \mathrm{E}+00$ & 0.0000 & $0.000 \mathrm{E}+00$ & 0.0000 & $0.000 \mathrm{E}+00$ & 0.0000 & $0.000 \mathrm{E}+00$ & 0.0000 \\
\hline 232 & $0.000 \mathrm{E}+00$ & 0.0000 & $0.000 \mathrm{E}+00$ & 0.0000 & $0.000 \mathrm{E}+00$ & 0.0000 & $0.000 \mathrm{E}+00$ & 0.0000 & $0.000 \mathrm{E}+00$ & 0.0000 & $0.000 \mathrm{E}+00$ & 0.0000 & $0.000 \mathrm{E}+00$ & 0.0000 \\
\hline & $0.000 \mathrm{E}+00$ & 0.0000 & $0.000 \mathrm{E}+00$ & 0.0000 & $0.000 \mathrm{E}+00$ & 0.0000 & $0.000 \mathrm{E}+00$ & 0.0000 & $0.000 \mathrm{E}+00$ & 0.0000 & $0.000 \mathrm{E}+00$ & 0.0000 & $0.000 \mathrm{E}+00$ & 0.0000 \\
\hline & $0.000 \mathrm{E}+00$ & 0.0000 & $0.000 \mathrm{E}+00$ & 0.0000 & $0.000 \mathrm{E}+00$ & 0.0000 & $0.000 \mathrm{E}+00$ & 0.0000 & $0.000 \mathrm{E}+00$ & 0.0000 & $0.000 \mathrm{E}+00$ & 0.0000 & $0.000 \mathrm{E}+00$ & 0.0000 \\
\hline & $0.000 \mathrm{E}+00$ & 0.0000 & $0.000 \mathrm{E}+00$ & 0.0000 & $0.000 \mathrm{E}+00$ & 0.0000 & $0.000 \mathrm{E}+00$ & 0.0000 & $0.000 \mathrm{E}+00$ & 0.0000 & $0.000 \mathrm{E}+00$ & 0.0000 & $0.000 \mathrm{E}+00$ & 0.0000 \\
\hline
\end{tabular}

Total Dose Contributions TDOSE (i,p,t) for Individual Radionuclides (i) and Pathways (p) As mrem/yr and Fraction of Total Dose At $t=1.000 \mathrm{E}+05$ years

Water Dependent Pathways

\begin{tabular}{|c|c|c|c|c|c|c|c|c|c|c|c|c|c|c|}
\hline \multirow[b]{2}{*}{ lide } & \multicolumn{2}{|c|}{ Water } & \multicolumn{2}{|c|}{ Fish } & \multicolumn{2}{|c|}{ Radon } & \multicolumn{2}{|c|}{ Plant } & \multicolumn{2}{|c|}{ Meat } & \multicolumn{2}{|c|}{ Milk } & \multicolumn{2}{|c|}{ All Pathways* } \\
\hline & mrem/yr & fract. & mrem/yr & fract. & mrem/yr & fract. & mrem/yr & fract. & nrem/yr & fract. & mrem/yr & fract. & mrem/yr & fract. \\
\hline & $0.000 \mathrm{E}+00$ & 0.0000 & $0.000 \mathrm{E}+00$ & 0.0000 & $0.000 E+00$ & 0.0000 & $0.000 \mathrm{E}+00$ & 0.0000 & $0.000 \mathrm{E}+00$ & 0.0000 & $0.000 \mathrm{E}+00$ & 0.0000 & $0.000 \mathrm{E}+00$ & 000 \\
\hline & $0.000 \mathrm{E}+00$ & 0.0000 & $0.000 \mathrm{E}+00$ & 0.0000 & $0.000 \mathrm{E}+00$ & 0.0000 & $0.000 \mathrm{E}+00$ & 0.0000 & $0.000 \mathrm{E}+00$ & 0.0000 & $0.000 \mathrm{E}+00$ & 0.0000 & $0.000 \mathrm{E}+00$ & 0.0000 \\
\hline 237 & $0.000 \mathrm{E}+00$ & 0.0000 & $0.000 \mathrm{E}+00$ & 0.0000 & $0.000 \mathrm{E}+00$ & 0.0000 & $0.000 \mathrm{E}+00$ & 0.0000 & $0.000 \mathrm{E}+00$ & 0.0000 & $0.000 \mathrm{E}+00$ & 0.0000 & $0.000 \mathrm{E}+00$ & 0.0000 \\
\hline 238 & $0.000 \mathrm{E}+00$ & 0.0000 & $0.000 \mathrm{E}+00$ & 0.0000 & $0.000 \mathrm{E}+00$ & 0.0000 & $0.000 \mathrm{E}+00$ & 0 & $0.000 \mathrm{E}+00$ & 0 & $0.000 \mathrm{E}+00$ & & $0.000 \mathrm{E}+00$ & 000 \\
\hline & $0.000 \mathrm{E}+00$ & 0 & $0.000 \mathrm{E}+00$ & & & & & & & & $0.000 \mathrm{E}+00$ & & $0.000 \mathrm{E}+00$ & 00 \\
\hline & $0.000 \mathrm{E}+00$ & 0.0 & $0.000 \mathrm{E}+00$ & 0 & $0.000 \mathrm{E}+00$ & 0.0 & $0.000 \mathrm{E}+00$ & 0.0 & $0 \mathrm{E}+00$ & 0 . & $0.000 \mathrm{E}+00$ & 00 & $0.000 \mathrm{E}+00$ & 000 \\
\hline & $0.000 \mathrm{E}+00$ & 0.0000 & $0.000 \mathrm{E}+00$ & 0.0000 & $0.000 E+00$ & 0.0000 & $0.000 \mathrm{E}+00$ & 0.0000 & $0.000 \mathrm{E}+00$ & 0.0000 & $0.000 \mathrm{E}+00$ & 0.0000 & $0.000 \mathrm{E}+00$ & 0.0000 \\
\hline 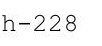 & $0.000 \mathrm{E}+00$ & 0.0000 & $0.000 \mathrm{E}+00$ & 0.0000 & $0.000 \mathrm{E}+00$ & 0.0000 & $0.000 \mathrm{E}+00$ & 0.0000 & $0.000 \mathrm{E}+00$ & 0.0000 & $0.000 \mathrm{E}+00$ & 0.0000 & $0.000 \mathrm{E}+00$ & 0.0000 \\
\hline & $0.000 \mathrm{E}+00$ & 0.0000 & $0.000 \mathrm{E}+00$ & 0.0000 & $0.000 \mathrm{E}+00$ & 0.0000 & $0.000 \mathrm{E}+00$ & 0.0000 & $0.000 \mathrm{E}+00$ & 0.0000 & $0.000 \mathrm{E}+00$ & 0.0000 & $0.000 \mathrm{E}+00$ & 0.0000 \\
\hline & $0.000 \mathrm{E}+00$ & 0.0000 & $0.000 \mathrm{E}+00$ & 0.0000 & $0.000 \mathrm{E}+00$ & 0.0000 & $0.000 \mathrm{E}+00$ & 0.0000 & $0.000 \mathrm{E}+00$ & 0.0000 & $0.000 \mathrm{E}+00$ & 0.0000 & $0.000 \mathrm{E}+00$ & 0.0000 \\
\hline & $0.000 \mathrm{E}+00$ & 0.0000 & $0.000 \mathrm{E}+00$ & 0.0000 & $0.000 \mathrm{E}+00$ & 0.0000 & $0.000 \mathrm{E}+00$ & 0.0000 & $0.000 \mathrm{E}+00$ & 0.0000 & $0.000 \mathrm{E}+00$ & 0.0000 & $0.000 \mathrm{E}+00$ & 0.0000 \\
\hline & $0.000 \mathrm{E}+00$ & 0.0000 & $0.000 \mathrm{E}+00$ & 0.0000 & $0.000 \mathrm{E}+00$ & 0.0000 & $0.000 \mathrm{E}+00$ & 0.0000 & $0.000 \mathrm{E}+00$ & 0.0000 & $0.000 \mathrm{E}+00$ & 0.0000 & $0.000 \mathrm{E}+00$ & 0.0000 \\
\hline & $0.000 \mathrm{E}+00$ & 0.0000 & $0.000 \mathrm{E}+00$ & 0.0000 & $0.000 \mathrm{E}+00$ & 0.0000 & $0.000 \mathrm{E}+00$ & 0.0000 & $0.000 \mathrm{E}+00$ & 0.0000 & $0.000 \mathrm{E}+00$ & 0.0000 & $0.000 \mathrm{E}+00$ & 0.0000 \\
\hline & & & +00 & 500 & $E+00$ & 000 & +00 & 00 & +00 & 000 & $E+00$ & 000 & $0.000 \mathrm{E}+00$ & \\
\hline
\end{tabular}

*Sum of all water independent and dependent pathways. 
RESRAD, Version $6.5 \quad \mathrm{~T}^{1 / 2}$ Limit $=180$ days

Summary : C746U Recreational User Deterministic Run

File : $\mathrm{X}: \backslash F I N A L$ V2 \DOE FWD RUNS $\backslash$ C746U RU DOE SG FWD-FV2-100000YR.RAD

Dose/Source Ratios Summed Over All Pathways

Parent and Progeny Principal Radionuclide Contributions Indicated

\begin{tabular}{|c|c|c|c|c|c|c|c|c|c|}
\hline Parent & Product & Thread & & $\operatorname{DSR}(j, t)$ & At Time ir & Years & (mrem/yr)/ & $\mathrm{pCi} / \mathrm{g})$ & \\
\hline (i) & (j) & Fraction & $0.000 \mathrm{E}+00$ & $1.000 \mathrm{E}+00$ & $5.000 \mathrm{E}+01$ & $1.000 \mathrm{E}+02$ & $5.000 \mathrm{E}+02$ & $1.000 \mathrm{E}+04$ & $1.000 \mathrm{E}+05$ \\
\hline $1-241$ & Am-241 & $1.000 \mathrm{E}+00$ & $1.862 \mathrm{E}-34$ & 1. $912 \mathrm{E}-34$ & $7.071 E-34$ & $2.685 E-33$ & $1.163 \mathrm{E}-28$ & $5.451 \mathrm{E}-10$ & $0.000 \mathrm{E}+00$ \\
\hline$n-241$ & $N p-237+D$ & $1.000 \mathrm{E}+00$ & $1.487 \mathrm{E}-20$ & $4.500 \mathrm{E}-20$ & $2.467 \mathrm{E}-18$ & $8.084 \mathrm{E}-18$ & $2.212 \mathrm{E}-15$ & $7.802 E-06$ & $0.000 \mathrm{E}+00$ \\
\hline $1-241$ & $U-233$ & $1.000 \mathrm{E}+00$ & $3.371 E-31$ & $2.384 \mathrm{E}-30$ & $4.682 E-27$ & $3.376 \mathrm{E}-26$ & $1.025 E-22$ & $5.052 \mathrm{E}-09$ & $0.000 \mathrm{E}+00$ \\
\hline$n-241$ & $T h-229+D$ & $1.000 \mathrm{E}+00$ & $2.306 E-27$ & $3.479 E-26$ & $1.645 \mathrm{E}-21$ & $1.799 \mathrm{E}-20$ & $3.100 \mathrm{E}-17$ & $2.585 E-07$ & $0.000 E+00$ \\
\hline$n-241$ & $\sum \operatorname{DSR}(j)$ & & $1.487 \mathrm{E}-20$ & $4.500 \mathrm{E}-20$ & $2.469 \mathrm{E}-18$ & $8.102 \mathrm{E}-18$ & $2.243 E-15$ & $8.067 \mathrm{E}-06$ & $0.000 \mathrm{E}+00$ \\
\hline$-137+D$ & $\mathrm{Cs}-137+\mathrm{D}$ & $1.000 \mathrm{E}+00$ & $1.213 \mathrm{E}-10$ & $1.196 \mathrm{E}-10$ & $5.821 E-11$ & $2.793 E-11$ & $7.847 \mathrm{E}-14$ & $0.000 \mathrm{E}+00$ & $0.000 \mathrm{E}+00$ \\
\hline$-237+D$ & $N p-237+D$ & $1.000 \mathrm{E}+00$ & $9.169 \mathrm{E}-14$ & $9.268 \mathrm{E}-14$ & $1.567 \mathrm{E}-13$ & $2.679 E-13$ & $1.952 \mathrm{E}-11$ & $3.681 E-02$ & $0.000 \mathrm{E}+00$ \\
\hline$-237+D$ & $U-233$ & $1.000 \mathrm{E}+00$ & $3.120 \mathrm{E}-24$ & $9.466 \mathrm{E}-24$ & $5.875 E-22$ & $2.184 \mathrm{E}-21$ & 1. $613 \mathrm{E}-18$ & $2.602 E-05$ & $0.000 \mathrm{E}+00$ \\
\hline$-237+D$ & $T h-229+D$ & $1.000 \mathrm{E}+00$ & $2.848 E-20$ & $2.006 \mathrm{E}-19$ & $3.076 \mathrm{E}-16$ & $1.723 E-15$ & $6.884 \mathrm{E}-13$ & $1.403 E-03$ & $0.000 \mathrm{E}+00$ \\
\hline$-237+D$ & $\sum \operatorname{DSR}(j)$ & & $9.169 \mathrm{E}-14$ & $9.268 \mathrm{E}-14$ & $1.570 \mathrm{E}-13$ & $2.696 \mathrm{E}-13$ & $2.021 \mathrm{E}-11$ & $3.824 \mathrm{E}-02$ & $0.000 \mathrm{E}+00$ \\
\hline-238 & $\mathrm{Pu}-238$ & $1.840 E-09$ & $2.079 E-34$ & $2.099 E-34$ & $3.386 E-34$ & $5.515 E-34$ & $2.732 E-32$ & $0.000 \mathrm{E}+00$ & $0.000 E+00$ \\
\hline-238 & $\mathrm{Pu}-238$ & $1.000 \mathrm{E}+00$ & $1.130 \mathrm{E}-25$ & $1.141 \mathrm{E}-25$ & $1.840 \mathrm{E}-25$ & $2.997 E-25$ & 1. $485 E-23$ & $1.081 \mathrm{E}-37$ & $0.000 \mathrm{E}+00$ \\
\hline-238 & $U-234$ & $1.000 \mathrm{E}+00$ & $9.402 \mathrm{E}-31$ & $2.855 E-30$ & $1.897 \mathrm{E}-28$ & 7. $660 \mathrm{E}-28$ & 1. $633 \mathrm{E}-24$ & $2.543 E-07$ & $0.000 \mathrm{E}+00$ \\
\hline$x-238$ & Th-230 & $1.000 \mathrm{E}+00$ & $9.887 \mathrm{E}-35$ & $7.005 E-34$ & $1.538 \mathrm{E}-30$ & $1.253 \mathrm{E}-29$ & $1.259 \mathrm{E}-25$ & $7.030 \mathrm{E}-08$ & $0.000 \mathrm{E}+00$ \\
\hline$x-238$ & $\mathrm{Ra}-226+\mathrm{D}$ & $1.000 \mathrm{E}+00$ & $7.713 E-24$ & $1.162 \mathrm{E}-22$ & $5.065 E-18$ & $5.122 \mathrm{E}-17$ & $5.408 E-14$ & $1.819 \mathrm{E}-05$ & $0.000 \mathrm{E}+00$ \\
\hline$x-238$ & $\mathrm{~Pb}-210+\mathrm{D}$ & $1.000 \mathrm{E}+00$ & $2.237 E-32$ & $6.933 E-31$ & $7.476 \mathrm{E}-25$ & $1.264 \mathrm{E}-23$ & $3.542 \mathrm{E}-20$ & $8.245 E-07$ & $0.000 \mathrm{E}+00$ \\
\hline-238 & $\sum \operatorname{DSR}(j)$ & & 7. $826 \mathrm{E}-24$ & $1.163 \mathrm{E}-22$ & $5.065 \mathrm{E}-18$ & $5.122 \mathrm{E}-17$ & $5.408 \mathrm{E}-14$ & $1.934 \mathrm{E}-05$ & $0.000 \mathrm{E}+00$ \\
\hline-239 & $\mathrm{Pu}-239$ & $1.000 \mathrm{E}+00$ & $1.156 \mathrm{E}-18$ & $1.170 \mathrm{E}-18$ & $2.100 \mathrm{E}-18$ & $3.815 E-18$ & 4. $526 E-16$ & $1.818 \mathrm{E}-03$ & $0.000 E+00$ \\
\hline-239 & $U-235+D$ & $1.000 \mathrm{E}+00$ & $5.899 \mathrm{E}-25$ & 1. $789 \mathrm{E}-24$ & $1.102 \mathrm{E}-22$ & $4.068 E-22$ & $2.830 \mathrm{E}-19$ & $4.215 E-07$ & $0.000 \mathrm{E}+00$ \\
\hline$x-239$ & $\mathrm{~Pa}-231$ & $1.000 \mathrm{E}+00$ & $9.281 E-29$ & $6.556 \mathrm{E}-28$ & 1. $203 E-24$ & $8.097 E-24$ & 1.394E-20 & $1.785 \mathrm{E}-08$ & $0.000 \mathrm{E}+00$ \\
\hline-239 & $A C-227+D$ & $1.000 \mathrm{E}+00$ & $2.200 \mathrm{E}-28$ & $3.302 \mathrm{E}-27$ & $1.227 \mathrm{E}-22$ & $1.125 \mathrm{E}-21$ & 1. $425 \mathrm{E}-18$ & $1.293 \mathrm{E}-07$ & $0.000 \mathrm{E}+00$ \\
\hline $1-239$ & $\sum \operatorname{DSR}(j)$ & & $1.156 \mathrm{E}-18$ & $1.170 \mathrm{E}-18$ & $2.100 \mathrm{E}-18$ & $3.817 \mathrm{E}-18$ & $4.543 E-16$ & $1.818 \mathrm{E}-03$ & $0.000 \mathrm{E}+00$ \\
\hline$a-240$ & $\mathrm{Pu}-240$ & $4.950 \mathrm{E}-08$ & $5.436 \mathrm{E}-33$ & $5.532 \mathrm{E}-33$ & $1.307 \mathrm{E}-32$ & $3.144 \mathrm{E}-32$ & $3.519 \mathrm{E}-29$ & $4.138 \mathrm{E}-11$ & $0.000 \mathrm{E}+00$ \\
\hline-240 & $\mathrm{Pu}-240$ & $1.000 \mathrm{E}+00$ & $1.098 \mathrm{E}-25$ & $1.118 \mathrm{E}-25$ & $2.641 E-25$ & $6.352 E-25$ & $7.109 \mathrm{E}-22$ & $8.359 E-04$ & $0.000 \mathrm{E}+00$ \\
\hline $1-240$ & $U-236$ & $1.000 \mathrm{E}+00$ & $2.079 E-33$ & $6.337 E-33$ & $5.132 \mathrm{E}-31$ & $2.504 \mathrm{E}-30$ & 1. $628 \mathrm{E}-26$ & $1.256 \mathrm{E}-07$ & $0.000 \mathrm{E}+00$ \\
\hline $1-240$ & $T h-232$ & $1.000 \mathrm{E}+00$ & $2.803 E-44$ & 1. $948 E-43$ & $5.271 E-40$ & $5.270 \mathrm{E}-39$ & $2.159 \mathrm{E}-34$ & $1.367 E-13$ & $0.000 \mathrm{E}+00$ \\
\hline-240 & $\mathrm{Ra}-228+\mathrm{D}$ & $1.000 \mathrm{E}+00$ & 1. $318 \mathrm{E}-29$ & $1.940 \mathrm{E}-28$ & $3.618 E-24$ & $2.445 E-23$ & 1. $417 \mathrm{E}-20$ & $2.429 E-11$ & $0.000 \mathrm{E}+00$ \\
\hline-240 & $T h-228+D$ & $1.000 \mathrm{E}+00$ & $7.799 \mathrm{E}-29$ & $2.244 \mathrm{E}-27$ & $2.540 E-22$ & 1. $691 \mathrm{E}-21$ & $5.366 \mathrm{E}-19$ & $3.687 \mathrm{E}-11$ & $0.000 \mathrm{E}+00$ \\
\hline-240 & $\sum \operatorname{DSR}(j)$ & & $1.099 \mathrm{E}-25$ & $1.142 \mathrm{E}-25$ & $2.579 E-22$ & $1.716 \mathrm{E}-21$ & $5.515 \mathrm{E}-19$ & $8.361 \mathrm{E}-04$ & $0.000 \mathrm{E}+00$ \\
\hline-99 & $\mathrm{TC}-99$ & $1.000 \mathrm{E}+00$ & $5.547 \mathrm{E}-27$ & $5.625 \mathrm{E}-27$ & $1.112 \mathrm{E}-26$ & $2.231 \mathrm{E}-26$ & $5.839 \mathrm{E}-24$ & $2.473 E-28$ & $0.000 \mathrm{E}+00$ \\
\hline$-228+D$ & $T h-228+D$ & $1.000 \mathrm{E}+00$ & $1.329 \mathrm{E}-07$ & $9.308 \mathrm{E}-08$ & $2.430 \mathrm{E}-15$ & $4.441 \mathrm{E}-23$ & $0.000 \mathrm{E}+00$ & $0.000 \mathrm{E}+00$ & $0.000 \mathrm{E}+00$ \\
\hline-230 & $\mathrm{Th}-230$ & $1.000 \mathrm{E}+00$ & $2.319 \mathrm{E}-23$ & $2.359 \mathrm{E}-23$ & $5.375 E-23$ & 1. $246 \mathrm{E}-22$ & $1.037 \mathrm{E}-19$ & $2.264 \mathrm{E}-03$ & $0.000 \mathrm{E}+00$ \\
\hline 30 & $\mathrm{Ra}-226+\mathrm{D}$ & $1.000 \mathrm{E}+00$ & 3. $629 \mathrm{E}-12$ & $1.095 \mathrm{E}-11$ & $5.116 \mathrm{E}-10$ & $1.423 E-09$ & $1.032 \mathrm{E}-07$ & $7.480 \mathrm{E}-01$ & $0.000 \mathrm{E}+00$ \\
\hline 30 & $\mathrm{~Pb}-210+\mathrm{D}$ & $1.000 \mathrm{E}+00$ & $1.749 \mathrm{E}-20$ & 1. $222 \mathrm{E}-19$ & $1.249 \mathrm{E}-16$ & $5.113 \mathrm{E}-16$ & $7.402 \mathrm{E}-14$ & $3.403 E-02$ & $0.000 \mathrm{E}+00$ \\
\hline & $\sum \operatorname{DSR}(j)$ & & 3. $629 \mathrm{E}-12$ & $1.095 \mathrm{E}-11$ & $5.116 \mathrm{E}-10$ & 1. $423 E-09$ & $1.032 \mathrm{E}-07$ & $7.843 E-01$ & $0.000 \mathrm{E}+00$ \\
\hline
\end{tabular}


RESRAD, Version $6.5 \quad \mathrm{~T}^{1 / 2}$ Limit $=180$ days

ummary : C746U Recreational User Deterministic Run

File : $\mathrm{X}: \backslash F I N A L$ V2 \DOE FWD RUNS \C746U RU DOE SG FWD-FV2-100000YR.RAD

Dose/Source Ratios Summed Over All Pathways

Parent and Progeny Principal Radionuclide Contributions Indicated

\begin{tabular}{|c|c|c|c|c|c|c|c|c|c|}
\hline Parent & Product & Thread & & $\operatorname{DSR}(j, t)$ & At Time $i$ & n Years & (mrem/yr) / & $\mathrm{Ci} / \mathrm{g})$ & \\
\hline (i) & (j) & Fraction & $0.000 \mathrm{E}+00$ & $1.000 \mathrm{E}+00$ & $5.000 \mathrm{E}+01$ & $1.000 \mathrm{E}+02$ & $5.000 \mathrm{E}+02$ & $1.000 \mathrm{E}+04$ & $1.000 \mathrm{E}+05$ \\
\hline $1-232$ & $T h-232$ & $1.000 \mathrm{E}+00$ & $1.121 \mathrm{E}-25$ & $1.142 \mathrm{E}-25$ & $2.836 E-25$ & $7.176 \mathrm{E}-25$ & $1.205 E-21$ & $2.761 \mathrm{E}-03$ & $0.000 \mathrm{E}+00$ \\
\hline-232 & $\mathrm{Ra}-228+\mathrm{D}$ & $1.000 \mathrm{E}+00$ & $1.065 \mathrm{E}-10$ & $3.052 \mathrm{E}-10$ & $2.678 E-09$ & $3.923 E-09$ & $8.176 \mathrm{E}-08$ & 4. $913 \mathrm{E}-01$ & $0.000 \mathrm{E}+00$ \\
\hline-232 & $\mathrm{Th}-228+\mathrm{D}$ & $1.000 \mathrm{E}+00$ & $1.026 \mathrm{E}-09$ & $6.328 E-09$ & $2.128 E-07$ & $2.877 E-07$ & $3.130 E-06$ & $7.461 \mathrm{E}-01$ & $0.000 \mathrm{E}+00$ \\
\hline$h-232$ & $\sum \operatorname{DSR}(j)$ & & $1.133 \mathrm{E}-09$ & $6.633 E-09$ & $2.155 E-07$ & $2.917 E-07$ & $3.212 E-06$ & $1.240 \mathrm{E}+00$ & $0.000 \mathrm{E}+00$ \\
\hline-234 & $\mathrm{U}-234$ & $1.000 \mathrm{E}+00$ & $6.631 \mathrm{E}-25$ & $6.749 \mathrm{E}-25$ & $1.607 \mathrm{E}-24$ & $3.895 E-24$ & 4. $636 \mathrm{E}-21$ & $7.080 \mathrm{E}-04$ & $0.000 \mathrm{E}+00$ \\
\hline-234 & $T h-230$ & $1.000 \mathrm{E}+00$ & $1.047 \mathrm{E}-28$ & $3.188 \mathrm{E}-28$ & $2.443 E-26$ & $1.127 \mathrm{E}-25$ & 4. $665 \mathrm{E}-22$ & $1.983 \mathrm{E}-04$ & $0.000 \mathrm{E}+00$ \\
\hline-234 & $\mathrm{Ra}-226+\mathrm{D}$ & $1.000 \mathrm{E}+00$ & $1.090 \mathrm{E}-17$ & $7.671 \mathrm{E}-17$ & $1.167 \mathrm{E}-13$ & $6.482 \mathrm{E}-13$ & $2.407 E-10$ & $5.151 \mathrm{E}-02$ & $0.000 \mathrm{E}+00$ \\
\hline-234 & $\mathrm{~Pb}-210+\mathrm{D}$ & $1.000 \mathrm{E}+00$ & $3.944 \mathrm{E}-26$ & $5.916 E-25$ & $2.118 \mathrm{E}-20$ & $1.862 \mathrm{E}-19$ & $1.619 \mathrm{E}-16$ & $2.335 E-03$ & $0.000 \mathrm{E}+00$ \\
\hline-234 & $\sum \operatorname{DSR}(j)$ & & $1.090 \mathrm{E}-17$ & $7.671 \mathrm{E}-17$ & $1.167 \mathrm{E}-13$ & $6.482 \mathrm{E}-13$ & $2.407 \mathrm{E}-10$ & $5.475 \mathrm{E}-02$ & $0.000 \mathrm{E}+00$ \\
\hline$-235+D$ & $\mathrm{U}-235+\mathrm{D}$ & $1.000 \mathrm{E}+00$ & $1.195 \mathrm{E}-15$ & $1.210 \mathrm{E}-15$ & $2.218 \mathrm{E}-15$ & $4.115 \mathrm{E}-15$ & $5.779 \mathrm{E}-13$ & $4.846 \mathrm{E}-02$ & $0.000 \mathrm{E}+00$ \\
\hline$-235+D$ & $\mathrm{~Pa}-231$ & $1.000 \mathrm{E}+00$ & $2.825 \mathrm{E}-19$ & $8.554 \mathrm{E}-19$ & $4.840 \mathrm{E}-17$ & $1.637 \mathrm{E}-16$ & $5.673 E-14$ & $3.830 \mathrm{E}-03$ & $0.000 \mathrm{E}+00$ \\
\hline$-235+D$ & $A C-227+D$ & $1.000 \mathrm{E}+00$ & $8.917 \mathrm{E}-19$ & $6.232 \mathrm{E}-18$ & $6.620 \mathrm{E}-15$ & $2.832 E-14$ & $6.156 \mathrm{E}-12$ & $2.782 \mathrm{E}-02$ & $0.000 \mathrm{E}+00$ \\
\hline$-235+D$ & $\sum \operatorname{DSR}(j)$ & & $1.197 \mathrm{E}-15$ & $1.217 \mathrm{E}-15$ & $8.886 E-15$ & $3.260 \mathrm{E}-14$ & $6.791 \mathrm{E}-12$ & $8.011 E-02$ & $0.000 E+00$ \\
\hline-238 & $\mathrm{U}-238$ & $5.400 \mathrm{E}-05$ & $0.000 \mathrm{E}+00$ & $0.000 \mathrm{E}+00$ & $0.000 \mathrm{E}+00$ & $0.000 \mathrm{E}+00$ & $0.000 \mathrm{E}+00$ & $3.473 E-08$ & $0.000 \mathrm{E}+00$ \\
\hline$-238+D$ & $\mathrm{U}-238+\mathrm{D}$ & $9.999 \mathrm{E}-01$ & $1.365 \mathrm{E}-11$ & $1.376 \mathrm{E}-11$ & $2.035 E-11$ & $3.035 \mathrm{E}-11$ & $7.419 \mathrm{E}-10$ & $1.135 \mathrm{E}-02$ & $0.000 \mathrm{E}+00$ \\
\hline$-238+D$ & $\mathrm{U}-234$ & $9.999 \mathrm{E}-01$ & $9.426 \mathrm{E}-31$ & $2.873 E-30$ & $2.301 \mathrm{E}-28$ & $1.110 \mathrm{E}-27$ & $6.582 \mathrm{E}-24$ & $2.036 \mathrm{E}-05$ & $0.000 \mathrm{E}+00$ \\
\hline$-238+D$ & Th-230 & $9.999 \mathrm{E}-01$ & $9.906 \mathrm{E}-35$ & $7.035 E-34$ & $1.749 \mathrm{E}-30$ & $1.605 \mathrm{E}-29$ & $3.309 E-25$ & $2.812 \mathrm{E}-06$ & $0.000 \mathrm{E}+00$ \\
\hline$-238+D$ & $\mathrm{Ra}-226+\mathrm{D}$ & $9.999 \mathrm{E}-01$ & 7. $725 \mathrm{E}-24$ & $1.165 \mathrm{E}-22$ & $5.580 \mathrm{E}-18$ & $6.178 \mathrm{E}-17$ & $1.159 \mathrm{E}-13$ & $6.081 \mathrm{E}-04$ & $0.000 \mathrm{E}+00$ \\
\hline$-238+D$ & $\mathrm{~Pb}-210+\mathrm{D}$ & $9.999 \mathrm{E}-01$ & $2.239 \mathrm{E}-32$ & $6.951 E-31$ & $8.109 \mathrm{E}-25$ & $1.488 \mathrm{E}-23$ & 7. $347 \mathrm{E}-20$ & $2.746 \mathrm{E}-05$ & $0.000 \mathrm{E}+00$ \\
\hline$-238+D$ & $\sum \operatorname{DSR}(j)$ & & 1. $365 \mathrm{E}-11$ & $1.376 \mathrm{E}-11$ & $2.035 E-11$ & $3.035 \mathrm{E}-11$ & 7. $420 \mathrm{E}-10$ & $1.201 \mathrm{E}-02$ & $0.000 \mathrm{E}+00$ \\
\hline
\end{tabular}

The DSR includes contributions from associated (half-life $\leq 180$ days) daughters. 
RESRAD, Version $6.5 \quad \mathrm{~T}^{1 / 2}$ Limit $=180$ days

ummary : C746U Recreational User Deterministic Run

File : $\mathrm{X}: \backslash F$ INAL V2 \DOE FWD RUNS \C746U RU DOE SG FWD-FV2-100000YR.RAD

Single Radionuclide Soil Guidelines $G(i, t)$ in $\mathrm{pCi} / \mathrm{g}$

Basic Radiation Dose Limit $=1.000 \mathrm{E}+00 \mathrm{mrem} / \mathrm{yr}$

Nuclide

\begin{tabular}{|c|c|c|c|c|c|c|c|}
\hline (i) & $t=0.000 \mathrm{E}+00$ & $1.000 \mathrm{E}+00$ & $5.000 \mathrm{E}+01$ & $1.000 \mathrm{E}+02$ & $5.000 \mathrm{E}+02$ & $1.000 \mathrm{E}+04$ & $1.000 \mathrm{E}+05$ \\
\hline$m-241$ & $\star 3.431 \mathrm{E}+12$ & $\star 3.431 \mathrm{E}+12$ & $\star 3.431 \mathrm{E}+12$ & $\star 3.431 \mathrm{E}+12$ & $\star 3.431 \mathrm{E}+12$ & $1.240 \mathrm{E}+05$ & $\star 3.431 \mathrm{E}+12$ \\
\hline$s-137$ & $8.242 E+09$ & $8.364 \mathrm{E}+09$ & $1.718 \mathrm{E}+10$ & $3.580 \mathrm{E}+10$ & $1.274 \mathrm{E}+13$ & $\star 8.704 \mathrm{E}+13$ & $\star 8.704 \mathrm{E}+13$ \\
\hline-237 & $\star 7.047 \mathrm{E}+08$ & $\star 7.047 \mathrm{E}+08$ & $\star 7.047 \mathrm{E}+08$ & $\star 7.047 \mathrm{E}+08$ & $\star 7.047 \mathrm{E}+08$ & $2.615 \mathrm{E}+01$ & $\star 7.047 \mathrm{E}+08$ \\
\hline $\mathrm{Pu}-238$ & $\star 1.712 \mathrm{E}+13$ & $\star 1.712 \mathrm{E}+13$ & $\star 1.712 \mathrm{E}+13$ & $\star 1.712 \mathrm{E}+13$ & $* 1.712 \mathrm{E}+13$ & $5.170 \mathrm{E}+04$ & $\star 1.712 \mathrm{E}+13$ \\
\hline $\mathrm{Pu}-239$ & $\star 6.214 \mathrm{E}+10$ & $\star 6.214 \mathrm{E}+10$ & $\star 6.214 \mathrm{E}+10$ & $\star 6.214 \mathrm{E}+10$ & $* 6.214 \mathrm{E}+10$ & $5.500 \mathrm{E}+02$ & $* 6.214 \mathrm{E}+10$ \\
\hline $\mathrm{Pu}-240$ & $\star 2.278 \mathrm{E}+11$ & $\star 2.278 \mathrm{E}+11$ & $\star 2.278 \mathrm{E}+11$ & $\star 2.278 \mathrm{E}+11$ & $\star 2.278 \mathrm{E}+11$ & $1.196 \mathrm{E}+03$ & $\star 2.278 \mathrm{E}+11$ \\
\hline TC-99 & $* 1.697 \mathrm{E}+10$ & $* 1.697 \mathrm{E}+10$ & $\star 1.697 \mathrm{E}+10$ & $\star 1.697 \mathrm{E}+10$ & $* 1.697 \mathrm{E}+10$ & $* 1.697 \mathrm{E}+10$ & $* 1.697 \mathrm{E}+10$ \\
\hline Th-228 & $7.523 \mathrm{E}+06$ & $1.074 \mathrm{E}+07$ & $4.116 \mathrm{E}+14$ & $\star 8.195 \mathrm{E}+14$ & $\star 8.195 \mathrm{E}+14$ & $\star 8.195 E+14$ & $\star 8.195 \mathrm{E}+14$ \\
\hline$T h-230$ & $\star 2.018 \mathrm{E}+10$ & $\star 2.018 \mathrm{E}+10$ & $1.955 \mathrm{E}+09$ & $7.028 \mathrm{E}+08$ & $9.688 \mathrm{E}+06$ & $1.275 \mathrm{E}+00$ & $\star 2.018 \mathrm{E}+10$ \\
\hline Th-232 & $* 1.097 \mathrm{E}+05$ & $* 1.097 \mathrm{E}+05$ & $\star 1.097 \mathrm{E}+05$ & $\star 1.097 \mathrm{E}+05$ & $* 1.097 \mathrm{E}+05$ & $8.064 \mathrm{E}-01$ & $\star 1.097 \mathrm{E}+05$ \\
\hline 34 & $\star 6.247 \mathrm{E}+09$ & $\star 6.247 \mathrm{E}+09$ & $* 6.247 \mathrm{E}+09$ & $\star 6.247 \mathrm{E}+09$ & $4.154 \mathrm{E}+09$ & $1.827 \mathrm{E}+01$ & $* 6.247 \mathrm{E}+09$ \\
\hline 35 & $\star 2.161 \mathrm{E}+06$ & $\star 2.161 \mathrm{E}+06$ & $\star 2.161 \mathrm{E}+06$ & $\star 2.161 \mathrm{E}+06$ & $\star 2.161 \mathrm{E}+06$ & $1.248 \mathrm{E}+01$ & $\star 2.161 \mathrm{E}+06$ \\
\hline 238 & $* 3.361 \mathrm{E}+05$ & $\star 3.361 \mathrm{E}+05$ & $\star 3.361 \mathrm{E}+05$ & $\star 3.361 \mathrm{E}+05$ & $\star 3.361 \mathrm{E}+05$ & $8.328 E+01$ & $\star 3.361 \mathrm{E}+05$ \\
\hline
\end{tabular}

${ }^{*}$ At specific activity limit

Summed Dose/Source Ratios DSR(i,t) in (mrem/yr)/(pCi/g) and Single Radionuclide Soil Guidelines $\mathrm{G}(i, t)$ in $\mathrm{pCi} / \mathrm{g}$

at $\operatorname{tmin}=$ time of minimum single radionuclide soil guideline and at tmax $=$ time of maximum total dose $=19739 \pm$ * years

\begin{tabular}{|c|c|c|c|c|c|c|}
\hline $\begin{array}{l}\text { uclide } \\
\text { (i) }\end{array}$ & $\begin{array}{l}\text { Initial } \\
(\mathrm{pCi} / \mathrm{g})\end{array}$ & $\begin{array}{c}\text { tmin } \\
\text { (years) }\end{array}$ & $\operatorname{DSR}(i, \operatorname{tmin})$ & $\begin{array}{c}\mathrm{G}(\mathrm{i}, \mathrm{tmin}) \\
(\mathrm{pCi} / \mathrm{g})\end{array}$ & $\operatorname{DSR}(i, \operatorname{tmax})$ & $\begin{array}{c}G(i, t \max ) \\
(\mathrm{pCi} / \mathrm{g})\end{array}$ \\
\hline 41 & $3.500 \mathrm{E}+01$ & $2534 \pm 5$ & $1.020 \mathrm{E}-04$ & $9.801 \mathrm{E}+03$ & $4.229 \mathrm{E}-06$ & $2.365 E+05$ \\
\hline-137 & $1.900 \mathrm{E}+01$ & $0.000 \mathrm{E}+00$ & $1.213 \mathrm{E}-10$ & $8.242 E+09$ & $0.000 \mathrm{E}+00$ & $\star 8.704 \mathrm{E}+13$ \\
\hline 237 & $5.500 \mathrm{E}+00$ & $2534 \pm 5$ & $6.642 \mathrm{E}-02$ & $1.506 \mathrm{E}+01$ & $2.018 \mathrm{E}-02$ & $4.955 E+01$ \\
\hline 238 & $3.900 \mathrm{E}+01$ & $24317 \pm *$ & $4.559 \mathrm{E}-05$ & $2.193 E+04$ & $3.838 \mathrm{E}-05$ & $2.606 \mathrm{E}+04$ \\
\hline-239 & $3.600 \mathrm{E}+01$ & $2534 \pm 5$ & $2.428 \mathrm{E}-03$ & $4.118 E+02$ & $1.247 \mathrm{E}-03$ & $8.020 E+02$ \\
\hline-240 & $3.600 \mathrm{E}+01$ & $2534 \pm 5$ & $1.988 \mathrm{E}-03$ & $5.031 E+02$ & $2.702 \mathrm{E}-04$ & $3.701 \mathrm{E}+03$ \\
\hline$c-99$ & $5.200 \mathrm{E}+01$ & $2535 \pm 5$ & $2.813 E-11$ & $\star 1.697 \mathrm{E}+10$ & $0.000 \mathrm{E}+00$ & $\star 1.697 \mathrm{E}+10$ \\
\hline 28 & $4.000 \mathrm{E}+00$ & $0.000 \mathrm{E}+00$ & $1.329 \mathrm{E}-07$ & $7.523 E+06$ & $0.000 \mathrm{E}+00$ & $\star 8.195 \mathrm{E}+14$ \\
\hline-230 & $1.000 \mathrm{E}+02$ & $8585 \pm *$ & $7.874 \mathrm{E}-01$ & $1.270 \mathrm{E}+00$ & $7.158 \mathrm{E}-01$ & $1.397 \mathrm{E}+00$ \\
\hline-232 & $4.000 \mathrm{E}+00$ & $2534 \pm 5$ & $1.256 \mathrm{E}+00$ & $7.961 \mathrm{E}-01$ & $1.220 \mathrm{E}+00$ & $8.200 \mathrm{E}-01$ \\
\hline 34 & $1.600 \mathrm{E}+02$ & $24317 \pm *$ & $1.277 \mathrm{E}-01$ & $7.829 \mathrm{E}+00$ & $1.077 \mathrm{E}-01$ & $9.288 \mathrm{E}+00$ \\
\hline & $6.500 \mathrm{E}+00$ & $24400 \pm *$ & $9.676 \mathrm{E}-02$ & $1.033 \mathrm{E}+01$ & $9.309 \mathrm{E}-02$ & $1.074 \mathrm{E}+01$ \\
\hline 238 & $1.600 \mathrm{E}+02$ & $24317 \pm *$ & $1.345 \mathrm{E}-02$ & $7.435 \mathrm{E}+01$ & $1.269 \mathrm{E}-02$ & $7.882 E+01$ \\
\hline
\end{tabular}

*At specific activity limit 
RESRAD, Version $6.5 \quad \mathrm{~T}^{1 / 2}$ Limit $=180$ days

Summary : C746U Recreational User Deterministic Run

File : $\mathrm{X}: \backslash F I N A L$ V2 \DOE FWD RUNS $\backslash$ C746U RU DOE SG FWD-FV2-100000YR.RAD

Individual Nuclide Dose Summed Over All Pathways

Parent Nuclide and Branch Fraction Indicated

Nuclide Parent THF(i) DOSE (j,t), mrem/yr

\begin{tabular}{|c|c|c|}
\hline (j) & (i) & \\
\hline$m-241$ & Am-241 & $1.000 \mathrm{E}+00$ \\
\hline$p-237$ & Am-241 & $1.000 \mathrm{E}+00$ \\
\hline-237 & $N p-237$ & $1.000 \mathrm{E}+00$ \\
\hline-237 & $\sum \mathrm{DOSE}$ & \\
\hline
\end{tabular}

$\mathrm{U}-233 \mathrm{Am}-241 \quad 1.000 \mathrm{E}+00$

$\mathrm{U}-233 \mathrm{~Np}-237 \quad 1.000 \mathrm{E}+00$

U-233 $\sum$ DOSE $(j)$

Th-229 Am-241 1.000E+00

$\mathrm{Th}-229 \quad \mathrm{~Np}-237 \quad 1.000 \mathrm{E}+00$

Th-229 ¿DOSE (j)

Cs-137 Cs-137 1.000E+00

Pu-238 Pu-238 1.840E-09

$\mathrm{Pu}-238 \quad \mathrm{Pu}-238 \quad 1.000 \mathrm{E}+00$

$\mathrm{Pu}-238 \quad \sum \mathrm{DOSE}(j)$

$\mathrm{U}-234$

$\mathrm{U}-234$

$\mathrm{U}-234$

$\mathrm{U}-234$

Th -230

$\mathrm{Th}-230$

$\mathrm{Th}-230$

$\mathrm{Th}-230$

$\mathrm{Th}-230$

$\mathrm{Ra}-226$

$\mathrm{Ra}-226$

$\mathrm{Ra}-226$

$\mathrm{Ra}-226$

$\mathrm{Ra}-226$

$\mathrm{Pb}-210$

$\mathrm{Pb}-210$

$\mathrm{Pb}-210$

$\mathrm{Pb}-210$

$\mathrm{Pb}-210$

$\mathrm{Pu}-239$

$\mathrm{Pu}-238 \quad 1.000 \mathrm{E}+00$

$\mathrm{U}-234 \quad 1.000 \mathrm{E}+00$

$\mathrm{U}-238 \quad 9.999 \mathrm{E}-01$

$\sum \operatorname{DOSE}(j)$

$\mathrm{Pu}-238 \quad 1.000 \mathrm{E}+00$

Th-230 1.000E+00

$\mathrm{U}-234 \quad 1.000 \mathrm{E}+00$

$\mathrm{U}-238 \quad 9.999 \mathrm{E}-01$

$\sum \operatorname{DOSE}(j)$

$\mathrm{Pu}-238 \quad 1.000 \mathrm{E}+00$

Th-230 1.000E+00

$\mathrm{U}-234 \quad 1.000 \mathrm{E}+00$

$\mathrm{U}-238 \quad 9.999 \mathrm{E}-01$

$\sum \operatorname{DOSE}(j)$

$\mathrm{Pu}-238$ 1.000E+00 Th-230 1.000E+00 $\mathrm{U}-234 \quad 1.000 \mathrm{E}+00$ U-238 9.999E-01 $\sum \operatorname{DOSE}(j)$

$\mathrm{Pu}-239$ 1.000E+00

$\mathrm{Pu}-239$ 1.000E+00 $\mathrm{U}-2351.000 \mathrm{E}+00$ $\sum \operatorname{DOSE}(j)$ $t=0.000 \mathrm{E}+00 \quad 1.000 \mathrm{E}+00 \quad 5.000 \mathrm{E}+01 \quad 1.000 \mathrm{E}+02 \quad 5.000 \mathrm{E}+02 \quad 1.000 \mathrm{E}+04 \quad 1.000 \mathrm{E}+05$

$0.000 \mathrm{E}+00 \quad 0.000 \mathrm{E}+00 \quad 0.000 \mathrm{E}+00 \quad 0.000 \mathrm{E}+00 \quad 4.069 \mathrm{E}-27 \quad \overline{1.908 \mathrm{E}-08} 0.000 \mathrm{E}+00$

$5.204 \mathrm{E}-19 \quad 1.575 \mathrm{E}-18 \quad 8.635 \mathrm{E}-17 \quad 2.829 \mathrm{E}-16 \quad 7.741 \mathrm{E}-14 \quad 2.731 \mathrm{E}-04 \quad 0.000 \mathrm{E}+00$

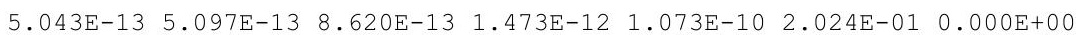
$\begin{array}{lllllll}5.043 \mathrm{E}-13 & 5.097 \mathrm{E}-13 & 8.621 \mathrm{E}-13 & 1.474 \mathrm{E}-12 & 1.074 \mathrm{E}-10 & 2.027 \mathrm{E}-01 & 0.000 \mathrm{E}+00\end{array}$

$0.000 \mathrm{E}+00 \quad 8.344 \mathrm{E}-29 \quad 1.639 \mathrm{E}-25 \quad 1.182 \mathrm{E}-24 \quad 3.586 \mathrm{E}-21 \quad 1.768 \mathrm{E}-07 \quad 0.000 \mathrm{E}+00$ $\begin{array}{lllllll}1.716 \mathrm{E}-23 & 5.206 \mathrm{E}-23 & 3.231 \mathrm{E}-21 & 1.201 \mathrm{E}-20 & 8.871 \mathrm{E}-18 & 1.431 \mathrm{E}-04 & 0.000 \mathrm{E}+00\end{array}$ $\begin{array}{lllllll}1.716 \mathrm{E}-23 & 5.206 \mathrm{E}-23 & 3.231 \mathrm{E}-21 & 1.201 \mathrm{E}-20 & 8.874 \mathrm{E}-18 & 1.433 \mathrm{E}-04 & 0.000 \mathrm{E}+00\end{array}$

8.073E-26 1.218E-24 5.759E-20 6.298E-19 $1.085 \mathrm{E}-15 \quad 9.049 \mathrm{E}-06 \quad 0.000 \mathrm{E}+00$ $1.567 \mathrm{E}-19 \quad 1.103 \mathrm{E}-18 \quad 1.692 \mathrm{E}-15 \quad 9.477 \mathrm{E}-15 \quad 3.786 \mathrm{E}-12 \quad 7.718 \mathrm{E}-03 \quad 0.000 \mathrm{E}+00$ $1.567 \mathrm{E}-19 \quad 1.103 \mathrm{E}-18 \quad 1.692 \mathrm{E}-15 \quad 9.478 \mathrm{E}-15 \quad 3.787 \mathrm{E}-12 \quad 7.727 \mathrm{E}-03 \quad 0.000 \mathrm{E}+00$ $2.305 E-092.272 E-09 \quad 1.106 E-09 \quad 5.307 E-10 \quad 1.491 E-12 \quad 0.000 E+00 \quad 0.000 E+00$ $\begin{array}{lllllll}0.000 \mathrm{E}+00 & 0.000 \mathrm{E}+00 & 0.000 \mathrm{E}+00 & 0.000 \mathrm{E}+00 & 0.000 \mathrm{E}+00 & 0.000 \mathrm{E}+00 & 0.000 \mathrm{E}+00\end{array}$ $4.406 \mathrm{E}-24 \quad 4.449 \mathrm{E}-24 \quad 7.176 \mathrm{E}-24 \quad 1.169 \mathrm{E}-23 \quad 5.791 \mathrm{E}-22 \quad 0.000 \mathrm{E}+00 \quad 0.000 \mathrm{E}+00$ $4.406 \mathrm{E}-24 \quad 4.449 \mathrm{E}-24 \quad 7.176 \mathrm{E}-24 \quad 1.169 \mathrm{E}-23 \quad 5.791 \mathrm{E}-22 \quad 0.000 \mathrm{E}+00 \quad 0.000 \mathrm{E}+00$ $0.000 \mathrm{E}+00 \quad 1.114 \mathrm{E}-28 \quad 7.400 \mathrm{E}-27 \quad 2.988 \mathrm{E}-26 \quad 6.368 \mathrm{E}-23 \quad 9.916 \mathrm{E}-06 \quad 0.000 \mathrm{E}+00$ $\begin{array}{lllllll}1.061 \mathrm{E}-22 & 1.080 \mathrm{E}-22 & 2.571 \mathrm{E}-22 & 6.232 \mathrm{E}-22 & 7.417 \mathrm{E}-19 & 1.133 \mathrm{E}-01 & 0.000 \mathrm{E}+00\end{array}$ $0.000 \mathrm{E}+00 \quad 4.596 \mathrm{E}-28 \quad 3.681 \mathrm{E}-26 \quad 1.776 \mathrm{E}-25 \quad 1.053 \mathrm{E}-21 \quad 3.257 \mathrm{E}-03 \quad 0.000 \mathrm{E}+00$ $\begin{array}{lllllll}1.061 \mathrm{E}-22 & 1.080 \mathrm{E}-22 & 2.572 \mathrm{E}-22 & 6.234 \mathrm{E}-22 & 7.428 \mathrm{E}-19 & 1.165 \mathrm{E}-01 & 0.000 \mathrm{E}+00\end{array}$

$0.000 \mathrm{E}+00 \quad 0.000 \mathrm{E}+00 \quad 5.998 \mathrm{E}-29 \quad 4.887 \mathrm{E}-28 \quad 4.910 \mathrm{E}-24 \quad 2.742 \mathrm{E}-06 \quad 0.000 \mathrm{E}+00$ $2.319 \mathrm{E}-212.359 \mathrm{E}-21 \quad 5.375 \mathrm{E}-21 \quad 1.246 \mathrm{E}-20 \quad 1.037 \mathrm{E}-17 \quad 2.264 \mathrm{E}-01 \quad 0.000 \mathrm{E}+00$ $\begin{array}{lllllll}1.675 E-26 & 5.101 \mathrm{E}-26 & 3.909 \mathrm{E}-24 & 1.803 \mathrm{E}-23 & 7.463 \mathrm{E}-20 & 3.173 \mathrm{E}-02 & 0.000 \mathrm{E}+00\end{array}$ $0.000 \mathrm{E}+00 \quad 0.000 \mathrm{E}+00 \quad 2.798 \mathrm{E}-28 \quad 2.568 \mathrm{E}-27 \quad 5.295 \mathrm{E}-23 \quad 4.499 \mathrm{E}-04 \quad 0.000 \mathrm{E}+00$ $\begin{array}{lllllllll}2.319 E-21 & 2.359 E-21 & 5.379 E-21 & 1.248 E-20 & 1.044 E-17 & 2.586 E-01 & 0.000 E+00\end{array}$

3.008E-22 4.531E-21 1.975E-16 1.997E-15 2.109E-12 7.095E-04 0.000E+00 3.629E-10 1.095E-09 5.116E-08 1.423E-07 1.032E-05 7.480E+01 $0.000 \mathrm{E}+00$ $\begin{array}{lllllll}1.743 E-15 & 1.227 E-14 & 1.867 E-11 & 1.037 \mathrm{E}-10 & 3.851 \mathrm{E}-08 & 8.241 \mathrm{E}+00 & 0.000 \mathrm{E}+00\end{array}$ $\begin{array}{lllllll}1.236 \mathrm{E}-21 & 1.865 \mathrm{E}-20 & 8.928 \mathrm{E}-16 & 9.885 \mathrm{E}-15 & 1.854 \mathrm{E}-11 & 9.730 \mathrm{E}-02 & 0.000 \mathrm{E}+00\end{array}$ $3.629 \mathrm{E}-10 \quad 1.095 \mathrm{E}-09 \quad 5.118 \mathrm{E}-08 \quad 1.424 \mathrm{E}-07 \quad 1.036 \mathrm{E}-05 \quad 8.314 \mathrm{E}+01 \quad 0.000 \mathrm{E}+00$

$0.000 \mathrm{E}+00 \quad 0.000 \mathrm{E}+00 \quad 2.916 \mathrm{E}-23 \quad 4.931 \mathrm{E}-22 \quad 1.381 \mathrm{E}-18 \quad 3.216 \mathrm{E}-05 \quad 0.000 \mathrm{E}+00$ $\begin{array}{lllllll}1.749 \mathrm{E}-18 & 1.222 \mathrm{E}-17 & 1.249 \mathrm{E}-14 & 5.113 \mathrm{E}-14 & 7.402 \mathrm{E}-12 & 3.403 \mathrm{E}+00 & 0.000 \mathrm{E}+00\end{array}$ $\begin{array}{llllllll}6.310 \mathrm{E}-24 & 9.466 \mathrm{E}-23 & 3.388 \mathrm{E}-18 & 2.979 \mathrm{E}-17 & 2.590 \mathrm{E}-14 & 3.735 \mathrm{E}-01 & 0.000 \mathrm{E}+00\end{array}$ $0.000 \mathrm{E}+00 \quad 0.000 \mathrm{E}+00 \quad 1.297 \mathrm{E}-22 \quad 2.380 \mathrm{E}-21 \quad 1.176 \mathrm{E}-17 \quad 4.394 \mathrm{E}-03 \quad 0.000 \mathrm{E}+00$ $\begin{array}{lllllll}1.749 \mathrm{E}-18 & 1.222 \mathrm{E}-17 & 1.250 \mathrm{E}-14 & 5.116 \mathrm{E}-14 & 7.428 \mathrm{E}-12 & 3.781 \mathrm{E}+00 & 0.000 \mathrm{E}+00\end{array}$

$4.161 \mathrm{E}-17 \quad 4.211 \mathrm{E}-17 \quad 7.560 \mathrm{E}-17 \quad 1.373 \mathrm{E}-16 \quad 1.629 \mathrm{E}-14 \quad 6.544 \mathrm{E}-02 \quad 0.000 \mathrm{E}+00$

$2.124 \mathrm{E}-23 \quad 6.441 \mathrm{E}-23 \quad 3.969 \mathrm{E}-21 \quad 1.465 \mathrm{E}-20 \quad 1.019 \mathrm{E}-17 \quad 1.517 \mathrm{E}-05 \quad 0.000 \mathrm{E}+00$ $7.771 \mathrm{E}-15 \quad 7.867 \mathrm{E}-15 \quad 1.442 \mathrm{E}-14 \quad 2.675 \mathrm{E}-14 \quad 3.756 \mathrm{E}-12 \quad 3.150 \mathrm{E}-01 \quad 0.000 \mathrm{E}+00$ $\begin{array}{lllllll}7.771 E-15 & 7.867 \mathrm{E}-15 & 1.442 \mathrm{E}-14 & 2.675 \mathrm{E}-14 & 3.756 \mathrm{E}-12 & 3.150 \mathrm{E}-01 & 0.000 \mathrm{E}+00\end{array}$ 
RESRAD, Version $6.5 \quad \mathrm{~T}^{1 / 2}$ Limit $=180$ days

ummary : C746U Recreational User Deterministic Run

File : $\mathrm{X}: \backslash F$ INAL V2 \DOE FWD RUNS \C746U RU DOE SG FWD-FV2-100000YR.RAD

Individual Nuclide Dose Summed Over All Pathways

Parent Nuclide and Branch Fraction Indicated

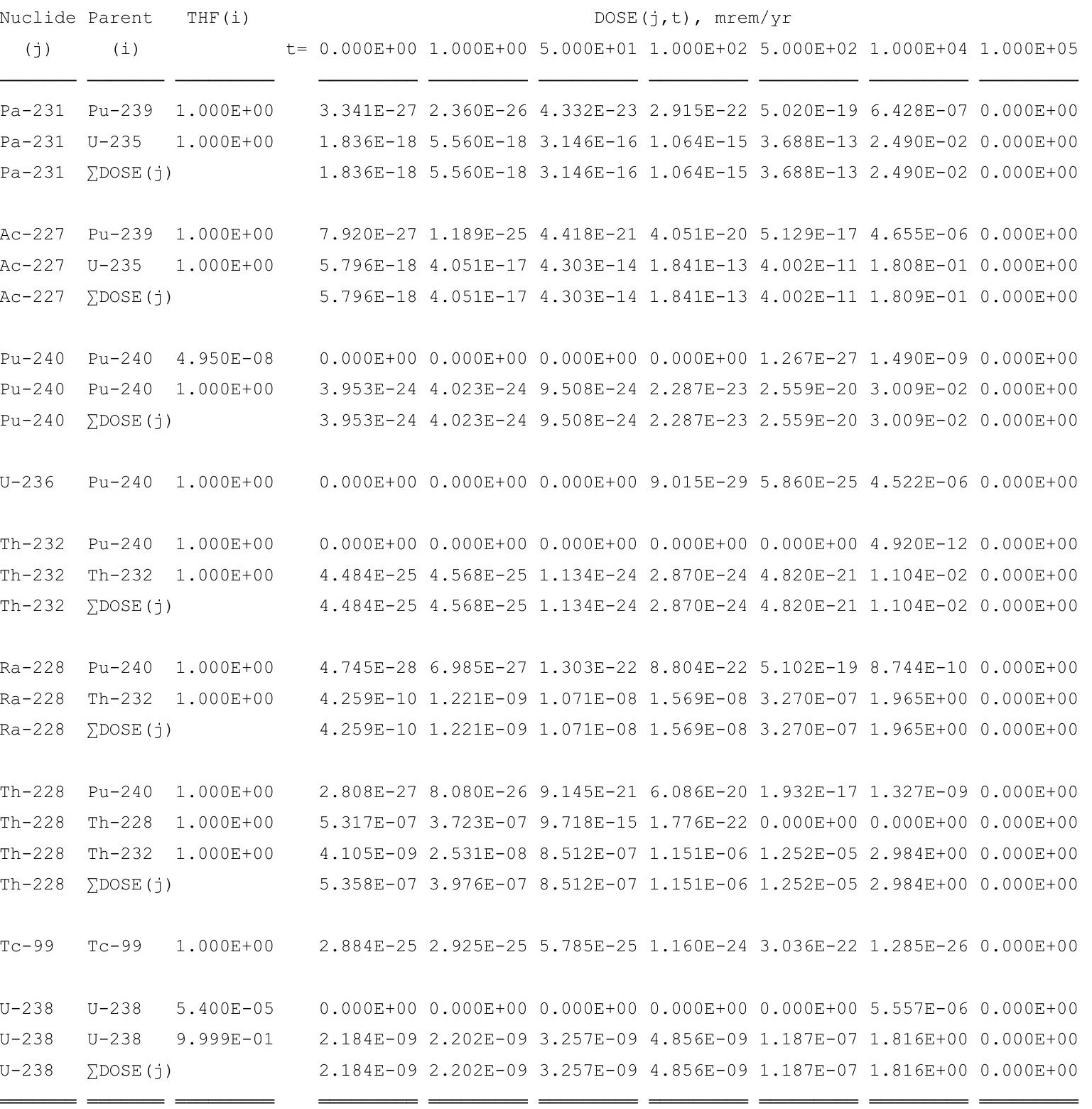

THF (i) is the thread fraction of the parent nuclide. 
RESRAD, Version 6.5

Summary : C746U Recreational User Deterministic Rur

File : $X: \backslash F I N A L$ V2 \DOE FWD RUNS \C746U RU DOE SG FWD-FV2-100000YR.RAD

Individual Nuclide Soil Concentration

Parent Nuclide and Branch Fraction Indicated

Nuclide Parent THF(

\section{(j)}

(i)

$A m-241$

Np-237

Np-237

Np-237

$\mathrm{U}-233$

$\mathrm{U}-233$

$\mathrm{U}-233$

Th-229

Th-229

Th-229

Cs -137

$\mathrm{Pu}-238$

$\mathrm{Pu}-238$

$\mathrm{Pu}-238$

$\mathrm{U}-234$

$\mathrm{U}-234$

$\mathrm{U}-234$

$\mathrm{U}-234$

Th-230

Th -230

Th-230

Th -230

Th-230

$\mathrm{Ra}-226$

$\mathrm{Ra}-226$

$\mathrm{Ra}-226$

$\mathrm{Ra}-226$

$\operatorname{Ra}-226$

$\mathrm{Pb}-210$

$\mathrm{Pb}-210$

$\mathrm{Pb}-210$

$\mathrm{Pb}-210$

$\mathrm{Pb}-210$

$\mathrm{Pu}-239$

$\mathrm{Pu}-239 \quad 1.000 \mathrm{E}+00$ $\mathrm{U}-235 \quad 1.000 \mathrm{E}+00$

$\sum S(j):$
$\mathrm{S}(j, \mathrm{t}), \mathrm{pCi} / \mathrm{g}$

$\mathrm{t}=0.000 \mathrm{E}+00 \quad 1.000 \mathrm{E}+00 \quad 5.000 \mathrm{E}+01 \quad 1.000 \mathrm{E}+02 \quad 5.000 \mathrm{E}+02 \quad 1.000 \mathrm{E}+04 \quad 1.000 \mathrm{E}+05$

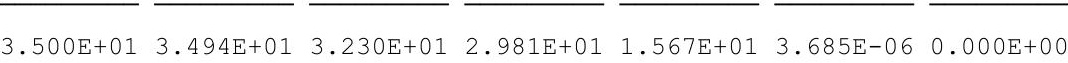

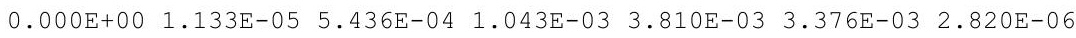
$\begin{array}{lllllll}5.500 \mathrm{E}+00 & 5.500 \mathrm{E}+00 & 5.478 \mathrm{E}+00 & 5.457 \mathrm{E}+00 & 5.288 \mathrm{E}+00 & 2.502 \mathrm{E}+00 & 2.090 \mathrm{E}-03\end{array}$ $\begin{array}{lllllll}5.500 \mathrm{E}+00 & 5.500 \mathrm{E}+00 & 5.479 \mathrm{E}+00 & 5.458 \mathrm{E}+00 & 5.291 \mathrm{E}+00 & 2.506 \mathrm{E}+00 & 2.093 \mathrm{E}-03\end{array}$

$\begin{array}{lllllll}0.000 \mathrm{E}+00 & 2.477 \mathrm{E}-11 & 6.025 \mathrm{E}-08 & 2.344 \mathrm{E}-07 & 4.742 \mathrm{E}-06 & 1.863 \mathrm{E}-04 & 8.634 \mathrm{E}-05\end{array}$ $\begin{array}{llllllll}0.000 \mathrm{E}+00 & 2.405 \mathrm{E}-05 & 1.200 \mathrm{E}-03 & 2.394 \mathrm{E}-03 & 1.174 \mathrm{E}-02 & 1.508 \mathrm{E}-01 & 6.656 \mathrm{E}-02\end{array}$ $0.000 \mathrm{E}+00 \quad 2.405 \mathrm{E}-05 \quad 1.200 \mathrm{E}-03 \quad 2.394 \mathrm{E}-03 \quad 1.174 \mathrm{E}-02 \quad 1.509 \mathrm{E}-01 \quad 6.665 \mathrm{E}-02$

$0.000 \mathrm{E}+00 \quad 7.799 \mathrm{E}-16 \quad 9.538 \mathrm{E}-11 \quad 7.463 \mathrm{E}-10 \quad 7.873 \mathrm{E}-08 \quad 7.107 \mathrm{E}-05 \quad 1.033 \mathrm{E}-04$ $0.000 \mathrm{E}+00 \quad 1.136 \mathrm{E}-09 \quad 2.830 \mathrm{E}-06 \quad 1.128 \mathrm{E}-05 \quad 2.750 \mathrm{E}-04 \quad 6.062 \mathrm{E}-02 \quad 7.967 \mathrm{E}-02$

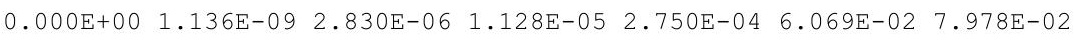

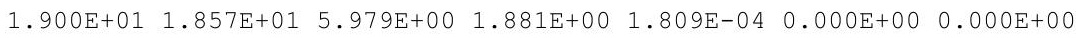

$\begin{array}{lllllll}7.176 \mathrm{E}-08 & 7.119 \mathrm{E}-08 & 4.832 \mathrm{E}-08 & 3.254 \mathrm{E}-08 & 1.375 \mathrm{E}-09 & 3.170 \mathrm{E}-42 & 0.000 \mathrm{E}+00\end{array}$ $\begin{array}{llllllllllll}3.900 \mathrm{E}+01 & 3.869 \mathrm{E}+01 & 2.626 \mathrm{E}+01 & 1.768 \mathrm{E}+01 & 7.472 \mathrm{E}-01 & 1.731 \mathrm{E}-33 & 0.000 \mathrm{E}+00\end{array}$ $\begin{array}{llllllllll}3.900 \mathrm{E}+01 & 3.869 \mathrm{E}+01 & 2.626 \mathrm{E}+01 & 1.768 \mathrm{E}+01 & 7.472 \mathrm{E}-01 & 1.731 \mathrm{E}-33 & 0.000 \mathrm{E}+00\end{array}$

$0.000 \mathrm{E}+00 \quad 1.101 \mathrm{E}-04 \quad 4.564 \mathrm{E}-03 \quad 7.633 \mathrm{E}-03 \quad 1.362 \mathrm{E}-02 \quad 1.191 \mathrm{E}-02 \quad 2.763 \mathrm{E}-03$

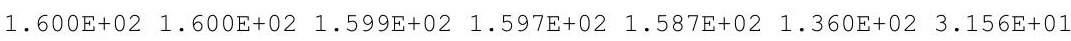
$\begin{array}{llllllll}0.000 \mathrm{E}+00 & 4.536 \mathrm{E}-04 & 2.266 \mathrm{E}-02 & 4.529 \mathrm{E}-02 & 2.251 \mathrm{E}-01 & 3.911 \mathrm{E}+00 & 1.034 \mathrm{E}+01\end{array}$ $\begin{array}{llllll}1.600 \mathrm{E}+02 & 1.600 \mathrm{E}+02 & 1.599 \mathrm{E}+02 & 1.598 \mathrm{E}+02 & 1.589 \mathrm{E}+02 & 1.399 \mathrm{E}+02 \quad 4.191 \mathrm{E}+01\end{array}$

$0.000 \mathrm{E}+00 \quad 4.963 \mathrm{E}-10 \quad 1.095 \mathrm{E}-06 \quad 3.884 \mathrm{E}-06 \quad 4.705 \mathrm{E}-05 \quad 1.088 \mathrm{E}-03 \quad 3.313 \mathrm{E}-03$ $\begin{array}{lllllllll}1.000 \mathrm{E}+02 & 1.000 \mathrm{E}+02 & 9.995 \mathrm{E}+01 & 9.989 \mathrm{E}+01 & 9.947 \mathrm{E}+01 & 8.984 \mathrm{E}+01 & 3.424 \mathrm{E}+01\end{array}$ $\begin{array}{llllllllll}0.000 \mathrm{E}+00 & 1.440 \mathrm{E}-03 & 7.197 \mathrm{E}-02 & 1.438 \mathrm{E}-01 & 7.153 \mathrm{E}-01 & 1.259 \mathrm{E}+01 & 3.791 \mathrm{E}+01\end{array}$ $\begin{array}{lllllll}0.000 \mathrm{E}+00 & 2.041 \mathrm{E}-09 & 5.100 \mathrm{E}-06 & 2.039 \mathrm{E}-05 & 5.070 \mathrm{E}-04 & 1.785 \mathrm{E}-01 & 5.353 \mathrm{E}+00\end{array}$

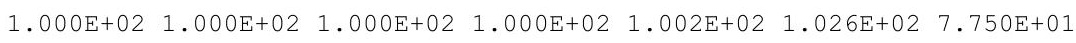

$0.000 \mathrm{E}+00 \quad 7.171 \mathrm{E}-14 \quad 8.112 \mathrm{E}-09 \quad 5.891 \mathrm{E}-08 \quad 3.952 \mathrm{E}-06 \quad 8.404 \mathrm{E}-04 \quad 3.253 \mathrm{E}-03$ $\begin{array}{llllllll}0.000 \mathrm{E}+00 & 4.331 \mathrm{E}-02 & 2.142 \mathrm{E}+00 & 4.235 \mathrm{E}+00 & 1.937 \mathrm{E}+01 & 8.860 \mathrm{E}+01 & 3.422 \mathrm{E}+01\end{array}$ $\begin{array}{llllllll}0.000 \mathrm{E}+00 & 3.119 \mathrm{E}-07 & 7.739 \mathrm{E}-04 & 3.071 \mathrm{E}-03 & 7.220 \mathrm{E}-02 & 9.761 \mathrm{E}+00 & 3.722 \mathrm{E}+01\end{array}$

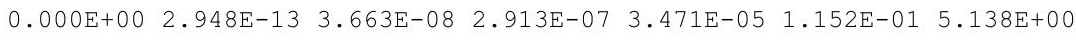
$\begin{array}{llllllll}0.000 \mathrm{E}+00 & 4.331 \mathrm{E}-02 & 2.142 \mathrm{E}+00 & 4.238 \mathrm{E}+00 & 1.944 \mathrm{E}+01 & 9.848 \mathrm{E}+01 & 7.658 \mathrm{E}+01\end{array}$

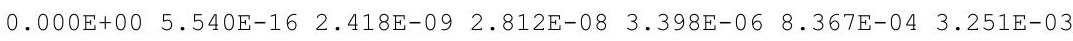
$\begin{array}{lllllllll}0.000 \mathrm{E}+00 & 6.663 \mathrm{E}-04 & 1.058 \mathrm{E}+00 & 2.946 \mathrm{E}+00 & 1.823 \mathrm{E}+01 & 8.856 \mathrm{E}+01 & 3.421 \mathrm{E}+01\end{array}$ $\begin{array}{lllllll}0.000 \mathrm{E}+00 & 3.207 \mathrm{E}-09 & 2.837 \mathrm{E}-04 & 1.706 \mathrm{E}-03 & 6.374 \mathrm{E}-02 & 9.719 \mathrm{E}+00 & 3.720 \mathrm{E}+01\end{array}$ $0.000 \mathrm{E}+00 \quad 2.276 \mathrm{E}-15 \quad 1.075 \mathrm{E}-08 \quad 1.356 \mathrm{E}-07 \quad 2.889 \mathrm{E}-05 \quad 1.143 \mathrm{E}-01 \quad 5.133 \mathrm{E}+00$ $\begin{array}{lllllll}0.000 \mathrm{E}+00 & 6.663 \mathrm{E}-04 & 1.058 \mathrm{E}+00 & 2.947 \mathrm{E}+00 & 1.830 \mathrm{E}+01 & 9.839 \mathrm{E}+01 & 7.654 \mathrm{E}+01\end{array}$ $\begin{array}{llllllll}3.600 \mathrm{E}+01 & 3.600 \mathrm{E}+01 & 3.593 \mathrm{E}+01 & 3.586 \mathrm{E}+01 & 3.531 \mathrm{E}+01 & 2.443 \mathrm{E}+01 & 7.441 \mathrm{E}-01\end{array}$

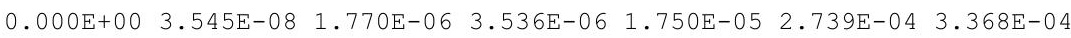
$\begin{array}{llllllll}6.500 \mathrm{E}+00 & 6.500 \mathrm{E}+00 & 6.496 \mathrm{E}+00 & 6.491 \mathrm{E}+00 & 6.457 \mathrm{E}+00 & 5.685 \mathrm{E}+00 & 1.702 \mathrm{E}+00\end{array}$

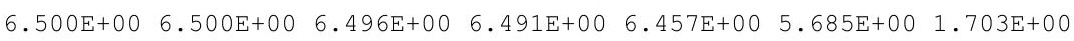


RESRAD, Version $6.5 \quad \mathrm{~T}^{1 / 2}$ Limit $=180$ days

mmary : C746U Recreational User Deterministic Run

File : $\mathrm{X}: \backslash F I N A L$ V2 $\backslash$ DOE FWD RUNS $\backslash C 746 U$ RU DOE SG FWD-FV2-100000YR.RAD

Individual Nuclide Soil Concentration

Parent Nuclide and Branch Fraction Indicated

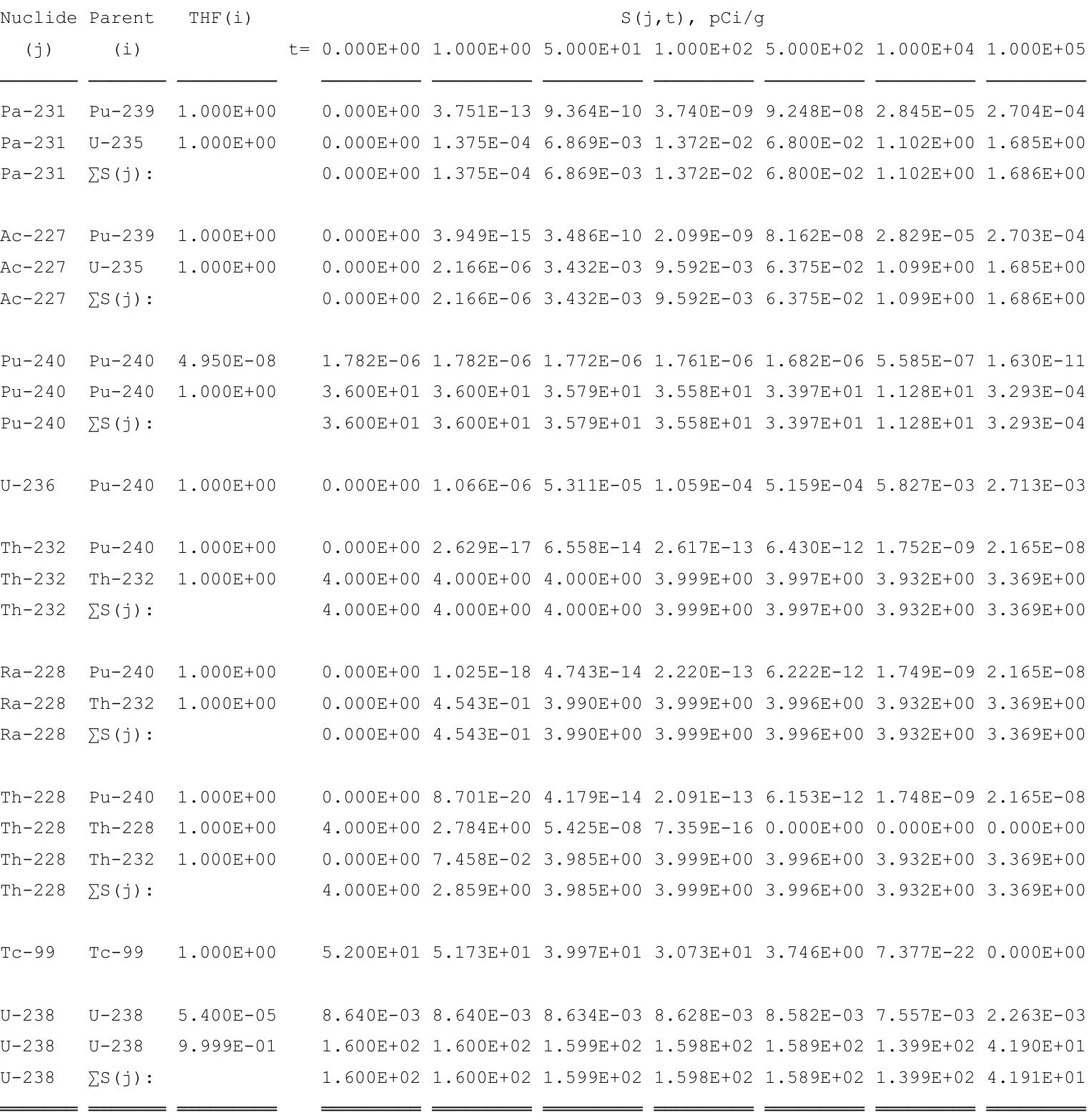

THF(i) is the thread fraction of the parent nuclide.

RESCALC.EXE execution time $=8.04$ seconds 


\section{Outdoor Worker}

\section{Summary Report \\ (Deterministic Analysis Report)}

First Peak Dose Assessment

Time Horizon: 1,050 yr 
THIS PAGE INTENTIONALLY LEFT BLANK 
RESRAD, Version 6.5

Summary : C746U Worker Deterministic Run

File : $\mathrm{X}: \backslash$ FINAL V2 \DOE FWD RUNS \C746U W DOE SG FWD-FV2-1050YR.RAD

Table of Contents

Part I: Mixture Sums and Single Radionuclide Guidelines

Dose Conversion Factor (and Related) Parameter Summary ... 2

Site-Specific Parameter Summary $\ldots \ldots \ldots \ldots \ldots \ldots \ldots \ldots \ldots$

Summary of Pathway Selections ................... 18

Contaminated Zone and Total Dose Summary ............. 19

Total Dose Components

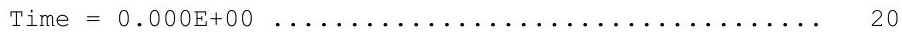

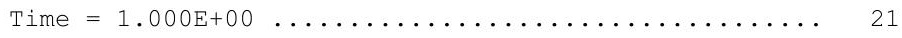

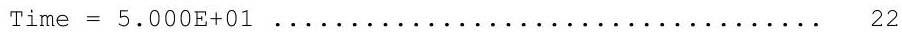

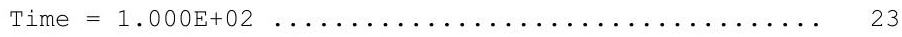

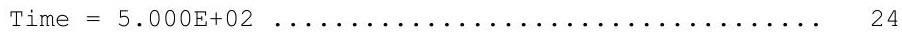

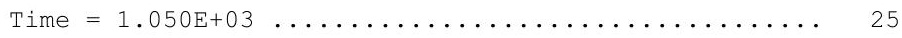

Dose/Source Ratios Summed Over All Pathways ............ 26

Single Radionuclide Soil Guidelines ................ 28

Dose Per Nuclide Summed Over All Pathways ............. 29

Soil Concentration Per Nuclide ................. 31 
RESRAD, Version $6.5 \quad T^{1 / 2}$ Limit $=180$ days

Summary : C746U Worker Deterministic Run

File : $\mathrm{X}: \backslash F I N A L$ V2 $\backslash$ DOE FWD RUNS $\backslash$ C746U W DOE SG FWD-FV2-1050YR.RAD

Dose Conversion Factor (and Related) Parameter Summary

Dose Library: ICRP 60 \& ICRP 72 (Adult)

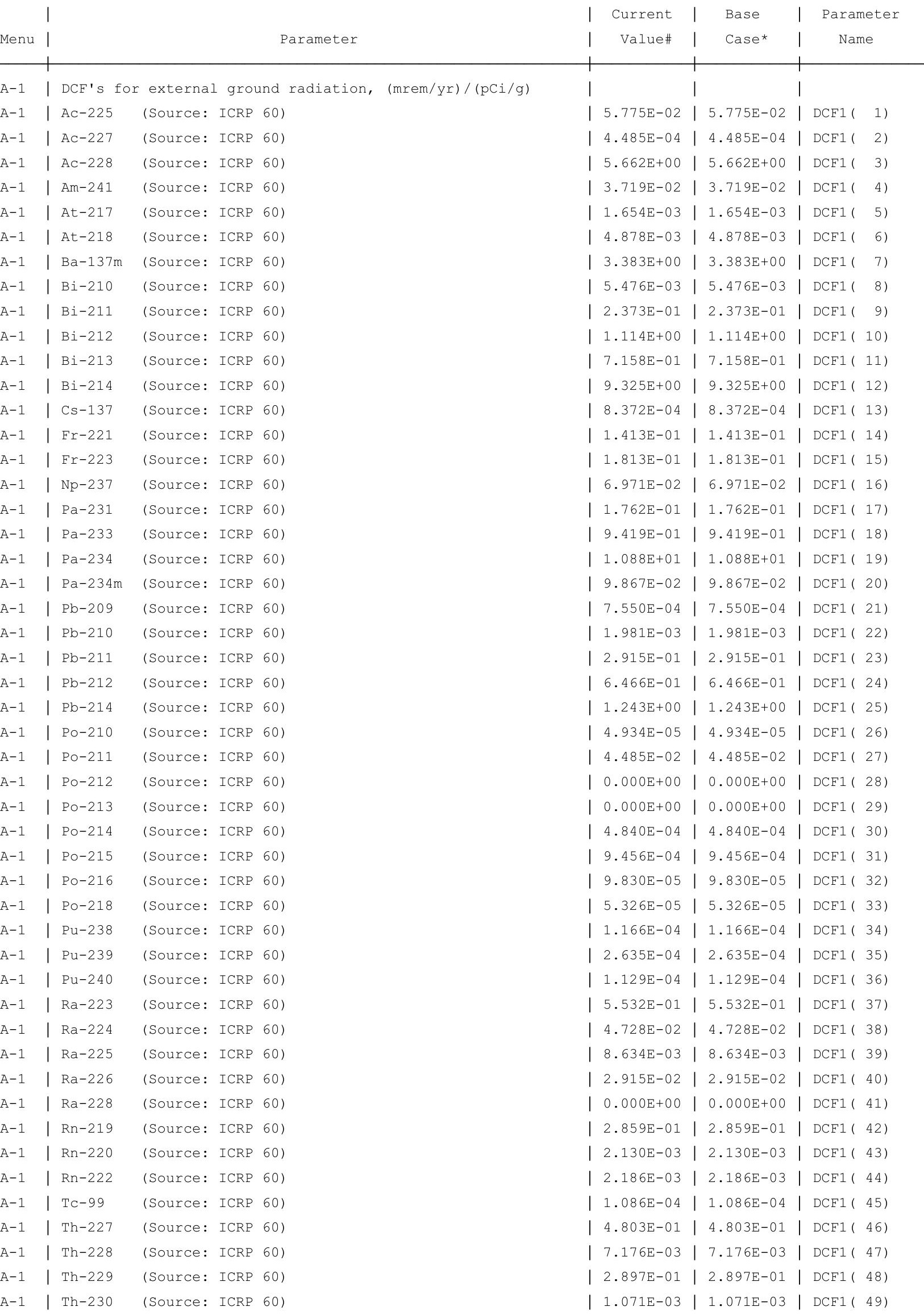


RESRAD, Version $6.5 \quad T^{1 / 2}$ Limit $=180$ days

Summary : C746U Worker Deterministic Run

File : $\mathrm{X}: \backslash F I N A L$ V2 $\backslash$ DOE FWD RUNS \C746U W DOE SG FWD-FV2-1050YR.RAD

Dose Conversion Factor (and Related) Parameter Summary (continued)

Dose Library: ICRP 60 \& ICRP 72 (Adult)

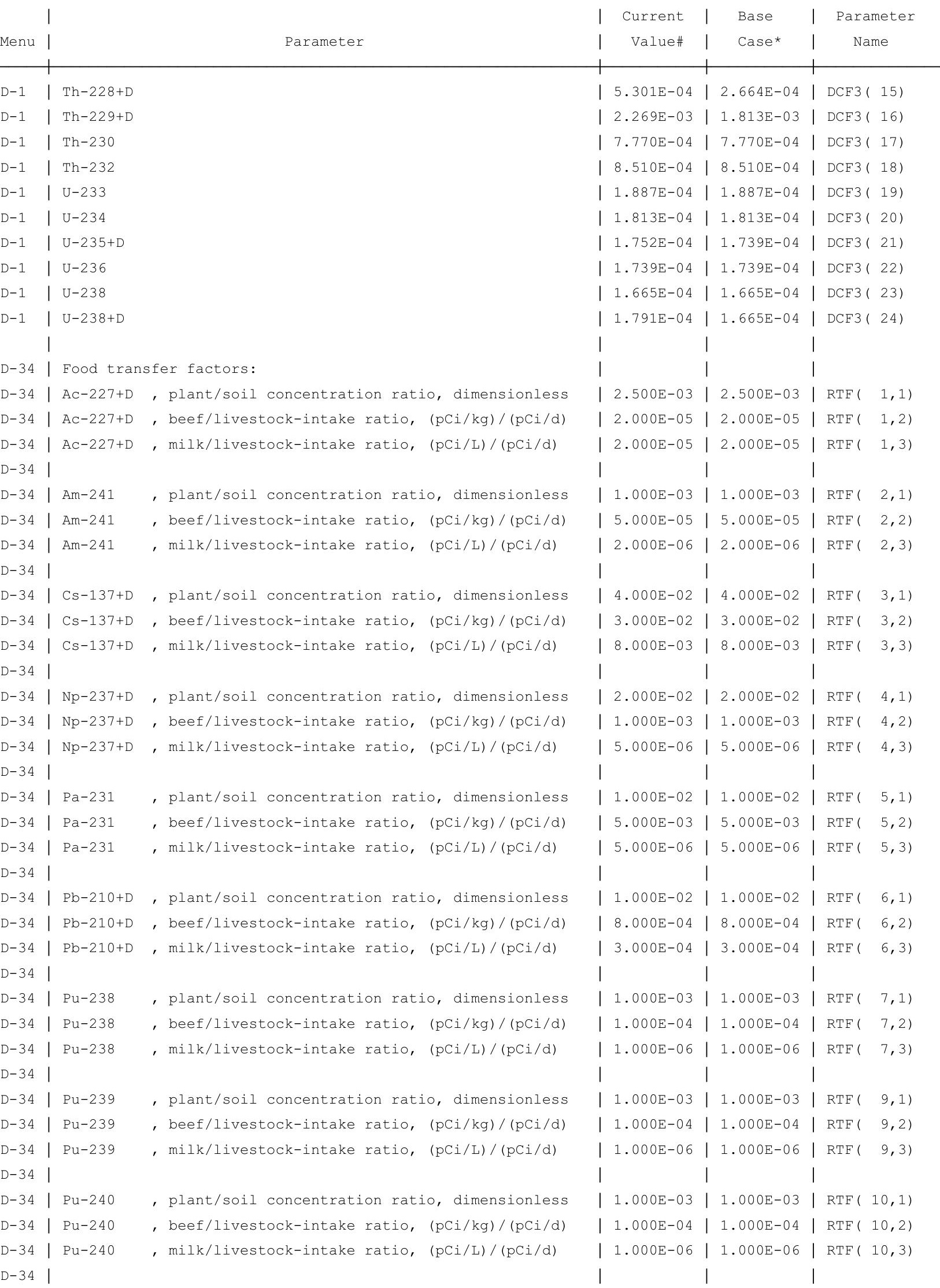


RESRAD, Version $6.5 \quad \mathrm{~T}^{1 / 2}$ Limit $=180$ days

Summary : C746U Worker Deterministic Run

File : X: $\backslash F I N A L$ V2 $\backslash$ DOE FWD RUNS \C746U W DOE SG FWD-FV2-1050YR. RAD

Dose Conversion Factor (and Related) Parameter Summary (continued)

Dose Library: ICRP 60 \& ICRP 72 (Adult)

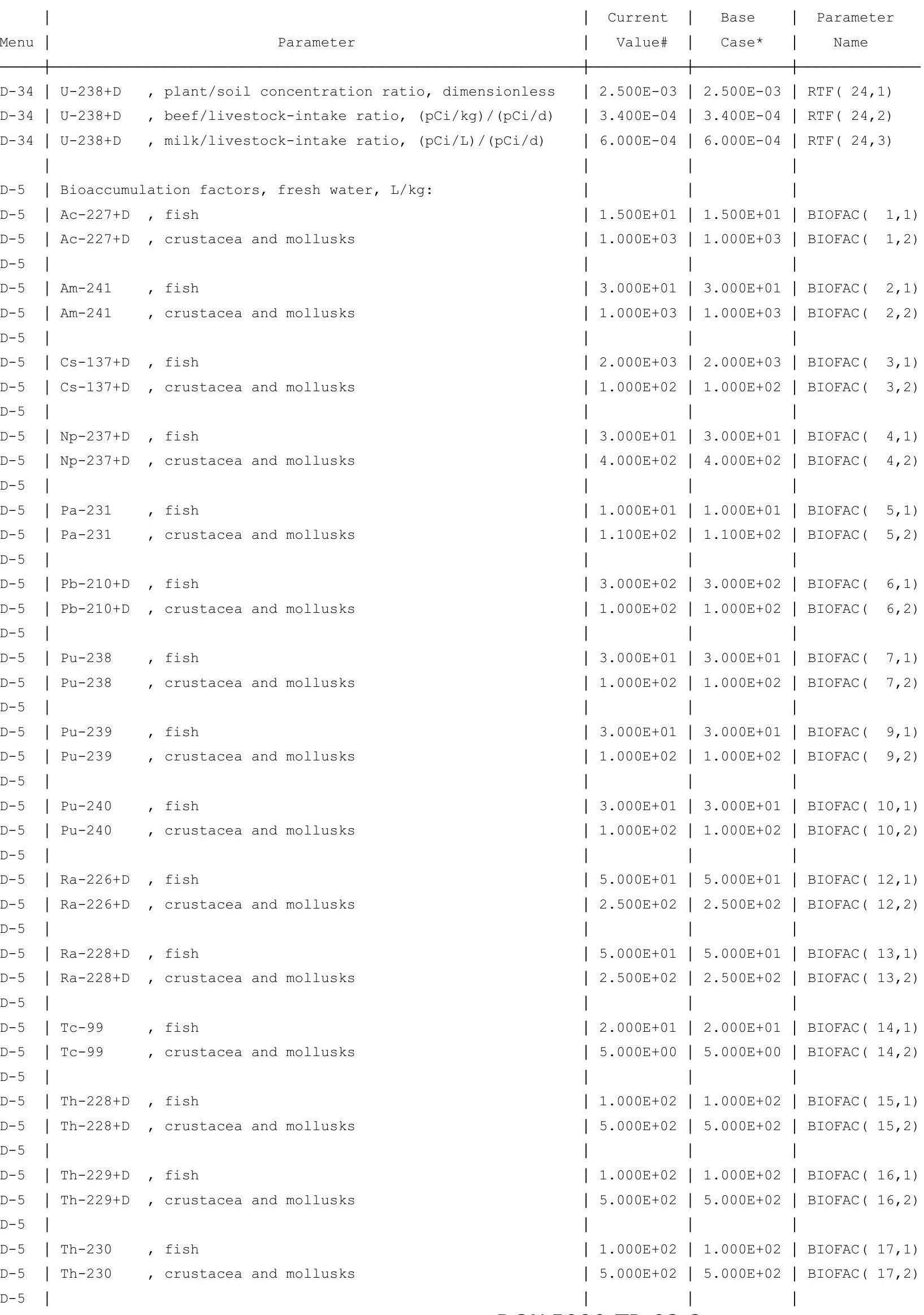


RESRAD, Version 6.5

Summary : C746U Worker Deterministic Run

File : $\mathrm{X}: \backslash F I N A L$ V2 $\backslash$ DOE FWD RUNS \C746U W DOE SG FWD-FV2-1050YR.RAD

Dose Conversion Factor (and Related) Parameter Summary (continued)

Dose Library: ICRP 60 \& ICRP 72 (Adult)

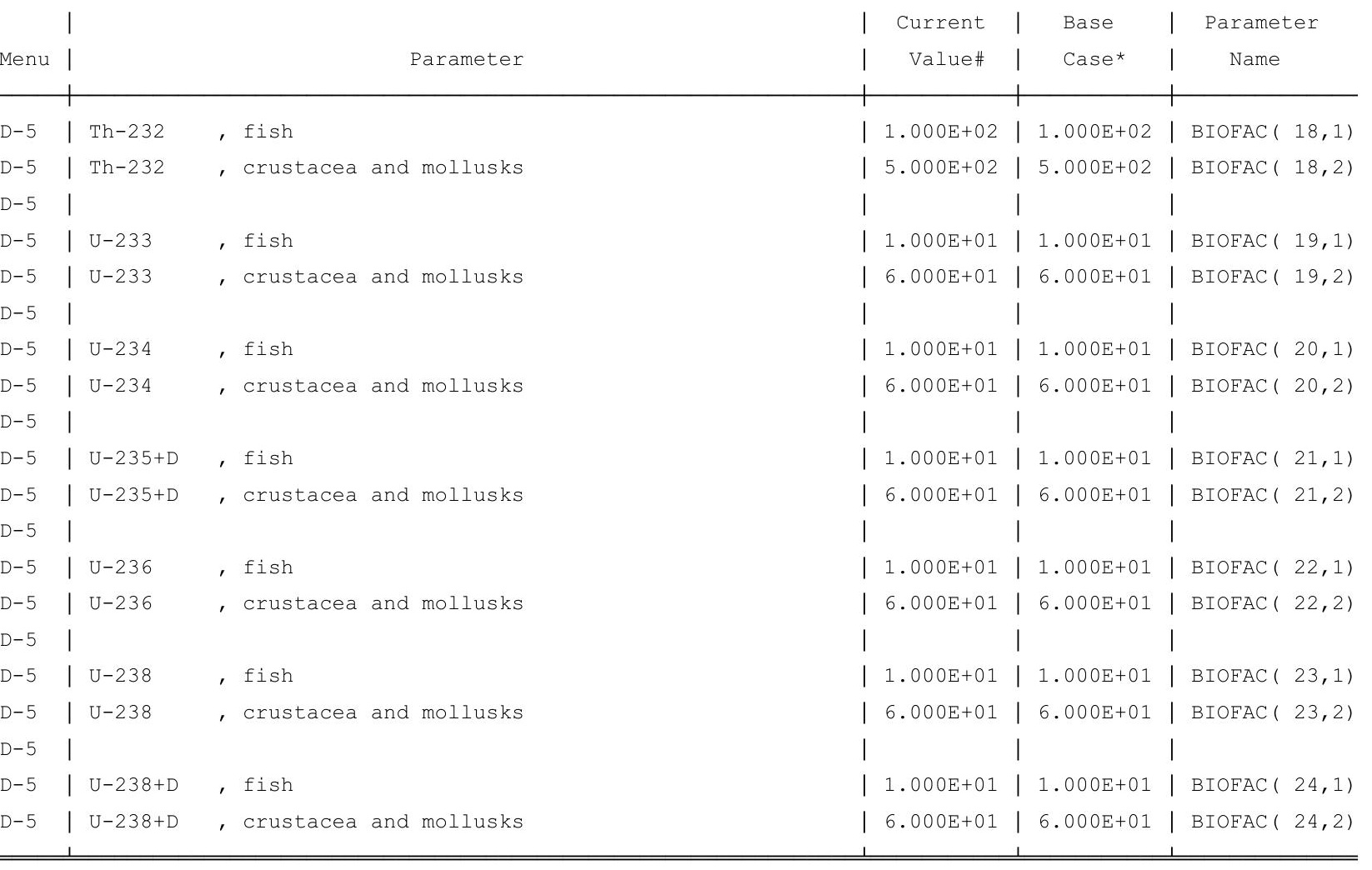

\#For DCFl(xxx) only, factors are for infinite depth \& area. See ETFG table in Ground Pathway of Detailed Report. *Base Case means Default.Lib w/o Associate Nuclide contributions. 
RESRAD, Version $6.5 \quad \mathrm{~T}^{1 / 2}$ Limit $=180$ days

Summary : C746U Worker Deterministic Run

File : $\mathrm{X}: \backslash F I N A L$ V2 $\backslash$ DOE FWD RUNS $\backslash C 746 U$ W DOE SG FWD-FV2-1050YR. RAD

Site-Specific Parameter Summary (continued)

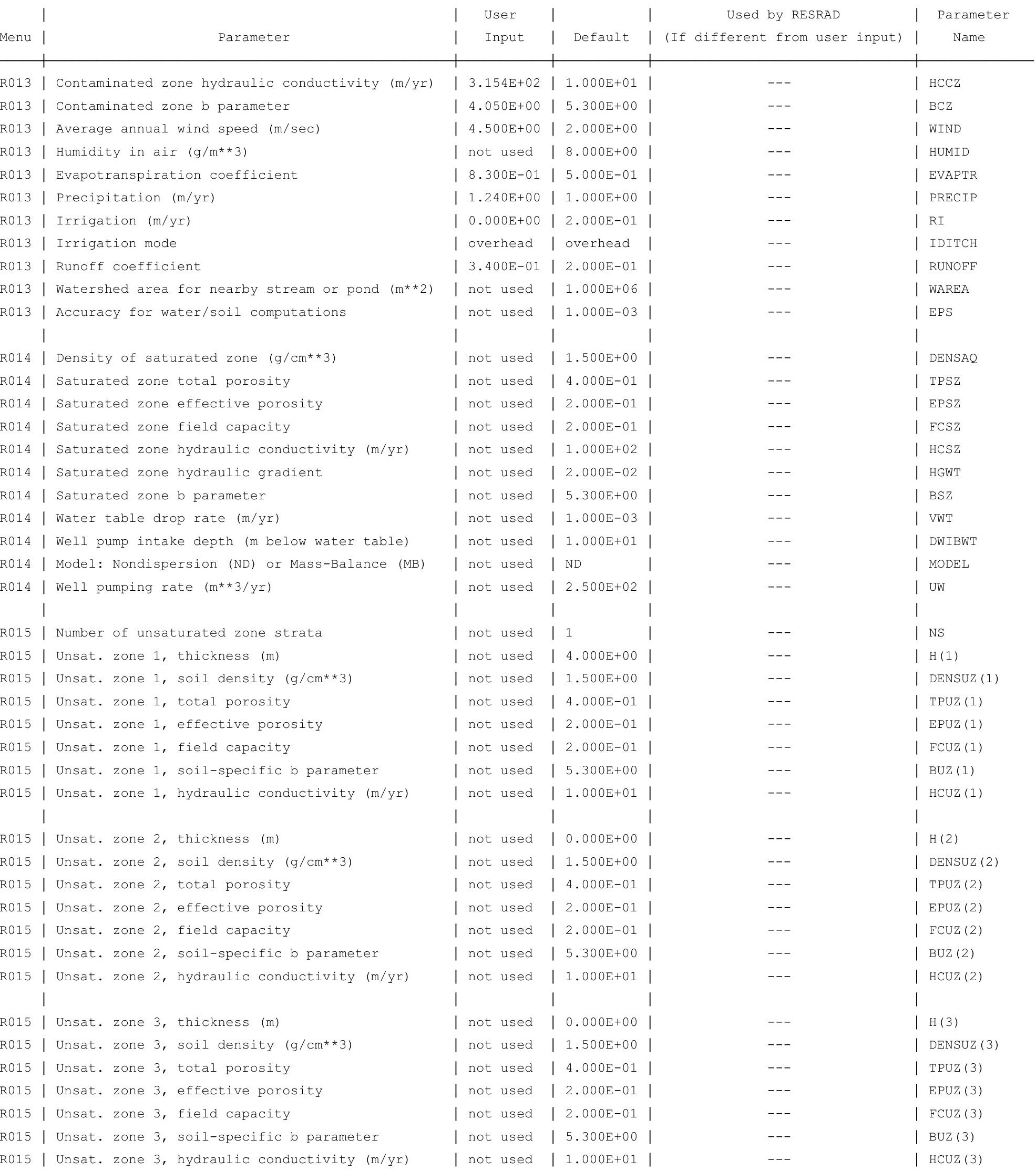


RESRAD, Version $6.5 \quad \mathrm{~T}^{1 / 2}$ Limit $=180$ days

Summary : C746U Worker Deterministic Run

File : $\mathrm{X}: \backslash F I N A L$ V2 $\backslash$ DOE FWD RUNS \C746U W DOE SG FWD-FV2-1050YR.RAD

Site-Specific Parameter Summary (continued)

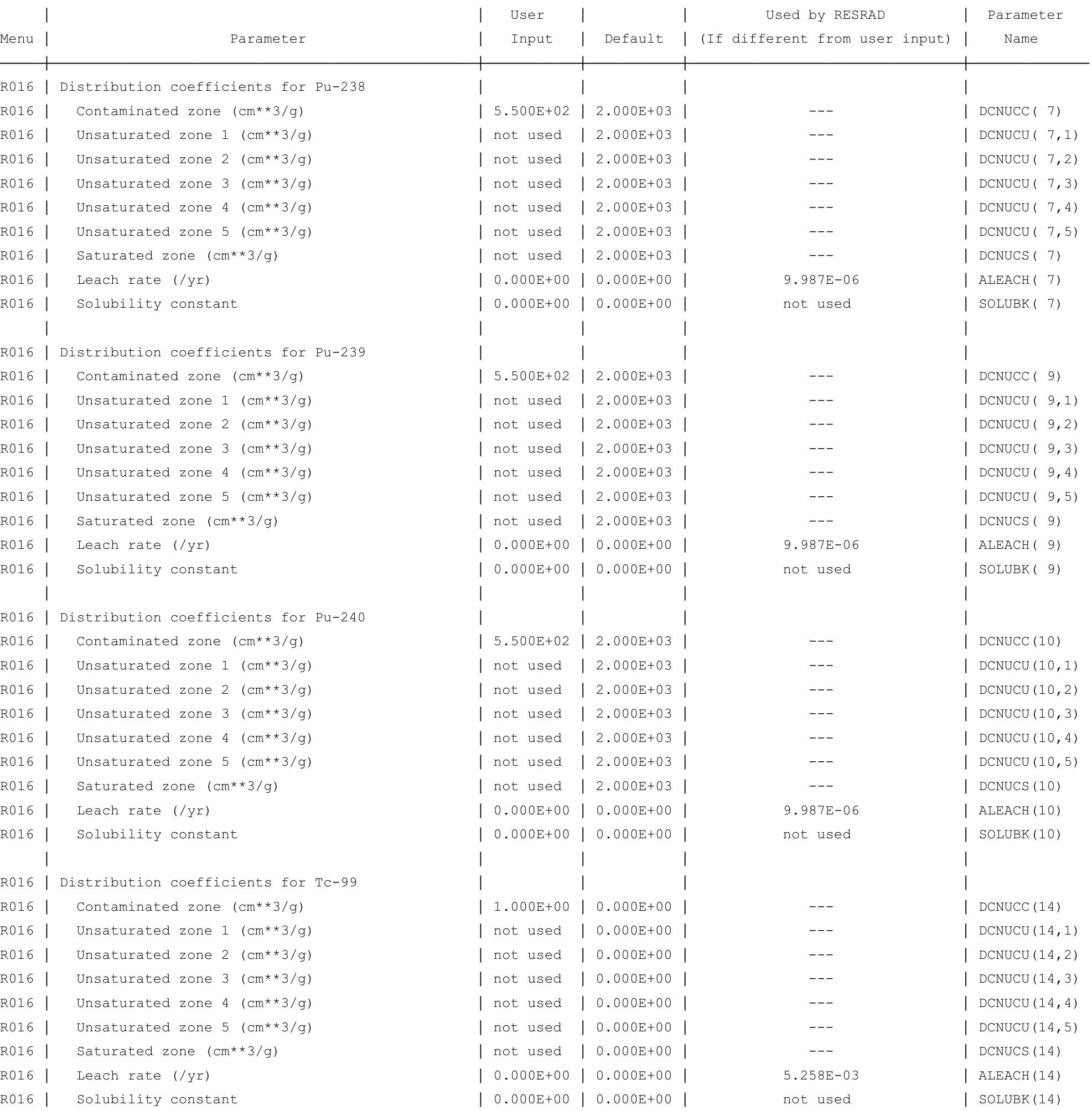


RESRAD, Version $6.5 \quad \mathrm{~T}^{1 / 2}$ Limit $=180$ days

Summary : C746U Worker Deterministic Run

File : $\mathrm{X}: \backslash F I N A L$ V2 $\backslash$ DOE FWD RUNS \C746U W DOE SG FWD-FV2-1050YR.RAD

Site-Specific Parameter Summary (continued)

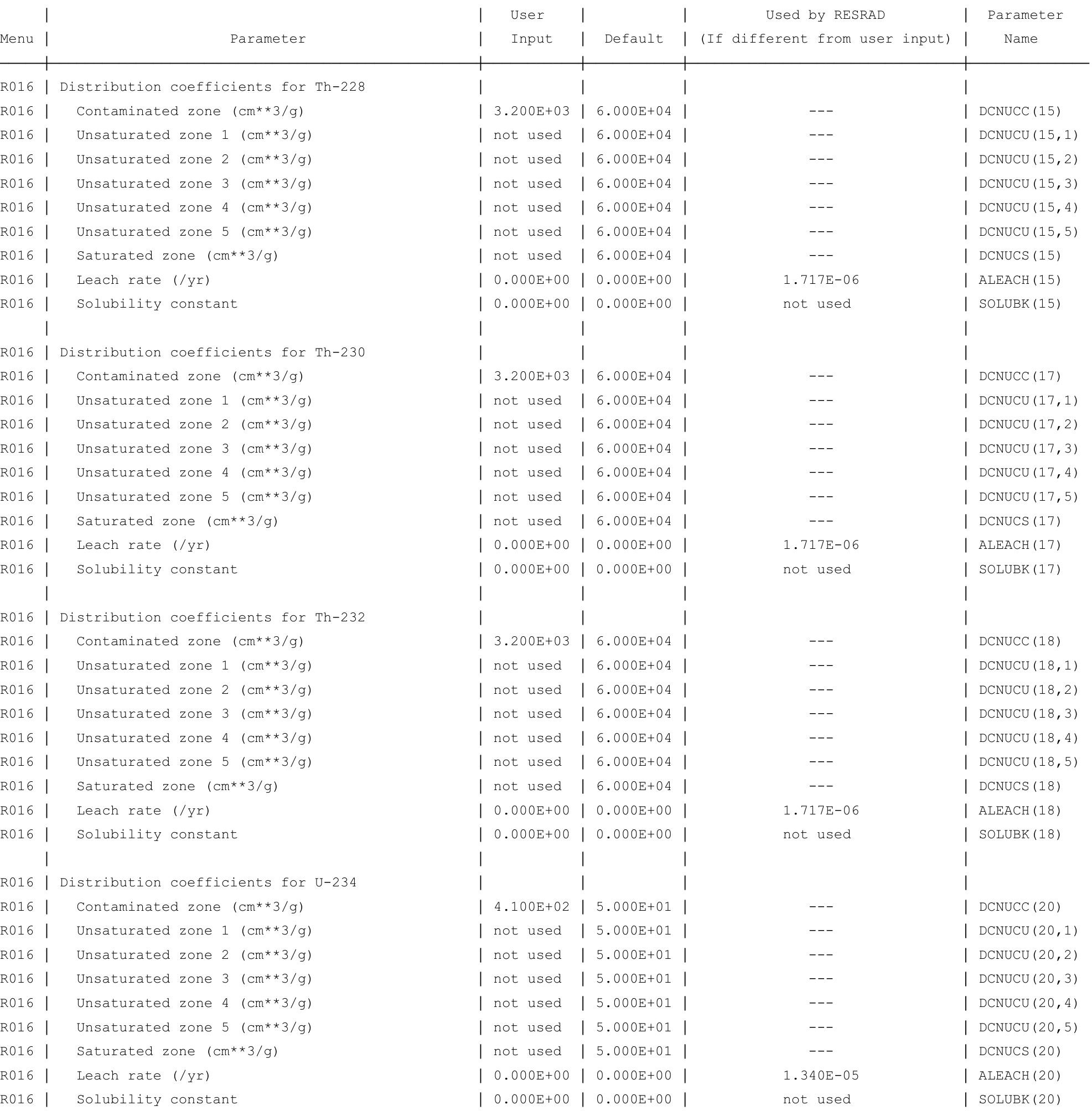


RESRAD, Version $6.5 \quad \mathrm{~T}^{1 / 2}$ Limit $=180$ days

Summary : C746U Worker Deterministic Run

File : $\mathrm{X}: \backslash F I N A L$ V2 $\backslash$ DOE FWD RUNS \C746U W DOE SG FWD-FV2-1050YR. RAD

Site-Specific Parameter Summary (continued)

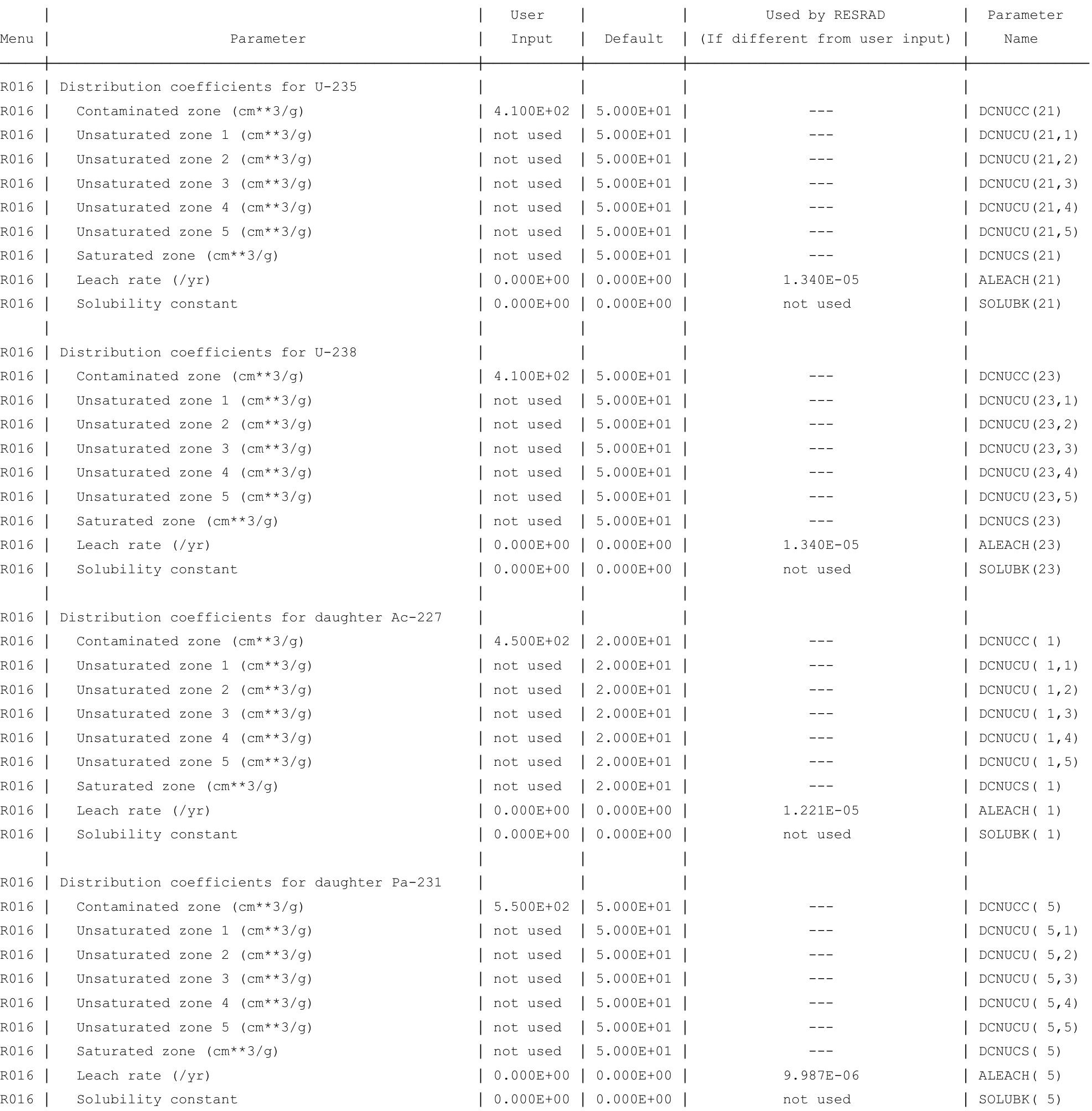


RESRAD, Version $6.5 \quad \mathrm{~T}^{1 / 2}$ Limit $=180$ days

Summary : C746U Worker Deterministic Run

File : $\mathrm{X}: \backslash F I N A L$ V2 $\backslash$ DOE FWD RUNS \C746U W DOE SG FWD-FV2-1050YR. RAD

Site-Specific Parameter Summary (continued)

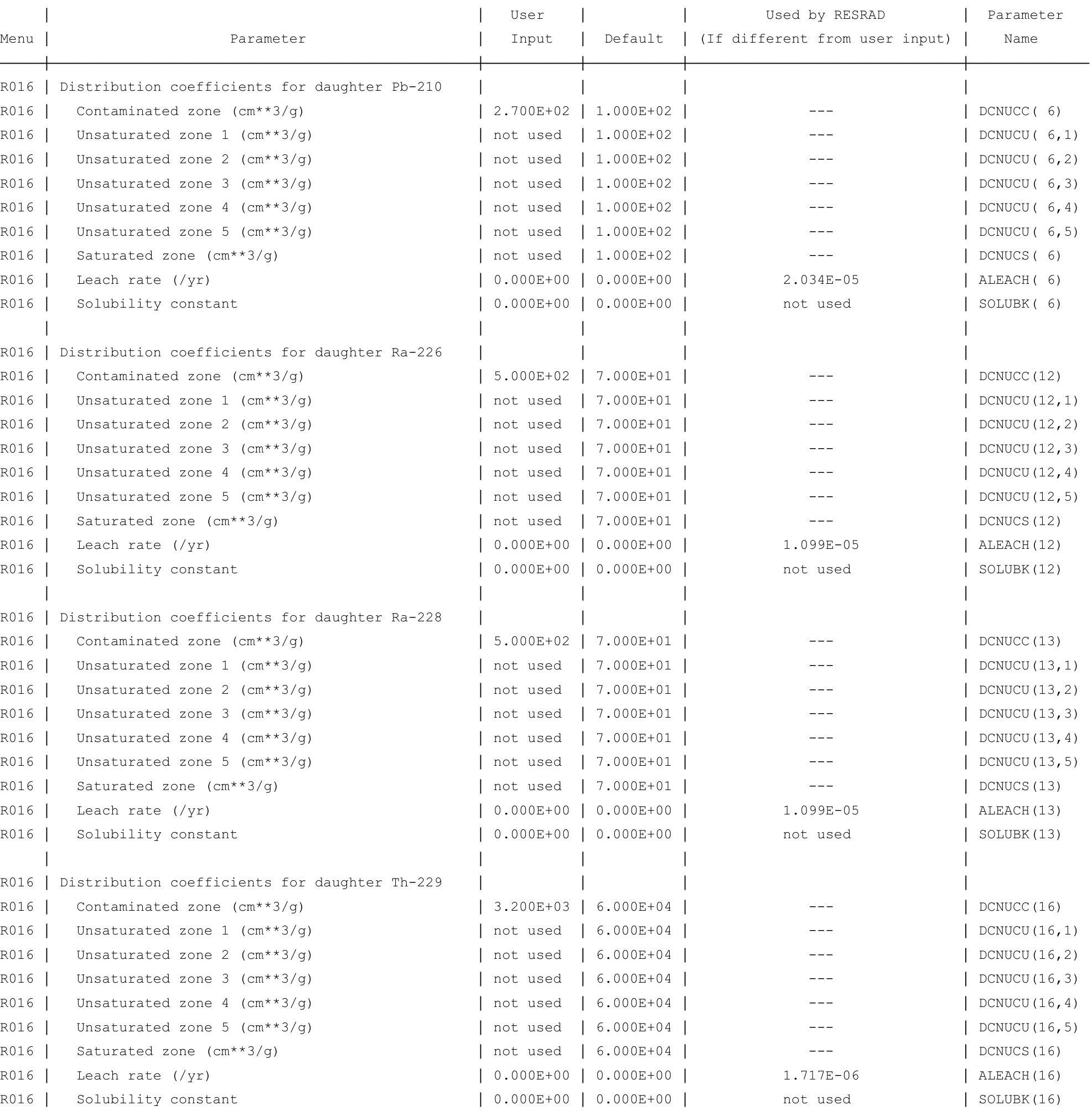


RESRAD, Version $6.5 \quad \mathrm{~T}^{1 / 2}$ Limit $=180$ days

Summary : C746U Worker Deterministic Run

File : $\mathrm{X}: \backslash F I N A L$ V2 $\backslash$ DOE FWD RUNS $\backslash C 746 U$ W DOE SG FWD-FV2-1050YR.RAD

Site-Specific Parameter Summary (continued)

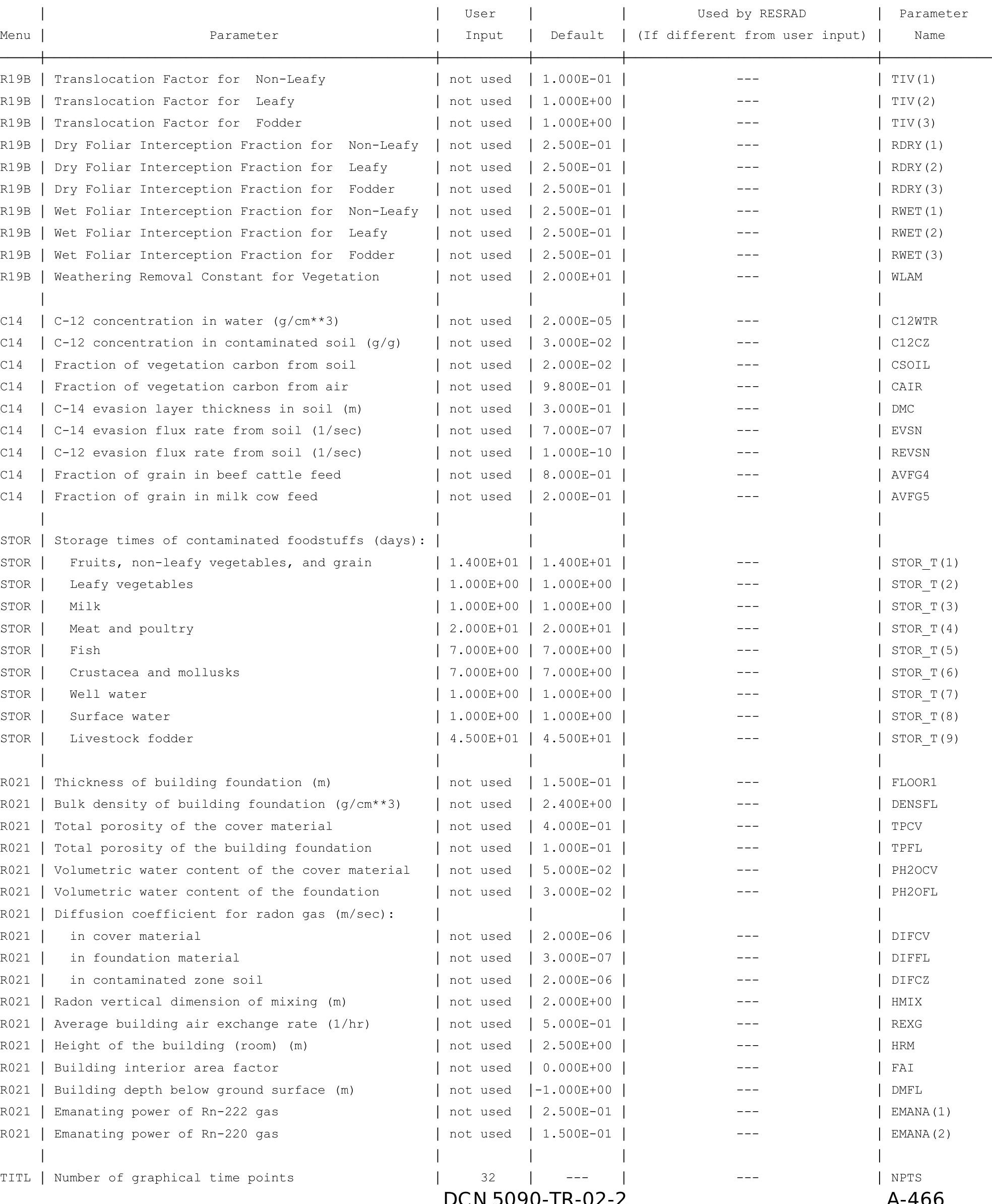


RESRAD, Version $6.5 \quad \mathrm{~T}^{3 / 2}$ Limit $=180$ days

Summary : C746U Worker Deterministic Run

File : $X: \backslash F I N A L$ V2 \DOE FWD RUNS \C746U W DOE SG FWD-FV2-1050YR.RAD

Contaminated Zone Dimensions

Area: $\quad 89436.00$ square meters

Thickness:

Cover Depth:
Initial Soil Concentrations, pci/g

$\begin{array}{ll}\text { Am-241 } & 3.500 \mathrm{E}+01 \\ \mathrm{Cs}-137 & 1.900 \mathrm{E}+01 \\ \mathrm{~Np}-237 & 5.500 \mathrm{E}+00 \\ \mathrm{Pu}-238 & 3.900 \mathrm{E}+01 \\ \mathrm{Pu}-239 & 3.600 \mathrm{E}+01 \\ \mathrm{Pu}-240 & 3.600 \mathrm{E}+01 \\ \mathrm{TC}-99 & 5.200 \mathrm{E}+01 \\ \mathrm{Th}-228 & 4.000 \mathrm{E}+00 \\ \mathrm{Th}-230 & 1.000 \mathrm{E}+02 \\ \mathrm{Th}-232 & 4.000 \mathrm{E}+00 \\ \mathrm{U}-234 & 1.600 \mathrm{E}+02 \\ \mathrm{U}-235 & 6.500 \mathrm{E}+00 \\ \mathrm{U}-238 & 1.600 \mathrm{E}+02\end{array}$

Total Dose TDOSE(t), mrem/yr

Basic Radiation Dose Limit $=1.000 \mathrm{E}+00 \mathrm{mrem} / \mathrm{yr}$

Total Mixture Sum $M(t)$ = Fraction of Basic Dose Limit Received at Time (t)

$\begin{array}{rllllll}t \text { (years }): & 0.000 \mathrm{E}+00 & 1.000 \mathrm{E}+00 & 5.000 \mathrm{E}+01 & 1.000 \mathrm{E}+02 & 5.000 \mathrm{E}+02 & 1.050 \mathrm{E}+03 \\ \mathrm{TDOSE}(\mathrm{t}): & 1.150 \mathrm{E}-06 & 8.594 \mathrm{E}-07 & 1.950 \mathrm{E}-06 & 2.793 \mathrm{E}-06 & 4.957 \mathrm{E}-05 & 2.632 \mathrm{E}-03 \\ \mathrm{M}(\mathrm{t}): & 1.150 \mathrm{E}-06 & 8.594 \mathrm{E}-07 & 1.950 \mathrm{E}-06 & 2.793 \mathrm{E}-06 & 4.957 \mathrm{E}-05 & 2.632 \mathrm{E}-03\end{array}$

Maximum TDOSE $(t): 2.632 \mathrm{E}-03 \mathrm{mrem} / \mathrm{yr}$ at $t=1.050 \mathrm{E}+03$ years 
RESRAD, Version 6.5

$\mathrm{T}^{1 / 2}$ Limit $=180$ days

Summary : C746U Worker Deterministic Run

File : $\mathrm{X}: \backslash F I N A L$ V2 \DOE FWD RUNS \C746U W DOE SG FWD-FV2-1050YR.RAD

Total Dose Contributions TDOSE(i,p,t) for Individual Radionuclides (i) and Pathways (p) As mrem/yr and Fraction of Total Dose At $t=0.000 \mathrm{E}+00$ years

Water Independent Pathways (Inhalation excludes radon)

\begin{tabular}{|c|c|c|c|c|c|c|c|c|c|c|c|c|c|c|}
\hline \multirow{2}{*}{ Nuclide } & \multicolumn{2}{|c|}{ Ground } & \multicolumn{2}{|c|}{ Inhalation } & \multicolumn{2}{|c|}{ Radon } & \multicolumn{2}{|c|}{ Plant } & \multicolumn{2}{|c|}{ Meat } & \multicolumn{2}{|c|}{ Milk } & \multicolumn{2}{|c|}{ Soil } \\
\hline & mrem/yr & fract. & mrem/yr & fract. & mrem/yr & fract. & mrem/yr & fract. & mrem/yr & fract. & mrem/yr & fract. & mrem/yr & fract. \\
\hline-241 & $1.106 \mathrm{E}-18$ & 0.0000 & $0.000 \mathrm{E}+00$ & 0.0000 & $0.000 \mathrm{E}+00$ & 0.0000 & $0.000 \mathrm{E}+00$ & 0.0000 & $0.000 \mathrm{E}+00$ & 0.0000 & $0.000 \mathrm{E}+00$ & 0.0000 & $0.000 \mathrm{E}+00$ & 0.0000 \\
\hline-137 & $4.898 E-09$ & 0.0043 & $0.000 \mathrm{E}+00$ & 0.0000 & $0.000 \mathrm{E}+00$ & 0.0000 & $0.000 \mathrm{E}+00$ & 0.0000 & $0.000 \mathrm{E}+00$ & 0.0000 & $0.000 \mathrm{E}+00$ & 0.0000 & $0.000 \mathrm{E}+00$ & 0.0000 \\
\hline-237 & $1.072 \mathrm{E}-12$ & 0.0000 & $0.000 \mathrm{E}+00$ & 0.0000 & $0.000 \mathrm{E}+00$ & 0.0000 & $0.000 \mathrm{E}+00$ & 0.0000 & $0.000 \mathrm{E}+00$ & 0.0000 & $0.000 \mathrm{E}+00$ & 0.0000 & $0.000 \mathrm{E}+00$ & 0.0000 \\
\hline-238 & $6.486 E-22$ & 0.0000 & $0.000 \mathrm{E}+00$ & 0.0000 & $0.000 \mathrm{E}+00$ & 0.0000 & $0.000 \mathrm{E}+00$ & 0.0000 & $0.000 \mathrm{E}+00$ & 0.0000 & $0.000 \mathrm{E}+00$ & 0.0000 & $0.000 \mathrm{E}+00$ & 0.0000 \\
\hline-239 & $8.843 E-17$ & 0.0000 & $0.000 \mathrm{E}+00$ & 0.0000 & $0.000 \mathrm{E}+00$ & 0.0000 & $0.000 \mathrm{E}+00$ & 0.0000 & $0.000 \mathrm{E}+00$ & 0.0000 & $0.000 \mathrm{E}+00$ & 0.0000 & $0.000 \mathrm{E}+00$ & 0.0000 \\
\hline-240 & $8.408 E-24$ & 0.0000 & $0.000 \mathrm{E}+00$ & 0.0000 & $0.000 \mathrm{E}+00$ & 0.0000 & $0.000 \mathrm{E}+00$ & 0.0000 & $0.000 \mathrm{E}+00$ & 0.0000 & $0.000 \mathrm{E}+00$ & 0.0000 & $0.000 \mathrm{E}+00$ & 0.0000 \\
\hline 99 & $6.129 \mathrm{E}-25$ & 0.0000 & $0.000 \mathrm{E}+00$ & 0.0000 & $0.000 \mathrm{E}+00$ & 0.0000 & $0.000 \mathrm{E}+00$ & 0.0000 & $0.000 \mathrm{E}+00$ & 0.0000 & $0.000 \mathrm{E}+00$ & 0.0000 & $0.000 \mathrm{E}+00$ & 0.0000 \\
\hline-228 & $1.130 \mathrm{E}-06$ & 0.9827 & $0.000 \mathrm{E}+00$ & 0.0000 & $0.000 \mathrm{E}+00$ & 0.0000 & $0.000 \mathrm{E}+00$ & 0.0000 & $0.000 \mathrm{E}+00$ & 0.0000 & $0.000 \mathrm{E}+00$ & 0.0000 & $0.000 \mathrm{E}+00$ & 0.0000 \\
\hline-230 & 7. $712 \mathrm{E}-10$ & 0.0007 & $0.000 \mathrm{E}+00$ & 0.0000 & $0.000 \mathrm{E}+00$ & 0.0000 & $0.000 \mathrm{E}+00$ & 0.0000 & $0.000 \mathrm{E}+00$ & 0.0000 & $0.000 \mathrm{E}+00$ & 0.0000 & $0.000 \mathrm{E}+00$ & 0.0000 \\
\hline-232 & $9.628 E-09$ & 0.0084 & $0.000 \mathrm{E}+00$ & 0.0000 & $0.000 \mathrm{E}+00$ & 0.0000 & $0.000 \mathrm{E}+00$ & 0.0000 & $0.000 \mathrm{E}+00$ & 0.0000 & $0.000 \mathrm{E}+00$ & 0.0000 & $0.000 \mathrm{E}+00$ & 0.0000 \\
\hline 234 & $3.705 E-15$ & 0.0000 & $0.000 \mathrm{E}+00$ & 0.0000 & $0.000 \mathrm{E}+00$ & 0.0000 & $0.000 \mathrm{E}+00$ & 0.0000 & $0.000 \mathrm{E}+00$ & 0.0000 & $0.000 \mathrm{E}+00$ & 0.0000 & $0.000 \mathrm{E}+00$ & 0.0000 \\
\hline 235 & $1.653 \mathrm{E}-14$ & 0.0000 & $0.000 \mathrm{E}+00$ & 0.0000 & $0.000 \mathrm{E}+00$ & 0.0000 & $0.000 \mathrm{E}+00$ & 0.0000 & $0.000 \mathrm{E}+00$ & 0.0000 & $0.000 \mathrm{E}+00$ & 0.0000 & $0.000 \mathrm{E}+00$ & 0.0000 \\
\hline 38 & $4.641 E-09$ & 0.0040 & $0.000 \mathrm{E}+00$ & 0.0000 & $0.000 \mathrm{E}+00$ & 0.0000 & $0.000 \mathrm{E}+00$ & 0.0000 & $0.000 \mathrm{E}+00$ & 0.0000 & $0.000 \mathrm{E}+00$ & 0.0000 & $0.000 \mathrm{E}+00$ & 0.0000 \\
\hline & $1.150 \mathrm{E}-06$ & 1.0000 & $0.000 \mathrm{E}+00$ & 0.0000 & $0.000 \mathrm{E}+00$ & 0.0000 & $0.000 \mathrm{E}+00$ & 0.0000 & $0.000 \mathrm{E}+00$ & 0.0000 & $0.000 \mathrm{E}+00$ & 0.0000 & $.000 \mathrm{E}+00$ & 0.0000 \\
\hline
\end{tabular}

Total Dose Contributions TDOSE (i,p,t) for Individual Radionuclides (i) and Pathways (p) As mrem/yr and Fraction of Total Dose At $t=0.000 \mathrm{E}+00$ years

Water Dependent Pathways

\begin{tabular}{|c|c|c|c|c|c|c|c|c|c|c|c|c|c|c|}
\hline & \multicolumn{2}{|c|}{ Water } & \multicolumn{2}{|c|}{ Fish } & \multicolumn{2}{|c|}{ Radon } & \multicolumn{2}{|c|}{ Plant } & \multicolumn{2}{|c|}{ Meat } & \multicolumn{2}{|c|}{ Milk } & \multicolumn{2}{|c|}{ All Pathways* } \\
\hline clide & mrem/yr & fract. & mrem/yr & fract. & mrem/yr & fract. & mrem/yr & fract. & mrem/yr & fract. & mrem/yr & fract. & mrem/yr & fract. \\
\hline-241 & $0.000 \mathrm{E}+00$ & 0.0000 & $0.000 \mathrm{E}+00$ & 0.0000 & $0.000 \mathrm{E}+00$ & 0.0000 & $0.000 \mathrm{E}+00$ & 0.0000 & $0.000 \mathrm{E}+00$ & 0.0000 & $0.000 \mathrm{E}+00$ & 0.0000 & $1.106 \mathrm{E}-18$ & 0.0000 \\
\hline-137 & $0.000 \mathrm{E}+00$ & 0.0000 & $0.000 \mathrm{E}+00$ & 0.0000 & $0.000 \mathrm{E}+00$ & 0.0000 & $0.000 \mathrm{E}+00$ & 0.0000 & $0.000 \mathrm{E}+00$ & 0.0000 & $0.000 \mathrm{E}+00$ & 0.0000 & $4.898 \mathrm{E}-09$ & 0.0043 \\
\hline-237 & $0.000 \mathrm{E}+00$ & 0.0000 & $0.000 \mathrm{E}+00$ & 0.0000 & $0.000 \mathrm{E}+00$ & 0.0000 & $0.000 \mathrm{E}+00$ & 0.0000 & $0.000 \mathrm{E}+00$ & 0.0000 & $0.000 \mathrm{E}+00$ & 0.0000 & $1.072 \mathrm{E}-12$ & 0.0000 \\
\hline-238 & $0.000 \mathrm{E}+00$ & 0.0000 & $0.000 \mathrm{E}+00$ & 0.0000 & $0.000 \mathrm{E}+00$ & 0.0000 & $0.000 \mathrm{E}+00$ & 0.0000 & $0.000 \mathrm{E}+00$ & 0.0000 & $0.000 \mathrm{E}+00$ & 0.0000 & $6.486 \mathrm{E}-22$ & 0.0000 \\
\hline-239 & $0.000 \mathrm{E}+00$ & 0.0000 & $0.000 \mathrm{E}+00$ & 0.0000 & $0.000 \mathrm{E}+00$ & 0.0000 & $0.000 \mathrm{E}+00$ & 0.0000 & $0.000 \mathrm{E}+00$ & 0.0000 & $0.000 E+00$ & 0.0000 & $8.843 E-17$ & 0.0000 \\
\hline-240 & $0.000 \mathrm{E}+00$ & 0.0000 & $0.000 \mathrm{E}+00$ & 0.0000 & $0.000 \mathrm{E}+00$ & 0.0000 & $0.000 \mathrm{E}+00$ & 0.0000 & $0.000 \mathrm{E}+00$ & 0.0000 & $0.000 E+00$ & 0.0000 & $8.408 E-24$ & 0.0000 \\
\hline-99 & $0.000 \mathrm{E}+00$ & 0.0000 & $0.000 \mathrm{E}+00$ & 0.0000 & $0.000 \mathrm{E}+00$ & 0.0000 & $0.000 \mathrm{E}+00$ & 0.0000 & $0.000 \mathrm{E}+00$ & 0.0000 & $0.000 \mathrm{E}+00$ & 0.0000 & $6.129 \mathrm{E}-25$ & 0.0000 \\
\hline-228 & $0.000 \mathrm{E}+00$ & 0.0000 & $0.000 \mathrm{E}+00$ & 0.0000 & $0.000 \mathrm{E}+00$ & 0.0000 & $0.000 \mathrm{E}+00$ & 0.0000 & $0.000 \mathrm{E}+00$ & 0.0000 & $0.000 \mathrm{E}+00$ & 0.0000 & $1.130 \mathrm{E}-06$ & 0.9827 \\
\hline-230 & $0.000 \mathrm{E}+00$ & 0.0000 & $0.000 \mathrm{E}+00$ & 0.0000 & $0.000 \mathrm{E}+00$ & 0.0000 & $0.000 \mathrm{E}+00$ & 0.0000 & $0.000 \mathrm{E}+00$ & 0.0000 & $0.000 E+00$ & 0.0000 & $7.712 \mathrm{E}-10$ & 0.0007 \\
\hline 232 & $0.000 \mathrm{E}+00$ & 0.0000 & $0.000 \mathrm{E}+00$ & 0.0000 & $0.000 \mathrm{E}+00$ & 0.0000 & $0.000 \mathrm{E}+00$ & 0.0000 & $0.000 \mathrm{E}+00$ & 0.0000 & $0.000 \mathrm{E}+00$ & 0.0000 & $9.628 \mathrm{E}-09$ & 0.0084 \\
\hline 34 & $0.000 \mathrm{E}+00$ & 0.0000 & $0.000 \mathrm{E}+00$ & 0.0000 & $0.000 \mathrm{E}+00$ & 0.0000 & $0.000 \mathrm{E}+00$ & 0.0000 & $0.000 \mathrm{E}+00$ & 0.0000 & $0.000 \mathrm{E}+00$ & 0.0000 & $3.705 E-15$ & 0.0000 \\
\hline 35 & $0.000 \mathrm{E}+00$ & 0.0000 & $0.000 \mathrm{E}+00$ & 0.0000 & $0.000 \mathrm{E}+00$ & 0.0000 & $0.000 \mathrm{E}+00$ & 0.0000 & $0.000 \mathrm{E}+00$ & 0.0000 & $0.000 E+00$ & 0.0000 & $1.653 \mathrm{E}-14$ & 0.0000 \\
\hline 38 & $0.000 \mathrm{E}+00$ & 0.0000 & $0.000 \mathrm{E}+00$ & 0.0000 & $0.000 \mathrm{E}+00$ & 0.0000 & $0.000 \mathrm{E}+00$ & 0.0000 & $0.000 \mathrm{E}+00$ & 0.0000 & $0.000 \mathrm{E}+00$ & 0.0000 & $4.641 \mathrm{E}-09$ & 0.0040 \\
\hline & $0.000 \mathrm{E}+00$ & 0.0000 & $0.000 \mathrm{E}+00$ & 0.0000 & $0.000 \mathrm{E}+00$ & 0.0000 & $0.000 \mathrm{E}+00$ & 0.0000 & $0.000 \mathrm{E}+00$ & 0.0000 & $0.000 \mathrm{E}+00$ & 0.0000 & $50 E-06$ & 1. \\
\hline
\end{tabular}

* Sum of all water independent and dependent pathways. 
RESRAD, Version 6.5

$\mathrm{T}^{1 / 2}$ Limit $=180$ days

Summary : C746U Worker Deterministic Run

File : $\mathrm{X}: \backslash F I N A L$ V2 \DOE FWD RUNS \C746U W DOE SG FWD-FV2-1050YR.RAD

Total Dose Contributions TDOSE(i,p,t) for Individual Radionuclides (i) and Pathways (p) As mrem/yr and Fraction of Total Dose At $t=1.000 \mathrm{E}+00$ years

Water Independent Pathways (Inhalation excludes radon)

\begin{tabular}{|c|c|c|c|c|c|c|c|c|c|c|c|c|c|c|}
\hline \multirow{2}{*}{ Nuclide } & \multicolumn{2}{|c|}{ Ground } & \multicolumn{2}{|c|}{ Inhalation } & \multicolumn{2}{|c|}{ Radon } & \multicolumn{2}{|c|}{ Plant } & \multicolumn{2}{|c|}{ Meat } & \multicolumn{2}{|c|}{ Milk } & \multicolumn{2}{|c|}{ Soil } \\
\hline & mrem/yr & fract. & mrem/yr & fract. & mrem/yr & fract. & mrem/yr & fract. & mrem/yr & fract. & mrem/yr & fract. & mrem/yr & fract. \\
\hline-241 & $3.347 \mathrm{E}-18$ & 0.0000 & $0.000 \mathrm{E}+00$ & 0.0000 & $0.000 \mathrm{E}+00$ & 0.0000 & $0.000 \mathrm{E}+00$ & 0.0000 & $0.000 \mathrm{E}+00$ & 0.0000 & $0.000 \mathrm{E}+00$ & 0.0000 & $0.000 \mathrm{E}+00$ & 0.0000 \\
\hline-137 & $4.827 E-09$ & 0.0056 & $0.000 \mathrm{E}+00$ & 0.0000 & $0.000 \mathrm{E}+00$ & 0.0000 & $0.000 \mathrm{E}+00$ & 0.0000 & $0.000 \mathrm{E}+00$ & 0.0000 & $0.000 \mathrm{E}+00$ & 0.0000 & $0.000 \mathrm{E}+00$ & 0.0000 \\
\hline-237 & $1.083 \mathrm{E}-12$ & 0.0000 & $0.000 \mathrm{E}+00$ & 0.0000 & $0.000 \mathrm{E}+00$ & 0.0000 & $0.000 \mathrm{E}+00$ & 0.0000 & $0.000 \mathrm{E}+00$ & 0.0000 & $0.000 \mathrm{E}+00$ & 0.0000 & $0.000 \mathrm{E}+00$ & 0.0000 \\
\hline-238 & $9.637 \mathrm{E}-21$ & 0.0000 & $0.000 \mathrm{E}+00$ & 0.0000 & $0.000 \mathrm{E}+00$ & 0.0000 & $0.000 \mathrm{E}+00$ & 0.0000 & $0.000 \mathrm{E}+00$ & 0.0000 & $0.000 \mathrm{E}+00$ & 0.0000 & $0.000 \mathrm{E}+00$ & 0.0000 \\
\hline-239 & $8.949 E-17$ & 0.0000 & $0.000 \mathrm{E}+00$ & 0.0000 & $0.000 \mathrm{E}+00$ & 0.0000 & $0.000 \mathrm{E}+00$ & 0.0000 & $0.000 \mathrm{E}+00$ & 0.0000 & $0.000 \mathrm{E}+00$ & 0.0000 & $0.000 \mathrm{E}+00$ & 0.0000 \\
\hline-240 & $8.736 \mathrm{E}-24$ & 0.0000 & $0.000 \mathrm{E}+00$ & 0.0000 & $0.000 \mathrm{E}+00$ & 0.0000 & $0.000 \mathrm{E}+00$ & 0.0000 & $0.000 \mathrm{E}+00$ & 0.0000 & $0.000 \mathrm{E}+00$ & 0.0000 & $0.000 \mathrm{E}+00$ & 0.0000 \\
\hline 99 & $6.215 E-25$ & 0.0000 & $0.000 \mathrm{E}+00$ & 0.0000 & $0.000 \mathrm{E}+00$ & 0.0000 & $0.000 \mathrm{E}+00$ & 0.0000 & $0.000 \mathrm{E}+00$ & 0.0000 & $0.000 \mathrm{E}+00$ & 0.0000 & $0.000 \mathrm{E}+00$ & 0.0000 \\
\hline-228 & 7. $912 \mathrm{E}-07$ & 0.9206 & $0.000 \mathrm{E}+00$ & 0.0000 & $0.000 \mathrm{E}+00$ & 0.0000 & $0.000 \mathrm{E}+00$ & 0.0000 & $0.000 \mathrm{E}+00$ & 0.0000 & $0.000 \mathrm{E}+00$ & 0.0000 & $0.000 \mathrm{E}+00$ & 0.0000 \\
\hline-230 & $2.327 E-09$ & 0.0027 & $0.000 \mathrm{E}+00$ & 0.0000 & $0.000 \mathrm{E}+00$ & 0.0000 & $0.000 \mathrm{E}+00$ & 0.0000 & $0.000 \mathrm{E}+00$ & 0.0000 & $0.000 \mathrm{E}+00$ & 0.0000 & $0.000 \mathrm{E}+00$ & 0.0000 \\
\hline-232 & $5.638 E-08$ & 0.0656 & $0.000 \mathrm{E}+00$ & 0.0000 & $0.000 \mathrm{E}+00$ & 0.0000 & $0.000 \mathrm{E}+00$ & 0.0000 & $0.000 \mathrm{E}+00$ & 0.0000 & $0.000 \mathrm{E}+00$ & 0.0000 & $0.000 \mathrm{E}+00$ & 0.0000 \\
\hline 234 & $2.608 E-14$ & 0.0000 & $0.000 \mathrm{E}+00$ & 0.0000 & $0.000 \mathrm{E}+00$ & 0.0000 & $0.000 \mathrm{E}+00$ & 0.0000 & $0.000 \mathrm{E}+00$ & 0.0000 & $0.000 \mathrm{E}+00$ & 0.0000 & $0.000 \mathrm{E}+00$ & 0.0000 \\
\hline 235 & $1.682 \mathrm{E}-14$ & 0.0000 & $0.000 \mathrm{E}+00$ & 0.0000 & $0.000 \mathrm{E}+00$ & 0.0000 & $0.000 \mathrm{E}+00$ & 0.0000 & $0.000 \mathrm{E}+00$ & 0.0000 & $0.000 \mathrm{E}+00$ & 0.0000 & $0.000 \mathrm{E}+00$ & 0.0000 \\
\hline 38 & $4.678 E-09$ & 0.0054 & $0.000 \mathrm{E}+00$ & 0.0000 & $0.000 \mathrm{E}+00$ & 0.0000 & $0.000 \mathrm{E}+00$ & 0.0000 & $0.000 \mathrm{E}+00$ & 0.0000 & $0.000 \mathrm{E}+00$ & 0.0000 & $0.000 \mathrm{E}+00$ & 0.0000 \\
\hline & $8.594 \mathrm{E}-07$ & 1.0000 & $0.000 \mathrm{E}+00$ & 0.0000 & $0.000 \mathrm{E}+00$ & 0.0000 & $0.000 \mathrm{E}+00$ & 0.0000 & $0.000 \mathrm{E}+00$ & 0.0000 & $0.000 \mathrm{E}+00$ & 0.0000 & $.000 \mathrm{E}+00$ & 0.0000 \\
\hline
\end{tabular}

Total Dose Contributions TDOSE (i,p,t) for Individual Radionuclides (i) and Pathways (p) As mrem/yr and Fraction of Total Dose At $t=1.000 \mathrm{E}+00$ years

Water Dependent Pathways

\begin{tabular}{|c|c|c|c|c|c|c|c|c|c|c|c|c|c|c|}
\hline & \multicolumn{2}{|c|}{ Water } & \multicolumn{2}{|c|}{ Fish } & \multicolumn{2}{|c|}{ Radon } & \multicolumn{2}{|c|}{ Plant } & \multicolumn{2}{|c|}{ Meat } & \multicolumn{2}{|c|}{ Milk } & \multicolumn{2}{|c|}{ All Pathways* } \\
\hline clide & mrem/yr & fract. & mrem/yr & fract. & mrem/yr & fract. & mrem/yr & fract. & mrem/yr & fract. & mrem/yr & fract. & mrem/yr & fract. \\
\hline 241 & $0.000 \mathrm{E}+00$ & 0.0000 & $0.000 \mathrm{E}+00$ & 0.0000 & $0.000 \mathrm{E}+00$ & 0.0000 & $0.000 \mathrm{E}+00$ & 0.0000 & $0.000 \mathrm{E}+00$ & 0.0000 & $0.000 \mathrm{E}+00$ & 0.0000 & $3.347 \mathrm{E}-18$ & 0.0000 \\
\hline-137 & $0.000 \mathrm{E}+00$ & 0.0000 & $0.000 \mathrm{E}+00$ & 0.0000 & $0.000 \mathrm{E}+00$ & 0.0000 & $0.000 \mathrm{E}+00$ & 0.0000 & $0.000 \mathrm{E}+00$ & 0.0000 & $0.000 \mathrm{E}+00$ & 0.0000 & $4.827 \mathrm{E}-09$ & 0.0056 \\
\hline-237 & $0.000 \mathrm{E}+00$ & 0.0000 & $0.000 \mathrm{E}+00$ & 0.0000 & $0.000 \mathrm{E}+00$ & 0.0000 & $0.000 \mathrm{E}+00$ & 0.0000 & $0.000 \mathrm{E}+00$ & 0.0000 & $0.000 \mathrm{E}+00$ & 0.0000 & $1.083 \mathrm{E}-12$ & 0.0000 \\
\hline-238 & $0.000 \mathrm{E}+00$ & 0.0000 & $0.000 \mathrm{E}+00$ & 0.0000 & $0.000 \mathrm{E}+00$ & 0.0000 & $0.000 \mathrm{E}+00$ & 0.0000 & $0.000 \mathrm{E}+00$ & 0.0000 & $0.000 \mathrm{E}+00$ & 0.0000 & $9.637 \mathrm{E}-21$ & 0.0000 \\
\hline-239 & $0.000 \mathrm{E}+00$ & 0.0000 & $0.000 \mathrm{E}+00$ & 0.0000 & $0.000 \mathrm{E}+00$ & 0.0000 & $0.000 \mathrm{E}+00$ & 0.0000 & $0.000 \mathrm{E}+00$ & 0.0000 & $0.000 E+00$ & 0.0000 & $8.949 \mathrm{E}-17$ & 0.0000 \\
\hline-240 & $0.000 \mathrm{E}+00$ & 0.0000 & $0.000 \mathrm{E}+00$ & 0.0000 & $0.000 \mathrm{E}+00$ & 0.0000 & $0.000 \mathrm{E}+00$ & 0.0000 & $0.000 \mathrm{E}+00$ & 0.0000 & $0.000 E+00$ & 0.0000 & $8.736 \mathrm{E}-24$ & 0.0000 \\
\hline-99 & $0.000 \mathrm{E}+00$ & 0.0000 & $0.000 \mathrm{E}+00$ & 0.0000 & $0.000 \mathrm{E}+00$ & 0.0000 & $0.000 \mathrm{E}+00$ & 0.0000 & $0.000 \mathrm{E}+00$ & 0.0000 & $0.000 \mathrm{E}+00$ & 0.0000 & $6.215 \mathrm{E}-25$ & 0.0000 \\
\hline-228 & $0.000 \mathrm{E}+00$ & 0.0000 & $0.000 \mathrm{E}+00$ & 0.0000 & $0.000 \mathrm{E}+00$ & 0.0000 & $0.000 \mathrm{E}+00$ & 0.0000 & $0.000 \mathrm{E}+00$ & 0.0000 & $0.000 \mathrm{E}+00$ & 0.0000 & $7.912 \mathrm{E}-07$ & 0.9206 \\
\hline-230 & $0.000 \mathrm{E}+00$ & 0.0000 & $0.000 \mathrm{E}+00$ & 0.0000 & $0.000 \mathrm{E}+00$ & 0.0000 & $0.000 \mathrm{E}+00$ & 0.0000 & $0.000 \mathrm{E}+00$ & 0.0000 & $0.000 E+00$ & 0.0000 & $2.327 \mathrm{E}-09$ & 0.0027 \\
\hline-232 & $0.000 \mathrm{E}+00$ & 0.0000 & $0.000 \mathrm{E}+00$ & 0.0000 & $0.000 \mathrm{E}+00$ & 0.0000 & $0.000 \mathrm{E}+00$ & 0.0000 & $0.000 \mathrm{E}+00$ & 0.0000 & $0.000 \mathrm{E}+00$ & 0.0000 & $5.638 \mathrm{E}-08$ & 0.0656 \\
\hline 34 & $0.000 \mathrm{E}+00$ & 0.0000 & $0.000 \mathrm{E}+00$ & 0.0000 & $0.000 \mathrm{E}+00$ & 0.0000 & $0.000 \mathrm{E}+00$ & 0.0000 & $0.000 \mathrm{E}+00$ & 0.0000 & $0.000 \mathrm{E}+00$ & 0.0000 & $2.608 \mathrm{E}-14$ & 0.0000 \\
\hline 35 & $0.000 \mathrm{E}+00$ & 0.0000 & $0.000 \mathrm{E}+00$ & 0.0000 & $0.000 \mathrm{E}+00$ & 0.0000 & $0.000 \mathrm{E}+00$ & 0.0000 & $0.000 \mathrm{E}+00$ & 0.0000 & $0.000 \mathrm{E}+00$ & 0.0000 & $1.682 \mathrm{E}-14$ & 0.0000 \\
\hline 38 & $0.000 \mathrm{E}+00$ & 0.0000 & $0.000 \mathrm{E}+00$ & 0.0000 & $0.000 \mathrm{E}+00$ & 0.0000 & $0.000 \mathrm{E}+00$ & 0.0000 & $0.000 \mathrm{E}+00$ & 0.0000 & $0.000 \mathrm{E}+00$ & 0.0000 & $4.678 \mathrm{E}-09$ & 0.0054 \\
\hline & $0.000 \mathrm{E}+00$ & 0.0000 & $0.000 \mathrm{E}+00$ & 0.0000 & $0.000 \mathrm{E}+00$ & 0.0000 & $0.000 \mathrm{E}+00$ & 0.0000 & $0.000 \mathrm{E}+00$ & 0.0000 & $0.000 \mathrm{E}+00$ & 0.0000 & $94 \mathrm{E}-07$ & 1.0000 \\
\hline
\end{tabular}

* Sum of all water independent and dependent pathways. 
RESRAD, Version 6.5

$\mathrm{T}^{1 / 2}$ Limit $=180$ days

Summary : C746U Worker Deterministic Run

File : $\mathrm{X}: \backslash F I N A L$ V2 \DOE FWD RUNS \C746U W DOE SG FWD-FV2-1050YR.RAD

Total Dose Contributions TDOSE(i,p,t) for Individual Radionuclides (i) and Pathways (p) As mrem/yr and Fraction of Total Dose At $t=5.000 \mathrm{E}+01$ years

Water Independent Pathways (Inhalation excludes radon)

\begin{tabular}{|c|c|c|c|c|c|c|c|c|c|c|c|c|c|c|}
\hline \multirow{2}{*}{ Nuclide } & \multicolumn{2}{|c|}{ Ground } & \multicolumn{2}{|c|}{ Inhalation } & \multicolumn{2}{|c|}{ Radon } & \multicolumn{2}{|c|}{ Plant } & \multicolumn{2}{|c|}{ Meat } & \multicolumn{2}{|c|}{ Milk } & \multicolumn{2}{|c|}{ Soil } \\
\hline & mrem/yr & fract. & mrem/yr & fract. & mrem/yr & fract. & mrem/yr & fract. & mrem/yr & fract. & mrem/yr & fract. & mrem/yr & fract. \\
\hline-241 & $1.836 \mathrm{E}-16$ & 0.0000 & $0.000 \mathrm{E}+00$ & 0.0000 & $0.000 \mathrm{E}+00$ & 0.0000 & $0.000 \mathrm{E}+00$ & 0.0000 & $0.000 \mathrm{E}+00$ & 0.0000 & $0.000 \mathrm{E}+00$ & 0.0000 & $0.000 \mathrm{E}+00$ & 0.0000 \\
\hline-137 & $2.350 E-09$ & 0.0012 & $0.000 \mathrm{E}+00$ & 0.0000 & $0.000 \mathrm{E}+00$ & 0.0000 & $0.000 \mathrm{E}+00$ & 0.0000 & $0.000 \mathrm{E}+00$ & 0.0000 & $0.000 \mathrm{E}+00$ & 0.0000 & $0.000 \mathrm{E}+00$ & 0.0000 \\
\hline-237 & $1.835 \mathrm{E}-12$ & 0.0000 & $0.000 \mathrm{E}+00$ & 0.0000 & $0.000 \mathrm{E}+00$ & 0.0000 & $0.000 \mathrm{E}+00$ & 0.0000 & $0.000 \mathrm{E}+00$ & 0.0000 & $0.000 \mathrm{E}+00$ & 0.0000 & $0.000 \mathrm{E}+00$ & 0.0000 \\
\hline-238 & $4.197 \mathrm{E}-16$ & 0.0000 & $0.000 \mathrm{E}+00$ & 0.0000 & $0.000 \mathrm{E}+00$ & 0.0000 & $0.000 \mathrm{E}+00$ & 0.0000 & $0.000 \mathrm{E}+00$ & 0.0000 & $0.000 \mathrm{E}+00$ & 0.0000 & $0.000 \mathrm{E}+00$ & 0.0000 \\
\hline-239 & $1.607 \mathrm{E}-16$ & 0.0000 & $0.000 \mathrm{E}+00$ & 0.0000 & $0.000 \mathrm{E}+00$ & 0.0000 & $0.000 \mathrm{E}+00$ & 0.0000 & $0.000 \mathrm{E}+00$ & 0.0000 & $0.000 \mathrm{E}+00$ & 0.0000 & $0.000 \mathrm{E}+00$ & 0.0000 \\
\hline-240 & $1.973 \mathrm{E}-20$ & 0.0000 & $0.000 \mathrm{E}+00$ & 0.0000 & $0.000 \mathrm{E}+00$ & 0.0000 & $0.000 \mathrm{E}+00$ & 0.0000 & $0.000 \mathrm{E}+00$ & 0.0000 & $0.000 \mathrm{E}+00$ & 0.0000 & $0.000 \mathrm{E}+00$ & 0.0000 \\
\hline 99 & $1.229 \mathrm{E}-24$ & 0.0000 & $0.000 \mathrm{E}+00$ & 0.0000 & $0.000 \mathrm{E}+00$ & 0.0000 & $0.000 \mathrm{E}+00$ & 0.0000 & $0.000 \mathrm{E}+00$ & 0.0000 & $0.000 \mathrm{E}+00$ & 0.0000 & $0.000 \mathrm{E}+00$ & 0.0000 \\
\hline-228 & $2.065 E-14$ & 0.0000 & $0.000 \mathrm{E}+00$ & 0.0000 & $0.000 \mathrm{E}+00$ & 0.0000 & $0.000 \mathrm{E}+00$ & 0.0000 & $0.000 \mathrm{E}+00$ & 0.0000 & $0.000 \mathrm{E}+00$ & 0.0000 & $0.000 \mathrm{E}+00$ & 0.0000 \\
\hline-230 & $1.087 \mathrm{E}-07$ & 0.0558 & $0.000 \mathrm{E}+00$ & 0.0000 & $0.000 \mathrm{E}+00$ & 0.0000 & $0.000 \mathrm{E}+00$ & 0.0000 & $0.000 \mathrm{E}+00$ & 0.0000 & $0.000 \mathrm{E}+00$ & 0.0000 & $0.000 \mathrm{E}+00$ & 0.0000 \\
\hline-232 & $1.832 \mathrm{E}-06$ & 0.9395 & $0.000 \mathrm{E}+00$ & 0.0000 & $0.000 \mathrm{E}+00$ & 0.0000 & $0.000 \mathrm{E}+00$ & 0.0000 & $0.000 \mathrm{E}+00$ & 0.0000 & $0.000 \mathrm{E}+00$ & 0.0000 & $0.000 \mathrm{E}+00$ & 0.0000 \\
\hline 234 & $3.968 \mathrm{E}-11$ & 0.0000 & $0.000 \mathrm{E}+00$ & 0.0000 & $0.000 \mathrm{E}+00$ & 0.0000 & $0.000 \mathrm{E}+00$ & 0.0000 & $0.000 \mathrm{E}+00$ & 0.0000 & $0.000 \mathrm{E}+00$ & 0.0000 & $0.000 \mathrm{E}+00$ & 0.0000 \\
\hline 235 & $1.227 \mathrm{E}-13$ & 0.0000 & $0.000 \mathrm{E}+00$ & 0.0000 & $0.000 \mathrm{E}+00$ & 0.0000 & $0.000 \mathrm{E}+00$ & 0.0000 & $0.000 \mathrm{E}+00$ & 0.0000 & $0.000 \mathrm{E}+00$ & 0.0000 & $0.000 \mathrm{E}+00$ & 0.0000 \\
\hline 38 & $6.920 E-09$ & 0.0035 & $0.000 \mathrm{E}+00$ & 0.0000 & $0.000 \mathrm{E}+00$ & 0.0000 & $0.000 \mathrm{E}+00$ & 0.0000 & $0.000 \mathrm{E}+00$ & 0.0000 & $0.000 \mathrm{E}+00$ & 0.0000 & $0.000 \mathrm{E}+00$ & 0.0000 \\
\hline & $1.950 \mathrm{E}-06$ & 1.0000 & $0.000 \mathrm{E}+00$ & 0.0000 & $0.000 \mathrm{E}+00$ & 0.0000 & $0.000 \mathrm{E}+00$ & 0.0000 & $0.000 \mathrm{E}+00$ & 0.0000 & $0.000 \mathrm{E}+00$ & 0.0000 & $.000 \mathrm{E}+00$ & 0.0000 \\
\hline
\end{tabular}

Total Dose Contributions TDOSE (i,p,t) for Individual Radionuclides (i) and Pathways (p) As mrem/yr and Fraction of Total Dose At $t=5.000 \mathrm{E}+01$ years

Water Dependent Pathways

\begin{tabular}{|c|c|c|c|c|c|c|c|c|c|c|c|c|c|c|}
\hline & \multicolumn{2}{|c|}{ Water } & \multicolumn{2}{|c|}{ Fish } & \multicolumn{2}{|c|}{ Radon } & \multicolumn{2}{|c|}{ Plant } & \multicolumn{2}{|c|}{ Meat } & \multicolumn{2}{|c|}{ Milk } & \multicolumn{2}{|c|}{ All Pathways* } \\
\hline clide & mrem/yr & fract. & mrem/yr & fract. & mrem/yr & fract. & mrem/yr & fract. & mrem/yr & fract. & mrem/yr & fract. & mrem/yr & fract. \\
\hline 241 & $0.000 \mathrm{E}+00$ & 0.0000 & $0.000 \mathrm{E}+00$ & 0.0000 & $0.000 \mathrm{E}+00$ & 0.0000 & $0.000 \mathrm{E}+00$ & 0.0000 & $0.000 \mathrm{E}+00$ & 0.0000 & $0.000 \mathrm{E}+00$ & 0.0000 & $1.836 \mathrm{E}-16$ & 0.0000 \\
\hline-137 & $0.000 \mathrm{E}+00$ & 0.0000 & $0.000 \mathrm{E}+00$ & 0.0000 & $0.000 \mathrm{E}+00$ & 0.0000 & $0.000 \mathrm{E}+00$ & 0.0000 & $0.000 \mathrm{E}+00$ & 0.0000 & $0.000 \mathrm{E}+00$ & 0.0000 & $2.350 \mathrm{E}-09$ & 0.0012 \\
\hline-237 & $0.000 \mathrm{E}+00$ & 0.0000 & $0.000 \mathrm{E}+00$ & 0.0000 & $0.000 \mathrm{E}+00$ & 0.0000 & $0.000 \mathrm{E}+00$ & 0.0000 & $0.000 \mathrm{E}+00$ & 0.0000 & $0.000 \mathrm{E}+00$ & 0.0000 & $1.835 \mathrm{E}-12$ & 0.0000 \\
\hline-238 & $0.000 \mathrm{E}+00$ & 0.0000 & $0.000 \mathrm{E}+00$ & 0.0000 & $0.000 \mathrm{E}+00$ & 0.0000 & $0.000 \mathrm{E}+00$ & 0.0000 & $0.000 \mathrm{E}+00$ & 0.0000 & $0.000 \mathrm{E}+00$ & 0.0000 & $4.197 \mathrm{E}-16$ & 0.0000 \\
\hline-239 & $0.000 \mathrm{E}+00$ & 0.0000 & $0.000 \mathrm{E}+00$ & 0.0000 & $0.000 \mathrm{E}+00$ & 0.0000 & $0.000 \mathrm{E}+00$ & 0.0000 & $0.000 \mathrm{E}+00$ & 0.0000 & $0.000 E+00$ & 0.0000 & $1.607 \mathrm{E}-16$ & 0.0000 \\
\hline-240 & $0.000 \mathrm{E}+00$ & 0.0000 & $0.000 \mathrm{E}+00$ & 0.0000 & $0.000 \mathrm{E}+00$ & 0.0000 & $0.000 \mathrm{E}+00$ & 0.0000 & $0.000 \mathrm{E}+00$ & 0.0000 & $0.000 E+00$ & 0.0000 & $1.973 \mathrm{E}-20$ & 0.0000 \\
\hline-99 & $0.000 \mathrm{E}+00$ & 0.0000 & $0.000 \mathrm{E}+00$ & 0.0000 & $0.000 \mathrm{E}+00$ & 0.0000 & $0.000 \mathrm{E}+00$ & 0.0000 & $0.000 \mathrm{E}+00$ & 0.0000 & $0.000 \mathrm{E}+00$ & 0.0000 & $1.229 \mathrm{E}-24$ & 0.0000 \\
\hline-228 & $0.000 \mathrm{E}+00$ & 0.0000 & $0.000 \mathrm{E}+00$ & 0.0000 & $0.000 \mathrm{E}+00$ & 0.0000 & $0.000 \mathrm{E}+00$ & 0.0000 & $0.000 \mathrm{E}+00$ & 0.0000 & $0.000 \mathrm{E}+00$ & 0.0000 & $2.065 E-14$ & 0.0000 \\
\hline-230 & $0.000 \mathrm{E}+00$ & 0.0000 & $0.000 \mathrm{E}+00$ & 0.0000 & $0.000 \mathrm{E}+00$ & 0.0000 & $0.000 \mathrm{E}+00$ & 0.0000 & $0.000 \mathrm{E}+00$ & 0.0000 & $0.000 E+00$ & 0.0000 & $1.087 \mathrm{E}-07$ & 0.0558 \\
\hline-232 & $0.000 \mathrm{E}+00$ & 0.0000 & $0.000 \mathrm{E}+00$ & 0.0000 & $0.000 \mathrm{E}+00$ & 0.0000 & $0.000 \mathrm{E}+00$ & 0.0000 & $0.000 \mathrm{E}+00$ & 0.0000 & $0.000 \mathrm{E}+00$ & 0.0000 & $1.832 \mathrm{E}-06$ & 0.9395 \\
\hline 34 & $0.000 \mathrm{E}+00$ & 0.0000 & $0.000 \mathrm{E}+00$ & 0.0000 & $0.000 \mathrm{E}+00$ & 0.0000 & $0.000 \mathrm{E}+00$ & 0.0000 & $0.000 \mathrm{E}+00$ & 0.0000 & $0.000 \mathrm{E}+00$ & 0.0000 & $3.968 \mathrm{E}-11$ & 0.0000 \\
\hline 35 & $0.000 \mathrm{E}+00$ & 0.0000 & $0.000 \mathrm{E}+00$ & 0.0000 & $0.000 \mathrm{E}+00$ & 0.0000 & $0.000 \mathrm{E}+00$ & 0.0000 & $0.000 \mathrm{E}+00$ & 0.0000 & $0.000 E+00$ & 0.0000 & $1.227 \mathrm{E}-13$ & 0.0000 \\
\hline 38 & $0.000 \mathrm{E}+00$ & 0.0000 & $0.000 \mathrm{E}+00$ & 0.0000 & $0.000 \mathrm{E}+00$ & 0.0000 & $0.000 \mathrm{E}+00$ & 0.0000 & $0.000 \mathrm{E}+00$ & 0.0000 & $0.000 \mathrm{E}+00$ & 0.0000 & $6.920 \mathrm{E}-09$ & 0.0035 \\
\hline & $0.000 \mathrm{E}+00$ & 0.0000 & $0.000 \mathrm{E}+00$ & 0.0000 & $0.000 \mathrm{E}+00$ & 0.0000 & $0.000 \mathrm{E}+00$ & 0.0000 & $0.000 \mathrm{E}+00$ & 0.0000 & $0.000 \mathrm{E}+00$ & 0.0000 & $50 E-06$ & 1. \\
\hline
\end{tabular}

* Sum of all water independent and dependent pathways. 
RESRAD, Version 6.5

$\mathrm{T}^{1 / 2}$ Limit $=180$ days

Summary : C746U Worker Deterministic Run

File : $\mathrm{X}: \backslash F I N A L$ V2 \DOE FWD RUNS \C746U W DOE SG FWD-FV2-1050YR.RAD

Total Dose Contributions TDOSE(i,p,t) for Individual Radionuclides (i) and Pathways (p) As mrem/yr and Fraction of Total Dose At $t=1.000 \mathrm{E}+02$ years

Water Independent Pathways (Inhalation excludes radon)

\begin{tabular}{|c|c|c|c|c|c|c|c|c|c|c|c|c|c|c|}
\hline \multirow{2}{*}{ Nuclide } & \multicolumn{2}{|c|}{ Ground } & \multicolumn{2}{|c|}{ Inhalation } & \multicolumn{2}{|c|}{ Radon } & \multicolumn{2}{|c|}{ Plant } & \multicolumn{2}{|c|}{ Meat } & \multicolumn{2}{|c|}{ Milk } & \multicolumn{2}{|c|}{ Soil } \\
\hline & mrem/yr & fract. & mrem/yr & fract. & mrem/yr & fract. & mrem/yr & fract. & mrem/yr & fract. & mrem/yr & fract. & mrem/yr & fract. \\
\hline-241 & $6.026 \mathrm{E}-16$ & 0.0000 & $0.000 \mathrm{E}+00$ & 0.0000 & $0.000 \mathrm{E}+00$ & 0.0000 & $0.000 \mathrm{E}+00$ & 0.0000 & $0.000 \mathrm{E}+00$ & 0.0000 & $0.000 \mathrm{E}+00$ & 0.0000 & $0.000 \mathrm{E}+00$ & 0.0000 \\
\hline-137 & $1.128 E-09$ & 0.0004 & $0.000 \mathrm{E}+00$ & 0.0000 & $0.000 \mathrm{E}+00$ & 0.0000 & $0.000 \mathrm{E}+00$ & 0.0000 & $0.000 \mathrm{E}+00$ & 0.0000 & $0.000 \mathrm{E}+00$ & 0.0000 & $0.000 \mathrm{E}+00$ & 0.0000 \\
\hline-237 & $3.151 \mathrm{E}-12$ & 0.0000 & $0.000 \mathrm{E}+00$ & 0.0000 & $0.000 \mathrm{E}+00$ & 0.0000 & $0.000 \mathrm{E}+00$ & 0.0000 & $0.000 \mathrm{E}+00$ & 0.0000 & $0.000 \mathrm{E}+00$ & 0.0000 & $0.000 \mathrm{E}+00$ & 0.0000 \\
\hline-238 & $4.245 E-15$ & 0.0000 & $0.000 \mathrm{E}+00$ & 0.0000 & $0.000 \mathrm{E}+00$ & 0.0000 & $0.000 \mathrm{E}+00$ & 0.0000 & $0.000 \mathrm{E}+00$ & 0.0000 & $0.000 \mathrm{E}+00$ & 0.0000 & $0.000 \mathrm{E}+00$ & 0.0000 \\
\hline-239 & $2.920 E-16$ & 0.0000 & $0.000 \mathrm{E}+00$ & 0.0000 & $0.000 \mathrm{E}+00$ & 0.0000 & $0.000 \mathrm{E}+00$ & 0.0000 & $0.000 \mathrm{E}+00$ & 0.0000 & $0.000 \mathrm{E}+00$ & 0.0000 & $0.000 \mathrm{E}+00$ & 0.0000 \\
\hline-240 & 1. $313 \mathrm{E}-19$ & 0.0000 & $0.000 \mathrm{E}+00$ & 0.0000 & $0.000 \mathrm{E}+00$ & 0.0000 & $0.000 \mathrm{E}+00$ & 0.0000 & $0.000 \mathrm{E}+00$ & 0.0000 & $0.000 \mathrm{E}+00$ & 0.0000 & $0.000 \mathrm{E}+00$ & 0.0000 \\
\hline 99 & $2.465 E-24$ & 0.0000 & $0.000 \mathrm{E}+00$ & 0.0000 & $0.000 \mathrm{E}+00$ & 0.0000 & $0.000 \mathrm{E}+00$ & 0.0000 & $0.000 \mathrm{E}+00$ & 0.0000 & $0.000 \mathrm{E}+00$ & 0.0000 & $0.000 \mathrm{E}+00$ & 0.0000 \\
\hline-228 & $3.775 E-22$ & 0.0000 & $0.000 \mathrm{E}+00$ & 0.0000 & $0.000 \mathrm{E}+00$ & 0.0000 & $0.000 \mathrm{E}+00$ & 0.0000 & $0.000 \mathrm{E}+00$ & 0.0000 & $0.000 \mathrm{E}+00$ & 0.0000 & $0.000 \mathrm{E}+00$ & 0.0000 \\
\hline-230 & $3.024 \mathrm{E}-07$ & 0.1082 & $0.000 \mathrm{E}+00$ & 0.0000 & $0.000 \mathrm{E}+00$ & 0.0000 & $0.000 \mathrm{E}+00$ & 0.0000 & $0.000 \mathrm{E}+00$ & 0.0000 & $0.000 \mathrm{E}+00$ & 0.0000 & $0.000 \mathrm{E}+00$ & 0.0000 \\
\hline-232 & $2.479 E-06$ & 0.8876 & $0.000 \mathrm{E}+00$ & 0.0000 & $0.000 \mathrm{E}+00$ & 0.0000 & $0.000 \mathrm{E}+00$ & 0.0000 & $0.000 \mathrm{E}+00$ & 0.0000 & $0.000 \mathrm{E}+00$ & 0.0000 & $0.000 \mathrm{E}+00$ & 0.0000 \\
\hline 234 & $2.204 \mathrm{E}-10$ & 0.0001 & $0.000 \mathrm{E}+00$ & 0.0000 & $0.000 \mathrm{E}+00$ & 0.0000 & $0.000 \mathrm{E}+00$ & 0.0000 & $0.000 \mathrm{E}+00$ & 0.0000 & $0.000 \mathrm{E}+00$ & 0.0000 & $0.000 \mathrm{E}+00$ & 0.0000 \\
\hline 235 & $4.503 E-13$ & 0.0000 & $0.000 \mathrm{E}+00$ & 0.0000 & $0.000 \mathrm{E}+00$ & 0.0000 & $0.000 \mathrm{E}+00$ & 0.0000 & $0.000 \mathrm{E}+00$ & 0.0000 & $0.000 \mathrm{E}+00$ & 0.0000 & $0.000 \mathrm{E}+00$ & 0.0000 \\
\hline 38 & $1.032 \mathrm{E}-08$ & 0.0037 & $0.000 \mathrm{E}+00$ & 0.0000 & $0.000 \mathrm{E}+00$ & 0.0000 & $0.000 \mathrm{E}+00$ & 0.0000 & $0.000 \mathrm{E}+00$ & 0.0000 & $0.000 \mathrm{E}+00$ & 0.0000 & $0.000 \mathrm{E}+00$ & 0.0000 \\
\hline & $2.793 E-06$ & 1.0000 & $0.000 \mathrm{E}+00$ & 0.0000 & $0.000 \mathrm{E}+00$ & 0.0000 & $0.000 \mathrm{E}+00$ & 0.0000 & $0.000 \mathrm{E}+00$ & 0.0000 & $0.000 \mathrm{E}+00$ & 0.0000 & $.000 \mathrm{E}+00$ & 0.0000 \\
\hline
\end{tabular}

Total Dose Contributions TDOSE (i,p,t) for Individual Radionuclides (i) and Pathways (p) As mrem/yr and Fraction of Total Dose At $t=1.000 \mathrm{E}+02$ years

Water Dependent Pathways

\begin{tabular}{|c|c|c|c|c|c|c|c|c|c|c|c|c|c|c|}
\hline & \multicolumn{2}{|c|}{ Water } & \multicolumn{2}{|c|}{ Fish } & \multicolumn{2}{|c|}{ Radon } & \multicolumn{2}{|c|}{ Plant } & \multicolumn{2}{|c|}{ Meat } & \multicolumn{2}{|c|}{ Milk } & \multicolumn{2}{|c|}{ All Pathways* } \\
\hline clide & mrem/yr & fract. & mrem/yr & fract. & mrem/yr & fract. & mrem/yr & fract. & mrem/yr & fract. & mrem/yr & fract. & mrem/yr & fract. \\
\hline 241 & $0.000 \mathrm{E}+00$ & 0.0000 & $0.000 \mathrm{E}+00$ & 0.0000 & $0.000 \mathrm{E}+00$ & 0.0000 & $0.000 \mathrm{E}+00$ & 0.0000 & $0.000 \mathrm{E}+00$ & 0.0000 & $0.000 \mathrm{E}+00$ & 0.0000 & $6.026 \mathrm{E}-16$ & 0.0000 \\
\hline-137 & $0.000 \mathrm{E}+00$ & 0.0000 & $0.000 \mathrm{E}+00$ & 0.0000 & $0.000 \mathrm{E}+00$ & 0.0000 & $0.000 \mathrm{E}+00$ & 0.0000 & $0.000 \mathrm{E}+00$ & 0.0000 & $0.000 \mathrm{E}+00$ & 0.0000 & $1.128 \mathrm{E}-09$ & 0.0004 \\
\hline-237 & $0.000 \mathrm{E}+00$ & 0.0000 & $0.000 \mathrm{E}+00$ & 0.0000 & $0.000 \mathrm{E}+00$ & 0.0000 & $0.000 \mathrm{E}+00$ & 0.0000 & $0.000 \mathrm{E}+00$ & 0.0000 & $0.000 \mathrm{E}+00$ & 0.0000 & $3.151 \mathrm{E}-12$ & 0.0000 \\
\hline-238 & $0.000 \mathrm{E}+00$ & 0.0000 & $0.000 \mathrm{E}+00$ & 0.0000 & $0.000 \mathrm{E}+00$ & 0.0000 & $0.000 \mathrm{E}+00$ & 0.0000 & $0.000 \mathrm{E}+00$ & 0.0000 & $0.000 \mathrm{E}+00$ & 0.0000 & $4.245 \mathrm{E}-15$ & 0.0000 \\
\hline-239 & $0.000 \mathrm{E}+00$ & 0.0000 & $0.000 \mathrm{E}+00$ & 0.0000 & $0.000 \mathrm{E}+00$ & 0.0000 & $0.000 \mathrm{E}+00$ & 0.0000 & $0.000 \mathrm{E}+00$ & 0.0000 & $0.000 E+00$ & 0.0000 & $2.920 \mathrm{E}-16$ & 0.0000 \\
\hline-240 & $0.000 \mathrm{E}+00$ & 0.0000 & $0.000 \mathrm{E}+00$ & 0.0000 & $0.000 \mathrm{E}+00$ & 0.0000 & $0.000 \mathrm{E}+00$ & 0.0000 & $0.000 \mathrm{E}+00$ & 0.0000 & $0.000 E+00$ & 0.0000 & $1.313 \mathrm{E}-19$ & 0.0000 \\
\hline-99 & $0.000 \mathrm{E}+00$ & 0.0000 & $0.000 \mathrm{E}+00$ & 0.0000 & $0.000 \mathrm{E}+00$ & 0.0000 & $0.000 \mathrm{E}+00$ & 0.0000 & $0.000 \mathrm{E}+00$ & 0.0000 & $0.000 \mathrm{E}+00$ & 0.0000 & $2.465 E-24$ & 0.0000 \\
\hline-228 & $0.000 \mathrm{E}+00$ & 0.0000 & $0.000 \mathrm{E}+00$ & 0.0000 & $0.000 \mathrm{E}+00$ & 0.0000 & $0.000 \mathrm{E}+00$ & 0.0000 & $0.000 \mathrm{E}+00$ & 0.0000 & $0.000 \mathrm{E}+00$ & 0.0000 & $3.775 E-22$ & 0.0000 \\
\hline-230 & $0.000 \mathrm{E}+00$ & 0.0000 & $0.000 \mathrm{E}+00$ & 0.0000 & $0.000 \mathrm{E}+00$ & 0.0000 & $0.000 \mathrm{E}+00$ & 0.0000 & $0.000 \mathrm{E}+00$ & 0.0000 & $0.000 E+00$ & 0.0000 & $3.024 \mathrm{E}-07$ & 0.1082 \\
\hline-232 & $0.000 \mathrm{E}+00$ & 0.0000 & $0.000 \mathrm{E}+00$ & 0.0000 & $0.000 \mathrm{E}+00$ & 0.0000 & $0.000 \mathrm{E}+00$ & 0.0000 & $0.000 \mathrm{E}+00$ & 0.0000 & $0.000 \mathrm{E}+00$ & 0.0000 & $2.479 E-06$ & 0.8876 \\
\hline 34 & $0.000 \mathrm{E}+00$ & 0.0000 & $0.000 \mathrm{E}+00$ & 0.0000 & $0.000 \mathrm{E}+00$ & 0.0000 & $0.000 \mathrm{E}+00$ & 0.0000 & $0.000 \mathrm{E}+00$ & 0.0000 & $0.000 \mathrm{E}+00$ & 0.0000 & $2.204 \mathrm{E}-10$ & 0.0001 \\
\hline 35 & $0.000 \mathrm{E}+00$ & 0.0000 & $0.000 \mathrm{E}+00$ & 0.0000 & $0.000 \mathrm{E}+00$ & 0.0000 & $0.000 \mathrm{E}+00$ & 0.0000 & $0.000 \mathrm{E}+00$ & 0.0000 & $0.000 E+00$ & 0.0000 & $4.503 E-13$ & 0.0000 \\
\hline 38 & $0.000 \mathrm{E}+00$ & 0.0000 & $0.000 \mathrm{E}+00$ & 0.0000 & $0.000 \mathrm{E}+00$ & 0.0000 & $0.000 \mathrm{E}+00$ & 0.0000 & $0.000 \mathrm{E}+00$ & 0.0000 & $0.000 \mathrm{E}+00$ & 0.0000 & $1.032 \mathrm{E}-08$ & 0.0037 \\
\hline & $0.000 \mathrm{E}+00$ & 0.0000 & $0.000 \mathrm{E}+00$ & 0.0000 & $0.000 \mathrm{E}+00$ & 0.0000 & $0.000 \mathrm{E}+00$ & 0.0000 & $0.000 \mathrm{E}+00$ & 0.0000 & $0.000 \mathrm{E}+00$ & 0.0000 & $3 E-06$ & 1. \\
\hline
\end{tabular}

* Sum of all water independent and dependent pathways. 
RESRAD, Version 6.5

$\mathrm{T}^{1 / 2}$ Limit $=180$ days

Summary : C746U Worker Deterministic Run

File : $\mathrm{X}: \backslash F I N A L$ V2 \DOE FWD RUNS \C746U W DOE SG FWD-FV2-1050YR.RAD

Total Dose Contributions TDOSE(i,p,t) for Individual Radionuclides (i) and Pathways (p) As mrem/yr and Fraction of Total Dose At $t=5.000 \mathrm{E}+02$ years

Water Independent Pathways (Inhalation excludes radon)

\begin{tabular}{|c|c|c|c|c|c|c|c|c|c|c|c|c|c|c|}
\hline \multirow{2}{*}{ Nuclide } & \multicolumn{2}{|c|}{ Ground } & \multicolumn{2}{|c|}{ Inhalation } & \multicolumn{2}{|c|}{ Radon } & \multicolumn{2}{|c|}{ Plant } & \multicolumn{2}{|c|}{ Meat } & \multicolumn{2}{|c|}{ Milk } & \multicolumn{2}{|c|}{ Soil } \\
\hline & mrem/yr & fract. & mrem/yr & fract. & mrem/yr & fract. & mrem/yr & fract. & mrem/yr & fract. & mrem/yr & fract. & mrem/yr & fract. \\
\hline-241 & $1.668 \mathrm{E}-13$ & 0.0000 & $0.000 \mathrm{E}+00$ & 0.0000 & $0.000 \mathrm{E}+00$ & 0.0000 & $0.000 \mathrm{E}+00$ & 0.0000 & $0.000 \mathrm{E}+00$ & 0.0000 & $0.000 \mathrm{E}+00$ & 0.0000 & $0.000 \mathrm{E}+00$ & 0.0000 \\
\hline-137 & $3.168 \mathrm{E}-12$ & 0.0000 & $0.000 \mathrm{E}+00$ & 0.0000 & $0.000 \mathrm{E}+00$ & 0.0000 & $0.000 \mathrm{E}+00$ & 0.0000 & $0.000 \mathrm{E}+00$ & 0.0000 & $0.000 \mathrm{E}+00$ & 0.0000 & $0.000 \mathrm{E}+00$ & 0.0000 \\
\hline-237 & $2.362 \mathrm{E}-10$ & 0.0000 & $0.000 \mathrm{E}+00$ & 0.0000 & $0.000 \mathrm{E}+00$ & 0.0000 & $0.000 \mathrm{E}+00$ & 0.0000 & $0.000 \mathrm{E}+00$ & 0.0000 & $0.000 \mathrm{E}+00$ & 0.0000 & $0.000 \mathrm{E}+00$ & 0.0000 \\
\hline-238 & $4.482 \mathrm{E}-12$ & 0.0000 & $0.000 \mathrm{E}+00$ & 0.0000 & $0.000 \mathrm{E}+00$ & 0.0000 & $0.000 \mathrm{E}+00$ & 0.0000 & $0.000 \mathrm{E}+00$ & 0.0000 & $0.000 \mathrm{E}+00$ & 0.0000 & $0.000 \mathrm{E}+00$ & 0.0000 \\
\hline-239 & $3.476 \mathrm{E}-14$ & 0.0000 & $0.000 \mathrm{E}+00$ & 0.0000 & $0.000 \mathrm{E}+00$ & 0.0000 & $0.000 \mathrm{E}+00$ & 0.0000 & $0.000 \mathrm{E}+00$ & 0.0000 & $0.000 \mathrm{E}+00$ & 0.0000 & $0.000 \mathrm{E}+00$ & 0.0000 \\
\hline-240 & $4.219 \mathrm{E}-17$ & 0.0000 & $0.000 \mathrm{E}+00$ & 0.0000 & $0.000 \mathrm{E}+00$ & 0.0000 & $0.000 \mathrm{E}+00$ & 0.0000 & $0.000 \mathrm{E}+00$ & 0.0000 & $0.000 \mathrm{E}+00$ & 0.0000 & $0.000 \mathrm{E}+00$ & 0.0000 \\
\hline 99 & $6.452 \mathrm{E}-22$ & 0.0000 & $0.000 \mathrm{E}+00$ & 0.0000 & $0.000 \mathrm{E}+00$ & 0.0000 & $0.000 \mathrm{E}+00$ & 0.0000 & $0.000 \mathrm{E}+00$ & 0.0000 & $0.000 \mathrm{E}+00$ & 0.0000 & $0.000 \mathrm{E}+00$ & 0.0000 \\
\hline-228 & $0.000 \mathrm{E}+00$ & 0.0000 & $0.000 \mathrm{E}+00$ & 0.0000 & $0.000 \mathrm{E}+00$ & 0.0000 & $0.000 \mathrm{E}+00$ & 0.0000 & $0.000 \mathrm{E}+00$ & 0.0000 & $0.000 \mathrm{E}+00$ & 0.0000 & $0.000 \mathrm{E}+00$ & 0.0000 \\
\hline-230 & $2.193 E-05$ & 0.4425 & $0.000 \mathrm{E}+00$ & 0.0000 & $0.000 \mathrm{E}+00$ & 0.0000 & $0.000 \mathrm{E}+00$ & 0.0000 & $0.000 \mathrm{E}+00$ & 0.0000 & $0.000 \mathrm{E}+00$ & 0.0000 & $0.000 \mathrm{E}+00$ & 0.0000 \\
\hline-232 & $2.730 E-05$ & 0.5508 & $0.000 \mathrm{E}+00$ & 0.0000 & $0.000 \mathrm{E}+00$ & 0.0000 & $0.000 \mathrm{E}+00$ & 0.0000 & $0.000 \mathrm{E}+00$ & 0.0000 & $0.000 \mathrm{E}+00$ & 0.0000 & $0.000 \mathrm{E}+00$ & 0.0000 \\
\hline 234 & $8.184 \mathrm{E}-08$ & 0.0017 & $0.000 \mathrm{E}+00$ & 0.0000 & $0.000 \mathrm{E}+00$ & 0.0000 & $0.000 \mathrm{E}+00$ & 0.0000 & $0.000 \mathrm{E}+00$ & 0.0000 & $0.000 \mathrm{E}+00$ & 0.0000 & $0.000 \mathrm{E}+00$ & 0.0000 \\
\hline 235 & $9.380 \mathrm{E}-11$ & 0.0000 & $0.000 \mathrm{E}+00$ & 0.0000 & $0.000 \mathrm{E}+00$ & 0.0000 & $0.000 \mathrm{E}+00$ & 0.0000 & $0.000 \mathrm{E}+00$ & 0.0000 & $0.000 \mathrm{E}+00$ & 0.0000 & $0.000 \mathrm{E}+00$ & 0.0000 \\
\hline 38 & $2.523 E-07$ & 0.0051 & $0.000 \mathrm{E}+00$ & 0.0000 & $0.000 \mathrm{E}+00$ & 0.0000 & $0.000 \mathrm{E}+00$ & 0.0000 & $0.000 \mathrm{E}+00$ & 0.0000 & $0.000 \mathrm{E}+00$ & 0.0000 & $0.000 \mathrm{E}+00$ & 0.0000 \\
\hline & $4.957 \mathrm{E}-05$ & 1.0000 & $0.000 \mathrm{E}+00$ & 0.0000 & $0.000 \mathrm{E}+00$ & 0.0000 & $0.000 \mathrm{E}+00$ & 0.0000 & $0.000 \mathrm{E}+00$ & 0.0000 & $0.000 \mathrm{E}+00$ & 0.0000 & $.000 \mathrm{E}+00$ & 0.0000 \\
\hline
\end{tabular}

Total Dose Contributions TDOSE (i,p,t) for Individual Radionuclides (i) and Pathways (p) As mrem/yr and Fraction of Total Dose At $t=5.000 \mathrm{E}+02$ years

Water Dependent Pathways

\begin{tabular}{|c|c|c|c|c|c|c|c|c|c|c|c|c|c|c|}
\hline & \multicolumn{2}{|c|}{ Water } & \multicolumn{2}{|c|}{ Fish } & \multicolumn{2}{|c|}{ Radon } & \multicolumn{2}{|c|}{ Plant } & \multicolumn{2}{|c|}{ Meat } & \multicolumn{2}{|c|}{ Milk } & \multicolumn{2}{|c|}{ All Pathways* } \\
\hline clide & mrem/yr & fract. & mrem/yr & fract. & mrem/yr & fract. & mrem/yr & fract. & mrem/yr & fract. & mrem/yr & fract. & mrem/yr & fract. \\
\hline-241 & $0.000 \mathrm{E}+00$ & 0.0000 & $0.000 \mathrm{E}+00$ & 0.0000 & $0.000 \mathrm{E}+00$ & 0.0000 & $0.000 \mathrm{E}+00$ & 0.0000 & $0.000 \mathrm{E}+00$ & 0.0000 & $0.000 \mathrm{E}+00$ & 0.0000 & $1.668 \mathrm{E}-13$ & 0.0000 \\
\hline-137 & $0.000 \mathrm{E}+00$ & 0.0000 & $0.000 \mathrm{E}+00$ & 0.0000 & $0.000 \mathrm{E}+00$ & 0.0000 & $0.000 \mathrm{E}+00$ & 0.0000 & $0.000 \mathrm{E}+00$ & 0.0000 & $0.000 \mathrm{E}+00$ & 0.0000 & $3.168 \mathrm{E}-12$ & 0.0000 \\
\hline-237 & $0.000 \mathrm{E}+00$ & 0.0000 & $0.000 \mathrm{E}+00$ & 0.0000 & $0.000 \mathrm{E}+00$ & 0.0000 & $0.000 \mathrm{E}+00$ & 0.0000 & $0.000 \mathrm{E}+00$ & 0.0000 & $0.000 \mathrm{E}+00$ & 0.0000 & $2.362 \mathrm{E}-10$ & 0.0000 \\
\hline-238 & $0.000 \mathrm{E}+00$ & 0.0000 & $0.000 \mathrm{E}+00$ & 0.0000 & $0.000 \mathrm{E}+00$ & 0.0000 & $0.000 \mathrm{E}+00$ & 0.0000 & $0.000 \mathrm{E}+00$ & 0.0000 & $0.000 \mathrm{E}+00$ & 0.0000 & $4.482 \mathrm{E}-12$ & 0.0000 \\
\hline-239 & $0.000 \mathrm{E}+00$ & 0.0000 & $0.000 \mathrm{E}+00$ & 0.0000 & $0.000 \mathrm{E}+00$ & 0.0000 & $0.000 \mathrm{E}+00$ & 0.0000 & $0.000 \mathrm{E}+00$ & 0.0000 & $0.000 E+00$ & 0.0000 & $3.476 \mathrm{E}-14$ & 0.0000 \\
\hline-240 & $0.000 \mathrm{E}+00$ & 0.0000 & $0.000 \mathrm{E}+00$ & 0.0000 & $0.000 \mathrm{E}+00$ & 0.0000 & $0.000 \mathrm{E}+00$ & 0.0000 & $0.000 \mathrm{E}+00$ & 0.0000 & $0.000 E+00$ & 0.0000 & $4.219 \mathrm{E}-17$ & 0.0000 \\
\hline 99 & $0.000 \mathrm{E}+00$ & 0.0000 & $0.000 \mathrm{E}+00$ & 0.0000 & $0.000 \mathrm{E}+00$ & 0.0000 & $0.000 \mathrm{E}+00$ & 0.0000 & $0.000 \mathrm{E}+00$ & 0.0000 & $0.000 \mathrm{E}+00$ & 0.0000 & $6.452 \mathrm{E}-22$ & 0.0000 \\
\hline-228 & $0.000 \mathrm{E}+00$ & 0.0000 & $0.000 \mathrm{E}+00$ & 0.0000 & $0.000 \mathrm{E}+00$ & 0.0000 & $0.000 \mathrm{E}+00$ & 0.0000 & $0.000 \mathrm{E}+00$ & 0.0000 & $0.000 \mathrm{E}+00$ & 0.0000 & $0.000 \mathrm{E}+00$ & 0.0000 \\
\hline-230 & $0.000 \mathrm{E}+00$ & 0.0000 & $0.000 \mathrm{E}+00$ & 0.0000 & $0.000 \mathrm{E}+00$ & 0.0000 & $0.000 \mathrm{E}+00$ & 0.0000 & $0.000 \mathrm{E}+00$ & 0.0000 & $0.000 E+00$ & 0.0000 & $2.193 E-05$ & 0.4425 \\
\hline 232 & $0.000 \mathrm{E}+00$ & 0.0000 & $0.000 \mathrm{E}+00$ & 0.0000 & $0.000 \mathrm{E}+00$ & 0.0000 & $0.000 \mathrm{E}+00$ & 0.0000 & $0.000 \mathrm{E}+00$ & 0.0000 & $0.000 \mathrm{E}+00$ & 0.0000 & $2.730 \mathrm{E}-05$ & 0.5508 \\
\hline 34 & $0.000 \mathrm{E}+00$ & 0.0000 & $0.000 \mathrm{E}+00$ & 0.0000 & $0.000 \mathrm{E}+00$ & 0.0000 & $0.000 \mathrm{E}+00$ & 0.0000 & $0.000 \mathrm{E}+00$ & 0.0000 & $0.000 \mathrm{E}+00$ & 0.0000 & $8.184 \mathrm{E}-08$ & 0.0017 \\
\hline 35 & $0.000 \mathrm{E}+00$ & 0.0000 & $0.000 \mathrm{E}+00$ & 0.0000 & $0.000 \mathrm{E}+00$ & 0.0000 & $0.000 \mathrm{E}+00$ & 0.0000 & $0.000 \mathrm{E}+00$ & 0.0000 & $0.000 E+00$ & 0.0000 & $9.380 \mathrm{E}-11$ & 0.0000 \\
\hline 38 & $0.000 \mathrm{E}+00$ & 0.0000 & $0.000 \mathrm{E}+00$ & 0.0000 & $0.000 \mathrm{E}+00$ & 0.0000 & $0.000 \mathrm{E}+00$ & 0.0000 & $0.000 \mathrm{E}+00$ & 0.0000 & $0.000 \mathrm{E}+00$ & 0.0000 & $2.523 E-07$ & 0.0051 \\
\hline & $0.000 \mathrm{E}+00$ & 0.0000 & $0.000 \mathrm{E}+00$ & 0.0000 & $0.000 \mathrm{E}+00$ & 0.0000 & $0.000 \mathrm{E}+00$ & 0.0000 & $0.000 \mathrm{E}+00$ & 0.0000 & $0.000 \mathrm{E}+00$ & 0.0000 & $57 E-05$ & 1.0000 \\
\hline
\end{tabular}

* Sum of all water independent and dependent pathways. 
RESRAD, Version 6.5

$\mathrm{T}^{1 / 2}$ Limit $=180$ days

\section{(A) Run \\ : $\mathrm{X}: \backslash F I N A L$ V2 $\backslash$ DOE FWD RUNS $\backslash C 746 U$ W DOE SG FWD-FV2-1050YR.RAD}

Total Dose Contributions TDOSE(i,p,t) for Individual Radionuclides (i) and Pathways (p) As mrem/yr and Fraction of Total Dose At $t=1.050 \mathrm{E}+03$ years

Water Independent Pathways (Inhalation excludes radon)

\begin{tabular}{|c|c|c|c|c|c|c|c|c|c|c|c|c|c|c|}
\hline \multirow[b]{2}{*}{ clide } & \multicolumn{2}{|c|}{ Ground } & \multicolumn{2}{|c|}{ Inhalation } & \multicolumn{2}{|c|}{ Radon } & \multicolumn{2}{|c|}{ Plant } & \multicolumn{2}{|c|}{ Meat } & \multicolumn{2}{|c|}{ Milk } & \multicolumn{2}{|c|}{ Soil } \\
\hline & mrem/yr & fract. & mrem/yr & fract. & mrem/yr & fract. & mrem/yr & fract. & mrem/yr & fract. & mrem/yr & fract. & mrem/yr & fract. \\
\hline 41 & $9.032 \mathrm{E}-11$ & 0.0000 & $0.000 \mathrm{E}+00$ & 0.0000 & $0.000 \mathrm{E}+00$ & 0.0000 & $0.000 \mathrm{E}+00$ & 0.0000 & $0.000 \mathrm{E}+00$ & 0.0000 & $0.000 \mathrm{E}+00$ & 0.0000 & $0.000 \mathrm{E}+00$ & 0.0000 \\
\hline 37 & $9.832 \mathrm{E}-16$ & 0.0000 & $0.000 \mathrm{E}+00$ & 0.0000 & $0.000 \mathrm{E}+00$ & 0.0000 & $0.000 \mathrm{E}+00$ & 0.0000 & $0.000 \mathrm{E}+00$ & 0.0000 & $0.000 \mathrm{E}+00$ & 0.0000 & $0.000 \mathrm{E}+00$ & 0.0000 \\
\hline 237 & $8.468 \mathrm{E}-08$ & 0.0000 & $0.000 \mathrm{E}+00$ & 0.0000 & $0.000 \mathrm{E}+00$ & 0.0000 & $0.000 \mathrm{E}+00$ & 0.0000 & $0.000 \mathrm{E}+00$ & 0.0000 & $0.000 \mathrm{E}+00$ & 0.0000 & $0.000 \mathrm{E}+00$ & 0.0000 \\
\hline 238 & $1.044 \mathrm{E}-09$ & 0.0000 & $0.000 \mathrm{E}+00$ & 0.0000 & $0.000 \mathrm{E}+00$ & 0.0000 & $0.000 \mathrm{E}+00$ & 0.0000 & $0.000 \mathrm{E}+00$ & 0.0000 & $0.000 \mathrm{E}+00$ & 0.0000 & $0.000 \mathrm{E}+00$ & 0.0000 \\
\hline 239 & $2.474 \mathrm{E}-11$ & 0.0000 & $0.000 \mathrm{E}+00$ & 0.0000 & $0.000 \mathrm{E}+00$ & 0.0000 & $0.000 \mathrm{E}+00$ & 0.0000 & $0.000 \mathrm{E}+00$ & 0.0000 & $0.000 \mathrm{E}+00$ & 0.0000 & $0.000 \mathrm{E}+00$ & 000 \\
\hline & $5.993 \mathrm{E}-15$ & 0. & $0.000 \mathrm{E}$ & 0 & $0.000 \mathrm{E}+00$ & 0 & $0.000 \mathrm{E}+00$ & 0 & $0.000 \mathrm{E}+00$ & 0 & $0.000 \mathrm{E}+00$ & 0 & $0.000 \mathrm{E}+00$ & 0000 \\
\hline-99 & $1.362 \mathrm{E}-18$ & 0.0000 & $0.000 \mathrm{E}+00$ & 0.0000 & $0.000 \mathrm{E}+00$ & 0.0000 & $0.000 \mathrm{E}+00$ & 0.0000 & $0.000 \mathrm{E}+00$ & 0.0000 & $0.000 \mathrm{E}+00$ & 0.0000 & $0.000 \mathrm{E}+00$ & 0.0000 \\
\hline 20 & $0.000 \mathrm{E}+00$ & 0.0000 & $0.000 \mathrm{E}+00$ & 0.0000 & $0.000 \mathrm{E}+00$ & 0.0000 & $0.000 \mathrm{E}+00$ & 0.0000 & $0.000 \mathrm{E}+00$ & 0.0000 & $0.000 \mathrm{E}+00$ & 0.0000 & $0.000 \mathrm{E}+00$ & 0.0000 \\
\hline 230 & $1.840 \mathrm{E}-03$ & 0.6991 & $0.000 \mathrm{E}+00$ & 0.0000 & $0.000 \mathrm{E}+00$ & 0.0000 & $0.000 \mathrm{E}+00$ & 0.0000 & $0.000 \mathrm{E}+00$ & 0.0000 & $0.000 \mathrm{E}+00$ & 0.0000 & $0.000 \mathrm{E}+00$ & 0.0000 \\
\hline & $7.565 \mathrm{E}-04$ & 0.2874 & $0.000 \mathrm{E}+00$ & 0.0000 & $0.000 \mathrm{E}+00$ & 0.0000 & $0.000 \mathrm{E}+00$ & 0.0000 & $0.000 \mathrm{E}+00$ & 0.0000 & $0.000 \mathrm{E}+00$ & 0.0000 & $0.000 \mathrm{E}+00$ & 0.0000 \\
\hline & $1.495 \mathrm{E}-05$ & 0.0057 & $0.000 \mathrm{E}+00$ & 0.0000 & $0.000 \mathrm{E}+00$ & 0.0000 & $0.000 \mathrm{E}+00$ & 0.0000 & $0.000 \mathrm{E}+00$ & 0.0000 & $0.000 \mathrm{E}+00$ & 0.0000 & $0.000 \mathrm{E}+00$ & 0.0000 \\
\hline & $3.148 \mathrm{E}-08$ & 0.0000 & $0.000 \mathrm{E}+00$ & 0.0000 & $0.000 \mathrm{E}+00$ & 0.0000 & $0.000 \mathrm{E}+00$ & 0.0000 & $0.000 \mathrm{E}+00$ & 0.0000 & $0.000 \mathrm{E}+00$ & 0.0000 & $0.000 \mathrm{E}+00$ & 0.0000 \\
\hline & $2.047 \mathrm{E}-05$ & 0.0078 & $0.000 \mathrm{E}+00$ & 0.0000 & $0.000 \mathrm{E}+00$ & 0.0000 & $0.000 \mathrm{E}+00$ & 0.0000 & $0.000 \mathrm{E}+00$ & 0.0000 & $0.000 \mathrm{E}+00$ & 0.0000 & $0.000 \mathrm{E}+00$ & 0.0000 \\
\hline & $2.632 \mathrm{E}-03$ & & $0.000 \mathrm{E}+00$ & 0.0000 & $0.000 \mathrm{E}+00$ & 0.0000 & $0.000 \mathrm{E}+00$ & 0.0000 & $0.000 \mathrm{E}+00$ & 0. & $0.000 \mathrm{E}+00$ & 0.0000 & $E+00$ & 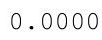 \\
\hline
\end{tabular}

Total Dose Contributions TDOSE (i,p,t) for Individual Radionuclides (i) and Pathways (p) As mrem/yr and Fraction of Total Dose At $t=1.050 \mathrm{E}+03$ years

Water Dependent Pathways

\begin{tabular}{|c|c|c|c|c|c|c|c|c|c|c|c|c|c|c|}
\hline \multirow[b]{2}{*}{ Nuclide } & \multicolumn{2}{|c|}{ Water } & \multicolumn{2}{|c|}{ Fish } & \multicolumn{2}{|c|}{ Radon } & \multicolumn{2}{|c|}{ Plant } & \multicolumn{2}{|c|}{ Meat } & \multicolumn{2}{|c|}{ Milk } & \multicolumn{2}{|c|}{ All Pathways* } \\
\hline & mrem/yr & fract. & $\mathrm{mrem} / \mathrm{yr}$ & fract. & $\mathrm{mrem} / \mathrm{yr}$ & fract. & mrem/yr & fract. & mrem/yr & fract. & $\mathrm{mrem} / \mathrm{yr}$ & fract. & $\mathrm{mrem} / \mathrm{yr}$ & fract. \\
\hline-241 & $0.000 \mathrm{E}+00$ & 0.0000 & $0.000 \mathrm{E}+00$ & 0.0000 & $0.000 \mathrm{E}+00$ & 0.0000 & $0.000 \mathrm{E}+00$ & 0.0000 & $0.000 \mathrm{E}+00$ & 0.0000 & $0.000 \mathrm{E}+00$ & 0.0000 & $9.032 \mathrm{E}-11$ & 0.0000 \\
\hline 37 & $0.000 \mathrm{E}+00$ & 0.0000 & $0.000 \mathrm{E}+00$ & 0.0000 & $0.000 \mathrm{E}+00$ & 0.0000 & $0.000 \mathrm{E}+00$ & 0.0000 & $0.000 \mathrm{E}+00$ & 0.0000 & $0.000 \mathrm{E}+00$ & 0.0000 & $9.832 \mathrm{E}-16$ & 0.0000 \\
\hline 37 & $0.000 \mathrm{E}+00$ & 0.0000 & $0.000 \mathrm{E}+00$ & 0.0000 & $0.000 \mathrm{E}+00$ & 0.0000 & $0.000 \mathrm{E}+00$ & 0.0000 & $0.000 \mathrm{E}+00$ & 0.0000 & $0.000 \mathrm{E}+00$ & 0.0000 & $8.468 \mathrm{E}-08$ & 0.0000 \\
\hline 238 & $0.000 \mathrm{E}+00$ & 0.0000 & $0.000 \mathrm{E}+00$ & 0.0000 & $0.000 \mathrm{E}+00$ & 0.0000 & $0.000 \mathrm{E}+00$ & 0.0000 & $0.000 \mathrm{E}+00$ & 0.0000 & $0.000 \mathrm{E}+00$ & 0.0000 & $1.044 \mathrm{E}-09$ & 0.0000 \\
\hline 239 & $0.000 \mathrm{E}+00$ & 0.0000 & $0.000 \mathrm{E}+00$ & 0.0000 & $0.000 \mathrm{E}+00$ & 0.0000 & $0.000 \mathrm{E}+00$ & 0.0000 & $0.000 \mathrm{E}+00$ & 0.0000 & $0.000 \mathrm{E}+00$ & 0.0000 & $2.474 \mathrm{E}-11$ & 0.0000 \\
\hline 240 & $0.000 \mathrm{E}+00$ & 0.0 & $0.000 \mathrm{E}+00$ & 0 & $0.000 \mathrm{E}+00$ & 0. & $0.000 \mathrm{E}+00$ & 0 & 00 & 0 & $0.000 \mathrm{E}+00$ & 0 & -15 & 000 \\
\hline 年 & $0.000 \mathrm{E}+00$ & 0 & $0.000 \mathrm{E}+00$ & 0 & $0.000 \mathrm{E}+00$ & 0 & $0.000 \mathrm{E}+00$ & 0.00 & $0.000 \mathrm{E}+00$ & 00 & $0.000 \mathrm{E}+00$ & 0 & $.362 \mathrm{E}-18$ & 0.0000 \\
\hline-228 & $0.000 \mathrm{E}+00$ & 0.0000 & $0.000 \mathrm{E}+00$ & 0.0000 & $0.000 \mathrm{E}+00$ & 0.0000 & $0.000 \mathrm{E}+00$ & 0.0000 & $0.000 \mathrm{E}+00$ & 0.0000 & $0.000 \mathrm{E}+00$ & 0.0000 & $0.000 \mathrm{E}+00$ & 0.0000 \\
\hline 230 & $0.000 \mathrm{E}+00$ & 0.0000 & $0.000 \mathrm{E}+00$ & 0.0000 & $0.000 \mathrm{E}+00$ & 0.0000 & $0.000 \mathrm{E}+00$ & 0.0000 & $0.000 \mathrm{E}+00$ & 0.0000 & $0.000 \mathrm{E}+00$ & 0.0000 & $1.840 \mathrm{E}-03$ & 0.6991 \\
\hline 232 & $0.000 \mathrm{E}+00$ & 0.0000 & $0.000 \mathrm{E}+00$ & 0.0000 & $0.000 \mathrm{E}+00$ & 0.0000 & $0.000 \mathrm{E}+00$ & 0.0000 & $0.000 \mathrm{E}+00$ & 0.0000 & $0.000 \mathrm{E}+00$ & 0.0000 & $7.565 \mathrm{E}-04$ & 0.2874 \\
\hline & $0.000 \mathrm{E}+00$ & 0.0000 & $0.000 \mathrm{E}+00$ & 0.0000 & $0.000 \mathrm{E}+00$ & 0.0000 & $0.000 \mathrm{E}+00$ & 0.0000 & $0.000 \mathrm{E}+00$ & 0.0000 & $0.000 \mathrm{E}+00$ & 0.0000 & $1.495 \mathrm{E}-05$ & 0.0057 \\
\hline & $0.000 \mathrm{E}+00$ & 0.0000 & $0.000 \mathrm{E}+00$ & 0.0000 & $0.000 \mathrm{E}+00$ & 0.0000 & $0.000 \mathrm{E}+00$ & 0.0000 & $0.000 \mathrm{E}+00$ & 0.0000 & $0.000 \mathrm{E}+00$ & 0.0000 & $3.148 \mathrm{E}-08$ & 0.0000 \\
\hline 38 & $0.000 \mathrm{E}+00$ & 0.0000 & $0.000 \mathrm{E}+00$ & 0.0000 & $0.000 \mathrm{E}+00$ & 0.0000 & $0.000 \mathrm{E}+00$ & 0.0000 & $0.000 \mathrm{E}+00$ & 0.0000 & $0.000 \mathrm{E}+00$ & 0.0000 & $2.047 \mathrm{E}-05$ & 0.0078 \\
\hline & & .0000 & $.000 \mathrm{E}+00$ & 000 & $E+00$ & 0.0000 & $.000 \mathrm{E}+00$ & .0000 & $.000 \mathrm{E}+00$ & 0 & $8+0$ & & $\angle .03 \angle E-0$ & \\
\hline
\end{tabular}

*Sum of all water independent and dependent pathways. 
RESRAD, Version 6.5

Summary : C746U Worker Deterministic Run

File : X: $\backslash F I N A L$ V2 \DOE FWD RUNS \C746U W DOE SG FWD-FV2-1050YR.RAD

Dose/Source Ratios Summed Over All Pathways

Parent and Progeny Principal Radionuclide Contributions Indicated

Parent Product Thread DSR $(j, t)$ At Time in Years (mrem/yr)/(pCi/g)

(i)

(j)

$\begin{array}{ll}\mathrm{Am}-241 & 1.000 \mathrm{E}+00 \\ \mathrm{~Np}-237+\mathrm{D} & 1.000 \mathrm{E}+00 \\ \mathrm{U}-233 & 1.000 \mathrm{E}+00 \\ \mathrm{Th}-229+\mathrm{D} & 1.000 \mathrm{E}+00 \\ \operatorname{\sum DSR}(j) & \end{array}$

Cs $-137+D$

$\mathrm{Np}-237+\mathrm{D}$

U-233

Th-229+D

$\sum \operatorname{DSR}(j)$

$\mathrm{Pu}-238$

$\mathrm{Pu}-238$

U-234

Th-230

Ra-226+D

$\mathrm{Pb}-210+\mathrm{D}$

$\sum \operatorname{DSR}(j)$

Pu-239

$\mathrm{U}-235+\mathrm{D}$

$\mathrm{Pa}-231$

AC-227+D

$\sum \operatorname{DSR}(j)$

Pu-2 40

$\mathrm{Pu}-240$

U-236

Th-232

$\mathrm{Ra}-228+\mathrm{D}$

Th-228+D

$\sum \mathrm{DSR}(j)$

TC-99

1. $000 \mathrm{E}+00$

Th-228+D

1. $000 \mathrm{E}+00$

Th-230

1. $000 \mathrm{E}+00$

Ra-226+D

$1.000 \mathrm{E}+00$

$\mathrm{Pb}-210+\mathrm{D}$

1. $000 \mathrm{E}+00$

$\sum \operatorname{DSR}(j)$

$.000 \mathrm{E}+00$

1. $000 \mathrm{E}+00$

1. $000 \mathrm{E}+00$
$0.000 \mathrm{E}+00 \quad 1.000 \mathrm{E}+00 \quad 5.000 \mathrm{E}+01 \quad 1.000 \mathrm{E}+02 \quad 5.000 \mathrm{E}+02 \quad 1.050 \mathrm{E}+03$

$\begin{array}{lllll}3.956 \mathrm{E}-34 & 4.063 \mathrm{E}-34 & 1.503 \mathrm{E}-33 & 5.707 \mathrm{E}-33 & 2.471 \mathrm{E}-28 \\ 5.859 \mathrm{E}-22\end{array}$

$\begin{array}{llllll}3.160 \mathrm{E}-20 & 9.563 \mathrm{E}-20 & 5.243 \mathrm{E}-18 & 1.718 \mathrm{E}-17 & 4.700 \mathrm{E}-15 & 2.556 \mathrm{E}-12\end{array}$

$\begin{array}{llllll}7.164 \mathrm{E}-31 & 5.066 \mathrm{E}-30 & 9.948 \mathrm{E}-27 & 7.175 \mathrm{E}-26 & 2.177 \mathrm{E}-22 & 7.342 \mathrm{E}-19\end{array}$

$\begin{array}{llllll}4.901 \mathrm{E}-27 & 7.393 \mathrm{E}-26 & 3.496 \mathrm{E}-21 & 3.824 \mathrm{E}-20 & 6.587 \mathrm{E}-17 & 2.426 \mathrm{E}-14\end{array}$

$3.160 \mathrm{E}-20 \quad 9.563 \mathrm{E}-20 \quad 5.246 \mathrm{E}-18 \quad 1.722 \mathrm{E}-17 \quad 4.766 \mathrm{E}-15 \quad 2.581 \mathrm{E}-12$

$\begin{array}{lllllll}1.000 \mathrm{E}+00 & 2.578 \mathrm{E}-10 & 2.541 \mathrm{E}-10 & 1.237 \mathrm{E}-10 & 5.936 \mathrm{E}-11 & 1.667 \mathrm{E}-13 & 5.175 \mathrm{E}-17\end{array}$

$\begin{array}{lllllll}1.000 \mathrm{E}+00 & 1.948 \mathrm{E}-13 & 1.969 \mathrm{E}-13 & 3.330 \mathrm{E}-13 & 5.693 \mathrm{E}-13 & 4.147 \mathrm{E}-11 & 1.509 \mathrm{E}-08\end{array}$

$\begin{array}{lllllll}1.000 \mathrm{E}+00 & 6.631 \mathrm{E}-24 & 2.011 \mathrm{E}-23 & 1.248 \mathrm{E}-21 & 4.641 \mathrm{E}-21 & 3.427 \mathrm{E}-18 & 6.954 \mathrm{E}-15\end{array}$

$6.053 \mathrm{E}-20 \quad 4.262 \mathrm{E}-19 \quad 6.537 \mathrm{E}-16 \quad 3.662 \mathrm{E}-15 \quad 1.463 \mathrm{E}-12 \quad 3.066 \mathrm{E}-10$

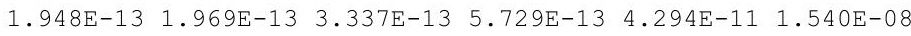

1.840E-09 4.417E-34 4.460E-34 7.195E-34 1.172E-33 5.806E-32 $1.243 \mathrm{E}-29$

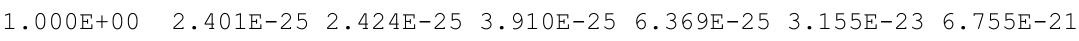

$\begin{array}{lllllll}1.000 \mathrm{E}+00 & 1.998 \mathrm{E}-30 & 6.068 \mathrm{E}-30 & 4.032 \mathrm{E}-28 & 1.628 \mathrm{E}-27 & 3.470 \mathrm{E}-24 & 5.993 \mathrm{E}-20\end{array}$

$\begin{array}{lllllll}1.000 \mathrm{E}+00 & 2.101 \mathrm{E}-34 & 1.489 \mathrm{E}-33 & 3.268 \mathrm{E}-30 & 2.663 \mathrm{E}-29 & 2.676 \mathrm{E}-25 & 6.795 \mathrm{E}-21\end{array}$

$\begin{array}{llllllll}1.000 \mathrm{E}+00 & 1.639 \mathrm{E}-23 & 2.469 \mathrm{E}-22 & 1.076 \mathrm{E}-17 & 1.088 \mathrm{E}-16 & 1.149 \mathrm{E}-13 & 2.677 \mathrm{E}-11\end{array}$

$\begin{array}{lllllll}4.753 \mathrm{E}-32 & 1.473 \mathrm{E}-30 & 1.589 \mathrm{E}-24 & 2.687 \mathrm{E}-23 & 7.527 \mathrm{E}-20 & 3.536 \mathrm{E}-17\end{array}$

$\begin{array}{llllll}1.663 \mathrm{E}-23 & 2.471 \mathrm{E}-22 & 1.076 \mathrm{E}-17 & 1.088 \mathrm{E}-16 & 1.149 \mathrm{E}-13 & 2.677 \mathrm{E}-11\end{array}$

$.000 \mathrm{E}+00 \quad 2.456 \mathrm{E}-18 \quad 2.486 \mathrm{E}-18 \quad 4.463 \mathrm{E}-18 \quad 8.107 \mathrm{E}-18 \quad 9.618 \mathrm{E}-16 \quad 6.841 \mathrm{E}-13$

$\begin{array}{lllllll}1.000 \mathrm{E}+00 & 1.254 \mathrm{E}-24 & 3.802 \mathrm{E}-24 & 2.343 \mathrm{E}-22 & 8.645 \mathrm{E}-22 & 6.015 \mathrm{E}-19 & 1.124 \mathrm{E}-15\end{array}$

$\begin{array}{lllllll}1.000 \mathrm{E}+00 & 1.972 \mathrm{E}-28 & 1.393 \mathrm{E}-27 & 2.557 \mathrm{E}-24 & 1.721 \mathrm{E}-23 & 2.963 \mathrm{E}-20 & 4.446 \mathrm{E}-17\end{array}$

$\begin{array}{lllllll}4.675 \mathrm{E}-28 & 7.017 \mathrm{E}-27 & 2.608 \mathrm{E}-22 & 2.391 \mathrm{E}-21 & 3.028 \mathrm{E}-18 & 1.826 \mathrm{E}-15\end{array}$

$2.456 \mathrm{E}-18 \quad 2.486 \mathrm{E}-18 \quad 4.463 \mathrm{E}-18 \quad 8.110 \mathrm{E}-18 \quad 9.655 \mathrm{E}-16 \quad 6.871 \mathrm{E}-13$

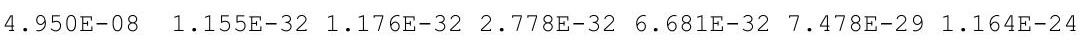

$\begin{array}{llllllll}1.000 \mathrm{E}+00 & 2.334 \mathrm{E}-25 & 2.375 \mathrm{E}-25 & 5.612 \mathrm{E}-25 & 1.350 \mathrm{E}-24 & 1.511 \mathrm{E}-21 & 2.352 \mathrm{E}-17\end{array}$

$\begin{array}{lllllll}1.000 \mathrm{E}+00 & 4.417 \mathrm{E}-33 & 1.347 \mathrm{E}-32 & 1.091 \mathrm{E}-30 & 5.321 \mathrm{E}-30 & 3.459 \mathrm{E}-26 & 1.397 \mathrm{E}-21\end{array}$

$\begin{array}{lllllll}1.000 \mathrm{E}+00 \quad 5.745 \mathrm{E}-44 & 4.148 \mathrm{E}-43 & 1.120 \mathrm{E}-39 & 1.120 \mathrm{E}-38 & 4.587 \mathrm{E}-34 & 5.372 \mathrm{E}-29\end{array}$

$\begin{array}{lllllll}1.000 \mathrm{E}+00 & 2.801 \mathrm{E}-29 & 4.123 \mathrm{E}-28 & 7.689 \mathrm{E}-24 & 5.197 \mathrm{E}-23 & 3.012 \mathrm{E}-20 & 8.590 \mathrm{E}-18\end{array}$

$1.000 \mathrm{E}+00 \quad 1.657 \mathrm{E}-28 \quad 4.769 \mathrm{E}-27 \quad 5.398 \mathrm{E}-22 \quad 3.593 \mathrm{E}-21 \quad 1.140 \mathrm{E}-18 \quad 1.344 \mathrm{E}-16$

$2.335 \mathrm{E}-25 \quad 2.427 \mathrm{E}-25 \quad 5.480 \mathrm{E}-22 \quad 3.646 \mathrm{E}-21 \quad 1.172 \mathrm{E}-18 \quad 1.665 \mathrm{E}-16$

$\begin{array}{llllll}1.179 \mathrm{E}-26 & 1.195 \mathrm{E}-26 & 2.364 \mathrm{E}-26 & 4.741 \mathrm{E}-26 & 1.241 \mathrm{E}-23 & 2.619 \mathrm{E}-20\end{array}$

$2.825 \mathrm{E}-07 \quad 1.978 \mathrm{E}-07 \quad 5.163 \mathrm{E}-15 \quad 9.437 \mathrm{E}-23 \quad 0.000 \mathrm{E}+00 \quad 0.000 \mathrm{E}+00$

$\begin{array}{llllll}4.929 E-23 & 5.012 \mathrm{E}-23 & 1.142 \mathrm{E}-22 & 2.647 \mathrm{E}-22 & 2.203 \mathrm{E}-19 & 2.282 \mathrm{E}-15\end{array}$

$\begin{array}{llllll}7.712 \mathrm{E}-12 & 2.327 \mathrm{E}-11 & 1.087 \mathrm{E}-09 & 3.024 \mathrm{E}-09 & 2.193 \mathrm{E}-07 & 1.840 \mathrm{E}-05\end{array}$

$\begin{array}{llllll}3.717 \mathrm{E}-20 & 2.596 \mathrm{E}-19 & 2.655 \mathrm{E}-16 & 1.087 \mathrm{E}-15 & 1.573 \mathrm{E}-13 & 2.528 \mathrm{E}-11\end{array}$

$\begin{array}{lllllll}7.712 \mathrm{E}-12 & 2.327 \mathrm{E}-11 & 1.087 \mathrm{E}-09 & 3.024 \mathrm{E}-09 & 2.193 \mathrm{E}-07 & 1.840 \mathrm{E}-05\end{array}$ 
RESRAD, Version 6.5

Summary : C746U Worker Deterministic Run

File : $\mathrm{x}: \backslash F I N A L$ V2 $\backslash$ DOE FWD RUNS $\backslash C 746 \mathrm{U}$ W DOE SG FWD-FV2-1050YR. RAD

Dose/Source Ratios Summed Over All Pathways

Parent and Progeny Principal Radionuclide Contributions Indicated

\begin{tabular}{|c|c|c|c|c|c|c|c|c|}
\hline $\begin{array}{c}\text { Parent } \\
\text { (i) }\end{array}$ & $\begin{array}{l}\text { Product } \\
(j)\end{array}$ & $\begin{array}{l}\text { Thread } \\
\text { Fraction }\end{array}$ & $\begin{array}{r}\text { DSR } \\
0.000 \mathrm{E}+00\end{array}$ & $\begin{array}{l}(j, t) \text { At } T \\
1.000 \mathrm{E}+00\end{array}$ & $\begin{array}{l}\text { ime in Yea } \\
5.000 \mathrm{E}+01\end{array}$ & $\begin{array}{l}\text { Es (mrem/ } \\
1.000 \mathrm{E}+02\end{array}$ & $\begin{array}{l}/ \mathrm{yr}) /(\mathrm{pCi} / \\
5.000 \mathrm{E}+02\end{array}$ & $\begin{array}{l}\text { g) } \\
1.050 \mathrm{E}+03\end{array}$ \\
\hline-232 & $\mathrm{Th}-232$ & $1.000 \mathrm{E}+00$ & $2.382 \mathrm{E}-25$ & $2.427 E-25$ & $6.027 \mathrm{E}-25$ & $1.525 E-24$ & $2.561 \mathrm{E}-21$ & $6.965 E-17$ \\
\hline-232 & $\mathrm{Ra}-228+\mathrm{D}$ & $1.000 \mathrm{E}+00$ & $2.263 E-10$ & $6.486 \mathrm{E}-10$ & $5.690 \mathrm{E}-09$ & $8.336 \mathrm{E}-09$ & $1.737 \mathrm{E}-07$ & $1.131 \mathrm{E}-05$ \\
\hline $1-232$ & $T h-228+D$ & $1.000 \mathrm{E}+00$ & $2.181 E-09$ & $1.345 \mathrm{E}-08$ & $4.522 \mathrm{E}-07$ & $6.114 \mathrm{E}-07$ & $6.652 E-06$ & $1.778 \mathrm{E}-04$ \\
\hline-232 & $\sum \operatorname{DSR}(j)$ & & $2.407 E-09$ & $1.410 \mathrm{E}-08$ & $4.579 \mathrm{E}-07$ & $6.198 \mathrm{E}-07$ & $6.825 E-06$ & $1.891 \mathrm{E}-04$ \\
\hline-234 & $\mathrm{U}-234$ & $1.000 \mathrm{E}+00$ & $1.409 \mathrm{E}-24$ & $1.434 \mathrm{E}-24$ & $3.415 \mathrm{E}-24$ & $8.276 \mathrm{E}-24$ & $9.851 E-21$ & $1.669 \mathrm{E}-16$ \\
\hline-234 & Th-230 & $1.000 \mathrm{E}+00$ & $2.225 E-28$ & $6.774 \mathrm{E}-28$ & $5.192 \mathrm{E}-26$ & $2.394 \mathrm{E}-25$ & $9.912 \mathrm{E}-22$ & $2.152 \mathrm{E}-17$ \\
\hline-234 & $\mathrm{Ra}-226+\mathrm{D}$ & $1.000 \mathrm{E}+00$ & $2.315 E-17$ & $1.630 \mathrm{E}-16$ & $2.480 \mathrm{E}-13$ & $1.377 \mathrm{E}-12$ & $5.115 \mathrm{E}-10$ & $9.341 \mathrm{E}-08$ \\
\hline-234 & $\mathrm{~Pb}-210+\mathrm{D}$ & $1.000 \mathrm{E}+00$ & $8.381 E-26$ & $1.257 \mathrm{E}-24$ & $4.500 \mathrm{E}-20$ & $3.956 \mathrm{E}-19$ & $3.440 \mathrm{E}-16$ & 1. $243 \mathrm{E}-13$ \\
\hline-234 & $\sum \operatorname{DSR}(j)$ & & $2.315 \mathrm{E}-17$ & $1.630 \mathrm{E}-16$ & $2.480 \mathrm{E}-13$ & $1.377 \mathrm{E}-12$ & $5.115 \mathrm{E}-10$ & $9.341 \mathrm{E}-08$ \\
\hline$-235+D$ & $\mathrm{U}-235+\mathrm{D}$ & $1.000 \mathrm{E}+00$ & $2.540 \mathrm{E}-15$ & $2.572 \mathrm{E}-15$ & $4.713 E-15$ & $8.745 E-15$ & 1. $228 \mathrm{E}-12$ & $1.101 \mathrm{E}-09$ \\
\hline$-235+D$ & $\mathrm{~Pa}-231$ & $1.000 \mathrm{E}+00$ & $6.002 \mathrm{E}-19$ & $1.818 \mathrm{E}-18$ & $1.028 \mathrm{E}-16$ & $3.478 \mathrm{E}-16$ & 1. $206 \mathrm{E}-13$ & $8.644 \mathrm{E}-11$ \\
\hline$-235+D$ & $A C-227+D$ & $1.000 \mathrm{E}+00$ & 1. $895 \mathrm{E}-18$ & 1. $324 \mathrm{E}-17$ & $1.407 \mathrm{E}-14$ & $6.019 \mathrm{E}-14$ & $1.308 \mathrm{E}-11$ & $3.655 \mathrm{E}-09$ \\
\hline$-235+D$ & $\sum \operatorname{DSR}(j)$ & & $2.543 E-15$ & $2.587 \mathrm{E}-15$ & $1.888 \mathrm{E}-14$ & $6.928 \mathrm{E}-14$ & $1.443 E-11$ & $4.843 E-09$ \\
\hline-238 & $U-238$ & $5.400 E-05$ & $0.000 \mathrm{E}+00$ & $0.000 \mathrm{E}+00$ & $0.000 \mathrm{E}+00$ & $0.000 \mathrm{E}+00$ & $0.000 \mathrm{E}+00$ & $3.476 \mathrm{E}-39$ \\
\hline$-238+D$ & $\mathrm{U}-238+\mathrm{D}$ & $9.999 \mathrm{E}-01$ & $2.901 \mathrm{E}-11$ & $2.924 \mathrm{E}-11$ & 4. $325 E-11$ & $6.449 \mathrm{E}-11$ & $1.576 \mathrm{E}-09$ & $1.279 \mathrm{E}-07$ \\
\hline$-238+D$ & $\mathrm{U}-234$ & $9.999 \mathrm{E}-01$ & $2.003 E-30$ & $6.105 \mathrm{E}-30$ & $4.889 \mathrm{E}-28$ & $2.358 \mathrm{E}-27$ & $1.399 \mathrm{E}-23$ & 4. $978 \mathrm{E}-19$ \\
\hline$-238+D$ & $\mathrm{Th}-230$ & $9.999 E-01$ & $2.105 E-34$ & $1.495 \mathrm{E}-33$ & $3.717 \mathrm{E}-30$ & $3.411 \mathrm{E}-29$ & $7.032 \mathrm{E}-25$ & $3.204 \mathrm{E}-20$ \\
\hline$-238+D$ & $\mathrm{Ra}-226+\mathrm{D}$ & $9.999 \mathrm{E}-01$ & $1.642 \mathrm{E}-23$ & $2.477 \mathrm{E}-22$ & $1.186 \mathrm{E}-17$ & $1.313 E-16$ & $2.462 \mathrm{E}-13$ & $9.612 \mathrm{E}-11$ \\
\hline$-238+D$ & $\mathrm{~Pb}-210+\mathrm{D}$ & $9.999 \mathrm{E}-01$ & $4.759 E-32$ & $1.477 \mathrm{E}-30$ & $1.723 E-24$ & $3.161 \mathrm{E}-23$ & $1.561 \mathrm{E}-19$ & 1. $240 \mathrm{E}-16$ \\
\hline$-238+D$ & $\sum \operatorname{DSR}(j)$ & & $2.901 \mathrm{E}-11$ & $2.924 \mathrm{E}-11$ & $4.325 \mathrm{E}-11$ & $6.449 \mathrm{E}-11$ & $1.577 \mathrm{E}-09$ & $1.280 \mathrm{E}-07$ \\
\hline
\end{tabular}

The DSR includes contributions from associated (half-life $\leq 180$ days) daughters. 
RESRAD, Version $6.5 \quad T^{1 / 2}$ Limit $=180$ days

Summary : C746U Worker Deterministic Run

File : $\mathrm{X}: \backslash F I N A L$ V2 $\backslash$ DOE FWD RUNS \C746U W DOE SG FWD-FV2-1050YR.RAD

Single Radionuclide Soil Guidelines G(i,t) in pCi/g

Basic Radiation Dose Limit $=1.000 \mathrm{E}+00 \mathrm{mrem} / \mathrm{yr}$

Nuclide

\begin{tabular}{|c|c|c|c|c|c|c|}
\hline (i) & $t=0.000 E+00$ & $1.000 \mathrm{E}+00$ & $5.000 \mathrm{E}+01$ & $1.000 \mathrm{E}+02$ & $5.000 \mathrm{E}+02$ & $1.050 \mathrm{E}+03$ \\
\hline $1-241$ & $\star 3.431 \mathrm{E}+12$ & $\star 3.431 \mathrm{E}+12$ & $\star 3.431 \mathrm{E}+12$ & $\star 3.431 \mathrm{E}+12$ & $\star 3.431 \mathrm{E}+12$ & $3.875 \mathrm{E}+11$ \\
\hline$s-137$ & $3.879 E+09$ & $3.936 \mathrm{E}+09$ & $8.084 E+09$ & $1.685 \mathrm{E}+10$ & $5.997 \mathrm{E}+12$ & $\star 8.704 \mathrm{E}+13$ \\
\hline-237 & $\star 7.047 \mathrm{E}+08$ & $\star 7.047 \mathrm{E}+08$ & $\star 7.047 \mathrm{E}+08$ & $\star 7.047 \mathrm{E}+08$ & $\star 7.047 \mathrm{E}+08$ & $6.495 \mathrm{E}+07$ \\
\hline$u-238$ & $\star 1.712 \mathrm{E}+13$ & $\star 1.712 \mathrm{E}+13$ & $\star 1.712 \mathrm{E}+13$ & $\star 1.712 \mathrm{E}+13$ & $8.701 \mathrm{E}+12$ & $3.735 \mathrm{E}+10$ \\
\hline $\mathrm{Pu}-239$ & $\star 6.214 \mathrm{E}+10$ & $\star 6.214 \mathrm{E}+10$ & $\star 6.214 \mathrm{E}+10$ & $\star 6.214 \mathrm{E}+10$ & $\star 6.214 \mathrm{E}+10$ & $\star 6.214 \mathrm{E}+10$ \\
\hline $\mathrm{Pu}-240$ & $\star 2.278 \mathrm{E}+11$ & $\star 2.278 \mathrm{E}+11$ & $\star 2.278 \mathrm{E}+11$ & $\star 2.278 \mathrm{E}+11$ & $\star 2.278 \mathrm{E}+11$ & $\star 2.278 \mathrm{E}+11$ \\
\hline TC-99 & $* 1.697 \mathrm{E}+10$ & $* 1.697 \mathrm{E}+10$ & $\star 1.697 \mathrm{E}+10$ & $* 1.697 \mathrm{E}+10$ & $\star 1.697 \mathrm{E}+10$ & $\star 1.697 \mathrm{E}+10$ \\
\hline Th-228 & $3.540 \mathrm{E}+06$ & $5.056 \mathrm{E}+06$ & $1.937 \mathrm{E}+14$ & $\star 8.195 \mathrm{E}+14$ & $\star 8.195 \mathrm{E}+14$ & $\star 8.195 \mathrm{E}+14$ \\
\hline Th -230 & $\star 2.018 \mathrm{E}+10$ & $\star 2.018 \mathrm{E}+10$ & $9.198 \mathrm{E}+08$ & $3.307 \mathrm{E}+08$ & $4.559 \mathrm{E}+06$ & $5.434 \mathrm{E}+04$ \\
\hline$T h-232$ & $\star 1.097 \mathrm{E}+05$ & $\star 1.097 \mathrm{E}+05$ & $\star 1.097 \mathrm{E}+05$ & $\star 1.097 \mathrm{E}+05$ & $\star 1.097 \mathrm{E}+05$ & $5.287 \mathrm{E}+03$ \\
\hline $\mathrm{U}-234$ & $\star 6.247 \mathrm{E}+09$ & $\star 6.247 \mathrm{E}+09$ & $\star 6.247 \mathrm{E}+09$ & $\star 6.247 \mathrm{E}+09$ & $1.955 E+09$ & $1.071 \mathrm{E}+07$ \\
\hline 35 & $\star 2.161 \mathrm{E}+06$ & $\star 2.161 \mathrm{E}+06$ & $\star 2.161 \mathrm{E}+06$ & $\star 2.161 \mathrm{E}+06$ & $\star 2.161 \mathrm{E}+06$ & $\star 2.161 \mathrm{E}+06$ \\
\hline 238 & $\star 3.361 \mathrm{E}+05$ & $\star 3.361 \mathrm{E}+05$ & $\star 3.361 \mathrm{E}+05$ & $\star 3.361 \mathrm{E}+05$ & $\star 3.361 \mathrm{E}+05$ & $\star 3.361 \mathrm{E}+05$ \\
\hline
\end{tabular}

*At specific activity limit

Summed Dose/Source Ratios DSR(i,t) in (mrem/yr)/(pCi/g) and Single Radionuclide Soil Guidelines $\mathrm{G}(i, t)$ in $\mathrm{pCi} / \mathrm{g}$

at tmin $=$ time of minimum single radionuclide soil guideline and at tmax $=$ time of maximum total dose $=1.050 \mathrm{E}+03$ years

\begin{tabular}{|c|c|c|c|c|c|c|}
\hline $\begin{array}{l}\text { Uclide } \\
\text { (i) }\end{array}$ & $\begin{array}{l}\text { Initial } \\
(\mathrm{pCi} / \mathrm{g})\end{array}$ & $\begin{array}{c}\text { tmin } \\
\text { (years) }\end{array}$ & $\operatorname{DSR}(i, \operatorname{tmin})$ & $\begin{array}{c}\mathrm{G}(\mathrm{i}, \mathrm{tmin}) \\
(\mathrm{pCi} / \mathrm{g})\end{array}$ & $\operatorname{DSR}(i, \operatorname{tmax})$ & $\begin{array}{l}G(i, t \max ) \\
(\mathrm{pCi} / \mathrm{g})\end{array}$ \\
\hline-241 & $3.500 \mathrm{E}+01$ & $1.050 \mathrm{E}+03$ & $2.581 \mathrm{E}-12$ & $3.875 E+11$ & $2.581 \mathrm{E}-12$ & $3.875 E+11$ \\
\hline-137 & $1.900 \mathrm{E}+01$ & $0.000 \mathrm{E}+00$ & $2.578 \mathrm{E}-10$ & $3.879 \mathrm{E}+09$ & $5.175 \mathrm{E}-17$ & $\star 8.704 \mathrm{E}+13$ \\
\hline 237 & $5.500 \mathrm{E}+00$ & $1.050 \mathrm{E}+03$ & $1.540 \mathrm{E}-08$ & $6.495 \mathrm{E}+07$ & $1.540 \mathrm{E}-08$ & $6.495 \mathrm{E}+07$ \\
\hline-238 & $3.900 \mathrm{E}+01$ & $1.050 \mathrm{E}+03$ & $2.677 \mathrm{E}-11$ & $3.735 \mathrm{E}+10$ & $2.677 \mathrm{E}-11$ & $3.735 \mathrm{E}+10$ \\
\hline-239 & $3.600 \mathrm{E}+01$ & $1.050 \mathrm{E}+03$ & $6.871 \mathrm{E}-13$ & $* 6.214 \mathrm{E}+10$ & $6.871 E-13$ & $\star 6.214 \mathrm{E}+10$ \\
\hline $\mathrm{Pu}-240$ & $3.600 \mathrm{E}+01$ & $1.050 \mathrm{E}+03$ & $1.665 \mathrm{E}-16$ & $\star 2.278 \mathrm{E}+11$ & $1.665 \mathrm{E}-16$ & $\star 2.278 \mathrm{E}+11$ \\
\hline-99 & $5.200 \mathrm{E}+01$ & $1.050 \mathrm{E}+03$ & $2.619 \mathrm{E}-20$ & $\star 1.697 \mathrm{E}+10$ & $2.619 \mathrm{E}-20$ & $* 1.697 \mathrm{E}+10$ \\
\hline Th -228 & $4.000 \mathrm{E}+00$ & $0.000 \mathrm{E}+00$ & $2.825 \mathrm{E}-07$ & $3.540 \mathrm{E}+06$ & $0.000 \mathrm{E}+00$ & $\star 8.195 \mathrm{E}+14$ \\
\hline-230 & $1.000 \mathrm{E}+02$ & $1.050 \mathrm{E}+03$ & $1.840 \mathrm{E}-05$ & $5.434 \mathrm{E}+04$ & $1.840 \mathrm{E}-05$ & $5.434 \mathrm{E}+04$ \\
\hline-232 & $4.000 \mathrm{E}+00$ & $1.050 \mathrm{E}+03$ & $1.891 \mathrm{E}-04$ & $5.287 E+03$ & $1.891 \mathrm{E}-04$ & $5.287 \mathrm{E}+03$ \\
\hline 34 & $1.600 \mathrm{E}+02$ & $1.050 \mathrm{E}+03$ & $9.341 \mathrm{E}-08$ & $1.071 \mathrm{E}+07$ & $9.341 \mathrm{E}-08$ & $1.071 \mathrm{E}+07$ \\
\hline 35 & $6.500 \mathrm{E}+00$ & $1.050 \mathrm{E}+03$ & $4.843 \mathrm{E}-09$ & $\star 2.161 \mathrm{E}+06$ & $4.843 \mathrm{E}-09$ & $\star 2.161 \mathrm{E}+06$ \\
\hline 238 & $1.600 \mathrm{E}+02$ & $1.050 \mathrm{E}+03$ & $1.280 \mathrm{E}-07$ & $\star 3.361 E+05$ & $1.280 \mathrm{E}-07$ & $* 3.361 \mathrm{E}+05$ \\
\hline
\end{tabular}

*At specific activity limit 
RESRAD, Version $6.5 \quad T^{1 / 2}$ Limit $=180$ days

Summary : C746U Worker Deterministic Run

File : $\mathrm{X}: \backslash F I N A L$ V2 $\backslash$ DOE FWD RUNS \C746U W DOE SG FWD-FV2-1050YR.RAD

Individual Nuclide Dose Summed Over All Pathways

Parent Nuclide and Branch Fraction Indicated

Nuclide Parent THF(i) DOSE $(j, t)$, mrem/yr

\begin{tabular}{|c|c|c|}
\hline (j) & (i) & \\
\hline$m-241$ & Am-241 & $1.000 \mathrm{E}+00$ \\
\hline$p-237$ & Am-241 & $1.000 \mathrm{E}+00$ \\
\hline$p-237$ & $N p-237$ & $1.000 \mathrm{E}+00$ \\
\hline 237 & $\sum \mathrm{DOSE}(j$ & \\
\hline
\end{tabular}

$\mathrm{U}-233 \quad \mathrm{Am}-241 \quad 1.000 \mathrm{E}+00$

$\mathrm{U}-233 \quad \mathrm{~Np}-237 \quad 1.000 \mathrm{E}+00$

U-233 $\quad$ DDOSE $(j)$

Th-229

$\mathrm{Th}-229$

Th-229

$\mathrm{Cs}-137$

$\mathrm{Pu}-238$

$\mathrm{Pu}-238$

$\mathrm{Pu}-238$

$\mathrm{U}-234$

$\mathrm{U}-234$

$\mathrm{U}-234$

$\mathrm{U}-234$

$\mathrm{Th}-230$

$\mathrm{Th}-230$

$\mathrm{Th}-230$

$\mathrm{Th}-230$

Th-230

$\mathrm{Ra}-226$

$\mathrm{Ra}-226$

$\mathrm{Ra}-226$

$\mathrm{Ra}-226$

$\mathrm{Ra}-226$

$\mathrm{Pb}-210$

$\mathrm{Pb}-210$

$\mathrm{Pb}-210$

$\mathrm{Pb}-210$

$\mathrm{Pb}-210$

Pu-239

$\mathrm{U}-235$

$\mathrm{U}-235$

$\mathrm{U}-235$
Am-241 1.000E+00

$\mathrm{Np}-237 \quad 1.000 \mathrm{E}+00$

$\sum \operatorname{DOSE}(j)$

Cs-137 1.000E+00

$\mathrm{Pu}-238$ 1.840E-09

$\mathrm{Pu}-238 \quad 1.000 \mathrm{E}+00$

$\sum \operatorname{DOSE}(j)$

$\mathrm{Pu}-238 \quad 1.000 \mathrm{E}+00$

$\mathrm{U}-234 \quad 1.000 \mathrm{E}+00$

U-238 9.999E-01

$\sum \operatorname{DOSE}(j)$

$\mathrm{Pu}-238 \quad 1.000 \mathrm{E}+00$

Th-230 1.000E+00

$\mathrm{U}-234 \quad 1.000 \mathrm{E}+00$

U-238 9.999E-01

$\sum \operatorname{DOSE}(j)$

$\mathrm{Pu}-238 \quad 1.000 \mathrm{E}+00$

Th-230 1.000E+00

U-238 9.999E-01

$\sum \operatorname{DOSE}(j)$

$\mathrm{Pu}-238 \quad 1.000 \mathrm{E}+00$

Th-230 1.000E+00

$\mathrm{U}-234 \quad 1.000 \mathrm{E}+00$

$\sum \operatorname{DOSE}(j)$

Pu-239 1.000E+00

Pu-239 1.000E+00

U-235 $1.000 \mathrm{E}+00$

$\sum \operatorname{DOSE}(j)$
$\mathrm{U}-234 \quad 1.000 \mathrm{E}+00$

$\mathrm{U}-2389.999 \mathrm{E}-01$ $t=0.000 \mathrm{E}+001.000 \mathrm{E}+00 \quad 5.000 \mathrm{E}+01 \quad 1.000 \mathrm{E}+02 \quad 5.000 \mathrm{E}+02 \quad 1.050 \mathrm{E}+03$

$\begin{array}{llllll}0.000 \mathrm{E}+00 & 0.000 \mathrm{E}+00 & 0.000 \mathrm{E}+00 & 0.000 \mathrm{E}+00 & 8.647 \mathrm{E}-27 & 2.051 \mathrm{E}-20\end{array}$

$\begin{array}{llllll}1.106 \mathrm{E}-18 & 3.347 \mathrm{E}-18 & 1.835 \mathrm{E}-16 & 6.012 \mathrm{E}-16 & 1.645 \mathrm{E}-13 & 8.947 \mathrm{E}-11\end{array}$

$\begin{array}{llllll}1.072 \mathrm{E}-12 & 1.083 \mathrm{E}-12 & 1.832 \mathrm{E}-12 & 3.131 \mathrm{E}-12 & 2.281 \mathrm{E}-10 & 8.299 \mathrm{E}-08\end{array}$

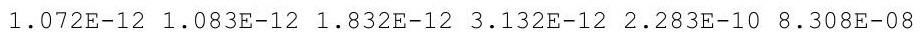

$\begin{array}{llllllll}0.000 E+00 & 1.773 E-28 & 3.482 E-25 & 2.511 E-24 & 7.620 E-21 & 2.570 E-17\end{array}$

$\begin{array}{lllllll}3.647 \mathrm{E}-23 & 1.106 \mathrm{E}-22 & 6.866 \mathrm{E}-21 & 2.553 \mathrm{E}-20 & 1.885 \mathrm{E}-17 & 3.825 \mathrm{E}-14\end{array}$

$3.647 \mathrm{E}-23 \quad 1.106 \mathrm{E}-22 \quad 6.867 \mathrm{E}-21 \quad 2.553 \mathrm{E}-20 \quad 1.886 \mathrm{E}-17 \quad 3.827 \mathrm{E}-14$

$\begin{array}{lllllll}1.715 \mathrm{E}-25 & 2.588 \mathrm{E}-24 & 1.224 \mathrm{E}-19 & 1.338 \mathrm{E}-18 & 2.306 \mathrm{E}-15 & 8.490 \mathrm{E}-13\end{array}$

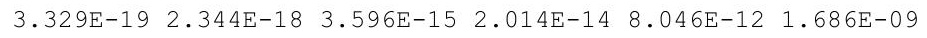

$\begin{array}{llllll}3.329 E-19 & 2.344 E-18 & 3.596 E-15 & 2.014 E-14 & 8.048 E-12 & 1.687 E-09\end{array}$

$\begin{array}{llllll}4.898 \mathrm{E}-09 & 4.827 \mathrm{E}-09 & 2.350 \mathrm{E}-09 & 1.128 \mathrm{E}-09 & 3.168 \mathrm{E}-12 & 9.832 \mathrm{E}-16\end{array}$

$0.000 \mathrm{E}+00 \quad 0.000 \mathrm{E}+00 \quad 0.000 \mathrm{E}+00 \quad 0.000 \mathrm{E}+00 \quad 0.000 \mathrm{E}+00 \quad 4.847 \mathrm{E}-28$

$\begin{array}{lllllll}9.362 \mathrm{E}-24 & 9.454 \mathrm{E}-24 & 1.525 \mathrm{E}-23 & 2.484 \mathrm{E}-23 & 1.231 \mathrm{E}-21 & 2.634 \mathrm{E}-19\end{array}$

$\begin{array}{llllll}9.362 \mathrm{E}-24 & 9.454 \mathrm{E}-24 & 1.525 \mathrm{E}-23 & 2.484 \mathrm{E}-23 & 1.231 \mathrm{E}-21 & 2.634 \mathrm{E}-19\end{array}$

$\begin{array}{llllll}7.792 E-29 & 2.366 E-28 & 1.573 E-26 & 6.349 E-26 & 1.353 E-22 & 2.337 E-18\end{array}$

$\begin{array}{lllllll}2.254 \mathrm{E}-22 & 2.295 \mathrm{E}-22 & 5.464 \mathrm{E}-22 & 1.324 \mathrm{E}-21 & 1.576 \mathrm{E}-18 & 2.670 \mathrm{E}-14\end{array}$

$\begin{array}{llllll}3.205 E-28 & 9.767 \mathrm{E}-28 & 7.823 \mathrm{E}-26 & 3.773 \mathrm{E}-25 & 2.238 \mathrm{E}-21 & 7.964 \mathrm{E}-17\end{array}$

$\begin{array}{lllllll}2.254 \mathrm{E}-22 & 2.295 \mathrm{E}-22 & 5.465 \mathrm{E}-22 & 1.325 \mathrm{E}-21 & 1.578 \mathrm{E}-18 & 2.679 \mathrm{E}-14\end{array}$

$\begin{array}{lllllll}0.000 \mathrm{E}+00 & 0.000 \mathrm{E}+00 & 1.275 \mathrm{E}-28 & 1.038 \mathrm{E}-27 & 1.043 \mathrm{E}-23 & 2.650 \mathrm{E}-19\end{array}$ $\begin{array}{llllllll}4.929 \mathrm{E}-21 & 5.012 \mathrm{E}-21 & 1.142 \mathrm{E}-20 & 2.647 \mathrm{E}-20 & 2.203 \mathrm{E}-17 & 2.282 \mathrm{E}-13\end{array}$ $3.559 \mathrm{E}-26 \quad 1.084 \mathrm{E}-25 \quad 8.307 \mathrm{E}-24 \quad 3.831 \mathrm{E}-23 \quad 1.586 \mathrm{E}-19 \quad 3.443 \mathrm{E}-15$ $0.000 \mathrm{E}+00 \quad 0.000 \mathrm{E}+00 \quad 5.947 \mathrm{E}-28 \quad 5.457 \mathrm{E}-27 \quad 1.125 \mathrm{E}-22 \quad 5.127 \mathrm{E}-18$ $\begin{array}{llllll}4.929 \mathrm{E}-21 & 5.012 \mathrm{E}-21 & 1.143 \mathrm{E}-20 & 2.651 \mathrm{E}-20 & 2.219 \mathrm{E}-17 & 2.317 \mathrm{E}-13\end{array}$

$6.392 \mathrm{E}-22 \quad 9.628 \mathrm{E}-21 \quad 4.197 \mathrm{E}-16 \quad 4.245 \mathrm{E}-15 \quad 4.482 \mathrm{E}-12 \quad 1.044 \mathrm{E}-09$ $\begin{array}{llllll}7.712 \mathrm{E}-10 & 2.327 \mathrm{E}-09 & 1.087 \mathrm{E}-07 & 3.024 \mathrm{E}-07 & 2.193 \mathrm{E}-05 & 1.840 \mathrm{E}-03\end{array}$ $\begin{array}{lllllll}3.705 \mathrm{E}-15 & 2.608 \mathrm{E}-14 & 3.968 \mathrm{E}-11 & 2.204 \mathrm{E}-10 & 8.184 \mathrm{E}-08 & 1.495 \mathrm{E}-05\end{array}$ $2.626 \mathrm{E}-21 \quad 3.963 \mathrm{E}-20 \quad 1.897 \mathrm{E}-15 \quad 2.100 \mathrm{E}-14 \quad 3.939 \mathrm{E}-11 \quad 1.538 \mathrm{E}-08$ $\begin{array}{lllllll}7.712 \mathrm{E}-10 & 2.327 \mathrm{E}-09 & 1.088 \mathrm{E}-07 & 3.026 \mathrm{E}-07 & 2.202 \mathrm{E}-05 & 1.855 \mathrm{E}-03\end{array}$

$0.000 \mathrm{E}+00 \quad 5.746 \mathrm{E}-29 \quad 6.196 \mathrm{E}-23 \quad 1.048 \mathrm{E}-21 \quad 2.936 \mathrm{E}-18 \quad 1.379 \mathrm{E}-15$ $\begin{array}{lllllll}3.717 \mathrm{E}-18 & 2.596 \mathrm{E}-17 & 2.655 \mathrm{E}-14 & 1.087 \mathrm{E}-13 & 1.573 \mathrm{E}-11 & 2.528 \mathrm{E}-09\end{array}$ $\begin{array}{lllllll}1.341 \mathrm{E}-23 & 2.012 \mathrm{E}-22 & 7.200 \mathrm{E}-18 & 6.329 \mathrm{E}-17 & 5.505 \mathrm{E}-14 & 1.988 \mathrm{E}-11\end{array}$ $\begin{array}{lllllll}0.000 \mathrm{E}+00 & 2.363 \mathrm{E}-28 & 2.757 \mathrm{E}-22 & 5.058 \mathrm{E}-21 & 2.498 \mathrm{E}-17 & 1.985 \mathrm{E}-14\end{array}$ $\begin{array}{lllllll}3.717 \mathrm{E}-18 & 2.596 \mathrm{E}-17 & 2.655 \mathrm{E}-14 & 1.087 \mathrm{E}-13 & 1.578 \mathrm{E}-11 & 2.548 \mathrm{E}-09\end{array}$ $\begin{array}{lllllll}8.843 E-17 & 8.949 E-17 & 1.607 E-16 & 2.919 E-16 & 3.463 E-14 & 2.463 E-11\end{array}$

$\begin{array}{llllll}4.513 E-23 & 1.369 \mathrm{E}-22 & 8.434 \mathrm{E}-21 & 3.112 \mathrm{E}-20 & 2.165 \mathrm{E}-17 & 4.048 \mathrm{E}-14\end{array}$ $\begin{array}{lllllll}1.651 \mathrm{E}-14 & 1.672 \mathrm{E}-14 & 3.064 \mathrm{E}-14 & 5.684 \mathrm{E}-14 & 7.982 \mathrm{E}-12 & 7.159 \mathrm{E}-09\end{array}$ $\begin{array}{llllll}1.651 \mathrm{E}-14 & 1.672 \mathrm{E}-14 & 3.064 \mathrm{E}-14 & 5.684 \mathrm{E}-14 & 7.982 \mathrm{E}-12 & 7.159 \mathrm{E}-09\end{array}$ 
RESRAD, Version $6.5 \quad T^{3 / 2}$ Limit $=180$ days

Summary : C746U Worker Deterministic Run

File : $\mathrm{X}: \backslash$ FINAL V2 \DOE FWD RUNS \C746U W DOE SG FWD-FV2-1050YR.RAD

Individual Nuclide Dose Summed Over All Pathways

Parent Nuclide and Branch Fraction Indicated

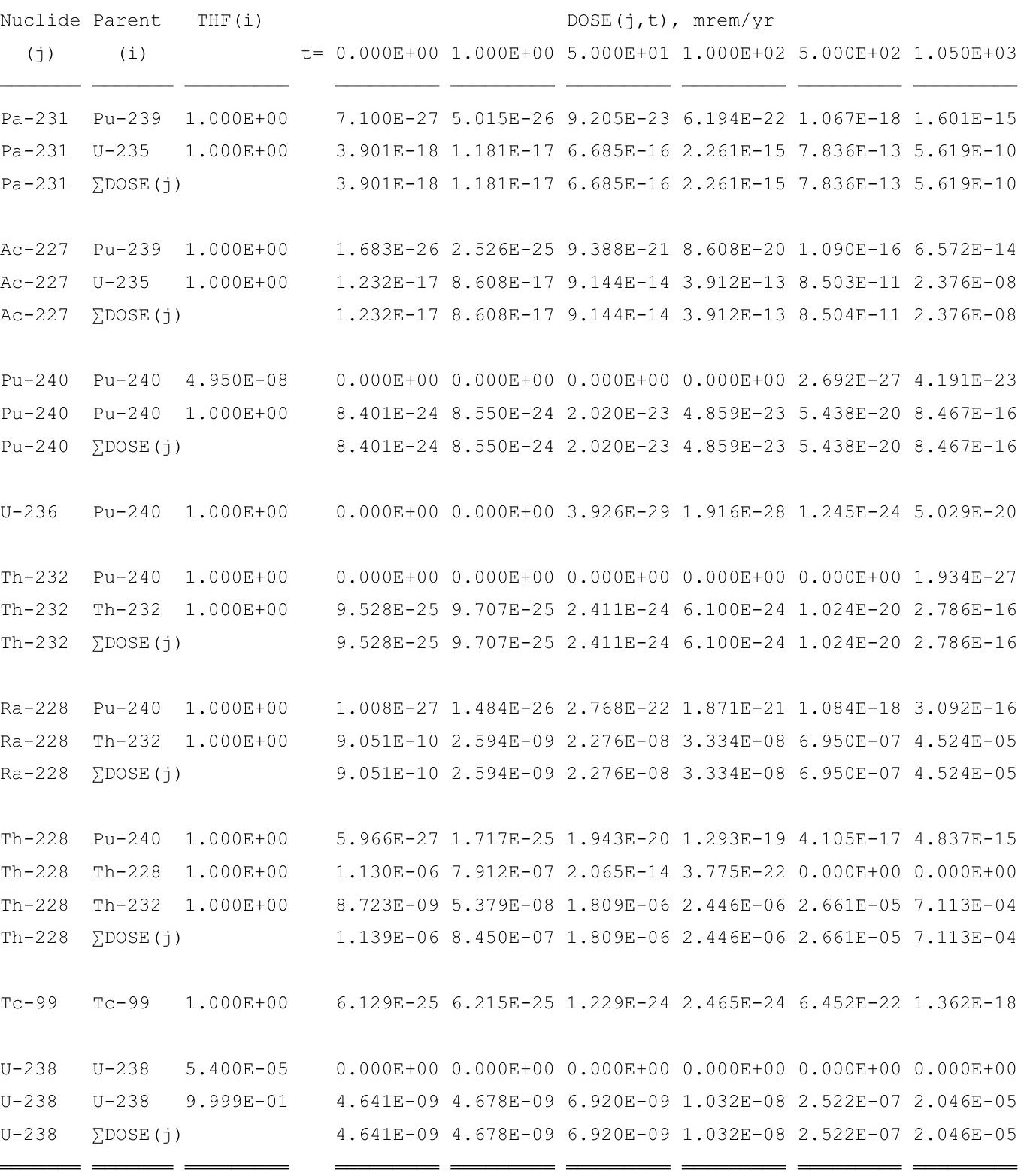

THF(i) is the thread fraction of the parent nuclide. 
RESRAD, Version $6.5 \quad T^{3 / 2}$ Limit $=180$ days

Summary : C746U Worker Deterministic Run

File : $\mathrm{X}: \backslash$ FINAL V2 \DOE FWD RUNS \C746U W DOE SG FWD-FV2-1050YR.RAD

Individual Nuclide Soil Concentration

Parent Nuclide and Branch Fraction Indicated

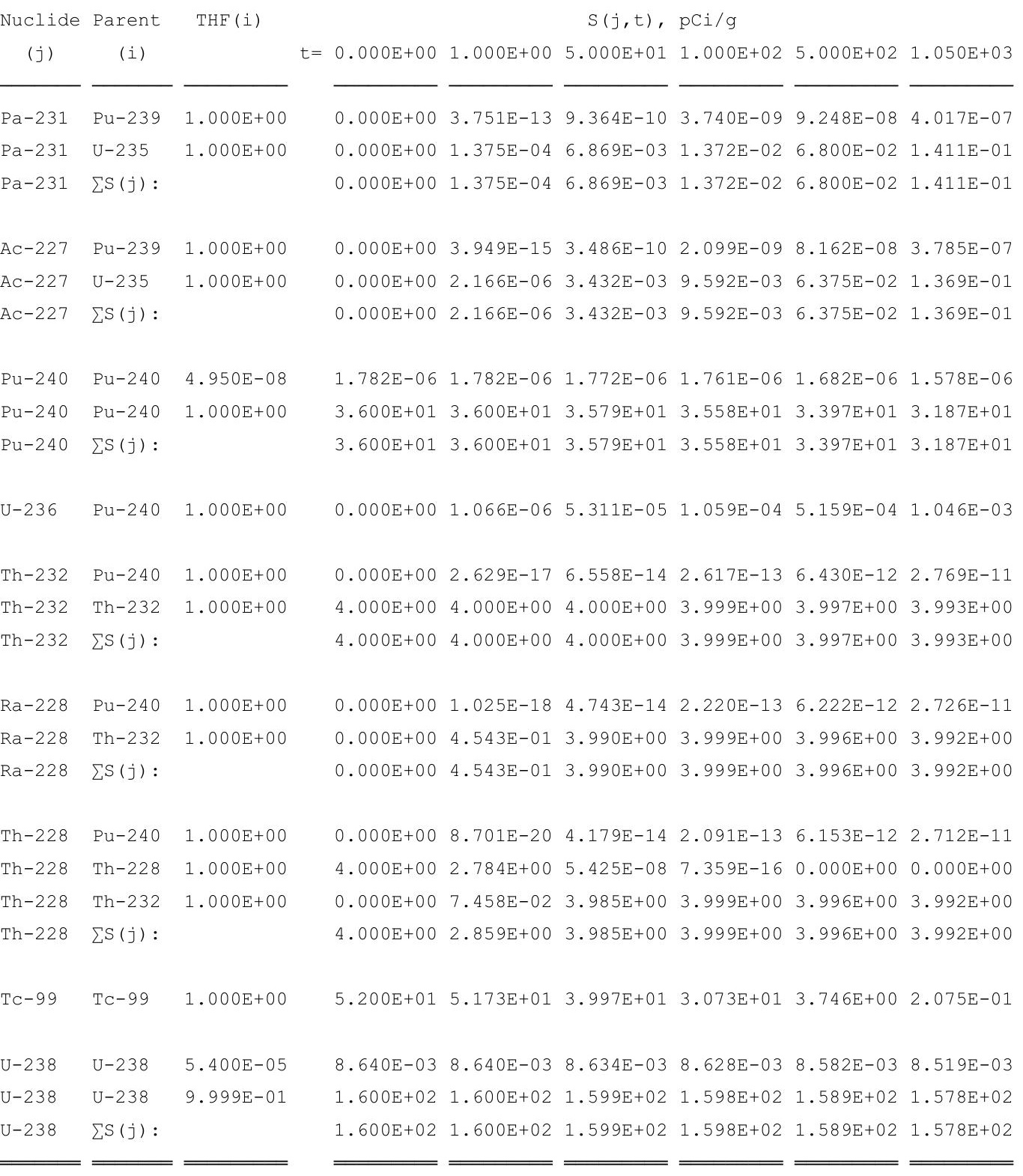

THF(i) is the thread fraction of the parent nuclide.

RESCALC.EXE execution time $=7.58$ seconds 


\title{
Outdoor Worker
}

\author{
Summary Report \\ (Deterministic Analysis Report)
}

Second Peak Dose Assessment

Time Horizon: 10,000 yr 
THIS PAGE INTENTIONALLY LEFT BLANK 
RESRAD, Version 6.5

Summary : C746U Worker Deterministic Run

File : X: \FINAL V2 \DOE FWD RUNS \C746U W DOE SG FWD-FV2-10000YR.RAD

Table of Contents

Part I: Mixture Sums and Single Radionuclide Guidelines

Dose Conversion Factor (and Related) Parameter Summary ... 2

Site-Specific Parameter Summary $\ldots \ldots \ldots \ldots \ldots \ldots \ldots \ldots \ldots$

Summary of Pathway Selections .................... 18

Contaminated Zone and Total Dose Summary ............. 19

Total Dose Components

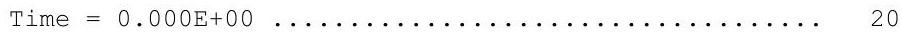

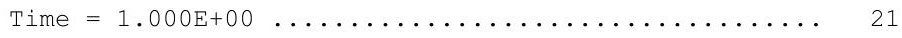

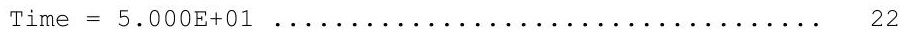

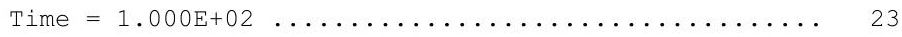

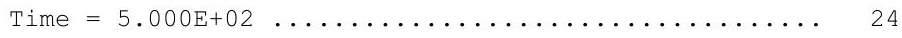

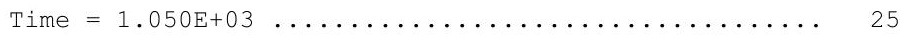

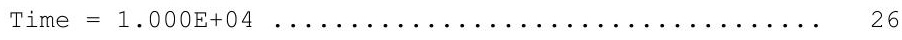

Dose/Source Ratios Summed Over All Pathways ............ 27

Single Radionuclide Soil Guidelines ............... 29

Dose Per Nuclide Summed Over All Pathways ............ 30

Soil Concentration Per Nuclide .................. 32 
RESRAD, Version $6.5 \quad T^{1 / 2}$ Limit $=180$ days

Summary : C746U Worker Deterministic Run

File : $\mathrm{X}: \backslash F I N A L$ V2 $\backslash$ DOE FWD RUNS $\backslash C 746 U$ W DOE SG FWD-FV2-10000YR.RAD

Dose Conversion Factor (and Related) Parameter Summary

Dose Library: ICRP 60 \& ICRP 72 (Adult)

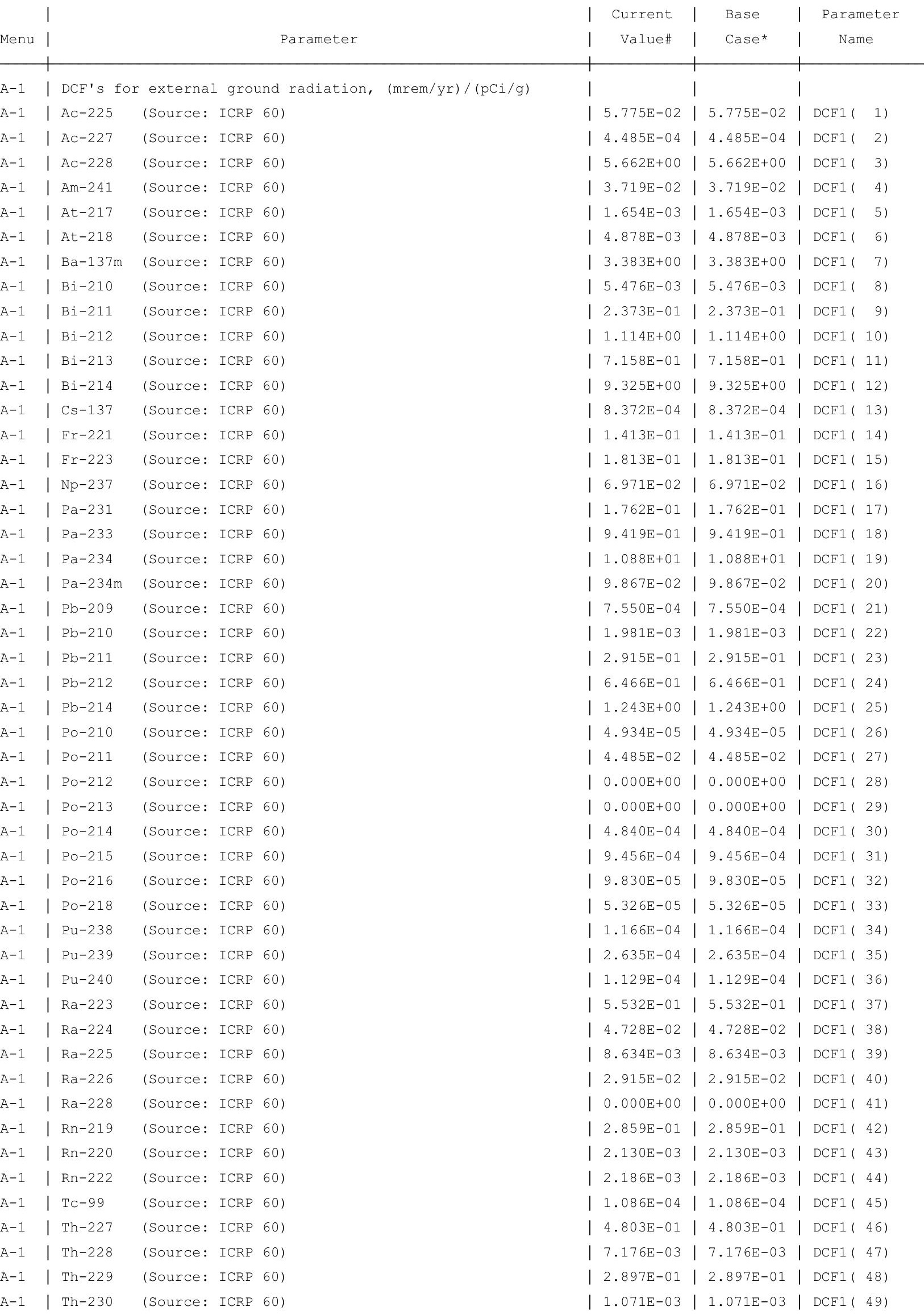


RESRAD, Version $6.5 \quad T^{1 / 2}$ Limit $=180$ days

Summary : C746U Worker Deterministic Run

File : $\mathrm{X}: \backslash F I N A L$ V2 $\backslash$ DOE FWD RUNS $\backslash C 746 U$ W DOE SG FWD-FV2-10000YR.RAD

Dose Conversion Factor (and Related) Parameter Summary (continued)

Dose Library: ICRP 60 \& ICRP 72 (Adult)

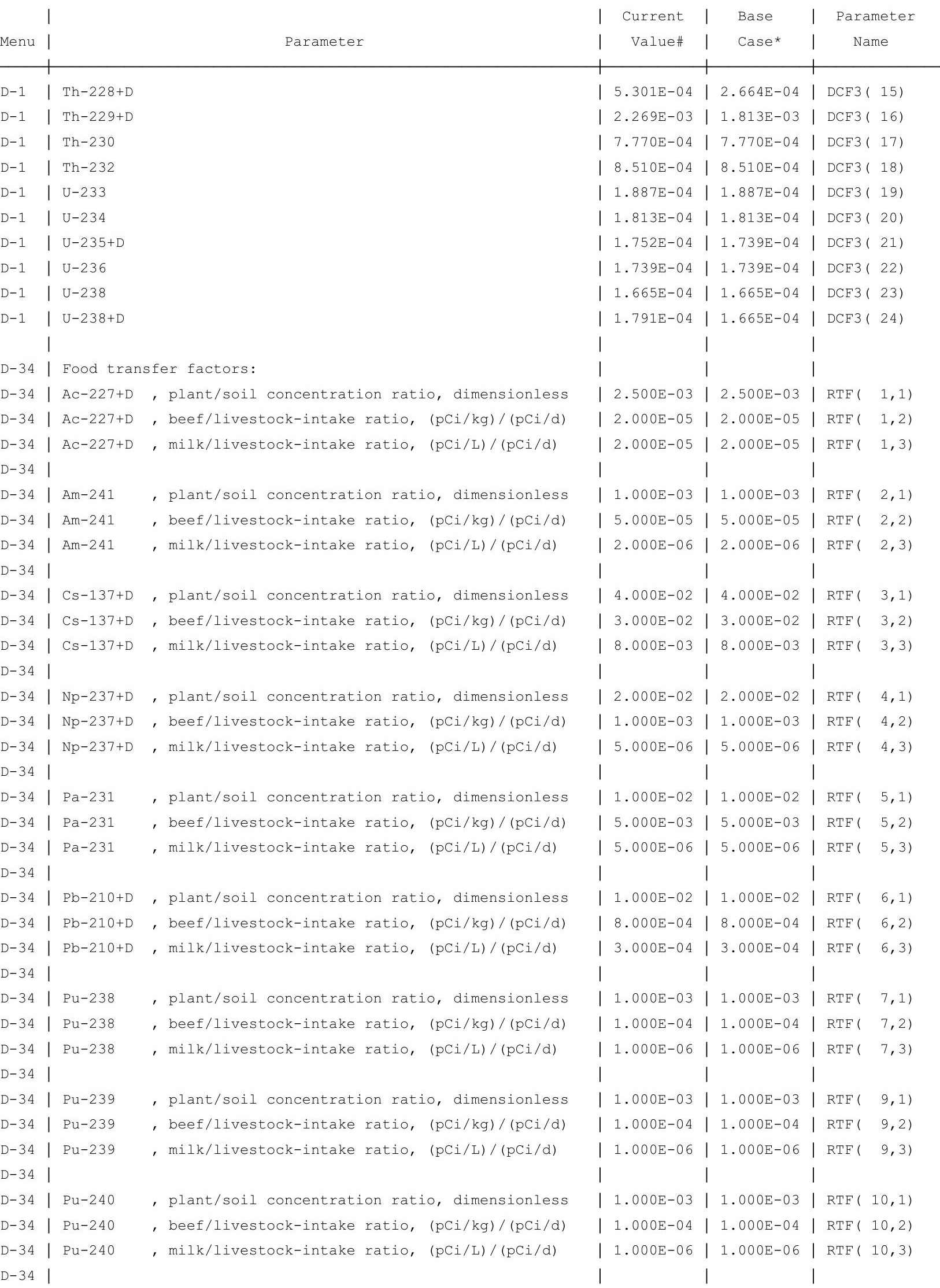


RESRAD, Version $6.5 \quad \mathrm{~T}^{1 / 2}$ Limit $=180$ days

Summary : C746U Worker Deterministic Run

File : $\mathrm{X}: \backslash F I N A L$ V2 $\backslash$ DOE FWD RUNS $\backslash C 746 U$ W DOE SG FWD-FV2-10000YR.RAD

Dose Conversion Factor (and Related) Parameter Summary (continued)

Dose Library: ICRP 60 \& ICRP 72 (Adult)

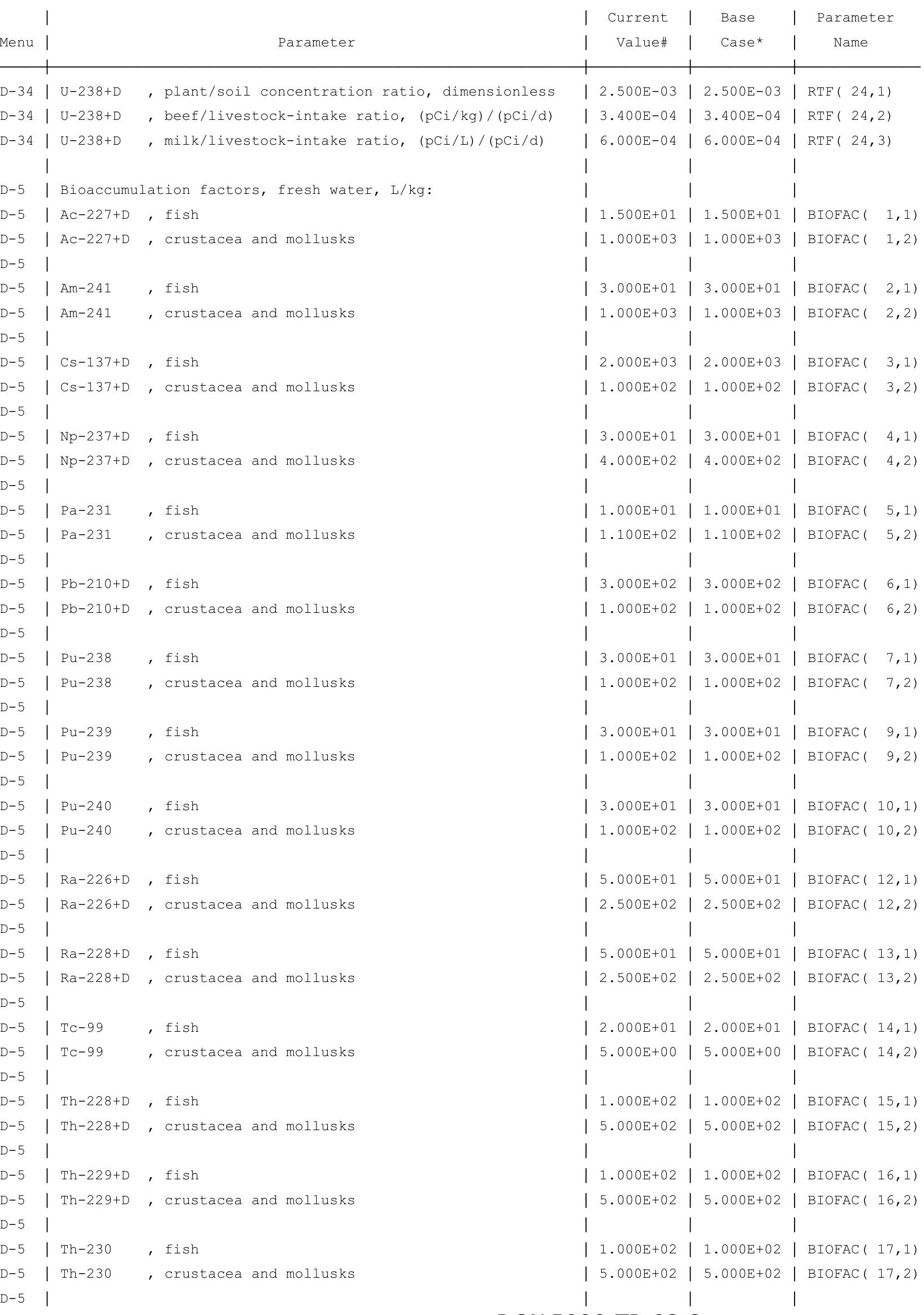


RESRAD, Version $6.5 \quad \mathrm{~T}^{3 / 2}$ Limit $=180$ days

Summary : C746U Worker Deterministic Run

File : $\mathrm{X}: \backslash F I N A L$ V2\DOE FWD RUNS \C746U W DOE SG FWD-FV2-10000YR.RAD

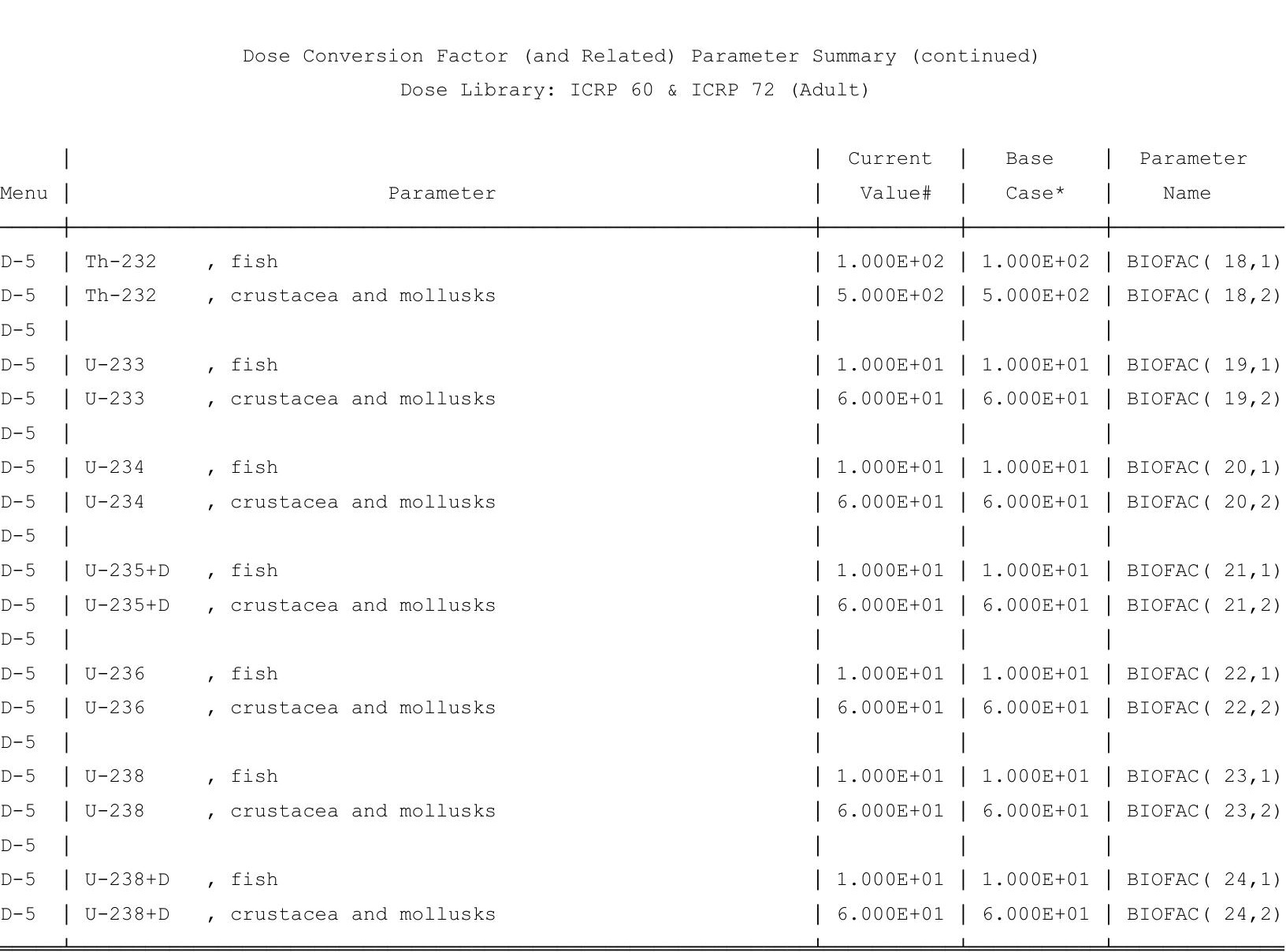

\#For DCFl(xx) only, factors are for infinite depth \& area. See ETFG table in Ground Pathway of Detailed Report. *Base Case means Default.Lib w/o Associate Nuclide contributions. 
RESRAD, Version $6.5 \quad \mathrm{~T}^{1 / 2}$ Limit $=180$ days

Summary : C746U Worker Deterministic Run

File : $\mathrm{X}: \backslash F I N A L$ V2 $\backslash$ DOE FWD RUNS $\backslash C 746 U$ W DOE SG FWD-FV2-10000YR. RAD

Site-Specific Parameter Summary (continued)

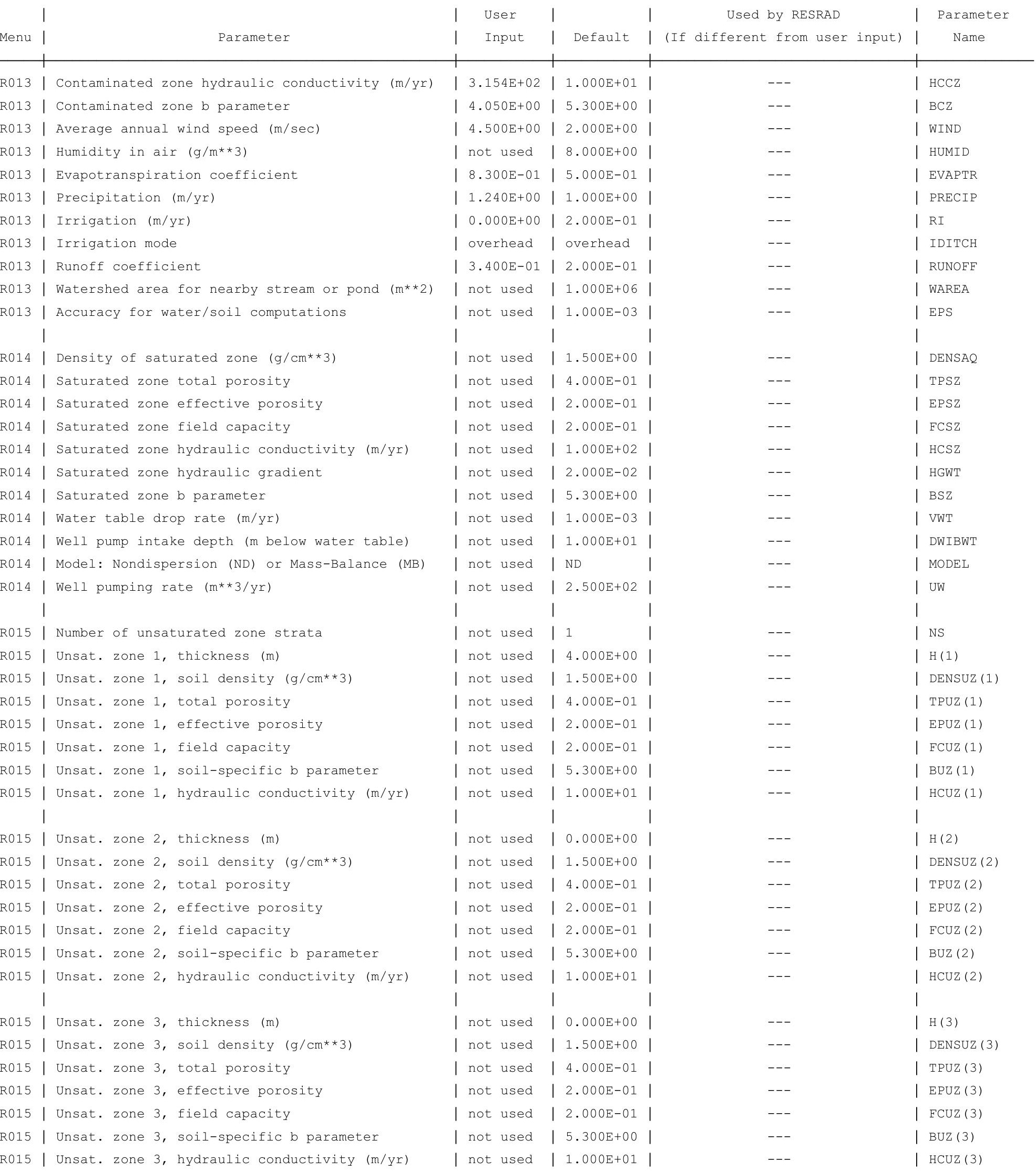


RESRAD, Version $6.5 \quad \mathrm{~T}^{1 / 2}$ Limit $=180$ days

Summary : C746U Worker Deterministic Run

File : $\mathrm{X}: \backslash F I N A L$ V2 $\backslash$ DOE FWD RUNS \C746U W DOE SG FWD-FV2-10000YR.RAD

Site-Specific Parameter Summary (continued)

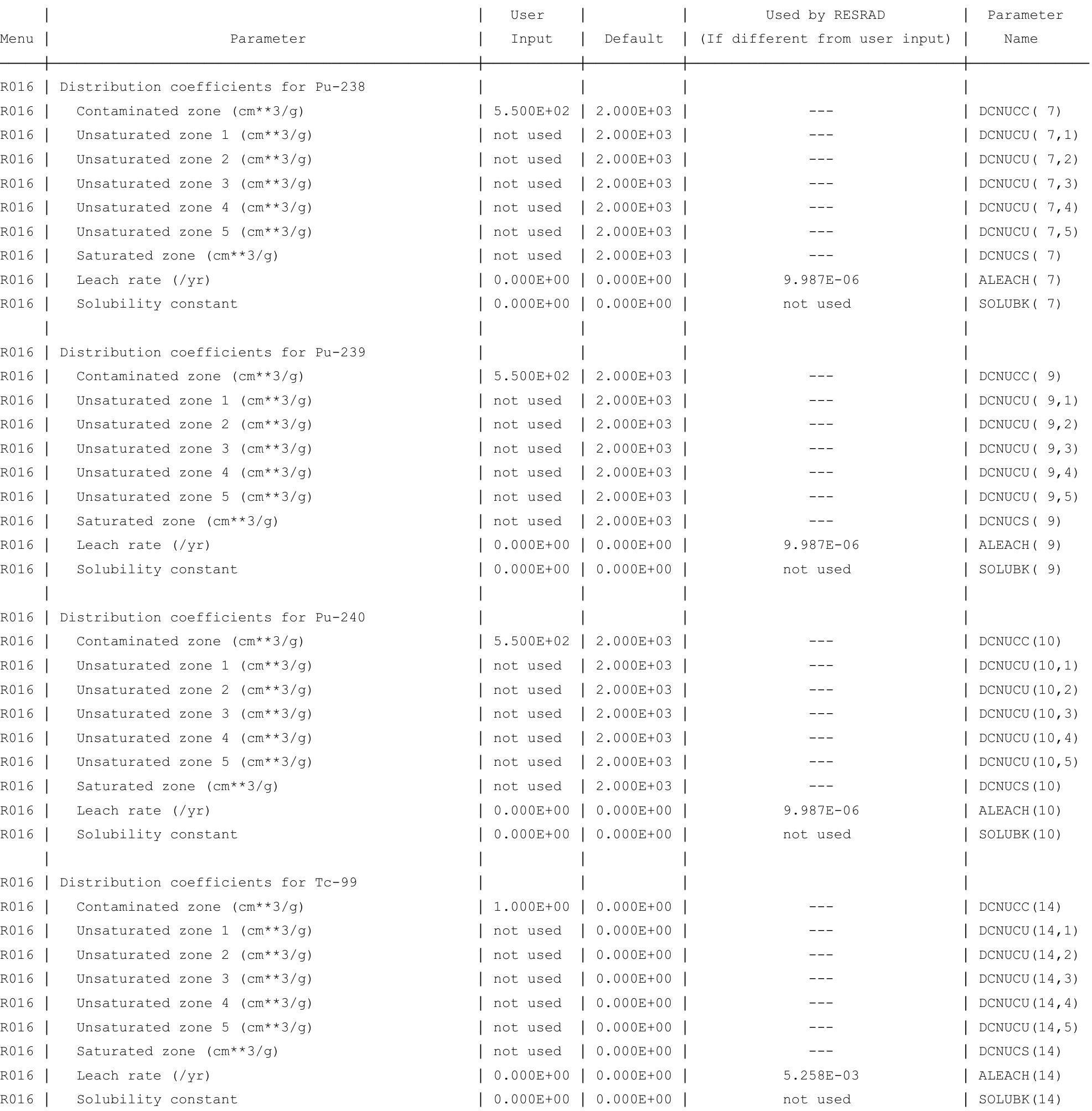


RESRAD, Version $6.5 \quad \mathrm{~T}^{1 / 2}$ Limit $=180$ days

Summary : C746U Worker Deterministic Run

File : $\mathrm{X}: \backslash F I N A L$ V2 $\backslash$ DOE FWD RUNS \C746U W DOE SG FWD-FV2-10000YR.RAD

Site-Specific Parameter Summary (continued)

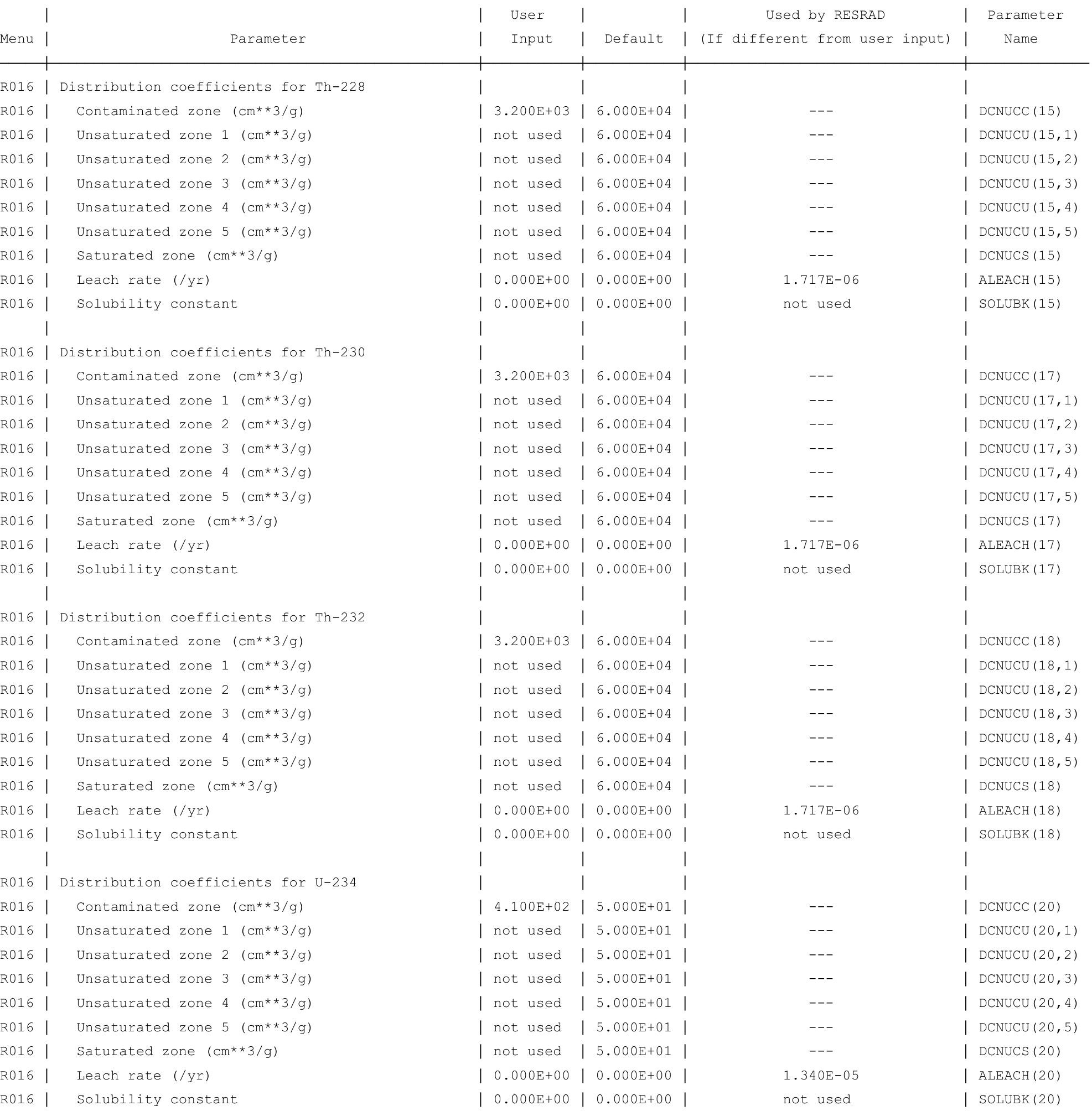


RESRAD, Version $6.5 \quad \mathrm{~T}^{1 / 2}$ Limit $=180$ days

Summary : C746U Worker Deterministic Run

File : $\mathrm{X}: \backslash F I N A L$ V2 $\backslash$ DOE FWD RUNS \C746U W DOE SG FWD-FV2-10000YR.RAD

Site-Specific Parameter Summary (continued)

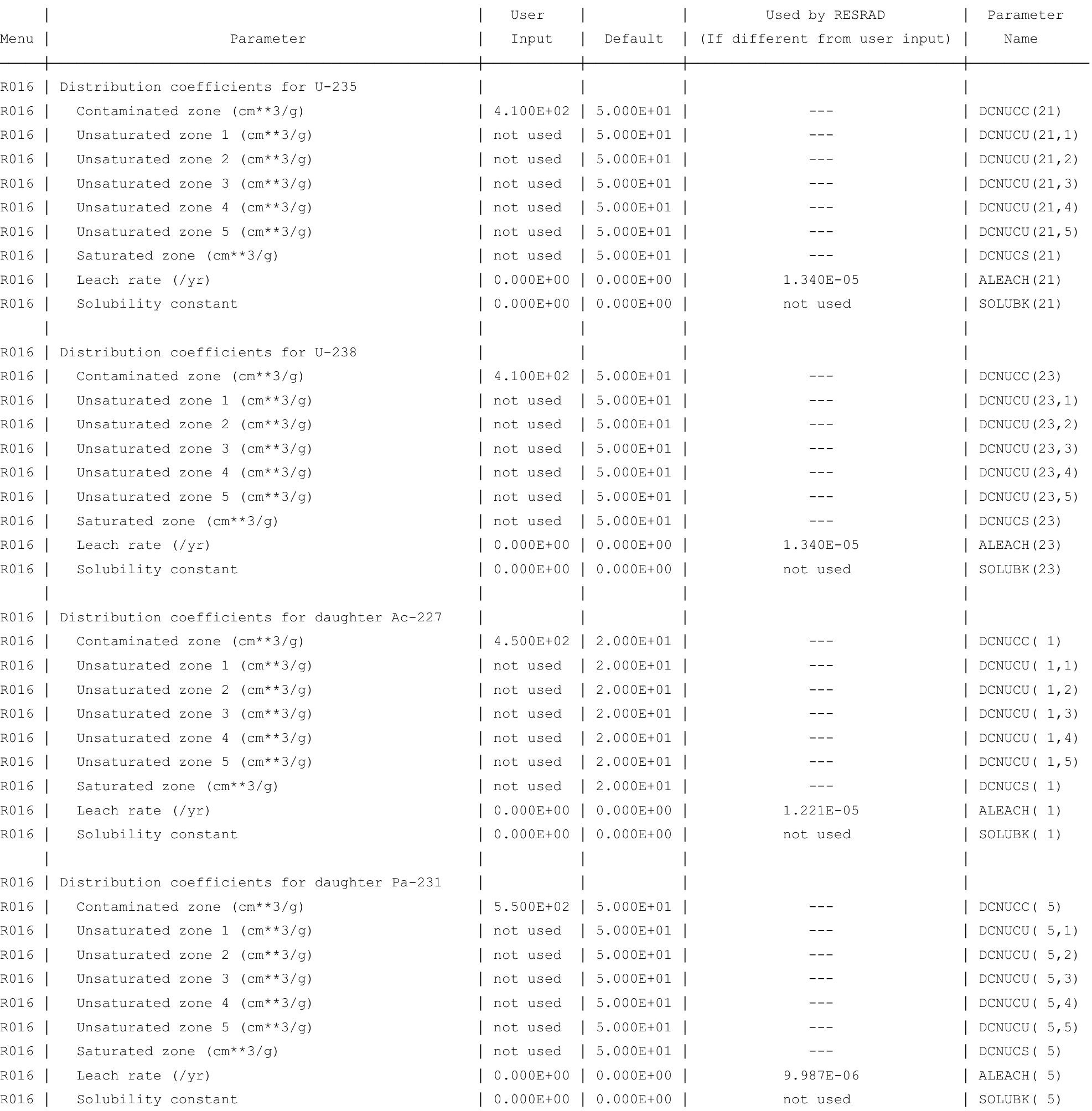


RESRAD, Version $6.5 \quad \mathrm{~T}^{1 / 2}$ Limit $=180$ days

Summary : C746U Worker Deterministic Run

File : $\mathrm{X}: \backslash F I N A L$ V2 $\backslash$ DOE FWD RUNS \C746U W DOE SG FWD-FV2-10000YR.RAD

Site-Specific Parameter Summary (continued)

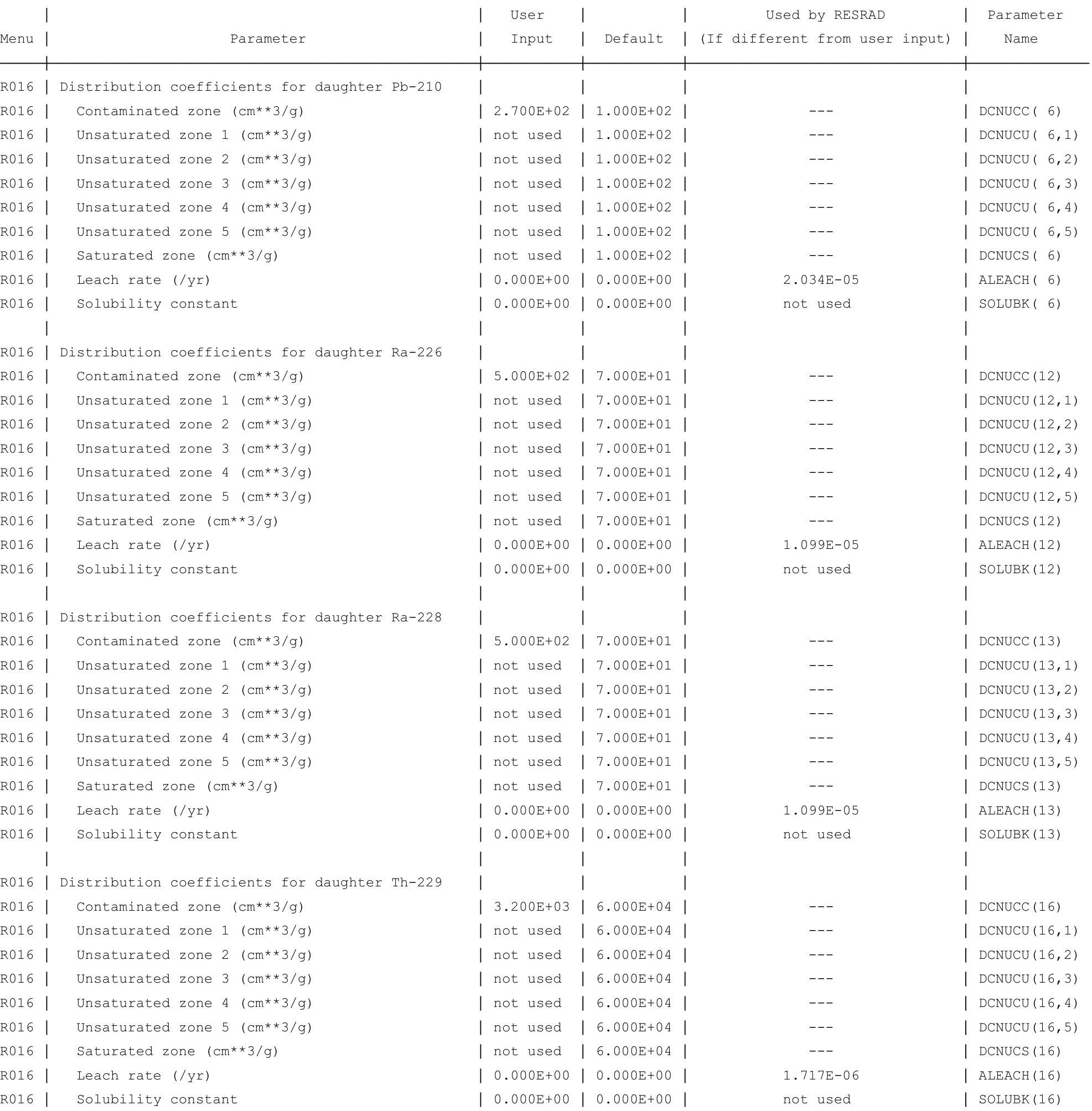


RESRAD, Version $6.5 \quad \mathrm{~T}^{1 / 2}$ Limit $=180$ days

Summary : C746U Worker Deterministic Run

File : $\mathrm{X}: \backslash \mathrm{FINAL}$ V2 \DOE FWD RUNS \C746U W DOE SG FWD-FV2-10000YR.RAD

Site-Specific Parameter Summary (continued)

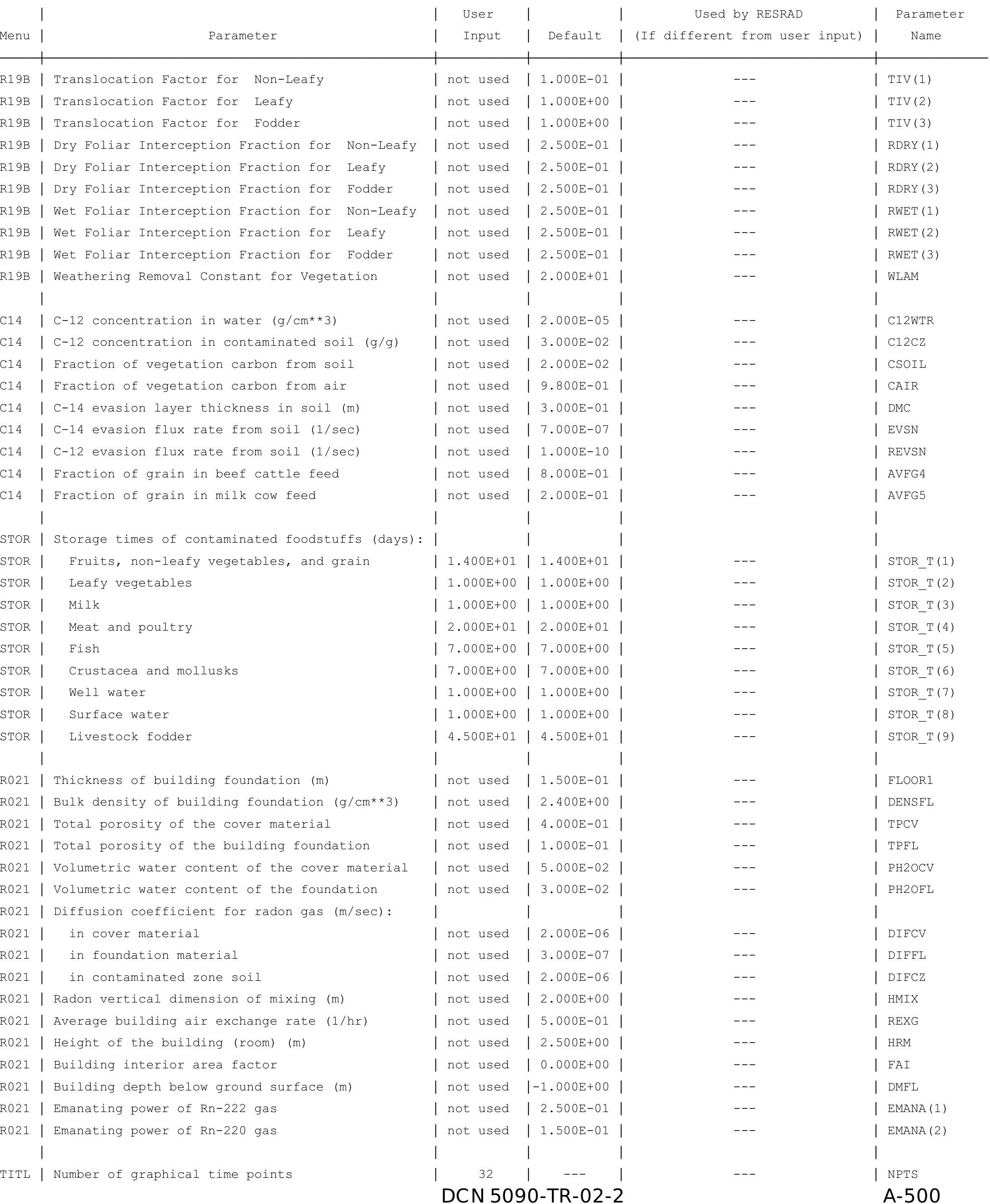


RESRAD, Version $6.5 \quad T^{1 / 2}$ Limit $=180$ days

Summary : C746U Worker Deterministic Run

File : $\mathrm{X}: \backslash$ FINAL V2 $\backslash$ DOE FWD RUNS $\backslash C 746 \mathrm{U} W$ DOE SG FWD-FV2-10000YR.RAD

Contaminated Zone Dimensions

Area: 89436.00 square meters

Thickness:

Cover Depth:

\begin{abstract}
13.40 meters
\end{abstract}
1.52 meters
Initial Soil Concentrations, pCi/g

$\begin{array}{ll}\text { Am-241 } & 3.500 \mathrm{E}+01 \\ \mathrm{Cs}-137 & 1.900 \mathrm{E}+01 \\ \mathrm{~Np}-237 & 5.500 \mathrm{E}+00 \\ \mathrm{Pu}-238 & 3.900 \mathrm{E}+01 \\ \mathrm{Pu}-239 & 3.600 \mathrm{E}+01 \\ \mathrm{Pu}-240 & 3.600 \mathrm{E}+01 \\ \mathrm{TC}-99 & 5.200 \mathrm{E}+01 \\ \mathrm{Th}-228 & 4.000 \mathrm{E}+00 \\ \mathrm{Th}-230 & 1.000 \mathrm{E}+02 \\ \mathrm{Th}-232 & 4.000 \mathrm{E}+00 \\ \mathrm{U}-234 & 1.600 \mathrm{E}+02 \\ \mathrm{U}-235 & 6.500 \mathrm{E}+00 \\ \mathrm{U}-238 & 1.600 \mathrm{E}+02\end{array}$

Total Dose TDOSE(t), mrem/yr

Basic Radiation Dose Limit $=1.000 \mathrm{E}+00 \mathrm{mrem} / \mathrm{yr}$

Total Mixture Sum $M(t)$ = Fraction of Basic Dose Limit Received at Time (t)

$\begin{array}{rlllllll}t \text { (years) }: & 0.000 \mathrm{E}+00 & 1.000 \mathrm{E}+00 & 5.000 \mathrm{E}+01 & 1.000 \mathrm{E}+02 & 5.000 \mathrm{E}+02 & 1.050 \mathrm{E}+03 & 1.000 \mathrm{E}+04 \\ \mathrm{TDOSE}(\mathrm{t}): & 1.150 \mathrm{E}-06 & 8.594 \mathrm{E}-07 & 1.950 \mathrm{E}-06 & 2.793 \mathrm{E}-06 & 4.957 \mathrm{E}-05 & 2.632 \mathrm{E}-03 & 2.178 \mathrm{E}+02 \\ \mathrm{M}(\mathrm{t}): & 1.150 \mathrm{E}-06 & 8.594 \mathrm{E}-07 & 1.950 \mathrm{E}-06 & 2.793 \mathrm{E}-06 & 4.957 \mathrm{E}-05 & 2.632 \mathrm{E}-03 & 2.178 \mathrm{E}+02\end{array}$

Maximum TDOSE(t): $2.178 \mathrm{E}+02 \mathrm{mrem} / \mathrm{yr}$ at $\mathrm{t}=1.000 \mathrm{E}+04$ years 
RESRAD, Version 6.5

$\mathrm{T}^{1 / 2}$ Limit $=180$ days

Summary : C746U Worker Deterministic Run

File : X: \FINAL V2 \DOE FWD RUNS \C746U W DOE SG FWD-FV2-10000YR.RAD

Total Dose Contributions TDOSE (i,p,t) for Individual Radionuclides (i) and Pathways (p) As mrem/yr and Fraction of Total Dose At $t=0.000 \mathrm{E}+00$ years

Water Independent Pathways (Inhalation excludes radon)

\begin{tabular}{lll} 
& & \multicolumn{2}{c}{ Ground } \\
Radio- & & \\
Nuclide & mrem/yr & fract. \\
\cline { 1 - 1 } Am-241 & $1.106 \mathrm{E}-18$ & 0.0000 \\
Cs-137 & $4.898 \mathrm{E}-09$ & 0.0043 \\
Np-237 & $1.072 \mathrm{E}-12$ & 0.0000 \\
Pu-238 & $6.486 \mathrm{E}-22$ & 0.0000 \\
Pu-239 & $8.843 \mathrm{E}-17$ & 0.0000 \\
Pu-240 & $8.408 \mathrm{E}-24$ & 0.0000 \\
$\mathrm{TC}-99$ & $6.129 \mathrm{E}-25$ & 0.0000 \\
$\mathrm{Th}-228$ & $1.130 \mathrm{E}-06$ & 0.9827 \\
$\mathrm{Th}-230$ & $7.712 \mathrm{E}-10$ & 0.0007 \\
$\mathrm{Th}-232$ & $9.628 \mathrm{E}-09$ & 0.0084 \\
$\mathrm{U}-234$ & $3.705 \mathrm{E}-15$ & 0.0000 \\
$\mathrm{U}-235$ & $1.653 \mathrm{E}-14$ & 0.0000 \\
$\mathrm{U}-238$ & $4.641 \mathrm{E}-09$ & 0.0040 \\
\hline \hline & & \\
\hline \hline
\end{tabular}

Total

\begin{abstract}
Inhalation
\end{abstract}
mrem/yr fract.

mrem/yr fract. mrem/yr fract.

$\overline{0.000 \mathrm{E}+00} \overline{0.0000}$

$0.000 \mathrm{E}+00 \quad 0.0000$

$0.000 \mathrm{E}+00 \quad 0.0000$

$0.000 \mathrm{E}+00 \quad 0.0000$

$0.000 \mathrm{E}+00 \quad 0.0000$

$0.000 \mathrm{E}+00 \quad 0.0000$

$0.000 \mathrm{E}+00 \quad 0.0000$

$0.000 \mathrm{E}+00 \quad 0.0000$

$0.000 \mathrm{E}+00 \quad 0.0000$

$0.000 \mathrm{E}+00 \quad 0.0000$

$0.000 \mathrm{E}+00 \quad 0.0000$

$0.000 \mathrm{E}+00 \quad 0.0000$

$0.000 \mathrm{E}+00 \quad 0.0000$

$\overline{0.000 \mathrm{E}+00} \overline{0.0000}$

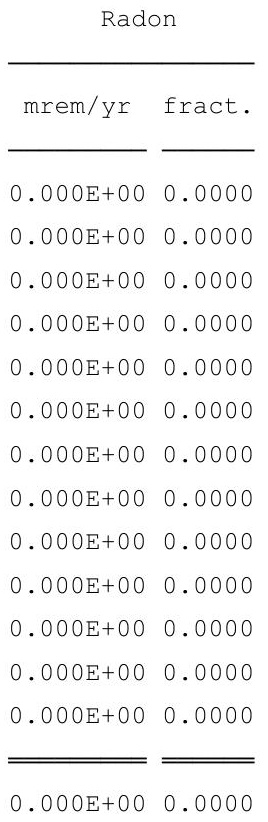

Plant

$\overline{\text { mrem/yr fract. }}$

$0.000 \mathrm{E}+00 \quad 0.0000$

$0.000 \mathrm{E}+00 \quad 0.0000$

$0.000 \mathrm{E}+00 \quad 0.0000$

$0.000 \mathrm{E}+00 \quad 0.0000$

$0.000 \mathrm{E}+00 \quad 0.0000$

$0.000 \mathrm{E}+00 \quad 0.0000$

$0.000 \mathrm{E}+00 \quad 0.0000$

$0.000 \mathrm{E}+00 \quad 0.0000$

$0.000 \mathrm{E}+00 \quad 0.0000$

$0.000 \mathrm{E}+00 \quad 0.0000$

$0.000 \mathrm{E}+00 \quad 0.0000$

$0.000 \mathrm{E}+00 \quad 0.0000$

$0.000 \mathrm{E}+00 \quad 0.0000$

$0.000 \mathrm{E}+00 \quad 0.0000$

\begin{tabular}{cc} 
Meat \\
\hline mrem/yr fract. \\
\hline $0.000 \mathrm{E}+00$ & 0.0000 \\
$0.000 \mathrm{E}+00$ & 0.0000 \\
$0.000 \mathrm{E}+00$ & 0.0000 \\
$0.000 \mathrm{E}+00$ & 0.0000 \\
$0.000 \mathrm{E}+00$ & 0.0000 \\
$0.000 \mathrm{E}+00$ & 0.0000 \\
$0.000 \mathrm{E}+00$ & 0.0000 \\
$0.000 \mathrm{E}+00$ & 0.0000 \\
$0.000 \mathrm{E}+00$ & 0.0000 \\
$0.000 \mathrm{E}+00$ & 0.0000 \\
$0.000 \mathrm{E}+00$ & 0.0000 \\
$0.000 \mathrm{E}+00$ & 0.0000 \\
$0.000 \mathrm{E}+00$ & 0.0000 \\
\hline \hline $0.000 \mathrm{E}+00$ & 0.0000
\end{tabular}

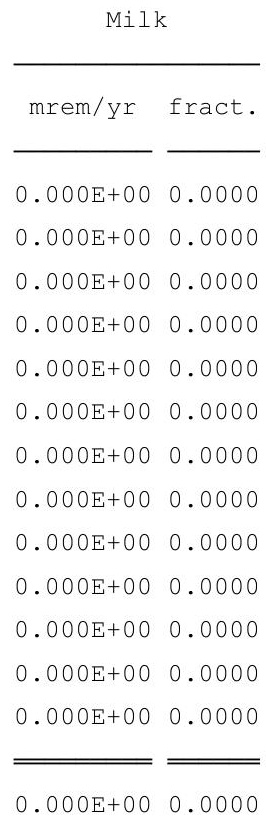

Soil mrem/yr fract. $0.000 \mathrm{E}+00 \quad 0.0000$ $0.000 \mathrm{E}+00 \quad 0.0000$ $0.000 \mathrm{E}+00 \quad 0.0000$ $0.000 \mathrm{E}+00 \quad 0.0000$ $0.000 \mathrm{E}+00 \quad 0.0000$ $0.000 \mathrm{E}+00 \quad 0.0000$ $0.000 \mathrm{E}+00 \quad 0.0000$ $0.000 \mathrm{E}+00 \quad 0.0000$ $0.000 \mathrm{E}+00 \quad 0.0000$ $0.000 \mathrm{E}+00 \quad 0.0000$ $0.000 \mathrm{E}+00 \quad 0.0000$ $0.000 \mathrm{E}+00 \quad 0.0000$ $0.000 \mathrm{E}+00 \quad 0.0000$ $0.000 \mathrm{E}+00 \quad 0.0000$

Total Dose Contributions TDOSE (i,p,t) for Individual Radionuclides (i) and Pathways (p) As mrem/yr and Fraction of Total Dose At $t=0.000 \mathrm{E}+00$ years

Water Dependent Pathways

\begin{tabular}{|c|c|c|c|c|c|c|}
\hline \multirow{2}{*}{ Nuclide } & \multicolumn{2}{|c|}{ Water } & \multicolumn{2}{|c|}{ Fish } & \multicolumn{2}{|c|}{ Radon } \\
\hline & $\mathrm{mrem} / \mathrm{yr}$ & fract. & mrem/yr & fract. & mrem/yr & fract. \\
\hline-241 & $0.000 \mathrm{E}+00$ & 0.0000 & $0.000 \mathrm{E}+00$ & 0.0000 & $0.000 \mathrm{E}+00$ & 0.0000 \\
\hline-137 & $0.000 \mathrm{E}+00$ & 0.0000 & $0.000 \mathrm{E}+00$ & 0.0000 & $0.000 \mathrm{E}+00$ & 0.0000 \\
\hline-237 & $0.000 \mathrm{E}+00$ & 0.0000 & $0.000 \mathrm{E}+00$ & 0.0000 & $0.000 \mathrm{E}+00$ & 0.0000 \\
\hline-238 & $0.000 \mathrm{E}+00$ & 0.0000 & $0.000 \mathrm{E}+00$ & 0.0000 & $0.000 \mathrm{E}+00$ & 0.0000 \\
\hline 239 & $0.000 \mathrm{E}+00$ & 0.0000 & $0.000 \mathrm{E}+00$ & 0.0000 & $0.000 \mathrm{E}+00$ & 0.0000 \\
\hline 240 & $0.000 \mathrm{E}+00$ & 0.0000 & $0.000 \mathrm{E}+00$ & 0.0000 & $0.000 \mathrm{E}+00$ & 0.0000 \\
\hline 99 & $0.000 \mathrm{E}+00$ & 0.0000 & $0.000 \mathrm{E}+00$ & 0.0000 & $0.000 \mathrm{E}+00$ & 0.0000 \\
\hline 228 & $0.000 \mathrm{E}+00$ & 0.0000 & $0.000 \mathrm{E}+00$ & 0.0000 & $0.000 \mathrm{E}+00$ & 0.0000 \\
\hline 230 & $0.000 \mathrm{E}+00$ & 0.0000 & $0.000 \mathrm{E}+00$ & 0.0000 & $0.000 \mathrm{E}+00$ & 0.0000 \\
\hline 232 & $0.000 \mathrm{E}+00$ & 0.0000 & $0.000 \mathrm{E}+00$ & 0.0000 & $0.000 \mathrm{E}+00$ & 0.0000 \\
\hline & $0.000 \mathrm{E}+00$ & 0.0000 & $0.000 \mathrm{E}+00$ & 0.0000 & $0.000 \mathrm{E}+00$ & 0.0000 \\
\hline 35 & $0.000 \mathrm{E}+00$ & 0.0000 & $0.000 \mathrm{E}+00$ & 0.0000 & $0.000 \mathrm{E}+00$ & 0.0000 \\
\hline & $0.000 \mathrm{E}+00$ & 0.0000 & $0.000 \mathrm{E}+00$ & 0.0000 & $0.000 \mathrm{E}+00$ & 0.0000 \\
\hline & D & .0000 & .0 & 0 & 0 & 0 \\
\hline
\end{tabular}

\begin{tabular}{ccc} 
Plant \\
\cline { 1 - 1 } mrem/yr fract. \\
\hline $0.000 \mathrm{E}+00$ & 0.0000 \\
$0.000 \mathrm{E}+00$ & 0.0000 \\
$0.000 \mathrm{E}+00$ & 0.0000 \\
$0.000 \mathrm{E}+00$ & 0.0000 \\
$0.000 \mathrm{E}+00$ & 0.0000 \\
$0.000 \mathrm{E}+00$ & 0.0000 \\
$0.000 \mathrm{E}+00$ & 0.0000 \\
$0.000 \mathrm{E}+00$ & 0.0000 \\
$0.000 \mathrm{E}+00$ & 0.0000 \\
$0.000 \mathrm{E}+00$ & 0.0000 \\
$0.000 \mathrm{E}+00$ & 0.0000 \\
$0.000 \mathrm{E}+00$ & 0.0000 \\
$0.000 \mathrm{E}+00$ & 0.0000 \\
\hline \hline
\end{tabular}

$0.000 \mathrm{E}+00 \quad 0.0000$

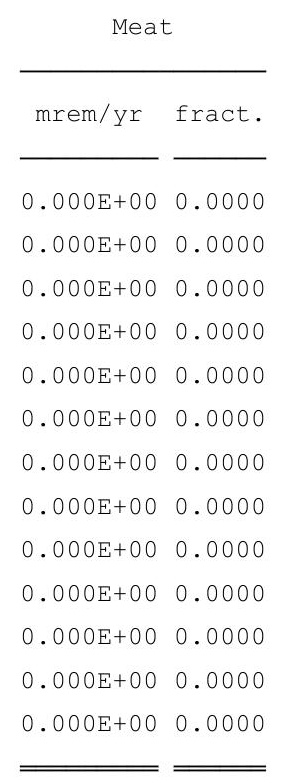

$0.000 \mathrm{E}+00 \quad 0.0000$

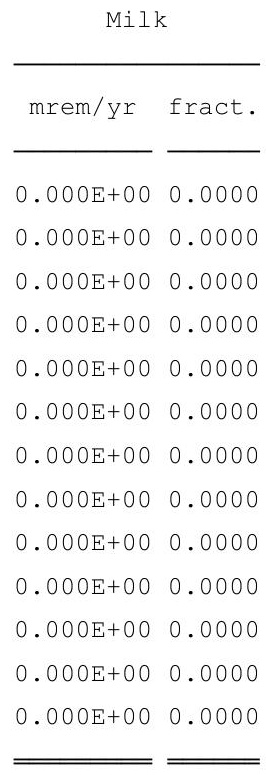

$0.000 \mathrm{E}+00 \quad 0.0000$
All Pathways* mrem/yr fract. $1.106 \mathrm{E}-18 \quad 0.0000$ $4.898 \mathrm{E}-09 \quad 0.0043$ $1.072 \mathrm{E}-12 \quad 0.0000$ $6.486 \mathrm{E}-220.0000$ $8.843 \mathrm{E}-17 \quad 0.0000$ $8.408 \mathrm{E}-24 \quad 0.0000$ $6.129 \mathrm{E}-25 \quad 0.0000$ $1.130 \mathrm{E}-06 \quad 0.9827$ $7.712 \mathrm{E}-10 \quad 0.0007$ $9.628 \mathrm{E}-09 \quad 0.0084$ $3.705 \mathrm{E}-15 \quad 0.0000$ $1.653 \mathrm{E}-14 \quad 0.0000$ $4.641 \mathrm{E}-09 \quad 0.0040$ $1.150 \mathrm{E}-06 \quad 1.0000$

*Sum of all water independent and dependent pathways. 
RESRAD, Version 6.5

$\mathrm{T}^{1} \frac{1}{2}$ Limit $=180$ days

Summary : C746U Worker Deterministic Run

File : $\mathrm{X}: \backslash F I N A L$ V2 $\backslash$ DOE FWD RUNS $\backslash C 746 U$ W DOE SG FWD-FV2-10000YR.RAD

Total Dose Contributions TDOSE (i,p,t) for Individual Radionuclides (i) and Pathways (p) As mrem/yr and Fraction of Total Dose At $t=1.000 \mathrm{E}+00$ years

Water Independent Pathways (Inhalation excludes radon)

\begin{tabular}{|c|c|c|}
\hline clide & mrem/yr & fract. \\
\hline-241 & $3.347 E-18$ & 0.0000 \\
\hline-137 & $4.827 E-09$ & 0.0056 \\
\hline-237 & $1.083 \mathrm{E}-12$ & 0.0000 \\
\hline-238 & $9.637 \mathrm{E}-21$ & 0.0000 \\
\hline-239 & $8.949 \mathrm{E}-17$ & 0.0000 \\
\hline-240 & $8.736 \mathrm{E}-24$ & 0.0000 \\
\hline-99 & $6.215 \mathrm{E}-25$ & 0.0000 \\
\hline-228 & $7.912 \mathrm{E}-07$ & 0.9206 \\
\hline-230 & $2.327 E-09$ & 0.0027 \\
\hline-232 & $5.638 \mathrm{E}-08$ & 0.0656 \\
\hline 234 & $2.608 E-14$ & 0.0000 \\
\hline 235 & $1.682 \mathrm{E}-14$ & 0.0000 \\
\hline 38 & $4.678 E-09$ & 0.0054 \\
\hline & $8.594 \mathrm{E}-07$ & 1.0000 \\
\hline
\end{tabular}

Total

\begin{abstract}
Inhalation
\end{abstract}
mrem/yr fract.

mrem/yr fract. mrem/yr fract.

$\overline{0.000 \mathrm{E}+00} \overline{0.0000}$

$0.000 \mathrm{E}+00 \quad 0.0000$

$0.000 \mathrm{E}+00 \quad 0.0000$

$0.000 \mathrm{E}+00 \quad 0.0000$

$0.000 \mathrm{E}+00 \quad 0.0000$

$0.000 \mathrm{E}+00 \quad 0.0000$

$0.000 E+00 \quad 0.0000$

$0.000 \mathrm{E}+00 \quad 0.0000$

$0.000 \mathrm{E}+00 \quad 0.0000$

$0.000 E+00 \quad 0.0000$

$0.000 \mathrm{E}+00 \quad 0.0000$

$0.000 E+00 \quad 0.0000$

$0.000 \mathrm{E}+00 \quad 0.0000$

$\overline{\overline{0.000 E+00}} \overline{0.0000}$

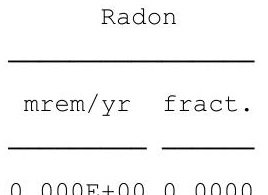

$0.000 \mathrm{E}+00 \quad 0.0000$

$0.000 E+00 \quad 0.0000$

$0.000 E+00 \quad 0.0000$

$0.000 E+00 \quad 0.0000$

$0.000 E+00 \quad 0.0000$

$0.000 E+00 \quad 0.0000$

$0.000 \mathrm{E}+00 \quad 0.0000$

$0.000 \mathrm{E}+00 \quad 0.0000$

$0.000 \mathrm{E}+00 \quad 0.0000$

$0.000 E+00 \quad 0.0000$

$0.000 E+00 \quad 0.0000$

$0.000 \mathrm{E}+00 \quad 0.0000$

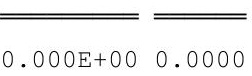

Plant

mrem/yr fract.

$\overline{0.000 E+00} 0.0000$

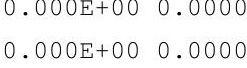

$0.000 \mathrm{E}+00 \quad 0.0000$

$0.000 \mathrm{E}+00 \quad 0.0000$

$0.000 \mathrm{E}+00 \quad 0.0000$

$0.000 \mathrm{E}+00 \quad 0.0000$

$0.000 \mathrm{E}+00 \quad 0.0000$

$0.000 \mathrm{E}+00 \quad 0.0000$

$0.000 \mathrm{E}+00 \quad 0.0000$

$0.000 \mathrm{E}+00 \quad 0.0000$

$0.000 \mathrm{E}+00 \quad 0.0000$

$0.000 \mathrm{E}+00 \quad 0.0000$

$0.000 \mathrm{E}+00 \quad 0.0000$

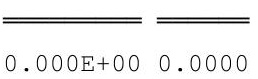

\begin{tabular}{ll} 
Meat \\
\hline mrem/yr fract. \\
\cline { 1 - 2 } $0.000 \mathrm{E}+00$ & 0.0000 \\
$0.000 \mathrm{E}+00$ & 0.0000 \\
$0.000 \mathrm{E}+00$ & 0.0000 \\
$0.000 \mathrm{E}+00$ & 0.0000 \\
$0.000 \mathrm{E}+00$ & 0.0000 \\
$0.000 \mathrm{E}+00$ & 0.0000 \\
$0.000 \mathrm{E}+00$ & 0.0000 \\
$0.000 \mathrm{E}+00$ & 0.0000 \\
$0.000 \mathrm{E}+00$ & 0.0000 \\
$0.000 \mathrm{E}+00$ & 0.0000 \\
$0.000 \mathrm{E}+00$ & 0.0000 \\
$0.000 \mathrm{E}+00$ & 0.0000 \\
$0.000 \mathrm{E}+00$ & 0.0000 \\
\hline \hline $0.000 \mathrm{E}+00$ & 0.0000
\end{tabular}

\begin{tabular}{cc} 
Milk \\
\hline mrem/yr fract. \\
\cline { 1 - 2 } $0.000 \mathrm{E}+00$ & 0.0000 \\
$0.000 \mathrm{E}+00$ & 0.0000 \\
$0.000 \mathrm{E}+00$ & 0.0000 \\
$0.000 \mathrm{E}+00$ & 0.0000 \\
$0.000 \mathrm{E}+00$ & 0.0000 \\
$0.000 \mathrm{E}+00$ & 0.0000 \\
$0.000 \mathrm{E}+00$ & 0.0000 \\
$0.000 \mathrm{E}+00$ & 0.0000 \\
$0.000 \mathrm{E}+00$ & 0.0000 \\
$0.000 \mathrm{E}+00$ & 0.0000 \\
$0.000 \mathrm{E}+00$ & 0.0000 \\
$0.000 \mathrm{E}+00$ & 0.0000 \\
$0.000 \mathrm{E}+00$ & 0.0000 \\
\hline \hline $0.000 \mathrm{E}+00$ & 0.0000
\end{tabular}

Soil

mrem/yr fract.

$0.000 \mathrm{E}+00 \quad 0.0000$

$0.000 \mathrm{E}+00 \quad 0.0000$

$0.000 \mathrm{E}+00 \quad 0.0000$

$0.000 \mathrm{E}+00 \quad 0.0000$

$0.000 \mathrm{E}+00 \quad 0.0000$

$0.000 \mathrm{E}+00 \quad 0.0000$

$0.000 \mathrm{E}+00 \quad 0.0000$

$0.000 \mathrm{E}+00 \quad 0.0000$

$0.000 \mathrm{E}+00 \quad 0.0000$

$0.000 \mathrm{E}+00 \quad 0.0000$

$0.000 \mathrm{E}+00 \quad 0.0000$

$0.000 \mathrm{E}+00 \quad 0.0000$

$0.000 \mathrm{E}+00 \quad 0.0000$

$0.000 \mathrm{E}+00 \quad 0.0000$

Total Dose Contributions TDOSE (i,p,t) for Individual Radionuclides (i) and Pathways (p) As mrem/yr and Fraction of Total Dose At $t=1.000 \mathrm{E}+00$ years

Water Dependent Pathways

\begin{tabular}{|c|c|c|c|c|c|c|}
\hline & \multicolumn{2}{|c|}{ Water } & \multicolumn{2}{|c|}{ Fish } & \multicolumn{2}{|c|}{ Radon } \\
\hline clide & mrem/yr & fract. & mrem/yr & fract. & mrem/yr & fract. \\
\hline 41 & $0.000 \mathrm{E}+00$ & 0.0000 & $0.000 \mathrm{E}+00$ & 0.0000 & $0.000 \mathrm{E}+00$ & 0.0000 \\
\hline-137 & $0.000 \mathrm{E}+00$ & 0.0000 & $0.000 \mathrm{E}+00$ & 0.0000 & $0.000 \mathrm{E}+00$ & 0.0000 \\
\hline-237 & $0.000 \mathrm{E}+00$ & 0.0000 & $0.000 \mathrm{E}+00$ & 0.0000 & $0.000 \mathrm{E}+00$ & 0.0000 \\
\hline-238 & $0.000 \mathrm{E}+00$ & 0.0000 & $0.000 \mathrm{E}+00$ & 0.0000 & $0.000 \mathrm{E}+00$ & 0.0000 \\
\hline-239 & $0.000 \mathrm{E}+00$ & 0.0000 & $0.000 \mathrm{E}+00$ & 0.0000 & $0.000 \mathrm{E}+00$ & 0.0000 \\
\hline-240 & $0.000 \mathrm{E}+00$ & 0.0000 & $0.000 \mathrm{E}+00$ & 0.0000 & $0.000 \mathrm{E}+00$ & 0.0000 \\
\hline-99 & $0.000 \mathrm{E}+00$ & 0.0000 & $0.000 \mathrm{E}+00$ & 0.0000 & $0.000 \mathrm{E}+00$ & 0.0000 \\
\hline-228 & $0.000 \mathrm{E}+00$ & 0.0000 & $0.000 \mathrm{E}+00$ & 0.0000 & $0.000 \mathrm{E}+00$ & 0.0000 \\
\hline-230 & $0.000 \mathrm{E}+00$ & 0.0000 & $0.000 \mathrm{E}+00$ & 0.0000 & $0.000 \mathrm{E}+00$ & 0.0000 \\
\hline-232 & $0.000 \mathrm{E}+00$ & 0.0000 & $0.000 \mathrm{E}+00$ & 0.0000 & $0.000 \mathrm{E}+00$ & 0.0000 \\
\hline 234 & $0.000 \mathrm{E}+00$ & 0.0000 & $0.000 \mathrm{E}+00$ & 0.0000 & $0.000 \mathrm{E}+00$ & 0.0000 \\
\hline 35 & $0.000 \mathrm{E}+00$ & 0.0000 & $0.000 \mathrm{E}+00$ & 0.0000 & $0.000 \mathrm{E}+00$ & 0.0000 \\
\hline 38 & $0.000 \mathrm{E}+00$ & 0.0000 & $0.000 \mathrm{E}+00$ & 0.0000 & $0.000 \mathrm{E}+00$ & 0.0000 \\
\hline & $0.000 \mathrm{E}+00$ & 0.0000 & $0.000 \mathrm{E}+00$ & 0.0000 & $0.000 \mathrm{E}+00$ & 0.0000 \\
\hline
\end{tabular}

\begin{tabular}{|c|c|c|c|}
\hline \multicolumn{2}{|c|}{ Plant } & \multicolumn{2}{|c|}{ Meat } \\
\hline mrem/yr & fract. & mrem/yr & fract. \\
\hline $0.000 \mathrm{E}+00$ & 0.0000 & $0.000 \mathrm{E}+00$ & 0.0000 \\
\hline $0.000 \mathrm{E}+00$ & 0.0000 & $0.000 \mathrm{E}+00$ & 0.0000 \\
\hline $0.000 \mathrm{E}+00$ & 0.0000 & $0.000 \mathrm{E}+00$ & 0.0000 \\
\hline $0.000 \mathrm{E}+00$ & 0.0000 & $0.000 \mathrm{E}+00$ & 0.0000 \\
\hline $0.000 \mathrm{E}+00$ & 0.0000 & $0.000 \mathrm{E}+00$ & 0.0000 \\
\hline $0.000 \mathrm{E}+00$ & 0.0000 & $0.000 \mathrm{E}+00$ & 0.0000 \\
\hline $0.000 \mathrm{E}+00$ & 0.0000 & $0.000 \mathrm{E}+00$ & 0.0000 \\
\hline $0.000 \mathrm{E}+00$ & 0.0000 & $0.000 \mathrm{E}+00$ & 0.0000 \\
\hline $0.000 \mathrm{E}+00$ & 0.0000 & $0.000 \mathrm{E}+00$ & 0.0000 \\
\hline $0.000 \mathrm{E}+00$ & 0.0000 & $0.000 \mathrm{E}+00$ & 0.0000 \\
\hline $0.000 \mathrm{E}+00$ & 0.0000 & $0.000 \mathrm{E}+00$ & 0.0000 \\
\hline $0.000 \mathrm{E}+00$ & 0.0000 & $0.000 \mathrm{E}+00$ & 0.0000 \\
\hline $0.000 \mathrm{E}+00$ & 0.0000 & $0.000 \mathrm{E}+00$ & 0.0000 \\
\hline
\end{tabular}

$0.000 \mathrm{E}+00 \quad 0.0000$

$0.000 \mathrm{E}+00 \quad 0.0000$

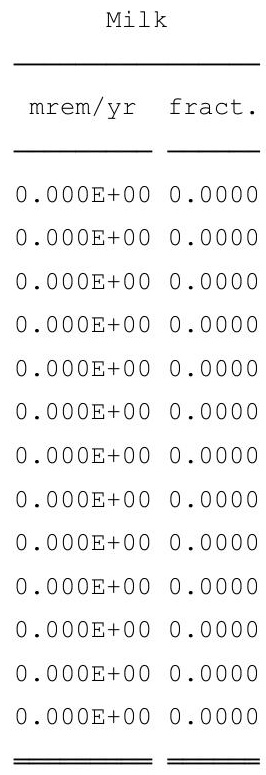

$0.000 \mathrm{E}+00 \quad 0.0000$
All Pathways * mrem/yr fract. $3.347 \mathrm{E}-18 \quad 0.0000$ $4.827 \mathrm{E}-090.0056$ $1.083 \mathrm{E}-120.0000$ $9.637 \mathrm{E}-210.0000$ $8.949 \mathrm{E}-170.0000$ $8.736 \mathrm{E}-240.0000$ $6.215 \mathrm{E}-250.0000$ $7.912 \mathrm{E}-07 \quad 0.9206$ $2.327 \mathrm{E}-090.0027$ $5.638 \mathrm{E}-08 \quad 0.0656$ $2.608 \mathrm{E}-14 \quad 0.0000$ $1.682 \mathrm{E}-14 \quad 0.0000$ $4.678 \mathrm{E}-09 \quad 0.0054$ $8.594 \mathrm{E}-07 \quad 1.0000$

* Sum of all water independent and dependent pathways. 
RESRAD, Version 6.5

$\mathrm{T}^{1} \frac{1}{2}$ Limit $=180$ days

Summary : C746U Worker Deterministic Run

File : $\mathrm{X}: \backslash F I N A L$ V2 $\backslash$ DOE FWD RUNS $\backslash C 746 U$ W DOE SG FWD-FV2-10000YR.RAD

Total Dose Contributions TDOSE (i,p,t) for Individual Radionuclides (i) and Pathways (p) As mrem/yr and Fraction of Total Dose At $t=5.000 \mathrm{E}+01$ years

Water Independent Pathways (Inhalation excludes radon)

\begin{tabular}{|c|c|c|}
\hline clide & mrem/yr & fract. \\
\hline-241 & $1.836 \mathrm{E}-16$ & 0.0000 \\
\hline-137 & $2.350 \mathrm{E}-09$ & 0.0012 \\
\hline-237 & $1.835 \mathrm{E}-12$ & 0.0000 \\
\hline-238 & $4.197 \mathrm{E}-16$ & 0.0000 \\
\hline-239 & $1.607 \mathrm{E}-16$ & 0.0000 \\
\hline-240 & 1. $973 \mathrm{E}-20$ & 0.0000 \\
\hline-99 & $1.229 \mathrm{E}-24$ & 0.0000 \\
\hline-228 & $2.065 \mathrm{E}-14$ & 0.0000 \\
\hline-230 & $1.087 \mathrm{E}-07$ & 0.0558 \\
\hline-232 & $1.832 \mathrm{E}-06$ & 0.9395 \\
\hline 34 & $3.968 \mathrm{E}-11$ & 0.0000 \\
\hline 35 & $1.227 \mathrm{E}-13$ & 0.0000 \\
\hline 38 & $6.920 \mathrm{E}-09$ & 0.0035 \\
\hline & 6 & 1.0000 \\
\hline
\end{tabular}

Total $1.950 \mathrm{E}-061.0000$

\begin{abstract}
Inhalation
\end{abstract}
mrem/yr fract.

$\longrightarrow$

$0.000 \mathrm{E}+00 \quad 0.0000$

$0.000 \mathrm{E}+00 \quad 0.0000$

$0.000 \mathrm{E}+00 \quad 0.0000$

$0.000 \mathrm{E}+00 \quad 0.0000$

$0.000 \mathrm{E}+00 \quad 0.0000$

$0.000 \mathrm{E}+00 \quad 0.0000$

$0.000 E+00 \quad 0.0000$

$0.000 \mathrm{E}+00 \quad 0.0000$

$0.000 \mathrm{E}+00 \quad 0.0000$

$0.000 \mathrm{E}+00 \quad 0.0000$

$0.000 \mathrm{E}+00 \quad 0.0000$

$0.000 E+00 \quad 0.0000$

$0.000 \mathrm{E}+00 \quad 0.0000$

$\overline{\overline{0.000 \mathrm{E}+00}} \overline{\overline{0.0000}}$

Radon
mrem/yr fract. $\overline{0.000 \mathrm{E}+00} \overline{0.0000}$ $0.000 \mathrm{E}+00 \quad 0.0000$ $0.000 E+00 \quad 0.0000$ $0.000 \mathrm{E}+00 \quad 0.0000$ $0.000 \mathrm{E}+00 \quad 0.0000$ $0.000 E+00 \quad 0.0000$ $0.000 E+00 \quad 0.0000$ $0.000 \mathrm{E}+00 \quad 0.0000$ $0.000 \mathrm{E}+00 \quad 0.0000$ $0.000 \mathrm{E}+00 \quad 0.0000$ $0.000 \mathrm{E}+00 \quad 0.0000$ $0.000 \mathrm{E}+00 \quad 0.0000$ $0.000 \mathrm{E}+00 \quad 0.0000$

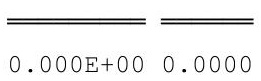

\begin{tabular}{|c|c|c|c|}
\hline \multicolumn{2}{|c|}{ Plant } & \multicolumn{2}{|c|}{ Meat } \\
\hline mrem/yr & fract. & mrem/yr & fract. \\
\hline $0.000 \mathrm{E}+00$ & 0.0000 & $0.000 \mathrm{E}+00$ & 0.0000 \\
\hline $0.000 \mathrm{E}+00$ & 0.0000 & $0.000 \mathrm{E}+00$ & 0.0000 \\
\hline $0.000 \mathrm{E}+00$ & 0.0000 & $0.000 \mathrm{E}+00$ & 0.0000 \\
\hline $0.000 \mathrm{E}+00$ & 0.0000 & $0.000 \mathrm{E}+00$ & 0.0000 \\
\hline $0.000 \mathrm{E}+00$ & 0.0000 & $0.000 \mathrm{E}+00$ & 0.0000 \\
\hline $0.000 \mathrm{E}+00$ & 0.0000 & $0.000 \mathrm{E}+00$ & 0.0000 \\
\hline $0.000 \mathrm{E}+00$ & 0.0000 & $0.000 \mathrm{E}+00$ & 0.0000 \\
\hline $0.000 \mathrm{E}+00$ & 0.0000 & $0.000 \mathrm{E}+00$ & 0.0000 \\
\hline $0.000 \mathrm{E}+00$ & 0.0000 & $0.000 \mathrm{E}+00$ & 0.0000 \\
\hline $0.000 \mathrm{E}+00$ & 0.0000 & $0.000 \mathrm{E}+00$ & 0.0000 \\
\hline $0.000 \mathrm{E}+00$ & 0.0000 & $0.000 \mathrm{E}+00$ & 0.0000 \\
\hline $0.000 \mathrm{E}+00$ & 0.0000 & $0.000 \mathrm{E}+00$ & 0.0000 \\
\hline $0.000 \mathrm{E}+00$ & 0.0000 & $0.000 \mathrm{E}+00$ & 0.0000 \\
\hline & & 0.00 & \\
\hline
\end{tabular}

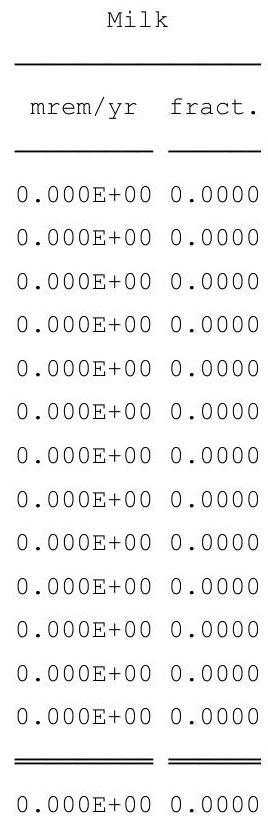

Soil mrem/yr fract. $0.000 \mathrm{E}+00 \quad 0.0000$ $0.000 \mathrm{E}+00 \quad 0.0000$ $0.000 \mathrm{E}+00 \quad 0.0000$ $0.000 \mathrm{E}+00 \quad 0.0000$ $0.000 \mathrm{E}+00 \quad 0.0000$ $0.000 \mathrm{E}+00 \quad 0.0000$ $0.000 \mathrm{E}+00 \quad 0.0000$ $0.000 \mathrm{E}+00 \quad 0.0000$ $0.000 \mathrm{E}+00 \quad 0.0000$ $0.000 \mathrm{E}+00 \quad 0.0000$ $0.000 \mathrm{E}+00 \quad 0.0000$ $0.000 \mathrm{E}+00 \quad 0.0000$ $0.000 \mathrm{E}+00 \quad 0.0000$ $0.000 \mathrm{E}+00 \quad 0.0000$

Total Dose Contributions TDOSE(i,p,t) for Individual Radionuclides (i) and Pathways (p) As mrem/yr and Fraction of Total Dose At $t=5.000 \mathrm{E}+01$ years

Water Dependent Pathways

\begin{tabular}{|c|c|c|c|c|c|c|}
\hline & \multicolumn{2}{|c|}{ Water } & \multicolumn{2}{|c|}{ Fish } & \multicolumn{2}{|c|}{ Radon } \\
\hline clide & mrem/yr & fract. & mrem/yr & fract. & mrem/yr & fract. \\
\hline 41 & $0.000 \mathrm{E}+00$ & 0.0000 & $0.000 \mathrm{E}+00$ & 0.0000 & $0.000 \mathrm{E}+00$ & 0.0000 \\
\hline-137 & $0.000 \mathrm{E}+00$ & 0.0000 & $0.000 \mathrm{E}+00$ & 0.0000 & $0.000 \mathrm{E}+00$ & 0.0000 \\
\hline-237 & $0.000 \mathrm{E}+00$ & 0.0000 & $0.000 \mathrm{E}+00$ & 0.0000 & $0.000 \mathrm{E}+00$ & 0.0000 \\
\hline-238 & $0.000 \mathrm{E}+00$ & 0.0000 & $0.000 \mathrm{E}+00$ & 0.0000 & $0.000 \mathrm{E}+00$ & 0.0000 \\
\hline-239 & $0.000 \mathrm{E}+00$ & 0.0000 & $0.000 \mathrm{E}+00$ & 0.0000 & $0.000 \mathrm{E}+00$ & 0.0000 \\
\hline-240 & $0.000 \mathrm{E}+00$ & 0.0000 & $0.000 \mathrm{E}+00$ & 0.0000 & $0.000 \mathrm{E}+00$ & 0.0000 \\
\hline-99 & $0.000 \mathrm{E}+00$ & 0.0000 & $0.000 \mathrm{E}+00$ & 0.0000 & $0.000 \mathrm{E}+00$ & 0.0000 \\
\hline-228 & $0.000 \mathrm{E}+00$ & 0.0000 & $0.000 \mathrm{E}+00$ & 0.0000 & $0.000 \mathrm{E}+00$ & 0.0000 \\
\hline-230 & $0.000 \mathrm{E}+00$ & 0.0000 & $0.000 \mathrm{E}+00$ & 0.0000 & $0.000 \mathrm{E}+00$ & 0.0000 \\
\hline-232 & $0.000 \mathrm{E}+00$ & 0.0000 & $0.000 \mathrm{E}+00$ & 0.0000 & $0.000 \mathrm{E}+00$ & 0.0000 \\
\hline 234 & $0.000 \mathrm{E}+00$ & 0.0000 & $0.000 \mathrm{E}+00$ & 0.0000 & $0.000 \mathrm{E}+00$ & 0.0000 \\
\hline 35 & $0.000 \mathrm{E}+00$ & 0.0000 & $0.000 \mathrm{E}+00$ & 0.0000 & $0.000 \mathrm{E}+00$ & 0.0000 \\
\hline 38 & $0.000 \mathrm{E}+00$ & 0.0000 & $0.000 \mathrm{E}+00$ & 0.0000 & $0.000 \mathrm{E}+00$ & 0.0000 \\
\hline & $0.000 \mathrm{E}+00$ & 0.0000 & $0.000 \mathrm{E}+00$ & 0.0000 & $0.000 \mathrm{E}+00$ & 0.0000 \\
\hline
\end{tabular}

\begin{tabular}{|c|c|c|c|}
\hline \multicolumn{2}{|c|}{ Plant } & \multicolumn{2}{|c|}{ Meat } \\
\hline $\mathrm{mrem} / \mathrm{yr}$ & fract. & $\mathrm{mrem} / \mathrm{yr}$ & fract. \\
\hline $0.000 \mathrm{E}+00$ & 0.0000 & $0.000 \mathrm{E}+00$ & 0.0000 \\
\hline $0.000 \mathrm{E}+00$ & 0.0000 & $0.000 \mathrm{E}+00$ & 0.0000 \\
\hline $0.000 \mathrm{E}+00$ & 0.0000 & $0.000 \mathrm{E}+00$ & 0.0000 \\
\hline $0.000 \mathrm{E}+00$ & 0.0000 & $0.000 \mathrm{E}+00$ & 0.0000 \\
\hline $0.000 \mathrm{E}+00$ & 0.0000 & $0.000 \mathrm{E}+00$ & 0.0000 \\
\hline $0.000 \mathrm{E}+00$ & 0.0000 & $0.000 \mathrm{E}+00$ & 0.0000 \\
\hline $0.000 \mathrm{E}+00$ & 0.0000 & $0.000 \mathrm{E}+00$ & 0.0000 \\
\hline $0.000 \mathrm{E}+00$ & 0.0000 & $0.000 \mathrm{E}+00$ & 0.0000 \\
\hline $0.000 \mathrm{E}+00$ & 0.0000 & $0.000 \mathrm{E}+00$ & 0.0000 \\
\hline $0.000 \mathrm{E}+00$ & 0.0000 & $0.000 \mathrm{E}+00$ & 0.0000 \\
\hline $0.000 \mathrm{E}+00$ & 0.0000 & $0.000 \mathrm{E}+00$ & 0.0000 \\
\hline $0.000 \mathrm{E}+00$ & 0.0000 & $0.000 \mathrm{E}+00$ & 0.0000 \\
\hline $0.000 \mathrm{E}+00$ & 0.0000 & $0.000 \mathrm{E}+00$ & 0.0000 \\
\hline
\end{tabular}

$0.000 \mathrm{E}+00 \quad 0.0000$

$0.000 \mathrm{E}+00 \quad 0.0000$

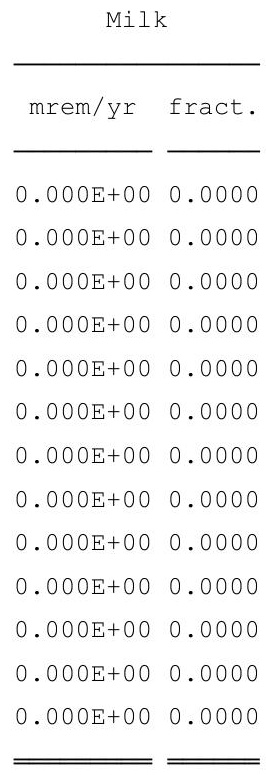

$0.000 \mathrm{E}+00 \quad 0.0000$
All Pathways* mrem/yr fract.

$1.836 \mathrm{E}-16 \quad 0.0000$ $2.350 \mathrm{E}-090.0012$ $1.835 \mathrm{E}-120.0000$ $4.197 \mathrm{E}-160.0000$ $1.607 \mathrm{E}-16 \quad 0.0000$ $1.973 \mathrm{E}-20 \quad 0.0000$ $1.229 \mathrm{E}-240.0000$ $2.065 \mathrm{E}-14 \quad 0.0000$ $1.087 \mathrm{E}-07 \quad 0.0558$ $1.832 \mathrm{E}-06 \quad 0.9395$ $3.968 \mathrm{E}-110.0000$ $1.227 \mathrm{E}-130.0000$ $6.920 \mathrm{E}-090.0035$ $1.950 \mathrm{E}-061.0000$

* Sum of all water independent and dependent pathways. 
RESRAD, Version 6.5

$\mathrm{T}^{1} \frac{1}{2}$ Limit $=180$ days

Summary : C746U Worker Deterministic Run

File : $\mathrm{X}: \backslash F I N A L$ V2 $\backslash$ DOE FWD RUNS $\backslash C 746 U$ W DOE SG FWD-FV2-10000YR.RAD

Total Dose Contributions TDOSE (i,p,t) for Individual Radionuclides (i) and Pathways (p) As mrem/yr and Fraction of Total Dose At $t=1.000 \mathrm{E}+02$ years

Water Independent Pathways (Inhalation excludes radon)

\begin{tabular}{|c|c|c|}
\hline clide & mrem/yr & fract. \\
\hline-241 & $6.026 \mathrm{E}-16$ & 0.0000 \\
\hline-137 & $1.128 \mathrm{E}-09$ & 0.0004 \\
\hline-237 & $3.151 E-12$ & 0.0000 \\
\hline-238 & $4.245 E-15$ & 0.0000 \\
\hline-239 & $2.920 \mathrm{E}-16$ & 0.0000 \\
\hline-240 & 1. $313 \mathrm{E}-19$ & 0.0000 \\
\hline-99 & $2.465 \mathrm{E}-24$ & 0.0000 \\
\hline-228 & $3.775 \mathrm{E}-22$ & 0.0000 \\
\hline-230 & $3.024 \mathrm{E}-07$ & 0.1082 \\
\hline-232 & $2.479 \mathrm{E}-06$ & 0.8876 \\
\hline 34 & $2.204 E-10$ & 0.0001 \\
\hline 235 & $4.503 E-13$ & 0.0000 \\
\hline 38 & $1.032 \mathrm{E}-08$ & 0.0037 \\
\hline & 06 & 1.0000 \\
\hline
\end{tabular}

Total 2.793E-06 1.0000

\begin{abstract}
Inhalation
\end{abstract}
mrem/yr fract.

mrem/yr fract. mrem/yr fract.

$\overline{0.000 \mathrm{E}+00} \overline{0.0000}$

$0.000 \mathrm{E}+00 \quad 0.0000$

$0.000 \mathrm{E}+00 \quad 0.0000$

$0.000 \mathrm{E}+00 \quad 0.0000$

$0.000 \mathrm{E}+00 \quad 0.0000$

$0.000 \mathrm{E}+00 \quad 0.0000$

$0.000 E+00 \quad 0.0000$

$0.000 \mathrm{E}+00 \quad 0.0000$

$0.000 \mathrm{E}+00 \quad 0.0000$

$0.000 E+00 \quad 0.0000$

$0.000 \mathrm{E}+00 \quad 0.0000$

$0.000 \mathrm{E}+00 \quad 0.0000$

$0.000 \mathrm{E}+00 \quad 0.0000$

$\overline{\overline{0.000 \mathrm{E}+00}} \overline{\overline{0.0000}}$

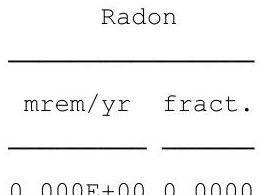

$0.000 \mathrm{E}+00 \quad 0.0000$

$0.000 \mathrm{E}+00 \quad 0.0000$

$0.000 \mathrm{E}+00 \quad 0.0000$

$0.000 \mathrm{E}+00 \quad 0.0000$

$0.000 \mathrm{E}+00 \quad 0.0000$

$0.000 \mathrm{E}+00 \quad 0.0000$

$0.000 \mathrm{E}+00 \quad 0.0000$

$0.000 \mathrm{E}+00 \quad 0.0000$

$0.000 \mathrm{E}+00 \quad 0.0000$

$0.000 \mathrm{E}+00 \quad 0.0000$

$0.000 \mathrm{E}+00 \quad 0.0000$

$0.000 \mathrm{E}+00 \quad 0.0000$

$0.000 \mathrm{E}+00 \quad 0.0000$

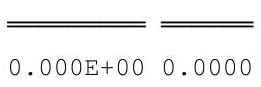

\begin{tabular}{|c|c|c|c|}
\hline \multicolumn{2}{|c|}{ Plant } & \multicolumn{2}{|c|}{ Meat } \\
\hline mrem/yr & fract. & mrem/yr & fract. \\
\hline $.000 \mathrm{E}+00$ & 0.0000 & $0.000 \mathrm{E}+00$ & 0.0000 \\
\hline $0.000 \mathrm{E}+00$ & 0.0000 & $0.000 \mathrm{E}+00$ & 0.0000 \\
\hline $0.000 \mathrm{E}+00$ & 0.0000 & $0.000 \mathrm{E}+00$ & 0.0000 \\
\hline $0.000 \mathrm{E}+00$ & 0.0000 & $0.000 \mathrm{E}+00$ & 0.0000 \\
\hline $0.000 \mathrm{E}+00$ & 0.0000 & $0.000 \mathrm{E}+00$ & 0.0000 \\
\hline $0.000 \mathrm{E}+00$ & 0.0000 & $0.000 \mathrm{E}+00$ & 0.0000 \\
\hline $0.000 \mathrm{E}+00$ & 0.0000 & $0.000 \mathrm{E}+00$ & 0.0000 \\
\hline $0.000 \mathrm{E}+00$ & 0.0000 & $0.000 \mathrm{E}+00$ & 0.0000 \\
\hline $0.000 \mathrm{E}+00$ & 0.0000 & $0.000 \mathrm{E}+00$ & 0.0000 \\
\hline $0.000 \mathrm{E}+00$ & 0.0000 & $0.000 \mathrm{E}+00$ & 0.0000 \\
\hline $0.000 \mathrm{E}+00$ & 0.0000 & $0.000 \mathrm{E}+00$ & 0.0000 \\
\hline $0.000 \mathrm{E}+00$ & 0.0000 & $0.000 \mathrm{E}+00$ & 0.0000 \\
\hline $0.000 \mathrm{E}+00$ & 0.0000 & $0.000 \mathrm{E}+00$ & 0.0000 \\
\hline & & 0.00 & . \\
\hline
\end{tabular}

\begin{tabular}{cc} 
Milk \\
\hline mrem/yr fract. \\
\cline { 1 - 2 } $0.000 \mathrm{E}+00$ & 0.0000 \\
$0.000 \mathrm{E}+00$ & 0.0000 \\
$0.000 \mathrm{E}+00$ & 0.0000 \\
$0.000 \mathrm{E}+00$ & 0.0000 \\
$0.000 \mathrm{E}+00$ & 0.0000 \\
$0.000 \mathrm{E}+00$ & 0.0000 \\
$0.000 \mathrm{E}+00$ & 0.0000 \\
$0.000 \mathrm{E}+00$ & 0.0000 \\
$0.000 \mathrm{E}+00$ & 0.0000 \\
$0.000 \mathrm{E}+00$ & 0.0000 \\
$0.000 \mathrm{E}+00$ & 0.0000 \\
$0.000 \mathrm{E}+00$ & 0.0000 \\
$0.000 \mathrm{E}+00$ & 0.0000 \\
\hline \hline $0.000 \mathrm{E}+00$ & 0.0000
\end{tabular}

Soil

mrem/yr fract.

$0.000 \mathrm{E}+00 \quad 0.0000$

$0.000 \mathrm{E}+00 \quad 0.0000$

$0.000 \mathrm{E}+00 \quad 0.0000$

$0.000 \mathrm{E}+00 \quad 0.0000$

$0.000 \mathrm{E}+00 \quad 0.0000$

$0.000 \mathrm{E}+00 \quad 0.0000$

$0.000 \mathrm{E}+00 \quad 0.0000$

$0.000 \mathrm{E}+00 \quad 0.0000$

$0.000 \mathrm{E}+00 \quad 0.0000$

$0.000 \mathrm{E}+00 \quad 0.0000$

$0.000 \mathrm{E}+00 \quad 0.0000$

$0.000 \mathrm{E}+00 \quad 0.0000$

$0.000 \mathrm{E}+00 \quad 0.0000$

$0.000 \mathrm{E}+00 \quad 0.0000$

Total Dose Contributions TDOSE (i,p,t) for Individual Radionuclides (i) and Pathways (p) As mrem/yr and Fraction of Total Dose At $t=1.000 \mathrm{E}+02$ years

Water Dependent Pathways

\begin{tabular}{|c|c|c|c|c|c|c|}
\hline & \multicolumn{2}{|c|}{ Water } & \multicolumn{2}{|c|}{ Fish } & \multicolumn{2}{|c|}{ Radon } \\
\hline clide & mrem/yr & fract. & mrem/yr & fract. & mrem/yr & fract. \\
\hline-241 & $0.000 \mathrm{E}+00$ & 0.0000 & $0.000 \mathrm{E}+00$ & 0.0000 & $0.000 \mathrm{E}+00$ & 0.0000 \\
\hline-137 & $0.000 \mathrm{E}+00$ & 0.0000 & $0.000 \mathrm{E}+00$ & 0.0000 & $0.000 \mathrm{E}+00$ & 0.0000 \\
\hline-237 & $0.000 \mathrm{E}+00$ & 0.0000 & $0.000 \mathrm{E}+00$ & 0.0000 & $0.000 \mathrm{E}+00$ & 0.0000 \\
\hline-238 & $0.000 \mathrm{E}+00$ & 0.0000 & $0.000 \mathrm{E}+00$ & 0.0000 & $0.000 \mathrm{E}+00$ & 0.0000 \\
\hline-239 & $0.000 \mathrm{E}+00$ & 0.0000 & $0.000 \mathrm{E}+00$ & 0.0000 & $0.000 \mathrm{E}+00$ & 0.0000 \\
\hline-240 & $0.000 \mathrm{E}+00$ & 0.0000 & $0.000 \mathrm{E}+00$ & 0.0000 & $0.000 \mathrm{E}+00$ & 0.0000 \\
\hline-99 & $0.000 \mathrm{E}+00$ & 0.0000 & $0.000 \mathrm{E}+00$ & 0.0000 & $0.000 \mathrm{E}+00$ & 0.0000 \\
\hline-228 & $0.000 \mathrm{E}+00$ & 0.0000 & $0.000 \mathrm{E}+00$ & 0.0000 & $0.000 \mathrm{E}+00$ & 0.0000 \\
\hline-230 & $0.000 \mathrm{E}+00$ & 0.0000 & $0.000 \mathrm{E}+00$ & 0.0000 & $0.000 \mathrm{E}+00$ & 0.0000 \\
\hline 232 & $0.000 \mathrm{E}+00$ & 0.0000 & $0.000 \mathrm{E}+00$ & 0.0000 & $0.000 \mathrm{E}+00$ & 0.0000 \\
\hline 34 & $0.000 \mathrm{E}+00$ & 0.0000 & $0.000 \mathrm{E}+00$ & 0.0000 & $0.000 \mathrm{E}+00$ & 0.0000 \\
\hline 35 & $0.000 \mathrm{E}+00$ & 0.0000 & $0.000 \mathrm{E}+00$ & 0.0000 & $0.000 \mathrm{E}+00$ & 0.0000 \\
\hline 38 & $0.000 \mathrm{E}+00$ & 0.0000 & $0.000 \mathrm{E}+00$ & 0.0000 & $0.000 \mathrm{E}+00$ & 0.0000 \\
\hline & $0.000 \mathrm{E}+00$ & 0.0000 & $0.000 \mathrm{E}+00$ & 0.0000 & $0.000 \mathrm{E}+00$ & 0.0000 \\
\hline
\end{tabular}

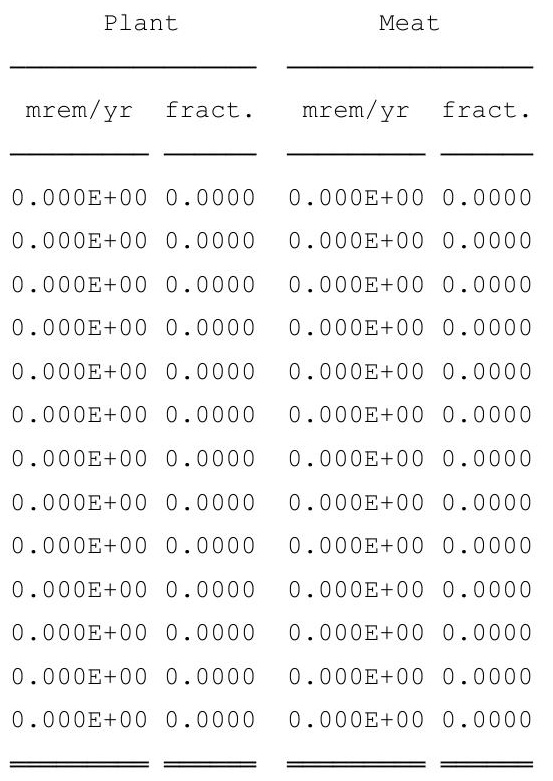

$0.000 \mathrm{E}+00 \quad 0.0000$

$0.000 \mathrm{E}+00 \quad 0.0000$

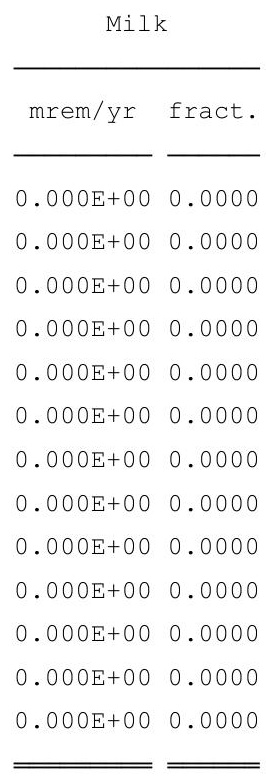

$0.000 \mathrm{E}+00 \quad 0.0000$
All Pathways * mrem/yr fract.

$6.026 \mathrm{E}-160.0000$ $1.128 \mathrm{E}-090.0004$ $3.151 \mathrm{E}-12 \quad 0.0000$ $4.245 \mathrm{E}-150.0000$ $2.920 \mathrm{E}-16 \quad 0.0000$ $1.313 \mathrm{E}-190.0000$ $2.465 \mathrm{E}-24 \quad 0.0000$ $3.775 \mathrm{E}-22 \quad 0.0000$ $3.024 \mathrm{E}-07 \quad 0.1082$ $2.479 \mathrm{E}-06 \quad 0.8876$ $2.204 \mathrm{E}-10 \quad 0.0001$ $4.503 \mathrm{E}-13 \quad 0.0000$ $1.032 \mathrm{E}-08 \quad 0.0037$ $2.793 E-061.0000$

* Sum of all water independent and dependent pathways. 
RESRAD, Version 6.5

$\mathrm{T}^{1 / 2}$ Limit $=180$ days

Summary : C746U Worker Deterministic Run

File : X: \FINAL V2 \DOE FWD RUNS \C746U W DOE SG FWD-FV2-10000YR.RAD

Total Dose Contributions TDOSE (i,p,t) for Individual Radionuclides (i) and Pathways (p) As mrem/yr and Fraction of Total Dose At $t=5.000 \mathrm{E}+02$ years

Water Independent Pathways (Inhalation excludes radon)

\begin{tabular}{|c|c|c|c|c|c|c|c|c|c|c|c|c|c|c|}
\hline \multirow[b]{2}{*}{ clide } & \multicolumn{2}{|c|}{ Ground } & \multicolumn{2}{|c|}{ Inhalation } & \multicolumn{2}{|c|}{ Radon } & \multicolumn{2}{|c|}{ Plant } & \multicolumn{2}{|c|}{ Meat } & \multicolumn{2}{|c|}{ Milk } & \multicolumn{2}{|l|}{ Soil } \\
\hline & mrem/yr & fract. & mrem/yr & fract. & mrem/yr & fract. & mrem/yr & fract. & mrem/yr & fract. & mrem/yr & fract. & mrem/yr & fract. \\
\hline 1 & $1.668 \mathrm{E}-13$ & 0.0000 & $0.000 \mathrm{E}+00$ & 0.0000 & $0.000 \mathrm{E}+00$ & 0.0000 & $0.000 \mathrm{E}+00$ & 0.0000 & $0.000 \mathrm{E}+00$ & 0.0000 & $0.000 \mathrm{E}+00$ & 0.0000 & $0.000 \mathrm{E}+00$ & 0.0000 \\
\hline 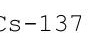 & $3.168 \mathrm{E}-12$ & 0.0000 & $0.000 \mathrm{E}+00$ & 0.0000 & $0.000 \mathrm{E}+00$ & 0.0000 & $0.000 \mathrm{E}+00$ & 0.0000 & $0.000 \mathrm{E}+00$ & 0.0000 & $0.000 \mathrm{E}+00$ & 0.0000 & $0.000 \mathrm{E}+00$ & 0.0000 \\
\hline 237 & $2.362 \mathrm{E}-10$ & 0.0000 & $0.000 \mathrm{E}+00$ & 0.0000 & $0.000 \mathrm{E}+00$ & 0.0000 & $0.000 \mathrm{E}+00$ & 0.0000 & $0.000 \mathrm{E}+00$ & 0.0000 & $0.000 \mathrm{E}+00$ & 0.0000 & $0.000 \mathrm{E}+00$ & 0.0000 \\
\hline 8 & $4.482 \mathrm{E}-12$ & 0.0000 & $0.000 \mathrm{E}+00$ & 0.0000 & $0.000 \mathrm{E}+00$ & 0.0000 & $0.000 \mathrm{E}+00$ & 0.0000 & $0.000 \mathrm{E}+00$ & 0.0000 & $0.000 \mathrm{E}+00$ & 0.0000 & $0.000 \mathrm{E}+00$ & 0.0000 \\
\hline & $3.476 \mathrm{E}-14$ & 0.0 & $0.000 \mathrm{E}$ & 0. & $0.000 \mathrm{E}+00$ & 0 & $0.000 \mathrm{E}+00$ & 0 & & & $0.000 \mathrm{E}+00$ & & $.000 \mathrm{E}+00$ & \\
\hline & $4.219 \mathrm{E}-17$ & 0.0 & 0. & 0.0 & $0.000 \mathrm{E}+00$ & 0.00 & $0.000 \mathrm{E}+00$ & 0.0 & $E+00$ & 0 & $0.000 \mathrm{E}+00$ & 00 & $000 \mathrm{E}+00$ & 000 \\
\hline & $6.452 \mathrm{E}-22$ & 0.0000 & $0.000 \mathrm{E}+00$ & 0.0000 & $0.000 \mathrm{E}+00$ & 0.0000 & $0.000 \mathrm{E}+00$ & 0.0000 & $0.000 \mathrm{E}+00$ & 0.0000 & $0.000 \mathrm{E}+00$ & 0.0000 & $0.000 \mathrm{E}+00$ & 0.0000 \\
\hline 8 & $0.000 \mathrm{E}+00$ & 0.0000 & $0.000 \mathrm{E}+00$ & 0.0000 & $0.000 \mathrm{E}+00$ & 0.0000 & $0.000 \mathrm{E}+00$ & 0.0000 & $0.000 \mathrm{E}+00$ & 0.0000 & $0.000 \mathrm{E}+00$ & 0.0000 & $0.000 \mathrm{E}+00$ & 0.0000 \\
\hline & $2.193 \mathrm{E}-05$ & 0.4425 & $0.000 \mathrm{E}+00$ & 0.0000 & $0.000 \mathrm{E}+00$ & 0.0000 & $0.000 \mathrm{E}+00$ & 0.0000 & $0.000 \mathrm{E}+00$ & 0.0000 & $0.000 \mathrm{E}+00$ & 0.0000 & $0.000 \mathrm{E}+00$ & 0.0000 \\
\hline 32 & $2.730 \mathrm{E}-05$ & 0.5508 & $0.000 \mathrm{E}+00$ & 0.0000 & $0.000 \mathrm{E}+00$ & 0.0000 & $0.000 \mathrm{E}+00$ & 0.0000 & $0.000 \mathrm{E}+00$ & 0.0000 & $0.000 \mathrm{E}+00$ & 0.0000 & $0.000 \mathrm{E}+00$ & 0.0000 \\
\hline & $8.184 \mathrm{E}-08$ & 0.0017 & $0.000 \mathrm{E}+00$ & 0.0000 & $0.000 \mathrm{E}+00$ & 0.0000 & $0.000 \mathrm{E}+00$ & 0.0000 & $0.000 \mathrm{E}+00$ & 0.0000 & $0.000 \mathrm{E}+00$ & 0.0000 & $0.000 \mathrm{E}+00$ & 0.0000 \\
\hline & $9.380 \mathrm{E}-11$ & 0.0000 & $0.000 \mathrm{E}+00$ & 0.0000 & $0.000 \mathrm{E}+00$ & 0.0000 & $0.000 \mathrm{E}+00$ & 0.0000 & $0.000 \mathrm{E}+00$ & 0.0000 & $0.000 \mathrm{E}+00$ & 0.0000 & $0.000 \mathrm{E}+00$ & 0.0000 \\
\hline & $2.523 \mathrm{E}-07$ & 0.0051 & $0.000 \mathrm{E}+00$ & 0.0000 & $0.000 \mathrm{E}+00$ & 0.0000 & $0.000 \mathrm{E}+00$ & 0.0000 & $0.000 \mathrm{E}+00$ & 0.0000 & $0.000 \mathrm{E}+00$ & 0.0000 & $0.000 \mathrm{E}+00$ & 0.0000 \\
\hline & & & +00 & 00 & +00 & 0 & +00 & & +00 & & +00 & & -00 & \\
\hline
\end{tabular}

Total Dose Contributions TDOSE (i,p,t) for Individual Radionuclides (i) and Pathways (p) As mrem/yr and Fraction of Total Dose At $t=5.000 \mathrm{E}+02$ years

Water Dependent Pathways

\begin{tabular}{|c|c|c|c|c|c|c|c|c|c|c|c|c|c|c|}
\hline \multirow[b]{2}{*}{ clide } & \multicolumn{2}{|c|}{ Water } & \multicolumn{2}{|c|}{ Fish } & \multicolumn{2}{|c|}{ Radon } & \multicolumn{2}{|c|}{ Plant } & \multicolumn{2}{|c|}{ Meat } & \multicolumn{2}{|c|}{ Milk } & \multicolumn{2}{|c|}{ All Pathways* } \\
\hline & mrem/yr & fract. & mrem/yr & fract. & mrem/yr & fract. & mrem/yr & fract. & mrem/yr & fract. & mrem/yr & fract. & mrem/yr & fract. \\
\hline-241 & $0.000 \mathrm{E}+00$ & 0.0000 & $0.000 \mathrm{E}+00$ & 0.0000 & $0.000 \mathrm{E}+00$ & 0.0000 & $0.000 \mathrm{E}+00$ & 0.0000 & $0.000 \mathrm{E}+00$ & 0.0000 & $0.000 \mathrm{E}+00$ & 0.0000 & $1.668 \mathrm{E}-13$ & 0.0000 \\
\hline - & $0.000 \mathrm{E}+00$ & 0.0000 & $0.000 \mathrm{E}+00$ & 0.0000 & $0.000 \mathrm{E}+00$ & 0.0000 & $0.000 \mathrm{E}+00$ & 0.0000 & $0.000 \mathrm{E}+00$ & 0.0000 & $0.000 \mathrm{E}+00$ & 0.0000 & $3.168 \mathrm{E}-12$ & 0.0000 \\
\hline 237 & $0.000 \mathrm{E}+00$ & 0.0 & $0.000 \mathrm{E}+00$ & 0 & $0.000 \mathrm{E}+00$ & 0 & $0.000 \mathrm{E}+00$ & 0 & $0.000 \mathrm{E}+00$ & 0 & $0.000 \mathrm{E}+00$ & 0 & $362 \mathrm{E}-10$ & 100 \\
\hline & $0.000 \mathrm{E}+00$ & 0 & $0.000 \mathrm{E}+00$ & 0 & $0.000 \mathrm{E}+00$ & 0 & $0.000 \mathrm{E}+00$ & 0 & $0.000 \mathrm{E}+00$ & 00 & $0.000 \mathrm{E}+00$ & 0 & -12 & 0000 \\
\hline 239 & $0.000 \mathrm{E}+00$ & 0.0000 & $0.000 \mathrm{E}+00$ & 0.0000 & $0.000 \mathrm{E}+00$ & 0.0000 & $0.000 \mathrm{E}+00$ & 0.0000 & $0.000 \mathrm{E}+00$ & 0.0000 & $0.000 \mathrm{E}+00$ & 0.0000 & $3.476 \mathrm{E}-14$ & 0.0000 \\
\hline 240 & $0.000 \mathrm{E}+00$ & 0.0000 & $0.000 \mathrm{E}+00$ & 0.0000 & $0.000 \mathrm{E}+00$ & 0.0000 & $0.000 \mathrm{E}+00$ & 0.0000 & $0.000 \mathrm{E}+00$ & 0.0000 & $0.000 \mathrm{E}+00$ & 0.0000 & $4.219 \mathrm{E}-17$ & 0.0000 \\
\hline & $0.000 \mathrm{E}+00$ & 0.0000 & $0.000 \mathrm{E}+00$ & 0.0000 & $0.000 \mathrm{E}+00$ & 0.0000 & $0.000 \mathrm{E}+00$ & 0.0000 & $0.000 \mathrm{E}+00$ & 0.0000 & $0.000 \mathrm{E}+00$ & 0.0000 & $6.452 \mathrm{E}-22$ & 0.0000 \\
\hline & $0.000 \mathrm{E}+00$ & 0.0000 & $0.000 \mathrm{E}+00$ & 0.0000 & $0.000 \mathrm{E}+00$ & 0.0000 & $0.000 \mathrm{E}+00$ & 0.0000 & $0.000 \mathrm{E}+00$ & 0.0000 & $0.000 \mathrm{E}+00$ & 0.0000 & $0.000 \mathrm{E}+00$ & 0.0000 \\
\hline & $0.000 \mathrm{E}+00$ & 0.0000 & $0.000 \mathrm{E}+00$ & 0.0000 & $0.000 \mathrm{E}+00$ & 0.0000 & $0.000 \mathrm{E}+00$ & 0.0000 & $0.000 \mathrm{E}+00$ & 0.0000 & $0.000 \mathrm{E}+00$ & 0.0000 & $2.193 \mathrm{E}-05$ & 0.4425 \\
\hline & $0.000 \mathrm{E}+00$ & 0.0000 & $0.000 \mathrm{E}+00$ & 0.0000 & $0.000 \mathrm{E}+00$ & 0.0000 & $0.000 \mathrm{E}+00$ & 0.0000 & $0.000 \mathrm{E}+00$ & 0.0000 & $0.000 \mathrm{E}+00$ & 0.0000 & $2.730 \mathrm{E}-05$ & 0.5508 \\
\hline & $0.000 \mathrm{E}+00$ & 0.0000 & $0.000 \mathrm{E}+00$ & 0.0000 & $0.000 \mathrm{E}+00$ & 0.0000 & $0.000 \mathrm{E}+00$ & 0.0000 & $0.000 \mathrm{E}+00$ & 0.0000 & $0.000 \mathrm{E}+00$ & 0.0000 & $.184 \mathrm{E}-08$ & 0.0017 \\
\hline & $0.000 \mathrm{E}+00$ & 0.0000 & $0.000 \mathrm{E}+00$ & 0.0000 & $0.000 \mathrm{E}+00$ & 0.0000 & $0.000 \mathrm{E}+00$ & 0.0000 & $0.000 \mathrm{E}+00$ & 0.0000 & $0.000 \mathrm{E}+00$ & 0.0000 & $9.380 \mathrm{E}-11$ & 0.0000 \\
\hline & $0.000 \mathrm{E}+00$ & 0.0000 & $0.000 \mathrm{E}+00$ & 0.0000 & $0.000 \mathrm{E}+00$ & 0.0000 & $0.000 \mathrm{E}+00$ & 0.0000 & $0.000 \mathrm{E}+00$ & 0.0000 & $0.000 \mathrm{E}+00$ & 0.0000 & $2.523 E-07$ & 0.0051 \\
\hline & . & 0000 & $.000 \mathrm{E}+00$ & 0.0000 & $0.000 \mathrm{E}+00$ & 0.0000 & $0.000 \mathrm{E}+00$ & 0.0000 & $.000 \mathrm{E}+00$ & 0.0000 & $0.000 \mathrm{E}+00$ & 0.0000 & $4.957 \mathrm{E}-05$ & 1.0000 \\
\hline
\end{tabular}

*Sum of all water independent and dependent pathways. 
RESRAD, Version 6.5

$\mathrm{T}^{1 / 2}$ Limit $=180$ days

\section{mary : C746u worker Deterministic Ru \\ : $\mathrm{X}: \backslash F I N A L$ V2 $\backslash$ DOE FWD RUNS \C746U W DOE SG FWD-FV2-10000YR.RAD}

Total Dose Contributions TDOSE (i,p,t) for Individual Radionuclides (i) and Pathways (p) As mrem/yr and Fraction of Total Dose At $t=1.050 \mathrm{E}+03$ years

Water Independent Pathways (Inhalation excludes radon)

\begin{tabular}{|c|c|c|c|c|c|c|c|c|c|c|c|c|c|c|}
\hline \multirow[b]{2}{*}{ clide } & \multicolumn{2}{|c|}{ Ground } & \multicolumn{2}{|c|}{ Inhalation } & \multicolumn{2}{|c|}{ Radon } & \multicolumn{2}{|c|}{ Plant } & \multicolumn{2}{|c|}{ Meat } & \multicolumn{2}{|c|}{ Milk } & \multicolumn{2}{|c|}{ Soil } \\
\hline & mrem/yr & fract. & mrem/yr & fract. & mrem/yr & fract. & mrem/yr & fract. & mrem/yr & fract. & mrem/yr & fract. & mrem/yr & fract. \\
\hline 41 & $9.032 \mathrm{E}-11$ & 0.0000 & $0.000 \mathrm{E}+00$ & 0.0000 & $0.000 \mathrm{E}+00$ & 0.0000 & $0.000 \mathrm{E}+00$ & 0.0000 & $0.000 \mathrm{E}+00$ & 0.0000 & $0.000 \mathrm{E}+00$ & 0.0000 & $0.000 \mathrm{E}+00$ & 0.0000 \\
\hline 37 & $9.832 \mathrm{E}-16$ & 0.0000 & $0.000 \mathrm{E}+00$ & 0.0000 & $0.000 \mathrm{E}+00$ & 0.0000 & $0.000 \mathrm{E}+00$ & 0.0000 & $0.000 \mathrm{E}+00$ & 0.0000 & $0.000 \mathrm{E}+00$ & 0.0000 & $0.000 \mathrm{E}+00$ & 0.0000 \\
\hline 237 & $8.468 \mathrm{E}-08$ & 0.0000 & $0.000 \mathrm{E}+00$ & 0.0000 & $0.000 \mathrm{E}+00$ & 0.0000 & $0.000 \mathrm{E}+00$ & 0.0000 & $0.000 \mathrm{E}+00$ & 0.0000 & $0.000 \mathrm{E}+00$ & 0.0000 & $0.000 \mathrm{E}+00$ & 0.0000 \\
\hline 238 & $1.044 \mathrm{E}-09$ & 0.0000 & $0.000 \mathrm{E}+00$ & 0.0000 & $0.000 \mathrm{E}+00$ & 0.0000 & $0.000 \mathrm{E}+00$ & 0.0000 & $0.000 \mathrm{E}+00$ & 0.0000 & $0.000 \mathrm{E}+00$ & 0.0000 & $0.000 \mathrm{E}+00$ & 0.0000 \\
\hline 239 & $2.474 \mathrm{E}-11$ & 0.0000 & $0.000 \mathrm{E}+00$ & 0.0000 & $0.000 \mathrm{E}+00$ & 0.0000 & $0.000 \mathrm{E}+00$ & 0.0000 & $0.000 \mathrm{E}+00$ & 0.0000 & $0.000 \mathrm{E}+00$ & 0.0000 & $0.000 \mathrm{E}+00$ & 000 \\
\hline & $5.993 \mathrm{E}-15$ & 0. & $0.000 \mathrm{E}$ & 0 & $0.000 \mathrm{E}+00$ & 0 & $0.000 \mathrm{E}+00$ & 0 & $0.000 \mathrm{E}+00$ & 0 & $0.000 \mathrm{E}+00$ & 0 & $0.000 \mathrm{E}+00$ & 0000 \\
\hline-99 & $1.362 \mathrm{E}-18$ & 0.0000 & $0.000 \mathrm{E}+00$ & 0.0000 & $0.000 \mathrm{E}+00$ & 0.0000 & $0.000 \mathrm{E}+00$ & 0.0000 & $0.000 \mathrm{E}+00$ & 0.0000 & $0.000 \mathrm{E}+00$ & 0.0000 & $0.000 \mathrm{E}+00$ & 0.0000 \\
\hline 20 & $0.000 \mathrm{E}+00$ & 0.0000 & $0.000 \mathrm{E}+00$ & 0.0000 & $0.000 \mathrm{E}+00$ & 0.0000 & $0.000 \mathrm{E}+00$ & 0.0000 & $0.000 \mathrm{E}+00$ & 0.0000 & $0.000 \mathrm{E}+00$ & 0.0000 & $0.000 \mathrm{E}+00$ & 0.0000 \\
\hline 230 & $1.840 \mathrm{E}-03$ & 0.6991 & $0.000 \mathrm{E}+00$ & 0.0000 & $0.000 \mathrm{E}+00$ & 0.0000 & $0.000 \mathrm{E}+00$ & 0.0000 & $0.000 \mathrm{E}+00$ & 0.0000 & $0.000 \mathrm{E}+00$ & 0.0000 & $0.000 \mathrm{E}+00$ & 0.0000 \\
\hline & $7.565 \mathrm{E}-04$ & 0.2874 & $0.000 \mathrm{E}+00$ & 0.0000 & $0.000 \mathrm{E}+00$ & 0.0000 & $0.000 \mathrm{E}+00$ & 0.0000 & $0.000 \mathrm{E}+00$ & 0.0000 & $0.000 \mathrm{E}+00$ & 0.0000 & $0.000 \mathrm{E}+00$ & 0.0000 \\
\hline & $1.495 \mathrm{E}-05$ & 0.0057 & $0.000 \mathrm{E}+00$ & 0.0000 & $0.000 \mathrm{E}+00$ & 0.0000 & $0.000 \mathrm{E}+00$ & 0.0000 & $0.000 \mathrm{E}+00$ & 0.0000 & $0.000 \mathrm{E}+00$ & 0.0000 & $0.000 \mathrm{E}+00$ & 0.0000 \\
\hline & $3.148 \mathrm{E}-08$ & 0.0000 & $0.000 \mathrm{E}+00$ & 0.0000 & $0.000 \mathrm{E}+00$ & 0.0000 & $0.000 \mathrm{E}+00$ & 0.0000 & $0.000 \mathrm{E}+00$ & 0.0000 & $0.000 \mathrm{E}+00$ & 0.0000 & $0.000 \mathrm{E}+00$ & 0.0000 \\
\hline & $2.047 \mathrm{E}-05$ & 0.0078 & $0.000 \mathrm{E}+00$ & 0.0000 & $0.000 \mathrm{E}+00$ & 0.0000 & $0.000 \mathrm{E}+00$ & 0.0000 & $0.000 \mathrm{E}+00$ & 0.0000 & $0.000 \mathrm{E}+00$ & 0.0000 & $0.000 \mathrm{E}+00$ & 0.0000 \\
\hline & $2.632 \mathrm{E}-03$ & & $0.000 \mathrm{E}+00$ & 0.0000 & $0.000 \mathrm{E}+00$ & 0.0000 & $0.000 \mathrm{E}+00$ & 0.0000 & $0.000 \mathrm{E}+00$ & 0. & $0.000 \mathrm{E}+00$ & 0.0000 & $E+00$ & 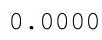 \\
\hline
\end{tabular}

Total Dose Contributions TDOSE (i,p,t) for Individual Radionuclides (i) and Pathways (p) As mrem/yr and Fraction of Total Dose At $t=1.050 \mathrm{E}+03$ years

Water Dependent Pathways

\begin{tabular}{|c|c|c|c|c|c|c|c|c|c|c|c|c|c|c|}
\hline \multirow[b]{2}{*}{ clide } & \multicolumn{2}{|c|}{ Water } & \multicolumn{2}{|c|}{ Fish } & \multicolumn{2}{|c|}{ Radon } & \multicolumn{2}{|c|}{ Plant } & \multicolumn{2}{|c|}{ Meat } & \multicolumn{2}{|l|}{ Milk } & \multicolumn{2}{|c|}{ All Pathways* } \\
\hline & mrem/yr & fract. & mrem/yr & fract. & mrem/yr & fract. & mrem/yr & fract. & mrem/yr & fract. & mrem/yr & fract. & mrem/yr & fract. \\
\hline 211 & $0.000 \mathrm{E}+00$ & 0.0000 & $0.000 \mathrm{E}+00$ & 0.0000 & $0.000 \mathrm{E}+00$ & 0.0000 & $0.000 \mathrm{E}+00$ & 0.0000 & $0.000 \mathrm{E}+00$ & 0.0000 & $0.000 \mathrm{E}+00$ & 0.0000 & $9.032 \mathrm{E}-11$ & 0.0000 \\
\hline . & $0.000 \mathrm{E}+00$ & 0.0000 & $0.000 \mathrm{E}+00$ & 0.0000 & $0.000 \mathrm{E}+00$ & 0.0000 & $0.000 \mathrm{E}+00$ & 0.0000 & $0.000 \mathrm{E}+00$ & 0.0000 & $0.000 \mathrm{E}+00$ & 0.0000 & $9.832 \mathrm{E}-16$ & 0.0000 \\
\hline 237 & $0.000 \mathrm{E}+00$ & 0.0 & $0.000 \mathrm{E}+00$ & 0 & $0.000 \mathrm{E}+00$ & 0 & $0.000 \mathrm{E}+00$ & 0 & $0.000 \mathrm{E}+00$ & 0 & $0.000 \mathrm{E}+00$ & 0 & $468 \mathrm{E}-08$ & 000 \\
\hline & $0.000 \mathrm{E}+00$ & 0 & $0.000 \mathrm{E}+00$ & 0 & $0.000 \mathrm{E}+00$ & 0 & $0.000 \mathrm{E}+00$ & 0 & $0.000 \mathrm{E}+00$ & 00 & $0.000 \mathrm{E}+00$ & 0 & -09 & 0000 \\
\hline 239 & $0.000 \mathrm{E}+00$ & 0.0000 & $0.000 \mathrm{E}+00$ & 0.0000 & $0.000 \mathrm{E}+00$ & 0.0000 & $0.000 \mathrm{E}+00$ & 0.0000 & $0.000 \mathrm{E}+00$ & 0.0000 & $0.000 \mathrm{E}+00$ & 0.0000 & $2.474 \mathrm{E}-11$ & 0.0000 \\
\hline 240 & $0.000 \mathrm{E}+00$ & 0.0000 & $0.000 \mathrm{E}+00$ & 0.0000 & $0.000 \mathrm{E}+00$ & 0.0000 & $0.000 \mathrm{E}+00$ & 0.0000 & $0.000 \mathrm{E}+00$ & 0.0000 & $0.000 \mathrm{E}+00$ & 0.0000 & $5.993 \mathrm{E}-15$ & 0.0000 \\
\hline & $0.000 \mathrm{E}+00$ & 0.0000 & $0.000 \mathrm{E}+00$ & 0.0000 & $0.000 \mathrm{E}+00$ & 0.0000 & $0.000 \mathrm{E}+00$ & 0.0000 & $0.000 \mathrm{E}+00$ & 0.0000 & $0.000 \mathrm{E}+00$ & 0.0000 & $1.362 \mathrm{E}-18$ & 0.0000 \\
\hline & $0.000 \mathrm{E}+00$ & 0.0000 & $0.000 \mathrm{E}+00$ & 0.0000 & $0.000 \mathrm{E}+00$ & 0.0000 & $0.000 \mathrm{E}+00$ & 0.0000 & $0.000 \mathrm{E}+00$ & 0.0000 & $0.000 \mathrm{E}+00$ & 0.0000 & $0.000 \mathrm{E}+00$ & 0.0000 \\
\hline & $0.000 \mathrm{E}+00$ & 0.0000 & $0.000 \mathrm{E}+00$ & 0.0000 & $0.000 \mathrm{E}+00$ & 0.0000 & $0.000 \mathrm{E}+00$ & 0.0000 & $0.000 \mathrm{E}+00$ & 0.0000 & $0.000 \mathrm{E}+00$ & 0.0000 & $1.840 \mathrm{E}-03$ & 0.6991 \\
\hline 32 & $0.000 \mathrm{E}+00$ & 0.0000 & $0.000 \mathrm{E}+00$ & 0.0000 & $0.000 \mathrm{E}+00$ & 0.0000 & $0.000 \mathrm{E}+00$ & 0.0000 & $0.000 \mathrm{E}+00$ & 0.0000 & $0.000 \mathrm{E}+00$ & 0.0000 & $7.565 \mathrm{E}-04$ & 0.2874 \\
\hline & $0.000 \mathrm{E}+00$ & 0.0000 & $0.000 \mathrm{E}+00$ & 0.0000 & $0.000 \mathrm{E}+00$ & 0.0000 & $0.000 \mathrm{E}+00$ & 0.0000 & $0.000 \mathrm{E}+00$ & 0.0000 & $0.000 \mathrm{E}+00$ & 0.0000 & $1.495 \mathrm{E}-05$ & 0.0057 \\
\hline & $0.000 \mathrm{E}+00$ & 0.0000 & $0.000 \mathrm{E}+00$ & 0.0000 & $0.000 \mathrm{E}+00$ & 0.0000 & $0.000 \mathrm{E}+00$ & 0.0000 & $0.000 \mathrm{E}+00$ & 0.0000 & $0.000 \mathrm{E}+00$ & 0.0000 & $3.148 \mathrm{E}-08$ & 0.0000 \\
\hline & $0.000 \mathrm{E}+00$ & 0.0000 & $0.000 \mathrm{E}+00$ & 0.0000 & $0.000 \mathrm{E}+00$ & 0.0000 & $0.000 \mathrm{E}+00$ & 0.0000 & $0.000 \mathrm{E}+00$ & 0.0000 & $0.000 \mathrm{E}+00$ & 0.0000 & $2.047 \mathrm{E}-05$ & 0.0078 \\
\hline & . & 0000 & $.000 \mathrm{E}+00$ & 0.0000 & $0.000 \mathrm{E}+00$ & 0.0000 & $0.000 \mathrm{E}+00$ & 0.0000 & $.000 \mathrm{E}+00$ & 0.0000 & $0.000 \mathrm{E}+00$ & 0.0000 & $2.632 \mathrm{E}-03$ & 1.0000 \\
\hline
\end{tabular}

*Sum of all water independent and dependent pathways. 
RESRAD, Version 6.5

$\mathrm{T}^{1} \frac{1}{2}$ Limit $=180$ days

Summary : C746U Worker Deterministic Run

File : $\mathrm{X}: \backslash F I N A L$ V2 $\backslash$ DOE FWD RUNS $\backslash C 746 U$ W DOE SG FWD-FV2-10000YR.RAD

Total Dose Contributions TDOSE (i,p,t) for Individual Radionuclides (i) and Pathways (p) As mrem/yr and Fraction of Total Dose At $t=1.000 \mathrm{E}+04$ years

Water Independent Pathways (Inhalation excludes radon)

\begin{tabular}{|c|c|c|}
\hline clide & mrem/yr & fract. \\
\hline-241 & $5.891 E-04$ & 0.0000 \\
\hline-137 & $0.000 \mathrm{E}+00$ & 0.0000 \\
\hline-237 & $4.387 \mathrm{E}-01$ & 0.0020 \\
\hline-238 & $1.481 \mathrm{E}-03$ & 0.0000 \\
\hline-239 & $1.122 \mathrm{E}-03$ & 0.0000 \\
\hline-240 & $2.161 \mathrm{E}-04$ & 0.0000 \\
\hline-99 & $1.346 \mathrm{E}-26$ & 0.0000 \\
\hline-228 & $0.000 \mathrm{E}+00$ & 0.0000 \\
\hline-230 & $1.560 \mathrm{E}+02$ & 0.7165 \\
\hline-232 & $1.001 \mathrm{E}+01$ & 0.0460 \\
\hline 234 & $1.720 \mathrm{E}+01$ & 0.0790 \\
\hline 235 & $1.036 \mathrm{E}+00$ & 0.0048 \\
\hline 38 & $3.831 \mathrm{E}+00$ & 0.0176 \\
\hline & $1.885 \mathrm{E}+02$ & 0.0 \\
\hline
\end{tabular}

\begin{abstract}
Inhalation
\end{abstract}

mrem/yr fract.

$\longrightarrow$

$3.560 \mathrm{E}-07 \quad 0.0000$

$0.000 \mathrm{E}+00 \quad 0.0000$

$2.675 \mathrm{E}-04 \quad 0.0000$

$4.462 \mathrm{E}-07 \quad 0.0000$

$5.517 \mathrm{E}-03 \quad 0.0000$

$2.548 \mathrm{E}-03 \quad 0.0000$

$0.000 E+00 \quad 0.0000$

$0.000 \mathrm{E}+00 \quad 0.0000$

2.016E-02 0.0001

$1.256 \mathrm{E}-030.0000$

$5.134 \mathrm{E}-030.0000$

$1.558 \mathrm{E}-030.0000$

$2.216 \mathrm{E}-030.0000$

$\overline{\overline{3.866 \mathrm{E}-02}} \overline{\overline{0.0002}}$

Radon
mrem/yr fract. $\overline{0.000 E+00} 0.0000$ $0.000 E+00 \quad 0.0000$ $0.000 E+00 \quad 0.0000$ $0.000 E+00 \quad 0.0000$ $0.000 E+00 \quad 0.0000$ $0.000 E+00 \quad 0.0000$ $0.000 \mathrm{E}+00 \quad 0.0000$ $0.000 \mathrm{E}+00 \quad 0.0000$ $0.000 \mathrm{E}+00 \quad 0.0000$ $0.000 \mathrm{E}+00 \quad 0.0000$ $0.000 \mathrm{E}+00 \quad 0.0000$ $0.000 \mathrm{E}+00 \quad 0.0000$ $0.000 \mathrm{E}+00 \quad 0.0000$

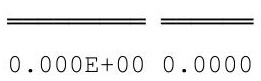

\begin{tabular}{|c|c|c|c|}
\hline \multicolumn{2}{|c|}{ Plant } & \multicolumn{2}{|c|}{ Meat } \\
\hline mrem/yr & fract. & mrem/yr & fract. \\
\hline $.000 \mathrm{E}+00$ & 0.0000 & $0.000 \mathrm{E}+00$ & 0.0000 \\
\hline $0.000 \mathrm{E}+00$ & 0.0000 & $0.000 \mathrm{E}+00$ & 0.0000 \\
\hline $0.000 \mathrm{E}+00$ & 0.0000 & $0.000 \mathrm{E}+00$ & 0.0000 \\
\hline $0.000 \mathrm{E}+00$ & 0.0000 & $0.000 \mathrm{E}+00$ & 0.0000 \\
\hline $0.000 \mathrm{E}+00$ & 0.0000 & $0.000 \mathrm{E}+00$ & 0.0000 \\
\hline $0.000 \mathrm{E}+00$ & 0.0000 & $0.000 \mathrm{E}+00$ & 0.0000 \\
\hline $0.000 \mathrm{E}+00$ & 0.0000 & $0.000 \mathrm{E}+00$ & 0.0000 \\
\hline $0.000 \mathrm{E}+00$ & 0.0000 & $0.000 \mathrm{E}+00$ & 0.0000 \\
\hline $0.000 \mathrm{E}+00$ & 0.0000 & $0.000 \mathrm{E}+00$ & 0.0000 \\
\hline $0.000 \mathrm{E}+00$ & 0.0000 & $0.000 \mathrm{E}+00$ & 0.0000 \\
\hline $0.000 \mathrm{E}+00$ & 0.0000 & $0.000 \mathrm{E}+00$ & 0.0000 \\
\hline $0.000 \mathrm{E}+00$ & 0.0000 & $0.000 \mathrm{E}+00$ & 0.0000 \\
\hline $0.000 \mathrm{E}+00$ & 0.0000 & $0.000 \mathrm{E}+00$ & 0.0000 \\
\hline & & 0.00 & . \\
\hline
\end{tabular}

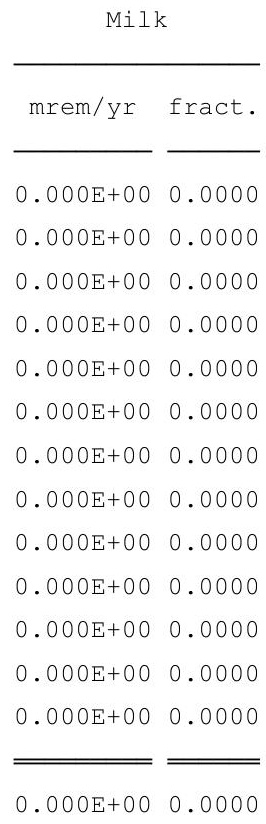

Soil mrem/yr fract. 4.717E-05 0.0000 $0.000 \mathrm{E}+00 \quad 0.0000$ $3.552 \mathrm{E}-02 \quad 0.0002$ 2.898E-04 0.0000 $6.729 \mathrm{E}-010.0031$ $3.109 \mathrm{E}-010.0014$ $5.190 \mathrm{E}-26 \quad 0.0000$ $0.000 \mathrm{E}+00 \quad 0.0000$ $2.327 \mathrm{E}+010.1069$ $4.609 \mathrm{E}-010.0021$ $3.353 \mathrm{E}+00 \quad 0.0154$ $2.623 \mathrm{E}-010.0012$ $7.990 \mathrm{E}-01 \quad 0.0037$ $2.917 \mathrm{E}+010.1339$

Total Dose Contributions TDOSE(i,p,t) for Individual Radionuclides (i) and Pathways (p) As mrem/yr and Fraction of Total Dose At $t=1.000 \mathrm{E}+04$ years

Water Dependent Pathways

\begin{tabular}{|c|c|c|c|c|c|c|}
\hline & \multicolumn{2}{|c|}{ Water } & \multicolumn{2}{|c|}{ Fish } & \multicolumn{2}{|c|}{ Radon } \\
\hline clide & mrem/yr & fract. & mrem/yr & fract. & mrem/yr & fract. \\
\hline 41 & $0.000 \mathrm{E}+00$ & 0.0000 & $0.000 \mathrm{E}+00$ & 0.0000 & $0.000 \mathrm{E}+00$ & 0.0000 \\
\hline-137 & $0.000 \mathrm{E}+00$ & 0.0000 & $0.000 \mathrm{E}+00$ & 0.0000 & $0.000 \mathrm{E}+00$ & 0.0000 \\
\hline-237 & $0.000 \mathrm{E}+00$ & 0.0000 & $0.000 \mathrm{E}+00$ & 0.0000 & $0.000 \mathrm{E}+00$ & 0.0000 \\
\hline-238 & $0.000 \mathrm{E}+00$ & 0.0000 & $0.000 \mathrm{E}+00$ & 0.0000 & $0.000 \mathrm{E}+00$ & 0.0000 \\
\hline-239 & $0.000 \mathrm{E}+00$ & 0.0000 & $0.000 \mathrm{E}+00$ & 0.0000 & $0.000 \mathrm{E}+00$ & 0.0000 \\
\hline-240 & $0.000 \mathrm{E}+00$ & 0.0000 & $0.000 \mathrm{E}+00$ & 0.0000 & $0.000 \mathrm{E}+00$ & 0.0000 \\
\hline-99 & $0.000 \mathrm{E}+00$ & 0.0000 & $0.000 \mathrm{E}+00$ & 0.0000 & $0.000 \mathrm{E}+00$ & 0.0000 \\
\hline-228 & $0.000 \mathrm{E}+00$ & 0.0000 & $0.000 \mathrm{E}+00$ & 0.0000 & $0.000 \mathrm{E}+00$ & 0.0000 \\
\hline-230 & $0.000 \mathrm{E}+00$ & 0.0000 & $0.000 \mathrm{E}+00$ & 0.0000 & $0.000 \mathrm{E}+00$ & 0.0000 \\
\hline-232 & $0.000 \mathrm{E}+00$ & 0.0000 & $0.000 \mathrm{E}+00$ & 0.0000 & $0.000 \mathrm{E}+00$ & 0.0000 \\
\hline 234 & $0.000 \mathrm{E}+00$ & 0.0000 & $0.000 \mathrm{E}+00$ & 0.0000 & $0.000 \mathrm{E}+00$ & 0.0000 \\
\hline 35 & $0.000 \mathrm{E}+00$ & 0.0000 & $0.000 \mathrm{E}+00$ & 0.0000 & $0.000 \mathrm{E}+00$ & 0.0000 \\
\hline 38 & $0.000 \mathrm{E}+00$ & 0.0000 & $0.000 \mathrm{E}+00$ & 0.0000 & $0.000 \mathrm{E}+00$ & 0.0000 \\
\hline & $0.000 \mathrm{E}+00$ & 0.0000 & $0.000 \mathrm{E}+00$ & 0.0000 & $0.000 \mathrm{E}+00$ & 0.0000 \\
\hline
\end{tabular}

\begin{tabular}{|c|c|c|c|}
\hline \multicolumn{2}{|c|}{ Plant } & \multicolumn{2}{|c|}{ Meat } \\
\hline $\mathrm{mrem} / \mathrm{yr}$ & fract. & $\mathrm{mrem} / \mathrm{yr}$ & fract. \\
\hline $0.000 \mathrm{E}+00$ & 0.0000 & $0.000 \mathrm{E}+00$ & 0.0000 \\
\hline $0.000 \mathrm{E}+00$ & 0.0000 & $0.000 \mathrm{E}+00$ & 0.0000 \\
\hline $0.000 \mathrm{E}+00$ & 0.0000 & $0.000 \mathrm{E}+00$ & 0.0000 \\
\hline $0.000 \mathrm{E}+00$ & 0.0000 & $0.000 \mathrm{E}+00$ & 0.0000 \\
\hline $0.000 \mathrm{E}+00$ & 0.0000 & $0.000 \mathrm{E}+00$ & 0.0000 \\
\hline $0.000 \mathrm{E}+00$ & 0.0000 & $0.000 \mathrm{E}+00$ & 0.0000 \\
\hline $0.000 \mathrm{E}+00$ & 0.0000 & $0.000 \mathrm{E}+00$ & 0.0000 \\
\hline $0.000 \mathrm{E}+00$ & 0.0000 & $0.000 \mathrm{E}+00$ & 0.0000 \\
\hline $0.000 \mathrm{E}+00$ & 0.0000 & $0.000 \mathrm{E}+00$ & 0.0000 \\
\hline $0.000 \mathrm{E}+00$ & 0.0000 & $0.000 \mathrm{E}+00$ & 0.0000 \\
\hline $0.000 \mathrm{E}+00$ & 0.0000 & $0.000 \mathrm{E}+00$ & 0.0000 \\
\hline $0.000 \mathrm{E}+00$ & 0.0000 & $0.000 \mathrm{E}+00$ & 0.0000 \\
\hline $0.000 \mathrm{E}+00$ & 0.0000 & $0.000 \mathrm{E}+00$ & 0.0000 \\
\hline
\end{tabular}

$0.000 \mathrm{E}+00 \quad 0.0000$

$0.000 \mathrm{E}+00 \quad 0.0000$

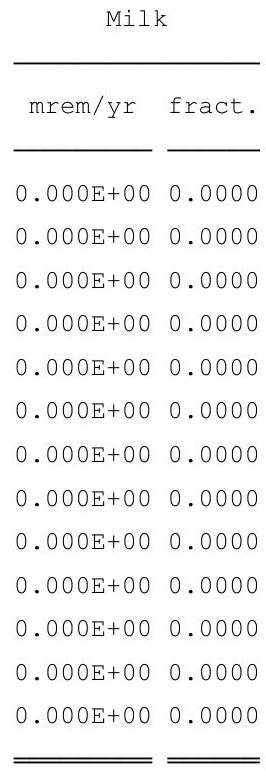

$0.000 \mathrm{E}+00 \quad 0.0000$
All Pathways* mrem/yr fract. $6.367 \mathrm{E}-04 \quad 0.0000$ $0.000 \mathrm{E}+00 \quad 0.0000$ $4.744 \mathrm{E}-010.0022$ $1.771 \mathrm{E}-03 \quad 0.0000$ $6.796 \mathrm{E}-010.0031$ $3.136 \mathrm{E}-010.0014$ $6.536 \mathrm{E}-26 \quad 0.0000$ $0.000 \mathrm{E}+00 \quad 0.0000$ $1.793 \mathrm{E}+02 \quad 0.8235$ $1.047 \mathrm{E}+010.0481$ $2.056 \mathrm{E}+01 \quad 0.0944$ $1.300 \mathrm{E}+00 \quad 0.0060$ $4.633 \mathrm{E}+00 \quad 0.0213$ $2.178 \mathrm{E}+02 \quad 1.0000$

* Sum of all water independent and dependent pathways. 
RESRAD, Version 6.5

Summary : C746U Worker Deterministic Run

File : $\mathrm{X}: \backslash F I N A L$ V2 $\backslash$ DOE FWD RUNS $\backslash C 746 U$ W DOE SG FWD-FV2-10000YR.RAD

Dose/Source Ratios Summed Over All Pathways

Parent and Progeny Principal Radionuclide Contributions Indicated

\begin{tabular}{|c|c|c|c|c|c|c|c|c|c|}
\hline Parent & Product & Thread & & $\operatorname{DSR}(j, t)$ & At Time ir & n Years & (mrem/yr) / & $\mathrm{pCi} / \mathrm{g})$ & \\
\hline (i) & $(j)$ & Fraction & $0.000 \mathrm{E}+00$ & $1.000 \mathrm{E}+00$ & $5.000 \mathrm{E}+01$ & $1.000 \mathrm{E}+02$ & $5.000 \mathrm{E}+02$ & $1.050 \mathrm{E}+03$ & $1.000 \mathrm{E}+04$ \\
\hline-241 & $A m-241$ & $1.000 \mathrm{E}+00$ & $3.956 E-34$ & $4.063 E-34$ & $1.503 E-33$ & $5.707 E-33$ & $2.471 E-28$ & $5.859 \mathrm{E}-22$ & $3.001 E-09$ \\
\hline-241 & $N p-237+D$ & $1.000 \mathrm{E}+00$ & $3.160 \mathrm{E}-20$ & $9.563 \mathrm{E}-20$ & $5.243 \mathrm{E}-18$ & $1.718 \mathrm{E}-17$ & $4.700 \mathrm{E}-15$ & $2.556 \mathrm{E}-12$ & $1.752 \mathrm{E}-05$ \\
\hline-241 & $\mathrm{U}-233$ & $1.000 \mathrm{E}+00$ & $7.164 \mathrm{E}-31$ & $5.066 \mathrm{E}-30$ & $9.948 \mathrm{E}-27$ & $7.175 \mathrm{E}-26$ & $2.177 \mathrm{E}-22$ & 7. $342 \mathrm{E}-19$ & $3.114 \mathrm{E}-08$ \\
\hline-241 & $\mathrm{Th}-229+\mathrm{D}$ & $1.000 \mathrm{E}+00$ & $4.901 E-27$ & 7. $393 E-26$ & $3.496 \mathrm{E}-21$ & $3.824 \mathrm{E}-20$ & $6.587 \mathrm{E}-17$ & $2.426 \mathrm{E}-14$ & $6.403 E-07$ \\
\hline-241 & $\sum \operatorname{DSR}(j)$ & & $3.160 \mathrm{E}-20$ & $9.563 \mathrm{E}-20$ & $5.246 \mathrm{E}-18$ & $1.722 \mathrm{E}-17$ & $4.766 \mathrm{E}-15$ & $2.581 \mathrm{E}-12$ & $1.819 \mathrm{E}-05$ \\
\hline$-137+D$ & $\mathrm{Cs}-137+\mathrm{D}$ & $1.000 \mathrm{E}+00$ & $2.578 \mathrm{E}-10$ & $2.541 \mathrm{E}-10$ & $1.237 \mathrm{E}-10$ & $5.936 \mathrm{E}-11$ & $1.667 \mathrm{E}-13$ & $5.175 \mathrm{E}-17$ & $0.000 \mathrm{E}+00$ \\
\hline$-237+D$ & $N p-237+D$ & $1.000 \mathrm{E}+00$ & $1.948 \mathrm{E}-13$ & $1.969 \mathrm{E}-13$ & $3.330 \mathrm{E}-13$ & $5.693 \mathrm{E}-13$ & $4.147 \mathrm{E}-11$ & $1.509 \mathrm{E}-08$ & $8.263 \mathrm{E}-02$ \\
\hline$-237+D$ & $\mathrm{U}-233$ & $1.000 \mathrm{E}+00$ & $6.631 \mathrm{E}-24$ & $2.011 \mathrm{E}-23$ & $1.248 \mathrm{E}-21$ & 4. $641 \mathrm{E}-21$ & $3.427 \mathrm{E}-18$ & $6.954 \mathrm{E}-15$ & $1.604 \mathrm{E}-04$ \\
\hline$-237+D$ & $\mathrm{Th}-229+\mathrm{D}$ & $1.000 \mathrm{E}+00$ & $6.053 \mathrm{E}-20$ & 4. $262 \mathrm{E}-19$ & $6.537 \mathrm{E}-16$ & $3.662 \mathrm{E}-15$ & $1.463 \mathrm{E}-12$ & $3.066 \mathrm{E}-10$ & $3.475 \mathrm{E}-03$ \\
\hline$-237+D$ & $\sum \operatorname{DSR}(j)$ & & $1.948 \mathrm{E}-13$ & $1.969 \mathrm{E}-13$ & $3.337 \mathrm{E}-13$ & $5.729 \mathrm{E}-13$ & $4.294 \mathrm{E}-11$ & $1.540 \mathrm{E}-08$ & $8.626 \mathrm{E}-02$ \\
\hline-238 & $\mathrm{Pu}-238$ & $1.840 \mathrm{E}-09$ & $4.417 \mathrm{E}-34$ & $4.460 \mathrm{E}-34$ & $7.195 \mathrm{E}-34$ & $1.172 \mathrm{E}-33$ & $5.806 \mathrm{E}-32$ & $1.243 E-29$ & 1. $401 \mathrm{E}-45$ \\
\hline-238 & $\mathrm{Pu}-238$ & $1.000 \mathrm{E}+00$ & $2.401 \mathrm{E}-25$ & $2.424 \mathrm{E}-25$ & $3.910 \mathrm{E}-25$ & $6.369 \mathrm{E}-25$ & $3.155 \mathrm{E}-23$ & $6.755 E-21$ & $1.131 \mathrm{E}-36$ \\
\hline-238 & $\mathrm{U}-234$ & $1.000 \mathrm{E}+00$ & $1.998 \mathrm{E}-30$ & $6.068 \mathrm{E}-30$ & $4.032 \mathrm{E}-28$ & $1.628 \mathrm{E}-27$ & $3.470 \mathrm{E}-24$ & $5.993 E-20$ & $1.672 \mathrm{E}-06$ \\
\hline-238 & Th-230 & $1.000 \mathrm{E}+00$ & $2.101 E-34$ & $1.489 \mathrm{E}-33$ & $3.268 \mathrm{E}-30$ & $2.663 E-29$ & $2.676 \mathrm{E}-25$ & $6.795 E-21$ & $6.557 \mathrm{E}-07$ \\
\hline-238 & $\mathrm{Ra}-226+\mathrm{D}$ & $1.000 \mathrm{E}+00$ & $1.639 \mathrm{E}-23$ & $2.469 \mathrm{E}-22$ & $1.076 \mathrm{E}-17$ & $1.088 \mathrm{E}-16$ & $1.149 \mathrm{E}-13$ & $2.677 \mathrm{E}-11$ & $3.858 \mathrm{E}-05$ \\
\hline-238 & $\mathrm{~Pb}-210+\mathrm{D}$ & $1.000 \mathrm{E}+00$ & $4.753 E-32$ & $1.473 \mathrm{E}-30$ & $1.589 \mathrm{E}-24$ & $2.687 \mathrm{E}-23$ & $7.527 \mathrm{E}-20$ & $3.536 \mathrm{E}-17$ & $4.499 \mathrm{E}-06$ \\
\hline-238 & $\sum \operatorname{DSR}(j)$ & & $1.663 \mathrm{E}-23$ & $2.471 E-22$ & $1.076 \mathrm{E}-17$ & $1.088 \mathrm{E}-16$ & $1.149 \mathrm{E}-13$ & $2.677 \mathrm{E}-11$ & $4.541 E-05$ \\
\hline-239 & $\mathrm{Pu}-239$ & $1.000 \mathrm{E}+00$ & $2.456 \mathrm{E}-18$ & $2.486 \mathrm{E}-18$ & $4.463 E-18$ & $8.107 \mathrm{E}-18$ & $9.618 \mathrm{E}-16$ & $6.841 \mathrm{E}-13$ & $1.888 \mathrm{E}-02$ \\
\hline-239 & $\mathrm{U}-235+\mathrm{D}$ & $1.000 \mathrm{E}+00$ & $1.254 \mathrm{E}-24$ & $3.802 \mathrm{E}-24$ & $2.343 E-22$ & $8.645 E-22$ & $6.015 \mathrm{E}-19$ & $1.124 \mathrm{E}-15$ & $9.231 \mathrm{E}-07$ \\
\hline-239 & $\mathrm{~Pa}-231$ & $1.000 \mathrm{E}+00$ & $1.972 \mathrm{E}-28$ & $1.393 \mathrm{E}-27$ & $2.557 \mathrm{E}-24$ & $1.721 \mathrm{E}-23$ & $2.963 E-20$ & $4.446 \mathrm{E}-17$ & $8.533 E-08$ \\
\hline-239 & $A C-227+D$ & $1.000 \mathrm{E}+00$ & $4.675 E-28$ & $7.017 \mathrm{E}-27$ & $2.608 E-22$ & $2.391 \mathrm{E}-21$ & $3.028 E-18$ & $1.826 \mathrm{E}-15$ & $3.511 \mathrm{E}-07$ \\
\hline-239 & $\sum \operatorname{DSR}(j)$ & & $2.456 E-18$ & $2.486 \mathrm{E}-18$ & $4.463 \mathrm{E}-18$ & $8.110 \mathrm{E}-18$ & $9.655 \mathrm{E}-16$ & $6.871 \mathrm{E}-13$ & $1.888 E-02$ \\
\hline-240 & $\mathrm{Pu}-240$ & $4.950 E-08$ & $1.155 \mathrm{E}-32$ & $1.176 \mathrm{E}-32$ & $2.778 E-32$ & $6.681 E-32$ & $7.478 E-29$ & $1.164 \mathrm{E}-24$ & 4. $312 \mathrm{E}-10$ \\
\hline-240 & $\mathrm{Pu}-240$ & $1.000 \mathrm{E}+00$ & $2.334 \mathrm{E}-25$ & $2.375 E-25$ & $5.612 \mathrm{E}-25$ & $1.350 \mathrm{E}-24$ & $1.511 \mathrm{E}-21$ & $2.352 \mathrm{E}-17$ & $8.711 \mathrm{E}-03$ \\
\hline-240 & $U-236$ & $1.000 \mathrm{E}+00$ & $4.417 E-33$ & $1.347 \mathrm{E}-32$ & $1.091 \mathrm{E}-30$ & $5.321 \mathrm{E}-30$ & $3.459 E-26$ & $1.397 E-21$ & $8.458 \mathrm{E}-07$ \\
\hline-240 & Th-232 & $1.000 \mathrm{E}+00$ & $5.745 E-44$ & $4.148 E-43$ & $1.120 \mathrm{E}-39$ & $1.120 \mathrm{E}-38$ & $4.587 E-34$ & $5.372 E-29$ & 1. $247 \mathrm{E}-12$ \\
\hline-240 & $\mathrm{Ra}-228+\mathrm{D}$ & $1.000 \mathrm{E}+00$ & $2.801 E-29$ & $4.123 E-28$ & 7. $689 \mathrm{E}-24$ & $5.197 \mathrm{E}-23$ & $3.012 E-20$ & $8.590 \mathrm{E}-18$ & $4.940 \mathrm{E}-11$ \\
\hline-240 & $T h-228+D$ & $1.000 \mathrm{E}+00$ & $1.657 \mathrm{E}-28$ & $4.769 \mathrm{E}-27$ & $5.398 E-22$ & $3.593 E-21$ & $1.140 \mathrm{E}-18$ & $1.344 \mathrm{E}-16$ & $7.877 \mathrm{E}-11$ \\
\hline-240 & $\sum \operatorname{DSR}(j)$ & & $2.335 E-25$ & $2.427 E-25$ & $5.480 \mathrm{E}-22$ & $3.646 \mathrm{E}-21$ & $1.172 \mathrm{E}-18$ & $1.665 E-16$ & $8.712 \mathrm{E}-03$ \\
\hline-99 & TC-99 & $1.000 \mathrm{E}+00$ & $1.179 \mathrm{E}-26$ & $1.195 \mathrm{E}-26$ & $2.364 \mathrm{E}-26$ & $4.741 \mathrm{E}-26$ & $1.241 \mathrm{E}-23$ & $2.619 \mathrm{E}-20$ & $1.257 \mathrm{E}-27$ \\
\hline$-228+D$ & $T h-228+D$ & $1.000 \mathrm{E}+00$ & $2.825 E-07$ & $1.978 \mathrm{E}-07$ & $5.163 \mathrm{E}-15$ & $9.437 \mathrm{E}-23$ & $0.000 \mathrm{E}+00$ & $0.000 \mathrm{E}+00$ & $0.000 \mathrm{E}+00$ \\
\hline 230 & $T h-230$ & $1.000 \mathrm{E}+00$ & $4.929 E-23$ & $5.012 \mathrm{E}-23$ & $1.142 \mathrm{E}-22$ & $2.647 \mathrm{E}-22$ & $2.203 E-19$ & $2.282 \mathrm{E}-15$ & $2.112 \mathrm{E}-02$ \\
\hline 230 & $\mathrm{Ra}-226+\mathrm{D}$ & $1.000 \mathrm{E}+00$ & 7. $712 \mathrm{E}-12$ & $2.327 E-11$ & $1.087 \mathrm{E}-09$ & $3.024 \mathrm{E}-09$ & $2.193 E-07$ & $1.840 E-05$ & $1.586 \mathrm{E}+00$ \\
\hline 230 & $\mathrm{~Pb}-210+\mathrm{D}$ & $1.000 \mathrm{E}+00$ & $3.717 \mathrm{E}-20$ & $2.596 \mathrm{E}-19$ & $2.655 E-16$ & $1.087 \mathrm{E}-15$ & $1.573 E-13$ & $2.528 E-11$ & $1.857 \mathrm{E}-01$ \\
\hline 230 & $\sum \operatorname{DSR}(j)$ & & 7. $712 \mathrm{E}-12$ & $2.327 \mathrm{E}-11$ & $1.087 \mathrm{E}-09$ & $3.024 \mathrm{E}-09$ & $2.193 E-07$ & $1.840 \mathrm{E}-05$ & $1.793 \mathrm{E}+00$ \\
\hline
\end{tabular}


RESRAD, Version 6.5

Summary : C746U Worker Deterministic Run

File : $\mathrm{X}: \backslash F I N A L$ V2\DOE FWD RUNS \C746U W DOE SG FWD-FV2-10000YR.RAD

Dose/Source Ratios Summed Over All Pathways

Parent and Progeny Principal Radionuclide Contributions Indicated

\begin{tabular}{|c|c|c|c|c|c|c|c|c|c|}
\hline Parent & Product & Thread & & $\operatorname{DSR}(j, t)$ & At Time ir & n Years & (mrem/yr) / & $(\mathrm{pCi} / \mathrm{g})$ & \\
\hline (i) & $(j)$ & Fraction & $0.000 \mathrm{E}+00$ & $1.000 \mathrm{E}+00$ & $5.000 \mathrm{E}+01$ & $1.000 \mathrm{E}+02$ & $5.000 \mathrm{E}+02$ & $1.050 \mathrm{E}+03$ & $1.000 \mathrm{E}+04$ \\
\hline-232 & $\mathrm{Th}-232$ & $1.000 \mathrm{E}+00$ & $2.382 \mathrm{E}-25$ & $2.427 E-25$ & $6.027 \mathrm{E}-25$ & $1.525 \mathrm{E}-24$ & $2.561 \mathrm{E}-21$ & $6.965 \mathrm{E}-17$ & $2.519 \mathrm{E}-02$ \\
\hline-232 & $\mathrm{Ra}-228+\mathrm{D}$ & $1.000 \mathrm{E}+00$ & $2.263 E-10$ & $6.486 \mathrm{E}-10$ & $5.690 \mathrm{E}-09$ & $8.336 \mathrm{E}-09$ & $1.737 \mathrm{E}-07$ & $1.131 \mathrm{E}-05$ & $9.991 \mathrm{E}-01$ \\
\hline $1-232$ & $\mathrm{Th}-228+\mathrm{D}$ & $1.000 \mathrm{E}+00$ & $2.181 E-09$ & $1.345 \mathrm{E}-08$ & $4.522 \mathrm{E}-07$ & $6.114 \mathrm{E}-07$ & $6.652 E-06$ & $1.778 \mathrm{E}-04$ & $1.594 \mathrm{E}+00$ \\
\hline-232 & $\sum \operatorname{DSR}(j)$ & & $2.407 E-09$ & $1.410 \mathrm{E}-08$ & $4.579 \mathrm{E}-07$ & $6.198 \mathrm{E}-07$ & $6.825 \mathrm{E}-06$ & $1.891 \mathrm{E}-04$ & $2.618 \mathrm{E}+00$ \\
\hline-234 & $\mathrm{U}-234$ & $1.000 \mathrm{E}+00$ & $1.409 \mathrm{E}-24$ & $1.434 \mathrm{E}-24$ & $3.415 \mathrm{E}-24$ & $8.276 \mathrm{E}-24$ & $9.851 \mathrm{E}-21$ & $1.669 \mathrm{E}-16$ & $4.655 E-03$ \\
\hline-234 & Th-230 & $1.000 \mathrm{E}+00$ & $2.225 E-28$ & $6.774 \mathrm{E}-28$ & $5.192 \mathrm{E}-26$ & $2.394 \mathrm{E}-25$ & $9.912 \mathrm{E}-22$ & $2.152 \mathrm{E}-17$ & $1.850 \mathrm{E}-03$ \\
\hline-234 & $\mathrm{Ra}-226+\mathrm{D}$ & $1.000 \mathrm{E}+00$ & $2.315 E-17$ & $1.630 \mathrm{E}-16$ & $2.480 \mathrm{E}-13$ & 1. $377 \mathrm{E}-12$ & $5.115 \mathrm{E}-10$ & $9.341 \mathrm{E}-08$ & 1.092E-01 \\
\hline-234 & $\mathrm{~Pb}-210+\mathrm{D}$ & $1.000 \mathrm{E}+00$ & $8.381 E-26$ & $1.257 \mathrm{E}-24$ & $4.500 \mathrm{E}-20$ & $3.956 \mathrm{E}-19$ & $3.440 \mathrm{E}-16$ & 1.243E-13 & $1.274 \mathrm{E}-02$ \\
\hline-234 & $\sum \operatorname{DSR}(j)$ & & $2.315 \mathrm{E}-17$ & $1.630 \mathrm{E}-16$ & $2.480 \mathrm{E}-13$ & 1. $377 \mathrm{E}-12$ & $5.115 \mathrm{E}-10$ & $9.341 \mathrm{E}-08$ & $1.285 \mathrm{E}-01$ \\
\hline$-235+D$ & $\mathrm{U}-235+\mathrm{D}$ & $1.000 \mathrm{E}+00$ & $2.540 \mathrm{E}-15$ & $2.572 \mathrm{E}-15$ & $4.713 E-15$ & $8.745 E-15$ & 1. $228 \mathrm{E}-12$ & $1.101 \mathrm{E}-09$ & $1.061 \mathrm{E}-01$ \\
\hline$-235+D$ & $\mathrm{~Pa}-231$ & $1.000 \mathrm{E}+00$ & $6.002 \mathrm{E}-19$ & $1.818 \mathrm{E}-18$ & $1.028 \mathrm{E}-16$ & $3.478 \mathrm{E}-16$ & $1.206 \mathrm{E}-13$ & $8.644 \mathrm{E}-11$ & $1.831 \mathrm{E}-02$ \\
\hline$-235+D$ & $A C-227+D$ & $1.000 \mathrm{E}+00$ & $1.895 \mathrm{E}-18$ & 1. $324 \mathrm{E}-17$ & 1. $407 \mathrm{E}-14$ & $6.019 \mathrm{E}-14$ & 1. $308 \mathrm{E}-11$ & $3.655 \mathrm{E}-09$ & $7.555 E-02$ \\
\hline$-235+D$ & $\sum \operatorname{DSR}(j)$ & & $2.543 E-15$ & $2.587 \mathrm{E}-15$ & $1.888 \mathrm{E}-14$ & $6.928 \mathrm{E}-14$ & 1. $443 \mathrm{E}-11$ & $4.843 E-09$ & $2.000 \mathrm{E}-01$ \\
\hline-238 & $U-238$ & $5.400 E-05$ & $0.000 \mathrm{E}+00$ & $0.000 \mathrm{E}+00$ & $0.000 \mathrm{E}+00$ & $0.000 \mathrm{E}+00$ & $0.000 \mathrm{E}+00$ & $3.476 \mathrm{E}-39$ & $2.356 \mathrm{E}-07$ \\
\hline$-238+D$ & $\mathrm{U}-238+\mathrm{D}$ & $9.999 \mathrm{E}-01$ & $2.901 \mathrm{E}-11$ & $2.924 \mathrm{E}-11$ & $4.325 E-11$ & $6.449 \mathrm{E}-11$ & $1.576 \mathrm{E}-09$ & $1.279 E-07$ & $2.735 E-02$ \\
\hline$-238+D$ & $U-234$ & $9.999 \mathrm{E}-01$ & $2.003 E-30$ & $6.105 E-30$ & $4.889 \mathrm{E}-28$ & $2.358 \mathrm{E}-27$ & $1.399 \mathrm{E}-23$ & $4.978 \mathrm{E}-19$ & $1.339 \mathrm{E}-04$ \\
\hline$-238+D$ & $\mathrm{Th}-230$ & $9.999 E-01$ & $2.105 E-34$ & $1.495 \mathrm{E}-33$ & $3.717 \mathrm{E}-30$ & $3.411 \mathrm{E}-29$ & $7.032 \mathrm{E}-25$ & $3.204 \mathrm{E}-20$ & $2.623 E-05$ \\
\hline$-238+D$ & $\mathrm{Ra}-226+\mathrm{D}$ & $9.999 \mathrm{E}-01$ & $1.642 \mathrm{E}-23$ & $2.477 \mathrm{E}-22$ & $1.186 \mathrm{E}-17$ & $1.313 \mathrm{E}-16$ & $2.462 E-13$ & $9.612 \mathrm{E}-11$ & $1.290 \mathrm{E}-03$ \\
\hline$-238+D$ & $\mathrm{~Pb}-210+\mathrm{D}$ & $9.999 \mathrm{E}-01$ & $4.759 \mathrm{E}-32$ & $1.477 \mathrm{E}-30$ & 1. $723 \mathrm{E}-24$ & $3.161 \mathrm{E}-23$ & $1.561 \mathrm{E}-19$ & $1.240 \mathrm{E}-16$ & 1. $499 \mathrm{E}-04$ \\
\hline$-238+D$ & $\sum \operatorname{DSR}(j)$ & & $2.901 \mathrm{E}-11$ & $2.924 \mathrm{E}-11$ & $4.325 \mathrm{E}-11$ & $6.449 \mathrm{E}-11$ & $1.577 \mathrm{E}-09$ & $1.280 \mathrm{E}-07$ & $2.895 \mathrm{E}-02$ \\
\hline
\end{tabular}

The DSR includes contributions from associated (half-life $\leq 180$ days) daughters. 
RESRAD, Version 6.5

$\mathrm{T}^{1 / 2}$ Limit $=180$ days

07/18/2011 13:45 Page

ummary : C746U Worker Deterministic Run

File : $\mathrm{X}: \backslash F I N A L$ V2 $\backslash$ DOE FWD RUNS $\backslash C 746 U$ W DOE SG FWD-FV2-10000YR.RAD

Single Radionuclide Soil Guidelines G(i,t) in pCi/g

Basic Radiation Dose Limit $=1.000 \mathrm{E}+00 \mathrm{mrem} / \mathrm{yr}$

Nuclide

\begin{tabular}{|c|c|c|c|c|c|c|c|}
\hline (i) & $t=0.000 E+00$ & $1.000 \mathrm{E}+00$ & $5.000 \mathrm{E}+01$ & $1.000 \mathrm{E}+02$ & $5.000 \mathrm{E}+02$ & $1.050 \mathrm{E}+03$ & $1.000 \mathrm{E}+0$ \\
\hline-241 & $\star 3.431 \mathrm{E}+12$ & $\star 3.431 \mathrm{E}+12$ & $\star 3.431 \mathrm{E}+12$ & $\star 3.431 \mathrm{E}+12$ & $\star 3.431 \mathrm{E}+12$ & $3.875 \mathrm{E}+11$ & $5.497 \mathrm{E}+04$ \\
\hline-137 & $3.879 \mathrm{E}+09$ & $3.936 \mathrm{E}+09$ & $8.084 E+09$ & $1.685 E+10$ & $5.997 E+12$ & $\star 8.704 \mathrm{E}+13$ & $\star 8.704 \mathrm{E}+13$ \\
\hline-237 & $\star 7.047 \mathrm{E}+08$ & $\star 7.047 \mathrm{E}+08$ & $\star 7.047 \mathrm{E}+08$ & $\star 7.047 \mathrm{E}+08$ & $\star 7.047 \mathrm{E}+08$ & $6.495 \mathrm{E}+07$ & $1.159 \mathrm{E}+01$ \\
\hline-238 & $* 1.712 \mathrm{E}+13$ & $\star 1.712 \mathrm{E}+13$ & $\star 1.712 \mathrm{E}+13$ & $\star 1.712 \mathrm{E}+13$ & $8.701 \mathrm{E}+12$ & $3.735 \mathrm{E}+10$ & $2.202 \mathrm{E}+04$ \\
\hline-239 & $* 6.214 \mathrm{E}+10$ & $* 6.214 \mathrm{E}+10$ & $* 6.214 \mathrm{E}+10$ & $* 6.214 \mathrm{E}+10$ & $* 6.214 \mathrm{E}+10$ & $* 6.214 \mathrm{E}+10$ & $5.298 \mathrm{E}+0$ \\
\hline-240 & $\star 2.278 \mathrm{E}+11$ & $\star 2.278 \mathrm{E}+11$ & $\star 2.278 \mathrm{E}+11$ & $\star 2.278 \mathrm{E}+11$ & $\star 2.278 \mathrm{E}+11$ & $\star 2.278 \mathrm{E}+11$ & $1.148 \mathrm{E}+02$ \\
\hline-99 & $\star 1.697 \mathrm{E}+10$ & $* 1.697 \mathrm{E}+10$ & $\star 1.697 \mathrm{E}+10$ & $\star 1.697 \mathrm{E}+10$ & $* 1.697 \mathrm{E}+10$ & $\star 1.697 \mathrm{E}+10$ & $\star 1.697 \mathrm{E}+1 \mathrm{C}$ \\
\hline$h-228$ & $3.540 \mathrm{E}+06$ & $5.056 \mathrm{E}+06$ & $1.937 \mathrm{E}+14$ & $\star 8.195 \mathrm{E}+14$ & $\star 8.195 \mathrm{E}+14$ & $* 8.195 \mathrm{E}+14$ & $* 8.195 \mathrm{E}+14$ \\
\hline$h-230$ & $\star 2.018 \mathrm{E}+10$ & $\star 2.018 \mathrm{E}+10$ & $9.198 \mathrm{E}+08$ & $3.307 \mathrm{E}+08$ & $4.559 \mathrm{E}+06$ & $5.434 \mathrm{E}+04$ & $5.576 \mathrm{E}-0$ \\
\hline Th-232 & $* 1.097 \mathrm{E}+05$ & $* 1.097 \mathrm{E}+05$ & $* 1.097 \mathrm{E}+05$ & $* 1.097 \mathrm{E}+05$ & $* 1.097 \mathrm{E}+05$ & $5.287 \mathrm{E}+03$ & $3.819 \mathrm{E}-01$ \\
\hline-234 & $* 6.247 \mathrm{E}+09$ & $\star 6.247 \mathrm{E}+09$ & $\star 6.247 \mathrm{E}+09$ & $* 6.247 \mathrm{E}+09$ & $1.955 \mathrm{E}+09$ & $1.071 \mathrm{E}+07$ & $7.783 \mathrm{E}+0$ \\
\hline 35 & $\star 2.161 \mathrm{E}+06$ & $\star 2.161 \mathrm{E}+06$ & $\star 2.161 \mathrm{E}+06$ & $\star 2.161 \mathrm{E}+06$ & $\star 2.161 \mathrm{E}+06$ & $\star 2.161 \mathrm{E}+06$ & $5.000 \mathrm{E}+0 \mathrm{C}$ \\
\hline 38 & $\star 3.361 \mathrm{E}+05$ & $\star 3.361 \mathrm{E}+05$ & $\star 3.361 \mathrm{E}+05$ & $\star 3.361 \mathrm{E}+05$ & $\star 3.361 \mathrm{E}+05$ & $\star 3.361 \mathrm{E}+05$ & $3.454 \mathrm{E}+01$ \\
\hline
\end{tabular}

*At specific activity limit

Summed Dose/Source Ratios DSR (i,t) in (mrem/yr)/(pCi/g)

and Single Radionuclide Soil Guidelines G(i,t) in pCi/g

at tmin = time of minimum single radionuclide soil guideline and at $\operatorname{tmax}=$ time of maximum total dose $=1.000 \mathrm{E}+04$ years

\begin{tabular}{|c|c|c|c|c|c|c|}
\hline $\begin{array}{l}\text { uclide } \\
\text { (i) }\end{array}$ & $\begin{array}{l}\text { Initial } \\
\text { (pCi/g) }\end{array}$ & $\begin{array}{c}\text { tmin } \\
\text { (years) }\end{array}$ & $\operatorname{DSR}(i, \operatorname{tmin})$ & $\begin{array}{c}\mathrm{G}(\mathrm{i}, \mathrm{tmin}) \\
(\mathrm{pCi} / \mathrm{g})\end{array}$ & $\operatorname{DSR}(i, t \max )$ & $\begin{array}{c}G(i, \operatorname{tmax}) \\
(\mathrm{pCi} / \mathrm{g})\end{array}$ \\
\hline $1-241$ & $3.500 \mathrm{E}+01$ & $2533 \pm 5$ & $5.176 \mathrm{E}-04$ & $1.932 \mathrm{E}+03$ & $1.819 \mathrm{E}-05$ & $5.497 \mathrm{E}+04$ \\
\hline-137 & $1.900 \mathrm{E}+01$ & $0.000 \mathrm{E}+00$ & $2.578 E-10$ & $3.879 E+09$ & $0.000 \mathrm{E}+00$ & $\star 8.704 \mathrm{E}+13$ \\
\hline-237 & $5.500 \mathrm{E}+00$ & $2536 \pm 5$ & 1. $491 \mathrm{E}-01$ & $6.705 \mathrm{E}+00$ & $8.626 \mathrm{E}-02$ & $1.159 \mathrm{E}+01$ \\
\hline-238 & $3.900 \mathrm{E}+01$ & $1.000 \mathrm{E}+04$ & $4.541 E-05$ & $2.202 E+04$ & $4.541 E-05$ & $2.202 \mathrm{E}+04$ \\
\hline-239 & $3.600 E+01$ & $2533 \pm 5$ & $2.521 E-02$ & $3.966 \mathrm{E}+01$ & $1.888 E-02$ & $5.298 E+01$ \\
\hline-240 & $3.600 \mathrm{E}+01$ & $2533 \pm 5$ & $2.071 \mathrm{E}-02$ & $4.827 \mathrm{E}+01$ & $8.712 \mathrm{E}-03$ & $1.148 \mathrm{E}+02$ \\
\hline-99 & $5.200 \mathrm{E}+01$ & $2534 \pm 5$ & $1.439 \mathrm{E}-10$ & $6.949 E+09$ & $1.257 \mathrm{E}-27$ & $* 1.697 \mathrm{E}+10$ \\
\hline-228 & $4.000 \mathrm{E}+00$ & $0.000 \mathrm{E}+00$ & $2.825 E-07$ & $3.540 \mathrm{E}+06$ & $0.000 \mathrm{E}+00$ & $\star 8.195 \mathrm{E}+14$ \\
\hline-230 & $1.000 \mathrm{E}+02$ & $1.000 \mathrm{E}+04$ & $1.793 \mathrm{E}+00$ & $5.576 \mathrm{E}-01$ & $1.793 E+00$ & $5.576 \mathrm{E}-01$ \\
\hline-232 & $4.000 E+00$ & $2536 \pm 5$ & $2.652 E+00$ & $3.771 E-01$ & $2.618 \mathrm{E}+00$ & $3.819 \mathrm{E}-01$ \\
\hline 234 & $1.600 \mathrm{E}+02$ & $1.000 \mathrm{E}+04$ & $1.285 \mathrm{E}-01$ & $7.783 \mathrm{E}+00$ & $1.285 E-01$ & $7.783 E+00$ \\
\hline 35 & $6.500 \mathrm{E}+00$ & $1.000 \mathrm{E}+04$ & $2.000 E-01$ & $5.000 \mathrm{E}+00$ & $2.000 E-01$ & $5.000 \mathrm{E}+00$ \\
\hline 238 & $1.600 \mathrm{E}+02$ & $2536 \pm 5$ & $3.032 \mathrm{E}-02$ & $3.299 \mathrm{E}+01$ & $2.895 \mathrm{E}-02$ & $3.454 \mathrm{E}+01$ \\
\hline
\end{tabular}

*At specific activity limit 
RESRAD, Version 6.5

Summary : C746U Worker Deterministic Run

File : $\mathrm{X}: \backslash F I N A L$ V2 $\backslash$ DOE FWD RUNS $\backslash C 746 U$ W DOE SG FWD-FV2-10000YR. RAD

Individual Nuclide Dose Summed Over All Pathways

Parent Nuclide and Branch Fraction Indicated

Nuclide Parent THF(i) DOSE $(j, t), \mathrm{mrem} / \mathrm{yr}$

\begin{tabular}{|c|c|c|}
\hline$(j)$ & (i) & \\
\hline $\mathrm{Am}-241$ & $A m-241$ & $1.000 \mathrm{E}+00$ \\
\hline$p-237$ & Am-241 & $1.000 \mathrm{E}+00$ \\
\hline-237 & $N p-237$ & $1.000 \mathrm{E}+00$ \\
\hline 237 & $\sum$ DOSE & \\
\hline
\end{tabular}

$\mathrm{U}-233 \mathrm{Am}-241 \quad 1.000 \mathrm{E}+00$

$\mathrm{U}-233 \quad \mathrm{~Np}-237 \quad 1.000 \mathrm{E}+00$

U-233 $\quad$ DDOSE $(j)$

Th-229 Am-241 1.000E+00

$\mathrm{Th}-229 \quad \mathrm{~Np}-237 \quad 1.000 \mathrm{E}+00$

Th-229 $\sum \operatorname{DOSE}(j)$

Cs-137 Cs-137 1.000E+00

$\mathrm{Pu}-238 \mathrm{Pu}-238 \quad 1.840 \mathrm{E}-09$

$\mathrm{Pu}-238 \quad \mathrm{Pu}-238 \quad 1.000 \mathrm{E}+00$

$\mathrm{Pu}-238 \quad \sum \mathrm{DOSE}(j)$

$\mathrm{U}-234$

$\mathrm{U}-234$

$\mathrm{U}-234$

$\mathrm{U}-234$

$\mathrm{Th}-230$

$\mathrm{Th}-230$

$\mathrm{Th}-230$

$\mathrm{Th}-230$

$\mathrm{Th}-230$

$\mathrm{Ra}-226$

$\mathrm{Ra}-226$

$\mathrm{Ra}-226$

$\mathrm{Ra}-226$

$\mathrm{Ra}-226$

$\mathrm{Pb}-210$

$\mathrm{Pb}-210$

$\mathrm{Pb}-210$

$\mathrm{Pb}-210$

$\mathrm{Pb}-210$

Pu-239

$\mathrm{Pu}-238$ 1.000E+00

$\mathrm{U}-234 \quad 1.000 \mathrm{E}+00$

U-238 9.999E-01

$\sum \operatorname{DOSE}(j)$

$\mathrm{Pu}-238 \quad 1.000 \mathrm{E}+00$

Th-230 1.000E+00

$\mathrm{U}-234 \quad 1.000 \mathrm{E}+00$

U-238 9.999E-01

$\sum \operatorname{DOSE}(j)$

$\mathrm{Pu}-238 \quad 1.000 \mathrm{E}+00$

Th-230 1.000E+00

$\mathrm{U}-234 \quad 1.000 \mathrm{E}+00$

$\mathrm{U}-238 \quad 9.999 \mathrm{E}-01$

$\sum \operatorname{DOSE}(j)$

$\mathrm{Pu}-238 \quad 1.000 \mathrm{E}+00$

Th-230 1.000E+00

$\mathrm{U}-234 \quad 1.000 \mathrm{E}+00$

U-238 9.999E-01

$\sum \operatorname{DOSE}(j)$

Pu-239 1.000E+00

Pu-239 1.000E+00

U-235 $1.000 \mathrm{E}+00$

$\sum \operatorname{DOSE}(j)$
$=0.000 \mathrm{E}+00 \quad 1.000 \mathrm{E}+00 \quad 5.000 \mathrm{E}+01 \quad 1.000 \mathrm{E}+02 \quad 5.000 \mathrm{E}+02 \quad 1.050 \mathrm{E}+03 \quad 1.000 \mathrm{E}+04$

$\begin{array}{llllllllll}0.000 \mathrm{E}+00 & 0.000 \mathrm{E}+00 & 0.000 \mathrm{E}+00 & 0.000 \mathrm{E}+00 & 8.647 \mathrm{E}-27 & 2.051 \mathrm{E}-20 & 1.050 \mathrm{E}-07\end{array}$

$\begin{array}{lllllll}1.106 \mathrm{E}-18 & 3.347 \mathrm{E}-18 & 1.835 \mathrm{E}-16 & 6.012 \mathrm{E}-16 & 1.645 \mathrm{E}-13 & 8.947 \mathrm{E}-11 & 6.131 \mathrm{E}-04\end{array}$

$\begin{array}{lllllll}1.072 \mathrm{E}-12 & 1.083 \mathrm{E}-12 & 1.832 \mathrm{E}-12 & 3.131 \mathrm{E}-12 & 2.281 \mathrm{E}-10 & 8.299 \mathrm{E}-08 & 4.544 \mathrm{E}-01\end{array}$

$\begin{array}{lllllll}1.072 \mathrm{E}-12 & 1.083 \mathrm{E}-12 & 1.832 \mathrm{E}-12 & 3.132 \mathrm{E}-12 & 2.283 \mathrm{E}-10 & 8.308 \mathrm{E}-08 & 4.551 \mathrm{E}-01\end{array}$

$\begin{array}{lllllllll}0.000 \mathrm{E}+00 & 1.773 \mathrm{E}-28 & 3.482 \mathrm{E}-25 & 2.511 \mathrm{E}-24 & 7.620 \mathrm{E}-21 & 2.570 \mathrm{E}-17 & 1.090 \mathrm{E}-06\end{array}$

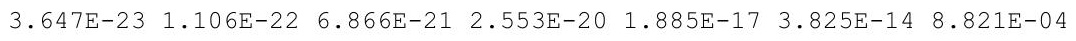

$\begin{array}{lllllll}3.647 \mathrm{E}-23 & 1.106 \mathrm{E}-22 & 6.867 \mathrm{E}-21 & 2.553 \mathrm{E}-20 & 1.886 \mathrm{E}-17 & 3.827 \mathrm{E}-14 & 8.832 \mathrm{E}-04\end{array}$

$\begin{array}{lllllll}1.715 \mathrm{E}-25 & 2.588 \mathrm{E}-24 & 1.224 \mathrm{E}-19 & 1.338 \mathrm{E}-18 & 2.306 \mathrm{E}-15 & 8.490 \mathrm{E}-13 & 2.241 \mathrm{E}-05\end{array}$

$\begin{array}{lllllll}3.329 \mathrm{E}-19 & 2.344 \mathrm{E}-18 & 3.596 \mathrm{E}-15 & 2.014 \mathrm{E}-14 & 8.046 \mathrm{E}-12 & 1.686 \mathrm{E}-09 & 1.911 \mathrm{E}-02\end{array}$

$\begin{array}{lllllll}3.329 \mathrm{E}-19 & 2.344 \mathrm{E}-18 & 3.596 \mathrm{E}-15 & 2.014 \mathrm{E}-14 & 8.048 \mathrm{E}-12 & 1.687 \mathrm{E}-09 & 1.914 \mathrm{E}-02\end{array}$

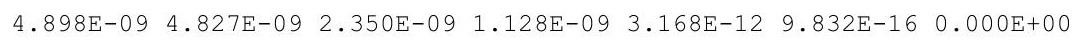

$0.000 \mathrm{E}+00 \quad 0.000 \mathrm{E}+00 \quad 0.000 \mathrm{E}+00 \quad 0.000 \mathrm{E}+00 \quad 0.000 \mathrm{E}+00 \quad 4.847 \mathrm{E}-28 \quad 0.000 \mathrm{E}+00$ $\begin{array}{llllllll}9.362 \mathrm{E}-24 & 9.454 \mathrm{E}-24 & 1.525 \mathrm{E}-23 & 2.484 \mathrm{E}-23 & 1.231 \mathrm{E}-21 & 2.634 \mathrm{E}-19 & 0.000 \mathrm{E}+00\end{array}$ $\begin{array}{lllllll}9.362 \mathrm{E}-24 & 9.454 \mathrm{E}-24 & 1.525 \mathrm{E}-23 & 2.484 \mathrm{E}-23 & 1.231 \mathrm{E}-21 & 2.634 \mathrm{E}-19 & 0.000 \mathrm{E}+00\end{array}$

$\begin{array}{lllllll}7.792 E-29 & 2.366 \mathrm{E}-28 & 1.573 \mathrm{E}-26 & 6.349 \mathrm{E}-26 & 1.353 \mathrm{E}-22 & 2.337 \mathrm{E}-18 & 6.520 \mathrm{E}-05\end{array}$ $\begin{array}{lllllllll}2.254 \mathrm{E}-22 & 2.295 \mathrm{E}-22 & 5.464 \mathrm{E}-22 & 1.324 \mathrm{E}-21 & 1.576 \mathrm{E}-18 & 2.670 \mathrm{E}-14 & 7.448 \mathrm{E}-01\end{array}$ $\begin{array}{llllllll}3.205 E-28 & 9.767 E-28 & 7.823 E-26 & 3.773 E-25 & 2.238 E-21 & 7.964 E-17 & 2.142 E-02\end{array}$ $\begin{array}{llllllll}2.254 \mathrm{E}-22 & 2.295 \mathrm{E}-22 & 5.465 \mathrm{E}-22 & 1.325 \mathrm{E}-21 & 1.578 \mathrm{E}-18 & 2.679 \mathrm{E}-14 & 7.663 \mathrm{E}-01\end{array}$

$\begin{array}{lllllll}0.000 \mathrm{E}+00 & 0.000 \mathrm{E}+00 & 1.275 \mathrm{E}-28 & 1.038 \mathrm{E}-27 & 1.043 \mathrm{E}-23 & 2.650 \mathrm{E}-19 & 2.557 \mathrm{E}-05\end{array}$ $\begin{array}{llllllll}4.929 \mathrm{E}-21 & 5.012 \mathrm{E}-21 & 1.142 \mathrm{E}-20 & 2.647 \mathrm{E}-20 & 2.203 \mathrm{E}-17 & 2.282 \mathrm{E}-13 & 2.112 \mathrm{E}+00\end{array}$ $\begin{array}{lllllll}3.559 \mathrm{E}-26 & 1.084 \mathrm{E}-25 & 8.307 \mathrm{E}-24 & 3.831 \mathrm{E}-23 & 1.586 \mathrm{E}-19 & 3.443 \mathrm{E}-15 & 2.960 \mathrm{E}-01\end{array}$ $0.000 \mathrm{E}+00 \quad 0.000 \mathrm{E}+00 \quad 5.947 \mathrm{E}-28 \quad 5.457 \mathrm{E}-27 \quad 1.125 \mathrm{E}-22 \quad 5.127 \mathrm{E}-18 \quad 4.196 \mathrm{E}-03$ $\begin{array}{llllllll}4.929 \mathrm{E}-21 & 5.012 \mathrm{E}-21 & 1.143 \mathrm{E}-20 & 2.651 \mathrm{E}-20 & 2.219 \mathrm{E}-17 & 2.317 \mathrm{E}-13 & 2.412 \mathrm{E}+00\end{array}$

$6.392 \mathrm{E}-22 \quad 9.628 \mathrm{E}-21 \quad 4.197 \mathrm{E}-16 \quad 4.245 \mathrm{E}-15 \quad 4.482 \mathrm{E}-12 \quad 1.044 \mathrm{E}-09 \quad 1.505 \mathrm{E}-03$ $\begin{array}{lllllll}7.712 \mathrm{E}-10 & 2.327 \mathrm{E}-09 & 1.087 \mathrm{E}-07 & 3.024 \mathrm{E}-07 & 2.193 \mathrm{E}-05 & 1.840 \mathrm{E}-03 & 1.586 \mathrm{E}+02\end{array}$ $\begin{array}{lllllllll}3.705 \mathrm{E}-15 & 2.608 \mathrm{E}-14 & 3.968 \mathrm{E}-11 & 2.204 \mathrm{E}-10 & 8.184 \mathrm{E}-08 & 1.495 \mathrm{E}-05 & 1.748 \mathrm{E}+01\end{array}$ $\begin{array}{lllllllll}2.626 \mathrm{E}-21 & 3.963 \mathrm{E}-20 & 1.897 \mathrm{E}-15 & 2.100 \mathrm{E}-14 & 3.939 \mathrm{E}-11 & 1.538 \mathrm{E}-08 & 2.064 \mathrm{E}-01\end{array}$ $\begin{array}{lllllll}7.712 \mathrm{E}-10 & 2.327 \mathrm{E}-09 & 1.088 \mathrm{E}-07 & 3.026 \mathrm{E}-07 & 2.202 \mathrm{E}-05 & 1.855 \mathrm{E}-03 & 1.763 \mathrm{E}+02\end{array}$

$0.000 \mathrm{E}+00 \quad 5.746 \mathrm{E}-29 \quad 6.196 \mathrm{E}-23 \quad 1.048 \mathrm{E}-21 \quad 2.936 \mathrm{E}-18 \quad 1.379 \mathrm{E}-15 \quad 1.755 \mathrm{E}-04$ $\begin{array}{llllllllll}3.717 \mathrm{E}-18 & 2.596 \mathrm{E}-17 & 2.655 \mathrm{E}-14 & 1.087 \mathrm{E}-13 & 1.573 \mathrm{E}-11 & 2.528 \mathrm{E}-09 & 1.857 \mathrm{E}+01\end{array}$ $\begin{array}{lllllllll}1.341 \mathrm{E}-23 & 2.012 \mathrm{E}-22 & 7.200 \mathrm{E}-18 & 6.329 \mathrm{E}-17 & 5.505 \mathrm{E}-14 & 1.988 \mathrm{E}-11 & 2.038 \mathrm{E}+00\end{array}$ $\begin{array}{lllllllll}0.000 \mathrm{E}+00 & 2.363 \mathrm{E}-28 & 2.757 \mathrm{E}-22 & 5.058 \mathrm{E}-21 & 2.498 \mathrm{E}-17 & 1.985 \mathrm{E}-14 & 2.398 \mathrm{E}-02\end{array}$ $\begin{array}{llllllll}3.717 \mathrm{E}-18 & 2.596 \mathrm{E}-17 & 2.655 \mathrm{E}-14 & 1.087 \mathrm{E}-13 & 1.578 \mathrm{E}-11 & 2.548 \mathrm{E}-09 & 2.063 \mathrm{E}+01\end{array}$

$\begin{array}{lllllllll}8.843 \mathrm{E}-17 & 8.949 \mathrm{E}-17 & 1.607 \mathrm{E}-16 & 2.919 \mathrm{E}-16 & 3.463 \mathrm{E}-14 & 2.463 \mathrm{E}-11 & 6.795 \mathrm{E}-01\end{array}$

$\begin{array}{lllllll}4.513 E-23 & 1.369 \mathrm{E}-22 & 8.434 \mathrm{E}-21 & 3.112 \mathrm{E}-20 & 2.165 \mathrm{E}-17 & 4.048 \mathrm{E}-14 & 3.323 \mathrm{E}-05\end{array}$ $\begin{array}{lllllll}1.651 \mathrm{E}-14 & 1.672 \mathrm{E}-14 & 3.064 \mathrm{E}-14 & 5.684 \mathrm{E}-14 & 7.982 \mathrm{E}-12 & 7.159 \mathrm{E}-09 & 6.898 \mathrm{E}-01\end{array}$ $\begin{array}{lllllll}1.651 \mathrm{E}-14 & 1.672 \mathrm{E}-14 & 3.064 \mathrm{E}-14 & 5.684 \mathrm{E}-14 & 7.982 \mathrm{E}-12 & 7.159 \mathrm{E}-09 & 6.899 \mathrm{E}-01\end{array}$ 
RESRAD, Version 6.5

Summary : C746U Worker Deterministic Run

File : $X: \backslash F I N A L$ V2 $\backslash$ DOE FWD RUNS \C746U W DOE SG FWD-FV2-10000YR.RAD

Individual Nuclide Soil Concentration

Parent Nuclide and Branch Fraction Indicated

Nuclide Parent THF(

(j)

Am-241

(i)

$\overline{\mathrm{Am}-241} \overline{1.000 \mathrm{E}+00}$

Np-237 Am-241 1.000E+00

$\mathrm{Np}-237 \quad \mathrm{~Np}-237 \quad 1.000 \mathrm{E}+00$

Np-237 $\sum S(j):$

$\mathrm{U}-233 \quad \mathrm{Am}-241 \quad 1.000 \mathrm{E}+00$

$\mathrm{U}-233 \quad \mathrm{~Np}-237 \quad 1.000 \mathrm{E}+00$

$\mathrm{U}-233 \sum \mathrm{S}(j):$

Th -229

Th-229

Th-229

Cs-137

$\mathrm{Pu}-238$

$\mathrm{Pu}-238$

$\mathrm{Pu}-238$

$\mathrm{U}-234$

$\mathrm{U}-234$

$\mathrm{U}-234$

$\mathrm{U}-234$

Th -230

Th-230

$\mathrm{Th}-230$

Th-230

Th-230

$\mathrm{Ra}-226$

$\mathrm{Ra}-226$

$\mathrm{Ra}-226$

$\mathrm{Ra}-226$

$\mathrm{Ra}-226$

$\mathrm{Pb}-210$

$\mathrm{Pb}-210$

$\mathrm{Pb}-210$

$\mathrm{Pb}-210$

$\mathrm{Pb}-210$

$\mathrm{Pu}-239$
Am-241 1.000E+00

$\mathrm{Np}-237 \quad 1.000 \mathrm{E}+00$

$\sum S(j):$

Cs-137 1.000E+00

Pu-238 1.840E-09

$\sum S(j):$

$\mathrm{Pu}-238 \quad 1.000 \mathrm{E}+00$

$\mathrm{U}-234 \quad 1.000 \mathrm{E}+00$

U-238 $9.999 \mathrm{E}-01$

$\sum S(j):$

$\mathrm{Pu}-238 \quad 1.000 \mathrm{E}+00$

Th-230 1.000E+00

U-238 $9.999 \mathrm{E}-01$

$\sum S(j):$

Pu-238 1.000E+00

Th-230 1.000E+00

$\mathrm{U}-234 \quad 1.000 \mathrm{E}+00$

$\mathrm{U}-238 \quad 9.999 \mathrm{E}-01$

$\sum S(j):$

$\mathrm{Pu}-238 \quad 1.000 \mathrm{E}+00$

$\mathrm{U}-234 \quad 1.000 \mathrm{E}+00$

U-238 9.999E-01

$\sum S(j):$

$\mathrm{Pu}-239 \quad 1.000 \mathrm{E}+00$

$\mathrm{Pu}-239 \quad 1.000 \mathrm{E}+00$

$\mathrm{U}-2351.000 \mathrm{E}+00$

$\sum S(j):$
Pu-238 1.000E+00

$\mathrm{U}-234 \quad 1.000 \mathrm{E}+00$

Th-230 1.000E+00
$\mathrm{S}(j, \mathrm{t}), \mathrm{pCi} / \mathrm{g}$

$t=0.000 \mathrm{E}+00 \quad 1.000 \mathrm{E}+00 \quad 5.000 \mathrm{E}+01 \quad 1.000 \mathrm{E}+02 \quad 5.000 \mathrm{E}+02 \quad 1.050 \mathrm{E}+03 \quad 1.000 \mathrm{E}+04$

$\begin{array}{lllllllll}3.500 \mathrm{E}+01 & 3.494 \mathrm{E}+01 & 3.230 \mathrm{E}+01 & 2.981 \mathrm{E}+01 & 1.567 \mathrm{E}+01 & 6.478 \mathrm{E}+00 & 3.685 \mathrm{E}-06\end{array}$

$0.000 \mathrm{E}+00 \quad 1.133 \mathrm{E}-05 \quad 5.436 \mathrm{E}-04 \quad 1.043 \mathrm{E}-03 \quad 3.810 \mathrm{E}-03 \quad 5.458 \mathrm{E}-03 \quad 3.376 \mathrm{E}-03$

$\begin{array}{lllllll}5.500 \mathrm{E}+00 & 5.500 \mathrm{E}+00 & 5.478 \mathrm{E}+00 & 5.457 \mathrm{E}+00 & 5.288 \mathrm{E}+00 & 5.064 \mathrm{E}+00 & 2.502 \mathrm{E}+00\end{array}$

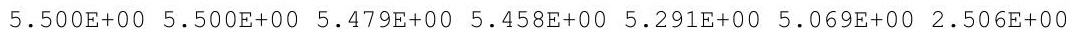

$\begin{array}{lllllll}0.000 \mathrm{E}+00 & 2.477 \mathrm{E}-11 & 6.025 \mathrm{E}-08 & 2.344 \mathrm{E}-07 & 4.742 \mathrm{E}-06 & 1.613 \mathrm{E}-05 & 1.863 \mathrm{E}-04\end{array}$

$\begin{array}{lllllll}0.000 \mathrm{E}+00 & 2.405 \mathrm{E}-05 & 1.200 \mathrm{E}-03 & 2.394 \mathrm{E}-03 & 1.174 \mathrm{E}-02 & 2.401 \mathrm{E}-02 & 1.508 \mathrm{E}-01\end{array}$

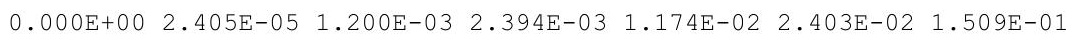

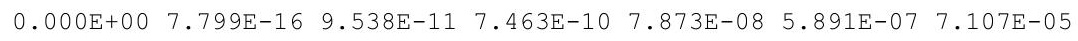

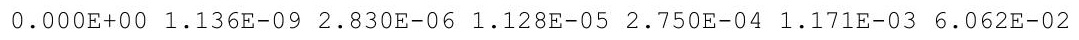

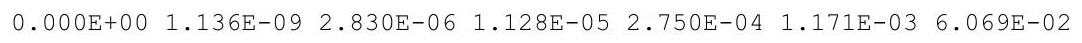

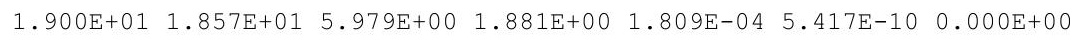

$\begin{array}{lllllll}7.176 \mathrm{E}-08 & 7.119 \mathrm{E}-08 & 4.832 \mathrm{E}-08 & 3.254 \mathrm{E}-08 & 1.375 \mathrm{E}-09 & 1.774 \mathrm{E}-11 & 3.170 \mathrm{E}-42\end{array}$

$\begin{array}{llllllll}3.900 \mathrm{E}+01 & 3.869 \mathrm{E}+01 & 2.626 \mathrm{E}+01 & 1.768 \mathrm{E}+01 & 7.472 \mathrm{E}-01 & 9.639 \mathrm{E}-03 & 1.731 \mathrm{E}-33\end{array}$

$\begin{array}{lllllllll}3.900 \mathrm{E}+01 & 3.869 \mathrm{E}+01 & 2.626 \mathrm{E}+01 & 1.768 \mathrm{E}+01 & 7.472 \mathrm{E}-01 & 9.639 \mathrm{E}-03 & 1.731 \mathrm{E}-33\end{array}$

$0.000 \mathrm{E}+00 \quad 1.101 \mathrm{E}-04 \quad 4.564 \mathrm{E}-03 \quad 7.633 \mathrm{E}-03 \quad 1.362 \mathrm{E}-02 \quad 1.377 \mathrm{E}-02 \quad 1.191 \mathrm{E}-02$

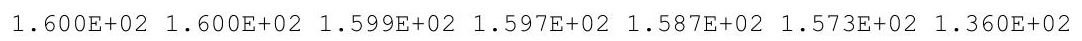

$\begin{array}{llllllll}0.000 \mathrm{E}+00 & 4.536 \mathrm{E}-04 & 2.266 \mathrm{E}-02 & 4.529 \mathrm{E}-02 & 2.251 \mathrm{E}-01 & 4.689 \mathrm{E}-01 & 3.911 \mathrm{E}+00\end{array}$

$\begin{array}{lllllll}1.600 \mathrm{E}+02 & 1.600 \mathrm{E}+02 & 1.599 \mathrm{E}+02 & 1.598 \mathrm{E}+02 & 1.589 \mathrm{E}+02 & 1.578 \mathrm{E}+02 & 1.399 \mathrm{E}+02\end{array}$

$0.000 \mathrm{E}+00 \quad 4.963 \mathrm{E}-10 \quad 1.095 \mathrm{E}-06 \quad 3.884 \mathrm{E}-06 \quad 4.705 \mathrm{E}-05 \quad 1.147 \mathrm{E}-04 \quad 1.088 \mathrm{E}-03$ $\begin{array}{llllllllll}1.000 \mathrm{E}+02 & 1.000 \mathrm{E}+02 & 9.995 \mathrm{E}+01 & 9.989 \mathrm{E}+01 & 9.947 \mathrm{E}+01 & 9.888 \mathrm{E}+01 & 8.984 \mathrm{E}+01\end{array}$ $\begin{array}{lllllll}0.000 \mathrm{E}+00 & 1.440 \mathrm{E}-03 & 7.197 \mathrm{E}-02 & 1.438 \mathrm{E}-01 & 7.153 \mathrm{E}-01 & 1.491 \mathrm{E}+00 & 1.259 \mathrm{E}+01\end{array}$ $\begin{array}{lllllll}0.000 \mathrm{E}+00 & 2.041 \mathrm{E}-09 & 5.100 \mathrm{E}-06 & 2.039 \mathrm{E}-05 & 5.070 \mathrm{E}-04 & 2.219 \mathrm{E}-03 & 1.785 \mathrm{E}-01\end{array}$

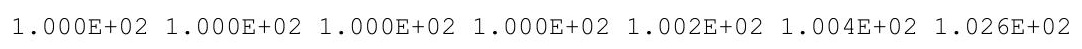

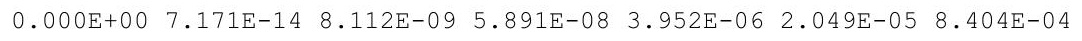
$\begin{array}{llllllll}0.000 \mathrm{E}+00 & 4.331 \mathrm{E}-02 & 2.142 \mathrm{E}+00 & 4.235 \mathrm{E}+00 & 1.937 \mathrm{E}+01 & 3.613 \mathrm{E}+01 & 8.860 \mathrm{E}+01\end{array}$ $\begin{array}{llllllll}0.000 \mathrm{E}+00 & 3.119 \mathrm{E}-07 & 7.739 \mathrm{E}-04 & 3.071 \mathrm{E}-03 & 7.220 \mathrm{E}-02 & 2.933 \mathrm{E}-01 & 9.761 \mathrm{E}+00\end{array}$ $\begin{array}{llllllll}0.000 \mathrm{E}+00 & 2.948 \mathrm{E}-13 & 3.663 \mathrm{E}-08 & 2.913 \mathrm{E}-07 & 3.471 \mathrm{E}-05 & 3.016 \mathrm{E}-04 & 1.152 \mathrm{E}-01\end{array}$ $\begin{array}{llllllll}0.000 \mathrm{E}+00 & 4.331 \mathrm{E}-02 & 2.142 \mathrm{E}+00 & 4.238 \mathrm{E}+00 & 1.944 \mathrm{E}+01 & 3.643 \mathrm{E}+01 & 9.848 \mathrm{E}+01\end{array}$

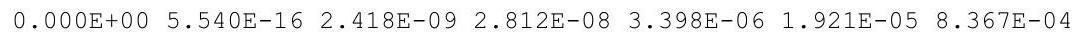
$\begin{array}{llllllll}0.000 \mathrm{E}+00 & 6.663 \mathrm{E}-04 & 1.058 \mathrm{E}+00 & 2.946 \mathrm{E}+00 & 1.823 \mathrm{E}+01 & 3.524 \mathrm{E}+01 & 8.856 \mathrm{E}+01\end{array}$ $\begin{array}{lllllll}0.000 \mathrm{E}+00 & 3.207 \mathrm{E}-09 & 2.837 \mathrm{E}-04 & 1.706 \mathrm{E}-03 & 6.374 \mathrm{E}-02 & 2.769 \mathrm{E}-01 & 9.719 \mathrm{E}+00\end{array}$ $\begin{array}{lllllll}0.000 \mathrm{E}+00 & 2.276 \mathrm{E}-15 & 1.075 \mathrm{E}-08 & 1.356 \mathrm{E}-07 & 2.889 \mathrm{E}-05 & 2.763 \mathrm{E}-04 & 1.143 \mathrm{E}-01\end{array}$ $\begin{array}{llllllll}0.000 \mathrm{E}+00 & 6.663 \mathrm{E}-04 & 1.058 \mathrm{E}+00 & 2.947 \mathrm{E}+00 & 1.830 \mathrm{E}+01 & 3.551 \mathrm{E}+01 & 9.839 \mathrm{E}+01\end{array}$

$\begin{array}{llllllll}3.600 \mathrm{E}+01 & 3.600 \mathrm{E}+01 & 3.593 \mathrm{E}+01 & 3.586 \mathrm{E}+01 & 3.531 \mathrm{E}+01 & 3.456 \mathrm{E}+01 & 2.443 \mathrm{E}+01\end{array}$

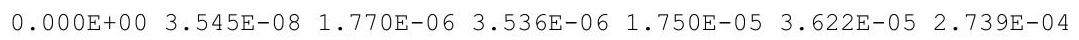

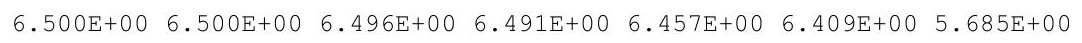

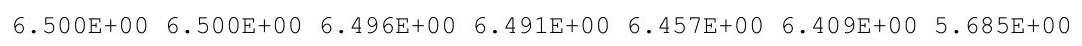




\section{Outdoor Worker}

\section{Summary Report \\ (Deterministic Analysis Report)}

Third Peak Dose Assessment

Time Horizon: 100,000 yr 
THIS PAGE INTENTIONALLY LEFT BLANK 
RESRAD, Version 6.5

Summary : C746U Worker Deterministic Run

File : $\mathrm{X}: \backslash F I N A L$ V2 $\backslash$ DOE FWD RUNS \C746U W DOE SG FWD-FV2-100000YR.RAD

Table of Contents

Part I: Mixture Sums and Single Radionuclide Guidelines

Dose Conversion Factor (and Related) Parameter Summary ... 2

Site-Specific Parameter Summary $\ldots \ldots \ldots \ldots \ldots \ldots \ldots \ldots \ldots$

Summary of Pathway Selections .................... 18

Contaminated Zone and Total Dose Summary ............. 19

Total Dose Components

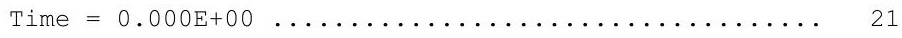

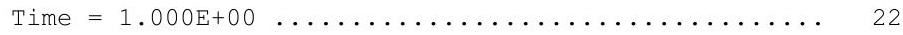

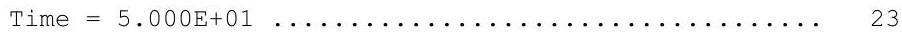

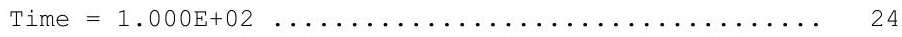

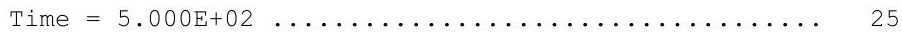

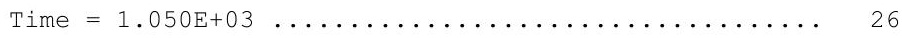

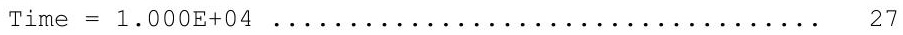

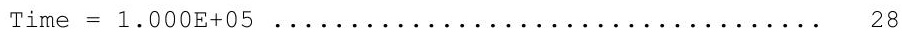

Dose/Source Ratios Summed Over All Pathways ............ 29

Single Radionuclide Soil Guidelines ............... 31

Dose Per Nuclide Summed Over All Pathways ............ 32

Soil Concentration Per Nuclide .................. 34 
RESRAD, Version $6.5 \quad T^{1 / 2}$ Limit $=180$ days

Summary : C746U Worker Deterministic Run

File : $\mathrm{X}: \backslash F I N A L$ V2 $\backslash$ DOE FWD RUNS $\backslash C 746 \mathrm{U}$ W DOE SG FWD-FV2-100000YR.RAD

Dose Conversion Factor (and Related) Parameter Summary

Dose Library: ICRP 60 \& ICRP 72 (Adult)

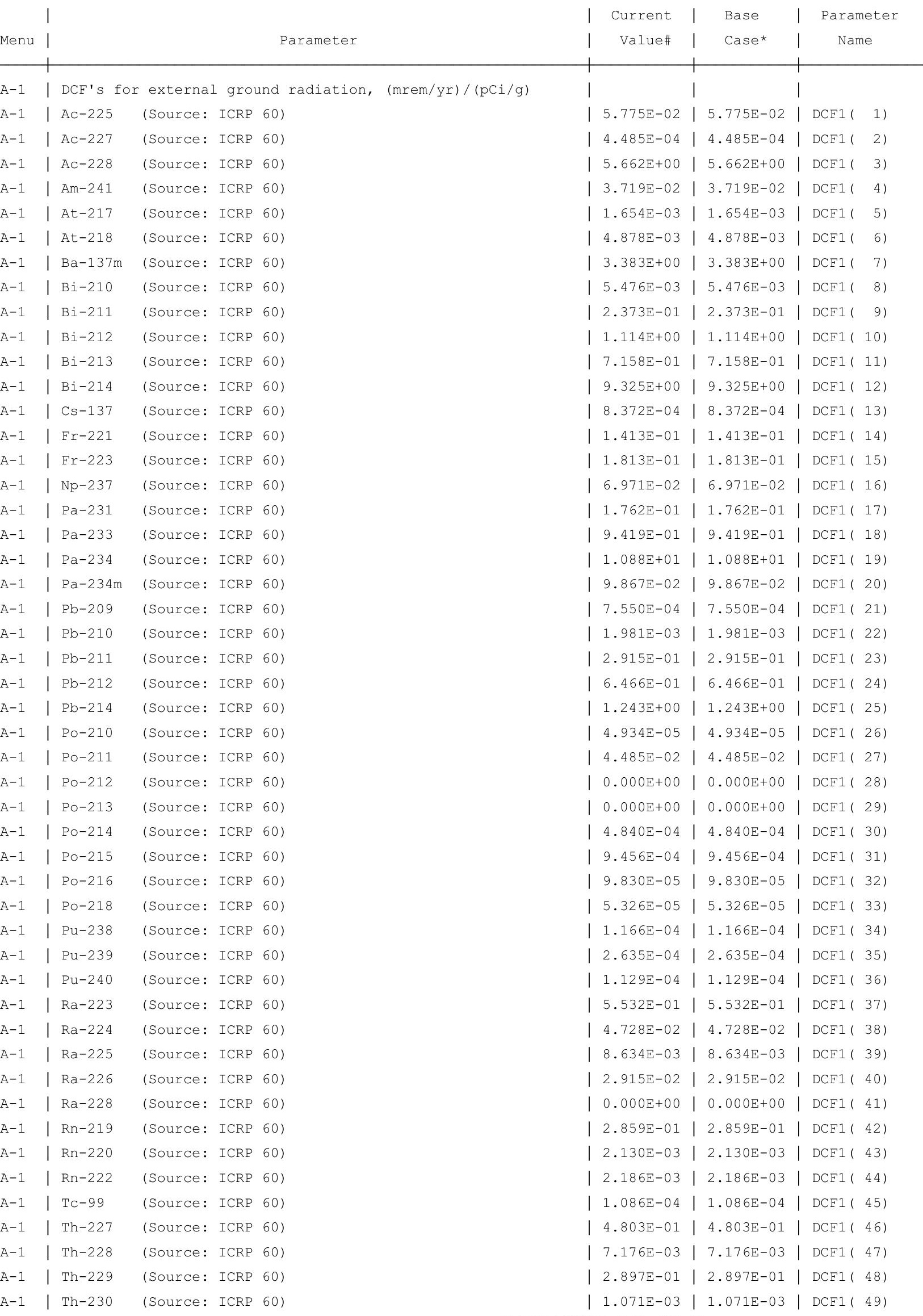


RESRAD, Version $6.5 \quad T^{1 / 2}$ Limit $=180$ days

Summary : C746U Worker Deterministic Run

File : $X: \backslash F I N A L$ V2\DOE FWD RUNS \C746U W DOE SG FWD-FV2-100000YR.RAD

Dose Conversion Factor (and Related) Parameter Summary (continued)

Dose Library: ICRP 60 \& ICRP 72 (Adult)

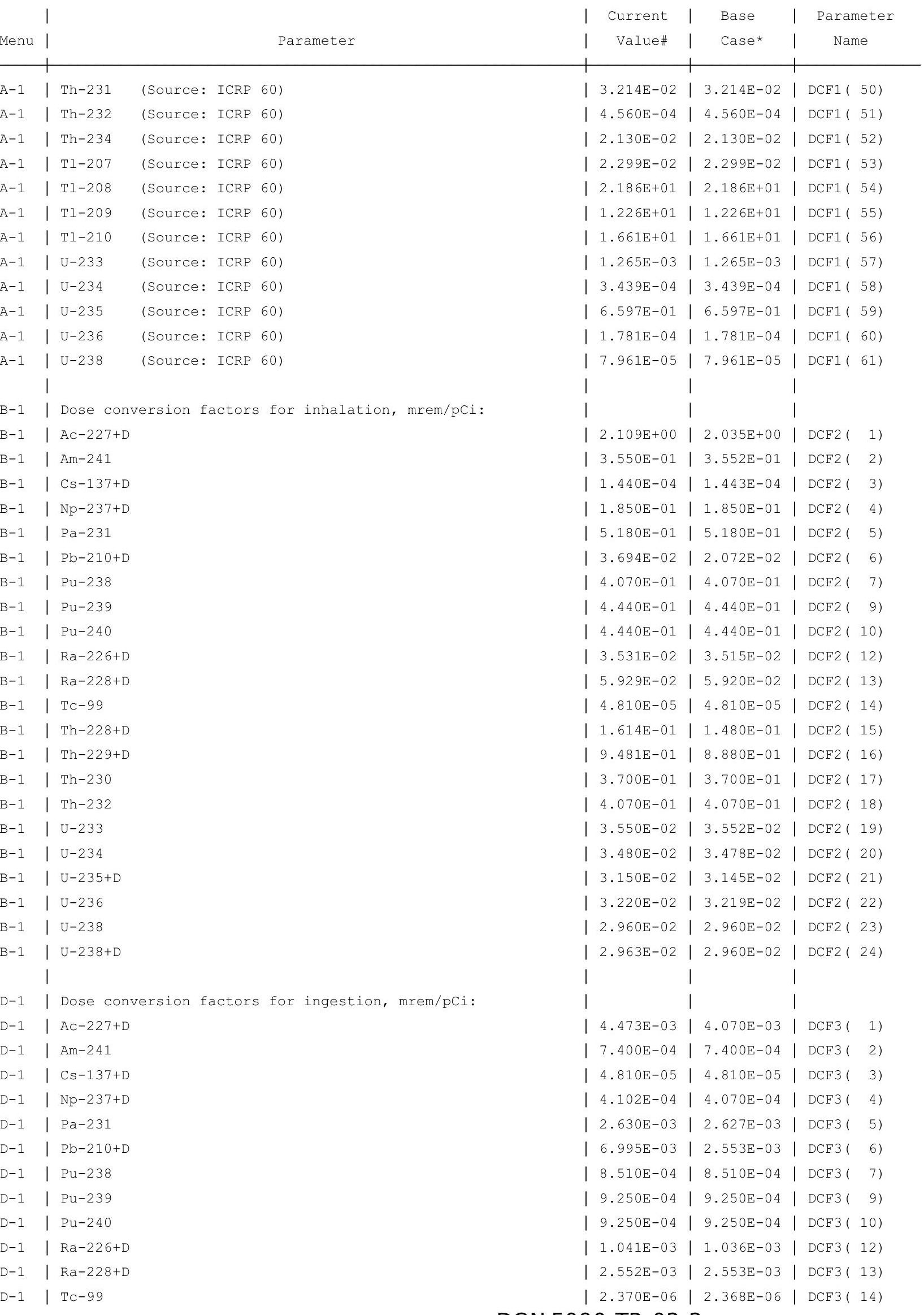


RESRAD, Version $6.5 \quad T^{1 / 2}$ Limit $=180$ days

Summary : C746U Worker Deterministic Run

File : $X: \backslash F I N A L$ V2 \DOE FWD RUNS \C746U W DOE SG FWD-FV2-100000YR.RAD

Dose Conversion Factor (and Related) Parameter Summary (continued)

Dose Library: ICRP 60 \& ICRP 72 (Adult)

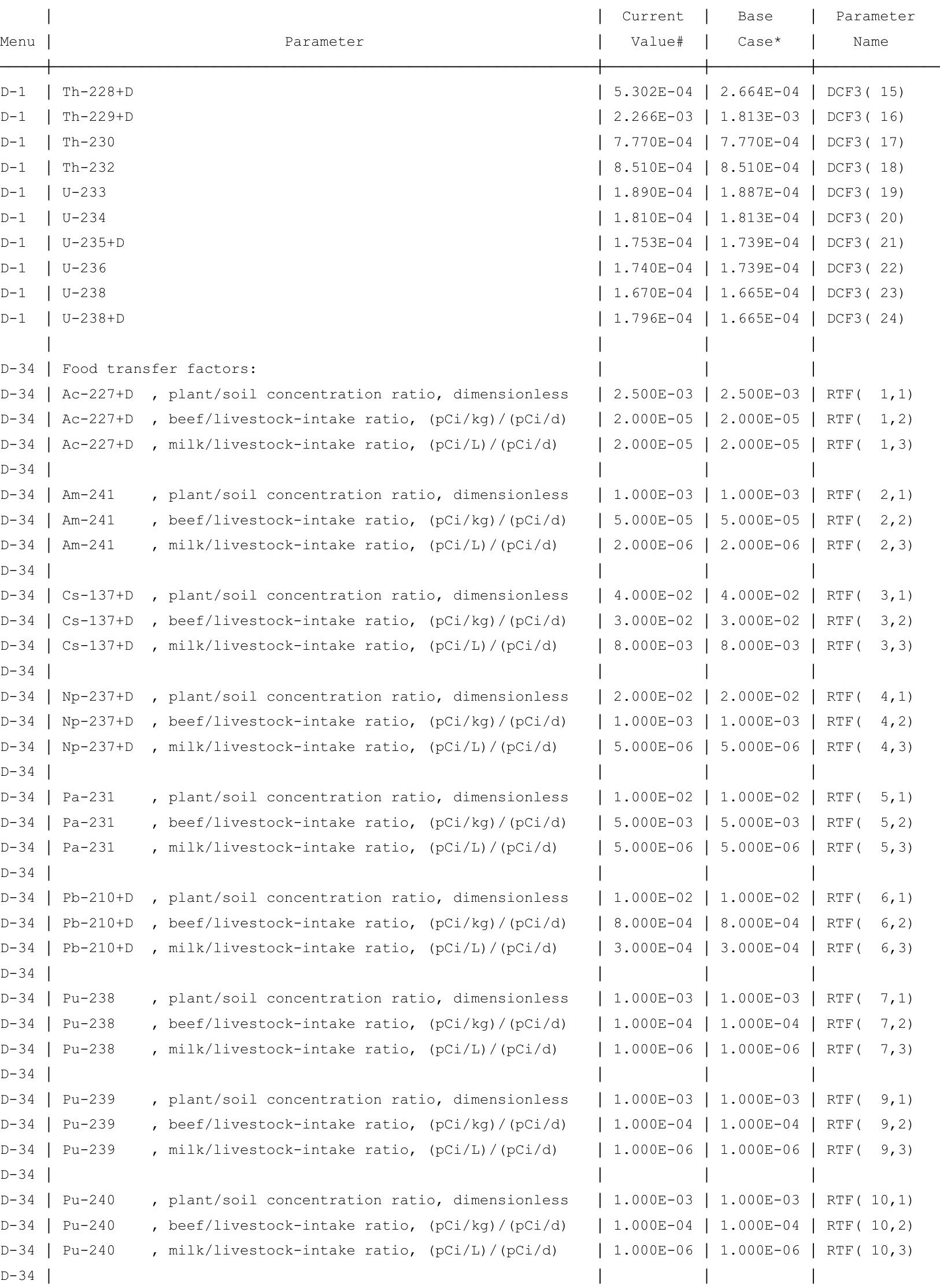


RESRAD, Version $6.5 \quad \mathrm{~T}^{1 / 2}$ Limit $=180$ days

Summary : C746U Worker Deterministic Run

File : $\mathrm{X}: \backslash F I N A L$ V2 \DOE FWD RUNS \C746U W DOE SG FWD-FV2-100000YR.RAD

Dose Conversion Factor (and Related) Parameter Summary (continued)

Dose Library: ICRP 60 \& ICRP 72 (Adult)

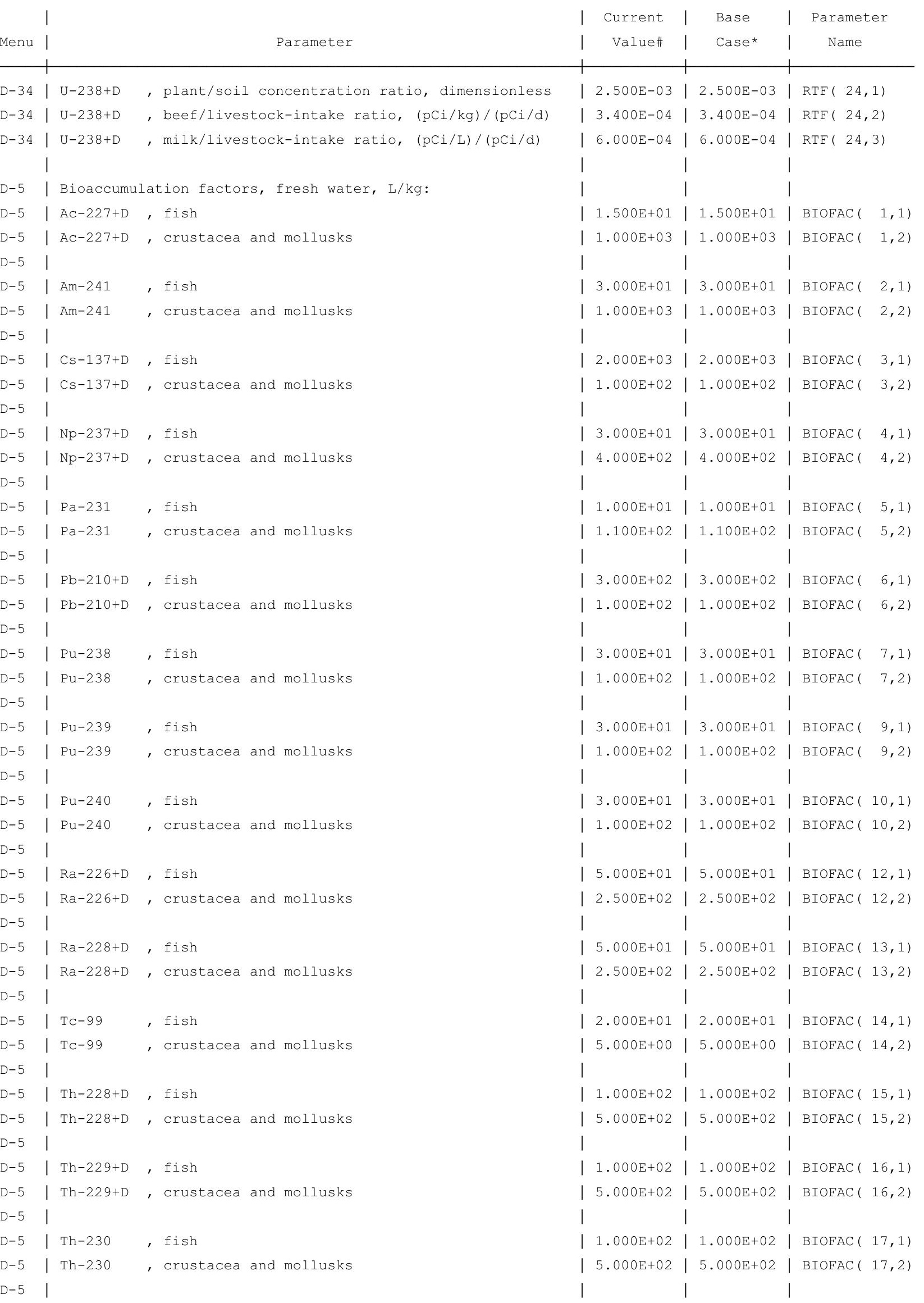


RESRAD, Version $6.5 \quad \mathrm{~T}^{1 / 2}$ Limit $=180$ days

Summary : C746U Worker Deterministic Run

File : $X: \backslash F I N A L$ V2\DOE FWD RUNS \C746U W DOE SG FWD-FV2-100000YR.RAD

Site-Specific Parameter Summary (continued)

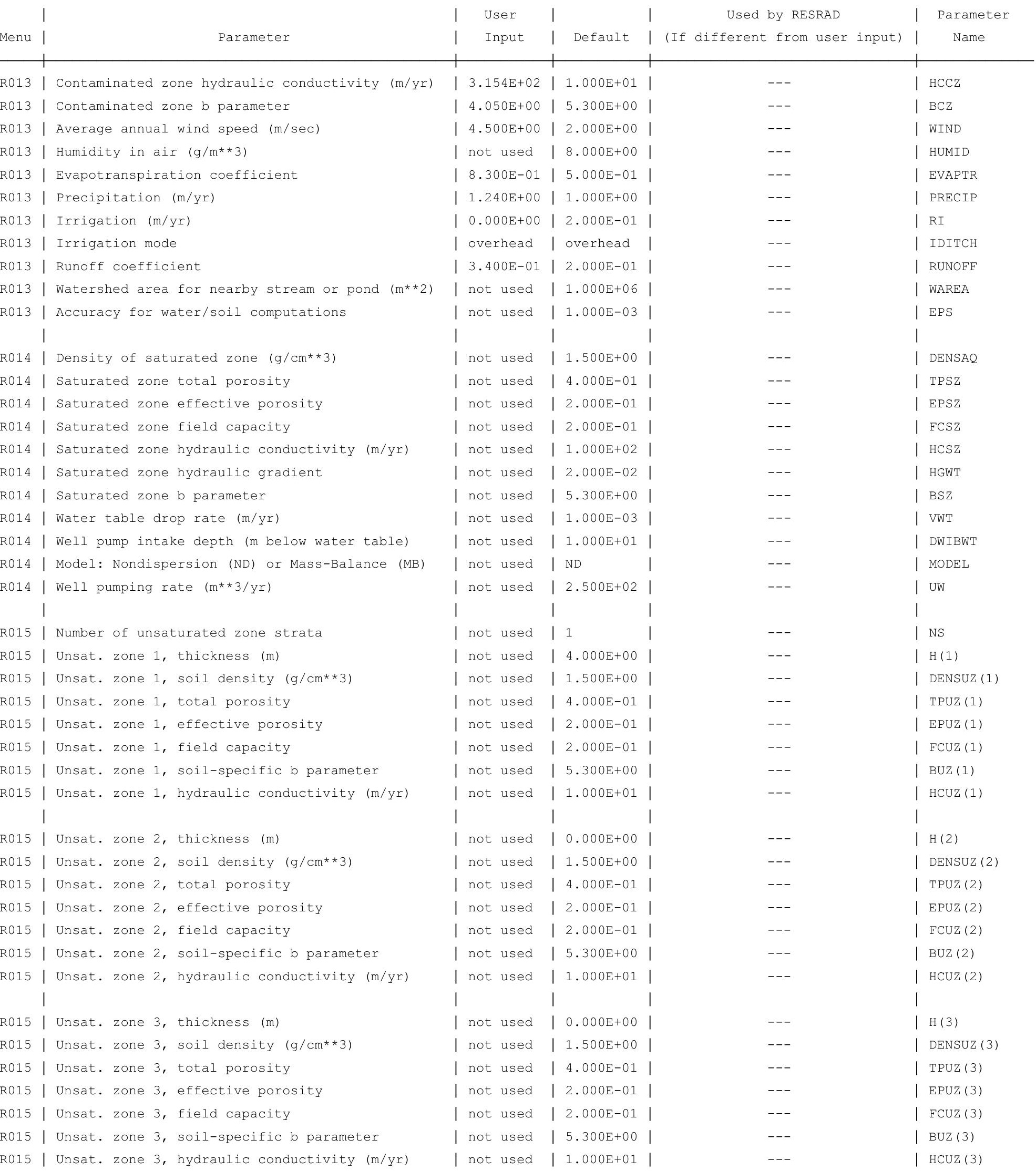


RESRAD, Version $6.5 \quad \mathrm{~T}^{1 / 2}$ Limit $=180$ days

Summary : C746U Worker Deterministic Run

File : $X: \backslash F I N A L$ V2\DOE FWD RUNS \C746U W DOE SG FWD-FV2-100000YR.RAD

Site-Specific Parameter Summary (continued)

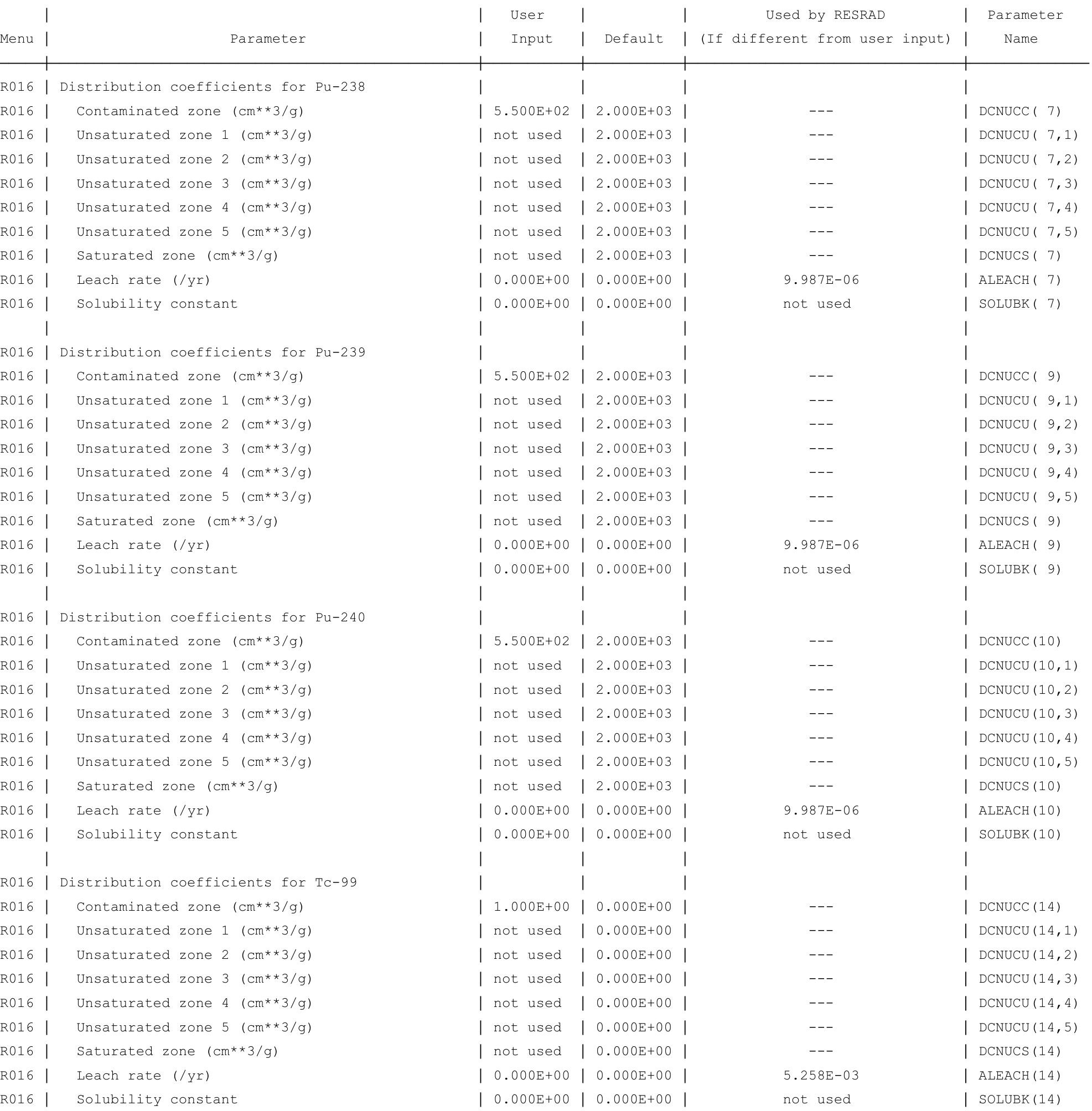


RESRAD, Version $6.5 \quad \mathrm{~T}^{1 / 2}$ Limit $=180$ days

Summary : C746U Worker Deterministic Run

File : $X: \backslash F I N A L$ V2\DOE FWD RUNS \C746U W DOE SG FWD-FV2-100000YR.RAD

Site-Specific Parameter Summary (continued)

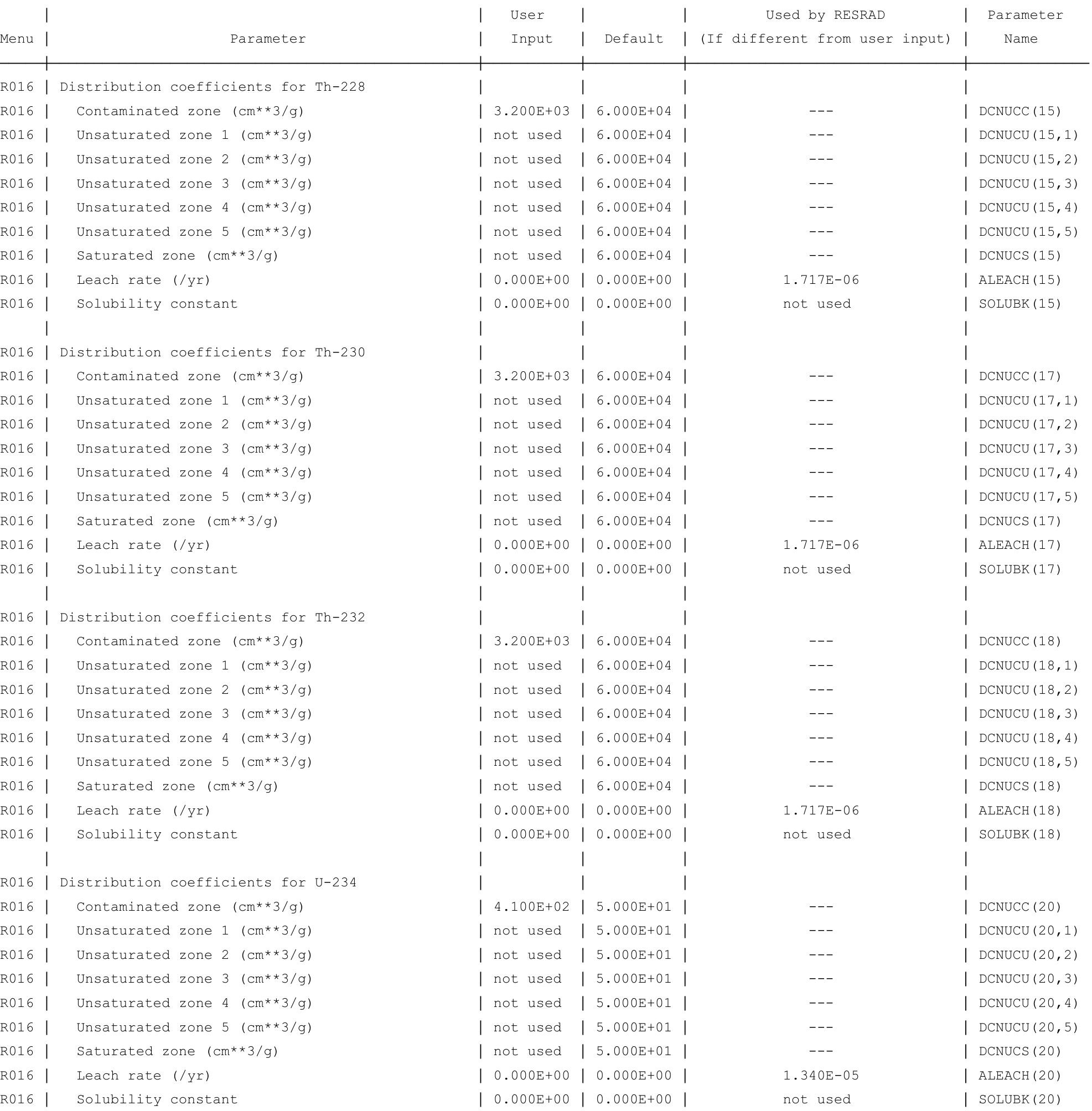


RESRAD, Version $6.5 \quad \mathrm{~T}^{1 / 2}$ Limit $=180$ days

Summary : C746U Worker Deterministic Run

File : $X: \backslash F I N A L$ V2\DOE FWD RUNS \C746U W DOE SG FWD-FV2-100000YR.RAD

Site-Specific Parameter Summary (continued)

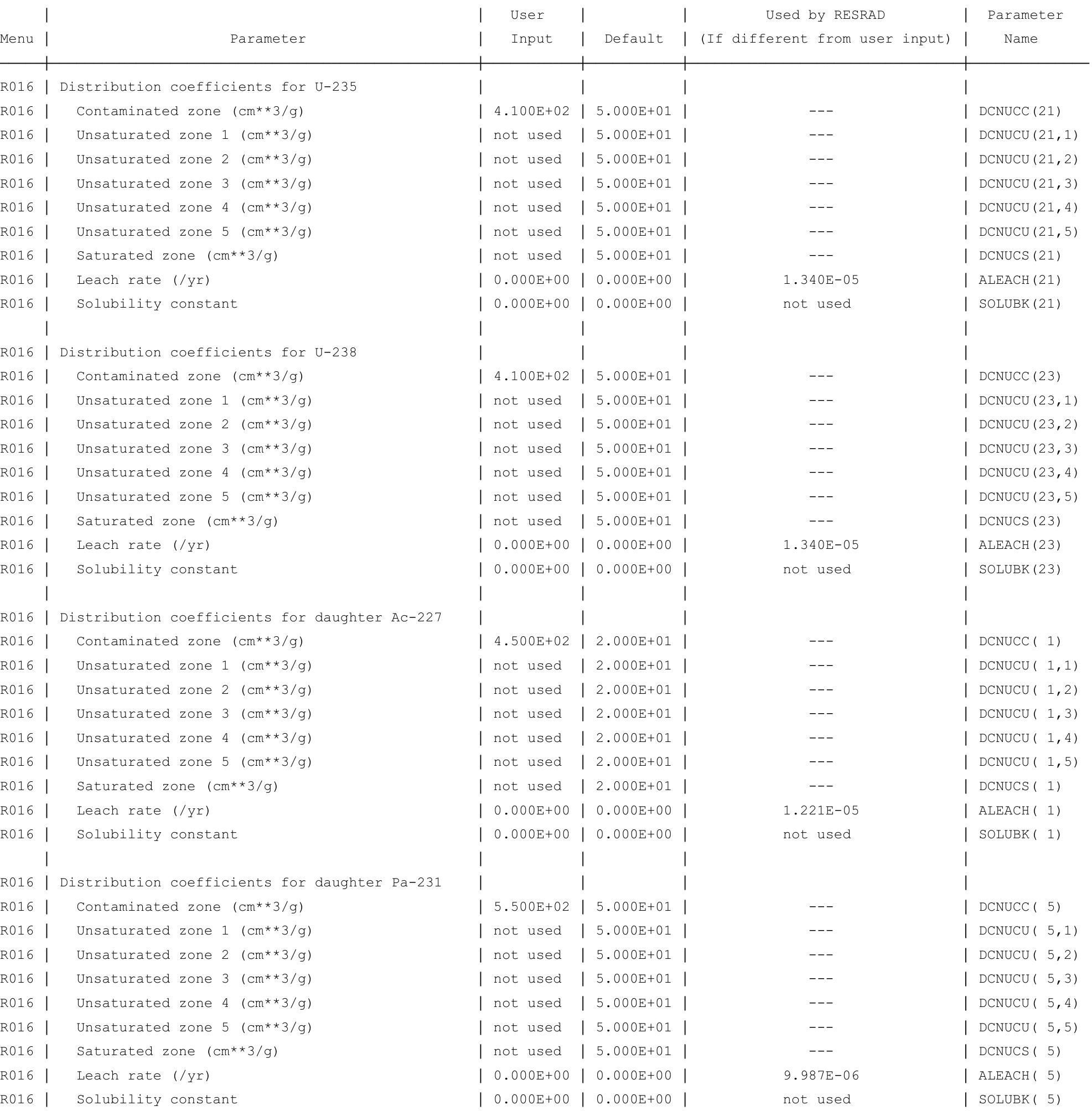


RESRAD, Version $6.5 \quad \mathrm{~T}^{1 / 2}$ Limit $=180$ days

Summary : C746U Worker Deterministic Run

File : $X: \backslash F I N A L$ V2\DOE FWD RUNS \C746U W DOE SG FWD-FV2-100000YR.RAD

Site-Specific Parameter Summary (continued)

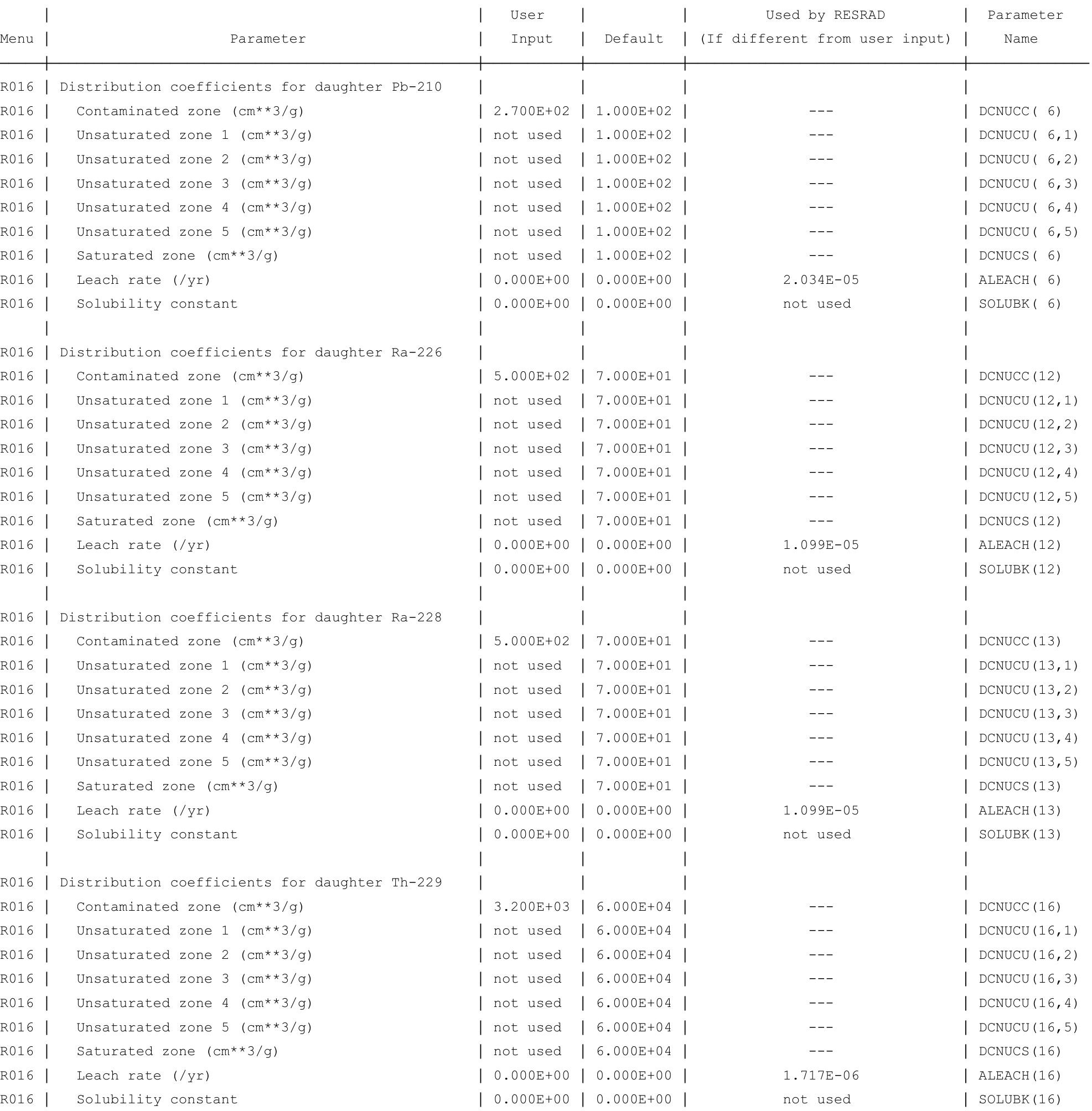


RESRAD, Version $6.5 \quad \mathrm{~T}^{1 / 2}$ Limit $=180$ days

Summary : C746U Worker Deterministic Run

File : $X: \backslash F I N A L$ V2 \DOE FWD RUNS \C746U W DOE SG FWD-FV2-100000YR.RAD

Site-Specific Parameter Summary (continued)

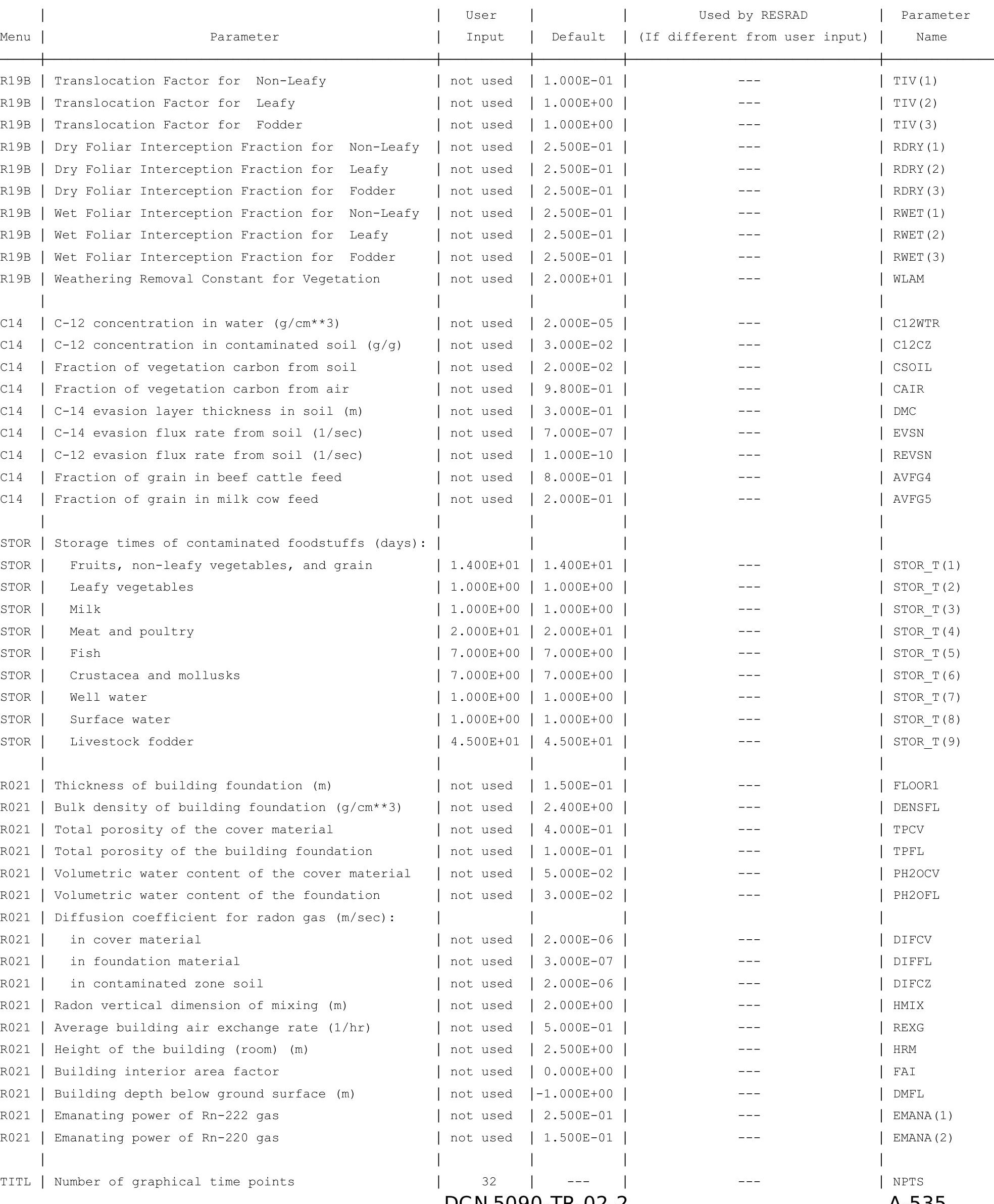


RESRAD, Version $6.5 \quad \mathrm{~T}^{1 / 2}$ Limit $=180$ days

Summary : C746U Worker Deterministic Run

File : $\mathrm{X}: \backslash F I N A L$ V2 $\backslash$ DOE FWD RUNS $\backslash C 746 \mathrm{U}$ W DOE SG FWD-FV2-100000YR.RAD

Contaminated Zone Dimensions

Area: 89436.00 square meters

Thickness:

Cover Depth:

$$
\begin{array}{r}
13.40 \text { meters } \\
1.52 \text { meters }
\end{array}
$$

Initial Soil Concentrations, pCi/g

$\begin{array}{ll}\mathrm{Am}-241 & 3.500 \mathrm{E}+01 \\ \mathrm{Cs}-137 & 1.900 \mathrm{E}+01 \\ \mathrm{~Np}-237 & 5.500 \mathrm{E}+00 \\ \mathrm{Pu}-238 & 3.900 \mathrm{E}+01 \\ \mathrm{Pu}-239 & 3.600 \mathrm{E}+01 \\ \mathrm{Pu}-240 & 3.600 \mathrm{E}+01 \\ \mathrm{TC}-99 & 5.200 \mathrm{E}+01 \\ \mathrm{Th}-228 & 4.000 \mathrm{E}+00 \\ \mathrm{Th}-230 & 1.000 \mathrm{E}+02 \\ \mathrm{Th}-232 & 4.000 \mathrm{E}+00 \\ \mathrm{U}-234 & 1.600 \mathrm{E}+02 \\ \mathrm{U}-235 & 6.500 \mathrm{E}+00 \\ \mathrm{U}-238 & 1.600 \mathrm{E}+02\end{array}$

Total Dose TDOSE(t), mrem/yr

Basic Radiation Dose Limit $=1.000 \mathrm{E}+00 \mathrm{mrem} / \mathrm{yr}$

Total Mixture Sum $M(t)$ = Fraction of Basic Dose Limit Received at Time (t)

$\begin{array}{rlllllllll}t \text { (years) : } & 0.000 \mathrm{E}+00 & 1.000 \mathrm{E}+00 & 5.000 \mathrm{E}+01 & 1.000 \mathrm{E}+02 & 5.000 \mathrm{E}+02 & 1.050 \mathrm{E}+03 & 1.000 \mathrm{E}+04 & 1.000 \mathrm{E}+05 \\ \mathrm{TDOSE}(\mathrm{t}): & 1.150 \mathrm{E}-06 & 8.594 \mathrm{E}-07 & 1.950 \mathrm{E}-06 & 2.793 \mathrm{E}-06 & 4.957 \mathrm{E}-05 & 2.632 \mathrm{E}-03 & 2.178 \mathrm{E}+02 & 0.000 \mathrm{E}+00 \\ \mathrm{M}(\mathrm{t}): & 1.150 \mathrm{E}-06 & 8.594 \mathrm{E}-07 & 1.950 \mathrm{E}-06 & 2.793 \mathrm{E}-06 & 4.957 \mathrm{E}-05 & 2.632 \mathrm{E}-03 & 2.178 \mathrm{E}+02 & 0.000 \mathrm{E}+00\end{array}$

Maximum TDOSE $(t): 2.211 \mathrm{E}+02 \mathrm{mrem} / \mathrm{yr}$ at $t=19045 \pm$ * years

Total Dose Contributions TDOSE (i,p,t) for Individual Radionuclides (i) and Pathways (p) As mrem/yr and Fraction of Total Dose At $t=1.904 \mathrm{E}+04$ years

\begin{tabular}{|c|c|c|c|c|c|c|c|c|c|c|c|c|c|c|}
\hline & \multicolumn{2}{|c|}{ Ground } & \multicolumn{2}{|c|}{ Inhalation } & \multicolumn{2}{|c|}{ Radon } & \multicolumn{2}{|c|}{ Plant } & \multicolumn{2}{|c|}{ Meat } & \multicolumn{2}{|c|}{ Milk } & \multicolumn{2}{|c|}{ Soil } \\
\hline clide & mrem/yr & fract. & mrem/yr & fract. & mrem/yr & fract. & mrem/yr & fract. & mrem/yr & fract. & mrem/yr & fract. & mrem/yr & fract. \\
\hline 241 & $3.197 E-04$ & 0.0000 & $2.370 \mathrm{E}-07$ & 0.0000 & $0.000 \mathrm{E}+00$ & 0.0000 & $0.000 \mathrm{E}+00$ & 0.0000 & $0.000 \mathrm{E}+00$ & 0.0000 & $0.000 \mathrm{E}+00$ & 0.0000 & $3.235 E-05$ & 0.0000 \\
\hline-137 & $0.000 \mathrm{E}+00$ & 0.0000 & $0.000 \mathrm{E}+00$ & 0.0000 & $0.000 \mathrm{E}+00$ & 0.0000 & $0.000 \mathrm{E}+00$ & 0.0000 & $0.000 \mathrm{E}+00$ & 0.0000 & $0.000 \mathrm{E}+00$ & 0.0000 & $0.000 \mathrm{E}+00$ & 0.0000 \\
\hline-237 & $2.395 E-01$ & 0.0011 & $1.807 \mathrm{E}-04$ & 0.0000 & $0.000 \mathrm{E}+00$ & 0.0000 & $0.000 \mathrm{E}+00$ & 0.0000 & $0.000 \mathrm{E}+00$ & 0.0000 & $0.000 \mathrm{E}+00$ & 0.0000 & $2.471 E-02$ & 0.0001 \\
\hline-238 & $2.868 E-03$ & 0.0000 & $5.892 \mathrm{E}-07$ & 0.0000 & $0.000 \mathrm{E}+00$ & 0.0000 & $0.000 \mathrm{E}+00$ & 0.0000 & $0.000 \mathrm{E}+00$ & 0.0000 & $0.000 \mathrm{E}+00$ & 0.0000 & $4.871 \mathrm{E}-04$ & 0.0000 \\
\hline-239 & $8.361 E-04$ & 0.0000 & $3.885 \mathrm{E}-03$ & 0.0000 & $0.000 \mathrm{E}+00$ & 0.0000 & $0.000 \mathrm{E}+00$ & 0.0000 & $0.000 \mathrm{E}+00$ & 0.0000 & $0.000 \mathrm{E}+00$ & 0.0000 & $4.738 E-01$ & 0.0021 \\
\hline-240 & $7.582 \mathrm{E}-05$ & 0.0000 & $8.924 E-04$ & 0.0000 & $0.000 \mathrm{E}+00$ & 0.0000 & $0.000 \mathrm{E}+00$ & 0.0000 & $0.000 \mathrm{E}+00$ & 0.0000 & $0.000 \mathrm{E}+00$ & 0.0000 & $1.089 \mathrm{E}-01$ & 0.0005 \\
\hline 99 & $0.000 \mathrm{E}+00$ & 0.0000 & $0.000 \mathrm{E}+00$ & 0.0000 & $0.000 \mathrm{E}+00$ & 0.0000 & $0.000 \mathrm{E}+00$ & 0.0000 & $0.000 \mathrm{E}+00$ & 0.0000 & $0.000 \mathrm{E}+00$ & 0.0000 & $0.000 \mathrm{E}+00$ & 0.0000 \\
\hline-228 & $0.000 \mathrm{E}+00$ & 0.0000 & $0.000 \mathrm{E}+00$ & 0.0000 & $0.000 \mathrm{E}+00$ & 0.0000 & $0.000 \mathrm{E}+00$ & 0.0000 & $0.000 \mathrm{E}+00$ & 0.0000 & $0.000 \mathrm{E}+00$ & 0.0000 & $0.000 \mathrm{E}+00$ & 0.0000 \\
\hline-230 & $1.435 E+02$ & 0.6490 & $1.834 \mathrm{E}-02$ & 0.0001 & $0.000 \mathrm{E}+00$ & 0.0000 & $0.000 \mathrm{E}+00$ & 0.0000 & $0.000 \mathrm{E}+00$ & 0.0000 & $0.000 \mathrm{E}+00$ & 0.0000 & $2.138 \mathrm{E}+01$ & 0.0967 \\
\hline-232 & $9.857 \mathrm{E}+00$ & 0.0446 & $1.236 \mathrm{E}-03$ & 0.0000 & $0.000 \mathrm{E}+00$ & 0.0000 & $0.000 \mathrm{E}+00$ & 0.0000 & $0.000 \mathrm{E}+00$ & 0.0000 & $0.000 \mathrm{E}+00$ & 0.0000 & $4.534 \mathrm{E}-01$ & 0.0021 \\
\hline 34 & $3.303 E+01$ & 0.1494 & $6.764 \mathrm{E}-03$ & 0.0000 & $0.000 \mathrm{E}+00$ & 0.0000 & $0.000 \mathrm{E}+00$ & 0.0000 & $0.000 \mathrm{E}+00$ & 0.0000 & $0.000 \mathrm{E}+00$ & 0.0000 & $5.604 \mathrm{E}+00$ & 0.0253 \\
\hline 35 & $1.173 E+00$ & 0.0053 & $2.379 E-03$ & 0.0000 & $0.000 \mathrm{E}+00$ & 0.0000 & $0.000 \mathrm{E}+00$ & 0.0000 & $0.000 \mathrm{E}+00$ & 0.0000 & $0.000 \mathrm{E}+00$ & 0.0000 & $3.903 E-01$ & 0.0018 \\
\hline 38 & $4.012 \mathrm{E}+00$ & 0.0182 & $2.108 \mathrm{E}-03$ & 0.0000 & $0.000 \mathrm{E}+00$ & 0.0000 & $0.000 \mathrm{E}+00$ & 0.0000 & $0.000 \mathrm{E}+00$ & 0.0000 & $0.000 \mathrm{E}+00$ & 0.0000 & $8.196 \mathrm{E}-01$ & 0.0037 \\
\hline & $3 E+02$ & 0. & $.579 \mathrm{E}-02$ & 0.0002 & $0.000 \mathrm{E}+00$ & 0.0000 & $0.000 \mathrm{E}+00$ & 000 & $0.000 \mathrm{E}+00$ & 0.0000 & $0.000 \mathrm{E}+00$ & 00 & +01 & 0 . \\
\hline
\end{tabular}

Water Independent Pathways (Inhalation excludes radon) 
RESRAD, Version $6.5 \quad T^{1 / 2}$ Limit $=180$ days

Summary : C746U Worker Deterministic Run

File : $X: \backslash F I N A L$ V2 \DOE FWD RUNS \C746U W DOE SG FWD-FV2-100000YR.RAD

Total Dose Contributions TDOSE (i,p,t) for Individual Radionuclides (i) and Pathways (p)

As mrem/yr and Fraction of Total Dose At $t=1.904 \mathrm{E}+04$ years

Water Dependent Pathways

\begin{tabular}{|c|c|c|c|c|c|c|c|c|c|c|c|c|c|c|}
\hline & \multicolumn{2}{|c|}{ Water } & \multicolumn{2}{|c|}{ Fish } & \multicolumn{2}{|c|}{ Radon } & \multicolumn{2}{|c|}{ Plant } & \multicolumn{2}{|c|}{ Meat } & \multicolumn{2}{|c|}{ Milk } & \multicolumn{2}{|c|}{ All Pathways* } \\
\hline ide & mrem/yr & fract. & mrem/yr & fract. & mrem/yr & fract. & mrem/yr & fract. & mrem/yr & fract. & mrem/yr & fract. & mrem/yr & fract. \\
\hline-241 & $0.000 \mathrm{E}+00$ & 0.0000 & $0.000 \mathrm{E}+00$ & 0.0000 & $0.000 \mathrm{E}+00$ & 0.0000 & $0.000 \mathrm{E}+00$ & 0.0000 & $0.000 \mathrm{E}+00$ & 0.0000 & $0.000 \mathrm{E}+00$ & 0.0000 & $3.523 E-04$ & 0.0000 \\
\hline-137 & $0.000 \mathrm{E}+00$ & 0.0000 & $0.000 \mathrm{E}+00$ & 0.0000 & $0.000 \mathrm{E}+00$ & 0.0000 & $0.000 \mathrm{E}+00$ & 0.0000 & $0.000 \mathrm{E}+00$ & 0.0000 & $0.000 \mathrm{E}+00$ & 0.0000 & $0.000 \mathrm{E}+00$ & 0.0000 \\
\hline-237 & $0.000 \mathrm{E}+00$ & 0.0000 & $0.000 \mathrm{E}+00$ & 0.0000 & $0.000 \mathrm{E}+00$ & 0.0000 & $0.000 \mathrm{E}+00$ & 0.0000 & $0.000 \mathrm{E}+00$ & 0.0000 & $0.000 \mathrm{E}+00$ & 0.0000 & $2.644 \mathrm{E}-01$ & 0.0012 \\
\hline-238 & $0.000 \mathrm{E}+00$ & 0.0000 & $0.000 \mathrm{E}+00$ & 0.0000 & $0.000 \mathrm{E}+00$ & 0.0000 & $0.000 \mathrm{E}+00$ & 0.0000 & $0.000 \mathrm{E}+00$ & 0.0000 & $0.000 \mathrm{E}+00$ & 0.0000 & $3.356 \mathrm{E}-03$ & 0.0000 \\
\hline-239 & $0.000 \mathrm{E}+00$ & 0.0000 & $0.000 \mathrm{E}+00$ & 0.0000 & $0.000 \mathrm{E}+00$ & 0.0000 & $0.000 \mathrm{E}+00$ & 0.0000 & $0.000 \mathrm{E}+00$ & 0.0000 & $0.000 \mathrm{E}+00$ & 0.0000 & $4.785 \mathrm{E}-01$ & 0.0022 \\
\hline-240 & $0.000 \mathrm{E}+00$ & 0.0000 & $0.000 \mathrm{E}+00$ & 0.0000 & $0.000 \mathrm{E}+00$ & 0.0000 & $0.000 \mathrm{E}+00$ & 0.0000 & $0.000 \mathrm{E}+00$ & 0.0000 & $0.000 \mathrm{E}+00$ & 0.0000 & $1.098 \mathrm{E}-01$ & 0.0005 \\
\hline 99 & $0.000 \mathrm{E}+00$ & 0.0000 & $0.000 \mathrm{E}+00$ & 0.0000 & $0.000 \mathrm{E}+00$ & 0.0000 & $0.000 \mathrm{E}+00$ & 0.0000 & $0.000 \mathrm{E}+00$ & 0.0000 & $0.000 \mathrm{E}+00$ & 0.0000 & $0.000 \mathrm{E}+00$ & 0.0000 \\
\hline-228 & $0.000 \mathrm{E}+00$ & 0.0000 & $0.000 \mathrm{E}+00$ & 0.0000 & $0.000 \mathrm{E}+00$ & 0.0000 & $0.000 \mathrm{E}+00$ & 0.0000 & $0.000 \mathrm{E}+00$ & 0.0000 & $0.000 \mathrm{E}+00$ & 0.0000 & $0.000 \mathrm{E}+00$ & 0.0000 \\
\hline-230 & $0.000 \mathrm{E}+00$ & 0.0000 & $0.000 \mathrm{E}+00$ & 0.0000 & $0.000 \mathrm{E}+00$ & 0.0000 & $0.000 \mathrm{E}+00$ & 0.0000 & $0.000 \mathrm{E}+00$ & 0.0000 & $0.000 \mathrm{E}+00$ & 0.0000 & $1.649 \mathrm{E}+02$ & 0.7457 \\
\hline 232 & $0.000 \mathrm{E}+00$ & 0.0000 & $0.000 \mathrm{E}+00$ & 0.0000 & $0.000 \mathrm{E}+00$ & 0.0000 & $0.000 \mathrm{E}+00$ & 0.0000 & $0.000 \mathrm{E}+00$ & 0.0000 & $0.000 \mathrm{E}+00$ & 0.0000 & $1.031 \mathrm{E}+01$ & 0.0466 \\
\hline & $0.000 \mathrm{E}+00$ & 0.0000 & $0.000 \mathrm{E}+00$ & 0.0000 & $0.000 \mathrm{E}+00$ & 0.0000 & $0.000 \mathrm{E}+00$ & 0.0000 & $0.000 \mathrm{E}+00$ & 0.0000 & $0.000 \mathrm{E}+00$ & 0.0000 & $3.864 \mathrm{E}+01$ & 0.1748 \\
\hline 35 & $0.000 \mathrm{E}+00$ & 0.0000 & $0.000 \mathrm{E}+00$ & 0.0000 & $0.000 \mathrm{E}+00$ & 0.0000 & $0.000 \mathrm{E}+00$ & 0.0000 & $0.000 \mathrm{E}+00$ & 0.0000 & $0.000 \mathrm{E}+00$ & 0.0000 & $1.566 \mathrm{E}+00$ & 0.0071 \\
\hline 38 & $0.000 \mathrm{E}+00$ & 0.0000 & $0.000 \mathrm{E}+00$ & 0.0000 & $0.000 \mathrm{E}+00$ & 0.0000 & $0.000 \mathrm{E}+00$ & 0.0000 & $0.000 \mathrm{E}+00$ & 0.0000 & $0.000 \mathrm{E}+00$ & 0.0000 & $4.834 \mathrm{E}+00$ & 0.0219 \\
\hline & $0.000 \mathrm{E}+00$ & 0.0000 & $.000 E+00$ & 0.0000 & $0.000 \mathrm{E}+00$ & 0.0000 & $0.000 \mathrm{E}+00$ & 0.0000 & $0.000 \mathrm{E}+00$ & 0.0000 & $0.000 \mathrm{E}+00$ & 0.0000 & 02 & 00 \\
\hline
\end{tabular}

* Sum of all water independent and dependent pathways.

DCN 5090-TR-02-2

A-538 
RESRAD, Version 6.5

$\mathrm{T}^{1 / 2}$ Limit $=180$ days

Summary : C746U Worker Deterministic Run
File : X: $\backslash$ FINAL V2 \DOE FWD RUNS \C746U W DOE SG FWD-FV2-100000YR.RAD

Total Dose Contributions TDOSE(i,p,t) for Individual Radionuclides (i) and Pathways (p) As mrem/yr and Fraction of Total Dose At $t=0.000 \mathrm{E}+00$ years

Water Independent Pathways (Inhalation excludes radon)

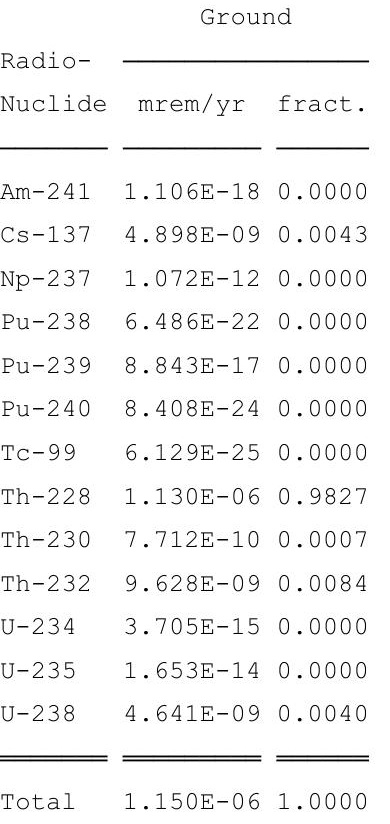

Radio-

Total

1.150E-06 1.0000

\begin{abstract}
Inhalation
\end{abstract}
mrem/yr fract.

$\overline{0.000 E+00}-\overline{0.0000}$

$0.000 \mathrm{E}+00 \quad 0.0000$

$0.000 \mathrm{E}+00 \quad 0.0000$

$0.000 \mathrm{E}+00 \quad 0.0000$

$0.000 \mathrm{E}+00 \quad 0.0000$

$0.000 \mathrm{E}+00 \quad 0.0000$

$0.000 E+00 \quad 0.0000$

$0.000 E+00 \quad 0.0000$

$0.000 \mathrm{E}+00 \quad 0.0000$

$0.000 E+00 \quad 0.0000$

$0.000 \mathrm{E}+00 \quad 0.0000$

$0.000 E+00 \quad 0.0000$

$0.000 \mathrm{E}+00 \quad 0.0000$

$\overline{\overline{0.000 \mathrm{E}+00}} \overline{\overline{0.0000}}$

Radon
mrem/yr fract. $\overline{0.000 \mathrm{E}+00} \overline{0.0000}$ $0.000 E+00 \quad 0.0000$ $0.000 E+00 \quad 0.0000$ $0.000 \mathrm{E}+00 \quad 0.0000$ $0.000 \mathrm{E}+00 \quad 0.0000$ $0.000 E+00 \quad 0.0000$ $0.000 \mathrm{E}+00 \quad 0.0000$ $0.000 \mathrm{E}+00 \quad 0.0000$ $0.000 \mathrm{E}+00 \quad 0.0000$ $0.000 \mathrm{E}+00 \quad 0.0000$ $0.000 \mathrm{E}+00 \quad 0.0000$ $0.000 \mathrm{E}+00 \quad 0.0000$ $0.000 \mathrm{E}+00 \quad 0.0000$

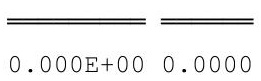

\begin{tabular}{|c|c|c|c|}
\hline \multicolumn{2}{|c|}{ Plant } & \multicolumn{2}{|c|}{ Meat } \\
\hline mrem/yr & fract. & mrem/yr & fract. \\
\hline $.000 \mathrm{E}+00$ & 0.0000 & $0.000 \mathrm{E}+00$ & 0.0000 \\
\hline $0.000 \mathrm{E}+00$ & 0.0000 & $0.000 \mathrm{E}+00$ & 0.0000 \\
\hline $0.000 \mathrm{E}+00$ & 0.0000 & $0.000 \mathrm{E}+00$ & 0.0000 \\
\hline $0.000 \mathrm{E}+00$ & 0.0000 & $0.000 \mathrm{E}+00$ & 0.0000 \\
\hline $0.000 \mathrm{E}+00$ & 0.0000 & $0.000 \mathrm{E}+00$ & 0.0000 \\
\hline $0.000 \mathrm{E}+00$ & 0.0000 & $0.000 \mathrm{E}+00$ & 0.0000 \\
\hline $0.000 \mathrm{E}+00$ & 0.0000 & $0.000 \mathrm{E}+00$ & 0.0000 \\
\hline $0.000 \mathrm{E}+00$ & 0.0000 & $0.000 \mathrm{E}+00$ & 0.0000 \\
\hline $0.000 \mathrm{E}+00$ & 0.0000 & $0.000 \mathrm{E}+00$ & 0.0000 \\
\hline $0.000 \mathrm{E}+00$ & 0.0000 & $0.000 \mathrm{E}+00$ & 0.0000 \\
\hline $0.000 \mathrm{E}+00$ & 0.0000 & $0.000 \mathrm{E}+00$ & 0.0000 \\
\hline $0.000 \mathrm{E}+00$ & 0.0000 & $0.000 \mathrm{E}+00$ & 0.0000 \\
\hline $0.000 \mathrm{E}+00$ & 0.0000 & $0.000 \mathrm{E}+00$ & 0.0000 \\
\hline & & 0.00 & . \\
\hline
\end{tabular}

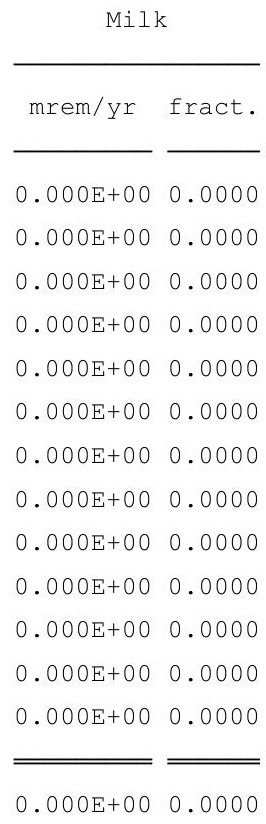

Soil mrem/yr fract. $0.000 \mathrm{E}+00 \quad 0.0000$ $0.000 \mathrm{E}+00 \quad 0.0000$ $0.000 \mathrm{E}+00 \quad 0.0000$ $0.000 \mathrm{E}+00 \quad 0.0000$ $0.000 \mathrm{E}+00 \quad 0.0000$ $0.000 \mathrm{E}+00 \quad 0.0000$ $0.000 \mathrm{E}+00 \quad 0.0000$ $0.000 \mathrm{E}+00 \quad 0.0000$ $0.000 \mathrm{E}+00 \quad 0.0000$ $0.000 \mathrm{E}+00 \quad 0.0000$ $0.000 \mathrm{E}+00 \quad 0.0000$ $0.000 \mathrm{E}+00 \quad 0.0000$ $0.000 \mathrm{E}+00 \quad 0.0000$ $0.000 \mathrm{E}+00 \quad 0.0000$

Total Dose Contributions TDOSE (i,p,t) for Individual Radionuclides (i) and Pathways (p) As mrem/yr and Fraction of Total Dose At $t=0.000 \mathrm{E}+00$ years

Water Dependent Pathways

\begin{tabular}{|c|c|c|c|c|c|c|}
\hline & \multicolumn{2}{|c|}{ Water } & \multicolumn{2}{|c|}{ Fish } & \multicolumn{2}{|c|}{ Radon } \\
\hline clide & mrem/yr & fract. & mrem/yr & fract. & mrem/yr & fract. \\
\hline 41 & $0.000 \mathrm{E}+00$ & 0.0000 & $0.000 \mathrm{E}+00$ & 0.0000 & $0.000 \mathrm{E}+00$ & 0.0000 \\
\hline-137 & $0.000 \mathrm{E}+00$ & 0.0000 & $0.000 \mathrm{E}+00$ & 0.0000 & $0.000 \mathrm{E}+00$ & 0.0000 \\
\hline-237 & $0.000 \mathrm{E}+00$ & 0.0000 & $0.000 \mathrm{E}+00$ & 0.0000 & $0.000 \mathrm{E}+00$ & 0.0000 \\
\hline-238 & $0.000 \mathrm{E}+00$ & 0.0000 & $0.000 \mathrm{E}+00$ & 0.0000 & $0.000 \mathrm{E}+00$ & 0.0000 \\
\hline-239 & $0.000 \mathrm{E}+00$ & 0.0000 & $0.000 \mathrm{E}+00$ & 0.0000 & $0.000 \mathrm{E}+00$ & 0.0000 \\
\hline-240 & $0.000 \mathrm{E}+00$ & 0.0000 & $0.000 \mathrm{E}+00$ & 0.0000 & $0.000 \mathrm{E}+00$ & 0.0000 \\
\hline-99 & $0.000 \mathrm{E}+00$ & 0.0000 & $0.000 \mathrm{E}+00$ & 0.0000 & $0.000 \mathrm{E}+00$ & 0.0000 \\
\hline-228 & $0.000 \mathrm{E}+00$ & 0.0000 & $0.000 \mathrm{E}+00$ & 0.0000 & $0.000 \mathrm{E}+00$ & 0.0000 \\
\hline-230 & $0.000 \mathrm{E}+00$ & 0.0000 & $0.000 \mathrm{E}+00$ & 0.0000 & $0.000 \mathrm{E}+00$ & 0.0000 \\
\hline-232 & $0.000 \mathrm{E}+00$ & 0.0000 & $0.000 \mathrm{E}+00$ & 0.0000 & $0.000 \mathrm{E}+00$ & 0.0000 \\
\hline 234 & $0.000 \mathrm{E}+00$ & 0.0000 & $0.000 \mathrm{E}+00$ & 0.0000 & $0.000 \mathrm{E}+00$ & 0.0000 \\
\hline 35 & $0.000 \mathrm{E}+00$ & 0.0000 & $0.000 \mathrm{E}+00$ & 0.0000 & $0.000 \mathrm{E}+00$ & 0.0000 \\
\hline 38 & $0.000 \mathrm{E}+00$ & 0.0000 & $0.000 \mathrm{E}+00$ & 0.0000 & $0.000 \mathrm{E}+00$ & 0.0000 \\
\hline & $0.000 \mathrm{E}+00$ & 0.0000 & $0.000 \mathrm{E}+00$ & 0.0000 & $0.000 \mathrm{E}+00$ & 0.0000 \\
\hline
\end{tabular}

\begin{tabular}{|c|c|c|c|}
\hline \multicolumn{2}{|c|}{ Plant } & \multicolumn{2}{|c|}{ Meat } \\
\hline mrem/yr & fract. & mrem/yr & fract. \\
\hline $0.000 \mathrm{E}+00$ & 0.0000 & $0.000 \mathrm{E}+00$ & 0.0000 \\
\hline $0.000 \mathrm{E}+00$ & 0.0000 & $0.000 \mathrm{E}+00$ & 0.0000 \\
\hline $0.000 \mathrm{E}+00$ & 0.0000 & $0.000 \mathrm{E}+00$ & 0.0000 \\
\hline $0.000 \mathrm{E}+00$ & 0.0000 & $0.000 \mathrm{E}+00$ & 0.0000 \\
\hline $0.000 \mathrm{E}+00$ & 0.0000 & $0.000 \mathrm{E}+00$ & 0.0000 \\
\hline $0.000 \mathrm{E}+00$ & 0.0000 & $0.000 \mathrm{E}+00$ & 0.0000 \\
\hline $0.000 \mathrm{E}+00$ & 0.0000 & $0.000 \mathrm{E}+00$ & 0.0000 \\
\hline $0.000 \mathrm{E}+00$ & 0.0000 & $0.000 \mathrm{E}+00$ & 0.0000 \\
\hline $0.000 \mathrm{E}+00$ & 0.0000 & $0.000 \mathrm{E}+00$ & 0.0000 \\
\hline $0.000 \mathrm{E}+00$ & 0.0000 & $0.000 \mathrm{E}+00$ & 0.0000 \\
\hline $0.000 \mathrm{E}+00$ & 0.0000 & $0.000 \mathrm{E}+00$ & 0.0000 \\
\hline $0.000 \mathrm{E}+00$ & 0.0000 & $0.000 \mathrm{E}+00$ & 0.0000 \\
\hline $0.000 \mathrm{E}+00$ & 0.0000 & $0.000 \mathrm{E}+00$ & 0.0000 \\
\hline
\end{tabular}

$0.000 \mathrm{E}+00 \quad 0.0000$

$0.000 \mathrm{E}+00 \quad 0.0000$

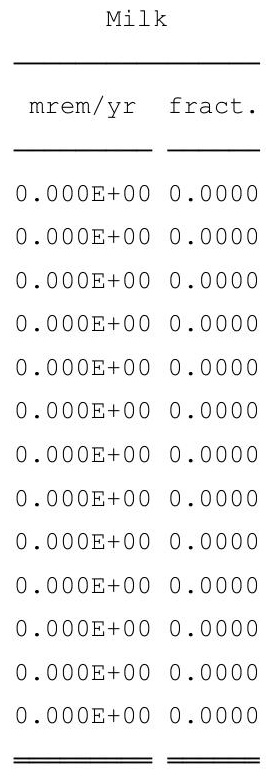

$0.000 \mathrm{E}+00 \quad 0.0000$
All Pathways* mrem/yr fract. $1.106 \mathrm{E}-18 \quad 0.0000$ $4.898 \mathrm{E}-090.0043$ $1.072 \mathrm{E}-120.0000$ $6.486 \mathrm{E}-22 \quad 0.0000$ $8.843 \mathrm{E}-170.0000$ $8.408 \mathrm{E}-240.0000$ $6.129 \mathrm{E}-250.0000$ $1.130 \mathrm{E}-06 \quad 0.9827$ $7.712 \mathrm{E}-10 \quad 0.0007$ $9.628 \mathrm{E}-09 \quad 0.0084$ $3.705 \mathrm{E}-150.0000$ $1.653 \mathrm{E}-14 \quad 0.0000$ $4.641 \mathrm{E}-090.0040$ $1.150 \mathrm{E}-061.0000$

* Sum of all water independent and dependent pathways. 
RESRAD, Version 6.5

$\mathrm{T}^{1} \frac{1}{2}$ Limit $=180$ days

Summary : C746U Worker Deterministic Run
File : X: $\backslash$ FINAL V2 \DOE FWD RUNS \C746U W DOE SG FWD-FV2-100000YR.RAD

Total Dose Contributions TDOSE (i,p,t) for Individual Radionuclides (i) and Pathways (p) As mrem/yr and Fraction of Total Dose At $t=1.000 \mathrm{E}+00$ years

Water Independent Pathways (Inhalation excludes radon)

\begin{tabular}{|c|c|c|}
\hline clide & mrem/yr & fract. \\
\hline-241 & $3.347 \mathrm{E}-18$ & 0.0000 \\
\hline-137 & $4.827 E-09$ & 0.0056 \\
\hline-237 & $1.083 \mathrm{E}-12$ & 0.0000 \\
\hline-238 & $9.637 \mathrm{E}-21$ & 0.0000 \\
\hline-239 & $8.949 E-17$ & 0.0000 \\
\hline-240 & $8.736 \mathrm{E}-24$ & 0.0000 \\
\hline-99 & $6.215 E-25$ & 0.0000 \\
\hline-228 & $7.912 \mathrm{E}-07$ & 0.9206 \\
\hline-230 & $2.327 \mathrm{E}-09$ & 0.0027 \\
\hline 232 & $5.638 \mathrm{E}-08$ & 0.0656 \\
\hline 234 & $2.608 E-14$ & 0.0000 \\
\hline 235 & $1.682 \mathrm{E}-14$ & 0.0000 \\
\hline 238 & $4.678 E-09$ & 0.0054 \\
\hline & $8.594 \mathrm{E}-01$ & 1.0000 \\
\hline
\end{tabular}

Radio-

Total

$8.594 \mathrm{E}-07 \quad 1.0000$

Inhalation

\section{mrem/yr fract.}

$\overline{0.000 \mathrm{E}+00} \overline{0.0000}$

$0.000 \mathrm{E}+00 \quad 0.0000$

$0.000 \mathrm{E}+00 \quad 0.0000$

$0.000 \mathrm{E}+00 \quad 0.0000$

$0.000 \mathrm{E}+00 \quad 0.0000$

$0.000 \mathrm{E}+00 \quad 0.0000$

$0.000 E+00 \quad 0.0000$

$0.000 \mathrm{E}+00 \quad 0.0000$

$0.000 \mathrm{E}+00 \quad 0.0000$

$0.000 E+00 \quad 0.0000$

$0.000 \mathrm{E}+00 \quad 0.0000$

$0.000 E+00 \quad 0.0000$

$0.000 \mathrm{E}+00 \quad 0.0000$

$\overline{\overline{0.000 \mathrm{E}+00}} \overline{\overline{0.0000}}$

Radon
mrem/yr fract. $\overline{0.000 \mathrm{E}+00} \overline{0.0000}$ $0.000 \mathrm{E}+00 \quad 0.0000$ $0.000 E+00 \quad 0.0000$ $0.000 \mathrm{E}+00 \quad 0.0000$ $0.000 \mathrm{E}+00 \quad 0.0000$ $0.000 E+00 \quad 0.0000$ $0.000 E+00 \quad 0.0000$ $0.000 \mathrm{E}+00 \quad 0.0000$ $0.000 \mathrm{E}+00 \quad 0.0000$ $0.000 \mathrm{E}+00 \quad 0.0000$ $0.000 \mathrm{E}+00 \quad 0.0000$ $0.000 \mathrm{E}+00 \quad 0.0000$ $0.000 \mathrm{E}+00 \quad 0.0000$

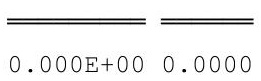

\begin{tabular}{|c|c|c|c|}
\hline \multicolumn{2}{|c|}{ Plant } & \multicolumn{2}{|c|}{ Meat } \\
\hline mrem/yr & fract. & mrem/yr & fract. \\
\hline $0.000 \mathrm{E}+00$ & 0.0000 & $0.000 \mathrm{E}+00$ & 0.0000 \\
\hline $0.000 \mathrm{E}+00$ & 0.0000 & $0.000 \mathrm{E}+00$ & 0.0000 \\
\hline $0.000 \mathrm{E}+00$ & 0.0000 & $0.000 \mathrm{E}+00$ & 0.0000 \\
\hline $0.000 \mathrm{E}+00$ & 0.0000 & $0.000 \mathrm{E}+00$ & 0.0000 \\
\hline $0.000 \mathrm{E}+00$ & 0.0000 & $0.000 \mathrm{E}+00$ & 0.0000 \\
\hline $0.000 \mathrm{E}+00$ & 0.0000 & $0.000 \mathrm{E}+00$ & 0.0000 \\
\hline $0.000 \mathrm{E}+00$ & 0.0000 & $0.000 \mathrm{E}+00$ & 0.0000 \\
\hline $0.000 \mathrm{E}+00$ & 0.0000 & $0.000 \mathrm{E}+00$ & 0.0000 \\
\hline $0.000 \mathrm{E}+00$ & 0.0000 & $0.000 \mathrm{E}+00$ & 0.0000 \\
\hline $0.000 \mathrm{E}+00$ & 0.0000 & $0.000 \mathrm{E}+00$ & 0.0000 \\
\hline $0.000 \mathrm{E}+00$ & 0.0000 & $0.000 \mathrm{E}+00$ & 0.0000 \\
\hline $0.000 \mathrm{E}+00$ & 0.0000 & $0.000 \mathrm{E}+00$ & 0.0000 \\
\hline $0.000 \mathrm{E}+00$ & 0.0000 & $0.000 \mathrm{E}+00$ & 0.0000 \\
\hline & & 0.00 & \\
\hline
\end{tabular}

\begin{tabular}{cc} 
Milk \\
\hline mrem/yr fract. \\
\cline { 1 - 2 } 0.000E+00 & 0.0000 \\
$0.000 \mathrm{E}+00$ & 0.0000 \\
$0.000 \mathrm{E}+00$ & 0.0000 \\
$0.000 \mathrm{E}+00$ & 0.0000 \\
$0.000 \mathrm{E}+00$ & 0.0000 \\
$0.000 \mathrm{E}+00$ & 0.0000 \\
$0.000 \mathrm{E}+00$ & 0.0000 \\
$0.000 \mathrm{E}+00$ & 0.0000 \\
$0.000 \mathrm{E}+00$ & 0.0000 \\
$0.000 \mathrm{E}+00$ & 0.0000 \\
$0.000 \mathrm{E}+00$ & 0.0000 \\
$0.000 \mathrm{E}+00$ & 0.0000 \\
$0.000 \mathrm{E}+00$ & 0.0000 \\
\hline \hline $0.000 \mathrm{E}+00$ & 0.0000
\end{tabular}

Soil mrem/yr fract. $0.000 \mathrm{E}+00 \quad 0.0000$ $0.000 \mathrm{E}+00 \quad 0.0000$ $0.000 \mathrm{E}+00 \quad 0.0000$ $0.000 \mathrm{E}+00 \quad 0.0000$ $0.000 \mathrm{E}+00 \quad 0.0000$ $0.000 \mathrm{E}+00 \quad 0.0000$ $0.000 \mathrm{E}+00 \quad 0.0000$ $0.000 \mathrm{E}+00 \quad 0.0000$ $0.000 \mathrm{E}+00 \quad 0.0000$ $0.000 \mathrm{E}+00 \quad 0.0000$ $0.000 \mathrm{E}+00 \quad 0.0000$ $0.000 \mathrm{E}+00 \quad 0.0000$ $0.000 \mathrm{E}+00 \quad 0.0000$ $0.000 \mathrm{E}+00 \quad 0.0000$

Total Dose Contributions TDOSE (i,p,t) for Individual Radionuclides (i) and Pathways (p) As mrem/yr and Fraction of Total Dose At $t=1.000 \mathrm{E}+00$ years

Water Dependent Pathways

\begin{tabular}{|c|c|c|c|c|c|c|}
\hline & \multicolumn{2}{|c|}{ Water } & \multicolumn{2}{|c|}{ Fish } & \multicolumn{2}{|c|}{ Radon } \\
\hline clide & mrem/yr & fract. & mrem/yr & fract. & mrem/yr & fract. \\
\hline 41 & $0.000 \mathrm{E}+00$ & 0.0000 & $0.000 \mathrm{E}+00$ & 0.0000 & $0.000 \mathrm{E}+00$ & 0.0000 \\
\hline-137 & $0.000 \mathrm{E}+00$ & 0.0000 & $0.000 \mathrm{E}+00$ & 0.0000 & $0.000 \mathrm{E}+00$ & 0.0000 \\
\hline-237 & $0.000 \mathrm{E}+00$ & 0.0000 & $0.000 \mathrm{E}+00$ & 0.0000 & $0.000 \mathrm{E}+00$ & 0.0000 \\
\hline-238 & $0.000 \mathrm{E}+00$ & 0.0000 & $0.000 \mathrm{E}+00$ & 0.0000 & $0.000 \mathrm{E}+00$ & 0.0000 \\
\hline-239 & $0.000 \mathrm{E}+00$ & 0.0000 & $0.000 \mathrm{E}+00$ & 0.0000 & $0.000 \mathrm{E}+00$ & 0.0000 \\
\hline-240 & $0.000 \mathrm{E}+00$ & 0.0000 & $0.000 \mathrm{E}+00$ & 0.0000 & $0.000 \mathrm{E}+00$ & 0.0000 \\
\hline-99 & $0.000 \mathrm{E}+00$ & 0.0000 & $0.000 \mathrm{E}+00$ & 0.0000 & $0.000 \mathrm{E}+00$ & 0.0000 \\
\hline-228 & $0.000 \mathrm{E}+00$ & 0.0000 & $0.000 \mathrm{E}+00$ & 0.0000 & $0.000 \mathrm{E}+00$ & 0.0000 \\
\hline-230 & $0.000 \mathrm{E}+00$ & 0.0000 & $0.000 \mathrm{E}+00$ & 0.0000 & $0.000 \mathrm{E}+00$ & 0.0000 \\
\hline-232 & $0.000 \mathrm{E}+00$ & 0.0000 & $0.000 \mathrm{E}+00$ & 0.0000 & $0.000 \mathrm{E}+00$ & 0.0000 \\
\hline 234 & $0.000 \mathrm{E}+00$ & 0.0000 & $0.000 \mathrm{E}+00$ & 0.0000 & $0.000 \mathrm{E}+00$ & 0.0000 \\
\hline 35 & $0.000 \mathrm{E}+00$ & 0.0000 & $0.000 \mathrm{E}+00$ & 0.0000 & $0.000 \mathrm{E}+00$ & 0.0000 \\
\hline 38 & $0.000 \mathrm{E}+00$ & 0.0000 & $0.000 \mathrm{E}+00$ & 0.0000 & $0.000 \mathrm{E}+00$ & 0.0000 \\
\hline & $0.000 \mathrm{E}+00$ & 0.0000 & $0.000 \mathrm{E}+00$ & 0.0000 & $0.000 \mathrm{E}+00$ & 0.0000 \\
\hline
\end{tabular}

\begin{tabular}{|c|c|c|c|}
\hline \multicolumn{2}{|c|}{ Plant } & \multicolumn{2}{|c|}{ Meat } \\
\hline mrem/yr & fract. & mrem/yr & fract. \\
\hline $0.000 \mathrm{E}+00$ & 0.0000 & $0.000 \mathrm{E}+00$ & 0.0000 \\
\hline $0.000 \mathrm{E}+00$ & 0.0000 & $0.000 \mathrm{E}+00$ & 0.0000 \\
\hline $0.000 \mathrm{E}+00$ & 0.0000 & $0.000 \mathrm{E}+00$ & 0.0000 \\
\hline $0.000 \mathrm{E}+00$ & 0.0000 & $0.000 \mathrm{E}+00$ & 0.0000 \\
\hline $0.000 \mathrm{E}+00$ & 0.0000 & $0.000 \mathrm{E}+00$ & 0.0000 \\
\hline $0.000 \mathrm{E}+00$ & 0.0000 & $0.000 \mathrm{E}+00$ & 0.0000 \\
\hline $0.000 \mathrm{E}+00$ & 0.0000 & $0.000 \mathrm{E}+00$ & 0.0000 \\
\hline $0.000 \mathrm{E}+00$ & 0.0000 & $0.000 \mathrm{E}+00$ & 0.0000 \\
\hline $0.000 \mathrm{E}+00$ & 0.0000 & $0.000 \mathrm{E}+00$ & 0.0000 \\
\hline $0.000 \mathrm{E}+00$ & 0.0000 & $0.000 \mathrm{E}+00$ & 0.0000 \\
\hline $0.000 \mathrm{E}+00$ & 0.0000 & $0.000 \mathrm{E}+00$ & 0.0000 \\
\hline $0.000 \mathrm{E}+00$ & 0.0000 & $0.000 \mathrm{E}+00$ & 0.0000 \\
\hline $0.000 \mathrm{E}+00$ & 0.0000 & $0.000 \mathrm{E}+00$ & 0.0000 \\
\hline
\end{tabular}

$0.000 \mathrm{E}+00 \quad 0.0000$

$0.000 \mathrm{E}+00 \quad 0.0000$

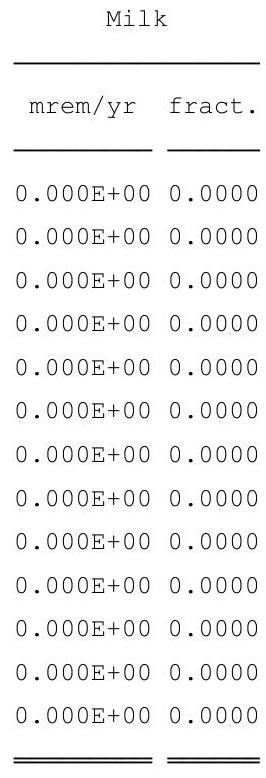

$0.000 \mathrm{E}+00 \quad 0.0000$
All Pathways* mrem/yr fract. $3.347 \mathrm{E}-18 \quad 0.0000$ $4.827 \mathrm{E}-090.0056$ $1.083 \mathrm{E}-120.0000$ $9.637 \mathrm{E}-210.0000$ $8.949 \mathrm{E}-170.0000$ $8.736 \mathrm{E}-240.0000$ $6.215 \mathrm{E}-250.0000$ $7.912 \mathrm{E}-07 \quad 0.9206$ $2.327 \mathrm{E}-090.0027$ $5.638 \mathrm{E}-08 \quad 0.0656$ $2.608 \mathrm{E}-14 \quad 0.0000$ $1.682 \mathrm{E}-14 \quad 0.0000$ $4.678 \mathrm{E}-09 \quad 0.0054$ $8.594 \mathrm{E}-07 \quad 1.0000$

* Sum of all water independent and dependent pathways. 
RESRAD, Version 6.5

$\mathrm{T}^{1 / 2}$ Limit $=180$ days

Summary : C746U Worker Deterministic Run
File : X: $\backslash$ FINAL V2 \DOE FWD RUNS \C746U W DOE SG FWD-FV2-100000YR.RAD

Total Dose Contributions TDOSE(i,p,t) for Individual Radionuclides (i) and Pathways (p) As mrem/yr and Fraction of Total Dose At $t=5.000 \mathrm{E}+01$ years

Water Independent Pathways (Inhalation excludes radon)

\begin{tabular}{|c|c|c|}
\hline clide & mrem/yr & fract. \\
\hline-241 & $1.836 \mathrm{E}-16$ & 0.0000 \\
\hline-137 & $2.350 E-09$ & 0.0012 \\
\hline-237 & $1.835 \mathrm{E}-12$ & 0.0000 \\
\hline-238 & $4.197 \mathrm{E}-16$ & 0.0000 \\
\hline-239 & $1.607 \mathrm{E}-16$ & 0.0000 \\
\hline-240 & $1.973 \mathrm{E}-20$ & 0.0000 \\
\hline-99 & 1. $229 \mathrm{E}-24$ & 0.0000 \\
\hline-228 & $2.065 E-14$ & 0.0000 \\
\hline-230 & $1.087 \mathrm{E}-07$ & 0.0558 \\
\hline-232 & $1.832 \mathrm{E}-06$ & 0.9395 \\
\hline 234 & $3.968 \mathrm{E}-11$ & 0.0000 \\
\hline 235 & $1.227 \mathrm{E}-13$ & 0.0000 \\
\hline 238 & $6.920 E-09$ & 0.0035 \\
\hline & 1.95 & 000 \\
\hline
\end{tabular}

\begin{abstract}
Inhalation
\end{abstract}

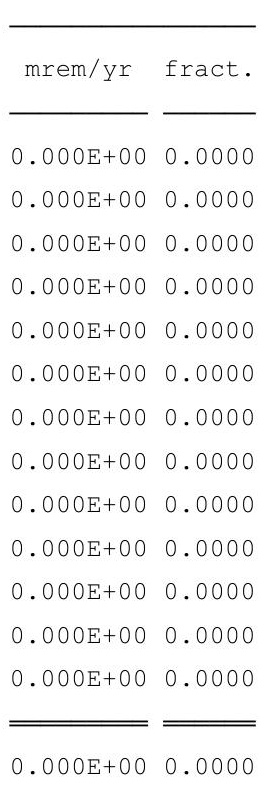

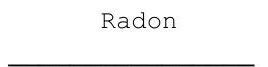

mrem/yr fract.

$\overline{0.000 E+00} 0.0000$

$0.000 E+00 \quad 0.0000$

$0.000 E+00 \quad 0.0000$

$0.000 E+00 \quad 0.0000$

$0.000 \mathrm{E}+00 \quad 0.0000$

$0.000 E+00 \quad 0.0000$

$0.000 E+00 \quad 0.0000$

$0.000 E+00 \quad 0.0000$

$0.000 E+00 \quad 0.0000$

$0.000 \mathrm{E}+00 \quad 0.0000$

$0.000 \mathrm{E}+00 \quad 0.0000$

$0.000 E+00 \quad 0.0000$

$0.000 \mathrm{E}+00 \quad 0.0000$

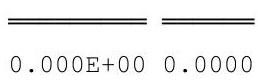

\begin{tabular}{|c|c|c|c|}
\hline \multicolumn{2}{|c|}{ Plant } & \multicolumn{2}{|c|}{ Meat } \\
\hline mrem/yr & fract. & mrem/yr & fract. \\
\hline $0.000 \mathrm{E}+00$ & 0.0000 & $0.000 \mathrm{E}+00$ & 0.0000 \\
\hline $0.000 \mathrm{E}+00$ & 0.0000 & $0.000 \mathrm{E}+00$ & 0.0000 \\
\hline $0.000 \mathrm{E}+00$ & 0.0000 & $0.000 \mathrm{E}+00$ & 0.0000 \\
\hline $0.000 \mathrm{E}+00$ & 0.0000 & $0.000 \mathrm{E}+00$ & 0.0000 \\
\hline $.000 \mathrm{E}+00$ & 0.0000 & $0.000 \mathrm{E}+00$ & 0.0000 \\
\hline $0.000 \mathrm{E}+00$ & 0.0000 & $0.000 \mathrm{E}+00$ & 0.0000 \\
\hline $0.000 \mathrm{E}+00$ & 0.0000 & $0.000 \mathrm{E}+00$ & 0.0000 \\
\hline $0.000 \mathrm{E}+00$ & 0.0000 & $0.000 \mathrm{E}+00$ & 0.0000 \\
\hline $0.000 \mathrm{E}+00$ & 0.0000 & $0.000 \mathrm{E}+00$ & 0.0000 \\
\hline $0.000 \mathrm{E}+00$ & 0.0000 & $0.000 \mathrm{E}+00$ & 0.0000 \\
\hline $0.000 \mathrm{E}+00$ & 0.0000 & $0.000 \mathrm{E}+00$ & 0.0000 \\
\hline $0.000 \mathrm{E}+00$ & 0.0000 & $0.000 \mathrm{E}+00$ & 0.0000 \\
\hline $0.000 \mathrm{E}+00$ & 0.0000 & $0.000 \mathrm{E}+00$ & 0.0000 \\
\hline & & .00 & 0.0 \\
\hline
\end{tabular}

\begin{tabular}{cc} 
Milk \\
\hline mrem/yr fract. \\
\cline { 1 - 2 } $0.000 \mathrm{E}+00$ & 0.0000 \\
$0.000 \mathrm{E}+00$ & 0.0000 \\
$0.000 \mathrm{E}+00$ & 0.0000 \\
$0.000 \mathrm{E}+00$ & 0.0000 \\
$0.000 \mathrm{E}+00$ & 0.0000 \\
$0.000 \mathrm{E}+00$ & 0.0000 \\
$0.000 \mathrm{E}+00$ & 0.0000 \\
$0.000 \mathrm{E}+00$ & 0.0000 \\
$0.000 \mathrm{E}+00$ & 0.0000 \\
$0.000 \mathrm{E}+00$ & 0.0000 \\
$0.000 \mathrm{E}+00$ & 0.0000 \\
$0.000 \mathrm{E}+00$ & 0.0000 \\
$0.000 \mathrm{E}+00$ & 0.0000 \\
\hline \hline $0.000 \mathrm{E}+00$ & 0.0000
\end{tabular}

Soil mrem/yr fract. $0.000 \mathrm{E}+00 \quad 0.0000$ $0.000 \mathrm{E}+00 \quad 0.0000$ $0.000 \mathrm{E}+00 \quad 0.0000$ $0.000 \mathrm{E}+00 \quad 0.0000$ $0.000 \mathrm{E}+00 \quad 0.0000$ $0.000 \mathrm{E}+00 \quad 0.0000$ $0.000 \mathrm{E}+00 \quad 0.0000$ $0.000 \mathrm{E}+00 \quad 0.0000$ $0.000 \mathrm{E}+00 \quad 0.0000$ $0.000 \mathrm{E}+00 \quad 0.0000$ $0.000 \mathrm{E}+00 \quad 0.0000$ $0.000 \mathrm{E}+00 \quad 0.0000$ $0.000 \mathrm{E}+00 \quad 0.0000$ $0.000 \mathrm{E}+00 \quad 0.0000$

Total Dose Contributions TDOSE (i,p,t) for Individual Radionuclides (i) and Pathways (p) As mrem/yr and Fraction of Total Dose At $t=5.000 \mathrm{E}+01$ years

Water Dependent Pathways

\begin{tabular}{|c|c|c|c|c|c|c|}
\hline & \multicolumn{2}{|c|}{ Water } & \multicolumn{2}{|c|}{ Fish } & \multicolumn{2}{|c|}{ Radon } \\
\hline clide & mrem/yr & fract. & mrem/yr & fract. & mrem/yr & fract. \\
\hline 41 & $0.000 \mathrm{E}+00$ & 0.0000 & $0.000 \mathrm{E}+00$ & 0.0000 & $0.000 \mathrm{E}+00$ & 0.0000 \\
\hline-137 & $0.000 \mathrm{E}+00$ & 0.0000 & $0.000 \mathrm{E}+00$ & 0.0000 & $0.000 \mathrm{E}+00$ & 0.0000 \\
\hline-237 & $0.000 \mathrm{E}+00$ & 0.0000 & $0.000 \mathrm{E}+00$ & 0.0000 & $0.000 \mathrm{E}+00$ & 0.0000 \\
\hline-238 & $0.000 \mathrm{E}+00$ & 0.0000 & $0.000 \mathrm{E}+00$ & 0.0000 & $0.000 \mathrm{E}+00$ & 0.0000 \\
\hline-239 & $0.000 \mathrm{E}+00$ & 0.0000 & $0.000 \mathrm{E}+00$ & 0.0000 & $0.000 \mathrm{E}+00$ & 0.0000 \\
\hline-240 & $0.000 \mathrm{E}+00$ & 0.0000 & $0.000 \mathrm{E}+00$ & 0.0000 & $0.000 \mathrm{E}+00$ & 0.0000 \\
\hline-99 & $0.000 \mathrm{E}+00$ & 0.0000 & $0.000 \mathrm{E}+00$ & 0.0000 & $0.000 \mathrm{E}+00$ & 0.0000 \\
\hline-228 & $0.000 \mathrm{E}+00$ & 0.0000 & $0.000 \mathrm{E}+00$ & 0.0000 & $0.000 \mathrm{E}+00$ & 0.0000 \\
\hline-230 & $0.000 \mathrm{E}+00$ & 0.0000 & $0.000 \mathrm{E}+00$ & 0.0000 & $0.000 \mathrm{E}+00$ & 0.0000 \\
\hline-232 & $0.000 \mathrm{E}+00$ & 0.0000 & $0.000 \mathrm{E}+00$ & 0.0000 & $0.000 \mathrm{E}+00$ & 0.0000 \\
\hline 234 & $0.000 \mathrm{E}+00$ & 0.0000 & $0.000 \mathrm{E}+00$ & 0.0000 & $0.000 \mathrm{E}+00$ & 0.0000 \\
\hline 35 & $0.000 \mathrm{E}+00$ & 0.0000 & $0.000 \mathrm{E}+00$ & 0.0000 & $0.000 \mathrm{E}+00$ & 0.0000 \\
\hline 38 & $0.000 \mathrm{E}+00$ & 0.0000 & $0.000 \mathrm{E}+00$ & 0.0000 & $0.000 \mathrm{E}+00$ & 0.0000 \\
\hline & $0.000 \mathrm{E}+00$ & 0.0000 & $0.000 \mathrm{E}+00$ & 0.0000 & $0.000 \mathrm{E}+00$ & 0.0000 \\
\hline
\end{tabular}

\begin{tabular}{|c|c|c|c|}
\hline \multicolumn{2}{|c|}{ Plant } & \multicolumn{2}{|c|}{ Meat } \\
\hline mrem/yr & fract. & mrem/yr & fract. \\
\hline $0.000 \mathrm{E}+00$ & 0.0000 & $0.000 \mathrm{E}+00$ & 0.0000 \\
\hline $0.000 \mathrm{E}+00$ & 0.0000 & $0.000 \mathrm{E}+00$ & 0.0000 \\
\hline $0.000 \mathrm{E}+00$ & 0.0000 & $0.000 \mathrm{E}+00$ & 0.0000 \\
\hline $0.000 \mathrm{E}+00$ & 0.0000 & $0.000 \mathrm{E}+00$ & 0.0000 \\
\hline $0.000 \mathrm{E}+00$ & 0.0000 & $0.000 \mathrm{E}+00$ & 0.0000 \\
\hline $0.000 \mathrm{E}+00$ & 0.0000 & $0.000 \mathrm{E}+00$ & 0.0000 \\
\hline $0.000 \mathrm{E}+00$ & 0.0000 & $0.000 \mathrm{E}+00$ & 0.0000 \\
\hline $0.000 \mathrm{E}+00$ & 0.0000 & $0.000 \mathrm{E}+00$ & 0.0000 \\
\hline $0.000 \mathrm{E}+00$ & 0.0000 & $0.000 \mathrm{E}+00$ & 0.0000 \\
\hline $0.000 \mathrm{E}+00$ & 0.0000 & $0.000 \mathrm{E}+00$ & 0.0000 \\
\hline $0.000 \mathrm{E}+00$ & 0.0000 & $0.000 \mathrm{E}+00$ & 0.0000 \\
\hline $0.000 \mathrm{E}+00$ & 0.0000 & $0.000 \mathrm{E}+00$ & 0.0000 \\
\hline $0.000 \mathrm{E}+00$ & 0.0000 & $0.000 \mathrm{E}+00$ & 0.0000 \\
\hline
\end{tabular}

$0.000 \mathrm{E}+00 \quad 0.0000$

$0.000 \mathrm{E}+00 \quad 0.0000$

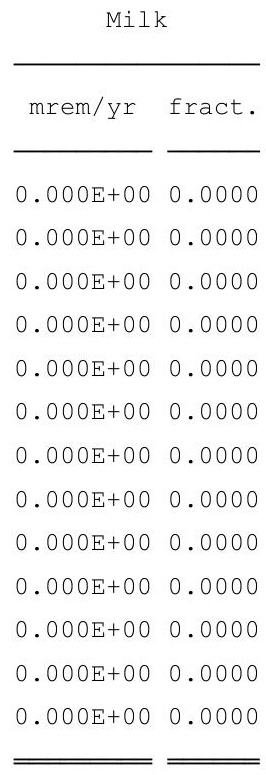

$0.000 \mathrm{E}+00 \quad 0.0000$
All Pathways * mrem/yr fract.

$1.836 \mathrm{E}-160.0000$ $2.350 \mathrm{E}-090.0012$ $1.835 \mathrm{E}-120.0000$ $4.197 \mathrm{E}-160.0000$ $1.607 \mathrm{E}-160.0000$ $1.973 \mathrm{E}-20 \quad 0.0000$ $1.229 \mathrm{E}-240.0000$ $2.065 \mathrm{E}-14 \quad 0.0000$ $1.087 \mathrm{E}-07 \quad 0.0558$ $1.832 \mathrm{E}-06 \quad 0.9395$ $3.968 \mathrm{E}-110.0000$ $1.227 \mathrm{E}-130.0000$ $6.920 \mathrm{E}-090.0035$ $1.950 \mathrm{E}-061.0000$

* Sum of all water independent and dependent pathways. 
RESRAD, Version 6.5

$\mathrm{T}^{1 / 2}$ Limit $=180$ days

Summary : C746U Worker Deterministic Run
File : X: $\backslash$ FINAL V2 \DOE FWD RUNS \C746U W DOE SG FWD-FV2-100000YR.RAD

Total Dose Contributions TDOSE (i,p,t) for Individual Radionuclides (i) and Pathways (p) As mrem/yr and Fraction of Total Dose At $t=1.000 \mathrm{E}+02$ years

Water Independent Pathways (Inhalation excludes radon)

\begin{tabular}{|c|c|c|c|c|c|c|c|c|c|c|c|c|c|c|}
\hline \multirow{2}{*}{$\begin{array}{l}\text { Radio- } \\
\text { Nuclide }\end{array}$} & \multicolumn{2}{|c|}{ Ground } & \multicolumn{2}{|c|}{ Inhalation } & \multicolumn{2}{|c|}{ Radon } & \multicolumn{2}{|c|}{ Plant } & \multicolumn{2}{|c|}{ Meat } & \multicolumn{2}{|c|}{ Milk } & \multicolumn{2}{|c|}{ Soil } \\
\hline & mrem/yr & fract. & mrem/yr & fract. & mrem/yr & fract. & mrem/yr & fract. & mrem/yr & fract. & mrem/yr & fract. & mrem/yr & fract. \\
\hline-241 & $6.026 \mathrm{E}-16$ & 0.0000 & $0.000 \mathrm{E}+00$ & 0.0000 & $0.000 \mathrm{E}+00$ & 0.0000 & $0.000 \mathrm{E}+00$ & 0.0000 & $0.000 \mathrm{E}+00$ & 0.0000 & $0.000 \mathrm{E}+00$ & 0.0000 & $0.000 \mathrm{E}+00$ & 0.0000 \\
\hline-137 & $1.128 \mathrm{E}-09$ & 0.0004 & $0.000 \mathrm{E}+00$ & 0.0000 & $0.000 \mathrm{E}+00$ & 0.0000 & $0.000 \mathrm{E}+00$ & 0.0000 & $0.000 \mathrm{E}+00$ & 0.0000 & $0.000 \mathrm{E}+00$ & 0.0000 & $0.000 \mathrm{E}+00$ & 0.0000 \\
\hline-237 & $3.151 \mathrm{E}-12$ & 0.0000 & $0.000 \mathrm{E}+00$ & 0.0000 & $0.000 \mathrm{E}+00$ & 0.0000 & $0.000 \mathrm{E}+00$ & 0.0000 & $0.000 \mathrm{E}+00$ & 0.0000 & $0.000 \mathrm{E}+00$ & 0.0000 & $0.000 \mathrm{E}+00$ & 0.0000 \\
\hline-238 & 4. $245 \mathrm{E}-15$ & 0.0000 & $0.000 \mathrm{E}+00$ & 0.0000 & $0.000 \mathrm{E}+00$ & 0.0000 & $0.000 \mathrm{E}+00$ & 0.0000 & $0.000 \mathrm{E}+00$ & 0.0000 & $0.000 \mathrm{E}+00$ & 0.0000 & $0.000 \mathrm{E}+00$ & 0.0000 \\
\hline-239 & $2.920 \mathrm{E}-16$ & 0.0000 & $0.000 \mathrm{E}+00$ & 0.0000 & $0.000 \mathrm{E}+00$ & 0.0000 & $0.000 \mathrm{E}+00$ & 0.0000 & $0.000 \mathrm{E}+00$ & 0.0000 & $0.000 \mathrm{E}+00$ & 0.0000 & $0.000 \mathrm{E}+00$ & 0.0000 \\
\hline-240 & 1. $313 \mathrm{E}-19$ & 0.0000 & $0.000 \mathrm{E}+00$ & 0.0000 & $0.000 \mathrm{E}+00$ & 0.0000 & $0.000 \mathrm{E}+00$ & 0.0000 & $0.000 \mathrm{E}+00$ & 0.0000 & $0.000 \mathrm{E}+00$ & 0.0000 & $0.000 \mathrm{E}+00$ & 0.0000 \\
\hline-99 & $2.465 E-24$ & 0.0000 & $0.000 \mathrm{E}+00$ & 0.0000 & $0.000 \mathrm{E}+00$ & 0.0000 & $0.000 \mathrm{E}+00$ & 0.0000 & $0.000 \mathrm{E}+00$ & 0.0000 & $0.000 \mathrm{E}+00$ & 0.0000 & $0.000 \mathrm{E}+00$ & 0.0000 \\
\hline-228 & $3.775 \mathrm{E}-22$ & 0.0000 & $0.000 \mathrm{E}+00$ & 0.0000 & $0.000 \mathrm{E}+00$ & 0.0000 & $0.000 \mathrm{E}+00$ & 0.0000 & $0.000 \mathrm{E}+00$ & 0.0000 & $0.000 \mathrm{E}+00$ & 0.0000 & $0.000 \mathrm{E}+00$ & 0.0000 \\
\hline-230 & $3.024 \mathrm{E}-07$ & 0.1082 & $0.000 \mathrm{E}+00$ & 0.0000 & $0.000 \mathrm{E}+00$ & 0.0000 & $0.000 \mathrm{E}+00$ & 0.0000 & $0.000 \mathrm{E}+00$ & 0.0000 & $0.000 \mathrm{E}+00$ & 0.0000 & $0.000 \mathrm{E}+00$ & 0.0000 \\
\hline-232 & $2.479 E-06$ & 0.8876 & $0.000 \mathrm{E}+00$ & 0.0000 & $0.000 \mathrm{E}+00$ & 0.0000 & $0.000 \mathrm{E}+00$ & 0.0000 & $0.000 \mathrm{E}+00$ & 0.0000 & $0.000 \mathrm{E}+00$ & 0.0000 & $0.000 \mathrm{E}+00$ & 0.0000 \\
\hline 34 & $2.204 \mathrm{E}-10$ & 0.0001 & $0.000 \mathrm{E}+00$ & 0.0000 & $0.000 \mathrm{E}+00$ & 0.0000 & $0.000 \mathrm{E}+00$ & 0.0000 & $0.000 \mathrm{E}+00$ & 0.0000 & $0.000 \mathrm{E}+00$ & 0.0000 & $0.000 \mathrm{E}+00$ & 0.0000 \\
\hline & $4.503 E-13$ & 0.0000 & $0.000 \mathrm{E}+00$ & 0.0000 & $0.000 \mathrm{E}+00$ & 0.0000 & $0.000 \mathrm{E}+00$ & 0.0000 & $0.000 \mathrm{E}+00$ & 0.0000 & $0.000 \mathrm{E}+00$ & 0.0000 & $0.000 \mathrm{E}+00$ & 0.0000 \\
\hline 38 & $1.032 \mathrm{E}-08$ & 0.0037 & $0.000 \mathrm{E}+00$ & 0.0000 & $0.000 \mathrm{E}+00$ & 0.0000 & $0.000 \mathrm{E}+00$ & 0.0000 & $0.000 \mathrm{E}+00$ & 0.0000 & $0.000 \mathrm{E}+00$ & 0.0000 & $0.000 \mathrm{E}+00$ & 0.0000 \\
\hline & $2.793 \mathrm{E}-06$ & 1.0000 & $0.000 \mathrm{E}+00$ & 0.0000 & $0.000 \mathrm{E}+00$ & 0.0000 & $0.000 \mathrm{E}+00$ & 0.0000 & $0.000 \mathrm{E}+00$ & 0.0000 & $0.000 \mathrm{E}+00$ & 000 & +00 & 000 \\
\hline
\end{tabular}

Total Dose Contributions TDOSE(i,p,t) for Individual Radionuclides (i) and Pathways (p) As mrem/yr and Fraction of Total Dose At $t=1.000 \mathrm{E}+02$ years

Water Dependent Pathways

\begin{tabular}{|c|c|c|c|c|c|c|c|c|c|c|c|c|c|c|}
\hline & \multicolumn{2}{|c|}{ Water } & \multicolumn{2}{|c|}{ Fish } & \multicolumn{2}{|c|}{ Radon } & \multicolumn{2}{|c|}{ Plant } & \multicolumn{2}{|c|}{ Meat } & \multicolumn{2}{|c|}{ Milk } & \multicolumn{2}{|c|}{ All Pathways* } \\
\hline clide & mrem/yr & fract. & mrem/yr & fract. & mrem/yr & fract. & mrem/yr & fract. & mrem/yr & fract. & mrem/yr & fract. & mrem/yr & fract. \\
\hline-241 & $0.000 \mathrm{E}+00$ & 0.0000 & $0.000 \mathrm{E}+00$ & 0.0000 & $0.000 \mathrm{E}+00$ & 0.0000 & $0.000 \mathrm{E}+00$ & 0.0000 & $0.000 \mathrm{E}+00$ & 0.0000 & $0.000 E+00$ & 0.0000 & $6.026 \mathrm{E}-16$ & 0.0000 \\
\hline-137 & $0.000 \mathrm{E}+00$ & 0.0000 & $0.000 \mathrm{E}+00$ & 0.0000 & $0.000 \mathrm{E}+00$ & 0.0000 & $0.000 \mathrm{E}+00$ & 0.0000 & $0.000 \mathrm{E}+00$ & 0.0000 & $0.000 \mathrm{E}+00$ & 0.0000 & $1.128 \mathrm{E}-09$ & 0.0004 \\
\hline-237 & $0.000 \mathrm{E}+00$ & 0.0000 & $0.000 \mathrm{E}+00$ & 0.0000 & $0.000 \mathrm{E}+00$ & 0.0000 & $0.000 \mathrm{E}+00$ & 0.0000 & $0.000 \mathrm{E}+00$ & 0.0000 & $0.000 \mathrm{E}+00$ & 0.0000 & $3.151 \mathrm{E}-12$ & 0.0000 \\
\hline 238 & $0.000 \mathrm{E}+00$ & 0.0000 & $0.000 \mathrm{E}+00$ & 0.0000 & $0.000 \mathrm{E}+00$ & 0.0000 & $0.000 \mathrm{E}+00$ & 0.0000 & $0.000 \mathrm{E}+00$ & 0.0000 & $0.000 \mathrm{E}+00$ & 0.0000 & $4.245 E-15$ & 0.0000 \\
\hline 239 & $0.000 \mathrm{E}+00$ & 0.0000 & $0.000 \mathrm{E}+00$ & 0.0000 & $0.000 \mathrm{E}+00$ & 0.0000 & $0.000 \mathrm{E}+00$ & 0.0000 & $0.000 \mathrm{E}+00$ & 0.0000 & $0.000 \mathrm{E}+00$ & 0.0000 & $2.920 \mathrm{E}-16$ & 0.0000 \\
\hline 240 & $0.000 \mathrm{E}+00$ & 0.0000 & $0.000 \mathrm{E}+00$ & 0.0000 & $0.000 \mathrm{E}+00$ & 0.0000 & $0.000 \mathrm{E}+00$ & 0.0000 & $0.000 \mathrm{E}+00$ & 0.0000 & $0.000 \mathrm{E}+00$ & 0.0000 & $1.313 \mathrm{E}-19$ & 0.0000 \\
\hline 99 & $0.000 \mathrm{E}+00$ & 0.0000 & $0.000 \mathrm{E}+00$ & 0.0000 & $0.000 \mathrm{E}+00$ & 0.0000 & $0.000 \mathrm{E}+00$ & 0.0000 & $0.000 \mathrm{E}+00$ & 0.0000 & $0.000 \mathrm{E}+00$ & 0.0000 & $2.465 \mathrm{E}-24$ & 0.0000 \\
\hline 228 & $0.000 \mathrm{E}+00$ & 0.0000 & $0.000 \mathrm{E}+00$ & 0.0000 & $0.000 \mathrm{E}+00$ & 0.0000 & $0.000 \mathrm{E}+00$ & 0.0000 & $0.000 \mathrm{E}+00$ & 0.0000 & $0.000 \mathrm{E}+00$ & 0.0000 & $3.775 \mathrm{E}-22$ & 0.0000 \\
\hline 230 & $0.000 \mathrm{E}+00$ & 0.0000 & $0.000 \mathrm{E}+00$ & 0.0000 & $0.000 \mathrm{E}+00$ & 0.0000 & $0.000 \mathrm{E}+00$ & 0.0000 & $0.000 \mathrm{E}+00$ & 0.0000 & $0.000 \mathrm{E}+00$ & 0.0000 & $3.024 \mathrm{E}-07$ & 0.1082 \\
\hline 232 & $0.000 \mathrm{E}+00$ & 0.0000 & $0.000 \mathrm{E}+00$ & 0.0000 & $0.000 \mathrm{E}+00$ & 0.0000 & $0.000 \mathrm{E}+00$ & 0.0000 & $0.000 \mathrm{E}+00$ & 0.0000 & $0.000 \mathrm{E}+00$ & 0.0000 & $2.479 E-06$ & 0.8876 \\
\hline 34 & $0.000 \mathrm{E}+00$ & 0.0000 & $0.000 \mathrm{E}+00$ & 0.0000 & $0.000 \mathrm{E}+00$ & 0.0000 & $0.000 \mathrm{E}+00$ & 0.0000 & $0.000 \mathrm{E}+00$ & 0.0000 & $0.000 \mathrm{E}+00$ & 0.0000 & $2.204 \mathrm{E}-10$ & 0.0001 \\
\hline 35 & $0.000 \mathrm{E}+00$ & 0.0000 & $0.000 \mathrm{E}+00$ & 0.0000 & $0.000 \mathrm{E}+00$ & 0.0000 & $0.000 \mathrm{E}+00$ & 0.0000 & $0.000 \mathrm{E}+00$ & 0.0000 & $0.000 \mathrm{E}+00$ & 0.0000 & $4.503 E-13$ & 0.0000 \\
\hline 38 & $0.000 \mathrm{E}+00$ & 0.0000 & $0.000 \mathrm{E}+00$ & 0.0000 & $0.000 \mathrm{E}+00$ & 0.0000 & $0.000 \mathrm{E}+00$ & 0.0000 & $0.000 \mathrm{E}+00$ & 0.0000 & $0.000 \mathrm{E}+00$ & 0.0000 & $1.032 \mathrm{E}-08$ & 0.0037 \\
\hline & $0.000 \mathrm{E}+00$ & 0.0000 & $0.000 \mathrm{E}+00$ & 0.0000 & $0.000 \mathrm{E}+00$ & 0.0000 & $0.000 \mathrm{E}+00$ & 0.0000 & $0.000 \mathrm{E}+00$ & 0.0000 & $0.000 \mathrm{E}+00$ & 000 & -06 & 1.0000 \\
\hline
\end{tabular}

* Sum of all water independent and dependent pathways. 
RESRAD, Version 6.5

$\mathrm{T}^{1 / 2}$ Limit $=180$ days

Summary : C746U Worker Deterministic Run
File : X: $\backslash$ FINAL V2 \DOE FWD RUNS \C746U W DOE SG FWD-FV2-100000YR.RAD

Total Dose Contributions TDOSE (i,p,t) for Individual Radionuclides (i) and Pathways (p) As mrem/yr and Fraction of Total Dose At $t=5.000 \mathrm{E}+02$ years

Water Independent Pathways (Inhalation excludes radon)

\begin{tabular}{|c|c|c|c|c|c|c|c|c|c|c|c|c|c|c|}
\hline \multirow{2}{*}{$\begin{array}{l}\text { Radio- } \\
\text { Nuclide }\end{array}$} & \multicolumn{2}{|c|}{ Ground } & \multicolumn{2}{|c|}{ Inhalation } & \multicolumn{2}{|c|}{ Radon } & \multicolumn{2}{|c|}{ Plant } & \multicolumn{2}{|c|}{ Meat } & \multicolumn{2}{|c|}{ Milk } & \multicolumn{2}{|c|}{ Soil } \\
\hline & mrem/yr & fract. & mrem/yr & fract. & mrem/yr & fract. & mrem/yr & fract. & mrem/yr & fract. & mrem/yr & fract. & mrem/yr & fract. \\
\hline-241 & $1.668 \mathrm{E}-13$ & 0.0000 & $0.000 \mathrm{E}+00$ & 0.0000 & $0.000 \mathrm{E}+00$ & 0.0000 & $0.000 \mathrm{E}+00$ & 0.0000 & $0.000 \mathrm{E}+00$ & 0.0000 & $0.000 \mathrm{E}+00$ & 0.0000 & $0.000 \mathrm{E}+00$ & 0.0000 \\
\hline-137 & $3.168 \mathrm{E}-12$ & 0.0000 & $0.000 \mathrm{E}+00$ & 0.0000 & $0.000 \mathrm{E}+00$ & 0.0000 & $0.000 \mathrm{E}+00$ & 0.0000 & $0.000 \mathrm{E}+00$ & 0.0000 & $0.000 \mathrm{E}+00$ & 0.0000 & $0.000 \mathrm{E}+00$ & 0.0000 \\
\hline-237 & $2.362 \mathrm{E}-10$ & 0.0000 & $0.000 \mathrm{E}+00$ & 0.0000 & $0.000 \mathrm{E}+00$ & 0.0000 & $0.000 \mathrm{E}+00$ & 0.0000 & $0.000 \mathrm{E}+00$ & 0.0000 & $0.000 \mathrm{E}+00$ & 0.0000 & $0.000 \mathrm{E}+00$ & 0.0000 \\
\hline-238 & 4. $482 \mathrm{E}-12$ & 0.0000 & $0.000 \mathrm{E}+00$ & 0.0000 & $0.000 \mathrm{E}+00$ & 0.0000 & $0.000 \mathrm{E}+00$ & 0.0000 & $0.000 \mathrm{E}+00$ & 0.0000 & $0.000 \mathrm{E}+00$ & 0.0000 & $0.000 \mathrm{E}+00$ & 0.0000 \\
\hline-239 & $3.476 \mathrm{E}-14$ & 0.0000 & $0.000 \mathrm{E}+00$ & 0.0000 & $0.000 \mathrm{E}+00$ & 0.0000 & $0.000 \mathrm{E}+00$ & 0.0000 & $0.000 \mathrm{E}+00$ & 0.0000 & $0.000 \mathrm{E}+00$ & 0.0000 & $0.000 \mathrm{E}+00$ & 0.0000 \\
\hline-240 & $4.219 \mathrm{E}-17$ & 0.0000 & $0.000 \mathrm{E}+00$ & 0.0000 & $0.000 \mathrm{E}+00$ & 0.0000 & $0.000 \mathrm{E}+00$ & 0.0000 & $0.000 \mathrm{E}+00$ & 0.0000 & $0.000 \mathrm{E}+00$ & 0.0000 & $0.000 \mathrm{E}+00$ & 0.0000 \\
\hline-99 & $6.452 \mathrm{E}-22$ & 0.0000 & $0.000 \mathrm{E}+00$ & 0.0000 & $0.000 \mathrm{E}+00$ & 0.0000 & $0.000 \mathrm{E}+00$ & 0.0000 & $0.000 \mathrm{E}+00$ & 0.0000 & $0.000 \mathrm{E}+00$ & 0.0000 & $0.000 \mathrm{E}+00$ & 0.0000 \\
\hline-228 & $0.000 \mathrm{E}+00$ & 0.0000 & $0.000 \mathrm{E}+00$ & 0.0000 & $0.000 \mathrm{E}+00$ & 0.0000 & $0.000 \mathrm{E}+00$ & 0.0000 & $0.000 \mathrm{E}+00$ & 0.0000 & $0.000 \mathrm{E}+00$ & 0.0000 & $0.000 \mathrm{E}+00$ & 0.0000 \\
\hline-230 & $2.193 \mathrm{E}-05$ & 0.4425 & $0.000 \mathrm{E}+00$ & 0.0000 & $0.000 \mathrm{E}+00$ & 0.0000 & $0.000 \mathrm{E}+00$ & 0.0000 & $0.000 \mathrm{E}+00$ & 0.0000 & $0.000 \mathrm{E}+00$ & 0.0000 & $0.000 \mathrm{E}+00$ & 0.0000 \\
\hline-232 & $2.730 E-05$ & 0.5508 & $0.000 \mathrm{E}+00$ & 0.0000 & $0.000 \mathrm{E}+00$ & 0.0000 & $0.000 \mathrm{E}+00$ & 0.0000 & $0.000 \mathrm{E}+00$ & 0.0000 & $0.000 \mathrm{E}+00$ & 0.0000 & $0.000 \mathrm{E}+00$ & 0.0000 \\
\hline 34 & $8.184 \mathrm{E}-08$ & 0.0017 & $0.000 \mathrm{E}+00$ & 0.0000 & $0.000 \mathrm{E}+00$ & 0.0000 & $0.000 \mathrm{E}+00$ & 0.0000 & $0.000 \mathrm{E}+00$ & 0.0000 & $0.000 \mathrm{E}+00$ & 0.0000 & $0.000 \mathrm{E}+00$ & 0.0000 \\
\hline & $9.380 \mathrm{E}-11$ & 0.0000 & $0.000 \mathrm{E}+00$ & 0.0000 & $0.000 \mathrm{E}+00$ & 0.0000 & $0.000 \mathrm{E}+00$ & 0.0000 & $0.000 \mathrm{E}+00$ & 0.0000 & $0.000 \mathrm{E}+00$ & 0.0000 & $0.000 \mathrm{E}+00$ & 0.0000 \\
\hline 38 & $2.523 E-07$ & 0.0051 & $0.000 \mathrm{E}+00$ & 0.0000 & $0.000 \mathrm{E}+00$ & 0.0000 & $0.000 \mathrm{E}+00$ & 0.0000 & $0.000 \mathrm{E}+00$ & 0.0000 & $0.000 \mathrm{E}+00$ & 0.0000 & $0.000 \mathrm{E}+00$ & 0.0000 \\
\hline & $7 E-05$ & 1.0000 & $0.000 \mathrm{E}+00$ & 0.0000 & $0.000 \mathrm{E}+00$ & 0.0000 & $0.000 \mathrm{E}+00$ & 0.0000 & $0.000 \mathrm{E}+00$ & 0.0000 & $0.000 \mathrm{E}+00$ & 000 & +00 & 000 \\
\hline
\end{tabular}

Total Dose Contributions TDOSE(i,p,t) for Individual Radionuclides (i) and Pathways (p) As mrem/yr and Fraction of Total Dose At $t=5.000 \mathrm{E}+02$ years

Water Dependent Pathways

\begin{tabular}{|c|c|c|c|c|c|c|c|c|c|c|c|c|c|c|}
\hline & \multicolumn{2}{|c|}{ Water } & \multicolumn{2}{|c|}{ Fish } & \multicolumn{2}{|c|}{ Radon } & \multicolumn{2}{|c|}{ Plant } & \multicolumn{2}{|c|}{ Meat } & \multicolumn{2}{|c|}{ Milk } & \multicolumn{2}{|c|}{ All Pathways* } \\
\hline clide & mrem/yr & fract. & mrem/yr & fract. & mrem/yr & fract. & mrem/yr & fract. & mrem/yr & fract. & mrem/yr & fract. & mrem/yr & fract. \\
\hline-241 & $0.000 \mathrm{E}+00$ & 0.0000 & $0.000 \mathrm{E}+00$ & 0.0000 & $0.000 \mathrm{E}+00$ & 0.0000 & $0.000 \mathrm{E}+00$ & 0.0000 & $0.000 \mathrm{E}+00$ & 0.0000 & $0.000 \mathrm{E}+00$ & 0.0000 & $1.668 \mathrm{E}-13$ & 0.0000 \\
\hline-137 & $0.000 \mathrm{E}+00$ & 0.0000 & $0.000 \mathrm{E}+00$ & 0.0000 & $0.000 \mathrm{E}+00$ & 0.0000 & $0.000 \mathrm{E}+00$ & 0.0000 & $0.000 \mathrm{E}+00$ & 0.0000 & $0.000 \mathrm{E}+00$ & 0.0000 & $3.168 \mathrm{E}-12$ & 0.0000 \\
\hline-237 & $0.000 \mathrm{E}+00$ & 0.0000 & $0.000 \mathrm{E}+00$ & 0.0000 & $0.000 \mathrm{E}+00$ & 0.0000 & $0.000 \mathrm{E}+00$ & 0.0000 & $0.000 \mathrm{E}+00$ & 0.0000 & $0.000 \mathrm{E}+00$ & 0.0000 & $2.362 \mathrm{E}-10$ & 0.0000 \\
\hline-238 & $0.000 \mathrm{E}+00$ & 0.0000 & $0.000 \mathrm{E}+00$ & 0.0000 & $0.000 \mathrm{E}+00$ & 0.0000 & $0.000 \mathrm{E}+00$ & 0.0000 & $0.000 \mathrm{E}+00$ & 0.0000 & $0.000 \mathrm{E}+00$ & 0.0000 & $4.482 \mathrm{E}-12$ & 0.0000 \\
\hline-239 & $0.000 \mathrm{E}+00$ & 0.0000 & $0.000 \mathrm{E}+00$ & 0.0000 & $0.000 \mathrm{E}+00$ & 0.0000 & $0.000 \mathrm{E}+00$ & 0.0000 & $0.000 \mathrm{E}+00$ & 0.0000 & $0.000 \mathrm{E}+00$ & 0.0000 & $3.476 \mathrm{E}-14$ & 0.0000 \\
\hline-240 & $0.000 \mathrm{E}+00$ & 0.0000 & $0.000 \mathrm{E}+00$ & 0.0000 & $0.000 \mathrm{E}+00$ & 0.0000 & $0.000 \mathrm{E}+00$ & 0.0000 & $0.000 \mathrm{E}+00$ & 0.0000 & $0.000 \mathrm{E}+00$ & 0.0000 & $4.219 \mathrm{E}-17$ & 0.0000 \\
\hline 99 & $0.000 \mathrm{E}+00$ & 0.0000 & $0.000 \mathrm{E}+00$ & 0.0000 & $0.000 \mathrm{E}+00$ & 0.0000 & $0.000 \mathrm{E}+00$ & 0.0000 & $0.000 \mathrm{E}+00$ & 0.0000 & $0.000 \mathrm{E}+00$ & 0.0000 & $6.452 \mathrm{E}-22$ & 0.0000 \\
\hline-228 & $0.000 \mathrm{E}+00$ & 0.0000 & $0.000 \mathrm{E}+00$ & 0.0000 & $0.000 \mathrm{E}+00$ & 0.0000 & $0.000 \mathrm{E}+00$ & 0.0000 & $0.000 \mathrm{E}+00$ & 0.0000 & $0.000 \mathrm{E}+00$ & 0.0000 & $0.000 \mathrm{E}+00$ & 0.0000 \\
\hline-230 & $0.000 \mathrm{E}+00$ & 0.0000 & $0.000 \mathrm{E}+00$ & 0.0000 & $0.000 \mathrm{E}+00$ & 0.0000 & $0.000 \mathrm{E}+00$ & 0.0000 & $0.000 \mathrm{E}+00$ & 0.0000 & $0.000 \mathrm{E}+00$ & 0.0000 & $2.193 E-05$ & 0.4425 \\
\hline-232 & $0.000 \mathrm{E}+00$ & 0.0000 & $0.000 \mathrm{E}+00$ & 0.0000 & $0.000 \mathrm{E}+00$ & 0.0000 & $0.000 \mathrm{E}+00$ & 0.0000 & $0.000 \mathrm{E}+00$ & 0.0000 & $0.000 \mathrm{E}+00$ & 0.0000 & $2.730 \mathrm{E}-05$ & 0.5508 \\
\hline 234 & $0.000 \mathrm{E}+00$ & 0.0000 & $0.000 \mathrm{E}+00$ & 0.0000 & $0.000 \mathrm{E}+00$ & 0.0000 & $0.000 \mathrm{E}+00$ & 0.0000 & $0.000 \mathrm{E}+00$ & 0.0000 & $0.000 \mathrm{E}+00$ & 0.0000 & $8.184 \mathrm{E}-08$ & 0.0017 \\
\hline 35 & $0.000 \mathrm{E}+00$ & 0.0000 & $0.000 \mathrm{E}+00$ & 0.0000 & $0.000 \mathrm{E}+00$ & 0.0000 & $0.000 \mathrm{E}+00$ & 0.0000 & $0.000 \mathrm{E}+00$ & 0.0000 & $0.000 \mathrm{E}+00$ & 0.0000 & $9.380 \mathrm{E}-11$ & 0.0000 \\
\hline 38 & $0.000 \mathrm{E}+00$ & 0.0000 & $0.000 \mathrm{E}+00$ & 0.0000 & $0.000 \mathrm{E}+00$ & 0.0000 & $0.000 \mathrm{E}+00$ & 0.0000 & $0.000 \mathrm{E}+00$ & 0.0000 & $0.000 \mathrm{E}+00$ & 0.0000 & $2.523 E-07$ & 0.0051 \\
\hline & $0.000 \mathrm{E}+00$ & 0.0000 & $0.000 \mathrm{E}+00$ & 0.0000 & $0.000 \mathrm{E}+00$ & 0.0000 & $0.000 \mathrm{E}+00$ & 0.0000 & $0.000 \mathrm{E}+00$ & 0.0000 & $0.000 \mathrm{E}+00$ & 0.0000 & $4.957 E-05$ & 1.0000 \\
\hline
\end{tabular}

* Sum of all water independent and dependent pathways. 
RESRAD, Version 6.5

$\mathrm{T}^{1 / 2}$ Limit $=180$ days

Summary : C746U Worker Deterministic Run
File : X: $\backslash F I N A L$ V2 $\backslash$ DOE FWD RUNS $\backslash C 746 U$ W DOE SG FWD-FV2-100000YR.RAD

Total Dose Contributions TDOSE(i,p,t) for Individual Radionuclides (i) and Pathways (p) As mrem/yr and Fraction of Total Dose At $t=1.050 \mathrm{E}+03$ years

Water Independent Pathways (Inhalation excludes radon)

\begin{tabular}{|c|c|c|}
\hline clide & mrem/yr & fract. \\
\hline-241 & $9.032 \mathrm{E}-11$ & 0.0000 \\
\hline-137 & $9.832 \mathrm{E}-16$ & 0.0000 \\
\hline-237 & $8.468 E-08$ & 0.0000 \\
\hline-238 & $1.044 \mathrm{E}-09$ & 0.0000 \\
\hline-239 & $2.474 \mathrm{E}-11$ & 0.0000 \\
\hline-240 & $5.993 \mathrm{E}-15$ & 0.0000 \\
\hline-99 & 1. $362 \mathrm{E}-18$ & 0.0000 \\
\hline-228 & $0.000 \mathrm{E}+00$ & 0.0000 \\
\hline-230 & $1.840 \mathrm{E}-03$ & 0.6991 \\
\hline-232 & $7.565 \mathrm{E}-04$ & 0.2874 \\
\hline 34 & $1.495 E-05$ & 0.0057 \\
\hline 35 & $3.148 \mathrm{E}-08$ & 0.0000 \\
\hline 38 & $2.047 \mathrm{E}-05$ & 0.0078 \\
\hline & 2.63 & 1.0000 \\
\hline
\end{tabular}

Inhalation

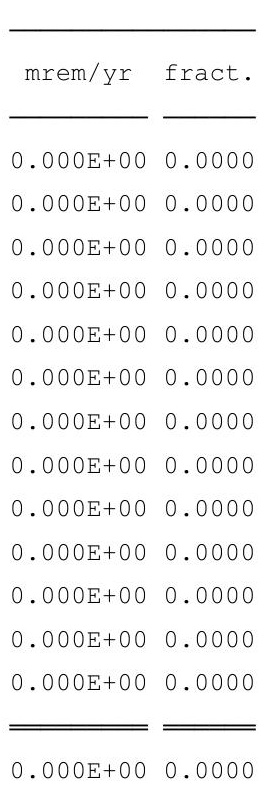

Radon

$\longrightarrow$

mrem/yr fract.

$0.000 E+00 \quad 0.0000$

$0.000 E+00 \quad 0.0000$

$0.000 \mathrm{E}+00 \quad 0.0000$

$0.000 E+00 \quad 0.0000$

$0.000 \mathrm{E}+00 \quad 0.0000$

$0.000 E+00 \quad 0.0000$

$0.000 E+00 \quad 0.0000$

$0.000 E+00 \quad 0.0000$

$0.000 E+00 \quad 0.0000$

$0.000 E+00 \quad 0.0000$

$0.000 \mathrm{E}+00 \quad 0.0000$

$0.000 E+00 \quad 0.0000$

$0.000 \mathrm{E}+00 \quad 0.0000$

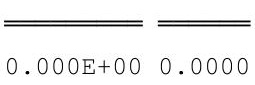

Plant

\section{mrem/yr fract.}

$\longrightarrow$

$0.000 \mathrm{E}+00 \quad 0.0000$

$0.000 \mathrm{E}+00 \quad 0.0000$

$0.000 \mathrm{E}+00 \quad 0.0000$

$0.000 \mathrm{E}+00 \quad 0.0000$

$0.000 \mathrm{E}+00 \quad 0.0000$

$0.000 \mathrm{E}+00 \quad 0.0000$

$0.000 \mathrm{E}+00 \quad 0.0000$

$0.000 \mathrm{E}+00 \quad 0.0000$

$0.000 \mathrm{E}+00 \quad 0.0000$

$0.000 \mathrm{E}+00 \quad 0.0000$

$0.000 \mathrm{E}+00 \quad 0.0000$

$0.000 \mathrm{E}+00 \quad 0.0000$

$0.000 \mathrm{E}+00 \quad 0.0000$

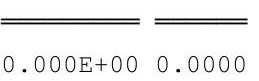

\begin{tabular}{cc} 
Meat \\
\hline mrem/yr fract. \\
& - \\
$0.000 \mathrm{E}+00$ & 0.0000 \\
$0.000 \mathrm{E}+00$ & 0.0000 \\
$0.000 \mathrm{E}+00$ & 0.0000 \\
$0.000 \mathrm{E}+00$ & 0.0000 \\
$0.000 \mathrm{E}+00$ & 0.0000 \\
$0.000 \mathrm{E}+00$ & 0.0000 \\
$0.000 \mathrm{E}+00$ & 0.0000 \\
$0.000 \mathrm{E}+00$ & 0.0000 \\
$0.000 \mathrm{E}+00$ & 0.0000 \\
$0.000 \mathrm{E}+00$ & 0.0000 \\
$0.000 \mathrm{E}+00$ & 0.0000 \\
$0.000 \mathrm{E}+00$ & 0.0000 \\
$0.000 \mathrm{E}+00$ & 0.0000 \\
\hline \hline $0.000 \mathrm{E}+00$ & 0.0000
\end{tabular}

\begin{tabular}{cc} 
Milk \\
\hline mrem/yr fract. \\
\cline { 1 - 2 } $0.000 \mathrm{E}+00$ & 0.0000 \\
$0.000 \mathrm{E}+00$ & 0.0000 \\
$0.000 \mathrm{E}+00$ & 0.0000 \\
$0.000 \mathrm{E}+00$ & 0.0000 \\
$0.000 \mathrm{E}+00$ & 0.0000 \\
$0.000 \mathrm{E}+00$ & 0.0000 \\
$0.000 \mathrm{E}+00$ & 0.0000 \\
$0.000 \mathrm{E}+00$ & 0.0000 \\
$0.000 \mathrm{E}+00$ & 0.0000 \\
$0.000 \mathrm{E}+00$ & 0.0000 \\
$0.000 \mathrm{E}+00$ & 0.0000 \\
$0.000 \mathrm{E}+00$ & 0.0000 \\
$0.000 \mathrm{E}+00$ & 0.0000 \\
\hline \hline $0.000 \mathrm{E}+00$ & 0.0000
\end{tabular}

Soil

mrem/yr fract.

$0.000 \mathrm{E}+00 \quad 0.0000$

$0.000 \mathrm{E}+00 \quad 0.0000$

$0.000 \mathrm{E}+00 \quad 0.0000$

$0.000 \mathrm{E}+00 \quad 0.0000$

$0.000 \mathrm{E}+00 \quad 0.0000$

$0.000 \mathrm{E}+00 \quad 0.0000$

$0.000 \mathrm{E}+00 \quad 0.0000$

$0.000 \mathrm{E}+00 \quad 0.0000$

$0.000 \mathrm{E}+00 \quad 0.0000$

$0.000 \mathrm{E}+00 \quad 0.0000$

$0.000 \mathrm{E}+00 \quad 0.0000$

$0.000 \mathrm{E}+00 \quad 0.0000$

$0.000 \mathrm{E}+00 \quad 0.0000$

$0.000 \mathrm{E}+00 \quad 0.0000$

Total Dose Contributions TDOSE (i,p,t) for Individual Radionuclides (i) and Pathways (p) As mrem/yr and Fraction of Total Dose At $t=1.050 \mathrm{E}+03$ years

Water Dependent Pathways

\begin{tabular}{|c|c|c|c|c|c|c|}
\hline & \multicolumn{2}{|c|}{ Water } & \multicolumn{2}{|c|}{ Fish } & \multicolumn{2}{|c|}{ Radon } \\
\hline clide & mrem/yr & fract. & mrem/yr & fract. & mrem/yr & fract. \\
\hline-241 & $0.000 \mathrm{E}+00$ & 0.0000 & $0.000 \mathrm{E}+00$ & 0.0000 & $0.000 \mathrm{E}+00$ & 0.0000 \\
\hline-137 & $0.000 \mathrm{E}+00$ & 0.0000 & $0.000 \mathrm{E}+00$ & 0.0000 & $0.000 \mathrm{E}+00$ & 0.0000 \\
\hline-237 & $0.000 \mathrm{E}+00$ & 0.0000 & $0.000 \mathrm{E}+00$ & 0.0000 & $0.000 \mathrm{E}+00$ & 0.0000 \\
\hline-238 & $0.000 \mathrm{E}+00$ & 0.0000 & $0.000 \mathrm{E}+00$ & 0.0000 & $0.000 \mathrm{E}+00$ & 0.0000 \\
\hline-239 & $0.000 \mathrm{E}+00$ & 0.0000 & $0.000 \mathrm{E}+00$ & 0.0000 & $0.000 \mathrm{E}+00$ & 0.0000 \\
\hline-240 & $0.000 \mathrm{E}+00$ & 0.0000 & $0.000 \mathrm{E}+00$ & 0.0000 & $0.000 \mathrm{E}+00$ & 0.0000 \\
\hline 99 & $0.000 \mathrm{E}+00$ & 0.0000 & $0.000 \mathrm{E}+00$ & 0.0000 & $0.000 \mathrm{E}+00$ & 0.0000 \\
\hline-228 & $0.000 \mathrm{E}+00$ & 0.0000 & $0.000 \mathrm{E}+00$ & 0.0000 & $0.000 \mathrm{E}+00$ & 0.0000 \\
\hline-230 & $0.000 \mathrm{E}+00$ & 0.0000 & $0.000 \mathrm{E}+00$ & 0.0000 & $0.000 \mathrm{E}+00$ & 0.0000 \\
\hline 232 & $0.000 \mathrm{E}+00$ & 0.0000 & $0.000 \mathrm{E}+00$ & 0.0000 & $0.000 \mathrm{E}+00$ & 0.0000 \\
\hline 234 & $0.000 \mathrm{E}+00$ & 0.0000 & $0.000 \mathrm{E}+00$ & 0.0000 & $0.000 \mathrm{E}+00$ & 0.0000 \\
\hline 235 & $0.000 \mathrm{E}+00$ & 0.0000 & $0.000 \mathrm{E}+00$ & 0.0000 & $0.000 \mathrm{E}+00$ & 0.0000 \\
\hline 238 & $0.000 \mathrm{E}+00$ & 0.0000 & $0.000 \mathrm{E}+00$ & 0.0000 & $0.000 \mathrm{E}+00$ & 0.0000 \\
\hline & $0.000 \mathrm{E}+00$ & 0.0000 & $0.000 \mathrm{E}+00$ & 0.0000 & $0.000 \mathrm{E}+00$ & 0.0000 \\
\hline
\end{tabular}

\begin{tabular}{|c|c|c|c|}
\hline \multicolumn{2}{|c|}{ Plant } & \multicolumn{2}{|c|}{ Meat } \\
\hline mrem/yr & fract. & mrem/yr & fract. \\
\hline $0.000 \mathrm{E}+00$ & 0.0000 & $0.000 \mathrm{E}+00$ & 0.0000 \\
\hline $0.000 \mathrm{E}+00$ & 0.0000 & $0.000 \mathrm{E}+00$ & 0.0000 \\
\hline $0.000 \mathrm{E}+00$ & 0.0000 & $0.000 \mathrm{E}+00$ & 0.0000 \\
\hline $0.000 \mathrm{E}+00$ & 0.0000 & $0.000 \mathrm{E}+00$ & 0.0000 \\
\hline $0.000 \mathrm{E}+00$ & 0.0000 & $0.000 \mathrm{E}+00$ & 0.0000 \\
\hline $0.000 \mathrm{E}+00$ & 0.0000 & $0.000 \mathrm{E}+00$ & 0.0000 \\
\hline $0.000 \mathrm{E}+00$ & 0.0000 & $0.000 \mathrm{E}+00$ & 0.0000 \\
\hline $0.000 \mathrm{E}+00$ & 0.0000 & $0.000 \mathrm{E}+00$ & 0.0000 \\
\hline $0.000 \mathrm{E}+00$ & 0.0000 & $0.000 \mathrm{E}+00$ & 0.0000 \\
\hline $0.000 \mathrm{E}+00$ & 0.0000 & $0.000 \mathrm{E}+00$ & 0.0000 \\
\hline $0.000 \mathrm{E}+00$ & 0.0000 & $0.000 \mathrm{E}+00$ & 0.0000 \\
\hline $0.000 \mathrm{E}+00$ & 0.0000 & $0.000 \mathrm{E}+00$ & 0.0000 \\
\hline $0.000 \mathrm{E}+00$ & 0.0000 & $0.000 \mathrm{E}+00$ & 0.0000 \\
\hline
\end{tabular}

$0.000 \mathrm{E}+00 \quad 0.0000$

$0.000 \mathrm{E}+00 \quad 0.0000$

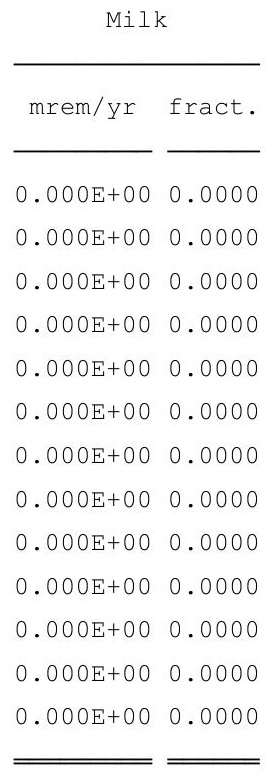

$0.000 \mathrm{E}+00 \quad 0.0000$
All Pathways *

mrem/yr fract.

$9.032 \mathrm{E}-110.0000$

$9.832 \mathrm{E}-160.0000$

$8.468 \mathrm{E}-08 \quad 0.0000$

$1.044 \mathrm{E}-090.0000$

$2.474 \mathrm{E}-110.0000$

$5.993 \mathrm{E}-150.0000$

1.362E-18 0.0000

$0.000 \mathrm{E}+00 \quad 0.0000$

$1.840 \mathrm{E}-03 \quad 0.6991$

$7.565 \mathrm{E}-04 \quad 0.2874$

$1.495 \mathrm{E}-050.0057$

$3.148 \mathrm{E}-08 \quad 0.0000$

$2.047 \mathrm{E}-05 \quad 0.0078$

$2.632 E-031.0000$

* Sum of all water independent and dependent pathways. 
RESRAD, Version 6.5

$\mathrm{T}^{1} \frac{1}{2}$ Limit $=180$ days

07/18/2011 15:12 Page

Summary : C746U Worker Deterministic Run
File : X: \FINAL V2\DOE FWD RUNS \C746U W DOE SG FWD-FV2-100000YR.RAD

Total Dose Contributions TDOSE(i,p,t) for Individual Radionuclides (i) and Pathways (p) As mrem/yr and Fraction of Total Dose At $t=1.000 \mathrm{E}+04$ years

Water Independent Pathways (Inhalation excludes radon)

\begin{tabular}{|c|c|c|}
\hline clide & mrem/yr & fract. \\
\hline-241 & $5.891 \mathrm{E}-04$ & 0.0000 \\
\hline-137 & $0.000 \mathrm{E}+00$ & 0.0000 \\
\hline-237 & $4.387 \mathrm{E}-01$ & 0.0020 \\
\hline-238 & $1.481 \mathrm{E}-03$ & 0.0000 \\
\hline-239 & $1.122 \mathrm{E}-03$ & 0.0000 \\
\hline-240 & $2.161 \mathrm{E}-04$ & 0.0000 \\
\hline-99 & $1.346 \mathrm{E}-26$ & 0.0000 \\
\hline-228 & $0.000 \mathrm{E}+00$ & 0.0000 \\
\hline-230 & $1.560 \mathrm{E}+02$ & 0.7165 \\
\hline-232 & $1.001 \mathrm{E}+01$ & 0.0460 \\
\hline 234 & $1.720 \mathrm{E}+01$ & 0.0790 \\
\hline 235 & $1.036 \mathrm{E}+00$ & 0.0048 \\
\hline 238 & $3.831 E+00$ & 0.0176 \\
\hline & $+0<$ & 0.8659 \\
\hline
\end{tabular}

\begin{abstract}
Inhalation
\end{abstract}

mrem/yr fract.

$\overline{3.560 \mathrm{E}-07} 0.0000$

$0.000 \mathrm{E}+00 \quad 0.0000$

$2.675 E-040.0000$

$4.464 \mathrm{E}-07 \quad 0.0000$

$5.517 E-030.0000$

$2.548 E-030.0000$

$0.000 E+00 \quad 0.0000$

$0.000 \mathrm{E}+00 \quad 0.0000$

2.017E-02 0.0001

$1.256 \mathrm{E}-030.0000$

$5.136 \mathrm{E}-030.0000$

$1.561 \mathrm{E}-03 \quad 0.0000$

$2.216 \mathrm{E}-03 \quad 0.0000$

$\overline{\overline{3.867 \mathrm{E}-02}} \overline{\overline{0.0002}}$

Radon
mrem/yr fract. $\overline{0.000 E+00} 0.0000$ $0.000 \mathrm{E}+00 \quad 0.0000$ $0.000 E+00 \quad 0.0000$ $0.000 \mathrm{E}+00 \quad 0.0000$ $0.000 E+00 \quad 0.0000$ $0.000 E+00 \quad 0.0000$ $0.000 E+00 \quad 0.0000$ $0.000 \mathrm{E}+00 \quad 0.0000$ $0.000 \mathrm{E}+00 \quad 0.0000$ $0.000 \mathrm{E}+00 \quad 0.0000$ $0.000 \mathrm{E}+00 \quad 0.0000$ $0.000 \mathrm{E}+00 \quad 0.0000$ $0.000 \mathrm{E}+00 \quad 0.0000$

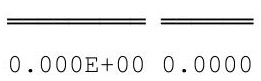

\begin{tabular}{|c|c|c|c|}
\hline \multicolumn{2}{|c|}{ Plant } & \multicolumn{2}{|c|}{ Meat } \\
\hline mrem/yr & fract. & mrem/yr & fract. \\
\hline $.000 \mathrm{E}+00$ & 0.0000 & $0.000 \mathrm{E}+00$ & 0.0000 \\
\hline $0.000 \mathrm{E}+00$ & 0.0000 & $0.000 \mathrm{E}+00$ & 0.0000 \\
\hline $0.000 \mathrm{E}+00$ & 0.0000 & $0.000 \mathrm{E}+00$ & 0.0000 \\
\hline $0.000 \mathrm{E}+00$ & 0.0000 & $0.000 \mathrm{E}+00$ & 0.0000 \\
\hline $0.000 \mathrm{E}+00$ & 0.0000 & $0.000 \mathrm{E}+00$ & 0.0000 \\
\hline $0.000 \mathrm{E}+00$ & 0.0000 & $0.000 \mathrm{E}+00$ & 0.0000 \\
\hline $0.000 \mathrm{E}+00$ & 0.0000 & $0.000 \mathrm{E}+00$ & 0.0000 \\
\hline $0.000 \mathrm{E}+00$ & 0.0000 & $0.000 \mathrm{E}+00$ & 0.0000 \\
\hline $0.000 \mathrm{E}+00$ & 0.0000 & $0.000 \mathrm{E}+00$ & 0.0000 \\
\hline $0.000 \mathrm{E}+00$ & 0.0000 & $0.000 \mathrm{E}+00$ & 0.0000 \\
\hline $0.000 \mathrm{E}+00$ & 0.0000 & $0.000 \mathrm{E}+00$ & 0.0000 \\
\hline $0.000 \mathrm{E}+00$ & 0.0000 & $0.000 \mathrm{E}+00$ & 0.0000 \\
\hline $0.000 \mathrm{E}+00$ & 0.0000 & $0.000 \mathrm{E}+00$ & 0.0000 \\
\hline & & 0.00 & . \\
\hline
\end{tabular}

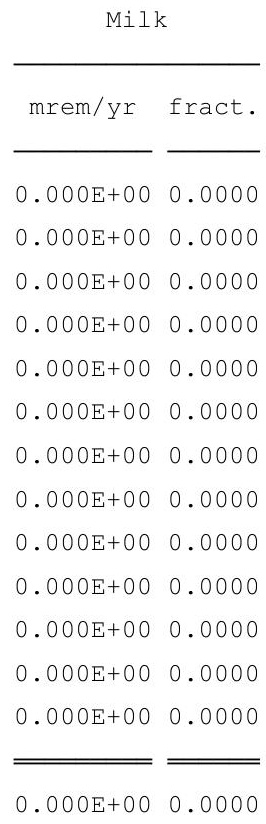

Soil mrem/yr fract. 4.717E-05 0.0000 $0.000 \mathrm{E}+00 \quad 0.0000$ $3.551 \mathrm{E}-02 \quad 0.0002$ 2.897E-04 0.0000 $6.729 \mathrm{E}-010.0031$ $3.109 \mathrm{E}-010.0014$ $5.194 \mathrm{E}-260.0000$ $0.000 \mathrm{E}+00 \quad 0.0000$ $2.328 \mathrm{E}+010.1069$ $4.605 \mathrm{E}-010.0021$ $3.352 \mathrm{E}+00 \quad 0.0154$ $2.624 \mathrm{E}-010.0012$ $8.012 \mathrm{E}-010.0037$ $2.917 \mathrm{E}+01 \quad 0.1340$

Total Dose Contributions TDOSE (i,p,t) for Individual Radionuclides (i) and Pathways (p) As mrem/yr and Fraction of Total Dose At $t=1.000 \mathrm{E}+04$ years

Water Dependent Pathways

\begin{tabular}{|c|c|c|c|c|c|c|}
\hline & \multicolumn{2}{|c|}{ Water } & \multicolumn{2}{|c|}{ Fish } & \multicolumn{2}{|c|}{ Radon } \\
\hline clide & mrem/yr & fract. & mrem/yr & fract. & mrem/yr & fract. \\
\hline 41 & $0.000 \mathrm{E}+00$ & 0.0000 & $0.000 \mathrm{E}+00$ & 0.0000 & $0.000 \mathrm{E}+00$ & 0.0000 \\
\hline-137 & $0.000 \mathrm{E}+00$ & 0.0000 & $0.000 \mathrm{E}+00$ & 0.0000 & $0.000 \mathrm{E}+00$ & 0.0000 \\
\hline-237 & $0.000 \mathrm{E}+00$ & 0.0000 & $0.000 \mathrm{E}+00$ & 0.0000 & $0.000 \mathrm{E}+00$ & 0.0000 \\
\hline-238 & $0.000 \mathrm{E}+00$ & 0.0000 & $0.000 \mathrm{E}+00$ & 0.0000 & $0.000 \mathrm{E}+00$ & 0.0000 \\
\hline-239 & $0.000 \mathrm{E}+00$ & 0.0000 & $0.000 \mathrm{E}+00$ & 0.0000 & $0.000 \mathrm{E}+00$ & 0.0000 \\
\hline-240 & $0.000 \mathrm{E}+00$ & 0.0000 & $0.000 \mathrm{E}+00$ & 0.0000 & $0.000 \mathrm{E}+00$ & 0.0000 \\
\hline-99 & $0.000 \mathrm{E}+00$ & 0.0000 & $0.000 \mathrm{E}+00$ & 0.0000 & $0.000 \mathrm{E}+00$ & 0.0000 \\
\hline-228 & $0.000 \mathrm{E}+00$ & 0.0000 & $0.000 \mathrm{E}+00$ & 0.0000 & $0.000 \mathrm{E}+00$ & 0.0000 \\
\hline-230 & $0.000 \mathrm{E}+00$ & 0.0000 & $0.000 \mathrm{E}+00$ & 0.0000 & $0.000 \mathrm{E}+00$ & 0.0000 \\
\hline-232 & $0.000 \mathrm{E}+00$ & 0.0000 & $0.000 \mathrm{E}+00$ & 0.0000 & $0.000 \mathrm{E}+00$ & 0.0000 \\
\hline 234 & $0.000 \mathrm{E}+00$ & 0.0000 & $0.000 \mathrm{E}+00$ & 0.0000 & $0.000 \mathrm{E}+00$ & 0.0000 \\
\hline 35 & $0.000 \mathrm{E}+00$ & 0.0000 & $0.000 \mathrm{E}+00$ & 0.0000 & $0.000 \mathrm{E}+00$ & 0.0000 \\
\hline 38 & $0.000 \mathrm{E}+00$ & 0.0000 & $0.000 \mathrm{E}+00$ & 0.0000 & $0.000 \mathrm{E}+00$ & 0.0000 \\
\hline & $0.000 \mathrm{E}+00$ & 0.0000 & $0.000 \mathrm{E}+00$ & 0.0000 & $0.000 \mathrm{E}+00$ & 0.0000 \\
\hline
\end{tabular}

\begin{tabular}{|c|c|c|c|}
\hline \multicolumn{2}{|c|}{ Plant } & \multicolumn{2}{|c|}{ Meat } \\
\hline mrem/yr & fract. & mrem/yr & fract. \\
\hline $0.000 \mathrm{E}+00$ & 0.0000 & $0.000 \mathrm{E}+00$ & 0.0000 \\
\hline $0.000 \mathrm{E}+00$ & 0.0000 & $0.000 \mathrm{E}+00$ & 0.0000 \\
\hline $0.000 \mathrm{E}+00$ & 0.0000 & $0.000 \mathrm{E}+00$ & 0.0000 \\
\hline $0.000 \mathrm{E}+00$ & 0.0000 & $0.000 \mathrm{E}+00$ & 0.0000 \\
\hline $0.000 \mathrm{E}+00$ & 0.0000 & $0.000 \mathrm{E}+00$ & 0.0000 \\
\hline $0.000 \mathrm{E}+00$ & 0.0000 & $0.000 \mathrm{E}+00$ & 0.0000 \\
\hline $0.000 \mathrm{E}+00$ & 0.0000 & $0.000 \mathrm{E}+00$ & 0.0000 \\
\hline $0.000 \mathrm{E}+00$ & 0.0000 & $0.000 \mathrm{E}+00$ & 0.0000 \\
\hline $0.000 \mathrm{E}+00$ & 0.0000 & $0.000 \mathrm{E}+00$ & 0.0000 \\
\hline $0.000 \mathrm{E}+00$ & 0.0000 & $0.000 \mathrm{E}+00$ & 0.0000 \\
\hline $0.000 \mathrm{E}+00$ & 0.0000 & $0.000 \mathrm{E}+00$ & 0.0000 \\
\hline $0.000 \mathrm{E}+00$ & 0.0000 & $0.000 \mathrm{E}+00$ & 0.0000 \\
\hline $0.000 \mathrm{E}+00$ & 0.0000 & $0.000 \mathrm{E}+00$ & 0.0000 \\
\hline
\end{tabular}

$0.000 \mathrm{E}+00 \quad 0.0000$

$0.000 \mathrm{E}+00 \quad 0.0000$

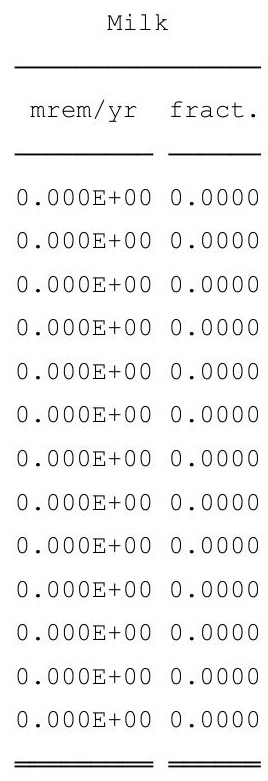

$0.000 \mathrm{E}+00 \quad 0.0000$
All Pathways* mrem/yr fract. 6.367E-04 0.0000 $0.000 \mathrm{E}+00 \quad 0.0000$ $4.744 \mathrm{E}-010.0022$ $1.771 \mathrm{E}-03 \quad 0.0000$ $6.796 \mathrm{E}-010.0031$ $3.136 \mathrm{E}-010.0014$ $6.540 \mathrm{E}-26 \quad 0.0000$ $0.000 \mathrm{E}+00 \quad 0.0000$ $1.793 \mathrm{E}+02 \quad 0.8235$ $1.047 \mathrm{E}+01 \quad 0.0481$ $2.056 \mathrm{E}+01 \quad 0.0944$ $1.300 \mathrm{E}+00 \quad 0.0060$ $4.635 \mathrm{E}+00 \quad 0.0213$ $2.178 \mathrm{E}+02 \quad 1.0000$

* Sum of all water independent and dependent pathways. 
RESRAD, Version 6.5

$\mathrm{T}^{1 / 2}$ Limit $=180$ days

Summary : C746U Worker Deterministic Run
File : X: \FINAL V2\DOE FWD RUNS \C746U W DOE SG FWD-FV2-100000YR.RAD

Total Dose Contributions TDOSE(i,p,t) for Individual Radionuclides (i) and Pathways (p) As mrem/yr and Fraction of Total Dose At $t=1.000 \mathrm{E}+05$ years

Water Independent Pathways (Inhalation excludes radon)

\begin{tabular}{|c|c|c|}
\hline clide & mrem/yr & fract. \\
\hline-241 & $0.000 \mathrm{E}+00$ & 0.0000 \\
\hline-137 & $0.000 \mathrm{E}+00$ & 0.0000 \\
\hline-237 & $0.000 \mathrm{E}+00$ & 0.0000 \\
\hline-238 & $0.000 \mathrm{E}+00$ & 0.0000 \\
\hline-239 & $0.000 \mathrm{E}+00$ & 0.0000 \\
\hline-240 & $0.000 \mathrm{E}+00$ & 0.0000 \\
\hline-99 & $0.000 \mathrm{E}+00$ & 0.0000 \\
\hline-228 & $0.000 \mathrm{E}+00$ & 0.0000 \\
\hline-230 & $0.000 \mathrm{E}+00$ & 0.0000 \\
\hline-232 & $0.000 \mathrm{E}+00$ & 0.0000 \\
\hline 34 & $0.000 \mathrm{E}+00$ & 0.0000 \\
\hline 235 & $0.000 \mathrm{E}+00$ & 0.0000 \\
\hline 38 & $0.000 \mathrm{E}+00$ & 0.0000 \\
\hline & 0.000 & 0.0000 \\
\hline
\end{tabular}

Radio-

Total

$0.000 \mathrm{E}+00 \quad 0.0000$

Inhalation

\section{mrem/yr fract.}

$\overline{0.000 \mathrm{E}+00} \overline{0.0000}$

$0.000 \mathrm{E}+00 \quad 0.0000$

$0.000 \mathrm{E}+00 \quad 0.0000$

$0.000 \mathrm{E}+00 \quad 0.0000$

$0.000 \mathrm{E}+00 \quad 0.0000$

$0.000 \mathrm{E}+00 \quad 0.0000$

$0.000 E+00 \quad 0.0000$

$0.000 \mathrm{E}+00 \quad 0.0000$

$0.000 \mathrm{E}+00 \quad 0.0000$

$0.000 \mathrm{E}+00 \quad 0.0000$

$0.000 \mathrm{E}+00 \quad 0.0000$

$0.000 E+00 \quad 0.0000$

$0.000 \mathrm{E}+00 \quad 0.0000$

$\overline{\overline{0.000 \mathrm{E}+00}} \overline{\overline{0.0000}}$

Radon
mrem/yr fract. $\overline{0.000 \mathrm{E}+00} \overline{0.0000}$ $0.000 E+00 \quad 0.0000$ $0.000 E+00 \quad 0.0000$ $0.000 E+00 \quad 0.0000$ $0.000 \mathrm{E}+00 \quad 0.0000$ $0.000 E+00 \quad 0.0000$ $0.000 E+00 \quad 0.0000$ $0.000 \mathrm{E}+00 \quad 0.0000$ $0.000 \mathrm{E}+00 \quad 0.0000$ $0.000 \mathrm{E}+00 \quad 0.0000$ $0.000 \mathrm{E}+00 \quad 0.0000$ $0.000 \mathrm{E}+00 \quad 0.0000$ $0.000 \mathrm{E}+00 \quad 0.0000$

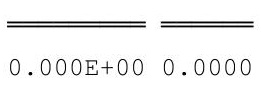

\begin{tabular}{|c|c|c|c|}
\hline \multicolumn{2}{|c|}{ Plant } & \multicolumn{2}{|c|}{ Meat } \\
\hline mrem/yr & fract. & mrem/yr & fract. \\
\hline $.000 \mathrm{E}+00$ & 0.0000 & $0.000 \mathrm{E}+00$ & 0.0000 \\
\hline $0.000 \mathrm{E}+00$ & 0.0000 & $0.000 \mathrm{E}+00$ & 0.0000 \\
\hline $0.000 \mathrm{E}+00$ & 0.0000 & $0.000 \mathrm{E}+00$ & 0.0000 \\
\hline $0.000 \mathrm{E}+00$ & 0.0000 & $0.000 \mathrm{E}+00$ & 0.0000 \\
\hline $0.000 \mathrm{E}+00$ & 0.0000 & $0.000 \mathrm{E}+00$ & 0.0000 \\
\hline $0.000 \mathrm{E}+00$ & 0.0000 & $0.000 \mathrm{E}+00$ & 0.0000 \\
\hline $0.000 \mathrm{E}+00$ & 0.0000 & $0.000 \mathrm{E}+00$ & 0.0000 \\
\hline $0.000 \mathrm{E}+00$ & 0.0000 & $0.000 \mathrm{E}+00$ & 0.0000 \\
\hline $0.000 \mathrm{E}+00$ & 0.0000 & $0.000 \mathrm{E}+00$ & 0.0000 \\
\hline $0.000 \mathrm{E}+00$ & 0.0000 & $0.000 \mathrm{E}+00$ & 0.0000 \\
\hline $0.000 \mathrm{E}+00$ & 0.0000 & $0.000 \mathrm{E}+00$ & 0.0000 \\
\hline $0.000 \mathrm{E}+00$ & 0.0000 & $0.000 \mathrm{E}+00$ & 0.0000 \\
\hline $0.000 \mathrm{E}+00$ & 0.0000 & $0.000 \mathrm{E}+00$ & 0.0000 \\
\hline & & 0.00 & . \\
\hline
\end{tabular}

\begin{tabular}{cc} 
Milk \\
\hline mrem/yr fract. \\
\cline { 1 - 2 } $0.000 \mathrm{E}+00$ & 0.0000 \\
$0.000 \mathrm{E}+00$ & 0.0000 \\
$0.000 \mathrm{E}+00$ & 0.0000 \\
$0.000 \mathrm{E}+00$ & 0.0000 \\
$0.000 \mathrm{E}+00$ & 0.0000 \\
$0.000 \mathrm{E}+00$ & 0.0000 \\
$0.000 \mathrm{E}+00$ & 0.0000 \\
$0.000 \mathrm{E}+00$ & 0.0000 \\
$0.000 \mathrm{E}+00$ & 0.0000 \\
$0.000 \mathrm{E}+00$ & 0.0000 \\
$0.000 \mathrm{E}+00$ & 0.0000 \\
$0.000 \mathrm{E}+00$ & 0.0000 \\
$0.000 \mathrm{E}+00$ & 0.0000 \\
\hline \hline $0.000 \mathrm{E}+00$ & 0.0000
\end{tabular}

Soil mrem/yr fract. $0.000 \mathrm{E}+00 \quad 0.0000$ $0.000 \mathrm{E}+00 \quad 0.0000$ $0.000 \mathrm{E}+00 \quad 0.0000$ $0.000 \mathrm{E}+00 \quad 0.0000$ $0.000 \mathrm{E}+00 \quad 0.0000$ $0.000 \mathrm{E}+00 \quad 0.0000$ $0.000 \mathrm{E}+00 \quad 0.0000$ $0.000 \mathrm{E}+00 \quad 0.0000$ $0.000 \mathrm{E}+00 \quad 0.0000$ $0.000 \mathrm{E}+00 \quad 0.0000$ $0.000 \mathrm{E}+00 \quad 0.0000$ $0.000 \mathrm{E}+00 \quad 0.0000$ $0.000 \mathrm{E}+00 \quad 0.0000$ $0.000 \mathrm{E}+00 \quad 0.0000$

Total Dose Contributions TDOSE (i,p,t) for Individual Radionuclides (i) and Pathways (p) As mrem/yr and Fraction of Total Dose At $t=1.000 \mathrm{E}+05$ years

Water Dependent Pathways

\begin{tabular}{|c|c|c|c|c|c|c|}
\hline & \multicolumn{2}{|c|}{ Water } & \multicolumn{2}{|c|}{ Fish } & \multicolumn{2}{|c|}{ Radon } \\
\hline clide & mrem/yr & fract. & mrem/yr & fract. & mrem/yr & fract. \\
\hline-241 & $0.000 \mathrm{E}+00$ & 0.0000 & $0.000 \mathrm{E}+00$ & 0.0000 & $0.000 \mathrm{E}+00$ & 0.0000 \\
\hline-137 & $0.000 \mathrm{E}+00$ & 0.0000 & $0.000 \mathrm{E}+00$ & 0.0000 & $0.000 \mathrm{E}+00$ & 0.0000 \\
\hline-237 & $0.000 \mathrm{E}+00$ & 0.0000 & $0.000 \mathrm{E}+00$ & 0.0000 & $0.000 \mathrm{E}+00$ & 0.0000 \\
\hline-238 & $0.000 \mathrm{E}+00$ & 0.0000 & $0.000 \mathrm{E}+00$ & 0.0000 & $0.000 \mathrm{E}+00$ & 0.0000 \\
\hline-239 & $0.000 \mathrm{E}+00$ & 0.0000 & $0.000 \mathrm{E}+00$ & 0.0000 & $0.000 \mathrm{E}+00$ & 0.0000 \\
\hline-240 & $0.000 \mathrm{E}+00$ & 0.0000 & $0.000 \mathrm{E}+00$ & 0.0000 & $0.000 \mathrm{E}+00$ & 0.0000 \\
\hline 99 & $0.000 \mathrm{E}+00$ & 0.0000 & $0.000 \mathrm{E}+00$ & 0.0000 & $0.000 \mathrm{E}+00$ & 0.0000 \\
\hline-228 & $0.000 \mathrm{E}+00$ & 0.0000 & $0.000 \mathrm{E}+00$ & 0.0000 & $0.000 \mathrm{E}+00$ & 0.0000 \\
\hline-230 & $0.000 \mathrm{E}+00$ & 0.0000 & $0.000 \mathrm{E}+00$ & 0.0000 & $0.000 \mathrm{E}+00$ & 0.0000 \\
\hline 232 & $0.000 \mathrm{E}+00$ & 0.0000 & $0.000 \mathrm{E}+00$ & 0.0000 & $0.000 \mathrm{E}+00$ & 0.0000 \\
\hline 234 & $0.000 \mathrm{E}+00$ & 0.0000 & $0.000 \mathrm{E}+00$ & 0.0000 & $0.000 \mathrm{E}+00$ & 0.0000 \\
\hline 235 & $0.000 \mathrm{E}+00$ & 0.0000 & $0.000 \mathrm{E}+00$ & 0.0000 & $0.000 \mathrm{E}+00$ & 0.0000 \\
\hline 238 & $0.000 \mathrm{E}+00$ & 0.0000 & $0.000 \mathrm{E}+00$ & 0.0000 & $0.000 \mathrm{E}+00$ & 0.0000 \\
\hline & $0.000 \mathrm{E}+00$ & 0.0000 & $0.000 \mathrm{E}+00$ & 0.0000 & $0.000 \mathrm{E}+00$ & 0.0000 \\
\hline
\end{tabular}

\begin{tabular}{|c|c|c|c|}
\hline \multicolumn{2}{|c|}{ Plant } & \multicolumn{2}{|c|}{ Meat } \\
\hline mrem/yr & fract. & mrem/yr & fract. \\
\hline $0.000 \mathrm{E}+00$ & 0.0000 & $0.000 \mathrm{E}+00$ & 0.0000 \\
\hline $0.000 \mathrm{E}+00$ & 0.0000 & $0.000 \mathrm{E}+00$ & 0.0000 \\
\hline $0.000 \mathrm{E}+00$ & 0.0000 & $0.000 \mathrm{E}+00$ & 0.0000 \\
\hline $0.000 \mathrm{E}+00$ & 0.0000 & $0.000 \mathrm{E}+00$ & 0.0000 \\
\hline $0.000 \mathrm{E}+00$ & 0.0000 & $0.000 \mathrm{E}+00$ & 0.0000 \\
\hline $0.000 \mathrm{E}+00$ & 0.0000 & $0.000 \mathrm{E}+00$ & 0.0000 \\
\hline $0.000 \mathrm{E}+00$ & 0.0000 & $0.000 \mathrm{E}+00$ & 0.0000 \\
\hline $0.000 \mathrm{E}+00$ & 0.0000 & $0.000 \mathrm{E}+00$ & 0.0000 \\
\hline $0.000 \mathrm{E}+00$ & 0.0000 & $0.000 \mathrm{E}+00$ & 0.0000 \\
\hline $0.000 \mathrm{E}+00$ & 0.0000 & $0.000 \mathrm{E}+00$ & 0.0000 \\
\hline $0.000 \mathrm{E}+00$ & 0.0000 & $0.000 \mathrm{E}+00$ & 0.0000 \\
\hline $0.000 \mathrm{E}+00$ & 0.0000 & $0.000 \mathrm{E}+00$ & 0.0000 \\
\hline $0.000 \mathrm{E}+00$ & 0.0000 & $0.000 \mathrm{E}+00$ & 0.0000 \\
\hline
\end{tabular}

$0.000 \mathrm{E}+00 \quad 0.0000$

$0.000 \mathrm{E}+00 \quad 0.0000$

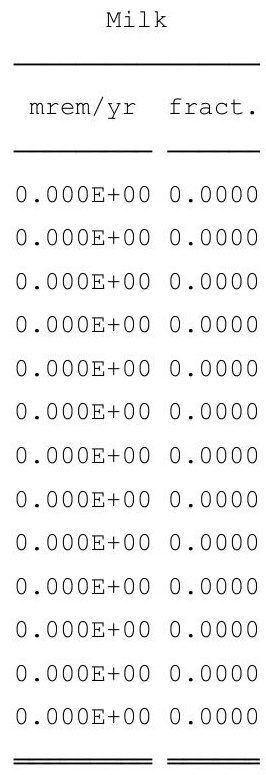

$0.000 \mathrm{E}+00 \quad 0.0000$
All Pathways* mrem/yr fract. $0.000 \mathrm{E}+00 \quad 0.0000$ $0.000 \mathrm{E}+00 \quad 0.0000$ $0.000 \mathrm{E}+00 \quad 0.0000$ $0.000 E+00 \quad 0.0000$ $0.000 \mathrm{E}+00 \quad 0.0000$ $0.000 \mathrm{E}+00 \quad 0.0000$ $0.000 \mathrm{E}+00 \quad 0.0000$ $0.000 \mathrm{E}+00 \quad 0.0000$ $0.000 \mathrm{E}+00 \quad 0.0000$ $0.000 \mathrm{E}+00 \quad 0.0000$ $0.000 \mathrm{E}+00 \quad 0.0000$ $0.000 \mathrm{E}+00 \quad 0.0000$ $0.000 \mathrm{E}+00 \quad 0.0000$ $0.000 E+00 \quad 0.0000$

* Sum of all water independent and dependent pathways. 
RESRAD, Version 6.5

ummary : C746U Worker Deterministic Run

File : $X: \backslash F I N A L$ V2 $\backslash$ DOE FWD RUNS \C746U W DOE SG FWD-FV2-100000YR.RAD

Dose/Source Ratios Summed Over All Pathways

Parent and Progeny Principal Radionuclide Contributions Indicated

\begin{tabular}{|c|c|c|c|c|c|c|c|c|c|c|}
\hline Parent & Product & Thread & & $\mathrm{DSR}$ & $(j, t)$ At $T$ & ime in Year & (mrem) & (yr)/(pCi/ & & \\
\hline (i) & $(j)$ & Fraction & $0.000 \mathrm{E}+00$ & $1.000 \mathrm{E}+00$ & $5.000 \mathrm{E}+01$ & $1.000 \mathrm{E}+02$ & $5.000 \mathrm{E}+02$ & $1.050 \mathrm{E}+03$ & $1.000 \mathrm{E}+04$ & $1.000 \mathrm{E}+05$ \\
\hline$m-241$ & $A m-241$ & $1.000 \mathrm{E}+00$ & $3.956 \mathrm{E}-34$ & $4.063 E-34$ & $1.503 E-33$ & $5.707 E-33$ & $2.471 \mathrm{E}-28$ & $5.859 \mathrm{E}-22$ & $3.001 \mathrm{E}-09$ & $0.000 \mathrm{E}+00$ \\
\hline$A m-241$ & $N p-237+D$ & $1.000 \mathrm{E}+00$ & $3.160 \mathrm{E}-20$ & $9.563 E-20$ & $5.243 E-18$ & $1.718 \mathrm{E}-17$ & $4.700 \mathrm{E}-15$ & $2.556 \mathrm{E}-12$ & $1.752 \mathrm{E}-05$ & $0.000 \mathrm{E}+00$ \\
\hline$A m-241$ & $\mathrm{U}-233$ & $1.000 \mathrm{E}+00$ & $7.164 \mathrm{E}-31$ & $5.066 \mathrm{E}-30$ & $9.948 E-27$ & $7.175 E-26$ & $2.177 E-22$ & 7. $342 \mathrm{E}-19$ & $3.119 \mathrm{E}-08$ & $0.000 \mathrm{E}+00$ \\
\hline $\mathrm{Am}-241$ & $T h-229+D$ & $1.000 \mathrm{E}+00$ & $4.901 \mathrm{E}-27$ & 7. $393 \mathrm{E}-26$ & $3.496 \mathrm{E}-21$ & $3.824 \mathrm{E}-20$ & $6.587 \mathrm{E}-17$ & $2.426 \mathrm{E}-14$ & $6.401 \mathrm{E}-07$ & $0.000 \mathrm{E}+00$ \\
\hline $\mathrm{Am}-241$ & $\sum \operatorname{DSR}(j)$ & & $3.160 \mathrm{E}-20$ & $9.563 \mathrm{E}-20$ & $5.246 \mathrm{E}-18$ & $1.722 \mathrm{E}-17$ & $4.766 \mathrm{E}-15$ & $2.581 \mathrm{E}-12$ & $1.819 \mathrm{E}-05$ & $0.000 \mathrm{E}+00$ \\
\hline $\mathrm{Cs}-137+\mathrm{D}$ & $\mathrm{Cs}-137+\mathrm{D}$ & $1.000 \mathrm{E}+00$ & $2.578 E-10$ & $2.541 E-10$ & $1.237 \mathrm{E}-10$ & $5.936 \mathrm{E}-11$ & $1.667 \mathrm{E}-13$ & $5.175 \mathrm{E}-17$ & $0.000 \mathrm{E}+00$ & $0.000 \mathrm{E}+00$ \\
\hline$p-237+D$ & $N p-237+D$ & $1.000 \mathrm{E}+00$ & $1.948 \mathrm{E}-13$ & $1.969 \mathrm{E}-13$ & $3.330 \mathrm{E}-13$ & $5.693 \mathrm{E}-13$ & $4.147 \mathrm{E}-11$ & $1.509 \mathrm{E}-08$ & $8.263 \mathrm{E}-02$ & $0.000 \mathrm{E}+00$ \\
\hline$p-237+D$ & $\mathrm{U}-233$ & $1.000 \mathrm{E}+00$ & $6.631 \mathrm{E}-24$ & $2.011 \mathrm{E}-23$ & 1. $248 \mathrm{E}-21$ & $4.641 \mathrm{E}-21$ & $3.427 \mathrm{E}-18$ & $6.954 \mathrm{E}-15$ & $1.606 \mathrm{E}-04$ & $0.000 \mathrm{E}+00$ \\
\hline$J p-237+D$ & $\mathrm{Th}-229+\mathrm{D}$ & $1.000 \mathrm{E}+00$ & $6.053 \mathrm{E}-20$ & 4. $262 \mathrm{E}-19$ & $6.537 \mathrm{E}-16$ & $3.662 \mathrm{E}-15$ & $1.463 \mathrm{E}-12$ & $3.066 \mathrm{E}-10$ & $3.474 \mathrm{E}-03$ & $0.000 \mathrm{E}+00$ \\
\hline$N p-237+D$ & $\sum \operatorname{DSR}(j)$ & & 1. $948 \mathrm{E}-13$ & $1.969 \mathrm{E}-13$ & $3.337 \mathrm{E}-13$ & $5.729 \mathrm{E}-13$ & $4.294 \mathrm{E}-11$ & $1.540 \mathrm{E}-08$ & $8.626 \mathrm{E}-02$ & $0.000 \mathrm{E}+00$ \\
\hline $\mathrm{Pu}-238$ & $\mathrm{Pu}-238$ & $1.840 E-09$ & $4.417 E-34$ & $4.460 \mathrm{E}-34$ & 7. $195 \mathrm{E}-34$ & $1.172 \mathrm{E}-33$ & $5.806 \mathrm{E}-32$ & 1. $243 E-29$ & $1.401 \mathrm{E}-45$ & $0.000 \mathrm{E}+00$ \\
\hline $\mathrm{Pu}-238$ & $\mathrm{Pu}-238$ & $1.000 \mathrm{E}+00$ & $2.401 \mathrm{E}-25$ & $2.424 \mathrm{E}-25$ & $3.910 \mathrm{E}-25$ & $6.369 E-25$ & $3.155 E-23$ & $6.755 \mathrm{E}-21$ & $1.131 \mathrm{E}-36$ & $0.000 \mathrm{E}+00$ \\
\hline $\mathrm{Pu}-238$ & $\mathrm{U}-234$ & $1.000 \mathrm{E}+00$ & $1.998 \mathrm{E}-30$ & $6.068 \mathrm{E}-30$ & $4.032 E-28$ & $1.628 \mathrm{E}-27$ & $3.470 \mathrm{E}-24$ & $5.993 E-20$ & $1.669 \mathrm{E}-06$ & $0.000 \mathrm{E}+00$ \\
\hline $\mathrm{Pu}-238$ & Th-230 & $1.000 \mathrm{E}+00$ & $2.101 E-34$ & $1.489 \mathrm{E}-33$ & $3.268 \mathrm{E}-30$ & $2.663 E-29$ & $2.676 \mathrm{E}-25$ & $6.795 E-21$ & $6.557 \mathrm{E}-07$ & $0.000 \mathrm{E}+00$ \\
\hline $\mathrm{Pu}-238$ & $\mathrm{Ra}-226+\mathrm{D}$ & $1.000 \mathrm{E}+00$ & $1.639 \mathrm{E}-23$ & $2.469 \mathrm{E}-22$ & $1.076 \mathrm{E}-17$ & $1.088 E-16$ & $1.149 \mathrm{E}-13$ & $2.677 \mathrm{E}-11$ & $3.859 \mathrm{E}-05$ & $0.000 \mathrm{E}+00$ \\
\hline $\mathrm{Pu}-238$ & $\mathrm{~Pb}-210+\mathrm{D}$ & $1.000 \mathrm{E}+00$ & $4.753 E-32$ & $1.473 E-30$ & $1.589 \mathrm{E}-24$ & $2.687 E-23$ & $7.527 \mathrm{E}-20$ & $3.536 \mathrm{E}-17$ & $4.497 \mathrm{E}-06$ & $0.000 \mathrm{E}+00$ \\
\hline $\mathrm{Pu}-238$ & $\sum \operatorname{DSR}(j)$ & & $1.663 \mathrm{E}-23$ & $2.471 \mathrm{E}-22$ & $1.076 \mathrm{E}-17$ & $1.088 \mathrm{E}-16$ & $1.149 \mathrm{E}-13$ & $2.677 \mathrm{E}-11$ & $4.541 E-05$ & $0.000 \mathrm{E}+00$ \\
\hline
\end{tabular}

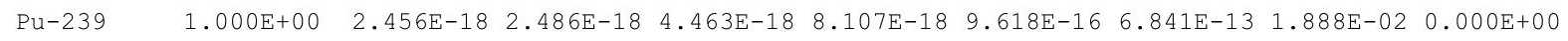

$\begin{array}{lllllllllll}\mathrm{U}-235+\mathrm{D} & 1.000 \mathrm{E}+00 & 1.254 \mathrm{E}-24 & 3.802 \mathrm{E}-24 & 2.343 \mathrm{E}-22 & 8.645 \mathrm{E}-22 & 6.015 \mathrm{E}-19 & 1.124 \mathrm{E}-15 & 9.231 \mathrm{E}-07 & 0.000 \mathrm{E}+00\end{array}$

$\begin{array}{llllllllll}\mathrm{Pa}-231 & 1.000 \mathrm{E}+00 & 1.972 \mathrm{E}-28 & 1.393 \mathrm{E}-27 & 2.557 \mathrm{E}-24 & 1.721 \mathrm{E}-23 & 2.963 \mathrm{E}-20 & 4.446 \mathrm{E}-17 & 8.540 \mathrm{E}-08 & 0.000 \mathrm{E}+00\end{array}$

$\mathrm{AC}-227+\mathrm{D} \quad 1.000 \mathrm{E}+00 \quad 4.675 \mathrm{E}-28 \quad 7.017 \mathrm{E}-27 \quad 2.608 \mathrm{E}-22 \quad 2.391 \mathrm{E}-21 \quad 3.028 \mathrm{E}-18 \quad 1.826 \mathrm{E}-15 \quad 3.511 \mathrm{E}-07 \quad 0.000 \mathrm{E}+00$

$\operatorname{EDSR}(j) \quad 2.456 \mathrm{E}-18 \quad 2.486 \mathrm{E}-18 \quad 4.463 \mathrm{E}-18 \quad 8.110 \mathrm{E}-18 \quad 9.655 \mathrm{E}-16 \quad 6.871 \mathrm{E}-13 \quad 1.888 \mathrm{E}-02 \quad 0.000 \mathrm{E}+00$

$\mathrm{Pu}-240 \quad 4.950 \mathrm{E}-08 \quad 1.155 \mathrm{E}-32 \quad 1.176 \mathrm{E}-32 \quad 2.778 \mathrm{E}-32 \quad 6.681 \mathrm{E}-32 \quad 7.478 \mathrm{E}-29 \quad 1.164 \mathrm{E}-24 \quad 4.312 \mathrm{E}-10 \quad 0.000 \mathrm{E}+00$

$\begin{array}{llllllllll}\mathrm{Pu}-240 & 1.000 \mathrm{E}+00 & 2.334 \mathrm{E}-25 & 2.375 \mathrm{E}-25 & 5.612 \mathrm{E}-25 & 1.350 \mathrm{E}-24 & 1.511 \mathrm{E}-21 & 2.352 \mathrm{E}-17 & 8.711 \mathrm{E}-03 \quad 0.000 \mathrm{E}+00\end{array}$

U-236 1.000E+00 4.417E-33 $1.347 \mathrm{E}-32 \quad 1.091 \mathrm{E}-30 \quad 5.321 \mathrm{E}-30 \quad 3.459 \mathrm{E}-26 \quad 1.397 \mathrm{E}-21 \quad 8.463 \mathrm{E}-07 \quad 0.000 \mathrm{E}+00$

Th-232 1.000E+00 5.745E-44 $4.148 \mathrm{E}-43 \quad 1.120 \mathrm{E}-39 \quad 1.120 \mathrm{E}-38 \quad 4.587 \mathrm{E}-34 \quad 5.372 \mathrm{E}-29 \quad 1.247 \mathrm{E}-12 \quad 0.000 \mathrm{E}+00$

$\mathrm{Ra}-228+\mathrm{D} \quad 1.000 \mathrm{E}+00 \quad 2.801 \mathrm{E}-29 \quad 4.123 \mathrm{E}-28 \quad 7.689 \mathrm{E}-24 \quad 5.197 \mathrm{E}-23 \quad 3.012 \mathrm{E}-20 \quad 8.590 \mathrm{E}-18 \quad 4.939 \mathrm{E}-11 \quad 0.000 \mathrm{E}+00$

$\mathrm{Th}-228+\mathrm{D} \quad 1.000 \mathrm{E}+00 \quad 1.657 \mathrm{E}-28 \quad 4.769 \mathrm{E}-27 \quad 5.398 \mathrm{E}-22 \quad 3.593 \mathrm{E}-21 \quad 1.140 \mathrm{E}-18 \quad 1.344 \mathrm{E}-16 \quad 7.877 \mathrm{E}-11 \quad 0.000 \mathrm{E}+00$

$\operatorname{LDSR}(j) \quad 2.335 \mathrm{E}-25 \quad 2.427 \mathrm{E}-25 \quad 5.480 \mathrm{E}-22 \quad 3.646 \mathrm{E}-21 \quad 1.172 \mathrm{E}-18 \quad 1.665 \mathrm{E}-16 \quad 8.712 \mathrm{E}-03 \quad 0.000 \mathrm{E}+00$

TC-99 1.000E+00 1.179E-26 $1.195 \mathrm{E}-26 \quad 2.364 \mathrm{E}-26 \quad 4.741 \mathrm{E}-26 \quad 1.241 \mathrm{E}-23 \quad 2.619 \mathrm{E}-20 \quad 1.258 \mathrm{E}-27 \quad 0.000 \mathrm{E}+00$

Th-228+D 1.000E+00 2.825E-07 1.978E-07 5.163E-15 9.437E-23 $0.000 \mathrm{E}+00 \quad 0.000 \mathrm{E}+00 \quad 0.000 \mathrm{E}+00 \quad 0.000 \mathrm{E}+00$

Th-230 1.000E+00 4.929E-23 5.012E-23 $1.142 \mathrm{E}-22 \quad 2.647 \mathrm{E}-22 \quad 2.203 \mathrm{E}-19 \quad 2.282 \mathrm{E}-15 \quad 2.112 \mathrm{E}-02 \quad 0.000 \mathrm{E}+00$

$\mathrm{Ra}-226+\mathrm{D} \quad 1.000 \mathrm{E}+00 \quad 7.712 \mathrm{E}-12 \quad 2.327 \mathrm{E}-11 \quad 1.087 \mathrm{E}-09 \quad 3.024 \mathrm{E}-09 \quad 2.193 \mathrm{E}-07 \quad 1.840 \mathrm{E}-05 \quad 1.587 \mathrm{E}+00 \quad 0.000 \mathrm{E}+00$

$\mathrm{Pb}-210+\mathrm{D} \quad 1.000 \mathrm{E}+00 \quad 3.717 \mathrm{E}-20 \quad 2.596 \mathrm{E}-19 \quad 2.655 \mathrm{E}-16 \quad 1.087 \mathrm{E}-15 \quad 1.573 \mathrm{E}-13 \quad 2.528 \mathrm{E}-11 \quad 1.856 \mathrm{E}-01 \quad 0.000 \mathrm{E}+00$

EDSR $(j) \quad 7.712 \mathrm{E}-12 \quad 2.327 \mathrm{E}-11 \quad 1.087 \mathrm{E}-09 \quad 3.024 \mathrm{E}-09 \quad 2.193 \mathrm{E}-07 \quad 1.840 \mathrm{E}-05 \quad 1.793 \mathrm{E}+00 \quad 0.000 \mathrm{E}+00$ 
RESRAD, Version 6.5

Summary : C746U Worker Deterministic Run

File : $\mathrm{X}: \backslash \mathrm{FINAL}$ V2 $\backslash$ DOE FWD RUNS \C746U W DOE SG FWD-FV2-100000YR.RAD

西

Dose/Source Ratios Summed Over All Pathways

Parent and Progeny Principal Radionuclide Contributions Indicated

\begin{tabular}{|c|c|c|c|c|c|c|c|c|c|c|}
\hline Parent & Product & Thread & & DSR & $(j, t)$ At $\mathrm{T}$ & ime in Year & (mrem & $\mathrm{pr}) /(\mathrm{pCi} /$ & & \\
\hline (i) & $(j)$ & Fraction & $0.000 \mathrm{E}+00$ & $1.000 \mathrm{E}+00$ & $5.000 \mathrm{E}+01$ & $1.000 \mathrm{E}+02$ & $5.000 \mathrm{E}+02$ & $1.050 \mathrm{E}+03$ & $1.000 \mathrm{E}+04$ & $1.000 \mathrm{E}+05$ \\
\hline-232 & Th-232 & $1.000 \mathrm{E}+00$ & $2.382 E-25$ & $2.427 E-25$ & $6.027 E-25$ & $1.525 E-24$ & $2.561 \mathrm{E}-21$ & $6.965 E-17$ & $2.519 E-02$ & $0.000 \mathrm{E}+00$ \\
\hline-232 & $\mathrm{Ra}-228+\mathrm{D}$ & $1.000 \mathrm{E}+00$ & $2.263 \mathrm{E}-10$ & $6.486 \mathrm{E}-10$ & $5.690 \mathrm{E}-09$ & $8.336 \mathrm{E}-09$ & $1.737 \mathrm{E}-07$ & $1.131 \mathrm{E}-05$ & $9.990 E-01$ & $0.000 \mathrm{E}+00$ \\
\hline-232 & $\mathrm{Th}-228+\mathrm{D}$ & $1.000 \mathrm{E}+00$ & $2.181 \mathrm{E}-09$ & $1.345 \mathrm{E}-08$ & $4.522 E-07$ & $6.114 \mathrm{E}-07$ & $6.652 \mathrm{E}-06$ & $1.778 \mathrm{E}-04$ & $1.594 \mathrm{E}+00$ & $0.000 \mathrm{E}+00$ \\
\hline-232 & $\sum \operatorname{DSR}(j)$ & & $2.407 E-09$ & $1.410 \mathrm{E}-08$ & $4.579 \mathrm{E}-07$ & $6.198 E-07$ & $6.825 E-06$ & $1.891 \mathrm{E}-04$ & $2.618 E+00$ & $0.000 \mathrm{E}+00$ \\
\hline-234 & $\mathrm{U}-234$ & $1.000 \mathrm{E}+00$ & $1.409 \mathrm{E}-24$ & $1.434 \mathrm{E}-24$ & $3.415 \mathrm{E}-24$ & $8.276 \mathrm{E}-24$ & $9.851 \mathrm{E}-21$ & $1.669 \mathrm{E}-16$ & $4.648 E-03$ & $0.000 \mathrm{E}+00$ \\
\hline-234 & Th-230 & $1.000 \mathrm{E}+00$ & $2.225 \mathrm{E}-28$ & $6.774 \mathrm{E}-28$ & $5.192 \mathrm{E}-26$ & $2.394 E-25$ & $9.912 \mathrm{E}-22$ & $2.152 \mathrm{E}-17$ & $1.850 \mathrm{E}-03$ & $0.000 \mathrm{E}+00$ \\
\hline-234 & $\mathrm{Ra}-226+\mathrm{D}$ & $1.000 \mathrm{E}+00$ & $2.315 \mathrm{E}-17$ & $1.630 \mathrm{E}-16$ & $2.480 \mathrm{E}-13$ & $1.377 \mathrm{E}-12$ & $5.115 \mathrm{E}-10$ & $9.341 \mathrm{E}-08$ & $1.092 \mathrm{E}-01$ & $0.000 \mathrm{E}+00$ \\
\hline-234 & $\mathrm{~Pb}-210+\mathrm{D}$ & $1.000 \mathrm{E}+00$ & $8.381 E-26$ & $1.257 \mathrm{E}-24$ & $4.500 \mathrm{E}-20$ & $3.956 \mathrm{E}-19$ & $3.440 \mathrm{E}-16$ & $1.243 E-13$ & $1.273 E-02$ & $0.000 \mathrm{E}+00$ \\
\hline-234 & $\sum \operatorname{DSR}(j)$ & & $2.315 E-17$ & $1.630 \mathrm{E}-16$ & $2.480 \mathrm{E}-13$ & $1.377 \mathrm{E}-12$ & $5.115 E-10$ & $9.341 \mathrm{E}-08$ & $1.285 \mathrm{E}-01$ & $0.000 \mathrm{E}+00$ \\
\hline$-235+D$ & $\mathrm{U}-235+\mathrm{D}$ & $1.000 \mathrm{E}+00$ & $2.540 \mathrm{E}-15$ & $2.572 \mathrm{E}-15$ & $4.713 E-15$ & $8.745 E-15$ & 1. $228 \mathrm{E}-12$ & $1.101 \mathrm{E}-09$ & $1.061 \mathrm{E}-01$ & $0.000 \mathrm{E}+00$ \\
\hline$-235+D$ & $\mathrm{~Pa}-231$ & $1.000 \mathrm{E}+00$ & $6.002 \mathrm{E}-19$ & $1.818 \mathrm{E}-18$ & $1.028 \mathrm{E}-16$ & $3.478 \mathrm{E}-16$ & 1. $206 \mathrm{E}-13$ & $8.644 \mathrm{E}-11$ & $1.832 \mathrm{E}-02$ & $0.000 \mathrm{E}+00$ \\
\hline$-235+D$ & $A C-227+D$ & $1.000 \mathrm{E}+00$ & $1.895 \mathrm{E}-18$ & 1. $324 \mathrm{E}-17$ & $1.407 \mathrm{E}-14$ & $6.019 \mathrm{E}-14$ & 1. $308 \mathrm{E}-11$ & $3.655 \mathrm{E}-09$ & $7.555 \mathrm{E}-02$ & $0.000 \mathrm{E}+00$ \\
\hline$-235+D$ & $\sum \operatorname{DSR}(j)$ & & $2.543 E-15$ & $2.587 \mathrm{E}-15$ & $1.888 \mathrm{E}-14$ & $6.928 E-14$ & $1.443 E-11$ & $4.843 E-09$ & $2.000 E-01$ & $0.000 \mathrm{E}+00$ \\
\hline-238 & $\mathrm{U}-238$ & $5.400 E-05$ & $0.000 \mathrm{E}+00$ & $0.000 \mathrm{E}+00$ & $0.000 \mathrm{E}+00$ & $0.000 \mathrm{E}+00$ & $0.000 \mathrm{E}+00$ & $3.476 \mathrm{E}-39$ & $2.363 E-07$ & $0.000 \mathrm{E}+00$ \\
\hline$-238+D$ & $\mathrm{U}-238+\mathrm{D}$ & $9.999 \mathrm{E}-01$ & $2.901 \mathrm{E}-11$ & $2.924 \mathrm{E}-11$ & 4. $325 \mathrm{E}-11$ & $6.449 \mathrm{E}-11$ & $1.576 \mathrm{E}-09$ & $1.279 \mathrm{E}-07$ & $2.737 \mathrm{E}-02$ & $0.000 \mathrm{E}+00$ \\
\hline$-238+D$ & $\mathrm{U}-234$ & $9.999 \mathrm{E}-01$ & $2.003 E-30$ & $6.105 \mathrm{E}-30$ & $4.889 \mathrm{E}-28$ & $2.358 \mathrm{E}-27$ & 1. $399 \mathrm{E}-23$ & $4.978 \mathrm{E}-19$ & $1.336 \mathrm{E}-04$ & $0.000 \mathrm{E}+00$ \\
\hline$-238+D$ & $T h-230$ & $9.999 \mathrm{E}-01$ & $2.105 E-34$ & $1.495 \mathrm{E}-33$ & $3.717 \mathrm{E}-30$ & $3.411 \mathrm{E}-29$ & $7.032 \mathrm{E}-25$ & $3.204 \mathrm{E}-20$ & $2.623 E-05$ & $0.000 \mathrm{E}+00$ \\
\hline$-238+D$ & $\mathrm{Ra}-226+\mathrm{D}$ & $9.999 \mathrm{E}-01$ & $1.642 \mathrm{E}-23$ & $2.477 E-22$ & $1.186 \mathrm{E}-17$ & $1.313 E-16$ & $2.462 \mathrm{E}-13$ & $9.612 \mathrm{E}-11$ & $1.290 E-03$ & $0.000 \mathrm{E}+00$ \\
\hline$-238+D$ & $\mathrm{~Pb}-210+\mathrm{D}$ & $9.999 \mathrm{E}-01$ & $4.759 \mathrm{E}-32$ & $1.477 \mathrm{E}-30$ & $1.723 E-24$ & $3.161 \mathrm{E}-23$ & $1.561 \mathrm{E}-19$ & 1. $240 \mathrm{E}-16$ & $1.498 E-04$ & $0.000 \mathrm{E}+00$ \\
\hline$-238+D$ & $\sum \operatorname{DSR}(j)$ & & $2.901 \mathrm{E}-11$ & $2.924 \mathrm{E}-11$ & $4.325 \mathrm{E}-11$ & $6.449 \mathrm{E}-11$ & $1.577 \mathrm{E}-09$ & $1.280 \mathrm{E}-07$ & $2.897 \mathrm{E}-02$ & $0.000 \mathrm{E}+00$ \\
\hline
\end{tabular}

The DSR includes contributions from associated (half-life $\leq 180$ days) daughters.

DCN 5090-TR-02-2

A-548 
RESRAD, Version 6.5

Summary : C746U Worker Deterministic Run

File : $X: \backslash F I N A L$ V2 \DOE FWD RUNS \C746U W DOE SG FWD-FV2-100000YR.RAD

Single Radionuclide Soil Guidelines $G(i, t)$ in $\mathrm{pCi} / \mathrm{g}$

Basic Radiation Dose Limit $=1.000 \mathrm{E}+00 \mathrm{mrem} / \mathrm{yr}$

\begin{tabular}{|c|c|c|c|c|c|c|c|c|}
\hline (i) & $t=0.000 \mathrm{E}+00$ & $1.000 \mathrm{E}+00$ & $5.000 \mathrm{E}+01$ & $1.000 \mathrm{E}+02$ & $5.000 \mathrm{E}+02$ & $1.050 \mathrm{E}+03$ & $1.000 \mathrm{E}+04$ & $1.000 \mathrm{E}+0$ \\
\hline-241 & $* 3.431 \mathrm{E}+12$ & $\star 3.431 \mathrm{E}+12$ & $\star 3.431 \mathrm{E}+12$ & $\star 3.431 \mathrm{E}+12$ & $\star 3.431 \mathrm{E}+12$ & $3.875 E+11$ & $5.497 \mathrm{E}+04$ & $\star 3.431 \mathrm{E}+12$ \\
\hline$s-137$ & $3.879 \mathrm{E}+09$ & $3.936 \mathrm{E}+09$ & $8.084 \mathrm{E}+09$ & $1.685 \mathrm{E}+10$ & $5.997 \mathrm{E}+12$ & $\star 8.704 \mathrm{E}+13$ & $\star 8.704 \mathrm{E}+13$ & $\star 8.704 \mathrm{E}+13$ \\
\hline $0-237$ & $\star 7.047 \mathrm{E}+08$ & $\star 7.047 \mathrm{E}+08$ & $\star 7.047 \mathrm{E}+08$ & $\star 7.047 \mathrm{E}+08$ & $\star 7.047 \mathrm{E}+08$ & $6.495 E+07$ & $1.159 \mathrm{E}+01$ & $\star 7.047 \mathrm{E}+08$ \\
\hline$u-238$ & $\star 1.712 \mathrm{E}+13$ & $\star 1.712 \mathrm{E}+13$ & $\star 1.712 \mathrm{E}+13$ & $\star 1.712 \mathrm{E}+13$ & $8.701 \mathrm{E}+12$ & $3.735 \mathrm{E}+10$ & $2.202 \mathrm{E}+04$ & $* 1.712 \mathrm{E}+13$ \\
\hline$x-239$ & $* 6.214 \mathrm{E}+10$ & $* 6.214 \mathrm{E}+10$ & $* 6.214 \mathrm{E}+10$ & $* 6.214 \mathrm{E}+10$ & $* 6.214 \mathrm{E}+10$ & $* 6.214 \mathrm{E}+10$ & $5.298 \mathrm{E}+01$ & $* 6.214 \mathrm{E}+1 \mathrm{C}$ \\
\hline-240 & $\star 2.278 \mathrm{E}+11$ & $\star 2.278 \mathrm{E}+11$ & $\star 2.278 \mathrm{E}+11$ & $\star 2.278 \mathrm{E}+11$ & $\star 2.278 \mathrm{E}+11$ & $\star 2.278 \mathrm{E}+11$ & $1.148 \mathrm{E}+02$ & $\star 2.278 \mathrm{E}+1 \mathrm{I}$ \\
\hline$=-99$ & $\star 1.697 \mathrm{E}+10$ & $\star 1.697 \mathrm{E}+10$ & $\star 1.697 \mathrm{E}+10$ & $\star 1.697 \mathrm{E}+10$ & $* 1.697 \mathrm{E}+10$ & $\star 1.697 \mathrm{E}+10$ & $\star 1.697 \mathrm{E}+10$ & $\star 1.697 \mathrm{E}+1 \mathrm{C}$ \\
\hline $1-228$ & $3.540 \mathrm{E}+06$ & $5.056 \mathrm{E}+06$ & $1.937 E+14$ & $\star 8.195 \mathrm{E}+14$ & $\star 8.195 \mathrm{E}+14$ & $\star 8.195 \mathrm{E}+14$ & $\star 8.195 \mathrm{E}+14$ & $\star 8.195 \mathrm{E}+1$ \\
\hline Th-230 & $* 2.018 \mathrm{E}+10$ & $\star 2.018 \mathrm{E}+10$ & $9.198 \mathrm{E}+08$ & $3.307 \mathrm{E}+08$ & $4.559 \mathrm{E}+06$ & $5.434 \mathrm{E}+04$ & $5.576 \mathrm{E}-01$ & $\star 2.018 \mathrm{E}+1 \mathrm{C}$ \\
\hline$h-232$ & $\star 1.097 \mathrm{E}+05$ & $\star 1.097 \mathrm{E}+05$ & $\star 1.097 \mathrm{E}+05$ & $\star 1.097 \mathrm{E}+05$ & $\star 1.097 \mathrm{E}+05$ & $5.287 \mathrm{E}+03$ & $3.819 \mathrm{E}-01$ & $\star 1.097 \mathrm{E}+0$ \\
\hline$U-234$ & $* 6.247 \mathrm{E}+09$ & $* 6.247 \mathrm{E}+09$ & $\star 6.247 \mathrm{E}+09$ & $* 6.247 \mathrm{E}+09$ & $1.955 \mathrm{E}+09$ & $1.071 \mathrm{E}+07$ & $7.784 \mathrm{E}+00$ & $* 6.247 \mathrm{E}+0$ \\
\hline 235 & $\star 2.161 \mathrm{E}+06$ & $\star 2.161 \mathrm{E}+06$ & $\star 2.161 \mathrm{E}+06$ & $\star 2.161 \mathrm{E}+06$ & $\star 2.161 \mathrm{E}+06$ & $\star 2.161 \mathrm{E}+06$ & $5.000 \mathrm{E}+00$ & $\star 2.161 \mathrm{E}+0$ \\
\hline 238 & $\star 3.361 \mathrm{E}+05$ & $\star 3.361 \mathrm{E}+05$ & $* 3.361 \mathrm{E}+05$ & $\star 3.361 \mathrm{E}+05$ & $* 3.361 \mathrm{E}+05$ & $* 3.361 \mathrm{E}+05$ & $3.452 \mathrm{E}+01$ & $* 3.361 \mathrm{E}+05$ \\
\hline
\end{tabular}

*At specific activity limit

Summed Dose/Source Ratios DSR(i,t) in (mrem/yr)/(pCi/g)

and Single Radionuclide Soil Guidelines $\mathrm{G}(i, t)$ in $\mathrm{pCi} / \mathrm{g}$

at tmin = time of minimum single radionuclide soil guideline and at $\operatorname{tmax}=$ time of maximum total dose $=19045 \pm *$ years

\begin{tabular}{|c|c|c|c|c|c|c|}
\hline $\begin{array}{l}\text { Uclide } \\
\text { (i) }\end{array}$ & $\begin{array}{l}\text { Initial } \\
(\mathrm{pCi} / \mathrm{g})\end{array}$ & $\begin{array}{c}\text { tmin } \\
\text { (years) }\end{array}$ & $\operatorname{DSR}(i, \operatorname{tmin})$ & $\begin{array}{c}\mathrm{G}(\mathrm{i}, \mathrm{tmin}) \\
\quad(\mathrm{pCi} / \mathrm{g})\end{array}$ & $\operatorname{DSR}(i, \operatorname{tmax})$ & $\begin{array}{c}G(i, t \max ) \\
(\mathrm{pCi} / \mathrm{g})\end{array}$ \\
\hline-241 & $3.500 \mathrm{E}+01$ & $2534 \pm 5$ & $5.173 \mathrm{E}-04$ & $1.933 E+03$ & $1.007 \mathrm{E}-05$ & $9.934 \mathrm{E}+04$ \\
\hline-137 & $1.900 \mathrm{E}+01$ & $0.000 \mathrm{E}+00$ & $2.578 \mathrm{E}-10$ & $3.879 E+09$ & $0.000 \mathrm{E}+00$ & $\star 8.704 \mathrm{E}+13$ \\
\hline-237 & $5.500 \mathrm{E}+00$ & $2534 \pm 5$ & $1.492 \mathrm{E}-01$ & $6.704 \mathrm{E}+00$ & $4.806 \mathrm{E}-02$ & $2.081 \mathrm{E}+01$ \\
\hline-238 & $3.900 \mathrm{E}+01$ & $24314 \pm *$ & $1.052 \mathrm{E}-04$ & $9.508 \mathrm{E}+03$ & $8.605 \mathrm{E}-05$ & $1.162 \mathrm{E}+04$ \\
\hline-239 & $3.600 \mathrm{E}+01$ & $2534 \pm 5$ & $2.522 \mathrm{E}-02$ & $3.966 \mathrm{E}+01$ & $1.329 \mathrm{E}-02$ & $7.523 E+01$ \\
\hline $\mathrm{Pu}-240$ & $3.600 \mathrm{E}+01$ & $2534 \pm 5$ & $2.071 \mathrm{E}-02$ & $4.828 \mathrm{E}+01$ & $3.051 \mathrm{E}-03$ & $3.277 \mathrm{E}+02$ \\
\hline $\mathrm{TC}-99$ & $5.200 \mathrm{E}+01$ & $2534 \pm 5$ & $1.441 \mathrm{E}-10$ & $6.940 \mathrm{E}+09$ & $0.000 \mathrm{E}+00$ & $* 1.697 \mathrm{E}+10$ \\
\hline$h-228$ & $4.000 \mathrm{E}+00$ & $0.000 \mathrm{E}+00$ & $2.825 \mathrm{E}-07$ & $3.540 \mathrm{E}+06$ & $0.000 \mathrm{E}+00$ & $\star 8.195 \mathrm{E}+14$ \\
\hline-230 & $1.000 \mathrm{E}+02$ & $8566 \pm *$ & $1.800 \mathrm{E}+00$ & $5.554 \mathrm{E}-01$ & $1.649 \mathrm{E}+00$ & $6.066 \mathrm{E}-01$ \\
\hline-232 & $4.000 \mathrm{E}+00$ & $2534 \pm 5$ & $2.652 \mathrm{E}+00$ & $3.771 \mathrm{E}-01$ & $2.578 \mathrm{E}+00$ & $3.879 \mathrm{E}-01$ \\
\hline 34 & $1.600 \mathrm{E}+02$ & $24313 \pm *$ & $2.946 \mathrm{E}-01$ & $3.394 \mathrm{E}+00$ & $2.415 \mathrm{E}-01$ & $4.141 \mathrm{E}+00$ \\
\hline 35 & $6.500 \mathrm{E}+00$ & $24411 \pm *$ & $2.557 \mathrm{E}-01$ & $3.911 E+00$ & $2.409 \mathrm{E}-01$ & $4.152 \mathrm{E}+00$ \\
\hline 238 & $1.600 \mathrm{E}+02$ & $2534 \pm 5$ & $3.033 \mathrm{E}-02$ & $3.297 E+01$ & $3.021 \mathrm{E}-02$ & $3.310 \mathrm{E}+01$ \\
\hline
\end{tabular}

*At specific activity limit 
RESRAD, Version 6.5

Summary : C746U Worker Deterministic Run

File : $X: \backslash F I N A L$ V2 $\backslash$ DOE FWD RUNS \C746U W DOE SG FWD-FV2-100000YR.RAD

Individual Nuclide Dose Summed Over All Pathways

Parent Nuclide and Branch Fraction Indicated

Nuclide Parent THF(i) DOSE $(j, t), \mathrm{mrem} / \mathrm{yr}$

\begin{tabular}{lll}
\multicolumn{1}{c}{$(j)$} & & (i) \\
\cline { 1 - 1 } $\mathrm{Am}-241$ & $\mathrm{Am}-241$ & $1.000 \mathrm{E}+00$ \\
$\mathrm{~Np}-237$ & $\mathrm{Am}-241$ & $1.000 \mathrm{E}+00$ \\
$\mathrm{~Np}-237$ & $\mathrm{~Np}-237$ & $1.000 \mathrm{E}+00$ \\
$\mathrm{~Np}-237$ & $\sum \operatorname{DOSE}(j)$
\end{tabular}

$\mathrm{U}-233 \quad \mathrm{Am}-241 \quad 1.000 \mathrm{E}+00$

$\mathrm{U}-233 \quad \mathrm{~Np}-237 \quad 1.000 \mathrm{E}+00$

U-233 $\quad$ DOSE $(j)$

Th-229 Am-241 $1.000 \mathrm{E}+00$

Th-229 Np-237 1.000E+00

Th-229 $\sum \operatorname{DOSE}(j)$

Cs $-137 \quad$ Cs $-137 \quad 1.000 E+00$

Pu-238 $\mathrm{Pu}-238 \quad 1.840 \mathrm{E}-09$

$\mathrm{Pu}-238 \mathrm{Pu}-238 \quad 1.000 \mathrm{E}+00$

$\mathrm{Pu}-238 \quad \sum \operatorname{DOSE}(j)$

$\mathrm{U}-234$

$\mathrm{U}-234$

$\mathrm{U}-234$

$\mathrm{U}-234$

Th-230

Th -230

Th -230

Th -230

$\mathrm{Th}-230$

$\mathrm{Ra}-226$

$\mathrm{Ra}-226$

$\mathrm{Ra}-226$

$\mathrm{Ra}-226$

$\operatorname{Ra}-226$

$\mathrm{Pb}-210$

$\mathrm{Pb}-210$

$\mathrm{Pb}-210$

$\mathrm{Pb}-210$

$\mathrm{Pb}-210$

$\mathrm{Pu}-239$

$\mathrm{Pu}-238 \quad 1.000 \mathrm{E}+00$ $\mathrm{U}-234 \quad 1.000 \mathrm{E}+00$ U-238 9.999E-01 $\operatorname{LDOSE}(j)$

$\mathrm{Pu}-238 \quad 1.000 \mathrm{E}+00$ Th-230 1.000E+00 $\mathrm{U}-234 \quad 1.000 \mathrm{E}+00$ $\mathrm{U}-238 \quad 9.999 \mathrm{E}-01$ $\sum \operatorname{DOSE}(j)$

$\mathrm{Pu}-238 \quad 1.000 \mathrm{E}+00$ Th-230 $1.000 \mathrm{E}+00$ $\mathrm{U}-234 \quad 1.000 \mathrm{E}+00$ $\mathrm{U}-238 \quad 9.999 \mathrm{E}-01$ ¿DOSE (j)

$\mathrm{Pu}-238 \quad 1.000 \mathrm{E}+00$ Th-230 1.000E+00 $\mathrm{U}-234 \quad 1.000 \mathrm{E}+00$ $\mathrm{U}-238 \quad 9.999 \mathrm{E}-01$ LDOSE (j)

Pu-239 1.000E+00

$\mathrm{Pu}-239 \quad 1.000 \mathrm{E}+00$ U-235 $1.000 \mathrm{E}+00$ $\sum \operatorname{DOSE}(j)$ $t=0.000 \mathrm{E}+00 \quad 1.000 \mathrm{E}+00 \quad 5.000 \mathrm{E}+01 \quad 1.000 \mathrm{E}+02 \quad 5.000 \mathrm{E}+02 \quad 1.050 \mathrm{E}+03 \quad 1.000 \mathrm{E}+04 \quad 1.000 \mathrm{E}+05$

$\begin{array}{llllllll}0.000 \mathrm{E}+00 & 0.000 \mathrm{E}+00 & 0.000 \mathrm{E}+00 & 0.000 \mathrm{E}+00 & 8.647 \mathrm{E}-27 & 2.051 \mathrm{E}-20 & 1.050 \mathrm{E}-07 & 0.000 \mathrm{E}+0\end{array}$

$\begin{array}{llllllll}1.106 \mathrm{E}-18 & 3.347 \mathrm{E}-18 & 1.835 \mathrm{E}-16 & 6.012 \mathrm{E}-16 & 1.645 \mathrm{E}-13 & 8.947 \mathrm{E}-11 & 6.131 \mathrm{E}-04 & 0.000 \mathrm{E}+00\end{array}$ $\begin{array}{llllllll}1.072 \mathrm{E}-12 & 1.083 \mathrm{E}-12 & 1.832 \mathrm{E}-12 & 3.131 \mathrm{E}-12 & 2.281 \mathrm{E}-10 & 8.299 \mathrm{E}-08 & 4.544 \mathrm{E}-01 & 0.000 \mathrm{E}+00\end{array}$ $\begin{array}{llllllll}1.072 \mathrm{E}-12 & 1.083 \mathrm{E}-12 & 1.832 \mathrm{E}-12 & 3.132 \mathrm{E}-12 & 2.283 \mathrm{E}-10 & 8.308 \mathrm{E}-08 & 4.551 \mathrm{E}-01 & 0.000 \mathrm{E}+00\end{array}$

$\begin{array}{llllllll}0.000 \mathrm{E}+00 & 1.773 \mathrm{E}-28 & 3.482 \mathrm{E}-25 & 2.511 \mathrm{E}-24 & 7.620 \mathrm{E}-21 & 2.570 \mathrm{E}-17 & 1.092 \mathrm{E}-06 & 0.000 \mathrm{E}+00\end{array}$ $\begin{array}{llllllll}3.647 \mathrm{E}-23 & 1.106 \mathrm{E}-22 & 6.866 \mathrm{E}-21 & 2.553 \mathrm{E}-20 & 1.885 \mathrm{E}-17 & 3.825 \mathrm{E}-14 & 8.834 \mathrm{E}-04 & 0.000 \mathrm{E}+00\end{array}$ $\begin{array}{llllllll}3.647 \mathrm{E}-23 & 1.106 \mathrm{E}-22 & 6.867 \mathrm{E}-21 & 2.553 \mathrm{E}-20 & 1.886 \mathrm{E}-17 & 3.827 \mathrm{E}-14 & 8.845 \mathrm{E}-04 & 0.000 \mathrm{E}+00\end{array}$

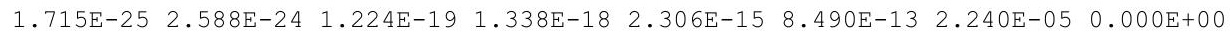

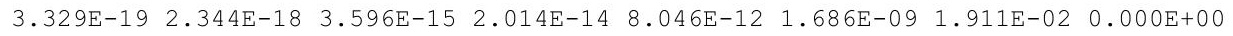
$\begin{array}{llllllll}3.329 \mathrm{E}-19 & 2.344 \mathrm{E}-18 & 3.596 \mathrm{E}-15 & 2.014 \mathrm{E}-14 & 8.048 \mathrm{E}-12 & 1.687 \mathrm{E}-09 & 1.913 \mathrm{E}-02 & 0.000 \mathrm{E}+00\end{array}$

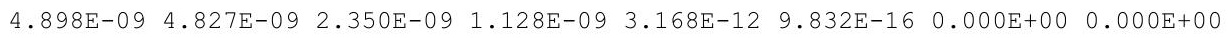

$\begin{array}{llllllll}0.000 \mathrm{E}+00 & 0.000 \mathrm{E}+00 & 0.000 \mathrm{E}+00 & 0.000 \mathrm{E}+00 & 0.000 \mathrm{E}+00 & 4.847 \mathrm{E}-28 & 0.000 \mathrm{E}+00 & 0.000 \mathrm{E}+00\end{array}$ $\begin{array}{lllllllll}9.362 \mathrm{E}-24 & 9.454 \mathrm{E}-24 & 1.525 \mathrm{E}-23 & 2.484 \mathrm{E}-23 & 1.231 \mathrm{E}-21 & 2.634 \mathrm{E}-19 & 0.000 \mathrm{E}+00 & 0.000 \mathrm{E}+00\end{array}$ $\begin{array}{llllllll}9.362 \mathrm{E}-24 & 9.454 \mathrm{E}-24 & 1.525 \mathrm{E}-23 & 2.484 \mathrm{E}-23 & 1.231 \mathrm{E}-21 & 2.634 \mathrm{E}-19 & 0.000 \mathrm{E}+00 & 0.000 \mathrm{E}+00\end{array}$

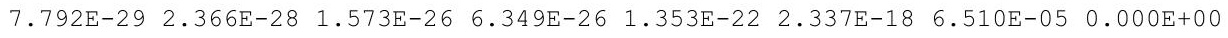
$\begin{array}{llllllll}2.254 \mathrm{E}-22 & 2.295 \mathrm{E}-22 & 5.464 \mathrm{E}-22 & 1.324 \mathrm{E}-21 & 1.576 \mathrm{E}-18 & 2.670 \mathrm{E}-14 & 7.436 \mathrm{E}-01 & 0.000 \mathrm{E}+00\end{array}$

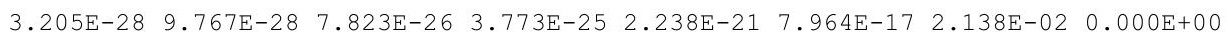
$\begin{array}{llllllll}2.254 \mathrm{E}-22 & 2.295 \mathrm{E}-22 & 5.465 \mathrm{E}-22 & 1.325 \mathrm{E}-21 & 1.578 \mathrm{E}-18 & 2.679 \mathrm{E}-14 & 7.651 \mathrm{E}-01 & 0.000 \mathrm{E}+00\end{array}$

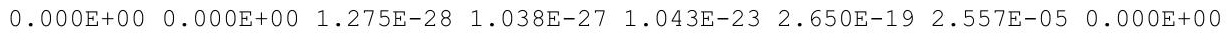
$\begin{array}{lllllllll}4.929 \mathrm{E}-21 & 5.012 \mathrm{E}-21 & 1.142 \mathrm{E}-20 & 2.647 \mathrm{E}-20 & 2.203 \mathrm{E}-17 & 2.282 \mathrm{E}-13 & 2.112 \mathrm{E}+00 & 0.000 \mathrm{E}+00\end{array}$ $\begin{array}{llllllll}3.559 \mathrm{E}-26 & 1.084 \mathrm{E}-25 & 8.307 \mathrm{E}-24 & 3.831 \mathrm{E}-23 & 1.586 \mathrm{E}-19 & 3.443 \mathrm{E}-15 & 2.960 \mathrm{E}-01 & 0.000 \mathrm{E}+00\end{array}$ $\begin{array}{llllllll}0.000 \mathrm{E}+00 & 0.000 \mathrm{E}+00 & 5.947 \mathrm{E}-28 & 5.457 \mathrm{E}-27 & 1.125 \mathrm{E}-22 & 5.127 \mathrm{E}-18 & 4.196 \mathrm{E}-03 & 0.000 \mathrm{E}+00\end{array}$

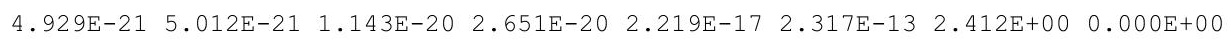

$6.392 \mathrm{E}-22 \quad 9.628 \mathrm{E}-21 \quad 4.197 \mathrm{E}-16 \quad 4.245 \mathrm{E}-15 \quad 4.482 \mathrm{E}-12 \quad 1.044 \mathrm{E}-09 \quad 1.505 \mathrm{E}-03 \quad 0.000 \mathrm{E}+00$

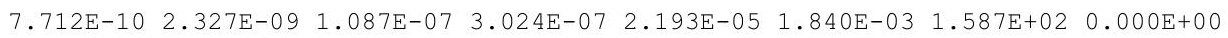

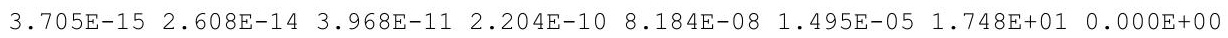
$\begin{array}{lllllllll}2.626 \mathrm{E}-21 & 3.963 \mathrm{E}-20 & 1.897 \mathrm{E}-15 & 2.100 \mathrm{E}-14 & 3.939 \mathrm{E}-11 & 1.538 \mathrm{E}-08 & 2.064 \mathrm{E}-01 & 0.000 \mathrm{E}+00\end{array}$ $\begin{array}{llllllll}7.712 \mathrm{E}-10 & 2.327 \mathrm{E}-09 & 1.088 \mathrm{E}-0 & 3.026 \mathrm{E}-07 & 2.202 \mathrm{E}-05 & 1.855 \mathrm{E}-03 & 1.763 \mathrm{E}+02 & 0.000 \mathrm{E}+00\end{array}$

$\begin{array}{llllllll}0.000 \mathrm{E}+00 & 5.746 \mathrm{E}-29 & 6.196 \mathrm{E}-23 & 1.048 \mathrm{E}-21 & 2.936 \mathrm{E}-18 & 1.379 \mathrm{E}-15 & 1.754 \mathrm{E}-04 & 0.000 \mathrm{E}+00\end{array}$ $\begin{array}{lllllllll}3.717 \mathrm{E}-18 & 2.596 \mathrm{E}-17 & 2.655 \mathrm{E}-14 & 1.087 \mathrm{E}-13 & 1.573 \mathrm{E}-11 & 2.528 \mathrm{E}-09 & 1.856 \mathrm{E}+01 & 0.000 \mathrm{E}+00\end{array}$ $\begin{array}{lllllllll}1.341 \mathrm{E}-23 & 2.012 \mathrm{E}-22 & 7.200 \mathrm{E}-18 & 6.329 \mathrm{E}-17 & 5.505 \mathrm{E}-14 & 1.988 \mathrm{E}-11 & 2.037 \mathrm{E}+00 & 0.000 \mathrm{E}+00\end{array}$ $\begin{array}{llllllllll}0.000 \mathrm{E}+00 & 2.363 \mathrm{E}-28 & 2.757 \mathrm{E}-22 & 5.058 \mathrm{E}-21 & 2.498 \mathrm{E}-17 & 1.985 \mathrm{E}-14 & 2.397 \mathrm{E}-02 & 0.000 \mathrm{E}+00\end{array}$ $\begin{array}{lllllllll}3.717 \mathrm{E}-18 & 2.596 \mathrm{E}-17 & 2.655 \mathrm{E}-14 & 1.087 \mathrm{E}-13 & 1.578 \mathrm{E}-11 & 2.548 \mathrm{E}-09 & 2.062 \mathrm{E}+01 & 0.000 \mathrm{E}+00\end{array}$

$\begin{array}{llllllll}8.843 \mathrm{E}-17 & 8.949 \mathrm{E}-17 & 1.607 \mathrm{E}-16 & 2.919 \mathrm{E}-16 & 3.463 \mathrm{E}-14 & 2.463 \mathrm{E}-11 & 6.795 \mathrm{E}-01 & 0.000 \mathrm{E}+00\end{array}$

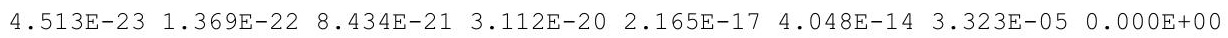
$\begin{array}{lllllllll}1.651 \mathrm{E}-14 & 1.672 \mathrm{E}-14 & 3.064 \mathrm{E}-14 & 5.684 \mathrm{E}-14 & 7.982 \mathrm{E}-12 & 7.159 \mathrm{E}-09 & 6.898 \mathrm{E}-01 & 0.000 \mathrm{E}+00\end{array}$ $\begin{array}{llllllll}1.651 \mathrm{E}-14 & 1.672 \mathrm{E}-14 & 3.064 \mathrm{E}-14 & 5.684 \mathrm{E}-14 & 7.982 \mathrm{E}-12 & 7.159 \mathrm{E}-09 & 6.899 \mathrm{E}-01 & 0.000 \mathrm{E}+00\end{array}$ 
RESRAD, Version 6.5

Summary : C746U Worker Deterministic Run

File : $X: \backslash F I N A L$ V2 \DOE FWD RUNS \C746U W DOE SG FWD-FV2-100000YR. RAD

Individual Nuclide Soil Concentration

Parent Nuclide and Branch Fraction Indicated

Nuclide Parent THF(

\section{(j)}

(i)

Am-241

$\overline{A m-241} \overline{1.000 E+00}$

Np-237 Am-241 1.000E+00

$\mathrm{Np}-237 \quad \mathrm{~Np}-237 \quad 1.000 \mathrm{E}+00$

Np-237 $\sum S(j):$

U-233 Am-241 $1.000 \mathrm{E}+00$

$\mathrm{U}-233 \quad \mathrm{~Np}-237 \quad 1.000 \mathrm{E}+00$

$\mathrm{U}-233 \sum \mathrm{S}(\mathrm{j}):$

Pu-239 $1.000 \mathrm{E}+00$ $\mathrm{U}-2351.000 \mathrm{E}+00$ $\sum S(j):$

Am-241 $1.000 \mathrm{E}+00$ $\mathrm{Np}-237 \quad 1.000 \mathrm{E}+00$ $\sum S(j):$

Cs-137 1.000E+00

Pu-238 1.840E-09 Pu-238 1.000E+00 $\sum S(j):$

$\mathrm{Pu}-238 \quad 1.000 \mathrm{E}+00$ $\mathrm{U}-234 \quad 1.000 \mathrm{E}+00$ $\sum S(j):$

Pu-238 1.000E+00 Th-230 1.000E+00 $\mathrm{U}-234 \quad 1.000 \mathrm{E}+00$ $\sum S(j):$

Pu-238 1.000E+00 Th-230 1.000E+00 $\mathrm{U}-234 \quad 1.000 \mathrm{E}+00$ $\mathrm{U}-238 \quad 9.999 \mathrm{E}-01$

$\mathrm{Pu}-238 \quad 1.000 \mathrm{E}+00$ Th-230 1.000E+00 $\mathrm{U}-234 \quad 1.000 \mathrm{E}+00$ $\mathrm{U}-238 \quad 9.999 \mathrm{E}-01$ $\sum S(j):$

$\mathrm{Pu}-239 \quad 1.000 \mathrm{E}+00$ U-238 $9.999 \mathrm{E}-01$ U-238 $9.999 \mathrm{E}-01$ $\begin{array}{lllllllll}3.600 \mathrm{E}+01 & 3.600 \mathrm{E}+01 & 3.593 \mathrm{E}+01 & 3.586 \mathrm{E}+01 & 3.531 \mathrm{E}+01 & 3.456 \mathrm{E}+01 & 2.443 \mathrm{E}+01 & 7.441 \mathrm{E}-01\end{array}$

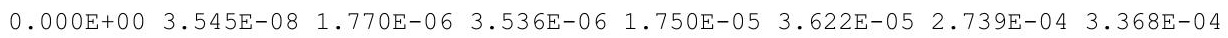

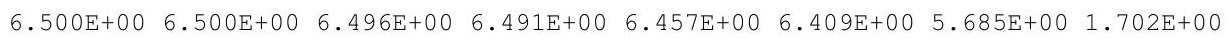

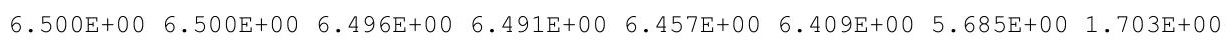




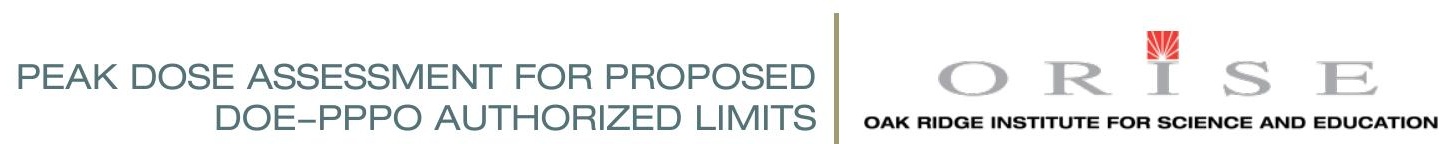

ATTACHMENT B: RESRAD-OFFSITE PARENT DOSE REPORTS 


\section{Table of Contents}

Offsite Resident Farmer Parent Dose Report (Deterministic Analysis Report) First Peak Dose Assessment: Time Horizon 1,050 yr ................................................................ B-3

Offsite Resident Farmer Parent Dose Report (Deterministic Analysis Report) Second Peak Dose Assessment: Time Horizon 10,000 yr..........................................B-68

Offsite Resident Farmer Parent Dose Report (Deterministic Analysis Report) Third Peak Dose Assessment: Time Horizon 100,000 yr ....................................................B-134 


\section{Offsite Resident Farmer}

\section{Parent Dose Report \\ (Deterministic Analysis Report)}

First Peak Dose Assessment

Time Horizon: 1,050 yr 
THIS PAGE INTENTIONALLY LEFT BLANK 
RESRAD-OFFSITE, Version 2.5

Parent Dose Report

Title : Offsite Resident Farmer Deterministic Run

File : RF DOE SG FWD-FV2-1050y.ROF

Dose Conversion Factor (and Related) Parameter Summary

Current Library: ICRP 60

Default Library: ICRP 60

\begin{tabular}{|c|c|c|c|c|c|c|c|c|c|c|}
\hline \multirow{2}{*}{ Menu } & & \multicolumn{2}{|c|}{ I Current } & | & | & \multicolumn{2}{|c|}{ Parameter } \\
\hline & & & & Parameter & | & Value & Default & & Name & \\
\hline SF & DCF's fo. & external & Lrou & and radiation, (mrem/yr)/(pci/g) & | & & $\mid$ & & & \\
\hline $\mathrm{SF}$ & $A c-225$ & (Source: & ICRP & $60)$ & | & $5.775 \mathrm{E}-02$ & | 5.775E-02 & $\mid$ & DCEEXT ( & 1) \\
\hline $\mathrm{SF}$ & Ac -227 & (Source: & ICRP & $60)$ & | & $4.485 E-04$ & | $4.485 \mathrm{E}-04$ & $\mid$ & DCEEXT ( & 2) \\
\hline$S F$ & $\mathrm{Ac}-228$ & (Source: & ICRP & $60)$ & | & $5.662 \mathrm{E}+00$ & $5.662 \mathrm{E}+00$ & † & DCEEXT ( & 3) \\
\hline$S F$ & Am-241 & (Source: & ICRP & $60)$ & | & $3.719 \mathrm{E}-02$ & | $3.719 \mathrm{E}-02$ & 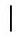 & DCEEXT ( & 4) \\
\hline $\mathrm{SE}$ & At -217 & (Source: & ICRP & $60)$ & | & $1.654 \mathrm{E}-03$ & | $1.654 \mathrm{E}-03$ & & DCFEXT ( & 5) \\
\hline$S F$ & At -218 & (Source: & ICRP & $60)$ & | & $4.878 E-03$ & | 4.878E-03 & $\mid$ & DCEEXT ( & 6) \\
\hline $\mathrm{SF}$ & $\mathrm{Ba}-137 \mathrm{~m}$ & (Source: & ICRP & 60) & | & $3.383 \mathrm{E}+00$ & | $3.383 \mathrm{E}+00$ & $\mid$ & DCEEXT ( & 7) \\
\hline $\mathrm{SF}$ & $\mathrm{Bi}-210$ & (Source: & ICRP & $60)$ & | & $5.476 \mathrm{E}-03$ & | 5.476E-03 & $\mid$ & DCEEXT ( & 8) \\
\hline $\mathrm{SF}$ & Bi-211 & (Source: & ICRP & $60)$ & | & $2.373 E-01$ & | 2.373E-01 & $\mid$ & DCEEXT ( & 9) \\
\hline $\mathrm{SF}$ & Bi-212 & (Source: & ICRP & $60)$ & | & $1.114 \mathrm{E}+00$ & | $1.114 \mathrm{E}+00$ & & DCEEXT ( & 10) \\
\hline SF & $\mathrm{Bi}-213$ & (Source: & ICRP & $60)$ & | & $7.158 \mathrm{E}-01$ & | $7.158 \mathrm{E}-01$ & 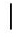 & DCEEXT ( & 11) \\
\hline $\mathrm{SF}$ & $\mathrm{Bi}-214$ & (Source: & ICRP & $60)$ & | & $9.325 \mathrm{E}+00$ & | $9.325 \mathrm{E}+00$ & & DCEEXT ( & 12) \\
\hline$S F$ & $\mathrm{Cs}-137$ & (Source: & ICRP & $60)$ & | & $8.372 E-04$ & | $8.372 \mathrm{E}-04$ & 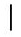 & DCEEXT ( & 13) \\
\hline $\mathrm{SF}$ & Fr-221 & (Source: & ICRP & $60)$ & | & $1.413 E-01$ & | 1.413E-01 & $\mid$ & DCEEXT ( & 14) \\
\hline SE & Fr-223 & (Source: & ICRP & $60)$ & | & $1.813 E-01$ & | 1.813E-01 & & DCEEXT ( & 15) \\
\hline SE & $\mathrm{Np}-237$ & (Source: & ICRP & $60)$ & | & $6.971 \mathrm{E}-02$ & | 6.971E-02 & & DCEEXT ( & 16) \\
\hline SF & $\mathrm{Pa}-231$ & (Source: & ICRP & $60)$ & I & $1.762 \mathrm{E}-01$ & | $1.762 \mathrm{E}-01$ & $\mid$ & DCEEXT ( & 17) \\
\hline $\mathrm{SE}$ & $\mathrm{Pa}-233$ & (Source: & ICRP & $60)$ & I & $9.419 \mathrm{E}-01$ & | 9.419E-01 & $\mid$ & DCEEXT ( & 18) \\
\hline$S F$ & $\mathrm{~Pa}-234$ & (Source: & ICRP & $60)$ & | & $1.088 \mathrm{E}+01$ & | $1.088 \mathrm{E}+01$ & 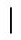 & DCEEXT ( & 19) \\
\hline $\mathrm{SF}$ & $\mathrm{Pa}-234 \mathrm{~m}$ & (Source: & ICRP & $60)$ & | & $9.867 \mathrm{E}-02$ & | 9.867E-02 & $\mid$ & DCEEXT ( & 20) \\
\hline $\mathrm{SF}$ & $\mathrm{Pb}-209$ & (Source: & ICRP & $60)$ & l & $7.550 \mathrm{E}-04$ & | $7.550 \mathrm{E}-04$ & & DCEEXT ( & 21) \\
\hline SE & $\mathrm{Pb}-210$ & (Source: & ICRP & $60)$ & | & $1.981 \mathrm{E}-03$ & | 1.981E-03 & & DCEEXT ( & 22) \\
\hline SF & $\mathrm{Pb}-211$ & (Source: & ICRP & $60)$ & l & $2.915 E-01$ & | 2.915E-01 & 1 & DCFEXT ( & 23) \\
\hline $\mathrm{SE}$ & $\mathrm{Pb}-212$ & (Source: & ICRP & $60)$ & l & $6.466 \mathrm{E}-01$ & | $6.466 \mathrm{E}-01$ & $\mid$ & DCEEXT ( & 24) \\
\hline $\mathrm{SF}$ & $\mathrm{Pb}-214$ & (Source: & ICRP & $60)$ & | & $1.243 \mathrm{E}+00$ & $1.243 \mathrm{E}+00$ & $\mid$ & DCEEXT ( & 25) \\
\hline $\mathrm{SF}$ & Po-210 & (Source: & ICRP & $60)$ & | & $4.934 \mathrm{E}-05$ & | 4.934E-05 & & DCEEXT ( & 26) \\
\hline $\mathrm{SF}$ & Po-211 & (Source: & ICRP & $60)$ & l & $4.485 E-02$ & | 4.485E-02 & & DCEEXT ( & 27) \\
\hline SF & Po-212 & (Source: & ICRP & $60)$ & l & $0.000 \mathrm{E}+00$ & $0.000 \mathrm{E}+00$ & & DCEEXT ( & 28) \\
\hline SF & Po-213 & (Source: & ICRP & $60)$ & l & $0.000 \mathrm{E}+00$ & | $0.000 \mathrm{E}+00$ & & DCEEXT ( & 29) \\
\hline $\mathrm{SF}$ & Po-214 & (Source: & ICRP & $60)$ & | & $4.840 \mathrm{E}-04$ & | $4.840 \mathrm{E}-04$ & | & DCEEXT ( & $30)$ \\
\hline $\mathrm{SF}$ & Po-215 & (Source: & ICRP & 60) & | & $9.456 \mathrm{E}-04$ & | $9.456 \mathrm{E}-04$ & $\mid$ & DCEEXT ( & 31) \\
\hline $\mathrm{SF}$ & Po-216 & (Source: & ICRP & $60)$ & l & $9.830 E-05$ & | $9.830 \mathrm{E}-05$ & & DCEEXT ( & $32)$ \\
\hline SF & Po-218 & (Source: & ICRP & $60)$ & | & $5.326 \mathrm{E}-05$ & | $5.326 \mathrm{E}-05$ & & DCEEXT ( & 33) \\
\hline SF & $\mathrm{Pu}-238$ & (Source: & ICRP & $60)$ & l & $1.166 \mathrm{E}-04$ & | $1.166 \mathrm{E}-04$ & & DCEEXT ( & 34) \\
\hline SF & $\mathrm{Pu}-239$ & (Source: & ICRP & $60)$ & I & $2.635 E-04$ & | $2.635 \mathrm{E}-04$ & & DCEEXT ( & 35) \\
\hline $\mathrm{SF}$ & $\mathrm{Pu}-240$ & (Source: & ICRP & $60)$ & | & $1.129 \mathrm{E}-04$ & | $1.129 \mathrm{E}-04$ & & DCEEXT ( & $36)$ \\
\hline SF & $\mathrm{Ra}-223$ & (Source: & ICRP & $60)$ & l & $5.532 \mathrm{E}-01$ & | 5.532E-01 & & DCEEXT ( & 37) \\
\hline SF & $\mathrm{Ra}-224$ & (Source: & ICRP & $60)$ & | & $4.728 E-02$ & | $4.728 \mathrm{E}-02$ & & DCEEXT ( & 38) \\
\hline SF & $R a-225$ & (Source: & ICRP & $60)$ & | & $8.634 \mathrm{E}-03$ & | $8.634 \mathrm{E}-03$ & & DCEEXT ( & 39) \\
\hline SF & $\mathrm{Ra}-226$ & (Source: & ICRP & $60)$ & l & $2.915 E-02$ & | 2.915E-02 & & DCEEXT ( & $40)$ \\
\hline SF & $\mathrm{Ra}-228$ & (Source: & ICRP & $60)$ & | & $0.000 \mathrm{E}+00$ & $0.000 \mathrm{E}+00$ & & DCEEXT ( & 41) \\
\hline$F$ & $R n-219$ & (Source: & ICRP & $60)$ & | & $2.859 E-01$ & | 2.859E-01 & & DCEEXT ( & 42) \\
\hline$\Gamma$ & $R n-220$ & (Source: & ICRP & $60)$ & 1 & $2.130 \mathrm{E}-03$ & | $2.130 \mathrm{E}-03$ & & DCEEXT ( & 43) \\
\hline $\mathrm{F}$ & $R n-222$ & (Source: & ICRP & $60)$ & & $2.186 \mathrm{E}-03$ & $2.186 \mathrm{E}-03$ & & DCEEXT ( & 44) \\
\hline
\end{tabular}


RESRAD-OFFSITE, Version $2.5 \quad \mathrm{~T}^{1 / 2}$ Limit $=180$ days

Parent Dose Report

Title : Offsite Resident Farmer Deterministic Run

File : RF DOE SG FWD-FV2-1050y.ROF

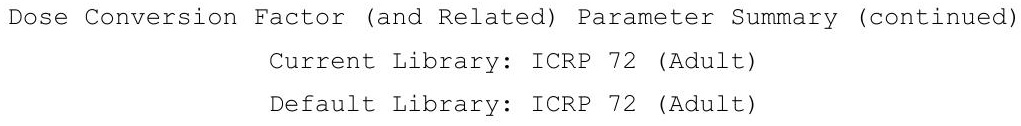

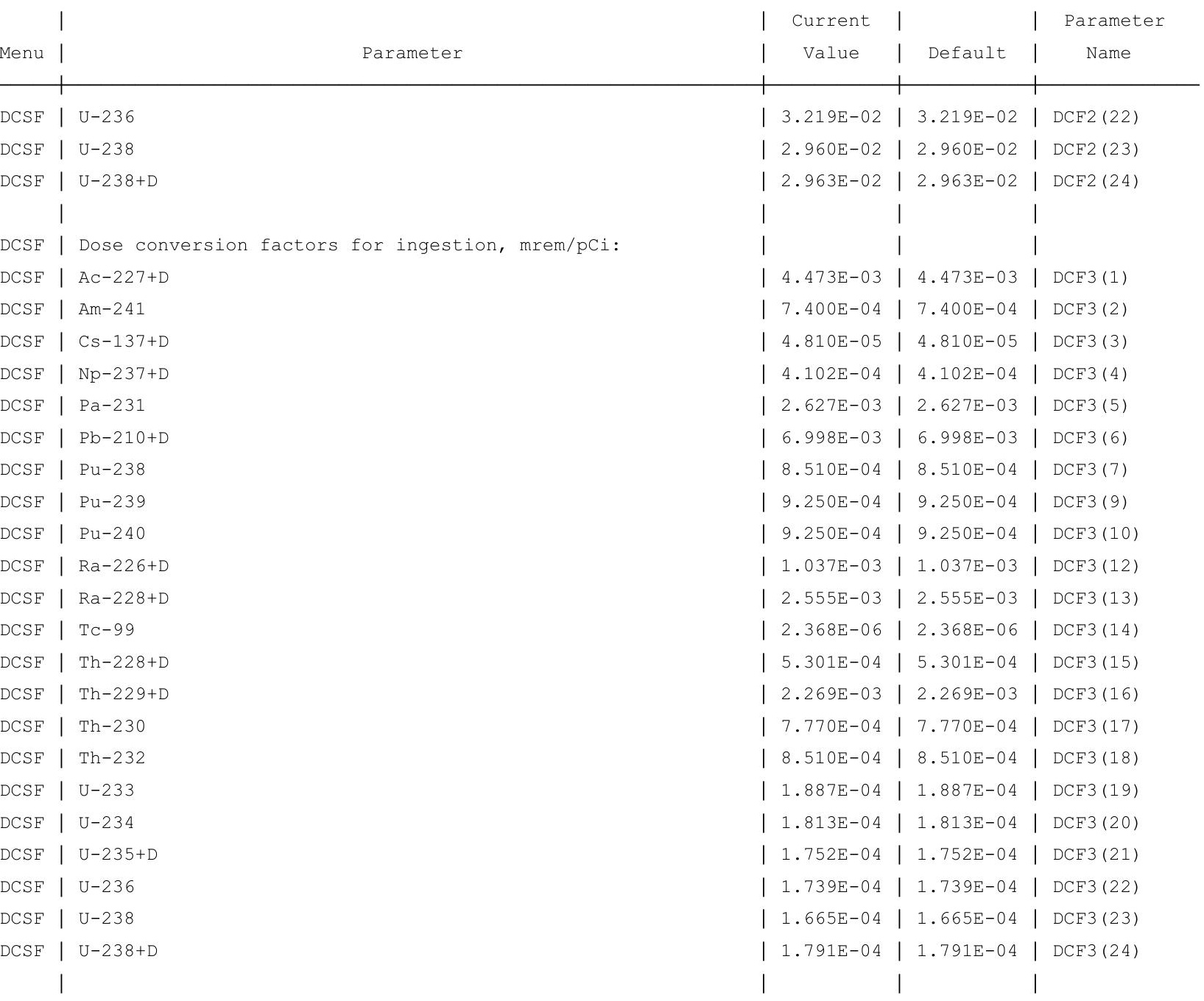


RESRAD-OFFSITE, Version 2.5

Parent Dose Report

Title : Offsite Resident Farmer Deterministic Run

File : RF DOE SG FWD-FV2-1050y.ROF

Dose Conversion Factor (and Related) Parameter Summary (continued)

Current Library: RESRAD Default Transfer factors

Default Library: RESRAD Default Transfer factors

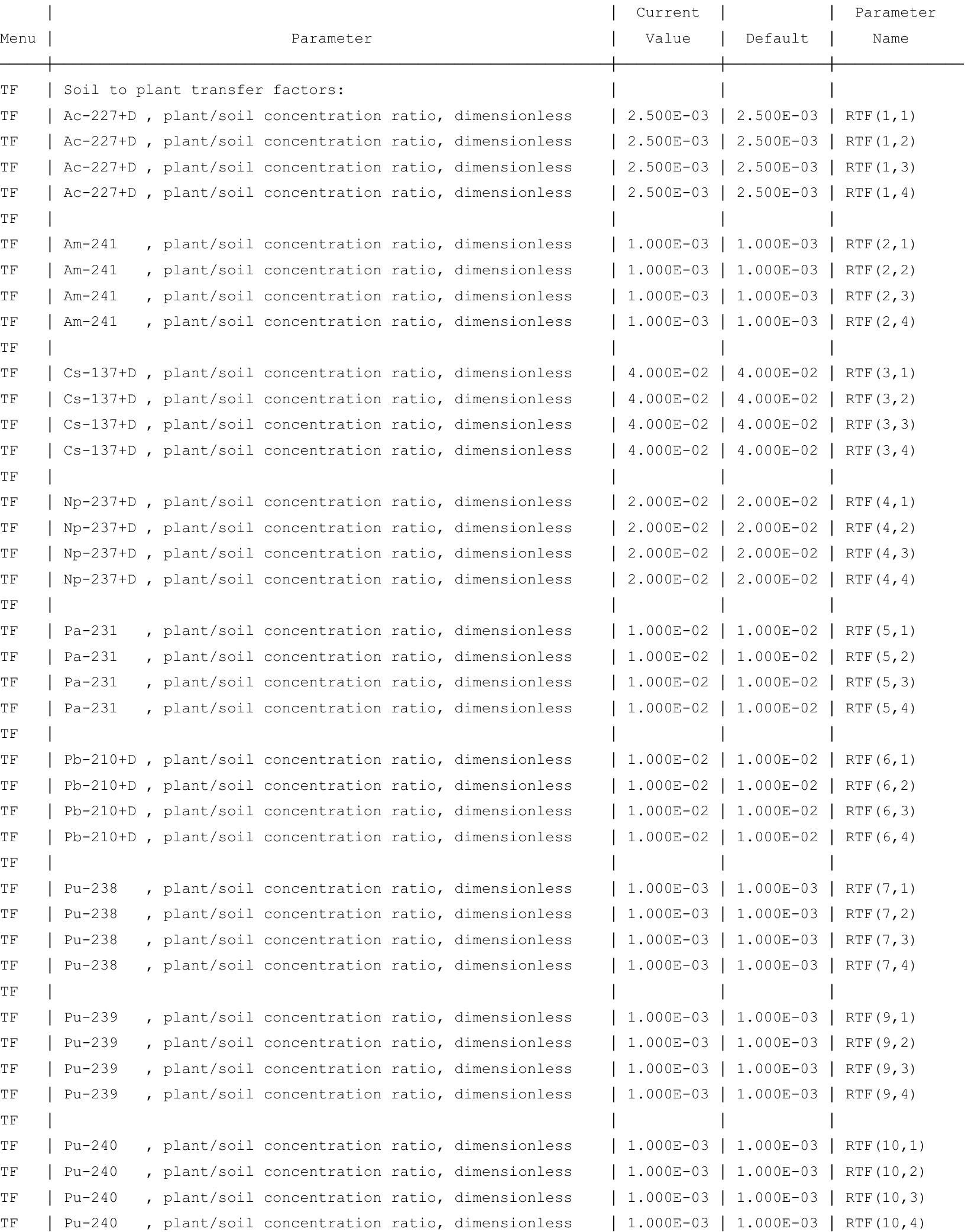


RESRAD-OFFSITE, Version 2.5

Parent Dose Report

Title : Offsite Resident Farmer Deterministic Run

File : RF DOE SG FWD-FV2-1050y.ROF

Dose Conversion Factor (and Related) Parameter Summary (continued)

Current Library: RESRAD Default Transfer factors

Default Library: RESRAD Default Transfer factors

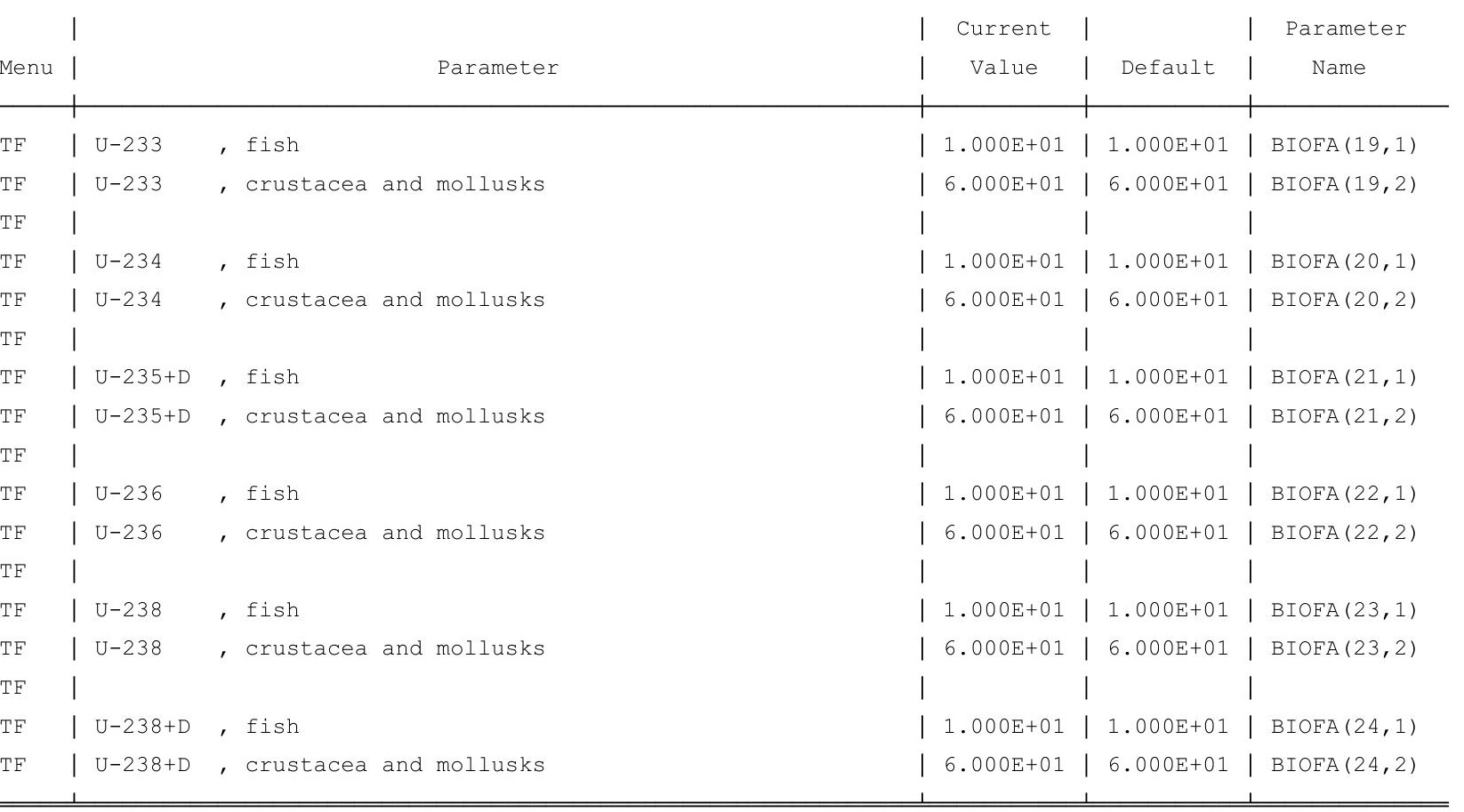


RESRAD-OFFSITE, Version $2.5 \quad \mathrm{~T}^{1 / 2}$ Limit $=180$ days

Parent Dose Report

Title : Offsite Resident Farmer Deterministic Run

File : RF DOE SG FWD-FV2-1050y.ROF

Site-Specific Parameter Summary

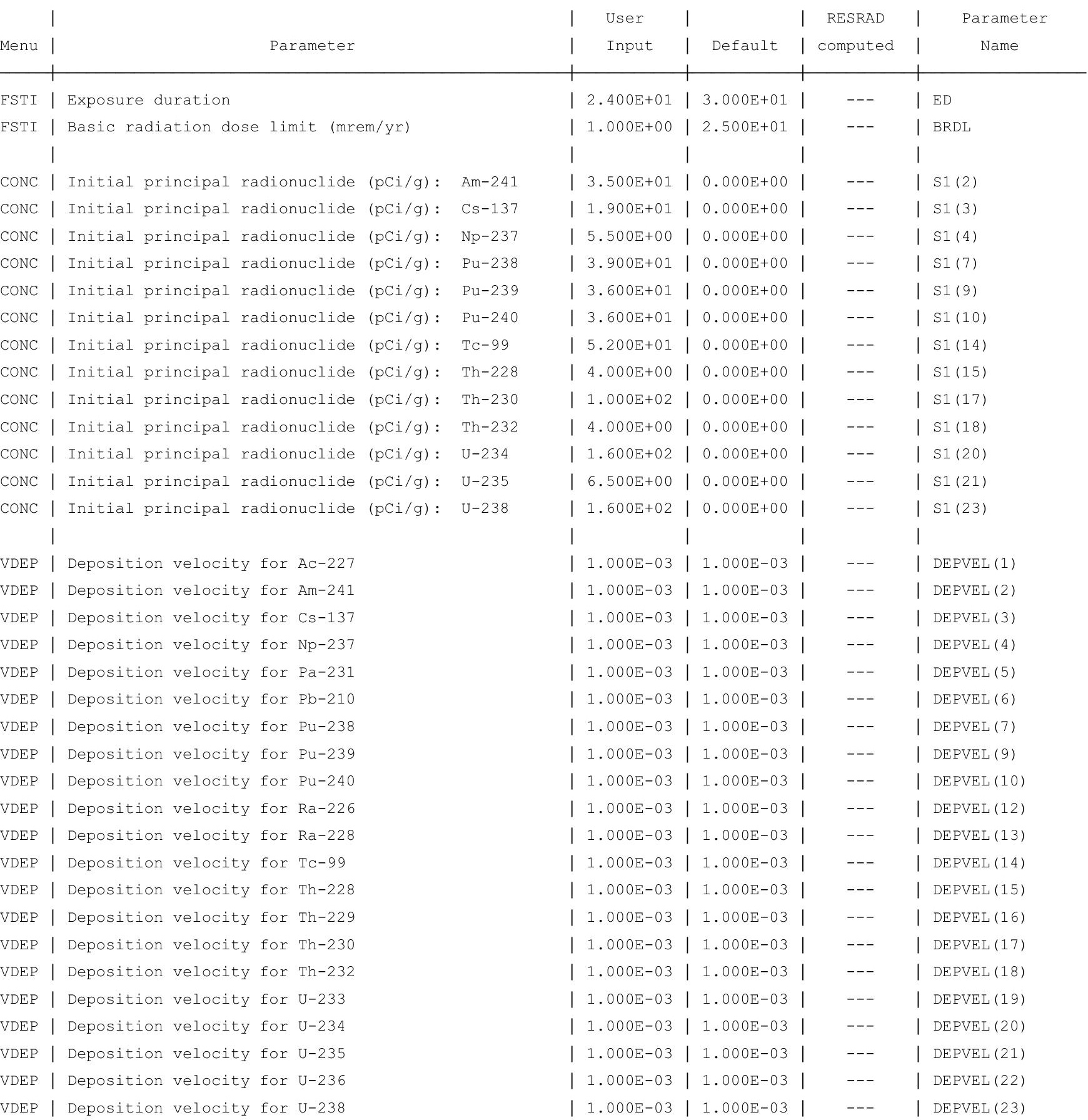


RESRAD-OFFSITE, Version $2.5 \quad \mathrm{~T}^{1 / 2}$ Limit $=180$ days

Parent Dose Report

Title : Offsite Resident Farmer Deterministic Run

File : RF DOE SG FWD-FV2-1050y.ROF

Site-Specific Parameter Summary (continued)

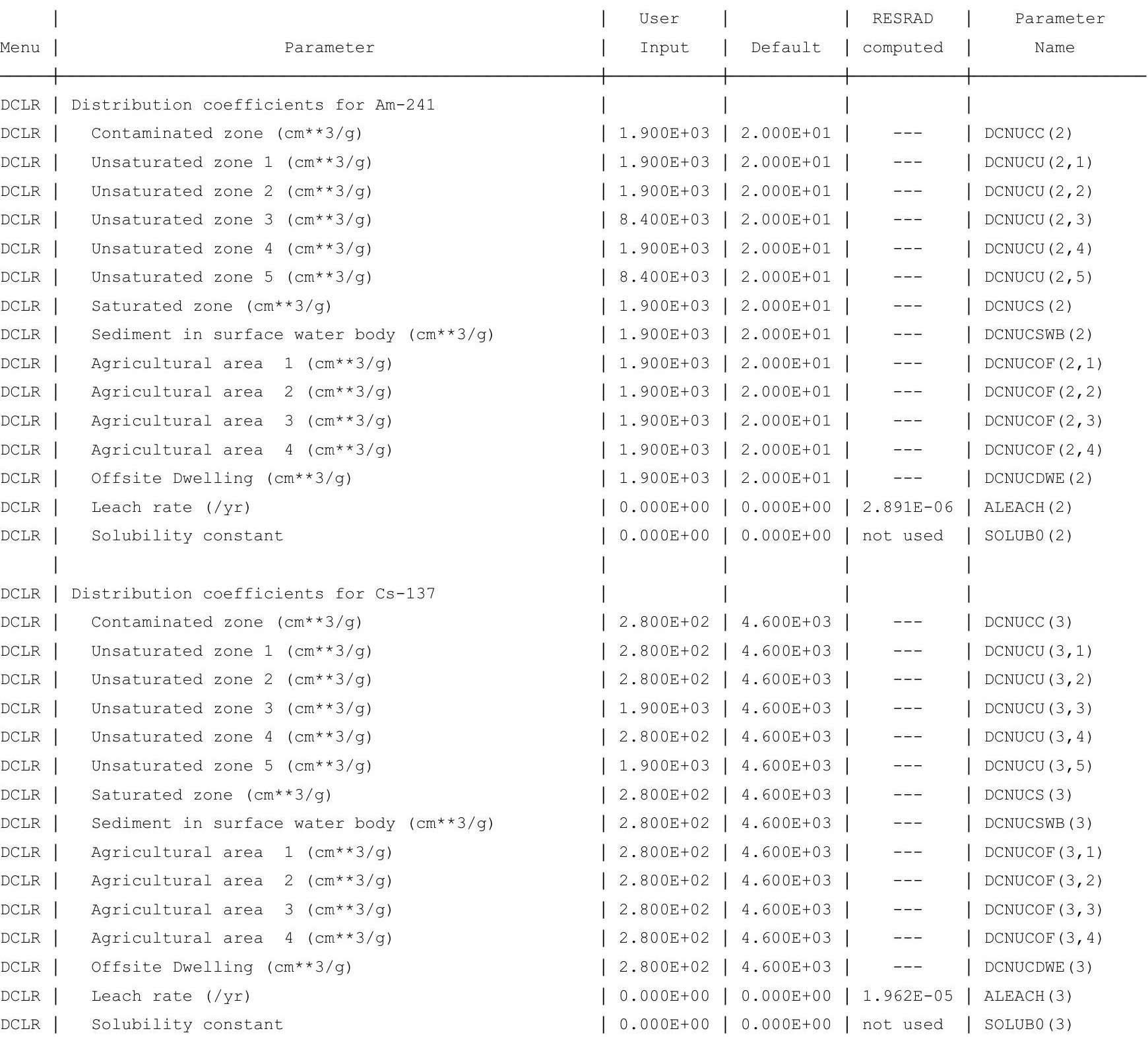


RESRAD-OFFSITE, Version $2.5 \quad \mathrm{~T}^{1 / 2}$ Limit $=180$ days

Parent Dose Report

Title : Offsite Resident Farmer Deterministic Run

File : RF DOE SG FWD-FV2-1050y.ROF

Site-Specific Parameter Summary (continued)

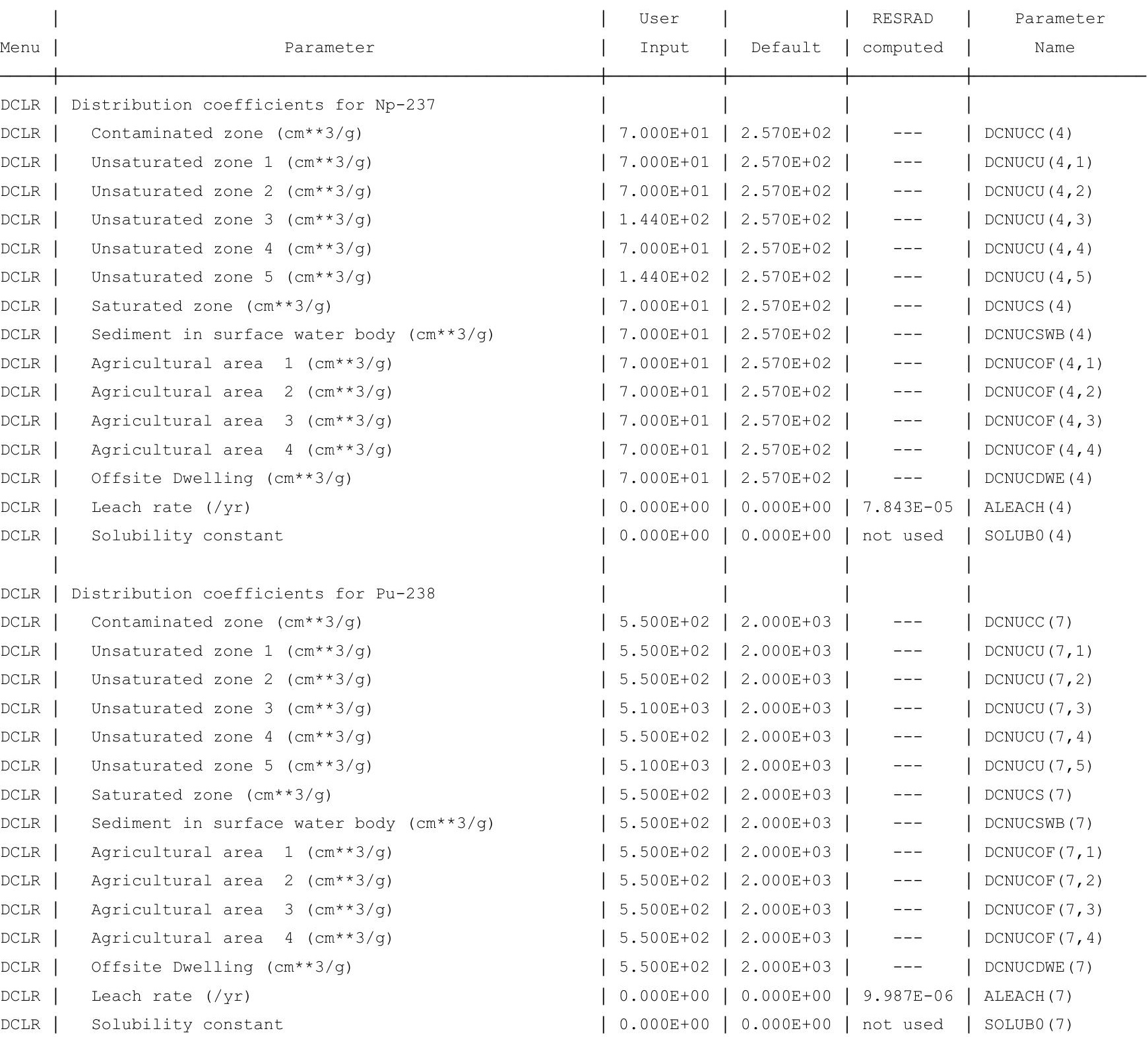


RESRAD-OFFSITE, Version $2.5 \quad \mathrm{~T}^{1 / 2}$ Limit $=180$ days

Parent Dose Report

Title : Offsite Resident Farmer Deterministic Run

File : RF DOE SG FWD-FV2-1050y.ROF

Site-Specific Parameter Summary (continued)

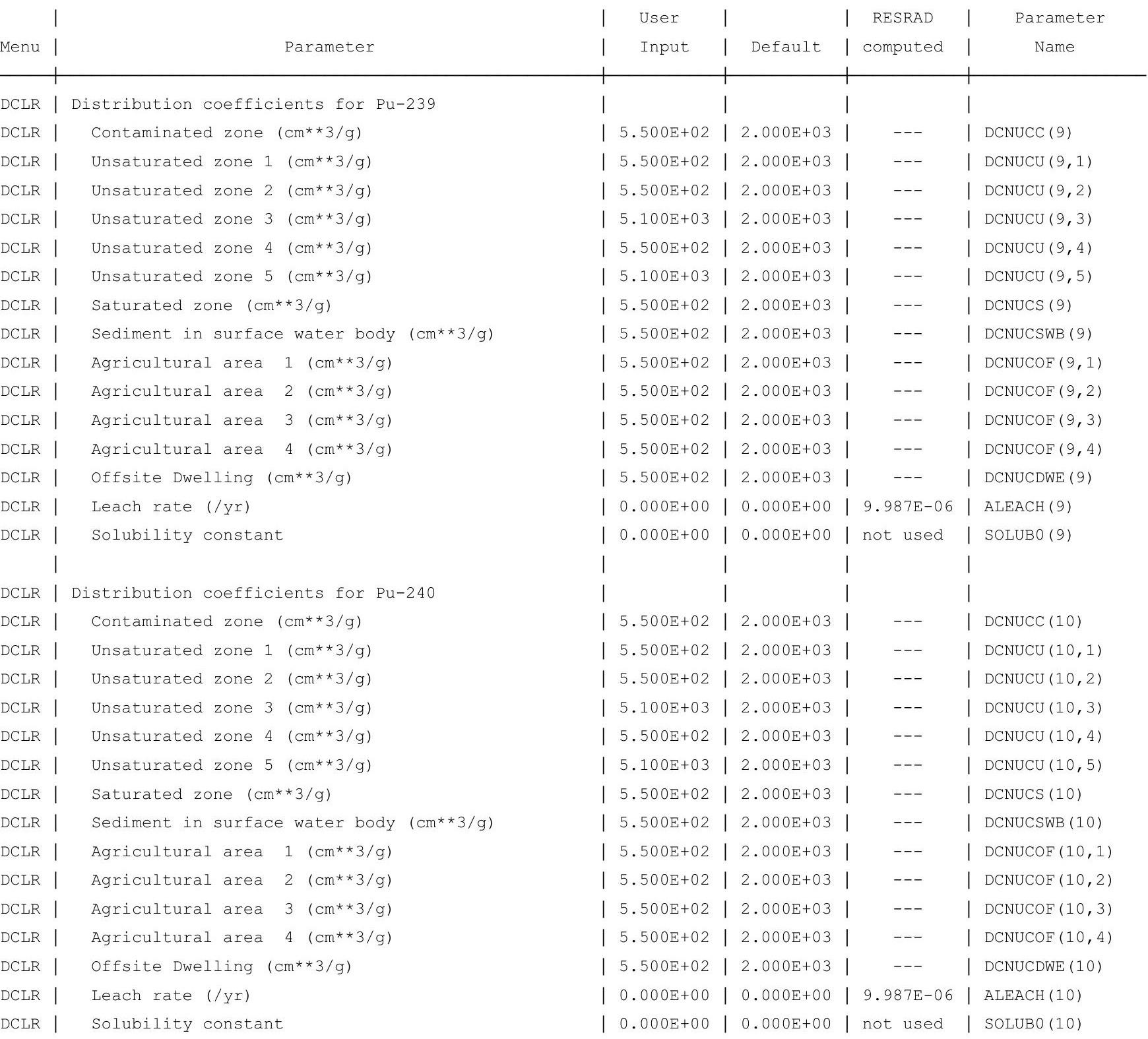


RESRAD-OFFSITE, Version $2.5 \quad \mathrm{~T}^{1 / 2}$ Limit $=180$ days

Parent Dose Report

Title : Offsite Resident Farmer Deterministic Run

File : RF DOE SG FWD-FV2-1050y.ROF

Site-Specific Parameter Summary (continued)

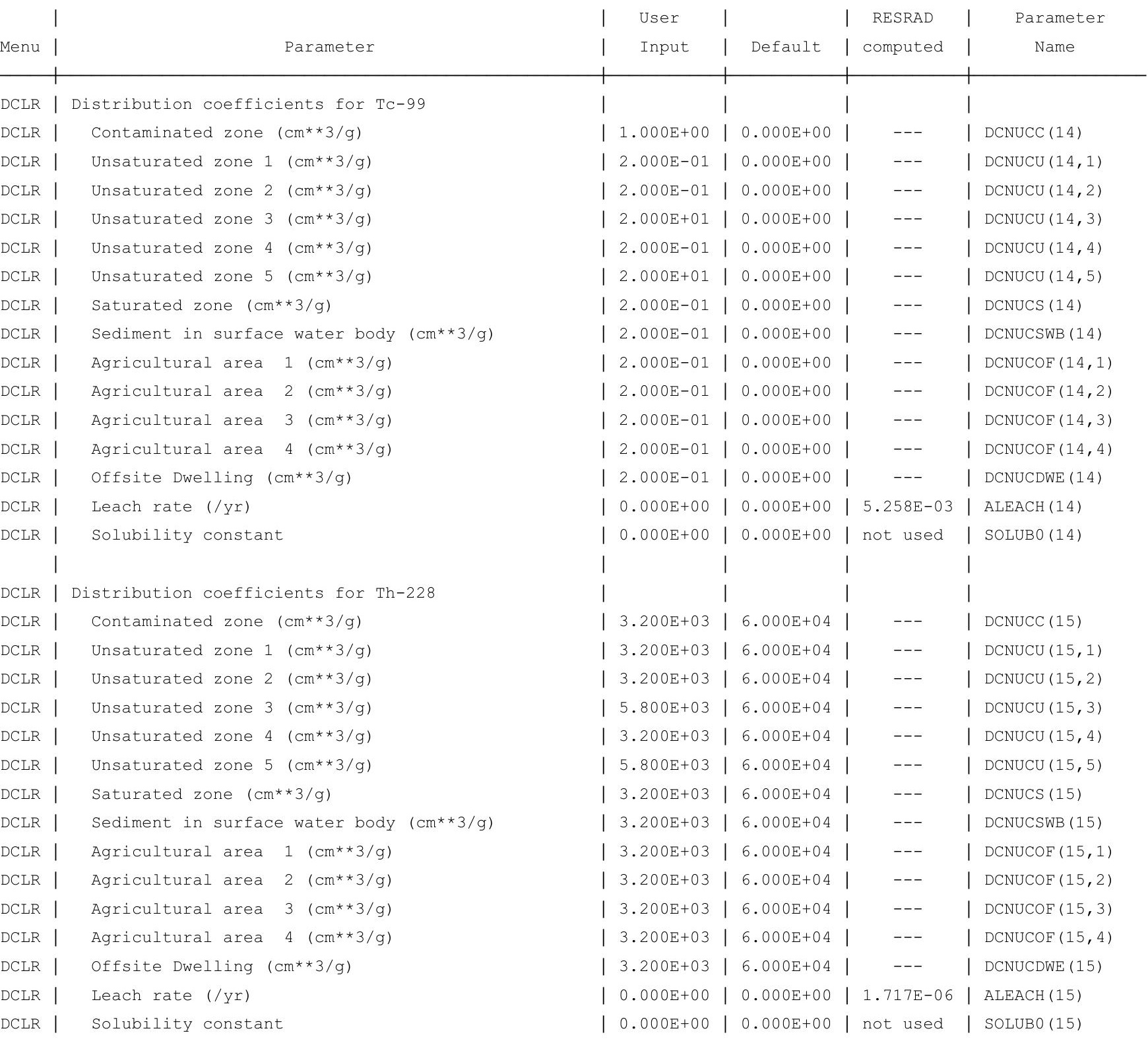


RESRAD-OFFSITE, Version $2.5 \quad \mathrm{~T}^{1 / 2}$ Limit $=180$ days

Parent Dose Report

Title : Offsite Resident Farmer Deterministic Run

File : RF DOE SG FWD-FV2-1050y.ROF

Site-Specific Parameter Summary (continued)

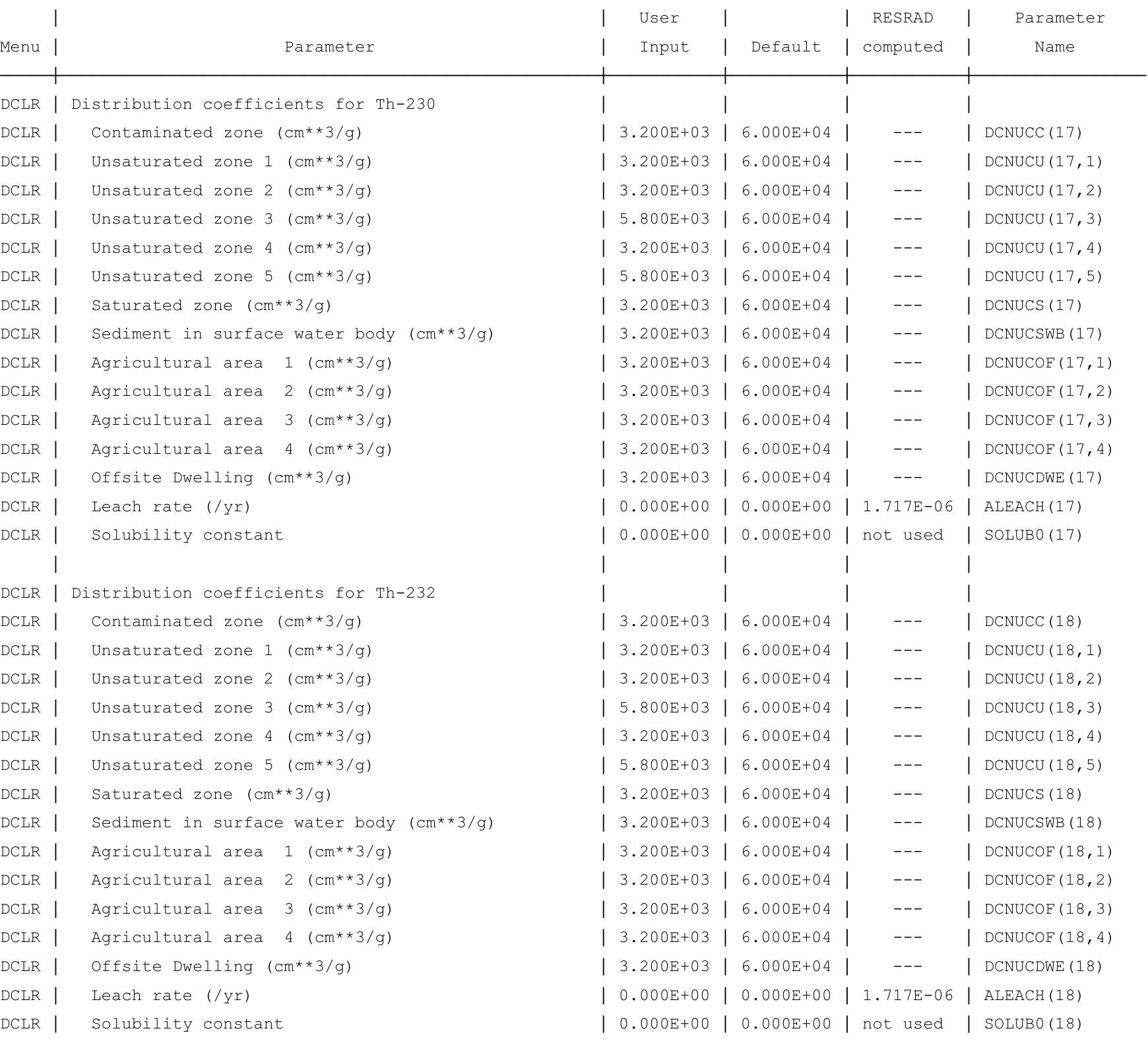


RESRAD-OFFSITE, Version $2.5 \quad \mathrm{~T}^{1 / 2}$ Limit $=180$ days

Parent Dose Report

Title : Offsite Resident Farmer Deterministic Run

File : RF DOE SG FWD-FV2-1050y.ROF

Site-Specific Parameter Summary (continued)

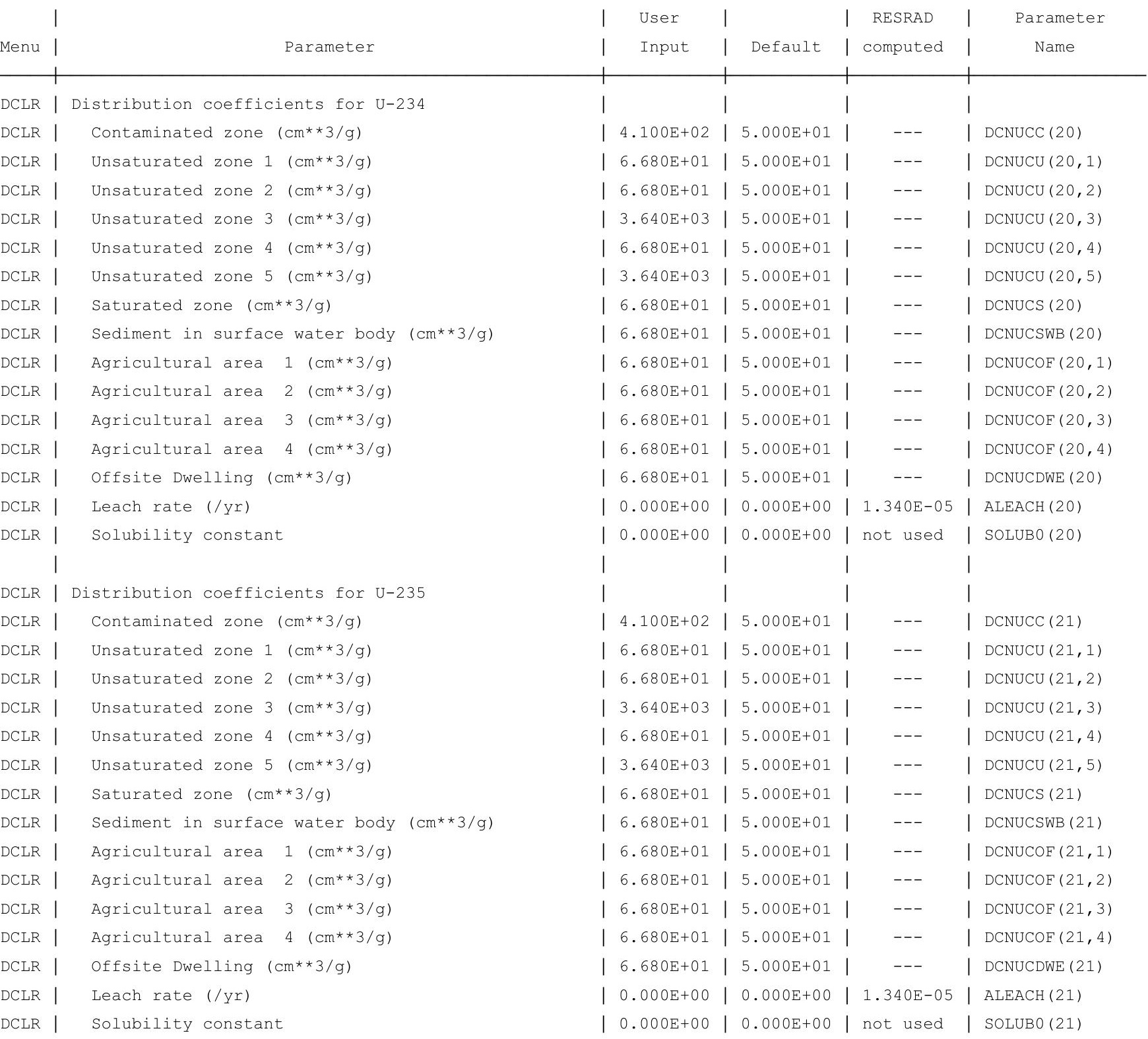


RESRAD-OFFSITE, Version $2.5 \quad \mathrm{~T}^{1 / 2}$ Limit $=180$ days

Parent Dose Report

Title : Offsite Resident Farmer Deterministic Run

File : RF DOE SG FWD-FV2-1050y.ROF

Site-Specific Parameter Summary (continued)

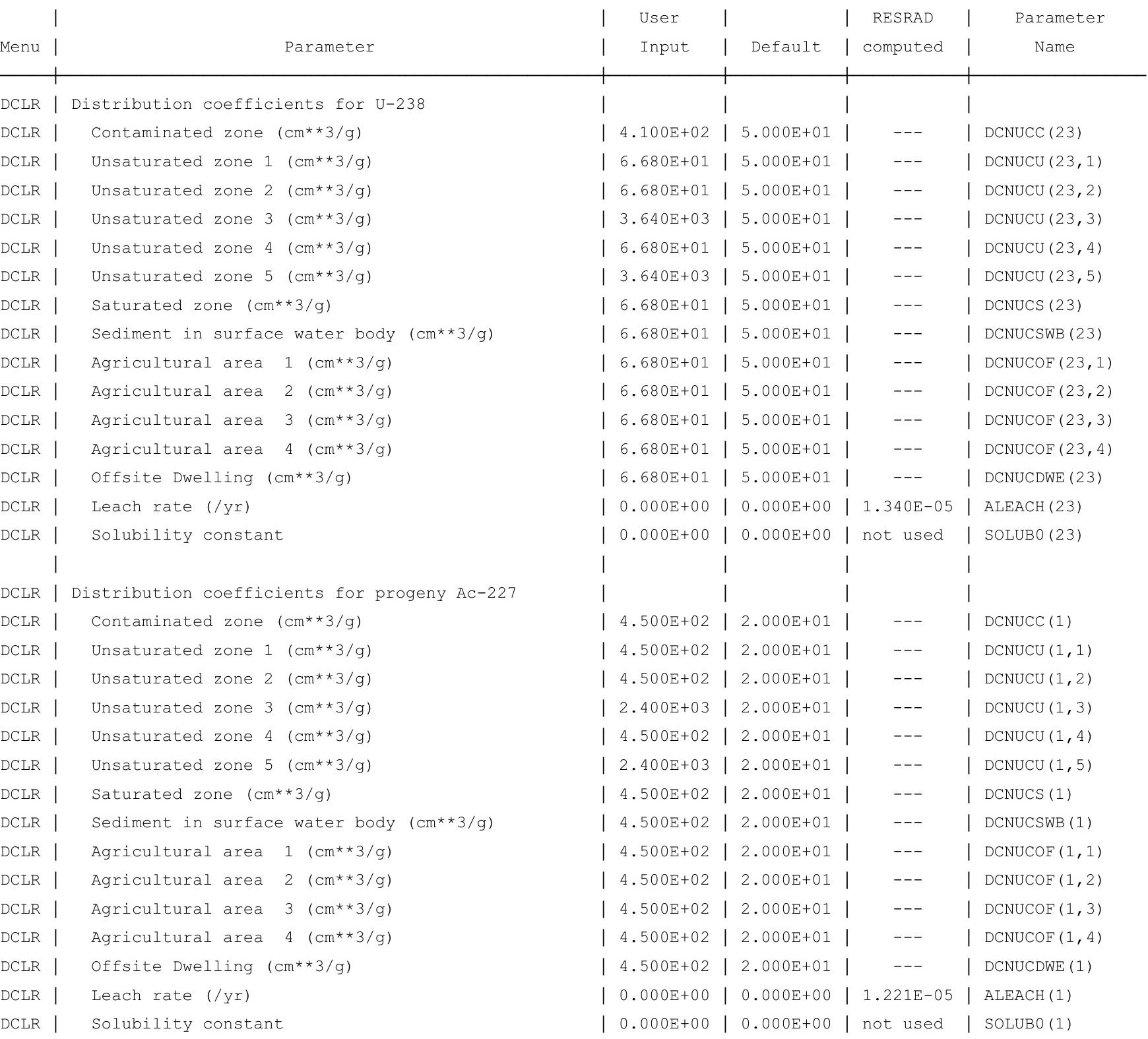


RESRAD-OFFSITE, Version $2.5 \quad \mathrm{~T}^{1 / 2}$ Limit $=180$ days

Parent Dose Report

Title : Offsite Resident Farmer Deterministic Run

File : RF DOE SG FWD-FV2-1050y.ROF

Site-Specific Parameter Summary (continued)

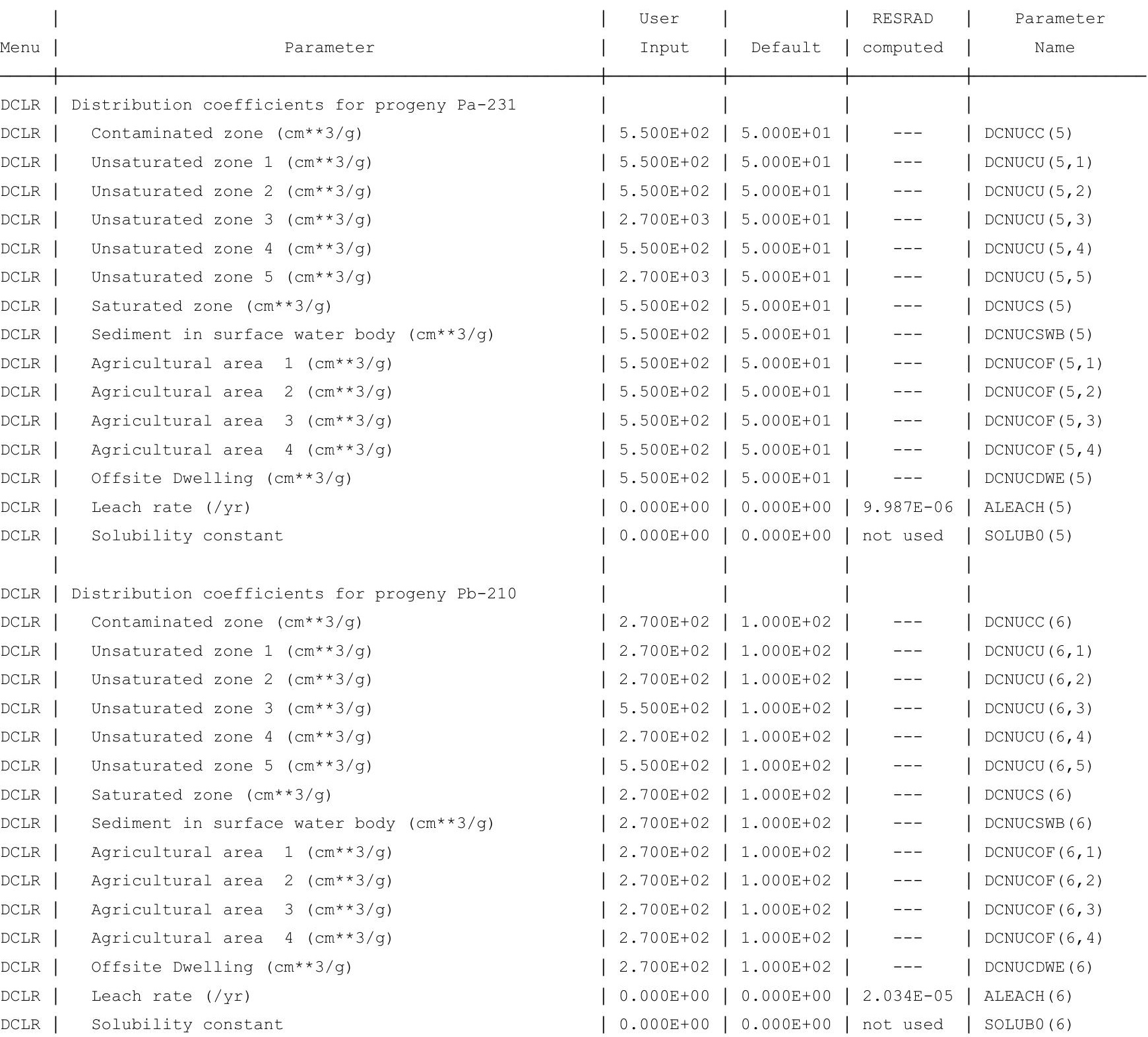


RESRAD-OFFSITE, Version $2.5 \quad \mathrm{~T}^{1 / 2}$ Limit $=180$ days

Parent Dose Report

Title : Offsite Resident Farmer Deterministic Run

File : RF DOE SG FWD-FV2-1050y.ROF

Site-Specific Parameter Summary (continued)

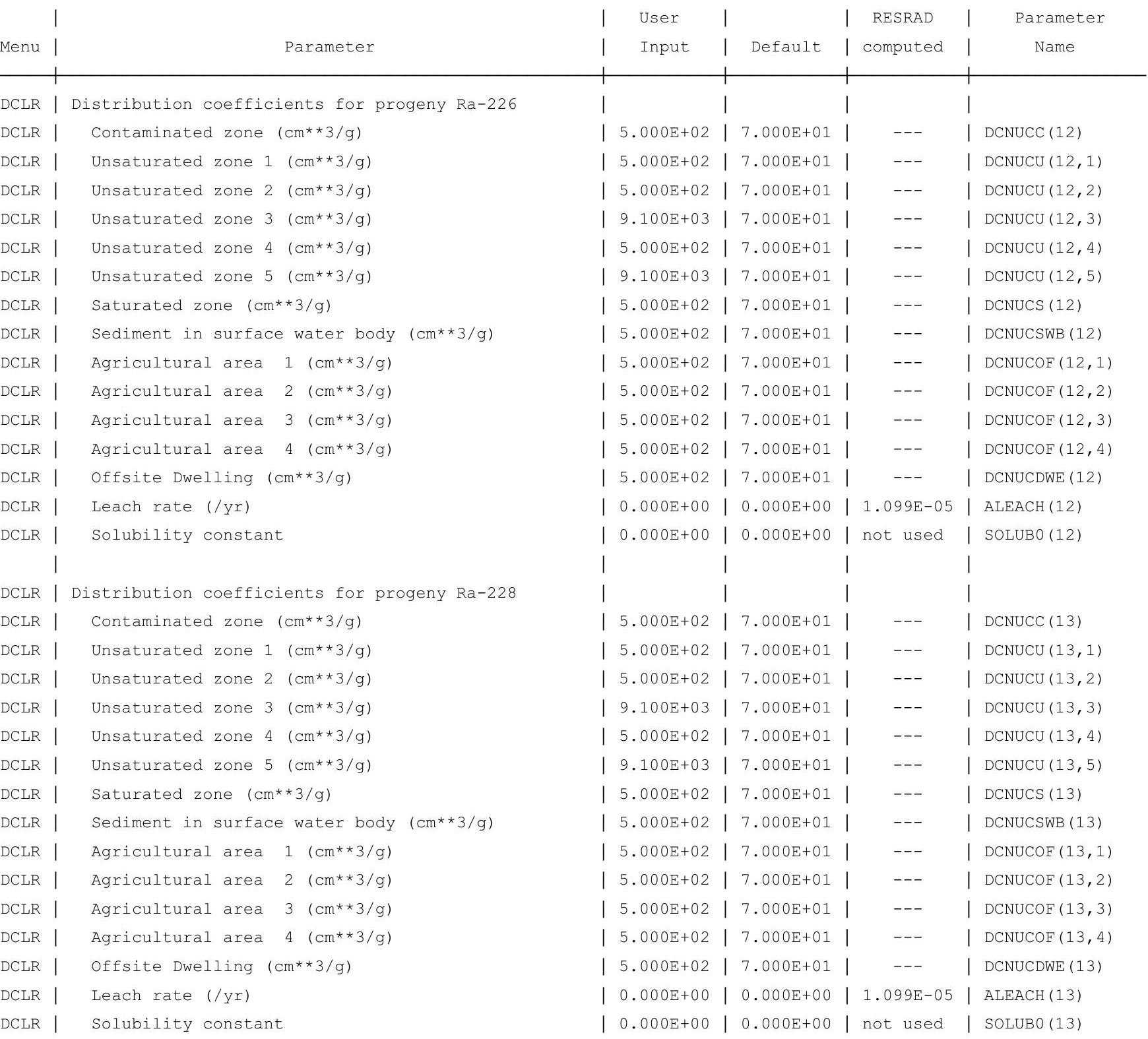


RESRAD-OFFSITE, Version $2.5 \quad \mathrm{~T}^{1 / 2}$ Limit $=180$ days

Parent Dose Report

Title : Offsite Resident Farmer Deterministic Run

File : RF DOE SG FWD-FV2-1050y.ROF

Site-Specific Parameter Summary (continued)

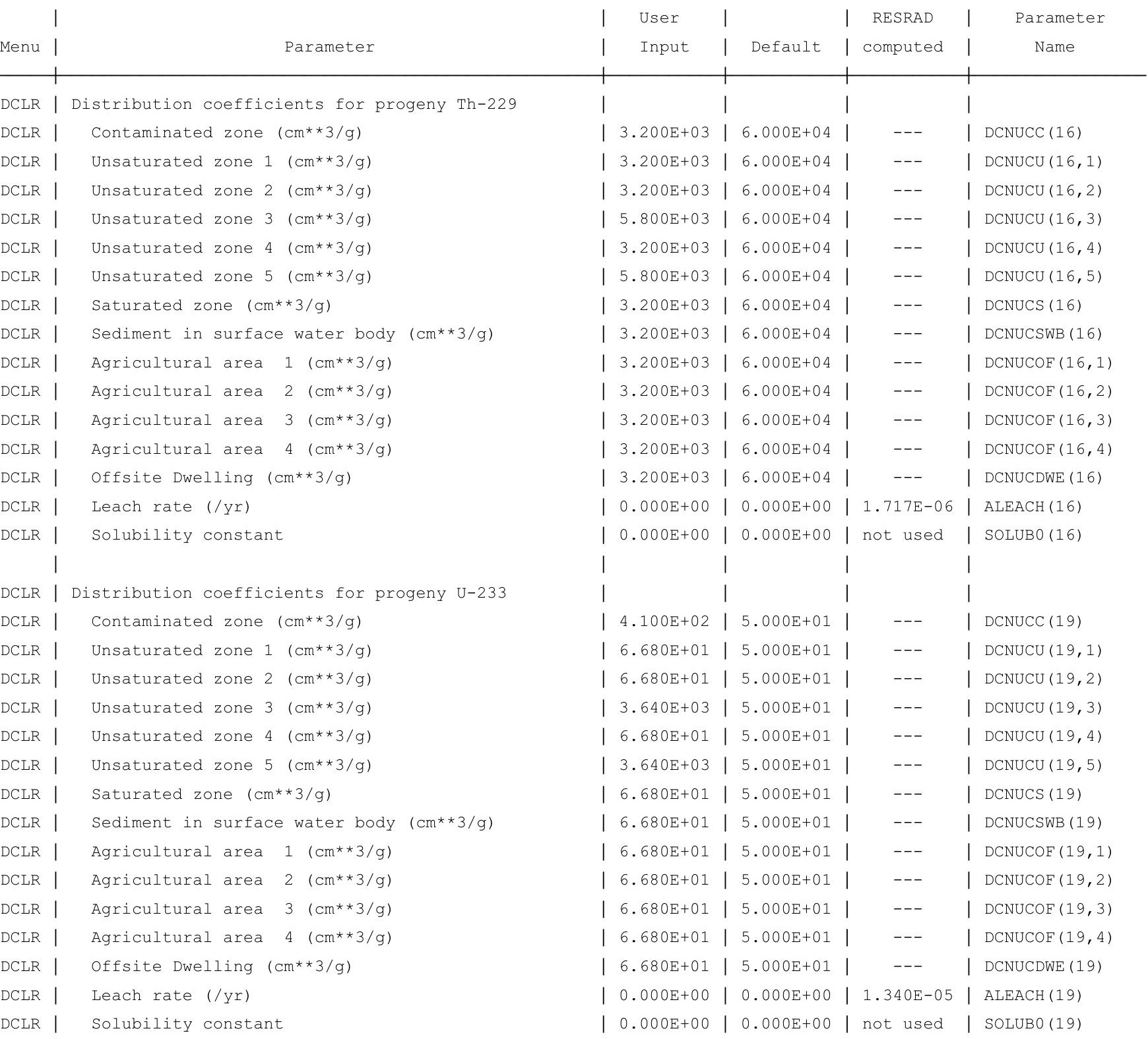


RESRAD-OFFSITE, Version 2.5

Parent Dose Report

Title : Offsite Resident Farmer Deterministic Run

File : RF DOE SG FWD-FV2-1050y.ROF

Site-Specific Parameter Summary (continued)

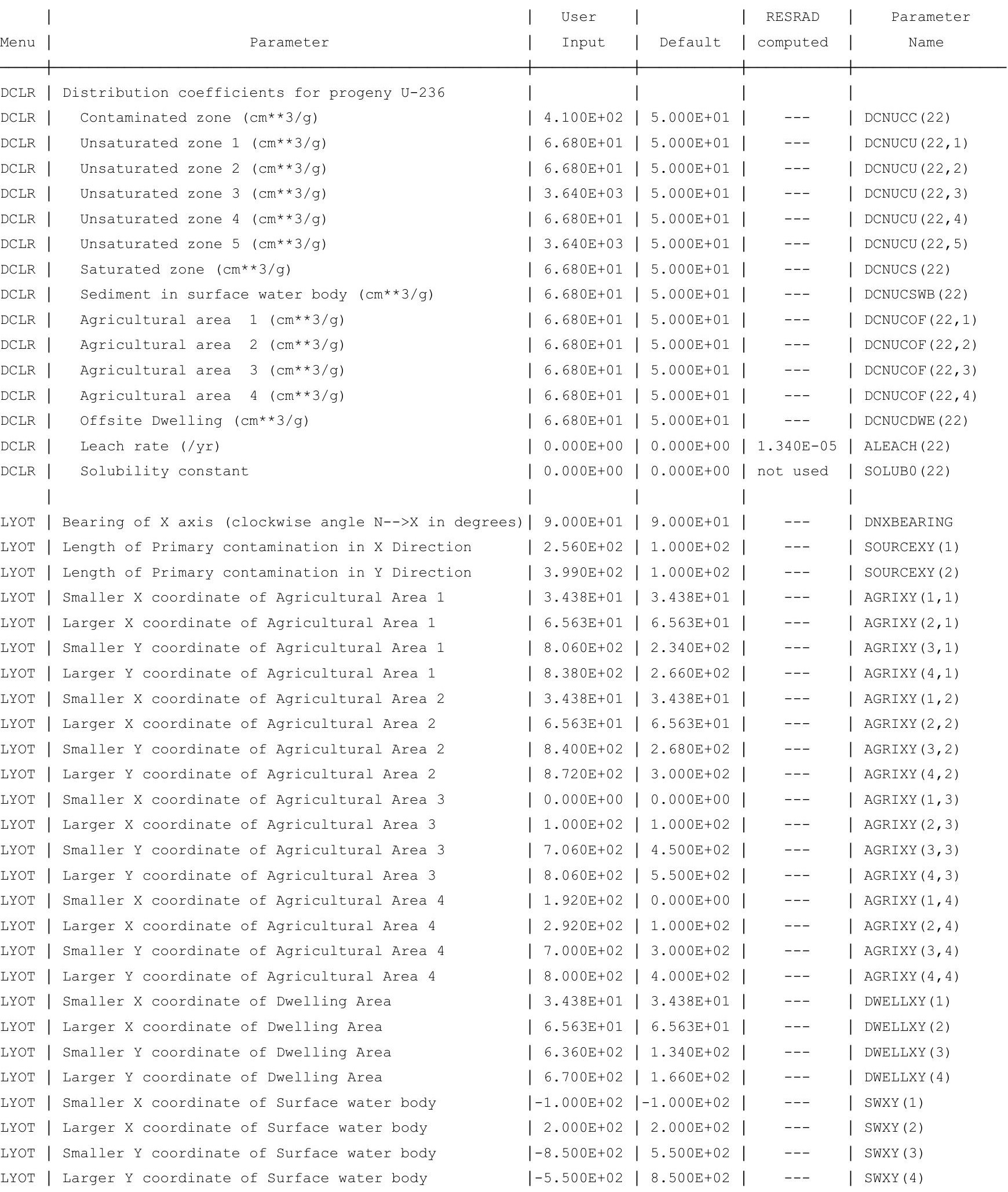


RESRAD-OFFSITE, Version 2.5

Parent Dose Report

Title : Offsite Resident Farmer Deterministic Run

File : RF DOE SG FWD-FV2-1050y.ROF

Site-Specific Parameter Summary (continued)

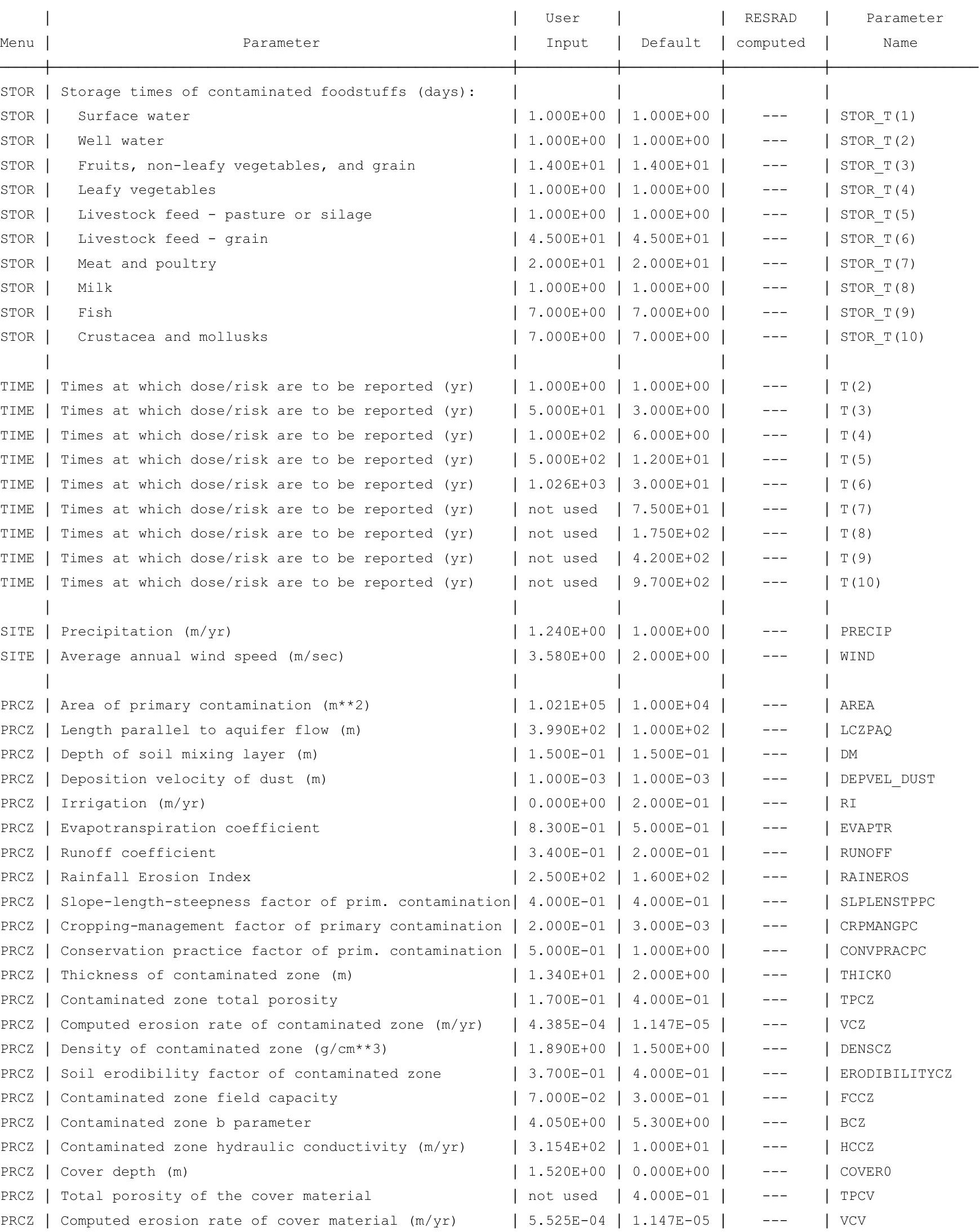


RESRAD-OFFSITE, Version 2.5

Parent Dose Report

Title : Offsite Resident Farmer Deterministic Run

File : RF DOE SG FWD-FV2-1050y.ROF

Site-Specific Parameter Summary (continued)

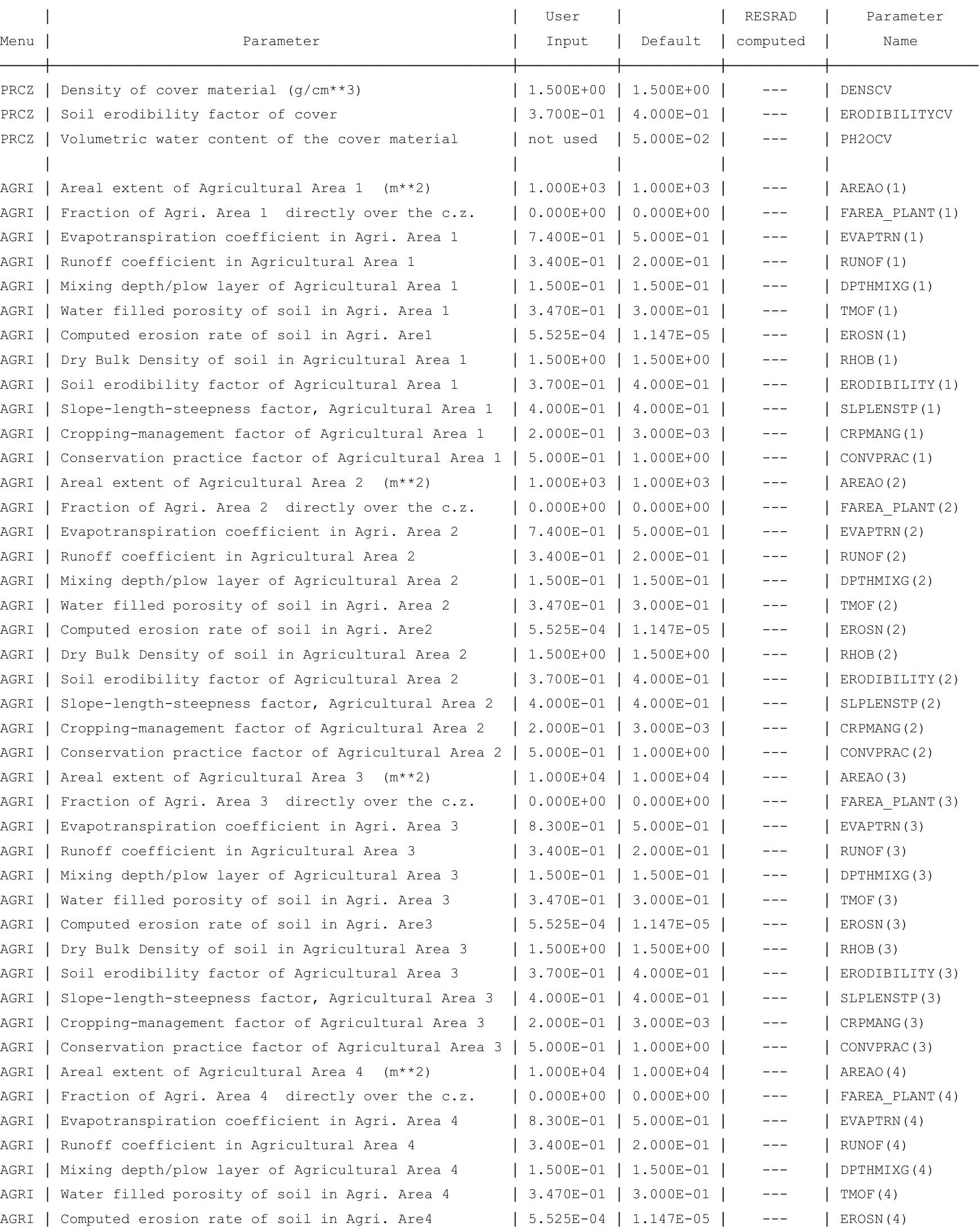


RESRAD-OFFSITE, Version 2.5

Parent Dose Report

Title : Offsite Resident Farmer Deterministic Run

File : RF DOE SG FWD-FV2-1050y.ROF

Site-Specific Parameter Summary (continued)

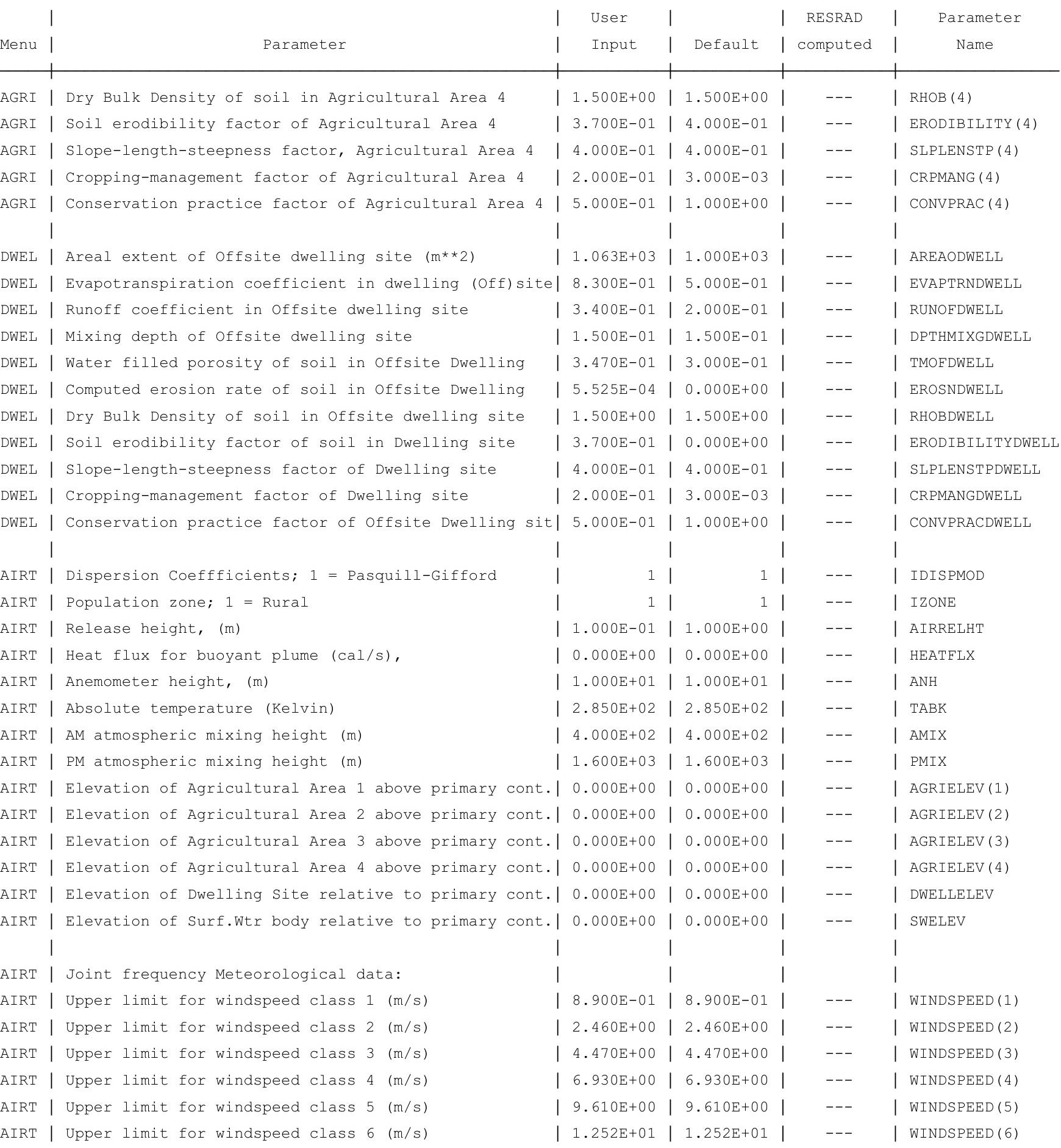


RESRAD-OFFSITE, Version 2.5

Parent Dose Report

Title : Offsite Resident Farmer Deterministic Run

File : RF DOE SG FWD-FV2-1050y.ROF

Site-Specific Parameter Summary (continued)

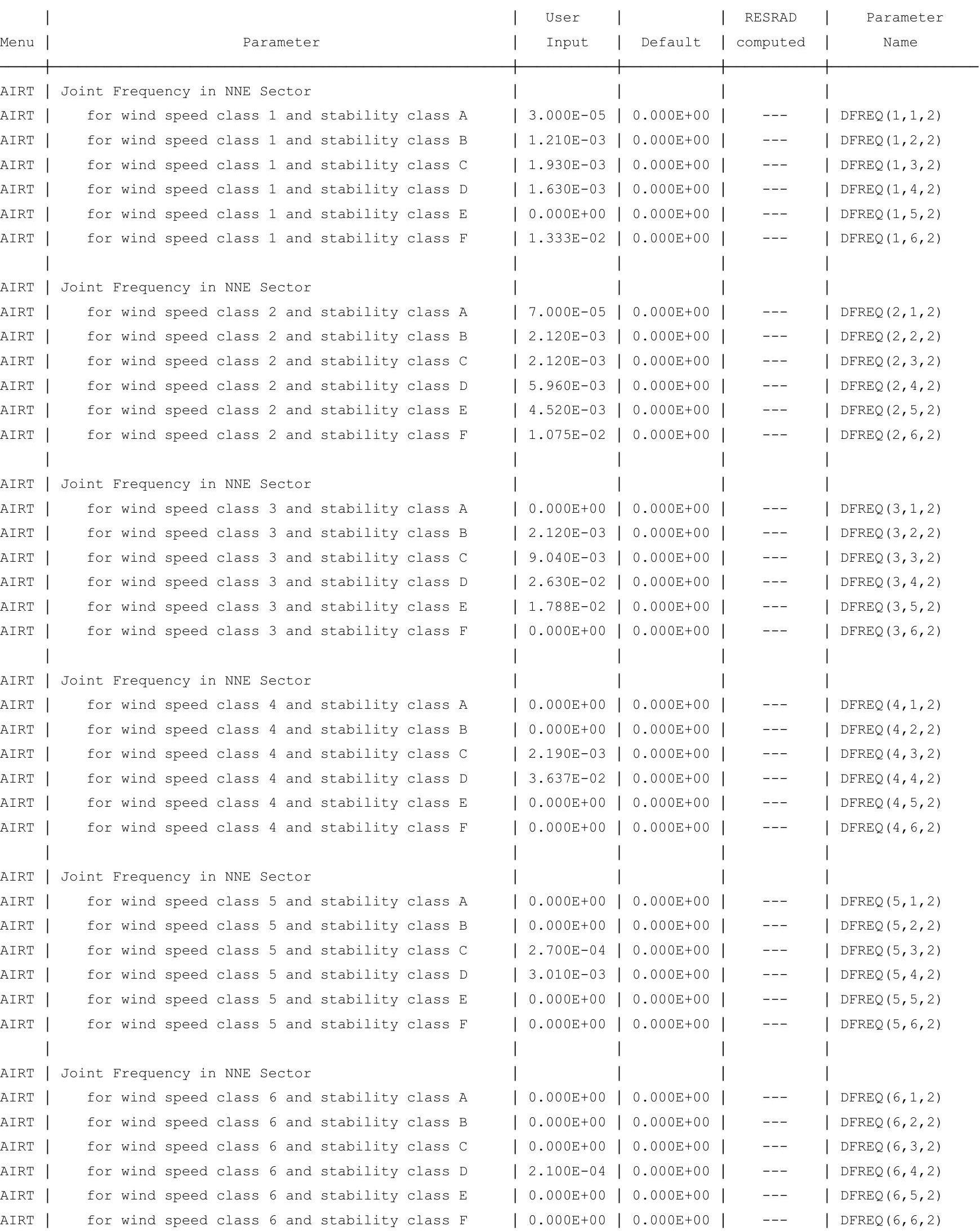


RESRAD-OFFSITE, Version 2.5

Parent Dose Report

Title : Offsite Resident Farmer Deterministic Run

File : RF DOE SG FWD-FV2-1050y.ROF

Site-Specific Parameter Summary (continued)

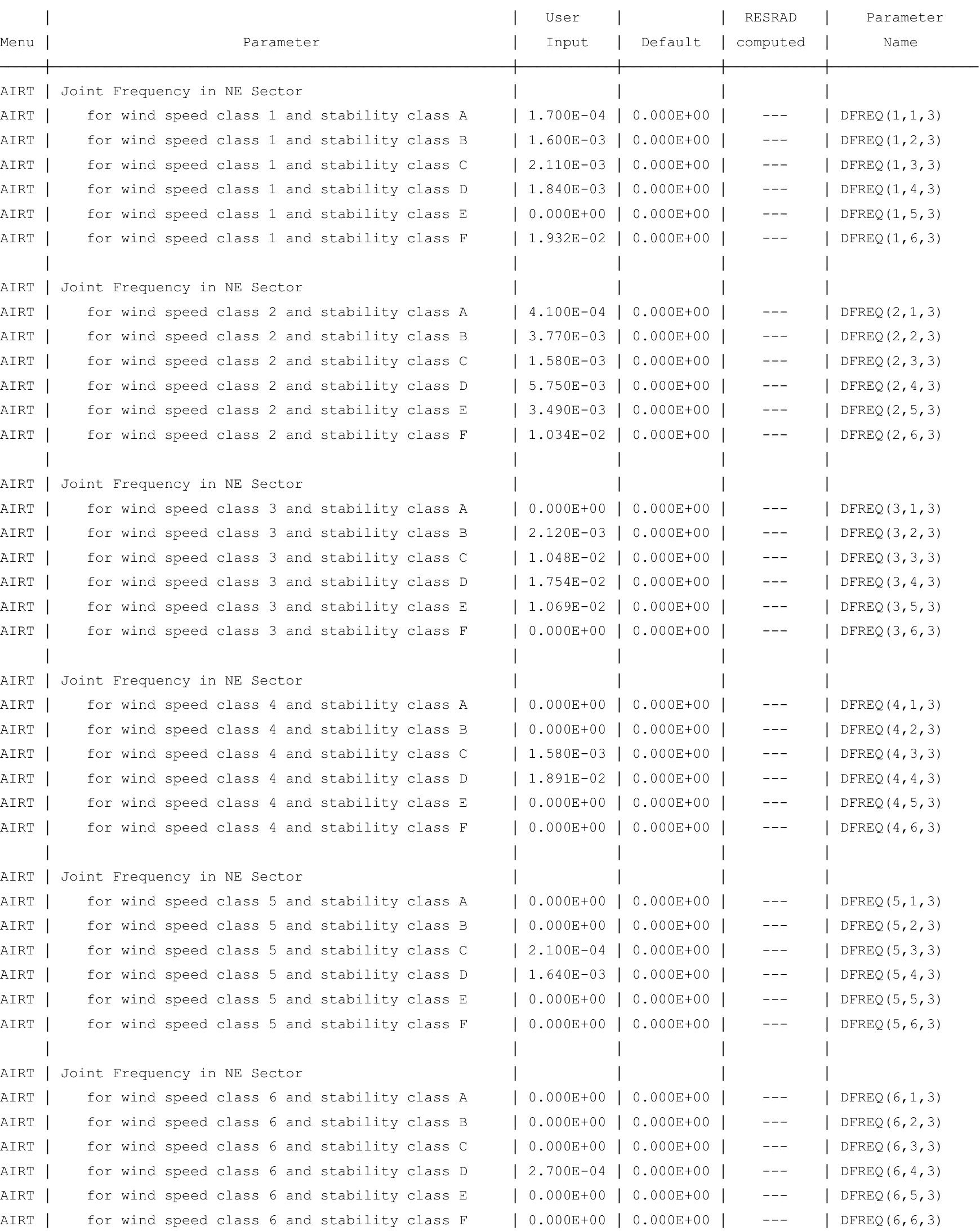


RESRAD-OFFSITE, Version 2.5

Parent Dose Report

Title : Offsite Resident Farmer Deterministic Run

File : RF DOE SG FWD-FV2-1050y.ROF

Site-Specific Parameter Summary (continued)

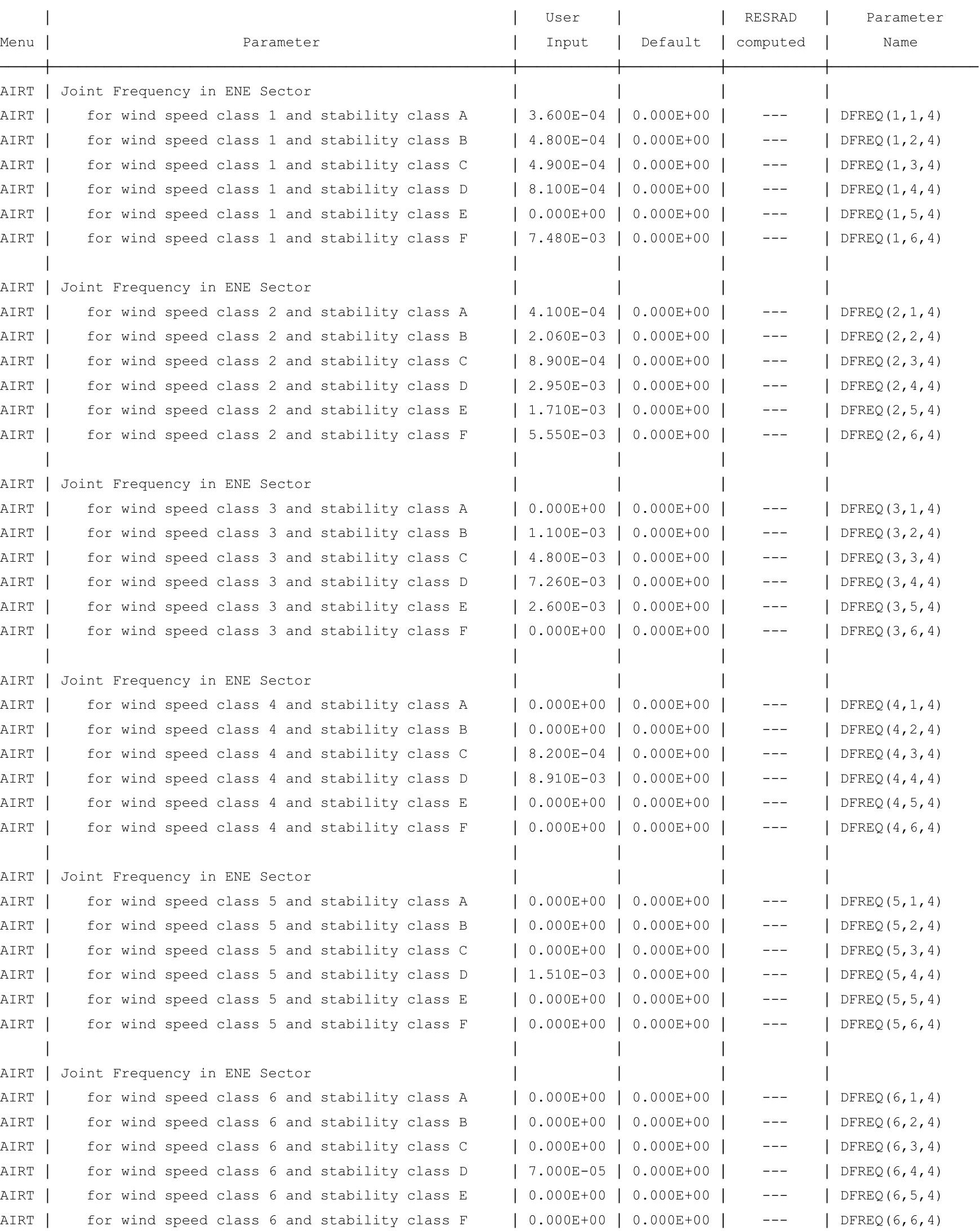


RESRAD-OFFSITE, Version 2.5

arent Dose Report

Title : Offsite Resident Farmer Deterministic Run

File : RF DOE SG FWD-FV2-1050y.ROF

Site-Specific Parameter Summary (continued)

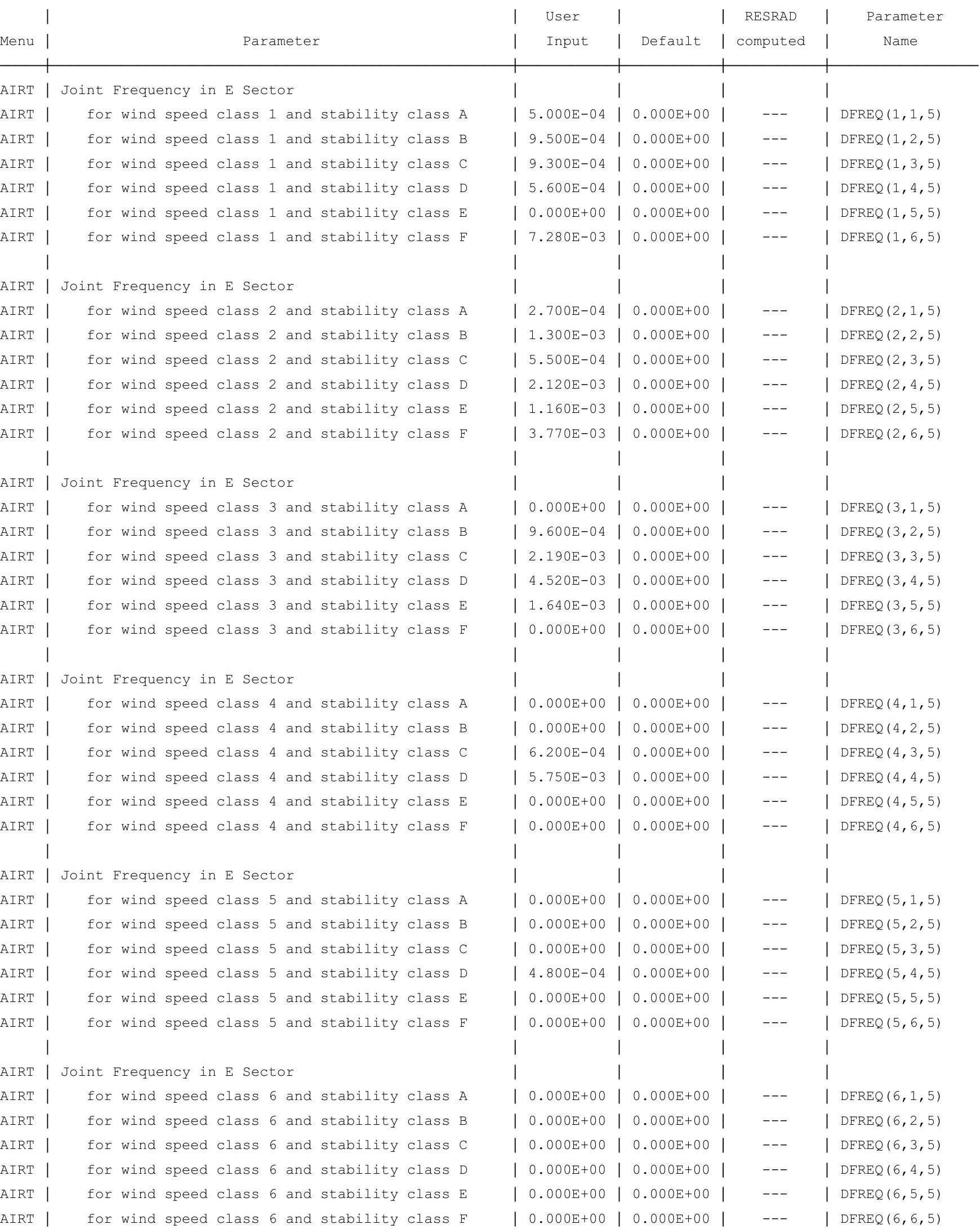


RESRAD-OFFSITE, Version 2.5

Parent Dose Report

Title : Offsite Resident Farmer Deterministic Run

File : RF DOE SG FWD-FV2-1050y.ROF

Site-Specific Parameter Summary (continued)

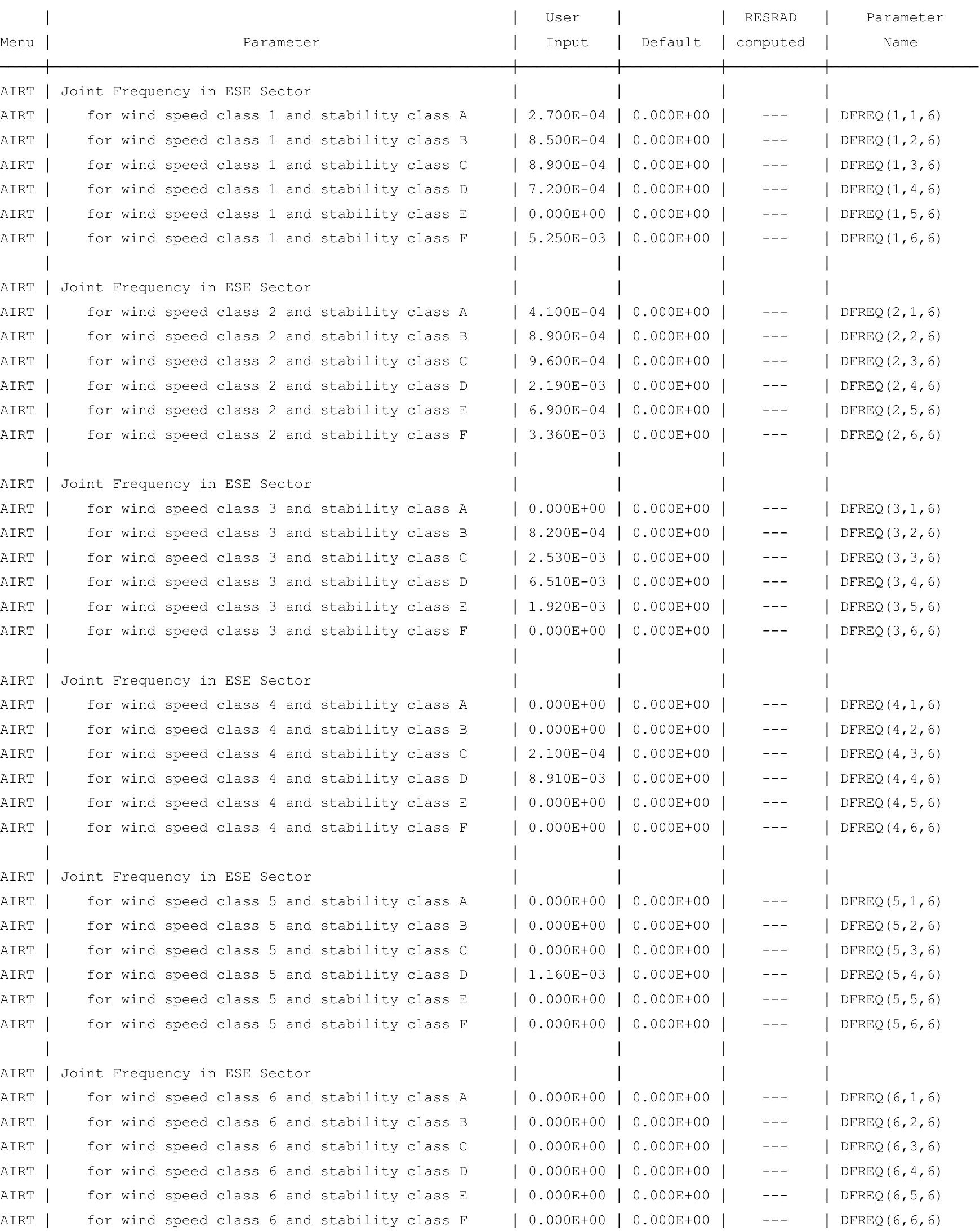


RESRAD-OFFSITE, Version 2.5

Parent Dose Report

Title : Offsite Resident Farmer Deterministic Run

File : RF DOE SG FWD-FV2-1050y.ROF

Site-Specific Parameter Summary (continued)

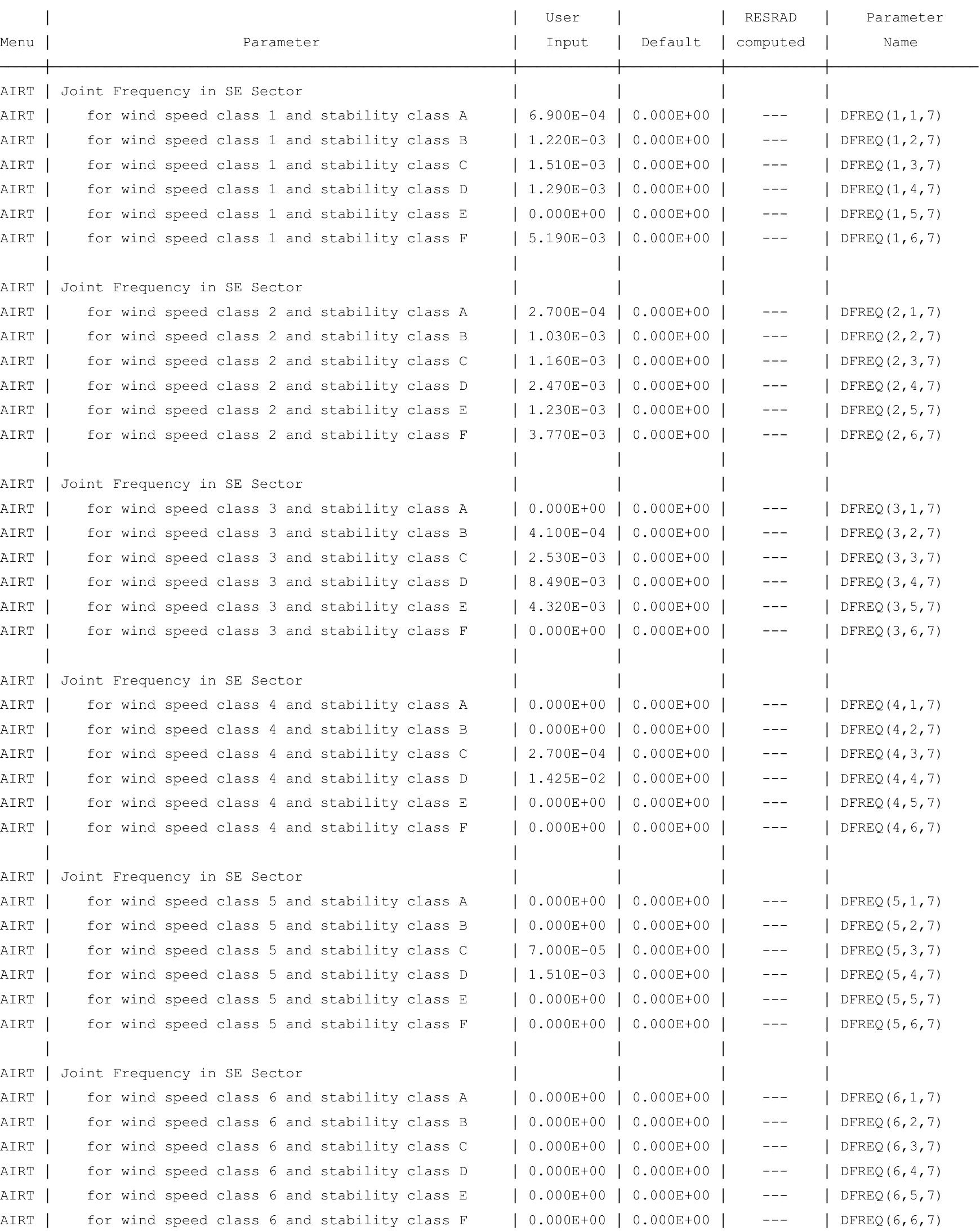


RESRAD-OFFSITE, Version 2.

Parent Dose Report

Title : Offsite Resident Farmer Deterministic Run

File : RF DOE SG FWD-FV2-1050y.ROF

Site-Specific Parameter Summary (continued)

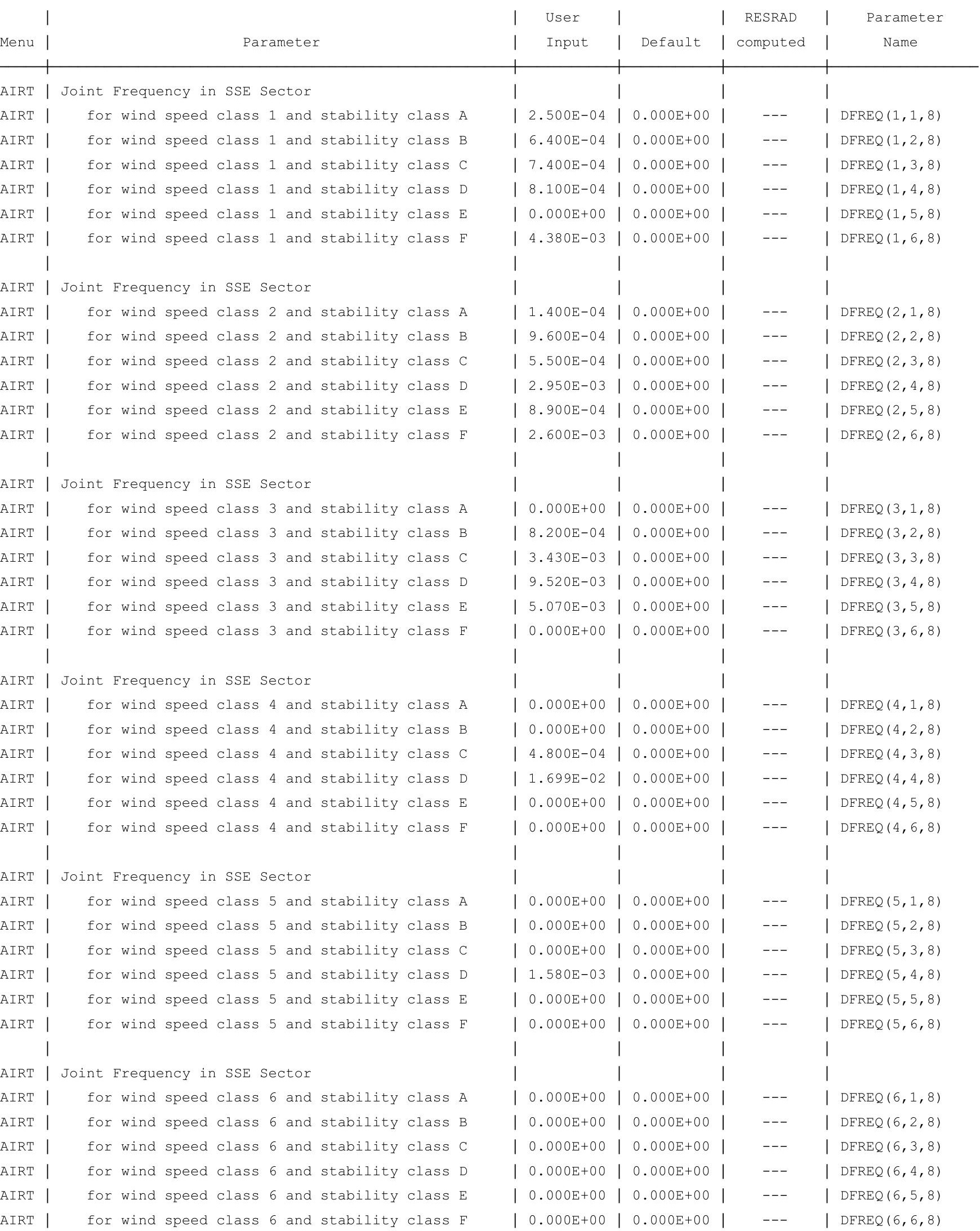


RESRAD-OFFSITE, Version 2.5

Parent Dose Report

Title : Offsite Resident Farmer Deterministic Run

File : RF DOE SG FWD-FV2-1050y.ROF

Site-Specific Parameter Summary (continued)

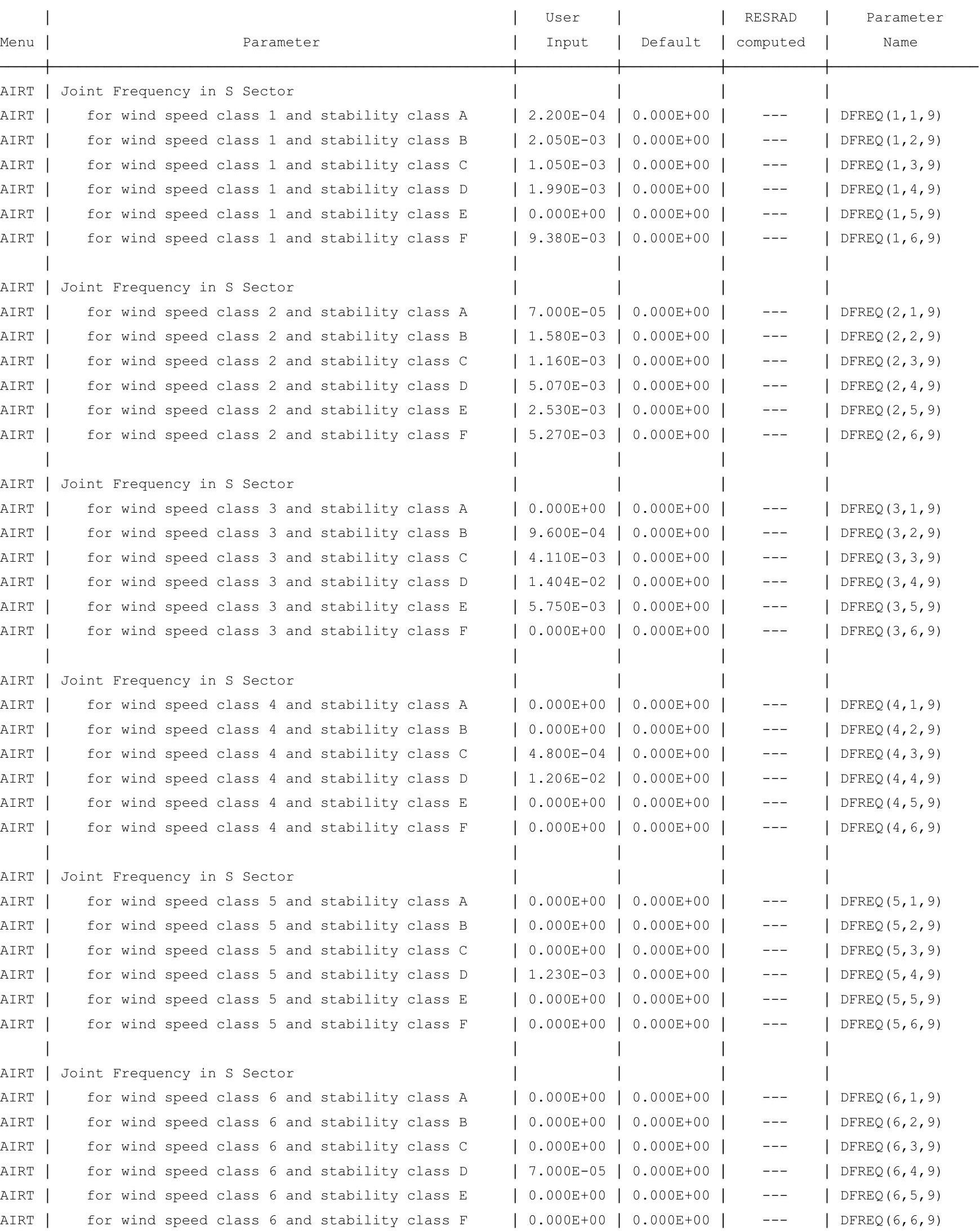


RESRAD-OFFSITE, Version 2.

Parent Dose Report

Title : Offsite Resident Farmer Deterministic Run

File : RF DOE SG FWD-FV2-1050y.ROF

Site-Specific Parameter Summary (continued)

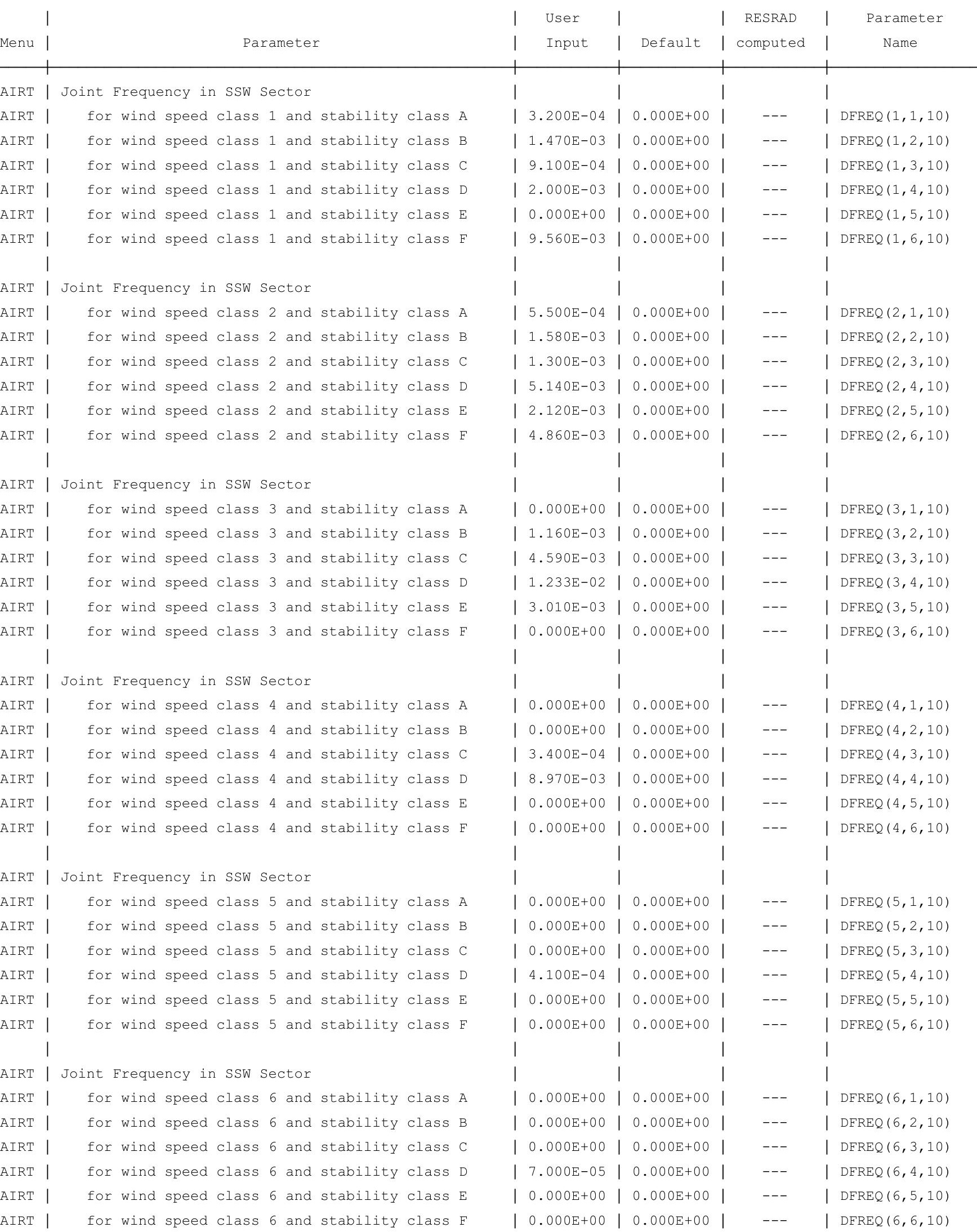


RESRAD-OFFSITE, Version 2.

Parent Dose Report

Title : Offsite Resident Farmer Deterministic Run

File : RF DOE SG FWD-FV2-1050y.ROF

Site-Specific Parameter Summary (continued)

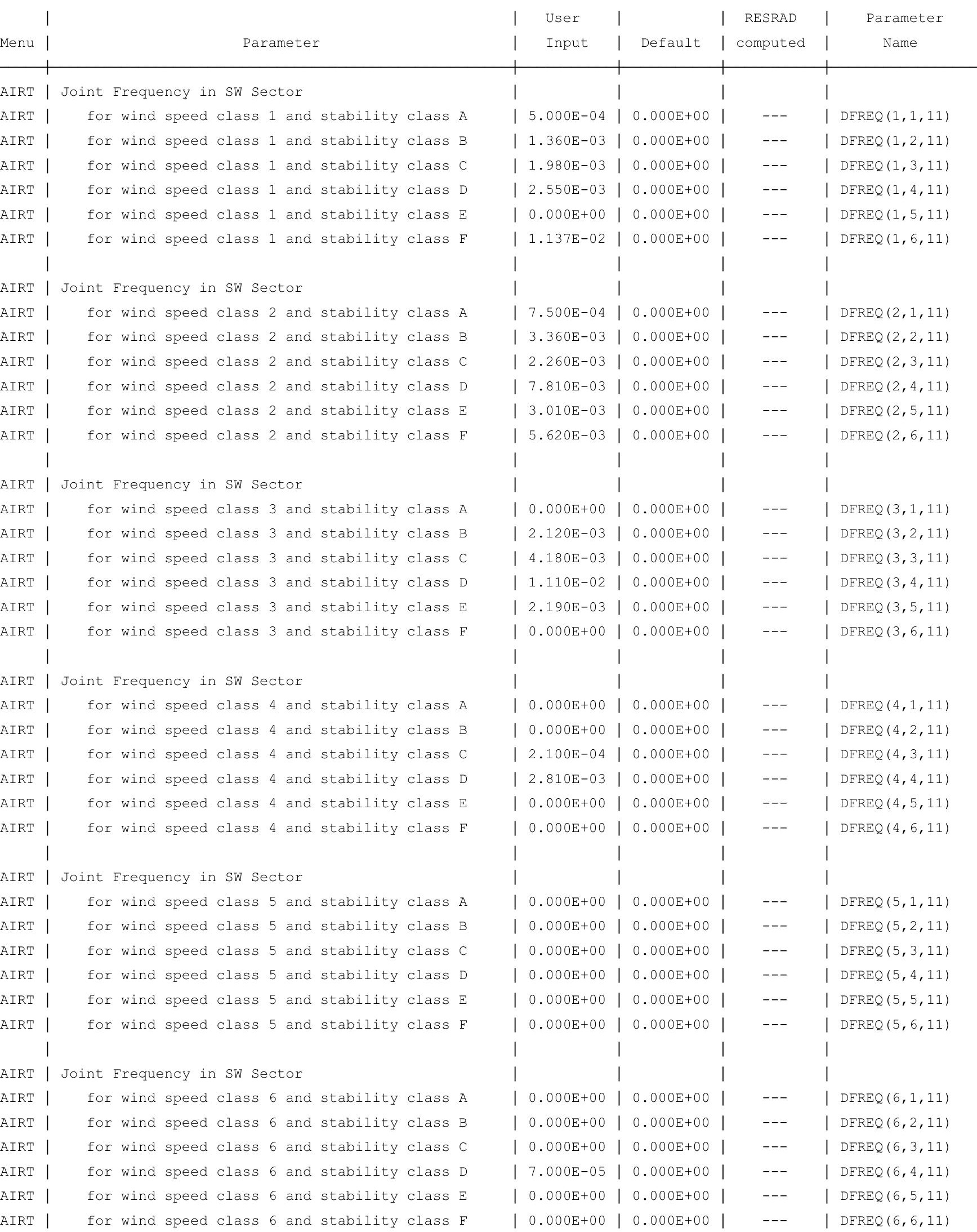


RESRAD-OFFSITE, Version 2.

Parent Dose Report

Title : Offsite Resident Farmer Deterministic Run

File : RF DOE SG FWD-FV2-1050y.ROF

Site-Specific Parameter Summary (continued)

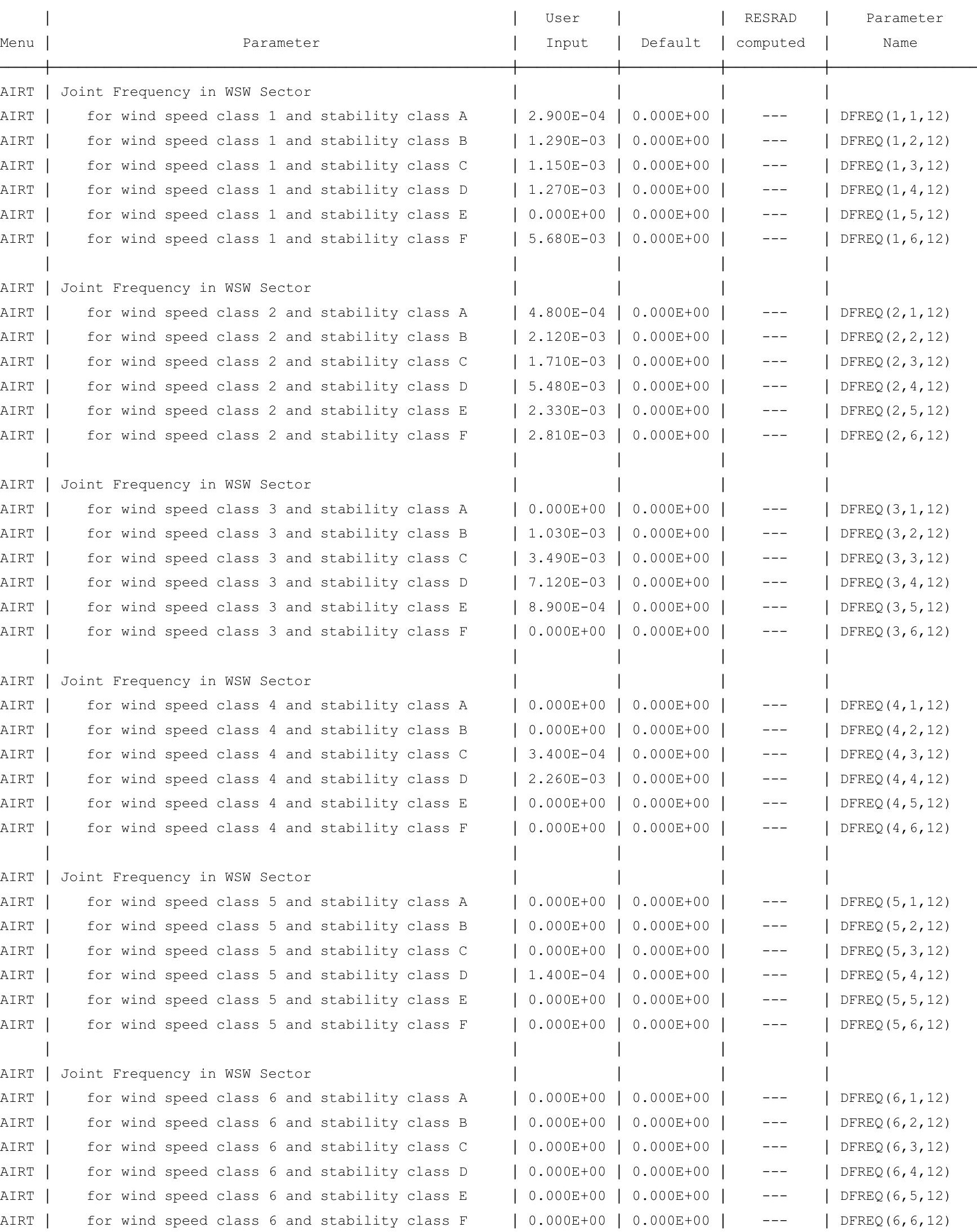


RESRAD-OFFSITE, Version 2.

Parent Dose Report

Title : Offsite Resident Farmer Deterministic Run

File : RF DOE SG FWD-FV2-1050y.ROF

Site-Specific Parameter Summary (continued)

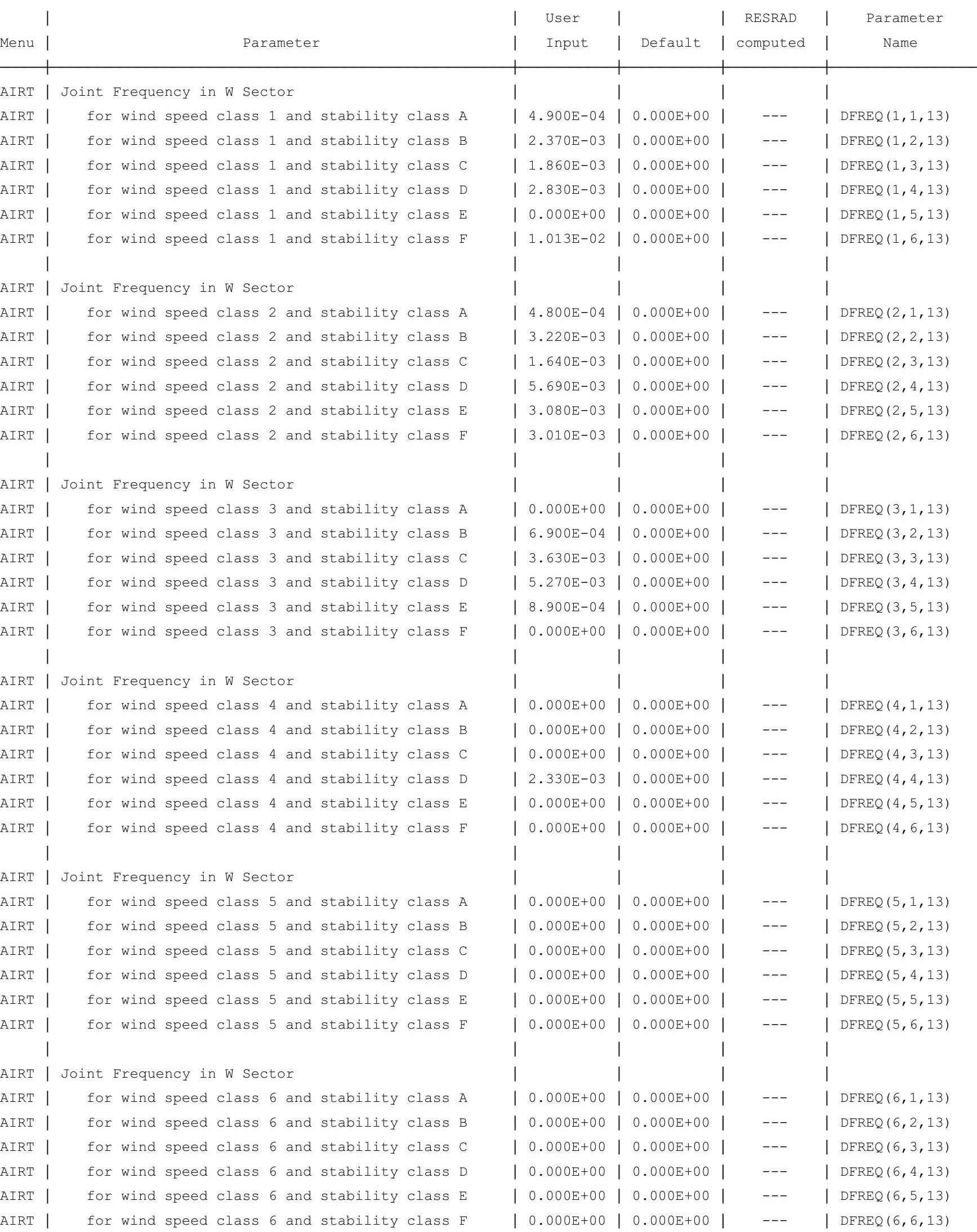


RESRAD-OFFSITE, Version 2.

Parent Dose Report

Title : Offsite Resident Farmer Deterministic Run

File : RF DOE SG FWD-FV2-1050y.ROF

Site-Specific Parameter Summary (continued)

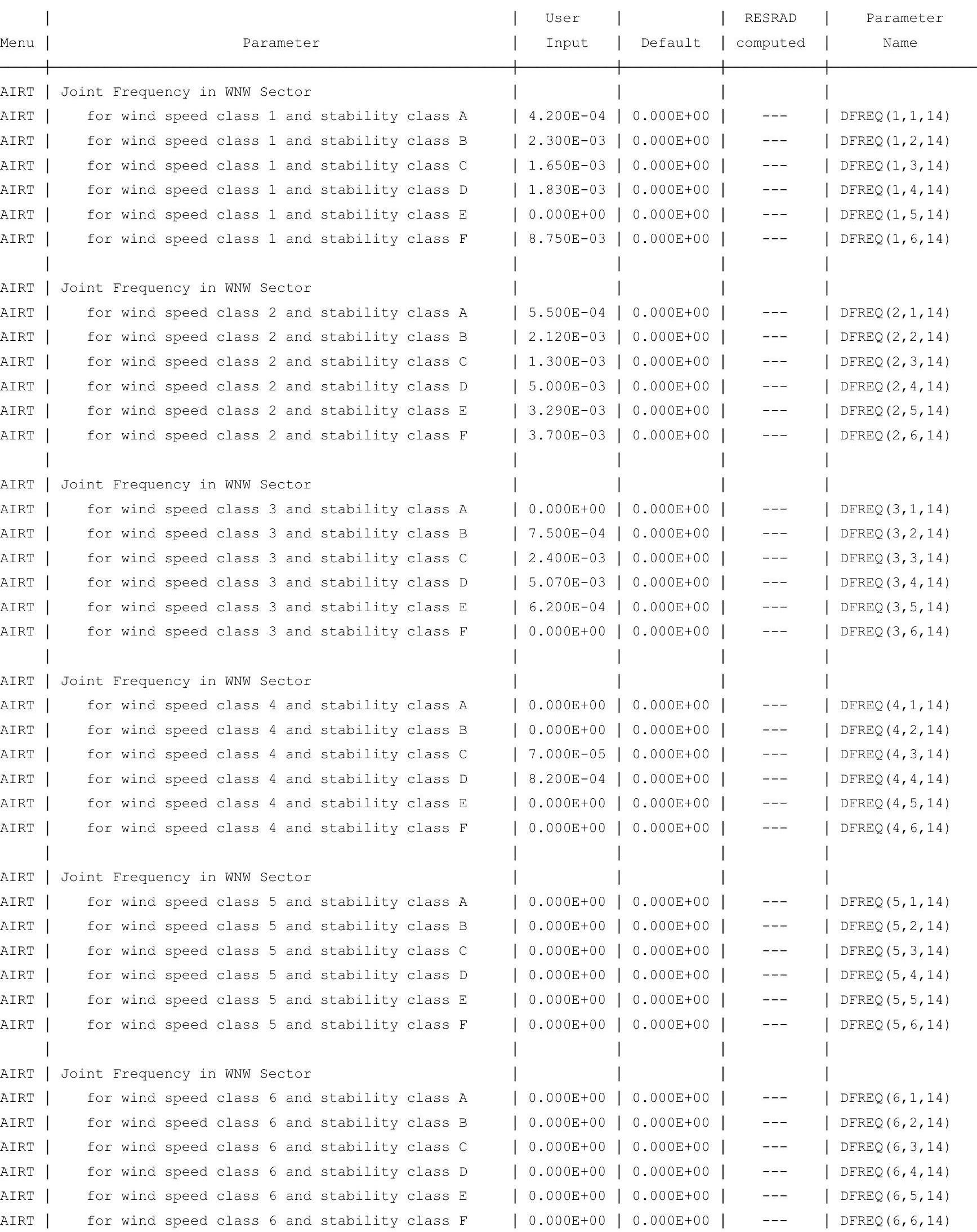


RESRAD-OFFSITE, Version 2.

Parent Dose Report

Title : Offsite Resident Farmer Deterministic Run

File : RF DOE SG FWD-FV2-1050y.ROF

Site-Specific Parameter Summary (continued)

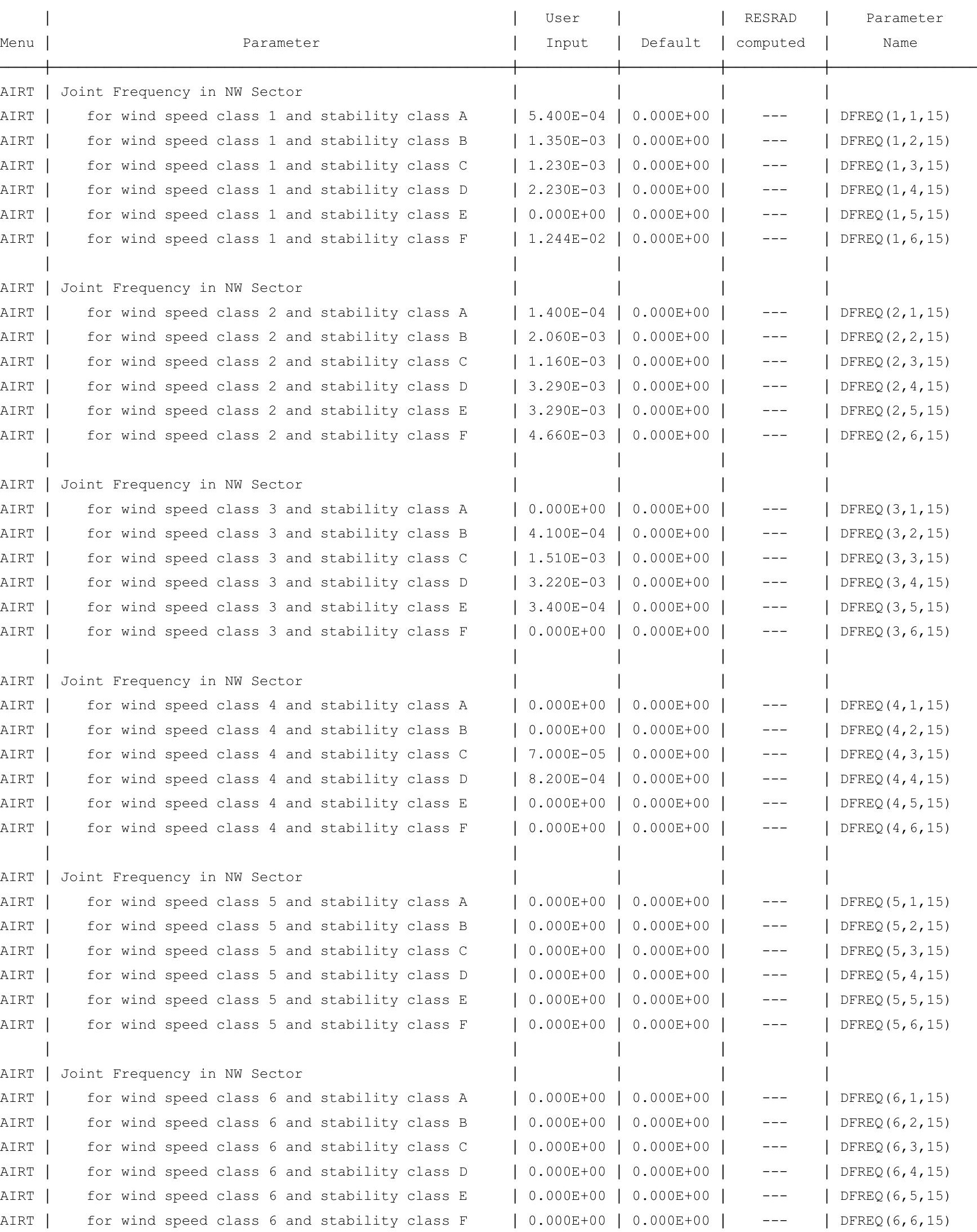


RESRAD-OFFSITE, Version 2.

Parent Dose Report

Title : Offsite Resident Farmer Deterministic Run

File : RF DOE SG FWD-FV2-1050y.ROF

Site-Specific Parameter Summary (continued)

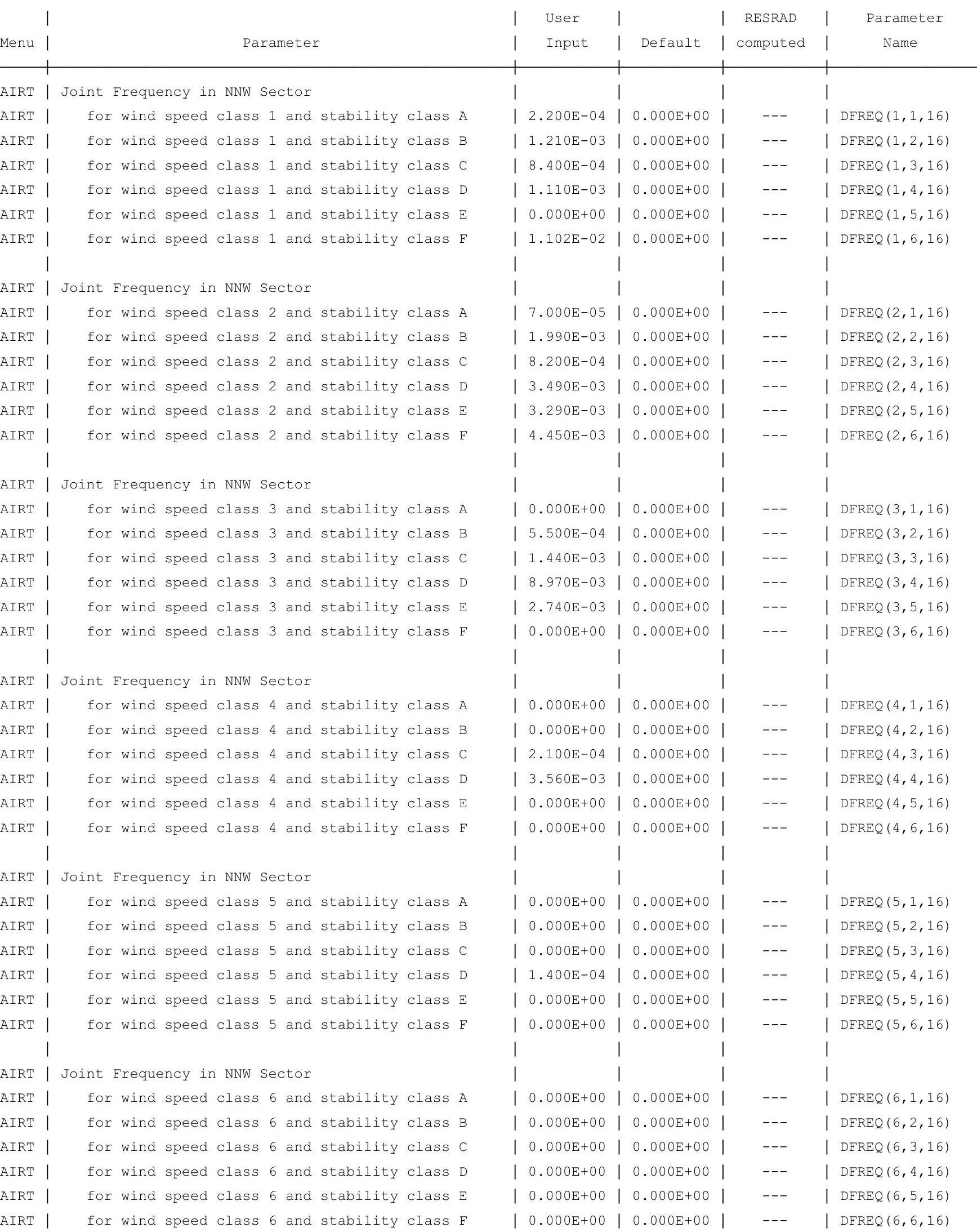


RESRAD-OFFSITE, Version 2.5

Parent Dose Report

Title : Offsite Resident Farmer Deterministic Run

File : RF DOE SG FWD-FV2-1050y.ROF

Site-Specific Parameter Summary (continued)

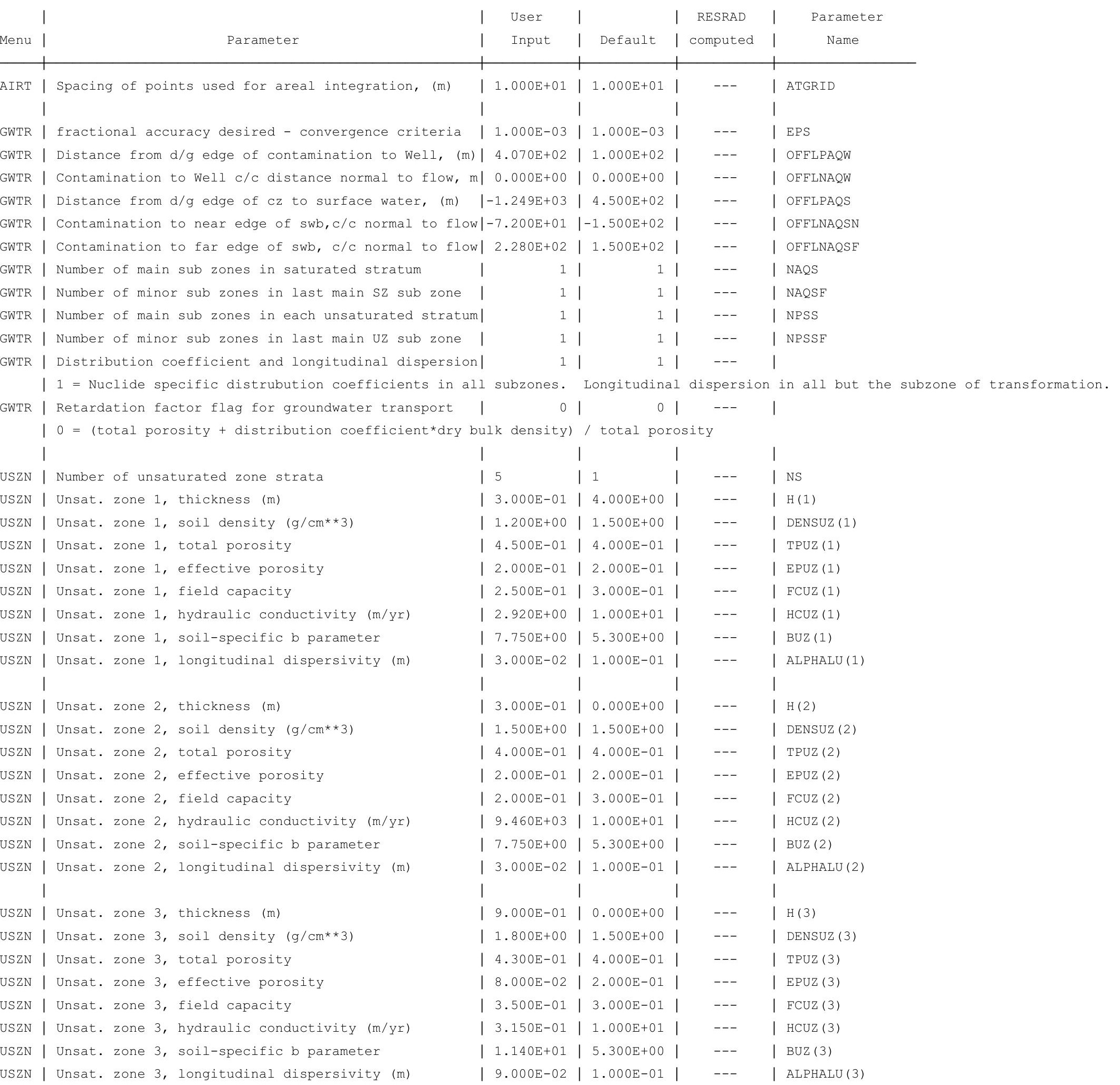


RESRAD-OFFSITE, Version 2.5

Parent Dose Report

Title : Offsite Resident Farmer Deterministic Run

File : RF DOE SG FWD-FV2-1050y.ROF

Site-Specific Parameter Summary (continued)

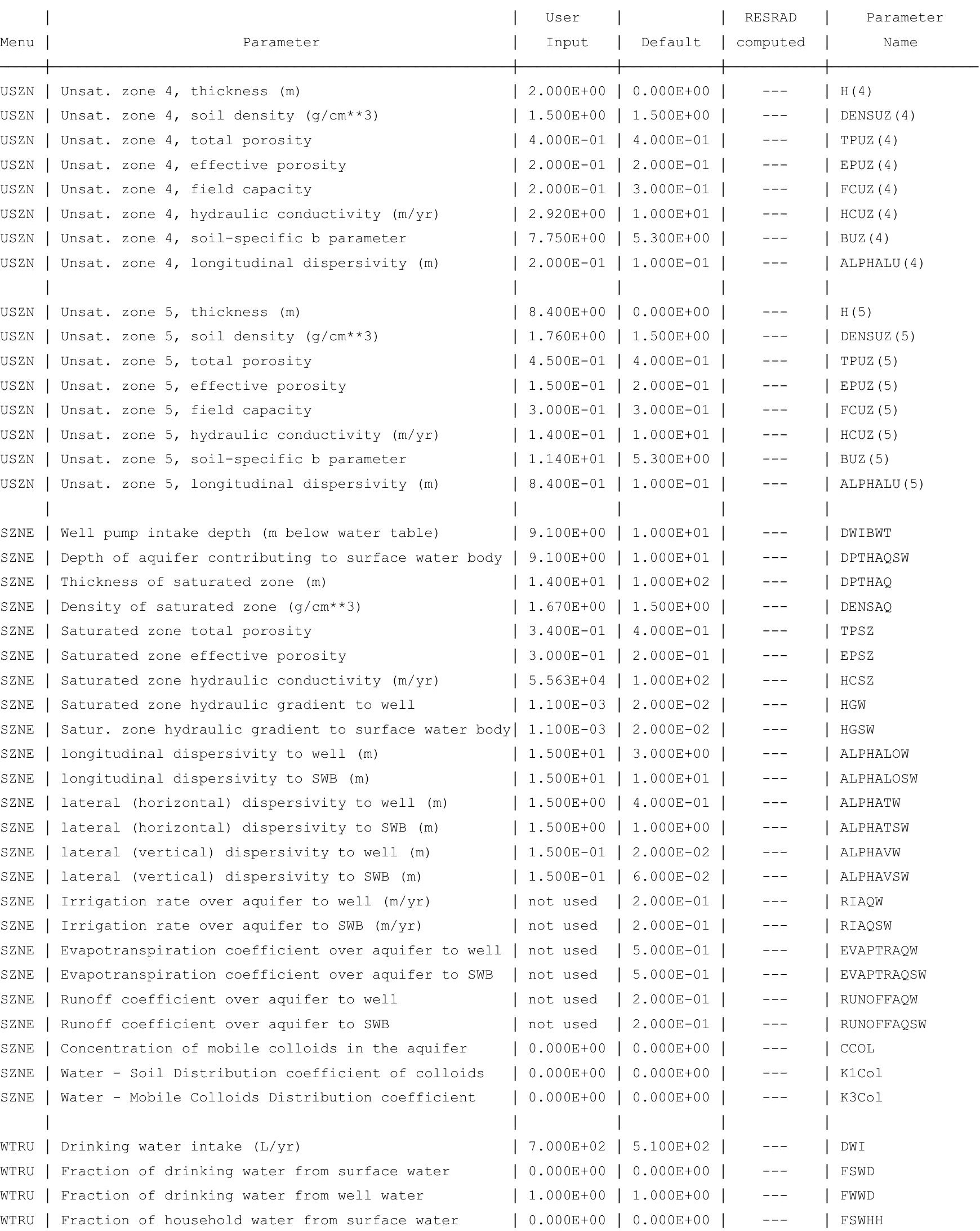


RESRAD-OFFSITE, Version 2.5

Parent Dose Report

Title : Offsite Resident Farmer Deterministic Run

File : RF DOE SG FWD-FV2-1050y.ROF

Site-Specific Parameter Summary (continued)

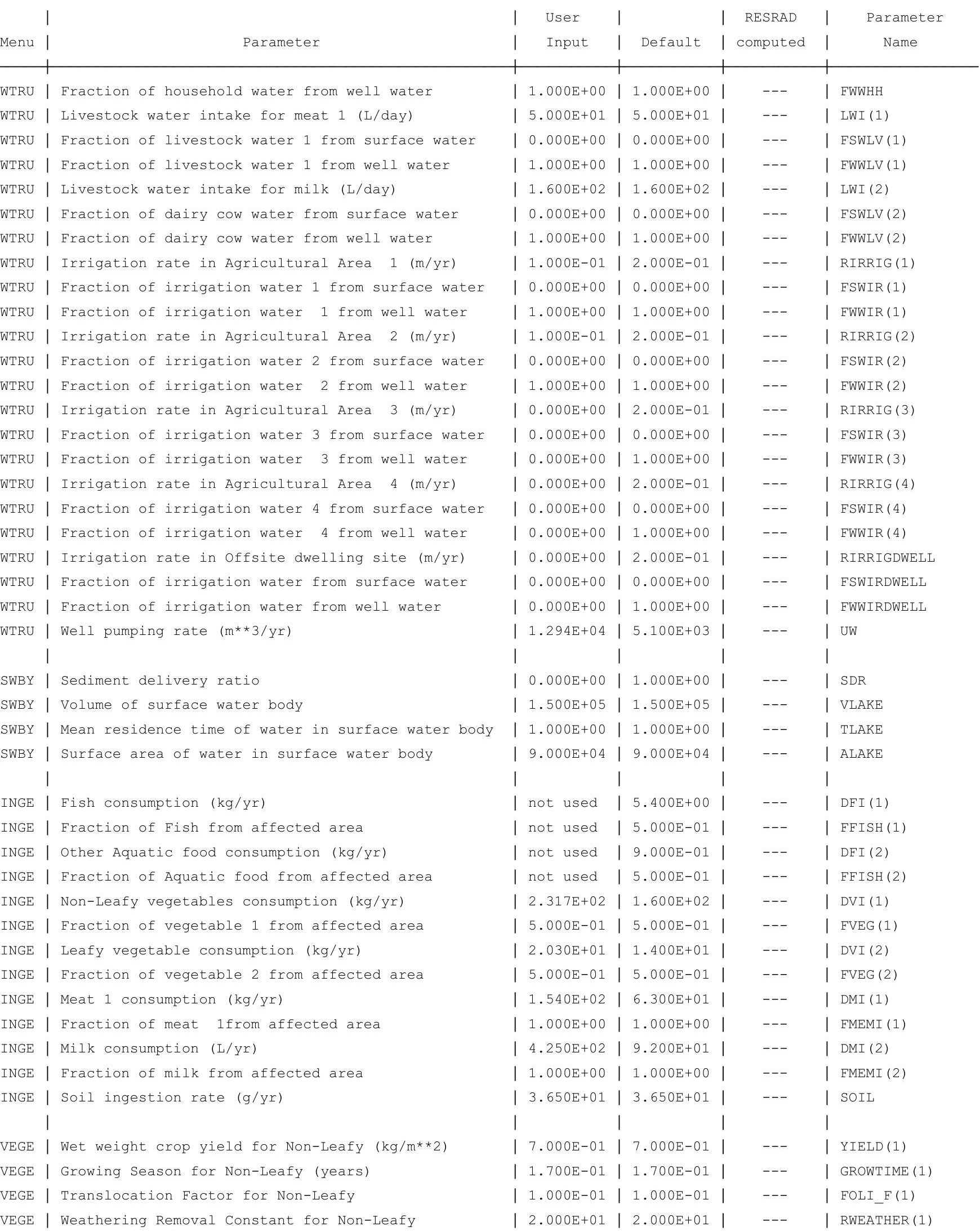


RESRAD-OFFSITE, Version 2.5

Parent Dose Report

Title : Offsite Resident Farmer Deterministic Run

File : RF DOE SG FWD-FV2-1050y.ROF

Site-Specific Parameter Summary (continued)

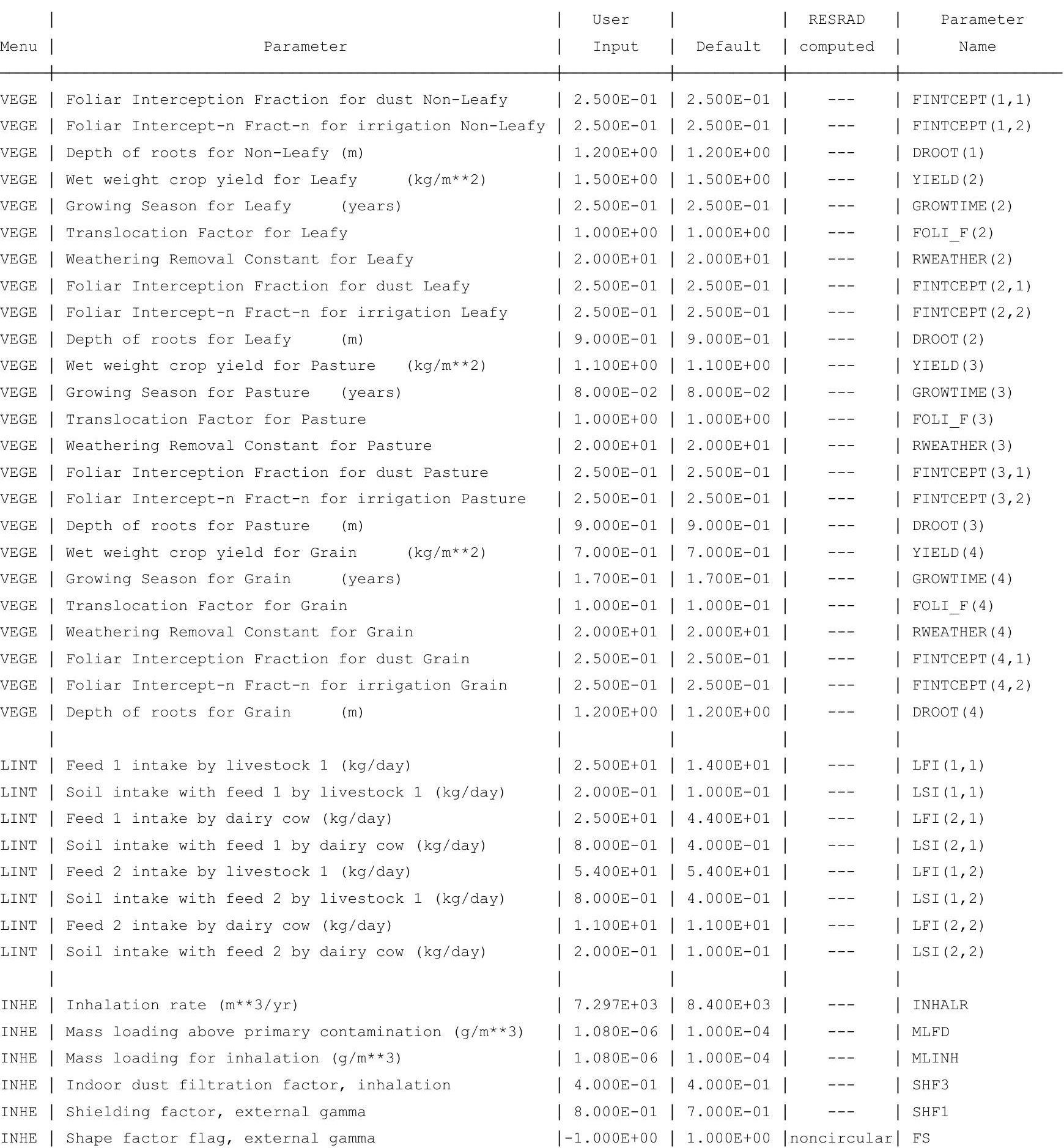


RESRAD-OFFSITE, Version $2.5 \quad \mathrm{~T}^{1 / 2}$ Limit $=180$ days

Parent Dose Report

Title : Offsite Resident Farmer Deterministic Run

File : RF DOE SG FWD-FV2-1050y.ROF

Site-Specific Parameter Summary (continued)

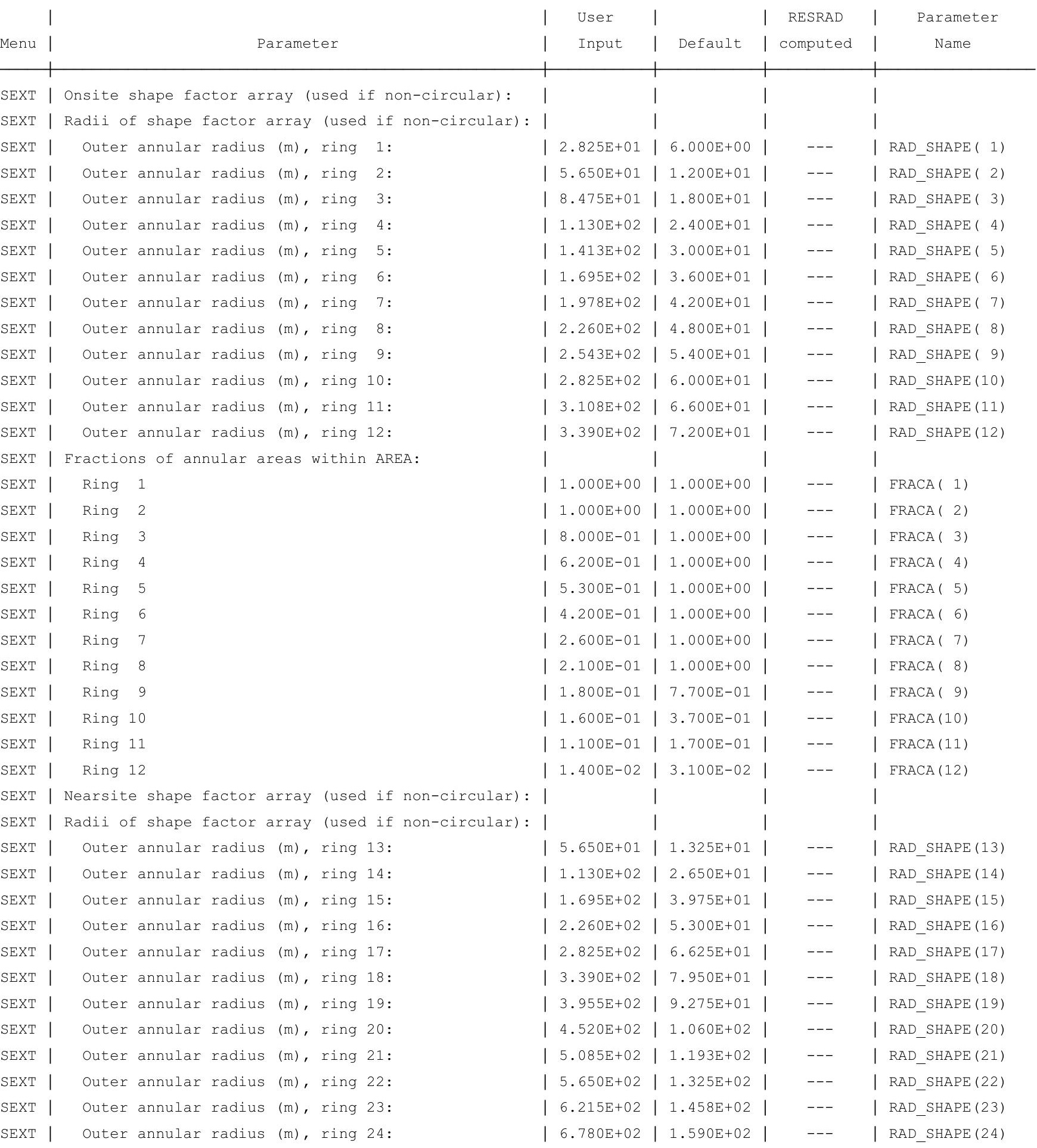


RESRAD-OFFSITE, Version $2.5 \quad \mathrm{~T}^{1 / 2}$ Limit $=180$ days

Parent Dose Report

Title : Offsite Resident Farmer Deterministic Run

File : RF DOE SG FWD-FV2-1050y.ROF

Site-Specific Parameter Summary (continued)

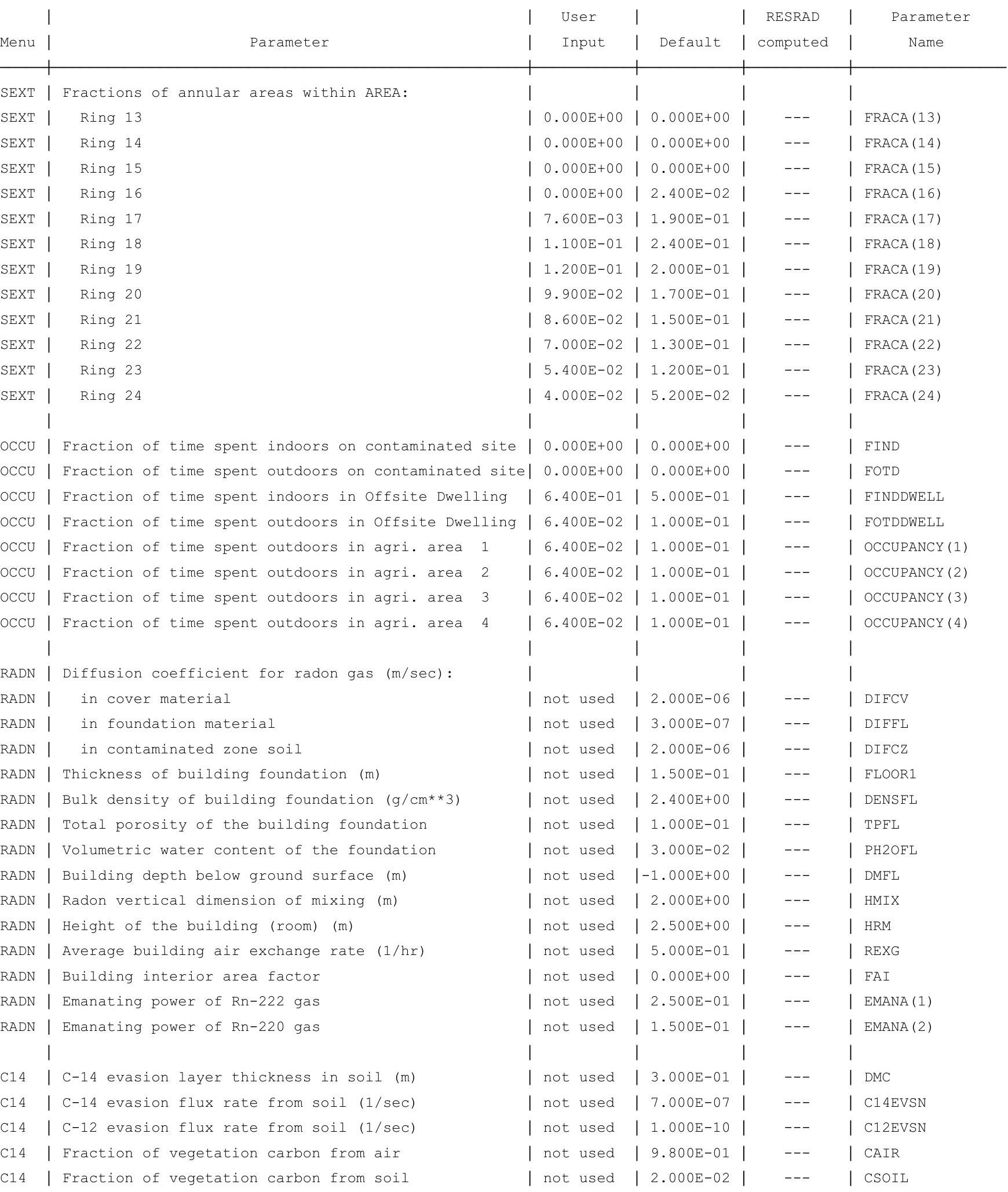


RESRAD-OFFSITE, Version 2.5

Parent Dose Report

Title : Offsite Resident Farmer Deterministic Run

File : RF DOE SG FWD-FV2-1050y.ROF

Site-Specific Parameter Summary (continued)

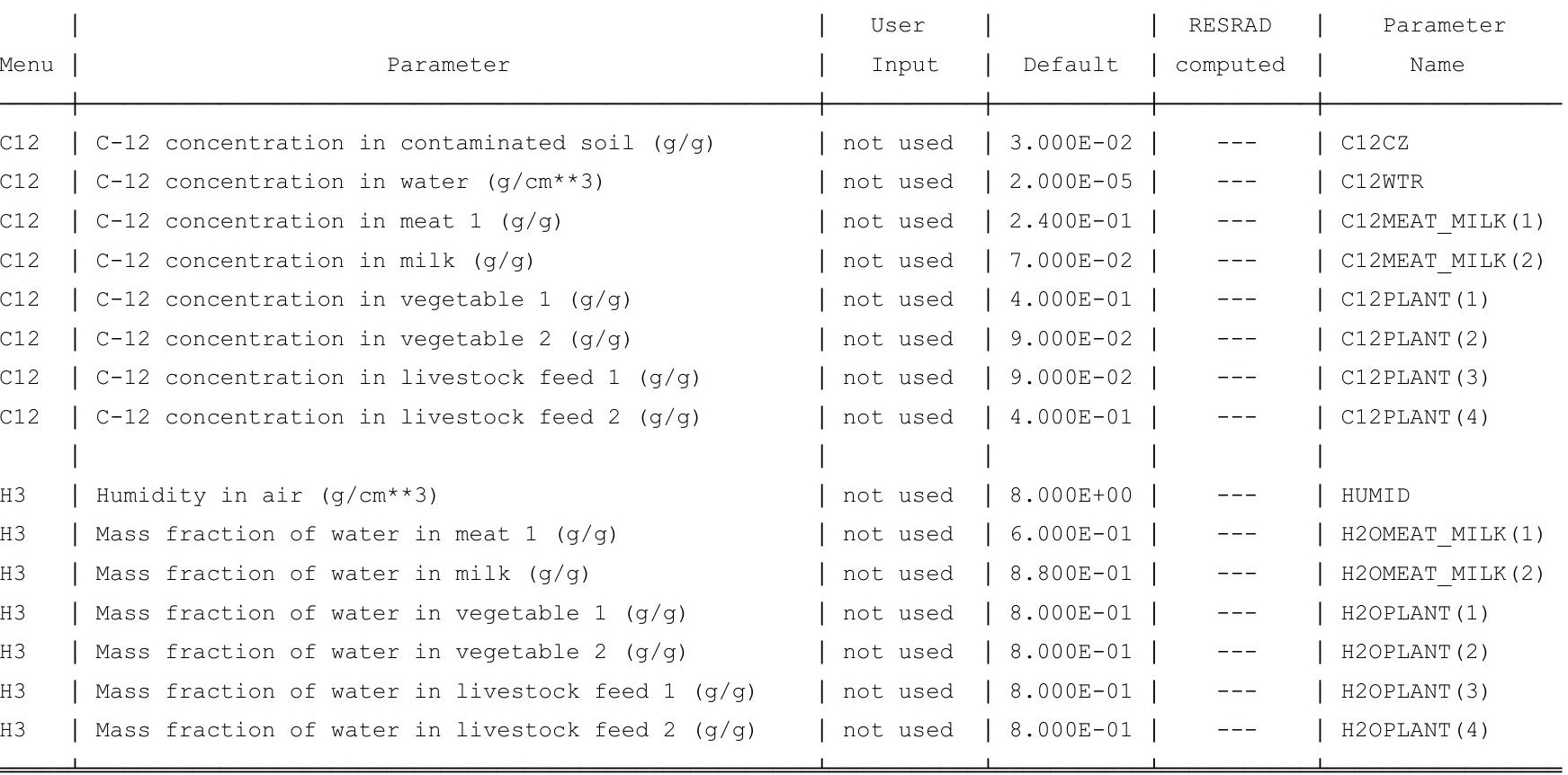

Summary of Pathway Selections

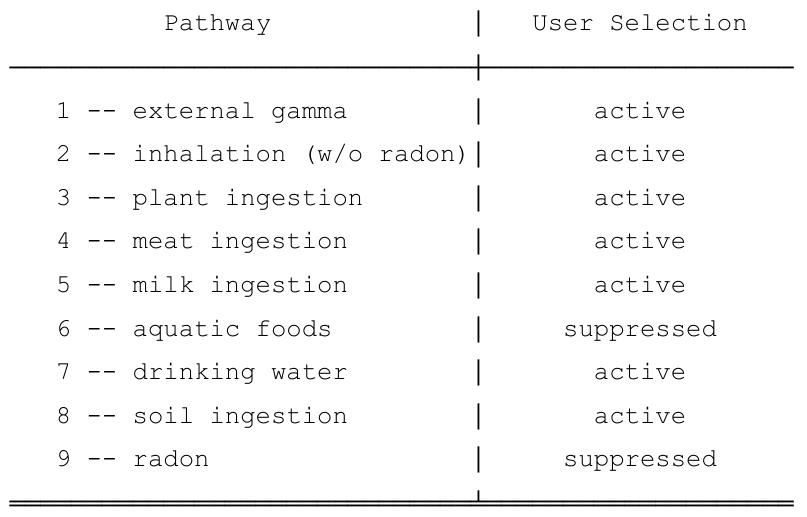


RESRAD-OFFSITE, Version $2.5 \quad \mathrm{~T}^{1 / 2}$ Limit $=180$ days

Parent Dose Report

Title : Offsite Resident Farmer Deterministic Run

File : RF DOE SG FWD-FV2-1050y.ROF

\section{Contaminated Zone Dimensions}

Area: 102144.00 square meters

Thickness:

Cover Depth:
Initial Soil Concentrations, pCi/g

$\begin{array}{ll}\text { Am-241 } & 3.500 \mathrm{E}+01 \\ \mathrm{Cs}-137 & 1.900 \mathrm{E}+01 \\ \mathrm{~Np}-237 & 5.500 \mathrm{E}+00 \\ \mathrm{Pu}-238 & 3.900 \mathrm{E}+01 \\ \mathrm{Pu}-239 & 3.600 \mathrm{E}+01 \\ \mathrm{Pu}-240 & 3.600 \mathrm{E}+01 \\ \mathrm{TC}-99 & 5.200 \mathrm{E}+01 \\ \mathrm{Th}-228 & 4.000 \mathrm{E}+00 \\ \mathrm{Th}-230 & 1.000 \mathrm{E}+02 \\ \mathrm{Th}-232 & 4.000 \mathrm{E}+00 \\ \mathrm{U}-234 & 1.600 \mathrm{E}+02 \\ \mathrm{U}-235 & 6.500 \mathrm{E}+00 \\ \mathrm{U}-238 & 1.600 \mathrm{E}+02\end{array}$

Total Dose TDOSE(t), mrem/yr

Basic Radiation Dose Limit $=1.000 \mathrm{E}+00 \mathrm{mrem} / \mathrm{yr}$

Total Mixture Sum $M(t)$ = Fraction of Basic Dose Limit Received at Time (t)

$\begin{array}{rllllll}t \text { (years) : } & 0.000 \mathrm{E}+00 & 1.000 \mathrm{E}+00 & 5.000 \mathrm{E}+01 & 1.000 \mathrm{E}+02 & 5.000 \mathrm{E}+02 & 1.026 \mathrm{E}+03 \\ \text { TDOSE }(\mathrm{t}): & 3.424 \mathrm{E}-14 & 2.560 \mathrm{E}-14 & 5.648 \mathrm{E}-14 & 7.897 \mathrm{E}-14 & 9.910 \mathrm{E}-01 & 1.436 \mathrm{E}+00 \\ \mathrm{M}(\mathrm{t}): & 3.424 \mathrm{E}-14 & 2.560 \mathrm{E}-14 & 5.648 \mathrm{E}-14 & 7.897 \mathrm{E}-14 & 9.910 \mathrm{E}-01 & 1.436 \mathrm{E}+00\end{array}$

Maximum TDOSE $(t): 1.868 \mathrm{E}+00 \mathrm{mrem} / \mathrm{yr}$ at $t=772$ years 
RESRAD-OFFSITE, Version 2 .

arent Dose Report

Title : Offsite Resident Farmer Deterministic Run

File : RF DOE SG FWD-FV2-1050y.ROF

Total Dose Contributions TDOSE (i,p,t) for Individual Radionuclides (i) and Pathways (p) in mrem/yr and as a Percentage of Total Dose at $t=0$ years

From releases to ground water and to surface water

\begin{tabular}{|c|c|c|c|c|c|c|c|c|c|c|c|c|c|c|c|c|}
\hline & \multicolumn{2}{|c|}{ Ground } & \multicolumn{2}{|l|}{ Fish } & \multicolumn{2}{|c|}{ Radon } & \multicolumn{2}{|c|}{ Plant } & \multicolumn{2}{|l|}{ Meat } & \multicolumn{2}{|l|}{ Milk } & \multicolumn{2}{|l|}{ Soil } & \multicolumn{2}{|c|}{ Water } \\
\hline ide & Dose & $\%$ & Dose & $\%$ & Dose & 응 & Dose & $\frac{\circ}{0}$ & Dose & 응 & Dose & 응 & Dose & $\%$ & Dose & $\%$ \\
\hline-241 & $0.00 \mathrm{E}+00$ & 0 & $0.00 E+00$ & 0 & $0.00 \mathrm{E}+00$ & 0 & $0.00 \mathrm{E}+00$ & 0 & $0.00 \mathrm{E}+00$ & 0 & $0.00 \mathrm{E}+00$ & 0 & $0.00 \mathrm{E}+00$ & 0 & $0.00 \mathrm{E}+00$ & 0 \\
\hline-137 & $0.00 \mathrm{E}+00$ & 0 & $0.00 \mathrm{E}+00$ & 0 & $0.00 \mathrm{E}+00$ & 0 & $0.00 \mathrm{E}+00$ & 0 & $0.00 \mathrm{E}+00$ & 0 & $0.00 \mathrm{E}+00$ & 0 & $0.00 \mathrm{E}+00$ & 0 & $0.00 \mathrm{E}+00$ & 0 \\
\hline-237 & $0.00 \mathrm{E}+00$ & 0 & $0.00 \mathrm{E}+00$ & 0 & $0.00 \mathrm{E}+00$ & 0 & $0.00 \mathrm{E}+00$ & 0 & $0.00 \mathrm{E}+00$ & 0 & $0.00 \mathrm{E}+00$ & 0 & $0.00 \mathrm{E}+00$ & 0 & $0.00 \mathrm{E}+00$ & 0 \\
\hline-238 & $0.00 \mathrm{E}+00$ & 0 & $0.00 \mathrm{E}+00$ & 0 & $0.00 E+00$ & 0 & $0.00 \mathrm{E}+00$ & 0 & $0.00 \mathrm{E}+00$ & 0 & $0.00 E+00$ & 0 & $0.00 \mathrm{E}+00$ & 0 & $0.00 \mathrm{E}+00$ & 0 \\
\hline-239 & $0.00 \mathrm{E}+00$ & 0 & $0.00 \mathrm{E}+00$ & 0 & $0.00 \mathrm{E}+00$ & 0 & $0.00 \mathrm{E}+00$ & 0 & $0.00 \mathrm{E}+00$ & 0 & $0.00 \mathrm{E}+00$ & 0 & $0.00 \mathrm{E}+00$ & 0 & $0.00 \mathrm{E}+00$ & 0 \\
\hline-240 & $0.00 \mathrm{E}+00$ & 0 & $0.00 \mathrm{E}+00$ & 0 & $0.00 \mathrm{E}+00$ & 0 & $0.00 \mathrm{E}+00$ & 0 & $0.00 \mathrm{E}+00$ & 0 & $0.00 \mathrm{E}+00$ & 0 & $0.00 \mathrm{E}+00$ & 0 & $0.00 \mathrm{E}+00$ & 0 \\
\hline-99 & $0.00 \mathrm{E}+00$ & 0 & $0.00 \mathrm{E}+00$ & 0 & $0.00 \mathrm{E}+00$ & 0 & $0.00 \mathrm{E}+00$ & 0 & $0.00 \mathrm{E}+00$ & 0 & $0.00 E+00$ & 0 & $0.00 \mathrm{E}+00$ & 0 & $0.00 \mathrm{E}+00$ & 0 \\
\hline-228 & $0.00 \mathrm{E}+00$ & 0 & $0.00 \mathrm{E}+00$ & 0 & $0.00 \mathrm{E}+00$ & 0 & $0.00 \mathrm{E}+00$ & 0 & $0.00 \mathrm{E}+00$ & 0 & $0.00 \mathrm{E}+00$ & 0 & $0.00 \mathrm{E}+00$ & 0 & $0.00 \mathrm{E}+00$ & 0 \\
\hline-230 & $0.00 \mathrm{E}+00$ & 0 & $0.00 \mathrm{E}+00$ & 0 & $0.00 \mathrm{E}+00$ & 0 & $0.00 \mathrm{E}+00$ & 0 & $0.00 \mathrm{E}+00$ & 0 & $0.00 \mathrm{E}+00$ & 0 & $0.00 \mathrm{E}+00$ & 0 & $0.00 \mathrm{E}+00$ & 0 \\
\hline-232 & $0.00 \mathrm{E}+00$ & 0 & $0.00 \mathrm{E}+00$ & 0 & $0.00 \mathrm{E}+00$ & 0 & $0.00 \mathrm{E}+00$ & 0 & $0.00 \mathrm{E}+00$ & 0 & $0.00 \mathrm{E}+00$ & 0 & $0.00 \mathrm{E}+00$ & 0 & $0.00 \mathrm{E}+00$ & 0 \\
\hline 34 & $0.00 \mathrm{E}+00$ & 0 & $0.00 \mathrm{E}+00$ & 0 & $0.00 \mathrm{E}+00$ & 0 & $0.00 \mathrm{E}+00$ & 0 & $0.00 \mathrm{E}+00$ & 0 & $0.00 \mathrm{E}+00$ & 0 & $0.00 \mathrm{E}+00$ & 0 & $0.00 \mathrm{E}+00$ & 0 \\
\hline 35 & $0.00 \mathrm{E}+00$ & 0 & $0.00 \mathrm{E}+00$ & 0 & $0.00 \mathrm{E}+00$ & 0 & $0.00 \mathrm{E}+00$ & 0 & $0.00 \mathrm{E}+00$ & 0 & $0.00 \mathrm{E}+00$ & 0 & $0.00 \mathrm{E}+00$ & 0 & $0.00 \mathrm{E}+00$ & 0 \\
\hline 38 & $0.00 \mathrm{E}+00$ & 0 & $0.00 \mathrm{E}+00$ & 0 & $0.00 E+00$ & 0 & $0.00 \mathrm{E}+00$ & 0 & $0.00 \mathrm{E}+00$ & 0 & $0.00 E+00$ & 0 & $0.00 \mathrm{E}+00$ & 0 & $0.00 \mathrm{E}+00$ & 0 \\
\hline & $0.00 \mathrm{E}+00$ & 0 & $0.00 E+00$ & 0 & $0.00 \mathrm{E}+00$ & 0 & $0.00 \mathrm{E}+00$ & 0 & $0.00 \mathrm{E}+00$ & 0 & $0.00 \mathrm{E}+00$ & 0 & $0.00 \mathrm{E}+00$ & 0 & $0.00 \mathrm{E}+00$ & 0 \\
\hline
\end{tabular}

Total Dose Contributions TDOSE(i,p,t) for Individual Radionuclides (i) and Pathways (p)

in mrem/yr and as a Percentage of Total Dose at $t=0$ years

Directly from primary contamination and from release to atmosphere (Inhalation excludes radon)

\begin{tabular}{|c|c|c|c|c|c|c|c|c|c|c|c|c|c|c|c|c|}
\hline & \multicolumn{2}{|c|}{ Ground } & \multicolumn{2}{|c|}{ Inhalation } & \multicolumn{2}{|c|}{ Radon } & \multicolumn{2}{|c|}{ Plant } & \multicolumn{2}{|l|}{ Meat } & \multicolumn{2}{|l|}{ Milk } & \multicolumn{2}{|l|}{ Soil } & \multicolumn{2}{|c|}{ All Pathways* } \\
\hline clide & Dose & $\%$ & Dose & $\%$ & Dose & $\%$ & Dose & 음 & Dose & $\%$ & Dose & 음 & Dose & $\%$ & Dose & $\%$ \\
\hline-241 & $3.28 E-26$ & 0 & $0.00 \mathrm{E}+00$ & 0 & $0.00 \mathrm{E}+00$ & 0 & $0.00 \mathrm{E}+00$ & 0 & $0.00 \mathrm{E}+00$ & 0 & $0.00 \mathrm{E}+00$ & 0 & $0.00 \mathrm{E}+00$ & 0 & $3.28 E-26$ & 0 \\
\hline-137 & 1. $45 E-16$ & 0 & $0.00 E+00$ & 0 & $0.00 E+00$ & 0 & $0.00 \mathrm{E}+00$ & 0 & $0.00 \mathrm{E}+00$ & 0 & $0.00 E+00$ & 0 & $0.00 \mathrm{E}+00$ & 0 & 1. $45 \mathrm{E}-16$ & 0 \\
\hline-237 & $3.18 \mathrm{E}-20$ & 0 & $0.00 \mathrm{E}+00$ & 0 & $0.00 E+00$ & 0 & $0.00 \mathrm{E}+00$ & 0 & $0.00 \mathrm{E}+00$ & 0 & $0.00 E+00$ & 0 & $0.00 \mathrm{E}+00$ & 0 & $3.18 E-20$ & 0 \\
\hline-238 & $2.45 E-29$ & 0 & $0.00 \mathrm{E}+00$ & 0 & $0.00 \mathrm{E}+00$ & 0 & $0.00 \mathrm{E}+00$ & 0 & $0.00 \mathrm{E}+00$ & 0 & $0.00 \mathrm{E}+00$ & 0 & $0.00 \mathrm{E}+00$ & 0 & $2.45 E-29$ & 0 \\
\hline-239 & $2.62 E-24$ & 0 & $0.00 \mathrm{E}+00$ & 0 & $0.00 \mathrm{E}+00$ & 0 & $0.00 \mathrm{E}+00$ & 0 & $0.00 \mathrm{E}+00$ & 0 & $0.00 \mathrm{E}+00$ & 0 & $0.00 \mathrm{E}+00$ & 0 & $2.62 \mathrm{E}-24$ & 0 \\
\hline-240 & $2.49 E-31$ & 0 & $0.00 \mathrm{E}+00$ & 0 & $0.00 \mathrm{E}+00$ & 0 & $0.00 \mathrm{E}+00$ & 0 & $0.00 \mathrm{E}+00$ & 0 & $0.00 \mathrm{E}+00$ & 0 & $0.00 \mathrm{E}+00$ & 0 & $2.49 \mathrm{E}-31$ & 0 \\
\hline-99 & $1.82 E-32$ & 0 & $0.00 \mathrm{E}+00$ & 0 & $0.00 \mathrm{E}+00$ & 0 & $0.00 \mathrm{E}+00$ & 0 & $0.00 \mathrm{E}+00$ & 0 & $0.00 E+00$ & 0 & $0.00 \mathrm{E}+00$ & 0 & 1. $82 \mathrm{E}-32$ & 0 \\
\hline-228 & $3.36 \mathrm{E}-14$ & 98 & $0.00 \mathrm{E}+00$ & 0 & $0.00 \mathrm{E}+00$ & 0 & $0.00 \mathrm{E}+00$ & 0 & $0.00 \mathrm{E}+00$ & 0 & $0.00 \mathrm{E}+00$ & 0 & $0.00 \mathrm{E}+00$ & 0 & $3.36 \mathrm{E}-14$ & 98 \\
\hline-230 & $2.29 E-17$ & 0 & $0.00 E+00$ & 0 & $0.00 \mathrm{E}+00$ & 0 & $0.00 \mathrm{E}+00$ & 0 & $0.00 \mathrm{E}+00$ & 0 & $0.00 E+00$ & 0 & $0.00 \mathrm{E}+00$ & 0 & $2.29 \mathrm{E}-17$ & 0 \\
\hline-232 & $3.16 \mathrm{E}-16$ & 1 & $0.00 \mathrm{E}+00$ & 0 & $0.00 \mathrm{E}+00$ & 0 & $0.00 \mathrm{E}+00$ & 0 & $0.00 \mathrm{E}+00$ & 0 & $0.00 \mathrm{E}+00$ & 0 & $0.00 \mathrm{E}+00$ & 0 & $3.16 \mathrm{E}-16$ & 1 \\
\hline 34 & 1. $25 \mathrm{E}-22$ & 0 & $0.00 \mathrm{E}+00$ & 0 & $0.00 \mathrm{E}+00$ & 0 & $0.00 \mathrm{E}+00$ & 0 & $0.00 \mathrm{E}+00$ & 0 & $0.00 \mathrm{E}+00$ & 0 & $0.00 \mathrm{E}+00$ & 0 & 1. $25 \mathrm{E}-22$ & 0 \\
\hline 35 & 4. $90 \mathrm{E}-22$ & 0 & $0.00 \mathrm{E}+00$ & 0 & $0.00 \mathrm{E}+00$ & 0 & $0.00 \mathrm{E}+00$ & 0 & $0.00 \mathrm{E}+00$ & 0 & $0.00 \mathrm{E}+00$ & 0 & $0.00 \mathrm{E}+00$ & 0 & $4.90 \mathrm{E}-22$ & 0 \\
\hline 38 & $1.38 E-16$ & 0 & $0.00 \mathrm{E}+00$ & 0 & $0.00 \mathrm{E}+00$ & 0 & $0.00 \mathrm{E}+00$ & 0 & $0.00 \mathrm{E}+00$ & 0 & $0.00 E+00$ & 0 & $0.00 \mathrm{E}+00$ & 0 & 1. $38 \mathrm{E}-16$ & 0 \\
\hline & $3.42 \mathrm{E}-14$ & 100 & $0.00 \mathrm{E}+00$ & 0 & $0.00 \mathrm{E}+00$ & 0 & $0.00 \mathrm{E}+00$ & 0 & $0.00 \mathrm{E}+00$ & 0 & $0.00 \mathrm{E}+00$ & 0 & $0.00 \mathrm{E}+00$ & 0 & 3. $42 \mathrm{E}-14$ & 100 \\
\hline
\end{tabular}

* Sum of dose from all releases and from primary contamination. 
RESRAD-OFFSITE, Version 2 .

Parent Dose Report

Title : Offsite Resident Farmer Deterministic Run

File : RF DOE SG FWD-FV2-1050y.ROF

Total Dose Contributions TDOSE (i,p,t) for Individual Radionuclides (i) and Pathways (p) in mrem/yr and as a Percentage of Total Dose at $t=1$ years

From releases to ground water and to surface water

\begin{tabular}{|c|c|c|c|c|c|c|c|c|c|c|c|c|c|c|c|c|}
\hline & \multicolumn{2}{|c|}{ Ground } & \multicolumn{2}{|l|}{ Fish } & \multicolumn{2}{|c|}{ Radon } & \multicolumn{2}{|c|}{ Plant } & \multicolumn{2}{|l|}{ Meat } & \multicolumn{2}{|l|}{ Milk } & \multicolumn{2}{|l|}{ Soil } & \multicolumn{2}{|c|}{ Water } \\
\hline ide & Dose & $\%$ & Dose & $\%$ & Dose & 응 & Dose & $\frac{\circ}{0}$ & Dose & 응 & Dose & 응 & Dose & $\%$ & Dose & $\%$ \\
\hline-241 & $0.00 \mathrm{E}+00$ & 0 & $0.00 E+00$ & 0 & $0.00 \mathrm{E}+00$ & 0 & $0.00 \mathrm{E}+00$ & 0 & $0.00 \mathrm{E}+00$ & 0 & $0.00 \mathrm{E}+00$ & 0 & $0.00 \mathrm{E}+00$ & 0 & $0.00 \mathrm{E}+00$ & 0 \\
\hline-137 & $0.00 \mathrm{E}+00$ & 0 & $0.00 \mathrm{E}+00$ & 0 & $0.00 \mathrm{E}+00$ & 0 & $0.00 \mathrm{E}+00$ & 0 & $0.00 \mathrm{E}+00$ & 0 & $0.00 \mathrm{E}+00$ & 0 & $0.00 \mathrm{E}+00$ & 0 & $0.00 \mathrm{E}+00$ & 0 \\
\hline-237 & $0.00 \mathrm{E}+00$ & 0 & $0.00 \mathrm{E}+00$ & 0 & $0.00 \mathrm{E}+00$ & 0 & $0.00 \mathrm{E}+00$ & 0 & $0.00 \mathrm{E}+00$ & 0 & $0.00 \mathrm{E}+00$ & 0 & $0.00 \mathrm{E}+00$ & 0 & $0.00 \mathrm{E}+00$ & 0 \\
\hline-238 & $0.00 \mathrm{E}+00$ & 0 & $0.00 \mathrm{E}+00$ & 0 & $0.00 E+00$ & 0 & $0.00 \mathrm{E}+00$ & 0 & $0.00 \mathrm{E}+00$ & 0 & $0.00 E+00$ & 0 & $0.00 \mathrm{E}+00$ & 0 & $0.00 \mathrm{E}+00$ & 0 \\
\hline-239 & $0.00 \mathrm{E}+00$ & 0 & $0.00 \mathrm{E}+00$ & 0 & $0.00 \mathrm{E}+00$ & 0 & $0.00 \mathrm{E}+00$ & 0 & $0.00 \mathrm{E}+00$ & 0 & $0.00 \mathrm{E}+00$ & 0 & $0.00 \mathrm{E}+00$ & 0 & $0.00 \mathrm{E}+00$ & 0 \\
\hline-240 & $0.00 \mathrm{E}+00$ & 0 & $0.00 \mathrm{E}+00$ & 0 & $0.00 \mathrm{E}+00$ & 0 & $0.00 \mathrm{E}+00$ & 0 & $0.00 \mathrm{E}+00$ & 0 & $0.00 \mathrm{E}+00$ & 0 & $0.00 \mathrm{E}+00$ & 0 & $0.00 \mathrm{E}+00$ & 0 \\
\hline-99 & $0.00 \mathrm{E}+00$ & 0 & $0.00 \mathrm{E}+00$ & 0 & $0.00 \mathrm{E}+00$ & 0 & $0.00 \mathrm{E}+00$ & 0 & $0.00 \mathrm{E}+00$ & 0 & $0.00 E+00$ & 0 & $0.00 \mathrm{E}+00$ & 0 & $0.00 \mathrm{E}+00$ & 0 \\
\hline-228 & $0.00 \mathrm{E}+00$ & 0 & $0.00 \mathrm{E}+00$ & 0 & $0.00 \mathrm{E}+00$ & 0 & $0.00 \mathrm{E}+00$ & 0 & $0.00 \mathrm{E}+00$ & 0 & $0.00 \mathrm{E}+00$ & 0 & $0.00 \mathrm{E}+00$ & 0 & $0.00 \mathrm{E}+00$ & 0 \\
\hline-230 & $0.00 \mathrm{E}+00$ & 0 & $0.00 \mathrm{E}+00$ & 0 & $0.00 \mathrm{E}+00$ & 0 & $0.00 \mathrm{E}+00$ & 0 & $0.00 \mathrm{E}+00$ & 0 & $0.00 \mathrm{E}+00$ & 0 & $0.00 \mathrm{E}+00$ & 0 & $0.00 \mathrm{E}+00$ & 0 \\
\hline-232 & $0.00 \mathrm{E}+00$ & 0 & $0.00 \mathrm{E}+00$ & 0 & $0.00 \mathrm{E}+00$ & 0 & $0.00 \mathrm{E}+00$ & 0 & $0.00 \mathrm{E}+00$ & 0 & $0.00 \mathrm{E}+00$ & 0 & $0.00 \mathrm{E}+00$ & 0 & $0.00 \mathrm{E}+00$ & 0 \\
\hline 34 & $0.00 \mathrm{E}+00$ & 0 & $0.00 \mathrm{E}+00$ & 0 & $0.00 \mathrm{E}+00$ & 0 & $0.00 \mathrm{E}+00$ & 0 & $0.00 \mathrm{E}+00$ & 0 & $0.00 \mathrm{E}+00$ & 0 & $0.00 \mathrm{E}+00$ & 0 & $0.00 \mathrm{E}+00$ & 0 \\
\hline 35 & $0.00 \mathrm{E}+00$ & 0 & $0.00 \mathrm{E}+00$ & 0 & $0.00 \mathrm{E}+00$ & 0 & $0.00 \mathrm{E}+00$ & 0 & $0.00 \mathrm{E}+00$ & 0 & $0.00 \mathrm{E}+00$ & 0 & $0.00 \mathrm{E}+00$ & 0 & $0.00 \mathrm{E}+00$ & 0 \\
\hline 38 & $0.00 \mathrm{E}+00$ & 0 & $0.00 \mathrm{E}+00$ & 0 & $0.00 E+00$ & 0 & $0.00 \mathrm{E}+00$ & 0 & $0.00 \mathrm{E}+00$ & 0 & $0.00 E+00$ & 0 & $0.00 \mathrm{E}+00$ & 0 & $0.00 \mathrm{E}+00$ & 0 \\
\hline & $0.00 \mathrm{E}+00$ & 0 & $0.00 E+00$ & 0 & $0.00 \mathrm{E}+00$ & 0 & $0.00 \mathrm{E}+00$ & 0 & $0.00 \mathrm{E}+00$ & 0 & $0.00 \mathrm{E}+00$ & 0 & $0.00 \mathrm{E}+00$ & 0 & $0.00 \mathrm{E}+00$ & 0 \\
\hline
\end{tabular}

Total Dose Contributions TDOSE(i,p,t) for Individual Radionuclides (i) and Pathways (p)

in mrem/yr and as a Percentage of Total Dose at $t=1$ years

Directly from primary contamination and from release to atmosphere (Inhalation excludes radon)

\begin{tabular}{|c|c|c|c|c|c|c|c|c|c|c|c|c|c|c|c|c|}
\hline & \multicolumn{2}{|c|}{ Ground } & \multicolumn{2}{|c|}{ Inhalation } & \multicolumn{2}{|c|}{ Radon } & \multicolumn{2}{|c|}{ Plant } & \multicolumn{2}{|l|}{ Meat } & \multicolumn{2}{|l|}{ Milk } & \multicolumn{2}{|l|}{ Soil } & \multicolumn{2}{|c|}{ All Pathways* } \\
\hline clide & Dose & \% & Dose & $\%$ & Dose & $\%$ & Dose & 음 & Dose & $\%$ & Dose & $\%$ & Dose & \% & Dose & $\frac{\circ}{0}$ \\
\hline-241 & $9.92 \mathrm{E}-26$ & 0 & $0.00 E+00$ & 0 & $0.00 \mathrm{E}+00$ & 0 & $0.00 \mathrm{E}+00$ & 0 & $0.00 \mathrm{E}+00$ & 0 & $0.00 \mathrm{E}+00$ & 0 & $0.00 \mathrm{E}+00$ & 0 & $9.92 \mathrm{E}-26$ & 0 \\
\hline-137 & 1. $43 \mathrm{E}-16$ & 1 & $0.00 \mathrm{E}+00$ & 0 & $0.00 \mathrm{E}+00$ & 0 & $0.00 \mathrm{E}+00$ & 0 & $0.00 \mathrm{E}+00$ & 0 & $0.00 \mathrm{E}+00$ & 0 & $0.00 \mathrm{E}+00$ & 0 & $1.43 E-16$ & 1 \\
\hline-237 & $3.21 \mathrm{E}-20$ & 0 & $0.00 \mathrm{E}+00$ & 0 & $0.00 \mathrm{E}+00$ & 0 & $0.00 \mathrm{E}+00$ & 0 & $0.00 \mathrm{E}+00$ & 0 & $0.00 \mathrm{E}+00$ & 0 & $0.00 \mathrm{E}+00$ & 0 & $3.21 E-20$ & 0 \\
\hline-238 & $3.05 E-28$ & 0 & $0.00 \mathrm{E}+00$ & 0 & $0.00 \mathrm{E}+00$ & 0 & $0.00 \mathrm{E}+00$ & 0 & $0.00 \mathrm{E}+00$ & 0 & $0.00 \mathrm{E}+00$ & 0 & $0.00 \mathrm{E}+00$ & 0 & $3.05 E-28$ & 0 \\
\hline-239 & $2.65 \mathrm{E}-24$ & 0 & $0.00 \mathrm{E}+00$ & 0 & $0.00 \mathrm{E}+00$ & 0 & $0.00 \mathrm{E}+00$ & 0 & $0.00 \mathrm{E}+00$ & 0 & $0.00 \mathrm{E}+00$ & 0 & $0.00 \mathrm{E}+00$ & 0 & $2.65 E-24$ & 0 \\
\hline-240 & $2.59 \mathrm{E}-31$ & 0 & $0.00 \mathrm{E}+00$ & 0 & $0.00 \mathrm{E}+00$ & 0 & $0.00 \mathrm{E}+00$ & 0 & $0.00 \mathrm{E}+00$ & 0 & $0.00 \mathrm{E}+00$ & 0 & $0.00 \mathrm{E}+00$ & 0 & $2.59 E-31$ & 0 \\
\hline-99 & $1.84 \mathrm{E}-32$ & 0 & $0.00 \mathrm{E}+00$ & 0 & $0.00 \mathrm{E}+00$ & 0 & $0.00 E+00$ & 0 & $0.00 \mathrm{E}+00$ & 0 & $0.00 \mathrm{E}+00$ & 0 & $0.00 \mathrm{E}+00$ & 0 & $1.84 \mathrm{E}-32$ & 0 \\
\hline-228 & $2.35 \mathrm{E}-14$ & 92 & $0.00 \mathrm{E}+00$ & 0 & $0.00 \mathrm{E}+00$ & 0 & $0.00 \mathrm{E}+00$ & 0 & $0.00 \mathrm{E}+00$ & 0 & $0.00 \mathrm{E}+00$ & 0 & $0.00 \mathrm{E}+00$ & 0 & $2.35 E-14$ & 92 \\
\hline-230 & $6.90 \mathrm{E}-17$ & 0 & $0.00 \mathrm{E}+00$ & 0 & $0.00 \mathrm{E}+00$ & 0 & $0.00 \mathrm{E}+00$ & 0 & $0.00 \mathrm{E}+00$ & 0 & $0.00 \mathrm{E}+00$ & 0 & $0.00 \mathrm{E}+00$ & 0 & $6.90 \mathrm{E}-17$ & 0 \\
\hline-232 & $1.70 \mathrm{E}-15$ & 7 & $0.00 \mathrm{E}+00$ & 0 & $0.00 \mathrm{E}+00$ & 0 & $0.00 \mathrm{E}+00$ & 0 & $0.00 \mathrm{E}+00$ & 0 & $0.00 \mathrm{E}+00$ & 0 & $0.00 \mathrm{E}+00$ & 0 & $1.70 \mathrm{E}-15$ & 7 \\
\hline 234 & $7.92 \mathrm{E}-22$ & 0 & $0.00 E+00$ & 0 & $0.00 \mathrm{E}+00$ & 0 & $0.00 E+00$ & 0 & $0.00 \mathrm{E}+00$ & 0 & $0.00 \mathrm{E}+00$ & 0 & $0.00 \mathrm{E}+00$ & 0 & 7. $92 \mathrm{E}-22$ & 0 \\
\hline 235 & $4.98 \mathrm{E}-22$ & 0 & $0.00 \mathrm{E}+00$ & 0 & $0.00 \mathrm{E}+00$ & 0 & $0.00 \mathrm{E}+00$ & 0 & $0.00 \mathrm{E}+00$ & 0 & $0.00 \mathrm{E}+00$ & 0 & $0.00 \mathrm{E}+00$ & 0 & $4.98 \mathrm{E}-22$ & 0 \\
\hline 38 & 1. $39 \mathrm{E}-16$ & 1 & $0.00 \mathrm{E}+00$ & 0 & $0.00 \mathrm{E}+00$ & 0 & $0.00 \mathrm{E}+00$ & 0 & $0.00 \mathrm{E}+00$ & 0 & $0.00 \mathrm{E}+00$ & 0 & $0.00 \mathrm{E}+00$ & 0 & 1. $39 \mathrm{E}-16$ & 1 \\
\hline & $2.56 \mathrm{E}-14$ & 100 & $0.00 \mathrm{E}+00$ & 0 & $0.00 \mathrm{E}+00$ & 0 & $0.00 \mathrm{E}+00$ & 0 & $0.00 \mathrm{E}+00$ & 0 & $0.00 \mathrm{E}+00$ & 0 & $0.00 \mathrm{E}+00$ & 0 & $2.56 \mathrm{E}-14$ & 100 \\
\hline
\end{tabular}

* Sum of dose from all releases and from primary contamination. 
RESRAD-OFFSITE, Version 2 .

arent Dose Report

Title : Offsite Resident Farmer Deterministic Run

File : RF DOE SG FWD-FV2-1050y.ROF

Total Dose Contributions TDOSE (i,p,t) for Individual Radionuclides (i) and Pathways (p) in mrem/yr and as a Percentage of Total Dose at $t=50$ years

From releases to ground water and to surface water

\begin{tabular}{|c|c|c|c|c|c|c|c|c|c|c|c|c|c|c|c|c|}
\hline & \multicolumn{2}{|c|}{ Ground } & \multicolumn{2}{|l|}{ Fish } & \multicolumn{2}{|c|}{ Radon } & \multicolumn{2}{|c|}{ Plant } & \multicolumn{2}{|l|}{ Meat } & \multicolumn{2}{|l|}{ Milk } & \multicolumn{2}{|l|}{ Soil } & \multicolumn{2}{|c|}{ Water } \\
\hline clide & Dose & \% & Dose & $\%$ & Dose & \% & Dose & \% & Dose & \% & Dose & \% & Dose & \% & Dose & $\%$ \\
\hline-241 & $0.00 \mathrm{E}+00$ & 0 & $0.00 \mathrm{E}+00$ & 0 & $0.00 \mathrm{E}+00$ & 0 & $0.00 \mathrm{E}+00$ & 0 & $0.00 \mathrm{E}+00$ & 0 & $0.00 \mathrm{E}+00$ & 0 & $0.00 \mathrm{E}+00$ & 0 & $0.00 \mathrm{E}+00$ & 0 \\
\hline-137 & $0.00 \mathrm{E}+00$ & 0 & $0.00 \mathrm{E}+00$ & 0 & $0.00 \mathrm{E}+00$ & 0 & $0.00 \mathrm{E}+00$ & 0 & $0.00 \mathrm{E}+00$ & 0 & $0.00 \mathrm{E}+00$ & 0 & $0.00 \mathrm{E}+00$ & 0 & $0.00 \mathrm{E}+00$ & 0 \\
\hline-237 & $0.00 \mathrm{E}+00$ & 0 & $0.00 \mathrm{E}+00$ & 0 & $0.00 \mathrm{E}+00$ & 0 & $0.00 \mathrm{E}+00$ & 0 & $0.00 \mathrm{E}+00$ & 0 & $0.00 \mathrm{E}+00$ & 0 & $0.00 \mathrm{E}+00$ & 0 & $0.00 \mathrm{E}+00$ & 0 \\
\hline-238 & $0.00 \mathrm{E}+00$ & 0 & $0.00 \mathrm{E}+00$ & 0 & $0.00 \mathrm{E}+00$ & 0 & $0.00 \mathrm{E}+00$ & 0 & $0.00 \mathrm{E}+00$ & 0 & $0.00 \mathrm{E}+00$ & 0 & $0.00 \mathrm{E}+00$ & 0 & $0.00 \mathrm{E}+00$ & 0 \\
\hline-239 & $0.00 \mathrm{E}+00$ & 0 & $0.00 \mathrm{E}+00$ & 0 & $0.00 \mathrm{E}+00$ & 0 & $0.00 \mathrm{E}+00$ & 0 & $0.00 \mathrm{E}+00$ & 0 & $0.00 E+00$ & 0 & $0.00 \mathrm{E}+00$ & 0 & $0.00 \mathrm{E}+00$ & 0 \\
\hline-240 & $0.00 \mathrm{E}+00$ & 0 & $0.00 \mathrm{E}+00$ & 0 & $0.00 \mathrm{E}+00$ & 0 & $0.00 \mathrm{E}+00$ & 0 & $0.00 \mathrm{E}+00$ & 0 & $0.00 \mathrm{E}+00$ & 0 & $0.00 \mathrm{E}+00$ & 0 & $0.00 \mathrm{E}+00$ & 0 \\
\hline-99 & $0.00 \mathrm{E}+00$ & 0 & $0.00 E+00$ & 0 & $0.00 E+00$ & 0 & $0.00 \mathrm{E}+00$ & 0 & $0.00 \mathrm{E}+00$ & 0 & $0.00 E+00$ & 0 & $0.00 \mathrm{E}+00$ & 0 & $0.00 \mathrm{E}+00$ & 0 \\
\hline-228 & $0.00 \mathrm{E}+00$ & 0 & $0.00 \mathrm{E}+00$ & 0 & $0.00 \mathrm{E}+00$ & 0 & $0.00 \mathrm{E}+00$ & 0 & $0.00 \mathrm{E}+00$ & 0 & $0.00 \mathrm{E}+00$ & 0 & $0.00 \mathrm{E}+00$ & 0 & $0.00 \mathrm{E}+00$ & 0 \\
\hline-230 & $0.00 \mathrm{E}+00$ & 0 & $0.00 \mathrm{E}+00$ & 0 & $0.00 \mathrm{E}+00$ & 0 & $0.00 \mathrm{E}+00$ & 0 & $0.00 \mathrm{E}+00$ & 0 & $0.00 \mathrm{E}+00$ & 0 & $0.00 \mathrm{E}+00$ & 0 & $0.00 \mathrm{E}+00$ & 0 \\
\hline-232 & $0.00 \mathrm{E}+00$ & 0 & $0.00 \mathrm{E}+00$ & 0 & $0.00 \mathrm{E}+00$ & 0 & $0.00 \mathrm{E}+00$ & 0 & $0.00 \mathrm{E}+00$ & 0 & $0.00 \mathrm{E}+00$ & 0 & $0.00 \mathrm{E}+00$ & 0 & $0.00 \mathrm{E}+00$ & 0 \\
\hline 234 & $0.00 \mathrm{E}+00$ & 0 & $0.00 \mathrm{E}+00$ & 0 & $0.00 \mathrm{E}+00$ & 0 & $0.00 \mathrm{E}+00$ & 0 & $0.00 \mathrm{E}+00$ & 0 & $0.00 \mathrm{E}+00$ & 0 & $0.00 \mathrm{E}+00$ & 0 & $0.00 \mathrm{E}+00$ & 0 \\
\hline 235 & $0.00 \mathrm{E}+00$ & 0 & $0.00 \mathrm{E}+00$ & 0 & $0.00 \mathrm{E}+00$ & 0 & $0.00 \mathrm{E}+00$ & 0 & $0.00 \mathrm{E}+00$ & 0 & $0.00 E+00$ & 0 & $0.00 \mathrm{E}+00$ & 0 & $0.00 \mathrm{E}+00$ & 0 \\
\hline 38 & $0.00 \mathrm{E}+00$ & 0 & $0.00 \mathrm{E}+00$ & 0 & $0.00 \mathrm{E}+00$ & 0 & $0.00 \mathrm{E}+00$ & 0 & $0.00 \mathrm{E}+00$ & 0 & $0.00 \mathrm{E}+00$ & 0 & $0.00 \mathrm{E}+00$ & 0 & $0.00 \mathrm{E}+00$ & 0 \\
\hline & $0.00 \mathrm{E}+00$ & 0 & $0.00 \mathrm{E}+00$ & 0 & $0.00 \mathrm{E}+00$ & 0 & $0.00 \mathrm{E}+00$ & 0 & $0.00 \mathrm{E}+00$ & 0 & $0.00 \mathrm{E}+00$ & 0 & $0.00 \mathrm{E}+00$ & 0 & $0.00 \mathrm{E}+00$ & 0 \\
\hline
\end{tabular}

Total Dose Contributions TDOSE (i,p,t) for Individual Radionuclides (i) and Pathways (p) in mrem/yr and as a Percentage of Total Dose at $t=50$ years

Directly from primary contamination and from release to atmosphere (Inhalation excludes radon)

\begin{tabular}{|c|c|c|c|c|c|c|c|c|c|c|c|c|c|c|c|c|}
\hline & \multicolumn{2}{|c|}{ Ground } & \multicolumn{2}{|c|}{ Inhalation } & \multicolumn{2}{|c|}{ Radon } & \multicolumn{2}{|c|}{ Plant } & \multicolumn{2}{|l|}{ Meat } & \multicolumn{2}{|l|}{ Milk } & \multicolumn{2}{|l|}{ Soil } & \multicolumn{2}{|c|}{ All Pathways* } \\
\hline clide & Dose & $\%$ & Dose & \% & Dose & $\%$ & Dose & 음 & Dose & $\%$ & Dose & 음 & Dose & $\%$ & Dose & $\%$ \\
\hline-241 & $5.22 E-24$ & 0 & $0.00 \mathrm{E}+00$ & 0 & $0.00 \mathrm{E}+00$ & 0 & $0.00 \mathrm{E}+00$ & 0 & $0.00 \mathrm{E}+00$ & 0 & $0.00 \mathrm{E}+00$ & 0 & $0.00 \mathrm{E}+00$ & 0 & 5. $22 \mathrm{E}-24$ & 0 \\
\hline-137 & $6.74 E-17$ & 0 & $0.00 E+00$ & 0 & $0.00 E+00$ & 0 & $0.00 \mathrm{E}+00$ & 0 & $0.00 \mathrm{E}+00$ & 0 & $0.00 E+00$ & 0 & $0.00 \mathrm{E}+00$ & 0 & $6.74 \mathrm{E}-17$ & 0 \\
\hline-237 & $5.22 E-20$ & 0 & $0.00 \mathrm{E}+00$ & 0 & $0.00 E+00$ & 0 & $0.00 \mathrm{E}+00$ & 0 & $0.00 \mathrm{E}+00$ & 0 & $0.00 E+00$ & 0 & $0.00 \mathrm{E}+00$ & 0 & $5.22 \mathrm{E}-20$ & 0 \\
\hline-238 & 1. $21 E-23$ & 0 & $0.00 \mathrm{E}+00$ & 0 & $0.00 \mathrm{E}+00$ & 0 & $0.00 \mathrm{E}+00$ & 0 & $0.00 \mathrm{E}+00$ & 0 & $0.00 \mathrm{E}+00$ & 0 & $0.00 \mathrm{E}+00$ & 0 & 1. $21 \mathrm{E}-23$ & 0 \\
\hline-239 & $4.55 \mathrm{E}-24$ & 0 & $0.00 \mathrm{E}+00$ & 0 & $0.00 \mathrm{E}+00$ & 0 & $0.00 \mathrm{E}+00$ & 0 & $0.00 \mathrm{E}+00$ & 0 & $0.00 \mathrm{E}+00$ & 0 & $0.00 \mathrm{E}+00$ & 0 & $4.55 E-24$ & 0 \\
\hline-240 & $5.72 E-28$ & 0 & $0.00 \mathrm{E}+00$ & 0 & $0.00 \mathrm{E}+00$ & 0 & $0.00 \mathrm{E}+00$ & 0 & $0.00 \mathrm{E}+00$ & 0 & $0.00 E+00$ & 0 & $0.00 \mathrm{E}+00$ & 0 & $5.72 \mathrm{E}-28$ & 0 \\
\hline-99 & $3.38 E-32$ & 0 & $0.00 \mathrm{E}+00$ & 0 & $0.00 \mathrm{E}+00$ & 0 & $0.00 \mathrm{E}+00$ & 0 & $0.00 \mathrm{E}+00$ & 0 & $0.00 E+00$ & 0 & $0.00 \mathrm{E}+00$ & 0 & $3.38 E-32$ & 0 \\
\hline-228 & $6.03 E-22$ & 0 & $0.00 \mathrm{E}+00$ & 0 & $0.00 \mathrm{E}+00$ & 0 & $0.00 \mathrm{E}+00$ & 0 & $0.00 \mathrm{E}+00$ & 0 & $0.00 \mathrm{E}+00$ & 0 & $0.00 \mathrm{E}+00$ & 0 & $6.03 E-22$ & 0 \\
\hline-230 & $3.14 \mathrm{E}-15$ & 6 & $0.00 \mathrm{E}+00$ & 0 & $0.00 \mathrm{E}+00$ & 0 & $0.00 \mathrm{E}+00$ & 0 & $0.00 \mathrm{E}+00$ & 0 & $0.00 \mathrm{E}+00$ & 0 & $0.00 \mathrm{E}+00$ & 0 & $3.14 \mathrm{E}-15$ & 6 \\
\hline-232 & $5.31 E-14$ & 94 & $0.00 \mathrm{E}+00$ & 0 & $0.00 \mathrm{E}+00$ & 0 & $0.00 \mathrm{E}+00$ & 0 & $0.00 \mathrm{E}+00$ & 0 & $0.00 \mathrm{E}+00$ & 0 & $0.00 \mathrm{E}+00$ & 0 & $5.31 \mathrm{E}-14$ & 94 \\
\hline 34 & $1.15 \mathrm{E}-18$ & 0 & $0.00 \mathrm{E}+00$ & 0 & $0.00 \mathrm{E}+00$ & 0 & $0.00 \mathrm{E}+00$ & 0 & $0.00 \mathrm{E}+00$ & 0 & $0.00 \mathrm{E}+00$ & 0 & $0.00 \mathrm{E}+00$ & 0 & 1. $15 \mathrm{E}-18$ & 0 \\
\hline 35 & $3.51 \mathrm{E}-21$ & 0 & $0.00 \mathrm{E}+00$ & 0 & $0.00 \mathrm{E}+00$ & 0 & $0.00 \mathrm{E}+00$ & 0 & $0.00 \mathrm{E}+00$ & 0 & $0.00 \mathrm{E}+00$ & 0 & $0.00 \mathrm{E}+00$ & 0 & $3.51 \mathrm{E}-21$ & 0 \\
\hline 38 & $1.99 E-16$ & 0 & $0.00 \mathrm{E}+00$ & 0 & $0.00 \mathrm{E}+00$ & 0 & $0.00 \mathrm{E}+00$ & 0 & $0.00 \mathrm{E}+00$ & 0 & $0.00 E+00$ & 0 & $0.00 \mathrm{E}+00$ & 0 & 1. $99 \mathrm{E}-16$ & 0 \\
\hline & $5.65 \mathrm{E}-14$ & 100 & $0.00 \mathrm{E}+00$ & 0 & $0.00 \mathrm{E}+00$ & 0 & $0.00 \mathrm{E}+00$ & 0 & $0.00 \mathrm{E}+00$ & 0 & $0.00 \mathrm{E}+00$ & 0 & $0.00 \mathrm{E}+00$ & 0 & $5.65 \mathrm{E}-14$ & 100 \\
\hline
\end{tabular}

* Sum of dose from all releases and from primary contamination. 
RESRAD-OFFSITE, Version 2 .

Parent Dose Report

Title : Offsite Resident Farmer Deterministic Run

File : RF DOE SG FWD-FV2-1050y.ROF

Total Dose Contributions TDOSE (i,p,t) for Individual Radionuclides (i) and Pathways (p) in mrem/yr and as a Percentage of Total Dose at $t=100$ years

From releases to ground water and to surface water

\begin{tabular}{|c|c|c|c|c|c|c|c|c|c|c|c|c|c|c|c|c|}
\hline & \multicolumn{2}{|c|}{ Ground } & \multicolumn{2}{|l|}{ Fish } & \multicolumn{2}{|c|}{ Radon } & \multicolumn{2}{|c|}{ Plant } & \multicolumn{2}{|l|}{ Meat } & \multicolumn{2}{|l|}{ Milk } & \multicolumn{2}{|l|}{ Soil } & \multicolumn{2}{|c|}{ Water } \\
\hline ide & Dose & $\%$ & Dose & $\%$ & Dose & 응 & Dose & $\frac{\circ}{0}$ & Dose & 응 & Dose & 응 & Dose & $\%$ & Dose & $\%$ \\
\hline-241 & $0.00 \mathrm{E}+00$ & 0 & $0.00 E+00$ & 0 & $0.00 \mathrm{E}+00$ & 0 & $0.00 \mathrm{E}+00$ & 0 & $0.00 \mathrm{E}+00$ & 0 & $0.00 \mathrm{E}+00$ & 0 & $0.00 \mathrm{E}+00$ & 0 & $0.00 \mathrm{E}+00$ & 0 \\
\hline-137 & $0.00 \mathrm{E}+00$ & 0 & $0.00 \mathrm{E}+00$ & 0 & $0.00 \mathrm{E}+00$ & 0 & $0.00 \mathrm{E}+00$ & 0 & $0.00 \mathrm{E}+00$ & 0 & $0.00 \mathrm{E}+00$ & 0 & $0.00 \mathrm{E}+00$ & 0 & $0.00 \mathrm{E}+00$ & 0 \\
\hline-237 & $0.00 \mathrm{E}+00$ & 0 & $0.00 \mathrm{E}+00$ & 0 & $0.00 \mathrm{E}+00$ & 0 & $0.00 \mathrm{E}+00$ & 0 & $0.00 \mathrm{E}+00$ & 0 & $0.00 \mathrm{E}+00$ & 0 & $0.00 \mathrm{E}+00$ & 0 & $0.00 \mathrm{E}+00$ & 0 \\
\hline-238 & $0.00 \mathrm{E}+00$ & 0 & $0.00 \mathrm{E}+00$ & 0 & $0.00 E+00$ & 0 & $0.00 \mathrm{E}+00$ & 0 & $0.00 \mathrm{E}+00$ & 0 & $0.00 E+00$ & 0 & $0.00 \mathrm{E}+00$ & 0 & $0.00 \mathrm{E}+00$ & 0 \\
\hline-239 & $0.00 \mathrm{E}+00$ & 0 & $0.00 \mathrm{E}+00$ & 0 & $0.00 \mathrm{E}+00$ & 0 & $0.00 \mathrm{E}+00$ & 0 & $0.00 \mathrm{E}+00$ & 0 & $0.00 \mathrm{E}+00$ & 0 & $0.00 \mathrm{E}+00$ & 0 & $0.00 \mathrm{E}+00$ & 0 \\
\hline-240 & $0.00 \mathrm{E}+00$ & 0 & $0.00 \mathrm{E}+00$ & 0 & $0.00 \mathrm{E}+00$ & 0 & $0.00 \mathrm{E}+00$ & 0 & $0.00 \mathrm{E}+00$ & 0 & $0.00 \mathrm{E}+00$ & 0 & $0.00 \mathrm{E}+00$ & 0 & $0.00 \mathrm{E}+00$ & 0 \\
\hline-99 & $0.00 \mathrm{E}+00$ & 0 & $0.00 \mathrm{E}+00$ & 0 & $0.00 \mathrm{E}+00$ & 0 & $0.00 \mathrm{E}+00$ & 0 & $0.00 \mathrm{E}+00$ & 0 & $0.00 E+00$ & 0 & $0.00 \mathrm{E}+00$ & 0 & $0.00 \mathrm{E}+00$ & 0 \\
\hline-228 & $0.00 \mathrm{E}+00$ & 0 & $0.00 \mathrm{E}+00$ & 0 & $0.00 \mathrm{E}+00$ & 0 & $0.00 \mathrm{E}+00$ & 0 & $0.00 \mathrm{E}+00$ & 0 & $0.00 \mathrm{E}+00$ & 0 & $0.00 \mathrm{E}+00$ & 0 & $0.00 \mathrm{E}+00$ & 0 \\
\hline-230 & $0.00 \mathrm{E}+00$ & 0 & $0.00 \mathrm{E}+00$ & 0 & $0.00 \mathrm{E}+00$ & 0 & $0.00 \mathrm{E}+00$ & 0 & $0.00 \mathrm{E}+00$ & 0 & $0.00 \mathrm{E}+00$ & 0 & $0.00 \mathrm{E}+00$ & 0 & $0.00 \mathrm{E}+00$ & 0 \\
\hline-232 & $0.00 \mathrm{E}+00$ & 0 & $0.00 \mathrm{E}+00$ & 0 & $0.00 \mathrm{E}+00$ & 0 & $0.00 \mathrm{E}+00$ & 0 & $0.00 \mathrm{E}+00$ & 0 & $0.00 \mathrm{E}+00$ & 0 & $0.00 \mathrm{E}+00$ & 0 & $0.00 \mathrm{E}+00$ & 0 \\
\hline 34 & $0.00 \mathrm{E}+00$ & 0 & $0.00 \mathrm{E}+00$ & 0 & $0.00 \mathrm{E}+00$ & 0 & $0.00 \mathrm{E}+00$ & 0 & $0.00 \mathrm{E}+00$ & 0 & $0.00 \mathrm{E}+00$ & 0 & $0.00 \mathrm{E}+00$ & 0 & $0.00 \mathrm{E}+00$ & 0 \\
\hline 35 & $0.00 \mathrm{E}+00$ & 0 & $0.00 \mathrm{E}+00$ & 0 & $0.00 \mathrm{E}+00$ & 0 & $0.00 \mathrm{E}+00$ & 0 & $0.00 \mathrm{E}+00$ & 0 & $0.00 \mathrm{E}+00$ & 0 & $0.00 \mathrm{E}+00$ & 0 & $0.00 \mathrm{E}+00$ & 0 \\
\hline 38 & $0.00 \mathrm{E}+00$ & 0 & $0.00 \mathrm{E}+00$ & 0 & $0.00 E+00$ & 0 & $0.00 \mathrm{E}+00$ & 0 & $0.00 \mathrm{E}+00$ & 0 & $0.00 E+00$ & 0 & $0.00 \mathrm{E}+00$ & 0 & $0.00 \mathrm{E}+00$ & 0 \\
\hline & $0.00 \mathrm{E}+00$ & 0 & $0.00 E+00$ & 0 & $0.00 \mathrm{E}+00$ & 0 & $0.00 \mathrm{E}+00$ & 0 & $0.00 \mathrm{E}+00$ & 0 & $0.00 \mathrm{E}+00$ & 0 & $0.00 \mathrm{E}+00$ & 0 & $0.00 \mathrm{E}+00$ & 0 \\
\hline
\end{tabular}

Total Dose Contributions TDOSE(i,p,t) for Individual Radionuclides (i) and Pathways (p) in mrem/yr and as a Percentage of Total Dose at $t=100$ years

Directly from primary contamination and from release to atmosphere (Inhalation excludes radon)

\begin{tabular}{|c|c|c|c|c|c|c|c|c|c|c|c|c|c|c|c|c|}
\hline & \multicolumn{2}{|c|}{ Ground } & \multicolumn{2}{|c|}{ Inhalation } & \multicolumn{2}{|c|}{ Radon } & \multicolumn{2}{|c|}{ Plant } & \multicolumn{2}{|l|}{ Meat } & \multicolumn{2}{|l|}{ Milk } & \multicolumn{2}{|l|}{ Soil } & \multicolumn{2}{|c|}{ All Pathways* } \\
\hline lide & Dose & $\%$ & Dose & $\%$ & Dose & $\%$ & Dose & 음 & Dose & $\%$ & Dose & 음 & Dose & $\%$ & Dose & $\%$ \\
\hline-241 & $1.64 \mathrm{E}-23$ & 0 & $0.00 \mathrm{E}+00$ & 0 & $0.00 \mathrm{E}+00$ & 0 & $0.00 \mathrm{E}+00$ & 0 & $0.00 \mathrm{E}+00$ & 0 & $0.00 \mathrm{E}+00$ & 0 & $0.00 \mathrm{E}+00$ & 0 & $1.64 \mathrm{E}-23$ & 0 \\
\hline-137 & $3.13 E-17$ & 0 & $0.00 E+00$ & 0 & $0.00 E+00$ & 0 & $0.00 \mathrm{E}+00$ & 0 & $0.00 \mathrm{E}+00$ & 0 & $0.00 E+00$ & 0 & $0.00 \mathrm{E}+00$ & 0 & $3.13 \mathrm{E}-17$ & 0 \\
\hline-237 & $8.58 E-20$ & 0 & $0.00 \mathrm{E}+00$ & 0 & $0.00 E+00$ & 0 & $0.00 \mathrm{E}+00$ & 0 & $0.00 \mathrm{E}+00$ & 0 & $0.00 E+00$ & 0 & $0.00 \mathrm{E}+00$ & 0 & $8.58 E-20$ & 0 \\
\hline-238 & 1. $19 \mathrm{E}-22$ & 0 & $0.00 \mathrm{E}+00$ & 0 & $0.00 \mathrm{E}+00$ & 0 & $0.00 \mathrm{E}+00$ & 0 & $0.00 \mathrm{E}+00$ & 0 & $0.00 \mathrm{E}+00$ & 0 & $0.00 \mathrm{E}+00$ & 0 & $1.19 \mathrm{E}-22$ & 0 \\
\hline-239 & $7.88 \mathrm{E}-24$ & 0 & $0.00 \mathrm{E}+00$ & 0 & $0.00 \mathrm{E}+00$ & 0 & $0.00 \mathrm{E}+00$ & 0 & $0.00 \mathrm{E}+00$ & 0 & $0.00 \mathrm{E}+00$ & 0 & $0.00 \mathrm{E}+00$ & 0 & $7.88 E-24$ & 0 \\
\hline-240 & $3.71 E-27$ & 0 & $0.00 \mathrm{E}+00$ & 0 & $0.00 \mathrm{E}+00$ & 0 & $0.00 \mathrm{E}+00$ & 0 & $0.00 \mathrm{E}+00$ & 0 & $0.00 E+00$ & 0 & $0.00 \mathrm{E}+00$ & 0 & $3.71 E-27$ & 0 \\
\hline-99 & $6.28 E-32$ & 0 & $0.00 \mathrm{E}+00$ & 0 & $0.00 \mathrm{E}+00$ & 0 & $0.00 \mathrm{E}+00$ & 0 & $0.00 \mathrm{E}+00$ & 0 & $0.00 E+00$ & 0 & $0.00 \mathrm{E}+00$ & 0 & $6.28 E-32$ & 0 \\
\hline-228 & $1.07 \mathrm{E}-29$ & 0 & $0.00 \mathrm{E}+00$ & 0 & $0.00 \mathrm{E}+00$ & 0 & $0.00 \mathrm{E}+00$ & 0 & $0.00 \mathrm{E}+00$ & 0 & $0.00 \mathrm{E}+00$ & 0 & $0.00 \mathrm{E}+00$ & 0 & $1.07 \mathrm{E}-29$ & 0 \\
\hline-230 & $8.49 \mathrm{E}-15$ & 11 & $0.00 \mathrm{E}+00$ & 0 & $0.00 \mathrm{E}+00$ & 0 & $0.00 \mathrm{E}+00$ & 0 & $0.00 \mathrm{E}+00$ & 0 & $0.00 \mathrm{E}+00$ & 0 & $0.00 \mathrm{E}+00$ & 0 & $8.49 \mathrm{E}-15$ & 11 \\
\hline-232 & $7.02 \mathrm{E}-14$ & 89 & $0.00 \mathrm{E}+00$ & 0 & $0.00 \mathrm{E}+00$ & 0 & $0.00 \mathrm{E}+00$ & 0 & $0.00 \mathrm{E}+00$ & 0 & $0.00 \mathrm{E}+00$ & 0 & $0.00 \mathrm{E}+00$ & 0 & $7.02 \mathrm{E}-14$ & 89 \\
\hline 34 & $6.19 \mathrm{E}-18$ & 0 & $0.00 \mathrm{E}+00$ & 0 & $0.00 \mathrm{E}+00$ & 0 & $0.00 \mathrm{E}+00$ & 0 & $0.00 \mathrm{E}+00$ & 0 & $0.00 \mathrm{E}+00$ & 0 & $0.00 \mathrm{E}+00$ & 0 & $6.19 \mathrm{E}-18$ & 0 \\
\hline 35 & $1.24 \mathrm{E}-20$ & 0 & $0.00 \mathrm{E}+00$ & 0 & $0.00 \mathrm{E}+00$ & 0 & $0.00 \mathrm{E}+00$ & 0 & $0.00 \mathrm{E}+00$ & 0 & $0.00 \mathrm{E}+00$ & 0 & $0.00 \mathrm{E}+00$ & 0 & $1.24 \mathrm{E}-20$ & 0 \\
\hline 38 & $2.87 E-16$ & 0 & $0.00 \mathrm{E}+00$ & 0 & $0.00 \mathrm{E}+00$ & 0 & $0.00 \mathrm{E}+00$ & 0 & $0.00 \mathrm{E}+00$ & 0 & $0.00 E+00$ & 0 & $0.00 \mathrm{E}+00$ & 0 & $2.87 E-16$ & 0 \\
\hline & $7.90 \mathrm{E}-14$ & 100 & $0.00 \mathrm{E}+00$ & 0 & $0.00 \mathrm{E}+00$ & 0 & $0.00 \mathrm{E}+00$ & 0 & $0.00 \mathrm{E}+00$ & 0 & $0.00 \mathrm{E}+00$ & 0 & $0.00 \mathrm{E}+00$ & 0 & $7.90 \mathrm{E}-14$ & 100 \\
\hline
\end{tabular}

* Sum of dose from all releases and from primary contamination. 
RESRAD-OFFSITE, Version 2 .

arent Dose Report

Title : Offsite Resident Farmer Deterministic Run

File : RF DOE SG FWD-FV2-1050y.ROF

Total Dose Contributions TDOSE (i,p,t) for Individual Radionuclides (i) and Pathways (p) in mrem/yr and as a Percentage of Total Dose at $t=500$ years

From releases to ground water and to surface water

\begin{tabular}{|c|c|c|c|c|c|c|c|c|c|c|c|c|c|c|c|c|}
\hline & \multicolumn{2}{|c|}{ Ground } & \multicolumn{2}{|l|}{ Fish } & \multicolumn{2}{|c|}{ Radon } & \multicolumn{2}{|c|}{ Plant } & \multicolumn{2}{|l|}{ Meat } & \multicolumn{2}{|l|}{ Milk } & \multicolumn{2}{|l|}{ Soil } & \multicolumn{2}{|c|}{ Water } \\
\hline ide & Dose & $\%$ & Dose & $\%$ & Dose & 응 & Dose & $\frac{\circ}{0}$ & Dose & 응 & Dose & 응 & Dose & $\%$ & Dose & $\%$ \\
\hline-241 & $0.00 \mathrm{E}+00$ & 0 & $0.00 E+00$ & 0 & $0.00 \mathrm{E}+00$ & 0 & $0.00 \mathrm{E}+00$ & 0 & $0.00 \mathrm{E}+00$ & 0 & $0.00 \mathrm{E}+00$ & 0 & $0.00 \mathrm{E}+00$ & 0 & $0.00 \mathrm{E}+00$ & 0 \\
\hline-137 & $0.00 \mathrm{E}+00$ & 0 & $0.00 \mathrm{E}+00$ & 0 & $0.00 \mathrm{E}+00$ & 0 & $0.00 \mathrm{E}+00$ & 0 & $0.00 \mathrm{E}+00$ & 0 & $0.00 \mathrm{E}+00$ & 0 & $0.00 \mathrm{E}+00$ & 0 & $0.00 \mathrm{E}+00$ & 0 \\
\hline-237 & $0.00 \mathrm{E}+00$ & 0 & $0.00 \mathrm{E}+00$ & 0 & $0.00 \mathrm{E}+00$ & 0 & $0.00 \mathrm{E}+00$ & 0 & $0.00 \mathrm{E}+00$ & 0 & $0.00 \mathrm{E}+00$ & 0 & $0.00 \mathrm{E}+00$ & 0 & $0.00 \mathrm{E}+00$ & 0 \\
\hline-238 & $0.00 \mathrm{E}+00$ & 0 & $0.00 \mathrm{E}+00$ & 0 & $0.00 E+00$ & 0 & $0.00 \mathrm{E}+00$ & 0 & $0.00 \mathrm{E}+00$ & 0 & $0.00 E+00$ & 0 & $0.00 \mathrm{E}+00$ & 0 & $0.00 \mathrm{E}+00$ & 0 \\
\hline-239 & $0.00 \mathrm{E}+00$ & 0 & $0.00 \mathrm{E}+00$ & 0 & $0.00 \mathrm{E}+00$ & 0 & $0.00 \mathrm{E}+00$ & 0 & $0.00 \mathrm{E}+00$ & 0 & $0.00 \mathrm{E}+00$ & 0 & $0.00 \mathrm{E}+00$ & 0 & $0.00 \mathrm{E}+00$ & 0 \\
\hline-240 & $0.00 \mathrm{E}+00$ & 0 & $0.00 \mathrm{E}+00$ & 0 & $0.00 \mathrm{E}+00$ & 0 & $0.00 \mathrm{E}+00$ & 0 & $0.00 \mathrm{E}+00$ & 0 & $0.00 \mathrm{E}+00$ & 0 & $0.00 \mathrm{E}+00$ & 0 & $0.00 \mathrm{E}+00$ & 0 \\
\hline-99 & $9.04 \mathrm{E}-07$ & 0 & $0.00 \mathrm{E}+00$ & 0 & $0.00 \mathrm{E}+00$ & 0 & $2.48 \mathrm{E}-01$ & 25 & $7.44 \mathrm{E}-04$ & 0 & $6.57 E-02$ & 7 & $7.63 E-07$ & 0 & $6.76 \mathrm{E}-01$ & 68 \\
\hline-228 & $0.00 \mathrm{E}+00$ & 0 & $0.00 \mathrm{E}+00$ & 0 & $0.00 \mathrm{E}+00$ & 0 & $0.00 \mathrm{E}+00$ & 0 & $0.00 \mathrm{E}+00$ & 0 & $0.00 \mathrm{E}+00$ & 0 & $0.00 \mathrm{E}+00$ & 0 & $0.00 \mathrm{E}+00$ & 0 \\
\hline-230 & $0.00 \mathrm{E}+00$ & 0 & $0.00 \mathrm{E}+00$ & 0 & $0.00 \mathrm{E}+00$ & 0 & $0.00 \mathrm{E}+00$ & 0 & $0.00 \mathrm{E}+00$ & 0 & $0.00 \mathrm{E}+00$ & 0 & $0.00 \mathrm{E}+00$ & 0 & $0.00 \mathrm{E}+00$ & 0 \\
\hline-232 & $0.00 \mathrm{E}+00$ & 0 & $0.00 \mathrm{E}+00$ & 0 & $0.00 \mathrm{E}+00$ & 0 & $0.00 \mathrm{E}+00$ & 0 & $0.00 \mathrm{E}+00$ & 0 & $0.00 \mathrm{E}+00$ & 0 & $0.00 \mathrm{E}+00$ & 0 & $0.00 \mathrm{E}+00$ & 0 \\
\hline 34 & $0.00 \mathrm{E}+00$ & 0 & $0.00 \mathrm{E}+00$ & 0 & $0.00 \mathrm{E}+00$ & 0 & $0.00 \mathrm{E}+00$ & 0 & $0.00 \mathrm{E}+00$ & 0 & $0.00 \mathrm{E}+00$ & 0 & $0.00 \mathrm{E}+00$ & 0 & $0.00 \mathrm{E}+00$ & 0 \\
\hline 35 & $0.00 \mathrm{E}+00$ & 0 & $0.00 \mathrm{E}+00$ & 0 & $0.00 \mathrm{E}+00$ & 0 & $0.00 \mathrm{E}+00$ & 0 & $0.00 \mathrm{E}+00$ & 0 & $0.00 \mathrm{E}+00$ & 0 & $0.00 \mathrm{E}+00$ & 0 & $0.00 \mathrm{E}+00$ & 0 \\
\hline 38 & $0.00 \mathrm{E}+00$ & 0 & $0.00 \mathrm{E}+00$ & 0 & $0.00 E+00$ & 0 & $0.00 \mathrm{E}+00$ & 0 & $0.00 \mathrm{E}+00$ & 0 & $0.00 E+00$ & 0 & $0.00 \mathrm{E}+00$ & 0 & $0.00 \mathrm{E}+00$ & 0 \\
\hline & $9.04 \mathrm{E}-07$ & 0 & $0.00 E+00$ & 0 & $0.00 \mathrm{E}+00$ & 0 & $2.48 \mathrm{E}-01$ & 25 & $7.44 \mathrm{E}-04$ & 0 & $6.57 E-02$ & 7 & $7.63 E-07$ & 0 & $6.76 \mathrm{E}-01$ & 68 \\
\hline
\end{tabular}

Total Dose Contributions TDOSE(i,p,t) for Individual Radionuclides (i) and Pathways (p) in mrem/yr and as a Percentage of Total Dose at $t=500$ years

Directly from primary contamination and from release to atmosphere (Inhalation excludes radon)

\begin{tabular}{|c|c|c|c|c|c|c|c|c|c|c|c|c|c|c|c|c|}
\hline & \multicolumn{2}{|c|}{ Ground } & \multicolumn{2}{|c|}{ Inhalation } & \multicolumn{2}{|c|}{ Radon } & \multicolumn{2}{|c|}{ Plant } & \multicolumn{2}{|l|}{ Meat } & \multicolumn{2}{|l|}{ Milk } & \multicolumn{2}{|l|}{ Soil } & \multicolumn{2}{|c|}{ All Pathways* } \\
\hline clide & Dose & $\%$ & Dose & $\%$ & Dose & $\%$ & Dose & 음 & Dose & $\%$ & Dose & 음 & Dose & $\%$ & Dose & $\%$ \\
\hline-241 & $3.23 E-21$ & 0 & $0.00 E+00$ & 0 & $0.00 E+00$ & 0 & $0.00 \mathrm{E}+00$ & 0 & $0.00 \mathrm{E}+00$ & 0 & $0.00 \mathrm{E}+00$ & 0 & $0.00 \mathrm{E}+00$ & 0 & $3.23 E-21$ & 0 \\
\hline-137 & $6.73 E-20$ & 0 & $0.00 E+00$ & 0 & $0.00 E+00$ & 0 & $0.00 \mathrm{E}+00$ & 0 & $0.00 \mathrm{E}+00$ & 0 & $0.00 E+00$ & 0 & $0.00 \mathrm{E}+00$ & 0 & $6.73 E-20$ & 0 \\
\hline-237 & $4.59 E-18$ & 0 & $0.00 E+00$ & 0 & $0.00 E+00$ & 0 & $0.00 \mathrm{E}+00$ & 0 & $0.00 \mathrm{E}+00$ & 0 & $0.00 E+00$ & 0 & $0.00 \mathrm{E}+00$ & 0 & $4.59 \mathrm{E}-18$ & 0 \\
\hline-238 & 1.01E-19 & 0 & $0.00 E+00$ & 0 & $0.00 \mathrm{E}+00$ & 0 & $0.00 \mathrm{E}+00$ & 0 & $0.00 \mathrm{E}+00$ & 0 & $0.00 \mathrm{E}+00$ & 0 & $0.00 \mathrm{E}+00$ & 0 & $1.01 \mathrm{E}-19$ & 0 \\
\hline-239 & $6.42 \mathrm{E}-22$ & 0 & $0.00 \mathrm{E}+00$ & 0 & $0.00 \mathrm{E}+00$ & 0 & $0.00 \mathrm{E}+00$ & 0 & $0.00 \mathrm{E}+00$ & 0 & $0.00 \mathrm{E}+00$ & 0 & $0.00 \mathrm{E}+00$ & 0 & $6.42 \mathrm{E}-22$ & 0 \\
\hline-240 & $9.86 \mathrm{E}-25$ & 0 & $0.00 \mathrm{E}+00$ & 0 & $0.00 \mathrm{E}+00$ & 0 & $0.00 \mathrm{E}+00$ & 0 & $0.00 \mathrm{E}+00$ & 0 & $0.00 \mathrm{E}+00$ & 0 & $0.00 \mathrm{E}+00$ & 0 & $9.86 \mathrm{E}-25$ & 0 \\
\hline-99 & $8.96 \mathrm{E}-30$ & 0 & $0.00 E+00$ & 0 & $0.00 \mathrm{E}+00$ & 0 & $0.00 \mathrm{E}+00$ & 0 & $0.00 \mathrm{E}+00$ & 0 & $0.00 E+00$ & 0 & $0.00 \mathrm{E}+00$ & 0 & $9.91 \mathrm{E}-01$ & 100 \\
\hline-228 & $0.00 \mathrm{E}+00$ & 0 & $0.00 \mathrm{E}+00$ & 0 & $0.00 \mathrm{E}+00$ & 0 & $0.00 \mathrm{E}+00$ & 0 & $0.00 \mathrm{E}+00$ & 0 & $0.00 \mathrm{E}+00$ & 0 & $0.00 \mathrm{E}+00$ & 0 & $0.00 \mathrm{E}+00$ & 0 \\
\hline-230 & $4.95 E-13$ & 0 & $0.00 E+00$ & 0 & $0.00 \mathrm{E}+00$ & 0 & $0.00 \mathrm{E}+00$ & 0 & $0.00 \mathrm{E}+00$ & 0 & $0.00 E+00$ & 0 & $0.00 \mathrm{E}+00$ & 0 & 4. $95 E-13$ & 0 \\
\hline-232 & $6.39 E-13$ & 0 & $0.00 E+00$ & 0 & $0.00 E+00$ & 0 & $0.00 \mathrm{E}+00$ & 0 & $0.00 \mathrm{E}+00$ & 0 & $0.00 E+00$ & 0 & $0.00 \mathrm{E}+00$ & 0 & $6.39 E-13$ & 0 \\
\hline 34 & $1.85 \mathrm{E}-15$ & 0 & $0.00 \mathrm{E}+00$ & 0 & $0.00 \mathrm{E}+00$ & 0 & $0.00 \mathrm{E}+00$ & 0 & $0.00 \mathrm{E}+00$ & 0 & $0.00 \mathrm{E}+00$ & 0 & $0.00 \mathrm{E}+00$ & 0 & $1.85 \mathrm{E}-15$ & 0 \\
\hline 35 & 1. $94 \mathrm{E}-18$ & 0 & $0.00 \mathrm{E}+00$ & 0 & $0.00 \mathrm{E}+00$ & 0 & $0.00 \mathrm{E}+00$ & 0 & $0.00 \mathrm{E}+00$ & 0 & $0.00 \mathrm{E}+00$ & 0 & $0.00 \mathrm{E}+00$ & 0 & $1.94 \mathrm{E}-18$ & 0 \\
\hline 38 & $5.45 E-15$ & 0 & $0.00 E+00$ & 0 & $0.00 \mathrm{E}+00$ & 0 & $0.00 \mathrm{E}+00$ & 0 & $0.00 \mathrm{E}+00$ & 0 & $0.00 E+00$ & 0 & $0.00 \mathrm{E}+00$ & 0 & $5.45 E-15$ & 0 \\
\hline & $1.14 \mathrm{E}-12$ & 0 & $0.00 \mathrm{E}+00$ & 0 & $0.00 \mathrm{E}+00$ & 0 & $0.00 \mathrm{E}+00$ & 0 & $0.00 \mathrm{E}+00$ & 0 & $0.00 \mathrm{E}+00$ & 0 & $0.00 \mathrm{E}+00$ & 0 & $9.91 \mathrm{E}-01$ & 100 \\
\hline
\end{tabular}

* Sum of dose from all releases and from primary contamination. 
RESRAD-OFFSITE, Version 2 .

arent Dose Report

Title : Offsite Resident Farmer Deterministic Run

File : RF DOE SG FWD-FV2-1050y.ROF

Total Dose Contributions TDOSE (i,p,t) for Individual Radionuclides (i) and Pathways (p) in mrem/yr and as a Percentage of Total Dose at $t=1026$ years

From releases to ground water and to surface water

\begin{tabular}{|c|c|c|c|c|c|c|c|c|c|c|c|c|c|c|c|c|}
\hline & \multicolumn{2}{|c|}{ Ground } & \multicolumn{2}{|l|}{ Fish } & \multicolumn{2}{|l|}{ Radon } & \multicolumn{2}{|c|}{ Plant } & \multicolumn{2}{|l|}{ Meat } & \multicolumn{2}{|l|}{ Milk } & \multicolumn{2}{|l|}{ Soil } & \multicolumn{2}{|c|}{ Water } \\
\hline clide & Dose & \% & Dose & $\%$ & Dose & 음 & Dose & 음 & Dose & \% & Dose & \% & Dose & 응 & Dose & $\%$ \\
\hline-241 & $0.00 \mathrm{E}+00$ & 0 & $0.00 \mathrm{E}+00$ & 0 & $0.00 \mathrm{E}+00$ & 0 & $0.00 \mathrm{E}+00$ & 0 & $0.00 \mathrm{E}+00$ & 0 & $0.00 \mathrm{E}+00$ & 0 & $0.00 \mathrm{E}+00$ & 0 & $0.00 \mathrm{E}+00$ & 0 \\
\hline-137 & $0.00 \mathrm{E}+00$ & 0 & $0.00 \mathrm{E}+00$ & 0 & $0.00 \mathrm{E}+00$ & 0 & $0.00 \mathrm{E}+00$ & 0 & $0.00 \mathrm{E}+00$ & 0 & $0.00 \mathrm{E}+00$ & 0 & $0.00 \mathrm{E}+00$ & 0 & $0.00 \mathrm{E}+00$ & 0 \\
\hline-237 & $0.00 \mathrm{E}+00$ & 0 & $0.00 \mathrm{E}+00$ & 0 & $0.00 \mathrm{E}+00$ & 0 & $0.00 \mathrm{E}+00$ & 0 & $0.00 \mathrm{E}+00$ & 0 & $0.00 \mathrm{E}+00$ & 0 & $0.00 \mathrm{E}+00$ & 0 & $0.00 \mathrm{E}+00$ & 0 \\
\hline-238 & $0.00 \mathrm{E}+00$ & 0 & $0.00 \mathrm{E}+00$ & 0 & $0.00 \mathrm{E}+00$ & 0 & $0.00 \mathrm{E}+00$ & 0 & $0.00 \mathrm{E}+00$ & 0 & $0.00 \mathrm{E}+00$ & 0 & $0.00 \mathrm{E}+00$ & 0 & $0.00 \mathrm{E}+00$ & 0 \\
\hline-239 & $0.00 \mathrm{E}+00$ & 0 & $0.00 \mathrm{E}+00$ & 0 & $0.00 \mathrm{E}+00$ & 0 & $0.00 \mathrm{E}+00$ & 0 & $0.00 \mathrm{E}+00$ & 0 & $0.00 \mathrm{E}+00$ & 0 & $0.00 \mathrm{E}+00$ & 0 & $0.00 \mathrm{E}+00$ & 0 \\
\hline-240 & $0.00 \mathrm{E}+00$ & 0 & $0.00 \mathrm{E}+00$ & 0 & $0.00 \mathrm{E}+00$ & 0 & $0.00 \mathrm{E}+00$ & 0 & $0.00 \mathrm{E}+00$ & 0 & $0.00 \mathrm{E}+00$ & 0 & $0.00 \mathrm{E}+00$ & 0 & $0.00 \mathrm{E}+00$ & 0 \\
\hline-99 & $1.31 \mathrm{E}-06$ & 0 & $0.00 \mathrm{E}+00$ & 0 & $0.00 \mathrm{E}+00$ & 0 & $3.60 \mathrm{E}-01$ & 25 & $1.08 \mathrm{E}-03$ & 0 & $9.52 \mathrm{E}-02$ & 7 & $1.11 \mathrm{E}-06$ & 0 & $9.80 \mathrm{E}-01$ & 68 \\
\hline-228 & $0.00 \mathrm{E}+00$ & 0 & $0.00 \mathrm{E}+00$ & 0 & $0.00 \mathrm{E}+00$ & 0 & $0.00 \mathrm{E}+00$ & 0 & $0.00 \mathrm{E}+00$ & 0 & $0.00 \mathrm{E}+00$ & 0 & $0.00 \mathrm{E}+00$ & 0 & $0.00 \mathrm{E}+00$ & 0 \\
\hline-230 & $0.00 \mathrm{E}+00$ & 0 & $0.00 \mathrm{E}+00$ & 0 & $0.00 \mathrm{E}+00$ & 0 & $0.00 \mathrm{E}+00$ & 0 & $0.00 \mathrm{E}+00$ & 0 & $0.00 \mathrm{E}+00$ & 0 & $0.00 \mathrm{E}+00$ & 0 & $0.00 \mathrm{E}+00$ & 0 \\
\hline-232 & $0.00 E+00$ & 0 & $0.00 \mathrm{E}+00$ & 0 & $0.00 \mathrm{E}+00$ & 0 & $0.00 \mathrm{E}+00$ & 0 & $0.00 \mathrm{E}+00$ & 0 & $0.00 \mathrm{E}+00$ & 0 & $0.00 \mathrm{E}+00$ & 0 & $0.00 \mathrm{E}+00$ & 0 \\
\hline 234 & $0.00 \mathrm{E}+00$ & 0 & $0.00 \mathrm{E}+00$ & 0 & $0.00 \mathrm{E}+00$ & 0 & $0.00 \mathrm{E}+00$ & 0 & $0.00 \mathrm{E}+00$ & 0 & $0.00 \mathrm{E}+00$ & 0 & $0.00 \mathrm{E}+00$ & 0 & $0.00 \mathrm{E}+00$ & 0 \\
\hline 235 & $0.00 \mathrm{E}+00$ & 0 & $0.00 \mathrm{E}+00$ & 0 & $0.00 \mathrm{E}+00$ & 0 & $0.00 \mathrm{E}+00$ & 0 & $0.00 \mathrm{E}+00$ & 0 & $0.00 \mathrm{E}+00$ & 0 & $0.00 \mathrm{E}+00$ & 0 & $0.00 \mathrm{E}+00$ & 0 \\
\hline 238 & $0.00 \mathrm{E}+00$ & 0 & $0.00 \mathrm{E}+00$ & 0 & $0.00 \mathrm{E}+00$ & 0 & $0.00 \mathrm{E}+00$ & 0 & $0.00 \mathrm{E}+00$ & 0 & $0.00 \mathrm{E}+00$ & 0 & $0.00 \mathrm{E}+00$ & 0 & $0.00 \mathrm{E}+00$ & 0 \\
\hline & $1.31 \mathrm{E}-06$ & 0 & $0.00 \mathrm{E}+00$ & 0 & $0.00 \mathrm{E}+00$ & 0 & $3.60 \mathrm{E}-01$ & 25 & $1.08 \mathrm{E}-03$ & 0 & $9.52 \mathrm{E}-02$ & 7 & $1.11 \mathrm{E}-06$ & 0 & $9.80 \mathrm{E}-01$ & 68 \\
\hline
\end{tabular}

Total Dose Contributions TDOSE (i,p,t) for Individual Radionuclides (i) and Pathways (p)

in mrem/yr and as a Percentage of Total Dose at $t=1026$ years

Directly from primary contamination and from release to atmosphere (Inhalation excludes radon)

\begin{tabular}{|c|c|c|c|c|c|c|c|c|c|c|c|c|c|c|c|c|}
\hline & \multicolumn{2}{|c|}{ Ground } & \multicolumn{2}{|c|}{ Inhalation } & \multicolumn{2}{|c|}{ Radon } & \multicolumn{2}{|c|}{ Plant } & \multicolumn{2}{|l|}{ Meat } & \multicolumn{2}{|l|}{ Milk } & \multicolumn{2}{|l|}{ Soil } & \multicolumn{2}{|c|}{ All Pathways* } \\
\hline clide & Dose & $\%$ & Dose & $\%$ & Dose & $\%$ & Dose & 음 & Dose & $\%$ & Dose & $\%$ & Dose & \% & Dose & $\%$ \\
\hline-241 & $8.57 E-19$ & 0 & $0.00 \mathrm{E}+00$ & 0 & $0.00 \mathrm{E}+00$ & 0 & $0.00 \mathrm{E}+00$ & 0 & $0.00 \mathrm{E}+00$ & 0 & $0.00 E+00$ & 0 & $0.00 E+00$ & 0 & $8.57 E-19$ & 0 \\
\hline-137 & $2.09 E-23$ & 0 & $0.00 \mathrm{E}+00$ & 0 & $0.00 \mathrm{E}+00$ & 0 & $0.00 \mathrm{E}+00$ & 0 & $0.00 \mathrm{E}+00$ & 0 & $0.00 \mathrm{E}+00$ & 0 & $0.00 \mathrm{E}+00$ & 0 & $2.09 E-23$ & 0 \\
\hline-237 & $8.15 \mathrm{E}-16$ & 0 & $0.00 \mathrm{E}+00$ & 0 & $0.00 \mathrm{E}+00$ & 0 & $0.00 \mathrm{E}+00$ & 0 & $0.00 \mathrm{E}+00$ & 0 & $0.00 \mathrm{E}+00$ & 0 & $0.00 \mathrm{E}+00$ & 0 & $8.15 E-16$ & 0 \\
\hline-238 & 1. $43 \mathrm{E}-17$ & 0 & $0.00 \mathrm{E}+00$ & 0 & $0.00 \mathrm{E}+00$ & 0 & $0.00 \mathrm{E}+00$ & 0 & $0.00 \mathrm{E}+00$ & 0 & $0.00 \mathrm{E}+00$ & 0 & $0.00 \mathrm{E}+00$ & 0 & $1.43 \mathrm{E}-17$ & 0 \\
\hline-239 & $2.09 \mathrm{E}-19$ & 0 & $0.00 \mathrm{E}+00$ & 0 & $0.00 \mathrm{E}+00$ & 0 & $0.00 \mathrm{E}+00$ & 0 & $0.00 \mathrm{E}+00$ & 0 & $0.00 \mathrm{E}+00$ & 0 & $0.00 \mathrm{E}+00$ & 0 & $2.09 \mathrm{E}-19$ & 0 \\
\hline-240 & $8.10 \mathrm{E}-23$ & 0 & $0.00 \mathrm{E}+00$ & 0 & $0.00 \mathrm{E}+00$ & 0 & $0.00 \mathrm{E}+00$ & 0 & $0.00 \mathrm{E}+00$ & 0 & $0.00 \mathrm{E}+00$ & 0 & $0.00 \mathrm{E}+00$ & 0 & $8.10 \mathrm{E}-23$ & 0 \\
\hline-99 & $6.10 \mathrm{E}-27$ & 0 & $0.00 \mathrm{E}+00$ & 0 & $0.00 \mathrm{E}+00$ & 0 & $0.00 \mathrm{E}+00$ & 0 & $0.00 \mathrm{E}+00$ & 0 & $0.00 \mathrm{E}+00$ & 0 & $0.00 \mathrm{E}+00$ & 0 & $1.44 \mathrm{E}+00$ & 100 \\
\hline-228 & $0.00 \mathrm{E}+00$ & 0 & $0.00 \mathrm{E}+00$ & 0 & $0.00 \mathrm{E}+00$ & 0 & $0.00 \mathrm{E}+00$ & 0 & $0.00 \mathrm{E}+00$ & 0 & $0.00 \mathrm{E}+00$ & 0 & $0.00 \mathrm{E}+00$ & 0 & $0.00 \mathrm{E}+00$ & 0 \\
\hline-230 & $2.59 \mathrm{E}-11$ & 0 & $0.00 \mathrm{E}+00$ & 0 & $0.00 \mathrm{E}+00$ & 0 & $0.00 \mathrm{E}+00$ & 0 & $0.00 \mathrm{E}+00$ & 0 & $0.00 \mathrm{E}+00$ & 0 & $0.00 \mathrm{E}+00$ & 0 & $2.59 \mathrm{E}-11$ & 0 \\
\hline-232 & $1.19 \mathrm{E}-11$ & 0 & $0.00 \mathrm{E}+00$ & 0 & $0.00 \mathrm{E}+00$ & 0 & $0.00 \mathrm{E}+00$ & 0 & $0.00 \mathrm{E}+00$ & 0 & $0.00 \mathrm{E}+00$ & 0 & $0.00 \mathrm{E}+00$ & 0 & 1. $19 \mathrm{E}-11$ & 0 \\
\hline 234 & $2.05 E-13$ & 0 & $0.00 \mathrm{E}+00$ & 0 & $0.00 \mathrm{E}+00$ & 0 & $0.00 \mathrm{E}+00$ & 0 & $0.00 \mathrm{E}+00$ & 0 & $0.00 \mathrm{E}+00$ & 0 & $0.00 \mathrm{E}+00$ & 0 & $2.05 E-13$ & 0 \\
\hline 235 & $3.32 \mathrm{E}-16$ & 0 & $0.00 \mathrm{E}+00$ & 0 & $0.00 \mathrm{E}+00$ & 0 & $0.00 \mathrm{E}+00$ & 0 & $0.00 \mathrm{E}+00$ & 0 & $0.00 \mathrm{E}+00$ & 0 & $0.00 \mathrm{E}+00$ & 0 & $3.32 \mathrm{E}-16$ & 0 \\
\hline 238 & $2.62 E-13$ & 0 & $0.00 \mathrm{E}+00$ & 0 & $0.00 \mathrm{E}+00$ & 0 & $0.00 \mathrm{E}+00$ & 0 & $0.00 \mathrm{E}+00$ & 0 & $0.00 \mathrm{E}+00$ & 0 & $0.00 \mathrm{E}+00$ & 0 & $2.62 \mathrm{E}-13$ & 0 \\
\hline$a_{1}$ & $3.82 \mathrm{E}-11$ & 0 & $0.00 \mathrm{E}+00$ & 0 & $0.00 \mathrm{E}+00$ & 0 & $0.00 \mathrm{E}+00$ & 0 & $0.00 \mathrm{E}+00$ & 0 & $0.00 \mathrm{E}+00$ & 0 & $0.00 \mathrm{E}+00$ & 0 & $1.44 \mathrm{E}+00$ & 100 \\
\hline
\end{tabular}

* Sum of dose from all releases and from primary contamination. 
RESRAD-OFFSITE, Version 2.

Parent Dose Report

Title : Offsite Resident Farmer Deterministic Run File : RF DOE SG FWD-FV2-1050y.ROF

Dose/Source Ratios Summed Over All Pathways

Parent and Progeny Principal Radionuclide Contributions Indicated

Parent Product Thread DSR $(j, \mathrm{t}) \quad(\mathrm{mrem} / \mathrm{yr}) /(\mathrm{pCi} / \mathrm{g})$

(i)

Am-241

Am-241

Am-241

Am-241

Am-241

Cs $-137+\mathrm{D}$

$\mathrm{Np}-237+\mathrm{D}$

$\mathrm{Np}-237+\mathrm{D}$

$\mathrm{Np}-237+\mathrm{D}$

Np-237

Pu-238

$\mathrm{Pu}-238$

$\mathrm{Pu}-238$

$\mathrm{Pu}-238$

$\mathrm{Pu}-238$

$\mathrm{Pu}-238$

$\mathrm{Pu}-238$

$\mathrm{Pu}-239$

$\mathrm{Pu}-239$

$\mathrm{Pu}-239$

$\mathrm{Pu}-239$

$\mathrm{Pu}-239$

$\mathrm{Pu}-24 \mathrm{C}$

$\mathrm{Pu}-240$

$\mathrm{Pu}-240$

$\mathrm{Pu}-240$

$\mathrm{Pu}-240$

$\mathrm{Pu}-240$

$\mathrm{Pu}-24 \mathrm{C}$

TC-9s

Th-228+D (j) Fraction

$\begin{array}{ll}\mathrm{Am}-241 & 1.000 \mathrm{E}+00 \\ \mathrm{~Np}-237+\mathrm{D} & 1.000 \mathrm{E}+00 \\ \mathrm{U}-233 & 1.000 \mathrm{E}+00 \\ \operatorname{Th}-229+\mathrm{D} & 1.000 \mathrm{E}+00 \\ \operatorname{\sum DSR}(j) & \end{array}$

Cs-137+D

$\mathrm{Np}-237+\mathrm{D}$

$\mathrm{U}-233$

Th-229+D

$\sum \operatorname{DSR}(j)$

$\mathrm{Pu}-238$

$\mathrm{Pu}-238$

$\mathrm{U}-234$

Th -230

Ra-226+D

$\mathrm{Pb}-210+\mathrm{D}$

$\sum \operatorname{DSR}(j)$

$\mathrm{Pu}-239$

U-235+D

$\mathrm{Pa}-231$

$A C-227+D$

$\operatorname{\sum DSR}(j)$

$\mathrm{Pu}-240$

$\mathrm{Pu}-240$

$\mathrm{U}-236$

Th-232

$\mathrm{Ra}-228+\mathrm{D}$

Th-228+D

$\sum \operatorname{DSR}(j)$

TC-99

$\mathrm{Th}-228+\mathrm{D}$

1. $000 \mathrm{E}+00$

$1.000 \mathrm{E}+00$

$1.000 \mathrm{E}+00$

$1.000 \mathrm{E}+00$
$0.000 \mathrm{E}+00 \quad 1.000 \mathrm{E}+00 \quad 5.000 \mathrm{E}+01 \quad 1.000 \mathrm{E}+02 \quad 5.000 \mathrm{E}+02 \quad 1.026 \mathrm{E}+03$

$\begin{array}{llllll}1.173 \mathrm{E}-41 & 1.202 \mathrm{E}-41 & 3.983 \mathrm{E}-41 & 1.352 \mathrm{E}-40 & 2.391 \mathrm{E}-36 & 9.208 \mathrm{E}-31\end{array}$

$\begin{array}{llllll}9.379 \mathrm{E}-28 & 2.835 \mathrm{E}-27 & 1.490 \mathrm{E}-25 & 4.678 \mathrm{E}-25 & 9.095 \mathrm{E}-23 & 2.417 \mathrm{E}-20\end{array}$

$2.412 \mathrm{E}-38 \quad 1.539 \mathrm{E}-37 \quad 2.808 \mathrm{E}-34 \quad 1.927 \mathrm{E}-33 \quad 3.932 \mathrm{E}-30 \quad 5.618 \mathrm{E}-27$

$\begin{array}{llllll}1.854 \mathrm{E}-34 & 2.341 \mathrm{E}-33 & 1.009 \mathrm{E}-28 & 1.073 \mathrm{E}-27 & 1.480 \mathrm{E}-24 & 3.195 \mathrm{E}-22\end{array}$ $\begin{array}{llllll}9.379 \mathrm{E}-28 & 2.835 \mathrm{E}-27 & 1.491 \mathrm{E}-25 & 4.689 \mathrm{E}-25 & 9.243 \mathrm{E}-23 & 2.449 \mathrm{E}-20\end{array}$

$\begin{array}{llllll}.649 \mathrm{E}-18 & 7.532 \mathrm{E}-18 & 3.550 \mathrm{E}-18 & 1.647 \mathrm{E}-18 & 3.543 \mathrm{E}-21 & 1.101 \mathrm{E}-24\end{array}$

$2.038 \mathrm{E}-27 \quad 1.295 \mathrm{E}-26 \quad 1.887 \mathrm{E}-23 \quad 1.028 \mathrm{E}-22 \quad 3.287 \mathrm{E}-20 \quad 4.103 \mathrm{E}-18$

$\begin{array}{llllll}5.780 \mathrm{E}-21 & 5.837 \mathrm{E}-21 & 9.485 \mathrm{E}-21 & 1.561 \mathrm{E}-20 & 8.354 \mathrm{E}-19 & 1.481 \mathrm{E}-16\end{array}$

$\begin{array}{lllllll}1.840 \mathrm{E}-09 & 1.310 \mathrm{E}-41 & 1.321 \mathrm{E}-41 & 1.990 \mathrm{E}-41 & 3.022 \mathrm{E}-41 & 8.560 \mathrm{E}-40 & 6.951 \mathrm{E}-38\end{array}$

$1.000 \mathrm{E}+00 \quad 7.119 \mathrm{E}-33 \quad 7.179 \mathrm{E}-33 \quad 1.081 \mathrm{E}-32 \quad 1.642 \mathrm{E}-32 \quad 4.652 \mathrm{E}-31 \quad 3.778 \mathrm{E}-29$

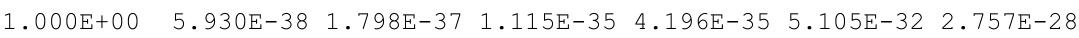

$1.000 \mathrm{E}+00 \quad 7.074 \mathrm{E}-42 \quad 4.520 \mathrm{E}-41 \quad 9.070 \mathrm{E}-38 \quad 6.913 \mathrm{E}-37 \quad 4.079 \mathrm{E}-33 \quad 3.348 \mathrm{E}-29$

$\begin{array}{lllllll}1.000 \mathrm{E}+00 & 6.200 \mathrm{E}-31 & 7.815 \mathrm{E}-30 & 3.107 \mathrm{E}-25 & 3.056 \mathrm{E}-24 & 2.593 \mathrm{E}-21 & 3.654 \mathrm{E}-19\end{array}$

$2.070 \mathrm{E}-39 \quad 4.917 \mathrm{E}-38 \quad 4.570 \mathrm{E}-32 \quad 7.489 \mathrm{E}-31 \quad 1.633 \mathrm{E}-27 \quad 4.208 \mathrm{E}-25$

$\begin{array}{llllll}6.271 E-31 & 7.822 E-30 & 3.107 E-25 & 3.056 E-24 & 2.593 E-21 & 3.654 E-19\end{array}$

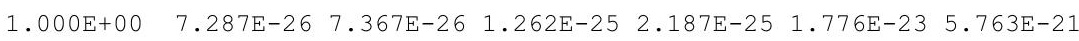

$\begin{array}{lllllll}1.000 \mathrm{E}+00 & 3.721 \mathrm{E}-32 & 1.127 \mathrm{E}-31 & 6.617 \mathrm{E}-30 & 2.325 \mathrm{E}-29 & 1.094 \mathrm{E}-26 & 8.874 \mathrm{E}-24\end{array}$

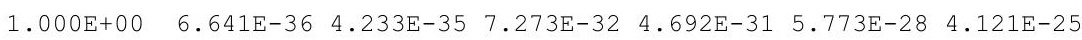

$\begin{array}{llllll}1.768 \mathrm{E}-35 & 2.220 \mathrm{E}-34 & 7.476 \mathrm{E}-30 & 6.622 \mathrm{E}-29 & 6.350 \mathrm{E}-26 & 2.019 \mathrm{E}-23\end{array}$

$\begin{array}{llllll}7.287 \mathrm{E}-26 & 7.367 \mathrm{E}-26 & 1.263 \mathrm{E}-25 & 2.188 \mathrm{E}-25 & 1.784 \mathrm{E}-23 & 5.792 \mathrm{E}-21\end{array}$

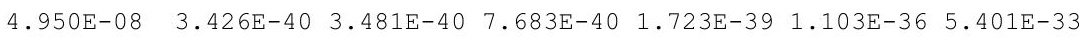

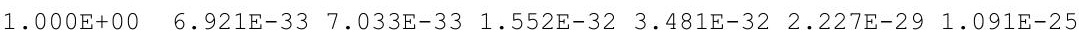

$\begin{array}{lllllll}1.000 \mathrm{E}+00 & 1.312 \mathrm{E}-40 & 3.990 \mathrm{E}-40 & 3.012 \mathrm{E}-38 & 1.369 \mathrm{E}-37 & 5.033 \mathrm{E}-34 & 6.106 \mathrm{E}-30\end{array}$

$\begin{array}{lllllll}1.000 \mathrm{E}+00 & 0.000 \mathrm{E}+00 & 0.000 \mathrm{E}+00 & 0.000 \mathrm{E}+00 & 0.000 \mathrm{E}+00 & 6.526 \mathrm{E}-42 & 2.161 \mathrm{E}-37\end{array}$

$\begin{array}{llllllll}1.000 \mathrm{E}+00 & 1.056 \mathrm{E}-36 & 1.302 \mathrm{E}-35 & 2.214 \mathrm{E}-31 & 1.452 \mathrm{E}-30 & 6.617 \mathrm{E}-28 & 1.096 \mathrm{E}-25\end{array}$

$\begin{array}{llllllll}1.000 \mathrm{E}+00 & 7.082 \mathrm{E}-36 & 1.578 \mathrm{E}-34 & 1.564 \mathrm{E}-29 & 1.017 \mathrm{E}-28 & 2.672 \mathrm{E}-26 & 2.030 \mathrm{E}-24\end{array}$

$\begin{array}{llllll}6.929 \mathrm{E}-33 & 7.204 \mathrm{E}-33 & 1.588 \mathrm{E}-29 & 1.032 \mathrm{E}-28 & 2.740 \mathrm{E}-26 & 2.249 \mathrm{E}-24\end{array}$

$\begin{array}{lllllll}1.000 E+00 & 3.496 \mathrm{E}-34 & 3.539 \mathrm{E}-34 & 6.498 \mathrm{E}-34 & 1.208 \mathrm{E}-33 & 1.906 \mathrm{E}-02 & 2.761 \mathrm{E}-02\end{array}$

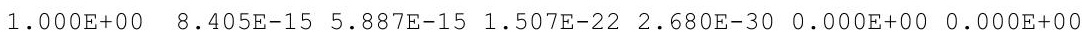


RESRAD-OFFSITE, Version 2.5

Parent Dose Report

Title : Offsite Resident Farmer Deterministic Run File : RF DOE SG FWD-FV2-1050y.ROF

Dose/Source Ratios Summed Over All Pathways

Parent and Progeny Principal Radionuclide Contributions Indicated

\begin{tabular}{|c|c|c|c|c|c|c|c|c|}
\hline Parent & Product & Thread & & $\operatorname{DSR}(j$, & t) $\quad(\mathrm{mrem} / \mathrm{y}$ & $/(\mathrm{pCi} / \mathrm{g})$ & & \\
\hline (i) & $(j)$ & Fraction & $0.000 \mathrm{E}+00$ & $1.000 \mathrm{E}+00$ & $5.000 \mathrm{E}+01$ & $1.000 \mathrm{E}+02$ & $5.000 \mathrm{E}+02$ & $1.026 \mathrm{E}+03$ \\
\hline-230 & $T h-230$ & $1.000 \mathrm{E}+00$ & $1.462 \mathrm{E}-30$ & $1.485 \mathrm{E}-30$ & $3.170 \mathrm{E}-30$ & $6.873 E-30$ & $3.359 \mathrm{E}-27$ & $1.154 \mathrm{E}-23$ \\
\hline-230 & $\mathrm{Ra}-226+\mathrm{D}$ & $1.000 \mathrm{E}+00$ & $2.288 E-19$ & $6.901 E-19$ & $3.138 \mathrm{E}-17$ & $8.491 \mathrm{E}-17$ & $4.948 E-15$ & $2.589 \mathrm{E}-13$ \\
\hline-230 & $\mathrm{~Pb}-210+\mathrm{D}$ & $1.000 \mathrm{E}+00$ & $1.250 \mathrm{E}-27$ & $7.883 \mathrm{E}-27$ & $7.635 \mathrm{E}-24$ & $3.029 \mathrm{E}-23$ & 3. $412 \mathrm{E}-21$ & $3.104 \mathrm{E}-19$ \\
\hline-230 & $\sum \operatorname{DSR}(j)$ & & $2.288 E-19$ & $6.901 \mathrm{E}-19$ & $3.138 \mathrm{E}-17$ & $8.491 \mathrm{E}-17$ & $4.948 E-15$ & $2.589 \mathrm{E}-13$ \\
\hline-232 & Th-232 & $1.000 \mathrm{E}+00$ & $7.064 \mathrm{E}-33$ & $7.186 \mathrm{E}-33$ & 1. $661 \mathrm{E}-32$ & $3.904 \mathrm{E}-32$ & 3. $643 \mathrm{E}-29$ & $2.931 \mathrm{E}-25$ \\
\hline-232 & $\mathrm{Ra}-228+\mathrm{D}$ & $1.000 \mathrm{E}+00$ & $6.681 \mathrm{E}-18$ & 1.919E-17 & $1.638 \mathrm{E}-16$ & $2.329 \mathrm{E}-16$ & $3.817 \mathrm{E}-15$ & 1. $510 \mathrm{E}-13$ \\
\hline-232 & $\mathrm{Th}-228+\mathrm{D}$ & $1.000 \mathrm{E}+00$ & $7.238 \mathrm{E}-17$ & $4.048 \mathrm{E}-16$ & $1.310 \mathrm{E}-14$ & $1.731 \mathrm{E}-14$ & $1.558 \mathrm{E}-13$ & $2.813 \mathrm{E}-12$ \\
\hline-232 & $\sum \operatorname{DSR}(j)$ & & $7.906 \mathrm{E}-17$ & $4.240 \mathrm{E}-16$ & $1.327 \mathrm{E}-14$ & $1.754 \mathrm{E}-14$ & $1.597 \mathrm{E}-13$ & $2.964 \mathrm{E}-12$ \\
\hline 234 & $\mathrm{U}-234$ & $1.000 \mathrm{E}+00$ & $4.179 E-32$ & $4.247 E-32$ & $9.442 \mathrm{E}-32$ & $2.133 E-31$ & 1. $449 \mathrm{E}-28$ & $7.680 \mathrm{E}-25$ \\
\hline-234 & $T h-230$ & $1.000 \mathrm{E}+00$ & $6.605 E-36$ & $2.007 E-35$ & $1.441 E-33$ & $6.216 E-33$ & $1.511 \mathrm{E}-29$ & $1.064 \mathrm{E}-25$ \\
\hline-234 & $\mathrm{Ra}-226+\mathrm{D}$ & $1.000 \mathrm{E}+00$ & $7.794 \mathrm{E}-25$ & $4.953 E-24$ & $7.158 \mathrm{E}-21$ & $3.868 \mathrm{E}-20$ & $1.154 \mathrm{E}-17$ & $1.282 \mathrm{E}-15$ \\
\hline-234 & $\mathrm{~Pb}-210+\mathrm{D}$ & $1.000 \mathrm{E}+00$ & $3.169 E-33$ & $3.978 E-32$ & $1.294 \mathrm{E}-27$ & $1.103 E-26$ & $7.464 \mathrm{E}-24$ & $1.487 \mathrm{E}-21$ \\
\hline-234 & $\sum \operatorname{DSR}(j)$ & & $7.794 E-25$ & $4.953 E-24$ & $7.158 \mathrm{E}-21$ & $3.868 E-20$ & $1.154 \mathrm{E}-17$ & $1.282 \mathrm{E}-15$ \\
\hline$-235+D$ & $\mathrm{U}-235+\mathrm{D}$ & $1.000 \mathrm{E}+00$ & $7.535 E-23$ & 7. $622 \mathrm{E}-23$ & $1.331 \mathrm{E}-22$ & $2.352 E-22$ & $2.233 E-20$ & $8.893 \mathrm{E}-18$ \\
\hline$-235+D$ & $\mathrm{~Pa}-231$ & $1.000 \mathrm{E}+00$ & 1. $782 \mathrm{E}-26$ & $5.389 \mathrm{E}-26$ & $2.925 E-24$ & $9.486 \mathrm{E}-24$ & 2. $349 \mathrm{E}-21$ & $8.198 \mathrm{E}-19$ \\
\hline$-235+D$ & $A c-227+D$ & $1.000 \mathrm{E}+00$ & $6.374 \mathrm{E}-26$ & $4.021 E-25$ & $4.032 E-22$ & $1.667 \mathrm{E}-21$ & $2.744 \mathrm{E}-19$ & $4.140 \mathrm{E}-17$ \\
\hline-235 & $\sum \operatorname{DSR}(j)$ & & $7.544 \mathrm{E}-23$ & 7. $667 \mathrm{E}-23$ & $5.393 E-22$ & $1.912 \mathrm{E}-21$ & $2.991 \mathrm{E}-19$ & $5.111 \mathrm{E}-17$ \\
\hline-238 & $\mathrm{U}-238$ & $5.400 \mathrm{E}-05$ & $0.000 \mathrm{E}+00$ & $0.000 \mathrm{E}+00$ & $0.000 \mathrm{E}+00$ & $0.000 \mathrm{E}+00$ & $0.000 \mathrm{E}+00$ & $0.000 \mathrm{E}+00$ \\
\hline$-238+D$ & $\mathrm{U}-238+\mathrm{D}$ & $9.999 \mathrm{E}-01$ & $8.606 \mathrm{E}-19$ & $8.669 \mathrm{E}-19$ & 1. $243 \mathrm{E}-18$ & $1.796 \mathrm{E}-18$ & $3.408 E-17$ & $1.635 E-15$ \\
\hline$-238+D$ & $U-234$ & $9.999 \mathrm{E}-01$ & $5.948 E-38$ & $1.809 E-37$ & $1.352 E-35$ & $6.079 E-35$ & $2.058 E-31$ & $2.238 E-27$ \\
\hline$-238+D$ & $\mathrm{Th}-230$ & $9.999 \mathrm{E}-01$ & $7.089 E-42$ & $4.540 \mathrm{E}-41$ & $1.031 \mathrm{E}-37$ & $8.855 E-37$ & $1.072 \mathrm{E}-32$ & $1.548 \mathrm{E}-28$ \\
\hline$-238+D$ & $\mathrm{Ra}-226+\mathrm{D}$ & $9.999 \mathrm{E}-01$ & $5.589 E-31$ & $7.732 \mathrm{E}-30$ & $3.423 E-25$ & $3.687 \mathrm{E}-24$ & $5.554 \mathrm{E}-21$ & 1. $288 \mathrm{E}-18$ \\
\hline$-238+D$ & $\mathrm{~Pb}-210+\mathrm{D}$ & $9.999 \mathrm{E}-01$ & $7.472 E-39$ & $3.324 E-38$ & $4.957 E-32$ & $8.813 E-31$ & $3.387 E-27$ & 1. $449 E-24$ \\
\hline-238 & $\sum \operatorname{DSR}(j)$ & & $8.606 \mathrm{E}-19$ & $8.669 \mathrm{E}-19$ & $1.243 \mathrm{E}-18$ & 1. $796 \mathrm{E}-18$ & $3.408 \mathrm{E}-17$ & $1.636 \mathrm{E}-15$ \\
\hline
\end{tabular}

The DSR includes contributions from associated (half-life $\leq 180$ days) daughters. 
RESRAD-OFFSITE, Version 2.5

Parent Dose Report

Title : Offsite Resident Farmer Deterministic Run

File : RF DOE SG FWD-FV2-1050y.ROF

Single Radionuclide Soil Guidelines G(i,t) in pCi/g

Basic Radiation Dose Limit $=1.000 \mathrm{E}+00 \mathrm{mrem} / \mathrm{yr}$

\begin{tabular}{|c|c|c|c|c|c|c|}
\hline (i) & $\mathrm{t}=0.000 \mathrm{E}+00$ & $1.000 \mathrm{E}+00$ & $5.000 \mathrm{E}+01$ & $1.000 \mathrm{E}+02$ & $5.000 \mathrm{E}+02$ & $1.026 \mathrm{E}+03$ \\
\hline-241 & $\star 3.431 E+12$ & $\star 3.431 \mathrm{E}+12$ & $\star 3.431 \mathrm{E}+12$ & $\star 3.431 \mathrm{E}+12$ & $\star 3.431 \mathrm{E}+12$ & $* 3.431 \mathrm{E}+12$ \\
\hline-137 & $\star 8.704 \mathrm{E}+13$ & $\star 8.704 \mathrm{E}+13$ & $\star 8.704 \mathrm{E}+13$ & $\star 8.704 \mathrm{E}+13$ & $\star 8.704 \mathrm{E}+13$ & $\star 8.704 \mathrm{E}+13$ \\
\hline-237 & $* 7.047 \mathrm{E}+08$ & $\star 7.047 \mathrm{E}+08$ & $\star 7.047 \mathrm{E}+08$ & $\star 7.047 \mathrm{E}+08$ & $\star 7.047 \mathrm{E}+08$ & $\star 7.047 \mathrm{E}+08$ \\
\hline$x-238$ & $\star 1.712 \mathrm{E}+13$ & $\star 1.712 \mathrm{E}+13$ & $* 1.712 \mathrm{E}+13$ & $\star 1.712 \mathrm{E}+13$ & $\star 1.712 \mathrm{E}+13$ & $\star 1.712 \mathrm{E}+13$ \\
\hline$u-239$ & $* 6.214 \mathrm{E}+10$ & $* 6.214 \mathrm{E}+10$ & $* 6.214 \mathrm{E}+10$ & $* 6.214 \mathrm{E}+10$ & $* 6.214 \mathrm{E}+10$ & $* 6.214 \mathrm{E}+10$ \\
\hline Pu-240 & $\star 2.278 \mathrm{E}+11$ & $\star 2.278 \mathrm{E}+11$ & $\star 2.278 \mathrm{E}+11$ & $\star 2.278 \mathrm{E}+11$ & $\star 2.278 \mathrm{E}+11$ & $\star 2.278 \mathrm{E}+11$ \\
\hline $\mathrm{TC}-99$ & $\star 1.697 \mathrm{E}+10$ & $\star 1.697 \mathrm{E}+10$ & $\star 1.697 \mathrm{E}+10$ & $\star 1.697 \mathrm{E}+10$ & $5.247 \mathrm{E}+01$ & $3.621 \mathrm{E}+01$ \\
\hline Th-228 & $1.190 \mathrm{E}+14$ & $1.699 \mathrm{E}+14$ & $\star 8.195 \mathrm{E}+14$ & $\star 8.195 \mathrm{E}+14$ & $* 8.195 \mathrm{E}+14$ & $\star 8.195 \mathrm{E}+14$ \\
\hline Th-230 & $\star 2.018 \mathrm{E}+10$ & $* 2.018 \mathrm{E}+10$ & $* 2.018 \mathrm{E}+10$ & $\star 2.018 \mathrm{E}+10$ & $* 2.018 \mathrm{E}+10$ & $* 2.018 \mathrm{E}+10$ \\
\hline-232 & $\star 1.097 \mathrm{E}+05$ & $\star 1.097 \mathrm{E}+05$ & $\star 1.097 \mathrm{E}+05$ & $\star 1.097 \mathrm{E}+05$ & $\star 1.097 \mathrm{E}+05$ & $\star 1.097 \mathrm{E}+05$ \\
\hline$J-234$ & $\star 6.247 \mathrm{E}+09$ & $\star 6.247 \mathrm{E}+09$ & $* 6.247 \mathrm{E}+09$ & $* 6.247 \mathrm{E}+09$ & $\star 6.247 \mathrm{E}+09$ & $* 6.247 \mathrm{E}+09$ \\
\hline 235 & $\star 2.161 \mathrm{E}+06$ & $\star 2.161 \mathrm{E}+06$ & $\star 2.161 \mathrm{E}+06$ & $\star 2.161 \mathrm{E}+06$ & $\star 2.161 \mathrm{E}+06$ & $\star 2.161 \mathrm{E}+06$ \\
\hline & $\star 3.361 \mathrm{E}+05$ & $\star 3.361 \mathrm{E}+05$ & $* 3.361 \mathrm{E}+05$ & $* 3.361 \mathrm{E}+05$ & $* 3.361 \mathrm{E}+05$ & $* 3.361 \mathrm{E}+05$ \\
\hline
\end{tabular}

*At specific activity limit

Summed Dose/Source Ratios DSR(i,t) in (mrem/yr)/(pCi/g)

and Single Radionuclide Soil Guidelines $G(i, t)$ in $\mathrm{pCi} / \mathrm{g}$

at $\operatorname{tmin}=$ time of minimum single radionuclide soil guideline

and at tmax $=$ time of maximum total dose $=772$ years

\begin{tabular}{|c|c|c|c|c|c|c|}
\hline $\begin{array}{l}\text { Tuclide } \\
\text { (i) }\end{array}$ & $\begin{array}{l}\text { Initial } \\
(\mathrm{pCi} / \mathrm{g})\end{array}$ & $\begin{array}{c}\text { tmin } \\
\text { (years) }\end{array}$ & $\operatorname{DSR}(i, \operatorname{tmin})$ & $\begin{array}{c}G(i, \operatorname{tmin}) \\
(\mathrm{pCi} / \mathrm{g})\end{array}$ & $\operatorname{DSR}(i, \operatorname{tmax})$ & $\begin{array}{c}G(i, t \max ) \\
(\mathrm{pCi} / \mathrm{g})\end{array}$ \\
\hline-241 & $3.500 \mathrm{E}+01$ & 1050 & $3.116 \mathrm{E}-20$ & $\star 3.431 \mathrm{E}+12$ & $1.747 \mathrm{E}-21$ & $\star 3.431 \mathrm{E}+12$ \\
\hline-137 & $1.900 \mathrm{E}+01$ & 0 & $7.649 \mathrm{E}-18$ & $\star 8.704 \mathrm{E}+13$ & $5.473 \mathrm{E}-23$ & $\star 8.704 \mathrm{E}+13$ \\
\hline 237 & $5.500 \mathrm{E}+00$ & 1050 & $1.866 \mathrm{E}-16$ & $\star 7.047 \mathrm{E}+08$ & $1.215 \mathrm{E}-17$ & $* 7.047 \mathrm{E}+08$ \\
\hline-238 & $3.900 \mathrm{E}+01$ & 1050 & $4.450 \mathrm{E}-19$ & $\star 1.712 \mathrm{E}+13$ & $3.924 \mathrm{E}-20$ & $\star 1.712 \mathrm{E}+13$ \\
\hline-239 & $3.600 E+01$ & 1050 & $7.500 \mathrm{E}-21$ & $\star 6.214 \mathrm{E}+10$ & $3.535 E-22$ & $\star 6.214 \mathrm{E}+10$ \\
\hline $\mathrm{Pu}-240$ & $3.600 \mathrm{E}+01$ & 1050 & $2.711 \mathrm{E}-24$ & $\star 2.278 \mathrm{E}+11$ & $2.966 \mathrm{E}-25$ & $\star 2.278 \mathrm{E}+11$ \\
\hline-99 & $5.200 \mathrm{E}+01$ & 772 & $3.593 \mathrm{E}-02$ & $2.783 E+01$ & $3.593 \mathrm{E}-02$ & $2.783 \mathrm{E}+01$ \\
\hline Th-228 & $4.000 \mathrm{E}+00$ & 0 & $8.405 \mathrm{E}-15$ & $1.190 \mathrm{E}+14$ & $0.000 \mathrm{E}+00$ & $\star 8.195 \mathrm{E}+14$ \\
\hline-230 & $1.000 \mathrm{E}+02$ & 1050 & $3.061 \mathrm{E}-13$ & $3.267 \mathrm{E}+12$ & $4.062 \mathrm{E}-14$ & $\star 2.018 \mathrm{E}+10$ \\
\hline-232 & $4.000 \mathrm{E}+00$ & 1050 & $3.379 \mathrm{E}-12$ & $* 1.097 \mathrm{E}+05$ & $7.193 \mathrm{E}-13$ & $\star 1.097 \mathrm{E}+05$ \\
\hline 234 & $1.600 \mathrm{E}+02$ & 1050 & $1.553 \mathrm{E}-15$ & $\star 6.247 \mathrm{E}+09$ & $1.488 \mathrm{E}-16$ & $* 6.247 \mathrm{E}+09$ \\
\hline 35 & $6.500 \mathrm{E}+00$ & 1050 & $6.404 \mathrm{E}-17$ & $\star 2.161 \mathrm{E}+06$ & $4.426 \mathrm{E}-18$ & $\star 2.161 \mathrm{E}+06$ \\
\hline 238 & $1.600 \mathrm{E}+02$ & 1050 & $1.945 \mathrm{E}-15$ & $\star 3.361 \mathrm{E}+05$ & $2.516 \mathrm{E}-16$ & $\star 3.361 \mathrm{E}+05$ \\
\hline
\end{tabular}

${ }^{*}$ At specific activity limit 
RESRAD-OFFSITE, Version 2.

Parent Dose Report

Title : Offsite Resident Farmer Deterministic Run

File : RF DOE SG FWD-FV2-1050y.ROF

Individual Nuclide Dose Summed Over All Pathways

Parent Nuclide and Thread Fraction Indicated

Nuclide Parent THF(i) DOSE $(j, t)$, mrem/yr

\begin{tabular}{|c|c|c|}
\hline (j) & (i) & \\
\hline$m-241$ & $A m-241$ & $1.000 \mathrm{E}+00$ \\
\hline-237 & $A m-241$ & $1.000 \mathrm{E}+00$ \\
\hline $\mathrm{Jp}-237$ & $\mathrm{~Np}-237$ & $1.000 \mathrm{E}+00$ \\
\hline-237 & $\sum$ DOSE & ): \\
\hline
\end{tabular}

$\mathrm{U}-233 \quad \mathrm{Am}-241 \quad 1.000 \mathrm{E}+00$

$\mathrm{U}-233 \quad \mathrm{~Np}-237 \quad 1.000 \mathrm{E}+00$

U-233 $\operatorname{DOSE}(j):$

Th-229 Am-241 $1.000 \mathrm{E}+00$

Th-229 Np-237 $1.000 \mathrm{E}+00$

Th-229 $\operatorname{DOSE}(j):$

Cs-137 Cs-137 1.000E+00

$\mathrm{Pu}-238$

$\mathrm{Pu}-238$

$\mathrm{Pu}-238$

$\mathrm{U}-234$

$\mathrm{U}-234$

$\mathrm{U}-234$

$\mathrm{U}-234$

Th -230

Th -230

Th -230

Th-230

Th-230

$\mathrm{Ra}-226$

$\mathrm{Ra}-226$

$\mathrm{Ra}-226$

$\mathrm{Ra}-226$

$\mathrm{Ra}-226$

$\mathrm{Pb}-210$

$\mathrm{Pb}-210$

$\mathrm{Pb}-210$

$\mathrm{Pb}-210$

$\mathrm{Pb}-210$

Pu-239 Pu-239 $1.000 E+00$ $t=0.000 \mathrm{E}+00 \quad 1.000 \mathrm{E}+00 \quad 5.000 \mathrm{E}+01 \quad 1.000 \mathrm{E}+02 \quad 5.000 \mathrm{E}+02 \quad 1.026 \mathrm{E}+03$

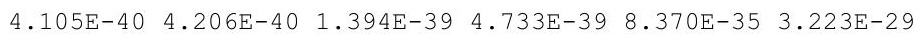

$3.283 \mathrm{E}-26 \quad 9.923 \mathrm{E}-26 \quad 5.216 \mathrm{E}-24 \quad 1.637 \mathrm{E}-23 \quad 3.183 \mathrm{E}-21 \quad 8.460 \mathrm{E}-19$

$3.179 \mathrm{E}-20 \quad 3.211 \mathrm{E}-20 \quad 5.207 \mathrm{E}-20 \quad 8.527 \mathrm{E}-20 \quad 4.414 \mathrm{E}-18 \quad 7.922 \mathrm{E}-16$

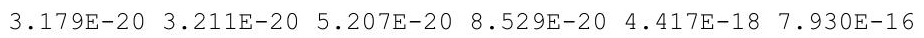

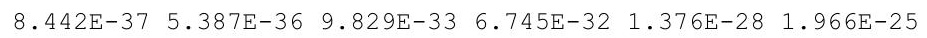

$\begin{array}{llllll}1.083 \mathrm{E}-30 & 3.280 \mathrm{E}-30 & 1.938 \mathrm{E}-28 & 6.856 \mathrm{E}-28 & 3.404 \mathrm{E}-25 & 2.967 \mathrm{E}-22\end{array}$

$\begin{array}{llllll}1.083 \mathrm{E}-30 & 3.280 \mathrm{E}-30 & 1.938 \mathrm{E}-28 & 6.857 \mathrm{E}-28 & 3.406 \mathrm{E}-25 & 2.969 \mathrm{E}-22\end{array}$

$6.490 \mathrm{E}-33 \quad 8.194 \mathrm{E}-32 \quad 3.532 \mathrm{E}-27 \quad 3.757 \mathrm{E}-26 \quad 5.180 \mathrm{E}-23 \quad 1.118 \mathrm{E}-20$

$\begin{array}{llllll}1.121 \mathrm{E}-26 & 7.124 \mathrm{E}-26 & 1.038 \mathrm{E}-22 & 5.653 \mathrm{E}-22 & 1.808 \mathrm{E}-19 & 2.257 \mathrm{E}-17\end{array}$

$\begin{array}{llllll}1.121 \mathrm{E}-26 & 7.124 \mathrm{E}-26 & 1.038 \mathrm{E}-22 & 5.654 \mathrm{E}-22 & 1.808 \mathrm{E}-19 & 2.258 \mathrm{E}-17\end{array}$

$\begin{array}{llllll}1.453 \mathrm{E}-16 & 1.431 \mathrm{E}-16 & 6.744 \mathrm{E}-17 & 3.130 \mathrm{E}-17 & 6.732 \mathrm{E}-20 & 2.092 \mathrm{E}-23\end{array}$

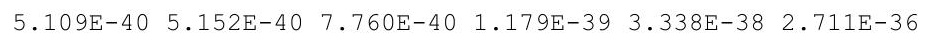

$\begin{array}{lllllll}2.777 \mathrm{E}-31 & 2.800 \mathrm{E}-31 & 4.217 \mathrm{E}-31 & 6.405 \mathrm{E}-31 & 1.814 \mathrm{E}-29 & 1.473 \mathrm{E}-27\end{array}$

$2.777 \mathrm{E}-31 \quad 2.800 \mathrm{E}-31 \quad 4.217 \mathrm{E}-31 \quad 6.405 \mathrm{E}-31 \quad 1.814 \mathrm{E}-29 \quad 1.473 \mathrm{E}-27$

$2.313 \mathrm{E}-36 \quad 7.011 \mathrm{E}-36 \quad 4.348 \mathrm{E}-34 \quad 1.636 \mathrm{E}-33 \quad 1.991 \mathrm{E}-30 \quad 1.075 \mathrm{E}-26$

$\begin{array}{llllll}6.686 \mathrm{E}-30 & 6.796 \mathrm{E}-30 & 1.511 \mathrm{E}-29 & 3.413 \mathrm{E}-29 & 2.319 \mathrm{E}-26 & 1.229 \mathrm{E}-22\end{array}$

$\begin{array}{llllll}9.516 \mathrm{E}-36 & 2.894 \mathrm{E}-35 & 2.163 \mathrm{E}-33 & 9.726 \mathrm{E}-33 & 3.292 \mathrm{E}-29 & 3.581 \mathrm{E}-25\end{array}$

$\begin{array}{llllll}6.686 \mathrm{E}-30 & 6.796 \mathrm{E}-30 & 1.511 \mathrm{E}-29 & 3.415 \mathrm{E}-29 & 2.322 \mathrm{E}-26 & 1.233 \mathrm{E}-22\end{array}$

$2.759 \mathrm{E}-40 \quad 1.763 \mathrm{E}-39 \quad 3.537 \mathrm{E}-36 \quad 2.696 \mathrm{E}-35 \quad 1.591 \mathrm{E}-31 \quad 1.306 \mathrm{E}-27$

$\begin{array}{llllll}1.462 \mathrm{E}-28 & 1.485 \mathrm{E}-28 & 3.170 \mathrm{E}-28 & 6.873 \mathrm{E}-28 & 3.359 \mathrm{E}-25 & 1.154 \mathrm{E}-21\end{array}$

$\begin{array}{lllllll}1.057 \mathrm{E}-33 & 3.212 \mathrm{E}-33 & 2.305 \mathrm{E}-31 & 9.946 \mathrm{E}-31 & 2.418 \mathrm{E}-27 & 1.702 \mathrm{E}-23\end{array}$

$\begin{array}{llllll}1.134 \mathrm{E}-39 & 7.264 \mathrm{E}-39 & 1.650 \mathrm{E}-35 & 1.417 \mathrm{E}-34 & 1.715 \mathrm{E}-30 & 2.476 \mathrm{E}-26\end{array}$

$\begin{array}{llllll}1.462 \mathrm{E}-28 & 1.485 \mathrm{E}-28 & 3.172 \mathrm{E}-28 & 6.883 \mathrm{E}-28 & 3.383 \mathrm{E}-25 & 1.171 \mathrm{E}-21\end{array}$

$2.418 \mathrm{E}-29 \quad 3.048 \mathrm{E}-28 \quad 1.212 \mathrm{E}-23 \quad 1.192 \mathrm{E}-22 \quad 1.011 \mathrm{E}-19 \quad 1.425 \mathrm{E}-17$

$\begin{array}{llllll}2.288 \mathrm{E}-17 & 6.901 \mathrm{E}-17 & 3.138 \mathrm{E}-15 & 8.491 \mathrm{E}-15 & 4.948 \mathrm{E}-13 & 2.589 \mathrm{E}-11\end{array}$

$\begin{array}{llllll}1.247 \mathrm{E}-22 & 7.925 \mathrm{E}-22 & 1.145 \mathrm{E}-18 & 6.189 \mathrm{E}-18 & 1.846 \mathrm{E}-15 & 2.051 \mathrm{E}-13\end{array}$

$\begin{array}{llllll}8.942 \mathrm{E}-29 & 1.237 \mathrm{E}-27 & 5.476 \mathrm{E}-23 & 5.899 \mathrm{E}-22 & 8.886 \mathrm{E}-19 & 2.061 \mathrm{E}-16\end{array}$

$\begin{array}{llllll}2.288 \mathrm{E}-17 & 6.901 \mathrm{E}-17 & 3.139 \mathrm{E}-15 & 8.497 \mathrm{E}-15 & 4.967 \mathrm{E}-13 & 2.609 \mathrm{E}-11\end{array}$

$\begin{array}{llllll}8.071 \mathrm{E}-38 & 1.918 \mathrm{E}-36 & 1.782 \mathrm{E}-30 & 2.921 \mathrm{E}-29 & 6.369 \mathrm{E}-26 & 1.641 \mathrm{E}-23\end{array}$

$\begin{array}{llllll}1.250 \mathrm{E}-25 & 7.883 \mathrm{E}-25 & 7.635 \mathrm{E}-22 & 3.029 \mathrm{E}-21 & 3.412 \mathrm{E}-19 & 3.104 \mathrm{E}-17\end{array}$

$\begin{array}{lllllll}5.070 \mathrm{E}-31 & 6.365 \mathrm{E}-30 & 2.071 \mathrm{E}-25 & 1.764 \mathrm{E}-24 & 1.194 \mathrm{E}-21 & 2.380 \mathrm{E}-19\end{array}$

$\begin{array}{llllll}1.196 \mathrm{E}-36 & 5.319 \mathrm{E}-36 & 7.931 \mathrm{E}-30 & 1.410 \mathrm{E}-28 & 5.419 \mathrm{E}-25 & 2.318 \mathrm{E}-22\end{array}$

$\begin{array}{llllll}1.250 \mathrm{E}-25 & 7.883 \mathrm{E}-25 & 7.637 \mathrm{E}-22 & 3.030 \mathrm{E}-21 & 3.424 \mathrm{E}-19 & 3.128 \mathrm{E}-17\end{array}$

$2.623 \mathrm{E}-24 \quad 2.652 \mathrm{E}-24 \quad 4.545 \mathrm{E}-24 \quad 7.875 \mathrm{E}-24 \quad 6.395 \mathrm{E}-22 \quad 2.075 \mathrm{E}-19$ 
RESRAD-OFFSITE, Version 2.

Parent Dose Report

Title : Offsite Resident Farmer Deterministic Run

File : RF DOE SG FWD-FV2-1050y.ROF

Individual Nuclide Dose Summed Over All Pathways

Parent Nuclide and Thread Fraction Indicated

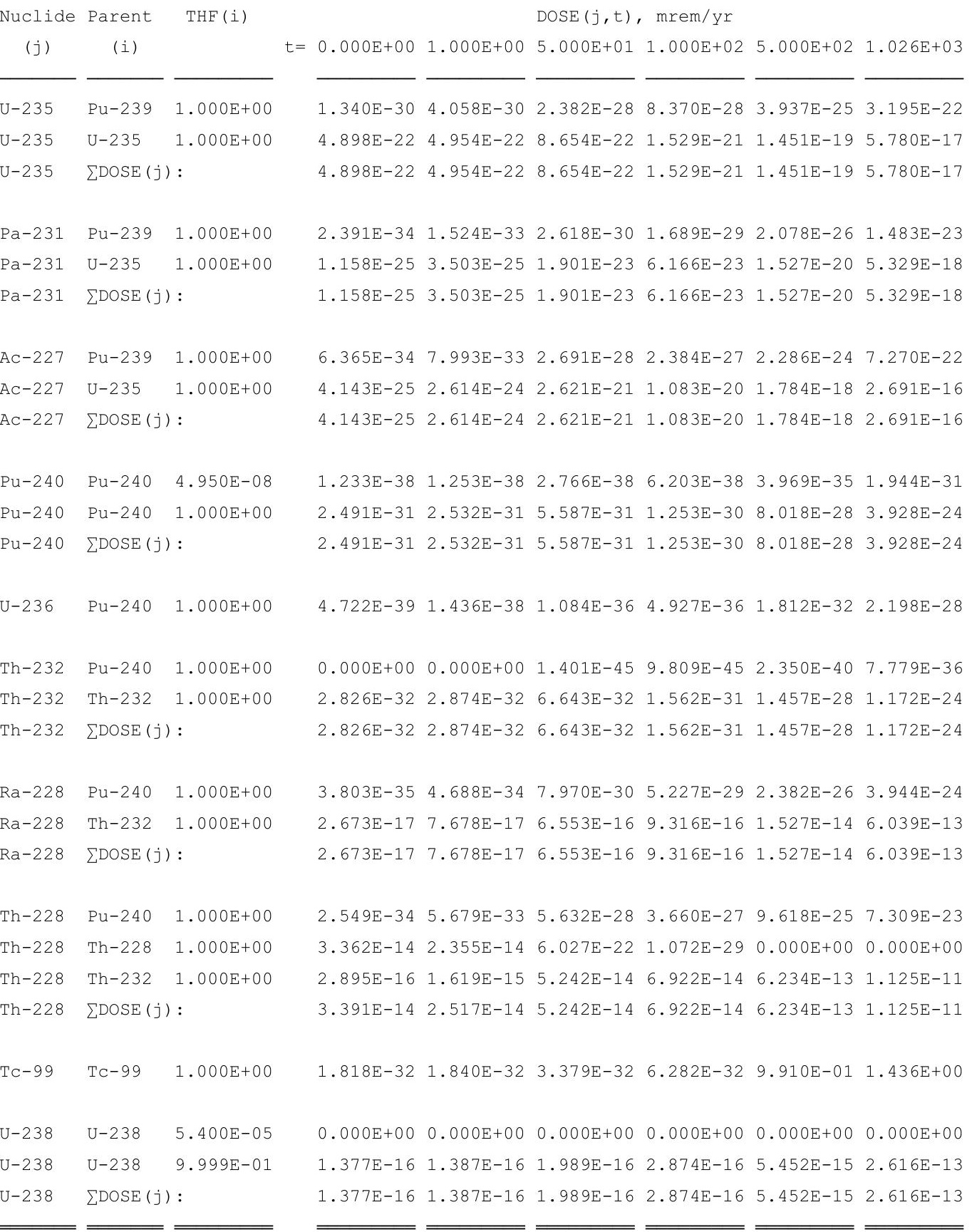

THF(i) is the thread fraction of the parent nuclide. 
RESRAD-OFFSITE, Version 2.

Parent Dose Report

Title : Offsite Resident Farmer Deterministic Run

File : RF DOE SG FWD-FV2-1050y.ROF

Individual Nuclide Soil Concentration

Parent Nuclide and Thread Fraction Indicated

\begin{tabular}{|c|c|c|c|c|c|c|c|c|c|}
\hline $\begin{array}{l}\text { aclide } \\
\text { (j) }\end{array}$ & $\begin{array}{c}\text { Parent } \\
\text { (i) }\end{array}$ & $\mathrm{THF}(i)$ & $t=$ & $0.000 \mathrm{E}+00$ & $1.000 \mathrm{E}+00$ & $\begin{array}{r}S(j, t), \\
5.000 E+01\end{array}$ & $\begin{array}{l}\mathrm{pCi} / \mathrm{g} \\
1.000 \mathrm{E}+02\end{array}$ & $5.000 \mathrm{E}+02$ & $1.026 \mathrm{E}+03$ \\
\hline $1-241$ & $A m-241$ & $1.000 \mathrm{E}+00$ & & $3.500 \mathrm{E}+01$ & $3.494 \mathrm{E}+01$ & $3.230 \mathrm{E}+01$ & $2.981 \mathrm{E}+01$ & $1.567 \mathrm{E}+01$ & $6.732 \mathrm{E}+00$ \\
\hline-237 & $A m-241$ & $1.000 \mathrm{E}+00$ & & $0.000 \mathrm{E}+00$ & $1.133 \mathrm{E}-05$ & $5.436 \mathrm{E}-04$ & $1.043 E-03$ & $3.810 \mathrm{E}-03$ & $5.417 \mathrm{E}-03$ \\
\hline-237 & $N p-237$ & $1.000 \mathrm{E}+00$ & & $5.500 \mathrm{E}+00$ & $5.500 \mathrm{E}+00$ & $5.478 \mathrm{E}+00$ & $5.457 \mathrm{E}+00$ & $5.288 \mathrm{E}+00$ & $5.073 \mathrm{E}+00$ \\
\hline-237 & $\sum S(j):$ & & & $5.500 \mathrm{E}+00$ & $5.500 \mathrm{E}+00$ & $5.479 \mathrm{E}+00$ & $5.458 \mathrm{E}+00$ & $5.291 \mathrm{E}+00$ & $5.078 \mathrm{E}+00$ \\
\hline-233 & $A m-241$ & $1.000 \mathrm{E}+00$ & & $0.000 \mathrm{E}+00$ & $2.508 \mathrm{E}-11$ & $6.025 E-08$ & $2.344 \mathrm{E}-07$ & $4.742 \mathrm{E}-06$ & $1.556 \mathrm{E}-05$ \\
\hline 233 & $\mathrm{~Np}-237$ & $1.000 \mathrm{E}+00$ & & $0.000 \mathrm{E}+00$ & $2.405 E-05$ & $1.200 \mathrm{E}-03$ & $2.394 \mathrm{E}-03$ & $1.174 \mathrm{E}-02$ & $2.349 \mathrm{E}-02$ \\
\hline 233 & $\sum S(j):$ & & & $0.000 \mathrm{E}+00$ & $2.405 E-05$ & $1.200 \mathrm{E}-03$ & $2.394 \mathrm{E}-03$ & $1.174 \mathrm{E}-02$ & $2.350 \mathrm{E}-02$ \\
\hline-229 & $A m-241$ & $1.000 \mathrm{E}+00$ & & $0.000 \mathrm{E}+00$ & $8.043 E-16$ & $9.538 \mathrm{E}-11$ & 7. $463 \mathrm{E}-10$ & $7.873 E-08$ & $5.545 \mathrm{E}-07$ \\
\hline-229 & $\mathrm{~Np}-237$ & $1.000 \mathrm{E}+00$ & & $0.000 \mathrm{E}+00$ & $1.150 \mathrm{E}-09$ & $2.830 \mathrm{E}-06$ & $1.128 \mathrm{E}-05$ & $2.750 \mathrm{E}-04$ & $1.119 \mathrm{E}-03$ \\
\hline-229 & $\sum S(j):$ & & & $0.000 \mathrm{E}+00$ & $1.150 E-09$ & $2.830 E-06$ & $1.128 E-05$ & $2.750 E-04$ & $1.120 \mathrm{E}-03$ \\
\hline-137 & $\mathrm{Cs}-137$ & $1.000 \mathrm{E}+00$ & & $1.900 \mathrm{E}+01$ & $1.857 \mathrm{E}+01$ & $5.979 \mathrm{E}+00$ & $1.881 E+00$ & $1.809 \mathrm{E}-04$ & $9.436 \mathrm{E}-10$ \\
\hline-238 & $\mathrm{Pu}-238$ & $1.840 \mathrm{E}-09$ & & $7.176 \mathrm{E}-08$ & $7.119 \mathrm{E}-08$ & $4.832 E-08$ & $3.254 E-08$ & $1.375 E-09$ & $2.144 \mathrm{E}-11$ \\
\hline-238 & $\mathrm{Pu}-238$ & $1.000 \mathrm{E}+00$ & & $3.900 \mathrm{E}+01$ & $3.869 \mathrm{E}+01$ & $2.626 \mathrm{E}+01$ & $1.768 \mathrm{E}+01$ & 7. $472 \mathrm{E}-01$ & $1.165 \mathrm{E}-02$ \\
\hline-238 & $\sum S(j):$ & & & $3.900 \mathrm{E}+01$ & $3.869 \mathrm{E}+01$ & $2.626 E+01$ & $1.768 \mathrm{E}+01$ & $7.472 \mathrm{E}-01$ & $1.165 E-02$ \\
\hline 34 & $\mathrm{Pu}-238$ & $1.000 \mathrm{E}+00$ & & $0.000 \mathrm{E}+00$ & $1.101 \mathrm{E}-04$ & $4.564 \mathrm{E}-03$ & $7.633 E-03$ & 1. $362 \mathrm{E}-02$ & $1.377 \mathrm{E}-02$ \\
\hline 234 & $\mathrm{U}-234$ & $1.000 \mathrm{E}+00$ & & $1.600 \mathrm{E}+02$ & $1.600 \mathrm{E}+02$ & $1.599 \mathrm{E}+02$ & $1.597 \mathrm{E}+02$ & $1.587 \mathrm{E}+02$ & $1.574 \mathrm{E}+02$ \\
\hline 234 & $\mathrm{U}-238$ & $9.999 \mathrm{E}-01$ & & $0.000 \mathrm{E}+00$ & $4.536 \mathrm{E}-04$ & $2.266 \mathrm{E}-02$ & $4.529 \mathrm{E}-02$ & $2.251 \mathrm{E}-01$ & $4.583 E-01$ \\
\hline & $\sum S(j):$ & & & $1.600 \mathrm{E}+02$ & 1. $600 \mathrm{E}+02$ & $1.599 \mathrm{E}+02$ & $1.598 \mathrm{E}+02$ & $1.589 \mathrm{E}+02$ & $1.578 \mathrm{E}+02$ \\
\hline
\end{tabular}

$\mathrm{Th}-230 \mathrm{Pu}-238 \quad 1.000 \mathrm{E}+00$

Th-230 Th-230 1.000E+00

$\mathrm{Th}-230 \mathrm{U}-234 \quad 1.000 \mathrm{E}+00$

Th-230 U-238 9.999E-01

Th-230 $\sum S(j):$

$0.000 \mathrm{E}+00 \quad 5.024 \mathrm{E}-10 \quad 1.095 \mathrm{E}-06 \quad 3.884 \mathrm{E}-06 \quad 4.705 \mathrm{E}-05 \quad 1.118 \mathrm{E}-04$ $\begin{array}{llllllll}1.000 \mathrm{E}+02 & 1.000 \mathrm{E}+02 & 9.995 \mathrm{E}+01 & 9.989 \mathrm{E}+01 & 9.947 \mathrm{E}+01 & 9.891 \mathrm{E}+01\end{array}$ $0.000 \mathrm{E}+00 \quad 1.440 \mathrm{E}-03 \quad 7.197 \mathrm{E}-02 \quad 1.438 \mathrm{E}-01 \quad 7.153 \mathrm{E}-01 \quad 1.457 \mathrm{E}+00$ $0.000 \mathrm{E}+00 \quad 2.067 \mathrm{E}-09 \quad 5.100 \mathrm{E}-06 \quad 2.039 \mathrm{E}-05 \quad 5.070 \mathrm{E}-04 \quad 2.120 \mathrm{E}-03$

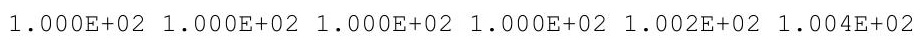

$0.000 \mathrm{E}+00 \quad 7.396 \mathrm{E}-14 \quad 8.112 \mathrm{E}-09 \quad 5.891 \mathrm{E}-08 \quad 3.952 \mathrm{E}-06 \quad 1.952 \mathrm{E}-05$ $0.000 \mathrm{E}+00 \quad 4.331 \mathrm{E}-02 \quad 2.142 \mathrm{E}+00 \quad 4.235 \mathrm{E}+00 \quad 1.937 \mathrm{E}+01 \quad 3.549 \mathrm{E}+01$ $0.000 \mathrm{E}+00 \quad 3.158 \mathrm{E}-07 \quad 7.739 \mathrm{E}-04 \quad 3.071 \mathrm{E}-03 \quad 7.220 \mathrm{E}-02 \quad 2.810 \mathrm{E}-01$ $\begin{array}{lllllll}0.000 E+00 & 3.103 E-13 & 3.663 E-08 & 2.913 E-07 & 3.471 E-05 & 2.822 E-04\end{array}$ $0.000 \mathrm{E}+00 \quad 4.331 \mathrm{E}-02 \quad 2.142 \mathrm{E}+00 \quad 4.238 \mathrm{E}+00 \quad 1.944 \mathrm{E}+01 \quad 3.577 \mathrm{E}+01$

$0.000 \mathrm{E}+00 \quad 5.853 \mathrm{E}-16 \quad 2.418 \mathrm{E}-09 \quad 2.812 \mathrm{E}-08 \quad 3.398 \mathrm{E}-06 \quad 1.827 \mathrm{E}-05$ $\begin{array}{lllllllll}0.000 \mathrm{E}+00 & 6.744 \mathrm{E}-04 & 1.058 \mathrm{E}+00 & 2.946 \mathrm{E}+00 & 1.823 \mathrm{E}+01 & 3.458 \mathrm{E}+01\end{array}$ $\begin{array}{llllll}0.000 \mathrm{E}+00 & 3.307 \mathrm{E}-09 & 2.837 \mathrm{E}-04 & 1.706 \mathrm{E}-03 & 6.374 \mathrm{E}-02 & 2.650 \mathrm{E}-01\end{array}$ $0.000 \mathrm{E}+00 \quad 9.890 \mathrm{E}-15 \quad 1.075 \mathrm{E}-08 \quad 1.356 \mathrm{E}-07 \quad 2.889 \mathrm{E}-05 \quad 2.580 \mathrm{E}-04$ $\begin{array}{lllllll}0.000 \mathrm{E}+00 & 6.744 \mathrm{E}-04 & 1.058 \mathrm{E}+00 & 2.947 \mathrm{E}+00 & 1.830 \mathrm{E}+01 & 3.485 \mathrm{E}+01\end{array}$ $\begin{array}{lllllll}3.600 \mathrm{E}+01 & 3.600 \mathrm{E}+01 & 3.593 \mathrm{E}+01 & 3.586 \mathrm{E}+01 & 3.531 \mathrm{E}+01 & 3.460 \mathrm{E}+01\end{array}$ 
RESRAD-OFFSITE, Version 2.

Parent Dose Report

Title : Offsite Resident Farmer Deterministic Run

File : RF DOE SG FWD-FV2-1050y.ROF

Individual Nuclide Soil Concentration

Parent Nuclide and Thread Fraction Indicated

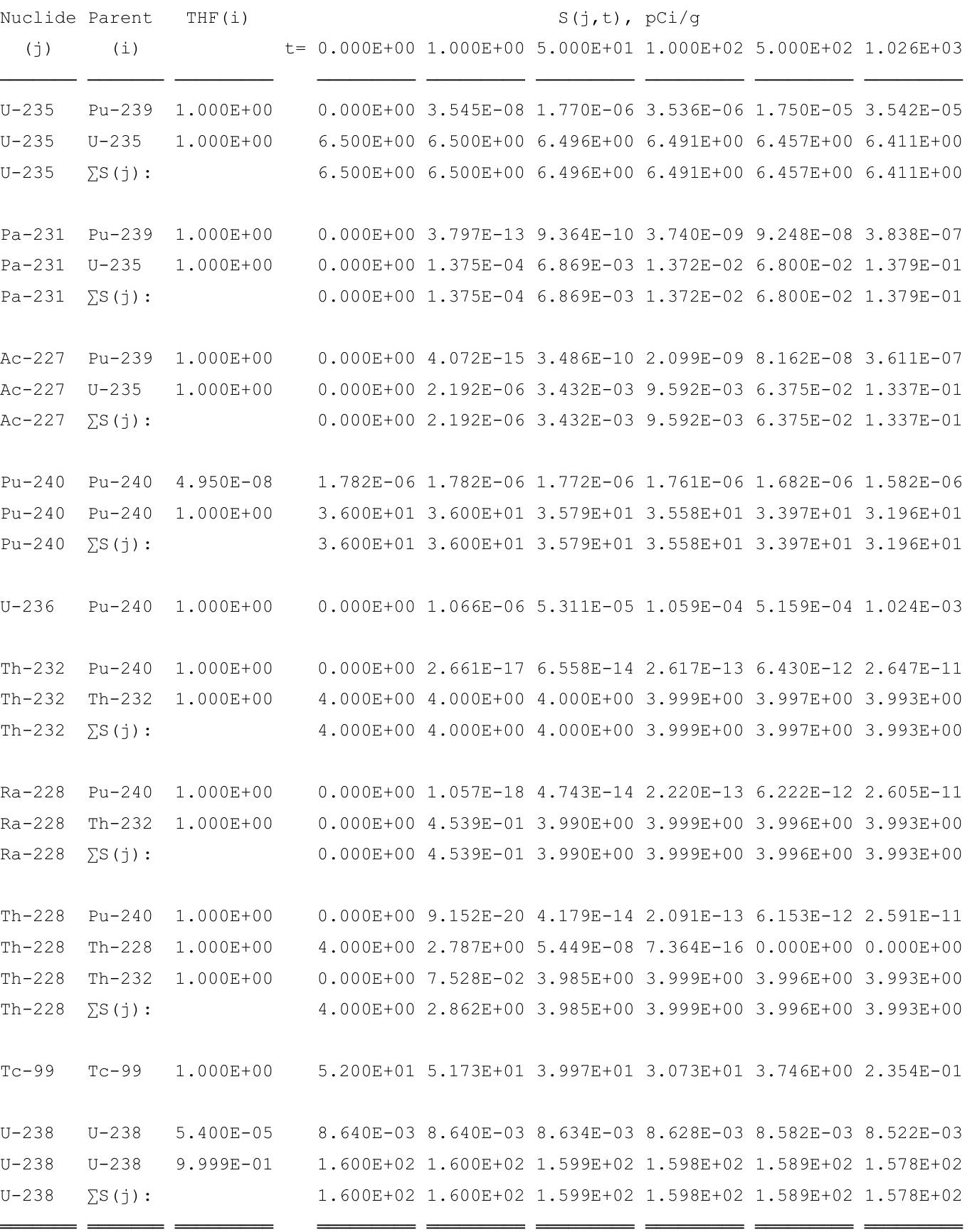

THF(i) is the thread fraction of the parent nuclide. 
RESRAD-OFFSITE, Version $2.5 \quad \mathrm{~T}^{1 / 2}$ Limit $=180$ days

Parent Dose Report

Title : Offsite Resident Farmer Deterministic Run

File : RF DOE SG FWD-FV2-1050y.ROF

Run Time Information

ResOCalc.EXE execution began at 16:13 on 07/15/2011

ResOCalc.EXE execution ended at 16:14 on 07/15/2011

ResOCalc.EXE execution time 34.952 seconds 


\title{
Offsite Resident Farmer
}

\author{
Parent Dose Report \\ (Deterministic Analysis Report) \\ Second Peak Dose Assessment \\ Time Horizon: 10,000 yr
}


THIS PAGE INTENTIONALLY LEFT BLANK 
RESRAD-OFFSITE, Version 2.5

Parent Dose Report

Title : Offsite Resident Farmer Deterministic Run

File : RF DOE SG FWD-FV2-10000Y.ROF

Dose Conversion Factor (and Related) Parameter Summary

Current Library: ICRP 60

Default Library: ICRP 60

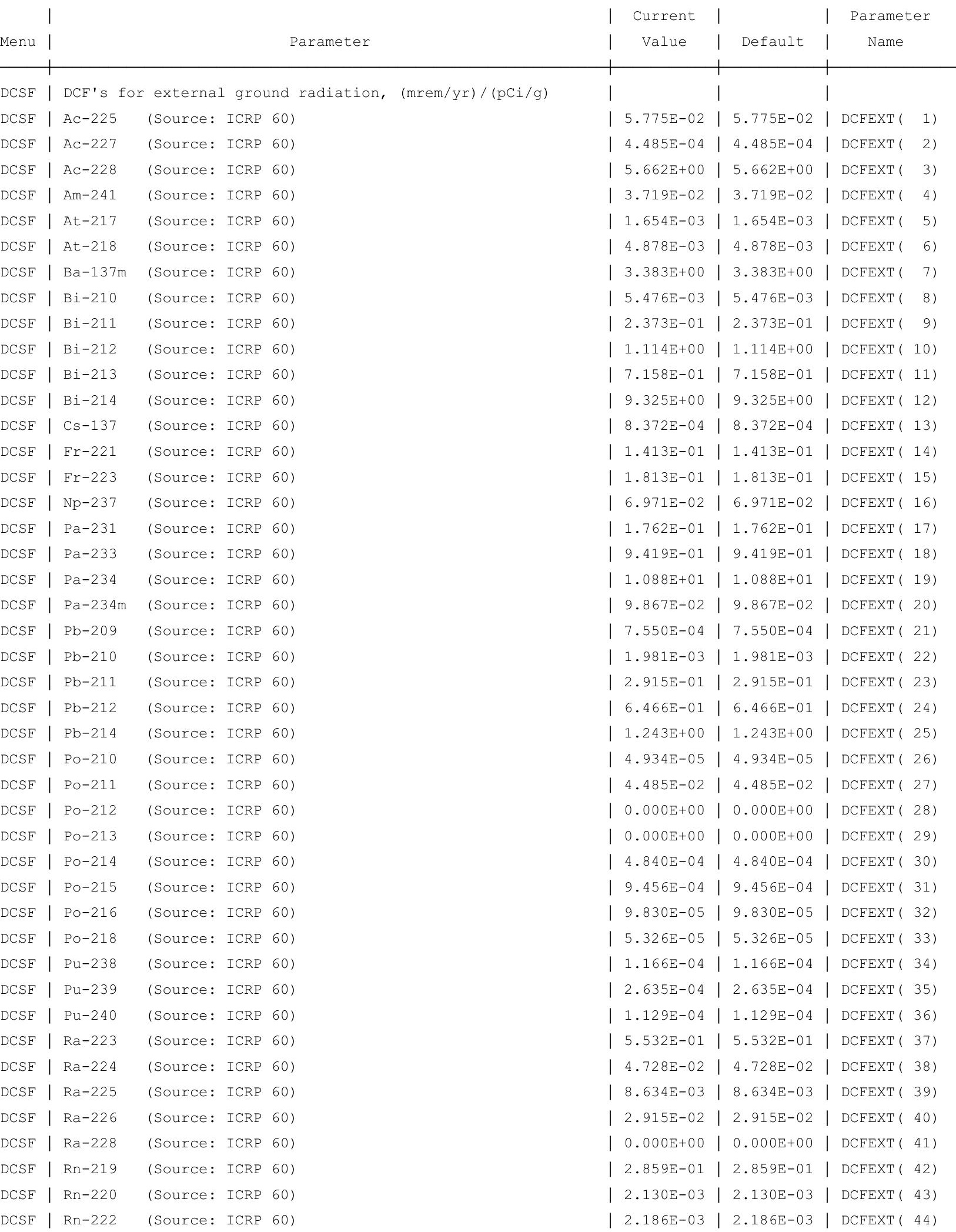


RESRAD-OFFSITE, Version $2.5 \quad \mathrm{~T}^{1 / 2}$ Limit $=180$ days

Parent Dose Report

Title : Offsite Resident Farmer Deterministic Run

File : RF DOE SG FWD-FV2-10000Y.ROF

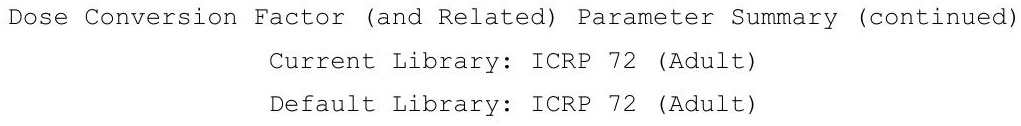

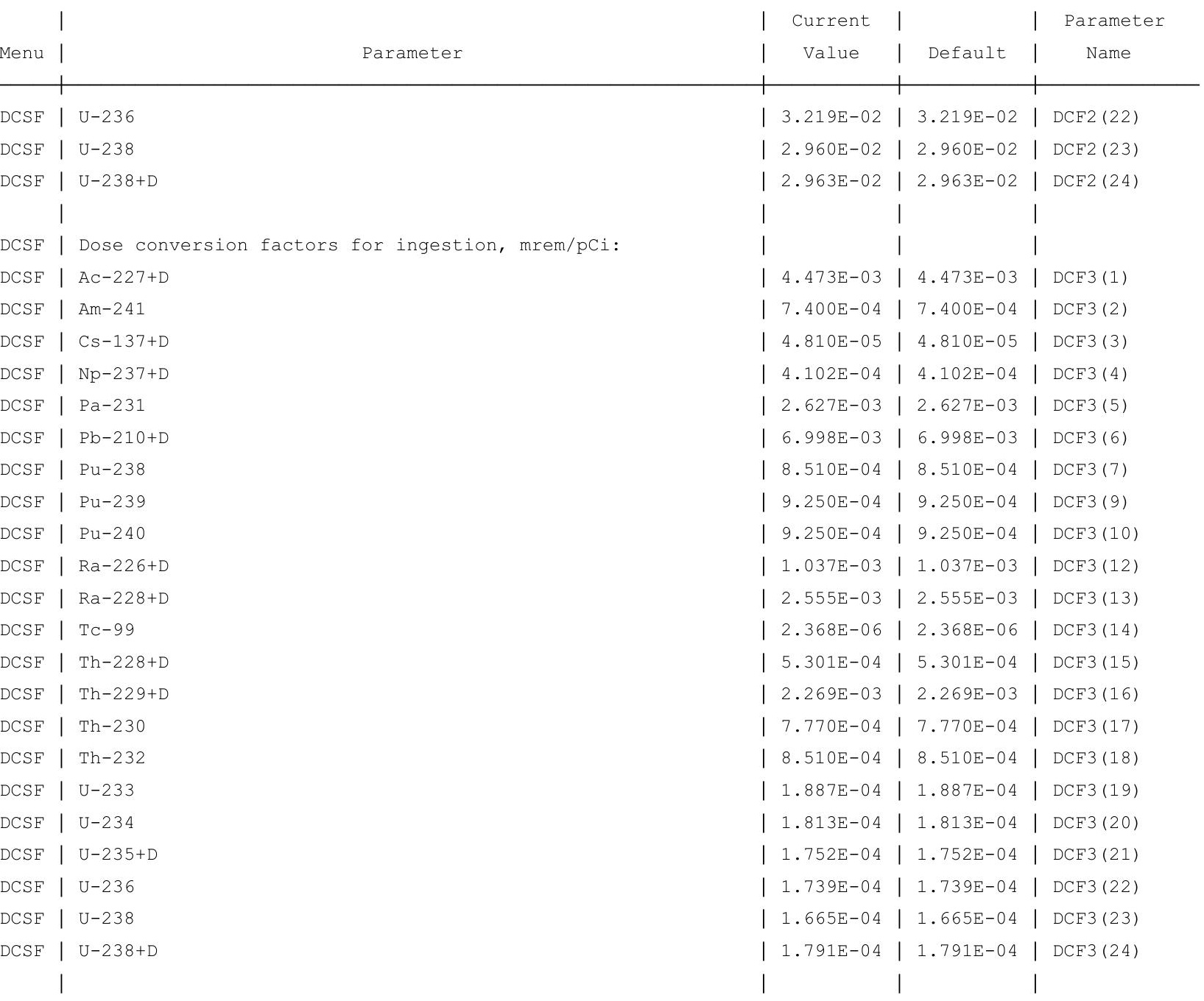


RESRAD-OFFSITE, Version 2.5

Parent Dose Report

Title : Offsite Resident Farmer Deterministic Run

File : RF DOE SG FWD-FV2-10000Y.ROF

Dose Conversion Factor (and Related) Parameter Summary (continued)

Current Library: RESRAD Default Transfer factors

Default Library: RESRAD Default Transfer factors

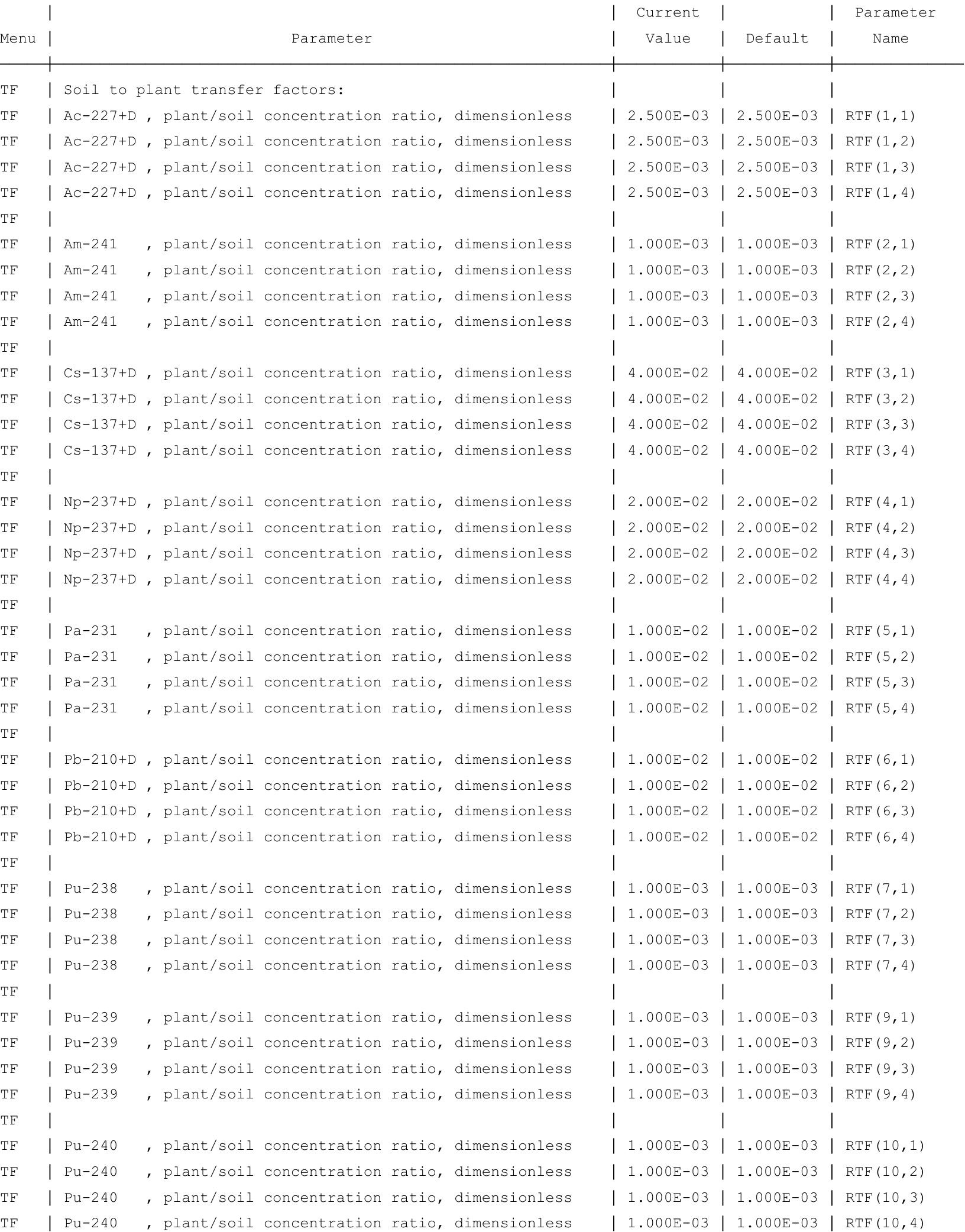


RESRAD-OFFSITE, Version 2.5

Parent Dose Report

Title : Offsite Resident Farmer Deterministic Run

File : RF DOE SG FWD-FV2-10000Y.ROF

Dose Conversion Factor (and Related) Parameter Summary (continued)

Current Library: RESRAD Default Transfer factors

Default Library: RESRAD Default Transfer factors

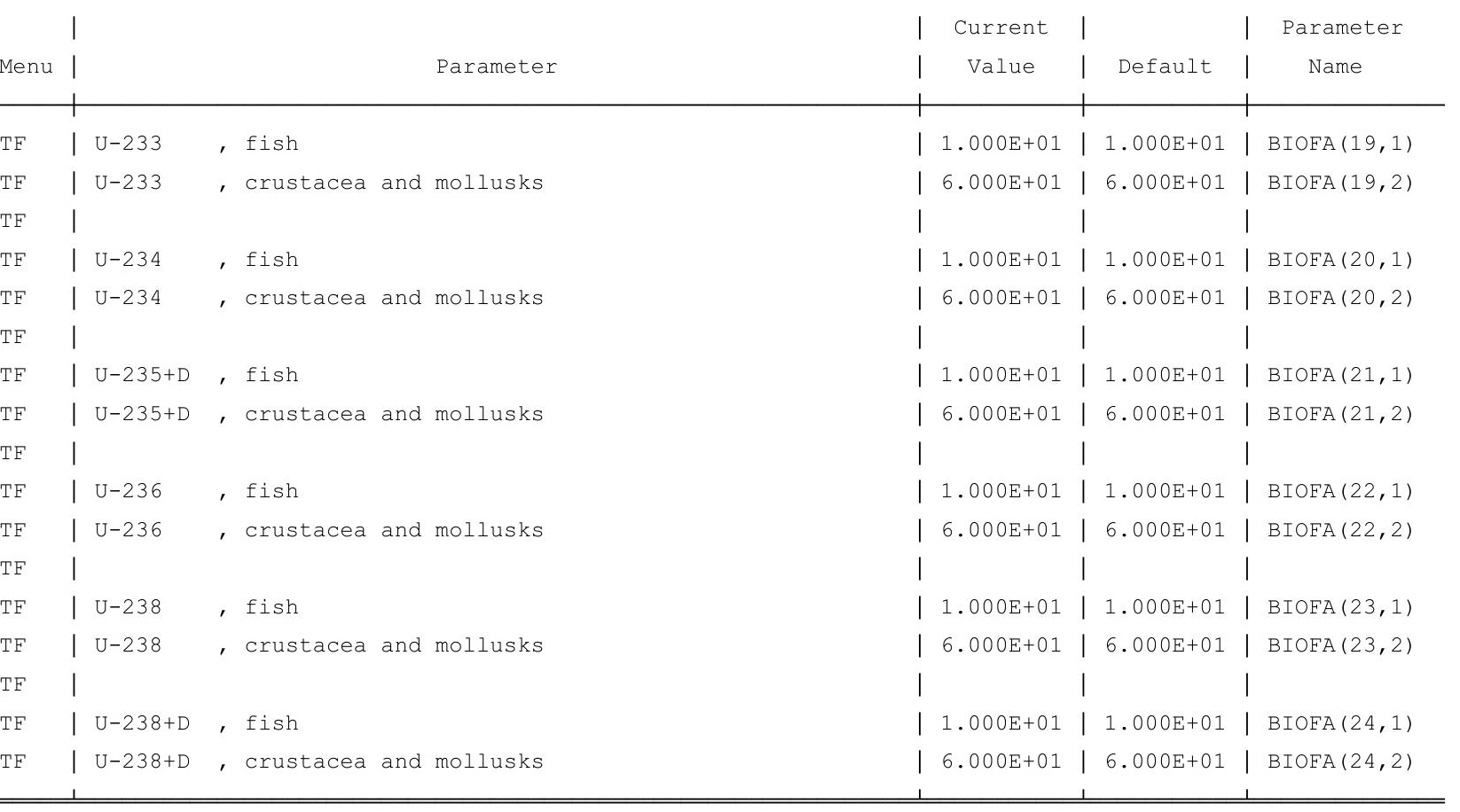


RESRAD-OFFSITE, Version $2.5 \quad \mathrm{~T}^{1 / 2}$ Limit $=180$ days

Parent Dose Report

Title : Offsite Resident Farmer Deterministic Run

File : RF DOE SG FWD-FV2-10000Y.ROF

Site-Specific Parameter Summary

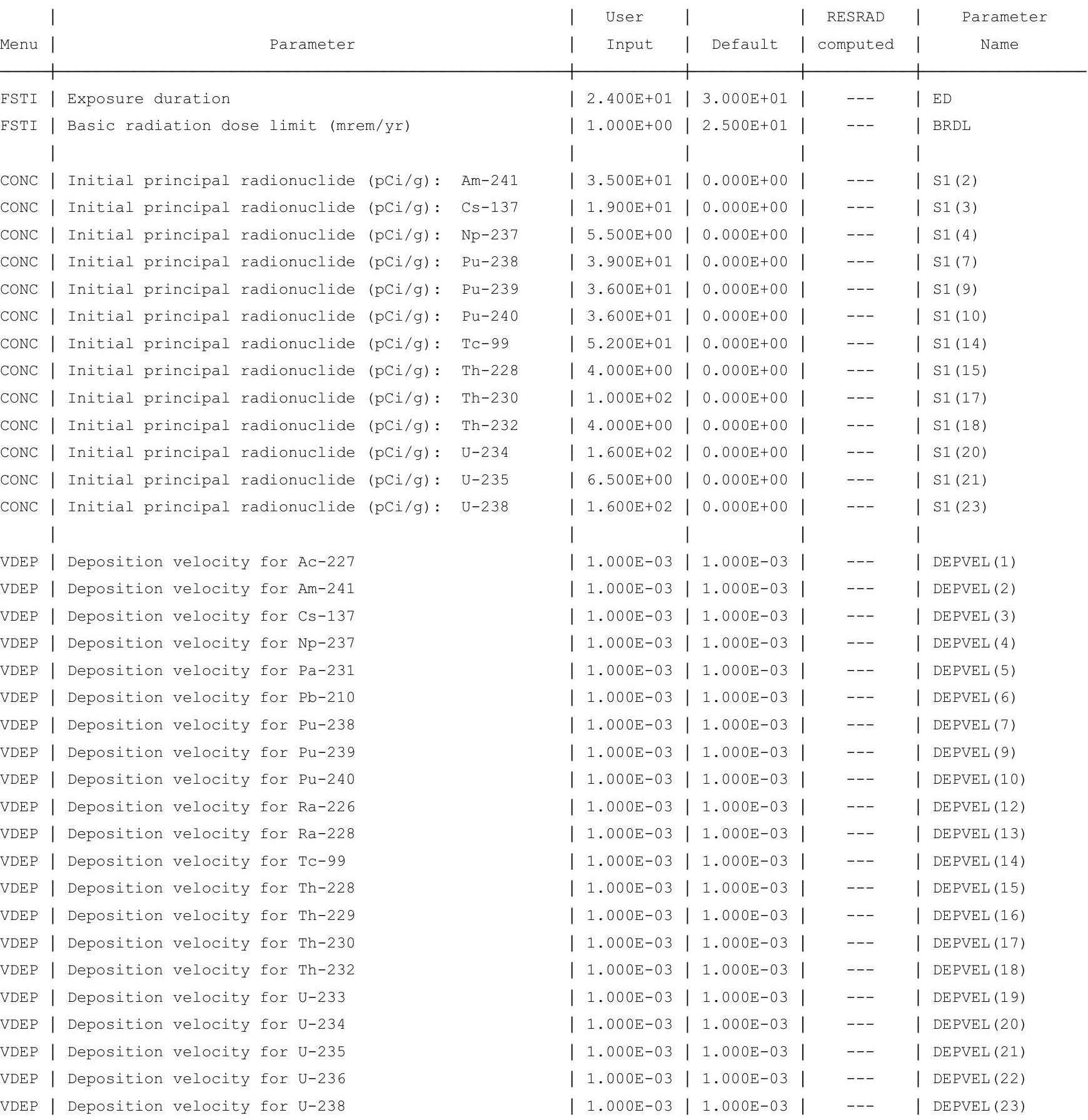


RESRAD-OFFSITE, Version $2.5 \quad \mathrm{~T}^{1 / 2}$ Limit $=180$ days

Parent Dose Report

Title : Offsite Resident Farmer Deterministic Run

File : RF DOE SG FWD-FV2-10000Y.ROF

Site-Specific Parameter Summary (continued)

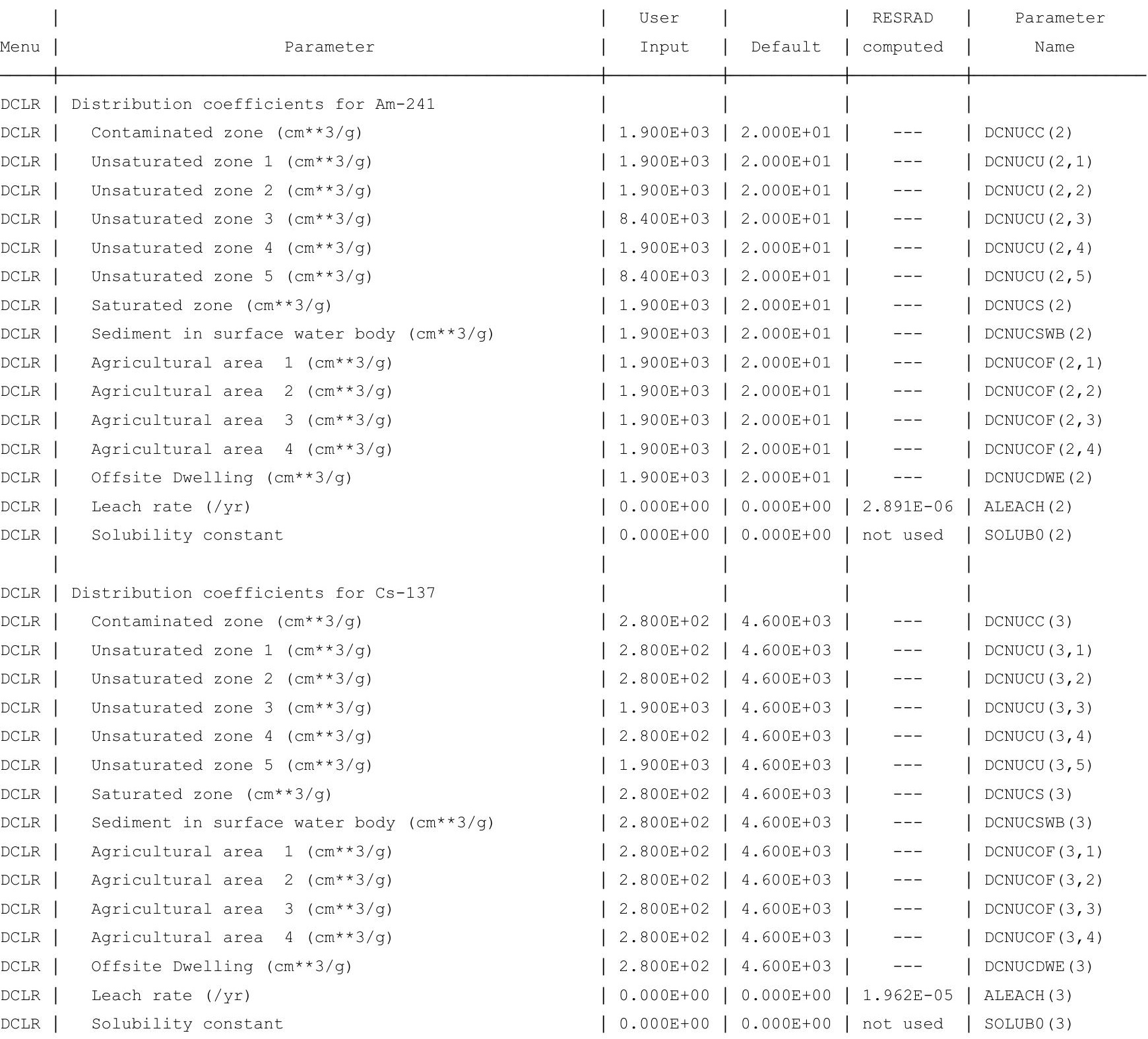


RESRAD-OFFSITE, Version $2.5 \quad \mathrm{~T}^{1 / 2}$ Limit $=180$ days

Parent Dose Report

Title : Offsite Resident Farmer Deterministic Run

File : RF DOE SG FWD-FV2-10000Y.ROF

Site-Specific Parameter Summary (continued)

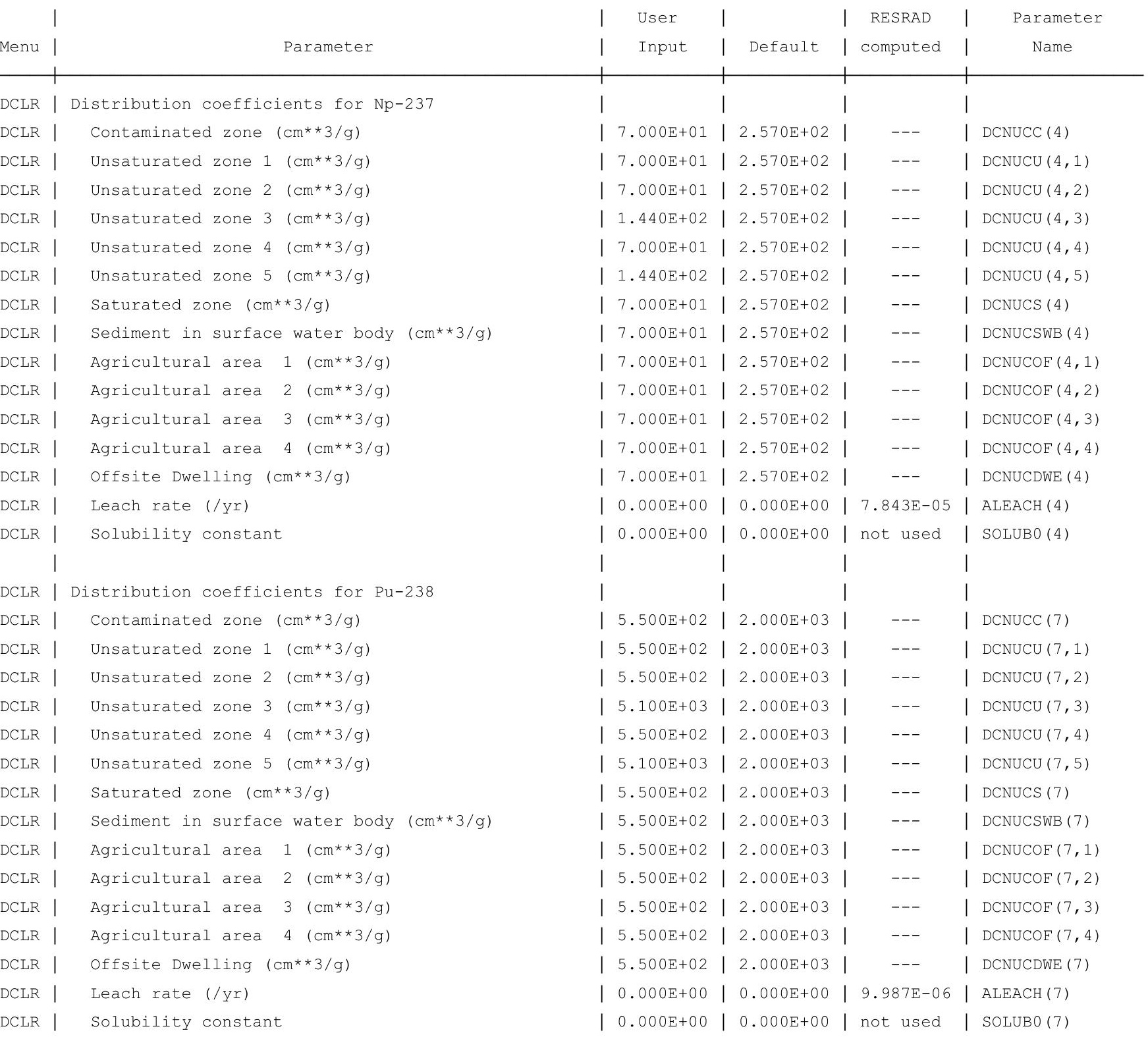


RESRAD-OFFSITE, Version $2.5 \quad \mathrm{~T}^{1 / 2}$ Limit $=180$ days

Parent Dose Report

Title : Offsite Resident Farmer Deterministic Run

File : RF DOE SG FWD-FV2-10000Y.ROF

Site-Specific Parameter Summary (continued)

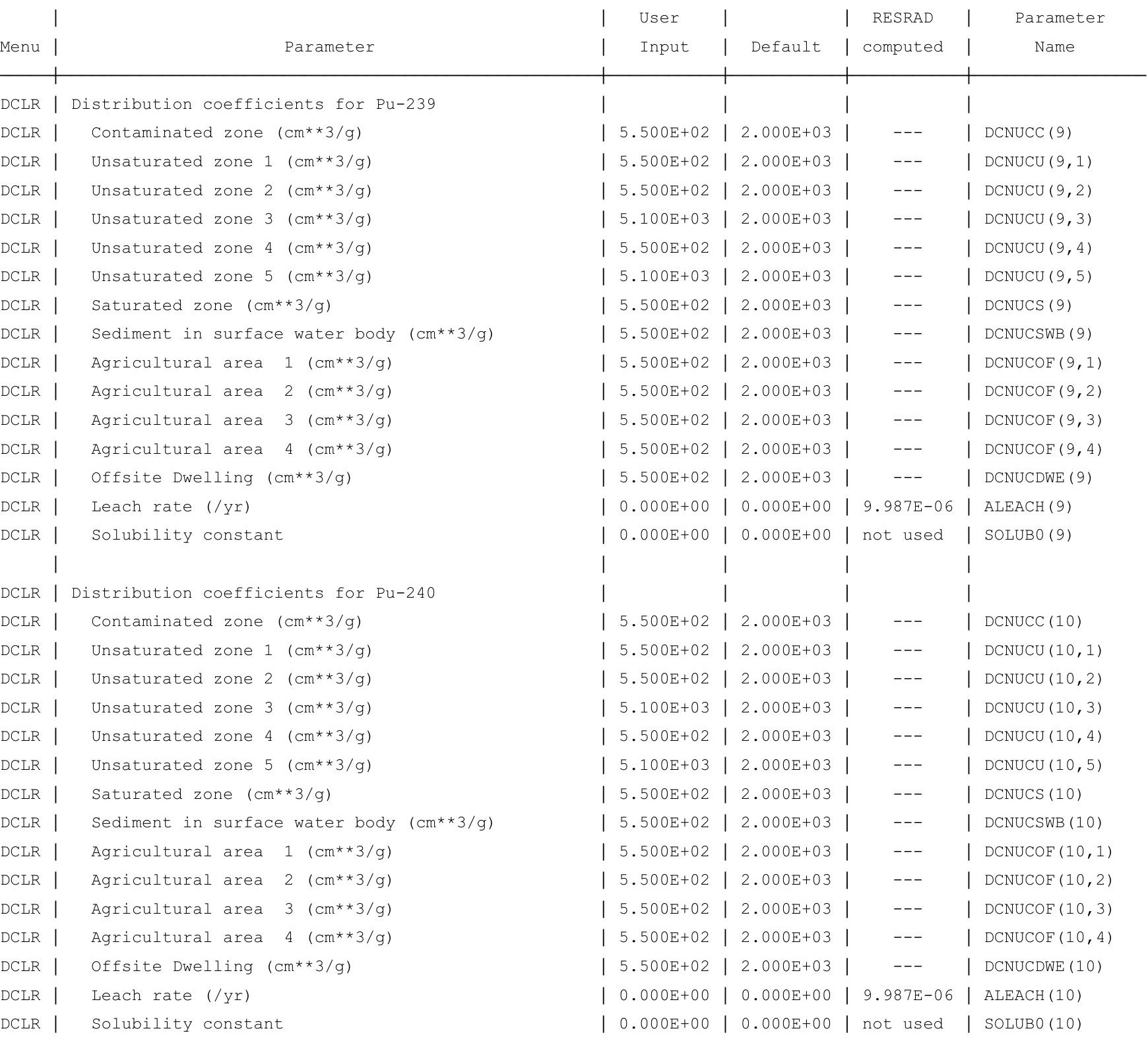


RESRAD-OFFSITE, Version $2.5, \mathrm{~T}^{1 / 2}$ Limit $=180$ days

Parent Dose Report

Title : Offsite Resident Farmer Deterministic Run

File : RF DOE SG FWD-FV2-10000Y.ROF

Site-Specific Parameter Summary (continued)

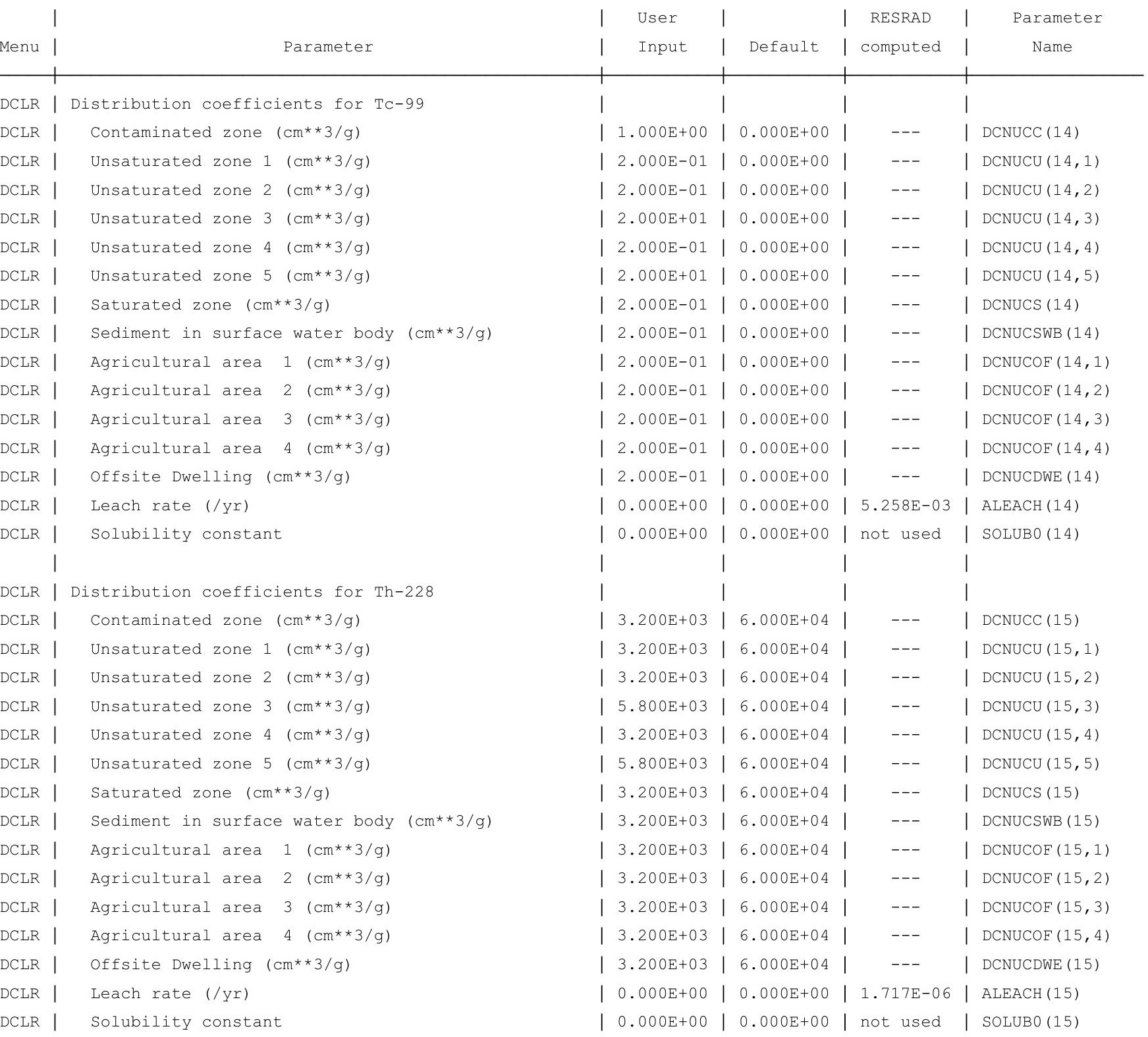


RESRAD-OFFSITE, Version $2.5, \mathrm{~T}^{1 / 2}$ Limit $=180$ days

Parent Dose Report

Title : Offsite Resident Farmer Deterministic Run

File : RF DOE SG FWD-FV2-10000Y.ROF

Site-Specific Parameter Summary (continued)

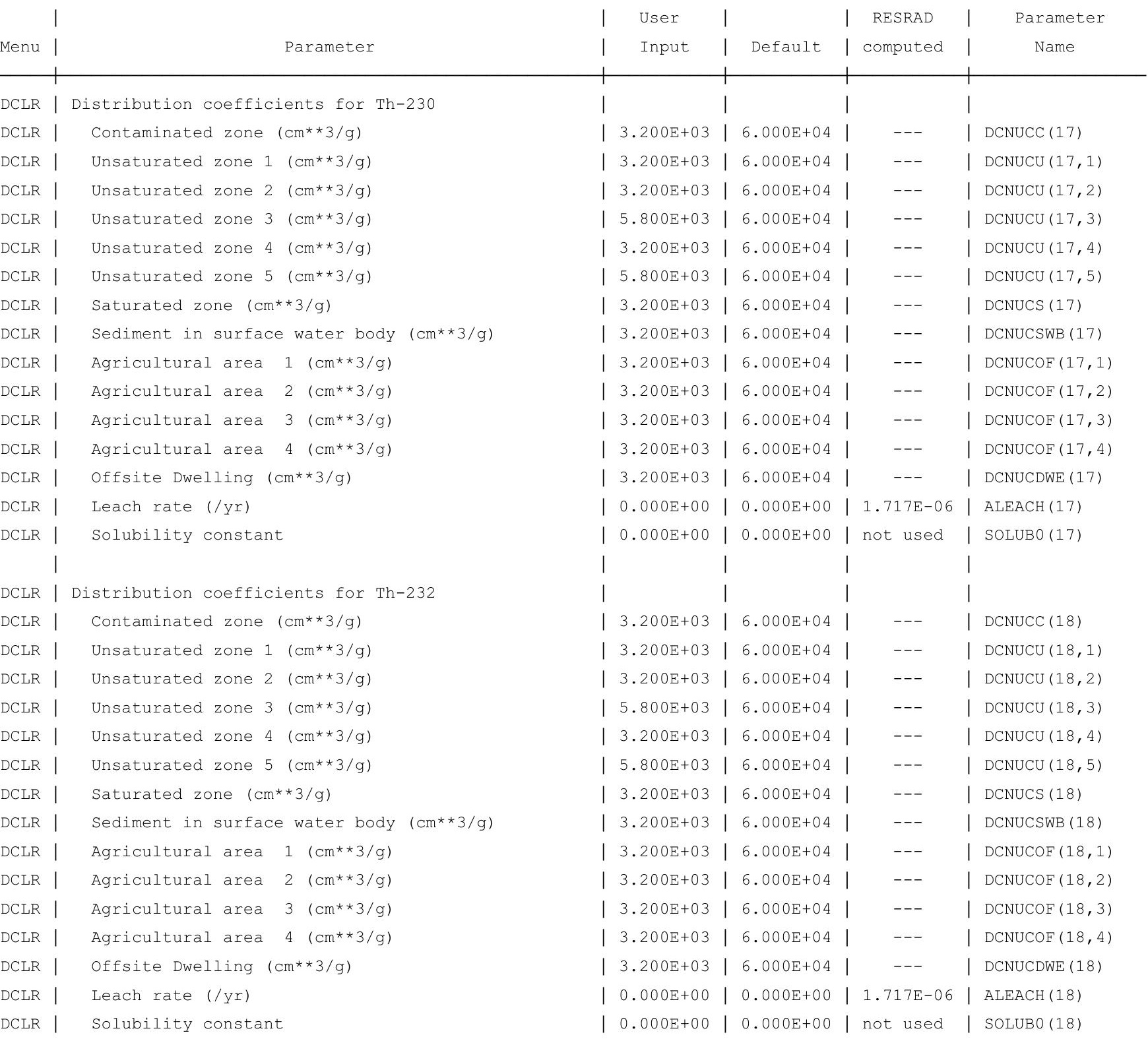


RESRAD-OFFSITE, Version $2.5 \quad \mathrm{~T}^{1 / 2}$ Limit $=180$ days

Parent Dose Report

Title : Offsite Resident Farmer Deterministic Run

File : RF DOE SG FWD-FV2-10000Y.ROF

Site-Specific Parameter Summary (continued)

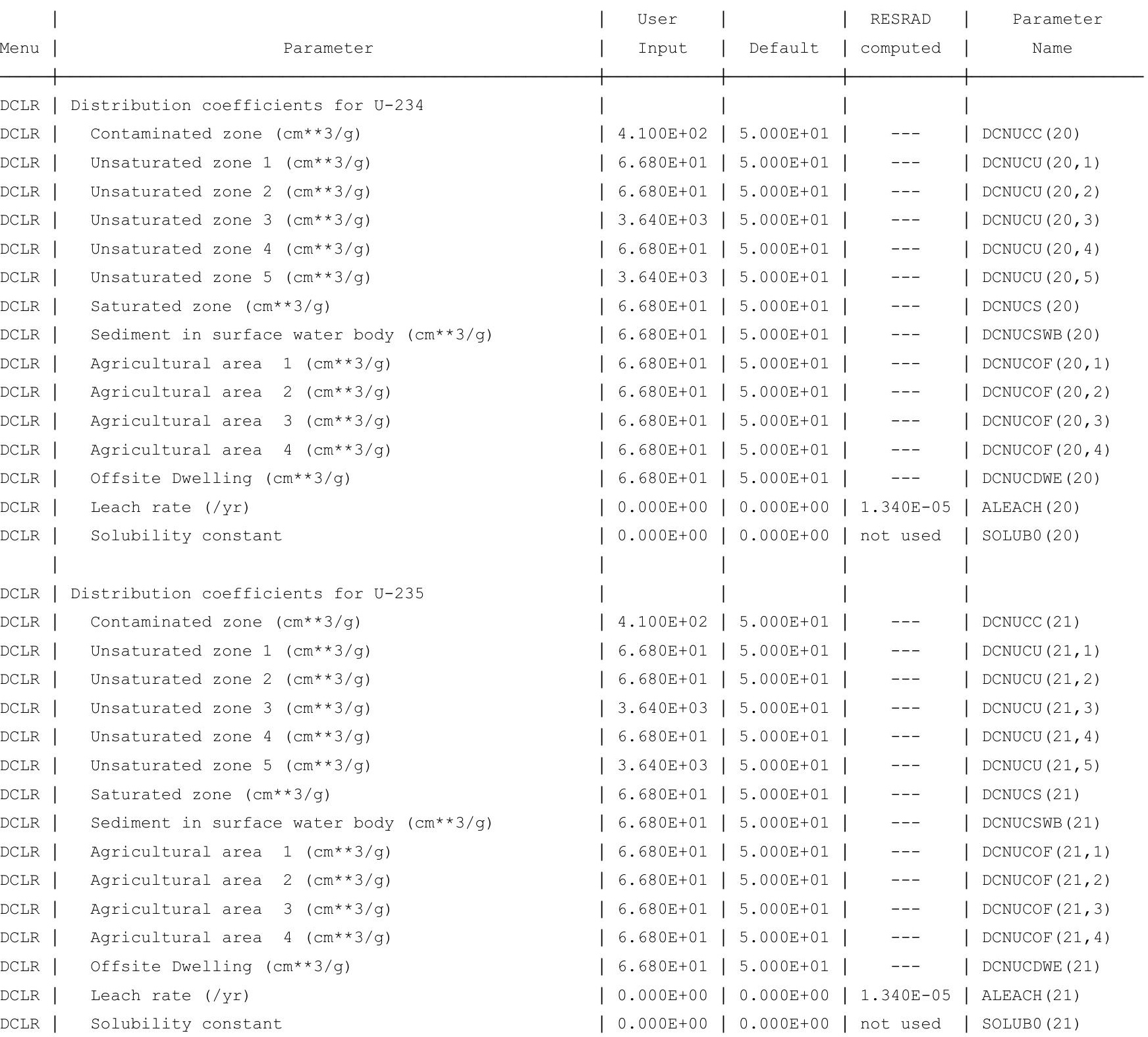


RESRAD-OFFSITE, Version $2.5 \quad \mathrm{~T}^{1 / 2}$ Limit $=180$ days

Parent Dose Report

Title : Offsite Resident Farmer Deterministic Run

File : RF DOE SG FWD-FV2-10000Y.ROF

Site-Specific Parameter Summary (continued)

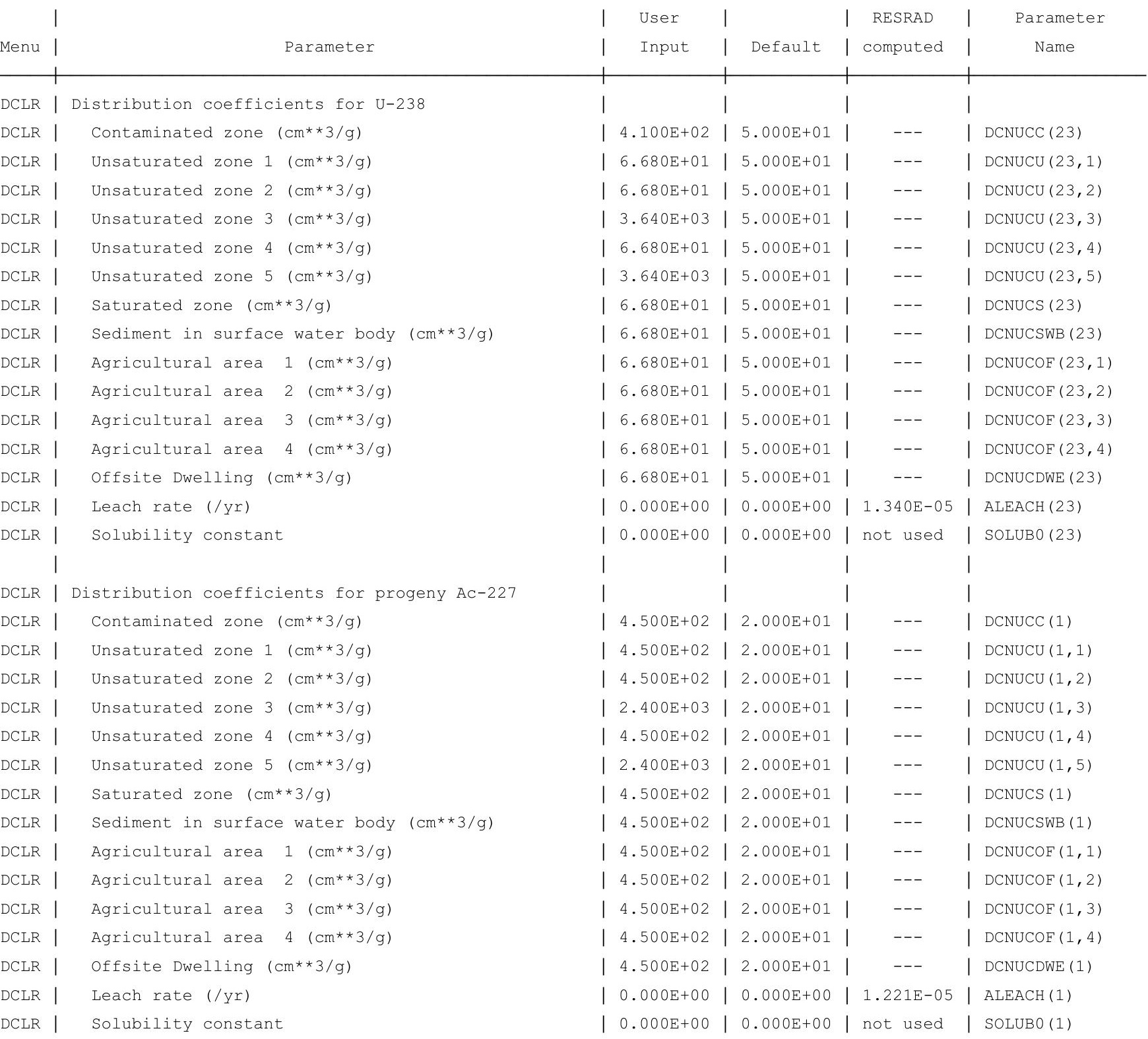


RESRAD-OFFSITE, Version $2.5 \quad \mathrm{~T}^{1 / 2}$ Limit $=180$ days

Parent Dose Report

Title : Offsite Resident Farmer Deterministic Run

File : RF DOE SG FWD-FV2-10000Y.ROF

Site-Specific Parameter Summary (continued)

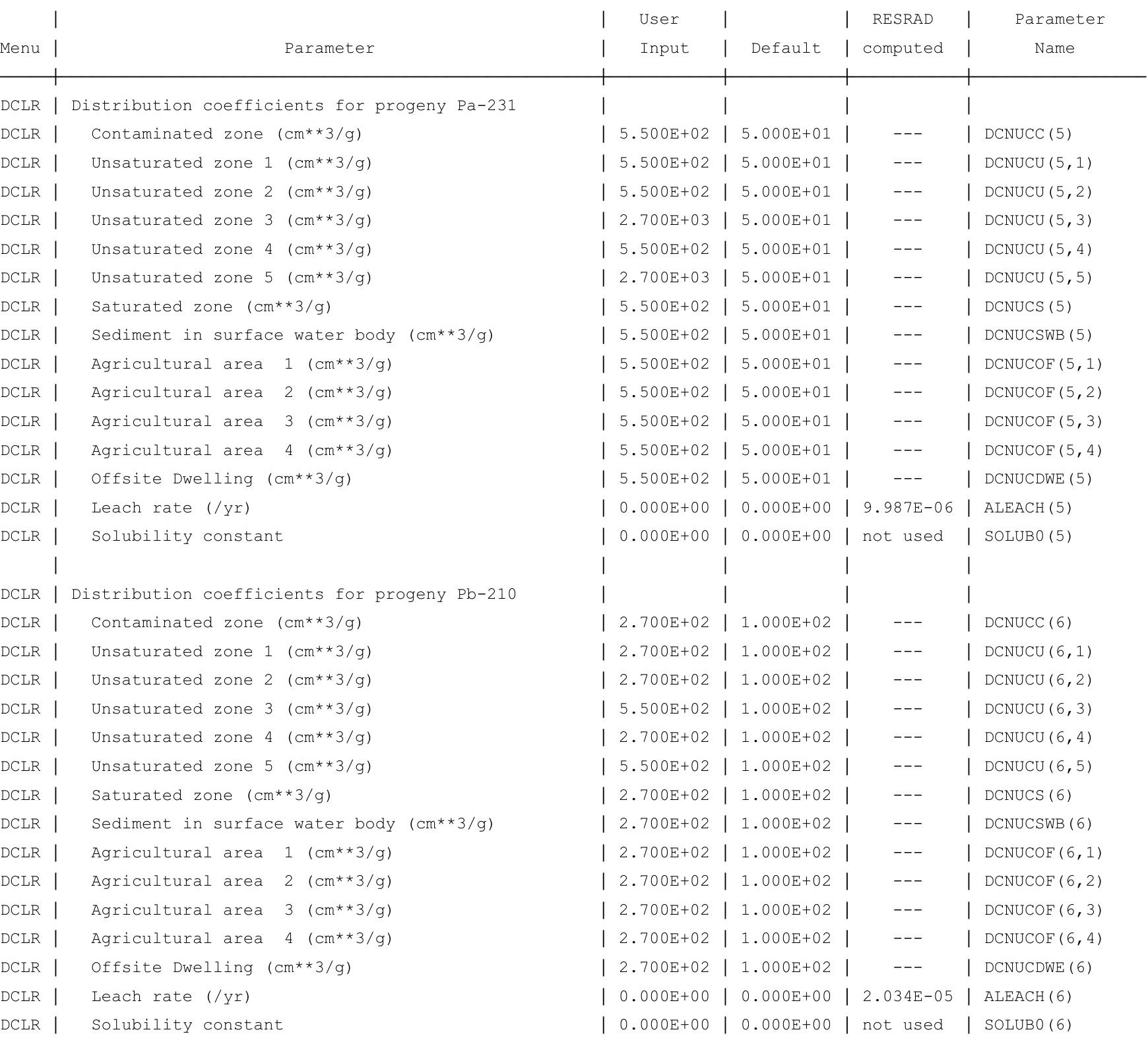


RESRAD-OFFSITE, Version $2.5 \quad \mathrm{~T}^{1 / 2}$ Limit $=180$ days

Parent Dose Report

Title : Offsite Resident Farmer Deterministic Run

File : RF DOE SG FWD-FV2-10000Y.ROF

Site-Specific Parameter Summary (continued)

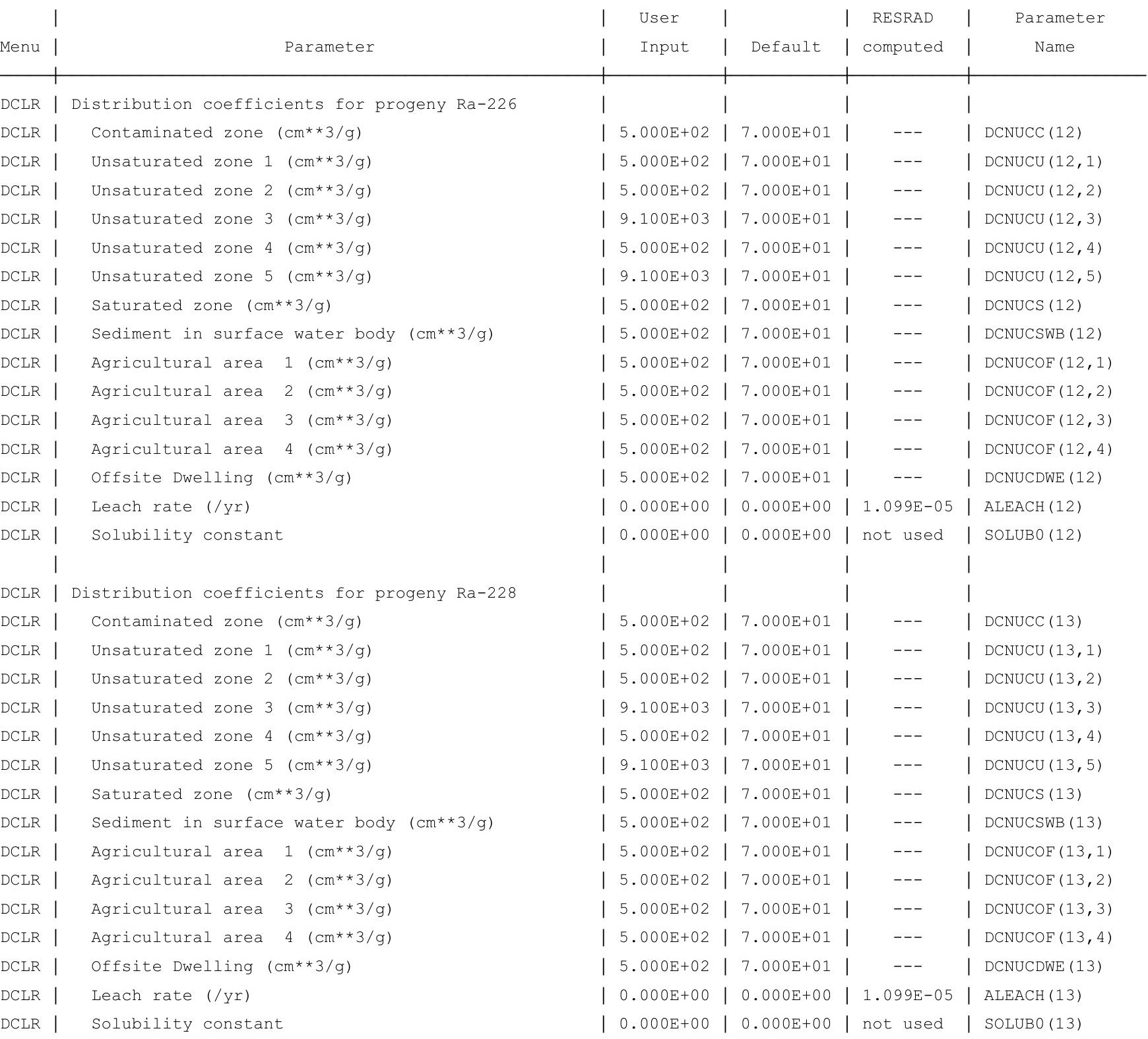


RESRAD-OFFSITE, Version $2.5 \quad \mathrm{~T}^{1 / 2}$ Limit $=180$ days

Parent Dose Report

Title : Offsite Resident Farmer Deterministic Run

File : RF DOE SG FWD-FV2-10000Y.ROF

Site-Specific Parameter Summary (continued)

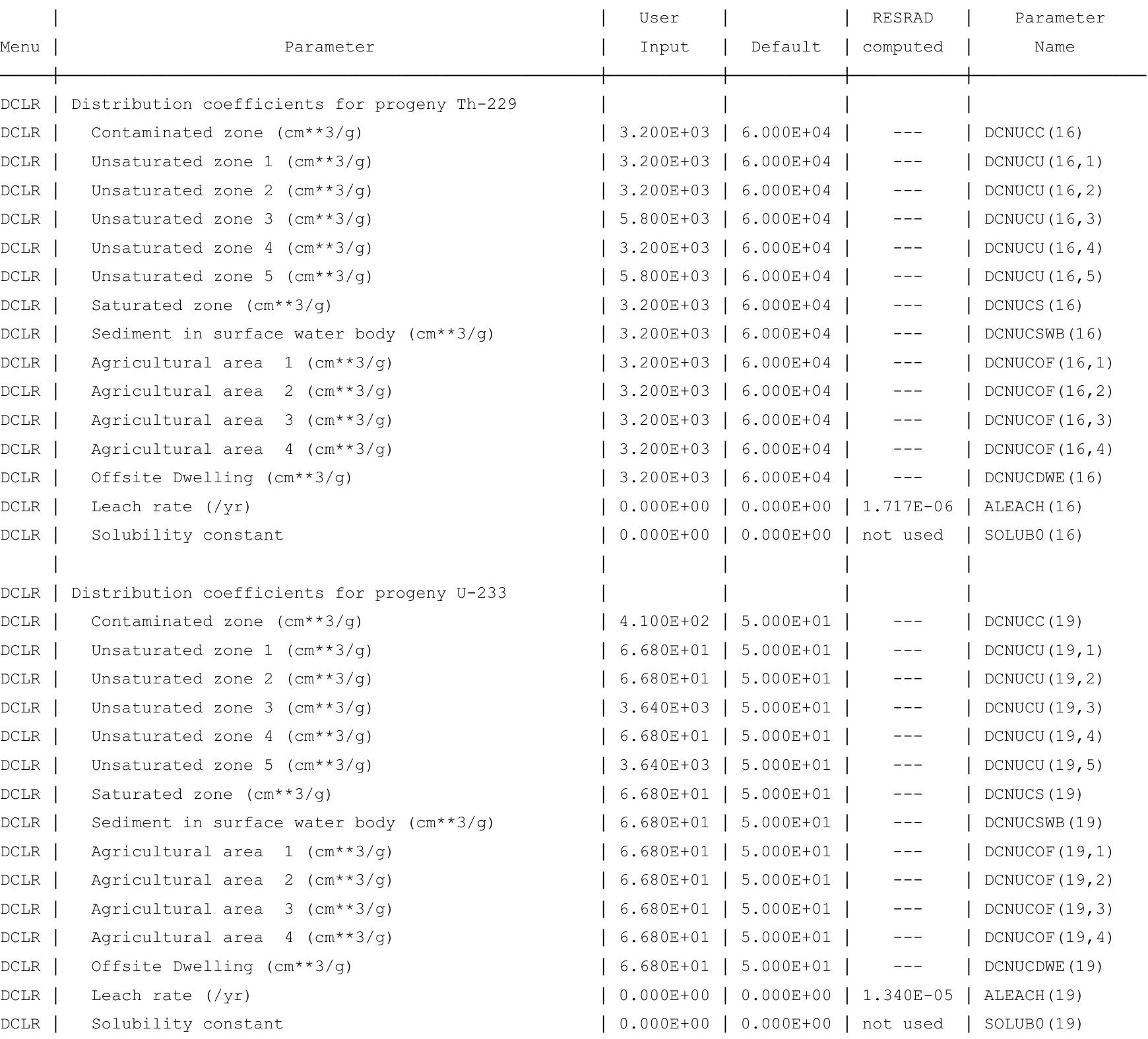


RESRAD-OFFSITE, Version 2.5

Parent Dose Report

Title : Offsite Resident Farmer Deterministic Run

File : RF DOE SG FWD-FV2-10000Y.ROF

Site-Specific Parameter Summary (continued)

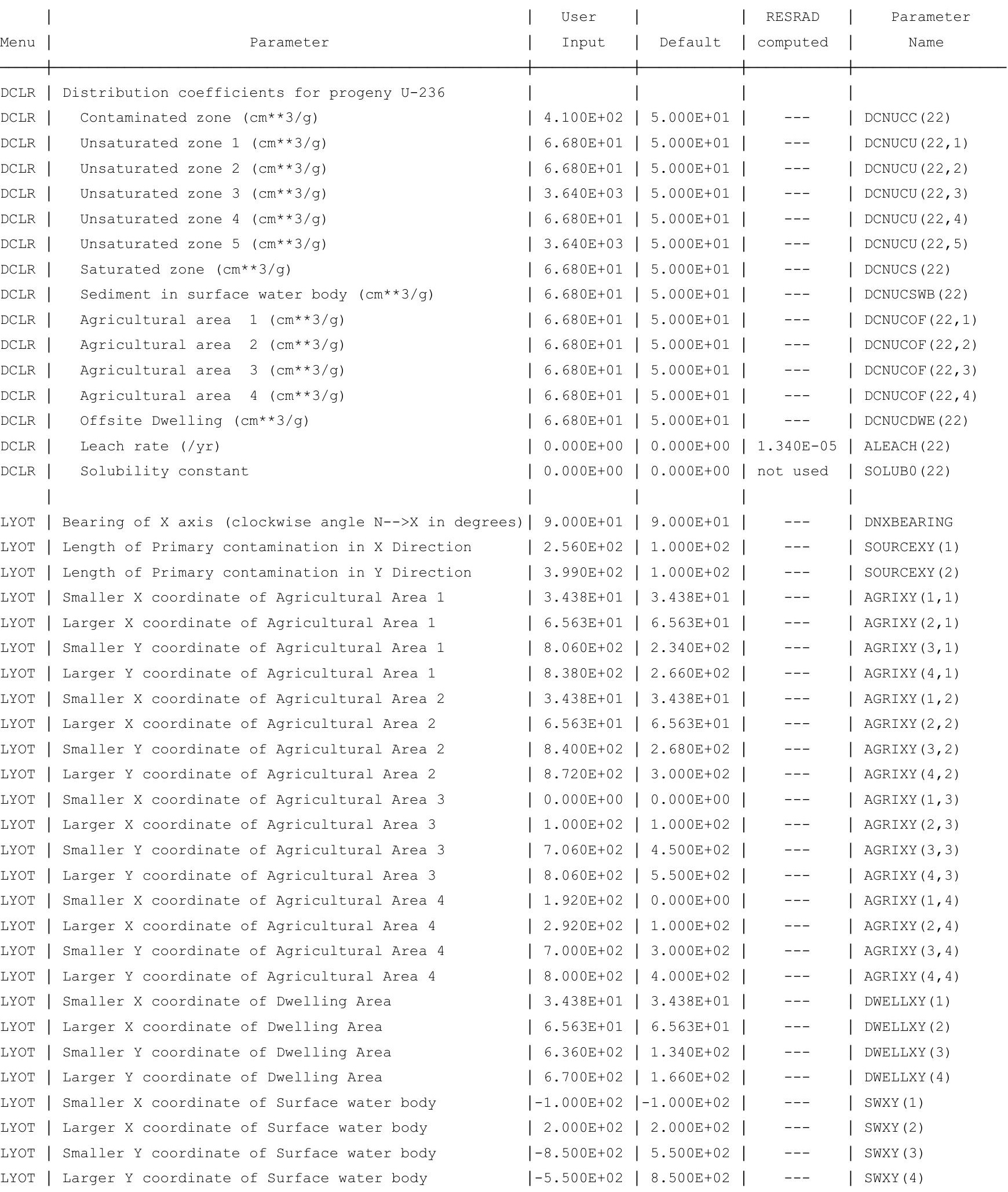


RESRAD-OFFSITE, Version 2.5

Parent Dose Report

Title : Offsite Resident Farmer Deterministic Run

File : RF DOE SG FWD-FV2-10000Y.ROF

Site-Specific Parameter Summary (continued)

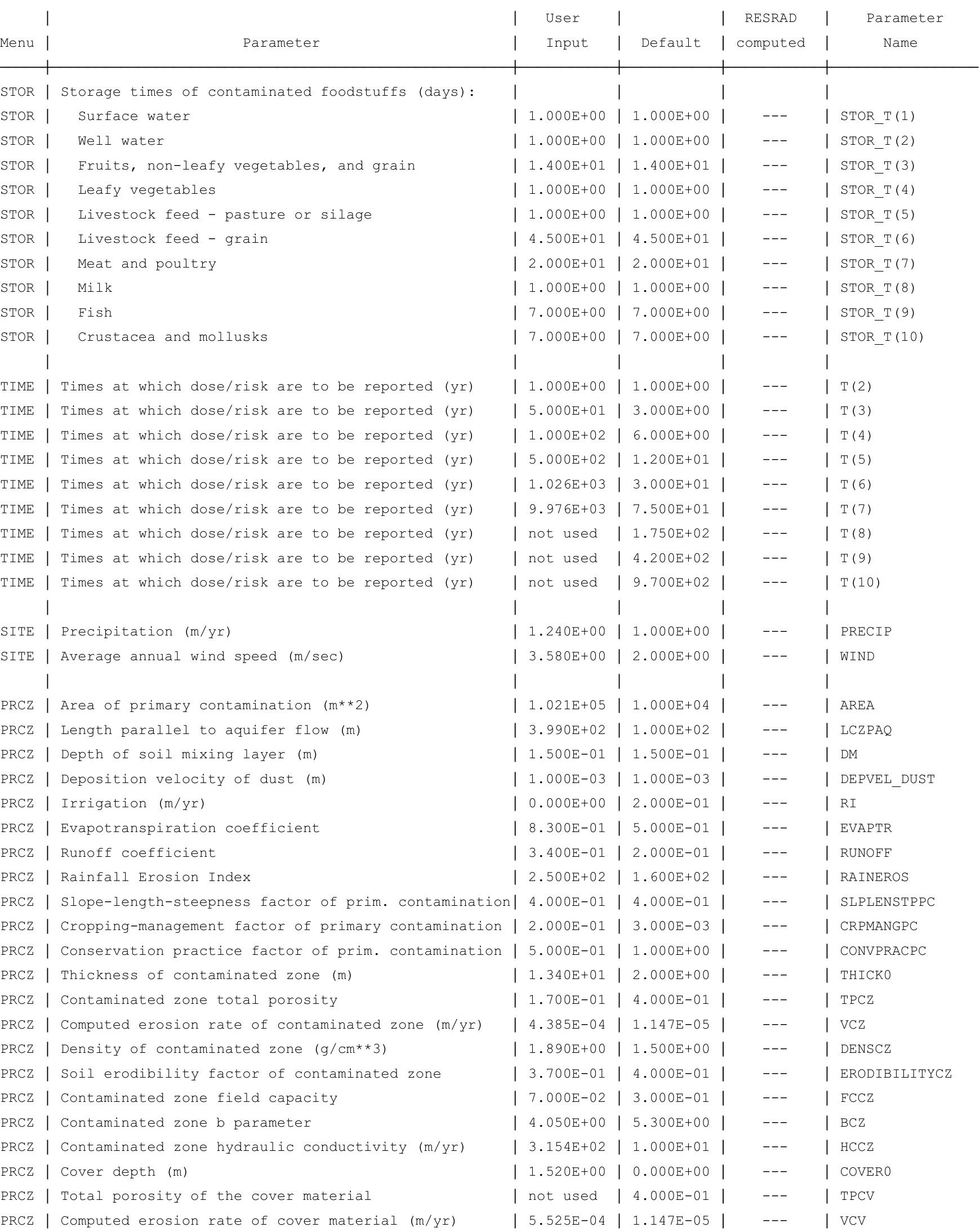


RESRAD-OFFSITE, Version $2.5 \quad \mathrm{~T}^{1 / 2}$ Limit $=180$ days

Title : Offsite Resident Farmer Deterministic Run

File : RF DOE SG FWD-FV2-10000Y.ROF

Site-Specific Parameter Summary (continued)

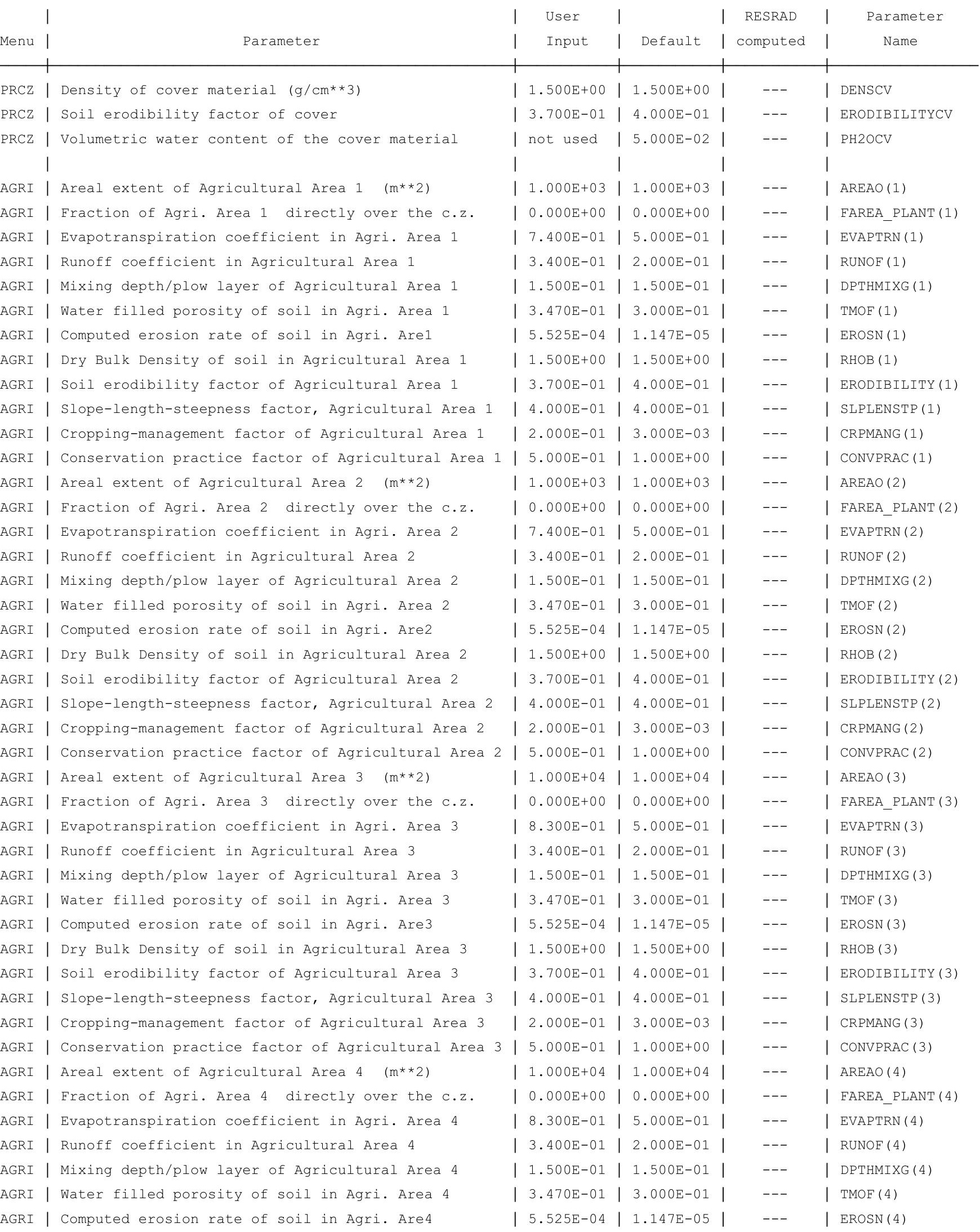


RESRAD-OFFSITE, Version 2.5

Parent Dose Report

Title : Offsite Resident Farmer Deterministic Run

File : RF DOE SG FWD-FV2-10000Y.ROF

Site-Specific Parameter Summary (continued)

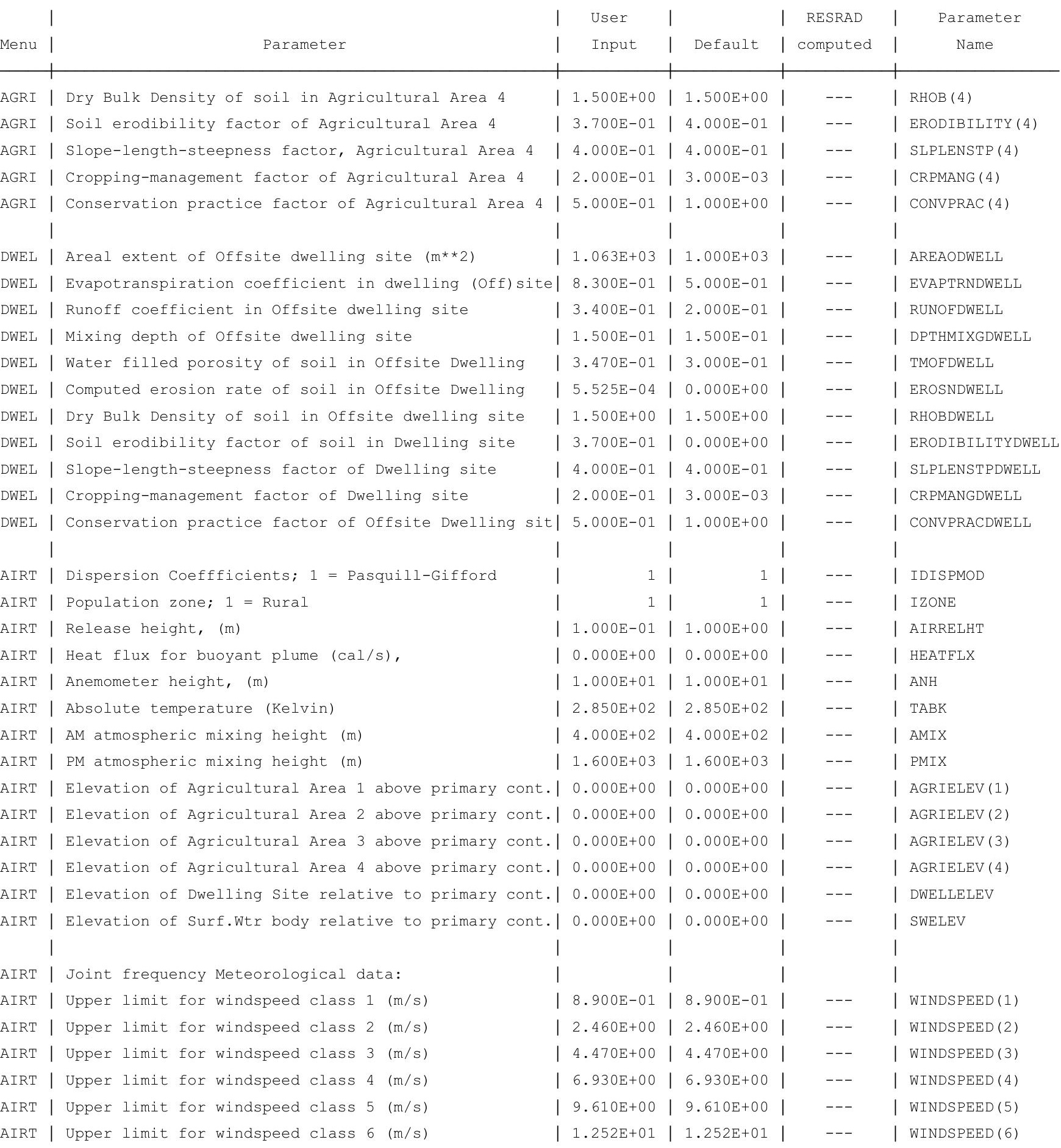


RESRAD-OFFSITE, Version 2.5

Parent Dose Report

Title : Offsite Resident Farmer Deterministic Run

File : RF DOE SG FWD-FV2-10000Y.ROF

Site-Specific Parameter Summary (continued)

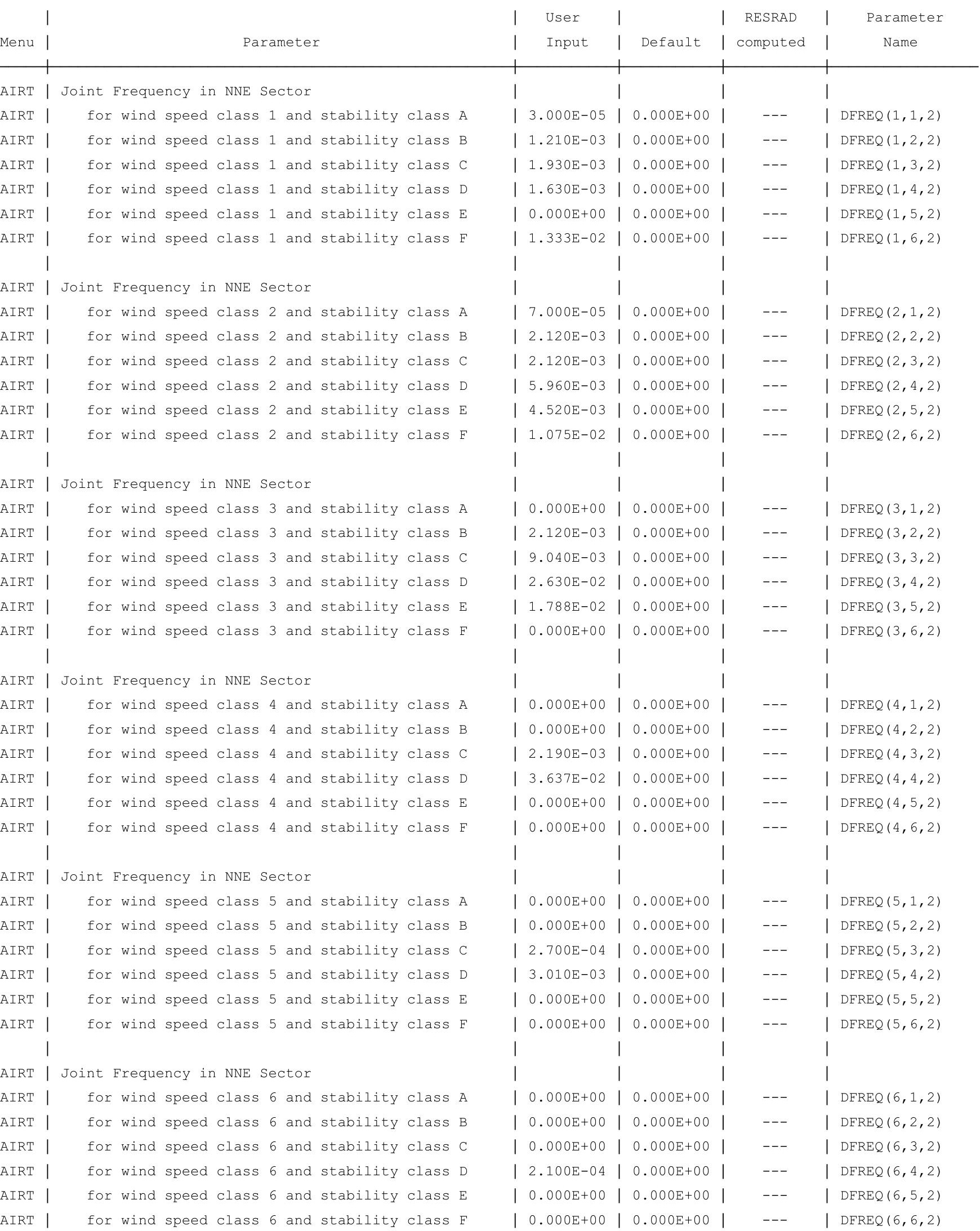


RESRAD-OFFSITE, Version 2.5

Parent Dose Report

Title : Offsite Resident Farmer Deterministic Run

File : RF DOE SG FWD-FV2-10000Y.ROF

Site-Specific Parameter Summary (continued)

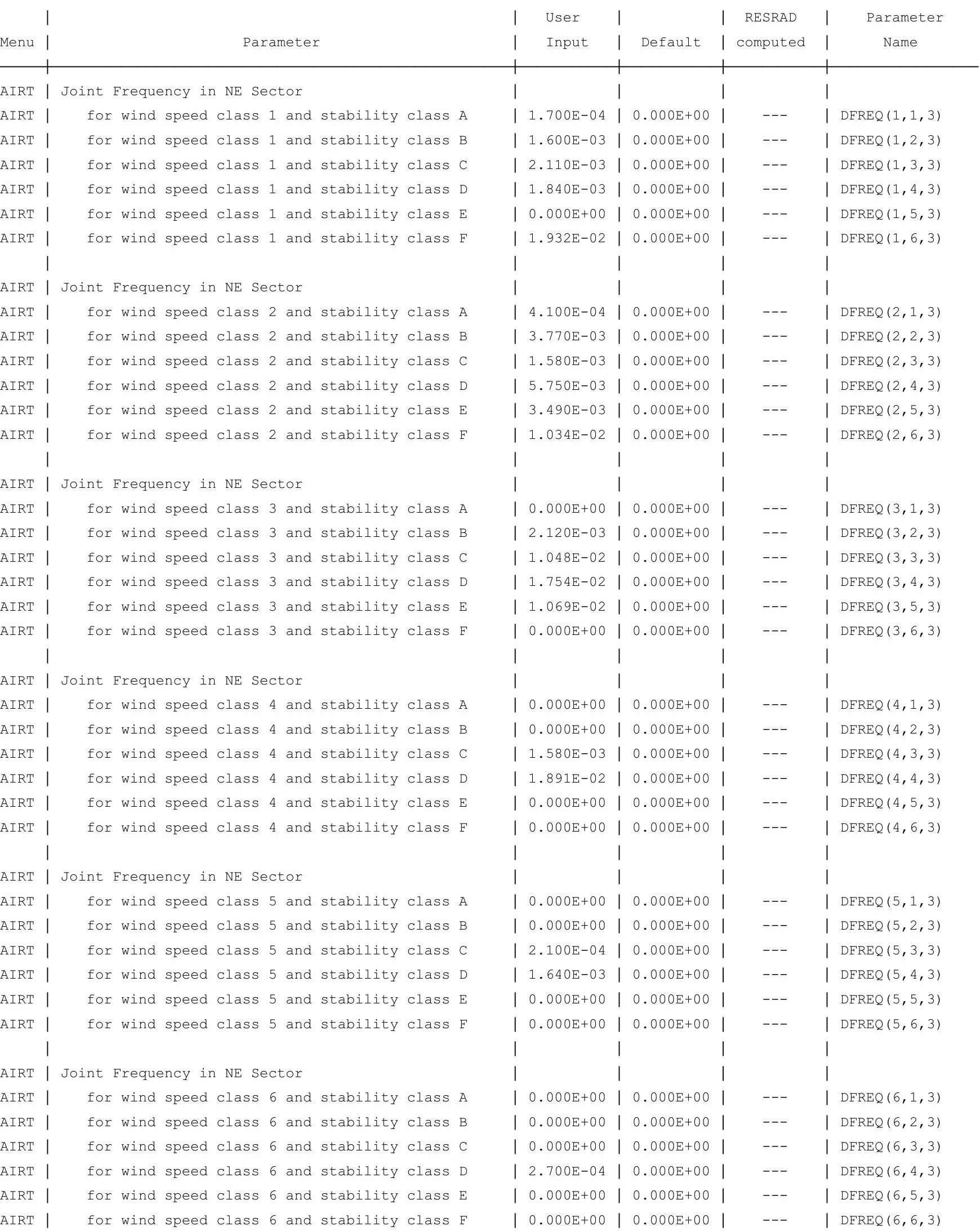


RESRAD-OFFSITE, Version 2.5

Parent Dose Report

Title : Offsite Resident Farmer Deterministic Run

File : RF DOE SG FWD-FV2-10000Y.ROF

Site-Specific Parameter Summary (continued)

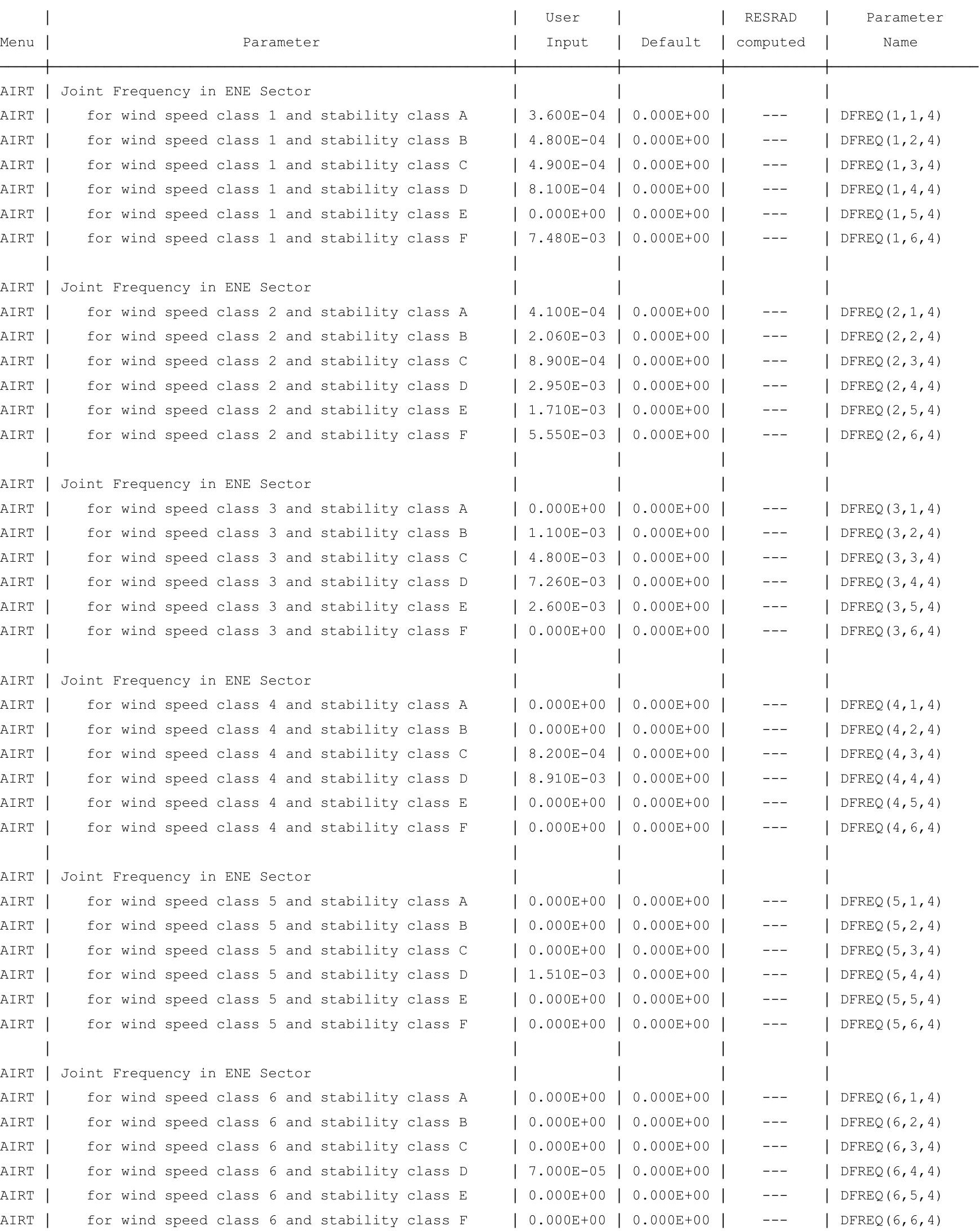


RESRAD-OFFSITE, Version 2.5

arent Dose Report

Title : Offsite Resident Farmer Deterministic Run

File : RF DOE SG FWD-FV2-10000Y.ROF

Site-Specific Parameter Summary (continued)

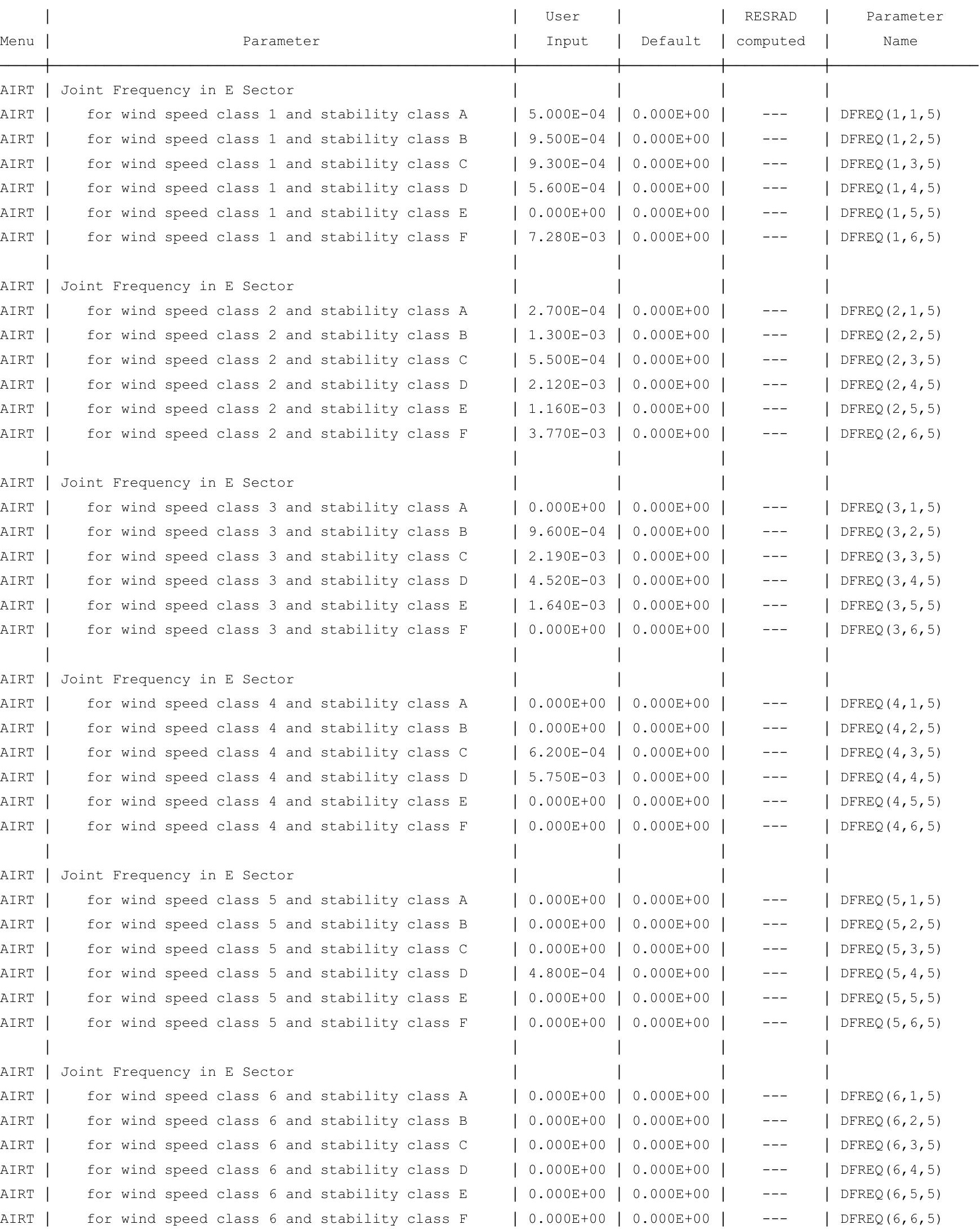


RESRAD-OFFSITE, Version 2.5

Parent Dose Report

Title : Offsite Resident Farmer Deterministic Run

File : RF DOE SG FWD-FV2-10000Y.ROF

Site-Specific Parameter Summary (continued)

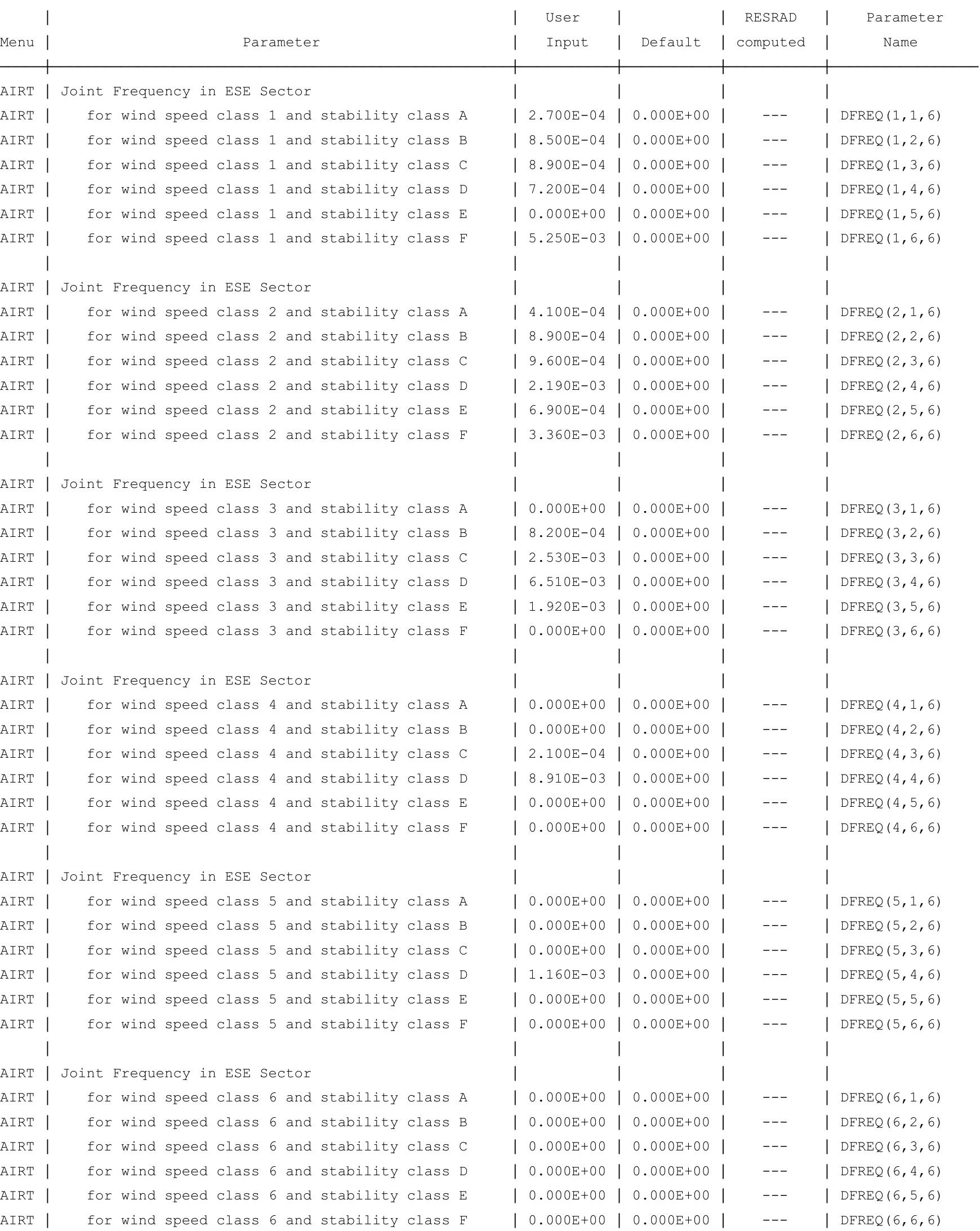


RESRAD-OFFSITE, Version 2.5

Parent Dose Report

Title : Offsite Resident Farmer Deterministic Run

File : RF DOE SG FWD-FV2-10000Y.ROF

Site-Specific Parameter Summary (continued)

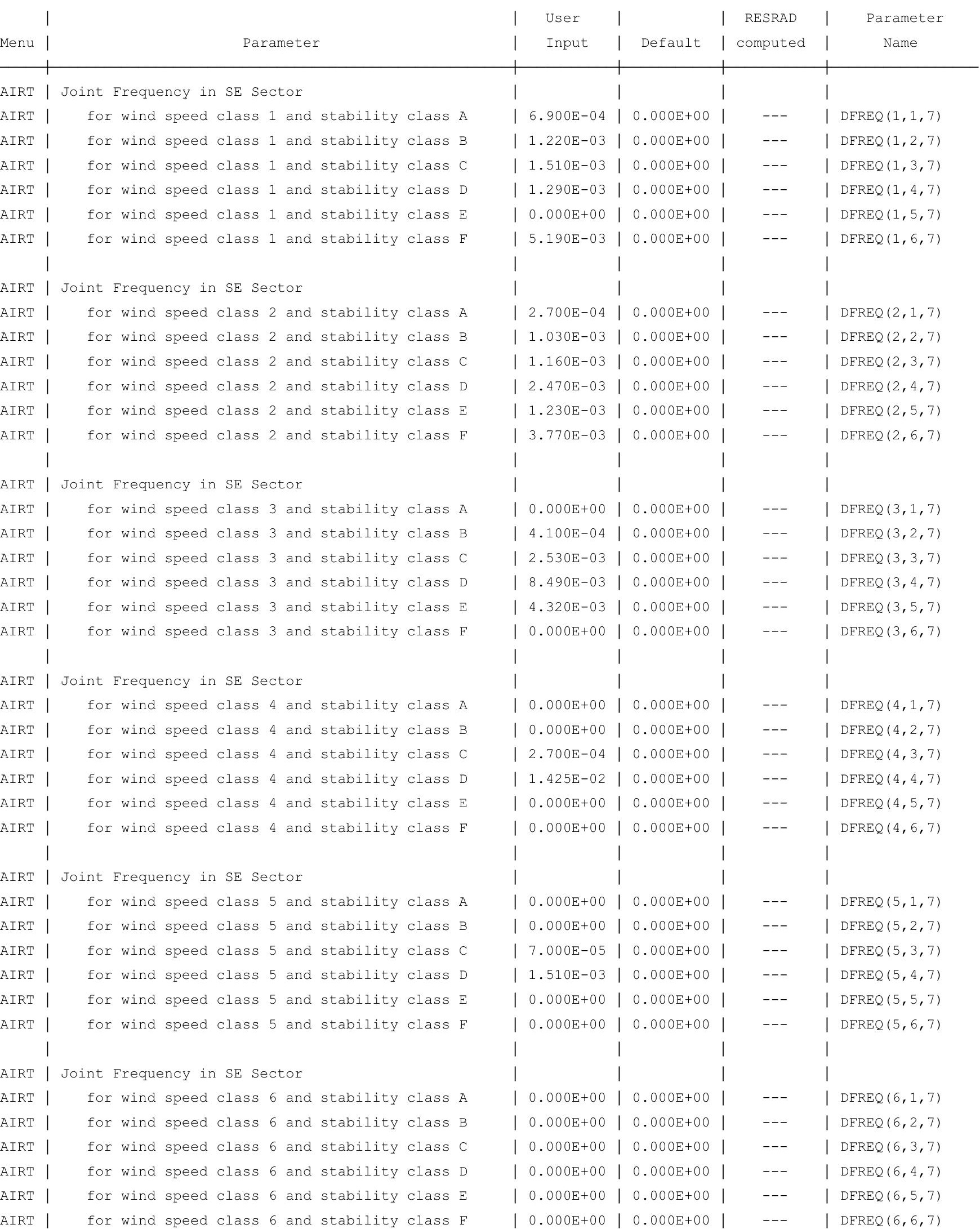


RESRAD-OFFSITE, Version 2.5

Parent Dose Report

Title : Offsite Resident Farmer Deterministic Run

File : RF DOE SG FWD-FV2-10000Y.ROF

Site-Specific Parameter Summary (continued)

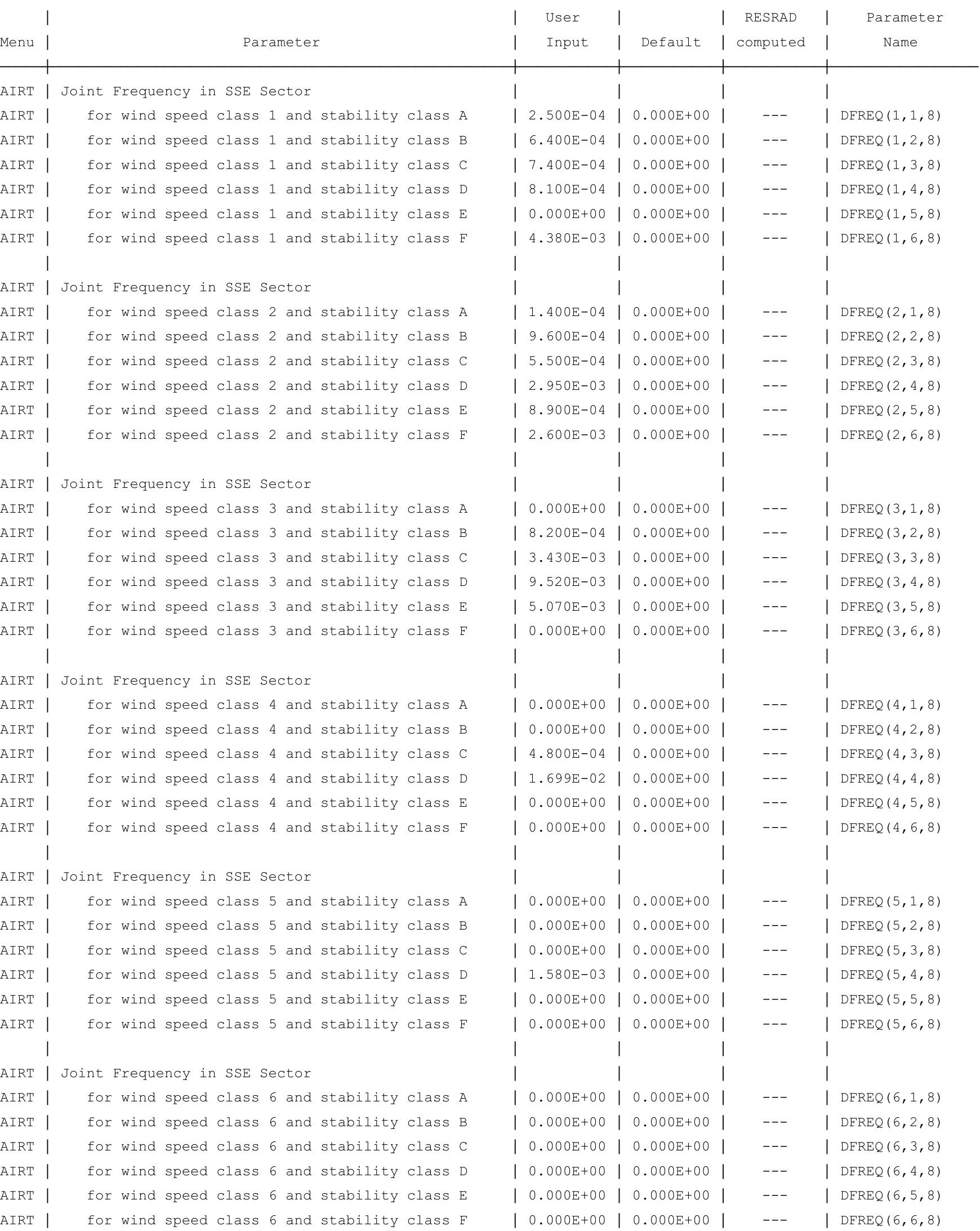


RESRAD-OFFSITE, Version 2.5

Parent Dose Report

Title : Offsite Resident Farmer Deterministic Run

File : RF DOE SG FWD-FV2-10000Y.ROF

Site-Specific Parameter Summary (continued)

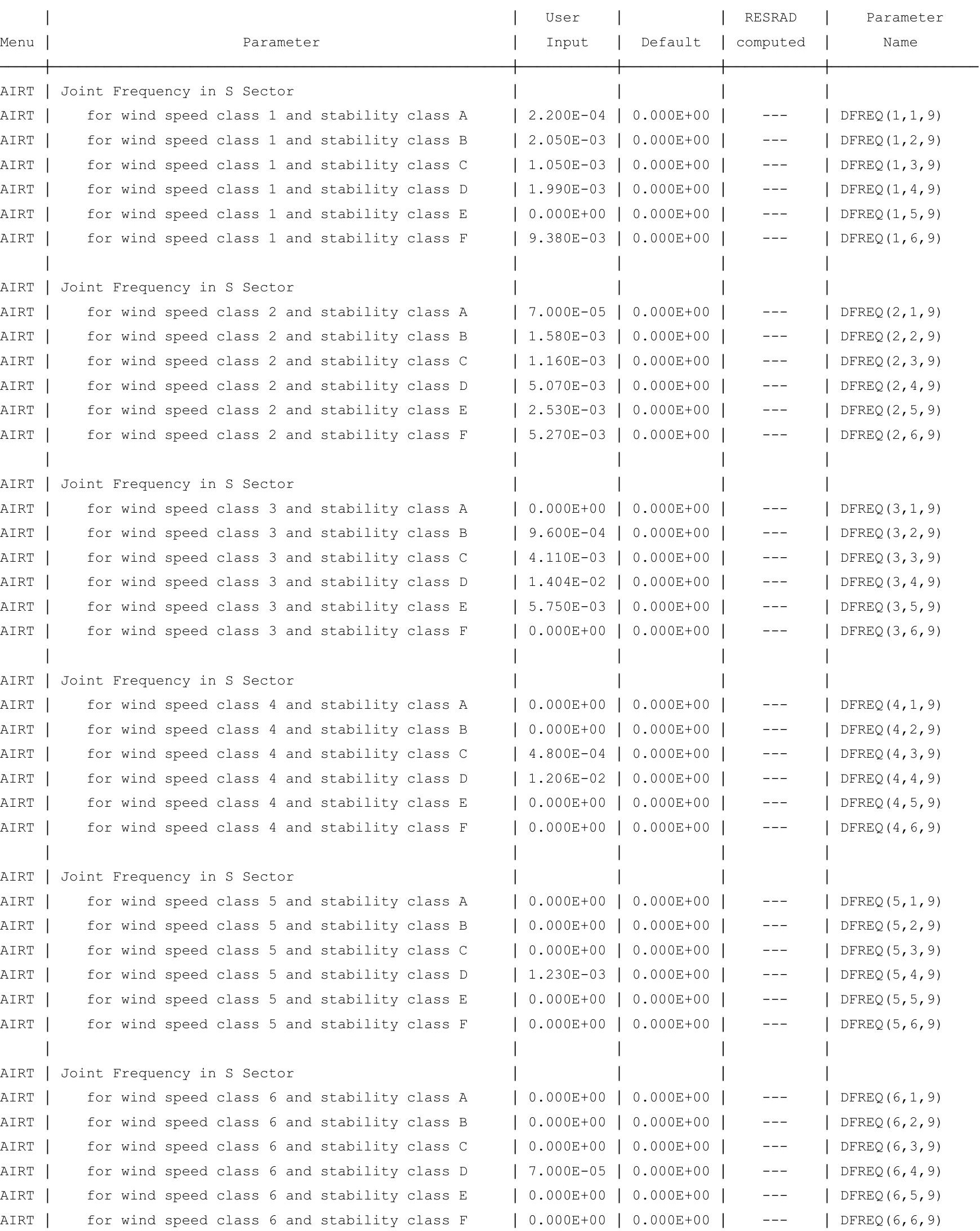


RESRAD-OFFSITE, Version 2.5

Parent Dose Report

Title : Offsite Resident Farmer Deterministic Run

File : RF DOE SG FWD-FV2-10000Y.ROF

Site-Specific Parameter Summary (continued)

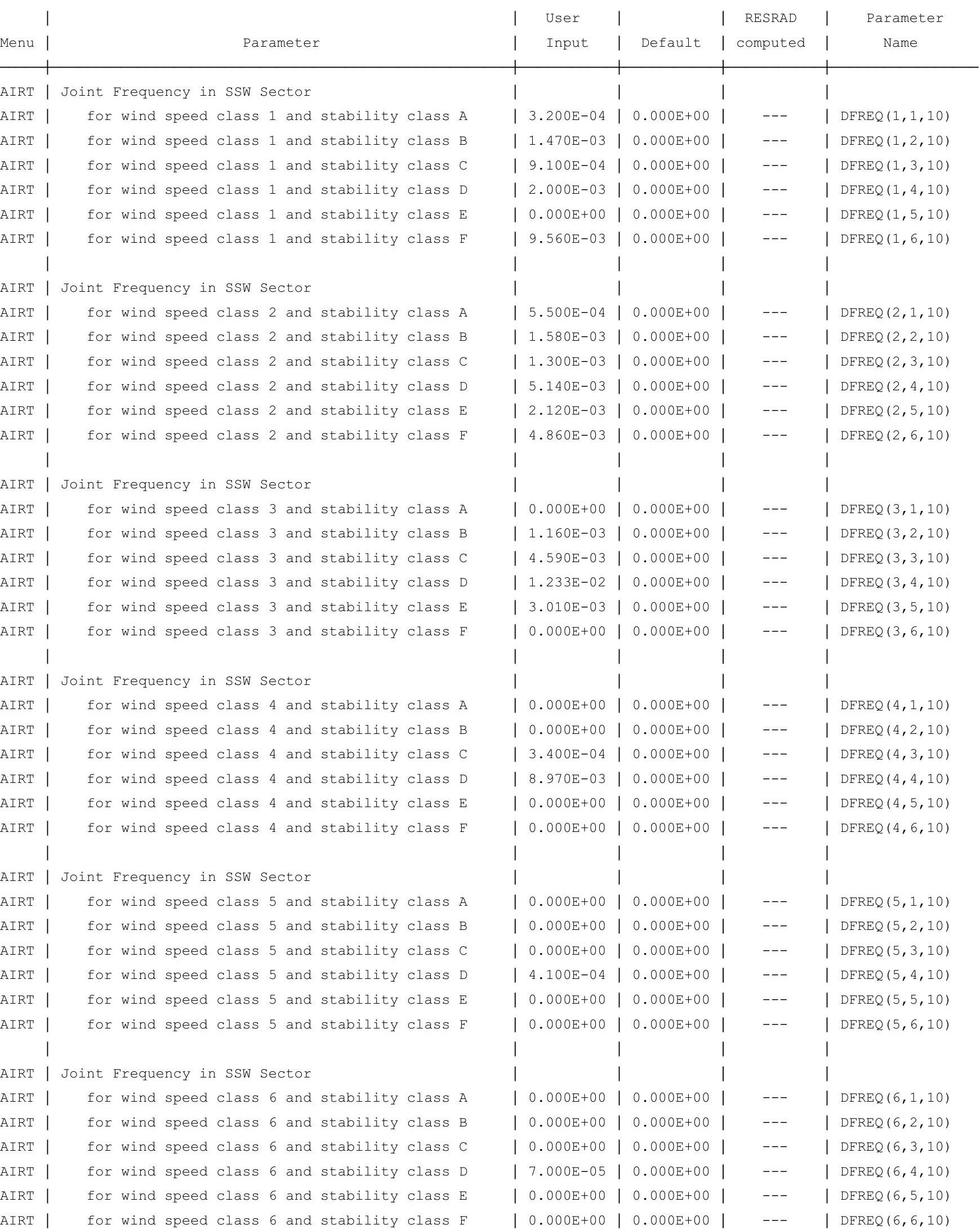


RESRAD-OFFSITE, Version 2.

Parent Dose Report

Title : Offsite Resident Farmer Deterministic Run

File : RF DOE SG FWD-FV2-10000Y.ROF

Site-Specific Parameter Summary (continued)

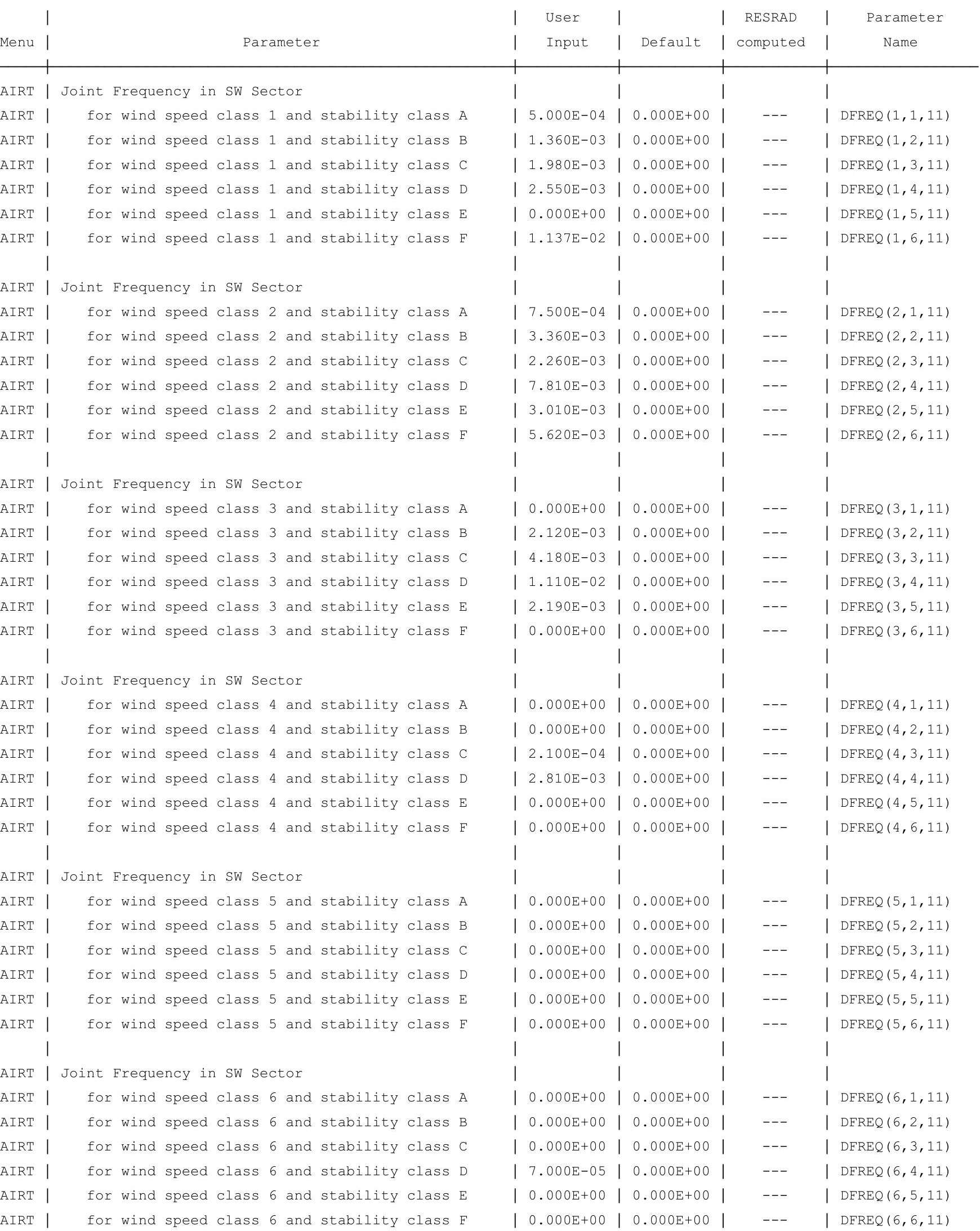


RESRAD-OFFSITE, Version 2.5

Parent Dose Report

Title : Offsite Resident Farmer Deterministic Run

File : RF DOE SG FWD-FV2-10000Y.ROF

Site-Specific Parameter Summary (continued)

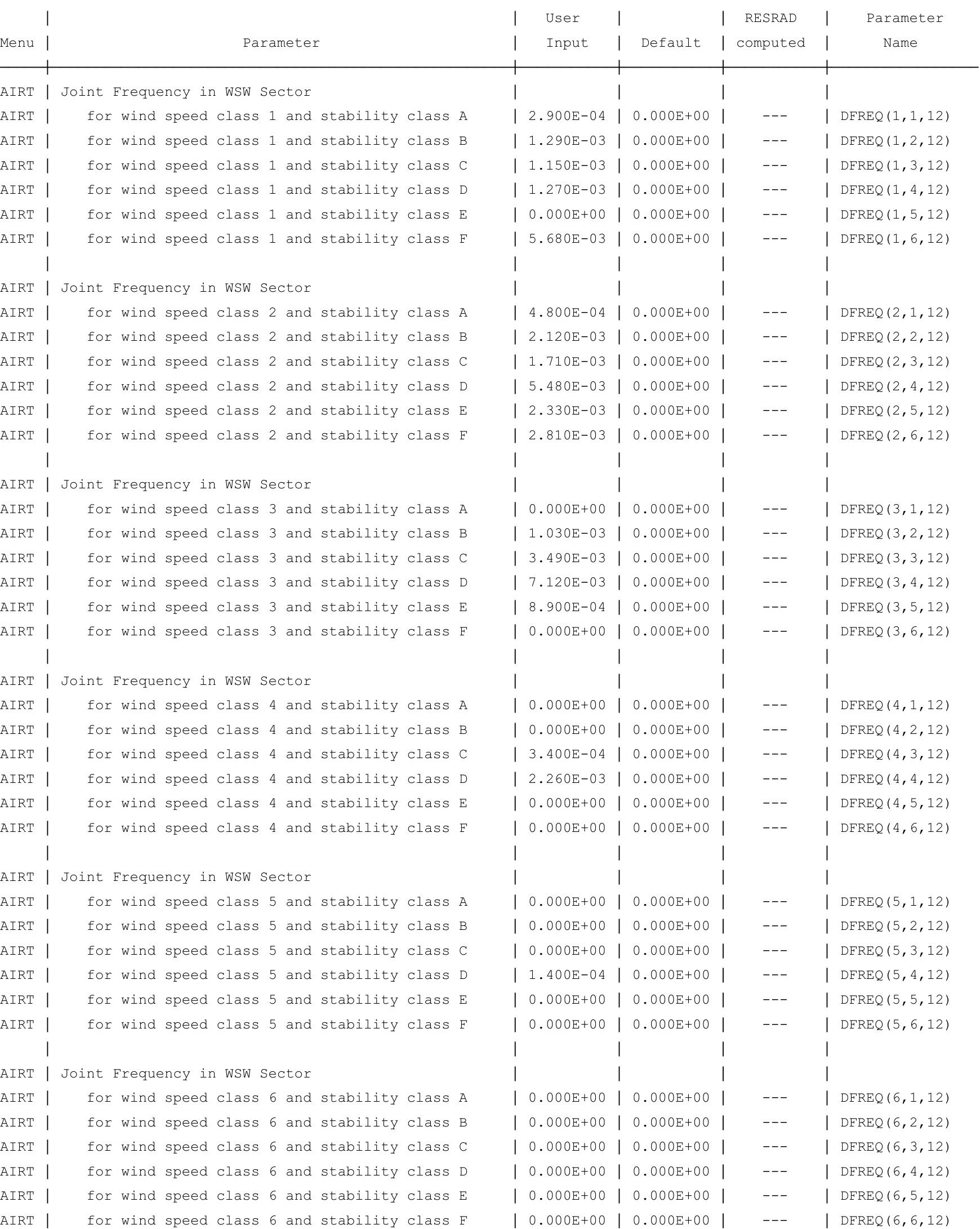


RESRAD-OFFSITE, Version 2.5

Parent Dose Report

Title : Offsite Resident Farmer Deterministic Run

File : RF DOE SG FWD-FV2-10000Y.ROF

Site-Specific Parameter Summary (continued)

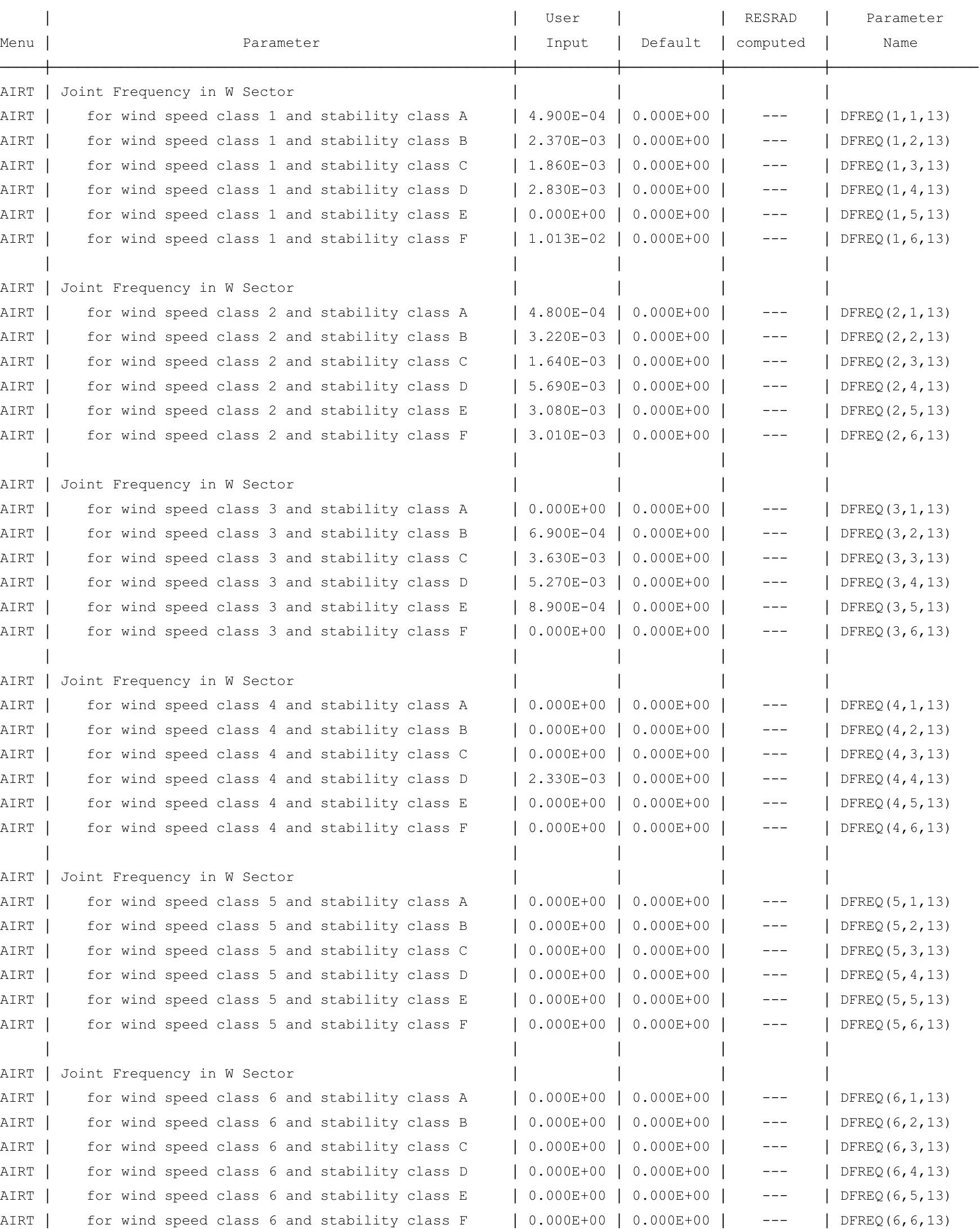


RESRAD-OFFSITE, Version 2.5

Parent Dose Report

Title : Offsite Resident Farmer Deterministic Run

File : RF DOE SG FWD-FV2-10000Y.ROF

Site-Specific Parameter Summary (continued)

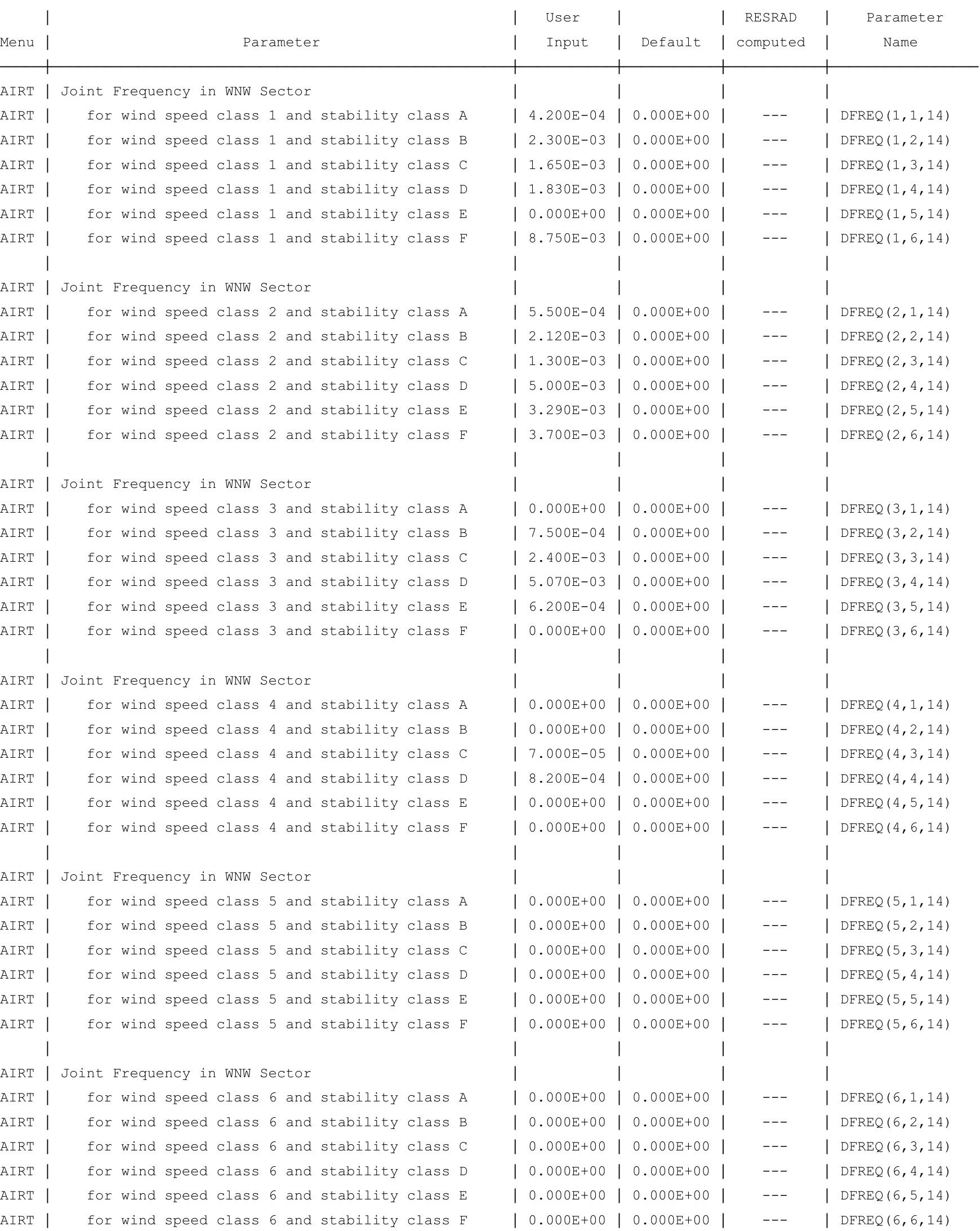


RESRAD-OFFSITE, Version 2.

Parent Dose Report

Title : Offsite Resident Farmer Deterministic Run

File : RF DOE SG FWD-FV2-10000Y.ROF

Site-Specific Parameter Summary (continued)

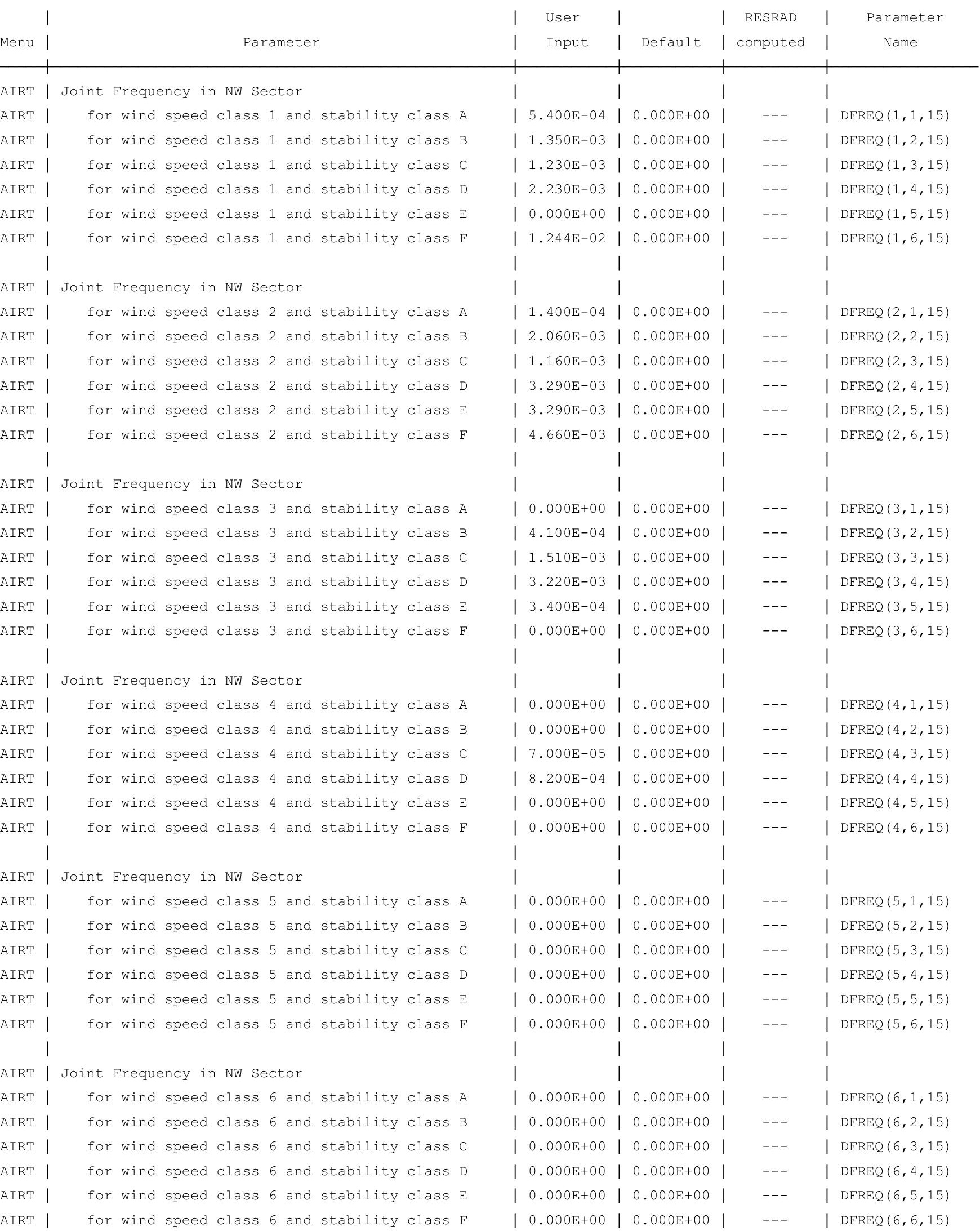


RESRAD-OFFSITE, Version 2.5

Parent Dose Report

Title : Offsite Resident Farmer Deterministic Run

File : RF DOE SG FWD-FV2-10000Y.ROF

Site-Specific Parameter Summary (continued)

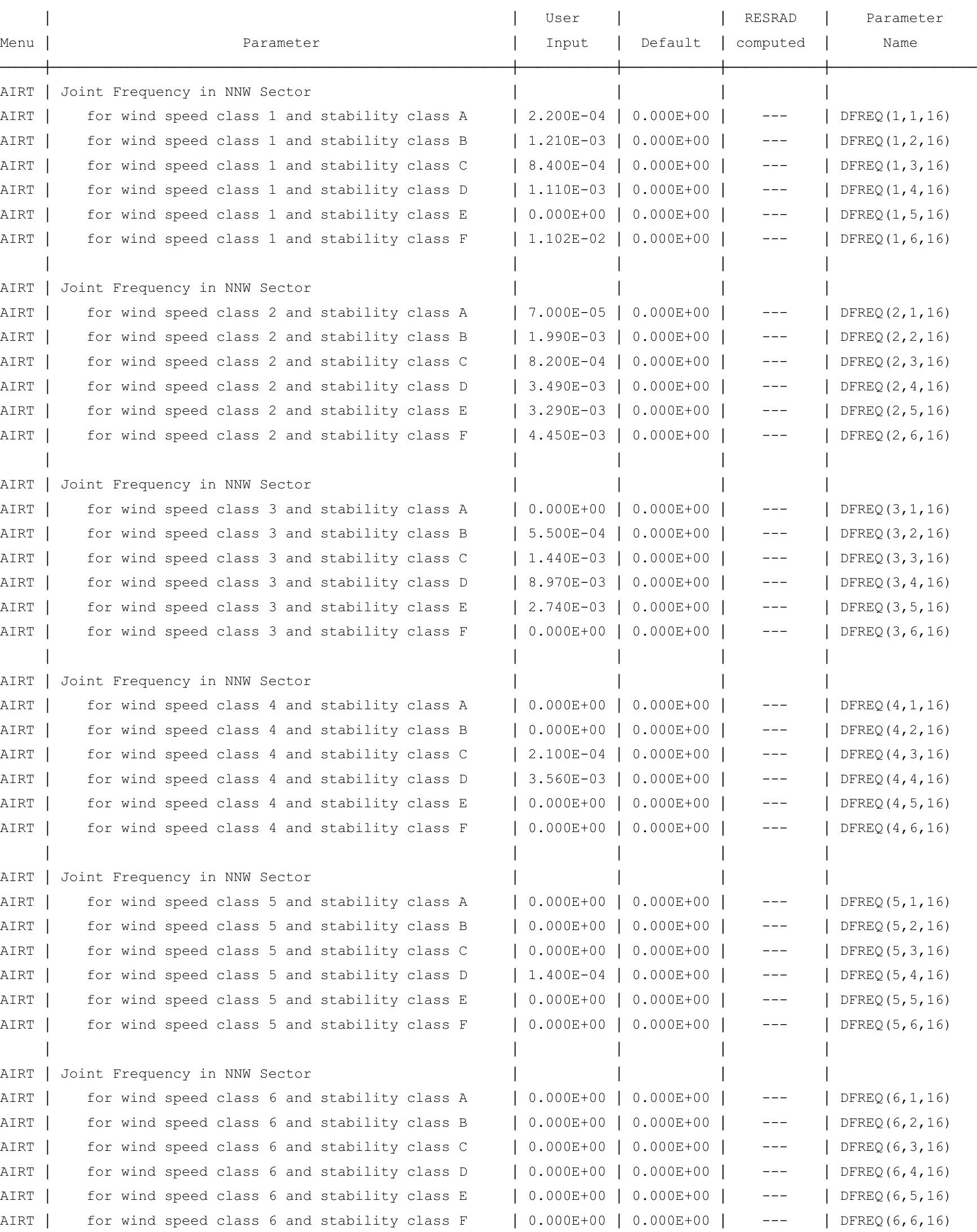


RESRAD-OFFSITE, Version 2.5

Parent Dose Report

Title : Offsite Resident Farmer Deterministic Run

File : RF DOE SG FWD-FV2-10000Y.ROF

Site-Specific Parameter Summary (continued)

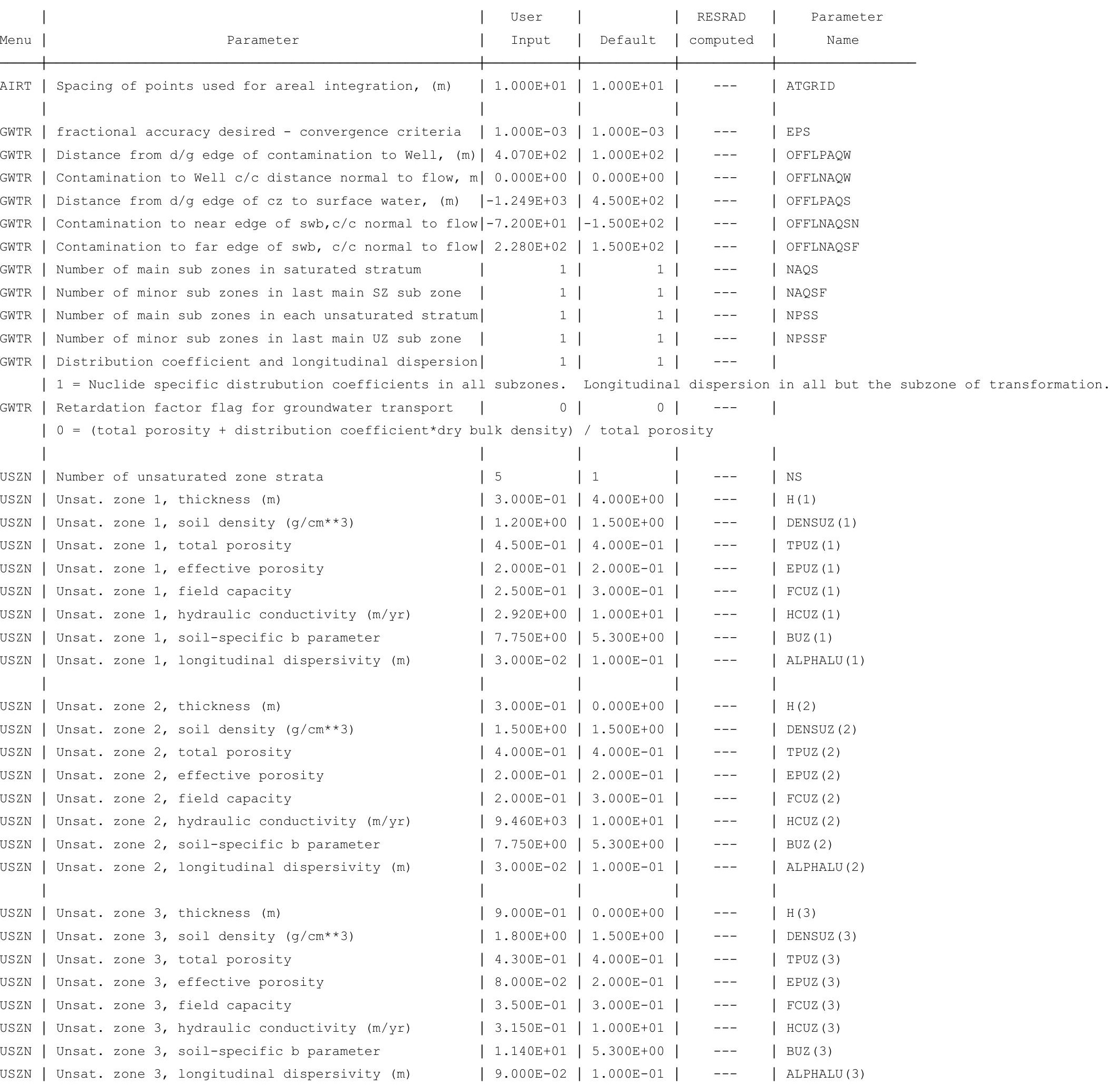


RESRAD-OFFSITE, Version 2.5

Parent Dose Report

Title : Offsite Resident Farmer Deterministic Run

File : RF DOE SG FWD-FV2-10000Y.ROF

Site-Specific Parameter Summary (continued)

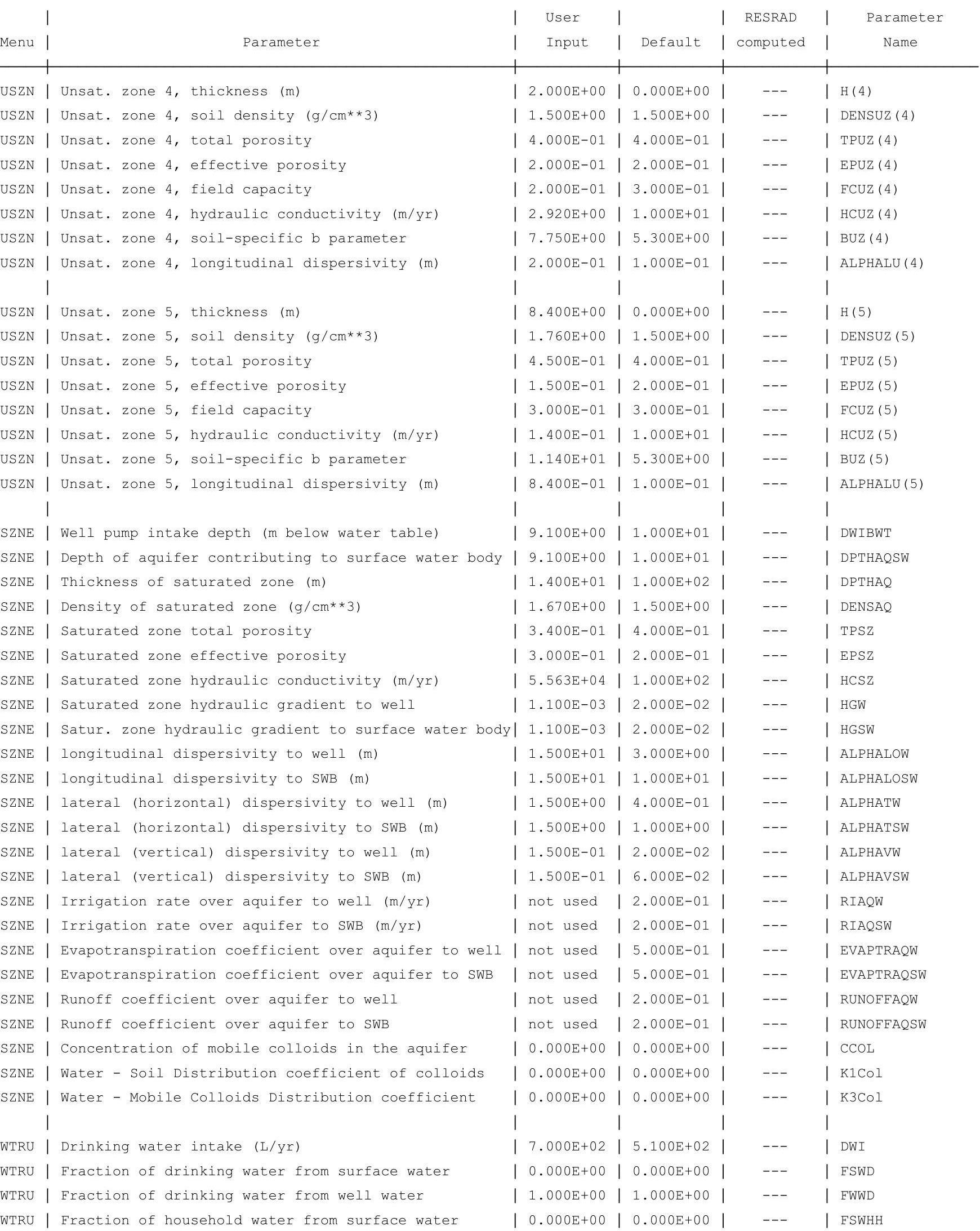


RESRAD-OFFSITE, Version 2.5

Parent Dose Report

Title : Offsite Resident Farmer Deterministic Run

File : RF DOE SG FWD-FV2-10000Y.ROF

Site-Specific Parameter Summary (continued)

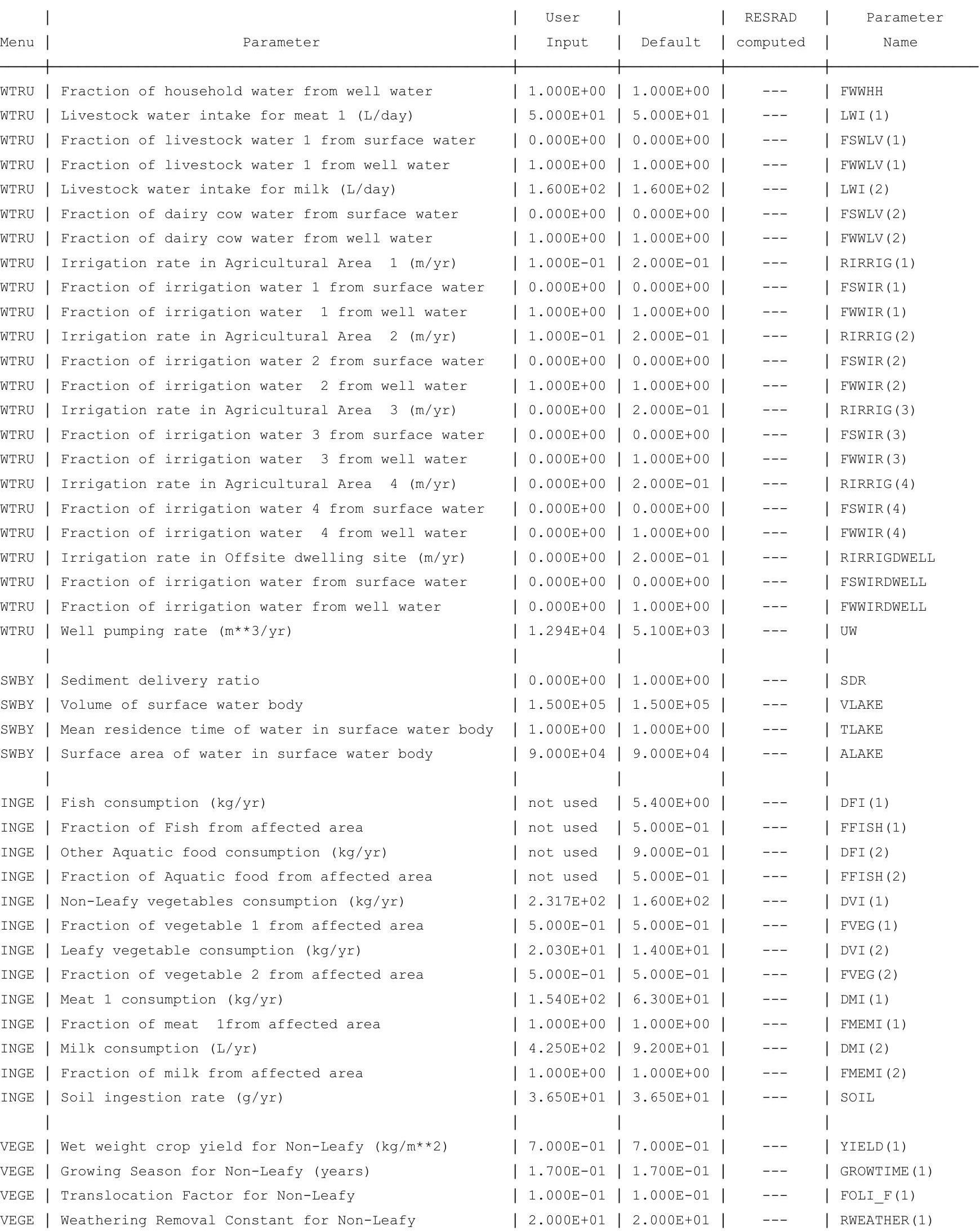


RESRAD-OFFSITE, Version 2.5

Parent Dose Report

Title : Offsite Resident Farmer Deterministic Run

File : RF DOE SG FWD-FV2-10000Y.ROF

Site-Specific Parameter Summary (continued)

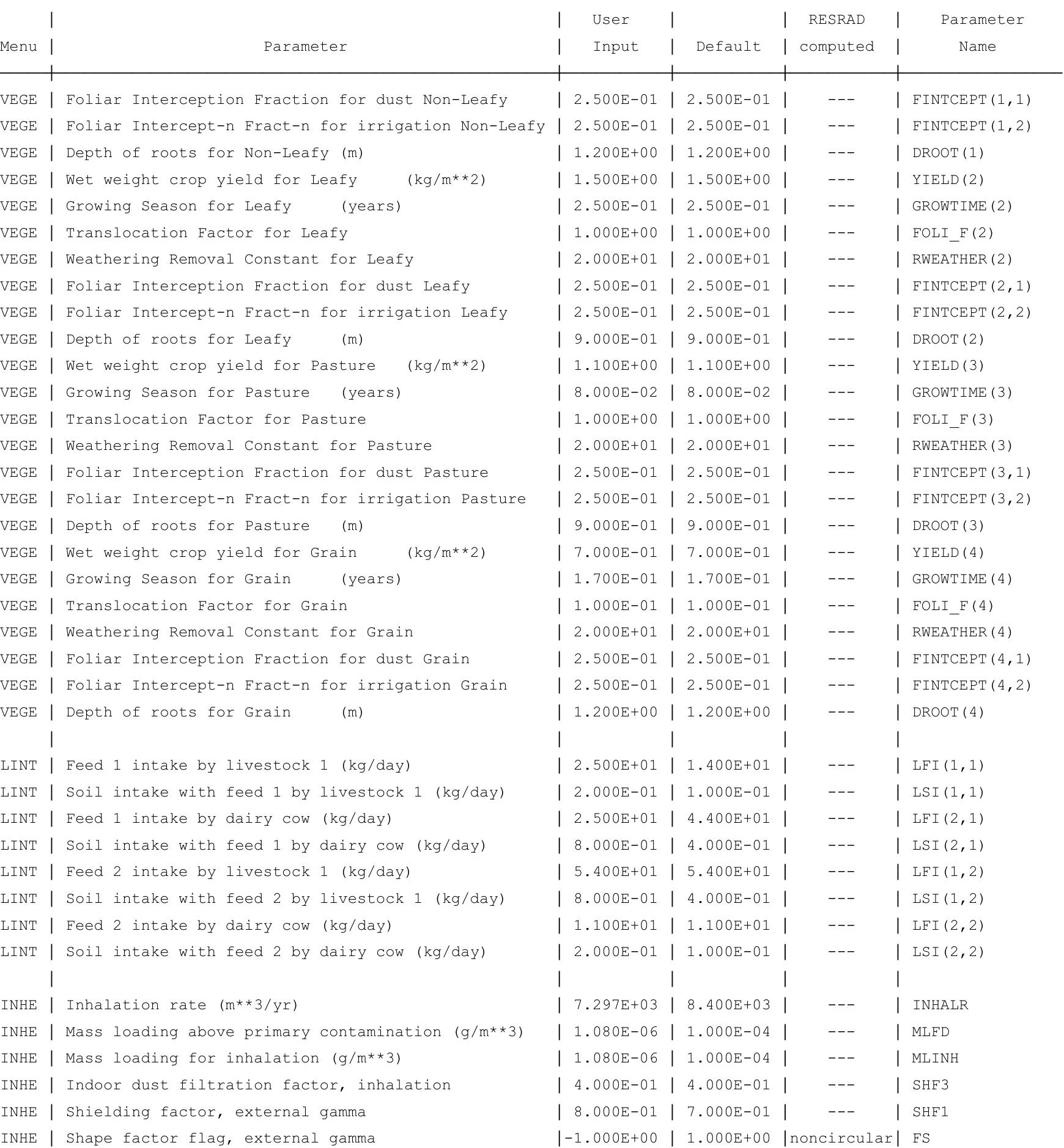


RESRAD-OFFSITE, Version $2.5 \quad \mathrm{~T}^{1 / 2}$ Limit $=180$ days

Parent Dose Report

Title : Offsite Resident Farmer Deterministic Run

File : RF DOE SG FWD-FV2-10000Y.ROF

Site-Specific Parameter Summary (continued)

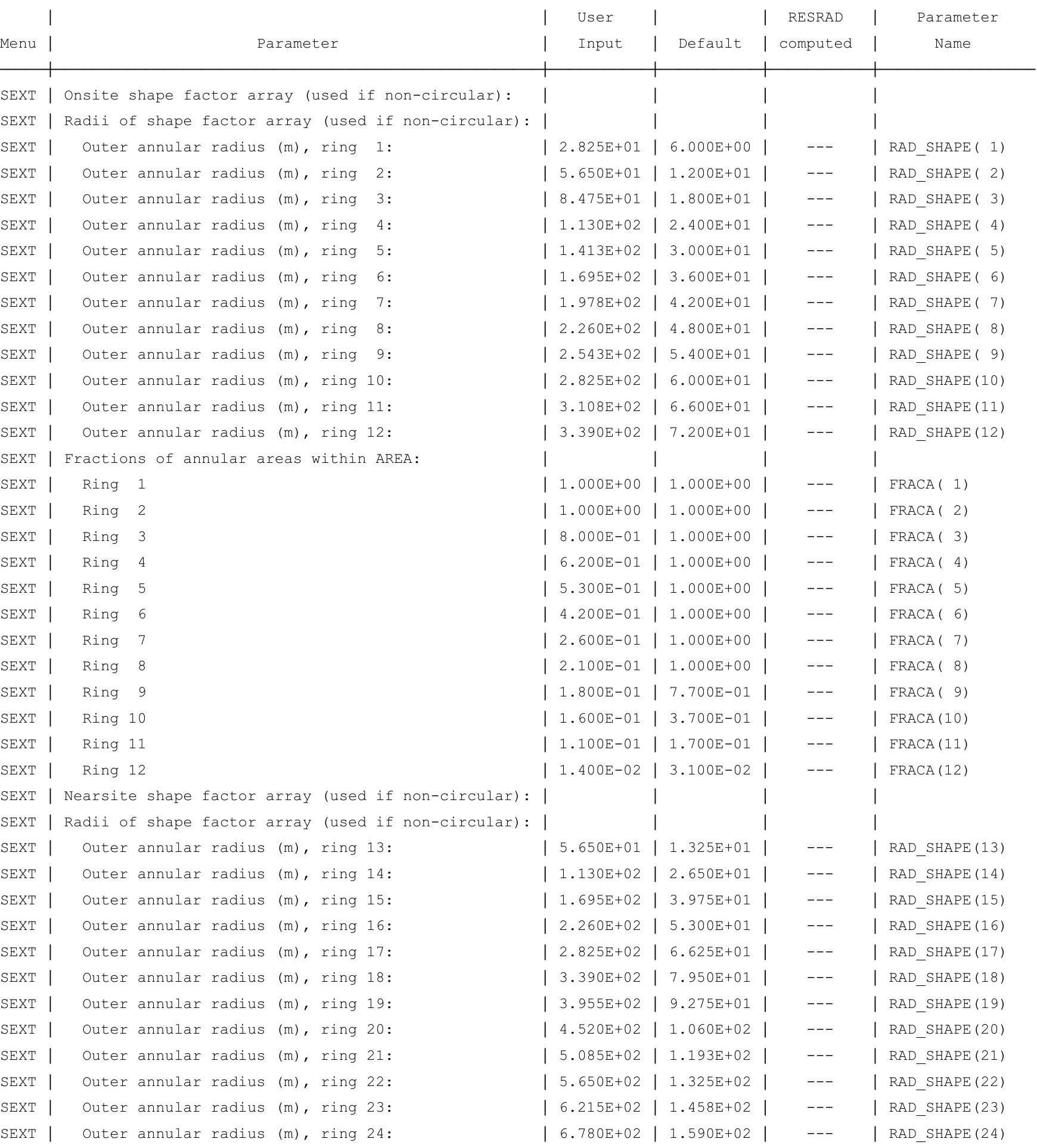


RESRAD-OFFSITE, Version $2.5 \quad \mathrm{~T}^{1 / 2}$ Limit $=180$ days

Parent Dose Report

Title : Offsite Resident Farmer Deterministic Run

File : RF DOE SG FWD-FV2-10000Y.ROF

Site-Specific Parameter Summary (continued)

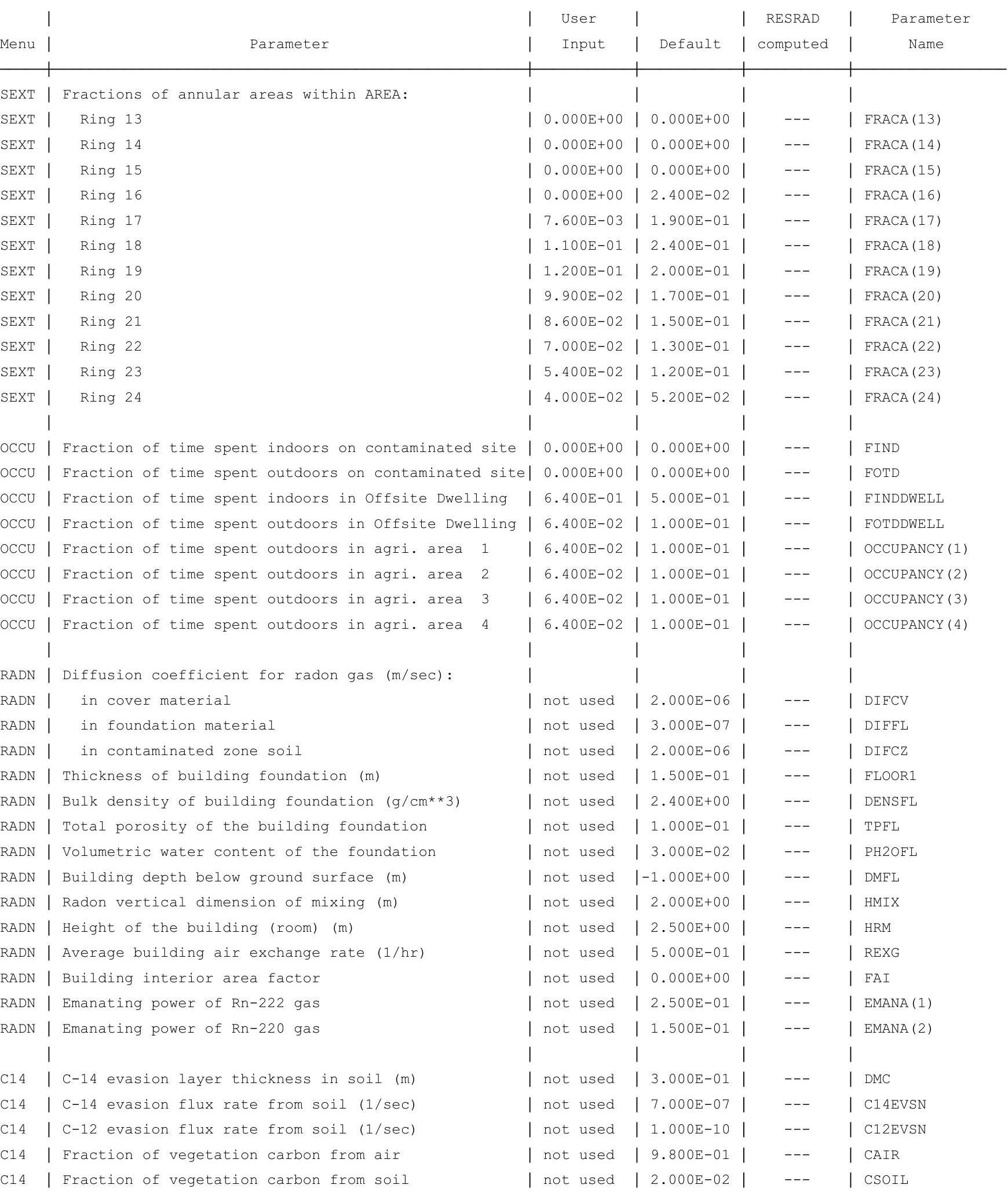


RESRAD-OFFSITE, Version 2.5

Parent Dose Report

Title : Offsite Resident Farmer Deterministic Run

File : RF DOE SG FWD-FV2-10000Y.ROF

Site-Specific Parameter Summary (continued)

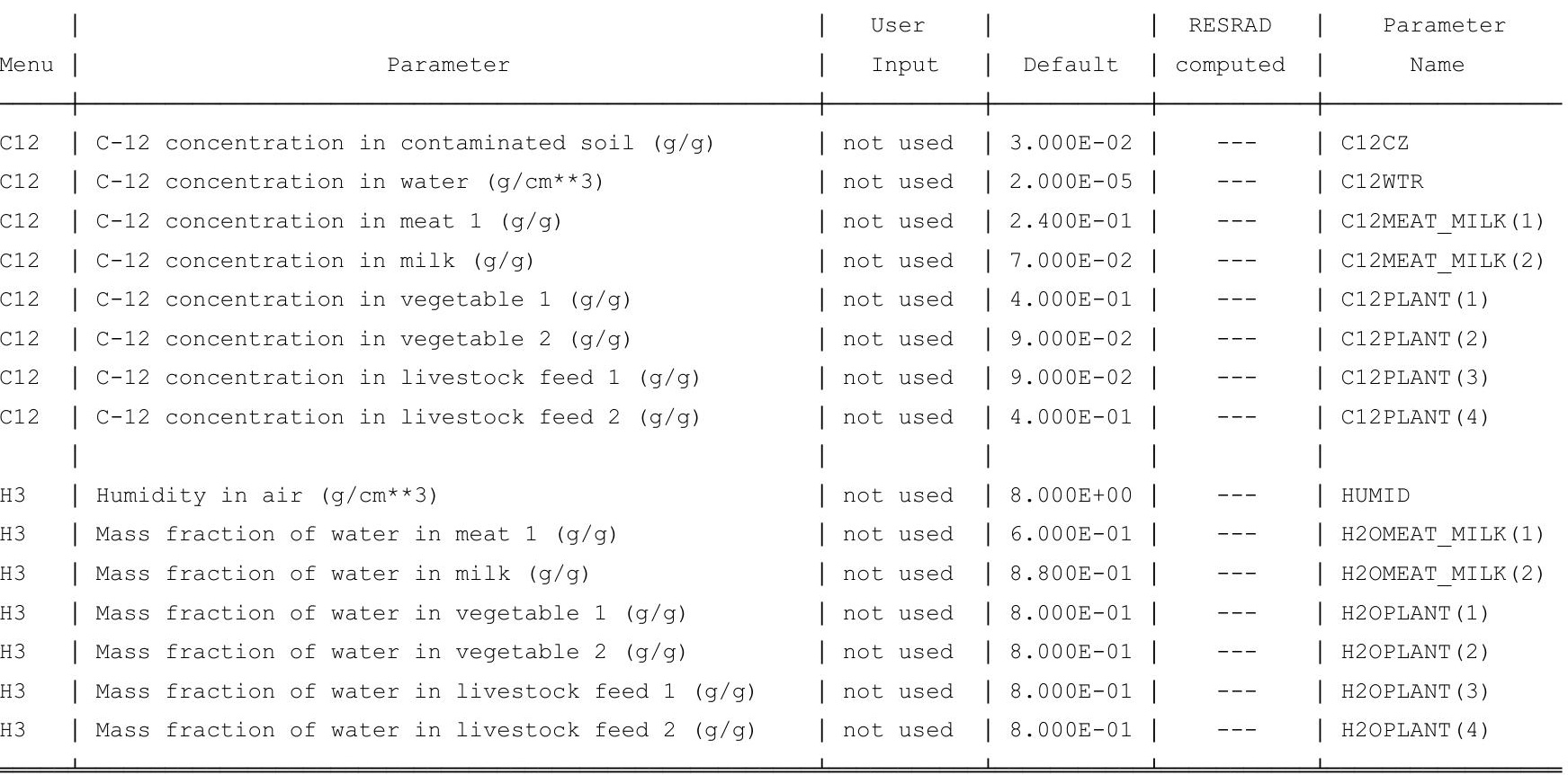

Summary of Pathway Selections

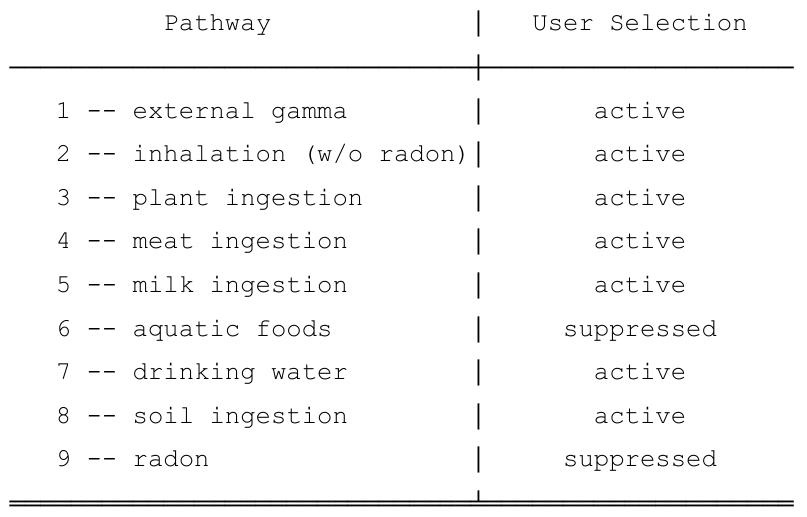


RESRAD-OFFSITE, Version $2.5 \quad \mathrm{~T}^{1 / 2}$ Limit $=180$ days

Parent Dose Report

Title : Offsite Resident Farmer Deterministic Run

File : RF DOE SG FWD-FV2-10000Y.ROF

\section{Contaminated Zone Dimensions}

Area: 102144.00 square meters

Thickness: $\quad 13.40$ meters

Cover Depth: $\quad 1.52$ meters
Initial Soil Concentrations, pci/g

$\begin{array}{ll}\text { Am-241 } & 3.500 \mathrm{E}+01 \\ \mathrm{Cs}-137 & 1.900 \mathrm{E}+01 \\ \mathrm{~Np}-237 & 5.500 \mathrm{E}+00 \\ \mathrm{Pu}-238 & 3.900 \mathrm{E}+01 \\ \mathrm{Pu}-239 & 3.600 \mathrm{E}+01 \\ \mathrm{Pu}-240 & 3.600 \mathrm{E}+01 \\ \mathrm{TC}-99 & 5.200 \mathrm{E}+01 \\ \mathrm{Th}-228 & 4.000 \mathrm{E}+00 \\ \mathrm{Th}-230 & 1.000 \mathrm{E}+02 \\ \mathrm{Th}-232 & 4.000 \mathrm{E}+00 \\ \mathrm{U}-234 & 1.600 \mathrm{E}+02 \\ \mathrm{U}-235 & 6.500 \mathrm{E}+00 \\ \mathrm{U}-238 & 1.600 \mathrm{E}+02\end{array}$

Total Dose TDOSE(t), mrem/yr

Basic Radiation Dose Limit $=1.000 \mathrm{E}+00 \mathrm{mrem} / \mathrm{yr}$

Total Mixture Sum $M(t)$ = Fraction of Basic Dose Limit Received at Time (t)

$\begin{array}{rlllllll}t \text { (years) : } & 0.000 \mathrm{E}+00 & 1.000 \mathrm{E}+00 & 5.000 \mathrm{E}+01 & 1.000 \mathrm{E}+02 & 5.000 \mathrm{E}+02 & 1.026 \mathrm{E}+03 & 9.976 \mathrm{E}+03 \\ \text { TDOSE }(\mathrm{t}): & 3.429 \mathrm{E}-14 & 2.578 \mathrm{E}-14 & 5.648 \mathrm{E}-14 & 7.897 \mathrm{E}-14 & 9.912 \mathrm{E}-01 & 1.436 \mathrm{E}+00 & 2.177 \mathrm{E}+00 \\ \mathrm{M}(\mathrm{t}): & 3.429 \mathrm{E}-14 & 2.578 \mathrm{E}-14 & 5.648 \mathrm{E}-14 & 7.897 \mathrm{E}-14 & 9.912 \mathrm{E}-01 & 1.436 \mathrm{E}+00 & 2.177 \mathrm{E}+00\end{array}$

Maximum TDOSE (t): $2.177 \mathrm{E}+00 \mathrm{mrem} / \mathrm{yr}$ at $t=10000$ years 
RESRAD-OFFSITE, Version 2 .

arent Dose Report

Title : Offsite Resident Farmer Deterministic Run

File : RF DOE SG FWD-FV2-10000Y.ROF

Total Dose Contributions TDOSE (i,p,t) for Individual Radionuclides (i) and Pathways (p) in mrem/yr and as a Percentage of Total Dose at $t=0$ years

From releases to ground water and to surface water

\begin{tabular}{|c|c|c|c|c|c|c|c|c|c|c|c|c|c|c|c|c|}
\hline & \multicolumn{2}{|c|}{ Ground } & \multicolumn{2}{|l|}{ Fish } & \multicolumn{2}{|c|}{ Radon } & \multicolumn{2}{|c|}{ Plant } & \multicolumn{2}{|l|}{ Meat } & \multicolumn{2}{|l|}{ Milk } & \multicolumn{2}{|l|}{ Soil } & \multicolumn{2}{|c|}{ Water } \\
\hline clide & Dose & \% & Dose & $\%$ & Dose & \% & Dose & \% & Dose & \% & Dose & \% & Dose & \% & Dose & $\%$ \\
\hline-241 & $0.00 \mathrm{E}+00$ & 0 & $0.00 \mathrm{E}+00$ & 0 & $0.00 \mathrm{E}+00$ & 0 & $0.00 \mathrm{E}+00$ & 0 & $0.00 \mathrm{E}+00$ & 0 & $0.00 \mathrm{E}+00$ & 0 & $0.00 \mathrm{E}+00$ & 0 & $0.00 \mathrm{E}+00$ & 0 \\
\hline-137 & $0.00 \mathrm{E}+00$ & 0 & $0.00 \mathrm{E}+00$ & 0 & $0.00 \mathrm{E}+00$ & 0 & $0.00 \mathrm{E}+00$ & 0 & $0.00 \mathrm{E}+00$ & 0 & $0.00 \mathrm{E}+00$ & 0 & $0.00 \mathrm{E}+00$ & 0 & $0.00 \mathrm{E}+00$ & 0 \\
\hline-237 & $0.00 \mathrm{E}+00$ & 0 & $0.00 \mathrm{E}+00$ & 0 & $0.00 \mathrm{E}+00$ & 0 & $0.00 \mathrm{E}+00$ & 0 & $0.00 \mathrm{E}+00$ & 0 & $0.00 \mathrm{E}+00$ & 0 & $0.00 \mathrm{E}+00$ & 0 & $0.00 \mathrm{E}+00$ & 0 \\
\hline-238 & $0.00 \mathrm{E}+00$ & 0 & $0.00 \mathrm{E}+00$ & 0 & $0.00 \mathrm{E}+00$ & 0 & $0.00 \mathrm{E}+00$ & 0 & $0.00 \mathrm{E}+00$ & 0 & $0.00 \mathrm{E}+00$ & 0 & $0.00 \mathrm{E}+00$ & 0 & $0.00 \mathrm{E}+00$ & 0 \\
\hline-239 & $0.00 \mathrm{E}+00$ & 0 & $0.00 \mathrm{E}+00$ & 0 & $0.00 \mathrm{E}+00$ & 0 & $0.00 \mathrm{E}+00$ & 0 & $0.00 \mathrm{E}+00$ & 0 & $0.00 E+00$ & 0 & $0.00 \mathrm{E}+00$ & 0 & $0.00 \mathrm{E}+00$ & 0 \\
\hline-240 & $0.00 \mathrm{E}+00$ & 0 & $0.00 \mathrm{E}+00$ & 0 & $0.00 \mathrm{E}+00$ & 0 & $0.00 \mathrm{E}+00$ & 0 & $0.00 \mathrm{E}+00$ & 0 & $0.00 \mathrm{E}+00$ & 0 & $0.00 \mathrm{E}+00$ & 0 & $0.00 \mathrm{E}+00$ & 0 \\
\hline-99 & $0.00 \mathrm{E}+00$ & 0 & $0.00 E+00$ & 0 & $0.00 E+00$ & 0 & $0.00 \mathrm{E}+00$ & 0 & $0.00 \mathrm{E}+00$ & 0 & $0.00 E+00$ & 0 & $0.00 \mathrm{E}+00$ & 0 & $0.00 \mathrm{E}+00$ & 0 \\
\hline-228 & $0.00 \mathrm{E}+00$ & 0 & $0.00 \mathrm{E}+00$ & 0 & $0.00 \mathrm{E}+00$ & 0 & $0.00 \mathrm{E}+00$ & 0 & $0.00 \mathrm{E}+00$ & 0 & $0.00 \mathrm{E}+00$ & 0 & $0.00 \mathrm{E}+00$ & 0 & $0.00 \mathrm{E}+00$ & 0 \\
\hline-230 & $0.00 \mathrm{E}+00$ & 0 & $0.00 \mathrm{E}+00$ & 0 & $0.00 \mathrm{E}+00$ & 0 & $0.00 \mathrm{E}+00$ & 0 & $0.00 \mathrm{E}+00$ & 0 & $0.00 \mathrm{E}+00$ & 0 & $0.00 \mathrm{E}+00$ & 0 & $0.00 \mathrm{E}+00$ & 0 \\
\hline-232 & $0.00 \mathrm{E}+00$ & 0 & $0.00 \mathrm{E}+00$ & 0 & $0.00 \mathrm{E}+00$ & 0 & $0.00 \mathrm{E}+00$ & 0 & $0.00 \mathrm{E}+00$ & 0 & $0.00 \mathrm{E}+00$ & 0 & $0.00 \mathrm{E}+00$ & 0 & $0.00 \mathrm{E}+00$ & 0 \\
\hline 234 & $0.00 \mathrm{E}+00$ & 0 & $0.00 \mathrm{E}+00$ & 0 & $0.00 \mathrm{E}+00$ & 0 & $0.00 \mathrm{E}+00$ & 0 & $0.00 \mathrm{E}+00$ & 0 & $0.00 \mathrm{E}+00$ & 0 & $0.00 \mathrm{E}+00$ & 0 & $0.00 \mathrm{E}+00$ & 0 \\
\hline 235 & $0.00 \mathrm{E}+00$ & 0 & $0.00 \mathrm{E}+00$ & 0 & $0.00 \mathrm{E}+00$ & 0 & $0.00 \mathrm{E}+00$ & 0 & $0.00 \mathrm{E}+00$ & 0 & $0.00 E+00$ & 0 & $0.00 \mathrm{E}+00$ & 0 & $0.00 \mathrm{E}+00$ & 0 \\
\hline 38 & $0.00 \mathrm{E}+00$ & 0 & $0.00 \mathrm{E}+00$ & 0 & $0.00 \mathrm{E}+00$ & 0 & $0.00 \mathrm{E}+00$ & 0 & $0.00 \mathrm{E}+00$ & 0 & $0.00 \mathrm{E}+00$ & 0 & $0.00 \mathrm{E}+00$ & 0 & $0.00 \mathrm{E}+00$ & 0 \\
\hline & $0.00 \mathrm{E}+00$ & 0 & $0.00 \mathrm{E}+00$ & 0 & $0.00 \mathrm{E}+00$ & 0 & $0.00 \mathrm{E}+00$ & 0 & $0.00 \mathrm{E}+00$ & 0 & $0.00 \mathrm{E}+00$ & 0 & $0.00 \mathrm{E}+00$ & 0 & $0.00 \mathrm{E}+00$ & 0 \\
\hline
\end{tabular}

Total Dose Contributions TDOSE (i,p,t) for Individual Radionuclides (i) and Pathways (p)

in mrem/yr and as a Percentage of Total Dose at $t=0$ years

Directly from primary contamination and from release to atmosphere (Inhalation excludes radon)

\begin{tabular}{|c|c|c|c|c|c|c|c|c|c|c|c|c|c|c|c|c|}
\hline & \multicolumn{2}{|c|}{ Ground } & \multicolumn{2}{|c|}{ Inhalation } & \multicolumn{2}{|c|}{ Radon } & \multicolumn{2}{|c|}{ Plant } & \multicolumn{2}{|l|}{ Meat } & \multicolumn{2}{|l|}{ Milk } & \multicolumn{2}{|l|}{ Soil } & \multicolumn{2}{|c|}{ All Pathways* } \\
\hline ide & Dose & $\%$ & Dose & $\%$ & Dose & $\%$ & Dose & 음 & Dose & $\%$ & Dose & 음 & Dose & $\%$ & Dose & $\%$ \\
\hline-241 & $3.28 E-26$ & 0 & $0.00 \mathrm{E}+00$ & 0 & $0.00 E+00$ & 0 & $0.00 \mathrm{E}+00$ & 0 & $0.00 \mathrm{E}+00$ & 0 & $0.00 \mathrm{E}+00$ & 0 & $0.00 \mathrm{E}+00$ & 0 & $3.28 E-26$ & 0 \\
\hline-137 & 1. $45 E-16$ & 0 & $0.00 E+00$ & 0 & $0.00 E+00$ & 0 & $0.00 \mathrm{E}+00$ & 0 & $0.00 \mathrm{E}+00$ & 0 & $0.00 E+00$ & 0 & $0.00 \mathrm{E}+00$ & 0 & 1. $45 \mathrm{E}-16$ & 0 \\
\hline-237 & $3.18 \mathrm{E}-20$ & 0 & $0.00 E+00$ & 0 & $0.00 E+00$ & 0 & $0.00 \mathrm{E}+00$ & 0 & $0.00 \mathrm{E}+00$ & 0 & $0.00 E+00$ & 0 & $0.00 \mathrm{E}+00$ & 0 & $3.18 E-20$ & 0 \\
\hline-238 & $2.73 E-29$ & 0 & $0.00 E+00$ & 0 & $0.00 \mathrm{E}+00$ & 0 & $0.00 \mathrm{E}+00$ & 0 & $0.00 \mathrm{E}+00$ & 0 & $0.00 \mathrm{E}+00$ & 0 & $0.00 \mathrm{E}+00$ & 0 & $2.73 E-29$ & 0 \\
\hline-239 & $2.62 E-24$ & 0 & $0.00 \mathrm{E}+00$ & 0 & $0.00 \mathrm{E}+00$ & 0 & $0.00 \mathrm{E}+00$ & 0 & $0.00 \mathrm{E}+00$ & 0 & $0.00 \mathrm{E}+00$ & 0 & $0.00 \mathrm{E}+00$ & 0 & $2.62 \mathrm{E}-24$ & 0 \\
\hline-240 & $2.49 E-31$ & 0 & $0.00 E+00$ & 0 & $0.00 \mathrm{E}+00$ & 0 & $0.00 \mathrm{E}+00$ & 0 & $0.00 \mathrm{E}+00$ & 0 & $0.00 E+00$ & 0 & $0.00 \mathrm{E}+00$ & 0 & $2.49 E-31$ & 0 \\
\hline-99 & $1.82 E-32$ & 0 & $0.00 E+00$ & 0 & $0.00 \mathrm{E}+00$ & 0 & $0.00 \mathrm{E}+00$ & 0 & $0.00 \mathrm{E}+00$ & 0 & $0.00 E+00$ & 0 & $0.00 \mathrm{E}+00$ & 0 & 1. $82 \mathrm{E}-32$ & 0 \\
\hline-228 & $3.37 E-14$ & 98 & $0.00 \mathrm{E}+00$ & 0 & $0.00 \mathrm{E}+00$ & 0 & $0.00 \mathrm{E}+00$ & 0 & $0.00 \mathrm{E}+00$ & 0 & $0.00 \mathrm{E}+00$ & 0 & $0.00 \mathrm{E}+00$ & 0 & $3.37 \mathrm{E}-14$ & 98 \\
\hline-230 & $2.29 E-17$ & 0 & $0.00 E+00$ & 0 & $0.00 \mathrm{E}+00$ & 0 & $0.00 \mathrm{E}+00$ & 0 & $0.00 \mathrm{E}+00$ & 0 & $0.00 E+00$ & 0 & $0.00 \mathrm{E}+00$ & 0 & $2.29 \mathrm{E}-17$ & 0 \\
\hline-232 & $3.29 \mathrm{E}-16$ & 1 & $0.00 E+00$ & 0 & $0.00 \mathrm{E}+00$ & 0 & $0.00 \mathrm{E}+00$ & 0 & $0.00 \mathrm{E}+00$ & 0 & $0.00 \mathrm{E}+00$ & 0 & $0.00 \mathrm{E}+00$ & 0 & $3.29 \mathrm{E}-16$ & 1 \\
\hline 34 & $1.31 \mathrm{E}-22$ & 0 & $0.00 \mathrm{E}+00$ & 0 & $0.00 \mathrm{E}+00$ & 0 & $0.00 \mathrm{E}+00$ & 0 & $0.00 \mathrm{E}+00$ & 0 & $0.00 \mathrm{E}+00$ & 0 & $0.00 \mathrm{E}+00$ & 0 & 1. $31 \mathrm{E}-22$ & 0 \\
\hline 235 & $4 \cdot 90 \mathrm{E}-22$ & 0 & $0.00 \mathrm{E}+00$ & 0 & $0.00 \mathrm{E}+00$ & 0 & $0.00 \mathrm{E}+00$ & 0 & $0.00 \mathrm{E}+00$ & 0 & $0.00 \mathrm{E}+00$ & 0 & $0.00 \mathrm{E}+00$ & 0 & $4.90 \mathrm{E}-22$ & 0 \\
\hline 38 & $1.38 E-16$ & 0 & $0.00 E+00$ & 0 & $0.00 \mathrm{E}+00$ & 0 & $0.00 \mathrm{E}+00$ & 0 & $0.00 \mathrm{E}+00$ & 0 & $0.00 E+00$ & 0 & $0.00 \mathrm{E}+00$ & 0 & 1. $38 \mathrm{E}-16$ & 0 \\
\hline & $3.43 E-14$ & 100 & $0.00 \mathrm{E}+00$ & 0 & $0.00 \mathrm{E}+00$ & 0 & $0.00 \mathrm{E}+00$ & 0 & $0.00 \mathrm{E}+00$ & 0 & $0.00 E+00$ & 0 & $0.00 \mathrm{E}+00$ & 0 & 3. $43 \mathrm{E}-14$ & 100 \\
\hline
\end{tabular}

* Sum of dose from all releases and from primary contamination. 
RESRAD-OFFSITE, Version 2 .

arent Dose Report

Title : Offsite Resident Farmer Deterministic Run

File : RF DOE SG FWD-FV2-10000Y.ROF

Total Dose Contributions TDOSE (i,p,t) for Individual Radionuclides (i) and Pathways (p) in mrem/yr and as a Percentage of Total Dose at $t=1$ years

From releases to ground water and to surface water

\begin{tabular}{|c|c|c|c|c|c|c|c|c|c|c|c|c|c|c|c|c|}
\hline & \multicolumn{2}{|c|}{ Ground } & \multicolumn{2}{|l|}{ Fish } & \multicolumn{2}{|c|}{ Radon } & \multicolumn{2}{|c|}{ Plant } & \multicolumn{2}{|l|}{ Meat } & \multicolumn{2}{|l|}{ Milk } & \multicolumn{2}{|l|}{ Soil } & \multicolumn{2}{|c|}{ Water } \\
\hline clide & Dose & \% & Dose & $\%$ & Dose & \% & Dose & \% & Dose & \% & Dose & \% & Dose & \% & Dose & $\%$ \\
\hline-241 & $0.00 \mathrm{E}+00$ & 0 & $0.00 \mathrm{E}+00$ & 0 & $0.00 \mathrm{E}+00$ & 0 & $0.00 \mathrm{E}+00$ & 0 & $0.00 \mathrm{E}+00$ & 0 & $0.00 \mathrm{E}+00$ & 0 & $0.00 \mathrm{E}+00$ & 0 & $0.00 \mathrm{E}+00$ & 0 \\
\hline-137 & $0.00 \mathrm{E}+00$ & 0 & $0.00 \mathrm{E}+00$ & 0 & $0.00 \mathrm{E}+00$ & 0 & $0.00 \mathrm{E}+00$ & 0 & $0.00 \mathrm{E}+00$ & 0 & $0.00 \mathrm{E}+00$ & 0 & $0.00 \mathrm{E}+00$ & 0 & $0.00 \mathrm{E}+00$ & 0 \\
\hline-237 & $0.00 \mathrm{E}+00$ & 0 & $0.00 \mathrm{E}+00$ & 0 & $0.00 \mathrm{E}+00$ & 0 & $0.00 \mathrm{E}+00$ & 0 & $0.00 \mathrm{E}+00$ & 0 & $0.00 \mathrm{E}+00$ & 0 & $0.00 \mathrm{E}+00$ & 0 & $0.00 \mathrm{E}+00$ & 0 \\
\hline-238 & $0.00 \mathrm{E}+00$ & 0 & $0.00 \mathrm{E}+00$ & 0 & $0.00 \mathrm{E}+00$ & 0 & $0.00 \mathrm{E}+00$ & 0 & $0.00 \mathrm{E}+00$ & 0 & $0.00 \mathrm{E}+00$ & 0 & $0.00 \mathrm{E}+00$ & 0 & $0.00 \mathrm{E}+00$ & 0 \\
\hline-239 & $0.00 \mathrm{E}+00$ & 0 & $0.00 \mathrm{E}+00$ & 0 & $0.00 \mathrm{E}+00$ & 0 & $0.00 \mathrm{E}+00$ & 0 & $0.00 \mathrm{E}+00$ & 0 & $0.00 E+00$ & 0 & $0.00 \mathrm{E}+00$ & 0 & $0.00 \mathrm{E}+00$ & 0 \\
\hline-240 & $0.00 \mathrm{E}+00$ & 0 & $0.00 \mathrm{E}+00$ & 0 & $0.00 \mathrm{E}+00$ & 0 & $0.00 \mathrm{E}+00$ & 0 & $0.00 \mathrm{E}+00$ & 0 & $0.00 \mathrm{E}+00$ & 0 & $0.00 \mathrm{E}+00$ & 0 & $0.00 \mathrm{E}+00$ & 0 \\
\hline-99 & $0.00 \mathrm{E}+00$ & 0 & $0.00 E+00$ & 0 & $0.00 E+00$ & 0 & $0.00 \mathrm{E}+00$ & 0 & $0.00 \mathrm{E}+00$ & 0 & $0.00 E+00$ & 0 & $0.00 \mathrm{E}+00$ & 0 & $0.00 \mathrm{E}+00$ & 0 \\
\hline-228 & $0.00 \mathrm{E}+00$ & 0 & $0.00 \mathrm{E}+00$ & 0 & $0.00 \mathrm{E}+00$ & 0 & $0.00 \mathrm{E}+00$ & 0 & $0.00 \mathrm{E}+00$ & 0 & $0.00 \mathrm{E}+00$ & 0 & $0.00 \mathrm{E}+00$ & 0 & $0.00 \mathrm{E}+00$ & 0 \\
\hline-230 & $0.00 \mathrm{E}+00$ & 0 & $0.00 \mathrm{E}+00$ & 0 & $0.00 \mathrm{E}+00$ & 0 & $0.00 \mathrm{E}+00$ & 0 & $0.00 \mathrm{E}+00$ & 0 & $0.00 \mathrm{E}+00$ & 0 & $0.00 \mathrm{E}+00$ & 0 & $0.00 \mathrm{E}+00$ & 0 \\
\hline-232 & $0.00 \mathrm{E}+00$ & 0 & $0.00 \mathrm{E}+00$ & 0 & $0.00 \mathrm{E}+00$ & 0 & $0.00 \mathrm{E}+00$ & 0 & $0.00 \mathrm{E}+00$ & 0 & $0.00 \mathrm{E}+00$ & 0 & $0.00 \mathrm{E}+00$ & 0 & $0.00 \mathrm{E}+00$ & 0 \\
\hline 234 & $0.00 \mathrm{E}+00$ & 0 & $0.00 \mathrm{E}+00$ & 0 & $0.00 \mathrm{E}+00$ & 0 & $0.00 \mathrm{E}+00$ & 0 & $0.00 \mathrm{E}+00$ & 0 & $0.00 \mathrm{E}+00$ & 0 & $0.00 \mathrm{E}+00$ & 0 & $0.00 \mathrm{E}+00$ & 0 \\
\hline 235 & $0.00 \mathrm{E}+00$ & 0 & $0.00 \mathrm{E}+00$ & 0 & $0.00 \mathrm{E}+00$ & 0 & $0.00 \mathrm{E}+00$ & 0 & $0.00 \mathrm{E}+00$ & 0 & $0.00 E+00$ & 0 & $0.00 \mathrm{E}+00$ & 0 & $0.00 \mathrm{E}+00$ & 0 \\
\hline 38 & $0.00 \mathrm{E}+00$ & 0 & $0.00 \mathrm{E}+00$ & 0 & $0.00 \mathrm{E}+00$ & 0 & $0.00 \mathrm{E}+00$ & 0 & $0.00 \mathrm{E}+00$ & 0 & $0.00 \mathrm{E}+00$ & 0 & $0.00 \mathrm{E}+00$ & 0 & $0.00 \mathrm{E}+00$ & 0 \\
\hline & $0.00 \mathrm{E}+00$ & 0 & $0.00 \mathrm{E}+00$ & 0 & $0.00 \mathrm{E}+00$ & 0 & $0.00 \mathrm{E}+00$ & 0 & $0.00 \mathrm{E}+00$ & 0 & $0.00 \mathrm{E}+00$ & 0 & $0.00 \mathrm{E}+00$ & 0 & $0.00 \mathrm{E}+00$ & 0 \\
\hline
\end{tabular}

Total Dose Contributions TDOSE (i,p,t) for Individual Radionuclides (i) and Pathways (p)

in mrem/yr and as a Percentage of Total Dose at $t=1$ years

Directly from primary contamination and from release to atmosphere (Inhalation excludes radon)

\begin{tabular}{|c|c|c|c|c|c|c|c|c|c|c|c|c|c|c|c|c|}
\hline & \multicolumn{2}{|c|}{ Ground } & \multicolumn{2}{|c|}{ Inhalation } & \multicolumn{2}{|c|}{ Radon } & \multicolumn{2}{|c|}{ Plant } & \multicolumn{2}{|l|}{ Meat } & \multicolumn{2}{|l|}{ Milk } & \multicolumn{2}{|l|}{ Soil } & \multicolumn{2}{|c|}{ All Pathways* } \\
\hline ide & Dose & $\%$ & Dose & $\%$ & Dose & $\%$ & Dose & 음 & Dose & $\%$ & Dose & 음 & Dose & $\%$ & Dose & $\%$ \\
\hline-241 & $9.93 E-26$ & 0 & $0.00 \mathrm{E}+00$ & 0 & $0.00 \mathrm{E}+00$ & 0 & $0.00 \mathrm{E}+00$ & 0 & $0.00 \mathrm{E}+00$ & 0 & $0.00 \mathrm{E}+00$ & 0 & $0.00 \mathrm{E}+00$ & 0 & $9.93 E-26$ & 0 \\
\hline-137 & 1. $43 E-16$ & 1 & $0.00 E+00$ & 0 & $0.00 E+00$ & 0 & $0.00 \mathrm{E}+00$ & 0 & $0.00 \mathrm{E}+00$ & 0 & $0.00 E+00$ & 0 & $0.00 \mathrm{E}+00$ & 0 & 1. $43 \mathrm{E}-16$ & 1 \\
\hline-237 & $3.21 E-20$ & 0 & $0.00 \mathrm{E}+00$ & 0 & $0.00 E+00$ & 0 & $0.00 \mathrm{E}+00$ & 0 & $0.00 \mathrm{E}+00$ & 0 & $0.00 E+00$ & 0 & $0.00 \mathrm{E}+00$ & 0 & $3.21 E-20$ & 0 \\
\hline-238 & $3.37 E-28$ & 0 & $0.00 \mathrm{E}+00$ & 0 & $0.00 \mathrm{E}+00$ & 0 & $0.00 \mathrm{E}+00$ & 0 & $0.00 \mathrm{E}+00$ & 0 & $0.00 \mathrm{E}+00$ & 0 & $0.00 \mathrm{E}+00$ & 0 & $3.37 E-28$ & 0 \\
\hline-239 & $2.65 E-24$ & 0 & $0.00 \mathrm{E}+00$ & 0 & $0.00 \mathrm{E}+00$ & 0 & $0.00 \mathrm{E}+00$ & 0 & $0.00 \mathrm{E}+00$ & 0 & $0.00 \mathrm{E}+00$ & 0 & $0.00 \mathrm{E}+00$ & 0 & $2.65 E-24$ & 0 \\
\hline-240 & $2.60 \mathrm{E}-31$ & 0 & $0.00 \mathrm{E}+00$ & 0 & $0.00 \mathrm{E}+00$ & 0 & $0.00 \mathrm{E}+00$ & 0 & $0.00 \mathrm{E}+00$ & 0 & $0.00 \mathrm{E}+00$ & 0 & $0.00 \mathrm{E}+00$ & 0 & $2.60 \mathrm{E}-31$ & 0 \\
\hline-99 & $1.84 E-32$ & 0 & $0.00 \mathrm{E}+00$ & 0 & $0.00 \mathrm{E}+00$ & 0 & $0.00 \mathrm{E}+00$ & 0 & $0.00 \mathrm{E}+00$ & 0 & $0.00 E+00$ & 0 & $0.00 \mathrm{E}+00$ & 0 & $1.84 \mathrm{E}-32$ & 0 \\
\hline-228 & $2.37 E-14$ & 92 & $0.00 \mathrm{E}+00$ & 0 & $0.00 \mathrm{E}+00$ & 0 & $0.00 \mathrm{E}+00$ & 0 & $0.00 \mathrm{E}+00$ & 0 & $0.00 \mathrm{E}+00$ & 0 & $0.00 \mathrm{E}+00$ & 0 & $2.37 E-14$ & 92 \\
\hline-230 & $6.90 \mathrm{E}-17$ & 0 & $0.00 E+00$ & 0 & $0.00 \mathrm{E}+00$ & 0 & $0.00 \mathrm{E}+00$ & 0 & $0.00 \mathrm{E}+00$ & 0 & $0.00 E+00$ & 0 & $0.00 \mathrm{E}+00$ & 0 & $6.90 \mathrm{E}-17$ & 0 \\
\hline-232 & $1.73 E-15$ & 7 & $0.00 \mathrm{E}+00$ & 0 & $0.00 \mathrm{E}+00$ & 0 & $0.00 \mathrm{E}+00$ & 0 & $0.00 \mathrm{E}+00$ & 0 & $0.00 \mathrm{E}+00$ & 0 & $0.00 \mathrm{E}+00$ & 0 & $1.73 E-15$ & 7 \\
\hline 34 & $8.24 \mathrm{E}-22$ & 0 & $0.00 \mathrm{E}+00$ & 0 & $0.00 \mathrm{E}+00$ & 0 & $0.00 \mathrm{E}+00$ & 0 & $0.00 \mathrm{E}+00$ & 0 & $0.00 \mathrm{E}+00$ & 0 & $0.00 \mathrm{E}+00$ & 0 & $8.24 \mathrm{E}-22$ & 0 \\
\hline 235 & $4 \cdot 98 \mathrm{E}-22$ & 0 & $0.00 \mathrm{E}+00$ & 0 & $0.00 \mathrm{E}+00$ & 0 & $0.00 \mathrm{E}+00$ & 0 & $0.00 \mathrm{E}+00$ & 0 & $0.00 \mathrm{E}+00$ & 0 & $0.00 \mathrm{E}+00$ & 0 & $4.98 \mathrm{E}-22$ & 0 \\
\hline 38 & 1. $39 \mathrm{E}-16$ & 1 & $0.00 \mathrm{E}+00$ & 0 & $0.00 \mathrm{E}+00$ & 0 & $0.00 \mathrm{E}+00$ & 0 & $0.00 \mathrm{E}+00$ & 0 & $0.00 E+00$ & 0 & $0.00 \mathrm{E}+00$ & 0 & 1. $39 \mathrm{E}-16$ & 1 \\
\hline & $2.58 E-14$ & 100 & $0.00 \mathrm{E}+00$ & 0 & $0.00 \mathrm{E}+00$ & 0 & $0.00 \mathrm{E}+00$ & 0 & $0.00 \mathrm{E}+00$ & 0 & $0.00 E+00$ & 0 & $0.00 \mathrm{E}+00$ & 0 & $2.58 \mathrm{E}-14$ & 100 \\
\hline
\end{tabular}

* Sum of dose from all releases and from primary contamination. 
RESRAD-OFFSITE, Version 2 .

arent Dose Report

Title : Offsite Resident Farmer Deterministic Run

File : RF DOE SG FWD-FV2-10000Y.ROF

Total Dose Contributions TDOSE (i,p,t) for Individual Radionuclides (i) and Pathways (p) in mrem/yr and as a Percentage of Total Dose at $t=50$ years

From releases to ground water and to surface water

\begin{tabular}{|c|c|c|c|c|c|c|c|c|c|c|c|c|c|c|c|c|}
\hline & \multicolumn{2}{|c|}{ Ground } & \multicolumn{2}{|l|}{ Fish } & \multicolumn{2}{|c|}{ Radon } & \multicolumn{2}{|c|}{ Plant } & \multicolumn{2}{|l|}{ Meat } & \multicolumn{2}{|l|}{ Milk } & \multicolumn{2}{|l|}{ Soil } & \multicolumn{2}{|c|}{ Water } \\
\hline ide & Dose & $\%$ & Dose & $\%$ & Dose & 응 & Dose & $\frac{\circ}{0}$ & Dose & 응 & Dose & 응 & Dose & $\%$ & Dose & $\%$ \\
\hline-241 & $0.00 \mathrm{E}+00$ & 0 & $0.00 E+00$ & 0 & $0.00 \mathrm{E}+00$ & 0 & $0.00 \mathrm{E}+00$ & 0 & $0.00 \mathrm{E}+00$ & 0 & $0.00 \mathrm{E}+00$ & 0 & $0.00 \mathrm{E}+00$ & 0 & $0.00 \mathrm{E}+00$ & 0 \\
\hline-137 & $0.00 \mathrm{E}+00$ & 0 & $0.00 \mathrm{E}+00$ & 0 & $0.00 \mathrm{E}+00$ & 0 & $0.00 \mathrm{E}+00$ & 0 & $0.00 \mathrm{E}+00$ & 0 & $0.00 \mathrm{E}+00$ & 0 & $0.00 \mathrm{E}+00$ & 0 & $0.00 \mathrm{E}+00$ & 0 \\
\hline-237 & $0.00 \mathrm{E}+00$ & 0 & $0.00 \mathrm{E}+00$ & 0 & $0.00 \mathrm{E}+00$ & 0 & $0.00 \mathrm{E}+00$ & 0 & $0.00 \mathrm{E}+00$ & 0 & $0.00 \mathrm{E}+00$ & 0 & $0.00 \mathrm{E}+00$ & 0 & $0.00 \mathrm{E}+00$ & 0 \\
\hline-238 & $0.00 \mathrm{E}+00$ & 0 & $0.00 \mathrm{E}+00$ & 0 & $0.00 E+00$ & 0 & $0.00 \mathrm{E}+00$ & 0 & $0.00 \mathrm{E}+00$ & 0 & $0.00 E+00$ & 0 & $0.00 \mathrm{E}+00$ & 0 & $0.00 \mathrm{E}+00$ & 0 \\
\hline-239 & $0.00 \mathrm{E}+00$ & 0 & $0.00 \mathrm{E}+00$ & 0 & $0.00 \mathrm{E}+00$ & 0 & $0.00 \mathrm{E}+00$ & 0 & $0.00 \mathrm{E}+00$ & 0 & $0.00 \mathrm{E}+00$ & 0 & $0.00 \mathrm{E}+00$ & 0 & $0.00 \mathrm{E}+00$ & 0 \\
\hline-240 & $0.00 \mathrm{E}+00$ & 0 & $0.00 \mathrm{E}+00$ & 0 & $0.00 \mathrm{E}+00$ & 0 & $0.00 \mathrm{E}+00$ & 0 & $0.00 \mathrm{E}+00$ & 0 & $0.00 \mathrm{E}+00$ & 0 & $0.00 \mathrm{E}+00$ & 0 & $0.00 \mathrm{E}+00$ & 0 \\
\hline-99 & $0.00 \mathrm{E}+00$ & 0 & $0.00 \mathrm{E}+00$ & 0 & $0.00 \mathrm{E}+00$ & 0 & $0.00 \mathrm{E}+00$ & 0 & $0.00 \mathrm{E}+00$ & 0 & $0.00 E+00$ & 0 & $0.00 \mathrm{E}+00$ & 0 & $0.00 \mathrm{E}+00$ & 0 \\
\hline-228 & $0.00 \mathrm{E}+00$ & 0 & $0.00 \mathrm{E}+00$ & 0 & $0.00 \mathrm{E}+00$ & 0 & $0.00 \mathrm{E}+00$ & 0 & $0.00 \mathrm{E}+00$ & 0 & $0.00 \mathrm{E}+00$ & 0 & $0.00 \mathrm{E}+00$ & 0 & $0.00 \mathrm{E}+00$ & 0 \\
\hline-230 & $0.00 \mathrm{E}+00$ & 0 & $0.00 \mathrm{E}+00$ & 0 & $0.00 \mathrm{E}+00$ & 0 & $0.00 \mathrm{E}+00$ & 0 & $0.00 \mathrm{E}+00$ & 0 & $0.00 \mathrm{E}+00$ & 0 & $0.00 \mathrm{E}+00$ & 0 & $0.00 \mathrm{E}+00$ & 0 \\
\hline-232 & $0.00 \mathrm{E}+00$ & 0 & $0.00 \mathrm{E}+00$ & 0 & $0.00 \mathrm{E}+00$ & 0 & $0.00 \mathrm{E}+00$ & 0 & $0.00 \mathrm{E}+00$ & 0 & $0.00 \mathrm{E}+00$ & 0 & $0.00 \mathrm{E}+00$ & 0 & $0.00 \mathrm{E}+00$ & 0 \\
\hline 34 & $0.00 \mathrm{E}+00$ & 0 & $0.00 \mathrm{E}+00$ & 0 & $0.00 \mathrm{E}+00$ & 0 & $0.00 \mathrm{E}+00$ & 0 & $0.00 \mathrm{E}+00$ & 0 & $0.00 \mathrm{E}+00$ & 0 & $0.00 \mathrm{E}+00$ & 0 & $0.00 \mathrm{E}+00$ & 0 \\
\hline 35 & $0.00 \mathrm{E}+00$ & 0 & $0.00 \mathrm{E}+00$ & 0 & $0.00 \mathrm{E}+00$ & 0 & $0.00 \mathrm{E}+00$ & 0 & $0.00 \mathrm{E}+00$ & 0 & $0.00 \mathrm{E}+00$ & 0 & $0.00 \mathrm{E}+00$ & 0 & $0.00 \mathrm{E}+00$ & 0 \\
\hline 38 & $0.00 \mathrm{E}+00$ & 0 & $0.00 \mathrm{E}+00$ & 0 & $0.00 E+00$ & 0 & $0.00 \mathrm{E}+00$ & 0 & $0.00 \mathrm{E}+00$ & 0 & $0.00 E+00$ & 0 & $0.00 \mathrm{E}+00$ & 0 & $0.00 \mathrm{E}+00$ & 0 \\
\hline & $0.00 \mathrm{E}+00$ & 0 & $0.00 E+00$ & 0 & $0.00 \mathrm{E}+00$ & 0 & $0.00 \mathrm{E}+00$ & 0 & $0.00 \mathrm{E}+00$ & 0 & $0.00 \mathrm{E}+00$ & 0 & $0.00 \mathrm{E}+00$ & 0 & $0.00 \mathrm{E}+00$ & 0 \\
\hline
\end{tabular}

Total Dose Contributions TDOSE(i,p,t) for Individual Radionuclides (i) and Pathways (p) in mrem/yr and as a Percentage of Total Dose at $t=50$ years

Directly from primary contamination and from release to atmosphere (Inhalation excludes radon)

\begin{tabular}{|c|c|c|c|c|c|c|c|c|c|c|c|c|c|c|c|c|}
\hline & \multicolumn{2}{|c|}{ Ground } & \multicolumn{2}{|c|}{ Inhalation } & \multicolumn{2}{|c|}{ Radon } & \multicolumn{2}{|c|}{ Plant } & \multicolumn{2}{|l|}{ Meat } & \multicolumn{2}{|l|}{ Milk } & \multicolumn{2}{|l|}{ Soil } & \multicolumn{2}{|c|}{ All Pathways* } \\
\hline clide & Dose & $\%$ & Dose & \% & Dose & $\%$ & Dose & 음 & Dose & $\%$ & Dose & 음 & Dose & $\%$ & Dose & $\%$ \\
\hline-241 & $5.22 E-24$ & 0 & $0.00 \mathrm{E}+00$ & 0 & $0.00 \mathrm{E}+00$ & 0 & $0.00 \mathrm{E}+00$ & 0 & $0.00 \mathrm{E}+00$ & 0 & $0.00 \mathrm{E}+00$ & 0 & $0.00 \mathrm{E}+00$ & 0 & 5. $22 \mathrm{E}-24$ & 0 \\
\hline-137 & $6.74 E-17$ & 0 & $0.00 E+00$ & 0 & $0.00 E+00$ & 0 & $0.00 \mathrm{E}+00$ & 0 & $0.00 \mathrm{E}+00$ & 0 & $0.00 E+00$ & 0 & $0.00 \mathrm{E}+00$ & 0 & $6.74 \mathrm{E}-17$ & 0 \\
\hline-237 & $5.22 E-20$ & 0 & $0.00 \mathrm{E}+00$ & 0 & $0.00 E+00$ & 0 & $0.00 \mathrm{E}+00$ & 0 & $0.00 \mathrm{E}+00$ & 0 & $0.00 E+00$ & 0 & $0.00 \mathrm{E}+00$ & 0 & $5.22 \mathrm{E}-20$ & 0 \\
\hline-238 & 1. $21 E-23$ & 0 & $0.00 \mathrm{E}+00$ & 0 & $0.00 \mathrm{E}+00$ & 0 & $0.00 \mathrm{E}+00$ & 0 & $0.00 \mathrm{E}+00$ & 0 & $0.00 \mathrm{E}+00$ & 0 & $0.00 \mathrm{E}+00$ & 0 & 1. $21 \mathrm{E}-23$ & 0 \\
\hline-239 & $4.55 \mathrm{E}-24$ & 0 & $0.00 \mathrm{E}+00$ & 0 & $0.00 \mathrm{E}+00$ & 0 & $0.00 \mathrm{E}+00$ & 0 & $0.00 \mathrm{E}+00$ & 0 & $0.00 \mathrm{E}+00$ & 0 & $0.00 \mathrm{E}+00$ & 0 & $4.55 E-24$ & 0 \\
\hline-240 & $5.72 E-28$ & 0 & $0.00 \mathrm{E}+00$ & 0 & $0.00 \mathrm{E}+00$ & 0 & $0.00 \mathrm{E}+00$ & 0 & $0.00 \mathrm{E}+00$ & 0 & $0.00 E+00$ & 0 & $0.00 \mathrm{E}+00$ & 0 & $5.72 \mathrm{E}-28$ & 0 \\
\hline-99 & $3.38 E-32$ & 0 & $0.00 \mathrm{E}+00$ & 0 & $0.00 \mathrm{E}+00$ & 0 & $0.00 \mathrm{E}+00$ & 0 & $0.00 \mathrm{E}+00$ & 0 & $0.00 E+00$ & 0 & $0.00 \mathrm{E}+00$ & 0 & $3.38 E-32$ & 0 \\
\hline-228 & $6.02 \mathrm{E}-22$ & 0 & $0.00 \mathrm{E}+00$ & 0 & $0.00 \mathrm{E}+00$ & 0 & $0.00 \mathrm{E}+00$ & 0 & $0.00 \mathrm{E}+00$ & 0 & $0.00 \mathrm{E}+00$ & 0 & $0.00 \mathrm{E}+00$ & 0 & $6.02 \mathrm{E}-22$ & 0 \\
\hline-230 & $3.14 \mathrm{E}-15$ & 6 & $0.00 \mathrm{E}+00$ & 0 & $0.00 \mathrm{E}+00$ & 0 & $0.00 \mathrm{E}+00$ & 0 & $0.00 \mathrm{E}+00$ & 0 & $0.00 \mathrm{E}+00$ & 0 & $0.00 \mathrm{E}+00$ & 0 & $3.14 \mathrm{E}-15$ & 6 \\
\hline-232 & $5.31 E-14$ & 94 & $0.00 \mathrm{E}+00$ & 0 & $0.00 \mathrm{E}+00$ & 0 & $0.00 \mathrm{E}+00$ & 0 & $0.00 \mathrm{E}+00$ & 0 & $0.00 \mathrm{E}+00$ & 0 & $0.00 \mathrm{E}+00$ & 0 & $5.31 \mathrm{E}-14$ & 94 \\
\hline 34 & $1.15 \mathrm{E}-18$ & 0 & $0.00 \mathrm{E}+00$ & 0 & $0.00 \mathrm{E}+00$ & 0 & $0.00 \mathrm{E}+00$ & 0 & $0.00 \mathrm{E}+00$ & 0 & $0.00 \mathrm{E}+00$ & 0 & $0.00 \mathrm{E}+00$ & 0 & 1. $15 \mathrm{E}-18$ & 0 \\
\hline 35 & $3.51 \mathrm{E}-21$ & 0 & $0.00 \mathrm{E}+00$ & 0 & $0.00 \mathrm{E}+00$ & 0 & $0.00 \mathrm{E}+00$ & 0 & $0.00 \mathrm{E}+00$ & 0 & $0.00 \mathrm{E}+00$ & 0 & $0.00 \mathrm{E}+00$ & 0 & $3.51 \mathrm{E}-21$ & 0 \\
\hline 38 & $1.99 E-16$ & 0 & $0.00 \mathrm{E}+00$ & 0 & $0.00 \mathrm{E}+00$ & 0 & $0.00 \mathrm{E}+00$ & 0 & $0.00 \mathrm{E}+00$ & 0 & $0.00 E+00$ & 0 & $0.00 \mathrm{E}+00$ & 0 & 1. $99 \mathrm{E}-16$ & 0 \\
\hline & $5.65 \mathrm{E}-14$ & 100 & $0.00 \mathrm{E}+00$ & 0 & $0.00 \mathrm{E}+00$ & 0 & $0.00 \mathrm{E}+00$ & 0 & $0.00 \mathrm{E}+00$ & 0 & $0.00 \mathrm{E}+00$ & 0 & $0.00 \mathrm{E}+00$ & 0 & $5.65 \mathrm{E}-14$ & 100 \\
\hline
\end{tabular}

* Sum of dose from all releases and from primary contamination. 
RESRAD-OFFSITE, Version 2 .

Parent Dose Report

Title : Offsite Resident Farmer Deterministic Run

File : RF DOE SG FWD-FV2-10000Y.ROF

Total Dose Contributions TDOSE (i,p,t) for Individual Radionuclides (i) and Pathways (p) in mrem/yr and as a Percentage of Total Dose at $t=100$ years

From releases to ground water and to surface water

\begin{tabular}{|c|c|c|c|c|c|c|c|c|c|c|c|c|c|c|c|c|}
\hline & \multicolumn{2}{|c|}{ Ground } & \multicolumn{2}{|l|}{ Fish } & \multicolumn{2}{|c|}{ Radon } & \multicolumn{2}{|c|}{ Plant } & \multicolumn{2}{|l|}{ Meat } & \multicolumn{2}{|l|}{ Milk } & \multicolumn{2}{|l|}{ Soil } & \multicolumn{2}{|c|}{ Water } \\
\hline ide & Dose & $\%$ & Dose & $\%$ & Dose & 응 & Dose & $\frac{\circ}{0}$ & Dose & 응 & Dose & 응 & Dose & $\%$ & Dose & $\%$ \\
\hline-241 & $0.00 \mathrm{E}+00$ & 0 & $0.00 E+00$ & 0 & $0.00 \mathrm{E}+00$ & 0 & $0.00 \mathrm{E}+00$ & 0 & $0.00 \mathrm{E}+00$ & 0 & $0.00 \mathrm{E}+00$ & 0 & $0.00 \mathrm{E}+00$ & 0 & $0.00 \mathrm{E}+00$ & 0 \\
\hline-137 & $0.00 \mathrm{E}+00$ & 0 & $0.00 \mathrm{E}+00$ & 0 & $0.00 \mathrm{E}+00$ & 0 & $0.00 \mathrm{E}+00$ & 0 & $0.00 \mathrm{E}+00$ & 0 & $0.00 \mathrm{E}+00$ & 0 & $0.00 \mathrm{E}+00$ & 0 & $0.00 \mathrm{E}+00$ & 0 \\
\hline-237 & $0.00 \mathrm{E}+00$ & 0 & $0.00 \mathrm{E}+00$ & 0 & $0.00 \mathrm{E}+00$ & 0 & $0.00 \mathrm{E}+00$ & 0 & $0.00 \mathrm{E}+00$ & 0 & $0.00 \mathrm{E}+00$ & 0 & $0.00 \mathrm{E}+00$ & 0 & $0.00 \mathrm{E}+00$ & 0 \\
\hline-238 & $0.00 \mathrm{E}+00$ & 0 & $0.00 \mathrm{E}+00$ & 0 & $0.00 E+00$ & 0 & $0.00 \mathrm{E}+00$ & 0 & $0.00 \mathrm{E}+00$ & 0 & $0.00 E+00$ & 0 & $0.00 \mathrm{E}+00$ & 0 & $0.00 \mathrm{E}+00$ & 0 \\
\hline-239 & $0.00 \mathrm{E}+00$ & 0 & $0.00 \mathrm{E}+00$ & 0 & $0.00 \mathrm{E}+00$ & 0 & $0.00 \mathrm{E}+00$ & 0 & $0.00 \mathrm{E}+00$ & 0 & $0.00 \mathrm{E}+00$ & 0 & $0.00 \mathrm{E}+00$ & 0 & $0.00 \mathrm{E}+00$ & 0 \\
\hline-240 & $0.00 \mathrm{E}+00$ & 0 & $0.00 \mathrm{E}+00$ & 0 & $0.00 \mathrm{E}+00$ & 0 & $0.00 \mathrm{E}+00$ & 0 & $0.00 \mathrm{E}+00$ & 0 & $0.00 \mathrm{E}+00$ & 0 & $0.00 \mathrm{E}+00$ & 0 & $0.00 \mathrm{E}+00$ & 0 \\
\hline-99 & $0.00 \mathrm{E}+00$ & 0 & $0.00 \mathrm{E}+00$ & 0 & $0.00 \mathrm{E}+00$ & 0 & $0.00 \mathrm{E}+00$ & 0 & $0.00 \mathrm{E}+00$ & 0 & $0.00 E+00$ & 0 & $0.00 \mathrm{E}+00$ & 0 & $0.00 \mathrm{E}+00$ & 0 \\
\hline-228 & $0.00 \mathrm{E}+00$ & 0 & $0.00 \mathrm{E}+00$ & 0 & $0.00 \mathrm{E}+00$ & 0 & $0.00 \mathrm{E}+00$ & 0 & $0.00 \mathrm{E}+00$ & 0 & $0.00 \mathrm{E}+00$ & 0 & $0.00 \mathrm{E}+00$ & 0 & $0.00 \mathrm{E}+00$ & 0 \\
\hline-230 & $0.00 \mathrm{E}+00$ & 0 & $0.00 \mathrm{E}+00$ & 0 & $0.00 \mathrm{E}+00$ & 0 & $0.00 \mathrm{E}+00$ & 0 & $0.00 \mathrm{E}+00$ & 0 & $0.00 \mathrm{E}+00$ & 0 & $0.00 \mathrm{E}+00$ & 0 & $0.00 \mathrm{E}+00$ & 0 \\
\hline-232 & $0.00 \mathrm{E}+00$ & 0 & $0.00 \mathrm{E}+00$ & 0 & $0.00 \mathrm{E}+00$ & 0 & $0.00 \mathrm{E}+00$ & 0 & $0.00 \mathrm{E}+00$ & 0 & $0.00 \mathrm{E}+00$ & 0 & $0.00 \mathrm{E}+00$ & 0 & $0.00 \mathrm{E}+00$ & 0 \\
\hline 34 & $0.00 \mathrm{E}+00$ & 0 & $0.00 \mathrm{E}+00$ & 0 & $0.00 \mathrm{E}+00$ & 0 & $0.00 \mathrm{E}+00$ & 0 & $0.00 \mathrm{E}+00$ & 0 & $0.00 \mathrm{E}+00$ & 0 & $0.00 \mathrm{E}+00$ & 0 & $0.00 \mathrm{E}+00$ & 0 \\
\hline 35 & $0.00 \mathrm{E}+00$ & 0 & $0.00 \mathrm{E}+00$ & 0 & $0.00 \mathrm{E}+00$ & 0 & $0.00 \mathrm{E}+00$ & 0 & $0.00 \mathrm{E}+00$ & 0 & $0.00 \mathrm{E}+00$ & 0 & $0.00 \mathrm{E}+00$ & 0 & $0.00 \mathrm{E}+00$ & 0 \\
\hline 38 & $0.00 \mathrm{E}+00$ & 0 & $0.00 \mathrm{E}+00$ & 0 & $0.00 E+00$ & 0 & $0.00 \mathrm{E}+00$ & 0 & $0.00 \mathrm{E}+00$ & 0 & $0.00 E+00$ & 0 & $0.00 \mathrm{E}+00$ & 0 & $0.00 \mathrm{E}+00$ & 0 \\
\hline & $0.00 \mathrm{E}+00$ & 0 & $0.00 E+00$ & 0 & $0.00 \mathrm{E}+00$ & 0 & $0.00 \mathrm{E}+00$ & 0 & $0.00 \mathrm{E}+00$ & 0 & $0.00 \mathrm{E}+00$ & 0 & $0.00 \mathrm{E}+00$ & 0 & $0.00 \mathrm{E}+00$ & 0 \\
\hline
\end{tabular}

Total Dose Contributions TDOSE(i,p,t) for Individual Radionuclides (i) and Pathways (p) in mrem/yr and as a Percentage of Total Dose at $t=100$ years

Directly from primary contamination and from release to atmosphere (Inhalation excludes radon)

\begin{tabular}{|c|c|c|c|c|c|c|c|c|c|c|c|c|c|c|c|c|}
\hline & \multicolumn{2}{|c|}{ Ground } & \multicolumn{2}{|c|}{ Inhalation } & \multicolumn{2}{|c|}{ Radon } & \multicolumn{2}{|c|}{ Plant } & \multicolumn{2}{|l|}{ Meat } & \multicolumn{2}{|l|}{ Milk } & \multicolumn{2}{|l|}{ Soil } & \multicolumn{2}{|c|}{ All Pathways* } \\
\hline lide & Dose & $\%$ & Dose & $\%$ & Dose & $\%$ & Dose & 음 & Dose & $\%$ & Dose & 음 & Dose & $\%$ & Dose & $\%$ \\
\hline-241 & $1.64 \mathrm{E}-23$ & 0 & $0.00 \mathrm{E}+00$ & 0 & $0.00 \mathrm{E}+00$ & 0 & $0.00 \mathrm{E}+00$ & 0 & $0.00 \mathrm{E}+00$ & 0 & $0.00 \mathrm{E}+00$ & 0 & $0.00 \mathrm{E}+00$ & 0 & $1.64 \mathrm{E}-23$ & 0 \\
\hline-137 & $3.13 E-17$ & 0 & $0.00 E+00$ & 0 & $0.00 E+00$ & 0 & $0.00 \mathrm{E}+00$ & 0 & $0.00 \mathrm{E}+00$ & 0 & $0.00 E+00$ & 0 & $0.00 \mathrm{E}+00$ & 0 & $3.13 \mathrm{E}-17$ & 0 \\
\hline-237 & $8.58 E-20$ & 0 & $0.00 \mathrm{E}+00$ & 0 & $0.00 E+00$ & 0 & $0.00 \mathrm{E}+00$ & 0 & $0.00 \mathrm{E}+00$ & 0 & $0.00 E+00$ & 0 & $0.00 \mathrm{E}+00$ & 0 & $8.58 E-20$ & 0 \\
\hline-238 & 1. $19 \mathrm{E}-22$ & 0 & $0.00 \mathrm{E}+00$ & 0 & $0.00 \mathrm{E}+00$ & 0 & $0.00 \mathrm{E}+00$ & 0 & $0.00 \mathrm{E}+00$ & 0 & $0.00 \mathrm{E}+00$ & 0 & $0.00 \mathrm{E}+00$ & 0 & $1.19 \mathrm{E}-22$ & 0 \\
\hline-239 & $7.88 \mathrm{E}-24$ & 0 & $0.00 \mathrm{E}+00$ & 0 & $0.00 \mathrm{E}+00$ & 0 & $0.00 \mathrm{E}+00$ & 0 & $0.00 \mathrm{E}+00$ & 0 & $0.00 \mathrm{E}+00$ & 0 & $0.00 \mathrm{E}+00$ & 0 & $7.88 E-24$ & 0 \\
\hline-240 & $3.71 E-27$ & 0 & $0.00 \mathrm{E}+00$ & 0 & $0.00 \mathrm{E}+00$ & 0 & $0.00 \mathrm{E}+00$ & 0 & $0.00 \mathrm{E}+00$ & 0 & $0.00 E+00$ & 0 & $0.00 \mathrm{E}+00$ & 0 & $3.71 E-27$ & 0 \\
\hline-99 & $6.28 E-32$ & 0 & $0.00 \mathrm{E}+00$ & 0 & $0.00 \mathrm{E}+00$ & 0 & $0.00 \mathrm{E}+00$ & 0 & $0.00 \mathrm{E}+00$ & 0 & $0.00 E+00$ & 0 & $0.00 \mathrm{E}+00$ & 0 & $6.28 E-32$ & 0 \\
\hline-228 & $1.08 \mathrm{E}-29$ & 0 & $0.00 \mathrm{E}+00$ & 0 & $0.00 \mathrm{E}+00$ & 0 & $0.00 \mathrm{E}+00$ & 0 & $0.00 \mathrm{E}+00$ & 0 & $0.00 \mathrm{E}+00$ & 0 & $0.00 \mathrm{E}+00$ & 0 & $1.08 \mathrm{E}-29$ & 0 \\
\hline-230 & $8.49 \mathrm{E}-15$ & 11 & $0.00 \mathrm{E}+00$ & 0 & $0.00 \mathrm{E}+00$ & 0 & $0.00 \mathrm{E}+00$ & 0 & $0.00 \mathrm{E}+00$ & 0 & $0.00 \mathrm{E}+00$ & 0 & $0.00 \mathrm{E}+00$ & 0 & $8.49 \mathrm{E}-15$ & 11 \\
\hline-232 & $7.02 \mathrm{E}-14$ & 89 & $0.00 \mathrm{E}+00$ & 0 & $0.00 \mathrm{E}+00$ & 0 & $0.00 \mathrm{E}+00$ & 0 & $0.00 \mathrm{E}+00$ & 0 & $0.00 \mathrm{E}+00$ & 0 & $0.00 \mathrm{E}+00$ & 0 & $7.02 \mathrm{E}-14$ & 89 \\
\hline 34 & $6.19 \mathrm{E}-18$ & 0 & $0.00 \mathrm{E}+00$ & 0 & $0.00 \mathrm{E}+00$ & 0 & $0.00 \mathrm{E}+00$ & 0 & $0.00 \mathrm{E}+00$ & 0 & $0.00 \mathrm{E}+00$ & 0 & $0.00 \mathrm{E}+00$ & 0 & $6.19 \mathrm{E}-18$ & 0 \\
\hline 35 & $1.24 \mathrm{E}-20$ & 0 & $0.00 \mathrm{E}+00$ & 0 & $0.00 \mathrm{E}+00$ & 0 & $0.00 \mathrm{E}+00$ & 0 & $0.00 \mathrm{E}+00$ & 0 & $0.00 \mathrm{E}+00$ & 0 & $0.00 \mathrm{E}+00$ & 0 & $1.24 \mathrm{E}-20$ & 0 \\
\hline 38 & $2.87 E-16$ & 0 & $0.00 \mathrm{E}+00$ & 0 & $0.00 \mathrm{E}+00$ & 0 & $0.00 \mathrm{E}+00$ & 0 & $0.00 \mathrm{E}+00$ & 0 & $0.00 E+00$ & 0 & $0.00 \mathrm{E}+00$ & 0 & $2.87 E-16$ & 0 \\
\hline & $7.90 \mathrm{E}-14$ & 100 & $0.00 \mathrm{E}+00$ & 0 & $0.00 \mathrm{E}+00$ & 0 & $0.00 \mathrm{E}+00$ & 0 & $0.00 \mathrm{E}+00$ & 0 & $0.00 \mathrm{E}+00$ & 0 & $0.00 \mathrm{E}+00$ & 0 & $7.90 \mathrm{E}-14$ & 100 \\
\hline
\end{tabular}

* Sum of dose from all releases and from primary contamination. 
RESRAD-OFFSITE, Version 2 .

Parent Dose Report

Title : Offsite Resident Farmer Deterministic Run

File : RF DOE SG FWD-FV2-10000Y.ROF

Total Dose Contributions TDOSE (i,p,t) for Individual Radionuclides (i) and Pathways (p) in mrem/yr and as a Percentage of Total Dose at $t=500$ years

From releases to ground water and to surface water

\begin{tabular}{|c|c|c|c|c|c|c|c|c|c|c|c|c|c|c|c|c|}
\hline & \multicolumn{2}{|c|}{ Ground } & \multicolumn{2}{|l|}{ Fish } & \multicolumn{2}{|c|}{ Radon } & \multicolumn{2}{|c|}{ Plant } & \multicolumn{2}{|l|}{ Meat } & \multicolumn{2}{|l|}{ Milk } & \multicolumn{2}{|l|}{ Soil } & \multicolumn{2}{|c|}{ Water } \\
\hline ide & Dose & $\%$ & Dose & $\%$ & Dose & 응 & Dose & $\frac{\circ}{0}$ & Dose & 응 & Dose & 응 & Dose & $\%$ & Dose & $\%$ \\
\hline-241 & $0.00 \mathrm{E}+00$ & 0 & $0.00 E+00$ & 0 & $0.00 \mathrm{E}+00$ & 0 & $0.00 \mathrm{E}+00$ & 0 & $0.00 \mathrm{E}+00$ & 0 & $0.00 \mathrm{E}+00$ & 0 & $0.00 \mathrm{E}+00$ & 0 & $0.00 \mathrm{E}+00$ & 0 \\
\hline-137 & $0.00 \mathrm{E}+00$ & 0 & $0.00 \mathrm{E}+00$ & 0 & $0.00 \mathrm{E}+00$ & 0 & $0.00 \mathrm{E}+00$ & 0 & $0.00 \mathrm{E}+00$ & 0 & $0.00 \mathrm{E}+00$ & 0 & $0.00 \mathrm{E}+00$ & 0 & $0.00 \mathrm{E}+00$ & 0 \\
\hline-237 & $0.00 \mathrm{E}+00$ & 0 & $0.00 \mathrm{E}+00$ & 0 & $0.00 \mathrm{E}+00$ & 0 & $0.00 \mathrm{E}+00$ & 0 & $0.00 \mathrm{E}+00$ & 0 & $0.00 \mathrm{E}+00$ & 0 & $0.00 \mathrm{E}+00$ & 0 & $0.00 \mathrm{E}+00$ & 0 \\
\hline-238 & $0.00 \mathrm{E}+00$ & 0 & $0.00 \mathrm{E}+00$ & 0 & $0.00 E+00$ & 0 & $0.00 \mathrm{E}+00$ & 0 & $0.00 \mathrm{E}+00$ & 0 & $0.00 E+00$ & 0 & $0.00 \mathrm{E}+00$ & 0 & $0.00 \mathrm{E}+00$ & 0 \\
\hline-239 & $0.00 \mathrm{E}+00$ & 0 & $0.00 \mathrm{E}+00$ & 0 & $0.00 \mathrm{E}+00$ & 0 & $0.00 \mathrm{E}+00$ & 0 & $0.00 \mathrm{E}+00$ & 0 & $0.00 \mathrm{E}+00$ & 0 & $0.00 \mathrm{E}+00$ & 0 & $0.00 \mathrm{E}+00$ & 0 \\
\hline-240 & $0.00 \mathrm{E}+00$ & 0 & $0.00 \mathrm{E}+00$ & 0 & $0.00 \mathrm{E}+00$ & 0 & $0.00 \mathrm{E}+00$ & 0 & $0.00 \mathrm{E}+00$ & 0 & $0.00 \mathrm{E}+00$ & 0 & $0.00 \mathrm{E}+00$ & 0 & $0.00 \mathrm{E}+00$ & 0 \\
\hline-99 & $9.04 \mathrm{E}-07$ & 0 & $0.00 \mathrm{E}+00$ & 0 & $0.00 \mathrm{E}+00$ & 0 & $2.48 \mathrm{E}-01$ & 25 & $7.44 \mathrm{E}-04$ & 0 & $6.57 E-02$ & 7 & $7.63 E-07$ & 0 & $6.77 \mathrm{E}-01$ & 68 \\
\hline-228 & $0.00 \mathrm{E}+00$ & 0 & $0.00 \mathrm{E}+00$ & 0 & $0.00 \mathrm{E}+00$ & 0 & $0.00 \mathrm{E}+00$ & 0 & $0.00 \mathrm{E}+00$ & 0 & $0.00 \mathrm{E}+00$ & 0 & $0.00 \mathrm{E}+00$ & 0 & $0.00 \mathrm{E}+00$ & 0 \\
\hline-230 & $0.00 \mathrm{E}+00$ & 0 & $0.00 \mathrm{E}+00$ & 0 & $0.00 \mathrm{E}+00$ & 0 & $0.00 \mathrm{E}+00$ & 0 & $0.00 \mathrm{E}+00$ & 0 & $0.00 \mathrm{E}+00$ & 0 & $0.00 \mathrm{E}+00$ & 0 & $0.00 \mathrm{E}+00$ & 0 \\
\hline-232 & $0.00 \mathrm{E}+00$ & 0 & $0.00 \mathrm{E}+00$ & 0 & $0.00 \mathrm{E}+00$ & 0 & $0.00 \mathrm{E}+00$ & 0 & $0.00 \mathrm{E}+00$ & 0 & $0.00 \mathrm{E}+00$ & 0 & $0.00 \mathrm{E}+00$ & 0 & $0.00 \mathrm{E}+00$ & 0 \\
\hline 34 & $0.00 \mathrm{E}+00$ & 0 & $0.00 \mathrm{E}+00$ & 0 & $0.00 \mathrm{E}+00$ & 0 & $0.00 \mathrm{E}+00$ & 0 & $0.00 \mathrm{E}+00$ & 0 & $0.00 \mathrm{E}+00$ & 0 & $0.00 \mathrm{E}+00$ & 0 & $0.00 \mathrm{E}+00$ & 0 \\
\hline 35 & $0.00 \mathrm{E}+00$ & 0 & $0.00 \mathrm{E}+00$ & 0 & $0.00 \mathrm{E}+00$ & 0 & $0.00 \mathrm{E}+00$ & 0 & $0.00 \mathrm{E}+00$ & 0 & $0.00 \mathrm{E}+00$ & 0 & $0.00 \mathrm{E}+00$ & 0 & $0.00 \mathrm{E}+00$ & 0 \\
\hline 38 & $0.00 \mathrm{E}+00$ & 0 & $0.00 \mathrm{E}+00$ & 0 & $0.00 E+00$ & 0 & $0.00 \mathrm{E}+00$ & 0 & $0.00 \mathrm{E}+00$ & 0 & $0.00 E+00$ & 0 & $0.00 \mathrm{E}+00$ & 0 & $0.00 \mathrm{E}+00$ & 0 \\
\hline & $9.04 \mathrm{E}-07$ & 0 & $0.00 E+00$ & 0 & $0.00 \mathrm{E}+00$ & 0 & $2.48 \mathrm{E}-01$ & 25 & $7.44 \mathrm{E}-04$ & 0 & $6.57 E-02$ & 7 & $7.63 E-07$ & 0 & $6.77 \mathrm{E}-01$ & 68 \\
\hline
\end{tabular}

Total Dose Contributions TDOSE (i,p,t) for Individual Radionuclides (i) and Pathways (p) in mrem/yr and as a Percentage of Total Dose at $t=500$ years

Directly from primary contamination and from release to atmosphere (Inhalation excludes radon)

\begin{tabular}{|c|c|c|c|c|c|c|c|c|c|c|c|c|c|c|c|c|}
\hline & \multicolumn{2}{|c|}{ Ground } & \multicolumn{2}{|c|}{ Inhalation } & \multicolumn{2}{|c|}{ Radon } & \multicolumn{2}{|c|}{ Plant } & \multicolumn{2}{|l|}{ Meat } & \multicolumn{2}{|l|}{ Milk } & \multicolumn{2}{|l|}{ Soil } & \multicolumn{2}{|c|}{ All Pathways* } \\
\hline clide & Dose & $\%$ & Dose & $\%$ & Dose & $\%$ & Dose & 음 & Dose & $\%$ & Dose & 음 & Dose & $\%$ & Dose & $\%$ \\
\hline-241 & $3.23 E-21$ & 0 & $0.00 E+00$ & 0 & $0.00 E+00$ & 0 & $0.00 \mathrm{E}+00$ & 0 & $0.00 \mathrm{E}+00$ & 0 & $0.00 \mathrm{E}+00$ & 0 & $0.00 \mathrm{E}+00$ & 0 & $3.23 E-21$ & 0 \\
\hline-137 & $6.73 E-20$ & 0 & $0.00 E+00$ & 0 & $0.00 E+00$ & 0 & $0.00 \mathrm{E}+00$ & 0 & $0.00 \mathrm{E}+00$ & 0 & $0.00 E+00$ & 0 & $0.00 \mathrm{E}+00$ & 0 & $6.73 E-20$ & 0 \\
\hline-237 & $4.59 E-18$ & 0 & $0.00 E+00$ & 0 & $0.00 E+00$ & 0 & $0.00 \mathrm{E}+00$ & 0 & $0.00 \mathrm{E}+00$ & 0 & $0.00 E+00$ & 0 & $0.00 \mathrm{E}+00$ & 0 & $4.59 \mathrm{E}-18$ & 0 \\
\hline-238 & 1.01E-19 & 0 & $0.00 E+00$ & 0 & $0.00 \mathrm{E}+00$ & 0 & $0.00 \mathrm{E}+00$ & 0 & $0.00 \mathrm{E}+00$ & 0 & $0.00 \mathrm{E}+00$ & 0 & $0.00 \mathrm{E}+00$ & 0 & $1.01 \mathrm{E}-19$ & 0 \\
\hline-239 & $6.42 \mathrm{E}-22$ & 0 & $0.00 \mathrm{E}+00$ & 0 & $0.00 \mathrm{E}+00$ & 0 & $0.00 \mathrm{E}+00$ & 0 & $0.00 \mathrm{E}+00$ & 0 & $0.00 \mathrm{E}+00$ & 0 & $0.00 \mathrm{E}+00$ & 0 & $6.42 \mathrm{E}-22$ & 0 \\
\hline-240 & $9.86 \mathrm{E}-25$ & 0 & $0.00 \mathrm{E}+00$ & 0 & $0.00 \mathrm{E}+00$ & 0 & $0.00 \mathrm{E}+00$ & 0 & $0.00 \mathrm{E}+00$ & 0 & $0.00 \mathrm{E}+00$ & 0 & $0.00 \mathrm{E}+00$ & 0 & $9.86 \mathrm{E}-25$ & 0 \\
\hline-99 & $8.96 \mathrm{E}-30$ & 0 & $0.00 E+00$ & 0 & $0.00 \mathrm{E}+00$ & 0 & $0.00 \mathrm{E}+00$ & 0 & $0.00 \mathrm{E}+00$ & 0 & $0.00 E+00$ & 0 & $0.00 \mathrm{E}+00$ & 0 & $9.91 \mathrm{E}-01$ & 100 \\
\hline-228 & $0.00 \mathrm{E}+00$ & 0 & $0.00 \mathrm{E}+00$ & 0 & $0.00 \mathrm{E}+00$ & 0 & $0.00 \mathrm{E}+00$ & 0 & $0.00 \mathrm{E}+00$ & 0 & $0.00 \mathrm{E}+00$ & 0 & $0.00 \mathrm{E}+00$ & 0 & $0.00 \mathrm{E}+00$ & 0 \\
\hline-230 & $4.95 E-13$ & 0 & $0.00 E+00$ & 0 & $0.00 \mathrm{E}+00$ & 0 & $0.00 \mathrm{E}+00$ & 0 & $0.00 \mathrm{E}+00$ & 0 & $0.00 E+00$ & 0 & $0.00 \mathrm{E}+00$ & 0 & 4. $95 E-13$ & 0 \\
\hline-232 & $6.39 E-13$ & 0 & $0.00 E+00$ & 0 & $0.00 E+00$ & 0 & $0.00 \mathrm{E}+00$ & 0 & $0.00 \mathrm{E}+00$ & 0 & $0.00 E+00$ & 0 & $0.00 \mathrm{E}+00$ & 0 & $6.39 E-13$ & 0 \\
\hline 34 & $1.85 \mathrm{E}-15$ & 0 & $0.00 \mathrm{E}+00$ & 0 & $0.00 \mathrm{E}+00$ & 0 & $0.00 \mathrm{E}+00$ & 0 & $0.00 \mathrm{E}+00$ & 0 & $0.00 \mathrm{E}+00$ & 0 & $0.00 \mathrm{E}+00$ & 0 & $1.85 \mathrm{E}-15$ & 0 \\
\hline 35 & 1. $94 \mathrm{E}-18$ & 0 & $0.00 \mathrm{E}+00$ & 0 & $0.00 \mathrm{E}+00$ & 0 & $0.00 \mathrm{E}+00$ & 0 & $0.00 \mathrm{E}+00$ & 0 & $0.00 \mathrm{E}+00$ & 0 & $0.00 \mathrm{E}+00$ & 0 & $1.94 \mathrm{E}-18$ & 0 \\
\hline 38 & $5.45 E-15$ & 0 & $0.00 E+00$ & 0 & $0.00 \mathrm{E}+00$ & 0 & $0.00 \mathrm{E}+00$ & 0 & $0.00 \mathrm{E}+00$ & 0 & $0.00 E+00$ & 0 & $0.00 \mathrm{E}+00$ & 0 & $5.45 E-15$ & 0 \\
\hline & $1.14 \mathrm{E}-12$ & 0 & $0.00 \mathrm{E}+00$ & 0 & $0.00 \mathrm{E}+00$ & 0 & $0.00 \mathrm{E}+00$ & 0 & $0.00 \mathrm{E}+00$ & 0 & $0.00 \mathrm{E}+00$ & 0 & $0.00 \mathrm{E}+00$ & 0 & $9.91 \mathrm{E}-01$ & 100 \\
\hline
\end{tabular}

* Sum of dose from all releases and from primary contamination. 
RESRAD-OFFSITE, Version 2 .

arent Dose Report

Title : Offsite Resident Farmer Deterministic Run

File : RF DOE SG FWD-FV2-10000Y.ROF

Total Dose Contributions TDOSE (i,p,t) for Individual Radionuclides (i) and Pathways (p) in mrem/yr and as a Percentage of Total Dose at $t=1026$ years

From releases to ground water and to surface water

\begin{tabular}{|c|c|c|c|c|c|c|c|c|c|c|c|c|c|c|c|c|}
\hline & \multicolumn{2}{|c|}{ Ground } & \multicolumn{2}{|l|}{ Fish } & \multicolumn{2}{|l|}{ Radon } & \multicolumn{2}{|c|}{ Plant } & \multicolumn{2}{|l|}{ Meat } & \multicolumn{2}{|l|}{ Milk } & \multicolumn{2}{|l|}{ Soil } & \multicolumn{2}{|c|}{ Water } \\
\hline clide & Dose & \% & Dose & $\%$ & Dose & 음 & Dose & $\%$ & Dose & \% & Dose & $\%$ & Dose & 응 & Dose & \% \\
\hline-241 & $0.00 \mathrm{E}+00$ & 0 & $0.00 \mathrm{E}+00$ & 0 & $0.00 \mathrm{E}+00$ & 0 & $0.00 \mathrm{E}+00$ & 0 & $0.00 \mathrm{E}+00$ & 0 & $0.00 \mathrm{E}+00$ & 0 & $0.00 \mathrm{E}+00$ & 0 & $0.00 \mathrm{E}+00$ & 0 \\
\hline-137 & $0.00 \mathrm{E}+00$ & 0 & $0.00 \mathrm{E}+00$ & 0 & $0.00 \mathrm{E}+00$ & 0 & $0.00 \mathrm{E}+00$ & 0 & $0.00 \mathrm{E}+00$ & 0 & $0.00 \mathrm{E}+00$ & 0 & $0.00 \mathrm{E}+00$ & 0 & $0.00 \mathrm{E}+00$ & 0 \\
\hline-237 & $0.00 \mathrm{E}+00$ & 0 & $0.00 \mathrm{E}+00$ & 0 & $0.00 \mathrm{E}+00$ & 0 & $0.00 \mathrm{E}+00$ & 0 & $0.00 \mathrm{E}+00$ & 0 & $0.00 \mathrm{E}+00$ & 0 & $0.00 \mathrm{E}+00$ & 0 & $0.00 \mathrm{E}+00$ & 0 \\
\hline-238 & $0.00 \mathrm{E}+00$ & 0 & $0.00 E+00$ & 0 & $0.00 \mathrm{E}+00$ & 0 & $0.00 \mathrm{E}+00$ & 0 & $0.00 \mathrm{E}+00$ & 0 & $0.00 \mathrm{E}+00$ & 0 & $0.00 \mathrm{E}+00$ & 0 & $0.00 \mathrm{E}+00$ & 0 \\
\hline-239 & $0.00 \mathrm{E}+00$ & 0 & $0.00 E+00$ & 0 & $0.00 \mathrm{E}+00$ & 0 & $0.00 \mathrm{E}+00$ & 0 & $0.00 \mathrm{E}+00$ & 0 & $0.00 \mathrm{E}+00$ & 0 & $0.00 \mathrm{E}+00$ & 0 & $0.00 \mathrm{E}+00$ & 0 \\
\hline-240 & $0.00 \mathrm{E}+00$ & 0 & $0.00 \mathrm{E}+00$ & 0 & $0.00 \mathrm{E}+00$ & 0 & $0.00 \mathrm{E}+00$ & 0 & $0.00 \mathrm{E}+00$ & 0 & $0.00 \mathrm{E}+00$ & 0 & $0.00 \mathrm{E}+00$ & 0 & $0.00 \mathrm{E}+00$ & 0 \\
\hline-99 & $1.31 \mathrm{E}-06$ & 0 & $0.00 \mathrm{E}+00$ & 0 & $0.00 \mathrm{E}+00$ & 0 & $3.60 \mathrm{E}-01$ & 25 & $1.08 E-03$ & 0 & $9.52 \mathrm{E}-02$ & 7 & $1.11 \mathrm{E}-06$ & 0 & $9.80 \mathrm{E}-01$ & 68 \\
\hline-228 & $0.00 \mathrm{E}+00$ & 0 & $0.00 \mathrm{E}+00$ & 0 & $0.00 \mathrm{E}+00$ & 0 & $0.00 \mathrm{E}+00$ & 0 & $0.00 \mathrm{E}+00$ & 0 & $0.00 \mathrm{E}+00$ & 0 & $0.00 \mathrm{E}+00$ & 0 & $0.00 \mathrm{E}+00$ & 0 \\
\hline-230 & $0.00 \mathrm{E}+00$ & 0 & $0.00 \mathrm{E}+00$ & 0 & $0.00 \mathrm{E}+00$ & 0 & $0.00 \mathrm{E}+00$ & 0 & $0.00 \mathrm{E}+00$ & 0 & $0.00 \mathrm{E}+00$ & 0 & $0.00 \mathrm{E}+00$ & 0 & $0.00 \mathrm{E}+00$ & 0 \\
\hline-232 & $0.00 \mathrm{E}+00$ & 0 & $0.00 E+00$ & 0 & $0.00 \mathrm{E}+00$ & 0 & $0.00 \mathrm{E}+00$ & 0 & $0.00 \mathrm{E}+00$ & 0 & $0.00 \mathrm{E}+00$ & 0 & $0.00 \mathrm{E}+00$ & 0 & $0.00 \mathrm{E}+00$ & 0 \\
\hline 234 & $0.00 \mathrm{E}+00$ & 0 & $0.00 \mathrm{E}+00$ & 0 & $0.00 \mathrm{E}+00$ & 0 & $0.00 \mathrm{E}+00$ & 0 & $0.00 \mathrm{E}+00$ & 0 & $0.00 \mathrm{E}+00$ & 0 & $0.00 \mathrm{E}+00$ & 0 & $0.00 \mathrm{E}+00$ & 0 \\
\hline 35 & $0.00 \mathrm{E}+00$ & 0 & $0.00 E+00$ & 0 & $0.00 \mathrm{E}+00$ & 0 & $0.00 \mathrm{E}+00$ & 0 & $0.00 \mathrm{E}+00$ & 0 & $0.00 \mathrm{E}+00$ & 0 & $0.00 \mathrm{E}+00$ & 0 & $0.00 \mathrm{E}+00$ & 0 \\
\hline 238 & $0.00 \mathrm{E}+00$ & 0 & $0.00 E+00$ & 0 & $0.00 \mathrm{E}+00$ & 0 & $0.00 \mathrm{E}+00$ & 0 & $0.00 \mathrm{E}+00$ & 0 & $0.00 \mathrm{E}+00$ & 0 & $0.00 \mathrm{E}+00$ & 0 & $0.00 \mathrm{E}+00$ & 0 \\
\hline & $1.31 \mathrm{E}-06$ & 0 & $0.00 \mathrm{E}+00$ & 0 & $0.00 \mathrm{E}+00$ & 0 & $3.60 \mathrm{E}-01$ & 25 & $1.08 E-03$ & 0 & $9.52 \mathrm{E}-02$ & 7 & $1.11 \mathrm{E}-06$ & 0 & $9.80 \mathrm{E}-01$ & 68 \\
\hline
\end{tabular}

Total Dose Contributions TDOSE (i,p,t) for Individual Radionuclides (i) and Pathways (p)

in mrem/yr and as a Percentage of Total Dose at $t=1026$ years

Directly from primary contamination and from release to atmosphere (Inhalation excludes radon)

\begin{tabular}{|c|c|c|c|c|c|c|c|c|c|c|c|c|c|c|c|c|}
\hline & \multicolumn{2}{|c|}{ Ground } & \multicolumn{2}{|c|}{ Inhalation } & \multicolumn{2}{|c|}{ Radon } & \multicolumn{2}{|c|}{ Plant } & \multicolumn{2}{|l|}{ Meat } & \multicolumn{2}{|l|}{ Milk } & \multicolumn{2}{|l|}{ Soil } & \multicolumn{2}{|c|}{ All Pathways* } \\
\hline clide & Dose & $\%$ & Dose & $\%$ & Dose & $\%$ & Dose & 음 & Dose & $\%$ & Dose & $\%$ & Dose & \% & Dose & $\%$ \\
\hline-241 & $8.57 E-19$ & 0 & $0.00 \mathrm{E}+00$ & 0 & $0.00 \mathrm{E}+00$ & 0 & $0.00 \mathrm{E}+00$ & 0 & $0.00 \mathrm{E}+00$ & 0 & $0.00 E+00$ & 0 & $0.00 E+00$ & 0 & $8.57 E-19$ & 0 \\
\hline-137 & $2.09 E-23$ & 0 & $0.00 \mathrm{E}+00$ & 0 & $0.00 \mathrm{E}+00$ & 0 & $0.00 \mathrm{E}+00$ & 0 & $0.00 \mathrm{E}+00$ & 0 & $0.00 \mathrm{E}+00$ & 0 & $0.00 \mathrm{E}+00$ & 0 & $2.09 E-23$ & 0 \\
\hline-237 & $8.15 \mathrm{E}-16$ & 0 & $0.00 \mathrm{E}+00$ & 0 & $0.00 \mathrm{E}+00$ & 0 & $0.00 \mathrm{E}+00$ & 0 & $0.00 \mathrm{E}+00$ & 0 & $0.00 \mathrm{E}+00$ & 0 & $0.00 \mathrm{E}+00$ & 0 & $8.15 E-16$ & 0 \\
\hline-238 & 1. $43 \mathrm{E}-17$ & 0 & $0.00 \mathrm{E}+00$ & 0 & $0.00 \mathrm{E}+00$ & 0 & $0.00 \mathrm{E}+00$ & 0 & $0.00 \mathrm{E}+00$ & 0 & $0.00 \mathrm{E}+00$ & 0 & $0.00 \mathrm{E}+00$ & 0 & $1.43 \mathrm{E}-17$ & 0 \\
\hline-239 & $2.09 \mathrm{E}-19$ & 0 & $0.00 \mathrm{E}+00$ & 0 & $0.00 \mathrm{E}+00$ & 0 & $0.00 \mathrm{E}+00$ & 0 & $0.00 \mathrm{E}+00$ & 0 & $0.00 \mathrm{E}+00$ & 0 & $0.00 \mathrm{E}+00$ & 0 & $2.09 \mathrm{E}-19$ & 0 \\
\hline-240 & $8.10 \mathrm{E}-23$ & 0 & $0.00 \mathrm{E}+00$ & 0 & $0.00 \mathrm{E}+00$ & 0 & $0.00 \mathrm{E}+00$ & 0 & $0.00 \mathrm{E}+00$ & 0 & $0.00 \mathrm{E}+00$ & 0 & $0.00 \mathrm{E}+00$ & 0 & $8.10 \mathrm{E}-23$ & 0 \\
\hline-99 & $6.10 \mathrm{E}-27$ & 0 & $0.00 \mathrm{E}+00$ & 0 & $0.00 \mathrm{E}+00$ & 0 & $0.00 \mathrm{E}+00$ & 0 & $0.00 \mathrm{E}+00$ & 0 & $0.00 \mathrm{E}+00$ & 0 & $0.00 \mathrm{E}+00$ & 0 & $1.44 \mathrm{E}+00$ & 100 \\
\hline-228 & $0.00 \mathrm{E}+00$ & 0 & $0.00 \mathrm{E}+00$ & 0 & $0.00 \mathrm{E}+00$ & 0 & $0.00 \mathrm{E}+00$ & 0 & $0.00 \mathrm{E}+00$ & 0 & $0.00 \mathrm{E}+00$ & 0 & $0.00 \mathrm{E}+00$ & 0 & $0.00 \mathrm{E}+00$ & 0 \\
\hline-230 & $2.59 \mathrm{E}-11$ & 0 & $0.00 \mathrm{E}+00$ & 0 & $0.00 \mathrm{E}+00$ & 0 & $0.00 \mathrm{E}+00$ & 0 & $0.00 \mathrm{E}+00$ & 0 & $0.00 \mathrm{E}+00$ & 0 & $0.00 \mathrm{E}+00$ & 0 & $2.59 \mathrm{E}-11$ & 0 \\
\hline-232 & $1.19 \mathrm{E}-11$ & 0 & $0.00 \mathrm{E}+00$ & 0 & $0.00 \mathrm{E}+00$ & 0 & $0.00 \mathrm{E}+00$ & 0 & $0.00 \mathrm{E}+00$ & 0 & $0.00 \mathrm{E}+00$ & 0 & $0.00 \mathrm{E}+00$ & 0 & 1. $19 \mathrm{E}-11$ & 0 \\
\hline 234 & $2.05 E-13$ & 0 & $0.00 \mathrm{E}+00$ & 0 & $0.00 \mathrm{E}+00$ & 0 & $0.00 \mathrm{E}+00$ & 0 & $0.00 \mathrm{E}+00$ & 0 & $0.00 \mathrm{E}+00$ & 0 & $0.00 \mathrm{E}+00$ & 0 & $2.05 E-13$ & 0 \\
\hline 235 & $3.32 \mathrm{E}-16$ & 0 & $0.00 \mathrm{E}+00$ & 0 & $0.00 \mathrm{E}+00$ & 0 & $0.00 \mathrm{E}+00$ & 0 & $0.00 \mathrm{E}+00$ & 0 & $0.00 \mathrm{E}+00$ & 0 & $0.00 \mathrm{E}+00$ & 0 & $3.32 \mathrm{E}-16$ & 0 \\
\hline 238 & $2.62 E-13$ & 0 & $0.00 \mathrm{E}+00$ & 0 & $0.00 \mathrm{E}+00$ & 0 & $0.00 \mathrm{E}+00$ & 0 & $0.00 \mathrm{E}+00$ & 0 & $0.00 \mathrm{E}+00$ & 0 & $0.00 \mathrm{E}+00$ & 0 & $2.62 \mathrm{E}-13$ & 0 \\
\hline$a_{1}$ & $3.82 \mathrm{E}-11$ & 0 & $0.00 \mathrm{E}+00$ & 0 & $0.00 \mathrm{E}+00$ & 0 & $0.00 \mathrm{E}+00$ & 0 & $0.00 \mathrm{E}+00$ & 0 & $0.00 \mathrm{E}+00$ & 0 & $0.00 \mathrm{E}+00$ & 0 & $1.44 \mathrm{E}+00$ & 100 \\
\hline
\end{tabular}

* Sum of dose from all releases and from primary contamination. 
RESRAD-OFFSITE, Version 2 .

Parent Dose Report

Title : Offsite Resident Farmer Deterministic Run

File : RF DOE SG FWD-FV2-10000Y.ROF

Total Dose Contributions TDOSE (i,p,t) for Individual Radionuclides (i) and Pathways (p) in mrem/yr and as a Percentage of Total Dose at $t=9976$ years

From releases to ground water and to surface water

\begin{tabular}{|c|c|c|c|c|c|c|c|c|c|c|c|c|c|c|c|c|}
\hline & \multicolumn{2}{|c|}{ Ground } & \multicolumn{2}{|l|}{ Fish } & \multicolumn{2}{|l|}{ Radon } & \multicolumn{2}{|c|}{ Plant } & \multicolumn{2}{|l|}{ Meat } & \multicolumn{2}{|l|}{ Milk } & \multicolumn{2}{|l|}{ Soil } & \multicolumn{2}{|c|}{ Water } \\
\hline clide & Dose & \% & Dose & $\%$ & Dose & 음 & Dose & 음 & Dose & \% & Dose & \% & Dose & 응 & Dose & 응 \\
\hline-241 & 1. $21 \mathrm{E}-05$ & 0 & $0.00 \mathrm{E}+00$ & 0 & $0.00 \mathrm{E}+00$ & 0 & 4.01E-04 & 0 & 1. $49 \mathrm{E}-05$ & 0 & $8.40 \mathrm{E}-07$ & 0 & $2.01 E-07$ & 0 & $1.36 \mathrm{E}-03$ & 0 \\
\hline-137 & $0.00 \mathrm{E}+00$ & 0 & $0.00 \mathrm{E}+00$ & 0 & $0.00 \mathrm{E}+00$ & 0 & $0.00 \mathrm{E}+00$ & 0 & $0.00 \mathrm{E}+00$ & 0 & $0.00 \mathrm{E}+00$ & 0 & $0.00 \mathrm{E}+00$ & 0 & $0.00 \mathrm{E}+00$ & 0 \\
\hline-237 & $8.70 \mathrm{E}-03$ & 0 & $0.00 \mathrm{E}+00$ & 0 & $0.00 \mathrm{E}+00$ & 0 & $2.89 \mathrm{E}-01$ & 13 & $1.07 \mathrm{E}-02$ & 0 & $6.08 \mathrm{E}-04$ & 0 & 1. $45 \mathrm{E}-04$ & 0 & $9.78 \mathrm{E}-01$ & 45 \\
\hline-238 & $0.00 \mathrm{E}+00$ & 0 & $0.00 \mathrm{E}+00$ & 0 & $0.00 \mathrm{E}+00$ & 0 & $0.00 \mathrm{E}+00$ & 0 & $0.00 \mathrm{E}+00$ & 0 & $0.00 \mathrm{E}+00$ & 0 & $0.00 \mathrm{E}+00$ & 0 & $0.00 \mathrm{E}+00$ & 0 \\
\hline-239 & $0.00 \mathrm{E}+00$ & 0 & $0.00 \mathrm{E}+00$ & 0 & $0.00 \mathrm{E}+00$ & 0 & $0.00 \mathrm{E}+00$ & 0 & $0.00 \mathrm{E}+00$ & 0 & $0.00 \mathrm{E}+00$ & 0 & $0.00 \mathrm{E}+00$ & 0 & $0.00 \mathrm{E}+00$ & 0 \\
\hline-240 & $0.00 \mathrm{E}+00$ & 0 & $0.00 \mathrm{E}+00$ & 0 & $0.00 \mathrm{E}+00$ & 0 & $0.00 \mathrm{E}+00$ & 0 & $0.00 \mathrm{E}+00$ & 0 & $0.00 \mathrm{E}+00$ & 0 & $0.00 \mathrm{E}+00$ & 0 & $0.00 \mathrm{E}+00$ & 0 \\
\hline-99 & $5.23 E-25$ & 0 & $0.00 \mathrm{E}+00$ & 0 & $0.00 \mathrm{E}+00$ & 0 & 1. $43 \mathrm{E}-19$ & 0 & $4.28 E-22$ & 0 & $3.78 \mathrm{E}-20$ & 0 & 4. $41 E-25$ & 0 & $3.89 \mathrm{E}-19$ & 0 \\
\hline-228 & $0.00 \mathrm{E}+00$ & 0 & $0.00 \mathrm{E}+00$ & 0 & $0.00 \mathrm{E}+00$ & 0 & $0.00 \mathrm{E}+00$ & 0 & $0.00 \mathrm{E}+00$ & 0 & $0.00 \mathrm{E}+00$ & 0 & $0.00 \mathrm{E}+00$ & 0 & $0.00 \mathrm{E}+00$ & 0 \\
\hline-230 & $0.00 \mathrm{E}+00$ & 0 & $0.00 \mathrm{E}+00$ & 0 & $0.00 \mathrm{E}+00$ & 0 & $0.00 \mathrm{E}+00$ & 0 & $0.00 \mathrm{E}+00$ & 0 & $0.00 \mathrm{E}+00$ & 0 & $0.00 \mathrm{E}+00$ & 0 & $0.00 \mathrm{E}+00$ & 0 \\
\hline-232 & $0.00 \mathrm{E}+00$ & 0 & $0.00 \mathrm{E}+00$ & 0 & $0.00 \mathrm{E}+00$ & 0 & $0.00 \mathrm{E}+00$ & 0 & $0.00 \mathrm{E}+00$ & 0 & $0.00 \mathrm{E}+00$ & 0 & $0.00 \mathrm{E}+00$ & 0 & $0.00 \mathrm{E}+00$ & 0 \\
\hline 234 & $0.00 \mathrm{E}+00$ & 0 & $0.00 \mathrm{E}+00$ & 0 & $0.00 \mathrm{E}+00$ & 0 & $0.00 \mathrm{E}+00$ & 0 & $0.00 \mathrm{E}+00$ & 0 & $0.00 \mathrm{E}+00$ & 0 & $0.00 \mathrm{E}+00$ & 0 & $0.00 \mathrm{E}+00$ & 0 \\
\hline 235 & $0.00 \mathrm{E}+00$ & 0 & $0.00 \mathrm{E}+00$ & 0 & $0.00 \mathrm{E}+00$ & 0 & $0.00 \mathrm{E}+00$ & 0 & $0.00 \mathrm{E}+00$ & 0 & $0.00 \mathrm{E}+00$ & 0 & $0.00 \mathrm{E}+00$ & 0 & $0.00 \mathrm{E}+00$ & 0 \\
\hline 238 & $0.00 \mathrm{E}+00$ & 0 & $0.00 \mathrm{E}+00$ & 0 & $0.00 \mathrm{E}+00$ & 0 & $0.00 \mathrm{E}+00$ & 0 & $0.00 \mathrm{E}+00$ & 0 & $0.00 \mathrm{E}+00$ & 0 & $0.00 \mathrm{E}+00$ & 0 & $0.00 \mathrm{E}+00$ & 0 \\
\hline & $8.71 E-03$ & 0 & $0.00 \mathrm{E}+00$ & 0 & $0.00 \mathrm{E}+00$ & 0 & $2.89 \mathrm{E}-01$ & 13 & 1. $08 \mathrm{E}-02$ & 0 & $6.08 \mathrm{E}-04$ & 0 & 1. $45 \mathrm{E}-04$ & 0 & $9.79 \mathrm{E}-01$ & 45 \\
\hline
\end{tabular}

Total Dose Contributions TDOSE (i,p,t) for Individual Radionuclides (i) and Pathways (p)

in mrem/yr and as a Percentage of Total Dose at $t=9976$ years

Directly from primary contamination and from release to atmosphere (Inhalation excludes radon)

\begin{tabular}{|c|c|c|c|c|c|c|c|c|c|c|c|c|c|c|c|c|}
\hline \multirow{2}{*}{$\begin{array}{l}\text { Radio- } \\
\text { Nuclide }\end{array}$} & \multicolumn{2}{|c|}{ Ground } & \multicolumn{2}{|c|}{ Inhalation } & \multicolumn{2}{|c|}{ Radon } & \multicolumn{2}{|c|}{ Plant } & \multicolumn{2}{|l|}{ Meat } & \multicolumn{2}{|l|}{ Milk } & \multicolumn{2}{|l|}{ Soil } & \multicolumn{2}{|c|}{ All Pathways* } \\
\hline & Dose & $\%$ & Dose & 응 & Dose & \% & Dose & 응 & Dose & 응 & Dose & $\frac{\circ}{0}$ & Dose & 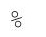 & Dose & \% \\
\hline-241 & $1.81 \mathrm{E}-06$ & 0 & $4.76 E-09$ & 0 & $0.00 \mathrm{E}+00$ & 0 & $4.46 \mathrm{E}-11$ & 0 & 1. $23 E-11$ & 0 & 3. $69 \mathrm{E}-13$ & 0 & 1. $29 \mathrm{E}-12$ & 0 & $1.79 E-03$ & 0 \\
\hline-137 & $1.02 E-43$ & 0 & $0.00 \mathrm{E}+00$ & 0 & $0.00 \mathrm{E}+00$ & 0 & $9.81 E-45$ & 0 & $3.64 E-44$ & 0 & $1.54 \mathrm{E}-44$ & 0 & $0.00 \mathrm{E}+00$ & 0 & $1.64 E-43$ & 0 \\
\hline-237 & $1.35 E-03$ & 0 & $3.58 \mathrm{E}-06$ & 0 & $0.00 \mathrm{E}+00$ & 0 & $3.33 E-08$ & 0 & $9.16 \mathrm{E}-09$ & 0 & $2.92 E-10$ & 0 & $9.92 \mathrm{E}-10$ & 0 & $1.29 \mathrm{E}+00$ & 59 \\
\hline-238 & $7.00 E-06$ & 0 & $5.96 E-09$ & 0 & $0.00 \mathrm{E}+00$ & 0 & $4.13 E-10$ & 0 & $9.43 E-11$ & 0 & $1.02 E-10$ & 0 & 1. $46 \mathrm{E}-11$ & 0 & $7.01 E-06$ & 0 \\
\hline-239 & $2.76 \mathrm{E}-06$ & 0 & $7.38 \mathrm{E}-05$ & 0 & $0.00 \mathrm{E}+00$ & 0 & $2.96 \mathrm{E}-07$ & 0 & $2.11 \mathrm{E}-08$ & 0 & $4.98 \mathrm{E}-10$ & 0 & $3.96 \mathrm{E}-08$ & 0 & $7.69 \mathrm{E}-05$ & 0 \\
\hline-240 & $9.81 \mathrm{E}-08$ & 0 & $3.41 \mathrm{E}-05$ & 0 & $0.00 \mathrm{E}+00$ & 0 & $1.37 \mathrm{E}-07$ & 0 & $9.75 \mathrm{E}-09$ & 0 & $2.37 \mathrm{E}-10$ & 0 & $1.83 E-08$ & 0 & $3.44 \mathrm{E}-05$ & 0 \\
\hline-99 & $2.26 E-29$ & 0 & $2.73 E-31$ & 0 & $0.00 \mathrm{E}+00$ & 0 & $9.63 E-32$ & 0 & $2.14 E-33$ & 0 & $2.94 E-32$ & 0 & $1.14 \mathrm{E}-35$ & 0 & $5.71 E-19$ & 0 \\
\hline-228 & $0.00 \mathrm{E}+00$ & 0 & $0.00 \mathrm{E}+00$ & 0 & $0.00 \mathrm{E}+00$ & 0 & $0.00 \mathrm{E}+00$ & 0 & $0.00 \mathrm{E}+00$ & 0 & $0.00 \mathrm{E}+00$ & 0 & $0.00 \mathrm{E}+00$ & 0 & $0.00 \mathrm{E}+00$ & 0 \\
\hline-230 & 7. $40 \mathrm{E}-01$ & 34 & $2.69 \mathrm{E}-04$ & 0 & $0.00 \mathrm{E}+00$ & 0 & $4.06 E-05$ & 0 & $9.55 \mathrm{E}-06$ & 0 & $9.24 \mathrm{E}-06$ & 0 & $1.36 \mathrm{E}-06$ & 0 & $7.41 \mathrm{E}-01$ & 34 \\
\hline-232 & $4.56 E-02$ & 2 & 1. $68 \mathrm{E}-05$ & 0 & $0.00 \mathrm{E}+00$ & 0 & $2.07 E-06$ & 0 & $3.61 \mathrm{E}-07$ & 0 & $5.58 E-07$ & 0 & $3.37 E-08$ & 0 & $4.56 \mathrm{E}-02$ & 2 \\
\hline 234 & $8.13 \mathrm{E}-02$ & 4 & $6.85 E-05$ & 0 & $0.00 \mathrm{E}+00$ & 0 & $4.80 \mathrm{E}-06$ & 0 & $1.09 \mathrm{E}-06$ & 0 & $1.18 \mathrm{E}-06$ & 0 & $1.70 \mathrm{E}-07$ & 0 & $8.14 \mathrm{E}-02$ & 4 \\
\hline 235 & $2.80 E-03$ & 0 & $2.08 E-05$ & 0 & $0.00 \mathrm{E}+00$ & 0 & $2.26 \mathrm{E}-07$ & 0 & $2.03 E-07$ & 0 & $9.38 E-09$ & 0 & $1.41 \mathrm{E}-08$ & 0 & $2.83 E-03$ & 0 \\
\hline 238 & $1.67 E-02$ & 1 & $2.96 \mathrm{E}-05$ & 0 & $0.00 \mathrm{E}+00$ & 0 & $3.66 \mathrm{E}-07$ & 0 & $5.72 \mathrm{E}-08$ & 0 & $1.87 E-07$ & 0 & $1.84 \mathrm{E}-08$ & 0 & 1. $67 \mathrm{E}-02$ & 1 \\
\hline$d \perp$ & $8.88 E-01$ & 41 & $5.17 \mathrm{E}-04$ & 0 & $0.00 \mathrm{E}+00$ & 0 & $4.85 E-05$ & 0 & $1.13 \mathrm{E}-05$ & 0 & $1.12 E-05$ & 0 & $1.66 E-06$ & 0 & $2.18 \mathrm{E}+00$ & 100 \\
\hline
\end{tabular}

* Sum of dose from all releases and from primary contamination. 
RESRAD-OFFSITE, Version 2.

Parent Dose Report

Title : Offsite Resident Farmer Deterministic Run

File : RF DOE SG FWD-FV2-10000Y.ROF

Dose/Source Ratios Summed Over All Pathways

Parent and Progeny Principal Radionuclide Contributions Indicated

\begin{tabular}{|c|c|c|c|c|c|c|c|c|c|}
\hline Parent & Product & Thread & & & $(j, t) \quad(\mathrm{mr}$ & $\mathrm{em} / \mathrm{yr}) /(\mathrm{pc}$ & i/g) & & \\
\hline (i) & $(j)$ & Fraction & $0.000 \mathrm{E}+00$ & $1.000 \mathrm{E}+00$ & $5.000 \mathrm{E}+01$ & $1.000 \mathrm{E}+02$ & $5.000 \mathrm{E}+02$ & $1.026 \mathrm{E}+03$ & $9.976 \mathrm{E}+03$ \\
\hline-241 & $A m-241$ & $1.000 \mathrm{E}+00$ & $1.173 \mathrm{E}-41$ & 1. $202 \mathrm{E}-41$ & $3.983 E-41$ & 1. $352 \mathrm{E}-40$ & $2.391 E-36$ & $9.208 E-31$ & 4. $317 \mathrm{E}-13$ \\
\hline-241 & $N p-237+D$ & $1.000 \mathrm{E}+00$ & $9.382 E-28$ & $2.837 E-27$ & $1.490 \mathrm{E}-25$ & $4.679 \mathrm{E}-25$ & $9.095 E-23$ & $2.417 E-20$ & $5.099 \mathrm{E}-05$ \\
\hline $1-241$ & $\mathrm{U}-233$ & $1.000 \mathrm{E}+00$ & $2.540 E-38$ & $1.601 \mathrm{E}-37$ & $2.808 E-34$ & $1.927 E-33$ & $3.932 E-30$ & $5.617 \mathrm{E}-27$ & $1.146 \mathrm{E}-07$ \\
\hline $1-241$ & $T h-229+D$ & $1.000 \mathrm{E}+00$ & $2.072 \mathrm{E}-34$ & $2.588 E-33$ & $1.009 \mathrm{E}-28$ & $1.073 \mathrm{E}-27$ & $1.480 \mathrm{E}-24$ & $3.195 E-22$ & $8.346 \mathrm{E}-09$ \\
\hline $1-241$ & $\sum \operatorname{DSR}(j)$ & & $9.382 E-28$ & $2.837 E-27$ & $1.491 \mathrm{E}-25$ & $4.689 \mathrm{E}-25$ & $9.243 E-23$ & $2.449 E-20$ & $5.111 \mathrm{E}-05$ \\
\hline$-137+D$ & $\mathrm{Cs}-137+\mathrm{D}$ & $1.000 \mathrm{E}+00$ & $7.649 \mathrm{E}-18$ & $7.532 \mathrm{E}-18$ & $3.550 \mathrm{E}-18$ & $1.647 \mathrm{E}-18$ & $3.543 E-21$ & $1.101 \mathrm{E}-24$ & $8.408 E-45$ \\
\hline$-237+D$ & $N p-237+D$ & $1.000 \mathrm{E}+00$ & $5.780 \mathrm{E}-21$ & $5.837 \mathrm{E}-21$ & $9.466 \mathrm{E}-21$ & 1. $550 \mathrm{E}-20$ & $8.026 E-19$ & 1. $440 \mathrm{E}-16$ & $2.336 \mathrm{E}-01$ \\
\hline$-237+D$ & $\mathrm{U}-233$ & $1.000 \mathrm{E}+00$ & $1.969 \mathrm{E}-31$ & $5.967 \mathrm{E}-31$ & $3.524 \mathrm{E}-29$ & $1.247 \mathrm{E}-28$ & $6.189 \mathrm{E}-26$ & $5.394 \mathrm{E}-23$ & $5.369 \mathrm{E}-04$ \\
\hline$-237+D$ & $T h-229+D$ & $1.000 \mathrm{E}+00$ & $2.145 E-27$ & $1.347 \mathrm{E}-26$ & $1.887 \mathrm{E}-23$ & $1.028 E-22$ & $3.287 E-20$ & $4.103 E-18$ & $4.415 E-05$ \\
\hline-237 & $\sum \operatorname{DSR}(j)$ & & $5.780 \mathrm{E}-21$ & $5.837 \mathrm{E}-21$ & $9.485 \mathrm{E}-21$ & $1.561 \mathrm{E}-20$ & $8.354 E-19$ & $1.481 E-16$ & $2.342 E-01$ \\
\hline-238 & $\mathrm{Pu}-238$ & $1.840 \mathrm{E}-09$ & $1.310 \mathrm{E}-41$ & 1. $321 \mathrm{E}-41$ & $1.990 \mathrm{E}-41$ & $3.022 E-41$ & $8.560 E-40$ & $6.951 \mathrm{E}-38$ & $0.000 \mathrm{E}+00$ \\
\hline-238 & $\mathrm{Pu}-238$ & $1.000 \mathrm{E}+00$ & $7.119 E-33$ & $7.179 \mathrm{E}-33$ & $1.081 \mathrm{E}-32$ & $1.642 E-32$ & $4.652 E-31$ & $3.778 E-29$ & $1.487 \mathrm{E}-40$ \\
\hline-238 & $\mathrm{U}-234$ & $1.000 \mathrm{E}+00$ & $5.933 E-38$ & $1.799 \mathrm{E}-37$ & $1.115 \mathrm{E}-35$ & $4.196 \mathrm{E}-35$ & $5.105 E-32$ & $2.757 E-28$ & $9.222 \mathrm{E}-11$ \\
\hline-238 & $T h-230$ & $1.000 \mathrm{E}+00$ & $7.448 E-42$ & $4.703 E-41$ & $9.070 \mathrm{E}-38$ & $6.913 E-37$ & $4.079 E-33$ & $3.348 E-29$ & $7.797 \mathrm{E}-11$ \\
\hline-238 & $\mathrm{Ra}-226+\mathrm{D}$ & $1.000 \mathrm{E}+00$ & $6.926 E-31$ & $8.638 E-30$ & $3.107 E-25$ & $3.057 \mathrm{E}-24$ & $2.593 E-21$ & $3.654 \mathrm{E}-19$ & $1.795 \mathrm{E}-07$ \\
\hline-238 & $\mathrm{~Pb}-210+\mathrm{D}$ & $1.000 \mathrm{E}+00$ & $2.498 E-39$ & $5.865 E-38$ & $4.570 E-32$ & $7.489 \mathrm{E}-31$ & $1.633 E-27$ & $4.208 E-25$ & $8.372 \mathrm{E}-11$ \\
\hline-238 & $\sum \operatorname{DSR}(j)$ & & $6.998 E-31$ & $8.645 E-30$ & $3.107 E-25$ & $3.057 \mathrm{E}-24$ & $2.593 E-21$ & $3.654 \mathrm{E}-19$ & $1.797 \mathrm{E}-07$ \\
\hline-239 & $\mathrm{Pu}-239$ & $1.000 \mathrm{E}+00$ & $7.287 \mathrm{E}-26$ & $7.367 \mathrm{E}-26$ & 1. $262 \mathrm{E}-25$ & $2.187 \mathrm{E}-25$ & $1.776 \mathrm{E}-23$ & $5.763 E-21$ & $2.133 E-06$ \\
\hline-239 & $\mathrm{U}-235+\mathrm{D}$ & $1.000 \mathrm{E}+00$ & $3.723 E-32$ & $1.128 \mathrm{E}-31$ & $6.617 \mathrm{E}-30$ & $2.325 E-29$ & $1.094 \mathrm{E}-26$ & $8.874 \mathrm{E}-24$ & $2.129 \mathrm{E}-09$ \\
\hline-239 & $\mathrm{~Pa}-231$ & $1.000 \mathrm{E}+00$ & $6.991 \mathrm{E}-36$ & $4.403 E-35$ & $7.273 E-32$ & $4.692 \mathrm{E}-31$ & $5.773 E-28$ & $4.121 E-25$ & $8.186 \mathrm{E}-11$ \\
\hline-239 & $A C-227+D$ & $1.000 \mathrm{E}+00$ & $1.974 \mathrm{E}-35$ & $2.453 E-34$ & $7.476 \mathrm{E}-30$ & $6.622 E-29$ & $6.350 E-26$ & $2.019 E-23$ & 7. $962 \mathrm{E}-10$ \\
\hline-239 & $\sum \operatorname{DSR}(j)$ & & $7.287 \mathrm{E}-26$ & $7.367 \mathrm{E}-26$ & $1.263 \mathrm{E}-25$ & $2.188 \mathrm{E}-25$ & $1.784 \mathrm{E}-23$ & $5.792 \mathrm{E}-21$ & $2.136 \mathrm{E}-06$ \\
\hline-240 & $\mathrm{Pu}-240$ & $4.950 \mathrm{E}-08$ & $3.426 \mathrm{E}-40$ & $3.481 \mathrm{E}-40$ & $7.683 E-40$ & $1.723 \mathrm{E}-39$ & $1.103 E-36$ & $5.401 \mathrm{E}-33$ & $4.730 \mathrm{E}-14$ \\
\hline-240 & $\mathrm{Pu}-240$ & $1.000 \mathrm{E}+00$ & $6.921 E-33$ & $7.033 E-33$ & 1. $552 \mathrm{E}-32$ & $3.481 E-32$ & $2.227 E-29$ & $1.091 \mathrm{E}-25$ & $9.556 \mathrm{E}-07$ \\
\hline-240 & $\mathrm{U}-236$ & $1.000 \mathrm{E}+00$ & 1. $313 \mathrm{E}-40$ & $3.994 \mathrm{E}-40$ & $3.012 \mathrm{E}-38$ & $1.369 \mathrm{E}-37$ & $5.033 E-34$ & $6.106 \mathrm{E}-30$ & $3.996 \mathrm{E}-11$ \\
\hline-240 & Th-232 & $1.000 \mathrm{E}+00$ & $0.000 \mathrm{E}+00$ & $0.000 \mathrm{E}+00$ & $0.000 \mathrm{E}+00$ & $0.000 \mathrm{E}+00$ & $6.527 \mathrm{E}-42$ & $2.161 E-37$ & 1. $383 \mathrm{E}-16$ \\
\hline-240 & $\mathrm{Ra}-228+\mathrm{D}$ & $1.000 \mathrm{E}+00$ & $1.178 \mathrm{E}-36$ & $1.434 \mathrm{E}-35$ & $2.214 \mathrm{E}-31$ & $1.452 \mathrm{E}-30$ & $6.617 \mathrm{E}-28$ & $1.096 \mathrm{E}-25$ & $2.174 \mathrm{E}-13$ \\
\hline-240 & $\mathrm{Th}-228+\mathrm{D}$ & $1.000 \mathrm{E}+00$ & $8.545 E-36$ & $1.856 \mathrm{E}-34$ & $1.564 \mathrm{E}-29$ & $1.017 \mathrm{E}-28$ & $2.672 \mathrm{E}-26$ & $2.030 E-24$ & $3.437 \mathrm{E}-13$ \\
\hline-240 & $\sum \operatorname{DSR}(j)$ & & $6.930 E-33$ & $7.233 E-33$ & $1.588 \mathrm{E}-29$ & $1.032 \mathrm{E}-28$ & $2.740 \mathrm{E}-26$ & $2.249 \mathrm{E}-24$ & $9.557 \mathrm{E}-07$ \\
\hline-99 & $\mathrm{TC}-99$ & $1.000 \mathrm{E}+00$ & $3.496 \mathrm{E}-34$ & $3.539 \mathrm{E}-34$ & $6.498 E-34$ & $1.208 E-33$ & $1.906 \mathrm{E}-02$ & $2.761 E-02$ & $1.098 \mathrm{E}-20$ \\
\hline $28+D$ & $T h-228+D$ & $1.000 \mathrm{E}+00$ & $8.415 E-15$ & $5.922 \mathrm{E}-15$ & $1.505 \mathrm{E}-22$ & $2.691 \mathrm{E}-30$ & $0.000 \mathrm{E}+00$ & $0.000 \mathrm{E}+00$ & $0.000 \mathrm{E}+00$ \\
\hline
\end{tabular}


RESRAD-OFFSITE, Version 2.

Parent Dose Report

Title : Offsite Resident Farmer Deterministic Run File : RF DOE SG FWD-FV2-10000Y.ROF

Dose/Source Ratios Summed Over All Pathways

Parent and Progeny Principal Radionuclide Contributions Indicated

\begin{tabular}{|c|c|c|c|c|c|c|c|c|c|}
\hline Parent & Product & Thread & & & $\mathrm{SR}(j, \mathrm{t}) \quad(\mathrm{mr}$ & $\mathrm{em} / \mathrm{yr}) /(\mathrm{p}$ & $i / g)$ & & \\
\hline (i) & $(j)$ & Fraction & $0.000 \mathrm{E}+00$ & $1.000 \mathrm{E}+00$ & $5.000 \mathrm{E}+01$ & $1.000 \mathrm{E}+02$ & $5.000 \mathrm{E}+02$ & $1.026 \mathrm{E}+03$ & $9.976 \mathrm{E}+03$ \\
\hline-230 & $\mathrm{Th}-230$ & $1.000 \mathrm{E}+00$ & $1.462 \mathrm{E}-30$ & 1. $485 \mathrm{E}-30$ & $3.170 \mathrm{E}-30$ & $6.873 E-30$ & $3.359 \mathrm{E}-27$ & $1.154 \mathrm{E}-23$ & $2.517 \mathrm{E}-06$ \\
\hline-230 & $\mathrm{Ra}-226+\mathrm{D}$ & $1.000 \mathrm{E}+00$ & $2.289 E-19$ & $6.903 E-19$ & $3.138 \mathrm{E}-17$ & $8.491 \mathrm{E}-17$ & $4.948 E-15$ & $2.589 E-13$ & $7.400 \mathrm{E}-03$ \\
\hline-230 & $\mathrm{~Pb}-210+\mathrm{D}$ & $1.000 \mathrm{E}+00$ & 1. $315 \mathrm{E}-27$ & $8.189 \mathrm{E}-27$ & $7.635 \mathrm{E}-24$ & $3.029 \mathrm{E}-23$ & $3.412 \mathrm{E}-21$ & $3.104 \mathrm{E}-19$ & $3.465 E-06$ \\
\hline-230 & $\sum \operatorname{DSR}(j)$ & & $2.289 \mathrm{E}-19$ & $6.903 E-19$ & $3.138 \mathrm{E}-17$ & $8.491 \mathrm{E}-17$ & $4.948 E-15$ & $2.589 \mathrm{E}-13$ & $7.406 \mathrm{E}-03$ \\
\hline $1-232$ & Th-232 & $1.000 \mathrm{E}+00$ & $7.064 \mathrm{E}-33$ & $7.186 \mathrm{E}-33$ & $1.661 \mathrm{E}-32$ & $3.904 \mathrm{E}-32$ & $3.643 E-29$ & $2.931 E-25$ & $2.805 E-06$ \\
\hline $1-232$ & $\mathrm{Ra}-228+\mathrm{D}$ & $1.000 \mathrm{E}+00$ & $6.668 \mathrm{E}-18$ & $1.914 \mathrm{E}-17$ & $1.638 \mathrm{E}-16$ & $2.329 \mathrm{E}-16$ & $3.817 \mathrm{E}-15$ & $1.510 \mathrm{E}-13$ & $4.414 \mathrm{E}-03$ \\
\hline-232 & $\mathrm{Th}-228+\mathrm{D}$ & $1.000 \mathrm{E}+00$ & $7.560 \mathrm{E}-17$ & $4.145 \mathrm{E}-16$ & 1. $310 \mathrm{E}-14$ & $1.731 \mathrm{E}-14$ & 1. $558 \mathrm{E}-13$ & $2.813 E-12$ & $6.982 \mathrm{E}-03$ \\
\hline $1-232$ & $\sum \operatorname{DSR}(j)$ & & $8.227 E-17$ & $4.336 \mathrm{E}-16$ & $1.327 \mathrm{E}-14$ & $1.754 \mathrm{E}-14$ & $1.597 \mathrm{E}-13$ & $2.964 \mathrm{E}-12$ & $1.140 \mathrm{E}-02$ \\
\hline-234 & $\mathrm{U}-234$ & $1.000 \mathrm{E}+00$ & $4.179 \mathrm{E}-32$ & $4.247 \mathrm{E}-32$ & $9.442 \mathrm{E}-32$ & $2.133 E-31$ & 1. $449 \mathrm{E}-28$ & $7.680 \mathrm{E}-25$ & $2.568 \mathrm{E}-07$ \\
\hline-234 & $T h-230$ & $1.000 \mathrm{E}+00$ & $6.609 E-36$ & $2.009 E-35$ & $1.441 E-33$ & $6.216 E-33$ & $1.511 \mathrm{E}-29$ & $1.064 E-25$ & $2.200 \mathrm{E}-07$ \\
\hline-234 & $\mathrm{Ra}-226+\mathrm{D}$ & $1.000 \mathrm{E}+00$ & $8.203 E-25$ & $5.150 \mathrm{E}-24$ & $7.158 \mathrm{E}-21$ & $3.868 \mathrm{E}-20$ & $1.154 \mathrm{E}-17$ & 1. $282 E-15$ & $5.081 \mathrm{E}-04$ \\
\hline-234 & $\mathrm{~Pb}-210+\mathrm{D}$ & $1.000 \mathrm{E}+00$ & $3.539 E-33$ & $4.394 E-32$ & $1.294 \mathrm{E}-27$ & $1.103 E-26$ & $7.464 \mathrm{E}-24$ & $1.487 \mathrm{E}-21$ & $2.371 E-07$ \\
\hline-234 & $\sum \operatorname{DSR}(j)$ & & $8.203 E-25$ & $5.150 \mathrm{E}-24$ & $7.158 \mathrm{E}-21$ & $3.868 E-20$ & $1.154 \mathrm{E}-17$ & 1. $282 E-15$ & $5.088 \mathrm{E}-04$ \\
\hline$-235+D$ & $\mathrm{U}-235+\mathrm{D}$ & $1.000 \mathrm{E}+00$ & $7.535 E-23$ & 7. $622 \mathrm{E}-23$ & 1. $331 \mathrm{E}-22$ & $2.352 \mathrm{E}-22$ & $2.233 E-20$ & $8.893 E-18$ & $2.453 \mathrm{E}-04$ \\
\hline$-235+D$ & $\mathrm{~Pa}-231$ & $1.000 \mathrm{E}+00$ & $1.782 \mathrm{E}-26$ & $5.393 E-26$ & $2.925 E-24$ & $9.487 E-24$ & $2.349 E-21$ & $8.198 E-19$ & $1.760 \mathrm{E}-05$ \\
\hline$-235+D$ & $A C-227+D$ & $1.000 \mathrm{E}+00$ & $6.706 \mathrm{E}-26$ & $4.177 E-25$ & $4.032 E-22$ & $1.667 \mathrm{E}-21$ & $2.744 \mathrm{E}-19$ & $4.140 E-17$ & $1.717 \mathrm{E}-04$ \\
\hline-235 & $\sum \operatorname{DSR}(j)$ & & $7.544 \mathrm{E}-23$ & $7.669 \mathrm{E}-23$ & $5.393 E-22$ & $1.912 \mathrm{E}-21$ & $2.991 E-19$ & $5.111 \mathrm{E}-17$ & $4.346 \mathrm{E}-04$ \\
\hline-238 & $\mathrm{U}-238$ & $5.400 \mathrm{E}-05$ & $0.000 \mathrm{E}+00$ & $0.000 \mathrm{E}+00$ & $0.000 \mathrm{E}+00$ & $0.000 \mathrm{E}+00$ & $0.000 \mathrm{E}+00$ & $0.000 \mathrm{E}+00$ & $9.672 \mathrm{E}-12$ \\
\hline$-238+D$ & $\mathrm{U}-238+\mathrm{D}$ & $9.999 \mathrm{E}-01$ & $8.606 \mathrm{E}-19$ & $8.669 \mathrm{E}-19$ & 1. $243 \mathrm{E}-18$ & $1.796 \mathrm{E}-18$ & $3.408 \mathrm{E}-17$ & $1.635 \mathrm{E}-15$ & $9.862 \mathrm{E}-05$ \\
\hline$-238+D$ & $\mathrm{U}-234$ & $9.999 E-01$ & $5.952 E-38$ & $1.811 E-37$ & $1.352 E-35$ & $6.079 E-35$ & $2.058 E-31$ & $2.238 E-27$ & $7.366 \mathrm{E}-09$ \\
\hline$-238+D$ & $\mathrm{Th}-230$ & $9.999 \mathrm{E}-01$ & $7.465 E-42$ & $4.725 E-41$ & $1.031 \mathrm{E}-37$ & $8.855 E-37$ & $1.072 \mathrm{E}-32$ & $1.548 E-28$ & $3.111 \mathrm{E}-09$ \\
\hline $238+D$ & $\mathrm{Ra}-226+\mathrm{D}$ & $9.999 \mathrm{E}-01$ & $6.374 \mathrm{E}-31$ & $8.587 \mathrm{E}-30$ & $3.423 E-25$ & $3.687 E-24$ & $5.554 \mathrm{E}-21$ & $1.288 E-18$ & $5.983 E-06$ \\
\hline$-238+D$ & $\mathrm{~Pb}-210+\mathrm{D}$ & $9.999 \mathrm{E}-01$ & $0.000 \mathrm{E}+00$ & $2.744 E-38$ & $4.957 E-32$ & $8.813 E-31$ & $3.387 E-27$ & $1.449 E-24$ & $2.782 E-09$ \\
\hline-238 & $\sum \operatorname{DSR}(j)$ & & $8.606 \mathrm{E}-19$ & $8.669 \mathrm{E}-19$ & $1.243 \mathrm{E}-18$ & 1. $796 \mathrm{E}-18$ & $3.408 \mathrm{E}-17$ & $1.636 \mathrm{E}-15$ & $1.046 \mathrm{E}-04$ \\
\hline
\end{tabular}

The DSR includes contributions from associated (half-life $\leq 180$ days) daughters. 
RESRAD-OFFSITE, Version 2.5

Parent Dose Report

Title : Offsite Resident Farmer Deterministic Run

File : RF DOE SG FWD-FV2-10000Y.ROF

Single Radionuclide Soil Guidelines G(i,t) in pCi/g

Basic Radiation Dose Limit $=1.000 \mathrm{E}+00 \mathrm{mrem} / \mathrm{yr}$

Nuclide

\begin{tabular}{|c|c|c|c|c|c|c|c|}
\hline (i) & $t=0.000 \mathrm{E}+00$ & $1.000 \mathrm{E}+00$ & $5.000 \mathrm{E}+01$ & $1.000 \mathrm{E}+02$ & $5.000 \mathrm{E}+02$ & $1.026 \mathrm{E}+03$ & $9.976 \mathrm{E}+03$ \\
\hline-241 & $\star 3.431 \mathrm{E}+12$ & $\star 3.431 \mathrm{E}+12$ & $\star 3.431 \mathrm{E}+12$ & $\star 3.431 \mathrm{E}+12$ & $\star 3.431 \mathrm{E}+12$ & $\star 3.431 \mathrm{E}+12$ & $1.957 \mathrm{E}+04$ \\
\hline$s-137$ & $\star 8.704 \mathrm{E}+13$ & $\star 8.704 \mathrm{E}+13$ & $\star 8.704 \mathrm{E}+13$ & $\star 8.704 \mathrm{E}+13$ & $\star 8.704 \mathrm{E}+13$ & $\star 8.704 \mathrm{E}+13$ & $\star 8.704 \mathrm{E}+13$ \\
\hline$p-237$ & $\star 7.047 \mathrm{E}+08$ & $\star 7.047 \mathrm{E}+08$ & $\star 7.047 \mathrm{E}+08$ & $\star 7.047 \mathrm{E}+08$ & $\star 7.047 \mathrm{E}+08$ & $\star 7.047 \mathrm{E}+08$ & $4.270 \mathrm{E}+00$ \\
\hline$u-238$ & $\star 1.712 \mathrm{E}+13$ & $\star 1.712 \mathrm{E}+13$ & $\star 1.712 \mathrm{E}+13$ & $\star 1.712 \mathrm{E}+13$ & $\star 1.712 \mathrm{E}+13$ & $\star 1.712 \mathrm{E}+13$ & $5.565 \mathrm{E}+06$ \\
\hline$u-239$ & $\star 6.214 \mathrm{E}+10$ & $\star 6.214 \mathrm{E}+10$ & $\star 6.214 \mathrm{E}+10$ & $\star 6.214 \mathrm{E}+10$ & $\star 6.214 \mathrm{E}+10$ & $\star 6.214 \mathrm{E}+10$ & $4.682 \mathrm{E}+05$ \\
\hline $\mathrm{Pu}-240$ & $\star 2.278 E+11$ & $\star 2.278 E+11$ & $\star 2.278 \mathrm{E}+11$ & $\star 2.278 \mathrm{E}+11$ & $\star 2.278 \mathrm{E}+11$ & $\star 2.278 \mathrm{E}+11$ & $1.046 \mathrm{E}+06$ \\
\hline TC-99 & $\star 1.697 \mathrm{E}+10$ & $\star 1.697 \mathrm{E}+10$ & $\star 1.697 \mathrm{E}+10$ & $\star 1.697 \mathrm{E}+10$ & $5.246 \mathrm{E}+01$ & $3.621 \mathrm{E}+01$ & $* 1.697 \mathrm{E}+10$ \\
\hline Th-228 & $1.188 \mathrm{E}+14$ & $1.688 \mathrm{E}+14$ & $\star 8.195 \mathrm{E}+14$ & $\star 8.195 \mathrm{E}+14$ & $\star 8.195 \mathrm{E}+14$ & $* 8.195 \mathrm{E}+14$ & $\star 8.195 \mathrm{E}+14$ \\
\hline$T h-230$ & $\star 2.018 \mathrm{E}+10$ & $\star 2.018 \mathrm{E}+10$ & $\star 2.018 \mathrm{E}+10$ & $\star 2.018 \mathrm{E}+10$ & $\star 2.018 \mathrm{E}+10$ & $\star 2.018 \mathrm{E}+10$ & $1.350 \mathrm{E}+02$ \\
\hline$T h-232$ & $\star 1.097 \mathrm{E}+05$ & $\star 1.097 \mathrm{E}+05$ & $\star 1.097 \mathrm{E}+05$ & $\star 1.097 \mathrm{E}+05$ & $\star 1.097 \mathrm{E}+05$ & $\star 1.097 \mathrm{E}+05$ & $8.773 \mathrm{E}+01$ \\
\hline $\mathrm{U}-234$ & $\star 6.247 \mathrm{E}+09$ & $* 6.247 \mathrm{E}+09$ & $* 6.247 \mathrm{E}+09$ & $\star 6.247 \mathrm{E}+09$ & $* 6.247 \mathrm{E}+09$ & $* 6.247 \mathrm{E}+09$ & $1.965 \mathrm{E}+03$ \\
\hline 35 & $\star 2.161 \mathrm{E}+06$ & $\star 2.161 \mathrm{E}+06$ & $\star 2.161 \mathrm{E}+06$ & $\star 2.161 \mathrm{E}+06$ & $\star 2.161 \mathrm{E}+06$ & $\star 2.161 \mathrm{E}+06$ & $2.301 \mathrm{E}+03$ \\
\hline 238 & $\star 3.361 \mathrm{E}+05$ & $\star 3.361 \mathrm{E}+05$ & $\star 3.361 \mathrm{E}+05$ & $\star 3.361 \mathrm{E}+05$ & $\star 3.361 \mathrm{E}+05$ & $\star 3.361 \mathrm{E}+05$ & $9.558 \mathrm{E}+03$ \\
\hline
\end{tabular}

*At specific activity limit

Summed Dose/Source Ratios DSR(i,t) in (mrem/yr)/(pCi/g)

and Single Radionuclide Soil Guidelines $G(i, t)$ in pCi/g

at tmin = time of minimum single radionuclide soil guideline

and at $\operatorname{tmax}=$ time of maximum total dose $=10000$ years

\begin{tabular}{|c|c|c|c|c|c|c|}
\hline $\begin{array}{l}\text { uclide } \\
\text { (i) }\end{array}$ & $\begin{array}{l}\text { Initial } \\
(\mathrm{pCi} / \mathrm{g})\end{array}$ & $\begin{array}{c}\text { tmin } \\
\text { (years) }\end{array}$ & $\operatorname{DSR}(i, \operatorname{tmin})$ & $\begin{array}{c}\mathrm{G}(\mathrm{i}, \mathrm{tmin}) \\
(\mathrm{pCi} / \mathrm{g})\end{array}$ & $\operatorname{DSR}(i, \operatorname{tmax})$ & $\begin{array}{c}G(i, t \max ) \\
(\mathrm{pCi} / \mathrm{g})\end{array}$ \\
\hline$m-241$ & $3.500 \mathrm{E}+01$ & 10000 & $5.115 \mathrm{E}-05$ & $1.955 \mathrm{E}+04$ & $5.115 \mathrm{E}-05$ & $1.955 \mathrm{E}+04$ \\
\hline-137 & $1.900 \mathrm{E}+01$ & 0 & 7. $649 \mathrm{E}-18$ & $\star 8.704 \mathrm{E}+13$ & $8.408 E-45$ & $\star 8.704 \mathrm{E}+13$ \\
\hline$p-237$ & $5.500 \mathrm{E}+00$ & 9976 & $2.342 \mathrm{E}-01$ & $4.270 \mathrm{E}+00$ & $2.342 E-01$ & $4.270 \mathrm{E}+00$ \\
\hline-238 & $3.900 E+01$ & 10000 & $1.802 \mathrm{E}-07$ & $5.549 \mathrm{E}+06$ & $1.802 E-07$ & $5.549 \mathrm{E}+06$ \\
\hline-239 & $3.600 \mathrm{E}+01$ & 3805 & $2.676 \mathrm{E}-06$ & $3.738 \mathrm{E}+05$ & $2.134 \mathrm{E}-06$ & $4.686 \mathrm{E}+05$ \\
\hline$u-240$ & $3.600 \mathrm{E}+01$ & 3452 & $1.960 \mathrm{E}-06$ & $5.102 \mathrm{E}+05$ & $9.531 \mathrm{E}-07$ & $1.049 \mathrm{E}+06$ \\
\hline-99 & $5.200 \mathrm{E}+01$ & 771 & $3.594 \mathrm{E}-02$ & $2.783 \mathrm{E}+01$ & $9.691 \mathrm{E}-21$ & $\star 1.697 \mathrm{E}+10$ \\
\hline $1-228$ & $4.000 \mathrm{E}+00$ & 0 & $8.415 \mathrm{E}-15$ & $1.188 \mathrm{E}+14$ & $0.000 \mathrm{E}+00$ & $\star 8.195 \mathrm{E}+14$ \\
\hline-230 & $1.000 \mathrm{E}+02$ & 8586 & $7.434 \mathrm{E}-03$ & $1.345 E+02$ & $7.405 E-03$ & $1.350 \mathrm{E}+02$ \\
\hline-232 & $4.000 \mathrm{E}+00$ & 2751 & $1.154 \mathrm{E}-02$ & $8.667 \mathrm{E}+01$ & $1.140 \mathrm{E}-02$ & $8.773 E+01$ \\
\hline 234 & $1.600 \mathrm{E}+02$ & 10000 & $5.102 \mathrm{E}-04$ & $1.960 \mathrm{E}+03$ & $5.102 \mathrm{E}-04$ & $1.960 \mathrm{E}+03$ \\
\hline-235 & $6.500 \mathrm{E}+00$ & 10000 & $4.349 \mathrm{E}-04$ & $2.299 \mathrm{E}+03$ & $4.349 E-04$ & $2.299 E+03$ \\
\hline-238 & $1.600 \mathrm{E}+02$ & 2751 & $1.088 \mathrm{E}-04$ & $9.189 \mathrm{E}+03$ & $1.046 \mathrm{E}-04$ & $9.558 \mathrm{E}+03$ \\
\hline
\end{tabular}

*At specific activity limit 
RESRAD-OFFSITE, Version 2.

Parent Dose Report

Title : Offsite Resident Farmer Deterministic Run

File : RF DOE SG FWD-FV2-10000Y.ROF

Individual Nuclide Dose Summed Over All Pathways

Parent Nuclide and Thread Fraction Indicated

Nuclide Parent THF(i) DOSE $(j, t)$, mrem/yr

\begin{tabular}{|c|c|c|}
\hline (j) & (i) & \\
\hline-241 & $A m-241$ & $1.000 \mathrm{E}+00$ \\
\hline-237 & $A m-241$ & $1.000 \mathrm{E}+00$ \\
\hline $\mathrm{Np}-237$ & $\mathrm{~Np}-237$ & $1.000 \mathrm{E}+00$ \\
\hline $\mathrm{Np}-237$ & $\sum \operatorname{DOSE}(j$ & \\
\hline
\end{tabular}

$\mathrm{U}-233 \quad \mathrm{Am}-241 \quad 1.000 \mathrm{E}+00$

$\mathrm{U}-233 \quad \mathrm{~Np}-237 \quad 1.000 \mathrm{E}+00$

U-233 $\operatorname{DOSE}(j):$

Th-229 Am-241 $1.000 \mathrm{E}+00$

Th-229 Np-237 $1.000 \mathrm{E}+00$

Th-229 $\operatorname{DOSE}(j):$

Cs-137 Cs-137 $1.000 E+00$

Pu-238 $\mathrm{Pu}-238 \quad 1.840 \mathrm{E}-09$

$\mathrm{Pu}-238 \mathrm{Pu}-238 \quad 1.000 \mathrm{E}+00$

$\operatorname{Pu}-238 \quad \sum \operatorname{DOSE}(j):$

$\mathrm{U}-234$

$\mathrm{U}-234$

$\mathrm{U}-234$

$\mathrm{U}-234$

Th -230

Th -230

Th -230

Th -230

Th-230

$\mathrm{Ra}-226$

$\mathrm{Ra}-226$

$\mathrm{Ra}-226$

$\mathrm{Ra}-226$

$\mathrm{Ra}-226$

$\mathrm{Pb}-210 \mathrm{Pu}-238 \quad 1.000 \mathrm{E}+00$

$\mathrm{Pb}-210 \mathrm{Th}-230 \quad 1.000 \mathrm{E}+00$

$\mathrm{Pb}-210 \mathrm{U}-234 \quad 1.000 \mathrm{E}+00$

$\mathrm{Pb}-210 \quad \mathrm{U}-238 \quad 9.999 \mathrm{E}-01$

$\mathrm{Pb}-210 \quad \sum \operatorname{DOSE}(j)$ :

Pu-239 Pu-239 $1.000 E+00$ $\mathrm{t}=0.000 \mathrm{E}+00 \quad 1.000 \mathrm{E}+00 \quad 5.000 \mathrm{E}+01 \quad 1.000 \mathrm{E}+02 \quad 5.000 \mathrm{E}+02 \quad 1.026 \mathrm{E}+03 \quad 9.976 \mathrm{E}+03$

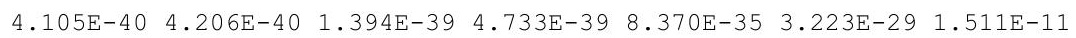

$3.284 \mathrm{E}-26 \quad 9.929 \mathrm{E}-26 \quad 5.216 \mathrm{E}-24 \quad 1.637 \mathrm{E}-23 \quad 3.183 \mathrm{E}-21 \quad 8.460 \mathrm{E}-19 \quad 1.785 \mathrm{E}-03$

$3.179 \mathrm{E}-20 \quad 3.211 \mathrm{E}-20 \quad 5.207 \mathrm{E}-20 \quad 8.527 \mathrm{E}-20 \quad 4.414 \mathrm{E}-18 \quad 7.922 \mathrm{E}-16 \quad 1.285 \mathrm{E}+00$

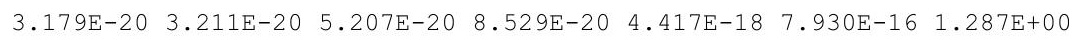

$8.888 \mathrm{E}-37 \quad 5.604 \mathrm{E}-36 \quad 9.829 \mathrm{E}-33 \quad 6.745 \mathrm{E}-32 \quad 1.376 \mathrm{E}-28 \quad 1.966 \mathrm{E}-25 \quad 4.013 \mathrm{E}-06$

$\begin{array}{lllllll}1.083 \mathrm{E}-30 & 3.282 \mathrm{E}-30 & 1.938 \mathrm{E}-28 & 6.856 \mathrm{E}-28 & 3.404 \mathrm{E}-25 & 2.967 \mathrm{E}-22 & 2.953 \mathrm{E}-03\end{array}$

$\begin{array}{lllllll}1.083 \mathrm{E}-30 & 3.282 \mathrm{E}-30 & 1.938 \mathrm{E}-28 & 6.857 \mathrm{E}-28 & 3.406 \mathrm{E}-25 & 2.969 \mathrm{E}-22 & 2.957 \mathrm{E}-03\end{array}$

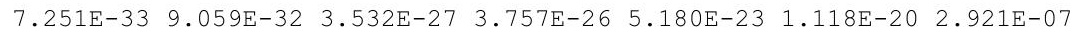

$\begin{array}{lllllll}1.180 \mathrm{E}-26 & 7.407 \mathrm{E}-26 & 1.038 \mathrm{E}-22 & 5.653 \mathrm{E}-22 & 1.808 \mathrm{E}-19 & 2.257 \mathrm{E}-17 & 2.428 \mathrm{E}-04\end{array}$

$\begin{array}{lllllll}1.180 \mathrm{E}-26 & 7.407 \mathrm{E}-26 & 1.038 \mathrm{E}-22 & 5.654 \mathrm{E}-22 & 1.808 \mathrm{E}-19 & 2.258 \mathrm{E}-17 & 2.431 \mathrm{E}-04\end{array}$

$\begin{array}{lllllll}1.453 \mathrm{E}-16 & 1.431 \mathrm{E}-16 & 6.744 \mathrm{E}-17 & 3.130 \mathrm{E}-17 & 6.732 \mathrm{E}-20 & 2.092 \mathrm{E}-23 & 1.640 \mathrm{E}-43\end{array}$

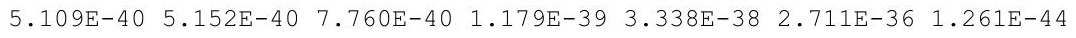

$\begin{array}{lllllll}2.777 \mathrm{E}-31 & 2.800 \mathrm{E}-31 & 4.217 \mathrm{E}-31 & 6.405 \mathrm{E}-31 & 1.814 \mathrm{E}-29 & 1.473 \mathrm{E}-27 & 5.799 \mathrm{E}-39\end{array}$

$\begin{array}{lllllll}2.777 E-31 & 2.800 E-31 & 4.217 \mathrm{E}-31 & 6.405 \mathrm{E}-31 & 1.814 \mathrm{E}-29 & 1.473 \mathrm{E}-27 & 5.799 \mathrm{E}-39\end{array}$

$2.314 \mathrm{E}-36 \quad 7.016 \mathrm{E}-36 \quad 4.348 \mathrm{E}-34 \quad 1.637 \mathrm{E}-33 \quad 1.991 \mathrm{E}-30 \quad 1.075 \mathrm{E}-26 \quad 3.597 \mathrm{E}-09$

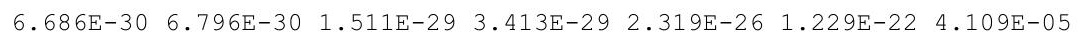

$\begin{array}{lllllll}9.522 \mathrm{E}-36 & 2.897 \mathrm{E}-35 & 2.163 \mathrm{E}-33 & 9.727 \mathrm{E}-33 & 3.292 \mathrm{E}-29 & 3.581 \mathrm{E}-25 & 1.179 \mathrm{E}-06\end{array}$

$\begin{array}{lllllll}6.686 \mathrm{E}-30 & 6.796 \mathrm{E}-30 & 1.511 \mathrm{E}-29 & 3.415 \mathrm{E}-29 & 2.322 \mathrm{E}-26 & 1.233 \mathrm{E}-22 & 4.227 \mathrm{E}-05\end{array}$

$2.905 \mathrm{E}-40 \quad 1.834 \mathrm{E}-39 \quad 3.537 \mathrm{E}-36 \quad 2.696 \mathrm{E}-35 \quad 1.591 \mathrm{E}-31 \quad 1.306 \mathrm{E}-27 \quad 3.041 \mathrm{E}-09$ $\begin{array}{llllllll}1.462 \mathrm{E}-28 & 1.485 \mathrm{E}-28 & 3.170 \mathrm{E}-28 & 6.873 \mathrm{E}-28 & 3.359 \mathrm{E}-25 & 1.154 \mathrm{E}-21 & 2.517 \mathrm{E}-04\end{array}$ $\begin{array}{lllllll}1.057 \mathrm{E}-33 & 3.215 \mathrm{E}-33 & 2.305 \mathrm{E}-31 & 9.946 \mathrm{E}-31 & 2.418 \mathrm{E}-27 & 1.702 \mathrm{E}-23 & 3.519 \mathrm{E}-05\end{array}$ $\begin{array}{lllllll}1.194 \mathrm{E}-39 & 7.560 \mathrm{E}-39 & 1.650 \mathrm{E}-35 & 1.417 \mathrm{E}-34 & 1.715 \mathrm{E}-30 & 2.476 \mathrm{E}-26 & 4.978 \mathrm{E}-07\end{array}$ $\begin{array}{lllllll}1.462 \mathrm{E}-28 & 1.485 \mathrm{E}-28 & 3.172 \mathrm{E}-28 & 6.883 \mathrm{E}-28 & 3.383 \mathrm{E}-25 & 1.171 \mathrm{E}-21 & 2.874 \mathrm{E}-04\end{array}$

$\begin{array}{lllllll}2.701 \mathrm{E}-29 & 3.369 \mathrm{E}-28 & 1.212 \mathrm{E}-23 & 1.192 \mathrm{E}-22 & 1.011 \mathrm{E}-19 & 1.425 \mathrm{E}-17 & 6.999 \mathrm{E}-06\end{array}$ $2.289 \mathrm{E}-17 \quad 6.903 \mathrm{E}-17 \quad 3.138 \mathrm{E}-15 \quad 8.491 \mathrm{E}-15 \quad 4.948 \mathrm{E}-13 \quad 2.589 \mathrm{E}-11 \quad 7.400 \mathrm{E}-01$ $\begin{array}{lllllll}1.313 \mathrm{E}-22 & 8.240 \mathrm{E}-22 & 1.145 \mathrm{E}-18 & 6.189 \mathrm{E}-18 & 1.846 \mathrm{E}-15 & 2.051 \mathrm{E}-13 & 8.130 \mathrm{E}-02\end{array}$ $\begin{array}{lllllll}1.020 \mathrm{E}-28 & 1.374 \mathrm{E}-27 & 5.476 \mathrm{E}-23 & 5.899 \mathrm{E}-22 & 8.886 \mathrm{E}-19 & 2.061 \mathrm{E}-16 & 9.572 \mathrm{E}-04\end{array}$ $\begin{array}{lllllll}2.289 \mathrm{E}-17 & 6.904 \mathrm{E}-17 & 3.139 \mathrm{E}-15 & 8.497 \mathrm{E}-15 & 4.967 \mathrm{E}-13 & 2.609 \mathrm{E}-11 & 8.223 \mathrm{E}-01\end{array}$

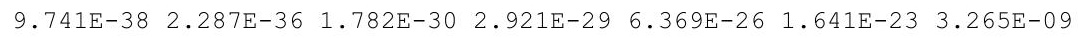
$\begin{array}{lllllll}1.315 \mathrm{E}-25 & 8.189 \mathrm{E}-25 & 7.635 \mathrm{E}-22 & 3.029 \mathrm{E}-21 & 3.412 \mathrm{E}-19 & 3.104 \mathrm{E}-17 & 3.465 \mathrm{E}-04\end{array}$ $\begin{array}{lllllll}5.663 \mathrm{E}-31 & 7.031 \mathrm{E}-30 & 2.071 \mathrm{E}-25 & 1.764 \mathrm{E}-24 & 1.194 \mathrm{E}-21 & 2.380 \mathrm{E}-19 & 3.793 \mathrm{E}-05\end{array}$ $\begin{array}{lllllll}0.000 \mathrm{E}+00 & 4.391 \mathrm{E}-36 & 7.930 \mathrm{E}-30 & 1.410 \mathrm{E}-28 & 5.419 \mathrm{E}-25 & 2.318 \mathrm{E}-22 & 4.451 \mathrm{E}-07\end{array}$ $\begin{array}{lllllll}1.315 \mathrm{E}-25 & 8.189 \mathrm{E}-25 & 7.637 \mathrm{E}-22 & 3.030 \mathrm{E}-21 & 3.424 \mathrm{E}-19 & 3.128 \mathrm{E}-17 & 3.848 \mathrm{E}-04\end{array}$

$2.623 \mathrm{E}-24 \quad 2.652 \mathrm{E}-24 \quad 4.545 \mathrm{E}-24 \quad 7.875 \mathrm{E}-24 \quad 6.395 \mathrm{E}-22 \quad 2.075 \mathrm{E}-19 \quad 7.678 \mathrm{E}-05$ 
RESRAD-OFFSITE, Version 2.

Parent Dose Report

Title : Offsite Resident Farmer Deterministic Run

File : RF DOE SG FWD-FV2-10000Y.ROF

Individual Nuclide Soil Concentration

Parent Nuclide and Thread Fraction Indicated

Nuclide Parent THF(

\section{(j)}

(i)

$A m-241$

Np-237

Np-237

Np-237

$\mathrm{U}-233$

$\mathrm{U}-233$

$\mathrm{U}-233$

Th-229

Th-229

Th-229

Cs-137

$\mathrm{Pu}-238$

$\mathrm{Pu}-238$

$\mathrm{Pu}-238$

$\mathrm{U}-234$

$\mathrm{U}-234$

$\mathrm{U}-234$

$\mathrm{U}-234$

Th -230

Th -230

Th -230

Th -230

Th-230

$\mathrm{Ra}-226$

$\mathrm{Ra}-226$

$\mathrm{Ra}-226$

$\mathrm{Ra}-226$

$\mathrm{Ra}-226$

$\mathrm{Pb}-210$

$\mathrm{Pb}-210$

$\mathrm{Pb}-210$

$\mathrm{Pb}-210$

$\mathrm{Pb}-210$

Pu-239 Pu-239 $1.000 E+00$
$S(j, t), p C i / g$

$t=0.000 \mathrm{E}+00 \quad 1.000 \mathrm{E}+00 \quad 5.000 \mathrm{E}+01 \quad 1.000 \mathrm{E}+02 \quad 5.000 \mathrm{E}+02 \quad 1.026 \mathrm{E}+03 \quad 9.976 \mathrm{E}+03$

$\begin{array}{llllllll}3.500 \mathrm{E}+01 & 3.494 \mathrm{E}+01 & 3.230 \mathrm{E}+01 & 2.981 \mathrm{E}+01 & 1.567 \mathrm{E}+01 & 6.732 \mathrm{E}+00 & 3.830 \mathrm{E}-06\end{array}$

$0.000 \mathrm{E}+00 \quad 1.133 \mathrm{E}-05 \quad 5.436 \mathrm{E}-04 \quad 1.043 \mathrm{E}-03 \quad 3.810 \mathrm{E}-03 \quad 5.417 \mathrm{E}-03 \quad 3.382 \mathrm{E}-03$

$\begin{array}{lllllll}5.500 \mathrm{E}+00 & 5.500 \mathrm{E}+00 & 5.478 \mathrm{E}+00 & 5.457 \mathrm{E}+00 & 5.288 \mathrm{E}+00 & 5.073 \mathrm{E}+00 & 2.507 \mathrm{E}+00\end{array}$

$\begin{array}{lllllll}5.500 \mathrm{E}+00 & 5.500 \mathrm{E}+00 & 5.479 \mathrm{E}+00 & 5.458 \mathrm{E}+00 & 5.291 \mathrm{E}+00 & 5.078 \mathrm{E}+00 & 2.510 \mathrm{E}+00\end{array}$

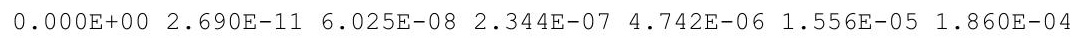

$\begin{array}{lllllll}0.000 \mathrm{E}+00 & 2.405 \mathrm{E}-05 & 1.200 \mathrm{E}-03 & 2.394 \mathrm{E}-03 & 1.174 \mathrm{E}-02 & 2.349 \mathrm{E}-02 & 1.506 \mathrm{E}-01\end{array}$

$\begin{array}{lllllll}0.000 \mathrm{E}+00 & 2.405 \mathrm{E}-05 & 1.200 \mathrm{E}-03 & 2.394 \mathrm{E}-03 & 1.174 \mathrm{E}-02 & 2.351 \mathrm{E}-02 & 1.507 \mathrm{E}-01\end{array}$

$0.000 \mathrm{E}+00 \quad 9.696 \mathrm{E}-16 \quad 9.538 \mathrm{E}-11 \quad 7.463 \mathrm{E}-10 \quad 7.873 \mathrm{E}-08 \quad 5.545 \mathrm{E}-07 \quad 7.082 \mathrm{E}-05$

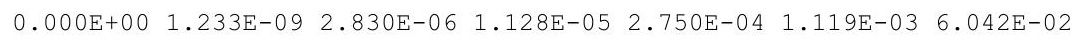

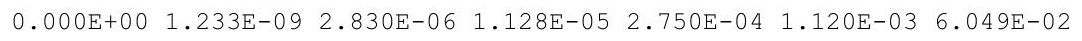

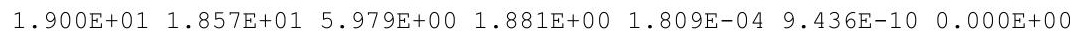

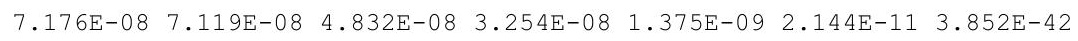

$\begin{array}{lllllllll}3.900 \mathrm{E}+01 & 3.869 \mathrm{E}+01 & 2.626 \mathrm{E}+01 & 1.768 \mathrm{E}+01 & 7.472 \mathrm{E}-01 & 1.165 \mathrm{E}-02 & 2.093 \mathrm{E}-33\end{array}$

$\begin{array}{lllllllll}3.900 \mathrm{E}+01 & 3.869 \mathrm{E}+01 & 2.626 \mathrm{E}+01 & 1.768 \mathrm{E}+01 & 7.472 \mathrm{E}-01 & 1.165 \mathrm{E}-02 & 2.093 \mathrm{E}-33\end{array}$

$0.000 \mathrm{E}+00 \quad 1.101 \mathrm{E}-04 \quad 4.564 \mathrm{E}-03 \quad 7.633 \mathrm{E}-03 \quad 1.362 \mathrm{E}-02 \quad 1.377 \mathrm{E}-02 \quad 1.191 \mathrm{E}-02$

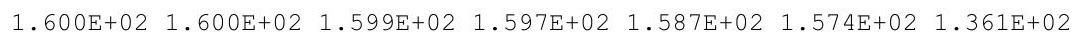

$\begin{array}{llllllll}0.000 \mathrm{E}+00 & 4.536 \mathrm{E}-04 & 2.266 \mathrm{E}-02 & 4.529 \mathrm{E}-02 & 2.251 \mathrm{E}-01 & 4.583 \mathrm{E}-01 & 3.903 \mathrm{E}+00\end{array}$

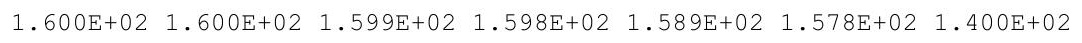

$0.000 \mathrm{E}+00 \quad 5.388 \mathrm{E}-10 \quad 1.095 \mathrm{E}-06 \quad 3.884 \mathrm{E}-06 \quad 4.705 \mathrm{E}-05 \quad 1.118 \mathrm{E}-04 \quad 1.085 \mathrm{E}-03$ $\begin{array}{lllllllll}1.000 \mathrm{E}+02 & 1.000 \mathrm{E}+02 & 9.995 \mathrm{E}+01 & 9.989 \mathrm{E}+01 & 9.947 \mathrm{E}+01 & 9.891 \mathrm{E}+01 & 8.986 \mathrm{E}+01\end{array}$ $\begin{array}{llllllll}0.000 \mathrm{E}+00 & 1.440 \mathrm{E}-03 & 7.197 \mathrm{E}-02 & 1.438 \mathrm{E}-01 & 7.153 \mathrm{E}-01 & 1.457 \mathrm{E}+00 & 1.256 \mathrm{E}+01\end{array}$ $\begin{array}{lllllll}0.000 \mathrm{E}+00 & 2.217 \mathrm{E}-09 & 5.100 \mathrm{E}-06 & 2.039 \mathrm{E}-05 & 5.070 \mathrm{E}-04 & 2.120 \mathrm{E}-03 & 1.777 \mathrm{E}-01\end{array}$

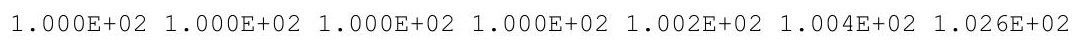

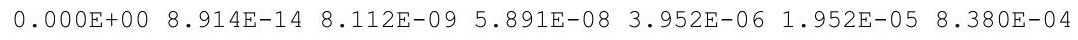
$\begin{array}{llllllll}0.000 \mathrm{E}+00 & 4.331 \mathrm{E}-02 & 2.142 \mathrm{E}+00 & 4.235 \mathrm{E}+00 & 1.937 \mathrm{E}+01 & 3.549 \mathrm{E}+01 & 8.861 \mathrm{E}+01\end{array}$ $\begin{array}{llllllll}0.000 \mathrm{E}+00 & 3.388 \mathrm{E}-07 & 7.739 \mathrm{E}-04 & 3.071 \mathrm{E}-03 & 7.220 \mathrm{E}-02 & 2.810 \mathrm{E}-01 & 9.734 \mathrm{E}+00\end{array}$ $\begin{array}{llllllll}0.000 \mathrm{E}+00 & 3.575 \mathrm{E}-13 & 3.663 \mathrm{E}-08 & 2.913 \mathrm{E}-07 & 3.471 \mathrm{E}-05 & 2.822 \mathrm{E}-04 & 1.146 \mathrm{E}-01\end{array}$ $\begin{array}{lllllll}0.000 \mathrm{E}+00 & 4.331 \mathrm{E}-02 & 2.142 \mathrm{E}+00 & 4.238 \mathrm{E}+00 & 1.944 \mathrm{E}+01 & 3.577 \mathrm{E}+01 & 9.846 \mathrm{E}+01\end{array}$

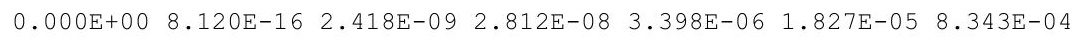
$\begin{array}{llllllll}0.000 \mathrm{E}+00 & 7.225 \mathrm{E}-04 & 1.058 \mathrm{E}+00 & 2.946 \mathrm{E}+00 & 1.823 \mathrm{E}+01 & 3.458 \mathrm{E}+01 & 8.857 \mathrm{E}+01\end{array}$ $\begin{array}{lllllll}0.000 \mathrm{E}+00 & 3.982 \mathrm{E}-09 & 2.837 \mathrm{E}-04 & 1.706 \mathrm{E}-03 & 6.374 \mathrm{E}-02 & 2.650 \mathrm{E}-01 & 9.692 \mathrm{E}+00\end{array}$ $\begin{array}{lllllll}0.000 \mathrm{E}+00 & 0.000 \mathrm{E}+00 & 1.075 \mathrm{E}-08 & 1.356 \mathrm{E}-07 & 2.889 \mathrm{E}-05 & 2.580 \mathrm{E}-04 & 1.137 \mathrm{E}-01\end{array}$ $\begin{array}{llllllll}0.000 \mathrm{E}+00 & 7.225 \mathrm{E}-04 & 1.058 \mathrm{E}+00 & 2.947 \mathrm{E}+00 & 1.830 \mathrm{E}+01 & 3.485 \mathrm{E}+01 & 9.838 \mathrm{E}+01\end{array}$

$\begin{array}{lllllll}3.600 \mathrm{E}+01 & 3.600 \mathrm{E}+01 & 3.593 \mathrm{E}+01 & 3.586 \mathrm{E}+01 & 3.531 \mathrm{E}+01 & 3.460 \mathrm{E}+01 & 2.445 \mathrm{E}+01\end{array}$ 
RESRAD-OFFSITE, Version $2.5 \quad \mathrm{~T}^{1} \frac{1}{2}$ Limit $=180$ days

Parent Dose Report

Title : Offsite Resident Farmer Deterministic Run

File : RF DOE SG FWD-FV2-10000Y.ROF

Run Time Information

ResOCalc.EXE execution began at 08:52 on 07/18/2011

ResOCalc.EXE execution ended at 09:12 on 07/18/2011

Resocalc.EXE execution time 19 minutes 47 seconds

DCN 5090-TR-02-2

B-133 


\section{Offsite Resident Farmer}

\section{Parent Dose Report \\ (Deterministic Analysis Report)}

Third Peak Dose Assessment

Time Horizon: 100,000 yr 
THIS PAGE INTENTIONALLY LEFT BLANK 
RESRAD-OFFSITE, Version 2.5

Parent Dose Report

Title : Offsite Resident Farmer Deterministic Run

File : RF DOE SG FWD-FV2-100000Y.ROF

Table of Contents

Part I: Mixture Sums and Single Radionuclide Guidelines

Dose Conversion Factor (and Related) Parameter Summary ... 2

Site-Specific Parameter Summary $\ldots \ldots \ldots \ldots \ldots \ldots \ldots \ldots \ldots \ldots \ldots \ldots$

Summary of Pathway Selections $\ldots \ldots \ldots \ldots \ldots \ldots \ldots \ldots \ldots .48$

Contaminated Zone and Total Dose Summary .............. 49

Total Dose Components

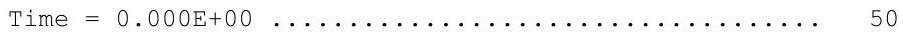

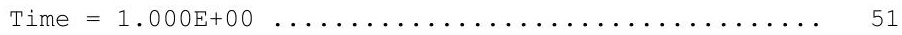

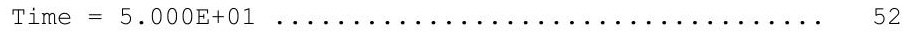

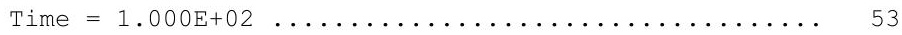

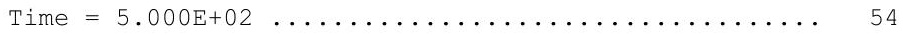

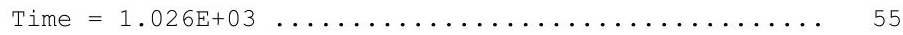

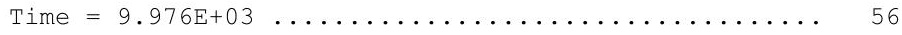

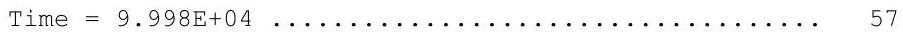

Dose/Source Ratios Summed Over All Pathways ............ 58

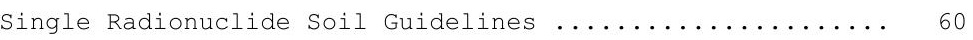

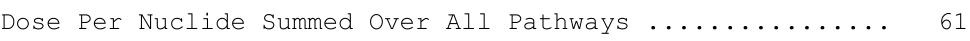

Soil Concentration Per Nuclide $\ldots \ldots \ldots \ldots \ldots \ldots \ldots \ldots \ldots .63$

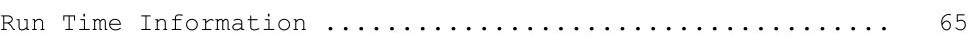


RESRAD-OFFSITE, Version 2.5

Parent Dose Report

Title : Offsite Resident Farmer Deterministic Run

File : RF DOE SG FWD-FV2-100000Y.ROF

Dose Conversion Factor (and Related) Parameter Summary

Current Library: ICRP 60

Default Library: ICRP 60

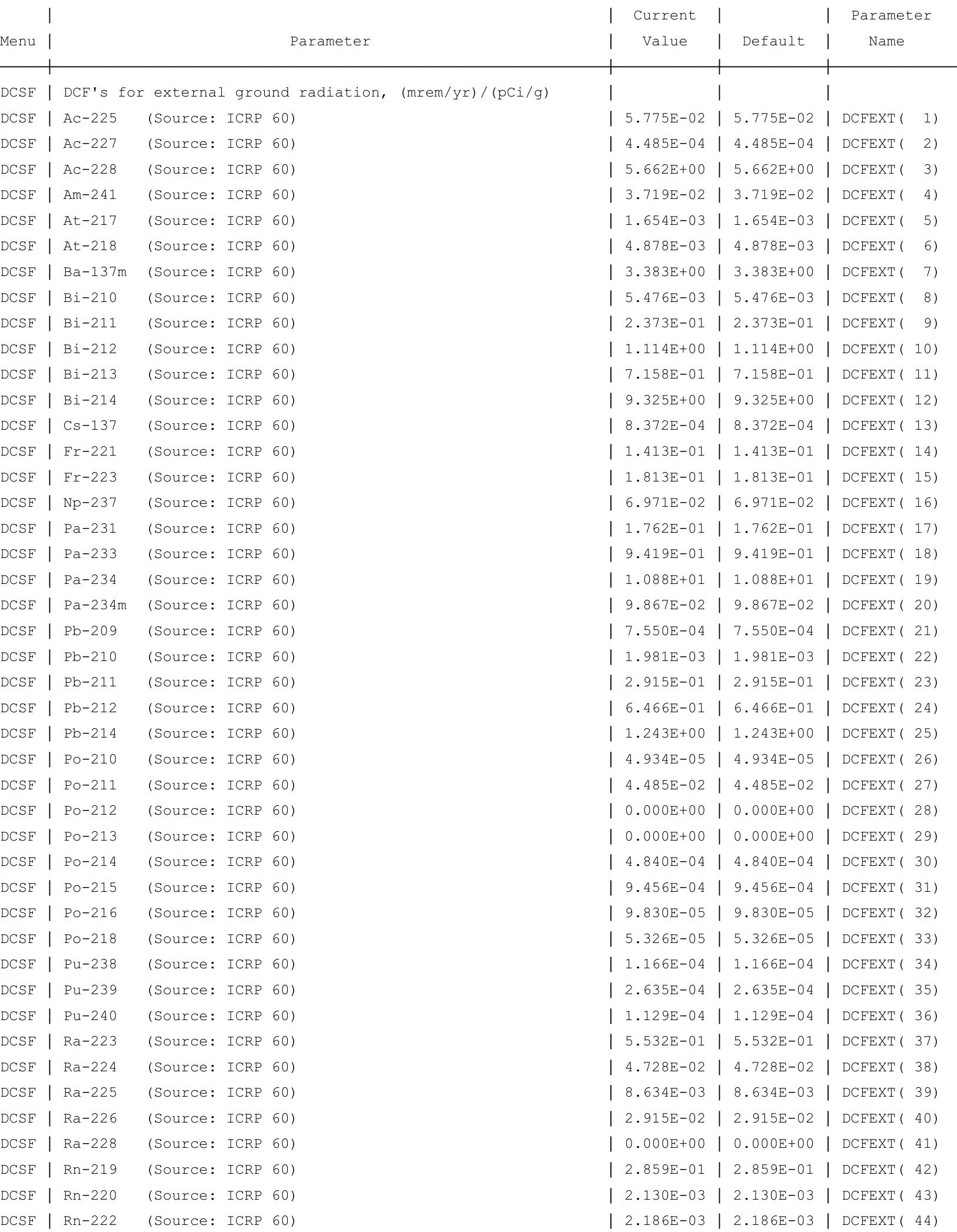


RESRAD-OFFSITE, Version $2.5 \quad \mathrm{~T}^{1 / 2}$ Limit $=180$ days

Parent Dose Report

Title : Offsite Resident Farmer Deterministic Run

File : RF DOE SG FWD-FV2-100000Y.ROF

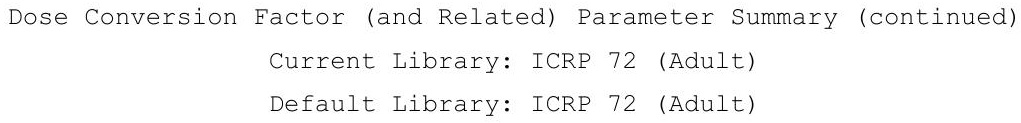

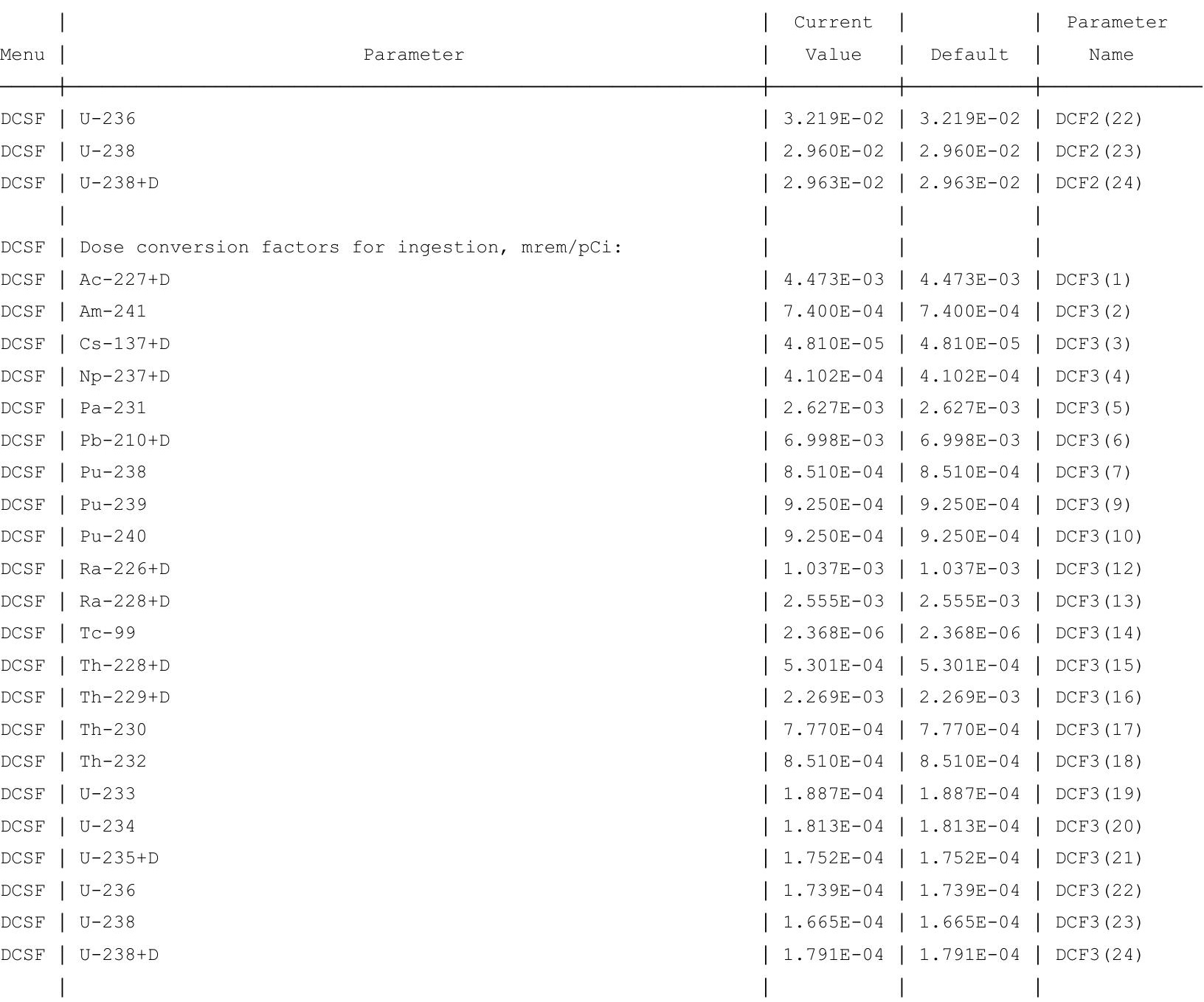


RESRAD-OFFSITE, Version 2.5

Parent Dose Report

Title : Offsite Resident Farmer Deterministic Run

File : RF DOE SG FWD-FV2-100000Y.ROF

Dose Conversion Factor (and Related) Parameter Summary (continued)

Current Library: RESRAD Default Transfer factors

Default Library: RESRAD Default Transfer factors

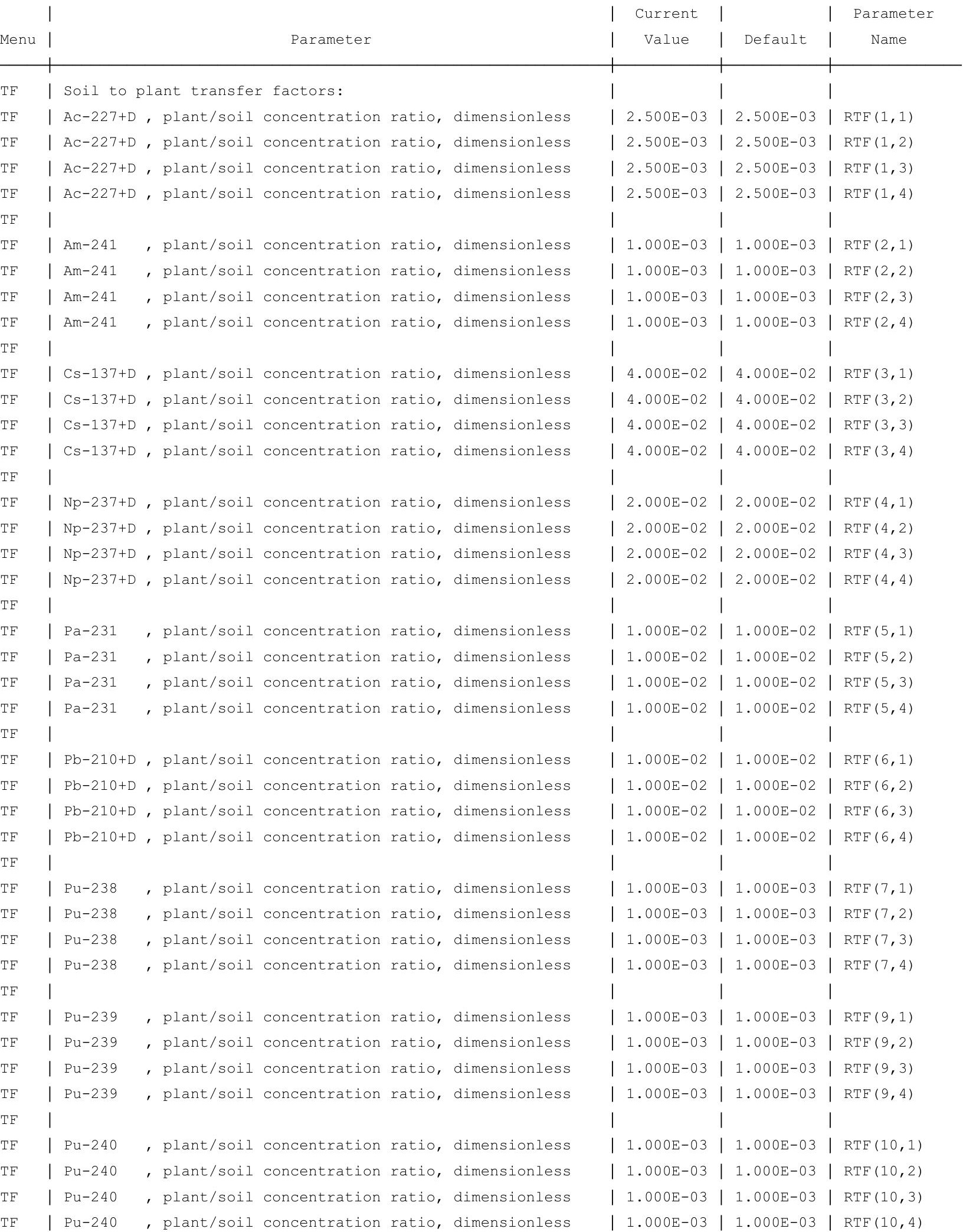


RESRAD-OFFSITE, Version 2.5

Parent Dose Report

Title : Offsite Resident Farmer Deterministic Run

File : RF DOE SG FWD-FV2-100000Y.ROF

Dose Conversion Factor (and Related) Parameter Summary (continued)

Current Library: RESRAD Default Transfer factors

Default Library: RESRAD Default Transfer factors

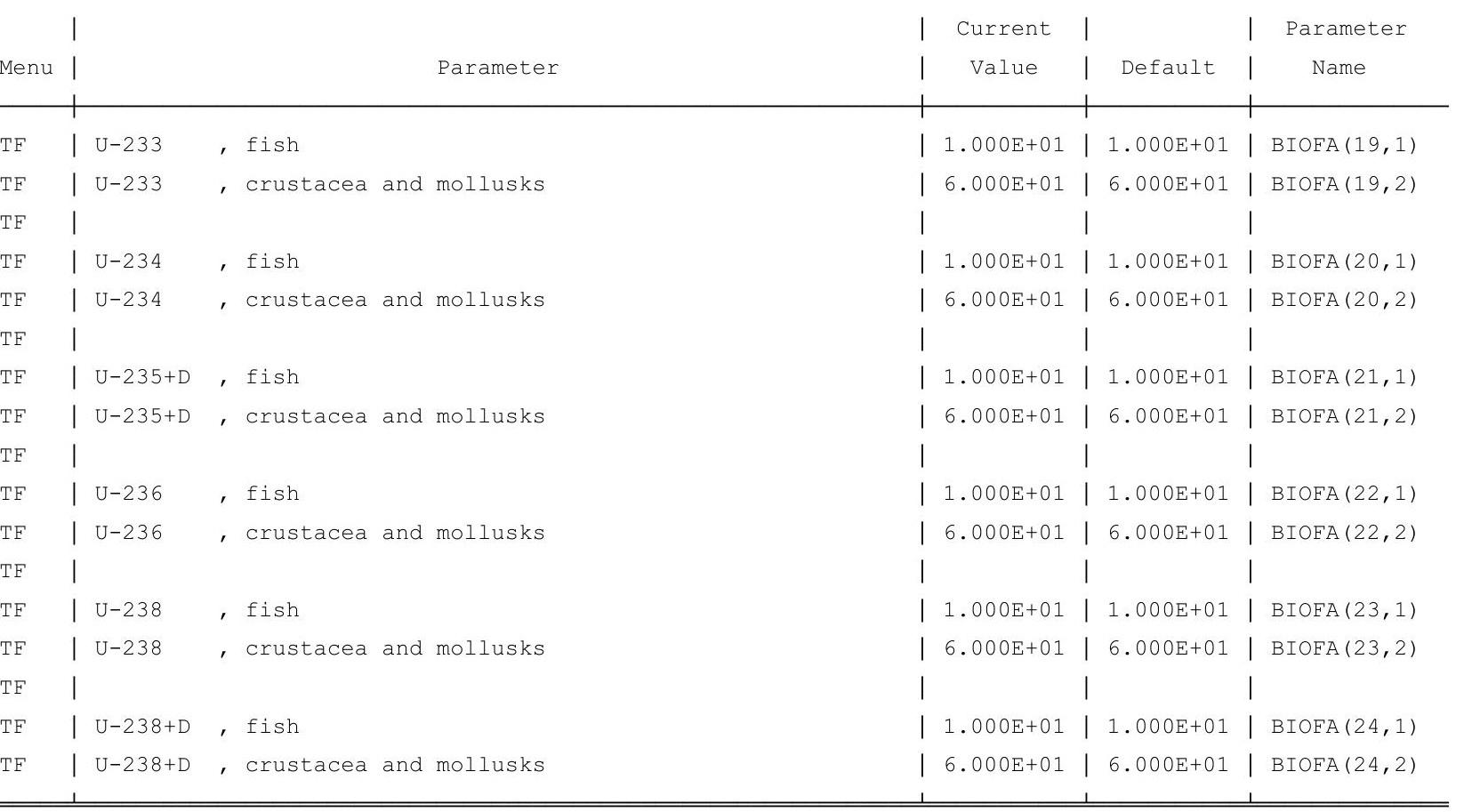


RESRAD-OFFSITE, Version $2.5 \quad \mathrm{~T}^{1 / 2}$ Limit $=180$ days

Parent Dose Report

Title : Offsite Resident Farmer Deterministic Run

File : RF DOE SG FWD-FV2-100000Y.ROF

Site-Specific Parameter Summary

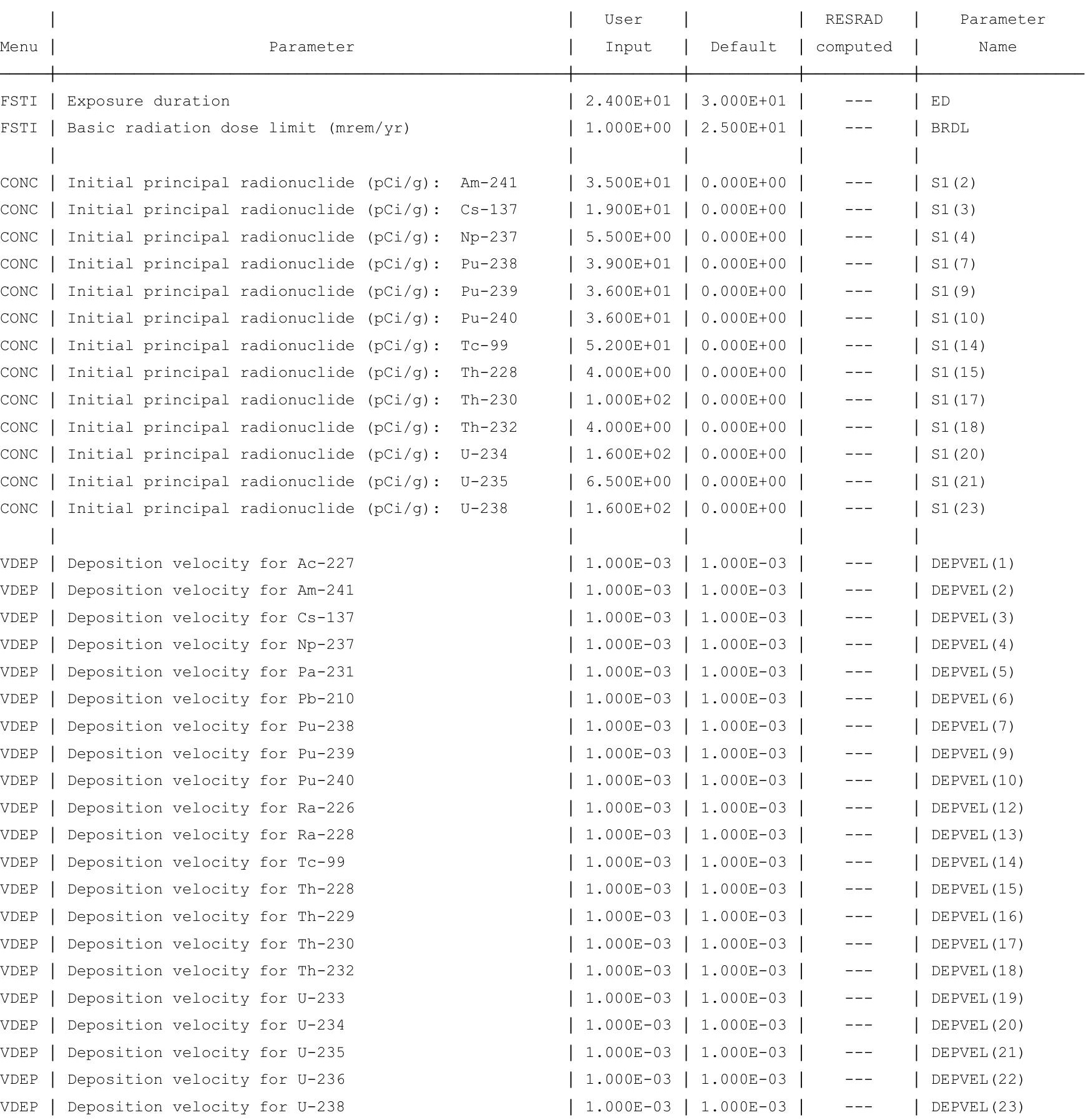


RESRAD-OFFSITE, Version $2.5 \quad \mathrm{~T}^{1 / 2}$ Limit $=180$ days

Parent Dose Report

Title : Offsite Resident Farmer Deterministic Run

File : RF DOE SG FWD-FV2-100000Y.ROF

Site-Specific Parameter Summary (continued)

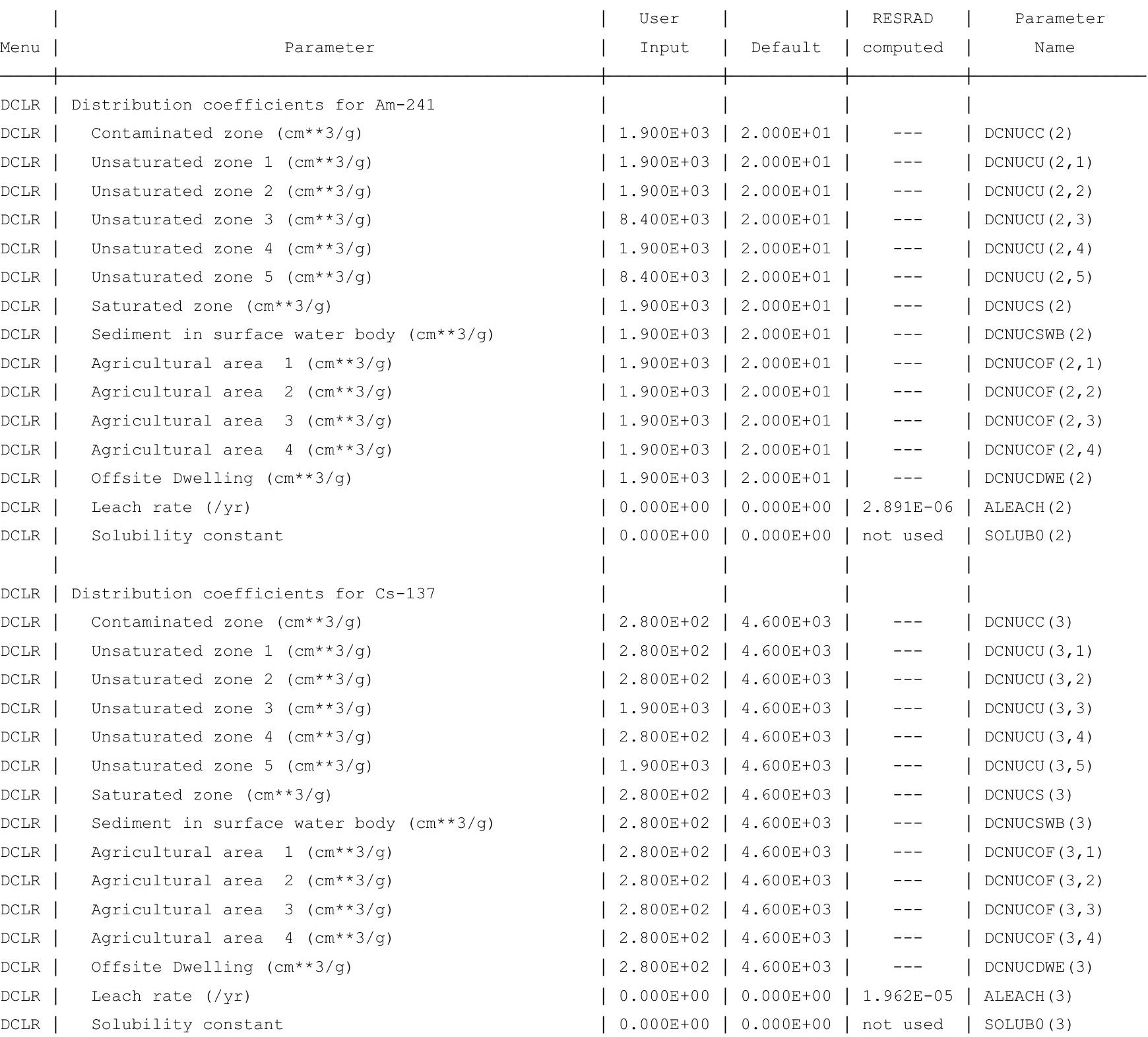


RESRAD-OFFSITE, Version $2.5 \quad \mathrm{~T}^{1 / 2}$ Limit $=180$ days

Parent Dose Report

Title : Offsite Resident Farmer Deterministic Run

File : RF DOE SG FWD-FV2-100000Y.ROF

Site-Specific Parameter Summary (continued)

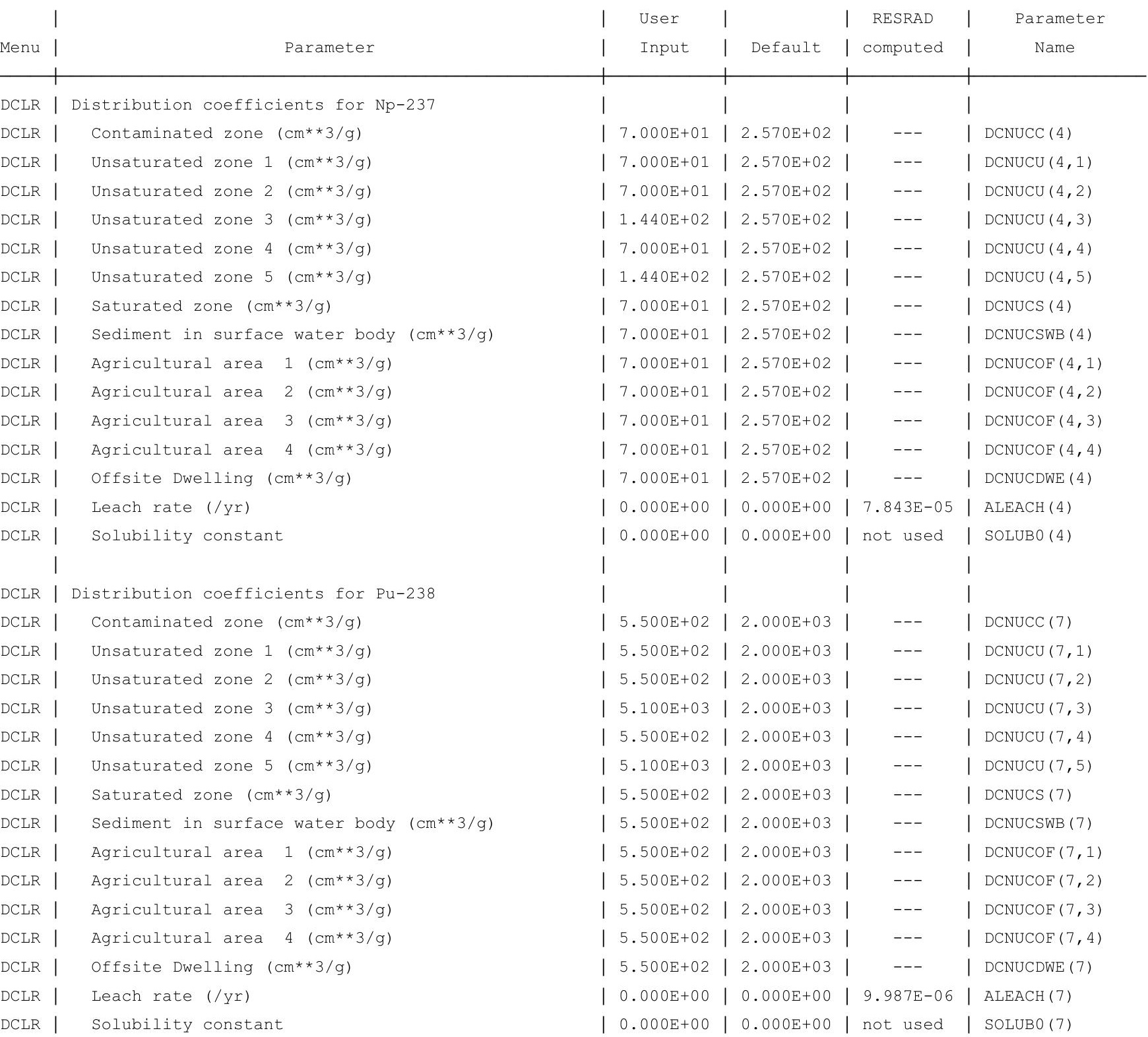


RESRAD-OFFSITE, Version $2.5 \quad \mathrm{~T}^{1 / 2}$ Limit $=180$ days

Parent Dose Report

Title : Offsite Resident Farmer Deterministic Run

File : RF DOE SG FWD-FV2-100000Y.ROF

Site-Specific Parameter Summary (continued)

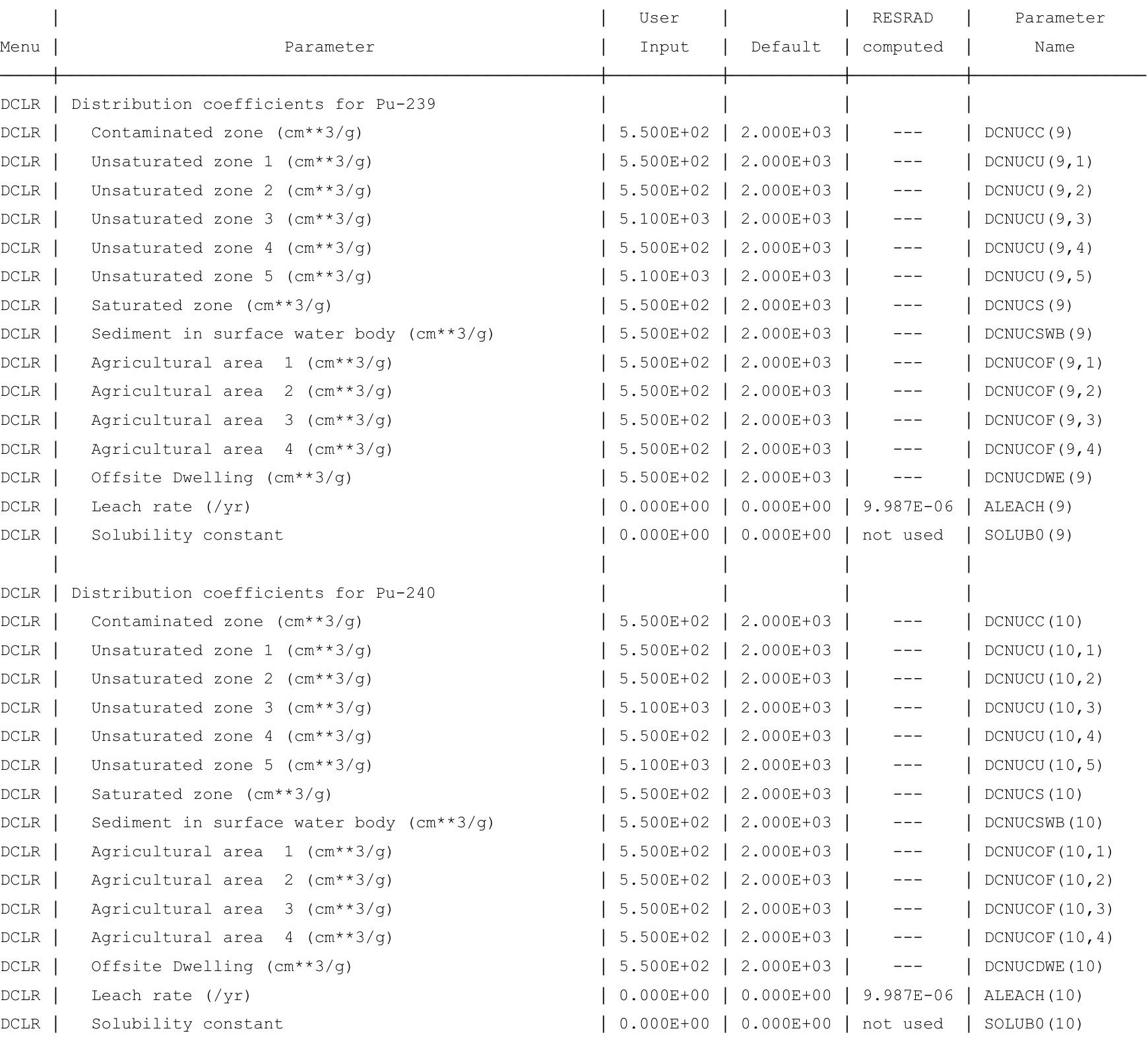


RESRAD-OFFSITE, Version $2.5 \quad \mathrm{~T}^{1 / 2}$ Limit $=180$ days

Parent Dose Report

Title : Offsite Resident Farmer Deterministic Run

File : RF DOE SG FWD-FV2-100000Y.ROF

Site-Specific Parameter Summary (continued)

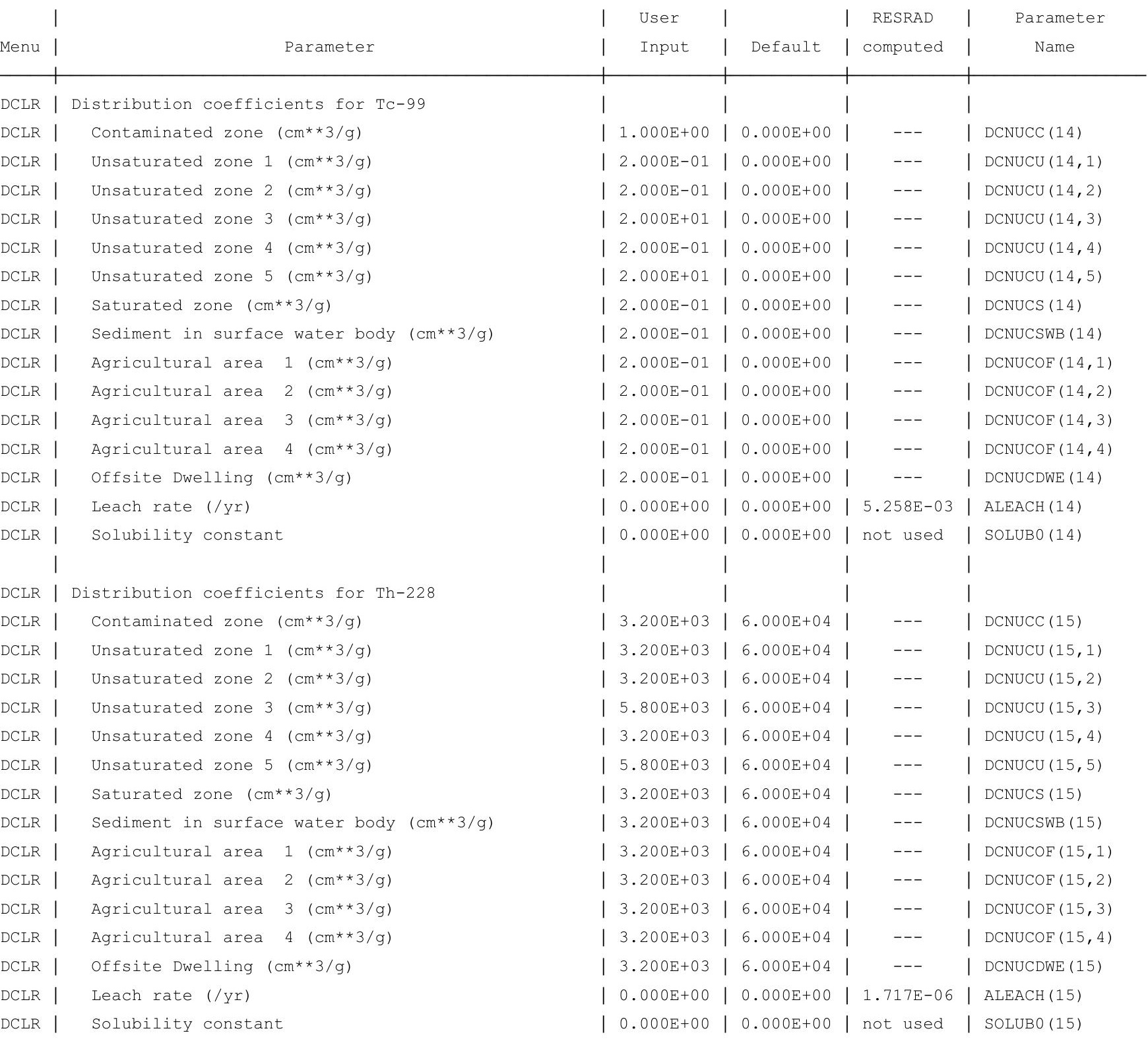


RESRAD-OFFSITE, Version $2.5 \quad \mathrm{~T}^{1 / 2}$ Limit $=180$ days

Parent Dose Report

Title : Offsite Resident Farmer Deterministic Run

File : RF DOE SG FWD-FV2-100000Y.ROF

Site-Specific Parameter Summary (continued)

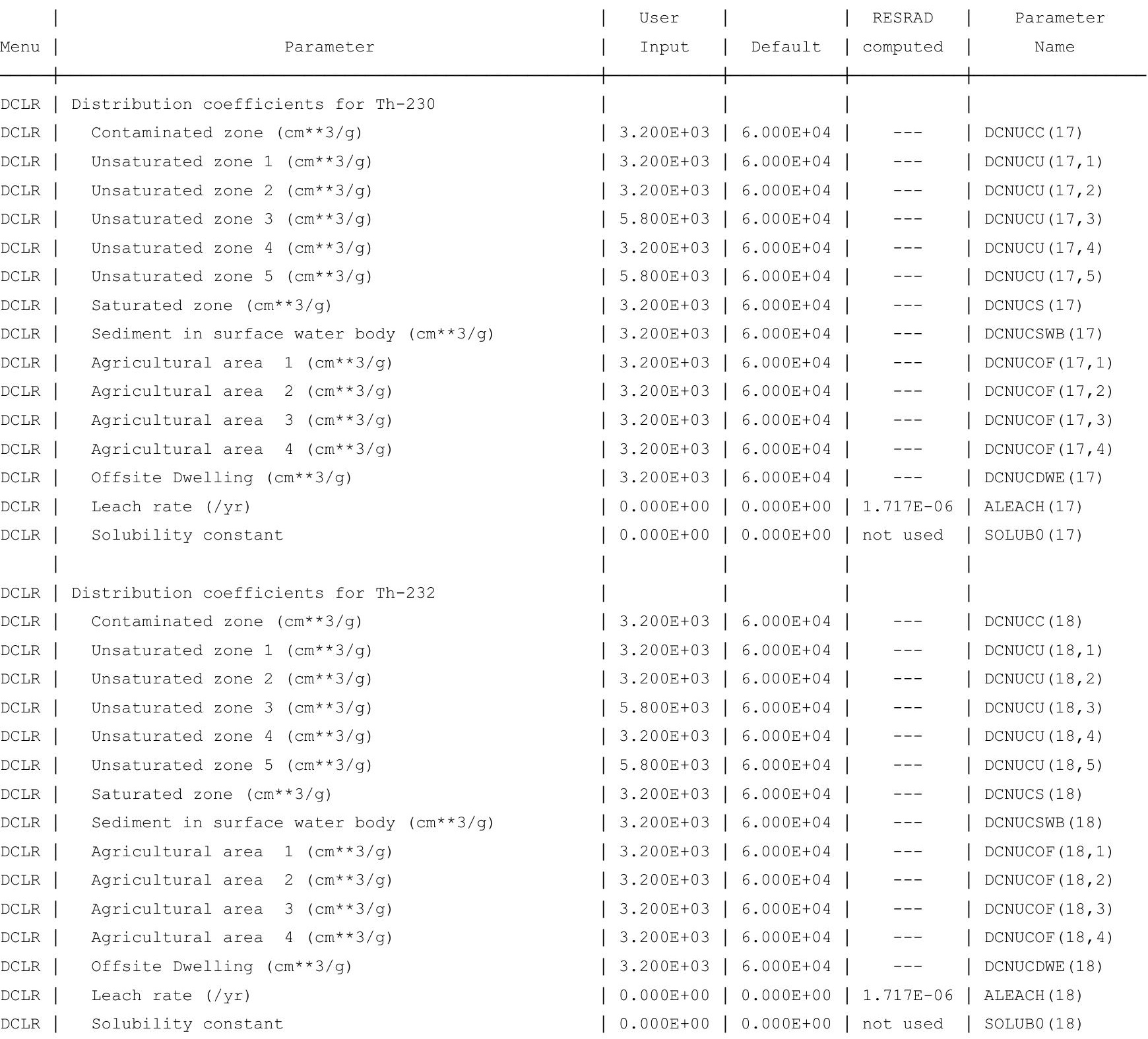


RESRAD-OFFSITE, Version $2.5, \mathrm{~T}^{1 / 2}$ Limit $=180$ days

Parent Dose Report

Title : Offsite Resident Farmer Deterministic Run

File : RF DOE SG FWD-FV2-100000Y.ROF

Site-Specific Parameter Summary (continued)

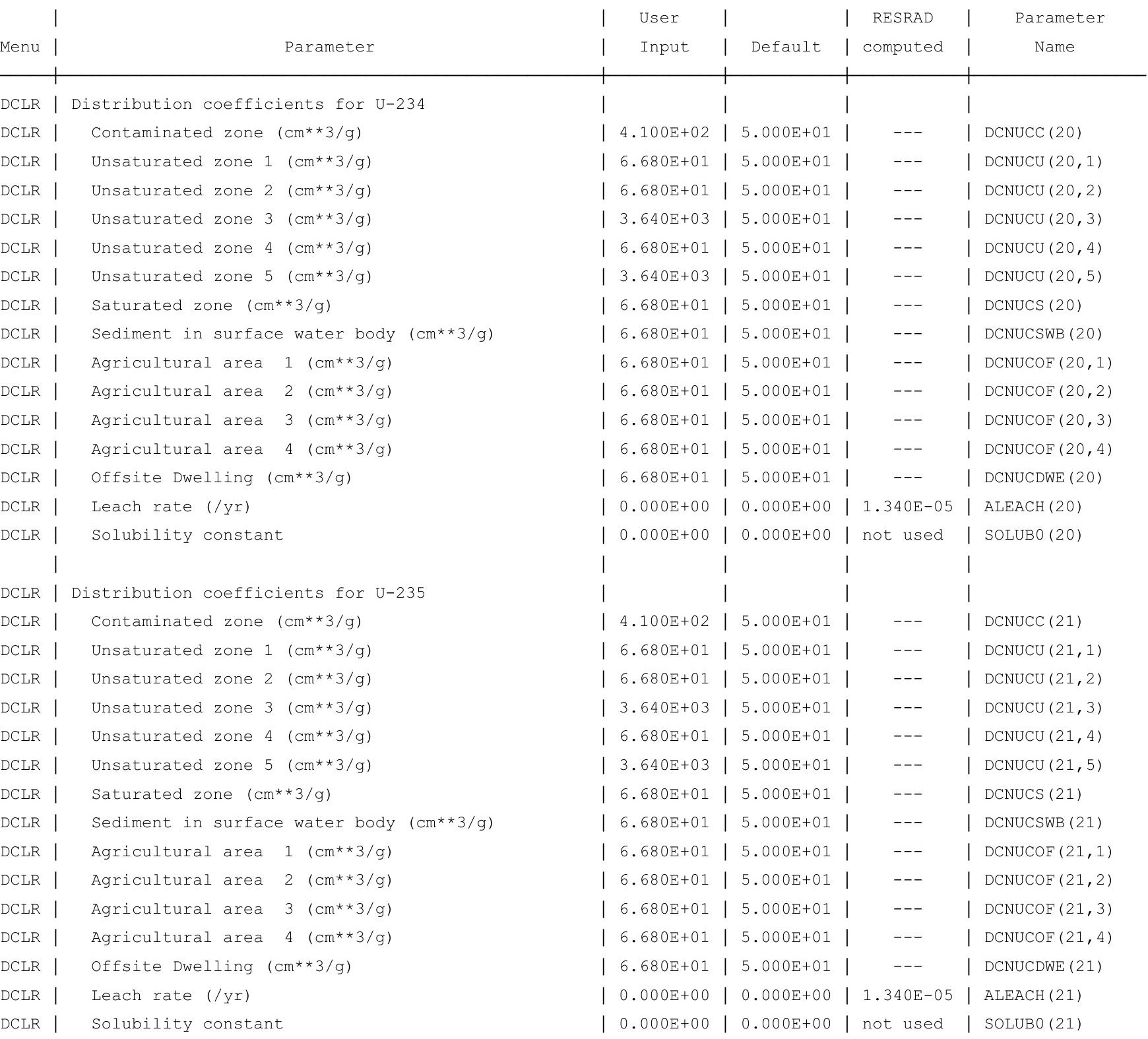


RESRAD-OFFSITE, Version $2.5 \quad \mathrm{~T}^{1 / 2}$ Limit $=180$ days

Parent Dose Report

Title : Offsite Resident Farmer Deterministic Run

File : RF DOE SG FWD-FV2-100000Y.ROF

Site-Specific Parameter Summary (continued)

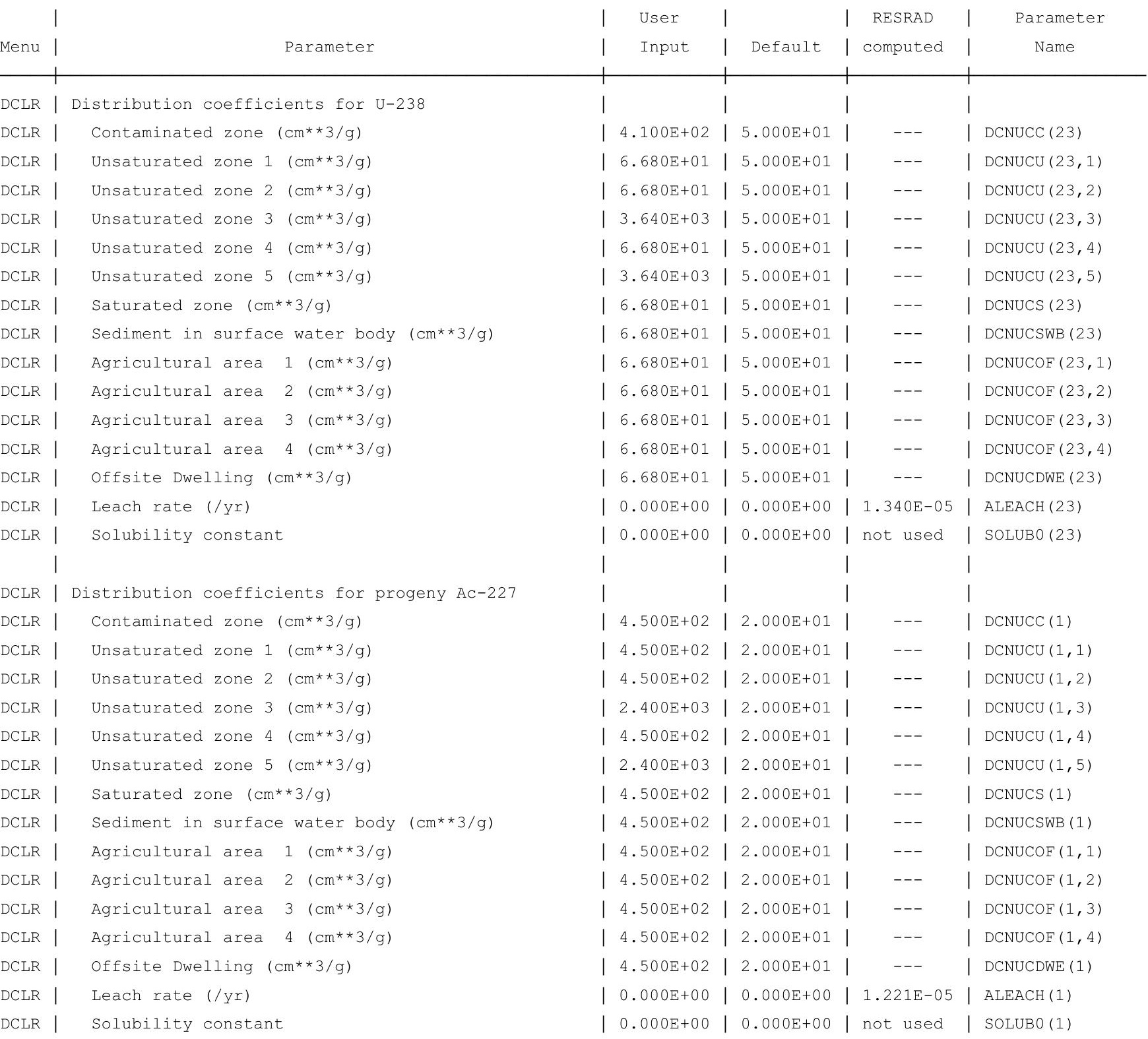


RESRAD-OFFSITE, Version $2.5 \quad \mathrm{~T}^{1 / 2}$ Limit $=180$ days

Parent Dose Report

Title : Offsite Resident Farmer Deterministic Run

File : RF DOE SG FWD-FV2-100000Y.ROF

Site-Specific Parameter Summary (continued)

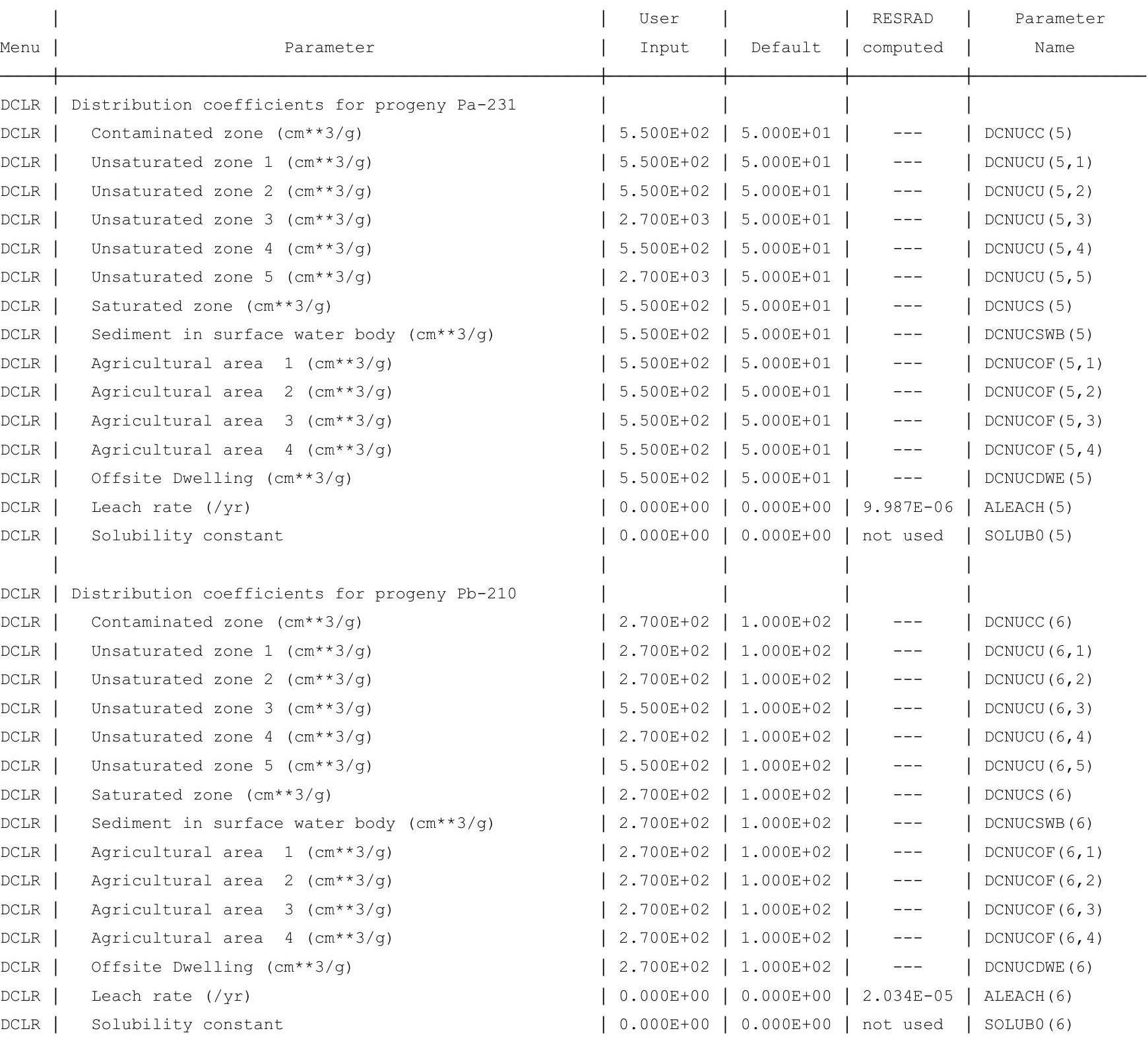


RESRAD-OFFSITE, Version $2.5 \quad \mathrm{~T}^{1 / 2}$ Limit $=180$ days

Parent Dose Report

Title : Offsite Resident Farmer Deterministic Run

File : RF DOE SG FWD-FV2-100000Y.ROF

Site-Specific Parameter Summary (continued)

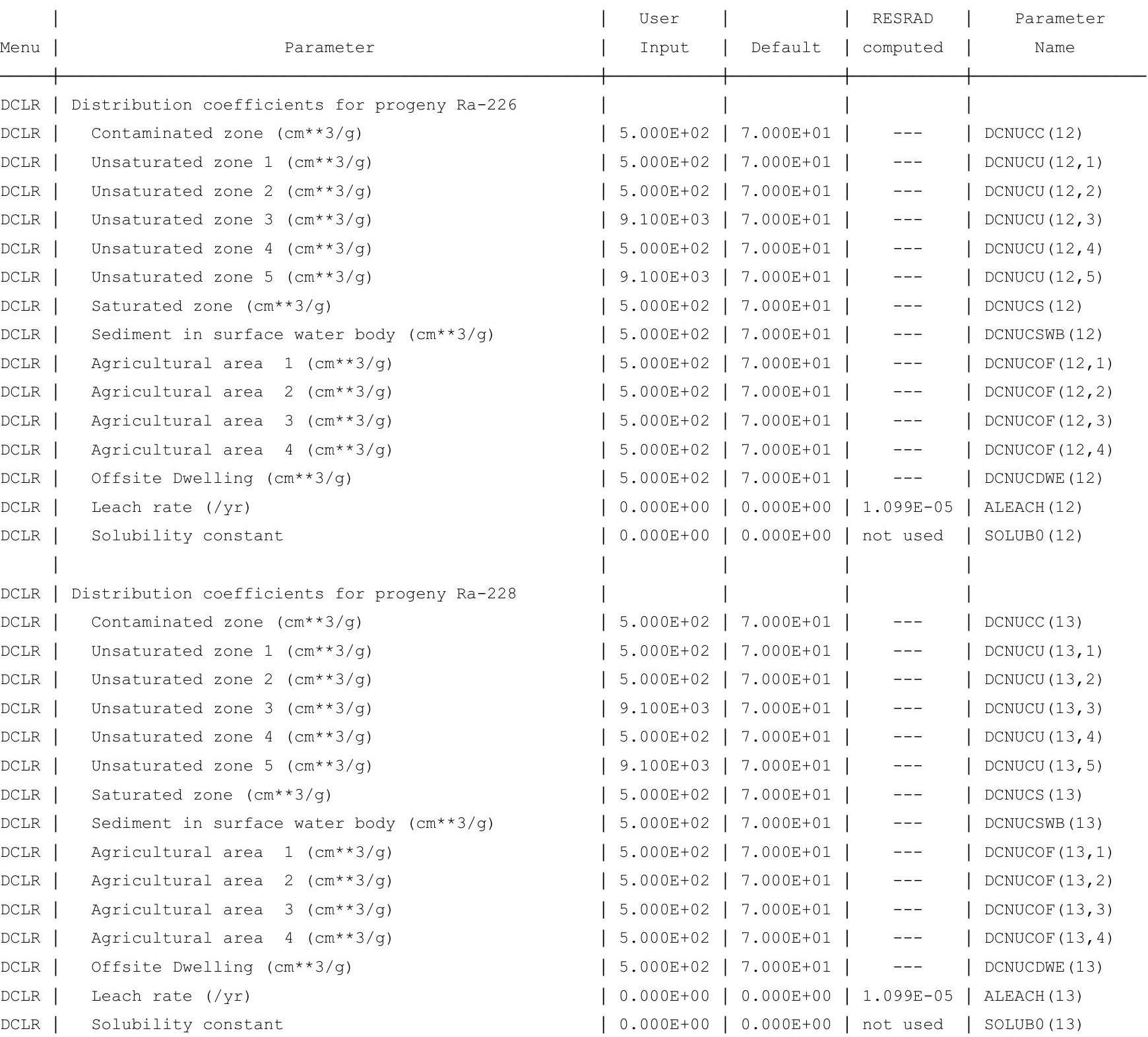


RESRAD-OFFSITE, Version $2.5, \mathrm{~T}^{1 / 2}$ Limit $=180$ days

Parent Dose Report

Title : Offsite Resident Farmer Deterministic Run

File : RF DOE SG FWD-FV2-100000Y.ROF

Site-Specific Parameter Summary (continued)

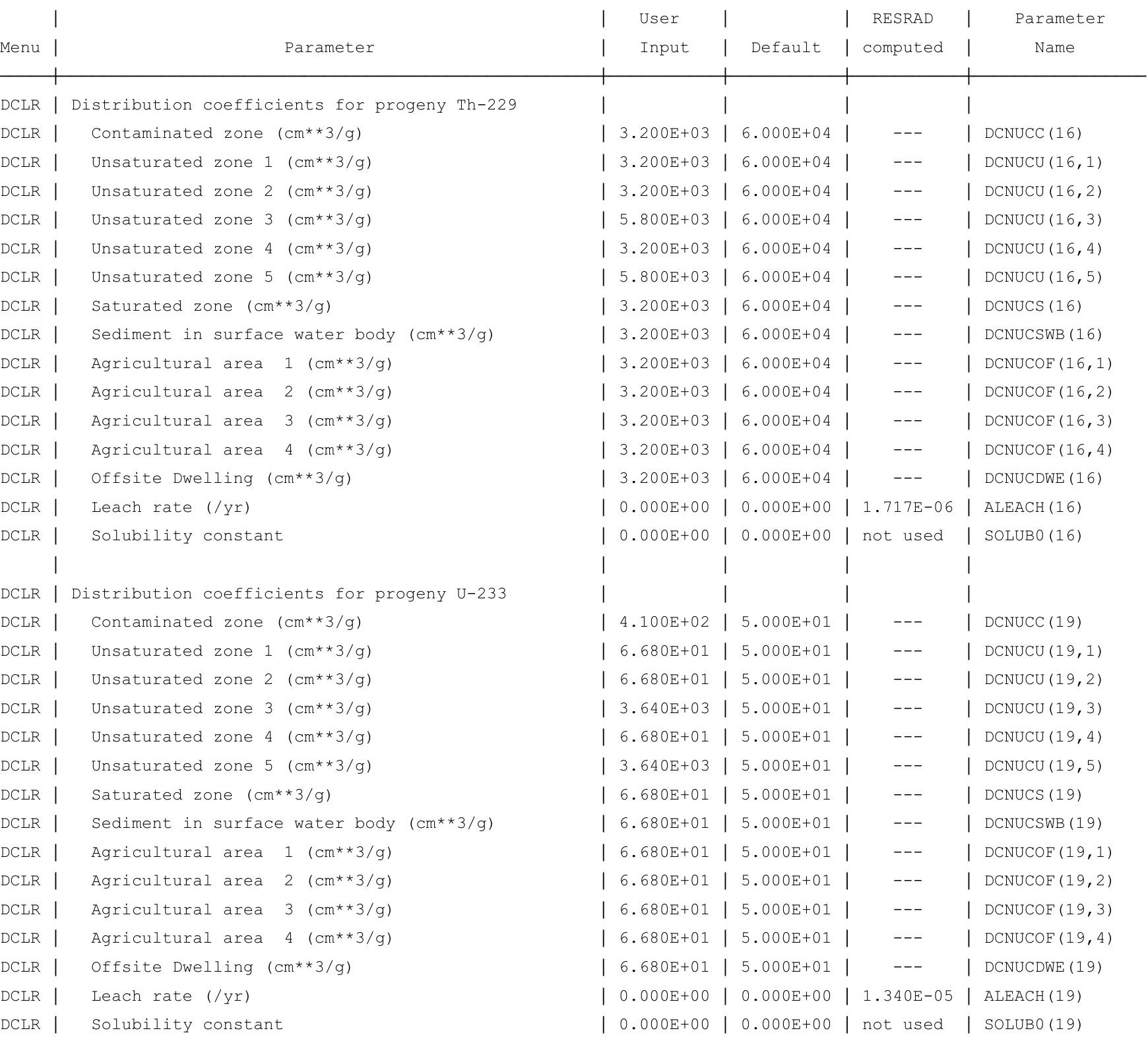


RESRAD-OFFSITE, Version 2.5

Parent Dose Report

Title : Offsite Resident Farmer Deterministic Run

File : RF DOE SG FWD-FV2-100000Y.ROF

Site-Specific Parameter Summary (continued)

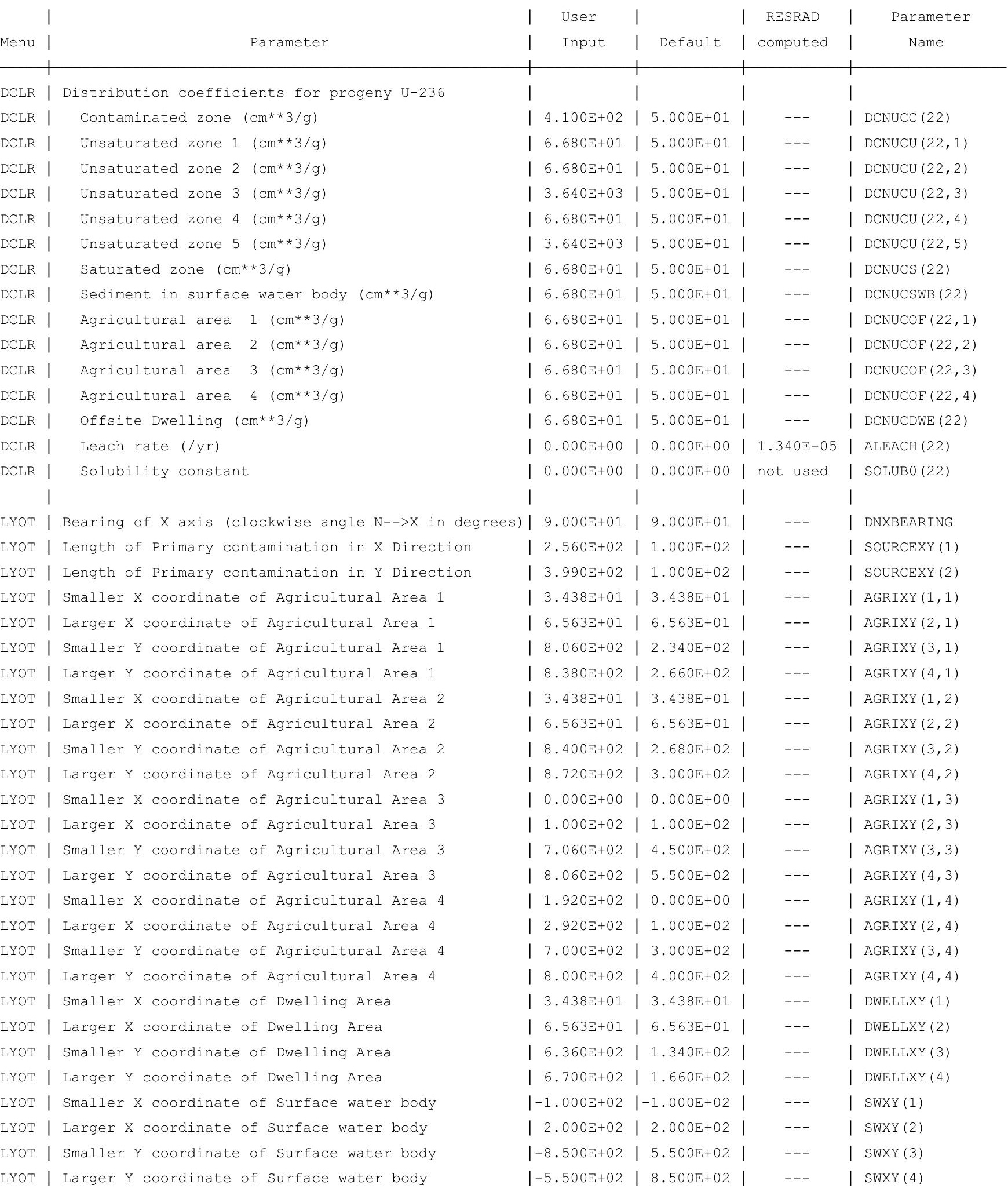


RESRAD-OFFSITE, Version 2.5

Parent Dose Report

Title : Offsite Resident Farmer Deterministic Run

File : RF DOE SG FWD-FV2-100000Y.ROF

Site-Specific Parameter Summary (continued)

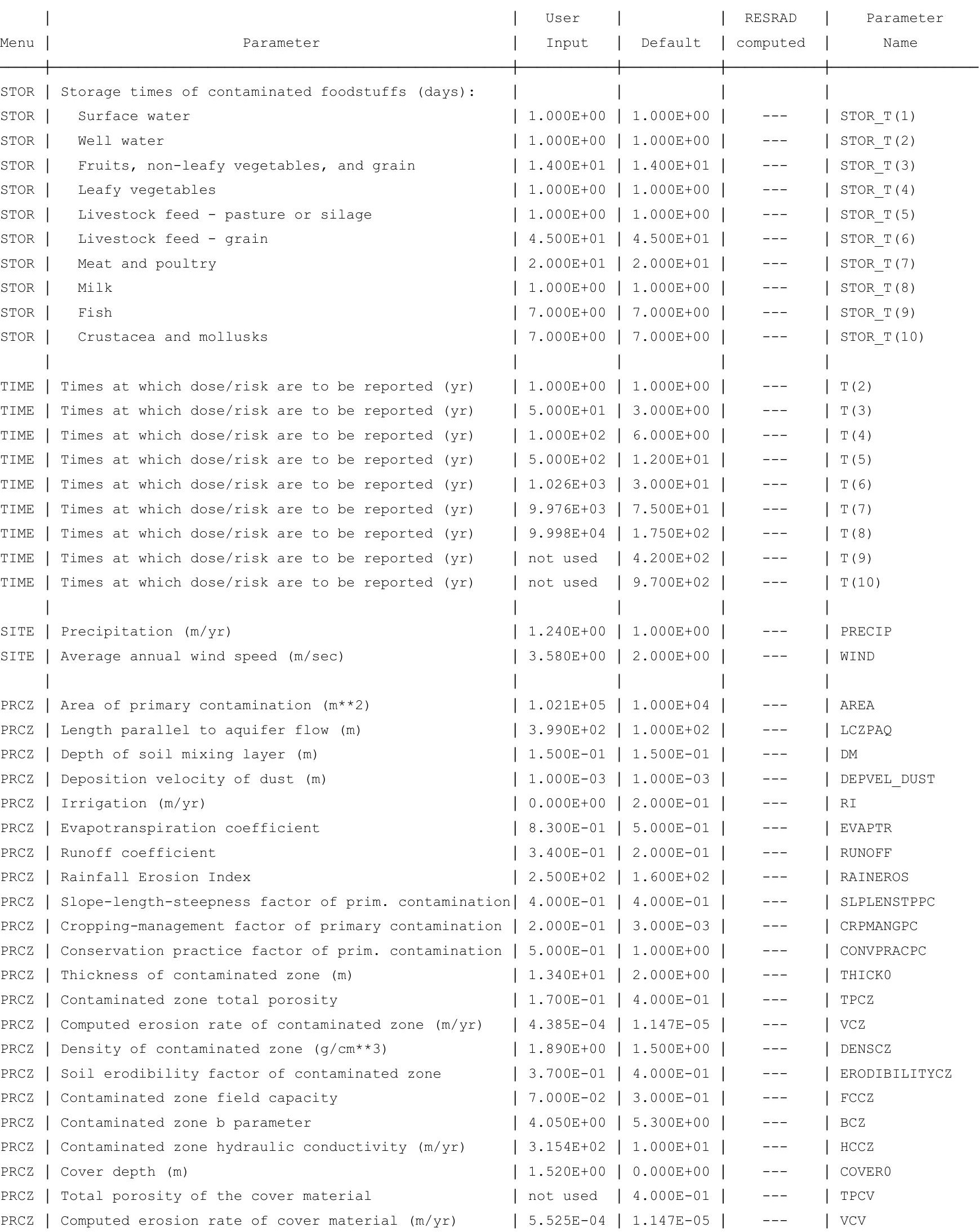


RESRAD-OFFSITE, Version 2.5

Parent Dose Report

Title : Offsite Resident Farmer Deterministic Run

File : RF DOE SG FWD-FV2-100000Y.ROF

Site-Specific Parameter Summary (continued)

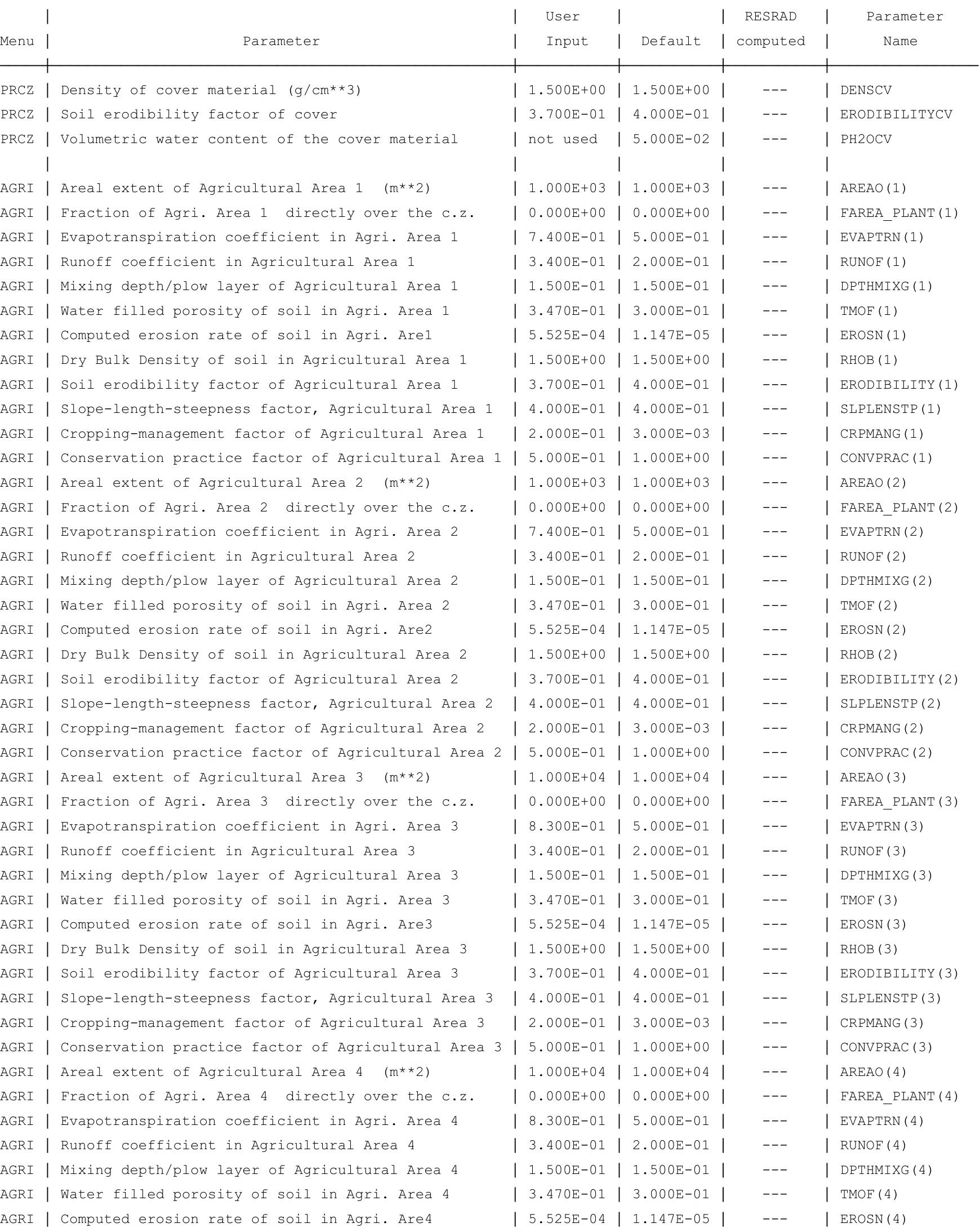


RESRAD-OFFSITE, Version 2.5

Parent Dose Report

Title : Offsite Resident Farmer Deterministic Run

File : RF DOE SG FWD-FV2-100000Y.ROF

Site-Specific Parameter Summary (continued)

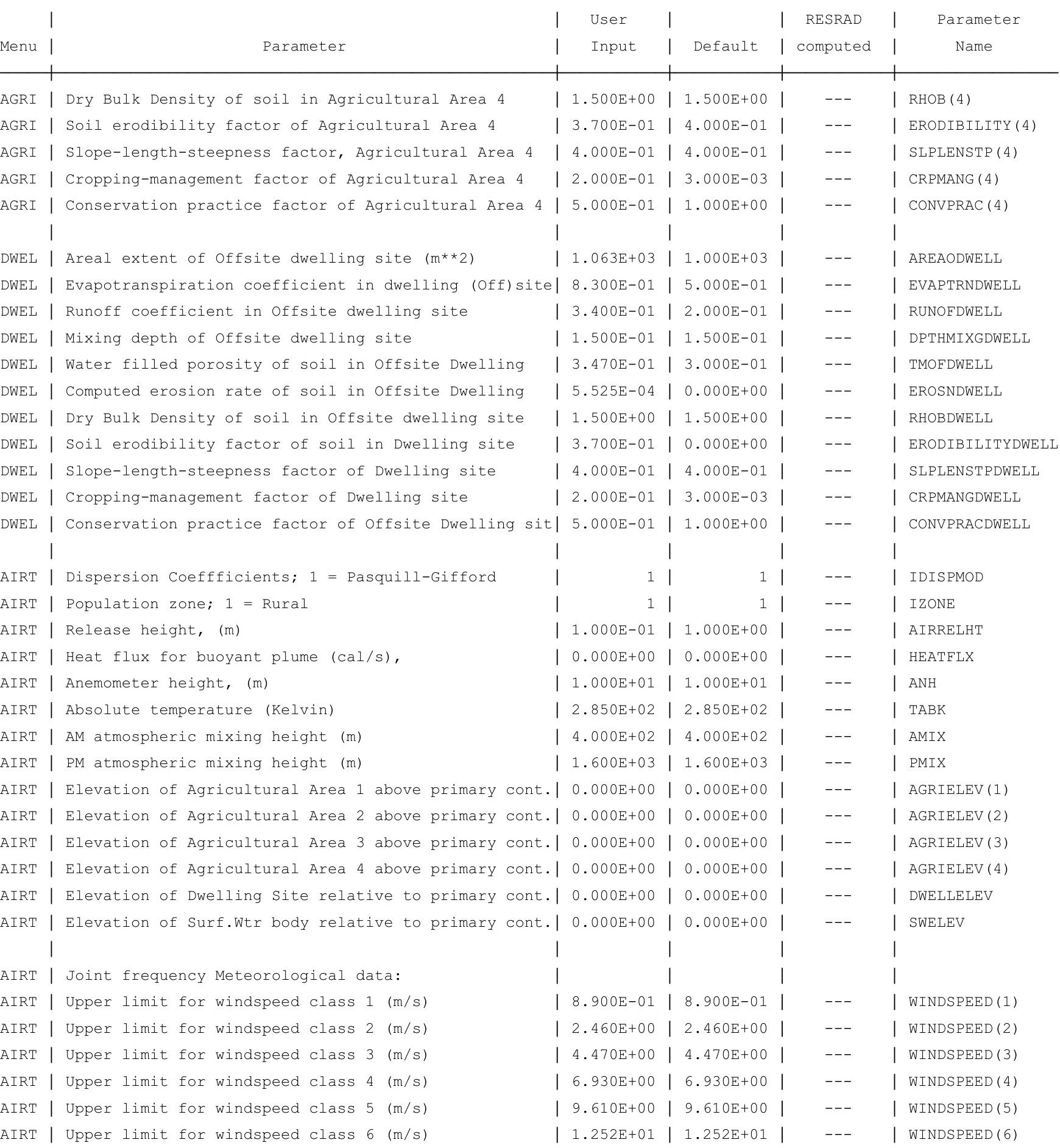


RESRAD-OFFSITE, Version 2.5

Parent Dose Report

Title : Offsite Resident Farmer Deterministic Run

File : RF DOE SG FWD-FV2-100000Y.ROF

Site-Specific Parameter Summary (continued)

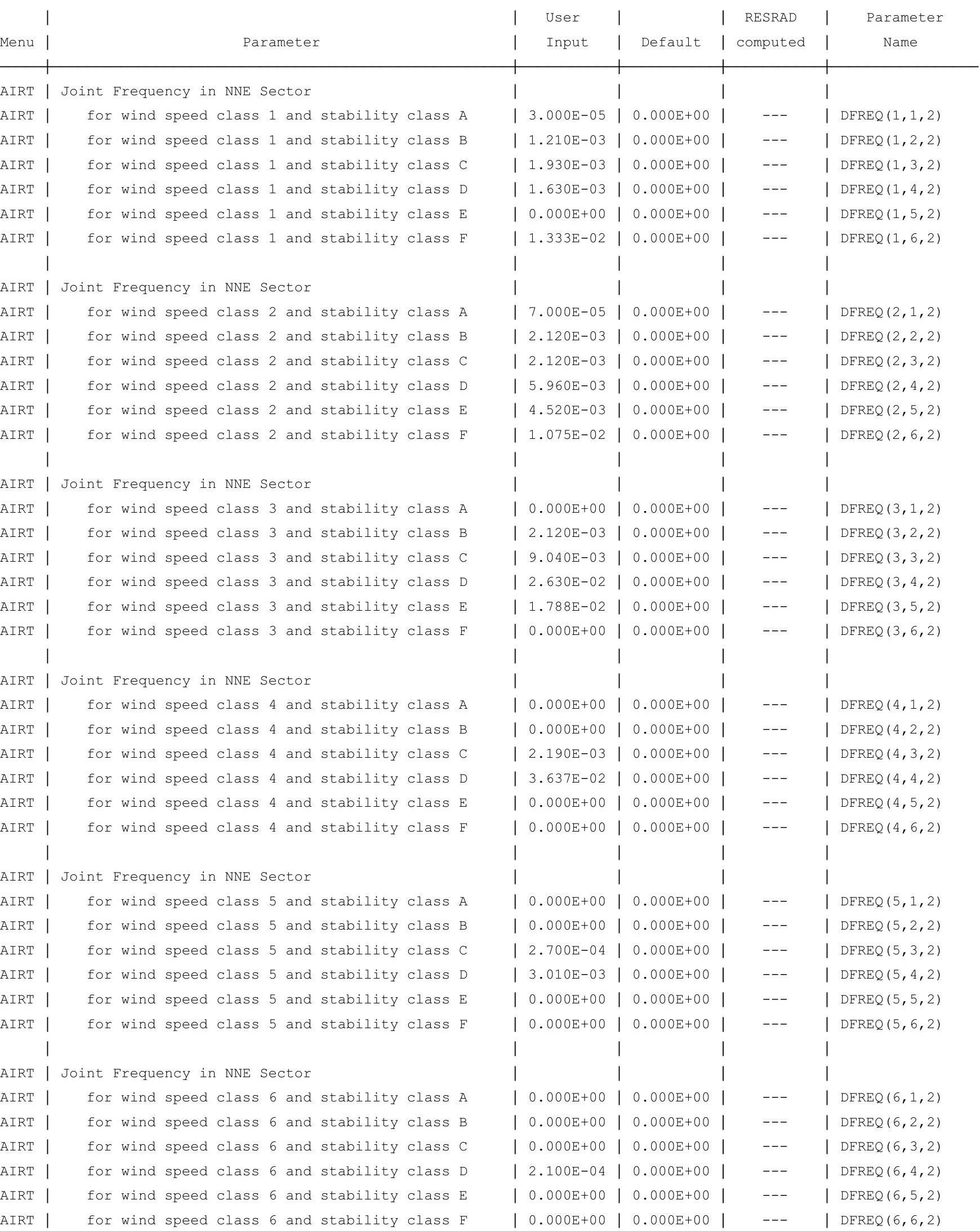


RESRAD-OFFSITE, Version 2.5

Parent Dose Report

Title : Offsite Resident Farmer Deterministic Run

File : RF DOE SG FWD-FV2-100000Y.ROF

Site-Specific Parameter Summary (continued)

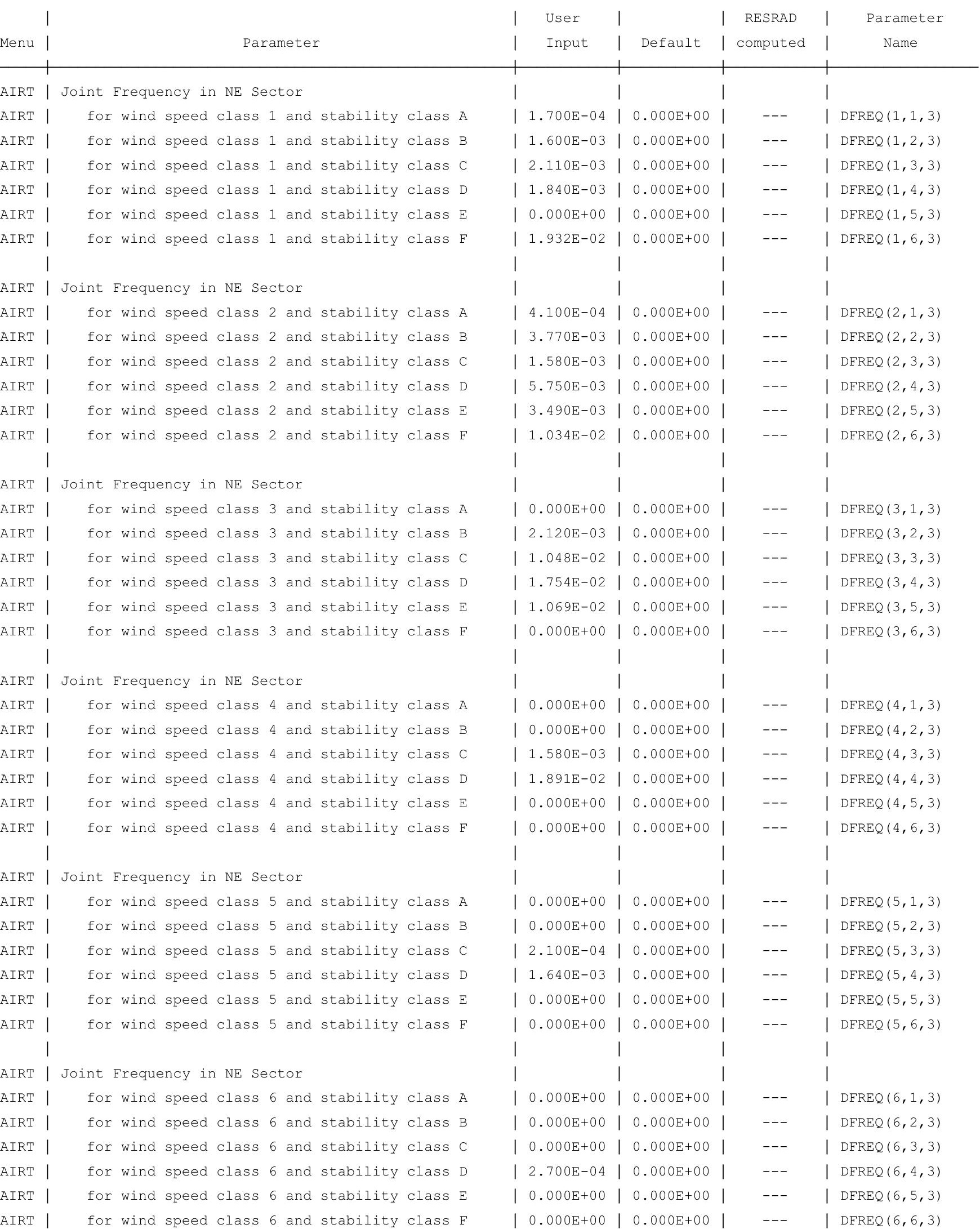


RESRAD-OFFSITE, Version 2.5

Parent Dose Report

Title : Offsite Resident Farmer Deterministic Run

File : RF DOE SG FWD-FV2-100000Y.ROF

Site-Specific Parameter Summary (continued)

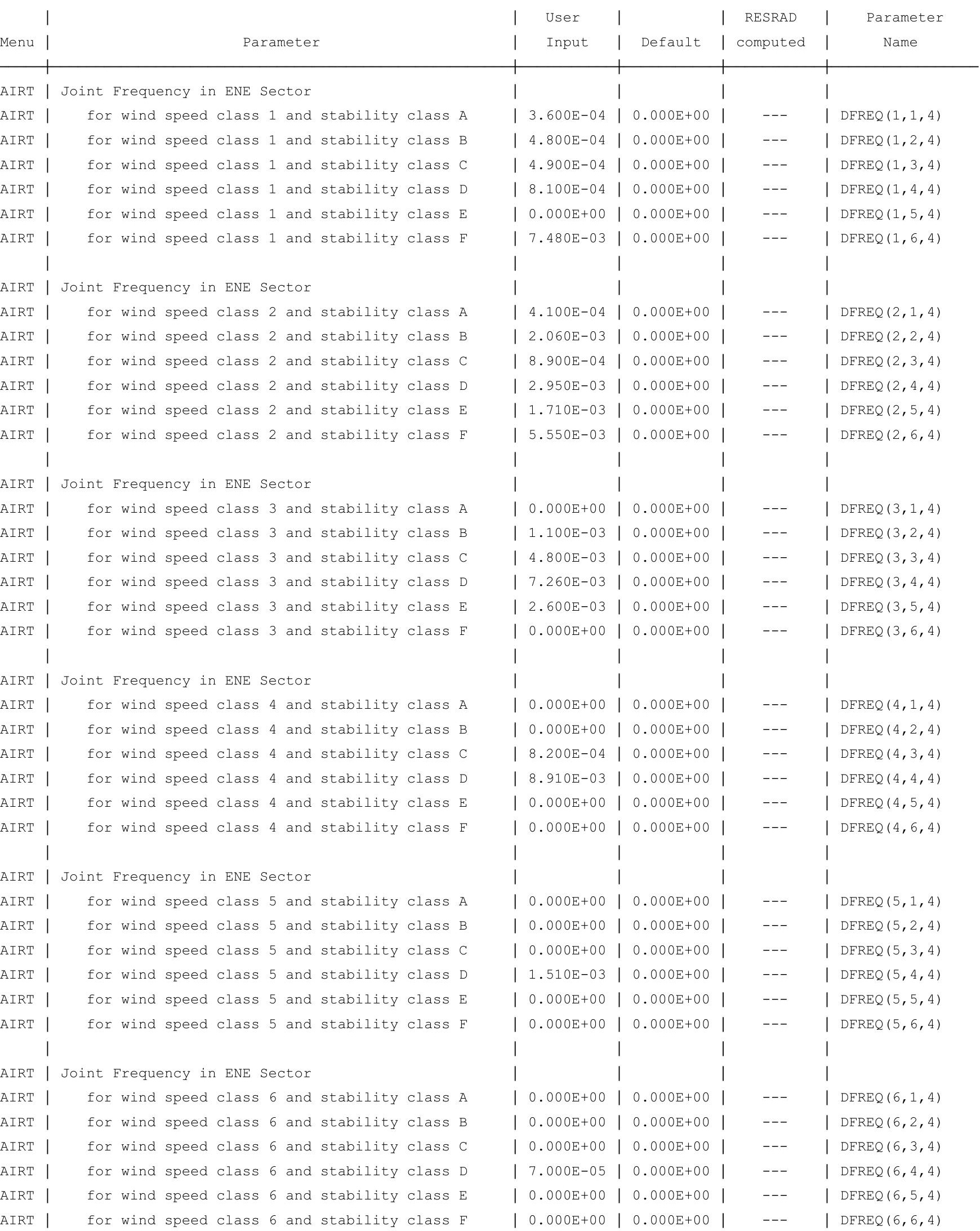


RESRAD-OFFSITE, Version 2.

Parent Dose Report

Title : Offsite Resident Farmer Deterministic Run

File : RF DOE SG FWD-FV2-100000Y.ROF

Site-Specific Parameter Summary (continued)

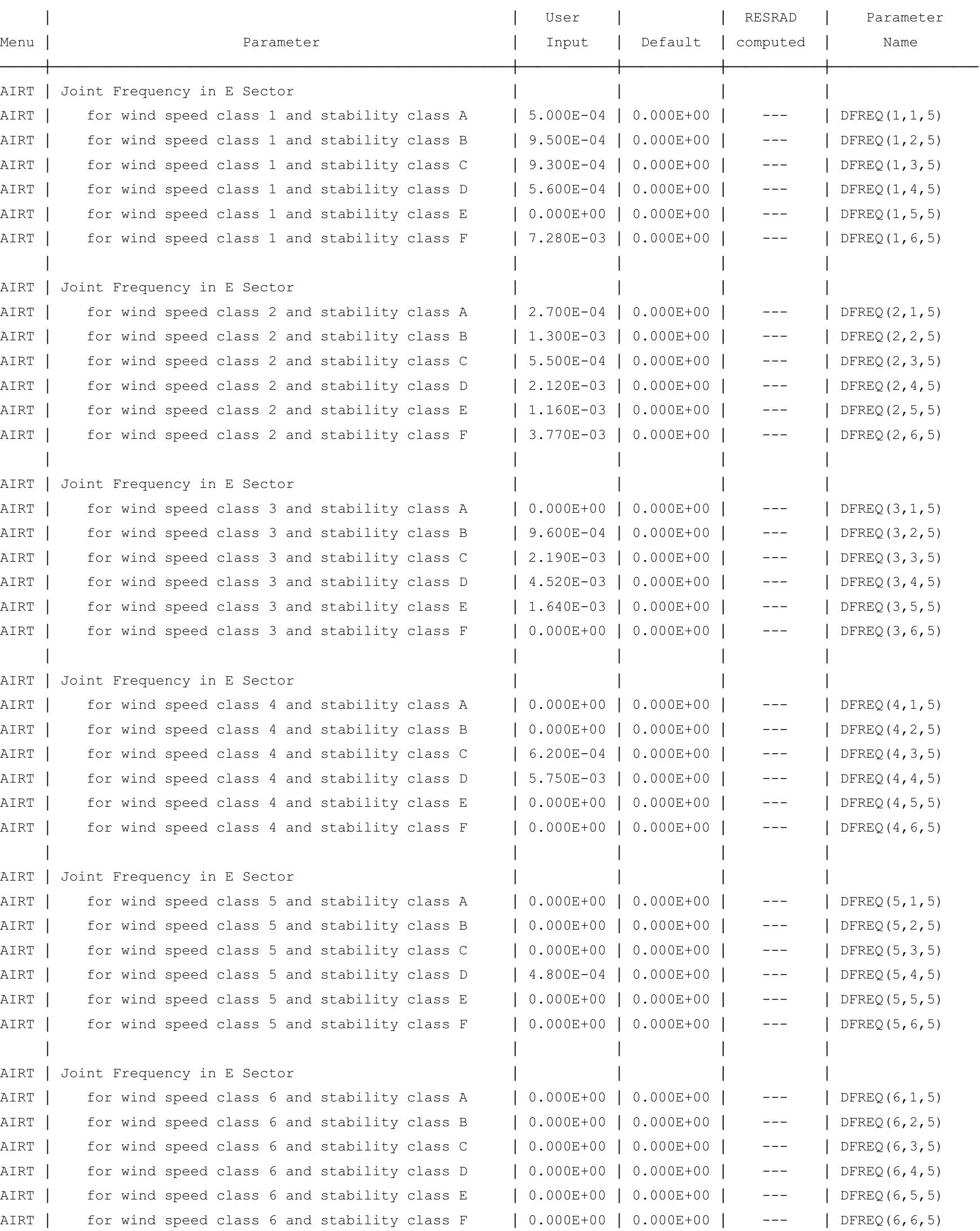


RESRAD-OFFSITE, Version 2.5

Parent Dose Report

Title : Offsite Resident Farmer Deterministic Run

File : RF DOE SG FWD-FV2-100000Y.ROF

Site-Specific Parameter Summary (continued)

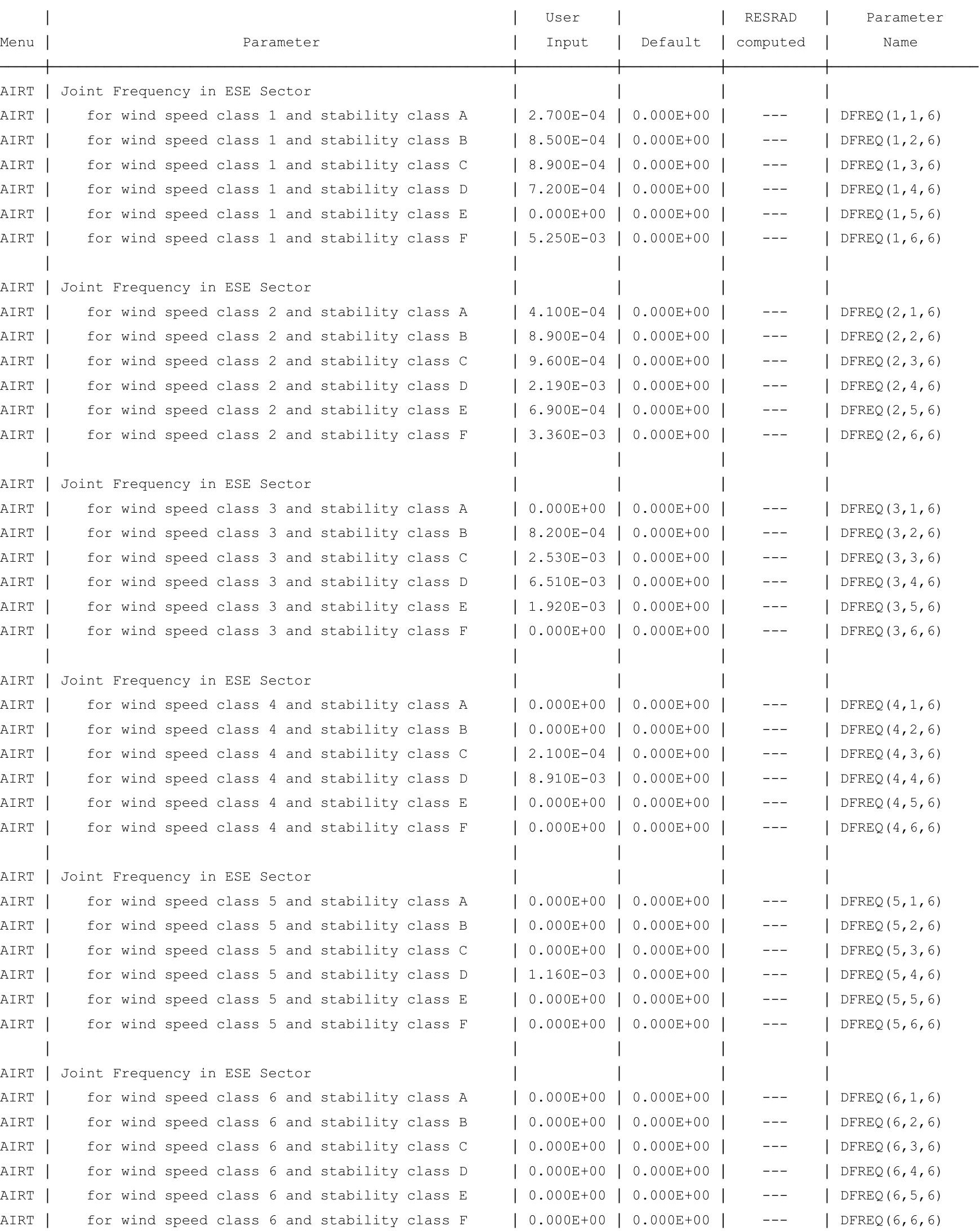


RESRAD-OFFSITE, Version 2.

Parent Dose Report

Title : Offsite Resident Farmer Deterministic Run

File : RF DOE SG FWD-FV2-100000Y.ROF

Site-Specific Parameter Summary (continued)

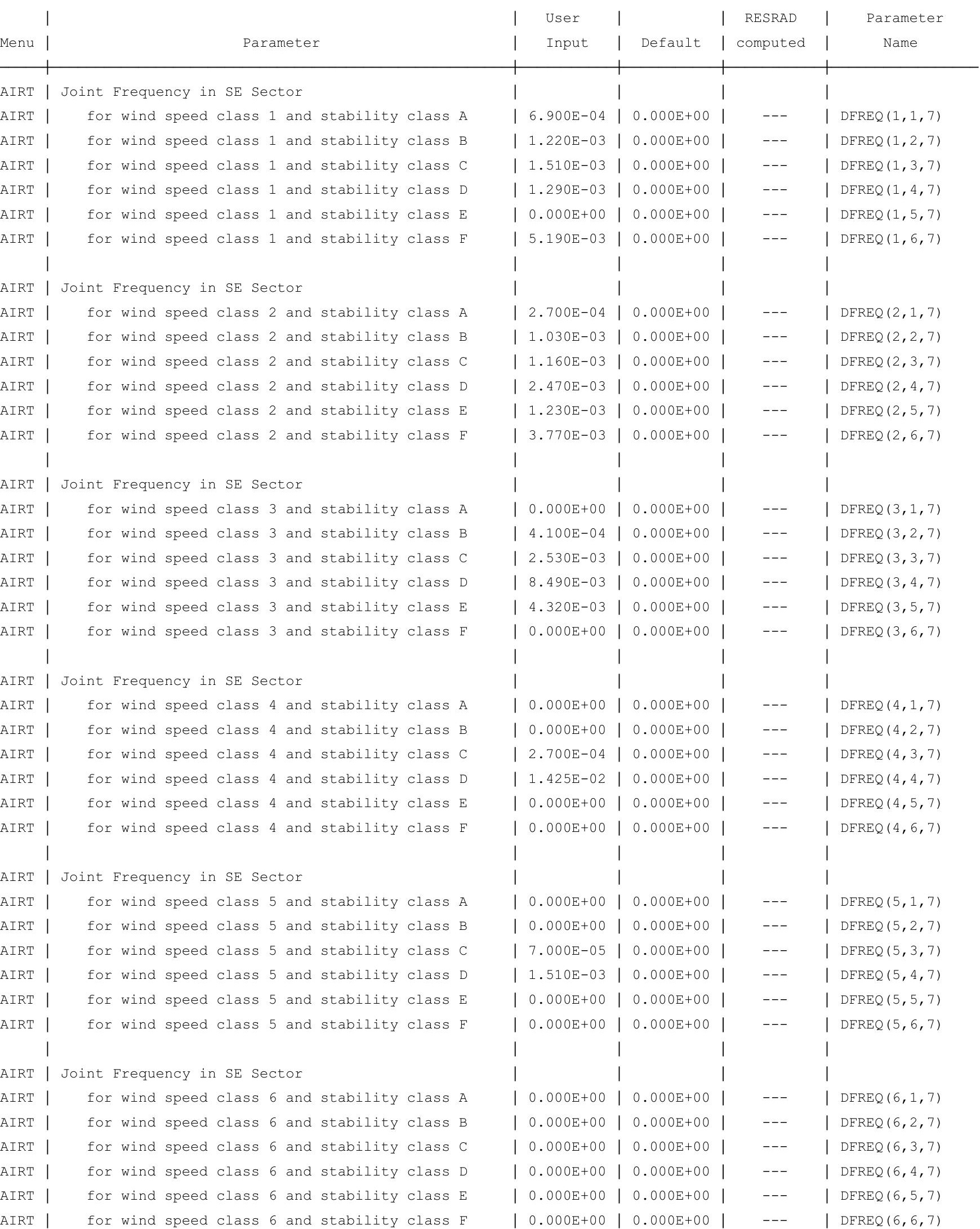


RESRAD-OFFSITE, Version 2.5

Parent Dose Report

Title : Offsite Resident Farmer Deterministic Run

File : RF DOE SG FWD-FV2-100000Y.ROF

Site-Specific Parameter Summary (continued)

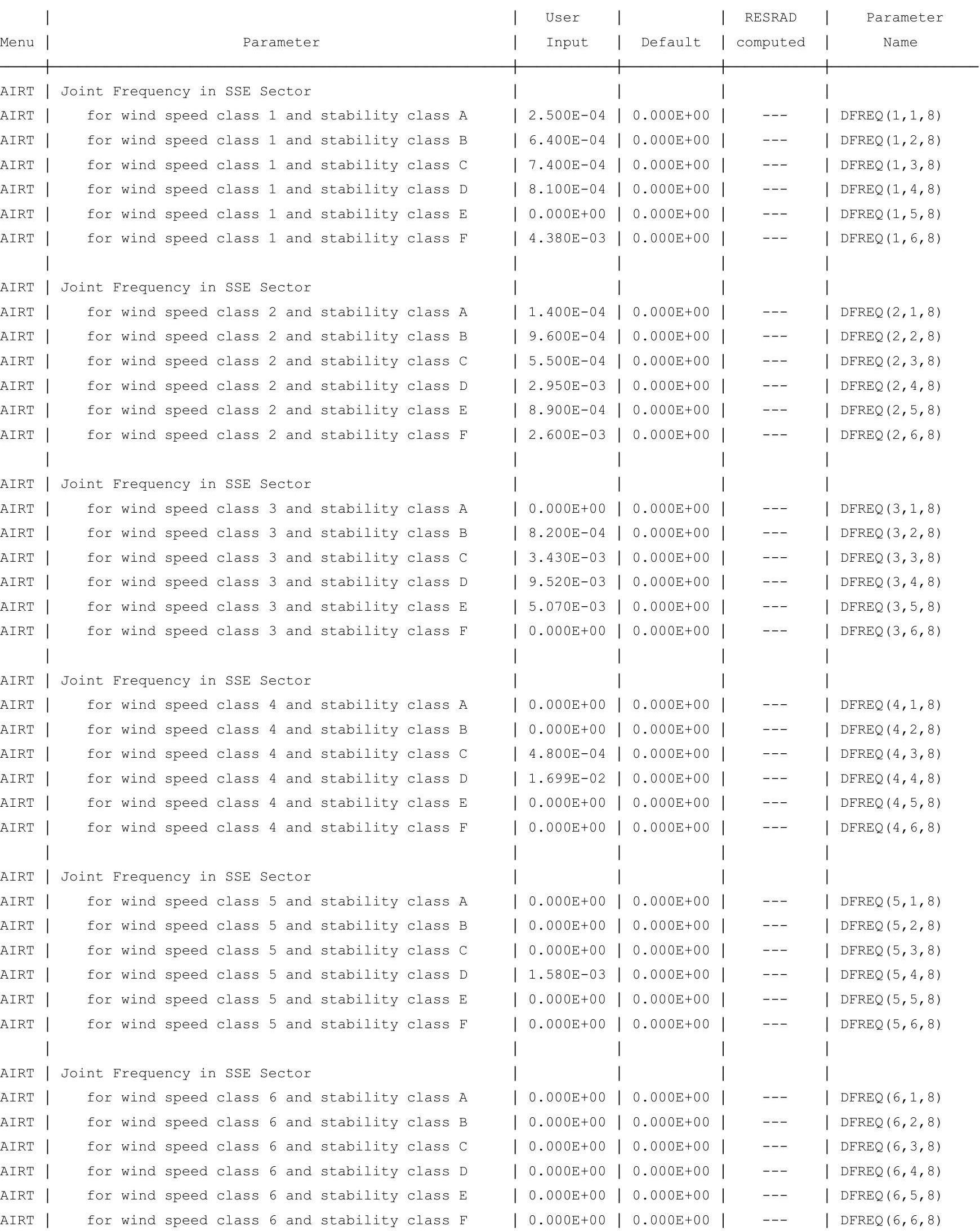


RESRAD-OFFSITE, Version 2.5

Parent Dose Report

Title : Offsite Resident Farmer Deterministic Run

File : RF DOE SG FWD-FV2-100000Y.ROF

Site-Specific Parameter Summary (continued)

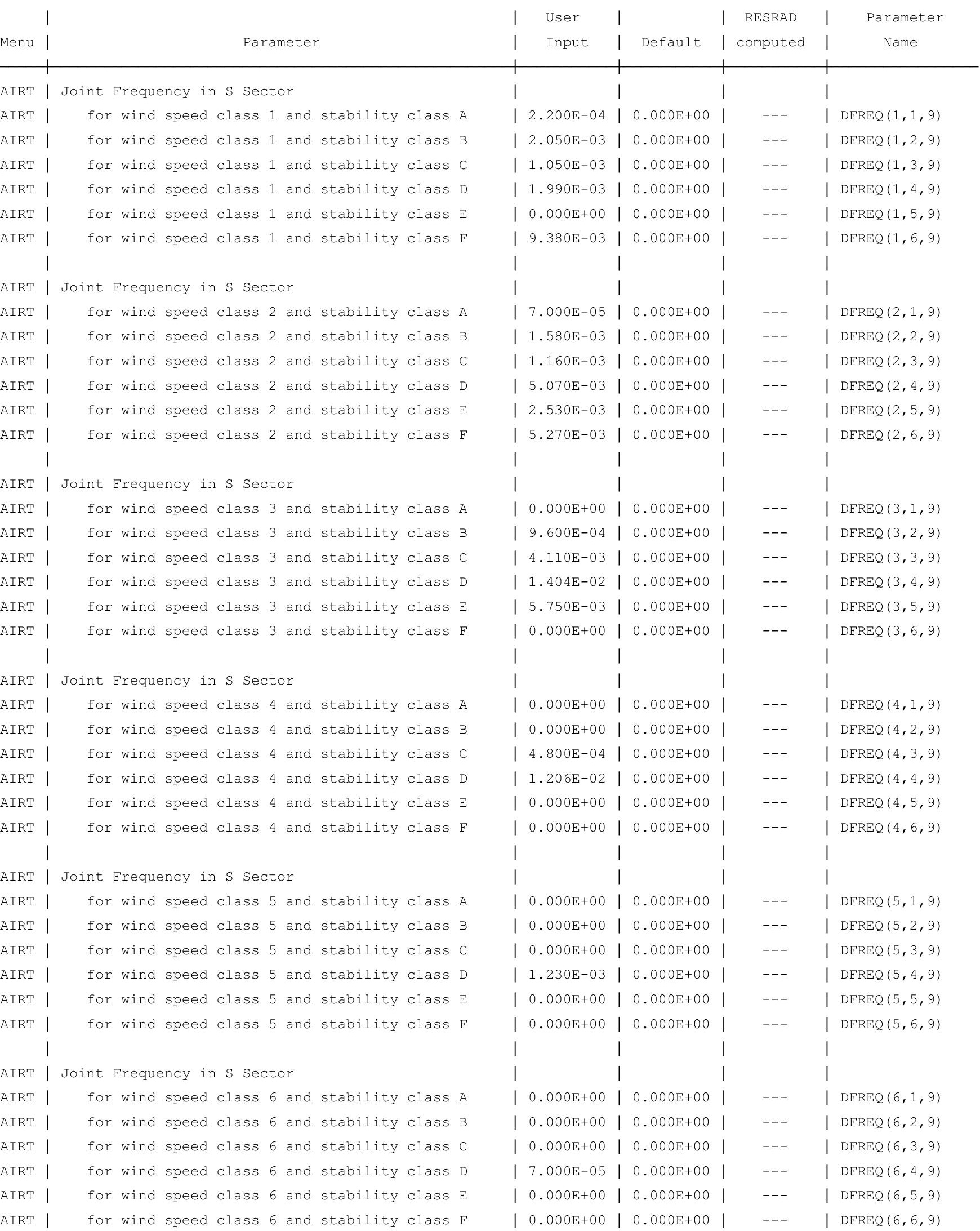


RESRAD-OFFSITE, Version 2.5

Parent Dose Report

Title : Offsite Resident Farmer Deterministic Run

File : RF DOE SG FWD-FV2-100000Y.ROF

Site-Specific Parameter Summary (continued)

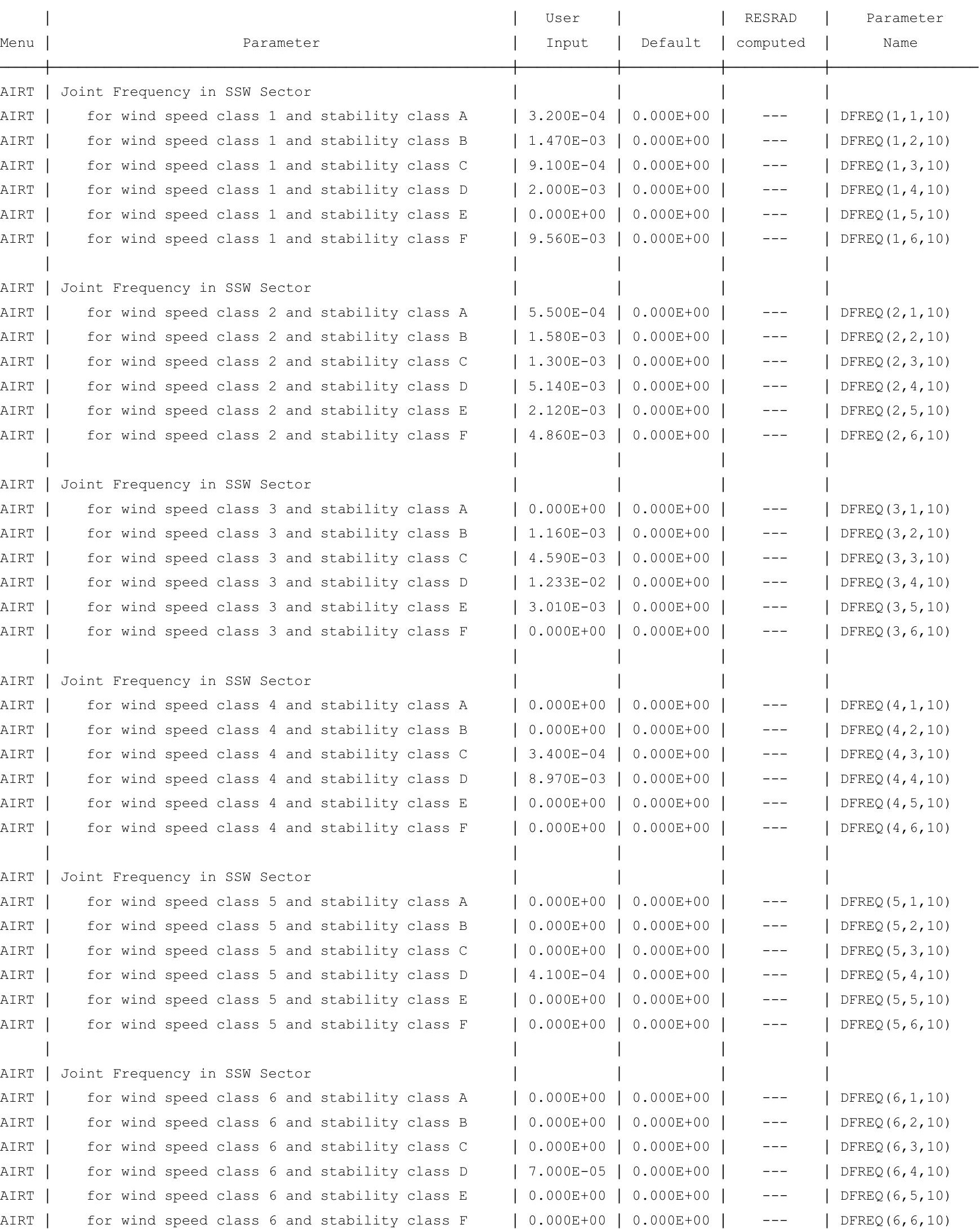


RESRAD-OFFSITE, Version 2.5

Parent Dose Report

Title : Offsite Resident Farmer Deterministic Run

File : RF DOE SG FWD-FV2-100000Y.ROF

Site-Specific Parameter Summary (continued)

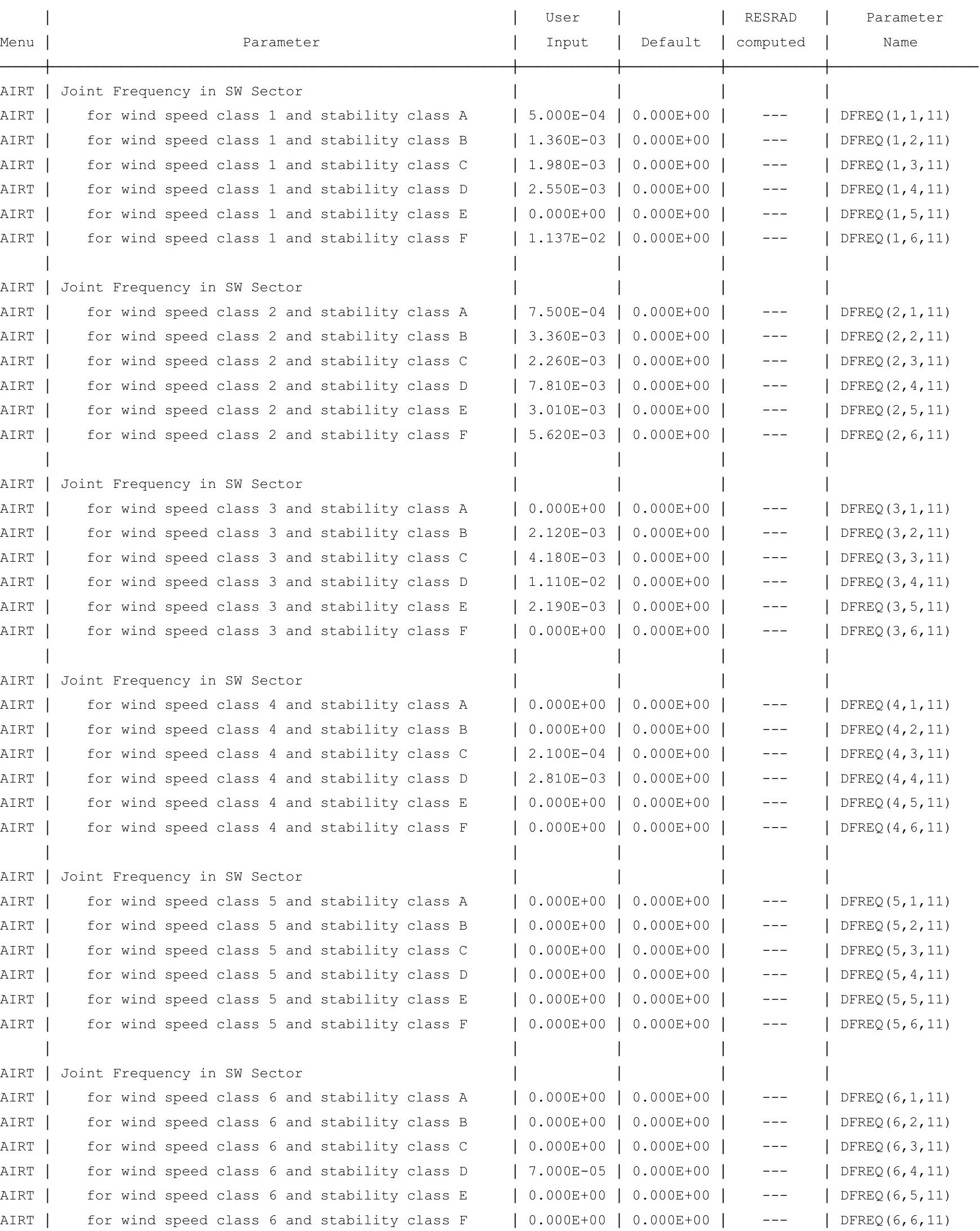


RESRAD-OFFSITE, Version 2.5

Parent Dose Report

Title : Offsite Resident Farmer Deterministic Run

File : RF DOE SG FWD-FV2-100000Y.ROF

Site-Specific Parameter Summary (continued)

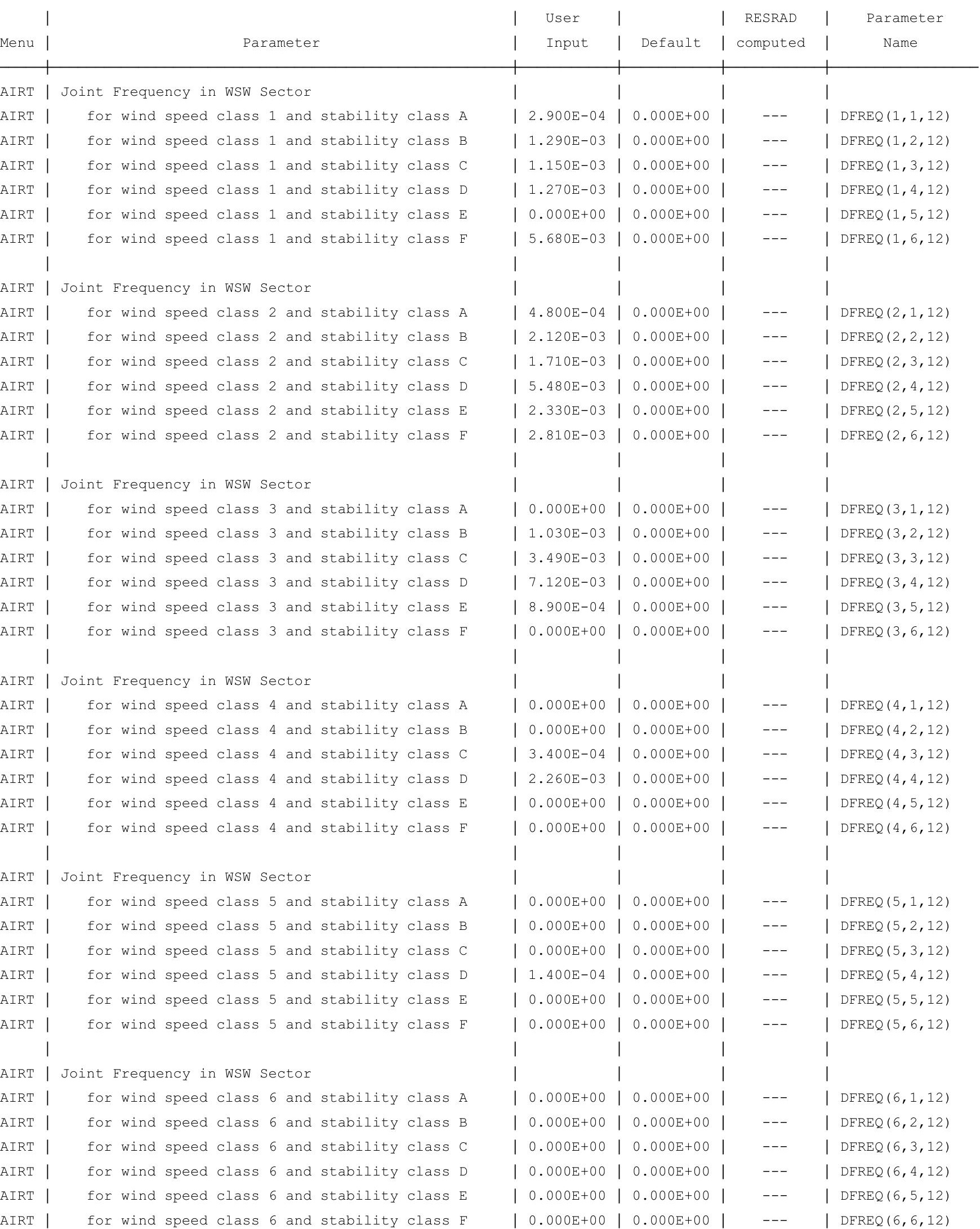


RESRAD-OFFSITE, Version 2.5

Parent Dose Report

Title : Offsite Resident Farmer Deterministic Run

File : RF DOE SG FWD-FV2-100000Y.ROF

Site-Specific Parameter Summary (continued)

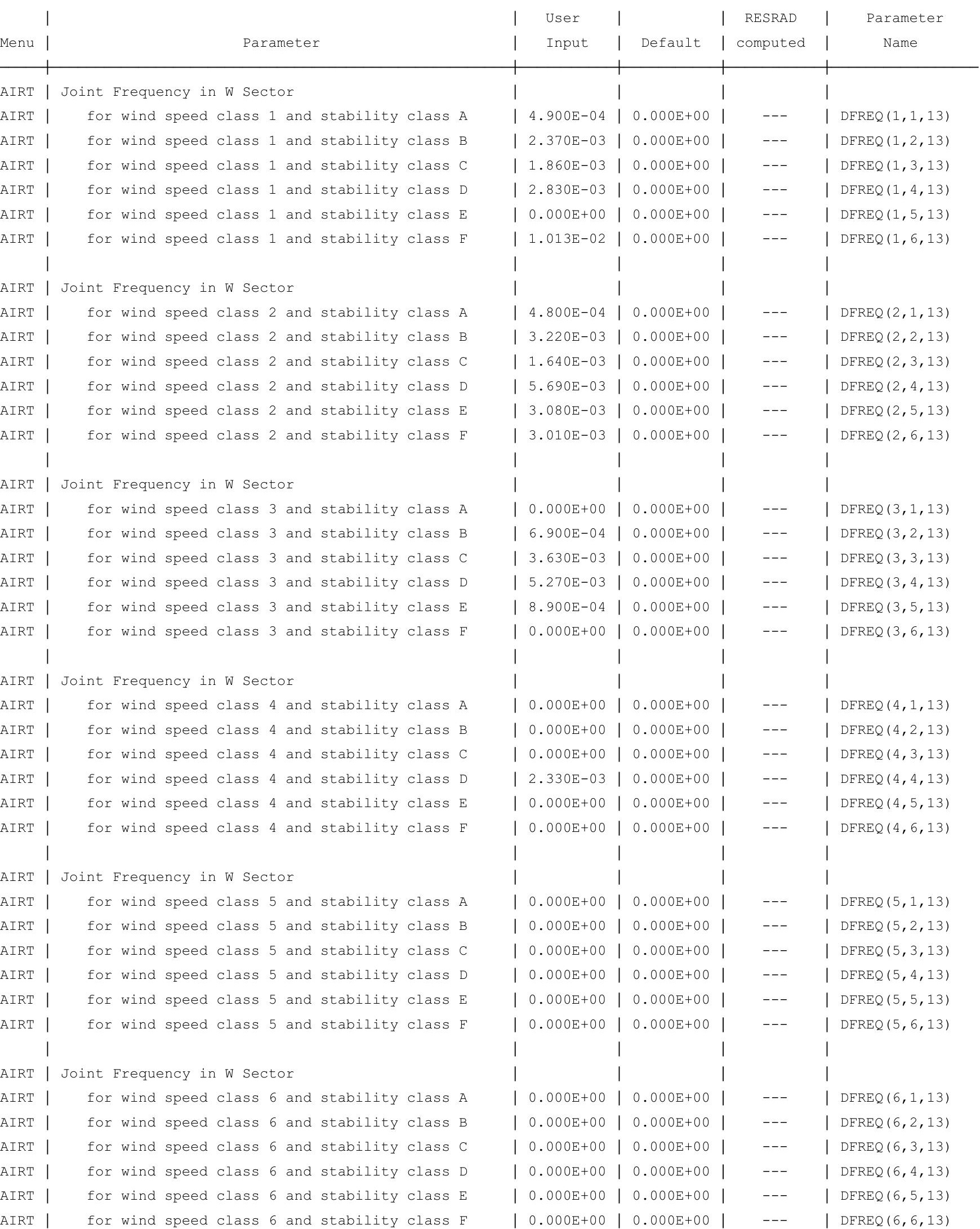


RESRAD-OFFSITE, Version 2.5

Parent Dose Report

Title : Offsite Resident Farmer Deterministic Run

File : RF DOE SG FWD-FV2-100000Y.ROF

Site-Specific Parameter Summary (continued)

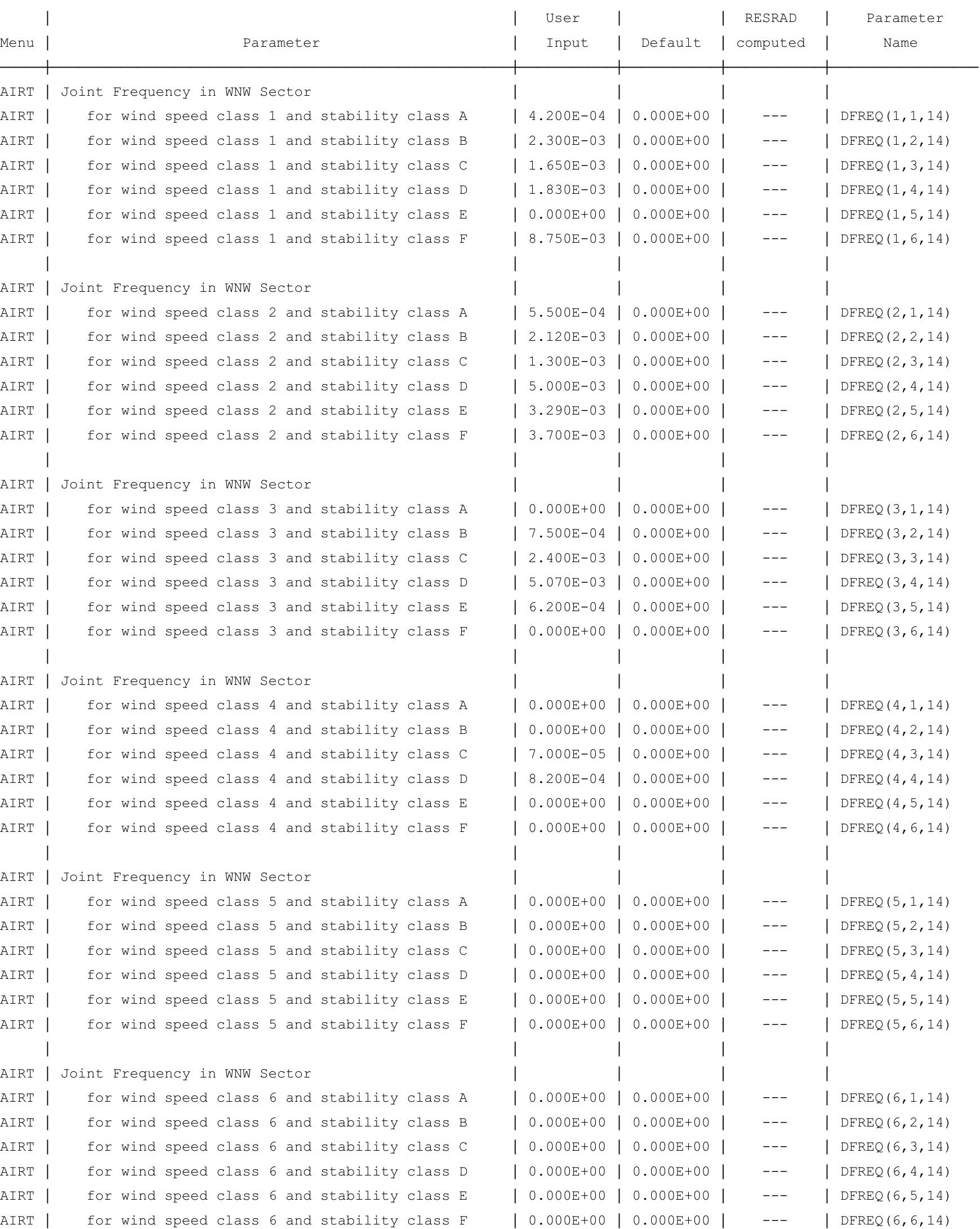


RESRAD-OFFSITE, Version 2.

Parent Dose Report

Title : Offsite Resident Farmer Deterministic Run

File : RF DOE SG FWD-FV2-100000Y.ROF

Site-Specific Parameter Summary (continued)

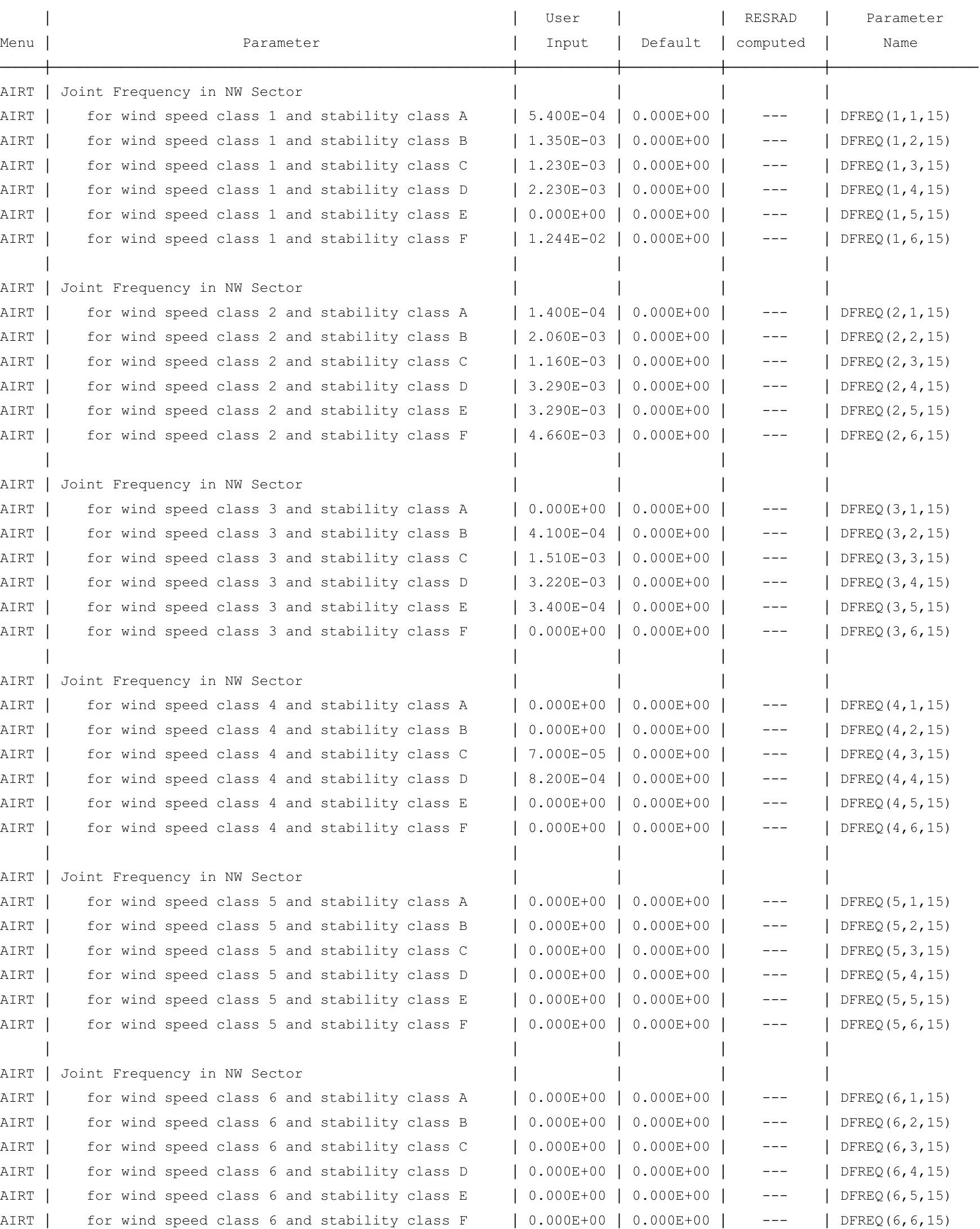


RESRAD-OFFSITE, Version 2.

Parent Dose Report

Title : Offsite Resident Farmer Deterministic Run

File : RF DOE SG FWD-FV2-100000Y.ROF

Site-Specific Parameter Summary (continued)

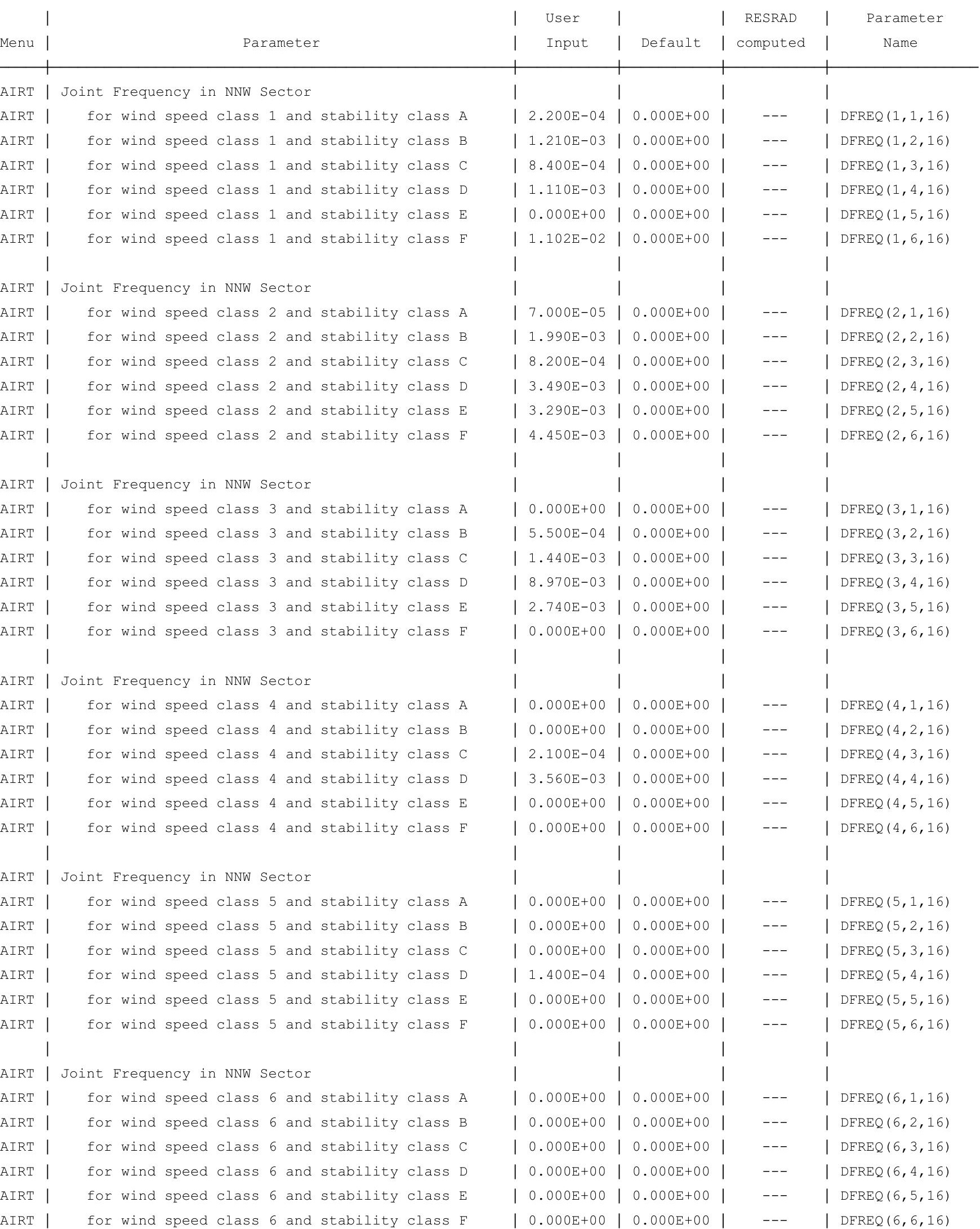


RESRAD-OFFSITE, Version 2.5

Parent Dose Report

Title : Offsite Resident Farmer Deterministic Run

File : RF DOE SG FWD-FV2-100000Y.ROF

Site-Specific Parameter Summary (continued)

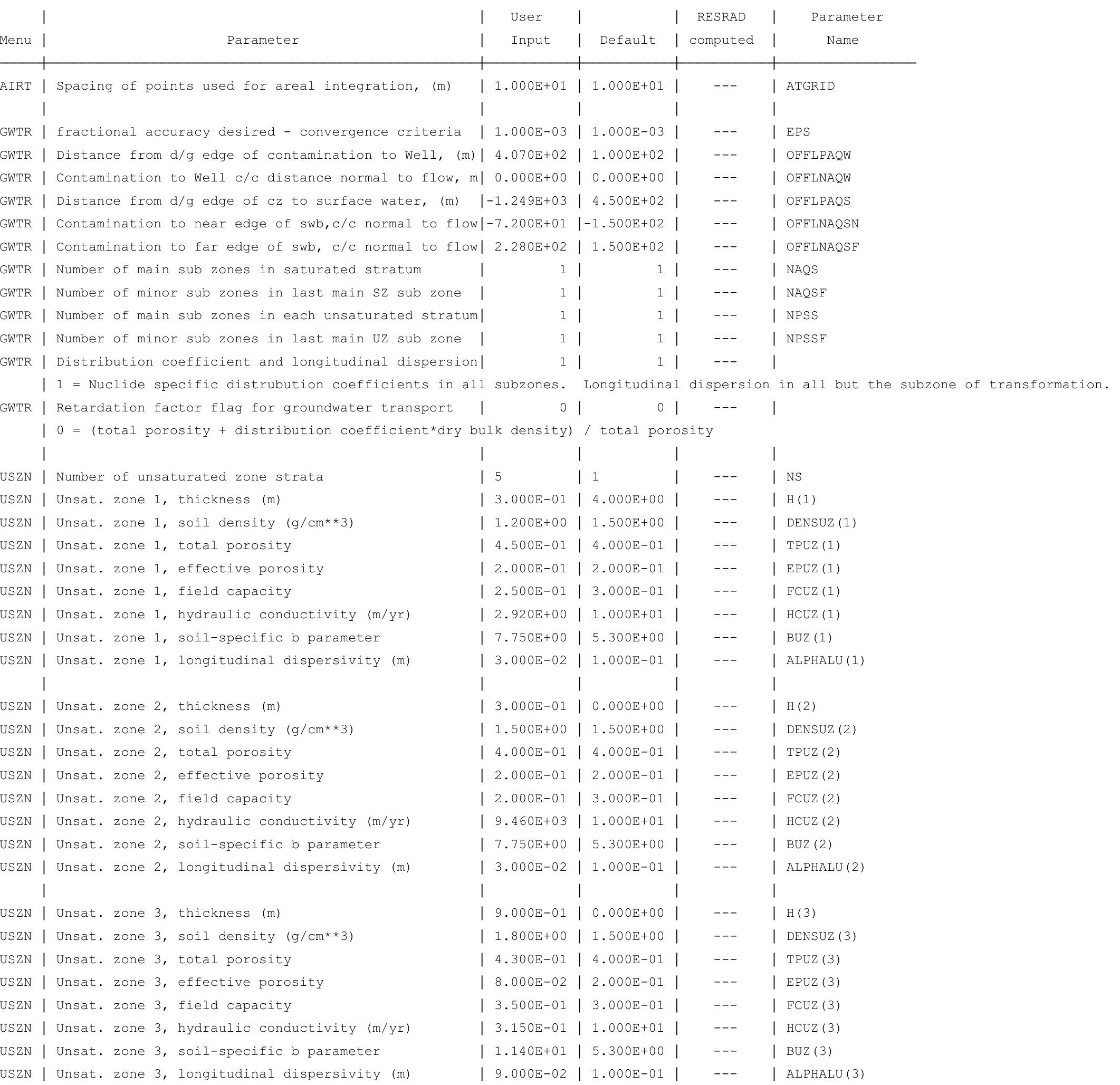


RESRAD-OFFSITE, Version 2.5

Parent Dose Report

Title : Offsite Resident Farmer Deterministic Run

File : RF DOE SG FWD-FV2-100000Y.ROF

Site-Specific Parameter Summary (continued)

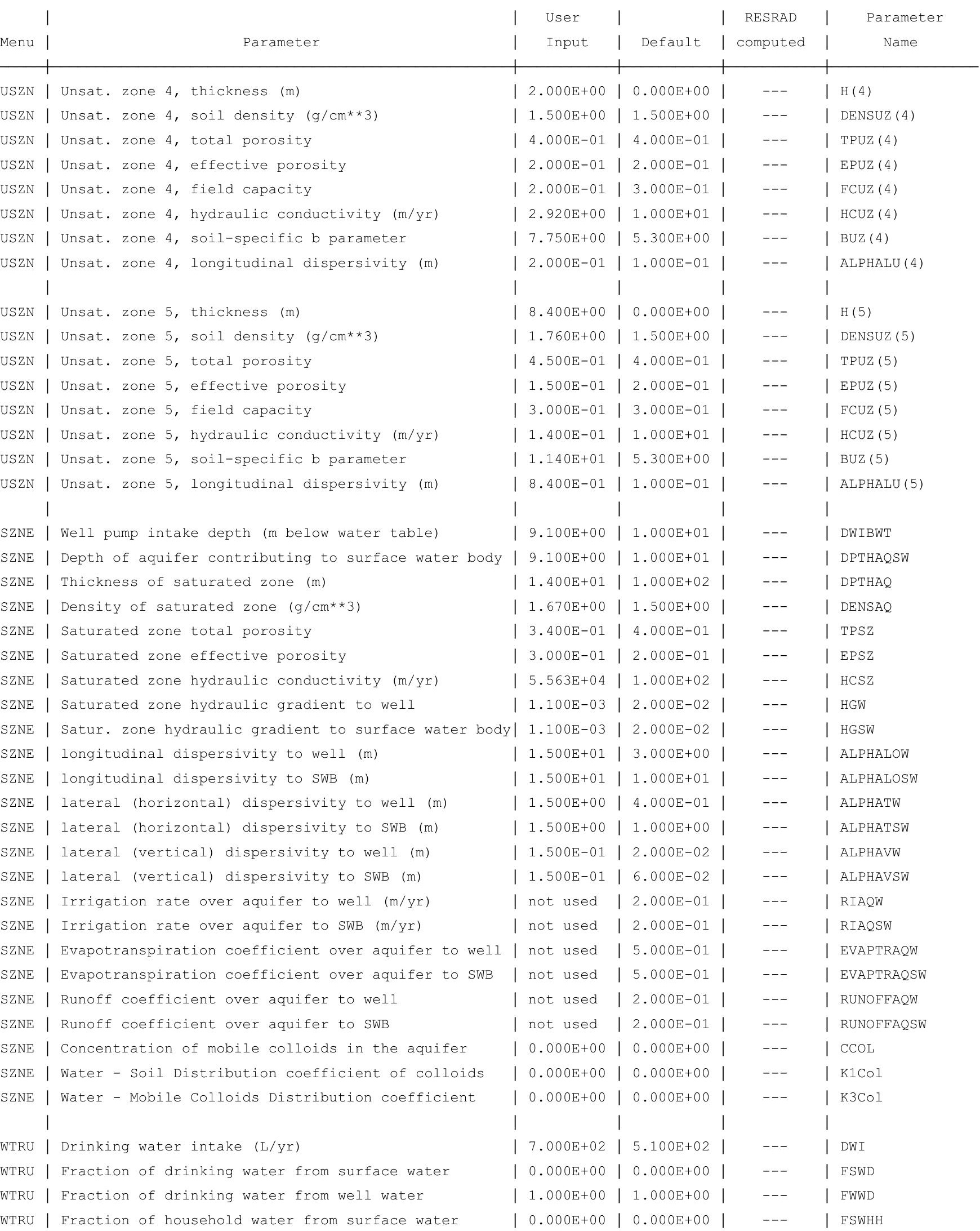


RESRAD-OFFSITE, Version $2.5 \quad \mathrm{~T}^{1 / 2}$ Limit $=180$ days

itle : Offsite Resident Farmer Deterministic Run

File : RF DOE SG FWD-FV2-100000Y.ROF

Site-Specific Parameter Summary (continued)

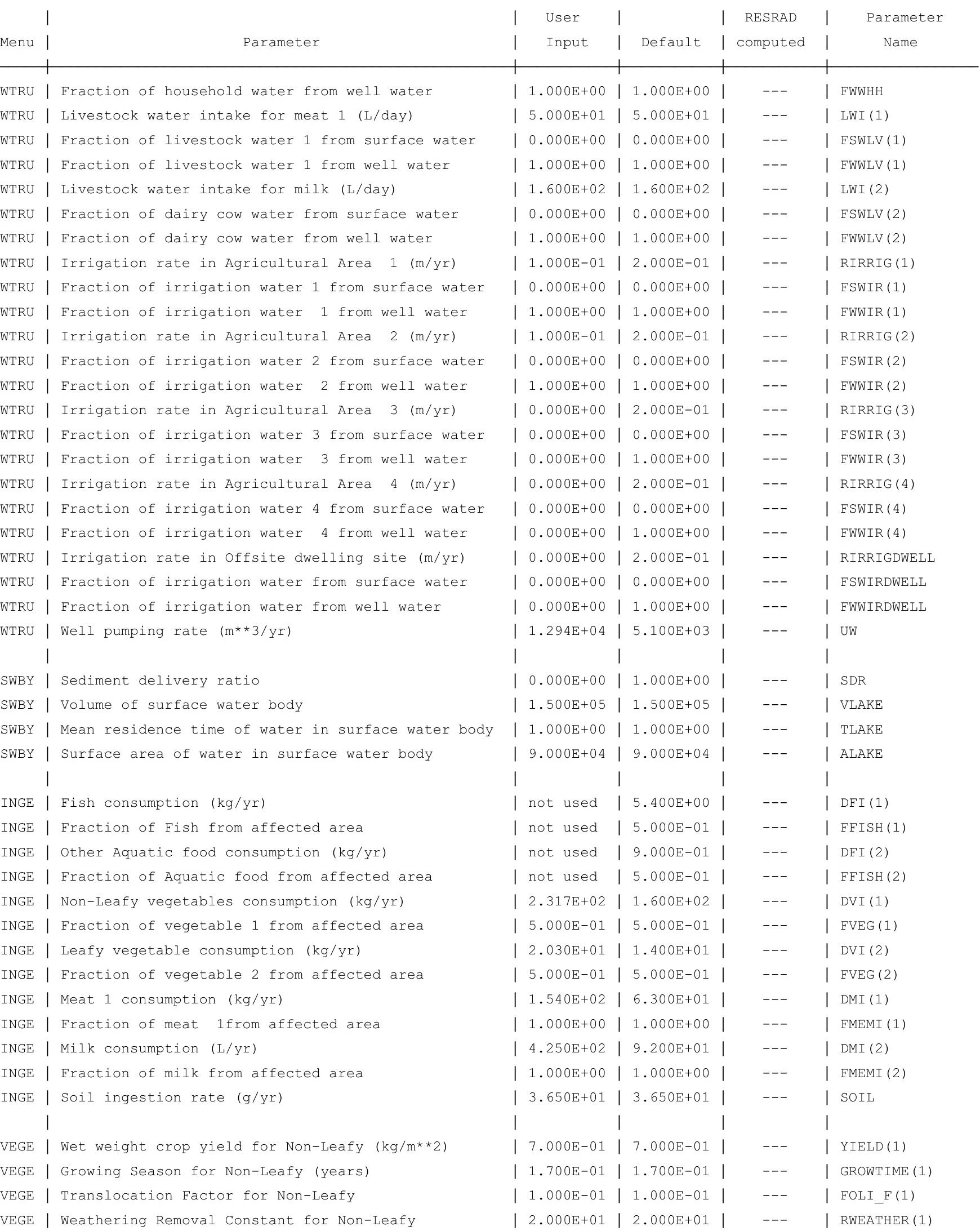


RESRAD-OFFSITE, Version 2.5

Parent Dose Report

Title : Offsite Resident Farmer Deterministic Run

File : RF DOE SG FWD-FV2-100000Y.ROF

Site-Specific Parameter Summary (continued)

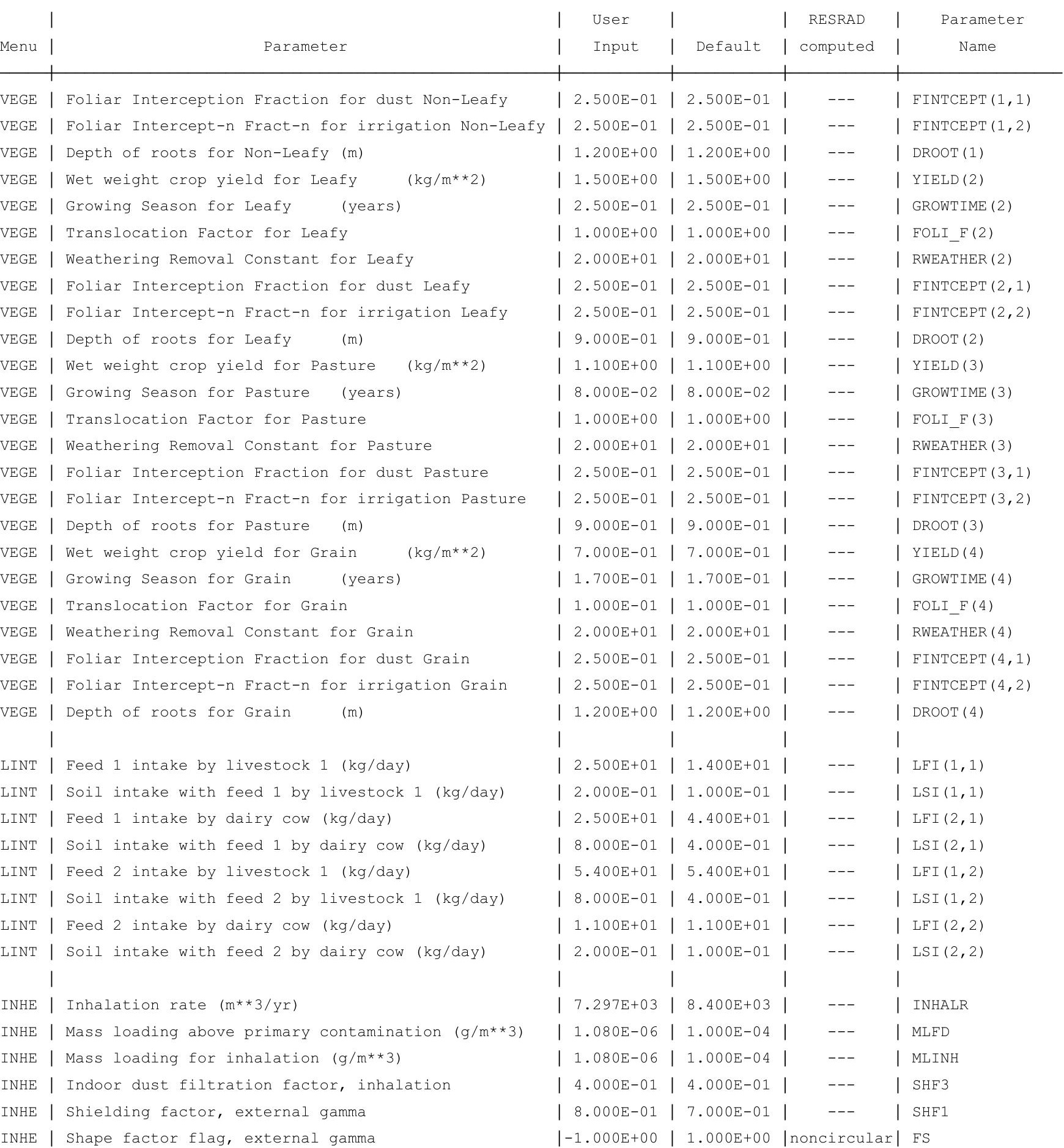


RESRAD-OFFSITE, Version $2.5 \quad \mathrm{~T}^{1 / 2}$ Limit $=180$ days

Parent Dose Report

Title : Offsite Resident Farmer Deterministic Run

File : RF DOE SG FWD-FV2-100000Y.ROF

Site-Specific Parameter Summary (continued)

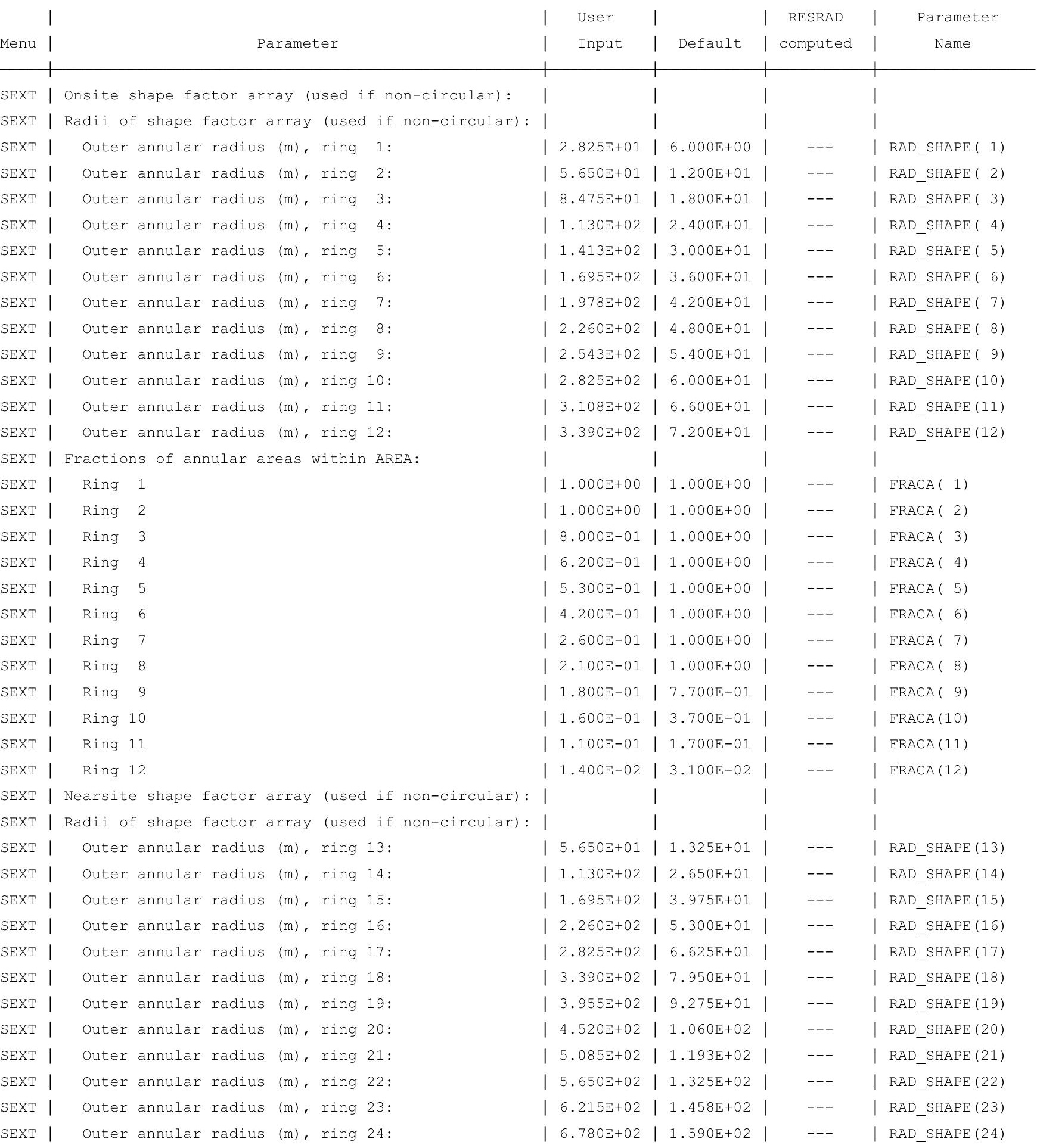


RESRAD-OFFSITE, Version $2.5 \quad \mathrm{~T}^{1 / 2}$ Limit $=180$ days

Parent Dose Report

Title : Offsite Resident Farmer Deterministic Run

File : RF DOE SG FWD-FV2-100000Y.ROF

Site-Specific Parameter Summary (continued)

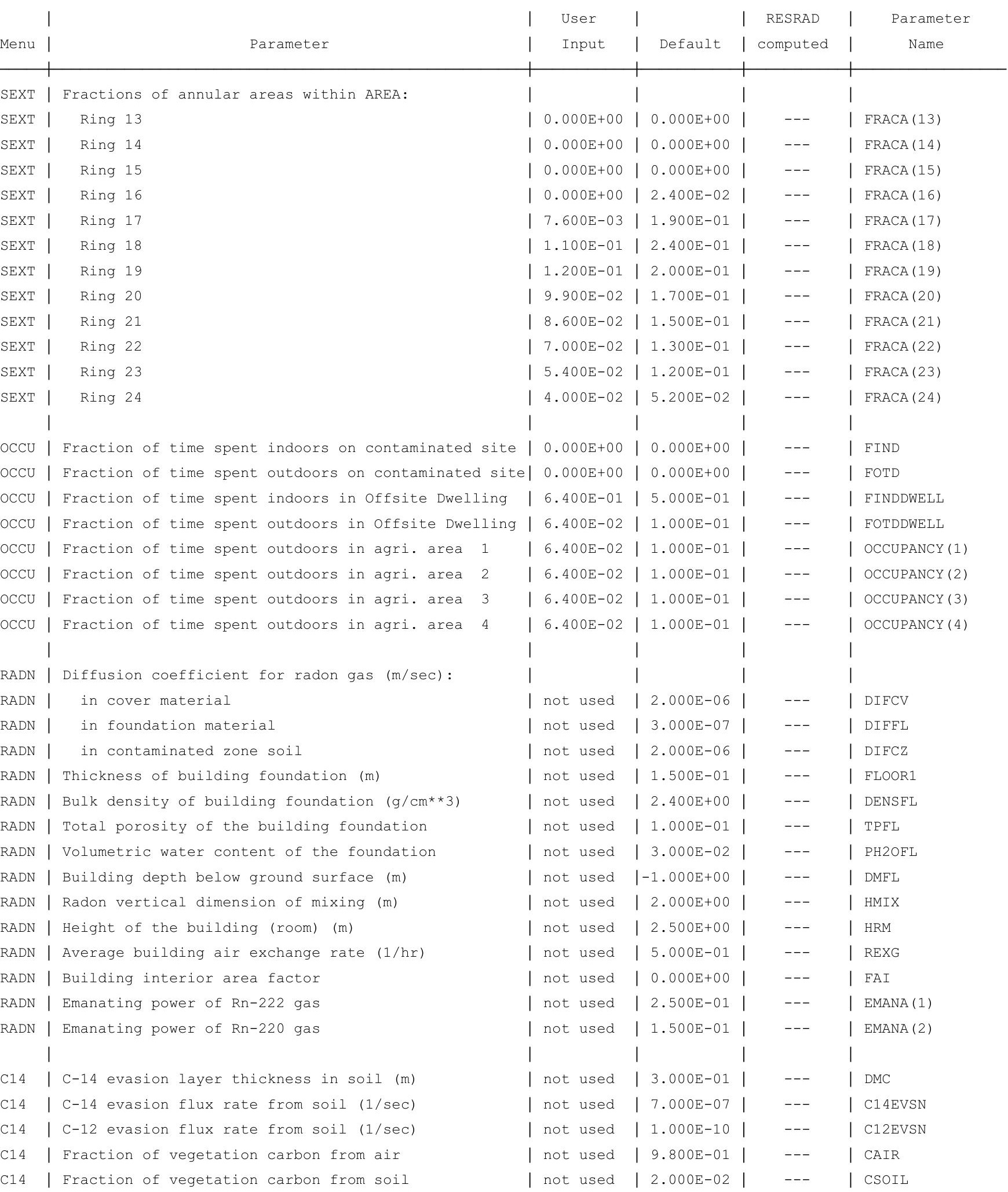


RESRAD-OFFSITE, Version 2.5

Parent Dose Report

Title : Offsite Resident Farmer Deterministic Run

File : RF DOE SG FWD-FV2-100000Y.ROF

Site-Specific Parameter Summary (continued)

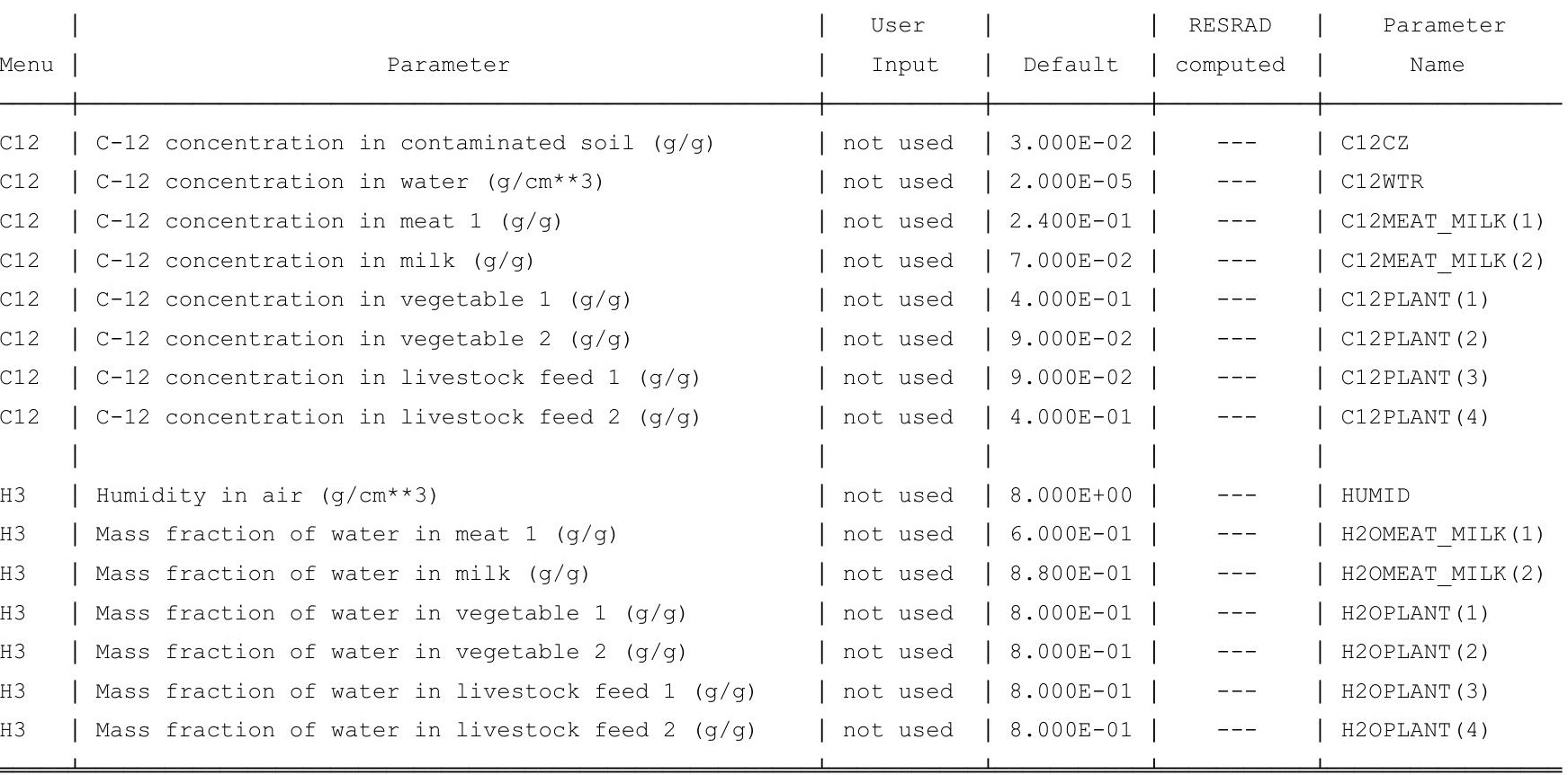

Summary of Pathway Selections

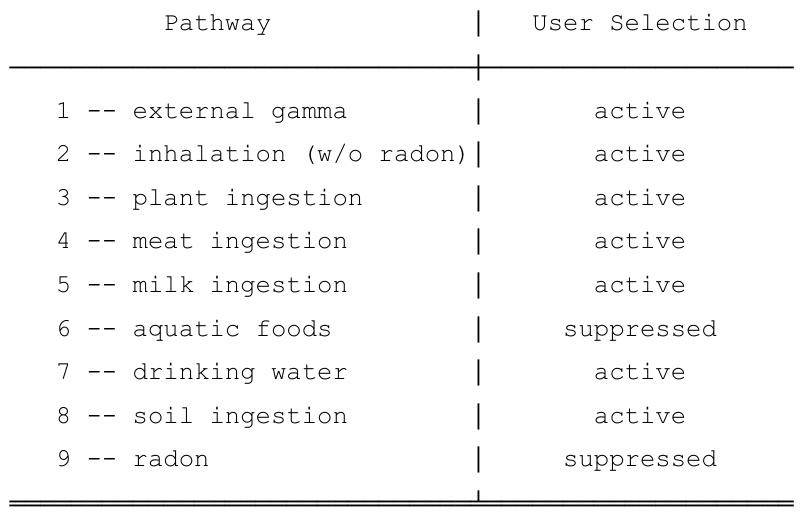


RESRAD-OFFSITE, Version $2.5 \quad \mathrm{~T}^{1 / 2}$ Limit $=180$ days

Parent Dose Report

Title : Offsite Resident Farmer Deterministic Run

File : RF DOE SG FWD-FV2-100000Y.ROF

\section{Contaminated Zone Dimensions}

Area: 102144.00 square meters

Thickness:

Cover Depth:
Initial Soil Concentrations, pCi/g

$\begin{array}{ll}\text { Am-241 } & 3.500 \mathrm{E}+01 \\ \mathrm{Cs}-137 & 1.900 \mathrm{E}+01 \\ \mathrm{~Np}-237 & 5.500 \mathrm{E}+00 \\ \mathrm{Pu}-238 & 3.900 \mathrm{E}+01 \\ \mathrm{Pu}-239 & 3.600 \mathrm{E}+01 \\ \mathrm{Pu}-240 & 3.600 \mathrm{E}+01 \\ \mathrm{TC}-99 & 5.200 \mathrm{E}+01 \\ \mathrm{Th}-228 & 4.000 \mathrm{E}+00 \\ \mathrm{Th}-230 & 1.000 \mathrm{E}+02 \\ \mathrm{Th}-232 & 4.000 \mathrm{E}+00 \\ \mathrm{U}-234 & 1.600 \mathrm{E}+02 \\ \mathrm{U}-235 & 6.500 \mathrm{E}+00 \\ \mathrm{U}-238 & 1.600 \mathrm{E}+02\end{array}$

Total Dose TDOSE(t), mrem/yr

Basic Radiation Dose Limit $=1.000 \mathrm{E}+00 \mathrm{mrem} / \mathrm{yr}$

Total Mixture Sum $M(t)=$ Fraction of Basic Dose Limit Received at Time (t)

$\begin{array}{rllllllll}t \text { (years }): & 0.000 \mathrm{E}+00 & 1.000 \mathrm{E}+00 & 5.000 \mathrm{E}+01 & 1.000 \mathrm{E}+02 & 5.000 \mathrm{E}+02 & 1.026 \mathrm{E}+03 & 9.976 \mathrm{E}+03 & 9.998 \mathrm{E}+04 \\ \text { TDOSE }(\mathrm{t}): & 3.843 \mathrm{E}-14 & 3.542 \mathrm{E}-14 & 5.648 \mathrm{E}-14 & 7.899 \mathrm{E}-14 & 1.141 \mathrm{E}-12 & 3.821 \mathrm{E}-11 & 2.177 \mathrm{E}+00 & 1.979 \mathrm{E}+00 \\ \mathrm{M}(\mathrm{t}): & 3.843 \mathrm{E}-14 & 3.542 \mathrm{E}-14 & 5.648 \mathrm{E}-14 & 7.899 \mathrm{E}-14 & 1.141 \mathrm{E}-12 & 3.821 \mathrm{E}-11 & 2.177 \mathrm{E}+00 & 1.979 \mathrm{E}+00\end{array}$

Maximum TDOSE(t): $2.178 \mathrm{E}+00 \mathrm{mrem} / \mathrm{yr}$ at $t=10065$ years 
RESRAD-OFFSITE, Version 2 .

arent Dose Report

Title : Offsite Resident Farmer Deterministic Run

File : RF DOE SG FWD-FV2-100000Y.ROF

Total Dose Contributions TDOSE (i,p,t) for Individual Radionuclides (i) and Pathways (p) in mrem/yr and as a Percentage of Total Dose at $t=0$ years

From releases to ground water and to surface water

\begin{tabular}{|c|c|c|c|c|c|c|c|c|c|c|c|c|c|c|c|c|}
\hline & \multicolumn{2}{|c|}{ Ground } & \multicolumn{2}{|l|}{ Fish } & \multicolumn{2}{|c|}{ Radon } & \multicolumn{2}{|c|}{ Plant } & \multicolumn{2}{|l|}{ Meat } & \multicolumn{2}{|l|}{ Milk } & \multicolumn{2}{|l|}{ Soil } & \multicolumn{2}{|c|}{ Water } \\
\hline clide & Dose & \% & Dose & $\%$ & Dose & \% & Dose & \% & Dose & \% & Dose & \% & Dose & \% & Dose & $\%$ \\
\hline-241 & $0.00 \mathrm{E}+00$ & 0 & $0.00 \mathrm{E}+00$ & 0 & $0.00 \mathrm{E}+00$ & 0 & $0.00 \mathrm{E}+00$ & 0 & $0.00 \mathrm{E}+00$ & 0 & $0.00 \mathrm{E}+00$ & 0 & $0.00 \mathrm{E}+00$ & 0 & $0.00 \mathrm{E}+00$ & 0 \\
\hline-137 & $0.00 \mathrm{E}+00$ & 0 & $0.00 \mathrm{E}+00$ & 0 & $0.00 \mathrm{E}+00$ & 0 & $0.00 \mathrm{E}+00$ & 0 & $0.00 \mathrm{E}+00$ & 0 & $0.00 \mathrm{E}+00$ & 0 & $0.00 \mathrm{E}+00$ & 0 & $0.00 \mathrm{E}+00$ & 0 \\
\hline-237 & $0.00 \mathrm{E}+00$ & 0 & $0.00 \mathrm{E}+00$ & 0 & $0.00 \mathrm{E}+00$ & 0 & $0.00 \mathrm{E}+00$ & 0 & $0.00 \mathrm{E}+00$ & 0 & $0.00 \mathrm{E}+00$ & 0 & $0.00 \mathrm{E}+00$ & 0 & $0.00 \mathrm{E}+00$ & 0 \\
\hline-238 & $0.00 \mathrm{E}+00$ & 0 & $0.00 \mathrm{E}+00$ & 0 & $0.00 \mathrm{E}+00$ & 0 & $0.00 \mathrm{E}+00$ & 0 & $0.00 \mathrm{E}+00$ & 0 & $0.00 \mathrm{E}+00$ & 0 & $0.00 \mathrm{E}+00$ & 0 & $0.00 \mathrm{E}+00$ & 0 \\
\hline-239 & $0.00 \mathrm{E}+00$ & 0 & $0.00 \mathrm{E}+00$ & 0 & $0.00 \mathrm{E}+00$ & 0 & $0.00 \mathrm{E}+00$ & 0 & $0.00 \mathrm{E}+00$ & 0 & $0.00 E+00$ & 0 & $0.00 \mathrm{E}+00$ & 0 & $0.00 \mathrm{E}+00$ & 0 \\
\hline-240 & $0.00 \mathrm{E}+00$ & 0 & $0.00 \mathrm{E}+00$ & 0 & $0.00 \mathrm{E}+00$ & 0 & $0.00 \mathrm{E}+00$ & 0 & $0.00 \mathrm{E}+00$ & 0 & $0.00 \mathrm{E}+00$ & 0 & $0.00 \mathrm{E}+00$ & 0 & $0.00 \mathrm{E}+00$ & 0 \\
\hline-99 & $0.00 \mathrm{E}+00$ & 0 & $0.00 E+00$ & 0 & $0.00 E+00$ & 0 & $0.00 \mathrm{E}+00$ & 0 & $0.00 \mathrm{E}+00$ & 0 & $0.00 E+00$ & 0 & $0.00 \mathrm{E}+00$ & 0 & $0.00 \mathrm{E}+00$ & 0 \\
\hline-228 & $0.00 \mathrm{E}+00$ & 0 & $0.00 \mathrm{E}+00$ & 0 & $0.00 \mathrm{E}+00$ & 0 & $0.00 \mathrm{E}+00$ & 0 & $0.00 \mathrm{E}+00$ & 0 & $0.00 \mathrm{E}+00$ & 0 & $0.00 \mathrm{E}+00$ & 0 & $0.00 \mathrm{E}+00$ & 0 \\
\hline-230 & $0.00 \mathrm{E}+00$ & 0 & $0.00 \mathrm{E}+00$ & 0 & $0.00 \mathrm{E}+00$ & 0 & $0.00 \mathrm{E}+00$ & 0 & $0.00 \mathrm{E}+00$ & 0 & $0.00 \mathrm{E}+00$ & 0 & $0.00 \mathrm{E}+00$ & 0 & $0.00 \mathrm{E}+00$ & 0 \\
\hline-232 & $0.00 \mathrm{E}+00$ & 0 & $0.00 \mathrm{E}+00$ & 0 & $0.00 \mathrm{E}+00$ & 0 & $0.00 \mathrm{E}+00$ & 0 & $0.00 \mathrm{E}+00$ & 0 & $0.00 \mathrm{E}+00$ & 0 & $0.00 \mathrm{E}+00$ & 0 & $0.00 \mathrm{E}+00$ & 0 \\
\hline 234 & $0.00 \mathrm{E}+00$ & 0 & $0.00 \mathrm{E}+00$ & 0 & $0.00 \mathrm{E}+00$ & 0 & $0.00 \mathrm{E}+00$ & 0 & $0.00 \mathrm{E}+00$ & 0 & $0.00 \mathrm{E}+00$ & 0 & $0.00 \mathrm{E}+00$ & 0 & $0.00 \mathrm{E}+00$ & 0 \\
\hline 235 & $0.00 \mathrm{E}+00$ & 0 & $0.00 \mathrm{E}+00$ & 0 & $0.00 \mathrm{E}+00$ & 0 & $0.00 \mathrm{E}+00$ & 0 & $0.00 \mathrm{E}+00$ & 0 & $0.00 E+00$ & 0 & $0.00 \mathrm{E}+00$ & 0 & $0.00 \mathrm{E}+00$ & 0 \\
\hline 38 & $0.00 \mathrm{E}+00$ & 0 & $0.00 \mathrm{E}+00$ & 0 & $0.00 \mathrm{E}+00$ & 0 & $0.00 \mathrm{E}+00$ & 0 & $0.00 \mathrm{E}+00$ & 0 & $0.00 \mathrm{E}+00$ & 0 & $0.00 \mathrm{E}+00$ & 0 & $0.00 \mathrm{E}+00$ & 0 \\
\hline & $0.00 \mathrm{E}+00$ & 0 & $0.00 \mathrm{E}+00$ & 0 & $0.00 \mathrm{E}+00$ & 0 & $0.00 \mathrm{E}+00$ & 0 & $0.00 \mathrm{E}+00$ & 0 & $0.00 \mathrm{E}+00$ & 0 & $0.00 \mathrm{E}+00$ & 0 & $0.00 \mathrm{E}+00$ & 0 \\
\hline
\end{tabular}

Total Dose Contributions TDOSE(i,p,t) for Individual Radionuclides (i) and Pathways (p)

in mrem/yr and as a Percentage of Total Dose at $t=0$ years

Directly from primary contamination and from release to atmosphere (Inhalation excludes radon)

\begin{tabular}{|c|c|c|c|c|c|c|c|c|c|c|c|c|c|c|c|c|}
\hline & \multicolumn{2}{|c|}{ Ground } & \multicolumn{2}{|c|}{ Inhalation } & \multicolumn{2}{|c|}{ Radon } & \multicolumn{2}{|c|}{ Plant } & \multicolumn{2}{|l|}{ Meat } & \multicolumn{2}{|l|}{ Milk } & \multicolumn{2}{|l|}{ Soil } & \multicolumn{2}{|c|}{ All Pathways* } \\
\hline ide & Dose & $\%$ & Dose & $\%$ & Dose & $\%$ & Dose & 음 & Dose & $\%$ & Dose & 음 & Dose & $\%$ & Dose & $\%$ \\
\hline-241 & $3.45 E-26$ & 0 & $0.00 \mathrm{E}+00$ & 0 & $0.00 E+00$ & 0 & $0.00 \mathrm{E}+00$ & 0 & $0.00 \mathrm{E}+00$ & 0 & $0.00 \mathrm{E}+00$ & 0 & $0.00 \mathrm{E}+00$ & 0 & $3.45 E-26$ & 0 \\
\hline-137 & 1. $45 E-16$ & 0 & $0.00 E+00$ & 0 & $0.00 E+00$ & 0 & $0.00 \mathrm{E}+00$ & 0 & $0.00 \mathrm{E}+00$ & 0 & $0.00 E+00$ & 0 & $0.00 \mathrm{E}+00$ & 0 & 1. $45 \mathrm{E}-16$ & 0 \\
\hline-237 & $3.18 \mathrm{E}-20$ & 0 & $0.00 E+00$ & 0 & $0.00 E+00$ & 0 & $0.00 \mathrm{E}+00$ & 0 & $0.00 \mathrm{E}+00$ & 0 & $0.00 E+00$ & 0 & $0.00 \mathrm{E}+00$ & 0 & $3.18 E-20$ & 0 \\
\hline-238 & 1. $45 E-27$ & 0 & $0.00 E+00$ & 0 & $0.00 \mathrm{E}+00$ & 0 & $0.00 \mathrm{E}+00$ & 0 & $0.00 \mathrm{E}+00$ & 0 & $0.00 \mathrm{E}+00$ & 0 & $0.00 \mathrm{E}+00$ & 0 & $1.45 E-27$ & 0 \\
\hline-239 & $2.62 E-24$ & 0 & $0.00 \mathrm{E}+00$ & 0 & $0.00 \mathrm{E}+00$ & 0 & $0.00 \mathrm{E}+00$ & 0 & $0.00 \mathrm{E}+00$ & 0 & $0.00 \mathrm{E}+00$ & 0 & $0.00 \mathrm{E}+00$ & 0 & $2.62 \mathrm{E}-24$ & 0 \\
\hline-240 & $3.17 \mathrm{E}-31$ & 0 & $0.00 \mathrm{E}+00$ & 0 & $0.00 \mathrm{E}+00$ & 0 & $0.00 \mathrm{E}+00$ & 0 & $0.00 \mathrm{E}+00$ & 0 & $0.00 \mathrm{E}+00$ & 0 & $0.00 \mathrm{E}+00$ & 0 & $3.17 \mathrm{E}-31$ & 0 \\
\hline-99 & $1.82 E-32$ & 0 & $0.00 E+00$ & 0 & $0.00 \mathrm{E}+00$ & 0 & $0.00 \mathrm{E}+00$ & 0 & $0.00 \mathrm{E}+00$ & 0 & $0.00 E+00$ & 0 & $0.00 \mathrm{E}+00$ & 0 & 1. $82 \mathrm{E}-32$ & 0 \\
\hline-228 & $3.70 \mathrm{E}-14$ & 96 & $0.00 \mathrm{E}+00$ & 0 & $0.00 \mathrm{E}+00$ & 0 & $0.00 \mathrm{E}+00$ & 0 & $0.00 \mathrm{E}+00$ & 0 & $0.00 \mathrm{E}+00$ & 0 & $0.00 \mathrm{E}+00$ & 0 & $3.70 \mathrm{E}-14$ & 96 \\
\hline-230 & $2.36 E-17$ & 0 & $0.00 E+00$ & 0 & $0.00 \mathrm{E}+00$ & 0 & $0.00 \mathrm{E}+00$ & 0 & $0.00 \mathrm{E}+00$ & 0 & $0.00 E+00$ & 0 & $0.00 \mathrm{E}+00$ & 0 & $2.36 \mathrm{E}-17$ & 0 \\
\hline-232 & $1.16 \mathrm{E}-15$ & 3 & $0.00 E+00$ & 0 & $0.00 \mathrm{E}+00$ & 0 & $0.00 \mathrm{E}+00$ & 0 & $0.00 \mathrm{E}+00$ & 0 & $0.00 \mathrm{E}+00$ & 0 & $0.00 \mathrm{E}+00$ & 0 & $1.16 \mathrm{E}-15$ & 3 \\
\hline 34 & $1.04 \mathrm{E}-21$ & 0 & $0.00 \mathrm{E}+00$ & 0 & $0.00 \mathrm{E}+00$ & 0 & $0.00 \mathrm{E}+00$ & 0 & $0.00 \mathrm{E}+00$ & 0 & $0.00 \mathrm{E}+00$ & 0 & $0.00 \mathrm{E}+00$ & 0 & $1.04 \mathrm{E}-21$ & 0 \\
\hline 235 & $4 \cdot 93 E-22$ & 0 & $0.00 \mathrm{E}+00$ & 0 & $0.00 \mathrm{E}+00$ & 0 & $0.00 \mathrm{E}+00$ & 0 & $0.00 \mathrm{E}+00$ & 0 & $0.00 \mathrm{E}+00$ & 0 & $0.00 \mathrm{E}+00$ & 0 & $4.93 E-22$ & 0 \\
\hline 38 & $1.38 E-16$ & 0 & $0.00 E+00$ & 0 & $0.00 \mathrm{E}+00$ & 0 & $0.00 \mathrm{E}+00$ & 0 & $0.00 \mathrm{E}+00$ & 0 & $0.00 E+00$ & 0 & $0.00 \mathrm{E}+00$ & 0 & 1. $38 \mathrm{E}-16$ & 0 \\
\hline & $3.84 \mathrm{E}-14$ & 100 & $0.00 \mathrm{E}+00$ & 0 & $0.00 \mathrm{E}+00$ & 0 & $0.00 \mathrm{E}+00$ & 0 & $0.00 \mathrm{E}+00$ & 0 & $0.00 E+00$ & 0 & $0.00 \mathrm{E}+00$ & 0 & $3.84 \mathrm{E}-14$ & 100 \\
\hline
\end{tabular}

* Sum of dose from all releases and from primary contamination. 
RESRAD-OFFSITE, Version 2 .

arent Dose Report

Title : Offsite Resident Farmer Deterministic Run

File : RF DOE SG FWD-FV2-100000Y.ROF

Total Dose Contributions TDOSE (i,p,t) for Individual Radionuclides (i) and Pathways (p) in mrem/yr and as a Percentage of Total Dose at $t=1$ years

From releases to ground water and to surface water

\begin{tabular}{|c|c|c|c|c|c|c|c|c|c|c|c|c|c|c|c|c|}
\hline & \multicolumn{2}{|c|}{ Ground } & \multicolumn{2}{|l|}{ Fish } & \multicolumn{2}{|c|}{ Radon } & \multicolumn{2}{|c|}{ Plant } & \multicolumn{2}{|l|}{ Meat } & \multicolumn{2}{|l|}{ Milk } & \multicolumn{2}{|l|}{ Soil } & \multicolumn{2}{|c|}{ Water } \\
\hline clide & Dose & \% & Dose & $\%$ & Dose & \% & Dose & \% & Dose & \% & Dose & \% & Dose & \% & Dose & $\%$ \\
\hline-241 & $0.00 \mathrm{E}+00$ & 0 & $0.00 \mathrm{E}+00$ & 0 & $0.00 \mathrm{E}+00$ & 0 & $0.00 \mathrm{E}+00$ & 0 & $0.00 \mathrm{E}+00$ & 0 & $0.00 \mathrm{E}+00$ & 0 & $0.00 \mathrm{E}+00$ & 0 & $0.00 \mathrm{E}+00$ & 0 \\
\hline-137 & $0.00 \mathrm{E}+00$ & 0 & $0.00 \mathrm{E}+00$ & 0 & $0.00 \mathrm{E}+00$ & 0 & $0.00 \mathrm{E}+00$ & 0 & $0.00 \mathrm{E}+00$ & 0 & $0.00 \mathrm{E}+00$ & 0 & $0.00 \mathrm{E}+00$ & 0 & $0.00 \mathrm{E}+00$ & 0 \\
\hline-237 & $0.00 \mathrm{E}+00$ & 0 & $0.00 \mathrm{E}+00$ & 0 & $0.00 \mathrm{E}+00$ & 0 & $0.00 \mathrm{E}+00$ & 0 & $0.00 \mathrm{E}+00$ & 0 & $0.00 \mathrm{E}+00$ & 0 & $0.00 \mathrm{E}+00$ & 0 & $0.00 \mathrm{E}+00$ & 0 \\
\hline-238 & $0.00 \mathrm{E}+00$ & 0 & $0.00 \mathrm{E}+00$ & 0 & $0.00 \mathrm{E}+00$ & 0 & $0.00 \mathrm{E}+00$ & 0 & $0.00 \mathrm{E}+00$ & 0 & $0.00 \mathrm{E}+00$ & 0 & $0.00 \mathrm{E}+00$ & 0 & $0.00 \mathrm{E}+00$ & 0 \\
\hline-239 & $0.00 \mathrm{E}+00$ & 0 & $0.00 \mathrm{E}+00$ & 0 & $0.00 \mathrm{E}+00$ & 0 & $0.00 \mathrm{E}+00$ & 0 & $0.00 \mathrm{E}+00$ & 0 & $0.00 E+00$ & 0 & $0.00 \mathrm{E}+00$ & 0 & $0.00 \mathrm{E}+00$ & 0 \\
\hline-240 & $0.00 \mathrm{E}+00$ & 0 & $0.00 \mathrm{E}+00$ & 0 & $0.00 \mathrm{E}+00$ & 0 & $0.00 \mathrm{E}+00$ & 0 & $0.00 \mathrm{E}+00$ & 0 & $0.00 \mathrm{E}+00$ & 0 & $0.00 \mathrm{E}+00$ & 0 & $0.00 \mathrm{E}+00$ & 0 \\
\hline-99 & $0.00 \mathrm{E}+00$ & 0 & $0.00 E+00$ & 0 & $0.00 E+00$ & 0 & $0.00 \mathrm{E}+00$ & 0 & $0.00 \mathrm{E}+00$ & 0 & $0.00 E+00$ & 0 & $0.00 \mathrm{E}+00$ & 0 & $0.00 \mathrm{E}+00$ & 0 \\
\hline-228 & $0.00 \mathrm{E}+00$ & 0 & $0.00 \mathrm{E}+00$ & 0 & $0.00 \mathrm{E}+00$ & 0 & $0.00 \mathrm{E}+00$ & 0 & $0.00 \mathrm{E}+00$ & 0 & $0.00 \mathrm{E}+00$ & 0 & $0.00 \mathrm{E}+00$ & 0 & $0.00 \mathrm{E}+00$ & 0 \\
\hline-230 & $0.00 \mathrm{E}+00$ & 0 & $0.00 \mathrm{E}+00$ & 0 & $0.00 \mathrm{E}+00$ & 0 & $0.00 \mathrm{E}+00$ & 0 & $0.00 \mathrm{E}+00$ & 0 & $0.00 \mathrm{E}+00$ & 0 & $0.00 \mathrm{E}+00$ & 0 & $0.00 \mathrm{E}+00$ & 0 \\
\hline-232 & $0.00 \mathrm{E}+00$ & 0 & $0.00 \mathrm{E}+00$ & 0 & $0.00 \mathrm{E}+00$ & 0 & $0.00 \mathrm{E}+00$ & 0 & $0.00 \mathrm{E}+00$ & 0 & $0.00 \mathrm{E}+00$ & 0 & $0.00 \mathrm{E}+00$ & 0 & $0.00 \mathrm{E}+00$ & 0 \\
\hline 234 & $0.00 \mathrm{E}+00$ & 0 & $0.00 \mathrm{E}+00$ & 0 & $0.00 \mathrm{E}+00$ & 0 & $0.00 \mathrm{E}+00$ & 0 & $0.00 \mathrm{E}+00$ & 0 & $0.00 \mathrm{E}+00$ & 0 & $0.00 \mathrm{E}+00$ & 0 & $0.00 \mathrm{E}+00$ & 0 \\
\hline 235 & $0.00 \mathrm{E}+00$ & 0 & $0.00 \mathrm{E}+00$ & 0 & $0.00 \mathrm{E}+00$ & 0 & $0.00 \mathrm{E}+00$ & 0 & $0.00 \mathrm{E}+00$ & 0 & $0.00 E+00$ & 0 & $0.00 \mathrm{E}+00$ & 0 & $0.00 \mathrm{E}+00$ & 0 \\
\hline 38 & $0.00 \mathrm{E}+00$ & 0 & $0.00 \mathrm{E}+00$ & 0 & $0.00 \mathrm{E}+00$ & 0 & $0.00 \mathrm{E}+00$ & 0 & $0.00 \mathrm{E}+00$ & 0 & $0.00 \mathrm{E}+00$ & 0 & $0.00 \mathrm{E}+00$ & 0 & $0.00 \mathrm{E}+00$ & 0 \\
\hline & $0.00 \mathrm{E}+00$ & 0 & $0.00 \mathrm{E}+00$ & 0 & $0.00 \mathrm{E}+00$ & 0 & $0.00 \mathrm{E}+00$ & 0 & $0.00 \mathrm{E}+00$ & 0 & $0.00 \mathrm{E}+00$ & 0 & $0.00 \mathrm{E}+00$ & 0 & $0.00 \mathrm{E}+00$ & 0 \\
\hline
\end{tabular}

Total Dose Contributions TDOSE (i,p,t) for Individual Radionuclides (i) and Pathways (p)

in mrem/yr and as a Percentage of Total Dose at $t=1$ years

Directly from primary contamination and from release to atmosphere (Inhalation excludes radon)

Radio-

Ground

Inhalation

Radon
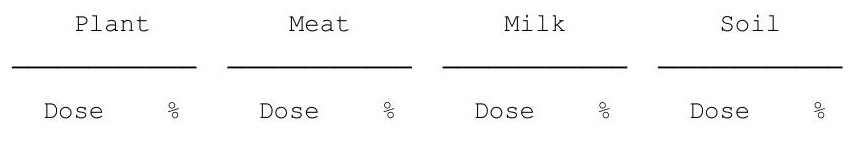

All Pathways*
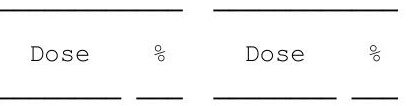

1. $04 \mathrm{E}-25$
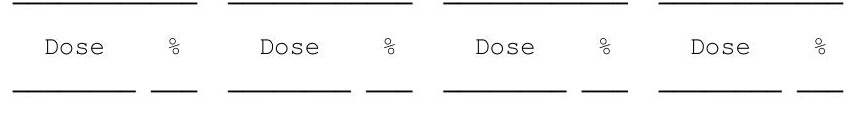

1. $43 \mathrm{E}-160.00 \mathrm{E}+00$

$0.00 \mathrm{E}+00$

$0.00 \mathrm{E}+00$

$0.00 \mathrm{E}+00$

0

3. $21 \mathrm{E}-20 \quad 0 \quad 0.00 \mathrm{E}+00$

$0.00 \mathrm{E}+00$

$0.00 \mathrm{E}+00$

$0.00 \mathrm{E}+00$

$0.00 \mathrm{E}+00$

$0.00 \mathrm{E}+00$

$0.00 \mathrm{E}+00$

$0.00 \mathrm{E}+00$

$0.00 \mathrm{E}+00$

$0.00 \mathrm{E}+00$

$0.00 \mathrm{E}+00$

$0.00 \mathrm{E}+00$

$0.00 \mathrm{E}+00$

$0.00 \mathrm{E}+00$

$0.00 \mathrm{E}+00$

$0.00 \mathrm{E}+00$

$0.00 E+00$

$0.00 \mathrm{E}+00$

$0.00 \mathrm{E}+00$

$0.00 \mathrm{E}+00$

$0.00 \mathrm{E}+00$

$0.00 \mathrm{E}+00$

$0.00 \mathrm{E}+00$

$0.00 E+00$

$0.00 \mathrm{E}+00$

$0.00 \mathrm{E}+00$

$0.00 \mathrm{E}+00$

$0.00 \mathrm{E}+00$

$0.00 \mathrm{E}+00$

$1.39 \mathrm{E}-16 \quad 0 \quad 0.00 \mathrm{E}+00$

$0.00 \mathrm{E}+00$

$0.00 \mathrm{E}+00$

$\overline{=}$

$3.54 \mathrm{E}-14 \quad 100 \quad 0.00 \mathrm{E}+00$

$0.00 \mathrm{E}+00$

$0 \quad 0.00 \mathrm{E}+00 \quad 0$

$0.00 \mathrm{E}+00$

$0.00 \mathrm{E}+00 \quad 0$

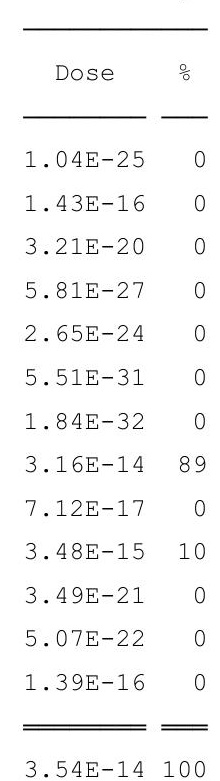

* Sum of dose from all releases and from primary contamination. 
RESRAD-OFFSITE, Version 2 .

arent Dose Report

Title : Offsite Resident Farmer Deterministic Run

File : RF DOE SG FWD-FV2-100000Y.ROF

Total Dose Contributions TDOSE (i,p,t) for Individual Radionuclides (i) and Pathways (p) in mrem/yr and as a Percentage of Total Dose at $t=50$ years

From releases to ground water and to surface water

\begin{tabular}{|c|c|c|c|c|c|c|c|c|c|c|c|c|c|c|c|c|}
\hline & \multicolumn{2}{|c|}{ Ground } & \multicolumn{2}{|l|}{ Fish } & \multicolumn{2}{|c|}{ Radon } & \multicolumn{2}{|c|}{ Plant } & \multicolumn{2}{|l|}{ Meat } & \multicolumn{2}{|l|}{ Milk } & \multicolumn{2}{|l|}{ Soil } & \multicolumn{2}{|c|}{ Water } \\
\hline ide & Dose & $\%$ & Dose & $\%$ & Dose & 응 & Dose & $\frac{\circ}{0}$ & Dose & 응 & Dose & 응 & Dose & $\%$ & Dose & $\%$ \\
\hline-241 & $0.00 \mathrm{E}+00$ & 0 & $0.00 E+00$ & 0 & $0.00 \mathrm{E}+00$ & 0 & $0.00 \mathrm{E}+00$ & 0 & $0.00 \mathrm{E}+00$ & 0 & $0.00 \mathrm{E}+00$ & 0 & $0.00 \mathrm{E}+00$ & 0 & $0.00 \mathrm{E}+00$ & 0 \\
\hline-137 & $0.00 \mathrm{E}+00$ & 0 & $0.00 \mathrm{E}+00$ & 0 & $0.00 \mathrm{E}+00$ & 0 & $0.00 \mathrm{E}+00$ & 0 & $0.00 \mathrm{E}+00$ & 0 & $0.00 \mathrm{E}+00$ & 0 & $0.00 \mathrm{E}+00$ & 0 & $0.00 \mathrm{E}+00$ & 0 \\
\hline-237 & $0.00 \mathrm{E}+00$ & 0 & $0.00 \mathrm{E}+00$ & 0 & $0.00 \mathrm{E}+00$ & 0 & $0.00 \mathrm{E}+00$ & 0 & $0.00 \mathrm{E}+00$ & 0 & $0.00 \mathrm{E}+00$ & 0 & $0.00 \mathrm{E}+00$ & 0 & $0.00 \mathrm{E}+00$ & 0 \\
\hline-238 & $0.00 \mathrm{E}+00$ & 0 & $0.00 \mathrm{E}+00$ & 0 & $0.00 E+00$ & 0 & $0.00 \mathrm{E}+00$ & 0 & $0.00 \mathrm{E}+00$ & 0 & $0.00 E+00$ & 0 & $0.00 \mathrm{E}+00$ & 0 & $0.00 \mathrm{E}+00$ & 0 \\
\hline-239 & $0.00 \mathrm{E}+00$ & 0 & $0.00 \mathrm{E}+00$ & 0 & $0.00 \mathrm{E}+00$ & 0 & $0.00 \mathrm{E}+00$ & 0 & $0.00 \mathrm{E}+00$ & 0 & $0.00 \mathrm{E}+00$ & 0 & $0.00 \mathrm{E}+00$ & 0 & $0.00 \mathrm{E}+00$ & 0 \\
\hline-240 & $0.00 \mathrm{E}+00$ & 0 & $0.00 \mathrm{E}+00$ & 0 & $0.00 \mathrm{E}+00$ & 0 & $0.00 \mathrm{E}+00$ & 0 & $0.00 \mathrm{E}+00$ & 0 & $0.00 \mathrm{E}+00$ & 0 & $0.00 \mathrm{E}+00$ & 0 & $0.00 \mathrm{E}+00$ & 0 \\
\hline-99 & $0.00 \mathrm{E}+00$ & 0 & $0.00 \mathrm{E}+00$ & 0 & $0.00 \mathrm{E}+00$ & 0 & $0.00 \mathrm{E}+00$ & 0 & $0.00 \mathrm{E}+00$ & 0 & $0.00 E+00$ & 0 & $0.00 \mathrm{E}+00$ & 0 & $0.00 \mathrm{E}+00$ & 0 \\
\hline-228 & $0.00 \mathrm{E}+00$ & 0 & $0.00 \mathrm{E}+00$ & 0 & $0.00 \mathrm{E}+00$ & 0 & $0.00 \mathrm{E}+00$ & 0 & $0.00 \mathrm{E}+00$ & 0 & $0.00 \mathrm{E}+00$ & 0 & $0.00 \mathrm{E}+00$ & 0 & $0.00 \mathrm{E}+00$ & 0 \\
\hline-230 & $0.00 \mathrm{E}+00$ & 0 & $0.00 \mathrm{E}+00$ & 0 & $0.00 \mathrm{E}+00$ & 0 & $0.00 \mathrm{E}+00$ & 0 & $0.00 \mathrm{E}+00$ & 0 & $0.00 \mathrm{E}+00$ & 0 & $0.00 \mathrm{E}+00$ & 0 & $0.00 \mathrm{E}+00$ & 0 \\
\hline-232 & $0.00 \mathrm{E}+00$ & 0 & $0.00 \mathrm{E}+00$ & 0 & $0.00 \mathrm{E}+00$ & 0 & $0.00 \mathrm{E}+00$ & 0 & $0.00 \mathrm{E}+00$ & 0 & $0.00 \mathrm{E}+00$ & 0 & $0.00 \mathrm{E}+00$ & 0 & $0.00 \mathrm{E}+00$ & 0 \\
\hline 34 & $0.00 \mathrm{E}+00$ & 0 & $0.00 \mathrm{E}+00$ & 0 & $0.00 \mathrm{E}+00$ & 0 & $0.00 \mathrm{E}+00$ & 0 & $0.00 \mathrm{E}+00$ & 0 & $0.00 \mathrm{E}+00$ & 0 & $0.00 \mathrm{E}+00$ & 0 & $0.00 \mathrm{E}+00$ & 0 \\
\hline 35 & $0.00 \mathrm{E}+00$ & 0 & $0.00 \mathrm{E}+00$ & 0 & $0.00 \mathrm{E}+00$ & 0 & $0.00 \mathrm{E}+00$ & 0 & $0.00 \mathrm{E}+00$ & 0 & $0.00 \mathrm{E}+00$ & 0 & $0.00 \mathrm{E}+00$ & 0 & $0.00 \mathrm{E}+00$ & 0 \\
\hline 38 & $0.00 \mathrm{E}+00$ & 0 & $0.00 \mathrm{E}+00$ & 0 & $0.00 E+00$ & 0 & $0.00 \mathrm{E}+00$ & 0 & $0.00 \mathrm{E}+00$ & 0 & $0.00 E+00$ & 0 & $0.00 \mathrm{E}+00$ & 0 & $0.00 \mathrm{E}+00$ & 0 \\
\hline & $0.00 \mathrm{E}+00$ & 0 & $0.00 E+00$ & 0 & $0.00 \mathrm{E}+00$ & 0 & $0.00 \mathrm{E}+00$ & 0 & $0.00 \mathrm{E}+00$ & 0 & $0.00 \mathrm{E}+00$ & 0 & $0.00 \mathrm{E}+00$ & 0 & $0.00 \mathrm{E}+00$ & 0 \\
\hline
\end{tabular}

Total Dose Contributions TDOSE(i,p,t) for Individual Radionuclides (i) and Pathways (p) in mrem/yr and as a Percentage of Total Dose at $t=50$ years

Directly from primary contamination and from release to atmosphere (Inhalation excludes radon)

\begin{tabular}{|c|c|c|c|c|c|c|c|c|c|c|c|c|c|c|c|c|}
\hline & \multicolumn{2}{|c|}{ Ground } & \multicolumn{2}{|c|}{ Inhalation } & \multicolumn{2}{|c|}{ Radon } & \multicolumn{2}{|c|}{ Plant } & \multicolumn{2}{|l|}{ Meat } & \multicolumn{2}{|l|}{ Milk } & \multicolumn{2}{|l|}{ Soil } & \multicolumn{2}{|c|}{ All Pathways* } \\
\hline clide & Dose & $\%$ & Dose & $\%$ & Dose & $\%$ & Dose & 음 & Dose & $\%$ & Dose & 음 & Dose & $\%$ & Dose & $\%$ \\
\hline-241 & $5.23 E-24$ & 0 & $0.00 \mathrm{E}+00$ & 0 & $0.00 \mathrm{E}+00$ & 0 & $0.00 \mathrm{E}+00$ & 0 & $0.00 \mathrm{E}+00$ & 0 & $0.00 \mathrm{E}+00$ & 0 & $0.00 \mathrm{E}+00$ & 0 & $5.23 E-24$ & 0 \\
\hline-137 & $6.75 E-17$ & 0 & $0.00 E+00$ & 0 & $0.00 E+00$ & 0 & $0.00 \mathrm{E}+00$ & 0 & $0.00 \mathrm{E}+00$ & 0 & $0.00 E+00$ & 0 & $0.00 \mathrm{E}+00$ & 0 & $6.75 E-17$ & 0 \\
\hline-237 & $5.22 E-20$ & 0 & $0.00 \mathrm{E}+00$ & 0 & $0.00 E+00$ & 0 & $0.00 \mathrm{E}+00$ & 0 & $0.00 \mathrm{E}+00$ & 0 & $0.00 E+00$ & 0 & $0.00 \mathrm{E}+00$ & 0 & $5.22 \mathrm{E}-20$ & 0 \\
\hline-238 & 1. $23 E-23$ & 0 & $0.00 \mathrm{E}+00$ & 0 & $0.00 \mathrm{E}+00$ & 0 & $0.00 \mathrm{E}+00$ & 0 & $0.00 \mathrm{E}+00$ & 0 & $0.00 \mathrm{E}+00$ & 0 & $0.00 \mathrm{E}+00$ & 0 & $1.23 E-23$ & 0 \\
\hline-239 & $4.55 \mathrm{E}-24$ & 0 & $0.00 \mathrm{E}+00$ & 0 & $0.00 \mathrm{E}+00$ & 0 & $0.00 \mathrm{E}+00$ & 0 & $0.00 \mathrm{E}+00$ & 0 & $0.00 \mathrm{E}+00$ & 0 & $0.00 \mathrm{E}+00$ & 0 & $4.55 E-24$ & 0 \\
\hline-240 & $5.76 \mathrm{E}-28$ & 0 & $0.00 \mathrm{E}+00$ & 0 & $0.00 \mathrm{E}+00$ & 0 & $0.00 \mathrm{E}+00$ & 0 & $0.00 \mathrm{E}+00$ & 0 & $0.00 E+00$ & 0 & $0.00 \mathrm{E}+00$ & 0 & $5.76 \mathrm{E}-28$ & 0 \\
\hline-99 & $3.38 E-32$ & 0 & $0.00 \mathrm{E}+00$ & 0 & $0.00 \mathrm{E}+00$ & 0 & $0.00 \mathrm{E}+00$ & 0 & $0.00 \mathrm{E}+00$ & 0 & $0.00 E+00$ & 0 & $0.00 \mathrm{E}+00$ & 0 & $3.38 E-32$ & 0 \\
\hline-228 & $8.32 E-22$ & 0 & $0.00 \mathrm{E}+00$ & 0 & $0.00 \mathrm{E}+00$ & 0 & $0.00 \mathrm{E}+00$ & 0 & $0.00 \mathrm{E}+00$ & 0 & $0.00 \mathrm{E}+00$ & 0 & $0.00 \mathrm{E}+00$ & 0 & $8.32 E-22$ & 0 \\
\hline-230 & $3.14 E-15$ & 6 & $0.00 E+00$ & 0 & $0.00 \mathrm{E}+00$ & 0 & $0.00 \mathrm{E}+00$ & 0 & $0.00 \mathrm{E}+00$ & 0 & $0.00 E+00$ & 0 & $0.00 \mathrm{E}+00$ & 0 & $3.14 \mathrm{E}-15$ & 6 \\
\hline-232 & $5.31 E-14$ & 94 & $0.00 \mathrm{E}+00$ & 0 & $0.00 E+00$ & 0 & $0.00 \mathrm{E}+00$ & 0 & $0.00 \mathrm{E}+00$ & 0 & $0.00 E+00$ & 0 & $0.00 \mathrm{E}+00$ & 0 & $5.31 E-14$ & 94 \\
\hline 34 & $1.15 \mathrm{E}-18$ & 0 & $0.00 \mathrm{E}+00$ & 0 & $0.00 \mathrm{E}+00$ & 0 & $0.00 \mathrm{E}+00$ & 0 & $0.00 \mathrm{E}+00$ & 0 & $0.00 \mathrm{E}+00$ & 0 & $0.00 \mathrm{E}+00$ & 0 & 1. $15 \mathrm{E}-18$ & 0 \\
\hline 35 & $3.52 \mathrm{E}-21$ & 0 & $0.00 \mathrm{E}+00$ & 0 & $0.00 \mathrm{E}+00$ & 0 & $0.00 \mathrm{E}+00$ & 0 & $0.00 \mathrm{E}+00$ & 0 & $0.00 \mathrm{E}+00$ & 0 & $0.00 \mathrm{E}+00$ & 0 & $3.52 \mathrm{E}-21$ & 0 \\
\hline 38 & $1.99 E-16$ & 0 & $0.00 \mathrm{E}+00$ & 0 & $0.00 \mathrm{E}+00$ & 0 & $0.00 \mathrm{E}+00$ & 0 & $0.00 \mathrm{E}+00$ & 0 & $0.00 E+00$ & 0 & $0.00 \mathrm{E}+00$ & 0 & 1. $99 \mathrm{E}-16$ & 0 \\
\hline & $5.65 \mathrm{E}-14$ & 100 & $0.00 \mathrm{E}+00$ & 0 & $0.00 \mathrm{E}+00$ & 0 & $0.00 \mathrm{E}+00$ & 0 & $0.00 \mathrm{E}+00$ & 0 & $0.00 \mathrm{E}+00$ & 0 & $0.00 \mathrm{E}+00$ & 0 & $5.65 \mathrm{E}-14$ & 100 \\
\hline
\end{tabular}

* Sum of dose from all releases and from primary contamination. 
RESRAD-OFFSITE, Version 2 .

arent Dose Report

Title : Offsite Resident Farmer Deterministic Run

File : RF DOE SG FWD-FV2-100000Y.ROF

Total Dose Contributions TDOSE (i,p,t) for Individual Radionuclides (i) and Pathways (p) in mrem/yr and as a Percentage of Total Dose at $t=100$ years

From releases to ground water and to surface water

\begin{tabular}{|c|c|c|c|c|c|c|c|c|c|c|c|c|c|c|c|c|}
\hline & \multicolumn{2}{|c|}{ Ground } & \multicolumn{2}{|l|}{ Fish } & \multicolumn{2}{|c|}{ Radon } & \multicolumn{2}{|c|}{ Plant } & \multicolumn{2}{|l|}{ Meat } & \multicolumn{2}{|l|}{ Milk } & \multicolumn{2}{|l|}{ Soil } & \multicolumn{2}{|c|}{ Water } \\
\hline ide & Dose & $\%$ & Dose & $\%$ & Dose & 응 & Dose & $\frac{\circ}{0}$ & Dose & 응 & Dose & 응 & Dose & $\%$ & Dose & $\%$ \\
\hline-241 & $0.00 \mathrm{E}+00$ & 0 & $0.00 E+00$ & 0 & $0.00 \mathrm{E}+00$ & 0 & $0.00 \mathrm{E}+00$ & 0 & $0.00 \mathrm{E}+00$ & 0 & $0.00 \mathrm{E}+00$ & 0 & $0.00 \mathrm{E}+00$ & 0 & $0.00 \mathrm{E}+00$ & 0 \\
\hline-137 & $0.00 \mathrm{E}+00$ & 0 & $0.00 \mathrm{E}+00$ & 0 & $0.00 \mathrm{E}+00$ & 0 & $0.00 \mathrm{E}+00$ & 0 & $0.00 \mathrm{E}+00$ & 0 & $0.00 \mathrm{E}+00$ & 0 & $0.00 \mathrm{E}+00$ & 0 & $0.00 \mathrm{E}+00$ & 0 \\
\hline-237 & $0.00 \mathrm{E}+00$ & 0 & $0.00 \mathrm{E}+00$ & 0 & $0.00 \mathrm{E}+00$ & 0 & $0.00 \mathrm{E}+00$ & 0 & $0.00 \mathrm{E}+00$ & 0 & $0.00 \mathrm{E}+00$ & 0 & $0.00 \mathrm{E}+00$ & 0 & $0.00 \mathrm{E}+00$ & 0 \\
\hline-238 & $0.00 \mathrm{E}+00$ & 0 & $0.00 \mathrm{E}+00$ & 0 & $0.00 E+00$ & 0 & $0.00 \mathrm{E}+00$ & 0 & $0.00 \mathrm{E}+00$ & 0 & $0.00 E+00$ & 0 & $0.00 \mathrm{E}+00$ & 0 & $0.00 \mathrm{E}+00$ & 0 \\
\hline-239 & $0.00 \mathrm{E}+00$ & 0 & $0.00 \mathrm{E}+00$ & 0 & $0.00 \mathrm{E}+00$ & 0 & $0.00 \mathrm{E}+00$ & 0 & $0.00 \mathrm{E}+00$ & 0 & $0.00 \mathrm{E}+00$ & 0 & $0.00 \mathrm{E}+00$ & 0 & $0.00 \mathrm{E}+00$ & 0 \\
\hline-240 & $0.00 \mathrm{E}+00$ & 0 & $0.00 \mathrm{E}+00$ & 0 & $0.00 \mathrm{E}+00$ & 0 & $0.00 \mathrm{E}+00$ & 0 & $0.00 \mathrm{E}+00$ & 0 & $0.00 \mathrm{E}+00$ & 0 & $0.00 \mathrm{E}+00$ & 0 & $0.00 \mathrm{E}+00$ & 0 \\
\hline-99 & $0.00 \mathrm{E}+00$ & 0 & $0.00 \mathrm{E}+00$ & 0 & $0.00 \mathrm{E}+00$ & 0 & $0.00 \mathrm{E}+00$ & 0 & $0.00 \mathrm{E}+00$ & 0 & $0.00 E+00$ & 0 & $0.00 \mathrm{E}+00$ & 0 & $0.00 \mathrm{E}+00$ & 0 \\
\hline-228 & $0.00 \mathrm{E}+00$ & 0 & $0.00 \mathrm{E}+00$ & 0 & $0.00 \mathrm{E}+00$ & 0 & $0.00 \mathrm{E}+00$ & 0 & $0.00 \mathrm{E}+00$ & 0 & $0.00 \mathrm{E}+00$ & 0 & $0.00 \mathrm{E}+00$ & 0 & $0.00 \mathrm{E}+00$ & 0 \\
\hline-230 & $0.00 \mathrm{E}+00$ & 0 & $0.00 \mathrm{E}+00$ & 0 & $0.00 \mathrm{E}+00$ & 0 & $0.00 \mathrm{E}+00$ & 0 & $0.00 \mathrm{E}+00$ & 0 & $0.00 \mathrm{E}+00$ & 0 & $0.00 \mathrm{E}+00$ & 0 & $0.00 \mathrm{E}+00$ & 0 \\
\hline-232 & $0.00 \mathrm{E}+00$ & 0 & $0.00 \mathrm{E}+00$ & 0 & $0.00 \mathrm{E}+00$ & 0 & $0.00 \mathrm{E}+00$ & 0 & $0.00 \mathrm{E}+00$ & 0 & $0.00 \mathrm{E}+00$ & 0 & $0.00 \mathrm{E}+00$ & 0 & $0.00 \mathrm{E}+00$ & 0 \\
\hline 34 & $0.00 \mathrm{E}+00$ & 0 & $0.00 \mathrm{E}+00$ & 0 & $0.00 \mathrm{E}+00$ & 0 & $0.00 \mathrm{E}+00$ & 0 & $0.00 \mathrm{E}+00$ & 0 & $0.00 \mathrm{E}+00$ & 0 & $0.00 \mathrm{E}+00$ & 0 & $0.00 \mathrm{E}+00$ & 0 \\
\hline 35 & $0.00 \mathrm{E}+00$ & 0 & $0.00 \mathrm{E}+00$ & 0 & $0.00 \mathrm{E}+00$ & 0 & $0.00 \mathrm{E}+00$ & 0 & $0.00 \mathrm{E}+00$ & 0 & $0.00 \mathrm{E}+00$ & 0 & $0.00 \mathrm{E}+00$ & 0 & $0.00 \mathrm{E}+00$ & 0 \\
\hline 38 & $0.00 \mathrm{E}+00$ & 0 & $0.00 \mathrm{E}+00$ & 0 & $0.00 E+00$ & 0 & $0.00 \mathrm{E}+00$ & 0 & $0.00 \mathrm{E}+00$ & 0 & $0.00 E+00$ & 0 & $0.00 \mathrm{E}+00$ & 0 & $0.00 \mathrm{E}+00$ & 0 \\
\hline & $0.00 \mathrm{E}+00$ & 0 & $0.00 E+00$ & 0 & $0.00 \mathrm{E}+00$ & 0 & $0.00 \mathrm{E}+00$ & 0 & $0.00 \mathrm{E}+00$ & 0 & $0.00 \mathrm{E}+00$ & 0 & $0.00 \mathrm{E}+00$ & 0 & $0.00 \mathrm{E}+00$ & 0 \\
\hline
\end{tabular}

Total Dose Contributions TDOSE(i,p,t) for Individual Radionuclides (i) and Pathways (p) in mrem/yr and as a Percentage of Total Dose at $t=100$ years

Directly from primary contamination and from release to atmosphere (Inhalation excludes radon)

\begin{tabular}{|c|c|c|c|c|c|c|c|c|c|c|c|c|c|c|c|c|}
\hline & \multicolumn{2}{|c|}{ Ground } & \multicolumn{2}{|c|}{ Inhalation } & \multicolumn{2}{|c|}{ Radon } & \multicolumn{2}{|c|}{ Plant } & \multicolumn{2}{|l|}{ Meat } & \multicolumn{2}{|l|}{ Milk } & \multicolumn{2}{|l|}{ Soil } & \multicolumn{2}{|c|}{ All Pathways* } \\
\hline lide & Dose & $\%$ & Dose & $\%$ & Dose & $\%$ & Dose & 음 & Dose & $\%$ & Dose & 음 & Dose & $\%$ & Dose & $\%$ \\
\hline-241 & $1.64 \mathrm{E}-23$ & 0 & $0.00 \mathrm{E}+00$ & 0 & $0.00 \mathrm{E}+00$ & 0 & $0.00 \mathrm{E}+00$ & 0 & $0.00 \mathrm{E}+00$ & 0 & $0.00 \mathrm{E}+00$ & 0 & $0.00 \mathrm{E}+00$ & 0 & $1.64 \mathrm{E}-23$ & 0 \\
\hline-137 & $3.13 E-17$ & 0 & $0.00 E+00$ & 0 & $0.00 E+00$ & 0 & $0.00 \mathrm{E}+00$ & 0 & $0.00 \mathrm{E}+00$ & 0 & $0.00 E+00$ & 0 & $0.00 \mathrm{E}+00$ & 0 & $3.13 \mathrm{E}-17$ & 0 \\
\hline-237 & $8.59 E-20$ & 0 & $0.00 \mathrm{E}+00$ & 0 & $0.00 E+00$ & 0 & $0.00 \mathrm{E}+00$ & 0 & $0.00 \mathrm{E}+00$ & 0 & $0.00 E+00$ & 0 & $0.00 \mathrm{E}+00$ & 0 & $8.59 E-20$ & 0 \\
\hline-238 & 1. $20 \mathrm{E}-22$ & 0 & $0.00 \mathrm{E}+00$ & 0 & $0.00 \mathrm{E}+00$ & 0 & $0.00 \mathrm{E}+00$ & 0 & $0.00 \mathrm{E}+00$ & 0 & $0.00 \mathrm{E}+00$ & 0 & $0.00 \mathrm{E}+00$ & 0 & 1. $20 \mathrm{E}-22$ & 0 \\
\hline-239 & $7.88 \mathrm{E}-24$ & 0 & $0.00 \mathrm{E}+00$ & 0 & $0.00 \mathrm{E}+00$ & 0 & $0.00 \mathrm{E}+00$ & 0 & $0.00 \mathrm{E}+00$ & 0 & $0.00 \mathrm{E}+00$ & 0 & $0.00 \mathrm{E}+00$ & 0 & $7.88 E-24$ & 0 \\
\hline-240 & $3.73 E-27$ & 0 & $0.00 \mathrm{E}+00$ & 0 & $0.00 \mathrm{E}+00$ & 0 & $0.00 \mathrm{E}+00$ & 0 & $0.00 \mathrm{E}+00$ & 0 & $0.00 E+00$ & 0 & $0.00 \mathrm{E}+00$ & 0 & $3.73 E-27$ & 0 \\
\hline-99 & $6.29 E-32$ & 0 & $0.00 \mathrm{E}+00$ & 0 & $0.00 \mathrm{E}+00$ & 0 & $0.00 \mathrm{E}+00$ & 0 & $0.00 \mathrm{E}+00$ & 0 & $0.00 E+00$ & 0 & $0.00 \mathrm{E}+00$ & 0 & $6.29 E-32$ & 0 \\
\hline-228 & $1.79 \mathrm{E}-29$ & 0 & $0.00 \mathrm{E}+00$ & 0 & $0.00 \mathrm{E}+00$ & 0 & $0.00 \mathrm{E}+00$ & 0 & $0.00 \mathrm{E}+00$ & 0 & $0.00 \mathrm{E}+00$ & 0 & $0.00 \mathrm{E}+00$ & 0 & 1. $79 \mathrm{E}-29$ & 0 \\
\hline-230 & $8.50 \mathrm{E}-15$ & 11 & $0.00 \mathrm{E}+00$ & 0 & $0.00 \mathrm{E}+00$ & 0 & $0.00 \mathrm{E}+00$ & 0 & $0.00 \mathrm{E}+00$ & 0 & $0.00 \mathrm{E}+00$ & 0 & $0.00 \mathrm{E}+00$ & 0 & $8.50 \mathrm{E}-15$ & 11 \\
\hline-232 & $7.02 \mathrm{E}-14$ & 89 & $0.00 \mathrm{E}+00$ & 0 & $0.00 \mathrm{E}+00$ & 0 & $0.00 \mathrm{E}+00$ & 0 & $0.00 \mathrm{E}+00$ & 0 & $0.00 \mathrm{E}+00$ & 0 & $0.00 \mathrm{E}+00$ & 0 & $7.02 \mathrm{E}-14$ & 89 \\
\hline 34 & $6.21 \mathrm{E}-18$ & 0 & $0.00 \mathrm{E}+00$ & 0 & $0.00 \mathrm{E}+00$ & 0 & $0.00 \mathrm{E}+00$ & 0 & $0.00 \mathrm{E}+00$ & 0 & $0.00 \mathrm{E}+00$ & 0 & $0.00 \mathrm{E}+00$ & 0 & $6.21 \mathrm{E}-18$ & 0 \\
\hline 35 & $1.24 \mathrm{E}-20$ & 0 & $0.00 \mathrm{E}+00$ & 0 & $0.00 \mathrm{E}+00$ & 0 & $0.00 \mathrm{E}+00$ & 0 & $0.00 \mathrm{E}+00$ & 0 & $0.00 \mathrm{E}+00$ & 0 & $0.00 \mathrm{E}+00$ & 0 & $1.24 \mathrm{E}-20$ & 0 \\
\hline 38 & $2.87 E-16$ & 0 & $0.00 \mathrm{E}+00$ & 0 & $0.00 \mathrm{E}+00$ & 0 & $0.00 \mathrm{E}+00$ & 0 & $0.00 \mathrm{E}+00$ & 0 & $0.00 E+00$ & 0 & $0.00 \mathrm{E}+00$ & 0 & $2.87 E-16$ & 0 \\
\hline & $7.90 \mathrm{E}-14$ & 100 & $0.00 \mathrm{E}+00$ & 0 & $0.00 \mathrm{E}+00$ & 0 & $0.00 \mathrm{E}+00$ & 0 & $0.00 \mathrm{E}+00$ & 0 & $0.00 \mathrm{E}+00$ & 0 & $0.00 \mathrm{E}+00$ & 0 & $7.90 \mathrm{E}-14$ & 100 \\
\hline
\end{tabular}

* Sum of dose from all releases and from primary contamination. 
RESRAD-OFFSITE, Version 2 .

arent Dose Report

Title : Offsite Resident Farmer Deterministic Run

File : RF DOE SG FWD-FV2-100000Y.ROF

Total Dose Contributions TDOSE (i,p,t) for Individual Radionuclides (i) and Pathways (p) in mrem/yr and as a Percentage of Total Dose at $t=500$ years

From releases to ground water and to surface water

\begin{tabular}{|c|c|c|c|c|c|c|c|c|c|c|c|c|c|c|c|c|}
\hline & \multicolumn{2}{|c|}{ Ground } & \multicolumn{2}{|l|}{ Fish } & \multicolumn{2}{|c|}{ Radon } & \multicolumn{2}{|c|}{ Plant } & \multicolumn{2}{|l|}{ Meat } & \multicolumn{2}{|l|}{ Milk } & \multicolumn{2}{|l|}{ Soil } & \multicolumn{2}{|c|}{ Water } \\
\hline ide & Dose & $\%$ & Dose & $\%$ & Dose & 응 & Dose & $\frac{\circ}{0}$ & Dose & 응 & Dose & 응 & Dose & $\%$ & Dose & $\%$ \\
\hline-241 & $0.00 \mathrm{E}+00$ & 0 & $0.00 E+00$ & 0 & $0.00 \mathrm{E}+00$ & 0 & $0.00 \mathrm{E}+00$ & 0 & $0.00 \mathrm{E}+00$ & 0 & $0.00 \mathrm{E}+00$ & 0 & $0.00 \mathrm{E}+00$ & 0 & $0.00 \mathrm{E}+00$ & 0 \\
\hline-137 & $0.00 \mathrm{E}+00$ & 0 & $0.00 \mathrm{E}+00$ & 0 & $0.00 \mathrm{E}+00$ & 0 & $0.00 \mathrm{E}+00$ & 0 & $0.00 \mathrm{E}+00$ & 0 & $0.00 \mathrm{E}+00$ & 0 & $0.00 \mathrm{E}+00$ & 0 & $0.00 \mathrm{E}+00$ & 0 \\
\hline-237 & $0.00 \mathrm{E}+00$ & 0 & $0.00 \mathrm{E}+00$ & 0 & $0.00 \mathrm{E}+00$ & 0 & $0.00 \mathrm{E}+00$ & 0 & $0.00 \mathrm{E}+00$ & 0 & $0.00 \mathrm{E}+00$ & 0 & $0.00 \mathrm{E}+00$ & 0 & $0.00 \mathrm{E}+00$ & 0 \\
\hline-238 & $0.00 \mathrm{E}+00$ & 0 & $0.00 \mathrm{E}+00$ & 0 & $0.00 E+00$ & 0 & $0.00 \mathrm{E}+00$ & 0 & $0.00 \mathrm{E}+00$ & 0 & $0.00 E+00$ & 0 & $0.00 \mathrm{E}+00$ & 0 & $0.00 \mathrm{E}+00$ & 0 \\
\hline-239 & $0.00 \mathrm{E}+00$ & 0 & $0.00 \mathrm{E}+00$ & 0 & $0.00 \mathrm{E}+00$ & 0 & $0.00 \mathrm{E}+00$ & 0 & $0.00 \mathrm{E}+00$ & 0 & $0.00 \mathrm{E}+00$ & 0 & $0.00 \mathrm{E}+00$ & 0 & $0.00 \mathrm{E}+00$ & 0 \\
\hline-240 & $0.00 \mathrm{E}+00$ & 0 & $0.00 \mathrm{E}+00$ & 0 & $0.00 \mathrm{E}+00$ & 0 & $0.00 \mathrm{E}+00$ & 0 & $0.00 \mathrm{E}+00$ & 0 & $0.00 \mathrm{E}+00$ & 0 & $0.00 \mathrm{E}+00$ & 0 & $0.00 \mathrm{E}+00$ & 0 \\
\hline-99 & $0.00 \mathrm{E}+00$ & 0 & $0.00 \mathrm{E}+00$ & 0 & $0.00 \mathrm{E}+00$ & 0 & $0.00 \mathrm{E}+00$ & 0 & $0.00 \mathrm{E}+00$ & 0 & $0.00 E+00$ & 0 & $0.00 \mathrm{E}+00$ & 0 & $0.00 \mathrm{E}+00$ & 0 \\
\hline-228 & $0.00 \mathrm{E}+00$ & 0 & $0.00 \mathrm{E}+00$ & 0 & $0.00 \mathrm{E}+00$ & 0 & $0.00 \mathrm{E}+00$ & 0 & $0.00 \mathrm{E}+00$ & 0 & $0.00 \mathrm{E}+00$ & 0 & $0.00 \mathrm{E}+00$ & 0 & $0.00 \mathrm{E}+00$ & 0 \\
\hline-230 & $0.00 \mathrm{E}+00$ & 0 & $0.00 \mathrm{E}+00$ & 0 & $0.00 \mathrm{E}+00$ & 0 & $0.00 \mathrm{E}+00$ & 0 & $0.00 \mathrm{E}+00$ & 0 & $0.00 \mathrm{E}+00$ & 0 & $0.00 \mathrm{E}+00$ & 0 & $0.00 \mathrm{E}+00$ & 0 \\
\hline-232 & $0.00 \mathrm{E}+00$ & 0 & $0.00 \mathrm{E}+00$ & 0 & $0.00 \mathrm{E}+00$ & 0 & $0.00 \mathrm{E}+00$ & 0 & $0.00 \mathrm{E}+00$ & 0 & $0.00 \mathrm{E}+00$ & 0 & $0.00 \mathrm{E}+00$ & 0 & $0.00 \mathrm{E}+00$ & 0 \\
\hline 34 & $0.00 \mathrm{E}+00$ & 0 & $0.00 \mathrm{E}+00$ & 0 & $0.00 \mathrm{E}+00$ & 0 & $0.00 \mathrm{E}+00$ & 0 & $0.00 \mathrm{E}+00$ & 0 & $0.00 \mathrm{E}+00$ & 0 & $0.00 \mathrm{E}+00$ & 0 & $0.00 \mathrm{E}+00$ & 0 \\
\hline 35 & $0.00 \mathrm{E}+00$ & 0 & $0.00 \mathrm{E}+00$ & 0 & $0.00 \mathrm{E}+00$ & 0 & $0.00 \mathrm{E}+00$ & 0 & $0.00 \mathrm{E}+00$ & 0 & $0.00 \mathrm{E}+00$ & 0 & $0.00 \mathrm{E}+00$ & 0 & $0.00 \mathrm{E}+00$ & 0 \\
\hline 38 & $0.00 \mathrm{E}+00$ & 0 & $0.00 \mathrm{E}+00$ & 0 & $0.00 E+00$ & 0 & $0.00 \mathrm{E}+00$ & 0 & $0.00 \mathrm{E}+00$ & 0 & $0.00 E+00$ & 0 & $0.00 \mathrm{E}+00$ & 0 & $0.00 \mathrm{E}+00$ & 0 \\
\hline & $0.00 \mathrm{E}+00$ & 0 & $0.00 E+00$ & 0 & $0.00 \mathrm{E}+00$ & 0 & $0.00 \mathrm{E}+00$ & 0 & $0.00 \mathrm{E}+00$ & 0 & $0.00 \mathrm{E}+00$ & 0 & $0.00 \mathrm{E}+00$ & 0 & $0.00 \mathrm{E}+00$ & 0 \\
\hline
\end{tabular}

Total Dose Contributions TDOSE(i,p,t) for Individual Radionuclides (i) and Pathways (p) in mrem/yr and as a Percentage of Total Dose at $t=500$ years

Directly from primary contamination and from release to atmosphere (Inhalation excludes radon)

\begin{tabular}{|c|c|c|c|c|c|c|c|c|c|c|c|c|c|c|c|c|}
\hline & \multicolumn{2}{|c|}{ Ground } & \multicolumn{2}{|c|}{ Inhalation } & \multicolumn{2}{|c|}{ Radon } & \multicolumn{2}{|c|}{ Plant } & \multicolumn{2}{|l|}{ Meat } & \multicolumn{2}{|l|}{ Milk } & \multicolumn{2}{|l|}{ Soil } & \multicolumn{2}{|c|}{ All Pathways* } \\
\hline clide & Dose & $\%$ & Dose & $\%$ & Dose & $\%$ & Dose & 음 & Dose & $\%$ & Dose & 음 & Dose & $\%$ & Dose & $\%$ \\
\hline-241 & $3.24 \mathrm{E}-21$ & 0 & $0.00 \mathrm{E}+00$ & 0 & $0.00 \mathrm{E}+00$ & 0 & $0.00 \mathrm{E}+00$ & 0 & $0.00 \mathrm{E}+00$ & 0 & $0.00 \mathrm{E}+00$ & 0 & $0.00 \mathrm{E}+00$ & 0 & $3.24 \mathrm{E}-21$ & 0 \\
\hline-137 & $6.74 E-20$ & 0 & $0.00 E+00$ & 0 & $0.00 E+00$ & 0 & $0.00 \mathrm{E}+00$ & 0 & $0.00 \mathrm{E}+00$ & 0 & $0.00 E+00$ & 0 & $0.00 \mathrm{E}+00$ & 0 & $6.74 \mathrm{E}-20$ & 0 \\
\hline-237 & 4. $60 \mathrm{E}-18$ & 0 & $0.00 \mathrm{E}+00$ & 0 & $0.00 E+00$ & 0 & $0.00 \mathrm{E}+00$ & 0 & $0.00 \mathrm{E}+00$ & 0 & $0.00 E+00$ & 0 & $0.00 \mathrm{E}+00$ & 0 & 4. $60 \mathrm{E}-18$ & 0 \\
\hline-238 & 1.01E-19 & 0 & $0.00 \mathrm{E}+00$ & 0 & $0.00 \mathrm{E}+00$ & 0 & $0.00 \mathrm{E}+00$ & 0 & $0.00 \mathrm{E}+00$ & 0 & $0.00 \mathrm{E}+00$ & 0 & $0.00 \mathrm{E}+00$ & 0 & $1.01 \mathrm{E}-19$ & 0 \\
\hline-239 & $6.42 \mathrm{E}-22$ & 0 & $0.00 \mathrm{E}+00$ & 0 & $0.00 \mathrm{E}+00$ & 0 & $0.00 \mathrm{E}+00$ & 0 & $0.00 \mathrm{E}+00$ & 0 & $0.00 \mathrm{E}+00$ & 0 & $0.00 \mathrm{E}+00$ & 0 & $6.42 \mathrm{E}-22$ & 0 \\
\hline-240 & $9.87 E-25$ & 0 & $0.00 \mathrm{E}+00$ & 0 & $0.00 \mathrm{E}+00$ & 0 & $0.00 \mathrm{E}+00$ & 0 & $0.00 \mathrm{E}+00$ & 0 & $0.00 E+00$ & 0 & $0.00 \mathrm{E}+00$ & 0 & $9.87 \mathrm{E}-25$ & 0 \\
\hline-99 & $8.96 \mathrm{E}-30$ & 0 & $0.00 \mathrm{E}+00$ & 0 & $0.00 \mathrm{E}+00$ & 0 & $0.00 \mathrm{E}+00$ & 0 & $0.00 \mathrm{E}+00$ & 0 & $0.00 E+00$ & 0 & $0.00 \mathrm{E}+00$ & 0 & $8.96 \mathrm{E}-30$ & 0 \\
\hline-228 & $0.00 \mathrm{E}+00$ & 0 & $0.00 \mathrm{E}+00$ & 0 & $0.00 \mathrm{E}+00$ & 0 & $0.00 \mathrm{E}+00$ & 0 & $0.00 \mathrm{E}+00$ & 0 & $0.00 \mathrm{E}+00$ & 0 & $0.00 \mathrm{E}+00$ & 0 & $0.00 \mathrm{E}+00$ & 0 \\
\hline-230 & 4. $95 \mathrm{E}-13$ & 43 & $0.00 \mathrm{E}+00$ & 0 & $0.00 \mathrm{E}+00$ & 0 & $0.00 \mathrm{E}+00$ & 0 & $0.00 \mathrm{E}+00$ & 0 & $0.00 \mathrm{E}+00$ & 0 & $0.00 \mathrm{E}+00$ & 0 & $4.95 \mathrm{E}-13$ & 43 \\
\hline-232 & $6.39 E-13$ & 56 & $0.00 \mathrm{E}+00$ & 0 & $0.00 E+00$ & 0 & $0.00 \mathrm{E}+00$ & 0 & $0.00 \mathrm{E}+00$ & 0 & $0.00 E+00$ & 0 & $0.00 \mathrm{E}+00$ & 0 & $6.39 E-13$ & 56 \\
\hline 34 & $1.85 \mathrm{E}-15$ & 0 & $0.00 \mathrm{E}+00$ & 0 & $0.00 \mathrm{E}+00$ & 0 & $0.00 \mathrm{E}+00$ & 0 & $0.00 \mathrm{E}+00$ & 0 & $0.00 \mathrm{E}+00$ & 0 & $0.00 \mathrm{E}+00$ & 0 & $1.85 \mathrm{E}-15$ & 0 \\
\hline 35 & 1. $94 \mathrm{E}-18$ & 0 & $0.00 \mathrm{E}+00$ & 0 & $0.00 \mathrm{E}+00$ & 0 & $0.00 \mathrm{E}+00$ & 0 & $0.00 \mathrm{E}+00$ & 0 & $0.00 \mathrm{E}+00$ & 0 & $0.00 \mathrm{E}+00$ & 0 & $1.94 \mathrm{E}-18$ & 0 \\
\hline 38 & $5.45 E-15$ & 0 & $0.00 \mathrm{E}+00$ & 0 & $0.00 \mathrm{E}+00$ & 0 & $0.00 \mathrm{E}+00$ & 0 & $0.00 \mathrm{E}+00$ & 0 & $0.00 E+00$ & 0 & $0.00 \mathrm{E}+00$ & 0 & $5.45 E-15$ & 0 \\
\hline & $1.14 \mathrm{E}-12$ & 100 & $0.00 \mathrm{E}+00$ & 0 & $0.00 \mathrm{E}+00$ & 0 & $0.00 \mathrm{E}+00$ & 0 & $0.00 \mathrm{E}+00$ & 0 & $0.00 \mathrm{E}+00$ & 0 & $0.00 \mathrm{E}+00$ & 0 & $1.14 \mathrm{E}-12$ & 100 \\
\hline
\end{tabular}

* Sum of dose from all releases and from primary contamination. 
RESRAD-OFFSITE, Version 2 .

arent Dose Report

Title : Offsite Resident Farmer Deterministic Run

File : RF DOE SG FWD-FV2-100000Y.ROF

Total Dose Contributions TDOSE (i,p,t) for Individual Radionuclides (i) and Pathways (p) in mrem/yr and as a Percentage of Total Dose at $t=1026$ years

From releases to ground water and to surface water

\begin{tabular}{|c|c|c|c|c|c|c|c|c|c|c|c|c|c|c|c|c|}
\hline & \multicolumn{2}{|c|}{ Ground } & \multicolumn{2}{|l|}{ Fish } & \multicolumn{2}{|c|}{ Radon } & \multicolumn{2}{|l|}{ Plant } & \multicolumn{2}{|l|}{ Meat } & \multicolumn{2}{|l|}{ Milk } & \multicolumn{2}{|l|}{ Soil } & \multicolumn{2}{|c|}{ Water } \\
\hline clide & Dose & \% & Dose & $\%$ & Dose & $\%$ & Dose & 음 & Dose & $\%$ & Dose & \% & Dose & \% & Dose & $\%$ \\
\hline-241 & $0.00 E+00$ & 0 & $0.00 \mathrm{E}+00$ & 0 & $0.00 \mathrm{E}+00$ & 0 & $0.00 \mathrm{E}+00$ & 0 & $0.00 E+00$ & 0 & $0.00 E+00$ & 0 & $0.00 \mathrm{E}+00$ & 0 & $0.00 \mathrm{E}+00$ & 0 \\
\hline-137 & $0.00 \mathrm{E}+00$ & 0 & $0.00 \mathrm{E}+00$ & 0 & $0.00 \mathrm{E}+00$ & 0 & $0.00 \mathrm{E}+00$ & 0 & $0.00 \mathrm{E}+00$ & 0 & $0.00 \mathrm{E}+00$ & 0 & $0.00 \mathrm{E}+00$ & 0 & $0.00 \mathrm{E}+00$ & 0 \\
\hline-237 & $0.00 \mathrm{E}+00$ & 0 & $0.00 \mathrm{E}+00$ & 0 & $0.00 \mathrm{E}+00$ & 0 & $0.00 \mathrm{E}+00$ & 0 & $0.00 E+00$ & 0 & $0.00 E+00$ & 0 & $0.00 \mathrm{E}+00$ & 0 & $0.00 \mathrm{E}+00$ & 0 \\
\hline-238 & $0.00 \mathrm{E}+00$ & 0 & $0.00 \mathrm{E}+00$ & 0 & $0.00 E+00$ & 0 & $0.00 \mathrm{E}+00$ & 0 & $0.00 \mathrm{E}+00$ & 0 & $0.00 E+00$ & 0 & $0.00 \mathrm{E}+00$ & 0 & $0.00 \mathrm{E}+00$ & 0 \\
\hline-239 & $0.00 \mathrm{E}+00$ & 0 & $0.00 \mathrm{E}+00$ & 0 & $0.00 \mathrm{E}+00$ & 0 & $0.00 \mathrm{E}+00$ & 0 & $0.00 \mathrm{E}+00$ & 0 & $0.00 \mathrm{E}+00$ & 0 & $0.00 \mathrm{E}+00$ & 0 & $0.00 \mathrm{E}+00$ & 0 \\
\hline-240 & $0.00 \mathrm{E}+00$ & 0 & $0.00 \mathrm{E}+00$ & 0 & $0.00 \mathrm{E}+00$ & 0 & $0.00 \mathrm{E}+00$ & 0 & $0.00 E+00$ & 0 & $0.00 \mathrm{E}+00$ & 0 & $0.00 \mathrm{E}+00$ & 0 & $0.00 \mathrm{E}+00$ & 0 \\
\hline-99 & $0.00 \mathrm{E}+00$ & 0 & $0.00 \mathrm{E}+00$ & 0 & $0.00 \mathrm{E}+00$ & 0 & $0.00 \mathrm{E}+00$ & 0 & $0.00 \mathrm{E}+00$ & 0 & $0.00 \mathrm{E}+00$ & 0 & $0.00 \mathrm{E}+00$ & 0 & $0.00 \mathrm{E}+00$ & 0 \\
\hline-228 & $0.00 \mathrm{E}+00$ & 0 & $0.00 \mathrm{E}+00$ & 0 & $0.00 \mathrm{E}+00$ & 0 & $0.00 \mathrm{E}+00$ & 0 & $0.00 \mathrm{E}+00$ & 0 & $0.00 \mathrm{E}+00$ & 0 & $0.00 \mathrm{E}+00$ & 0 & $0.00 \mathrm{E}+00$ & 0 \\
\hline-230 & $0.00 \mathrm{E}+00$ & 0 & $0.00 \mathrm{E}+00$ & 0 & $0.00 \mathrm{E}+00$ & 0 & $0.00 \mathrm{E}+00$ & 0 & $0.00 E+00$ & 0 & $0.00 \mathrm{E}+00$ & 0 & $0.00 \mathrm{E}+00$ & 0 & $0.00 \mathrm{E}+00$ & 0 \\
\hline-232 & $0.00 \mathrm{E}+00$ & 0 & $0.00 \mathrm{E}+00$ & 0 & $0.00 \mathrm{E}+00$ & 0 & $0.00 \mathrm{E}+00$ & 0 & $0.00 \mathrm{E}+00$ & 0 & $0.00 \mathrm{E}+00$ & 0 & $0.00 \mathrm{E}+00$ & 0 & $0.00 \mathrm{E}+00$ & 0 \\
\hline 234 & $0.00 \mathrm{E}+00$ & 0 & $0.00 \mathrm{E}+00$ & 0 & $0.00 \mathrm{E}+00$ & 0 & $0.00 \mathrm{E}+00$ & 0 & $0.00 \mathrm{E}+00$ & 0 & $0.00 \mathrm{E}+00$ & 0 & $0.00 \mathrm{E}+00$ & 0 & $0.00 \mathrm{E}+00$ & 0 \\
\hline 235 & $0.00 \mathrm{E}+00$ & 0 & $0.00 \mathrm{E}+00$ & 0 & $0.00 \mathrm{E}+00$ & 0 & $0.00 \mathrm{E}+00$ & 0 & $0.00 \mathrm{E}+00$ & 0 & $0.00 E+00$ & 0 & $0.00 \mathrm{E}+00$ & 0 & $0.00 \mathrm{E}+00$ & 0 \\
\hline 238 & $0.00 \mathrm{E}+00$ & 0 & $0.00 \mathrm{E}+00$ & 0 & $0.00 \mathrm{E}+00$ & 0 & $0.00 \mathrm{E}+00$ & 0 & $0.00 \mathrm{E}+00$ & 0 & $0.00 \mathrm{E}+00$ & 0 & $0.00 \mathrm{E}+00$ & 0 & $0.00 \mathrm{E}+00$ & 0 \\
\hline & $0.00 \mathrm{E}+00$ & 0 & $0.00 \mathrm{E}+00$ & 0 & $0.00 \mathrm{E}+00$ & 0 & $0.00 \mathrm{E}+00$ & 0 & $0.00 \mathrm{E}+00$ & 0 & $0.00 \mathrm{E}+00$ & 0 & $0.00 \mathrm{E}+00$ & 0 & $0.00 \mathrm{E}+00$ & 0 \\
\hline
\end{tabular}

Total Dose Contributions TDOSE (i,p,t) for Individual Radionuclides (i) and Pathways (p) in mrem/yr and as a Percentage of Total Dose at $t=1026$ years

Directly from primary contamination and from release to atmosphere (Inhalation excludes radon)

\begin{tabular}{|c|c|c|c|c|c|c|c|c|c|c|c|c|c|c|c|c|}
\hline & \multicolumn{2}{|c|}{ Ground } & \multicolumn{2}{|c|}{ Inhalation } & \multicolumn{2}{|c|}{ Radon } & \multicolumn{2}{|c|}{ Plant } & \multicolumn{2}{|l|}{ Meat } & \multicolumn{2}{|l|}{ Milk } & \multicolumn{2}{|l|}{ Soil } & \multicolumn{2}{|c|}{ All Pathways* } \\
\hline clide & Dose & $\%$ & Dose & $\%$ & Dose & $\%$ & Dose & \% & Dose & $\%$ & Dose & \% & Dose & \% & Dose & $\%$ \\
\hline-241 & $8.57 \mathrm{E}-19$ & 0 & $0.00 \mathrm{E}+00$ & 0 & $0.00 \mathrm{E}+00$ & 0 & $0.00 \mathrm{E}+00$ & 0 & $0.00 \mathrm{E}+00$ & 0 & $0.00 \mathrm{E}+00$ & 0 & $0.00 \mathrm{E}+00$ & 0 & $8.57 \mathrm{E}-19$ & 0 \\
\hline-137 & $2.09 \mathrm{E}-23$ & 0 & $0.00 \mathrm{E}+00$ & 0 & $0.00 \mathrm{E}+00$ & 0 & $0.00 \mathrm{E}+00$ & 0 & $0.00 \mathrm{E}+00$ & 0 & $0.00 \mathrm{E}+00$ & 0 & $0.00 \mathrm{E}+00$ & 0 & $2.09 \mathrm{E}-23$ & 0 \\
\hline-237 & $8.15 \mathrm{E}-16$ & 0 & $0.00 \mathrm{E}+00$ & 0 & $0.00 \mathrm{E}+00$ & 0 & $0.00 \mathrm{E}+00$ & 0 & $0.00 \mathrm{E}+00$ & 0 & $0.00 \mathrm{E}+00$ & 0 & $0.00 \mathrm{E}+00$ & 0 & $8.15 \mathrm{E}-16$ & 0 \\
\hline-238 & 1. $43 \mathrm{E}-17$ & 0 & $0.00 \mathrm{E}+00$ & 0 & $0.00 \mathrm{E}+00$ & 0 & $0.00 \mathrm{E}+00$ & 0 & $0.00 \mathrm{E}+00$ & 0 & $0.00 \mathrm{E}+00$ & 0 & $0.00 \mathrm{E}+00$ & 0 & $1.43 \mathrm{E}-17$ & 0 \\
\hline-239 & $2.09 \mathrm{E}-19$ & 0 & $0.00 \mathrm{E}+00$ & 0 & $0.00 \mathrm{E}+00$ & 0 & $0.00 \mathrm{E}+00$ & 0 & $0.00 \mathrm{E}+00$ & 0 & $0.00 \mathrm{E}+00$ & 0 & $0.00 \mathrm{E}+00$ & 0 & $2.09 \mathrm{E}-19$ & 0 \\
\hline-240 & $8.10 \mathrm{E}-23$ & 0 & $0.00 \mathrm{E}+00$ & 0 & $0.00 \mathrm{E}+00$ & 0 & $0.00 \mathrm{E}+00$ & 0 & $0.00 \mathrm{E}+00$ & 0 & $0.00 \mathrm{E}+00$ & 0 & $0.00 \mathrm{E}+00$ & 0 & $8.10 \mathrm{E}-23$ & 0 \\
\hline-99 & $6.10 \mathrm{E}-27$ & 0 & $0.00 \mathrm{E}+00$ & 0 & $0.00 \mathrm{E}+00$ & 0 & $0.00 \mathrm{E}+00$ & 0 & $0.00 \mathrm{E}+00$ & 0 & $0.00 \mathrm{E}+00$ & 0 & $0.00 \mathrm{E}+00$ & 0 & $6.10 \mathrm{E}-27$ & 0 \\
\hline-228 & $0.00 \mathrm{E}+00$ & 0 & $0.00 \mathrm{E}+00$ & 0 & $0.00 \mathrm{E}+00$ & 0 & $0.00 \mathrm{E}+00$ & 0 & $0.00 \mathrm{E}+00$ & 0 & $0.00 \mathrm{E}+00$ & 0 & $0.00 \mathrm{E}+00$ & 0 & $0.00 \mathrm{E}+00$ & 0 \\
\hline-230 & $2.59 \mathrm{E}-11$ & 68 & $0.00 \mathrm{E}+00$ & 0 & $0.00 \mathrm{E}+00$ & 0 & $0.00 \mathrm{E}+00$ & 0 & $0.00 \mathrm{E}+00$ & 0 & $0.00 \mathrm{E}+00$ & 0 & $0.00 \mathrm{E}+00$ & 0 & $2.59 \mathrm{E}-11$ & 68 \\
\hline-232 & $1.19 \mathrm{E}-11$ & 31 & $0.00 \mathrm{E}+00$ & 0 & $0.00 \mathrm{E}+00$ & 0 & $0.00 \mathrm{E}+00$ & 0 & $0.00 \mathrm{E}+00$ & 0 & $0.00 \mathrm{E}+00$ & 0 & $0.00 \mathrm{E}+00$ & 0 & $1.19 \mathrm{E}-11$ & 31 \\
\hline 234 & $2.05 E-13$ & 1 & $0.00 \mathrm{E}+00$ & 0 & $0.00 \mathrm{E}+00$ & 0 & $0.00 \mathrm{E}+00$ & 0 & $0.00 \mathrm{E}+00$ & 0 & $0.00 \mathrm{E}+00$ & 0 & $0.00 \mathrm{E}+00$ & 0 & $2.05 E-13$ & 1 \\
\hline 235 & $3.32 \mathrm{E}-16$ & 0 & $0.00 \mathrm{E}+00$ & 0 & $0.00 \mathrm{E}+00$ & 0 & $0.00 \mathrm{E}+00$ & 0 & $0.00 \mathrm{E}+00$ & 0 & $0.00 \mathrm{E}+00$ & 0 & $0.00 \mathrm{E}+00$ & 0 & $3 \cdot 32 \mathrm{E}-16$ & 0 \\
\hline 38 & $2.62 E-13$ & 1 & $0.00 \mathrm{E}+00$ & 0 & $0.00 \mathrm{E}+00$ & 0 & $0.00 \mathrm{E}+00$ & 0 & $0.00 \mathrm{E}+00$ & 0 & $0.00 \mathrm{E}+00$ & 0 & $0.00 \mathrm{E}+00$ & 0 & $2.62 \mathrm{E}-13$ & 1 \\
\hline & $3.82 \mathrm{E}-11$ & 100 & $0.00 \mathrm{E}+00$ & 0 & $0.00 \mathrm{E}+00$ & 0 & $0.00 \mathrm{E}+00$ & 0 & $0.00 \mathrm{E}+00$ & 0 & $0.00 \mathrm{E}+00$ & 0 & $0.00 \mathrm{E}+00$ & 0 & 3.82 & 100 \\
\hline
\end{tabular}

* Sum of dose from all releases and from primary contamination. 
RESRAD-OFFSITE, Version 2 .

Parent Dose Report

Title : Offsite Resident Farmer Deterministic Run

File : RF DOE SG FWD-FV2-100000Y.ROF

Total Dose Contributions TDOSE (i,p,t) for Individual Radionuclides (i) and Pathways (p) in mrem/yr and as a Percentage of Total Dose at $t=9976$ years

From releases to ground water and to surface water

\begin{tabular}{|c|c|c|c|c|c|c|c|c|c|c|c|c|c|c|c|c|}
\hline & \multicolumn{2}{|c|}{ Ground } & \multicolumn{2}{|l|}{ Fish } & \multicolumn{2}{|l|}{ Radon } & \multicolumn{2}{|c|}{ Plant } & \multicolumn{2}{|l|}{ Meat } & \multicolumn{2}{|l|}{ Milk } & \multicolumn{2}{|l|}{ Soil } & \multicolumn{2}{|c|}{ Water } \\
\hline clide & Dose & \% & Dose & $\%$ & Dose & 음 & Dose & 음 & Dose & \% & Dose & \% & Dose & 응 & Dose & 응 \\
\hline-241 & 1. $21 \mathrm{E}-05$ & 0 & $0.00 \mathrm{E}+00$ & 0 & $0.00 \mathrm{E}+00$ & 0 & 4.01E-04 & 0 & 1. $49 \mathrm{E}-05$ & 0 & $8.40 \mathrm{E}-07$ & 0 & $2.01 E-07$ & 0 & $1.36 \mathrm{E}-03$ & 0 \\
\hline-137 & $0.00 \mathrm{E}+00$ & 0 & $0.00 \mathrm{E}+00$ & 0 & $0.00 \mathrm{E}+00$ & 0 & $0.00 \mathrm{E}+00$ & 0 & $0.00 \mathrm{E}+00$ & 0 & $0.00 \mathrm{E}+00$ & 0 & $0.00 \mathrm{E}+00$ & 0 & $0.00 \mathrm{E}+00$ & 0 \\
\hline-237 & $8.70 \mathrm{E}-03$ & 0 & $0.00 \mathrm{E}+00$ & 0 & $0.00 \mathrm{E}+00$ & 0 & $2.89 \mathrm{E}-01$ & 13 & $1.07 \mathrm{E}-02$ & 0 & $6.08 \mathrm{E}-04$ & 0 & 1. $45 \mathrm{E}-04$ & 0 & $9.78 \mathrm{E}-01$ & 45 \\
\hline-238 & $0.00 \mathrm{E}+00$ & 0 & $0.00 \mathrm{E}+00$ & 0 & $0.00 \mathrm{E}+00$ & 0 & $0.00 \mathrm{E}+00$ & 0 & $0.00 \mathrm{E}+00$ & 0 & $0.00 \mathrm{E}+00$ & 0 & $0.00 \mathrm{E}+00$ & 0 & $0.00 \mathrm{E}+00$ & 0 \\
\hline-239 & $0.00 \mathrm{E}+00$ & 0 & $0.00 \mathrm{E}+00$ & 0 & $0.00 \mathrm{E}+00$ & 0 & $0.00 \mathrm{E}+00$ & 0 & $0.00 \mathrm{E}+00$ & 0 & $0.00 \mathrm{E}+00$ & 0 & $0.00 \mathrm{E}+00$ & 0 & $0.00 \mathrm{E}+00$ & 0 \\
\hline-240 & $0.00 \mathrm{E}+00$ & 0 & $0.00 \mathrm{E}+00$ & 0 & $0.00 \mathrm{E}+00$ & 0 & $0.00 \mathrm{E}+00$ & 0 & $0.00 \mathrm{E}+00$ & 0 & $0.00 \mathrm{E}+00$ & 0 & $0.00 \mathrm{E}+00$ & 0 & $0.00 \mathrm{E}+00$ & 0 \\
\hline-99 & $0.00 \mathrm{E}+00$ & 0 & $0.00 \mathrm{E}+00$ & 0 & $0.00 \mathrm{E}+00$ & 0 & $0.00 \mathrm{E}+00$ & 0 & $0.00 \mathrm{E}+00$ & 0 & $0.00 \mathrm{E}+00$ & 0 & $0.00 \mathrm{E}+00$ & 0 & $0.00 \mathrm{E}+00$ & 0 \\
\hline-228 & $0.00 \mathrm{E}+00$ & 0 & $0.00 \mathrm{E}+00$ & 0 & $0.00 \mathrm{E}+00$ & 0 & $0.00 \mathrm{E}+00$ & 0 & $0.00 \mathrm{E}+00$ & 0 & $0.00 \mathrm{E}+00$ & 0 & $0.00 \mathrm{E}+00$ & 0 & $0.00 \mathrm{E}+00$ & 0 \\
\hline-230 & $0.00 \mathrm{E}+00$ & 0 & $0.00 \mathrm{E}+00$ & 0 & $0.00 \mathrm{E}+00$ & 0 & $0.00 \mathrm{E}+00$ & 0 & $0.00 \mathrm{E}+00$ & 0 & $0.00 \mathrm{E}+00$ & 0 & $0.00 \mathrm{E}+00$ & 0 & $0.00 \mathrm{E}+00$ & 0 \\
\hline-232 & $0.00 \mathrm{E}+00$ & 0 & $0.00 \mathrm{E}+00$ & 0 & $0.00 \mathrm{E}+00$ & 0 & $0.00 \mathrm{E}+00$ & 0 & $0.00 \mathrm{E}+00$ & 0 & $0.00 \mathrm{E}+00$ & 0 & $0.00 \mathrm{E}+00$ & 0 & $0.00 \mathrm{E}+00$ & 0 \\
\hline 234 & $0.00 \mathrm{E}+00$ & 0 & $0.00 \mathrm{E}+00$ & 0 & $0.00 \mathrm{E}+00$ & 0 & $0.00 \mathrm{E}+00$ & 0 & $0.00 \mathrm{E}+00$ & 0 & $0.00 \mathrm{E}+00$ & 0 & $0.00 \mathrm{E}+00$ & 0 & $0.00 \mathrm{E}+00$ & 0 \\
\hline 235 & $0.00 \mathrm{E}+00$ & 0 & $0.00 \mathrm{E}+00$ & 0 & $0.00 \mathrm{E}+00$ & 0 & $0.00 \mathrm{E}+00$ & 0 & $0.00 \mathrm{E}+00$ & 0 & $0.00 \mathrm{E}+00$ & 0 & $0.00 \mathrm{E}+00$ & 0 & $0.00 \mathrm{E}+00$ & 0 \\
\hline 238 & $0.00 \mathrm{E}+00$ & 0 & $0.00 \mathrm{E}+00$ & 0 & $0.00 \mathrm{E}+00$ & 0 & $0.00 \mathrm{E}+00$ & 0 & $0.00 \mathrm{E}+00$ & 0 & $0.00 \mathrm{E}+00$ & 0 & $0.00 \mathrm{E}+00$ & 0 & $0.00 \mathrm{E}+00$ & 0 \\
\hline & $8.71 E-03$ & 0 & $0.00 \mathrm{E}+00$ & 0 & $0.00 \mathrm{E}+00$ & 0 & $2.89 \mathrm{E}-01$ & 13 & 1. $08 \mathrm{E}-02$ & 0 & $6.08 \mathrm{E}-04$ & 0 & 1. $45 \mathrm{E}-04$ & 0 & $9.79 \mathrm{E}-01$ & 45 \\
\hline
\end{tabular}

Total Dose Contributions TDOSE (i,p,t) for Individual Radionuclides (i) and Pathways (p)

in mrem/yr and as a Percentage of Total Dose at $t=9976$ years

Directly from primary contamination and from release to atmosphere (Inhalation excludes radon)

\begin{tabular}{|c|c|c|c|c|c|c|c|c|c|c|c|c|c|c|c|c|}
\hline & \multicolumn{2}{|l|}{ Ground } & \multicolumn{2}{|c|}{ Inhalation } & \multicolumn{2}{|c|}{ Radon } & \multicolumn{2}{|c|}{ Plant } & \multicolumn{2}{|l|}{ Meat } & \multicolumn{2}{|l|}{ Milk } & \multicolumn{2}{|l|}{ Soil } & \multicolumn{2}{|c|}{ All Pathways* } \\
\hline clide & Dose & \% & Dose & $\%$ & Dose & $\%$ & Dose & 음 & Dose & $\%$ & Dose & $\%$ & Dose & \% & Dose & $\%$ \\
\hline-241 & $1.81 E-06$ & 0 & 4. $76 E-09$ & 0 & $0.00 \mathrm{E}+00$ & 0 & $4.46 \mathrm{E}-11$ & 0 & 1. $23 \mathrm{E}-11$ & 0 & $3.69 \mathrm{E}-13$ & 0 & 1. $29 \mathrm{E}-12$ & 0 & $1.79 \mathrm{E}-03$ & 0 \\
\hline-137 & $1.12 \mathrm{E}-44$ & 0 & $0.00 \mathrm{E}+00$ & 0 & $0.00 \mathrm{E}+00$ & 0 & $0.00 \mathrm{E}+00$ & 0 & $4.20 E-45$ & 0 & 1. $40 \mathrm{E}-45$ & 0 & $0.00 \mathrm{E}+00$ & 0 & 1. $68 \mathrm{E}-44$ & 0 \\
\hline-237 & $1.35 \mathrm{E}-03$ & 0 & $3.58 E-06$ & 0 & $0.00 \mathrm{E}+00$ & 0 & $3.33 E-08$ & 0 & $9.16 \mathrm{E}-09$ & 0 & 2. $92 \mathrm{E}-10$ & 0 & $9.92 \mathrm{E}-10$ & 0 & $1.29 \mathrm{E}+00$ & 59 \\
\hline-238 & $7.00 \mathrm{E}-06$ & 0 & $5.96 \mathrm{E}-09$ & 0 & $0.00 \mathrm{E}+00$ & 0 & $4.13 \mathrm{E}-10$ & 0 & $9.43 E-11$ & 0 & $1.02 \mathrm{E}-10$ & 0 & 1. $46 \mathrm{E}-11$ & 0 & $7.01 \mathrm{E}-06$ & 0 \\
\hline-239 & $2.76 \mathrm{E}-06$ & 0 & $7.38 \mathrm{E}-05$ & 0 & $0.00 \mathrm{E}+00$ & 0 & $2.96 \mathrm{E}-07$ & 0 & $2.11 \mathrm{E}-08$ & 0 & $4.98 \mathrm{E}-10$ & 0 & $3.96 \mathrm{E}-08$ & 0 & $7.69 \mathrm{E}-05$ & 0 \\
\hline-240 & $9.81 E-08$ & 0 & $3.41 E-05$ & 0 & $0.00 \mathrm{E}+00$ & 0 & $1.37 \mathrm{E}-07$ & 0 & $9.75 E-09$ & 0 & $2.37 E-10$ & 0 & $1.83 \mathrm{E}-08$ & 0 & $3.44 E-05$ & 0 \\
\hline-99 & $2.26 \mathrm{E}-29$ & 0 & $2.73 E-31$ & 0 & $0.00 \mathrm{E}+00$ & 0 & $9.63 E-32$ & 0 & $2.14 \mathrm{E}-33$ & 0 & $2.94 \mathrm{E}-32$ & 0 & $1.14 \mathrm{E}-35$ & 0 & $2.30 \mathrm{E}-29$ & 0 \\
\hline-228 & $0.00 \mathrm{E}+00$ & 0 & $0.00 \mathrm{E}+00$ & 0 & $0.00 \mathrm{E}+00$ & 0 & $0.00 \mathrm{E}+00$ & 0 & $0.00 \mathrm{E}+00$ & 0 & $0.00 \mathrm{E}+00$ & 0 & $0.00 \mathrm{E}+00$ & 0 & $0.00 \mathrm{E}+00$ & 0 \\
\hline-230 & $7.40 \mathrm{E}-01$ & 34 & $2.69 \mathrm{E}-04$ & 0 & $0.00 \mathrm{E}+00$ & 0 & $4.06 \mathrm{E}-05$ & 0 & $9.55 E-06$ & 0 & $9.24 \mathrm{E}-06$ & 0 & $1.36 \mathrm{E}-06$ & 0 & $7.41 \mathrm{E}-01$ & 34 \\
\hline-232 & $4.56 \mathrm{E}-02$ & 2 & $1.68 E-05$ & 0 & $0.00 \mathrm{E}+00$ & 0 & $2.07 E-06$ & 0 & $3.61 E-07$ & 0 & $5.58 E-07$ & 0 & $3.37 E-08$ & 0 & $4.56 \mathrm{E}-02$ & 2 \\
\hline 234 & $8.13 \mathrm{E}-02$ & 4 & $6.85 E-05$ & 0 & $0.00 \mathrm{E}+00$ & 0 & $4.80 \mathrm{E}-06$ & 0 & $1.09 \mathrm{E}-06$ & 0 & $1.18 \mathrm{E}-06$ & 0 & $1.70 \mathrm{E}-07$ & 0 & $8.14 \mathrm{E}-02$ & 4 \\
\hline 235 & $2.80 \mathrm{E}-03$ & 0 & $2.08 \mathrm{E}-05$ & 0 & $0.00 \mathrm{E}+00$ & 0 & $2.26 \mathrm{E}-07$ & 0 & $2.03 E-07$ & 0 & $9.38 \mathrm{E}-09$ & 0 & 1. $41 \mathrm{E}-08$ & 0 & $2.83 E-03$ & 0 \\
\hline 238 & $1.67 \mathrm{E}-02$ & 1 & $2.96 E-05$ & 0 & $0.00 \mathrm{E}+00$ & 0 & $3.66 \mathrm{E}-07$ & 0 & $5.72 \mathrm{E}-08$ & 0 & $1.87 E-07$ & 0 & $1.84 \mathrm{E}-08$ & 0 & 1. $67 \mathrm{E}-02$ & 1 \\
\hline$a$ & $8.88 E-01$ & 41 & $5.17 \mathrm{E}-04$ & 0 & $0.00 \mathrm{E}+00$ & 0 & $4.85 E-05$ & 0 & $1.13 \mathrm{E}-05$ & 0 & $1.12 \mathrm{E}-05$ & 0 & $1.66 \mathrm{E}-06$ & 0 & $2.18 \mathrm{E}+00$ & 100 \\
\hline
\end{tabular}

* Sum of dose from all releases and from primary contamination. 
RESRAD-OFFSITE, Version 2.

Parent Dose Report

Title : Offsite Resident Farmer Deterministic Run

File : RF DOE SG FWD-FV2-100000Y.ROF

Total Dose Contributions TDOSE (i,p,t) for Individual Radionuclides (i) and Pathways (p) in mrem/yr and as a Percentage of Total Dose at $t=99976$ years

From releases to ground water and to surface water

\begin{tabular}{|c|c|c|c|c|c|c|c|c|c|c|c|c|c|c|c|c|}
\hline & \multicolumn{2}{|c|}{ Ground } & \multicolumn{2}{|l|}{ Fish } & \multicolumn{2}{|c|}{ Radon } & \multicolumn{2}{|c|}{ Plant } & \multicolumn{2}{|l|}{ Meat } & \multicolumn{2}{|l|}{ Milk } & \multicolumn{2}{|l|}{ Soil } & \multicolumn{2}{|c|}{ Water } \\
\hline ide & Dose & $\%$ & Dose & $\%$ & Dose & 응 & Dose & 음 & Dose & 응 & Dose & 응 & Dose & $\%$ & Dose & $\%$ \\
\hline-241 & $6.49 \mathrm{E}-08$ & 0 & $0.00 E+00$ & 0 & $0.00 \mathrm{E}+00$ & 0 & $5.47 E-06$ & 0 & $7.63 E-08$ & 0 & $1.10 \mathrm{E}-06$ & 0 & $6.86 \mathrm{E}-09$ & 0 & $2.40 E-05$ & 0 \\
\hline-137 & $0.00 \mathrm{E}+00$ & 0 & $0.00 \mathrm{E}+00$ & 0 & $0.00 \mathrm{E}+00$ & 0 & $0.00 \mathrm{E}+00$ & 0 & $0.00 \mathrm{E}+00$ & 0 & $0.00 \mathrm{E}+00$ & 0 & $0.00 \mathrm{E}+00$ & 0 & $0.00 \mathrm{E}+00$ & 0 \\
\hline-237 & $4.66 \mathrm{E}-05$ & 0 & $0.00 \mathrm{E}+00$ & 0 & $0.00 \mathrm{E}+00$ & 0 & $3.90 \mathrm{E}-03$ & 0 & $5.43 E-05$ & 0 & $7.85 E-04$ & 0 & $4.91 E-06$ & 0 & $1.71 \mathrm{E}-02$ & 1 \\
\hline-238 & $3.68 \mathrm{E}-07$ & 0 & $0.00 \mathrm{E}+00$ & 0 & $0.00 \mathrm{E}+00$ & 0 & $2.23 E-05$ & 0 & $5.48 E-07$ & 0 & $3.39 \mathrm{E}-06$ & 0 & $1.85 \mathrm{E}-08$ & 0 & $7.88 \mathrm{E}-05$ & 0 \\
\hline-239 & $4.31 \mathrm{E}-08$ & 0 & $0.00 \mathrm{E}+00$ & 0 & $0.00 \mathrm{E}+00$ & 0 & $7.18 \mathrm{E}-04$ & 0 & $3.52 \mathrm{E}-06$ & 0 & $3.89 \mathrm{E}-07$ & 0 & $1.54 \mathrm{E}-06$ & 0 & $3.13 \mathrm{E}-03$ & 0 \\
\hline-240 & $7.83 \mathrm{E}-11$ & 0 & $0.00 \mathrm{E}+00$ & 0 & $0.00 \mathrm{E}+00$ & 0 & $4.78 E-06$ & 0 & $7.56 \mathrm{E}-08$ & 0 & $1.15 E-06$ & 0 & $3.51 E-09$ & 0 & $2.12 \mathrm{E}-05$ & 0 \\
\hline-99 & $0.00 \mathrm{E}+00$ & 0 & $0.00 \mathrm{E}+00$ & 0 & $0.00 \mathrm{E}+00$ & 0 & $0.00 \mathrm{E}+00$ & 0 & $0.00 \mathrm{E}+00$ & 0 & $0.00 E+00$ & 0 & $0.00 \mathrm{E}+00$ & 0 & $0.00 \mathrm{E}+00$ & 0 \\
\hline-228 & $0.00 \mathrm{E}+00$ & 0 & $0.00 \mathrm{E}+00$ & 0 & $0.00 \mathrm{E}+00$ & 0 & $0.00 \mathrm{E}+00$ & 0 & $0.00 \mathrm{E}+00$ & 0 & $0.00 \mathrm{E}+00$ & 0 & $0.00 \mathrm{E}+00$ & 0 & $0.00 \mathrm{E}+00$ & 0 \\
\hline-230 & $4.95 \mathrm{E}-06$ & 0 & $0.00 \mathrm{E}+00$ & 0 & $0.00 \mathrm{E}+00$ & 0 & $2.23 E-04$ & 0 & $6.39 \mathrm{E}-06$ & 0 & $2.43 E-05$ & 0 & $1.90 \mathrm{E}-07$ & 0 & $7.13 \mathrm{E}-04$ & 0 \\
\hline-232 & $4.70 E-09$ & 0 & $0.00 \mathrm{E}+00$ & 0 & $0.00 \mathrm{E}+00$ & 0 & $4.73 E-08$ & 0 & $1.70 \mathrm{E}-10$ & 0 & $1.31 E-09$ & 0 & $5.74 \mathrm{E}-11$ & 0 & $3.38 E-08$ & 0 \\
\hline 4 & $3.66 \mathrm{E}-03$ & 0 & $0.00 \mathrm{E}+00$ & 0 & $0.00 \mathrm{E}+00$ & 0 & $2.22 E-01$ & 11 & $5.44 E-03$ & 0 & $3.36 E-02$ & 2 & $1.83 E-04$ & 0 & 7. $82 \mathrm{E}-01$ & 40 \\
\hline 35 & 4. $23 E-04$ & 0 & $0.00 \mathrm{E}+00$ & 0 & $0.00 \mathrm{E}+00$ & 0 & $2.22 E-02$ & 1 & $1.27 \mathrm{E}-03$ & 0 & $9.86 \mathrm{E}-04$ & 0 & $3.21 \mathrm{E}-05$ & 0 & $8.27 \mathrm{E}-02$ & 4 \\
\hline 38 & $2.09 \mathrm{E}-03$ & 0 & $0.00 \mathrm{E}+00$ & 0 & $0.00 E+00$ & 0 & $1.50 \mathrm{E}-01$ & 8 & $2.96 E-03$ & 0 & $3.24 E-02$ & 2 & $1.06 \mathrm{E}-04$ & 0 & $6.11 \mathrm{E}-01$ & 31 \\
\hline & $6.22 \mathrm{E}-03$ & 0 & $0.00 E+00$ & 0 & $0.00 \mathrm{E}+00$ & 0 & $3.99 \mathrm{E}-01$ & 20 & $9.74 \mathrm{E}-03$ & 0 & $6.78 E-02$ & 3 & $3.29 \mathrm{E}-04$ & 0 & $1.50 \mathrm{E}+00$ & 76 \\
\hline
\end{tabular}

Total Dose Contributions TDOSE (i,p,t) for Individual Radionuclides (i) and Pathways (p) in mrem/yr and as a Percentage of Total Dose at $t=99976$ years

Directly from primary contamination and from release to atmosphere (Inhalation excludes radon)

\begin{tabular}{|c|c|c|c|c|c|c|c|c|c|c|c|c|c|c|c|c|}
\hline & \multicolumn{2}{|c|}{ Ground } & \multicolumn{2}{|c|}{ Inhalation } & \multicolumn{2}{|c|}{ Radon } & \multicolumn{2}{|c|}{ Plant } & \multicolumn{2}{|l|}{ Meat } & \multicolumn{2}{|l|}{ Milk } & \multicolumn{2}{|l|}{ Soil } & \multicolumn{2}{|c|}{ All Pathways* } \\
\hline clide & Dose & $\%$ & Dose & $\%$ & Dose & $\%$ & Dose & 음 & Dose & $\%$ & Dose & 음 & Dose & $\%$ & Dose & $\%$ \\
\hline-241 & $4.20 E-44$ & 0 & $0.00 \mathrm{E}+00$ & 0 & $0.00 \mathrm{E}+00$ & 0 & $1.54 \mathrm{E}-44$ & 0 & $2.80 E-45$ & 0 & $0.00 \mathrm{E}+00$ & 0 & $2.80 E-45$ & 0 & $3.07 E-05$ & 0 \\
\hline-137 & $1.12 E-44$ & 0 & $0.00 E+00$ & 0 & $0.00 E+00$ & 0 & $0.00 \mathrm{E}+00$ & 0 & 4. $20 E-45$ & 0 & 1. $40 E-45$ & 0 & $0.00 \mathrm{E}+00$ & 0 & 1. $68 \mathrm{E}-44$ & 0 \\
\hline-237 & $4 \cdot 20 E-44$ & 0 & $0.00 E+00$ & 0 & $0.00 E+00$ & 0 & $1.40 E-44$ & 0 & $2.80 E-45$ & 0 & $0.00 E+00$ & 0 & $2.80 E-45$ & 0 & $2.19 \mathrm{E}-02$ & 1 \\
\hline-238 & 1. $92 E-43$ & 0 & $0.00 E+00$ & 0 & $0.00 \mathrm{E}+00$ & 0 & $2.69 E-43$ & 0 & $5.04 \mathrm{E}-44$ & 0 & $5.47 E-44$ & 0 & $8.41 E-45$ & 0 & $1.05 E-04$ & 0 \\
\hline-239 & $4.06 \mathrm{E}-44$ & 0 & $0.00 \mathrm{E}+00$ & 0 & $0.00 \mathrm{E}+00$ & 0 & $9.25 E-44$ & 0 & $8.55 E-44$ & 0 & $0.00 \mathrm{E}+00$ & 0 & $7.01 E-45$ & 0 & $3.86 \mathrm{E}-03$ & 0 \\
\hline-240 & $3.24 E-43$ & 0 & $0.00 E+00$ & 0 & $0.00 \mathrm{E}+00$ & 0 & $3.53 E-43$ & 0 & $4.48 E-44$ & 0 & $7.43 E-44$ & 0 & $7.01 E-45$ & 0 & $2.72 \mathrm{E}-05$ & 0 \\
\hline-99 & $0.00 \mathrm{E}+00$ & 0 & $0.00 E+00$ & 0 & $0.00 \mathrm{E}+00$ & 0 & $0.00 \mathrm{E}+00$ & 0 & $0.00 \mathrm{E}+00$ & 0 & $0.00 E+00$ & 0 & $0.00 \mathrm{E}+00$ & 0 & $0.00 \mathrm{E}+00$ & 0 \\
\hline-228 & $0.00 \mathrm{E}+00$ & 0 & $0.00 \mathrm{E}+00$ & 0 & $0.00 \mathrm{E}+00$ & 0 & $0.00 \mathrm{E}+00$ & 0 & $0.00 \mathrm{E}+00$ & 0 & $0.00 \mathrm{E}+00$ & 0 & $0.00 \mathrm{E}+00$ & 0 & $0.00 \mathrm{E}+00$ & 0 \\
\hline-230 & $1.92 E-43$ & 0 & $0.00 E+00$ & 0 & $0.00 \mathrm{E}+00$ & 0 & $2.66 E-43$ & 0 & $5.04 E-44$ & 0 & $5.47 E-44$ & 0 & $8.41 E-45$ & 0 & $9.72 \mathrm{E}-04$ & 0 \\
\hline-232 & $3.24 E-43$ & 0 & $0.00 E+00$ & 0 & $0.00 E+00$ & 0 & $3.48 E-43$ & 0 & 4. $48 E-44$ & 0 & $7.43 E-44$ & 0 & $4.20 E-45$ & 0 & $8.74 E-08$ & 0 \\
\hline 34 & 1. $92 \mathrm{E}-43$ & 0 & $0.00 \mathrm{E}+00$ & 0 & $0.00 \mathrm{E}+00$ & 0 & $2.66 \mathrm{E}-43$ & 0 & $5.04 \mathrm{E}-44$ & 0 & $5.47 \mathrm{E}-44$ & 0 & $8.41 E-45$ & 0 & $1.05 \mathrm{E}+00$ & 53 \\
\hline 35 & $4.06 \mathrm{E}-44$ & 0 & $0.00 \mathrm{E}+00$ & 0 & $0.00 \mathrm{E}+00$ & 0 & $8.97 E-44$ & 0 & $8.55 E-44$ & 0 & $0.00 \mathrm{E}+00$ & 0 & $5.61 E-45$ & 0 & $1.08 \mathrm{E}-01$ & 5 \\
\hline 38 & $1.93 E-43$ & 0 & $0.00 E+00$ & 0 & $0.00 \mathrm{E}+00$ & 0 & $2.66 E-43$ & 0 & $5.04 E-44$ & 0 & $5.47 E-44$ & 0 & $8.41 E-45$ & 0 & 7. $98 \mathrm{E}-01$ & 40 \\
\hline & 1. $59 \mathrm{E}-42$ & 0 & $0.00 \mathrm{E}+00$ & 0 & $0.00 \mathrm{E}+00$ & 0 & 1. $98 \mathrm{E}-42$ & 0 & $4.72 E-43$ & 0 & $3.69 E-43$ & 0 & $6.31 E-44$ & 0 & $1.98 \mathrm{E}+00$ & 100 \\
\hline
\end{tabular}

* Sum of dose from all releases and from primary contamination. 
RESRAD-OFFSITE, Version 2.

Parent Dose Report

Title : Offsite Resident Farmer Deterministic Run

File : RF DOE SG FWD-FV2-100000Y.ROF

Dose/Source Ratios Summed Over All Pathways

Parent and Progeny Principal Radionuclide Contributions Indicated

\begin{tabular}{|c|c|c|c|c|c|c|c|c|c|c|}
\hline Parent & Product & Thread & & & $\operatorname{DSR}(j, t$ & (mrem/yr & )/(pCi/g) & & & \\
\hline (i) & $(j)$ & Fraction & $0.000 \mathrm{E}+00$ & $1.000 \mathrm{E}+00$ & $5.000 \mathrm{E}+01$ & $1.000 \mathrm{E}+02$ & $5.000 \mathrm{E}+02$ & $1.026 \mathrm{E}+03$ & $9.976 \mathrm{E}+03$ & $9.998 \mathrm{E}+04$ \\
\hline-241 & $A m-241$ & $1.000 \mathrm{E}+00$ & $1.174 \mathrm{E}-41$ & $1.205 E-41$ & $3.993 E-41$ & $1.357 E-40$ & $2.395 E-36$ & $9.225 E-31$ & $4.317 E-13$ & $0.000 \mathrm{E}+00$ \\
\hline-241 & $N p-237+D$ & $1.000 \mathrm{E}+00$ & $9.847 \mathrm{E}-28$ & $2.972 E-27$ & $1.493 \mathrm{E}-25$ & $4.686 \mathrm{E}-25$ & $9.097 \mathrm{E}-23$ & $2.418 \mathrm{E}-20$ & $5.099 \mathrm{E}-05$ & $0.000 \mathrm{E}+00$ \\
\hline $1-241$ & $\mathrm{U}-233$ & $1.000 \mathrm{E}+00$ & $2.063 E-37$ & $6.958 \mathrm{E}-37$ & $2.830 E-34$ & $1.936 \mathrm{E}-33$ & $3.934 \mathrm{E}-30$ & $5.620 \mathrm{E}-27$ & $1.146 \mathrm{E}-07$ & $6.953 E-07$ \\
\hline-241 & $T h-229+D$ & $1.000 \mathrm{E}+00$ & $1.118 \mathrm{E}-32$ & $4.508 E-32$ & $1.023 E-28$ & $1.080 \mathrm{E}-27$ & $1.481 \mathrm{E}-24$ & $3.196 \mathrm{E}-22$ & $8.344 E-09$ & $1.815 \mathrm{E}-07$ \\
\hline $1-241$ & $\sum \operatorname{DSR}(j)$ & & $9.847 \mathrm{E}-28$ & $2.973 E-27$ & $1.494 \mathrm{E}-25$ & $4.696 \mathrm{E}-25$ & $9.246 \mathrm{E}-23$ & $2.450 \mathrm{E}-20$ & $5.111 \mathrm{E}-05$ & $8.768 \mathrm{E}-07$ \\
\hline$-137+D$ & $\mathrm{Cs}-137+\mathrm{D}$ & $1.000 \mathrm{E}+00$ & 7. $651 \mathrm{E}-18$ & 7. $539 \mathrm{E}-18$ & $3.553 E-18$ & 1. $649 \mathrm{E}-18$ & $3.545 E-21$ & $1.102 E-24$ & $1.401 E-45$ & $1.401 \mathrm{E}-45$ \\
\hline$-237+D$ & $N p-237+D$ & $1.000 \mathrm{E}+00$ & $5.781 \mathrm{E}-21$ & $5.840 \mathrm{E}-21$ & $9.470 \mathrm{E}-21$ & $1.551 \mathrm{E}-20$ & $8.028 E-19$ & $1.441 \mathrm{E}-16$ & $2.337 E-01$ & $2.803 E-45$ \\
\hline$-237+D$ & $\mathrm{U}-233$ & $1.000 \mathrm{E}+00$ & $2.093 E-31$ & $6.330 \mathrm{E}-31$ & $3.533 E-29$ & 1. $249 \mathrm{E}-28$ & $6.192 \mathrm{E}-26$ & $5.396 E-23$ & $5.369 E-04$ & $3.146 \mathrm{E}-03$ \\
\hline$-237+D$ & $\mathrm{Th}-229+\mathrm{D}$ & $1.000 \mathrm{E}+00$ & 1. $701 \mathrm{E}-26$ & $5.704 \mathrm{E}-26$ & $1.898 \mathrm{E}-23$ & $1.031 \mathrm{E}-22$ & $3.287 \mathrm{E}-20$ & $4.104 \mathrm{E}-18$ & $4.414 \mathrm{E}-05$ & $8.325 E-04$ \\
\hline-237 & $\sum \operatorname{DSR}(j)$ & & $5.781 \mathrm{E}-21$ & $5.840 \mathrm{E}-21$ & $9.489 \mathrm{E}-21$ & $1.562 \mathrm{E}-20$ & $8.357 E-19$ & 1. $482 \mathrm{E}-16$ & $2.342 E-01$ & $3.978 E-03$ \\
\hline-238 & $\mathrm{Pu}-238$ & $1.840 \mathrm{E}-09$ & $1.310 \mathrm{E}-41$ & $1.321 \mathrm{E}-41$ & $1.990 \mathrm{E}-41$ & $3.023 E-41$ & $8.562 E-40$ & $6.953 E-38$ & $0.000 \mathrm{E}+00$ & $0.000 \mathrm{E}+00$ \\
\hline-238 & $\mathrm{Pu}-238$ & $1.000 \mathrm{E}+00$ & $7.120 \mathrm{E}-33$ & $7.181 \mathrm{E}-33$ & $1.082 \mathrm{E}-32$ & $1.643 E-32$ & $4.653 E-31$ & $3.779 E-29$ & 1. $487 \mathrm{E}-40$ & $0.000 \mathrm{E}+00$ \\
\hline-238 & $\mathrm{U}-234$ & $1.000 \mathrm{E}+00$ & $6.336 \mathrm{E}-38$ & $1.917 \mathrm{E}-37$ & $1.118 \mathrm{E}-35$ & $4.207 E-35$ & $5.109 \mathrm{E}-32$ & $2.760 \mathrm{E}-28$ & $9.222 \mathrm{E}-11$ & $9.721 \mathrm{E}-07$ \\
\hline-238 & $\mathrm{Th}-230$ & $1.000 \mathrm{E}+00$ & $6.109 \mathrm{E}-41$ & $2.066 \mathrm{E}-40$ & $9.148 \mathrm{E}-38$ & $6.949 \mathrm{E}-37$ & $4.083 E-33$ & $3.351 E-29$ & $7.797 \mathrm{E}-11$ & 1. $680 \mathrm{E}-08$ \\
\hline-238 & $\mathrm{Ra}-226+\mathrm{D}$ & $1.000 \mathrm{E}+00$ & $3.705 E-29$ & $1.489 \mathrm{E}-28$ & $3.146 \mathrm{E}-25$ & $3.072 \mathrm{E}-24$ & $2.593 E-21$ & $3.655 E-19$ & $1.795 \mathrm{E}-07$ & $1.782 \mathrm{E}-07$ \\
\hline$x-238$ & $\mathrm{~Pb}-210+\mathrm{D}$ & $1.000 \mathrm{E}+00$ & $7.989 E-37$ & $4.224 E-36$ & $4.667 \mathrm{E}-32$ & $7.546 \mathrm{E}-31$ & $1.634 \mathrm{E}-27$ & $4.209 E-25$ & $8.372 \mathrm{E}-11$ & $1.536 \mathrm{E}-06$ \\
\hline$x-238$ & $\sum \operatorname{DSR}(j)$ & & $3.706 E-29$ & $1.489 \mathrm{E}-28$ & $3.146 \mathrm{E}-25$ & $3.072 E-24$ & $2.593 E-21$ & $3.655 E-19$ & $1.797 \mathrm{E}-07$ & $2.703 E-06$ \\
\hline-239 & $\mathrm{Pu}-239$ & $1.000 \mathrm{E}+00$ & $7.288 E-26$ & $7.371 \mathrm{E}-26$ & $1.263 \mathrm{E}-25$ & $2.189 \mathrm{E}-25$ & $1.777 \mathrm{E}-23$ & $5.765 E-21$ & $2.133 E-06$ & $1.069 \mathrm{E}-04$ \\
\hline-239 & $\mathrm{U}-235+\mathrm{D}$ & $1.000 \mathrm{E}+00$ & $3.955 E-32$ & $1.196 \mathrm{E}-31$ & $6.634 E-30$ & $2.330 E-29$ & $1.094 \mathrm{E}-26$ & $8.878 E-24$ & $2.129 E-09$ & $4.867 E-08$ \\
\hline-239 & $\mathrm{~Pa}-231$ & $1.000 \mathrm{E}+00$ & $5.642 E-35$ & $1.900 \mathrm{E}-34$ & 7. $325 E-32$ & $4.711 \mathrm{E}-31$ & $5.776 \mathrm{E}-28$ & $4.122 E-25$ & $8.186 \mathrm{E}-11$ & $5.413 E-08$ \\
\hline-239 & $A C-227+D$ & $1.000 \mathrm{E}+00$ & $1.034 \mathrm{E}-33$ & $4.121 \mathrm{E}-33$ & $7.560 \mathrm{E}-30$ & $6.652 \mathrm{E}-29$ & $6.352 \mathrm{E}-26$ & $2.020 E-23$ & $7.962 \mathrm{E}-10$ & $1.006 \mathrm{E}-07$ \\
\hline$u-239$ & $\sum \operatorname{DSR}(j)$ & & $7.288 E-26$ & $7.371 E-26$ & $1.263 E-25$ & $2.190 \mathrm{E}-25$ & $1.784 \mathrm{E}-23$ & $5.795 E-21$ & $2.136 \mathrm{E}-06$ & $1.071 \mathrm{E}-04$ \\
\hline$x-240$ & $\mathrm{Pu}-240$ & $4.950 E-08$ & $3.427 E-40$ & $3.485 E-40$ & $7.691 \mathrm{E}-40$ & $1.726 E-39$ & $1.103 E-36$ & $5.405 E-33$ & $4.730 \mathrm{E}-14$ & $2.351 \mathrm{E}-15$ \\
\hline-240 & $\mathrm{Pu}-240$ & $1.000 \mathrm{E}+00$ & $6.923 E-33$ & $7.041 E-33$ & $1.554 \mathrm{E}-32$ & $3.486 \mathrm{E}-32$ & $2.229 E-29$ & $1.092 E-25$ & $9.556 \mathrm{E}-07$ & $4.749 \mathrm{E}-08$ \\
\hline-240 & $U-236$ & $1.000 \mathrm{E}+00$ & $1.433 E-40$ & $4.348 E-40$ & $3.024 E-38$ & $1.373 E-37$ & $5.038 E-34$ & $6.112 \mathrm{E}-30$ & $3.996 \mathrm{E}-11$ & $7.082 E-07$ \\
\hline-240 & Th-232 & $1.000 \mathrm{E}+00$ & $0.000 \mathrm{E}+00$ & $0.000 \mathrm{E}+00$ & $0.000 \mathrm{E}+00$ & $0.000 \mathrm{E}+00$ & $6.534 \mathrm{E}-42$ & $2.163 E-37$ & 1. $383 \mathrm{E}-16$ & $8.103 E-14$ \\
\hline-240 & $\mathrm{Ra}-228+\mathrm{D}$ & $1.000 \mathrm{E}+00$ & $5.526 \mathrm{E}-35$ & $2.123 E-34$ & $2.231 \mathrm{E}-31$ & $1.457 \mathrm{E}-30$ & $6.619 \mathrm{E}-28$ & $1.096 \mathrm{E}-25$ & $2.174 \mathrm{E}-13$ & $1.841 \mathrm{E}-12$ \\
\hline-240 & $T h-228+D$ & $1.000 \mathrm{E}+00$ & $1.826 E-33$ & $8.064 E-33$ & $1.576 \mathrm{E}-29$ & $1.020 \mathrm{E}-28$ & $2.672 E-26$ & $2.031 E-24$ & $3.437 \mathrm{E}-13$ & $6.498 E-14$ \\
\hline-240 & $\sum \operatorname{DSR}(j)$ & & $8.804 E-33$ & $1.532 \mathrm{E}-32$ & $1.600 \mathrm{E}-29$ & $1.035 E-28$ & $2.741 E-26$ & $2.249 \mathrm{E}-24$ & $9.557 \mathrm{E}-07$ & $7.557 \mathrm{E}-07$ \\
\hline$c-99$ & $\mathrm{TC}-99$ & $1.000 \mathrm{E}+00$ & $3.496 \mathrm{E}-34$ & $3.541 \mathrm{E}-34$ & $6.502 E-34$ & $1.209 E-33$ & $1.724 \mathrm{E}-31$ & $1.173 E-28$ & $4.416 E-31$ & $0.000 \mathrm{E}+00$ \\
\hline $228+D$ & $\mathrm{Th}-228+\mathrm{D}$ & $1.000 \mathrm{E}+00$ & $9.241 \mathrm{E}-15$ & $7.899 \mathrm{E}-15$ & $2.079 E-22$ & $4.482 E-30$ & $0.000 \mathrm{E}+00$ & $0.000 \mathrm{E}+00$ & $0.000 \mathrm{E}+00$ & $0.000 \mathrm{E}+00$ \\
\hline
\end{tabular}


RESRAD-OFFSITE, Version 2.5

Parent Dose Report

Title : Offsite Resident Farmer Deterministic Run

File : RF DOE SG FWD-FV2-100000Y.ROF

Dose/Source Ratios Summed Over All Pathways

Parent and Progeny Principal Radionuclide Contributions Indicated

\begin{tabular}{|c|c|c|c|c|c|c|c|c|c|c|}
\hline Parent & Product & Thread & & & $\operatorname{DSR}(j, t$ & (mrem/y & c) / ( $\mathrm{pCi} / \mathrm{g})$ & & & \\
\hline (i) & (j) & Fraction & $0.000 \mathrm{E}+00$ & $1.000 \mathrm{E}+00$ & $5.000 \mathrm{E}+01$ & $1.000 \mathrm{E}+02$ & $5.000 \mathrm{E}+02$ & $1.026 \mathrm{E}+03$ & $9.976 \mathrm{E}+03$ & $9.998 \mathrm{E}+04$ \\
\hline-230 & Th-230 & $1.000 \mathrm{E}+00$ & $1.462 \mathrm{E}-30$ & 1. $486 \mathrm{E}-30$ & $3.173 E-30$ & $6.882 E-30$ & $3.361 \mathrm{E}-27$ & $1.155 E-23$ & $2.517 \mathrm{E}-06$ & $2.298 E-09$ \\
\hline-230 & $\mathrm{Ra}-226+\mathrm{D}$ & $1.000 \mathrm{E}+00$ & $2.365 E-19$ & $7.124 \mathrm{E}-19$ & $3.142 \mathrm{E}-17$ & $8.499 \mathrm{E}-17$ & $4.949 E-15$ & $2.589 E-13$ & $7.400 \mathrm{E}-03$ & $9.671 E-07$ \\
\hline $1-230$ & $\mathrm{~Pb}-210+\mathrm{D}$ & $1.000 \mathrm{E}+00$ & $9.929 E-27$ & $3.293 E-26$ & $7.659 \mathrm{E}-24$ & $3.033 E-23$ & $3.413 E-21$ & $3.104 \mathrm{E}-19$ & $3.465 E-06$ & $8.750 E-06$ \\
\hline-230 & $\sum \operatorname{DSR}(j)$ & & $2.365 E-19$ & $7.124 \mathrm{E}-19$ & $3.142 \mathrm{E}-17$ & $8.499 \mathrm{E}-17$ & $4.949 \mathrm{E}-15$ & $2.589 \mathrm{E}-13$ & $7.406 \mathrm{E}-03$ & $9.719 \mathrm{E}-06$ \\
\hline-232 & Th-232 & $1.000 \mathrm{E}+00$ & $7.067 E-33$ & $7.194 \mathrm{E}-33$ & $1.663 E-32$ & $3.911 \mathrm{E}-32$ & $3.646 E-29$ & $2.934 E-25$ & $2.805 E-06$ & $6.182 \mathrm{E}-09$ \\
\hline-232 & $\mathrm{Ra}-228+\mathrm{D}$ & $1.000 \mathrm{E}+00$ & $5.136 \mathrm{E}-18$ & $1.503 \mathrm{E}-17$ & $1.638 \mathrm{E}-16$ & $2.330 \mathrm{E}-16$ & $3.818 \mathrm{E}-15$ & $1.510 \mathrm{E}-13$ & $4.414 \mathrm{E}-03$ & $1.473 \mathrm{E}-08$ \\
\hline$h-232$ & $T h-228+D$ & $1.000 \mathrm{E}+00$ & $2.841 E-16$ & $8.539 E-16$ & 1. $310 \mathrm{E}-14$ & $1.731 \mathrm{E}-14$ & $1.559 \mathrm{E}-13$ & $2.813 E-12$ & $6.982 E-03$ & $9.335 \mathrm{E}-10$ \\
\hline$h-232$ & $\sum \operatorname{DSR}(j)$ & & $2.893 E-16$ & $8.690 \mathrm{E}-16$ & $1.327 \mathrm{E}-14$ & $1.754 \mathrm{E}-14$ & $1.597 \mathrm{E}-13$ & $2.964 \mathrm{E}-12$ & $1.140 \mathrm{E}-02$ & $2.184 \mathrm{E}-08$ \\
\hline-234 & $\mathrm{U}-234$ & $1.000 \mathrm{E}+00$ & $4.180 E-32$ & $4.252 E-32$ & $9.453 E-32$ & $2.137 E-31$ & 1. $450 \mathrm{E}-28$ & $7.686 \mathrm{E}-25$ & $2.568 E-07$ & $2.351 E-03$ \\
\hline-234 & Th-230 & $1.000 \mathrm{E}+00$ & $7.175 E-36$ & $2.176 \mathrm{E}-35$ & $1.446 \mathrm{E}-33$ & $6.236 \mathrm{E}-33$ & $1.513 \mathrm{E}-29$ & $1.065 \mathrm{E}-25$ & $2.200 \mathrm{E}-07$ & $4.064 \mathrm{E}-05$ \\
\hline-234 & $\mathrm{Ra}-226+\mathrm{D}$ & $1.000 \mathrm{E}+00$ & $6.500 \mathrm{E}-24$ & $2.179 \mathrm{E}-23$ & 7. 199E-21 & $3.879 \mathrm{E}-20$ & $1.154 \mathrm{E}-17$ & 1. $282 \mathrm{E}-15$ & $5.081 \mathrm{E}-04$ & 4. $312 \mathrm{E}-04$ \\
\hline-234 & $\mathrm{~Pb}-210+\mathrm{D}$ & $1.000 \mathrm{E}+00$ & $1.847 \mathrm{E}-31$ & $7.353 E-31$ & $1.308 \mathrm{E}-27$ & $1.107 \mathrm{E}-26$ & $7.466 \mathrm{E}-24$ & 1. $488 \mathrm{E}-21$ & $2.371 E-07$ & $3.718 E-03$ \\
\hline-234 & $\sum \operatorname{DSR}(j)$ & & $6.500 \mathrm{E}-24$ & $2.179 \mathrm{E}-23$ & 7.199E-21 & $3.879 \mathrm{E}-20$ & $1.154 \mathrm{E}-17$ & 1. $282 \mathrm{E}-15$ & $5.088 \mathrm{E}-04$ & $6.540 \mathrm{E}-03$ \\
\hline$-235+D$ & $\mathrm{U}-235+\mathrm{D}$ & $1.000 \mathrm{E}+00$ & $7.537 E-23$ & $7.626 \mathrm{E}-23$ & 1. $332 \mathrm{E}-22$ & $2.354 \mathrm{E}-22$ & $2.233 E-20$ & $8.896 \mathrm{E}-18$ & $2.453 E-04$ & $3.048 E-03$ \\
\hline$-235+D$ & $\mathrm{~Pa}-231$ & $1.000 \mathrm{E}+00$ & $1.877 \mathrm{E}-26$ & $5.670 \mathrm{E}-26$ & $2.931 \mathrm{E}-24$ & $9.502 \mathrm{E}-24$ & $2.350 \mathrm{E}-21$ & $8.201 E-19$ & $1.760 \mathrm{E}-05$ & $4.726 \mathrm{E}-03$ \\
\hline$-235+D$ & $A C-227+D$ & $1.000 \mathrm{E}+00$ & $5.079 \mathrm{E}-25$ & $1.686 \mathrm{E}-24$ & $4.046 \mathrm{E}-22$ & $1.670 \mathrm{E}-21$ & $2.745 E-19$ & $4.141 \mathrm{E}-17$ & $1.717 \mathrm{E}-04$ & $8.783 \mathrm{E}-03$ \\
\hline-235 & $\sum \operatorname{DSR}(j)$ & & $7.589 \mathrm{E}-23$ & $7.800 \mathrm{E}-23$ & $5.408 \mathrm{E}-22$ & $1.915 \mathrm{E}-21$ & $2.991 \mathrm{E}-19$ & $5.112 \mathrm{E}-17$ & $4.346 \mathrm{E}-04$ & $1.656 \mathrm{E}-02$ \\
\hline-238 & $\mathrm{U}-238$ & $5.400 \mathrm{E}-05$ & $0.000 \mathrm{E}+00$ & $0.000 \mathrm{E}+00$ & $0.000 \mathrm{E}+00$ & $0.000 \mathrm{E}+00$ & $0.000 \mathrm{E}+00$ & $0.000 \mathrm{E}+00$ & $9.672 \mathrm{E}-12$ & $1.548 \mathrm{E}-07$ \\
\hline$-238+D$ & $\mathrm{U}-238+\mathrm{D}$ & $9.999 \mathrm{E}-01$ & $8.606 \mathrm{E}-19$ & $8.671 \mathrm{E}-19$ & $1.243 \mathrm{E}-18$ & $1.797 \mathrm{E}-18$ & $3.408 \mathrm{E}-17$ & $1.635 \mathrm{E}-15$ & $9.862 \mathrm{E}-05$ & $3.090 \mathrm{E}-03$ \\
\hline$-238+D$ & $\mathrm{U}-234$ & $9.999 \mathrm{E}-01$ & $6.489 \mathrm{E}-38$ & $1.969 \mathrm{E}-37$ & $1.357 \mathrm{E}-35$ & $6.100 \mathrm{E}-35$ & $2.060 \mathrm{E}-31$ & $2.240 \mathrm{E}-27$ & 7. $366 \mathrm{E}-09$ & $7.698 \mathrm{E}-04$ \\
\hline$-238+D$ & $\mathrm{Th}-230$ & $9.999 \mathrm{E}-01$ & $6.207 E-41$ & $2.106 \mathrm{E}-40$ & $1.042 \mathrm{E}-37$ & $8.910 E-37$ & $1.073 E-32$ & $1.549 \mathrm{E}-28$ & $3.111 \mathrm{E}-09$ & $1.103 \mathrm{E}-05$ \\
\hline$-238+D$ & $\mathrm{Ra}-226+\mathrm{D}$ & $9.999 \mathrm{E}-01$ & $3.749 E-29$ & $1.512 \mathrm{E}-28$ & $3.470 \mathrm{E}-25$ & $3.708 \mathrm{E}-24$ & $5.556 \mathrm{E}-21$ & 1. $288 \mathrm{E}-18$ & $5.983 E-06$ & $1.162 \mathrm{E}-04$ \\
\hline$-238+D$ & $\mathrm{~Pb}-210+\mathrm{D}$ & $9.999 \mathrm{E}-01$ & $8.034 \mathrm{E}-37$ & $4.276 \mathrm{E}-36$ & $5.069 \mathrm{E}-32$ & $8.887 E-31$ & $3.389 \mathrm{E}-27$ & $1.449 \mathrm{E}-24$ & $2.782 \mathrm{E}-09$ & $1.002 \mathrm{E}-03$ \\
\hline-238 & $\sum \operatorname{DSR}(j)$ & & $8.606 \mathrm{E}-19$ & $8.671 \mathrm{E}-19$ & $1.243 \mathrm{E}-18$ & $1.797 \mathrm{E}-18$ & $3.409 \mathrm{E}-17$ & $1.636 \mathrm{E}-15$ & $1.046 \mathrm{E}-04$ & $4.989 \mathrm{E}-03$ \\
\hline
\end{tabular}

The DSR includes contributions from associated (half-life $\leq 180$ days) daughters. 
RESRAD-OFFSITE, Version 2.

Parent Dose Report

Title : Offsite Resident Farmer Deterministic Run

File : RF DOE SG FWD-FV2-100000Y.ROF

Single Radionuclide Soil Guidelines G(i,t) in pCi/g

Basic Radiation Dose Limit $=1.000 \mathrm{E}+00 \mathrm{mrem} / \mathrm{yr}$

Nuclide

\begin{tabular}{|c|c|c|c|c|c|c|c|c|}
\hline (i) & $t=0.000 \mathrm{E}+00$ & $1.000 \mathrm{E}+00$ & $5.000 \mathrm{E}+01$ & $1.000 \mathrm{E}+02$ & $5.000 \mathrm{E}+02$ & $1.026 \mathrm{E}+03$ & $9.976 \mathrm{E}+03$ & $9.998 \mathrm{E}+04$ \\
\hline-241 & $\star 3.431 \mathrm{E}+12$ & $\star 3.431 \mathrm{E}+12$ & $\star 3.431 \mathrm{E}+12$ & $\star 3.431 \mathrm{E}+12$ & $\star 3.431 \mathrm{E}+12$ & $\star 3.431 \mathrm{E}+12$ & $1.956 \mathrm{E}+04$ & $1.140 \mathrm{E}+06$ \\
\hline-137 & $\star 8.704 \mathrm{E}+13$ & $\star 8.704 \mathrm{E}+13$ & $\star 8.704 \mathrm{E}+13$ & $\star 8.704 \mathrm{E}+13$ & $\star 8.704 \mathrm{E}+13$ & $\star 8.704 \mathrm{E}+13$ & $\star 8.704 \mathrm{E}+13$ & $\star 8.704 \mathrm{E}+13$ \\
\hline-237 & $\star 7.047 \mathrm{E}+08$ & $\star 7.047 \mathrm{E}+08$ & $\star 7.047 \mathrm{E}+08$ & $\star 7.047 \mathrm{E}+08$ & $\star 7.047 \mathrm{E}+08$ & $\star 7.047 \mathrm{E}+08$ & $4.269 \mathrm{E}+00$ & $2.514 \mathrm{E}+02$ \\
\hline-238 & $\star 1.712 \mathrm{E}+13$ & $* 1.712 \mathrm{E}+13$ & $\star 1.712 \mathrm{E}+13$ & $* 1.712 \mathrm{E}+13$ & $\star 1.712 \mathrm{E}+13$ & $\star 1.712 \mathrm{E}+13$ & $5.565 \mathrm{E}+06$ & $3.699 \mathrm{E}+05$ \\
\hline-239 & $\star 6.214 \mathrm{E}+10$ & $* 6.214 \mathrm{E}+10$ & $\star 6.214 \mathrm{E}+10$ & $\star 6.214 \mathrm{E}+10$ & $\star 6.214 \mathrm{E}+10$ & $* 6.214 \mathrm{E}+10$ & $4.682 \mathrm{E}+05$ & $9.333 \mathrm{E}+03$ \\
\hline-240 & $\star 2.278 \mathrm{E}+11$ & $\star 2.278 \mathrm{E}+11$ & $\star 2.278 \mathrm{E}+11$ & $\star 2.278 \mathrm{E}+11$ & $\star 2.278 \mathrm{E}+11$ & $\star 2.278 \mathrm{E}+11$ & $1.046 \mathrm{E}+06$ & $1.323 \mathrm{E}+06$ \\
\hline$c-99$ & $\star 1.697 \mathrm{E}+10$ & $* 1.697 \mathrm{E}+10$ & $\star 1.697 \mathrm{E}+10$ & $* 1.697 \mathrm{E}+10$ & $\star 1.697 \mathrm{E}+10$ & $* 1.697 \mathrm{E}+10$ & $* 1.697 \mathrm{E}+10$ & $\star 1.697 \mathrm{E}+10$ \\
\hline$h-228$ & $1.082 \mathrm{E}+14$ & $1.266 \mathrm{E}+14$ & $\star 8.195 \mathrm{E}+14$ & $\star 8.195 E+14$ & $\star 8.195 \mathrm{E}+14$ & $\star 8.195 \mathrm{E}+14$ & $\star 8.195 \mathrm{E}+14$ & $\star 8.195 \mathrm{E}+14$ \\
\hline Th-230 & $\star 2.018 \mathrm{E}+10$ & $\star 2.018 \mathrm{E}+10$ & $\star 2.018 \mathrm{E}+10$ & $\star 2.018 \mathrm{E}+10$ & $\star 2.018 \mathrm{E}+10$ & $\star 2.018 \mathrm{E}+10$ & $1.350 \mathrm{E}+02$ & $1.029 \mathrm{E}+05$ \\
\hline 232 & $* 1.097 \mathrm{E}+05$ & $* 1.097 \mathrm{E}+05$ & $\star 1.097 \mathrm{E}+05$ & $* 1.097 \mathrm{E}+05$ & $* 1.097 \mathrm{E}+05$ & *1.097E+05 & $8.773 E+01$ & $* 1.097 \mathrm{E}+05$ \\
\hline 34 & $* 6.247 \mathrm{E}+09$ & $* 6.247 \mathrm{E}+09$ & $\star 6.247 \mathrm{E}+09$ & $* 6.247 \mathrm{E}+09$ & $* 6.247 \mathrm{E}+09$ & $* 6.247 \mathrm{E}+09$ & $1.965 \mathrm{E}+03$ & $1.529 \mathrm{E}+02$ \\
\hline 35 & $\star 2.161 \mathrm{E}+06$ & $\star 2.161 \mathrm{E}+06$ & $\star 2.161 \mathrm{E}+06$ & $\star 2.161 \mathrm{E}+06$ & $\star 2.161 \mathrm{E}+06$ & $\star 2.161 \mathrm{E}+06$ & $2.301 \mathrm{E}+03$ & $6.040 \mathrm{E}+01$ \\
\hline 38 & $\star 3.361 \mathrm{E}+05$ & $\star 3.361 \mathrm{E}+05$ & $\star 3.361 \mathrm{E}+05$ & $\star 3.361 E+05$ & $\star 3.361 \mathrm{E}+05$ & $\star 3.361 \mathrm{E}+05$ & $9.558 \mathrm{E}+03$ & $2.005 E+02$ \\
\hline
\end{tabular}

*At specific activity limit

Summed Dose/Source Ratios DSR(i,t) in (mrem/yr)/(pCi/g)

and Single Radionuclide Soil Guidelines G(i,t) in pCi/g

at tmin = time of minimum single radionuclide soil guideline

and at $\operatorname{tmax}=$ time of maximum total dose $=10065$ years

\begin{tabular}{|c|c|c|c|c|c|c|}
\hline $\begin{array}{l}\text { uclide } \\
\text { (i) }\end{array}$ & $\begin{array}{l}\text { Initial } \\
(\mathrm{pCi} / \mathrm{g})\end{array}$ & $\begin{array}{c}\text { tmin } \\
\text { (years) }\end{array}$ & $\operatorname{DSR}(i, \operatorname{tmin})$ & $\begin{array}{c}G(i, \operatorname{tmin}) \\
(\mathrm{pci} / \mathrm{g})\end{array}$ & $\operatorname{DSR}(i, t \max )$ & $\begin{array}{c}G(i, t \max ) \\
(\mathrm{pC} i / g)\end{array}$ \\
\hline$m-241$ & $3.500 \mathrm{E}+01$ & 10590 & $5.165 \mathrm{E}-05$ & $1.936 \mathrm{E}+04$ & $5.126 \mathrm{E}-05$ & $1.951 \mathrm{E}+04$ \\
\hline$s-137$ & $1.900 \mathrm{E}+01$ & 0 & 7. $651 \mathrm{E}-18$ & $\star 8.704 \mathrm{E}+13$ & 1. $401 \mathrm{E}-45$ & $\star 8.704 \mathrm{E}+13$ \\
\hline-237 & $5.500 \mathrm{E}+00$ & 9979 & $2.342 \mathrm{E}-01$ & $4.269 \mathrm{E}+00$ & $2.342 \mathrm{E}-01$ & $4.270 E+00$ \\
\hline$x-238$ & $3.900 \mathrm{E}+01$ & 99989 & $2.704 \mathrm{E}-06$ & $3.698 E+05$ & $1.816 \mathrm{E}-07$ & $5.508 E+06$ \\
\hline$u-239$ & $3.600 \mathrm{E}+01$ & 99989 & $1.072 \mathrm{E}-04$ & $9.329 \mathrm{E}+03$ & $2.129 \mathrm{E}-06$ & $4.698 \mathrm{E}+05$ \\
\hline$x-240$ & $3.600 \mathrm{E}+01$ & 3455 & $1.960 \mathrm{E}-06$ & $5.102 E+05$ & $9.459 \mathrm{E}-07$ & $1.057 \mathrm{E}+06$ \\
\hline-99 & $5.200 \mathrm{E}+01$ & 2753 & 1. $401 \mathrm{E}-14$ & $\star 1.697 \mathrm{E}+10$ & $2.769 \mathrm{E}-31$ & $\star 1.697 \mathrm{E}+10$ \\
\hline $1-228$ & $4.000 \mathrm{E}+00$ & 0 & $9.241 \mathrm{E}-15$ & $1.082 \mathrm{E}+14$ & $0.000 \mathrm{E}+00$ & $\star 8.195 \mathrm{E}+14$ \\
\hline-230 & $1.000 \mathrm{E}+02$ & 8588 & $7.434 \mathrm{E}-03$ & $1.345 E+02$ & $7.403 E-03$ & $1.351 \mathrm{E}+02$ \\
\hline-232 & $4.000 \mathrm{E}+00$ & 2753 & $1.154 \mathrm{E}-02$ & $8.667 E+01$ & $1.140 \mathrm{E}-02$ & $8.774 \mathrm{E}+01$ \\
\hline-234 & $1.600 \mathrm{E}+02$ & 99989 & $6.542 \mathrm{E}-03$ & 1. $529 \mathrm{E}+02$ & $5.140 \mathrm{E}-04$ & $1.946 \mathrm{E}+03$ \\
\hline-235 & $6.500 \mathrm{E}+00$ & 97255 & $1.663 \mathrm{E}-02$ & $6.014 E+01$ & $4.357 E-04$ & $2.295 E+03$ \\
\hline-238 & $1.600 \mathrm{E}+02$ & 99989 & $4.990 \mathrm{E}-03$ & $2.004 E+02$ & $1.046 \mathrm{E}-04$ & $9.558 E+03$ \\
\hline
\end{tabular}

${ }^{*}$ At specific activity limit 
RESRAD-OFFSITE, Version 2.

Parent Dose Report

Title : Offsite Resident Farmer Deterministic Run

File : RF DOE SG FWD-FV2-100000Y.ROF

Individual Nuclide Dose Summed Over All Pathways

Parent Nuclide and Thread Fraction Indicated

Nuclide Parent THF(i) DOSE $(j, t), \mathrm{mrem} / \mathrm{yr}$

\begin{tabular}{|c|c|c|}
\hline (j) & (i) & \\
\hline$n-241$ & $A m-241$ & $1.000 \mathrm{E}+00$ \\
\hline-237 & $A m-241$ & $1.000 \mathrm{E}+00$ \\
\hline-237 & $\mathrm{~Np}-237$ & $1.000 \mathrm{E}+00$ \\
\hline 237 & $\sum \operatorname{DOSE}($ & : \\
\hline
\end{tabular}

$\mathrm{U}-233 \quad \mathrm{Am}-241 \quad 1.000 \mathrm{E}+00$

$\mathrm{U}-233 \quad \mathrm{~Np}-237 \quad 1.000 \mathrm{E}+00$

U-233 $\operatorname{DOSE}(j):$

Th-229 Am-241 $1.000 \mathrm{E}+00$

Th-229 Np-237 $1.000 \mathrm{E}+00$

Th-229 $\operatorname{DOSE}(j):$

Cs-137 Cs-137 $1.000 \mathrm{E}+00$

Pu-238 $\mathrm{Pu}-238 \quad 1.840 \mathrm{E}-09$

$\mathrm{Pu}-238 \mathrm{Pu}-238 \quad 1.000 \mathrm{E}+00$

$\operatorname{Pu}-238 \quad \sum \operatorname{DOSE}(j):$

$\mathrm{U}-234$

$\mathrm{U}-234$

$\mathrm{U}-234$

$\mathrm{U}-234$

Th -230

Th -230

Th -230

Th -230

Th-230

$\mathrm{Ra}-226$

$\mathrm{Ra}-226$

$\mathrm{Ra}-226$

$\mathrm{Ra}-226$

$\mathrm{Ra}-226$

$\mathrm{Pb}-210 \quad \mathrm{Pu}-238 \quad 1.000 \mathrm{E}+00$

$\mathrm{Pb}-210 \mathrm{Th}-230 \quad 1.000 \mathrm{E}+00$

$\mathrm{Pb}-210 \mathrm{U}-234 \quad 1.000 \mathrm{E}+00$

$\mathrm{Pb}-210 \quad \mathrm{U}-238 \quad 9.999 \mathrm{E}-01$

$\mathrm{Pb}-210 \quad \sum \operatorname{DOSE}(j)$ :

Pu-239 Pu-239 $1.000 E+00$ $t=0.000 \mathrm{E}+00 \quad 1.000 \mathrm{E}+00 \quad 5.000 \mathrm{E}+01 \quad 1.000 \mathrm{E}+02 \quad 5.000 \mathrm{E}+02 \quad 1.026 \mathrm{E}+03 \quad 9.976 \mathrm{E}+03 \quad 9.998 \mathrm{E}+04$

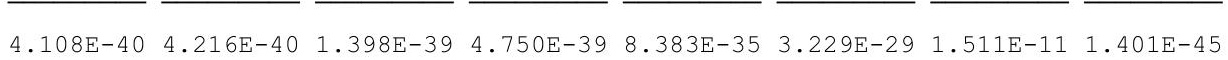

$3.446 \mathrm{E}-26 \quad 1.040 \mathrm{E}-25 \quad 5.226 \mathrm{E}-24 \quad 1.640 \mathrm{E}-23 \quad 3.184 \mathrm{E}-21 \quad 8.463 \mathrm{E}-19 \quad 1.785 \mathrm{E}-03 \quad 1.822 \mathrm{E}-44$ $3.179 \mathrm{E}-20 \quad 3.212 \mathrm{E}-20 \quad 5.209 \mathrm{E}-20 \quad 8.532 \mathrm{E}-20 \quad 4.415 \mathrm{E}-18 \quad 7.924 \mathrm{E}-16 \quad 1.285 \mathrm{E}+00 \quad 1.822 \mathrm{E}-44$

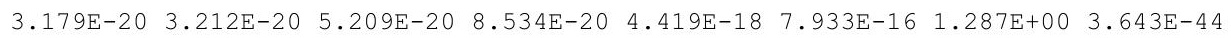

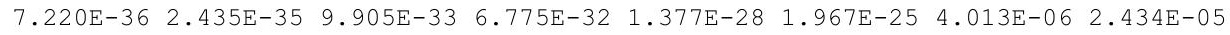
$\begin{array}{llllllll}1.151 \mathrm{E}-30 & 3.482 \mathrm{E}-30 & 1.943 \mathrm{E}-28 & 6.871 \mathrm{E}-28 & 3.406 \mathrm{E}-25 & 2.968 \mathrm{E}-22 & 2.953 \mathrm{E}-03 & 1.730 \mathrm{E}-02\end{array}$

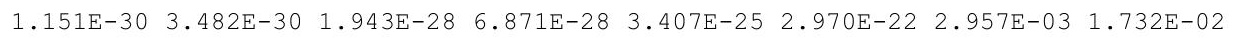

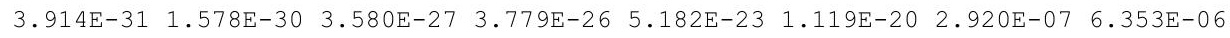
$\begin{array}{llllllll}9.355 \mathrm{E}-26 & 3.137 \mathrm{E}-25 & 1.044 \mathrm{E}-22 & 5.669 \mathrm{E}-22 & 1.808 \mathrm{E}-19 & 2.257 \mathrm{E}-17 & 2.428 \mathrm{E}-04 & 4.579 \mathrm{E}-03\end{array}$ $\begin{array}{llllllll}9.355 \mathrm{E}-26 & 3.137 \mathrm{E}-25 & 1.044 \mathrm{E}-22 & 5.670 \mathrm{E}-22 & 1.809 \mathrm{E}-19 & 2.258 \mathrm{E}-17 & 2.430 \mathrm{E}-04 & 4.585 \mathrm{E}-03\end{array}$

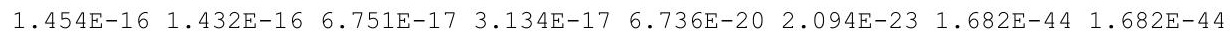

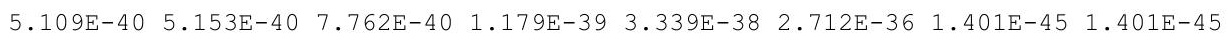
$\begin{array}{llllllll}2.777 \mathrm{E}-31 & 2.801 \mathrm{E}-31 & 4.219 \mathrm{E}-31 & 6.408 \mathrm{E}-31 & 1.815 \mathrm{E}-29 & 1.474 \mathrm{E}-27 & 5.801 \mathrm{E}-39 & 1.401 \mathrm{E}-45\end{array}$ $\begin{array}{llllllll}2.777 \mathrm{E}-31 & 2.801 \mathrm{E}-31 & 4.219 \mathrm{E}-31 & 6.408 \mathrm{E}-31 & 1.815 \mathrm{E}-29 & 1.474 \mathrm{E}-27 & 5.801 \mathrm{E}-39 & 2.803 \mathrm{E}-45\end{array}$

$2.471 \mathrm{E}-36 \quad 7.477 \mathrm{E}-36 \quad 4.360 \mathrm{E}-34 \quad 1.641 \mathrm{E}-33 \quad 1.992 \mathrm{E}-30 \quad 1.076 \mathrm{E}-26 \quad 3.597 \mathrm{E}-09 \quad 3.791 \mathrm{E}-05$ $\begin{array}{llllllll}6.688 \mathrm{E}-30 & 6.803 \mathrm{E}-30 & 1.512 \mathrm{E}-29 & 3.419 \mathrm{E}-29 & 2.321 \mathrm{E}-26 & 1.230 \mathrm{E}-22 & 4.109 \mathrm{E}-05 & 3.761 \mathrm{E}-01\end{array}$ $\begin{array}{llllllll}1.038 \mathrm{E}-35 & 3.151 \mathrm{E}-35 & 2.172 \mathrm{E}-33 & 9.760 \mathrm{E}-33 & 3.295 \mathrm{E}-29 & 3.584 \mathrm{E}-25 & 1.179 \mathrm{E}-06 & 1.232 \mathrm{E}-01\end{array}$

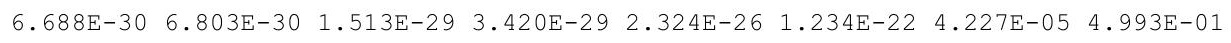

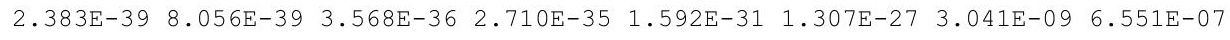
$\begin{array}{llllllll}1.462 \mathrm{E}-28 & 1.486 \mathrm{E}-28 & 3.173 \mathrm{E}-28 & 6.882 \mathrm{E}-28 & 3.361 \mathrm{E}-25 & 1.155 \mathrm{E}-21 & 2.517 \mathrm{E}-04 & 2.298 \mathrm{E}-07\end{array}$ $\begin{array}{llllllll}1.148 \mathrm{E}-33 & 3.481 \mathrm{E}-33 & 2.314 \mathrm{E}-31 & 9.978 \mathrm{E}-31 & 2.420 \mathrm{E}-27 & 1.703 \mathrm{E}-23 & 3.519 \mathrm{E}-05 & 6.503 \mathrm{E}-03\end{array}$

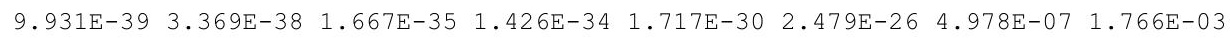
$\begin{array}{llllllll}1.462 \mathrm{E}-28 & 1.486 \mathrm{E}-28 & 3.175 \mathrm{E}-28 & 6.892 \mathrm{E}-28 & 3.385 \mathrm{E}-25 & 1.172 \mathrm{E}-21 & 2.874 \mathrm{E}-04 & 8.270 \mathrm{E}-03\end{array}$

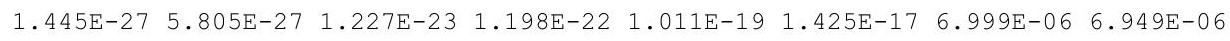
$2.365 \mathrm{E}-17 \quad 7.124 \mathrm{E}-17 \quad 3.142 \mathrm{E}-15 \quad 8.499 \mathrm{E}-15 \quad 4.949 \mathrm{E}-13 \quad 2.589 \mathrm{E}-11 \quad 7.400 \mathrm{E}-01 \quad 9.671 \mathrm{E}-05$ $\begin{array}{llllllll}1.040 \mathrm{E}-21 & 3.487 \mathrm{E}-21 & 1.152 \mathrm{E}-18 & 6.206 \mathrm{E}-18 & 1.847 \mathrm{E}-15 & 2.051 \mathrm{E}-13 & 8.130 \mathrm{E}-02 & 6.898 \mathrm{E}-02\end{array}$ $\begin{array}{llllllll}5.998 \mathrm{E}-27 & 2.420 \mathrm{E}-26 & 5.552 \mathrm{E}-23 & 5.933 \mathrm{E}-22 & 8.890 \mathrm{E}-19 & 2.061 \mathrm{E}-16 & 9.572 \mathrm{E}-04 & 1.859 \mathrm{E}-02\end{array}$ $\begin{array}{lllllllll}2.365 \mathrm{E}-17 & 7.125 \mathrm{E}-17 & 3.143 \mathrm{E}-15 & 8.505 \mathrm{E}-15 & 4.968 \mathrm{E}-13 & 2.610 \mathrm{E}-11 & 8.223 \mathrm{E}-01 & 8.767 \mathrm{E}-02\end{array}$

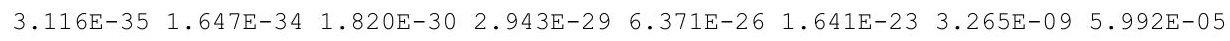
$\begin{array}{lllllllll}9.929 \mathrm{E}-25 & 3.293 \mathrm{E}-24 & 7.659 \mathrm{E}-22 & 3.033 \mathrm{E}-21 & 3.413 \mathrm{E}-19 & 3.104 \mathrm{E}-17 & 3.465 \mathrm{E}-04 & 8.750 \mathrm{E}-04\end{array}$ $2.956 \mathrm{E}-29 \quad 1.176 \mathrm{E}-28 \quad 2.093 \mathrm{E}-25 \quad 1.772 \mathrm{E}-24 \quad 1.195 \mathrm{E}-21 \quad 2.380 \mathrm{E}-19 \quad 3.793 \mathrm{E}-05 \quad 5.948 \mathrm{E}-01$ $\begin{array}{lllllllll}1.285 \mathrm{E}-34 & 6.842 \mathrm{E}-34 & 8.110 \mathrm{E}-30 & 1.422 \mathrm{E}-28 & 5.422 \mathrm{E}-25 & 2.319 \mathrm{E}-22 & 4.451 \mathrm{E}-07 & 1.603 \mathrm{E}-01\end{array}$ $\begin{array}{llllllll}9.929 \mathrm{E}-25 & 3.293 \mathrm{E}-24 & 7.661 \mathrm{E}-22 & 3.035 \mathrm{E}-21 & 3.425 \mathrm{E}-19 & 3.128 \mathrm{E}-17 & 3.848 \mathrm{E}-04 & 7.561 \mathrm{E}-01\end{array}$

$2.624 \mathrm{E}-24 \quad 2.653 \mathrm{E}-24 \quad 4.547 \mathrm{E}-24 \quad 7.880 \mathrm{E}-24 \quad 6.397 \mathrm{E}-22 \quad 2.075 \mathrm{E}-19 \quad 7.678 \mathrm{E}-05 \quad 3.850 \mathrm{E}-03$ 
RESRAD-OFFSITE, Version 2.

Parent Dose Report

Title : Offsite Resident Farmer Deterministic Run

File : RF DOE SG FWD-FV2-100000Y.ROF

Individual Nuclide Dose Summed Over All Pathways

Parent Nuclide and Thread Fraction Indicated

\begin{tabular}{|c|c|c|c|c|c|c|c|c|c|c|c|}
\hline $\begin{array}{l}\text { aclide } \\
\text { (j) }\end{array}$ & $\begin{array}{c}\text { Parent } \\
\text { (i) }\end{array}$ & THF (i) & $t=$ & $0.000 \mathrm{E}+00$ & $1.000 \mathrm{E}+00$ & $5.000 \mathrm{E}+01$ & $\begin{array}{l}\operatorname{DOSE}(j, t), \\
1.000 \mathrm{E}+02\end{array}$ & $\begin{array}{c}\text { mrem/yr } \\
5.000 \mathrm{E}+02\end{array}$ & $1.026 \mathrm{E}+03$ & $9.976 \mathrm{E}+03$ & $9.998 \mathrm{E}+04$ \\
\hline-235 & $\mathrm{Pu}-239$ & $1.000 \mathrm{E}+00$ & & $1.424 \mathrm{E}-30$ & $4.305 E-30$ & $2.388 E-28$ & $8.388 E-28$ & $3.939 \mathrm{E}-25$ & $3.196 \mathrm{E}-22$ & 7. $666 \mathrm{E}-08$ & $1.752 \mathrm{E}-06$ \\
\hline-235 & $\mathrm{U}-235$ & $1.000 \mathrm{E}+00$ & & $4.899 E-22$ & $4.957 E-22$ & $8.658 E-22$ & $1.530 \mathrm{E}-21$ & 1. $452 \mathrm{E}-19$ & $5.783 \mathrm{E}-17$ & $1.595 \mathrm{E}-03$ & 1. $981 E-02$ \\
\hline-235 & $\sum \operatorname{DOSE}(j)$ & : & & $4.899 E-22$ & $4.957 E-22$ & $8.658 E-22$ & $1.530 \mathrm{E}-21$ & 1. $452 \mathrm{E}-19$ & $5.783 \mathrm{E}-17$ & $1.595 \mathrm{E}-03$ & $1.981 \mathrm{E}-02$ \\
\hline-231 & $\mathrm{Pu}-239$ & $1.000 \mathrm{E}+00$ & & $2.031 E-33$ & $6.841 E-33$ & $2.637 E-30$ & $1.696 \mathrm{E}-29$ & $2.079 E-26$ & $1.484 \mathrm{E}-23$ & $2.947 \mathrm{E}-09$ & 1.949E-06 \\
\hline-231 & $\mathrm{U}-235$ & $1.000 \mathrm{E}+00$ & & $1.220 \mathrm{E}-25$ & $3.685 E-25$ & $1.905 E-23$ & $6.177 \mathrm{E}-23$ & 1. $527 \mathrm{E}-20$ & $5.330 \mathrm{E}-18$ & $1.144 \mathrm{E}-04$ & $3.072 \mathrm{E}-02$ \\
\hline-231 & $\sum \operatorname{DOSE}(j)$ & : & & $1.220 \mathrm{E}-25$ & $3.685 E-25$ & 1. $905 E-23$ & $6.177 \mathrm{E}-23$ & $1.527 \mathrm{E}-20$ & $5.330 \mathrm{E}-18$ & $1.144 \mathrm{E}-04$ & $3.072 \mathrm{E}-02$ \\
\hline$=-227$ & $\mathrm{Pu}-239$ & $1.000 \mathrm{E}+00$ & & $3.722 \mathrm{E}-32$ & $1.484 \mathrm{E}-31$ & $2.722 E-28$ & $2.395 E-27$ & $2.287 \mathrm{E}-24$ & $7.272 \mathrm{E}-22$ & $2.866 \mathrm{E}-08$ & $3.622 \mathrm{E}-06$ \\
\hline$=-227$ & $\mathrm{U}-235$ & $1.000 \mathrm{E}+00$ & & $3.301 E-24$ & $1.096 \mathrm{E}-23$ & $2.630 E-21$ & $1.085 E-20$ & 1. $784 \mathrm{E}-18$ & $2.691 \mathrm{E}-16$ & $1.116 \mathrm{E}-03$ & $5.709 E-02$ \\
\hline$x-240$ & $\mathrm{Pu}-240$ & $4.950 \mathrm{E}-08$ & & $1.234 \mathrm{E}-38$ & $1.255 E-38$ & $2.769 E-38$ & $6.212 E-38$ & $3.972 \mathrm{E}-35$ & $1.946 \mathrm{E}-31$ & 1. $703 \mathrm{E}-12$ & $8.463 E-14$ \\
\hline$x-240$ & $\mathrm{Pu}-240$ & $1.000 \mathrm{E}+00$ & & $2.492 E-31$ & $2.535 E-31$ & $5.594 E-31$ & $1.255 E-30$ & $8.024 E-28$ & $3.931 E-24$ & $3.440 \mathrm{E}-05$ & $1.710 \mathrm{E}-06$ \\
\hline$x-240$ & $\sum \operatorname{DOSE}(j)$ & : & & $2.492 \mathrm{E}-31$ & $2.535 E-31$ & $5.594 \mathrm{E}-31$ & $1.255 E-30$ & $8.024 \mathrm{E}-28$ & $3.931 \mathrm{E}-24$ & $3.440 \mathrm{E}-05$ & $1.710 \mathrm{E}-06$ \\
\hline 236 & $\mathrm{Pu}-240$ & $1.000 \mathrm{E}+00$ & & $5.158 E-39$ & $1.565 E-38$ & $1.089 E-36$ & $4.944 E-36$ & $1.814 \mathrm{E}-32$ & $2.200 \mathrm{E}-28$ & $1.439 \mathrm{E}-09$ & $2.549 E-05$ \\
\hline-232 & $\mathrm{Pu}-240$ & $1.000 \mathrm{E}+00$ & & $0.000 \mathrm{E}+00$ & $0.000 \mathrm{E}+00$ & $1.401 E-45$ & $9.809 E-45$ & $2.352 E-40$ & $7.787 \mathrm{E}-36$ & 4. $980 \mathrm{E}-15$ & $2.917 \mathrm{E}-12$ \\
\hline-232 & Th-232 & $1.000 \mathrm{E}+00$ & & $2.827 E-32$ & $2.878 E-32$ & $6.652 E-32$ & $1.564 \mathrm{E}-31$ & 1. $459 \mathrm{E}-28$ & $1.173 \mathrm{E}-24$ & $1.122 \mathrm{E}-05$ & $2.473 E-08$ \\
\hline-232 & $\sum \operatorname{DOSE}(j)$ & : & & $2.827 E-32$ & $2.878 E-32$ & $6.652 \mathrm{E}-32$ & $1.564 \mathrm{E}-31$ & $1.459 \mathrm{E}-28$ & $1.173 E-24$ & $1.122 \mathrm{E}-05$ & $2.473 E-08$ \\
\hline-228 & $\sum \operatorname{DOSE}(j)$ & : & & $2.055 E-17$ & $6.010 \mathrm{E}-17$ & $6.553 E-16$ & $9.318 E-16$ & $1.527 \mathrm{E}-14$ & $6.040 \mathrm{E}-13$ & $1.766 \mathrm{E}-02$ & $5.898 E-08$ \\
\hline-228 & $\mathrm{Pu}-240$ & $1.000 \mathrm{E}+00$ & & $6.574 \mathrm{E}-32$ & $2.903 E-31$ & $5.675 E-28$ & $3.671 \mathrm{E}-27$ & $9.620 \mathrm{E}-25$ & $7.310 \mathrm{E}-23$ & $1.237 \mathrm{E}-11$ & $2.339 E-12$ \\
\hline-228 & $\mathrm{Th}-228$ & $1.000 \mathrm{E}+00$ & & $3.696 \mathrm{E}-14$ & $3.159 \mathrm{E}-14$ & $8.318 E-22$ & 1. $793 \mathrm{E}-29$ & $0.000 \mathrm{E}+00$ & $0.000 \mathrm{E}+00$ & $0.000 \mathrm{E}+00$ & $0.000 \mathrm{E}+00$ \\
\hline-228 & Th-232 & $1.000 \mathrm{E}+00$ & & $1.136 \mathrm{E}-15$ & $3.416 \mathrm{E}-15$ & $5.242 \mathrm{E}-14$ & $6.923 E-14$ & $6.234 \mathrm{E}-13$ & 1. $125 \mathrm{E}-11$ & $2.793 E-02$ & $3.734 \mathrm{E}-09$ \\
\hline-228 & $\sum \operatorname{DOSE}(j)$ & : & & $3.810 \mathrm{E}-14$ & $3.501 \mathrm{E}-14$ & $5.242 \mathrm{E}-14$ & $6.923 E-14$ & $6.234 \mathrm{E}-13$ & $1.125 \mathrm{E}-11$ & $2.793 \mathrm{E}-02$ & $3.736 \mathrm{E}-09$ \\
\hline-99 & TC-99 & $1.000 \mathrm{E}+00$ & & $1.818 \mathrm{E}-32$ & $1.841 \mathrm{E}-32$ & $3.381 E-32$ & $6.287 E-32$ & $8.964 E-30$ & $6.100 \mathrm{E}-27$ & $2.296 E-29$ & $0.000 \mathrm{E}+00$ \\
\hline 238 & $\mathrm{U}-238$ & $5.400 \mathrm{E}-05$ & & $0.000 \mathrm{E}+00$ & $0.000 \mathrm{E}+00$ & $0.000 \mathrm{E}+00$ & $0.000 \mathrm{E}+00$ & $0.000 \mathrm{E}+00$ & $0.000 \mathrm{E}+00$ & $1.547 \mathrm{E}-09$ & $2.476 E-05$ \\
\hline 238 & $\mathrm{U}-238$ & $9.999 \mathrm{E}-01$ & & $1.377 \mathrm{E}-16$ & $1.387 \mathrm{E}-16$ & $1.990 \mathrm{E}-16$ & $2.874 \mathrm{E}-16$ & $5.453 \mathrm{E}-15$ & $2.616 \mathrm{E}-13$ & $1.578 \mathrm{E}-02$ & 4. $943 E-01$ \\
\hline 8 & $\sum \operatorname{DOSE}(j)$ & : & & $1.377 \mathrm{E}-16$ & $1.387 \mathrm{E}-16$ & 1. $990 \mathrm{E}-16$ & $2.874 \mathrm{E}-16$ & $5.453 E-15$ & $2.616 \mathrm{E}-13$ & $1.578 \mathrm{E}-02$ & $4.944 \mathrm{E}-01$ \\
\hline
\end{tabular}

THF(i) is the thread fraction of the parent nuclide. 
RESRAD-OFFSITE, Version 2.

Parent Dose Report

Title : Offsite Resident Farmer Deterministic Run

File : RF DOE SG FWD-FV2-100000Y.ROF

Individual Nuclide Soil Concentration

Parent Nuclide and Thread Fraction Indicated

Nuclide Parent THF(

\section{(j)}

(i)

$A m-241$

Am-241 $1.000 \mathrm{E}+00$

Np-237

Np-237

Np-237

Am-241 1.000E+00

$\mathrm{Np}-237 \quad 1.000 \mathrm{E}+00$

$\sum S(j)$ :

$\mathrm{Am}-241 \quad 1.000 \mathrm{E}+00$

Np-237 $1.000 \mathrm{E}+00$

$\sum S(j):$

Am-241 $1.000 \mathrm{E}+00$

$\mathrm{Np}-237 \quad 1.000 \mathrm{E}+00$

Th-229 $\sum S(j):$

Cs-137 Cs-137 $1.000 E+00$

$\mathrm{Pu}-238$

$\mathrm{Pu}-238$

$\mathrm{Pu}-238$

$\mathrm{U}-234$

$\mathrm{U}-234$

$\mathrm{U}-234$

$\mathrm{U}-234$

Th -230

Th -230

Th -230

Th -230

Th -230

$\mathrm{Ra}-226$

$\mathrm{Ra}-226$

$\mathrm{Ra}-226$

$\mathrm{Ra}-226$

$\mathrm{Ra}-226$

$\mathrm{Pb}-210$

$\mathrm{Pb}-210$

$\mathrm{Pb}-210$

$\mathrm{Pb}-210$

$\mathrm{Pb}-210$

Pu-239 Pu-239 $1.000 E+00$
$\mathrm{Pu}-238 \quad 1.840 \mathrm{E}-09$

Pu-238 1.000E+00

$\sum S(j)$ :

$\mathrm{Pu}-238 \quad 1.000 \mathrm{E}+00$

$\mathrm{U}-234 \quad 1.000 \mathrm{E}+00$

$\mathrm{U}-238 \quad 9.999 \mathrm{E}-01$

$\sum S(j):$

Pu-238 1.000E+00

Th-230 1.000E+00

$\mathrm{U}-234 \quad 1.000 \mathrm{E}+00$

$\sum S(j):$

Pu-238 1.000E+00

Th-230 1.000E+00

$\mathrm{U}-234 \quad 1.000 \mathrm{E}+00$

$\mathrm{U}-238 \quad 9.999 \mathrm{E}-01$

$\sum S(j):$

$\mathrm{Pu}-238 \quad 1.000 \mathrm{E}+00$ Th-230 1.000E+00 $\mathrm{U}-2341.000 \mathrm{E}+00$ $\mathrm{U}-238 \quad 9.999 \mathrm{E}-01$ $\sum S(j):$
$\mathrm{U}-238 \quad 9.999 \mathrm{E}-01$ $t=0.000 \mathrm{E}+00 \quad 1.000 \mathrm{E}+00 \quad 5.000 \mathrm{E}+01 \quad 1.000 \mathrm{E}+02 \quad 5.000 \mathrm{E}+02 \quad 1.026 \mathrm{E}+03 \quad 9.976 \mathrm{E}+03 \quad 9.998 \mathrm{E}+04$

$\begin{array}{llllllllllll}3.500 \mathrm{E}+01 & 3.494 \mathrm{E}+01 & 3.230 \mathrm{E}+01 & 2.981 \mathrm{E}+01 & 1.567 \mathrm{E}+01 & 6.732 \mathrm{E}+00 & 3.830 \mathrm{E}-06 & 0.000 \mathrm{E}+00\end{array}$

$0.000 \mathrm{E}+00 \quad 1.128 \mathrm{E}-05 \quad 5.435 \mathrm{E}-04 \quad 1.043 \mathrm{E}-03 \quad 3.810 \mathrm{E}-03 \quad 5.417 \mathrm{E}-03 \quad 3.382 \mathrm{E}-03 \quad 2.825 \mathrm{E}-06$

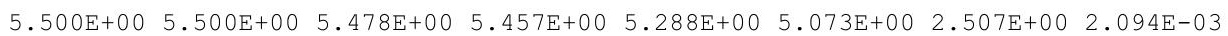

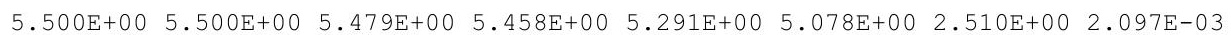

$\begin{array}{llllllll}0.000 \mathrm{E}+00 & 1.508 \mathrm{E}-10 & 6.038 \mathrm{E}-08 & 2.345 \mathrm{E}-07 & 4.742 \mathrm{E}-06 & 1.556 \mathrm{E}-05 & 1.860 \mathrm{E}-04 & 8.638 \mathrm{E}-05\end{array}$

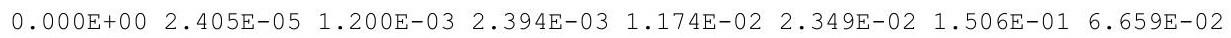

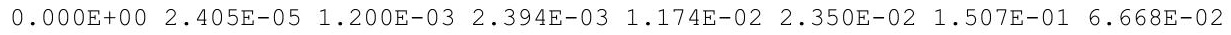

$0.000 \mathrm{E}+00 \quad 2.899 \mathrm{E}-14 \quad 9.604 \mathrm{E}-11 \quad 7.482 \mathrm{E}-10 \quad 7.873 \mathrm{E}-08 \quad 5.545 \mathrm{E}-07 \quad 7.082 \mathrm{E}-05 \quad 1.034 \mathrm{E}-04$

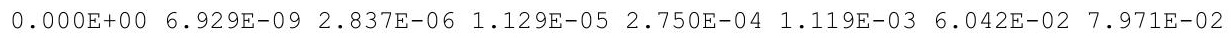

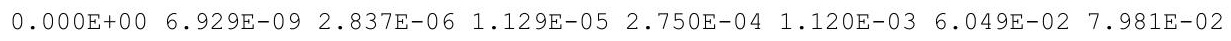

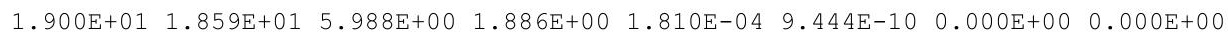

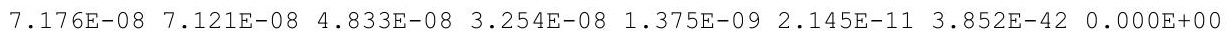
$\begin{array}{lllllllllll}3.900 \mathrm{E}+01 & 3.870 \mathrm{E}+01 & 2.627 \mathrm{E}+01 & 1.769 \mathrm{E}+01 & 7.473 \mathrm{E}-01 & 1.166 \mathrm{E}-02 & 2.094 \mathrm{E}-33 & 0.000 \mathrm{E}+00\end{array}$ $\begin{array}{llllllllllll}3.900 \mathrm{E}+01 & 3.870 \mathrm{E}+01 & 2.627 \mathrm{E}+01 & 1.769 \mathrm{E}+01 & 7.473 \mathrm{E}-01 & 1.166 \mathrm{E}-02 & 2.094 \mathrm{E}-33 & 0.000 \mathrm{E}+00\end{array}$

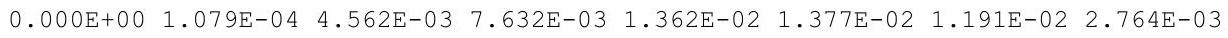

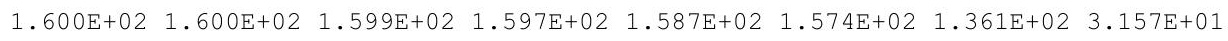
$\begin{array}{llllllll}0.000 \mathrm{E}+00 & 4.535 \mathrm{E}-04 & 2.266 \mathrm{E}-02 & 4.529 \mathrm{E}-02 & 2.251 \mathrm{E}-01 & 4.583 \mathrm{E}-01 & 3.903 \mathrm{E}+00 & 1.035 \mathrm{E}+01\end{array}$ $\begin{array}{lllllll}1.600 \mathrm{E}+02 & 1.600 \mathrm{E}+02 & 1.599 \mathrm{E}+02 & 1.598 \mathrm{E}+02 & 1.589 \mathrm{E}+02 & 1.578 \mathrm{E}+02 & 1.400 \mathrm{E}+02 \quad 4.192 \mathrm{E}+01\end{array}$

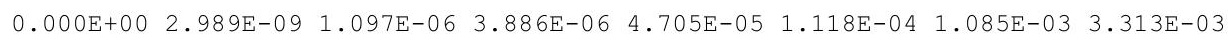
$\begin{array}{lllllllllll}1.000 \mathrm{E}+02 & 1.000 \mathrm{E}+02 & 9.995 \mathrm{E}+01 & 9.989 \mathrm{E}+01 & 9.947 \mathrm{E}+01 & 9.891 \mathrm{E}+01 & 8.986 \mathrm{E}+01 & 3.425 \mathrm{E}+01\end{array}$ $0.000 \mathrm{E}+00 \quad 1.440 \mathrm{E}-03 \quad 7.197 \mathrm{E}-02 \quad 1.438 \mathrm{E}-01 \quad 7.153 \mathrm{E}-01 \quad 1.457 \mathrm{E}+00 \quad 1.256 \mathrm{E}+01 \quad 3.791 \mathrm{E}+01$ $0.000 \mathrm{E}+00 \quad 1.246 \mathrm{E}-08 \quad 5.112 \mathrm{E}-06 \quad 2.041 \mathrm{E}-05 \quad 5.070 \mathrm{E}-04 \quad 2.120 \mathrm{E}-03 \quad 1.777 \mathrm{E}-01 \quad 5.352 \mathrm{E}+00$

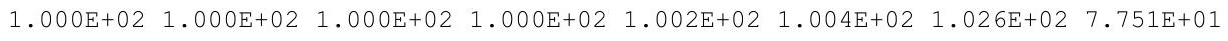

$0.000 \mathrm{E}+00 \quad 2.643 \mathrm{E}-12 \quad 8.164 \mathrm{E}-09 \quad 5.904 \mathrm{E}-08 \quad 3.952 \mathrm{E}-06 \quad 1.952 \mathrm{E}-05 \quad 8.380 \mathrm{E}-04 \quad 3.253 \mathrm{E}-03$ $\begin{array}{llllllllll}0.000 \mathrm{E}+00 & 4.326 \mathrm{E}-02 & 2.142 \mathrm{E}+00 & 4.235 \mathrm{E}+00 & 1.937 \mathrm{E}+01 & 3.549 \mathrm{E}+01 & 8.861 \mathrm{E}+01 & 3.422 \mathrm{E}+01\end{array}$ $\begin{array}{llllllll}0.000 \mathrm{E}+00 & 1.902 \mathrm{E}-06 & 7.756 \mathrm{E}-04 & 3.074 \mathrm{E}-03 & 7.220 \mathrm{E}-02 & 2.810 \mathrm{E}-01 & 9.734 \mathrm{E}+00 & 3.722 \mathrm{E}+01\end{array}$

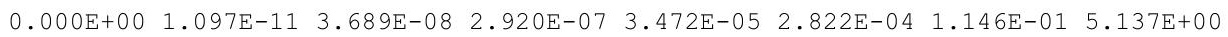
$\begin{array}{lllllllll}0.000 \mathrm{E}+00 & 4.326 \mathrm{E}-02 & 2.142 \mathrm{E}+00 & 4.238 \mathrm{E}+00 & 1.944 \mathrm{E}+01 & 3.577 \mathrm{E}+01 & 9.846 \mathrm{E}+01 & 7.659 \mathrm{E}+01\end{array}$

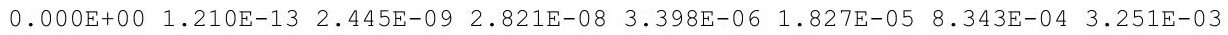
$\begin{array}{llllllllll}0.000 \mathrm{E}+00 & 3.858 \mathrm{E}-03 & 1.058 \mathrm{E}+00 & 2.946 \mathrm{E}+00 & 1.823 \mathrm{E}+01 & 3.458 \mathrm{E}+01 & 8.857 \mathrm{E}+01 & 3.421 \mathrm{E}+01\end{array}$ $\begin{array}{lllllllll}0.000 \mathrm{E}+00 & 1.148 \mathrm{E}-07 & 2.851 \mathrm{E}-04 & 1.709 \mathrm{E}-03 & 6.374 \mathrm{E}-02 & 2.650 \mathrm{E}-01 & 9.692 \mathrm{E}+00 & 3.720 \mathrm{E}+01\end{array}$ $0.000 \mathrm{E}+00 \quad 4.994 \mathrm{E}-13 \quad 1.088 \mathrm{E}-08 \quad 1.362 \mathrm{E}-07 \quad 2.890 \mathrm{E}-05 \quad 2.580 \mathrm{E}-04 \quad 1.137 \mathrm{E}-01 \quad 5.133 \mathrm{E}+00$ $\begin{array}{lllllllll}0.000 \mathrm{E}+00 & 3.858 \mathrm{E}-03 & 1.059 \mathrm{E}+00 & 2.947 \mathrm{E}+00 & 1.830 \mathrm{E}+01 & 3.485 \mathrm{E}+01 & 9.838 \mathrm{E}+01 & 7.655 \mathrm{E}+01\end{array}$

$\begin{array}{lllllllll}3.600 \mathrm{E}+01 & 3.600 \mathrm{E}+01 & 3.593 \mathrm{E}+01 & 3.586 \mathrm{E}+01 & 3.531 \mathrm{E}+01 & 3.460 \mathrm{E}+01 & 2.445 \mathrm{E}+01 & 7.448 \mathrm{E}-01\end{array}$ 
RESRAD-OFFSITE, Version $2.5 \quad \mathrm{~T}^{1 / 2}$ Limit $=180$ days

Parent Dose Report

Title : Offsite Resident Farmer Deterministic Run

File : RF DOE SG FWD-FV2-100000Y.ROF

Run Time Information

ResOCalc.EXE execution began at 11:16 on 07/18/2011

ResOCalc.EXE execution ended at 11:33 on 07/18/2011

Resocalc.EXE execution time 16 minutes 48 seconds 


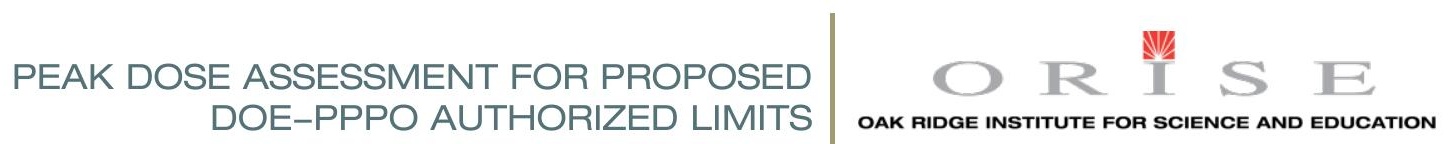

ATTACHMENT C: RESRAD-OFFSITE PARENT DOSEREPORTS AND UNCERTAINTY ANALYSIS REPORTS FOR THE TC-99 RUNS 


\section{Table of Contents}

Offsite Resident Farmer Parent Dose Report (Deterministic Analysis Report) First

Run: Time Horizon 1,050 yr ............................................................................................. C-3

Offsite Resident Farmer Uncertainty Analysis Report First Run: Time Horizon

$1,050 \mathrm{yr}$

Offsite Resident Farmer Parent Dose Report (Deterministic Analysis Report)

Second Run: Time Horizon 1,050 yr .

Offsite Resident Farmer Uncertainty Analysis Report Second Run: Time Horizon

$1,050 \mathrm{yr}$

Offsite Resident Farmer Parent Dose Report (Deterministic Analysis Report) Third Run: Time Horizon 1,050 yr C-481

Offsite Resident Farmer Uncertainty Analysis Report Third Run: Time Horizon $1,050 \mathrm{yr}$ C-523 


\section{Offsite Resident Farmer}

\section{Parent Dose Report \\ (Deterministic Analysis Report)}

First Run

Time Horizon: 1,050 yr 
THIS PAGE INTENTIONALLY LEFT BLANK 
RESRAD-OFFSITE, Version $2.5 \quad \mathrm{~T}^{1 / 2}$ Limit $=180$ days

Parent Dose Report

Title : Offsite Resident Farmer Deterministic Run

File : RF TC99 DOESG FWD-FV2.ROF

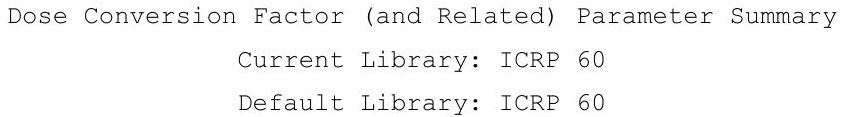

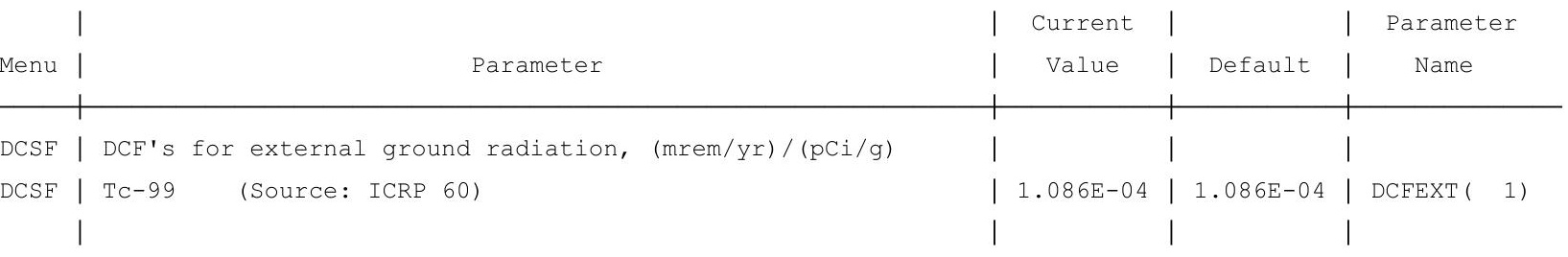

Current Library: ICRP 72 (Adult)

Default Library: ICRP 72 (Adult)

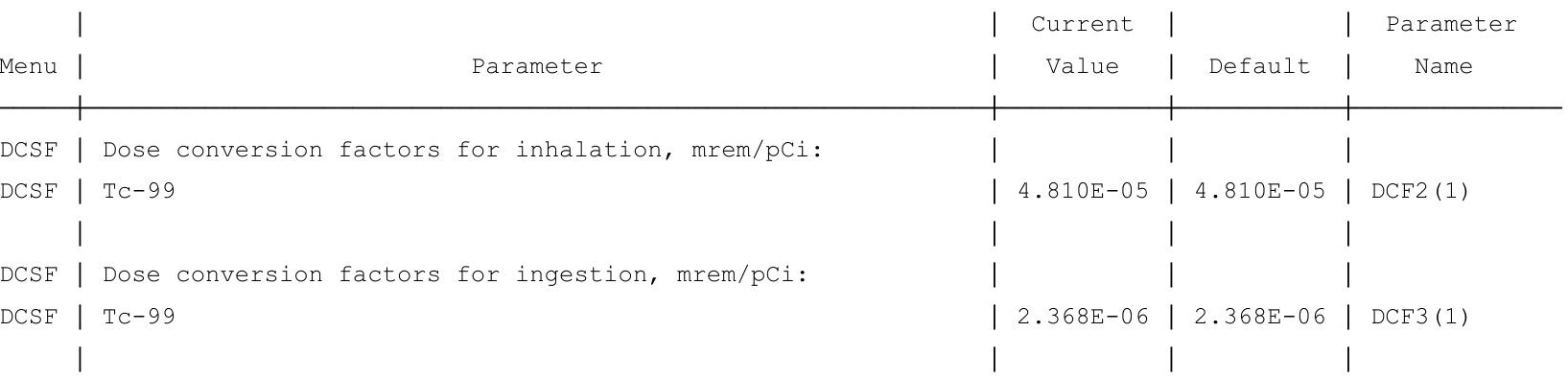


RESRAD-OFFSITE, Version 2.5

Parent Dose Report

Title : Offsite Resident Farmer Deterministic Run

File : RF TC99 DOESG FWD-FV2.ROF

Dose Conversion Factor (and Related) Parameter Summary (continued)

Current Library: RESRAD Default Transfer factors

Default Library: RESRAD Default Transfer factors

Parameter
Menu


RESRAD-OFFSITE, Version 2.5

Parent Dose Report

Title : Offsite Resident Farmer Deterministic Run

File : RF TC99 DOESG FWD-FV2.ROF

Site-Specific Parameter Summary

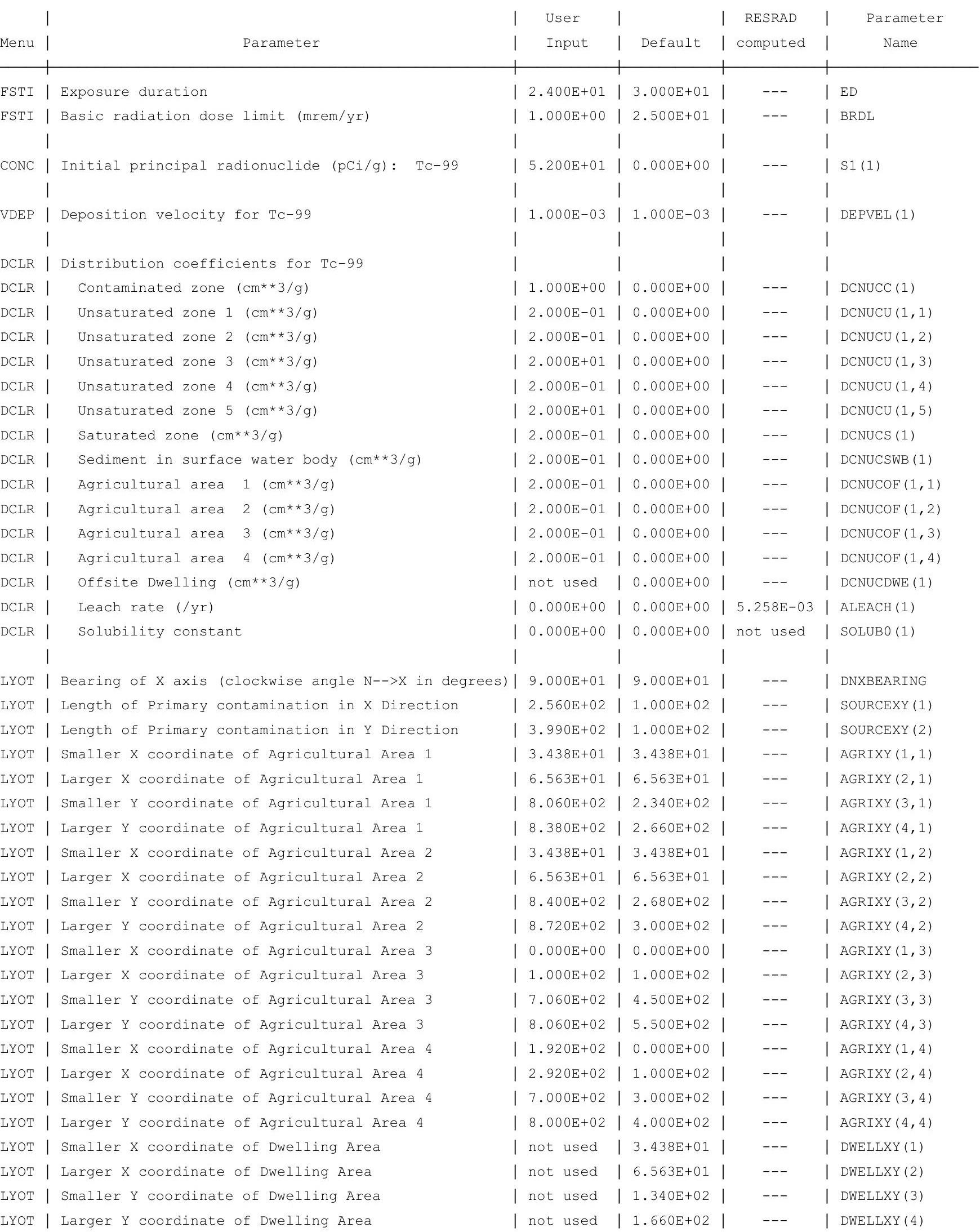


RESRAD-OFFSITE, Version 2.5

Parent Dose Report

Title : Offsite Resident Farmer Deterministic Run

File : RF TC99 DOESG FWD-FV2.ROF

Site-Specific Parameter Summary (continued)

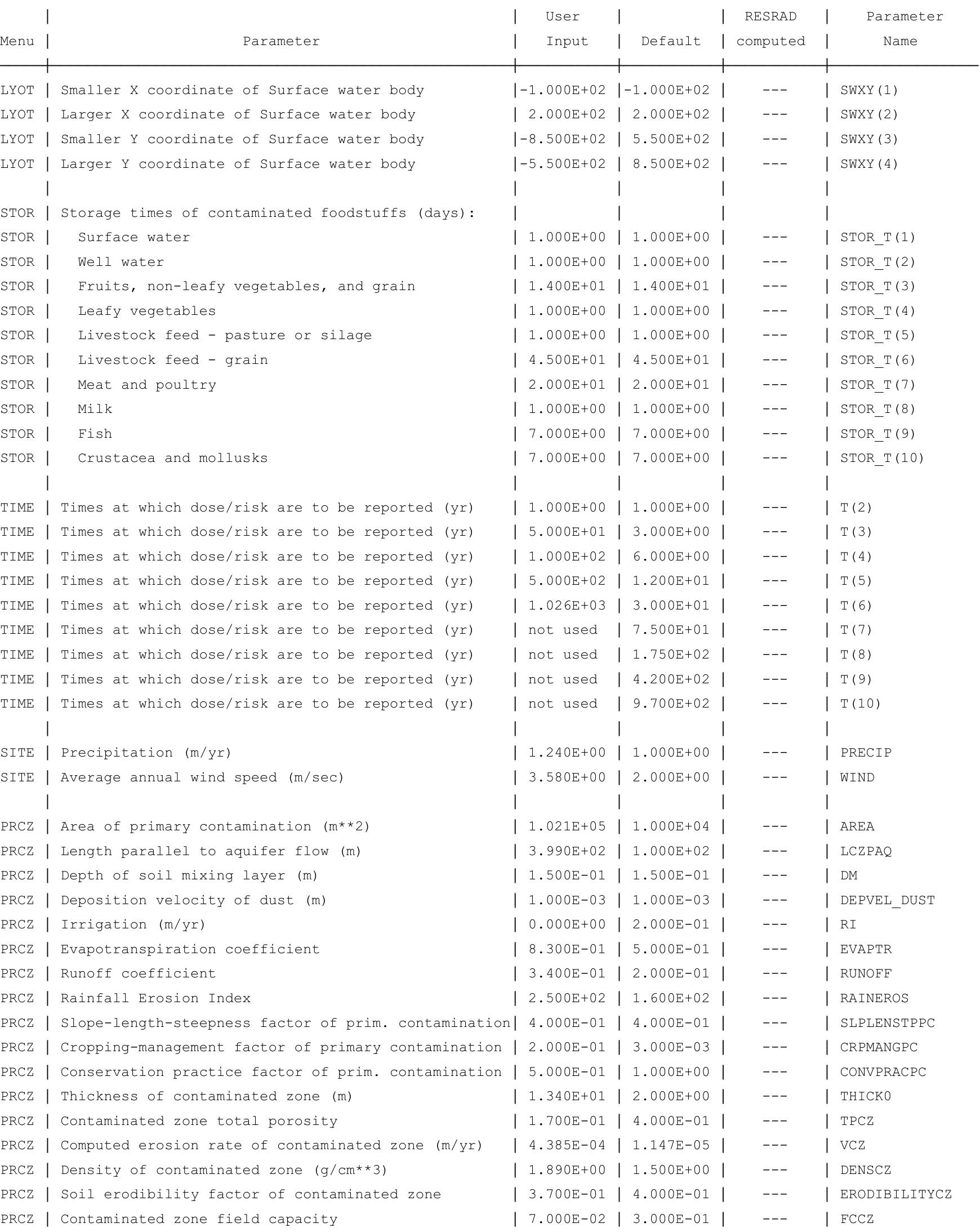


RESRAD-OFFSITE, Version 2.5

Parent Dose Report

Title : Offsite Resident Farmer Deterministic Run

File : RF TC99 DOESG FWD-FV2.ROF

Site-Specific Parameter Summary (continued)

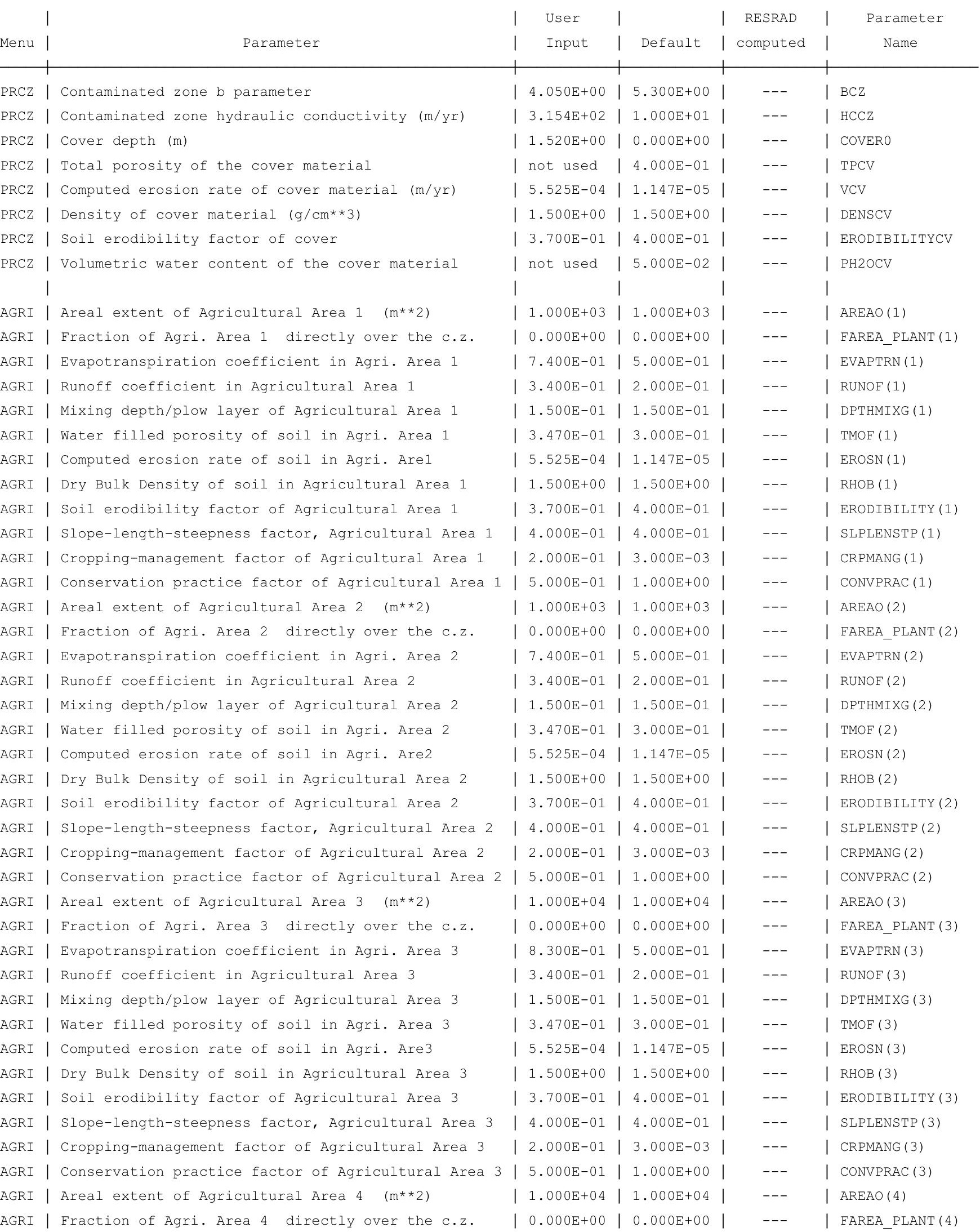


RESRAD-OFFSITE, Version 2.5

Parent Dose Report

Title : Offsite Resident Farmer Deterministic Run

File : RF TC99 DOESG FWD-FV2.ROF

Site-Specific Parameter Summary (continued)

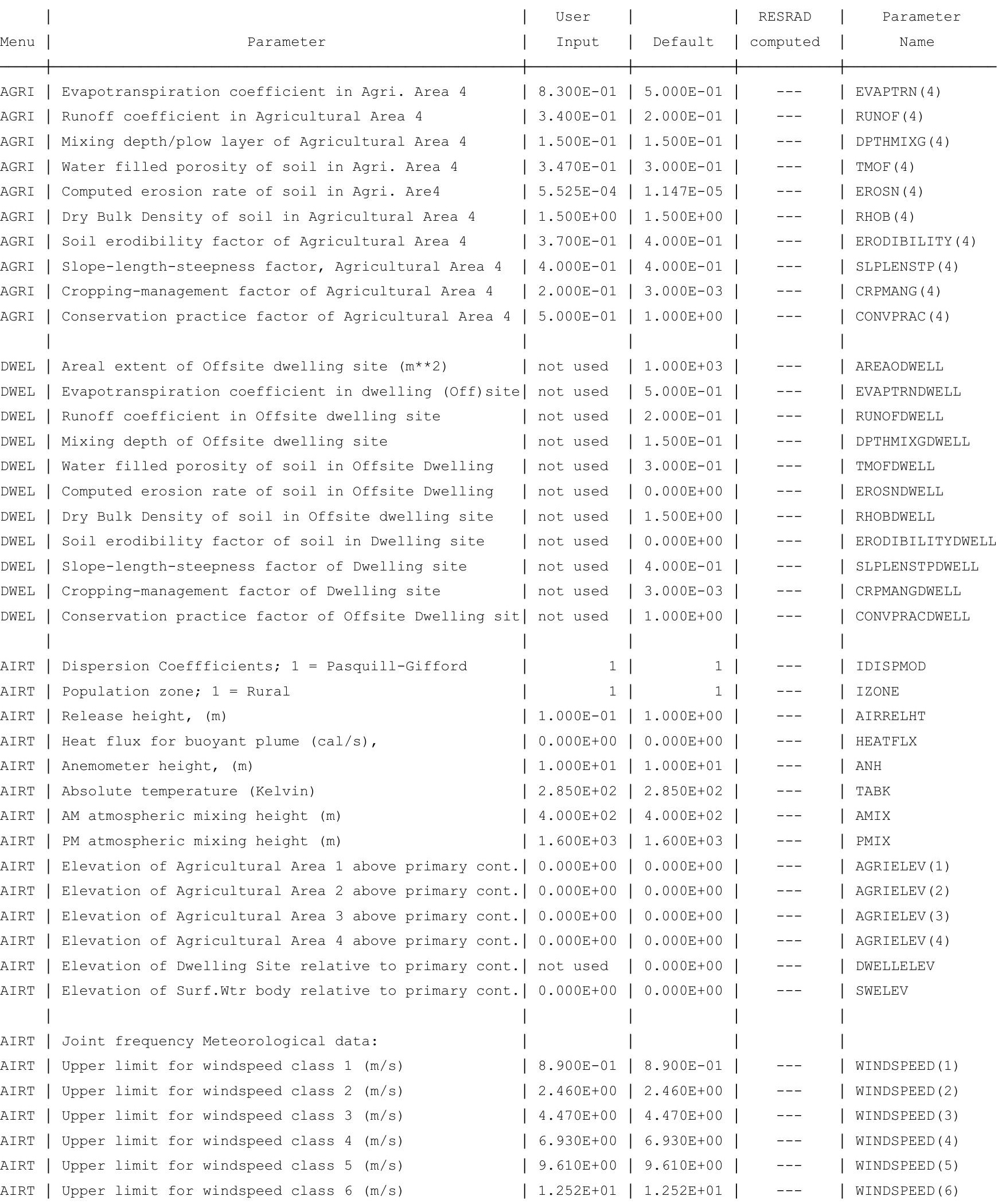


RESRAD-OFFSITE, Version 2.

Parent Dose Report

Title : Offsite Resident Farmer Deterministic Run

File : RF TC99 DOESG FWD-FV2.ROF

Site-Specific Parameter Summary (continued)

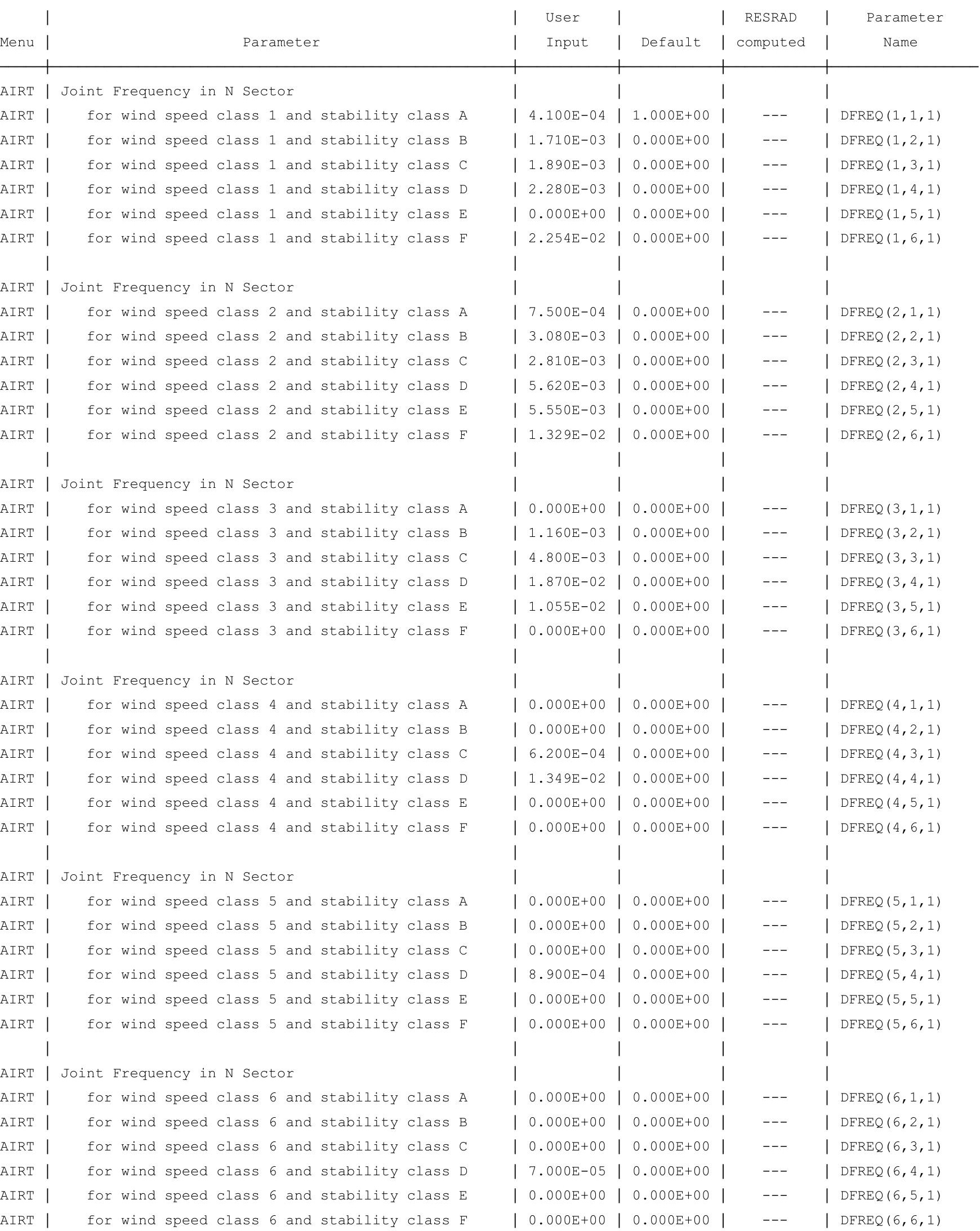


RESRAD-OFFSITE, Version 2.5

itle : Offsite Resident Farmer Deterministic Run

File : RF TC99 DOESG FWD-FV2.ROF

Site-Specific Parameter Summary (continued)

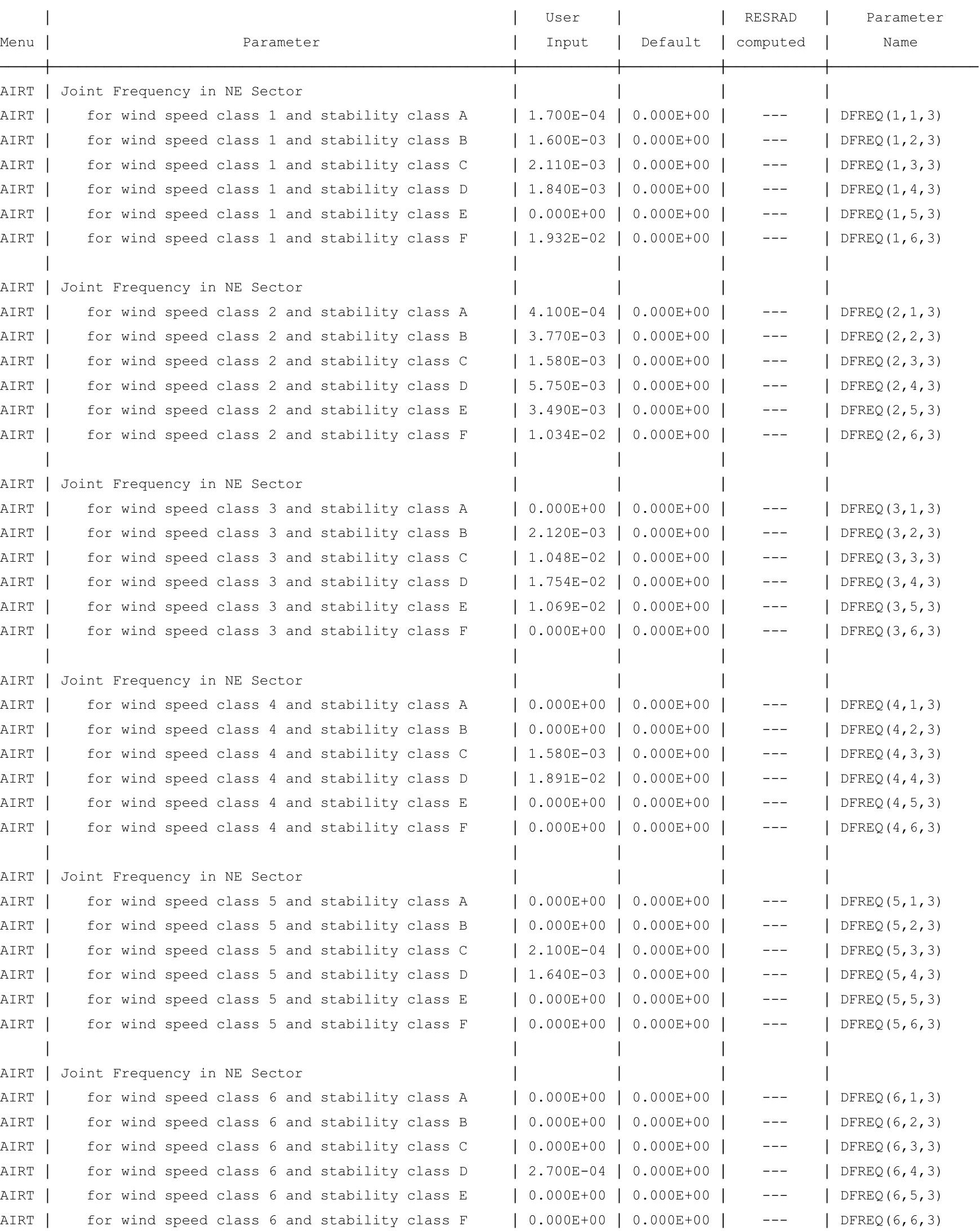


RESRAD-OFFSITE, Version 2.5

arent Dose Report

Title : Offsite Resident Farmer Deterministic Run

File : RF TC99 DOESG FWD-FV2.ROF

Site-Specific Parameter Summary (continued)

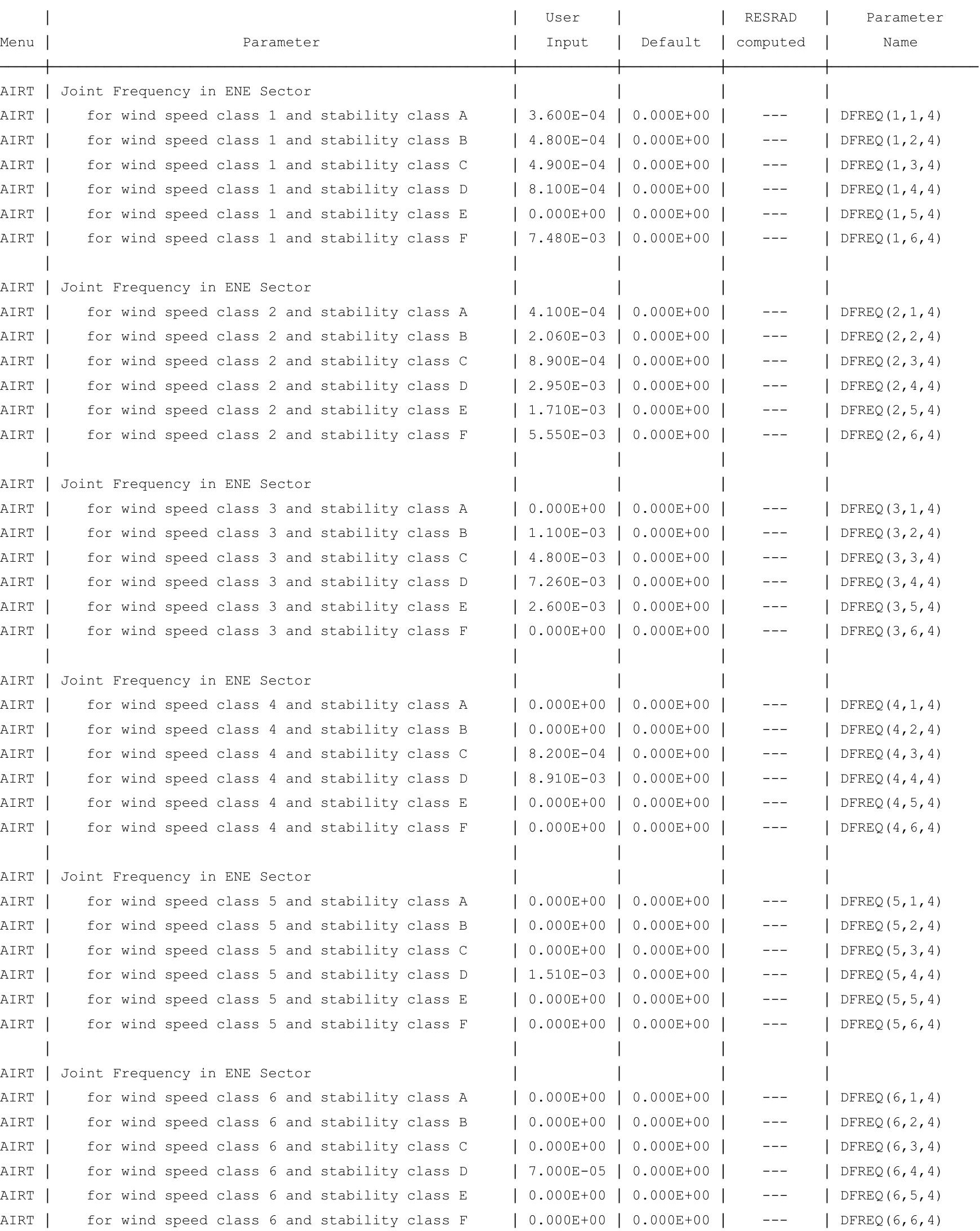


RESRAD-OFFSITE, Version 2.5

arent Dose Report

Title : Offsite Resident Farmer Deterministic Run

File : RF TC99 DOESG FWD-FV2.ROF

Site-Specific Parameter Summary (continued)

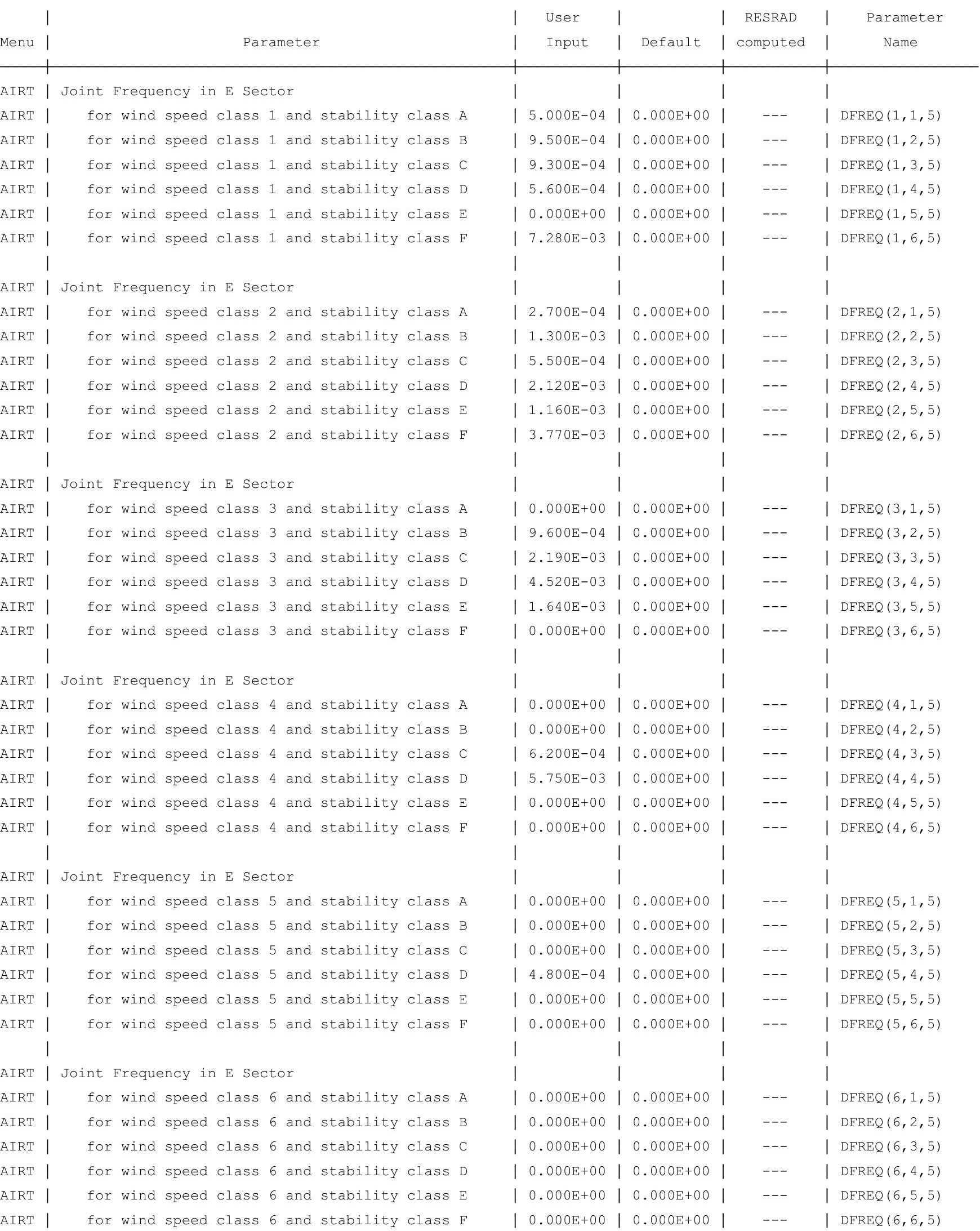


RESRAD-OFFSITE, Version 2.5

arent Dose Report

Title : Offsite Resident Farmer Deterministic Run

File : RF TC99 DOESG FWD-FV2.ROF

Site-Specific Parameter Summary (continued)

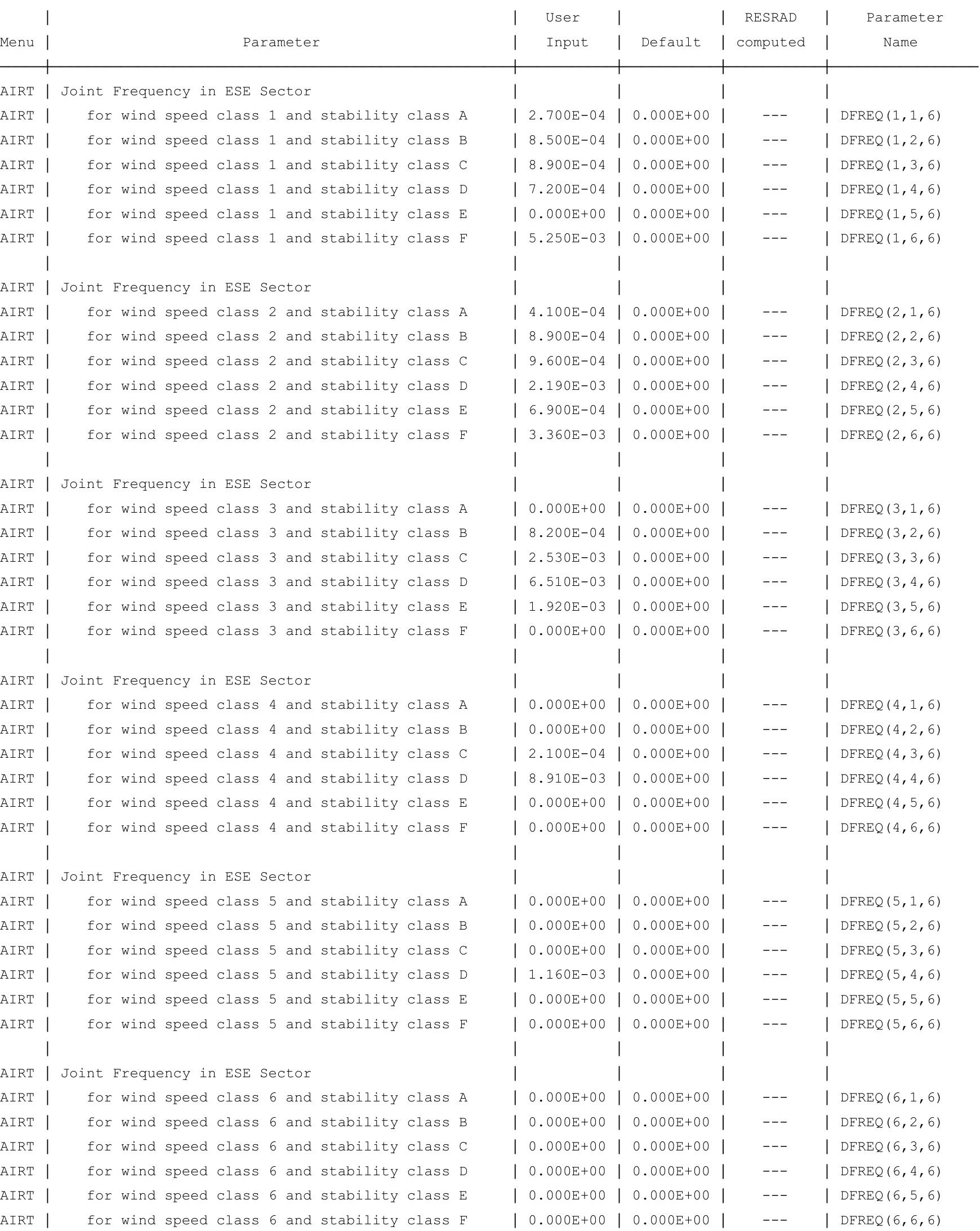


RESRAD-OFFSITE, Version 2.5

itle : Offsite Resident Farmer Deterministic Run

File : RF TC99 DOESG FWD-FV2.ROF

Site-Specific Parameter Summary (continued)

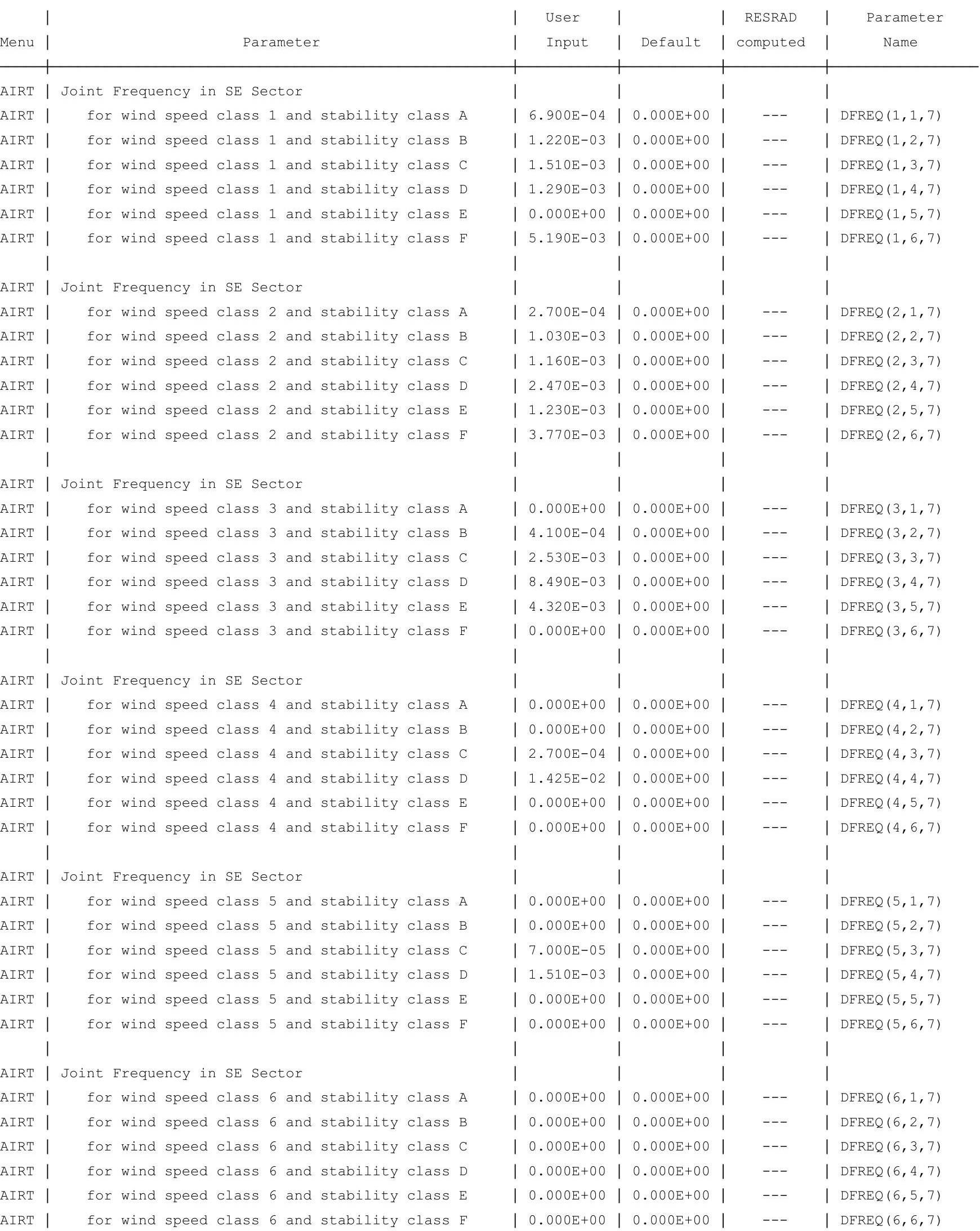


RESRAD-OFFSITE, Version 2.

Parent Dose Report

Title : Offsite Resident Farmer Deterministic Run

File : RF TC99 DOESG FWD-FV2.ROF

Site-Specific Parameter Summary (continued)

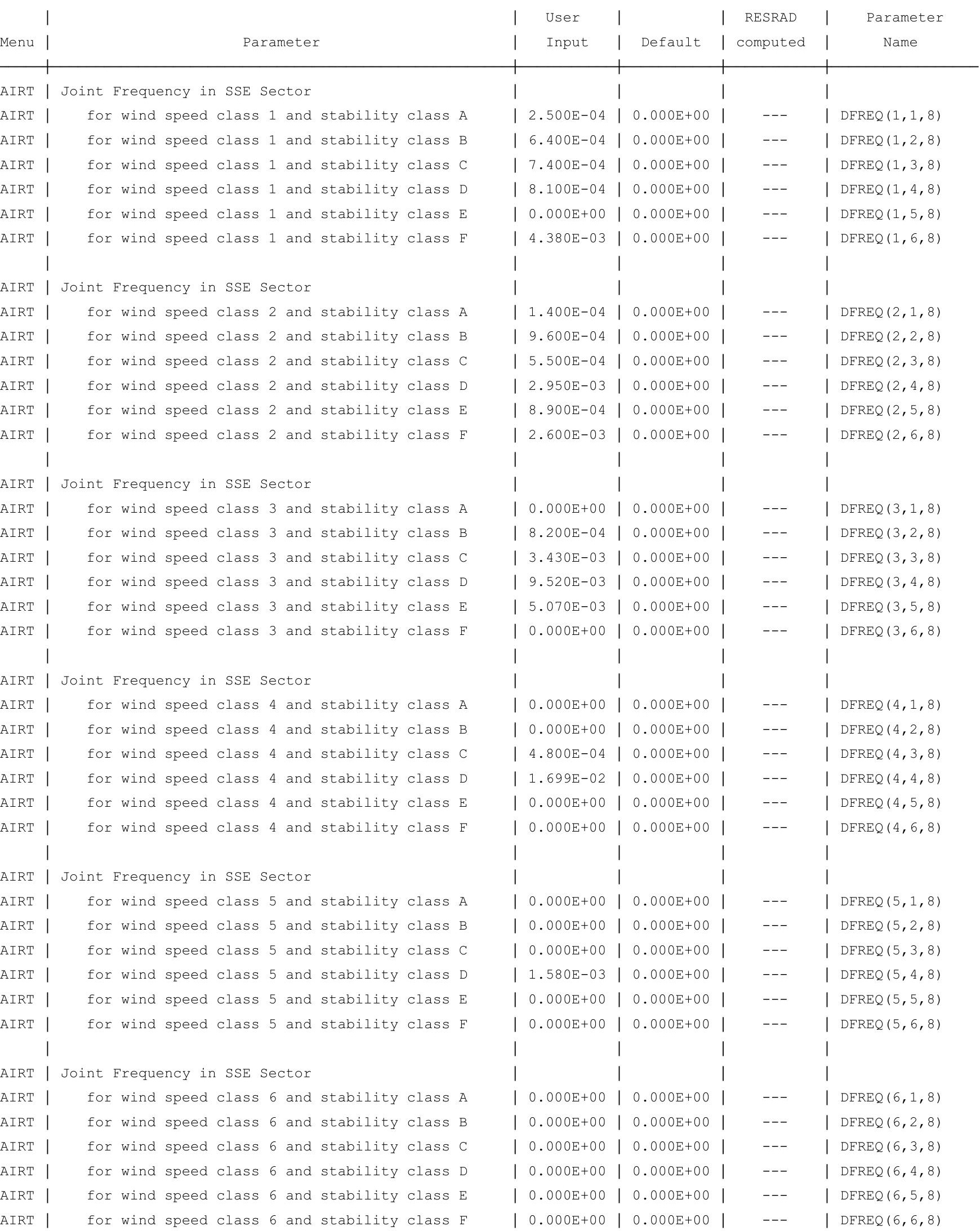


RESRAD-OFFSITE, Version 2.5

arent Dose Report

Title : Offsite Resident Farmer Deterministic Run

File : RF TC99 DOESG FWD-FV2.ROF

Site-Specific Parameter Summary (continued)

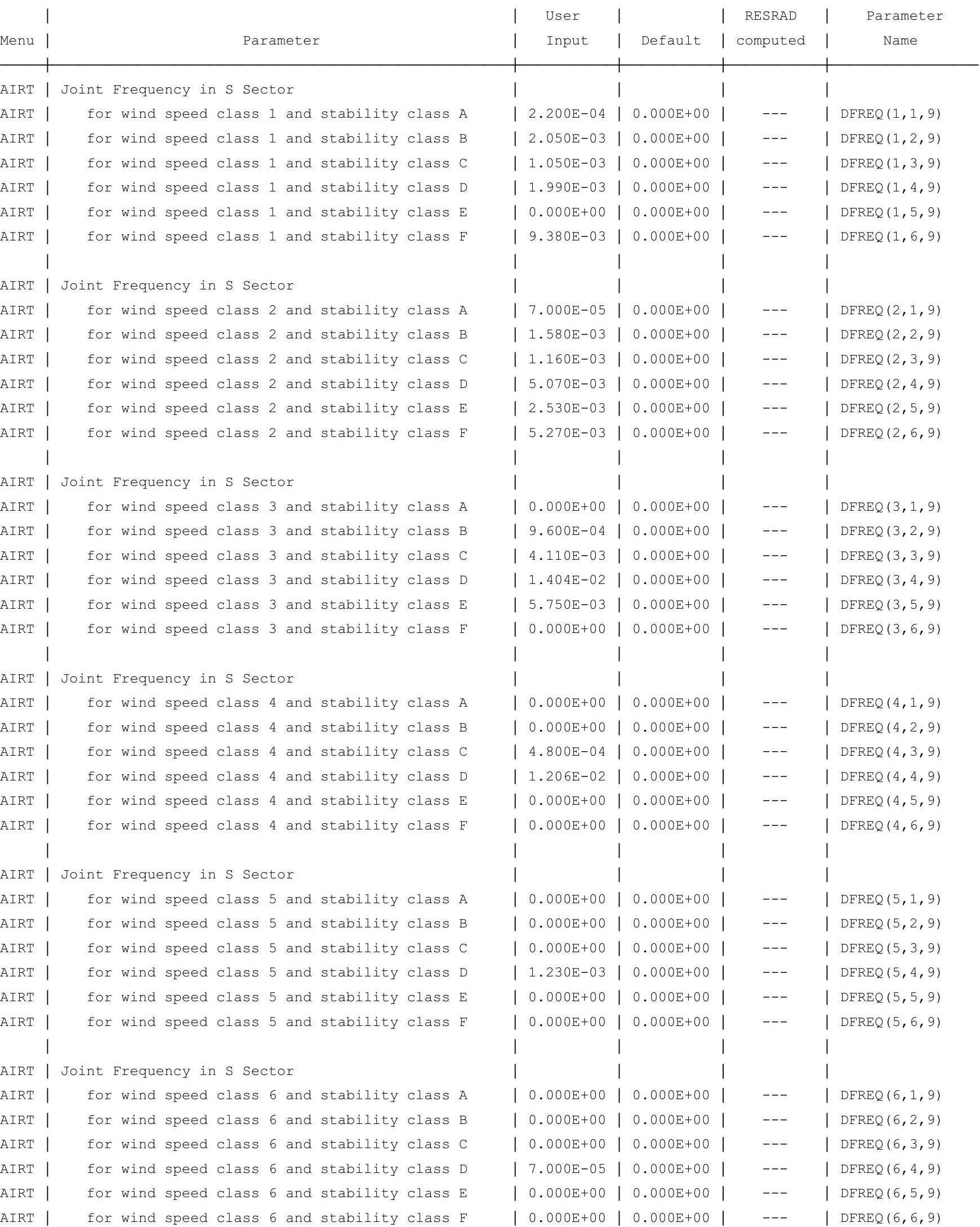


RESRAD-OFFSITE, Version 2.

Parent Dose Report

Title : Offsite Resident Farmer Deterministic Run

File : RF TC99 DOESG FWD-FV2.ROF

Site-Specific Parameter Summary (continued)

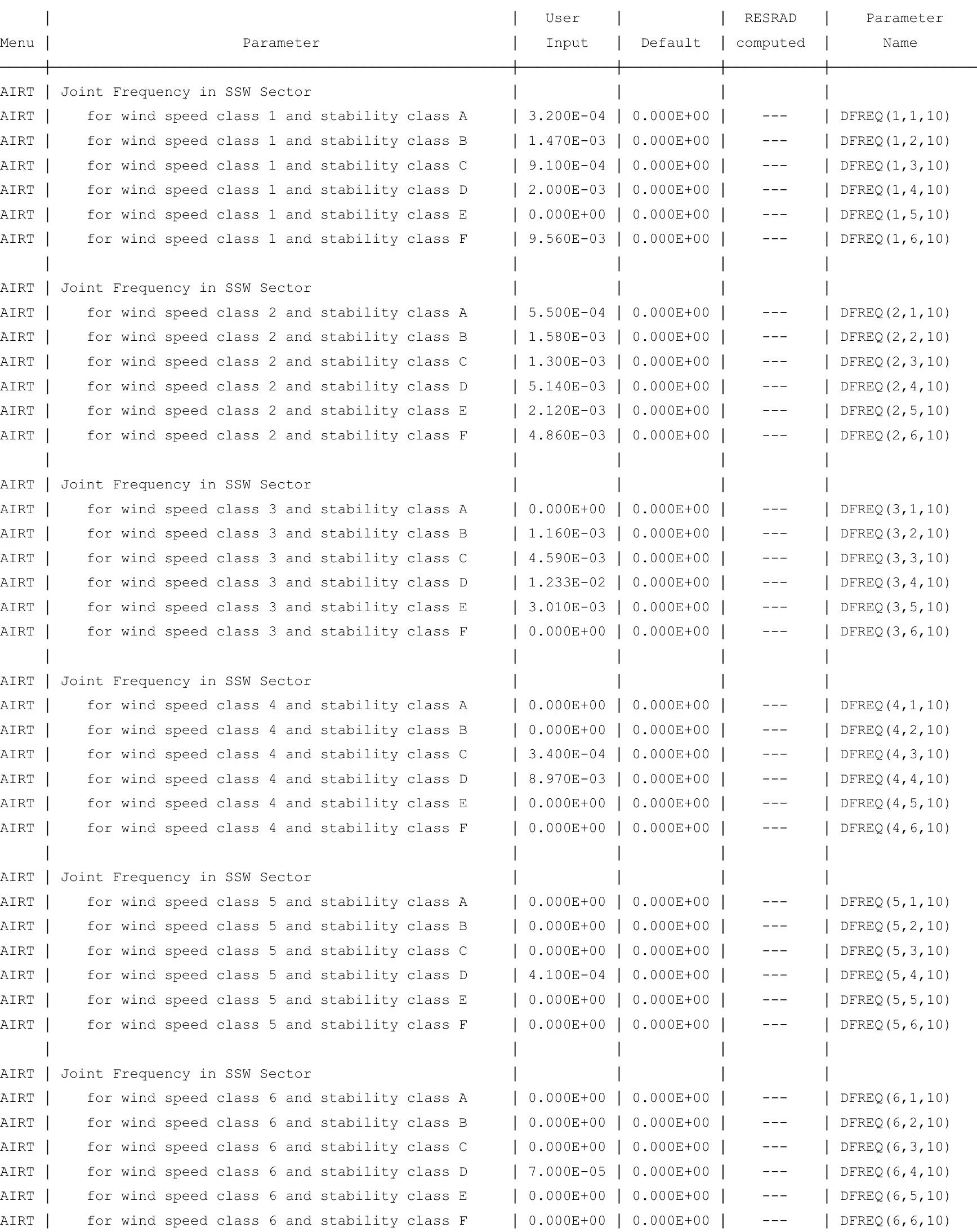


RESRAD-OFFSITE, Version 2.

Parent Dose Report

Title : Offsite Resident Farmer Deterministic Run

File : RF TC99 DOESG FWD-FV2.ROF

Site-Specific Parameter Summary (continued)

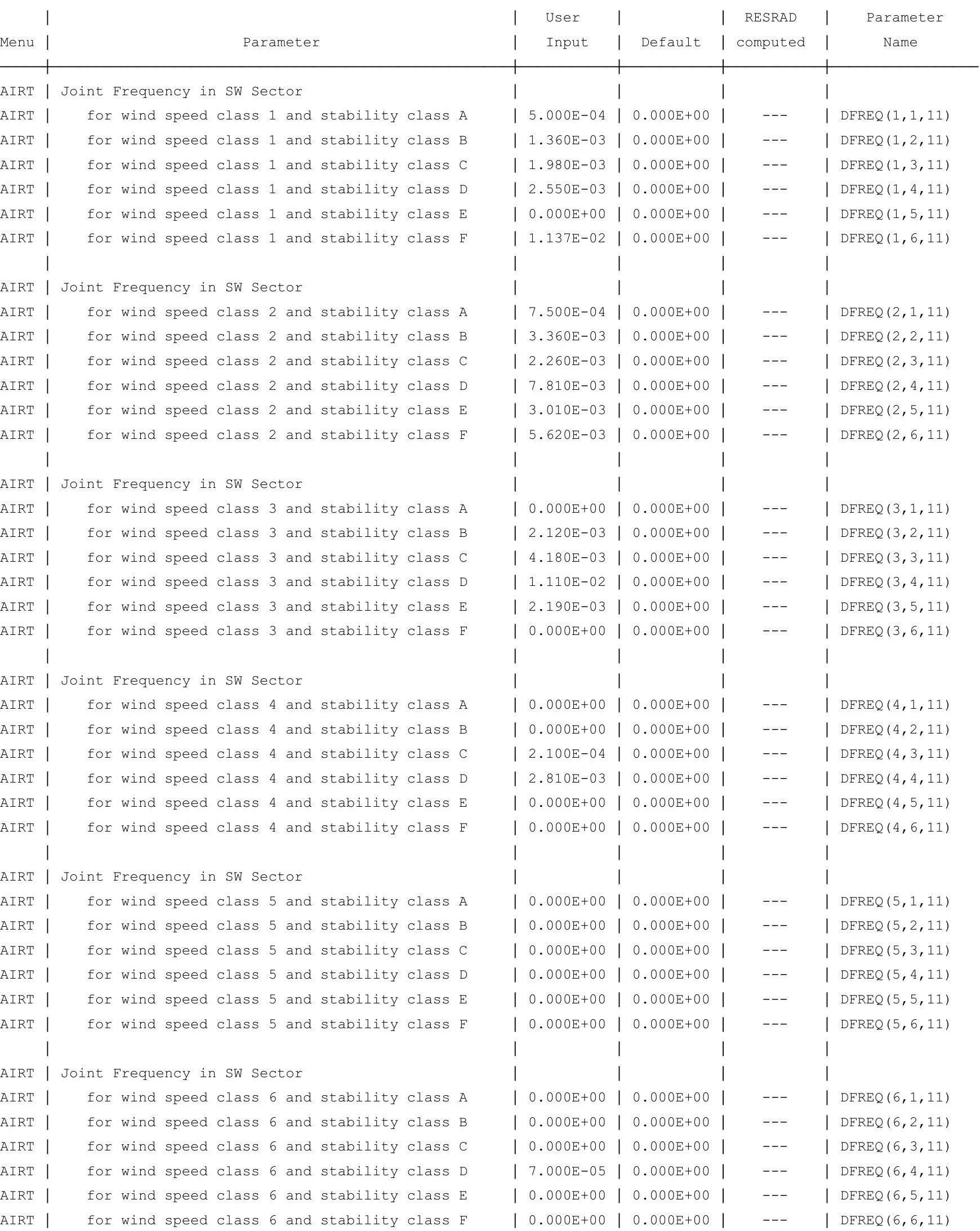


RESRAD-OFFSITE, Version 2.

Parent Dose Report

Title : Offsite Resident Farmer Deterministic Run

File : RF TC99 DOESG FWD-FV2.ROF

Site-Specific Parameter Summary (continued)

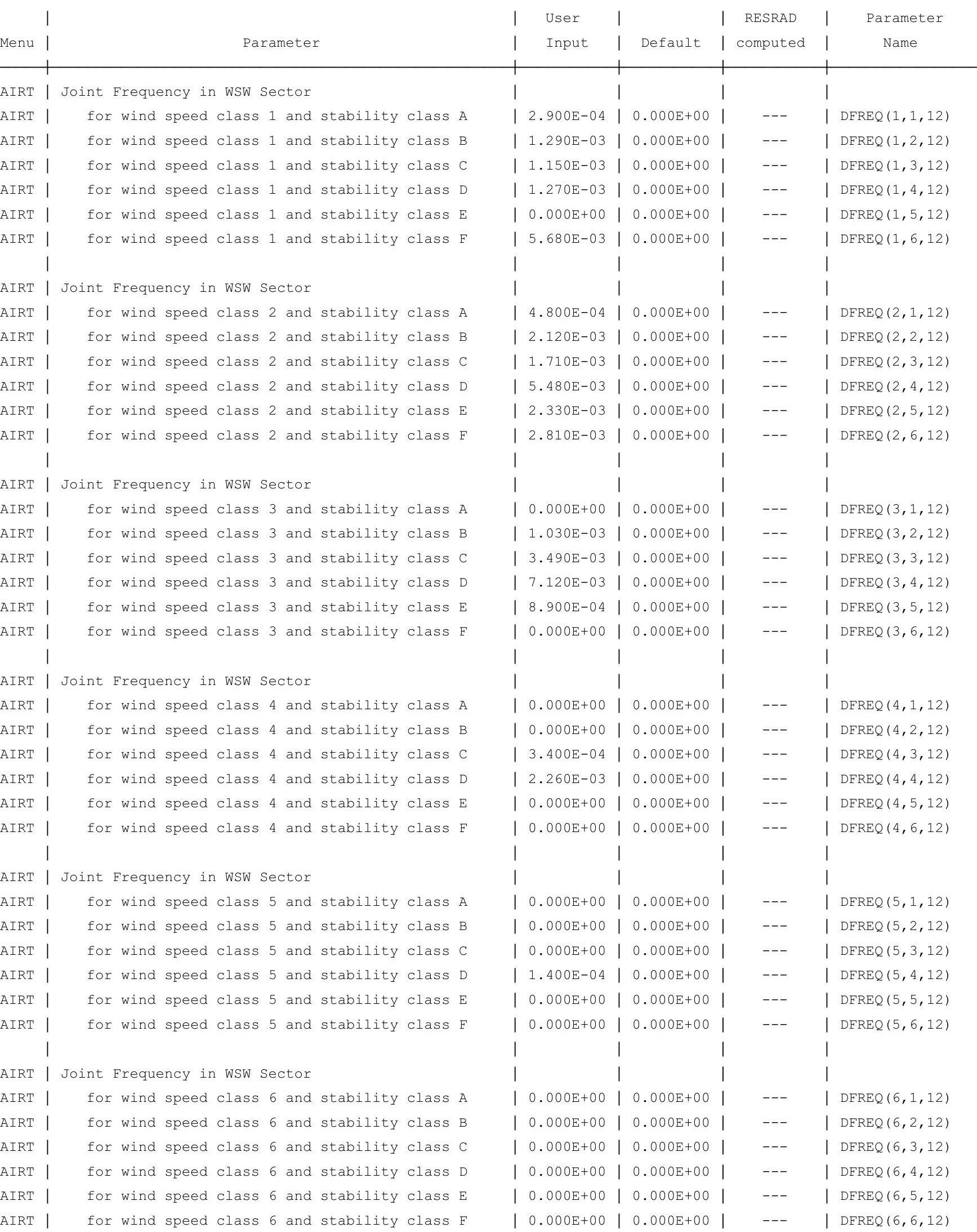


RESRAD-OFFSITE, Version 2.

Parent Dose Report

Title : Offsite Resident Farmer Deterministic Run

File : RF TC99 DOESG FWD-FV2.ROF

Site-Specific Parameter Summary (continued)

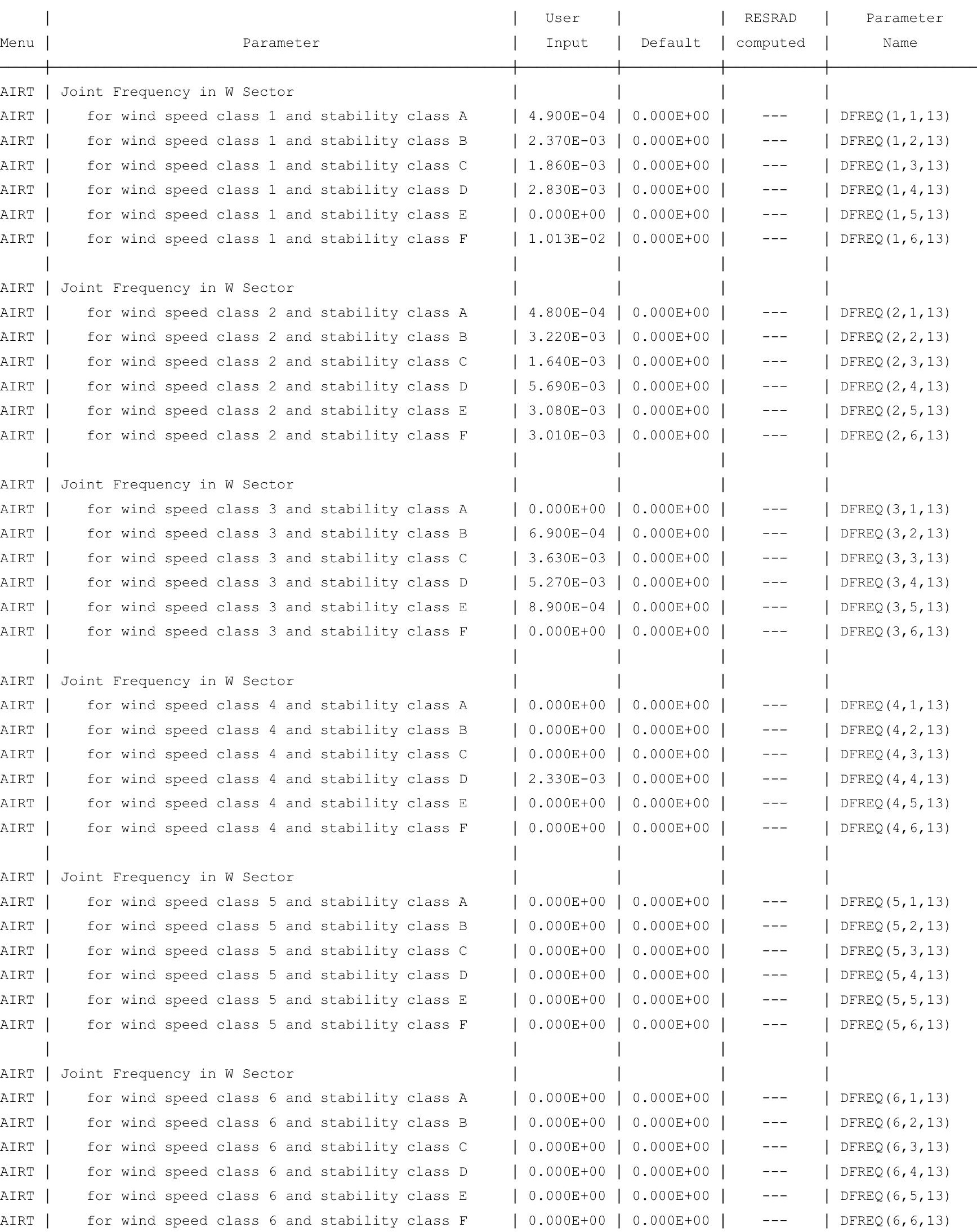


RESRAD-OFFSITE, Version 2.

Parent Dose Report

Title : Offsite Resident Farmer Deterministic Run

File : RF TC99 DOESG FWD-FV2.ROF

Site-Specific Parameter Summary (continued)

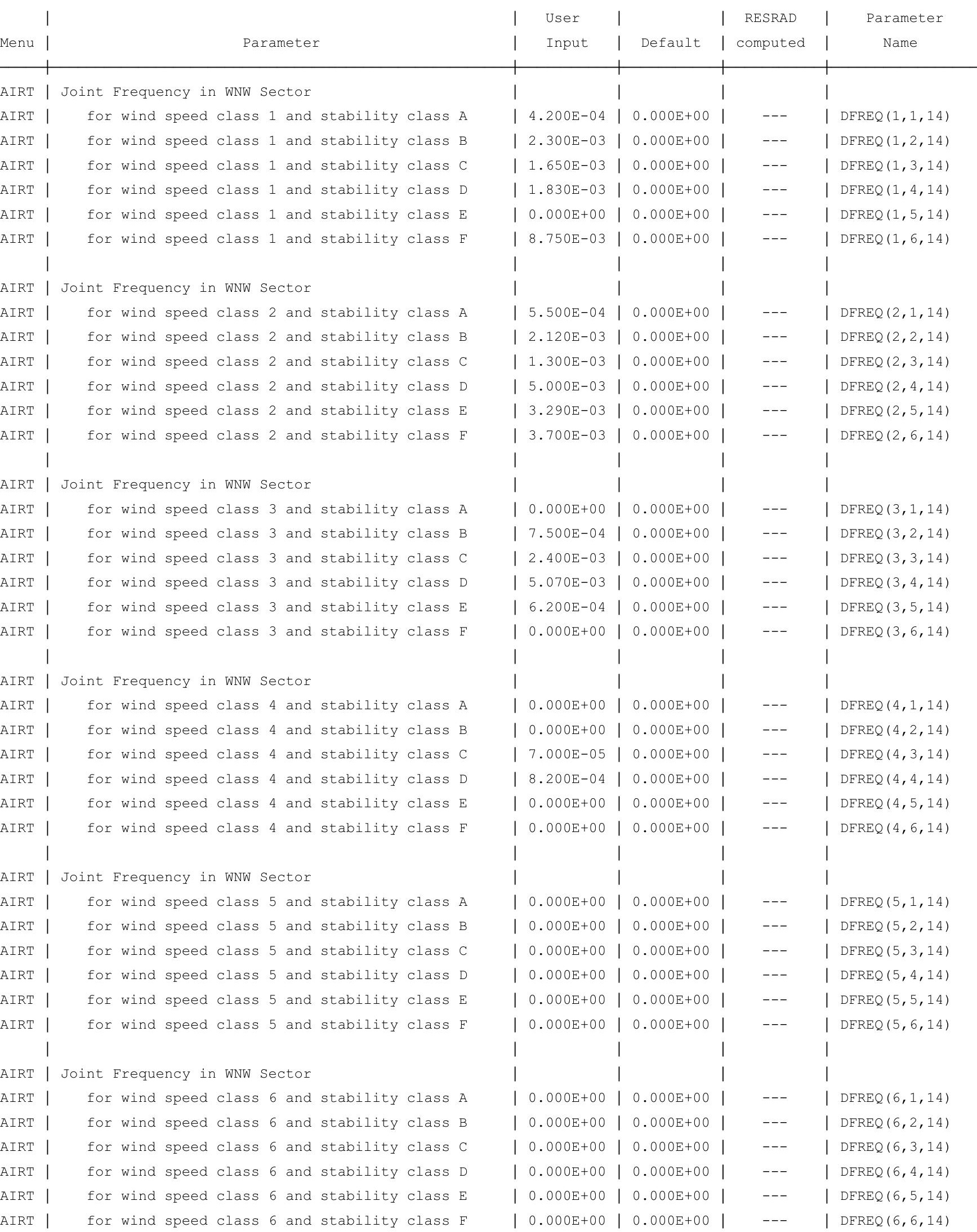


RESRAD-OFFSITE, Version 2.

Parent Dose Report

Title : Offsite Resident Farmer Deterministic Run

File : RF TC99 DOESG FWD-FV2.ROF

Site-Specific Parameter Summary (continued)

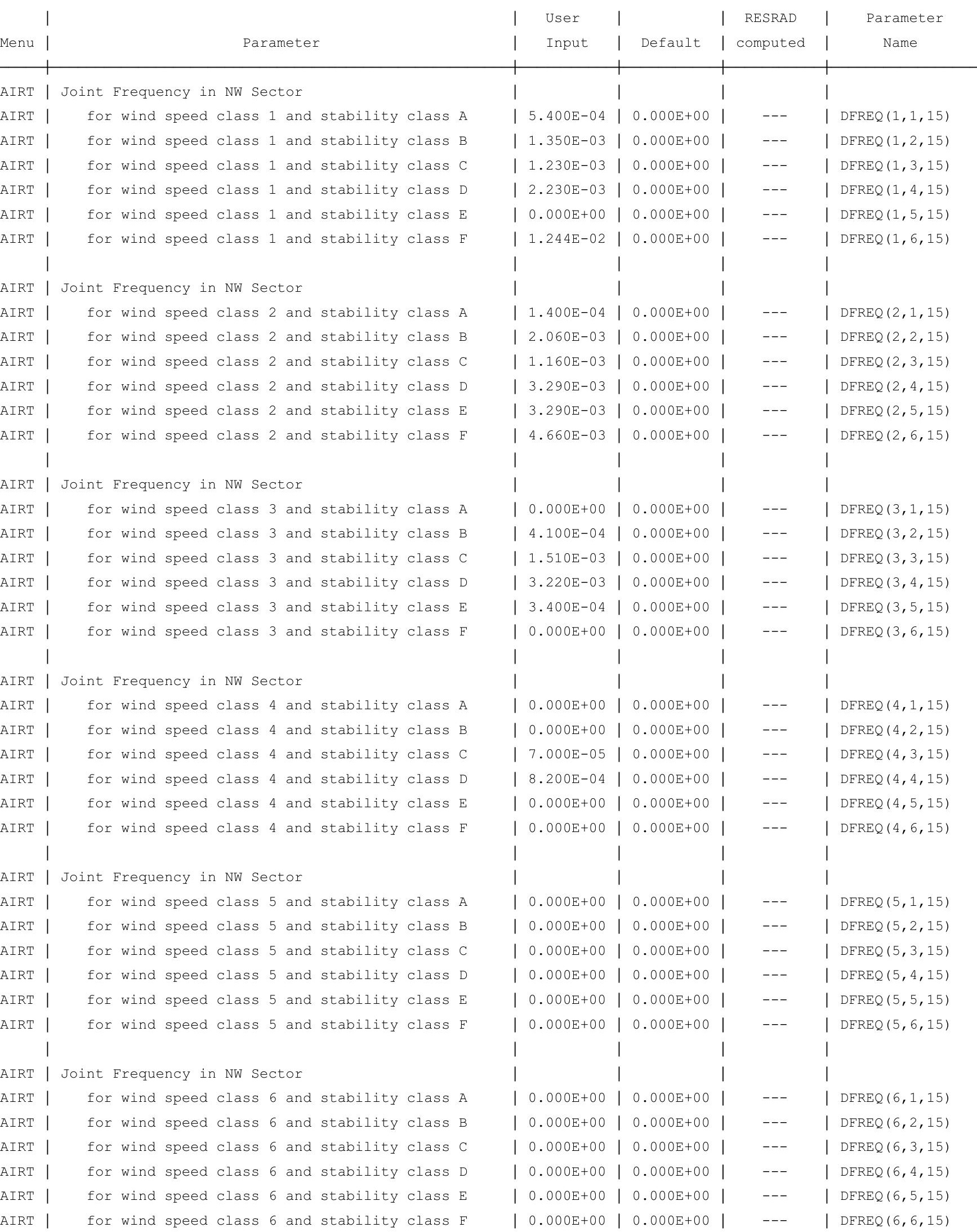


RESRAD-OFFSITE, Version 2.

Parent Dose Report

Title : Offsite Resident Farmer Deterministic Run

File : RF TC99 DOESG FWD-FV2.ROF

Site-Specific Parameter Summary (continued)

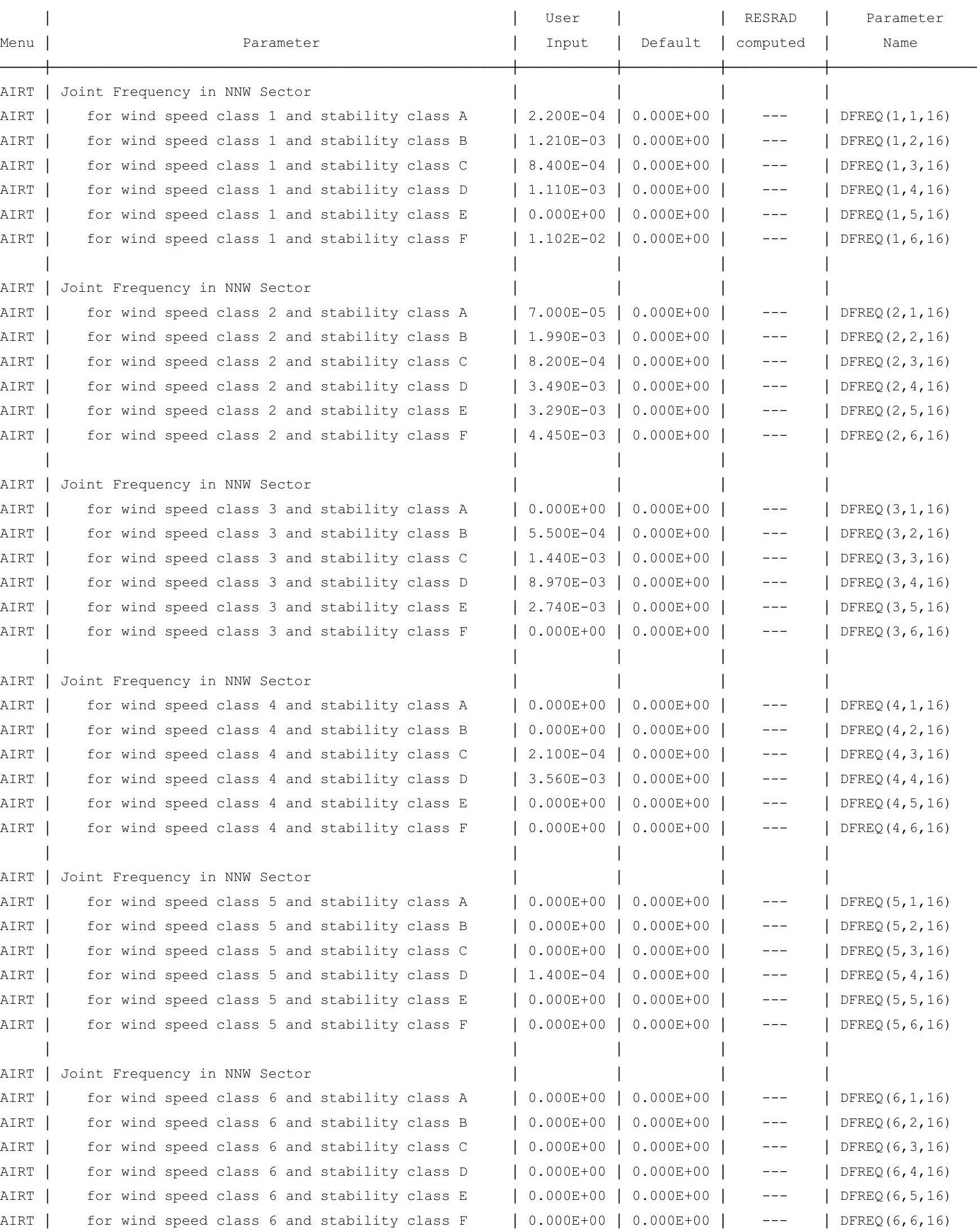


RESRAD-OFFSITE, Version 2.5

Parent Dose Report

Title : Offsite Resident Farmer Deterministic Run

File : RF TC99 DOESG FWD-FV2.ROF

Site-Specific Parameter Summary (continued)

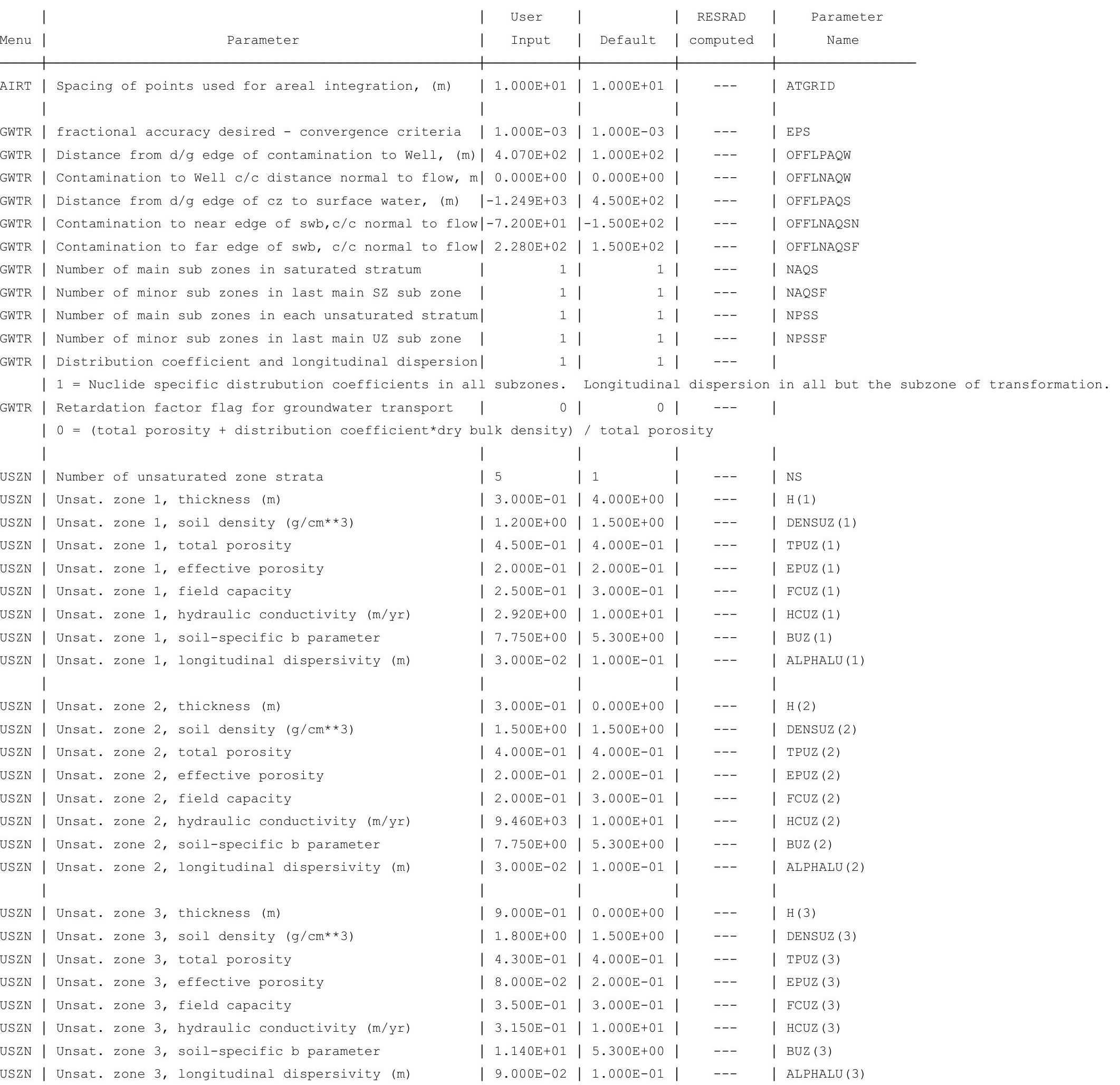


RESRAD-OFFSITE, Version 2.5

Parent Dose Report

Title : Offsite Resident Farmer Deterministic Run

File : RF TC99 DOESG FWD-FV2.ROF

Site-Specific Parameter Summary (continued)

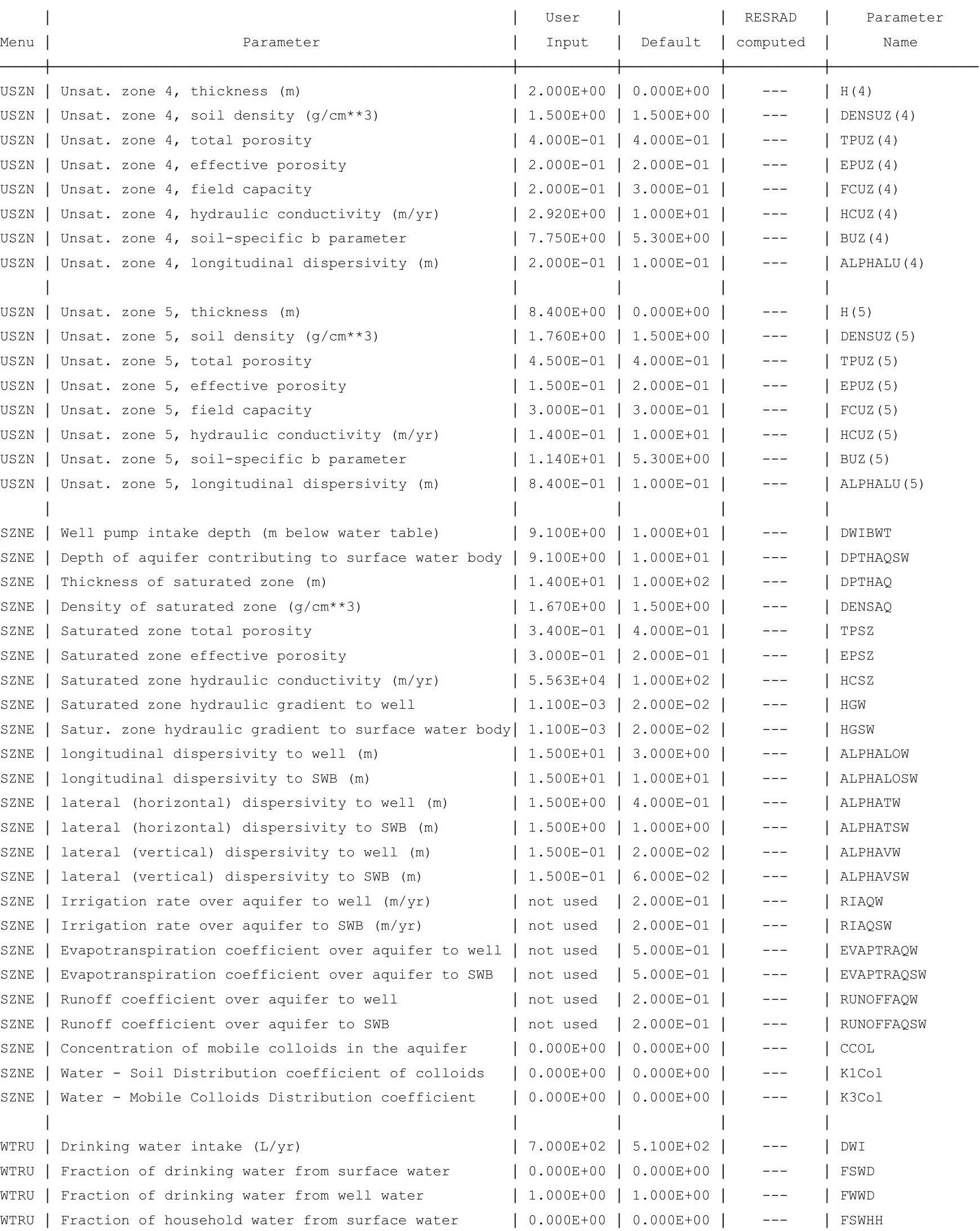


RESRAD-OFFSITE, Version 2.5

$\mathrm{T}^{1} / 2$ Limit $=180$ days

Parent Dose Report

Title : Offsite Resident Farmer Deterministic Run

File : RF TC99 DOESG FWD-FV2.ROF

Site-Specific Parameter Summary (continued)

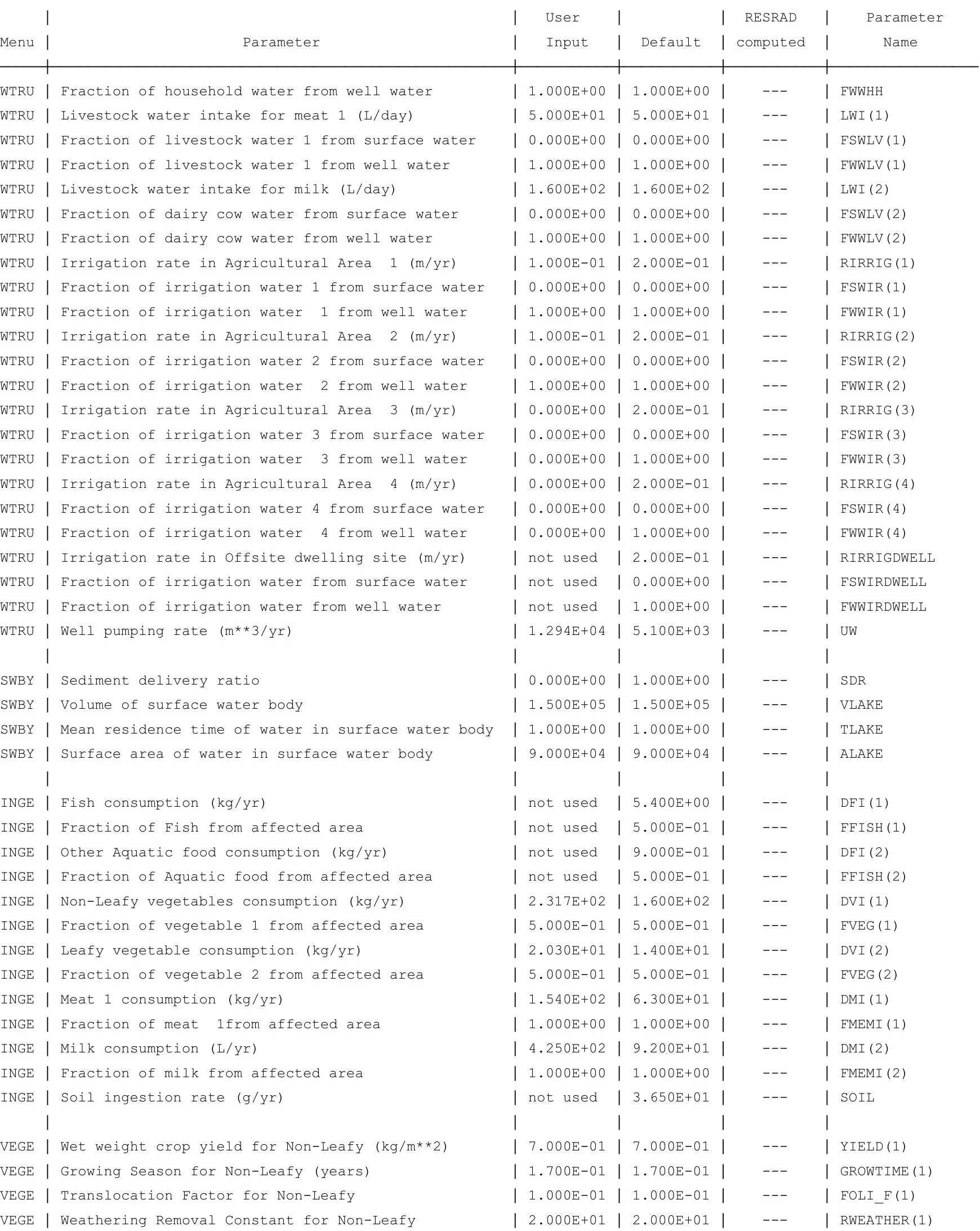


RESRAD-OFFSITE, Version 2.5

$\mathrm{T}^{1} / 2$ Limit $=180$ days

Parent Dose Report

Title : Offsite Resident Farmer Deterministic Run

File : RF TC99 DOESG FWD-FV2.ROF

Site-Specific Parameter Summary (continued)

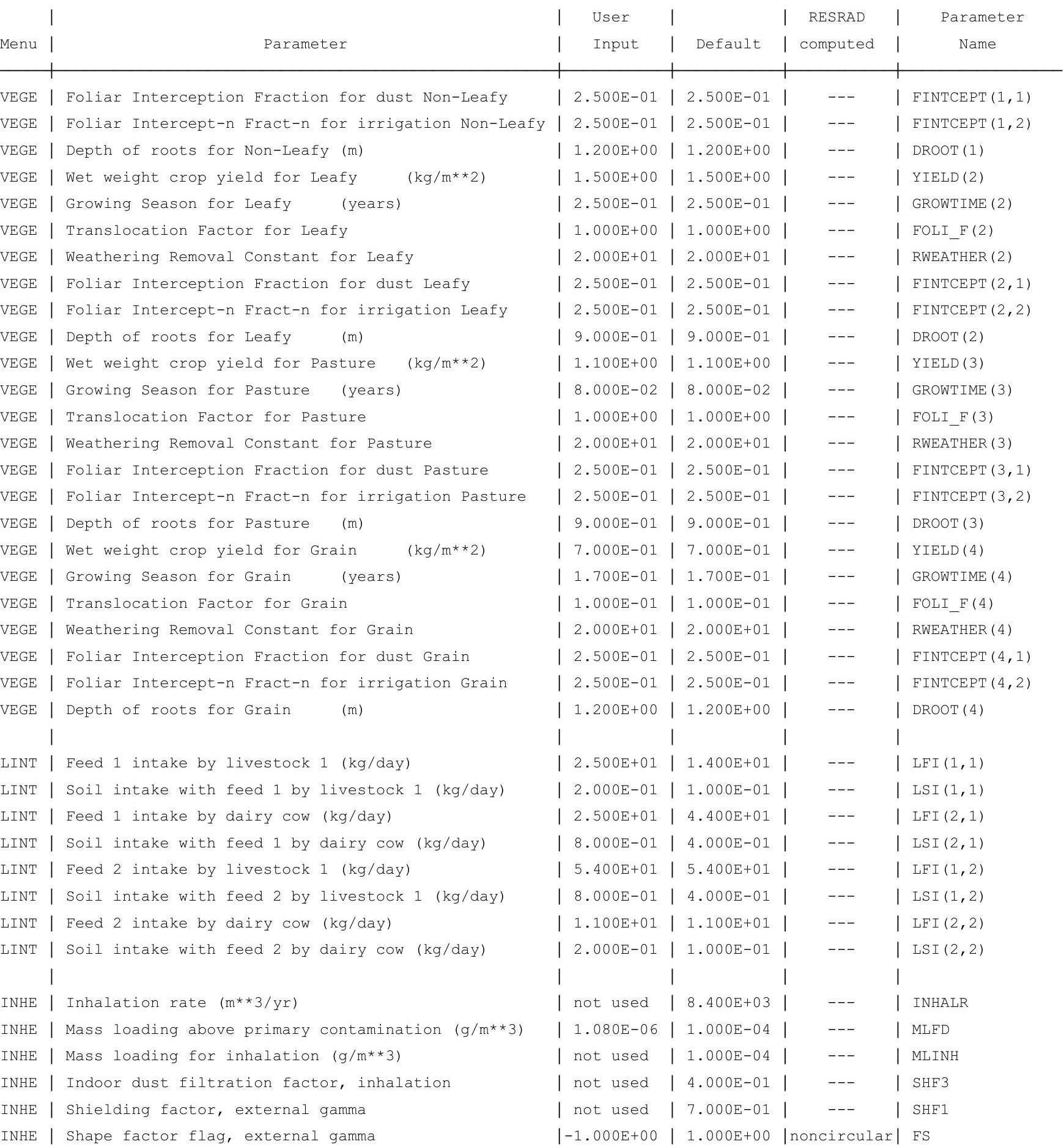


RESRAD-OFFSITE, Version $2.5 \quad \mathrm{~T}^{1 / 2}$ Limit $=180$ days

Parent Dose Report

Title : Offsite Resident Farmer Deterministic Run

File : RF TC99 DOESG FWD-FV2.ROF

Site-Specific Parameter Summary (continued)

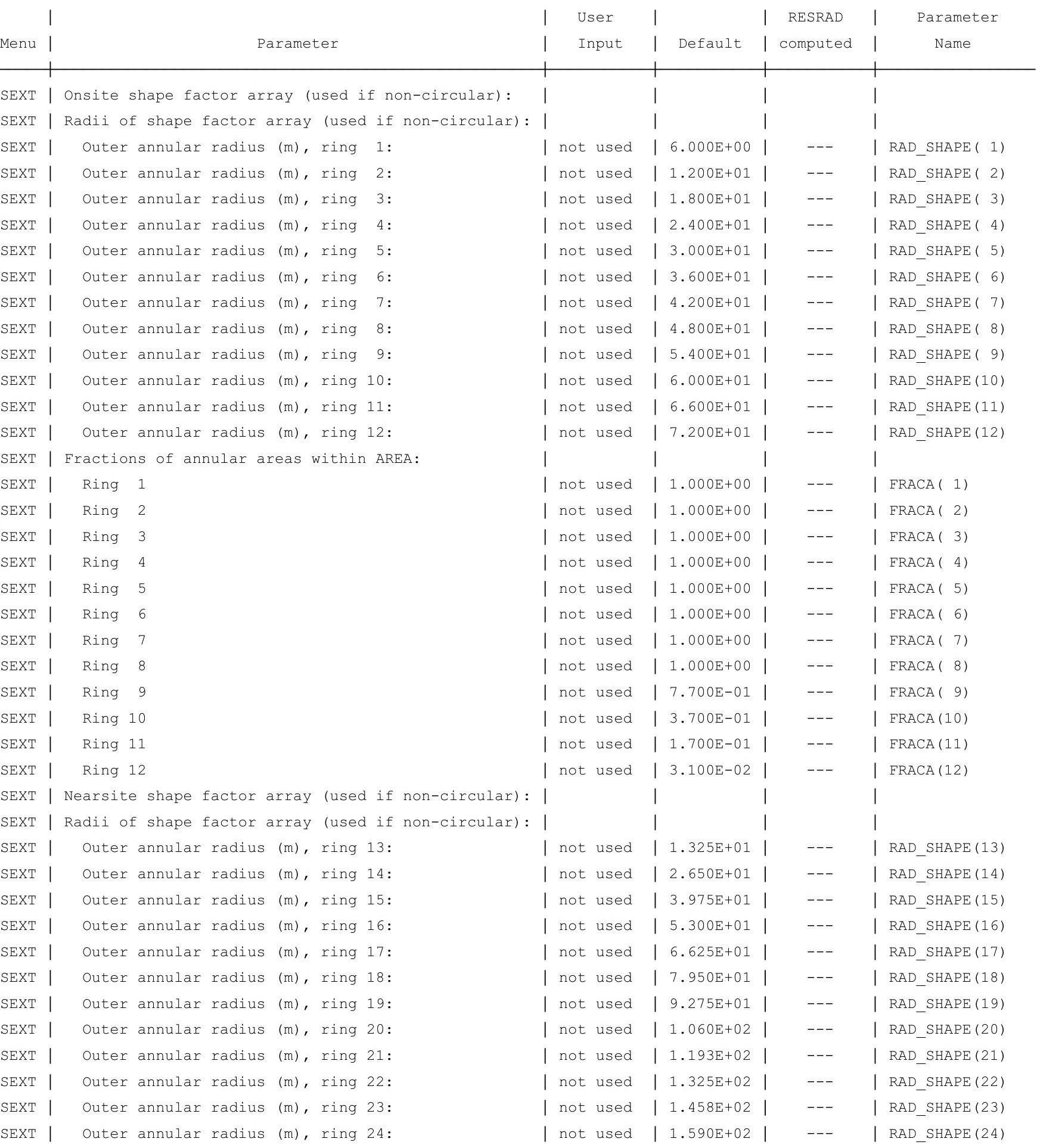


RESRAD-OFFSITE, Version $2.5 \quad \mathrm{~T}^{1 / 2}$ Limit $=180$ days

Parent Dose Report

Title : Offsite Resident Farmer Deterministic Run

File : RF TC99 DOESG FWD-FV2.ROF

Site-Specific Parameter Summary (continued)

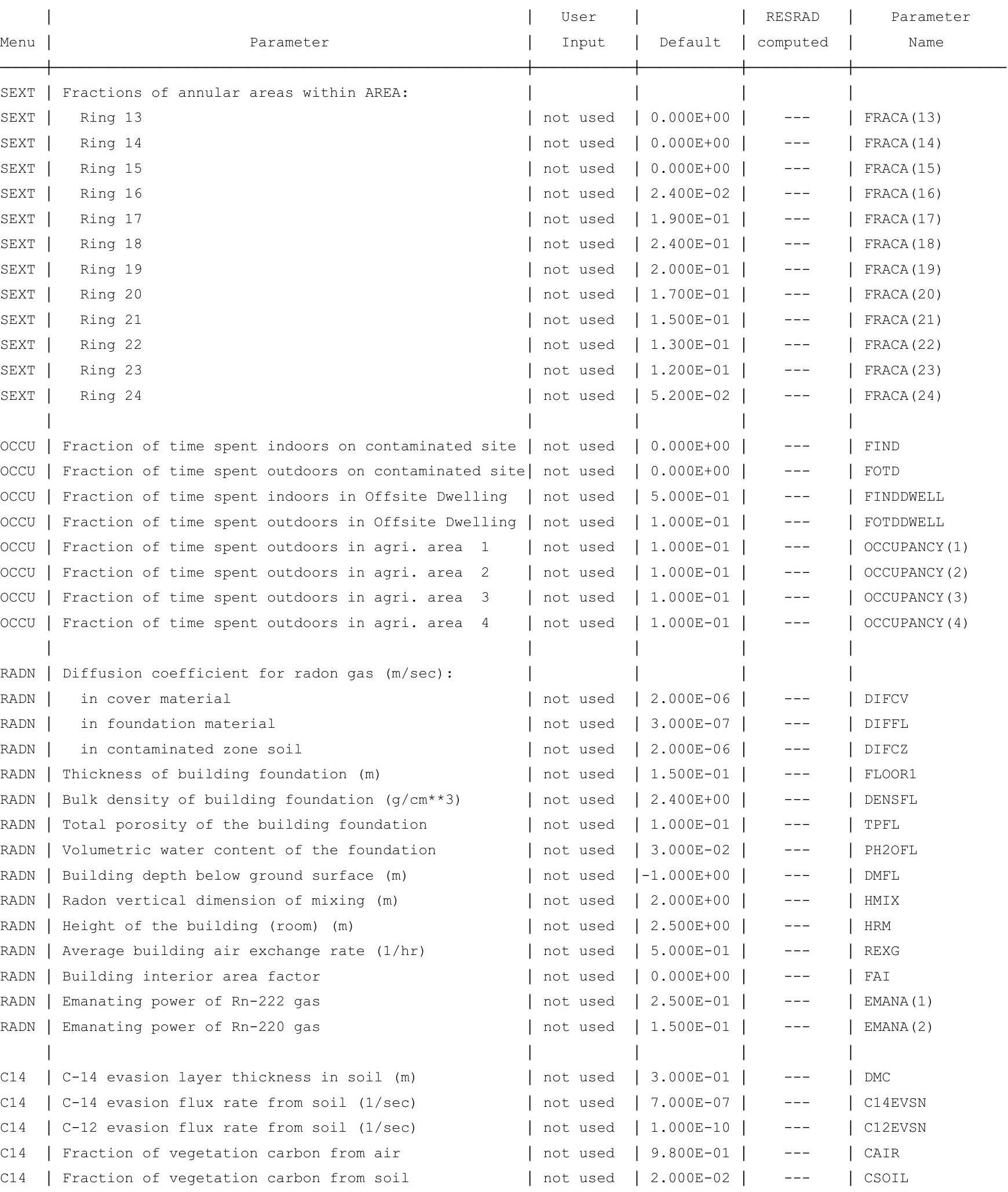


RESRAD-OFFSITE, Version 2.5

Parent Dose Report

Title : Offsite Resident Farmer Deterministic Run

File : RF TC99 DOESG FWD-FV2.ROF

Site-Specific Parameter Summary (continued)

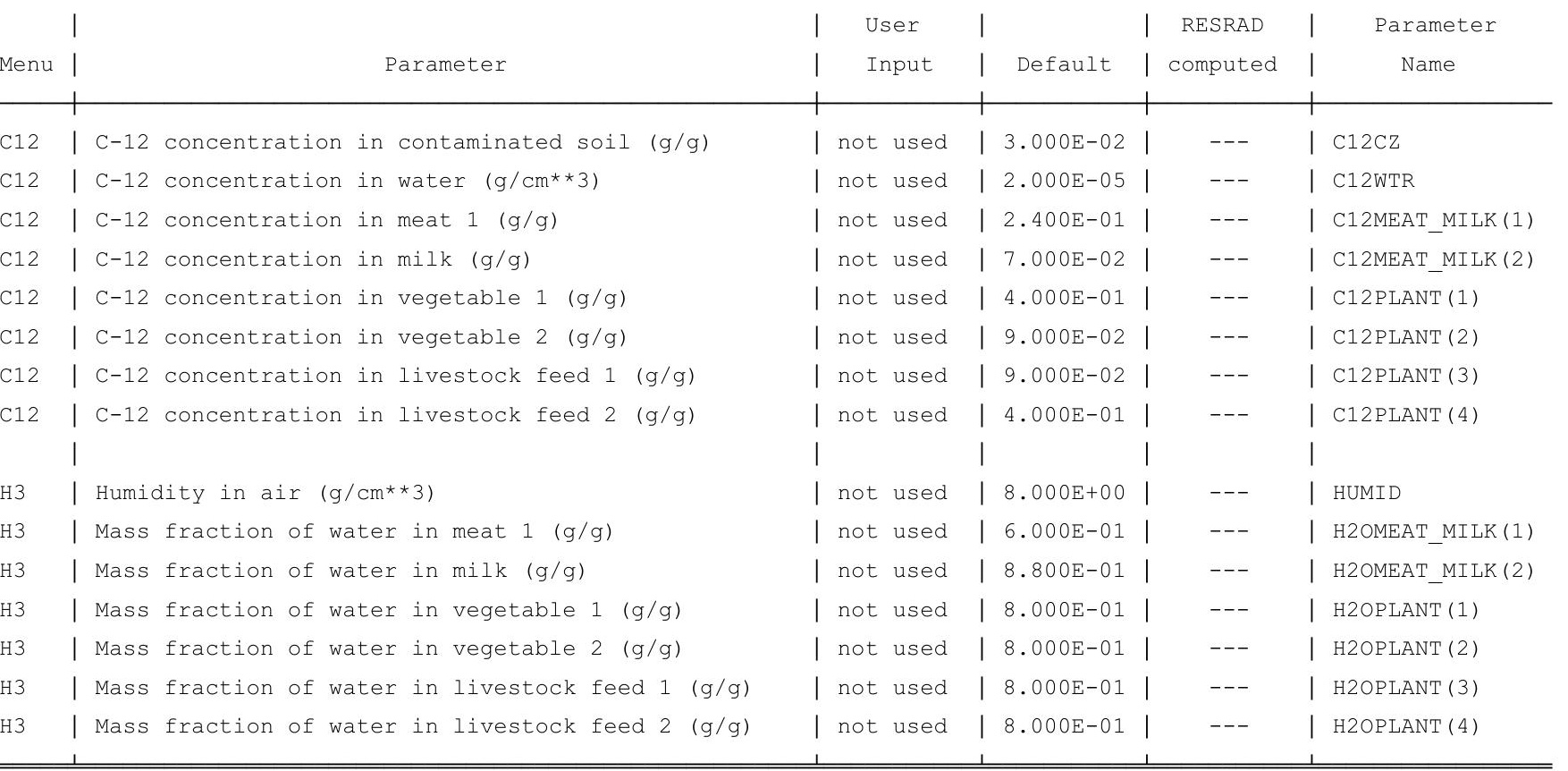

Summary of Pathway Selections

\begin{tabular}{|c|c|c|}
\hline & Pathway & User Selection \\
\hline 1 & -- external gamma & suppressed \\
\hline 2 & -- inhalation (w/o radon) & suppressed \\
\hline 3 & -- plant ingestion & active \\
\hline 4 & -- meat ingestion & active \\
\hline 5 & -- milk ingestion & active \\
\hline 6 & -- aquatic foods & suppressed \\
\hline 7 & -- drinking water & active \\
\hline 8 & -- soil ingestion & suppressed \\
\hline 9 & -- radon & suppressed \\
\hline
\end{tabular}


RESRAD-OFFSITE, Version $2.5 \quad \mathrm{~T}^{1 / 2}$ Limit $=180$ days

Parent Dose Report

Title : Offsite Resident Farmer Deterministic Run

File : RF TC99 DOESG FWD-FV2.ROF

\section{Contaminated Zone Dimensions}

Area: 102144.00 square meters

Thickness: $\quad 13.40$ meters

Cover Depth: $\quad 1.52$ meters

Total Dose TDOSE(t), mrem/yr

Basic Radiation Dose Limit $=1.000 \mathrm{E}+00 \mathrm{mrem} / \mathrm{yr}$

Total Mixture Sum $M(t)$ = Fraction of Basic Dose Limit Received at Time (t)
$t$ (years): $0.000 \mathrm{E}+00$
1.000E+00 5.000E+01
1. $000 \mathrm{E}+02$
5.000E+02 1.026E+03
TDOSE $(t): 0.000 E+00$
$0.000 \mathrm{E}+00 \quad 0.000 \mathrm{E}+00$
$0.000 \mathrm{E}+00$
9.910E-01 1.436E+00
$M(t): 0.000 E+00$
$0.000 \mathrm{E}+00 \quad 0.000 \mathrm{E}+00$
$0.000 \mathrm{E}+00$
9. $910 \mathrm{E}-01 \quad 1.436 \mathrm{E}+00$

Maximum TDOSE(t): $1.868 \mathrm{E}+00 \mathrm{mrem} / \mathrm{yr}$ at $t=772$ years 
RESRAD-OFFSITE, Version 2.5

Parent Dose Report

Title : Offsite Resident Farmer Deterministic Run

File : RF TC99 DOESG FWD-FV2.ROF

Total Dose Contributions TDOSE(i,p,t) for Individual Radionuclides (i) and Pathways (p) in mrem/yr and as a Percentage of Total Dose at $t=0$ years

From releases to ground water and to surface water

\begin{tabular}{|c|c|c|c|c|c|c|c|c|c|c|c|c|c|c|c|}
\hline \multicolumn{2}{|c|}{ Ground } & \multicolumn{2}{|l|}{ Fish } & \multicolumn{2}{|c|}{ Radon } & \multicolumn{2}{|c|}{ Plant } & \multicolumn{2}{|l|}{ Meat } & \multicolumn{2}{|l|}{ Milk } & \multicolumn{2}{|l|}{ Soil } & \multicolumn{2}{|c|}{ Water } \\
\hline Dose & $\%$ & Dose & $\%$ & Dose & 응 & Dose & 음 & Dose & $\%$ & Dose & 응 & Dose & 응 & Dose & $\frac{\circ}{0}$ \\
\hline $0.00 \mathrm{E}+00$ & 0 & $0.00 \mathrm{E}+00$ & 0 & $0.00 \mathrm{E}+00$ & 0 & $0.00 \mathrm{E}+00$ & 0 & $0.00 E+00$ & 0 & $0.00 \mathrm{E}+00$ & 0 & $0.00 \mathrm{E}+00$ & 0 & $0.00 \mathrm{E}+00$ & 0 \\
\hline $0.00 \mathrm{E}+00$ & 0 & $0.00 \mathrm{E}+00$ & 0 & $0.00 \mathrm{E}+00$ & 0 & $0.00 \mathrm{E}+00$ & 0 & $0.00 \mathrm{E}+00$ & 0 & $0.00 \mathrm{E}+00$ & 0 & $0.00 \mathrm{E}+00$ & 0 & $0.00 \mathrm{E}+00$ & \\
\hline
\end{tabular}

Total Dose Contributions TDOSE(i,p,t) for Individual Radionuclides (i) and Pathways (p)

in mrem/yr and as a Percentage of Total Dose at $t=0$ years

Directly from primary contamination and from release to atmosphere (Inhalation excludes radon)

\begin{tabular}{|c|c|c|c|c|c|c|c|c|c|c|c|c|c|c|c|c|}
\hline & \multicolumn{2}{|c|}{ Ground } & \multicolumn{2}{|c|}{ Inhalation } & \multicolumn{2}{|c|}{ Radon } & \multicolumn{2}{|c|}{ Plant } & \multicolumn{2}{|l|}{ Meat } & \multicolumn{2}{|l|}{ Milk } & \multicolumn{2}{|l|}{ Soil } & \multicolumn{2}{|c|}{ All Pathways* } \\
\hline uclide & Dose & $\%$ & Dose & $\%$ & Dose & $\%$ & Dose & 음 & Dose & $\%$ & Dose & \% & Dose & $\%$ & Dose & $\%$ \\
\hline-99 & $0.00 \mathrm{E}+00$ & 0 & $0.00 \mathrm{E}+00$ & 0 & $0.00 \mathrm{E}+00$ & 0 & $0.00 \mathrm{E}+00$ & 0 & $0.00 \mathrm{E}+00$ & 0 & $0.00 \mathrm{E}+00$ & 0 & $0.00 \mathrm{E}+00$ & 0 & $0.00 \mathrm{E}+00$ & 0 \\
\hline :al & $0.00 \mathrm{E}+00$ & 0 & $0.00 \mathrm{E}+00$ & 0 & $0.00 \mathrm{E}+00$ & 0 & $0.00 \mathrm{E}+00$ & 0 & $0.00 \mathrm{E}+00$ & 0 & $0.00 \mathrm{E}+00$ & 0 & $0.00 \mathrm{E}+00$ & 0 & $0.00 \mathrm{E}+00$ & 0 \\
\hline
\end{tabular}

* Sum of dose from all releases and from primary contamination. 
RESRAD-OFFSITE, Version 2.5

Parent Dose Report

Title : Offsite Resident Farmer Deterministic Run

File : RF TC99 DOESG FWD-FV2.ROF

Total Dose Contributions TDOSE(i,p,t) for Individual Radionuclides (i) and Pathways (p) in mrem/yr and as a Percentage of Total Dose at $t=1$ years

From releases to ground water and to surface water

\begin{tabular}{|c|c|c|c|c|c|c|c|c|c|c|c|c|c|c|c|c|}
\hline & \multicolumn{2}{|c|}{ Ground } & \multicolumn{2}{|l|}{ Fish } & \multicolumn{2}{|c|}{ Radon } & \multicolumn{2}{|c|}{ Plant } & \multicolumn{2}{|l|}{ Meat } & \multicolumn{2}{|l|}{ Milk } & \multicolumn{2}{|l|}{ Soil } & \multicolumn{2}{|c|}{ Water } \\
\hline dclide & Dose & \% & Dose & $\%$ & Dose & 음 & Dose & 음 & Dose & $\%$ & Dose & 음 & Dose & $\%$ & Dose & 응 \\
\hline-99 & $0.00 \mathrm{E}+00$ & 0 & $0.00 \mathrm{E}+00$ & 0 & $0.00 \mathrm{E}+00$ & 0 & $0.00 \mathrm{E}+00$ & 0 & $0.00 \mathrm{E}+00$ & 0 & $0.00 \mathrm{E}+00$ & 0 & $0.00 \mathrm{E}+00$ & 0 & $0.00 \mathrm{E}+00$ & 0 \\
\hline ta] & $0.00 \mathrm{E}+00$ & 0 & $0.00 \mathrm{E}+00$ & 0 & $0.00 \mathrm{E}+00$ & 0 & $0.00 \mathrm{E}+00$ & 0 & $0.00 \mathrm{E}+00$ & 0 & $0.00 \mathrm{E}+00$ & 0 & $0.00 \mathrm{E}+00$ & 0 & $0.00 \mathrm{E}+00$ & 0 \\
\hline
\end{tabular}

Total Dose Contributions TDOSE(i,p,t) for Individual Radionuclides (i) and Pathways (p)

in mrem/yr and as a Percentage of Total Dose at $t=1$ years

Directly from primary contamination and from release to atmosphere (Inhalation excludes radon)

\begin{tabular}{|c|c|c|c|c|c|c|c|c|c|c|c|c|c|c|c|c|}
\hline & \multicolumn{2}{|c|}{ Ground } & \multicolumn{2}{|c|}{ Inhalation } & \multicolumn{2}{|c|}{ Radon } & \multicolumn{2}{|c|}{ Plant } & \multicolumn{2}{|l|}{ Meat } & \multicolumn{2}{|l|}{ Milk } & \multicolumn{2}{|l|}{ Soil } & \multicolumn{2}{|c|}{ All Pathways* } \\
\hline clide & Dose & \% & Dose & $\%$ & Dose & $\%$ & Dose & 음 & Dose & $\%$ & Dose & 응 & Dose & 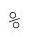 & Dose & $\%$ \\
\hline-99 & $0.00 \mathrm{E}+00$ & 0 & $0.00 \mathrm{E}+00$ & 0 & $0.00 \mathrm{E}+00$ & 0 & $0.00 \mathrm{E}+00$ & 0 & $0.00 \mathrm{E}+00$ & 0 & $0.00 \mathrm{E}+00$ & 0 & $0.00 \mathrm{E}+00$ & 0 & $0.00 \mathrm{E}+00$ & 0 \\
\hline to & $0.00 \mathrm{E}+00$ & 0 & $0.00 \mathrm{E}+00$ & 0 & $0.00 \mathrm{E}+00$ & 0 & $0.00 \mathrm{E}+00$ & 0 & $0.00 \mathrm{E}+00$ & 0 & $0.00 \mathrm{E}+00$ & 0 & $0.00 \mathrm{E}+00$ & 0 & $0.00 \mathrm{E}+00$ & 0 \\
\hline
\end{tabular}

* Sum of dose from all releases and from primary contamination. 
RESRAD-OFFSITE, Version 2.5

Parent Dose Report

Title : Offsite Resident Farmer Deterministic Run

File : RF TC99 DOESG FWD-FV2.ROF

Total Dose Contributions TDOSE(i,p,t) for Individual Radionuclides (i) and Pathways (p) in mrem/yr and as a Percentage of Total Dose at $t=50$ years

From releases to ground water and to surface water

\begin{tabular}{|c|c|c|c|c|c|c|c|c|c|c|c|c|c|c|c|c|}
\hline & \multicolumn{2}{|c|}{ Ground } & \multicolumn{2}{|l|}{ Fish } & \multicolumn{2}{|c|}{ Radon } & \multicolumn{2}{|c|}{ Plant } & \multicolumn{2}{|l|}{ Meat } & \multicolumn{2}{|l|}{ Milk } & \multicolumn{2}{|l|}{ Soil } & \multicolumn{2}{|c|}{ Water } \\
\hline dclide & Dose & \% & Dose & $\%$ & Dose & 음 & Dose & 음 & Dose & $\%$ & Dose & 음 & Dose & $\%$ & Dose & 응 \\
\hline-99 & $0.00 \mathrm{E}+00$ & 0 & $0.00 \mathrm{E}+00$ & 0 & $0.00 \mathrm{E}+00$ & 0 & $0.00 \mathrm{E}+00$ & 0 & $0.00 \mathrm{E}+00$ & 0 & $0.00 \mathrm{E}+00$ & 0 & $0.00 \mathrm{E}+00$ & 0 & $0.00 \mathrm{E}+00$ & 0 \\
\hline ta] & $0.00 \mathrm{E}+00$ & 0 & $0.00 \mathrm{E}+00$ & 0 & $0.00 \mathrm{E}+00$ & 0 & $0.00 \mathrm{E}+00$ & 0 & $0.00 \mathrm{E}+00$ & 0 & $0.00 \mathrm{E}+00$ & 0 & $0.00 \mathrm{E}+00$ & 0 & $0.00 \mathrm{E}+00$ & 0 \\
\hline
\end{tabular}

Total Dose Contributions TDOSE(i,p,t) for Individual Radionuclides (i) and Pathways (p) in mrem/yr and as a Percentage of Total Dose at $t=50$ years

Directly from primary contamination and from release to atmosphere (Inhalation excludes radon)

\begin{tabular}{|c|c|c|c|c|c|c|c|c|c|c|c|c|c|c|c|c|}
\hline & \multicolumn{2}{|c|}{ Ground } & \multicolumn{2}{|c|}{ Inhalation } & \multicolumn{2}{|c|}{ Radon } & \multicolumn{2}{|c|}{ Plant } & \multicolumn{2}{|l|}{ Meat } & \multicolumn{2}{|l|}{ Milk } & \multicolumn{2}{|l|}{ Soil } & \multicolumn{2}{|c|}{ All Pathways* } \\
\hline clide & Dose & \% & Dose & $\%$ & Dose & $\%$ & Dose & 음 & Dose & $\%$ & Dose & 응 & Dose & 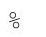 & Dose & $\%$ \\
\hline-99 & $0.00 \mathrm{E}+00$ & 0 & $0.00 \mathrm{E}+00$ & 0 & $0.00 \mathrm{E}+00$ & 0 & $0.00 \mathrm{E}+00$ & 0 & $0.00 \mathrm{E}+00$ & 0 & $0.00 \mathrm{E}+00$ & 0 & $0.00 \mathrm{E}+00$ & 0 & $0.00 \mathrm{E}+00$ & 0 \\
\hline to & $0.00 \mathrm{E}+00$ & 0 & $0.00 \mathrm{E}+00$ & 0 & $0.00 \mathrm{E}+00$ & 0 & $0.00 \mathrm{E}+00$ & 0 & $0.00 \mathrm{E}+00$ & 0 & $0.00 \mathrm{E}+00$ & 0 & $0.00 \mathrm{E}+00$ & 0 & $0.00 \mathrm{E}+00$ & 0 \\
\hline
\end{tabular}

* Sum of dose from all releases and from primary contamination. 
RESRAD-OFFSITE, Version 2.5

Parent Dose Report

Title : Offsite Resident Farmer Deterministic Run

File : RF TC99 DOESG FWD-FV2.ROF

Total Dose Contributions TDOSE (i,p,t) for Individual Radionuclides (i) and Pathways (p) in mrem/yr and as a Percentage of Total Dose at $t=100$ years

From releases to ground water and to surface water

\begin{tabular}{|c|c|c|c|c|c|c|c|c|c|c|c|c|c|c|c|}
\hline \multicolumn{2}{|c|}{ Ground } & \multicolumn{2}{|l|}{ Fish } & \multicolumn{2}{|c|}{ Radon } & \multicolumn{2}{|c|}{ Plant } & \multicolumn{2}{|l|}{ Meat } & \multicolumn{2}{|l|}{ Milk } & \multicolumn{2}{|l|}{ Soil } & \multicolumn{2}{|c|}{ Water } \\
\hline Dose & $\%$ & Dose & $\%$ & Dose & \% & Dose & \% & Dose & $\%$ & Dose & \% & Dose & $\frac{\circ}{0}$ & Dose & $\%$ \\
\hline $0.00 \mathrm{E}+00$ & 0 & $0.00 \mathrm{E}+00$ & 0 & $0.00 \mathrm{E}+00$ & 0 & $0.00 \mathrm{E}+00$ & 0 & $0.00 \mathrm{E}+00$ & 0 & $0.00 \mathrm{E}+00$ & 0 & $0.00 \mathrm{E}+00$ & 0 & $0.00 \mathrm{E}+00$ & 0 \\
\hline $0.00 \mathrm{E}+00$ & 0 & $0.00 \mathrm{E}+00$ & 0 & $0.00 \mathrm{E}+00$ & 0 & $0.00 \mathrm{E}+00$ & 0 & $0.00 \mathrm{E}+00$ & 0 & $0.00 \mathrm{E}+00$ & 0 & $0.00 \mathrm{E}+00$ & 0 & $0.00 \mathrm{E}+00$ & \\
\hline
\end{tabular}

Total Dose Contributions TDOSE (i,p,t) for Individual Radionuclides (i) and Pathways (p) in mrem/yr and as a Percentage of Total Dose at $t=100$ years

Directly from primary contamination and from release to atmosphere (Inhalation excludes radon)

\begin{tabular}{|c|c|c|c|c|c|c|c|c|c|c|c|c|c|c|c|c|}
\hline & \multicolumn{2}{|c|}{ Ground } & \multicolumn{2}{|c|}{ Inhalation } & \multicolumn{2}{|c|}{ Radon } & \multicolumn{2}{|c|}{ Plant } & \multicolumn{2}{|l|}{ Meat } & \multicolumn{2}{|l|}{ Milk } & \multicolumn{2}{|l|}{ Soil } & \multicolumn{2}{|c|}{ All Pathways* } \\
\hline uclide & Dose & $\%$ & Dose & $\%$ & Dose & $\%$ & Dose & 음 & Dose & $\%$ & Dose & \% & Dose & $\%$ & Dose & $\%$ \\
\hline-99 & $0.00 \mathrm{E}+00$ & 0 & $0.00 \mathrm{E}+00$ & 0 & $0.00 \mathrm{E}+00$ & 0 & $0.00 \mathrm{E}+00$ & 0 & $0.00 \mathrm{E}+00$ & 0 & $0.00 \mathrm{E}+00$ & 0 & $0.00 \mathrm{E}+00$ & 0 & $0.00 \mathrm{E}+00$ & 0 \\
\hline :al & $0.00 \mathrm{E}+00$ & 0 & $0.00 \mathrm{E}+00$ & 0 & $0.00 \mathrm{E}+00$ & 0 & $0.00 \mathrm{E}+00$ & 0 & $0.00 \mathrm{E}+00$ & 0 & $0.00 \mathrm{E}+00$ & 0 & $0.00 \mathrm{E}+00$ & 0 & $0.00 \mathrm{E}+00$ & 0 \\
\hline
\end{tabular}

* Sum of dose from all releases and from primary contamination. 
RESRAD-OFFSITE, Version 2.5

Parent Dose Report

Title : Offsite Resident Farmer Deterministic Run

File : RF TC99 DOESG FWD-FV2.ROF

Total Dose Contributions TDOSE(i,p,t) for Individual Radionuclides (i) and Pathways (p) in mrem/yr and as a Percentage of Total Dose at $t=500$ years

From releases to ground water and to surface water

\begin{tabular}{|c|c|c|c|c|c|c|c|c|c|c|c|c|c|c|c|}
\hline \multicolumn{2}{|c|}{ Ground } & \multicolumn{2}{|l|}{ Fish } & \multicolumn{2}{|c|}{ Radon } & \multicolumn{2}{|c|}{ Plant } & \multicolumn{2}{|l|}{ Meat } & \multicolumn{2}{|l|}{ Milk } & \multicolumn{2}{|l|}{ Soil } & \multicolumn{2}{|c|}{ Water } \\
\hline Dose & $\%$ & Dose & $\%$ & Dose & 응 & Dose & 음 & Dose & \% & Dose & 응 & Dose & 응 & Dose & $\%$ \\
\hline $0.00 \mathrm{E}+00$ & 0 & $0.00 \mathrm{E}+00$ & 0 & $0.00 \mathrm{E}+00$ & 0 & $2.48 \mathrm{E}-01$ & 25 & $7.44 \mathrm{E}-04$ & 0 & $6.57 \mathrm{E}-02$ & 7 & $0.00 \mathrm{E}+00$ & 0 & $6.76 E-01$ & 68 \\
\hline $0.00 \mathrm{E}+00$ & 0 & $0.00 \mathrm{E}+00$ & 0 & $0.00 \mathrm{E}+00$ & 0 & $2.48 \mathrm{E}-01$ & 25 & 7. $44 \mathrm{E}-04$ & 0 & $6.57 \mathrm{E}-02$ & 7 & $0.00 \mathrm{E}+00$ & 0 & $6.76 E-01$ & 68 \\
\hline
\end{tabular}

Total Dose Contributions TDOSE (i,p,t) for Individual Radionuclides (i) and Pathways (p)

in mrem/yr and as a Percentage of Total Dose at $t=500$ years

Directly from primary contamination and from release to atmosphere (Inhalation excludes radon)

\begin{tabular}{|c|c|c|c|c|c|c|c|c|c|c|c|c|c|c|c|c|}
\hline & \multicolumn{2}{|c|}{ Ground } & \multicolumn{2}{|c|}{ Inhalation } & \multicolumn{2}{|c|}{ Radon } & \multicolumn{2}{|c|}{ Plant } & \multicolumn{2}{|l|}{ Meat } & \multicolumn{2}{|l|}{ Milk } & \multicolumn{2}{|l|}{ Soil } & \multicolumn{2}{|c|}{ All Pathways* } \\
\hline Juclide & Dose & \% & Dose & $\%$ & Dose & 응 & Dose & 음 & Dose & \% & Dose & \% & Dose & \% & Dose & $\%$ \\
\hline-99 & $0.00 \mathrm{E}+00$ & 0 & $0.00 \mathrm{E}+00$ & 0 & $0.00 E+00$ & 0 & $0.00 \mathrm{E}+00$ & 0 & $0.00 \mathrm{E}+00$ & 0 & $0.00 E+00$ & 0 & $0.00 \mathrm{E}+00$ & 0 & $9.91 \mathrm{E}-01$ & 100 \\
\hline ta & $0.00 \mathrm{E}+00$ & 0 & $0.00 \mathrm{E}+00$ & 0 & $0.00 \mathrm{E}+00$ & 0 & $0.00 \mathrm{E}+00$ & 0 & $0.00 \mathrm{E}+00$ & 0 & $0.00 \mathrm{E}+00$ & 0 & $0.00 \mathrm{E}+00$ & 0 & $9.91 \mathrm{E}-01$ & 100 \\
\hline
\end{tabular}

* Sum of dose from all releases and from primary contamination. 
RESRAD-OFFSITE, Version 2.5

Parent Dose Report

Title : Offsite Resident Farmer Deterministic Run

File : RF TC99 DOESG FWD-FV2.ROF

Total Dose Contributions TDOSE (i,p,t) for Individual Radionuclides (i) and Pathways (p) in mrem/yr and as a Percentage of Total Dose at $t=1026$ years

From releases to ground water and to surface water

\begin{tabular}{|c|c|c|c|c|c|c|c|c|c|c|c|c|c|c|c|c|}
\hline & \multicolumn{2}{|c|}{ Ground } & \multicolumn{2}{|l|}{ Fish } & \multicolumn{2}{|c|}{ Radon } & \multicolumn{2}{|c|}{ Plant } & \multicolumn{2}{|l|}{ Meat } & \multicolumn{2}{|l|}{ Milk } & \multicolumn{2}{|l|}{ Soil } & \multicolumn{2}{|c|}{ Water } \\
\hline clide & Dose & \% & Dose & $\%$ & Dose & $\%$ & Dose & 음 & Dose & $\%$ & Dose & \% & Dose & \% & Dose & $\frac{\circ}{0}$ \\
\hline$=-99$ & $0.00 \mathrm{E}+00$ & 0 & $0.00 \mathrm{E}+00$ & 0 & $0.00 \mathrm{E}+00$ & 0 & $3.60 \mathrm{E}-01$ & 25 & $1.08 \mathrm{E}-03$ & 0 & $9.52 \mathrm{E}-02$ & 7 & $0.00 \mathrm{E}+00$ & 0 & $9.80 \mathrm{E}-01$ & 68 \\
\hline a) & $0.00 \mathrm{E}+00$ & 0 & $0.00 \mathrm{E}+00$ & 0 & $0.00 \mathrm{E}+00$ & 0 & $3.60 \mathrm{E}-01$ & 25 & $1.08 \mathrm{E}-03$ & 0 & $9.52 E-02$ & 7 & $0.00 \mathrm{E}+00$ & 0 & $9.80 \mathrm{E}-01$ & 68 \\
\hline
\end{tabular}

Total Dose Contributions TDOSE(i,p,t) for Individual Radionuclides (i) and Pathways (p)

in mrem/yr and as a Percentage of Total Dose at $t=1026$ years

Directly from primary contamination and from release to atmosphere (Inhalation excludes radon)

\begin{tabular}{|c|c|c|c|c|c|c|c|c|c|c|c|c|c|c|c|c|}
\hline & \multicolumn{2}{|c|}{ Ground } & \multicolumn{2}{|c|}{ Inhalation } & \multicolumn{2}{|c|}{ Radon } & \multicolumn{2}{|c|}{ Plant } & \multicolumn{2}{|l|}{ Meat } & \multicolumn{2}{|l|}{ Milk } & \multicolumn{2}{|l|}{ Soil } & \multicolumn{2}{|c|}{ All Pathways* } \\
\hline dclide & Dose & \% & Dose & $\%$ & Dose & $\%$ & Dose & 음 & Dose & $\%$ & Dose & 응 & Dose & 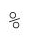 & Dose & $\%$ \\
\hline-99 & $0.00 \mathrm{E}+00$ & 0 & $0.00 \mathrm{E}+00$ & 0 & $0.00 \mathrm{E}+00$ & 0 & $0.00 \mathrm{E}+00$ & 0 & $0.00 \mathrm{E}+00$ & 0 & $0.00 \mathrm{E}+00$ & 0 & $0.00 \mathrm{E}+00$ & 0 & $1.44 \mathrm{E}+00$ & 100 \\
\hline to & $0.00 \mathrm{E}+00$ & 0 & $0.00 \mathrm{E}+00$ & 0 & $0.00 \mathrm{E}+00$ & 0 & $0.00 \mathrm{E}+00$ & 0 & $0.00 \mathrm{E}+00$ & 0 & $0.00 \mathrm{E}+00$ & 0 & $0.00 \mathrm{E}+00$ & 0 & $1.44 \mathrm{E}+00$ & 100 \\
\hline
\end{tabular}

* Sum of dose from all releases and from primary contamination. 
RESRAD-OFFSITE, Version $2.5 \quad \mathrm{~T}^{1 / 2}$ Limit $=180$ days

Parent Dose Report

Title : Offsite Resident Farmer Deterministic Run

File : RF TC99 DOESG FWD-FV2.ROF

Individual Nuclide Dose Summed Over All Pathways

Parent Nuclide and Thread Fraction Indicated

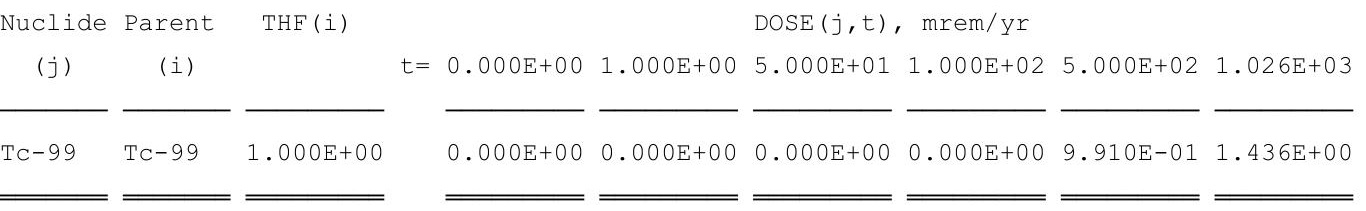

THF (i) is the thread fraction of the parent nuclide.

Individual Nuclide Soil Concentration

Parent Nuclide and Thread Fraction Indicated

\begin{tabular}{|c|c|c|c|c|c|c|c|c|c|}
\hline $\begin{array}{c}\text { Nuclide } \\
(j)\end{array}$ & $\begin{array}{c}\text { Parent } \\
\text { (i) }\end{array}$ & THF (i) & $t=$ & $0.000 \mathrm{E}+00$ & $1.000 \mathrm{E}+00$ & $\begin{array}{r}S(j, t), \\
5.000 E+01\end{array}$ & $\begin{array}{l}\mathrm{pCi} / \mathrm{g} \\
1.000 \mathrm{E}+02\end{array}$ & $5.000 \mathrm{E}+02$ & $1.026 \mathrm{E}+03$ \\
\hline 9 & TC-99 & $1.000 \mathrm{E}+00$ & & $5.200 \mathrm{E}+01$ & $5.173 \mathrm{E}+01$ & $3.997 \mathrm{E}+01$ & $3.073 E+01$ & $3.746 \mathrm{E}+00$ & $2.354 \mathrm{E}-01$ \\
\hline
\end{tabular}

THF(i) is the thread fraction of the parent nuclide. 
RESRAD-OFFSITE, Version $2.5 \quad \mathrm{~T}^{1 / 2}$ Limit $=180$ days

Parent Dose Report

Title : Offsite Resident Farmer Deterministic Run

File : RF TC99 DOESG FWD-FV2.ROF

Run Time Information

ResOCalc.EXE execution began at 17:59 on 07/14/2011

ResOCalc.EXE execution ended at 22:43 on 07/14/2011

ResOCalc.EXE execution time 4 hours 44 minutes

DCN 5090-TR-02-2 


\section{Offsite Resident Farmer}

\section{Uncertainty Analysis Report}

First Run

Time Horizon: 1,050 yr 
THIS PAGE INTENTIONALLY LEFT BLANK 
RESRAD-OFFSITE, Version 2.5

obabilistic Dose and Risk Report

Title : Offsite Resident Farmer Deterministic Run File : RF TC99 DOESG FWD-FV2.ROF

Table of Contents

Part V: Uncertainty Analysis

RESRAD Uncertainty Analysis Results

Probabilistic Inputs .......................... 2

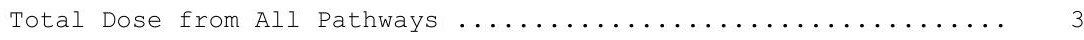

Total Risk from All Pathways ..................... 4

Ground External (water release) Pathway Dose .............. 5

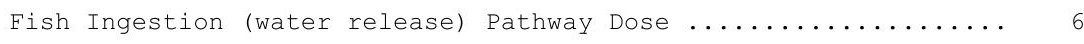

Radon Inhalation (water release) Pathway Dose ............ 7

Vegetable Ingestion (water release) Pathway Dose ............ 8

Meat Ingestion (water release) Pathway Dose .............. 9

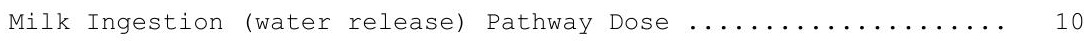

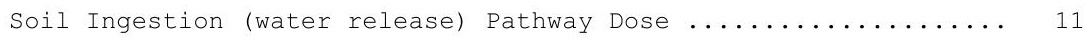

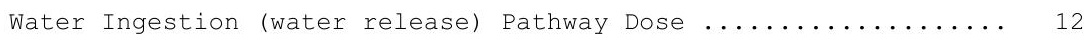

Ground External (direct \& air release) Pathway Dose .......... 13

Inhalation (w/o Radon) (direct \& air) Pathway Dose .......... 14

Radon Inhalation (direct \& air release) Pathway Dose ........ 15

Vegetable Ingestion (direct \& air release) Pathway Dose ....... 16

Meat Ingestion (direct \& air release) Pathway Dose ......... 17

Milk Ingestion (direct \& air release) Pathway Dose .......... 18

Soil Ingestion (direct \& air release) Pathway Dose .......... 19

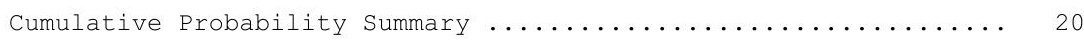

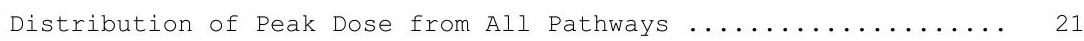

Distribution of Peak Dose from External Ground(Wreleas) ....... 22

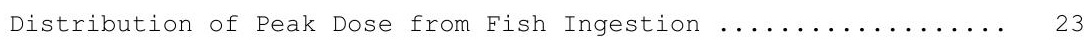

Distribution of Peak Dose from Radon (Waterrelease) ......... 24

Distribution of Peak Dose from Plant (Waterrelease) ......... 25

Distribution of Peak Dose from Meat (Waterrelease) ......... 26

Distribution of Peak Dose from Milk (Waterrelease) ......... 27

Distribution of Peak Dose from Soil Ingestion(Wrelease) ....... 28

Distribution of Peak Dose from Water Ingestion ............ 29

Distribution of Peak Dose from External Ground (CZ\&Air) ....... 30

Distribution of Peak Dose from Inhalation ExcludingRn ........ 31

Distribution of Peak Dose from Radon (CZandAir) ........... 32

Distribution of Peak Dose from Plant (CzandAir) ........... 33

Distribution of Peak Dose from Meat (CZandAir) ............ 34

Distribution of Peak Dose from Milk (CzandAir) ........... 35

Distribution of Peak Dose from Soil Ingestion(CZandAir) ...... 36

Distribution of Peak Risk from All Pathways ............. 37

Distribution of Peak Risk from External Ground(Wreleas) ...... 38

Distribution of Peak Risk from Fish Ingestion ............. 39

Distribution of Peak Risk from Radon (Waterrelease) ......... 40

Distribution of Peak Risk from Plant (Waterrelease) ......... 41

Distribution of Peak Risk from Meat (Waterrelease) .......... 42

Distribution of Peak Risk from Milk (Waterrelease) .......... 43

Distribution of Peak Risk from Soil Ingestion(Wrelease) ....... 44

Distribution of Peak Risk from Water Ingestion ............ 45

Distribution of Peak Risk from External Ground(CZ\&Air) ....... 46

Distribution of Peak Risk from Inhalation ExcludingRn ........ 47

Distribution of Peak Risk from Radon (CZandAir) ........... 48

Distribution of Peak Risk from Plant (CzandAir) ........... 49

Distribution of Peak Risk from Meat (CZandAir) ........... 50

Distribution of Peak Risk from Milk (CzandAir) ........... 51

Distribution of Peak Risk from Soil Ingestion(CZandAir) ....... 52 
C -48

DCN 5090-TR-02-2 
C- 49

DCN 5090-TR-02-2 
C -51

DCN 5090-TR-02-2 
C -53

DCN 5090-TR-02-2 
RESRAD-OFFSITE, Version 2.5

Probabilistic Dose and Risk Report

Title : Offsite Resident Farmer Deterministic Run

File : RF TC99 DOESG FWD-FV2.ROF

Probabilistic Inputs

Number of Sample Runs: 6000

\begin{tabular}{cll} 
& & \\
\cline { 1 - 1 } 1 & & DCACTC $(1)$ \\
2 & & DENSCZ \\
3 & EPUZ $(5)$ \\
4 & HCSZ \\
5 & TPSZ \\
6 & EPSZ \\
\hline \hline
\end{tabular}

\begin{tabular}{l} 
Distribution \\
\hline TRIANGULAR \\
TRIANGULAR \\
TRIANGULAR \\
TRIANGULAR \\
TRIANGULAR \\
TRIANGULAR \\
\hline \hline
\end{tabular}

\begin{tabular}{lll} 
Parameters & \\
\hline .1 & 1 & 10 \\
1.5 & 1.85 & 2.5 \\
.1 & .25 & .4 \\
27034 & 38938 & 67642 \\
.27 & .39 & .54 \\
.22 & .3 & .35 \\
\hline \hline
\end{tabular}


RESRAD-OFFSITE, Version 2.5

Probabilistic Dose and Risk Report

Title : Offsite Resident Farmer Deterministic Run

File : RF TC99 DOESG FWD-FV2.ROF

\begin{tabular}{|c|c|c|c|c|c|c|c|c|c|}
\hline Nuclide & Peak & Peak & & & & $\operatorname{DOSE}(j, t)$, & mrem/yr & & \\
\hline$(j)$ & Time & Dose & $t=$ & $0.00 \mathrm{E}+00$ & $1.00 \mathrm{E}+00$ & $5.00 \mathrm{E}+01$ & $1.00 \mathrm{E}+02$ & $5.00 \mathrm{E}+02$ & $1.03 E+03$ \\
\hline \multicolumn{10}{|l|}{ TC-99 } \\
\hline Min & $5.57 \mathrm{E}+02$ & $1.18 \mathrm{E}-01$ & & $0.00 \mathrm{E}+00$ & $0.00 \mathrm{E}+00$ & $0.00 \mathrm{E}+00$ & $0.00 \mathrm{E}+00$ & $4.94 \mathrm{E}-04$ & $1.08 \mathrm{E}-01$ \\
\hline Max & $1.05 \mathrm{E}+03$ & $4.63 E+00$ & & $0.00 \mathrm{E}+00$ & $0.00 \mathrm{E}+00$ & $0.00 \mathrm{E}+00$ & $0.00 \mathrm{E}+00$ & $3.79 \mathrm{E}+00$ & $3.28 \mathrm{E}+00$ \\
\hline Avg & $1.03 E+03$ & $1.01 \mathrm{E}+00$ & & $0.00 \mathrm{E}+00$ & $0.00 \mathrm{E}+00$ & $0.00 \mathrm{E}+00$ & $0.00 \mathrm{E}+00$ & $1.58 \mathrm{E}-01$ & $9.59 \mathrm{E}-01$ \\
\hline Std & $6.08 \mathrm{E}+01$ & $5.91 \mathrm{E}-01$ & & $0.00 \mathrm{E}+00$ & $0.00 \mathrm{E}+00$ & $0.00 \mathrm{E}+00$ & $0.00 \mathrm{E}+00$ & $2.98 \mathrm{E}-01$ & 5. $42 \mathrm{E}-01$ \\
\hline \multicolumn{10}{|l|}{$\sum A L L$} \\
\hline Min & $5.57 \mathrm{E}+02$ & $1.18 \mathrm{E}-01$ & & $0.00 \mathrm{E}+00$ & $0.00 \mathrm{E}+00$ & $0.00 \mathrm{E}+00$ & $0.00 \mathrm{E}+00$ & $4.94 \mathrm{E}-04$ & $1.08 \mathrm{E}-01$ \\
\hline $\operatorname{Max}$ & $1.05 E+03$ & $4.63 E+00$ & & $0.00 \mathrm{E}+00$ & $0.00 \mathrm{E}+00$ & $0.00 \mathrm{E}+00$ & $0.00 \mathrm{E}+00$ & $3.79 \mathrm{E}+00$ & $3.28 \mathrm{E}+00$ \\
\hline Avg & $1.03 E+03$ & $1.01 \mathrm{E}+00$ & & $0.00 \mathrm{E}+00$ & $0.00 \mathrm{E}+00$ & $0.00 \mathrm{E}+00$ & $0.00 \mathrm{E}+00$ & $1.58 E-01$ & $9.59 \mathrm{E}-01$ \\
\hline Std & $6.08 \mathrm{E}+01$ & $5.91 \mathrm{E}-01$ & & $0.00 \mathrm{E}+00$ & $0.00 \mathrm{E}+00$ & $0.00 \mathrm{E}+00$ & $0.00 \mathrm{E}+00$ & $2.98 \mathrm{E}-01$ & $5.42 \mathrm{E}-01$ \\
\hline
\end{tabular}

MALL is total dose summed for all nuclides. 
RESRAD-OFFSITE, Version 2.5

Probabilistic Dose and Risk Report

Title : Offsite Resident Farmer Deterministic Run

File : RF TC99 DOESG FWD-FV2.ROF

Probabilistic Total Risk Summary

\begin{tabular}{|c|c|c|c|c|c|c|c|}
\hline \multirow{2}{*}{$\begin{array}{c}\text { Nuclide } \\
\text { (j) }\end{array}$} & \multicolumn{7}{|c|}{$\operatorname{RISK}(j, t)$} \\
\hline & $t=$ & $0.00 \mathrm{E}+00$ & $1.00 \mathrm{E}+00$ & $5.00 \mathrm{E}+01$ & $1.00 \mathrm{E}+02$ & $5.00 \mathrm{E}+02$ & $1.03 E+03$ \\
\hline \multicolumn{8}{|l|}{$\mathrm{TC}-99$} \\
\hline Min & & $0.00 \mathrm{E}+00$ & $0.00 \mathrm{E}+00$ & $0.00 \mathrm{E}+00$ & $0.00 \mathrm{E}+00$ & $2.14 \mathrm{E}-08$ & $3.58 \mathrm{E}-06$ \\
\hline $\operatorname{Max}$ & & $0.00 \mathrm{E}+00$ & $0.00 \mathrm{E}+00$ & $0.00 \mathrm{E}+00$ & 1. $75 \mathrm{E}-12$ & 1.23E-04 & $1.03 E-04$ \\
\hline Avg & & $0.00 \mathrm{E}+00$ & $0.00 \mathrm{E}+00$ & $0.00 \mathrm{E}+00$ & $4.18 \mathrm{E}-16$ & $5.54 \mathrm{E}-06$ & $3.09 \mathrm{E}-05$ \\
\hline std & & $0.00 \mathrm{E}+00$ & $0.00 \mathrm{E}+00$ & $0.00 \mathrm{E}+00$ & $2.30 \mathrm{E}-14$ & $1.01 \mathrm{E}-05$ & $1.71 \mathrm{E}-05$ \\
\hline \multicolumn{8}{|l|}{$\sum \mathrm{ALL}$} \\
\hline $\operatorname{Min}$ & & $0.00 \mathrm{E}+00$ & $0.00 \mathrm{E}+00$ & $0.00 \mathrm{E}+00$ & $0.00 \mathrm{E}+00$ & $2.14 \mathrm{E}-08$ & $3.58 \mathrm{E}-06$ \\
\hline $\operatorname{Max}$ & & $0.00 \mathrm{E}+00$ & $0.00 \mathrm{E}+00$ & $0.00 \mathrm{E}+00$ & $1.75 \mathrm{E}-12$ & $1.23 \mathrm{E}-04$ & $1.03 \mathrm{E}-04$ \\
\hline Avg & & $0.00 \mathrm{E}+00$ & $0.00 \mathrm{E}+00$ & $0.00 \mathrm{E}+00$ & $4.18 \mathrm{E}-16$ & $5.54 \mathrm{E}-06$ & $3.09 \mathrm{E}-05$ \\
\hline Std & & $0.00 \mathrm{E}+00$ & $0.00 \mathrm{E}+00$ & $0.00 \mathrm{E}+00$ & $2.30 \mathrm{E}-14$ & $1.01 \mathrm{E}-05$ & $1.71 \mathrm{E}-05$ \\
\hline
\end{tabular}

MALL is total risk summed for all nuclides. 
RESRAD-OFFSITE, Version 2.5

Probabilistic Dose and Risk Report

Title : Offsite Resident Farmer Deterministic Run

File : RF TC99 DOESG FWD-FV2.ROF

Probabilistic Dose vs Pathway(i): Fish Ingestion (water release)

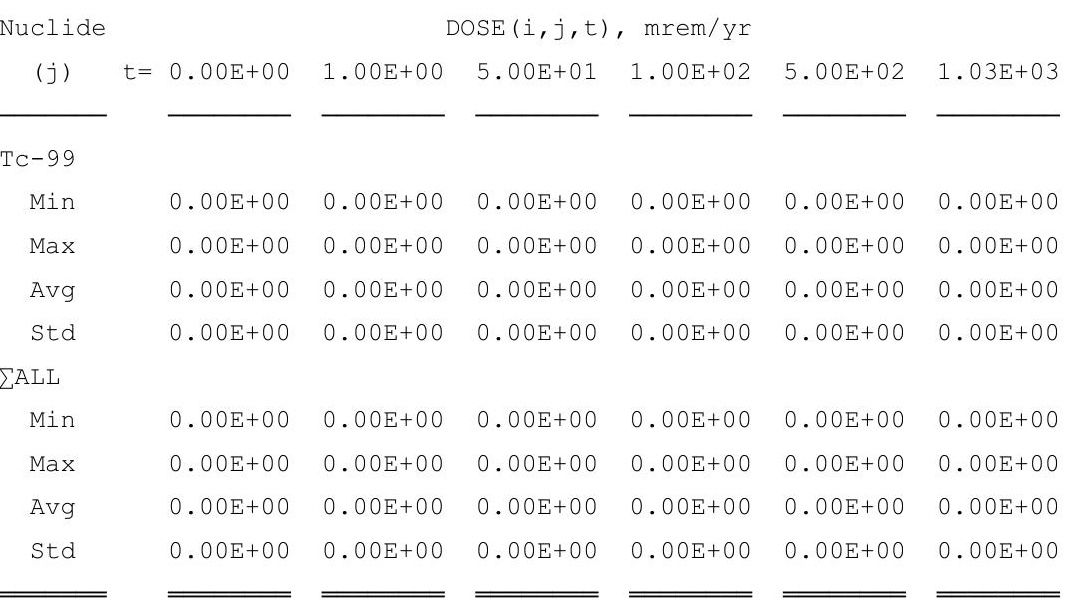

¿ALL is total pathway dose summed for all nuclides. 
RESRAD-OFFSITE, Version 2.5

Probabilistic Dose and Risk Report

Title : Offsite Resident Farmer Deterministic Run

File : RF TC99 DOESG FWD-FV2.ROF

Probabilistic Dose vs Pathway(i): Radon Inhalation (water release)

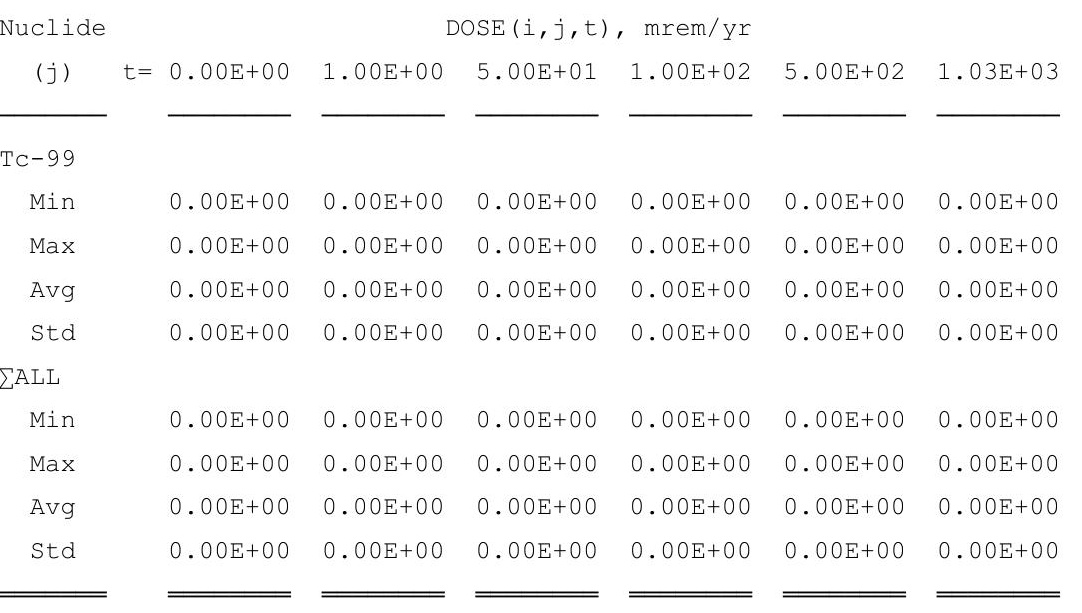

¿ALL is total pathway dose summed for all nuclides. 
RESRAD-OFFSITE, Version 2.5

Probabilistic Dose and Risk Report

Title : Offsite Resident Farmer Deterministic Run

File : RF TC99 DOESG FWD-FV2.ROF

Probabilistic Dose vs Pathway(i): Vegetable Ingestion (water release)

\begin{tabular}{|c|c|c|c|c|c|c|c|}
\hline \multirow{2}{*}{$\begin{array}{c}\text { Nuclide } \\
\text { (j) }\end{array}$} & \multicolumn{7}{|c|}{$\operatorname{DOSE}(i, j, t), \mathrm{mrem} / \mathrm{yr}$} \\
\hline & $t=$ & $0.00 \mathrm{E}+00$ & $1.00 \mathrm{E}+00$ & $5.00 \mathrm{E}+01$ & $1.00 \mathrm{E}+02$ & $5.00 \mathrm{E}+02$ & $1.03 E+03$ \\
\hline \multicolumn{8}{|l|}{ TC-99 } \\
\hline Min & & $0.00 \mathrm{E}+00$ & $0.00 \mathrm{E}+00$ & $0.00 \mathrm{E}+00$ & $0.00 \mathrm{E}+00$ & $1.23 \mathrm{E}-04$ & $2.69 \mathrm{E}-02$ \\
\hline Max & & $0.00 \mathrm{E}+00$ & $0.00 \mathrm{E}+00$ & $0.00 \mathrm{E}+00$ & $0.00 \mathrm{E}+00$ & $9.49 \mathrm{E}-01$ & $8.21 E-01$ \\
\hline Avg & & $0.00 \mathrm{E}+00$ & $0.00 \mathrm{E}+00$ & $0.00 \mathrm{E}+00$ & $0.00 \mathrm{E}+00$ & $3.95 \mathrm{E}-02$ & $2.40 \mathrm{E}-01$ \\
\hline Std & & $0.00 \mathrm{E}+00$ & $0.00 \mathrm{E}+00$ & $0.00 \mathrm{E}+00$ & $0.00 \mathrm{E}+00$ & $7.47 \mathrm{E}-02$ & $1.36 \mathrm{E}-01$ \\
\hline \multicolumn{8}{|l|}{$\sum \mathrm{ALL}$} \\
\hline Min & & $0.00 \mathrm{E}+00$ & $0.00 \mathrm{E}+00$ & $0.00 \mathrm{E}+00$ & $0.00 \mathrm{E}+00$ & $1.23 E-04$ & $2.69 \mathrm{E}-02$ \\
\hline $\operatorname{Max}$ & & $0.00 \mathrm{E}+00$ & $0.00 \mathrm{E}+00$ & $0.00 \mathrm{E}+00$ & $0.00 \mathrm{E}+00$ & $9.49 \mathrm{E}-01$ & $8.21 \mathrm{E}-01$ \\
\hline Avg & & $0.00 \mathrm{E}+00$ & $0.00 \mathrm{E}+00$ & $0.00 \mathrm{E}+00$ & $0.00 \mathrm{E}+00$ & $3.95 \mathrm{E}-02$ & 2. $40 \mathrm{E}-01$ \\
\hline Std & & $0.00 \mathrm{E}+00$ & $0.00 \mathrm{E}+00$ & $0.00 \mathrm{E}+00$ & $0.00 \mathrm{E}+00$ & $7.47 \mathrm{E}-02$ & 1. $36 \mathrm{E}-01$ \\
\hline
\end{tabular}

¿ALL is total pathway dose summed for all nuclides. 
RESRAD-OFFSITE, Version 2.5

Probabilistic Dose and Risk Report

Title : Offsite Resident Farmer Deterministic Run

File : RF TC99 DOESG FWD-FV2.ROF

Probabilistic Dose vs Pathway(i): Meat Ingestion (water release)

\begin{tabular}{|c|c|c|c|c|c|c|c|}
\hline \multirow{2}{*}{$\begin{array}{c}\text { Nuclide } \\
\text { (j) }\end{array}$} & \multicolumn{7}{|c|}{$\operatorname{DOSE}(i, j, t)$, mrem/yr } \\
\hline & $t=$ & $0.00 \mathrm{E}+00$ & $1.00 \mathrm{E}+00$ & $5.00 \mathrm{E}+01$ & $1.00 \mathrm{E}+02$ & $5.00 \mathrm{E}+02$ & $1.03 E+03$ \\
\hline \multicolumn{8}{|l|}{ TC-99 } \\
\hline Min & & $0.00 \mathrm{E}+00$ & $0.00 \mathrm{E}+00$ & $0.00 \mathrm{E}+00$ & $0.00 \mathrm{E}+00$ & $3.71 \mathrm{E}-07$ & $8.07 \mathrm{E}-05$ \\
\hline $\operatorname{Max}$ & & $0.00 \mathrm{E}+00$ & $0.00 \mathrm{E}+00$ & $0.00 \mathrm{E}+00$ & $0.00 \mathrm{E}+00$ & $2.84 \mathrm{E}-03$ & $2.46 \mathrm{E}-03$ \\
\hline Avg & & $0.00 \mathrm{E}+00$ & $0.00 \mathrm{E}+00$ & $0.00 \mathrm{E}+00$ & $0.00 \mathrm{E}+00$ & $1.18 \mathrm{E}-04$ & $7.20 \mathrm{E}-04$ \\
\hline Std & & $0.00 \mathrm{E}+00$ & $0.00 \mathrm{E}+00$ & $0.00 \mathrm{E}+00$ & $0.00 \mathrm{E}+00$ & $2.24 \mathrm{E}-04$ & $4.07 \mathrm{E}-04$ \\
\hline \multicolumn{8}{|l|}{$\sum \mathrm{ALL}$} \\
\hline Min & & $0.00 \mathrm{E}+00$ & $0.00 \mathrm{E}+00$ & $0.00 \mathrm{E}+00$ & $0.00 \mathrm{E}+00$ & $3.71 \mathrm{E}-07$ & $8.07 E-05$ \\
\hline $\operatorname{Max}$ & & $0.00 \mathrm{E}+00$ & $0.00 \mathrm{E}+00$ & $0.00 \mathrm{E}+00$ & $0.00 \mathrm{E}+00$ & $2.84 \mathrm{E}-03$ & $2.46 \mathrm{E}-03$ \\
\hline Avg & & $0.00 \mathrm{E}+00$ & $0.00 \mathrm{E}+00$ & $0.00 \mathrm{E}+00$ & $0.00 \mathrm{E}+00$ & $1.18 \mathrm{E}-04$ & $7.20 \mathrm{E}-04$ \\
\hline Std & & $0.00 \mathrm{E}+00$ & $0.00 \mathrm{E}+00$ & $0.00 \mathrm{E}+00$ & $0.00 \mathrm{E}+00$ & $2.24 \mathrm{E}-04$ & $4.07 \mathrm{E}-04$ \\
\hline
\end{tabular}

¿ALL is total pathway dose summed for all nuclides. 
RESRAD-OFFSITE, Version 2.5

Probabilistic Dose and Risk Report

Title : Offsite Resident Farmer Deterministic Run

File : RF TC99 DOESG FWD-FV2.ROF

Probabilistic Dose vs Pathway(i): Milk Ingestion (water release)

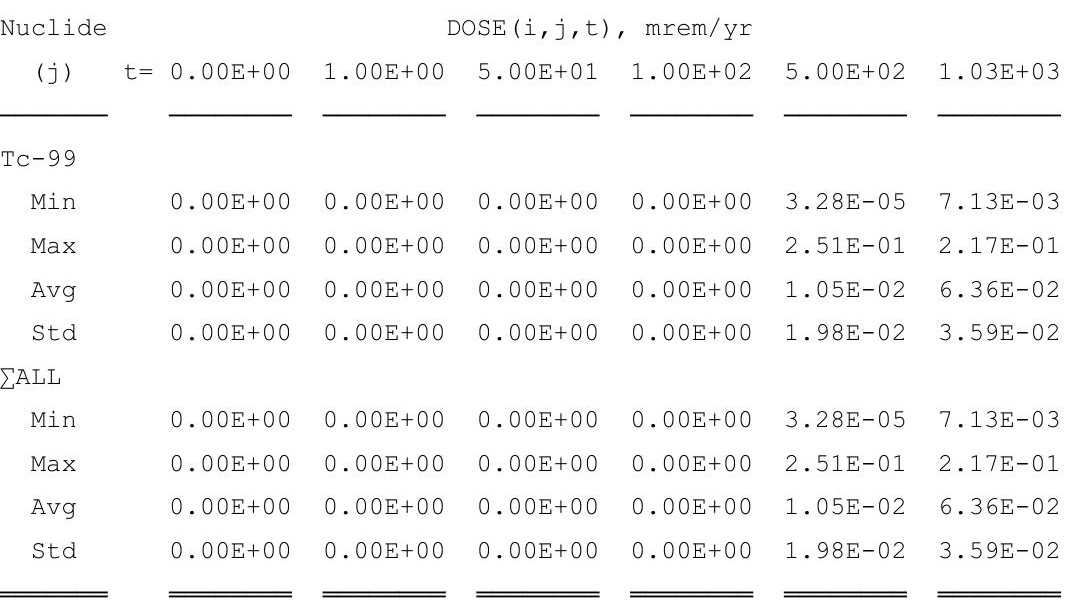

¿ALL is total pathway dose summed for all nuclides. 
RESRAD-OFFSITE, Version 2.5

Probabilistic Dose and Risk Report

Title : Offsite Resident Farmer Deterministic Run

File : RF TC99 DOESG FWD-FV2.ROF

Probabilistic Dose vs Pathway(i): Soil Ingestion (water release)

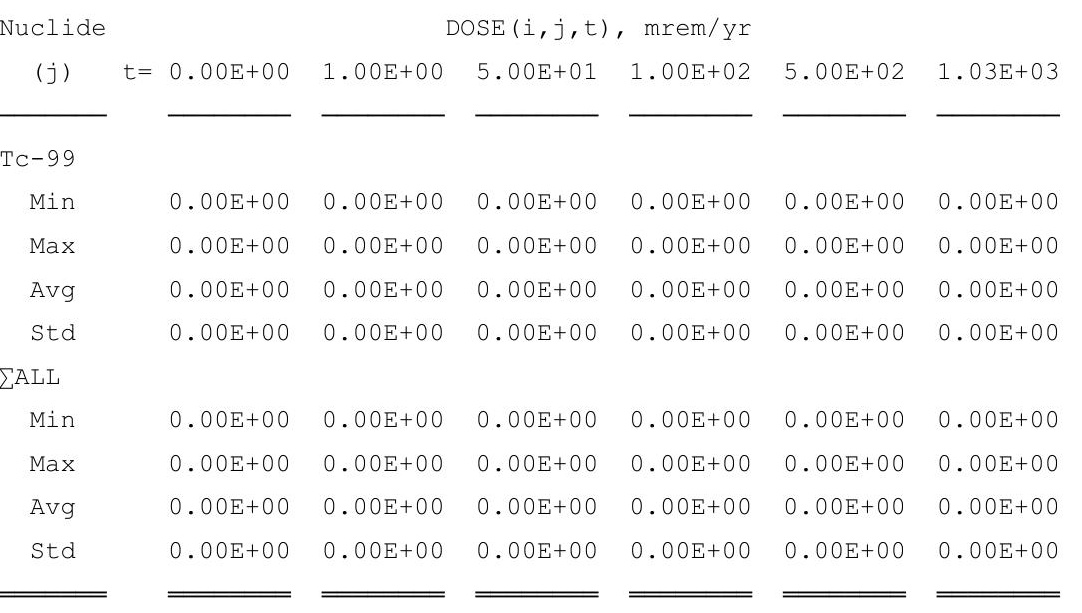

MALL is total pathway dose summed for all nuclides. 
RESRAD-OFFSITE, Version 2.5

Probabilistic Dose and Risk Report

Title : Offsite Resident Farmer Deterministic Run

File : RF TC99 DOESG FWD-FV2.ROF

Probabilistic Dose vs Pathway(i): Water Ingestion (water release)

\begin{tabular}{|c|c|c|c|c|c|c|c|}
\hline Juclide & & & & $\operatorname{SEE}(i, j$, & mrem/yr & & \\
\hline$(j)$ & $t=$ & $0.00 \mathrm{E}+00$ & $1.00 \mathrm{E}+00$ & $5.00 \mathrm{E}+01$ & $1.00 \mathrm{E}+02$ & $5.00 \mathrm{E}+02$ & $1.03 E+03$ \\
\hline 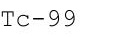 & & & & & & & \\
\hline Min & & $0.00 \mathrm{E}+00$ & $0.00 \mathrm{E}+00$ & $0.00 \mathrm{E}+00$ & $0.00 \mathrm{E}+00$ & $3.38 \mathrm{E}-04$ & $7.34 \mathrm{E}-02$ \\
\hline Max & & $0.00 \mathrm{E}+00$ & $0.00 \mathrm{E}+00$ & $0.00 \mathrm{E}+00$ & $0.00 \mathrm{E}+00$ & $2.59 \mathrm{E}+00$ & $2.24 E+00$ \\
\hline Avg & & $0.00 \mathrm{E}+00$ & $0.00 \mathrm{E}+00$ & $0.00 \mathrm{E}+00$ & $0.00 \mathrm{E}+00$ & $1.08 \mathrm{E}-01$ & $6.54 \mathrm{E}-01$ \\
\hline Std & & $0.00 \mathrm{E}+00$ & $0.00 \mathrm{E}+00$ & $0.00 \mathrm{E}+00$ & $0.00 \mathrm{E}+00$ & $2.04 E-01$ & $3.70 \mathrm{E}-01$ \\
\hline ALL & & & & & & & \\
\hline Min & & $0.00 \mathrm{E}+00$ & $0.00 \mathrm{E}+00$ & $0.00 \mathrm{E}+00$ & $0.00 \mathrm{E}+00$ & $3.38 E-04$ & $7.34 \mathrm{E}-02$ \\
\hline $\operatorname{Max}$ & & $0.00 \mathrm{E}+00$ & $0.00 \mathrm{E}+00$ & $0.00 \mathrm{E}+00$ & $0.00 \mathrm{E}+00$ & $2.59 \mathrm{E}+00$ & $2.24 \mathrm{E}+00$ \\
\hline Avg & & $0.00 \mathrm{E}+00$ & $0.00 \mathrm{E}+00$ & $0.00 \mathrm{E}+00$ & $0.00 \mathrm{E}+00$ & $1.08 E-01$ & $6.54 \mathrm{E}-01$ \\
\hline Std & & $0.00 \mathrm{E}+00$ & $0.00 \mathrm{E}+00$ & $0.00 \mathrm{E}+00$ & $0.00 \mathrm{E}+00$ & $2.04 \mathrm{E}-01$ & 3. $70 \mathrm{E}-01$ \\
\hline
\end{tabular}

¿ALL is total pathway dose summed for all nuclides. 
RESRAD-OFFSITE, Version 2.5

Probabilistic Dose and Risk Report

Title : Offsite Resident Farmer Deterministic Run

File : RF TC99 DOESG FWD-FV2.ROF

Probabilistic Dose vs Pathway(i): Ground External (direct \& air release)

\begin{tabular}{|c|c|c|c|c|c|c|c|}
\hline Nuclide & & & & $\operatorname{DSE}(i, j$, & mrem/yr & & \\
\hline$(j)$ & $t=$ & $0.00 \mathrm{E}+00$ & $1.00 \mathrm{E}+00$ & $5.00 \mathrm{E}+01$ & $1.00 \mathrm{E}+02$ & $5.00 \mathrm{E}+02$ & $1.03 E+03$ \\
\hline $\mathrm{TC}-99$ & & & & & & & \\
\hline Min & & $0.00 \mathrm{E}+00$ & $0.00 \mathrm{E}+00$ & $0.00 \mathrm{E}+00$ & $0.00 \mathrm{E}+00$ & $0.00 \mathrm{E}+00$ & $0.00 \mathrm{E}+00$ \\
\hline Max & & $0.00 \mathrm{E}+00$ & $0.00 \mathrm{E}+00$ & $0.00 \mathrm{E}+00$ & $0.00 \mathrm{E}+00$ & $0.00 \mathrm{E}+00$ & $0.00 \mathrm{E}+00$ \\
\hline Avg & & $0.00 \mathrm{E}+00$ & $0.00 \mathrm{E}+00$ & $0.00 \mathrm{E}+00$ & $0.00 \mathrm{E}+00$ & $0.00 \mathrm{E}+00$ & $0.00 \mathrm{E}+00$ \\
\hline Std & & $0.00 \mathrm{E}+00$ & $0.00 \mathrm{E}+00$ & $0.00 \mathrm{E}+00$ & $0.00 \mathrm{E}+00$ & $0.00 \mathrm{E}+00$ & $0.00 \mathrm{E}+00$ \\
\hline ¿ALL & & & & & & & \\
\hline Min & & $0.00 \mathrm{E}+00$ & $0.00 \mathrm{E}+00$ & $0.00 \mathrm{E}+00$ & $0.00 \mathrm{E}+00$ & $0.00 \mathrm{E}+00$ & $0.00 \mathrm{E}+00$ \\
\hline Max & & $0.00 \mathrm{E}+00$ & $0.00 E+00$ & $0.00 E+00$ & $0.00 \mathrm{E}+00$ & $0.00 \mathrm{E}+00$ & $0.00 \mathrm{E}+00$ \\
\hline Avg & & $0.00 \mathrm{E}+00$ & $0.00 E+00$ & $0.00 E+00$ & $0.00 \mathrm{E}+00$ & $0.00 \mathrm{E}+00$ & $0.00 \mathrm{E}+00$ \\
\hline Std & & $0.00 \mathrm{E}+00$ & $0.00 \mathrm{E}+00$ & $0.00 \mathrm{E}+00$ & $0.00 \mathrm{E}+00$ & $0.00 \mathrm{E}+00$ & $0.00 \mathrm{E}+00$ \\
\hline
\end{tabular}

¿ALL is total pathway dose summed for all nuclides. 
RESRAD-OFFSITE, Version 2.5

Probabilistic Dose and Risk Report

Title : Offsite Resident Farmer Deterministic Run

File : RF TC99 DOESG FWD-FV2.ROF

Probabilistic Dose vs Pathway(i): Inhalation (w/o Radon) (direct \& air)

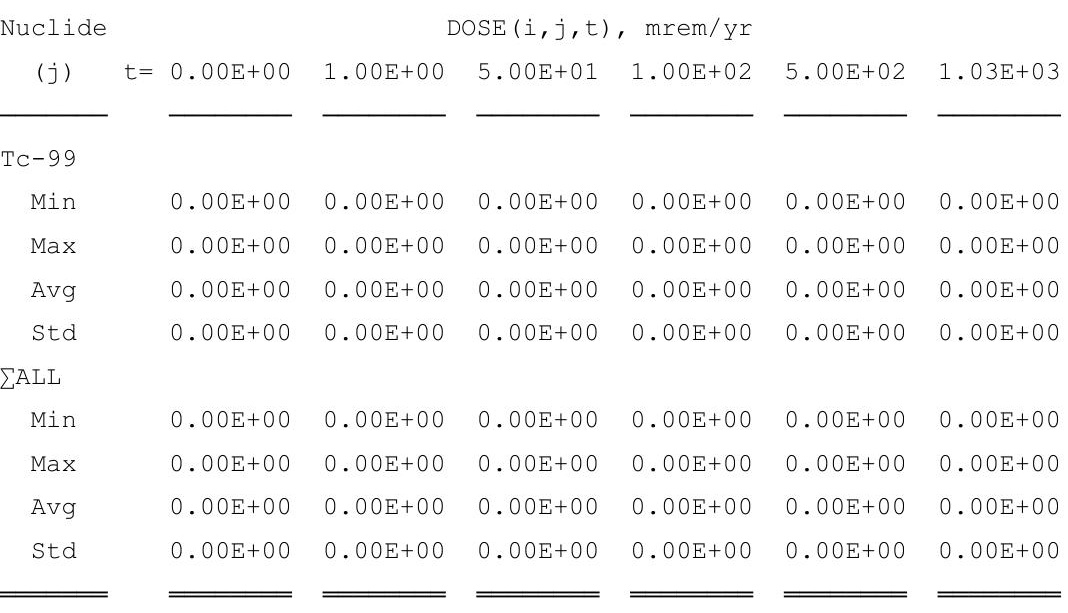

¿ALL is total pathway dose summed for all nuclides. 
RESRAD-OFFSITE, Version 2.5

Probabilistic Dose and Risk Report

Title : Offsite Resident Farmer Deterministic Run

File : RF TC99 DOESG FWD-FV2.ROF

Probabilistic Dose vs Pathway(i): Radon Inhalation (direct \& air release)

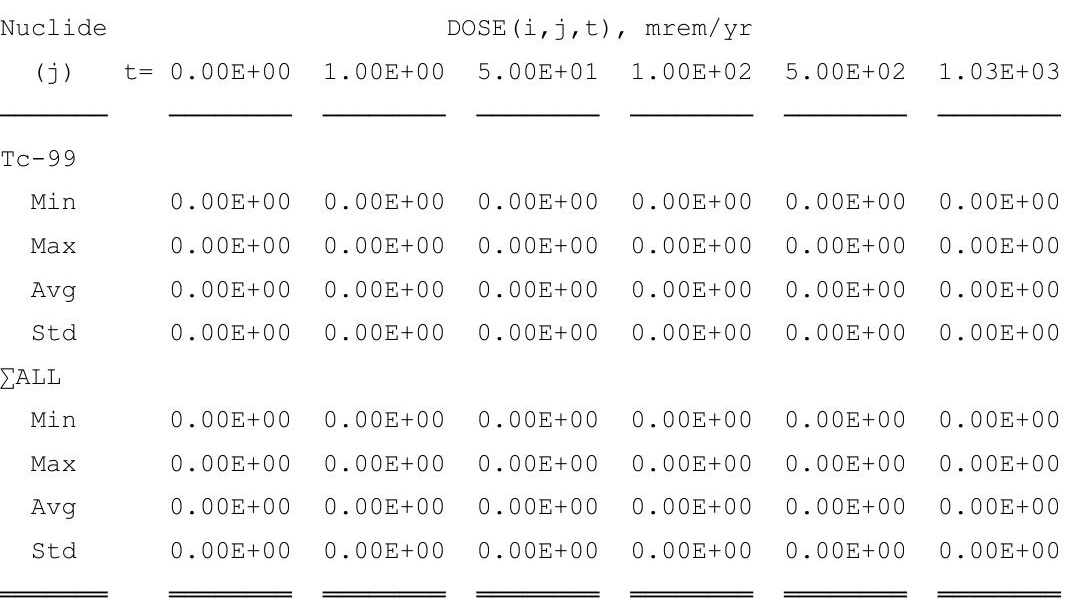

¿ALL is total pathway dose summed for all nuclides. 
RESRAD-OFFSITE, Version 2.5

Probabilistic Dose and Risk Report

Title : Offsite Resident Farmer Deterministic Run

File : RF TC99 DOESG FWD-FV2.ROF

Probabilistic Dose vs Pathway(i): Vegetable Ingestion (direct \& air release)

\begin{tabular}{|c|c|c|c|c|c|c|c|}
\hline \multirow{2}{*}{$\begin{array}{c}\text { Nuclide } \\
\text { (j) }\end{array}$} & \multicolumn{7}{|c|}{$\operatorname{DOSE}(i, j, t), \mathrm{mrem} / \mathrm{yr}$} \\
\hline & $t=$ & $0.00 \mathrm{E}+00$ & $1.00 \mathrm{E}+00$ & $5.00 \mathrm{E}+01$ & $1.00 \mathrm{E}+02$ & $5.00 \mathrm{E}+02$ & $1.03 E+03$ \\
\hline \multicolumn{8}{|l|}{$\mathrm{TC}-99$} \\
\hline Min & & $0.00 \mathrm{E}+00$ & $0.00 \mathrm{E}+00$ & $0.00 \mathrm{E}+00$ & $0.00 \mathrm{E}+00$ & $0.00 \mathrm{E}+00$ & $0.00 \mathrm{E}+00$ \\
\hline $\operatorname{Max}$ & & $0.00 \mathrm{E}+00$ & $0.00 \mathrm{E}+00$ & $0.00 \mathrm{E}+00$ & $0.00 \mathrm{E}+00$ & $0.00 \mathrm{E}+00$ & $0.00 \mathrm{E}+00$ \\
\hline Avg & & $0.00 \mathrm{E}+00$ & $0.00 \mathrm{E}+00$ & $0.00 \mathrm{E}+00$ & $0.00 \mathrm{E}+00$ & $0.00 \mathrm{E}+00$ & $0.00 \mathrm{E}+00$ \\
\hline Std & & $0.00 \mathrm{E}+00$ & $0.00 \mathrm{E}+00$ & $0.00 \mathrm{E}+00$ & $0.00 \mathrm{E}+00$ & $0.00 \mathrm{E}+00$ & $0.00 \mathrm{E}+00$ \\
\hline \multicolumn{8}{|l|}{$\sum \mathrm{ALL}$} \\
\hline Min & & $0.00 \mathrm{E}+00$ & $0.00 \mathrm{E}+00$ & $0.00 \mathrm{E}+00$ & $0.00 \mathrm{E}+00$ & $0.00 \mathrm{E}+00$ & $0.00 \mathrm{E}+00$ \\
\hline $\operatorname{Max}$ & & $0.00 \mathrm{E}+00$ & $0.00 \mathrm{E}+00$ & $0.00 \mathrm{E}+00$ & $0.00 \mathrm{E}+00$ & $0.00 \mathrm{E}+00$ & $0.00 \mathrm{E}+00$ \\
\hline Avg & & $0.00 \mathrm{E}+00$ & $0.00 \mathrm{E}+00$ & $0.00 \mathrm{E}+00$ & $0.00 \mathrm{E}+00$ & $0.00 \mathrm{E}+00$ & $0.00 \mathrm{E}+00$ \\
\hline Std & & $0.00 \mathrm{E}+00$ & $0.00 \mathrm{E}+00$ & $0.00 \mathrm{E}+00$ & $0.00 \mathrm{E}+00$ & $0.00 \mathrm{E}+00$ & $0.00 \mathrm{E}+00$ \\
\hline
\end{tabular}

¿ALL is total pathway dose summed for all nuclides. 
RESRAD-OFFSITE, Version 2.5

Probabilistic Dose and Risk Report

Title : Offsite Resident Farmer Deterministic Run

File : RF TC99 DOESG FWD-FV2.ROF

Probabilistic Dose vs Pathway(i): Meat Ingestion (direct \& air release)

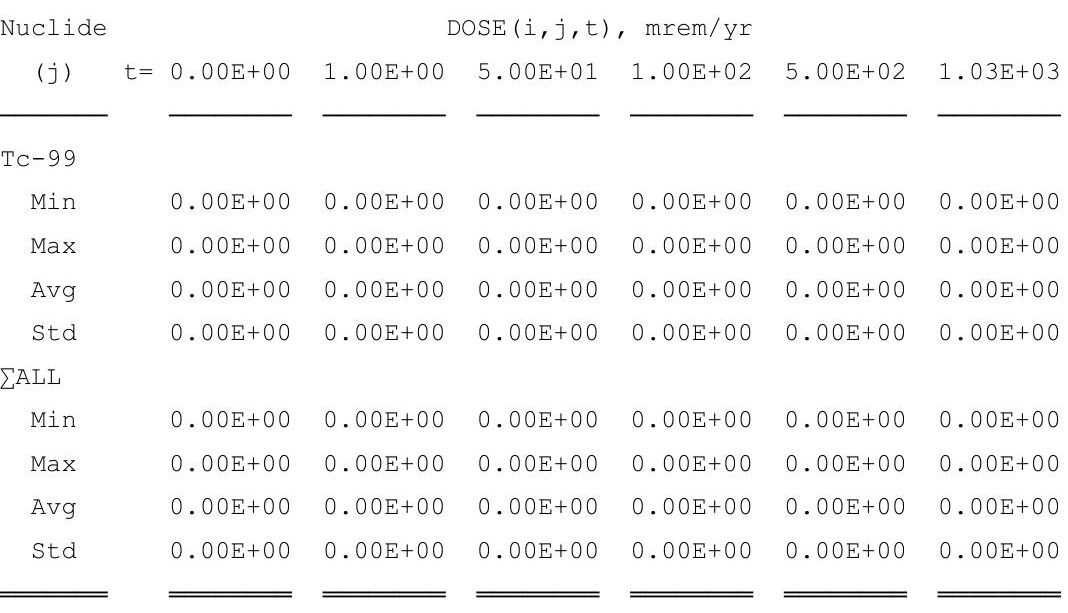

¿ALL is total pathway dose summed for all nuclides. 
RESRAD-OFFSITE, Version 2.5

Probabilistic Dose and Risk Report

Title : Offsite Resident Farmer Deterministic Run

File : RF TC99 DOESG FWD-FV2.ROF

Probabilistic Dose vs Pathway(i): Milk Ingestion (direct \& air release)

\begin{tabular}{|c|c|c|c|c|c|c|c|}
\hline Nuclide & & & & $\operatorname{DSE}(i, j$, & mrem/yr & & \\
\hline$(j)$ & $t=$ & $0.00 \mathrm{E}+00$ & $1.00 \mathrm{E}+00$ & $5.00 \mathrm{E}+01$ & $1.00 \mathrm{E}+02$ & $5.00 \mathrm{E}+02$ & $1.03 E+03$ \\
\hline TC-99 & & & & & & & \\
\hline Min & & $0.00 \mathrm{E}+00$ & $0.00 \mathrm{E}+00$ & $0.00 \mathrm{E}+00$ & $0.00 \mathrm{E}+00$ & $0.00 \mathrm{E}+00$ & $0.00 \mathrm{E}+00$ \\
\hline Max & & $0.00 \mathrm{E}+00$ & $0.00 \mathrm{E}+00$ & $0.00 \mathrm{E}+00$ & $0.00 \mathrm{E}+00$ & $0.00 \mathrm{E}+00$ & $0.00 \mathrm{E}+00$ \\
\hline Avg & & $0.00 \mathrm{E}+00$ & $0.00 \mathrm{E}+00$ & $0.00 \mathrm{E}+00$ & $0.00 \mathrm{E}+00$ & $0.00 \mathrm{E}+00$ & $0.00 \mathrm{E}+00$ \\
\hline Std & & $0.00 \mathrm{E}+00$ & $0.00 \mathrm{E}+00$ & $0.00 \mathrm{E}+00$ & $0.00 \mathrm{E}+00$ & $0.00 \mathrm{E}+00$ & $0.00 \mathrm{E}+00$ \\
\hline ALL & & & & & & & \\
\hline Min & & $0.00 \mathrm{E}+00$ & $0.00 \mathrm{E}+00$ & $0.00 \mathrm{E}+00$ & $0.00 \mathrm{E}+00$ & $0.00 \mathrm{E}+00$ & $0.00 \mathrm{E}+00$ \\
\hline $\operatorname{Max}$ & & $0.00 \mathrm{E}+00$ & $0.00 \mathrm{E}+00$ & $0.00 \mathrm{E}+00$ & $0.00 E+00$ & $0.00 E+00$ & $0.00 \mathrm{E}+00$ \\
\hline Avg & & $0.00 \mathrm{E}+00$ & $0.00 \mathrm{E}+00$ & $0.00 \mathrm{E}+00$ & $0.00 E+00$ & $0.00 \mathrm{E}+00$ & $0.00 \mathrm{E}+00$ \\
\hline Std & & $0.00 \mathrm{E}+00$ & $0.00 \mathrm{E}+00$ & $0.00 \mathrm{E}+00$ & $0.00 \mathrm{E}+00$ & $0.00 \mathrm{E}+00$ & $0.00 \mathrm{E}+00$ \\
\hline
\end{tabular}

¿ALL is total pathway dose summed for all nuclides. 
RESRAD-OFFSITE, Version 2.5

Probabilistic Dose and Risk Report

Title : Offsite Resident Farmer Deterministic Run

File : RF TC99 DOESG FWD-FV2.ROF

Probabilistic Dose vs Pathway(i): Soil Ingestion (direct \& air release)

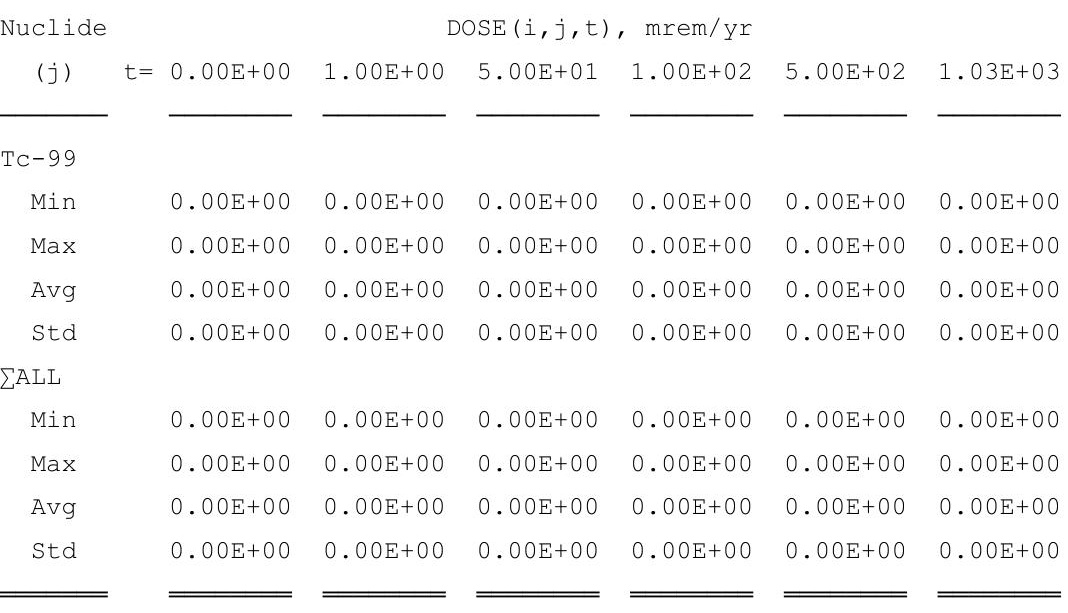

¿ALL is total pathway dose summed for all nuclides. 
RESRAD-OFFSITE, Version 2.5

$\mathrm{T}^{1 / 2}$ Limit $=180$ days

Title : Offsite Resident Farmer Deterministic Run

File : RF TC99 DOESG FWD-FV2.ROF

Cumulative Probability Summary for: Total Dose Over all Pathways

\begin{tabular}{|c|c|c|c|c|c|c|c|}
\hline \multicolumn{4}{|l|}{ Cumulative } & \multicolumn{4}{|c|}{ Dose $(t)$, mrem/yr } \\
\hline Probability & $t=$ & $0.00 \mathrm{E}+00$ & $1.00 \mathrm{E}+00$ & $5.00 \mathrm{E}+01$ & $1.00 \mathrm{E}+02$ & $5.00 \mathrm{E}+02$ & 1.03E+03 \\
\hline 0.025 & & $0.00 \mathrm{E}+00$ & $0.00 \mathrm{E}+00$ & $0.00 \mathrm{E}+00$ & $0.00 \mathrm{E}+00$ & $1.84 \mathrm{E}-03$ & $2.09 \mathrm{E}-01$ \\
\hline 0.050 & & $0.00 \mathrm{E}+00$ & $0.00 \mathrm{E}+00$ & $0.00 \mathrm{E}+00$ & $0.00 \mathrm{E}+00$ & $2.88 E-03$ & $2.60 \mathrm{E}-01$ \\
\hline 0.075 & & $0.00 \mathrm{E}+00$ & $0.00 \mathrm{E}+00$ & $0.00 \mathrm{E}+00$ & $0.00 \mathrm{E}+00$ & $3.95 \mathrm{E}-03$ & $3.01 \mathrm{E}-01$ \\
\hline 0.100 & & $0.00 \mathrm{E}+00$ & $0.00 \mathrm{E}+00$ & $0.00 \mathrm{E}+00$ & $0.00 \mathrm{E}+00$ & $5.21 \mathrm{E}-03$ & $3.46 \mathrm{E}-01$ \\
\hline 0.125 & & $0.00 \mathrm{E}+00$ & $0.00 \mathrm{E}+00$ & $0.00 \mathrm{E}+00$ & $0.00 \mathrm{E}+00$ & $6.42 \mathrm{E}-03$ & $3.80 \mathrm{E}-01$ \\
\hline 0.150 & & $0.00 \mathrm{E}+00$ & $0.00 \mathrm{E}+00$ & $0.00 \mathrm{E}+00$ & $0.00 \mathrm{E}+00$ & $7.65 \mathrm{E}-03$ & 4. 12E-01 \\
\hline 0.175 & & $0.00 \mathrm{E}+00$ & $0.00 \mathrm{E}+00$ & $0.00 \mathrm{E}+00$ & $0.00 \mathrm{E}+00$ & $9.20 \mathrm{E}-03$ & $4.40 E-01$ \\
\hline 0.200 & & $0.00 \mathrm{E}+00$ & $0.00 \mathrm{E}+00$ & $0.00 \mathrm{E}+00$ & $0.00 \mathrm{E}+00$ & 1.10E-02 & $4.74 \mathrm{E}-01$ \\
\hline 0.225 & & $0.00 \mathrm{E}+00$ & $0.00 \mathrm{E}+00$ & $0.00 \mathrm{E}+00$ & $0.00 \mathrm{E}+00$ & $1.31 \mathrm{E}-02$ & $5.06 \mathrm{E}-01$ \\
\hline 0.250 & & $0.00 \mathrm{E}+00$ & $0.00 \mathrm{E}+00$ & $0.00 \mathrm{E}+00$ & $0.00 \mathrm{E}+00$ & $1.50 \mathrm{E}-02$ & $5.34 \mathrm{E}-01$ \\
\hline 0.275 & & $0.00 \mathrm{E}+00$ & $0.00 \mathrm{E}+00$ & $0.00 \mathrm{E}+00$ & $0.00 \mathrm{E}+00$ & $1.72 \mathrm{E}-02$ & $5.64 \mathrm{E}-01$ \\
\hline 0.300 & & $0.00 \mathrm{E}+00$ & $0.00 \mathrm{E}+00$ & $0.00 \mathrm{E}+00$ & $0.00 \mathrm{E}+00$ & $1.96 \mathrm{E}-02$ & $5.98 \mathrm{E}-01$ \\
\hline 0.325 & & $0.00 \mathrm{E}+00$ & $0.00 \mathrm{E}+00$ & $0.00 \mathrm{E}+00$ & $0.00 \mathrm{E}+00$ & $2.23 E-02$ & $6.30 \mathrm{E}-01$ \\
\hline 0.350 & & $0.00 \mathrm{E}+00$ & $0.00 \mathrm{E}+00$ & $0.00 \mathrm{E}+00$ & $0.00 \mathrm{E}+00$ & $2.50 \mathrm{E}-02$ & $6.60 \mathrm{E}-01$ \\
\hline 0.375 & & $0.00 \mathrm{E}+00$ & $0.00 \mathrm{E}+00$ & $0.00 \mathrm{E}+00$ & $0.00 \mathrm{E}+00$ & $2.82 \mathrm{E}-02$ & $6.94 \mathrm{E}-01$ \\
\hline 0.400 & & $0.00 \mathrm{E}+00$ & $0.00 \mathrm{E}+00$ & $0.00 \mathrm{E}+00$ & $0.00 E+00$ & $3.15 E-02$ & $7.26 \mathrm{E}-01$ \\
\hline 0.425 & & $0.00 \mathrm{E}+00$ & $0.00 \mathrm{E}+00$ & $0.00 \mathrm{E}+00$ & $0.00 \mathrm{E}+00$ & $3.50 \mathrm{E}-02$ & $7.54 \mathrm{E}-01$ \\
\hline 0.450 & & $0.00 \mathrm{E}+00$ & $0.00 \mathrm{E}+00$ & $0.00 \mathrm{E}+00$ & $0.00 \mathrm{E}+00$ & $3.96 \mathrm{E}-02$ & $7.87 \mathrm{E}-01$ \\
\hline 0.475 & & $0.00 \mathrm{E}+00$ & $0.00 \mathrm{E}+00$ & $0.00 \mathrm{E}+00$ & $0.00 \mathrm{E}+00$ & $4.48 E-02$ & $8.19 \mathrm{E}-01$ \\
\hline 0.500 & & $0.00 \mathrm{E}+00$ & $0.00 \mathrm{E}+00$ & $0.00 \mathrm{E}+00$ & $0.00 \mathrm{E}+00$ & $4.96 \mathrm{E}-02$ & $8.55 E-01$ \\
\hline 0.525 & & $0.00 \mathrm{E}+00$ & $0.00 \mathrm{E}+00$ & $0.00 \mathrm{E}+00$ & $0.00 \mathrm{E}+00$ & $5.57 \mathrm{E}-02$ & $8.92 \mathrm{E}-01$ \\
\hline 0.550 & & $0.00 \mathrm{E}+00$ & $0.00 \mathrm{E}+00$ & $0.00 \mathrm{E}+00$ & $0.00 \mathrm{E}+00$ & $6.30 \mathrm{E}-02$ & $9.30 \mathrm{E}-01$ \\
\hline 0.575 & & $0.00 \mathrm{E}+00$ & $0.00 \mathrm{E}+00$ & $0.00 \mathrm{E}+00$ & $0.00 \mathrm{E}+00$ & $7.00 \mathrm{E}-02$ & $9.68 \mathrm{E}-01$ \\
\hline 0.600 & & $0.00 \mathrm{E}+00$ & $0.00 \mathrm{E}+00$ & $0.00 \mathrm{E}+00$ & $0.00 \mathrm{E}+00$ & $7.78 \mathrm{E}-02$ & $1.01 \mathrm{E}+00$ \\
\hline 0.625 & & $0.00 \mathrm{E}+00$ & $0.00 \mathrm{E}+00$ & $0.00 \mathrm{E}+00$ & $0.00 \mathrm{E}+00$ & $8.75 E-02$ & 1. $05 \mathrm{E}+00$ \\
\hline 0.650 & & $0.00 \mathrm{E}+00$ & $0.00 \mathrm{E}+00$ & $0.00 \mathrm{E}+00$ & $0.00 \mathrm{E}+00$ & $9.87 E-02$ & $1.09 \mathrm{E}+00$ \\
\hline 0.675 & & $0.00 E+00$ & $0.00 \mathrm{E}+00$ & $0.00 \mathrm{E}+00$ & $0.00 E+00$ & $1.10 \mathrm{E}-01$ & $1.13 \mathrm{E}+00$ \\
\hline 0.700 & & $0.00 \mathrm{E}+00$ & $0.00 \mathrm{E}+00$ & $0.00 \mathrm{E}+00$ & $0.00 \mathrm{E}+00$ & $1.27 \mathrm{E}-01$ & $1.19 \mathrm{E}+00$ \\
\hline 0.725 & & $0.00 \mathrm{E}+00$ & $0.00 \mathrm{E}+00$ & $0.00 \mathrm{E}+00$ & $0.00 \mathrm{E}+00$ & $1.44 \mathrm{E}-01$ & $1.24 \mathrm{E}+00$ \\
\hline 0.750 & & $0.00 \mathrm{E}+00$ & $0.00 \mathrm{E}+00$ & $0.00 \mathrm{E}+00$ & $0.00 \mathrm{E}+00$ & $1.64 \mathrm{E}-01$ & $1.29 \mathrm{E}+00$ \\
\hline 0.775 & & $0.00 \mathrm{E}+00$ & $0.00 \mathrm{E}+00$ & $0.00 \mathrm{E}+00$ & $0.00 \mathrm{E}+00$ & $1.87 \mathrm{E}-01$ & $1.34 \mathrm{E}+00$ \\
\hline 0.800 & & $0.00 \mathrm{E}+00$ & $0.00 \mathrm{E}+00$ & $0.00 \mathrm{E}+00$ & $0.00 \mathrm{E}+00$ & $2.16 \mathrm{E}-01$ & $1.40 \mathrm{E}+00$ \\
\hline 0.825 & & $0.00 \mathrm{E}+00$ & $0.00 \mathrm{E}+00$ & $0.00 \mathrm{E}+00$ & $0.00 \mathrm{E}+00$ & $2.50 E-01$ & $1.47 \mathrm{E}+00$ \\
\hline 0.850 & & $0.00 \mathrm{E}+00$ & $0.00 \mathrm{E}+00$ & $0.00 \mathrm{E}+00$ & $0.00 \mathrm{E}+00$ & $2.88 E-01$ & $1.55 \mathrm{E}+00$ \\
\hline 0.875 & & $0.00 \mathrm{E}+00$ & $0.00 \mathrm{E}+00$ & $0.00 \mathrm{E}+00$ & $0.00 \mathrm{E}+00$ & $3.35 E-01$ & $1.64 \mathrm{E}+00$ \\
\hline 0.900 & & $0.00 \mathrm{E}+00$ & $0.00 \mathrm{E}+00$ & $0.00 \mathrm{E}+00$ & $0.00 \mathrm{E}+00$ & $4.13 E-01$ & $1.73 E+00$ \\
\hline 0.925 & & $0.00 \mathrm{E}+00$ & $0.00 \mathrm{E}+00$ & $0.00 \mathrm{E}+00$ & $0.00 \mathrm{E}+00$ & $5.23 E-01$ & $1.84 \mathrm{E}+00$ \\
\hline 0.950 & & $0.00 \mathrm{E}+00$ & $0.00 \mathrm{E}+00$ & $0.00 \mathrm{E}+00$ & $0.00 \mathrm{E}+00$ & $6.74 \mathrm{E}-01$ & $2.00 E+00$ \\
\hline 0.975 & & $0.00 \mathrm{E}+00$ & $0.00 \mathrm{E}+00$ & $0.00 \mathrm{E}+00$ & $0.00 \mathrm{E}+00$ & $1.04 \mathrm{E}+00$ & $2.24 \mathrm{E}+00$ \\
\hline 1.000 & & $0.00 \mathrm{E}+00$ & $0.00 \mathrm{E}+00$ & $0.00 \mathrm{E}+00$ & $0.00 \mathrm{E}+00$ & $3.79 \mathrm{E}+00$ & $3.28 \mathrm{E}+00$ \\
\hline
\end{tabular}


RESRAD-OFFSITE, Version 2.5

Probabilistic Dose and Risk Report

Title : Offsite Resident Farmer Deterministic Run

File : RF TC99 DOESG FWD-FV2.ROF

Retition

Statistics and Cumulative distribution function of Peak Dose from All Pathways in mrem/yr

$\begin{array}{rcccc}\text { Repetition }= & 1 & 2 & 3 \\ \text { Mean } & 1.01 \mathrm{E}+00 & 1.01 \mathrm{E}+00 & 1.01 \mathrm{E}+00 \\ \text { Std. Dev. } & 5.91 \mathrm{E}-01 & 5.91 \mathrm{E}-01 & 5.92 \mathrm{E}-01 \\ \text { Minimum } & 1.21 \mathrm{E}-01 & 1.21 \mathrm{E}-01 & 1.21 \mathrm{E}-01 \\ \text { Maximum } & 4.59 \mathrm{E}+00 & 4.59 \mathrm{E}+00 & 4.59 \mathrm{E}+00\end{array}$

Percentile

$0.010 \quad 1.93 \mathrm{E}-01 \quad 1.93 \mathrm{E}-01 \quad 1.93 \mathrm{E}-01$

$0.025 \quad 2.26 \mathrm{E}-01 \quad 2.26 \mathrm{E}-01 \quad 2.26 \mathrm{E}-01$

\begin{tabular}{l}
$0.050 \quad 2.89 \mathrm{E}-01 \quad 2.89 \mathrm{E}-01 \quad 2.89 \mathrm{E}-01$ \\
\hline
\end{tabular}

$0.075 \quad 3.23 \mathrm{E}-01 \quad 3.23 \mathrm{E}-01 \quad 3.23 \mathrm{E}-01$

$0.100 \quad 3.66 \mathrm{E}-01 \quad 3.66 \mathrm{E}-01 \quad 3.66 \mathrm{E}-01$

$0.125 \quad 3.97 \mathrm{E}-01 \quad 3.97 \mathrm{E}-01 \quad 3.97 \mathrm{E}-01$

$0.1504 .25 \mathrm{E}-01 \quad 4.25 \mathrm{E}-01 \quad 4.25 \mathrm{E}-01$

$0.175 \quad 4.63 \mathrm{E}-01 \quad 4.63 \mathrm{E}-01 \quad 4.63 \mathrm{E}-01$

$0.200 \quad 4.91 \mathrm{E}-01 \quad 4.91 \mathrm{E}-01 \quad 4.91 \mathrm{E}-01$

$0.225 \quad 5.30 \mathrm{E}-01 \quad 5.29 \mathrm{E}-01 \quad 5.29 \mathrm{E}-01$

$0.250 \quad 5.55 \mathrm{E}-01 \quad 5.55 \mathrm{E}-01 \quad 5.55 \mathrm{E}-01$

$0.275 \quad 5.86 \mathrm{E}-01 \quad 5.86 \mathrm{E}-01 \quad 5.86 \mathrm{E}-01$

$\begin{array}{llll}0.300 & 6.17 \mathrm{E}-01 & 6.17 \mathrm{E}-01 & 6.17 \mathrm{E}-01\end{array}$

$\begin{array}{llll}0.325 & 6.52 \mathrm{E}-01 & 6.51 \mathrm{E}-01 & 6.51 \mathrm{E}-01\end{array}$

$\begin{array}{llll}0.350 & 6.91 \mathrm{E}-01 & 6.90 \mathrm{E}-01 & 6.90 \mathrm{E}-01\end{array}$

$\begin{array}{llll}0.375 & 7.27 \mathrm{E}-01 & 7.26 \mathrm{E}-01 & 7.26 \mathrm{E}-01\end{array}$

$0.400 \quad 7.54 \mathrm{E}-01 \quad 7.53 \mathrm{E}-01 \quad 7.53 \mathrm{E}-01$

$\begin{array}{llll}0.425 & 7.88 \mathrm{E}-01 & 7.87 \mathrm{E}-01 & 7.87 \mathrm{E}-01\end{array}$

$0.450 \quad 8.19 \mathrm{E}-01 \quad 8.19 \mathrm{E}-01 \quad 8.19 \mathrm{E}-01$
0.475

$0.475 \quad 8.57 \mathrm{E}-01 \quad 8.55 \mathrm{E}-01 \quad 8.57 \mathrm{E}-01$
0.500

$0.500 \quad 8.95 \mathrm{E}-01 \quad 8.94 \mathrm{E}-01 \quad 8.95 \mathrm{E}-01$

$\begin{array}{llll}0.525 & 9.36 \mathrm{E}-01 & 9.35 \mathrm{E}-01 & 9.36 \mathrm{E}-01\end{array}$

$0.550 \quad 9.67 \mathrm{E}-01 \quad 9.66 \mathrm{E}-01 \quad 9.68 \mathrm{E}-01$
0.575

$\begin{array}{llll}0.575 & 1.00 \mathrm{E}+00 & 1.00 \mathrm{E}+00 & 1.00 \mathrm{E}+00\end{array}$

$\begin{array}{llll}0.600 & 1.05 \mathrm{E}+00 & 1.04 \mathrm{E}+00 & 1.05 \mathrm{E}+00\end{array}$

$\begin{array}{llll}0.625 & 1.09 \mathrm{E}+00 & 1.08 \mathrm{E}+00 & 1.09 \mathrm{E}+00\end{array}$

$\begin{array}{llll}0.650 & 1.13 \mathrm{E}+00 & 1.12 \mathrm{E}+00 & 1.13 \mathrm{E}+00\end{array}$

$\begin{array}{llll}0.675 & 1.16 \mathrm{E}+00 & 1.16 \mathrm{E}+00 & 1.16 \mathrm{E}+00\end{array}$

$\begin{array}{llll}0.700 & 1.23 \mathrm{E}+00 & 1.23 \mathrm{E}+00 & 1.23 \mathrm{E}+00\end{array}$

$\begin{array}{llll}0.725 & 1.26 \mathrm{E}+00 & 1.26 \mathrm{E}+00 & 1.26 \mathrm{E}+00\end{array}$

$\begin{array}{llll}0.750 & 1.33 \mathrm{E}+00 & 1.33 \mathrm{E}+00 & 1.33 \mathrm{E}+00\end{array}$

$\begin{array}{llll}0.775 & 1.39 \mathrm{E}+00 & 1.39 \mathrm{E}+00 & 1.39 \mathrm{E}+00\end{array}$

$\begin{array}{llll}0.800 & 1.45 \mathrm{E}+00 & 1.44 \mathrm{E}+00 & 1.45 \mathrm{E}+00\end{array}$

$\begin{array}{llll}0.825 & 1.51 \mathrm{E}+00 & 1.51 \mathrm{E}+00 & 1.51 \mathrm{E}+00\end{array}$

$\begin{array}{llll}0.850 & 1.59 \mathrm{E}+00 & 1.59 \mathrm{E}+00 & 1.59 \mathrm{E}+00\end{array}$

$\begin{array}{llll}0.875 & 1.68 \mathrm{E}+00 & 1.68 \mathrm{E}+00 & 1.69 \mathrm{E}+00\end{array}$

$\begin{array}{llll}0.900 & 1.82 \mathrm{E}+00 & 1.82 \mathrm{E}+00 & 1.82 \mathrm{E}+00\end{array}$

$\begin{array}{llll}0.925 & 1.97 \mathrm{E}+00 & 1.97 \mathrm{E}+00 & 1.97 \mathrm{E}+00\end{array}$

$\begin{array}{lll}0.950 \quad 2.14 \mathrm{E}+00 \quad 2.14 \mathrm{E}+00 \quad 2.14 \mathrm{E}+00 & 0\end{array}$

$\begin{array}{llll}0.975 & 2.45 \mathrm{E}+00 \quad 2.45 \mathrm{E}+00 \quad 2.45 \mathrm{E}+00\end{array}$

$\begin{array}{llll}0.990 & 2.77 \mathrm{E}+00 \quad 2.77 \mathrm{E}+00 \quad 2.77 \mathrm{E}+00\end{array}$ 
RESRAD-OFFSITE, Version 2.5

Probabilistic Dose and Risk Report

Title : Offsite Resident Farmer Deterministic Run

File : RF TC99 DOESG FWD-FV2.ROF

Mean

Std. Dev.

Minimum

Maximum

Percentile

0.010

0.025

0.050

0.075

0.100

0.125

0.150

0.175

0.200

0.225

0.250

0.275

0.300

0.325

0.350

0.375

0.400

0.425

0.450

0.475

0.500

0.525

0.550

0.575

0.600

0.625

0.650

0.675

0.700

0.725

0.750

0.775

0.800

0.825

0.850

0.875

0.900

0.925

0.950

0.975

0.990

Statistics and Cumulative distribution function of Peak Dose from External Ground(Wreleas) in mrem/yr

$\begin{array}{cccc}1 & 2 & 3 \\ 0.00 \mathrm{E}+00 & 0.00 \mathrm{E}+00 & 0.00 \mathrm{E}+00 \\ 0.00 \mathrm{E}+00 & 0.00 \mathrm{E}+00 & 0.00 \mathrm{E}+00 \\ 0.00 \mathrm{E}+00 & 0.00 \mathrm{E}+00 & 0.00 \mathrm{E}+00 \\ 0.00 \mathrm{E}+00 & 0.00 \mathrm{E}+00 & 0.00 \mathrm{E}+00\end{array}$

$0.00 \mathrm{E}+00 \quad 0.00 \mathrm{E}+00 \quad 0.00 \mathrm{E}+00$

$0.00 \mathrm{E}+00 \quad 0.00 \mathrm{E}+00 \quad 0.00 \mathrm{E}+00$

$0.00 \mathrm{E}+00 \quad 0.00 \mathrm{E}+00 \quad 0.00 \mathrm{E}+00$

$0.00 \mathrm{E}+00 \quad 0.00 \mathrm{E}+00 \quad 0.00 \mathrm{E}+00$

$0.00 \mathrm{E}+00 \quad 0.00 \mathrm{E}+00 \quad 0.00 \mathrm{E}+00$

$0.00 \mathrm{E}+00 \quad 0.00 \mathrm{E}+00 \quad 0.00 \mathrm{E}+00$

$0.00 \mathrm{E}+00 \quad 0.00 \mathrm{E}+00 \quad 0.00 \mathrm{E}+00$

$0.00 \mathrm{E}+00 \quad 0.00 \mathrm{E}+00 \quad 0.00 \mathrm{E}+00$

$0.00 \mathrm{E}+00 \quad 0.00 \mathrm{E}+00 \quad 0.00 \mathrm{E}+00$

$0.00 \mathrm{E}+00 \quad 0.00 \mathrm{E}+00 \quad 0.00 \mathrm{E}+00$

$0.00 \mathrm{E}+00 \quad 0.00 \mathrm{E}+00 \quad 0.00 \mathrm{E}+00$

$0.00 \mathrm{E}+00 \quad 0.00 \mathrm{E}+00 \quad 0.00 \mathrm{E}+00$

$0.00 \mathrm{E}+00 \quad 0.00 \mathrm{E}+00 \quad 0.00 \mathrm{E}+00$

$0.00 \mathrm{E}+00 \quad 0.00 \mathrm{E}+00 \quad 0.00 \mathrm{E}+00$

$0.00 \mathrm{E}+00 \quad 0.00 \mathrm{E}+00 \quad 0.00 \mathrm{E}+00$

$0.00 \mathrm{E}+00 \quad 0.00 \mathrm{E}+00 \quad 0.00 \mathrm{E}+00$

$0.00 \mathrm{E}+00 \quad 0.00 \mathrm{E}+00 \quad 0.00 \mathrm{E}+00$

$0.00 \mathrm{E}+00 \quad 0.00 \mathrm{E}+00 \quad 0.00 \mathrm{E}+00$

$0.00 \mathrm{E}+00 \quad 0.00 \mathrm{E}+00 \quad 0.00 \mathrm{E}+00$

$0.00 \mathrm{E}+00 \quad 0.00 \mathrm{E}+00 \quad 0.00 \mathrm{E}+00$

$0.00 \mathrm{E}+00 \quad 0.00 \mathrm{E}+00 \quad 0.00 \mathrm{E}+00$

$0.00 \mathrm{E}+00 \quad 0.00 \mathrm{E}+00 \quad 0.00 \mathrm{E}+00$

$0.00 \mathrm{E}+00 \quad 0.00 \mathrm{E}+00 \quad 0.00 \mathrm{E}+00$

$0.00 \mathrm{E}+00 \quad 0.00 \mathrm{E}+00 \quad 0.00 \mathrm{E}+00$

$0.00 \mathrm{E}+00 \quad 0.00 \mathrm{E}+00 \quad 0.00 \mathrm{E}+00$

$0.00 \mathrm{E}+00 \quad 0.00 \mathrm{E}+00 \quad 0.00 \mathrm{E}+00$

$0.00 \mathrm{E}+00 \quad 0.00 \mathrm{E}+00 \quad 0.00 \mathrm{E}+00$

$0.00 \mathrm{E}+00 \quad 0.00 \mathrm{E}+00 \quad 0.00 \mathrm{E}+00$

$0.00 \mathrm{E}+00 \quad 0.00 \mathrm{E}+00 \quad 0.00 \mathrm{E}+00$

$0.00 \mathrm{E}+00 \quad 0.00 \mathrm{E}+00 \quad 0.00 \mathrm{E}+00$

$0.00 \mathrm{E}+00 \quad 0.00 \mathrm{E}+00 \quad 0.00 \mathrm{E}+00$

$0.00 \mathrm{E}+00 \quad 0.00 \mathrm{E}+00 \quad 0.00 \mathrm{E}+00$

$0.00 \mathrm{E}+00 \quad 0.00 \mathrm{E}+00 \quad 0.00 \mathrm{E}+00$

$0.00 \mathrm{E}+00 \quad 0.00 \mathrm{E}+00 \quad 0.00 \mathrm{E}+00$

$0.00 \mathrm{E}+00 \quad 0.00 \mathrm{E}+00 \quad 0.00 \mathrm{E}+00$

$0.00 \mathrm{E}+00 \quad 0.00 \mathrm{E}+00 \quad 0.00 \mathrm{E}+00$

$0.00 \mathrm{E}+00 \quad 0.00 \mathrm{E}+00 \quad 0.00 \mathrm{E}+00$

$0.00 \mathrm{E}+00 \quad 0.00 \mathrm{E}+00 \quad 0.00 \mathrm{E}+00$

$0.00 \mathrm{E}+00 \quad 0.00 \mathrm{E}+00 \quad 0.00 \mathrm{E}+00$

$0.00 \mathrm{E}+00 \quad 0.00 \mathrm{E}+00 \quad 0.00 \mathrm{E}+00$

$0.00 \mathrm{E}+00 \quad 0.00 \mathrm{E}+00 \quad 0.00 \mathrm{E}+00$ 
RESRAD-OFFSITE, Version 2.5

Probabilistic Dose and Risk Report

Title : Offsite Resident Farmer Deterministic Run

File : RF TC99 DOESG FWD-FV2.ROF

Mean

Std. Dev.

Minimum

Maximum

Percentile

0.010

0.025

0.050

0.075

0.100

0.125

0.150

0.175

0.200

0.225

0.250

0.275

0.300

0.325

0.350

0.375

0.400

0.425

0.450

0.475

0.500

0.525

0.550

0.575

0.600

0.625

0.650

0.675

0.700

0.725

0.750

0.775

0.800

0.825

0.850

0.875

0.900

0.925

0.950

0.975

0.990

Statistics and Cumulative distribution function of Peak Dose from Fish Ingestion in mrem/yr

$\begin{array}{cccc}1 & 2 & 3 \\ 0.00 \mathrm{E}+00 & 0.00 \mathrm{E}+00 & 0.00 \mathrm{E}+00 \\ 0.00 \mathrm{E}+00 & 0.00 \mathrm{E}+00 & 0.00 \mathrm{E}+00 \\ 0.00 \mathrm{E}+00 & 0.00 \mathrm{E}+00 & 0.00 \mathrm{E}+00 \\ 0.00 \mathrm{E}+00 & 0.00 \mathrm{E}+00 & 0.00 \mathrm{E}+00\end{array}$

$0.00 \mathrm{E}+00 \quad 0.00 \mathrm{E}+00 \quad 0.00 \mathrm{E}+00$

$0.00 \mathrm{E}+00 \quad 0.00 \mathrm{E}+00 \quad 0.00 \mathrm{E}+00$

$0.00 \mathrm{E}+00 \quad 0.00 \mathrm{E}+00 \quad 0.00 \mathrm{E}+00$

$0.00 \mathrm{E}+00 \quad 0.00 \mathrm{E}+00 \quad 0.00 \mathrm{E}+00$

$0.00 \mathrm{E}+00 \quad 0.00 \mathrm{E}+00 \quad 0.00 \mathrm{E}+00$

$0.00 \mathrm{E}+00 \quad 0.00 \mathrm{E}+00 \quad 0.00 \mathrm{E}+00$

$0.00 \mathrm{E}+00 \quad 0.00 \mathrm{E}+00 \quad 0.00 \mathrm{E}+00$

$0.00 \mathrm{E}+00 \quad 0.00 \mathrm{E}+00 \quad 0.00 \mathrm{E}+00$

$0.00 \mathrm{E}+00 \quad 0.00 \mathrm{E}+00 \quad 0.00 \mathrm{E}+00$

$0.00 \mathrm{E}+00 \quad 0.00 \mathrm{E}+00 \quad 0.00 \mathrm{E}+00$

$0.00 \mathrm{E}+00 \quad 0.00 \mathrm{E}+00 \quad 0.00 \mathrm{E}+00$

$0.00 \mathrm{E}+00 \quad 0.00 \mathrm{E}+00 \quad 0.00 \mathrm{E}+00$

$0.00 \mathrm{E}+00 \quad 0.00 \mathrm{E}+00 \quad 0.00 \mathrm{E}+00$

$0.00 \mathrm{E}+00 \quad 0.00 \mathrm{E}+00 \quad 0.00 \mathrm{E}+00$

$0.00 \mathrm{E}+00 \quad 0.00 \mathrm{E}+00 \quad 0.00 \mathrm{E}+00$

$0.00 \mathrm{E}+00 \quad 0.00 \mathrm{E}+00 \quad 0.00 \mathrm{E}+00$

$0.00 \mathrm{E}+00 \quad 0.00 \mathrm{E}+00 \quad 0.00 \mathrm{E}+00$

$0.00 \mathrm{E}+00 \quad 0.00 \mathrm{E}+00 \quad 0.00 \mathrm{E}+00$

$0.00 \mathrm{E}+00 \quad 0.00 \mathrm{E}+00 \quad 0.00 \mathrm{E}+00$

$0.00 \mathrm{E}+00 \quad 0.00 \mathrm{E}+00 \quad 0.00 \mathrm{E}+00$

$0.00 \mathrm{E}+00 \quad 0.00 \mathrm{E}+00 \quad 0.00 \mathrm{E}+00$

$0.00 \mathrm{E}+00 \quad 0.00 \mathrm{E}+00 \quad 0.00 \mathrm{E}+00$

$0.00 \mathrm{E}+00 \quad 0.00 \mathrm{E}+00 \quad 0.00 \mathrm{E}+00$

$0.00 \mathrm{E}+00 \quad 0.00 \mathrm{E}+00 \quad 0.00 \mathrm{E}+00$

$0.00 \mathrm{E}+00 \quad 0.00 \mathrm{E}+00 \quad 0.00 \mathrm{E}+00$

$0.00 \mathrm{E}+00 \quad 0.00 \mathrm{E}+00 \quad 0.00 \mathrm{E}+00$

$0.00 \mathrm{E}+00 \quad 0.00 \mathrm{E}+00 \quad 0.00 \mathrm{E}+00$

$0.00 \mathrm{E}+00 \quad 0.00 \mathrm{E}+00 \quad 0.00 \mathrm{E}+00$

$0.00 \mathrm{E}+00 \quad 0.00 \mathrm{E}+00 \quad 0.00 \mathrm{E}+00$

$0.00 \mathrm{E}+00 \quad 0.00 \mathrm{E}+00 \quad 0.00 \mathrm{E}+00$

$0.00 \mathrm{E}+00 \quad 0.00 \mathrm{E}+00 \quad 0.00 \mathrm{E}+00$

$0.00 \mathrm{E}+00 \quad 0.00 \mathrm{E}+00 \quad 0.00 \mathrm{E}+00$

$0.00 \mathrm{E}+00 \quad 0.00 \mathrm{E}+00 \quad 0.00 \mathrm{E}+00$

$0.00 \mathrm{E}+00 \quad 0.00 \mathrm{E}+00 \quad 0.00 \mathrm{E}+00$

$0.00 \mathrm{E}+00 \quad 0.00 \mathrm{E}+00 \quad 0.00 \mathrm{E}+00$

$0.00 \mathrm{E}+00 \quad 0.00 \mathrm{E}+00 \quad 0.00 \mathrm{E}+00$

$0.00 \mathrm{E}+00 \quad 0.00 \mathrm{E}+00 \quad 0.00 \mathrm{E}+00$

$0.00 \mathrm{E}+00 \quad 0.00 \mathrm{E}+00 \quad 0.00 \mathrm{E}+00$

$0.00 \mathrm{E}+00 \quad 0.00 \mathrm{E}+00 \quad 0.00 \mathrm{E}+00$

$0.00 \mathrm{E}+00 \quad 0.00 \mathrm{E}+00 \quad 0.00 \mathrm{E}+00$

$0.00 \mathrm{E}+00 \quad 0.00 \mathrm{E}+00 \quad 0.00 \mathrm{E}+00$ 
RESRAD-OFFSITE, Version 2.5

Probabilistic Dose and Risk Report

Title : Offsite Resident Farmer Deterministic Run

File : RF TC99 DOESG FWD-FV2.ROF

Mean

Std. Dev.

Minimum

Maximum

Percentile

0.010

0.025

0.050

0.075

0.100

0.125

0.150

0.175

0.200

0.225

0.250

0.275

0.300

0.325

0.350

0.375

0.400

0.425

0.450

0.475

0.500

0.525

0.550

0.575

0.600

0.625

0.650

0.675

0.700

0.725

0.750

0.775

0.800

0.825

0.850

0.875

0.900

0.925

0.950

0.975

0.990

Statistics and Cumulative distribution function of Peak Dose from Radon (Waterrelease) in mrem/yr

$\begin{array}{cccc}1 & 2 & 3 \\ 0.00 \mathrm{E}+00 & 0.00 \mathrm{E}+00 & 0.00 \mathrm{E}+00 \\ 0.00 \mathrm{E}+00 & 0.00 \mathrm{E}+00 & 0.00 \mathrm{E}+00 \\ 0.00 \mathrm{E}+00 & 0.00 \mathrm{E}+00 & 0.00 \mathrm{E}+00 \\ 0.00 \mathrm{E}+00 & 0.00 \mathrm{E}+00 & 0.00 \mathrm{E}+00\end{array}$

$0.00 \mathrm{E}+00 \quad 0.00 \mathrm{E}+00 \quad 0.00 \mathrm{E}+00$

$0.00 \mathrm{E}+00 \quad 0.00 \mathrm{E}+00 \quad 0.00 \mathrm{E}+00$

$0.00 \mathrm{E}+00 \quad 0.00 \mathrm{E}+00 \quad 0.00 \mathrm{E}+00$

$0.00 \mathrm{E}+00 \quad 0.00 \mathrm{E}+00 \quad 0.00 \mathrm{E}+00$

$0.00 \mathrm{E}+00 \quad 0.00 \mathrm{E}+00 \quad 0.00 \mathrm{E}+00$

$0.00 \mathrm{E}+00 \quad 0.00 \mathrm{E}+00 \quad 0.00 \mathrm{E}+00$

$0.00 \mathrm{E}+00 \quad 0.00 \mathrm{E}+00 \quad 0.00 \mathrm{E}+00$

$0.00 \mathrm{E}+00 \quad 0.00 \mathrm{E}+00 \quad 0.00 \mathrm{E}+00$

$0.00 \mathrm{E}+00 \quad 0.00 \mathrm{E}+00 \quad 0.00 \mathrm{E}+00$

$0.00 \mathrm{E}+00 \quad 0.00 \mathrm{E}+00 \quad 0.00 \mathrm{E}+00$

$0.00 \mathrm{E}+00 \quad 0.00 \mathrm{E}+00 \quad 0.00 \mathrm{E}+00$

$0.00 \mathrm{E}+00 \quad 0.00 \mathrm{E}+00 \quad 0.00 \mathrm{E}+00$

$0.00 \mathrm{E}+00 \quad 0.00 \mathrm{E}+00 \quad 0.00 \mathrm{E}+00$

$0.00 \mathrm{E}+00 \quad 0.00 \mathrm{E}+00 \quad 0.00 \mathrm{E}+00$

$0.00 \mathrm{E}+00 \quad 0.00 \mathrm{E}+00 \quad 0.00 \mathrm{E}+00$

$0.00 \mathrm{E}+00 \quad 0.00 \mathrm{E}+00 \quad 0.00 \mathrm{E}+00$

$0.00 \mathrm{E}+00 \quad 0.00 \mathrm{E}+00 \quad 0.00 \mathrm{E}+00$

$0.00 \mathrm{E}+00 \quad 0.00 \mathrm{E}+00 \quad 0.00 \mathrm{E}+00$

$0.00 \mathrm{E}+00 \quad 0.00 \mathrm{E}+00 \quad 0.00 \mathrm{E}+00$

$0.00 \mathrm{E}+00 \quad 0.00 \mathrm{E}+00 \quad 0.00 \mathrm{E}+00$

$0.00 \mathrm{E}+00 \quad 0.00 \mathrm{E}+00 \quad 0.00 \mathrm{E}+00$

$0.00 \mathrm{E}+00 \quad 0.00 \mathrm{E}+00 \quad 0.00 \mathrm{E}+00$

$0.00 \mathrm{E}+00 \quad 0.00 \mathrm{E}+00 \quad 0.00 \mathrm{E}+00$

$0.00 \mathrm{E}+00 \quad 0.00 \mathrm{E}+00 \quad 0.00 \mathrm{E}+00$

$0.00 \mathrm{E}+00 \quad 0.00 \mathrm{E}+00 \quad 0.00 \mathrm{E}+00$

$0.00 \mathrm{E}+00 \quad 0.00 \mathrm{E}+00 \quad 0.00 \mathrm{E}+00$

$0.00 \mathrm{E}+00 \quad 0.00 \mathrm{E}+00 \quad 0.00 \mathrm{E}+00$

$0.00 \mathrm{E}+00 \quad 0.00 \mathrm{E}+00 \quad 0.00 \mathrm{E}+00$

$0.00 \mathrm{E}+00 \quad 0.00 \mathrm{E}+00 \quad 0.00 \mathrm{E}+00$

$0.00 \mathrm{E}+00 \quad 0.00 \mathrm{E}+00 \quad 0.00 \mathrm{E}+00$

$0.00 \mathrm{E}+00 \quad 0.00 \mathrm{E}+00 \quad 0.00 \mathrm{E}+00$

$0.00 \mathrm{E}+00 \quad 0.00 \mathrm{E}+00 \quad 0.00 \mathrm{E}+00$

$0.00 \mathrm{E}+00 \quad 0.00 \mathrm{E}+00 \quad 0.00 \mathrm{E}+00$

$0.00 \mathrm{E}+00 \quad 0.00 \mathrm{E}+00 \quad 0.00 \mathrm{E}+00$

$0.00 \mathrm{E}+00 \quad 0.00 \mathrm{E}+00 \quad 0.00 \mathrm{E}+00$

$0.00 \mathrm{E}+00 \quad 0.00 \mathrm{E}+00 \quad 0.00 \mathrm{E}+00$

$0.00 \mathrm{E}+00 \quad 0.00 \mathrm{E}+00 \quad 0.00 \mathrm{E}+00$

$0.00 \mathrm{E}+00 \quad 0.00 \mathrm{E}+00 \quad 0.00 \mathrm{E}+00$

$0.00 \mathrm{E}+00 \quad 0.00 \mathrm{E}+00 \quad 0.00 \mathrm{E}+00$

$0.00 \mathrm{E}+00 \quad 0.00 \mathrm{E}+00 \quad 0.00 \mathrm{E}+00$

$0.00 \mathrm{E}+00 \quad 0.00 \mathrm{E}+00 \quad 0.00 \mathrm{E}+00$ 
RESRAD-OFFSITE, Version 2.5

Probabilistic Dose and Risk Report

Title : Offsite Resident Farmer Deterministic Run

File : RF TC99 DOESG FWD-FV2.ROF

Retition $=$

Mean

Statistics and Cumulative distribution function of Peak Dose from Plant (Waterrelease) in mrem/yr

Std. Dev.

Minimum

Maximum

\begin{tabular}{cccc}
1 & & 2 & 3 \\
\cline { 1 - 1 } $2.52 \mathrm{E}-01$ & $2.52 \mathrm{E}-01$ & $2.52 \mathrm{E}-01$ \\
$1.48 \mathrm{E}-01$ & $1.48 \mathrm{E}-01$ & $1.48 \mathrm{E}-01$ \\
$3.02 \mathrm{E}-02$ & $3.02 \mathrm{E}-02$ & $3.02 \mathrm{E}-02$ \\
$1.15 \mathrm{E}+00$ & $1.15 \mathrm{E}+00$ & $1.15 \mathrm{E}+00$
\end{tabular}

Percentile

0.010

4.83E-02 4.83E-02 4.83E-02

0.025

$5.67 \mathrm{E}-02 \quad 5.67 \mathrm{E}-02 \quad 5.67 \mathrm{E}-02$

0.050

7.24E-02 7.24E-02 7.24E-02

0.075

8.10E-02 8.10E-02 8.10E-02

0.100

$9.16 \mathrm{E}-02 \quad 9.16 \mathrm{E}-02 \quad 9.16 \mathrm{E}-02$

0.125

9.95E-02 9.95E-02 9.95E-02

0.150

$1.07 \mathrm{E}-01 \quad 1.07 \mathrm{E}-01 \quad 1.07 \mathrm{E}-01$

0.175

$1.16 \mathrm{E}-01 \quad 1.16 \mathrm{E}-01 \quad 1.16 \mathrm{E}-01$

0.200

$1.23 \mathrm{E}-01 \quad 1.23 \mathrm{E}-01 \quad 1.23 \mathrm{E}-01$

0.225

0.250

1.33E-01 1.32E-01 1.32E-01

$\begin{array}{lll}1.39 \mathrm{E}-01 & 1.39 \mathrm{E}-01 & 1.39 \mathrm{E}-01\end{array}$

$1.47 \mathrm{E}-01 \quad 1.47 \mathrm{E}-01 \quad 1.47 \mathrm{E}-01$

$1.55 \mathrm{E}-01 \quad 1.55 \mathrm{E}-01 \quad 1.54 \mathrm{E}-01$

$1.63 \mathrm{E}-01 \quad 1.63 \mathrm{E}-01 \quad 1.63 \mathrm{E}-01$

$1.73 \mathrm{E}-01 \quad 1.73 \mathrm{E}-01 \quad 1.73 \mathrm{E}-01$

$1.82 \mathrm{E}-01 \quad 1.82 \mathrm{E}-01 \quad 1.82 \mathrm{E}-01$

$\begin{array}{lll}1.89 \mathrm{E}-01 & 1.89 \mathrm{E}-01 & 1.89 \mathrm{E}-01\end{array}$

$1.97 \mathrm{E}-01 \quad 1.97 \mathrm{E}-01 \quad 1.97 \mathrm{E}-01$

2.05E-01 2.05E-01 2.05E-01

$2.15 \mathrm{E}-01 \quad 2.14 \mathrm{E}-01 \quad 2.15 \mathrm{E}-01$

2.24E-01 2.24E-01 2.24E-01

2.34E-01 2.34E-01 2.35E-01

2. $42 \mathrm{E}-01 \quad 2.42 \mathrm{E}-01 \quad 2.42 \mathrm{E}-01$

$2.51 \mathrm{E}-01 \quad 2.51 \mathrm{E}-01 \quad 2.51 \mathrm{E}-01$

2. $62 \mathrm{E}-01 \quad 2.62 \mathrm{E}-01 \quad 2.62 \mathrm{E}-01$

$2.72 \mathrm{E}-01 \quad 2.72 \mathrm{E}-01 \quad 2.72 \mathrm{E}-01$

$2.82 \mathrm{E}-01 \quad 2.82 \mathrm{E}-01 \quad 2.82 \mathrm{E}-01$

$2.91 \mathrm{E}-01 \quad 2.91 \mathrm{E}-01 \quad 2.91 \mathrm{E}-01$

$3.07 \mathrm{E}-01 \quad 3.07 \mathrm{E}-01 \quad 3.07 \mathrm{E}-01$

$3.17 \mathrm{E}-01 \quad 3.17 \mathrm{E}-01 \quad 3.17 \mathrm{E}-01$

3.34E-01 3.34E-01 3.34E-01

$3.47 \mathrm{E}-01 \quad 3.47 \mathrm{E}-01 \quad 3.47 \mathrm{E}-01$

3. $62 \mathrm{E}-01 \quad 3.62 \mathrm{E}-01 \quad 3.62 \mathrm{E}-01$

$3.78 \mathrm{E}-01 \quad 3.78 \mathrm{E}-01 \quad 3.79 \mathrm{E}-01$

$3.98 \mathrm{E}-01 \quad 3.98 \mathrm{E}-01 \quad 3.99 \mathrm{E}-01$

4.22E-01 4.22E-01 4.23E-01

4.55E-01 4.55E-01 4.55E-01

4.93E-01 4.93E-01 4.93E-01

$5.36 \mathrm{E}-01 \quad 5.36 \mathrm{E}-01 \quad 5.36 \mathrm{E}-01$

$6.15 \mathrm{E}-01 \quad 6.15 \mathrm{E}-01 \quad 6.15 \mathrm{E}-01$

6.93E-01 6.93E-01 6.93E-01 
RESRAD-OFFSITE, Version 2.5

Probabilistic Dose and Risk Report

Title : Offsite Resident Farmer Deterministic Run

File : RF TC99 DOESG FWD-FV2.ROF

Retition $=$

Mean

Statistics and Cumulative distribution function of Peak Dose from Meat (Waterrelease) in mrem/yr

Std. Dev.

Minimum

Maximum

\begin{tabular}{|c|c|c|}
\hline 1 & 2 & 3 \\
\hline $7.56 \mathrm{E}-04$ & $7.55 \mathrm{E}-04$ & $7.56 \mathrm{E}-04$ \\
\hline $4.44 \mathrm{E}-04$ & $4.44 E-04$ & $4.44 \mathrm{E}-04$ \\
\hline $9.06 \mathrm{E}-05$ & $9.06 \mathrm{E}-05$ & $9.06 \mathrm{E}-05$ \\
\hline $3.45 E-03$ & $3.45 E-03$ & $3.45 E-03$ \\
\hline
\end{tabular}

Percentile

0.010

1. 45E-04 1.45E-04 1.45E-04

0.025

1.70E-04 1.70E-04 1.70E-04

0.050

$2.17 \mathrm{E}-04 \quad 2.17 \mathrm{E}-04 \quad 2.17 \mathrm{E}-04$

0.075

2. 43E-04 2.43E-04 2.43E-04

0.100

$2.75 \mathrm{E}-04 \quad 2.75 \mathrm{E}-04 \quad 2.75 \mathrm{E}-04$

0.125

2. $98 \mathrm{E}-04 \quad 2.98 \mathrm{E}-04 \quad 2.98 \mathrm{E}-04$

$3.19 \mathrm{E}-04 \quad 3.19 \mathrm{E}-04 \quad 3.19 \mathrm{E}-04$

$3.48 \mathrm{E}-04 \quad 3.47 \mathrm{E}-04 \quad 3.47 \mathrm{E}-04$

$3.69 \mathrm{E}-04 \quad 3.68 \mathrm{E}-04 \quad 3.68 \mathrm{E}-04$

$3.98 \mathrm{E}-04 \quad 3.97 \mathrm{E}-04 \quad 3.97 \mathrm{E}-04$

4.17E-04 4.17E-04 4.17E-04

4.40E-04 4.40E-04 4.40E-04

4.63E-04 4.63E-04 4.63E-04

4.89E-04 4.88E-04 4.88E-04

5.19E-04 5.18E-04 5.18E-04

5.45E-04 5.45E-04 5.45E-04

$5.66 \mathrm{E}-04 \quad 5.65 \mathrm{E}-04 \quad 5.65 \mathrm{E}-04$

5.91E-04 5.91E-04 5.91E-04

$6.15 \mathrm{E}-04 \quad 6.14 \mathrm{E}-04 \quad 6.14 \mathrm{E}-04$

$6.43 \mathrm{E}-04 \quad 6.42 \mathrm{E}-04 \quad 6.43 \mathrm{E}-04$

$6.72 \mathrm{E}-04 \quad 6.71 \mathrm{E}-04 \quad 6.72 \mathrm{E}-04$

$7.02 \mathrm{E}-04 \quad 7.02 \mathrm{E}-04 \quad 7.03 \mathrm{E}-04$

$7.26 \mathrm{E}-04 \quad 7.25 \mathrm{E}-04 \quad 7.26 \mathrm{E}-04$

$7.54 \mathrm{E}-04 \quad 7.53 \mathrm{E}-04 \quad 7.54 \mathrm{E}-04$

$7.84 \mathrm{E}-04 \quad 7.84 \mathrm{E}-04 \quad 7.84 \mathrm{E}-04$

$8.16 \mathrm{E}-04 \quad 8.14 \mathrm{E}-04 \quad 8.16 \mathrm{E}-04$

8.45E-04 8.44E-04 8.45E-04

$8.73 E-04 \quad 8.73 E-04 \quad 8.73 E-04$

$9.20 \mathrm{E}-04 \quad 9.20 \mathrm{E}-04 \quad 9.20 \mathrm{E}-04$

9.49E-04 9.49E-04 9.49E-04

$1.00 \mathrm{E}-03 \quad 1.00 \mathrm{E}-03 \quad 1.00 \mathrm{E}-03$

$1.04 \mathrm{E}-03 \quad 1.04 \mathrm{E}-03 \quad 1.04 \mathrm{E}-03$

$1.08 \mathrm{E}-03 \quad 1.08 \mathrm{E}-03 \quad 1.08 \mathrm{E}-03$

$1.13 \mathrm{E}-03 \quad 1.13 \mathrm{E}-03 \quad 1.14 \mathrm{E}-03$

$1.19 \mathrm{E}-03 \quad 1.19 \mathrm{E}-03 \quad 1.19 \mathrm{E}-03$

$1.26 \mathrm{E}-03 \quad 1.26 \mathrm{E}-03 \quad 1.27 \mathrm{E}-03$

$1.36 \mathrm{E}-03 \quad 1.36 \mathrm{E}-03 \quad 1.36 \mathrm{E}-03$

$1.48 \mathrm{E}-03 \quad 1.48 \mathrm{E}-03 \quad 1.48 \mathrm{E}-03$

$1.60 \mathrm{E}-03 \quad 1.60 \mathrm{E}-03 \quad 1.60 \mathrm{E}-03$

$1.84 \mathrm{E}-03 \quad 1.84 \mathrm{E}-03 \quad 1.84 \mathrm{E}-03$

$2.08 \mathrm{E}-03 \quad 2.08 \mathrm{E}-03 \quad 2.08 \mathrm{E}-03$ 
RESRAD-OFFSITE, Version 2.5

Probabilistic Dose and Risk Report

Title : Offsite Resident Farmer Deterministic Run

File : RF TC99 DOESG FWD-FV2.ROF

Retition $=$

Statistics and Cumulative distribution function of Peak Dose from Milk (Waterrelease) in mrem/yr

$\begin{array}{ccccc}\text { Repetition }= & 1 & 2 & 3 \\ \text { Mean } & 6.68 \mathrm{E}-02 & 6.67 \mathrm{E}-02 & 6.68 \mathrm{E}-02 \\ \text { Std. Dev. } & 3.92 \mathrm{E}-02 & 3.92 \mathrm{E}-02 & 3.92 \mathrm{E}-02 \\ \text { Minimum } & 8.00 \mathrm{E}-03 & 8.00 \mathrm{E}-03 & 8.00 \mathrm{E}-03 \\ \text { Maximum } & 3.05 \mathrm{E}-01 & 3.05 \mathrm{E}-01 & 3.05 \mathrm{E}-01\end{array}$

Percentile

$0.010 \quad 1.28 \mathrm{E}-02 \quad 1.28 \mathrm{E}-02 \quad 1.28 \mathrm{E}-02$

$0.0251 .50 \mathrm{E}-02 \quad 1.50 \mathrm{E}-02 \quad 1.50 \mathrm{E}-02$

$0.050 \quad 1.92 \mathrm{E}-02 \quad 1.92 \mathrm{E}-02 \quad 1.92 \mathrm{E}-02$

$0.075 \quad 2.14 \mathrm{E}-02 \quad 2.14 \mathrm{E}-02 \quad 2.14 \mathrm{E}-02$

$0.100 \quad 2.43 \mathrm{E}-02 \quad 2.43 \mathrm{E}-02 \quad 2.43 \mathrm{E}-02$

$\begin{array}{llll}0.125 & 2.64 \mathrm{E}-02 & 2.63 \mathrm{E}-02 & 2.63 \mathrm{E}-02\end{array}$

$0.150 \quad 2.82 \mathrm{E}-02 \quad 2.82 \mathrm{E}-02 \quad 2.82 \mathrm{E}-02$

$0.175 \quad 3.07 \mathrm{E}-02 \quad 3.07 \mathrm{E}-02 \quad 3.07 \mathrm{E}-02$

$0.200 \quad 3.26 \mathrm{E}-02 \quad 3.25 \mathrm{E}-02 \quad 3.25 \mathrm{E}-02$

$0.225 \quad 3.51 \mathrm{E}-02 \quad 3.50 \mathrm{E}-02 \quad 3.50 \mathrm{E}-02$

$0.250 \quad 3.68 \mathrm{E}-02 \quad 3.68 \mathrm{E}-02 \quad 3.68 \mathrm{E}-02$

$0.275 \quad 3.89 \mathrm{E}-02 \quad 3.89 \mathrm{E}-02 \quad 3.89 \mathrm{E}-02$

$0.300 \quad 4.09 \mathrm{E}-02 \quad 4.09 \mathrm{E}-02 \quad 4.09 \mathrm{E}-02$

$0.325 \quad 4.32 \mathrm{E}-02 \quad 4.31 \mathrm{E}-02 \quad 4.31 \mathrm{E}-02$

$0.350 \quad 4.58 \mathrm{E}-02 \quad 4.57 \mathrm{E}-02 \quad 4.57 \mathrm{E}-02$

$0.375 \quad 4.82 \mathrm{E}-02 \quad 4.81 \mathrm{E}-02 \quad 4.81 \mathrm{E}-02$

$0.400 \quad 5.00 \mathrm{E}-02 \quad 4.99 \mathrm{E}-02 \quad 4.99 \mathrm{E}-02$

$0.425 \quad 5.22 \mathrm{E}-02 \quad 5.22 \mathrm{E}-02 \quad 5.22 \mathrm{E}-02$

$0.450 \quad 5.43 \mathrm{E}-02 \quad 5.43 \mathrm{E}-02 \quad 5.43 \mathrm{E}-02$

$0.475 \quad 5.68 \mathrm{E}-02 \quad 5.67 \mathrm{E}-02 \quad 5.68 \mathrm{E}-02$

$0.500 \quad 5.93 \mathrm{E}-02 \quad 5.93 \mathrm{E}-02 \quad 5.93 \mathrm{E}-02$

$0.525 \quad 6.20 \mathrm{E}-02 \quad 6.20 \mathrm{E}-02 \quad 6.21 \mathrm{E}-02$

$0.550 \quad 6.41 \mathrm{E}-02 \quad 6.40 \mathrm{E}-02 \quad 6.42 \mathrm{E}-02$

$0.575 \quad 6.65 \mathrm{E}-02 \quad 6.65 \mathrm{E}-02 \quad 6.65 \mathrm{E}-02$

$0.600 \quad 6.93 \mathrm{E}-02 \quad 6.93 \mathrm{E}-02 \quad 6.93 \mathrm{E}-02$

$0.625 \quad 7.21 \mathrm{E}-02 \quad 7.19 \mathrm{E}-02 \quad 7.21 \mathrm{E}-02$

$0.650 \quad 7.46 \mathrm{E}-02 \quad 7.46 \mathrm{E}-02 \quad 7.46 \mathrm{E}-02$

$0.675 \quad 7.71 \mathrm{E}-02 \quad 7.71 \mathrm{E}-02 \quad 7.71 \mathrm{E}-02$

$0.700 \quad 8.13 \mathrm{E}-02 \quad 8.12 \mathrm{E}-02 \quad 8.13 \mathrm{E}-02$

$0.725 \quad 8.38 \mathrm{E}-02 \quad 8.38 \mathrm{E}-02 \quad 8.38 \mathrm{E}-02$

$0.750 \quad 8.84 \mathrm{E}-02 \quad 8.83 \mathrm{E}-02 \quad 8.84 \mathrm{E}-02$

\begin{tabular}{l}
$0.775 \quad 9.19 \mathrm{E}-02 \quad 9.19 \mathrm{E}-02 \quad 9.19 \mathrm{E}-02$ \\
\hline
\end{tabular}

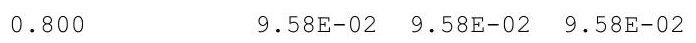

$\begin{array}{llll}0.825 & 1.00 \mathrm{E}-01 & 1.00 \mathrm{E}-01 & 1.00 \mathrm{E}-01\end{array}$

$\begin{array}{llll}0.850 & 1.05 \mathrm{E}-01 & 1.05 \mathrm{E}-01 & 1.05 \mathrm{E}-01\end{array}$

$\begin{array}{llll}0.875 & 1.12 \mathrm{E}-01 & 1.12 \mathrm{E}-01 & 1.12 \mathrm{E}-01\end{array}$

$0.900 \quad 1.20 \mathrm{E}-01 \quad 1.20 \mathrm{E}-01 \quad 1.20 \mathrm{E}-01$

$\begin{array}{llll}0.925 & 1.31 \mathrm{E}-01 & 1.31 \mathrm{E}-01 & 1.31 \mathrm{E}-01\end{array}$

$0.950 \quad 1.42 \mathrm{E}-01 \quad 1.42 \mathrm{E}-01 \quad 1.42 \mathrm{E}-01$

$0.975 \quad 1.63 \mathrm{E}-01 \quad 1.63 \mathrm{E}-01 \quad 1.63 \mathrm{E}-01$

$0.990 \quad 1.83 \mathrm{E}-01 \quad 1.83 \mathrm{E}-01 \quad 1.83 \mathrm{E}-01$ 
RESRAD-OFFSITE, Version 2.5

Probabilistic Dose and Risk Report

Title : Offsite Resident Farmer Deterministic Run

File : RF TC99 DOESG FWD-FV2.ROF

Mean

Std. Dev.

Minimum

Maximum

Percentile

0.010

0.025

0.050

0.075

0.100

0.125

0.150

0.175

0.200

0.225

0.250

0.275

0.300

0.325

0.350

0.375

0.400

0.425

0.450

0.475

0.500

0.525

0.550

0.575

0.600

0.625

0.650

0.675

0.700

0.725

0.750

0.775

0.800

0.825

0.850

0.875

0.900

0.925

0.950

0.975

0.990

Statistics and Cumulative distribution function of Peak Dose from Soil Ingestion(Wrelease) in mrem/yr

$\begin{array}{cccc}1 & 2 & 3 \\ 0.00 \mathrm{E}+00 & 0.00 \mathrm{E}+00 & 0.00 \mathrm{E}+00 \\ 0.00 \mathrm{E}+00 & 0.00 \mathrm{E}+00 & 0.00 \mathrm{E}+00 \\ 0.00 \mathrm{E}+00 & 0.00 \mathrm{E}+00 & 0.00 \mathrm{E}+00 \\ 0.00 \mathrm{E}+00 & 0.00 \mathrm{E}+00 & 0.00 \mathrm{E}+00\end{array}$

$0.00 \mathrm{E}+00 \quad 0.00 \mathrm{E}+00 \quad 0.00 \mathrm{E}+00$

$0.00 \mathrm{E}+00 \quad 0.00 \mathrm{E}+00 \quad 0.00 \mathrm{E}+00$

$0.00 \mathrm{E}+00 \quad 0.00 \mathrm{E}+00 \quad 0.00 \mathrm{E}+00$

$0.00 \mathrm{E}+00 \quad 0.00 \mathrm{E}+00 \quad 0.00 \mathrm{E}+00$

$0.00 \mathrm{E}+00 \quad 0.00 \mathrm{E}+00 \quad 0.00 \mathrm{E}+00$

$0.00 \mathrm{E}+00 \quad 0.00 \mathrm{E}+00 \quad 0.00 \mathrm{E}+00$

$0.00 \mathrm{E}+00 \quad 0.00 \mathrm{E}+00 \quad 0.00 \mathrm{E}+00$

$0.00 \mathrm{E}+00 \quad 0.00 \mathrm{E}+00 \quad 0.00 \mathrm{E}+00$

$0.00 \mathrm{E}+00 \quad 0.00 \mathrm{E}+00 \quad 0.00 \mathrm{E}+00$

$0.00 \mathrm{E}+00 \quad 0.00 \mathrm{E}+00 \quad 0.00 \mathrm{E}+00$

$0.00 \mathrm{E}+00 \quad 0.00 \mathrm{E}+00 \quad 0.00 \mathrm{E}+00$

$0.00 \mathrm{E}+00 \quad 0.00 \mathrm{E}+00 \quad 0.00 \mathrm{E}+00$

$0.00 \mathrm{E}+00 \quad 0.00 \mathrm{E}+00 \quad 0.00 \mathrm{E}+00$

$0.00 \mathrm{E}+00 \quad 0.00 \mathrm{E}+00 \quad 0.00 \mathrm{E}+00$

$0.00 \mathrm{E}+00 \quad 0.00 \mathrm{E}+00 \quad 0.00 \mathrm{E}+00$

$0.00 \mathrm{E}+00 \quad 0.00 \mathrm{E}+00 \quad 0.00 \mathrm{E}+00$

$0.00 \mathrm{E}+00 \quad 0.00 \mathrm{E}+00 \quad 0.00 \mathrm{E}+00$

$0.00 \mathrm{E}+00 \quad 0.00 \mathrm{E}+00 \quad 0.00 \mathrm{E}+00$

$0.00 \mathrm{E}+00 \quad 0.00 \mathrm{E}+00 \quad 0.00 \mathrm{E}+00$

$0.00 \mathrm{E}+00 \quad 0.00 \mathrm{E}+00 \quad 0.00 \mathrm{E}+00$

$0.00 \mathrm{E}+00 \quad 0.00 \mathrm{E}+00 \quad 0.00 \mathrm{E}+00$

$0.00 \mathrm{E}+00 \quad 0.00 \mathrm{E}+00 \quad 0.00 \mathrm{E}+00$

$0.00 \mathrm{E}+00 \quad 0.00 \mathrm{E}+00 \quad 0.00 \mathrm{E}+00$

$0.00 \mathrm{E}+00 \quad 0.00 \mathrm{E}+00 \quad 0.00 \mathrm{E}+00$

$0.00 \mathrm{E}+00 \quad 0.00 \mathrm{E}+00 \quad 0.00 \mathrm{E}+00$

$0.00 \mathrm{E}+00 \quad 0.00 \mathrm{E}+00 \quad 0.00 \mathrm{E}+00$

$0.00 \mathrm{E}+00 \quad 0.00 \mathrm{E}+00 \quad 0.00 \mathrm{E}+00$

$0.00 \mathrm{E}+00 \quad 0.00 \mathrm{E}+00 \quad 0.00 \mathrm{E}+00$

$0.00 \mathrm{E}+00 \quad 0.00 \mathrm{E}+00 \quad 0.00 \mathrm{E}+00$

$0.00 \mathrm{E}+00 \quad 0.00 \mathrm{E}+00 \quad 0.00 \mathrm{E}+00$

$0.00 \mathrm{E}+00 \quad 0.00 \mathrm{E}+00 \quad 0.00 \mathrm{E}+00$

$0.00 \mathrm{E}+00 \quad 0.00 \mathrm{E}+00 \quad 0.00 \mathrm{E}+00$

$0.00 \mathrm{E}+00 \quad 0.00 \mathrm{E}+00 \quad 0.00 \mathrm{E}+00$

$0.00 \mathrm{E}+00 \quad 0.00 \mathrm{E}+00 \quad 0.00 \mathrm{E}+00$

$0.00 \mathrm{E}+00 \quad 0.00 \mathrm{E}+00 \quad 0.00 \mathrm{E}+00$

$0.00 \mathrm{E}+00 \quad 0.00 \mathrm{E}+00 \quad 0.00 \mathrm{E}+00$

$0.00 \mathrm{E}+00 \quad 0.00 \mathrm{E}+00 \quad 0.00 \mathrm{E}+00$

$0.00 \mathrm{E}+00 \quad 0.00 \mathrm{E}+00 \quad 0.00 \mathrm{E}+00$

$0.00 \mathrm{E}+00 \quad 0.00 \mathrm{E}+00 \quad 0.00 \mathrm{E}+00$

$0.00 \mathrm{E}+00 \quad 0.00 \mathrm{E}+00 \quad 0.00 \mathrm{E}+00$

$0.00 \mathrm{E}+00 \quad 0.00 \mathrm{E}+00 \quad 0.00 \mathrm{E}+00$ 
RESRAD-OFFSITE, Version 2.5

Probabilistic Dose and Risk Report

Title : Offsite Resident Farmer Deterministic Run

File : RF TC99 DOESG FWD-FV2.ROF

Retition $=$

Mean

Statistics and Cumulative distribution function of Peak Dose from Water Ingestion in mrem/yr

Std. Dev.

Minimum

Maximum

\begin{tabular}{|c|c|c|}
\hline 1 & 2 & 3 \\
\hline $6.87 E-01$ & $6.87 \mathrm{E}-01$ & $6.87 \mathrm{E}-01$ \\
\hline $4.04 \mathrm{E}-01$ & $4.04 \mathrm{E}-01$ & $4.04 \mathrm{E}-01$ \\
\hline $8.23 E-02$ & $8.23 E-02$ & $8.23 E-02$ \\
\hline $3.13 \mathrm{E}+00$ & $3.13 \mathrm{E}+00$ & $3.13 \mathrm{E}+00$ \\
\hline
\end{tabular}

Percentile

0.010

1.32E-01 1.32E-01 1.32E-01

0.025

$1.55 \mathrm{E}-01 \quad 1.55 \mathrm{E}-01 \quad 1.55 \mathrm{E}-01$

0.050

$1.97 \mathrm{E}-01 \quad 1.97 \mathrm{E}-01 \quad 1.97 \mathrm{E}-01$

0.075

$2.21 \mathrm{E}-01 \quad 2.21 \mathrm{E}-01 \quad 2.21 \mathrm{E}-01$

0.100

$2.50 \mathrm{E}-01 \quad 2.50 \mathrm{E}-01 \quad 2.50 \mathrm{E}-01$

0.125

$2.71 \mathrm{E}-01 \quad 2.71 \mathrm{E}-01 \quad 2.71 \mathrm{E}-01$

0.150

2.90E-01 2.90E-01 2.90E-01

0.175

$3.16 \mathrm{E}-01 \quad 3.16 \mathrm{E}-01 \quad 3.16 \mathrm{E}-01$

0.200

$3.35 \mathrm{E}-01 \quad 3.35 \mathrm{E}-01 \quad 3.35 \mathrm{E}-01$

0.225

3. $61 \mathrm{E}-01 \quad 3.61 \mathrm{E}-01 \quad 3.61 \mathrm{E}-01$

0.250

$3.79 \mathrm{E}-01 \quad 3.79 \mathrm{E}-01 \quad 3.79 \mathrm{E}-01$

4.00E-01 4.00E-01 4.00E-01

4.21E-01 4.21E-01 4.21E-01

4.45E-01 4.44E-01 4.44E-01

4.71E-01 4.71E-01 4.71E-01

4.96E-01 4.96E-01 4.96E-01

$5.14 \mathrm{E}-01 \quad 5.14 \mathrm{E}-01 \quad 5.14 \mathrm{E}-01$

$5.38 \mathrm{E}-01 \quad 5.37 \mathrm{E}-01 \quad 5.37 \mathrm{E}-01$

$5.59 \mathrm{E}-01 \quad 5.59 \mathrm{E}-01 \quad 5.59 \mathrm{E}-01$

$5.85 \mathrm{E}-01 \quad 5.84 \mathrm{E}-01 \quad 5.85 \mathrm{E}-01$

$6.11 \mathrm{E}-01 \quad 6.10 \mathrm{E}-01 \quad 6.11 \mathrm{E}-01$

$6.39 \mathrm{E}-01 \quad 6.38 \mathrm{E}-01 \quad 6.39 \mathrm{E}-01$

$6.60 \mathrm{E}-01 \quad 6.59 \mathrm{E}-01 \quad 6.60 \mathrm{E}-01$

$6.85 \mathrm{E}-01 \quad 6.85 \mathrm{E}-01 \quad 6.85 \mathrm{E}-01$

$7.13 \mathrm{E}-01 \quad 7.13 \mathrm{E}-01 \quad 7.13 \mathrm{E}-01$

$7.42 \mathrm{E}-01 \quad 7.40 \mathrm{E}-01 \quad 7.42 \mathrm{E}-01$

$7.68 \mathrm{E}-01 \quad 7.67 \mathrm{E}-01 \quad 7.68 \mathrm{E}-01$

$7.93 \mathrm{E}-01 \quad 7.93 \mathrm{E}-01 \quad 7.93 \mathrm{E}-01$

$8.37 \mathrm{E}-01 \quad 8.36 \mathrm{E}-01 \quad 8.37 \mathrm{E}-01$

8.63E-01 8.63E-01 8.63E-01

$9.10 \mathrm{E}-01 \quad 9.09 \mathrm{E}-01 \quad 9.10 \mathrm{E}-01$

$9.46 \mathrm{E}-01 \quad 9.46 \mathrm{E}-01 \quad 9.46 \mathrm{E}-01$

$9.86 \mathrm{E}-01 \quad 9.86 \mathrm{E}-01 \quad 9.86 \mathrm{E}-01$

$1.03 \mathrm{E}+00 \quad 1.03 \mathrm{E}+00 \quad 1.03 \mathrm{E}+00$

$1.08 \mathrm{E}+00 \quad 1.08 \mathrm{E}+00 \quad 1.09 \mathrm{E}+00$

$1.15 \mathrm{E}+00 \quad 1.15 \mathrm{E}+00 \quad 1.15 \mathrm{E}+00$

$1.24 \mathrm{E}+00 \quad 1.24 \mathrm{E}+00 \quad 1.24 \mathrm{E}+00$

$1.34 \mathrm{E}+00 \quad 1.34 \mathrm{E}+00 \quad 1.34 \mathrm{E}+00$

$1.46 \mathrm{E}+00 \quad 1.46 \mathrm{E}+00 \quad 1.46 \mathrm{E}+00$

$1.67 \mathrm{E}+00 \quad 1.67 \mathrm{E}+00 \quad 1.67 \mathrm{E}+00$

$1.89 \mathrm{E}+00 \quad 1.89 \mathrm{E}+00 \quad 1.89 \mathrm{E}+00$ 
RESRAD-OFFSITE, Version 2.5

Probabilistic Dose and Risk Report

Title : Offsite Resident Farmer Deterministic Run

File : RF TC99 DOESG FWD-FV2.ROF

Mean

Std. Dev.

Minimum

Maximum

Percentile

0.010

0.025

0.050

0.075

0.100

0.125

0.150

0.175

0.200

0.225

0.250

0.275

0.300

0.325

0.350

0.375

0.400

0.425

0.450

0.475

0.500

0.525

0.550

0.575

0.600

0.625

0.650

0.675

0.700

0.725

0.750

0.775

0.800

0.825

0.850

0.875

0.900

0.925

0.950

0.975

0.990

Statistics and Cumulative distribution function of Peak Dose from External Ground(Cz\&Air) in mrem/yr

$\begin{array}{cccc}1 & 2 & 3 \\ 0.00 \mathrm{E}+00 & 0.00 \mathrm{E}+00 & 0.00 \mathrm{E}+00 \\ 0.00 \mathrm{E}+00 & 0.00 \mathrm{E}+00 & 0.00 \mathrm{E}+00 \\ 0.00 \mathrm{E}+00 & 0.00 \mathrm{E}+00 & 0.00 \mathrm{E}+00 \\ 0.00 \mathrm{E}+00 & 0.00 \mathrm{E}+00 & 0.00 \mathrm{E}+00\end{array}$

$0.00 \mathrm{E}+00 \quad 0.00 \mathrm{E}+00 \quad 0.00 \mathrm{E}+00$

$0.00 \mathrm{E}+00 \quad 0.00 \mathrm{E}+00 \quad 0.00 \mathrm{E}+00$

$0.00 \mathrm{E}+00 \quad 0.00 \mathrm{E}+00 \quad 0.00 \mathrm{E}+00$

$0.00 \mathrm{E}+00 \quad 0.00 \mathrm{E}+00 \quad 0.00 \mathrm{E}+00$

$0.00 \mathrm{E}+00 \quad 0.00 \mathrm{E}+00 \quad 0.00 \mathrm{E}+00$

$0.00 \mathrm{E}+00 \quad 0.00 \mathrm{E}+00 \quad 0.00 \mathrm{E}+00$

$0.00 \mathrm{E}+00 \quad 0.00 \mathrm{E}+00 \quad 0.00 \mathrm{E}+00$

$0.00 \mathrm{E}+00 \quad 0.00 \mathrm{E}+00 \quad 0.00 \mathrm{E}+00$

$0.00 \mathrm{E}+00 \quad 0.00 \mathrm{E}+00 \quad 0.00 \mathrm{E}+00$

$0.00 \mathrm{E}+00 \quad 0.00 \mathrm{E}+00 \quad 0.00 \mathrm{E}+00$

$0.00 \mathrm{E}+00 \quad 0.00 \mathrm{E}+00 \quad 0.00 \mathrm{E}+00$

$0.00 \mathrm{E}+00 \quad 0.00 \mathrm{E}+00 \quad 0.00 \mathrm{E}+00$

$0.00 \mathrm{E}+00 \quad 0.00 \mathrm{E}+00 \quad 0.00 \mathrm{E}+00$

$0.00 \mathrm{E}+00 \quad 0.00 \mathrm{E}+00 \quad 0.00 \mathrm{E}+00$

$0.00 \mathrm{E}+00 \quad 0.00 \mathrm{E}+00 \quad 0.00 \mathrm{E}+00$

$0.00 \mathrm{E}+00 \quad 0.00 \mathrm{E}+00 \quad 0.00 \mathrm{E}+00$

$0.00 \mathrm{E}+00 \quad 0.00 \mathrm{E}+00 \quad 0.00 \mathrm{E}+00$

$0.00 \mathrm{E}+00 \quad 0.00 \mathrm{E}+00 \quad 0.00 \mathrm{E}+00$

$0.00 \mathrm{E}+00 \quad 0.00 \mathrm{E}+00 \quad 0.00 \mathrm{E}+00$

$0.00 \mathrm{E}+00 \quad 0.00 \mathrm{E}+00 \quad 0.00 \mathrm{E}+00$

$0.00 \mathrm{E}+00 \quad 0.00 \mathrm{E}+00 \quad 0.00 \mathrm{E}+00$

$0.00 \mathrm{E}+00 \quad 0.00 \mathrm{E}+00 \quad 0.00 \mathrm{E}+00$

$0.00 \mathrm{E}+00 \quad 0.00 \mathrm{E}+00 \quad 0.00 \mathrm{E}+00$

$0.00 \mathrm{E}+00 \quad 0.00 \mathrm{E}+00 \quad 0.00 \mathrm{E}+00$

$0.00 \mathrm{E}+00 \quad 0.00 \mathrm{E}+00 \quad 0.00 \mathrm{E}+00$

$0.00 \mathrm{E}+00 \quad 0.00 \mathrm{E}+00 \quad 0.00 \mathrm{E}+00$

$0.00 \mathrm{E}+00 \quad 0.00 \mathrm{E}+00 \quad 0.00 \mathrm{E}+00$

$0.00 \mathrm{E}+00 \quad 0.00 \mathrm{E}+00 \quad 0.00 \mathrm{E}+00$

$0.00 \mathrm{E}+00 \quad 0.00 \mathrm{E}+00 \quad 0.00 \mathrm{E}+00$

$0.00 \mathrm{E}+00 \quad 0.00 \mathrm{E}+00 \quad 0.00 \mathrm{E}+00$

$0.00 \mathrm{E}+00 \quad 0.00 \mathrm{E}+00 \quad 0.00 \mathrm{E}+00$

$0.00 \mathrm{E}+00 \quad 0.00 \mathrm{E}+00 \quad 0.00 \mathrm{E}+00$

$0.00 \mathrm{E}+00 \quad 0.00 \mathrm{E}+00 \quad 0.00 \mathrm{E}+00$

$0.00 \mathrm{E}+00 \quad 0.00 \mathrm{E}+00 \quad 0.00 \mathrm{E}+00$

$0.00 \mathrm{E}+00 \quad 0.00 \mathrm{E}+00 \quad 0.00 \mathrm{E}+00$

$0.00 \mathrm{E}+00 \quad 0.00 \mathrm{E}+00 \quad 0.00 \mathrm{E}+00$

$0.00 \mathrm{E}+00 \quad 0.00 \mathrm{E}+00 \quad 0.00 \mathrm{E}+00$

$0.00 \mathrm{E}+00 \quad 0.00 \mathrm{E}+00 \quad 0.00 \mathrm{E}+00$

$0.00 \mathrm{E}+00 \quad 0.00 \mathrm{E}+00 \quad 0.00 \mathrm{E}+00$

$0.00 \mathrm{E}+00 \quad 0.00 \mathrm{E}+00 \quad 0.00 \mathrm{E}+00$

$0.00 \mathrm{E}+00 \quad 0.00 \mathrm{E}+00 \quad 0.00 \mathrm{E}+00$ 
RESRAD-OFFSITE, Version 2.5

Probabilistic Dose and Risk Report

Title : Offsite Resident Farmer Deterministic Run

File : RF TC99 DOESG FWD-FV2.ROF

Mean

Std. Dev.

Minimum

Maximum

Percentile

0.010

0.025

0.050

0.075

0.100

0.125

0.150

0.175

0.200

0.225

0.250

0.275

0.300

0.325

0.350

0.375

0.400

0.425

0.450

0.475

0.500

0.525

0.550

0.575

0.600

0.625

0.650

0.675

0.700

0.725

0.750

0.775

0.800

0.825

0.850

0.875

0.900

0.925

0.950

0.975

0.990

\begin{tabular}{|c|c|c|}
\hline 1 & 2 & 3 \\
\hline $0.00 \mathrm{E}+00$ & $0.00 \mathrm{E}+00$ & $0.00 \mathrm{E}+00$ \\
\hline $0.00 \mathrm{E}+00$ & $0.00 \mathrm{E}+00$ & $0.00 \mathrm{E}+00$ \\
\hline $0.00 \mathrm{E}+00$ & $0.00 \mathrm{E}+00$ & $0.00 \mathrm{E}+00$ \\
\hline $0.00 \mathrm{E}+00$ & $0.00 \mathrm{E}+00$ & $0.00 \mathrm{E}+00$ \\
\hline
\end{tabular}

\begin{tabular}{|c|c|c|}
\hline $\mathrm{DE}+00$ & $00 E+00$ & 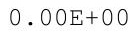 \\
\hline 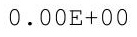 & 0 & \\
\hline $\mathrm{OE}+\mathrm{C}$ & 0 & مि+Fחم \\
\hline $0 \mathrm{E}+00$ & $00 \mathrm{E}+00$ & $00 \mathrm{E}+0$ \\
\hline $0 \mathrm{E}+00$ & $00 \mathrm{E}+00$ & $00 \mathrm{E}+0$ \\
\hline $0 \mathrm{E}+00$ & $00 \mathrm{E}+00$ & $\cap \cap F+$ \\
\hline-00 & +00 & $\cap \cap \mathrm{F}-\mathrm{C}$ \\
\hline & & $.00 \mathrm{E}+0 \mathrm{O}$ \\
\hline $0 \mathrm{E}+00$ & $.00 \mathrm{E}+00$ & 年 \\
\hline+00 & +00 & $F+$ \\
\hline+ & $0 E+00$ & 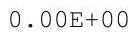 \\
\hline 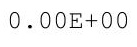 & ك & 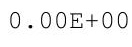 \\
\hline & $0.00 \mathrm{E}+00$ & ק תחم ת \\
\hline 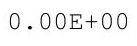 & 0 & 00 \\
\hline+00 & $\mathrm{E}+00$ & $O E$ \\
\hline+00 & $00 \mathrm{E}+00$ & OOE+ \\
\hline 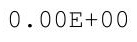 & $0 F+00$ & + \\
\hline & & \\
\hline & $0.00 \mathrm{E}+00$ & \\
\hline$E+00$ & 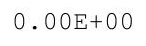 & 00 \\
\hline $00 \mathrm{E}+00$ & $00 E+00$ & $00 E+00$ \\
\hline $0 \mathrm{E}+00$ & $00 \mathrm{E}+00$ & $00 E+00$ \\
\hline 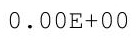 & $00 E+00$ & 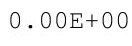 \\
\hline & & \\
\hline 0 & 0 & $0 \mathrm{E}+00$ \\
\hline$E+00$ & $.00 E+00$ & $.00 \mathrm{E}+0 \mathrm{C}$ \\
\hline . & $.00 \mathrm{E}+00$ & $00 \mathrm{E}+0$ \\
\hline $0 \mathrm{E}+0$ & $00 \mathrm{E}+\mathrm{C}$ & \\
\hline $\mathrm{E}+00$ & & \\
\hline & & \\
\hline & 0 & $.00 E+00$ \\
\hline $.00 E+00$ & $0.00 \mathrm{E}+00$ & $0.00 \mathrm{E}+00$ \\
\hline $00 \mathrm{E}+00$ & $0.00 \mathrm{E}+00$ & $0.00 \mathrm{E}+00$ \\
\hline & .0 & 年 \\
\hline & 0 & $00 E+00$ \\
\hline & 0 & $.00 \mathrm{E}$ \\
\hline $\mathrm{OE}+0$ & $0.00 \mathrm{E}+00$ & $0.00 \mathrm{E}+00$ \\
\hline$+C$ & $0.00 \mathrm{E}+$ & 0.00 \\
\hline & & \\
\hline & . & $0.00 \mathrm{E}+00$ \\
\hline $\mathrm{E}+\mathrm{C}$ & . & . \\
\hline
\end{tabular}


RESRAD-OFFSITE, Version 2.5

Probabilistic Dose and Risk Report

Title : Offsite Resident Farmer Deterministic Run

File : RF TC99 DOESG FWD-FV2.ROF

Mean

Std. Dev.

Minimum

Maximum

Percentile

0.010

0.025

0.050

0.075

0.100

0.125

0.150

0.175

0.200

0.225

0.250

0.275

0.300

0.325

0.350

0.375

0.400

0.425

0.450

0.475

0.500

0.525

0.550

0.575

0.600

0.625

0.650

0.675

0.700

0.725

0.750

0.775

0.800

0.825

0.850

0.875

0.900

0.925

0.950

0.975

0.990

Statistics and Cumulative distribution function of Peak Dose from Radon (CZandAir) in mrem/yr

$\begin{array}{cccc}1 & 2 & 3 \\ 0.00 \mathrm{E}+00 & 0.00 \mathrm{E}+00 & 0.00 \mathrm{E}+00 \\ 0.00 \mathrm{E}+00 & 0.00 \mathrm{E}+00 & 0.00 \mathrm{E}+00 \\ 0.00 \mathrm{E}+00 & 0.00 \mathrm{E}+00 & 0.00 \mathrm{E}+00 \\ 0.00 \mathrm{E}+00 & 0.00 \mathrm{E}+00 & 0.00 \mathrm{E}+00\end{array}$

$0.00 \mathrm{E}+00 \quad 0.00 \mathrm{E}+00 \quad 0.00 \mathrm{E}+00$

$0.00 \mathrm{E}+00 \quad 0.00 \mathrm{E}+00 \quad 0.00 \mathrm{E}+00$

$0.00 \mathrm{E}+00 \quad 0.00 \mathrm{E}+00 \quad 0.00 \mathrm{E}+00$

$0.00 \mathrm{E}+00 \quad 0.00 \mathrm{E}+00 \quad 0.00 \mathrm{E}+00$

$0.00 \mathrm{E}+00 \quad 0.00 \mathrm{E}+00 \quad 0.00 \mathrm{E}+00$

$0.00 \mathrm{E}+00 \quad 0.00 \mathrm{E}+00 \quad 0.00 \mathrm{E}+00$

$0.00 \mathrm{E}+00 \quad 0.00 \mathrm{E}+00 \quad 0.00 \mathrm{E}+00$

$0.00 \mathrm{E}+00 \quad 0.00 \mathrm{E}+00 \quad 0.00 \mathrm{E}+00$

$0.00 \mathrm{E}+00 \quad 0.00 \mathrm{E}+00 \quad 0.00 \mathrm{E}+00$

$0.00 \mathrm{E}+00 \quad 0.00 \mathrm{E}+00 \quad 0.00 \mathrm{E}+00$

$0.00 \mathrm{E}+00 \quad 0.00 \mathrm{E}+00 \quad 0.00 \mathrm{E}+00$

$0.00 \mathrm{E}+00 \quad 0.00 \mathrm{E}+00 \quad 0.00 \mathrm{E}+00$

$0.00 \mathrm{E}+00 \quad 0.00 \mathrm{E}+00 \quad 0.00 \mathrm{E}+00$

$0.00 \mathrm{E}+00 \quad 0.00 \mathrm{E}+00 \quad 0.00 \mathrm{E}+00$

$0.00 \mathrm{E}+00 \quad 0.00 \mathrm{E}+00 \quad 0.00 \mathrm{E}+00$

$0.00 \mathrm{E}+00 \quad 0.00 \mathrm{E}+00 \quad 0.00 \mathrm{E}+00$

$0.00 \mathrm{E}+00 \quad 0.00 \mathrm{E}+00 \quad 0.00 \mathrm{E}+00$

$0.00 \mathrm{E}+00 \quad 0.00 \mathrm{E}+00 \quad 0.00 \mathrm{E}+00$

$0.00 \mathrm{E}+00 \quad 0.00 \mathrm{E}+00 \quad 0.00 \mathrm{E}+00$

$0.00 \mathrm{E}+00 \quad 0.00 \mathrm{E}+00 \quad 0.00 \mathrm{E}+00$

$0.00 \mathrm{E}+00 \quad 0.00 \mathrm{E}+00 \quad 0.00 \mathrm{E}+00$

$0.00 \mathrm{E}+00 \quad 0.00 \mathrm{E}+00 \quad 0.00 \mathrm{E}+00$

$0.00 \mathrm{E}+00 \quad 0.00 \mathrm{E}+00 \quad 0.00 \mathrm{E}+00$

$0.00 \mathrm{E}+00 \quad 0.00 \mathrm{E}+00 \quad 0.00 \mathrm{E}+00$

$0.00 \mathrm{E}+00 \quad 0.00 \mathrm{E}+00 \quad 0.00 \mathrm{E}+00$

$0.00 \mathrm{E}+00 \quad 0.00 \mathrm{E}+00 \quad 0.00 \mathrm{E}+00$

$0.00 \mathrm{E}+00 \quad 0.00 \mathrm{E}+00 \quad 0.00 \mathrm{E}+00$

$0.00 \mathrm{E}+00 \quad 0.00 \mathrm{E}+00 \quad 0.00 \mathrm{E}+00$

$0.00 \mathrm{E}+00 \quad 0.00 \mathrm{E}+00 \quad 0.00 \mathrm{E}+00$

$0.00 \mathrm{E}+00 \quad 0.00 \mathrm{E}+00 \quad 0.00 \mathrm{E}+00$

$0.00 \mathrm{E}+00 \quad 0.00 \mathrm{E}+00 \quad 0.00 \mathrm{E}+00$

$0.00 \mathrm{E}+00 \quad 0.00 \mathrm{E}+00 \quad 0.00 \mathrm{E}+00$

$0.00 \mathrm{E}+00 \quad 0.00 \mathrm{E}+00 \quad 0.00 \mathrm{E}+00$

$0.00 \mathrm{E}+00 \quad 0.00 \mathrm{E}+00 \quad 0.00 \mathrm{E}+00$

$0.00 \mathrm{E}+00 \quad 0.00 \mathrm{E}+00 \quad 0.00 \mathrm{E}+00$

$0.00 \mathrm{E}+00 \quad 0.00 \mathrm{E}+00 \quad 0.00 \mathrm{E}+00$

$0.00 \mathrm{E}+00 \quad 0.00 \mathrm{E}+00 \quad 0.00 \mathrm{E}+00$

$0.00 \mathrm{E}+00 \quad 0.00 \mathrm{E}+00 \quad 0.00 \mathrm{E}+00$

$0.00 \mathrm{E}+00 \quad 0.00 \mathrm{E}+00 \quad 0.00 \mathrm{E}+00$

$0.00 \mathrm{E}+00 \quad 0.00 \mathrm{E}+00 \quad 0.00 \mathrm{E}+00$

$\begin{array}{lll}0.00 \mathrm{E}+00 & 0.00 \mathrm{E}+00 \quad 0.00 \mathrm{E}+00\end{array}$ 
RESRAD-OFFSITE, Version 2.5

Probabilistic Dose and Risk Report

Title : Offsite Resident Farmer Deterministic Run

File : RF TC99 DOESG FWD-FV2.ROF

Mean

Std. Dev.

Minimum

Maximum

Percentile

0.010

0.025

0.050

0.075

0.100

0.125

0.150

0.175

0.200

0.225

0.250

0.275

0.300

0.325

0.350

0.375

0.400

0.425

0.450

0.475

0.500

0.525

0.550

0.575

0.600

0.625

0.650

0.675

0.700

0.725

0.750

0.775

0.800

0.825

0.850

0.875

0.900

0.925

0.950

0.975

0.990

Statistics and Cumulative distribution function of Peak Dose from Plant (CzandAir) in mrem/yr

$\begin{array}{cccc}1 & 2 & 3 \\ 0.00 \mathrm{E}+00 & 0.00 \mathrm{E}+00 & 0.00 \mathrm{E}+00 \\ 0.00 \mathrm{E}+00 & 0.00 \mathrm{E}+00 & 0.00 \mathrm{E}+00 \\ 0.00 \mathrm{E}+00 & 0.00 \mathrm{E}+00 & 0.00 \mathrm{E}+00 \\ 0.00 \mathrm{E}+00 & 0.00 \mathrm{E}+00 & 0.00 \mathrm{E}+00\end{array}$

$0.00 \mathrm{E}+00 \quad 0.00 \mathrm{E}+00 \quad 0.00 \mathrm{E}+00$

$0.00 \mathrm{E}+00 \quad 0.00 \mathrm{E}+00 \quad 0.00 \mathrm{E}+00$

$0.00 \mathrm{E}+00 \quad 0.00 \mathrm{E}+00 \quad 0.00 \mathrm{E}+00$

$0.00 \mathrm{E}+00 \quad 0.00 \mathrm{E}+00 \quad 0.00 \mathrm{E}+00$

$0.00 \mathrm{E}+00 \quad 0.00 \mathrm{E}+00 \quad 0.00 \mathrm{E}+00$

$0.00 \mathrm{E}+00 \quad 0.00 \mathrm{E}+00 \quad 0.00 \mathrm{E}+00$

$0.00 \mathrm{E}+00 \quad 0.00 \mathrm{E}+00 \quad 0.00 \mathrm{E}+00$

$0.00 \mathrm{E}+00 \quad 0.00 \mathrm{E}+00 \quad 0.00 \mathrm{E}+00$

$0.00 \mathrm{E}+00 \quad 0.00 \mathrm{E}+00 \quad 0.00 \mathrm{E}+00$

$0.00 \mathrm{E}+00 \quad 0.00 \mathrm{E}+00 \quad 0.00 \mathrm{E}+00$

$0.00 \mathrm{E}+00 \quad 0.00 \mathrm{E}+00 \quad 0.00 \mathrm{E}+00$

$0.00 \mathrm{E}+00 \quad 0.00 \mathrm{E}+00 \quad 0.00 \mathrm{E}+00$

$0.00 \mathrm{E}+00 \quad 0.00 \mathrm{E}+00 \quad 0.00 \mathrm{E}+00$

$0.00 \mathrm{E}+00 \quad 0.00 \mathrm{E}+00 \quad 0.00 \mathrm{E}+00$

$0.00 \mathrm{E}+00 \quad 0.00 \mathrm{E}+00 \quad 0.00 \mathrm{E}+00$

$0.00 \mathrm{E}+00 \quad 0.00 \mathrm{E}+00 \quad 0.00 \mathrm{E}+00$

$0.00 \mathrm{E}+00 \quad 0.00 \mathrm{E}+00 \quad 0.00 \mathrm{E}+00$

$0.00 \mathrm{E}+00 \quad 0.00 \mathrm{E}+00 \quad 0.00 \mathrm{E}+00$

$0.00 \mathrm{E}+00 \quad 0.00 \mathrm{E}+00 \quad 0.00 \mathrm{E}+00$

$0.00 \mathrm{E}+00 \quad 0.00 \mathrm{E}+00 \quad 0.00 \mathrm{E}+00$

$0.00 \mathrm{E}+00 \quad 0.00 \mathrm{E}+00 \quad 0.00 \mathrm{E}+00$

$0.00 \mathrm{E}+00 \quad 0.00 \mathrm{E}+00 \quad 0.00 \mathrm{E}+00$

$0.00 \mathrm{E}+00 \quad 0.00 \mathrm{E}+00 \quad 0.00 \mathrm{E}+00$

$0.00 \mathrm{E}+00 \quad 0.00 \mathrm{E}+00 \quad 0.00 \mathrm{E}+00$

$0.00 \mathrm{E}+00 \quad 0.00 \mathrm{E}+00 \quad 0.00 \mathrm{E}+00$

$0.00 \mathrm{E}+00 \quad 0.00 \mathrm{E}+00 \quad 0.00 \mathrm{E}+00$

$0.00 \mathrm{E}+00 \quad 0.00 \mathrm{E}+00 \quad 0.00 \mathrm{E}+00$

$0.00 \mathrm{E}+00 \quad 0.00 \mathrm{E}+00 \quad 0.00 \mathrm{E}+00$

$0.00 \mathrm{E}+00 \quad 0.00 \mathrm{E}+00 \quad 0.00 \mathrm{E}+00$

$0.00 \mathrm{E}+00 \quad 0.00 \mathrm{E}+00 \quad 0.00 \mathrm{E}+00$

$0.00 \mathrm{E}+00 \quad 0.00 \mathrm{E}+00 \quad 0.00 \mathrm{E}+00$

$0.00 \mathrm{E}+00 \quad 0.00 \mathrm{E}+00 \quad 0.00 \mathrm{E}+00$

$0.00 \mathrm{E}+00 \quad 0.00 \mathrm{E}+00 \quad 0.00 \mathrm{E}+00$

$0.00 \mathrm{E}+00 \quad 0.00 \mathrm{E}+00 \quad 0.00 \mathrm{E}+00$

$0.00 \mathrm{E}+00 \quad 0.00 \mathrm{E}+00 \quad 0.00 \mathrm{E}+00$

$0.00 \mathrm{E}+00 \quad 0.00 \mathrm{E}+00 \quad 0.00 \mathrm{E}+00$

$0.00 \mathrm{E}+00 \quad 0.00 \mathrm{E}+00 \quad 0.00 \mathrm{E}+00$

$0.00 \mathrm{E}+00 \quad 0.00 \mathrm{E}+00 \quad 0.00 \mathrm{E}+00$

$0.00 \mathrm{E}+00 \quad 0.00 \mathrm{E}+00 \quad 0.00 \mathrm{E}+00$

$0.00 \mathrm{E}+00 \quad 0.00 \mathrm{E}+00 \quad 0.00 \mathrm{E}+00$

$0.00 \mathrm{E}+00 \quad 0.00 \mathrm{E}+00 \quad 0.00 \mathrm{E}+00$ 
RESRAD-OFFSITE, Version 2.5

Probabilistic Dose and Risk Report

Title : Offsite Resident Farmer Deterministic Run

File : RF TC99 DOESG FWD-FV2.ROF

Mean

Std. Dev.

Minimum

Maximum

Percentile

0.010

0.025

0.050

0.075

0.100

0.125

0.150

0.175

0.200

0.225

0.250

0.275

0.300

0.325

0.350

0.375

0.400

0.425

0.450

0.475

0.500

0.525

0.550

0.575

0.600

0.625

0.650

0.675

0.700

0.725

0.750

0.775

0.800

0.825

0.850

0.875

0.900

0.925

0.950

0.975

0.990

Statistics and Cumulative distribution function of Peak Dose from Meat (CZandAir) in mrem/yr

$\begin{array}{cccc}1 & 2 & 3 \\ 0.00 \mathrm{E}+00 & 0.00 \mathrm{E}+00 & 0.00 \mathrm{E}+00 \\ 0.00 \mathrm{E}+00 & 0.00 \mathrm{E}+00 & 0.00 \mathrm{E}+00 \\ 0.00 \mathrm{E}+00 & 0.00 \mathrm{E}+00 & 0.00 \mathrm{E}+00 \\ 0.00 \mathrm{E}+00 & 0.00 \mathrm{E}+00 & 0.00 \mathrm{E}+00\end{array}$

$0.00 \mathrm{E}+00 \quad 0.00 \mathrm{E}+00 \quad 0.00 \mathrm{E}+00$

$0.00 \mathrm{E}+00 \quad 0.00 \mathrm{E}+00 \quad 0.00 \mathrm{E}+00$

$0.00 \mathrm{E}+00 \quad 0.00 \mathrm{E}+00 \quad 0.00 \mathrm{E}+00$

$0.00 \mathrm{E}+00 \quad 0.00 \mathrm{E}+00 \quad 0.00 \mathrm{E}+00$

$\begin{array}{lll}0.00 \mathrm{E}+00 & 0.00 \mathrm{E}+00 \quad 0.00 \mathrm{E}+00\end{array}$

$\begin{array}{lll}0.00 \mathrm{E}+00 & 0.00 \mathrm{E}+00 \quad 0.00 \mathrm{E}+00\end{array}$

$0.00 \mathrm{E}+00 \quad 0.00 \mathrm{E}+00 \quad 0.00 \mathrm{E}+00$

$0.00 \mathrm{E}+00 \quad 0.00 \mathrm{E}+00 \quad 0.00 \mathrm{E}+00$

$0.00 \mathrm{E}+00 \quad 0.00 \mathrm{E}+00 \quad 0.00 \mathrm{E}+00$

$0.00 \mathrm{E}+00 \quad 0.00 \mathrm{E}+00 \quad 0.00 \mathrm{E}+00$

$0.00 \mathrm{E}+00 \quad 0.00 \mathrm{E}+00 \quad 0.00 \mathrm{E}+00$

$0.00 \mathrm{E}+00 \quad 0.00 \mathrm{E}+00 \quad 0.00 \mathrm{E}+00$

$0.00 \mathrm{E}+00 \quad 0.00 \mathrm{E}+00 \quad 0.00 \mathrm{E}+00$

$0.00 \mathrm{E}+00 \quad 0.00 \mathrm{E}+00 \quad 0.00 \mathrm{E}+00$

$0.00 \mathrm{E}+00 \quad 0.00 \mathrm{E}+00 \quad 0.00 \mathrm{E}+00$

$0.00 \mathrm{E}+00 \quad 0.00 \mathrm{E}+00 \quad 0.00 \mathrm{E}+00$

$0.00 \mathrm{E}+00 \quad 0.00 \mathrm{E}+00 \quad 0.00 \mathrm{E}+00$

$0.00 \mathrm{E}+00 \quad 0.00 \mathrm{E}+00 \quad 0.00 \mathrm{E}+00$

$0.00 \mathrm{E}+00 \quad 0.00 \mathrm{E}+00 \quad 0.00 \mathrm{E}+00$

$0.00 \mathrm{E}+00 \quad 0.00 \mathrm{E}+00 \quad 0.00 \mathrm{E}+00$

$0.00 \mathrm{E}+00 \quad 0.00 \mathrm{E}+00 \quad 0.00 \mathrm{E}+00$

$0.00 \mathrm{E}+00 \quad 0.00 \mathrm{E}+00 \quad 0.00 \mathrm{E}+00$

$0.00 \mathrm{E}+00 \quad 0.00 \mathrm{E}+00 \quad 0.00 \mathrm{E}+00$

$0.00 \mathrm{E}+00 \quad 0.00 \mathrm{E}+00 \quad 0.00 \mathrm{E}+00$

$0.00 \mathrm{E}+00 \quad 0.00 \mathrm{E}+00 \quad 0.00 \mathrm{E}+00$

$0.00 \mathrm{E}+00 \quad 0.00 \mathrm{E}+00 \quad 0.00 \mathrm{E}+00$

$0.00 \mathrm{E}+00 \quad 0.00 \mathrm{E}+00 \quad 0.00 \mathrm{E}+00$

$0.00 \mathrm{E}+00 \quad 0.00 \mathrm{E}+00 \quad 0.00 \mathrm{E}+00$

$0.00 \mathrm{E}+00 \quad 0.00 \mathrm{E}+00 \quad 0.00 \mathrm{E}+00$

$0.00 \mathrm{E}+00 \quad 0.00 \mathrm{E}+00 \quad 0.00 \mathrm{E}+00$

$0.00 \mathrm{E}+00 \quad 0.00 \mathrm{E}+00 \quad 0.00 \mathrm{E}+00$

$0.00 \mathrm{E}+00 \quad 0.00 \mathrm{E}+00 \quad 0.00 \mathrm{E}+00$

$0.00 \mathrm{E}+00 \quad 0.00 \mathrm{E}+00 \quad 0.00 \mathrm{E}+00$

$0.00 \mathrm{E}+00 \quad 0.00 \mathrm{E}+00 \quad 0.00 \mathrm{E}+00$

$0.00 \mathrm{E}+00 \quad 0.00 \mathrm{E}+00 \quad 0.00 \mathrm{E}+00$

$0.00 \mathrm{E}+00 \quad 0.00 \mathrm{E}+00 \quad 0.00 \mathrm{E}+00$

$0.00 \mathrm{E}+00 \quad 0.00 \mathrm{E}+00 \quad 0.00 \mathrm{E}+00$

$0.00 \mathrm{E}+00 \quad 0.00 \mathrm{E}+00 \quad 0.00 \mathrm{E}+00$

$0.00 \mathrm{E}+00 \quad 0.00 \mathrm{E}+00 \quad 0.00 \mathrm{E}+00$

$0.00 \mathrm{E}+00 \quad 0.00 \mathrm{E}+00 \quad 0.00 \mathrm{E}+00$

$0.00 \mathrm{E}+00 \quad 0.00 \mathrm{E}+00 \quad 0.00 \mathrm{E}+00$ 
RESRAD-OFFSITE, Version 2.5

Probabilistic Dose and Risk Report

Title : Offsite Resident Farmer Deterministic Run

File : RF TC99 DOESG FWD-FV2.ROF

Mean

Std. Dev.

Minimum

Maximum

Percentile

0.010

0.025

0.050

0.075

0.100

0.125

0.150

0.175

0.200

0.225

0.250

0.275

0.300

0.325

0.350

0.375

0.400

0.425

0.450

0.475

0.500

0.525

0.550

0.575

0.600

0.625

0.650

0.675

0.700

0.725

0.750

0.775

0.800

0.825

0.850

0.875

0.900

0.925

0.950

0.975

0.990

Statistics and Cumulative distribution function of Peak Dose from Milk (CzandAir) in mrem/yr

$\begin{array}{cccc}1 & 2 & 3 \\ 0.00 \mathrm{E}+00 & 0.00 \mathrm{E}+00 & 0.00 \mathrm{E}+00 \\ 0.00 \mathrm{E}+00 & 0.00 \mathrm{E}+00 & 0.00 \mathrm{E}+00 \\ 0.00 \mathrm{E}+00 & 0.00 \mathrm{E}+00 & 0.00 \mathrm{E}+00 \\ 0.00 \mathrm{E}+00 & 0.00 \mathrm{E}+00 & 0.00 \mathrm{E}+00\end{array}$

$0.00 \mathrm{E}+00 \quad 0.00 \mathrm{E}+00 \quad 0.00 \mathrm{E}+00$

$0.00 \mathrm{E}+00 \quad 0.00 \mathrm{E}+00 \quad 0.00 \mathrm{E}+00$

$0.00 \mathrm{E}+00 \quad 0.00 \mathrm{E}+00 \quad 0.00 \mathrm{E}+00$

$0.00 \mathrm{E}+00 \quad 0.00 \mathrm{E}+00 \quad 0.00 \mathrm{E}+00$

$\begin{array}{lll}0.00 \mathrm{E}+00 & 0.00 \mathrm{E}+00 \quad 0.00 \mathrm{E}+00\end{array}$

$\begin{array}{lll}0.00 \mathrm{E}+00 & 0.00 \mathrm{E}+00 \quad 0.00 \mathrm{E}+00\end{array}$

$0.00 \mathrm{E}+00 \quad 0.00 \mathrm{E}+00 \quad 0.00 \mathrm{E}+00$

$0.00 \mathrm{E}+00 \quad 0.00 \mathrm{E}+00 \quad 0.00 \mathrm{E}+00$

$0.00 \mathrm{E}+00 \quad 0.00 \mathrm{E}+00 \quad 0.00 \mathrm{E}+00$

$0.00 \mathrm{E}+00 \quad 0.00 \mathrm{E}+00 \quad 0.00 \mathrm{E}+00$

$0.00 \mathrm{E}+00 \quad 0.00 \mathrm{E}+00 \quad 0.00 \mathrm{E}+00$

$0.00 \mathrm{E}+00 \quad 0.00 \mathrm{E}+00 \quad 0.00 \mathrm{E}+00$

$0.00 \mathrm{E}+00 \quad 0.00 \mathrm{E}+00 \quad 0.00 \mathrm{E}+00$

$0.00 \mathrm{E}+00 \quad 0.00 \mathrm{E}+00 \quad 0.00 \mathrm{E}+00$

$0.00 \mathrm{E}+00 \quad 0.00 \mathrm{E}+00 \quad 0.00 \mathrm{E}+00$

$0.00 \mathrm{E}+00 \quad 0.00 \mathrm{E}+00 \quad 0.00 \mathrm{E}+00$

$0.00 \mathrm{E}+00 \quad 0.00 \mathrm{E}+00 \quad 0.00 \mathrm{E}+00$

$0.00 \mathrm{E}+00 \quad 0.00 \mathrm{E}+00 \quad 0.00 \mathrm{E}+00$

$0.00 \mathrm{E}+00 \quad 0.00 \mathrm{E}+00 \quad 0.00 \mathrm{E}+00$

$0.00 \mathrm{E}+00 \quad 0.00 \mathrm{E}+00 \quad 0.00 \mathrm{E}+00$

$0.00 \mathrm{E}+00 \quad 0.00 \mathrm{E}+00 \quad 0.00 \mathrm{E}+00$

$0.00 \mathrm{E}+00 \quad 0.00 \mathrm{E}+00 \quad 0.00 \mathrm{E}+00$

$0.00 \mathrm{E}+00 \quad 0.00 \mathrm{E}+00 \quad 0.00 \mathrm{E}+00$

$0.00 \mathrm{E}+00 \quad 0.00 \mathrm{E}+00 \quad 0.00 \mathrm{E}+00$

$0.00 \mathrm{E}+00 \quad 0.00 \mathrm{E}+00 \quad 0.00 \mathrm{E}+00$

$0.00 \mathrm{E}+00 \quad 0.00 \mathrm{E}+00 \quad 0.00 \mathrm{E}+00$

$0.00 \mathrm{E}+00 \quad 0.00 \mathrm{E}+00 \quad 0.00 \mathrm{E}+00$

$0.00 \mathrm{E}+00 \quad 0.00 \mathrm{E}+00 \quad 0.00 \mathrm{E}+00$

$0.00 \mathrm{E}+00 \quad 0.00 \mathrm{E}+00 \quad 0.00 \mathrm{E}+00$

$0.00 \mathrm{E}+00 \quad 0.00 \mathrm{E}+00 \quad 0.00 \mathrm{E}+00$

$0.00 \mathrm{E}+00 \quad 0.00 \mathrm{E}+00 \quad 0.00 \mathrm{E}+00$

$0.00 \mathrm{E}+00 \quad 0.00 \mathrm{E}+00 \quad 0.00 \mathrm{E}+00$

$0.00 \mathrm{E}+00 \quad 0.00 \mathrm{E}+00 \quad 0.00 \mathrm{E}+00$

$0.00 \mathrm{E}+00 \quad 0.00 \mathrm{E}+00 \quad 0.00 \mathrm{E}+00$

$0.00 \mathrm{E}+00 \quad 0.00 \mathrm{E}+00 \quad 0.00 \mathrm{E}+00$

$0.00 \mathrm{E}+00 \quad 0.00 \mathrm{E}+00 \quad 0.00 \mathrm{E}+00$

$0.00 \mathrm{E}+00 \quad 0.00 \mathrm{E}+00 \quad 0.00 \mathrm{E}+00$

$0.00 \mathrm{E}+00 \quad 0.00 \mathrm{E}+00 \quad 0.00 \mathrm{E}+00$

$0.00 \mathrm{E}+00 \quad 0.00 \mathrm{E}+00 \quad 0.00 \mathrm{E}+00$

$0.00 \mathrm{E}+00 \quad 0.00 \mathrm{E}+00 \quad 0.00 \mathrm{E}+00$

$0.00 \mathrm{E}+00 \quad 0.00 \mathrm{E}+00 \quad 0.00 \mathrm{E}+00$ 
RESRAD-OFFSITE, Version 2.5

Probabilistic Dose and Risk Report

Title : Offsite Resident Farmer Deterministic Run

File : RF TC99 DOESG FWD-FV2.ROF

Mean

Std. Dev.

Minimum

Maximum

Percentile

0.010

0.025

0.050

0.075

0.100

0.125

0.150

0.175

0.200

0.225

0.250

0.275

0.300

0.325

0.350

0.375

0.400

0.425

0.450

0.475

0.500

0.525

0.550

0.575

0.600

0.625

0.650

0.675

0.700

0.725

0.750

0.775

0.800

0.825

0.850

0.875

0.900

0.925

0.950

0.975

0.990

Statistics and Cumulative distribution function of Peak Dose from Soil Ingestion(CZandAir) in mrem/yr

$\begin{array}{cccc}1 & 2 & 3 \\ 0.00 \mathrm{E}+00 & 0.00 \mathrm{E}+00 & 0.00 \mathrm{E}+00 \\ 0.00 \mathrm{E}+00 & 0.00 \mathrm{E}+00 & 0.00 \mathrm{E}+00 \\ 0.00 \mathrm{E}+00 & 0.00 \mathrm{E}+00 & 0.00 \mathrm{E}+00 \\ 0.00 \mathrm{E}+00 & 0.00 \mathrm{E}+00 & 0.00 \mathrm{E}+00\end{array}$

$0.00 \mathrm{E}+00 \quad 0.00 \mathrm{E}+00 \quad 0.00 \mathrm{E}+00$

$0.00 \mathrm{E}+00 \quad 0.00 \mathrm{E}+00 \quad 0.00 \mathrm{E}+00$

$0.00 \mathrm{E}+00 \quad 0.00 \mathrm{E}+00 \quad 0.00 \mathrm{E}+00$

$0.00 \mathrm{E}+00 \quad 0.00 \mathrm{E}+00 \quad 0.00 \mathrm{E}+00$

$0.00 \mathrm{E}+00 \quad 0.00 \mathrm{E}+00 \quad 0.00 \mathrm{E}+00$

$0.00 \mathrm{E}+00 \quad 0.00 \mathrm{E}+00 \quad 0.00 \mathrm{E}+00$

$0.00 \mathrm{E}+00 \quad 0.00 \mathrm{E}+00 \quad 0.00 \mathrm{E}+00$

$0.00 \mathrm{E}+00 \quad 0.00 \mathrm{E}+00 \quad 0.00 \mathrm{E}+00$

$0.00 \mathrm{E}+00 \quad 0.00 \mathrm{E}+00 \quad 0.00 \mathrm{E}+00$

$0.00 \mathrm{E}+00 \quad 0.00 \mathrm{E}+00 \quad 0.00 \mathrm{E}+00$

$0.00 \mathrm{E}+00 \quad 0.00 \mathrm{E}+00 \quad 0.00 \mathrm{E}+00$

$0.00 \mathrm{E}+00 \quad 0.00 \mathrm{E}+00 \quad 0.00 \mathrm{E}+00$

$0.00 \mathrm{E}+00 \quad 0.00 \mathrm{E}+00 \quad 0.00 \mathrm{E}+00$

$0.00 \mathrm{E}+00 \quad 0.00 \mathrm{E}+00 \quad 0.00 \mathrm{E}+00$

$0.00 \mathrm{E}+00 \quad 0.00 \mathrm{E}+00 \quad 0.00 \mathrm{E}+00$

$0.00 \mathrm{E}+00 \quad 0.00 \mathrm{E}+00 \quad 0.00 \mathrm{E}+00$

$0.00 \mathrm{E}+00 \quad 0.00 \mathrm{E}+00 \quad 0.00 \mathrm{E}+00$

$0.00 \mathrm{E}+00 \quad 0.00 \mathrm{E}+00 \quad 0.00 \mathrm{E}+00$

$0.00 \mathrm{E}+00 \quad 0.00 \mathrm{E}+00 \quad 0.00 \mathrm{E}+00$

$0.00 \mathrm{E}+00 \quad 0.00 \mathrm{E}+00 \quad 0.00 \mathrm{E}+00$

$0.00 \mathrm{E}+00 \quad 0.00 \mathrm{E}+00 \quad 0.00 \mathrm{E}+00$

$0.00 \mathrm{E}+00 \quad 0.00 \mathrm{E}+00 \quad 0.00 \mathrm{E}+00$

$0.00 \mathrm{E}+00 \quad 0.00 \mathrm{E}+00 \quad 0.00 \mathrm{E}+00$

$0.00 \mathrm{E}+00 \quad 0.00 \mathrm{E}+00 \quad 0.00 \mathrm{E}+00$

$0.00 \mathrm{E}+00 \quad 0.00 \mathrm{E}+00 \quad 0.00 \mathrm{E}+00$

$0.00 \mathrm{E}+00 \quad 0.00 \mathrm{E}+00 \quad 0.00 \mathrm{E}+00$

$0.00 \mathrm{E}+00 \quad 0.00 \mathrm{E}+00 \quad 0.00 \mathrm{E}+00$

$0.00 \mathrm{E}+00 \quad 0.00 \mathrm{E}+00 \quad 0.00 \mathrm{E}+00$

$0.00 \mathrm{E}+00 \quad 0.00 \mathrm{E}+00 \quad 0.00 \mathrm{E}+00$

$0.00 \mathrm{E}+00 \quad 0.00 \mathrm{E}+00 \quad 0.00 \mathrm{E}+00$

$0.00 \mathrm{E}+00 \quad 0.00 \mathrm{E}+00 \quad 0.00 \mathrm{E}+00$

$0.00 \mathrm{E}+00 \quad 0.00 \mathrm{E}+00 \quad 0.00 \mathrm{E}+00$

$0.00 \mathrm{E}+00 \quad 0.00 \mathrm{E}+00 \quad 0.00 \mathrm{E}+00$

$0.00 \mathrm{E}+00 \quad 0.00 \mathrm{E}+00 \quad 0.00 \mathrm{E}+00$

$0.00 \mathrm{E}+00 \quad 0.00 \mathrm{E}+00 \quad 0.00 \mathrm{E}+00$

$0.00 \mathrm{E}+00 \quad 0.00 \mathrm{E}+00 \quad 0.00 \mathrm{E}+00$

$0.00 \mathrm{E}+00 \quad 0.00 \mathrm{E}+00 \quad 0.00 \mathrm{E}+00$

$0.00 \mathrm{E}+00 \quad 0.00 \mathrm{E}+00 \quad 0.00 \mathrm{E}+00$

$0.00 \mathrm{E}+00 \quad 0.00 \mathrm{E}+00 \quad 0.00 \mathrm{E}+00$

$0.00 \mathrm{E}+00 \quad 0.00 \mathrm{E}+00 \quad 0.00 \mathrm{E}+00$

$0.00 \mathrm{E}+00 \quad 0.00 \mathrm{E}+00 \quad 0.00 \mathrm{E}+00$ 
RESRAD-OFFSITE, Version 2.5

Probabilistic Dose and Risk Report

Title : Offsite Resident Farmer Deterministic Run

File : RF TC99 DOESG FWD-FV2.ROF

Retition

Statistics and Cumulative distribution function of Peak Risk from All Pathways

\begin{tabular}{ccccc} 
Repetition $=$ & 1 & 2 & 3 \\
\cline { 5 - 5 } Mean & $3.21 \mathrm{E}-05$ & $3.21 \mathrm{E}-05$ & $3.21 \mathrm{E}-05$ \\
Std. Dev. & $1.89 \mathrm{E}-05$ & $1.89 \mathrm{E}-05$ & $1.89 \mathrm{E}-05$ \\
Minimum & $3.85 \mathrm{E}-06$ & $3.85 \mathrm{E}-06$ & $3.85 \mathrm{E}-06$ \\
Maximum & $1.46 \mathrm{E}-04$ & $1.46 \mathrm{E}-04$ & $1.46 \mathrm{E}-04$
\end{tabular}

Percentile

0.010

$6.15 \mathrm{E}-06 \quad 6.15 \mathrm{E}-06 \quad 6.15 \mathrm{E}-06$

0.025

7.22E-06 7.22E-06 7.22E-06

0.050

9.22E-06 9.22E-06 9.22E-06

0.075

$1.03 E-05 \quad 1.03 E-05 \quad 1.03 E-05$

0.100

$1.17 \mathrm{E}-05 \quad 1.17 \mathrm{E}-05 \quad 1.17 \mathrm{E}-05$

0.125

$1.27 \mathrm{E}-05 \quad 1.27 \mathrm{E}-05 \quad 1.27 \mathrm{E}-05$

0.150

$1.36 \mathrm{E}-05 \quad 1.36 \mathrm{E}-05 \quad 1.36 \mathrm{E}-05$

0.175

$1.48 \mathrm{E}-05 \quad 1.48 \mathrm{E}-05 \quad 1.48 \mathrm{E}-05$

0.200

$1.57 \mathrm{E}-05 \quad 1.57 \mathrm{E}-05 \quad 1.57 \mathrm{E}-05$

0.225

$1.69 \mathrm{E}-05 \quad 1.69 \mathrm{E}-05 \quad 1.69 \mathrm{E}-05$

0.250

$1.77 \mathrm{E}-05$

$1.77 \mathrm{E}-05 \quad 1.77 \mathrm{E}-05$

$1.87 \mathrm{E}-05 \quad 1.87 \mathrm{E}-05 \quad 1.87 \mathrm{E}-05$

0.300

$1.97 \mathrm{E}-05 \quad 1.97 \mathrm{E}-05 \quad 1.97 \mathrm{E}-05$

$2.08 E-05 \quad 2.08 E-05 \quad 2.08 E-05$

$\begin{array}{lll}2.20 \mathrm{E}-05 & 2.20 \mathrm{E}-05 & 2.20 \mathrm{E}-05\end{array}$

$2.32 E-05 \quad 2.32 E-05 \quad 2.32 E-05$

$2.40 E-05 \quad 2.40 E-05 \quad 2.40 E-05$

$2.51 \mathrm{E}-05 \quad 2.51 \mathrm{E}-05 \quad 2.51 \mathrm{E}-05$

$2.61 E-05 \quad 2.61 E-05 \quad 2.61 E-05$

$2.73 E-05 \quad 2.73 E-05 \quad 2.73 E-05$

$2.85 \mathrm{E}-05 \quad 2.85 \mathrm{E}-05 \quad 2.85 \mathrm{E}-05$

$2.98 \mathrm{E}-05 \quad 2.98 \mathrm{E}-05 \quad 2.99 \mathrm{E}-05$

$3.08 \mathrm{E}-05 \quad 3.08 \mathrm{E}-05 \quad 3.09 \mathrm{E}-05$

3.20E-05 3.20E-05 3.20E-05

3.33E-05 3.33E-05 3.33E-05

$3.47 \mathrm{E}-05 \quad 3.46 \mathrm{E}-05 \quad 3.47 \mathrm{E}-05$

$3.59 \mathrm{E}-05 \quad 3.59 \mathrm{E}-05 \quad 3.59 \mathrm{E}-05$

$3.71 \mathrm{E}-05 \quad 3.71 \mathrm{E}-05 \quad 3.71 \mathrm{E}-05$

$3.91 \mathrm{E}-05 \quad 3.91 \mathrm{E}-05 \quad 3.91 \mathrm{E}-05$

4.03E-05 4.03E-05 4.03E-05

4.26E-05 4.25E-05 4.26E-05

4. 42E-05 4.42E-05 4.42E-05

4.61E-05 4.61E-05 4.61E-05

4.82E-05 4.82E-05 4.83E-05

$5.07 \mathrm{E}-05 \quad 5.07 \mathrm{E}-05 \quad 5.08 \mathrm{E}-05$

$5.37 \mathrm{E}-05 \quad 5.37 \mathrm{E}-05 \quad 5.38 \mathrm{E}-05$

$5.79 \mathrm{E}-05 \quad 5.79 \mathrm{E}-05 \quad 5.79 \mathrm{E}-05$

$6.28 \mathrm{E}-05 \quad 6.28 \mathrm{E}-05 \quad 6.28 \mathrm{E}-05$

$6.82 \mathrm{E}-05 \quad 6.82 \mathrm{E}-05 \quad 6.82 \mathrm{E}-05$

$7.82 \mathrm{E}-05 \quad 7.82 \mathrm{E}-05 \quad 7.82 \mathrm{E}-05$

$8.82 \mathrm{E}-05 \quad 8.82 \mathrm{E}-05 \quad 8.82 \mathrm{E}-05$ 
RESRAD-OFFSITE, Version 2.5

Probabilistic Dose and Risk Report

Title : Offsite Resident Farmer Deterministic Run

File : RF TC99 DOESG FWD-FV2.ROF

Mean

Std. Dev.

Minimum

Maximum

Percentile

0.010

0.025

0.050

0.075

0.100

0.125

0.150

0.175

0.200

0.225

0.250

0.275

0.300

0.325

0.350

0.375

0.400

0.425

0.450

0.475

0.500

0.525

0.550

0.575

0.600

0.625

0.650

0.675

0.700

0.725

0.750

0.775

0.800

0.825

0.850

0.875

0.900

0.925

0.950

0.975

0.990

Statistics and Cumulative distribution function of Peak Risk from External Ground(Wreleas)

$\begin{array}{cccc}1 & 2 & 3 \\ 0.00 \mathrm{E}+00 & 0.00 \mathrm{E}+00 & 0.00 \mathrm{E}+00 \\ 0.00 \mathrm{E}+00 & 0.00 \mathrm{E}+00 & 0.00 \mathrm{E}+00 \\ 0.00 \mathrm{E}+00 & 0.00 \mathrm{E}+00 & 0.00 \mathrm{E}+00 \\ 0.00 \mathrm{E}+00 & 0.00 \mathrm{E}+00 & 0.00 \mathrm{E}+00\end{array}$

$0.00 \mathrm{E}+00 \quad 0.00 \mathrm{E}+00 \quad 0.00 \mathrm{E}+00$

$0.00 \mathrm{E}+00 \quad 0.00 \mathrm{E}+00 \quad 0.00 \mathrm{E}+00$

$0.00 \mathrm{E}+00 \quad 0.00 \mathrm{E}+00 \quad 0.00 \mathrm{E}+00$

$0.00 \mathrm{E}+00 \quad 0.00 \mathrm{E}+00 \quad 0.00 \mathrm{E}+00$

$0.00 \mathrm{E}+00 \quad 0.00 \mathrm{E}+00 \quad 0.00 \mathrm{E}+00$

$0.00 \mathrm{E}+00 \quad 0.00 \mathrm{E}+00 \quad 0.00 \mathrm{E}+00$

$0.00 \mathrm{E}+00 \quad 0.00 \mathrm{E}+00 \quad 0.00 \mathrm{E}+00$

$0.00 \mathrm{E}+00 \quad 0.00 \mathrm{E}+00 \quad 0.00 \mathrm{E}+00$

$0.00 \mathrm{E}+00 \quad 0.00 \mathrm{E}+00 \quad 0.00 \mathrm{E}+00$

$0.00 \mathrm{E}+00 \quad 0.00 \mathrm{E}+00 \quad 0.00 \mathrm{E}+00$

$0.00 \mathrm{E}+00 \quad 0.00 \mathrm{E}+00 \quad 0.00 \mathrm{E}+00$

$0.00 \mathrm{E}+00 \quad 0.00 \mathrm{E}+00 \quad 0.00 \mathrm{E}+00$

$0.00 \mathrm{E}+00 \quad 0.00 \mathrm{E}+00 \quad 0.00 \mathrm{E}+00$

$0.00 \mathrm{E}+00 \quad 0.00 \mathrm{E}+00 \quad 0.00 \mathrm{E}+00$

$0.00 \mathrm{E}+00 \quad 0.00 \mathrm{E}+00 \quad 0.00 \mathrm{E}+00$

$0.00 \mathrm{E}+00 \quad 0.00 \mathrm{E}+00 \quad 0.00 \mathrm{E}+00$

$0.00 \mathrm{E}+00 \quad 0.00 \mathrm{E}+00 \quad 0.00 \mathrm{E}+00$

$0.00 \mathrm{E}+00 \quad 0.00 \mathrm{E}+00 \quad 0.00 \mathrm{E}+00$

$0.00 \mathrm{E}+00 \quad 0.00 \mathrm{E}+00 \quad 0.00 \mathrm{E}+00$

$0.00 \mathrm{E}+00 \quad 0.00 \mathrm{E}+00 \quad 0.00 \mathrm{E}+00$

$0.00 \mathrm{E}+00 \quad 0.00 \mathrm{E}+00 \quad 0.00 \mathrm{E}+00$

$0.00 \mathrm{E}+00 \quad 0.00 \mathrm{E}+00 \quad 0.00 \mathrm{E}+00$

$0.00 \mathrm{E}+00 \quad 0.00 \mathrm{E}+00 \quad 0.00 \mathrm{E}+00$

$0.00 \mathrm{E}+00 \quad 0.00 \mathrm{E}+00 \quad 0.00 \mathrm{E}+00$

$0.00 \mathrm{E}+00 \quad 0.00 \mathrm{E}+00 \quad 0.00 \mathrm{E}+00$

$0.00 \mathrm{E}+00 \quad 0.00 \mathrm{E}+00 \quad 0.00 \mathrm{E}+00$

$0.00 \mathrm{E}+00 \quad 0.00 \mathrm{E}+00 \quad 0.00 \mathrm{E}+00$

$0.00 \mathrm{E}+00 \quad 0.00 \mathrm{E}+00 \quad 0.00 \mathrm{E}+00$

$0.00 \mathrm{E}+00 \quad 0.00 \mathrm{E}+00 \quad 0.00 \mathrm{E}+00$

$0.00 \mathrm{E}+00 \quad 0.00 \mathrm{E}+00 \quad 0.00 \mathrm{E}+00$

$0.00 \mathrm{E}+00 \quad 0.00 \mathrm{E}+00 \quad 0.00 \mathrm{E}+00$

$0.00 \mathrm{E}+00 \quad 0.00 \mathrm{E}+00 \quad 0.00 \mathrm{E}+00$

$0.00 \mathrm{E}+00 \quad 0.00 \mathrm{E}+00 \quad 0.00 \mathrm{E}+00$

$0.00 \mathrm{E}+00 \quad 0.00 \mathrm{E}+00 \quad 0.00 \mathrm{E}+00$

$0.00 \mathrm{E}+00 \quad 0.00 \mathrm{E}+00 \quad 0.00 \mathrm{E}+00$

$0.00 \mathrm{E}+00 \quad 0.00 \mathrm{E}+00 \quad 0.00 \mathrm{E}+00$

$0.00 \mathrm{E}+00 \quad 0.00 \mathrm{E}+00 \quad 0.00 \mathrm{E}+00$

$0.00 \mathrm{E}+00 \quad 0.00 \mathrm{E}+00 \quad 0.00 \mathrm{E}+00$

$0.00 \mathrm{E}+00 \quad 0.00 \mathrm{E}+00 \quad 0.00 \mathrm{E}+00$

$0.00 \mathrm{E}+00 \quad 0.00 \mathrm{E}+00 \quad 0.00 \mathrm{E}+00$

$0.00 \mathrm{E}+00 \quad 0.00 \mathrm{E}+00 \quad 0.00 \mathrm{E}+00$ 
RESRAD-OFFSITE, Version 2.5

Probabilistic Dose and Risk Report

Title : Offsite Resident Farmer Deterministic Run

File : RF TC99 DOESG FWD-FV2.ROF

Statistics and Cumulative distribution function of Peak Risk from Fish Ingestion

$\begin{array}{ccccc}\text { Repetition }= & 1 & 2 & 3 \\ \begin{array}{c}\text { Mean } \\ \text { Std. Dev. }\end{array} & 0.00 \mathrm{E}+00 & 0.00 \mathrm{E}+00 & 0.00 \mathrm{E}+00 \\ \text { Minimum } & 0.00 \mathrm{E}+00 & 0.00 \mathrm{E}+00 & 0.00 \mathrm{E}+00 \\ \text { Maximum } & 0.00 \mathrm{E}+00 & 0.00 \mathrm{E}+00 & 0.00 \mathrm{E}+00 \\ & 0.00 \mathrm{E}+00 & 0.00 \mathrm{E}+00 & 0.00 \mathrm{E}+00\end{array}$

Percentile

$\begin{array}{llll}0.010 & 0.00 \mathrm{E}+00 & 0.00 \mathrm{E}+00 & 0.00 \mathrm{E}+00\end{array}$

$\begin{array}{llll}0.025 & 0.00 \mathrm{E}+00 & 0.00 \mathrm{E}+00 & 0.00 \mathrm{E}+00\end{array}$

$\begin{array}{lllll}0.050 & 0.00 E+00 & 0.00 E+00 & 0.00 E+00\end{array}$

$\begin{array}{llll}0.075 & 0.00 \mathrm{E}+00 & 0.00 \mathrm{E}+00 & 0.00 \mathrm{E}+00\end{array}$

$\begin{array}{llll}0.100 & 0.00 \mathrm{E}+00 & 0.00 \mathrm{E}+00 & 0.00 \mathrm{E}+00\end{array}$

$\begin{array}{llll}0.125 & 0.00 \mathrm{E}+00 & 0.00 \mathrm{E}+00 & 0.00 \mathrm{E}+00\end{array}$

$\begin{array}{llll}0.150 & 0.00 \mathrm{E}+00 & 0.00 \mathrm{E}+00 & 0.00 \mathrm{E}+00\end{array}$

$\begin{array}{llll}0.175 & 0.00 \mathrm{E}+00 & 0.00 \mathrm{E}+00 & 0.00 \mathrm{E}+00\end{array}$

$\begin{array}{llll}0.200 & 0.00 \mathrm{E}+00 & 0.00 \mathrm{E}+00 & 0.00 \mathrm{E}+00\end{array}$

$\begin{array}{llll}0.225 & 0.00 \mathrm{E}+00 & 0.00 \mathrm{E}+00 & 0.00 \mathrm{E}+00\end{array}$

$\begin{array}{llll}0.250 & 0.00 \mathrm{E}+00 & 0.00 \mathrm{E}+00 & 0.00 \mathrm{E}+00\end{array}$

$\begin{array}{llll}0.275 & 0.00 \mathrm{E}+00 & 0.00 \mathrm{E}+00 & 0.00 \mathrm{E}+00\end{array}$

$\begin{array}{lllll}0.300 & 0.00 \mathrm{E}+00 & 0.00 \mathrm{E}+00 & 0.00 \mathrm{E}+00\end{array}$

$\begin{array}{lllll}0.325 & 0.00 \mathrm{E}+00 & 0.00 \mathrm{E}+00 & 0.00 \mathrm{E}+00\end{array}$

$\begin{array}{lllll}0.350 & 0.00 \mathrm{E}+00 & 0.00 \mathrm{E}+00 & 0.00 \mathrm{E}+00\end{array}$

$\begin{array}{lllll}0.375 & 0.00 \mathrm{E}+00 & 0.00 \mathrm{E}+00 & 0.00 \mathrm{E}+00\end{array}$

$\begin{array}{lllll}0.400 & 0.00 \mathrm{E}+00 & 0.00 \mathrm{E}+00 & 0.00 \mathrm{E}+00\end{array}$

$\begin{array}{lllll}0.425 & 0.00 \mathrm{E}+00 & 0.00 \mathrm{E}+00 & 0.00 \mathrm{E}+00\end{array}$

$\begin{array}{lllll}0.450 & 0.00 \mathrm{E}+00 & 0.00 \mathrm{E}+00 & 0.00 \mathrm{E}+00\end{array}$

$\begin{array}{lllll}0.475 & 0.00 \mathrm{E}+00 & 0.00 \mathrm{E}+00 & 0.00 \mathrm{E}+00\end{array}$

$\begin{array}{lllll}0.500 & 0.00 \mathrm{E}+00 & 0.00 \mathrm{E}+00 & 0.00 \mathrm{E}+00\end{array}$

$\begin{array}{lllll}0.525 & 0.00 \mathrm{E}+00 & 0.00 \mathrm{E}+00 & 0.00 \mathrm{E}+00\end{array}$

$\begin{array}{lllll}0.550 & 0.00 \mathrm{E}+00 & 0.00 \mathrm{E}+00 & 0.00 \mathrm{E}+00\end{array}$

$\begin{array}{llll}0.575 & 0.00 \mathrm{E}+00 & 0.00 \mathrm{E}+00 & 0.00 \mathrm{E}+00\end{array}$

$\begin{array}{lllll}0.600 & 0.00 \mathrm{E}+00 & 0.00 \mathrm{E}+00 & 0.00 \mathrm{E}+00\end{array}$

$\begin{array}{lllll}0.625 & 0.00 \mathrm{E}+00 & 0.00 \mathrm{E}+00 & 0.00 \mathrm{E}+00\end{array}$

$\begin{array}{lllll}0.650 & 0.00 \mathrm{E}+00 & 0.00 \mathrm{E}+00 & 0.00 \mathrm{E}+00\end{array}$

$\begin{array}{lllll}0.675 & 0.00 \mathrm{E}+00 & 0.00 \mathrm{E}+00 & 0.00 \mathrm{E}+00\end{array}$

$\begin{array}{lllll}0.700 & 0.00 \mathrm{E}+00 & 0.00 \mathrm{E}+00 & 0.00 \mathrm{E}+00\end{array}$

$\begin{array}{lllll}0.725 & 0.00 \mathrm{E}+00 & 0.00 \mathrm{E}+00 & 0.00 \mathrm{E}+00\end{array}$

$\begin{array}{lllll}0.750 & 0.00 \mathrm{E}+00 & 0.00 \mathrm{E}+00 & 0.00 \mathrm{E}+00\end{array}$

$\begin{array}{lllll}0.775 & 0.00 \mathrm{E}+00 & 0.00 \mathrm{E}+00 & 0.00 \mathrm{E}+00\end{array}$

$\begin{array}{lllll}0.800 & 0.00 \mathrm{E}+00 & 0.00 \mathrm{E}+00 & 0.00 \mathrm{E}+00\end{array}$

$\begin{array}{lllll}0.825 & 0.00 \mathrm{E}+00 & 0.00 \mathrm{E}+00 & 0.00 \mathrm{E}+00\end{array}$

$\begin{array}{lllll}0.850 & 0.00 \mathrm{E}+00 & 0.00 \mathrm{E}+00 & 0.00 \mathrm{E}+00\end{array}$

$\begin{array}{llll}0.875 & 0.00 \mathrm{E}+00 & 0.00 \mathrm{E}+00 & 0.00 \mathrm{E}+00\end{array}$

$\begin{array}{lllll}0.900 & 0.00 \mathrm{E}+00 & 0.00 \mathrm{E}+00 & 0.00 \mathrm{E}+00\end{array}$

$\begin{array}{llll}0.925 & 0.00 \mathrm{E}+00 & 0.00 \mathrm{E}+00 & 0.00 \mathrm{E}+00\end{array}$

$\begin{array}{lllll}0.950 & 0.00 \mathrm{E}+00 & 0.00 \mathrm{E}+00 & 0.00 \mathrm{E}+00\end{array}$

$\begin{array}{lllll}0.975 & 0.00 \mathrm{E}+00 & 0.00 \mathrm{E}+00 & 0.00 \mathrm{E}+00\end{array}$

$\begin{array}{lllll}0.990 & 0.00 \mathrm{E}+00 & 0.00 \mathrm{E}+00 & 0.00 \mathrm{E}+00\end{array}$ 
RESRAD-OFFSITE, Version 2.5

Probabilistic Dose and Risk Report

Title : Offsite Resident Farmer Deterministic Run

File : RF TC99 DOESG FWD-FV2.ROF

Mean

Std. Dev.

Minimum

Maximum

Percentile

0.010

0.025

0.050

0.075

0.100

0.125

0.150

0.175

0.200

0.225

0.250

0.275

0.300

0.325

0.350

0.375

0.400

0.425

0.450

0.475

0.500

0.525

0.550

0.575

0.600

0.625

0.650

0.675

0.700

0.725

0.750

0.775

0.800

0.825

0.850

0.875

0.900

0.925

0.950

0.975

0.990

Statistics and Cumulative distribution function of Peak Risk from Radon (Waterrelease)

$\begin{array}{cccc}1 & 2 & 3 \\ 0.00 \mathrm{E}+00 & 0.00 \mathrm{E}+00 & 0.00 \mathrm{E}+00 \\ 0.00 \mathrm{E}+00 & 0.00 \mathrm{E}+00 & 0.00 \mathrm{E}+00 \\ 0.00 \mathrm{E}+00 & 0.00 \mathrm{E}+00 & 0.00 \mathrm{E}+00 \\ 0.00 \mathrm{E}+00 & 0.00 \mathrm{E}+00 & 0.00 \mathrm{E}+00\end{array}$

$0.00 \mathrm{E}+00 \quad 0.00 \mathrm{E}+00 \quad 0.00 \mathrm{E}+00$

$0.00 \mathrm{E}+00 \quad 0.00 \mathrm{E}+00 \quad 0.00 \mathrm{E}+00$

$0.00 \mathrm{E}+00 \quad 0.00 \mathrm{E}+00 \quad 0.00 \mathrm{E}+00$

$0.00 \mathrm{E}+00 \quad 0.00 \mathrm{E}+00 \quad 0.00 \mathrm{E}+00$

$0.00 \mathrm{E}+00 \quad 0.00 \mathrm{E}+00 \quad 0.00 \mathrm{E}+00$

$0.00 \mathrm{E}+00 \quad 0.00 \mathrm{E}+00 \quad 0.00 \mathrm{E}+00$

$0.00 \mathrm{E}+00 \quad 0.00 \mathrm{E}+00 \quad 0.00 \mathrm{E}+00$

$0.00 \mathrm{E}+00 \quad 0.00 \mathrm{E}+00 \quad 0.00 \mathrm{E}+00$

$0.00 \mathrm{E}+00 \quad 0.00 \mathrm{E}+00 \quad 0.00 \mathrm{E}+00$

$0.00 \mathrm{E}+00 \quad 0.00 \mathrm{E}+00 \quad 0.00 \mathrm{E}+00$

$0.00 \mathrm{E}+00 \quad 0.00 \mathrm{E}+00 \quad 0.00 \mathrm{E}+00$

$0.00 \mathrm{E}+00 \quad 0.00 \mathrm{E}+00 \quad 0.00 \mathrm{E}+00$

$0.00 \mathrm{E}+00 \quad 0.00 \mathrm{E}+00 \quad 0.00 \mathrm{E}+00$

$0.00 \mathrm{E}+00 \quad 0.00 \mathrm{E}+00 \quad 0.00 \mathrm{E}+00$

$0.00 \mathrm{E}+00 \quad 0.00 \mathrm{E}+00 \quad 0.00 \mathrm{E}+00$

$0.00 \mathrm{E}+00 \quad 0.00 \mathrm{E}+00 \quad 0.00 \mathrm{E}+00$

$0.00 \mathrm{E}+00 \quad 0.00 \mathrm{E}+00 \quad 0.00 \mathrm{E}+00$

$0.00 \mathrm{E}+00 \quad 0.00 \mathrm{E}+00 \quad 0.00 \mathrm{E}+00$

$0.00 \mathrm{E}+00 \quad 0.00 \mathrm{E}+00 \quad 0.00 \mathrm{E}+00$

$0.00 \mathrm{E}+00 \quad 0.00 \mathrm{E}+00 \quad 0.00 \mathrm{E}+00$

$0.00 \mathrm{E}+00 \quad 0.00 \mathrm{E}+00 \quad 0.00 \mathrm{E}+00$

$0.00 \mathrm{E}+00 \quad 0.00 \mathrm{E}+00 \quad 0.00 \mathrm{E}+00$

$0.00 \mathrm{E}+00 \quad 0.00 \mathrm{E}+00 \quad 0.00 \mathrm{E}+00$

$0.00 \mathrm{E}+00 \quad 0.00 \mathrm{E}+00 \quad 0.00 \mathrm{E}+00$

$0.00 \mathrm{E}+00 \quad 0.00 \mathrm{E}+00 \quad 0.00 \mathrm{E}+00$

$0.00 \mathrm{E}+00 \quad 0.00 \mathrm{E}+00 \quad 0.00 \mathrm{E}+00$

$0.00 \mathrm{E}+00 \quad 0.00 \mathrm{E}+00 \quad 0.00 \mathrm{E}+00$

$0.00 \mathrm{E}+00 \quad 0.00 \mathrm{E}+00 \quad 0.00 \mathrm{E}+00$

$0.00 \mathrm{E}+00 \quad 0.00 \mathrm{E}+00 \quad 0.00 \mathrm{E}+00$

$0.00 \mathrm{E}+00 \quad 0.00 \mathrm{E}+00 \quad 0.00 \mathrm{E}+00$

$0.00 \mathrm{E}+00 \quad 0.00 \mathrm{E}+00 \quad 0.00 \mathrm{E}+00$

$0.00 \mathrm{E}+00 \quad 0.00 \mathrm{E}+00 \quad 0.00 \mathrm{E}+00$

$0.00 \mathrm{E}+00 \quad 0.00 \mathrm{E}+00 \quad 0.00 \mathrm{E}+00$

$0.00 \mathrm{E}+00 \quad 0.00 \mathrm{E}+00 \quad 0.00 \mathrm{E}+00$

$0.00 \mathrm{E}+00 \quad 0.00 \mathrm{E}+00 \quad 0.00 \mathrm{E}+00$

$0.00 \mathrm{E}+00 \quad 0.00 \mathrm{E}+00 \quad 0.00 \mathrm{E}+00$

$0.00 \mathrm{E}+00 \quad 0.00 \mathrm{E}+00 \quad 0.00 \mathrm{E}+00$

$0.00 \mathrm{E}+00 \quad 0.00 \mathrm{E}+00 \quad 0.00 \mathrm{E}+00$

$0.00 \mathrm{E}+00 \quad 0.00 \mathrm{E}+00 \quad 0.00 \mathrm{E}+00$

$0.00 \mathrm{E}+00 \quad 0.00 \mathrm{E}+00 \quad 0.00 \mathrm{E}+00$

$0.00 \mathrm{E}+00 \quad 0.00 \mathrm{E}+00 \quad 0.00 \mathrm{E}+00$ 
RESRAD-OFFSITE, Version 2.5

Probabilistic Dose and Risk Report

Title : Offsite Resident Farmer Deterministic Run

File : RF TC99 DOESG FWD-FV2.ROF

Retition $=$

Statistics and Cumulative distribution function of Peak Risk from Plant (Waterrelease)

$\begin{array}{rlll}\text { Mean } & 1.02 \mathrm{E}-05 & 1.02 \mathrm{E}-05 & 1.02 \mathrm{E}-05 \\ \text { td. Dev. } & 6.01 \mathrm{E}-06 & 6.01 \mathrm{E}-06 & 6.01 \mathrm{E}-06 \\ \text { Minimum } & 1.22 \mathrm{E}-06 & 1.22 \mathrm{E}-06 & 1.22 \mathrm{E}-06 \\ \text { Maximum } & 4.66 \mathrm{E}-05 & 4.66 \mathrm{E}-05 & 4.66 \mathrm{E}-05\end{array}$

Percentile

$0.010 \quad 1.96 \mathrm{E}-06 \quad 1.96 \mathrm{E}-06 \quad 1.96 \mathrm{E}-06$

$0.025 \quad 2.30 \mathrm{E}-06 \quad 2.30 \mathrm{E}-06 \quad 2.30 \mathrm{E}-06$

$0.050 \quad 2.93 E-06 \quad 2.93 E-06 \quad 2.93 E-06$

$0.075 \quad 3.28 \mathrm{E}-06 \quad 3.28 \mathrm{E}-06 \quad 3.28 \mathrm{E}-06$

$0.100 \quad 3.71 \mathrm{E}-06 \quad 3.71 \mathrm{E}-06 \quad 3.71 \mathrm{E}-06$

$0.125 \quad 4.04 \mathrm{E}-06 \quad 4.03 \mathrm{E}-06 \quad 4.03 \mathrm{E}-06$

$0.150 \quad 4.32 \mathrm{E}-06 \quad 4.32 \mathrm{E}-06 \quad 4.32 \mathrm{E}-06$

$0.175 \quad 4.70 \mathrm{E}-06 \quad 4.70 \mathrm{E}-06 \quad 4.70 \mathrm{E}-06$

$0.200 \quad 4.99 \mathrm{E}-06 \quad 4.98 \mathrm{E}-06 \quad 4.98 \mathrm{E}-06$

$0.225 \quad 5.38 \mathrm{E}-06 \quad 5.37 \mathrm{E}-06 \quad 5.37 \mathrm{E}-06$
0.2506

$0.250 \quad 5.64 \mathrm{E}-06 \quad 5.64 \mathrm{E}-06 \quad 5.64 \mathrm{E}-06$

$0.275 \quad 5.95 \mathrm{E}-06 \quad 5.95 \mathrm{E}-06 \quad 5.95 \mathrm{E}-06$

$0.300 \quad 6.27 \mathrm{E}-06 \quad 6.26 \mathrm{E}-06 \quad 6.26 \mathrm{E}-06$

$0.325 \quad 6.62 \mathrm{E}-06 \quad 6.61 \mathrm{E}-06 \quad 6.61 \mathrm{E}-06$

$0.350 \quad 7.01 \mathrm{E}-06 \quad 7.01 \mathrm{E}-06 \quad 7.01 \mathrm{E}-06$

$0.375 \quad 7.38 \mathrm{E}-06 \quad 7.37 \mathrm{E}-06 \quad 7.37 \mathrm{E}-06$

$0.400 \quad 7.65 \mathrm{E}-06 \quad 7.65 \mathrm{E}-06 \quad 7.65 \mathrm{E}-06$

$0.425 \quad 8.00 \mathrm{E}-06 \quad 7.99 \mathrm{E}-06 \quad 7.99 \mathrm{E}-06$

$0.450 \quad 8.32 \mathrm{E}-06 \quad 8.31 \mathrm{E}-06 \quad 8.31 \mathrm{E}-06$

$\begin{array}{llll}0.475 & 8.70 \mathrm{E}-06 & 8.68 \mathrm{E}-06 & 8.70 \mathrm{E}-06\end{array}$

$0.500 \quad 9.09 \mathrm{E}-06 \quad 9.08 \mathrm{E}-06 \quad 9.09 \mathrm{E}-06$

$0.5259 .50 \mathrm{E}-06 \quad 9.49 \mathrm{E}-06 \quad 9.51 \mathrm{E}-06$
0.550

$0.550 \quad 9.82 \mathrm{E}-06 \quad 9.81 \mathrm{E}-06 \quad 9.83 \mathrm{E}-06$
0.575

$0.575 \quad 1.02 \mathrm{E}-05 \quad 1.02 \mathrm{E}-05 \quad 1.02 \mathrm{E}-05$

$0.600 \quad 1.06 \mathrm{E}-05 \quad 1.06 \mathrm{E}-05 \quad 1.06 \mathrm{E}-05$

$0.625 \quad 1.10 \mathrm{E}-05 \quad 1.10 \mathrm{E}-05 \quad 1.10 \mathrm{E}-05$

$0.650 \quad 1.14 \mathrm{E}-05 \quad 1.14 \mathrm{E}-05 \quad 1.14 \mathrm{E}-05$

$0.675 \quad 1.18 \mathrm{E}-05 \quad 1.18 \mathrm{E}-05 \quad 1.18 \mathrm{E}-05$

$0.700 \quad 1.24 \mathrm{E}-05 \quad 1.24 \mathrm{E}-05 \quad 1.24 \mathrm{E}-05$

$0.725 \quad 1.28 \mathrm{E}-05 \quad 1.28 \mathrm{E}-05 \quad 1.28 \mathrm{E}-05$

$0.750 \quad 1.35 \mathrm{E}-05 \quad 1.35 \mathrm{E}-05 \quad 1.35 \mathrm{E}-05$

$0.775 \quad 1.41 \mathrm{E}-05 \quad 1.41 \mathrm{E}-05 \quad 1.41 \mathrm{E}-05$

$0.800 \quad 1.47 \mathrm{E}-05 \quad 1.47 \mathrm{E}-05 \quad 1.47 \mathrm{E}-05$

$0.825 \quad 1.53 \mathrm{E}-05 \quad 1.53 \mathrm{E}-05 \quad 1.54 \mathrm{E}-05$

$0.850 \quad 1.61 \mathrm{E}-05 \quad 1.61 \mathrm{E}-05 \quad 1.62 \mathrm{E}-05$

$0.875 \quad 1.71 \mathrm{E}-05 \quad 1.71 \mathrm{E}-05 \quad 1.71 \mathrm{E}-05$

$0.900 \quad 1.84 \mathrm{E}-05 \quad 1.84 \mathrm{E}-05 \quad 1.84 \mathrm{E}-05$

$0.925 \quad 2.00 \mathrm{E}-05 \quad 2.00 \mathrm{E}-05 \quad 2.00 \mathrm{E}-05$

$0.950 \quad 2.17 \mathrm{E}-05 \quad 2.17 \mathrm{E}-05 \quad 2.17 \mathrm{E}-05$

$\begin{array}{llll}0.975 & 2.49 \mathrm{E}-05 & 2.49 \mathrm{E}-05 & 2.49 \mathrm{E}-05\end{array}$

$0.990 \quad 2.81 E-05 \quad 2.81 E-05 \quad 2.81 E-05$ 
RESRAD-OFFSITE, Version 2.5

Probabilistic Dose and Risk Report

Title : Offsite Resident Farmer Deterministic Run

File : RF TC99 DOESG FWD-FV2.ROF

epetition

Mean

Statistics and Cumulative distribution function of Peak Risk from Meat (Waterrelease)

Std. Dev.

Minimum

Maximum

\begin{tabular}{|c|c|c|}
\hline 1 & 2 & 3 \\
\hline $3.06 \mathrm{E}-08$ & $3.06 \mathrm{E}-08$ & $3.06 \mathrm{E}-08$ \\
\hline $1.80 \mathrm{E}-08$ & $1.80 \mathrm{E}-08$ & $1.80 \mathrm{E}-08$ \\
\hline $3.67 \mathrm{E}-09$ & $3.67 \mathrm{E}-09$ & $3.67 \mathrm{E}-09$ \\
\hline 1. $40 \mathrm{E}-07$ & $1.40 \mathrm{E}-07$ & $1.40 \mathrm{E}-07$ \\
\hline
\end{tabular}

Percentile

0.010

$5.87 \mathrm{E}-09 \quad 5.87 \mathrm{E}-09 \quad 5.87 \mathrm{E}-09$

0.025

$6.89 \mathrm{E}-09 \quad 6.89 \mathrm{E}-09 \quad 6.89 \mathrm{E}-09$

0.050

8.80E-09 8.80E-09 8.80E-09

0.075

$9.84 \mathrm{E}-09 \quad 9.84 \mathrm{E}-09 \quad 9.84 \mathrm{E}-09$

0.100

$1.11 \mathrm{E}-08 \quad 1.11 \mathrm{E}-08 \quad 1.11 \mathrm{E}-08$

0.125

$1.21 \mathrm{E}-08 \quad 1.21 \mathrm{E}-08 \quad 1.21 \mathrm{E}-08$

0.150

$\begin{array}{lll}1.29 \mathrm{E}-08 & 1.29 \mathrm{E}-08 & 1.29 \mathrm{E}-08\end{array}$

0.175

$1.41 \mathrm{E}-08 \quad 1.41 \mathrm{E}-08 \quad 1.41 \mathrm{E}-08$

0.200

$1.50 \mathrm{E}-08 \quad 1.49 \mathrm{E}-08 \quad 1.49 \mathrm{E}-08$

0.225

$1.61 \mathrm{E}-08 \quad 1.61 \mathrm{E}-08 \quad 1.61 \mathrm{E}-08$

0.250

$1.69 \mathrm{E}-08 \quad 1.69 \mathrm{E}-08 \quad 1.69 \mathrm{E}-08$

0.275

$1.78 \mathrm{E}-08 \quad 1.78 \mathrm{E}-08 \quad 1.78 \mathrm{E}-08$

0.300

$1.88 \mathrm{E}-08 \quad 1.88 \mathrm{E}-08 \quad 1.88 \mathrm{E}-08$

0.325

$1.98 \mathrm{E}-08 \quad 1.98 \mathrm{E}-08 \quad 1.98 \mathrm{E}-08$

0.350

$2.10 \mathrm{E}-08 \quad 2.10 \mathrm{E}-08 \quad 2.10 \mathrm{E}-08$

0.375

$2.21 \mathrm{E}-08 \quad 2.21 \mathrm{E}-08 \quad 2.21 \mathrm{E}-08$

0.400

$\begin{array}{lll}2.29 \mathrm{E}-08 & 2.29 \mathrm{E}-08 & 2.29 \mathrm{E}-08\end{array}$

0.425

$2.40 \mathrm{E}-08 \quad 2.40 \mathrm{E}-08 \quad 2.40 \mathrm{E}-08$

0.450

$2.49 \mathrm{E}-08 \quad 2.49 \mathrm{E}-08 \quad 2.49 \mathrm{E}-08$

0.475

$2.61 \mathrm{E}-08 \quad 2.60 \mathrm{E}-08 \quad 2.61 \mathrm{E}-08$

0.500

$2.72 \mathrm{E}-08 \quad 2.72 \mathrm{E}-08 \quad 2.72 \mathrm{E}-08$

$2.85 \mathrm{E}-08 \quad 2.84 \mathrm{E}-08 \quad 2.85 \mathrm{E}-08$

$2.94 \mathrm{E}-08 \quad 2.94 \mathrm{E}-08 \quad 2.94 \mathrm{E}-08$

$3.05 \mathrm{E}-08 \quad 3.05 \mathrm{E}-08 \quad 3.05 \mathrm{E}-08$

$3.18 \mathrm{E}-08 \quad 3.18 \mathrm{E}-08 \quad 3.18 \mathrm{E}-08$

$\begin{array}{lll}3.31 E-08 & 3.30 E-08 & 3.31 E-08\end{array}$

$3.43 \mathrm{E}-08 \quad 3.42 \mathrm{E}-08 \quad 3.43 \mathrm{E}-08$

$3.54 \mathrm{E}-08 \quad 3.54 \mathrm{E}-08 \quad 3.54 \mathrm{E}-08$

$3.73 \mathrm{E}-08 \quad 3.73 \mathrm{E}-08 \quad 3.73 \mathrm{E}-08$

$3.85 \mathrm{E}-08 \quad 3.85 \mathrm{E}-08 \quad 3.85 \mathrm{E}-08$

$4.06 \mathrm{E}-08 \quad 4.06 \mathrm{E}-08 \quad 4.06 \mathrm{E}-08$

4.22 E-08 4.22E-08 4.22E-08

4. $40 \mathrm{E}-08 \quad 4.40 \mathrm{E}-08 \quad 4.40 \mathrm{E}-08$

4. $60 \mathrm{E}-08 \quad 4.60 \mathrm{E}-08 \quad 4.60 \mathrm{E}-08$

$4.84 \mathrm{E}-08 \quad 4.84 \mathrm{E}-08 \quad 4.84 \mathrm{E}-08$

$5.13 \mathrm{E}-08 \quad 5.13 \mathrm{E}-08 \quad 5.13 \mathrm{E}-08$

$5.53 \mathrm{E}-08 \quad 5.53 \mathrm{E}-08 \quad 5.53 \mathrm{E}-08$

$5.99 \mathrm{E}-08 \quad 5.99 \mathrm{E}-08 \quad 5.99 \mathrm{E}-08$

$6.51 \mathrm{E}-08 \quad 6.51 \mathrm{E}-08 \quad 6.51 \mathrm{E}-08$

$\begin{array}{lll}7.47 \mathrm{E}-08 \quad 7.47 \mathrm{E}-08 \quad 7.47 \mathrm{E}-08 & 08\end{array}$

$8.42 \mathrm{E}-08 \quad 8.42 \mathrm{E}-08 \quad 8.42 \mathrm{E}-08$ 
RESRAD-OFFSITE, Version 2.5

Probabilistic Dose and Risk Report

Title : Offsite Resident Farmer Deterministic Run

File : RF TC99 DOESG FWD-FV2.ROF

Retition

Statistics and Cumulative distribution function of Peak Risk from Milk (Waterrelease)

$\begin{array}{rlll}\text { Mean } & 2.71 \mathrm{E}-06 & 2.70 \mathrm{E}-06 & 2.71 \mathrm{E}-06 \\ \text { td. Dev. } & 1.59 \mathrm{E}-06 & 1.59 \mathrm{E}-06 & 1.59 \mathrm{E}-06 \\ \text { Minimum } & 3.24 \mathrm{E}-07 & 3.24 \mathrm{E}-07 & 3.24 \mathrm{E}-07 \\ \text { Maximum } & 1.23 \mathrm{E}-05 & 1.23 \mathrm{E}-05 & 1.23 \mathrm{E}-05\end{array}$

Percentile

0.010

$5.18 \mathrm{E}-07 \quad 5.18 \mathrm{E}-07 \quad 5.18 \mathrm{E}-07$

0.025

6.09E-07 6.09E-07 6.09E-07

0.050

$7.77 \mathrm{E}-07 \quad 7.77 \mathrm{E}-07 \quad 7.77 \mathrm{E}-07$

0.075

$8.69 \mathrm{E}-07 \quad 8.69 \mathrm{E}-07 \quad 8.69 \mathrm{E}-07$

0.100

9.83E-07 9.83E-07 9.83E-07

0.125

$1.07 \mathrm{E}-06 \quad 1.07 \mathrm{E}-06 \quad 1.07 \mathrm{E}-06$

0.150

$1.14 \mathrm{E}-06 \quad 1.14 \mathrm{E}-06 \quad 1.14 \mathrm{E}-06$

0.175

1.25E-06 1.24E-06 1.24E-06

$1.32 \mathrm{E}-06 \quad 1.32 \mathrm{E}-06 \quad 1.32 \mathrm{E}-06$

$1.42 \mathrm{E}-06 \quad 1.42 \mathrm{E}-06 \quad 1.42 \mathrm{E}-06$

$1.49 \mathrm{E}-06 \quad 1.49 \mathrm{E}-06 \quad 1.49 \mathrm{E}-06$

$1.58 \mathrm{E}-06 \quad 1.58 \mathrm{E}-06 \quad 1.58 \mathrm{E}-06$

$1.66 \mathrm{E}-06 \quad 1.66 \mathrm{E}-06 \quad 1.66 \mathrm{E}-06$

$1.75 \mathrm{E}-06 \quad 1.75 \mathrm{E}-06 \quad 1.75 \mathrm{E}-06$

$1.86 \mathrm{E}-06 \quad 1.85 \mathrm{E}-06 \quad 1.85 \mathrm{E}-06$

$1.95 \mathrm{E}-06 \quad 1.95 \mathrm{E}-06 \quad 1.95 \mathrm{E}-06$

$2.03 E-06 \quad 2.02 E-06 \quad 2.02 E-06$

$2.12 \mathrm{E}-06 \quad 2.12 \mathrm{E}-06 \quad 2.12 \mathrm{E}-06$

2.20E-06 2.20E-06 2.20E-06

$\begin{array}{lll}2.30 \mathrm{E}-06 & 2.30 \mathrm{E}-06 & 2.30 \mathrm{E}-06\end{array}$

$2.40 \mathrm{E}-06 \quad 2.40 \mathrm{E}-06 \quad 2.40 \mathrm{E}-06$

$2.51 \mathrm{E}-06 \quad 2.51 \mathrm{E}-06 \quad 2.52 \mathrm{E}-06$

$2.60 \mathrm{E}-06 \quad 2.60 \mathrm{E}-06 \quad 2.60 \mathrm{E}-06$

$2.70 \mathrm{E}-06 \quad 2.70 \mathrm{E}-06 \quad 2.70 \mathrm{E}-06$

$2.81 \mathrm{E}-06 \quad 2.81 \mathrm{E}-06 \quad 2.81 \mathrm{E}-06$

2.92E-06 2.91E-06 2.92E-06

$3.03 E-06 \quad 3.02 E-06 \quad 3.03 E-06$

$3.12 \mathrm{E}-06 \quad 3.12 \mathrm{E}-06 \quad 3.12 \mathrm{E}-06$

$3.29 \mathrm{E}-06 \quad 3.29 \mathrm{E}-06 \quad 3.29 \mathrm{E}-06$

$3.40 \mathrm{E}-06 \quad 3.40 \mathrm{E}-06 \quad 3.40 \mathrm{E}-06$

$3.59 \mathrm{E}-06 \quad 3.58 \mathrm{E}-06 \quad 3.59 \mathrm{E}-06$

$3.73 E-06 \quad 3.73 E-06 \quad 3.73 E-06$

$3.88 \mathrm{E}-06 \quad 3.88 \mathrm{E}-06 \quad 3.88 \mathrm{E}-06$

$4.06 \mathrm{E}-06 \quad 4.06 \mathrm{E}-06 \quad 4.07 \mathrm{E}-06$

$4.27 \mathrm{E}-06 \quad 4.27 \mathrm{E}-06 \quad 4.28 \mathrm{E}-06$

4.53E-06 4.53E-06 4.53E-06

4.88E-06 4.88E-06 4.88E-06

$5.29 \mathrm{E}-06 \quad 5.29 \mathrm{E}-06 \quad 5.29 \mathrm{E}-06$

$5.74 \mathrm{E}-06 \quad 5.74 \mathrm{E}-06 \quad 5.74 \mathrm{E}-06$

6.59E-06 6.59E-06 6.59E-06

7.43E-06 7.43E-06 7.43E-06 
RESRAD-OFFSITE, Version 2.5

Probabilistic Dose and Risk Report

Title : Offsite Resident Farmer Deterministic Run

File : RF TC99 DOESG FWD-FV2.ROF

Mean

Std. Dev.

Minimum

Maximum

Percentile

0.010

0.025

0.050

0.075

0.100

0.125

0.150

0.175

0.200

0.225

0.250

0.275

0.300

0.325

0.350

0.375

0.400

0.425

0.450

0.475

0.500

0.525

0.550

0.575

0.600

0.625

0.650

0.675

0.700

0.725

0.750

0.775

0.800

0.825

0.850

0.875

0.900

0.925

0.950

0.975

0.990

Statistics and Cumulative distribution function of Peak Risk from Soil Ingestion(Wrelease)

$\begin{array}{cccc}1 & 2 & 3 \\ 0.00 \mathrm{E}+00 & 0.00 \mathrm{E}+00 & 0.00 \mathrm{E}+00 \\ 0.00 \mathrm{E}+00 & 0.00 \mathrm{E}+00 & 0.00 \mathrm{E}+00 \\ 0.00 \mathrm{E}+00 & 0.00 \mathrm{E}+00 & 0.00 \mathrm{E}+00 \\ 0.00 \mathrm{E}+00 & 0.00 \mathrm{E}+00 & 0.00 \mathrm{E}+00\end{array}$

$0.00 \mathrm{E}+00 \quad 0.00 \mathrm{E}+00 \quad 0.00 \mathrm{E}+00$

$0.00 \mathrm{E}+00 \quad 0.00 \mathrm{E}+00 \quad 0.00 \mathrm{E}+00$

$0.00 \mathrm{E}+00 \quad 0.00 \mathrm{E}+00 \quad 0.00 \mathrm{E}+00$

$0.00 \mathrm{E}+00 \quad 0.00 \mathrm{E}+00 \quad 0.00 \mathrm{E}+00$

$0.00 \mathrm{E}+00 \quad 0.00 \mathrm{E}+00 \quad 0.00 \mathrm{E}+00$

$0.00 \mathrm{E}+00 \quad 0.00 \mathrm{E}+00 \quad 0.00 \mathrm{E}+00$

$0.00 \mathrm{E}+00 \quad 0.00 \mathrm{E}+00 \quad 0.00 \mathrm{E}+00$

$0.00 \mathrm{E}+00 \quad 0.00 \mathrm{E}+00 \quad 0.00 \mathrm{E}+00$

$0.00 \mathrm{E}+00 \quad 0.00 \mathrm{E}+00 \quad 0.00 \mathrm{E}+00$

$0.00 \mathrm{E}+00 \quad 0.00 \mathrm{E}+00 \quad 0.00 \mathrm{E}+00$

$0.00 \mathrm{E}+00 \quad 0.00 \mathrm{E}+00 \quad 0.00 \mathrm{E}+00$

$0.00 \mathrm{E}+00 \quad 0.00 \mathrm{E}+00 \quad 0.00 \mathrm{E}+00$

$0.00 \mathrm{E}+00 \quad 0.00 \mathrm{E}+00 \quad 0.00 \mathrm{E}+00$

$0.00 \mathrm{E}+00 \quad 0.00 \mathrm{E}+00 \quad 0.00 \mathrm{E}+00$

$0.00 \mathrm{E}+00 \quad 0.00 \mathrm{E}+00 \quad 0.00 \mathrm{E}+00$

$0.00 \mathrm{E}+00 \quad 0.00 \mathrm{E}+00 \quad 0.00 \mathrm{E}+00$

$0.00 \mathrm{E}+00 \quad 0.00 \mathrm{E}+00 \quad 0.00 \mathrm{E}+00$

$0.00 \mathrm{E}+00 \quad 0.00 \mathrm{E}+00 \quad 0.00 \mathrm{E}+00$

$0.00 \mathrm{E}+00 \quad 0.00 \mathrm{E}+00 \quad 0.00 \mathrm{E}+00$

$0.00 \mathrm{E}+00 \quad 0.00 \mathrm{E}+00 \quad 0.00 \mathrm{E}+00$

$0.00 \mathrm{E}+00 \quad 0.00 \mathrm{E}+00 \quad 0.00 \mathrm{E}+00$

$0.00 \mathrm{E}+00 \quad 0.00 \mathrm{E}+00 \quad 0.00 \mathrm{E}+00$

$0.00 \mathrm{E}+00 \quad 0.00 \mathrm{E}+00 \quad 0.00 \mathrm{E}+00$

$0.00 \mathrm{E}+00 \quad 0.00 \mathrm{E}+00 \quad 0.00 \mathrm{E}+00$

$0.00 \mathrm{E}+00 \quad 0.00 \mathrm{E}+00 \quad 0.00 \mathrm{E}+00$

$0.00 \mathrm{E}+00 \quad 0.00 \mathrm{E}+00 \quad 0.00 \mathrm{E}+00$

$0.00 \mathrm{E}+00 \quad 0.00 \mathrm{E}+00 \quad 0.00 \mathrm{E}+00$

$0.00 \mathrm{E}+00 \quad 0.00 \mathrm{E}+00 \quad 0.00 \mathrm{E}+00$

$0.00 \mathrm{E}+00 \quad 0.00 \mathrm{E}+00 \quad 0.00 \mathrm{E}+00$

$0.00 \mathrm{E}+00 \quad 0.00 \mathrm{E}+00 \quad 0.00 \mathrm{E}+00$

$0.00 \mathrm{E}+00 \quad 0.00 \mathrm{E}+00 \quad 0.00 \mathrm{E}+00$

$0.00 \mathrm{E}+00 \quad 0.00 \mathrm{E}+00 \quad 0.00 \mathrm{E}+00$

$0.00 \mathrm{E}+00 \quad 0.00 \mathrm{E}+00 \quad 0.00 \mathrm{E}+00$

$0.00 \mathrm{E}+00 \quad 0.00 \mathrm{E}+00 \quad 0.00 \mathrm{E}+00$

$0.00 \mathrm{E}+00 \quad 0.00 \mathrm{E}+00 \quad 0.00 \mathrm{E}+00$

$0.00 \mathrm{E}+00 \quad 0.00 \mathrm{E}+00 \quad 0.00 \mathrm{E}+00$

$0.00 \mathrm{E}+00 \quad 0.00 \mathrm{E}+00 \quad 0.00 \mathrm{E}+00$

$0.00 \mathrm{E}+00 \quad 0.00 \mathrm{E}+00 \quad 0.00 \mathrm{E}+00$

$0.00 \mathrm{E}+00 \quad 0.00 \mathrm{E}+00 \quad 0.00 \mathrm{E}+00$

$0.00 \mathrm{E}+00 \quad 0.00 \mathrm{E}+00 \quad 0.00 \mathrm{E}+00$

$0.00 \mathrm{E}+00 \quad 0.00 \mathrm{E}+00 \quad 0.00 \mathrm{E}+00$ 
RESRAD-OFFSITE, Version 2.5

Probabilistic Dose and Risk Report

Title : Offsite Resident Farmer Deterministic Run

File : RF TC99 DOESG FWD-FV2.ROF

petition $=$

Statistics and Cumulative distribution function of Peak Risk from Water Ingestion

\begin{tabular}{ccccc} 
Repetition $=$ & 1 & 2 & 3 \\
\cline { 5 - 5 } Mean & $1.92 \mathrm{E}-05$ & $1.91 \mathrm{E}-05$ & $1.92 \mathrm{E}-05$ \\
Std. Dev. & $1.12 \mathrm{E}-05$ & $1.12 \mathrm{E}-05$ & $1.13 \mathrm{E}-05$ \\
Minimum & $2.29 \mathrm{E}-06$ & $2.29 \mathrm{E}-06$ & $2.29 \mathrm{E}-06$ \\
Maximum & $8.73 \mathrm{E}-05$ & $8.73 \mathrm{E}-05$ & $8.73 \mathrm{E}-05$
\end{tabular}

Percentile

0.010

$3.67 \mathrm{E}-06 \quad 3.67 \mathrm{E}-06 \quad 3.67 \mathrm{E}-06$

0.025

4.31E-06 4.31E-06 4.31E-06

0.050

5.50E-06 5.50E-06 5.50E-06

0.075

6.15E-06 6.15E-06 6.15E-06

0.100

$6.96 \mathrm{E}-06 \quad 6.96 \mathrm{E}-06 \quad 6.96 \mathrm{E}-06$

0.125

$7.56 \mathrm{E}-06 \quad 7.56 \mathrm{E}-06 \quad 7.56 \mathrm{E}-06$

0.150

8.09E-06 8.09E-06 8.09E-06

0.175

8.81E-06 8.80E-06 8.80E-06

9.35E-06 9.34E-06 9.34E-06

0.225

$1.01 \mathrm{E}-05 \quad 1.01 \mathrm{E}-05 \quad 1.01 \mathrm{E}-05$

0.250

$1.06 \mathrm{E}-05 \quad 1.06 \mathrm{E}-05 \quad 1.06 \mathrm{E}-05$

0.275

$1.12 \mathrm{E}-05 \quad 1.12 \mathrm{E}-05 \quad 1.12 \mathrm{E}-05$

0.300

$1.17 \mathrm{E}-05 \quad 1.17 \mathrm{E}-05 \quad 1.17 \mathrm{E}-05$

0.325

$1.24 \mathrm{E}-05 \quad 1.24 \mathrm{E}-05 \quad 1.24 \mathrm{E}-05$

0.350

$1.31 \mathrm{E}-05 \quad 1.31 \mathrm{E}-05 \quad 1.31 \mathrm{E}-05$

$1.38 \mathrm{E}-05 \quad 1.38 \mathrm{E}-05 \quad 1.38 \mathrm{E}-05$

1.43E-05 1.43E-05 1.43E-05

$1.50 \mathrm{E}-05 \quad 1.50 \mathrm{E}-05 \quad 1.50 \mathrm{E}-05$

$1.56 \mathrm{E}-05 \quad 1.56 \mathrm{E}-05 \quad 1.56 \mathrm{E}-05$

$1.63 \mathrm{E}-05 \quad 1.63 \mathrm{E}-05 \quad 1.63 \mathrm{E}-05$

$1.70 \mathrm{E}-05 \quad 1.70 \mathrm{E}-05 \quad 1.70 \mathrm{E}-05$

$1.78 \mathrm{E}-05 \quad 1.78 \mathrm{E}-05 \quad 1.78 \mathrm{E}-05$

$1.84 \mathrm{E}-05 \quad 1.84 \mathrm{E}-05 \quad 1.84 \mathrm{E}-05$

$1.91 \mathrm{E}-05 \quad 1.91 \mathrm{E}-05 \quad 1.91 \mathrm{E}-05$

$1.99 \mathrm{E}-05 \quad 1.99 \mathrm{E}-05 \quad 1.99 \mathrm{E}-05$

$2.07 \mathrm{E}-05 \quad 2.06 \mathrm{E}-05 \quad 2.07 \mathrm{E}-05$

$2.14 \mathrm{E}-05 \quad 2.14 \mathrm{E}-05 \quad 2.14 \mathrm{E}-05$

$2.21 \mathrm{E}-05 \quad 2.21 \mathrm{E}-05 \quad 2.21 \mathrm{E}-05$

2.33E-05 2.33E-05 2.33E-05

2. $41 \mathrm{E}-05 \quad 2.40 \mathrm{E}-05 \quad 2.41 \mathrm{E}-05$

$2.54 \mathrm{E}-05 \quad 2.53 \mathrm{E}-05 \quad 2.54 \mathrm{E}-05$

$2.64 \mathrm{E}-05 \quad 2.64 \mathrm{E}-05 \quad 2.64 \mathrm{E}-05$

$2.75 \mathrm{E}-05 \quad 2.75 \mathrm{E}-05 \quad 2.75 \mathrm{E}-05$

$2.87 \mathrm{E}-05 \quad 2.87 \mathrm{E}-05 \quad 2.88 \mathrm{E}-05$

$3.02 \mathrm{E}-05 \quad 3.02 \mathrm{E}-05 \quad 3.03 \mathrm{E}-05$

$3.20 \mathrm{E}-05 \quad 3.20 \mathrm{E}-05 \quad 3.21 \mathrm{E}-05$

$3.45 \mathrm{E}-05 \quad 3.45 \mathrm{E}-05 \quad 3.45 \mathrm{E}-05$

$3.74 \mathrm{E}-05 \quad 3.74 \mathrm{E}-05 \quad 3.74 \mathrm{E}-05$

$4.07 \mathrm{E}-05 \quad 4.07 \mathrm{E}-05 \quad 4.07 \mathrm{E}-05$

$4.67 \mathrm{E}-05 \quad 4.67 \mathrm{E}-05 \quad 4.67 \mathrm{E}-05$

$5.26 \mathrm{E}-05 \quad 5.26 \mathrm{E}-05 \quad 5.26 \mathrm{E}-05$ 
RESRAD-OFFSITE, Version 2.5

Probabilistic Dose and Risk Report

Title : Offsite Resident Farmer Deterministic Run

File : RF TC99 DOESG FWD-FV2.ROF

Mean

Std. Dev.

Minimum

Maximum

Percentile

0.010

0.025

0.050

0.075

0.100

0.125

0.150

0.175

0.200

0.225

0.250

0.275

0.300

0.325

0.350

0.375

0.400

0.425

0.450

0.475

0.500

0.525

0.550

0.575

0.600

0.625

0.650

0.675

0.700

0.725

0.750

0.775

0.800

0.825

0.850

0.875

0.900

0.925

0.950

0.975

0.990

Statistics and Cumulative distribution function of Peak Risk from External Ground(Cz\&Air)

$\begin{array}{cccc}1 & 2 & 3 \\ 0.00 \mathrm{E}+00 & 0.00 \mathrm{E}+00 & 0.00 \mathrm{E}+00 \\ 0.00 \mathrm{E}+00 & 0.00 \mathrm{E}+00 & 0.00 \mathrm{E}+00 \\ 0.00 \mathrm{E}+00 & 0.00 \mathrm{E}+00 & 0.00 \mathrm{E}+00 \\ 0.00 \mathrm{E}+00 & 0.00 \mathrm{E}+00 & 0.00 \mathrm{E}+00\end{array}$

$0.00 \mathrm{E}+00 \quad 0.00 \mathrm{E}+00 \quad 0.00 \mathrm{E}+00$

$0.00 \mathrm{E}+00 \quad 0.00 \mathrm{E}+00 \quad 0.00 \mathrm{E}+00$

$0.00 \mathrm{E}+00 \quad 0.00 \mathrm{E}+00 \quad 0.00 \mathrm{E}+00$

$0.00 \mathrm{E}+00 \quad 0.00 \mathrm{E}+00 \quad 0.00 \mathrm{E}+00$

$0.00 \mathrm{E}+00 \quad 0.00 \mathrm{E}+00 \quad 0.00 \mathrm{E}+00$

$0.00 \mathrm{E}+00 \quad 0.00 \mathrm{E}+00 \quad 0.00 \mathrm{E}+00$

$0.00 \mathrm{E}+00 \quad 0.00 \mathrm{E}+00 \quad 0.00 \mathrm{E}+00$

$0.00 \mathrm{E}+00 \quad 0.00 \mathrm{E}+00 \quad 0.00 \mathrm{E}+00$

$0.00 \mathrm{E}+00 \quad 0.00 \mathrm{E}+00 \quad 0.00 \mathrm{E}+00$

$0.00 \mathrm{E}+00 \quad 0.00 \mathrm{E}+00 \quad 0.00 \mathrm{E}+00$

$0.00 \mathrm{E}+00 \quad 0.00 \mathrm{E}+00 \quad 0.00 \mathrm{E}+00$

$0.00 \mathrm{E}+00 \quad 0.00 \mathrm{E}+00 \quad 0.00 \mathrm{E}+00$

$0.00 \mathrm{E}+00 \quad 0.00 \mathrm{E}+00 \quad 0.00 \mathrm{E}+00$

$0.00 \mathrm{E}+00 \quad 0.00 \mathrm{E}+00 \quad 0.00 \mathrm{E}+00$

$0.00 \mathrm{E}+00 \quad 0.00 \mathrm{E}+00 \quad 0.00 \mathrm{E}+00$

$0.00 \mathrm{E}+00 \quad 0.00 \mathrm{E}+00 \quad 0.00 \mathrm{E}+00$

$0.00 \mathrm{E}+00 \quad 0.00 \mathrm{E}+00 \quad 0.00 \mathrm{E}+00$

$0.00 \mathrm{E}+00 \quad 0.00 \mathrm{E}+00 \quad 0.00 \mathrm{E}+00$

$0.00 \mathrm{E}+00 \quad 0.00 \mathrm{E}+00 \quad 0.00 \mathrm{E}+00$

$0.00 \mathrm{E}+00 \quad 0.00 \mathrm{E}+00 \quad 0.00 \mathrm{E}+00$

$0.00 \mathrm{E}+00 \quad 0.00 \mathrm{E}+00 \quad 0.00 \mathrm{E}+00$

$0.00 \mathrm{E}+00 \quad 0.00 \mathrm{E}+00 \quad 0.00 \mathrm{E}+00$

$0.00 \mathrm{E}+00 \quad 0.00 \mathrm{E}+00 \quad 0.00 \mathrm{E}+00$

$0.00 \mathrm{E}+00 \quad 0.00 \mathrm{E}+00 \quad 0.00 \mathrm{E}+00$

$0.00 \mathrm{E}+00 \quad 0.00 \mathrm{E}+00 \quad 0.00 \mathrm{E}+00$

$0.00 \mathrm{E}+00 \quad 0.00 \mathrm{E}+00 \quad 0.00 \mathrm{E}+00$

$0.00 \mathrm{E}+00 \quad 0.00 \mathrm{E}+00 \quad 0.00 \mathrm{E}+00$

$0.00 \mathrm{E}+00 \quad 0.00 \mathrm{E}+00 \quad 0.00 \mathrm{E}+00$

$0.00 \mathrm{E}+00 \quad 0.00 \mathrm{E}+00 \quad 0.00 \mathrm{E}+00$

$0.00 \mathrm{E}+00 \quad 0.00 \mathrm{E}+00 \quad 0.00 \mathrm{E}+00$

$0.00 \mathrm{E}+00 \quad 0.00 \mathrm{E}+00 \quad 0.00 \mathrm{E}+00$

$\begin{array}{lll}0.00 \mathrm{E}+00 & 0.00 \mathrm{E}+00 \quad 0.00 \mathrm{E}+00\end{array}$

$0.00 \mathrm{E}+00 \quad 0.00 \mathrm{E}+00 \quad 0.00 \mathrm{E}+00$

$0.00 \mathrm{E}+00 \quad 0.00 \mathrm{E}+00 \quad 0.00 \mathrm{E}+00$

$0.00 \mathrm{E}+00 \quad 0.00 \mathrm{E}+00 \quad 0.00 \mathrm{E}+00$

$0.00 \mathrm{E}+00 \quad 0.00 \mathrm{E}+00 \quad 0.00 \mathrm{E}+00$

$0.00 \mathrm{E}+00 \quad 0.00 \mathrm{E}+00 \quad 0.00 \mathrm{E}+00$

$0.00 \mathrm{E}+00 \quad 0.00 \mathrm{E}+00 \quad 0.00 \mathrm{E}+00$

$0.00 \mathrm{E}+00 \quad 0.00 \mathrm{E}+00 \quad 0.00 \mathrm{E}+00$

$0.00 \mathrm{E}+00 \quad 0.00 \mathrm{E}+00 \quad 0.00 \mathrm{E}+00$

$0.00 \mathrm{E}+00 \quad 0.00 \mathrm{E}+00 \quad 0.00 \mathrm{E}+00$ 
RESRAD-OFFSITE, Version 2.5

Probabilistic Dose and Risk Report

Title : Offsite Resident Farmer Deterministic Run

File : RF TC99 DOESG FWD-FV2.ROF

Statistics and Cumulative distribution function of Peak Risk from Inhalation ExcludingRn

$\begin{array}{ccccc}\text { Repetition }= & 1 & 2 & 3 \\ \begin{array}{c}\text { Mean } \\ \text { Std. Dev. }\end{array} & 0.00 \mathrm{E}+00 & 0.00 \mathrm{E}+00 & 0.00 \mathrm{E}+00 \\ \text { Minimum } & 0.00 \mathrm{E}+00 & 0.00 \mathrm{E}+00 & 0.00 \mathrm{E}+00 \\ \text { Maximum } & 0.00 \mathrm{E}+00 & 0.00 \mathrm{E}+00 & 0.00 \mathrm{E}+00 \\ & 0.00 \mathrm{E}+00 & 0.00 \mathrm{E}+00 & 0.00 \mathrm{E}+00\end{array}$

Percentile

$\begin{array}{llll}0.010 & 0.00 \mathrm{E}+00 & 0.00 \mathrm{E}+00 & 0.00 \mathrm{E}+00\end{array}$

$\begin{array}{llll}0.025 & 0.00 \mathrm{E}+00 & 0.00 \mathrm{E}+00 & 0.00 \mathrm{E}+00\end{array}$

$\begin{array}{lllll}0.050 & 0.00 \mathrm{E}+00 & 0.00 \mathrm{E}+00 & 0.00 \mathrm{E}+00\end{array}$

$\begin{array}{llll}0.075 & 0.00 \mathrm{E}+00 & 0.00 \mathrm{E}+00 & 0.00 \mathrm{E}+00\end{array}$

$\begin{array}{llll}0.100 & 0.00 \mathrm{E}+00 & 0.00 \mathrm{E}+00 & 0.00 \mathrm{E}+00\end{array}$

$\begin{array}{llll}0.125 & 0.00 \mathrm{E}+00 & 0.00 \mathrm{E}+00 & 0.00 \mathrm{E}+00\end{array}$

$\begin{array}{llll}0.150 & 0.00 \mathrm{E}+00 & 0.00 \mathrm{E}+00 & 0.00 \mathrm{E}+00\end{array}$

$\begin{array}{llll}0.175 & 0.00 \mathrm{E}+00 & 0.00 \mathrm{E}+00 & 0.00 \mathrm{E}+00\end{array}$

$\begin{array}{lllll}0.200 & 0.00 \mathrm{E}+00 & 0.00 \mathrm{E}+00 & 0.00 \mathrm{E}+00\end{array}$

$\begin{array}{lllll}0.225 & 0.00 \mathrm{E}+00 & 0.00 \mathrm{E}+00 & 0.00 \mathrm{E}+00\end{array}$

$\begin{array}{llll}0.250 & 0.00 \mathrm{E}+00 & 0.00 \mathrm{E}+00 & 0.00 \mathrm{E}+00\end{array}$

$\begin{array}{llll}0.275 & 0.00 \mathrm{E}+00 & 0.00 \mathrm{E}+00 & 0.00 \mathrm{E}+00\end{array}$

$\begin{array}{lllll}0.300 & 0.00 \mathrm{E}+00 & 0.00 \mathrm{E}+00 & 0.00 \mathrm{E}+00\end{array}$

$\begin{array}{lllll}0.325 & 0.00 \mathrm{E}+00 & 0.00 \mathrm{E}+00 & 0.00 \mathrm{E}+00\end{array}$

$\begin{array}{lllll}0.350 & 0.00 \mathrm{E}+00 & 0.00 \mathrm{E}+00 & 0.00 \mathrm{E}+00\end{array}$

$\begin{array}{lllll}0.375 & 0.00 \mathrm{E}+00 & 0.00 \mathrm{E}+00 & 0.00 \mathrm{E}+00\end{array}$

$\begin{array}{lllll}0.400 & 0.00 \mathrm{E}+00 & 0.00 \mathrm{E}+00 & 0.00 \mathrm{E}+00\end{array}$

$\begin{array}{lllll}0.425 & 0.00 \mathrm{E}+00 & 0.00 \mathrm{E}+00 & 0.00 \mathrm{E}+00\end{array}$

$\begin{array}{lllll}0.450 & 0.00 \mathrm{E}+00 & 0.00 \mathrm{E}+00 & 0.00 \mathrm{E}+00\end{array}$

$\begin{array}{lllll}0.475 & 0.00 \mathrm{E}+00 & 0.00 \mathrm{E}+00 & 0.00 \mathrm{E}+00\end{array}$

$\begin{array}{lllll}0.500 & 0.00 \mathrm{E}+00 & 0.00 \mathrm{E}+00 & 0.00 \mathrm{E}+00\end{array}$

$\begin{array}{lllll}0.525 & 0.00 \mathrm{E}+00 & 0.00 \mathrm{E}+00 & 0.00 \mathrm{E}+00\end{array}$

$\begin{array}{lllll}0.550 & 0.00 \mathrm{E}+00 & 0.00 \mathrm{E}+00 & 0.00 \mathrm{E}+00\end{array}$

$\begin{array}{lllll}0.575 & 0.00 \mathrm{E}+00 & 0.00 \mathrm{E}+00 & 0.00 \mathrm{E}+00\end{array}$

$\begin{array}{lllll}0.600 & 0.00 \mathrm{E}+00 & 0.00 \mathrm{E}+00 & 0.00 \mathrm{E}+00\end{array}$

$\begin{array}{lllll}0.625 & 0.00 \mathrm{E}+00 & 0.00 \mathrm{E}+00 & 0.00 \mathrm{E}+00\end{array}$

$\begin{array}{lllll}0.650 & 0.00 \mathrm{E}+00 & 0.00 \mathrm{E}+00 & 0.00 \mathrm{E}+00\end{array}$

$\begin{array}{lllll}0.675 & 0.00 \mathrm{E}+00 & 0.00 \mathrm{E}+00 & 0.00 \mathrm{E}+00\end{array}$

$\begin{array}{lllll}0.700 & 0.00 \mathrm{E}+00 & 0.00 \mathrm{E}+00 & 0.00 \mathrm{E}+00\end{array}$

$\begin{array}{lllll}0.725 & 0.00 \mathrm{E}+00 & 0.00 \mathrm{E}+00 & 0.00 \mathrm{E}+00\end{array}$

$\begin{array}{lllll}0.750 & 0.00 \mathrm{E}+00 & 0.00 \mathrm{E}+00 & 0.00 \mathrm{E}+00\end{array}$

$\begin{array}{lllll}0.775 & 0.00 \mathrm{E}+00 & 0.00 \mathrm{E}+00 & 0.00 \mathrm{E}+00\end{array}$

$\begin{array}{lllll}0.800 & 0.00 \mathrm{E}+00 & 0.00 \mathrm{E}+00 & 0.00 \mathrm{E}+00\end{array}$

$\begin{array}{lllll}0.825 & 0.00 \mathrm{E}+00 & 0.00 \mathrm{E}+00 & 0.00 \mathrm{E}+00\end{array}$

$\begin{array}{lllll}0.850 & 0.00 \mathrm{E}+00 & 0.00 \mathrm{E}+00 & 0.00 \mathrm{E}+00\end{array}$

$\begin{array}{lllll}0.875 & 0.00 \mathrm{E}+00 & 0.00 \mathrm{E}+00 & 0.00 \mathrm{E}+00\end{array}$

$\begin{array}{lllll}0.900 & 0.00 \mathrm{E}+00 & 0.00 \mathrm{E}+00 & 0.00 \mathrm{E}+00\end{array}$

$\begin{array}{llll}0.925 & 0.00 \mathrm{E}+00 & 0.00 \mathrm{E}+00 & 0.00 \mathrm{E}+00\end{array}$

$\begin{array}{lllll}0.950 & 0.00 \mathrm{E}+00 & 0.00 \mathrm{E}+00 & 0.00 \mathrm{E}+00\end{array}$

$\begin{array}{lllll}0.975 & 0.00 \mathrm{E}+00 & 0.00 \mathrm{E}+00 & 0.00 \mathrm{E}+00\end{array}$

$\begin{array}{lllll}0.990 & 0.00 \mathrm{E}+00 & 0.00 \mathrm{E}+00 & 0.00 \mathrm{E}+00\end{array}$ 
RESRAD-OFFSITE, Version 2.5

Probabilistic Dose and Risk Report

Title : Offsite Resident Farmer Deterministic Run

File : RF TC99 DOESG FWD-FV2.ROF

Statistics and Cumulative distribution function of Peak Risk from Radon (CZandAir)

$\begin{array}{ccccc}\text { Repetition }= & 1 & 2 & 3 \\ \begin{array}{c}\text { Mean } \\ \text { Std. Dev. }\end{array} & 0.00 \mathrm{E}+00 & 0.00 \mathrm{E}+00 & 0.00 \mathrm{E}+00 \\ \text { Minimum } & 0.00 \mathrm{E}+00 & 0.00 \mathrm{E}+00 & 0.00 \mathrm{E}+00 \\ \text { Maximum } & 0.00 \mathrm{E}+00 & 0.00 \mathrm{E}+00 & 0.00 \mathrm{E}+00 \\ & 0.00 \mathrm{E}+00 & 0.00 \mathrm{E}+00 & 0.00 \mathrm{E}+00\end{array}$

Percentile

$\begin{array}{llll}0.010 & 0.00 \mathrm{E}+00 & 0.00 \mathrm{E}+00 & 0.00 \mathrm{E}+00\end{array}$

$\begin{array}{llll}0.025 & 0.00 \mathrm{E}+00 & 0.00 \mathrm{E}+00 & 0.00 \mathrm{E}+00\end{array}$

$\begin{array}{lllll}0.050 & 0.00 E+00 & 0.00 E+00 & 0.00 E+00\end{array}$

$\begin{array}{llll}0.075 & 0.00 \mathrm{E}+00 & 0.00 \mathrm{E}+00 & 0.00 \mathrm{E}+00\end{array}$

$\begin{array}{llll}0.100 & 0.00 \mathrm{E}+00 & 0.00 \mathrm{E}+00 & 0.00 \mathrm{E}+00\end{array}$

$\begin{array}{llll}0.125 & 0.00 \mathrm{E}+00 & 0.00 \mathrm{E}+00 & 0.00 \mathrm{E}+00\end{array}$

$\begin{array}{llll}0.150 & 0.00 \mathrm{E}+00 & 0.00 \mathrm{E}+00 & 0.00 \mathrm{E}+00\end{array}$

$\begin{array}{llll}0.175 & 0.00 \mathrm{E}+00 & 0.00 \mathrm{E}+00 & 0.00 \mathrm{E}+00\end{array}$

$\begin{array}{llll}0.200 & 0.00 \mathrm{E}+00 & 0.00 \mathrm{E}+00 & 0.00 \mathrm{E}+00\end{array}$

$\begin{array}{llll}0.225 & 0.00 \mathrm{E}+00 & 0.00 \mathrm{E}+00 & 0.00 \mathrm{E}+00\end{array}$

$\begin{array}{llll}0.250 & 0.00 \mathrm{E}+00 & 0.00 \mathrm{E}+00 & 0.00 \mathrm{E}+00\end{array}$

$\begin{array}{llll}0.275 & 0.00 \mathrm{E}+00 & 0.00 \mathrm{E}+00 & 0.00 \mathrm{E}+00\end{array}$

$\begin{array}{lllll}0.300 & 0.00 \mathrm{E}+00 & 0.00 \mathrm{E}+00 & 0.00 \mathrm{E}+00\end{array}$

$\begin{array}{lllll}0.325 & 0.00 \mathrm{E}+00 & 0.00 \mathrm{E}+00 & 0.00 \mathrm{E}+00\end{array}$

$\begin{array}{lllll}0.350 & 0.00 \mathrm{E}+00 & 0.00 \mathrm{E}+00 & 0.00 \mathrm{E}+00\end{array}$

$\begin{array}{lllll}0.375 & 0.00 \mathrm{E}+00 & 0.00 \mathrm{E}+00 & 0.00 \mathrm{E}+00\end{array}$

$\begin{array}{lllll}0.400 & 0.00 \mathrm{E}+00 & 0.00 \mathrm{E}+00 & 0.00 \mathrm{E}+00\end{array}$

$\begin{array}{lllll}0.425 & 0.00 \mathrm{E}+00 & 0.00 \mathrm{E}+00 & 0.00 \mathrm{E}+00\end{array}$

$\begin{array}{lllll}0.450 & 0.00 \mathrm{E}+00 & 0.00 \mathrm{E}+00 & 0.00 \mathrm{E}+00\end{array}$

$\begin{array}{lllll}0.475 & 0.00 \mathrm{E}+00 & 0.00 \mathrm{E}+00 & 0.00 \mathrm{E}+00\end{array}$

$\begin{array}{lllll}0.500 & 0.00 \mathrm{E}+00 & 0.00 \mathrm{E}+00 & 0.00 \mathrm{E}+00\end{array}$

$\begin{array}{lllll}0.525 & 0.00 \mathrm{E}+00 & 0.00 \mathrm{E}+00 & 0.00 \mathrm{E}+00\end{array}$

$\begin{array}{lllll}0.550 & 0.00 \mathrm{E}+00 & 0.00 \mathrm{E}+00 & 0.00 \mathrm{E}+00\end{array}$

$\begin{array}{llll}0.575 & 0.00 \mathrm{E}+00 & 0.00 \mathrm{E}+00 & 0.00 \mathrm{E}+00\end{array}$

$\begin{array}{lllll}0.600 & 0.00 \mathrm{E}+00 & 0.00 \mathrm{E}+00 & 0.00 \mathrm{E}+00\end{array}$

$\begin{array}{lllll}0.625 & 0.00 \mathrm{E}+00 & 0.00 \mathrm{E}+00 & 0.00 \mathrm{E}+00\end{array}$

$\begin{array}{lllll}0.650 & 0.00 \mathrm{E}+00 & 0.00 \mathrm{E}+00 & 0.00 \mathrm{E}+00\end{array}$

$\begin{array}{lllll}0.675 & 0.00 \mathrm{E}+00 & 0.00 \mathrm{E}+00 & 0.00 \mathrm{E}+00\end{array}$

$\begin{array}{lllll}0.700 & 0.00 \mathrm{E}+00 & 0.00 \mathrm{E}+00 & 0.00 \mathrm{E}+00\end{array}$

$\begin{array}{lllll}0.725 & 0.00 \mathrm{E}+00 & 0.00 \mathrm{E}+00 & 0.00 \mathrm{E}+00\end{array}$

$\begin{array}{lllll}0.750 & 0.00 \mathrm{E}+00 & 0.00 \mathrm{E}+00 & 0.00 \mathrm{E}+00\end{array}$

$\begin{array}{lllll}0.775 & 0.00 \mathrm{E}+00 & 0.00 \mathrm{E}+00 & 0.00 \mathrm{E}+00\end{array}$

$\begin{array}{lllll}0.800 & 0.00 \mathrm{E}+00 & 0.00 \mathrm{E}+00 & 0.00 \mathrm{E}+00\end{array}$

$\begin{array}{lllll}0.825 & 0.00 \mathrm{E}+00 & 0.00 \mathrm{E}+00 & 0.00 \mathrm{E}+00\end{array}$

$\begin{array}{lllll}0.850 & 0.00 \mathrm{E}+00 & 0.00 \mathrm{E}+00 & 0.00 \mathrm{E}+00\end{array}$

$\begin{array}{llll}0.875 & 0.00 \mathrm{E}+00 & 0.00 \mathrm{E}+00 & 0.00 \mathrm{E}+00\end{array}$

$\begin{array}{lllll}0.900 & 0.00 \mathrm{E}+00 & 0.00 \mathrm{E}+00 & 0.00 \mathrm{E}+00\end{array}$

$\begin{array}{llll}0.925 & 0.00 \mathrm{E}+00 & 0.00 \mathrm{E}+00 & 0.00 \mathrm{E}+00\end{array}$

$\begin{array}{lllll}0.950 & 0.00 \mathrm{E}+00 & 0.00 \mathrm{E}+00 & 0.00 \mathrm{E}+00\end{array}$

$\begin{array}{lllll}0.975 & 0.00 \mathrm{E}+00 & 0.00 \mathrm{E}+00 & 0.00 \mathrm{E}+00\end{array}$

$\begin{array}{lllll}0.990 & 0.00 \mathrm{E}+00 & 0.00 \mathrm{E}+00 & 0.00 \mathrm{E}+00\end{array}$ 
RESRAD-OFFSITE, Version 2.5

Probabilistic Dose and Risk Report

Title : Offsite Resident Farmer Deterministic Run

File : RF TC99 DOESG FWD-FV2.ROF

Statistics and Cumulative distribution function of Peak Risk from Plant (CzandAir)

$\begin{array}{ccccc}\text { Repetition }= & 1 & 2 & 3 \\ \text { Mean } & 0.00 \mathrm{E}+00 & 0.00 \mathrm{E}+00 & 0.00 \mathrm{E}+00 \\ \text { Std. Dev. } & 0.00 \mathrm{E}+00 & 0.00 \mathrm{E}+00 & 0.00 \mathrm{E}+00 \\ \text { Minimum } & 0.00 \mathrm{E}+00 & 0.00 \mathrm{E}+00 & 0.00 \mathrm{E}+00 \\ \text { Maximum } & 0.00 \mathrm{E}+00 & 0.00 \mathrm{E}+00 & 0.00 \mathrm{E}+00\end{array}$

Percentile

$\begin{array}{llll}0.010 & 0.00 \mathrm{E}+00 & 0.00 \mathrm{E}+00 & 0.00 \mathrm{E}+00\end{array}$

$\begin{array}{llll}0.025 & 0.00 \mathrm{E}+00 & 0.00 \mathrm{E}+00 & 0.00 \mathrm{E}+00\end{array}$

$\begin{array}{lllll}0.050 & 0.00 E+00 & 0.00 E+00 & 0.00 E+00\end{array}$

$\begin{array}{llll}0.075 & 0.00 \mathrm{E}+00 & 0.00 \mathrm{E}+00 & 0.00 \mathrm{E}+00\end{array}$

$\begin{array}{llll}0.100 & 0.00 \mathrm{E}+00 & 0.00 \mathrm{E}+00 & 0.00 \mathrm{E}+00\end{array}$

$\begin{array}{llll}0.125 & 0.00 \mathrm{E}+00 & 0.00 \mathrm{E}+00 & 0.00 \mathrm{E}+00\end{array}$

$\begin{array}{llll}0.150 & 0.00 \mathrm{E}+00 & 0.00 \mathrm{E}+00 & 0.00 \mathrm{E}+00\end{array}$

$\begin{array}{llll}0.175 & 0.00 \mathrm{E}+00 & 0.00 \mathrm{E}+00 & 0.00 \mathrm{E}+00\end{array}$

$\begin{array}{llll}0.200 & 0.00 \mathrm{E}+00 & 0.00 \mathrm{E}+00 & 0.00 \mathrm{E}+00\end{array}$

$\begin{array}{llll}0.225 & 0.00 \mathrm{E}+00 & 0.00 \mathrm{E}+00 & 0.00 \mathrm{E}+00\end{array}$

$\begin{array}{llll}0.250 & 0.00 \mathrm{E}+00 & 0.00 \mathrm{E}+00 & 0.00 \mathrm{E}+00\end{array}$

$\begin{array}{llll}0.275 & 0.00 \mathrm{E}+00 & 0.00 \mathrm{E}+00 & 0.00 \mathrm{E}+00\end{array}$

$\begin{array}{lllll}0.300 & 0.00 \mathrm{E}+00 & 0.00 \mathrm{E}+00 & 0.00 \mathrm{E}+00\end{array}$

$\begin{array}{lllll}0.325 & 0.00 \mathrm{E}+00 & 0.00 \mathrm{E}+00 & 0.00 \mathrm{E}+00\end{array}$

$\begin{array}{lllll}0.350 & 0.00 \mathrm{E}+00 & 0.00 \mathrm{E}+00 & 0.00 \mathrm{E}+00\end{array}$

$\begin{array}{lllll}0.375 & 0.00 \mathrm{E}+00 & 0.00 \mathrm{E}+00 & 0.00 \mathrm{E}+00\end{array}$

$\begin{array}{lllll}0.400 & 0.00 \mathrm{E}+00 & 0.00 \mathrm{E}+00 & 0.00 \mathrm{E}+00\end{array}$

$\begin{array}{lllll}0.425 & 0.00 \mathrm{E}+00 & 0.00 \mathrm{E}+00 & 0.00 \mathrm{E}+00\end{array}$

$\begin{array}{lllll}0.450 & 0.00 \mathrm{E}+00 & 0.00 \mathrm{E}+00 & 0.00 \mathrm{E}+00\end{array}$

$\begin{array}{lllll}0.475 & 0.00 \mathrm{E}+00 & 0.00 \mathrm{E}+00 & 0.00 \mathrm{E}+00\end{array}$

$\begin{array}{lllll}0.500 & 0.00 \mathrm{E}+00 & 0.00 \mathrm{E}+00 & 0.00 \mathrm{E}+00\end{array}$

$\begin{array}{lllll}0.525 & 0.00 \mathrm{E}+00 & 0.00 \mathrm{E}+00 & 0.00 \mathrm{E}+00\end{array}$

$\begin{array}{lllll}0.550 & 0.00 \mathrm{E}+00 & 0.00 \mathrm{E}+00 & 0.00 \mathrm{E}+00\end{array}$

$\begin{array}{llll}0.575 & 0.00 \mathrm{E}+00 & 0.00 \mathrm{E}+00 & 0.00 \mathrm{E}+00\end{array}$

$\begin{array}{lllll}0.600 & 0.00 \mathrm{E}+00 & 0.00 \mathrm{E}+00 & 0.00 \mathrm{E}+00\end{array}$

$\begin{array}{lllll}0.625 & 0.00 \mathrm{E}+00 & 0.00 \mathrm{E}+00 & 0.00 \mathrm{E}+00\end{array}$

$\begin{array}{lllll}0.650 & 0.00 \mathrm{E}+00 & 0.00 \mathrm{E}+00 & 0.00 \mathrm{E}+00\end{array}$

$\begin{array}{lllll}0.675 & 0.00 \mathrm{E}+00 & 0.00 \mathrm{E}+00 & 0.00 \mathrm{E}+00\end{array}$

$\begin{array}{lllll}0.700 & 0.00 \mathrm{E}+00 & 0.00 \mathrm{E}+00 & 0.00 \mathrm{E}+00\end{array}$

$\begin{array}{lllll}0.725 & 0.00 \mathrm{E}+00 & 0.00 \mathrm{E}+00 & 0.00 \mathrm{E}+00\end{array}$

$\begin{array}{lllll}0.750 & 0.00 \mathrm{E}+00 & 0.00 \mathrm{E}+00 & 0.00 \mathrm{E}+00\end{array}$

$\begin{array}{lllll}0.775 & 0.00 \mathrm{E}+00 & 0.00 \mathrm{E}+00 & 0.00 \mathrm{E}+00\end{array}$

$\begin{array}{lllll}0.800 & 0.00 \mathrm{E}+00 & 0.00 \mathrm{E}+00 & 0.00 \mathrm{E}+00\end{array}$

$\begin{array}{lllll}0.825 & 0.00 \mathrm{E}+00 & 0.00 \mathrm{E}+00 & 0.00 \mathrm{E}+00\end{array}$

$\begin{array}{lllll}0.850 & 0.00 \mathrm{E}+00 & 0.00 \mathrm{E}+00 & 0.00 \mathrm{E}+00\end{array}$

$\begin{array}{llll}0.875 & 0.00 \mathrm{E}+00 & 0.00 \mathrm{E}+00 & 0.00 \mathrm{E}+00\end{array}$

$\begin{array}{lllll}0.900 & 0.00 \mathrm{E}+00 & 0.00 \mathrm{E}+00 & 0.00 \mathrm{E}+00\end{array}$

$\begin{array}{llll}0.925 & 0.00 \mathrm{E}+00 & 0.00 \mathrm{E}+00 & 0.00 \mathrm{E}+00\end{array}$

$\begin{array}{lllll}0.950 & 0.00 \mathrm{E}+00 & 0.00 \mathrm{E}+00 & 0.00 \mathrm{E}+00\end{array}$

$\begin{array}{lllll}0.975 & 0.00 \mathrm{E}+00 & 0.00 \mathrm{E}+00 & 0.00 \mathrm{E}+00\end{array}$

$\begin{array}{lllll}0.990 & 0.00 \mathrm{E}+00 & 0.00 \mathrm{E}+00 & 0.00 \mathrm{E}+00\end{array}$

C- 101

DCN 5090-TR-02-2 
RESRAD-OFFSITE, Version 2.5

Probabilistic Dose and Risk Report

Title : Offsite Resident Farmer Deterministic Run

File : RF TC99 DOESG FWD-FV2.ROF

Mean

Std. Dev.

Minimum

Maximum

Percentile

0.010

0.025

0.050

0.075

0.100

0.125

0.150

0.175

0.200

0.225

0.250

0.275

0.300

0.325

0.350

0.375

0.400

0.425

0.450

0.475

0.500

0.525

0.550

0.575

0.600

0.625

0.650

0.675

0.700

0.725

0.750

0.775

0.800

0.825

0.850

0.875

0.900

0.925

0.950

0.975

0.990

Statistics and Cumulative distribution function of Peak Risk from Meat (CZandAir)

$\begin{array}{cccc}1 & 2 & 3 \\ 0.00 \mathrm{E}+00 & 0.00 \mathrm{E}+00 & 0.00 \mathrm{E}+00 \\ 0.00 \mathrm{E}+00 & 0.00 \mathrm{E}+00 & 0.00 \mathrm{E}+00 \\ 0.00 \mathrm{E}+00 & 0.00 \mathrm{E}+00 & 0.00 \mathrm{E}+00 \\ 0.00 \mathrm{E}+00 & 0.00 \mathrm{E}+00 & 0.00 \mathrm{E}+00\end{array}$

$0.00 \mathrm{E}+00 \quad 0.00 \mathrm{E}+00 \quad 0.00 \mathrm{E}+00$

$0.00 \mathrm{E}+00 \quad 0.00 \mathrm{E}+00 \quad 0.00 \mathrm{E}+00$

$0.00 \mathrm{E}+00 \quad 0.00 \mathrm{E}+00 \quad 0.00 \mathrm{E}+00$

$0.00 \mathrm{E}+00 \quad 0.00 \mathrm{E}+00 \quad 0.00 \mathrm{E}+00$

$0.00 \mathrm{E}+00 \quad 0.00 \mathrm{E}+00 \quad 0.00 \mathrm{E}+00$

$0.00 \mathrm{E}+00 \quad 0.00 \mathrm{E}+00 \quad 0.00 \mathrm{E}+00$

$0.00 \mathrm{E}+00 \quad 0.00 \mathrm{E}+00 \quad 0.00 \mathrm{E}+00$

$0.00 \mathrm{E}+00 \quad 0.00 \mathrm{E}+00 \quad 0.00 \mathrm{E}+00$

$0.00 \mathrm{E}+00 \quad 0.00 \mathrm{E}+00 \quad 0.00 \mathrm{E}+00$

$0.00 \mathrm{E}+00 \quad 0.00 \mathrm{E}+00 \quad 0.00 \mathrm{E}+00$

$0.00 \mathrm{E}+00 \quad 0.00 \mathrm{E}+00 \quad 0.00 \mathrm{E}+00$

$0.00 \mathrm{E}+00 \quad 0.00 \mathrm{E}+00 \quad 0.00 \mathrm{E}+00$

$0.00 \mathrm{E}+00 \quad 0.00 \mathrm{E}+00 \quad 0.00 \mathrm{E}+00$

$0.00 \mathrm{E}+00 \quad 0.00 \mathrm{E}+00 \quad 0.00 \mathrm{E}+00$

$0.00 \mathrm{E}+00 \quad 0.00 \mathrm{E}+00 \quad 0.00 \mathrm{E}+00$

$0.00 \mathrm{E}+00 \quad 0.00 \mathrm{E}+00 \quad 0.00 \mathrm{E}+00$

$0.00 \mathrm{E}+00 \quad 0.00 \mathrm{E}+00 \quad 0.00 \mathrm{E}+00$

$0.00 \mathrm{E}+00 \quad 0.00 \mathrm{E}+00 \quad 0.00 \mathrm{E}+00$

$0.00 \mathrm{E}+00 \quad 0.00 \mathrm{E}+00 \quad 0.00 \mathrm{E}+00$

$0.00 \mathrm{E}+00 \quad 0.00 \mathrm{E}+00 \quad 0.00 \mathrm{E}+00$

$0.00 \mathrm{E}+00 \quad 0.00 \mathrm{E}+00 \quad 0.00 \mathrm{E}+00$

$0.00 \mathrm{E}+00 \quad 0.00 \mathrm{E}+00 \quad 0.00 \mathrm{E}+00$

$0.00 \mathrm{E}+00 \quad 0.00 \mathrm{E}+00 \quad 0.00 \mathrm{E}+00$

$0.00 \mathrm{E}+00 \quad 0.00 \mathrm{E}+00 \quad 0.00 \mathrm{E}+00$

$0.00 \mathrm{E}+00 \quad 0.00 \mathrm{E}+00 \quad 0.00 \mathrm{E}+00$

$0.00 \mathrm{E}+00 \quad 0.00 \mathrm{E}+00 \quad 0.00 \mathrm{E}+00$

$0.00 \mathrm{E}+00 \quad 0.00 \mathrm{E}+00 \quad 0.00 \mathrm{E}+00$

$0.00 \mathrm{E}+00 \quad 0.00 \mathrm{E}+00 \quad 0.00 \mathrm{E}+00$

$0.00 \mathrm{E}+00 \quad 0.00 \mathrm{E}+00 \quad 0.00 \mathrm{E}+00$

$0.00 \mathrm{E}+00 \quad 0.00 \mathrm{E}+00 \quad 0.00 \mathrm{E}+00$

$0.00 \mathrm{E}+00 \quad 0.00 \mathrm{E}+00 \quad 0.00 \mathrm{E}+00$

$0.00 \mathrm{E}+00 \quad 0.00 \mathrm{E}+00 \quad 0.00 \mathrm{E}+00$

$0.00 \mathrm{E}+00 \quad 0.00 \mathrm{E}+00 \quad 0.00 \mathrm{E}+00$

$0.00 \mathrm{E}+00 \quad 0.00 \mathrm{E}+00 \quad 0.00 \mathrm{E}+00$

$0.00 \mathrm{E}+00 \quad 0.00 \mathrm{E}+00 \quad 0.00 \mathrm{E}+00$

$0.00 \mathrm{E}+00 \quad 0.00 \mathrm{E}+00 \quad 0.00 \mathrm{E}+00$

$0.00 \mathrm{E}+00 \quad 0.00 \mathrm{E}+00 \quad 0.00 \mathrm{E}+00$

$0.00 \mathrm{E}+00 \quad 0.00 \mathrm{E}+00 \quad 0.00 \mathrm{E}+00$

$0.00 \mathrm{E}+00 \quad 0.00 \mathrm{E}+00 \quad 0.00 \mathrm{E}+00$

$0.00 \mathrm{E}+00 \quad 0.00 \mathrm{E}+00 \quad 0.00 \mathrm{E}+00$

$0.00 \mathrm{E}+00 \quad 0.00 \mathrm{E}+00 \quad 0.00 \mathrm{E}+00$ 
RESRAD-OFFSITE, Version 2.5

Probabilistic Dose and Risk Report

Title : Offsite Resident Farmer Deterministic Run

File : RF TC99 DOESG FWD-FV2.ROF

Mean

Std. Dev.

Minimum

Maximum

Percentile

0.010

0.025

0.050

0.075

0.100

0.125

0.150

0.175

0.200

0.225

0.250

0.275

0.300

0.325

0.350

0.375

0.400

0.425

0.450

0.475

0.500

0.525

0.550

0.575

0.600

0.625

0.650

0.675

0.700

0.725

0.750

0.775

0.800

0.825

0.850

0.875

0.900

0.925

0.950

0.975

0.990

Statistics and Cumulative distribution function of Peak Risk from Milk (CzandAir)

$\begin{array}{cccc}1 & 2 & 3 \\ 0.00 \mathrm{E}+00 & 0.00 \mathrm{E}+00 & 0.00 \mathrm{E}+00 \\ 0.00 \mathrm{E}+00 & 0.00 \mathrm{E}+00 & 0.00 \mathrm{E}+00 \\ 0.00 \mathrm{E}+00 & 0.00 \mathrm{E}+00 & 0.00 \mathrm{E}+00 \\ 0.00 \mathrm{E}+00 & 0.00 \mathrm{E}+00 & 0.00 \mathrm{E}+00\end{array}$

$0.00 \mathrm{E}+00 \quad 0.00 \mathrm{E}+00 \quad 0.00 \mathrm{E}+00$

$0.00 \mathrm{E}+00 \quad 0.00 \mathrm{E}+00 \quad 0.00 \mathrm{E}+00$

$0.00 \mathrm{E}+00 \quad 0.00 \mathrm{E}+00 \quad 0.00 \mathrm{E}+00$

$0.00 \mathrm{E}+00 \quad 0.00 \mathrm{E}+00 \quad 0.00 \mathrm{E}+00$

$\begin{array}{lll}0.00 \mathrm{E}+00 & 0.00 \mathrm{E}+00 \quad 0.00 \mathrm{E}+00\end{array}$

$\begin{array}{lll}0.00 \mathrm{E}+00 & 0.00 \mathrm{E}+00 \quad 0.00 \mathrm{E}+00\end{array}$

$0.00 \mathrm{E}+00 \quad 0.00 \mathrm{E}+00 \quad 0.00 \mathrm{E}+00$

$0.00 \mathrm{E}+00 \quad 0.00 \mathrm{E}+00 \quad 0.00 \mathrm{E}+00$

$0.00 \mathrm{E}+00 \quad 0.00 \mathrm{E}+00 \quad 0.00 \mathrm{E}+00$

$0.00 \mathrm{E}+00 \quad 0.00 \mathrm{E}+00 \quad 0.00 \mathrm{E}+00$

$0.00 \mathrm{E}+00 \quad 0.00 \mathrm{E}+00 \quad 0.00 \mathrm{E}+00$

$0.00 \mathrm{E}+00 \quad 0.00 \mathrm{E}+00 \quad 0.00 \mathrm{E}+00$

$0.00 \mathrm{E}+00 \quad 0.00 \mathrm{E}+00 \quad 0.00 \mathrm{E}+00$

$0.00 \mathrm{E}+00 \quad 0.00 \mathrm{E}+00 \quad 0.00 \mathrm{E}+00$

$0.00 \mathrm{E}+00 \quad 0.00 \mathrm{E}+00 \quad 0.00 \mathrm{E}+00$

$0.00 \mathrm{E}+00 \quad 0.00 \mathrm{E}+00 \quad 0.00 \mathrm{E}+00$

$0.00 \mathrm{E}+00 \quad 0.00 \mathrm{E}+00 \quad 0.00 \mathrm{E}+00$

$0.00 \mathrm{E}+00 \quad 0.00 \mathrm{E}+00 \quad 0.00 \mathrm{E}+00$

$0.00 \mathrm{E}+00 \quad 0.00 \mathrm{E}+00 \quad 0.00 \mathrm{E}+00$

$0.00 \mathrm{E}+00 \quad 0.00 \mathrm{E}+00 \quad 0.00 \mathrm{E}+00$

$0.00 \mathrm{E}+00 \quad 0.00 \mathrm{E}+00 \quad 0.00 \mathrm{E}+00$

$0.00 \mathrm{E}+00 \quad 0.00 \mathrm{E}+00 \quad 0.00 \mathrm{E}+00$

$0.00 \mathrm{E}+00 \quad 0.00 \mathrm{E}+00 \quad 0.00 \mathrm{E}+00$

$0.00 \mathrm{E}+00 \quad 0.00 \mathrm{E}+00 \quad 0.00 \mathrm{E}+00$

$0.00 \mathrm{E}+00 \quad 0.00 \mathrm{E}+00 \quad 0.00 \mathrm{E}+00$

$0.00 \mathrm{E}+00 \quad 0.00 \mathrm{E}+00 \quad 0.00 \mathrm{E}+00$

$0.00 \mathrm{E}+00 \quad 0.00 \mathrm{E}+00 \quad 0.00 \mathrm{E}+00$

$0.00 \mathrm{E}+00 \quad 0.00 \mathrm{E}+00 \quad 0.00 \mathrm{E}+00$

$\begin{array}{lll}0.00 \mathrm{E}+00 \quad 0.00 \mathrm{E}+00 \quad 0.00 \mathrm{E}+00 & 0.00 \mathrm{E}+00\end{array}$

$0.00 \mathrm{E}+00 \quad 0.00 \mathrm{E}+00 \quad 0.00 \mathrm{E}+00$

$0.00 \mathrm{E}+00 \quad 0.00 \mathrm{E}+00 \quad 0.00 \mathrm{E}+00$

$0.00 \mathrm{E}+00 \quad 0.00 \mathrm{E}+00 \quad 0.00 \mathrm{E}+00$

$0.00 \mathrm{E}+00 \quad 0.00 \mathrm{E}+00 \quad 0.00 \mathrm{E}+00$

$0.00 \mathrm{E}+00 \quad 0.00 \mathrm{E}+00 \quad 0.00 \mathrm{E}+00$

$0.00 \mathrm{E}+00 \quad 0.00 \mathrm{E}+00 \quad 0.00 \mathrm{E}+00$

$0.00 \mathrm{E}+00 \quad 0.00 \mathrm{E}+00 \quad 0.00 \mathrm{E}+00$

$0.00 \mathrm{E}+00 \quad 0.00 \mathrm{E}+00 \quad 0.00 \mathrm{E}+00$

$0.00 \mathrm{E}+00 \quad 0.00 \mathrm{E}+00 \quad 0.00 \mathrm{E}+00$

$0.00 \mathrm{E}+00 \quad 0.00 \mathrm{E}+00 \quad 0.00 \mathrm{E}+00$

$0.00 \mathrm{E}+00 \quad 0.00 \mathrm{E}+00 \quad 0.00 \mathrm{E}+00$

$0.00 \mathrm{E}+00 \quad 0.00 \mathrm{E}+00 \quad 0.00 \mathrm{E}+00$ 
RESRAD-OFFSITE, Version 2.5

Probabilistic Dose and Risk Report

Title : Offsite Resident Farmer Deterministic Run

File : RF TC99 DOESG FWD-FV2.ROF

Mean

Std. Dev.

Minimum

Maximum

Statistics and Cumulative distribution function of Peak Risk from Soil Ingestion(CZandAir)

Percentile

0.010

0.025

0.050

0.075

0.100

0.125

0.150

0.175

0.200

0.225

0.250

0.275

0.300

0.325

0.350

0.375

0.400

0.425

0.450

0.475

0.500

0.525

0.550

0.575

0.600

0.625

0.650

0.675

0.700

0.725

0.750

0.775

0.800

0.825

0.850

0.875

0.900

0.925

0.950

0.975

0.990

$\begin{array}{cccc}1 & 2 & 3 \\ 0.00 \mathrm{E}+00 & 0.00 \mathrm{E}+00 & 0.00 \mathrm{E}+00 \\ 0.00 \mathrm{E}+00 & 0.00 \mathrm{E}+00 & 0.00 \mathrm{E}+00 \\ 0.00 \mathrm{E}+00 & 0.00 \mathrm{E}+00 & 0.00 \mathrm{E}+00 \\ 0.00 \mathrm{E}+00 & 0.00 \mathrm{E}+00 & 0.00 \mathrm{E}+00\end{array}$

$0.00 \mathrm{E}+00 \quad 0.00 \mathrm{E}+00 \quad 0.00 \mathrm{E}+00$

$0.00 \mathrm{E}+00 \quad 0.00 \mathrm{E}+00 \quad 0.00 \mathrm{E}+00$

$0.00 \mathrm{E}+00 \quad 0.00 \mathrm{E}+00 \quad 0.00 \mathrm{E}+00$

$0.00 \mathrm{E}+00 \quad 0.00 \mathrm{E}+00 \quad 0.00 \mathrm{E}+00$

$0.00 \mathrm{E}+00 \quad 0.00 \mathrm{E}+00 \quad 0.00 \mathrm{E}+00$

$0.00 \mathrm{E}+00 \quad 0.00 \mathrm{E}+00 \quad 0.00 \mathrm{E}+00$

$0.00 \mathrm{E}+00 \quad 0.00 \mathrm{E}+00 \quad 0.00 \mathrm{E}+00$

$0.00 \mathrm{E}+00 \quad 0.00 \mathrm{E}+00 \quad 0.00 \mathrm{E}+00$

$0.00 \mathrm{E}+00 \quad 0.00 \mathrm{E}+00 \quad 0.00 \mathrm{E}+00$

$0.00 \mathrm{E}+00 \quad 0.00 \mathrm{E}+00 \quad 0.00 \mathrm{E}+00$

$0.00 \mathrm{E}+00 \quad 0.00 \mathrm{E}+00 \quad 0.00 \mathrm{E}+00$

$0.00 \mathrm{E}+00 \quad 0.00 \mathrm{E}+00 \quad 0.00 \mathrm{E}+00$

$0.00 \mathrm{E}+00 \quad 0.00 \mathrm{E}+00 \quad 0.00 \mathrm{E}+00$

$0.00 \mathrm{E}+00 \quad 0.00 \mathrm{E}+00 \quad 0.00 \mathrm{E}+00$

$0.00 \mathrm{E}+00 \quad 0.00 \mathrm{E}+00 \quad 0.00 \mathrm{E}+00$

$0.00 \mathrm{E}+00 \quad 0.00 \mathrm{E}+00 \quad 0.00 \mathrm{E}+00$

$0.00 \mathrm{E}+00 \quad 0.00 \mathrm{E}+00 \quad 0.00 \mathrm{E}+00$

$0.00 \mathrm{E}+00 \quad 0.00 \mathrm{E}+00 \quad 0.00 \mathrm{E}+00$

$0.00 \mathrm{E}+00 \quad 0.00 \mathrm{E}+00 \quad 0.00 \mathrm{E}+00$

$0.00 \mathrm{E}+00 \quad 0.00 \mathrm{E}+00 \quad 0.00 \mathrm{E}+00$

$0.00 \mathrm{E}+00 \quad 0.00 \mathrm{E}+00 \quad 0.00 \mathrm{E}+00$

$0.00 \mathrm{E}+00 \quad 0.00 \mathrm{E}+00 \quad 0.00 \mathrm{E}+00$

$0.00 \mathrm{E}+00 \quad 0.00 \mathrm{E}+00 \quad 0.00 \mathrm{E}+00$

$0.00 \mathrm{E}+00 \quad 0.00 \mathrm{E}+00 \quad 0.00 \mathrm{E}+00$

$0.00 \mathrm{E}+00 \quad 0.00 \mathrm{E}+00 \quad 0.00 \mathrm{E}+00$

$0.00 \mathrm{E}+00 \quad 0.00 \mathrm{E}+00 \quad 0.00 \mathrm{E}+00$

$0.00 \mathrm{E}+00 \quad 0.00 \mathrm{E}+00 \quad 0.00 \mathrm{E}+00$

$0.00 \mathrm{E}+00 \quad 0.00 \mathrm{E}+00 \quad 0.00 \mathrm{E}+00$

$0.00 \mathrm{E}+00 \quad 0.00 \mathrm{E}+00 \quad 0.00 \mathrm{E}+00$

$0.00 \mathrm{E}+00 \quad 0.00 \mathrm{E}+00 \quad 0.00 \mathrm{E}+00$

$0.00 \mathrm{E}+00 \quad 0.00 \mathrm{E}+00 \quad 0.00 \mathrm{E}+00$

$0.00 \mathrm{E}+00 \quad 0.00 \mathrm{E}+00 \quad 0.00 \mathrm{E}+00$

$0.00 \mathrm{E}+00 \quad 0.00 \mathrm{E}+00 \quad 0.00 \mathrm{E}+00$

$0.00 \mathrm{E}+00 \quad 0.00 \mathrm{E}+00 \quad 0.00 \mathrm{E}+00$

$0.00 \mathrm{E}+00 \quad 0.00 \mathrm{E}+00 \quad 0.00 \mathrm{E}+00$

$0.00 \mathrm{E}+00 \quad 0.00 \mathrm{E}+00 \quad 0.00 \mathrm{E}+00$

$0.00 \mathrm{E}+00 \quad 0.00 \mathrm{E}+00 \quad 0.00 \mathrm{E}+00$

$0.00 \mathrm{E}+00 \quad 0.00 \mathrm{E}+00 \quad 0.00 \mathrm{E}+00$

$0.00 \mathrm{E}+00 \quad 0.00 \mathrm{E}+00 \quad 0.00 \mathrm{E}+00$

$0.00 \mathrm{E}+00 \quad 0.00 \mathrm{E}+00 \quad 0.00 \mathrm{E}+00$

$0.00 \mathrm{E}+00 \quad 0.00 \mathrm{E}+00 \quad 0.00 \mathrm{E}+00$ 
RESRAD-OFFSITE, Version 2.5

Title : Offsite Resident Farmer Deterministic Run

File : RF TC99 DOESG FWD-FV2.ROF

Time

Years

$0.00 \mathrm{E}+00$

$5.13 \mathrm{E}-01$

$1.03 \mathrm{E}+00$

$1.54 \mathrm{E}+00$

$2.05 \mathrm{E}+00$

$2.56 \mathrm{E}+00$

$3.08 \mathrm{E}+00$

$3.59 \mathrm{E}+00$

$4.10 \mathrm{E}+00$

$4.61 \mathrm{E}+00$

$5.13 \mathrm{E}+00$

$5.64 \mathrm{E}+00$

$6.15 \mathrm{E}+00$

$6.67 \mathrm{E}+00$

$7.18 \mathrm{E}+00$

7. $69 \mathrm{E}+00$

$8.20 \mathrm{E}+00$

$8.72 \mathrm{E}+00$

$9.23 \mathrm{E}+00$

$9.74 \mathrm{E}+00$

1. $03 \mathrm{E}+01$

$1.08 \mathrm{E}+01$

1. $13 \mathrm{E}+01$

1. $18 \mathrm{E}+01$

1. $23 \mathrm{E}+01$

1. $28 \mathrm{E}+01$

1. $33 \mathrm{E}+01$

1. $38 \mathrm{E}+01$

1. $44 \mathrm{E}+01$

1. $49 \mathrm{E}+01$

1. $54 \mathrm{E}+01$

1. $59 \mathrm{E}+01$

1. $64 \mathrm{E}+01$

1. $69 \mathrm{E}+01$

$1.74 \mathrm{E}+01$

$1.79 \mathrm{E}+01$

1. $85 \mathrm{E}+01$

1. $90 \mathrm{E}+01$

1. $95 \mathrm{E}+01$

2. $00 \mathrm{E}+01$

2. $05 E+01$

$2.10 \mathrm{E}+01$

$2.15 \mathrm{E}+01$

2. $20 \mathrm{E}+01$

2. $26 \mathrm{E}+01$

2. $31 E+01$
Summary of dose at graphical times, reptition 1

Dose statistics at graphical times, mrem/yr

\begin{tabular}{|c|c|c|c|c|c|c|c|}
\hline Minimum & laximum & Mean & Median & $90 \%$ & $95 \%$ & $97.5 \%$ & $9 \%$ \\
\hline $.00 \mathrm{E}+00$ & $0.00 \mathrm{E}+00$ & $0.00 \mathrm{E}+00$ & $0.00 \mathrm{E}+00$ & $\mathrm{DE}+00$ & $\mathrm{DE}+00$ & $E+00$ & +00 \\
\hline 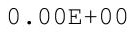 & $0.00 \mathrm{E}+00$ & $0.00 \mathrm{E}+00$ & $.00 \mathrm{E}+00$ & $0.00 \mathrm{E}+00$ & $00 \mathrm{E}+00$ & +00 & $0 \mathrm{E}+00$ \\
\hline$E+00$ & $0 \mathrm{E}+00$ & $O E+$ & 0 & $0 \mathrm{E}+00$ & $00 \mathrm{E}+00$ & +00 & $00 \mathrm{E}+00$ \\
\hline$E+00$ & $\Xi+00$ & $F+$ & 0 & 0 & 0 & 0 & $0 \mathrm{E}+00$ \\
\hline+00 & +00 & +00 & 0 & E+ & 0 & -00 & $0 \mathrm{E}+00$ \\
\hline$E+00$ & & & & 0 & 0 & 00 & $E+00$ \\
\hline ( & to & 0 & 0 & 0 & 0 & 00 & $0 E+00$ \\
\hline $.00 \mathrm{E}+00$ & $0.00 \mathrm{E}+00$ & $0 E+00$ & $.00 E+00$ & $0 \mathrm{E}+00$ & 0 & +00 & $0 \mathrm{E}+00$ \\
\hline 年 & 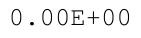 & $0.00 \mathrm{E}+00$ & $.00 \mathrm{E}+00$ & $0.00 \mathrm{E}+00$ & $0.00 \mathrm{E}+00$ & $0.00 \mathrm{E}+00$ & $.00 \mathrm{E}+00$ \\
\hline$E+00$ & $\mathrm{E}+00$ & $\mathrm{DE}+00$ & $E+00$ & $0 \mathrm{E}+00$ & 0 & -00 & +00 \\
\hline $.00 E+00$ & $0.00 \mathrm{E}+00$ & & & $E+$ & & & +00 \\
\hline $2 F+0$ & $F+0,0$ & DF & $E+00$ & 0 & 0 & 0 & +00 \\
\hline+00 & $\mathrm{~F}+\mathrm{C}-2 \cdot-2$ & 0 & 0 & 0 & 0 & +00 & $\mathrm{OE}+00$ \\
\hline $.00 E+00$ & $0.00 \mathrm{E}+00$ & $0.00 \mathrm{E}+00$ & $.00 E+00$ & $0 \mathrm{E}+00$ & OOE+ & मTO & +00 \\
\hline $.00 \mathrm{E}+00$ & 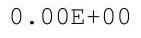 & $0.00 \mathrm{E}+00$ & $0.00 \mathrm{E}+00$ & 年 & 年 & 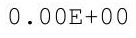 & \pm+00 \\
\hline $.00 \mathrm{E}+00$ & . & $0.00 \mathrm{E}+00$ & $.00 \mathrm{E}+00$ & 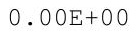 & 0 & 00 & 00 \\
\hline $.00 \mathrm{E}+00$ & $0.00 \mathrm{E}+00$ & $0.00 \mathrm{E}+00$ & & $0.00 \mathrm{E}+00$ & & $0.00 \mathrm{E}+00$ & $0 E+00$ \\
\hline $.00 \mathrm{E}+00$ & $0.00 \mathrm{E}+00$ & $0.00 \mathrm{E}+00$ & $0.00 \mathrm{E}+00$ & $0.00 \mathrm{E}+00$ & $0.00 \mathrm{E}+00$ & $0.00 \mathrm{E}+00$ & $.00 \mathrm{E}+00$ \\
\hline$E+00$ & $00 \mathrm{E}+00$ & $00 \mathrm{E}+00$ & $.00 \mathrm{E}+00$ & $\mathrm{DE}+00$ & + & $0 \mathrm{E}+00$ & $00 \mathrm{E}+00$ \\
\hline $.00 \mathrm{E}+00$ & $0.00 \mathrm{E}+00$ & $0.00 \mathrm{E}+00$ & $.00 \mathrm{E}+00$ & $0.00 \mathrm{E}+00$ & $0.00 \mathrm{E}+00$ & $0 E+00$ & $00 E+00$ \\
\hline . & . & $0.00 \mathrm{E}+00$ & $.00 \mathrm{E}+00$ & . & 0 & 100 & +00 \\
\hline . & 年 & $0.00 \mathrm{E}+00$ & & & & & +00 \\
\hline $.00 \mathrm{E}+00$ & $0.00 \mathrm{E}+00$ & $0.00 \mathrm{E}+00$ & $.00 \mathrm{E}+00$ & 然 & $0.00 \mathrm{E}+00$ & 0 & 0 \\
\hline $.00 \mathrm{E}+00$ & $0.00 \mathrm{E}+00$ & $0.00 \mathrm{E}+00$ & $0.00 \mathrm{E}+00$ & $00 \mathrm{E}+00$ & ل & $0 \mathrm{E}+00$ & $00 \mathrm{E}+00$ \\
\hline $.00 \mathrm{E}+00$ & $0.00 \mathrm{E}+00$ & $0.00 \mathrm{E}+00$ & $0.00 \mathrm{E}+00$ & $0.00 \mathrm{E}+00$ & + & $.00 \mathrm{E}+00$ & $00 \mathrm{E}+00$ \\
\hline$E+00$ & $0.00 \mathrm{E}+00$ & $.00 E+00$ & $.00 E+00$ & $00 E+00$ & + & $0 \mathrm{E}+00$ & $00 E+00$ \\
\hline $\mathrm{E}+00$ & $0.00 \mathrm{E}+00$ & $0 E+00$ & $0 \mathrm{E}+00$ & $0 \mathrm{E}+00$ & 0 & $\mathrm{E}+00$ & +00 \\
\hline 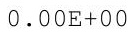 & $0.00 \mathrm{E}+00$ & $0.00 E+00$ & 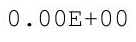 & 然 & & & \\
\hline $.00 \mathrm{E}+00$ & $0.00 \mathrm{E}+00$ & $0.00 \mathrm{E}+00$ & $0.00 \mathrm{E}+00$ & $0.00 \mathrm{E}+00$ & $0.00 \mathrm{E}+00$ & $0.00 \mathrm{E}+00$ & $0.00 \mathrm{E}+00$ \\
\hline $.00 \mathrm{E}+00$ & 0 & - & 然 & 然 & 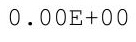 & $.00 \mathrm{E}+00$ & $.00 E+00$ \\
\hline $.00 E+00$ & $\mathrm{~F}$ & D & 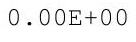 & ل & 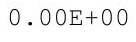 & $0.00 \mathrm{E}+00$ & OE \\
\hline$F+00$ & مी & $.00 \mathrm{E}+00$ & $.00 \mathrm{E}+00$ & 䧄 & 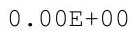 & $0 E+00$ & $0 \mathrm{E}+00$ \\
\hline $\mathrm{E}+00$ & $0.00 \mathrm{E}+00$ & $0.00 \mathrm{E}+$ & $0 \mathrm{E}+$ & $.00 E+00$ & $00 \mathrm{~F}+\mathrm{H}-\mathrm{s}$ & $00 \mathrm{E}+00$ & $00 \mathrm{E}+00$ \\
\hline $.00 E+00$ & $0.00 \mathrm{E}+00$ & $0.00 \mathrm{E}+$ & 0 & 0 & 0 & 00 & 00 \\
\hline . & $0.00 \mathrm{E}+00$ & $0.00 \mathrm{E}+00$ & $.00 \mathrm{E}+00$ & . U U一兀 & 年 & $0.00 \mathrm{E}+00$ & $0.00 \mathrm{E}+00$ \\
\hline 舟 & . & $0.00 \mathrm{E}+00$ & & . U DT & & & $0.00 \mathrm{E}+00$ \\
\hline-5 & 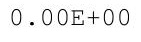 & $0.00 \mathrm{E}+0$ & $0.00 \mathrm{E}+00$ & 0 & & 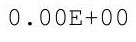 & $00 E+00$ \\
\hline OPOA & POF+ & $0.00 \mathrm{E}+00$ & $0.00 \mathrm{E}+00$ & $0.00 \mathrm{E}+00$ & $00 \mathrm{E}+00$ & $0.00 \mathrm{E}+00$ & $00 \mathrm{E}+00$ \\
\hline$F+00$ & & & 00 & 0 & 0 & 0 & 00 \\
\hline$E+00$ & 0.0 & 0 . & +00 & $E+00$ & 0 & -00 & $\mathrm{DE}+00$ \\
\hline $\mathrm{E}+00$ & 0.001 & 0. & 0 & 0 & & 00 & 00 \\
\hline $\mathrm{E}+$ & $.00 \mathrm{E}+\mathrm{C}$ & $0.00 \mathrm{E}+$ & & $0.00 \mathrm{E}+$ & & & $.00 \mathrm{E}+00$ \\
\hline 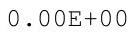 & . vo म & $0.00 \mathrm{E}+00$ & $0.00 \mathrm{E}+00$ & $0.00 \mathrm{E}+00$ & - & $0.00 \mathrm{E}+00$ & $0.00 \mathrm{E}+00$ \\
\hline . & $.00 \mathrm{~L}$ & $0.00 \mathrm{E}+$ & $0.00 \mathrm{E}+$ & $0.00 \mathrm{E}+$ & $0.00 \mathrm{E}+$ & & \\
\hline ( & & & & $.00 \mathrm{E}$ & 0 & $.00 \mathrm{E}+00$ & $00 E+00$ \\
\hline $.00 E+00$ & $00 \mathrm{E}+00$ & $0.00 E+00$ & $.00 \mathrm{E}+00$ & $.00 E+00$ & $.00 E+00$ & $\mathrm{E}+00$ & $0.00 \mathrm{E}+00$ \\
\hline
\end{tabular}


RESRAD-OFFSITE, Version 2.5

Title : Offsite Resident Farmer Deterministic Run

File : RF TC99 DOESG FWD-FV2.ROF

Summary of dose at graphical times, reptition 1 (continued)

Time

Years

2. $36 \mathrm{E}+01$

$2.41 \mathrm{E}+01$

$2.46 \mathrm{E}+01$

$2.51 \mathrm{E}+01$

$2.56 \mathrm{E}+01$

$2.61 \mathrm{E}+01$

$2.67 \mathrm{E}+01$

$2.72 \mathrm{E}+01$

$2.77 \mathrm{E}+01$

2. $82 \mathrm{E}+01$

$2.87 \mathrm{E}+01$

2. $92 \mathrm{E}+01$

2. $97 \mathrm{E}+01$

$3.02 E+01$

$3.08 \mathrm{E}+01$

$3.13 \mathrm{E}+01$

3. $18 \mathrm{E}+01$

3. $23 \mathrm{E}+01$

3. $28 \mathrm{E}+01$

3. $33 \mathrm{E}+01$

3. $38 \mathrm{E}+01$

3. $44 \mathrm{E}+01$

3. $49 \mathrm{E}+01$

$3.54 \mathrm{E}+01$

3. $59 \mathrm{E}+01$

3. $64 \mathrm{E}+01$

$3.69 \mathrm{E}+01$

$3.74 \mathrm{E}+01$

3. $79 \mathrm{E}+01$

3. $85 \mathrm{E}+01$

3. $90 \mathrm{E}+01$

$3.95 \mathrm{E}+01$

$4.00 \mathrm{E}+01$

$4.05 \mathrm{E}+01$

$4.10 \mathrm{E}+01$

$4.15 \mathrm{E}+01$

4. $20 \mathrm{E}+01$

4. $26 \mathrm{E}+01$

$4.31 E+01$

4. $36 \mathrm{E}+01$

$4.41 \mathrm{E}+01$

4. $46 \mathrm{E}+01$

4. $51 \mathrm{E}+01$

4. $56 \mathrm{E}+01$

4. $61 \mathrm{E}+01$

$4.67 \mathrm{E}+01$
Dose statistics at graphical times, mrem/yr

\begin{tabular}{|c|c|c|c|c|c|c|c|}
\hline inimum & aximum & lean & edian & & & $\%$ & $9 \%$ \\
\hline $.00 E+00$ & $0.00 \mathrm{E}+00$ & $0.00 \mathrm{E}+00$ & $0.00 \mathrm{E}+00$ & $00 \mathrm{E}+00$ & $0.00 \mathrm{E}+00$ & $0.00 \mathrm{E}+00$ & $0.00 \mathrm{E}+00$ \\
\hline $.00 \mathrm{E}+00$ & $0.00 \mathrm{E}+00$ & $.00 \mathrm{E}+00$ & $.00 \mathrm{E}+00$ & $0.00 \mathrm{E}+00$ & $0.00 \mathrm{E}+00$ & $0.00 \mathrm{E}+00$ & $00 \mathrm{E}+00$ \\
\hline $00 \mathrm{E}+00$ & $0 \mathrm{E}+00$ & $00 E+00$ & $00 E+00$ & $00 \mathrm{E}+00$ & $00 E+00$ & 00 & $0 E+00$ \\
\hline+00 & 00 & 00 & 00 & 0 & 0 & 00 & $00 \mathrm{E}+00$ \\
\hline$E+00$ & 0 & & & & & & +00 \\
\hline $00 \mathrm{E}+00$ & & & & & & & $\Xi+00$ \\
\hline$E+00$ & $E+00$ & 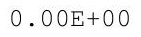 & $\mathrm{E}+00$ & $E+00$ & 0 & +00 & $E+00$ \\
\hline $.00 \mathrm{E}+00$ & $0.00 \mathrm{E}+00$ & $0 \mathrm{E}+00$ & $0 \mathrm{E}+00$ & $00 \mathrm{E}+00$ & $00 \mathrm{E}+00$ & $E+00$ & $00 \mathrm{E}+00$ \\
\hline $00 E+00$ & $00 F+0$ & $00 \mathrm{~F}+\ell-8$ & $.00 E+00$ & $0 \cap \mathrm{F}+$ & $\mathrm{O} \cap \mathrm{F}+\mathrm{r}-\mathrm{s}$ & $00 F+00$ & $00 E+00$ \\
\hline$E+00$ & $0.00 \mathrm{E}+00$ & & & & & 0 & 00 \\
\hline $.00 E+00$ & $0.00 \mathrm{E}+00$ & 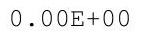 & 00 & 0 & 0 & 0 & $E+00$ \\
\hline $.00 \mathrm{E}+00$ & $0.00 \mathrm{E}+00$ & $0.00 \mathrm{E}+00$ & $0.00 \mathrm{E}+00$ & & & & $0.00 \mathrm{E}+00$ \\
\hline $.00 E+00$ & $0.00 \mathrm{E}+00$ & $0.00 \mathrm{E}+00$ & $0.00 \mathrm{E}+00$ & $0.00 \mathrm{E}+00$ & $0.00 \mathrm{E}+00$ & $E+00$ & $0.00 \mathrm{E}+00$ \\
\hline$E+00$ & $E+00$ & $E+00$ & $E+00$ & & & +00 & $00 \mathrm{E}+00$ \\
\hline $.00 E+00$ & $.00 E+00$ & $.00 E+00$ & $.00 E+00$ & $.00 \mathrm{E}+$ & 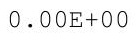 & 0 & +00 \\
\hline$E+00$ & ( & $0.00 \mathrm{E}+00$ & & $0.00 \mathrm{E}+00$ & $00 E+00$ & $E+00$ & 0 \\
\hline $0 \cap F+00$ & $F+00$ & $5+0$ & & & & -00 & 00 \\
\hline $.00 \mathrm{E}+00$ & $0.00 \mathrm{E}+00$ & $0.00 \mathrm{E}+00$ & $0.00 \mathrm{E}+00$ & $0.00 \mathrm{E}+00$ & $0.00 \mathrm{E}+00$ & $0.00 \mathrm{E}+00$ & $.00 \mathrm{E}+00$ \\
\hline $.00 \mathrm{E}+00$ & $.00 \mathrm{E}+00$ & $.00 \mathrm{E}+00$ & $0.00 \mathrm{E}+00$ & $0.00 \mathrm{E}+00$ & $0.00 \mathrm{E}+00$ & $.00 E+00$ & $.00 E+00$ \\
\hline$E+00$ & $00 E+00$ & $00 F+0=$ & $.00 E+00$ & $0 \mathrm{E}+00$ & 0 & $0 \mathrm{E}+00$ & $00 E+00$ \\
\hline 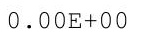 & 然 & $0.00 \mathrm{E}+00$ & $.00 E+00$ & 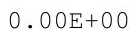 & 0 & 0 & +00 \\
\hline $.00 \mathrm{E}+00$ & . & 然 & & & & & 00 \\
\hline $.00 E+00$ & $.00 \mathrm{E}+00$ & ) & $0 E+00$ & مF+ & 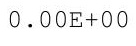 & 0 & $E+00$ \\
\hline $0 \cap F+00$ & COF+O & ) & $0.00 \mathrm{E}+00$ & $.00 \mathrm{E}+00$ & $.00 \mathrm{E}+$ & $00 \mathrm{E}+00$ & $00 E+00$ \\
\hline $00 F+00$ & 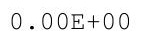 & 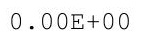 & $0.00 \mathrm{E}+00$ & $.00 \mathrm{E}+00$ & ח & $.00 E+00$ & $.00 \mathrm{E}+00$ \\
\hline$F+00$ & $0.00 \mathrm{E}+00$ & $00 E+00$ & $.00 E+00$ & $0 E+00$ & 0 & $0 E+00$ & $00 E+00$ \\
\hline & & & & & & $E+00$ & \\
\hline & & & & 0.0 & e & & +00 \\
\hline $.00 \mathrm{E}+00$ & $0.00 \mathrm{E}+00$ & $0.00 \mathrm{E}+00$ & $.00 \mathrm{E}+00$ & . & . & $0.00 \mathrm{E}+00$ & $.00 E+00$ \\
\hline $0 \mathrm{E}+00$ & $00 \mathrm{E}+00$ & $0.00 \mathrm{E}+0$ & $0.00 \mathrm{E}+00$ & $0.00 \mathrm{E}+00$ & $0.00 \mathrm{E}+\mathrm{C}$ & $0.00 \mathrm{E}+00$ & $.00 \mathrm{E}+00$ \\
\hline $00 \mathrm{E}+\mathrm{C}$ & $.00 E+00$ & & $0.00 \mathrm{E}+00$ & & & $0.00 \mathrm{E}+00$ & $.00 \mathrm{E}+00$ \\
\hline مि & $00 F+00$ & $0 \cap \cap \cap F+\cap 0$ & $00 F+00$ & $.00 E+00$ & & $0 E+00$ & $.00 E+00$ \\
\hline F & & & & & & & \\
\hline & & & & & & 00 & \\
\hline $.00 E+00$ & $0.00 \mathrm{E}+00$ & $0.00 \mathrm{E}+00$ & $0.00 \mathrm{E}+00$ & $0.00 \mathrm{E}+00$ & . & $0.00 \mathrm{E}+00$ & $.00 \mathrm{E}+00$ \\
\hline • & . & . & & & & & $0.00 \mathrm{E}+00$ \\
\hline 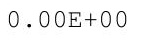 & ( & $0.00 \mathrm{E}+$ & $0.00 \mathrm{E}+$ & $0.00 \mathrm{E}+$ & $0.00 \mathrm{E}$ & $0.00 \mathrm{E}+00$ & $0.00 \mathrm{E}+00$ \\
\hline (1) & & & $0.00 \mathrm{E}+00$ & & & $0.00 \mathrm{E}+00$ & $.00 \mathrm{E}+00$ \\
\hline $0=+0$ & & $0.00 \mathrm{E}+$ & $0.00 \mathrm{E}+00$ & $00 E+00$ & 0 & $0 E+00$ & $00 E+00$ \\
\hline $.00 \mathrm{E}+00$ & $0.00 \mathrm{E}+00$ & $0.00 \mathrm{E}+$ & $0.00 \mathrm{E}$ & $0.00 \mathrm{E}$ & 0 & 00 & $0.00 \mathrm{E}+00$ \\
\hline $\mathrm{E}+00$ & $0.00 \mathrm{E}+00$ & 0.00 & 0 & 0 & & & $00 \mathrm{E}+00$ \\
\hline 年 & . & $0.00 \mathrm{E}+00$ & & $.00 \mathrm{E}+00$ & & & $.00 \mathrm{E}+00$ \\
\hline 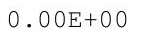 & 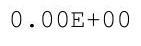 & $0.00 \mathrm{E}+00$ & $0.00 \mathrm{E}+00$ & $0.00 \mathrm{E}+00$ & $0.00 \mathrm{E}+00$ & $0.00 \mathrm{E}+00$ & $0.00 \mathrm{E}+00$ \\
\hline $0 E+00$ & $0.00 \mathrm{E}+00$ & $0.00 \mathrm{E}+00$ & $0.00 \mathrm{E}+00$ & & $0.00 \mathrm{E}+00$ & & $0.00 \mathrm{E}+00$ \\
\hline & & $0.00 \mathrm{E}+00$ & & $0.00 \mathrm{E}+00$ & $0.00 \mathrm{E}+00$ & $0.00 \mathrm{E}+00$ & $0.00 \mathrm{E}+00$ \\
\hline $.00 E+00$ & $.00 \mathrm{E}+00$ & $.00 E+00$ & $.00 \mathrm{E}+00$ & $.00 \mathrm{E}+00$ & $0.00 \mathrm{E}+00$ & $0.00 \mathrm{E}+00$ & $0.00 \mathrm{E}+00$ \\
\hline
\end{tabular}


Probabilistic Dose and Risk Report

Title : Offsite Resident Farmer Deterministic Run

File : RF TC99 DOESG FWD-FV2.ROF

Summary of dose at graphical times, reptition 1 (continued)

Time

Years

$4.72 \mathrm{E}+01$

$4.77 \mathrm{E}+01$

$4.82 \mathrm{E}+01$

$4.87 \mathrm{E}+01$

4. $92 \mathrm{E}+01$

$4.97 \mathrm{E}+01$

$5.02 \mathrm{E}+01$

$5.08 \mathrm{E}+01$

$5.13 \mathrm{E}+01$

$5.18 \mathrm{E}+01$

$5.23 E+01$

$5.28 \mathrm{E}+01$

$5.33 \mathrm{E}+01$

$5.38 \mathrm{E}+01$

$5.43 \mathrm{E}+01$

$5.49 \mathrm{E}+01$

$5.54 \mathrm{E}+01$

$5.59 \mathrm{E}+01$

$5.64 \mathrm{E}+01$

$5.69 \mathrm{E}+01$

$5.74 \mathrm{E}+01$

$5.79 \mathrm{E}+01$

$5.84 \mathrm{E}+01$

$5.90 \mathrm{E}+01$

$5.95 \mathrm{E}+01$

$6.00 \mathrm{E}+01$

$6.05 \mathrm{E}+01$

$6.10 \mathrm{E}+01$

$6.15 \mathrm{E}+01$

$6.20 \mathrm{E}+01$

$6.25 \mathrm{E}+01$

$6.31 \mathrm{E}+01$

$6.36 \mathrm{E}+01$

$6.41 \mathrm{E}+01$

$6.46 \mathrm{E}+01$

$6.51 \mathrm{E}+01$

$6.56 \mathrm{E}+01$

$6.61 \mathrm{E}+01$

$6.67 \mathrm{E}+01$

$6.72 \mathrm{E}+01$

$6.77 \mathrm{E}+01$

$6.82 \mathrm{E}+01$

$6.87 \mathrm{E}+01$

$6.92 \mathrm{E}+01$

$6.97 \mathrm{E}+01$

$7.02 \mathrm{E}+01$
Dose statistics at graphical times, mrem/yr

\begin{tabular}{|c|c|c|c|c|c|c|c|}
\hline inimum & aximum & lean & edian & & & $\%$ & $9 \%$ \\
\hline $.00 E+00$ & $0.00 \mathrm{E}+00$ & $0.00 \mathrm{E}+00$ & $0.00 \mathrm{E}+00$ & $00 \mathrm{E}+00$ & $0.00 \mathrm{E}+00$ & $0.00 \mathrm{E}+00$ & $0.00 \mathrm{E}+00$ \\
\hline $.00 \mathrm{E}+00$ & $0.00 \mathrm{E}+00$ & $.00 \mathrm{E}+00$ & $.00 \mathrm{E}+00$ & $0.00 \mathrm{E}+00$ & $0.00 \mathrm{E}+00$ & $0.00 \mathrm{E}+00$ & $00 \mathrm{E}+00$ \\
\hline $00 \mathrm{E}+00$ & $0 \mathrm{E}+00$ & $00 E+00$ & $00 E+00$ & $00 \mathrm{E}+00$ & $00 E+00$ & 00 & $0 E+00$ \\
\hline+00 & 00 & 00 & 00 & 0 & 0 & 00 & $00 \mathrm{E}+00$ \\
\hline$E+00$ & 0 & & & & & & +00 \\
\hline $00 \mathrm{E}+00$ & & & & & & & $\Xi+00$ \\
\hline$E+00$ & $E+00$ & 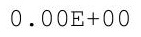 & $\mathrm{E}+00$ & $E+00$ & 0 & +00 & $E+00$ \\
\hline $.00 \mathrm{E}+00$ & $0.00 \mathrm{E}+00$ & $0 \mathrm{E}+00$ & $0 \mathrm{E}+00$ & $00 \mathrm{E}+00$ & $00 \mathrm{E}+00$ & $E+00$ & $00 \mathrm{E}+00$ \\
\hline $00 E+00$ & $00 F+0$ & $00 \mathrm{~F}+\ell-8$ & $.00 E+00$ & $0 \cap \mathrm{F}+$ & $\mathrm{O} \cap \mathrm{F}+\mathrm{r}-\mathrm{s}$ & $00 F+00$ & $00 E+00$ \\
\hline$E+00$ & $0.00 \mathrm{E}+00$ & & & & & 0 & 00 \\
\hline $.00 E+00$ & $0.00 \mathrm{E}+00$ & 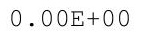 & 00 & 0 & 0 & 0 & $E+00$ \\
\hline $.00 \mathrm{E}+00$ & $0.00 \mathrm{E}+00$ & $0.00 \mathrm{E}+00$ & $0.00 \mathrm{E}+00$ & & & & $0.00 \mathrm{E}+00$ \\
\hline $.00 E+00$ & $0.00 \mathrm{E}+00$ & $0.00 \mathrm{E}+00$ & $0.00 \mathrm{E}+00$ & $0.00 \mathrm{E}+00$ & $0.00 \mathrm{E}+00$ & $E+00$ & $0.00 \mathrm{E}+00$ \\
\hline$E+00$ & $E+00$ & $E+00$ & $E+00$ & & & +00 & $00 \mathrm{E}+00$ \\
\hline $.00 E+00$ & $.00 E+00$ & $.00 E+00$ & $.00 E+00$ & $.00 \mathrm{E}+$ & 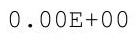 & 0 & +00 \\
\hline$E+00$ & ( & $0.00 \mathrm{E}+00$ & & $0.00 \mathrm{E}+00$ & $00 E+00$ & $E+00$ & 0 \\
\hline $0 \cap F+00$ & $F+00$ & $5+0$ & & & & -00 & 00 \\
\hline $.00 \mathrm{E}+00$ & $0.00 \mathrm{E}+00$ & $0.00 \mathrm{E}+00$ & $0.00 \mathrm{E}+00$ & $0.00 \mathrm{E}+00$ & $0.00 \mathrm{E}+00$ & $0.00 \mathrm{E}+00$ & $.00 \mathrm{E}+00$ \\
\hline $.00 \mathrm{E}+00$ & $.00 \mathrm{E}+00$ & $.00 \mathrm{E}+00$ & $0.00 \mathrm{E}+00$ & $0.00 \mathrm{E}+00$ & $0.00 \mathrm{E}+00$ & $.00 E+00$ & $.00 E+00$ \\
\hline$E+00$ & $00 E+00$ & $00 F+0=$ & $.00 E+00$ & $0 \mathrm{E}+00$ & 0 & $0 \mathrm{E}+00$ & $00 E+00$ \\
\hline 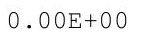 & 然 & $0.00 \mathrm{E}+00$ & $.00 E+00$ & 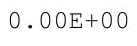 & 0 & 0 & +00 \\
\hline $.00 \mathrm{E}+00$ & . & 然 & & & & & 00 \\
\hline $.00 E+00$ & $.00 \mathrm{E}+00$ & ) & $0 E+00$ & مF+ & 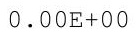 & 0 & $E+00$ \\
\hline $0 \cap F+00$ & COF+O & ) & $0.00 \mathrm{E}+00$ & $.00 \mathrm{E}+00$ & $.00 \mathrm{E}+$ & $00 \mathrm{E}+00$ & $00 E+00$ \\
\hline $00 F+00$ & 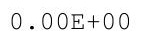 & 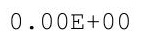 & $0.00 \mathrm{E}+00$ & $.00 \mathrm{E}+00$ & ח & $.00 E+00$ & $.00 \mathrm{E}+00$ \\
\hline$F+00$ & $0.00 \mathrm{E}+00$ & $00 E+00$ & $.00 E+00$ & $0 E+00$ & 0 & $0 E+00$ & $00 E+00$ \\
\hline & & & & & & $E+00$ & \\
\hline & & & & 0.0 & e & & +00 \\
\hline $.00 \mathrm{E}+00$ & $0.00 \mathrm{E}+00$ & $0.00 \mathrm{E}+00$ & $.00 \mathrm{E}+00$ & . & . & $0.00 \mathrm{E}+00$ & $.00 E+00$ \\
\hline $0 \mathrm{E}+00$ & $00 \mathrm{E}+00$ & $0.00 \mathrm{E}+0$ & $0.00 \mathrm{E}+00$ & $0.00 \mathrm{E}+00$ & $0.00 \mathrm{E}+\mathrm{C}$ & $0.00 \mathrm{E}+00$ & $.00 \mathrm{E}+00$ \\
\hline $00 \mathrm{E}+\mathrm{C}$ & $.00 E+00$ & & $0.00 \mathrm{E}+00$ & & & $0.00 \mathrm{E}+00$ & $.00 \mathrm{E}+00$ \\
\hline مि & $00 F+00$ & $0 \cap \cap \cap F+\cap 0$ & $00 F+00$ & $.00 E+00$ & & $0 E+00$ & $.00 E+00$ \\
\hline F & & & & & & & \\
\hline & & & & & & 00 & \\
\hline $.00 E+00$ & $0.00 \mathrm{E}+00$ & $0.00 \mathrm{E}+00$ & $0.00 \mathrm{E}+00$ & $0.00 \mathrm{E}+00$ & . & $0.00 \mathrm{E}+00$ & $.00 \mathrm{E}+00$ \\
\hline • & . & . & & & & & $0.00 \mathrm{E}+00$ \\
\hline 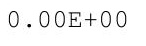 & ( & $0.00 \mathrm{E}+$ & $0.00 \mathrm{E}+$ & $0.00 \mathrm{E}+$ & $0.00 \mathrm{E}$ & $0.00 \mathrm{E}+00$ & $0.00 \mathrm{E}+00$ \\
\hline (1) & & & $0.00 \mathrm{E}+00$ & & & $0.00 \mathrm{E}+00$ & $.00 \mathrm{E}+00$ \\
\hline $0=+0$ & & $0.00 \mathrm{E}+$ & $0.00 \mathrm{E}+00$ & $00 E+00$ & 0 & $0 E+00$ & $00 E+00$ \\
\hline $.00 \mathrm{E}+00$ & $0.00 \mathrm{E}+00$ & $0.00 \mathrm{E}+$ & $0.00 \mathrm{E}$ & $0.00 \mathrm{E}$ & 0 & 00 & $0.00 \mathrm{E}+00$ \\
\hline $\mathrm{E}+00$ & $0.00 \mathrm{E}+00$ & 0.00 & 0 & 0 & & & $00 \mathrm{E}+00$ \\
\hline 年 & . & $0.00 \mathrm{E}+00$ & & $.00 \mathrm{E}+00$ & & & $.00 \mathrm{E}+00$ \\
\hline 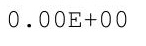 & 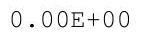 & $0.00 \mathrm{E}+00$ & $0.00 \mathrm{E}+00$ & $0.00 \mathrm{E}+00$ & $0.00 \mathrm{E}+00$ & $0.00 \mathrm{E}+00$ & $0.00 \mathrm{E}+00$ \\
\hline $0 E+00$ & $0.00 \mathrm{E}+00$ & $0.00 \mathrm{E}+00$ & $0.00 \mathrm{E}+00$ & & $0.00 \mathrm{E}+00$ & & $0.00 \mathrm{E}+00$ \\
\hline & & $0.00 \mathrm{E}+00$ & & $0.00 \mathrm{E}+00$ & $0.00 \mathrm{E}+00$ & $0.00 \mathrm{E}+00$ & $0.00 \mathrm{E}+00$ \\
\hline $.00 E+00$ & $.00 \mathrm{E}+00$ & $.00 E+00$ & $.00 \mathrm{E}+00$ & $.00 \mathrm{E}+00$ & $0.00 \mathrm{E}+00$ & $0.00 \mathrm{E}+00$ & $0.00 \mathrm{E}+00$ \\
\hline
\end{tabular}


RESRAD-OFFSITE, Version 2.5

Title : Offsite Resident Farmer Deterministic Run

File : RF TC99 DOESG FWD-FV2.ROF

Summary of dose at graphical times, reptition 1 (continued)

Time

Years

7. $08 \mathrm{E}+01$

7. $13 \mathrm{E}+01$

7. $18 \mathrm{E}+01$

7. $23 \mathrm{E}+01$

$7.28 \mathrm{E}+01$

7. $33 \mathrm{E}+01$

7. $38 \mathrm{E}+01$

7. $43 \mathrm{E}+01$

7. $49 \mathrm{E}+01$

7. $54 \mathrm{E}+01$

$7.59 \mathrm{E}+01$

7. $64 \mathrm{E}+01$

7. $69 \mathrm{E}+01$

7. $74 \mathrm{E}+01$

7. $79 \mathrm{E}+01$

7. $84 \mathrm{E}+01$

7. $90 \mathrm{E}+01$

7. $95 \mathrm{E}+01$

8. $00 \mathrm{E}+01$

$8.05 \mathrm{E}+01$

8. $10 \mathrm{E}+01$

$8.15 \mathrm{E}+01$

8. $20 \mathrm{E}+01$

$8.25 \mathrm{E}+01$

8. $31 \mathrm{E}+01$

8. $36 \mathrm{E}+01$

8. $41 \mathrm{E}+01$

8. $46 \mathrm{E}+01$

8. $51 \mathrm{E}+01$

8. $56 \mathrm{E}+01$

8. $61 \mathrm{E}+01$

8. $66 \mathrm{E}+01$

$8.72 \mathrm{E}+01$

$8.77 \mathrm{E}+01$

$8.82 \mathrm{E}+01$

$8.87 \mathrm{E}+01$

8. $92 \mathrm{E}+01$

$8.97 \mathrm{E}+01$

$9.02 \mathrm{E}+01$

$9.07 \mathrm{E}+01$

$9.13 \mathrm{E}+01$

$9.18 \mathrm{E}+01$

$9.23 \mathrm{E}+01$

$9.28 \mathrm{E}+01$

9. $33 \mathrm{E}+01$

9. $38 \mathrm{E}+01$
Dose statistics at graphical times, mrem/yr

\begin{tabular}{|c|c|c|c|c|c|c|c|}
\hline inimum & aximum & lean & edian & & & $\%$ & $9 \%$ \\
\hline $.00 E+00$ & $0.00 \mathrm{E}+00$ & $0.00 \mathrm{E}+00$ & $0.00 \mathrm{E}+00$ & $00 \mathrm{E}+00$ & $0.00 \mathrm{E}+00$ & $0.00 \mathrm{E}+00$ & $0.00 \mathrm{E}+00$ \\
\hline $.00 \mathrm{E}+00$ & $0.00 \mathrm{E}+00$ & $.00 \mathrm{E}+00$ & $.00 \mathrm{E}+00$ & $0.00 \mathrm{E}+00$ & $0.00 \mathrm{E}+00$ & $0.00 \mathrm{E}+00$ & $00 \mathrm{E}+00$ \\
\hline $00 \mathrm{E}+00$ & $0 \mathrm{E}+00$ & $00 E+00$ & $00 E+00$ & $00 \mathrm{E}+00$ & $00 E+00$ & 00 & $0 E+00$ \\
\hline+00 & 00 & 00 & 00 & 0 & 0 & 00 & $00 \mathrm{E}+00$ \\
\hline$E+00$ & 0 & & & & & & +00 \\
\hline $00 \mathrm{E}+00$ & & & & & & & $\Xi+00$ \\
\hline$E+00$ & $E+00$ & 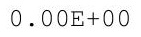 & $\mathrm{E}+00$ & $E+00$ & 0 & +00 & $E+00$ \\
\hline $.00 \mathrm{E}+00$ & $0.00 \mathrm{E}+00$ & $0 \mathrm{E}+00$ & $0 \mathrm{E}+00$ & $00 \mathrm{E}+00$ & $00 \mathrm{E}+00$ & $E+00$ & $00 \mathrm{E}+00$ \\
\hline $00 E+00$ & $00 F+0$ & $00 \mathrm{~F}+\ell-8$ & $.00 E+00$ & $0 \cap \mathrm{F}+$ & $\mathrm{O} \cap \mathrm{F}+\mathrm{r}-\mathrm{s}$ & $00 F+00$ & $00 E+00$ \\
\hline$E+00$ & $0.00 \mathrm{E}+00$ & & & & & 0 & 00 \\
\hline $.00 E+00$ & $0.00 \mathrm{E}+00$ & 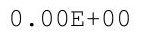 & 00 & 0 & 0 & 0 & $E+00$ \\
\hline $.00 \mathrm{E}+00$ & $0.00 \mathrm{E}+00$ & $0.00 \mathrm{E}+00$ & $0.00 \mathrm{E}+00$ & & & & $0.00 \mathrm{E}+00$ \\
\hline $.00 E+00$ & $0.00 \mathrm{E}+00$ & $0.00 \mathrm{E}+00$ & $0.00 \mathrm{E}+00$ & $0.00 \mathrm{E}+00$ & $0.00 \mathrm{E}+00$ & $E+00$ & $0.00 \mathrm{E}+00$ \\
\hline$E+00$ & $E+00$ & $E+00$ & $E+00$ & & & +00 & $00 \mathrm{E}+00$ \\
\hline $.00 E+00$ & $.00 E+00$ & $.00 E+00$ & $.00 E+00$ & $.00 \mathrm{E}+$ & 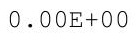 & 0 & +00 \\
\hline$E+00$ & ( & $0.00 \mathrm{E}+00$ & & $0.00 \mathrm{E}+00$ & $00 E+00$ & $E+00$ & 0 \\
\hline $0 \cap F+00$ & $F+00$ & $5+0$ & & & & -00 & 00 \\
\hline $.00 \mathrm{E}+00$ & $0.00 \mathrm{E}+00$ & $0.00 \mathrm{E}+00$ & $0.00 \mathrm{E}+00$ & $0.00 \mathrm{E}+00$ & $0.00 \mathrm{E}+00$ & $0.00 \mathrm{E}+00$ & $.00 \mathrm{E}+00$ \\
\hline $.00 \mathrm{E}+00$ & $.00 \mathrm{E}+00$ & $.00 \mathrm{E}+00$ & $0.00 \mathrm{E}+00$ & $0.00 \mathrm{E}+00$ & $0.00 \mathrm{E}+00$ & $.00 E+00$ & $.00 E+00$ \\
\hline$E+00$ & $00 E+00$ & $00 F+0=$ & $.00 E+00$ & $0 \mathrm{E}+00$ & 0 & $0 \mathrm{E}+00$ & $00 E+00$ \\
\hline 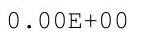 & 然 & $0.00 \mathrm{E}+00$ & $.00 E+00$ & 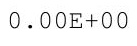 & 0 & 0 & +00 \\
\hline $.00 \mathrm{E}+00$ & . & 然 & & & & & 00 \\
\hline $.00 E+00$ & $.00 \mathrm{E}+00$ & ) & $0 E+00$ & مF+ & 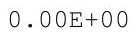 & 0 & $E+00$ \\
\hline $0 \cap F+00$ & COF+O & ) & $0.00 \mathrm{E}+00$ & $.00 \mathrm{E}+00$ & $.00 \mathrm{E}+$ & $00 \mathrm{E}+00$ & $00 E+00$ \\
\hline $00 F+00$ & 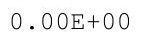 & 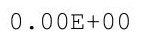 & $0.00 \mathrm{E}+00$ & $.00 \mathrm{E}+00$ & ח & $.00 E+00$ & $.00 \mathrm{E}+00$ \\
\hline$F+00$ & $0.00 \mathrm{E}+00$ & $00 E+00$ & $.00 E+00$ & $0 E+00$ & 0 & $0 E+00$ & $00 E+00$ \\
\hline & & & & & & $E+00$ & \\
\hline & & & & 0.0 & e & & +00 \\
\hline $.00 \mathrm{E}+00$ & $0.00 \mathrm{E}+00$ & $0.00 \mathrm{E}+00$ & $.00 \mathrm{E}+00$ & . & . & $0.00 \mathrm{E}+00$ & $.00 E+00$ \\
\hline $0 \mathrm{E}+00$ & $00 \mathrm{E}+00$ & $0.00 \mathrm{E}+0$ & $0.00 \mathrm{E}+00$ & $0.00 \mathrm{E}+00$ & $0.00 \mathrm{E}+\mathrm{C}$ & $0.00 \mathrm{E}+00$ & $.00 \mathrm{E}+00$ \\
\hline $00 \mathrm{E}+\mathrm{C}$ & $.00 E+00$ & & $0.00 \mathrm{E}+00$ & & & $0.00 \mathrm{E}+00$ & $.00 \mathrm{E}+00$ \\
\hline مि & $00 F+00$ & $0 \cap \cap \cap F+\cap 0$ & $00 F+00$ & $.00 E+00$ & & $0 E+00$ & $.00 E+00$ \\
\hline F & & & & & & & \\
\hline & & & & & & 00 & \\
\hline $.00 E+00$ & $0.00 \mathrm{E}+00$ & $0.00 \mathrm{E}+00$ & $0.00 \mathrm{E}+00$ & $0.00 \mathrm{E}+00$ & . & $0.00 \mathrm{E}+00$ & $.00 \mathrm{E}+00$ \\
\hline • & . & . & & & & & $0.00 \mathrm{E}+00$ \\
\hline 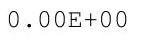 & ( & $0.00 \mathrm{E}+$ & $0.00 \mathrm{E}+$ & $0.00 \mathrm{E}+$ & $0.00 \mathrm{E}$ & $0.00 \mathrm{E}+00$ & $0.00 \mathrm{E}+00$ \\
\hline (1) & & & $0.00 \mathrm{E}+00$ & & & $0.00 \mathrm{E}+00$ & $.00 \mathrm{E}+00$ \\
\hline $0=+0$ & & $0.00 \mathrm{E}+$ & $0.00 \mathrm{E}+00$ & $00 E+00$ & 0 & $0 E+00$ & $00 E+00$ \\
\hline $.00 \mathrm{E}+00$ & $0.00 \mathrm{E}+00$ & $0.00 \mathrm{E}+$ & $0.00 \mathrm{E}$ & $0.00 \mathrm{E}$ & 0 & 00 & $0.00 \mathrm{E}+00$ \\
\hline $\mathrm{E}+00$ & $0.00 \mathrm{E}+00$ & 0.00 & 0 & 0 & & & $00 \mathrm{E}+00$ \\
\hline 年 & . & $0.00 \mathrm{E}+00$ & & $.00 \mathrm{E}+00$ & & & $.00 \mathrm{E}+00$ \\
\hline 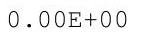 & 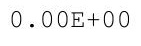 & $0.00 \mathrm{E}+00$ & $0.00 \mathrm{E}+00$ & $0.00 \mathrm{E}+00$ & $0.00 \mathrm{E}+00$ & $0.00 \mathrm{E}+00$ & $0.00 \mathrm{E}+00$ \\
\hline $0 E+00$ & $0.00 \mathrm{E}+00$ & $0.00 \mathrm{E}+00$ & $0.00 \mathrm{E}+00$ & & $0.00 \mathrm{E}+00$ & & $0.00 \mathrm{E}+00$ \\
\hline & & $0.00 \mathrm{E}+00$ & & $0.00 \mathrm{E}+00$ & $0.00 \mathrm{E}+00$ & $0.00 \mathrm{E}+00$ & $0.00 \mathrm{E}+00$ \\
\hline $.00 E+00$ & $.00 \mathrm{E}+00$ & $.00 E+00$ & $.00 \mathrm{E}+00$ & $.00 \mathrm{E}+00$ & $0.00 \mathrm{E}+00$ & $0.00 \mathrm{E}+00$ & $0.00 \mathrm{E}+00$ \\
\hline
\end{tabular}


Probabilistic Dose and Risk Report

Title : Offsite Resident Farmer Deterministic Run

File : RF TC99 DOESG FWD-FV2.ROF

Summary of dose at graphical times, reptition 1 (continued)

Time

Years

9. $43 \mathrm{E}+01$

$9.48 \mathrm{E}+01$

9. $54 \mathrm{E}+01$

9. $59 \mathrm{E}+01$

9. $64 \mathrm{E}+01$

$9.69 \mathrm{E}+01$

$9.74 \mathrm{E}+01$

9. $79 \mathrm{E}+01$

$9.84 \mathrm{E}+01$

9. $90 \mathrm{E}+01$

9. $95 \mathrm{E}+01$

$1.00 \mathrm{E}+02$

$1.00 \mathrm{E}+02$

$1.01 \mathrm{E}+02$

1. $02 \mathrm{E}+02$

$1.02 \mathrm{E}+02$

$1.03 \mathrm{E}+02$

$1.03 \mathrm{E}+02$

1. $04 \mathrm{E}+02$

$1.04 \mathrm{E}+02$

$1.05 \mathrm{E}+02$

$1.05 \mathrm{E}+02$

$1.06 \mathrm{E}+02$

$1.06 \mathrm{E}+02$

$1.07 \mathrm{E}+02$

$1.07 \mathrm{E}+02$

$1.08 \mathrm{E}+02$

$1.08 \mathrm{E}+02$

1. $09 \mathrm{E}+02$

$1.09 \mathrm{E}+02$

1. $10 \mathrm{E}+02$

1. $10 \mathrm{E}+02$

1. $11 \mathrm{E}+02$

1. $11 \mathrm{E}+02$

1. $12 \mathrm{E}+02$

1. $12 \mathrm{E}+02$

1. $13 \mathrm{E}+02$

1. $13 \mathrm{E}+02$

1. $14 \mathrm{E}+02$

1. $14 \mathrm{E}+02$

1. $15 \mathrm{E}+02$

1. $15 \mathrm{E}+02$

$1.16 \mathrm{E}+02$

$1.16 \mathrm{E}+02$

$1.17 \mathrm{E}+02$

1. $17 \mathrm{E}+02$

Dose statistics at graphical times, mrem/yr

\begin{tabular}{|c|c|c|c|c|c|c|c|}
\hline Minimum & Maximum & Mean & Median & $90 \%$ & $95 \%$ & $97.5 \%$ & $99 \%$ \\
\hline $0.00 \mathrm{E}+00$ & $0.00 \mathrm{E}+00$ & $0.00 \mathrm{E}+00$ & $0.00 \mathrm{E}+00$ & $0.00 \mathrm{E}+00$ & $0.00 \mathrm{E}+00$ & $0.00 \mathrm{E}+00$ & $0.00 \mathrm{E}+00$ \\
\hline $0.00 \mathrm{E}+00$ & $0.00 \mathrm{E}+00$ & $0.00 \mathrm{E}+00$ & $0.00 \mathrm{E}+00$ & $0.00 \mathrm{E}+00$ & $0.00 \mathrm{E}+00$ & $0.00 \mathrm{E}+00$ & $0.00 \mathrm{E}+00$ \\
\hline $0.00 \mathrm{E}+00$ & $0.00 \mathrm{E}+00$ & $0.00 \mathrm{E}+00$ & $0.00 \mathrm{E}+00$ & $0.00 \mathrm{E}+00$ & $0.00 \mathrm{E}+00$ & $0.00 \mathrm{E}+00$ & $0.00 \mathrm{E}+00$ \\
\hline $0.00 \mathrm{E}+00$ & $0.00 \mathrm{E}+00$ & $0.00 \mathrm{E}+00$ & $0.00 \mathrm{E}+00$ & $0.00 \mathrm{E}+00$ & $0.00 \mathrm{E}+00$ & $0.00 \mathrm{E}+00$ & $0.00 \mathrm{E}+00$ \\
\hline $0.00 \mathrm{E}+00$ & $0.00 \mathrm{E}+00$ & $0.00 \mathrm{E}+00$ & $0.00 \mathrm{E}+00$ & $0.00 \mathrm{E}+00$ & $0.00 \mathrm{E}+00$ & $0.00 \mathrm{E}+00$ & $0.00 \mathrm{E}+00$ \\
\hline $0.00 \mathrm{E}+00$ & $0.00 \mathrm{E}+00$ & $0.00 \mathrm{E}+00$ & $0.00 \mathrm{E}+00$ & $0.00 \mathrm{E}+00$ & $0.00 \mathrm{E}+00$ & $0.00 \mathrm{E}+00$ & $0.00 \mathrm{E}+00$ \\
\hline $0.00 \mathrm{E}+00$ & $0.00 \mathrm{E}+00$ & $0.00 \mathrm{E}+00$ & $0.00 \mathrm{E}+00$ & $0.00 \mathrm{E}+00$ & $0.00 \mathrm{E}+00$ & $0.00 \mathrm{E}+00$ & $0.00 \mathrm{E}+00$ \\
\hline $0.00 \mathrm{E}+00$ & $0.00 \mathrm{E}+00$ & $0.00 \mathrm{E}+00$ & $0.00 \mathrm{E}+00$ & $0.00 \mathrm{E}+00$ & $0.00 \mathrm{E}+00$ & $0.00 \mathrm{E}+00$ & $0.00 \mathrm{E}+00$ \\
\hline $0.00 \mathrm{E}+00$ & $0.00 \mathrm{E}+00$ & $0.00 \mathrm{E}+00$ & $0.00 \mathrm{E}+00$ & $0.00 \mathrm{E}+00$ & $0.00 \mathrm{E}+00$ & $0.00 \mathrm{E}+00$ & $0.00 \mathrm{E}+00$ \\
\hline $0.00 \mathrm{E}+00$ & $0.00 \mathrm{E}+00$ & $0.00 \mathrm{E}+00$ & $0.00 \mathrm{E}+00$ & $0.00 \mathrm{E}+00$ & $0.00 \mathrm{E}+00$ & $0.00 \mathrm{E}+00$ & $0.00 \mathrm{E}+00$ \\
\hline $0.00 \mathrm{E}+00$ & $0.00 \mathrm{E}+00$ & $0.00 \mathrm{E}+00$ & $0.00 \mathrm{E}+00$ & $0.00 \mathrm{E}+00$ & $0.00 \mathrm{E}+00$ & $0.00 \mathrm{E}+00$ & $0.00 \mathrm{E}+00$ \\
\hline $0.00 \mathrm{E}+00$ & $0.00 \mathrm{E}+00$ & $0.00 \mathrm{E}+00$ & $0.00 \mathrm{E}+00$ & $0.00 \mathrm{E}+00$ & $0.00 \mathrm{E}+00$ & $0.00 \mathrm{E}+00$ & $0.00 \mathrm{E}+00$ \\
\hline $0.00 \mathrm{E}+00$ & $0.00 \mathrm{E}+00$ & $0.00 \mathrm{E}+00$ & $0.00 \mathrm{E}+00$ & $0.00 \mathrm{E}+00$ & $0.00 \mathrm{E}+00$ & $0.00 \mathrm{E}+00$ & $0.00 \mathrm{E}+00$ \\
\hline $0.00 \mathrm{E}+00$ & $0.00 \mathrm{E}+00$ & $0.00 \mathrm{E}+00$ & $0.00 \mathrm{E}+00$ & $0.00 \mathrm{E}+00$ & $0.00 \mathrm{E}+00$ & $0.00 \mathrm{E}+00$ & $0.00 \mathrm{E}+00$ \\
\hline $0.00 \mathrm{E}+00$ & $0.00 \mathrm{E}+00$ & $0.00 \mathrm{E}+00$ & $0.00 \mathrm{E}+00$ & $0.00 \mathrm{E}+00$ & $0.00 \mathrm{E}+00$ & $0.00 \mathrm{E}+00$ & $0.00 \mathrm{E}+00$ \\
\hline $0.00 \mathrm{E}+00$ & $0.00 \mathrm{E}+00$ & $0.00 \mathrm{E}+00$ & $0.00 \mathrm{E}+00$ & $0.00 \mathrm{E}+00$ & $0.00 \mathrm{E}+00$ & $0.00 \mathrm{E}+00$ & $0.00 \mathrm{E}+00$ \\
\hline $0.00 \mathrm{E}+00$ & $0.00 \mathrm{E}+00$ & $0.00 \mathrm{E}+00$ & $0.00 \mathrm{E}+00$ & $0.00 \mathrm{E}+00$ & $0.00 \mathrm{E}+00$ & $0.00 \mathrm{E}+00$ & $0.00 \mathrm{E}+00$ \\
\hline $0.00 \mathrm{E}+00$ & $0.00 \mathrm{E}+00$ & $0.00 \mathrm{E}+00$ & $0.00 \mathrm{E}+00$ & $0.00 \mathrm{E}+00$ & $0.00 \mathrm{E}+00$ & $0.00 \mathrm{E}+00$ & $0.00 \mathrm{E}+00$ \\
\hline $0.00 \mathrm{E}+00$ & $0.00 \mathrm{E}+00$ & $0.00 \mathrm{E}+00$ & $0.00 \mathrm{E}+00$ & $0.00 \mathrm{E}+00$ & $0.00 \mathrm{E}+00$ & $0.00 \mathrm{E}+00$ & $0.00 \mathrm{E}+00$ \\
\hline $0.00 \mathrm{E}+00$ & $0.00 \mathrm{E}+00$ & $0.00 \mathrm{E}+00$ & $0.00 \mathrm{E}+00$ & $0.00 \mathrm{E}+00$ & $0.00 \mathrm{E}+00$ & $0.00 \mathrm{E}+00$ & $0.00 \mathrm{E}+00$ \\
\hline $0.00 \mathrm{E}+00$ & $0.00 \mathrm{E}+00$ & $0.00 \mathrm{E}+00$ & $0.00 \mathrm{E}+00$ & $0.00 \mathrm{E}+00$ & $0.00 \mathrm{E}+00$ & $0.00 \mathrm{E}+00$ & $0.00 \mathrm{E}+00$ \\
\hline $0.00 \mathrm{E}+00$ & $0.00 \mathrm{E}+00$ & $0.00 \mathrm{E}+00$ & $0.00 \mathrm{E}+00$ & $0.00 \mathrm{E}+00$ & $0.00 \mathrm{E}+00$ & $0.00 \mathrm{E}+00$ & $0.00 \mathrm{E}+00$ \\
\hline $0.00 \mathrm{E}+00$ & $0.00 \mathrm{E}+00$ & $0.00 \mathrm{E}+00$ & $0.00 \mathrm{E}+00$ & $0.00 \mathrm{E}+00$ & $0.00 \mathrm{E}+00$ & $0.00 \mathrm{E}+00$ & $0.00 \mathrm{E}+00$ \\
\hline $0.00 \mathrm{E}+00$ & $0.00 \mathrm{E}+00$ & $0.00 \mathrm{E}+00$ & $0.00 \mathrm{E}+00$ & $0.00 \mathrm{E}+00$ & $0.00 \mathrm{E}+00$ & $0.00 \mathrm{E}+00$ & $0.00 \mathrm{E}+00$ \\
\hline $0.00 \mathrm{E}+00$ & $0.00 \mathrm{E}+00$ & $0.00 \mathrm{E}+00$ & $0.00 \mathrm{E}+00$ & $0.00 \mathrm{E}+00$ & $0.00 \mathrm{E}+00$ & $0.00 \mathrm{E}+00$ & $0.00 \mathrm{E}+00$ \\
\hline $0.00 \mathrm{E}+00$ & $0.00 \mathrm{E}+00$ & $0.00 \mathrm{E}+00$ & $0.00 \mathrm{E}+00$ & $0.00 \mathrm{E}+00$ & $0.00 \mathrm{E}+00$ & $0.00 \mathrm{E}+00$ & $0.00 \mathrm{E}+00$ \\
\hline $0.00 \mathrm{E}+00$ & $0.00 \mathrm{E}+00$ & $0.00 \mathrm{E}+00$ & $0.00 \mathrm{E}+00$ & $0.00 \mathrm{E}+00$ & $0.00 \mathrm{E}+00$ & $0.00 \mathrm{E}+00$ & $0.00 \mathrm{E}+00$ \\
\hline $0.00 \mathrm{E}+00$ & $0.00 \mathrm{E}+00$ & $0.00 \mathrm{E}+00$ & $0.00 \mathrm{E}+00$ & $0.00 \mathrm{E}+00$ & $0.00 \mathrm{E}+00$ & $0.00 \mathrm{E}+00$ & $0.00 \mathrm{E}+00$ \\
\hline $0.00 \mathrm{E}+00$ & $0.00 \mathrm{E}+00$ & $0.00 \mathrm{E}+00$ & $0.00 \mathrm{E}+00$ & $0.00 \mathrm{E}+00$ & $0.00 \mathrm{E}+00$ & $0.00 \mathrm{E}+00$ & $0.00 \mathrm{E}+00$ \\
\hline $0.00 \mathrm{E}+00$ & $0.00 \mathrm{E}+00$ & $0.00 \mathrm{E}+00$ & $0.00 \mathrm{E}+00$ & $0.00 \mathrm{E}+00$ & $0.00 \mathrm{E}+00$ & $0.00 \mathrm{E}+00$ & $0.00 \mathrm{E}+00$ \\
\hline $0.00 \mathrm{E}+00$ & $1.07 \mathrm{E}-22$ & $5.33 E-26$ & $0.00 \mathrm{E}+00$ & $0.00 \mathrm{E}+00$ & $0.00 \mathrm{E}+00$ & $0.00 \mathrm{E}+00$ & $0.00 \mathrm{E}+00$ \\
\hline $0.00 \mathrm{E}+00$ & $1.91 \mathrm{E}-20$ & $9.54 \mathrm{E}-24$ & $0.00 \mathrm{E}+00$ & $0.00 \mathrm{E}+00$ & $0.00 \mathrm{E}+00$ & $0.00 \mathrm{E}+00$ & $0.00 \mathrm{E}+00$ \\
\hline $0.00 \mathrm{E}+00$ & $8.69 \mathrm{E}-19$ & $4.34 \mathrm{E}-22$ & $0.00 \mathrm{E}+00$ & $0.00 \mathrm{E}+00$ & $0.00 \mathrm{E}+00$ & $0.00 \mathrm{E}+00$ & $0.00 \mathrm{E}+00$ \\
\hline $0.00 \mathrm{E}+00$ & $1.88 \mathrm{E}-17$ & $9.40 \mathrm{E}-21$ & $0.00 \mathrm{E}+00$ & $0.00 \mathrm{E}+00$ & $0.00 \mathrm{E}+00$ & $0.00 \mathrm{E}+00$ & $0.00 \mathrm{E}+00$ \\
\hline $0.00 \mathrm{E}+00$ & $2.43 E-16$ & 1. $22 \mathrm{E}-19$ & $0.00 \mathrm{E}+00$ & $0.00 \mathrm{E}+00$ & $0.00 \mathrm{E}+00$ & $0.00 \mathrm{E}+00$ & $0.00 \mathrm{E}+00$ \\
\hline $0.00 \mathrm{E}+00$ & $2.16 \mathrm{E}-15$ & 1. $08 \mathrm{E}-18$ & $0.00 \mathrm{E}+00$ & $0.00 \mathrm{E}+00$ & $0.00 \mathrm{E}+00$ & $0.00 \mathrm{E}+00$ & $.00 \mathrm{E}+00$ \\
\hline $0.00 \mathrm{E}+00$ & $1.43 \mathrm{E}-14$ & $7.17 \mathrm{E}-18$ & $0.00 \mathrm{E}+00$ & $0.00 \mathrm{E}+00$ & $0.00 \mathrm{E}+00$ & $0.00 \mathrm{E}+00$ & $0.00 \mathrm{E}+00$ \\
\hline $0.00 \mathrm{E}+00$ & $7.42 \mathrm{E}-14$ & $3.76 \mathrm{E}-17$ & $0.00 \mathrm{E}+00$ & $0.00 \mathrm{E}+00$ & $0.00 \mathrm{E}+00$ & $0.00 \mathrm{E}+00$ & $0.00 \mathrm{E}+00$ \\
\hline $0.00 \mathrm{E}+00$ & $3.16 \mathrm{E}-13$ & $1.62 \mathrm{E}-16$ & $0.00 \mathrm{E}+00$ & $0.00 \mathrm{E}+00$ & $0.00 \mathrm{E}+00$ & $0.00 \mathrm{E}+00$ & $0.00 \mathrm{E}+00$ \\
\hline $0.00 \mathrm{E}+00$ & $1.14 \mathrm{E}-12$ & $5.98 E-16$ & $0.00 \mathrm{E}+00$ & $0.00 \mathrm{E}+00$ & $0.00 \mathrm{E}+00$ & $0.00 \mathrm{E}+00$ & $0.00 \mathrm{E}+00$ \\
\hline $0.00 \mathrm{E}+00$ & $3.59 \mathrm{E}-12$ & 1. $93 E-15$ & $0.00 \mathrm{E}+00$ & $0.00 \mathrm{E}+00$ & $0.00 \mathrm{E}+00$ & $0.00 \mathrm{E}+00$ & $0.00 \mathrm{E}+00$ \\
\hline $0.00 \mathrm{E}+00$ & $1.00 \mathrm{E}-11$ & $5.59 \mathrm{E}-15$ & $0.00 \mathrm{E}+00$ & $0.00 \mathrm{E}+00$ & $0.00 \mathrm{E}+00$ & $0.00 \mathrm{E}+00$ & $0.00 \mathrm{E}+00$ \\
\hline $0.00 \mathrm{E}+00$ & $2.52 \mathrm{E}-11$ & $1.47 \mathrm{E}-14$ & $0.00 \mathrm{E}+00$ & $0.00 \mathrm{E}+00$ & $0.00 \mathrm{E}+00$ & $0.00 \mathrm{E}+00$ & $0.00 \mathrm{E}+00$ \\
\hline $0 \mathrm{E}+00$ & $5.83 E-11$ & $6 E-14$ & $0.00 \mathrm{E}+00$ & $0.00 \mathrm{E}+00$ & $0.00 \mathrm{E}+00$ & $0.00 \mathrm{E}+00$ & $0.00 \mathrm{E}+00$ \\
\hline $0.00 \mathrm{E}+00$ & $1.25 \mathrm{E}-10$ & $8.05 E-14$ & $0.00 \mathrm{E}+00$ & $0.00 \mathrm{E}+00$ & $0.00 \mathrm{E}+00$ & $0.00 \mathrm{E}+00$ & $0.00 \mathrm{E}+00$ \\
\hline $0.00 \mathrm{E}+00$ & $2.52 \mathrm{E}-10$ & $1.71 E-13$ & $0.00 \mathrm{E}+00$ & $0.00 \mathrm{E}+00$ & $0.00 \mathrm{E}+00$ & $0.00 \mathrm{E}+00$ & $0.00 \mathrm{E}+00$ \\
\hline
\end{tabular}


RESRAD-OFFSITE, Version 2.5

obabilistic Dose and Risk Report

Title : Offsite Resident Farmer Deterministic Run

File : RF TC99 DOESG FWD-FV2.ROF

Summary of dose at graphical times, reptition 1 (continued)

Time

Years

$1.18 \mathrm{E}+02$

$1.18 \mathrm{E}+02$

$1.19 \mathrm{E}+02$

$1.19 \mathrm{E}+02$

1. $20 \mathrm{E}+02$

1. $20 \mathrm{E}+02$

1. $21 \mathrm{E}+02$

1. $22 \mathrm{E}+02$

1. $22 \mathrm{E}+02$

1. $23 \mathrm{E}+02$

1. $23 \mathrm{E}+02$

1. $24 \mathrm{E}+02$

1. $24 \mathrm{E}+02$

1. $25 \mathrm{E}+02$

1. $25 \mathrm{E}+02$

1. $26 \mathrm{E}+02$

1. $26 \mathrm{E}+02$

1. $27 \mathrm{E}+02$

$1.27 \mathrm{E}+02$

1. $28 \mathrm{E}+02$

1. $28 \mathrm{E}+02$

1. $29 \mathrm{E}+02$

1. $29 \mathrm{E}+02$

1. $30 \mathrm{E}+02$

1. $30 \mathrm{E}+02$

1. $31 \mathrm{E}+02$

1. $31 \mathrm{E}+02$

1. $32 \mathrm{E}+02$

1. $32 \mathrm{E}+02$

1. $33 \mathrm{E}+02$

1. $33 \mathrm{E}+02$

1. $34 \mathrm{E}+02$

1. $34 \mathrm{E}+02$

1. $35 \mathrm{E}+02$

1. $35 \mathrm{E}+02$

1. $36 \mathrm{E}+02$

1. $36 \mathrm{E}+02$

1. $37 \mathrm{E}+02$

1. $37 \mathrm{E}+02$

1. $38 \mathrm{E}+02$

1. $38 \mathrm{E}+02$

1. $39 \mathrm{E}+02$

1. $39 \mathrm{E}+02$

1. $40 \mathrm{E}+02$

1. $40 \mathrm{E}+02$

1. $41 \mathrm{E}+02$

Dose statistics at graphical times, mrem/yr

\begin{tabular}{|c|c|c|c|c|c|c|c|}
\hline Minimum & Maximum & Mean & Median & $90 \%$ & $95 \%$ & $97.5 \%$ & $99 \%$ \\
\hline $0.00 \mathrm{E}+00$ & $4.81 \mathrm{E}-10$ & $3.43 E-13$ & $0.00 \mathrm{E}+00$ & $0.00 \mathrm{E}+00$ & $0.00 \mathrm{E}+00$ & $0.00 \mathrm{E}+00$ & $0.00 \mathrm{E}+00$ \\
\hline $0.00 \mathrm{E}+00$ & $8.72 \mathrm{E}-10$ & $6.55 E-13$ & $0.00 \mathrm{E}+00$ & $0.00 \mathrm{E}+00$ & $0.00 \mathrm{E}+00$ & $0.00 \mathrm{E}+00$ & $0.00 \mathrm{E}+00$ \\
\hline $0.00 \mathrm{E}+00$ & $1.52 \mathrm{E}-09$ & 1. $20 \mathrm{E}-12$ & $0.00 \mathrm{E}+00$ & $0.00 \mathrm{E}+00$ & $0.00 \mathrm{E}+00$ & $0.00 \mathrm{E}+00$ & $0.00 \mathrm{E}+00$ \\
\hline $0.00 \mathrm{E}+00$ & $2.54 \mathrm{E}-09$ & $2.11 E-12$ & $0.00 \mathrm{E}+00$ & $0.00 \mathrm{E}+00$ & $0.00 \mathrm{E}+00$ & $0.00 \mathrm{E}+00$ & $0.00 \mathrm{E}+00$ \\
\hline $0.00 \mathrm{E}+00$ & $4.12 \mathrm{E}-09$ & $3.58 \mathrm{E}-12$ & $0.00 \mathrm{E}+00$ & $0.00 \mathrm{E}+00$ & $0.00 \mathrm{E}+00$ & $0.00 \mathrm{E}+00$ & $0.00 \mathrm{E}+00$ \\
\hline $0.00 \mathrm{E}+00$ & $6.47 \mathrm{E}-09$ & $5.89 \mathrm{E}-12$ & $0.00 \mathrm{E}+00$ & $0.00 \mathrm{E}+00$ & $0.00 \mathrm{E}+00$ & $0.00 \mathrm{E}+00$ & $0.00 \mathrm{E}+00$ \\
\hline $0.00 \mathrm{E}+00$ & $9.91 E-09$ & $9.43 E-12$ & $0.00 \mathrm{E}+00$ & $.00 \mathrm{E}+00$ & $0.00 \mathrm{E}+00$ & $0.00 \mathrm{E}+00$ & $0.00 \mathrm{E}+00$ \\
\hline $0.00 \mathrm{E}+00$ & 1. $48 \mathrm{E}-08$ & $1.47 \mathrm{E}-11$ & $0.00 \mathrm{E}+00$ & $0.00 \mathrm{E}+00$ & $0.00 \mathrm{E}+00$ & $0.00 \mathrm{E}+00$ & $0.00 \mathrm{E}+00$ \\
\hline $0.00 \mathrm{E}+00$ & $2.16 \mathrm{E}-08$ & $2.24 E-11$ & $0.00 \mathrm{E}+00$ & $0.00 \mathrm{E}+00$ & $0.00 \mathrm{E}+00$ & $0.00 \mathrm{E}+00$ & $0.00 \mathrm{E}+00$ \\
\hline $0.00 \mathrm{E}+00$ & $3.26 \mathrm{E}-08$ & $3.34 \mathrm{E}-11$ & $0.00 \mathrm{E}+00$ & $0.00 \mathrm{E}+00$ & $0.00 \mathrm{E}+00$ & $0.00 \mathrm{E}+00$ & $0.00 \mathrm{E}+00$ \\
\hline $0.00 \mathrm{E}+00$ & $4.85 E-08$ & $4.88 E-11$ & $0.00 \mathrm{E}+00$ & $0.00 \mathrm{E}+00$ & $0.00 \mathrm{E}+00$ & $0.00 \mathrm{E}+00$ & $0.00 \mathrm{E}+00$ \\
\hline $0.00 \mathrm{E}+00$ & $7.06 \mathrm{E}-08$ & $7.00 \mathrm{E}-11$ & $0.00 \mathrm{E}+00$ & $0.00 \mathrm{E}+00$ & $0.00 \mathrm{E}+00$ & $0.00 \mathrm{E}+00$ & $0.00 \mathrm{E}+00$ \\
\hline $0.00 \mathrm{E}+00$ & $1.01 \mathrm{E}-07$ & $9.89 \mathrm{E}-11$ & $0.00 \mathrm{E}+00$ & $0.00 \mathrm{E}+00$ & $0.00 \mathrm{E}+00$ & $0.00 \mathrm{E}+00$ & $0.00 \mathrm{E}+00$ \\
\hline $0.00 \mathrm{E}+00$ & $1.41 \mathrm{E}-07$ & 1. $38 \mathrm{E}-10$ & $0.00 \mathrm{E}+00$ & $0.00 \mathrm{E}+00$ & $0.00 \mathrm{E}+00$ & $0.00 \mathrm{E}+00$ & $0.00 \mathrm{E}+00$ \\
\hline $0.00 \mathrm{E}+00$ & $1.94 \mathrm{E}-07$ & $1.89 \mathrm{E}-10$ & $0.00 \mathrm{E}+00$ & $0.00 \mathrm{E}+00$ & $0.00 \mathrm{E}+00$ & $0.00 \mathrm{E}+00$ & $0.00 \mathrm{E}+00$ \\
\hline $0.00 \mathrm{E}+00$ & $2.63 E-07$ & $2.55 E-10$ & $0.00 \mathrm{E}+00$ & $0.00 \mathrm{E}+00$ & $0.00 \mathrm{E}+00$ & $0.00 \mathrm{E}+00$ & $2.03 E-23$ \\
\hline $0.00 \mathrm{E}+00$ & $3.52 \mathrm{E}-07$ & $3.41 E-10$ & $0.00 \mathrm{E}+00$ & $0.00 \mathrm{E}+00$ & $0.00 \mathrm{E}+00$ & $0.00 \mathrm{E}+00$ & $6.00 \mathrm{E}-21$ \\
\hline $0.00 \mathrm{E}+00$ & $4.64 \mathrm{E}-07$ & $4.51 E-10$ & $0.00 \mathrm{E}+00$ & $0.00 \mathrm{E}+00$ & $0.00 \mathrm{E}+00$ & $0.00 \mathrm{E}+00$ & 4. $20 \mathrm{E}-19$ \\
\hline $0.00 \mathrm{E}+00$ & $6.05 E-07$ & $5.89 \mathrm{E}-10$ & $0.00 \mathrm{E}+00$ & $0.00 \mathrm{E}+00$ & $0.00 \mathrm{E}+00$ & $0.00 \mathrm{E}+00$ & $1.18 \mathrm{E}-17$ \\
\hline $0.00 \mathrm{E}+00$ & $7.79 \mathrm{E}-07$ & 7. $62 \mathrm{E}-10$ & $0.00 \mathrm{E}+00$ & $0.00 \mathrm{E}+00$ & $0.00 \mathrm{E}+00$ & $0.00 \mathrm{E}+00$ & $1.80 \mathrm{E}-16$ \\
\hline $0.00 \mathrm{E}+00$ & $9.91 \mathrm{E}-07$ & $9.77 \mathrm{E}-10$ & $0.00 \mathrm{E}+00$ & $0.00 \mathrm{E}+00$ & $0.00 \mathrm{E}+00$ & $0.00 \mathrm{E}+00$ & 1. $77 \mathrm{E}-15$ \\
\hline $0.00 \mathrm{E}+00$ & $1.25 E-06$ & $1.24 \mathrm{E}-09$ & $0.00 \mathrm{E}+00$ & $0.00 \mathrm{E}+00$ & $0.00 \mathrm{E}+00$ & $0.00 \mathrm{E}+00$ & $1.26 \mathrm{E}-14$ \\
\hline $0.00 E+00$ & $1.56 \mathrm{E}-06$ & $1.56 \mathrm{E}-09$ & $0.00 \mathrm{E}+00$ & $0.00 \mathrm{E}+00$ & $0.00 \mathrm{E}+00$ & $0.00 \mathrm{E}+00$ & $6.88 E-14$ \\
\hline $0.00 \mathrm{E}+00$ & $1.93 E-06$ & $1.95 E-09$ & $0.00 \mathrm{E}+00$ & $0.00 \mathrm{E}+00$ & $0.00 \mathrm{E}+00$ & $0.00 \mathrm{E}+00$ & $3.05 E-13$ \\
\hline $0.00 \mathrm{E}+00$ & $2.37 E-06$ & $2.42 E-09$ & $0.00 \mathrm{E}+00$ & $0.00 \mathrm{E}+00$ & $0.00 \mathrm{E}+00$ & $0.00 \mathrm{E}+00$ & 1. $13 \mathrm{E}-12$ \\
\hline $0.00 \mathrm{E}+00$ & $2.88 E-06$ & $2.98 E-09$ & $0.00 \mathrm{E}+00$ & $0.00 \mathrm{E}+00$ & $0.00 \mathrm{E}+00$ & $0.00 \mathrm{E}+00$ & $3.63 E-12$ \\
\hline $0.00 \mathrm{E}+00$ & $3.49 \mathrm{E}-06$ & $3.64 \mathrm{E}-09$ & $0.00 \mathrm{E}+00$ & $0.00 \mathrm{E}+00$ & $0.00 \mathrm{E}+00$ & $0.00 \mathrm{E}+00$ & $1.03 E-11$ \\
\hline $0.00 \mathrm{E}+00$ & $4.18 \mathrm{E}-06$ & 4. 42E-09 & $0.00 \mathrm{E}+00$ & $0.00 \mathrm{E}+00$ & $0.00 \mathrm{E}+00$ & $0.00 \mathrm{E}+00$ & $2.64 \mathrm{E}-11$ \\
\hline $0.00 E+00$ & $4.98 E-06$ & $5.34 E-09$ & $0.00 \mathrm{E}+00$ & $0.00 \mathrm{E}+00$ & $0.00 \mathrm{E}+00$ & $0.00 \mathrm{E}+00$ & $6.35 E-11$ \\
\hline $0.00 \mathrm{E}+00$ & $5.90 \mathrm{E}-06$ & $6.41 E-09$ & $0.00 \mathrm{E}+00$ & $0.00 \mathrm{E}+00$ & $0.00 \mathrm{E}+00$ & $0.00 \mathrm{E}+00$ & 1. $42 \mathrm{E}-10$ \\
\hline $0.00 \mathrm{E}+00$ & $6.95 E-06$ & 7. $66 \mathrm{E}-09$ & $0.00 \mathrm{E}+00$ & $0.00 \mathrm{E}+00$ & $0.00 \mathrm{E}+00$ & $0.00 \mathrm{E}+00$ & $2.96 \mathrm{E}-10$ \\
\hline $0.00 \mathrm{E}+00$ & $8.14 \mathrm{E}-06$ & $9.10 \mathrm{E}-09$ & $0.00 \mathrm{E}+00$ & $0.00 \mathrm{E}+00$ & $0.00 \mathrm{E}+00$ & $0.00 \mathrm{E}+00$ & $5.83 E-10$ \\
\hline $0.00 \mathrm{E}+00$ & $9.47 \mathrm{E}-06$ & $1.08 \mathrm{E}-08$ & $0.00 \mathrm{E}+00$ & $0.00 \mathrm{E}+00$ & $0.00 \mathrm{E}+00$ & $0.00 \mathrm{E}+00$ & 1.09E-09 \\
\hline $0.00 \mathrm{E}+00$ & $1.10 \mathrm{E}-05$ & 1.27E-08 & $0.00 \mathrm{E}+00$ & $0.00 \mathrm{E}+00$ & $0.00 \mathrm{E}+00$ & $0.00 \mathrm{E}+00$ & 1. $96 \mathrm{E}-09$ \\
\hline $0.00 \mathrm{E}+00$ & $.27 E-05$ & 1. $48 \mathrm{E}-08$ & $0.00 \mathrm{E}+00$ & $0.00 \mathrm{E}+00$ & $0.00 \mathrm{E}+00$ & $0.00 \mathrm{E}+00$ & $3.38 \mathrm{E}-09$ \\
\hline $0.00 \mathrm{E}+00$ & $1.45 \mathrm{E}-05$ & $1.73 E-08$ & $0.00 \mathrm{E}+00$ & $0.00 \mathrm{E}+00$ & $0.00 \mathrm{E}+00$ & $0.00 \mathrm{E}+00$ & $5.62 \mathrm{E}-09$ \\
\hline $0.00 \mathrm{E}+00$ & $1.66 \mathrm{E}-05$ & $2.01 E-08$ & $0.00 \mathrm{E}+00$ & $0.00 \mathrm{E}+00$ & $0.00 \mathrm{E}+00$ & $0.00 \mathrm{E}+00$ & $9.06 \mathrm{E}-09$ \\
\hline $0.00 \mathrm{E}+00$ & $1.89 \mathrm{E}-05$ & $2.33 E-08$ & $0.00 \mathrm{E}+00$ & $0.00 \mathrm{E}+00$ & $0.00 \mathrm{E}+00$ & $0.00 \mathrm{E}+00$ & 1. $42 \mathrm{E}-08$ \\
\hline $0.00 \mathrm{E}+00$ & $2.14 \mathrm{E}-05$ & $2.69 \mathrm{E}-08$ & $0.00 \mathrm{E}+00$ & $0.00 \mathrm{E}+00$ & $0.00 \mathrm{E}+00$ & $2.61 E-23$ & $2.17 \mathrm{E}-08$ \\
\hline $0.00 \mathrm{E}+00$ & $2.42 E-05$ & $3.10 \mathrm{E}-08$ & $0.00 \mathrm{E}+00$ & $0.00 \mathrm{E}+00$ & $0.00 \mathrm{E}+00$ & $6.78 E-21$ & $3.20 E-08$ \\
\hline $0.00 \mathrm{E}+00$ & $2.73 E-05$ & $3.56 \mathrm{E}-08$ & $0.00 \mathrm{E}+00$ & $0.00 \mathrm{E}+00$ & $0.00 \mathrm{E}+00$ & $4.52 E-19$ & $4.45 E-08$ \\
\hline $0.00 \mathrm{E}+00$ & $3.06 \mathrm{E}-05$ & $4.07 E-08$ & $0.00 \mathrm{E}+00$ & $0.00 \mathrm{E}+00$ & $0.00 \mathrm{E}+00$ & $1.29 \mathrm{E}-17$ & $6.10 \mathrm{E}-08$ \\
\hline $0.00 \mathrm{E}+00$ & $3.42 \mathrm{E}-05$ & $4.64 \mathrm{E}-08$ & $0.00 \mathrm{E}+00$ & $0.00 \mathrm{E}+00$ & $0.00 \mathrm{E}+00$ & $2.06 \mathrm{E}-16$ & $8.22 \mathrm{E}-08$ \\
\hline $0.00 \mathrm{E}+00$ & $3.82 \mathrm{E}-05$ & $5.28 E-08$ & $0.00 \mathrm{E}+00$ & $0.00 \mathrm{E}+00$ & $0.00 \mathrm{E}+00$ & $2.16 \mathrm{E}-15$ & $1.10 \mathrm{E}-07$ \\
\hline $0.00 \mathrm{E}+00$ & $4.25 E-05$ & $5.99 E-08$ & $0.00 \mathrm{E}+00$ & $0.00 \mathrm{E}+00$ & $0.00 \mathrm{E}+00$ & $1.64 \mathrm{E}-14$ & $1.47 \mathrm{E}-07$ \\
\hline $0.00 \mathrm{E}+00$ & $4.71 \mathrm{E}-05$ & $6.79 E-08$ & $0.00 \mathrm{E}+00$ & $0.00 \mathrm{E}+00$ & $0.00 \mathrm{E}+00$ & $9.57 \mathrm{E}-14$ & $1.94 \mathrm{E}-07$ \\
\hline
\end{tabular}


RESRAD-OFFSITE, Version 2.5

obabilistic Dose and Risk Report

Title : Offsite Resident Farmer Deterministic Run

File : RF TC99 DOESG FWD-FV2.ROF

Summary of dose at graphical times, reptition 1 (continued)

Time

Years

1. $42 \mathrm{E}+02$

$1.42 \mathrm{E}+02$

$1.43 \mathrm{E}+02$

$1.43 \mathrm{E}+02$

1. $44 \mathrm{E}+02$

$1.44 \mathrm{E}+02$

$1.45 \mathrm{E}+02$

1. $45 \mathrm{E}+02$

1. $46 \mathrm{E}+02$

1. $46 \mathrm{E}+02$

1. $47 \mathrm{E}+02$

1. $47 \mathrm{E}+02$

1. $48 \mathrm{E}+02$

1. $48 \mathrm{E}+02$

1. $49 \mathrm{E}+02$

1. $49 \mathrm{E}+02$

1. $50 \mathrm{E}+02$

1. $50 \mathrm{E}+02$

1. $51 \mathrm{E}+02$

1. $51 \mathrm{E}+02$

1. $52 \mathrm{E}+02$

1. $52 \mathrm{E}+02$

$1.53 \mathrm{E}+02$

1. $53 \mathrm{E}+02$

$1.54 \mathrm{E}+02$

$1.54 \mathrm{E}+02$

1. $55 \mathrm{E}+02$

1. $55 \mathrm{E}+02$

1. $56 \mathrm{E}+02$

1. $56 \mathrm{E}+02$

1. $57 \mathrm{E}+02$

1. $57 \mathrm{E}+02$

1. $58 \mathrm{E}+02$

1. $58 \mathrm{E}+02$

1. $59 \mathrm{E}+02$

1. $59 \mathrm{E}+02$

1. $60 \mathrm{E}+02$

$1.60 \mathrm{E}+02$

1. $61 \mathrm{E}+02$

1. $61 \mathrm{E}+02$

1. $62 \mathrm{E}+02$

1. $63 \mathrm{E}+02$

1. $63 \mathrm{E}+02$

1. $64 \mathrm{E}+02$

1. $64 \mathrm{E}+02$

1. $65 \mathrm{E}+02$
Dose statistics at graphical times, mrem/yr

\begin{tabular}{|c|c|c|c|c|c|c|c|}
\hline Minimum & Maximum & Mean & Median & $90 \%$ & $95 \%$ & $97.5 \%$ & $99 \%$ \\
\hline $0.00 \mathrm{E}+00$ & $5.21 E-05$ & $7.67 \mathrm{E}-08$ & $0.00 \mathrm{E}+00$ & $0.00 \mathrm{E}+00$ & $0.00 \mathrm{E}+00$ & $4.52 E-13$ & $2.53 E-07$ \\
\hline $0.00 \mathrm{E}+00$ & $5.75 E-05$ & $8.65 E-08$ & $0.00 \mathrm{E}+00$ & $0.00 \mathrm{E}+00$ & $0.00 \mathrm{E}+00$ & 1. $79 \mathrm{E}-12$ & $3.27 \mathrm{E}-07$ \\
\hline $0.00 \mathrm{E}+00$ & $6.32 E-05$ & $9.73 E-08$ & $0.00 \mathrm{E}+00$ & $0.00 \mathrm{E}+00$ & $0.00 \mathrm{E}+00$ & $6.06 \mathrm{E}-12$ & $4.18 \mathrm{E}-07$ \\
\hline $0.00 \mathrm{E}+00$ & $6.94 E-05$ & $1.09 \mathrm{E}-07$ & $0.00 \mathrm{E}+00$ & $0.00 \mathrm{E}+00$ & $0.00 \mathrm{E}+00$ & $1.81 \mathrm{E}-11$ & $5.28 E-07$ \\
\hline $0.00 \mathrm{E}+00$ & $7.61 \mathrm{E}-05$ & 1.22E-07 & $0.00 \mathrm{E}+00$ & $0.00 \mathrm{E}+00$ & $0.00 \mathrm{E}+00$ & $4.47 \mathrm{E}-11$ & $6.63 E-07$ \\
\hline $0.00 \mathrm{E}+00$ & $8.32 E-05$ & $1.37 \mathrm{E}-07$ & $0.00 \mathrm{E}+00$ & $0.00 \mathrm{E}+00$ & $0.00 \mathrm{E}+00$ & $9.91 \mathrm{E}-11$ & $8.24 \mathrm{E}-07$ \\
\hline $0.00 \mathrm{E}+00$ & $9.08 E-05$ & $1.53 E-07$ & $0.00 \mathrm{E}+00$ & $.00 \mathrm{E}+00$ & $0.00 \mathrm{E}+00$ & $2.06 \mathrm{E}-10$ & $1.02 E-06$ \\
\hline $0.00 \mathrm{E}+00$ & $9.89 \mathrm{E}-05$ & $1.71 \mathrm{E}-07$ & $0.00 \mathrm{E}+00$ & $0.00 \mathrm{E}+00$ & $0.00 \mathrm{E}+00$ & $4.06 \mathrm{E}-10$ & $1.24 \mathrm{E}-06$ \\
\hline $0.00 \mathrm{E}+00$ & $1.07 E-04$ & $1.90 \mathrm{E}-07$ & $0.00 \mathrm{E}+00$ & $0.00 \mathrm{E}+00$ & $0.00 \mathrm{E}+00$ & $7.60 \mathrm{E}-10$ & $1.56 \mathrm{E}-06$ \\
\hline $0.00 \mathrm{E}+00$ & $1.17 \mathrm{E}-04$ & $2.11 \mathrm{E}-07$ & $0.00 \mathrm{E}+00$ & $0.00 \mathrm{E}+00$ & $0.00 \mathrm{E}+00$ & $1.36 E-09$ & $1.95 \mathrm{E}-06$ \\
\hline $0.00 \mathrm{E}+00$ & $1.26 \mathrm{E}-04$ & $2.35 E-07$ & $0.00 \mathrm{E}+00$ & $0.00 \mathrm{E}+00$ & $0.00 \mathrm{E}+00$ & $2.34 \mathrm{E}-09$ & $2.42 \mathrm{E}-06$ \\
\hline $0.00 \mathrm{E}+00$ & $1.37 E-04$ & $2.60 \mathrm{E}-07$ & $0.00 \mathrm{E}+00$ & $0.00 \mathrm{E}+00$ & $0.00 \mathrm{E}+00$ & $3.90 E-09$ & $2.97 E-06$ \\
\hline $0.00 \mathrm{E}+00$ & $1.48 \mathrm{E}-04$ & $2.88 E-07$ & $0.00 \mathrm{E}+00$ & $0.00 \mathrm{E}+00$ & $0.00 \mathrm{E}+00$ & $6.27 E-09$ & $3.63 E-06$ \\
\hline $0.00 \mathrm{E}+00$ & $1.59 \mathrm{E}-04$ & $3.18 \mathrm{E}-07$ & $0.00 \mathrm{E}+00$ & $0.00 \mathrm{E}+00$ & $0.00 \mathrm{E}+00$ & $9.78 \mathrm{E}-09$ & $4.39 E-06$ \\
\hline $0.00 \mathrm{E}+00$ & 1. $71 \mathrm{E}-04$ & $3.51 E-07$ & $0.00 \mathrm{E}+00$ & $0.00 \mathrm{E}+00$ & $0.00 \mathrm{E}+00$ & $1.48 E-08$ & $5.28 E-06$ \\
\hline $0.00 \mathrm{E}+00$ & $1.84 \mathrm{E}-04$ & $3.87 E-07$ & $0.00 \mathrm{E}+00$ & $0.00 \mathrm{E}+00$ & $0.00 \mathrm{E}+00$ & $2.22 E-08$ & $6.32 E-06$ \\
\hline $0.00 \mathrm{E}+00$ & $1.98 E-04$ & $4.26 E-07$ & $0.00 \mathrm{E}+00$ & $0.00 \mathrm{E}+00$ & $0.00 \mathrm{E}+00$ & $3.25 E-08$ & $7.51 E-06$ \\
\hline $0.00 \mathrm{E}+00$ & $2.12 \mathrm{E}-04$ & $4.68 E-07$ & $0.00 \mathrm{E}+00$ & $0.00 \mathrm{E}+00$ & $0.00 \mathrm{E}+00$ & $4.67 E-08$ & $8.87 E-06$ \\
\hline $0.00 \mathrm{E}+00$ & $2.27 E-04$ & $5.14 \mathrm{E}-07$ & $0.00 \mathrm{E}+00$ & $0.00 \mathrm{E}+00$ & $0.00 \mathrm{E}+00$ & $6.59 \mathrm{E}-08$ & $1.04 \mathrm{E}-05$ \\
\hline $0.00 \mathrm{E}+00$ & $2.43 E-04$ & $5.64 \mathrm{E}-07$ & $0.00 \mathrm{E}+00$ & $0.00 \mathrm{E}+00$ & $2.21 E-22$ & $9.15 \mathrm{E}-08$ & $1.21 \mathrm{E}-05$ \\
\hline $0.00 \mathrm{E}+00$ & $2.60 E-04$ & $6.18 \mathrm{E}-07$ & $0.00 \mathrm{E}+00$ & $0.00 \mathrm{E}+00$ & $4.08 E-20$ & $1.25 E-07$ & $1.39 \mathrm{E}-05$ \\
\hline $0.00 \mathrm{E}+00$ & $2.77 E-04$ & $6.76 \mathrm{E}-07$ & $0.00 \mathrm{E}+00$ & $0.00 \mathrm{E}+00$ & $1.95 \mathrm{E}-18$ & $1.69 \mathrm{E}-07$ & $1.59 \mathrm{E}-05$ \\
\hline $0.00 E+00$ & $2.95 E-04$ & $7.38 E-07$ & $0.00 \mathrm{E}+00$ & $0.00 \mathrm{E}+00$ & $4.44 E-17$ & $2.28 E-07$ & $1.81 \mathrm{E}-05$ \\
\hline $0.00 \mathrm{E}+00$ & $3.15 \mathrm{E}-04$ & $8.06 \mathrm{E}-07$ & $0.00 \mathrm{E}+00$ & $0.00 \mathrm{E}+00$ & $6.03 E-16$ & $3.04 \mathrm{E}-07$ & $2.06 \mathrm{E}-05$ \\
\hline $0.00 \mathrm{E}+00$ & $3.35 \mathrm{E}-04$ & $8.79 E-07$ & $0.00 \mathrm{E}+00$ & $0.00 \mathrm{E}+00$ & $5.59 \mathrm{E}-15$ & $3.96 \mathrm{E}-07$ & $2.33 E-05$ \\
\hline $0.00 \mathrm{E}+00$ & $3.56 \mathrm{E}-04$ & $9.57 E-07$ & $0.00 \mathrm{E}+00$ & $0.00 \mathrm{E}+00$ & $3.86 \mathrm{E}-14$ & $5.02 E-07$ & $2.63 E-05$ \\
\hline $0.00 \mathrm{E}+00$ & $3.78 \mathrm{E}-04$ & $1.04 \mathrm{E}-06$ & $0.00 \mathrm{E}+00$ & $0.00 \mathrm{E}+00$ & $2.11 E-13$ & $6.30 \mathrm{E}-07$ & $2.96 \mathrm{E}-05$ \\
\hline $0.00 \mathrm{E}+00$ & $4.01 \mathrm{E}-04$ & $1.13 E-06$ & $0.00 \mathrm{E}+00$ & $0.00 \mathrm{E}+00$ & $9.39 E-13$ & $7.80 \mathrm{E}-07$ & $3.36 \mathrm{E}-05$ \\
\hline $0.00 E+00$ & $4.25 E-04$ & $1.23 E-06$ & $0.00 \mathrm{E}+00$ & $0.00 \mathrm{E}+00$ & $3.52 E-12$ & $9.49 \mathrm{E}-07$ & $3.80 E-05$ \\
\hline $0.00 \mathrm{E}+00$ & $4.50 \mathrm{E}-04$ & $1.33 E-06$ & $0.00 \mathrm{E}+00$ & $0.00 \mathrm{E}+00$ & $1.14 \mathrm{E}-11$ & $1.15 E-06$ & $4.24 \mathrm{E}-05$ \\
\hline $0.00 \mathrm{E}+00$ & $4.77 \mathrm{E}-04$ & $1.44 \mathrm{E}-06$ & $0.00 \mathrm{E}+00$ & $0.00 \mathrm{E}+00$ & $2.97 \mathrm{E}-11$ & $1.38 \mathrm{E}-06$ & 4. $67 \mathrm{E}-05$ \\
\hline $0.00 \mathrm{E}+00$ & $5.04 \mathrm{E}-04$ & $1.56 \mathrm{E}-06$ & $0.00 \mathrm{E}+00$ & $0.00 \mathrm{E}+00$ & $7.05 E-11$ & $1.66 \mathrm{E}-06$ & $5.13 E-05$ \\
\hline $0.00 \mathrm{E}+00$ & $5.33 E-04$ & $1.69 \mathrm{E}-06$ & $0.00 \mathrm{E}+00$ & $0.00 \mathrm{E}+00$ & $1.55 \mathrm{E}-10$ & $1.97 \mathrm{E}-06$ & $5.62 E-05$ \\
\hline $0.00 \mathrm{E}+00$ & $5.62 \mathrm{E}-04$ & $1.83 E-06$ & $0.00 \mathrm{E}+00$ & $0.00 \mathrm{E}+00$ & $3.19 \mathrm{E}-10$ & $2.33 E-06$ & $6.16 \mathrm{E}-05$ \\
\hline $0.00 \mathrm{E}+00$ & $5.93 E-04$ & $1.97 E-06$ & $0.00 \mathrm{E}+00$ & $0.00 \mathrm{E}+00$ & $6.20 \mathrm{E}-10$ & $2.78 E-06$ & $6.73 E-05$ \\
\hline $0.00 \mathrm{E}+00$ & $6.26 \mathrm{E}-04$ & $2.12 \mathrm{E}-06$ & $0.00 \mathrm{E}+00$ & $0.00 \mathrm{E}+00$ & $1.14 \mathrm{E}-09$ & $3.32 E-06$ & $7.34 \mathrm{E}-05$ \\
\hline $0.00 \mathrm{E}+00$ & $6.59 \mathrm{E}-04$ & $2.29 E-06$ & $0.00 \mathrm{E}+00$ & $0.00 \mathrm{E}+00$ & $2.01 E-09$ & $3.95 E-06$ & $8.00 E-05$ \\
\hline $0.00 \mathrm{E}+00$ & $6.94 \mathrm{E}-04$ & $2.46 E-06$ & $0.00 \mathrm{E}+00$ & $0.00 \mathrm{E}+00$ & $3.40 \mathrm{E}-09$ & $4.57 \mathrm{E}-06$ & $8.69 E-05$ \\
\hline $0.00 \mathrm{E}+00$ & $7.31 \mathrm{E}-04$ & $2.65 E-06$ & $0.00 \mathrm{E}+00$ & $0.00 \mathrm{E}+00$ & $5.67 E-09$ & $5.20 E-06$ & $9.43 E-05$ \\
\hline $0.00 \mathrm{E}+00$ & $7.68 \mathrm{E}-04$ & $2.84 E-06$ & $0.00 \mathrm{E}+00$ & $0.00 \mathrm{E}+00$ & $9.23 E-09$ & $5.90 E-06$ & $1.02 E-04$ \\
\hline $0.00 \mathrm{E}+00$ & $8.07 \mathrm{E}-04$ & $3.05 E-06$ & $0.00 \mathrm{E}+00$ & $0.00 \mathrm{E}+00$ & $1.45 E-08$ & $6.66 \mathrm{E}-06$ & $1.09 \mathrm{E}-04$ \\
\hline $0.00 \mathrm{E}+00$ & $8.48 \mathrm{E}-04$ & $3.27 \mathrm{E}-06$ & $0.00 \mathrm{E}+00$ & $0.00 \mathrm{E}+00$ & $2.23 E-08$ & $7.56 \mathrm{E}-06$ & $1.17 \mathrm{E}-04$ \\
\hline $0.00 \mathrm{E}+00$ & $8.90 \mathrm{E}-04$ & $3.51 \mathrm{E}-06$ & $0.00 \mathrm{E}+00$ & $0.00 \mathrm{E}+00$ & $3.33 E-08$ & $8.73 E-06$ & $1.24 \mathrm{E}-04$ \\
\hline $0.00 \mathrm{E}+00$ & $9.34 \mathrm{E}-04$ & $3.76 \mathrm{E}-06$ & $0.00 \mathrm{E}+00$ & $0.00 \mathrm{E}+00$ & $4.85 E-08$ & $1.00 \mathrm{E}-05$ & 1. $32 \mathrm{E}-04$ \\
\hline $0.00 \mathrm{E}+00$ & $9.80 \mathrm{E}-04$ & $4.02 E-06$ & $0.00 \mathrm{E}+00$ & $0.00 \mathrm{E}+00$ & $6.93 E-08$ & $1.15 \mathrm{E}-05$ & $1.41 \mathrm{E}-04$ \\
\hline $0.00 \mathrm{E}+00$ & $1.03 \mathrm{E}-03$ & $4.29 \mathrm{E}-06$ & $0.00 \mathrm{E}+00$ & $0.00 \mathrm{E}+00$ & $9.59 \mathrm{E}-08$ & $1.31 \mathrm{E}-05$ & $1.50 \mathrm{E}-04$ \\
\hline
\end{tabular}


RESRAD-OFFSITE, Version 2.5

obabilistic Dose and Risk Report

Title : Offsite Resident Farmer Deterministic Run

File : RF TC99 DOESG FWD-FV2.ROF

Summary of dose at graphical times, reptition 1 (continued)

Time

Years

1. $65 \mathrm{E}+02$

$1.66 \mathrm{E}+02$

$1.66 \mathrm{E}+02$

$1.67 \mathrm{E}+02$

$1.67 \mathrm{E}+02$

$1.68 \mathrm{E}+02$

$1.68 \mathrm{E}+02$

1. $69 \mathrm{E}+02$

1. $69 \mathrm{E}+02$

1. $70 \mathrm{E}+02$

1. $70 \mathrm{E}+02$

1. $71 \mathrm{E}+02$

1. $71 \mathrm{E}+02$

1. $72 \mathrm{E}+02$

1. $72 \mathrm{E}+02$

1. $73 \mathrm{E}+02$

1. $73 \mathrm{E}+02$

1. $74 \mathrm{E}+02$

1. $74 \mathrm{E}+02$

1. $75 \mathrm{E}+02$

1. $75 \mathrm{E}+02$

$1.76 \mathrm{E}+02$

$1.76 \mathrm{E}+02$

$1.77 \mathrm{E}+02$

1. $77 \mathrm{E}+02$

1. $78 \mathrm{E}+02$

1. $78 \mathrm{E}+02$

$1.79 \mathrm{E}+02$

1. $79 \mathrm{E}+02$

1. $80 \mathrm{E}+02$

1. $80 \mathrm{E}+02$

$1.81 \mathrm{E}+02$

$1.81 \mathrm{E}+02$

1. $82 \mathrm{E}+02$

$1.83 \mathrm{E}+02$

$1.83 \mathrm{E}+02$

$1.84 \mathrm{E}+02$

1. $84 \mathrm{E}+02$

1. $85 \mathrm{E}+02$

$1.85 \mathrm{E}+02$

$1.86 \mathrm{E}+02$

$1.86 \mathrm{E}+02$

$1.87 \mathrm{E}+02$

$1.87 \mathrm{E}+02$

$1.88 \mathrm{E}+02$

1. $88 \mathrm{E}+02$
Dose statistics at graphical times, mrem/yr

\begin{tabular}{|c|c|c|c|c|c|c|c|}
\hline inimum & aximum & lean & edian & & & $\%$ & \\
\hline+00 & -03 & -06 & +00 & +00 & 07 & 05 & -04 \\
\hline $.00 \mathrm{E}+00$ & $1.13 \mathrm{E}-03$ & $0 E-06$ & $0 \mathrm{E}+00$ & $00 \mathrm{E}+00$ & $1.74 \mathrm{E}-07$ & $1.69 \mathrm{E}-05$ & $1.75 E-04$ \\
\hline $00 F+00$ & $8 F-03$ & $22 F-06$ & $.00 E+00$ & $.00 \mathrm{E}+00$ & $0 F-07$ & $90 F-05$ & -04 \\
\hline $.00 \mathrm{E}+00$ & $1.23 E-03$ & $5.56 \mathrm{E}-06$ & $.00 \mathrm{E}+00$ & $.00 \mathrm{E}+00$ & $.05 E-07$ & 05 & -04 \\
\hline $.00 \mathrm{E}+00$ & 03 & 6 & & & & & -04 \\
\hline $.00 E+00$ & $1.35 E-03$ & & & & & & -04 \\
\hline$\Xi+00$ & 03 & 0 & $\mathrm{E}+00$ & 0 & 7 & 5 & $33 E-04$ \\
\hline $.00 \mathrm{E}+00$ & $1.47 \mathrm{E}-03$ & $2 E-06$ & $O E+00$ & $0 \mathrm{E}+00$ & $47 E-07$ & $1 \mathrm{E}-05$ & $46 E-04$ \\
\hline $.00 E+00$ & $53 E-03$ & $6 F-0-0-2-2$ & $.00 E+00$ & $00 F+00$ & $5 \mathrm{~F}-$ & 50 & $60 E-04$ \\
\hline$E+00$ & $1.60 \mathrm{E}-03$ & $8.02 E-06$ & & $8.14 \mathrm{E}-23$ & 6 & $.89 E-05$ & 4 \\
\hline $.00 E+00$ & 1.6 & $1 \mathrm{~F}$ & 0 & $E-20$ & 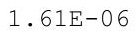 & 5 & $E-04$ \\
\hline $.00 \mathrm{E}+00$ & $1.74 \mathrm{E}-03$ & & & & & & $3.05 E-04$ \\
\hline $.00 E+00$ & $1.81 E-03$ & $9.55 E-06$ & $0.00 \mathrm{E}+00$ & $2.84 E-17$ & $2.35 E-06$ & -05 & $3.25 E-04$ \\
\hline$E+00$ & 03 & -05 & & & & & -04 \\
\hline $.00 E+00$ & 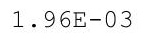 & ( & $.00 E+00$ & 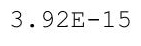 & 6 & 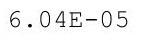 & -04 \\
\hline$E+00$ & 2 & $1.13 E-05$ & 0 & 4 & 5 & $56 E-05$ & 4 \\
\hline $0 \cap F+00$ & 2 . & $1.19 \mathrm{E}-05$ & $\mathrm{E}+00$ & 3 & 6 & $7.11 E-05$ & -04 \\
\hline $.00 \mathrm{E}+00$ & $2.21 E-03$ & 1. $26 \mathrm{E}-05$ & $0.00 \mathrm{E}+00$ & & $4.93 E-06$ & & $4.17 \mathrm{E}-04$ \\
\hline $.00 \mathrm{E}+00$ & $2.29 \mathrm{E}-03$ & $.33 E-05$ & $0.00 \mathrm{E}+00$ & $6 \mathrm{E}-12$ & 505 & & $36 E-04$ \\
\hline+00 & $2.38 E-03$ & -05 & $.00 E+00$ & -12 & D & 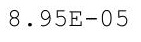 & $57 E-04$ \\
\hline קתחم תמת & to & •. 40 प & $00 E+00$ & -11 & 0 & & -04 \\
\hline $.00 E+00$ & 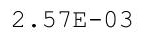 & (n) & & & 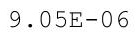 & & 04 \\
\hline $.00 E+00$ & 2. & 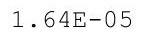 & $0.00 \mathrm{E}+00$ & 1 & 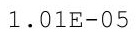 & $1.11 \mathrm{E}-04$ & -04 \\
\hline$\cap \cap F+\cap \cap$ & 2775- & $73 F$ & $.00 \mathrm{E}+00$ & $.97 E-10$ & $3 \mathrm{~F}$ & $9 F_{-}$ & $56 E-04$ \\
\hline $.00 \mathrm{E}+00$ & $287 \mathrm{~F}-03$ & $182=0$ & $0.00 \mathrm{E}+00$ & $90 E-10$ & $265-0$ & 275 & $85 E-04$ \\
\hline $.00 E+00$ & $2.98 E-03$ & $1 F-0.5$ & $E+00$ & $7 E-10$ & & 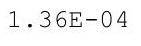 & $18 E-04$ \\
\hline & & & & & & & -04 \\
\hline $.00 \mathrm{E}+00$ & $3.20 \mathrm{E}-03$ & 2 & $0.00 \mathrm{E}+00$ & 09 & . & & $39 E-04$ \\
\hline $.00 \mathrm{E}+00$ & $3.32 E-03$ & $2 \cdot 2+100$ & $0.00 \mathrm{E}+00$ & $4.56 \mathrm{E}-09$ & I. & म.Uनע & $7.22 E-04$ \\
\hline $00 \mathrm{E}+00$ & 3 & $2.32 \mathrm{E}-$ & $0.00 \mathrm{E}+00$ & 20 & $11 \mathrm{E}-$ & $1.83 E-0$ & $.56 \mathrm{E}-04$ \\
\hline $00 \mathrm{E}+\mathrm{C}$ & $3.56 \mathrm{E}-03$ & $.44 \mathrm{E}-$ & & 112 & & $1.97 \mathrm{E}-$ & $90 \mathrm{E}$ \\
\hline $.00 E+00$ & $F-03$ & 2 & $.00 \mathrm{E}+00$ & & & & 04 \\
\hline & 03 & & & & & & 04 \\
\hline $\mathrm{E}+00$ & $3.95 E-03$ & 05 & 0 & 8 & & & -04 \\
\hline $.00 \mathrm{E}+00$ & $4.08 E-03$ & $2.94 E-05$ & $0.00 \mathrm{E}+00$ & $5.02 \mathrm{E}-08$ & . & $2.095-04$ & $.42 E-04$ \\
\hline •. & $4.22 E-03$ & $\begin{array}{ccc}.00 \\
0\end{array}$ & & & & & $9.83 E-04$ \\
\hline $5=$ & 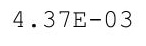 & 5 & $0.00 \mathrm{E}+$ & 8 & 5 & 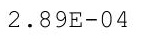 & 03 \\
\hline 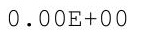 & 4 & $3.37 E-05$ & & & & & 03 \\
\hline $.00 E+00$ & 3 & 5 & $0 E+00$ & 7 & 5 & 4 & 03 \\
\hline $0 E+00$ & $4.82 E-03$ & $3.68 E-05$ & $0.00 \mathrm{E}+00$ & & & & -03 \\
\hline $\mathrm{E}+00$ & 4.9 & 5 & 0 & & & & -03 \\
\hline (6) & & & & & & & $.28 E-03$ \\
\hline 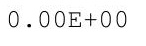 & . & . & $0.00 \mathrm{E}+00$ & $4.10 E-01$ & 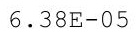 & 4 & $1.33 E-03$ \\
\hline $00 E+00$ & $5.48 E-03$ & & & & $6.87 E-05$ & $4.15 E-04$ & $1.38 E-03$ \\
\hline & & & $0.00 \mathrm{E}+00$ & $1.44 E-01$ & $1.44 \mathrm{D}$ & $4.34 \mathrm{E}-$ & 1.44 \\
\hline $.00 E+00$ & $E-03$ & $5 E-05$ & $.00 \mathrm{E}+00$ & $.22 E-07$ & $07 E-05$ & $4.54 \mathrm{E}-04$ & $1.49 \mathrm{E}-03$ \\
\hline
\end{tabular}


RESRAD-OFFSITE, Version 2.5

obabilistic Dose and Risk Report

Title : Offsite Resident Farmer Deterministic Run

File : RF TC99 DOESG FWD-FV2.ROF

Summary of dose at graphical times, reptition 1 (continued)

Time

Years

$1.89 \mathrm{E}+02$

$1.89 \mathrm{E}+02$

$1.90 \mathrm{E}+02$

$1.90 \mathrm{E}+02$

$1.91 \mathrm{E}+02$

$1.91 \mathrm{E}+02$

$1.92 \mathrm{E}+02$

1. $92 \mathrm{E}+02$

1. $93 \mathrm{E}+02$

1. $93 \mathrm{E}+02$

1. $94 \mathrm{E}+02$

$1.94 \mathrm{E}+02$

$1.95 \mathrm{E}+02$

$1.95 \mathrm{E}+02$

$1.96 \mathrm{E}+02$

$1.96 \mathrm{E}+02$

$1.97 \mathrm{E}+02$

$1.97 \mathrm{E}+02$

$1.98 \mathrm{E}+02$

$1.98 \mathrm{E}+02$

$1.99 \mathrm{E}+02$

$1.99 \mathrm{E}+02$

$2.00 \mathrm{E}+02$

$2.00 \mathrm{E}+02$

$2.01 \mathrm{E}+02$

$2.01 \mathrm{E}+02$

$2.02 \mathrm{E}+02$

$2.03 \mathrm{E}+02$

$2.03 E+02$

$2.04 \mathrm{E}+02$

$2.04 \mathrm{E}+02$

$2.05 \mathrm{E}+02$

$2.05 \mathrm{E}+02$

$2.06 \mathrm{E}+02$

$2.06 \mathrm{E}+02$

$2.07 \mathrm{E}+02$

$2.07 \mathrm{E}+02$

$2.08 \mathrm{E}+02$

$2.08 \mathrm{E}+02$

$2.09 \mathrm{E}+02$

$2.09 \mathrm{E}+02$

$2.10 \mathrm{E}+02$

$2.10 \mathrm{E}+02$

$2.11 \mathrm{E}+02$

2. $11 \mathrm{E}+02$

$2.12 \mathrm{E}+02$
Dose statistics at graphical times, mrem/yr

\begin{tabular}{|c|c|c|c|c|c|c|c|}
\hline m & axin & ean & ledian & & & $\%$ & \\
\hline $.00 \mathrm{E}+00$ & $6.01 E-03$ & $4.96 \mathrm{E}-05$ & $0.00 \mathrm{E}+00$ & $1.14 \mathrm{E}-06$ & -05 & -04 & -Us \\
\hline $.00 \mathrm{E}+00$ & $6.20 \mathrm{E}-03$ & $7 E-05$ & $.00 \mathrm{E}+00$ & $1.39 \mathrm{E}-06$ & -05 & -04 & -03 \\
\hline$E+00$ & $6.39 \mathrm{E}-03$ & $5.38 \mathrm{E}-05$ & $0 E+00$ & $1.69 \mathrm{E}-06$ & -04 & -04 & $1.67 \mathrm{E}-03$ \\
\hline $.00 E+00$ & $9 E-03$ & $0 F-05$ & $.00 \mathrm{E}+00$ & $.03 E-06$ & $07 E-04$ & $8 E-04$ & $1.73 E-03$ \\
\hline $.00 \mathrm{E}+00$ & $.79 \mathrm{E}-03$ & $83 E-05$ & $.00 \mathrm{E}+00$ & $.41 \mathrm{E}-06$ & E-04 & $5 E-04$ & .03 \\
\hline$E+00$ & 03 & 5 & & 6 & 4 & 4 & -03 \\
\hline $.00 \mathrm{E}+00$ & 03 & $6.32 \mathrm{E}$ & & 6 & 4 & 4 & -03 \\
\hline $.00 \mathrm{E}+00$ & & & & & & & -03 \\
\hline$E+00$ & $E-03$ & $F-\Omega(2-2)$ & & 06 & 50 & -04 & $08 E-03$ \\
\hline $00 \mathrm{E}+00$ & 3 & $7.10 \mathrm{E}-05$ & $.00 \mathrm{E}+00$ & 6 & $1.60 \mathrm{E}-04$ & -04 & -03 \\
\hline $.00 \mathrm{E}+00$ & B & $7.38 E-05$ & & 6 & 4 & $7.54 \mathrm{E}-04$ & -03 \\
\hline $.00 \mathrm{E}+00$ & & & & & & & -03 \\
\hline $\mathrm{F}+00$ & $8 \quad 57 \mathrm{~F}-03$ & $F_{-}(2-3)$ & & 6 & 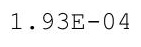 & -04 & -03 \\
\hline $.00 \mathrm{E}+00$ & $8.81 \mathrm{E}-03$ & $8.26 \mathrm{E}-05$ & $0.00 \mathrm{E}+00$ & $8.45 E-06$ & $2.06 \mathrm{E}-04$ & $8.58 \mathrm{E}-04$ & $2.48 \mathrm{E}-03$ \\
\hline $.00 \mathrm{E}+00$ & $E-03$ & $\mathrm{~F}$ & $E+00$ & 06 & 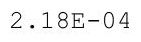 & -04 & $E-03$ \\
\hline$E+00$ & & & & & & & -03 \\
\hline $.00 \mathrm{E}+00$ & -03 & . & 00 & 5 & & & 03 \\
\hline $00 \mathrm{E}+00$ & 3 & & & & & & 3 \\
\hline $.00 E+00$ & $.01 \mathrm{E}-02$ & & $0 \mathrm{E}+00$ & 535 & & & -03 \\
\hline $.00 \mathrm{E}+00$ & $.04 \mathrm{E}-02$ & $1.03 \mathrm{E}-0$ & $0.00 \mathrm{E}+00$ & $.75 E-05$ & $2.80 \mathrm{E}-$ & $E-03$ & -03 \\
\hline $.00 \mathrm{E}+00$ & $07 E-02$ & $.07 E-0$ & $.00 \mathrm{E}+00$ & -05 & 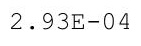 & $E-03$ & -03 \\
\hline & & & & & & & \\
\hline & & & & & & & \\
\hline $.00 \mathrm{E}+00$ & 02 & $\perp \cdot \pm 0+$ & & 5 & $3.35 E-04$ & & 03 \\
\hline $00 \mathrm{E}+00$ & 2 & 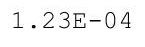 & $0.00 \mathrm{E}+00$ & 5 & $3.50 \mathrm{E}-04$ & 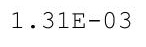 & 03 \\
\hline $.00 \mathrm{E}+00$ & $.22 \mathrm{E}-02$ & م & $.00 \mathrm{E}+00$ & $09 E-05$ & 665 & $1.36 \mathrm{E}-03$ & $69 E-03$ \\
\hline $.00 E+00$ & $25 \mathrm{~F}-02$ & $131 \mathrm{~F}=0$ & $0.00 \mathrm{E}+00$ & תחת קו & & $41 F-03$ & $81 \mathrm{~F}-03$ \\
\hline & & & & & & & 03 \\
\hline $00 \mathrm{E}+00$ & $1.32 \mathrm{~F}$ & & & & & & \\
\hline $.00 \mathrm{E}+00$ & $1.35 \mathrm{E}-02$ & $1.40 \pm-4$ & . $00 \mathrm{E}+0 \mathrm{U}$ & $4.37 E-05$ & (10) & 03 & -03 \\
\hline $.00 \mathrm{E}+00$ & $1.38 \mathrm{E}-02$ & $\begin{array}{lll}0 \\
\text {. }\end{array}$ & $0.00 \mathrm{E}+00$ & $4.70 E-05$ & $10<-$ & ser & $.32 E-03$ \\
\hline $.00 \mathrm{E}+00$ & $1.42 \mathrm{E}-02$ & 土. & & & & 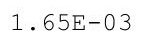 & $4.45 E-03$ \\
\hline $.00 E+00$ & 105 & & $0.00 \mathrm{E}+00$ & קרק & & & $57 \mathrm{~F}-03$ \\
\hline مח & & & & & & & 3 \\
\hline & 2 & & & -05 & & -03 & 03 \\
\hline $0 E+00$ & $1.56 \mathrm{E}$ & $1.77 \mathrm{E}$ & $.00 \mathrm{E}+00$ & .00 & 3.001 & 03 & -03 \\
\hline $.00 \mathrm{E}+00$ & $1.60 \mathrm{E}$ & & & & & & \\
\hline $00 \mathrm{E}+00$ & $1.64 \mathrm{E}-02$ & & & & & & 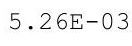 \\
\hline 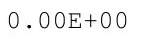 & $+\cdots$ & + & - & 5 & & 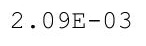 & 3 \\
\hline O & & & & & & & 3 \\
\hline & 02 & 2.0 & $0.00 \mathrm{E}+00$ & 5 & & 3 & 03 \\
\hline $\mathrm{E}+00$ & $1.81 \mathrm{E}-02$ & $2.13 \mathrm{E}-04$ & $0.00 \mathrm{E}+00$ & 1.04 & & 03 & -03 \\
\hline & & & & & & & \\
\hline & \pm 0 & 5. & . U मे & +0 & & & $18 \mathrm{E}-03$ \\
\hline & $+\cdots$ & 2.0 & & 4 & 4 & 3 & $5-20$ \\
\hline $00 E+00$ & $E-02$ & $1 E-04$ & $.00 E+00$ & $E-04$ & $E-04$ & $2 E-03$ & -03 \\
\hline
\end{tabular}


RESRAD-OFFSITE, Version 2.5

obabilistic Dose and Risk Report

Title : Offsite Resident Farmer Deterministic Run

File : RF TC99 DOESG FWD-FV2.ROF

Summary of dose at graphical times, reptition 1 (continued)

Time

Years

$2.12 \mathrm{E}+02$

$2.13 \mathrm{E}+02$

$2.13 \mathrm{E}+02$

$2.14 \mathrm{E}+02$

$2.14 \mathrm{E}+02$

$2.15 \mathrm{E}+02$

$2.15 \mathrm{E}+02$

$2.16 \mathrm{E}+02$

$2.16 \mathrm{E}+02$

$2.17 \mathrm{E}+02$

$2.17 \mathrm{E}+02$

$2.18 \mathrm{E}+02$

$2.18 \mathrm{E}+02$

$2.19 \mathrm{E}+02$

$2.19 \mathrm{E}+02$

$2.20 \mathrm{E}+02$

$2.20 \mathrm{E}+02$

$2.21 \mathrm{E}+02$

2. $21 E+02$

2. $22 \mathrm{E}+02$

$2.23 E+02$

$2.23 E+02$

2. $24 \mathrm{E}+02$

$2.24 \mathrm{E}+02$

2. $25 \mathrm{E}+02$

$2.25 \mathrm{E}+02$

2. $26 \mathrm{E}+02$

$2.26 \mathrm{E}+02$

$2.27 \mathrm{E}+02$

$2.27 \mathrm{E}+02$

2. $28 \mathrm{E}+02$

$2.28 \mathrm{E}+02$

$2.29 \mathrm{E}+02$

2. $29 \mathrm{E}+02$

2. $30 \mathrm{E}+02$

2. $30 E+02$

$2.31 \mathrm{E}+02$

2. $31 E+02$

2. $32 \mathrm{E}+02$

2. $32 E+02$

$2.33 E+02$

2. $33 \mathrm{E}+02$

$2.34 \mathrm{E}+02$

2. $34 \mathrm{E}+02$

$2.35 E+02$

$2.35 \mathrm{E}+02$
Dose statistics at graphical times, mrem/yr

\begin{tabular}{|c|c|c|c|c|c|c|c|}
\hline $\mathrm{m}$ & aximum & ea & ec & $0 \%$ & & $\%$ & \\
\hline $.00 \mathrm{E}+00$ & $2.03 E-02$ & 04 & $0.00 \mathrm{E}+00$ & 4 & 04 & 03 & $0.09 E-02$ \\
\hline+00 & $2.07 E-02$ & $2.56 \mathrm{E}-04$ & $0.00 \mathrm{E}+00$ & $1 E-04$ & $5 E-04$ & $2.78 E-03$ & $38 E-03$ \\
\hline $.00 \mathrm{E}+00$ & $12 E-02$ & $64 E-04$ & $.00 \mathrm{E}+00$ & $59 E-04$ & $41 E-04$ & $.86 E-03$ & $8 E-03$ \\
\hline $00 \mathrm{E}+00$ & $17 \mathrm{E}-02$ & $72 \mathrm{~F}-04$ & $.00 \mathrm{E}+00$ & $.67 E-04$ & $979 F-04$ & $95 \mathrm{~F}-03$ & $28 F-03$ \\
\hline $.00 \mathrm{E}+00$ & $22 E-02$ & $80 \mathrm{~F}-2-5$ & & 4 & 3 & 3 & -03 \\
\hline $.00 \mathrm{E}+00$ & $2.26 \mathrm{E}-02$ & & & & & & \\
\hline $.00 E+00$ & $2.32 \mathrm{E}-02$ & & & 4 & & & \\
\hline $.00 \mathrm{E}+00$ & $2.37 \mathrm{E}-02$ & 4 & +00 & 4 & 3 & -03 & -03 \\
\hline$E+00$ & $42 E-02$ & - St & $.00 \mathrm{E}+00$ & -04 & 3 & -03 & $35 E-03$ \\
\hline $.00 E+00$ & $47 E-02$ & קבקט & $.00 \mathrm{E}+00$ & 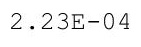 & ק1 & $.53 E-03$ & 3 \\
\hline $.00 E+00$ & -02 & 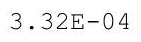 & & 2.3 & & & 03 \\
\hline $.00 \mathrm{E}+00$ & $2.58 \mathrm{E}-02$ & 3 & & 4 & 3 & 3 & -03 \\
\hline $.00 \mathrm{E}+00$ & $2.63 E-02$ & $3.51 \mathrm{E}-04$ & & $2.54 E-04$ & $1.32 E-03$ & & $E-03$ \\
\hline $.00 \mathrm{E}+00$ & $2.69 \mathrm{E}-02$ & $.61 E-04$ & $0.00 \mathrm{E}+00$ & $2.66 \mathrm{E}-04$ & 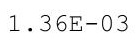 & -03 & $E-03$ \\
\hline$\Xi+00$ & $75 E-02$ & $71 T^{-1}$ & 0 & 4 & & -03 & -03 \\
\hline $.00 \mathrm{E}+00$ & 02 & 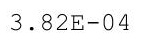 & 00 & $291 \mathrm{~F}-04$ & & 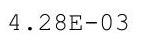 & 02 \\
\hline$E+00$ & 2 & $3.92 E-04$ & & & & & 2 \\
\hline $.00 \mathrm{E}+00$ & 2 & 4 & & & 3 & 3 & 2 \\
\hline $.00 \mathrm{E}+00$ & $3.03 E-02$ & $4.14 \mathrm{E}-04$ & $0.00 \mathrm{E}+00$ & $3.33 E-0$ & $1.56 \mathrm{E}-03$ & $4.69 E-03$ & 1. $09 \mathrm{E}-02$ \\
\hline $.00 \mathrm{E}+00$ & $3.11 \mathrm{E}-02$ & $4.25 \mathrm{E}-04$ & $0.00 \mathrm{E}+00$ & $.46 \mathrm{E}-04$ & $1.60 \mathrm{E}-$ & $E-03$ & $12 E-02$ \\
\hline $00 \mathrm{E}+00$ & -02 & & & & & & $5 E-02$ \\
\hline $00 \mathrm{E}+00$ & 2 & - 1 & $0.00 \mathrm{E}+$ & to & 3 & & \\
\hline $00 \mathrm{E}+00$ & 02 & $4.61 \mathrm{E}-04$ & & & 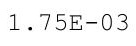 & & 2 \\
\hline $.00 E+00$ & 02 & $4.73 E-04$ & 0 & $17 \mathrm{~F}-\mathrm{O}$ & P & & 02 \\
\hline $.00 \mathrm{E}+00$ & $53 E-02$ & 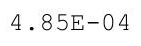 & $.00 \mathrm{E}+00$ & ת7 תר & 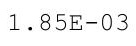 & $E-03$ & $27 \mathrm{E}-$ \\
\hline $0 \cap \mathrm{F}+0 \cap 0$ & $.61 E-02$ & $.98 E-0$ & $0.00 \mathrm{E}+00$ & $4.46 \mathrm{E}-$ & $.91 \mathrm{E}-$ & $=0$ & $.30 E-02$ \\
\hline $.00 \mathrm{E}+00$ & $1 E-02$ & . & & $62 \mathrm{~F}_{-}$ & & & $32 E-02$ \\
\hline & & & & & & & \\
\hline & & 0.30 & 0.0 & 4 & 3 & & -02 \\
\hline $.00 \mathrm{E}+00$ & $3.99 \mathrm{E}-02$ & $\begin{array}{ll}02 \square \\
0\end{array}$ & $0.00 \mathrm{E}+00$ & $\cdot+00$ & $2 \cdot 13 \pm-03$ & 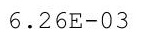 & $.43 E-02$ \\
\hline $.00 \mathrm{E}+00$ & $08 E-02$ & 更 & $0.00 \mathrm{E}+00$ & . & $2 \cdot 24+$ & 4 & $1.46 \mathrm{E}-02$ \\
\hline $.00 \mathrm{E}+0$ & 2 & & & & & & \\
\hline $.00 E+00$ & 2 & & & & & & 02 \\
\hline & & & & & & & \\
\hline & & $6.25 \mathrm{E}$ & $0.00 \mathrm{E}+00$ & 4 & 3 & & 02 \\
\hline $.00 \mathrm{E}+00$ & $4.59 \mathrm{E}-02$ & $0.4 \perp E-04$ & $.00 E+00$ & 0.210 & $2.0<$ & & $.64 \mathrm{E}-02$ \\
\hline $.00 E+00$ & $4.10 E-02$ & & & & & & $1.0 / \mathrm{E}-\mathrm{U} 2$ \\
\hline 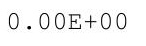 & 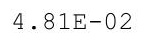 & 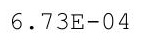 & $0.00 \mathrm{E}+00$ & 列 & & & $1.71 \mathrm{E}-02$ \\
\hline $.00 E+0$ & $4.92 \mathrm{E}-02$ & $6.89 \mathrm{E}-04$ & $0.00 \mathrm{E}+00$ & 0 & 2.00 & & 2 \\
\hline & 2 & 4 & $0.00 \mathrm{E}+00$ & 4 & 2.93 & 3 & 02 \\
\hline $0 \mathrm{E}+00$ & $5.15 \mathrm{E}-02$ & $7.23 E-04$ & $.00 \mathrm{E}$ & $7.35 \mathrm{E}$ & 3 & & -02 \\
\hline & 02 & 4 & & & & & \\
\hline טע山 & 2 & & $0.00 E+00$ & & & & $1.91 \mathrm{E}-\mathrm{U} 2$ \\
\hline $.00 E+00$ & $5.3 \perp E-U \angle$ & . & $0.00 \mathrm{E}+00$ & $8.05 E-04$ & $3.23 E-03$ & $8.09 E-03$ & $1.96 \mathrm{E}-02$ \\
\hline $.00 \mathrm{E}+00$ & $5.63 E-02$ & . & $0.00 \mathrm{E}+00$ & $8.29 E-04$ & . & $.00 \mathrm{H}$ & $.00 E-02$ \\
\hline$E+00$ & $E-02$ & $E-04$ & $.00 \mathrm{E}+00$ & $.54 \mathrm{E}-04$ & -03 & 3 & $2.04 \mathrm{E}-02$ \\
\hline
\end{tabular}


RESRAD-OFFSITE, Version 2.5

obabilistic Dose and Risk Report

Title : Offsite Resident Farmer Deterministic Run

File : RF TC99 DOESG FWD-FV2.ROF

Summary of dose at graphical times, reptition 1 (continued)

Time

Years

$2.36 \mathrm{E}+02$

2. $36 \mathrm{E}+02$

2. $37 \mathrm{E}+02$

2. $37 \mathrm{E}+02$

2. $38 \mathrm{E}+02$

2. $38 \mathrm{E}+02$

$2.39 \mathrm{E}+02$

2. $39 \mathrm{E}+02$

$2.40 \mathrm{E}+02$

$2.40 \mathrm{E}+02$

$2.41 E+02$

2. $41 \mathrm{E}+02$

2. $42 \mathrm{E}+02$

$2.43 E+02$

2. $43 \mathrm{E}+02$

2. $44 \mathrm{E}+02$

2. $44 \mathrm{E}+02$

$2.45 \mathrm{E}+02$

2. $45 \mathrm{E}+02$

$2.46 \mathrm{E}+02$

$2.46 \mathrm{E}+02$

$2.47 \mathrm{E}+02$

$2.47 \mathrm{E}+02$

2. $48 \mathrm{E}+02$

2. $48 \mathrm{E}+02$

2. $49 \mathrm{E}+02$

2. $49 \mathrm{E}+02$

$2.50 \mathrm{E}+02$

2. $50 \mathrm{E}+02$

2. $51 \mathrm{E}+02$

2. $51 \mathrm{E}+02$

2. $52 \mathrm{E}+02$

$2.52 \mathrm{E}+02$

2. $53 \mathrm{E}+02$

$2.53 \mathrm{E}+02$

2. $54 \mathrm{E}+02$

$2.54 \mathrm{E}+02$

$2.55 \mathrm{E}+02$

2. $55 \mathrm{E}+02$

$2.56 \mathrm{E}+02$

$2.56 \mathrm{E}+02$

$2.57 \mathrm{E}+02$

$2.57 \mathrm{E}+02$

$2.58 \mathrm{E}+02$

$2.58 \mathrm{E}+02$

$2.59 \mathrm{E}+02$
Dose statistics at graphical times, mrem/yr

\begin{tabular}{|c|c|c|c|c|c|c|c|}
\hline m & aximum & ea & ec & & & & \\
\hline $.00 \mathrm{E}+00$ & $5.89 \mathrm{E}-02$ & $0.35 E$ & $0.00 \mathrm{E}+00$ & עם & 然 & 03 & -02 \\
\hline+00 & $6.01 E-02$ & $8.53 E-04$ & $0.00 \mathrm{E}+00$ & $E-04$ & $9 E-03$ & -03 & $13 E-02$ \\
\hline $.00 E+00$ & $15 E-02$ & $3 F-04$ & $.00 \mathrm{E}+00$ & $35 E-04$ & $69 E-03$ & $69 E-03$ & $18 E-02$ \\
\hline $00 \mathrm{E}+00$ & $28 E-02$ & $93 F-04$ & $.00 \mathrm{E}+00$ & $68 \mathrm{~F}-04$ & $795-03$ & $90 F-03$ & $.23 E-02$ \\
\hline+00 & -02 & 4 & & 3 & 3 & 2 & -02 \\
\hline $.00 E+00$ & & & & & & & -02 \\
\hline $.00 E+00$ & -02 & & & & & & $E-02$ \\
\hline+00 & -02 & 4 & +00 & 3 & 3 & -02 & $2 E-02$ \\
\hline$E+00$ & -02 & -0 & $.00 \mathrm{E}+00$ & 3 & 3 & -02 & $47 E-02$ \\
\hline $00 E+00$ & $13 E-02$ & תרק & $.00 \mathrm{E}+00$ & 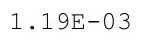 & תרכ2 & $.13 E-02$ & $52 E-02$ \\
\hline+00 & 02 & & & & & & -02 \\
\hline $.00 \mathrm{E}+00$ & $.42 E-02$ & 1 & & 3 & 3 & 2 & -02 \\
\hline $.00 \mathrm{E}+00$ & $7.58 \mathrm{E}-02$ & $1.09 \mathrm{E}-03$ & & $1.29 E-03$ & & -02 & $2.68 \mathrm{E}-02$ \\
\hline $.00 \mathrm{E}+00$ & $7.73 E-02$ & $1 \cdot 12 \mathrm{~L}-U \mathrm{~S}$ & & 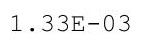 & 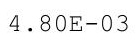 & -02 & $2.73 E-02$ \\
\hline$E+00$ & -02 & $1.14 \mathrm{E}-03$ & 0 & 3 & 3 & -02 & $79 E-02$ \\
\hline $.00 \mathrm{E}+00$ & -02 & $1.16 \mathrm{E}-03$ & $0 \mathrm{E}+00$ & $141 \mathrm{~F}-03$ & 3 & 2 & 02 \\
\hline$E+00$ & 2 & 1.19E-03 & & & & & 2 \\
\hline $.00 \mathrm{E}+00$ & 2 & 1. $22 \mathrm{E}-03$ & & 3 & 3 & 2 & 02 \\
\hline $.00 E+00$ & $.54 E-02$ & $1.24 \mathrm{E}-03$ & $0.00 \mathrm{E}+00$ & $1.53 \mathrm{E}-03$ & $.42 E-03$ & 1. $38 E-02$ & $3.02 E-02$ \\
\hline $.00 \mathrm{E}+00$ & $.71 \mathrm{E}-02$ & $1.27 \mathrm{E}-0$ & $0.00 \mathrm{E}+00$ & $1.57 \mathrm{E}-03$ & $5.54 \mathrm{E}-$ & $E-02$ & $08 E-02$ \\
\hline $.00 \mathrm{E}+00$ & -02 & & & & & 2 & -02 \\
\hline $00 E+00$ & & & & 3 & 3 & -02 & -02 \\
\hline $.00 E+00$ & 2 & $\perp$ & $.00 \mathrm{E}+00$ & 1. & P & & -02 \\
\hline $.00 \mathrm{E}+00$ & 02 & $1.38 \mathrm{E}-03$ & 0 & $\perp$ & $6.11 \mathrm{E}-03$ & 2 & -02 \\
\hline $.00 \mathrm{E}+00$ & $60 \mathrm{E}-02$ & קח & $.00 E+00$ & בת & $27 \mathrm{E}-$ & $5 E-02$ & $E-02$ \\
\hline $0 \cap F+0 \cap$ & $.78 \mathrm{E}-02$ & $.44 \mathrm{E}-0$ & $0.00 \mathrm{E}+00$ & $1.84 \mathrm{E}-\mathrm{C}$ & תריה & $58 E-02$ & $.45 E-02$ \\
\hline $.00 \mathrm{E}+00$ & $.97 E-02$ & & & תمח0 1 & & & $52 E-02$ \\
\hline & & & & & & & -02 \\
\hline & & $1 \cdot 3$ & 19 & & o & & -02 \\
\hline $.00 \mathrm{E}+00$ & $1.05 E-01$ & 1.0050 & $-90 \pm-17$ & 2.001 & .00 D & $1.70 \mathrm{E}-02$ & $.72 E-02$ \\
\hline $.00 \mathrm{E}+00$ & $1.07 \mathrm{E}-01$ & $1.00+v_{0}$ & $2.315-10$ & $2.12 \mathrm{E}-$ & 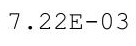 & $1.74 \mathrm{E}-02$ & $.79 E-02$ \\
\hline $.00 \mathrm{E}+0$ & 1 & & & & & $1.77 \mathrm{E}-0$ & 2 \\
\hline $.00 E+00$ & 1. $11 \mathrm{E}-01$ & & & & & & 02 \\
\hline & & & 14 & & & & \\
\hline & & 3 & 13 & 3 & 3 & & \\
\hline $.00 \mathrm{E}+00$ & $1.18 \mathrm{E}-01$ & I. $10 \mathrm{E}-\mathrm{T}$ & 12 & 2.100 & o & $.90 E-02$ & $.14 \mathrm{E}-02$ \\
\hline . & $1.20 \mathrm{E}-01$ & & & & & & $4 \cdot \angle \angle E-U \angle$ \\
\hline ( & 1.2 & & $5-\perp$ & & & & $.29 \mathrm{E}-02$ \\
\hline $00 \mathrm{E}+0 \mathrm{C}$ & 1. $24 \mathrm{E}-01$ & $1.86 \mathrm{E}-03$ & $2.56 \mathrm{E}-11$ & 3 & 3 & $2.02 \mathrm{E}-02$ & 02 \\
\hline & 1 & & 11 & 3 & & & 02 \\
\hline $0 \mathrm{E}+00$ & $1.28 \mathrm{E}-01$ & 1.9 & $26 \mathrm{E}-10$ & & & & $52 E-02$ \\
\hline & $1.31 \mathrm{E}$ & $\perp$ & & & & & -02 \\
\hline प्रा & $1 \cdot 0$ & & & & & & $.68 E-U 2$ \\
\hline $00 E+00$ & $1.35 E-01$ & $5.002-03$ & $0.0<1-0$ & $2.89 \mathrm{E}-03$ & $9.57 E-03$ & $2.23 E-02$ & $4.76 E-02$ \\
\hline $.00 \mathrm{E}+0$ & 1. $38 \mathrm{E}-01$ & 2.0 & & $2 \cdot 000$ & $9.80 \mathrm{E}-03$ & & $4.85 E-02$ \\
\hline $\mathrm{E}+0$ & $.40 E-01$ & $.13 E-03$ & $.45 E-09$ & $.02 E-03$ & $1.00 \mathrm{E}-02$ & $2.32 E-02$ & $4.93 E-02$ \\
\hline
\end{tabular}


RESRAD-OFFSITE, Version 2.5

obabilistic Dose and Risk Report

Title : Offsite Resident Farmer Deterministic Run

File : RF TC99 DOESG FWD-FV2.ROF

Summary of dose at graphical times, reptition 1 (continued)

Time

Years

$2.59 \mathrm{E}+02$

2. $60 \mathrm{E}+02$

$2.60 \mathrm{E}+02$

2. $61 \mathrm{E}+02$

2. $61 \mathrm{E}+02$

2. $62 \mathrm{E}+02$

$2.63 \mathrm{E}+02$

2. $63 \mathrm{E}+02$

2. $64 \mathrm{E}+02$

2. $64 \mathrm{E}+02$

$2.65 E+02$

2. $65 \mathrm{E}+02$

$2.66 \mathrm{E}+02$

$2.66 \mathrm{E}+02$

$2.67 \mathrm{E}+02$

$2.67 \mathrm{E}+02$

$2.68 \mathrm{E}+02$

$2.68 \mathrm{E}+02$

$2.69 \mathrm{E}+02$

$2.69 \mathrm{E}+02$

$2.70 \mathrm{E}+02$

$2.70 \mathrm{E}+02$

$2.71 \mathrm{E}+02$

$2.71 E+02$

2. $72 \mathrm{E}+02$

$2.72 E+02$

$2.73 E+02$

$2.73 E+02$

2. $74 \mathrm{E}+02$

$2.74 \mathrm{E}+02$

$2.75 \mathrm{E}+02$

$2.75 \mathrm{E}+02$

$2.76 \mathrm{E}+02$

$2.76 \mathrm{E}+02$

$2.77 \mathrm{E}+02$

$2.77 \mathrm{E}+02$

$2.78 \mathrm{E}+02$

$2.78 \mathrm{E}+02$

$2.79 \mathrm{E}+02$

$2.79 \mathrm{E}+02$

$2.80 \mathrm{E}+02$

$2.80 \mathrm{E}+02$

$2.81 \mathrm{E}+02$

$2.81 \mathrm{E}+02$

$2.82 \mathrm{E}+02$

$2.82 \mathrm{E}+02$
Dose statistics at graphical times, mrem/yr

\begin{tabular}{|c|c|c|c|c|c|c|c|}
\hline m & aximum & e & 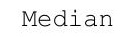 & & & & \\
\hline $.00 \mathrm{E}+00$ & -01 & 3 & $4.06 \mathrm{E}-09$ & 3 & $1.03 E-02$ & 02 & -02 \\
\hline $.00 \mathrm{E}+00$ & $1.45 \mathrm{E}-01$ & $2.21 E-03$ & $6.34 \mathrm{E}-09$ & $6 \mathrm{E}-03$ & $05 E-02$ & -02 & $0 E-02$ \\
\hline $.00 E+00$ & $1.47 \mathrm{E}-01$ & $5 E-03$ & $.41 E-09$ & $3 E-03$ & $07 E-02$ & $46 E-02$ & $8 E-02$ \\
\hline $00 \mathrm{E}+00$ & $.50 \mathrm{E}-01$ & $29 F-03$ & $45 E-08$ & $31 F-03$ & $09-02$ & $51 \mathrm{~F}-02$ & $27 E-02$ \\
\hline $.00 \mathrm{E}+00$ & 1.521 & $F$ & -08 & 3 & 2 & -02 & -02 \\
\hline $.00 E+00$ & $1.55 \mathrm{E}$ & & & & & & -02 \\
\hline $.00 E+00$ & $1.57 \mathrm{E}-01$ & & & & & & -02 \\
\hline+00 & 1.601 & 3 & 08 & 3 & 02 & -02 & -02 \\
\hline $00 \mathrm{E}+00$ & $1.63 \mathrm{E}-01$ & -0 & -08 & & -02 & -02 & $E-02$ \\
\hline $.00 \mathrm{E}+00$ & $65 E-01$ & 5 & 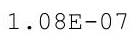 & 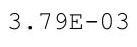 & קว קว & $.78 E-02$ & -02 \\
\hline $.00 E+00$ & 1.681 & & & & & 2 & -02 \\
\hline $.00 \mathrm{E}+00$ & $1.71 \mathrm{E}-01$ & 5 & -07 & 3 & 2 & 2 & -02 \\
\hline $.00 \mathrm{E}+00$ & $1.74 \mathrm{E}-01$ & & $2.37 E-07$ & $4.05 E-03$ & $1.30 \mathrm{E}-02$ & $2.91 E-02$ & $03 E-02$ \\
\hline $.00 E+00$ & $1.76 \mathrm{E}-01$ & $2.74 \mathrm{E}-03$ & $2.97 \mathrm{E}-07$ & & 1. $32 \mathrm{E}-02$ & -02 & $E-02$ \\
\hline $\mathrm{E}+00$ & 1.791 & 它 & -07 & 3 & 2 & -02 & $E-02$ \\
\hline $.00 \mathrm{E}+00$ & 1.02 & $2.84 E-03$ & t & 3 & 2 & 2 & 02 \\
\hline$E+00$ & 1 & & & & 2 & & 2 \\
\hline $.00 E+00$ & 1. & $2.94 E-03$ & 7 & 3 & 2 & 2 & 02 \\
\hline $.00 \mathrm{E}+00$ & 1.91E-01 & $.99 E-03$ & $.24 \mathrm{E}-07$ & $4.61 \mathrm{E}-03$ & 1. $45 \mathrm{E}-02$ & $3.22 \mathrm{E}-02$ & $.58 E-02$ \\
\hline $.00 \mathrm{E}+00$ & 1. $94 \mathrm{E}-01$ & $.04 E-03$ & $9.77 E-07$ & 4. $71 \mathrm{E}-03$ & $1.47 \mathrm{E}-02$ & $E-02$ & $.68 E-02$ \\
\hline $.00 \mathrm{E}+00$ & 01 & & & & & 2 & -02 \\
\hline $00 \mathrm{E}+00$ & & & & & 2 & & 02 \\
\hline $00 E+00$ & & 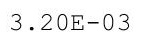 & 6 & & 2 & 2 & -02 \\
\hline $.00 \mathrm{E}+00$ & 1 & $326 \mathrm{~F}-03$ & 06 & ? & 2 & 2 & -02 \\
\hline $.00 \mathrm{E}+00$ & $.09 E-01$ & ק & $2.24 \mathrm{E}-06$ & ח & 10 & 2 & $19 E-02$ \\
\hline $0 \cap F+0 \cap$ & $.12 \mathrm{E}-01$ & $37 E-0$ & $2.65 \mathrm{E}-06$ & $35 \mathrm{E}-$ & $1.64 \mathrm{E}-02$ & $3 E-02$ & $30 E-02$ \\
\hline $.00 \mathrm{E}+00$ & $.15 \mathrm{E}-01$ & & & & $67 \mathrm{E}-02$ & $E-02$ & $41 E-02$ \\
\hline & & & & & & 2 & \\
\hline & & 3.0 & 06 & & 02 & -02 & -02 \\
\hline $.00 \mathrm{E}+00$ & $2.25 E-01$ & $\begin{array}{ll}0.000 \\
0\end{array}$ & $4.67 E-06$ & . $19 \mathrm{E}-\mathrm{U}$ & $1.76 \mathrm{E}-02$ & $3.87 E-02$ & $.76 E-02$ \\
\hline $.00 \mathrm{E}+00$ & $2.28 E-01$ & . & $.38 E-06$ & 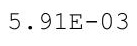 & 1. $79 \mathrm{E}-02$ & $E-02$ & $.88 E-02$ \\
\hline $.00 \mathrm{E}+0$ & 32 & & & & & & 2 \\
\hline $.00 E+00$ & & & & & & & 02 \\
\hline & 1 & & & & & 2 & \\
\hline & & 3.9 & 6 & 3 & 02 & -02 & \\
\hline $.00 \mathrm{E}+00$ & $2.45 \mathrm{E}-01$ & $3.97 E-03$ & $9.56 \mathrm{E}-06$ & 3 & 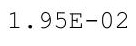 & $E-02$ & $.49 E-02$ \\
\hline . & $.49 \mathrm{E}-01$ & & & & & & $8.0< \pm-U<$ \\
\hline ( & $2 \cdot 0$ & & & & & & $75 E-02$ \\
\hline $00 \mathrm{E}+0 \mathrm{C}$ & 1 & 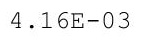 & 5 & . & $2 \cdot 0$ & 2 & 02 \\
\hline & 1 & & 5 & & 02 & 02 & 02 \\
\hline $0 \mathrm{E}+00$ & $2.63 E-01$ & $4.30 \mathrm{E}$ & 1. $53 \mathrm{E}-05$ & 3 & $2.12 \mathrm{E}$ & & -02 \\
\hline$E+00$ & 1 & 3 & & & & & -02 \\
\hline . & 1 & & & & & & $4 \perp E-U 2$ \\
\hline $00 E+00$ & $2.14 E-01$ & $4.50 \mathrm{E}-03$ & $1.96 \mathrm{E}-05$ & $7.67 \mathrm{E}-03$ & $2.23 E-02$ & $4.73 E-02$ & $9.55 E-02$ \\
\hline $.00 \mathrm{E}+00$ & $2.78 \mathrm{E}-01$ & $4.5 / E-03$ & $2.13 E-05$ & . & $2.27 \mathrm{E}-02$ & & $9.69 \mathrm{E}-02$ \\
\hline$E+00$ & $.82 E-01$ & $.64 E-03$ & $32 E-05$ & $E-03$ & -02 & $4.85 E-02$ & $.83 E-02$ \\
\hline
\end{tabular}


RESRAD-OFFSITE, Version 2.5

obabilistic Dose and Risk Report

Title : Offsite Resident Farmer Deterministic Run

File : RF TC99 DOESG FWD-FV2.ROF

Summary of dose at graphical times, reptition 1 (continued)

Time

Years

$2.83 E+02$

$2.84 \mathrm{E}+02$

$2.84 \mathrm{E}+02$

$2.85 \mathrm{E}+02$

$2.85 \mathrm{E}+02$

$2.86 \mathrm{E}+02$

$2.86 \mathrm{E}+02$

$2.87 \mathrm{E}+02$

$2.87 \mathrm{E}+02$

$2.88 \mathrm{E}+02$

$2.88 \mathrm{E}+02$

$2.89 \mathrm{E}+02$

$2.89 \mathrm{E}+02$

2. $90 \mathrm{E}+02$

2. $90 \mathrm{E}+02$

2. $91 E+02$

2. $91 \mathrm{E}+02$

2. $92 \mathrm{E}+02$

2. $92 \mathrm{E}+02$

2. $93 \mathrm{E}+02$

2. $93 \mathrm{E}+02$

2. $94 \mathrm{E}+02$

2. $94 \mathrm{E}+02$

2. $95 \mathrm{E}+02$

2. $95 \mathrm{E}+02$

2. $96 \mathrm{E}+02$

2. $96 \mathrm{E}+02$

2. $97 \mathrm{E}+02$

2. $97 \mathrm{E}+02$

2. $98 \mathrm{E}+02$

2. $98 \mathrm{E}+02$

$2.99 \mathrm{E}+02$

2. $99 \mathrm{E}+02$

$3.00 \mathrm{E}+02$

$3.00 \mathrm{E}+02$

$3.01 \mathrm{E}+02$

$3.01 E+02$

$3.02 \mathrm{E}+02$

$3.02 \mathrm{E}+02$

$3.03 \mathrm{E}+02$

$3.04 \mathrm{E}+02$

$3.04 \mathrm{E}+02$

$3.05 \mathrm{E}+02$

$3.05 E+02$

$3.06 \mathrm{E}+02$

$3.06 \mathrm{E}+02$
Dose statistics at graphical times, mrem/yr

\begin{tabular}{|c|c|c|c|c|c|c|c|}
\hline m & m & ea & ledian & & & $\%$ & \\
\hline $.00 \mathrm{E}+00$ & $2.85 \mathrm{E}-01$ & $4.72 \mathrm{E}$ & -05 & $8.15 \mathrm{E}-03$ & $2.35 \mathrm{E}-02$ & -02 & $-0<$ \\
\hline+00 & 01 & 03 & 05 & 3 & 02 & -02 & -01 \\
\hline$E+00$ & $2.93 E-01$ & $36 E-03$ & $2.98 \mathrm{E}-05$ & $45 E-03$ & $2.42 \mathrm{E}-02$ & -02 & $1.03 E-01$ \\
\hline $.00 \mathrm{E}+00$ & $2.97 E-01$ & $4.94 \mathrm{E}-03$ & $0 E-05$ & $8.60 \mathrm{E}-03$ & $46 E-02$ & $10 E-02$ & $.04 \mathrm{E}-01$ \\
\hline $0 \mathrm{E}+00$ & 1 & $5.01 E-03$ & $3.41 E-05$ & $8.75 E-03$ & 02 & -02 & -01 \\
\hline+00 & 01 & 03 & 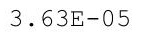 & 3 & 02 & -02 & -01 \\
\hline $.00 \mathrm{E}+00$ & 01 & & & & & 02 & -01 \\
\hline+00 & & & & & & & -01 \\
\hline+00 & -01 & $F-0$ & 5 & 3 & 02 & -02 & -01 \\
\hline $.00 \mathrm{E}+00$ & 1 & $5.40 \mathrm{E}-03$ & $4.62 \mathrm{E}-05$ & a $52 \mathrm{~F}-03$ & 2 & 2 & -01 \\
\hline 0 & 1 & $5.48 E-03$ & $4.94 \mathrm{E}-05$ & 3 & 2 & 2 & -01 \\
\hline $.00 \mathrm{E}+00$ & & & & & 2 & & -01 \\
\hline $.00 \mathrm{E}+00$ & -01 & 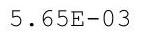 & $7 \mathrm{~F}-2010$ & 2 & 2 & -02 & -01 \\
\hline $.00 \mathrm{E}+00$ & $3.38 \mathrm{E}-01$ & $5.73 \mathrm{E}-03$ & $5.92 \mathrm{E}-05$ & $1.02 \mathrm{E}-02$ & $2.92 \mathrm{E}-02$ & $5.76 \mathrm{E}-02$ & $1.19 \mathrm{E}-01$ \\
\hline$E+00$ & 01 & -03 & & 2 & 2 & -02 & -01 \\
\hline $.00 E+00$ & 1 & $5.90 \mathrm{E}-03$ & $9 E-05$ & 2 & -02 & 02 & -01 \\
\hline $0 \mathrm{E}+00$ & . & 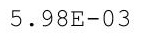 & & 2 & 2 & 2 & 01 \\
\hline $00 \mathrm{E}+00$ & $3.55 \mathrm{E}-01$ & & & & & & 01 \\
\hline $.00 E+00$ & $.60 \mathrm{E}-01$ & $6 \Gamma^{0} 0$ & & 117 & 2 & -02 & -01 \\
\hline $.00 \mathrm{E}+00$ & $.64 \mathrm{E}-01$ & $6.25 \mathrm{E}-03$ & $35-0$ & $.13 \mathrm{E}-02$ & $.19 \mathrm{E}-02$ & -02 & 1. $28 \mathrm{E}-01$ \\
\hline $.00 \mathrm{E}+00$ & $3.69 \mathrm{E}-01$ & $6.34 \mathrm{E}-03$ & 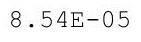 & $1.15 \mathrm{E}-02$ & $24 \mathrm{E}-02$ & $E-02$ & $1.30 \mathrm{E}-01$ \\
\hline & & & & & & -02 & -01 \\
\hline 0 & & & & & & & 01 \\
\hline $.00 \mathrm{E}+00$ & 3.0 & 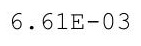 & & 1.24 & 2 & & -01 \\
\hline $00 \mathrm{E}+00$ & 1 & 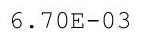 & $1.04 \mathrm{E}-04$ & 2 & 2 & 2 & -01 \\
\hline $.00 \mathrm{E}+00$ & $025-01$ & $5.80 \mathrm{E}-03$ & 1 & 1. $26 \mathrm{E}-02$ & $.45 E-02$ & $.62 E-02$ & 1. $38 \mathrm{E}-01$ \\
\hline $.00 \mathrm{E}+00$ & $F-01$ & $89 F-03$ & 1 & 128 & $50 \mathrm{E}-02$ & $=-02$ & $.40 E-01$ \\
\hline $00 \mathrm{~F}+00$ & & & & & & & -01 \\
\hline & & & & & & & \\
\hline $.00 \mathrm{E}+00$ & $4.11 \mathrm{E}-01$ & $7.19 \mathrm{E}-03$ & $1.325-04$ & $1.35 \mathrm{E}-02$ & 02 & 02 & -01 \\
\hline $.00 \mathrm{E}+00$ & $4.10 \mathrm{E}-1$ & $1.28 \mathrm{E}-03$ & 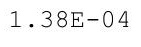 & $1.38 \mathrm{E}-02$ & $3.70 \mathrm{E}-02$ & $.00 E-02$ & $1.46 \mathrm{E}-01$ \\
\hline $.00 \mathrm{E}+00$ & tren & 年 & 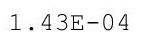 & 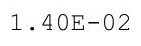 & 2 & 02 & $1.48 \mathrm{E}-01$ \\
\hline O & $T_{-1}$ & 7.4 & & 1 & & & .5 \\
\hline مח & & & & & & & \\
\hline & & & & 2 & & 2 & 01 \\
\hline $0 E+00$ & $4.40 \mathrm{E}$ & 03 & $1.67 \mathrm{E}-04$ & $\perp \cdot J 0 \amalg$ & 2 & 02 & $1.55 E-01$ \\
\hline $.00 \mathrm{E}+00$ & 1 & & & 2 & & & -01 \\
\hline $00 \mathrm{E}+00$ & & & & & & & $1.59 \mathrm{E}-01$ \\
\hline tor & 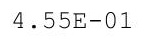 & 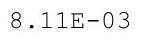 & $1.87 \mathrm{E}-04$ & 2 & 2 & 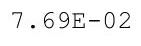 & 01 \\
\hline & & & & & & & 1 \\
\hline & & 3 & 2 & 2 & 2 & 2 & 01 \\
\hline $00 \mathrm{E}+00$ & 4. $71 \mathrm{E}-01$ & -03 & 2. & 1 . & -02 & 02 & -01 \\
\hline & & & & & & & \\
\hline & $\perp$ & 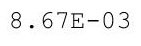 & & & & & $1.70 E-U 1$ \\
\hline 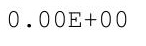 & 7.0 & 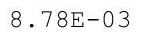 & 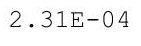 & & & 02 & -01 \\
\hline $00 E+00$ & $2 E-01$ & $9 E-03$ & $38 E-04$ & $E-02$ & -02 & $7 E-02$ & -01 \\
\hline
\end{tabular}


RESRAD-OFFSITE, Version 2.5

obabilistic Dose and Risk Report

Title : Offsite Resident Farmer Deterministic Run

File : RF TC99 DOESG FWD-FV2.ROF

Summary of dose at graphical times, reptition 1 (continued)

Time

Years

$3.07 \mathrm{E}+02$

$3.07 \mathrm{E}+02$

$3.08 \mathrm{E}+02$

$3.08 \mathrm{E}+02$

$3.09 \mathrm{E}+02$

$3.09 \mathrm{E}+02$

$3.10 \mathrm{E}+02$

$3.10 \mathrm{E}+02$

3. $11 \mathrm{E}+02$

3. $11 \mathrm{E}+02$

3. $12 \mathrm{E}+02$

3. $12 \mathrm{E}+02$

$3.13 \mathrm{E}+02$

$3.13 \mathrm{E}+02$

3. $14 \mathrm{E}+02$

$3.14 \mathrm{E}+02$

$3.15 \mathrm{E}+02$

$3.15 \mathrm{E}+02$

$3.16 \mathrm{E}+02$

$3.16 \mathrm{E}+02$

3. $17 \mathrm{E}+02$

$3.17 \mathrm{E}+02$

$3.18 \mathrm{E}+02$

$3.18 \mathrm{E}+02$

$3.19 \mathrm{E}+02$

$3.19 \mathrm{E}+02$

$3.20 \mathrm{E}+02$

$3.20 \mathrm{E}+02$

$3.21 \mathrm{E}+02$

$3.21 \mathrm{E}+02$

3. $22 \mathrm{E}+02$

3. $22 \mathrm{E}+02$

$3.23 \mathrm{E}+02$

$3.24 \mathrm{E}+02$

$3.24 \mathrm{E}+02$

3. $25 \mathrm{E}+02$

$3.25 \mathrm{E}+02$

$3.26 \mathrm{E}+02$

$3.26 \mathrm{E}+02$

$3.27 \mathrm{E}+02$

$3.27 \mathrm{E}+02$

$3.28 \mathrm{E}+02$

$3.28 \mathrm{E}+02$

$3.29 \mathrm{E}+02$

$3.29 \mathrm{E}+02$

3. $30 \mathrm{E}+02$
Dose statistics at graphical times, mrem/yr

\begin{tabular}{|c|c|c|c|c|c|c|c|}
\hline m & aximum & ea & 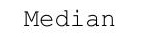 & & & & \\
\hline $.00 \mathrm{E}+00$ & -01 & $9.01 E-03$ & 4 & 1. $78 \mathrm{E}-02$ & $4.58 \mathrm{E}-02$ & 02 & $-130-01$ \\
\hline+00 & $5.03 E-01$ & $3 E-03$ & $2.54 \mathrm{E}-04$ & $1.81 \mathrm{E}-02$ & -02 & -02 & $7 E-01$ \\
\hline $.00 \mathrm{E}+00$ & $08 E-01$ & $4 F-03$ & $62 E-04$ & $84 E-02$ & $70 E-02$ & $67 E-02$ & $79 E-01$ \\
\hline $00 \mathrm{E}+00$ & $14 \mathrm{E}-01$ & $36 \mathrm{~F}-03$ & $.70 E-04$ & $86 \mathrm{~F}-02$ & $477 F-0 ?$ & $78 \mathrm{~F}-02$ & $81 F-01$ \\
\hline $.00 \mathrm{E}+00$ & -01 & $9.48 E-03$ & 4 & 2 & 2 & -02 & -01 \\
\hline $.00 \mathrm{E}+00$ & & & & & & & 01 \\
\hline $.00 E+00$ & $5.30 \mathrm{E}-01$ & & & & & & $87 E-01$ \\
\hline+00 & 01 & 3 & -04 & 2 & 02 & -02 & $E-01$ \\
\hline $.00 \mathrm{E}+00$ & $5.41 \mathrm{E}-01$ & $7 E-0$ & -04 & -02 & -02 & -02 & $1 E-01$ \\
\hline $.00 E+00$ & $47 E-01$ & ק & $.24 \mathrm{E}-04$ & $.04 \mathrm{E}-02$ & ת7 - 2 - 1 & $3 E-02$ & $E-01$ \\
\hline $.00 E+00$ & 5.5 & & & & & & 01 \\
\hline $.00 \mathrm{E}+00$ & $E-01$ & & 4 & 2 & 2 & 2 & -01 \\
\hline $.00 \mathrm{E}+00$ & $5.64 \mathrm{E}-01$ & $1.05 E-02$ & $3.61 \mathrm{E}-04$ & $2.12 E-02$ & & $9.77 \mathrm{E}-02$ & $1.99 \mathrm{E}-01$ \\
\hline $.00 \mathrm{E}+00$ & $5.70 \mathrm{E}-01$ & $.06 \mathrm{E}-02$ & $3.71 \mathrm{E}-04$ & $2.15 \mathrm{E}-02$ & & -02 & $2.02 \mathrm{E}-01$ \\
\hline$E+00$ & -01 & & -04 & 2 & & -01 & $4 \mathrm{E}-01$ \\
\hline $.00 \mathrm{E}+00$ & $\perp$ & 1.09E-02 & 4 & 2 & & 1 & 01 \\
\hline$E+00$ & 1 & & & & & & 1 \\
\hline $.00 E+00$ & 1 & 1.11E-02 & 4 & 2 & 2 & 1 & 01 \\
\hline $.00 \mathrm{E}+00$ & $5.99 \mathrm{E}-01$ & $1.13 \mathrm{E}-02$ & $4.31 E-04$ & $2.33 E-02$ & $.86 \mathrm{E}-02$ & $1.05 E-01$ & $2.13 E-01$ \\
\hline $.00 \mathrm{E}+00$ & $.05 E-01$ & $.14 \mathrm{E}-02$ & $4.43 E-04$ & $2.36 \mathrm{E}-02$ & $.95 E-02$ & $.06 \mathrm{E}-01$ & $2.15 \mathrm{E}-01$ \\
\hline $.00 \mathrm{E}+00$ & 01 & & & & & -01 & E-01 \\
\hline $.00 E+00$ & & & & 02 & & 1 & -01 \\
\hline $00 \mathrm{E}+00$ & & $1.18 \mathrm{E}-02$ & 4 & & & 1 & -01 \\
\hline $.00 E+00$ & 1 & 1.20E-02 & 4 & 2 & 2 & 1 & -01 \\
\hline $.00 \mathrm{E}+00$ & -01 & קח & $4 E-04$ & $.55 E-02$ & 2 & $2 \mathrm{E}-01$ & $27 E-01$ \\
\hline $0 \cap \mathrm{F}+0 \cap 0$ & $5.42 \mathrm{E}-01$ & $1.23 \mathrm{E}-02$ & $16 \mathrm{E}-04$ & $.59 \mathrm{E}-02$ & $47 E-02$ & $.13 E-01$ & $.29 E-01$ \\
\hline $.00 \mathrm{E}+00$ & $48 E-01$ & & & $2.62 \mathrm{E}-02$ & $56 \mathrm{E}-02$ & $E-01$ & 2. $31 E-01$ \\
\hline & & & & & & & 01 \\
\hline & & 1.2 & 04 & 02 & -02 & -01 & 01 \\
\hline $.00 \mathrm{E}+00$ & $6.67 \mathrm{E}-01$ & $\perp \cdot 201-2<$ & $5.73 E-04$ & $2.75 E-02$ & $6.82 E-02$ & $1.17 \mathrm{E}-01$ & $2.38 E-01$ \\
\hline $.00 \mathrm{E}+00$ & $6.73 E-01$ & $1.30 \mathrm{E}-02$ & $.005-4$ & $2.79 \mathrm{E}-02$ & $6.89 \mathrm{E}-02$ & $1.19 \mathrm{E}-01$ & $2.41 \mathrm{E}-01$ \\
\hline $.00 \mathrm{E}+0$ & 1 & & & & & $1.20 \mathrm{E}-01$ & $.43 E-01$ \\
\hline $.00 E+00$ & 1 & & & & & & 01 \\
\hline & & & & & & & $3 E-01$ \\
\hline & & 1.36 & & 02 & 02 & 01 & \\
\hline $.00 \mathrm{E}+00$ & $7.05 \mathrm{E}-01$ & $1.30 E-02$ & $.67 E-04$ & -02 & 02 & $.24 E-01$ & $2.53 E-01$ \\
\hline . & & & & & & & $2.50 E-01$ \\
\hline 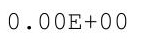 & 1 & 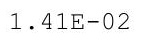 & $9 E-04$ & & & $1.27 \mathrm{E}-01$ & $.58 E-01$ \\
\hline $.00 E+0$ & 1 & ( & $7.16 \mathrm{E}-04$ & 2 & 2 & 1 & 01 \\
\hline & 1 & 2 & 4 & 02 & 2 & -01 & 01 \\
\hline $0 \mathrm{E}+00$ & $7.38 \mathrm{E}-01$ & $6 \mathrm{E}-02$ & $E-04$ & 02 & & & $2.66 \mathrm{E}$ \\
\hline$E+00$ & 1 & $1.4 / 5$ & & & & & \\
\hline 0 & 1 & & & & & & $2.11 \mathrm{E}-01$ \\
\hline $00 \mathrm{E}+00$ & $1.58 E-01$ & $1.51 \mathrm{E}-02$ & 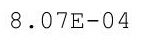 & $3.34 \mathrm{E}-02$ & $7.85 E-02$ & $1.35 E-01$ & $2.14 \mathrm{E}-01$ \\
\hline $.00 \mathrm{E}+0 \mathrm{C}$ & $7.65 \mathrm{E}-01$ & $1 \cdot 02+02$ & & & $7.92 \mathrm{E}-02$ & 1. $36 \mathrm{E}-01$ & $2.76 \mathrm{E}-01$ \\
\hline$E+00$ & $E-01$ & $.54 \mathrm{E}-02$ & $.50 \mathrm{E}-04$ & $.43 E-02$ & $3.00 \mathrm{E}-02$ & 01 & $2.79 \mathrm{E}-01$ \\
\hline
\end{tabular}


RESRAD-OFFSITE, Version 2.5

obabilistic Dose and Risk Report

Title : Offsite Resident Farmer Deterministic Run

File : RF TC99 DOESG FWD-FV2.ROF

Summary of dose at graphical times, reptition 1 (continued)

Time

Years

$3.30 \mathrm{E}+02$

$3.31 \mathrm{E}+02$

$3.31 \mathrm{E}+02$

$3.32 \mathrm{E}+02$

$3.32 \mathrm{E}+02$

$3.33 \mathrm{E}+02$

$3.33 \mathrm{E}+02$

$3.34 \mathrm{E}+02$

$3.34 \mathrm{E}+02$

$3.35 \mathrm{E}+02$

$3.35 \mathrm{E}+02$

$3.36 \mathrm{E}+02$

$3.36 \mathrm{E}+02$

$3.37 \mathrm{E}+02$

$3.37 \mathrm{E}+02$

$3.38 \mathrm{E}+02$

$3.38 \mathrm{E}+02$

$3.39 \mathrm{E}+02$

$3.39 \mathrm{E}+02$

3. $40 \mathrm{E}+02$

$3.40 \mathrm{E}+02$

$3.41 \mathrm{E}+02$

$3.41 \mathrm{E}+02$

$3.42 \mathrm{E}+02$

3. $42 \mathrm{E}+02$

$3.43 \mathrm{E}+02$

$3.44 \mathrm{E}+02$

$3.44 \mathrm{E}+02$

$3.45 \mathrm{E}+02$

$3.45 \mathrm{E}+02$

$3.46 \mathrm{E}+02$

$3.46 \mathrm{E}+02$

$3.47 \mathrm{E}+02$

$3.47 \mathrm{E}+02$

$3.48 \mathrm{E}+02$

$3.48 \mathrm{E}+02$

$3.49 \mathrm{E}+02$

$3.49 \mathrm{E}+02$

$3.50 \mathrm{E}+02$

$3.50 \mathrm{E}+02$

$3.51 \mathrm{E}+02$

$3.51 \mathrm{E}+02$

$3.52 \mathrm{E}+02$

$3.52 \mathrm{E}+02$

$3.53 \mathrm{E}+02$

$3.53 \mathrm{E}+02$
Dose statistics at graphical times, mrem/yr

\begin{tabular}{|c|c|c|c|c|c|c|c|}
\hline m & $\operatorname{axi}$ & ea & ledian & & & $\%$ & \\
\hline $.00 \mathrm{E}+00$ & $7.79 \mathrm{E}-01$ & $1.56 \mathrm{E}-02$ & $8.67 \mathrm{E}-04$ & $3.47 \mathrm{E}-02$ & $8.08 \mathrm{E}-02$ & -01 & -01 \\
\hline $.00 \mathrm{E}+00$ & 7. $86 \mathrm{E}-01$ & $7 E-02$ & $8.84 \mathrm{E}-04$ & $51 E-02$ & 02 & -01 & -01 \\
\hline $.00 \mathrm{E}+00$ & $7.93 \mathrm{E}-01$ & 1. 59E-02 & $9.03 \mathrm{E}-04$ & $.56 \mathrm{E}-02$ & $8.23 E-02$ & 1. $42 \mathrm{E}-01$ & $2.87 \mathrm{E}-01$ \\
\hline $.00 \mathrm{E}+00$ & $.99 \mathrm{E}-01$ & 1. $61 \mathrm{E}-02$ & $9.21 \mathrm{E}-04$ & $.60 \mathrm{E}-02$ & $1 E-02$ & $1.44 \mathrm{E}-01$ & $2.90 \mathrm{E}-01$ \\
\hline $.00 \mathrm{E}+00$ & $06 \mathrm{E}-01$ & $1.63 \mathrm{E}-02$ & -04 & 02 & 02 & 01 & -01 \\
\hline$E+00$ & 1 & 2 & 4 & 2 & & 1 & -01 \\
\hline $.00 \mathrm{E}+00$ & 01 & $1.66 \mathrm{E}$ & & 2 & 2 & 1 & -01 \\
\hline $.00 \mathrm{E}+00$ & & & & & & & -01 \\
\hline $.00 \mathrm{E}+00$ & -01 & $E-02$ & -03 & -02 & -02 & -01 & $04 \mathrm{E}-01$ \\
\hline $.00 \mathrm{E}+00$ & 1 & $1.71 \mathrm{E}-02$ & 3 & 2 & 2 & -01 & -01 \\
\hline $.00 \mathrm{E}+00$ & 1 & $1.73 E-02$ & 3 & 2 & 2 & 1 & -01 \\
\hline+00 & & & & 2 & 2 & 1 & -01 \\
\hline $\mathrm{F}+00$ & $E-01$ & 1. & 3 & 2 & 02 & -01 & -01 \\
\hline $.00 \mathrm{E}+00$ & $8.70 \mathrm{E}-01$ & $1.79 \mathrm{E}-02$ & $1.15 \mathrm{E}-03$ & $4.08 \mathrm{E}-02$ & $9.11 \mathrm{E}-02$ & $1.59 \mathrm{E}-01$ & $3.18 \mathrm{E}-01$ \\
\hline $.00 \mathrm{E}+00$ & $7 E-01$ & -02 & -03 & -02 & & -01 & -01 \\
\hline $.00 E+00$ & & & & 2 & & 1 & -01 \\
\hline$\cap \cap F+\cap \cap$ & & $1.85 \mathrm{E}-02$ & & -02 & 2 & 1 & -01 \\
\hline $.00 \mathrm{E}+00$ & & $1.87 \mathrm{E}-02$ & & & & 1 & 01 \\
\hline $.00 E+00$ & $9.06 \mathrm{E}-01$ & $188 \mathrm{~F}-$ & 1.29E-03 & 2 & 2 & -01 & -01 \\
\hline $.00 \mathrm{E}+00$ & $4 \mathrm{E}-01$ & $0=-02$ & $.31 E-03$ & $40 E-02$ & -02 & $.68 \mathrm{E}-01$ & $35 E-01$ \\
\hline $.00 \mathrm{E}+00$ & $.21 E-01$ & 1. $92 \mathrm{E}-02$ & -03 & -02 & -02 & $.69 \mathrm{E}-01$ & -01 \\
\hline & & & & & & & -01 \\
\hline & & & & & & 1 & 01 \\
\hline & & $+\cdots$ & & 02 & & 01 & 01 \\
\hline $.00 E+00$ & 1 & 0 & 3 & 2 & 1 & 1 & 01 \\
\hline $.00 E+00$ & $.58 E-01$ & م חקר ח & 1. $49 \mathrm{E}-03$ & $.70 E-02$ & $1.01 \mathrm{E}-01$ & $1.78 \mathrm{E}-01$ & $51 E-01$ \\
\hline $.00 E+00$ & $F-01$ & $204 \mathrm{~F}-02$ & $E-03$ & $.76 \mathrm{E}-02$ & -01 & $E-01$ & $54 \mathrm{E}-01$ \\
\hline & & & & & & & -01 \\
\hline & & & & & & & 01 \\
\hline & & 2 & 03 & -02 & $1.05 \mathrm{E}-01$ & -01 & 01 \\
\hline $.00 \mathrm{E}+00$ & $9.96 \mathrm{E}-01$ & $\angle \cdot 13 \pm-0<$ & $1.64 \mathrm{E}-03$ & $.00 E-02$ & $1.06 \mathrm{E}-01$ & $1.86 \mathrm{E}-01$ & 3. $65 \mathrm{E}-01$ \\
\hline $.00 \mathrm{E}+00$ & 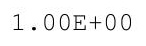 & $2 \cdot+\sqrt{2}$ & $1.67 \mathrm{E}-03$ & $.07 E-02$ & $1.07 \mathrm{E}-01$ & 01 & $68 E-01$ \\
\hline $.00 E+00$ & $1.01 \mathrm{E}+$ & & $1 E-03$ & 13 & & & 01 \\
\hline & & & & & & & 01 \\
\hline & & 2 & 03 & 2 & 1 & & -01 \\
\hline $0 \mathrm{E}+00$ & $1.04 \mathrm{E}$ & 2.241 & 03 & $\cdot 3<+$ & 1 & 01 & 01 \\
\hline $.00 \mathrm{E}+00$ & $1.04 \mathrm{E}+00$ & 2.2 & 03 & & & & $3.82 \mathrm{E}-01$ \\
\hline $.00 \mathrm{E}+00$ & 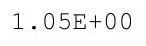 & & & & & $1.97 \mathrm{~L}-\mathrm{L}$ & . $025-U 1$ \\
\hline 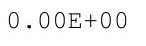 & t. & 2.0 & & 2 & 1 & $+\cdots$ & -01 \\
\hline & $1.07 \mathrm{E}+$ & & & & & & \\
\hline $00 E+00$ & $1.07 \mathrm{E}+00$ & 2 & 03 & 02 & 1 & 1 & \\
\hline $00 \mathrm{E}+00$ & $1.08 \mathrm{E}+00$ & $E-02$ & 2. & -02 & 1.20 & & -01 \\
\hline & & & & & & & \\
\hline $00 \mathrm{E}+00$ & म. & $=$ & & 2 & 1.22E-01 & & $4.03 E-01$ \\
\hline $.00 E+00$ & $1.11 \mathrm{E}+00$ & 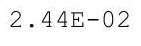 & & 2 & 01 & 2.00 & $5-01$ \\
\hline $00 E+00$ & $.11 E+00$ & $5 E-02$ & $16 \mathrm{E}-03$ & $E-02$ & $25 E-01$ & 01 & -01 \\
\hline
\end{tabular}


RESRAD-OFFSITE, Version 2.5

obabilistic Dose and Risk Report

Title : Offsite Resident Farmer Deterministic Run

File : RF TC99 DOESG FWD-FV2.ROF

Summary of dose at graphical times, reptition 1 (continued)

Time

Years

$3.54 \mathrm{E}+02$

$3.54 \mathrm{E}+02$

3. $55 \mathrm{E}+02$

$3.55 \mathrm{E}+02$

$3.56 \mathrm{E}+02$

3. $56 \mathrm{E}+02$

$3.57 \mathrm{E}+02$

3. $57 \mathrm{E}+02$

$3.58 \mathrm{E}+02$

$3.58 \mathrm{E}+02$

$3.59 \mathrm{E}+02$

3. $59 \mathrm{E}+02$

$3.60 E+02$

$3.60 E+02$

$3.61 \mathrm{E}+02$

3. $61 \mathrm{E}+02$

3. $62 \mathrm{E}+02$

$3.62 \mathrm{E}+02$

$3.63 \mathrm{E}+02$

$3.64 \mathrm{E}+02$

$3.64 \mathrm{E}+02$

$3.65 \mathrm{E}+02$

$3.65 \mathrm{E}+02$

$3.66 \mathrm{E}+02$

$3.66 \mathrm{E}+02$

$3.67 \mathrm{E}+02$

3. $67 \mathrm{E}+02$

$3.68 \mathrm{E}+02$

$3.68 \mathrm{E}+02$

$3.69 \mathrm{E}+02$

3. $69 \mathrm{E}+02$

$3.70 \mathrm{E}+02$

$3.70 \mathrm{E}+02$

$3.71 \mathrm{E}+02$

$3.71 \mathrm{E}+02$

$3.72 \mathrm{E}+02$

$3.72 \mathrm{E}+02$

3. $73 \mathrm{E}+02$

$3.73 E+02$

$3.74 \mathrm{E}+02$

$3.74 \mathrm{E}+02$

$3.75 E+02$

$3.75 \mathrm{E}+02$

$3.76 \mathrm{E}+02$

$3.76 \mathrm{E}+02$

$3.77 \mathrm{E}+02$

Dose statistics at graphical times, mrem/yr

\begin{tabular}{|c|c|c|c|c|c|c|c|}
\hline m & aximum & ea & ec & & & & \\
\hline $.00 \mathrm{E}+00$ & $.12 \mathrm{E}+00$ & 02 & 3 & 2 & 01 & 01 & $\cdot 1 J E-U \perp$ \\
\hline $.00 \mathrm{E}+00$ & $1.13 E+00$ & $2.51 E-02$ & $E-03$ & $8 E-02$ & 1. $28 \mathrm{E}-01$ & $2.12 \mathrm{E}-01$ & $16 E-01$ \\
\hline $.00 \mathrm{E}+00$ & $14 \mathrm{E}+00$ & $53 E-02$ & $26 E-03$ & $14 E-02$ & $29 E-01$ & $14 \mathrm{E}-01$ & $0 E-01$ \\
\hline $.00 E+00$ & $.15 E+00$ & $56 \mathrm{~F}-02$ & $30 \mathrm{~F}-03$ & $19 F-02$ & $31 \mathrm{~F}-01$ & $2 \quad 16 \mathrm{~F}-01$ & $.23 E-01$ \\
\hline $.00 \mathrm{E}+00$ & $.15 \mathrm{E}+00$ & 0 & $7-03$ & 2 & $32 \mathrm{E}$ & 1 & -01 \\
\hline $.00 E+00$ & $.16 \mathrm{E}+00$ & & & & & & -01 \\
\hline $.00 E+00$ & $1.17 \mathrm{E}+00$ & & 03 & & & & -01 \\
\hline $.00 \mathrm{E}+00$ & $1.18 \mathrm{E}+00$ & $-0<$ & -03 & -02 & 01 & -01 & $36 \mathrm{E}-01$ \\
\hline $.00 \mathrm{E}+00$ & $1.19 \mathrm{E}+00$ & $8 E-02$ & $E-03$ & -02 & $38 E-01$ & -01 & $39 E-01$ \\
\hline $.00 E+00$ & $.20 \mathrm{E}+00$ & 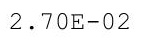 & $.53 E-03$ & קרי & 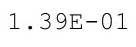 & $28 \mathrm{~F}-\mathrm{C}$ & -01 \\
\hline$\Xi+00$ & $E+00$ & & & & & & -01 \\
\hline $.00 \mathrm{E}+00$ & $1.21 \mathrm{E}+00$ & $5 F-02$ & -03 & 2 & 1 & 1 & -01 \\
\hline $.00 \mathrm{E}+00$ & $1.22 \mathrm{E}+00$ & $2.78 E-02$ & $2.65 E-03$ & $6.78 E-02$ & & $E-01$ & $.52 E-01$ \\
\hline $.00 \mathrm{E}+00$ & $1.23 E+00$ & $.80 \mathrm{E}-02$ & $2.70 \mathrm{E}-03$ & $6.85 \mathrm{E}-02$ & 1. $45 \mathrm{E}-01$ & $E-01$ & $55 E-01$ \\
\hline$E+00$ & +00 & 2 & -03 & 2 & 47 & -01 & $E-01$ \\
\hline $.00 \mathrm{E}+00$ & $1.24 \mathrm{E}+00$ & $2.85 E-02$ & $2.78 E-03$ & 2 & L & 1 & 01 \\
\hline$E+00$ & 00 & & & & $50 E-01$ & & 1 \\
\hline $.00 E+00$ & $1.26 \mathrm{E}+00$ & $2.90 \mathrm{E}-02$ & 3 & 2 & L & 1 & 01 \\
\hline $0 \cap \mathrm{F}+0$ & $1.27 \mathrm{E}+00$ & $3 F-02$ & $2 E-03$ & $20 E-02$ & $53 F-$ & $8 E-01$ & $71 E-01$ \\
\hline $.00 \mathrm{E}+00$ & $1.28 \mathrm{E}+00$ & $.96 \mathrm{E}-02$ & $2.97 \mathrm{E}-03$ & $7.26 \mathrm{E}-02$ & $1.54 \mathrm{E}-01$ & $2.50 \mathrm{E}-01$ & $4.75 E-01$ \\
\hline $.00 \mathrm{E}+00$ & $1.29 \mathrm{E}+00$ & & & & & $\perp$ & $E-01$ \\
\hline $00 \mathrm{E}+00$ & & & 3 & 02 & 1 & & 01 \\
\hline $00 \mathrm{E}+00$ & $1.30 \mathrm{E}+00$ & ¿ & 3 & & 1 & & -01 \\
\hline $.00 E+00$ & $1.31 E+00$ & $=$ & 3 & 2 & L & L & -01 \\
\hline $.00 \mathrm{E}+00$ & $1.32 \mathrm{E}+00$ & م & 吅 & $1 \mathrm{E}-02$ & ต२๊ & $1 \mathrm{E}-$ & $91 E-01$ \\
\hline $0 \cap \mathrm{F}+0 \cap 0$ & $1.33 E+00$ & $12 \mathrm{~F}-02$ & $.26 \mathrm{E}-03$ & $68 E-02$ & $1.64 \mathrm{E}-$ & $.63 E-0$ & $94 E-01$ \\
\hline $.00 \mathrm{E}+00$ & $1.34 \mathrm{E}+00$ & & & & $165 \mathrm{~F}$ & & $98 E-01$ \\
\hline & & & & & & & 01 \\
\hline & & 02 & 03 & -02 & +.00 & & -01 \\
\hline $.00 \mathrm{E}+00$ & $1.36 \mathrm{E}+00$ & . & $3.46 \mathrm{E}-03$ & $8.01 \mathrm{E}-02$ & $1.09 E-01$ & $2.71 \mathrm{E}-01$ & $.08 E-01$ \\
\hline $.00 \mathrm{E}+00$ & $1.37 \mathrm{E}+00$ & $.25 E-02$ & $.51 \mathrm{E}-03$ & $.09 E-02$ & 土. & $2.75 \mathrm{~L}-\mathrm{L}$ & $.11 \mathrm{E}-01$ \\
\hline $.00 \mathrm{E}+0$ & $1.38 \mathrm{E}+00$ & 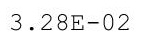 & & & & & $15 E-01$ \\
\hline $.00 E+00$ & $1.39 \mathrm{E}+00$ & 2 & & & & & $8 E-01$ \\
\hline & & & 03 & 02 & & 1 & 01 \\
\hline & & 02 & 03 & 02 & 01 & & 01 \\
\hline $.00 \mathrm{E}+00$ & $1.42 \mathrm{E}+00$ & $3.40 \mathrm{E}-02$ & $3.77 \mathrm{E}-03$ & . 1 t & 土. & $2.84 \mathrm{E}-01$ & $.28 E-01$ \\
\hline 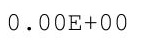 & $1.42 \mathrm{E}+00$ & $3.43 E-02$ & & & & & $.3 \angle E-U \perp$ \\
\hline 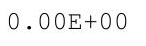 & $1.43 E+00$ & 2 & & & 1. $79 \mathrm{E}-01$ & & $35 E-01$ \\
\hline $.00 E+0$ & $1.44 \mathrm{E}+00$ & . & 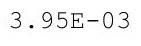 & 2 & 1 & $2 \cdot 2+1$ & 01 \\
\hline & $1.45 E+00$ & 2 & 3 & 02 & 1 & & 01 \\
\hline $0 \mathrm{E}+00$ & $1.46 \mathrm{E}+00$ & $3.54 \mathrm{E}-02$ & $07 E-03$ & 02 & $1.82 \mathrm{E}$ & $2.95 E-01$ & $45 E-01$ \\
\hline & $1.47 \mathrm{E}+00$ & $3.57 \mathrm{E}-02$ & & & 1.84 & & $E-01$ \\
\hline 0 & $1.48 \mathrm{E}+00$ & & & & & & $.5 \angle E-U \perp$ \\
\hline $00 \mathrm{E}+00$ & $1.49 \mathrm{E}+00$ & $3.00 \mathrm{~L}-02$ & $4.24 \mathrm{E}-03$ & $9.12 \mathrm{E}-02$ & $1.87 \mathrm{E}-01$ & $3.01 \mathrm{E}-01$ & $5.56 \mathrm{E}-01$ \\
\hline $.00 \mathrm{E}+0 \mathrm{C}$ & $1.49 \mathrm{E}+00$ & 3.000 - 2 & $.295-42$ & $9.20 \mathrm{E}-02$ & $1.00 \mathrm{~L}$ & .00 & $5.59 \mathrm{E}-01$ \\
\hline$E+00$ & $1.50 \mathrm{E}+00$ & $9 E-02$ & $.35 E-03$ & $E-02$ & 1.8 & 1 & $5.63 E-01$ \\
\hline
\end{tabular}


RESRAD-OFFSITE, Version 2.5

obabilistic Dose and Risk Report

Title : Offsite Resident Farmer Deterministic Run

File : RF TC99 DOESG FWD-FV2.ROF

Summary of dose at graphical times, reptition 1 (continued)

Time

Years

$3.77 \mathrm{E}+02$

$3.78 \mathrm{E}+02$

$3.78 \mathrm{E}+02$

$3.79 \mathrm{E}+02$

3. $79 \mathrm{E}+02$

$3.80 \mathrm{E}+02$

$3.80 \mathrm{E}+02$

3. $81 \mathrm{E}+02$

3. $81 \mathrm{E}+02$

3. $82 \mathrm{E}+02$

3. $82 \mathrm{E}+02$

$3.83 E+02$

$3.83 E+02$

$3.84 \mathrm{E}+02$

$3.85 \mathrm{E}+02$

$3.85 \mathrm{E}+02$

$3.86 \mathrm{E}+02$

$3.86 \mathrm{E}+02$

$3.87 \mathrm{E}+02$

$3.87 \mathrm{E}+02$

$3.88 \mathrm{E}+02$

$3.88 \mathrm{E}+02$

$3.89 \mathrm{E}+02$

3. $89 \mathrm{E}+02$

3. $90 \mathrm{E}+02$

$3.90 \mathrm{E}+02$

3. $91 \mathrm{E}+02$

3. $91 \mathrm{E}+02$

3. $92 \mathrm{E}+02$

3. $92 \mathrm{E}+02$

3. $93 \mathrm{E}+02$

$3.93 \mathrm{E}+02$

$3.94 \mathrm{E}+02$

$3.94 \mathrm{E}+02$

$3.95 \mathrm{E}+02$

$3.95 \mathrm{E}+02$

$3.96 \mathrm{E}+02$

$3.96 \mathrm{E}+02$

$3.97 \mathrm{E}+02$

$3.97 \mathrm{E}+02$

$3.98 \mathrm{E}+02$

$3.98 \mathrm{E}+02$

$3.99 \mathrm{E}+02$

$3.99 \mathrm{E}+02$

$4.00 \mathrm{E}+02$

$4.00 \mathrm{E}+02$
Dose statistics at graphical times, mrem/yr

\begin{tabular}{|c|c|c|c|c|c|c|c|}
\hline Minimum & Maximum & Mean & Median & $90 \%$ & $95 \%$ & $97.5 \%$ & $99 \%$ \\
\hline $0.00 \mathrm{E}+00$ & $1.51 \mathrm{E}+00$ & $3.72 E-02$ & $4.41 E-03$ & $9.36 \mathrm{E}-02$ & $1.91 E-01$ & $3.08 E-01$ & $5.66 \mathrm{E}-01$ \\
\hline $0.00 \mathrm{E}+00$ & $1.52 \mathrm{E}+00$ & $3.75 E-02$ & $4.48 E-03$ & $9.45 E-02$ & 1.92E-01 & $3.10 \mathrm{E}-01$ & $5.70 \mathrm{E}-01$ \\
\hline $0.00 \mathrm{E}+00$ & $1.53 \mathrm{E}+00$ & $3.78 \mathrm{E}-02$ & $4.54 \mathrm{E}-03$ & $9.53 E-02$ & $1.94 \mathrm{E}-01$ & $3.13 \mathrm{E}-01$ & $5.73 E-01$ \\
\hline $0.00 \mathrm{E}+00$ & $1.54 \mathrm{E}+00$ & $3.81 \mathrm{E}-02$ & $4.61 \mathrm{E}-03$ & $9.61 \mathrm{E}-02$ & $1.95 \mathrm{E}-01$ & $3.15 \mathrm{E}-01$ & $5.77 \mathrm{E}-01$ \\
\hline $0.00 \mathrm{E}+00$ & $1.55 \mathrm{E}+00$ & $3.85 E-02$ & $4.67 E-03$ & $9.69 E-02$ & $1.97 \mathrm{E}-01$ & $3.17 \mathrm{E}-01$ & $5.81 E-01$ \\
\hline $0.00 \mathrm{E}+00$ & $1.56 \mathrm{E}+00$ & $3.88 \mathrm{E}-02$ & $4.74 E-03$ & $9.78 \mathrm{E}-02$ & $1.98 \mathrm{E}-01$ & $3.20 \mathrm{E}-01$ & $5.84 \mathrm{E}-01$ \\
\hline $0.00 \mathrm{E}+00$ & $1.57 \mathrm{E}+00$ & $3.91 \mathrm{E}-02$ & $4.80 E-03$ & $9.86 \mathrm{E}-02$ & $1.99 \mathrm{E}-01$ & $3.22 \mathrm{E}-01$ & $5.88 E-01$ \\
\hline $0.00 \mathrm{E}+00$ & $1.57 \mathrm{E}+00$ & $3.94 \mathrm{E}-02$ & $4.87 E-03$ & $9.95 E-02$ & $2.01 E-01$ & $3.25 E-01$ & $5.91 E-01$ \\
\hline $0.00 \mathrm{E}+00$ & $1.58 \mathrm{E}+00$ & $3.97 \mathrm{E}-02$ & $4.94 E-03$ & 1.00E-01 & $2.03 E-01$ & $3.27 E-01$ & $5.95 E-01$ \\
\hline $0.00 \mathrm{E}+00$ & $1.59 \mathrm{E}+00$ & $4.00 \mathrm{E}-02$ & $5.00 \mathrm{E}-03$ & $1.01 \mathrm{E}-01$ & $2.04 \mathrm{E}-01$ & $3.29 \mathrm{E}-01$ & $5.99 \mathrm{E}-01$ \\
\hline $0.00 \mathrm{E}+00$ & $1.60 \mathrm{E}+00$ & $4.04 \mathrm{E}-02$ & $5.07 E-03$ & $1.02 \mathrm{E}-01$ & $2.06 \mathrm{E}-01$ & $3.32 \mathrm{E}-01$ & $6.02 \mathrm{E}-01$ \\
\hline $0.00 \mathrm{E}+00$ & $1.61 \mathrm{E}+00$ & $4.07 E-02$ & $5.14 \mathrm{E}-03$ & $1.03 E-01$ & $2.07 \mathrm{E}-01$ & $3.34 \mathrm{E}-01$ & $6.06 \mathrm{E}-01$ \\
\hline $0.00 \mathrm{E}+00$ & $1.62 \mathrm{E}+00$ & $4.10 \mathrm{E}-02$ & $5.21 E-03$ & $1.03 E-01$ & $2.09 E-01$ & $3.37 E-01$ & $6.09 \mathrm{E}-01$ \\
\hline $0.00 \mathrm{E}+00$ & $1.63 \mathrm{E}+00$ & $4.13 \mathrm{E}-02$ & $5.28 E-03$ & $1.04 \mathrm{E}-01$ & $2.10 \mathrm{E}-01$ & $3.39 \mathrm{E}-01$ & $6.13 \mathrm{E}-01$ \\
\hline $0.00 \mathrm{E}+00$ & $1.64 \mathrm{E}+00$ & $4.17 E-02$ & $5.36 E-03$ & 1. $05 \mathrm{E}-01$ & $2.11 \mathrm{E}-01$ & $3.42 \mathrm{E}-01$ & $6.17 \mathrm{E}-01$ \\
\hline $0.00 \mathrm{E}+00$ & $1.65 \mathrm{E}+00$ & $4.20 E-02$ & $5.43 E-03$ & $1.06 \mathrm{E}-01$ & $2.13 E-01$ & $3.44 \mathrm{E}-01$ & $6.20 E-01$ \\
\hline $0.00 \mathrm{E}+00$ & $1.66 \mathrm{E}+00$ & $4.23 E-02$ & $5.51 E-03$ & $1.07 \mathrm{E}-01$ & 2.1 & $3.47 \mathrm{E}-01$ & $6.24 \mathrm{E}-01$ \\
\hline $0.00 \mathrm{E}+00$ & $1.66 \mathrm{E}+00$ & $4.26 E-02$ & $5.58 E-03$ & $1.08 \mathrm{E}-01$ & $2.16 \mathrm{E}-01$ & $3.49 \mathrm{E}-01$ & $6.28 E-01$ \\
\hline $0.00 \mathrm{E}+00$ & $1.67 \mathrm{E}+00$ & $4.30 \mathrm{E}-02$ & $5.67 E-03$ & $1.09 \mathrm{E}-01$ & $2.17 \mathrm{E}-01$ & $3.52 E-01$ & $6.31 E-01$ \\
\hline $0.00 \mathrm{E}+00$ & $1.68 \mathrm{E}+00$ & $4.33 E-02$ & $5.75 E-03$ & $1.09 \mathrm{E}-01$ & $2.19 \mathrm{E}-01$ & $3.55 \mathrm{E}-01$ & $6.35 E-01$ \\
\hline $0.00 \mathrm{E}+00$ & $1.69 \mathrm{E}+00$ & $4.36 \mathrm{E}-02$ & $83 E-03$ & 1.10E-01 & $2.20 \mathrm{E}-01$ & $3.57 \mathrm{E}-01$ & $6.39 \mathrm{E}-01$ \\
\hline $1.04 \mathrm{E}-24$ & $1.70 \mathrm{E}+00$ & $4.40 \mathrm{E}-02$ & $5.91 \mathrm{E}-03$ & $1.11 \mathrm{E}-01$ & $2.22 E-01$ & $3.59 \mathrm{E}-01$ & $6.42 E-01$ \\
\hline 4. $31 \mathrm{E}-22$ & $1.71 \mathrm{E}+00$ & $4.43 E-02$ & $6.00 E-03$ & 1.12E-01 & $2.23 \mathrm{E}-01$ & $3.62 \mathrm{E}-01$ & $6.46 \mathrm{E}-01$ \\
\hline $3.42 \mathrm{E}-20$ & $1.72 \mathrm{E}+00$ & $4.47 \mathrm{E}-02$ & $6.09 \mathrm{E}-03$ & $1.13 \mathrm{E}-01$ & $2.25 \mathrm{E}-01$ & $3.64 \mathrm{E}-01$ & $6.49 \mathrm{E}-01$ \\
\hline $1.05 \mathrm{E}-18$ & $1.73 E+00$ & $4.50 \mathrm{E}-02$ & $6.17 \mathrm{E}-03$ & $1.14 \mathrm{E}-01$ & $2.26 \mathrm{E}-01$ & $3.67 \mathrm{E}-01$ & $6.53 \mathrm{E}-01$ \\
\hline $1.71 \mathrm{E}-17$ & $1.74 \mathrm{E}+00$ & $4.54 \mathrm{E}-02$ & $6.26 E-03$ & $1.15 \mathrm{E}-01$ & $2.27 E-01$ & $3.69 \mathrm{E}-01$ & $6.56 \mathrm{E}-01$ \\
\hline $1.81 \mathrm{E}-16$ & $1.75 \mathrm{E}+00$ & $4.57 \mathrm{E}-02$ & $6.34 \mathrm{E}-03$ & $1.16 \mathrm{E}-01$ & $2.29 \mathrm{E}-01$ & $3.71 \mathrm{E}-01$ & $6.60 \mathrm{E}-01$ \\
\hline 1. $38 \mathrm{E}-15$ & $1.76 \mathrm{E}+00$ & $4.60 \mathrm{E}-02$ & $6.42 \mathrm{E}-03$ & 1.17E-01 & $2.30 \mathrm{E}-01$ & $3.74 \mathrm{E}-01$ & $6.63 E-01$ \\
\hline $8.18 \mathrm{E}-15$ & $1.77 \mathrm{E}+00$ & $4.64 \mathrm{E}-02$ & $6.50 E-03$ & 1. $18 \mathrm{E}-01$ & $2.32 \mathrm{E}-01$ & $3.76 \mathrm{E}-01$ & $6.67 \mathrm{E}-01$ \\
\hline $3.90 \mathrm{E}-14$ & $1.77 \mathrm{E}+00$ & $4.68 E-02$ & $6.59 E-03$ & 1.19E-01 & $2.33 E-01$ & $3.78 \mathrm{E}-01$ & $6.70 \mathrm{E}-01$ \\
\hline 1. $56 \mathrm{E}-13$ & $1.78 \mathrm{E}+00$ & $4.71 \mathrm{E}-02$ & $6.67 E-03$ & 1.19E-01 & $2.34 \mathrm{E}-01$ & $3.81 \mathrm{E}-01$ & $6.73 E-01$ \\
\hline $5.35 \mathrm{E}-13$ & $1.79 \mathrm{E}+00$ & $4.75 E-02$ & $6.76 \mathrm{E}-03$ & 1.20E-01 & $2.36 \mathrm{E}-01$ & $3.83 \mathrm{E}-01$ & $6.77 \mathrm{E}-01$ \\
\hline 1. $62 \mathrm{E}-12$ & $1.80 \mathrm{E}+00$ & $.78 E-02$ & $6.86 E-03$ & $1.21 \mathrm{E}-01$ & $2.37 E-01$ & $3.86 \mathrm{E}-01$ & $6.80 \mathrm{E}-01$ \\
\hline 4. $38 \mathrm{E}-12$ & $1.81 \mathrm{E}+00$ & $4.82 \mathrm{E}-02$ & $6.95 E-03$ & 1. $22 \mathrm{E}-01$ & $2.39 \mathrm{E}-01$ & $3.88 \mathrm{E}-01$ & $6.84 \mathrm{E}-01$ \\
\hline $1.08 \mathrm{E}-11$ & $1.82 \mathrm{E}+00$ & $4.85 E-02$ & $7.04 \mathrm{E}-03$ & 1.23E-01 & $2.40 \mathrm{E}-01$ & $3.90 \mathrm{E}-01$ & $6.87 \mathrm{E}-01$ \\
\hline $2.45 E-11$ & $1.83 \mathrm{E}+00$ & $4.89 E-02$ & $7.13 E-03$ & $1.24 \mathrm{E}-01$ & $2.42 \mathrm{E}-01$ & $3.93 E-01$ & $6.91 \mathrm{E}-01$ \\
\hline $5.19 \mathrm{E}-11$ & $1.84 \mathrm{E}+00$ & $4.93 E-02$ & $7.22 \mathrm{E}-03$ & 1.25E-01 & $2.44 \mathrm{E}-01$ & $3.95 \mathrm{E}-01$ & $6.95 E-01$ \\
\hline $1.04 \mathrm{E}-10$ & $1.85 \mathrm{E}+00$ & $4.96 \mathrm{E}-02$ & $7.31 \mathrm{E}-03$ & 1. $26 \mathrm{E}-01$ & $2.45 \mathrm{E}-01$ & $3.98 \mathrm{E}-01$ & $6.99 \mathrm{E}-01$ \\
\hline $96 \mathrm{E}-10$ & $1.86 \mathrm{E}+00$ & $5.00 \mathrm{E}-02$ & $7.40 E-03$ & $1.27 E-01$ & $2.47 \mathrm{E}-01$ & $4.00 \mathrm{E}-01$ & $7.03 E-01$ \\
\hline $3.53 \mathrm{E}-10$ & $1.87 \mathrm{E}+00$ & $5.04 \mathrm{E}-02$ & $7.49 E-03$ & $1.28 \mathrm{E}-01$ & $2.49 \mathrm{E}-01$ & $4.02 E-01$ & $7.07 \mathrm{E}-01$ \\
\hline $6.12 \mathrm{E}-10$ & $1.88 \mathrm{E}+00$ & $5.07 \mathrm{E}-02$ & $7.58 \mathrm{E}-03$ & 1.29E-01 & $2.50 \mathrm{E}-01$ & $4.05 E-01$ & $7.11 \mathrm{E}-01$ \\
\hline $1.02 \mathrm{E}-09$ & $1.88 \mathrm{E}+00$ & $5.11 \mathrm{E}-02$ & $7.67 E-03$ & $1.30 E-01$ & $2.52 \mathrm{E}-01$ & $4.07 E-01$ & $7.15 E-01$ \\
\hline $1.65 \mathrm{E}-09$ & $1.89 \mathrm{E}+00$ & $5.15 \mathrm{E}-02$ & $7.76 \mathrm{E}-03$ & 1. $31 \mathrm{E}-01$ & $2.54 \mathrm{E}-01$ & $4.10 \mathrm{E}-01$ & $7.19 \mathrm{E}-01$ \\
\hline $2.59 \mathrm{E}-09$ & $1.90 \mathrm{E}+00$ & $5.18 \mathrm{E}-02$ & $7.86 E-03$ & $1.32 \mathrm{E}-01$ & $2.56 \mathrm{E}-01$ & $4.12 \mathrm{E}-01$ & $7.23 E-01$ \\
\hline $3.97 \mathrm{E}-09$ & $1.91 \mathrm{E}+00$ & $5.22 E-02$ & $7.96 E-03$ & $1.33 E-01$ & $2.57 E-01$ & $4.15 E-01$ & $7.27 E-01$ \\
\hline $5.92 \mathrm{E}-09$ & $1.92 \mathrm{E}+00$ & $5.26 \mathrm{E}-02$ & $8.06 E-03$ & 1. $34 \mathrm{E}-01$ & $2.59 \mathrm{E}-01$ & $4.17 \mathrm{E}-01$ & 7. $31 \mathrm{E}-01$ \\
\hline
\end{tabular}


RESRAD-OFFSITE, Version 2.5

obabilistic Dose and Risk Report

Title : Offsite Resident Farmer Deterministic Run

File : RF TC99 DOESG FWD-FV2.ROF

Summary of dose at graphical times, reptition 1 (continued)

Time

Years

4. $01 \mathrm{E}+02$

$4.01 E+02$

$4.02 \mathrm{E}+02$

4. $02 \mathrm{E}+02$

$4.03 E+02$

$4.03 E+02$

$4.04 \mathrm{E}+02$

$4.05 \mathrm{E}+02$

$4.05 \mathrm{E}+02$

$4.06 \mathrm{E}+02$

$4.06 \mathrm{E}+02$

$4.07 \mathrm{E}+02$

$4.07 \mathrm{E}+02$

$4.08 \mathrm{E}+02$

$4.08 \mathrm{E}+02$

$4.09 \mathrm{E}+02$

$4.09 \mathrm{E}+02$

$4.10 \mathrm{E}+02$

$4.10 \mathrm{E}+02$

$4.11 \mathrm{E}+02$

$4.11 \mathrm{E}+02$

$4.12 \mathrm{E}+02$

$4.12 \mathrm{E}+02$

$4.13 \mathrm{E}+02$

$4.13 \mathrm{E}+02$

$4.14 \mathrm{E}+02$

$4.14 \mathrm{E}+02$

$4.15 \mathrm{E}+02$

4. $15 \mathrm{E}+02$

$4.16 \mathrm{E}+02$

4. $16 \mathrm{E}+02$

4.17E+02

$4.17 \mathrm{E}+02$

4. $18 \mathrm{E}+02$

$4.18 \mathrm{E}+02$

4. $19 \mathrm{E}+02$

$4.19 \mathrm{E}+02$

$4.20 \mathrm{E}+02$

$4.20 \mathrm{E}+02$

$4.21 \mathrm{E}+02$

$4.21 \mathrm{E}+02$

$4.22 \mathrm{E}+02$

4. $22 \mathrm{E}+02$

$4.23 \mathrm{E}+02$

$4.23 E+02$

$4.24 \mathrm{E}+02$
Dose statistics at graphical times, mrem/yr

\begin{tabular}{|c|c|c|c|c|c|c|c|}
\hline inimum & aximum & lean & edi & & & & \\
\hline 09 & 00 & 02 & 03 & 01 & 01 & 01 & -01 \\
\hline $4 E-08$ & $1.94 \mathrm{E}+00$ & $4 E-02$ & $6 E-03$ & 1. $36 \mathrm{E}-01$ & $2.63 \mathrm{E}-01$ & 4. $22 \mathrm{E}-01$ & $7.39 \mathrm{E}-01$ \\
\hline $.74 E-08$ & $1.95 E+00$ & $37 \mathrm{E}-02$ & $36 E-03$ & $.37 E-01$ & $2.65 \mathrm{E}-01$ & $.24 \mathrm{E}-01$ & $.43 E-01$ \\
\hline $41 \mathrm{E}-08$ & $1.96 \mathrm{E}+00$ & $41 E-02$ & $45 E-03$ & 1. $38 \mathrm{E}-01$ & $2.67 \mathrm{E}-01$ & $7 E-01$ & $7 E-01$ \\
\hline $27 \mathrm{E}-08$ & $1.97 \mathrm{E}+00$ & & & 1 & & & -01 \\
\hline $.39 E-08$ & & & & & & 1 & -01 \\
\hline $81 E-08$ & $1.99 \mathrm{E}+00$ & - & -03 & 01 & $2.73 E-01$ & $E-01$ & $59 E-01$ \\
\hline $.58 \mathrm{E}-08$ & $2.00 \mathrm{E}+00$ & $7 E-02$ & $8 E-03$ & $42 E-01$ & $2.75 E-01$ & -01 & $63 E-01$ \\
\hline $78 \mathrm{~F}-08$ & $.01 E+00$ & $61 F-0$ & $00 E-03$ & $43 E-01$ & $.77 E-01$ & $.39 E-01$ & $E-01$ \\
\hline 07 & & $5.65 \mathrm{E}-02$ & 3 & 1 & 1 & 1 & -01 \\
\hline $58 \mathrm{E}-07$ & $2.02 F+00$ & 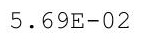 & $2 E-03$ & $45 \mathrm{~F}-\mathrm{C}-\mathrm{C}$ & 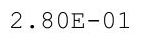 & 1 & $E-01$ \\
\hline $.97 \mathrm{E}-07$ & & & & & & & $.79 E-01$ \\
\hline $44 \mathrm{E}-07$ & $2.04 \mathrm{E}+00$ & $.77 E-02$ & $9.45 E-03$ & $1.47 E-01$ & $2.84 E-01$ & 4. $49 \mathrm{E}-01$ & $.83 E-01$ \\
\hline $.00 E-07$ & & & -03 & & & -01 & $\Xi-01$ \\
\hline 7 & $2.06 \mathrm{E}+00$ & 2 & 3 & - & 1 & 1 & -01 \\
\hline 07 & 2 & $5.89 E-02$ & & 1 & 1 & \pm & 01 \\
\hline $29 E-07$ & $208 F+00$ & $5.93 \mathrm{E}-02$ & 3 & - & 1 & 1 & -01 \\
\hline $31 E-07$ & $209 F+00$ & $97 \mathrm{~F}-0$ & $1 E-02$ & $53 E-01$ & 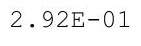 & $E-01$ & $4 E-01$ \\
\hline $46 \mathrm{E}-07$ & $2.10 \mathrm{E}+00$ & $01 \mathrm{E}-02$ & $2 \mathrm{E}-02$ & $1.54 \mathrm{E}-$ & $2.94 \mathrm{E}-01$ & $4.65 E-01$ & $08 E-01$ \\
\hline E-07 & $.11 E+00$ & $E-02$ & -02 & -01 & $96 E-01$ & -01 & $E-01$ \\
\hline & & & & & & & -01 \\
\hline 0 & $2.13 E+00$ & & & 土. & & & 01 \\
\hline $38 E-06$ & $2.14 \mathrm{E}+00$ & $6.17 \mathrm{E}-02$ & 2 & 1 & 1 & 1 & -01 \\
\hline $59 \mathrm{~F}-06$ & $.15 \mathrm{E}+00$ & 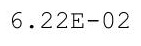 & $8 E-02$ & $16 \cap 5$ & 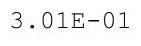 & $78 E-01$ & $29 E-01$ \\
\hline $81 \mathrm{~F}-06$ & $.15 \mathrm{E}+00$ & $.26 E-02$ & $1.09 \mathrm{E}-02$ & 1. $61 \mathrm{E}-01$ & $.03 E-01$ & $.80 E-01$ & $33 E-01$ \\
\hline $07 \mathrm{~F}-06$ & $2.16 \mathrm{E}+00$ & $30 E-02$ & $E-02$ & & & $E-01$ & $37 E-01$ \\
\hline$F-06$ & & & & & & & $E-01$ \\
\hline & & & 02 & 1.04 & & & 01 \\
\hline $.98 E-06$ & $2.19 \mathrm{E}+00$ & $6.43 E-02$ & $1.14 \mathrm{E}-02$ & $1.66 \mathrm{E}-01$ & $3.11 \mathrm{E}-01$ & 円 & $50 E-01$ \\
\hline 6 & $2.20 E+00$ & $.47 E-02$ & 2 & ton & 1 & $4.94 \mathrm{E}-01$ & $.54 E-01$ \\
\hline $3 E-$ & $2.21 \mathrm{E}+00$ & & $1.17 \mathrm{E}-0$ & $1.68 \mathrm{E}-\mathrm{C}$ & & $4.96 \mathrm{E}-01$ & $.58 \mathrm{E}-01$ \\
\hline $16 F-06$ & $2.22 E+00$ & $6 E-02$ & $1.18 \mathrm{E}-02$ & & & & $53 E-01$ \\
\hline & & & & & & & 01 \\
\hline$E-06$ & & & 02 & 01 & & & -01 \\
\hline $.62 \mathrm{E}-06$ & $2.25 \mathrm{E}+00$ & $6.69 \mathrm{E}-02$ & 1.22E-02 & $1.73 \mathrm{E}-01$ & $3.22 \mathrm{E}-01$ & $5.08 \mathrm{E}-01$ & $8.75 E-01$ \\
\hline$\cdot .0 \mathrm{E}-00$ & $2.20 E+00$ & & & $1.74 \mathrm{E}-01$ & $3.24 \mathrm{E}-01$ & & $8.80 \mathrm{E}-01$ \\
\hline . & 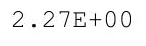 & ( & 2 & 1 & 1 & & $84 E-01$ \\
\hline $7.41 \mathrm{E}-06$ & $2.28 \mathrm{E}+00$ & s & 2 & 1 & 1 & 1 & 01 \\
\hline & & & & 1 & & 1 & 01 \\
\hline$E-06$ & & 02 & -02 & 01 & & 01 & 01 \\
\hline$E-06$ & $2.30 \mathrm{E}+00$ & & 2 & 1 & & & -01 \\
\hline & $2.31 \mathrm{E}$ & & & $\pm .0+1$ & & & $05 E-01$ \\
\hline 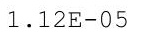 & $2.32 E+00$ & $7.04 \mathrm{E}-02$ & $1.33 E-02$ & +00 & (.) & $-9 E-U \perp$ & $09 E-U \perp$ \\
\hline 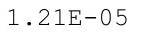 & $2.33 E+00$ & (1.0 & $1.35 \mathrm{E}-02$ & & & & $9.13 E-01$ \\
\hline 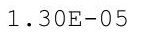 & $.34 \mathrm{E}+00$ & & & & & 1 & $9.17 \mathrm{E}-01$ \\
\hline $39 E-05$ & $.35 E+00$ & $E-02$ & $38 E-02$ & $87 \mathrm{E}-$ & 1 & 1 & 01 \\
\hline
\end{tabular}


RESRAD-OFFSITE, Version 2.5

obabilistic Dose and Risk Report

Title : Offsite Resident Farmer Deterministic Run

File : RF TC99 DOESG FWD-FV2.ROF

Summary of dose at graphical times, reptition 1 (continued)

Time

Years

$4.25 \mathrm{E}+02$

$4.25 \mathrm{E}+02$

$4.26 \mathrm{E}+02$

$4.26 \mathrm{E}+02$

$4.27 \mathrm{E}+02$

$4.27 \mathrm{E}+02$

$4.28 \mathrm{E}+02$

$4.28 \mathrm{E}+02$

$4.29 \mathrm{E}+02$

$4.29 \mathrm{E}+02$

$4.30 \mathrm{E}+02$

$4.30 \mathrm{E}+02$

$4.31 \mathrm{E}+02$

$4.31 \mathrm{E}+02$

$4.32 \mathrm{E}+02$

4. $32 \mathrm{E}+02$

4. $33 \mathrm{E}+02$

4. $33 \mathrm{E}+02$

$4.34 \mathrm{E}+02$

4. $34 \mathrm{E}+02$

$4.35 \mathrm{E}+02$

$4.35 \mathrm{E}+02$

$4.36 \mathrm{E}+02$

$4.36 \mathrm{E}+02$

$4.37 \mathrm{E}+02$

$4.37 \mathrm{E}+02$

$4.38 \mathrm{E}+02$

$4.38 \mathrm{E}+02$

$4.39 \mathrm{E}+02$

$4.39 \mathrm{E}+02$

$4.40 \mathrm{E}+02$

$4.40 \mathrm{E}+02$

$4.41 \mathrm{E}+02$

4. $41 \mathrm{E}+02$

4. $42 \mathrm{E}+02$

$4.42 \mathrm{E}+02$

$4.43 E+02$

$4.43 E+02$

4. $44 \mathrm{E}+02$

4. $45 \mathrm{E}+02$

$4.45 \mathrm{E}+02$

$4.46 \mathrm{E}+02$

$4.46 \mathrm{E}+02$

$4.47 \mathrm{E}+02$

$4.47 \mathrm{E}+02$

$4.48 \mathrm{E}+02$
Dose statistics at graphical times, mrem/yr

\begin{tabular}{|c|c|c|c|c|c|c|c|}
\hline$m$ & $\mathrm{~m}$ & ea & 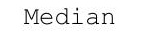 & & & $\%$ & \\
\hline $.50 \mathrm{E}-05$ & $2.36 \mathrm{E}+00$ & $7.22 \mathrm{E}-02$ & 1. $39 \mathrm{E}-02$ & $1.88 \mathrm{E}-01$ & $3.50 \mathrm{E}-01$ & -01 & -01 \\
\hline $60 E-05$ & +00 & 02 & -02 & 01 & 01 & -01 & -01 \\
\hline $.71 \mathrm{E}-05$ & $2.38 \mathrm{E}+00$ & $.32 E-02$ & 1. $42 \mathrm{E}-02$ & 1.91E-01 & $55 E-01$ & $.45 E-01$ & $.34 \mathrm{E}-01$ \\
\hline $83 E-05$ & $2.39 \mathrm{E}+00$ & $.36 \mathrm{E}-02$ & $.43 E-02$ & $1.92 \mathrm{E}-01$ & $57 \mathrm{E}-01$ & $5.47 \mathrm{E}-01$ & $38 E-01$ \\
\hline $95 \mathrm{~F}-05$ & $40 E+00$ & $1 F-02$ & $5 E-02$ & $3 F-01$ & $.60 E-01$ & $O F-01$ & -01 \\
\hline $.07 E-05$ & & $5=0$ & 2 & $95 \mathrm{E}$ & 1 & -01 & -01 \\
\hline $20 E-05$ & $2.41 \mathrm{E}+00$ & 2 & & & 1 & 1 & -01 \\
\hline $33 E-05$ & & & & & & -01 & -01 \\
\hline $47 E-05$ & $2.43 E+00$ & $E-02$ & $E-02$ & $99 E-01$ & -01 & -01 & -01 \\
\hline $.62 \mathrm{E}-0$ & $44 \mathrm{E}+00$ & $7.64 \mathrm{E}-02$ & 2 & 1 & 1 & -01 & -01 \\
\hline$E-05$ & $.45 E+00$ & 7. $69 \mathrm{E}-02$ & 2 & 1 & 1 & -01 & -01 \\
\hline 5 & & & & $2.03 \mathrm{E}$ & 1 & 1 & -01 \\
\hline $08 F-05$ & $7 \mathrm{E}+00$ & $9 F-0$ & 2 & 2 & 1 & 1 & -01 \\
\hline $.24 \mathrm{E}-05$ & $2.48 \mathrm{E}+00$ & $7.83 \mathrm{E}-02$ & 1. $59 \mathrm{E}-02$ & $2.06 \mathrm{E}-01$ & $3.79 \mathrm{E}-01$ & $.73 E-01$ & $81 E-01$ \\
\hline $41 E-05$ & $2.49 \mathrm{E}+00$ & $7.88 \mathrm{E}-02$ & $1.60 \mathrm{E}-02$ & $2.01 \mathrm{E}-U \perp$ & $.0 \angle E-U 1$ & $5.76 \mathrm{E}-01$ & $85 E-01$ \\
\hline & $.50 \mathrm{E}+00$ & & & & & 01 & -01 \\
\hline $7 F-05$ & & & & & & 1 & 01 \\
\hline 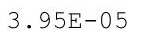 & $2.52 \mathrm{E}+$ & $8.03 E-02$ & & & & 1 & 1 \\
\hline $14 \mathrm{E}-05$ & $.53 E+00$ & 吅 & $1.67 \mathrm{E}-02$ & 5 & & -01 & +00 \\
\hline $.33 E-05$ & $2.53 \mathrm{E}+00$ & $.12 \mathrm{E}-02$ & 1. $68 \mathrm{E}-02$ & $2.14 \mathrm{E}-01$ & -01 & $E-01$ & $.01 E+00$ \\
\hline$F-05$ & $.54 \mathrm{E}+00$ & $17 \mathrm{E}-02$ & -02 & -01 & $\perp$ & $E-01$ & $01 \mathrm{E}+00$ \\
\hline & & & & & & -01 & +00 \\
\hline$=$ & & & & & & & +00 \\
\hline $.17 \mathrm{E}-0$ & $2.57 \mathrm{E}+00$ & $8.32 E-02$ & $1 \cdot$ & 1 & & 01 & 00 \\
\hline 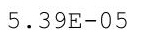 & $2.58 \mathrm{E}+00$ & 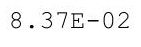 & 2 & - & 1 & 1 & $03 E+00$ \\
\hline$F-0$ & $.59 \mathrm{E}+00$ & ט & $1.79 \mathrm{E}-02$ & שית & 055 & $5 E-01$ & $1.03 E+00$ \\
\hline$F-0$ & $2.60 \mathrm{E}+00$ & $47 \mathrm{~F}-02$ & $E-02$ & $223 F_{1}$ & $07 E-01$ & $8 E-01$ & $1.04 \mathrm{E}+00$ \\
\hline & & & & & & & \\
\hline & $2.62 \mathrm{E}+00$ & & & & & & \\
\hline $57 E-05$ & $2.63 E+00$ & $0.0<+42$ & $1.86 \mathrm{E}-02$ & $2.27 E-01$ & 01 & 01 & $1.05 E+00$ \\
\hline elch vo & $2.63 E+00$ & .0ta dz & $1.8 / E-02$ & $2.29 \mathrm{E}-01$ & $.14 \mathrm{E}-01$ & $.19 \mathrm{E}-01$ & $1.05 E+00$ \\
\hline C & $2.64 \mathrm{E}+00$ & e. & $1.89 \mathrm{E}-02$ & & 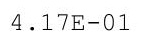 & $0.2 \angle L-1$ & $1.06 \mathrm{E}+00$ \\
\hline 5 & $2.65 \mathrm{E}+00$ & & & ת1 2 & & & $1.06 \mathrm{E}+00$ \\
\hline & & & & & & & $.07 E+00$ \\
\hline $5-0$ & & 2 & 02 & 1 & 01 & & \\
\hline 5 & $2.68 \mathrm{E}+00$ & 02 & 02 & $2 \cdot 005$ & 1 & 01 & $1.07 \mathrm{E}+00$ \\
\hline 正 & $2.69 \mathrm{E}+00$ & & & 2.00 & & & $1.08 \mathrm{E}+00$ \\
\hline & $.70 \mathrm{E}+00$ & & & & & $0.4 \perp E-0 \perp$ & $1.08 \mathrm{E}+00$ \\
\hline $8 \cap \square \bigcirc$ & . & 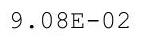 & ? & 1 & & $\perp$ & $1.09 \mathrm{E}+00$ \\
\hline & & & & & & & $1.09 \mathrm{E}+0 \mathrm{C}$ \\
\hline & & 9 & 02 & & 1 & 1 & $1.10 \mathrm{E}+00$ \\
\hline$E-05$ & $2.73 E+00$ & $E-02$ & 2.08 & 2.41 & -01 & 01 & $1.10 \mathrm{E}+00$ \\
\hline & & & & & & & \\
\hline & $2.75 \mathrm{E}+00$ & s. & 2 & 2. & & & $1.11 \mathrm{E}+00$ \\
\hline 40 & $2.76 \mathrm{E}+00$ & . & & (.) & 1 & 1 & $1.11 \mathrm{E}+00$ \\
\hline-04 & $.77 \mathrm{E}+00$ & $5 E-02$ & $16 E-02$ & $E-01$ & $E-01$ & 01 & $.12 \mathrm{E}+00$ \\
\hline
\end{tabular}


RESRAD-OFFSITE, Version 2.5

obabilistic Dose and Risk Report

Title : Offsite Resident Farmer Deterministic Run

File : RF TC99 DOESG FWD-FV2.ROF

Summary of dose at graphical times, reptition 1 (continued)

Time

Years

$4.48 \mathrm{E}+02$

$4.49 \mathrm{E}+02$

$4.49 \mathrm{E}+02$

$4.50 \mathrm{E}+02$

$4.50 \mathrm{E}+02$

$4.51 \mathrm{E}+02$

$4.51 \mathrm{E}+02$

$4.52 \mathrm{E}+02$

$4.52 \mathrm{E}+02$

$4.53 \mathrm{E}+02$

$4.53 \mathrm{E}+02$

$4.54 \mathrm{E}+02$

$4.54 \mathrm{E}+02$

$4.55 \mathrm{E}+02$

$4.55 \mathrm{E}+02$

$4.56 \mathrm{E}+02$

$4.56 \mathrm{E}+02$

$4.57 \mathrm{E}+02$

$4.57 \mathrm{E}+02$

$4.58 \mathrm{E}+02$

$4.58 \mathrm{E}+02$

$4.59 \mathrm{E}+02$

$4.59 \mathrm{E}+02$

$4.60 \mathrm{E}+02$

$4.60 \mathrm{E}+02$

$4.61 \mathrm{E}+02$

$4.61 \mathrm{E}+02$

$4.62 \mathrm{E}+02$

4. $62 \mathrm{E}+02$

4. $63 \mathrm{E}+02$

4. $63 \mathrm{E}+02$

$4.64 \mathrm{E}+02$

$4.65 \mathrm{E}+02$

$4.65 \mathrm{E}+02$

$4.66 \mathrm{E}+02$

$4.66 \mathrm{E}+02$

$4.67 \mathrm{E}+02$

$4.67 \mathrm{E}+02$

$4.68 \mathrm{E}+02$

$4.68 \mathrm{E}+02$

$4.69 \mathrm{E}+02$

$4.69 \mathrm{E}+02$

$4.70 \mathrm{E}+02$

$4.70 \mathrm{E}+02$

$4.71 \mathrm{E}+02$

$4.71 \mathrm{E}+02$
Dose statistics at graphical times, mrem/yr

\begin{tabular}{|c|c|c|c|c|c|c|c|}
\hline$m$ & $\mathrm{~m}$ & ea & ledian & & & $\%$ & \\
\hline $.09 \mathrm{E}-04$ & $.78 \mathrm{E}+00$ & $9.51 \mathrm{E}-02$ & $2.18 \mathrm{E}-02$ & $2.47 \mathrm{E}-01$ & $4.46 \mathrm{E}-01$ & -01 & +00 \\
\hline $.11 \mathrm{E}-04$ & $2.79 \mathrm{E}+00$ & $.56 \mathrm{E}-02$ & $2.20 \mathrm{E}-02$ & 01 & 01 & -01 & $1.12 \mathrm{E}+00$ \\
\hline $.14 \mathrm{E}-04$ & $2.80 \mathrm{E}+00$ & $9.61 \mathrm{E}-02$ & $2.22 \mathrm{E}-02$ & $2.50 \mathrm{E}-01$ & $4.50 \mathrm{E}-01$ & $6.75 \mathrm{E}-01$ & $1.13 \mathrm{E}+00$ \\
\hline $17 \mathrm{E}-04$ & $2.81 E+00$ & $9.67 \mathrm{E}-02$ & $2.24 \mathrm{E}-02$ & $2.51 \mathrm{E}-01$ & $4.51 \mathrm{E}-01$ & $6.78 \mathrm{E}-01$ & $1.13 \mathrm{E}+00$ \\
\hline $9 E-04$ & $.81 E+00$ & $2 \mathrm{E}-02$ & $2.26 \mathrm{E}$ & $53 E-01$ & $53 E-01$ & $31 E-01$ & $1.14 \mathrm{E}+00$ \\
\hline $22 \mathrm{E}-04$ & $82 \mathrm{E}+00$ & 2 & 2 & 1 & 1 & 1 & +00 \\
\hline $25 E-04$ & $2.83 \mathrm{E}+00$ & 2 & 2 & 1 & 1 & & +00 \\
\hline $28 \mathrm{E}-04$ & & & & $\perp$ & & & $15 E+00$ \\
\hline $.31 E-04$ & $2.85 \mathrm{E}+00$ & -02 & $E-02$ & $58 E-01$ & $59 E-01$ & -01 & $15 E+00$ \\
\hline 3 & $86 \mathrm{E}+00$ & $9.99 \mathrm{E}-02$ & -02 & $\perp$ & 1 & -01 & +00 \\
\hline 4 & $.87 \mathrm{E}+00$ & 1.00E-01 & 2 & 1 & 1 & 1 & $.16 \mathrm{E}+00$ \\
\hline$\triangle \cap F-04$ & $E+00$ & & & & & & +00 \\
\hline $43 F-04$ & $3 E+00$ & $25-0$ & $E-02$ & 1 & 1 & -01 & +00 \\
\hline $.46 \mathrm{E}-04$ & $2.89 \mathrm{E}+00$ & $1.02 \mathrm{E}-01$ & $2.44 \mathrm{E}-02$ & $2.65 \mathrm{E}-01$ & $4.68 \mathrm{E}-01$ & $7.09 \mathrm{E}-01$ & $1.17 \mathrm{E}+00$ \\
\hline $49 E-04$ & $2.90 \mathrm{E}+00$ & $3 E-01$ & $6 E-02$ & 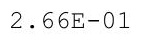 & 01 & -01 & $17 \mathrm{E}+00$ \\
\hline 4 & & & & & & 1 & 00 \\
\hline $5 E-04$ & & $4 E-01$ & & - & 5 & & 00 \\
\hline $59 \mathrm{E}-$ & & & & & $.76 \mathrm{E}-01$ & & 00 \\
\hline $62 E-04$ & $2.94 \mathrm{E}+00$ & $5 \mathrm{~F}-1$ & $5 E-02$ & $272 \mathrm{~F}$ & 1 & -01 & $19 \mathrm{E}+00$ \\
\hline $65 E-04$ & $2.95 \mathrm{E}+00$ & 1. $05 \mathrm{E}-01$ & $2.57 \mathrm{E}-02$ & $2.74 \mathrm{E}-01$ & $.81 E-01$ & $E-01$ & $1.19 \mathrm{E}+00$ \\
\hline$F-04$ & $.95 E+00$ & $.06 \mathrm{E}-0$ & -02 & $.75 \mathrm{E}-01$ & $.83 E-01$ & $.29 \mathrm{E}-01$ & L. $20 \mathrm{E}+00$ \\
\hline 04 & & & & & & -01 & \\
\hline & & & & & & & 00 \\
\hline $.79 E-04$ & $2.98 \mathrm{E}+00$ & +.000 & 2 & & & 01 & 00 \\
\hline 4 & $2.99 \mathrm{E}+00$ & 1. $08 \mathrm{E}-01$ & 2 & $\perp$ & $\perp$ & 1 & $21 E+00$ \\
\hline $86 E-04$ & $.00 \mathrm{E}+00$ & م & $2.71 \mathrm{E}-02$ & م२ & $.94 E-01$ & $7.44 \mathrm{E}-01$ & $1.22 \mathrm{E}+00$ \\
\hline-04 & $3.01 \mathrm{E}+00$ & $=01$ & $2.74 \mathrm{E}-02$ & $85 F_{-}$ & $4.97 \mathrm{E}-01$ & $.47 E-01$ & $1.22 \mathrm{E}+00$ \\
\hline 4 & & & & & & & \\
\hline-04 & $3.02 \mathrm{E}+00$ & & & & & & 00 \\
\hline$\cdot 01 E-04$ & $3.03 E+00$ & $\perp \cdot \perp \perp \perp-$ & $2.81 E-02$ & $2 \cdot 20$ & $5.05 E-01$ & -01 & $1.23 E+00$ \\
\hline $.035-4$ & $3.04 \mathrm{E}+00$ & $\perp \cdot \perp \angle \dot{0}$ & $2.84 \mathrm{E}-02$ & $2.92 E-01$ & $3.01 \mathrm{~L}-0 \perp$ & $7.59 \mathrm{E}-01$ & $1.23 \mathrm{E}+00$ \\
\hline 然 & $3.05 \mathrm{E}+00$ & 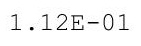 & 年 & (2) & 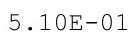 & $=0$ & $1.24 \mathrm{E}+00$ \\
\hline 10 & $3.06 \mathrm{E}+00$ & 135 & תم: תم & $0.5 \Gamma$ & & & $1.24 \mathrm{E}+00$ \\
\hline & & & & & & & $.25 \mathrm{E}+00$ \\
\hline$E-04$ & $3.07 E+00$ & & 02 & 1 & 1 & & $1.25 \mathrm{E}+00$ \\
\hline $24 E-04$ & $3.08 \mathrm{E}+00$ & $1.15 \mathrm{E}-01$ & $2.96 \mathrm{E}-02$ & 3.014 & 1 & 01 & $1.25 \mathrm{E}+00$ \\
\hline $5-04$ & $3.09 \mathrm{E}+00$ & & & & & & $1.26 \mathrm{E}+00$ \\
\hline $\begin{array}{ll}04 \\
4\end{array}$ & & & & & & & $1.26 \mathrm{E}+00$ \\
\hline $37 F-04$ & ent & $+\cdots$ & 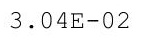 & $\perp$ & & 1 & $1.26 \mathrm{E}+00$ \\
\hline & & & & & & & $.27 E+00$ \\
\hline 04 & $3.12 \mathrm{E}+00$ & & 02 & 1 & 1 & 1 & $1.27 E+00$ \\
\hline$E-04$ & $3.13 \mathrm{E}+00$ & 1.1 & 3. & 01 & 01 & 1 & $1.27 \mathrm{E}+00$ \\
\hline & & & & & & & 00 \\
\hline & $3.15 \mathrm{E}+00$ & 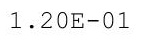 & & & & & $1.28 \mathrm{E}+00$ \\
\hline 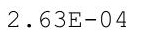 & $3.16 \mathrm{E}+00$ & $\perp \cdot 20+$ & & 1 & & 0.025 & $1.29 \mathrm{E}+00$ \\
\hline-04 & $.16 \mathrm{E}+00$ & $1 \mathrm{E}-01$ & $2 E-02$ & $E-01$ & $E-01$ & 1 & $1.29 \mathrm{E}+00$ \\
\hline
\end{tabular}


RESRAD-OFFSITE, Version 2.5

obabilistic Dose and Risk Report

Title : Offsite Resident Farmer Deterministic Run

File : RF TC99 DOESG FWD-FV2.ROF

Summary of dose at graphical times, reptition 1 (continued)

Time

Years

$4.72 \mathrm{E}+02$

$4.72 \mathrm{E}+02$

$4.73 \mathrm{E}+02$

$4.73 \mathrm{E}+02$

$4.74 \mathrm{E}+02$

$4.74 \mathrm{E}+02$

$4.75 \mathrm{E}+02$

$4.75 \mathrm{E}+02$

$4.76 \mathrm{E}+02$

$4.76 \mathrm{E}+02$

$4.77 \mathrm{E}+02$

$4.77 \mathrm{E}+02$

$4.78 \mathrm{E}+02$

$4.78 \mathrm{E}+02$

$4.79 \mathrm{E}+02$

$4.79 \mathrm{E}+02$

$4.80 \mathrm{E}+02$

$4.80 \mathrm{E}+02$

$4.81 \mathrm{E}+02$

$4.81 \mathrm{E}+02$

$4.82 \mathrm{E}+02$

$4.82 \mathrm{E}+02$

$4.83 \mathrm{E}+02$

$4.83 \mathrm{E}+02$

$4.84 \mathrm{E}+02$

$4.84 \mathrm{E}+02$

$4.85 \mathrm{E}+02$

$4.86 \mathrm{E}+02$

$4.86 \mathrm{E}+02$

$4.87 \mathrm{E}+02$

$4.87 \mathrm{E}+02$

$4.88 \mathrm{E}+02$

$4.88 \mathrm{E}+02$

$4.89 \mathrm{E}+02$

$4.89 \mathrm{E}+02$

4. $90 \mathrm{E}+02$

$4.90 \mathrm{E}+02$

4. $91 \mathrm{E}+02$

4. $91 \mathrm{E}+02$

4. $92 \mathrm{E}+02$

$4.92 \mathrm{E}+02$

$4.93 \mathrm{E}+02$

$4.93 \mathrm{E}+02$

4. $94 \mathrm{E}+02$

4. $94 \mathrm{E}+02$

4. $95 \mathrm{E}+02$

Dose statistics at graphical times, mrem/yr

\begin{tabular}{|c|c|c|c|c|c|c|c|}
\hline $\mathrm{m}$ & aximum & lea & ec & & & & $\%$ \\
\hline $.72 E-04$ & $.17 \mathrm{E}+00$ & 1.21E-01 & $.25 E-02$ & $3.18 \mathrm{E}-01$ & 01 & 01 & $.29 E+00$ \\
\hline $.76 E-04$ & $3.18 \mathrm{E}+00$ & $1.22 \mathrm{E}-01$ & $3.28 \mathrm{E}-02$ & $19 E-01$ & $8 E-01$ & $8.11 \mathrm{E}-01$ & $1.30 \mathrm{E}+00$ \\
\hline $81 E-04$ & $19 \mathrm{E}+00$ & $23 E-01$ & $31 E-02$ & $21 E-01$ & $50 E-01$ & $14 \mathrm{E}-01$ & $30 E+00$ \\
\hline $86 E-04$ & $.20 E+00$ & $23 F-01$ & $34 \mathrm{E}-02$ & $23 F-01$ & $53 F-01$ & $17 \mathrm{~F}-01$ & 1. $30 \mathrm{E}+00$ \\
\hline $90 E-04$ & $\mathrm{E}+00$ & 4 & -02 & 1 & 1 & 1 & $E+00$ \\
\hline 04 & $21 E+00$ & 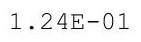 & 2 & & & & +00 \\
\hline $.00 E-04$ & $3.22 \mathrm{E}+00$ & $1.25 \mathrm{E}$ & -02 & & & & $.32 E+00$ \\
\hline-04 & +00 & $\perp$ & -02 & 1 & 1 & 01 & $\mathrm{E}+00$ \\
\hline $10 E-04$ & $3.24 \mathrm{E}+00$ & $.26 \mathrm{E}-0$. & $\Xi-02$ & $31 E-01$ & - & $E-01$ & $2 \mathrm{E}+00$ \\
\hline$E-04$ & $.25 E+00$ & $27 \mathrm{~F}-1$ & $1 E-02$ & & & קטק & $.33 E+00$ \\
\hline 04 & $3.25 \mathrm{E}+00$ & .27 & 2 & & & & +00 \\
\hline $25 E-04$ & +00 & $1.28 \mathrm{E}$ & $E-02$ & 6 & 1 & 1 & +00 \\
\hline $30 E-04$ & $3.27 \mathrm{E}+00$ & $1.29 \mathrm{E}-01$ & $3.59 \mathrm{E}-02$ & $3.38 \mathrm{E}-01$ & $5.75 \mathrm{E}-01$ & & $1.34 \mathrm{E}+00$ \\
\hline $35 E-04$ & $3.28 \mathrm{E}+00$ & 1.29E-01 & $.62 E-02$ & 1 & 1 & 1 & $1.34 \mathrm{E}+00$ \\
\hline-04 & +00 & $30 \mathrm{~F}-1$ & $E-02$ & & & 1 & $\mathrm{E}+00$ \\
\hline 4 & $.29 \mathrm{E}+00$ & - e & -02 & & 1 & $\perp$ & 00 \\
\hline 4 & 0 & 1. $31 \mathrm{E}-01$ & 2 & & $85 E-01$ & 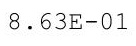 & 0 \\
\hline 4 & $3315+0$ & 1. $32 \mathrm{E}-01$ & 2 & $\perp$ & 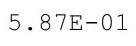 & 1 & 00 \\
\hline $62 E-04$ & $3.32 \mathrm{E}+00$ & $1.33 E-01$ & $3.75 E-02$ & $3.48 \mathrm{E}-01$ & $.90 E-01$ & $8.69 \mathrm{E}-01$ & $1.36 \mathrm{E}+00$ \\
\hline $68 E-04$ & $.33 E+00$ & $.33 E-01$ & $.78 E-02$ & $0 E-01$ & $92 \mathrm{E}-01$ & 8. $72 \mathrm{E}-01$ & $1.36 \mathrm{E}+00$ \\
\hline 04 & $33 E+00$ & 3 & 2 & & & & $\mathrm{E}+00$ \\
\hline 4 & & 1 & & 1 & & & \\
\hline 04 & & $1 \cdot 0$ & 2 & & & & $1.38 \mathrm{E}$ \\
\hline $1 E-04$ & $36 \mathrm{E}+00$ & $1.36 \mathrm{E}-01$ & 2 & 1 & 1 & - & +00 \\
\hline 4 & $.36 \mathrm{E}+00$ & 365 & $3 E-02$ & תח & $5 E-$ & $E-$ & $1.39 \mathrm{E}+00$ \\
\hline $.03 E-04$ & $37 \mathrm{E}+00$ & $1.37 \mathrm{E}-01$ & $5 E-02$ & תח & 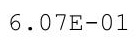 & $.90 E-01$ & $1.39 \mathrm{E}+00$ \\
\hline$E-04$ & $38 E+00$ & $38=-01$ & $99 E-02$ & & & $3 E-01$ & L. $40 \mathrm{E}+00$ \\
\hline & & & & & & & \\
\hline 4 & & 1.3 & 02 & & 1 & & $1.41 \mathrm{E}+00$ \\
\hline $.27 E-04$ & $3.40 \mathrm{E}+00$ & $\perp \cdot 4 U D-1$ & $4.08 E-02$ & $3.67 \mathrm{E}-01$ & $\cdot \perp / E-U \perp$ & $2 E-U 1$ & 1. $41 \mathrm{E}+00$ \\
\hline $33 E-04$ & $3.41 \mathrm{E}+00$ & $+\cdot 10+$ & $.11 \mathrm{E}-02$ & ( & - & .0 & $1.42 \mathrm{E}+00$ \\
\hline 4 & $3.42 \mathrm{E}+00$ & 1.41 & 2 & 1 & & & $1.42 \mathrm{E}+00$ \\
\hline & & & & & & & $42 E+00$ \\
\hline 4 & & & 02 & & & 1 & $1.43 E+00$ \\
\hline $9 E-04$ & $3.44 \mathrm{E}+00$ & $1.43 \mathrm{E}$ & 02 & 1 & 1 & & $1.43 \mathrm{E}+00$ \\
\hline $.65 E-04$ & $3.45 \mathrm{E}+00$ & $1.445-01$ & $7 E-02$ & 18 & $\perp$ & & $1.44 \mathrm{E}+00$ \\
\hline $72 E-04$ & $3.46 \mathrm{E}+00$ & $\perp \cdot 110$ - & & & & & $1.44 \mathrm{E}+00$ \\
\hline 4 & $3.46 \mathrm{E}+00$ & 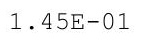 & 2 & & & & $1.45 \mathrm{E}+00$ \\
\hline 4 & $3.47 \mathrm{E}+00$ & 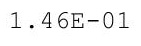 & 2 & 1 & & 1 & 1. $45 \mathrm{E}+00$ \\
\hline 4 & & & 2 & 1 & & 1 & \\
\hline $9 E-04$ & $3.49 \mathrm{E}+00$ & $1.47 \mathrm{E}-01$ & $2 E-02$ & & 01 & & $1.46 \mathrm{E}+00$ \\
\hline$E-04$ & $3.49 \pm+00$ & $1.40 \mathrm{I}$ & & & & & $1.47 \mathrm{E}+00$ \\
\hline $13 E-04$ & . & $1 \cdot$ & & & & & $1.47 \mathrm{E}+00$ \\
\hline $20 E-04$ & $3.51 \mathrm{E}+00$ & $\perp \cdot 47 \pm-01$ & $4.53 E-02$ & $3.91 \mathrm{E}-01$ & $6.53 E-01$ & $9.48 \mathrm{E}-01$ & $1.47 \mathrm{E}+00$ \\
\hline $27 E-04$ & $3.51 \mathrm{E}+00$ & $1.30 \mathrm{~L}-0$ & $4.57 \mathrm{E}-02$ & $3.93 \mathrm{E}-01$ & & $9.51 \mathrm{E}-01$ & $1.48 \mathrm{E}+00$ \\
\hline$E-04$ & $.52 \mathrm{E}+00$ & $E-01$ & $.60 \mathrm{E}-02$ & $95 E-01$ & $.58 E-01$ & 01 & $1.48 \mathrm{E}+00$ \\
\hline
\end{tabular}


RESRAD-OFFSITE, Version 2.5 
RESRAD-OFFSITE, Version 2.5

obabilistic Dose and Risk Report

Title : Offsite Resident Farmer Deterministic Run

File : RF TC99 DOESG FWD-FV2.ROF

Summary of dose at graphical times, reptition 1 (continued)

Time

Years

$5.19 \mathrm{E}+02$

$5.19 \mathrm{E}+02$

$5.20 \mathrm{E}+02$

$5.20 \mathrm{E}+02$

$5.21 \mathrm{E}+02$

$5.21 \mathrm{E}+02$

$5.22 \mathrm{E}+02$

$5.22 \mathrm{E}+02$

$5.23 \mathrm{E}+02$

$5.23 \mathrm{E}+02$

$5.24 \mathrm{E}+02$

$5.24 \mathrm{E}+02$

$5.25 \mathrm{E}+02$

$5.26 \mathrm{E}+02$

$5.26 \mathrm{E}+02$

$5.27 \mathrm{E}+02$

$5.27 \mathrm{E}+02$

$5.28 \mathrm{E}+02$

$5.28 \mathrm{E}+02$

$5.29 \mathrm{E}+02$

$5.29 \mathrm{E}+02$

$5.30 \mathrm{E}+02$

$5.30 \mathrm{E}+02$

$5.31 \mathrm{E}+02$

$5.31 \mathrm{E}+02$

$5.32 \mathrm{E}+02$

$5.32 \mathrm{E}+02$

$5.33 \mathrm{E}+02$

$5.33 \mathrm{E}+02$

$5.34 \mathrm{E}+02$

$5.34 \mathrm{E}+02$

$5.35 \mathrm{E}+02$

$5.35 \mathrm{E}+02$

$5.36 \mathrm{E}+02$

$5.36 \mathrm{E}+02$

$5.37 \mathrm{E}+02$

$5.37 \mathrm{E}+02$

$5.38 \mathrm{E}+02$

$5.38 \mathrm{E}+02$

$5.39 \mathrm{E}+02$

$5.39 \mathrm{E}+02$

$5.40 \mathrm{E}+02$

$5.40 \mathrm{E}+02$

$5.41 \mathrm{E}+02$

$5.41 \mathrm{E}+02$

$5.42 \mathrm{E}+02$

Dose statistics at graphical times, mrem/yr

\begin{tabular}{|c|c|c|c|c|c|c|c|}
\hline Minimum & Maximum & Mean & Median & $90 \%$ & $95 \%$ & $97.5 \%$ & $99 \%$ \\
\hline $9.58 \mathrm{E}-04$ & $3.84 \mathrm{E}+00$ & $1.83 E-01$ & $6.37 E-02$ & $4.78 E-01$ & $7.73 E-01$ & $1.11 \mathrm{E}+00$ & $1.69 \mathrm{E}+00$ \\
\hline $9.69 \mathrm{E}-04$ & $3.85 \mathrm{E}+00$ & $1.84 \mathrm{E}-01$ & $6.42 E-02$ & $4.80 E-01$ & $7.75 \mathrm{E}-01$ & $1.11 \mathrm{E}+00$ & $1.70 \mathrm{E}+00$ \\
\hline $9.81 E-04$ & $3.85 \mathrm{E}+00$ & $1.85 \mathrm{E}-01$ & $6.47 E-02$ & $4.82 E-01$ & $7.78 \mathrm{E}-01$ & $1.11 \mathrm{E}+00$ & $1.70 \mathrm{E}+00$ \\
\hline $9.92 \mathrm{E}-04$ & $3.86 \mathrm{E}+00$ & $1.86 \mathrm{E}-01$ & $6.52 \mathrm{E}-02$ & $4.84 \mathrm{E}-01$ & $7.80 \mathrm{E}-01$ & $1.12 \mathrm{E}+00$ & $1.71 \mathrm{E}+00$ \\
\hline $1.00 \mathrm{E}-03$ & $3.86 \mathrm{E}+00$ & $1.86 \mathrm{E}-01$ & $6.57 \mathrm{E}-02$ & $4.86 \mathrm{E}-01$ & $7.83 \mathrm{E}-01$ & $1.12 \mathrm{E}+00$ & 1. $71 \mathrm{E}+00$ \\
\hline $1.01 \mathrm{E}-03$ & $3.87 \mathrm{E}+00$ & $1.87 \mathrm{E}-01$ & $6.61 \mathrm{E}-02$ & 4. $88 \mathrm{E}-01$ & $7.85 \mathrm{E}-01$ & $1.12 \mathrm{E}+00$ & $1.71 \mathrm{E}+00$ \\
\hline $1.03 E-03$ & $3.88 \mathrm{E}+00$ & $1.88 \mathrm{E}-01$ & $6.65 E-02$ & $4.89 \mathrm{E}-01$ & $7.87 \mathrm{E}-01$ & $1.13 \mathrm{E}+00$ & $1.72 \mathrm{E}+00$ \\
\hline $1.04 E-03$ & $3.88 \mathrm{E}+00$ & $1.89 \mathrm{E}-01$ & $6.70 E-02$ & $4.91 E-01$ & $7.89 \mathrm{E}-01$ & $1.13 \mathrm{E}+00$ & $1.72 \mathrm{E}+00$ \\
\hline $1.05 E-03$ & $3.89 \mathrm{E}+00$ & $1.89 \mathrm{E}-01$ & $6.75 E-02$ & 4. $93 \mathrm{E}-01$ & $7.91 \mathrm{E}-01$ & $1.13 \mathrm{E}+00$ & $1.73 E+00$ \\
\hline $1.06 \mathrm{E}-03$ & $3.89 \mathrm{E}+00$ & $1.90 \mathrm{E}-01$ & $6.79 \mathrm{E}-02$ & $4.95 E-01$ & $7.93 E-01$ & $1.14 \mathrm{E}+00$ & $1.73 E+00$ \\
\hline $1.07 \mathrm{E}-03$ & $3.90 \mathrm{E}+00$ & 1.91E-01 & $6.84 \mathrm{E}-02$ & $4.97 \mathrm{E}-01$ & $7.96 \mathrm{E}-01$ & $1.14 \mathrm{E}+00$ & $1.74 \mathrm{E}+00$ \\
\hline $1.09 E-03$ & $3.91 \mathrm{E}+00$ & $1.92 \mathrm{E}-01$ & $6.89 \mathrm{E}-02$ & 4. $99 \mathrm{E}-01$ & $7.98 \mathrm{E}-01$ & $1.14 \mathrm{E}+00$ & $1.74 \mathrm{E}+00$ \\
\hline $1.10 \mathrm{E}-03$ & $3.91 \mathrm{E}+00$ & $1.92 \mathrm{E}-01$ & $6.94 \mathrm{E}-02$ & $5.01 \mathrm{E}-01$ & $8.00 \mathrm{E}-01$ & $1.15 \mathrm{E}+00$ & $1.74 \mathrm{E}+00$ \\
\hline $1.11 \mathrm{E}-03$ & $3.92 \mathrm{E}+00$ & $1.93 \mathrm{E}-01$ & $6.98 \mathrm{E}-02$ & $5.03 E-01$ & $8.02 \mathrm{E}-01$ & $1.15 \mathrm{E}+00$ & $1.75 \mathrm{E}+00$ \\
\hline $1.12 \mathrm{E}-03$ & $3.92 \mathrm{E}+00$ & $1.94 \mathrm{E}-01$ & $7.03 E-02$ & $5.05 \mathrm{E}-01$ & $8.04 \mathrm{E}-01$ & $1.15 \mathrm{E}+00$ & $1.75 \mathrm{E}+00$ \\
\hline $1.13 E-03$ & $3.93 \mathrm{E}+00$ & $1.95 \mathrm{E}-01$ & $7.08 E-02$ & $5.07 E-01$ & $8.06 \mathrm{E}-01$ & $.15 E+00$ & $.76 \mathrm{E}+00$ \\
\hline $1.15 \mathrm{E}-03$ & $3.94 \mathrm{E}+00$ & $1.95 \mathrm{E}-01$ & $7.13 E-02$ & $5.10 \mathrm{E}-01$ & $8.08 E-01$ & $1.16 \mathrm{E}+00$ & $1.76 \mathrm{E}+00$ \\
\hline $1.16 \mathrm{E}-03$ & $3.94 \mathrm{E}+00$ & $1.96 \mathrm{E}-01$ & $7.18 \mathrm{E}-02$ & $5.12 \mathrm{E}-01$ & $8.11 \mathrm{E}-01$ & $1.16 \mathrm{E}+00$ & $1.77 \mathrm{E}+00$ \\
\hline $1.17 \mathrm{E}-03$ & $3.95 \mathrm{E}+00$ & $1.97 \mathrm{E}-01$ & $7.24 \mathrm{E}-02$ & $5.14 \mathrm{E}-01$ & $8.13 \mathrm{E}-01$ & $1.16 \mathrm{E}+00$ & $1.77 \mathrm{E}+00$ \\
\hline $1.18 \mathrm{E}-03$ & $3.95 \mathrm{E}+00$ & $1.98 \mathrm{E}-01$ & $7.28 \mathrm{E}-02$ & $5.16 \mathrm{E}-01$ & $8.16 \mathrm{E}-01$ & $1.17 \mathrm{E}+00$ & $1.77 \mathrm{E}+00$ \\
\hline $1.20 \mathrm{E}-03$ & $3.96 \mathrm{E}+00$ & $1.98 \mathrm{E}-01$ & $7.33 E-02$ & $5.19 \mathrm{E}-01$ & $8.18 \mathrm{E}-01$ & $1.17 \mathrm{E}+00$ & $1.78 \mathrm{E}+00$ \\
\hline $1.21 \mathrm{E}-03$ & $3.96 \mathrm{E}+00$ & $1.99 \mathrm{E}-01$ & $7.37 \mathrm{E}-02$ & $5.21 \mathrm{E}-01$ & $8.21 \mathrm{E}-01$ & $1.17 \mathrm{E}+00$ & $1.78 \mathrm{E}+00$ \\
\hline $1.22 \mathrm{E}-03$ & $3.97 \mathrm{E}+00$ & $2.00 \mathrm{E}-01$ & $7.42 E-02$ & $5.23 E-01$ & $8.23 E-01$ & $1.18 \mathrm{E}+00$ & $1.79 \mathrm{E}+00$ \\
\hline $1.24 \mathrm{E}-03$ & $3.98 \mathrm{E}+00$ & $2.01 \mathrm{E}-01$ & $7.47 \mathrm{E}-02$ & $5.25 E-01$ & $8.26 \mathrm{E}-01$ & $1.18 \mathrm{E}+00$ & $1.79 \mathrm{E}+00$ \\
\hline $1.25 E-03$ & $3.98 \mathrm{E}+00$ & $2.02 \mathrm{E}-01$ & 7. $52 \mathrm{E}-02$ & $5.27 \mathrm{E}-01$ & $8.28 \mathrm{E}-01$ & $1.18 \mathrm{E}+00$ & $1.79 \mathrm{E}+00$ \\
\hline $1.26 \mathrm{E}-03$ & $3.99 \mathrm{E}+00$ & $2.02 \mathrm{E}-01$ & $7.57 \mathrm{E}-02$ & $5.28 \mathrm{E}-01$ & $8.31 \mathrm{E}-01$ & $1.19 \mathrm{E}+00$ & $1.80 \mathrm{E}+00$ \\
\hline $1.28 E-03$ & $3.99 \mathrm{E}+00$ & $2.03 E-01$ & $7.62 \mathrm{E}-02$ & $5.30 \mathrm{E}-01$ & $8.34 \mathrm{E}-01$ & $1.19 \mathrm{E}+00$ & $1.80 \mathrm{E}+00$ \\
\hline $1.29 \mathrm{E}-03$ & $4.00 \mathrm{E}+00$ & $2.04 \mathrm{E}-01$ & $7.66 \mathrm{E}-02$ & $5.31 \mathrm{E}-01$ & $8.37 \mathrm{E}-01$ & $1.19 \mathrm{E}+00$ & $1.80 \mathrm{E}+00$ \\
\hline $1.30 E-03$ & $4.00 \mathrm{E}+00$ & $2.05 E-01$ & $7.71 \mathrm{E}-02$ & $5.33 E-01$ & $8.41 \mathrm{E}-01$ & $1.19 \mathrm{E}+00$ & $1.81 \mathrm{E}+00$ \\
\hline $1.32 E-03$ & $4.01 \mathrm{E}+00$ & $2.05 E-01$ & $7.76 \mathrm{E}-02$ & $5.35 E-01$ & $8.44 \mathrm{E}-01$ & $1.20 \mathrm{E}+00$ & $1.81 \mathrm{E}+00$ \\
\hline $1.33 E-03$ & $4.01 E+00$ & $2.06 \mathrm{E}-01$ & $7.80 \mathrm{E}-02$ & $5.37 \mathrm{E}-01$ & $8.47 \mathrm{E}-01$ & $1.20 \mathrm{E}+00$ & $1.82 \mathrm{E}+00$ \\
\hline 1. $35 E-03$ & $4.02 \mathrm{E}+00$ & $2.07 E-01$ & $7.85 E-02$ & $5.39 \mathrm{E}-01$ & $8.50 \mathrm{E}-01$ & $1.20 \mathrm{E}+00$ & $1.82 \mathrm{E}+00$ \\
\hline $1.36 E-03$ & $4.02 \mathrm{E}+00$ & $2.08 \mathrm{E}-01$ & $7.90 E-02$ & $5.41 E-01$ & $8.53 E-01$ & $1.21 \mathrm{E}+00$ & $1.82 \mathrm{E}+00$ \\
\hline $1.38 \mathrm{E}-03$ & $4.03 E+00$ & $2.09 \mathrm{E}-01$ & $7.95 E-02$ & $5.43 E-01$ & $8.56 \mathrm{E}-01$ & $1.21 \mathrm{E}+00$ & $1.83 \mathrm{E}+00$ \\
\hline $1.39 \mathrm{E}-03$ & $4.04 \mathrm{E}+00$ & $2.09 \mathrm{E}-01$ & $8.00 E-02$ & $5.44 \mathrm{E}-01$ & $8.59 \mathrm{E}-01$ & $1.21 \mathrm{E}+00$ & $1.83 \mathrm{E}+00$ \\
\hline $1.40 \mathrm{E}-03$ & $4.04 \mathrm{E}+00$ & $2.10 \mathrm{E}-01$ & $8.05 E-02$ & $5.46 \mathrm{E}-01$ & $8.61 \mathrm{E}-01$ & $1.22 \mathrm{E}+00$ & $1.83 \mathrm{E}+00$ \\
\hline $1.42 \mathrm{E}-03$ & $4.05 E+00$ & $2.11 \mathrm{E}-01$ & $8.10 \mathrm{E}-02$ & $5.48 \mathrm{E}-01$ & $8.63 \mathrm{E}-01$ & $1.22 \mathrm{E}+00$ & $1.84 \mathrm{E}+00$ \\
\hline $1.43 E-03$ & $4.05 \mathrm{E}+00$ & $2.12 \mathrm{E}-01$ & $8.15 E-02$ & $5.49 \mathrm{E}-01$ & $8.66 \mathrm{E}-01$ & $1.22 \mathrm{E}+00$ & $1.84 \mathrm{E}+00$ \\
\hline $1.45 E-03$ & $4.06 \mathrm{E}+00$ & $2.12 \mathrm{E}-01$ & $8.20 E-02$ & $5.51 \mathrm{E}-01$ & $8.68 \mathrm{E}-01$ & $1.23 \mathrm{E}+00$ & $1.85 \mathrm{E}+00$ \\
\hline $1.46 \mathrm{E}-03$ & $4.06 \mathrm{E}+00$ & $2.13 \mathrm{E}-01$ & $8.25 E-02$ & $5.52 \mathrm{E}-01$ & $8.70 \mathrm{E}-01$ & $1.23 \mathrm{E}+00$ & $1.85 \mathrm{E}+00$ \\
\hline $1.48 \mathrm{E}-03$ & $4.07 \mathrm{E}+00$ & $2.14 \mathrm{E}-01$ & $8.30 E-02$ & $5.54 \mathrm{E}-01$ & $8.73 \mathrm{E}-01$ & $1.23 \mathrm{E}+00$ & $1.85 \mathrm{E}+00$ \\
\hline $1.49 E-03$ & $4.07 \mathrm{E}+00$ & $2.15 \mathrm{E}-01$ & $8.35 E-02$ & $5.55 E-01$ & $8.75 E-01$ & $1.24 \mathrm{E}+00$ & $1.86 \mathrm{E}+00$ \\
\hline $1.51 \mathrm{E}-03$ & $4.08 \mathrm{E}+00$ & $2.16 \mathrm{E}-01$ & $8.40 E-02$ & $5.57 \mathrm{E}-01$ & $8.77 \mathrm{E}-01$ & $1.24 \mathrm{E}+00$ & $1.86 \mathrm{E}+00$ \\
\hline $1.52 E-03$ & $4.08 \mathrm{E}+00$ & $2.16 \mathrm{E}-01$ & $8.45 E-02$ & $5.58 \mathrm{E}-01$ & $8.80 \mathrm{E}-01$ & $1.24 \mathrm{E}+00$ & $1.86 \mathrm{E}+00$ \\
\hline $1.54 \mathrm{E}-03$ & $4.09 \mathrm{E}+00$ & $2.17 E-01$ & $8.51 E-02$ & $5.60 E-01$ & $8.82 E-01$ & $1.25 \mathrm{E}+00$ & $1.87 \mathrm{E}+00$ \\
\hline $1.56 \mathrm{E}-03$ & $4.09 E+00$ & $2.18 \mathrm{E}-01$ & $8.56 E-02$ & $5.61 \mathrm{E}-01$ & $8.84 \mathrm{E}-01$ & $1.25 \mathrm{E}+00$ & $1.87 \mathrm{E}+00$ \\
\hline
\end{tabular}


RESRAD-OFFSITE, Version 2.5

obabilistic Dose and Risk Report

Title : Offsite Resident Farmer Deterministic Run

File : RF TC99 DOESG FWD-FV2.ROF

Summary of dose at graphical times, reptition 1 (continued)

Time

Years

$5.42 \mathrm{E}+02$

$5.43 \mathrm{E}+02$

$5.43 \mathrm{E}+02$

$5.44 \mathrm{E}+02$

$5.44 \mathrm{E}+02$

$5.45 \mathrm{E}+02$

$5.46 \mathrm{E}+02$

$5.46 \mathrm{E}+02$

$5.47 \mathrm{E}+02$

$5.47 \mathrm{E}+02$

$5.48 \mathrm{E}+02$

$5.48 \mathrm{E}+02$

$5.49 \mathrm{E}+02$

$5.49 \mathrm{E}+02$

$5.50 \mathrm{E}+02$

$5.50 \mathrm{E}+02$

$5.51 \mathrm{E}+02$

$5.51 \mathrm{E}+02$

$5.52 \mathrm{E}+02$

$5.52 \mathrm{E}+02$

$5.53 \mathrm{E}+02$

$5.53 \mathrm{E}+02$

$5.54 \mathrm{E}+02$

$5.54 \mathrm{E}+02$

$5.55 \mathrm{E}+02$

$5.55 \mathrm{E}+02$

$5.56 \mathrm{E}+02$

$5.56 \mathrm{E}+02$

$5.57 \mathrm{E}+02$

$5.57 \mathrm{E}+02$

$5.58 \mathrm{E}+02$

$5.58 \mathrm{E}+02$

$5.59 \mathrm{E}+02$

$5.59 \mathrm{E}+02$

$5.60 \mathrm{E}+02$

$5.60 \mathrm{E}+02$

$5.61 \mathrm{E}+02$

$5.61 \mathrm{E}+02$

$5.62 \mathrm{E}+02$

$5.62 \mathrm{E}+02$

$5.63 \mathrm{E}+02$

$5.63 \mathrm{E}+02$

$5.64 \mathrm{E}+02$

$5.64 \mathrm{E}+02$

$5.65 \mathrm{E}+02$

$5.66 \mathrm{E}+02$

Dose statistics at graphical times, mrem/yr

\begin{tabular}{|c|c|c|c|c|c|c|c|}
\hline Minimum & Maximum & Mean & Median & $90 \%$ & $95 \%$ & $97.5 \%$ & $99 \%$ \\
\hline $1.57 \mathrm{E}-03$ & $4.10 \mathrm{E}+00$ & $2.19 E-01$ & $8.61 \mathrm{E}-02$ & $5.63 \mathrm{E}-01$ & $8.87 \mathrm{E}-01$ & $1.25 \mathrm{E}+00$ & $1.87 \mathrm{E}+00$ \\
\hline $1.59 \mathrm{E}-03$ & $4.10 \mathrm{E}+00$ & $2.20 E-01$ & $8.67 \mathrm{E}-02$ & $5.65 \mathrm{E}-01$ & $8.89 \mathrm{E}-01$ & $1.26 \mathrm{E}+00$ & $1.88 \mathrm{E}+00$ \\
\hline $1.60 \mathrm{E}-03$ & $4.11 E+00$ & $2.20 E-01$ & $8.72 E-02$ & $5.67 E-01$ & $8.92 E-01$ & $1.26 \mathrm{E}+00$ & $1.88 \mathrm{E}+00$ \\
\hline $1.62 \mathrm{E}-03$ & $4.11 E+00$ & $2.21 E-01$ & $8.77 \mathrm{E}-02$ & $5.69 \mathrm{E}-01$ & $8.95 \mathrm{E}-01$ & $1.26 \mathrm{E}+00$ & $1.89 \mathrm{E}+00$ \\
\hline $1.64 \mathrm{E}-03$ & $4.12 \mathrm{E}+00$ & $2.22 \mathrm{E}-01$ & $8.82 \mathrm{E}-02$ & $5.71 \mathrm{E}-01$ & $8.98 \mathrm{E}-01$ & $1.27 \mathrm{E}+00$ & $1.89 \mathrm{E}+00$ \\
\hline $1.65 E-03$ & $4.12 \mathrm{E}+00$ & $2.23 E-01$ & $8.88 E-02$ & $5.73 E-01$ & $9.01 \mathrm{E}-01$ & $1.27 E+00$ & $.89 E+00$ \\
\hline $1.67 \mathrm{E}-03$ & $4.13 E+00$ & $2.24 E-01$ & $8.94 \mathrm{E}-02$ & $5.75 E-01$ & $9.04 \mathrm{E}-01$ & $1.27 \mathrm{E}+00$ & $1.90 \mathrm{E}+00$ \\
\hline 1. $69 \mathrm{E}-03$ & $4.13 E+00$ & $2.24 \mathrm{E}-01$ & $8.99 \mathrm{E}-02$ & $5.77 \mathrm{E}-01$ & $9.07 \mathrm{E}-01$ & $1.28 \mathrm{E}+00$ & $1.90 \mathrm{E}+00$ \\
\hline $1.70 \mathrm{E}-03$ & $4.14 \mathrm{E}+00$ & $2.25 E-01$ & $9.05 E-02$ & $.80 E-01$ & $9.10 \mathrm{E}-01$ & $1.28 \mathrm{E}+00$ & $1.91 \mathrm{E}+00$ \\
\hline $1.72 \mathrm{E}-03$ & $4.14 \mathrm{E}+00$ & $2.26 \mathrm{E}-01$ & $.10 \mathrm{E}-02$ & $5.82 \mathrm{E}-01$ & $9.12 \mathrm{E}-01$ & $1.28 \mathrm{E}+00$ & 1. $91 \mathrm{E}+00$ \\
\hline $1.74 \mathrm{E}-03$ & $4.15 \mathrm{E}+00$ & $2.27 E-01$ & $9.15 \mathrm{E}-02$ & $5.83 E-01$ & $9.15 \mathrm{E}-01$ & $1.29 \mathrm{E}+00$ & $1.91 \mathrm{E}+00$ \\
\hline $1.75 E-03$ & $4.15 E+00$ & $2.28 E-01$ & $9.20 \mathrm{E}-02$ & $5.85 E-01$ & $9.18 \mathrm{E}-01$ & $1.29 \mathrm{E}+00$ & $1.92 \mathrm{E}+00$ \\
\hline $1.77 E-03$ & $4.16 \mathrm{E}+00$ & $2.28 E-01$ & $9.26 \mathrm{E}-02$ & $5.87 E-01$ & $9.21 \mathrm{E}-01$ & $1.29 \mathrm{E}+00$ & $1.92 \mathrm{E}+00$ \\
\hline $1.79 \mathrm{E}-03$ & $4.16 \mathrm{E}+00$ & $2.29 E-01$ & $9.31 \mathrm{E}-02$ & $5.89 \mathrm{E}-01$ & $9.23 E-01$ & $1.30 \mathrm{E}+00$ & $1.93 \mathrm{E}+00$ \\
\hline $1.81 \mathrm{E}-03$ & $4.17 \mathrm{E}+00$ & $2.30 E-01$ & $9.36 \mathrm{E}-02$ & $5.91 \mathrm{E}-01$ & $9.26 \mathrm{E}-01$ & $1.30 \mathrm{E}+00$ & $1.93 E+00$ \\
\hline $1.82 \mathrm{E}-03$ & $4.17 \mathrm{E}+00$ & $2.31 E-01$ & $41 E-02$ & $93 E-01$ & $29 \mathrm{E}-01$ & $1.30 \mathrm{E}+00$ & $.93 E+00$ \\
\hline $1.84 \mathrm{E}-03$ & $4.17 \mathrm{E}+00$ & $2.32 E-01$ & $9.47 \mathrm{E}-02$ & $5.95 \mathrm{E}-01$ & $9.32 \mathrm{E}-01$ & $1.31 \mathrm{E}+00$ & $1.94 \mathrm{E}+00$ \\
\hline $1.86 \mathrm{E}-03$ & $4.18 \mathrm{E}+00$ & $2.32 E-01$ & $9.53 E-02$ & $5.97 \mathrm{E}-01$ & $9.35 E-01$ & $1.31 \mathrm{E}+00$ & $1.94 \mathrm{E}+00$ \\
\hline $1.88 \mathrm{E}-03$ & $4.18 \mathrm{E}+00$ & $2.33 E-01$ & $9.59 \mathrm{E}-02$ & $5.99 \mathrm{E}-01$ & $9.37 \mathrm{E}-01$ & 1. $32 \mathrm{E}+00$ & $1.94 \mathrm{E}+00$ \\
\hline $1.90 \mathrm{E}-03$ & $4.19 \mathrm{E}+00$ & $2.34 E-01$ & $9.65 E-02$ & $6.01 \mathrm{E}-01$ & $9.40 \mathrm{E}-01$ & $1.32 \mathrm{E}+00$ & $1.95 \mathrm{E}+00$ \\
\hline $1.91 \mathrm{E}-03$ & $4.19 \mathrm{E}+00$ & $2.35 E-01$ & $9.70 \mathrm{E}-02$ & $6.03 E-01$ & $9.43 \mathrm{E}-01$ & $1.32 \mathrm{E}+00$ & $1.95 \mathrm{E}+00$ \\
\hline $1.93 E-03$ & $4.20 \mathrm{E}+00$ & $2.36 \mathrm{E}-01$ & $9.76 \mathrm{E}-02$ & $.05 E-01$ & $.46 \mathrm{E}-01$ & $1.33 \mathrm{E}+00$ & $1.96 \mathrm{E}+00$ \\
\hline $1.95 \mathrm{E}-03$ & $4.20 \mathrm{E}+00$ & $2.36 E-01$ & $9.82 \mathrm{E}-02$ & $6.07 \mathrm{E}-01$ & $9.48 \mathrm{E}-01$ & $1.33 \mathrm{E}+00$ & $1.96 \mathrm{E}+00$ \\
\hline $1.97 \mathrm{E}-03$ & $4.21 \mathrm{E}+00$ & $2.37 E-01$ & $9.87 \mathrm{E}-02$ & $6.09 \mathrm{E}-01$ & $9.51 \mathrm{E}-01$ & $1.33 E+00$ & $1 \cdot 97 \mathrm{E}+00$ \\
\hline $1.99 \mathrm{E}-03$ & $4.21 \mathrm{E}+00$ & $2.38 E-01$ & $9.93 E-02$ & $6.11 \mathrm{E}-01$ & $9.54 \mathrm{E}-01$ & $1.34 \mathrm{E}+00$ & $1.97 \mathrm{E}+00$ \\
\hline $2.01 E-03$ & $4.21 E+00$ & $2.39 E-01$ & $9.98 E-02$ & $6.13 E-01$ & $9.57 E-01$ & $1.34 \mathrm{E}+00$ & $1.97 \mathrm{E}+00$ \\
\hline $2.03 E-03$ & $4.22 \mathrm{E}+00$ & $2.40 E-01$ & $1.00 \mathrm{E}-01$ & $6.14 \mathrm{E}-01$ & $9.60 \mathrm{E}-01$ & $1.35 \mathrm{E}+00$ & $1.98 \mathrm{E}+00$ \\
\hline $2.05 E-03$ & $4.22 \mathrm{E}+00$ & $2.41 E-01$ & $1.01 \mathrm{E}-01$ & $6.16 \mathrm{E}-01$ & $9.62 \mathrm{E}-01$ & $1.35 \mathrm{E}+00$ & $1.98 \mathrm{E}+00$ \\
\hline $2.06 \mathrm{E}-03$ & $4.23 E+00$ & $2.41 E-01$ & $1.01 \mathrm{E}-01$ & $6.17 \mathrm{E}-01$ & $9.65 \mathrm{E}-01$ & $1.35 \mathrm{E}+00$ & 1. $99 \mathrm{E}+00$ \\
\hline $2.08 E-03$ & $4.23 E+00$ & $2.42 E-01$ & $1.02 \mathrm{E}-01$ & $19 \mathrm{E}-01$ & $68 \mathrm{E}-01$ & $1.36 \mathrm{E}+00$ & 1. $99 \mathrm{E}+00$ \\
\hline $2.10 \mathrm{E}-03$ & $4.24 \mathrm{E}+00$ & $2.43 E-01$ & $1.02 \mathrm{E}-01$ & $6.21 \mathrm{E}-01$ & $9.71 \mathrm{E}-01$ & $1.36 \mathrm{E}+00$ & $1.99 \mathrm{E}+00$ \\
\hline $2.12 \mathrm{E}-03$ & $4.24 \mathrm{E}+00$ & $2.44 E-01$ & $1.03 E-01$ & $6.22 E-01$ & $9.73 E-01$ & $1.37 \mathrm{E}+00$ & $2.00 \mathrm{E}+00$ \\
\hline $2.14 \mathrm{E}-03$ & $4.24 \mathrm{E}+00$ & $2.45 E-01$ & $1.04 \mathrm{E}-01$ & $6.25 \mathrm{E}-01$ & $.76 \mathrm{E}-01$ & $1.37 \mathrm{E}+00$ & $2.00 \mathrm{E}+00$ \\
\hline $2.16 \mathrm{E}-03$ & $4.25 \mathrm{E}+00$ & $2.46 \mathrm{E}-01$ & $1.04 \mathrm{E}-01$ & $6.27 \mathrm{E}-01$ & $9.79 \mathrm{E}-01$ & $1.37 \mathrm{E}+00$ & $2.01 E+00$ \\
\hline $2.18 \mathrm{E}-03$ & $4.25 E+00$ & $2.46 \mathrm{E}-01$ & $1.05 \mathrm{E}-01$ & $6.29 \mathrm{E}-01$ & $9.82 \mathrm{E}-01$ & $1.38 \mathrm{E}+00$ & $2.01 \mathrm{E}+00$ \\
\hline $2.20 \mathrm{E}-03$ & $4.26 \mathrm{E}+00$ & $2.47 E-01$ & $1.05 \mathrm{E}-01$ & $6.31 \mathrm{E}-01$ & $9.85 \mathrm{E}-01$ & $1.38 \mathrm{E}+00$ & $2.02 \mathrm{E}+00$ \\
\hline $2.22 E-03$ & $4.26 \mathrm{E}+00$ & $2.48 E-01$ & $1.06 \mathrm{E}-01$ & $6.33 E-01$ & $9.87 \mathrm{E}-01$ & $1.38 \mathrm{E}+00$ & $2.02 E+00$ \\
\hline $2.24 \mathrm{E}-03$ & $4.27 \mathrm{E}+00$ & $2.49 E-01$ & $1.06 \mathrm{E}-01$ & $6.35 \mathrm{E}-01$ & $9.90 \mathrm{E}-01$ & $1.39 \mathrm{E}+00$ & $2.02 E+00$ \\
\hline $2.27 E-03$ & $4.27 \mathrm{E}+00$ & $2.50 E-01$ & $1.07 \mathrm{E}-01$ & $6.38 \mathrm{E}-01$ & $9.93 \mathrm{E}-01$ & $1.39 \mathrm{E}+00$ & $2.03 E+00$ \\
\hline $2.29 E-03$ & $4.27 E+00$ & $2.50 E-01$ & $1.08 \mathrm{E}-01$ & $6.40 \mathrm{E}-01$ & $9.96 \mathrm{E}-01$ & $1.40 \mathrm{E}+00$ & $2.03 E+00$ \\
\hline $2.31 E-03$ & $4.28 \mathrm{E}+00$ & $2.51 E-01$ & $1.08 \mathrm{E}-01$ & $6.43 E-01$ & $9.98 \mathrm{E}-01$ & $1.40 \mathrm{E}+00$ & $2.04 \mathrm{E}+00$ \\
\hline $2.33 E-03$ & $4.28 \mathrm{E}+00$ & $2.52 E-01$ & $1.09 \mathrm{E}-01$ & $6.45 \mathrm{E}-01$ & $1.00 \mathrm{E}+00$ & $1.40 \mathrm{E}+00$ & $2.04 \mathrm{E}+00$ \\
\hline $2.35 E-03$ & $4.29 \mathrm{E}+00$ & $2.53 E-01$ & $1.09 \mathrm{E}-01$ & $6.48 \mathrm{E}-01$ & $1.00 \mathrm{E}+00$ & $1.41 \mathrm{E}+00$ & $2.04 E+00$ \\
\hline $2.37 \mathrm{E}-03$ & $4.29 \mathrm{E}+00$ & $2.54 \mathrm{E}-01$ & $1.10 \mathrm{E}-01$ & $6.50 \mathrm{E}-01$ & $1.01 \mathrm{E}+00$ & $1.41 \mathrm{E}+00$ & $2.05 \mathrm{E}+00$ \\
\hline $2.39 \mathrm{E}-03$ & $4.29 E+00$ & $2.55 E-01$ & 1.11E-01 & $6.52 \mathrm{E}-01$ & $1.01 \mathrm{E}+00$ & $1.42 \mathrm{E}+00$ & $2.05 \mathrm{E}+00$ \\
\hline $2.41 \mathrm{E}-03$ & $4.30 \mathrm{E}+00$ & $2.56 \mathrm{E}-01$ & 1. $11 \mathrm{E}-01$ & $6.54 \mathrm{E}-01$ & $1.01 \mathrm{E}+00$ & $1.42 \mathrm{E}+00$ & $2.06 \mathrm{E}+00$ \\
\hline
\end{tabular}


RESRAD-OFFSITE, Version 2.5

obabilistic Dose and Risk Report

Title : Offsite Resident Farmer Deterministic Run

File : RF TC99 DOESG FWD-FV2.ROF

Summary of dose at graphical times, reptition 1 (continued)

Time

Years

$5.66 \mathrm{E}+02$

$5.67 \mathrm{E}+02$

$5.67 \mathrm{E}+02$

$5.68 \mathrm{E}+02$

$5.68 \mathrm{E}+02$

$5.69 \mathrm{E}+02$

$5.69 \mathrm{E}+02$

$5.70 \mathrm{E}+02$

$5.70 \mathrm{E}+02$

$5.71 \mathrm{E}+02$

$5.71 E+02$

$5.72 \mathrm{E}+02$

$5.72 \mathrm{E}+02$

$5.73 \mathrm{E}+02$

$5.73 \mathrm{E}+02$

$5.74 \mathrm{E}+02$

$5.74 \mathrm{E}+02$

$5.75 \mathrm{E}+02$

$5.75 \mathrm{E}+02$

$5.76 \mathrm{E}+02$

$5.76 \mathrm{E}+02$

$5.77 \mathrm{E}+02$

$5.77 \mathrm{E}+02$

$5.78 \mathrm{E}+02$

$5.78 \mathrm{E}+02$

$5.79 \mathrm{E}+02$

$5.79 \mathrm{E}+02$

$5.80 \mathrm{E}+02$

$5.80 \mathrm{E}+02$

$5.81 \mathrm{E}+02$

$5.81 \mathrm{E}+02$

$5.82 \mathrm{E}+02$

$5.82 \mathrm{E}+02$

$5.83 \mathrm{E}+02$

$5.83 \mathrm{E}+02$

$5.84 \mathrm{E}+02$

$5.84 \mathrm{E}+02$

$5.85 \mathrm{E}+02$

$5.85 \mathrm{E}+02$

$5.86 \mathrm{E}+02$

$5.87 \mathrm{E}+02$

$5.87 \mathrm{E}+02$

$5.88 \mathrm{E}+02$

$5.88 \mathrm{E}+02$

$5.89 \mathrm{E}+02$

$5.89 \mathrm{E}+02$
Dose statistics at graphical times, mrem/yr

\begin{tabular}{|c|c|c|c|c|c|c|c|}
\hline inimum & laximum & Mean & ledian & $\%$ & $\div$ & $97.5 \%$ & $\%$ \\
\hline $.44 \mathrm{E}-03$ & $4.30 E+00$ & $2.56 \mathrm{E}-01$ & $.12 \mathrm{E}-01$ & $6.56 \mathrm{E}-01$ & $1.01 \mathrm{E}+00$ & $1.42 \mathrm{E}+00$ & $2.06 \mathrm{E}+00$ \\
\hline$E-03$ & $E+00$ & 1 & 1 & 1 & 0 & +00 & $5 E+00$ \\
\hline 03 & +00 & 01 & & & & 00 & +00 \\
\hline 03 & $E+00$ & & & & & & +00 \\
\hline $.53 E-03$ & $2 \mathrm{E}+00$ & & & & 00 & +00 & $E+00$ \\
\hline $.55 E-03$ & $4.32 E+00$ & $E-01$ & $5 E-01$ & $6 E-01$ & $1.02 \mathrm{E}+00$ & $E+00$ & $E+00$ \\
\hline 03 & $.32 E+00$ & 01 & 01 & $6.67 \mathrm{E}-01$ & 0 & $45 E+00$ & +00 \\
\hline $.59 E-03$ & $4.33 E+00$ & 2.02501 & & & 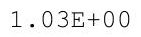 & +00 & +00 \\
\hline 03 & $3 E+00$ & & & & & +00 & +00 \\
\hline $.64 \mathrm{E}-03$ & $4.33 E+00$ & $4 \mathrm{E}-01$ & & $73 \mathrm{E}-$ & & $.46 \mathrm{E}+00$ & $.0 \mathrm{E}+00$ \\
\hline-03 & $E+00$ & $E-01$ & -01 & 1 & 0 & $E+00$ & $\mathrm{E}+00$ \\
\hline-03 & $E+00$ & $E-01$ & 01 & $\perp$ & 0 & $E+00$ & $\mathrm{E}+00$ \\
\hline $71 \mathrm{E}-03$ & $4.34 \mathrm{E}+00$ & -01 & 01 & $\perp$ & 0 & $E+00$ & +00 \\
\hline 3 & $35 E+00$ & $2.67 \mathrm{E}-01$ & $\perp$ & $6.82 \mathrm{E}-01$ & & $7 E+00$ & 00 \\
\hline 3 & $4.35 E+00$ & & & & 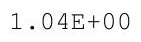 & 0 & 0 \\
\hline $.78 E-03$ & $4.35 E+00$ & $2.69 \mathrm{E}-01$ & $1.21 \mathrm{E}-01$ & & $1.04 \mathrm{E}+00$ & $1.48 \mathrm{E}+00$ & $2.12 \mathrm{E}+00$ \\
\hline $81 E-03$ & 4. $36 \mathrm{E}+00$ & $2.70 \mathrm{E}-01$ & 1. $21 E-01$ & $6.89 \mathrm{E}-01$ & $1.04 \mathrm{E}+00$ & $1.48 \mathrm{E}+00$ & $2.12 \mathrm{E}+00$ \\
\hline $83 E-03$ & $4.36 \mathrm{E}+00$ & $2.71 E-01$ & 1. $22 \mathrm{E}-01$ & $91 \mathrm{E}-$ & $1.05 \mathrm{E}+00$ & $1.49 \mathrm{E}+00$ & $13 E+00$ \\
\hline 03 & 00 & & & & & 00 & -00 \\
\hline 3 & & $\perp$ & & 1 & 0 & 00 & +00 \\
\hline 3 & $4.37 \mathrm{E}+00$ & & $\perp$ & & & 0 & 00 \\
\hline $93 E-03$ & $37 E+00$ & 1 & 1 & & & & 00 \\
\hline $96 E-03$ & $4.38 \mathrm{E}+00$ & $75 \mathrm{~F}-01$ & $1.25 \mathrm{E}-01$ & 䧄 & $1.06 \mathrm{E}+0$ & $.50 \mathrm{E}+00$ & $.14 \mathrm{E}+00$ \\
\hline $98 \mathrm{~F}-03$ & $4.38 \mathrm{E}+00$ & $76 E-01$ & $5-01$ & 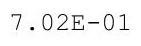 & $1.06 \mathrm{E}+$ & $.50 \mathrm{E}+00$ & $.15 \mathrm{E}+00$ \\
\hline-03 & $38 E+00$ & & & & & & $.15 E+00$ \\
\hline & & & & & & & $2.15 E+00$ \\
\hline $.06 \mathrm{E}-03$ & $4.39 \mathrm{E}+00$ & $2 \cdot 19 \pm$ & $1 \cdot 2$ & & آن & 00 & 00 \\
\hline $.09 E-03$ & $4.39 \mathrm{E}+00$ & $2.19 \pm-0 \perp$ & $1 \cdot 201$ & . & I. UО⿴囗十丁 & $1.51 \mathrm{E}+00$ & $2.16 \mathrm{E}+00$ \\
\hline 33 & $4.40 \mathrm{E}+00$ & 1 & 1 & קת & 1.07E+ & 1. $52 \mathrm{E}+00$ & $2.16 \mathrm{E}+00$ \\
\hline-03 & $4.40 \mathrm{E}+00$ & & & & & 1. $52 \mathrm{E}+00$ & $2.16 \mathrm{E}+00$ \\
\hline-03 & $4.40 \mathrm{E}+00$ & & & & & $2 \mathrm{E}+00$ & $2.16 \mathrm{E}+00$ \\
\hline 3 & & & & & & & $2.17 \mathrm{E}+00$ \\
\hline $2 E-03$ & $4.41 E+00$ & $2.84 \mathrm{E}-01$ & 1. & 1 & $1.00 \mathrm{E}$ & $3 E+00$ & +00 \\
\hline $.25 E-03$ & $4.41 \mathrm{E}+00$ & $2.85 E-01$ & $1.32 \mathrm{E}-01$ & $\cdot 245$ & $1.0 O \mathrm{LT}$ & $1.54 \mathrm{E}+00$ & $2.17 \mathrm{E}+00$ \\
\hline $210-03$ & $4.42 \mathrm{E}+00$ & $2.005-U 1$ & $1.3 J 5-U 1$ & $7.27 \mathrm{E}-01$ & & $1.54 \mathrm{E}+00$ & $2.17 \mathrm{E}+00$ \\
\hline $.30 E-03$ & $4.42 \mathrm{E}+00$ & & + & & & $1.54 \mathrm{E}+00$ & $2.18 \mathrm{E}+00$ \\
\hline $.33 E-03$ & $4.2 F+0$ & & & & & $1.55 \mathrm{E}+00$ & $2.18 \mathrm{E}+00$ \\
\hline 3 & & & 1 & 1 & & $5 E+00$ & \\
\hline-03 & & 01 & 01 & 01 & 1.09E+ & $5 E+00$ & $2.18 \mathrm{E}+00$ \\
\hline$E-03$ & $4.43 E+00$ & 1 & $1.36 \mathrm{E}$ & 1 & $1.09 \mathrm{E}+$ & & $2.19 \mathrm{E}+00$ \\
\hline $44 \mathrm{E}-03$ & $4.43 E+00$ & $2 \cdot 9 \perp E-U \perp$ & $1.36 \pm-01$ & • & & & $2.19 \mathrm{E}+00$ \\
\hline $25-20$ & $4.44 \mathrm{E}+00$ & $2.925-U \perp$ & $\perp \cdot J / L-U \perp$ & 1 & $1.10 \mathrm{E}+00$ & $1.57 \mathrm{E}+00$ & $2.19 \mathrm{E}+00$ \\
\hline 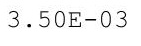 & $4.44 \mathrm{E}+00$ & . & 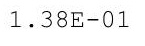 & & $1.10 \mathrm{E}+00$ & $1.57 \mathrm{E}+00$ & $2.19 \mathrm{E}+00$ \\
\hline $3.53 E-03$ & & & & 1 & $1.10 \mathrm{E}+00$ & $1.57 \mathrm{E}+00$ & $2.20 \mathrm{E}+00$ \\
\hline$E-03$ & $4.44 \mathrm{E}+00$ & $2.94 \mathrm{E}-01$ & $1.39 E-01$ & $7.46 \mathrm{E}-01$ & $1.10 \mathrm{E}+00$ & 1. $58 \mathrm{E}+00$ & $2.20 \mathrm{E}+00$ \\
\hline$E-03$ & $45 E+00$ & $95 \mathrm{E}-01$ & 1. $40 \mathrm{E}-01$ & $7.48 \mathrm{E}-01$ & $1.11 \mathrm{E}+00$ & $1.58 \mathrm{E}+00$ & $2.20 \mathrm{E}+00$ \\
\hline
\end{tabular}


RESRAD-OFFSITE, Version 2.5

obabilistic Dose and Risk Report

Title : Offsite Resident Farmer Deterministic Run

File : RF TC99 DOESG FWD-FV2.ROF

Summary of dose at graphical times, reptition 1 (continued)

Time

Years

$5.90 \mathrm{E}+02$

$5.90 \mathrm{E}+02$

$5.91 \mathrm{E}+02$

$5.91 \mathrm{E}+02$

$5.92 \mathrm{E}+02$

$5.92 \mathrm{E}+02$

$5.93 \mathrm{E}+02$

$5.93 \mathrm{E}+02$

$5.94 \mathrm{E}+02$

$5.94 \mathrm{E}+02$

$5.95 \mathrm{E}+02$

$5.95 \mathrm{E}+02$

$5.96 \mathrm{E}+02$

$5.96 \mathrm{E}+02$

$5.97 \mathrm{E}+02$

$5.97 \mathrm{E}+02$

$5.98 \mathrm{E}+02$

$5.98 \mathrm{E}+02$

$5.99 \mathrm{E}+02$

$5.99 \mathrm{E}+02$

$6.00 \mathrm{E}+02$

$6.00 \mathrm{E}+02$

$6.01 \mathrm{E}+02$

$6.01 \mathrm{E}+02$

$6.02 \mathrm{E}+02$

$6.02 \mathrm{E}+02$

$6.03 E+02$

$6.03 \mathrm{E}+02$

$6.04 \mathrm{E}+02$

$6.04 \mathrm{E}+02$

$6.05 \mathrm{E}+02$

$6.05 \mathrm{E}+02$

$6.06 \mathrm{E}+02$

$6.07 \mathrm{E}+02$

$6.07 \mathrm{E}+02$

$6.08 \mathrm{E}+02$

$6.08 \mathrm{E}+02$

$6.09 \mathrm{E}+02$

$6.09 \mathrm{E}+02$

$6.10 \mathrm{E}+02$

$6.10 \mathrm{E}+02$

$6.11 \mathrm{E}+02$

$6.11 \mathrm{E}+02$

$6.12 \mathrm{E}+02$

$6.12 \mathrm{E}+02$

$6.13 \mathrm{E}+02$
Dose statistics at graphical times, mrem/yr

\begin{tabular}{|c|c|c|c|c|c|c|c|}
\hline$m$ & $\operatorname{axi}$ & e & 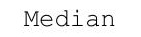 & & & $\%$ & \\
\hline 03 & $4.45 \mathrm{E}+00$ & 01 & 1 & 01 & 00 & $1.58 \mathrm{E}+00$ & - $20 E+U 0$ \\
\hline $64 E-03$ & $4.45 E+00$ & $2.97 E-01$ & $1.41 \mathrm{E}-01$ & $52 E-01$ & $11 \mathrm{E}+00$ & $1.59 \mathrm{E}+00$ & $2.21 \mathrm{E}+00$ \\
\hline $67 E-03$ & $.45 E+00$ & $2.98 \mathrm{E}-01$ & 1. $42 \mathrm{E}-01$ & $54 \mathrm{E}-01$ & $1.12 \mathrm{E}+00$ & $1.59 \mathrm{E}+00$ & $2.21 \mathrm{E}+00$ \\
\hline$E-03$ & $.46 E+00$ & $99 F-01$ & $42 \mathrm{~F}-01$ & $55 F-01$ & $112 \mathrm{~F}+0$ & $.60 \mathrm{E}+00$ & $2.21 \mathrm{E}+00$ \\
\hline $.73 E-03$ & $4.46 \mathrm{E}+00$ & $9 \mathrm{E}-01$ & .4 & 68 & & +00 & $21 E+00$ \\
\hline 03 & +00 & & & & & & 00 \\
\hline $.79 E-03$ & +00 & & & & & & $2.22 \mathrm{E}+00$ \\
\hline $.82 E-03$ & +00 & $\perp$ & $\perp$ & 1 & 00 & +00 & $2.22 \mathrm{E}+00$ \\
\hline $85 E-03$ & $4.47 \mathrm{E}+00$ & $3 E-01$ & -01 & 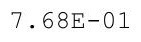 & +00 & $E+00$ & $.22 \mathrm{E}+00$ \\
\hline$E-03$ & $47 E+00$ & $4 \mathrm{E}-01$ & $16 \mathrm{~F}_{-}$ & 1 & ו & $.62 E+00$ & $.22 \mathrm{E}+00$ \\
\hline 03 & $4.47 E+00$ & & 西 & & & -00 & $E+00$ \\
\hline$E-03$ & +00 & 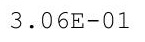 & $1.48 \mathrm{E}$ & $74 F-01$ & & 0 & +00 \\
\hline $98 E-03$ & $4.48 E+00$ & & $1.48 \mathrm{E}-01$ & 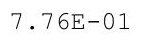 & & $1.62 \mathrm{E}+00$ & $2.23 E+00$ \\
\hline $.01 E-03$ & $4.48 \mathrm{E}+00$ & $.07 E-01$ & 1. $49 \mathrm{E}-01$ & $7.79 \mathrm{E}-$ & $\perp \cdot 15 E+U U$ & $1.63 \mathrm{E}+00$ & $2.23 E+00$ \\
\hline$E-03$ & $3 E+00$ & $E-01$ & F- 0 & $\perp$ & & +00 & $23 E+00$ \\
\hline 3 & 0 & & $\pm \cdot 0$ & & & 0 & 00 \\
\hline 3 & & & $1.51 \mathrm{E}-01$ & & & $\Xi+00$ & 0 \\
\hline 3 & $4.49 E+00$ & $3.11 \mathrm{E}-01$ & 1. $52 \mathrm{E}-01$ & $788 \mathrm{~F}-01$ & & 0 & 0 \\
\hline $17 E-03$ & $4.49 \mathrm{E}+00$ & $3-12 F-01$ & $153=0$ & 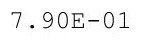 & 165 & $E+00$ & $24 E+00$ \\
\hline$E-03$ & $4.49 \mathrm{E}+00$ & $.13 E-01$ & 1. $53 \mathrm{E}-01$ & $2 \mathrm{~F}-\mathrm{C}-\mathrm{C}$ & $1.16 \mathrm{E}+$ & $1.64 \mathrm{E}+00$ & $2.25 \mathrm{E}+00$ \\
\hline 03 & $E+00$ & & & & & +00 & $5 E+00$ \\
\hline 3 & & & & & & & \\
\hline 03 & $4.50 \mathrm{E}+00$ & & 1.00 & & & & \\
\hline $4 E-03$ & $4.50 \mathrm{E}+00$ & $\perp$ & 1. & - & the & 1.OJETU & 00 \\
\hline 3 & $4.50 \mathrm{E}+00$ & $3.17 \mathrm{E}-01$ & 1. $56 \mathrm{E}-01$ & - & $1.18 \mathrm{E}+$ & 1. $65 \mathrm{E}+0$ & $2.25 E+00$ \\
\hline $40 E-03$ & $4.51 \mathrm{E}+00$ & $3-18 F-01$ & $157=0$ & 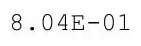 & $1.18 \mathrm{E}+$ & $1.65 \mathrm{E}+00$ & $2.26 \mathrm{E}+00$ \\
\hline $4 F-03$ & $4.51 \mathrm{E}+00$ & & & & & $1.65 E+00$ & $2.26 E+00$ \\
\hline & & & & & & & \\
\hline 3 & $4.51 \mathrm{E}+00$ & 3.2 & & & & & $6 \mathrm{E}+00$ \\
\hline $.54 \mathrm{E}-03$ & $4.51 \mathrm{E}+00$ & $.2 \angle L-1$ & 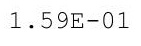 & $8.13 \mathrm{E}-01$ & 1.19E+ & $1.66 \mathrm{E}+00$ & $2.26 \mathrm{E}+00$ \\
\hline $.58 \mathrm{E}-03$ & $4.52 \mathrm{E}+00$ & $3.23 E-01$ & $+\cdot 00$ & - & $1.19 \mathrm{E}+00$ & $1.66 \mathrm{E}+00$ & $2.26 \mathrm{E}+00$ \\
\hline 3 & $4.52 \mathrm{E}+00$ & 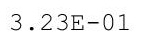 & 5 & $8 \quad 17 \mathrm{~F}-01$ & $1.19 \mathrm{E}+$ & & \\
\hline 3 & $4.52 \mathrm{E}+00$ & & & & & & $2.27 \mathrm{E}+00$ \\
\hline & & & 1 & & & & $2.27 \mathrm{E}+00$ \\
\hline$E-03$ & $4.52 \mathrm{E}+00$ & 1 & 1 . & 1 & & & \\
\hline $.75 E-03$ & $4.53 E+00$ & $3.27 E-01$ & 1. $63 \mathrm{E}-01$ & $0.20 \mathrm{~L}$ & $1 \cdot 20 \mathrm{E}$ & 1.010 & $2.27 \mathrm{E}+00$ \\
\hline $.79 E-03$ & $4.53 E+00$ & 3.20101 & $1.04 \perp-1$ & . & 1.200 & & $2.27 \mathrm{E}+00$ \\
\hline & $4.53 E+00$ & & $1.65 \mathrm{E}-01$ & & 1. $20 \mathrm{E}+00$ & & $2.27 \mathrm{E}+00$ \\
\hline 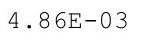 & $4.53 \mathrm{E}+$ & - &.+ & 1 & 1.20E+ & $1.68 \mathrm{E}+00$ & $2.27 E+00$ \\
\hline & $4.53 E+00$ & & $1.66 \mathrm{E}-01$ & 1 & 1.21E+ & & $.27 E+00$ \\
\hline $4 E-03$ & $4.53 E+00$ & $3.32 E-01$ & $1.67 \mathrm{E}-01$ & 1 & $1.21 \mathrm{E}$ & $1.68 \mathrm{E}+00$ & $2.28 \mathrm{E}+00$ \\
\hline$E-03$ & $4.54 \mathrm{E}+00$ & 3.3 & 1. & 1 & 1.21E+ & $1.68 \mathrm{E}+00$ & $2.28 \mathrm{E}+00$ \\
\hline & $4.54 \mathrm{E}+00$ & & & & & & \\
\hline$E-03$ & $4.54 \mathrm{E}+00$ & $3.34 \mathrm{E}-01$ & $\pm \cdot 02$ & . & $1 \cdot 2 \perp E+U 0$ & $1.69 \mathrm{E}+00$ & $2.28 \mathrm{E}+00$ \\
\hline & $4.54 \mathrm{E}+00$ & ent & $1.00 \mathrm{C}$ & & $1.22 \mathrm{E}+00$ & $1.69 \mathrm{E}+00$ & $2.28 \mathrm{E}+00$ \\
\hline 03 & $4.54 \mathrm{E}+00$ & $6 E-01$ & $70 E-01$ & $E-01$ & $1.22 \mathrm{E}+00$ & $1.69 \mathrm{E}+00$ & $2.28 \mathrm{E}+00$ \\
\hline
\end{tabular}


RESRAD-OFFSITE, Version 2.5 
RESRAD-OFFSITE, Version 2.5 
RESRAD-OFFSITE, Version 2.5

Title : Offsite Resident Farmer Deterministic Run

File : RF TC99 DOESG FWD-FV2.ROF

Summary of dose at graphical times, reptition 1 (continued)

Time

Years

$6.60 \mathrm{E}+02$

$6.61 \mathrm{E}+02$

$6.61 \mathrm{E}+02$

$6.62 \mathrm{E}+02$

$6.62 \mathrm{E}+02$

$6.63 \mathrm{E}+02$

$6.63 \mathrm{E}+02$

$6.64 \mathrm{E}+02$

$6.64 \mathrm{E}+02$

$6.65 \mathrm{E}+02$

$6.65 \mathrm{E}+02$

$6.66 \mathrm{E}+02$

$6.67 \mathrm{E}+02$

$6.67 \mathrm{E}+02$

$6.68 \mathrm{E}+02$

$6.68 \mathrm{E}+02$

$6.69 \mathrm{E}+02$

$6.69 \mathrm{E}+02$

$6.70 \mathrm{E}+02$

$6.70 \mathrm{E}+02$

$6.71 \mathrm{E}+02$

$6.71 \mathrm{E}+02$

$6.72 \mathrm{E}+02$

$6.72 \mathrm{E}+02$

$6.73 E+02$

$6.73 \mathrm{E}+02$

$6.74 \mathrm{E}+02$

$6.74 \mathrm{E}+02$

$6.75 \mathrm{E}+02$

$6.75 \mathrm{E}+02$

$6.76 \mathrm{E}+02$

$6.76 \mathrm{E}+02$

$6.77 \mathrm{E}+02$

$6.77 \mathrm{E}+02$

$6.78 \mathrm{E}+02$

$6.78 \mathrm{E}+02$

$6.79 \mathrm{E}+02$

$6.79 \mathrm{E}+02$

$6.80 \mathrm{E}+02$

$6.80 \mathrm{E}+02$

$6.81 \mathrm{E}+02$

$6.81 \mathrm{E}+02$

$6.82 \mathrm{E}+02$

$6.82 \mathrm{E}+02$

$6.83 \mathrm{E}+02$

$6.83 \mathrm{E}+02$
Dose statistics at graphical times, mrem/yr

\begin{tabular}{|c|c|c|c|c|c|c|c|}
\hline$m$ & aximum & lea & 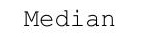 & & & $\%$ & $\%$ \\
\hline-03 & $4.59 \mathrm{E}+00$ & $4 . \angle \angle E$ & 1 & $03 E+00$ & 0 & -00 & . $40 \mathrm{E}+U \mathrm{U}$ \\
\hline $34 E-03$ & $4.59 E+00$ & $4.23 E-01$ & $2.44 \mathrm{E}-01$ & $3 E+00$ & $4 E+00$ & 1.93E+00 & $7 E+00$ \\
\hline-03 & $59 E+00$ & $24 E-01$ & $.45 E-01$ & $.03 E+00$ & $.44 E+00$ & L.93E+00 & $2.47 \mathrm{E}+00$ \\
\hline$E-03$ & $.59 \mathrm{E}+00$ & $25 \mathrm{~F}-01$ & $46 \mathrm{~F}-01$ & $.03 E+00$ & 1. $45 \mathrm{E}+00$ & $1.93 \mathrm{E}+00$ & $2.47 E+00$ \\
\hline $51 E-03$ & $4.59 \mathrm{E}+00$ & $26 \mathrm{~F}-0$ & 1 & 0 & $\mathrm{~F}+00$ & $E+00$ & $E+00$ \\
\hline 03 & +00 & & & & & & 0 \\
\hline $62 E-03$ & $8 E+00$ & 1 & & & & & $2.48 \mathrm{E}+00$ \\
\hline $67 E-03$ & $4.58 E+00$ & 1 & $\perp$ & $5+00$ & 00 & +00 & $48 E+00$ \\
\hline $73 E-03$ & $4.58 \mathrm{E}+00$ & $30 E-01$ & -01 & $5 \mathrm{E}+00$ & $46 \mathrm{E}+$ & +00 & $8 \mathrm{E}+00$ \\
\hline$E-03$ & $.58 \mathrm{E}+00$ & $31=-01$ & $51 \mathrm{~F}-01$ & $.05 E+00$ & $16 \mathrm{~F}+$ & $.94 E+00$ & $.49 \mathrm{E}+00$ \\
\hline 3 & $3 E+00$ & $32 E-01$ & & & & 0 & $9 E+00$ \\
\hline $90 E-03$ & +00 & 325 & 2 & & 0 & & +00 \\
\hline $95 E-03$ & $4.58 E+00$ & $4.33 E-01$ & & & $1.47 \mathrm{E}+00$ & 1. $95 \mathrm{E}+00$ & $2.49 \mathrm{E}+00$ \\
\hline $.00 \mathrm{E}-02$ & $4.58 \mathrm{E}+00$ & $4.34 \mathrm{E}-01$ & $2.55 \mathrm{E}-01$ & $1.06 \mathrm{E}+00$ & $1.48 \mathrm{E}+00$ & $1.95 \mathrm{E}+00$ & $2.50 \mathrm{E}+00$ \\
\hline-02 & $\Xi+00$ & $35 F-0$ & $F-0-0 \cdot 2-2$ & 0 & 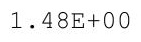 & +00 & $\mathrm{E}+00$ \\
\hline 2 & 0 & 4. $36 \mathrm{E}-01$ & $\perp$ & 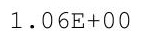 & $.48 \mathrm{E}+00$ & & \\
\hline 2 & $58 \mathrm{E}+00$ & & & & 0 & 0 & 0 \\
\hline $2 E-02$ & $4.58 \mathrm{E}+00$ & $4.38 E-01$ & $2.58 \mathrm{E}-01$ & & 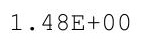 & $5 E+00$ & 0 \\
\hline $.03 E-02$ & $4.58 \mathrm{E}+00$ & $39 F-0$ & $9=-01$ & 政 & 㧒 & $\mathrm{F}+00$ & $1 \mathrm{E}+00$ \\
\hline $04 \mathrm{E}-02$ & $4.58 \mathrm{E}+00$ & $.40 E-01$ & $2.60 \mathrm{E}-01$ & $1.07 \mathrm{E}+00$ & 1. $49 \mathrm{E}+$ & $1.97 \mathrm{E}+00$ & $2.51 E+00$ \\
\hline 02 & $57 E+00$ & $11 \mathrm{~B}$ & & & 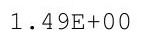 & +00 & $2 \mathrm{E}+00$ \\
\hline 2 & & & & & & & \\
\hline 02 & $4.57 \mathrm{E}+00$ & $43 \mathrm{E}$ & & & 1. $49 \mathrm{E}+$ & & \\
\hline 02 & $4.57 \mathrm{E}+00$ & $1+$ & $2.63 E-01$ & OLTO & ( & 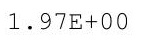 & 00 \\
\hline 2 & $4.57 \mathrm{E}+00$ & $4.45 \mathrm{E}-01$ & $\perp$ & $1.08 \mathrm{E}+00$ & 1. $50 \mathrm{E}+$ & 1. $98 \mathrm{E}+\mathrm{C}$ & $3 E+00$ \\
\hline $.07 E-02$ & $4.57 \mathrm{E}+00$ & $4.46 \mathrm{E}-0$ & $2.65 \mathrm{E}-01$ & $1.08 \mathrm{E}+00$ & $1.50 \mathrm{E}+\mathrm{C}$ & $1.98 \mathrm{E}+00$ & $.53 E+00$ \\
\hline$E-02$ & $4.57 \mathrm{E}+00$ & $17 \mathrm{~F}-0$ & & & & $1.98 \mathrm{E}+00$ & $.53 E+00$ \\
\hline & & & & & & & \\
\hline 02 & $4.57 \mathrm{E}+00$ & 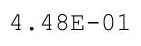 & (2. & 1.00 & $1.51 \mathrm{E}+$ & & \\
\hline $.10 \mathrm{E}-02$ & $4.57 \mathrm{E}+00$ & 1.100 - 1 & $2.07 \mathrm{~L}-\mathrm{L}$ & 1.09E+00 & $1.51 \mathrm{E}+00$ & $1.99 \mathrm{E}+00$ & $2.54 \mathrm{E}+00$ \\
\hline $10 \mathrm{E}-02$ & $4.57 \mathrm{E}+00$ & 1.00 & 2.00101 & 1. $09 \mathrm{E}+00$ & 1. $51 \mathrm{E}+00$ & $1.99 \mathrm{E}+00$ & $2.54 \mathrm{E}+00$ \\
\hline 2 & $4.56 \mathrm{E}+00$ & 20 & 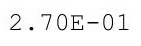 & $1.09 \mathrm{E}+$ & $1.51 \mathrm{E}+$ & & \\
\hline $.11 \mathrm{E}-02$ & & & & & & & 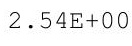 \\
\hline 02 & $4.56 \mathrm{E}+00$ & 1 & & & & & \\
\hline$E-02$ & $4.56 \mathrm{E}+00$ & 1 & 01 & 0 & $\perp$ & & 00 \\
\hline $13 E-02$ & $4.56 \mathrm{E}+00$ & $4.55 E-U 1$ & $2.14 \mathrm{E}-01$ & $1.10 \mathrm{E}+00$ & $\perp \cdot \circlearrowright<\amalg$ & $2.00 \mathrm{E}+00$ & $2.55 E+00$ \\
\hline $14 \mathrm{E}-02$ & $4.56 \mathrm{E}+00$ & . & & $1 \cdot 1 U E+U 0$ & •・U⿺辶寸 & & $2.55 \mathrm{E}+00$ \\
\hline & $4.56 \mathrm{E}+00$ & & & $1.10 \mathrm{E}+$ & $1.53 \mathrm{E}+$ & & $2.55 E+00$ \\
\hline 2 & $4.56 \mathrm{E}+$ & 1.0 & 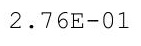 & 1.10E+ & $1.53 \mathrm{E}+$ & & $2.55 E+00$ \\
\hline 2 & $4.56 \mathrm{E}+00$ & & 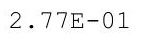 & $1.10 \mathrm{E}+00$ & $1.53 \mathrm{E}+00$ & & $5 E+00$ \\
\hline$E-02$ & $4.55 E+00$ & $4.60 \mathrm{E}-01$ & $2.78 \mathrm{E}-01$ & 1. $10 \mathrm{E}+00$ & 1 . & $1 E+00$ & $2.55 E+00$ \\
\hline $7 E-02$ & $4.55 E+00$ & $4.61 \mathrm{E}$ & .7 & & 1. $54 \mathrm{E}+$ & 2. & $5 E+00$ \\
\hline & 0 & & & & & & \\
\hline$E-02$ & $4.55 E+00$ & . & 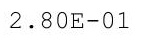 & $\perp \cdot 1 \perp E+U 0$ & $1.54 \mathrm{E}+00$ & $2.02 E+00$ & $2.55 E+00$ \\
\hline & $4.55 E+00$ & . & & $1.11 \mathrm{E}+00$ & $1.54 \mathrm{E}+00$ & $2.02 E+00$ & $2.55 E+00$ \\
\hline 2 & $4.55 \mathrm{E}+00$ & $E-01$ & $81 \mathrm{E}-01$ & $.11 \mathrm{E}+00$ & 1. $55 \mathrm{E}+00$ & $2.02 \mathrm{E}+00$ & $.56 \mathrm{E}+00$ \\
\hline
\end{tabular}


RESRAD-OFFSITE, Version 2.5 
RESRAD-OFFSITE, Version 2.5

$\mathrm{T}^{1 / 2}$ Limit $=180$ days

itle : Offsite Resident Farmer Deterministic Run

File : RF TC99 DOESG FWD-FV2.ROF

Summary of dose at graphical times, reptition 1 (continued)

Time

Years

$7.08 \mathrm{E}+02$

$7.08 \mathrm{E}+02$

$7.09 \mathrm{E}+02$

$7.09 \mathrm{E}+02$

$7.10 \mathrm{E}+02$

7. $10 \mathrm{E}+02$

$7.11 \mathrm{E}+02$

$7.11 \mathrm{E}+02$

$7.12 \mathrm{E}+02$

$7.12 \mathrm{E}+02$

$7.13 \mathrm{E}+02$

7. $13 \mathrm{E}+02$

$7.14 \mathrm{E}+02$

$7.14 \mathrm{E}+02$

$7.15 \mathrm{E}+02$

$7.15 \mathrm{E}+02$

$7.16 \mathrm{E}+02$

7. $16 \mathrm{E}+02$

$7.17 \mathrm{E}+02$

$7.17 \mathrm{E}+02$

$7.18 \mathrm{E}+02$

$7.18 \mathrm{E}+02$

7. $19 \mathrm{E}+02$

$7.19 \mathrm{E}+02$

$7.20 \mathrm{E}+02$

$7.20 \mathrm{E}+02$

$7.21 \mathrm{E}+02$

$7.21 \mathrm{E}+02$

$7.22 \mathrm{E}+02$

7. $22 \mathrm{E}+02$

7. $23 \mathrm{E}+02$

$7.23 \mathrm{E}+02$

$7.24 \mathrm{E}+02$

$7.24 \mathrm{E}+02$

$7.25 \mathrm{E}+02$

7. $25 \mathrm{E}+02$

7. $26 \mathrm{E}+02$

$7.26 \mathrm{E}+02$

$7.27 \mathrm{E}+02$

$7.28 \mathrm{E}+02$

$7.28 \mathrm{E}+02$

$7.29 \mathrm{E}+02$

$7.29 \mathrm{E}+02$

$7.30 \mathrm{E}+02$

7. $30 \mathrm{E}+02$

7. $31 \mathrm{E}+02$
Dose statistics at graphical times, mrem/yr

\begin{tabular}{|c|c|c|c|c|c|c|c|}
\hline m & um & ea & 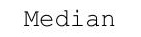 & & & $\%$ & \\
\hline 02 & $4.47 \mathrm{E}+00$ & $09 E-01$ & 1 & $19 \mathrm{E}+00$ & $.65 E+00$ & $08 E+00$ & . $01 \mathrm{E}+U 0$ \\
\hline $.53 E-02$ & $4.47 E+00$ & -01 & $3.24 \mathrm{E}-01$ & $20 E+00$ & $5 E+00$ & $2.08 \mathrm{E}+00$ & $62 E+00$ \\
\hline $54 E-02$ & $47 \mathrm{E}+00$ & $0 E-01$ & $5 E-01$ & $.20 \mathrm{E}+00$ & $.65 E+00$ & $2.08 E+00$ & $2.62 \mathrm{E}+00$ \\
\hline $5 E-02$ & $4.46 E+00$ & $11 \mathrm{~F}-01$ & $25 \mathrm{~F}-01$ & $.20 \mathrm{E}+00$ & $165 \mathrm{~F}+00$ & $2.08 E+00$ & $2.62 \mathrm{E}+00$ \\
\hline$E-02$ & $E+00$ & 1 & -01 & & & $E+00$ & $2 \mathrm{E}+00$ \\
\hline 02 & $4.46 E+00$ & & & & & & 00 \\
\hline $.57 E-02$ & +00 & & & & & & $62 \mathrm{E}+00$ \\
\hline $58 \mathrm{E}-02$ & $6 \mathrm{E}+00$ & 1 & $\perp$ & $1.20 \mathrm{E}+00$ & $E+00$ & +00 & $52 \mathrm{E}+00$ \\
\hline $58 E-02$ & $4.45 E+00$ & -01 & -01 & $1.21 \mathrm{E}+00$ & $66 \mathrm{E}+00$ & $E+00$ & $62 E+00$ \\
\hline$E-02$ & $.45 E+00$ & $17 E-01$ & 210 & $1215+$ & 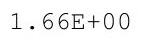 & $.09 E+00$ & $.62 E+00$ \\
\hline 02 & $E+00$ & & & & & 00 & $62 E+00$ \\
\hline $61 E-02$ & $E+00$ & 1 & $3.33 \mathrm{E}-01$ & $.21 \mathrm{E}+$ & & & $52 \mathrm{E}+00$ \\
\hline $.62 E-02$ & $4.45 E+00$ & & & $1.21 \mathrm{E}+00$ & & & $2.63 E+00$ \\
\hline $62 E-02$ & $4.44 \mathrm{E}+00$ & $.21 \mathrm{E}-01$ & $.35 E-01$ & $1.21 \mathrm{E}+00$ & & $2.09 E+00$ & $2.63 E+00$ \\
\hline-02 & $E+00$ & $2 E-01$ & -0 & 21 & & +00 & $53 \mathrm{E}+00$ \\
\hline 2 & $E+00$ & & $\perp$ & .22 & $.67 E+00$ & 0 & 00 \\
\hline 2 & 00 & & & 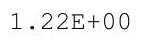 & 0 & 0 & 0 \\
\hline $6 \mathrm{E}-02$ & $4.43 E+00$ & $5.24 \mathrm{E}-01$ & 3. 39E-01 & $20 \mathrm{~F}+1$ & & 0 & 0 \\
\hline $66 \mathrm{E}-02$ & $4.43 E+00$ & $5 F-01$ & $9 F-01$ & 1 & 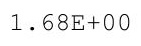 & $E+00$ & $63 E+00$ \\
\hline $67 E-02$ & $4.43 E+00$ & $.26 \mathrm{E}-01$ & $E-01$ & $1.22 \mathrm{E}+00$ & 1. $68 \mathrm{E}+$ & $2.09 \mathrm{E}+00$ & $2.63 E+00$ \\
\hline 02 & $4.43 E+00$ & & & 0 & & +00 & $E+00$ \\
\hline & & & & & & & \\
\hline 02 & $4.42 \mathrm{E}+00$ & .2 & & 1.23E+ & & & \\
\hline$E-02$ & $4.42 \mathrm{E}+00$ & 1 & & 1.23E+ & - & 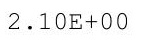 & 00 \\
\hline 2 & $4.42 \mathrm{E}+00$ & $5.31 \mathrm{E}-01$ & $\perp$ & $1.23 \mathrm{E}+\mathrm{C}$ & & $\mathrm{E}+\mathrm{C}$ & $63 E+00$ \\
\hline $.72 E-02$ & $4.42 \mathrm{E}+00$ & $32 \mathrm{~F}-01$ & $46 \mathrm{~F}-01$ & 1. $24 \mathrm{E}+00$ & $1.68 \mathrm{E}+\mathrm{C}$ & $10 \mathrm{E}+00$ & $.64 \mathrm{E}+00$ \\
\hline $.73 E-02$ & $4.41 E+00$ & & & & & $2.10 \mathrm{E}+00$ & 2. $64 \mathrm{E}+00$ \\
\hline 02 & & & & & & & \\
\hline 2 & $4.41 E+00$ & 0 & & $1.24 \mathrm{E}+$ & & & \\
\hline $75 E-02$ & $4.41 E+00$ & . & . & $1.24 \mathrm{E}+00$ & $1.69 \mathrm{E}+00$ & $2.10 \mathrm{E}+00$ & $2.64 \mathrm{E}+00$ \\
\hline $76 \mathrm{E}-02$ & $4.40 \mathrm{E}+00$ & $5.36 \mathrm{E}-01$ & 然 & $1.25 \mathrm{E}+00$ & 1. $70 \mathrm{E}+00$ & $2.10 \mathrm{E}+00$ & $2.64 \mathrm{E}+00$ \\
\hline 2 & $4.40 \mathrm{E}+00$ & - & $3.52 \mathrm{E}-01$ & 1.25E+ & & & $2.64 \mathrm{E}+$ \\
\hline $.78 E-02$ & & & & & & & \\
\hline 02 & & & & & & & \\
\hline$E-02$ & $4.39 E+00$ & & & 1 . & & & \\
\hline $80 E-02$ & $4.39 \mathrm{E}+00$ & $5.41 E-01$ & $3.35 \pm-01$ & $1.25 \mathrm{E}+00$ & $\perp \cdot 1 \perp$ & $2.10 \mathrm{U}$ & $2.64 \mathrm{E}+00$ \\
\hline $81 \mathrm{E}-02$ & $4.39 \mathrm{E}+00$ & $.4 \angle L-4$ & & $1.26 E+00$ & & & $2.64 \mathrm{E}+00$ \\
\hline $82 E-02$ & $4.39 \mathrm{E}+00$ & .尹U士 U & & $1.26 \mathrm{E}+00$ & $1.71 \mathrm{E}+$ & & $2.64 \mathrm{E}+00$ \\
\hline 2 & $4.38 \mathrm{E}+00$ & 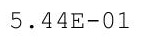 & 1 & $1.26 \mathrm{E}+00$ & $1.71 \mathrm{E}+$ & & $2.64 \mathrm{E}+00$ \\
\hline 2 & $4.38 E+00$ & 1 & 1 & $1.26 \mathrm{E}+00$ & $171=$ & & $54 \mathrm{E}+00$ \\
\hline $5 E-02$ & $4.38 E+00$ & -01 & $E-01$ & $E+00$ & $1.72 \mathrm{E}$ & $11 E+00$ & $54 \mathrm{E}+00$ \\
\hline$E-02$ & $4.38 E+00$ & 5.4 & & $1.27 \mathrm{E}+00$ & & 2. & $2.64 \mathrm{E}+00$ \\
\hline & $4 \cdot 3$ & & & & & & $2.64 \mathrm{E}+00$ \\
\hline$E-02$ & $4.37 \mathrm{E}+00$ & . & $2+$ & $1.27 E+00$ & $1.72 \mathrm{E}+00$ & $2.11 \mathrm{E}+00$ & $2.64 \mathrm{E}+00$ \\
\hline $88 E-02$ & $4.37 E+00$ & & & $1.27 \mathrm{E}+00$ & $1.72 \mathrm{E}+00$ & $2.11 \mathrm{E}+00$ & $2.64 \mathrm{E}+00$ \\
\hline$E-02$ & $4.37 E+00$ & $E-01$ & $4 E-01$ & $.27 \mathrm{E}+00$ & $1.73 E+00$ & $2.11 \mathrm{E}+00$ & $.64 E+00$ \\
\hline
\end{tabular}


RESRAD-OFFSITE, Version 2.5 
RESRAD-OFFSITE, Version 2.5

obabilistic Dose and Risk Report

Title : Offsite Resident Farmer Deterministic Run

File : RF TC99 DOESG FWD-FV2.ROF

Summary of dose at graphical times, reptition 1 (continued)

Time

Years

7. $55 \mathrm{E}+02$

$7.55 \mathrm{E}+02$

7. $56 \mathrm{E}+02$

$7.56 \mathrm{E}+02$

$7.57 \mathrm{E}+02$

7. $57 \mathrm{E}+02$

$7.58 \mathrm{E}+02$

7. $58 \mathrm{E}+02$

$7.59 \mathrm{E}+02$

7. $59 \mathrm{E}+02$

7. $60 \mathrm{E}+02$

$7.60 \mathrm{E}+02$

7. $61 \mathrm{E}+02$

$7.61 \mathrm{E}+02$

7. $62 \mathrm{E}+02$

7. $62 \mathrm{E}+02$

7. $63 \mathrm{E}+02$

7. $63 \mathrm{E}+02$

7. $64 \mathrm{E}+02$

7. $64 \mathrm{E}+02$

$7.65 \mathrm{E}+02$

$7.65 \mathrm{E}+02$

7. $66 \mathrm{E}+02$

7. $66 \mathrm{E}+02$

$7.67 \mathrm{E}+02$

$7.68 \mathrm{E}+02$

$7.68 \mathrm{E}+02$

7. $69 \mathrm{E}+02$

$7.69 \mathrm{E}+02$

$7.70 \mathrm{E}+02$

7. $70 \mathrm{E}+02$

$7.71 \mathrm{E}+02$

7. $71 \mathrm{E}+02$

7. $72 \mathrm{E}+02$

7. $72 \mathrm{E}+02$

7. $73 \mathrm{E}+02$

$7.73 E+02$

7. $74 \mathrm{E}+02$

$7.74 \mathrm{E}+02$

$7.75 \mathrm{E}+02$

$7.75 \mathrm{E}+02$

$7.76 \mathrm{E}+02$

$7.76 \mathrm{E}+02$

$7.77 \mathrm{E}+02$

$7.77 \mathrm{E}+02$

$7.78 \mathrm{E}+02$
Dose statistics at graphical times, mrem/yr

\begin{tabular}{|c|c|c|c|c|c|c|c|}
\hline m & m & Mean & ledian & & & $\%$ & $\%$ \\
\hline 02 & $4.23 E+00$ & $5.93 E-01$ & $4.08 E-01$ & $1.35 \mathrm{E}+00$ & $1.82 \mathrm{E}+00$ & +00 & $2.63 E+00$ \\
\hline-02 & +00 & 01 & 01 & $35 E+00$ & 00 & +00 & $\mathrm{E}+00$ \\
\hline $.34 \mathrm{E}-02$ & $4.23 E+00$ & $95 E-01$ & $0 E-01$ & $1.36 \mathrm{E}+00$ & $1.82 \mathrm{E}+00$ & $2.17 \mathrm{E}+00$ & $2.63 E+00$ \\
\hline $35 E-02$ & $4.22 \mathrm{E}+00$ & $.96 \mathrm{E}-01$ & $1 E-01$ & $1.36 \mathrm{E}+00$ & 1. $82 \mathrm{E}+00$ & $2.18 \mathrm{E}+00$ & $63 E+00$ \\
\hline 02 & $2 E+00$ & $7 E-01$ & 01 & $1.36 \mathrm{E}+00$ & $1.82 \mathrm{E}$ & 00 & $3 E+00$ \\
\hline-02 & $2 \mathrm{E}+00$ & 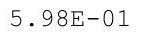 & + & 0 & 0 & -00 & +00 \\
\hline $38 \mathrm{E}-02$ & $4.22 \mathrm{E}+00$ & & & & & & $3 E+00$ \\
\hline $.40 \mathrm{E}-02$ & $4.21 E+00$ & 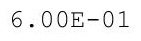 & & & 00 & & +00 \\
\hline-02 & $4.21 E+00$ & -0 & -01 & $37 \mathrm{E}+00$ & $83 \mathrm{E}+$ & +00 & $63 E+00$ \\
\hline 02 & $4.21 \mathrm{E}+00$ & $6.01 \mathrm{E}-01$ & 1 & $1.37 \mathrm{E}+$ & $83 \mathrm{E}+$ & $E+00$ & $63 E+00$ \\
\hline 02 & $20 \mathrm{E}+00$ & $\mathrm{~F}$ & - & $137 \mathrm{~F}+0 \Omega$ & קח & $8 E+00$ & +00 \\
\hline 22 & $0 E+00$ & & & .37 & 0 & & -00 \\
\hline $45 \mathrm{~F}-02$ & $4.20 E+00$ & 5 & 4 & $1.37 \mathrm{E}+$ & 0 & & +00 \\
\hline $46 \mathrm{E}-02$ & $4.19 \mathrm{E}+00$ & $6.05 \mathrm{E}-01$ & $4.20 \mathrm{E}-01$ & $1.37 \mathrm{E}+00$ & $1.83 \mathrm{E}+00$ & $2.19 \mathrm{E}+00$ & $2.63 E+00$ \\
\hline $47 E-02$ & $4.19 \mathrm{E}+00$ & $F-0$ & 1 & $1.37 \mathrm{E}+00$ & $83 \mathrm{E}+$ & $\mathrm{E}+00$ & $63 \mathrm{E}+00$ \\
\hline 2 & $19 \mathrm{E}+00$ & & & & & & +00 \\
\hline $.49 E-02$ & & $6.08 \mathrm{E}-01$ & 1 & T & 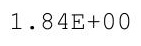 & 0 & 00 \\
\hline 2 & & & & & & & 0 \\
\hline $51 \mathrm{~F}-02$ & $4.18 \mathrm{E}+00$ & F & 5 & $1.38 \mathrm{E}+00$ & & +00 & $E+00$ \\
\hline $52 E-02$ & $4.17 \mathrm{E}+00$ & $.10 \mathrm{E}-0$ & $4.26 \mathrm{E}-01$ & $1.38 \mathrm{E}+00$ & $1.84 \mathrm{E}+0$ & $2.19 \mathrm{E}+00$ & $2.64 \mathrm{E}+00$ \\
\hline $.53 E-02$ & $.17 \mathrm{E}+00$ & $5=0$ & 4.27 & 1. $38 \mathrm{E}+00$ & $.84 \mathrm{E}+$ & $.19 \mathrm{E}+00$ & $.64 \mathrm{E}+00$ \\
\hline 02 & & & & & & & $.64 \mathrm{E}+00$ \\
\hline 2 & & & & 1.38 & & & \\
\hline $56 \mathrm{E}-02$ & $4.16 \mathrm{E}+00$ & & & $\perp \cdot 00$ - & & & 00 \\
\hline 2 & 16 & $6.15 \mathrm{E}-01$ & $\perp$ & 130 & 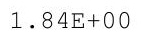 & 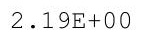 & 00 \\
\hline $58 \mathrm{~F}-02$ & $4.15 E+00$ & - $16=0$ & $31 E-01$ & $1.38 \mathrm{E}+00$ & $105 \mathrm{~F}$ & $2.20 E+00$ & $2.64 \mathrm{E}+00$ \\
\hline$-0 ?$ & $4.15 E+00$ & $17 F-0$ & 4. $32 E-01$ & $1.38 \mathrm{E}+00$ & $1.85 \mathrm{E}+$ & $2.20 \mathrm{E}+00$ & $2.64 \mathrm{E}+00$ \\
\hline 02 & & & & & & & \\
\hline 02 & $4 E+U 0$ & & & 1.000 & $-\sigma_{-1}$ & & \\
\hline $62 E-02$ & $4 \cdot 14 E+00$ & . & $4.35 E-01$ & $1.38 \mathrm{E}+00$ & 土. & $2.20 E+00$ & $2.64 \mathrm{E}+00$ \\
\hline $.035-42$ & $4.14 \mathrm{E}+00$ & 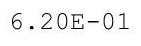 & $4.36 \mathrm{E}-01$ & $1.38 \mathrm{E}+00$ & 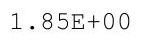 & $2 . \angle U D T O 0$ & $2.64 \mathrm{E}+00$ \\
\hline 年 & $4.13 \mathrm{E}+00$ & 然 & 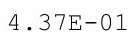 & $1.38 \mathrm{E}+00$ & 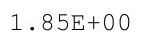 & & $2.64 \mathrm{E}+00$ \\
\hline F & $4.13 E+00$ & תר? & З & $1.39 \mathrm{E}+00$ & & & $2.64 \mathrm{E}+00$ \\
\hline $.67 \mathrm{E}-02$ & & & & & & & \\
\hline-02 & & & & & & & \\
\hline $69 E-02$ & $4.12 \mathrm{E}+00$ & $6.25 E-01$ & $.41 \pm$ & 1.39E+ & 土.OU & 2.2 & $2.65 E+00$ \\
\hline$\pm-0<$ & $4.12 \mathrm{E}+00$ & & 1. & ז. & t. & & $2.65 E+00$ \\
\hline $1 \perp \pm-U 2$ & $4.11 \mathrm{E}+00$ & & & 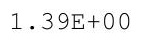 & & & $2.65 E+00$ \\
\hline $.72 E-02$ & 1. & $6.27 \mathrm{E}-01$ & 1 & t. & $1.87 \mathrm{E}$ & & $2.65 E+00$ \\
\hline & & & & $40 E+00$ & & & \\
\hline 2 & & 6 & 1 & $1.40 \mathrm{E}+00$ & $1.87 \mathrm{E}+$ & $2.21 \mathrm{E}+00$ & $2.65 E+00$ \\
\hline $75 E-02$ & $4.10 \mathrm{E}+00$ & 6.3 & $4.47 \mathrm{E}-01$ & 1.40 & $1.87 \mathrm{E}+$ & 00 & $5 E+00$ \\
\hline & & & & & & & \\
\hline & $4.09 \mathrm{E}+00$ & . & & $1.40 E+00$ & 土. & $2.21 \mathrm{E}+00$ & $2.65 E+00$ \\
\hline 40 & $4.09 E+00$ & . & & $1.40 \mathrm{E}+00$ & $1.88 \mathrm{E}+00$ & $2.21 E+00$ & $2.65 E+00$ \\
\hline-02 & $4.09 \mathrm{E}+00$ & $3 E-01$ & $50 E-01$ & $1.40 \mathrm{E}+00$ & $1.88 \mathrm{E}+00$ & $2.21 \mathrm{E}+00$ & $.65 E+00$ \\
\hline
\end{tabular}


RESRAD-OFFSITE, Version 2.5

obabilistic Dose and Risk Report

Title : Offsite Resident Farmer Deterministic Run

File : RF TC99 DOESG FWD-FV2.ROF

Summary of dose at graphical times, reptition 1 (continued)

Time

Years

$7.78 \mathrm{E}+02$

$7.79 \mathrm{E}+02$

$7.79 \mathrm{E}+02$

$7.80 \mathrm{E}+02$

$7.80 \mathrm{E}+02$

$7.81 \mathrm{E}+02$

$7.81 \mathrm{E}+02$

$7.82 \mathrm{E}+02$

$7.82 \mathrm{E}+02$

$7.83 \mathrm{E}+02$

$7.83 \mathrm{E}+02$

$7.84 \mathrm{E}+02$

$7.84 \mathrm{E}+02$

$7.85 \mathrm{E}+02$

$7.85 \mathrm{E}+02$

$7.86 \mathrm{E}+02$

$7.86 \mathrm{E}+02$

$7.87 \mathrm{E}+02$

$7.88 \mathrm{E}+02$

$7.88 \mathrm{E}+02$

$7.89 \mathrm{E}+02$

$7.89 \mathrm{E}+02$

$7.90 \mathrm{E}+02$

$7.90 \mathrm{E}+02$

7. $91 \mathrm{E}+02$

$7.91 \mathrm{E}+02$

7. $92 \mathrm{E}+02$

$7.92 \mathrm{E}+02$

7. $93 \mathrm{E}+02$

7. $93 \mathrm{E}+02$

7. $94 \mathrm{E}+02$

$7.94 \mathrm{E}+02$

$7.95 \mathrm{E}+02$

$7.95 \mathrm{E}+02$

$7.96 \mathrm{E}+02$

7. $96 \mathrm{E}+02$

$7.97 \mathrm{E}+02$

7. $97 \mathrm{E}+02$

$7.98 \mathrm{E}+02$

$7.98 \mathrm{E}+02$

$7.99 \mathrm{E}+02$

$7.99 \mathrm{E}+02$

$8.00 \mathrm{E}+02$

$8.00 \mathrm{E}+02$

$8.01 \mathrm{E}+02$

$8.01 \mathrm{E}+02$
Dose statistics at graphical times, mrem/yr

\begin{tabular}{|c|c|c|c|c|c|c|c|}
\hline m & num & 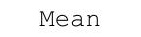 & -5 & & & & \\
\hline 02 & $4.08 E+00$ & $6.34 \mathrm{E}-01$ & 01 & $.41 E+00$ & $1.88 \mathrm{E}+00$ & -00 & . OJETU \\
\hline $82 E-02$ & $4.08 E+00$ & $6.35 E-01$ & $4.52 \mathrm{E}-01$ & 1. $41 \mathrm{E}+00$ & $88 \mathrm{E}+00$ & $E+00$ & $5 E+00$ \\
\hline $83 E-02$ & $08 E+00$ & $36 E-01$ & $3 E-01$ & $.41 E+00$ & $.88 E+00$ & $.21 E+00$ & $2.65 E+00$ \\
\hline $84 \mathrm{E}-02$ & $4.07 E+00$ & $37 \mathrm{~F}-01$ & $53 \mathrm{~F}-01$ & $.41 E+00$ & $1.88 \mathrm{E}+00$ & $2.21 \mathrm{E}+00$ & $2.65 E+00$ \\
\hline $85 E-02$ & $\mathrm{E}+00$ & $38 F-01$ & -01 & $F+00$ & $8 \mathrm{~F}+00$ & $1 E+00$ & $65 E+00$ \\
\hline-02 & $4.07 E+00$ & & & & & & 00 \\
\hline $88 E-02$ & $4.06 \mathrm{E}+00$ & & & & & +00 & $5 \mathrm{E}+00$ \\
\hline $.89 E-02$ & $4.06 \mathrm{E}+00$ & $\perp$ & $E-01$ & 1. $42 \mathrm{E}+00$ & $89 \mathrm{E}+00$ & \pm+00 & $E+00$ \\
\hline $90 \mathrm{E}-02$ & $4.06 \mathrm{E}+00$ & $1 E-01$ & $E-01$ & $1.42 \mathrm{E}+00$ & $89 E+00$ & $.21 \mathrm{E}+00$ & $6 \mathrm{E}+00$ \\
\hline $91 \mathrm{E}-02$ & $.05 \mathrm{E}+00$ & $12=-01$ & $60=-$ & $.42 E+00$ & $.89 \mathrm{E}+00$ & $21 E+00$ & $.66 \mathrm{E}+00$ \\
\hline$E-02$ & $5 E+00$ & $6.43 E-01$ & & $143 F+00$ & 0 & +00 & $66 \mathrm{E}+00$ \\
\hline $93 E-02$ & +00 & te & $F_{2}$ & 1. $43 \mathrm{E}+00$ & & -00 & $E+00$ \\
\hline $94 \mathrm{E}-02$ & $4.04 E+00$ & - & 4. $63 \mathrm{E}-01$ & $1.43 E+00$ & & $2.22 E+00$ & $2.65 \mathrm{E}+00$ \\
\hline $95 E-02$ & $4.04 \mathrm{E}+00$ & $6.46 \mathrm{E}-01$ & $4.64 \mathrm{E}-01$ & $1.43 \mathrm{E}+00$ & & $2.22 E+00$ & $2.65 \mathrm{E}+00$ \\
\hline$E-02$ & $E+00$ & $7 F-0-2-2-5$ & $5 E-01$ & 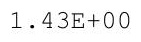 & & $E+00$ & $5 E+00$ \\
\hline 2 & $4.03 E+$ & & & & & 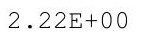 & 00 \\
\hline 2 & & & & חכרי & & 0 & 0 \\
\hline 2 & $4.02 \mathrm{E}+00$ & $6 \quad 495-01$ & $4.67 E-01$ & זכרק & & 0 & 0 \\
\hline $.01 E-02$ & $4.02 E+00$ & -0 & $F-0$ & $135+0$ & 5 & $E+00$ & $E+00$ \\
\hline$E-02$ & $4.02 \mathrm{E}+00$ & $.51 E-01$ & $.69 \mathrm{E}-01$ & $1.43 \mathrm{E}+00$ & $1.91 \mathrm{E}+$ & $2.23 E+00$ & $2.64 \mathrm{E}+00$ \\
\hline 02 & $4.01 E+00$ & & $\perp$ & 0 & & $.23 E+00$ & $E+00$ \\
\hline 2 & & & & & & & \\
\hline 2 & $4.01 \mathrm{E}+00$ & & & 1. $44 \mathrm{E}+$ & & & \\
\hline-02 & $4.00 \mathrm{E}+00$ & $6.54 \mathrm{E}-01$ & $4.73 E-01$ & $1.445 T 00$ & -5 & 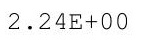 & 0 \\
\hline 2 & $4.00 \mathrm{E}+00$ & $6.55 \mathrm{E}-01$ & $\perp$ & $1.44 \mathrm{E}+00$ & 1. $91 \mathrm{E}+$ & $2.24 \mathrm{E}+00$ & $4 \mathrm{E}+00$ \\
\hline$E-02$ & $4.00 \mathrm{E}+00$ & $.56 \mathrm{E}-0$ & $45 \mathrm{~F}-01$ & 1. $44 \mathrm{E}+00$ & $1.91 \mathrm{E}+$ & $2.24 \mathrm{E}+00$ & $.63 E+00$ \\
\hline$E-02$ & $3.99 \mathrm{E}+00$ & & $6 E-01$ & 1. $45 \mathrm{E}+00$ & & $2.24 \mathrm{E}+00$ & $2.63 E+00$ \\
\hline & & & & & & & \\
\hline 2 & & & & 1. $45 \mathrm{E}+$ & & & \\
\hline $.14 \mathrm{E}-02$ & $3.98 \mathrm{E}+00$ & . & . & $1.4 J E+00$ & म. & $2.24 \mathrm{E}+00$ & $2.63 E+00$ \\
\hline $15 \mathrm{E}-02$ & $3.98 \mathrm{E}+00$ & . & 1.00 & 1. $45 \mathrm{E}+00$ & $\perp \cdot 9 \perp$ पTU & $2.24 \mathrm{E}+00$ & $2.63 E+00$ \\
\hline 2 & $3.97 \mathrm{E}+00$ & - & 事 & 1. $45 \mathrm{E}+$ & & & \\
\hline 2 & $3.97 \mathrm{E}+00$ & & & & & & $2.62 \mathrm{E}+00$ \\
\hline & & & & & & & \\
\hline 02 & & & & & & & \\
\hline $21 E-02$ & $3.96 \mathrm{E}+00$ & $0.00 \mathrm{~L}$ & $4.84 \mathrm{E}-01$ & $1.46 \mathrm{E}+00$ & $1.92 \mathrm{E}+$ & $2.24 \mathrm{E}+00$ & $2.62 E+00$ \\
\hline $23 E-02$ & $3.95 \mathrm{E}+00$ & $0.00 \mathrm{~L}$ & & $1.46 E+00$ & मी & & $2.62 E+00$ \\
\hline-02 & $3.95 \mathrm{E}+00$ & & & $1.46 \mathrm{E}+00$ & 1. $92 \mathrm{E}+00$ & & $2.62 \mathrm{E}+00$ \\
\hline 2 & 1. & 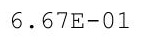 & . & $1.46 \mathrm{E}+00$ & 1.92E+ & $2.24 \mathrm{E}+00$ & $2.62 E+00$ \\
\hline 2 & & & 1 & $1.46 \mathrm{E}+00$ & $1.93 \mathrm{E}+00$ & & $2.62 \mathrm{E}+00$ \\
\hline$E-02$ & $3.94 \mathrm{E}+00$ & $6.69 \mathrm{E}-01$ & $4.89 \mathrm{E}-01$ & 1. $47 \mathrm{E}+00$ & $1.93 \mathrm{E}$ & $2.25 \mathrm{E}+00$ & $2.62 \mathrm{E}+00$ \\
\hline$E-02$ & $3.94 \mathrm{E}+00$ & 6.7 & 4. & $1.47 \mathrm{E}+00$ & 1.93E+ & $2.25 E+00$ & $2 E+00$ \\
\hline & $3.90 \mathrm{w}$ & & & $\perp \cdot 4$ & & & $2.62 E+00$ \\
\hline$E-02$ & $3.93 E+00$ & . & 10 & $1.4 / E+00$ & $1.93 E+00$ & $2.25 E+00$ & $2.62 \mathrm{E}+00$ \\
\hline $5-02$ & $3.93 E+00$ & $\angle D=1$ & & $1.47 \mathrm{E}+00$ & $1.93 \mathrm{E}+00$ & $2.25 E+00$ & $2.62 \mathrm{E}+00$ \\
\hline$E-02$ & $3.92 \mathrm{E}+00$ & $E-01$ & $94 \mathrm{E}-01$ & $1.47 \mathrm{E}+00$ & $1.94 \mathrm{E}+00$ & $2.25 E+00$ & $2.62 E+00$ \\
\hline
\end{tabular}


RESRAD-OFFSITE, Version 2.5

Title : Offsite Resident Farmer Deterministic Run

File : RF TC99 DOESG FWD-FV2.ROF

Summary of dose at graphical times, reptition 1 (continued)

Time

Years

$8.02 \mathrm{E}+02$

$8.02 \mathrm{E}+02$

$8.03 \mathrm{E}+02$

$8.03 \mathrm{E}+02$

$8.04 \mathrm{E}+02$

$8.04 \mathrm{E}+02$

$8.05 \mathrm{E}+02$

$8.05 \mathrm{E}+02$

$8.06 \mathrm{E}+02$

$8.06 \mathrm{E}+02$

$8.07 \mathrm{E}+02$

$8.07 \mathrm{E}+02$

$8.08 \mathrm{E}+02$

$8.09 \mathrm{E}+02$

$8.09 \mathrm{E}+02$

$8.10 \mathrm{E}+02$

$8.10 \mathrm{E}+02$

$8.11 \mathrm{E}+02$

$8.11 \mathrm{E}+02$

$8.12 \mathrm{E}+02$

$8.12 \mathrm{E}+02$

$8.13 \mathrm{E}+02$

$8.13 \mathrm{E}+02$

$8.14 \mathrm{E}+02$

$8.14 \mathrm{E}+02$

$8.15 \mathrm{E}+02$

$8.15 \mathrm{E}+02$

$8.16 \mathrm{E}+02$

$8.16 \mathrm{E}+02$

$8.17 \mathrm{E}+02$

$8.17 \mathrm{E}+02$

$8.18 \mathrm{E}+02$

$8.18 \mathrm{E}+02$

$8.19 \mathrm{E}+02$

$8.19 \mathrm{E}+02$

$8.20 \mathrm{E}+02$

$8.20 \mathrm{E}+02$

$8.21 \mathrm{E}+02$

$8.21 \mathrm{E}+02$

$8.22 \mathrm{E}+02$

$8.22 \mathrm{E}+02$

8. $23 \mathrm{E}+02$

$8.23 \mathrm{E}+02$

$8.24 \mathrm{E}+02$

$8.24 \mathrm{E}+02$

$8.25 \mathrm{E}+02$
Dose statistics at graphical times, mrem/yr

\begin{tabular}{|c|c|c|c|c|c|c|c|}
\hline m & aximum & lea & - & & & & \\
\hline 02 & $3.92 \mathrm{E}+00$ & $6.74 \mathrm{E}-01$ & (4) & $.47 \mathrm{E}+00$ & 00 & -00 & $.0 \angle E+U 0$ \\
\hline $36 E-02$ & $3.91 E+00$ & $6.75 E-01$ & $4.96 \mathrm{E}-01$ & 1. $47 \mathrm{E}+00$ & $94 \mathrm{E}+00$ & $2.25 \mathrm{E}+00$ & $62 E+00$ \\
\hline-02 & $91 E+00$ & $76 \mathrm{E}-01$ & $97 E-01$ & $.48 E+00$ & $94 \mathrm{E}+00$ & $2.25 E+00$ & $2.62 \mathrm{E}+00$ \\
\hline-02 & $91 E+00$ & $77 \mathrm{~F}-01$ & $98 \mathrm{~F}-01$ & $.48 E+00$ & $9 \triangle F+00$ & $2.25 \mathrm{E}+00$ & $2.62 \mathrm{E}+00$ \\
\hline-02 & $E+00$ & $8 E-01$ & 1 & 0 & & +00 & $2 E+00$ \\
\hline 02 & $90 \mathrm{E}+00$ & & & & & & 00 \\
\hline $42 \mathrm{E}-02$ & $3.90 \mathrm{E}+00$ & 1 & & & & +00 & $2.62 \mathrm{E}+00$ \\
\hline $43 E-02$ & $3.89 \mathrm{E}+00$ & $\perp$ & -01 & $1.48 \mathrm{E}+00$ & $94 \mathrm{E}+00$ & $E+00$ & $52 \mathrm{E}+00$ \\
\hline$E-02$ & $.89 \mathrm{E}+00$ & $6.81 E-01$ & -01 & $1.48 \mathrm{E}+00$ & $94 \mathrm{E}+00$ & $E+00$ & $62 \mathrm{E}+00$ \\
\hline$E-02$ & $.88 \mathrm{E}+00$ & $82 E-01$ & $5 E-01$ & $.49 \mathrm{E}+00$ & 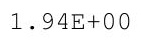 & $.25 E+00$ & $.62 E+00$ \\
\hline 02 & +00 & $83 E-01$ & & & & 0 & $2 E+00$ \\
\hline $48 E-02$ & +00 & 6 & $E-01$ & $x^{2}+$ & & 0 & 00 \\
\hline $50 E-02$ & $3.87 \mathrm{E}+00$ & $6.84 \mathrm{E}-01$ & $5.08 \mathrm{E}-01$ & $1.49 \mathrm{E}+00$ & & $2.25 E+00$ & $2.62 \mathrm{E}+00$ \\
\hline $51 E-02$ & $3.87 \mathrm{E}+00$ & $6.85 \mathrm{E}-01$ & $.09 \mathrm{E}-01$ & 1. $49 \mathrm{E}+00$ & & $2.24 \mathrm{E}+00$ & $2.62 \mathrm{E}+00$ \\
\hline-02 & $\mathrm{E}+00$ & -01 & ( & 491 & & +00 & $62 \mathrm{E}+00$ \\
\hline 2 & 0 & & & 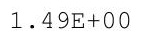 & & 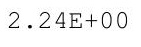 & 00 \\
\hline 2 & & $\perp$ & & لح & & 0 & 0 \\
\hline 2 & $.85 E+00$ & $6.88 \mathrm{E}-01$ & $5.14 \mathrm{E}-01$ & תח & & & 0 \\
\hline$E-02$ & $.85 E+00$ & $89 F-01$ & $4 E-01$ & 50 5 & 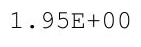 & $E+00$ & $62 E+00$ \\
\hline$E-02$ & $.85 E+00$ & $90 E-01$ & $.16 \mathrm{E}-01$ & $1.50 \mathrm{E}+00$ & 1. $95 \mathrm{E}+$ & $2.24 \mathrm{E}+00$ & $2.62 E+00$ \\
\hline 02 & +00 & & & & & +00 & $2 \mathrm{E}+00$ \\
\hline & & & & & & & \\
\hline 2 & $.83 E+00$ & 1 & & $1.50 \mathrm{E}+$ & & & \\
\hline 02 & $83 E+00$ & 1 & $5.20 E-01$ & エ・ル上 & . & 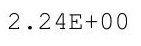 & 0 \\
\hline 2 & $.83 E+00$ & $6.94 \mathrm{E}-01$ & $5.20 \mathrm{E}-01$ & $1.51 \mathrm{E}+00$ & $1.95 \mathrm{E}+$ & $4 \mathrm{E}+00$ & $.62 \mathrm{E}+00$ \\
\hline$E-02$ & $.82 E+00$ & $695-01$ & $5-21 \mathrm{~F}-01$ & 1. $51 \mathrm{E}+00$ & $.95 E+00$ & $.24 \mathrm{E}+00$ & $.62 E+00$ \\
\hline$E-02$ & $3.82 \mathrm{E}+00$ & $96 \mathrm{~F}-01$ & & & & $2.25 E+00$ & $2.62 \mathrm{E}+00$ \\
\hline 02 & & & & & & & \\
\hline & & & & $1.52 \mathrm{E}+$ & & & \\
\hline $.72 E-02$ & $3.81 \mathrm{E}+00$ & $0.90 \mathrm{~L}$ & . $2 U \Delta-1$ & $1.3 \angle E+00$ & 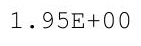 & $2.25 E+00$ & $2.62 \mathrm{E}+00$ \\
\hline $3 E-02$ & $3.80 \mathrm{E}+00$ & $.99 E-01$ & - & 1. $52 \mathrm{E}+00$ & 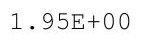 & $2.25 \mathrm{E}+00$ & $2.62 \mathrm{E}+00$ \\
\hline 2 & $3.80 \mathrm{E}+00$ & $\theta^{\circ}$ & 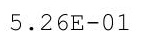 & 1. $52 \mathrm{E}+00$ & & & \\
\hline$E-02$ & $3.80 \mathrm{E}+00$ & & & $1.52 \mathrm{E}+00$ & & & $2.62 \mathrm{E}+00$ \\
\hline 02 & & & & & & & \\
\hline$E-02$ & & & & & & & \\
\hline 02 & $E+00$ & 01 & 01 & $1.53 \mathrm{E}+00$ & $1.95 \mathrm{E}$ & $2.25 E+00$ & $2.62 E+00$ \\
\hline $81 E-02$ & $3.78 \mathrm{E}+00$ & •. प4- 01 & & $1.53 E+00$ & $1.95 E+00$ & & $2.62 \mathrm{E}+00$ \\
\hline-02 & $3.78 \mathrm{E}+00$ & 年 & & $1.53 \mathrm{E}+00$ & 1. $96 \mathrm{E}+00$ & & $2.62 \mathrm{E}+00$ \\
\hline 2 & e. & .0 & 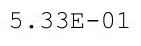 & $1.53 \mathrm{E}+$ & $1.96 \mathrm{E}+$ & $2.25 E+00$ & $2.62 E+00$ \\
\hline 2 & $3.77 \mathrm{E}+00$ & .0 & 1 & $1.53 \mathrm{E}+00$ & & & $2.62 \mathrm{E}+00$ \\
\hline-02 & $3.76 \mathrm{E}+00$ & $7.08 E-01$ & $5.34 \mathrm{E}-01$ & $1.53 \mathrm{E}+00$ & & $2.25 \mathrm{E}+00$ & $2.62 E+00$ \\
\hline$E-02$ & $3.76 \mathrm{E}+00$ & 01 & 1 & $1.54 \mathrm{E}+00$ & $1.96 \mathrm{E}+$ & $E+00$ & $2.62 \mathrm{E}+00$ \\
\hline & 0 & & & & & & $2.62 E+00$ \\
\hline $5-0<$ & $3.75 \mathrm{E}+00$ & 1 & 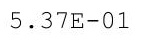 & $1.34 E+00$ & $1.96 E+00$ & $2.25 E+00$ & $2.62 \mathrm{E}+00$ \\
\hline & $3.75 \mathrm{E}+00$ & - $-\infty$ & & $1.54 \mathrm{E}+00$ & $1.96 \mathrm{E}+00$ & $2.25 E+00$ & $2.62 \mathrm{E}+00$ \\
\hline 02 & $.74 \mathrm{E}+00$ & $E-01$ & $9 E-01$ & $.54 \mathrm{E}+00$ & $1.96 \mathrm{E}+00$ & $2.25 E+00$ & $2.62 E+00$ \\
\hline
\end{tabular}


RESRAD-OFFSITE, Version 2.5 
RESRAD-OFFSITE, Version 2.5 
RESRAD-OFFSITE, Version 2.5 
RESRAD-OFFSITE, Version 2.5

$\mathrm{T}^{1 / 2}$ Limit $=180$ days

obabilistic Dose and Risk Report

Title : Offsite Resident Farmer Deterministic Run

File : RF TC99 DOESG FWD-FV2.ROF

Summary of dose at graphical times, reptition 1 (continued)

Time

Years

$8.96 \mathrm{E}+02$

$8.97 \mathrm{E}+02$

$8.97 \mathrm{E}+02$

$8.98 \mathrm{E}+02$

$8.98 \mathrm{E}+02$

$8.99 \mathrm{E}+02$

$8.99 \mathrm{E}+02$

$9.00 \mathrm{E}+02$

$9.00 \mathrm{E}+02$

$9.01 \mathrm{E}+02$

$9.01 \mathrm{E}+02$

$9.02 \mathrm{E}+02$

$9.02 \mathrm{E}+02$

$9.03 \mathrm{E}+02$

$9.03 E+02$

$9.04 \mathrm{E}+02$

$9.04 \mathrm{E}+02$

$9.05 \mathrm{E}+02$

$9.05 \mathrm{E}+02$

$9.06 \mathrm{E}+02$

$9.06 \mathrm{E}+02$

$9.07 \mathrm{E}+02$

$9.07 \mathrm{E}+02$

$9.08 \mathrm{E}+02$

$9.08 \mathrm{E}+02$

$9.09 \mathrm{E}+02$

$9.10 \mathrm{E}+02$

$9.10 \mathrm{E}+02$

$9.11 \mathrm{E}+02$

$9.11 \mathrm{E}+02$

$9.12 \mathrm{E}+02$

9. $12 \mathrm{E}+02$

9. $13 \mathrm{E}+02$

9. $13 \mathrm{E}+02$

$9.14 \mathrm{E}+02$

$9.14 \mathrm{E}+02$

$9.15 \mathrm{E}+02$

$9.15 \mathrm{E}+02$

$9.16 \mathrm{E}+02$

$9.16 \mathrm{E}+02$

$9.17 \mathrm{E}+02$

$9.17 \mathrm{E}+02$

$9.18 \mathrm{E}+02$

$9.18 \mathrm{E}+02$

$9.19 \mathrm{E}+02$

$9.19 \mathrm{E}+02$
Dose statistics at graphical times, mrem/yr

\begin{tabular}{|c|c|c|c|c|c|c|c|}
\hline m & m & Mean & ledian & & & $\%$ & \\
\hline 02 & $3.52 \mathrm{E}+00$ & $8.17 \mathrm{E}-01$ & $6.70 \mathrm{E}-01$ & $1.67 \mathrm{E}+00$ & $2.03 E+00$ & $2.30 \mathrm{E}+00$ & $2.65 E+00$ \\
\hline $.07 E-02$ & $2 E+00$ & 01 & -01 & $7 \mathrm{E}+00$ & $2.03 E+00$ & $2.30 \mathrm{E}+00$ & $5 \mathrm{E}+00$ \\
\hline $.09 \mathrm{E}-02$ & $3.52 \mathrm{E}+00$ & $18 E-01$ & $6.72 \mathrm{E}-01$ & $1.67 \mathrm{E}+00$ & $2.03 E+00$ & $2.30 \mathrm{E}+00$ & $55 E+00$ \\
\hline $10 \mathrm{E}-02$ & $3.52 \mathrm{E}+00$ & $9 E-01$ & $6.73 E-01$ & $1.67 \mathrm{E}+00$ & $2.02 E+00$ & $2.30 \mathrm{E}+00$ & $2.65 E+00$ \\
\hline 2 & 0 & 1 & 3 & 0 & 0 & 0 & $2.65 E+00$ \\
\hline-02 & -00 & 1 & & 0 & & & +00 \\
\hline $16 \mathrm{E}-02$ & & 1 & & & & & $E+00$ \\
\hline $.17 \mathrm{E}-02$ & & & & & 00 & & +00 \\
\hline$E-02$ & +00 & $E-01$ & $\perp$ & $68 E+00$ & 00 & +00 & $E+00$ \\
\hline 2 & $51 E+00$ & 1 & $\perp$ & $.68 \mathrm{E}+$ & $0 ? \mathrm{~F}+$ & $E+00$ & $65 \mathrm{E}+00$ \\
\hline 02 & $3.51 \mathrm{E}+00$ & $8.24 \mathrm{E}-01$ & $6.78 \mathrm{E}-01$ & $168=+$ & ค2F+ & $\mathrm{E}+00$ & $66 E+00$ \\
\hline 2 & -00 & & & 0 & 0 & 0 & -00 \\
\hline $5-02$ & $\mathrm{~F}+00$ & 5 & 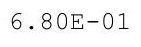 & 0 & 0 & 0 & +00 \\
\hline $.28 \mathrm{E}-02$ & $3.50 \mathrm{E}+00$ & $8.26 \mathrm{E}-01$ & $6.80 \mathrm{E}-01$ & $1.68 \mathrm{E}+00$ & $2.02 \mathrm{E}+00$ & $2.30 \mathrm{E}+00$ & $2.66 \mathrm{E}+00$ \\
\hline $29 \mathrm{E}-02$ & $E+00$ & $E-01$ & 1 & $1.68 \mathrm{E}+00$ & $02 \mathrm{E}+$ & $\mathrm{E}+00$ & $56 \mathrm{E}+00$ \\
\hline 2 & & & & & & 0 & 00 \\
\hline $.33 E-02$ & & & & 0 & 0 & & 00 \\
\hline 2 & & $8.29 \mathrm{E}-01$ & & 0 & & & 0 \\
\hline $36 E-02$ & $0 \mathrm{E}+00$ & $9 F-01$ & 5 & $1.69 \mathrm{E}+00$ & 0 & +00 & $6 E+00$ \\
\hline $38 E-02$ & $3.50 \mathrm{E}+00$ & $30 E-01$ & $.85 E-01$ & $1.69 \mathrm{E}+00$ & $2.02 \mathrm{E}+00$ & $2.30 \mathrm{E}+00$ & $2.66 \mathrm{E}+00$ \\
\hline $10 \mathrm{E}-02$ & $.50 \mathrm{E}+00$ & $E-01$ & -01 & 1. $69 \mathrm{E}+00$ & 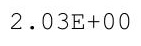 & $.30 E+00$ & $.66 \mathrm{E}+00$ \\
\hline 02 & & & & & & & $.66 \mathrm{E}+00$ \\
\hline & & & & $.69 \mathrm{E}$ & & & -00 \\
\hline-02 & $3.49 \mathrm{E}+00$ & $\perp$ & & $\perp \cdot 0,1$ & $03 \mathrm{E}+$ & & 00 \\
\hline 2 & $.49 \mathrm{E}+00$ & $8.33 \mathrm{E}-01$ & $6.88 \mathrm{E}-01$ & 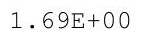 & 03 & 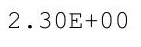 & 00 \\
\hline $9 E-02$ & $.49 \mathrm{E}+00$ & $34 \mathrm{~F}-01$ & تص & 1. $69 \mathrm{E}+00$ & $.03 E+C$ & $30 E+00$ & $66 \mathrm{E}+00$ \\
\hline$F-02$ & $3.49 \mathrm{E}+00$ & $5=01$ & $0 F-01$ & $1.69 \mathrm{E}+00$ & 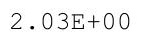 & $30 E+00$ & $2.66 \mathrm{E}+00$ \\
\hline 02 & & & & & & & \\
\hline 02 & & & & $.69 \mathrm{E}+$ & & & \\
\hline $6 E-02$ & $3.49 \mathrm{E}+00$ & $0.01+4$ & . & $1.69 \mathrm{E}+00$ & $2.0<D$ & $2.30 \mathrm{E}+00$ & $2.65 E+00$ \\
\hline . & $3.48 \mathrm{E}+00$ & . & $\cdot 9 \angle L-U 1$ & $1.70 \mathrm{E}+00$ & $\angle .0 \angle \mathrm{LT} 0$ & $\angle .30 \mathrm{LT} 0$ & $2.65 E+00$ \\
\hline 年 & . & 管 & & 1. $70 \mathrm{E}+00$ & $2.02 \mathrm{E}+$ & & $2.65 \mathrm{E}+00$ \\
\hline 5 & $3.48 \mathrm{E}+00$ & 1 & $3 E-01$ & $1.70 \mathrm{E}+00$ & & & $2.65 E+00$ \\
\hline & & & & & & & \\
\hline 02 & & & & & & & \\
\hline 02 & $3.48 \mathrm{E}+$ & 1 & & $1.10 E T$ & $2.02 \mathrm{E}$ & $2.30 \mathrm{E}$ & $2.65 E+00$ \\
\hline $5-0<$ & & 1 & & 1.70E+ & & & $5 E+00$ \\
\hline . 100 2 & & & & & & & $2.65 E+00$ \\
\hline 2 & 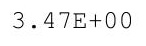 & * & & ter & $2.02 \mathrm{E}+$ & & $2.65 E+00$ \\
\hline & & & & $70 \mathrm{E}+00$ & & & \\
\hline 2 & & 1 & & $1.70 \mathrm{E}+00$ & $2.02 E+00$ & $\mathrm{E}+00$ & $5 E+00$ \\
\hline $.77 E-02$ & $3.47 \mathrm{E}+00$ & $4 E-01$ & 01 & $1.70 \mathrm{E}+00$ & $2.02 \mathrm{E}+$ & 00 & +00 \\
\hline & & & & & & & \\
\hline & & . & & $1.10 E+U 0$ & $2.02 E+00$ & $2.30 \mathrm{E}+00$ & $2.64 \mathrm{E}+00$ \\
\hline 02 & & . & & $1.70 \mathrm{E}+00$ & $2.02 E+00$ & $2.30 \mathrm{E}+00$ & $2.64 \mathrm{E}+00$ \\
\hline $4 E-02$ & $.46 E+00$ & $E-01$ & $6 E-01$ & $.70 E+00$ & $.03 E+00$ & $.30 E+00$ & $.64 E+00$ \\
\hline
\end{tabular}


RESRAD-OFFSITE, Version 2.5

obabilistic Dose and Risk Report

Title : Offsite Resident Farmer Deterministic Run

File : RF TC99 DOESG FWD-FV2.ROF

Summary of dose at graphical times, reptition 1 (continued)

Time

Years

$9.20 \mathrm{E}+02$

$9.20 \mathrm{E}+02$

$9.21 \mathrm{E}+02$

$9.21 \mathrm{E}+02$

$9.22 \mathrm{E}+02$

$9.22 \mathrm{E}+02$

$9.23 \mathrm{E}+02$

$9.23 \mathrm{E}+02$

$9.24 \mathrm{E}+02$

$9.24 \mathrm{E}+02$

$9.25 \mathrm{E}+02$

$9.25 \mathrm{E}+02$

$9.26 \mathrm{E}+02$

$9.26 \mathrm{E}+02$

$9.27 \mathrm{E}+02$

$9.27 \mathrm{E}+02$

$9.28 \mathrm{E}+02$

$9.28 \mathrm{E}+02$

$9.29 \mathrm{E}+02$

$9.30 \mathrm{E}+02$

$9.30 \mathrm{E}+02$

$9.31 \mathrm{E}+02$

9. $31 \mathrm{E}+02$

9. $32 \mathrm{E}+02$

9. $32 \mathrm{E}+02$

$9.33 \mathrm{E}+02$

$9.33 \mathrm{E}+02$

$9.34 \mathrm{E}+02$

$9.34 \mathrm{E}+02$

9. $35 \mathrm{E}+02$

$9.35 \mathrm{E}+02$

$9.36 \mathrm{E}+02$

9. $36 \mathrm{E}+02$

9. $37 \mathrm{E}+02$

$9.37 \mathrm{E}+02$

$9.38 \mathrm{E}+02$

$9.38 \mathrm{E}+02$

$9.39 \mathrm{E}+02$

9. $39 \mathrm{E}+02$

$9.40 \mathrm{E}+02$

$9.40 \mathrm{E}+02$

$9.41 \mathrm{E}+02$

$9.41 \mathrm{E}+02$

$9.42 \mathrm{E}+02$

$9.42 \mathrm{E}+02$

$9.43 \mathrm{E}+02$
Dose statistics at graphical times, mrem/yr

\begin{tabular}{|c|c|c|c|c|c|c|c|}
\hline$m$ & m & Mean & ledian & & & $\%$ & \\
\hline $86 \mathrm{E}-02$ & $3.46 \mathrm{E}+00$ & $8.48 \mathrm{E}-01$ & $7.07 \mathrm{E}-01$ & $1.70 \mathrm{E}+00$ & $2.03 E+00$ & $2.30 \mathrm{E}+00$ & $2.64 \mathrm{E}+00$ \\
\hline $88 \mathrm{E}-02$ & $3.46 \mathrm{E}+00$ & $3.48 \mathrm{E}-01$ & $7.08 \mathrm{E}-01$ & $1.70 \mathrm{E}+00$ & $2.03 E+00$ & $2.30 \mathrm{E}+00$ & $64 \mathrm{E}+00$ \\
\hline $.90 \mathrm{E}-02$ & $3.46 \mathrm{E}+00$ & $8.49 \mathrm{E}-01$ & $7.09 \mathrm{E}-01$ & 1. $70 \mathrm{E}+00$ & $2.03 E+00$ & $2.30 \mathrm{E}+00$ & $2.64 \mathrm{E}+00$ \\
\hline $91 \mathrm{E}-02$ & $.46 \mathrm{E}+00$ & $.50 \mathrm{E}-01$ & $0 E-01$ & $1.70 \mathrm{E}+00$ & $2.03 E+00$ & $2.30 \mathrm{E}+00$ & $2.64 \mathrm{E}+00$ \\
\hline $3 E-02$ & 0 & 1 & & & 0 & 0 & $4 \mathrm{E}+00$ \\
\hline$E-02$ & +00 & -1 & & & & & +00 \\
\hline $.97 E-02$ & $3.45 \mathrm{E}+$ & 1 & & & & & +00 \\
\hline $.99 \mathrm{E}-02$ & & & & & & & $2.63 E+00$ \\
\hline-02 & $E+00$ & $E-01$ & $\perp$ & $E+00$ & 00 & +00 & $\mathrm{\Xi}+00$ \\
\hline 2 & $45 E+00$ & 1 & $7.16 \mathrm{E}-01$ & + & $01 \mathrm{~F}+$ & $E+00$ & $63 E+00$ \\
\hline 2 & $3.45 \mathrm{E}+00$ & $8.54 \mathrm{E}-01$ & 7. $17 \mathrm{E}-01$ & $170=+$ & 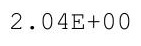 & $E+00$ & $.63 E+00$ \\
\hline$E-02$ & +00 & & & & & 0 & +00 \\
\hline $\mathrm{F}-02$ & $E+00$ & 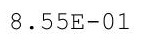 & $7.19 \mathrm{E}-01$ & & & & +00 \\
\hline $.10 \mathrm{E}-02$ & $3.44 \mathrm{E}+00$ & $8.56 \mathrm{E}-01$ & 7. $20 \mathrm{E}-01$ & 1. $70 \mathrm{E}+00$ & $2.04 \mathrm{E}+00$ & $2.30 \mathrm{E}+00$ & $2.62 \mathrm{E}+00$ \\
\hline $12 \mathrm{E}-02$ & $E+00$ & $E-01$ & & $E+00$ & $04 \mathrm{E}+$ & $\mathrm{E}+00$ & +00 \\
\hline 2 & 0 & & & 0 & & 00 & $62 \mathrm{E}+00$ \\
\hline $5 E-02$ & & & & & & & 00 \\
\hline 2 & & & & & & & 00 \\
\hline $19 \mathrm{E}-02$ & $.44 \mathrm{E}+00$ & $9 F-01$ & 5 & $1.70 \mathrm{E}+00$ & & +00 & $1 \mathrm{E}+00$ \\
\hline $.21 E-02$ & $3.44 \mathrm{E}+00$ & $60 \mathrm{E}-01$ & 7. $26 \mathrm{E}-01$ & 1. $70 \mathrm{E}+00$ & $2.04 \mathrm{E}+00$ & $2.30 \mathrm{E}+00$ & $2.61 E+00$ \\
\hline $3 E-02$ & $.43 E+00$ & $61 E-01$ & -01 & 1. $70 \mathrm{E}+00$ & 0 & $.30 \mathrm{E}+00$ & 2. $60 \mathrm{E}+00$ \\
\hline & & & & & & & $.60 E+00$ \\
\hline & & & & & & & $2.60 \mathrm{E}+00$ \\
\hline & & & & & & & 00 \\
\hline $30 E-02$ & $3.43 E+00$ & 1 & $\perp$ & $.70 E+00$ & $04 \mathrm{E}+$ & $E+00$ & $59 E+00$ \\
\hline $32 \mathrm{~F}-02$ & $.43 E+00$ & $6 \Delta \mathrm{F}-01$ & $731 \mathrm{~F}-01$ & 1. $70 \mathrm{E}+00$ & $.04 \mathrm{E}+0$ & $.30 E+00$ & $59 \mathrm{E}+00$ \\
\hline$F-02$ & $3.42 \mathrm{E}+00$ & $64 \mathrm{~F}-01$ & $7.31 \mathrm{E}-01$ & $1.71 \mathrm{E}+00$ & 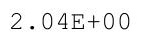 & $2.30 \mathrm{E}+00$ & $2.59 \mathrm{E}+00$ \\
\hline 02 & & & & & & & \\
\hline & & & & & & & \\
\hline $.39 E-02$ & $3.42 \mathrm{E}+00$ & $0.00 \mathrm{~L}-1$ & $7.34 \mathrm{E}-01$ & $1.71 \mathrm{E}+00$ & 2.010 & $2.30 \mathrm{E}+00$ & $2.59 \mathrm{E}+00$ \\
\hline $.41 \mathrm{E}-02$ & $3.42 \mathrm{E}+00$ & $0.01 \mathrm{~L}-U 1$ & $.345-0 \perp$ & 1. $71 \mathrm{E}+00$ & $2.045 T 00$ & Z.JUET & $2.58 \mathrm{E}+00$ \\
\hline 2 & $3.42 \mathrm{E}+00$ & 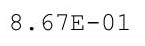 & 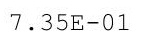 & 1. $71 \mathrm{E}+00$ & $2.04 \mathrm{E}+$ & & $2.58 \mathrm{E}+00$ \\
\hline (5工 & $3.42 \mathrm{E}+00$ & $68=-01$ & $5 E-01$ & $1.71 \mathrm{E}+00$ & & & $2.58 \mathrm{E}+00$ \\
\hline 2 & & & & & & & $58 \mathrm{E}+00$ \\
\hline$E-02$ & & 1 & 01 & & & & \\
\hline 02 & $3.41 \mathrm{E}+$ & $0.10 \mathrm{E}$ & 1.501 & $1.71 \mathrm{E}+00$ & $2.04 \mathrm{E}+$ & $2.30 \mathrm{E}+$ & $2.58 \mathrm{E}+00$ \\
\hline $.53 E-02$ & $3.41 \mathrm{E}+00$ & 1 & . 0 is & 1. $71 \mathrm{E}+$ & & & +00 \\
\hline 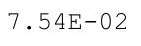 & $3.41 \mathrm{E}+00$ & & & $\perp \cdot T \perp$ LTU & & & $2.58 \mathrm{E}+00$ \\
\hline $.56 \mathrm{E}-02$ & enta & 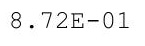 & 1 & ter & $2.05 \mathrm{E}+$ & $2.29 \mathrm{E}+00$ & $2.58 \mathrm{E}+00$ \\
\hline & & & & $71 \mathrm{E}+00$ & & & (le \\
\hline 2 & & & 1 & & $2.05 \mathrm{E}+$ & $2.29 \mathrm{E}+00$ & \\
\hline $62 \mathrm{E}-02$ & $3.40 \mathrm{E}+00$ & $8.74 E-01$ & 7.42 & $1.71 \mathrm{E}+00$ & $2.05 E+00$ & $9 E+00$ & $8 \mathrm{E}+00$ \\
\hline & & & & & & & \\
\hline & $3.40 \mathrm{E}+00$ & 1 & & $1.1 \perp E+U 0$ & $2.05 E+00$ & $2.29 \mathrm{E}+00$ & $2.58 \mathrm{E}+00$ \\
\hline 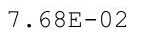 & $3.40 \mathrm{E}+00$ & $0.10 \pm-0 \perp$ & & $1.71 \mathrm{E}+00$ & $2.05 E+00$ & $2.29 \mathrm{E}+00$ & $2.58 \mathrm{E}+00$ \\
\hline$E-02$ & $\mathrm{E}+00$ & $5 E-01$ & $5 E-01$ & $.71 E+00$ & $.05 E+00$ & $2.29 \mathrm{E}+00$ & $.58 E+00$ \\
\hline
\end{tabular}


RESRAD-OFFSITE, Version 2.5 
RESRAD-OFFSITE, Version 2.5

obabilistic Dose and Risk Report

Title : Offsite Resident Farmer Deterministic Run

File : RF TC99 DOESG FWD-FV2.ROF

Summary of dose at graphical times, reptition 1 (continued)

Time

Years

9. $67 \mathrm{E}+02$

$9.67 \mathrm{E}+02$

9. $68 \mathrm{E}+02$

$9.68 \mathrm{E}+02$

$9.69 \mathrm{E}+02$

$9.70 \mathrm{E}+02$

$9.70 \mathrm{E}+02$

9. $71 \mathrm{E}+02$

$9.71 \mathrm{E}+02$

9. $72 \mathrm{E}+02$

$9.72 \mathrm{E}+02$

$9.73 \mathrm{E}+02$

9. $73 \mathrm{E}+02$

$9.74 \mathrm{E}+02$

9. $74 \mathrm{E}+02$

$9.75 \mathrm{E}+02$

9. $75 \mathrm{E}+02$

$9.76 \mathrm{E}+02$

$9.76 \mathrm{E}+02$

$9.77 \mathrm{E}+02$

$9.77 \mathrm{E}+02$

$9.78 \mathrm{E}+02$

$9.78 \mathrm{E}+02$

$9.79 \mathrm{E}+02$

$9.79 \mathrm{E}+02$

$9.80 \mathrm{E}+02$

$9.80 \mathrm{E}+02$

$9.81 \mathrm{E}+02$

$9.81 \mathrm{E}+02$

$9.82 \mathrm{E}+02$

$9.82 \mathrm{E}+02$

$9.83 \mathrm{E}+02$

$9.83 \mathrm{E}+02$

$9.84 \mathrm{E}+02$

$9.84 \mathrm{E}+02$

$9.85 \mathrm{E}+02$

$9.85 \mathrm{E}+02$

$9.86 \mathrm{E}+02$

$9.86 \mathrm{E}+02$

$9.87 \mathrm{E}+02$

$9.87 \mathrm{E}+02$

$9.88 \mathrm{E}+02$

$9.88 \mathrm{E}+02$

$9.89 \mathrm{E}+02$

$9.90 \mathrm{E}+02$

9. $90 \mathrm{E}+02$
Dose statistics at graphical times, mrem/yr

\begin{tabular}{|c|c|c|c|c|c|c|c|}
\hline linimum & Maximum & Mean & Median & 900 & $95 \%$ & $97.5 \%$ & $9 \%$ \\
\hline 2 & $31 E+00$ & 1 & $36 E-01$ & $71 E+00$ & 055 & 2.30 & +00 \\
\hline-02 & $1 \mathrm{E}+00$ & $4 E-01$ & $87 E-01$ & $1.71 \mathrm{E}+00$ & $05 E+00$ & +00 & $55 E+00$ \\
\hline$E-02$ & -00 & $4 E-01$ & $88 E-01$ & 0 & 0 & Do & $5 E+00$ \\
\hline$E-02$ & +00 & $E-01$ & 01 & 0 & & Do & $\mathrm{E}+00$ \\
\hline $69 \mathrm{E}-02$ & $3.31 E+00$ & & & & $05 E+00$ & $E+00$ & $55 E+00$ \\
\hline $.71 \mathrm{E}-02$ & 00 & 1 & & & & 00 & $5 E+00$ \\
\hline $.73 E-02$ & $3.30 \mathrm{E}+00$ & $6 E-01$ & $92 E-01$ & $1.71 \mathrm{E}+00$ & $4 \mathrm{E}+$ & +00 & $5 E+00$ \\
\hline $.75 E-02$ & $3.30 E+00$ & . & $7.92 \mathrm{E}-01$ & $1.71 \mathrm{E}+00$ & $2.04 \mathrm{E}+00$ & \pm+00 & $2.55 E+00$ \\
\hline$E-02$ & +00 & $E-01$ & 01 & $1.71 \mathrm{E}$ & 0 & 00 & 00 \\
\hline $9 E-02$ & $3.30 \mathrm{E}+00$ & 9 & & $1.71 \mathrm{I}$ & $\mathrm{S}^{-1}$ & 00 & $E+00$ \\
\hline$E-02$ & & 9 & & & & & $\mathrm{E}+00$ \\
\hline-02 & +00 & 1 & 1 & $71=$ & 0 & Do & $E+00$ \\
\hline $.86 \mathrm{E}-02$ & $3.29 \mathrm{E}+00$ & $9.1 U E-U 1$ & $7.95 \mathrm{E}-01$ & $1.11 E+00$ & ИБT & $2.3 \perp E+U 0$ & $5 E+00$ \\
\hline $.88 E-02$ & $3.29 \mathrm{E}+00$ & $. \perp U E-U \perp$ & $7.96 \mathrm{E}-01$ & $\perp \cdot T \perp E T U U$ & $2.045 T 00$ & 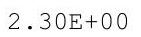 & $E+00$ \\
\hline$E-02$ & $3.29 \mathrm{E}+00$ & . & & 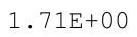 & $2.01+4$ & 00 & -00 \\
\hline $.92 \mathrm{E}-02$ & $3.29 \mathrm{E}+00$ & $9.11 \mathrm{E}-01$ & $7.98 \mathrm{E}-01$ & $1.71 \mathrm{E}+00$ & $2.04 \mathrm{E}+00$ & $2.30 \mathrm{E}+00$ & $4 \mathrm{E}+00$ \\
\hline $.94 E-02$ & $3.28 E+00$ & $9.12 \mathrm{E}-01$ & $7.99 \mathrm{E}-01$ & & & $\mathrm{DE}+00$ & $4 E+00$ \\
\hline $6 E-02$ & $\mathrm{E}+00$ & $2 E-01$ & $E-01$ & 17 & 0 & 0 & $4 E+00$ \\
\hline $.98 \mathrm{E}-02$ & $3.28 \mathrm{E}+00$ & $9.13 \mathrm{E}-01$ & $8.00 \mathrm{E}-01$ & $1.71 \mathrm{E}+00$ & $2.04 \mathrm{E}+00$ & 2 . & $4 \mathrm{E}+00$ \\
\hline $.00 E-02$ & $3.28 \mathrm{E}+00$ & $4+-U 1$ & 01 & $1.1 \angle \mathrm{E}$ & 0 & 00 & +00 \\
\hline $.02 E-02$ & $3.28 E+00$ & $9.14 \mathrm{E}-01$ & & I. ILLTU & & 0 & +00 \\
\hline $.04 \mathrm{E}-02$ & $3.27 E+00$ & $9.15 \mathrm{E}-$ & 1 & $1 \cdot 7 \angle \mathrm{D}$ & 2.040 & 00 & $\mathrm{E}+00$ \\
\hline $.06 E-02$ & $3.27 E+00$ & $5 E-$ & $4 E-01$ & $1.72 \mathrm{E}+00$ & $2.04 \mathrm{E}+$ & $0 E+00$ & $4 \mathrm{E}+00$ \\
\hline $.08 E-02$ & $3.27 E+00$ & $E-01$ & $4 E-01$ & $1.72 \mathrm{E}+$ & $2.04 \mathrm{E}+$ & $2.30 E+00$ & $3 E+00$ \\
\hline$E-02$ & $3.27 \mathrm{E}+00$ & $E-01$ & 01 & $1.72 \mathrm{E}+$ & 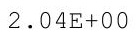 & & $3 E+00$ \\
\hline$E-02$ & $E+00$ & 1 & 1 & 1.72 & U & 00 & +00 \\
\hline$E-02$ & $3.26 \mathrm{E}+00$ & $7 \pm-01$ & $.05 E-01$ & $1.72 \mathrm{E}+00$ & 1 & & $3 E+00$ \\
\hline $16 \mathrm{E}-02$ & $3.26 \mathrm{E}+00$ & $9.18 \mathrm{E}-01$ & $8.06 \mathrm{E}-01$ & $1.72 \mathrm{E}+00$ & $2.04 \mathrm{E}+00$ & $2.30 \mathrm{E}+00$ & $2.53 E+00$ \\
\hline $.18 E-02$ & . 20 स & $9.18 \mathrm{E}-01$ & $8.06 \mathrm{E}-01$ & $1.72 \mathrm{E}+00$ & 2.04010 & $2.00 \mathrm{~L}$ & $2.53 E+00$ \\
\hline 2 & $3.26 \mathrm{E}+00$ & & 1 & 1. $72 \mathrm{E}+$ & $2.04 \mathrm{E}$ & 2 . & $2 \mathrm{E}+00$ \\
\hline 02 & $3.26 \mathrm{E}+00$ & 1 & 1 & $172 \mathrm{~F}+$ & 0 & $0 E+00$ & $2 E+00$ \\
\hline$E-02$ & $\mathrm{E}+00$ & 9 & 1 & $1.72 \mathrm{E}$ & U & $E+00$ & -00 \\
\hline $26 \mathrm{E}-02$ & $3.25 \mathrm{E}+00$ & $9.20 \mathrm{E}-01$ & $0 E-01$ & $1.72 \mathrm{E}+$ & 2. & 00 & $2 \mathrm{E}+00$ \\
\hline $.28 \mathrm{E}-02$ & $3.25 \mathrm{E}+00$ & $9.21 \mathrm{E}-01$ & $8.10 \mathrm{E}-01$ & $1.72 \mathrm{E}+00$ & $2.04 \mathrm{E}+00$ & $2.30 \mathrm{E}+00$ & $2.52 \mathrm{E}+00$ \\
\hline $31 \mathrm{E}-02$ & $3 . \angle 3 E+U 0$ & $9.21 \mathrm{E}-$ & & $1.72 \mathrm{E}+00$ & $2.03 E+00$ & & $2.52 E+00$ \\
\hline $.33 E-02$ & & & & & 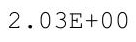 & & 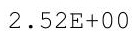 \\
\hline 2 & 只 & 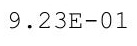 & . & גיתר & (2) & $0 \mathrm{E}+00$ & $2 \mathrm{E}+00$ \\
\hline 2 & $.24 \mathrm{E}+00$ & 1 & & 0 & 0 & 00 & \\
\hline 2 & & 9. & & 1.7 & 2.03 & & $2 \mathrm{E}+00$ \\
\hline $41 \mathrm{E}-02$ & $3.24 \mathrm{E}+00$ & 9. & & 1.72 & 0 & & $2.52 \mathrm{E}+00$ \\
\hline$E-02$ & $3.24 \mathrm{E}+00$ & 1 & & 1. $72 \mathrm{E}+$ & $2.03 E+$ & & $2.52 \mathrm{E}+00$ \\
\hline $5 E-02$ & $3.23 E+00$ & 1 & 1 & 1. $72 \mathrm{E}+00$ & 2.035 & $2.30 \mathrm{E}+00$ & $2.52 E+00$ \\
\hline$Z$ & $\mathrm{~s}$ & 9 & 1 & 0 & $2.03 \mathrm{E}$ & $2.50 \mathrm{E}$ & 2.025 \\
\hline 2 & & & & 00 & 2. & $2.29 \mathrm{E}$ & $2.52 \mathrm{E}$ \\
\hline-02 & $E+00$ & $E-01$ & 8.1 & 1. $72 \mathrm{E}+00$ & $2.03 \mathrm{E}$ & $E+00$ & $2.52 \mathrm{E}+00$ \\
\hline $.53 E-02$ & $23 E+00$ & $27 E-01$ & $.16 \mathrm{E}-01$ & $1.73 \mathrm{E}+00$ & $E+00$ & $2.29 E+00$ & $2.52 \mathrm{E}+00$ \\
\hline
\end{tabular}


RESRAD-OFFSITE, Version 2.5

robabilistic Dose and Risk Report

Title : Offsite Resident Farmer Deterministic Run

File : RF TC99 DOESG FWD-FV2.ROF

Summary of dose at graphical times, reptition 1 (continued)

Time

Years

9. $91 \mathrm{E}+02$

$9.91 \mathrm{E}+02$

9. $92 \mathrm{E}+02$

9. $92 \mathrm{E}+02$

$9.93 \mathrm{E}+02$

$9.93 \mathrm{E}+02$

9. $94 \mathrm{E}+02$

9. $94 \mathrm{E}+02$

9. $95 \mathrm{E}+02$

9. $95 \mathrm{E}+02$

$9.96 \mathrm{E}+02$

9. $96 \mathrm{E}+02$

9. $97 \mathrm{E}+02$

$9.97 \mathrm{E}+02$

9. $98 \mathrm{E}+02$

9. $98 \mathrm{E}+02$

9. $99 \mathrm{E}+02$

$9.99 \mathrm{E}+02$

$1.00 \mathrm{E}+03$

$1.00 \mathrm{E}+03$

$1.00 \mathrm{E}+03$

$1.00 \mathrm{E}+03$

$1.00 \mathrm{E}+03$

$1.00 \mathrm{E}+03$

$1.00 \mathrm{E}+03$

$1.00 \mathrm{E}+03$

$1.00 \mathrm{E}+03$

$1.00 \mathrm{E}+03$

$1.00 \mathrm{E}+03$

$1.01 \mathrm{E}+03$

1. $01 \mathrm{E}+03$

$1.01 \mathrm{E}+03$

$1.01 \mathrm{E}+03$

1. $01 \mathrm{E}+03$

$1.01 \mathrm{E}+03$

$1.01 \mathrm{E}+03$

$1.01 \mathrm{E}+03$

1. $01 \mathrm{E}+03$

$1.01 \mathrm{E}+03$

$1.01 \mathrm{E}+03$

$1.01 \mathrm{E}+03$

$1.01 \mathrm{E}+03$

$1.01 \mathrm{E}+03$

$1.01 \mathrm{E}+03$

$1.01 \mathrm{E}+03$

$1.01 \mathrm{E}+03$
Dose statistics at graphical times, mrem/yr

\begin{tabular}{|c|c|c|c|c|c|c|c|}
\hline$m$ & aximum & lean & ed & & & & \\
\hline $.55 E-02$ & $3.22 \mathrm{E}+00$ & $8 \mathrm{E}-01$ & $-6 E-01$ & 0 & 00 & +00 & +00 \\
\hline$E-02$ & $2 \mathrm{E}+00$ & $8 E-01$ & $7 E-01$ & $.73 E+00$ & $.03 E+00$ & $29 \mathrm{E}+00$ & $2 E+00$ \\
\hline$E-02$ & $22 F+00$ & $29 F-01$ & $17 \mathrm{~F}-01$ & $.73 E+00$ & $.03 E+00$ & $2.29 \mathrm{E}+00$ & $2.51 \mathrm{E}+00$ \\
\hline$E-02$ & $22 \mathrm{E}+00$ & $9 F-0-2-2-5$ & $8 \mathrm{~F}-01$ & $3 F+00$ & $03 E+00$ & $F+00$ & $51 \mathrm{E}+00$ \\
\hline$E-02$ & 00 & $9.30 \mathrm{E}-01$ & & & & & $1 \mathrm{E}+00$ \\
\hline$E-02$ & & $9.30 \mathrm{E}-01$ & & & & 0 & +00 \\
\hline $68 E-02$ & $3.21 \mathrm{E}+00$ & 1 & 1 & $1.73 \mathrm{E}+00$ & $03 E+00$ & $2.28 \mathrm{E}+00$ & $51 \mathrm{E}+00$ \\
\hline $70 E-02$ & $3.21 \mathrm{E}+00$ & $F-0$ & $2 E-01$ & $73 E+00$ & $03 E+00$ & $.28 E+00$ & $50 \mathrm{E}+00$ \\
\hline 7 & 211 & & & 0 & $03 F$ & 0 & $50 E+00$ \\
\hline 2 & $21 \mathrm{~F}+00$ & $9.32 \mathrm{E}-01$ & $8.24 \mathrm{E}-01$ & $73 F+00$ & 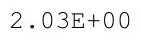 & $E+00$ & $E+00$ \\
\hline $76 \mathrm{E}-02$ & $3.20 F+00$ & $3 F-(-2-r)$ & $5 \mathrm{~F}$ & $3 E+00$ & 0 & +00 & $50 \mathrm{E}+00$ \\
\hline$E-02$ & & $\mathrm{~F}$ & & & & & +00 \\
\hline $.81 E-02$ & $3.20 \mathrm{E}+00$ & $9.34 \mathrm{E}-01$ & $8.26 \mathrm{E}-01$ & 1. $73 \mathrm{E}+00$ & $2.03 E+00$ & $2.28 \mathrm{E}+00$ & $2.50 \mathrm{E}+00$ \\
\hline-02 & $\mathrm{E}+00$ & $5-0$ & & & & +00 & $E+00$ \\
\hline 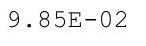 & & & & & & & 00 \\
\hline $.87 E-02$ & & & $8.29 \mathrm{E}-01$ & $1735+$ & 0 & 0 & 0 \\
\hline $89 \mathrm{~F}-02$ & $319 F+00$ & $9.36 \mathrm{E}-01$ & $8.30 E-01$ & $173 F+0$ & 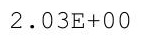 & -00 & $0 E+00$ \\
\hline $91 \mathrm{E}-02$ & $9 \mathrm{E}+00$ & $6 \mathrm{~F}-0$ & $1 \mathrm{~F}-01$ & $1.73 \mathrm{E}+00$ & $3 E+00$ & $E+00$ & $\mathrm{DE}+00$ \\
\hline $3 E-02$ & $.19 \mathrm{E}+00$ & $.37 E-01$ & $32 \mathrm{E}-01$ & 1. $73 \mathrm{E}+00$ & $2.03 E+00$ & $2.27 \mathrm{E}+00$ & $2.50 E+00$ \\
\hline$E-02$ & $.18 \mathrm{E}+00$ & $F-0$ & -01 & 0 & & $2.27 \mathrm{E}+00$ & $50 E+00$ \\
\hline & & & & & & & \\
\hline $.00 \mathrm{E}-$ & $.18 \mathrm{E}+00$ & ( & & $1.73 \mathrm{E}+$ & & & \\
\hline $0 E-01$ & $.18 \mathrm{E}+00$ & F & 1 & $1.73 \mathrm{E}+$ & ק & $3 E+00$ & $E+00$ \\
\hline $00 E-01$ & $.18 \mathrm{E}+00$ & $9 F-8-8-5$ & 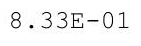 & $1.73 E+00$ & $.04 \mathrm{E}+\mathrm{C}$ & $2.28 E+00$ & $50 E+00$ \\
\hline $01 \mathrm{E}-01$ & $.17 \mathrm{E}+00$ & $\Delta 0 \mathrm{~F}-01$ & $33 E-01$ & $1.73 \mathrm{E}+00$ & $.04 \mathrm{E}+0$ & $.28 E+00$ & $50 E+00$ \\
\hline$F-01$ & $17 F+00$ & & & $1.73 \mathrm{E}+00$ & & & $50 E+00$ \\
\hline & & & & & & & \\
\hline & & & & $1.73 \mathrm{E}+$ & & & \\
\hline $.01 \mathrm{E}-01$ & $3.17 \mathrm{E}+00$ & enta & $8.35 E-01$ & $1.73 \mathrm{E}+00$ & $2.04 \mathrm{E}+00$ & $2.27 \mathrm{E}+00$ & $2.50 \mathrm{E}+00$ \\
\hline 1 & $3.16 \mathrm{E}+00$ & 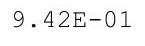 & 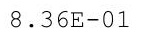 & $1.73 E+00$ & $2.04 \mathrm{E}+00$ & $2.27 E+00$ & $2.50 \mathrm{E}+00$ \\
\hline 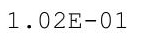 & $3.16 \mathrm{E}+00$ & $9.42 \mathrm{E}-$ & $.37 E-01$ & $1.73 E+00$ & & $2.27 E+00$ & $2.50 \mathrm{E}+00$ \\
\hline$F-01$ & $3.16 \mathrm{E}+00$ & & & & - & & $0 \mathrm{E}+00$ \\
\hline 1 & & & & & & & \\
\hline$E-01$ & & & 01 & & & $2.27 E+00$ & \\
\hline $.03 E-01$ & $3.15 \mathrm{E}+00$ & $9.44 \mathrm{~L}-\mathrm{O}$ & $8.40 \mathrm{E}-01$ & $1.73 \mathrm{E}+00$ & $2.04 \mathrm{E}+00$ & $2.27 E+00$ & $2.50 \mathrm{E}+00$ \\
\hline $.03 E-U 1$ & $3.15 \mathrm{E}+00$ & 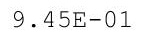 & & $1.13 E+U 0$ & $2.04 E+00$ & $2.27 E+00$ & $2.50 \mathrm{E}+00$ \\
\hline 1 & $3.15 E+0$ & 1 & 1 & $1.73 \mathrm{E}+$ & $2.04 \mathrm{E}+$ & & $2.50 E+00$ \\
\hline $.03 E-01$ & $3.15 \mathrm{E}+0$ & 1 & & $1.73 \mathrm{E}+00$ & $2.04 \mathrm{E}+00$ & $2.27 \mathrm{E}+00$ & $2.49 E+00$ \\
\hline $.04 E-01$ & & & & $1.73 \mathrm{E}+00$ & & & \\
\hline $4 E-01$ & & & 01 & $1.73 E+00$ & & $2.27 E+00$ & $2.49 E+00$ \\
\hline $04 \mathrm{E}-01$ & $3.14 \mathrm{E}+00$ & 1 & & $1.73 \mathrm{E}+$ & & & $2.49 \mathrm{E}+00$ \\
\hline & & & & & & & $2.49 \mathrm{E}+00$ \\
\hline . & $3.14 \mathrm{E}+00$ & . 10 L & $0.4 J E-01$ & $1.73 \mathrm{E}+00$ & $2.04 \mathrm{E}+00$ & $2.27 E+00$ & $2.49 E+00$ \\
\hline+1 & & . 1 t & & $1.73 \mathrm{E}+00$ & $2.04 \mathrm{E}+00$ & $2.27 E+00$ & $2.49 E+00$ \\
\hline & & & & $1.73 \mathrm{E}+$ & $2.04 \mathrm{E}+$ & $2.27 \mathrm{E}+00$ & $2.49 E+00$ \\
\hline-01 & $.13 E+00$ & $.49 \mathrm{E}-01$ & $.48 E-01$ & $1.73 E+00$ & $2.04 \mathrm{E}+00$ & $2.27 E+00$ & $2.49 \mathrm{E}+00$ \\
\hline
\end{tabular}


RESRAD-OFFSITE, Version 2.5

obabilistic Dose and Risk Report

Title : Offsite Resident Farmer Deterministic Run

File : RF TC99 DOESG FWD-FV2.ROF

Summary of dose at graphical times, reptition 1 (continued)

Time

Years

$1.01 \mathrm{E}+03$

$1.01 \mathrm{E}+03$

1. $02 \mathrm{E}+03$

$1.02 \mathrm{E}+03$

$1.02 \mathrm{E}+03$

$1.02 \mathrm{E}+03$

$1.02 \mathrm{E}+03$

1. $02 \mathrm{E}+03$

1. $02 \mathrm{E}+03$

1. $02 \mathrm{E}+03$

1. $02 \mathrm{E}+03$

1. $02 \mathrm{E}+03$

1. $02 \mathrm{E}+03$

1. $02 \mathrm{E}+03$

$1.02 \mathrm{E}+03$

1. $02 \mathrm{E}+03$

$1.02 \mathrm{E}+03$

$1.02 \mathrm{E}+03$

1. $02 \mathrm{E}+03$

1. $02 \mathrm{E}+03$

$1.02 \mathrm{E}+03$

1. $02 \mathrm{E}+03$

$1.03 E+03$

1. $03 \mathrm{E}+03$

$1.03 \mathrm{E}+03$

$1.03 E+03$

$1.03 E+03$

$1.03 E+03$

$1.03 \mathrm{E}+03$

1. $03 \mathrm{E}+03$

$1.03 E+03$

$1.03 \mathrm{E}+03$

$1.03 \mathrm{E}+03$

$1.03 \mathrm{E}+03$

$1.03 \mathrm{E}+03$

$1.03 E+03$

$1.03 \mathrm{E}+03$

$1.03 E+03$

$1.03 E+03$

$1.03 E+03$

$1.03 \mathrm{E}+03$

$1.04 \mathrm{E}+03$

$1.04 \mathrm{E}+03$

$1.04 \mathrm{E}+03$

$1.04 \mathrm{E}+03$

$1.04 \mathrm{E}+03$

Dose statistics at graphical times, mrem/yr

\begin{tabular}{|c|c|c|c|c|c|c|c|}
\hline inimum & laximum & Mean & ledian & $\%$ & $5 \%$ & $97.5 \%$ & $\%$ \\
\hline $5 E-01$ & $3.13 \mathrm{E}+00$ & $9.50 \mathrm{E}-01$ & $.49 \mathrm{E}-01$ & $1.73 \mathrm{E}+00$ & $2.04 \mathrm{E}+00$ & $2.27 E+00$ & $2.49 \mathrm{E}+00$ \\
\hline$E-01$ & +00 & 1 & 1 & 0 & 00 & +00 & $9 E+00$ \\
\hline$E-01$ & +00 & 01 & 01 & & & 00 & +00 \\
\hline 01 & $E+00$ & & & & & 00 & +00 \\
\hline-01 & +00 & 1 & & $73 E+00$ & & +00 & $49 E+00$ \\
\hline $.06 \mathrm{E}-01$ & $3.12 \mathrm{E}+00$ & $2 E-01$ & -01 & $1.73 \mathrm{E}+00$ & $4 \mathrm{E}+00$ & $E+00$ & $49 E+00$ \\
\hline 01 & $11 \mathrm{E}+00$ & 01 & 1 & 0 & 0 & $6 \mathrm{E}+00$ & $49 E+00$ \\
\hline $.07 E-01$ & $3.11 E+00$ & . & & 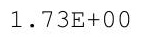 & 2.00100 & +00 & +00 \\
\hline $.07 E-01$ & $E+00$ & & & & & +00 & \pm+00 \\
\hline $.07 \mathrm{E}-01$ & $3.11 \mathrm{E}+00$ & $4 E-01$ & & & & & $49 E+00$ \\
\hline$E-01$ & $E+00$ & $E-01$ & 1 & 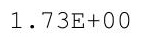 & 0 & $E+00$ & $9 E+00$ \\
\hline-01 & $10 \mathrm{E}+00$ & -01 & & 00 & 0 & $E+00$ & $49 E+00$ \\
\hline $08 \mathrm{E}-01$ & $3.10 \mathrm{E}+00$ & $\perp$ & 01 & $1.13 \mathrm{E}+00$ & . & +00 & $\mathrm{E}+00$ \\
\hline 01 & 0 & $9.56 \mathrm{E}-01$ & $8.58 \mathrm{E}-01$ & 0 & 0 & 0 & 00 \\
\hline 01 & $E+00$ & & & $\cdots 1$ & & 0 & 00 \\
\hline $.09 \mathrm{E}-01$ & $\mathrm{E}+00$ & 1 & & 0 & 0 & +00 & $9 \mathrm{E}+00$ \\
\hline $09 E-01$ & $3.09 \mathrm{E}+00$ & $9.57 \mathrm{E}-01$ & $8.61 \mathrm{E}-01$ & $1.72 \mathrm{E}+00$ & $2.02 \mathrm{E}+00$ & $2.25 \mathrm{E}+00$ & $2.49 \mathrm{E}+00$ \\
\hline-01 & $.09 E+00$ & $3 E-01$ & $E-01$ & $1.72 \mathrm{E}+00$ & 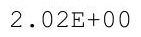 & $2.25 E+00$ & $2.49 \mathrm{E}+00$ \\
\hline 01 & +00 & & & & & 0 & -00 \\
\hline 01 & $E+00$ & $\perp$ & $0 \perp$ & $1.72 \mathrm{E}+00$ & 0 & 0 & +00 \\
\hline 1 & 0 & $9.59 \mathrm{E}-01$ & & 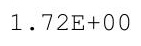 & & & 00 \\
\hline$E-01$ & $.08 E+00$ & 1 & $\perp$ & 1 & & & $E+00$ \\
\hline$E-01$ & $.08 E+00$ & $0 F-01$ & $.65 E-01$ & $1.72 \mathrm{E}+00$ & $02 E+00$ & $.24 \mathrm{E}+00$ & $.49 E+00$ \\
\hline-01 & $.08 E+00$ & $=01$ & $=01$ & 1. $72 \mathrm{E}+00$ & $.02 \mathrm{E}+00$ & $.24 \mathrm{E}+00$ & $.49 E+00$ \\
\hline 01 & $07 E+00$ & & & 0 & & $4 \mathrm{E}+00$ & $.49 \mathrm{E}+00$ \\
\hline & & & & & & & 00 \\
\hline & & & & $1.72 \mathrm{E}+00$ & & 00 & +00 \\
\hline $11 \mathrm{E}-01$ & $3.07 \mathrm{E}+00$ & $\cdot 0<+$ & .00 & $1.72 \mathrm{E}+00$ & $2.02 E+00$ & $.25 E+00$ & $2.49 \mathrm{E}+00$ \\
\hline 1 & $3.07 \mathrm{E}+00$ & 1 & 1 & $1.72 \mathrm{E}+00$ & $2.02 \mathrm{E}+$ & $2.25 \mathrm{E}+00$ & $.49 E+00$ \\
\hline $2 \mathrm{~F}-01$ & $3.06 \mathrm{E}+00$ & $=01$ & & 1. $72 \mathrm{E}+00$ & & $25 F+00$ & $2.49 \mathrm{E}+00$ \\
\hline 01 & $3.06 \mathrm{E}+00$ & & & & & & \\
\hline 01 & & & & & & & $2.49 \mathrm{E}+00$ \\
\hline 01 & & & & $1 \cdot 12$ & $2.0<1$ & $E+00$ & +00 \\
\hline $.13 E-01$ & $3.05 \mathrm{E}+00$ & $9.05 E-U 1$ & $8.68 \mathrm{E}-01$ & $1.72 \mathrm{E}+00$ & $2.0<D 1$ & $2.25 \mathrm{E}+00$ & $2.49 \mathrm{E}+00$ \\
\hline $13 E-01$ & $3.05 \mathrm{E}+00$ & $9.035-U 1$ & & $1.1 \angle E+U 0$ & & & $2.49 \mathrm{E}+00$ \\
\hline 1 & $3.05 \mathrm{E}+$ & 1 & 1 & & & & $2.49 \mathrm{E}+00$ \\
\hline 1 & & & & & & & $2.49 \mathrm{E}+00$ \\
\hline 1 & & $9.66 \mathrm{E}-01$ & 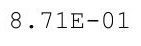 & & & & \\
\hline$E-01$ & & 01 & 01 & $1 \mathrm{E}+00$ & $2.02 \mathrm{E}$ & $2.24 \mathrm{E}+00$ & $2.49 \mathrm{E}+00$ \\
\hline $14 \mathrm{E}-01$ & $3.04 \mathrm{E}+00$ & $9.01 \mathrm{E}$ & 1 & $1.71 \mathrm{E}+00$ & - & & $2.49 \mathrm{E}+00$ \\
\hline $4 E-01$ & $3.04 \mathrm{E}+00$ & .000 & $\perp$ & $1.1 \perp \mathrm{E}$ & & & $2.49 \mathrm{E}+00$ \\
\hline $4 E-01$ & $3.04 \mathrm{E}+00$ & $9.00 \mathrm{~L}-\mathrm{L}$ & $45-01$ & $1.71 \mathrm{E}+00$ & $2.02 \mathrm{E}+00$ & $2.23 E+00$ & $2.49 \mathrm{E}+00$ \\
\hline 1 & $3.03 E+00$ & $9.00 \mathrm{~L}$ & & $1.71 \mathrm{E}+00$ & $2.01 E+00$ & $2.23 E+00$ & $2.49 \mathrm{E}+00$ \\
\hline 1 & $3.03 E+00$ & & 1 & $71 \mathrm{E}+00$ & $01 E+00$ & $2.23 E+00$ & $2.48 \mathrm{E}+00$ \\
\hline $5 E-01$ & $3.03 E+00$ & $E-01$ & $E-01$ & $1.71 \mathrm{E}+00$ & $2.01 E+00$ & $2.23 \mathrm{E}+00$ & $2.48 \mathrm{E}+00$ \\
\hline$E-01$ & $03 E+00$ & $0 \mathrm{E}-01$ & $77 \mathrm{E}-01$ & $1.71 \mathrm{E}+00$ & $01 E+00$ & $.23 E+00$ & $2.48 \mathrm{E}+00$ \\
\hline
\end{tabular}


RESRAD-OFFSITE, Version 2.5

$\mathrm{T}^{1 / 2}$ Limit $=180$ days

robabilistic Dose and Risk Report

Title : Offsite Resident Farmer Deterministic Run

File : RF TC99 DOESG FWD-FV2.ROF

Time

Years

$1.04 \mathrm{E}+03$

$1.04 \mathrm{E}+03$

$1.04 \mathrm{E}+03$

$1.04 \mathrm{E}+03$

$1.04 \mathrm{E}+03$

$1.04 \mathrm{E}+03$

$1.04 \mathrm{E}+03$

1. $04 \mathrm{E}+03$

$1.04 \mathrm{E}+03$

1. $04 \mathrm{E}+03$

$1.04 \mathrm{E}+03$

1. $04 \mathrm{E}+03$

1. $04 \mathrm{E}+03$

1. $04 \mathrm{E}+03$

1. $04 \mathrm{E}+03$

1. $05 \mathrm{E}+03$

1. $05 \mathrm{E}+03$

1. $05 \mathrm{E}+03$

1. $05 \mathrm{E}+03$

1. $05 \mathrm{E}+03$

1. $05 \mathrm{E}+03$

1. $05 \mathrm{E}+03$

$1.05 \mathrm{E}+03$

1. $05 \mathrm{E}+03$

1. $05 \mathrm{E}+03$
Summary of dose at graphical times, reptition 1 (continued)

Dose statistics at graphical times, mrem/yr

\begin{tabular}{|c|c|c|c|c|c|c|c|}
\hline m & $a x$ & ean & Median & $90 \%$ & & $\%$ & $\%$ \\
\hline 01 & $3.02 \mathrm{E}+00$ & 01 & $8.78 \mathrm{E}-01$ & 1.7 & 00 & +00 & $2.48 \mathrm{E}+00$ \\
\hline $16 \mathrm{E}-01$ & 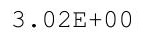 & 1 & 01 & $1.71 \mathrm{E}+00$ & $1 \mathrm{E}+00$ & $\mathrm{E}+00$ & $2.48 \mathrm{E}+00$ \\
\hline-01 & +00 & $1 \mathrm{E}-01$ & $0 \mathrm{E}-01$ & $1.71 \mathrm{E}+00$ & $01 \mathrm{E}+00$ & $2.23 \mathrm{E}+00$ & $2.48 \mathrm{E}+00$ \\
\hline $16 \mathrm{E}-01$ & $3.02 E+00$ & $9.71 \mathrm{E}-01$ & 01 & $1.71 \mathrm{E}+00$ & $2.01 E+00$ & $E+00$ & $2.48 \mathrm{E}+00$ \\
\hline $6 \mathrm{~F}-01$ & : & 21 & $81 \mathrm{~F}^{2}$ & 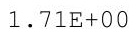 & $1 F+00$ & $23 E+00$ & +00 \\
\hline 01 & $3.01 \mathrm{E}+00$ & 9. & & $1.71 \mathrm{E}+$ & & & $\Xi+00$ \\
\hline $17 \mathrm{~F}-01$ & $301 \mathrm{~F}+00$ & 9. & 3 & $171 \mathrm{~F}+00$ & & & $48 \mathrm{E}+00$ \\
\hline $.17 \mathrm{E}-01$ & $3.01 \mathrm{E}+00$ & $9.73 \mathrm{E}-01$ & & $1.71 \mathrm{E}+00$ & $2.01 \mathrm{E}+00$ & $2.23 E+00$ & $2.48 \mathrm{E}+00$ \\
\hline $.17 \mathrm{E}-01$ & $3.01 \mathrm{E}+00$ & $E-01$ & & $1.71 \mathrm{E}+00$ & & & +00 \\
\hline$\cdot \sqcup$ & & 1 & & $1.71 \mathrm{E}+$ & & 0 & $E+00$ \\
\hline - & 3.0 & 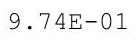 & $\perp$ & $\perp \cdot 1 \pm$ & & & 00 \\
\hline .100 & $3.00 \mathrm{E}+$ & 0. & & $1.71 \pm$ & & & 00 \\
\hline .1 & $3.00 \mathrm{E}+00$ & 9 & $8.86 \mathrm{E}-01$ & $1.71 \mathrm{E}+$ & $2 \cdot 0+1$ & 2.201 & $47 E+00$ \\
\hline $18 \mathrm{~F}-0$ & $2.99 \mathrm{E}+00$ & $9.75 \mathrm{E}-0$ & $.87 \mathrm{E}-01$ & $1.71 \mathrm{E}+00$ & $2.01 \mathrm{E}+00$ & $2.23 E+00$ & $2.47 \mathrm{E}+00$ \\
\hline $19 F-01$ & $2.99 \mathrm{E}+00$ & $.76 E-0$ & $.88 E-01$ & 1. $71 \mathrm{E}+00$ & $2.01 \mathrm{E}+0$ & $2.23 E+00$ & $2.47 \mathrm{E}+00$ \\
\hline$F-01$ & $2.99 \mathrm{E}+00$ & & 1 & $1.71 \mathrm{E}+00$ & & & $2.47 \mathrm{E}+00$ \\
\hline 1 & & & & & & & \\
\hline 1 & & & & & & & $2.47 \mathrm{E}+00$ \\
\hline $.19 \mathrm{E}-01$ & $2.98 \mathrm{E}+00$ & $9.77 \mathrm{E}-01$ & $8.91 E-01$ & $1.71 \mathrm{E}+00$ & $2.01 \mathrm{E}+$ & $2.23 E+00$ & $2.47 \mathrm{E}+00$ \\
\hline $.20 E-01$ & $2.98 \mathrm{E}+00$ & $9.78 \mathrm{E}-01$ & $8.92 \mathrm{E}-01$ & $1.71 \mathrm{E}+00$ & $2.0 \perp E+00$ & $2.22 \mathrm{E}+00$ & $2.47 \mathrm{E}+00$ \\
\hline $.20 \mathrm{E}-01$ & $2 \cdot \pi 0$ - 100 & $9.78 \mathrm{E}-01$ & & 1. $71 \mathrm{E}+00$ & $2.01 \mathrm{E}+00$ & $2.22 \mathrm{E}+00$ & $2.47 \mathrm{E}+00$ \\
\hline * $20+-1$ & $2.98 \mathrm{E}+$ & $9.79 \mathrm{E}-$ & $8.94 \mathrm{E}-01$ & $1.71 \mathrm{E}+00$ & $2.01 \mathrm{E}+00$ & $2.22 \mathrm{E}+00$ & $2.47 \mathrm{E}+00$ \\
\hline $0 \mathrm{E}-$ & $2.97 \mathrm{E}+00$ & $9.79 \mathrm{E}-$ & & $1.72 \mathrm{E}+00$ & $2.01 \mathrm{E}+00$ & $2.22 E+00$ & $2.47 \mathrm{E}+00$ \\
\hline $21 E-01$ & $2.97 \mathrm{E}+00$ & 9.7 & $.95 E-01$ & 1. $72 \mathrm{E}+00$ & $2.01 \mathrm{E}+00$ & $2.22 \mathrm{E}+00$ & $2.47 \mathrm{E}+00$ \\
\hline $21 E-01$ & $2.97 \mathrm{E}+00$ & $9.79 \mathrm{E}-01$ & $8.95 \mathrm{E}-01$ & $1.72 \mathrm{E}+00$ & $2.01 \mathrm{E}+00$ & $2.22 \mathrm{E}+00$ & $2.47 \mathrm{E}+00$ \\
\hline
\end{tabular}

C- 149

DCN 5090-TR-02-2 
RESRAD-OFFSITE, Version 2.5

robabilistic Dose and Risk Report

Title : Offsite Resident Farmer Deterministic Run

File : RF TC99 DOESG FWD-FV2.ROF

Time

Years

$0.00 \mathrm{E}+00$

$5.13 \mathrm{E}-01$

$1.03 \mathrm{E}+00$

$1.54 \mathrm{E}+00$

$2.05 \mathrm{E}+00$

$2.56 \mathrm{E}+00$

$3.08 \mathrm{E}+00$

$3.59 \mathrm{E}+00$

$4.10 \mathrm{E}+00$

$4.61 \mathrm{E}+00$

$5.13 \mathrm{E}+00$

$5.64 \mathrm{E}+00$

$6.15 \mathrm{E}+00$

$6.67 \mathrm{E}+00$

$7.18 \mathrm{E}+00$

$7.69 \mathrm{E}+00$

$8.20 \mathrm{E}+00$

$8.72 \mathrm{E}+00$

$9.23 \mathrm{E}+00$

$9.74 \mathrm{E}+00$

$1.03 \mathrm{E}+01$

$1.08 \mathrm{E}+01$

1. $13 \mathrm{E}+01$

$1.18 \mathrm{E}+01$

$1.23 \mathrm{E}+01$

$1.28 \mathrm{E}+01$

$1.33 \mathrm{E}+01$

$1.38 \mathrm{E}+01$

$1.44 \mathrm{E}+01$

$1.49 \mathrm{E}+01$

$1.54 \mathrm{E}+01$

$1.59 \mathrm{E}+01$

$1.64 \mathrm{E}+01$

$1.69 \mathrm{E}+01$

$1.74 \mathrm{E}+01$

$1.79 \mathrm{E}+01$

$1.85 \mathrm{E}+01$

$1.90 \mathrm{E}+01$

$1.95 \mathrm{E}+01$

$2.00 \mathrm{E}+01$

$2.05 \mathrm{E}+01$

$2.10 \mathrm{E}+01$

$2.15 \mathrm{E}+01$

$2.20 \mathrm{E}+01$

$2.26 \mathrm{E}+01$

$2.31 \mathrm{E}+01$
Summary of dose at graphical times, reptition 2

Dose statistics at graphical times, mrem/yr

\begin{tabular}{|c|c|c|c|c|c|c|c|}
\hline Iin & laximum & Mean & ledian & 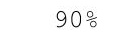 & $\%$ & $97.5 \%$ & \% \\
\hline 0 & 00 & 00 & +00 & 0 & 0 & -00 & +00 \\
\hline 00 & 00 & 00 & & 0 & & +00 & +00 \\
\hline $.00 \mathrm{E}+00$ & $0.00 \mathrm{E}+00$ & $0.00 \mathrm{E}+00$ & $.00 \mathrm{E}+00$ & $.00 \mathrm{E}+00$ & $00 \mathrm{E}+00$ & $.00 \mathrm{E}+00$ & $.00 E+00$ \\
\hline $.00 \mathrm{E}+00$ & $0.00 \mathrm{E}+00$ & $0.00 \mathrm{E}+00$ & $0.00 \mathrm{E}+00$ & $0.00 \mathrm{E}+00$ & $0.00 \mathrm{E}+00$ & $0.00 \mathrm{E}+00$ & $0.00 \mathrm{E}+00$ \\
\hline $.00 \mathrm{E}+00$ & $0.00 \mathrm{E}+00$ & $0.00 \mathrm{E}+00$ & $0.00 \mathrm{E}+00$ & $0.00 \mathrm{E}+00$ & $0.00 \mathrm{E}+00$ & $0.00 \mathrm{E}+00$ & $D E+00$ \\
\hline مF+0 & $0 \cap F+\cap 0$ & $.00 \mathrm{E}+00$ & $.00 \mathrm{E}+00$ & $.00 \mathrm{E}+00$ & $.00 \mathrm{E}+00$ & $.00 \mathrm{E}+00$ & $00 \mathrm{E}+00$ \\
\hline $.00 \mathrm{E}+00$ & $0.00 \mathrm{E}+00$ & $0.00 \mathrm{E}+00$ & $.00 \mathrm{E}+00$ & 年 & $0.00 \mathrm{E}+00$ & $0.00 \mathrm{E}+00$ & $.00 \mathrm{E}+00$ \\
\hline $.00 \mathrm{E}+00$ & $\mathrm{E}+00$ & 0 & & 0 & & 0 & +00 \\
\hline $.00 \mathrm{E}+00$ & $0.00 \mathrm{E}+00$ & $0.00 \mathrm{E}+00$ & & $.00 \mathrm{E}+00$ & & $00 \mathrm{E}+00$ & $00 \mathrm{E}+00$ \\
\hline $.00 E+00$ & $E+00$ & $\mathrm{DE}+00$ & $\mathrm{E}+00$ & $0 \mathrm{E}+00$ & 0 & $E+00$ & $\mathrm{E}+00$ \\
\hline $.00 \mathrm{E}+00$ & $0.00 \mathrm{E}+00$ & $00 \mathrm{E}+00$ & $0 \mathrm{E}+00$ & $00 \mathrm{E}+00$ & $00 \mathrm{E}+00$ & $E+00$ & $00 \mathrm{E}+00$ \\
\hline $\mathrm{E}+00$ & 00 & ( & 00 & 0 & 0 & +00 & +00 \\
\hline 00 & 0 & 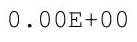 & & 0 & & 0 & 00 \\
\hline $.00 \mathrm{E}+00$ & $.00 \mathrm{E}+00$ & $.00 \mathrm{E}+0$ & 0 & T & 0 & 0 & 00 \\
\hline $.00 \mathrm{E}+00$ & $0.00 \mathrm{E}+00$ & $0.00 \mathrm{E}+00$ & $0.00 \mathrm{E}+00$ & $0.00 \mathrm{E}+00$ & $0.00 \mathrm{E}+00$ & $0.00 \mathrm{E}+00$ & $0.00 \mathrm{E}+00$ \\
\hline $.00 \mathrm{E}+00$ & $0.00 \mathrm{E}+00$ & $0.00 \mathrm{E}+00$ & $0.00 \mathrm{E}+00$ & $0.00 \mathrm{E}+00$ & $0.00 \mathrm{E}+00$ & $0.00 \mathrm{E}+00$ & $0.00 \mathrm{E}+00$ \\
\hline $.00 \mathrm{E}+00$ & $0.00 \mathrm{E}+00$ & $O E+00$ & $.00 \mathrm{E}+00$ & $00 \mathrm{E}+00$ & 0 & $E+00$ & +00 \\
\hline $.00 \mathrm{E}+00$ & $.00 \mathrm{E}+00$ & $0 E+00$ & $0 E+00$ & $.00 \mathrm{E}+$ & 0 & $E+00$ & +00 \\
\hline$E+00$ & $.00 \mathrm{E}+00$ & $0.00 \mathrm{E}+00$ & $.00 E+00$ & $.00 \mathrm{E}+$ & 0 & +00 & 00 \\
\hline $\mathrm{E}+00$ & 0 & c & 0 & 0 & & 0 & 00 \\
\hline $.00 \mathrm{E}+00$ & $.00 E+00$ & $0.00 \mathrm{E}+0$ & $0 \mathrm{E}+00$ & Feto & 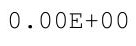 & $\mathrm{E}+00$ & $\mathrm{DE}+00$ \\
\hline O $\cap$ F $+\cap 0$ & $.00 \mathrm{E}+00$ & $.00 \mathrm{E}+00$ & $0 \mathrm{E}+00$ & $.00 \mathrm{E}+00$ & OOE+ & $.00 \mathrm{E}+00$ & $00 \mathrm{E}+00$ \\
\hline $.00 \mathrm{E}+00$ & $0.00 \mathrm{E}+00$ & $.00 \mathrm{E}+00$ & $.00 \mathrm{E}+00$ & $.00 \mathrm{E}+00$ & ב תחم: & $.00 \mathrm{E}+00$ & $.00 \mathrm{E}+00$ \\
\hline $00 E+00$ & & & & & & & $00 E+00$ \\
\hline NOE +00 & & & & & & & 00 \\
\hline נקט & & & & & & 0 & 00 \\
\hline $.00 \mathrm{E}+00$ & ( & OOE+ & $00 \mathrm{E}+$ & $00 \mathrm{E}+$ & $.00 \mathrm{E}+$ & $0.00 \mathrm{E}+00$ & $.00 \mathrm{E}+00$ \\
\hline $0 \mathrm{E}+00$ & 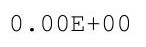 & 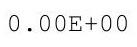 & $.00 \mathrm{E}+00$ & 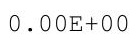 & ג & $.00 \mathrm{E}+00$ & $.00 \mathrm{E}+00$ \\
\hline$F+0 \Omega$ & $.00 \mathrm{E}+00$ & $0.00 \mathrm{E}+00$ & $.00 \mathrm{E}+00$ & $.00 E+00$ & 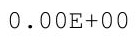 & $0 \mathrm{E}+00$ & $.00 E+00$ \\
\hline$\cap \cap F+\cap \Omega$ & & & & & & $E+00$ & $00 E+00$ \\
\hline & & & & & & & \\
\hline $\mathrm{OE}+$ & 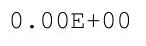 & & & 0 & & & \\
\hline $.00 \mathrm{E}+00$ & $0.00 \mathrm{E}+00$ & $0.00 \mathrm{E}+00$ & $0.00 \mathrm{E}+00$ & $0.00 \mathrm{E}+00$ & $.00 \mathrm{E}+0 \mathrm{O}$ & $0.00 \mathrm{E}+00$ & $0.00 \mathrm{E}+00$ \\
\hline (2) & & & & & & $0.00 \mathrm{E}+00$ & $0.00 \mathrm{E}+00$ \\
\hline$F+0$ & 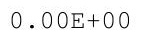 & $.00 \mathrm{E}+00$ & $.00 E+00$ & $.00 E+00$ & 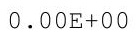 & $0 \mathrm{E}+00$ & $00 E+00$ \\
\hline مח & $0.00 \mathrm{E}+00$ & & & & & & $\mathrm{E}+00$ \\
\hline $0=0+0$ & $0.00 \mathrm{E}+00$ & & $.00 E+00$ & & & $E+00$ & \\
\hline $.00 \mathrm{E}+00$ & $0.00 \mathrm{E}+00$ & $0.00 \mathrm{E}+00$ & $0.00 \mathrm{E}+00$ & $0.00 \mathrm{E}+00$ & $0.00 \mathrm{E}+$ & $0.00 \mathrm{E}+00$ & $0.00 \mathrm{E}+00$ \\
\hline $.00 E+00$ & $0.00 E+00$ & $0.00 \mathrm{ET}$ & $0.00 \mathrm{E}+00$ & . OULT & & $0.00+00$ & $0.00 \mathrm{E}+00$ \\
\hline . & $.00 \mathrm{E}+00$ & $0.00 \mathrm{E}+00$ & $0.00 \mathrm{E}+00$ & $0.00 \mathrm{E}+00$ & $0.00 \mathrm{E}+00$ & $0.00 \mathrm{E}+00$ & $0.00 \mathrm{E}+00$ \\
\hline $00 \mathrm{E}+$ & $0.00 \mathrm{E}+00$ & $0.00 \mathrm{E}+00$ & $0.00 \mathrm{E}+00$ & $0.00 \mathrm{E}+00$ & $0.00 \mathrm{E}+00$ & $0.00 \mathrm{E}+00$ & $0.00 \mathrm{E}+00$ \\
\hline-00 & & 0.00 & 0 & 0 & 0 & $E+00$ & $E+00$ \\
\hline $.00 \mathrm{E}+00$ & $0.00 \mathrm{E}+00$ & $0.00 \mathrm{E}+00$ & $0.00 \mathrm{E}+00$ & $0.00 \mathrm{E}+00$ & $0.00 \mathrm{E}+00$ & $0.00 \mathrm{E}+00$ & $0.00 \mathrm{E}+00$ \\
\hline $.00 E+00$ & $0.00 \mathrm{E}+00$ & $0.00 \mathrm{E}+00$ & $E+00$ & $00 E+00$ & 0 & 00 & $0.00 \mathrm{E}+00$ \\
\hline & & & & & & & $0.00 \mathrm{E}+00$ \\
\hline$E+00$ & $00 \mathrm{E}+00$ & $.00 \mathrm{E}+00$ & $.00 \mathrm{E}+00$ & $.00 \mathrm{E}+00$ & $.00 \mathrm{E}+00$ & 00 & $.00 \mathrm{E}+00$ \\
\hline
\end{tabular}


RESRAD-OFFSITE, Version 2.5 
Probabilistic Dose and Risk Report

Title : Offsite Resident Farmer Deterministic Run

File : RF TC99 DOESG FWD-FV2.ROF

Summary of dose at graphical times, reptition 2 (continued)

Time

Years

$4.72 \mathrm{E}+01$

$4.77 \mathrm{E}+01$

4. $82 \mathrm{E}+01$

$4.87 \mathrm{E}+01$

4. $92 \mathrm{E}+01$

$4.97 \mathrm{E}+01$

$5.02 \mathrm{E}+01$

$5.08 \mathrm{E}+01$

$5.13 \mathrm{E}+01$

$5.18 \mathrm{E}+01$

$5.23 \mathrm{E}+01$

$5.28 \mathrm{E}+01$

$5.33 \mathrm{E}+01$

$5.38 \mathrm{E}+01$

$5.43 \mathrm{E}+01$

$5.49 \mathrm{E}+01$

$5.54 \mathrm{E}+01$

$5.59 \mathrm{E}+01$

$5.64 \mathrm{E}+01$

$5.69 \mathrm{E}+01$

$5.74 \mathrm{E}+01$

$5.79 \mathrm{E}+01$

$5.84 \mathrm{E}+01$

$5.90 \mathrm{E}+01$

$5.95 \mathrm{E}+01$

$6.00 \mathrm{E}+01$

$6.05 \mathrm{E}+01$

$6.10 \mathrm{E}+01$

$6.15 \mathrm{E}+01$

$6.20 \mathrm{E}+01$

$6.25 \mathrm{E}+01$

$6.31 \mathrm{E}+01$

$6.36 \mathrm{E}+01$

$6.41 \mathrm{E}+01$

$6.46 \mathrm{E}+01$

$6.51 \mathrm{E}+01$

$6.56 \mathrm{E}+01$

$6.61 \mathrm{E}+01$

$6.67 \mathrm{E}+01$

$6.72 \mathrm{E}+01$

$6.77 \mathrm{E}+01$

$6.82 \mathrm{E}+01$

$6.87 \mathrm{E}+01$

$6.92 \mathrm{E}+01$

$6.97 \mathrm{E}+01$

$7.02 \mathrm{E}+01$
Dose statistics at graphical times, mrem/yr

\begin{tabular}{|c|c|c|c|c|c|c|c|}
\hline inimum & aximum & lean & edian & & & $\%$ & $9 \%$ \\
\hline $.00 E+00$ & $0.00 \mathrm{E}+00$ & $0.00 \mathrm{E}+00$ & $0.00 \mathrm{E}+00$ & $00 \mathrm{E}+00$ & $0.00 \mathrm{E}+00$ & $0.00 \mathrm{E}+00$ & $0.00 \mathrm{E}+00$ \\
\hline $.00 \mathrm{E}+00$ & $0.00 \mathrm{E}+00$ & $.00 \mathrm{E}+00$ & $.00 \mathrm{E}+00$ & $0.00 \mathrm{E}+00$ & $0.00 \mathrm{E}+00$ & $0.00 \mathrm{E}+00$ & $00 \mathrm{E}+00$ \\
\hline $00 \mathrm{E}+00$ & $0 \mathrm{E}+00$ & $00 E+00$ & $00 E+00$ & $00 \mathrm{E}+00$ & $00 E+00$ & 00 & $0 E+00$ \\
\hline+00 & 00 & 00 & 00 & 0 & 0 & 00 & $00 \mathrm{E}+00$ \\
\hline$E+00$ & 0 & & & & & & +00 \\
\hline $00 \mathrm{E}+00$ & & & & & & & $\Xi+00$ \\
\hline$E+00$ & $E+00$ & 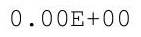 & $\mathrm{E}+00$ & $E+00$ & 0 & +00 & $E+00$ \\
\hline $.00 \mathrm{E}+00$ & $0.00 \mathrm{E}+00$ & $0 \mathrm{E}+00$ & $0 \mathrm{E}+00$ & $00 \mathrm{E}+00$ & $00 \mathrm{E}+00$ & $E+00$ & $00 \mathrm{E}+00$ \\
\hline $00 E+00$ & $00 F+0$ & $00 \mathrm{~F}+\ell-8$ & $.00 E+00$ & $0 \cap \mathrm{F}+$ & $\mathrm{O} \cap \mathrm{F}+\mathrm{r}-\mathrm{s}$ & $00 F+00$ & $00 E+00$ \\
\hline$E+00$ & $0.00 \mathrm{E}+00$ & & & & & 0 & 00 \\
\hline $.00 E+00$ & $0.00 \mathrm{E}+00$ & 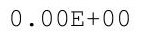 & 00 & 0 & 0 & 0 & $E+00$ \\
\hline $.00 \mathrm{E}+00$ & $0.00 \mathrm{E}+00$ & $0.00 \mathrm{E}+00$ & $0.00 \mathrm{E}+00$ & & & & $0.00 \mathrm{E}+00$ \\
\hline $.00 E+00$ & $0.00 \mathrm{E}+00$ & $0.00 \mathrm{E}+00$ & $0.00 \mathrm{E}+00$ & $0.00 \mathrm{E}+00$ & $0.00 \mathrm{E}+00$ & $E+00$ & $0.00 \mathrm{E}+00$ \\
\hline$E+00$ & $E+00$ & $E+00$ & $E+00$ & & & +00 & $00 \mathrm{E}+00$ \\
\hline $.00 E+00$ & $.00 E+00$ & $.00 E+00$ & $.00 E+00$ & $.00 \mathrm{E}+$ & 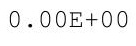 & 0 & +00 \\
\hline$E+00$ & ( & $0.00 \mathrm{E}+00$ & & $0.00 \mathrm{E}+00$ & $00 E+00$ & $E+00$ & 0 \\
\hline $0 \cap F+00$ & $F+00$ & $5+0$ & & & & -00 & 00 \\
\hline $.00 \mathrm{E}+00$ & $0.00 \mathrm{E}+00$ & $0.00 \mathrm{E}+00$ & $0.00 \mathrm{E}+00$ & $0.00 \mathrm{E}+00$ & $0.00 \mathrm{E}+00$ & $0.00 \mathrm{E}+00$ & $.00 \mathrm{E}+00$ \\
\hline $.00 \mathrm{E}+00$ & $.00 \mathrm{E}+00$ & $.00 \mathrm{E}+00$ & $0.00 \mathrm{E}+00$ & $0.00 \mathrm{E}+00$ & $0.00 \mathrm{E}+00$ & $.00 E+00$ & $.00 E+00$ \\
\hline$E+00$ & $00 E+00$ & $00 F+0=$ & $.00 E+00$ & $0 \mathrm{E}+00$ & 0 & $0 \mathrm{E}+00$ & $00 E+00$ \\
\hline 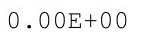 & 然 & $0.00 \mathrm{E}+00$ & $.00 E+00$ & 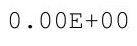 & 0 & 0 & +00 \\
\hline $.00 \mathrm{E}+00$ & . & 然 & & & & & 00 \\
\hline $.00 E+00$ & $.00 \mathrm{E}+00$ & ) & $0 E+00$ & مF+ & 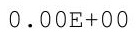 & 0 & $E+00$ \\
\hline $0 \cap F+00$ & COF+O & ) & $0.00 \mathrm{E}+00$ & $.00 \mathrm{E}+00$ & $.00 \mathrm{E}+$ & $00 \mathrm{E}+00$ & $00 E+00$ \\
\hline $00 F+00$ & 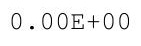 & 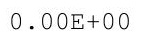 & $0.00 \mathrm{E}+00$ & $.00 \mathrm{E}+00$ & ח & $.00 E+00$ & $.00 \mathrm{E}+00$ \\
\hline$F+00$ & $0.00 \mathrm{E}+00$ & $00 E+00$ & $.00 E+00$ & $0 E+00$ & 0 & $0 E+00$ & $00 E+00$ \\
\hline & & & & & & $E+00$ & \\
\hline & & & & 0.0 & e & & +00 \\
\hline $.00 \mathrm{E}+00$ & $0.00 \mathrm{E}+00$ & $0.00 \mathrm{E}+00$ & $.00 \mathrm{E}+00$ & . & . & $0.00 \mathrm{E}+00$ & $.00 E+00$ \\
\hline $0 \mathrm{E}+00$ & $00 \mathrm{E}+00$ & $0.00 \mathrm{E}+0$ & $0.00 \mathrm{E}+00$ & $0.00 \mathrm{E}+00$ & $0.00 \mathrm{E}+\mathrm{C}$ & $0.00 \mathrm{E}+00$ & $.00 \mathrm{E}+00$ \\
\hline $00 \mathrm{E}+\mathrm{C}$ & $.00 E+00$ & & $0.00 \mathrm{E}+00$ & & & $0.00 \mathrm{E}+00$ & $.00 \mathrm{E}+00$ \\
\hline مि & $00 F+00$ & $0 \cap \cap \cap F+\cap 0$ & $00 F+00$ & $.00 E+00$ & & $0 E+00$ & $.00 E+00$ \\
\hline F & & & & & & & \\
\hline & & & & & & 00 & \\
\hline $.00 E+00$ & $0.00 \mathrm{E}+00$ & $0.00 \mathrm{E}+00$ & $0.00 \mathrm{E}+00$ & $0.00 \mathrm{E}+00$ & . & $0.00 \mathrm{E}+00$ & $.00 \mathrm{E}+00$ \\
\hline • & . & . & & & & & $0.00 \mathrm{E}+00$ \\
\hline 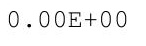 & ( & $0.00 \mathrm{E}+$ & $0.00 \mathrm{E}+$ & $0.00 \mathrm{E}+$ & $0.00 \mathrm{E}$ & $0.00 \mathrm{E}+00$ & $0.00 \mathrm{E}+00$ \\
\hline (1) & & & $0.00 \mathrm{E}+00$ & & & $0.00 \mathrm{E}+00$ & $.00 \mathrm{E}+00$ \\
\hline $0=+0$ & & $0.00 \mathrm{E}+$ & $0.00 \mathrm{E}+00$ & $00 E+00$ & 0 & $0 E+00$ & $00 E+00$ \\
\hline $.00 \mathrm{E}+00$ & $0.00 \mathrm{E}+00$ & $0.00 \mathrm{E}+$ & $0.00 \mathrm{E}$ & $0.00 \mathrm{E}$ & 0 & 00 & $0.00 \mathrm{E}+00$ \\
\hline $\mathrm{E}+00$ & $0.00 \mathrm{E}+00$ & 0.00 & 0 & 0 & & & $00 \mathrm{E}+00$ \\
\hline 年 & . & $0.00 \mathrm{E}+00$ & & $.00 \mathrm{E}+00$ & & & $.00 \mathrm{E}+00$ \\
\hline 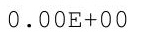 & 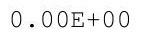 & $0.00 \mathrm{E}+00$ & $0.00 \mathrm{E}+00$ & $0.00 \mathrm{E}+00$ & $0.00 \mathrm{E}+00$ & $0.00 \mathrm{E}+00$ & $0.00 \mathrm{E}+00$ \\
\hline $0 E+00$ & $0.00 \mathrm{E}+00$ & $0.00 \mathrm{E}+00$ & $0.00 \mathrm{E}+00$ & & $0.00 \mathrm{E}+00$ & & $0.00 \mathrm{E}+00$ \\
\hline & & $0.00 \mathrm{E}+00$ & & $0.00 \mathrm{E}+00$ & $0.00 \mathrm{E}+00$ & $0.00 \mathrm{E}+00$ & $0.00 \mathrm{E}+00$ \\
\hline $.00 E+00$ & $.00 \mathrm{E}+00$ & $.00 E+00$ & $.00 \mathrm{E}+00$ & $.00 \mathrm{E}+00$ & $0.00 \mathrm{E}+00$ & $0.00 \mathrm{E}+00$ & $0.00 \mathrm{E}+00$ \\
\hline
\end{tabular}


RESRAD-OFFSITE, Version 2.5

obabilistic Dose and Risk Report

Title : Offsite Resident Farmer Deterministic Run

File : RF TC99 DOESG FWD-FV2.ROF

Summary of dose at graphical times, reptition 2 (continued)

Time

Years

7. $08 \mathrm{E}+01$

7. $13 \mathrm{E}+01$

7. $18 \mathrm{E}+01$

7. $23 \mathrm{E}+01$

7. $28 \mathrm{E}+01$

7. $33 \mathrm{E}+01$

7. $38 \mathrm{E}+01$

7. $43 \mathrm{E}+01$

7. $49 \mathrm{E}+01$

7. $54 \mathrm{E}+01$

$7.59 \mathrm{E}+01$

7. $64 \mathrm{E}+01$

7. $69 \mathrm{E}+01$

7. $74 \mathrm{E}+01$

7. $79 \mathrm{E}+01$

7. $84 \mathrm{E}+01$

7. $90 \mathrm{E}+01$

7. $95 \mathrm{E}+01$

8. $00 \mathrm{E}+01$

$8.05 \mathrm{E}+01$

$8.10 \mathrm{E}+01$

$8.15 \mathrm{E}+01$

8. $20 \mathrm{E}+01$

$8.25 \mathrm{E}+01$

8. $31 \mathrm{E}+01$

8. $36 \mathrm{E}+01$

8. $41 \mathrm{E}+01$

8. $46 \mathrm{E}+01$

8. $51 \mathrm{E}+01$

8. $56 \mathrm{E}+01$

8. $61 \mathrm{E}+01$

8. $66 \mathrm{E}+01$

$8.72 \mathrm{E}+01$

$8.77 \mathrm{E}+01$

$8.82 \mathrm{E}+01$

$8.87 \mathrm{E}+01$

8. $92 \mathrm{E}+01$

$8.97 \mathrm{E}+01$

$9.02 \mathrm{E}+01$

$9.07 \mathrm{E}+01$

$9.13 \mathrm{E}+01$

$9.18 \mathrm{E}+01$

$9.23 \mathrm{E}+01$

$9.28 \mathrm{E}+01$

9. $33 \mathrm{E}+01$

9. $38 \mathrm{E}+01$
Dose statistics at graphical times, mrem/yr

\begin{tabular}{|c|c|c|c|c|c|c|c|}
\hline inimum & aximum & lean & edian & & & $\%$ & $9 \%$ \\
\hline $.00 E+00$ & $0.00 \mathrm{E}+00$ & $0.00 \mathrm{E}+00$ & $0.00 \mathrm{E}+00$ & $00 \mathrm{E}+00$ & $0.00 \mathrm{E}+00$ & $0.00 \mathrm{E}+00$ & $0.00 \mathrm{E}+00$ \\
\hline $.00 \mathrm{E}+00$ & $0.00 \mathrm{E}+00$ & $.00 \mathrm{E}+00$ & $.00 \mathrm{E}+00$ & $0.00 \mathrm{E}+00$ & $0.00 \mathrm{E}+00$ & $0.00 \mathrm{E}+00$ & $00 \mathrm{E}+00$ \\
\hline $00 \mathrm{E}+00$ & $0 \mathrm{E}+00$ & $00 E+00$ & $00 E+00$ & $00 \mathrm{E}+00$ & $00 E+00$ & 00 & $0 E+00$ \\
\hline+00 & 00 & 00 & 00 & 0 & 0 & 00 & $00 \mathrm{E}+00$ \\
\hline$E+00$ & 0 & & & & & & +00 \\
\hline $00 \mathrm{E}+00$ & & & & & & & $\Xi+00$ \\
\hline$E+00$ & $E+00$ & 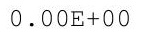 & $\mathrm{E}+00$ & $E+00$ & 0 & +00 & $E+00$ \\
\hline $.00 \mathrm{E}+00$ & $0.00 \mathrm{E}+00$ & $0 \mathrm{E}+00$ & $0 \mathrm{E}+00$ & $00 \mathrm{E}+00$ & $00 \mathrm{E}+00$ & $E+00$ & $00 \mathrm{E}+00$ \\
\hline $00 E+00$ & $00 F+0$ & $00 \mathrm{~F}+\ell-8$ & $.00 E+00$ & $0 \cap \mathrm{F}+$ & $\mathrm{O} \cap \mathrm{F}+\mathrm{r}-\mathrm{s}$ & $00 F+00$ & $00 E+00$ \\
\hline$E+00$ & $0.00 \mathrm{E}+00$ & & & & & 0 & 00 \\
\hline $.00 E+00$ & $0.00 \mathrm{E}+00$ & 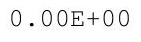 & 00 & 0 & 0 & 0 & $E+00$ \\
\hline $.00 \mathrm{E}+00$ & $0.00 \mathrm{E}+00$ & $0.00 \mathrm{E}+00$ & $0.00 \mathrm{E}+00$ & & & & $0.00 \mathrm{E}+00$ \\
\hline $.00 E+00$ & $0.00 \mathrm{E}+00$ & $0.00 \mathrm{E}+00$ & $0.00 \mathrm{E}+00$ & $0.00 \mathrm{E}+00$ & $0.00 \mathrm{E}+00$ & $E+00$ & $0.00 \mathrm{E}+00$ \\
\hline$E+00$ & $E+00$ & $E+00$ & $E+00$ & & & +00 & $00 \mathrm{E}+00$ \\
\hline $.00 E+00$ & $.00 E+00$ & $.00 E+00$ & $.00 E+00$ & $.00 \mathrm{E}+$ & 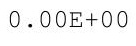 & 0 & +00 \\
\hline$E+00$ & ( & $0.00 \mathrm{E}+00$ & & $0.00 \mathrm{E}+00$ & $00 E+00$ & $E+00$ & 0 \\
\hline $0 \cap F+00$ & $F+00$ & $5+0$ & & & & -00 & 00 \\
\hline $.00 \mathrm{E}+00$ & $0.00 \mathrm{E}+00$ & $0.00 \mathrm{E}+00$ & $0.00 \mathrm{E}+00$ & $0.00 \mathrm{E}+00$ & $0.00 \mathrm{E}+00$ & $0.00 \mathrm{E}+00$ & $.00 \mathrm{E}+00$ \\
\hline $.00 \mathrm{E}+00$ & $.00 \mathrm{E}+00$ & $.00 \mathrm{E}+00$ & $0.00 \mathrm{E}+00$ & $0.00 \mathrm{E}+00$ & $0.00 \mathrm{E}+00$ & $.00 E+00$ & $.00 E+00$ \\
\hline$E+00$ & $00 E+00$ & $00 F+0=$ & $.00 E+00$ & $0 \mathrm{E}+00$ & 0 & $0 \mathrm{E}+00$ & $00 E+00$ \\
\hline 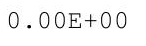 & 然 & $0.00 \mathrm{E}+00$ & $.00 E+00$ & 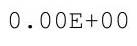 & 0 & 0 & +00 \\
\hline $.00 \mathrm{E}+00$ & . & 然 & & & & & 00 \\
\hline $.00 E+00$ & $.00 \mathrm{E}+00$ & ) & $0 E+00$ & مF+ & 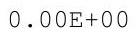 & 0 & $E+00$ \\
\hline $0 \cap F+00$ & COF+O & ) & $0.00 \mathrm{E}+00$ & $.00 \mathrm{E}+00$ & $.00 \mathrm{E}+$ & $00 \mathrm{E}+00$ & $00 E+00$ \\
\hline $00 F+00$ & 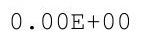 & 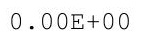 & $0.00 \mathrm{E}+00$ & $.00 \mathrm{E}+00$ & ח & $.00 E+00$ & $.00 \mathrm{E}+00$ \\
\hline$F+00$ & $0.00 \mathrm{E}+00$ & $00 E+00$ & $.00 E+00$ & $0 E+00$ & 0 & $0 E+00$ & $00 E+00$ \\
\hline & & & & & & $E+00$ & \\
\hline & & & & 0.0 & e & & +00 \\
\hline $.00 \mathrm{E}+00$ & $0.00 \mathrm{E}+00$ & $0.00 \mathrm{E}+00$ & $.00 \mathrm{E}+00$ & . & . & $0.00 \mathrm{E}+00$ & $.00 E+00$ \\
\hline $0 \mathrm{E}+00$ & $00 \mathrm{E}+00$ & $0.00 \mathrm{E}+0$ & $0.00 \mathrm{E}+00$ & $0.00 \mathrm{E}+00$ & $0.00 \mathrm{E}+\mathrm{C}$ & $0.00 \mathrm{E}+00$ & $.00 \mathrm{E}+00$ \\
\hline $00 \mathrm{E}+\mathrm{C}$ & $.00 E+00$ & & $0.00 \mathrm{E}+00$ & & & $0.00 \mathrm{E}+00$ & $.00 \mathrm{E}+00$ \\
\hline مि & $00 F+00$ & $0 \cap \cap \cap F+\cap 0$ & $00 F+00$ & $.00 E+00$ & & $0 E+00$ & $.00 E+00$ \\
\hline F & & & & & & & \\
\hline & & & & & & 00 & \\
\hline $.00 E+00$ & $0.00 \mathrm{E}+00$ & $0.00 \mathrm{E}+00$ & $0.00 \mathrm{E}+00$ & $0.00 \mathrm{E}+00$ & . & $0.00 \mathrm{E}+00$ & $.00 \mathrm{E}+00$ \\
\hline • & . & . & & & & & $0.00 \mathrm{E}+00$ \\
\hline 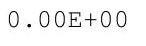 & ( & $0.00 \mathrm{E}+$ & $0.00 \mathrm{E}+$ & $0.00 \mathrm{E}+$ & $0.00 \mathrm{E}$ & $0.00 \mathrm{E}+00$ & $0.00 \mathrm{E}+00$ \\
\hline (1) & & & $0.00 \mathrm{E}+00$ & & & $0.00 \mathrm{E}+00$ & $.00 \mathrm{E}+00$ \\
\hline $0=+0$ & & $0.00 \mathrm{E}+$ & $0.00 \mathrm{E}+00$ & $00 E+00$ & 0 & $0 E+00$ & $00 E+00$ \\
\hline $.00 \mathrm{E}+00$ & $0.00 \mathrm{E}+00$ & $0.00 \mathrm{E}+$ & $0.00 \mathrm{E}$ & $0.00 \mathrm{E}$ & 0 & 00 & $0.00 \mathrm{E}+00$ \\
\hline $\mathrm{E}+00$ & $0.00 \mathrm{E}+00$ & 0.00 & 0 & 0 & & & $00 \mathrm{E}+00$ \\
\hline 年 & . & $0.00 \mathrm{E}+00$ & & $.00 \mathrm{E}+00$ & & & $.00 \mathrm{E}+00$ \\
\hline 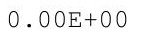 & 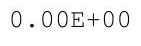 & $0.00 \mathrm{E}+00$ & $0.00 \mathrm{E}+00$ & $0.00 \mathrm{E}+00$ & $0.00 \mathrm{E}+00$ & $0.00 \mathrm{E}+00$ & $0.00 \mathrm{E}+00$ \\
\hline $0 E+00$ & $0.00 \mathrm{E}+00$ & $0.00 \mathrm{E}+00$ & $0.00 \mathrm{E}+00$ & & $0.00 \mathrm{E}+00$ & & $0.00 \mathrm{E}+00$ \\
\hline & & $0.00 \mathrm{E}+00$ & & $0.00 \mathrm{E}+00$ & $0.00 \mathrm{E}+00$ & $0.00 \mathrm{E}+00$ & $0.00 \mathrm{E}+00$ \\
\hline $.00 E+00$ & $.00 \mathrm{E}+00$ & $.00 E+00$ & $.00 \mathrm{E}+00$ & $.00 \mathrm{E}+00$ & $0.00 \mathrm{E}+00$ & $0.00 \mathrm{E}+00$ & $0.00 \mathrm{E}+00$ \\
\hline
\end{tabular}


Probabilistic Dose and Risk Report

Title : Offsite Resident Farmer Deterministic Run

File : RF TC99 DOESG FWD-FV2.ROF

Summary of dose at graphical times, reptition 2 (continued)

Time

Years

9. $43 \mathrm{E}+01$

$9.48 \mathrm{E}+01$

9. $54 \mathrm{E}+01$

$9.59 \mathrm{E}+01$

9. $64 \mathrm{E}+01$

$9.69 \mathrm{E}+01$

$9.74 \mathrm{E}+01$

9. $79 \mathrm{E}+01$

$9.84 \mathrm{E}+01$

9. $90 \mathrm{E}+01$

9. $95 \mathrm{E}+01$

$1.00 \mathrm{E}+02$

$1.00 \mathrm{E}+02$

$1.01 \mathrm{E}+02$

1. $02 \mathrm{E}+02$

$1.02 \mathrm{E}+02$

$1.03 \mathrm{E}+02$

$1.03 \mathrm{E}+02$

1. $04 \mathrm{E}+02$

$1.04 \mathrm{E}+02$

$1.05 \mathrm{E}+02$

$1.05 \mathrm{E}+02$

$1.06 \mathrm{E}+02$

$1.06 \mathrm{E}+02$

$1.07 \mathrm{E}+02$

$1.07 \mathrm{E}+02$

$1.08 \mathrm{E}+02$

$1.08 \mathrm{E}+02$

1. $09 \mathrm{E}+02$

$1.09 \mathrm{E}+02$

1. $10 \mathrm{E}+02$

1. $10 \mathrm{E}+02$

1. $11 \mathrm{E}+02$

1. $11 \mathrm{E}+02$

1. $12 \mathrm{E}+02$

1. $12 \mathrm{E}+02$

1. $13 \mathrm{E}+02$

1. $13 \mathrm{E}+02$

1. $14 \mathrm{E}+02$

1. $14 \mathrm{E}+02$

1. $15 \mathrm{E}+02$

1. $15 \mathrm{E}+02$

$1.16 \mathrm{E}+02$

$1.16 \mathrm{E}+02$

$1.17 \mathrm{E}+02$

1. $17 \mathrm{E}+02$

Dose statistics at graphical times, mrem/yr

\begin{tabular}{|c|c|c|c|c|c|c|c|}
\hline Minimum & Maximum & Mean & Median & $90 \%$ & $95 \%$ & $97.5 \%$ & $99 \%$ \\
\hline $0.00 \mathrm{E}+00$ & $0.00 \mathrm{E}+00$ & $0.00 \mathrm{E}+00$ & $0.00 \mathrm{E}+00$ & $0.00 \mathrm{E}+00$ & $0.00 \mathrm{E}+00$ & $0.00 \mathrm{E}+00$ & $0.00 \mathrm{E}+00$ \\
\hline $0.00 \mathrm{E}+00$ & $0.00 \mathrm{E}+00$ & $0.00 \mathrm{E}+00$ & $0.00 \mathrm{E}+00$ & $0.00 \mathrm{E}+00$ & $0.00 \mathrm{E}+00$ & $0.00 \mathrm{E}+00$ & $0.00 \mathrm{E}+00$ \\
\hline $0.00 \mathrm{E}+00$ & $0.00 \mathrm{E}+00$ & $0.00 E+00$ & $0.00 \mathrm{E}+00$ & $0.00 \mathrm{E}+00$ & $0.00 \mathrm{E}+00$ & $0.00 \mathrm{E}+00$ & $0.00 \mathrm{E}+00$ \\
\hline $0.00 \mathrm{E}+00$ & $0.00 \mathrm{E}+00$ & $0.00 \mathrm{E}+00$ & $0.00 \mathrm{E}+00$ & $0.00 \mathrm{E}+00$ & $0.00 \mathrm{E}+00$ & $0.00 \mathrm{E}+00$ & $0.00 \mathrm{E}+00$ \\
\hline $0.00 \mathrm{E}+00$ & $0.00 \mathrm{E}+00$ & $0.00 \mathrm{E}+00$ & $0.00 \mathrm{E}+00$ & $0.00 \mathrm{E}+00$ & $0.00 \mathrm{E}+00$ & $0.00 \mathrm{E}+00$ & $0.00 \mathrm{E}+00$ \\
\hline $0.00 \mathrm{E}+00$ & $0.00 \mathrm{E}+00$ & $0.00 \mathrm{E}+00$ & $0.00 \mathrm{E}+00$ & $0.00 \mathrm{E}+00$ & $0.00 \mathrm{E}+00$ & $0.00 \mathrm{E}+00$ & $0.00 \mathrm{E}+00$ \\
\hline $0.00 \mathrm{E}+00$ & $0.00 \mathrm{E}+00$ & $0.00 E+00$ & $0.00 E+00$ & $0.00 \mathrm{E}+00$ & $0.00 \mathrm{E}+00$ & $0.00 \mathrm{E}+00$ & $0.00 \mathrm{E}+00$ \\
\hline $0.00 \mathrm{E}+00$ & $0.00 \mathrm{E}+00$ & $0.00 \mathrm{E}+00$ & $0.00 \mathrm{E}+00$ & $0.00 \mathrm{E}+00$ & $0.00 \mathrm{E}+00$ & $0.00 \mathrm{E}+00$ & $0.00 \mathrm{E}+00$ \\
\hline $0.00 \mathrm{E}+00$ & $0.00 \mathrm{E}+00$ & $0.00 \mathrm{E}+00$ & $0.00 \mathrm{E}+00$ & $0.00 E+00$ & $0.00 \mathrm{E}+00$ & $0.00 \mathrm{E}+00$ & $0.00 \mathrm{E}+00$ \\
\hline $00 \mathrm{E}+00$ & $0.00 \mathrm{E}+00$ & $0.00 \mathrm{E}+00$ & $0.00 \mathrm{E}+00$ & $0.00 \mathrm{E}+00$ & $0.00 \mathrm{E}+00$ & $0.00 \mathrm{E}+00$ & $00 \mathrm{E}+00$ \\
\hline $0.00 \mathrm{E}+00$ & $0.00 E+00$ & $0.00 E+00$ & $0.00 \mathrm{E}+00$ & $0.00 \mathrm{E}+00$ & $0.00 \mathrm{E}+00$ & $0.00 \mathrm{E}+00$ & $0.00 \mathrm{E}+00$ \\
\hline $0.00 \mathrm{E}+00$ & $0.00 \mathrm{E}+00$ & $0.00 E+00$ & $0.00 \mathrm{E}+00$ & $0.00 \mathrm{E}+00$ & $0.00 \mathrm{E}+00$ & $0.00 \mathrm{E}+00$ & $0.00 \mathrm{E}+00$ \\
\hline $0.00 \mathrm{E}+00$ & $0.00 E+00$ & $0.00 E+00$ & $0.00 \mathrm{E}+00$ & $0.00 \mathrm{E}+00$ & $0.00 \mathrm{E}+00$ & $0.00 \mathrm{E}+00$ & $0.00 \mathrm{E}+00$ \\
\hline $0.00 \mathrm{E}+00$ & $0.00 \mathrm{E}+00$ & $0.00 E+00$ & $0.00 E+00$ & $0.00 \mathrm{E}+00$ & $0.00 \mathrm{E}+00$ & $0.00 \mathrm{E}+00$ & $0.00 \mathrm{E}+00$ \\
\hline $0.00 \mathrm{E}+00$ & $0.00 \mathrm{E}+00$ & $0.00 E+00$ & $0.00 \mathrm{E}+00$ & $0.00 \mathrm{E}+00$ & $0.00 \mathrm{E}+00$ & $0.00 \mathrm{E}+00$ & $0.00 \mathrm{E}+00$ \\
\hline $0.00 \mathrm{E}+00$ & $0.00 \mathrm{E}+00$ & $0.00 E+00$ & $0.00 E+00$ & $0.00 \mathrm{E}+00$ & $0.00 \mathrm{E}+00$ & $0.00 \mathrm{E}+00$ & $0.00 \mathrm{E}+00$ \\
\hline $0.00 \mathrm{E}+00$ & $0.00 \mathrm{E}+00$ & $0.00 E+00$ & $0.00 \mathrm{E}+00$ & $0.00 \mathrm{E}+00$ & $0.00 \mathrm{E}+00$ & $0.00 \mathrm{E}+00$ & $0.00 \mathrm{E}+00$ \\
\hline $0.00 \mathrm{E}+00$ & $0.00 \mathrm{E}+00$ & $0.00 E+00$ & $0.00 E+00$ & $0.00 \mathrm{E}+00$ & $0.00 \mathrm{E}+00$ & $0.00 \mathrm{E}+00$ & $0.00 \mathrm{E}+00$ \\
\hline $0.00 \mathrm{E}+00$ & $0.00 \mathrm{E}+00$ & $0.00 \mathrm{E}+00$ & $0.00 \mathrm{E}+00$ & $0.00 \mathrm{E}+00$ & $0.00 \mathrm{E}+00$ & $0.00 \mathrm{E}+00$ & $0.00 \mathrm{E}+00$ \\
\hline $0.00 \mathrm{E}+00$ & $0.00 \mathrm{E}+00$ & $0.00 \mathrm{E}+00$ & $0.00 \mathrm{E}+00$ & $0.00 \mathrm{E}+00$ & $0.00 \mathrm{E}+00$ & $0.00 \mathrm{E}+00$ & $0.00 \mathrm{E}+00$ \\
\hline $0.00 \mathrm{E}+00$ & $0.00 \mathrm{E}+00$ & $0.00 \mathrm{E}+00$ & $0.00 \mathrm{E}+00$ & $0.00 \mathrm{E}+00$ & $0.00 \mathrm{E}+00$ & $0.00 \mathrm{E}+00$ & $0.00 \mathrm{E}+00$ \\
\hline $0.00 \mathrm{E}+00$ & $0.00 \mathrm{E}+00$ & $0.00 \mathrm{E}+00$ & $0.00 \mathrm{E}+00$ & $0.00 \mathrm{E}+00$ & $0.00 \mathrm{E}+00$ & $0.00 \mathrm{E}+00$ & $0.00 \mathrm{E}+00$ \\
\hline $0.00 \mathrm{E}+00$ & $0.00 \mathrm{E}+00$ & $0.00 E+00$ & $0.00 \mathrm{E}+00$ & $0.00 \mathrm{E}+00$ & $0.00 \mathrm{E}+00$ & $0.00 \mathrm{E}+00$ & $0.00 \mathrm{E}+00$ \\
\hline $0.00 \mathrm{E}+00$ & $0.00 \mathrm{E}+00$ & $0.00 E+00$ & $0.00 \mathrm{E}+00$ & $0.00 \mathrm{E}+00$ & $0.00 \mathrm{E}+00$ & $0.00 \mathrm{E}+00$ & $0.00 \mathrm{E}+00$ \\
\hline $0.00 \mathrm{E}+00$ & $0.00 \mathrm{E}+00$ & $0.00 \mathrm{E}+00$ & $0.00 \mathrm{E}+00$ & $0.00 \mathrm{E}+00$ & $0.00 \mathrm{E}+00$ & $0.00 \mathrm{E}+00$ & $0.00 \mathrm{E}+00$ \\
\hline $0.00 \mathrm{E}+00$ & $0.00 \mathrm{E}+00$ & $0.00 E+00$ & $0.00 \mathrm{E}+00$ & $0.00 \mathrm{E}+00$ & $0.00 \mathrm{E}+00$ & $0.00 \mathrm{E}+00$ & $0.00 \mathrm{E}+00$ \\
\hline $0.00 \mathrm{E}+00$ & $0.00 \mathrm{E}+00$ & $0.00 \mathrm{E}+00$ & $0.00 \mathrm{E}+00$ & $0.00 \mathrm{E}+00$ & $0.00 \mathrm{E}+00$ & $0.00 \mathrm{E}+00$ & $0.00 \mathrm{E}+00$ \\
\hline $0.00 \mathrm{E}+00$ & $0.00 \mathrm{E}+00$ & $0.00 \mathrm{E}+00$ & $0.00 \mathrm{E}+00$ & $0.00 \mathrm{E}+00$ & $0.00 \mathrm{E}+00$ & $0.00 \mathrm{E}+00$ & $0.00 \mathrm{E}+00$ \\
\hline $0.00 \mathrm{E}+00$ & $0.00 \mathrm{E}+00$ & $0.00 \mathrm{E}+00$ & $0.00 \mathrm{E}+00$ & $0.00 E+00$ & $0.00 \mathrm{E}+00$ & $0.00 \mathrm{E}+00$ & $0.00 \mathrm{E}+00$ \\
\hline $0.00 \mathrm{E}+00$ & $4.23 E-23$ & $2.12 \mathrm{E}-26$ & $0.00 \mathrm{E}+00$ & $0.00 \mathrm{E}+00$ & $0.00 \mathrm{E}+00$ & $0.00 \mathrm{E}+00$ & $0.00 \mathrm{E}+00$ \\
\hline $0.00 \mathrm{E}+00$ & $9.08 E-21$ & $4.57 E-24$ & $0.00 \mathrm{E}+00$ & $0.00 \mathrm{E}+00$ & $0.00 \mathrm{E}+00$ & $0.00 \mathrm{E}+00$ & $0.00 \mathrm{E}+00$ \\
\hline $0.00 \mathrm{E}+00$ & $5.02 E-19$ & $2.61 E-22$ & $0.00 \mathrm{E}+00$ & $0.00 \mathrm{E}+00$ & $0.00 \mathrm{E}+00$ & $0.00 \mathrm{E}+00$ & $0.00 \mathrm{E}+00$ \\
\hline $0.00 \mathrm{E}+00$ & $1.26 \mathrm{E}-17$ & $6.96 \mathrm{E}-21$ & $0.00 \mathrm{E}+00$ & $0.00 \mathrm{E}+00$ & $0.00 \mathrm{E}+00$ & $0.00 \mathrm{E}+00$ & $0.00 \mathrm{E}+00$ \\
\hline $0.00 \mathrm{E}+00$ & $1.82 \mathrm{E}-16$ & 1.09E-19 & $0.00 \mathrm{E}+00$ & $0.00 \mathrm{E}+00$ & $0.00 \mathrm{E}+00$ & $0.00 \mathrm{E}+00$ & $0.00 \mathrm{E}+00$ \\
\hline $0.00 \mathrm{E}+00$ & $1.76 \mathrm{E}-15$ & 1. $14 \mathrm{E}-18$ & $0.00 \mathrm{E}+00$ & $0.00 \mathrm{E}+00$ & $0.00 \mathrm{E}+00$ & $0.00 \mathrm{E}+00$ & $0.00 \mathrm{E}+00$ \\
\hline $0.00 \mathrm{E}+00$ & 1. $25 \mathrm{E}-14$ & $8.75 E-18$ & $0.00 \mathrm{E}+00$ & $0.00 \mathrm{E}+00$ & $0.00 \mathrm{E}+00$ & $0.00 \mathrm{E}+00$ & $0.00 \mathrm{E}+00$ \\
\hline $0.00 \mathrm{E}+00$ & $6.94 \mathrm{E}-14$ & $5.19 \mathrm{E}-17$ & $0.00 \mathrm{E}+00$ & $0.00 \mathrm{E}+00$ & $0.00 \mathrm{E}+00$ & $0.00 \mathrm{E}+00$ & $0.00 \mathrm{E}+00$ \\
\hline $0.00 \mathrm{E}+00$ & $3.13 \mathrm{E}-13$ & $48 E-16$ & $0.00 \mathrm{E}+00$ & $0.00 \mathrm{E}+00$ & $0.00 \mathrm{E}+00$ & $0.00 \mathrm{E}+00$ & $0.00 \mathrm{E}+00$ \\
\hline $0.00 \mathrm{E}+00$ & 1 & -16 & $0.00 \mathrm{E}+00$ & $0.00 \mathrm{E}+00$ & $0.00 \mathrm{E}+00$ & $0.00 \mathrm{E}+00$ & $0.00 \mathrm{E}+00$ \\
\hline $0.00 \mathrm{E}+00$ & $3.91 \mathrm{E}-12$ & $3.38 E-15$ & $0.00 \mathrm{E}+00$ & $0.00 E+00$ & $0.00 \mathrm{E}+00$ & $0.00 \mathrm{E}+00$ & $0.00 \mathrm{E}+00$ \\
\hline $0.00 \mathrm{E}+00$ & $1.14 \mathrm{E}-11$ & 1.01E-14 & $0.00 \mathrm{E}+00$ & $0.00 \mathrm{E}+00$ & $0.00 \mathrm{E}+00$ & $0.00 \mathrm{E}+00$ & $0.00 \mathrm{E}+00$ \\
\hline $0.00 \mathrm{E}+00$ & $2.98 E-11$ & $2.70 E-14$ & $0.00 \mathrm{E}+00$ & $0.00 \mathrm{E}+00$ & $0.00 \mathrm{E}+00$ & $0.00 \mathrm{E}+00$ & $0.00 \mathrm{E}+00$ \\
\hline $0.00 \mathrm{E}+00$ & $7.11 \mathrm{E}-11$ & $6.57 E-14$ & $0.00 \mathrm{E}+00$ & $0.00 \mathrm{E}+00$ & $0.00 \mathrm{E}+00$ & $0.00 \mathrm{E}+00$ & $0.00 \mathrm{E}+00$ \\
\hline $0.00 \mathrm{E}+00$ & 1. 57E-10 & $1.47 E-13$ & $0.00 \mathrm{E}+00$ & $0.00 \mathrm{E}+00$ & $0.00 \mathrm{E}+00$ & $0.00 \mathrm{E}+00$ & $0.00 \mathrm{E}+00$ \\
\hline $0.00 \mathrm{E}+00$ & $3.26 \mathrm{E}-10$ & $3.08 E-13$ & $0.00 \mathrm{E}+00$ & $0.00 \mathrm{E}+00$ & $0.00 \mathrm{E}+00$ & $0.00 \mathrm{E}+00$ & $0.00 \mathrm{E}+00$ \\
\hline $0.00 \mathrm{E}+00$ & $6.36 \mathrm{E}-10$ & $6.05 E-13$ & $0.00 \mathrm{E}+00$ & $0.00 \mathrm{E}+00$ & $0.00 \mathrm{E}+00$ & $0.00 \mathrm{E}+00$ & $0.00 \mathrm{E}+00$ \\
\hline
\end{tabular}


RESRAD-OFFSITE, Version 2.5

itle : Offsite Resident Farmer Deterministic Run

File : RF TC99 DOESG FWD-FV2.ROF

Summary of dose at graphical times, reptition 2 (continued)

Time

Years

$1.18 \mathrm{E}+02$

$1.18 \mathrm{E}+02$

$1.19 \mathrm{E}+02$

1.19E+02

1. $20 \mathrm{E}+02$

1. $20 \mathrm{E}+02$

1. $21 \mathrm{E}+02$

1. $22 \mathrm{E}+02$

1. $22 \mathrm{E}+02$

1. $23 \mathrm{E}+02$

1. $23 \mathrm{E}+02$

1. $24 \mathrm{E}+02$

1. $24 \mathrm{E}+02$

1. $25 \mathrm{E}+02$

1. $25 \mathrm{E}+02$

1. $26 \mathrm{E}+02$

1. $26 \mathrm{E}+02$

1. $27 \mathrm{E}+02$

1. $27 \mathrm{E}+02$

1. $28 \mathrm{E}+02$

1. $28 \mathrm{E}+02$

1. $29 \mathrm{E}+02$

1. $29 \mathrm{E}+02$

1. $30 \mathrm{E}+02$

1. $30 \mathrm{E}+02$

1. $31 \mathrm{E}+02$

1. $31 \mathrm{E}+02$

1. $32 \mathrm{E}+02$

1. $32 \mathrm{E}+02$

1. $33 \mathrm{E}+02$

1. $33 \mathrm{E}+02$

1. $34 \mathrm{E}+02$

1. $34 \mathrm{E}+02$

1. $35 \mathrm{E}+02$

1. $35 \mathrm{E}+02$

1. $36 \mathrm{E}+02$

1. $36 \mathrm{E}+02$

1. $37 \mathrm{E}+02$

1. $37 \mathrm{E}+02$

1. $38 \mathrm{E}+02$

1. $38 \mathrm{E}+02$

1. $39 \mathrm{E}+02$

1. $39 \mathrm{E}+02$

1. $40 \mathrm{E}+02$

1. $40 \mathrm{E}+02$

1. $41 \mathrm{E}+02$

Dose statistics at graphical times, mrem/yr

\begin{tabular}{|c|c|c|c|c|c|c|c|}
\hline Minimum & Maximum & Mean & Median & $90 \%$ & $95 \%$ & $97.5 \%$ & $99 \%$ \\
\hline $0.00 \mathrm{E}+00$ & 1.18E-09 & $1.13 E-12$ & $0.00 \mathrm{E}+00$ & $0.00 \mathrm{E}+00$ & $0.00 \mathrm{E}+00$ & $0.00 \mathrm{E}+00$ & $0.00 \mathrm{E}+00$ \\
\hline $0.00 \mathrm{E}+00$ & $2.09 E-09$ & $2.01 E-12$ & $0.00 \mathrm{E}+00$ & $0.00 \mathrm{E}+00$ & $0.00 \mathrm{E}+00$ & $0.00 \mathrm{E}+00$ & $0.00 \mathrm{E}+00$ \\
\hline $0.00 \mathrm{E}+00$ & $3.57 \mathrm{E}-09$ & 3. $45 \mathrm{E}-12$ & $0.00 \mathrm{E}+00$ & $0.00 \mathrm{E}+00$ & $0.00 \mathrm{E}+00$ & $0.00 \mathrm{E}+00$ & $0.00 \mathrm{E}+00$ \\
\hline $0.00 \mathrm{E}+00$ & $5.89 \mathrm{E}-09$ & $5.72 \mathrm{E}-12$ & $0.00 \mathrm{E}+00$ & $0.00 \mathrm{E}+00$ & $0.00 \mathrm{E}+00$ & $0.00 \mathrm{E}+00$ & $0.00 \mathrm{E}+00$ \\
\hline $0.00 \mathrm{E}+00$ & $9.42 E-09$ & $9.18 \mathrm{E}-12$ & $0.00 \mathrm{E}+00$ & $0.00 \mathrm{E}+00$ & $0.00 \mathrm{E}+00$ & $0.00 \mathrm{E}+00$ & $0.00 \mathrm{E}+00$ \\
\hline $0.00 \mathrm{E}+00$ & 1. $46 \mathrm{E}-08$ & $1.43 \mathrm{E}-11$ & $0.00 \mathrm{E}+00$ & $0.00 \mathrm{E}+00$ & $0.00 \mathrm{E}+00$ & $0.00 \mathrm{E}+00$ & $0.00 \mathrm{E}+00$ \\
\hline $0.00 \mathrm{E}+00$ & $2.22 \mathrm{E}-08$ & $2.18 \mathrm{E}-11$ & $0.00 \mathrm{E}+00$ & $0.00 \mathrm{E}+00$ & $0.00 \mathrm{E}+00$ & $0.00 \mathrm{E}+00$ & $0.00 \mathrm{E}+00$ \\
\hline $0.00 \mathrm{E}+00$ & $3.28 E-08$ & $3.25 E-11$ & $0.00 E+00$ & $0.00 \mathrm{E}+00$ & $0.00 \mathrm{E}+00$ & $0.00 \mathrm{E}+00$ & $0.00 \mathrm{E}+00$ \\
\hline $0.00 \mathrm{E}+00$ & $4.76 \mathrm{E}-08$ & $4.76 \mathrm{E}-11$ & $0.00 \mathrm{E}+00$ & $0.00 \mathrm{E}+00$ & $0.00 \mathrm{E}+00$ & $0.00 \mathrm{E}+00$ & $0.00 \mathrm{E}+00$ \\
\hline $0.00 \mathrm{E}+00$ & $6.77 \mathrm{E}-08$ & $6.83 \mathrm{E}-11$ & $0.00 \mathrm{E}+00$ & $0.00 \mathrm{E}+00$ & $0.00 \mathrm{E}+00$ & $0.00 \mathrm{E}+00$ & $0.00 \mathrm{E}+00$ \\
\hline $0.00 \mathrm{E}+00$ & $9.46 \mathrm{E}-08$ & $9.67 \mathrm{E}-11$ & $0.00 \mathrm{E}+00$ & $0.00 \mathrm{E}+00$ & $0.00 \mathrm{E}+00$ & $0.00 \mathrm{E}+00$ & $0.00 \mathrm{E}+00$ \\
\hline $0.00 \mathrm{E}+00$ & $1.30 \mathrm{E}-07$ & 1. $35 \mathrm{E}-10$ & $0.00 \mathrm{E}+00$ & $0.00 \mathrm{E}+00$ & $0.00 \mathrm{E}+00$ & $0.00 \mathrm{E}+00$ & $0.00 \mathrm{E}+00$ \\
\hline $0.00 \mathrm{E}+00$ & $1.76 \mathrm{E}-07$ & $1.86 \mathrm{E}-10$ & $0.00 \mathrm{E}+00$ & $0.00 \mathrm{E}+00$ & $0.00 \mathrm{E}+00$ & $0.00 \mathrm{E}+00$ & $0.00 \mathrm{E}+00$ \\
\hline $0.00 \mathrm{E}+00$ & $2.35 E-07$ & $2.53 \mathrm{E}-10$ & $0.00 \mathrm{E}+00$ & $0.00 \mathrm{E}+00$ & $0.00 \mathrm{E}+00$ & $0.00 \mathrm{E}+00$ & $0.00 \mathrm{E}+00$ \\
\hline $0.00 \mathrm{E}+00$ & $3.10 \mathrm{E}-07$ & $3.40 \mathrm{E}-10$ & $0.00 \mathrm{E}+00$ & $0.00 \mathrm{E}+00$ & $0.00 \mathrm{E}+00$ & $0.00 \mathrm{E}+00$ & $0.00 \mathrm{E}+00$ \\
\hline $0.00 \mathrm{E}+00$ & $4.04 \mathrm{E}-07$ & $4.53 E-10$ & $0.00 \mathrm{E}+00$ & $0.00 \mathrm{E}+00$ & $00 E+00$ & $\mathrm{DE}+00$ & $6 E-23$ \\
\hline $0.00 \mathrm{E}+00$ & $5.20 \mathrm{E}-07$ & $5.99 \mathrm{E}-10$ & $0.00 \mathrm{E}+00$ & $0.00 \mathrm{E}+00$ & $0.00 \mathrm{E}+00$ & $0.00 \mathrm{E}+00$ & $4.53 E-21$ \\
\hline $0.00 \mathrm{E}+00$ & $6.62 \mathrm{E}-07$ & $7.84 \mathrm{E}-10$ & $0.00 \mathrm{E}+00$ & $0.00 \mathrm{E}+00$ & $0.00 \mathrm{E}+00$ & $0.00 \mathrm{E}+00$ & $3.11 E-19$ \\
\hline $0.00 \mathrm{E}+00$ & $8.35 E-07$ & $1.02 \mathrm{E}-09$ & $0.00 \mathrm{E}+00$ & $0.00 \mathrm{E}+00$ & $0.00 \mathrm{E}+00$ & $0.00 \mathrm{E}+00$ & $8.94 \mathrm{E}-18$ \\
\hline $0.00 \mathrm{E}+00$ & $1.04 \mathrm{E}-06$ & $1.31 \mathrm{E}-09$ & $0.00 \mathrm{E}+00$ & $0.00 \mathrm{E}+00$ & $0.00 \mathrm{E}+00$ & $0.00 \mathrm{E}+00$ & $1.42 \mathrm{E}-16$ \\
\hline $0.00 \mathrm{E}+00$ & $1.29 \mathrm{E}-06$ & $1.68 \mathrm{E}-09$ & $0.00 \mathrm{E}+00$ & $0.00 \mathrm{E}+00$ & $0.00 \mathrm{E}+00$ & $0.00 \mathrm{E}+00$ & $1.48 \mathrm{E}-15$ \\
\hline $0.00 \mathrm{E}+00$ & $1.59 \mathrm{E}-06$ & $2.14 \mathrm{E}-09$ & $0.00 \mathrm{E}+00$ & $0.00 \mathrm{E}+00$ & $0.00 \mathrm{E}+00$ & $0.00 \mathrm{E}+00$ & $1.12 \mathrm{E}-14$ \\
\hline $0.00 \mathrm{E}+00$ & $1.93 E-06$ & $2.70 \mathrm{E}-09$ & $0.00 \mathrm{E}+00$ & $0.00 \mathrm{E}+00$ & $0.00 \mathrm{E}+00$ & $0.00 \mathrm{E}+00$ & $6.61 \mathrm{E}-14$ \\
\hline $0.00 \mathrm{E}+00$ & $2.34 \mathrm{E}-06$ & $3.39 E-09$ & $0.00 \mathrm{E}+00$ & $0.00 \mathrm{E}+00$ & $0.00 \mathrm{E}+00$ & $0.00 \mathrm{E}+00$ & $3.15 \mathrm{E}-13$ \\
\hline $0.00 \mathrm{E}+00$ & $2.81 \mathrm{E}-06$ & $4.23 E-09$ & $0.00 \mathrm{E}+00$ & $0.00 \mathrm{E}+00$ & $0.00 \mathrm{E}+00$ & $0.00 \mathrm{E}+00$ & 1. $26 \mathrm{E}-12$ \\
\hline $0.00 \mathrm{E}+00$ & $3.35 E-06$ & $5.25 E-09$ & $0.00 \mathrm{E}+00$ & $0.00 \mathrm{E}+00$ & $0.00 \mathrm{E}+00$ & $0.00 \mathrm{E}+00$ & 4. $34 \mathrm{E}-12$ \\
\hline $0.00 \mathrm{E}+00$ & $3.97 \mathrm{E}-06$ & $6.47 E-09$ & $0.00 \mathrm{E}+00$ & $0.00 \mathrm{E}+00$ & $0.00 \mathrm{E}+00$ & $0.00 \mathrm{E}+00$ & 1. $32 \mathrm{E}-11$ \\
\hline $0.00 \mathrm{E}+00$ & $4.68 \mathrm{E}-06$ & $7.93 E-09$ & $0.00 \mathrm{E}+00$ & $0.00 \mathrm{E}+00$ & $0.00 \mathrm{E}+00$ & $0.00 \mathrm{E}+00$ & $3.59 \mathrm{E}-11$ \\
\hline $0.00 \mathrm{E}+00$ & $5.49 \mathrm{E}-06$ & $9.67 \mathrm{E}-09$ & $0.00 \mathrm{E}+00$ & $0.00 \mathrm{E}+00$ & $0.00 \mathrm{E}+00$ & $0.00 \mathrm{E}+00$ & $8.90 \mathrm{E}-11$ \\
\hline $0.00 \mathrm{E}+00$ & $6.40 E-06$ & $1.17 \mathrm{E}-08$ & $0.00 \mathrm{E}+00$ & $0.00 \mathrm{E}+00$ & $0.00 \mathrm{E}+00$ & $0.00 \mathrm{E}+00$ & $2.03 E-10$ \\
\hline $0.00 \mathrm{E}+00$ & $7.61 \mathrm{E}-06$ & $1.41 \mathrm{E}-08$ & $0.00 \mathrm{E}+00$ & $0.00 \mathrm{E}+00$ & $0.00 \mathrm{E}+00$ & $0.00 \mathrm{E}+00$ & $4.34 \mathrm{E}-10$ \\
\hline $0.00 \mathrm{E}+00$ & $9.40 \mathrm{E}-06$ & 1. $70 \mathrm{E}-08$ & $0.00 \mathrm{E}+00$ & $0.00 \mathrm{E}+00$ & $0.00 \mathrm{E}+00$ & $0.00 \mathrm{E}+00$ & $8.56 \mathrm{E}-10$ \\
\hline $0.00 \mathrm{E}+00$ & $5-05$ & $3 E-08$ & $0.00 \mathrm{E}+00$ & $0.00 \mathrm{E}+00$ & $0.00 \mathrm{E}+00$ & $0.00 \mathrm{E}+00$ & $.50 E-09$ \\
\hline $0.00 \mathrm{E}+00$ & $1.40 \mathrm{E}-05$ & $2.41 \mathrm{E}-08$ & $0.00 \mathrm{E}+00$ & $0.00 \mathrm{E}+00$ & $0.00 \mathrm{E}+00$ & $0.00 \mathrm{E}+00$ & $2.53 E-09$ \\
\hline $0.00 \mathrm{E}+00$ & $1.69 \mathrm{E}-05$ & $2.85 E-08$ & $0.00 \mathrm{E}+00$ & $0.00 \mathrm{E}+00$ & $0.00 \mathrm{E}+00$ & $0.00 \mathrm{E}+00$ & $4.15 E-09$ \\
\hline $0.00 \mathrm{E}+00$ & $2.03 E-05$ & $3.36 \mathrm{E}-08$ & $0.00 \mathrm{E}+00$ & $0.00 \mathrm{E}+00$ & $0.00 \mathrm{E}+00$ & $0.00 \mathrm{E}+00$ & $6.61 \mathrm{E}-09$ \\
\hline $0.00 \mathrm{E}+00$ & $2.41 E-05$ & $3.94 \mathrm{E}-08$ & $0.00 \mathrm{E}+00$ & $0.00 \mathrm{E}+00$ & $0.00 \mathrm{E}+00$ & $0.00 \mathrm{E}+00$ & $1.03 E-08$ \\
\hline $0.00 \mathrm{E}+00$ & $2.86 \mathrm{E}-05$ & $4.61 \mathrm{E}-08$ & $0.00 \mathrm{E}+00$ & $0.00 \mathrm{E}+00$ & $0.00 \mathrm{E}+00$ & $0.00 \mathrm{E}+00$ & $1.56 \mathrm{E}-08$ \\
\hline $00 E+00$ & $3.36 \mathrm{E}-$ & $5.36 \mathrm{E}$ & $0.00 \mathrm{E}+00$ & $0.00 \mathrm{E}+00$ & $0.00 \mathrm{E}+00$ & $0.00 \mathrm{E}+00$ & $2.32 E-08$ \\
\hline $0.00 \mathrm{E}+00$ & $3.93 E-05$ & $6.21 \mathrm{E}-08$ & $0.00 \mathrm{E}+00$ & $0.00 \mathrm{E}+00$ & $0.00 \mathrm{E}+00$ & $1.09 \mathrm{E}-21$ & $3.38 E-08$ \\
\hline $0.00 \mathrm{E}+00$ & $4.58 E-05$ & $7.17 \mathrm{E}-08$ & $0.00 \mathrm{E}+00$ & $0.00 \mathrm{E}+00$ & $0.00 \mathrm{E}+00$ & $1.37 \mathrm{E}-19$ & $4.84 \mathrm{E}-08$ \\
\hline $0.00 \mathrm{E}+00$ & $5.30 \mathrm{E}-05$ & $8.25 E-08$ & $0.00 \mathrm{E}+00$ & $0.00 \mathrm{E}+00$ & $0.00 \mathrm{E}+00$ & $4.97 \mathrm{E}-18$ & $6.82 \mathrm{E}-08$ \\
\hline $0.00 \mathrm{E}+00$ & $6.11 \mathrm{E}-05$ & $9.46 \mathrm{E}-08$ & $0.00 \mathrm{E}+00$ & $0.00 \mathrm{E}+00$ & $0.00 \mathrm{E}+00$ & $9.01 \mathrm{E}-17$ & $9.44 \mathrm{E}-08$ \\
\hline $0.00 \mathrm{E}+00$ & $7.00 E-05$ & $1.08 \mathrm{E}-07$ & $0.00 \mathrm{E}+00$ & $0.00 \mathrm{E}+00$ & $0.00 \mathrm{E}+00$ & $1.03 E-15$ & $1.29 \mathrm{E}-07$ \\
\hline $0.00 \mathrm{E}+00$ & $8.00 E-05$ & $1.23 E-07$ & $0.00 E+00$ & $0.00 \mathrm{E}+00$ & $0.00 \mathrm{E}+00$ & $8.27 E-15$ & $1.73 E-07$ \\
\hline $0.00 \mathrm{E}+00$ & $9.10 E-05$ & $1.40 \mathrm{E}-07$ & $0.00 \mathrm{E}+00$ & $0.00 \mathrm{E}+00$ & $0.00 \mathrm{E}+00$ & $5.07 \mathrm{E}-14$ & $2.30 \mathrm{E}-07$ \\
\hline
\end{tabular}


RESRAD-OFFSITE, Version 2.5

$\mathrm{T}^{1 / 2}$ Limit $=180$ days

obabilistic Dose and Risk Report

Title : Offsite Resident Farmer Deterministic Run

File : RF TC99 DOESG FWD-FV2.ROF

Summary of dose at graphical times, reptition 2 (continued)

Time

Years

1. $42 \mathrm{E}+02$

1. $42 \mathrm{E}+02$

1. $43 \mathrm{E}+02$

1. $43 \mathrm{E}+02$

1. $44 \mathrm{E}+02$

1. $44 \mathrm{E}+02$

1. $45 \mathrm{E}+02$

1. $45 \mathrm{E}+02$

1. $46 \mathrm{E}+02$

1. $46 \mathrm{E}+02$

1. $47 \mathrm{E}+02$

1. $47 \mathrm{E}+02$

1. $48 \mathrm{E}+02$

1. $48 \mathrm{E}+02$

1. $49 \mathrm{E}+02$

1. $49 \mathrm{E}+02$

1. $50 \mathrm{E}+02$

1. $50 \mathrm{E}+02$

1. $51 \mathrm{E}+02$

1. $51 \mathrm{E}+02$

1. $52 \mathrm{E}+02$

1. $52 \mathrm{E}+02$

1. $53 \mathrm{E}+02$

1. $53 \mathrm{E}+02$

$1.54 \mathrm{E}+02$

$1.54 \mathrm{E}+02$

1. $55 \mathrm{E}+02$

1. $55 \mathrm{E}+02$

1. $56 \mathrm{E}+02$

1. $56 \mathrm{E}+02$

1. $57 \mathrm{E}+02$

1. $57 \mathrm{E}+02$

1. $58 \mathrm{E}+02$

1. $58 \mathrm{E}+02$

1. $59 \mathrm{E}+02$

1. $59 \mathrm{E}+02$

1. $60 \mathrm{E}+02$

1. $60 \mathrm{E}+02$

1. $61 \mathrm{E}+02$

1. $61 \mathrm{E}+02$

1. $62 \mathrm{E}+02$

1. $63 \mathrm{E}+02$

1. $63 \mathrm{E}+02$

1. $64 \mathrm{E}+02$

1. $64 \mathrm{E}+02$

1. $65 \mathrm{E}+02$
Dose statistics at graphical times, mrem/yr

\begin{tabular}{|c|c|c|c|c|c|c|c|}
\hline inimum & aximum & lean & edian & & & & \\
\hline+00 & 04 & -07 & +00 & +00 & 0 & 13 & -07 \\
\hline $.00 \mathrm{E}+00$ & $1.17 \mathrm{E}-04$ & $1.79 \mathrm{E}-07$ & $00 \mathrm{E}+00$ & $0.00 \mathrm{E}+00$ & $0.00 \mathrm{E}+00$ & -13 & $2 E-07$ \\
\hline $0 F+00$ & $31 \mathrm{E}-04$ & $01 \mathrm{~F}-07$ & $.00 E+00$ & $0 \mathrm{E}+00$ & $0 \mathrm{E}+00$ & $07 E-12$ & 07 \\
\hline+00 & & $2.26 \mathrm{E}-07$ & & & & 2 & -07 \\
\hline $\mathrm{E}+00$ & 04 & $2.53 \mathrm{E}-07$ & & & & & -07 \\
\hline $00 \mathrm{E}+00$ & 04 & 0 & & & & & -06 \\
\hline$E+00$ & 04 & 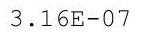 & $\mathrm{E}+00$ & $E+00$ & 0 & -10 & $4 \mathrm{E}-06$ \\
\hline $.00 \mathrm{E}+00$ & $2.26 \mathrm{E}-04$ & $1 \mathrm{E}-07$ & $0 \mathrm{E}+00$ & $00 \mathrm{E}+00$ & $00 \mathrm{E}+00$ & $E-10$ & $53 E-06$ \\
\hline $00 \mathrm{E}+00$ & 4 & -0 & $.00 E+00$ & $0 \cap \mathrm{F}+$ & + & -10 & 06 \\
\hline$E+00$ & $2.75 E-04$ & $4.32 E-07$ & & & & 0 & 6 \\
\hline $.00 E+00$ & 3.0 & 4.7 & 0 & 0 & 0 & 9 & -06 \\
\hline $.00 \mathrm{E}+00$ & $3.32 \mathrm{E}-04$ & $5.27 \mathrm{E}-07$ & & & & & $50 E-06$ \\
\hline $.00 E+00$ & $3.63 E-04$ & $5.81 E-07$ & $0.00 \mathrm{E}+00$ & $0.00 \mathrm{E}+00$ & $0.00 \mathrm{E}+00$ & $E-09$ & $22 E-06$ \\
\hline $\mathrm{E}+00$ & 4 & & & & & -09 & -06 \\
\hline $.00 E+00$ & 4 & . & $.00 \mathrm{E}+$ & $\mathrm{EE}+00$ & 0 & 9 & -06 \\
\hline $\mathrm{OE}+00$ & 4 & $7.69 \mathrm{E}-07$ & 0 & D & & 8 & 6 \\
\hline $0 \cap F+00$ & 5 & $8.41 E-07$ & $E+00$ & & & 8 & -06 \\
\hline $.00 \mathrm{E}+00$ & $5.54 \mathrm{E}-04$ & $9.19 \mathrm{E}-07$ & $0.00 \mathrm{E}+00$ & $0.00 \mathrm{E}+00$ & $0.00 \mathrm{E}+00$ & $E-08$ & $9.24 \mathrm{E}-06$ \\
\hline $.00 \mathrm{E}+00$ & $6.00 \mathrm{E}-04$ & $0 F-06$ & $0.00 \mathrm{E}+00$ & $0.00 \mathrm{E}+00$ & 3 & $5 E-08$ & $05 E-05$ \\
\hline$E+00$ & $6.48 E-04$ & $9 E-06$ & $.00 E+00$ & 0 & -20 & -08 & $19 E-05$ \\
\hline & & & & +00 & & & -05 \\
\hline $.00 \mathrm{E}+00$ & . & cos & & & & & 05 \\
\hline $.00 E+00$ & 04 & 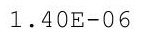 & $0 E+00$ & & & 7 & -05 \\
\hline $.00 E+00$ & $1 \mathrm{~F}$ & $25-0$ & $.00 \mathrm{E}+00$ & $0 \mathrm{E}+\mathrm{C}$ & 50 & $70 E-07$ & $15 E-05$ \\
\hline $.00 \mathrm{E}+00$ & $345-04$ & $65=-0$ & $0.00 \mathrm{E}+00$ & $.00 \mathrm{E}+00$ & $69 \mathrm{E}-14$ & $.18 E-07$ & $.46 E-05$ \\
\hline$E+00$ & $100 F-03$ & & $.00 E+00$ & & & $1 E-07$ & $.81 E-05$ \\
\hline & 3 & & & & & & $E-05$ \\
\hline & & & & & & 07 & 05 \\
\hline $.00 \mathrm{E}+00$ & $1.22 \mathrm{E}-03$ & $2 \cdot 24+00$ & $0.00 \mathrm{E}+00$ & $.00 \mathrm{E}+00$ & $1.01 \mathrm{E}-11$ & $5.64 \mathrm{E}-07$ & $4.04 \mathrm{E}-05$ \\
\hline $00 \mathrm{E}+00$ & 3 & $41 E-06$ & $0.00 \mathrm{E}+00$ & $0.00 \mathrm{E}+00$ & $2.67 E-11$ & $7.04 \mathrm{E}-07$ & $.48 E-05$ \\
\hline $00 \mathrm{E}+$ & 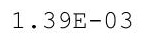 & $.59 E-06$ & & & & $8.88 E-07$ & $.95 E-05$ \\
\hline $.00 E+00$ & $18=0$ & $.78 E-06$ & $.00 E+00$ & $.00 E+00$ & $1 \quad 11=$ & & $7 E-05$ \\
\hline 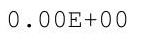 & 1 & & & & & & 05 \\
\hline & 1 . & 06 & & & 10 & -06 & 05 \\
\hline $.00 E+00$ & $1.77 \mathrm{E}-03$ & $3.45 \mathrm{E}-0$ & $.00 \mathrm{E}+00$ & $0.00 \mathrm{E}+00$ & $.13 E-09$ & $2.06 E-06$ & $.27 E-05$ \\
\hline •. & $\begin{array}{c}1.010 \\
0\end{array}$ & 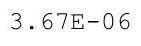 & & & & & $7.97 \mathrm{E}-05$ \\
\hline 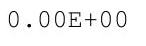 & 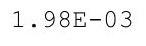 & 6 & $0.00 \mathrm{E}+00$ & $0.00 \mathrm{E}+$ & 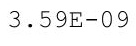 & & $73 E-05$ \\
\hline ب & $2.10 \mathrm{E}-03$ & . & $0.00 \mathrm{E}+00$ & $0.00 \mathrm{E}+00$ & 9 & 6 & 05 \\
\hline & & 6 & & $.00 E+00$ & 9 & 6 & 4 \\
\hline $0 \mathrm{E}+00$ & $2.35 E-03$ & $3 E-06$ & $0.00 \mathrm{E}+00$ & 0. & 08 & 06 & 04 \\
\hline $.00 \mathrm{E}+00$ & $2.48 E-03$ & 3 & 0 & 0 & & & $22 E-04$ \\
\hline 年 & OL- & & & $.00 \mathrm{E}+00$ & & & L. $32 E-04$ \\
\hline 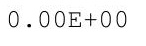 & $2 \cdot 10 \mathrm{~L}-0 \mathrm{~s}$ & 解 & $0.00 \mathrm{E}+00$ & $0.00 \mathrm{E}+00$ & $4.31 E-08$ & $7.28 E-06$ & $1.42 \mathrm{E}-04$ \\
\hline $00 \mathrm{E}+00$ & $2.90 \mathrm{E}-03$ & & & $0.00 \mathrm{E}+00$ & & & $1.53 E-04$ \\
\hline & & & & $0.00 \mathrm{E}+00$ & • & $9.44 \mathrm{E}-06$ & $1.64 \mathrm{E}-04$ \\
\hline $.00 E+00$ & $21 E-03$ & $.93 E-06$ & $.00 \mathrm{E}+00$ & $.00 E+00$ & $1.06 \mathrm{E}-07$ & 7E-05 & $1.76 \mathrm{E}-04$ \\
\hline
\end{tabular}


RESRAD-OFFSITE, Version 2.5

itle : Offsite Resident Farmer Deterministic Run

File : RF TC99 DOESG FWD-FV2.ROF

Summary of dose at graphical times, reptition 2 (continued)

Time

Years

1. $65 \mathrm{E}+02$

$1.66 \mathrm{E}+02$

1. $66 \mathrm{E}+02$

$1.67 \mathrm{E}+02$

1. $67 \mathrm{E}+02$

1. $68 \mathrm{E}+02$

1. $68 \mathrm{E}+02$

1. $69 \mathrm{E}+02$

1. $69 \mathrm{E}+02$

1. $70 \mathrm{E}+02$

1. $70 \mathrm{E}+02$

1. $71 \mathrm{E}+02$

1. $71 \mathrm{E}+02$

1. $72 \mathrm{E}+02$

$1.72 \mathrm{E}+02$

1. $73 \mathrm{E}+02$

1. $73 \mathrm{E}+02$

1. $74 \mathrm{E}+02$

1. $74 \mathrm{E}+02$

1. $75 \mathrm{E}+02$

1. $75 \mathrm{E}+02$

$1.76 \mathrm{E}+02$

$1.76 \mathrm{E}+02$

$1.77 \mathrm{E}+02$

$1.77 \mathrm{E}+02$

$1.78 \mathrm{E}+02$

$1.78 \mathrm{E}+02$

$1.79 \mathrm{E}+02$

$1.79 \mathrm{E}+02$

$1.80 \mathrm{E}+02$

$1.80 \mathrm{E}+02$

1. $81 \mathrm{E}+02$

1. $81 \mathrm{E}+02$

1. $82 \mathrm{E}+02$

1. $83 \mathrm{E}+02$

1. $83 \mathrm{E}+02$

1. $84 \mathrm{E}+02$

1. $84 \mathrm{E}+02$

1. $85 \mathrm{E}+02$

$1.85 \mathrm{E}+02$

$1.86 \mathrm{E}+02$

$1.86 \mathrm{E}+02$

$1.87 \mathrm{E}+02$

$1.87 \mathrm{E}+02$

$1.88 \mathrm{E}+02$

1. $88 \mathrm{E}+02$
Dose statistics at graphical times, mrem/yr

\begin{tabular}{|c|c|c|c|c|c|c|c|}
\hline m & aximum & ea & ed & $0 \%$ & & $\%$ & $\%$ \\
\hline $.00 \mathrm{E}+00$ & $3.38 E-03$ & $7.36 \mathrm{E}$ & $0.00 \mathrm{E}+00$ & $00 \mathrm{E}+00$ & 07 & 5 & $.09 E-04$ \\
\hline+00 & $3.55 E-03$ & $7.81 \mathrm{E}-06$ & $0.00 \mathrm{E}+00$ & $0 \mathrm{E}+00$ & $82 E-07$ & 1. $38 \mathrm{E}-05$ & $02 E-04$ \\
\hline $.00 \mathrm{E}+00$ & $72 E-03$ & $27 E-06$ & $.00 E+00$ & $0.00 \mathrm{E}+00$ & $36 E-07$ & $.55 E-05$ & $.16 \mathrm{E}-04$ \\
\hline $00 \mathrm{E}+00$ & $91 \mathrm{E}-03$ & $76 \mathrm{~F}-06$ & $.00 \mathrm{E}+00$ & $.00 \mathrm{E}+00$ & $3 \quad 08 F-07$ & $75 F-05$ & $.31 \mathrm{E}-04$ \\
\hline $.00 \mathrm{E}+00$ & -03 & 06 & & & 7 & 5 & -04 \\
\hline $.00 E+00$ & & & & & & & 04 \\
\hline $.00 E+00$ & $50 E-03$ & & & & & & $85 E-04$ \\
\hline+00 & -03 & 3 & +00 & 0 & 1 & 5 & $E-04$ \\
\hline$E+00$ & $4.93 E-03$ & -0 & $.00 \mathrm{E}+00$ & $00 \mathrm{E}+00$ & $94 \mathrm{E}-$ & -05 & $7 E-04$ \\
\hline $.00 E+00$ & $15 E-03$ & ת? תק & $.00 \mathrm{E}+00$ & $57 \mathrm{~F}-23$ & (25 & קרק & -04 \\
\hline $.00 E+00$ & 03 & te $>$ & & & & & 04 \\
\hline $.00 \mathrm{E}+00$ & $5.63 E-03$ & $6 \mathrm{~F}$ & & 9 & & 5 & -04 \\
\hline $.00 \mathrm{E}+00$ & $5.88 E-03$ & $1.43 E-05$ & & & & & $4.19 \mathrm{E}-04$ \\
\hline $.00 \mathrm{E}+00$ & $6.14 \mathrm{E}-03$ & 1. $51 \mathrm{E}-05$ & $0.00 \mathrm{E}+00$ & $9.58 \mathrm{E}-17$ & 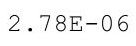 & 5 & $4.45 E-04$ \\
\hline+00 & $40 E-03$ & 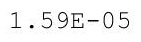 & 0 & 6 & & 5 & $71 E-04$ \\
\hline $.00 E+00$ & 03 & $\perp$ & -00 & & 6 & 5 & 04 \\
\hline$E+00$ & 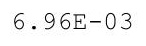 & & & & & & 4 \\
\hline $.00 \mathrm{E}+00$ & 3 & 1 & & 3 & $5.52 \mathrm{E}-06$ & 5 & 04 \\
\hline $.00 \mathrm{E}+00$ & 7. $55 \mathrm{E}-03$ & $1.94 \mathrm{E}-05$ & $0.00 \mathrm{E}+00$ & $7.43 E-13$ & $6.45 E-06$ & $8.45 E-05$ & $.88 E-04$ \\
\hline $.00 \mathrm{E}+00$ & $.87 E-03$ & $.04 E-05$ & $0.00 \mathrm{E}+00$ & $.50 \mathrm{E}-12$ & $7.50 \mathrm{E}-$ & -05 & $6.20 \mathrm{E}-04$ \\
\hline $0 \mathrm{E}+00$ & -03 & & & & & -04 & -04 \\
\hline $.00 E+00$ & 3 & 2 & $0.00 \mathrm{E}+00$ & 1 & 6 & 04 & -04 \\
\hline $.00 E+00$ & 3 & 2 & $0.00 \mathrm{E}+00$ & & & 04 & 04 \\
\hline $.00 \mathrm{E}+00$ & 3 & $2.47 E-05$ & > & 0 & 1.28E-05 & 1. $28 \mathrm{E}-04$ & -04 \\
\hline $.00 E+00$ & (57 - & م 50 & $.00 E+00$ & $.08 E-10$ & 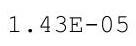 & קט & $E-04$ \\
\hline $0 \cap \mathrm{F}+0 \cap 0$ & $94 \mathrm{~F}-03$ & $.71 E-05$ & $0.00 \mathrm{E}+00$ & $.02 \mathrm{E}-10$ & $1.61 \mathrm{E}-$ & $.48 E-04$ & $42 E-04$ \\
\hline $.00 \mathrm{E}+00$ & $03 E-02$ & & & $7.39 \mathrm{E}-10$ & 70 Г & $9 E-04$ & $84 E-04$ \\
\hline $0 E+00$ & & & & & & & \\
\hline $.00 \mathrm{E}+00$ & $1.11 \mathrm{E}-02$ & $3.10 E-U 5$ & $0.00 \mathrm{E}+00$ & -09 & - 1 t & & $73 E-04$ \\
\hline $.00 \mathrm{E}+00$ & $1.15 \mathrm{E}-02$ & . $20 \pm-4 J$ & $0.00 \mathrm{E}+00$ & $.68 E-09$ & . & {$[-24$} & $.02 E-03$ \\
\hline $.00 \mathrm{E}+00$ & 2 & - & $0.00 \mathrm{E}+00$ & $90 E-09$ & (2.0. & $2.075-4$ & $1.07 \mathrm{E}-03$ \\
\hline $.00 \mathrm{E}+0$ & 0 & & & & & $9 E-04$ & $.11 \mathrm{E}-03$ \\
\hline $.00 E+00$ & 1. $29 \mathrm{E}-02$ & & & & & & 03 \\
\hline & $1.33 \mathrm{E}$ & & & & & & \\
\hline $00 E+00$ & 1. $38 \mathrm{E}-02$ & $4.04 \mathrm{E}-05$ & $0.00 \mathrm{E}+00$ & $2.00 \mathrm{E}$ & 3.01 & & $1.25 E-03$ \\
\hline $00 \mathrm{E}+00$ & $1.43 E-02$ & $4.2 \perp E-03$ & $0.00 \mathrm{E}+00$ & $1.01 \mathrm{t}$ & 0.00 & & $.30 E-03$ \\
\hline 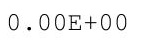 & $1.48 \mathrm{E}-02$ & & & & & & $1.500-0$ \\
\hline o & $\perp$ & & $0.00 \mathrm{E}+00$ & 8 & & & $.41 E-03$ \\
\hline $00 \mathrm{E}+0$ & $\perp$ & $4.77 \mathrm{E}-05$ & $0.00 \mathrm{E}+00$ & 7 & 5 & & 03 \\
\hline & 1.64 & 5 & $0.00 \mathrm{E}+00$ & 7 & 5 & 4 & 03 \\
\hline$E+00$ & $1.69 \mathrm{E}-02$ & $5.18 E-05$ & 0.0 & 7 & 5 & & $E-03$ \\
\hline$E+00$ & $1.75 \mathrm{E}$ & & & & & & \\
\hline טע山 & 2 & & $0.00 \mathrm{E}+00$ & & & & $1.71 E-03$ \\
\hline $00 E+00$ & $1.8 / E-02$ & $.00 \mathrm{~L}-0 \mathrm{~J}$ & $0.00 \mathrm{E}+00$ & $3.92 \mathrm{E}-07$ & $7.08 E-05$ & $4.27 E-04$ & $1.18 \mathrm{E}-03$ \\
\hline $.00 \mathrm{E}+00$ & $1.93 \mathrm{E}-02$ & & $0.00 \mathrm{E}+00$ & $5.01 \mathrm{E}-07$ & $1.00 \mathrm{~L}$ & $4.4 / 2$ & $.86 E-03$ \\
\hline$E+00$ & $E-02$ & $.33 E-05$ & $.00 \mathrm{E}+00$ & -07 & $35 \mathrm{E}$ & 4. & $E-03$ \\
\hline
\end{tabular}


RESRAD-OFFSITE, Version 2.5

itle : Offsite Resident Farmer Deterministic Run

File : RF TC99 DOESG FWD-FV2.ROF

Summary of dose at graphical times, reptition 2 (continued)

Time

Years

$1.89 \mathrm{E}+02$

$1.89 \mathrm{E}+02$

1. $90 \mathrm{E}+02$

1. $90 \mathrm{E}+02$

1. $91 \mathrm{E}+02$

1. $91 \mathrm{E}+02$

1. $92 \mathrm{E}+02$

1. $92 \mathrm{E}+02$

1. $93 \mathrm{E}+02$

1. $93 \mathrm{E}+02$

1. $94 \mathrm{E}+02$

$1.94 \mathrm{E}+02$

1. $95 \mathrm{E}+02$

1. $95 \mathrm{E}+02$

$1.96 \mathrm{E}+02$

1. $96 \mathrm{E}+02$

1. $97 \mathrm{E}+02$

1. $97 \mathrm{E}+02$

1. $98 \mathrm{E}+02$

1. $98 \mathrm{E}+02$

1. $99 \mathrm{E}+02$

1. $99 \mathrm{E}+02$

$2.00 \mathrm{E}+02$

$2.00 \mathrm{E}+02$

$2.01 \mathrm{E}+02$

$2.01 \mathrm{E}+02$

$2.02 \mathrm{E}+02$

$2.03 \mathrm{E}+02$

$2.03 E+02$

$2.04 \mathrm{E}+02$

$2.04 \mathrm{E}+02$

$2.05 \mathrm{E}+02$

$2.05 \mathrm{E}+02$

$2.06 \mathrm{E}+02$

$2.06 \mathrm{E}+02$

$2.07 \mathrm{E}+02$

$2.07 \mathrm{E}+02$

$2.08 \mathrm{E}+02$

$2.08 \mathrm{E}+02$

2. $09 \mathrm{E}+02$

$2.09 \mathrm{E}+02$

$2.10 \mathrm{E}+02$

$2.10 \mathrm{E}+02$

$2.11 \mathrm{E}+02$

$2.11 \mathrm{E}+02$

$2.12 \mathrm{E}+02$
Dose statistics at graphical times, mrem/yr

\begin{tabular}{|c|c|c|c|c|c|c|c|}
\hline $\mathrm{m}$ & aximum & ea & ed & & & & \\
\hline $.00 \mathrm{E}+00$ & $2.06 \mathrm{E}-02$ & $6.58 \mathrm{E}$ & $0.00 \mathrm{E}+00$ & $7.98 \mathrm{E}-07$ & 05 & 04 & $.02 \mathrm{~V}-U 3$ \\
\hline $.00 \mathrm{E}+00$ & $2.13 E-02$ & $6.84 \mathrm{E}-05$ & $0.00 \mathrm{E}+00$ & $7 E-07$ & $79 E-05$ & $E-04$ & $10 E-03$ \\
\hline $.00 \mathrm{E}+00$ & $19 E-02$ & $1 E-05$ & $.00 \mathrm{E}+00$ & $-5 E-06$ & $04 E-04$ & $37 E-04$ & $19 E-03$ \\
\hline $00 \mathrm{E}+00$ & $26 E-02$ & $38 \mathrm{~F}-05$ & $.00 \mathrm{E}+00$ & $.36 E-06$ & $11 \mathrm{~F}-04$ & $61 \mathrm{~F}-04$ & $.28 E-03$ \\
\hline $.00 \mathrm{E}+00$ & $33 E-02$ & 7 & & 6 & 4 & -04 & -03 \\
\hline $.00 E+00$ & -02 & & & & & & 03 \\
\hline $.00 E+00$ & $2.48 E-02$ & & & 6 & & & -03 \\
\hline+00 & -02 & 8 & +00 & 6 & 4 & -04 & $56 \mathrm{E}-03$ \\
\hline $.00 \mathrm{E}+00$ & $2.64 \mathrm{E}-02$ & $\varepsilon$ & $.00 \mathrm{E}+00$ & 06 & $59 \mathrm{E}-$ & -04 & $76 E-03$ \\
\hline $.00 E+00$ & $72 E-02$ & קم & $.00 \mathrm{E}+00$ & 邽 & $71 \pi$ & $22 \mathrm{~F}-8$ & $.86 E-03$ \\
\hline $.00 E+00$ & 02 & & & & & 4 & 03 \\
\hline $.00 \mathrm{E}+00$ & $2.88 E-02$ & 9 & & 6 & & 4 & 03 \\
\hline $.00 \mathrm{E}+00$ & $2.97 \mathrm{E}-02$ & $1.03 E-04$ & & & -0 & $E-04$ & $3.20 \mathrm{E}-03$ \\
\hline $.00 \mathrm{E}+00$ & $E-02$ & $1.07 \mathrm{E}-04$ & $0.00 \mathrm{E}+00$ & $6.01 \mathrm{E}-06$ & & -04 & $E-03$ \\
\hline$\Xi+00$ & -02 & 1 & 0 & 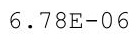 & 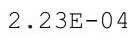 & -04 & $\mathrm{~g}-03$ \\
\hline $.00 \mathrm{E}+00$ & 02 & 1 & 00 & 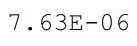 & $2.35 E-04$ & 4 & 3 \\
\hline$E+00$ & 2 & & & & & & 3 \\
\hline $.00 \mathrm{E}+00$ & 2 & 1 & & & $2.59 \mathrm{E}-04$ & 4 & 3 \\
\hline $.00 \mathrm{E}+00$ & $3.52 \mathrm{E}-02$ & $1.27 \mathrm{E}-04$ & $0.00 \mathrm{E}+00$ & $.07 E-05$ & $2.71 \mathrm{E}-$ & $E-03$ & $.94 E-03$ \\
\hline $.00 \mathrm{E}+00$ & $3.62 \mathrm{E}-02$ & 1. $31 \mathrm{E}-04$ & $0.00 \mathrm{E}+00$ & $.20 E-05$ & $2.84 \mathrm{E}-$ & $.07 E-03$ & $4.06 \mathrm{E}-03$ \\
\hline $0 \mathrm{E}+00$ & -02 & & & & & & $E-03$ \\
\hline $0 \mathrm{E}+00$ & & 1.40 & & 10 & 4 & 3 & \\
\hline חمחניחתמ & 02 & $1 \cdot$ & 0 & 0 & & & 3 \\
\hline $.00 E+00$ & 02 & $\perp$ & & ? & $3.49 \mathrm{E}-04$ & 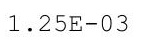 & 03 \\
\hline $.00 \mathrm{E}+00$ & $.14 \mathrm{E}-02$ & 1 & $.00 \mathrm{E}+00$ & 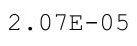 & (2) & $E-03$ & $69 \mathrm{E}-$ \\
\hline $0 \cap \mathrm{F}+0 \cap 0$ & $4.25 E-02$ & $E-04$ & $0.00 \mathrm{E}+00$ & $2.32 \mathrm{E}-0$ & תרת ת & $.35 E-03$ & $.84 E-03$ \\
\hline $.00 \mathrm{E}+00$ & $37 E-02$ & $165 \mathrm{~F}-0$ & & & & $E-03$ & $00 E-03$ \\
\hline & & & & & & & \\
\hline $.00 \mathrm{E}+00$ & $4.60 \mathrm{E}-02$ & $1.76 \mathrm{E}-0$ & $0.00 \mathrm{E}+00$ & 3 & 4 & & $E-03$ \\
\hline $.00 \mathrm{E}+00$ & $4.72 E-02$ & $1.82 \mathrm{E}-04$ & $0.00 \mathrm{E}+00$ & • $29+400$ & 1. & 1.3/E-U3 & $.49 E-03$ \\
\hline $.00 \mathrm{E}+00$ & $84 E-02$ & $1.00 \mathrm{~L}$ & $0.00 \mathrm{E}+00$ & -5 & 1. & I.0UT & 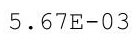 \\
\hline $.00 \mathrm{E}+0$ & 2 & & & & & $.72 \mathrm{E}-\mathrm{C}$ & 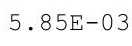 \\
\hline $.00 E+00$ & & & & & & & 23 \\
\hline & -02 & & & & & & \\
\hline $00 E+00$ & $5.36 \mathrm{E}-02$ & $2.13 E-04$ & $0.00 \mathrm{E}+00$ & 5 & 4 & 3 & -03 \\
\hline $00 \mathrm{E}+00$ & $5.50 \mathrm{E}-02$ & $2.20 E-04$ & $.00 \mathrm{E}+00$ & 年 & 0.17 & 03 & $E-03$ \\
\hline 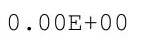 & $3.03 E-02$ & & & & & & $0.075-0$ \\
\hline ( & 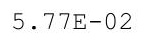 & 2 & $0.00 \mathrm{E}+00$ & & 4 & 3 & 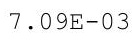 \\
\hline 䧄 & $5.92 \mathrm{E}-02$ & 2 & $0.00 \mathrm{E}+00$ & 5 & 4 & 3 & 03 \\
\hline & 2 & 2. & $0.00 \mathrm{E}+00$ & 05 & 4 & 3 & 03 \\
\hline$E+00$ & $6.21 E-02$ & $2.55 \mathrm{E}-04$ & $.00 \mathrm{E}+$ & 5 & 4 & & 03 \\
\hline$E+00$ & 02 & & & & & & \\
\hline טע山 & & & $0.00 E+00$ & & & & $26 E-03$ \\
\hline $00 \mathrm{E}+00$ & $0.0 / E-02$ & $2.79 E-04$ & $0.00 \mathrm{E}+00$ & $9.02 E-05$ & $7.78 E-04$ & $2.55 E-03$ & $0.49 \mathrm{~L}-03$ \\
\hline $.00 \mathrm{E}+00$ & $6.82 \mathrm{E}-02$ & $2.87 \mathrm{E}-04$ & $0.00 \mathrm{E}+00$ & . & $8.07 \mathrm{E}-04$ & $2.63 E-03$ & $8.72 E-03$ \\
\hline$E+00$ & $E-02$ & $96 E-04$ & $.00 \mathrm{E}+00$ & $.03 E-04$ & -04 & 2. & 03 \\
\hline
\end{tabular}


RESRAD-OFFSITE, Version 2.5

obabilistic Dose and Risk Report

Title : Offsite Resident Farmer Deterministic Run

File : RF TC99 DOESG FWD-FV2.ROF

Summary of dose at graphical times, reptition 2 (continued)

Time

Years

$2.12 \mathrm{E}+02$

$2.13 \mathrm{E}+02$

$2.13 \mathrm{E}+02$

$2.14 \mathrm{E}+02$

$2.14 \mathrm{E}+02$

$2.15 \mathrm{E}+02$

$2.15 \mathrm{E}+02$

$2.16 \mathrm{E}+02$

$2.16 \mathrm{E}+02$

$2.17 \mathrm{E}+02$

$2.17 \mathrm{E}+02$

$2.18 \mathrm{E}+02$

$2.18 \mathrm{E}+02$

$2.19 \mathrm{E}+02$

$2.19 \mathrm{E}+02$

$2.20 \mathrm{E}+02$

$2.20 \mathrm{E}+02$

$2.21 E+02$

2. $21 E+02$

2. $22 \mathrm{E}+02$

$2.23 E+02$

$2.23 E+02$

2. $24 \mathrm{E}+02$

$2.24 \mathrm{E}+02$

2. $25 \mathrm{E}+02$

$2.25 \mathrm{E}+02$

2. $26 \mathrm{E}+02$

$2.26 \mathrm{E}+02$

$2.27 \mathrm{E}+02$

$2.27 \mathrm{E}+02$

2. $28 \mathrm{E}+02$

$2.28 \mathrm{E}+02$

$2.29 \mathrm{E}+02$

2. $29 \mathrm{E}+02$

2. $30 \mathrm{E}+02$

2. $30 E+02$

$2.31 \mathrm{E}+02$

2. $31 E+02$

2. $32 \mathrm{E}+02$

2. $32 E+02$

$2.33 E+02$

2. $33 \mathrm{E}+02$

$2.34 \mathrm{E}+02$

2. $34 \mathrm{E}+02$

$2.35 E+02$

$2.35 \mathrm{E}+02$
Dose statistics at graphical times, mrem/yr

\begin{tabular}{|c|c|c|c|c|c|c|c|}
\hline $\mathrm{m}$ & aximum & lea & ed & $0 \%$ & & $\%$ & \\
\hline $.00 \mathrm{E}+00$ & -02 & $3.04 \mathrm{E}-04$ & $0.00 \mathrm{E}+00$ & 4 & 04 & -03 & -03 \\
\hline+00 & $7.31 E-02$ & $3 E-04$ & $E+00$ & $8 E-04$ & $6 E-04$ & $2.89 E-03$ & $46 \mathrm{E}-03$ \\
\hline $.00 \mathrm{E}+00$ & $48 E-02$ & $2 E-04$ & $.00 \mathrm{E}+00$ & $26 E-04$ & $27 E-04$ & $98 E-03$ & $1 E-03$ \\
\hline $00 E+00$ & $66 \mathrm{E}-02$ & $31 E-04$ & $.00 \mathrm{E}+00$ & $.34 \mathrm{E}-04$ & $6 \cap F-04$ & $07 F-03$ & $97 \mathrm{~F}-03$ \\
\hline $.00 \mathrm{E}+00$ & -02 & 4 & & 4 & 4 & 3 & -02 \\
\hline $.00 \mathrm{E}+00$ & & & & & & & -02 \\
\hline $.00 E+00$ & -02 & & & 4 & & & -02 \\
\hline+00 & -02 & 4 & +00 & 4 & 3 & 3 & -02 \\
\hline$E+00$ & -02 & -0 & $.00 \mathrm{E}+00$ & 04 & 3 & -03 & $14 \mathrm{E}-02$ \\
\hline $.00 E+00$ & 02 & 101 ק & $.00 \mathrm{E}+00$ & 865 & תי & $.67 E-03$ & $16 \mathrm{E}-02$ \\
\hline $.00 E+00$ & 02 & & & & & 3 & -02 \\
\hline $.00 \mathrm{E}+00$ & $E-02$ & 4 & & 2 & 3 & 3 & -02 \\
\hline $.00 \mathrm{E}+00$ & $9.33 E-02$ & & & $2.19 E-04$ & $1.29 E-03$ & & $1.26 \mathrm{E}-02$ \\
\hline $.00 \mathrm{E}+00$ & -02 & $4.35 \mathrm{E}-04$ & $0.00 \mathrm{E}+00$ & $2.31 E-04$ & 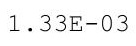 & -03 & $E-02$ \\
\hline+00 & -02 & 4 & 0 & 4 & 3 & -03 & $E-02$ \\
\hline $.00 \mathrm{E}+00$ & 02 & 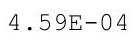 & 00 & $257 \mathrm{~F}-04$ & & 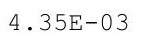 & 02 \\
\hline$E+00$ & 1 & & & & & & 2 \\
\hline $.00 \mathrm{E}+00$ & 1 & 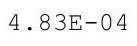 & & & 3 & 3 & 02 \\
\hline $.00 \mathrm{E}+00$ & $1.06 \mathrm{E}-01$ & $4.96 \mathrm{E}-04$ & $0.00 \mathrm{E}+00$ & $2.98 E-0$ & $1.53 E-03$ & $4.71 E-03$ & 1. $48 \mathrm{E}-02$ \\
\hline $.00 \mathrm{E}+00$ & $.08 E-01$ & $5.09 \mathrm{E}-04$ & $0.00 \mathrm{E}+00$ & $4 E-04$ & $1.57 \mathrm{E}-$ & $4 \mathrm{E}-03$ & 1. $52 \mathrm{E}-02$ \\
\hline $0 \mathrm{E}+00$ & -01 & & & & & & $E-02$ \\
\hline $0 \mathrm{E}+00$ & -01 & & $0.00 \mathrm{E}+00$ & 4 & 3 & & -02 \\
\hline $.00 E+00$ & 1 & ( & $.00 \mathrm{E}+00$ & $35 \cap \square \cap 0$ & 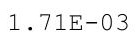 & & 02 \\
\hline $.00 \mathrm{E}+00$ & 01 & 5 & 0 & $370=50$ & P & o & 02 \\
\hline $.00 E+00$ & $E-01$ & م & $.00 \mathrm{E}+00$ & 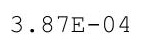 & ת ח & $F-03$ & זכיקה \\
\hline $0 \cap \mathrm{F}+0 \cap 0$ & $.22 \mathrm{E}-01$ & $5.92 \mathrm{E}-04$ & $0.00 \mathrm{E}+00$ & $.04 \mathrm{E}-$ & $1.86 \mathrm{E}-$ & $E-0$ & 1. $78 \mathrm{E}-02$ \\
\hline $.00 \mathrm{E}+00$ & $.24 \mathrm{E}-01$ & & & & 1 & & $.82 E-02$ \\
\hline & & & & & & & \\
\hline $.00 \mathrm{E}+00$ & $1.29 \mathrm{E}-01$ & $6.38 \mathrm{E}-0$ & $0.00 \mathrm{E}+00$ & 4.491 & o & & $92 E-02$ \\
\hline $.00 \mathrm{E}+00$ & $1.32 \mathrm{E}-01$ & $6.54 \mathrm{E}-04$ & $0.00 \mathrm{E}+00$ & .00 & $2.075-03$ & . $104-03$ & $.96 E-02$ \\
\hline $.00 \mathrm{E}+00$ & $1.34 \mathrm{E}-01$ & 0.1000 & $0.00 \mathrm{E}+00$ & $4.015-04$ & $2.13 \mathrm{E}$ & 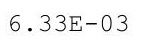 & $2.01 \mathrm{E}-02$ \\
\hline $.00 \mathrm{E}+0$ & 1 & & & & $.18 \mathrm{E}-$ & & $.06 E-02$ \\
\hline $.00 E+00$ & 1 & & & & & & $11 E-02$ \\
\hline & 01 & & & & & & \\
\hline $00 E+00$ & $1.45 E-01$ & $7.37 \mathrm{E}-04$ & $0.00 \mathrm{E}+00$ & $3.39 \mathrm{E}$ & 2.37 & & -02 \\
\hline $00 \mathrm{E}+00$ & $1.48 \mathrm{E}-01$ & $7.55 E-04$ & $.00 \mathrm{E}+00$ & 5.001 & $2 \cdot 11$ & & $2.26 E-02$ \\
\hline 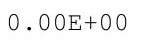 & $1.50 \mathrm{E}-01$ & & & & & & $2.31 \mathrm{E}-02$ \\
\hline o & 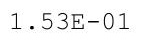 & & $0.00 \mathrm{E}+00$ & 然 & $2 \cdot 00$ & & $2.36 \mathrm{E}-02$ \\
\hline (1) & $\perp$ & $8.10 \mathrm{E}-04$ & $0.00 \mathrm{E}+00$ & 4 & 3 & 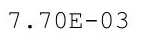 & . $1+x^{2}$ \\
\hline & 1 & 4 & $0.00 \mathrm{E}+00$ & 4 & 2.7 & 3 & 02 \\
\hline $0 \mathrm{E}+00$ & $1.62 \mathrm{E}-01$ & $8.48 E-04$ & $.00 \mathrm{E}$ & 4 & 2.81 & & $2 E-02$ \\
\hline$E+00$ & $1.65 \mathrm{E}$ & & & & & & \\
\hline ט & 1 & & & & & & $2.64 \mathrm{E}-\mathrm{U} 2$ \\
\hline $.00 \mathrm{E}+00$ & $\perp \cdot T \perp-U \perp$ & $9.08 E-04$ & $0.00 \mathrm{E}+00$ & $8.11 \mathrm{E}-04$ & $3.06 E-03$ & $8.08 E-03$ & $2.69 E-02$ \\
\hline $.00 \mathrm{E}+00$ & $1.74 \mathrm{E}-01$ & $9.29 \mathrm{E}-04$ & $0.00 \mathrm{E}+00$ & $0.095-04$ & 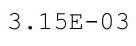 & $0.01 \mathrm{~L}$ & $2.75 E-02$ \\
\hline$E+00$ & $1.77 \mathrm{E}-01$ & $.50 E-04$ & $.00 \mathrm{E}+00$ & $.69 \mathrm{E}-04$ & -03 & 3 & $.81 \mathrm{E}$ \\
\hline
\end{tabular}


RESRAD-OFFSITE, Version 2.5

Title : Offsite Resident Farmer Deterministic Run

File : RF TC99 DOESG FWD-FV2.ROF

Summary of dose at graphical times, reptition 2 (continued)

Time

Years

$2.36 \mathrm{E}+02$

2. $36 \mathrm{E}+02$

$2.37 \mathrm{E}+02$

$2.37 \mathrm{E}+02$

2. $38 \mathrm{E}+02$

2. $38 \mathrm{E}+02$

$2.39 \mathrm{E}+02$

2. $39 \mathrm{E}+02$

2. $40 \mathrm{E}+02$

$2.40 \mathrm{E}+02$

$2.41 \mathrm{E}+02$

2. $41 \mathrm{E}+02$

$2.42 \mathrm{E}+02$

2. $43 \mathrm{E}+02$

$2.43 E+02$

$2.44 \mathrm{E}+02$

$2.44 \mathrm{E}+02$

$2.45 \mathrm{E}+02$

$2.45 \mathrm{E}+02$

$2.46 \mathrm{E}+02$

$2.46 \mathrm{E}+02$

$2.47 \mathrm{E}+02$

$2.47 \mathrm{E}+02$

2. $48 \mathrm{E}+02$

$2.48 \mathrm{E}+02$

2. $49 \mathrm{E}+02$

$2.49 \mathrm{E}+02$

$2.50 \mathrm{E}+02$

$2.50 \mathrm{E}+02$

$2.51 \mathrm{E}+02$

$2.51 \mathrm{E}+02$

$2.52 \mathrm{E}+02$

$2.52 \mathrm{E}+02$

$2.53 \mathrm{E}+02$

$2.53 \mathrm{E}+02$

$2.54 \mathrm{E}+02$

$2.54 \mathrm{E}+02$

$2.55 \mathrm{E}+02$

$2.55 \mathrm{E}+02$

$2.56 \mathrm{E}+02$

$2.56 \mathrm{E}+02$

$2.57 \mathrm{E}+02$

$2.57 \mathrm{E}+02$

$2.58 \mathrm{E}+02$

$2.58 \mathrm{E}+02$

$2.59 \mathrm{E}+02$
Dose statistics at graphical times, mrem/yr

\begin{tabular}{|c|c|c|c|c|c|c|c|}
\hline m & aximum & lea & ed & & & & \\
\hline $.00 \mathrm{E}+00$ & $1.80 \mathrm{E}-01$ & $9.72 \mathrm{E}$ & $0.00 \mathrm{E}+00$ & 4 & 3 & 03 & $-0<$ \\
\hline $.00 \mathrm{E}+00$ & $1.83 \mathrm{E}-01$ & $9.94 \mathrm{E}-04$ & $0.00 \mathrm{E}+00$ & $8 E-04$ & $9 E-03$ & $6 E-03$ & $3 E-02$ \\
\hline $.00 E+00$ & $86 E-01$ & $2 F-03$ & $.00 \mathrm{E}+00$ & $71 E-04$ & 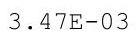 & $66 E-03$ & $00 E-02$ \\
\hline $.00 E+00$ & $1.90 \mathrm{E}-01$ & $.04 E-03$ & $0.00 \mathrm{E}+00$ & $.01 E-03$ & $55 E-03$ & $87 E-03$ & $06 E-02$ \\
\hline $\mathrm{E}+00$ & $1.93 \mathrm{E}$ & 3 & & 3 & 3 & 2 & -02 \\
\hline $.00 E+00$ & 01 & & & & & & -02 \\
\hline $.00 E+00$ & 01 & & & & & & $E-02$ \\
\hline+00 & 01 & 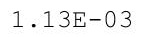 & +00 & 3 & 3 & -02 & -02 \\
\hline $00 \mathrm{E}+00$ & -01 & -0 & $.00 \mathrm{E}+00$ & 3 & 3 & -02 & $3 E-02$ \\
\hline $0 E+00$ & $10 E-01$ & תم 10 & $.00 \mathrm{E}+00$ & 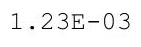 & 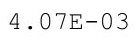 & $.12 \mathrm{E}-02$ & -02 \\
\hline $.00 E+00$ & 2.13 & & & & & & -02 \\
\hline $.00 \mathrm{E}+00$ & $2.17 \mathrm{E}-01$ & 1 & & 3 & 3 & 2 & -02 \\
\hline $.00 \mathrm{E}+00$ & $2.20 \mathrm{E}-01$ & $1.26 \mathrm{E}-03$ & & $1.36 \mathrm{E}-03$ & & $1.19 \mathrm{E}-02$ & $65 E-02$ \\
\hline $.00 E+00$ & $2.24 \mathrm{E}-01$ & 3 & & 3 & & -02 & $E-02$ \\
\hline$E+00$ & $28 \mathrm{E}-01$ & 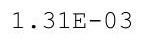 & & 3 & 3 & -02 & $E-02$ \\
\hline $.00 \mathrm{E}+00$ & 2.31 & $1.34 \mathrm{E}-03$ & 00 & $1.50 \mathrm{E}-03$ & 3 & 2 & -02 \\
\hline$E+00$ & 1 & $1.37 \mathrm{E}-03$ & & & 3 & -02 & 2 \\
\hline $00 \mathrm{E}+00$ & 1 & 1 & & 3 & 3 & 2 & 02 \\
\hline $.00 E+00$ & $2.43 E-01$ & $1.43 E-03$ & $0.00 \mathrm{E}+00$ & $1.62 \mathrm{E}-03$ & $.03 E-03$ & $1.35 E-02$ & $.07 E-02$ \\
\hline $.00 \mathrm{E}+00$ & $.47 \mathrm{E}-01$ & $1.46 \mathrm{E}-03$ & $0.00 \mathrm{E}+00$ & $1.66 \mathrm{E}-03$ & $.15 \mathrm{E}-$ & $E-02$ & $4.15 E-02$ \\
\hline $00 \mathrm{E}+00$ & 01 & & & & & 2 & $E-02$ \\
\hline $00 E+00$ & 1 & 1.32 & $0.00 \mathrm{E}+00$ & 土. & 3 & -02 & -02 \\
\hline $.00 E+00$ & 1 & $\perp$ & $.00 \mathrm{E}+00$ & 3 & & & 02 \\
\hline $.00 \mathrm{E}+00$ & 1 & 1 & > & ? & & 2 & -02 \\
\hline $.00 E+00$ & $66 \mathrm{E}-01$ & 1015 & $.00 E+00$ & 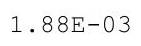 & ת & $6 \mathrm{E}-02$ & $54 \mathrm{E}-02$ \\
\hline $0 \cap F+0 \cap$ & $.70 \mathrm{E}-01$ & $1 \quad 6 \Delta \mathrm{F}-0$ & $0.00 \mathrm{E}+00$ & 1 & 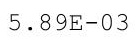 & $60 E-02$ & $.62 E-02$ \\
\hline $.00 \mathrm{E}+00$ & $75 E-01$ & & $.05 E-22$ & & & $3 E-02$ & $70 E-02$ \\
\hline & & & & & & & -02 \\
\hline $.00 \mathrm{E}+00$ & $2.83 E-01$ & $1.74 \mathrm{E}$ & -18 & 3 & t & \pm-02 & $36 E-02$ \\
\hline $.00 \mathrm{E}+00$ & $2.87 \mathrm{E}-01$ & $1.10 \pm-00$ & $2 \cdot 10 \pm-1 t$ & $2 \cdot \pm ル 4$ & trat & $1.74 \mathrm{E}-02$ & $.95 E-02$ \\
\hline $.00 \mathrm{E}+00$ & $91 \mathrm{E}-01$ & $1.01+4$ & $4 \cdot 195-10$ & $2.00 \mathrm{~s}$ & - & 1. $78 \mathrm{E}-02$ & $.04 E-02$ \\
\hline $00 \mathrm{E}+0$ & 1 & & & & & & 2 \\
\hline $.00 E+00$ & & & & & & & 02 \\
\hline & 01 & & & & & & \\
\hline $00 \mathrm{E}+00$ & $3.09 \mathrm{E}-01$ & $1.96 \mathrm{E}-03$ & $5.28 \mathrm{E}-13$ & $2.4 \angle \mathrm{F}$ & 3 & & -02 \\
\hline $.00 E+00$ & $3.13 E-01$ & $1.99 E-03$ & 12 & 2.100 & 21 & 02 & -02 \\
\hline . & $3.18 \mathrm{E}-01$ & & & & & & $.0 \angle E-U \angle$ \\
\hline ( & 1 & 2 & $\sqcup \perp$ & & 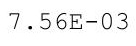 & $2.06 \mathrm{E}-02$ & 02 \\
\hline $00 E+00$ & 1 & $2.11 \mathrm{E}-03$ & & 3 & 3 & 2 & 02 \\
\hline & 1 & & 11 & 2 & 3 & 02 & \\
\hline $\mathrm{E}+00$ & $3.36 \mathrm{E}-01$ & 2.1 & -10 & & 3 & & -02 \\
\hline$E+00$ & $3.41 \mathrm{E}$ & & & & & & 02 \\
\hline प्रा & . & & & & & & $.25 \mathrm{E}-\mathrm{U} 2$ \\
\hline $00 E+00$ & $3.51 \mathrm{E}-01$ & $5 \cdot 3+2-0$ & . & $3.00 \mathrm{E}-03$ & $8.48 E-03$ & $2.33 E-02$ & $6.36 E-02$ \\
\hline $.00 \mathrm{E}+0$ & $3.55 \mathrm{E}-01$ & $2.305-$ & $\perp \cdot 00 \mathrm{D}$ & .001 & .000 & $2.37 \mathrm{E}-02$ & $.47 E-02$ \\
\hline$E+00$ & $E-01$ & $.40 \mathrm{E}-03$ & $.37 E-09$ & $.15 E-03$ & -03 & $E-02$ & $5.58 E-02$ \\
\hline
\end{tabular}


RESRAD-OFFSITE, Version 2.5

Title : Offsite Resident Farmer Deterministic Run

File : RF TC99 DOESG FWD-FV2.ROF

Summary of dose at graphical times, reptition 2 (continued)

Time

Years

$2.59 \mathrm{E}+02$

$2.60 \mathrm{E}+02$

$2.60 \mathrm{E}+02$

$2.61 \mathrm{E}+02$

$2.61 \mathrm{E}+02$

$2.62 \mathrm{E}+02$

$2.63 \mathrm{E}+02$

$2.63 \mathrm{E}+02$

$2.64 \mathrm{E}+02$

$2.64 \mathrm{E}+02$

$2.65 \mathrm{E}+02$

$2.65 \mathrm{E}+02$

$2.66 \mathrm{E}+02$

$2.66 \mathrm{E}+02$

$2.67 \mathrm{E}+02$

$2.67 \mathrm{E}+02$

$2.68 \mathrm{E}+02$

$2.68 \mathrm{E}+02$

$2.69 \mathrm{E}+02$

$2.69 \mathrm{E}+02$

$2.70 \mathrm{E}+02$

$2.70 \mathrm{E}+02$

$2.71 \mathrm{E}+02$

$2.71 \mathrm{E}+02$

$2.72 \mathrm{E}+02$

$2.72 \mathrm{E}+02$

$2.73 E+02$

$2.73 \mathrm{E}+02$

$2.74 \mathrm{E}+02$

$2.74 \mathrm{E}+02$

$2.75 \mathrm{E}+02$

$2.75 \mathrm{E}+02$

$2.76 \mathrm{E}+02$

$2.76 \mathrm{E}+02$

$2.77 \mathrm{E}+02$

$2.77 \mathrm{E}+02$

$2.78 \mathrm{E}+02$

$2.78 \mathrm{E}+02$

$2.79 \mathrm{E}+02$

$2.79 \mathrm{E}+02$

$2.80 \mathrm{E}+02$

$2.80 \mathrm{E}+02$

$2.81 \mathrm{E}+02$

$2.81 \mathrm{E}+02$

$2.82 \mathrm{E}+02$

$2.82 \mathrm{E}+02$
Dose statistics at graphical times, mrem/yr

\begin{tabular}{|c|c|c|c|c|c|c|c|}
\hline m & axis & a & 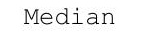 & & & $\%$ & \\
\hline $.00 \mathrm{E}+00$ & $3.65 \mathrm{E}-01$ & $2.44 \mathrm{E}-03$ & $3.95 E-09$ & $3.22 \mathrm{E}-03$ & 8.99 & -02 & $-0<$ \\
\hline+00 & 01 & 03 & -09 & 3 & 03 & -02 & -02 \\
\hline$E+00$ & $3.75 \mathrm{E}-01$ & $3 E-03$ & $.65 E-09$ & $.38 E-03$ & -03 & -02 & -02 \\
\hline $.00 \mathrm{E}+00$ & $3.80 \mathrm{E}-01$ & $2.58 E-03$ & $E-08$ & $47 E-03$ & 03 & $52 E-02$ & $07 E-02$ \\
\hline $0 \mathrm{E}+00$ & 1 & $2.62 \mathrm{E}-03$ & 08 & 3 & & -02 & -02 \\
\hline+00 & 01 & 03 & 08 & 3 & 3 & -02 & -02 \\
\hline $.00 \mathrm{E}+00$ & 01 & & & 3 & & -02 & -02 \\
\hline+00 & & & & & & & -02 \\
\hline+00 & -01 & $F-0$ & -08 & 3 & 02 & -02 & -02 \\
\hline $.00 \mathrm{E}+00$ & $4.11 \mathrm{E}-01$ & 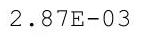 & 4 & $4.00 \mathrm{E}-03$ & 2 & 2 & -02 \\
\hline-00 & 01 & - & 07 & 3 & 02 & -02 & -02 \\
\hline $.00 \mathrm{E}+00$ & & & & & & & -02 \\
\hline $.00 \mathrm{E}+00$ & $4.27 E-01$ & $2 \mathrm{E}-0$ & $9 E-07$ & $4.31 \mathrm{E}$ & 02 & -02 & -02 \\
\hline$\Xi+00$ & $2 E-01$ & $7 E-03$ & -07 & $125-$ & 2 & -02 & -02 \\
\hline$E+00$ & $3-01$ & $2 E-03$ & 7 & 3 & & -02 & -02 \\
\hline $.00 E+00$ & -01 & 3 & 7 & 3 & 2 & -02 & -02 \\
\hline $.00 E+00$ & 01 & $3.23 E-03$ & 7 & 3 & 2 & 2 & -02 \\
\hline $.00 \mathrm{E}+00$ & & & & & & & 2 \\
\hline $.00 \mathrm{E}+00$ & 4. $60 \mathrm{E}-01$ & $3.34 \mathrm{E}-03$ & $9.16 \mathrm{E}-07$ & $4.94 \mathrm{E}$ & $1.26 \mathrm{~F}$ & 02 & -02 \\
\hline $.00 \mathrm{E}+00$ & $4.66 \mathrm{E}-01$ & $3.39 \mathrm{E}-03$ & $D E-06$ & $.05 \mathrm{E}-0$ & $.28 \mathrm{E}-02$ & $.45 E-02$ & -02 \\
\hline $.00 \mathrm{E}+00$ & $4.71 \mathrm{E}-01$ & $3.45 E-03$ & 1. $32 \mathrm{E}-06$ & 3 & $1.31 \mathrm{E}-02$ & $1 E-02$ & $38 E-02$ \\
\hline $0 E+00$ & & & & & & -02 & -02 \\
\hline 0 & 1 & & & & & & 02 \\
\hline $.00 \mathrm{E}+00$ & 7 & 5.0 & & & 2 & & -02 \\
\hline $00 \mathrm{E}+00$ & 1 & 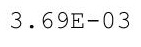 & 6 & 3 & 2 & 2 & -02 \\
\hline $.00 \mathrm{E}+00$ & $.00 \mathrm{E}-01$ & $75 \pi-100$ & $.74 \mathrm{E}-06$ & תח & 1 & $.79 E-02$ & $.01 \mathrm{E}-01$ \\
\hline$F+00$ & 01 & $81 F-03$ & $3 E-06$ & & 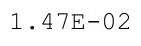 & $5-02$ & $.03 E-01$ \\
\hline $00 E+00$ & & & & & & & -01 \\
\hline & & & & & & & 01 \\
\hline $.00 \mathrm{E}+00$ & $5.24 \mathrm{E}-01$ & $3.29 E-03$ & $4.83 E-06$ & $\cdot \pm 0$ & $\perp \cdot \sigma 0$ & 02 & -01 \\
\hline $.00 \mathrm{E}+00$ & $.30 \mathrm{E}-\mathrm{C}$ & $4.06 E-03$ & $5.54 \mathrm{E}-06$ & . & $1.59 \mathrm{E}-02$ & 4.07E-02 & $.09 E-01$ \\
\hline $.00 \mathrm{E}+00$ & ( & 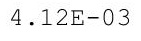 & 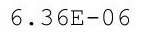 & & & 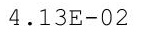 & $1.10 \mathrm{E}-01$ \\
\hline$F+0$ & 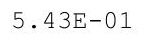 & & ( & & & & 1 \\
\hline مח & & & & & & & \\
\hline & & & & & & 2 & 01 \\
\hline 0 & $3.01 \mathrm{E}$ & 03 & 06 & 政 & $1 \cdot 121$ & & 01 \\
\hline $.00 \mathrm{E}+00$ & & & & & & & -01 \\
\hline 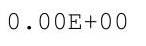 & & & & & & & $1.20 \mathrm{E}-01$ \\
\hline 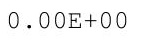 & 1 & 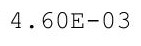 & s & 3 & 2 & 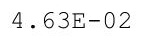 & 01 \\
\hline & & & & & & & \\
\hline & 1 & & 05 & & 2 & 2 & 01 \\
\hline $\mathrm{E}+00$ & $E-01$ & -03 & 1.7 & 03 & 1 & 02 & -01 \\
\hline & & & & & & & \\
\hline & & & & & & & I. \\
\hline 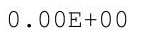 & & & & 3 & 2 & & $1.32 \mathrm{E}-01$ \\
\hline $00 \mathrm{E}+00$ & $E-01$ & $1 E-03$ & $33 E-05$ & $E-03$ & -02 & 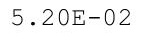 & -01 \\
\hline
\end{tabular}


RESRAD-OFFSITE, Version 2.5

Title : Offsite Resident Farmer Deterministic Run

File : RF TC99 DOESG FWD-FV2.ROF

Summary of dose at graphical times, reptition 2 (continued)

Time

Years

$2.83 \mathrm{E}+02$

$2.84 \mathrm{E}+02$

$2.84 \mathrm{E}+02$

$2.85 \mathrm{E}+02$

$2.85 \mathrm{E}+02$

$2.86 \mathrm{E}+02$

$2.86 \mathrm{E}+02$

$2.87 \mathrm{E}+02$

$2.87 \mathrm{E}+02$

$2.88 \mathrm{E}+02$

2. $88 \mathrm{E}+02$

$2.89 \mathrm{E}+02$

$2.89 \mathrm{E}+02$

2. $90 \mathrm{E}+02$

$2.90 \mathrm{E}+02$

2. $91 \mathrm{E}+02$

2. $91 \mathrm{E}+02$

2. $92 \mathrm{E}+02$

2. $92 \mathrm{E}+02$

2. $93 \mathrm{E}+02$

$2.93 \mathrm{E}+02$

2. $94 \mathrm{E}+02$

$2.94 \mathrm{E}+02$

2. $95 \mathrm{E}+02$

$2.95 \mathrm{E}+02$

2. $96 \mathrm{E}+02$

$2.96 \mathrm{E}+02$

$2.97 \mathrm{E}+02$

$2.97 \mathrm{E}+02$

$2.98 \mathrm{E}+02$

$2.98 \mathrm{E}+02$

$2.99 \mathrm{E}+02$

2. $99 \mathrm{E}+02$

$3.00 \mathrm{E}+02$

$3.00 \mathrm{E}+02$

3. $01 \mathrm{E}+02$

$3.01 \mathrm{E}+02$

$3.02 \mathrm{E}+02$

$3.02 \mathrm{E}+02$

$3.03 \mathrm{E}+02$

$3.04 \mathrm{E}+02$

$3.04 \mathrm{E}+02$

$3.05 \mathrm{E}+02$

$3.05 \mathrm{E}+02$

$3.06 \mathrm{E}+02$

$3.06 \mathrm{E}+02$
Dose statistics at graphical times, mrem/yr

\begin{tabular}{|c|c|c|c|c|c|c|c|}
\hline m & $\mathrm{m}$ & Mean & ledian & & & $\%$ & \\
\hline $.00 \mathrm{E}+00$ & 01 & -03 & $2.50 \mathrm{E}-05$ & -03 & -02 & -02 & -01 \\
\hline+00 & 01 & 03 & 05 & 3 & 02 & -02 & -01 \\
\hline$E+00$ & $6.46 \mathrm{E}-01$ & $4 E-03$ & $2.89 \mathrm{E}-05$ & $3 E-03$ & $2.14 \mathrm{E}-02$ & -02 & $1.39 \mathrm{E}-01$ \\
\hline $.00 \mathrm{E}+00$ & $6.53 E-01$ & $2 E-03$ & $3.08 E-05$ & $37 E-03$ & $17 \mathrm{E}-02$ & $2 E-02$ & $1.41 \mathrm{E}-01$ \\
\hline $.00 \mathrm{E}+00$ & 01 & 03 & $x^{-2}$ & $x_{-1}$ & & 02 & 01 \\
\hline+00 & 01 & 3 & & & 2 & -02 & -01 \\
\hline $.00 \mathrm{E}+00$ & 01 & & & 3 & 02 & 02 & -01 \\
\hline+00 & & & & & & & -01 \\
\hline$E+00$ & -01 & -03 & & 3 & -02 & -02 & $49 E-01$ \\
\hline $0 \mathrm{E}+00$ & 1 & 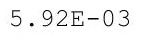 & $4.60 E-05$ & $987 F-03$ & 2 & 2 & -01 \\
\hline $00 \mathrm{E}+00$ & 01 & $6.00 \mathrm{E}-03$ & 5 & 2 & 2 & $6.12 \mathrm{E}-02$ & -01 \\
\hline $.00 \mathrm{E}+00$ & & & & & 2 & & -01 \\
\hline $.00 \mathrm{E}+00$ & $5 E-01$ & $3 F-03$ & 5 & 2 & -02 & -02 & -01 \\
\hline $.00 \mathrm{E}+00$ & $7.22 \mathrm{E}-01$ & $6.27 \mathrm{E}-03$ & $5.87 \mathrm{E}-05$ & $1.05 \mathrm{E}-02$ & $2.54 \mathrm{E}-02$ & $6.36 \mathrm{E}-02$ & $1.59 \mathrm{E}-01$ \\
\hline $.00 \mathrm{E}+00$ & $29 E-01$ & $5 E-03$ & & 2 & -02 & -02 & -01 \\
\hline $.00 E+00$ & & 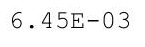 & & 2 & 2 & 2 & -01 \\
\hline $00 \mathrm{E}+00$ & $\perp$ & 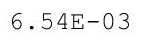 & & 2 & 2 & & 01 \\
\hline $00 \mathrm{E}+00$ & & & & & & & 01 \\
\hline $.00 E+00$ & $7.58 \mathrm{E}-01$ & $6.72 F-03$ & & 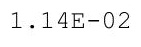 & 2 & & -01 \\
\hline $.00 \mathrm{E}+00$ & $7.66 \mathrm{E}-01$ & $.81 E-03$ & $15-0$ & $6 E-02$ & $2.80 \mathrm{E}-02$ & $.86 \mathrm{E}-02$ & 1. $71 \mathrm{E}-01$ \\
\hline $.00 \mathrm{E}+00$ & $7.73 E-01$ & $91 E-03$ & & 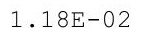 & -02 & $E-02$ & $1.73 E-01$ \\
\hline & & & & & & 02 & -01 \\
\hline $00 \mathrm{E}+00$ & & & & & & & 01 \\
\hline $.00 \mathrm{E}+00$ & . & $-e^{-1}$ & & 1.25 & & & -01 \\
\hline $00 \mathrm{E}+00$ & 1 & 3 & $1.04 \mathrm{E}-04$ & 2 & 2 & 2 & -01 \\
\hline $.00 \mathrm{E}+00$ & $.10 \mathrm{E}-01$ & $7.40 \mathrm{E}-03$ & & קרת & $06 \mathrm{E}-02$ & $.39 E-02$ & $1.84 \mathrm{E}-01$ \\
\hline $.00 \mathrm{E}+00$ & 01 & $50 F-03$ & & & -02 & $48 \mathrm{~F}-02$ & $.86 E-01$ \\
\hline & & & & & & & -01 \\
\hline & & & & & & & \\
\hline $.00 \mathrm{E}+00$ & $8.40 \mathrm{E}-01$ & $7.80 \mathrm{E}-03$ & $1.34 \mathrm{E}-04$ & $1.36 \mathrm{E}-02$ & 3.20 & $7.77 \mathrm{E}-02$ & -01 \\
\hline $.00 \mathrm{E}+00$ & $0.40 \mathrm{E}-1$ & $1.21 \mathrm{~L}-03$ & $1.40 \mathrm{E}-04$ & $1.38 \mathrm{E}-02$ & $3.30 \mathrm{E}-02$ & $7.87 \mathrm{E}-02$ & $1.95 E-01$ \\
\hline $.00 \mathrm{E}+00$ & 年 & 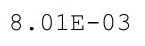 & & & & 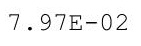 & $1.97 \mathrm{E}-01$ \\
\hline $.00 E+00$ & 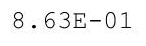 & ת? 10 & & $1.43 E-$ & & & $.99 \mathrm{E}-$ \\
\hline $.00 \mathrm{E}+00$ & & & & & & & \\
\hline & & & & & 02 & 2 & \\
\hline $0 E+00$ & $0.01 \mathrm{E}$ & 03 & $1.1 \angle \mathrm{E}$ & $\perp \cdot 00$ & 3.02 & 02 & 01 \\
\hline $.00 \mathrm{E}+00$ & 然 & & & 1.53 & & & -01 \\
\hline 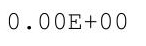 & & & & & & & $2.10 \mathrm{E}-01$ \\
\hline (c) & 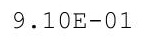 & 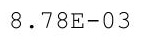 & $1.93 \mathrm{E}-04$ & 2 & & 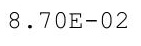 & 01 \\
\hline 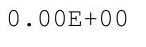 & & & & 2 & & & \\
\hline & 1 & & 2 & 2 & 2 & 2 & 01 \\
\hline $00 \mathrm{E}+00$ & $9.34 \mathrm{E}-01$ & 03 & 2. & 1. & -02 & 02 & -01 \\
\hline & & & & & & & \\
\hline & $\perp$ & 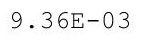 & & & & & $2.23 E-01$ \\
\hline $.00 E+00$ & 0 & . & 2 & & 02 & 02 & $2.26 \mathrm{E}-01$ \\
\hline $00 E+00$ & $6 E-01$ & $D E-03$ & $47 E-04$ & $E-02$ & $E-02$ & -02 & -01 \\
\hline
\end{tabular}


RESRAD-OFFSITE, Version 2.5

Title : Offsite Resident Farmer Deterministic Run

File : RF TC99 DOESG FWD-FV2.ROF

Summary of dose at graphical times, reptition 2 (continued)

Time

Years

$3.07 \mathrm{E}+02$

$3.07 \mathrm{E}+02$

$3.08 \mathrm{E}+02$

$3.08 \mathrm{E}+02$

$3.09 \mathrm{E}+02$

$3.09 \mathrm{E}+02$

$3.10 \mathrm{E}+02$

$3.10 \mathrm{E}+02$

$3.11 \mathrm{E}+02$

$3.11 \mathrm{E}+02$

3. $12 \mathrm{E}+02$

$3.12 \mathrm{E}+02$

$3.13 \mathrm{E}+02$

$3.13 \mathrm{E}+02$

$3.14 \mathrm{E}+02$

$3.14 \mathrm{E}+02$

$3.15 \mathrm{E}+02$

$3.15 \mathrm{E}+02$

$3.16 \mathrm{E}+02$

$3.16 \mathrm{E}+02$

$3.17 \mathrm{E}+02$

$3.17 \mathrm{E}+02$

$3.18 \mathrm{E}+02$

$3.18 \mathrm{E}+02$

$3.19 \mathrm{E}+02$

$3.19 \mathrm{E}+02$

$3.20 \mathrm{E}+02$

$3.20 \mathrm{E}+02$

$3.21 \mathrm{E}+02$

$3.21 \mathrm{E}+02$

$3.22 \mathrm{E}+02$

3. $22 \mathrm{E}+02$

$3.23 \mathrm{E}+02$

$3.24 \mathrm{E}+02$

$3.24 \mathrm{E}+02$

$3.25 \mathrm{E}+02$

$3.25 \mathrm{E}+02$

$3.26 \mathrm{E}+02$

$3.26 \mathrm{E}+02$

$3.27 \mathrm{E}+02$

$3.27 \mathrm{E}+02$

$3.28 \mathrm{E}+02$

$3.28 \mathrm{E}+02$

$3.29 \mathrm{E}+02$

$3.29 \mathrm{E}+02$

$3.30 \mathrm{E}+02$
Dose statistics at graphical times, mrem/yr

\begin{tabular}{|c|c|c|c|c|c|c|c|}
\hline m & m & ea & 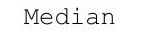 & & & $\%$ & \\
\hline $.00 \mathrm{E}+00$ & 01 & $9.72 E-03$ & $2.55 \mathrm{E}-04$ & $1.81 \mathrm{E}-02$ & -02 & -02 & -01 \\
\hline $.00 \mathrm{E}+00$ & $.82 \mathrm{E}-01$ & 03 & $3 E-04$ & $1.83 E-02$ & -02 & -02 & -01 \\
\hline$E+00$ & $9.91 \mathrm{E}-01$ & $7 E-03$ & $2.72 \mathrm{E}-04$ & $1.86 \mathrm{E}-02$ & $4.25 \mathrm{E}-02$ & $E-02$ & $2.35 E-01$ \\
\hline $.00 \mathrm{E}+00$ & $.99 E-01$ & $1 E-02$ & $2.81 \mathrm{E}-04$ & $1.88 \mathrm{E}-02$ & $4.31 \mathrm{E}-02$ & $3 \mathrm{E}-02$ & $37 E-01$ \\
\hline $.00 \mathrm{E}+00$ & $.01 E+00$ & 02 & 04 & -02 & 02 & 02 & -01 \\
\hline+00 & 00 & 2 & 4 & 2 & 02 & 01 & -01 \\
\hline $.00 \mathrm{E}+00$ & & & & 2 & & 1 & -01 \\
\hline $.00 \mathrm{E}+00$ & & & & & & & -01 \\
\hline$E+00$ & $1.04 \mathrm{E}+00$ & -02 & -04 & -02 & -02 & -01 & $9 E-01$ \\
\hline $00 \mathrm{E}+00$ & $.05 E+00$ & 2 & 4 & 2 & -02 & -01 & -01 \\
\hline $00 \mathrm{E}+00$ & $1.06 \mathrm{E}+00$ & $1.10 \mathrm{E}-02$ & $3.53 E-04$ & $2.09 E-02$ & 2 & 1 & -01 \\
\hline$\Xi+00$ & & & & & 2 & & -01 \\
\hline $.00 \mathrm{E}+00$ & & $3 F-02$ & 4 & $5 E-02$ & 2 & -01 & -01 \\
\hline $.00 \mathrm{E}+00$ & $1.08 \mathrm{E}+00$ & $1.14 \mathrm{E}-02$ & $3.89 \mathrm{E}-04$ & $2.18 \mathrm{E}-02$ & $4.97 \mathrm{E}-02$ & $1.11 \mathrm{E}-01$ & $E-01$ \\
\hline $.00 \mathrm{E}+00$ & $E+00$ & $5 E-02$ & -04 & -02 & 02 & -01 & -01 \\
\hline $.00 E+00$ & & 2 & & & & 1 & -01 \\
\hline مח + & 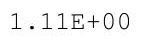 & 2 & & 2 & 2 & 1 & 01 \\
\hline $00 \mathrm{E}+00$ & $12 \mathrm{E}$ & & & & & & 01 \\
\hline $.00 E+00$ & $1.12 \mathrm{E}+00$ & $21 \mathrm{~F}-02$ & $O E-04$ & 2 & 2 & $E-01$ & -01 \\
\hline $.00 \mathrm{E}+00$ & $1.13 \mathrm{E}+00$ & $.22 \mathrm{E}-02$ & $4.62 \mathrm{E}-04$ & $.37 E-02$ & $.38 E-02$ & $7 E-01$ & $2.76 \mathrm{E}-01$ \\
\hline $.00 \mathrm{E}+00$ & $.14 \mathrm{E}+00$ & $24 E-02$ & -04 & -02 & -02 & $.18 E-01$ & $79 E-01$ \\
\hline & & & & & & -01 & $31 E-01$ \\
\hline & & & & & & & 01 \\
\hline $.00 \mathrm{E}+00$ & $1.17 \mathrm{E}+00$ & 02 & 4 & 2 & & -01 & $t-01$ \\
\hline $00 \mathrm{E}+00$ & $.18 \mathrm{E}$ & 2 & 4 & 2 & 2 & 1 & -01 \\
\hline $.00 \mathrm{E}+00$ & $118 F+00$ & 1. $31 \mathrm{E}-02$ & $4 E-04$ & $.58 \mathrm{E}-02$ & $82 E-02$ & 1. $24 \mathrm{E}-01$ & $.92 E-01$ \\
\hline $.00 E+00$ & $1.19 \mathrm{E}+00$ & $33 F-02$ & $E-04$ & $62 \mathrm{E}-02$ & $89 \mathrm{E}-02$ & $E-01$ & $.94 \mathrm{E}-01$ \\
\hline & & & & & & & $97 E-01$ \\
\hline & $1.21 \mathrm{E}+00$ & 02 & & & & & 01 \\
\hline $.00 \mathrm{E}+00$ & $1.22 \mathrm{E}+00$ & $1.37 \mathrm{E}-02$ & $E-04$ & $2.73 E-02$ & $\cdot \pm 2$ & 01 & -01 \\
\hline $.00 \mathrm{E}+00$ & 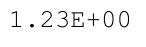 & $1.395-02$ & $6.19 \mathrm{E}-04$ & $2.76 \mathrm{E}-02$ & $.20 \mathrm{E}-02$ & $1.31 \mathrm{E}-01$ & $3.05 E-01$ \\
\hline . & म.2भप & 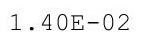 & 0.3404 & 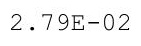 & & 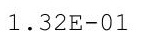 & $3.08 \mathrm{E}-01$ \\
\hline $.00 E+00$ & $1.25 \mathrm{E}+00$ & 10 & & 8?" & & & 1 \\
\hline مח & & & & & & & \\
\hline & & 2 & 4 & 02 & & & -01 \\
\hline $0 E+00$ & $1.27 \mathrm{E}$ & 02 & 04 & 2.90 & 2 & 01 & 01 \\
\hline $.00 \mathrm{E}+00$ & $1.28 \mathrm{E}+00$ & 1. & & & & & -01 \\
\hline $.00 \mathrm{E}+00$ & 土.2 & & & & & & $\cdot 245-U 1$ \\
\hline 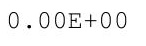 & t. 0 - & $+\cdots$ & 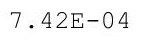 & 2 & 2 & $+\cdots$ & -01 \\
\hline $.00 \mathrm{E}+00$ & 1. $31 \mathrm{E}+0$ & & & & & & 1 \\
\hline & $1.32 \mathrm{E}+00$ & 02 & 4 & 02 & 2 & & 01 \\
\hline $\mathrm{E}+00$ & $1.33 \mathrm{E}+00$ & -02 & 7.9 & -02 & -02 & 01 & -01 \\
\hline & $1 \cdot 3$ & & & & & & \\
\hline & 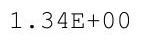 & $+0^{\circ}$ a & 4 & & & & $4 \perp-O \perp$ \\
\hline $.00 E+00$ & $1.35 E+00$ &.+ & & 2 & 02 & & 01 \\
\hline $00 E+00$ & $1.36 \mathrm{E}+00$ & $4 E-02$ & $4 E-04$ & $E-02$ & -02 & -01 & -01 \\
\hline
\end{tabular}


RESRAD-OFFSITE, Version 2.5

obabilistic Dose and Risk Report

Title : Offsite Resident Farmer Deterministic Run

File : RF TC99 DOESG FWD-FV2.ROF

Summary of dose at graphical times, reptition 2 (continued)

Time

Years

$3.30 \mathrm{E}+02$

$3.31 \mathrm{E}+02$

$3.31 \mathrm{E}+02$

$3.32 \mathrm{E}+02$

$3.32 \mathrm{E}+02$

$3.33 \mathrm{E}+02$

$3.33 \mathrm{E}+02$

$3.34 \mathrm{E}+02$

$3.34 \mathrm{E}+02$

$3.35 \mathrm{E}+02$

$3.35 \mathrm{E}+02$

$3.36 \mathrm{E}+02$

$3.36 \mathrm{E}+02$

$3.37 \mathrm{E}+02$

$3.37 \mathrm{E}+02$

$3.38 \mathrm{E}+02$

$3.38 \mathrm{E}+02$

$3.39 \mathrm{E}+02$

$3.39 \mathrm{E}+02$

3. $40 \mathrm{E}+02$

$3.40 \mathrm{E}+02$

$3.41 \mathrm{E}+02$

$3.41 \mathrm{E}+02$

$3.42 \mathrm{E}+02$

$3.42 \mathrm{E}+02$

$3.43 \mathrm{E}+02$

$3.44 \mathrm{E}+02$

$3.44 \mathrm{E}+02$

$3.45 \mathrm{E}+02$

$3.45 \mathrm{E}+02$

$3.46 \mathrm{E}+02$

$3.46 \mathrm{E}+02$

$3.47 \mathrm{E}+02$

$3.47 \mathrm{E}+02$

$3.48 \mathrm{E}+02$

$3.48 \mathrm{E}+02$

$3.49 \mathrm{E}+02$

$3.49 \mathrm{E}+02$

$3.50 \mathrm{E}+02$

$3.50 \mathrm{E}+02$

$3.51 \mathrm{E}+02$

$3.51 \mathrm{E}+02$

$3.52 \mathrm{E}+02$

$3.52 \mathrm{E}+02$

$3.53 \mathrm{E}+02$

$3.53 \mathrm{E}+02$
Dose statistics at graphical times, mrem/yr

\begin{tabular}{|c|c|c|c|c|c|c|c|}
\hline m & aximum & ea & - & & & & \\
\hline $.00 \mathrm{E}+00$ & $1.37 \mathrm{E}+00$ & 1. $65 \mathrm{E}-02$ & $8.83 E-04$ & $3.35 \mathrm{E}-02$ & $7.43 E-02$ & 01 & $9 \pm-U 1$ \\
\hline+00 & $1.38 \mathrm{E}+00$ & $1.67 \mathrm{E}-02$ & $9.04 \mathrm{E}-04$ & $9 E-02$ & $52 E-02$ & $1.52 \mathrm{E}-01$ & $2 E-01$ \\
\hline $.00 \mathrm{E}+00$ & $.39 E+00$ & $69 E-02$ & $6 \mathrm{E}-04$ & $3 E-02$ & $1 E-02$ & $54 E-01$ & $5 E-01$ \\
\hline $00 \mathrm{E}+00$ & $.40 E+00$ & $71 \mathrm{~F}-02$ & $50 \mathrm{E}-04$ & $47 F-02$ & $.69 \mathrm{E}-02$ & -01 & $58 \mathrm{~F}-01$ \\
\hline $.00 \mathrm{E}+00$ & $.41 \mathrm{E}+00$ & $=0$ & 4 & 2 & 2 & 1 & -01 \\
\hline $.00 E+00$ & $1.42 \mathrm{E}+00$ & & & & & & 01 \\
\hline $.00 E+00$ & $1.43 E+00$ & $1.76 \mathrm{E}$ & & & & & -01 \\
\hline $.00 \mathrm{E}+00$ & $1.43 E+00$ & 02 & -03 & 02 & -02 & -01 & -01 \\
\hline$E+00$ & $1.44 \mathrm{E}+00$ & $1.80 \mathrm{E}-02$ & -03 & -02 & -02 & -01 & $3 E-01$ \\
\hline $.00 E+00$ & $.45 E+00$ & ת חרים & 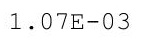 & 2 & 2 & $.63 E-01$ & $E-01$ \\
\hline+00 & $1.46 \mathrm{E}+00$ & 1 & & & & 1 & 01 \\
\hline $.00 \mathrm{E}+00$ & $1.47 \mathrm{E}+00$ & $1 . \varepsilon$ & 3 & 2 & 2 & 1 & -01 \\
\hline $.00 \mathrm{E}+00$ & $1.48 E+00$ & $1.87 \mathrm{E}-02$ & & $3.85 E-02$ & & & $85 E-01$ \\
\hline $.00 \mathrm{E}+00$ & $1.49 \mathrm{E}+00$ & $1.89 \mathrm{E}-02$ & $1.16 \mathrm{E}-03$ & 2 & 2 & -01 & $38 E-01$ \\
\hline$\Xi+00$ & $1.50 \mathrm{E}+00$ & $F-0$ & -03 & 2 & 02 & 1 & $E-01$ \\
\hline $.00 E+00$ & $.51 E+00$ & $\perp$ & 3 & & 2 & $\perp$ & 01 \\
\hline$E+00$ & 00 & 1. $95 \mathrm{E}-02$ & & 2 & 2 & $\perp$ & 1 \\
\hline $00 \mathrm{E}+00$ & $.53 E+00$ & 1.97E-02 & 3 & & 2 & $1.75 \mathrm{E}-01$ & 01 \\
\hline $.00 E+00$ & $1.54 \mathrm{E}+00$ & $995-02$ & $8 E-03$ & & 2 & $E-01$ & $03 E-01$ \\
\hline $.00 \mathrm{E}+00$ & $1.54 \mathrm{E}+00$ & $2.01 \mathrm{E}-02$ & $1.30 \mathrm{E}-03$ & $.17 \mathrm{E}-02$ & $.07 E-02$ & $1.79 \mathrm{E}-01$ & $.06 E-01$ \\
\hline $.00 \mathrm{E}+00$ & $1.55 \mathrm{E}+00$ & 2 & & & & 1 & $9 E-01$ \\
\hline & & & & & & & 01 \\
\hline $00 \mathrm{E}+00$ & $1.57 \mathrm{E}+00$ & $2 \cdot$ & 3 & 2 & & & -01 \\
\hline $.00 \mathrm{E}+00$ & $1.58 \mathrm{E}+00$ & 2 & 3 & 2 & & & -01 \\
\hline $00 \mathrm{E}+00$ & $1.59 \mathrm{E}+00$ & $2.12 \mathrm{E}-02$ & O & 2 & 2 & 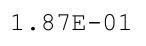 & $21 E-01$ \\
\hline $.00 \mathrm{E}+00$ & $1.60 \mathrm{E}+00$ & $.14 \mathrm{E}-0$ & $1.45 \mathrm{E}-03$ & 50 ת م & $62 E-02$ & $1.88 \mathrm{E}-01$ & $24 \mathrm{E}-01$ \\
\hline $.00 \mathrm{E}+00$ & $1.61 \mathrm{E}+00$ & $216 \mathrm{~F}-02$ & $.48 E-03$ & & & $\mathrm{DE}-01$ & $27 E-01$ \\
\hline & & & & & & & $E-01$ \\
\hline & $1.63 \mathrm{E}+00$ & $2 \cdot 2$ & & 2 & & & -01 \\
\hline $.00 \mathrm{E}+00$ & $1.64 \mathrm{E}+00$ & $2 \cdot 2 \angle \dot{0} 02$ & $1.57 \mathrm{E}-03$ & $4.74 \mathrm{E}-02$ & $1.00 \mathrm{E}-01$ & $1.905-01$ & $.36 E-01$ \\
\hline $.00 \mathrm{E}+00$ & $1.65 \mathrm{E}+00$ & $2.215-02$ & $E-03$ & $4.79 \mathrm{E}-02$ & $1.01 \mathrm{E}-01$ & 舟 & $39 E-01$ \\
\hline $.00 \mathrm{E}+00$ & $1.66 \mathrm{E}+00$ & . & 3 & 2 & 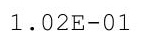 & 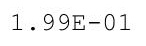 & $42 E-01$ \\
\hline $.00 E+00$ & $1.67 \mathrm{E}+00$ & & & & & & $45 E-01$ \\
\hline & $1.68 \mathrm{E}+00$ & & & 2 & & & $8 \mathrm{E}-01$ \\
\hline $0 \mathrm{E}+00$ & & 2 . & 03 & 02 & & 1 & -01 \\
\hline $.00 \mathrm{E}+00$ & $1.69 \mathrm{E}+00$ & $2.35 E-02$ & $1.75 E-03$ & 2 & 1 & & $E-01$ \\
\hline $.00 E+00$ & $1.70 \mathrm{E}+00$ & 2.000 & & & & & $.57 E-01$ \\
\hline $00 \mathrm{E}+00$ & $1.71 \mathrm{E}+00$ & $2.40 \mathrm{E}-02$ & & & & & $.60 E-01$ \\
\hline ( & $\pm \cdot 12$ & . & 3 & 2 & - & 1 & 01 \\
\hline & $1.73 E+00$ & & 3 & 2 & & & 01 \\
\hline $0 \mathrm{E}+00$ & $1.74 \mathrm{E}+00$ & $2.47 \mathrm{E}-02$ & 1.91E-03 & 2 & $110 \mathrm{~F}$ & $5 E-01$ & $59 \mathrm{E}-01$ \\
\hline$E+00$ & $1.75 E+00$ & 2.4 & 1. & & & & -01 \\
\hline & $1 \cdot 7$ & & & & & & -01 \\
\hline $.00 \mathrm{E}+00$ & $1.77 \mathrm{E}+00$ & . & $2.01 E-03$ & . & 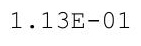 & $2.20 \mathrm{E}-01$ & $4.18 \mathrm{E}-01$ \\
\hline $.00 E+00$ & $1.78 \mathrm{E}+00$ & $2.00+02$ & 2.001 & & & & $4.81 E-01$ \\
\hline $0 \mathrm{E}+00$ & $1.79 \mathrm{E}+00$ & $3 E-02$ & $08 E-03$ & $E-02$ & $E-01$ & $4 \mathrm{E}-01$ & -01 \\
\hline
\end{tabular}


RESRAD-OFFSITE, Version 2.5

Title : Offsite Resident Farmer Deterministic Run

File : RF TC99 DOESG FWD-FV2.ROF

Summary of dose at graphical times, reptition 2 (continued)

Time

Years

$3.54 \mathrm{E}+02$

$3.54 \mathrm{E}+02$

3. $55 \mathrm{E}+02$

$3.55 \mathrm{E}+02$

3. $56 \mathrm{E}+02$

3. $56 \mathrm{E}+02$

$3.57 \mathrm{E}+02$

3. $57 \mathrm{E}+02$

$3.58 \mathrm{E}+02$

3. $58 \mathrm{E}+02$

$3.59 \mathrm{E}+02$

3. $59 \mathrm{E}+02$

$3.60 E+02$

$3.60 E+02$

$3.61 \mathrm{E}+02$

3. $61 \mathrm{E}+02$

3. $62 \mathrm{E}+02$

$3.62 \mathrm{E}+02$

$3.63 E+02$

$3.64 \mathrm{E}+02$

$3.64 \mathrm{E}+02$

$3.65 \mathrm{E}+02$

$3.65 \mathrm{E}+02$

$3.66 \mathrm{E}+02$

$3.66 \mathrm{E}+02$

$3.67 \mathrm{E}+02$

3. $67 \mathrm{E}+02$

$3.68 \mathrm{E}+02$

$3.68 \mathrm{E}+02$

$3.69 \mathrm{E}+02$

3. $69 \mathrm{E}+02$

3. $70 \mathrm{E}+02$

$3.70 \mathrm{E}+02$

$3.71 \mathrm{E}+02$

$3.71 \mathrm{E}+02$

3. $72 \mathrm{E}+02$

$3.72 \mathrm{E}+02$

3. $73 \mathrm{E}+02$

$3.73 E+02$

$3.74 \mathrm{E}+02$

$3.74 \mathrm{E}+02$

$3.75 \mathrm{E}+02$

$3.75 \mathrm{E}+02$

$3.76 \mathrm{E}+02$

$3.76 \mathrm{E}+02$

$3.77 \mathrm{E}+02$

Dose statistics at graphical times, mrem/yr

\begin{tabular}{|c|c|c|c|c|c|c|c|}
\hline Minimum & Maximum & Mean & Median & $90 \%$ & $95 \%$ & $97.5 \%$ & $99 \%$ \\
\hline $0.00 \mathrm{E}+00$ & $1.80 \mathrm{E}+00$ & $2.61 E-02$ & $2.12 \mathrm{E}-03$ & $5.81 E-02$ & $1.16 \mathrm{E}-01$ & $2.26 \mathrm{E}-01$ & $4.87 E-01$ \\
\hline $0.00 \mathrm{E}+00$ & $1.81 \mathrm{E}+00$ & $2.63 E-02$ & $2.15 \mathrm{E}-03$ & $5.89 \mathrm{E}-02$ & $1.17 \mathrm{E}-01$ & $2.28 \mathrm{E}-01$ & 4. $90 \mathrm{E}-01$ \\
\hline $0.00 \mathrm{E}+00$ & $1.82 \mathrm{E}+00$ & $2.66 \mathrm{E}-02$ & $2.18 \mathrm{E}-03$ & $5.96 \mathrm{E}-02$ & $1.18 \mathrm{E}-01$ & $2.29 \mathrm{E}-01$ & 4. $93 E-01$ \\
\hline $0.00 \mathrm{E}+00$ & $1.83 \mathrm{E}+00$ & $2.68 \mathrm{E}-02$ & $2.22 \mathrm{E}-03$ & $6.03 E-02$ & $1.19 \mathrm{E}-01$ & $2.31 \mathrm{E}-01$ & $4.96 \mathrm{E}-01$ \\
\hline $0.00 \mathrm{E}+00$ & $1.83 \mathrm{E}+00$ & $2.71 E-02$ & $2.25 E-03$ & $6.11 E-02$ & 1.20E-01 & $2.33 E-01$ & $4.99 E-01$ \\
\hline $0.00 \mathrm{E}+00$ & $1.84 \mathrm{E}+00$ & $2.73 E-02$ & $2.29 \mathrm{E}-03$ & $6.18 \mathrm{E}-02$ & $1.21 \mathrm{E}-01$ & $2.35 \mathrm{E}-01$ & $5.02 \mathrm{E}-01$ \\
\hline $0.00 \mathrm{E}+00$ & $1.85 \mathrm{E}+00$ & $2.75 \mathrm{E}-02$ & $2.33 E-03$ & $6.25 E-02$ & $1.22 \mathrm{E}-01$ & $2.37 E-01$ & $5.05 E-01$ \\
\hline $0.00 \mathrm{E}+00$ & $1.86 \mathrm{E}+00$ & $2.78 \mathrm{E}-02$ & $2.37 \mathrm{E}-03$ & $6.31 E-02$ & $1.23 \mathrm{E}-01$ & $2.39 E-01$ & $5.08 E-01$ \\
\hline $0.00 \mathrm{E}+00$ & $1.87 \mathrm{E}+00$ & $2.80 E-02$ & $2.41 E-03$ & $6.38 \mathrm{E}-02$ & 1. $24 \mathrm{E}-01$ & $2.41 \mathrm{E}-01$ & $5.11 \mathrm{E}-01$ \\
\hline $0.00 \mathrm{E}+00$ & $1.88 \mathrm{E}+00$ & $2.83 E-02$ & $2.46 \mathrm{E}-03$ & $6.44 \mathrm{E}-02$ & $1.26 \mathrm{E}-01$ & $2.43 E-01$ & $5.15 \mathrm{E}-01$ \\
\hline $0.00 \mathrm{E}+00$ & $1.89 \mathrm{E}+00$ & $2.86 \mathrm{E}-02$ & $2.50 \mathrm{E}-03$ & $6.51 \mathrm{E}-02$ & $1.27 \mathrm{E}-01$ & $2.45 \mathrm{E}-01$ & $5.18 \mathrm{E}-01$ \\
\hline $0.00 \mathrm{E}+00$ & 1.90E+00 & $2.88 E-02$ & $2.55 \mathrm{E}-03$ & $6.57 \mathrm{E}-02$ & $1.28 \mathrm{E}-01$ & $2.47 \mathrm{E}-01$ & $5.21 \mathrm{E}-01$ \\
\hline $0.00 \mathrm{E}+00$ & $1.91 \mathrm{E}+00$ & $2.91 \mathrm{E}-02$ & $2.60 \mathrm{E}-03$ & $6.63 E-02$ & $1.29 \mathrm{E}-01$ & $2.49 \mathrm{E}-01$ & $5.24 \mathrm{E}-01$ \\
\hline $0.00 \mathrm{E}+00$ & 1.92E+00 & $2.93 \mathrm{E}-02$ & $2.65 \mathrm{E}-03$ & $6.69 \mathrm{E}-02$ & $1.31 \mathrm{E}-01$ & $2.51 \mathrm{E}-01$ & $5.27 \mathrm{E}-01$ \\
\hline $0.00 \mathrm{E}+00$ & $1.93 \mathrm{E}+00$ & $2.96 \mathrm{E}-02$ & $2.69 E-03$ & $6.75 E-02$ & 1. $32 \mathrm{E}-01$ & $2.53 E-01$ & $5.30 \mathrm{E}-01$ \\
\hline $0.00 \mathrm{E}+00$ & $1.94 \mathrm{E}+00$ & $2.98 E-02$ & $2.74 \mathrm{E}-03$ & $6.81 E-02$ & $1.33 E-01$ & $2.55 E-01$ & $.33 E-01$ \\
\hline $0.00 \mathrm{E}+00$ & 1. $95 \mathrm{E}+00$ & $3.01 E-02$ & $2.79 \mathrm{E}-03$ & $6.87 E-02$ & $1.34 \mathrm{E}-01$ & $2.56 \mathrm{E}-01$ & $5.36 \mathrm{E}-01$ \\
\hline $0.00 \mathrm{E}+00$ & $1.96 \mathrm{E}+00$ & $3.04 E-02$ & $2.84 \mathrm{E}-03$ & $6.94 \mathrm{E}-02$ & $1.36 \mathrm{E}-01$ & $2.58 \mathrm{E}-01$ & $5.40 \mathrm{E}-01$ \\
\hline $0.00 \mathrm{E}+00$ & $1.97 \mathrm{E}+00$ & $3.06 \mathrm{E}-02$ & $2.88 \mathrm{E}-03$ & $7.00 \mathrm{E}-02$ & $1.37 \mathrm{E}-01$ & $2.60 \mathrm{E}-01$ & $5.43 E-01$ \\
\hline $0.00 \mathrm{E}+00$ & 1. $98 \mathrm{E}+00$ & $3.09 \mathrm{E}-02$ & $2.93 E-03$ & $7.06 \mathrm{E}-02$ & $1.38 \mathrm{E}-01$ & $2.63 \mathrm{E}-01$ & $5.46 \mathrm{E}-01$ \\
\hline $0.00 \mathrm{E}+00$ & $1.98 \mathrm{E}+00$ & $3.12 \mathrm{E}-02$ & $2.98 E-03$ & $7.12 \mathrm{E}-02$ & $1.39 \mathrm{E}-01$ & $2.65 \mathrm{E}-01$ & $5.49 \mathrm{E}-01$ \\
\hline $0.00 \mathrm{E}+00$ & $1.99 \mathrm{E}+00$ & $3.14 \mathrm{E}-02$ & $3.02 E-03$ & $7.19 \mathrm{E}-02$ & $1.41 \mathrm{E}-01$ & $2.67 E-01$ & $5.52 \mathrm{E}-01$ \\
\hline $0.00 \mathrm{E}+00$ & $2.00 \mathrm{E}+00$ & $3.17 \mathrm{E}-02$ & $3.07 \mathrm{E}-03$ & 7. $25 \mathrm{E}-02$ & $1.42 \mathrm{E}-01$ & $2.69 \mathrm{E}-01$ & $5.55 \mathrm{E}-01$ \\
\hline $0.00 \mathrm{E}+00$ & $2.01 \mathrm{E}+00$ & $3.20 \mathrm{E}-02$ & $3.11 \mathrm{E}-03$ & $7.31 \mathrm{E}-02$ & $1.44 \mathrm{E}-01$ & $2.71 \mathrm{E}-01$ & $5.59 \mathrm{E}-01$ \\
\hline $0.00 \mathrm{E}+00$ & $2.02 \mathrm{E}+00$ & $3.23 E-02$ & $3.15 \mathrm{E}-03$ & 7. $38 \mathrm{E}-02$ & $1.45 \mathrm{E}-01$ & $2.73 \mathrm{E}-01$ & $5.62 \mathrm{E}-01$ \\
\hline $0.00 \mathrm{E}+00$ & $2.03 E+00$ & $3.25 E-02$ & $3.20 \mathrm{E}-03$ & 7. $45 \mathrm{E}-02$ & $1.47 \mathrm{E}-01$ & $2.75 \mathrm{E}-01$ & $5.65 \mathrm{E}-01$ \\
\hline $0.00 \mathrm{E}+00$ & $2.04 \mathrm{E}+00$ & $3.28 E-02$ & $3.26 \mathrm{E}-03$ & $7.52 \mathrm{E}-02$ & $1.48 \mathrm{E}-01$ & $2.77 \mathrm{E}-01$ & $5.68 \mathrm{E}-01$ \\
\hline $0.00 \mathrm{E}+00$ & $2.05 \mathrm{E}+00$ & $3.31 \mathrm{E}-02$ & $3.31 \mathrm{E}-03$ & $7.58 \mathrm{E}-02$ & $1.50 \mathrm{E}-01$ & $2.79 \mathrm{E}-01$ & $5.71 \mathrm{E}-01$ \\
\hline $0.00 \mathrm{E}+00$ & $2.06 \mathrm{E}+00$ & $3.34 \mathrm{E}-02$ & $3.36 \mathrm{E}-03$ & 7. $65 \mathrm{E}-02$ & 1. $51 \mathrm{E}-01$ & $2.82 \mathrm{E}-01$ & $5.74 \mathrm{E}-01$ \\
\hline $0.00 \mathrm{E}+00$ & $2.07 E+00$ & $3.37 \mathrm{E}-02$ & $3.42 \mathrm{E}-03$ & $7.71 \mathrm{E}-02$ & $1.53 \mathrm{E}-01$ & $2.84 \mathrm{E}-01$ & $5.78 \mathrm{E}-01$ \\
\hline $0.00 \mathrm{E}+00$ & $2.08 \mathrm{E}+00$ & $3.39 \mathrm{E}-02$ & $3.47 \mathrm{E}-03$ & $7.78 \mathrm{E}-02$ & $1.54 \mathrm{E}-01$ & $2.86 \mathrm{E}-01$ & $5.81 \mathrm{E}-01$ \\
\hline $0.00 \mathrm{E}+00$ & $2.09 \mathrm{E}+00$ & $.42 E-02$ & $3.52 \mathrm{E}-03$ & $7.84 \mathrm{E}-02$ & $1.55 \mathrm{E}-01$ & $2.88 \mathrm{E}-01$ & $5.84 \mathrm{E}-01$ \\
\hline $0.00 \mathrm{E}+00$ & $2.10 \mathrm{E}+00$ & $3.45 E-02$ & $3.58 \mathrm{E}-03$ & $7.91 \mathrm{E}-02$ & $1.57 \mathrm{E}-01$ & $2.90 \mathrm{E}-01$ & $5.87 E-01$ \\
\hline $0.00 \mathrm{E}+00$ & $2.11 \mathrm{E}+00$ & $3.48 \mathrm{E}-02$ & $3.64 \mathrm{E}-03$ & $7.97 \mathrm{E}-02$ & $1.58 \mathrm{E}-01$ & $2.92 \mathrm{E}-01$ & $5.91 \mathrm{E}-01$ \\
\hline $0.00 \mathrm{E}+00$ & $2.12 \mathrm{E}+00$ & $3.51 \mathrm{E}-02$ & $3.69 \mathrm{E}-03$ & $8.04 \mathrm{E}-02$ & $1.59 \mathrm{E}-01$ & $2.94 \mathrm{E}-01$ & $5.94 \mathrm{E}-01$ \\
\hline $0.00 \mathrm{E}+00$ & $2.12 \mathrm{E}+00$ & $3.54 \mathrm{E}-02$ & $3.75 E-03$ & $8.12 \mathrm{E}-02$ & $1.61 \mathrm{E}-01$ & $2.96 \mathrm{E}-01$ & $5.97 \mathrm{E}-01$ \\
\hline $0.00 \mathrm{E}+00$ & $2.13 \mathrm{E}+00$ & $3.57 \mathrm{E}-02$ & $3.82 \mathrm{E}-03$ & $8.19 \mathrm{E}-02$ & $1.62 \mathrm{E}-01$ & $2.98 \mathrm{E}-01$ & $6.00 \mathrm{E}-01$ \\
\hline $0.00 \mathrm{E}+00$ & $2.14 \mathrm{E}+00$ & $3.60 \mathrm{E}-02$ & $3.88 \mathrm{E}-03$ & $8.27 E-02$ & $1.64 \mathrm{E}-01$ & $3.00 \mathrm{E}-01$ & $6.03 E-01$ \\
\hline $0.00 \mathrm{E}+00$ & $2.15 \mathrm{E}+00$ & $3.63 \mathrm{E}-$ & 3.9 & $8.34 \mathrm{E}-02$ & $1.65 \mathrm{E}-01$ & $3.02 \mathrm{E}-01$ & $6.07 E-01$ \\
\hline $0.00 \mathrm{E}+00$ & $2.16 \mathrm{E}+00$ & $3.66 \mathrm{E}-02$ & $4.01 E-03$ & $8.42 E-02$ & $1.66 \mathrm{E}-01$ & $3.04 \mathrm{E}-01$ & $6.10 \mathrm{E}-01$ \\
\hline $0.00 \mathrm{E}+00$ & $2.17 \mathrm{E}+00$ & $3.69 \mathrm{E}-02$ & $4.06 \mathrm{E}-03$ & $8.49 E-02$ & $1.68 \mathrm{E}-01$ & $3.06 \mathrm{E}-01$ & $6.13 \mathrm{E}-01$ \\
\hline $0.00 \mathrm{E}+00$ & $2.18 \mathrm{E}+00$ & $3.72 \mathrm{E}-02$ & $4.12 \mathrm{E}-03$ & $8.57 \mathrm{E}-02$ & $1.69 \mathrm{E}-01$ & $3.08 \mathrm{E}-01$ & $6.16 \mathrm{E}-01$ \\
\hline $0.00 \mathrm{E}+00$ & $2.19 \mathrm{E}+00$ & $3.75 \mathrm{E}-02$ & $4.18 \mathrm{E}-03$ & $8.65 E-02$ & 1. $71 \mathrm{E}-01$ & $3.10 \mathrm{E}-01$ & $6.20 \mathrm{E}-01$ \\
\hline $0.00 \mathrm{E}+00$ & $2.20 \mathrm{E}+00$ & $3.78 \mathrm{E}-02$ & $4.24 \mathrm{E}-03$ & $8.73 E-02$ & $1.72 \mathrm{E}-01$ & $3.12 \mathrm{E}-01$ & $6.23 E-01$ \\
\hline $0.00 \mathrm{E}+00$ & $2.21 \mathrm{E}+00$ & $3.81 E-02$ & $4.30 \mathrm{E}-03$ & $8.80 \mathrm{E}-02$ & $1.74 \mathrm{E}-01$ & $3.14 \mathrm{E}-01$ & $6.26 \mathrm{E}-01$ \\
\hline $0.00 \mathrm{E}+00$ & $2.22 \mathrm{E}+00$ & $3.84 \mathrm{E}-02$ & $4.36 \mathrm{E}-03$ & $8.87 \mathrm{E}-02$ & $1.75 \mathrm{E}-01$ & $3.17 \mathrm{E}-01$ & $6.29 \mathrm{E}-01$ \\
\hline
\end{tabular}


RESRAD-OFFSITE, Version 2.5

Title : Offsite Resident Farmer Deterministic Run

File : RF TC99 DOESG FWD-FV2.ROF

Summary of dose at graphical times, reptition 2 (continued)

Time

Years

$3.77 \mathrm{E}+02$

$3.78 \mathrm{E}+02$

$3.78 \mathrm{E}+02$

3. $79 \mathrm{E}+02$

$3.79 \mathrm{E}+02$

3. $80 \mathrm{E}+02$

$3.80 \mathrm{E}+02$

$3.81 \mathrm{E}+02$

3. $81 \mathrm{E}+02$

$3.82 \mathrm{E}+02$

3. $82 \mathrm{E}+02$

$3.83 \mathrm{E}+02$

$3.83 E+02$

$3.84 \mathrm{E}+02$

$3.85 \mathrm{E}+02$

$3.85 \mathrm{E}+02$

$3.86 \mathrm{E}+02$

$3.86 \mathrm{E}+02$

$3.87 \mathrm{E}+02$

$3.87 \mathrm{E}+02$

$3.88 \mathrm{E}+02$

$3.88 \mathrm{E}+02$

$3.89 \mathrm{E}+02$

3. $89 \mathrm{E}+02$

3. $90 \mathrm{E}+02$

$3.90 \mathrm{E}+02$

3. $91 \mathrm{E}+02$

3. $91 \mathrm{E}+02$

3. $92 \mathrm{E}+02$

3. $92 \mathrm{E}+02$

3. $93 \mathrm{E}+02$

3. $93 \mathrm{E}+02$

$3.94 \mathrm{E}+02$

$3.94 \mathrm{E}+02$

$3.95 \mathrm{E}+02$

$3.95 \mathrm{E}+02$

$3.96 \mathrm{E}+02$

$3.96 \mathrm{E}+02$

3. $97 \mathrm{E}+02$

3. $97 \mathrm{E}+02$

$3.98 \mathrm{E}+02$

3. $98 \mathrm{E}+02$

$3.99 \mathrm{E}+02$

$3.99 \mathrm{E}+02$

4. $00 \mathrm{E}+02$

$4.00 \mathrm{E}+02$
Dose statistics at graphical times, mrem/yr

\begin{tabular}{|c|c|c|c|c|c|c|c|}
\hline Minimum & Maximum & Mean & Median & $90 \%$ & $95 \%$ & $97.5 \%$ & $99 \%$ \\
\hline $0.00 \mathrm{E}+00$ & $2.23 \mathrm{E}+00$ & $3.87 E-02$ & $4.42 E-03$ & $8.95 E-02$ & $1.77 E-01$ & $3.19 \mathrm{E}-01$ & $6.33 E-01$ \\
\hline $0.00 \mathrm{E}+00$ & $2.24 \mathrm{E}+00$ & $3.90 \mathrm{E}-02$ & $4.49 E-03$ & $9.03 E-02$ & $1.79 \mathrm{E}-01$ & $3.21 \mathrm{E}-01$ & $6.36 \mathrm{E}-01$ \\
\hline $0.00 \mathrm{E}+00$ & $2.24 \mathrm{E}+00$ & $3.93 E-02$ & $4.56 \mathrm{E}-03$ & $9.11 \mathrm{E}-02$ & $1.80 \mathrm{E}-01$ & $3.23 \mathrm{E}-01$ & $6.39 \mathrm{E}-01$ \\
\hline $0.00 \mathrm{E}+00$ & $2.25 \mathrm{E}+00$ & $3.96 \mathrm{E}-02$ & $4.62 \mathrm{E}-03$ & $9.19 \mathrm{E}-02$ & $1.82 \mathrm{E}-01$ & $3.25 \mathrm{E}-01$ & $6.43 \mathrm{E}-01$ \\
\hline $0.00 \mathrm{E}+00$ & $2.26 \mathrm{E}+00$ & $3.99 \mathrm{E}-02$ & $4.69 \mathrm{E}-03$ & $9.27 \mathrm{E}-02$ & $1.84 \mathrm{E}-01$ & $3.27 \mathrm{E}-01$ & $6.46 \mathrm{E}-01$ \\
\hline $0.00 \mathrm{E}+00$ & $2.27 \mathrm{E}+00$ & $4.03 E-02$ & $4.75 E-03$ & $9.37 E-02$ & $1.86 \mathrm{E}-01$ & $3.29 \mathrm{E}-01$ & $6.49 \mathrm{E}-01$ \\
\hline $0.00 \mathrm{E}+00$ & $2.28 \mathrm{E}+00$ & $4.06 \mathrm{E}-02$ & $4.82 E-03$ & $9.47 \mathrm{E}-02$ & $1.87 \mathrm{E}-01$ & $3.31 E-01$ & $6.52 \mathrm{E}-01$ \\
\hline $0.00 \mathrm{E}+00$ & $2.29 \mathrm{E}+00$ & $4.09 \mathrm{E}-02$ & $4.89 \mathrm{E}-03$ & $9.56 \mathrm{E}-02$ & $1.89 \mathrm{E}-01$ & $3.34 \mathrm{E}-01$ & $6.56 \mathrm{E}-01$ \\
\hline $0.00 \mathrm{E}+00$ & $2.30 \mathrm{E}+00$ & $4.12 \mathrm{E}-02$ & $4.95 E-03$ & $9.65 E-02$ & $1.91 \mathrm{E}-01$ & $3.36 \mathrm{E}-01$ & $6.59 \mathrm{E}-01$ \\
\hline $0.00 \mathrm{E}+00$ & $2.31 \mathrm{E}+00$ & $4.15 \mathrm{E}-02$ & $5.02 E-03$ & $9.74 \mathrm{E}-02$ & $1.92 \mathrm{E}-01$ & $3.38 E-01$ & $6.62 \mathrm{E}-01$ \\
\hline $0.00 \mathrm{E}+00$ & $2.32 \mathrm{E}+00$ & $4.19 \mathrm{E}-02$ & $5.09 E-03$ & $9.83 E-02$ & $1.93 \mathrm{E}-01$ & $3.40 \mathrm{E}-01$ & $6.66 \mathrm{E}-01$ \\
\hline $0.00 \mathrm{E}+00$ & $2.33 E+00$ & $4.22 E-02$ & $5.16 \mathrm{E}-03$ & $9.92 \mathrm{E}-02$ & $1.94 \mathrm{E}-01$ & $3.42 \mathrm{E}-01$ & $6.69 \mathrm{E}-01$ \\
\hline $0.00 \mathrm{E}+00$ & $2.34 \mathrm{E}+00$ & $4.25 \mathrm{E}-02$ & $5.23 E-03$ & $1.00 \mathrm{E}-01$ & $1.96 \mathrm{E}-01$ & $3.44 \mathrm{E}-01$ & $6.72 \mathrm{E}-01$ \\
\hline $0.00 \mathrm{E}+00$ & $2.34 \mathrm{E}+00$ & $4.29 \mathrm{E}-02$ & $5.30 E-03$ & $1.01 \mathrm{E}-01$ & $1.97 \mathrm{E}-01$ & $3.47 \mathrm{E}-01$ & $6.75 \mathrm{E}-01$ \\
\hline $0.00 \mathrm{E}+00$ & $2.35 E+00$ & $4.32 E-02$ & $5.38 E-03$ & 1.02E-01 & $1.98 \mathrm{E}-01$ & $3.49 \mathrm{E}-01$ & $6.79 \mathrm{E}-01$ \\
\hline $0.00 \mathrm{E}+00$ & $2.36 \mathrm{E}+00$ & $4.35 E-02$ & $5.45 E-03$ & $1.03 E-01$ & $2.00 E-01$ & $3.51 \mathrm{E}-01$ & $6.82 E-01$ \\
\hline $0.00 \mathrm{E}+00$ & $2.37 \mathrm{E}+00$ & $4.39 E-02$ & $5.53 E-03$ & $1.04 \mathrm{E}-01$ & $2.01 \mathrm{E}-01$ & $3.53 \mathrm{E}-01$ & $6.85 E-01$ \\
\hline $0.00 \mathrm{E}+00$ & $2.38 \mathrm{E}+00$ & $4.42 E-02$ & $5.61 E-03$ & $1.04 \mathrm{E}-01$ & $2.03 E-01$ & $3.55 \mathrm{E}-01$ & $6.89 \mathrm{E}-01$ \\
\hline $0.00 \mathrm{E}+00$ & $2.39 \mathrm{E}+00$ & $4.45 E-02$ & $5.70 \mathrm{E}-03$ & $1.05 E-01$ & $2.04 \mathrm{E}-01$ & $3.58 \mathrm{E}-01$ & $6.92 E-01$ \\
\hline $0.00 \mathrm{E}+00$ & $2.40 \mathrm{E}+00$ & $4.49 \mathrm{E}-02$ & $5.78 E-03$ & $1.06 \mathrm{E}-01$ & $2.06 \mathrm{E}-01$ & $3.60 \mathrm{E}-01$ & $6.95 E-01$ \\
\hline $0.00 \mathrm{E}+00$ & $2.41 \mathrm{E}+00$ & $4.52 \mathrm{E}-02$ & $5.86 \mathrm{E}-03$ & $1.07 \mathrm{E}-01$ & $2.07 \mathrm{E}-01$ & $3.62 \mathrm{E}-01$ & $6.99 \mathrm{E}-01$ \\
\hline $0.00 \mathrm{E}+00$ & $2.42 \mathrm{E}+00$ & $4.56 \mathrm{E}-02$ & $5.93 E-03$ & $1.08 E-01$ & $2.09 E-01$ & $3.64 \mathrm{E}-01$ & $7.02 E-01$ \\
\hline $0.00 \mathrm{E}+00$ & $2.43 \mathrm{E}+00$ & $4.59 \mathrm{E}-02$ & $6.01 E-03$ & 1.09E-01 & $2.11 \mathrm{E}-01$ & $3.67 \mathrm{E}-01$ & $7.05 E-01$ \\
\hline $1.56 \mathrm{E}-22$ & $2.43 \mathrm{E}+00$ & $4.62 \mathrm{E}-02$ & $6.10 \mathrm{E}-03$ & 1.10E-01 & $2.12 \mathrm{E}-01$ & $3.69 \mathrm{E}-01$ & $7.09 \mathrm{E}-01$ \\
\hline $2.99 E-20$ & $2.44 \mathrm{E}+00$ & $4.66 \mathrm{E}-02$ & $6.18 \mathrm{E}-03$ & $1.11 \mathrm{E}-01$ & $2.14 \mathrm{E}-01$ & $3.71 \mathrm{E}-01$ & $7.12 \mathrm{E}-01$ \\
\hline $1.48 \mathrm{E}-18$ & $2.45 \mathrm{E}+00$ & $4.69 \mathrm{E}-02$ & $6.26 E-03$ & 1.12E-01 & $2.16 \mathrm{E}-01$ & $3.73 \mathrm{E}-01$ & $7.15 \mathrm{E}-01$ \\
\hline $3.42 \mathrm{E}-17$ & $2.46 \mathrm{E}+00$ & $4.73 E-02$ & $6.36 \mathrm{E}-03$ & $1.13 \mathrm{E}-01$ & $2.17 \mathrm{E}-01$ & $3.76 \mathrm{E}-01$ & $7.19 \mathrm{E}-01$ \\
\hline $4.65 E-16$ & $2.47 \mathrm{E}+00$ & $4.76 \mathrm{E}-02$ & $6.45 E-03$ & $1.14 \mathrm{E}-01$ & $2.19 \mathrm{E}-01$ & $3.78 \mathrm{E}-01$ & $7.22 \mathrm{E}-01$ \\
\hline $4.29 E-15$ & $2.48 \mathrm{E}+00$ & $4.80 E-02$ & $6.55 E-03$ & $1.15 \mathrm{E}-01$ & $2.21 \mathrm{E}-01$ & $3.80 \mathrm{E}-01$ & 7. $25 \mathrm{E}-01$ \\
\hline $2.93 E-14$ & $2.49 \mathrm{E}+00$ & $4.83 E-02$ & $6.64 \mathrm{E}-03$ & $1.16 \mathrm{E}-01$ & $2.22 \mathrm{E}-01$ & $3.82 \mathrm{E}-01$ & $7.29 \mathrm{E}-01$ \\
\hline $1.57 \mathrm{E}-13$ & $2.50 \mathrm{E}+00$ & $4.87 \mathrm{E}-02$ & $6.74 \mathrm{E}-03$ & $1.17 \mathrm{E}-01$ & $2.23 E-01$ & $3.85 \mathrm{E}-01$ & $7.32 E-01$ \\
\hline $6.84 \mathrm{E}-13$ & $2.51 \mathrm{E}+00$ & $4.91 \mathrm{E}-02$ & $6.84 \mathrm{E}-03$ & 1.17E-01 & $2.25 \mathrm{E}-01$ & $3.87 \mathrm{E}-01$ & 7. $35 \mathrm{E}-01$ \\
\hline $2.52 \mathrm{E}-12$ & $2.51 \mathrm{E}+00$ & $4.94 \mathrm{E}-02$ & $6.92 E-03$ & $1.18 \mathrm{E}-01$ & $2.26 \mathrm{E}-01$ & $3.88 E-01$ & $7.39 \mathrm{E}-01$ \\
\hline $8.07 E-12$ & $2.52 \mathrm{E}+00$ & $4.98 \mathrm{E}-02$ & $7.01 \mathrm{E}-03$ & 1.19E-01 & $2.28 \mathrm{E}-01$ & $3.90 \mathrm{E}-01$ & $7.42 \mathrm{E}-01$ \\
\hline $2.29 \mathrm{E}-11$ & $2.53 \mathrm{E}+00$ & $5.01 \mathrm{E}-02$ & $7.09 E-03$ & 1.20E-01 & $2.29 \mathrm{E}-01$ & $3.92 \mathrm{E}-01$ & $7.45 \mathrm{E}-01$ \\
\hline $5.85 E-11$ & $2.54 \mathrm{E}+00$ & $5.05 E-02$ & $7.18 E-03$ & $1.21 \mathrm{E}-01$ & $2.31 \mathrm{E}-01$ & $3.94 \mathrm{E}-01$ & $7.49 \mathrm{E}-01$ \\
\hline $1.37 E-10$ & $2.55 \mathrm{E}+00$ & $5.09 E-02$ & $7.26 E-03$ & 1.22E-01 & $2.32 E-01$ & $3.96 \mathrm{E}-01$ & $7.52 \mathrm{E}-01$ \\
\hline $2.45 \mathrm{E}-10$ & $2.56 \mathrm{E}+00$ & $5.12 \mathrm{E}-02$ & $7.34 \mathrm{E}-03$ & 1.23E-01 & $2.34 \mathrm{E}-01$ & $3.98 \mathrm{E}-01$ & 7. $55 \mathrm{E}-01$ \\
\hline $4.20 E-10$ & $2.57 \mathrm{E}+00$ & $5.16 \mathrm{E}-02$ & $7.43 E-03$ & $1.24 \mathrm{E}-01$ & $2.35 E-01$ & $4.00 \mathrm{E}-01$ & $7.59 \mathrm{E}-01$ \\
\hline $6.96 \mathrm{E}-10$ & $2.57 \mathrm{E}+00$ & $5.20 \mathrm{E}-02$ & $7.52 \mathrm{E}-03$ & $1.25 E-01$ & $2.37 \mathrm{E}-01$ & $4.02 E-01$ & $7.62 \mathrm{E}-01$ \\
\hline $1.12 \mathrm{E}-09$ & $2.58 \mathrm{E}+00$ & $5.24 \mathrm{E}-02$ & $7.61 \mathrm{E}-03$ & 1. $26 \mathrm{E}-01$ & $2.38 \mathrm{E}-01$ & $4.04 \mathrm{E}-01$ & 7. $65 \mathrm{E}-01$ \\
\hline $1.74 \mathrm{E}-09$ & $2.59 \mathrm{E}+00$ & $5.27 \mathrm{E}-02$ & $7.71 E-03$ & $1.27 E-01$ & $2.40 \mathrm{E}-01$ & $4.06 \mathrm{E}-01$ & $7.69 \mathrm{E}-01$ \\
\hline $2.65 E-09$ & $2.60 \mathrm{E}+00$ & $5.31 \mathrm{E}-02$ & $7.82 \mathrm{E}-03$ & 1. $28 \mathrm{E}-01$ & $2.41 \mathrm{E}-01$ & $4.09 \mathrm{E}-01$ & 7. $72 \mathrm{E}-01$ \\
\hline $3.93 E-09$ & $2.61 E+00$ & $5.35 E-02$ & $7.92 E-03$ & $1.29 \mathrm{E}-01$ & $2.43 E-01$ & $4.11 \mathrm{E}-01$ & 7. $76 \mathrm{E}-01$ \\
\hline $5.72 E-09$ & $2.62 \mathrm{E}+00$ & $5.39 E-02$ & $8.02 E-03$ & $1.30 \mathrm{E}-01$ & $2.45 E-01$ & $4.13 E-01$ & $7.79 E-01$ \\
\hline $8.14 E-09$ & $2.63 \mathrm{E}+00$ & $5.43 E-02$ & $8.11 \mathrm{E}-03$ & 1. $31 \mathrm{E}-01$ & $2.46 \mathrm{E}-01$ & $4.15 \mathrm{E}-01$ & $7.82 \mathrm{E}-01$ \\
\hline
\end{tabular}


RESRAD-OFFSITE, Version 2.5

obabilistic Dose and Risk Report

Title : Offsite Resident Farmer Deterministic Run

File : RF TC99 DOESG FWD-FV2.ROF

Summary of dose at graphical times, reptition 2 (continued)

Time

Years

4. $01 \mathrm{E}+02$

$4.01 E+02$

$4.02 \mathrm{E}+02$

4. $02 \mathrm{E}+02$

$4.03 \mathrm{E}+02$

$4.03 E+02$

$4.04 \mathrm{E}+02$

$4.05 \mathrm{E}+02$

$4.05 \mathrm{E}+02$

$4.06 \mathrm{E}+02$

$4.06 \mathrm{E}+02$

$4.07 \mathrm{E}+02$

$4.07 \mathrm{E}+02$

$4.08 \mathrm{E}+02$

$4.08 \mathrm{E}+02$

$4.09 \mathrm{E}+02$

$4.09 \mathrm{E}+02$

$4.10 \mathrm{E}+02$

$4.10 \mathrm{E}+02$

$4.11 \mathrm{E}+02$

$4.11 \mathrm{E}+02$

$4.12 \mathrm{E}+02$

$4.12 \mathrm{E}+02$

$4.13 \mathrm{E}+02$

$4.13 \mathrm{E}+02$

$4.14 \mathrm{E}+02$

$4.14 \mathrm{E}+02$

$4.15 \mathrm{E}+02$

4. $15 \mathrm{E}+02$

$4.16 \mathrm{E}+02$

4. $16 \mathrm{E}+02$

4.17E+02

$4.17 \mathrm{E}+02$

4. $18 \mathrm{E}+02$

$4.18 \mathrm{E}+02$

4. $19 \mathrm{E}+02$

$4.19 \mathrm{E}+02$

$4.20 \mathrm{E}+02$

$4.20 \mathrm{E}+02$

$4.21 \mathrm{E}+02$

$4.21 \mathrm{E}+02$

$4.22 \mathrm{E}+02$

$4.22 \mathrm{E}+02$

$4.23 \mathrm{E}+02$

$4.23 E+02$

$4.24 \mathrm{E}+02$
Dose statistics at graphical times, mrem/yr

\begin{tabular}{|c|c|c|c|c|c|c|c|}
\hline num & aximum & lean & edi & & & & \\
\hline 8 & 00 & 02 & 03 & 1 & 01 & 01 & -01 \\
\hline $.57 E-08$ & $64 \mathrm{E}+00$ & $5.50 \mathrm{E}-02$ & $31 E-03$ & $1.33 \mathrm{E}-01$ & $2.49 \mathrm{E}-01$ & 4. 20E-01 & $7.89 \mathrm{E}-01$ \\
\hline$E-08$ & $.65 E+00$ & $54 F-02$ & $41 E-03$ & $34 E-01$ & $2.51 E-01$ & $22 E-01$ & $.92 E-01$ \\
\hline $83 E-08$ & $66 \mathrm{E}+00$ & $5.58 E-02$ & $51 E-03$ & 1. $35 \mathrm{E}-01$ & $2.53 E-01$ & 01 & $.96 E-01$ \\
\hline $73 E-08$ & 00 & 2 & & 1 & & & -01 \\
\hline $.86 E-08$ & & & & & & & -01 \\
\hline $.24 E-08$ & $2.69 E+00$ & 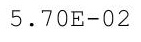 & -03 & $1.38 E-01$ & $7 E-01$ & $E-01$ & $06 E-01$ \\
\hline $.94 \mathrm{E}-08$ & $69 \mathrm{E}+00$ & $4 E-02$ & $3 E-03$ & $39 E-01$ & $59 E-01$ & $E-01$ & $09 E-01$ \\
\hline $9 E-08$ & $.70 E+00$ & $78 \mathrm{~F}-0-0$ & $04 E-03$ & $4 \cap \mathrm{F}-$ & 605 & 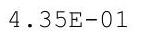 & 01 \\
\hline $5 F-0$ & $71 \mathrm{~F}+0$ & $5.82 \mathrm{E}-02$ & 3 & 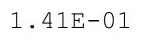 & 1 & 1 & 1 \\
\hline $54 \mathrm{E}-07$ & $2.72 F+00$ & $6 \mathrm{~F}-8 \cdot 2 \mathrm{c}$ & 3 & $42 \mathrm{~F}$ & 1 & 1 & -01 \\
\hline $.88 \mathrm{E}-07$ & $2.73 E+00$ & & & $1.43 E-01$ & & & $8.23 E-01$ \\
\hline $.29 E-07$ & $2.74 \mathrm{E}+00$ & $94 E-02$ & $9.50 \mathrm{E}-03$ & $1.44 E-01$ & $2.66 \mathrm{E}-01$ & $E-01$ & $.28 E-01$ \\
\hline $.76 E-07$ & $74 \mathrm{E}+00$ & $E-02$ & -03 & $45 \mathrm{E}$ & & -01 & $\Xi-01$ \\
\hline 7 & $2.75 \mathrm{E}+00$ & 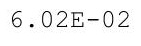 & 3 & $\pm \cdot 10$ & + & 01 & -01 \\
\hline 7 & 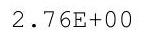 & $6.06 \mathrm{E}-02$ & 3 & . & 1 & + & 01 \\
\hline $2 E-07$ & $277 \mathrm{~F}+00$ & $6.10 \mathrm{E}-02$ & 3 & . & 1 & 1 & -01 \\
\hline $.42 \mathrm{E}-07$ & $2.78 E+00$ & $6.14 \mathrm{E}-02$ & $1.00 \mathrm{E}-02$ & $1.49 \mathrm{E}-01$ & $2.74 \mathrm{E}-01$ & $4.57 \mathrm{E}-01$ & $8.48 \mathrm{E}-01$ \\
\hline $33 E-07$ & $.78 \mathrm{E}+00$ & $18 \mathrm{E}-02$ & $2 \mathrm{E}-02$ & 1. $51 \mathrm{E}-01$ & $2.76 \mathrm{E}-01$ & $E-01$ & $52 E-01$ \\
\hline$E-07$ & $79 E+00$ & -02 & -02 & .52 & -01 & -01 & $56 E-01$ \\
\hline & & & & & 1 & & 01 \\
\hline 7 & $2.81 E+00$ & & & & & & 01 \\
\hline $.11 E-06$ & $.82 E+00$ & 2 & 02 & 1 & 1 & 1 & -01 \\
\hline $5-06$ & $.82 E+00$ & $F-$ & $7 E-02$ & 1565 & $85 \mathrm{~F}_{-}$ & $75 E-01$ & $73 E-01$ \\
\hline $43 E-06$ & $.83 E+00$ & $.43 E-02$ & $1.09 \mathrm{E}-02$ & 1575 & $2.87 \mathrm{E}-01$ & $.78 E-01$ & $.77 \mathrm{E}-01$ \\
\hline$F-06$ & $.84 E+00$ & & $E-02$ & & & $E-01$ & $81 E-01$ \\
\hline 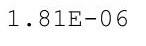 & & & & & & & -01 \\
\hline 6 & & & & $1.6 C$ & & & -01 \\
\hline $26 \mathrm{E}-06$ & $2.86 \mathrm{E}+00$ & $6.60 E-02$ & $1.13 \mathrm{E}-02$ & $1.61 \mathrm{E}-01$ & $2.94 \mathrm{E}-01$ & 円 & $93 E-01$ \\
\hline 6 & $2.87 E+00$ & $6.64 \mathrm{E}-02$ & 2 & $=0$ & $2.95 \mathrm{E}-01$ & $4.94 \mathrm{E}-01$ & $.97 E-01$ \\
\hline $\mathrm{E}-$ & $.88 E+00$ & $.69 \mathrm{E}-0$ & $1.16 \mathrm{E}-0$ & $1.63 E-$ & & $4.97 E-0$ & $01 E-01$ \\
\hline$F-06$ & $2.89 E+00$ & $.73 E-02$ & $1.17 \mathrm{E}-02$ & $16 \wedge \mathrm{F}$ & & $F-01$ & $6 E-01$ \\
\hline & & & & 1 & & & 01 \\
\hline 06 & & & 02 & 01 & 01 & 01 & 01 \\
\hline $.07 \mathrm{E}-06$ & $2.91 \mathrm{E}+00$ & $6.86 \mathrm{E}-02$ & 1.21E-02 & $1.67 \mathrm{E}-01$ & $3.03 E-01$ & $5.10 \mathrm{E}-01$ & $9.18 \mathrm{E}-01$ \\
\hline $.45 E-00$ & $2.9 \angle E+00$ & & & $1.68 \mathrm{E}-01$ & $3.05 E-01$ & & $9.22 \mathrm{E}-01$ \\
\hline 6 & 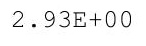 & ( & ? & 1 & 1 & & -01 \\
\hline $.27 E-06$ & $93 E+0$ & s & 2 & 1 & & 1 & 01 \\
\hline & $2.94 \mathrm{E}+00$ & & & 1 & & 1 & 01 \\
\hline $18 \mathrm{E}-06$ & $2.95 E+00$ & $7.08 E-02$ & -02 & 1.731 & 01 & -01 & \\
\hline $.68 E-06$ & $2.96 \mathrm{E}+00$ & & & 1 & & & -01 \\
\hline E-06 & Z. VIDTU & & & 土. & & & $9.47 E-01$ \\
\hline $\begin{array}{l}.740-00 \\
0\end{array}$ & 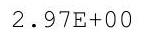 & $7.22 \mathrm{E}-02$ & 1. $32 \mathrm{E}-02$ & 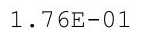 & ent & $5.36 \mathrm{E}-01$ & $9.51 E-01$ \\
\hline 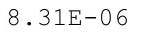 & $2.98 E+00$ & . 200 & 1. 33E-02 & & & & $9.56 \mathrm{E}-01$ \\
\hline$E-$ & $2.99 \mathrm{E}+00$ & & - & & 1 & 1 & $.60 E-01$ \\
\hline $52 E-06$ & $.00 \mathrm{E}+00$ & $.36 E-02$ & $.36 E-02$ & $80 E-01$ & 1 & $6 E-01$ & 01 \\
\hline
\end{tabular}


RESRAD-OFFSITE, Version 2.5

Title : Offsite Resident Farmer Deterministic Run

File : RF TC99 DOESG FWD-FV2.ROF

Summary of dose at graphical times, reptition 2 (continued)

Time

Years

$4.25 E+02$

$4.25 \mathrm{E}+02$

$4.26 \mathrm{E}+02$

$4.26 \mathrm{E}+02$

$4.27 \mathrm{E}+02$

$4.27 \mathrm{E}+02$

$4.28 \mathrm{E}+02$

$4.28 \mathrm{E}+02$

$4.29 \mathrm{E}+02$

$4.29 \mathrm{E}+02$

$4.30 \mathrm{E}+02$

$4.30 \mathrm{E}+02$

4. $31 \mathrm{E}+02$

$4.31 \mathrm{E}+02$

4. $32 \mathrm{E}+02$

4. $32 \mathrm{E}+02$

4. $33 \mathrm{E}+02$

4. $33 \mathrm{E}+02$

$4.34 \mathrm{E}+02$

4. $34 \mathrm{E}+02$

$4.35 \mathrm{E}+02$

$4.35 \mathrm{E}+02$

$4.36 \mathrm{E}+02$

$4.36 \mathrm{E}+02$

$4.37 \mathrm{E}+02$

$4.37 \mathrm{E}+02$

$4.38 \mathrm{E}+02$

$4.38 \mathrm{E}+02$

$4.39 \mathrm{E}+02$

$4.39 \mathrm{E}+02$

$4.40 \mathrm{E}+02$

4. $40 \mathrm{E}+02$

$4.41 \mathrm{E}+02$

$4.41 \mathrm{E}+02$

4. $42 \mathrm{E}+02$

4. $42 \mathrm{E}+02$

$4.43 E+02$

$4.43 E+02$

4. $44 \mathrm{E}+02$

4. $45 \mathrm{E}+02$

$4.45 \mathrm{E}+02$

$4.46 \mathrm{E}+02$

$4.46 \mathrm{E}+02$

$4.47 \mathrm{E}+02$

$4.47 \mathrm{E}+02$

$4.48 \mathrm{E}+02$
Dose statistics at graphical times, mrem/yr

\begin{tabular}{|c|c|c|c|c|c|c|c|}
\hline m & $\operatorname{axi}$ & a & 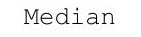 & & & $\%$ & \\
\hline $.02 E-05$ & $3.00 \mathrm{E}+00$ & $7.40 \mathrm{E}-02$ & $1.37 \mathrm{E}-02$ & $1.81 \mathrm{E}-01$ & -01 & -01 & 00 \\
\hline $.08 E-05$ & $3.01 \mathrm{E}+00$ & $5 E-02$ & $39 E-02$ & $1.82 \mathrm{E}-01$ & $3.26 \mathrm{E}-01$ & $5.52 \mathrm{E}-01$ & -01 \\
\hline $.16 \mathrm{E}-05$ & $3.02 \mathrm{E}+00$ & $7.49 \mathrm{E}-02$ & 1. $40 \mathrm{E}-02$ & $1.83 \mathrm{E}-01$ & $3.28 \mathrm{E}-01$ & $.56 \mathrm{E}-01$ & $.77 E-01$ \\
\hline $23 E-05$ & $3.03 E+00$ & $.54 \mathrm{E}-02$ & 1. $42 \mathrm{E}-02$ & $1.84 \mathrm{E}-01$ & $3.30 \mathrm{E}-01$ & $5.59 \mathrm{E}-01$ & $81 E-01$ \\
\hline $30 \mathrm{E}-05$ & $3.03 E+00$ & $9 \mathrm{E}-02$ & 02 & $1.85 \mathrm{E}-01$ & 01 & $E-01$ & 01 \\
\hline $38 E-05$ & & 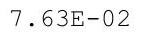 & 2 & 1 & 1 & 1 & -01 \\
\hline $46 \mathrm{E}-05$ & & & & 1 & & & -01 \\
\hline $.55 E-05$ & & & & & & & -01 \\
\hline-05 & +00 & $E-02$ & -02 & $90 \mathrm{E}-\mathrm{C}$ & 1 & $E-01$ & +00 \\
\hline .7 & $.07 \mathrm{E}+00$ & 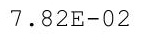 & 2 & $\perp$ & $\perp$ & -01 & +00 \\
\hline 5 & $.08 E+00$ & $7.87 E-02$ & 1 & $1.93 \mathrm{E}-01$ & 1 & 1 & $01 \mathrm{E}+00$ \\
\hline 0 & 00 & & & & 01 & 1 & +00 \\
\hline $01 \mathrm{~F}-05$ & $F+00$ & $5-0-0$ & -02 & $5 \mathrm{~F}$ & 1 & 1 & +00 \\
\hline $.12 E-05$ & $3.10 \mathrm{E}+00$ & $8.01 \mathrm{E}-02$ & $1.58 \mathrm{E}-02$ & $1.97 \mathrm{E}-01$ & $3.49 \mathrm{E}-01$ & $.93 E-01$ & $1.03 E+00$ \\
\hline $22 E-05$ & $\mathrm{E}+00$ & $6 E-02$ & -02 & $8 F$ & 1 & -01 & $03 E+00$ \\
\hline 3 & & & & & & 1 & 00 \\
\hline $.44 E-05$ & & $8.16 \mathrm{E}-02$ & -02 & 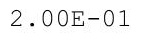 & $.55 E-01$ & 1 & -00 \\
\hline ח & & $8.21 E-02$ & & & $57 E-01$ & 1 & 00 \\
\hline $67 \mathrm{~F}-05$ & $.13 \mathrm{E}+00$ & 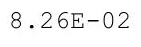 & $E-02$ & קטת & 1 & -01 & $E+00$ \\
\hline $.79 E-05$ & $3.14 \mathrm{E}+00$ & $.30 E-02$ & 1. $68 \mathrm{E}-02$ & $2.03 E-0$ & $.61 \mathrm{E}-0$ & $13 E-01$ & $.06 \mathrm{E}+00$ \\
\hline $91 \mathrm{E}-05$ & $.15 \mathrm{E}+00$ & $\mathrm{~F}-02$ & -02 & -01 & $\perp$ & $.17 \mathrm{E}-01$ & $.07 \mathrm{E}+00$ \\
\hline & & & & & & & $E+00$ \\
\hline 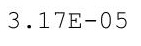 & & & 2 & & & & 00 \\
\hline+ & $3.17 \mathrm{E}+00$ & $8.50 \mathrm{E}-02$ & $1 \cdot$ & & & -01 & 00 \\
\hline • & .17 & $8.55 E-02$ & 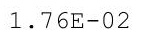 & $\perp$ & $3.70 \mathrm{E}-01$ & 1 & 00 \\
\hline $57 \mathrm{~F}-05$ & $.18 \mathrm{E}+00$ & (2) & 1. $78 \mathrm{E}-02$ & קב & $.72 \mathrm{E}-01$ & $36 E-01$ & $1.09 \mathrm{E}+00$ \\
\hline$F-0$ & $3.19 \mathrm{E}+00$ & $365 \mathrm{~F}-02$ & $E-02$ & תבת 12 & (79 & $.40 E-01$ & $1.10 \mathrm{E}+00$ \\
\hline & & & & & & & \\
\hline 00 & $3.20 \mathrm{E}+00$ & . & & & & & \\
\hline $.16 \mathrm{E}-05$ & $3.21 \mathrm{E}+00$ & $0.00 \mathrm{~L}-2$ & $1.85 \mathrm{E}-02$ & $2 \cdot \perp / \mathrm{L}$ & .00 & -01 & $1.11 \mathrm{E}+00$ \\
\hline entrive & $3.21 E+00$ & .0तम va & $1.8 / E-02$ & $2.19 \mathrm{E}-01$ & $.81 E-01$ & $.56 E-01$ & $1.12 \mathrm{E}+00$ \\
\hline t & 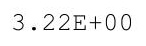 & 然然 & - & & $x^{2}+2$ & -01 & $1.12 \mathrm{E}+00$ \\
\hline 江 & $3.23 E+00$ & 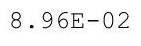 & 10 & חק? כ & & & $1.13 \mathrm{E}+00$ \\
\hline 7 & & & & & & & \\
\hline 5 & $3.24 \mathrm{E}+00$ & & 02 & 1 & 01 & & $1.14 \mathrm{E}+00$ \\
\hline $13 E-05$ & $3.25 \mathrm{E}+00$ & $9.1 \perp E-U Z$ & $1.96 \mathrm{E}-02$ & 2.200 & 1 & 1 & $1.14 \mathrm{E}+00$ \\
\hline 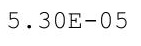 & $3.25 \mathrm{E}+00$ & & & 2. & & & $1.15 \mathrm{E}+00$ \\
\hline 年 & $3.26 \mathrm{E}+00$ & & & & & & $1.16 \mathrm{E}+00$ \\
\hline $66 \mathrm{~F}-05$ & (. & 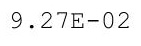 & 2 & 2 & & 1 & $+. \pm 0-10$ \\
\hline & & & & & & & \\
\hline 05 & $3.28 \mathrm{E}+00$ & 9 & 2 & 1 & 1 & & $1.17 \mathrm{E}+00$ \\
\hline$E-05$ & $3.29 \mathrm{E}+00$ & $9.42 \mathrm{E}-02$ & 2.0 & 2 . & -01 & 1 & $1.18 \mathrm{E}+00$ \\
\hline & & & & & & & \\
\hline & $3.30 \mathrm{E}+00$ & . & & & & & 1.190 \\
\hline De & $3.30 \mathrm{E}+00$ & 0.00 & ए & - & 1 & 1 & $1.19 \mathrm{E}+00$ \\
\hline$E-05$ & $3.31 \mathrm{E}+00$ & $3 E-02$ & $5 E-02$ & $E-01$ & -01 & 1 & $1.20 \mathrm{E}+00$ \\
\hline
\end{tabular}


RESRAD-OFFSITE, Version 2.5

obabilistic Dose and Risk Report

Title : Offsite Resident Farmer Deterministic Run

File : RF TC99 DOESG FWD-FV2.ROF

Summary of dose at graphical times, reptition 2 (continued)

Time

Years

$4.48 \mathrm{E}+02$

$4.49 \mathrm{E}+02$

4. $49 \mathrm{E}+02$

$4.50 \mathrm{E}+02$

$4.50 \mathrm{E}+02$

$4.51 \mathrm{E}+02$

$4.51 \mathrm{E}+02$

4. $52 \mathrm{E}+02$

$4.52 \mathrm{E}+02$

$4.53 \mathrm{E}+02$

$4.53 \mathrm{E}+02$

$4.54 \mathrm{E}+02$

4. $54 \mathrm{E}+02$

$4.55 \mathrm{E}+02$

$4.55 \mathrm{E}+02$

$4.56 \mathrm{E}+02$

$4.56 \mathrm{E}+02$

$4.57 \mathrm{E}+02$

$4.57 \mathrm{E}+02$

$4.58 \mathrm{E}+02$

$4.58 \mathrm{E}+02$

$4.59 \mathrm{E}+02$

$4.59 \mathrm{E}+02$

$4.60 \mathrm{E}+02$

$4.60 \mathrm{E}+02$

$4.61 \mathrm{E}+02$

4. $61 \mathrm{E}+02$

$4.62 \mathrm{E}+02$

4. $62 \mathrm{E}+02$

$4.63 \mathrm{E}+02$

$4.63 \mathrm{E}+02$

4. $64 \mathrm{E}+02$

4. $65 \mathrm{E}+02$

4. $65 \mathrm{E}+02$

4. $66 \mathrm{E}+02$

4. $66 \mathrm{E}+02$

$4.67 \mathrm{E}+02$

$4.67 \mathrm{E}+02$

$4.68 \mathrm{E}+02$

$4.68 \mathrm{E}+02$

$4.69 \mathrm{E}+02$

$4.69 \mathrm{E}+02$

$4.70 \mathrm{E}+02$

$4.70 \mathrm{E}+02$

$4.71 \mathrm{E}+02$

$4.71 \mathrm{E}+02$
Dose statistics at graphical times, mrem/yr

\begin{tabular}{|c|c|c|c|c|c|c|c|}
\hline m & $\mathrm{m}$ & Mean & ledian & & & $\%$ & \\
\hline 05 & $3.32 \mathrm{E}+00$ & $9.69 \mathrm{E}-02$ & $2.17 \mathrm{E}-02$ & $2.39 \mathrm{E}-01$ & $4.14 \mathrm{E}-01$ & -01 & $1.20 \mathrm{E}+00$ \\
\hline $.42 E-05$ & $3.32 \mathrm{E}+00$ & $4 \mathrm{E}-02$ & $2.19 \mathrm{E}-02$ & 01 & 1 & -01 & $1.21 \mathrm{E}+00$ \\
\hline $.63 E-05$ & $3.33 \mathrm{E}+00$ & $9 E-02$ & $2.22 \mathrm{E}-02$ & $2.42 \mathrm{E}-01$ & $4.19 \mathrm{E}-01$ & 7. $28 \mathrm{E}-01$ & $1.21 \mathrm{E}+00$ \\
\hline $.85 E-05$ & $3.34 \mathrm{E}+00$ & $.85 E-02$ & $2.24 \mathrm{E}-02$ & $2.43 E-01$ & $4.21 \mathrm{E}-01$ & 7. 33E-01 & $1.22 \mathrm{E}+00$ \\
\hline $7 \mathrm{E}-05$ & $3.34 \mathrm{E}+00$ & $0 \mathrm{E}-02$ & $6 \mathrm{E}$ & 01 & $3 E-01$ & $.36 \mathrm{E}-01$ & $1.23 E+00$ \\
\hline 05 & & 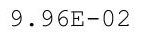 & 2 & 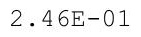 & 1 & 1 & +00 \\
\hline $.51 E-05$ & & & 2 & 1 & 1 & & +00 \\
\hline $.74 \mathrm{E}-05$ & & & & & & & $1.24 \mathrm{E}+00$ \\
\hline $98 E-05$ & $3.37 \mathrm{E}+00$ & $E-01$ & $E-02$ & $50 \mathrm{E}-01$ & -01 & -01 & $.25 E+00$ \\
\hline . 2 & $37 \mathrm{E}+00$ & $1.02 \mathrm{E}-01$ & 2 & $\perp$ & 1 & -01 & +00 \\
\hline 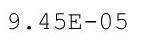 & $.38 E+00$ & $1.02 \mathrm{E}-01$ & $2.40 E-02$ & 1 & 1 & -01 & $.26 E+00$ \\
\hline 15 & $E+00$ & & & & & 1 & +00 \\
\hline$F-05$ & $E+00$ & $3 F-0$ & 02 & 6 & 1 & 1 & +00 \\
\hline $.02 E-04$ & $3.40 \mathrm{E}+00$ & $1.04 \mathrm{E}-01$ & $2.46 \mathrm{E}-02$ & $2.57 \mathrm{E}-01$ & $4.45 \mathrm{E}-01$ & $7.69 \mathrm{E}-01$ & $1.27 \mathrm{E}+00$ \\
\hline $04 \mathrm{E}-04$ & $3.40 \mathrm{E}+00$ & $5 E-01$ & $3 E-02$ & $59 \mathrm{E}-$ & 01 & -01 & $.28 \mathrm{E}+00$ \\
\hline 4 & 0 & & 2 & & & 01 & 00 \\
\hline $.10 \mathrm{E}-04$ & & $6 E-01$ & & +0 & 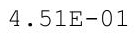 & 1 & 00 \\
\hline קת & & & & & 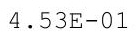 & 1 & 00 \\
\hline $15 E-04$ & $.42 \mathrm{E}+00$ & 1075 & $6 E-02$ & $66 \mathrm{~F}$ & $5 \Gamma$ & -01 & $30 E+00$ \\
\hline $18 \mathrm{E}-04$ & $3.43 \mathrm{E}+00$ & $1.07 \mathrm{E}-01$ & $2.59 \mathrm{E}-02$ & $2.67 \mathrm{E}-01$ & $4.57 \mathrm{E}-01$ & $E-01$ & $1.31 \mathrm{E}+00$ \\
\hline $20 \mathrm{E}-04$ & $.44 \mathrm{E}+00$ & $.08 E-01$ & $E-02$ & $.69 E-01$ & $.59 \mathrm{E}-01$ & $.94 \mathrm{E}-01$ & 1. $31 \mathrm{E}+00$ \\
\hline 2 & & & & & & -01 & $32 E+00$ \\
\hline & & & & & & & 1. $32 \mathrm{E}+00$ \\
\hline $29 \mathrm{E}-04$ & $3.45 \mathrm{E}+00$ & 10 & 2 & -2 & 1 & 01 & 1.000 \\
\hline 4 & $3.46 \mathrm{E}+00$ & 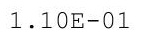 & 2 & ( & - & 1 & $.33 E+00$ \\
\hline $35 E-04$ & $.46 E+00$ & $11 \mathrm{~F}-0$ & $2.72 \mathrm{E}-02$ & קית77 & ח & $.12 \mathrm{E}-01$ & $1.34 \mathrm{E}+00$ \\
\hline$=0$ & $3.47 \mathrm{E}+00$ & $111 \mathrm{~F}=01$ & $2.75 \mathrm{E}-02$ & תחק & $4.71 \mathrm{E}-01$ & $16 \mathrm{E}-01$ & $1.35 \mathrm{E}+00$ \\
\hline 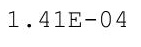 & & & & & & & \\
\hline 4 & & & & & & & $.36 E+00$ \\
\hline $.47 E-04$ & $3.48 \mathrm{E}+00$ & $\perp \cdot \perp \sqcup-\Delta \perp$ & $2.83 E-02$ & $2.01+$ & $4.77 E-01$ & 01 & $1.36 \mathrm{E}+00$ \\
\hline 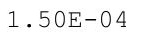 & $3.49 \mathrm{E}+00$ & $\perp \cdot \perp+40$ & $2.86 E-02$ & $2.86 \mathrm{E}-01$ & $4.195-01$ & $8.31 E-01$ & $1.37 \mathrm{E}+00$ \\
\hline ה & $3.49 \mathrm{E}+00$ & 20.25 & 2.00102 & 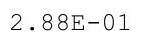 & 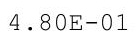 & . & $1.37 \mathrm{E}+00$ \\
\hline 575 & $3.50 \mathrm{E}+00$ & 155 & $.90 E-02$ & תم:م & & & $1.38 \mathrm{E}+00$ \\
\hline $.60 \mathrm{E}-04$ & & & & & & & $1.38 E+00$ \\
\hline$E-04$ & & & 02 & & 1 & & \\
\hline 04 & $3.52 \mathrm{E}+$ & 01 & 02 & 2.90 & 1 & 01 & $1.39 \mathrm{E}+00$ \\
\hline $.70 \mathrm{E}-04$ & $3.52 \mathrm{E}+00$ & & & & $\perp$ & & 1. $40 \mathrm{E}+00$ \\
\hline 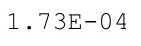 & $3.53 \mathrm{E}+00$ & & & & & & $1.41 \mathrm{E}+00$ \\
\hline • & e. & t & ? & 1 & & 1 & 1. $41 \mathrm{E}+00$ \\
\hline $.80 E-04$ & & & & & & & 1. $42 \mathrm{E}+00$ \\
\hline 4 & & & 02 & 1 & 1 & 1 & 1. $42 E+00$ \\
\hline $87 \mathrm{E}-04$ & $3.55 \mathrm{E}+00$ & 1.20 & 3. & 01 & 4.9 & 8 & 1.4 \\
\hline 4 & & & & & & & 1.4 \\
\hline & $3.56 \mathrm{E}+00$ & $1.21+$ & & $\perp$ & & & 1.110100 \\
\hline . & $3.56 \mathrm{E}+00$ & $\perp \cdot 2<\amalg$ & & 1 & 3.075 & . & $1.44 \mathrm{E}+00$ \\
\hline$E-04$ & $3.57 \mathrm{E}+00$ & $3 E-01$ & $5 E-02$ & $E-01$ & $E-01$ & $8.78 E-01$ & $1.45 \mathrm{E}+00$ \\
\hline
\end{tabular}


RESRAD-OFFSITE, Version 2.5 
RESRAD-OFFSITE, Version 2.5

Title : Offsite Resident Farmer Deterministic Run

File : RF TC99 DOESG FWD-FV2.ROF

Summary of dose at graphical times, reptition 2 (continued)

Time

Years

$4.95 E+02$

$4.96 \mathrm{E}+02$

$4.96 \mathrm{E}+02$

$4.97 \mathrm{E}+02$

$4.97 \mathrm{E}+02$

$4.98 \mathrm{E}+02$

$4.98 \mathrm{E}+02$

$4.99 \mathrm{E}+02$

$4.99 \mathrm{E}+02$

$5.00 \mathrm{E}+02$

$5.00 \mathrm{E}+02$

$5.01 E+02$

$5.01 \mathrm{E}+02$

$5.02 \mathrm{E}+02$

$5.02 \mathrm{E}+02$

$5.03 E+02$

$5.03 E+02$

$5.04 \mathrm{E}+02$

$5.04 \mathrm{E}+02$

$5.05 \mathrm{E}+02$

$5.06 \mathrm{E}+02$

$5.06 \mathrm{E}+02$

$5.07 \mathrm{E}+02$

$5.07 \mathrm{E}+02$

$5.08 \mathrm{E}+02$

$5.08 \mathrm{E}+02$

$5.09 \mathrm{E}+02$

$5.09 \mathrm{E}+02$

$5.10 \mathrm{E}+02$

$5.10 \mathrm{E}+02$

$5.11 \mathrm{E}+02$

$5.11 \mathrm{E}+02$

$5.12 \mathrm{E}+02$

$5.12 \mathrm{E}+02$

$5.13 \mathrm{E}+02$

$5.13 \mathrm{E}+02$

$5.14 \mathrm{E}+02$

$5.14 \mathrm{E}+02$

$5.15 \mathrm{E}+02$

$5.15 \mathrm{E}+02$

$5.16 \mathrm{E}+02$

$5.16 \mathrm{E}+02$

$5.17 \mathrm{E}+02$

$5.17 \mathrm{E}+02$

$5.18 \mathrm{E}+02$

$5.18 \mathrm{E}+02$
Dose statistics at graphical times, mrem/yr

\begin{tabular}{|c|c|c|c|c|c|c|c|}
\hline Iinimum & Maximum & Mean & Median & 900 & $90 \%$ & $97.5 \%$ & $9 \%$ \\
\hline-04 & $6 E+00$ & $3 E-01$ & $64 E-02$ & $85 E-01$ & 1 & $1.05 \mathrm{E}+00$ & +00 \\
\hline$E-04$ & $6 \mathrm{E}+00$ & $3 E-01$ & $67 E-02$ & $3.87 \mathrm{E}$ & 1 & $.05 E+00$ & $64 \mathrm{E}+00$ \\
\hline $7 E-04$ & $76 \mathrm{E}+00$ & $4 \mathrm{E}-01$ & $0 \mathrm{E}-02$ & 1 & $6.32 \mathrm{E}$ & -00 & $55 \mathrm{E}+00$ \\
\hline $3 E-04$ & $E+00$ & $5 E-01$ & $3 E-02$ & 1 & $5 \mathrm{E}$ & 0 & $5 E+00$ \\
\hline$O E-04$ & $3.77 \mathrm{E}+00$ & & -02 & & & & $65 E+00$ \\
\hline $66 \mathrm{E}-04$ & 00 & 1 & -02 & & & 00 & $66 \mathrm{E}+00$ \\
\hline $.73 E-04$ & $3.78 \mathrm{E}+00$ & $1.57 \mathrm{E}-01$ & $4.82 \mathrm{E}-02$ & $6 E-01$ & 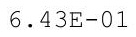 & +00 & $66 \mathrm{E}+00$ \\
\hline $.79 E-04$ & $3.78 \mathrm{E}+00$ & $\perp$. U一 & $4.85 E-02$ & 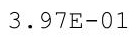 & $0.4 J-4 \perp$ & +00 & $1.66 \mathrm{E}+00$ \\
\hline $5-04$ & +00 & $8 E-01$ & 02 & 1 & 1 & 00 & $57 \mathrm{E}+00$ \\
\hline $3 E-04$ & $9 \mathrm{E}+00$ & $1.59 \mathrm{E}$ & 2 & & & & $E+00$ \\
\hline$E-04$ & 3. & 1 & 2 & 1 & 1 & & $3 E+00$ \\
\hline-04 & +00 & 1 & 2 & 1 & 1 & & $E+00$ \\
\hline $.13 E-04$ & $3.80 \mathrm{E}+00$ & 1. $61 \mathrm{E}-01$ & $2 E-02$ & UE-U工 & $9 \bar{L}-01$ & $4+00$ & $9 E+00$ \\
\hline $.21 E-04$ & $3.80 \mathrm{E}+00$ & 1. $61 \mathrm{E}-01$ & $5.06 \mathrm{E}-02$ & $4.07 \mathrm{E}-01$ & $0.0 \angle L-01$ & 1.1 & $9 \mathrm{E}+00$ \\
\hline $28 E-04$ & $3.80 \mathrm{E}+00$ & $1.62 \mathrm{E}-01$ & 02 & 1 & $\perp$ & 00 & $9 \mathrm{E}+00$ \\
\hline $35 E-04$ & $3.81 E+00$ & $1.63 E-0$ & -02 & - & $67 \mathrm{E}-$ & $1.11 \mathrm{E}+00$ & $\mathrm{OE}+00$ \\
\hline $.42 E-04$ & $3.81 E+00$ & $1.64 \mathrm{E}-01$ & $5.16 \mathrm{E}-02$ & $4.11 \mathrm{E}-01$ & $6.70 \mathrm{E}-01$ & $1.12 \mathrm{E}+00$ & $1.70 \mathrm{E}+00$ \\
\hline $9 E-04$ & $1 \mathrm{E}+00$ & $E-01$ & -02 & 1 & 1 & 0 & $70 E+00$ \\
\hline $.57 E-04$ & $3.81 \mathrm{E}+00$ & $1.65 \mathrm{E}-01$ & $4 E-02$ & +1 & & $1.1 \angle \mathrm{B}$ & $71 \mathrm{E}+00$ \\
\hline $64 \mathrm{E}-04$ & $3.82 \mathrm{E}+00$ & $1.66 \mathrm{E}-01$ & 02 & $\perp$ & $\perp$ & 1 & +00 \\
\hline $.72 E-04$ & $3.82 E+00$ & $1.66 \mathrm{E}-01$ & 02 & S. & 我 & & $.72 \mathrm{E}+00$ \\
\hline $.79 E-04$ & $3.82 \mathrm{E}+00$ & $1.67 \mathrm{E}-0$ & 2 & $1 .+0$ & 0 & 00 & $.72 E+00$ \\
\hline $.87 E-04$ & $3.82 \mathrm{E}+00$ & $8 E-$ & $0 E-02$ & 䟚 & ت7 & $4 \mathrm{E}+00$ & $1.72 E+00$ \\
\hline $.95 E-04$ & $3.83 E+00$ & $1.68 \mathrm{E}-01$ & -02 & 4.22 & קח תمמ & $1.14 \mathrm{E}+$ & $73 E+00$ \\
\hline$E-04$ & $.83 E+00$ & 1 . & 02 & & & & $73 E+00$ \\
\hline$E-04$ & $3.83 E+00$ & $1.70 \mathrm{E}$ & 02 & 1 & & $1.15 \mathrm{H}$ & +00 \\
\hline $8 E-04$ & $3.84 \mathrm{E}+00$ & $1.71 \mathrm{E}-01$ & $5 E-02$ & CIL & $\perp$ & 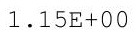 & $74 \mathrm{E}+00$ \\
\hline $.26 \mathrm{E}-04$ & $3.84 \mathrm{E}+00$ & $1.71 \mathrm{E}-01$ & $5.58 \mathrm{E}-02$ & $4.28 \mathrm{E}-01$ & $7.00 \mathrm{E}-01$ & $1.15 \mathrm{E}+00$ & $1.74 \mathrm{E}+00$ \\
\hline $.345-4$ & .045 & $1.72 \mathrm{E}-01$ & $5.62 E-02$ & $1.00-8$ & P. & $1.15 \mathrm{E}+00$ & $1.75 E+00$ \\
\hline $2 E-04$ & $3.84 \mathrm{E}+00$ & $1.73 \mathrm{E}$ & 2 & & $.04 \mathrm{E}-01$ & 0 & $1.75 \mathrm{E}+00$ \\
\hline 04 & $.85 E+00$ & 1 . & 2 & 1 & L & $E+00$ & $5 E+00$ \\
\hline $9 E-04$ & $3.85 E+00$ & $1.74 \mathrm{E}-$ & 02 & 1 & 1 & 1. & 00 \\
\hline $.67 E-04$ & $3.85 \mathrm{E}+00$ & $1.75 \mathrm{E}-01$ & $5.78 \mathrm{E}-02$ & $4.37 \mathrm{E}-$ &.$\perp \perp \mathrm{L}$ & $1.16 \mathrm{E}+00$ & $1.76 \mathrm{E}+00$ \\
\hline $.76 \mathrm{E}-04$ & $3.85 \mathrm{E}+00$ & $1.76 \mathrm{E}-01$ & $5.82 \mathrm{E}-02$ & $4.38 \mathrm{E}-01$ & $7.14 \mathrm{E}-01$ & $1.16 \mathrm{E}+00$ & $1.76 \mathrm{E}+00$ \\
\hline $.84 \mathrm{E}-04$ & $3.00 \mathrm{E}+00$ & $1.76 \mathrm{E}-01$ & & & & & $1.77 \mathrm{E}+00$ \\
\hline 年 & & $7 E-01$ & & & & & $1.77 \mathrm{E}+00$ \\
\hline 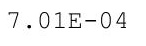 & 0 & 1 & 2 & 1 & 1 & $7 \mathrm{E}+00$ & ג גר ג \\
\hline 4 & $E+00$ & 1 & 02 & 1 & 1 & 0 & $8 \mathrm{E}+00$ \\
\hline $9 E-04$ & $3.86 \mathrm{E}+00$ & 1. $79 \mathrm{E}-01$ & $3 E-02$ & $47 \mathrm{E}$ & 1 & 00 & 00 \\
\hline $3 E-04$ & $3.87 \mathrm{E}$ & 1. & & & & & $9 E+00$ \\
\hline$E-04$ & $7 \mathrm{E}+00$ & 1 & & 1 & & & $1.79 \mathrm{E}+00$ \\
\hline $6 E-04$ & $3.01 E+00$ & $+\infty$ & 2 & 1 & 1 & $1.18 \mathrm{E}$ & $1.79 \mathrm{E}+00$ \\
\hline 4 & 3.0 & 1 & 2 & 1 & 1 & +0 & 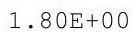 \\
\hline 4 & & & & & & & \\
\hline-04 & $E+00$ & $3 E-01$ & 6.2 & 4. & 7. & 1 . & $1.80 \mathrm{E}+00$ \\
\hline $.83 E-04$ & $88 E+00$ & $1.84 \mathrm{E}-01$ & $.31 E-02$ & $4.62 \mathrm{E}-01$ & $7.41 \mathrm{E}-01$ & 1.19E+00 & $1.81 \mathrm{E}+00$ \\
\hline
\end{tabular}


RESRAD-OFFSITE, Version 2.5

obabilistic Dose and Risk Report

Title : Offsite Resident Farmer Deterministic Run

File : RF TC99 DOESG FWD-FV2.ROF

Summary of dose at graphical times, reptition 2 (continued)

Time

Years

$5.19 \mathrm{E}+02$

$5.19 \mathrm{E}+02$

$5.20 \mathrm{E}+02$

$5.20 \mathrm{E}+02$

$5.21 \mathrm{E}+02$

$5.21 \mathrm{E}+02$

$5.22 \mathrm{E}+02$

$5.22 \mathrm{E}+02$

$5.23 \mathrm{E}+02$

$5.23 \mathrm{E}+02$

$5.24 \mathrm{E}+02$

$5.24 \mathrm{E}+02$

$5.25 \mathrm{E}+02$

$5.26 \mathrm{E}+02$

$5.26 \mathrm{E}+02$

$5.27 \mathrm{E}+02$

$5.27 \mathrm{E}+02$

$5.28 \mathrm{E}+02$

$5.28 \mathrm{E}+02$

$5.29 \mathrm{E}+02$

$5.29 \mathrm{E}+02$

$5.30 \mathrm{E}+02$

$5.30 \mathrm{E}+02$

$5.31 \mathrm{E}+02$

$5.31 \mathrm{E}+02$

$5.32 \mathrm{E}+02$

$5.32 \mathrm{E}+02$

$5.33 \mathrm{E}+02$

$5.33 \mathrm{E}+02$

$5.34 \mathrm{E}+02$

$5.34 \mathrm{E}+02$

$5.35 \mathrm{E}+02$

$5.35 \mathrm{E}+02$

$5.36 \mathrm{E}+02$

$5.36 \mathrm{E}+02$

$5.37 \mathrm{E}+02$

$5.37 \mathrm{E}+02$

$5.38 \mathrm{E}+02$

$5.38 \mathrm{E}+02$

$5.39 \mathrm{E}+02$

$5.39 \mathrm{E}+02$

$5.40 \mathrm{E}+02$

$5.40 \mathrm{E}+02$

$5.41 \mathrm{E}+02$

$5.41 \mathrm{E}+02$

$5.42 \mathrm{E}+02$

Dose statistics at graphical times, mrem/yr

\begin{tabular}{|c|c|c|c|c|c|c|c|}
\hline Minimum & Maximum & Mean & Median & $90 \%$ & $95 \%$ & $97.5 \%$ & $99 \%$ \\
\hline $7.93 E-04$ & $3.88 \mathrm{E}+00$ & $1.85 \mathrm{E}-01$ & $6.35 \mathrm{E}-02$ & $4.64 \mathrm{E}-01$ & $7.45 \mathrm{E}-01$ & $1.19 \mathrm{E}+00$ & $1.81 E+00$ \\
\hline $8.02 E-04$ & $3.88 \mathrm{E}+00$ & $1.86 \mathrm{E}-01$ & $6.39 \mathrm{E}-02$ & $4.66 \mathrm{E}-01$ & $7.48 \mathrm{E}-01$ & $1.19 \mathrm{E}+00$ & $1.81 \mathrm{E}+00$ \\
\hline $8.12 E-04$ & $3.89 \mathrm{E}+00$ & $1.86 \mathrm{E}-01$ & $6.43 E-02$ & $4.68 E-01$ & $7.51 \mathrm{E}-01$ & $1.20 \mathrm{E}+00$ & $1.82 E+00$ \\
\hline $8.22 E-04$ & $3.89 \mathrm{E}+00$ & $1.87 \mathrm{E}-01$ & $6.47 \mathrm{E}-02$ & $4.69 \mathrm{E}-01$ & $7.54 \mathrm{E}-01$ & $1.20 \mathrm{E}+00$ & $1.82 \mathrm{E}+00$ \\
\hline $8.31 E-04$ & $3.89 \mathrm{E}+00$ & $1.88 \mathrm{E}-01$ & $6.51 \mathrm{E}-02$ & 4.71E-01 & $7.57 \mathrm{E}-01$ & $1.20 \mathrm{E}+00$ & $1.82 \mathrm{E}+00$ \\
\hline $8.41 E-04$ & $3.89 \mathrm{E}+00$ & $1.89 \mathrm{E}-01$ & $6.56 \mathrm{E}-02$ & $4.73 E-01$ & $7.60 \mathrm{E}-01$ & $1.20 \mathrm{E}+00$ & $1.83 E+00$ \\
\hline $8.51 \mathrm{E}-04$ & $3.89 \mathrm{E}+00$ & $1.89 \mathrm{E}-01$ & $6.60 \mathrm{E}-02$ & $4.74 \mathrm{E}-01$ & $7.63 \mathrm{E}-01$ & 1.20E+00 & $1.83 E+00$ \\
\hline $8.61 E-04$ & $3.89 \mathrm{E}+00$ & $1.90 \mathrm{E}-01$ & $6.64 \mathrm{E}-02$ & 4. $76 \mathrm{E}-01$ & $7.66 \mathrm{E}-01$ & $1.21 E+00$ & $1.83 E+00$ \\
\hline $8.71 E-04$ & $3.90 \mathrm{E}+00$ & $1.91 \mathrm{E}-01$ & $6.69 \mathrm{E}-02$ & $4.77 E-01$ & $7.69 \mathrm{E}-01$ & $1.21 E+00$ & $1.84 \mathrm{E}+00$ \\
\hline $8.82 E-04$ & $3.90 \mathrm{E}+00$ & $1.92 \mathrm{E}-01$ & $6.73 E-02$ & $4.79 \mathrm{E}-01$ & $7.73 E-01$ & $1.21 E+00$ & $1.84 \mathrm{E}+00$ \\
\hline $8.92 E-04$ & $3.90 \mathrm{E}+00$ & $1.92 \mathrm{E}-01$ & $6.78 E-02$ & $4.81 E-01$ & $7.76 \mathrm{E}-01$ & $1.21 \mathrm{E}+00$ & $1.85 E+00$ \\
\hline $9.02 E-04$ & $3.90 \mathrm{E}+00$ & 1. $93 \mathrm{E}-01$ & $6.82 \mathrm{E}-02$ & $4.82 E-01$ & $7.79 \mathrm{E}-01$ & $1.21 \mathrm{E}+00$ & $1.85 \mathrm{E}+00$ \\
\hline $9.13 E-04$ & $3.90 \mathrm{E}+00$ & 1. $94 \mathrm{E}-01$ & $6.86 \mathrm{E}-02$ & $4.84 \mathrm{E}-01$ & $7.82 \mathrm{E}-01$ & $1.22 \mathrm{E}+00$ & $1.86 \mathrm{E}+00$ \\
\hline $9.24 \mathrm{E}-04$ & $3.91 \mathrm{E}+00$ & 1.95E-01 & $6.90 \mathrm{E}-02$ & $4.86 E-01$ & $7.85 \mathrm{E}-01$ & $1.22 \mathrm{E}+00$ & $1.86 \mathrm{E}+00$ \\
\hline $9.34 \mathrm{E}-04$ & $3.91 \mathrm{E}+00$ & 1. $95 \mathrm{E}-01$ & $6.94 \mathrm{E}-02$ & $4.88 E-01$ & $7.88 \mathrm{E}-01$ & $1.22 \mathrm{E}+00$ & $1.87 \mathrm{E}+00$ \\
\hline $9.45 E-04$ & $3.91 \mathrm{E}+00$ & 1. $96 \mathrm{E}-01$ & $6.97 \mathrm{E}-02$ & $4.90 \mathrm{E}-01$ & $7.91 \mathrm{E}-01$ & $1.22 \mathrm{E}+00$ & $1.87 \mathrm{E}+00$ \\
\hline $9.56 \mathrm{E}-04$ & $3.91 \mathrm{E}+00$ & 1.97E-01 & $7.01 \mathrm{E}-02$ & 4. $92 \mathrm{E}-01$ & $7.94 \mathrm{E}-01$ & $1.22 \mathrm{E}+00$ & $1.88 \mathrm{E}+00$ \\
\hline $9.67 \mathrm{E}-04$ & $3.91 \mathrm{E}+00$ & 1. $98 E-01$ & $7.05 E-02$ & $4.94 \mathrm{E}-01$ & $7.97 \mathrm{E}-01$ & $1.23 E+00$ & $1.88 \mathrm{E}+00$ \\
\hline $9.78 E-04$ & $3.91 \mathrm{E}+00$ & 1. $98 \mathrm{E}-01$ & $7.10 \mathrm{E}-02$ & $4.96 \mathrm{E}-01$ & $8.00 \mathrm{E}-01$ & $1.23 E+00$ & $1.89 \mathrm{E}+00$ \\
\hline $9.89 \mathrm{E}-04$ & $3.91 \mathrm{E}+00$ & $1.99 \mathrm{E}-01$ & $7.14 \mathrm{E}-02$ & $4.98 E-01$ & $8.03 E-01$ & $1.23 \mathrm{E}+00$ & $1.89 \mathrm{E}+00$ \\
\hline $1.00 E-03$ & $3.92 \mathrm{E}+00$ & $2.00 E-01$ & $9 \mathrm{E}-02$ & $5.00 E-01$ & 8.06 & $1.23 \mathrm{E}+00$ & $1.90 \mathrm{E}+00$ \\
\hline $1.01 \mathrm{E}-03$ & $3.92 \mathrm{E}+00$ & $2.01 \mathrm{E}-01$ & $7.24 \mathrm{E}-02$ & $5.01 \mathrm{E}-01$ & $8.09 \mathrm{E}-01$ & $1.24 \mathrm{E}+00$ & $1.90 \mathrm{E}+00$ \\
\hline $1.02 \mathrm{E}-03$ & $3.92 \mathrm{E}+00$ & $2.01 \mathrm{E}-01$ & $7.28 \mathrm{E}-02$ & $5.03 E-01$ & $8.12 \mathrm{E}-01$ & $1.24 \mathrm{E}+00$ & $1.91 \mathrm{E}+00$ \\
\hline $1.03 E-03$ & $3.92 \mathrm{E}+00$ & $2.02 E-01$ & $7.32 \mathrm{E}-02$ & $5.05 \mathrm{E}-01$ & $8.15 \mathrm{E}-01$ & $1.24 \mathrm{E}+00$ & $1.91 \mathrm{E}+00$ \\
\hline $1.05 E-03$ & $3.92 \mathrm{E}+00$ & $2.03 E-01$ & $7.36 \mathrm{E}-02$ & $5.07 \mathrm{E}-01$ & $8.18 \mathrm{E}-01$ & $1.24 \mathrm{E}+00$ & $1.92 \mathrm{E}+00$ \\
\hline $1.06 \mathrm{E}-03$ & $3.92 \mathrm{E}+00$ & $2.04 E-01$ & $7.40 \mathrm{E}-02$ & $09 E-01$ & $8.21 E-01$ & $1.25 \mathrm{E}+00$ & $1.92 \mathrm{E}+00$ \\
\hline $1.07 E-03$ & $3.92 \mathrm{E}+00$ & $2.04 E-01$ & $7.45 E-02$ & $5.10 \mathrm{E}-01$ & $8.24 \mathrm{E}-01$ & $1.25 \mathrm{E}+00$ & $1.93 \mathrm{E}+00$ \\
\hline $1.08 \mathrm{E}-03$ & $3.93 E+00$ & $2.05 E-01$ & $7.50 \mathrm{E}-02$ & $5.12 \mathrm{E}-01$ & $8.26 \mathrm{E}-01$ & $1.25 \mathrm{E}+00$ & $1.93 \mathrm{E}+00$ \\
\hline $1.09 \mathrm{E}-03$ & $3.93 \mathrm{E}+00$ & $2.06 \mathrm{E}-01$ & $7.54 \mathrm{E}-02$ & $5.15 \mathrm{E}-01$ & $8.30 \mathrm{E}-01$ & $1.26 \mathrm{E}+00$ & $1.94 \mathrm{E}+00$ \\
\hline $1.11 \mathrm{E}-03$ & $3.93 \mathrm{E}+00$ & $2.07 E-01$ & $7.58 \mathrm{E}-02$ & $5.17 \mathrm{E}-01$ & $8.33 \mathrm{E}-01$ & $1.26 \mathrm{E}+00$ & $1.94 \mathrm{E}+00$ \\
\hline $1.12 \mathrm{E}-03$ & $3.93 \mathrm{E}+00$ & $2.08 E-01$ & $7.63 E-02$ & $5.19 \mathrm{E}-01$ & $8.36 \mathrm{E}-01$ & $1.26 \mathrm{E}+00$ & $1.95 \mathrm{E}+00$ \\
\hline $1.13 E-03$ & $3.93 E+00$ & $2.08 E-01$ & $7.68 \mathrm{E}-02$ & $5.21 E-01$ & $8.39 E-01$ & $1.27 \mathrm{E}+00$ & $1.95 \mathrm{E}+00$ \\
\hline $1.14 \mathrm{E}-03$ & $3.93 \mathrm{E}+00$ & $2.09 E-01$ & $7.73 E-02$ & $5.24 \mathrm{E}-01$ & $8.42 \mathrm{E}-01$ & $1.27 \mathrm{E}+00$ & $1.96 \mathrm{E}+00$ \\
\hline $1.15 E-03$ & $3.93 \mathrm{E}+00$ & $2.10 \mathrm{E}-01$ & $7.78 \mathrm{E}-02$ & $5.26 E-01$ & $8.44 \mathrm{E}-01$ & $1.28 \mathrm{E}+00$ & $1.96 \mathrm{E}+00$ \\
\hline $1.17 \mathrm{E}-03$ & $3.93 \mathrm{E}+00$ & $2.11 \mathrm{E}-01$ & $7.83 E-02$ & $5.28 \mathrm{E}-01$ & $8.47 \mathrm{E}-01$ & $1.28 \mathrm{E}+00$ & $1.96 \mathrm{E}+00$ \\
\hline $1.18 \mathrm{E}-03$ & $3.93 \mathrm{E}+00$ & $2.11 \mathrm{E}-01$ & $7.87 \mathrm{E}-02$ & $5.30 \mathrm{E}-01$ & $8.49 \mathrm{E}-01$ & $1.29 \mathrm{E}+00$ & $1.97 \mathrm{E}+00$ \\
\hline $1.19 \mathrm{E}-03$ & $3.94 \mathrm{E}+00$ & $2.12 \mathrm{E}-01$ & $7.92 \mathrm{E}-02$ & $5.33 E-$ & $8.52 \mathrm{E}-01$ & $1.29 \mathrm{E}+00$ & $1.97 \mathrm{E}+00$ \\
\hline $1.21 \mathrm{E}-03$ & $3.94 \mathrm{E}+00$ & $3 E-01$ & 02 & 5.35 & 01 & $1.30 \mathrm{E}+00$ & $1.98 \mathrm{E}+00$ \\
\hline $1.22 E-03$ & $3.94 \mathrm{E}+00$ & $2.14 \mathrm{E}-01$ & $8.01 E-02$ & $5.38 E-01$ & $8.57 E-01$ & $1.30 E+00$ & $1.98 \mathrm{E}+00$ \\
\hline $1.23 E-03$ & $3.94 \mathrm{E}+00$ & $2.15 E-01$ & $8.06 \mathrm{E}-02$ & $5.40 E-01$ & $8.60 \mathrm{E}-01$ & 1. $30 \mathrm{E}+00$ & $1.98 \mathrm{E}+00$ \\
\hline $1.24 \mathrm{E}-03$ & $3.94 \mathrm{E}+00$ & $2.15 E-01$ & $8.10 \mathrm{E}-02$ & $5.42 \mathrm{E}-01$ & $8.63 \mathrm{E}-01$ & $1.31 \mathrm{E}+00$ & $1.99 \mathrm{E}+00$ \\
\hline $1.26 \mathrm{E}-03$ & $3.94 \mathrm{E}+00$ & $2.16 E-01$ & $8.15 \mathrm{E}-02$ & $5.45 E-01$ & $8.66 \mathrm{E}-01$ & $1.31 \mathrm{E}+00$ & $1.99 \mathrm{E}+00$ \\
\hline $1.27 E-03$ & $3.94 \mathrm{E}+00$ & $2.17 E-01$ & $8.20 E-02$ & $5.47 E-01$ & $8.68 \mathrm{E}-01$ & $1.32 E+00$ & $2.00 E+00$ \\
\hline $1.29 \mathrm{E}-03$ & $3.94 \mathrm{E}+00$ & $2.18 E-01$ & $8.25 E-02$ & $5.49 E-01$ & $8.71 E-01$ & $1.32 \mathrm{E}+00$ & $2.00 \mathrm{E}+00$ \\
\hline $1.30 \mathrm{E}-03$ & $3.94 \mathrm{E}+00$ & $2.18 E-01$ & $8.30 E-02$ & $5.51 \mathrm{E}-01$ & $8.74 \mathrm{E}-01$ & $1.33 \mathrm{E}+00$ & $2.00 \mathrm{E}+00$ \\
\hline $1.31 \mathrm{E}-03$ & $3.94 \mathrm{E}+00$ & $2.19 \mathrm{E}-01$ & $8.34 \mathrm{E}-02$ & $5.53 \mathrm{E}-01$ & $8.76 \mathrm{E}-01$ & $1.33 \mathrm{E}+00$ & $2.01 \mathrm{E}+00$ \\
\hline
\end{tabular}


RESRAD-OFFSITE, Version 2.5

obabilistic Dose and Risk Report

Title : Offsite Resident Farmer Deterministic Run

File : RF TC99 DOESG FWD-FV2.ROF

Summary of dose at graphical times, reptition 2 (continued)

Time

Years

$5.42 \mathrm{E}+02$

$5.43 \mathrm{E}+02$

$5.43 \mathrm{E}+02$

$5.44 \mathrm{E}+02$

$5.44 \mathrm{E}+02$

$5.45 \mathrm{E}+02$

$5.46 \mathrm{E}+02$

$5.46 \mathrm{E}+02$

$5.47 \mathrm{E}+02$

$5.47 \mathrm{E}+02$

$5.48 \mathrm{E}+02$

$5.48 \mathrm{E}+02$

$5.49 \mathrm{E}+02$

$5.49 \mathrm{E}+02$

$5.50 \mathrm{E}+02$

$5.50 \mathrm{E}+02$

$5.51 \mathrm{E}+02$

$5.51 \mathrm{E}+02$

$5.52 \mathrm{E}+02$

$5.52 \mathrm{E}+02$

$5.53 \mathrm{E}+02$

$5.53 \mathrm{E}+02$

$5.54 \mathrm{E}+02$

$5.54 \mathrm{E}+02$

$5.55 \mathrm{E}+02$

$5.55 \mathrm{E}+02$

$5.56 \mathrm{E}+02$

$5.56 \mathrm{E}+02$

$5.57 \mathrm{E}+02$

$5.57 \mathrm{E}+02$

$5.58 \mathrm{E}+02$

$5.58 \mathrm{E}+02$

$5.59 \mathrm{E}+02$

$5.59 \mathrm{E}+02$

$5.60 \mathrm{E}+02$

$5.60 \mathrm{E}+02$

$5.61 \mathrm{E}+02$

$5.61 \mathrm{E}+02$

$5.62 \mathrm{E}+02$

$5.62 \mathrm{E}+02$

$5.63 \mathrm{E}+02$

$5.63 \mathrm{E}+02$

$5.64 \mathrm{E}+02$

$5.64 \mathrm{E}+02$

$5.65 \mathrm{E}+02$

$5.66 \mathrm{E}+02$
Dose statistics at graphical times, mrem/yr

\begin{tabular}{|c|c|c|c|c|c|c|c|}
\hline m & um & e & 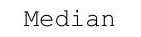 & & & & \\
\hline $33 E-03$ & $.94 \mathrm{E}+00$ & 01 & 02 & $.56 \mathrm{E}-01$ & 01 & -00 & $.0 \perp E+U U$ \\
\hline $34 E-03$ & $3.94 \mathrm{E}+00$ & $2.21 E-01$ & $8.44 \mathrm{E}-02$ & $8 E-01$ & $1 E-01$ & $1.34 \mathrm{E}+00$ & $2.02 E+00$ \\
\hline $35 E-03$ & $95 \mathrm{E}+00$ & $2.22 \mathrm{E}-01$ & $8.48 \mathrm{E}-02$ & $60 \mathrm{E}-01$ & $8.83 \mathrm{E}-01$ & $1.34 \mathrm{E}+00$ & $2.02 \mathrm{E}+00$ \\
\hline $37 E-03$ & $95 E+00$ & $22 \mathrm{~F}-01$ & $.53 E-02$ & $62 F-01$ & $86 \mathrm{~F}-01$ & $1.35 \mathrm{E}+00$ & $2.03 E+00$ \\
\hline $38 E-03$ & $3.95 E+00$ & $E-01$ & -02 & 1 & 1 & $E+00$ & $E+00$ \\
\hline 03 & +00 & & & & & & 00 \\
\hline $41 E-03$ & $3.95 \mathrm{E}+00$ & & & & & +00 & $\mathrm{E}+00$ \\
\hline-03 & +00 & 1 & 2 & $\perp$ & $\perp$ & +00 & $E+00$ \\
\hline $44 \mathrm{E}-03$ & $.95 E+00$ & $26 E-01$ & -02 & $\perp-U \perp$ & 品 & $E+00$ & $5 \mathrm{E}+00$ \\
\hline $46 \mathrm{E}-03$ & $.95 \mathrm{E}+00$ & $27 E-01$ & $83 E-02$ & תכ קר & $01 E-01$ & $.38 E+00$ & $.05 E+00$ \\
\hline 03 & $\mathrm{E}+00$ & & & & & -00 & $05 E+00$ \\
\hline $49 E-03$ & +00 & 1 & $E-02$ & 6 & & 0 & +00 \\
\hline $.50 E-03$ & $3.95 E+00$ & & & $5.18 \mathrm{E}-\mathrm{U}$ & & $1.39 \mathrm{E}+00$ & $2.06 \mathrm{E}+00$ \\
\hline $52 E-03$ & $3.95 \mathrm{E}+00$ & $2.30 \mathrm{E}-01$ & $9.03 E-02$ & 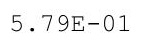 & $9.07 \mathrm{E}-U \perp$ & $1.39 \mathrm{E}+00$ & $2.07 \mathrm{E}+00$ \\
\hline-03 & +00 & $1 \mathrm{E}-01$ & $E-02$ & $\perp$ & & +00 & $7 \mathrm{E}+00$ \\
\hline 3 & +00 & $2.32 E-01$ & 2 & $\perp$ & & 0 & 00 \\
\hline 3 & 00 & $\perp$ & & & & 0 & 00 \\
\hline 3 & $3.96 \mathrm{E}+00$ & $2.34 \mathrm{E}-01$ & 2 & & & 0 & 0 \\
\hline $.59 E-03$ & $6 \mathrm{E}+00$ & $34 \mathrm{~F}-01$ & $7 E-02$ & 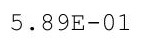 & تص8 & $E+00$ & $9 \mathrm{E}+00$ \\
\hline $61 \mathrm{E}-03$ & $.97 E+00$ & $2.35 E-01$ & $9.32 \mathrm{E}-02$ & $15-$ & ק & 1. $42 \mathrm{E}+00$ & $2.09 \mathrm{E}+00$ \\
\hline 03 & +00 & & & & & +00 & $E+00$ \\
\hline 3 & & & & & & & \\
\hline 03 & $3.99 \mathrm{E}+00$ & $2.38 \mathrm{E}$ & & & & & \\
\hline $67 E-03$ & $99 \mathrm{E}+00$ & $\perp$ & 2 & . & & CTO & 00 \\
\hline 3 & $4.00 \mathrm{E}+00$ & ? & $z$ & - & 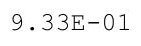 & $1.44 \mathrm{E}+\mathrm{C}$ & $2.11 \mathrm{E}+00$ \\
\hline $.71 E-03$ & $4.00 \mathrm{E}+00$ & $.40 \mathrm{E}-01$ & $9.62 \mathrm{E}-02$ & 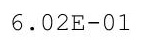 & $35 \pi$ & $1.45 \mathrm{E}+00$ & $2.11 \mathrm{E}+00$ \\
\hline $72 \mathrm{~F}-03$ & $4.01 E+00$ & & $67 E-02$ & & & $1.45 E+00$ & $2.12 \mathrm{E}+00$ \\
\hline 03 & & & & & & & \\
\hline 3 & $4.02 \mathrm{E}+00$ & & & & & & 00 \\
\hline $78 E-03$ & $4.03 E+00$ & $2.40 \pm-1$ & $9.025-0 \angle$ & $6.10 \mathrm{E}-01$ & $9.47 \mathrm{E}-01$ & $1.46 \mathrm{E}+00$ & $2.13 E+00$ \\
\hline $79 \mathrm{E}-03$ & $4.03 E+00$ & $2.44 \mathrm{E}-01$ & $.005-U 2$ & 列 & - & $1.46 \mathrm{E}+00$ & $2.13 E+00$ \\
\hline 3 & $4.04 \mathrm{E}+00$ & es & 2 & & & & $2.13 \mathrm{E}+00$ \\
\hline 3 & & & & & & & \\
\hline 03 & & & 01 & & & & $2.14 \mathrm{E}+00$ \\
\hline $6 E-03$ & $4.05 E+00$ & 1 & 1 & 1 & & & \\
\hline $88 E-03$ & $4.06 \mathrm{E}+00$ & $2.48 E-01$ & 1. $02 \mathrm{E}-01$ & $2 \perp+$ & 1 & 00 & $2.14 \mathrm{E}+00$ \\
\hline $90 E-03$ & $4.06 \mathrm{E}+00$ & $2.49 \pm-01$ & & & & & $2.15 E+00$ \\
\hline $92 E-03$ & $4.07 \mathrm{E}+00$ & 2.0001 & & & & & $2.15 E+00$ \\
\hline 3 & 1.01 & . & 1 & 1 & & 1. $49 \mathrm{E}+00$ & $2.15 E+00$ \\
\hline & & & & & 1 & & $2.16 \mathrm{E}+00$ \\
\hline $7 E-03$ & $4.08 \mathrm{E}+00$ & $2.52 \mathrm{E}-01$ & 1. $04 \mathrm{E}-01$ & 01 & 1 & $1.50 \mathrm{E}+00$ & $2.16 \mathrm{E}+00$ \\
\hline$E-03$ & $4.09 E+00$ & 2.5 & 1 & & & $E+00$ & $2.16 \mathrm{E}+00$ \\
\hline & 0 & & & & & & \\
\hline E-03 & $4.10 \mathrm{E}+00$ & 1 & $1.06 \mathrm{E}-01$ & . & 1 & $1.51 \mathrm{E}+00$ & $2.17 \mathrm{E}+00$ \\
\hline & $4.10 \mathrm{E}+00$ & $2.305-01$ & & & 1 & $1.51 \mathrm{E}+00$ & $2.17 \mathrm{E}+00$ \\
\hline 03 & $4.11 E+00$ & $E-01$ & $E-01$ & $E-01$ & $E-01$ & $1.51 \mathrm{E}+00$ & $.17 E+00$ \\
\hline
\end{tabular}


RESRAD-OFFSITE, Version 2.5

obabilistic Dose and Risk Report

Title : Offsite Resident Farmer Deterministic Run

File : RF TC99 DOESG FWD-FV2.ROF

Summary of dose at graphical times, reptition 2 (continued)

Time

Years

$5.66 \mathrm{E}+02$

$5.67 \mathrm{E}+02$

$5.67 \mathrm{E}+02$

$5.68 \mathrm{E}+02$

$5.68 \mathrm{E}+02$

$5.69 \mathrm{E}+02$

$5.69 \mathrm{E}+02$

$5.70 \mathrm{E}+02$

$5.70 \mathrm{E}+02$

$5.71 \mathrm{E}+02$

$5.71 E+02$

$5.72 \mathrm{E}+02$

$5.72 \mathrm{E}+02$

$5.73 \mathrm{E}+02$

$5.73 \mathrm{E}+02$

$5.74 \mathrm{E}+02$

$5.74 \mathrm{E}+02$

$5.75 \mathrm{E}+02$

$5.75 \mathrm{E}+02$

$5.76 \mathrm{E}+02$

$5.76 \mathrm{E}+02$

$5.77 \mathrm{E}+02$

$5.77 \mathrm{E}+02$

$5.78 \mathrm{E}+02$

$5.78 \mathrm{E}+02$

$5.79 \mathrm{E}+02$

$5.79 \mathrm{E}+02$

$5.80 \mathrm{E}+02$

$5.80 \mathrm{E}+02$

$5.81 \mathrm{E}+02$

$5.81 \mathrm{E}+02$

$5.82 \mathrm{E}+02$

$5.82 \mathrm{E}+02$

$5.83 \mathrm{E}+02$

$5.83 \mathrm{E}+02$

$5.84 \mathrm{E}+02$

$5.84 \mathrm{E}+02$

$5.85 \mathrm{E}+02$

$5.85 \mathrm{E}+02$

$5.86 \mathrm{E}+02$

$5.87 \mathrm{E}+02$

$5.87 \mathrm{E}+02$

$5.88 \mathrm{E}+02$

$5.88 \mathrm{E}+02$

$5.89 \mathrm{E}+02$

$5.89 \mathrm{E}+02$
Dose statistics at graphical times, mrem/yr

\begin{tabular}{|c|c|c|c|c|c|c|c|}
\hline m & aximum & ea & -5 & & & $\%$ & $\%$ \\
\hline $.09 \mathrm{E}-03$ & $4.11 \mathrm{E}+00$ & $57 E-01$ & $1.08 \mathrm{E}-01$ & $E-01$ & $9.92 E-01$ & $1.52 \mathrm{E}+00$ & 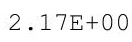 \\
\hline $11 \mathrm{E}-03$ & $4.12 E+00$ & $2.58 \mathrm{E}-01$ & $1.08 \mathrm{E}-01$ & $3 E-01$ & $4 E-01$ & $1.52 \mathrm{E}+00$ & $2.18 \mathrm{E}+00$ \\
\hline $13 E-03$ & $12 \mathrm{E}+00$ & $59 E-01$ & $.09 E-01$ & $45 E-01$ & $97 E-01$ & $52 E+00$ & $18 \mathrm{E}+00$ \\
\hline $15 E-03$ & $4.13 E+00$ & $60=-01$ & $09 \mathrm{~F}-01$ & $47 \mathrm{~F}-01$ & $99 F-01$ & $52 \mathrm{~F}+00$ & $2.18 \mathrm{E}+00$ \\
\hline $.17 E-03$ & $4.13 E+00$ & ( & $1.10 \mathrm{E}-01$ & 1 & & \pm+00 & $19 \mathrm{E}+00$ \\
\hline 03 & +00 & & & & & 00 & 00 \\
\hline $21 E-03$ & +00 & & & 1 & & & $19 E+00$ \\
\hline $23 E-03$ & $E+00$ & 1 & $\perp$ & 1 & 0 & \pm+00 & $19 E+00$ \\
\hline $25 E-03$ & $15 \mathrm{E}+00$ & $4 E-01$ & $E-01$ & $6 \mathrm{E}-$ & $01 \mathrm{E}+00$ & +00 & $20 E+00$ \\
\hline $27 E-03$ & $.16 \mathrm{E}+00$ & $65=-01$ & 12 ת & 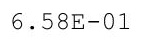 & 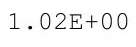 & $.54 E+00$ & $.20 \mathrm{E}+00$ \\
\hline 03 & \pm 00 & & & & & -00 & $E+00$ \\
\hline $31 E-03$ & $E+00$ & $7 \mathrm{~F}$ & 1 . & 62 & $1.02 \mathrm{E}+00$ & 0 & +00 \\
\hline $33 E-03$ & $4.17 E+00$ & $2.67 \mathrm{E}-01$ & & . & & $1.55 \mathrm{E}+00$ & $2.21 E+00$ \\
\hline $35 E-03$ & $4.18 \mathrm{E}+00$ & $2.68 \mathrm{E}-01$ & 1. $15 \mathrm{E}-01$ & $6.66 \mathrm{E}-$ & $1.03 \mathrm{E}+00$ & $1.55 \mathrm{E}+00$ & $2.21 E+00$ \\
\hline-03 & $E+00$ & $9 F-0$ & F- 0 & 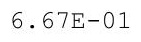 & $35+$ & +00 & $21 E+00$ \\
\hline 3 & $4.19 \mathrm{E}+00$ & $2.70 \mathrm{E}-01$ & $1.16 \mathrm{E}-01$ & 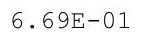 & $04 \mathrm{E}+00$ & 0 & 00 \\
\hline 3 & 0 & $2.71 E-01$ & & & & 0 & 0 \\
\hline 3 & $4.20 \mathrm{E}+00$ & $2.72 \mathrm{E}-01$ & $1.17 \mathrm{E}-01$ & $6.73 \mathrm{E}-01$ & & $6 E+00$ & 0 \\
\hline $.46 E-03$ & $4.20 \mathrm{E}+00$ & $2.73 E-01$ & 1. $18 \mathrm{E}-01$ & $6.75 \mathrm{E}-01$ & $1.04 \mathrm{E}+00$ & $1.56 \mathrm{E}+00$ & $2.22 E+00$ \\
\hline $48 E-03$ & $4.21 E+00$ & $2.73 E-01$ & 1. $18 \mathrm{E}-01$ & $6.77 \mathrm{E}-01$ & $1.05 \mathrm{E}+$ & $1.56 \mathrm{E}+00$ & $2.23 E+00$ \\
\hline 03 & $4.21 E+00$ & & & & & +00 & $3 E+00$ \\
\hline 3 & & & & & & & \\
\hline $55 E-03$ & $4.22 \mathrm{E}+00$ & 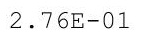 & 1. & 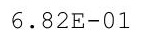 & & & \\
\hline-03 & $4.22 \mathrm{E}+00$ & $2.77 \mathrm{E}-01$ & 1 . & $6.84 \mathrm{E}-01$ & 年 & 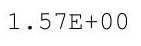 & 0 \\
\hline 3 & $4.23 E+00$ & $2.78 \mathrm{E}-01$ & , & 1 & $.06 \mathrm{E}+$ & $7 \mathrm{E}+\mathrm{C}$ & $2.24 \mathrm{E}+00$ \\
\hline $62 E-03$ & $4.23 E+00$ & م & 1.22E-01 & 6 & $1.07 \mathrm{E}+$ & $1.58 \mathrm{E}+00$ & $2.24 \mathrm{E}+00$ \\
\hline$F-03$ & $4.24 \mathrm{E}+00$ & 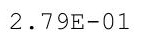 & $123 \mathrm{~F}-01$ & & & $8 \mathrm{E}+00$ & $2.24 \mathrm{E}+00$ \\
\hline 03 & & & & & & & \\
\hline 03 & $4.25 \mathrm{E}+00$ & $2.01+$ & 1.2 & & 20 & & 00 \\
\hline $.71 E-03$ & $4.25 E+00$ & $2.02 \perp-1$ & $1 . \angle J E-U \perp$ & $6.95 \mathrm{E}-01$ & 土. & $1.58 \mathrm{E}+00$ & $2.25 E+00$ \\
\hline $73 E-03$ & $4.25 E+00$ & 2.001 & $+\cdot 20+$ & 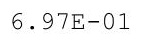 & $1.08 \mathrm{E}+00$ & $1.59 \mathrm{E}+00$ & $2.25 E+00$ \\
\hline 3 & $4.26 \mathrm{E}+00$ & er & 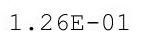 & $699 F-01$ & & & $2.26 \mathrm{E}+$ \\
\hline 7 & & & & & & & 0 \\
\hline 03 & $4.27 \mathrm{E}+00$ & 2 & & 1 & & & \\
\hline$E-03$ & $4.27 E+00$ & 2 & 1 . & 1 & & & 00 \\
\hline $.85 E-03$ & $4.28 \mathrm{E}+00$ & $2.8 / E-01$ & 1. $28 \mathrm{E}-01$ & 舟 & $\perp \cdot 02$ & 1.000 & $2.27 \mathrm{E}+00$ \\
\hline $88 E-03$ & $4.28 \mathrm{E}+00$ & 2.00101 & $1.29 E-U 1$ & & 土. & & $2.27 \mathrm{E}+00$ \\
\hline 03 & $4.28 \mathrm{E}+00$ & 2.0 & I.20 & & 1.10E+ & & $2.27 \mathrm{E}+00$ \\
\hline 3 & 4.29E+ & 2 & 1 & 1 & 1.10E+ & $1.60 \mathrm{E}+00$ & $2.27 E+00$ \\
\hline 3 & & & 1 & - & $1.10 \mathrm{E}+$ & & $.28 E+00$ \\
\hline $98 E-03$ & $4.30 \mathrm{E}+00$ & $2.91 \mathrm{E}-01$ & 1. $31 \mathrm{E}-01$ & 7155 & 1 & 1. $61 \mathrm{E}+00$ & $2.28 \mathrm{E}+00$ \\
\hline $.00 E-03$ & $4.30 E+00$ & 2.9 & 1. & & 1.11E+ & 1. & $2.28 \mathrm{E}+00$ \\
\hline & $4.30 \mathrm{E}+00$ & & & & & & \\
\hline $.03 E-03$ & $4.31 E+00$ & - & I. & . 00 & $1.11 \mathrm{E}+00$ & $1.61 \mathrm{E}+00$ & $2.29 \mathrm{E}+00$ \\
\hline 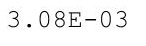 & $4.31 E+00$ & & 1.000 & & & $1.62 \mathrm{E}+00$ & $2.29 \mathrm{E}+00$ \\
\hline 03 & $4.32 \mathrm{E}+00$ & $6 E-01$ & $34 E-01$ & $E-01$ & 1. $12 \mathrm{E}+00$ & $1.62 \mathrm{E}+00$ & $2.29 \mathrm{E}+00$ \\
\hline
\end{tabular}


RESRAD-OFFSITE, Version 2.5

$\mathrm{T}^{1 / 2}$ Limit $=180$ days

robabilistic Dose and Risk Report

Title : Offsite Resident Farmer Deterministic Run

File : RF TC99 DOESG FWD-FV2.ROF

Summary of dose at graphical times, reptition 2 (continued)

Time

Years

$5.90 \mathrm{E}+02$

$5.90 \mathrm{E}+02$

$5.91 \mathrm{E}+02$

$5.91 \mathrm{E}+02$

$5.92 \mathrm{E}+02$

$5.92 \mathrm{E}+02$

$5.93 \mathrm{E}+02$

$5.93 \mathrm{E}+02$

$5.94 \mathrm{E}+02$

$5.94 \mathrm{E}+02$

$5.95 \mathrm{E}+02$

$5.95 \mathrm{E}+02$

$5.96 \mathrm{E}+02$

$5.96 \mathrm{E}+02$

$5.97 \mathrm{E}+02$

$5.97 \mathrm{E}+02$

$5.98 \mathrm{E}+02$

$5.98 \mathrm{E}+02$

$5.99 \mathrm{E}+02$

$5.99 \mathrm{E}+02$

$6.00 \mathrm{E}+02$

$6.00 \mathrm{E}+02$

$6.01 \mathrm{E}+02$

$6.01 \mathrm{E}+02$

$6.02 \mathrm{E}+02$

$6.02 \mathrm{E}+02$

$6.03 E+02$

$6.03 \mathrm{E}+02$

$6.04 \mathrm{E}+02$

$6.04 \mathrm{E}+02$

$6.05 \mathrm{E}+02$

$6.05 \mathrm{E}+02$

$6.06 \mathrm{E}+02$

$6.07 \mathrm{E}+02$

$6.07 \mathrm{E}+02$

$6.08 \mathrm{E}+02$

$6.08 \mathrm{E}+02$

$6.09 \mathrm{E}+02$

$6.09 \mathrm{E}+02$

$6.10 \mathrm{E}+02$

$6.10 \mathrm{E}+02$

$6.11 \mathrm{E}+02$

$6.11 \mathrm{E}+02$

$6.12 \mathrm{E}+02$

$6.12 \mathrm{E}+02$

$6.13 \mathrm{E}+02$
Dose statistics at graphical times, mrem/yr

\begin{tabular}{|c|c|c|c|c|c|c|c|}
\hline Iinimum & laximum & Mean & Median & $90 \%$ & $95 \%$ & $97.5 \%$ & $9 \%$ \\
\hline 3 & $32 \mathrm{E}+00$ & 01 & 1 & 1 & 0 & זר?6 & +00 \\
\hline 03 & $2 E+00$ & $7 E-01$ & $35 E-01$ & 01 & $12 \mathrm{E}+00$ & $.63 E+00$ & $29 E+00$ \\
\hline $3 E-03$ & $3 E+00$ & $8 E-01$ & $36 E-01$ & 1 & 0 & 0 & $30 E+00$ \\
\hline$E-03$ & $\exists+00$ & $E-01$ & $5 E-01$ & 1 & $13 E$ & 00 & $0 E+00$ \\
\hline $4 E-03$ & 0 & $\perp$ & & 1 & 0 & 00 & $30 \mathrm{E}+00$ \\
\hline $.27 E-03$ & D & $\perp$ & & 1 & 0 & 00 & $30 E+00$ \\
\hline $.29 E-03$ & $4.34 \mathrm{E}+00$ & $3.02 E-01$ & $1.38 \mathrm{E}-01$ & $29 E-01$ & $1.14 \mathrm{E}+00$ & +00 & $31 E+00$ \\
\hline $.32 E-03$ & 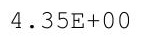 & . & $1.39 \mathrm{E}-01$ & $7.30 \mathrm{E}-01$ & $1.14 \mathrm{E}+00$ & $1.64 \mathrm{E}+00$ & $2.31 E+00$ \\
\hline$E-03$ & $5 \mathrm{E}+00$ & 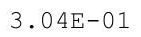 & 01 & 1 & $14 \mathrm{E}$ & 00 & +00 \\
\hline$E-03$ & $E+00$ & $4 \mathrm{E}-01$ & & $\perp$ & - & .65 & $E+00$ \\
\hline$E-03$ & 4 & 3 & 1 & & 0 & & $1 E+00$ \\
\hline-03 & $1+8$ & $\perp$ & 1 & 1 & 0 & 0 & $2 E+00$ \\
\hline $.46 \mathrm{E}-03$ & $4.36 \mathrm{E}+00$ & $7 L-01$ & 1. $42 \mathrm{E}-01$ & $30 \mathrm{E}-\mathrm{C}$ & $1.15 \mathrm{E}+00$ & $1.66 E+00$ & 2. $32 \mathrm{E}+00$ \\
\hline $.49 E-03$ & $4.37 \mathrm{E}+00$ & . & $1.43 \mathrm{E}-01$ & (.JT- & $1.16 \mathrm{E}+00$ & 1.04 & $2 E+00$ \\
\hline $.52 E-03$ & 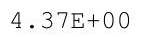 & 1 & 01 & 年 & $\perp \cdot \perp$ OT U & 00 & $2 E+00$ \\
\hline $.54 \mathrm{E}-03$ & $4.37 \mathrm{E}+00$ & . & $1.44 \mathrm{E}-01$ & . & $1.16 \mathrm{E}+$ & $1.66 \mathrm{E}+00$ & $3 E+00$ \\
\hline $.57 E-03$ & $4.38 E+00$ & 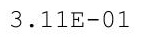 & 1. $45 \mathrm{E}-01$ & $7.41 \mathrm{E}-01$ & $1.16 \mathrm{E}+00$ & $1.67 \mathrm{E}+00$ & $2.33 E+00$ \\
\hline$E-03$ & $8 \mathrm{E}+00$ & ה & $5 E-01$ & $42 E-01$ & 0 & 0 & $3 E+00$ \\
\hline $.63 E-03$ & $4.39 \mathrm{E}+00$ & $3.12 \mathrm{E}-01$ & $1.46 \mathrm{E}-01$ & 10 & $1.17 \mathrm{E}+00$ & $1.67 \mathrm{E}+00$ & $33 E+00$ \\
\hline $66 \mathrm{E}-03$ & $4.39 E+00$ & 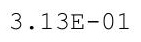 & 1.44 & 40 & 1 & 00 & $E+00$ \\
\hline $.69 E-03$ & 4. & & 1.9715 & 10 & $1.17 \mathrm{E}+$ & 1.001 & $E+00$ \\
\hline $.72 E-03$ & 4. 40400 & . & 1.401 & 1. & $\perp \cdot \perp 0 \mathrm{H}$ & 00 & +00 \\
\hline $.75 E-03$ & $4.40 \mathrm{E}+00$ & 6 & $1.49 \mathrm{E}-$ & $49 \mathrm{E}$ & $1.18 \mathrm{E}+00$ & $1.68 \mathrm{E}+00$ & $34 E+00$ \\
\hline $.78 E-03$ & $4.40 \mathrm{E}+00$ & $7 E-01$ & 01 & 511 & $1.18 \mathrm{E}+$ & $1.68 \mathrm{E}+$ & $34 E+00$ \\
\hline$E-03$ & $4.41 \mathrm{E}+00$ & 01 & 01 & 1 & 1.18E+ & 00 & $34 \mathrm{E}+00$ \\
\hline$E-03$ & $E+00$ & $\perp$ & 1 . & $5 \mathrm{E}$ & $1.19 \mathrm{E}$ & 00 & $5 E+00$ \\
\hline $7 E-03$ & $E+00$ & $3.20 E-41$ & $1.51 \mathrm{E}$ & 年 & $\perp \cdot 19 \mathrm{E}$ & 1.09 & $5 E+00$ \\
\hline $.90 \mathrm{E}-03$ & $4.41 \mathrm{E}+00$ & $3.20 \mathrm{E}-01$ & 1. $52 \mathrm{E}-01$ & $7.59 \mathrm{E}-01$ & $1.19 \mathrm{E}+00$ & $1.69 \mathrm{E}+00$ & $2.35 E+00$ \\
\hline $.93 E-03$ & $4.4 \angle D T 00$ & $.2 \perp+-1$ & $1.52 \mathrm{E}-01$ & $7.61 \mathrm{E}-01$ & 土. & 1. $10 E+00$ & $2.35 E+00$ \\
\hline 3 & $4.42 \mathrm{E}+00$ & 1 & 1.04 & 1 & $20 \mathrm{E}$ & 0 & $6 \mathrm{E}+00$ \\
\hline 03 & $4.42 E+00$ & 1 & 1 & 1 & $1.20 \mathrm{E}+$ & $E+00$ & $6 \mathrm{E}+00$ \\
\hline$E-03$ & $E+00$ & 3 & 1 & 1 & 1 & 00 & 00 \\
\hline $.06 \mathrm{E}-03$ & $4.43 \mathrm{E}+00$ & $3.25 \mathrm{E}-01$ & 1. $55 \mathrm{E}-01$ & $1.10 \mathrm{E}-$ & 1.21E+ & 1. $71 \mathrm{E}+00$ & $2.36 \mathrm{E}+00$ \\
\hline $.09 \mathrm{E}-03$ & $4.43 \mathrm{E}+00$ & $3.26 \mathrm{E}-01$ & $1.55 \mathrm{E}-01$ & $7.72 \mathrm{E}-01$ & $1.21 \mathrm{E}+00$ & $1.71 \mathrm{E}+00$ & $2.36 \mathrm{E}+00$ \\
\hline $.12 E-03$ & $4.44 \mathrm{E}+00$ & $3.275-01$ & $1.56 \mathrm{E}-01$ & $7.74 \mathrm{E}-01$ & $1.21 \mathrm{E}+$ & & $2.37 \mathrm{E}+00$ \\
\hline $.15 \mathrm{E}-03$ & $4.44 \mathrm{E}+$ & & & & & & $2.37 \mathrm{E}+00$ \\
\hline $195-03$ & ( & & 1 & & 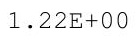 & $2 \mathrm{E}+00$ & $7 E+00$ \\
\hline $4.22 \mathrm{E}-03$ & $.45 E+00$ & 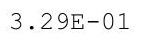 & 1 & 1 & 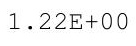 & 1. & $8 E+00$ \\
\hline 3 & & 3. & 1 . & 01 & 1.22 & 00 & $8 \mathrm{E}+00$ \\
\hline $9 E-03$ & $4.45 \mathrm{E}+00$ & $3.31 \mathrm{E}$ & 1. & 1 & 1.22 & & 00 \\
\hline $.32 \mathrm{E}-03$ & $4.45 E+00$ & s & & & 1. $22 \mathrm{E}+$ & & $2.38 \mathrm{E}+00$ \\
\hline $8+03$ & $4.40 E+00$ & 1 & 1.01 & 1 & $1.23 \mathrm{E}$ & 1. $73 \mathrm{E}+00$ & $2.39 \mathrm{E}+00$ \\
\hline $4.39 E-03$ & 4 & $3.34 \mathrm{E}-01$ & 0 & 1 & (n) & - & 2.00 \\
\hline 3 & & & & & & & \\
\hline-03 & $4.47 E+00$ & 3.3 & 1.6 & 7 & $1.23 \mathrm{E}$ & 1 . & 2 . \\
\hline $.49 E-03$ & $4.47 \mathrm{E}+00$ & $36 E-01$ & $1.64 \mathrm{E}-01$ & $8.01 \mathrm{E}-01$ & $1.24 \mathrm{E}+00$ & $1.74 \mathrm{E}+00$ & $2.40 \mathrm{E}+00$ \\
\hline
\end{tabular}


RESRAD-OFFSITE, Version 2.5

robabilistic Dose and Risk Report

Title : Offsite Resident Farmer Deterministic Run

File : RF TC99 DOESG FWD-FV2.ROF

Summary of dose at graphical times, reptition 2 (continued)

Time

Years

$6.13 \mathrm{E}+02$

$6.14 \mathrm{E}+02$

$6.14 \mathrm{E}+02$

$6.15 \mathrm{E}+02$

$6.15 \mathrm{E}+02$

$6.16 \mathrm{E}+02$

$6.16 \mathrm{E}+02$

$6.17 \mathrm{E}+02$

$6.17 \mathrm{E}+02$

$6.18 \mathrm{E}+02$

$6.18 \mathrm{E}+02$

$6.19 \mathrm{E}+02$

$6.19 \mathrm{E}+02$

$6.20 \mathrm{E}+02$

$6.20 \mathrm{E}+02$

$6.21 \mathrm{E}+02$

$6.21 \mathrm{E}+02$

$6.22 \mathrm{E}+02$

$6.22 \mathrm{E}+02$

$6.23 \mathrm{E}+02$

$6.23 \mathrm{E}+02$

$6.24 \mathrm{E}+02$

$6.24 \mathrm{E}+02$

$6.25 \mathrm{E}+02$

$6.25 \mathrm{E}+02$

$6.26 \mathrm{E}+02$

$6.27 \mathrm{E}+02$

$6.27 \mathrm{E}+02$

$6.28 \mathrm{E}+02$

$6.28 \mathrm{E}+02$

$6.29 \mathrm{E}+02$

$6.29 \mathrm{E}+02$

$6.30 \mathrm{E}+02$

$6.30 \mathrm{E}+02$

$6.31 \mathrm{E}+02$

$6.31 \mathrm{E}+02$

$6.32 \mathrm{E}+02$

$6.32 \mathrm{E}+02$

$6.33 \mathrm{E}+02$

$6.33 E+02$

$6.34 \mathrm{E}+02$

$6.34 \mathrm{E}+02$

$6.35 \mathrm{E}+02$

$6.35 \mathrm{E}+02$

$6.36 \mathrm{E}+02$

$6.36 \mathrm{E}+02$

Dose statistics at graphical times, mrem/yr

\begin{tabular}{|c|c|c|c|c|c|c|c|}
\hline Minimum & Maximum & Mean & Median & $90 \%$ & $95 \%$ & $97.5 \%$ & $99 \%$ \\
\hline $4.52 E-03$ & $4.47 \mathrm{E}+00$ & $3.37 E-01$ & 1. $64 \mathrm{E}-01$ & $8.04 \mathrm{E}-01$ & $1.24 \mathrm{E}+00$ & $1.74 \mathrm{E}+00$ & $2.40 \mathrm{E}+00$ \\
\hline $4.56 \mathrm{E}-03$ & $4.47 \mathrm{E}+00$ & 3. $38 E-01$ & $1.65 \mathrm{E}-01$ & $8.06 \mathrm{E}-01$ & $1.24 \mathrm{E}+00$ & $1.74 \mathrm{E}+00$ & $2.40 \mathrm{E}+00$ \\
\hline $4.59 E-03$ & $4.48 \mathrm{E}+00$ & $3.39 E-01$ & $1.65 \mathrm{E}-01$ & $8.08 E-01$ & $1.24 \mathrm{E}+00$ & $1.75 \mathrm{E}+00$ & $2.40 E+00$ \\
\hline $4.63 E-03$ & $4.48 E+00$ & $3.40 \mathrm{E}-01$ & $1.66 \mathrm{E}-01$ & $8.10 \mathrm{E}-01$ & $1.24 \mathrm{E}+00$ & $1.75 \mathrm{E}+00$ & $2.40 E+00$ \\
\hline $4.66 \mathrm{E}-03$ & $4.48 \mathrm{E}+00$ & $3.41 \mathrm{E}-01$ & $1.67 \mathrm{E}-01$ & $8.12 \mathrm{E}-01$ & $1.25 \mathrm{E}+00$ & $1.75 \mathrm{E}+00$ & $2.41 E+00$ \\
\hline $4.70 E-03$ & $4.48 \mathrm{E}+00$ & $3.42 E-01$ & $1.67 \mathrm{E}-01$ & $8.14 \mathrm{E}-01$ & $1.25 \mathrm{E}+00$ & $1.75 \mathrm{E}+00$ & $2.41 E+00$ \\
\hline $4.73 E-03$ & $4.49 E+00$ & $3.43 E-01$ & $1.68 \mathrm{E}-01$ & $8.16 \mathrm{E}-01$ & $1.25 \mathrm{E}+00$ & $1.75 E+00$ & $2.41 E+00$ \\
\hline $4.77 E-03$ & $4.49 \mathrm{E}+00$ & $3.44 \mathrm{E}-01$ & $1.69 \mathrm{E}-01$ & $8.18 \mathrm{E}-01$ & $1.25 \mathrm{E}+00$ & $1.75 \mathrm{E}+00$ & $2.41 E+00$ \\
\hline $4.80 E-03$ & $4.49 \mathrm{E}+00$ & $3.45 E-01$ & $1.69 \mathrm{E}-01$ & $8.19 \mathrm{E}-01$ & $1.26 \mathrm{E}+00$ & $1.76 \mathrm{E}+00$ & $2.41 E+00$ \\
\hline $4.84 \mathrm{E}-03$ & $4.49 \mathrm{E}+00$ & $3.46 \mathrm{E}-01$ & 1. $70 \mathrm{E}-01$ & $8.21 \mathrm{E}-01$ & $1.26 \mathrm{E}+00$ & $1.76 \mathrm{E}+00$ & $2.42 E+00$ \\
\hline $4.87 E-03$ & $4.50 \mathrm{E}+00$ & $3.46 E-01$ & $1.71 \mathrm{E}-01$ & $8.22 E-01$ & $1.26 \mathrm{E}+00$ & $1.76 \mathrm{E}+00$ & $2.42 E+00$ \\
\hline $4.91 E-03$ & $4.50 \mathrm{E}+00$ & $3.47 E-01$ & $1.71 \mathrm{E}-01$ & $8.23 E-01$ & $1.26 \mathrm{E}+00$ & $1.76 \mathrm{E}+00$ & $2.42 E+00$ \\
\hline $4.95 E-03$ & $4.50 \mathrm{E}+00$ & $3.48 E-01$ & $1.72 \mathrm{E}-01$ & $8.24 \mathrm{E}-01$ & $1.26 \mathrm{E}+00$ & $1.76 \mathrm{E}+00$ & $2.42 \mathrm{E}+00$ \\
\hline $4.98 E-03$ & $4.50 \mathrm{E}+00$ & $3.49 E-01$ & $1.73 \mathrm{E}-01$ & $8.26 E-01$ & $1.27 \mathrm{E}+00$ & $1.76 \mathrm{E}+00$ & $2.42 \mathrm{E}+00$ \\
\hline $5.02 E-03$ & $4.51 E+00$ & $3.50 \mathrm{E}-01$ & $1.73 \mathrm{E}-01$ & $8.27 E-01$ & $1.27 \mathrm{E}+00$ & $1.77 \mathrm{E}+00$ & $2.43 E+00$ \\
\hline $5.06 \mathrm{E}-03$ & $4.51 E+00$ & $3.51 E-01$ & $1.74 \mathrm{E}-01$ & $8.28 E-01$ & $1.27 \mathrm{E}+00$ & $1.77 \mathrm{E}+00$ & $2.43 E+00$ \\
\hline $5.10 E-03$ & $4.51 E+00$ & $3.52 E-01$ & $1.75 \mathrm{E}-01$ & $8.30 \mathrm{E}-01$ & $1.27 \mathrm{E}+00$ & $1.77 \mathrm{E}+00$ & $2.43 E+00$ \\
\hline $5.13 E-03$ & $4.51 E+00$ & $3.53 E-01$ & $1.75 E-01$ & $8.31 \mathrm{E}-01$ & $1.28 \mathrm{E}+00$ & $1.77 \mathrm{E}+00$ & $2.43 E+00$ \\
\hline $5.17 \mathrm{E}-03$ & $4.52 \mathrm{E}+00$ & $3.54 \mathrm{E}-01$ & $1.76 \mathrm{E}-01$ & $8.32 \mathrm{E}-01$ & $1.28 \mathrm{E}+00$ & $1.77 \mathrm{E}+00$ & $2.43 E+00$ \\
\hline $5.21 \mathrm{E}-03$ & $4.52 \mathrm{E}+00$ & $3.55 E-01$ & $1.77 \mathrm{E}-01$ & $8.33 E-01$ & $1.28 \mathrm{E}+00$ & $1.77 \mathrm{E}+00$ & $2.43 E+00$ \\
\hline $5.25 \mathrm{E}-03$ & $4.52 E+00$ & $3.55 E-01$ & $1.77 \mathrm{E}-01$ & $8.35 E-01$ & $1.28 \mathrm{E}+00$ & $1.78 \mathrm{E}+00$ & $2.44 \mathrm{E}+00$ \\
\hline $5.29 \mathrm{E}-03$ & $4.52 \mathrm{E}+00$ & $3.56 \mathrm{E}-01$ & $1.78 \mathrm{E}-01$ & $8.37 \mathrm{E}-01$ & $1.28 \mathrm{E}+00$ & $1.78 \mathrm{E}+00$ & $2.44 \mathrm{E}+00$ \\
\hline $5.32 E-03$ & $4.53 \mathrm{E}+00$ & $3.57 \mathrm{E}-01$ & $1.79 \mathrm{E}-01$ & $8.39 \mathrm{E}-01$ & $1.29 \mathrm{E}+00$ & $1.78 \mathrm{E}+00$ & $2.44 \mathrm{E}+00$ \\
\hline $5.36 \mathrm{E}-03$ & $4.53 \mathrm{E}+00$ & $3.58 \mathrm{E}-01$ & $1.79 \mathrm{E}-01$ & $8.40 \mathrm{E}-01$ & $1.29 \mathrm{E}+00$ & 1. $78 \mathrm{E}+00$ & $2.44 \mathrm{E}+00$ \\
\hline $5.40 \mathrm{E}-03$ & $4.53 \mathrm{E}+00$ & $3.59 \mathrm{E}-01$ & $1.80 \mathrm{E}-01$ & $8.42 \mathrm{E}-01$ & $1.29 \mathrm{E}+00$ & $1.78 \mathrm{E}+00$ & $2.44 \mathrm{E}+00$ \\
\hline $5.44 E-03$ & $4.53 E+00$ & $3.60 E-01$ & $1.81 \mathrm{E}-01$ & $8.43 E-01$ & $1.29 \mathrm{E}+00$ & $1.78 \mathrm{E}+00$ & $2.44 \mathrm{E}+00$ \\
\hline $5.48 E-03$ & $4.53 E+00$ & $3.61 E-01$ & $1.81 \mathrm{E}-01$ & $8.45 E-01$ & $1.30 \mathrm{E}+00$ & $1.78 \mathrm{E}+00$ & $2.45 E+00$ \\
\hline $5.52 E-03$ & $4.54 \mathrm{E}+00$ & $3.62 \mathrm{E}-01$ & $1.82 \mathrm{E}-01$ & $8.46 E-01$ & $1.30 \mathrm{E}+00$ & $1.79 \mathrm{E}+00$ & $2.45 E+00$ \\
\hline $5.56 \mathrm{E}-03$ & $4.54 \mathrm{E}+00$ & $3.63 E-01$ & $1.83 \mathrm{E}-01$ & $8.47 \mathrm{E}-01$ & $1.30 \mathrm{E}+00$ & $1.79 \mathrm{E}+00$ & $2.45 \mathrm{E}+00$ \\
\hline $5.60 \mathrm{E}-03$ & $4.54 \mathrm{E}+00$ & $3.64 \mathrm{E}-01$ & $1.84 \mathrm{E}-01$ & $8.49 \mathrm{E}-01$ & $1.30 \mathrm{E}+00$ & 1. $79 \mathrm{E}+00$ & $2.45 \mathrm{E}+00$ \\
\hline $5.64 \mathrm{E}-03$ & $4.54 \mathrm{E}+00$ & $3.65 E-01$ & $1.84 \mathrm{E}-01$ & $8.51 E-01$ & $1.31 \mathrm{E}+00$ & $1.79 \mathrm{E}+00$ & $2.45 E+00$ \\
\hline $5.68 E-03$ & $4.54 \mathrm{E}+00$ & $3.66 \mathrm{E}-01$ & $1.85 \mathrm{E}-01$ & $8.53 E-01$ & $1.31 \mathrm{E}+00$ & $1.79 \mathrm{E}+00$ & $2.46 \mathrm{E}+00$ \\
\hline $5.72 \mathrm{E}-03$ & $4.55 \mathrm{E}+00$ & $3.66 \mathrm{E}-01$ & $1.86 \mathrm{E}-01$ & $8.55 E-01$ & $1.31 \mathrm{E}+00$ & $1.79 \mathrm{E}+00$ & $2.46 \mathrm{E}+00$ \\
\hline $5.76 \mathrm{E}-03$ & $4.55 \mathrm{E}+00$ & $3.67 \mathrm{E}-01$ & $1.87 \mathrm{E}-01$ & $8.57 E-01$ & $1.31 \mathrm{E}+00$ & $1.79 \mathrm{E}+00$ & $2.46 \mathrm{E}+00$ \\
\hline $5.80 E-03$ & $4.55 \mathrm{E}+00$ & $3.68 \mathrm{E}-01$ & $1.87 \mathrm{E}-01$ & $8.59 \mathrm{E}-01$ & $1.32 \mathrm{E}+00$ & $1.80 \mathrm{E}+00$ & $2.46 \mathrm{E}+00$ \\
\hline $5.85 \mathrm{E}-03$ & $4.55 \mathrm{E}+00$ & $3.69 \mathrm{E}-01$ & $1.88 \mathrm{E}-01$ & $8.61 \mathrm{E}-01$ & $1.32 \mathrm{E}+00$ & $1.80 \mathrm{E}+00$ & $2.46 \mathrm{E}+00$ \\
\hline $5.89 E-03$ & $4.55 \mathrm{E}+00$ & $0 E-01$ & $89 E-01$ & $64 \mathrm{E}-$ & $1.32 \mathrm{E}+00$ & $.80 \mathrm{E}+00$ & $2.46 \mathrm{E}+00$ \\
\hline $5.93 E-03$ & $4.56 \mathrm{E}+00$ & $3.71 \mathrm{E}-01$ & $E-01$ & 01 & $1.32 \mathrm{E}+00$ & $1.80 \mathrm{E}+00$ & $2.46 \mathrm{E}+00$ \\
\hline $5.97 \mathrm{E}-03$ & $4.56 \mathrm{E}+00$ & $3.72 \mathrm{E}-01$ & $1.90 \mathrm{E}-01$ & $8.69 \mathrm{E}-01$ & $1.33 \mathrm{E}+00$ & $1.80 \mathrm{E}+00$ & $2.47 \mathrm{E}+00$ \\
\hline $6.01 E-03$ & $4.56 \mathrm{E}+00$ & $3.73 E-01$ & 1.91E-01 & $8.71 \mathrm{E}-01$ & $1.33 \mathrm{E}+00$ & $1.80 \mathrm{E}+00$ & $2.47 \mathrm{E}+00$ \\
\hline $6.06 \mathrm{E}-03$ & $4.56 \mathrm{E}+00$ & $3.74 \mathrm{E}-01$ & 1.92E-01 & $8.74 \mathrm{E}-01$ & $1.33 \mathrm{E}+00$ & $1.80 \mathrm{E}+00$ & $2.47 \mathrm{E}+00$ \\
\hline $6.10 E-03$ & $4.56 \mathrm{E}+00$ & $3.75 E-01$ & $1.92 \mathrm{E}-01$ & $8.76 \mathrm{E}-01$ & $1.33 \mathrm{E}+00$ & $1.81 \mathrm{E}+00$ & $2.47 \mathrm{E}+00$ \\
\hline $6.14 E-03$ & $4.56 \mathrm{E}+00$ & $3.76 E-01$ & $1.93 \mathrm{E}-01$ & $8.78 E-01$ & $1.34 \mathrm{E}+00$ & $1.81 E+00$ & $2.47 E+00$ \\
\hline $6.18 E-03$ & $4.57 \mathrm{E}+00$ & $77 E-01$ & $1.94 \mathrm{E}-01$ & $8.81 E-01$ & $1.34 \mathrm{E}+00$ & $1.81 E+00$ & $2.47 E+00$ \\
\hline $6.23 E-03$ & $4.57 \mathrm{E}+00$ & $3.77 E-01$ & $1.95 \mathrm{E}-01$ & $8.84 \mathrm{E}-01$ & $1.34 \mathrm{E}+00$ & $1.81 \mathrm{E}+00$ & $2.47 \mathrm{E}+00$ \\
\hline $6.27 E-03$ & $4.57 \mathrm{E}+00$ & $3.78 \mathrm{E}-01$ & 1. $96 \mathrm{E}-01$ & $8.86 \mathrm{E}-01$ & $1.35 \mathrm{E}+00$ & $1.81 \mathrm{E}+00$ & $2.47 \mathrm{E}+00$ \\
\hline
\end{tabular}


RESRAD-OFFSITE, Version 2.5

Probabilistic Dose and Risk Report

Title : Offsite Resident Farmer Deterministic Run

File : RF TC99 DOESG FWD-FV2.ROF

Summary of dose at graphical times, reptition 2 (continued)

Time

Years

$6.37 \mathrm{E}+02$

$6.37 \mathrm{E}+02$

$6.38 \mathrm{E}+02$

$6.38 \mathrm{E}+02$

$6.39 \mathrm{E}+02$

$6.39 \mathrm{E}+02$

$6.40 \mathrm{E}+02$

$6.40 \mathrm{E}+02$

$6.41 \mathrm{E}+02$

$6.41 \mathrm{E}+02$

$6.42 \mathrm{E}+02$

$6.42 \mathrm{E}+02$

$6.43 \mathrm{E}+02$

$6.43 \mathrm{E}+02$

$6.44 \mathrm{E}+02$

$6.44 \mathrm{E}+02$

$6.45 \mathrm{E}+02$

$6.45 \mathrm{E}+02$

$6.46 \mathrm{E}+02$

$6.47 \mathrm{E}+02$

$6.47 \mathrm{E}+02$

$6.48 \mathrm{E}+02$

$6.48 \mathrm{E}+02$

$6.49 \mathrm{E}+02$

$6.49 \mathrm{E}+02$

$6.50 \mathrm{E}+02$

$6.50 \mathrm{E}+02$

$6.51 \mathrm{E}+02$

$6.51 \mathrm{E}+02$

$6.52 \mathrm{E}+02$

$6.52 \mathrm{E}+02$

$6.53 \mathrm{E}+02$

$6.53 \mathrm{E}+02$

$6.54 \mathrm{E}+02$

$6.54 \mathrm{E}+02$

$6.55 \mathrm{E}+02$

$6.55 \mathrm{E}+02$

$6.56 \mathrm{E}+02$

$6.56 \mathrm{E}+02$

$6.57 \mathrm{E}+02$

$6.57 \mathrm{E}+02$

$6.58 \mathrm{E}+02$

$6.58 \mathrm{E}+02$

$6.59 \mathrm{E}+02$

$6.59 \mathrm{E}+02$

$6.60 \mathrm{E}+02$
Dose statistics at graphical times, mrem/yr

\begin{tabular}{|c|c|c|c|c|c|c|c|}
\hline Minimum & laximum & Mean & Median & 900 & $5 \%$ & $97.5 \%$ & $9 \%$ \\
\hline 3 & $7 E+00$ & 1 & 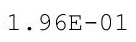 & 1 & 355 & 01 & +00 \\
\hline 3 & $57 E+00$ & OE- & 01 & 01 & $35 E+00$ & $1.82 \mathrm{E}+$ & $7 E+00$ \\
\hline $\mathrm{DE}-03$ & $7 \mathrm{E}+00$ & $1 \mathrm{E}$ & $98 E-01$ & 1 & $35 \mathrm{E}$ & 0 & $7 E+00$ \\
\hline $5 E-03$ & $8 E+00$ & $82 E-01$ & $98 \mathrm{E}-01$ & 1 & 0 & 0 & $7 \mathrm{E}+00$ \\
\hline $49 \mathrm{E}-03$ & $8 \mathrm{E}+00$ & 1 & & & $36 \mathrm{E}+00$ & & $47 \mathrm{E}+00$ \\
\hline-03 & 0 & & & 1 & 0 & 00 & $7 \mathrm{E}+00$ \\
\hline $.58 E-03$ & $4.58 E+00$ & $85 E-01$ & -01 & -01 & $1.36 \mathrm{E}+$ & 0 & $47 \mathrm{E}+00$ \\
\hline $.63 E-03$ & $4.58 E+00$ & $3.00 \mathrm{~L}-01$ & $2.02 \mathrm{E}-01$ & 每 & $1 \cdot 37 \mathrm{E}+00$ & $1.82 \mathrm{E}+00$ & $2.47 \mathrm{E}+00$ \\
\hline$E-03$ & +00 & 1 & 01 & 1 & $1.37 \mathrm{E}$ & 00 & $48 E+00$ \\
\hline $.72 E-03$ & $E+00$ & $38 E-01$ & $\perp$ & & $1 \cdot 37 \mathrm{E}+00$ & 00 & $\mathrm{E}+00$ \\
\hline$E-03$ & & 3 & & & & & $48 E+00$ \\
\hline-03 & +00 & 1 & 1 & & 0 & & $48 E+00$ \\
\hline $.86 E-03$ & $4.59 \mathrm{E}+00$ & 90E-01 & $2.06 \mathrm{E}-01$ & $\perp$ LU & $1.38 \mathrm{E}+00$ & $1.84 \mathrm{E}+0 \mathrm{U}$ & $2.48 \mathrm{E}+00$ \\
\hline $.90 E-03$ & $4.59 E+00$ & $3.91 \mathrm{~L}-1$ & $2.07 \mathrm{E}-01$ & • & $1.38 \mathrm{E}+00$ & $1.04 \mathrm{~s}-\mathrm{s}$ & $2.48 \mathrm{E}+00$ \\
\hline $5 E-03$ & $4.59 \mathrm{E}+00$ & 3 & 01 & 0.20 & 工. & 00 & $2.48 E+00$ \\
\hline $.00 \mathrm{E}-03$ & $4.59 \mathrm{E}+00$ & $3.93 \mathrm{E}-\mathrm{C}$ & 2.00 & 舟 & 1. $39 \mathrm{E}+$ & 1. & $2.48 \mathrm{E}+00$ \\
\hline $.05 E-03$ & $4.59 E+00$ & $3.94 \mathrm{E}-01$ & 2.0 & Sorte & 1. 39E+00 & $1.84 \mathrm{E}+00$ & $2.48 \mathrm{E}+00$ \\
\hline$E-03$ & $\mathrm{E}+00$ & $5 E-01$ & -01 & 1 & 0 & 0 & $48 E+00$ \\
\hline $.14 \mathrm{E}-03$ & $4.60 \mathrm{E}+00$ & $6 E-01$ & $0 E-01$ & ت & 1. $39 \mathrm{E}+00$ & $1.85 \mathrm{E}+00$ & $2.48 \mathrm{E}+00$ \\
\hline $.19 \mathrm{E}-03$ & $4.60 \mathrm{E}+00$ & 3 . & 1 & ( & 1. & 00 & $\mathrm{~s}+00$ \\
\hline $.24 E-03$ & $4.60 E+00$ & & & (15 & & 1.01 & $48 E+00$ \\
\hline $.29 \mathrm{E}-03$ & $4.00 \mathrm{E}+00$ & $3.99 \mathrm{E}-$ & 1 & 0.00 & $1.40 \mathrm{U}$ & 00 & $48 \mathrm{E}+00$ \\
\hline $.33 E-03$ & $4.60 \mathrm{E}+00$ & F & 1 & $9.37 \mathrm{E}-$ & 1. $40 \mathrm{E}+$ & $5 E+00$ & $2.48 E+00$ \\
\hline $.38 E-03$ & $4.60 \mathrm{E}+00$ & -01 & 01 & 1 & 1. $40 \mathrm{E}+$ & $1.85 \mathrm{E}+$ & $.48 E+00$ \\
\hline 03 & $4.60 \mathrm{E}+00$ & 1 & 1 & & & $E+00$ & $.48 E+00$ \\
\hline$E-03$ & $4.61 E+00$ & 1 & & $\perp$ & 1 & 00 & -00 \\
\hline $3 E-03$ & $4.61 E+00$ & $3 E-U 1$ & & $\perp$ & $\perp .4 \perp E$ & 1.00 & $2.48 E+00$ \\
\hline $.58 \mathrm{E}-03$ & $4.61 \mathrm{E}+00$ & $4.04 \mathrm{E}-01$ & $2.17 \mathrm{E}-01$ & $9.48 \mathrm{E}-01$ & 1. $41 \mathrm{E}+00$ & $1.86 \mathrm{E}+00$ & $2.48 \mathrm{E}+00$ \\
\hline $.63 E-03$ & $4.61 \mathrm{E}+00$ & $4.05 \mathrm{E}-$ & $2 \cdot 1,+4$ & (. & 1. $41 \mathrm{E}+$ & $1.80 \mathrm{E}+00$ & 2. $48 \mathrm{E}+00$ \\
\hline 3 & $4.61 E+00$ & & 1 & & $1.42 \mathrm{E}$ & 1. & $48 E+00$ \\
\hline 03 & $4.61 E+00$ & 1 & 1 & 1 & 1. $42 \mathrm{E}+$ & $E+00$ & $.48 E+00$ \\
\hline$E-03$ & $4.61 E+00$ & 4 & 1 & 1 & 1 & 0 & 00 \\
\hline $.83 E-03$ & $4.61 \mathrm{E}+00$ & $4.09 \mathrm{E}-01$ & $2.21 \mathrm{E}-01$ & $9.57 \mathrm{E}-$ & 1. $42 \mathrm{E}+$ & $1.87 \mathrm{E}+00$ & $2.48 \mathrm{E}+00$ \\
\hline $.89 \mathrm{E}-03$ & $4.61 E+00$ & $4.10 \mathrm{E}-01$ & $2.22 \mathrm{E}-01$ & $9.59 \mathrm{E}-01$ & 1. $43 \mathrm{E}+00$ & $1.87 \mathrm{E}+00$ & $2.48 \mathrm{E}+00$ \\
\hline $.94 E-03$ & $4.01 E+00$ & & & & 1. $43 \mathrm{E}+$ & & $2.48 \mathrm{E}+00$ \\
\hline $7.99 \mathrm{E}-03$ & $4.62 \mathrm{E}+00$ & & & & $1.43 \mathrm{E}$ & & $2.48 \mathrm{E}+00$ \\
\hline 3 & קת & 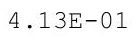 & 1 & - & 0 & $7 E+00$ & $48 E+00$ \\
\hline $9 \mathrm{E}-03$ & $62 \mathrm{E}+00$ & 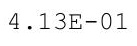 & 1 & 1 & 0 & 0 & 30 \\
\hline 3 & & & -01 & 9 & 1. & 00 & $2.48 \mathrm{E}$ \\
\hline$E-03$ & 4. $62 \mathrm{E}+$ & 4 & & & $1.44 \mathrm{E}+$ & & $2.48 \mathrm{E}+00$ \\
\hline$E-03$ & 4. $62 \mathrm{E}+00$ & 4 & & & 1. $44 \mathrm{E}+$ & $1.88 \mathrm{E}+$ & $2.49 \mathrm{E}+00$ \\
\hline 3 & $4.0 \angle E+00$ & 4 . & 1 & 1 & $1.44 \mathrm{E}$ & $1.88 \mathrm{E}+00$ & $2.49 \mathrm{E}+00$ \\
\hline 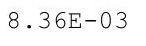 & 4.02 & 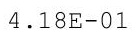 & 2. & 1 & 0 & 1.00 & 2.150 \\
\hline & 4 & & & & 1 . & & \\
\hline-03 & $4.62 \mathrm{E}+00$ & $E-01$ & 2.3 & 9. & 1.4 & 1 . & $\mathrm{E}+00$ \\
\hline $.52 E-03$ & $4.62 E+00$ & $.21 E-01$ & $.33 E-01$ & $9.86 \mathrm{E}-01$ & 1. $45 \mathrm{E}+00$ & $1.89 \mathrm{E}+00$ & $2.50 \mathrm{E}+00$ \\
\hline
\end{tabular}


RESRAD-OFFSITE, Version 2.5

obabilistic Dose and Risk Report

Title : Offsite Resident Farmer Deterministic Run

File : RF TC99 DOESG FWD-FV2.ROF

Summary of dose at graphical times, reptition 2 (continued)

Time

Years

$6.60 \mathrm{E}+02$

$6.61 \mathrm{E}+02$

$6.61 \mathrm{E}+02$

$6.62 \mathrm{E}+02$

$6.62 \mathrm{E}+02$

$6.63 \mathrm{E}+02$

$6.63 \mathrm{E}+02$

$6.64 \mathrm{E}+02$

$6.64 \mathrm{E}+02$

$6.65 \mathrm{E}+02$

$6.65 \mathrm{E}+02$

$6.66 \mathrm{E}+02$

$6.67 \mathrm{E}+02$

$6.67 \mathrm{E}+02$

$6.68 \mathrm{E}+02$

$6.68 \mathrm{E}+02$

$6.69 \mathrm{E}+02$

$6.69 \mathrm{E}+02$

$6.70 \mathrm{E}+02$

$6.70 \mathrm{E}+02$

$6.71 \mathrm{E}+02$

$6.71 \mathrm{E}+02$

$6.72 \mathrm{E}+02$

$6.72 \mathrm{E}+02$

$6.73 E+02$

$6.73 \mathrm{E}+02$

$6.74 \mathrm{E}+02$

$6.74 \mathrm{E}+02$

$6.75 \mathrm{E}+02$

$6.75 \mathrm{E}+02$

$6.76 \mathrm{E}+02$

$6.76 \mathrm{E}+02$

$6.77 \mathrm{E}+02$

$6.77 \mathrm{E}+02$

$6.78 \mathrm{E}+02$

$6.78 \mathrm{E}+02$

$6.79 \mathrm{E}+02$

$6.79 \mathrm{E}+02$

$6.80 \mathrm{E}+02$

$6.80 \mathrm{E}+02$

$6.81 \mathrm{E}+02$

$6.81 \mathrm{E}+02$

$6.82 \mathrm{E}+02$

$6.82 \mathrm{E}+02$

$6.83 \mathrm{E}+02$

$6.83 \mathrm{E}+02$
Dose statistics at graphical times, mrem/yr

\begin{tabular}{|c|c|c|c|c|c|c|c|}
\hline inimum & aximum & Mean & ledian & $\%$ & $\div$ & $97.5 \%$ & $\%$ \\
\hline-03 & $4.62 \mathrm{E}+00$ & $4.22 E-01$ & $2.33 E-01$ & $9.88 \mathrm{E}-01$ & 1. $45 \mathrm{E}+00$ & $1.90 \mathrm{E}+00$ & $E+00$ \\
\hline 03 & +00 & 1 & 1 & 1 & 00 & -00 & +00 \\
\hline 03 & -00 & 01 & & & & 00 & +00 \\
\hline 03 & +00 & & & & & & +00 \\
\hline$E-03$ & $3 E+00$ & 1 & & & 00 & +00 & $52 \mathrm{E}+00$ \\
\hline $.85 E-03$ & $4.63 E+00$ & 4. $26 E-01$ & $8 E-01$ & $99 E-01$ & $46 E+00$ & $E+00$ & $E+00$ \\
\hline 03 & $.63 E+00$ & 01 & 01 & 0 & $66 \mathrm{~F}+$ & $1 \mathrm{E}+00$ & +00 \\
\hline 03 & $4.63 E+00$ & 1 & & 然 & 00 & 00 & 00 \\
\hline$E-03$ & $E+00$ & & & & & 00 & +00 \\
\hline $3 E-03$ & $4.63 E+00$ & $4.30 E-01$ & & & $47 \mathrm{E}+00$ & & $3 E+00$ \\
\hline-03 & $E+00$ & 1 & 1 & 0 & 0 & +00 & +00 \\
\hline-03 & $E+00$ & $2 E-01$ & -01 & 0 & $47 E+$ & $E+00$ & $\mathrm{E}+00$ \\
\hline$E-03$ & 4. $63 E+00$ & 01 & 01 & $1.0+\Delta$ & $1.47 \mathrm{E}+00$ & $E+00$ & +00 \\
\hline 03 & $3 E+00$ & 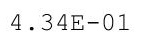 & $\perp$ & קט & 0 & $2 \mathrm{E}+00$ & $55 E+00$ \\
\hline 3 & $4.63 E+00$ & 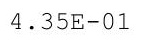 & & 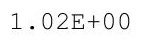 & 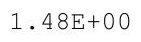 & 0 & 0 \\
\hline$E-03$ & $E+00$ & $6 \mathrm{E}-01$ & $E-01$ & תריט & 0 & +00 & $E+00$ \\
\hline $.48 E-03$ & 4. $63 \mathrm{E}+00$ & $4.37 E-01$ & $2.46 \mathrm{E}-01$ & $1.02 \mathrm{E}+00$ & $1.48 \mathrm{E}+00$ & $1.92 \mathrm{E}+00$ & $2.56 \mathrm{E}+00$ \\
\hline $54 E-03$ & $4.63 \mathrm{E}+00$ & $.38 E-01$ & $2.47 E-01$ & $1.03 \mathrm{E}+$ & 1. $48 \mathrm{E}+$ & 1. $93 \mathrm{E}+00$ & $2.56 \mathrm{E}+00$ \\
\hline & +00 & & & & & & 00 \\
\hline & & & & & 0 & & +00 \\
\hline 3 & $.63 E+00$ & $\perp$ & & & & & 00 \\
\hline $3 E-03$ & $63 E+00$ & 1 & 1 & 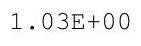 & & 0 & $\Xi+00$ \\
\hline $4 E-03$ & $.63 E+00$ & $12 \mathrm{~F}-01$ & $1 E-01$ & $04 E+C$ & $.50 \mathrm{E}+00$ & $.94 E+00$ & $57 E+00$ \\
\hline$F-03$ & $4.63 E+00$ & $43 E-01$ & $2 \mathrm{~F}-01$ & $.04 \mathrm{E}+$ & $.50 \mathrm{E}+$ & $.94 E+00$ & $.58 \mathrm{E}+00$ \\
\hline$E-03$ & $63 E+00$ & & & & & $E+00$ & $58 E+00$ \\
\hline & & & & & & & \\
\hline & & & & & .50 & 00 & +00 \\
\hline $.01 E-02$ & $4.63 E+00$ & $4.4 / 2-0 \perp$ & $2.045-01$ & 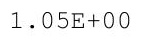 & $\perp \cdot U \perp \mathrm{LT} U$ & 1. $95 \mathrm{E}+00$ & $2.59 \mathrm{E}+00$ \\
\hline 02 & $4.63 E+00$ & 1 & 1 & $1.05 \mathrm{E}+$ & 1. $51 \mathrm{E}+$ & 1. $95 \mathrm{E}+00$ & $2.59 E+00$ \\
\hline$F-02$ & $4.63 E+00$ & & & & & 1. $95 \mathrm{E}+00$ & $2.60 \mathrm{E}+00$ \\
\hline 02 & $4.63 E+00$ & & & & & & \\
\hline 02 & & & & & & & \\
\hline 02 & & & & 0 & 1.02 & & \\
\hline $.05 E-02$ & $4.63 E+00$ & $4.33 E-01$ & $2.60 \mathrm{E}-01$ & $1.06 E+U 0$ & $\perp \cdot J \angle L T$ & $1.96 \mathrm{E}+00$ & 2. $61 \mathrm{E}+00$ \\
\hline $06 \mathrm{E}-02$ & $4.63 E+00$ & $4.35-U 1$ & & & 1. $52 \mathrm{E}+00$ & म.9ILTU & 2. $61 \mathrm{E}+00$ \\
\hline 2 & $4.63 E+00$ & & & & & $1.97 \mathrm{E}+00$ & $2.61 \mathrm{E}+00$ \\
\hline 2 & $4.63 E+00$ & & & 1 & & $1.97 \mathrm{E}+00$ & \\
\hline 2 & & & 1 & & 0 & $7 E+00$ & \\
\hline$E-02$ & & 01 & $4 E-01$ & $1.07 \mathrm{E}+$ & $1.53 \mathrm{E}+00$ & $3 E+00$ & $2.62 E+00$ \\
\hline $.09 \mathrm{E}-02$ & $4.63 E+00$ & 1 & 1 & $1.07 \mathrm{E}$ & $1.53 \mathrm{E}$ & 00 & $62 E+00$ \\
\hline $5-0<$ & 4.635 & 4.095 & . 0 - & $1.0 / \mathrm{E}$ & 1.00 & & $2 \mathrm{E}+00$ \\
\hline $5-2<$ & $4.63 E+00$ & $4.00 \mathrm{~L}-01$ & $2.67 \mathrm{E}-01$ & 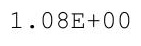 & $1.54 \mathrm{E}+00$ & $1.98 \mathrm{E}+00$ & $2.63 E+00$ \\
\hline 2 & $4.63 E+00$ & $.0 \perp+-1$ & $2.001-1$ & $1.08 \mathrm{E}+00$ & $1.54 \mathrm{E}+00$ & $1.99 \mathrm{E}+00$ & $2.63 E+00$ \\
\hline & $4.63 E+00$ & & & $1.08 \mathrm{E}+00$ & $1.54 \mathrm{E}+00$ & $1.99 \mathrm{E}+00$ & $2.63 E+00$ \\
\hline 20 & $4.63 E+00$ & 01 & -01 & $1.08 \mathrm{E}+00$ & $1.54 \mathrm{E}+00$ & $1.99 \mathrm{E}+00$ & $2.64 \mathrm{E}+00$ \\
\hline $13 E-02$ & $.63 E+00$ & $64 \mathrm{E}-01$ & $71 E-01$ & $1.08 \mathrm{E}+00$ & $1.54 \mathrm{E}+00$ & $1.99 \mathrm{E}+00$ & $2.64 \mathrm{E}+00$ \\
\hline
\end{tabular}


RESRAD-OFFSITE, Version 2.5

Title : Offsite Resident Farmer Deterministic Run

File : RF TC99 DOESG FWD-FV2.ROF

Summary of dose at graphical times, reptition 2 (continued)

Time

Years

$6.84 \mathrm{E}+02$

$6.84 \mathrm{E}+02$

$6.85 \mathrm{E}+02$

$6.85 \mathrm{E}+02$

$6.86 \mathrm{E}+02$

$6.86 \mathrm{E}+02$

$6.87 \mathrm{E}+02$

$6.88 \mathrm{E}+02$

$6.88 \mathrm{E}+02$

$6.89 \mathrm{E}+02$

$6.89 \mathrm{E}+02$

$6.90 \mathrm{E}+02$

$6.90 \mathrm{E}+02$

$6.91 E+02$

$6.91 \mathrm{E}+02$

$6.92 \mathrm{E}+02$

$6.92 \mathrm{E}+02$

$6.93 \mathrm{E}+02$

$6.93 \mathrm{E}+02$

$6.94 \mathrm{E}+02$

$6.94 \mathrm{E}+02$

$6.95 \mathrm{E}+02$

$6.95 \mathrm{E}+02$

$6.96 \mathrm{E}+02$

$6.96 \mathrm{E}+02$

$6.97 \mathrm{E}+02$

$6.97 \mathrm{E}+02$

$6.98 \mathrm{E}+02$

$6.98 \mathrm{E}+02$

$6.99 \mathrm{E}+02$

$6.99 \mathrm{E}+02$

$7.00 \mathrm{E}+02$

$7.00 \mathrm{E}+02$

$7.01 \mathrm{E}+02$

$7.01 \mathrm{E}+02$

$7.02 \mathrm{E}+02$

$7.02 \mathrm{E}+02$

$7.03 \mathrm{E}+02$

$7.03 E+02$

$7.04 \mathrm{E}+02$

$7.04 \mathrm{E}+02$

$7.05 \mathrm{E}+02$

$7.05 \mathrm{E}+02$

$7.06 \mathrm{E}+02$

$7.06 \mathrm{E}+02$

$7.07 \mathrm{E}+02$
Dose statistics at graphical times, mrem/yr

\begin{tabular}{|c|c|c|c|c|c|c|c|}
\hline Iinimum & laximum & Mean & Median & 900 & $0 \%$ & $97.5 \%$ & \% \\
\hline 2 & $3 E+00$ & $5 E-01$ & $2 F-01$ & $09 E+00$ & $5 E+00$ & $.00 E+00$ & +00 \\
\hline 02 & $4.63 E+00$ & $6 \mathrm{E}$ & 01 & $09 \mathrm{E}+00$ & $55 E+00$ & +00 & $54 \mathrm{E}+00$ \\
\hline$E-02$ & $E+00$ & $67 E-01$ & $3 E-01$ & 0 & 0 & 0 & $5 E+00$ \\
\hline$E-02$ & $E+00$ & $8 E-01$ & 01 & 0 & & & $E+00$ \\
\hline $.16 \mathrm{E}-02$ & & & & & & & $5 E+00$ \\
\hline $17 E-02$ & $3 E+00$ & 1 & & +00 & $56 E+00$ & 00 & $66 \mathrm{E}+00$ \\
\hline $.18 E-02$ & $4.63 E+00$ & 4. $70 \mathrm{E}-01$ & $2.77 \mathrm{E}-01$ & $1.10 \mathrm{E}+00$ & $1.56 \mathrm{E}+00$ & $E+00$ & $6 E+00$ \\
\hline $.18 E-02$ & $4.63 E+00$ & . & $2.7 \mathrm{~L}-\mathrm{O}$ & $\perp \cdot \perp$ - & $1.56 \mathrm{E}+00$ & +00 & $2.66 \mathrm{E}+00$ \\
\hline$E-02$ & $3 E+00$ & $2 E$ & 01 & 0 & 0 & 00 & +00 \\
\hline $20 \mathrm{E}-02$ & $4.63 E+00$ & 4 & \pm & $10 \mathrm{E}+00$ & 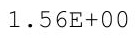 & 0 & $E+00$ \\
\hline$E-02$ & $E+00$ & 4 & 1 & & & & $7 \mathrm{E}+00$ \\
\hline-02 & +00 & $5=0$ & 1 & & 0 & & $5 \mathrm{E}+00$ \\
\hline $22 \mathrm{E}-02$ & $4.63 E+00$ & $4.76 \mathrm{E}-01$ & $2.8 \perp \pm-U \perp$ & $\perp \cdot \perp \perp E+U U$ & $1.57 \mathrm{E}+$ & C. & $E+00$ \\
\hline $.22 \mathrm{E}-02$ & $4.63 E+00$ & $4.77 \mathrm{E}-01$ & $2.0 \angle \mathrm{L}-U \perp$ & $\perp \cdot \perp \perp E T U U$ & I.UILTU & 2.0 & $68 \mathrm{E}+00$ \\
\hline $.23 E-02$ & $4.63 E+00$ & $4.78 \mathrm{E}$ & 20 & $\perp \cdot \perp \perp-T 0$ & 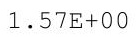 & 00 & 00 \\
\hline $24 \mathrm{E}-02$ & $4.63 E+00$ & $4.79 \mathrm{E}-0$ & $2.83 E-01$ & $1.11 \mathrm{E}+00$ & $1.57 \mathrm{E}+$ & $03 E+00$ & $8 \mathrm{E}+00$ \\
\hline $.25 E-02$ & $4.63 E+00$ & $4.80 \mathrm{E}-01$ & $2.84 \mathrm{E}-01$ & $1.11 \mathrm{E}+00$ & 1. $58 \mathrm{E}+00$ & $2.03 E+00$ & $59 \mathrm{E}+00$ \\
\hline$E-02$ & $3 E+00$ & $1 E-01$ & $5 E-01$ & $1.12 \mathrm{E}+$ & ג䧄 & $.03 E+00$ & $59 \mathrm{E}+00$ \\
\hline 02 & 4. $63 \mathrm{E}+00$ & 4 & $\perp$ & $1.12 \mathrm{E}+00$ & St & 00 & $E+00$ \\
\hline $.27 E-02$ & $4.63 E+00$ & $4.82 \mathrm{E}-01$ & $2.86 \mathrm{E}-0 \perp$ & $\perp \cdot \perp \angle L T$ & 1.00 & 00 & +00 \\
\hline $.27 E-02$ & $4.63 E+00$ & & & $\perp \cdot \perp \angle \amalg$ & & & $\mathrm{E}+00$ \\
\hline $28 \mathrm{E}-02$ & $4.62 E+00$ & 4.8 & $2.88 \mathrm{E}-01$ & $1.12 \mathrm{E}+$ & $1.58 \mathrm{E}+$ & 0 & $E+00$ \\
\hline $.29 E-02$ & $4.62 E+00$ & $4.85 E-01$ & $9 E-01$ & $1.12 \mathrm{E}+00$ & $1.59 \mathrm{E}+00$ & $2.04 \mathrm{E}+00$ & $70 E+00$ \\
\hline $.30 E-02$ & $4.62 E+00$ & $4.86 \mathrm{E}-01$ & $2.90 \mathrm{E}-01$ & $1.12 \mathrm{E}+00$ & $1.59 \mathrm{E}+$ & $2.04 E+00$ & $70 E+00$ \\
\hline 02 & $4.62 \mathrm{E}+00$ & 1 & $1 E-01$ & 1.12E+ & & & $70 \mathrm{E}+00$ \\
\hline$E-02$ & $2 \mathrm{E}+00$ & 1 & 1 & 0 & & & \\
\hline $32 E-02$ & $4.62 E+00$ & $4.89 \mathrm{E}-$ & & 1.13E+ & וע & & $E+00$ \\
\hline $33 E-02$ & $4.02 \mathrm{E}+U \mathrm{U}$ & $4.90 E-01$ & $2 \cdot$ & (4) & ועם & $2.04 E+00$ & $2.70 \mathrm{E}+00$ \\
\hline 02 & $.62 \mathrm{E}+$ & 4 & 1 & 13 & 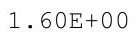 & $.04 \mathrm{E}+00$ & $.71 \mathrm{E}+00$ \\
\hline 2 & $1625+00$ & 4 & 1 & $13 \Gamma$ & 1 & & $2.71 \mathrm{E}+00$ \\
\hline 02 & $42 F+00$ & חק & T & 1 & 1 & $2.05 E+00$ & $2.71 \mathrm{E}+00$ \\
\hline$E-02$ & $4.62 \mathrm{E}+00$ & & & & & & \\
\hline $36 \mathrm{E}-02$ & $4.62 \mathrm{E}+00$ & 4. & 1 & $1.14 \mathrm{E}$ & 1 . & 00 & $1 E+00$ \\
\hline $.37 E-02$ & $4.62 \mathrm{E}+00$ & $4.96 \mathrm{E}-01$ & $2.98 \mathrm{E}-01$ & $1 \cdot 14 \mathrm{E}+U \mathrm{U}$ & $1.00 \mathrm{ET}$ & $2.05 \mathrm{E}+00$ & $2.70 \mathrm{E}+00$ \\
\hline $.305-02$ & $4.0 \angle E+U$ & $4.96 \mathrm{E}-01$ & & $\perp \cdot 14 E+U 0$ & & & $2.71 \mathrm{E}+00$ \\
\hline 2 & 4. $61 \mathrm{E}+$ & & & & & & 00 \\
\hline 2 & 4.6 & & & & & & \\
\hline 2 & & 1 & 1 & 11 & 0 & & 00 \\
\hline $41 \mathrm{E}-02$ & $4.61 \mathrm{E}+00$ & $E-01$ & 01 & $1.15 \mathrm{E}$ & 1 . & & 00 \\
\hline $42 E-02$ & $4.61 \mathrm{Et}$ & & & 1.15 & 1 . & & 00 \\
\hline 02 & 4. $61 \mathrm{E}+00$ & & & $1.15 \mathrm{E}+$ & 1. $62 \mathrm{E}+$ & & $2.72 \mathrm{E}+00$ \\
\hline $5-0<$ & $4.01 E+U 0$ & 1 & $\perp$ & $1 \cdot 10 E+00$ & $1.62 \mathrm{E}+00$ & $2.06 \mathrm{E}+00$ & $2.72 \mathrm{E}+00$ \\
\hline 2 & $4.01 \mathrm{LT}$ & & & 0 & 0 & 0 & $72 \mathrm{E}$ \\
\hline & & 1 & 1 & $1.16 \mathrm{E}$ & $1.62 \mathrm{E}$ & $2.06 \mathrm{E}+00$ & $2.72 \mathrm{E}+00$ \\
\hline $46 E-02$ & $4.61 E+00$ & 5.0 & 3.0 & $1.16 \mathrm{E}+00$ & 1. $62 \mathrm{E}+$ & $E+00$ & $2.72 \mathrm{E}+00$ \\
\hline $46 E-02$ & $4.61 E+00$ & $.07 E-01$ & $.10 \mathrm{E}-01$ & $1.16 \mathrm{E}+00$ & 1. $63 \mathrm{E}+00$ & $2.06 \mathrm{E}+00$ & $2.72 \mathrm{E}+00$ \\
\hline
\end{tabular}


RESRAD-OFFSITE, Version 2.5

$\mathrm{T}^{1 / 2}$ Limit $=180$ days

robabilistic Dose and Risk Report

Title : Offsite Resident Farmer Deterministic Run

File : RF TC99 DOESG FWD-FV2.ROF

Summary of dose at graphical times, reptition 2 (continued)

Time

Years

7. $08 \mathrm{E}+02$

$7.08 \mathrm{E}+02$

$7.09 \mathrm{E}+02$

$7.09 \mathrm{E}+02$

$7.10 \mathrm{E}+02$

$7.10 \mathrm{E}+02$

$7.11 \mathrm{E}+02$

$7.11 \mathrm{E}+02$

$7.12 \mathrm{E}+02$

$7.12 \mathrm{E}+02$

$7.13 \mathrm{E}+02$

$7.13 \mathrm{E}+02$

$7.14 \mathrm{E}+02$

$7.14 \mathrm{E}+02$

7. $15 \mathrm{E}+02$

$7.15 \mathrm{E}+02$

$7.16 \mathrm{E}+02$

$7.16 \mathrm{E}+02$

$7.17 \mathrm{E}+02$

$7.17 \mathrm{E}+02$

$7.18 \mathrm{E}+02$

$7.18 \mathrm{E}+02$

$7.19 \mathrm{E}+02$

$7.19 \mathrm{E}+02$

$7.20 \mathrm{E}+02$

$7.20 \mathrm{E}+02$

$7.21 \mathrm{E}+02$

$7.21 \mathrm{E}+02$

7. $22 \mathrm{E}+02$

$7.22 \mathrm{E}+02$

7. $23 \mathrm{E}+02$

7. $23 \mathrm{E}+02$

$7.24 \mathrm{E}+02$

$7.24 \mathrm{E}+02$

$7.25 \mathrm{E}+02$

7. $25 \mathrm{E}+02$

7. $26 \mathrm{E}+02$

$7.26 \mathrm{E}+02$

$7.27 \mathrm{E}+02$

$7.28 \mathrm{E}+02$

$7.28 \mathrm{E}+02$

$7.29 \mathrm{E}+02$

$7.29 \mathrm{E}+02$

$7.30 \mathrm{E}+02$

7. $30 \mathrm{E}+02$

7. $31 \mathrm{E}+02$
Dose statistics at graphical times, mrem/yr

\begin{tabular}{|c|c|c|c|c|c|c|c|}
\hline m & um & e & ledian & & & $\%$ & \\
\hline 02 & $4.60 \mathrm{E}+00$ & $08 E-01$ & 1 & $17 E+00$ & $.63 E+00$ & -00 & - $12 \mathrm{E}+U \mathrm{U}$ \\
\hline $48 E-02$ & $4.60 E+00$ & $9 E-01$ & $3.11 \mathrm{E}-01$ & $17 E+00$ & $63 E+00$ & $2.06 \mathrm{E}+00$ & $3 E+00$ \\
\hline $49 E-02$ & $60 \mathrm{E}+00$ & $9 E-01$ & $2 E-01$ & $.17 E+00$ & $.63 E+00$ & $2.06 \mathrm{E}+00$ & $73 E+00$ \\
\hline $50 \mathrm{E}-02$ & $4.60 \mathrm{E}+00$ & $10 \mathrm{~F}-01$ & $13 F-01$ & $.17 \mathrm{E}+00$ & $163 E+00$ & $2.06 \mathrm{E}+00$ & $2.73 E+00$ \\
\hline-02 & $4.60 \mathrm{E}+00$ & 01 & $3.13 \mathrm{E}-01$ & & & $E+00$ & +00 \\
\hline 02 & $4.60 \mathrm{E}+00$ & & & & & & 00 \\
\hline $52 E-02$ & $60 \mathrm{E}+00$ & & & & & & $73 E+00$ \\
\hline $53 E-02$ & $4.60 \mathrm{E}+00$ & 1 & $\perp$ & $1.18 \mathrm{E}+00$ & 00 & +00 & $E+00$ \\
\hline $54 \mathrm{E}-02$ & $4.60 \mathrm{E}+00$ & $5 E-01$ & $E-01$ & $18 \mathrm{E}+00$ & $64 \mathrm{E}+00$ & $.07 \mathrm{E}+00$ & $3 E+00$ \\
\hline$E-02$ & $.59 \mathrm{E}+00$ & $16 \mathrm{E}-01$ & 10 & $.18 \mathrm{E}+00$ & 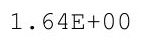 & $.07 E+00$ & $.73 E+00$ \\
\hline 2 & $9 \mathrm{E}+00$ & $7 E-01$ & & & & -00 & $3 E+00$ \\
\hline $56 \mathrm{E}-02$ & $4.59 \mathrm{E}+00$ & 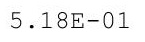 & & 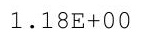 & 0 & 0 & +00 \\
\hline $.57 E-02$ & $4.59 \mathrm{E}+00$ & & & & & $2.08 E+00$ & $2.74 \mathrm{E}+00$ \\
\hline $58 E-02$ & $4.59 \mathrm{E}+00$ & $.20 \mathrm{E}-01$ & $.20 \mathrm{E}-01$ & $1.19 \mathrm{E}+00$ & & $2.08 E+00$ & $2.74 \mathrm{E}+00$ \\
\hline-02 & $59 \mathrm{E}+00$ & $\Xi-01$ & 制 & 0 & & $E+00$ & $4 \mathrm{E}+00$ \\
\hline .5 & 0 & & & & & 0 & 00 \\
\hline 2 & $9 E+00$ & & & 100 & & 0 & 0 \\
\hline $61 E-02$ & $4.58 \mathrm{E}+00$ & $5.23 E-01$ & $3235-01$ & ניחק & & 0 & 0 \\
\hline $62 E-02$ & $4.58 \mathrm{E}+00$ & $24 F-01$ & $\Delta F-01$ & 1 & $66 \sigma^{\circ}$ & $F+00$ & $5 E+00$ \\
\hline $63 E-02$ & $4.58 \mathrm{E}+00$ & $.25 E-01$ & $.25 \mathrm{E}-01$ & $1.20 \mathrm{E}+00$ & $1.66 \mathrm{E}+$ & $2.09 \mathrm{E}+00$ & $2.75 E+00$ \\
\hline 02 & $58 E+00$ & & & & & +00 & $5 \mathrm{E}+00$ \\
\hline 2 & & & & & & & \\
\hline 02 & $4.58 \mathrm{E}+00$ & .2 & & 1.20E+ & & & \\
\hline 02 & $4.58 \mathrm{E}+00$ & $\perp$ & $3.29 \mathrm{E}-01$ & 1.2 & - & $0 E+00$ & 00 \\
\hline 2 & $4.58 \mathrm{E}+00$ & $5.30 \mathrm{E}-01$ & $\perp$ & $1.21 \mathrm{E}+\mathrm{C}$ & $1.66 \mathrm{E}+$ & $2.10 \mathrm{E}+\mathrm{C}$ & $75 E+00$ \\
\hline $68 E-02$ & $4.57 \mathrm{E}+00$ & $31 \mathrm{~F}-01$ & $3 \quad 31 F-01$ & 1. $21 \mathrm{E}+00$ & $.66 \mathrm{E}+\mathrm{C}$ & $.11 \mathrm{E}+00$ & $76 E+00$ \\
\hline$E-02$ & $4.57 \mathrm{E}+00$ & זרכי & & 1. $21 \mathrm{E}+00$ & & $2.11 E+00$ & $.76 \mathrm{E}+00$ \\
\hline 02 & & & & & & & \\
\hline 2 & $4.57 \mathrm{E}+00$ & & & 1.21E+ & $0+\sigma_{0}$ & & $.76 \mathrm{E}+00$ \\
\hline $.71 E-02$ & $4.57 \mathrm{E}+00$ & . 3451 & $\begin{array}{lll}30 \mathrm{~L} \\
\end{array}$ & $1.22 \mathrm{E}+00$ & $1.66 \mathrm{E}+00$ & $2.11 \mathrm{E}+00$ & $2.76 \mathrm{E}+00$ \\
\hline $72 \mathrm{E}-02$ & $4.57 \mathrm{E}+00$ & $5.35 E-01$ & . & 1. $22 \mathrm{E}+00$ & $1.67 \mathrm{E}+00$ & $2.12 \mathrm{E}+00$ & $2.76 \mathrm{E}+00$ \\
\hline 2 & $4.57 \mathrm{E}+00$ & ? & 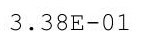 & 1.22E+ & & & $2.76 \mathrm{E}+$ \\
\hline 7 & & & & & & & 0 \\
\hline $\mathrm{E}-02$ & $4.56 \mathrm{E}+00$ & & 1 & & & & \\
\hline$E-02$ & $4.56 \mathrm{E}+00$ & 1 & & $1.22 \mathrm{E}$ & & & 00 \\
\hline $.77 E-02$ & $4.56 \mathrm{E}+00$ & $5.40 \mathrm{E}-01$ & $3.4 \angle E-01$ & $1.23 \mathrm{E}+00$ & 土.OTH & $2.13 E+00$ & $2.77 \mathrm{E}+00$ \\
\hline $78 E-02$ & $4.56 \mathrm{E}+00$ & $.4 \perp L-4$ & & $1.23 E+00$ & & & $2.77 \mathrm{E}+00$ \\
\hline 02 & $4.56 \mathrm{E}+00$ & 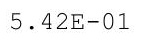 & & $1.23 \mathrm{E}+00$ & $1.67 \mathrm{E}+$ & & $2.77 \mathrm{E}+00$ \\
\hline 2 & 4. $55 \mathrm{E}+$ & $u$ & 1 & $1.23 \mathrm{E}+00$ & $1.68 \mathrm{E}+$ & $2.13 \mathrm{E}+$ & $2.77 \mathrm{E}+00$ \\
\hline 2 & $4.55 E+00$ & 1 & 1 & $1.23 \mathrm{E}+00$ & $1.68 \mathrm{E}+$ & $2.13 E+00$ & $2.77 \mathrm{E}+00$ \\
\hline $81 \mathrm{E}-02$ & $4.55 E+00$ & $5.45 E-01$ & $5 E-01$ & 1. $23 \mathrm{E}+00$ & 1 . & $4 \mathrm{E}+00$ & $2.77 \mathrm{E}+00$ \\
\hline $82 E-02$ & $4.55 E+00$ & 01 & & $1.23 \mathrm{E}+00$ & & 2 & $2.78 \mathrm{E}+00$ \\
\hline & 0 & & & & & & \\
\hline$E-02$ & $4.55 E+00$ & 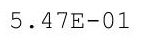 & 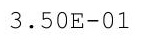 & $1.24 E+U 0$ & $1.68 \mathrm{E}+00$ & $2.14 \mathrm{E}+00$ & $2.78 \mathrm{E}+00$ \\
\hline $85 E-02$ & $4.55 E+00$ & & & $1.24 \mathrm{E}+00$ & $1.69 \mathrm{E}+00$ & $2.15 E+00$ & $2.78 \mathrm{E}+00$ \\
\hline 02 & $4.54 \mathrm{E}+00$ & $E-01$ & $E-01$ & $.24 \mathrm{E}+00$ & $1.69 \mathrm{E}+00$ & $2.15 \mathrm{E}+00$ & $.78 E+00$ \\
\hline
\end{tabular}


RESRAD-OFFSITE, Version 2.5

Title : Offsite Resident Farmer Deterministic Run

File : RF TC99 DOESG FWD-FV2.ROF

Summary of dose at graphical times, reptition 2 (continued)

Time

Years

7. $31 \mathrm{E}+02$

$7.32 \mathrm{E}+02$

7. $32 \mathrm{E}+02$

7. $33 \mathrm{E}+02$

$7.33 \mathrm{E}+02$

7. $34 \mathrm{E}+02$

$7.34 \mathrm{E}+02$

$7.35 \mathrm{E}+02$

$7.35 \mathrm{E}+02$

$7.36 \mathrm{E}+02$

$7.36 \mathrm{E}+02$

$7.37 \mathrm{E}+02$

$7.37 \mathrm{E}+02$

$7.38 \mathrm{E}+02$

$7.38 \mathrm{E}+02$

$7.39 \mathrm{E}+02$

7. $39 \mathrm{E}+02$

7. $40 \mathrm{E}+02$

$7.40 \mathrm{E}+02$

$7.41 \mathrm{E}+02$

$7.41 \mathrm{E}+02$

$7.42 \mathrm{E}+02$

7. $42 \mathrm{E}+02$

$7.43 \mathrm{E}+02$

$7.43 \mathrm{E}+02$

$7.44 \mathrm{E}+02$

$7.44 \mathrm{E}+02$

$7.45 \mathrm{E}+02$

$7.45 \mathrm{E}+02$

$7.46 \mathrm{E}+02$

$7.46 \mathrm{E}+02$

$7.47 \mathrm{E}+02$

$7.48 \mathrm{E}+02$

$7.48 \mathrm{E}+02$

$7.49 \mathrm{E}+02$

$7.49 \mathrm{E}+02$

$7.50 \mathrm{E}+02$

$7.50 \mathrm{E}+02$

$7.51 \mathrm{E}+02$

$7.51 \mathrm{E}+02$

$7.52 \mathrm{E}+02$

$7.52 \mathrm{E}+02$

$7.53 \mathrm{E}+02$

$7.53 \mathrm{E}+02$

$7.54 \mathrm{E}+02$

$7.54 \mathrm{E}+02$
Dose statistics at graphical times, mrem/yr

\begin{tabular}{|c|c|c|c|c|c|c|c|}
\hline m & $\operatorname{axi}$ & 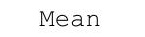 & 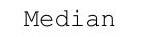 & & & & \\
\hline 02 & $4.54 \mathrm{E}+00$ & 01 & $.53 E-01$ & $.24 \mathrm{E}+00$ & 00 & -00 & $.10 \mathrm{E}+U 0$ \\
\hline $88 E-02$ & $4.54 \mathrm{E}+00$ & $1 E-01$ & $4 E-01$ & $.24 E+00$ & $9 E+00$ & $2.15 \mathrm{E}+00$ & $2.78 \mathrm{E}+00$ \\
\hline $89 \mathrm{E}-02$ & $4.54 \mathrm{E}+00$ & $52 \mathrm{E}-01$ & $55 E-01$ & $.25 E+00$ & $.69 \mathrm{E}+00$ & $2.15 \mathrm{E}+00$ & $2.78 \mathrm{E}+00$ \\
\hline-02 & $4.54 \mathrm{E}+00$ & $53 \mathrm{~F}-01$ & $55 \mathrm{~F}-01$ & $.25 E+00$ & $69 F+00$ & $.16 \mathrm{E}+00$ & $2.78 \mathrm{E}+00$ \\
\hline-02 & +00 & 01 & 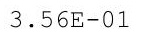 & $.25 \mathrm{E}+$ & & $E+00$ & +00 \\
\hline 02 & $3 E+00$ & & & & & & 00 \\
\hline $93 E-02$ & $3 E+00$ & & & 00 & & +00 & $79 E+00$ \\
\hline $94 \mathrm{E}-02$ & $3 E+00$ & 1 & $\perp$ & $1.25 \mathrm{E}+00$ & & +00 & $79 \mathrm{E}+00$ \\
\hline $94 \mathrm{E}-02$ & $4.53 E+00$ & $7 \mathrm{E}-01$ & -01 & $1.26 \mathrm{E}+00$ & $70 \mathrm{E}+00$ & $E+00$ & $79 E+00$ \\
\hline$E-02$ & $.53 E+00$ & $8 E-01$ & Г & 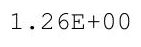 & ו חקר & $17 E+00$ & $.79 \mathrm{E}+00$ \\
\hline 02 & $2 E+00$ & & & 0 & & 0 & $9 \mathrm{E}+00$ \\
\hline $97 E-02$ & $4.52 \mathrm{E}+00$ & $0=$ & & $.26 \mathrm{E}+$ & & -00 & +00 \\
\hline $.98 E-02$ & $4.52 E+00$ & & & & & & $2.79 \mathrm{E}+00$ \\
\hline $99 E-02$ & $4.52 \mathrm{E}+00$ & $.62 \mathrm{E}-01$ & $.65 \mathrm{E}-01$ & $1.26 \mathrm{E}+00$ & & $2.18 \mathrm{E}+00$ & $2.79 \mathrm{E}+00$ \\
\hline-02 & $E+00$ & $E-01$ & $5-0$ & $27 \mathrm{E}+$ & & +00 & $80 \mathrm{E}+00$ \\
\hline 2 & $4.52 \mathrm{E}+$ & & & $\cdot 2$ & 0 & 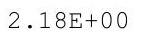 & 00 \\
\hline 2 & $51 E+00$ & & & - & 0 & 0 & 0 \\
\hline 2 & $4.51 \mathrm{E}+00$ & $5.66 \mathrm{E}-01$ & 3. $69 \mathrm{E}-01$ & 271 & 20 & 0 & 0 \\
\hline $.04 E-02$ & $4.51 E+00$ & $77 \mathrm{~F}-01$ & $F-01$ & 27 & 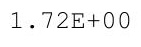 & $E+00$ & $0 \mathrm{E}+00$ \\
\hline $.05 E-02$ & $4.51 E+00$ & $.67 E-01$ & $.71 \mathrm{E}-01$ & $1.27 \mathrm{E}+00$ & $1.72 \mathrm{E}+\mathrm{C}$ & $2.19 \mathrm{E}+00$ & $2.80 E+00$ \\
\hline 02 & $4.51 E+00$ & & & 0 & & $.19 \mathrm{E}+00$ & $E+00$ \\
\hline 2 & & & & & & & \\
\hline 2 & $4.50 \mathrm{E}+00$ & 1 & & 1.28E+ & & & 00 \\
\hline$E-02$ & $4.50 \mathrm{E}+00$ & 1 & & $1.28 \mathrm{E}+$ & (2) & 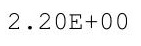 & 00 \\
\hline 2 & $.50 \mathrm{E}+00$ & $5.72 \mathrm{E}-01$ & $\perp$ & $1.28 \mathrm{E}+$ & $1.73 \mathrm{E}+$ & $.20 E+00$ & $80 \mathrm{E}+00$ \\
\hline $.11 E-02$ & $4.50 \mathrm{E}+00$ & $73 F-01$ & $6 \mathrm{~F}-01$ & 1. $28 \mathrm{E}+00$ & $1.73 \mathrm{E}+$ & $20 \mathrm{E}+00$ & $2.81 \mathrm{E}+00$ \\
\hline $12 \mathrm{E}-02$ & $4.49 \mathrm{E}+00$ & & & $1.28 \mathrm{E}+00$ & & $2.20 \mathrm{E}+00$ & 2. $81 \mathrm{E}+00$ \\
\hline 02 & & & & & & & \\
\hline 2 & $4.49 \mathrm{E}+00$ & & & 1.29E+ & & & \\
\hline $15 \mathrm{E}-02$ & $4.49 \mathrm{E}+00$ & $5.77 \mathrm{E}-01$ & $3.00 \mathrm{~L}-\mathrm{L}$ & $1.29 \mathrm{E}+00$ & 土. & $2.21 \mathrm{E}+00$ & $2.81 E+00$ \\
\hline $16 \mathrm{E}-02$ & $4.49 \mathrm{E}+00$ & $5.77 \mathrm{E}-01$ & - & 1. $29 \mathrm{E}+00$ & 1. & $2.21 \mathrm{E}+00$ & $2.81 \mathrm{E}+00$ \\
\hline 2 & $4.48 \mathrm{E}+00$ & $5.78 \mathrm{E}-01$ & $3.82 \mathrm{E}-01$ & 1.29E+ & & & \\
\hline 2 & & & & & & & $2.81 \mathrm{E}+00$ \\
\hline & & & & & & & \\
\hline 02 & & & & & & & \\
\hline 02 & $4.48 \mathrm{E}+00$ & $5.82 \mathrm{E}-01$ & $3.85 E-01$ & $1.30 \mathrm{E}+00$ & 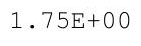 & $2.22 \mathrm{E}+$ & $2.81 E+00$ \\
\hline $23 E-02$ & $4.47 \mathrm{E}+00$ & $.00 \pm-1$ & & $1.30 E+00$ & & & $2.81 E+00$ \\
\hline $24 E-02$ & $4.47 \mathrm{E}+00$ & & & $1.30 \mathrm{E}+00$ & 1. $75 \mathrm{E}+00$ & $2.22 \mathrm{E}+00$ & $2.81 \mathrm{E}+00$ \\
\hline 2 & 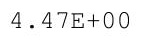 & 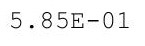 & 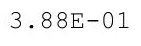 & $1.30 \mathrm{E}+00$ & $1.75 \mathrm{E}+00$ & $2.22 \mathrm{E}+00$ & $2.82 E+00$ \\
\hline & & $5.86 \mathrm{E}-01$ & 1 & $1.30 \mathrm{E}+00$ & & & $.82 E+00$ \\
\hline $7 E-02$ & $4.46 \mathrm{E}+00$ & -01 & -01 & $1.30 \mathrm{E}+00$ & $1.75 \mathrm{E}+00$ & $2.22 \mathrm{E}+00$ & $2.82 E+00$ \\
\hline$E-02$ & $4.46 \mathrm{E}+00$ & 01 & 1 & $1.30 \mathrm{E}+00$ & & $E+00$ & $2 E+00$ \\
\hline & $4 \cdot 4$ & & & & & & $2.82 E+00$ \\
\hline$E-02$ & $4.46 \mathrm{E}+00$ & $5.89 \mathrm{E}-01$ & 2 & $1.30 E+00$ & $1.76 \mathrm{E}+00$ & $2.22 \mathrm{E}+00$ & $2.82 \mathrm{E}+00$ \\
\hline $3 \perp+-02$ & $4.46 \mathrm{E}+00$ & & & $1.31 \mathrm{E}+00$ & $1.76 \mathrm{E}+00$ & $2.22 E+00$ & $2.82 \mathrm{E}+00$ \\
\hline 02 & $4.45 \mathrm{E}+00$ & $1 E-01$ & $3 E-01$ & 1. $31 \mathrm{E}+00$ & 1. $76 \mathrm{E}+00$ & $2.23 E+00$ & $2.82 E+00$ \\
\hline
\end{tabular}


RESRAD-OFFSITE, Version 2.5

Title : Offsite Resident Farmer Deterministic Run

File : RF TC99 DOESG FWD-FV2.ROF

Summary of dose at graphical times, reptition 2 (continued)

Time

Years

$7.55 \mathrm{E}+02$

$7.55 \mathrm{E}+02$

$7.56 \mathrm{E}+02$

$7.56 \mathrm{E}+02$

$7.57 \mathrm{E}+02$

$7.57 \mathrm{E}+02$

$7.58 \mathrm{E}+02$

$7.58 \mathrm{E}+02$

$7.59 \mathrm{E}+02$

$7.59 \mathrm{E}+02$

$7.60 \mathrm{E}+02$

$7.60 \mathrm{E}+02$

$7.61 \mathrm{E}+02$

$7.61 \mathrm{E}+02$

$7.62 \mathrm{E}+02$

7. $62 \mathrm{E}+02$

$7.63 \mathrm{E}+02$

$7.63 \mathrm{E}+02$

$7.64 \mathrm{E}+02$

$7.64 \mathrm{E}+02$

$7.65 \mathrm{E}+02$

$7.65 \mathrm{E}+02$

7. $66 \mathrm{E}+02$

7. $66 \mathrm{E}+02$

$7.67 \mathrm{E}+02$

$7.68 \mathrm{E}+02$

$7.68 \mathrm{E}+02$

$7.69 \mathrm{E}+02$

$7.69 \mathrm{E}+02$

$7.70 \mathrm{E}+02$

$7.70 \mathrm{E}+02$

$7.71 \mathrm{E}+02$

$7.71 \mathrm{E}+02$

7. $72 \mathrm{E}+02$

$7.72 \mathrm{E}+02$

$7.73 \mathrm{E}+02$

$7.73 \mathrm{E}+02$

$7.74 \mathrm{E}+02$

$7.74 \mathrm{E}+02$

$7.75 \mathrm{E}+02$

$7.75 \mathrm{E}+02$

$7.76 \mathrm{E}+02$

$7.76 \mathrm{E}+02$

$7.77 \mathrm{E}+02$

$7.77 \mathrm{E}+02$

$7.78 \mathrm{E}+02$
Dose statistics at graphical times, mrem/yr

\begin{tabular}{|c|c|c|c|c|c|c|c|}
\hline m & $\operatorname{axi}$ & ea & 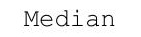 & & & & \\
\hline $33 E-02$ & $4.45 E+00$ & 01 & 1 & $.31 E+00$ & $76 E+00$ & -00 & $.0 \angle E+U U$ \\
\hline $34 E-02$ & $4.45 E+00$ & $93 E-01$ & $3.95 \mathrm{E}-01$ & 1. $31 E+00$ & $76 \mathrm{E}+00$ & $2.23 E+00$ & $82 E+00$ \\
\hline $35 E-02$ & $45 E+00$ & $94 \mathrm{E}-01$ & $96 E-01$ & $.31 E+00$ & $76 \mathrm{E}+00$ & $.23 E+00$ & $82 \mathrm{E}+00$ \\
\hline $37 E-02$ & $4.44 \mathrm{E}+00$ & $95 F-01$ & $97 \mathrm{~F}-01$ & $.31 E+00$ & $76 \mathrm{~F}+00$ & $2.23 E+00$ & $2.82 E+00$ \\
\hline $38 E-02$ & $4.44 E+00$ & $5 \mathrm{~F}-2$ & 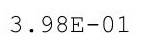 & $.32 E+00$ & $\mathrm{~F}+00$ & $E+00$ & $.82 E+00$ \\
\hline 02 & +00 & & & & & & 00 \\
\hline $40 E-02$ & +00 & & & & & & $82 E+00$ \\
\hline $41 E-02$ & $4 \mathrm{E}+00$ & 1 & $\perp$ & $1.32 \mathrm{E}+00$ & $E+00$ & +00 & $2 \mathrm{E}+00$ \\
\hline $42 E-02$ & $43 E+00$ & $9 E-01$ & -01 & $1.32 \mathrm{E}+00$ & $77 \mathrm{E}+00$ & $E+00$ & $32 \mathrm{E}+00$ \\
\hline $43 E-02$ & $43 E+00$ & תمि תم & תרקט & $.32 E+00$ & & $.24 \mathrm{E}+00$ & $81 E+00$ \\
\hline 02 & +00 & & & & & 00 & $\mathrm{E}+00$ \\
\hline $45 E-02$ & +00 & 28 & & 335 & & 0 & +00 \\
\hline $47 E-02$ & $4.42 E+00$ & $6.03 E-01$ & & & & $E+00$ & $2.81 E+00$ \\
\hline $48 E-02$ & $4.42 E+00$ & $6.04 \mathrm{E}-01$ & $4.06 \mathrm{E}-01$ & $1.33 \mathrm{E}+00$ & $1.78 \mathrm{E}+00$ & $2.24 \mathrm{E}+00$ & $2.81 E+00$ \\
\hline$E-02$ & $42 \mathrm{E}+00$ & $F=0$ & $F-0$ & $335+$ & & +00 & $30 \mathrm{E}+00$ \\
\hline 2 & $4.42 E+00$ & $6.05 E-01$ & & $+\cdots$ & & 0 & 00 \\
\hline 2 & 00 & & & 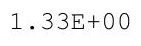 & & 0 & 0 \\
\hline 2 & $4.41 E+00$ & $6075-01$ & 4.09E-01 & קת קט & & & 0 \\
\hline $.53 E-02$ & $4.41 E+00$ & $6.08 \mathrm{E}-01$ & $4.10 \mathrm{E}-01$ & $1.33 \mathrm{E}+00$ & 1. $79 \mathrm{E}+00$ & $2.24 \mathrm{E}+00$ & $2.80 E+00$ \\
\hline $54 \mathrm{E}-02$ & $4.41 E+00$ & $.09 E-01$ & $1 E-01$ & $1.33 \mathrm{E}+00$ & $1.79 \mathrm{E}+$ & $2.24 \mathrm{E}+00$ & $2.79 \mathrm{E}+00$ \\
\hline 02 & $4.40 E+00$ & & & & & $.24 \mathrm{E}+00$ & $9 \mathrm{E}+00$ \\
\hline & & & & & & & \\
\hline 02 & $4.40 E+00$ & & & $1.34 \mathrm{E}+$ & & & \\
\hline 02 & $4.40 E+00$ & $6.12 \mathrm{E}-01$ & & 土. & - & 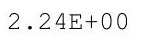 & 0 \\
\hline 2 & $4.39 \mathrm{E}+00$ & $6.13 \mathrm{E}-01$ & $\perp$ & 1. $34 \mathrm{E}+$ & & $2.24 \mathrm{E}+0$ & $78 \mathrm{E}+00$ \\
\hline $61 E-02$ & $4.39 E+00$ & $1 \cap \square$ & $6 \mathrm{~F}-01$ & 1. $34 \mathrm{E}+00$ & $1.79 \mathrm{E}+$ & $2.24 \mathrm{E}+00$ & $.78 \mathrm{E}+00$ \\
\hline$E-02$ & $4.39 E+00$ & $15 \mathrm{~F}-01$ & & & & $.24 E+00$ & $2.78 \mathrm{E}+00$ \\
\hline 02 & & & & & & & \\
\hline 02 & $4.38 E+00$ & & & $1.35 \mathrm{E}+$ & & & \\
\hline $66 E-02$ & $4.38 E+00$ & $\begin{array}{lll}.+10 \\
0\end{array}$ & . $20 \perp-1$ & $1.35 \mathrm{E}+00$ & $1.80 \mathrm{E}+00$ & $2.24 \mathrm{E}+00$ & $2.77 \mathrm{E}+00$ \\
\hline $67 E-02$ & $4.38 E+00$ & 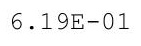 & $1 \cdot 2+1$ & 1. $35 \mathrm{E}+00$ & $1.80 \mathrm{E}+00$ & $2.24 \mathrm{E}+00$ & $2.77 \mathrm{E}+00$ \\
\hline 2 & $4.38 E+00$ & $6.19 \mathrm{E}-01$ & $4.22 \mathrm{E}-01$ & 1. $35 \mathrm{E}+$ & & & $2.77 \mathrm{E}+$ \\
\hline 7 & & & & & & & 0 \\
\hline 2 & $4.37 E+00$ & & 1 & & & & \\
\hline 02 & +00 & & & $1.35 \mathrm{E}$ & & & 00 \\
\hline $.73 E-02$ & $4.37 E+00$ & $6.23 E-U 1$ & $4.26 \mathrm{E}-01$ & $1.35 \mathrm{E}+00$ & $\perp .01 \mathrm{~L}$ & 2.210 & $2.77 \mathrm{E}+00$ \\
\hline $74 \mathrm{E}-02$ & 4. $36 \mathrm{E}+00$ & & & $1.36 E+00$ & & & $2.77 \mathrm{E}+00$ \\
\hline 02 & $4.36 E+00$ & $5 E-01$ & & $1.36 \mathrm{E}+00$ & $1.81 \mathrm{E}+\mathrm{C}$ & & $2.77 \mathrm{E}+00$ \\
\hline 2 & 4. $36 \mathrm{E}+$ & 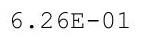 & 1 & $1.36 \mathrm{E}+00$ & $1.81 \mathrm{E}+$ & $2.23 E+$ & $2.77 \mathrm{E}+00$ \\
\hline & $4.36 E+00$ & & 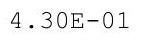 & $1.36 \mathrm{E}+00$ & & & $2.77 \mathrm{E}+00$ \\
\hline $.79 E-02$ & $4.35 E+00$ & $7 E-01$ & $4.31 \mathrm{E}-01$ & $1.36 \mathrm{E}+00$ & $1.81 \mathrm{E}$ & $2.24 \mathrm{E}+00$ & $2.77 \mathrm{E}+00$ \\
\hline$E-02$ & $4.35 E+00$ & 6 & 4.3 & $1.36 \mathrm{E}+00$ & & $E+00$ & $2.77 \mathrm{E}+00$ \\
\hline & $4.35 E+00$ & & & & & & $2.77 \mathrm{E}+00$ \\
\hline $83 E-02$ & $4.35 E+00$ & . & te. & $1.3 / E+00$ & $1.81 \mathrm{E}+00$ & $2.24 \mathrm{E}+00$ & $2.77 \mathrm{E}+00$ \\
\hline $.045-02$ & $4.34 \mathrm{E}+00$ & ( & & $1.37 \mathrm{E}+00$ & $1.82 \mathrm{E}+00$ & $2.24 \mathrm{E}+00$ & $2.77 \mathrm{E}+00$ \\
\hline 02 & $4.34 \mathrm{E}+00$ & $E-01$ & $35 E-01$ & $1.37 \mathrm{E}+00$ & $1.82 \mathrm{E}+00$ & $2.24 \mathrm{E}+00$ & $2.77 \mathrm{E}+00$ \\
\hline
\end{tabular}


RESRAD-OFFSITE, Version 2.5

$\mathrm{T}^{1 / 2}$ Limit $=180$ days

robabilistic Dose and Risk Report

Title : Offsite Resident Farmer Deterministic Run

File : RF TC99 DOESG FWD-FV2.ROF

Summary of dose at graphical times, reptition 2 (continued)

Time

Years

7. $78 \mathrm{E}+02$

$7.79 \mathrm{E}+02$

$7.79 \mathrm{E}+02$

$7.80 \mathrm{E}+02$

$7.80 \mathrm{E}+02$

7. $81 \mathrm{E}+02$

$7.81 \mathrm{E}+02$

7. $82 \mathrm{E}+02$

7. $82 \mathrm{E}+02$

$7.83 \mathrm{E}+02$

7. $83 \mathrm{E}+02$

$7.84 \mathrm{E}+02$

$7.84 \mathrm{E}+02$

$7.85 \mathrm{E}+02$

$7.85 \mathrm{E}+02$

$7.86 \mathrm{E}+02$

$7.86 \mathrm{E}+02$

$7.87 \mathrm{E}+02$

$7.88 \mathrm{E}+02$

$7.88 \mathrm{E}+02$

$7.89 \mathrm{E}+02$

$7.89 \mathrm{E}+02$

$7.90 \mathrm{E}+02$

$7.90 \mathrm{E}+02$

7. $91 \mathrm{E}+02$

7. $91 \mathrm{E}+02$

7. $92 \mathrm{E}+02$

7. $92 \mathrm{E}+02$

7. $93 \mathrm{E}+02$

7. $93 \mathrm{E}+02$

7. $94 \mathrm{E}+02$

7. $94 \mathrm{E}+02$

7. $95 \mathrm{E}+02$

7. $95 \mathrm{E}+02$

7. $96 \mathrm{E}+02$

7. $96 \mathrm{E}+02$

$7.97 \mathrm{E}+02$

7. $97 \mathrm{E}+02$

$7.98 \mathrm{E}+02$

$7.98 \mathrm{E}+02$

7. $99 \mathrm{E}+02$

$7.99 \mathrm{E}+02$

8. $00 \mathrm{E}+02$

$8.00 \mathrm{E}+02$

$8.01 \mathrm{E}+02$

8. $01 \mathrm{E}+02$

Dose statistics at graphical times, mrem/yr

\begin{tabular}{|c|c|c|c|c|c|c|c|}
\hline Minimum & Maximum & Mean & Median & $90 \%$ & $95 \%$ & $97.5 \%$ & $99 \%$ \\
\hline $2.87 \mathrm{E}-02$ & $4.34 \mathrm{E}+00$ & $6.33 E-01$ & $4.36 \mathrm{E}-01$ & $1.38 E+00$ & $1.82 \mathrm{E}+00$ & $2.24 E+00$ & $2.77 E+00$ \\
\hline $2.88 \mathrm{E}-02$ & $4.34 E+00$ & $6.34 \mathrm{E}-01$ & $4.37 \mathrm{E}-01$ & $1.38 \mathrm{E}+00$ & $1.82 \mathrm{E}+00$ & $2.24 E+00$ & $2.77 \mathrm{E}+00$ \\
\hline $2.89 E-02$ & $4.33 \mathrm{E}+00$ & $6.34 \mathrm{E}-01$ & $4.38 \mathrm{E}-01$ & $1.38 \mathrm{E}+00$ & $1.82 \mathrm{E}+00$ & $2.24 \mathrm{E}+00$ & $2.77 \mathrm{E}+00$ \\
\hline $2.90 \mathrm{E}-02$ & $4.33 E+00$ & $6.35 \mathrm{E}-01$ & $4.39 \mathrm{E}-01$ & $1.38 \mathrm{E}+00$ & $1.82 \mathrm{E}+00$ & $2.24 \mathrm{E}+00$ & $2.77 \mathrm{E}+00$ \\
\hline $2.92 \mathrm{E}-02$ & $4.33 \mathrm{E}+00$ & $6.36 \mathrm{E}-01$ & $4.40 \mathrm{E}-01$ & $.38 \mathrm{E}+00$ & $1.82 \mathrm{E}+00$ & $2.24 \mathrm{E}+00$ & $2.77 \mathrm{E}+00$ \\
\hline $2.93 E-02$ & $4.32 \mathrm{E}+00$ & $6.37 \mathrm{E}-01$ & $4.41 \mathrm{E}-01$ & $.39 E+00$ & $83 E+00$ & $2.24 \mathrm{E}+00$ & $2.77 \mathrm{E}+00$ \\
\hline $2.94 \mathrm{E}-02$ & $4.32 \mathrm{E}+00$ & $6.38 E-01$ & $4.42 \mathrm{E}-01$ & $1.39 \mathrm{E}+00$ & $1.83 \mathrm{E}+00$ & $2.25 \mathrm{E}+00$ & $2.77 \mathrm{E}+00$ \\
\hline $2.95 E-02$ & $4.32 E+00$ & $6.39 \mathrm{E}-01$ & $4.43 E-01$ & $1.39 E+00$ & $1.83 \mathrm{E}+00$ & $2.25 E+00$ & $2.77 \mathrm{E}+00$ \\
\hline $2.97 \mathrm{E}-02$ & $4.32 \mathrm{E}+00$ & $6.40 \mathrm{E}-01$ & $4.44 \mathrm{E}-01$ & $1.39 \mathrm{E}+00$ & $1.83 \mathrm{E}+00$ & $2.25 \mathrm{E}+00$ & $2.77 \mathrm{E}+00$ \\
\hline $2.98 \mathrm{E}-02$ & $4.31 \mathrm{E}+00$ & $6.41 \mathrm{E}-01$ & $4.45 \mathrm{E}-01$ & $.39 E+00$ & $1.83 \mathrm{E}+00$ & $.25 E+00$ & $.77 E+00$ \\
\hline $2.99 \mathrm{E}-02$ & $4.31 E+00$ & $6.41 \mathrm{E}-01$ & $4.46 \mathrm{E}-01$ & $1.39 \mathrm{E}+00$ & $.83 E+00$ & $2.25 \mathrm{E}+00$ & $2.77 \mathrm{E}+00$ \\
\hline $3.00 \mathrm{E}-02$ & $4.31 E+00$ & $6.42 \mathrm{E}-01$ & $4.47 \mathrm{E}-01$ & $1.40 \mathrm{E}+00$ & $1.83 \mathrm{E}+00$ & $2.25 \mathrm{E}+00$ & $2.77 \mathrm{E}+00$ \\
\hline $3.02 \mathrm{E}-02$ & $4.30 \mathrm{E}+00$ & $6.43 E-01$ & $4.47 \mathrm{E}-01$ & $1.40 \mathrm{E}+00$ & $1.84 \mathrm{E}+00$ & $2.25 \mathrm{E}+00$ & $2.77 \mathrm{E}+00$ \\
\hline $3.03 E-02$ & $4.30 \mathrm{E}+00$ & $6.44 \mathrm{E}-01$ & $4.48 \mathrm{E}-01$ & $1.40 \mathrm{E}+00$ & $1.84 \mathrm{E}+00$ & $2.25 \mathrm{E}+00$ & $2.77 \mathrm{E}+00$ \\
\hline $3.04 \mathrm{E}-02$ & $4.30 \mathrm{E}+00$ & $6.45 \mathrm{E}-01$ & $4.49 \mathrm{E}-01$ & $1.40 \mathrm{E}+00$ & $1.84 \mathrm{E}+00$ & $2.25 \mathrm{E}+00$ & $2.76 \mathrm{E}+00$ \\
\hline $3.06 \mathrm{E}-02$ & $4.30 \mathrm{E}+00$ & $6.46 E-01$ & $4.50 E-01$ & $40 \mathrm{E}+00$ & $.84 \mathrm{E}+$ & $.25 E+00$ & $76 E+00$ \\
\hline $3.07 \mathrm{E}-02$ & $4.29 \mathrm{E}+00$ & $6.47 \mathrm{E}-01$ & $50 E-01$ & $40 \mathrm{E}+00$ & $84 \mathrm{E}+00$ & $2.25 \mathrm{E}+00$ & $.76 E+00$ \\
\hline $3.08 \mathrm{E}-02$ & $4.29 \mathrm{E}+00$ & $6.47 \mathrm{E}-01$ & $4.51 \mathrm{E}-01$ & $1.40 \mathrm{E}+00$ & $1.84 \mathrm{E}+00$ & $2.25 \mathrm{E}+00$ & $2.76 \mathrm{E}+00$ \\
\hline $3.09 \mathrm{E}-02$ & $4.29 \mathrm{E}+00$ & $6.48 E-01$ & $4.52 E-01$ & $1.41 E+00$ & $1.84 \mathrm{E}+00$ & $2.25 \mathrm{E}+00$ & $2.76 \mathrm{E}+00$ \\
\hline $3.11 \mathrm{E}-02$ & $4.28 \mathrm{E}+00$ & $6.49 \mathrm{E}-01$ & $4.53 E-01$ & $1.41 \mathrm{E}+00$ & $1.85 \mathrm{E}+00$ & $2.25 \mathrm{E}+00$ & $2.75 \mathrm{E}+00$ \\
\hline $3.12 \mathrm{E}-02$ & $4.28 E+00$ & $6.50 \mathrm{E}-01$ & $4.54 \mathrm{E}-01$ & $1.41 \mathrm{E}+00$ & $1.85 \mathrm{E}+00$ & $2.25 \mathrm{E}+00$ & $2.75 \mathrm{E}+00$ \\
\hline $3.13 E-02$ & $4.28 E+00$ & $6.51 \mathrm{E}-01$ & $55 E-01$ & $41 E+00$ & $1.85 \mathrm{E}+00$ & $2.25 \mathrm{E}+00$ & $2.75 E+00$ \\
\hline $3.15 \mathrm{E}-02$ & $4.28 \mathrm{E}+00$ & $6.52 \mathrm{E}-01$ & $4.56 \mathrm{E}-01$ & $1.41 E+00$ & $1.85 \mathrm{E}+00$ & $2.25 \mathrm{E}+00$ & $2.75 E+00$ \\
\hline $3.16 \mathrm{E}-02$ & $4.27 \mathrm{E}+00$ & $6.53 \mathrm{E}-01$ & $4.57 \mathrm{E}-01$ & $1.41 \mathrm{E}+00$ & $1.85 \mathrm{E}+00$ & $2.25 \mathrm{E}+00$ & $2.75 \mathrm{E}+00$ \\
\hline $3.17 \mathrm{E}-02$ & $4.27 \mathrm{E}+00$ & $6.53 E-01$ & $4.58 \mathrm{E}-01$ & $1.42 E+00$ & $1.85 \mathrm{E}+00$ & $2.25 \mathrm{E}+00$ & $2.74 \mathrm{E}+00$ \\
\hline $3.19 \mathrm{E}-02$ & $4.27 \mathrm{E}+00$ & $6.54 \mathrm{E}-01$ & $4.58 \mathrm{E}-01$ & $1.42 \mathrm{E}+00$ & $1.85 \mathrm{E}+00$ & $2.24 \mathrm{E}+00$ & $2.74 \mathrm{E}+00$ \\
\hline $3.20 \mathrm{E}-02$ & $4.26 \mathrm{E}+00$ & $6.55 \mathrm{E}-01$ & $4.59 \mathrm{E}-01$ & $1.42 \mathrm{E}+00$ & $1.86 \mathrm{E}+00$ & $2.24 \mathrm{E}+00$ & $2.74 \mathrm{E}+00$ \\
\hline $3.21 E-02$ & $4.26 \mathrm{E}+00$ & $6.56 \mathrm{E}-01$ & $4.60 \mathrm{E}-01$ & $1.42 \mathrm{E}+00$ & $1.86 \mathrm{E}+00$ & $2.24 E+00$ & $2.74 \mathrm{E}+00$ \\
\hline $3.23 E-02$ & $4.26 \mathrm{E}+00$ & $6.57 \mathrm{E}-01$ & $4.61 \mathrm{E}-01$ & $1.42 \mathrm{E}+00$ & $1.86 \mathrm{E}+00$ & $2.24 \mathrm{E}+00$ & $2.74 \mathrm{E}+00$ \\
\hline $3.24 \mathrm{E}-02$ & $4.26 \mathrm{E}+00$ & $6.58 \mathrm{E}-01$ & $4.62 E-01$ & $1.43 E+00$ & $1.86 \mathrm{E}+00$ & $2.24 \mathrm{E}+00$ & $2.73 E+00$ \\
\hline $3.25 E-02$ & $4.25 E+00$ & $6.59 \mathrm{E}-01$ & $4.63 E-01$ & $1.43 E+00$ & $1.86 \mathrm{E}+00$ & $2.24 \mathrm{E}+00$ & $2.73 E+00$ \\
\hline $3.27 \mathrm{E}-02$ & $4.25 \mathrm{E}+00$ & $6.60 \mathrm{E}-01$ & $4.63 \mathrm{E}-01$ & $1.43 E+00$ & $1.86 \mathrm{E}+00$ & $2.24 \mathrm{E}+00$ & $2.73 E+00$ \\
\hline $3.28 \mathrm{E}-02$ & $4.25 E+00$ & $6.60 \mathrm{E}-01$ & $4.64 \mathrm{E}-01$ & $1.43 E+00$ & $1.86 \mathrm{E}+00$ & $2.24 \mathrm{E}+00$ & $2.73 E+00$ \\
\hline $3.29 \mathrm{E}-02$ & $4.24 \mathrm{E}+00$ & $6.61 \mathrm{E}-01$ & $4.65 E-01$ & $1.43 E+00$ & $1.87 \mathrm{E}+00$ & $2.24 \mathrm{E}+00$ & $2.73 E+00$ \\
\hline $3.31 E-02$ & $4.24 \mathrm{E}+00$ & $6.62 E-01$ & $4.66 \mathrm{E}-01$ & $1.43 E+00$ & $1.87 \mathrm{E}+00$ & $2.24 E+00$ & $2.72 E+00$ \\
\hline $3.32 E-02$ & $4.24 \mathrm{E}+00$ & $6.63 E-01$ & $4.67 E-01$ & $1.44 \mathrm{E}+00$ & $1.87 \mathrm{E}+00$ & $2.24 \mathrm{E}+00$ & $2.72 \mathrm{E}+00$ \\
\hline $3.33 E-02$ & $4.24 \mathrm{E}+00$ & $6.64 \mathrm{E}-01$ & $4.68 \mathrm{E}-01$ & $1.44 \mathrm{E}+00$ & $1.87 \mathrm{E}+00$ & $2.24 \mathrm{E}+00$ & $2.72 E+00$ \\
\hline $3.34 \mathrm{E}-02$ & $4.23 E+00$ & $6.65 \mathrm{E}-01$ & $4.68 \mathrm{E}-01$ & $1.44 \mathrm{E}+00$ & $1.87 \mathrm{E}+00$ & $2.24 \mathrm{E}+00$ & $2.72 \mathrm{E}+00$ \\
\hline $3.36 \mathrm{E}-02$ & $4.23 E+00$ & $6.65 E-01$ & $4.69 \mathrm{E}-01$ & $1.44 \mathrm{E}+00$ & $1.87 \mathrm{E}+00$ & $2.25 \mathrm{E}+00$ & $2.72 E+00$ \\
\hline $3.37 \mathrm{E}-02$ & $4.23 E+00$ & $6.66 \mathrm{E}-01$ & $4.70 \mathrm{E}-01$ & $1.44 \mathrm{E}+00$ & $1.87 \mathrm{E}+00$ & $2.25 \mathrm{E}+00$ & $2.72 \mathrm{E}+00$ \\
\hline $3.38 \mathrm{E}-02$ & $4.22 \mathrm{E}+00$ & $6.67 \mathrm{E}-01$ & $4.71 E-01$ & $1.44 \mathrm{E}+00$ & $1.87 \mathrm{E}+00$ & $2.25 \mathrm{E}+00$ & $2.72 \mathrm{E}+00$ \\
\hline $3.40 \mathrm{E}-02$ & $4.22 \mathrm{E}+00$ & $6.68 \mathrm{E}-01$ & $4.71 E-01$ & $1.45 E+00$ & $1.87 \mathrm{E}+00$ & $2.25 \mathrm{E}+00$ & $2.71 \mathrm{E}+00$ \\
\hline $3.41 \mathrm{E}-02$ & $4.22 \mathrm{E}+00$ & $6.69 \mathrm{E}-01$ & $4.72 \mathrm{E}-01$ & $1.45 \mathrm{E}+00$ & $1.87 \mathrm{E}+00$ & $2.25 \mathrm{E}+00$ & $2.71 E+00$ \\
\hline $3.42 \mathrm{E}-02$ & $4.21 \mathrm{E}+00$ & $6.70 \mathrm{E}-01$ & $4.73 E-01$ & $1.45 \mathrm{E}+00$ & $1.87 \mathrm{E}+00$ & $2.25 \mathrm{E}+00$ & $2.71 \mathrm{E}+00$ \\
\hline $3.44 \mathrm{E}-02$ & $4.21 E+00$ & $6.71 E-01$ & $4.74 E-01$ & $1.45 \mathrm{E}+00$ & $1.87 \mathrm{E}+00$ & $2.25 E+00$ & $2.71 E+00$ \\
\hline $3.45 E-02$ & $4.21 \mathrm{E}+00$ & $6.71 \mathrm{E}-01$ & $4.76 \mathrm{E}-01$ & $1.45 E+00$ & $1.87 \mathrm{E}+00$ & $2.25 \mathrm{E}+00$ & $2.71 E+00$ \\
\hline
\end{tabular}


RESRAD-OFFSITE, Version 2.5

robabilistic Dose and Risk Report

Title : Offsite Resident Farmer Deterministic Run

File : RF TC99 DOESG FWD-FV2.ROF

Summary of dose at graphical times, reptition 2 (continued)

Time

Years

$8.02 \mathrm{E}+02$

$8.02 \mathrm{E}+02$

$8.03 \mathrm{E}+02$

$8.03 \mathrm{E}+02$

$8.04 \mathrm{E}+02$

$8.04 \mathrm{E}+02$

$8.05 \mathrm{E}+02$

$8.05 \mathrm{E}+02$

$8.06 \mathrm{E}+02$

$8.06 \mathrm{E}+02$

$8.07 \mathrm{E}+02$

$8.07 \mathrm{E}+02$

$8.08 \mathrm{E}+02$

$8.09 \mathrm{E}+02$

$8.09 \mathrm{E}+02$

$8.10 \mathrm{E}+02$

$8.10 \mathrm{E}+02$

$8.11 \mathrm{E}+02$

$8.11 \mathrm{E}+02$

$8.12 \mathrm{E}+02$

$8.12 \mathrm{E}+02$

$8.13 \mathrm{E}+02$

$8.13 \mathrm{E}+02$

$8.14 \mathrm{E}+02$

8. $14 \mathrm{E}+02$

$8.15 \mathrm{E}+02$

$8.15 \mathrm{E}+02$

$8.16 \mathrm{E}+02$

$8.16 \mathrm{E}+02$

$8.17 \mathrm{E}+02$

$8.17 \mathrm{E}+02$

$8.18 \mathrm{E}+02$

$8.18 \mathrm{E}+02$

$8.19 \mathrm{E}+02$

$8.19 \mathrm{E}+02$

8. $20 \mathrm{E}+02$

$8.20 \mathrm{E}+02$

$8.21 E+02$

$8.21 E+02$

$8.22 \mathrm{E}+02$

$8.22 \mathrm{E}+02$

$8.23 \mathrm{E}+02$

8. $23 \mathrm{E}+02$

$8.24 \mathrm{E}+02$

8. $24 \mathrm{E}+02$

$8.25 E+02$
Dose statistics at graphical times, mrem/yr

\begin{tabular}{|c|c|c|c|c|c|c|c|}
\hline num & aximum & lean & edi & & & & \\
\hline 02 & +00 & 01 & 01 & 0 & 0 & 00 & +00 \\
\hline $48 \mathrm{E}-02$ & $0 \mathrm{E}+00$ & $3 E-01$ & $8 E-01$ & $.45 E+00$ & $.88 \mathrm{E}+00$ & $26 \mathrm{E}+00$ & $1 E+00$ \\
\hline$E-02$ & $4.20 \mathrm{E}+00$ & $74 \mathrm{~F}-01$ & $.79 E-01$ & $.45 E+00$ & $1.88 \mathrm{E}+00$ & $2.26 \mathrm{E}+00$ & $2.71 \mathrm{E}+00$ \\
\hline$E-02$ & $4.20 \mathrm{E}+00$ & $5 \mathrm{~F}-0$ & $30 E-01$ & $45 E+00$ & $87 \mathrm{~F}+$ & $26 \mathrm{~F}+00$ & $71 \mathrm{E}+00$ \\
\hline 02 & 00 & $6.76 \mathrm{E}-01$ & & & & & +00 \\
\hline 02 & & $6.76 \mathrm{E}-01$ & & & & & +00 \\
\hline $.55 E-02$ & $4.19 \mathrm{E}+00$ & (D) & -01 & $1.46 \mathrm{E}+00$ & $88 \mathrm{E}+00$ & $2.27 \mathrm{E}+00$ & $2.71 \mathrm{E}+00$ \\
\hline $56 \mathrm{E}-02$ & $4.18 \mathrm{E}+00$ & $8 E-01$ & $4.84 \mathrm{E}-01$ & $46 E+00$ & $1.88 \mathrm{E}+00$ & $.27 E+00$ & $71 \mathrm{E}+00$ \\
\hline $57 \mathrm{~F}-02$ & $.18 \mathrm{E}+00$ & $795-8-8$ & $35 F-8-8-2$ & $.46 E+00$ & $88 \mathrm{~F}+$ & $227 \mathrm{~F}+$ & $.71 E+00$ \\
\hline 2 & $4.18 \mathrm{E}+00$ & $6.80 \mathrm{E}-01$ & . & $46 \mathrm{~F}+00$ & $88 \mathrm{~F}$ & 1 & $71 E+00$ \\
\hline $60 E-02$ & $4.17 \mathrm{E}+00$ & $\mathrm{~F}_{2}$ & 4 & $46 \mathrm{~F}$ & 0 & +00 & $2 \mathrm{E}+00$ \\
\hline$E-02$ & $.17 \mathrm{E}+0$ & 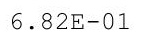 & 1 & $1.46 \mathrm{E}+$ & & 0 & $E+00$ \\
\hline $63 E-02$ & $4.17 \mathrm{E}+00$ & $6.82 \mathrm{E}-01$ & $4.89 \mathrm{E}-01$ & 1. $46 \mathrm{E}+00$ & $1.88 \mathrm{E}+00$ & $2.27 \mathrm{E}+00$ & $2.72 \mathrm{E}+00$ \\
\hline$E-02$ & $E+00$ & $\mathrm{~F}-0$ & & 46 & & +00 & $72 E+00$ \\
\hline 2 & & & & $6 \mathrm{~F}^{+}-2 \mathrm{C}$ & & & 0 \\
\hline 2 & 1 $165+$ & & & $146 \mathrm{~F}+$ & 0 & 0 & $72 E+00$ \\
\hline$E-02$ & $4.16 \mathrm{E}+0$ & $6.86 \mathrm{E}-01$ & - & $146 \mathrm{~F}$ & & 0 & $2 \mathrm{E}+00$ \\
\hline $70 \mathrm{~F}-02$ & $5 \mathrm{~F}+00$ & $87 \mathrm{~F}-01$ & $4 E-01$ & $1.47 \mathrm{E}+00$ & 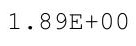 & $E+00$ & $72 \mathrm{E}+00$ \\
\hline$E-02$ & $.15 \mathrm{E}+00$ & $.87 E-01$ & 4. $95 \mathrm{E}-01$ & 1. $47 \mathrm{E}+00$ & $1.89 \mathrm{E}+00$ & $2.28 \mathrm{E}+00$ & $2.72 \mathrm{E}+00$ \\
\hline $3 E-02$ & $4.15 \mathrm{E}+00$ & $3 F-0$ & -01 & $1.47 \mathrm{E}+00$ & & $2.29 \mathrm{E}+00$ & $.72 E+00$ \\
\hline 2 & & & & & & & \\
\hline $.76 \mathrm{E}$ & $4.14 \mathrm{E}+00$ & & & 1. $47 \mathrm{E}+$ & & & $72 E+00$ \\
\hline 02 & $4.14 \mathrm{E}+00$ & $6.91 \mathrm{E}-01$ & - & 1. $47 \mathrm{E}+$ & $180 \mathrm{~F}^{\prime}$ & 0 & $2 E+00$ \\
\hline$E-02$ & $4.13 E+0$ & 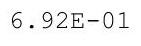 & $9 F_{-}$ & $1.48 \mathrm{E}+\mathrm{C}$ & $1.89 \mathrm{E}+$ & $2.29 \mathrm{E}+00$ & $.72 E+00$ \\
\hline$E-02$ & $4.13 \mathrm{E}+00$ & $6.92 E-01$ & $5.00 \mathrm{E}-01$ & 1. $48 \mathrm{E}+00$ & $1.89 \mathrm{E}+0$ & $.29 \mathrm{E}+00$ & $.73 E+00$ \\
\hline$E-02$ & $4.13 E+00$ & $93 E-01$ & & $1.48 \mathrm{E}+00$ & & $2.29 E+00$ & $2.73 E+00$ \\
\hline 2 & & & & & & & \\
\hline 2 & & & & 1. $48 \mathrm{E}+$ & $1.90 \mathrm{E}+00$ & & $2.73 E+00$ \\
\hline $.86 E-02$ & $4.12 \mathrm{E}+00$ & $\begin{array}{lll} \\
\end{array}$ & $5.04 \mathrm{E}-01$ & $1.48 \mathrm{E}+00$ & 土. & $2.29 E+00$ & $2.73 E+00$ \\
\hline 2 & $4.11 \mathrm{E}+00$ & 然 & 1 & 1. $48 \mathrm{E}+00$ & 1. $90 \mathrm{E}+00$ & $2.29 \mathrm{E}+00$ & $2.73 E+00$ \\
\hline 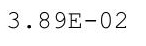 & $4.11 \mathrm{E}+00$ & $.97 E-0$ & $.07 \mathrm{E}-0$ & $1.48 \mathrm{E}+00$ & & $2.29 \mathrm{E}+00$ & $2.73 E+00$ \\
\hline$F-02$ & $4.11 E+00$ & $.98 E-01$ & $.08 E-01$ & $1.49 \mathrm{E}+00$ & $1.90 \mathrm{E}+00$ & $2.29 E+00$ & $2.72 E+00$ \\
\hline 2 & & & 1 & $1.49 \mathrm{E}+00$ & & & \\
\hline 02 & & & & 1. $49 \mathrm{E}+$ & & & $2.72 \mathrm{E}+00$ \\
\hline $.94 \mathrm{E}-02$ & $4.10 \mathrm{E}+00$ & $\cdot 0 \perp[-U 1$ & $5.10 \mathrm{E}-01$ & $1.49 \mathrm{E}+00$ & 1.91E+ & $2.30 \mathrm{E}+00$ & $2.72 \mathrm{E}+00$ \\
\hline . & $4.09 \mathrm{E}+00$ & & & 1. $49 \mathrm{E}+00$ & & & $2.72 \mathrm{E}+00$ \\
\hline 2 & $4.09 \mathrm{E}+00$ & 1 & 1 & $1.49 \mathrm{E}+00$ & $1.91 \mathrm{E}+$ & & $2.72 E+00$ \\
\hline $.99 \mathrm{E}-02$ & $4.09 \mathrm{E}+00$ & 1 & & $1.49 \mathrm{E}+00$ & 1.91E+00 & $2.30 \mathrm{E}+00$ & $2.72 \mathrm{E}+00$ \\
\hline & & & & $1 \quad 19=+$ & 1 & $2.30 \mathrm{E}+00$ & \\
\hline $2 E-02$ & & $7.05 E-01$ & & $1.50 \mathrm{E}+00$ & & $2.31 E+00$ & $2.71 E+00$ \\
\hline$E-02$ & $4.08 E+00$ & 1 & & 1. $50 \mathrm{E}+$ & $1.91 \mathrm{E}$ & & $2.71 \mathrm{E}+00$ \\
\hline & $4.07 E+00$ & & & $1.50 \mathrm{E}+00$ & & & $2.71 E+00$ \\
\hline ए & $4.07 E+00$ & $.07 E-01$ & $.18 \mathrm{E}-01$ & $1.50 \mathrm{E}+00$ & $1.91 \mathrm{E}+00$ & $2.31 E+00$ & $2.71 E+00$ \\
\hline 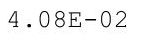 & $4.07 E+00$ & (.) & & $1.50 \mathrm{E}+00$ & $1.92 \mathrm{E}+00$ & $2.30 \mathrm{E}+00$ & $2.71 E+00$ \\
\hline & $4.06 \mathrm{E}+00$ & & & $1.50 \mathrm{E}+00$ & $1.92 \mathrm{E}+00$ & $2.30 \mathrm{E}+00$ & $2.71 E+00$ \\
\hline $1 E-02$ & $.06 \mathrm{E}+00$ & $.10 E-01$ & $.22 E-01$ & $1.51 \mathrm{E}+00$ & 1.92E+00 & $2.30 \mathrm{E}+00$ & $2.71 E+00$ \\
\hline
\end{tabular}


RESRAD-OFFSITE, Version 2.5 
RESRAD-OFFSITE, Version 2.5 
RESRAD-OFFSITE, Version 2.5

robabilistic Dose and Risk Report

Title : Offsite Resident Farmer Deterministic Run

File : RF TC99 DOESG FWD-FV2.ROF

Summary of dose at graphical times, reptition 2 (continued)

Time

Years

$8.73 \mathrm{E}+02$

$8.73 \mathrm{E}+02$

$8.74 \mathrm{E}+02$

$8.74 \mathrm{E}+02$

$8.75 \mathrm{E}+02$

$8.75 \mathrm{E}+02$

$8.76 \mathrm{E}+02$

$8.76 \mathrm{E}+02$

$8.77 \mathrm{E}+02$

$8.77 \mathrm{E}+02$

$8.78 \mathrm{E}+02$

$8.78 \mathrm{E}+02$

$8.79 \mathrm{E}+02$

$8.79 \mathrm{E}+02$

$8.80 \mathrm{E}+02$

$8.80 \mathrm{E}+02$

$8.81 \mathrm{E}+02$

$8.81 \mathrm{E}+02$

$8.82 \mathrm{E}+02$

$8.82 \mathrm{E}+02$

$8.83 \mathrm{E}+02$

$8.83 E+02$

$8.84 \mathrm{E}+02$

$8.84 \mathrm{E}+02$

$8.85 \mathrm{E}+02$

$8.85 \mathrm{E}+02$

$8.86 \mathrm{E}+02$

$8.86 \mathrm{E}+02$

$8.87 \mathrm{E}+02$

$8.87 E+02$

$8.88 \mathrm{E}+02$

$8.89 \mathrm{E}+02$

$8.89 \mathrm{E}+02$

$8.90 \mathrm{E}+02$

$8.90 \mathrm{E}+02$

$8.91 \mathrm{E}+02$

$8.91 \mathrm{E}+02$

8. $92 \mathrm{E}+02$

8. $92 \mathrm{E}+02$

$8.93 \mathrm{E}+02$

$8.93 \mathrm{E}+02$

8. $94 \mathrm{E}+02$

$8.94 \mathrm{E}+02$

$8.95 \mathrm{E}+02$

$8.95 \mathrm{E}+02$

$8.96 \mathrm{E}+02$
Dose statistics at graphical times, mrem/yr

\begin{tabular}{|c|c|c|c|c|c|c|c|}
\hline linimum & laximum & Mean & Median & $90 \%$ & $95 \%$ & $97.5 \%$ & $9 \%$ \\
\hline 2 & $3 E+00$ & 1 & $8 E-01$ & $1.61 \mathrm{E}+00$ & 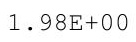 & 0 & +00 \\
\hline-02 & $3 E+00$ & $82 E-01$ & -01 & $1.61 \mathrm{E}+00$ & $98 \mathrm{E}+00$ & \pm+00 & $66 E+00$ \\
\hline $4 E-02$ & $3 E+00$ & $83 E-01$ & $E-01$ & 0 & 0 & Do & $66 \mathrm{E}+00$ \\
\hline $5-02$ & $E+00$ & $4 E-01$ & 01 & 0 & & Do & $6 E+00$ \\
\hline $7 E-02$ & $2 E+00$ & $\perp$ & 1 & & & & $66 E+00$ \\
\hline $69 \mathrm{E}-02$ & 00 & $\perp$ & & 0 & 0 & 00 & $66 \mathrm{E}+00$ \\
\hline $.71 E-02$ & $3.71 E+00$ & $7.86 \mathrm{E}-01$ & -01 & $1.62 \mathrm{E}+00$ & $1.98 \mathrm{E}+$ & 0 & $66 \mathrm{E}+00$ \\
\hline $.73 E-02$ & $3.71 E+00$ & 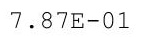 & $6.15 \mathrm{E}-01$ & $1.62 \mathrm{E}+00$ & $1.99 \mathrm{E}+00$ & $2.30 \mathrm{E}+00$ & $2.66 \mathrm{E}+00$ \\
\hline$E-02$ & +00 & 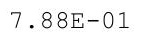 & 01 & $1.62 \mathrm{E}$ & 0 & 00 & \pm+00 \\
\hline $6 E-02$ & $E+00$ & $8 \mathrm{E}$ & & 1. $62 \mathrm{E}+$ & 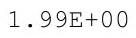 & 00 & $E+00$ \\
\hline$E-02$ & 3. & 5 & 1 & 0 & & & $E+00$ \\
\hline-02 & +00 & $\perp$ & & 00 & 0 & & $6 \mathrm{E}+00$ \\
\hline $82 E-02$ & $3.69 \mathrm{E}+00$ & 年 & 1 & $\perp \cdot 0<\mathrm{T}$ & 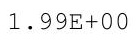 & 0 & $6 \mathrm{E}+00$ \\
\hline $.83 E-02$ & $3.69 \mathrm{E}+00$ & . & $6.21 \mathrm{E}-01$ & I. OLLTU & $\perp$. & $2.00+2-1$ & $66 \mathrm{E}+00$ \\
\hline $5 E-02$ & $3.68 \mathrm{E}+00$ & $\perp$ & 01 & 土. & 1. & 00 & 00 \\
\hline $.87 \mathrm{E}-02$ & $3.68 \mathrm{E}+00$ & 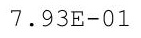 & $6.23 \mathrm{E}-01$ & $1.63 \mathrm{E}+00$ & & +00 & $66 \mathrm{E}+00$ \\
\hline $.89 E-02$ & $3.67 E+00$ & $7.93 \mathrm{E}-01$ & 6.23 & $1.63 \mathrm{E}+00$ & & $2.30 \mathrm{E}+00$ & $2.66 \mathrm{E}+00$ \\
\hline$E-02$ & $\mathrm{E}+00$ & $E-01$ & 1 & 0 & 0 & & $7 E+00$ \\
\hline $.92 E-02$ & $3.67 \mathrm{E}+00$ & $1.95 \mathrm{E}-\mathrm{U}$ & $6.25 \mathrm{E}-01$ & $1.63 \mathrm{E}+00$ & $99 \mathrm{E}+$ & 2 . & $66 \mathrm{E}+00$ \\
\hline $94 \mathrm{E}-02$ & $3.66 \mathrm{E}+00$ & $1.90 \mathrm{~L}-0 \perp$ & 0.201 & $1.63 \mathrm{E}+$ & $\perp$ & 0 & $E+00$ \\
\hline $96 \mathrm{E}-02$ & $3.66 \mathrm{E}+00$ & & & I. OJETU & & & $\mathrm{E}+00$ \\
\hline $.98 \mathrm{E}-02$ & $3.66 \mathrm{E}+00$ & 年 & $0 .{ }^{2}$ & 1.001 & 1. & • & $66 \mathrm{E}+00$ \\
\hline $.99 \mathrm{E}-02$ & $3.65 \mathrm{E}+00$ & $7.98 \mathrm{E}-01$ & $6.28 \mathrm{E}-01$ & $1.64 \mathrm{E}+00$ & $1.99 \mathrm{E}+00$ & $2.30 \mathrm{E}+00$ & $2.66 \mathrm{E}+00$ \\
\hline $.01 E-02$ & $3.65 E+00$ & $8 E-01$ & 01 & $1.64 \mathrm{E}+$ & $1.99 \mathrm{E}+$ & $2.30 \mathrm{E}+$ & $66 \mathrm{E}+00$ \\
\hline $3 E-02$ & $4 \mathrm{E}+00$ & 01 & 01 & $1.64 \mathrm{E}+$ & & & $66 \mathrm{E}+00$ \\
\hline$E-02$ & $3.64 \mathrm{E}+00$ & 1 & 1 & $1.64 \mathrm{E}+00$ & 1 & & +00 \\
\hline $7 E-02$ & $3.64 \mathrm{E}+00$ & 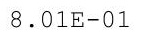 & 01 & $1.04 \mathrm{E}$ & 这 & & $66 \mathrm{E}+00$ \\
\hline $.09 E-02$ & $3.63 \mathrm{E}+00$ & $8.01 \mathrm{E}-01$ & $6.32 \mathrm{E}-01$ & $1.64 \mathrm{E}+00$ & $1.99 \mathrm{E}+00$ & $2.30 \mathrm{E}+00$ & $2.66 \mathrm{E}+00$ \\
\hline 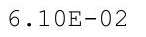 & $3.63 E+00$ & . & ( & $1.64 \mathrm{E}+$ & 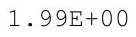 & 2.0040 & 2. $65 \mathrm{E}+00$ \\
\hline 2 & $3.63 \mathrm{E}+00$ & 8 & 1 & $1.64 \mathrm{E}+$ & & 00 & $5 \mathrm{E}+00$ \\
\hline 02 & $3.62 \mathrm{E}+00$ & 1 & 1 & $164 \mathrm{~F}+$ & 0 & $\mathrm{E}+00$ & $55 \mathrm{E}+00$ \\
\hline$E-02$ & $3.62 \mathrm{E}+00$ & 1 & 1 & $1.64 \mathrm{E}+$ & 1 & & 00 \\
\hline $.18 \mathrm{E}-02$ & $3.61 \mathrm{E}+00$ & $8.05 \mathrm{E}-01$ & $6.37 \mathrm{E}-01$ & $1.64 \mathrm{E}+$ & 1.99E+ & $2.30 \mathrm{E}+00$ & $2.65 \mathrm{E}+00$ \\
\hline $.19 \mathrm{E}-02$ & $3.61 \mathrm{E}+00$ & $8.05 \mathrm{E}-01$ & $6.37 \mathrm{E}-01$ & $1.64 \mathrm{E}+00$ & $1.99 \mathrm{E}+00$ & $2.30 \mathrm{E}+00$ & $2.65 E+00$ \\
\hline $.21 E-02$ & $3.01 \mathrm{E}+00$ & & & $1.65 \mathrm{E}+00$ & & & $2.64 \mathrm{E}+00$ \\
\hline $6.23 E-02$ & $3.60 \mathrm{E}+0 \mathrm{C}$ & & & $1.65 \mathrm{E}+$ & & & $2.64 \mathrm{E}+00$ \\
\hline 2 & 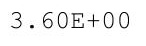 & 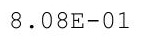 & . & $655+2010$ & 0 & $0 \mathrm{E}+00$ & $4 \mathrm{E}+00$ \\
\hline 2 & $E+00$ & $8.08 E-01$ & 1 & $165 \mathrm{~F}$ & 2 & 0 & $4 \mathrm{E}+00$ \\
\hline 02 & & & 6 & $1.65 \mathrm{E}$ & 2 & 00 & $A E+00$ \\
\hline $1 E-02$ & $3.59 \mathrm{E}+00$ & 1 & & $1.65 \mathrm{E}$ & & & $A \mathrm{E}+00$ \\
\hline$E-02$ & 0 & & & $1.05 \mathrm{~T}$ & & & $2.64 \mathrm{E}+00$ \\
\hline 22 & $3.58 \mathrm{E}+00$ & 1 & 1 & 1.035 & $2.00 \mathrm{E}$ & $2.29 \mathrm{E}$ & $2.64 \mathrm{E}+00$ \\
\hline 2 & 0 & 0 & 1 & 0 & 2 & 0 & 2.015 \\
\hline & & & & & 00 & 2 . & \\
\hline-02 & $E+00$ & $E-01$ & 6. & 1. $65 \mathrm{E}+00$ & 2 . & 2 . & $4 \mathrm{E}+00$ \\
\hline $42 E-02$ & $57 E+00$ & $14 \mathrm{E}-01$ & $.47 E-01$ & $1.65 \mathrm{E}+00$ & $2.00 \mathrm{E}+00$ & $2.29 E+00$ & $2.64 \mathrm{E}+00$ \\
\hline
\end{tabular}


RESRAD-OFFSITE, Version 2.5

$\mathrm{T}^{1 / 2}$ Limit $=180$ days

Title : Offsite Resident Farmer Deterministic Run

File : RF TC99 DOESG FWD-FV2.ROF

Summary of dose at graphical times, reptition 2 (continued)

Time

Years

$8.96 \mathrm{E}+02$

$8.97 \mathrm{E}+02$

$8.97 \mathrm{E}+02$

$8.98 \mathrm{E}+02$

$8.98 \mathrm{E}+02$

$8.99 \mathrm{E}+02$

$8.99 \mathrm{E}+02$

$9.00 \mathrm{E}+02$

$9.00 \mathrm{E}+02$

$9.01 \mathrm{E}+02$

$9.01 \mathrm{E}+02$

$9.02 \mathrm{E}+02$

$9.02 \mathrm{E}+02$

$9.03 \mathrm{E}+02$

$9.03 E+02$

$9.04 \mathrm{E}+02$

$9.04 \mathrm{E}+02$

$9.05 \mathrm{E}+02$

$9.05 \mathrm{E}+02$

$9.06 \mathrm{E}+02$

$9.06 \mathrm{E}+02$

$9.07 \mathrm{E}+02$

$9.07 \mathrm{E}+02$

$9.08 \mathrm{E}+02$

$9.08 \mathrm{E}+02$

$9.09 \mathrm{E}+02$

$9.10 \mathrm{E}+02$

$9.10 \mathrm{E}+02$

$9.11 \mathrm{E}+02$

$9.11 \mathrm{E}+02$

$9.12 \mathrm{E}+02$

9. $12 \mathrm{E}+02$

9. $13 \mathrm{E}+02$

9. $13 \mathrm{E}+02$

$9.14 \mathrm{E}+02$

$9.14 \mathrm{E}+02$

$9.15 \mathrm{E}+02$

$9.15 \mathrm{E}+02$

$9.16 \mathrm{E}+02$

$9.16 \mathrm{E}+02$

$9.17 \mathrm{E}+02$

$9.17 \mathrm{E}+02$

$9.18 \mathrm{E}+02$

$9.18 \mathrm{E}+02$

$9.19 \mathrm{E}+02$

$9.19 \mathrm{E}+02$
Dose statistics at graphical times, mrem/yr

\begin{tabular}{|c|c|c|c|c|c|c|c|}
\hline m & $\mathrm{m}$ & Mean & ledian & & & $\%$ & \\
\hline 02 & $3.56 \mathrm{E}+00$ & $8.15 E-01$ & $6.48 \mathrm{E}-01$ & $1.65 \mathrm{E}+00$ & $2.00 \mathrm{E}+00$ & $2.29 \mathrm{E}+00$ & $2.63 E+00$ \\
\hline $45 E-02$ & $3.56 \mathrm{E}+00$ & 01 & 01 & 1. $65 \mathrm{E}+00$ & $2.00 \mathrm{E}+00$ & $2.29 \mathrm{E}+00$ & $2.63 E+00$ \\
\hline $.47 E-02$ & $5 \mathrm{E}+00$ & $8.16 \mathrm{E}-01$ & $6.50 \mathrm{E}-01$ & $1.65 \mathrm{E}+00$ & $2.00 \mathrm{E}+00$ & $2.29 \mathrm{E}+00$ & $63 E+00$ \\
\hline $49 \mathrm{E}-02$ & $3.55 \mathrm{E}+00$ & $7 E-01$ & $6.50 \mathrm{E}-01$ & 1. $65 \mathrm{E}+00$ & $2.01 \mathrm{E}+00$ & $2.29 \mathrm{E}+00$ & $2.63 E+00$ \\
\hline$E-02$ & $3.55 \mathrm{E}+00$ & 01 & $1 E-01$ & $1.65 \mathrm{E}+00$ & $1 \mathrm{E}+00$ & $2.29 \mathrm{E}+00$ & $2.63 \mathrm{E}+00$ \\
\hline 02 & & -1 & & & & & +00 \\
\hline-02 & & & & & & & +00 \\
\hline $.57 \mathrm{E}-02$ & & & & & & & +00 \\
\hline$E-02$ & +00 & $\exists-01$ & $\perp$ & $66 \mathrm{E}+00$ & 00 & +00 & +00 \\
\hline 2 & $E+00$ & 1 & $\perp$ & $66 \mathrm{~F}+$ & + & $.29 \mathrm{E}+00$ & $62 \mathrm{E}+00$ \\
\hline 02 & $3.52 \mathrm{E}+00$ & $8.21 \mathrm{E}-01$ & $6.57 \mathrm{E}-01$ & $166 \mathrm{~F}+0 \Omega$ & 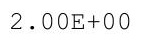 & $E+00$ & $.62 \mathrm{E}+00$ \\
\hline 2 & 00 & & & 0 & & 0 & +00 \\
\hline$E-02$ & $\mathrm{~F}+00$ & $8.23 E-01$ & $6.59 \mathrm{E}-01$ & 0 & & 0 & +00 \\
\hline $.68 \mathrm{E}-02$ & $3.51 \mathrm{E}+00$ & $8.23 E-01$ & $6.60 \mathrm{E}-01$ & $1.66 \mathrm{E}+00$ & $2.00 \mathrm{E}+00$ & $2.30 \mathrm{E}+00$ & $2.61 E+00$ \\
\hline$E-02$ & $E+00$ & 01 & & $66 \mathrm{E}+00$ & 0 & $\mathrm{E}+00$ & $61 \mathrm{E}+00$ \\
\hline 2 & & & & ل & & & 00 \\
\hline .7 & & & & ل & & 0 & 00 \\
\hline 2 & & $8.26 \mathrm{E}-01$ & & $6 c^{2}-190$ & & & 0 \\
\hline$E-02$ & $9 \mathrm{E}+00$ & $7 F-01$ & & $.66 \mathrm{E}+00$ & 0 & $29 E+00$ & $0 \mathrm{E}+00$ \\
\hline $.80 E-02$ & $3.49 \mathrm{E}+00$ & $28 E-01$ & $.65 \mathrm{E}-01$ & $1.66 \mathrm{E}+00$ & $2.00 \mathrm{E}+00$ & $2.29 \mathrm{E}+00$ & $2.60 \mathrm{E}+00$ \\
\hline $32 E-02$ & $.49 \mathrm{E}+00$ & $28 E-01$ & -01 & $1.66 \mathrm{E}+00$ & & $.28 E+00$ & $.60 \mathrm{E}+00$ \\
\hline 02 & & & & & & & $.60 E+00$ \\
\hline 2 & & & & $1.66 \mathrm{E}$ & & & 00 \\
\hline $.8 / \mathrm{E}-02$ & $3.48 \mathrm{E}+00$ & $\perp$ & & $\perp \cdot 00 \mathrm{H}$ & & 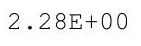 & 00 \\
\hline 2 & $3.47 \mathrm{E}+00$ & $8.31 \mathrm{E}-01$ & $\perp$ & $1.66 \mathrm{E}+00$ & $00 \mathrm{E}+$ & .28 & 00 \\
\hline $91 E-02$ & $.47 \mathrm{E}+00$ & $32 \mathrm{~F}-01$ & $6.71 \mathrm{E}-01$ & $1.67 \mathrm{E}+00$ & $.00 \mathrm{E}+0$ & $.28 E+00$ & $59 E+00$ \\
\hline $3 F-02$ & $3.46 \mathrm{E}+00$ & $32 \mathrm{~F}-01$ & $672 \mathrm{~F}-01$ & $1.66 \mathrm{E}+00$ & & $2.28 \mathrm{E}+00$ & $2.59 \mathrm{E}+00$ \\
\hline 02 & & & & & & & \\
\hline 02 & $E+00$ & & & $.66 \mathrm{E}+$ & & & \\
\hline $99 \mathrm{E}-02$ & $3.45 \mathrm{E}+00$ & 0.0451 & $6.74 \mathrm{E}-01$ & $1.66 \mathrm{E}+00$ & 2.001 & $2.28 \mathrm{E}+00$ & $2.59 \mathrm{E}+00$ \\
\hline$\cdot 01 \mathrm{C}-\mathrm{ZL}$ & $3.45 \mathrm{E}+00$ & $0.375-21$ & $0.10 \mathrm{~L}-U$ & $1.67 \mathrm{E}+00$ & 2. ООЕТ & Z. $21 \mathrm{ET} U 0$ & $2.59 \mathrm{E}+00$ \\
\hline 2 & $3.45 \mathrm{E}+00$ & 管 & 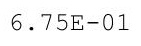 & $1.67 \mathrm{E}+00$ & & & $2.59 \mathrm{E}+00$ \\
\hline$F-0 ?$ & $3.44 \mathrm{E}+00$ & > > & $6 \mathrm{E}-01$ & $1.67 \mathrm{E}+00$ & & & $2.59 \mathrm{E}+00$ \\
\hline 2 & & & & & & & \\
\hline-02 & & & 01 & & & & $59 \mathrm{E}+00$ \\
\hline $1 E-02$ & $3.43 \mathrm{E}+00$ & $8.38 E-01$ & $9 E-01$ & $1.0 / \mathrm{ET}$ & 2.001 & $2.27 \mathrm{E}+00$ & $2.59 \mathrm{E}+00$ \\
\hline $3 \pm-U 2$ & $3.43 E+00$ & & & $1.67 \mathrm{E}+00$ & & & $2.59 \mathrm{E}+00$ \\
\hline • & & & & 1.OILTU & & & $2.59 \mathrm{E}+00$ \\
\hline $.17 E-02$ & e. & " & 1 & $1.67 \mathrm{E}+00$ & $2.00 \mathrm{E}+$ & & $2.58 \mathrm{E}+00$ \\
\hline & & & & $E+00$ & & & (le \\
\hline 2 & $3.41 E+00$ & 1 & 1 & $1.67 \mathrm{E}+00$ & $199 \mathrm{~F}+$ & $2.28 \mathrm{E}+00$ & $8 E+00$ \\
\hline $23 E-02$ & $3.41 \mathrm{E}+00$ & $8.42 E-01$ & 6. & $1.68 \mathrm{E}+00$ & 1.99E+ & 00 & $8 E+00$ \\
\hline & & & & & & & \\
\hline & $3.40 \mathrm{E}+00$ & 1 & & $1.68 E+00$ & म. & $2.28 E+00$ & $2.58 \mathrm{E}+00$ \\
\hline एᄂ口 & & $5-01$ & & $1.68 \mathrm{E}+00$ & $1.99 \mathrm{E}+00$ & $2.28 E+00$ & $2.58 \mathrm{E}+00$ \\
\hline $1 E-02$ & $9 E+00$ & $E-01$ & $87 E-01$ & $68 E+00$ & $.99 \mathrm{E}+00$ & $.27 E+00$ & $.58 E+00$ \\
\hline
\end{tabular}


RESRAD-OFFSITE, Version 2.5

Title : Offsite Resident Farmer Deterministic Run

File : RF TC99 DOESG FWD-FV2.ROF

Summary of dose at graphical times, reptition 2 (continued)

Time

Years

$9.20 \mathrm{E}+02$

$9.20 \mathrm{E}+02$

$9.21 \mathrm{E}+02$

$9.21 \mathrm{E}+02$

$9.22 \mathrm{E}+02$

$9.22 \mathrm{E}+02$

$9.23 \mathrm{E}+02$

$9.23 \mathrm{E}+02$

$9.24 \mathrm{E}+02$

$9.24 \mathrm{E}+02$

$9.25 \mathrm{E}+02$

$9.25 \mathrm{E}+02$

$9.26 \mathrm{E}+02$

$9.26 \mathrm{E}+02$

$9.27 \mathrm{E}+02$

$9.27 \mathrm{E}+02$

$9.28 \mathrm{E}+02$

$9.28 \mathrm{E}+02$

$9.29 \mathrm{E}+02$

$9.30 \mathrm{E}+02$

$9.30 \mathrm{E}+02$

$9.31 \mathrm{E}+02$

9. $31 \mathrm{E}+02$

9. $32 \mathrm{E}+02$

9. $32 \mathrm{E}+02$

$9.33 \mathrm{E}+02$

$9.33 \mathrm{E}+02$

$9.34 \mathrm{E}+02$

$9.34 \mathrm{E}+02$

9. $35 \mathrm{E}+02$

$9.35 \mathrm{E}+02$

$9.36 \mathrm{E}+02$

9. $36 \mathrm{E}+02$

9. $37 \mathrm{E}+02$

$9.37 \mathrm{E}+02$

$9.38 \mathrm{E}+02$

$9.38 \mathrm{E}+02$

$9.39 \mathrm{E}+02$

$9.39 \mathrm{E}+02$

$9.40 \mathrm{E}+02$

$9.40 \mathrm{E}+02$

$9.41 \mathrm{E}+02$

$9.41 \mathrm{E}+02$

$9.42 \mathrm{E}+02$

$9.42 \mathrm{E}+02$

$9.43 \mathrm{E}+02$
Dose statistics at graphical times, mrem/yr

\begin{tabular}{|c|c|c|c|c|c|c|c|}
\hline m & $\mathrm{am}$ & ean & ledian & & & $\%$ & \\
\hline 02 & $3.39 \mathrm{E}+00$ & $8.45 E-01$ & $6.88 \mathrm{E}-01$ & $1.68 \mathrm{E}+00$ & $1.99 \mathrm{E}+00$ & $\Xi+00$ & $2.58 \mathrm{E}+00$ \\
\hline-02 & $3.38 \mathrm{E}+00$ & 01 & -01 & +00 & 00 & +00 & $3 E+00$ \\
\hline $.37 E-02$ & $3.38 \mathrm{E}+00$ & $7 E-01$ & $6.90 \mathrm{E}-01$ & $1.68 \mathrm{E}+00$ & 1. $99 \mathrm{E}+00$ & $2.28 \mathrm{E}+00$ & $57 \mathrm{E}+00$ \\
\hline $.39 \mathrm{E}-02$ & $3.38 E+00$ & $.47 \mathrm{E}-01$ & $90 E-01$ & 1. $68 \mathrm{E}+00$ & 1. $99 \mathrm{E}+00$ & $2.28 \mathrm{E}+00$ & $57 \mathrm{E}+00$ \\
\hline$E-02$ & $3.37 \mathrm{E}+00$ & $8 \mathrm{E}-01$ & 01 & $1.68 \mathrm{E}+00$ & 1. $99 \mathrm{E}+00$ & $8 \mathrm{E}+00$ & $7 E+00$ \\
\hline $3 E-02$ & $37 E+00$ & 1 & 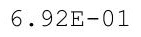 & & & & +00 \\
\hline $45 E-02$ & & 1 & & & & & $\mathrm{E}+00$ \\
\hline $.47 \mathrm{E}-02$ & $3.36 \mathrm{E}+00$ & & & & & $2.28 \mathrm{E}+00$ & $56 \mathrm{E}+00$ \\
\hline $49 \mathrm{E}-02$ & $3.36 \mathrm{E}+00$ & -01 & -01 & $1.68 \mathrm{E}+00$ & 00 & +00 & $E+00$ \\
\hline 02 & $35 E+00$ & 1 & $\perp$ & $1.68 \mathrm{E}+$ & 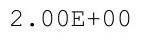 & $E+00$ & $5 E+00$ \\
\hline 02 & $3.35 \mathrm{E}+00$ & $8.52 \mathrm{E}-01$ & $6.95 \mathrm{E}-01$ & $68 E+00$ & ג תחم: & $E+00$ & $56 \mathrm{E}+00$ \\
\hline 02 & -00 & & & 0 & 0 & & +00 \\
\hline $57 \mathrm{~F}-02$ & $E+00$ & $3 F_{-}$ & $6.97 \mathrm{E}-01$ & 0 & & 0 & +00 \\
\hline $.59 \mathrm{E}-02$ & $3.34 \mathrm{E}+00$ & $8.54 \mathrm{E}-01$ & $6.98 \mathrm{E}-01$ & $1.68 \mathrm{E}+00$ & $2.00 \mathrm{E}+00$ & $2.29 \mathrm{E}+00$ & $2.56 \mathrm{E}+00$ \\
\hline $61 E-02$ & $3.34 \mathrm{E}+00$ & $E-01$ & 1 & $1.68 \mathrm{E}+00$ & $00 \mathrm{E}+$ & $\mathrm{E}+00$ & $E+00$ \\
\hline 2 & 0 & & & 0 & & 00 & 00 \\
\hline 2 & & & & .68 & & 0 & 00 \\
\hline 2 & קחרט & & & 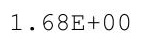 & & & 00 \\
\hline $69 \mathrm{E}-02$ & $32 \mathrm{E}+00$ & $7 \mathrm{~F}-01$ & קט & $1.68 \mathrm{E}+00$ & 0 & $E+00$ & $E+00$ \\
\hline $71 \mathrm{E}-02$ & $3.32 \mathrm{E}+00$ & $.58 \mathrm{E}-01$ & $3 E-01$ & $1.68 \mathrm{E}+00$ & $2.00 \mathrm{E}+00$ & $2.28 \mathrm{E}+00$ & $2.56 \mathrm{E}+00$ \\
\hline $.73 E-02$ & $31 E+00$ & $58 E-01$ & -01 & 1. $68 \mathrm{E}+00$ & 0 & $.28 E+00$ & $.56 \mathrm{E}+00$ \\
\hline 02 & & & & & & & $6 \mathrm{E}+00$ \\
\hline - & & & & & & & $56 \mathrm{E}+00$ \\
\hline 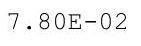 & & & & & & & 00 \\
\hline $32 E-02$ & $.30 E+00$ & $8.61 \mathrm{E}-01$ & $\perp$ & $1.68 \mathrm{E}+00$ & $00 \mathrm{E}+$ & $.28 \mathrm{E}+$ & $6 E+00$ \\
\hline $84 F-02$ & $.29 \mathrm{E}+00$ & $61 \mathrm{~F}-01$ & $7 \quad 07 \mathrm{~F}-01$ & 1. $68 \mathrm{E}+00$ & $2.00 \mathrm{E}+$ & $2.28 E+00$ & $56 E+00$ \\
\hline $\mathrm{E}-02$ & $3.29 \mathrm{E}+00$ & $62 \mathrm{~F}-01$ & $7 \mathrm{~F}-01$ & $1.68 \mathrm{E}+00$ & $.00 \mathrm{E}+00$ & $2.27 \mathrm{E}+00$ & $2.56 \mathrm{E}+00$ \\
\hline 02 & & & & & & & \\
\hline & & & & $1.68 \mathrm{E}+$ & & & \\
\hline $92 E-02$ & $3.28 \mathrm{E}+00$ & $0.045-1$ & $E-01$ & $1.68 \mathrm{E}+00$ & 2.001 & $2.27 \mathrm{E}+00$ & $2.56 \mathrm{E}+00$ \\
\hline • $945-02$ & $3.28 \mathrm{E}+00$ & $0.04 \mathrm{~L}-01$ & $.10 \mathrm{~L}-\mathrm{D}$ & $1.68 \mathrm{E}+00$ & 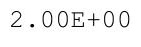 & $\angle . \angle I L T O 0$ & $2.56 \mathrm{E}+00$ \\
\hline ( & $3.27 \mathrm{E}+00$ & 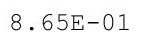 & 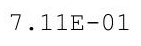 & 土. & & $2.27 \mathrm{E}+00$ & $2.56 \mathrm{E}+00$ \\
\hline 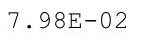 & $3.27 \mathrm{E}+00$ & 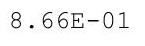 & $E-01$ & $1.68 \mathrm{E}+00$ & & & $2.56 \mathrm{E}+00$ \\
\hline $.00 \mathrm{E}-02$ & & & & & & & \\
\hline-02 & & 1 & 01 & & & & \\
\hline 2 & $3.26 \mathrm{E}+$ & 1 & & $1.68 \mathrm{E}+00$ & $2.00 \mathrm{E}+$ & $2 \cdot 21$ & $2.56 \mathrm{E}+00$ \\
\hline $5-02$ & $3.25 \mathrm{E}+00$ & 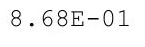 & & 1. $68 \mathrm{E}+$ & & & $E+00$ \\
\hline पम & $3.25 \mathrm{E}+00$ & & & 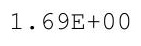 & & & $2.56 \mathrm{E}+00$ \\
\hline $.11 \mathrm{E}-02$ & - 201 & 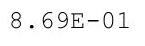 & 1 & $1.69 \mathrm{E}+00$ & & $2.26 \mathrm{E}+00$ & $2.56 \mathrm{E}+00$ \\
\hline & & & & $1.69 \mathrm{E}+00$ & & & 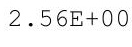 \\
\hline 2 & & 1 & 1 & $1.69 \mathrm{E}+00$ & $2.00 \mathrm{E}+$ & $2.26 \mathrm{E}+00$ & $6 \mathrm{E}+00$ \\
\hline$E-02$ & $3.23 E+00$ & $8.71 E-01$ & 7.18 & $1.69 \mathrm{E}+00$ & & 00 & $6 E+00$ \\
\hline & & & & & & & \\
\hline & $3.23 E+00$ & . & & $1.09 E+00$ & $2.00 \mathrm{E}+00$ & $2.26 \mathrm{E}+00$ & $2.56 \mathrm{E}+00$ \\
\hline 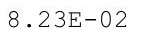 & & . & & $1.69 \mathrm{E}+00$ & & $2.26 \mathrm{E}+00$ & $2.56 \mathrm{E}+00$ \\
\hline-02 & $.22 \mathrm{E}+00$ & $E-01$ & $21 E-01$ & $1.69 \mathrm{E}+00$ & $.00 \mathrm{E}+00$ & $2.26 \mathrm{E}+00$ & $.56 E+00$ \\
\hline
\end{tabular}


RESRAD-OFFSITE, Version 2.5

obabilistic Dose and Risk Report

Title : Offsite Resident Farmer Deterministic Run

File : RF TC99 DOESG FWD-FV2.ROF

Summary of dose at graphical times, reptition 2 (continued)

Time

Years

9. $43 \mathrm{E}+02$

$9.44 \mathrm{E}+02$

9. $44 \mathrm{E}+02$

9. $45 \mathrm{E}+02$

9. $45 \mathrm{E}+02$

$9.46 \mathrm{E}+02$

$9.46 \mathrm{E}+02$

$9.47 \mathrm{E}+02$

9. $47 \mathrm{E}+02$

9. $48 \mathrm{E}+02$

9. $48 \mathrm{E}+02$

9. $49 \mathrm{E}+02$

9. $50 \mathrm{E}+02$

9. $50 \mathrm{E}+02$

9. $51 \mathrm{E}+02$

9. $51 \mathrm{E}+02$

9. $52 \mathrm{E}+02$

9. $52 \mathrm{E}+02$

$9.53 \mathrm{E}+02$

$9.53 \mathrm{E}+02$

$9.54 \mathrm{E}+02$

$9.54 \mathrm{E}+02$

$9.55 \mathrm{E}+02$

9. $55 \mathrm{E}+02$

9. $56 \mathrm{E}+02$

$9.56 \mathrm{E}+02$

9. $57 \mathrm{E}+02$

9. $57 \mathrm{E}+02$

9. $58 \mathrm{E}+02$

$9.58 \mathrm{E}+02$

9. $59 \mathrm{E}+02$

$9.59 \mathrm{E}+02$

$9.60 \mathrm{E}+02$

$9.60 \mathrm{E}+02$

$9.61 \mathrm{E}+02$

$9.61 \mathrm{E}+02$

$9.62 \mathrm{E}+02$

$9.62 \mathrm{E}+02$

$9.63 \mathrm{E}+02$

$9.63 \mathrm{E}+02$

$9.64 \mathrm{E}+02$

$9.64 \mathrm{E}+02$

$9.65 \mathrm{E}+02$

$9.65 \mathrm{E}+02$

$9.66 \mathrm{E}+02$

$9.66 \mathrm{E}+02$
Dose statistics at graphical times, mrem/yr

\begin{tabular}{|c|c|c|c|c|c|c|c|}
\hline linimum & Maximum & Mean & Median & $90 \%$ & $95 \%$ & $97.5 \%$ & $9 \%$ \\
\hline 2 & $21 E+00$ & 1 & 1 & $1.69 \mathrm{E}+00$ & 0 & 2) & +00 \\
\hline 02 & $3.21 \mathrm{E}+00$ & $5 E-$ & 01 & 1. $69 \mathrm{E}+00$ & $2.00 \mathrm{E}+00$ & $2.25 \mathrm{E}+00$ & $56 \mathrm{E}+00$ \\
\hline $2 E-02$ & +00 & $5 E-01$ & $23 E-01$ & 0 & 0 & 0 & $56 \mathrm{E}+00$ \\
\hline$E-02$ & $E+00$ & $E-01$ & 01 & 0 & & 00 & $\mathrm{E}+00$ \\
\hline $36 \mathrm{E}-02$ & $3.21 E+00$ & 1 & 1 & $.70 \mathrm{E}+00$ & $00 \mathrm{E}+00$ & $.25 E+00$ & $56 \mathrm{E}+00$ \\
\hline $38 E-02$ & 00 & 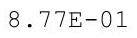 & & & 0 & 00 & $56 \mathrm{E}+00$ \\
\hline $40 E-02$ & $3.21 E+00$ & $8 E-01$ & $7.26 \mathrm{E}-01$ & $1.70 \mathrm{E}+00$ & 0 & +00 & $6 \mathrm{E}+00$ \\
\hline $.43 E-02$ & $3.21 E+00$ & $0.10 \mathrm{~L}-\mathrm{L}$ & $7.27 \mathrm{E}-01$ & $1.70 \mathrm{E}+00$ & $2.00 \mathrm{E}+00$ & $2.25 \mathrm{E}+00$ & $2.56 \mathrm{E}+00$ \\
\hline$E-02$ & +00 & 01 & 01 & $1.70 \mathrm{E}+00$ & 0 & 00 & $\Xi+00$ \\
\hline $47 E-02$ & $E+00$ & 工 & & $1.70 \mathrm{E}+00$ & 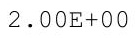 & 00 & $E+00$ \\
\hline$E-02$ & 0 & 8 & 1 & & & & $\mathrm{E}+00$ \\
\hline-02 & +00 & 1 & 1 & 1. & 0 & 0 & $7 E+00$ \\
\hline $53 E-02$ & $3.20 \mathrm{E}+00$ & $8.81 \mathrm{E}-01$ & $1 E-01$ & $1.10 \mathrm{E}+00$ & 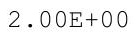 & $2.25 \mathrm{E}+00$ & $57 \mathrm{E}+00$ \\
\hline $.55 E-02$ & $3.20 \mathrm{E}+00$ & $8.82 \mathrm{E}-01$ & $7.31 \mathrm{E}-01$ & 1. IUETU & 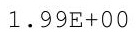 & $2.2 y+2 y$ & $7 \mathrm{E}+00$ \\
\hline $.58 E-02$ & $3.20 E+00$ & 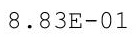 & 01 & $1.90 \mathrm{C}$ & I. & 00 & 00 \\
\hline $.60 E-02$ & $3.20 \mathrm{E}+00$ & $8.83 E-01$ & 7. 33E-0 01 & $1.70 \mathrm{E}+00$ & & $2.24 \mathrm{E}$ & $7 E+00$ \\
\hline $.62 E-02$ & $3.20 \mathrm{E}+00$ & $8.84 \mathrm{E}-01$ & $7.34 \mathrm{E}-01$ & & & $2.24 \mathrm{E}+00$ & $57 E+00$ \\
\hline$E-02$ & $E+00$ & $4 E-01$ & $5 E-01$ & 0 & 只 & +00 & $7 E+00$ \\
\hline $66 \mathrm{E}-02$ & $3.20 \mathrm{E}+00$ & $8.85 E-01$ & $7.36 \mathrm{E}-01$ & $1.71 \mathrm{E}+00$ & $1.99 \mathrm{E}+00$ & $2.24 \mathrm{E}+00$ & $57 \mathrm{E}+00$ \\
\hline $68 E-02$ & $3.20 \mathrm{E}+00$ & $8.85 E-01$ & 1.011 & $1.11 \mathrm{E}$ & 0 & 00 & $\mathrm{E}+00$ \\
\hline $.71 E-02$ & $3.20 \mathrm{E}+00$ & 正 & $7.37 \mathrm{E}-01$ & 1. & 我 & 00 & $\mathrm{E}+00$ \\
\hline $.73 E-02$ & $3.20 \mathrm{E}+00$ & 8.8 & . & 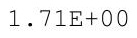 & 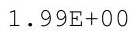 & 00 & $\mathrm{E}+00$ \\
\hline $.75 E-02$ & $3.20 \mathrm{E}+00$ & 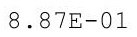 & $9 E-01$ & $1.71 \mathrm{E}+00$ & $1.99 \mathrm{E}$ & $2.24 \mathrm{E}+00$ & $7 E+00$ \\
\hline $.77 E-02$ & $3.20 \mathrm{E}+00$ & $8 E-01$ & 01 & $1.71 \mathrm{E}+$ & $1.99 \mathrm{E}+$ & $2.24 \mathrm{E}+$ & $7 \mathrm{E}+00$ \\
\hline$E-02$ & $19 \mathrm{E}+00$ & $3 E-01$ & 1 & 1 & & & $7 \mathrm{E}+00$ \\
\hline$E-02$ & $9 E+00$ & 1 & & $1.71 \mathrm{E}+00$ & 0 & 00 & $7 E+00$ \\
\hline $.84 E-02$ & $3.19 \mathrm{E}+00$ & JE-01 & & $1.71 \mathrm{E}$ & 政 & 2.2018 & $7 \mathrm{E}+00$ \\
\hline $.86 \mathrm{E}-02$ & $3.19 \mathrm{E}+00$ & $8.90 \mathrm{E}-01$ & $7.43 \mathrm{E}-01$ & $1.71 \mathrm{E}+00$ & $1.99 \mathrm{E}+00$ & $.25 E+00$ & $2.57 \mathrm{E}+00$ \\
\hline $.88 \mathrm{E}-02$ & . & $8.91 \mathrm{E}-01$ & $7.44 \mathrm{E}-01$ & $1.71 \mathrm{E}+00$ & 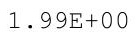 & $2.25 \mathrm{E}+00$ & $2.57 \mathrm{E}+00$ \\
\hline 2 & $3.19 \mathrm{E}+00$ & 1 & 1 & $1.71 \mathrm{E}+$ & & 0 & $7 \mathrm{E}+00$ \\
\hline 02 & $9 E+00$ & 1 & 1 & $171 \mathrm{~F}+$ & נ 1 & $E+00$ & $7 E+00$ \\
\hline$E-02$ & $\mathrm{E}+00$ & $\varepsilon$ & 1 & $1.71 \mathrm{E}$ & U & 00 & 00 \\
\hline $.97 \mathrm{E}-02$ & $3.19 \mathrm{E}+00$ & $8.93 E-01$ & $8 E-01$ & $1.71 \mathrm{E}$ & $1.99 \mathrm{E}$ & $2.25 \mathrm{E}$ & $7 \mathrm{E}+00$ \\
\hline $.99 \mathrm{E}-02$ & $3.19 \mathrm{E}+00$ & $8.94 \mathrm{E}-01$ & $7.48 \mathrm{E}-01$ & $1.71 \mathrm{E}+00$ & $1.99 \mathrm{E}+00$ & $2.25 \mathrm{E}+00$ & $2.57 \mathrm{E}+00$ \\
\hline $.01 \mathrm{E}-02$ & $3.19 \mathrm{E}+00$ & $8.94 \mathrm{E}-01$ & & $1.71 \mathrm{E}+00$ & זעל & & $2.57 \mathrm{E}+00$ \\
\hline $.03 E-02$ & & & & $1.71 \mathrm{E}+$ & $1.99 \mathrm{E}$ & & $2.57 \mathrm{E}+00$ \\
\hline 2 & 1 & $\varepsilon$ & . & 10 & ( & $2.26 \mathrm{E}+00$ & $7 E+00$ \\
\hline 2 & $E+00$ & 1 & 1 & $71 \mathrm{~F}+$ & 0 & 2. & $7 \mathrm{E}+00$ \\
\hline 22 & & & & 1.71 & $1.99 \mathrm{E}$ & 2 . & $7 \mathrm{E}+00$ \\
\hline $12 \mathrm{E}-02$ & $3.18 \mathrm{E}+00$ & 1 & & 1.7 & $1 \cdot 9$ & 2 . & $7 \mathrm{E}+00$ \\
\hline$E-02$ & $8 \mathrm{E}+$ & 1 & 1 & $1.1 \angle E+$ & 1.9957 & $2.26 \mathrm{E}+$ & $.57 E+00$ \\
\hline 02 & OETU & 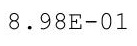 & 1 & $\perp \cdot 1 \angle \mathrm{ET}$ & $1.99 \mathrm{E}$ & $2.26 \mathrm{E}+00$ & $2.57 \mathrm{E}+00$ \\
\hline 2 & $\mathrm{~s}$ & 8 & 1 & 0 & 舟 & 0 & 2.00 \\
\hline 2 & & & & 0 & 1. & 2 . & $2.58 \mathrm{E}$ \\
\hline-02 & $E+00$ & -01 & 7. & $\mathrm{E}+00$ & $1.99 \mathrm{E}$ & 2.2 & $B E+00$ \\
\hline $.26 E-02$ & $18 \mathrm{E}+00$ & $00 E-01$ & $7.56 \mathrm{E}-01$ & $1.72 \mathrm{E}+00$ & 1.99E+00 & $2.26 \mathrm{E}+00$ & $3 E+00$ \\
\hline
\end{tabular}


RESRAD-OFFSITE, Version 2.5

obabilistic Dose and Risk Report

Title : Offsite Resident Farmer Deterministic Run

File : RF TC99 DOESG FWD-FV2.ROF

Summary of dose at graphical times, reptition 2 (continued)

Time

Years

9. $67 \mathrm{E}+02$

$9.67 \mathrm{E}+02$

$9.68 \mathrm{E}+02$

9. $68 \mathrm{E}+02$

$9.69 \mathrm{E}+02$

$9.70 \mathrm{E}+02$

$9.70 \mathrm{E}+02$

9. $71 \mathrm{E}+02$

$9.71 \mathrm{E}+02$

9. $72 \mathrm{E}+02$

$9.72 \mathrm{E}+02$

$9.73 \mathrm{E}+02$

$9.73 \mathrm{E}+02$

9. $74 \mathrm{E}+02$

9. $74 \mathrm{E}+02$

$9.75 \mathrm{E}+02$

9. $75 \mathrm{E}+02$

$9.76 \mathrm{E}+02$

$9.76 \mathrm{E}+02$

$9.77 \mathrm{E}+02$

$9.77 \mathrm{E}+02$

$9.78 \mathrm{E}+02$

$9.78 \mathrm{E}+02$

$9.79 \mathrm{E}+02$

$9.79 \mathrm{E}+02$

$9.80 \mathrm{E}+02$

$9.80 \mathrm{E}+02$

$9.81 \mathrm{E}+02$

$9.81 \mathrm{E}+02$

$9.82 \mathrm{E}+02$

$9.82 \mathrm{E}+02$

$9.83 E+02$

$9.83 \mathrm{E}+02$

$9.84 \mathrm{E}+02$

$9.84 \mathrm{E}+02$

$9.85 \mathrm{E}+02$

$9.85 \mathrm{E}+02$

$9.86 \mathrm{E}+02$

$9.86 \mathrm{E}+02$

$9.87 \mathrm{E}+02$

$9.87 \mathrm{E}+02$

$9.88 \mathrm{E}+02$

$9.88 \mathrm{E}+02$

$9.89 \mathrm{E}+02$

$9.90 \mathrm{E}+02$

9. $90 \mathrm{E}+02$
Dose statistics at graphical times, mrem/yr

\begin{tabular}{|c|c|c|c|c|c|c|c|}
\hline Iinimum & Maximum & Mean & Median & $90 \%$ & $90 \%$ & $97.5 \%$ & $9 \%$ \\
\hline 2 & $7 \mathrm{E}+00$ & 1 & $7 E-01$ & $1.72 \mathrm{E}+00$ & $99 \mathrm{E}+00$ & $.26 E+00$ & +00 \\
\hline 02 & $E+00$ & $1 E$ & 01 & $.72 \mathrm{E}$ & $98 \mathrm{E}+00$ & $.25 E+00$ & $57 E+00$ \\
\hline$E-02$ & $E+00$ & $02 E-01$ & $7 E-01$ & 0 & 0 & 0 & $7 E+00$ \\
\hline$E-02$ & $\mathrm{E}+00$ & $3 E-01$ & 01 & 0 & & 0 & $7 E+00$ \\
\hline $37 E-02$ & $3.17 \mathrm{E}+00$ & & & & & & $57 \mathrm{E}+00$ \\
\hline $39 E-02$ & $3.17 \mathrm{E}+00$ & & & $72 E+00$ & $99 \mathrm{E}+00$ & $E+00$ & $7 \mathrm{E}+00$ \\
\hline $41 E-02$ & $3.17 \mathrm{E}+00$ & $9.04 \mathrm{E}-01$ & $1 E-01$ & $1.72 \mathrm{E}+00$ & $1.99 \mathrm{E}+00$ & +00 & $7 E+00$ \\
\hline $.44 \mathrm{E}-02$ & $3.17 E+00$ & . & $7.62 \mathrm{E}-01$ & $1.73 \mathrm{E}+00$ & $1.99 \mathrm{E}+00$ & $2.25 \mathrm{E}+00$ & $2.57 \mathrm{E}+00$ \\
\hline-02 & $E+00$ & - & 01 & $1.73 \mathrm{E}$ & 0 & 00 & $7 E+00$ \\
\hline $3 E-02$ & $E+00$ & 9 & & $1.73 \mathrm{E}+00$ & 00 & $\mathrm{E}+00$ & $E+00$ \\
\hline$E-02$ & & 9 & & & & & $\mathrm{E}+00$ \\
\hline-02 & +00 & 田 & 1 & 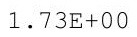 & 0 & 00 & $7 E+00$ \\
\hline $55 E-02$ & $3.16 \mathrm{E}+00$ & $9.08 \mathrm{E}-U 1$ & 7. $66 \mathrm{E}-01$ & $1.13 E+00$ & 1 لـ & $E+U 0$ & $E+00$ \\
\hline $.57 E-02$ & $3.16 \mathrm{E}+00$ & . & $7.67 \mathrm{E}-01$ & 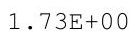 & I. & Z.ZULTU & $57 \mathrm{E}+00$ \\
\hline $9 E-02$ & $6 \mathrm{E}+00$ & . & 01 & 土. & 1. & 00 & 00 \\
\hline $.62 E-02$ & $3.16 \mathrm{E}+00$ & $9.09 \mathrm{E}-\mathrm{C}$ & 7. $69 \mathrm{E}-01$ & $1.73 \mathrm{E}+00$ & & $2.25 \mathrm{E}+00$ & $6 \mathrm{E}+00$ \\
\hline $.64 E-02$ & $3.16 \mathrm{E}+00$ & $9.10 \mathrm{E}-01$ & $7.70 \mathrm{E}-01$ & $1.73 \mathrm{E}+00$ & $1.98 \mathrm{E}+00$ & $2.25 \mathrm{E}+00$ & $56 \mathrm{E}+00$ \\
\hline$E-02$ & $16 \mathrm{E}+00$ & $E-01$ & $E-01$ & $735+$ & 0 & $5 E+00$ & $6 \mathrm{E}+00$ \\
\hline $68 \mathrm{E}-02$ & $3.16 \mathrm{E}+00$ & $9.11 \mathrm{E}-01$ & 7. $72 \mathrm{E}-01$ & $1.74 \mathrm{E}+00$ & $1.98 \mathrm{E}+00$ & $2.25 \mathrm{E}+00$ & $6 \mathrm{E}+00$ \\
\hline $.71 \mathrm{E}-02$ & $3.15 \mathrm{E}+00$ & $9.11 \mathrm{E}-01$ & $7.73 E-01$ & 1. $14 \mathrm{Et}$ & 1.90 & -00 & +00 \\
\hline $3 E-02$ & $3.15 E+00$ & $9.12 \mathrm{E}-01$ & & 1.74 & I. & & $E+00$ \\
\hline $.75 E-02$ & $3.15 \mathrm{E}+00$ & 9.7 & . & $1.74 \mathrm{E}+$ & $1.99 \mathrm{E}+$ & $.25 E+00$ & $E+00$ \\
\hline $.78 E-02$ & $3.15 \mathrm{E}+00$ & $3 E-01$ & $6 E-01$ & $1.74 \mathrm{E}+00$ & $1.99 \mathrm{E}+00$ & $2.25 \mathrm{E}+00$ & $56 \mathrm{E}+00$ \\
\hline $.80 E-02$ & $3.15 E+00$ & $3 E-01$ & $7 E-01$ & $1.74 \mathrm{E}+00$ & 1.99E+ & $2.25 \mathrm{E}+00$ & $56 E+00$ \\
\hline$E-02$ & $3.15 \mathrm{E}+00$ & 01 & -01 & $1.74 \mathrm{E}+$ & & & $6 \mathrm{E}+00$ \\
\hline$E-02$ & $\mathrm{E}+00$ & 1 & 1 & +00 & & 00 & 00 \\
\hline $87 E-02$ & $3.15 \mathrm{E}+0 \mathrm{U}$ & $9.15 \mathrm{E}-$ & & $1.14 \mathrm{E}+$ & I. & 2.201 & $5 E+00$ \\
\hline $.89 \mathrm{E}-02$ & $3.15 \mathrm{E}+00$ & $9.16 \mathrm{E}-01$ & $7.81 \mathrm{E}-01$ & $1.74 \mathrm{E}+00$ & $1.98 \mathrm{E}+00$ & $2.25 \mathrm{E}+00$ & $2.55 E+00$ \\
\hline 02 & 0 & 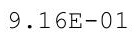 & 1 & 0 & 政 & $.25 E+00$ & $.55 E+00$ \\
\hline 2 & 1 & 1 & 1 & $170=$ & & $2.25 \mathrm{E}+00$ & $5 E+00$ \\
\hline 02 & $3.14 F+00$ & 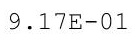 & 1 & 17 & ניתم 1 & $2.25 \mathrm{E}+00$ & $5 E+00$ \\
\hline$E-02$ & $E+00$ & 9 & 1 & $74 \mathrm{~F}+$ & $8 \mathrm{~F}+2+2 \cdot$ & $5 E+00$ & $5 \mathrm{E}+00$ \\
\hline$O E-01$ & $3.14 \mathrm{E}+00$ & $8 E-01$ & 1 & $1.74 \mathrm{E}$ & $1.98 \mathrm{E}$ & 2.24 & $5 E+00$ \\
\hline $.00 \mathrm{E}-01$ & $3.14 \mathrm{E}+00$ & $9.19 \mathrm{E}-01$ & $7.86 \mathrm{E}-01$ & $1.14 \mathrm{E}+0 \mathrm{U}$ & $1.90 \mathrm{ET}$ & $2.24 \mathrm{E}+00$ & $5 \mathrm{E}+00$ \\
\hline $.01 \mathrm{E}-01$ & $3.14 E+U$ & & & $1.74 \mathrm{E}+00$ & & & $2.55 E+00$ \\
\hline 1 & & & & & & & 0 \\
\hline 1 & $314 F+00$ & & & & & & $56 \mathrm{E}+00$ \\
\hline 1 & & & & 0 & 0 & 00 & 00 \\
\hline$E-01$ & & 1 & 01 & 1. & 1 . & 2.2 & $5 \mathrm{E}+00$ \\
\hline $.02 E-01$ & $3.13 \mathrm{E}+00$ & 9. & 1 & 1.7 & & & $E+00$ \\
\hline$E-01$ & $3.13 E+00$ & & & $1.74 \mathrm{E}+$ & 1. $98 \mathrm{E}+$ & & $2.55 E+00$ \\
\hline $2 E-01$ & $3 \cdot \perp J E+U 0$ & 9 & 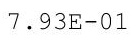 & 1. $74 \mathrm{E}+00$ & $1 \cdot 98 \mathrm{E}+00$ & $2.24 \mathrm{E}+00$ & $2.55 E+00$ \\
\hline 1 & 0 & 9. & & 0 & $\mathrm{~S}_{3}$ & 0.00 & \\
\hline 1 & & & 01 & +00 & 1. & $2.24 \mathrm{E}$ & $2.55 E+00$ \\
\hline$E-01$ & $3.13 \mathrm{E}+00$ & 9.2 & 7. & $1.74 \mathrm{E}+00$ & 1. $98 \mathrm{E}+$ & $2.24 \mathrm{E}+00$ & $5 E+00$ \\
\hline $.03 E-01$ & $12 \mathrm{E}+00$ & $25 E-01$ & $7.97 \mathrm{E}-01$ & $1.74 \mathrm{E}+00$ & $1.98 \mathrm{E}+00$ & $2.24 E+00$ & $\mathrm{E}+00$ \\
\hline
\end{tabular}


RESRAD-OFFSITE, Version 2.5

robabilistic Dose and Risk Report

Title : Offsite Resident Farmer Deterministic Run

File : RF TC99 DOESG FWD-FV2.ROF

Summary of dose at graphical times, reptition 2 (continued)

Time

Years

9. $91 \mathrm{E}+02$

9. $91 \mathrm{E}+02$

9. $92 \mathrm{E}+02$

9. $92 \mathrm{E}+02$

$9.93 \mathrm{E}+02$

$9.93 \mathrm{E}+02$

9. $94 \mathrm{E}+02$

9. $94 \mathrm{E}+02$

9. $95 \mathrm{E}+02$

9. $95 \mathrm{E}+02$

9. $96 \mathrm{E}+02$

9. $96 \mathrm{E}+02$

9. $97 \mathrm{E}+02$

$9.97 \mathrm{E}+02$

9. $98 \mathrm{E}+02$

9. $98 \mathrm{E}+02$

9. $99 \mathrm{E}+02$

$9.99 \mathrm{E}+02$

$1.00 \mathrm{E}+03$

$1.00 \mathrm{E}+03$

$1.00 \mathrm{E}+03$

$1.00 \mathrm{E}+03$

$1.00 \mathrm{E}+03$

$1.00 \mathrm{E}+03$

$1.00 \mathrm{E}+03$

$1.00 \mathrm{E}+03$

$1.00 \mathrm{E}+03$

$1.00 \mathrm{E}+03$

$1.00 \mathrm{E}+03$

$1.01 \mathrm{E}+03$

1. $01 \mathrm{E}+03$

$1.01 \mathrm{E}+03$

$1.01 \mathrm{E}+03$

$1.01 \mathrm{E}+03$

$1.01 \mathrm{E}+03$

$1.01 \mathrm{E}+03$

$1.01 \mathrm{E}+03$

1. $01 \mathrm{E}+03$

$1.01 \mathrm{E}+03$

$1.01 \mathrm{E}+03$

$1.01 \mathrm{E}+03$

$1.01 \mathrm{E}+03$

$1.01 \mathrm{E}+03$

$1.01 \mathrm{E}+03$

$1.01 \mathrm{E}+03$

$1.01 \mathrm{E}+03$
Dose statistics at graphical times, mrem/yr

\begin{tabular}{|c|c|c|c|c|c|c|c|}
\hline$m$ & aximum & lean & ed & & & & \\
\hline $.03 E-01$ & $3.12 \mathrm{E}+00$ & $5 E-01$ & $98 E-01$ & 0 & 0 & -00 & +00 \\
\hline $04 \mathrm{E}-01$ & $12 \mathrm{E}+00$ & $6 \mathrm{E}-01$ & $8 E-01$ & $1.74 \mathrm{E}+00$ & $98 \mathrm{E}+00$ & $24 \mathrm{E}+00$ & $4 \mathrm{E}+00$ \\
\hline$E=01$ & $12 F+00$ & $26 \mathrm{~F}-01$ & $99 E-01$ & $.74 E+00$ & $.98 \mathrm{E}+00$ & $2.24 \mathrm{E}+00$ & $2.54 \mathrm{E}+00$ \\
\hline$E-01$ & $12 \mathrm{~F}+00$ & $7 F-0-2-2-5$ & $0 E-01$ & $74 \mathrm{~F}+00$ & $98 \mathrm{~F}+00$ & $24 \mathrm{~F}+00$ & $4 \mathrm{E}+00$ \\
\hline$E-01$ & -00 & $9.27 \mathrm{E}-01$ & & & & & +00 \\
\hline$E-01$ & & $F$ & & & & 0 & +00 \\
\hline $05 E-01$ & $3.12 \mathrm{E}+00$ & Oت & -01 & 1. $74 \mathrm{E}+00$ & $98 \mathrm{E}+00$ & $2.24 \mathrm{E}+00$ & $54 \mathrm{E}+00$ \\
\hline $05 E-01$ & $3.12 \mathrm{E}+00$ & $9 E-0$ & $3 E-01$ & $.74 \mathrm{E}+00$ & $98 E+00$ & $.24 E+00$ & $54 \mathrm{E}+00$ \\
\hline $05 \mathrm{~F}-01$ & $11 \mathrm{~F}+0$ & $\mathrm{~F}$ & it & $.74 \mathrm{E}+$ & $98 \mathrm{F+}$ & $.23 E+$ & $54 \mathrm{E}+00$ \\
\hline 1 & $3.11 \mathrm{~F}+00$ & $9.30 \mathrm{E}-01$ & $8.05 \mathrm{E}-01$ & $74 \mathrm{~F}+00$ & & $.23 E+00$ & $4 E+00$ \\
\hline $06 \mathrm{E}-01$ & $3.11 E+00$ & 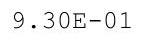 & 1 & 0 & 0 & +00 & $A \mathrm{E}+00$ \\
\hline$E-01$ & & & & 0 & & & +00 \\
\hline $.06 \mathrm{E}-01$ & $3.11 \mathrm{E}+00$ & $9.31 \mathrm{E}-01$ & $8.07 \mathrm{E}-01$ & 1. $74 \mathrm{E}+00$ & $1.98 \mathrm{E}+00$ & $2.23 E+00$ & $54 \mathrm{E}+00$ \\
\hline 01 & $11 E+00$ & $F=0$ & & & & +00 & $3 E+00$ \\
\hline - & - & & & & & & 00 \\
\hline $.07 E-01$ & & $9.33 E-01$ & $8.09 \mathrm{E}-01$ & $171 \mathrm{~F}+$ & 0 & $27+x-10$ & 0 \\
\hline $07 \mathrm{~F}-01$ & $3.10 F+00$ & $9.33 E-01$ & $8.10 E-01$ & $17 \Delta \mathrm{F}+$ & & +00 & $E+00$ \\
\hline $.07 E-01$ & $3.10 \mathrm{E}+00$ & $4 F-0$ & $1 \mathrm{~F}-01$ & $1.74 \mathrm{E}+00$ & $8 E+00$ & $22 E+00$ & $3 E+00$ \\
\hline $3 E-01$ & $.10 \mathrm{E}+00$ & $4 F-0$ & $.11 \mathrm{E}-01$ & 1. $74 \mathrm{E}+00$ & 1. $98 \mathrm{E}+00$ & $2.22 \mathrm{E}+00$ & $2.53 E+00$ \\
\hline-01 & $.10 \mathrm{E}+00$ & $F=0$ & -01 & 0 & & $2.22 \mathrm{E}+00$ & $.53 E+00$ \\
\hline & & & & & & & \\
\hline $08 E-01$ & $.10 \mathrm{E}+00$ & ( & & 1. $74 \mathrm{E}+$ & & & 00 \\
\hline 01 & $.10 \mathrm{E}+00$ & 6 & 35 & $1.74 \mathrm{E}+$ & $8 F+$ & $2.22 E+00$ & $3 E+00$ \\
\hline $09 E-01$ & $.10 \mathrm{E}+00$ & 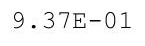 & $\mathrm{F}-0$ & $1.74 \mathrm{E}+00$ & $.98 \mathrm{E}+\mathrm{C}$ & $2.21 E+00$ & $53 E+00$ \\
\hline $09 \mathrm{E}-01$ & $.09 \mathrm{E}+00$ & $37 \mathrm{~F}-01$ & $14 \mathrm{E}-01$ & 1. $74 \mathrm{E}+00$ & 1. $98 \mathrm{E}+0$ & $21 \mathrm{E}+00$ & $53 E+00$ \\
\hline-01 & $3.09 \mathrm{E}+00$ & & & & & & $5 E+00$ \\
\hline & & & & & & & \\
\hline & & & & $1.74 \mathrm{E}+00$ & $1.98 \mathrm{E}+00$ & $2.21 E+00$ & $2.53 E+00$ \\
\hline $.10 \mathrm{E}-01$ & $3.09 \mathrm{E}+00$ & . & $8.16 \mathrm{E}-01$ & $1.74 \mathrm{E}+00$ & $1.98 \mathrm{E}+00$ & $2.21 \mathrm{E}+00$ & $2.53 E+00$ \\
\hline 1 & $3.09 E+00$ & 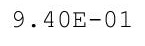 & 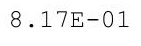 & $1.74 \mathrm{E}+00$ & $1.98 \mathrm{E}+00$ & $2.21 E+00$ & $2.53 E+00$ \\
\hline 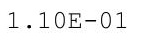 & $3.09 \mathrm{E}+00$ & & $.18 \mathrm{E}-01$ & $1.74 \mathrm{E}+00$ & & $2.21 \mathrm{E}+00$ & $2.53 E+00$ \\
\hline$F-01$ & $3.08 \mathrm{E}+00$ & & & $1.74 \mathrm{E}+$ & 0 & & $3 E+00$ \\
\hline 1 & & & & & & & \\
\hline 01 & & & & & & $2.21 \mathrm{E}+00$ & $2.53 \mathrm{E}+00$ \\
\hline $.11 \mathrm{E}-01$ & $3.08 \mathrm{E}+00$ & $9.4 \angle 2-01$ & $8.21 \mathrm{E}-01$ & $1.74 \mathrm{E}+00$ & 1.98E+ & $2.21 E+00$ & $2.53 \mathrm{E}+00$ \\
\hline$\cdot \triangle \angle E-U \perp$ & $3.08 \mathrm{E}+00$ & 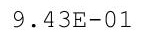 & & $1.74 \mathrm{E}+00$ & & $2.21 E+00$ & $2.53 E+00$ \\
\hline 1 & $3.08 \mathrm{E}+$ & 1 & 1 & $1.74 \mathrm{E}+00$ & $1.98 \mathrm{E}+$ & $2.21 E+00$ & $2.53 E+00$ \\
\hline $.12 \mathrm{E}-01$ & $3.08 \mathrm{E}+0$ & 1 & & $1.74 \mathrm{E}+00$ & $1.98 \mathrm{E}+00$ & $2.21 E+00$ & $2.53 \mathrm{E}+00$ \\
\hline $.12 E-01$ & & & & $170=+$ & $1.98 \mathrm{E}+00$ & $2.21 E+00$ & \\
\hline $3 E-01$ & & 01 & 01 & 1.74 & $1.98 \mathrm{E}+00$ & $2.21 E+00$ & $3 E+00$ \\
\hline $13 \mathrm{E}-01$ & +00 & . & & 1. $74 \mathrm{E}+00$ & 1 . & & $3 E+00$ \\
\hline & & & & 1. & & & $2.53 E+00$ \\
\hline • $\perp U E-U \perp$ & $3.07 \mathrm{E}+00$ & . 1 प d & $0.275-01$ & $1.74 \mathrm{E}+00$ & $1.98 \mathrm{E}+00$ & $2.21 E+00$ & $2.53 E+00$ \\
\hline $14 D-01$ & $3.07 \mathrm{E}+00$ & . 100 & & $1.75 \mathrm{E}+00$ & & $2.21 E+00$ & $2.53 \mathrm{E}+00$ \\
\hline 1 & & & & $1.75 \mathrm{E}+00$ & $1.98 \mathrm{E}+00$ & $2.21 E+00$ & $2.53 E+00$ \\
\hline-01 & $.07 E+00$ & $.47 E-01$ & $.28 E-01$ & $1.74 \mathrm{E}+00$ & $1.98 \mathrm{E}+00$ & $2.21 \mathrm{E}+00$ & $2.53 E+00$ \\
\hline
\end{tabular}


RESRAD-OFFSITE, Version 2.5

$\mathrm{T}^{1 / 2}$ Limit $=180$ days

obabilistic Dose and Risk Report

Title : Offsite Resident Farmer Deterministic Run

File : RF TC99 DOESG FWD-FV2.ROF

Summary of dose at graphical times, reptition 2 (continued)

Time

Years

1. $01 \mathrm{E}+03$

$1.01 \mathrm{E}+03$

$1.02 \mathrm{E}+03$

1. $02 \mathrm{E}+03$

1. $02 \mathrm{E}+03$

$1.02 \mathrm{E}+03$

$1.02 \mathrm{E}+03$

$1.02 \mathrm{E}+03$

$1.02 \mathrm{E}+03$

1. $02 \mathrm{E}+03$

$1.02 \mathrm{E}+03$

$1.02 \mathrm{E}+03$

1. $02 \mathrm{E}+03$

$1.02 \mathrm{E}+03$

$1.02 \mathrm{E}+03$

$1.02 \mathrm{E}+03$

$1.02 \mathrm{E}+03$

$1.02 \mathrm{E}+03$

$1.02 \mathrm{E}+03$

$1.02 \mathrm{E}+03$

$1.02 \mathrm{E}+03$

$1.02 \mathrm{E}+03$

$1.03 \mathrm{E}+03$

$1.03 \mathrm{E}+03$

$1.03 \mathrm{E}+03$

$1.03 E+03$

$1.03 \mathrm{E}+03$

$1.03 E+03$

$1.03 \mathrm{E}+03$

$1.03 E+03$

$1.03 \mathrm{E}+03$

$1.03 E+03$

$1.03 \mathrm{E}+03$

1. $03 \mathrm{E}+03$

$1.03 E+03$

$1.03 \mathrm{E}+03$

1. $03 \mathrm{E}+03$

1. $03 \mathrm{E}+03$

$1.03 E+03$

$1.03 \mathrm{E}+03$

$1.03 E+03$

$1.04 \mathrm{E}+03$

$1.04 \mathrm{E}+03$

$1.04 \mathrm{E}+03$

$1.04 \mathrm{E}+03$

$1.04 \mathrm{E}+03$
Dose statistics at graphical times, mrem/yr

\begin{tabular}{|c|c|c|c|c|c|c|c|}
\hline Iinimum & Maximum & Mean & Median & 900 & $0 \%$ & $97.5 \%$ & \% \\
\hline 1 & $6 \mathrm{E}+00$ & $8 E-01$ & $F-01$ & $74 E+00$ & $98 E+00$ & +00 & +00 \\
\hline$E-01$ & $6 E+00$ & $8 E-01$ & 01 & $1.74 \mathrm{E}+00$ & $98 \mathrm{E}+00$ & +00 & $53 E+00$ \\
\hline$E-01$ & $E+00$ & $9 E-01$ & $0 E-01$ & 0 & 0 & 0 & $3 E+00$ \\
\hline$E-01$ & $\Xi+00$ & $E-01$ & 01 & 0 & 0 & 0 & $\Xi+00$ \\
\hline $.15 \mathrm{E}-01$ & +00 & 1 & & $E+00$ & $E+00$ & 00 & $53 E+00$ \\
\hline $16 \mathrm{E}-01$ & $6 \mathrm{E}+00$ & 1 & & $E+00$ & 0 & 00 & $3 E+00$ \\
\hline $16 \mathrm{E}-01$ & $3.06 \mathrm{E}+00$ & $1 E-01$ & $2 E-01$ & $1.74 \mathrm{E}+00$ & $1.98 \mathrm{E}+00$ & $E+00$ & $2 E+00$ \\
\hline $.16 \mathrm{E}-01$ & $3.05 E+00$ & . U上L & $0.35-U \perp$ & $1.74 \mathrm{E}+00$ & $1.98 \mathrm{E}+00$ & $2.21 \mathrm{E}+00$ & $2.52 \mathrm{E}+00$ \\
\hline$E-01$ & $E+00$ & 01 & 01 & $1.74 \mathrm{E}$ & 0 & 00 & $\Xi+00$ \\
\hline $5 E-01$ & \pm+00 & 9 & & $1.74 \mathrm{E}+00$ & 0 & 0 & $2 E+00$ \\
\hline$E-01$ & & 9 & & & & & $E+00$ \\
\hline$E-01$ & +00 & 田 & 1 & 0 & 0 & & $2 E+00$ \\
\hline $17 \mathrm{E}-01$ & $3.05 \mathrm{E}+00$ & $9.53 \mathrm{E}-0$ & $5 E-U 1$ & $1.14 \mathrm{E}+0 \mathrm{U}$ & 1 & 00 & $E+00$ \\
\hline $.17 \mathrm{E}-01$ & $3.05 \mathrm{E}+00$ & . $345-01$ & 1 & $1.94 \mathrm{LT} 0$ & & $2.2 v$ & $52 E+00$ \\
\hline $.18 \mathrm{E}-01$ & $3.04 \mathrm{E}+00$ & . & $U_{1}$ & 1.9400 & ע & 00 & -00 \\
\hline $.18 \mathrm{E}-01$ & $3.04 \mathrm{E}+00$ & $9.55 \mathrm{E}-01$ & $.37 \mathrm{E}-01$ & $1.74 \mathrm{E}+00$ & & $2.20 \mathrm{E}+00$ & $2 \mathrm{E}+00$ \\
\hline $.18 \mathrm{E}-01$ & $3.04 \mathrm{E}+00$ & $9.55 \mathrm{E}-01$ & $8.38 \mathrm{E}-01$ & $1.74 \mathrm{E}+00$ & 1.99E+00 & $2.20 \mathrm{E}+00$ & $51 E+00$ \\
\hline $8 E-01$ & $4 E+00$ & $6 E-01$ & $E-01$ & $1.74 \mathrm{E}+$ & ג & $20 E+00$ & $1 E+00$ \\
\hline$E-01$ & $3.04 \mathrm{E}+00$ & -01 & $\perp$ & $1.74 \mathrm{E}+00$ & 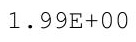 & 00 & $E+00$ \\
\hline $19 \mathrm{E}-01$ & $3.04 \mathrm{E}+00$ & $9.56 \mathrm{E}-01$ & $8.39 \mathrm{E}-U \perp$ & I.14ГТ & 1.995 & 00 & +00 \\
\hline $.19 \mathrm{E}-01$ & $3.04 \mathrm{E}+00$ & & & 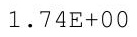 & & & $E+00$ \\
\hline $.19 \mathrm{E}-01$ & $3.03 E+00$ & 9.5 & $\perp$ & $1.74 \mathrm{E}+$ & $1.99 \mathrm{E}+$ & 0 & $1 \mathrm{E}+00$ \\
\hline $.20 E-01$ & $3.03 E+00$ & $8 E-01$ & $1 E-01$ & $1.74 \mathrm{E}+00$ & $1.99 \mathrm{E}+00$ & $2.20 \mathrm{E}+00$ & $51 E+00$ \\
\hline $.20 E-01$ & $3.03 E+00$ & $9.58 \mathrm{E}-01$ & $.41 E-01$ & $1.74 \mathrm{E}+00$ & $1.99 \mathrm{E}+$ & $2.20 \mathrm{E}+00$ & $.51 E+00$ \\
\hline$E-01$ & $3.03 E+00$ & -01 & 1 & $1.74 \mathrm{E}+$ & & & $1 \mathrm{E}+00$ \\
\hline$E-01$ & $3 E+00$ & 1 & 1 & 0 & & 00 & \\
\hline $21 \mathrm{E}-01$ & $3.03 E+00$ & $9.59 \mathrm{E}-$ & & $1.14 \mathrm{E}+$ & וע & 0 & $0 E+00$ \\
\hline $.21 E-01$ & $3.03 E+U 0$ & 9.6 & 0.14 & $145+00$ & 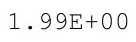 & $20 E+00$ & $2.50 \mathrm{E}+00$ \\
\hline 01 & 0 & 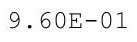 & 1 & 0 & 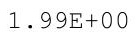 & . & $50 \mathrm{E}+00$ \\
\hline$\Gamma$ & (2) & 1 & 1 & & & & $0 \mathrm{E}+00$ \\
\hline 01 & $.02 E+00$ & 1 & 1 & 17 & נ 1 & $2.20 \mathrm{E}+00$ & $0 \mathrm{E}+00$ \\
\hline $2 E-01$ & $2 \mathrm{E}+$ & & & & & & \\
\hline $22 \mathrm{E}-01$ & $3.02 \mathrm{E}+00$ & $9.62 \mathrm{E}-01$ & 1 & $1.74 \mathrm{E}$ & $1.99 \mathrm{E}$ & 00 & $O E+00$ \\
\hline $22 \mathrm{E}-01$ & $3.02 \mathrm{E}+00$ & $9.63 \mathrm{E}-01$ & $8.46 \mathrm{E}-01$ & $1.14 \mathrm{E}+0 \mathrm{U}$ & 1.99ET & $2.20 \mathrm{E}+00$ & $50 \mathrm{E}+00$ \\
\hline $23 E-01$ & $3.0 \angle E+00$ & & & $1.74 \mathrm{E}+00$ & & & $2.50 \mathrm{E}+00$ \\
\hline 1 & . & . & & & & & 00 \\
\hline 1 & & & & & & & 00 \\
\hline 1 & & 1 & 1 & 0 & & 0 & 00 \\
\hline $24 \mathrm{E}-01$ & $3.01 \mathrm{E}+00$ & $E-01$ & $E-01$ & 1. & 1. & & -00 \\
\hline $24 \mathrm{E}-01$ & $3.01 \mathrm{E}$ & 9. & & 1.7 & & & 00 \\
\hline$E-01$ & $3.01 E+00$ & 9 & & $1.74 \mathrm{E}+$ & & & $2.50 \mathrm{E}+00$ \\
\hline $5-U \perp$ & $3.00 \mathrm{E}+00$ & 9 & $\perp$ & 1. $74 \mathrm{E}+00$ & 1. $99 \mathrm{E}+00$ & $2.19 \mathrm{E}+00$ & $2.50 \mathrm{E}+00$ \\
\hline 1 & 3 & 9. & & 0 & $9 \mathrm{E}+00$ & $19 E+00$ & 50 \\
\hline 1 & & & 01 & $1.74 \mathrm{E}$ & $1.99 \mathrm{E}$ & $2.19 \mathrm{E}$ & $2.50 \mathrm{E}+00$ \\
\hline$E-01$ & $3.00 \mathrm{E}+00$ & $E-01$ & $E-01$ & $1.74 \mathrm{E}+00$ & 1. $98 \mathrm{E}+$ & $2.19 \mathrm{E}+00$ & $0 E+00$ \\
\hline $25 E-01$ & $E+00$ & $68 E-01$ & $.55 E-01$ & $1.74 \mathrm{E}+00$ & $1.98 \mathrm{E}+00$ & $2.19 \mathrm{E}+00$ & $2.50 \mathrm{E}+00$ \\
\hline
\end{tabular}


RESRAD-OFFSITE, Version 2.5

$\mathrm{T}^{1 / 2}$ Limit $=180$ days

robabilistic Dose and Risk Report

Title : Offsite Resident Farmer Deterministic Run

File : RF TC99 DOESG FWD-FV2.ROF

Time

Years

$1.04 \mathrm{E}+03$

$1.04 \mathrm{E}+03$

$1.04 \mathrm{E}+03$

$1.04 \mathrm{E}+03$

$1.04 \mathrm{E}+03$

$1.04 \mathrm{E}+03$

$1.04 \mathrm{E}+03$

$1.04 \mathrm{E}+03$

$1.04 \mathrm{E}+03$

$1.04 \mathrm{E}+03$

$1.04 \mathrm{E}+03$

$1.04 \mathrm{E}+03$

$1.04 \mathrm{E}+03$

$1.04 \mathrm{E}+03$

$1.04 \mathrm{E}+03$

$1.05 \mathrm{E}+03$

$1.05 \mathrm{E}+03$

$1.05 \mathrm{E}+03$

$1.05 \mathrm{E}+03$

$1.05 \mathrm{E}+03$

$1.05 \mathrm{E}+03$

$1.05 \mathrm{E}+03$

$1.05 \mathrm{E}+03$

$1.05 \mathrm{E}+03$

$1.05 \mathrm{E}+03$
Summary of dose at graphical times, reptition 2 (continued)

Dose statistics at graphical times, mrem/yr

\begin{tabular}{|c|c|c|c|c|c|c|c|}
\hline Iini & laximum & lean & ledian & & & $\%$ & $\%$ \\
\hline $26 \mathrm{E}-01$ & $.00 \mathrm{E}+00$ & $68 E-01$ & $.56 \mathrm{E}-01$ & $.74 \mathrm{E}+00$ & 1. $98 \mathrm{E}+00$ & $19 E+00$ & $E+00$ \\
\hline $26 \mathrm{E}-01$ & $.00 E+00$ & $8 E-01$ & $7 E-01$ & $1.74 \mathrm{E}+00$ & $1.98 \mathrm{E}+00$ & $2.19 \mathrm{E}+00$ & $0 \mathrm{E}+00$ \\
\hline $26 \mathrm{~F}-01$ & 2 & $69=-01$ & $.58 E-01$ & $1.74 \mathrm{E}+00$ & 1. $98 \mathrm{E}+00$ & $2.19 \mathrm{E}+00$ & $2507+00$ \\
\hline 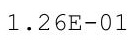 & 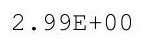 & $9.69 \mathrm{E}-01$ & $8.59 \mathrm{E}-01$ & $1.74 \mathrm{E}+$ & 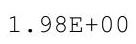 & $E+00$ & 政 \\
\hline $27 F_{1}$ & $F+00$ & 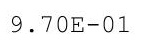 & 1 & 0 & & & $E+00$ \\
\hline $27 \mathrm{~F}-01$ & & 0 & 1 & 西 & & & $\mathrm{E}+00$ \\
\hline $.27 E-01$ & $2.99 \mathrm{E}+00$ & $9.71 \mathrm{E}-01$ & $8.61 \mathrm{E}-01$ & $1.74 \mathrm{E}+00$ & 1. $98 \mathrm{E}+00$ & $2.18 \mathrm{E}+00$ & $2.50 \mathrm{E}+00$ \\
\hline-01 & 䧄 & م 10 & $E-01$ & $70 F+$ & תم & & $0 E+00$ \\
\hline 28 & & & & 1.7 & & & 00 \\
\hline $.200-0$ & & 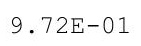 & & $1.74 \mathrm{E}+$ & & & 00 \\
\hline $.28 E-01$ & (2007 & $9.72 \mathrm{E}-01$ & & 1750 & & & 0 \\
\hline $.28 E-01$ & 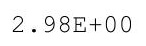 & ח תרת & 01 & $1.75 E+00$ & $1.98 \mathrm{E}+$ & $2.18 \mathrm{E}+00$ & $9 \mathrm{E}+00$ \\
\hline $29=-01$ & مח ניתمח & م & $8.65 E-01$ & $1.75 E+00$ & $1.98 \mathrm{E}+00$ & $2.18 \mathrm{E}+00$ & $.49 \mathrm{E}+00$ \\
\hline $29=-01$ & $2.98 \mathrm{E}+00$ & & 0 & $1.75 \mathrm{E}+00$ & 1. $98 \mathrm{E}+00$ & $218 F+00$ & $.49 \mathrm{E}+00$ \\
\hline 0 & & & & & & & \\
\hline & & & & & & & \\
\hline $30 E-01$ & $2.97 \mathrm{E}+00$ & $9.15 \mathrm{E}-\mathrm{C}$ & & $1.75 \mathrm{E}+$ & $1.98 \mathrm{E}+$ & & $9 \mathrm{E}+00$ \\
\hline $.30 E-01$ & $2.97 \mathrm{t}+00$ & $9.15 \mathrm{E}-\mathrm{U} \perp$ & $8.69 \mathrm{E}-01$ & $1.75 E+00$ & $1.98 \mathrm{E}+00$ & $2.18 \mathrm{E}+00$ & $2.49 \mathrm{E}+00$ \\
\hline $.30 E-01$ & $2.97 \mathrm{E}+00$ & $9.75 E-01$ & & $1.75 E+00$ & $1.98 \mathrm{E}+00$ & & $2.48 \mathrm{E}+00$ \\
\hline $31 \mathrm{E}-\mathrm{C}$ & $2.97 \mathrm{E}+00$ & - & & $1.75 \mathrm{E}+00$ & 1. $98 \mathrm{E}+00$ & $2.18 \mathrm{E}+00$ & $2.48 \mathrm{E}+00$ \\
\hline 1. $31 \mathrm{E}-01$ & & & & & & & $2.48 \mathrm{E}+00$ \\
\hline $31 E-01$ & $2.96 \mathrm{E}+00$ & $9.77 \mathrm{E}-\mathrm{C}$ & $8.71 \mathrm{E}-$ & $1.75 \mathrm{E}+00$ & 1. $99 \mathrm{E}+00$ & $2.18 \mathrm{E}+00$ & $2.47 \mathrm{E}+00$ \\
\hline $31 E-01$ & $2.96 \mathrm{E}+00$ & $9.77 \mathrm{E}-01$ & $8.71 \mathrm{E}-01$ & $1.75 \mathrm{E}+00$ & 1. $99 \mathrm{E}+00$ & $2.18 \mathrm{E}+00$ & $2.47 \mathrm{E}+00$ \\
\hline-01 & 2.96 & $E-01$ & $8.72 \mathrm{E}-0$ & 1.7 & 1.99 & $2.18 \mathrm{E}+00$ & $2.47 \mathrm{E}+00$ \\
\hline 1 & $.96 \mathrm{E}+00$ & -01 & -01 & 1.7 & $1.99 \mathrm{E}+00$ & $E+00$ & $2.47 \mathrm{E}$ \\
\hline
\end{tabular}

C- 194

DCN 5090-TR-02-2 
RESRAD-OFFSITE, Version 2.5

Title : Offsite Resident Farmer Deterministic Run

File : RF TC99 DOESG FWD-FV2.ROF

Time

Years

$0.00 \mathrm{E}+00$

$5.13 \mathrm{E}-01$

$1.03 \mathrm{E}+00$

$1.54 \mathrm{E}+00$

$2.05 \mathrm{E}+00$

$2.56 \mathrm{E}+00$

$3.08 \mathrm{E}+00$

$3.59 \mathrm{E}+00$

$4.10 \mathrm{E}+00$

$4.61 \mathrm{E}+00$

$5.13 \mathrm{E}+00$

$5.64 \mathrm{E}+00$

$6.15 \mathrm{E}+00$

$6.67 \mathrm{E}+00$

$7.18 \mathrm{E}+00$

$7.69 \mathrm{E}+00$

$8.20 \mathrm{E}+00$

$8.72 \mathrm{E}+00$

$9.23 \mathrm{E}+00$

$9.74 \mathrm{E}+00$

$1.03 \mathrm{E}+01$

$1.08 \mathrm{E}+01$

1. $13 \mathrm{E}+01$

$1.18 \mathrm{E}+01$

$1.23 \mathrm{E}+01$

$1.28 \mathrm{E}+01$

$1.33 \mathrm{E}+01$

$1.38 \mathrm{E}+01$

$1.44 \mathrm{E}+01$

$1.49 \mathrm{E}+01$

$1.54 \mathrm{E}+01$

$1.59 \mathrm{E}+01$

$1.64 \mathrm{E}+01$

$1.69 \mathrm{E}+01$

$1.74 \mathrm{E}+01$

$1.79 \mathrm{E}+01$

$1.85 \mathrm{E}+01$

$1.90 \mathrm{E}+01$

$1.95 \mathrm{E}+01$

$2.00 \mathrm{E}+01$

$2.05 \mathrm{E}+01$

$2.10 \mathrm{E}+01$

$2.15 \mathrm{E}+01$

$2.20 \mathrm{E}+01$

$2.26 \mathrm{E}+01$

$2.31 \mathrm{E}+01$
Summary of dose at graphical times, reptition 3

Dose statistics at graphical times, mrem/yr

\begin{tabular}{|c|c|c|c|c|c|c|c|}
\hline Minimum & laximum & Mean & Median & $90 \%$ & $95 \%$ & $97.5 \%$ & $9 \%$ \\
\hline $.00 \mathrm{E}+00$ & $0.00 \mathrm{E}+00$ & $0.00 \mathrm{E}+00$ & $0.00 \mathrm{E}+00$ & $\mathrm{DE}+00$ & $\mathrm{DE}+00$ & $E+00$ & +00 \\
\hline 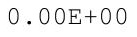 & $0.00 \mathrm{E}+00$ & $0.00 \mathrm{E}+00$ & $.00 \mathrm{E}+00$ & $0.00 \mathrm{E}+00$ & $00 \mathrm{E}+00$ & +00 & $0 \mathrm{E}+00$ \\
\hline$E+00$ & $0 \mathrm{E}+00$ & $O E+$ & 0 & $0 \mathrm{E}+00$ & $00 \mathrm{E}+00$ & +00 & $00 \mathrm{E}+00$ \\
\hline$E+00$ & $\Xi+00$ & $F+$ & 0 & 0 & 0 & 0 & $0 \mathrm{E}+00$ \\
\hline+00 & +00 & +00 & 0 & E+ & 0 & -00 & $0 \mathrm{E}+00$ \\
\hline$E+00$ & & & & 0 & 0 & 00 & $E+00$ \\
\hline ( & to & 0 & 0 & 0 & 0 & 00 & $0 E+00$ \\
\hline $.00 \mathrm{E}+00$ & $0.00 \mathrm{E}+00$ & $0 E+00$ & $.00 E+00$ & $0 \mathrm{E}+00$ & 0 & +00 & $0 \mathrm{E}+00$ \\
\hline 年 & 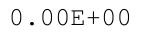 & $0.00 \mathrm{E}+00$ & $.00 \mathrm{E}+00$ & $0.00 \mathrm{E}+00$ & $0.00 \mathrm{E}+00$ & $0.00 \mathrm{E}+00$ & $.00 \mathrm{E}+00$ \\
\hline$E+00$ & $\mathrm{E}+00$ & $\mathrm{DE}+00$ & $E+00$ & $0 \mathrm{E}+00$ & 0 & -00 & +00 \\
\hline $.00 E+00$ & $0.00 \mathrm{E}+00$ & & & $E+$ & & & +00 \\
\hline $2 F+0$ & $F+0,0$ & DF & $E+00$ & 0 & 0 & 0 & +00 \\
\hline+00 & $\mathrm{~F}+\mathrm{C}-2 \cdot-2$ & 0 & 0 & 0 & 0 & +00 & $\mathrm{OE}+00$ \\
\hline $.00 E+00$ & $0.00 \mathrm{E}+00$ & $0.00 \mathrm{E}+00$ & $.00 E+00$ & $0 \mathrm{E}+00$ & OOE+ & मTO & +00 \\
\hline $.00 \mathrm{E}+00$ & 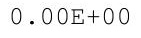 & $0.00 \mathrm{E}+00$ & $0.00 \mathrm{E}+00$ & 年 & 年 & 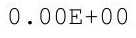 & \pm+00 \\
\hline $.00 \mathrm{E}+00$ & . & $0.00 \mathrm{E}+00$ & $.00 \mathrm{E}+00$ & 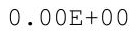 & 0 & 00 & 00 \\
\hline $.00 \mathrm{E}+00$ & $0.00 \mathrm{E}+00$ & $0.00 \mathrm{E}+00$ & & $0.00 \mathrm{E}+00$ & & $0.00 \mathrm{E}+00$ & $0 E+00$ \\
\hline $.00 \mathrm{E}+00$ & $0.00 \mathrm{E}+00$ & $0.00 \mathrm{E}+00$ & $0.00 \mathrm{E}+00$ & $0.00 \mathrm{E}+00$ & $0.00 \mathrm{E}+00$ & $0.00 \mathrm{E}+00$ & $.00 \mathrm{E}+00$ \\
\hline$E+00$ & $00 \mathrm{E}+00$ & $00 \mathrm{E}+00$ & $.00 \mathrm{E}+00$ & $\mathrm{DE}+00$ & + & $0 \mathrm{E}+00$ & $00 \mathrm{E}+00$ \\
\hline $.00 \mathrm{E}+00$ & $0.00 \mathrm{E}+00$ & $0.00 \mathrm{E}+00$ & $.00 \mathrm{E}+00$ & $0.00 \mathrm{E}+00$ & $0.00 \mathrm{E}+00$ & $0 E+00$ & $00 E+00$ \\
\hline . & . & $0.00 \mathrm{E}+00$ & $.00 \mathrm{E}+00$ & . & 0 & 100 & +00 \\
\hline . & 年 & $0.00 \mathrm{E}+00$ & & & & & +00 \\
\hline $.00 \mathrm{E}+00$ & $0.00 \mathrm{E}+00$ & $0.00 \mathrm{E}+00$ & $.00 \mathrm{E}+00$ & 然 & $0.00 \mathrm{E}+00$ & 0 & 0 \\
\hline $.00 \mathrm{E}+00$ & $0.00 \mathrm{E}+00$ & $0.00 \mathrm{E}+00$ & $0.00 \mathrm{E}+00$ & $00 \mathrm{E}+00$ & ل & $0 \mathrm{E}+00$ & $00 \mathrm{E}+00$ \\
\hline $.00 \mathrm{E}+00$ & $0.00 \mathrm{E}+00$ & $0.00 \mathrm{E}+00$ & $0.00 \mathrm{E}+00$ & $0.00 \mathrm{E}+00$ & + & $.00 \mathrm{E}+00$ & $00 \mathrm{E}+00$ \\
\hline$E+00$ & $0.00 \mathrm{E}+00$ & $.00 E+00$ & $.00 E+00$ & $00 E+00$ & + & $0 \mathrm{E}+00$ & $00 E+00$ \\
\hline $\mathrm{E}+00$ & $0.00 \mathrm{E}+00$ & $0 E+00$ & $0 \mathrm{E}+00$ & $0 \mathrm{E}+00$ & 0 & $\mathrm{E}+00$ & +00 \\
\hline 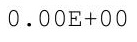 & $0.00 \mathrm{E}+00$ & $0.00 E+00$ & 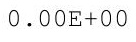 & 然 & & & \\
\hline $.00 \mathrm{E}+00$ & $0.00 \mathrm{E}+00$ & $0.00 \mathrm{E}+00$ & $0.00 \mathrm{E}+00$ & $0.00 \mathrm{E}+00$ & $0.00 \mathrm{E}+00$ & $0.00 \mathrm{E}+00$ & $0.00 \mathrm{E}+00$ \\
\hline $.00 \mathrm{E}+00$ & 0 & - & 然 & 然 & 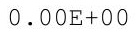 & $.00 \mathrm{E}+00$ & $.00 E+00$ \\
\hline $.00 E+00$ & $\mathrm{~F}$ & D & 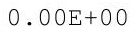 & ل & 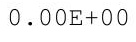 & $0.00 \mathrm{E}+00$ & OE \\
\hline$F+00$ & مी & $.00 \mathrm{E}+00$ & $.00 \mathrm{E}+00$ & 䧄 & 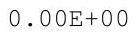 & $0 E+00$ & $0 \mathrm{E}+00$ \\
\hline $\mathrm{E}+00$ & $0.00 \mathrm{E}+00$ & $0.00 \mathrm{E}+$ & $0 \mathrm{E}+$ & $.00 E+00$ & $00 \mathrm{~F}+\mathrm{H}-\mathrm{s}$ & $00 \mathrm{E}+00$ & $00 \mathrm{E}+00$ \\
\hline $.00 E+00$ & $0.00 \mathrm{E}+00$ & $0.00 \mathrm{E}+$ & 0 & 0 & 0 & 00 & 00 \\
\hline . & $0.00 \mathrm{E}+00$ & $0.00 \mathrm{E}+00$ & $.00 \mathrm{E}+00$ & . U U一兀 & 年 & $0.00 \mathrm{E}+00$ & $0.00 \mathrm{E}+00$ \\
\hline 舟 & . & $0.00 \mathrm{E}+00$ & & . U DT & & & $0.00 \mathrm{E}+00$ \\
\hline-5 & 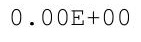 & $0.00 \mathrm{E}+0$ & $0.00 \mathrm{E}+00$ & 0 & & 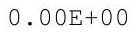 & $00 E+00$ \\
\hline OPOA & POF+ & $0.00 \mathrm{E}+00$ & $0.00 \mathrm{E}+00$ & $0.00 \mathrm{E}+00$ & $00 \mathrm{E}+00$ & $0.00 \mathrm{E}+00$ & $00 \mathrm{E}+00$ \\
\hline$F+00$ & & & 00 & 0 & 0 & 0 & 00 \\
\hline$E+00$ & 0.0 & 0 . & +00 & $E+00$ & 0 & -00 & $\mathrm{DE}+00$ \\
\hline $\mathrm{E}+00$ & 0.001 & 0. & 0 & 0 & & 00 & 00 \\
\hline $\mathrm{E}+$ & $.00 \mathrm{E}+\mathrm{C}$ & $0.00 \mathrm{E}+$ & & $0.00 \mathrm{E}+$ & & & $.00 \mathrm{E}+00$ \\
\hline 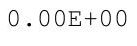 & . vo म & $0.00 \mathrm{E}+00$ & $0.00 \mathrm{E}+00$ & $0.00 \mathrm{E}+00$ & - & $0.00 \mathrm{E}+00$ & $0.00 \mathrm{E}+00$ \\
\hline . & $.00 \mathrm{~L}$ & $0.00 \mathrm{E}+$ & $0.00 \mathrm{E}+$ & $0.00 \mathrm{E}+$ & $0.00 \mathrm{E}+$ & & \\
\hline ( & & & & $.00 \mathrm{E}$ & 0 & $.00 \mathrm{E}+00$ & $00 E+00$ \\
\hline $.00 E+00$ & $00 \mathrm{E}+00$ & $0.00 E+00$ & $.00 \mathrm{E}+00$ & $.00 E+00$ & $.00 E+00$ & $\mathrm{E}+00$ & $0.00 \mathrm{E}+00$ \\
\hline
\end{tabular}


RESRAD-OFFSITE, Version 2.5 
Probabilistic Dose and Risk Report

Title : Offsite Resident Farmer Deterministic Run

File : RF TC99 DOESG FWD-FV2.ROF

Summary of dose at graphical times, reptition 3 (continued)

Time

Years

$4.72 \mathrm{E}+01$

$4.77 \mathrm{E}+01$

4. $82 \mathrm{E}+01$

$4.87 \mathrm{E}+01$

4. $92 \mathrm{E}+01$

$4.97 \mathrm{E}+01$

$5.02 \mathrm{E}+01$

$5.08 \mathrm{E}+01$

$5.13 \mathrm{E}+01$

$5.18 \mathrm{E}+01$

$5.23 \mathrm{E}+01$

$5.28 \mathrm{E}+01$

$5.33 \mathrm{E}+01$

$5.38 \mathrm{E}+01$

$5.43 \mathrm{E}+01$

$5.49 \mathrm{E}+01$

$5.54 \mathrm{E}+01$

$5.59 \mathrm{E}+01$

$5.64 \mathrm{E}+01$

$5.69 \mathrm{E}+01$

$5.74 \mathrm{E}+01$

$5.79 \mathrm{E}+01$

$5.84 \mathrm{E}+01$

$5.90 \mathrm{E}+01$

$5.95 \mathrm{E}+01$

$6.00 \mathrm{E}+01$

$6.05 \mathrm{E}+01$

$6.10 \mathrm{E}+01$

$6.15 \mathrm{E}+01$

$6.20 \mathrm{E}+01$

$6.25 \mathrm{E}+01$

$6.31 \mathrm{E}+01$

$6.36 \mathrm{E}+01$

$6.41 \mathrm{E}+01$

$6.46 \mathrm{E}+01$

$6.51 \mathrm{E}+01$

$6.56 \mathrm{E}+01$

$6.61 \mathrm{E}+01$

$6.67 \mathrm{E}+01$

$6.72 \mathrm{E}+01$

$6.77 \mathrm{E}+01$

$6.82 \mathrm{E}+01$

$6.87 \mathrm{E}+01$

$6.92 \mathrm{E}+01$

$6.97 \mathrm{E}+01$

$7.02 \mathrm{E}+01$
Dose statistics at graphical times, mrem/yr

\begin{tabular}{|c|c|c|c|c|c|c|c|}
\hline inimum & aximum & lean & edian & & & $\%$ & $9 \%$ \\
\hline $.00 E+00$ & $0.00 \mathrm{E}+00$ & $0.00 \mathrm{E}+00$ & $0.00 \mathrm{E}+00$ & $00 \mathrm{E}+00$ & $0.00 \mathrm{E}+00$ & $0.00 \mathrm{E}+00$ & $0.00 \mathrm{E}+00$ \\
\hline $.00 \mathrm{E}+00$ & $0.00 \mathrm{E}+00$ & $.00 \mathrm{E}+00$ & $.00 \mathrm{E}+00$ & $0.00 \mathrm{E}+00$ & $0.00 \mathrm{E}+00$ & $0.00 \mathrm{E}+00$ & $00 \mathrm{E}+00$ \\
\hline $00 \mathrm{E}+00$ & $0 \mathrm{E}+00$ & $00 E+00$ & $00 E+00$ & $00 \mathrm{E}+00$ & $00 E+00$ & 00 & $0 E+00$ \\
\hline+00 & 00 & 00 & 00 & 0 & 0 & 00 & $00 \mathrm{E}+00$ \\
\hline$E+00$ & 0 & & & & & & +00 \\
\hline $00 \mathrm{E}+00$ & & & & & & & $\Xi+00$ \\
\hline$E+00$ & $E+00$ & 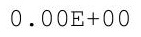 & $\mathrm{E}+00$ & $E+00$ & 0 & +00 & $E+00$ \\
\hline $.00 \mathrm{E}+00$ & $0.00 \mathrm{E}+00$ & $0 \mathrm{E}+00$ & $0 \mathrm{E}+00$ & $00 \mathrm{E}+00$ & $00 \mathrm{E}+00$ & $E+00$ & $00 \mathrm{E}+00$ \\
\hline $00 E+00$ & $00 F+0$ & $00 \mathrm{~F}+\ell-8$ & $.00 E+00$ & $0 \cap \mathrm{F}+$ & $\mathrm{O} \cap \mathrm{F}+\mathrm{r}-\mathrm{s}$ & $00 F+00$ & $00 E+00$ \\
\hline$E+00$ & $0.00 \mathrm{E}+00$ & & & & & 0 & 00 \\
\hline $.00 E+00$ & $0.00 \mathrm{E}+00$ & 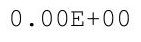 & 00 & 0 & 0 & 0 & $E+00$ \\
\hline $.00 \mathrm{E}+00$ & $0.00 \mathrm{E}+00$ & $0.00 \mathrm{E}+00$ & $0.00 \mathrm{E}+00$ & & & & $0.00 \mathrm{E}+00$ \\
\hline $.00 E+00$ & $0.00 \mathrm{E}+00$ & $0.00 \mathrm{E}+00$ & $0.00 \mathrm{E}+00$ & $0.00 \mathrm{E}+00$ & $0.00 \mathrm{E}+00$ & $E+00$ & $0.00 \mathrm{E}+00$ \\
\hline$E+00$ & $E+00$ & $E+00$ & $E+00$ & & & +00 & $00 \mathrm{E}+00$ \\
\hline $.00 E+00$ & $.00 E+00$ & $.00 E+00$ & $.00 E+00$ & $.00 \mathrm{E}+$ & 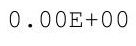 & 0 & +00 \\
\hline$E+00$ & ( & $0.00 \mathrm{E}+00$ & & $0.00 \mathrm{E}+00$ & $00 E+00$ & $E+00$ & 0 \\
\hline $0 \cap F+00$ & $F+00$ & $5+0$ & & & & -00 & 00 \\
\hline $.00 \mathrm{E}+00$ & $0.00 \mathrm{E}+00$ & $0.00 \mathrm{E}+00$ & $0.00 \mathrm{E}+00$ & $0.00 \mathrm{E}+00$ & $0.00 \mathrm{E}+00$ & $0.00 \mathrm{E}+00$ & $.00 \mathrm{E}+00$ \\
\hline $.00 \mathrm{E}+00$ & $.00 \mathrm{E}+00$ & $.00 \mathrm{E}+00$ & $0.00 \mathrm{E}+00$ & $0.00 \mathrm{E}+00$ & $0.00 \mathrm{E}+00$ & $.00 E+00$ & $.00 E+00$ \\
\hline$E+00$ & $00 E+00$ & $00 F+0=$ & $.00 E+00$ & $0 \mathrm{E}+00$ & 0 & $0 \mathrm{E}+00$ & $00 E+00$ \\
\hline 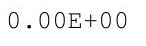 & 然 & $0.00 \mathrm{E}+00$ & $.00 E+00$ & 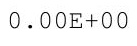 & 0 & 0 & +00 \\
\hline $.00 \mathrm{E}+00$ & . & 然 & & & & & 00 \\
\hline $.00 E+00$ & $.00 \mathrm{E}+00$ & ) & $0 E+00$ & مF+ & 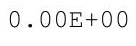 & 0 & $E+00$ \\
\hline $0 \cap F+00$ & COF+O & ) & $0.00 \mathrm{E}+00$ & $.00 \mathrm{E}+00$ & $.00 \mathrm{E}+$ & $00 \mathrm{E}+00$ & $00 E+00$ \\
\hline $00 F+00$ & 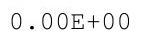 & 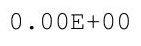 & $0.00 \mathrm{E}+00$ & $.00 \mathrm{E}+00$ & ח & $.00 E+00$ & $.00 \mathrm{E}+00$ \\
\hline$F+00$ & $0.00 \mathrm{E}+00$ & $00 E+00$ & $.00 E+00$ & $0 E+00$ & 0 & $0 E+00$ & $00 E+00$ \\
\hline & & & & & & $E+00$ & \\
\hline & & & & 0.0 & e & & +00 \\
\hline $.00 \mathrm{E}+00$ & $0.00 \mathrm{E}+00$ & $0.00 \mathrm{E}+00$ & $.00 \mathrm{E}+00$ & . & . & $0.00 \mathrm{E}+00$ & $.00 E+00$ \\
\hline $0 \mathrm{E}+00$ & $00 \mathrm{E}+00$ & $0.00 \mathrm{E}+0$ & $0.00 \mathrm{E}+00$ & $0.00 \mathrm{E}+00$ & $0.00 \mathrm{E}+\mathrm{C}$ & $0.00 \mathrm{E}+00$ & $.00 \mathrm{E}+00$ \\
\hline $00 \mathrm{E}+\mathrm{C}$ & $.00 E+00$ & & $0.00 \mathrm{E}+00$ & & & $0.00 \mathrm{E}+00$ & $.00 \mathrm{E}+00$ \\
\hline مि & $00 F+00$ & $0 \cap \cap \cap F+\cap 0$ & $00 F+00$ & $.00 E+00$ & & $0 E+00$ & $.00 E+00$ \\
\hline F & & & & & & & \\
\hline & & & & & & 00 & \\
\hline $.00 E+00$ & $0.00 \mathrm{E}+00$ & $0.00 \mathrm{E}+00$ & $0.00 \mathrm{E}+00$ & $0.00 \mathrm{E}+00$ & . & $0.00 \mathrm{E}+00$ & $.00 \mathrm{E}+00$ \\
\hline • & . & . & & & & & $0.00 \mathrm{E}+00$ \\
\hline 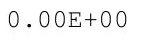 & ( & $0.00 \mathrm{E}+$ & $0.00 \mathrm{E}+$ & $0.00 \mathrm{E}+$ & $0.00 \mathrm{E}$ & $0.00 \mathrm{E}+00$ & $0.00 \mathrm{E}+00$ \\
\hline (1) & & & $0.00 \mathrm{E}+00$ & & & $0.00 \mathrm{E}+00$ & $.00 \mathrm{E}+00$ \\
\hline $0=+0$ & & $0.00 \mathrm{E}+$ & $0.00 \mathrm{E}+00$ & $00 E+00$ & 0 & $0 E+00$ & $00 E+00$ \\
\hline $.00 \mathrm{E}+00$ & $0.00 \mathrm{E}+00$ & $0.00 \mathrm{E}+$ & $0.00 \mathrm{E}$ & $0.00 \mathrm{E}$ & 0 & 00 & $0.00 \mathrm{E}+00$ \\
\hline $\mathrm{E}+00$ & $0.00 \mathrm{E}+00$ & 0.00 & 0 & 0 & & & $00 \mathrm{E}+00$ \\
\hline 年 & . & $0.00 \mathrm{E}+00$ & & $.00 \mathrm{E}+00$ & & & $.00 \mathrm{E}+00$ \\
\hline 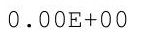 & 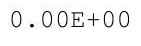 & $0.00 \mathrm{E}+00$ & $0.00 \mathrm{E}+00$ & $0.00 \mathrm{E}+00$ & $0.00 \mathrm{E}+00$ & $0.00 \mathrm{E}+00$ & $0.00 \mathrm{E}+00$ \\
\hline $0 E+00$ & $0.00 \mathrm{E}+00$ & $0.00 \mathrm{E}+00$ & $0.00 \mathrm{E}+00$ & & $0.00 \mathrm{E}+00$ & & $0.00 \mathrm{E}+00$ \\
\hline & & $0.00 \mathrm{E}+00$ & & $0.00 \mathrm{E}+00$ & $0.00 \mathrm{E}+00$ & $0.00 \mathrm{E}+00$ & $0.00 \mathrm{E}+00$ \\
\hline $.00 E+00$ & $.00 \mathrm{E}+00$ & $.00 E+00$ & $.00 \mathrm{E}+00$ & $.00 \mathrm{E}+00$ & $0.00 \mathrm{E}+00$ & $0.00 \mathrm{E}+00$ & $0.00 \mathrm{E}+00$ \\
\hline
\end{tabular}


RESRAD-OFFSITE, Version 2.5

Title : Offsite Resident Farmer Deterministic Run

File : RF TC99 DOESG FWD-FV2.ROF

Summary of dose at graphical times, reptition 3 (continued)

Time

Years

7. $08 \mathrm{E}+01$

7. $13 \mathrm{E}+01$

7. $18 \mathrm{E}+01$

7. $23 \mathrm{E}+01$

7. $28 \mathrm{E}+01$

7. $33 \mathrm{E}+01$

7. $38 \mathrm{E}+01$

7. $43 \mathrm{E}+01$

7. $49 \mathrm{E}+01$

7. $54 \mathrm{E}+01$

7. $59 \mathrm{E}+01$

7. $64 \mathrm{E}+01$

7. $69 \mathrm{E}+01$

7. $74 \mathrm{E}+01$

7. $79 \mathrm{E}+01$

7. $84 \mathrm{E}+01$

7. $90 \mathrm{E}+01$

7. $95 \mathrm{E}+01$

8. $00 \mathrm{E}+01$

$8.05 \mathrm{E}+01$

$8.10 \mathrm{E}+01$

$8.15 \mathrm{E}+01$

8. $20 \mathrm{E}+01$

$8.25 \mathrm{E}+01$

8. $31 \mathrm{E}+01$

8. $36 \mathrm{E}+01$

8. $41 \mathrm{E}+01$

8. $46 \mathrm{E}+01$

8. $51 \mathrm{E}+01$

8. $56 \mathrm{E}+01$

8. $61 \mathrm{E}+01$

8. $66 \mathrm{E}+01$

$8.72 \mathrm{E}+01$

$8.77 \mathrm{E}+01$

$8.82 \mathrm{E}+01$

$8.87 \mathrm{E}+01$

8. $92 \mathrm{E}+01$

$8.97 \mathrm{E}+01$

$9.02 \mathrm{E}+01$

$9.07 \mathrm{E}+01$

$9.13 \mathrm{E}+01$

$9.18 \mathrm{E}+01$

$9.23 \mathrm{E}+01$

$9.28 \mathrm{E}+01$

9. $33 \mathrm{E}+01$

9. $38 \mathrm{E}+01$
Dose statistics at graphical times, mrem/yr

\begin{tabular}{|c|c|c|c|c|c|c|c|}
\hline inimum & aximum & lean & edian & & & $\%$ & $9 \%$ \\
\hline $.00 E+00$ & $0.00 \mathrm{E}+00$ & $0.00 \mathrm{E}+00$ & $0.00 \mathrm{E}+00$ & $00 \mathrm{E}+00$ & $0.00 \mathrm{E}+00$ & $0.00 \mathrm{E}+00$ & $0.00 \mathrm{E}+00$ \\
\hline $.00 \mathrm{E}+00$ & $0.00 \mathrm{E}+00$ & $.00 \mathrm{E}+00$ & $.00 \mathrm{E}+00$ & $0.00 \mathrm{E}+00$ & $0.00 \mathrm{E}+00$ & $0.00 \mathrm{E}+00$ & $00 \mathrm{E}+00$ \\
\hline $00 \mathrm{E}+00$ & $0 \mathrm{E}+00$ & $00 E+00$ & $00 E+00$ & $00 \mathrm{E}+00$ & $00 E+00$ & 00 & $0 E+00$ \\
\hline+00 & 00 & 00 & 00 & 0 & 0 & 00 & $00 \mathrm{E}+00$ \\
\hline$E+00$ & 0 & & & & & & +00 \\
\hline $00 \mathrm{E}+00$ & & & & & & & $\Xi+00$ \\
\hline$E+00$ & $E+00$ & 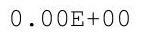 & $\mathrm{E}+00$ & $E+00$ & 0 & +00 & $E+00$ \\
\hline $.00 \mathrm{E}+00$ & $0.00 \mathrm{E}+00$ & $0 \mathrm{E}+00$ & $0 \mathrm{E}+00$ & $00 \mathrm{E}+00$ & $00 \mathrm{E}+00$ & $E+00$ & $00 \mathrm{E}+00$ \\
\hline $00 E+00$ & $00 F+0$ & $00 \mathrm{~F}+\ell-8$ & $.00 E+00$ & $0 \cap \mathrm{F}+$ & $\mathrm{O} \cap \mathrm{F}+\mathrm{r}-\mathrm{s}$ & $00 F+00$ & $00 E+00$ \\
\hline$E+00$ & $0.00 \mathrm{E}+00$ & & & & & 0 & 00 \\
\hline $.00 E+00$ & $0.00 \mathrm{E}+00$ & 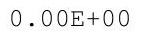 & 00 & 0 & 0 & 0 & $E+00$ \\
\hline $.00 \mathrm{E}+00$ & $0.00 \mathrm{E}+00$ & $0.00 \mathrm{E}+00$ & $0.00 \mathrm{E}+00$ & & & & $0.00 \mathrm{E}+00$ \\
\hline $.00 E+00$ & $0.00 \mathrm{E}+00$ & $0.00 \mathrm{E}+00$ & $0.00 \mathrm{E}+00$ & $0.00 \mathrm{E}+00$ & $0.00 \mathrm{E}+00$ & $E+00$ & $0.00 \mathrm{E}+00$ \\
\hline$E+00$ & $E+00$ & $E+00$ & $E+00$ & & & +00 & $00 \mathrm{E}+00$ \\
\hline $.00 E+00$ & $.00 E+00$ & $.00 E+00$ & $.00 E+00$ & $.00 \mathrm{E}+$ & 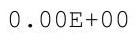 & 0 & +00 \\
\hline$E+00$ & ( & $0.00 \mathrm{E}+00$ & & $0.00 \mathrm{E}+00$ & $00 E+00$ & $E+00$ & 0 \\
\hline $0 \cap F+00$ & $F+00$ & $5+0$ & & & & -00 & 00 \\
\hline $.00 \mathrm{E}+00$ & $0.00 \mathrm{E}+00$ & $0.00 \mathrm{E}+00$ & $0.00 \mathrm{E}+00$ & $0.00 \mathrm{E}+00$ & $0.00 \mathrm{E}+00$ & $0.00 \mathrm{E}+00$ & $.00 \mathrm{E}+00$ \\
\hline $.00 \mathrm{E}+00$ & $.00 \mathrm{E}+00$ & $.00 \mathrm{E}+00$ & $0.00 \mathrm{E}+00$ & $0.00 \mathrm{E}+00$ & $0.00 \mathrm{E}+00$ & $.00 E+00$ & $.00 E+00$ \\
\hline$E+00$ & $00 E+00$ & $00 F+0=$ & $.00 E+00$ & $0 \mathrm{E}+00$ & 0 & $0 \mathrm{E}+00$ & $00 E+00$ \\
\hline 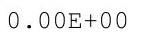 & 然 & $0.00 \mathrm{E}+00$ & $.00 E+00$ & 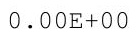 & 0 & 0 & +00 \\
\hline $.00 \mathrm{E}+00$ & . & 然 & & & & & 00 \\
\hline $.00 E+00$ & $.00 \mathrm{E}+00$ & ) & $0 E+00$ & مF+ & 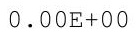 & 0 & $E+00$ \\
\hline $0 \cap F+00$ & COF+O & ) & $0.00 \mathrm{E}+00$ & $.00 \mathrm{E}+00$ & $.00 \mathrm{E}+$ & $00 \mathrm{E}+00$ & $00 E+00$ \\
\hline $00 F+00$ & 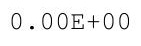 & 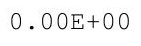 & $0.00 \mathrm{E}+00$ & $.00 \mathrm{E}+00$ & ח & $.00 E+00$ & $.00 \mathrm{E}+00$ \\
\hline$F+00$ & $0.00 \mathrm{E}+00$ & $00 E+00$ & $.00 E+00$ & $0 E+00$ & 0 & $0 E+00$ & $00 E+00$ \\
\hline & & & & & & $E+00$ & \\
\hline & & & & 0.0 & e & & +00 \\
\hline $.00 \mathrm{E}+00$ & $0.00 \mathrm{E}+00$ & $0.00 \mathrm{E}+00$ & $.00 \mathrm{E}+00$ & . & . & $0.00 \mathrm{E}+00$ & $.00 E+00$ \\
\hline $0 \mathrm{E}+00$ & $00 \mathrm{E}+00$ & $0.00 \mathrm{E}+0$ & $0.00 \mathrm{E}+00$ & $0.00 \mathrm{E}+00$ & $0.00 \mathrm{E}+\mathrm{C}$ & $0.00 \mathrm{E}+00$ & $.00 \mathrm{E}+00$ \\
\hline $00 \mathrm{E}+\mathrm{C}$ & $.00 E+00$ & & $0.00 \mathrm{E}+00$ & & & $0.00 \mathrm{E}+00$ & $.00 \mathrm{E}+00$ \\
\hline مि & $00 F+00$ & $0 \cap \cap \cap F+\cap 0$ & $00 F+00$ & $.00 E+00$ & & $0 E+00$ & $.00 E+00$ \\
\hline F & & & & & & & \\
\hline & & & & & & 00 & \\
\hline $.00 E+00$ & $0.00 \mathrm{E}+00$ & $0.00 \mathrm{E}+00$ & $0.00 \mathrm{E}+00$ & $0.00 \mathrm{E}+00$ & . & $0.00 \mathrm{E}+00$ & $.00 \mathrm{E}+00$ \\
\hline • & . & . & & & & & $0.00 \mathrm{E}+00$ \\
\hline 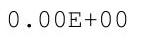 & ( & $0.00 \mathrm{E}+$ & $0.00 \mathrm{E}+$ & $0.00 \mathrm{E}+$ & $0.00 \mathrm{E}$ & $0.00 \mathrm{E}+00$ & $0.00 \mathrm{E}+00$ \\
\hline (1) & & & $0.00 \mathrm{E}+00$ & & & $0.00 \mathrm{E}+00$ & $.00 \mathrm{E}+00$ \\
\hline $0=+0$ & & $0.00 \mathrm{E}+$ & $0.00 \mathrm{E}+00$ & $00 E+00$ & 0 & $0 E+00$ & $00 E+00$ \\
\hline $.00 \mathrm{E}+00$ & $0.00 \mathrm{E}+00$ & $0.00 \mathrm{E}+$ & $0.00 \mathrm{E}$ & $0.00 \mathrm{E}$ & 0 & 00 & $0.00 \mathrm{E}+00$ \\
\hline $\mathrm{E}+00$ & $0.00 \mathrm{E}+00$ & 0.00 & 0 & 0 & & & $00 \mathrm{E}+00$ \\
\hline 年 & . & $0.00 \mathrm{E}+00$ & & $.00 \mathrm{E}+00$ & & & $.00 \mathrm{E}+00$ \\
\hline 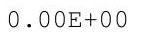 & 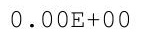 & $0.00 \mathrm{E}+00$ & $0.00 \mathrm{E}+00$ & $0.00 \mathrm{E}+00$ & $0.00 \mathrm{E}+00$ & $0.00 \mathrm{E}+00$ & $0.00 \mathrm{E}+00$ \\
\hline $0 E+00$ & $0.00 \mathrm{E}+00$ & $0.00 \mathrm{E}+00$ & $0.00 \mathrm{E}+00$ & & $0.00 \mathrm{E}+00$ & & $0.00 \mathrm{E}+00$ \\
\hline & & $0.00 \mathrm{E}+00$ & & $0.00 \mathrm{E}+00$ & $0.00 \mathrm{E}+00$ & $0.00 \mathrm{E}+00$ & $0.00 \mathrm{E}+00$ \\
\hline $.00 E+00$ & $.00 \mathrm{E}+00$ & $.00 E+00$ & $.00 \mathrm{E}+00$ & $.00 \mathrm{E}+00$ & $0.00 \mathrm{E}+00$ & $0.00 \mathrm{E}+00$ & $0.00 \mathrm{E}+00$ \\
\hline
\end{tabular}


Probabilistic Dose and Risk Report

Title : Offsite Resident Farmer Deterministic Run

File : RF TC99 DOESG FWD-FV2.ROF

Summary of dose at graphical times, reptition 3 (continued)

Time

Years

9. $43 \mathrm{E}+01$

$9.48 \mathrm{E}+01$

9. $54 \mathrm{E}+01$

$9.59 \mathrm{E}+01$

9. $64 \mathrm{E}+01$

$9.69 \mathrm{E}+01$

$9.74 \mathrm{E}+01$

9. $79 \mathrm{E}+01$

$9.84 \mathrm{E}+01$

9. $90 \mathrm{E}+01$

9. $95 \mathrm{E}+01$

$1.00 \mathrm{E}+02$

$1.00 \mathrm{E}+02$

$1.01 \mathrm{E}+02$

1. $02 \mathrm{E}+02$

$1.02 \mathrm{E}+02$

$1.03 \mathrm{E}+02$

$1.03 \mathrm{E}+02$

1. $04 \mathrm{E}+02$

$1.04 \mathrm{E}+02$

$1.05 \mathrm{E}+02$

$1.05 \mathrm{E}+02$

$1.06 \mathrm{E}+02$

$1.06 \mathrm{E}+02$

$1.07 \mathrm{E}+02$

$1.07 \mathrm{E}+02$

$1.08 \mathrm{E}+02$

$1.08 \mathrm{E}+02$

1. $09 \mathrm{E}+02$

$1.09 \mathrm{E}+02$

1. $10 \mathrm{E}+02$

1. $10 \mathrm{E}+02$

1. $11 \mathrm{E}+02$

1. $11 \mathrm{E}+02$

1. $12 \mathrm{E}+02$

1. $12 \mathrm{E}+02$

1. $13 \mathrm{E}+02$

1. $13 \mathrm{E}+02$

1. $14 \mathrm{E}+02$

1. $14 \mathrm{E}+02$

1. $15 \mathrm{E}+02$

1. $15 \mathrm{E}+02$

$1.16 \mathrm{E}+02$

$1.16 \mathrm{E}+02$

$1.17 \mathrm{E}+02$

1. $17 \mathrm{E}+02$

Dose statistics at graphical times, mrem/yr

\begin{tabular}{|c|c|c|c|c|c|c|c|}
\hline Minimum & Maximum & Mean & Median & $90 \%$ & $95 \%$ & $97.5 \%$ & $99 \%$ \\
\hline $0.00 \mathrm{E}+00$ & $0.00 \mathrm{E}+00$ & $0.00 \mathrm{E}+00$ & $0.00 \mathrm{E}+00$ & $0.00 \mathrm{E}+00$ & $0.00 \mathrm{E}+00$ & $0.00 \mathrm{E}+00$ & $0.00 \mathrm{E}+00$ \\
\hline $0.00 \mathrm{E}+00$ & $0.00 \mathrm{E}+00$ & $0.00 \mathrm{E}+00$ & $0.00 \mathrm{E}+00$ & $0.00 \mathrm{E}+00$ & $0.00 \mathrm{E}+00$ & $0.00 \mathrm{E}+00$ & $0.00 \mathrm{E}+00$ \\
\hline $0.00 \mathrm{E}+00$ & $0.00 \mathrm{E}+00$ & $0.00 E+00$ & $0.00 \mathrm{E}+00$ & $0.00 \mathrm{E}+00$ & $0.00 \mathrm{E}+00$ & $0.00 \mathrm{E}+00$ & $0.00 \mathrm{E}+00$ \\
\hline $0.00 \mathrm{E}+00$ & $0.00 \mathrm{E}+00$ & $0.00 E+00$ & $0.00 \mathrm{E}+00$ & $0.00 \mathrm{E}+00$ & $0.00 \mathrm{E}+00$ & $0.00 \mathrm{E}+00$ & $0.00 \mathrm{E}+00$ \\
\hline $0.00 \mathrm{E}+00$ & $0.00 \mathrm{E}+00$ & $0.00 \mathrm{E}+00$ & $0.00 \mathrm{E}+00$ & $0.00 \mathrm{E}+00$ & $0.00 \mathrm{E}+00$ & $0.00 \mathrm{E}+00$ & $0.00 \mathrm{E}+00$ \\
\hline $0.00 \mathrm{E}+00$ & $0.00 \mathrm{E}+00$ & $0.00 \mathrm{E}+00$ & $0.00 \mathrm{E}+00$ & $0.00 \mathrm{E}+00$ & $0.00 \mathrm{E}+00$ & $0.00 \mathrm{E}+00$ & $0.00 \mathrm{E}+00$ \\
\hline $0.00 \mathrm{E}+00$ & $0.00 \mathrm{E}+00$ & $0.00 E+00$ & $0.00 E+00$ & $0.00 \mathrm{E}+00$ & $0.00 \mathrm{E}+00$ & $0.00 \mathrm{E}+00$ & $0.00 \mathrm{E}+00$ \\
\hline $0.00 \mathrm{E}+00$ & $0.00 \mathrm{E}+00$ & $0.00 E+00$ & $0.00 \mathrm{E}+00$ & $0.00 \mathrm{E}+00$ & $0.00 \mathrm{E}+00$ & $0.00 \mathrm{E}+00$ & $0.00 \mathrm{E}+00$ \\
\hline $0.00 \mathrm{E}+00$ & $0.00 \mathrm{E}+00$ & $0.00 \mathrm{E}+00$ & $0.00 \mathrm{E}+00$ & $0.00 E+00$ & $0.00 \mathrm{E}+00$ & $0.00 \mathrm{E}+00$ & $0.00 \mathrm{E}+00$ \\
\hline $00 \mathrm{E}+00$ & $0.00 \mathrm{E}+00$ & $0.00 E+00$ & $0.00 \mathrm{E}+00$ & $0.00 \mathrm{E}+00$ & $0.00 \mathrm{E}+00$ & $0.00 \mathrm{E}+00$ & $0.00 \mathrm{E}+00$ \\
\hline $0.00 \mathrm{E}+00$ & $0.00 \mathrm{E}+00$ & $0.00 \mathrm{E}+00$ & $0.00 \mathrm{E}+00$ & $0.00 \mathrm{E}+00$ & $0.00 \mathrm{E}+00$ & $0.00 \mathrm{E}+00$ & $0.00 \mathrm{E}+00$ \\
\hline $0.00 \mathrm{E}+00$ & $0.00 \mathrm{E}+00$ & $0.00 E+00$ & $0.00 \mathrm{E}+00$ & $0.00 \mathrm{E}+00$ & $0.00 \mathrm{E}+00$ & $0.00 \mathrm{E}+00$ & $0.00 \mathrm{E}+00$ \\
\hline $0.00 \mathrm{E}+00$ & $0.00 E+00$ & $0.00 E+00$ & $0.00 \mathrm{E}+00$ & $0.00 \mathrm{E}+00$ & $0.00 \mathrm{E}+00$ & $0.00 \mathrm{E}+00$ & $0.00 \mathrm{E}+00$ \\
\hline $0.00 \mathrm{E}+00$ & $0.00 \mathrm{E}+00$ & $0.00 E+00$ & $0.00 E+00$ & $0.00 \mathrm{E}+00$ & $0.00 \mathrm{E}+00$ & $0.00 \mathrm{E}+00$ & $0.00 \mathrm{E}+00$ \\
\hline $0.00 \mathrm{E}+00$ & $0.00 \mathrm{E}+00$ & $0.00 E+00$ & $0.00 \mathrm{E}+00$ & $0.00 \mathrm{E}+00$ & $0.00 \mathrm{E}+00$ & $0.00 \mathrm{E}+00$ & $0.00 \mathrm{E}+00$ \\
\hline $0.00 \mathrm{E}+00$ & $0.00 \mathrm{E}+00$ & $0.00 E+00$ & $0.00 E+00$ & $0.00 \mathrm{E}+00$ & $0.00 \mathrm{E}+00$ & $0.00 \mathrm{E}+00$ & $0.00 \mathrm{E}+00$ \\
\hline $0.00 \mathrm{E}+00$ & $0.00 \mathrm{E}+00$ & $0.00 E+00$ & $0.00 \mathrm{E}+00$ & $0.00 \mathrm{E}+00$ & $0.00 \mathrm{E}+00$ & $0.00 \mathrm{E}+00$ & $0.00 \mathrm{E}+00$ \\
\hline $0.00 \mathrm{E}+00$ & $0.00 \mathrm{E}+00$ & $0.00 E+00$ & $0.00 \mathrm{E}+00$ & $0.00 \mathrm{E}+00$ & $0.00 \mathrm{E}+00$ & $0.00 \mathrm{E}+00$ & $0.00 \mathrm{E}+00$ \\
\hline $0.00 \mathrm{E}+00$ & $0.00 \mathrm{E}+00$ & $0.00 \mathrm{E}+00$ & $0.00 \mathrm{E}+00$ & $0.00 \mathrm{E}+00$ & $0.00 \mathrm{E}+00$ & $0.00 \mathrm{E}+00$ & $0.00 \mathrm{E}+00$ \\
\hline $0.00 \mathrm{E}+00$ & $0.00 \mathrm{E}+00$ & $0.00 E+00$ & $0.00 E+00$ & $0.00 \mathrm{E}+00$ & $0.00 \mathrm{E}+00$ & $0.00 \mathrm{E}+00$ & $0.00 \mathrm{E}+00$ \\
\hline $0.00 \mathrm{E}+00$ & $0.00 \mathrm{E}+00$ & $0.00 \mathrm{E}+00$ & $0.00 \mathrm{E}+00$ & $0.00 \mathrm{E}+00$ & $0.00 \mathrm{E}+00$ & $0.00 \mathrm{E}+00$ & $.00 \mathrm{E}+00$ \\
\hline $0.00 \mathrm{E}+00$ & $0.00 \mathrm{E}+00$ & $0.00 \mathrm{E}+00$ & $0.00 \mathrm{E}+00$ & $0.00 E+00$ & $0.00 \mathrm{E}+00$ & $0.00 \mathrm{E}+00$ & $0.00 \mathrm{E}+00$ \\
\hline $0.00 \mathrm{E}+00$ & $0.00 \mathrm{E}+00$ & $0.00 E+00$ & $0.00 \mathrm{E}+00$ & $0.00 \mathrm{E}+00$ & $0.00 \mathrm{E}+00$ & $0.00 \mathrm{E}+00$ & $0.00 \mathrm{E}+00$ \\
\hline $0.00 \mathrm{E}+00$ & $0.00 \mathrm{E}+00$ & $0.00 E+00$ & $0.00 \mathrm{E}+00$ & $0.00 \mathrm{E}+00$ & $0.00 \mathrm{E}+00$ & $0.00 \mathrm{E}+00$ & $0.00 \mathrm{E}+00$ \\
\hline $0.00 \mathrm{E}+00$ & $0.00 \mathrm{E}+00$ & $0.00 \mathrm{E}+00$ & $0.00 \mathrm{E}+00$ & $0.00 \mathrm{E}+00$ & $0.00 \mathrm{E}+00$ & $0.00 \mathrm{E}+00$ & $0.00 \mathrm{E}+00$ \\
\hline $0.00 \mathrm{E}+00$ & $8.27 E-22$ & $4.13 E-25$ & $0.00 \mathrm{E}+00$ & $0.00 \mathrm{E}+00$ & $0.00 \mathrm{E}+00$ & $0.00 \mathrm{E}+00$ & $0.00 \mathrm{E}+00$ \\
\hline $0.00 \mathrm{E}+00$ & $1.08 \mathrm{E}-19$ & $5.42 E-23$ & $0.00 \mathrm{E}+00$ & $0.00 \mathrm{E}+00$ & $0.00 \mathrm{E}+00$ & $0.00 \mathrm{E}+00$ & $0.00 \mathrm{E}+00$ \\
\hline $0.00 \mathrm{E}+00$ & $3.88 \mathrm{E}-18$ & 1. $94 \mathrm{E}-21$ & $0.00 \mathrm{E}+00$ & $0.00 \mathrm{E}+00$ & $0.00 \mathrm{E}+00$ & $0.00 \mathrm{E}+00$ & $0.00 \mathrm{E}+00$ \\
\hline $0.00 \mathrm{E}+00$ & $6.95 E-17$ & $3.47 E-20$ & $0.00 \mathrm{E}+00$ & $0.00 E+00$ & $0.00 \mathrm{E}+00$ & $0.00 \mathrm{E}+00$ & $0.00 \mathrm{E}+00$ \\
\hline $0.00 \mathrm{E}+00$ & $7.90 \mathrm{E}-16$ & $3.95 E-19$ & $0.00 \mathrm{E}+00$ & $0.00 \mathrm{E}+00$ & $0.00 \mathrm{E}+00$ & $0.00 \mathrm{E}+00$ & $0.00 \mathrm{E}+00$ \\
\hline $0.00 \mathrm{E}+00$ & $6.40 \mathrm{E}-15$ & $3.20 E-18$ & $0.00 \mathrm{E}+00$ & $0.00 \mathrm{E}+00$ & $0.00 \mathrm{E}+00$ & $0.00 \mathrm{E}+00$ & $0.00 \mathrm{E}+00$ \\
\hline $0.00 \mathrm{E}+00$ & $3.97 \mathrm{E}-14$ & $1.99 \mathrm{E}-17$ & $0.00 \mathrm{E}+00$ & $0.00 \mathrm{E}+00$ & $0.00 \mathrm{E}+00$ & $0.00 \mathrm{E}+00$ & $0.00 \mathrm{E}+00$ \\
\hline $0.00 \mathrm{E}+00$ & 1. $98 \mathrm{E}-13$ & $9.90 \mathrm{E}-17$ & $0.00 \mathrm{E}+00$ & $0.00 \mathrm{E}+00$ & $0.00 \mathrm{E}+00$ & $0.00 \mathrm{E}+00$ & $0.00 \mathrm{E}+00$ \\
\hline $0.00 \mathrm{E}+00$ & $8.23 E-13$ & $4.11 \mathrm{E}-16$ & $0.00 \mathrm{E}+00$ & $0.00 \mathrm{E}+00$ & $0.00 \mathrm{E}+00$ & $0.00 \mathrm{E}+00$ & $0.00 \mathrm{E}+00$ \\
\hline $0.00 \mathrm{E}+00$ & $2.93 E-12$ & 1. $46 \mathrm{E}-15$ & $0.00 \mathrm{E}+00$ & $0.00 \mathrm{E}+00$ & $0.00 \mathrm{E}+00$ & $0.00 \mathrm{E}+00$ & $0.00 \mathrm{E}+00$ \\
\hline $0.00 \mathrm{E}+00$ & $9.15 \mathrm{E}-12$ & $4.57 \mathrm{E}-15$ & $0.00 \mathrm{E}+00$ & $0.00 \mathrm{E}+00$ & $0.00 \mathrm{E}+00$ & $0.00 \mathrm{E}+00$ & $0.00 \mathrm{E}+00$ \\
\hline $0.00 \mathrm{E}+00$ & $2.55 E-11$ & $1.28 \mathrm{E}-14$ & $0.00 \mathrm{E}+00$ & $0.00 \mathrm{E}+00$ & $0.00 \mathrm{E}+00$ & $0.00 \mathrm{E}+00$ & $0.00 \mathrm{E}+00$ \\
\hline $0.00 \mathrm{E}+00$ & $7 E-11$ & $24 E-14$ & $0.00 \mathrm{E}+00$ & $0.00 \mathrm{E}+00$ & $0.00 \mathrm{E}+00$ & $0.00 \mathrm{E}+00$ & $0.00 \mathrm{E}+00$ \\
\hline $0 E+00$ & $E-10$ & 7.5 & $0.00 \mathrm{E}+00$ & $0.00 \mathrm{E}+00$ & $0.00 \mathrm{E}+00$ & $0.00 \mathrm{E}+00$ & $0.00 \mathrm{E}+00$ \\
\hline $0.00 \mathrm{E}+00$ & $3.28 \mathrm{E}-10$ & 1. $64 \mathrm{E}-13$ & $0.00 \mathrm{E}+00$ & $0.00 E+00$ & $0.00 \mathrm{E}+00$ & $0.00 \mathrm{E}+00$ & $0.00 \mathrm{E}+00$ \\
\hline $0.00 \mathrm{E}+00$ & $6.68 \mathrm{E}-10$ & $3.34 \mathrm{E}-13$ & $0.00 \mathrm{E}+00$ & $0.00 \mathrm{E}+00$ & $0.00 \mathrm{E}+00$ & $0.00 \mathrm{E}+00$ & $0.00 \mathrm{E}+00$ \\
\hline $0.00 \mathrm{E}+00$ & $1.29 \mathrm{E}-09$ & $6.45 E-13$ & $0.00 \mathrm{E}+00$ & $0.00 \mathrm{E}+00$ & $0.00 \mathrm{E}+00$ & $0.00 \mathrm{E}+00$ & $0.00 \mathrm{E}+00$ \\
\hline $0.00 \mathrm{E}+00$ & $2.37 E-09$ & 1. 19E-12 & $0.00 \mathrm{E}+00$ & $0.00 \mathrm{E}+00$ & $0.00 \mathrm{E}+00$ & $0.00 \mathrm{E}+00$ & $0.00 \mathrm{E}+00$ \\
\hline $0.00 \mathrm{E}+00$ & $4.19 \mathrm{E}-09$ & $2.10 \mathrm{E}-12$ & $0.00 \mathrm{E}+00$ & $0.00 \mathrm{E}+00$ & $0.00 \mathrm{E}+00$ & $0.00 \mathrm{E}+00$ & $0.00 \mathrm{E}+00$ \\
\hline $0.00 \mathrm{E}+00$ & $7.12 \mathrm{E}-09$ & $3.56 \mathrm{E}-12$ & $0.00 \mathrm{E}+00$ & $0.00 \mathrm{E}+00$ & $0.00 \mathrm{E}+00$ & $0.00 \mathrm{E}+00$ & $0.00 \mathrm{E}+00$ \\
\hline $0.00 \mathrm{E}+00$ & $1.17 \mathrm{E}-08$ & $5.86 \mathrm{E}-12$ & $0.00 \mathrm{E}+00$ & $0.00 \mathrm{E}+00$ & $0.00 \mathrm{E}+00$ & $0.00 \mathrm{E}+00$ & $0.00 \mathrm{E}+00$ \\
\hline
\end{tabular}


RESRAD-OFFSITE, Version 2.5

Title : Offsite Resident Farmer Deterministic Run

File : RF TC99 DOESG FWD-FV2.ROF

Summary of dose at graphical times, reptition 3 (continued)

Time

Years

$1.18 \mathrm{E}+02$

$1.18 \mathrm{E}+02$

1.19E+02

$1.19 \mathrm{E}+02$

1. $20 \mathrm{E}+02$

1. $20 \mathrm{E}+02$

1. $21 \mathrm{E}+02$

1. $22 \mathrm{E}+02$

1. $22 \mathrm{E}+02$

1. $23 \mathrm{E}+02$

1. $23 \mathrm{E}+02$

1. $24 \mathrm{E}+02$

1. $24 \mathrm{E}+02$

1. $25 \mathrm{E}+02$

1. $25 \mathrm{E}+02$

1. $26 \mathrm{E}+02$

1. $26 \mathrm{E}+02$

1. $27 \mathrm{E}+02$

1. $27 \mathrm{E}+02$

1. $28 \mathrm{E}+02$

1. $28 \mathrm{E}+02$

1. $29 \mathrm{E}+02$

1. $29 \mathrm{E}+02$

1. $30 \mathrm{E}+02$

1. $30 \mathrm{E}+02$

1. $31 \mathrm{E}+02$

1. $31 \mathrm{E}+02$

1. $32 \mathrm{E}+02$

1. $32 \mathrm{E}+02$

1. $33 \mathrm{E}+02$

1. $33 \mathrm{E}+02$

1. $34 \mathrm{E}+02$

1. $34 \mathrm{E}+02$

1. $35 \mathrm{E}+02$

1. $35 \mathrm{E}+02$

1. $36 \mathrm{E}+02$

1. $36 \mathrm{E}+02$

1. $37 \mathrm{E}+02$

1. $37 \mathrm{E}+02$

1. $38 \mathrm{E}+02$

1. $38 \mathrm{E}+02$

1. $39 \mathrm{E}+02$

1. $39 \mathrm{E}+02$

1. $40 \mathrm{E}+02$

1. $40 \mathrm{E}+02$

1. $41 \mathrm{E}+02$

Dose statistics at graphical times, mrem/yr

\begin{tabular}{|c|c|c|c|c|c|c|c|}
\hline Minimum & Maximum & Mean & Median & $90 \%$ & $95 \%$ & $97.5 \%$ & $99 \%$ \\
\hline $0.00 \mathrm{E}+00$ & $1.87 \mathrm{E}-08$ & $9.36 \mathrm{E}-12$ & $0.00 \mathrm{E}+00$ & $0.00 \mathrm{E}+00$ & $0.00 \mathrm{E}+00$ & $0.00 \mathrm{E}+00$ & $0.00 \mathrm{E}+00$ \\
\hline $0.00 \mathrm{E}+00$ & $2.90 \mathrm{E}-08$ & $1.46 \mathrm{E}-11$ & $0.00 \mathrm{E}+00$ & $0.00 \mathrm{E}+00$ & $0.00 \mathrm{E}+00$ & $0.00 \mathrm{E}+00$ & $0.00 \mathrm{E}+00$ \\
\hline $0.00 \mathrm{E}+00$ & $4.39 E-08$ & $2.21 \mathrm{E}-11$ & $0.00 \mathrm{E}+00$ & $0.00 \mathrm{E}+00$ & $0.00 \mathrm{E}+00$ & $0.00 \mathrm{E}+00$ & $0.00 \mathrm{E}+00$ \\
\hline $0.00 \mathrm{E}+00$ & $6.51 \mathrm{E}-08$ & $3.29 \mathrm{E}-11$ & $0.00 \mathrm{E}+00$ & $0.00 \mathrm{E}+00$ & $0.00 \mathrm{E}+00$ & $0.00 \mathrm{E}+00$ & $0.00 \mathrm{E}+00$ \\
\hline $0.00 \mathrm{E}+00$ & $9.45 \mathrm{E}-08$ & $4.79 E-11$ & $0.00 \mathrm{E}+00$ & $0.00 \mathrm{E}+00$ & $0.00 \mathrm{E}+00$ & $0.00 \mathrm{E}+00$ & $0.00 \mathrm{E}+00$ \\
\hline $0.00 \mathrm{E}+00$ & 1. $35 \mathrm{E}-07$ & $6.86 \mathrm{E}-11$ & $0.00 \mathrm{E}+00$ & $0.00 \mathrm{E}+00$ & $0.00 \mathrm{E}+00$ & $0.00 \mathrm{E}+00$ & $0.00 \mathrm{E}+00$ \\
\hline $0.00 \mathrm{E}+00$ & $1.89 \mathrm{E}-07$ & $9.66 \mathrm{E}-11$ & $0.00 \mathrm{E}+00$ & $0.00 \mathrm{E}+00$ & $0.00 \mathrm{E}+00$ & $0.00 \mathrm{E}+00$ & $0.00 \mathrm{E}+00$ \\
\hline $0.00 \mathrm{E}+00$ & $2.60 \mathrm{E}-07$ & $1.34 \mathrm{E}-10$ & $0.00 E+00$ & $0.00 \mathrm{E}+00$ & $0.00 \mathrm{E}+00$ & $0.00 \mathrm{E}+00$ & $0.00 \mathrm{E}+00$ \\
\hline $0.00 \mathrm{E}+00$ & $3.53 E-07$ & $1.83 \mathrm{E}-10$ & $0.00 \mathrm{E}+00$ & $0.00 \mathrm{E}+00$ & $0.00 \mathrm{E}+00$ & $0.00 \mathrm{E}+00$ & $0.00 \mathrm{E}+00$ \\
\hline $.00 E+00$ & $4.73 E-07$ & $2.48 \mathrm{E}-10$ & $0.00 \mathrm{E}+00$ & $0.00 \mathrm{E}+00$ & $0.00 \mathrm{E}+00$ & $0.00 \mathrm{E}+00$ & $0.00 \mathrm{E}+00$ \\
\hline $0.00 \mathrm{E}+00$ & $6.25 \mathrm{E}-07$ & $3.30 \mathrm{E}-10$ & $0.00 \mathrm{E}+00$ & $0.00 \mathrm{E}+00$ & $0.00 \mathrm{E}+00$ & $0.00 \mathrm{E}+00$ & $0.00 \mathrm{E}+00$ \\
\hline $0.00 \mathrm{E}+00$ & $8.17 \mathrm{E}-07$ & $4.36 \mathrm{E}-10$ & $0.00 \mathrm{E}+00$ & $0.00 \mathrm{E}+00$ & $0.00 \mathrm{E}+00$ & $0.00 \mathrm{E}+00$ & $0.00 \mathrm{E}+00$ \\
\hline $0.00 \mathrm{E}+00$ & $1.05 \mathrm{E}-06$ & $5.70 \mathrm{E}-10$ & $0.00 \mathrm{E}+00$ & $0.00 \mathrm{E}+00$ & $0.00 \mathrm{E}+00$ & $0.00 \mathrm{E}+00$ & $0.00 \mathrm{E}+00$ \\
\hline $0.00 \mathrm{E}+00$ & $1.35 \mathrm{E}-06$ & $7.37 \mathrm{E}-10$ & $0.00 \mathrm{E}+00$ & $0.00 \mathrm{E}+00$ & $0.00 \mathrm{E}+00$ & $0.00 \mathrm{E}+00$ & $0.00 \mathrm{E}+00$ \\
\hline $0.00 \mathrm{E}+00$ & $1.71 \mathrm{E}-06$ & $9.45 \mathrm{E}-10$ & $0.00 \mathrm{E}+00$ & $0.00 \mathrm{E}+00$ & $0.00 \mathrm{E}+00$ & $0.00 \mathrm{E}+00$ & $0.00 \mathrm{E}+00$ \\
\hline $0.00 \mathrm{E}+00$ & $2.14 \mathrm{E}-06$ & $.20 E-09$ & $0 E+00$ & $0 E+00$ & $00 E+00$ & $0 E+00$ & $.56 E-22$ \\
\hline $0.00 \mathrm{E}+00$ & $2.66 \mathrm{E}-06$ & $1.51 \mathrm{E}-09$ & $0.00 \mathrm{E}+00$ & $0.00 \mathrm{E}+00$ & $0.00 \mathrm{E}+00$ & $0.00 \mathrm{E}+00$ & 1. $33 \mathrm{E}-19$ \\
\hline $0.00 \mathrm{E}+00$ & $3.28 \mathrm{E}-06$ & 1.90E-09 & $0.00 \mathrm{E}+00$ & $0.00 \mathrm{E}+00$ & $0.00 \mathrm{E}+00$ & $0.00 \mathrm{E}+00$ & $5.86 \mathrm{E}-18$ \\
\hline $0.00 \mathrm{E}+00$ & $4.01 E-06$ & $2.36 \mathrm{E}-09$ & $0.00 \mathrm{E}+00$ & $0.00 \mathrm{E}+00$ & $0.00 \mathrm{E}+00$ & $0.00 \mathrm{E}+00$ & $1.24 \mathrm{E}-16$ \\
\hline $0.00 \mathrm{E}+00$ & $4.86 \mathrm{E}-06$ & $2.91 E-09$ & $0.00 \mathrm{E}+00$ & $0.00 \mathrm{E}+00$ & $0.00 \mathrm{E}+00$ & $0.00 \mathrm{E}+00$ & $1.57 \mathrm{E}-15$ \\
\hline $0.00 \mathrm{E}+00$ & $5.86 \mathrm{E}-06$ & $3.57 \mathrm{E}-09$ & $0.00 \mathrm{E}+00$ & $0.00 \mathrm{E}+00$ & $0.00 \mathrm{E}+00$ & $0.00 \mathrm{E}+00$ & $1.37 \mathrm{E}-14$ \\
\hline $0.00 \mathrm{E}+00$ & $7.02 \mathrm{E}-06$ & $4.35 E-09$ & $0.00 \mathrm{E}+00$ & $0.00 \mathrm{E}+00$ & $0.00 \mathrm{E}+00$ & $0.00 \mathrm{E}+00$ & $8.97 E-14$ \\
\hline $0.00 \mathrm{E}+00$ & $8.35 E-06$ & $5.27 \mathrm{E}-09$ & $0.00 \mathrm{E}+00$ & $0.00 \mathrm{E}+00$ & $0.00 \mathrm{E}+00$ & $0.00 \mathrm{E}+00$ & $4.62 \mathrm{E}-13$ \\
\hline $0.00 \mathrm{E}+00$ & $9.88 \mathrm{E}-06$ & $6.35 E-09$ & $0.00 \mathrm{E}+00$ & $0.00 \mathrm{E}+00$ & $0.00 \mathrm{E}+00$ & $0.00 \mathrm{E}+00$ & 1. $94 \mathrm{E}-12$ \\
\hline $0.00 \mathrm{E}+00$ & $1.16 \mathrm{E}-05$ & $7.62 \mathrm{E}-09$ & $0.00 \mathrm{E}+00$ & $0.00 \mathrm{E}+00$ & $0.00 \mathrm{E}+00$ & $0.00 \mathrm{E}+00$ & $5.50 \mathrm{E}-12$ \\
\hline $0.00 \mathrm{E}+00$ & $1.36 \mathrm{E}-05$ & $9.09 \mathrm{E}-09$ & $0.00 \mathrm{E}+00$ & $0.00 \mathrm{E}+00$ & $0.00 \mathrm{E}+00$ & $0.00 \mathrm{E}+00$ & $1.42 \mathrm{E}-11$ \\
\hline $0.00 \mathrm{E}+00$ & $1.58 \mathrm{E}-05$ & $1.08 \mathrm{E}-08$ & $0.00 \mathrm{E}+00$ & $0.00 \mathrm{E}+00$ & $0.00 \mathrm{E}+00$ & $0.00 \mathrm{E}+00$ & $3.37 \mathrm{E}-11$ \\
\hline $0.00 \mathrm{E}+00$ & $1.83 \mathrm{E}-05$ & $1.28 \mathrm{E}-08$ & $0.00 \mathrm{E}+00$ & $0.00 \mathrm{E}+00$ & $0.00 \mathrm{E}+00$ & $0.00 \mathrm{E}+00$ & $7.51 E-11$ \\
\hline $0.00 \mathrm{E}+00$ & $2.11 \mathrm{E}-05$ & $1.50 \mathrm{E}-08$ & $0.00 \mathrm{E}+00$ & $0.00 \mathrm{E}+00$ & $0.00 \mathrm{E}+00$ & $0.00 \mathrm{E}+00$ & $1.58 \mathrm{E}-10$ \\
\hline $0.00 \mathrm{E}+00$ & $2.43 E-05$ & $1.76 \mathrm{E}-08$ & $0.00 \mathrm{E}+00$ & $0.00 \mathrm{E}+00$ & $0.00 \mathrm{E}+00$ & $0.00 \mathrm{E}+00$ & $3.15 \mathrm{E}-10$ \\
\hline $0.00 \mathrm{E}+00$ & $2.77 \mathrm{E}-05$ & $2.05 E-08$ & $0.00 \mathrm{E}+00$ & $0.00 \mathrm{E}+00$ & $0.00 \mathrm{E}+00$ & $0.00 \mathrm{E}+00$ & $5.99 \mathrm{E}-10$ \\
\hline $0.00 \mathrm{E}+00$ & $3.16 \mathrm{E}-05$ & $2.39 E-08$ & $0.00 \mathrm{E}+00$ & $0.00 \mathrm{E}+00$ & $0.00 \mathrm{E}+00$ & $0.00 \mathrm{E}+00$ & $1.09 \mathrm{E}-09$ \\
\hline $0.00 \mathrm{E}+00$ & $3.58 \mathrm{E}-05$ & $7 E-08$ & $0.00 \mathrm{E}+00$ & $0.00 \mathrm{E}+00$ & $0.00 \mathrm{E}+00$ & $0.00 \mathrm{E}+00$ & $.92 E-09$ \\
\hline $0.00 \mathrm{E}+00$ & $4.05 E-05$ & $3.20 \mathrm{E}-08$ & $0.00 \mathrm{E}+00$ & $0.00 \mathrm{E}+00$ & $0.00 \mathrm{E}+00$ & $0.00 \mathrm{E}+00$ & $3.27 E-09$ \\
\hline $0.00 \mathrm{E}+00$ & $4.56 \mathrm{E}-05$ & $3.68 \mathrm{E}-08$ & $0.00 \mathrm{E}+00$ & $0.00 \mathrm{E}+00$ & $0.00 \mathrm{E}+00$ & $0.00 \mathrm{E}+00$ & $5.37 \mathrm{E}-09$ \\
\hline $0.00 \mathrm{E}+00$ & $5.12 \mathrm{E}-05$ & $4.23 E-08$ & $0.00 \mathrm{E}+00$ & $0.00 \mathrm{E}+00$ & $0.00 \mathrm{E}+00$ & $0.00 \mathrm{E}+00$ & $8.58 E-09$ \\
\hline $0.00 \mathrm{E}+00$ & $5.74 \mathrm{E}-05$ & $4.84 \mathrm{E}-08$ & $0.00 \mathrm{E}+00$ & $0.00 \mathrm{E}+00$ & $0.00 \mathrm{E}+00$ & $0.00 \mathrm{E}+00$ & $1.33 E-08$ \\
\hline $0.00 \mathrm{E}+00$ & $6.40 \mathrm{E}-05$ & $5.52 \mathrm{E}-08$ & $0.00 \mathrm{E}+00$ & $0.00 \mathrm{E}+00$ & $0.00 \mathrm{E}+00$ & $0.00 \mathrm{E}+00$ & $2.02 \mathrm{E}-08$ \\
\hline $00 \mathrm{E}+00$ & $7.12 \mathrm{E}-05$ & $6.28 E-08$ & $0.00 \mathrm{E}+00$ & $0.00 \mathrm{E}+00$ & $0.00 \mathrm{E}+00$ & $4.26 \mathrm{E}-24$ & $3.00 E-08$ \\
\hline $0.00 \mathrm{E}+00$ & $7.91 \mathrm{E}-05$ & $7.12 \mathrm{E}-08$ & $0.00 \mathrm{E}+00$ & $0.00 \mathrm{E}+00$ & $0.00 \mathrm{E}+00$ & $1.73 E-21$ & $4.36 E-08$ \\
\hline $0.00 \mathrm{E}+00$ & $8.75 E-05$ & $8.06 \mathrm{E}-08$ & $0.00 \mathrm{E}+00$ & $0.00 \mathrm{E}+00$ & $0.00 \mathrm{E}+00$ & $1.36 \mathrm{E}-19$ & $6.21 \mathrm{E}-08$ \\
\hline $0.00 \mathrm{E}+00$ & $9.67 \mathrm{E}-05$ & $9.11 \mathrm{E}-08$ & $0.00 \mathrm{E}+00$ & $0.00 \mathrm{E}+00$ & $0.00 \mathrm{E}+00$ & $4.17 E-18$ & $8.69 E-08$ \\
\hline $0.00 \mathrm{E}+00$ & $1.07 \mathrm{E}-04$ & $1.03 E-07$ & $0.00 \mathrm{E}+00$ & $0.00 \mathrm{E}+00$ & $0.00 \mathrm{E}+00$ & $6.83 \mathrm{E}-17$ & $1.20 \mathrm{E}-07$ \\
\hline $0.00 \mathrm{E}+00$ & $1.17 \mathrm{E}-04$ & $1.15 \mathrm{E}-07$ & $0.00 \mathrm{E}+00$ & $0.00 \mathrm{E}+00$ & $0.00 \mathrm{E}+00$ & $7.31 \mathrm{E}-16$ & $1.62 \mathrm{E}-07$ \\
\hline $0.00 \mathrm{E}+00$ & $1.28 \mathrm{E}-04$ & $1.29 \mathrm{E}-07$ & $0.00 E+00$ & $0.00 \mathrm{E}+00$ & $0.00 \mathrm{E}+00$ & $5.68 E-15$ & $2.17 E-07$ \\
\hline $0.00 \mathrm{E}+00$ & $1.41 \mathrm{E}-04$ & $1.45 \mathrm{E}-07$ & $0.00 \mathrm{E}+00$ & $0.00 \mathrm{E}+00$ & $0.00 \mathrm{E}+00$ & $3.41 \mathrm{E}-14$ & $2.86 \mathrm{E}-07$ \\
\hline
\end{tabular}


RESRAD-OFFSITE, Version 2.5

Title : Offsite Resident Farmer Deterministic Run

File : RF TC99 DOESG FWD-FV2.ROF

Summary of dose at graphical times, reptition 3 (continued)

Time

Years

1. $42 \mathrm{E}+02$

$1.42 \mathrm{E}+02$

1. $43 \mathrm{E}+02$

$1.43 \mathrm{E}+02$

1. $44 \mathrm{E}+02$

1. $44 \mathrm{E}+02$

1. $45 \mathrm{E}+02$

1. $45 \mathrm{E}+02$

1. $46 \mathrm{E}+02$

1. $46 \mathrm{E}+02$

1. $47 \mathrm{E}+02$

1. $47 \mathrm{E}+02$

1. $48 \mathrm{E}+02$

1. $48 \mathrm{E}+02$

1. $49 \mathrm{E}+02$

1. $49 \mathrm{E}+02$

1. $50 \mathrm{E}+02$

1. $50 \mathrm{E}+02$

1. $51 \mathrm{E}+02$

1. $51 \mathrm{E}+02$

1. $52 \mathrm{E}+02$

1. $52 \mathrm{E}+02$

1. $53 \mathrm{E}+02$

1. $53 \mathrm{E}+02$

$1.54 \mathrm{E}+02$

$1.54 \mathrm{E}+02$

1. $55 \mathrm{E}+02$

1. $55 \mathrm{E}+02$

1. $56 \mathrm{E}+02$

1. $56 \mathrm{E}+02$

1. $57 \mathrm{E}+02$

1. $57 \mathrm{E}+02$

1. $58 \mathrm{E}+02$

1. $58 \mathrm{E}+02$

1. $59 \mathrm{E}+02$

1. $59 \mathrm{E}+02$

1. $60 \mathrm{E}+02$

1. $60 \mathrm{E}+02$

1. $61 \mathrm{E}+02$

1. $61 \mathrm{E}+02$

1. $62 \mathrm{E}+02$

1. $63 \mathrm{E}+02$

1. $63 \mathrm{E}+02$

1. $64 \mathrm{E}+02$

1. $64 \mathrm{E}+02$

1. $65 \mathrm{E}+02$
Dose statistics at graphical times, mrem/yr

\begin{tabular}{|c|c|c|c|c|c|c|c|}
\hline inimum & aximum & lean & edian & & & & \\
\hline+00 & 04 & 07 & +00 & 0 & -00 & 13 & -07 \\
\hline $.00 \mathrm{E}+00$ & $1.67 \mathrm{E}-04$ & $1.80 \mathrm{E}-07$ & $00 \mathrm{E}+00$ & $00 \mathrm{E}+00$ & $0.00 \mathrm{E}+00$ & $6.78 \mathrm{E}-13$ & $4.79 E-07$ \\
\hline $0 F+00$ & $82 F-04$ & $00 F-07$ & $.00 E+00$ & $.00 E+00$ & $00 F+00$ & $16 F-12$ & 07 \\
\hline+00 & & $2.23 E-07$ & 0 & & & 2 & -07 \\
\hline$E+00$ & & $2.47 \mathrm{E}-07$ & & & & & $8 E-07$ \\
\hline $00 \mathrm{E}+00$ & 04 & 0 & & & & & -06 \\
\hline$E+00$ & 04 & 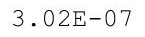 & $\mathrm{E}+00$ & $E+00$ & 0 & -11 & $48 E-06$ \\
\hline $.00 \mathrm{E}+00$ & $2.71 E-04$ & $3 E-07$ & $0 \mathrm{E}+00$ & $00 \mathrm{E}+00$ & $00 \mathrm{E}+00$ & $5 E-10$ & $.82 E-06$ \\
\hline $00 \mathrm{E}+00$ & $92 \mathrm{~F}-\mathrm{r}-\mathrm{C}$ & $67 \mathrm{~F}-0$ & $.00 E+00$ & 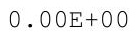 & + & -10 & 06 \\
\hline$E+00$ & $3.15 \mathrm{E}-04$ & $4.03 E-07$ & & & & 0 & 6 \\
\hline $.00 E+00$ & $3 \cdot 3$ & 4. & 0 & 0 & 0 & 9 & $E-06$ \\
\hline $.00 \mathrm{E}+00$ & $3.63 E-04$ & $4.85 E-07$ & & & & & $3.73 E-06$ \\
\hline $.00 E+00$ & $3.89 E-04$ & $5.31 E-07$ & $0.00 \mathrm{E}+00$ & $0.00 \mathrm{E}+00$ & $.00 E+00$ & $E-09$ & $4.37 E-06$ \\
\hline$E+00$ & 4 & -0 & & & & -09 & -06 \\
\hline $.00 E+00$ & 4 & 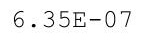 & $.00 \mathrm{E}+$ & 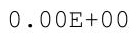 & 0 & 88 & -06 \\
\hline $\mathrm{OE}+00$ & 4 & $6.92 \mathrm{E}-07$ & 0 & D & 0 & 8 & 06 \\
\hline $0 \cap F+00$ & 5 & $7.54 \mathrm{E}-07$ & $E+00$ & & & 8 & -06 \\
\hline $.00 \mathrm{E}+00$ & $5.42 \mathrm{E}-04$ & $8.20 E-07$ & $0.00 \mathrm{E}+00$ & $0.00 \mathrm{E}+00$ & $0.00 \mathrm{E}+00$ & $2 E-08$ & $8.98 E-06$ \\
\hline $.00 \mathrm{E}+00$ & $5.78 \mathrm{E}-04$ & $91 E-07$ & $0.00 \mathrm{E}+00$ & $0.00 \mathrm{E}+00$ & $.51 E-22$ & $E-08$ & $02 E-05$ \\
\hline$E+00$ & $6.15 \mathrm{E}-04$ & $7 F-0$ & $.00 E+00$ & 0 & -20 & -08 & $16 E-05$ \\
\hline & & & & $00 \mathrm{E}+$ & & & 05 \\
\hline $.00 \mathrm{E}+00$ & . 11 & ( & & & & & 05 \\
\hline $.00 E+00$ & 04 & 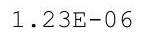 & $0 \mathrm{E}+00$ & & 5 & 7 & $E-05$ \\
\hline $.00 E+00$ & $15=$ & $33 F-0$ & $0.00 \mathrm{E}+00$ & $0 \mathrm{E}+$ & $265-$ & $D E-07$ & $86 E-05$ \\
\hline $.00 \mathrm{E}+00$ & $28 \mathrm{~F}-04$ & $143=0$ & $0.00 \mathrm{E}+00$ & $.00 \mathrm{E}+00$ & $02 \mathrm{E}-14$ & $29 \mathrm{E}-07$ & $07 E-05$ \\
\hline $00 E+00$ & $8.76 \mathrm{~F}-04$ & & $.00 E+00$ & & $98 E-14$ & $E-07$ & $30 E-05$ \\
\hline & & $E-06$ & & & & & $E-05$ \\
\hline & & & & & & & 05 \\
\hline $.00 \mathrm{E}+00$ & $1.03 E-03$ & 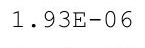 & $0.00 \mathrm{E}+00$ & . & $5.95 \mathrm{E}-12$ & $8.36 \mathrm{E}-07$ & $.18 E-05$ \\
\hline $.00 E+00$ & 3 & (ent & $0.00 \mathrm{E}+00$ & $0.00 \mathrm{E}+00$ & $68 E-11$ & $.02 E-06$ & $.54 E-05$ \\
\hline $00 \mathrm{E}+$ & 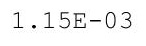 & $.22 E-06$ & & & & $1.24 \mathrm{E}-06$ & $94 E-05$ \\
\hline $.00 E+00$ & $21 \mathrm{~F}$ & $385-8010$ & $.00 E+00$ & $.00 E+00$ & & & $6 E-05$ \\
\hline 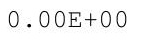 & 1. & & & & & & 05 \\
\hline & 1 . & & & & 10 & -06 & 05 \\
\hline $.00 \mathrm{E}+00$ & $1.42 \mathrm{E}-03$ & $2.9<\mathrm{L}-00$ & $0.00 \mathrm{E}+00$ & $0.00 \mathrm{E}+00$ & $6.51 \mathrm{E}-10$ & $2.49 E-06$ & $5.84 \mathrm{E}-05$ \\
\hline •. & 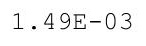 & 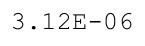 & & & & & $6.41 \mathrm{E}-05$ \\
\hline 皮 & 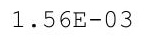 & $3.33 E-06$ & $0.00 \mathrm{E}+00$ & 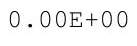 & 9 & & $02 E-05$ \\
\hline קח & 1 & $3.56 \mathrm{E}-06$ & $0.00 \mathrm{E}+00$ & $0.00 \mathrm{E}+00$ & & 6 & 05 \\
\hline $0 E+00$ & 1 & 6 & $0 E+00$ & $.00 E+00$ & 9 & 6 & 05 \\
\hline $0 \mathrm{E}+00$ & $1.81 \mathrm{E}-03$ & $E-06$ & $0.00 \mathrm{E}+00$ & $0.00 \mathrm{E}$ & -09 & 06 & \\
\hline $.00 \mathrm{E}+00$ & $1.89 \mathrm{E}-03$ & 4.3 & 0 & 0 & & 06 & $9.84 \mathrm{E}-05$ \\
\hline ט & I. & & & $.00 \mathrm{E}+00$ & & & $.06 \mathrm{E}-04$ \\
\hline 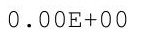 & $2.00 \mathrm{~L}-0 \mathrm{~s}$ & 1.0ta & $0.00 \mathrm{E}+00$ & $0.00 \mathrm{E}+00$ & $2.93 E-08$ & $9.73 E-06$ & $1.15 \mathrm{E}-04$ \\
\hline $00 E+00$ & $2.18 E-03$ & & $0.00 \mathrm{E}+00$ & & $4.11 \mathrm{E}-08$ & & $1.23 E-04$ \\
\hline $00 \mathrm{E}+0$ & & & $0.00 \mathrm{E}+00$ & $0.00 \mathrm{E}+00$ & $5.68 \mathrm{E}-08$ & $1.39 E-05$ & -04 \\
\hline $.00 E+00$ & $.38 E-03$ & $.83 E-06$ & $.00 \mathrm{E}+00$ & $.00 E+00$ & $.79 E-08$ & $7 E-05$ & 1. $41 E-04$ \\
\hline
\end{tabular}


RESRAD-OFFSITE, Version 2.5

obabilistic Dose and Risk Report

Title : Offsite Resident Farmer Deterministic Run

File : RF TC99 DOESG FWD-FV2.ROF

Summary of dose at graphical times, reptition 3 (continued)

Time

Years

1. $65 \mathrm{E}+02$

$1.66 \mathrm{E}+02$

$1.66 \mathrm{E}+02$

$1.67 \mathrm{E}+02$

1. $67 \mathrm{E}+02$

1. $68 \mathrm{E}+02$

1. $68 \mathrm{E}+02$

1. $69 \mathrm{E}+02$

1. $69 \mathrm{E}+02$

1. $70 \mathrm{E}+02$

1. $70 \mathrm{E}+02$

1. $71 \mathrm{E}+02$

1. $71 \mathrm{E}+02$

1. $72 \mathrm{E}+02$

1. $72 \mathrm{E}+02$

1. $73 \mathrm{E}+02$

1. $73 \mathrm{E}+02$

1. $74 \mathrm{E}+02$

1. $74 \mathrm{E}+02$

1. $75 \mathrm{E}+02$

1. $75 \mathrm{E}+02$

1. $76 \mathrm{E}+02$

$1.76 \mathrm{E}+02$

$1.77 \mathrm{E}+02$

1. $77 \mathrm{E}+02$

$1.78 \mathrm{E}+02$

$1.78 \mathrm{E}+02$

$1.79 \mathrm{E}+02$

$1.79 \mathrm{E}+02$

$1.80 \mathrm{E}+02$

$1.80 \mathrm{E}+02$

$1.81 \mathrm{E}+02$

$1.81 \mathrm{E}+02$

1. $82 \mathrm{E}+02$

1. $83 \mathrm{E}+02$

1. $83 \mathrm{E}+02$

1. $84 \mathrm{E}+02$

1. $84 \mathrm{E}+02$

1. $85 \mathrm{E}+02$

$1.85 \mathrm{E}+02$

$1.86 \mathrm{E}+02$

$1.86 \mathrm{E}+02$

$1.87 \mathrm{E}+02$

$1.87 \mathrm{E}+02$

$1.88 \mathrm{E}+02$

1. $88 \mathrm{E}+02$
Dose statistics at graphical times, mrem/yr

\begin{tabular}{|c|c|c|c|c|c|c|c|}
\hline $\mathrm{m}$ & aximum & lea & - & $0 \%$ & & $\%$ & \\
\hline $.00 \mathrm{E}+00$ & $2.49 \mathrm{E}-03$ & $6.19 \mathrm{E}-06$ & $0.00 \mathrm{E}+00$ & $00 \mathrm{E}+00$ & 07 & 05 & -04 \\
\hline+00 & $2.60 E-03$ & $6.56 \mathrm{E}-06$ & $0.00 \mathrm{E}+00$ & $0 \mathrm{E}+00$ & $52 E-07$ & $E-05$ & $51 E-04$ \\
\hline $.00 \mathrm{E}+00$ & $72 E-03$ & $5 E-06$ & $.00 E+00$ & $0.00 \mathrm{E}+00$ & $08 E-07$ & $24 E-05$ & $.72 E-04$ \\
\hline $00 \mathrm{E}+00$ & $84 E-03$ & $36 E-06$ & $.00 \mathrm{E}+00$ & $.00 \mathrm{E}+00$ & $268=-07$ & $50 F-05$ & $.84 \mathrm{E}-04$ \\
\hline+00 & -03 & 6 & 0 & & 7 & 5 & -04 \\
\hline $.00 E+00$ & & & & & & & 04 \\
\hline $.00 E+00$ & 03 & & & & & & -04 \\
\hline+00 & -03 & 6 & +00 & 0 & 7 & 5 & $36 E-04$ \\
\hline $.00 \mathrm{E}+00$ & $3.49 \mathrm{E}-03$ & -06 & $.00 \mathrm{E}+00$ & $.00 \mathrm{E}+00$ & $81 E-07$ & -05 & $51 E-04$ \\
\hline $.00 E+00$ & $64 E-03$ & $03 E-05$ & $.00 \mathrm{E}+00$ & $33 F-22$ & $11 \Gamma$ & קטק & $68 \mathrm{~F}-04$ \\
\hline $.00 E+00$ & 03 & 5 & & & & & 04 \\
\hline $.00 \mathrm{E}+00$ & -03 & 1 & & & 6 & 5 & -04 \\
\hline $.00 \mathrm{E}+00$ & $4.10 E-03$ & $1.20 \mathrm{E}-05$ & & & $2.03 E-06$ & & $3.25 E-04$ \\
\hline $.00 \mathrm{E}+00$ & $4.26 \mathrm{E}-03$ & $1.27 \mathrm{E}-05$ & $0.00 \mathrm{E}+00$ & $4.29 \mathrm{E}-16$ & 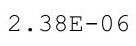 & 05 & $E-04$ \\
\hline+00 & -03 & -05 & & 5 & 7 & 3 & $E-04$ \\
\hline $.00 E+00$ & 03 & 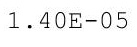 & -00 & 4 & 6 & 5 & -04 \\
\hline$E+00$ & 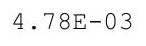 & & & & & & 4 \\
\hline $00 \mathrm{E}+00$ & 4 & $1.55 \mathrm{E}-05$ & & & $4.27 E-06$ & 5 & -04 \\
\hline $.00 \mathrm{E}+00$ & $5.15 \mathrm{E}-03$ & $1.63 E-05$ & $0.00 \mathrm{E}+00$ & $.32 E-12$ & $4.87 E-06$ & $7 E-05$ & $4.39 E-04$ \\
\hline $.00 \mathrm{E}+00$ & $35 E-03$ & $.71 \mathrm{E}-05$ & $0.00 \mathrm{E}+00$ & $0 E-12$ & $5.61 \mathrm{E}-$ & -05 & 4. $59 \mathrm{E}-04$ \\
\hline $.00 \mathrm{E}+00$ & & & & & & -04 & $E-04$ \\
\hline $.00 E+00$ & -03 & $1 \cdot 0$ & $.00 \mathrm{E}+00$ & 1 & 6 & 04 & -04 \\
\hline $.00 E+00$ & 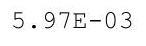 & $1.98 \mathrm{E}-05$ & $.00 \mathrm{E}+00$ & & & 4 & 04 \\
\hline $00 \mathrm{E}+00$ & 3 & 5 & > & 0 & $9.16 \mathrm{E}-06$ & 4 & -04 \\
\hline $.00 E+00$ & 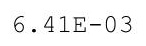 & $.18 E-05$ & & $20 E-10$ & 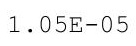 & $B E-$ & $72 E-04$ \\
\hline $0 \cap \mathrm{F}+0 \cap 0$ & $64 \mathrm{~F}-03$ & $.28 E-05$ & $0.00 \mathrm{E}+00$ & $66 \mathrm{E}-10$ & $1.17 \mathrm{E}-$ & $.46 E-04$ & $.06 \mathrm{E}-04$ \\
\hline $.00 \mathrm{E}+00$ & $87 E-03$ & $39 E-05$ & $.00 \mathrm{E}+00$ & $1.35 \mathrm{E}-09$ & & $E-04$ & $46 E-04$ \\
\hline $0 E+00$ & & & & & & & \\
\hline $.00 \mathrm{E}+00$ & $7.37 \mathrm{E}-03$ & $2.025-03$ & $0.00 \mathrm{E}+00$ & 0.18 & 有 & & $34 \mathrm{E}-04$ \\
\hline $.00 \mathrm{E}+00$ & $1.025-03$ & $2.13 \pm-03$ & $0.00 \mathrm{E}+00$ & $6.05 E-09$ & 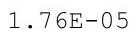 & $1.015-04$ & $.74 E-04$ \\
\hline $.00 \mathrm{E}+00$ & 3 & $2.01 \mathrm{H}$ & $0.00 \mathrm{E}+00$ & $9.46 \mathrm{E}-09$ & $=0$ & -04 & $.09 E-04$ \\
\hline $.00 \mathrm{E}+0$ & 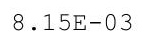 & & & & & $D E-04$ & $45 E-04$ \\
\hline $.00 E+00$ & $8.43 E-03$ & & & & & -04 & 04 \\
\hline $\mathrm{E}+00$ & 3 & & & & & & \\
\hline $00 E+00$ & $9.00 \mathrm{E}-03$ & $3.43 E-05$ & $0.00 \mathrm{E}+00$ & 08 & 5 & & $E-04$ \\
\hline $00 \mathrm{E}+00$ & $9.30 \mathrm{E}-03$ & $3.58 E-05$ & $.00 \mathrm{E}+00$ & $\cdot 021$ & 5.20 & & $.97 E-04$ \\
\hline 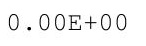 & . & $3.74 \mathrm{E}-05$ & & & & & $1.045-03$ \\
\hline ( & 3 & 5 & $0.00 \mathrm{E}+00$ & $13 E-07$ & & 2.00 & 03 \\
\hline $00 \mathrm{E}+0 \mathrm{C}$ & $1.02 \mathrm{E}-02$ & 5 & $0.00 \mathrm{E}+00$ & $+x^{2}$ & & & 03 \\
\hline & 2 & 5 & $0.00 \mathrm{E}+00$ & 7 & 5 & 3. & 03 \\
\hline $0 \mathrm{E}+00$ & $1.09 \mathrm{E}-02$ & $2 E-05$ & .0 & 7 & 5 & 4 & 03 \\
\hline$E+00$ & $1.13 \mathrm{E}$ & & & & & & \\
\hline טע山 & & & & & & & $3 \perp E-U 3$ \\
\hline $00 \mathrm{E}+00$ & $1 . \angle U E-U \angle$ & $5.00 E-05$ & $0.00 \mathrm{E}+00$ & $5.03 E-07$ & $6.83 E-05$ & $3.86 \mathrm{E}-04$ & $1.30 \mathrm{E}-03$ \\
\hline $.00 \mathrm{E}+00$ & $1.23 E-02$ & $\cdot 2 \perp+$ & $0.00 \mathrm{E}+00$ & $6.45 \mathrm{E}-07$ & $1.40 \mathrm{~L}$ & & $1.41 \mathrm{E}-03$ \\
\hline$E+00$ & $1.27 \mathrm{E}-02$ & $2 E-05$ & $.00 \mathrm{E}+00$ & $.18 \mathrm{E}-07$ & -05 & 4. & $1.47 \mathrm{E}$ \\
\hline
\end{tabular}


RESRAD-OFFSITE, Version 2.5

itle : Offsite Resident Farmer Deterministic Run

File : RF TC99 DOESG FWD-FV2.ROF

Summary of dose at graphical times, reptition 3 (continued)

Time

Years

$1.89 \mathrm{E}+02$

$1.89 \mathrm{E}+02$

1. $90 \mathrm{E}+02$

1. $90 \mathrm{E}+02$

1. $91 \mathrm{E}+02$

1. $91 \mathrm{E}+02$

1. $92 \mathrm{E}+02$

1. $92 \mathrm{E}+02$

$1.93 \mathrm{E}+02$

1. $93 \mathrm{E}+02$

$1.94 \mathrm{E}+02$

$1.94 \mathrm{E}+02$

1. $95 \mathrm{E}+02$

1. $95 \mathrm{E}+02$

1. $96 \mathrm{E}+02$

1. $96 \mathrm{E}+02$

1. $97 \mathrm{E}+02$

$1.97 \mathrm{E}+02$

$1.98 \mathrm{E}+02$

$1.98 \mathrm{E}+02$

1. $99 \mathrm{E}+02$

$1.99 \mathrm{E}+02$

$2.00 \mathrm{E}+02$

$2.00 \mathrm{E}+02$

$2.01 \mathrm{E}+02$

$2.01 \mathrm{E}+02$

$2.02 \mathrm{E}+02$

$2.03 \mathrm{E}+02$

$2.03 E+02$

$2.04 \mathrm{E}+02$

$2.04 \mathrm{E}+02$

$2.05 \mathrm{E}+02$

$2.05 \mathrm{E}+02$

$2.06 \mathrm{E}+02$

$2.06 \mathrm{E}+02$

$2.07 \mathrm{E}+02$

$2.07 \mathrm{E}+02$

$2.08 \mathrm{E}+02$

$2.08 \mathrm{E}+02$

$2.09 \mathrm{E}+02$

$2.09 \mathrm{E}+02$

$2.10 \mathrm{E}+02$

$2.10 \mathrm{E}+02$

$2.11 \mathrm{E}+02$

2. $11 \mathrm{E}+02$

$2.12 \mathrm{E}+02$
Dose statistics at graphical times, mrem/yr

\begin{tabular}{|c|c|c|c|c|c|c|c|}
\hline $\mathrm{m}$ & aximum & lea & ed & $0 \%$ & & & \\
\hline $.00 \mathrm{E}+00$ & 1. $31 \mathrm{E}-02$ & $5.64 \mathrm{E}-05$ & $0.00 \mathrm{E}+00$ & $1.03 E-06$ & 5 & 04 & $.32 \mathrm{E}-03$ \\
\hline $.00 \mathrm{E}+00$ & $1.35 E-02$ & $5.87 \mathrm{E}-05$ & $0 E+00$ & $28 E-06$ & $20 E-05$ & $61 E-04$ & $8 E-03$ \\
\hline $.00 \mathrm{E}+00$ & $39 E-02$ & $1 F-05$ & $.00 \mathrm{E}+00$ & $56 E-06$ & $76 E-05$ & $82 E-04$ & $5 E-03$ \\
\hline $00 \mathrm{E}+00$ & $43 E-02$ & $35 \mathrm{~F}-05$ & $.00 \mathrm{E}+00$ & $.86 \mathrm{E}-06$ & $04 \mathrm{~F}-04$ & $05 E-04$ & $72 \mathrm{~F}-03$ \\
\hline $.00 \mathrm{E}+00$ & $1.47 \mathrm{~F}$ & $6.60 \mathrm{E}-05$ & & 6 & 4 & 4 & -03 \\
\hline $.00 E+00$ & $1.52 \mathrm{E}-02$ & & & & & & 03 \\
\hline $.00 E+00$ & $1.56 \mathrm{E}-02$ & & & & 4 & & \\
\hline $.00 \mathrm{E}+00$ & -02 & 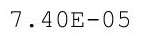 & +00 & 06 & 4 & -04 & -03 \\
\hline $\mathrm{E}+00$ & $1.65 \mathrm{E}-02$ & $3 F-0-2-2$ & $.00 \mathrm{E}+00$ & $4 E-06$ & $46 E-04$ & -04 & $12 E-03$ \\
\hline $.00 E+00$ & $.70 \mathrm{E}-02$ & 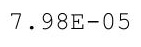 & $.00 \mathrm{E}+00$ & $.19 \mathrm{E}-06$ & 5 & $.53 E-04$ & $21 E-03$ \\
\hline $.00 E+00$ & 1.75 & & & & & 4 & 03 \\
\hline $.00 \mathrm{E}+00$ & $1.80 \mathrm{E}-02$ & 8 & & 6 & $1.74 \mathrm{E}-$ & 4 & 03 \\
\hline $.00 \mathrm{E}+00$ & $1.85 \mathrm{E}-02$ & & & & & $E-04$ & $9 E-03$ \\
\hline $.00 \mathrm{E}+00$ & $E-02$ & $9.24 \mathrm{E}-0$ & $0.00 \mathrm{E}+00$ & $8.37 \mathrm{E}-06$ & $1.96 \mathrm{E}-$ & -04 & $2.59 \mathrm{E}-03$ \\
\hline+00 & $E-02$ & $3 F-6 \cdot 2-25$ & $E+00$ & $1 E-06$ & 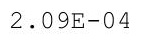 & -04 & $E-03$ \\
\hline $.00 E+00$ & $2.00 \mathrm{E}-02$ & . $92 \square$ & 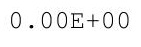 & 5 & \pm & 4 & 03 \\
\hline$E+00$ & 2 & $1.03 E-04$ & & & & & 3 \\
\hline $00 \mathrm{E}+00$ & 2 & & & 5 & $2.50 \mathrm{E}-04$ & 4 & 3 \\
\hline $.00 E+00$ & $.17 \mathrm{E}-02$ & م 10 & $0 \mathrm{E}+00$ & $.47 E-05$ & 650 & $7 E-04$ & $2 E-03$ \\
\hline $.00 \mathrm{E}+00$ & $2.23 \mathrm{E}-02$ & $1.14 \mathrm{E}-0$ & $0.00 \mathrm{E}+00$ & $1.60 \mathrm{E}-05$ & $2.80 \mathrm{E}-$ & $2 E-03$ & $24 E-03$ \\
\hline $\mathrm{E}+00$ & -02 & & & & & -03 & $E-03$ \\
\hline $\mathrm{E}+00$ & & & & & & & \\
\hline $00 E+00$ & $2 \cdot 4$ & 1.2 & & 5 & & & \\
\hline $.00 \mathrm{E}+00$ & 2 & $\perp$ & $.00 \mathrm{E}+00$ & 5 & & 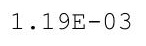 & 3 \\
\hline $00 \mathrm{E}+00$ & 2 & . & $0.00 \mathrm{E}+00$ & 5 & $3.59 \mathrm{E}-04$ & 3 & 3 \\
\hline $.00 \mathrm{E}+00$ & $.60 \mathrm{E}-02$ & 1 & $0.00 \mathrm{E}+00$ & 67 ח & 70 & $.28 E-03$ & $93 F-03$ \\
\hline $.00 \mathrm{E}+00$ & $2.66 \mathrm{E}-02$ & & & & & $.34 E-03$ & $05 E-03$ \\
\hline & 02 & & & & & & \\
\hline $0 \mathrm{E}+00$ & $2.80 \mathrm{E}-02$ & $1.30 \mathrm{E}$ & $0.00 \mathrm{E}+00$ & 0.00 & 4 & & \\
\hline $.00 \mathrm{E}+00$ & $2.87 \mathrm{E}-02$ & $1.00 \mathrm{~L}-04$ & $0.00 \mathrm{E}+00$ & $3.62 E-05$ & 1. & $1.52 \mathrm{E}-03$ & $4.40 \mathrm{E}-03$ \\
\hline $.00 \mathrm{E}+00$ & $2.94 \mathrm{E}-02$ & $+\cdot 0-1$ & $0.00 \mathrm{E}+00$ & . & . & 1.29L-0 & $.53 E-03$ \\
\hline $.00 \mathrm{E}+00$ & 0 & 5 & & 5 & 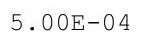 & 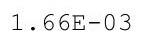 & \\
\hline $.00 E+00$ & & & & & & & 03 \\
\hline & -02 & 18 & & & & & \\
\hline $\mathrm{E}+00$ & $3.24 \mathrm{E}-02$ & 1. & 0 & 5 & & & 03 \\
\hline $.00 \mathrm{E}+00$ & $3.32 E-02$ & $1.95 E-04$ & $.00 \mathrm{E}+00$ & $3.04 \omega$ & $0.90 \mathrm{t}$ & -03 & $9 E-03$ \\
\hline $.00 E+00$ & $3.39 E-02$ & $2 \cdot 000$ - & $0.00 \mathrm{E}+00$ & $6.09 \mathrm{E}-05$ & & & $3.300-0$ \\
\hline $00 \mathrm{E}+00$ & $3.47 \mathrm{E}-02$ & & $0.00 \mathrm{E}+00$ & & & & $48 E-03$ \\
\hline+ & 2 & - & $0.00 \mathrm{E}+00$ & 5 & . & 3 & 3 \\
\hline $00 \mathrm{E}+00$ & 2 & & & 5 & 4 & 3 & 03 \\
\hline$O E+00$ & $3.72 \mathrm{E}-02$ & $2.26 \mathrm{E}-04$ & $0.00 \mathrm{E}+00$ & $7.81 \mathrm{E}-05$ & 4 & $0 E-03$ & -03 \\
\hline$E+00$ & $3.81 E-02$ & 2.3 & & & 4 & & 03 \\
\hline & $3.90 \mathrm{E}-02$ & & & & & & \\
\hline $.00 E+00$ & $3.98 \mathrm{E}-02$ & ent & $0.00 \mathrm{E}+00$ & e. & $\cdot \pm \perp$ & $2.56 \mathrm{E}-03$ & $.0 .40-05$ \\
\hline $.00 E+00$ & $4.012-02$ & 2.010 & $0.00 \mathrm{E}+00$ & 土. & & & $0.012-U 3$ \\
\hline $0 \mathrm{E}+00$ & $E-02$ & $62 E-04$ & $.00 \mathrm{E}+00$ & $E-04$ & $3 E-04$ & 03 & 03 \\
\hline
\end{tabular}


RESRAD-OFFSITE, Version 2.5

obabilistic Dose and Risk Report

Title : Offsite Resident Farmer Deterministic Run

File : RF TC99 DOESG FWD-FV2.ROF

Summary of dose at graphical times, reptition 3 (continued)

Time

Years

$2.12 \mathrm{E}+02$

$2.13 \mathrm{E}+02$

$2.13 \mathrm{E}+02$

$2.14 \mathrm{E}+02$

$2.14 \mathrm{E}+02$

$2.15 \mathrm{E}+02$

$2.15 \mathrm{E}+02$

$2.16 \mathrm{E}+02$

$2.16 \mathrm{E}+02$

$2.17 \mathrm{E}+02$

$2.17 \mathrm{E}+02$

$2.18 \mathrm{E}+02$

$2.18 \mathrm{E}+02$

$2.19 \mathrm{E}+02$

$2.19 \mathrm{E}+02$

$2.20 \mathrm{E}+02$

2. $20 \mathrm{E}+02$

$2.21 \mathrm{E}+02$

2. $21 E+02$

2. $22 \mathrm{E}+02$

$2.23 E+02$

$2.23 E+02$

$2.24 \mathrm{E}+02$

$2.24 \mathrm{E}+02$

2. $25 \mathrm{E}+02$

$2.25 \mathrm{E}+02$

2. $26 \mathrm{E}+02$

$2.26 \mathrm{E}+02$

$2.27 \mathrm{E}+02$

$2.27 \mathrm{E}+02$

2. $28 \mathrm{E}+02$

$2.28 \mathrm{E}+02$

$2.29 \mathrm{E}+02$

2. $29 \mathrm{E}+02$

2. $30 E+02$

2. $30 E+02$

$2.31 \mathrm{E}+02$

2. $31 E+02$

2. $32 \mathrm{E}+02$

2. $32 E+02$

$2.33 E+02$

2. $33 \mathrm{E}+02$

$2.34 \mathrm{E}+02$

2. $34 \mathrm{E}+02$

$2.35 E+02$

$2.35 \mathrm{E}+02$

Dose statistics at graphical times, mrem/yr

\begin{tabular}{|c|c|c|c|c|c|c|c|}
\hline Minimum & Maximum & Mean & Median & $90 \%$ & $95 \%$ & $97.5 \%$ & $99 \%$ \\
\hline $0.00 \mathrm{E}+00$ & $4.26 \mathrm{E}-02$ & $2.70 E-04$ & $0.00 \mathrm{E}+00$ & 1. $18 \mathrm{E}-04$ & $9.09 E-04$ & $2.84 E-03$ & $6.91 E-03$ \\
\hline $0.00 \mathrm{E}+00$ & $4.35 E-02$ & $2.78 E-04$ & $0.00 \mathrm{E}+00$ & $1.25 E-04$ & $9.49 \mathrm{E}-04$ & $2.93 E-03$ & $7.08 E-03$ \\
\hline $0.00 \mathrm{E}+00$ & $4.45 E-02$ & $2.86 E-04$ & $0.00 \mathrm{E}+00$ & $1.33 E-04$ & $9.89 \mathrm{E}-04$ & $3.03 E-03$ & $7.26 \mathrm{E}-03$ \\
\hline $0.00 \mathrm{E}+00$ & $4.55 \mathrm{E}-02$ & $2.94 \mathrm{E}-04$ & $0.00 \mathrm{E}+00$ & $1.41 \mathrm{E}-04$ & $1.03 \mathrm{E}-03$ & $3.12 \mathrm{E}-03$ & $7.44 \mathrm{E}-03$ \\
\hline $0.00 \mathrm{E}+00$ & $4.64 \mathrm{E}-02$ & $3.03 E-04$ & $0.00 \mathrm{E}+00$ & 1. $49 \mathrm{E}-04$ & $1.07 \mathrm{E}-03$ & $3.21 \mathrm{E}-03$ & $7.63 E-03$ \\
\hline $0.00 \mathrm{E}+00$ & $4.75 E-02$ & $3.11 \mathrm{E}-04$ & $0.00 \mathrm{E}+00$ & 1. 59E-04 & $1.11 \mathrm{E}-03$ & $3.31 E-03$ & $7.82 \mathrm{E}-03$ \\
\hline $0.00 \mathrm{E}+00$ & $4.85 E-02$ & $3.20 E-04$ & $0.00 \mathrm{E}+00$ & $1.68 \mathrm{E}-04$ & $1.15 \mathrm{E}-03$ & $3.41 \mathrm{E}-03$ & $8.01 \mathrm{E}-03$ \\
\hline $0.00 \mathrm{E}+00$ & $4.95 \mathrm{E}-02$ & $3.29 E-04$ & $0.00 E+00$ & $1.77 E-04$ & $1.20 \mathrm{E}-03$ & $3.51 E-03$ & $8.20 E-03$ \\
\hline $0.00 \mathrm{E}+00$ & $5.06 \mathrm{E}-02$ & $3.39 E-04$ & $0.00 \mathrm{E}+00$ & $1.86 \mathrm{E}-04$ & $1.24 \mathrm{E}-03$ & $3.61 \mathrm{E}-03$ & $8.40 E-03$ \\
\hline $.00 \mathrm{E}+00$ & $5.16 \mathrm{E}-02$ & $3.48 E-04$ & $0.00 \mathrm{E}+00$ & $1.98 \mathrm{E}-04$ & $1.28 \mathrm{E}-03$ & $3.73 E-03$ & 8. $60 \mathrm{E}-03$ \\
\hline $0.00 \mathrm{E}+00$ & $5.27 \mathrm{E}-02$ & $3.58 \mathrm{E}-04$ & $0.00 \mathrm{E}+00$ & $2.09 E-04$ & $1.32 \mathrm{E}-03$ & $3.85 \mathrm{E}-03$ & $8.81 \mathrm{E}-03$ \\
\hline $0.00 \mathrm{E}+00$ & $5.38 \mathrm{E}-02$ & $3.68 \mathrm{E}-04$ & $0.00 \mathrm{E}+00$ & $2.18 \mathrm{E}-04$ & $1.36 \mathrm{E}-03$ & $3.98 E-03$ & $9.02 \mathrm{E}-03$ \\
\hline $0.00 \mathrm{E}+00$ & $5.49 \mathrm{E}-02$ & $3.78 \mathrm{E}-04$ & $0.00 \mathrm{E}+00$ & $2.27 E-04$ & $1.41 \mathrm{E}-03$ & $4.10 \mathrm{E}-03$ & $9.23 E-03$ \\
\hline $0.00 \mathrm{E}+00$ & $5.60 \mathrm{E}-02$ & $3.88 \mathrm{E}-04$ & $0.00 \mathrm{E}+00$ & $2.36 \mathrm{E}-04$ & $1.45 \mathrm{E}-03$ & $4.23 E-03$ & $9.45 E-03$ \\
\hline $0.00 \mathrm{E}+00$ & $5.72 \mathrm{E}-02$ & $3.99 \mathrm{E}-04$ & $0.00 \mathrm{E}+00$ & $2.46 \mathrm{E}-04$ & $1.49 \mathrm{E}-03$ & $4.36 \mathrm{E}-03$ & $9.67 \mathrm{E}-03$ \\
\hline $0.00 \mathrm{E}+00$ & $5.84 \mathrm{E}-02$ & $4.10 E-04$ & $0 E+00$ & $2.56 E-04$ & $1.54 \mathrm{E}-03$ & $.48 E-03$ & $.89 E-03$ \\
\hline $0.00 \mathrm{E}+00$ & $5.95 \mathrm{E}-02$ & $4.21 \mathrm{E}-04$ & $0.00 \mathrm{E}+00$ & $2.66 \mathrm{E}-04$ & $1.59 \mathrm{E}-03$ & $4.60 \mathrm{E}-03$ & $1.01 \mathrm{E}-02$ \\
\hline $0.00 \mathrm{E}+00$ & $6.07 \mathrm{E}-02$ & 4. $32 E-04$ & $0.00 \mathrm{E}+00$ & $2.76 \mathrm{E}-04$ & $1.64 \mathrm{E}-03$ & $4.72 E-03$ & $1.04 \mathrm{E}-02$ \\
\hline $0.00 \mathrm{E}+00$ & $6.19 \mathrm{E}-02$ & $4.44 E-04$ & $0.00 \mathrm{E}+00$ & $2.87 E-04$ & $1.70 \mathrm{E}-03$ & $4.85 E-03$ & $1.06 \mathrm{E}-02$ \\
\hline $0.00 \mathrm{E}+00$ & $6.32 \mathrm{E}-02$ & $4.56 \mathrm{E}-04$ & $0.00 \mathrm{E}+00$ & $2.98 E-04$ & $1.76 \mathrm{E}-03$ & $4.97 \mathrm{E}-03$ & $1.08 \mathrm{E}-02$ \\
\hline $0.00 \mathrm{E}+00$ & $6.44 \mathrm{E}-02$ & $4.68 E-04$ & $0.00 \mathrm{E}+00$ & $3.09 \mathrm{E}-04$ & $1.84 \mathrm{E}-03$ & $5.11 \mathrm{E}-03$ & $1.11 \mathrm{E}-02$ \\
\hline $0.00 \mathrm{E}+00$ & $6.57 \mathrm{E}-02$ & $4.80 E-04$ & $0.00 \mathrm{E}+00$ & $3.21 E-04$ & $1.91 \mathrm{E}-03$ & $.25 E-03$ & $1.14 \mathrm{E}-02$ \\
\hline $0.00 \mathrm{E}+00$ & $6.70 \mathrm{E}-02$ & $4.93 E-04$ & $0.00 \mathrm{E}+00$ & $3.33 E-04$ & $1.98 \mathrm{E}-03$ & $5.40 \mathrm{E}-03$ & $1.16 \mathrm{E}-02$ \\
\hline $0.00 \mathrm{E}+00$ & $6.83 E-02$ & $5.05 E-04$ & $0.00 \mathrm{E}+00$ & $3.45 E-04$ & $2.06 \mathrm{E}-03$ & $5.54 \mathrm{E}-03$ & $1.19 \mathrm{E}-02$ \\
\hline $0.00 \mathrm{E}+00$ & $6.96 \mathrm{E}-02$ & $5.19 \mathrm{E}-04$ & $0.00 \mathrm{E}+00$ & $3.59 \mathrm{E}-04$ & $2.14 \mathrm{E}-03$ & $5.68 \mathrm{E}-03$ & 1. $22 \mathrm{E}-02$ \\
\hline $0.00 \mathrm{E}+00$ & $7.09 \mathrm{E}-02$ & $5.32 E-04$ & $0.00 \mathrm{E}+00$ & $3.74 \mathrm{E}-04$ & $2.22 \mathrm{E}-03$ & $5.83 E-03$ & $1.25 \mathrm{E}-02$ \\
\hline $0.00 \mathrm{E}+00$ & $7.22 \mathrm{E}-02$ & $5.46 \mathrm{E}-04$ & $0.00 \mathrm{E}+00$ & $3.92 \mathrm{E}-04$ & $2.30 \mathrm{E}-03$ & $5.97 \mathrm{E}-03$ & 1. $28 \mathrm{E}-02$ \\
\hline $0.00 \mathrm{E}+00$ & $7.36 \mathrm{E}-02$ & $5.59 \mathrm{E}-04$ & $0.00 \mathrm{E}+00$ & $4.12 E-04$ & $2.37 E-03$ & $6.12 \mathrm{E}-03$ & $1.31 E-02$ \\
\hline $0.00 \mathrm{E}+00$ & $7.50 \mathrm{E}-02$ & $5.74 \mathrm{E}-04$ & $0.00 \mathrm{E}+00$ & $4.32 E-04$ & $2.43 E-03$ & $6.27 E-03$ & $1.34 \mathrm{E}-02$ \\
\hline $0.00 \mathrm{E}+00$ & $7.64 \mathrm{E}-02$ & $5.88 E-04$ & $0.00 \mathrm{E}+00$ & $4.53 E-04$ & $2.50 \mathrm{E}-03$ & $6.43 E-03$ & $1.37 \mathrm{E}-02$ \\
\hline $0.00 \mathrm{E}+00$ & $7.78 \mathrm{E}-02$ & $6.03 E-04$ & $0.00 \mathrm{E}+00$ & $4.75 E-04$ & $2.56 \mathrm{E}-03$ & $6.59 \mathrm{E}-03$ & $1.40 \mathrm{E}-02$ \\
\hline $0.00 \mathrm{E}+00$ & $7.93 E-02$ & $6.18 \mathrm{E}-04$ & $0.00 \mathrm{E}+00$ & $4.97 E-04$ & $2.63 E-03$ & $6.75 E-03$ & $1.43 E-02$ \\
\hline $0.00 \mathrm{E}+00$ & $8.07 E-02$ & $6.33 E-04$ & $0.00 \mathrm{E}+00$ & $5.20 E-04$ & $2.70 \mathrm{E}-03$ & $6.91 E-03$ & $1.47 \mathrm{E}-02$ \\
\hline $0.00 \mathrm{E}+00$ & $8.22 \mathrm{E}-02$ & $6.49 \mathrm{E}-04$ & $0.00 \mathrm{E}+00$ & $5.44 E-04$ & $2.77 \mathrm{E}-03$ & $7.08 E-03$ & $1.50 \mathrm{E}-02$ \\
\hline $0.00 \mathrm{E}+00$ & $8.37 \mathrm{E}-02$ & $6.65 E-04$ & $0.00 \mathrm{E}+00$ & $5.65 E-04$ & $2.85 E-03$ & $7.25 \mathrm{E}-03$ & $1.53 \mathrm{E}-02$ \\
\hline $0.00 \mathrm{E}+00$ & $8.52 \mathrm{E}-02$ & $6.81 E-04$ & $0.00 \mathrm{E}+00$ & $5.86 \mathrm{E}-04$ & $2.93 E-03$ & $7.42 \mathrm{E}-03$ & $1.57 \mathrm{E}-02$ \\
\hline $0.00 \mathrm{E}+00$ & $8.67 \mathrm{E}-02$ & $6.97 E-04$ & $0.00 \mathrm{E}+00$ & $6.07 E-04$ & $3.01 \mathrm{E}-03$ & $7.58 \mathrm{E}-03$ & $1.60 \mathrm{E}-02$ \\
\hline $0.00 \mathrm{E}+00$ & $8.83 E-02$ & $7.14 \mathrm{E}-04$ & $0.00 \mathrm{E}+00$ & $6.39 \mathrm{E}-04$ & $3.09 \mathrm{E}-03$ & $7.75 \mathrm{E}-03$ & $1.64 \mathrm{E}-02$ \\
\hline $00 E+00$ & $8.98 \mathrm{E}-$ & $7.31 \mathrm{E}-04$ & $0.00 \mathrm{E}+00$ & $6.62 \mathrm{E}-04$ & $3.18 E-03$ & $7.91 \mathrm{E}-03$ & $1.67 \mathrm{E}-02$ \\
\hline $0.00 \mathrm{E}+00$ & $9.14 \mathrm{E}-02$ & $7.49 E-04$ & $0.00 \mathrm{E}+00$ & $6.82 E-04$ & $3.26 \mathrm{E}-03$ & $8.08 E-03$ & 1. $71 \mathrm{E}-02$ \\
\hline $0.00 \mathrm{E}+00$ & $9.30 \mathrm{E}-02$ & $7.67 \mathrm{E}-04$ & $0.00 \mathrm{E}+00$ & $7.09 \mathrm{E}-04$ & $3.35 \mathrm{E}-03$ & $8.25 E-03$ & 1. $75 \mathrm{E}-02$ \\
\hline $0.00 \mathrm{E}+00$ & $9.46 \mathrm{E}-02$ & $7.85 E-04$ & $0.00 \mathrm{E}+00$ & $7.40 E-04$ & $3.44 \mathrm{E}-03$ & $8.43 E-03$ & $1.78 \mathrm{E}-02$ \\
\hline $0.00 \mathrm{E}+00$ & $9.63 \mathrm{E}-02$ & $8.03 E-04$ & $0.00 \mathrm{E}+00$ & $7.74 \mathrm{E}-04$ & $3.54 \mathrm{E}-03$ & $8.61 \mathrm{E}-03$ & $1.82 \mathrm{E}-02$ \\
\hline $0.00 \mathrm{E}+00$ & $9.79 \mathrm{E}-02$ & $8.22 E-04$ & $0.00 \mathrm{E}+00$ & $8.06 E-04$ & $3.63 E-03$ & $8.79 E-03$ & $1.86 \mathrm{E}-02$ \\
\hline $0.00 \mathrm{E}+00$ & $9.96 \mathrm{E}-02$ & $8.41 E-04$ & $0.00 E+00$ & $8.47 E-04$ & $3.72 E-03$ & $8.97 E-03$ & $1.90 \mathrm{E}-02$ \\
\hline $0.00 \mathrm{E}+00$ & $1.01 \mathrm{E}-01$ & $8.61 \mathrm{E}-04$ & $0.00 \mathrm{E}+00$ & $8.83 E-04$ & $3.81 \mathrm{E}-03$ & $9.16 \mathrm{E}-03$ & $1.94 \mathrm{E}-02$ \\
\hline
\end{tabular}


RESRAD-OFFSITE, Version 2.5

obabilistic Dose and Risk Report

Title : Offsite Resident Farmer Deterministic Run

File : RF TC99 DOESG FWD-FV2.ROF

Summary of dose at graphical times, reptition 3 (continued)

Time

Years

$2.36 \mathrm{E}+02$

$2.36 \mathrm{E}+02$

$2.37 \mathrm{E}+02$

2. $37 \mathrm{E}+02$

$2.38 \mathrm{E}+02$

$2.38 \mathrm{E}+02$

$2.39 \mathrm{E}+02$

2. $39 \mathrm{E}+02$

$2.40 \mathrm{E}+02$

$2.40 E+02$

2. $41 \mathrm{E}+02$

2. $41 \mathrm{E}+02$

2. $42 \mathrm{E}+02$

$2.43 E+02$

2. $43 \mathrm{E}+02$

2. $44 \mathrm{E}+02$

2. $44 \mathrm{E}+02$

$2.45 \mathrm{E}+02$

2. $45 \mathrm{E}+02$

2. $46 \mathrm{E}+02$

$2.46 \mathrm{E}+02$

$2.47 \mathrm{E}+02$

$2.47 \mathrm{E}+02$

2. $48 \mathrm{E}+02$

2. $48 \mathrm{E}+02$

2. $49 \mathrm{E}+02$

2. $49 \mathrm{E}+02$

$2.50 \mathrm{E}+02$

2. $50 \mathrm{E}+02$

2. $51 \mathrm{E}+02$

2. $51 \mathrm{E}+02$

2. $52 \mathrm{E}+02$

$2.52 \mathrm{E}+02$

2. $53 \mathrm{E}+02$

$2.53 \mathrm{E}+02$

$2.54 \mathrm{E}+02$

$2.54 \mathrm{E}+02$

$2.55 \mathrm{E}+02$

2. $55 \mathrm{E}+02$

$2.56 \mathrm{E}+02$

$2.56 \mathrm{E}+02$

$2.57 \mathrm{E}+02$

$2.57 \mathrm{E}+02$

$2.58 \mathrm{E}+02$

$2.58 \mathrm{E}+02$

$2.59 \mathrm{E}+02$
Dose statistics at graphical times, mrem/yr

\begin{tabular}{|c|c|c|c|c|c|c|c|}
\hline $\mathrm{m}$ & aximum & e & ed & & & & \\
\hline $.00 \mathrm{E}+00$ & $1.03 E-01$ & 04 & $0.00 \mathrm{E}+00$ & 4 & 3 & 03 & $\cdot 90 \mathrm{E}-\mathrm{U}$ \\
\hline $.00 \mathrm{E}+00$ & $1.05 E-01$ & $1 E-04$ & $0.00 \mathrm{E}+00$ & $6 \mathrm{E}-04$ & $0 E-03$ & $E-03$ & $02 E-02$ \\
\hline $.00 \mathrm{E}+00$ & $07 E-01$ & $21 \mathrm{~F}-04$ & $.00 \mathrm{E}+00$ & $79 E-04$ & $10 E-03$ & $73 E-03$ & $.06 \mathrm{E}-02$ \\
\hline $00 \mathrm{E}+00$ & $08 E-01$ & $42 \mathrm{~F}-04$ & $.00 \mathrm{E}+00$ & $01 \mathrm{~F}-03$ & $20 F-03$ & -03 & $.11 \mathrm{E}-02$ \\
\hline $.00 \mathrm{E}+00$ & -01 & 4 & & 3 & 3 & 2 & -02 \\
\hline $.00 \mathrm{E}+00$ & & & & & & & -02 \\
\hline $.00 E+00$ & $1.14 \mathrm{E}-01$ & & & & & & $E-02$ \\
\hline+00 & 01 & 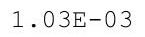 & +00 & 3 & 3 & -02 & $E-02$ \\
\hline $.00 \mathrm{E}+00$ & $1.17 \mathrm{E}-01$ & -0 & $.00 \mathrm{E}+00$ & 3 & te & -02 & $34 \mathrm{E}-02$ \\
\hline $.00 E+00$ & $19 \mathrm{E}-01$ & תم: תم & $.00 \mathrm{E}+00$ & תח & תרים & $.12 \mathrm{E}-02$ & $.39 E-02$ \\
\hline $.00 E+00$ & 1.21 & & & & & & -02 \\
\hline $.00 \mathrm{E}+00$ & $1.23 \mathrm{E}-01$ & 1 & & 3 & & 2 & -02 \\
\hline $.00 \mathrm{E}+00$ & $1.25 \mathrm{E}-01$ & $1.15 \mathrm{E}-03$ & & $1.34 E-03$ & & $1.19 \mathrm{E}-02$ & $E-02$ \\
\hline $.00 \mathrm{E}+00$ & $1.27 \mathrm{E}-01$ & $1.17 \mathrm{E}-03$ & & 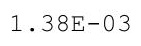 & & -02 & $E-02$ \\
\hline$\Xi+00$ & $E-01$ & 它 & 0 & 3 & 3 & -02 & $E-02$ \\
\hline $.00 \mathrm{E}+00$ & 01 & $\perp \cdot 2 \angle+40$ & 00 & $1.47 \mathrm{E}-03$ & 3 & 2 & 02 \\
\hline$E+00$ & 1 & & & & $.88 E-03$ & & 2 \\
\hline $.00 E+00$ & 1 . & 1 & & $1.56 \mathrm{E}-03$ & & 2 & 02 \\
\hline $.00 \mathrm{E}+00$ & $1.37 \mathrm{E}-01$ & $1.30 \mathrm{E}-03$ & $0.00 \mathrm{E}+00$ & $1.60 \mathrm{E}-03$ & $.14 \mathrm{E}-03$ & 1. $34 \mathrm{E}-02$ & $2.87 E-02$ \\
\hline $.00 \mathrm{E}+00$ & 1. 39E-01 & $1.33 \mathrm{E}-03$ & $0.00 \mathrm{E}+00$ & $1.65 \mathrm{E}-03$ & $6.28 \mathrm{E}-$ & $1.37 \mathrm{E}-02$ & $2.93 E-02$ \\
\hline $.00 \mathrm{E}+00$ & 1 & & & & & 2 & $E-02$ \\
\hline $00 \mathrm{E}+00$ & & & & 3 & & 2 & -02 \\
\hline $.00 E+00$ & 1. & $\perp$ & $.00 \mathrm{E}+00$ & 3 & & & 02 \\
\hline $.00 \mathrm{E}+00$ & 1. & $1.44 \mathrm{E}-03$ & (2) & ? & $6.83 E-03$ & 2 & -02 \\
\hline $.00 \mathrm{E}+00$ & $.50 \mathrm{E}-01$ & م & $.00 \mathrm{E}+0$ & חרית & תרי & 2 & $24 \mathrm{E}-02$ \\
\hline $0 \cap \mathrm{F}+0 \cap 0$ & 1. $52 \mathrm{E}-01$ & $150=0$ & $0.00 \mathrm{E}+00$ & 1 & ת & $3 E-02$ & $.30 E-02$ \\
\hline $.00 \mathrm{E}+00$ & $.55 \mathrm{E}-01$ & & $21 E-22$ & & & $6 E-02$ & $.36 E-02$ \\
\hline & & & & & & & -02 \\
\hline $.00 \mathrm{E}+00$ & $1.59 \mathrm{E}-01$ & $1.00 \mathrm{E}$ & 19 & O & o & -02 & $9 E-02$ \\
\hline $.00 \mathrm{E}+00$ & $1.61 \mathrm{E}-01$ & $1.00 \mathrm{~L}-0 \mathrm{~s}$ & $.005-1 /$ & $2 \cdot \pm 01$ & • $11+\mathrm{L}$ U & $1.65 \mathrm{E}-02$ & $.55 E-02$ \\
\hline $.00 \mathrm{E}+00$ & $1.64 \mathrm{E}-01$ & 1.000 - & $\angle \cdot \perp \angle L-\perp 0$ & $2.18 \mathrm{E}-$ & - & म. $00 \mathrm{E}-02$ & $.62 E-02$ \\
\hline $00 \mathrm{E}+0$ & 1 & & & & & & 2 \\
\hline $.00 E+00$ & 1 & & & & & & $5 E-02$ \\
\hline & 01 & & 4 & & & & -02 \\
\hline $00 E+00$ & $1.73 \mathrm{E}-01$ & $1.80 \mathrm{E}-03$ & $9 \mathrm{E}-13$ & 2.411 & 3 & & -02 \\
\hline $.00 E+O U$ & $1.76 \mathrm{E}-01$ & $1.03 E-03$ & $.15 E-12$ & 2.11 & . & 02 & $.98 E-02$ \\
\hline . & 1. $78 \mathrm{E}-01$ & & & & & & $4.05 \pm-02$ \\
\hline ( & \pm & & & 3 & & & $13 E-02$ \\
\hline $00 \mathrm{E}+00$ & 1 & $1.94 \mathrm{E}-03$ & & 3 & & 2 & 02 \\
\hline & 1 & & 11 & 3 & 3 & 2 & 02 \\
\hline $0 \mathrm{E}+00$ & $1.88 \mathrm{E}-01$ & 2.02 & $E-10$ & 2 . & & & -02 \\
\hline & 1.9 & & & & & & \\
\hline טע山 & 1 & & & & & & $4 / E-U 2$ \\
\hline $00 \mathrm{E}+00$ & $1.90 E-01$ & 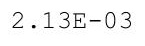 & $\begin{array}{ll}-10+ & 10\end{array}$ & $3.03 E-03$ & $1.01 \mathrm{E}-02$ & $2.15 E-02$ & $4.54 \mathrm{E}-02$ \\
\hline $.00 \mathrm{E}+0$ & 1.98E-01 & 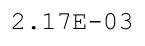 & & $\cdot 1+$ & $1.03 E-02$ & $2.19 \mathrm{E}-02$ & $4.62 E-02$ \\
\hline$E+00$ & $.01 E-01$ & $.21 E-03$ & $.35 E-09$ & $.20 \mathrm{E}-03$ & -02 & $2.24 \mathrm{E}-$ & $E-02$ \\
\hline
\end{tabular}


RESRAD-OFFSITE, Version 2.5

itle : Offsite Resident Farmer Deterministic Run

File : RF TC99 DOESG FWD-FV2.ROF

Summary of dose at graphical times, reptition 3 (continued)

Time

Years

$2.59 \mathrm{E}+02$

$2.60 \mathrm{E}+02$

$2.60 \mathrm{E}+02$

$2.61 \mathrm{E}+02$

$2.61 \mathrm{E}+02$

2. $62 \mathrm{E}+02$

2. $63 \mathrm{E}+02$

$2.63 \mathrm{E}+02$

$2.64 \mathrm{E}+02$

$2.64 \mathrm{E}+02$

$2.65 \mathrm{E}+02$

$2.65 \mathrm{E}+02$

$2.66 \mathrm{E}+02$

$2.66 \mathrm{E}+02$

$2.67 \mathrm{E}+02$

$2.67 \mathrm{E}+02$

$2.68 \mathrm{E}+02$

$2.68 \mathrm{E}+02$

$2.69 \mathrm{E}+02$

$2.69 \mathrm{E}+02$

$2.70 \mathrm{E}+02$

$2.70 \mathrm{E}+02$

$2.71 \mathrm{E}+02$

$2.71 \mathrm{E}+02$

2. $72 \mathrm{E}+02$

2. $72 \mathrm{E}+02$

$2.73 E+02$

$2.73 \mathrm{E}+02$

$2.74 \mathrm{E}+02$

$2.74 \mathrm{E}+02$

$2.75 \mathrm{E}+02$

$2.75 \mathrm{E}+02$

$2.76 \mathrm{E}+02$

$2.76 \mathrm{E}+02$

$2.77 \mathrm{E}+02$

$2.77 \mathrm{E}+02$

$2.78 \mathrm{E}+02$

$2.78 \mathrm{E}+02$

$2.79 \mathrm{E}+02$

$2.79 \mathrm{E}+02$

$2.80 \mathrm{E}+02$

$2.80 \mathrm{E}+02$

$2.81 \mathrm{E}+02$

$2.81 \mathrm{E}+02$

$2.82 \mathrm{E}+02$

$2.82 \mathrm{E}+02$
Dose statistics at graphical times, mrem/yr

\begin{tabular}{|c|c|c|c|c|c|c|c|}
\hline m & aximum & ea & 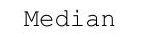 & & & & \\
\hline $.00 \mathrm{E}+00$ & -01 & 03 & $3.88 \mathrm{E}-09$ & 3 & $07 E-02$ & 02 & $4.10 \pm-02$ \\
\hline+00 & $2.06 \mathrm{E}-01$ & $0 E-03$ & $6.14 \mathrm{E}-09$ & $35 E-03$ & $09 E-02$ & $2.33 E-02$ & $85 E-02$ \\
\hline $.00 \mathrm{E}+00$ & $09 E-01$ & $34 \mathrm{~F}-03$ & $6 E-09$ & $3 E-03$ & $11 E-02$ & $.38 E-02$ & $92 E-02$ \\
\hline $00 \mathrm{E}+00$ & $12 \mathrm{E}-01$ & $38 \mathrm{~F}-03$ & $.36 \mathrm{E}-08$ & $51 \mathrm{~F}-03$ & $13 \mathrm{~F}-02$ & $43 F-02$ & $00 E-02$ \\
\hline $.00 \mathrm{E}+00$ & -01 & 3 & 8 & 3 & 2 & -02 & -02 \\
\hline $.00 \mathrm{E}+00$ & & & & & & & -02 \\
\hline $.00 E+00$ & 01 & 3 & -08 & & & & $E-02$ \\
\hline+00 & 01 & $\Omega$ & 08 & 3 & 02 & -02 & -02 \\
\hline$O E+00$ & $25 E-01$ & -0 & -08 & 政 & -02 & -02 & $3 E-02$ \\
\hline $.00 E+00$ & $28 \mathrm{E}-01$ & (6) & $.02 \mathrm{E}-07$ & 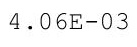 & 26 & $.73 E-02$ & $E-02$ \\
\hline $.00 E+00$ & 2.3 & & & & & & -02 \\
\hline $.00 \mathrm{E}+00$ & $2.34 \mathrm{E}-01$ & $5 F-8$ & -07 & 3 & 2 & -02 & -02 \\
\hline $.00 \mathrm{E}+00$ & $2.37 \mathrm{E}-01$ & & $2.30 E-07$ & $4.39 E-03$ & $1.34 \mathrm{E}-02$ & $2.89 E-02$ & $71 E-02$ \\
\hline $.00 \mathrm{E}+00$ & $2.40 \mathrm{E}-01$ & $2.84 \mathrm{E}-03$ & $2.89 \mathrm{E}-07$ & 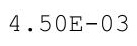 & 2 & -02 & $9 E-02$ \\
\hline$\Xi+00$ & -01 & 它 & -07 & & 2 & -02 & $E-02$ \\
\hline $.00 \mathrm{E}+00$ & 1 & $2.94 E-03$ & 1 & 3 & & 2 & 02 \\
\hline$E+00$ & 1 & & & & & & 2 \\
\hline $.00 \mathrm{E}+00$ & 1 & $3.05 E-03$ & 7 & 3 & 2 & 2 & 02 \\
\hline $.00 \mathrm{E}+00$ & $2.55 \mathrm{E}-01$ & $3.10 \mathrm{E}-03$ & $7.97 \mathrm{E}-07$ & $.06 \mathrm{E}-03$ & $1.50 \mathrm{E}-02$ & $3.22 \mathrm{E}-02$ & $21 E-02$ \\
\hline $.00 \mathrm{E}+00$ & $2.58 \mathrm{E}-01$ & $3.15 \mathrm{E}-03$ & $9.48 \mathrm{E}-07$ & $5.17 \mathrm{E}-03$ & 1. 53E-02 & $E-02$ & $.30 E-02$ \\
\hline $.00 \mathrm{E}+00$ & & & & & & -02 & -02 \\
\hline $00 \mathrm{E}+00$ & & & & 3 & 2 & 2 & -02 \\
\hline $.00 E+00$ & 1 & 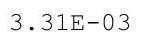 & 6 & & & -02 & 02 \\
\hline $.00 \mathrm{E}+00$ & 1 & $3.37 \mathrm{E}-03$ & 06 & ? & 2 & 2 & -02 \\
\hline $.00 \mathrm{E}+00$ & $.73 E-01$ & חרקו & $2.09 \mathrm{E}-06$ & חכרי & 1 & 2 & $75 E-02$ \\
\hline $0 \cap \mathrm{F}+0 \cap 0$ & $76 \mathrm{E}-01$ & $48 \mathrm{E}-0$ & $E-06$ & $85 E-$ & 1. $70 \mathrm{E}-02$ & $65 E-02$ & $84 \mathrm{E}-02$ \\
\hline $.00 \mathrm{E}+00$ & & & & & $1.73 \mathrm{E}-02$ & & $94 \mathrm{E}-02$ \\
\hline & & & & & & & -02 \\
\hline & & 3.0 & & 3 & 2 & -02 & -02 \\
\hline $.00 \mathrm{E}+00$ & $2.89 E-01$ & $3.72 \mathrm{E}-0$ & $3.88 E-06$ & $.30 E-03$ & $1.83 E-02$ & $0.01 \mathrm{E}-\mathrm{UL}$ & $.27 E-02$ \\
\hline $.00 \mathrm{E}+00$ & $92 \mathrm{E}-01$ & (7) & $4.40 \mathrm{E}-06$ & - & $1.87 \mathrm{E}-02$ & -02 & $.38 E-02$ \\
\hline $.00 \mathrm{E}+00$ & 1 & & & & & $8 E-02$ & $49 E-02$ \\
\hline $.00 E+00$ & & & & & & & $D E-02$ \\
\hline & 01 & & 06 & & & & -02 \\
\hline $00 E+00$ & $3.06 \mathrm{E}-01$ & $4.03 E-03$ & $E-06$ & 3 & 2 & & $83 E-02$ \\
\hline $.00 E+U 0$ & $3.09 \mathrm{E}-01$ & $4.09 E-03$ & $7.75 E-06$ & 3 & 02 & -02 & $94 E-02$ \\
\hline 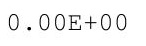 & $3.12 \mathrm{E}-01$ & & & & & & $00 E-02$ \\
\hline ( & 1 & & 6 & & & & $17 E-02$ \\
\hline $00 \mathrm{E}+0 \mathrm{C}$ & 1 & s & 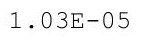 & 3 & 16 & 2 & 02 \\
\hline & 1 & & 5 & 3 & 2.2 & & 02 \\
\hline $0 \mathrm{E}+00$ & $3.26 \mathrm{E}-01$ & 4. & -05 & $8 \mathrm{E}$ & & & -02 \\
\hline & -01 & & & & & & -02 \\
\hline 0 & 1 & & & & & & $1 / E-02$ \\
\hline $00 \mathrm{E}+00$ & $3.37 \mathrm{E}-01$ & $4.64 \mathrm{E}-03$ & $1.64 \mathrm{E}-05$ & $8.33 E-03$ & $2.37 E-02$ & $4.72 \mathrm{E}-02$ & $8.90 E-02$ \\
\hline $.00 \mathrm{E}+00$ & $.40 \mathrm{~L}$ & 月. & & . & $2.40 \mathrm{E}-02$ & & $9.02 E-02$ \\
\hline$E+00$ & $E-01$ & $.78 E-03$ & $.96 \mathrm{E}-05$ & $.66 \mathrm{E}-03$ & -02 & $4.85 E-02$ & $9.15 E-02$ \\
\hline
\end{tabular}


RESRAD-OFFSITE, Version 2.5

obabilistic Dose and Risk Report

Title : Offsite Resident Farmer Deterministic Run

File : RF TC99 DOESG FWD-FV2.ROF

Summary of dose at graphical times, reptition 3 (continued)

Time

Years

$2.83 E+02$

$2.84 \mathrm{E}+02$

$2.84 \mathrm{E}+02$

$2.85 \mathrm{E}+02$

$2.85 \mathrm{E}+02$

2. $86 \mathrm{E}+02$

$2.86 \mathrm{E}+02$

$2.87 \mathrm{E}+02$

$2.87 \mathrm{E}+02$

$2.88 \mathrm{E}+02$

$2.88 \mathrm{E}+02$

$2.89 \mathrm{E}+02$

$2.89 \mathrm{E}+02$

$2.90 \mathrm{E}+02$

2. $90 \mathrm{E}+02$

2. $91 \mathrm{E}+02$

2. $91 \mathrm{E}+02$

2. $92 \mathrm{E}+02$

2. $92 \mathrm{E}+02$

2. $93 \mathrm{E}+02$

2. $93 \mathrm{E}+02$

2. $94 \mathrm{E}+02$

2. $94 \mathrm{E}+02$

2. $95 \mathrm{E}+02$

2. $95 \mathrm{E}+02$

2. $96 \mathrm{E}+02$

2. $96 \mathrm{E}+02$

2. $97 \mathrm{E}+02$

2. $97 \mathrm{E}+02$

2. $98 \mathrm{E}+02$

2. $98 \mathrm{E}+02$

$2.99 \mathrm{E}+02$

2. $99 \mathrm{E}+02$

$3.00 \mathrm{E}+02$

$3.00 \mathrm{E}+02$

$3.01 \mathrm{E}+02$

$3.01 E+02$

$3.02 \mathrm{E}+02$

$3.02 \mathrm{E}+02$

$3.03 \mathrm{E}+02$

$3.04 \mathrm{E}+02$

$3.04 \mathrm{E}+02$

$3.05 \mathrm{E}+02$

$3.05 E+02$

$3.06 \mathrm{E}+02$

$3.06 \mathrm{E}+02$
Dose statistics at graphical times, mrem/yr

\begin{tabular}{|c|c|c|c|c|c|c|c|}
\hline m & aximum & lea & - & & & & \\
\hline $.00 \mathrm{E}+00$ & -01 & $86 E-03$ & $2.09 E-05$ & 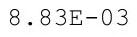 & $.48 E-02$ & $4.92 E-02$ & $9 . \angle O E-U \angle$ \\
\hline $.00 \mathrm{E}+00$ & $3.51 \mathrm{E}-01$ & $3 E-03$ & $2.25 E-05$ & $0 E-03$ & $52 E-02$ & $4.98 E-02$ & $D E-02$ \\
\hline $.00 \mathrm{E}+00$ & $54 \mathrm{E}-01$ & $0 E-03$ & $.44 E-05$ & $-7 E-03$ & $57 E-02$ & $5 E-02$ & $E-02$ \\
\hline $00 \mathrm{E}+00$ & $58 E-01$ & $08 E-03$ & $60 \mathrm{~F}-05$ & $35 F-03$ & $61 \mathrm{~F}-02$ & -02 & $66 E-02$ \\
\hline $.00 \mathrm{E}+00$ & -01 & 3 & 5 & 3 & 2 & -02 & -02 \\
\hline $.00 \mathrm{E}+00$ & & & & & & & -02 \\
\hline $.00 E+00$ & -01 & & & & & & -01 \\
\hline+00 & -01 & 3 & 5 & 2 & 02 & -02 & $E-01$ \\
\hline $00 E+00$ & $76 \mathrm{E}-01$ & $47 E-03$ & -05 & -02 & $5 E-02$ & -02 & $3 E-01$ \\
\hline $.00 E+00$ & $80 \mathrm{E}-01$ & 5 & 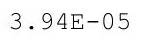 & 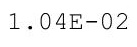 & ? & $3 E-02$ & -01 \\
\hline $.00 E+00$ & 01 & & & & & & -01 \\
\hline $.00 \mathrm{E}+00$ & $3.88 \mathrm{E}-01$ & 5.7 & -05 & 2 & 2 & 2 & -01 \\
\hline $.00 \mathrm{E}+00$ & $3.92 \mathrm{E}-01$ & $5.80 E-03$ & $4.82 E-05$ & $1.09 \mathrm{E}-02$ & $3.03 E-02$ & $5.74 \mathrm{E}-02$ & $1.08 \mathrm{E}-01$ \\
\hline $.00 E+00$ & $95 \mathrm{E}-01$ & 3 & -05 & & 02 & -02 & $10 E-01$ \\
\hline $\mathrm{E}+00$ & -01 & & -05 & & & -02 & $E-01$ \\
\hline $.00 \mathrm{E}+00$ & -01 & 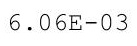 & 5 & 2 & & 2 & 01 \\
\hline$E+00$ & 1 & & & & & & 1 \\
\hline $.00 E+00$ & 1 & 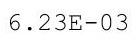 & 5 & 2 & 2 & 2 & 01 \\
\hline $.00 \mathrm{E}+00$ & $4.15 \mathrm{E}-01$ & $6.32 E-03$ & $7.01 \mathrm{E}-05$ & $1.21 \mathrm{E}-02$ & $3.29 E-02$ & $.19 E-02$ & $1.18 \mathrm{E}-01$ \\
\hline $.00 \mathrm{E}+00$ & $4.19 \mathrm{E}-01$ & $6.41 \mathrm{E}-03$ & 7. $34 \mathrm{E}-05$ & 1.23E-02 & $.34 E-02$ & $.26 \mathrm{E}-02$ & 1. $19 \mathrm{E}-01$ \\
\hline $.00 \mathrm{E}+00$ & $23 E-01$ & & & & & 2 & $E-01$ \\
\hline $.00 E+00$ & & & & 2 & & -02 & 01 \\
\hline חمחניחתמ & & 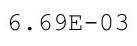 & & 2 & & 2 & 01 \\
\hline مि & & ( & 5 & 2 & 2 & 2 & 01 \\
\hline $.00 E+00$ & 1 & 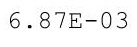 & 5 & 12 & 2 & $E-02$ & $27 E-01$ \\
\hline $0 \cap \mathrm{F}+0 \cap 0$ & $4.43 E-01$ & $.97 E-0$ & $F-05$ & $1.36 \mathrm{E}-$ & $64 E-02$ & $73 E-02$ & $.29 E-01$ \\
\hline $.00 \mathrm{E}+00$ & $47 E-01$ & $.07 E-03$ & $E-04$ & 1. $38 \mathrm{E}-02$ & $.70 E-02$ & $1 E-02$ & $.30 E-01$ \\
\hline & & & & & & & \\
\hline & & & & & 02 & -02 & 01 \\
\hline $.00 \mathrm{E}+00$ & $4.59 \mathrm{E}-01$ & $1.30 E-03$ & $1.14 \mathrm{E}-04$ & $1.44 \mathrm{E}-02$ & $.86 E-02$ & $7.05 \mathrm{E}-02$ & $1.35 \mathrm{E}-01$ \\
\hline $.00 \mathrm{E}+00$ & $4.63 E-01$ & $1.405-03$ & 1. $18 \mathrm{E}-04$ & $1.47 \mathrm{E}-02$ & $.92 \mathrm{E}-02$ & $7.13 \mathrm{E}-02$ & $.37 E-01$ \\
\hline $.00 \mathrm{E}+0$ & 1 & & & $1.49 \mathrm{E}-$ & & $E-02$ & $.39 E-01$ \\
\hline $.00 E+00$ & & & & & & & $D E-01$ \\
\hline & & & & & & & -01 \\
\hline & & & & 2 & 02 & 02 & \\
\hline $.00 \mathrm{E}+00$ & $4.84 \mathrm{E}-01$ & $7.98 E-03$ & $1.45 \mathrm{E}-04$ & $+.02+$ & 02 & -02 & $1.45 \mathrm{E}-01$ \\
\hline . & $4.88 \mathrm{E}-01$ & & & & & & $1.46 \mathrm{E}-01$ \\
\hline ( & 1 & 3 & 4 & $\pm \cdot 00$ & & & $1.48 \mathrm{E}-01$ \\
\hline $00 \mathrm{E}+0 \mathrm{C}$ & 1 & $\varepsilon$ & 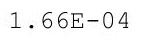 & +.0 & 1.0 & $E-02$ & 01 \\
\hline & 1 & & & 2 & 2 & & 01 \\
\hline $0 \mathrm{E}+00$ & $5.05 \mathrm{E}-01$ & $8.52 \mathrm{E}$ & 1. $79 \mathrm{E}$ & $1.73 \mathrm{E}$ & 02 & & $1.53 E-01$ \\
\hline & 1 & & & & & & -01 \\
\hline טע山 & & & & & & & $1.5 / \mathrm{E}-01$ \\
\hline $00 \mathrm{E}+00$ & $3.18 E-01$ & $8.80 E-03$ & $2.001-4$ & $1.81 \mathrm{E}-02$ & $4.67 E-02$ & $8.22 \mathrm{E}-02$ & $1.59 \mathrm{E}-01$ \\
\hline $.00 \mathrm{E}+00$ & $0<2 \square$ & $0.912-03$ & 2.00104 & $1.84 \mathrm{E}-02$ & & & $1.61 \mathrm{E}-01$ \\
\hline$E+00$ & $E-01$ & $.09 E-03$ & $.12 \mathrm{E}-04$ & $.86 E-02$ & -02 & $2 E-02$ & $1.63 E-01$ \\
\hline
\end{tabular}


RESRAD-OFFSITE, Version 2.5

Title : Offsite Resident Farmer Deterministic Run

File : RF TC99 DOESG FWD-FV2.ROF

Summary of dose at graphical times, reptition 3 (continued)

Time

Years

$3.07 \mathrm{E}+02$

$3.07 \mathrm{E}+02$

$3.08 \mathrm{E}+02$

$3.08 \mathrm{E}+02$

$3.09 \mathrm{E}+02$

$3.09 \mathrm{E}+02$

$3.10 \mathrm{E}+02$

$3.10 \mathrm{E}+02$

$3.11 \mathrm{E}+02$

$3.11 \mathrm{E}+02$

$3.12 \mathrm{E}+02$

3. $12 \mathrm{E}+02$

$3.13 \mathrm{E}+02$

$3.13 \mathrm{E}+02$

$3.14 \mathrm{E}+02$

$3.14 \mathrm{E}+02$

$3.15 \mathrm{E}+02$

3. $15 \mathrm{E}+02$

$3.16 \mathrm{E}+02$

$3.16 \mathrm{E}+02$

$3.17 \mathrm{E}+02$

$3.17 \mathrm{E}+02$

$3.18 \mathrm{E}+02$

$3.18 \mathrm{E}+02$

$3.19 \mathrm{E}+02$

$3.19 \mathrm{E}+02$

$3.20 \mathrm{E}+02$

$3.20 \mathrm{E}+02$

$3.21 \mathrm{E}+02$

$3.21 \mathrm{E}+02$

$3.22 \mathrm{E}+02$

3. $22 \mathrm{E}+02$

$3.23 \mathrm{E}+02$

$3.24 \mathrm{E}+02$

$3.24 \mathrm{E}+02$

$3.25 \mathrm{E}+02$

$3.25 \mathrm{E}+02$

$3.26 \mathrm{E}+02$

$3.26 \mathrm{E}+02$

$3.27 \mathrm{E}+02$

$3.27 \mathrm{E}+02$

$3.28 \mathrm{E}+02$

$3.28 \mathrm{E}+02$

$3.29 \mathrm{E}+02$

$3.29 \mathrm{E}+02$

$3.30 \mathrm{E}+02$
Dose statistics at graphical times, mrem/yr

\begin{tabular}{|c|c|c|c|c|c|c|c|}
\hline m & aximum & ea & ec & & & & \\
\hline $.00 \mathrm{E}+00$ & $31 \mathrm{E}-01$ & $9.21 \mathrm{E}-03$ & 4 & $1.89 \mathrm{E}-02$ & $4.84 \mathrm{E}-02$ & 02 & $4-01$ \\
\hline+00 & $5.35 E-01$ & $32 E-03$ & $2.28 \mathrm{E}-04$ & 1. $92 \mathrm{E}-02$ & $9 E-02$ & $62 E-02$ & $66 \mathrm{E}-01$ \\
\hline $.00 E+00$ & $40 E-01$ & $4 \mathrm{~F}-03$ & $.37 E-04$ & $95 E-02$ & $95 E-02$ & $72 E-02$ & $68 E-01$ \\
\hline $00 \mathrm{E}+00$ & $44 \mathrm{E}-01$ & $56 \mathrm{~F}-03$ & $45 E-04$ & $98 \mathrm{~F}-02$ & $01 \mathrm{~F}-02$ & -02 & $70 F-01$ \\
\hline $.00 \mathrm{E}+00$ & 01 & $8 \mathrm{~F}$ & 4 & 2 & 2 & -02 & -01 \\
\hline $.00 E+00$ & & & & & & & 01 \\
\hline $.00 E+00$ & $58 E-01$ & & & & & & $.76 E-01$ \\
\hline $.00 \mathrm{E}+00$ & -01 & 02 & -04 & -02 & -02 & -02 & $1.78 \mathrm{E}-01$ \\
\hline $\mathrm{E}+00$ & $5.67 \mathrm{E}-01$ & $02 E-02$ & $E-04$ & -02 & -02 & -02 & $1.80 \mathrm{E}-01$ \\
\hline $.00 \mathrm{E}+00$ & $71 \mathrm{E}-01$ & 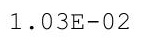 & $.02 E-04$ & $16 \pi$ & $36 \mathrm{E}-02$ & $E-02$ & $.82 E-01$ \\
\hline+00 & 01 & & & & & 2 & 01 \\
\hline $.00 \mathrm{E}+00$ & $5.80 \mathrm{E}-01$ & $6 \mathrm{~F}$ & -04 & 20 & 2 & 2 & $E-01$ \\
\hline $.00 \mathrm{E}+00$ & $5.85 E-01$ & & $3.34 \mathrm{E}-04$ & $2.25 E-02$ & & & $1.88 \mathrm{E}-01$ \\
\hline $.00 E+00$ & $5.89 \mathrm{E}-01$ & 1. $08 \mathrm{E}-02$ & $3.46 \mathrm{E}-04$ & $2.28 \mathrm{E}-02$ & & -02 & 1. $90 \mathrm{E}-01$ \\
\hline$E+00$ & $E-01$ & -0 & $E-04$ & 2 & & -01 & $E-01$ \\
\hline $.00 E+00$ & 5.0 & $1.11 \mathrm{E}-02$ & $3.69 \mathrm{E}-04$ & 2 & & $\perp$ & -01 \\
\hline$E+00$ & 1 & $12 \mathrm{E}-02$ & & & 2 & 1 & 1 \\
\hline $00 E+00$ & 1 & $114 F-02$ & $3.95 E-04$ & & 2 & 1 & 01 \\
\hline $.00 E+00$ & $5.12 \mathrm{E}-01$ & $5 \mathrm{~F}-\Omega(-2-1$ & $8 E-04$ & $5 E-02$ & 2 & $5-01$ & $9 \mathrm{E}-01$ \\
\hline $.00 \mathrm{E}+00$ & $.17 \mathrm{E}-01$ & $.16 \mathrm{E}-02$ & $4.22 E-04$ & $2.48 \mathrm{E}-02$ & $.98 E-02$ & $1.07 \mathrm{E}-01$ & $2.01 \mathrm{E}-01$ \\
\hline $.00 \mathrm{E}+00$ & $E-01$ & & 4 & & & -01 & $3 E-01$ \\
\hline $.00 \mathrm{E}+00$ & & & & & & & 01 \\
\hline $00 E+00$ & 01 & 1.21 & & 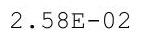 & & & -01 \\
\hline $.00 \mathrm{E}+00$ & 1 & $\perp$ & 4 & $z$ & 2 & 1 & -01 \\
\hline $00 E+00$ & 1 & , & 4 & 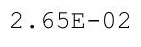 & 2 & 1 & $10 E-01$ \\
\hline $.00 \mathrm{E}+00$ & $.45 E-01$ & $1.25 \mathrm{E}-0$ & $5.00 E-04$ & $.69 \mathrm{E}-0$ & $39 E-02$ & $.15 E-01$ & $12 \mathrm{E}-01$ \\
\hline $.00 \mathrm{E}+00$ & $50 E-01$ & & $12 \mathrm{E}-04$ & & & $6 E-01$ & $.14 \mathrm{E}-01$ \\
\hline & & & & & & $E-01$ & $6 E-01$ \\
\hline & 01 & $1 \cdot 2$ & 4 & & & & $E-01$ \\
\hline $.00 \mathrm{E}+00$ & $6.64 \mathrm{E}-01$ & $\perp \cdot J \perp+0<$ & $5.52 \mathrm{E}-04$ & $2.83 E-02$ & $6.68 \mathrm{E}-02$ & $1.20 \mathrm{E}-01$ & $2.20 \mathrm{E}-01$ \\
\hline $.00 \mathrm{E}+00$ & $6.69 \mathrm{E}-01$ & 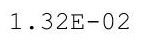 & $.69 \mathrm{E}-04$ & 2.000 & - & 1. $22 \mathrm{E}-01$ & $2.22 \mathrm{E}-01$ \\
\hline $.00 \mathrm{E}+00$ & 1 & $2 \cdot 0$ & 4 & & & 50 & $.24 \mathrm{E}-01$ \\
\hline $.00 E+00$ & & & & & & & 01 \\
\hline & 1 & & & 2 & & $E-01$ & 01 \\
\hline $0 \mathrm{E}+00$ & 01 & & 04 & & 2 & -01 & -01 \\
\hline $.00 \mathrm{E}+00$ & $6.93 \mathrm{E}-01$ & 1. $40 \mathrm{E}-02$ & $6.47 \mathrm{E}-04$ & 3.00 & 2 & $E-01$ & $2.32 E-01$ \\
\hline $.00 \mathrm{E}+00$ & $0.98 \mathrm{E}-01$ & $\perp \cdot 12+$ & & & & & $2.34 E-01$ \\
\hline $00 \mathrm{E}+00$ & 1 & & & & & & $2.36 \mathrm{E}-01$ \\
\hline 0 & 1 &.+ & 然 & 2 & 2 & 1 & 01 \\
\hline & & 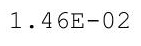 & & 2 & & & \\
\hline $0 \mathrm{E}+00$ & $.18 \mathrm{E}-01$ & 1. $48 \mathrm{E}-02$ & $7.35 \mathrm{E}-04$ & $326 \mathrm{~F}$ & $755 \mathrm{~F}$ & $1.36 \mathrm{E}-01$ & $2.43 E-01$ \\
\hline$E+00$ & $7.23 \mathrm{E}$ & 1.5 & 04 & & & 01 & -01 \\
\hline & & & & & & & $2.47 \mathrm{E}-01$ \\
\hline $.00 \mathrm{E}+00$ & $7.33 E-01$ & $\perp \cdot 0)$ & TL- 4 & . & (. & $1.40 \mathrm{E}-01$ & $2.49 \mathrm{E}-01$ \\
\hline $.00 E+00$ & . & 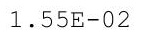 & & & & & -01 \\
\hline $0 \mathrm{E}+00$ & $E-01$ & $.56 \mathrm{E}-02$ & $6 E-04$ & $E-02$ & $5 E-02$ & 01 & -01 \\
\hline
\end{tabular}


RESRAD-OFFSITE, Version 2.5

Title : Offsite Resident Farmer Deterministic Run

File : RF TC99 DOESG FWD-FV2.ROF

Summary of dose at graphical times, reptition 3 (continued)

Time

Years

3. $30 \mathrm{E}+02$

3. $31 \mathrm{E}+02$

$3.31 \mathrm{E}+02$

3. $32 \mathrm{E}+02$

3. $32 \mathrm{E}+02$

3. $33 \mathrm{E}+02$

$3.33 \mathrm{E}+02$

$3.34 \mathrm{E}+02$

$3.34 \mathrm{E}+02$

3. $35 \mathrm{E}+02$

$3.35 \mathrm{E}+02$

3. $36 \mathrm{E}+02$

3. $36 \mathrm{E}+02$

3. $37 \mathrm{E}+02$

3. $37 \mathrm{E}+02$

3. $38 \mathrm{E}+02$

$3.38 \mathrm{E}+02$

$3.39 \mathrm{E}+02$

3. $39 \mathrm{E}+02$

3. $40 \mathrm{E}+02$

$3.40 \mathrm{E}+02$

$3.41 \mathrm{E}+02$

3. $41 \mathrm{E}+02$

3. $42 \mathrm{E}+02$

$3.42 \mathrm{E}+02$

3. $43 \mathrm{E}+02$

$3.44 \mathrm{E}+02$

$3.44 \mathrm{E}+02$

$3.45 \mathrm{E}+02$

$3.45 \mathrm{E}+02$

$3.46 \mathrm{E}+02$

$3.46 \mathrm{E}+02$

$3.47 \mathrm{E}+02$

$3.47 \mathrm{E}+02$

$3.48 \mathrm{E}+02$

$3.48 \mathrm{E}+02$

$3.49 \mathrm{E}+02$

3. $49 \mathrm{E}+02$

$3.50 \mathrm{E}+02$

$3.50 \mathrm{E}+02$

$3.51 \mathrm{E}+02$

3. $51 \mathrm{E}+02$

$3.52 \mathrm{E}+02$

$3.52 \mathrm{E}+02$

3. $53 \mathrm{E}+02$

$3.53 \mathrm{E}+02$
Dose statistics at graphical times, mrem/yr

\begin{tabular}{|c|c|c|c|c|c|c|c|}
\hline m & $\operatorname{axi}$ & a & ledian & & & $\%$ & \\
\hline $.00 \mathrm{E}+00$ & 01 & $1.58 \mathrm{E}-02$ & $E-04$ & -02 & -02 & -01 & -01 \\
\hline $.00 \mathrm{E}+00$ & $.52 E-01$ & $0 E-02$ & -04 & $55 E-02$ & 02 & -01 & -01 \\
\hline$E+00$ & $7.57 \mathrm{E}-01$ & 1. $62 \mathrm{E}-02$ & $8.84 \mathrm{E}-04$ & $.59 E-02$ & $8.23 \mathrm{E}-02$ & $1.48 \mathrm{E}-01$ & $60 \mathrm{E}-01$ \\
\hline $.00 \mathrm{E}+00$ & $7.62 \mathrm{E}-01$ & 1. $63 \mathrm{E}-02$ & $9.03 E-04$ & $.63 E-02$ & $1 E-02$ & $1.50 \mathrm{E}-01$ & $63 E-01$ \\
\hline $.00 \mathrm{E}+00$ & $67 E-01$ & $1.65 \mathrm{E}-02$ & -04 & & & 01 & 01 \\
\hline+00 & 1 & 1 & 4 & 2 & 2 & 1 & -01 \\
\hline $.00 \mathrm{E}+00$ & $3 E-01$ & 2 & & 2 & 2 & 01 & -01 \\
\hline $.00 \mathrm{E}+00$ & & & & & & & -01 \\
\hline$E+00$ & -01 & $\mathrm{~g}-02$ & -03 & -02 & -02 & -01 & $75 E-01$ \\
\hline $.00 \mathrm{E}+00$ & 1 & s & 3 & 02 & -02 & -01 & -01 \\
\hline $00 \mathrm{E}+00$ & $7.98 \mathrm{E}-01$ & 1 & $1.06 E-03$ & $92 E-02$ & 2 & 1 & -01 \\
\hline$\Xi+00$ & & & & 2 & & & -01 \\
\hline $.00 \mathrm{E}+00$ & $3 E-01$ & $1 . \varepsilon$ & 3 & 2 & 2 & -01 & -01 \\
\hline $.00 \mathrm{E}+00$ & $8.13 \mathrm{E}-01$ & $1.82 \mathrm{E}-02$ & $1.14 \mathrm{E}-03$ & $4.06 \mathrm{E}-02$ & $9.17 \mathrm{E}-02$ & $1.68 \mathrm{E}-01$ & $2.88 \mathrm{E}-01$ \\
\hline $.00 \mathrm{E}+00$ & $E-01$ & -02 & -03 & -02 & 02 & -01 & -01 \\
\hline $.00 E+00$ & & & & & & 1 & -01 \\
\hline $00 \mathrm{E}+00$ & $\perp$ & $\perp \cdot$ & 3 & 2 & & 1 & 01 \\
\hline$E+00$ & $8.34 \mathrm{E}-01$ & & & & & $\perp$ & 01 \\
\hline $.00 E+00$ & $.39 E-01$ & $191 \mathrm{~F}-$ & $26 \sigma^{2}$ & 2 & & -01 & -01 \\
\hline $.00 \mathrm{E}+00$ & $.44 \mathrm{E}-01$ & $1.93 \mathrm{E}-02$ & $1.29 \mathrm{E}-03$ & $.35 E-02$ & $73 E-02$ & $E-01$ & $E-01$ \\
\hline $.00 \mathrm{E}+00$ & $49 \mathrm{E}-01$ & 1. $95 \mathrm{E}-02$ & -03 & -02 & -02 & $.82 E-01$ & -01 \\
\hline & & & & & & -01 & -01 \\
\hline & & & & & & & -01 \\
\hline $.00 \mathrm{E}+00$ & $\perp$ & $.0+\Delta$ & 1. & 2 & 1 & & -01 \\
\hline $00 \mathrm{E}+00$ & 1 & cos & 3 & 2 & 1 & 1 & -01 \\
\hline $.00 \mathrm{E}+00$ & $.75 \mathrm{E}-01$ & (2) & 1. $43 \mathrm{E}-03$ & $65 E-02$ & $1.04 \mathrm{E}-01$ & 1. $92 \mathrm{E}-01$ & $21 E-01$ \\
\hline $.00 \mathrm{E}+00$ & $F-01$ & 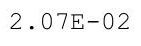 & $E-03$ & -02 & $.05 \mathrm{E}-01$ & $.94 E-01$ & $.23 E-01$ \\
\hline & & & & & & & -01 \\
\hline & & & & & & & \\
\hline $.00 \mathrm{E}+00$ & $8.96 \mathrm{E}-01$ & $2 \cdot 14+02$ & $1.55 \mathrm{E}-03$ & $4.86 \mathrm{E}-02$ & +.00 & $.00 \mathrm{E}-01$ & -01 \\
\hline $.00 \mathrm{E}+00$ & $9.0 \perp \mathrm{L}-01$ & $\angle .10 \mathrm{E}-2<$ & $1.59 \mathrm{E}-03$ & $91 \mathrm{E}-02$ & $1.10 \mathrm{E}-01$ & $2.02 \mathrm{E}-01$ & 3. $35 E-01$ \\
\hline $.00 \mathrm{E}+00$ & 年 & 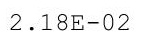 & $-\theta_{0}$ & $.97 \mathrm{E}-02$ & -01 & 01 & $3.38 \mathrm{E}-01$ \\
\hline $.00 E+00$ & ק? & & & תמת ת מ & & & 1 \\
\hline $.00 \mathrm{E}+00$ & & & & & & & \\
\hline & & & & 02 & & & -01 \\
\hline $0 E+00$ & $9.21 \mathrm{E}$ & 2.201 & 03 & 2 & 1 & & \\
\hline $.00 \mathrm{E}+00$ & . & 2.2 & & & & & -01 \\
\hline 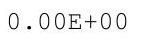 & & & & & & & . \\
\hline o & 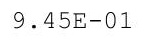 & 2 & 3 & & 1 & \pm & 01 \\
\hline $00 \mathrm{E}+00$ & & & & & & & 1 \\
\hline & & 2 & 03 & 02 & 1 & 1 & \\
\hline $00 \mathrm{E}+00$ & $9.63 \mathrm{E}-01$ & -02 & 1 . & 02 & -01 & & -01 \\
\hline & & & & & & & \\
\hline & .1 & . & & & & & $3.13 \mathrm{E}-01$ \\
\hline $.00 E+00$ & 1 & 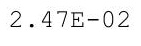 & & 2 & 1.00 & $2.21=$ & $5-01$ \\
\hline $00 E+00$ & $E-01$ & $9 \mathrm{E}-02$ & $08 E-03$ & $E-02$ & $E-01$ & 01 & -01 \\
\hline
\end{tabular}


RESRAD-OFFSITE, Version 2.5

$\mathrm{T}^{1 / 2}$ Limit $=180$ days

obabilistic Dose and Risk Report

Title : Offsite Resident Farmer Deterministic Run

File : RF TC99 DOESG FWD-FV2.ROF

Summary of dose at graphical times, reptition 3 (continued)

Time

Years

$3.54 \mathrm{E}+02$

$3.54 \mathrm{E}+02$

$3.55 \mathrm{E}+02$

$3.55 \mathrm{E}+02$

$3.56 \mathrm{E}+02$

$3.56 \mathrm{E}+02$

$3.57 \mathrm{E}+02$

3. $57 \mathrm{E}+02$

$3.58 \mathrm{E}+02$

3. $58 \mathrm{E}+02$

$3.59 \mathrm{E}+02$

3. $59 \mathrm{E}+02$

$3.60 E+02$

$3.60 E+02$

$3.61 \mathrm{E}+02$

$3.61 \mathrm{E}+02$

3. $62 \mathrm{E}+02$

$3.62 \mathrm{E}+02$

$3.63 \mathrm{E}+02$

$3.64 \mathrm{E}+02$

3. $64 \mathrm{E}+02$

$3.65 \mathrm{E}+02$

$3.65 \mathrm{E}+02$

$3.66 \mathrm{E}+02$

$3.66 \mathrm{E}+02$

$3.67 \mathrm{E}+02$

3. $67 \mathrm{E}+02$

$3.68 \mathrm{E}+02$

$3.68 \mathrm{E}+02$

$3.69 \mathrm{E}+02$

3. $69 \mathrm{E}+02$

$3.70 \mathrm{E}+02$

3. $70 \mathrm{E}+02$

3. $71 \mathrm{E}+02$

$3.71 \mathrm{E}+02$

3. $72 \mathrm{E}+02$

3. $72 \mathrm{E}+02$

3. $73 \mathrm{E}+02$

$3.73 E+02$

$3.74 \mathrm{E}+02$

$3.74 \mathrm{E}+02$

$3.75 \mathrm{E}+02$

$3.75 \mathrm{E}+02$

$3.76 \mathrm{E}+02$

$3.76 \mathrm{E}+02$

$3.77 \mathrm{E}+02$

Dose statistics at graphical times, mrem/yr

\begin{tabular}{|c|c|c|c|c|c|c|c|}
\hline Minimum & Maximum & Mean & Median & $90 \%$ & $95 \%$ & $97.5 \%$ & $99 \%$ \\
\hline $0.00 \mathrm{E}+00$ & $9.94 \mathrm{E}-01$ & $2.51 E-02$ & $2.11 E-03$ & $5.84 E-02$ & $1.27 E-01$ & $2.31 E-01$ & $3.82 \mathrm{E}-01$ \\
\hline $0.00 \mathrm{E}+00$ & $1.00 \mathrm{E}+00$ & $2.54 \mathrm{E}-02$ & $2.15 \mathrm{E}-03$ & $5.90 \mathrm{E}-02$ & $1.28 \mathrm{E}-01$ & $2.33 E-01$ & $3.85 E-01$ \\
\hline $0.00 \mathrm{E}+00$ & $1.01 \mathrm{E}+00$ & $2.56 \mathrm{E}-02$ & $2.18 \mathrm{E}-03$ & $5.97 \mathrm{E}-02$ & $1.29 \mathrm{E}-01$ & $2.35 \mathrm{E}-01$ & $3.88 E-01$ \\
\hline $0.00 \mathrm{E}+00$ & $1.01 \mathrm{E}+00$ & $2.59 \mathrm{E}-02$ & $2.22 \mathrm{E}-03$ & $6.04 \mathrm{E}-02$ & $1.30 \mathrm{E}-01$ & $2.37 \mathrm{E}-01$ & $3.91 \mathrm{E}-01$ \\
\hline $0.00 \mathrm{E}+00$ & $1.02 \mathrm{E}+00$ & $2.61 \mathrm{E}-02$ & $2.26 \mathrm{E}-03$ & $6.11 \mathrm{E}-02$ & $1.31 \mathrm{E}-01$ & $2.40 \mathrm{E}-01$ & $3.94 \mathrm{E}-01$ \\
\hline $0.00 \mathrm{E}+00$ & $1.02 \mathrm{E}+00$ & $2.63 E-02$ & $2.31 \mathrm{E}-03$ & $6.17 \mathrm{E}-02$ & $1.32 \mathrm{E}-01$ & $2.42 \mathrm{E}-01$ & $3.97 \mathrm{E}-01$ \\
\hline $0.00 \mathrm{E}+00$ & $1.03 \mathrm{E}+00$ & $2.66 \mathrm{E}-02$ & $2.35 E-03$ & $6.24 \mathrm{E}-02$ & $1.33 \mathrm{E}-01$ & $2.44 \mathrm{E}-01$ & $4.00 \mathrm{E}-01$ \\
\hline $0.00 \mathrm{E}+00$ & $1.04 \mathrm{E}+00$ & $2.68 \mathrm{E}-02$ & $2.40 \mathrm{E}-03$ & $6.31 E-02$ & $1.34 \mathrm{E}-01$ & $2.46 \mathrm{E}-01$ & $4.03 E-01$ \\
\hline $0.00 \mathrm{E}+00$ & $1.04 \mathrm{E}+00$ & $2.71 E-02$ & $2.44 E-03$ & $6.38 E-02$ & 1. $35 \mathrm{E}-01$ & $2.49 \mathrm{E}-01$ & $4.06 \mathrm{E}-01$ \\
\hline $00 \mathrm{E}+00$ & $1.05 \mathrm{E}+00$ & $2.73 E-02$ & $2.48 \mathrm{E}-03$ & $6.45 \mathrm{E}-02$ & $1.36 \mathrm{E}-01$ & $2.51 \mathrm{E}-01$ & $4.10 \mathrm{E}-01$ \\
\hline $0.00 \mathrm{E}+00$ & $1.06 \mathrm{E}+00$ & $2.76 \mathrm{E}-02$ & $2.53 E-03$ & $6.51 \mathrm{E}-02$ & $1.37 \mathrm{E}-01$ & $2.53 \mathrm{E}-01$ & $4.13 E-01$ \\
\hline $0.00 \mathrm{E}+00$ & $1.06 \mathrm{E}+00$ & $2.78 E-02$ & $2.57 \mathrm{E}-03$ & $6.58 \mathrm{E}-02$ & $1.38 \mathrm{E}-01$ & $2.55 \mathrm{E}-01$ & $4.16 \mathrm{E}-01$ \\
\hline $0.00 \mathrm{E}+00$ & $1.07 \mathrm{E}+00$ & $2.81 \mathrm{E}-02$ & $2.62 \mathrm{E}-03$ & $6.65 \mathrm{E}-02$ & $1.39 \mathrm{E}-01$ & $2.57 \mathrm{E}-01$ & $4.19 \mathrm{E}-01$ \\
\hline $0.00 \mathrm{E}+00$ & $1.07 \mathrm{E}+00$ & $2.83 E-02$ & $2.67 \mathrm{E}-03$ & $6.71 \mathrm{E}-02$ & $1.41 \mathrm{E}-01$ & $2.59 \mathrm{E}-01$ & $4.22 \mathrm{E}-01$ \\
\hline $0.00 \mathrm{E}+00$ & $1.08 \mathrm{E}+00$ & $2.86 \mathrm{E}-02$ & $2.72 \mathrm{E}-03$ & $6.78 \mathrm{E}-02$ & 1. $42 \mathrm{E}-01$ & $2.61 \mathrm{E}-01$ & $4.25 E-01$ \\
\hline $0.00 \mathrm{E}+00$ & $1.09 \mathrm{E}+00$ & $8 E-02$ & $7 E-03$ & $6.85 E-02$ & $1.43 E-01$ & $2.63 E-01$ & $29 E-01$ \\
\hline $0.00 \mathrm{E}+00$ & $1.09 \mathrm{E}+00$ & $2.91 \mathrm{E}-02$ & $2.82 \mathrm{E}-03$ & $6.91 \mathrm{E}-02$ & $1.44 \mathrm{E}-01$ & $2.66 \mathrm{E}-01$ & 4. $32 \mathrm{E}-01$ \\
\hline $0.00 \mathrm{E}+00$ & $1.10 \mathrm{E}+00$ & $2.94 E-02$ & $2.86 \mathrm{E}-03$ & $6.98 \mathrm{E}-02$ & $1.45 \mathrm{E}-01$ & $2.68 \mathrm{E}-01$ & 4. $35 E-01$ \\
\hline $0.00 \mathrm{E}+00$ & $1.11 \mathrm{E}+00$ & $2.96 \mathrm{E}-02$ & $2.91 \mathrm{E}-03$ & $7.06 \mathrm{E}-02$ & $1.46 \mathrm{E}-01$ & $2.70 \mathrm{E}-01$ & $4.38 E-01$ \\
\hline $0.00 \mathrm{E}+00$ & $1.11 \mathrm{E}+00$ & $2.99 \mathrm{E}-02$ & $2.96 \mathrm{E}-03$ & $7.13 \mathrm{E}-02$ & $1.48 \mathrm{E}-01$ & $2.72 \mathrm{E}-01$ & 4. $42 \mathrm{E}-01$ \\
\hline $0.00 \mathrm{E}+00$ & $1.12 \mathrm{E}+00$ & $3.01 \mathrm{E}-02$ & $3.00 \mathrm{E}-03$ & $7.19 \mathrm{E}-02$ & $1.49 \mathrm{E}-01$ & $2.74 \mathrm{E}-01$ & 4. $45 \mathrm{E}-01$ \\
\hline $0.00 \mathrm{E}+00$ & $1.13 \mathrm{E}+00$ & $3.04 \mathrm{E}-02$ & $3.05 E-03$ & $26 E-02$ & $1.51 \mathrm{E}-01$ & $2.76 \mathrm{E}-01$ & $4.48 E-01$ \\
\hline $0.00 \mathrm{E}+00$ & $1.13 \mathrm{E}+00$ & $3.07 \mathrm{E}-02$ & $3.10 \mathrm{E}-03$ & $7.33 E-02$ & $1.52 \mathrm{E}-01$ & $2.78 \mathrm{E}-01$ & $4.51 \mathrm{E}-01$ \\
\hline $0.00 \mathrm{E}+00$ & $1.14 \mathrm{E}+00$ & $3.10 \mathrm{E}-02$ & $3.15 \mathrm{E}-03$ & $7.40 \mathrm{E}-02$ & $1.54 \mathrm{E}-01$ & $2.81 \mathrm{E}-01$ & $4.55 \mathrm{E}-01$ \\
\hline $0.00 \mathrm{E}+00$ & $1.14 \mathrm{E}+00$ & $3.12 \mathrm{E}-02$ & $3.20 E-03$ & $7.47 \mathrm{E}-02$ & $1.55 \mathrm{E}-01$ & $2.84 \mathrm{E}-01$ & $4.58 \mathrm{E}-01$ \\
\hline $0.00 \mathrm{E}+00$ & $1.15 \mathrm{E}+00$ & $3.15 \mathrm{E}-02$ & $3.25 \mathrm{E}-03$ & $7.55 \mathrm{E}-02$ & $1.56 \mathrm{E}-01$ & $2.86 \mathrm{E}-01$ & 4. $61 \mathrm{E}-01$ \\
\hline $0.00 \mathrm{E}+00$ & $1.16 \mathrm{E}+00$ & $3.18 \mathrm{E}-02$ & $3.31 \mathrm{E}-03$ & $7.62 \mathrm{E}-02$ & $1.57 \mathrm{E}-01$ & $2.89 \mathrm{E}-01$ & 4. $65 \mathrm{E}-01$ \\
\hline $0.00 \mathrm{E}+00$ & $1.16 \mathrm{E}+00$ & $3.20 \mathrm{E}-02$ & $3.36 \mathrm{E}-03$ & $7.69 \mathrm{E}-02$ & $1.59 \mathrm{E}-01$ & $2.91 E-01$ & 4. $68 \mathrm{E}-01$ \\
\hline $0.00 \mathrm{E}+00$ & $1.17 \mathrm{E}+00$ & $3.23 E-02$ & $3.41 \mathrm{E}-03$ & $7.76 \mathrm{E}-02$ & $1.60 \mathrm{E}-01$ & $2.94 \mathrm{E}-01$ & 4. $72 \mathrm{E}-01$ \\
\hline $0.00 \mathrm{E}+00$ & $1.18 \mathrm{E}+00$ & $3.26 \mathrm{E}-02$ & $3.46 \mathrm{E}-03$ & $7.84 \mathrm{E}-02$ & $1.61 \mathrm{E}-01$ & $2.96 \mathrm{E}-01$ & $4.75 E-01$ \\
\hline $0.00 \mathrm{E}+00$ & $1.18 \mathrm{E}+00$ & $3.29 \mathrm{E}-02$ & $3.51 \mathrm{E}-03$ & $7.91 \mathrm{E}-02$ & $1.63 \mathrm{E}-01$ & $2.99 \mathrm{E}-01$ & $4.79 \mathrm{E}-01$ \\
\hline $0.00 \mathrm{E}+00$ & $1.19 \mathrm{E}+00$ & $3.32 \mathrm{E}-02$ & $3.56 \mathrm{E}-03$ & $7.99 \mathrm{E}-02$ & $1.64 \mathrm{E}-01$ & $3.02 \mathrm{E}-01$ & $4.82 \mathrm{E}-01$ \\
\hline $0.00 \mathrm{E}+00$ & $1.20 \mathrm{E}+00$ & $3.34 \mathrm{E}-02$ & $2 E-03$ & $06 \mathrm{E}-02$ & $1.66 \mathrm{E}-01$ & $3.04 \mathrm{E}-01$ & $4.86 \mathrm{E}-01$ \\
\hline $0.00 \mathrm{E}+00$ & $1.20 \mathrm{E}+00$ & $3.37 \mathrm{E}-02$ & $3.67 \mathrm{E}-03$ & $8.13 \mathrm{E}-02$ & $1.67 \mathrm{E}-01$ & $3.07 \mathrm{E}-01$ & $4.89 \mathrm{E}-01$ \\
\hline $0.00 \mathrm{E}+00$ & $1.21 \mathrm{E}+00$ & $3.40 \mathrm{E}-02$ & $3.73 E-03$ & $8.20 \mathrm{E}-02$ & $1.69 \mathrm{E}-01$ & $3.10 \mathrm{E}-01$ & 4. $93 \mathrm{E}-01$ \\
\hline $0.00 \mathrm{E}+00$ & $1.21 \mathrm{E}+00$ & $3.43 E-02$ & $3.79 E-03$ & $8.27 E-02$ & $1.70 \mathrm{E}-01$ & $3.12 \mathrm{E}-01$ & $4.96 \mathrm{E}-01$ \\
\hline $0.00 \mathrm{E}+00$ & $1.22 \mathrm{E}+00$ & $3.46 \mathrm{E}-02$ & $3.85 E-03$ & $8.35 E-02$ & $1.72 \mathrm{E}-01$ & $3.15 \mathrm{E}-01$ & $5.00 \mathrm{E}-01$ \\
\hline $0.00 \mathrm{E}+00$ & $1.23 \mathrm{E}+00$ & $3.49 \mathrm{E}-02$ & $3.91 \mathrm{E}-03$ & $8.42 \mathrm{E}-02$ & $1.73 \mathrm{E}-01$ & $3.18 \mathrm{E}-01$ & $5.03 E-01$ \\
\hline $00 E+00$ & $1.23 \mathrm{E}+00$ & $3.52 \mathrm{E}$ & $3.97 E-03$ & $8.49 \mathrm{E}-02$ & $1.74 \mathrm{E}-01$ & $3.20 \mathrm{E}-01$ & $5.07 E-01$ \\
\hline $0.00 \mathrm{E}+00$ & $1.24 \mathrm{E}+00$ & $3.55 \mathrm{E}-02$ & $4.03 E-03$ & $8.56 \mathrm{E}-02$ & $1.76 \mathrm{E}-01$ & $3.23 \mathrm{E}-01$ & $5.10 \mathrm{E}-01$ \\
\hline $0.00 \mathrm{E}+00$ & $1.25 \mathrm{E}+00$ & $3.58 \mathrm{E}-02$ & $4.09 \mathrm{E}-03$ & $8.64 \mathrm{E}-02$ & $1.77 \mathrm{E}-01$ & $3.26 \mathrm{E}-01$ & $5.14 \mathrm{E}-01$ \\
\hline $0.00 \mathrm{E}+00$ & $1.25 \mathrm{E}+00$ & $3.61 E-02$ & $4.14 \mathrm{E}-03$ & $8.71 E-02$ & $1.79 \mathrm{E}-01$ & $3.29 E-01$ & $5.18 \mathrm{E}-01$ \\
\hline $0.00 \mathrm{E}+00$ & $1.26 \mathrm{E}+00$ & $3.64 \mathrm{E}-02$ & $4.21 \mathrm{E}-03$ & $8.78 \mathrm{E}-02$ & $1.80 \mathrm{E}-01$ & $3.31 \mathrm{E}-01$ & $5.21 \mathrm{E}-01$ \\
\hline $0.00 \mathrm{E}+00$ & $1.27 \mathrm{E}+00$ & $3.67 \mathrm{E}-02$ & $4.27 E-03$ & $8.86 \mathrm{E}-02$ & $1.82 \mathrm{E}-01$ & $3.33 E-01$ & $5.24 \mathrm{E}-01$ \\
\hline $0.00 \mathrm{E}+00$ & $1.27 \mathrm{E}+00$ & $3.70 E-02$ & $4.34 \mathrm{E}-03$ & $8.93 E-02$ & $1.83 \mathrm{E}-01$ & $3.35 E-01$ & $5.27 E-01$ \\
\hline $0.00 \mathrm{E}+00$ & $1.28 \mathrm{E}+00$ & $3.73 E-02$ & $4.40 \mathrm{E}-03$ & $9.00 \mathrm{E}-02$ & $1.84 \mathrm{E}-01$ & $3.38 \mathrm{E}-01$ & $5.30 \mathrm{E}-01$ \\
\hline
\end{tabular}


RESRAD-OFFSITE, Version 2.5

obabilistic Dose and Risk Report

Title : Offsite Resident Farmer Deterministic Run

File : RF TC99 DOESG FWD-FV2.ROF

Summary of dose at graphical times, reptition 3 (continued)

Time

Years

$3.77 \mathrm{E}+02$

$3.78 \mathrm{E}+02$

$3.78 \mathrm{E}+02$

$3.79 \mathrm{E}+02$

3. $79 \mathrm{E}+02$

$3.80 \mathrm{E}+02$

$3.80 \mathrm{E}+02$

3. $81 \mathrm{E}+02$

3. $81 \mathrm{E}+02$

3. $82 \mathrm{E}+02$

3. $82 \mathrm{E}+02$

$3.83 E+02$

$3.83 E+02$

$3.84 \mathrm{E}+02$

$3.85 \mathrm{E}+02$

$3.85 \mathrm{E}+02$

$3.86 \mathrm{E}+02$

$3.86 \mathrm{E}+02$

$3.87 \mathrm{E}+02$

$3.87 \mathrm{E}+02$

$3.88 \mathrm{E}+02$

$3.88 \mathrm{E}+02$

$3.89 \mathrm{E}+02$

3. $89 \mathrm{E}+02$

3. $90 \mathrm{E}+02$

$3.90 \mathrm{E}+02$

3. $91 \mathrm{E}+02$

3. $91 \mathrm{E}+02$

3. $92 \mathrm{E}+02$

3. $92 \mathrm{E}+02$

3. $93 \mathrm{E}+02$

$3.93 \mathrm{E}+02$

$3.94 \mathrm{E}+02$

3. $94 \mathrm{E}+02$

$3.95 \mathrm{E}+02$

$3.95 \mathrm{E}+02$

$3.96 \mathrm{E}+02$

$3.96 \mathrm{E}+02$

$3.97 \mathrm{E}+02$

$3.97 \mathrm{E}+02$

$3.98 \mathrm{E}+02$

$3.98 \mathrm{E}+02$

$3.99 \mathrm{E}+02$

$3.99 \mathrm{E}+02$

$4.00 \mathrm{E}+02$

$4.00 \mathrm{E}+02$
Dose statistics at graphical times, mrem/yr

\begin{tabular}{|c|c|c|c|c|c|c|c|}
\hline Minimum & Maximum & Mean & Median & $90 \%$ & $95 \%$ & $97.5 \%$ & $99 \%$ \\
\hline $0.00 \mathrm{E}+00$ & $1.29 \mathrm{E}+00$ & $3.76 \mathrm{E}-02$ & $4.46 E-03$ & $9.08 E-02$ & $1.86 \mathrm{E}-01$ & $3.40 \mathrm{E}-01$ & $5.34 \mathrm{E}-01$ \\
\hline $0.00 \mathrm{E}+00$ & $1.29 \mathrm{E}+00$ & $3.79 E-02$ & $4.52 E-03$ & $9.17 \mathrm{E}-02$ & $1.87 \mathrm{E}-01$ & $3.42 \mathrm{E}-01$ & $5.37 \mathrm{E}-01$ \\
\hline $0.00 \mathrm{E}+00$ & $1.30 \mathrm{E}+00$ & $3.82 \mathrm{E}-02$ & $4.59 \mathrm{E}-03$ & $9.25 E-02$ & $1.89 \mathrm{E}-01$ & $3.44 \mathrm{E}-01$ & $5.40 \mathrm{E}-01$ \\
\hline $0.00 \mathrm{E}+00$ & $1.30 \mathrm{E}+00$ & $3.85 \mathrm{E}-02$ & $4.65 \mathrm{E}-03$ & $9.33 \mathrm{E}-02$ & $1.90 \mathrm{E}-01$ & $3.47 \mathrm{E}-01$ & $5.44 \mathrm{E}-01$ \\
\hline $0.00 \mathrm{E}+00$ & $1.31 \mathrm{E}+00$ & $3.88 E-02$ & $4.71 E-03$ & $9.41 E-02$ & 1.92E-01 & $3.49 \mathrm{E}-01$ & $5.47 E-01$ \\
\hline $0.00 \mathrm{E}+00$ & 1. $32 \mathrm{E}+00$ & $3.91 \mathrm{E}-02$ & $4.78 E-03$ & $9.50 \mathrm{E}-02$ & $1.93 \mathrm{E}-01$ & $3.51 \mathrm{E}-01$ & $5.51 \mathrm{E}-01$ \\
\hline $0.00 \mathrm{E}+00$ & $1.32 \mathrm{E}+00$ & $3.94 \mathrm{E}-02$ & $4.85 E-03$ & $9.58 \mathrm{E}-02$ & $1.95 \mathrm{E}-01$ & $3.53 \mathrm{E}-01$ & $5.54 \mathrm{E}-01$ \\
\hline $0.00 \mathrm{E}+00$ & $1.33 \mathrm{E}+00$ & $3.97 \mathrm{E}-02$ & $4.92 E-03$ & $9.66 \mathrm{E}-02$ & $1.96 \mathrm{E}-01$ & $3.54 \mathrm{E}-01$ & $5.58 \mathrm{E}-01$ \\
\hline $0.00 \mathrm{E}+00$ & $1.34 \mathrm{E}+00$ & $4.01 E-02$ & $4.99 E-03$ & $9.74 \mathrm{E}-02$ & $1.98 \mathrm{E}-01$ & $3.56 \mathrm{E}-01$ & $5.61 \mathrm{E}-01$ \\
\hline $0.00 \mathrm{E}+00$ & $1.34 \mathrm{E}+00$ & $4.04 \mathrm{E}-02$ & $5.06 \mathrm{E}-03$ & $9.82 \mathrm{E}-02$ & $1.99 \mathrm{E}-01$ & $3.58 \mathrm{E}-01$ & $5.65 \mathrm{E}-01$ \\
\hline $0.00 \mathrm{E}+00$ & $1.35 \mathrm{E}+00$ & $4.07 \mathrm{E}-02$ & $5.14 \mathrm{E}-03$ & $9.90 \mathrm{E}-02$ & $2.01 \mathrm{E}-01$ & $3.60 \mathrm{E}-01$ & $5.68 \mathrm{E}-01$ \\
\hline $0.00 \mathrm{E}+00$ & $1.36 \mathrm{E}+00$ & $4.10 \mathrm{E}-02$ & $5.22 E-03$ & $9.98 \mathrm{E}-02$ & $2.02 \mathrm{E}-01$ & $3.61 \mathrm{E}-01$ & $5.72 \mathrm{E}-01$ \\
\hline $0.00 \mathrm{E}+00$ & $1.36 \mathrm{E}+00$ & $4.13 \mathrm{E}-02$ & $5.29 \mathrm{E}-03$ & 1.01E-01 & $2.04 \mathrm{E}-01$ & $3.64 \mathrm{E}-01$ & $5.75 E-01$ \\
\hline $0.00 \mathrm{E}+00$ & $1.37 \mathrm{E}+00$ & $4.17 \mathrm{E}-02$ & $5.37 E-03$ & $1.01 \mathrm{E}-01$ & $2.05 \mathrm{E}-01$ & $3.66 \mathrm{E}-01$ & $5.79 \mathrm{E}-01$ \\
\hline $0.00 \mathrm{E}+00$ & 1. $38 \mathrm{E}+00$ & $4.20 E-02$ & $5.44 E-03$ & 1.02E-01 & $2.07 E-01$ & $3.68 \mathrm{E}-01$ & $5.82 \mathrm{E}-01$ \\
\hline $0.00 \mathrm{E}+00$ & $1.38 \mathrm{E}+00$ & $4.23 E-02$ & $5.52 E-03$ & $1.03 E-01$ & $2.08 E-01$ & $3.70 E-01$ & $.86 E-01$ \\
\hline $0.00 \mathrm{E}+00$ & $1.39 \mathrm{E}+00$ & $4.27 E-02$ & $5.59 E-03$ & $1.04 \mathrm{E}-01$ & $2.09 \mathrm{E}-01$ & $3.73 \mathrm{E}-01$ & $5.89 \mathrm{E}-01$ \\
\hline $0.00 \mathrm{E}+00$ & $1.40 \mathrm{E}+00$ & $4.30 E-02$ & $5.66 \mathrm{E}-03$ & $1.05 \mathrm{E}-01$ & $2.10 \mathrm{E}-01$ & $3.75 \mathrm{E}-01$ & $5.93 E-01$ \\
\hline $0.00 \mathrm{E}+00$ & $1.40 \mathrm{E}+00$ & $4.33 E-02$ & $5.74 E-03$ & $1.06 \mathrm{E}-01$ & $2.11 \mathrm{E}-01$ & $3.77 E-01$ & $5.96 \mathrm{E}-01$ \\
\hline $0.00 \mathrm{E}+00$ & $1.41 \mathrm{E}+00$ & $4.37 \mathrm{E}-02$ & $5.82 E-03$ & $1.07 \mathrm{E}-01$ & $2.13 \mathrm{E}-01$ & $3.80 \mathrm{E}-01$ & $6.00 \mathrm{E}-01$ \\
\hline $0.00 \mathrm{E}+00$ & $1.41 \mathrm{E}+00$ & $4.40 \mathrm{E}-02$ & $5.90 \mathrm{E}-03$ & $1.08 \mathrm{E}-01$ & $2.14 \mathrm{E}-01$ & $3.83 E-01$ & $6.03 E-01$ \\
\hline $0.00 \mathrm{E}+00$ & $1.42 \mathrm{E}+00$ & $4.43 E-02$ & $5.97 \mathrm{E}-03$ & $1.09 E-01$ & $2.16 \mathrm{E}-01$ & $3.85 E-01$ & $6.07 E-01$ \\
\hline $0.00 \mathrm{E}+00$ & $1.43 E+00$ & $4.47 \mathrm{E}-02$ & $6.05 E-03$ & $1.09 \mathrm{E}-01$ & $2.17 \mathrm{E}-01$ & $3.88 \mathrm{E}-01$ & $6.10 \mathrm{E}-01$ \\
\hline $0.00 \mathrm{E}+00$ & $1.43 \mathrm{E}+00$ & $4.50 \mathrm{E}-02$ & $6.13 E-03$ & 1.10E-01 & $2.19 \mathrm{E}-01$ & $3.91 \mathrm{E}-01$ & $6.14 \mathrm{E}-01$ \\
\hline $2.80 E-23$ & $1.44 \mathrm{E}+00$ & $4.54 \mathrm{E}-02$ & $6.21 E-03$ & 1.11E-01 & $2.20 \mathrm{E}-01$ & $3.94 \mathrm{E}-01$ & $6.18 \mathrm{E}-01$ \\
\hline $4.50 \mathrm{E}-21$ & $1.45 \mathrm{E}+00$ & $4.57 \mathrm{E}-02$ & $6.29 E-03$ & 1.12E-01 & $2.22 \mathrm{E}-01$ & $3.96 \mathrm{E}-01$ & $6.21 \mathrm{E}-01$ \\
\hline $1.75 \mathrm{E}-19$ & $1.45 \mathrm{E}+00$ & 4. $61 \mathrm{E}-02$ & $6.37 \mathrm{E}-03$ & $1.13 \mathrm{E}-01$ & $2.23 E-01$ & $3.99 \mathrm{E}-01$ & $6.25 \mathrm{E}-01$ \\
\hline $3.34 \mathrm{E}-18$ & $1.46 \mathrm{E}+00$ & $4.64 \mathrm{E}-02$ & $6.45 E-03$ & $1.14 \mathrm{E}-01$ & $2.25 \mathrm{E}-01$ & $4.02 E-01$ & $6.28 \mathrm{E}-01$ \\
\hline $4.00 \mathrm{E}-17$ & $1.47 \mathrm{E}+00$ & $4.68 E-02$ & $6.54 \mathrm{E}-03$ & 1. $15 \mathrm{E}-01$ & $2.26 \mathrm{E}-01$ & 4. $05 \mathrm{E}-01$ & $6.32 \mathrm{E}-01$ \\
\hline $3.38 E-16$ & $1.47 \mathrm{E}+00$ & $4.71 E-02$ & $6.62 E-03$ & $1.16 \mathrm{E}-01$ & $2.28 E-01$ & $4.07 E-01$ & $6.36 \mathrm{E}-01$ \\
\hline $2.17 \mathrm{E}-15$ & $1.48 \mathrm{E}+00$ & $4.75 E-02$ & $6.71 \mathrm{E}-03$ & $1.17 \mathrm{E}-01$ & $2.30 \mathrm{E}-01$ & $4.10 \mathrm{E}-01$ & $6.39 \mathrm{E}-01$ \\
\hline $1.12 \mathrm{E}-14$ & $1.49 \mathrm{E}+00$ & $4.78 E-02$ & $6.79 E-03$ & 1. $18 \mathrm{E}-01$ & $2.31 \mathrm{E}-01$ & $4.13 \mathrm{E}-01$ & $6.43 E-01$ \\
\hline $4.77 E-14$ & $1.49 \mathrm{E}+00$ & $.82 E-02$ & $6.88 E-03$ & $1.19 \mathrm{E}-01$ & $2.33 E-01$ & $4.16 \mathrm{E}-01$ & $6.47 E-01$ \\
\hline $1.74 \mathrm{E}-13$ & $1.50 \mathrm{E}+00$ & $4.85 E-02$ & $6.97 \mathrm{E}-03$ & 1.19E-01 & $2.35 \mathrm{E}-01$ & $4.18 \mathrm{E}-01$ & $6.50 \mathrm{E}-01$ \\
\hline $5.54 \mathrm{E}-13$ & $1.51 \mathrm{E}+00$ & $4.89 \mathrm{E}-02$ & $7.06 \mathrm{E}-03$ & 1.20E-01 & $2.37 \mathrm{E}-01$ & $4.21 \mathrm{E}-01$ & $6.54 \mathrm{E}-01$ \\
\hline $1.57 \mathrm{E}-12$ & $1.51 \mathrm{E}+00$ & $4.93 E-02$ & $7.15 E-03$ & $1.21 \mathrm{E}-01$ & $2.38 \mathrm{E}-01$ & $4.24 \mathrm{E}-01$ & $6.57 \mathrm{E}-01$ \\
\hline $4.05 E-12$ & $1.52 \mathrm{E}+00$ & $4.96 \mathrm{E}-02$ & $7.25 E-03$ & 1.22E-01 & $2.40 \mathrm{E}-01$ & $4.27 \mathrm{E}-01$ & $6.61 \mathrm{E}-01$ \\
\hline $9.59 \mathrm{E}-12$ & $1.52 \mathrm{E}+00$ & $5.00 \mathrm{E}-02$ & $7.35 E-03$ & 1.23E-01 & $2.42 \mathrm{E}-01$ & $4.30 \mathrm{E}-01$ & $6.65 \mathrm{E}-01$ \\
\hline $11 \mathrm{E}-11$ & $1.53 \mathrm{E}+00$ & $5.03 E-02$ & $7.45 E-03$ & $1.24 \mathrm{E}-01$ & $2.44 \mathrm{E}-01$ & $4.33 E-01$ & $6.68 \mathrm{E}-01$ \\
\hline $4.34 \mathrm{E}-11$ & $1.54 \mathrm{E}+00$ & $5.07 E-02$ & $7.53 E-03$ & $1.25 E-01$ & $2.45 \mathrm{E}-01$ & $4.35 E-01$ & $6.72 \mathrm{E}-01$ \\
\hline $8.46 \mathrm{E}-11$ & $1.54 \mathrm{E}+00$ & $5.11 \mathrm{E}-02$ & $7.62 \mathrm{E}-03$ & 1. $26 \mathrm{E}-01$ & $2.47 \mathrm{E}-01$ & $4.38 E-01$ & $6.76 \mathrm{E}-01$ \\
\hline $1.57 \mathrm{E}-10$ & $1.55 \mathrm{E}+00$ & $5.15 \mathrm{E}-02$ & $7.72 E-03$ & $1.27 E-01$ & $2.49 \mathrm{E}-01$ & $4.41 E-01$ & $6.80 E-01$ \\
\hline $2.79 \mathrm{E}-10$ & $1.56 \mathrm{E}+00$ & $5.18 \mathrm{E}-02$ & $7.81 \mathrm{E}-03$ & 1. $29 \mathrm{E}-01$ & $2.51 \mathrm{E}-01$ & $4.44 \mathrm{E}-01$ & $6.83 E-01$ \\
\hline $4.76 \mathrm{E}-10$ & $1.56 \mathrm{E}+00$ & $5.22 \mathrm{E}-02$ & $7.90 E-03$ & $1.30 \mathrm{E}-01$ & $2.52 \mathrm{E}-01$ & $4.47 E-01$ & $6.87 \mathrm{E}-01$ \\
\hline $7.86 \mathrm{E}-10$ & $1.57 \mathrm{E}+00$ & $5.26 E-02$ & $7.99 E-03$ & $1.31 E-01$ & $2.54 \mathrm{E}-01$ & $4.50 E-01$ & $6.91 E-01$ \\
\hline $1.26 \mathrm{E}-09$ & $1.58 \mathrm{E}+00$ & $5.30 \mathrm{E}-02$ & $8.08 E-03$ & 1. $32 \mathrm{E}-01$ & $2.55 \mathrm{E}-01$ & $4.53 E-01$ & $6.94 \mathrm{E}-01$ \\
\hline
\end{tabular}


RESRAD-OFFSITE, Version 2.5

obabilistic Dose and Risk Report

Title : Offsite Resident Farmer Deterministic Run

File : RF TC99 DOESG FWD-FV2.ROF

Summary of dose at graphical times, reptition 3 (continued)

Time

Years

4. $01 \mathrm{E}+02$

$4.01 \mathrm{E}+02$

$4.02 \mathrm{E}+02$

4. $02 \mathrm{E}+02$

$4.03 E+02$

$4.03 E+02$

$4.04 \mathrm{E}+02$

$4.05 \mathrm{E}+02$

$4.05 \mathrm{E}+02$

$4.06 \mathrm{E}+02$

$4.06 \mathrm{E}+02$

$4.07 \mathrm{E}+02$

$4.07 \mathrm{E}+02$

$4.08 \mathrm{E}+02$

$4.08 \mathrm{E}+02$

$4.09 \mathrm{E}+02$

$4.09 \mathrm{E}+02$

$4.10 \mathrm{E}+02$

$4.10 \mathrm{E}+02$

$4.11 \mathrm{E}+02$

$4.11 \mathrm{E}+02$

$4.12 \mathrm{E}+02$

$4.12 \mathrm{E}+02$

$4.13 \mathrm{E}+02$

$4.13 \mathrm{E}+02$

$4.14 \mathrm{E}+02$

4. $14 \mathrm{E}+02$

$4.15 \mathrm{E}+02$

4. $15 \mathrm{E}+02$

$4.16 \mathrm{E}+02$

4. $16 \mathrm{E}+02$

4.17E+02

$4.17 \mathrm{E}+02$

$4.18 \mathrm{E}+02$

$4.18 \mathrm{E}+02$

4. $19 \mathrm{E}+02$

$4.19 \mathrm{E}+02$

$4.20 \mathrm{E}+02$

$4.20 \mathrm{E}+02$

$4.21 \mathrm{E}+02$

$4.21 \mathrm{E}+02$

$4.22 \mathrm{E}+02$

4. $22 \mathrm{E}+02$

$4.23 \mathrm{E}+02$

$4.23 E+02$

$4.24 \mathrm{E}+02$

Dose statistics at graphical times, mrem/yr

\begin{tabular}{|c|c|c|c|c|c|c|c|}
\hline m & aximum & ea & - & & & & \\
\hline $.96 \mathrm{E}-09$ & $1.58 \mathrm{E}+00$ & $5.33 E-02$ & $8.18 \mathrm{E}-03$ & $1.33 \mathrm{E}-01$ & $57 E-01$ & $.56 \mathrm{E}-01$ & $0.90 \pm-01$ \\
\hline $98 E-09$ & $1.59 \mathrm{E}+00$ & $7 E-02$ & $8.27 \mathrm{E}-03$ & $1.34 \mathrm{E}-01$ & $58 E-01$ & $E-01$ & $02 E-01$ \\
\hline $.43 E-09$ & $1.60 \mathrm{E}+00$ & $1 E-02$ & $8.37 \mathrm{E}-03$ & 1. $35 E-01$ & $2.60 \mathrm{E}-01$ & $4.62 \mathrm{E}-01$ & $06 \mathrm{E}-01$ \\
\hline $44 \mathrm{E}-09$ & $1.60 \mathrm{E}+00$ & $45 E-02$ & $46 \mathrm{~F}-03$ & $36 \mathrm{~F}-01$ & $262 F-01$ & $65 \mathrm{~F}-01$ & $9 F-01$ \\
\hline-09 & $.61 \mathrm{E}+00$ & 2 & -03 & 1 & 1 & 1 & -01 \\
\hline 08 & $1.61 E+00$ & & & & & & -01 \\
\hline $.77 \mathrm{E}-08$ & $1.62 \mathrm{E}+00$ & & & & & & -01 \\
\hline $41 \mathrm{E}-08$ & $1.63 E+00$ & 02 & -03 & 01 & 01 & -01 & $24 \mathrm{E}-01$ \\
\hline $22 \mathrm{E}-08$ & $1.63 \mathrm{E}+00$ & -02 & $E-03$ & $1.42 \mathrm{E}-01$ & $71 \mathrm{E}-01$ & -01 & $28 E-01$ \\
\hline $26 \mathrm{E}-08$ & $.64 \mathrm{E}+00$ & 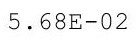 & $.10 \mathrm{E}-03$ & 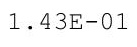 & תרקר & $835-8$ & $32 E-01$ \\
\hline 08 & $1.65 E+00$ & & & & & & -01 \\
\hline$E-08$ & $1.65 E+00$ & se & -03 & 5 & 1 & 1 & -01 \\
\hline $.14 \mathrm{E}-08$ & $1.66 \mathrm{E}+00$ & & $9.45 E-03$ & $1.46 \mathrm{E}-01$ & $2.77 E-01$ & & 7. $43 \mathrm{E}-01$ \\
\hline $15 E-07$ & $1.67 \mathrm{E}+00$ & $5.84 \mathrm{E}-02$ & $9.56 \mathrm{E}-03$ & $1.47 \mathrm{E}-01$ & $2.79 \mathrm{E}-01$ & $4.95 \mathrm{E}-01$ & $7.47 \mathrm{E}-01$ \\
\hline-07 & $1.67 \mathrm{E}+00$ & -02 & -03 & & & -01 & $E-01$ \\
\hline 07 & $1.68 \mathrm{E}+00$ & 2 & 3 & $\perp$ & 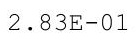 & $1 E-01$ & 01 \\
\hline 77 & 0 & 2 & & & & & 1 \\
\hline$B E-07$ & $1.69 \mathrm{E}+00$ & 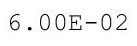 & 2 & $\perp$ & 1 & $07 E-01$ & 01 \\
\hline $24 \mathrm{E}-07$ & $1.70 \mathrm{E}+00$ & $05 E-02$ & $1 \mathrm{E}-02$ & 1. $53 \mathrm{E}-01$ & $88 E-01$ & 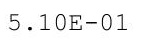 & $66 \mathrm{E}-01$ \\
\hline $89 E-07$ & $1.70 \mathrm{E}+00$ & $6.09 \mathrm{E}-02$ & $.02 E-02$ & $1.54 \mathrm{E}-01$ & $2.90 \mathrm{E}-01$ & $\mathrm{~F}=0$ & 7. $70 \mathrm{E}-01$ \\
\hline 07 & $1.71 \mathrm{E}+00$ & & 2 & & & & $E-01$ \\
\hline $49 E-07$ & & & & 1 & & & 01 \\
\hline $46 \mathrm{E}-07$ & $1.72 \mathrm{E}+00$ & & 02 & $\perp \cdot$ & & & 01 \\
\hline $56 E-07$ & $1.73 E+00$ & 2 & 2 & 1 & 1 & $5.24 \mathrm{E}-01$ & -01 \\
\hline$E-07$ & $1.73 \mathrm{E}+00$ & $9 E-02$ & مص & 1) 50 ت & $99 \mathrm{E}-$ & 7 & $39 E-01$ \\
\hline $02 \mathrm{~F}-06$ & $1.74 \mathrm{E}+00$ & $6.34 \mathrm{E}-02$ & 1.10E-02 & 1 & $.01 \mathrm{E}-$ & $E-01$ & $.93 E-01$ \\
\hline $.17 \mathrm{E}-06$ & $1.75 \mathrm{E}+00$ & $6.38 E-02$ & $1.11 \mathrm{E}-02$ & & & $E-01$ & $.97 E-01$ \\
\hline & & & & & & & 01 \\
\hline 6 & & & 02 & 1.00 & 1 & & -01 \\
\hline $.74 E-06$ & $1.77 \mathrm{E}+00$ & $6.51 \mathrm{E}-02$ & $1.15 \mathrm{E}-02$ & $1.64 \mathrm{E}-01$ & $3.00 \pm-01$ & $2+-01$ & $8.08 E-01$ \\
\hline $97 E-06$ & $1.77 \mathrm{E}+00$ & $6.55 \mathrm{E}-02$ & $1.17 \mathrm{E}-02$ & $+\cdot 00$ & - & 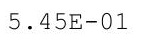 & $.12 \mathrm{E}-01$ \\
\hline 6 & $1.78 \mathrm{E}+0$ & 2 & 2 & & & & $16 E-01$ \\
\hline & $1.78 \mathrm{E}+00$ & & & & & & 01 \\
\hline 6 & $1.79 \mathrm{E}+00$ & 02 & 02 & & & & 01 \\
\hline 06 & 1.801 & 02 & 02 & 1.69 & & 1 & \\
\hline $45 E-06$ & $1.80 \mathrm{E}+00$ & $6.77 E-02$ & 1.23E-02 & $\perp \cdot 10 \mathrm{~L}$ & $3 . \pm$ & $0 \perp$ & $.32 E-01$ \\
\hline $82 E-06$ & $1.81 \mathrm{E}+00$ & & & & & & $8.35 E-01$ \\
\hline - & $1.82 \mathrm{E}+00$ & 2 & 2 & $+\cdot 12+$ & & & $39 E-01$ \\
\hline 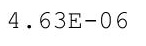 & $1.82 \mathrm{E}+00$ & 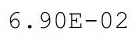 & ? & 1 & 1 & 1 & 01 \\
\hline 6 & & & 02 & 1 & 1 & 1 & \\
\hline $7 E-06$ & $1.83 E+00$ & $99 E-02$ & $1.30 \mathrm{E}$ & 1 . & & 1 & -01 \\
\hline $3 E-06$ & $1.84 \mathrm{E}+00$ & & $1 \cdot 3$ & & & & $E-01$ \\
\hline & $1.85 E+00$ & & & & & & $.39 E-U 1$ \\
\hline $20 E-06$ & $1.85 \mathrm{E}+00$ & $7.12 \mathrm{E}-02$ & 1. $35 \mathrm{E}-02$ & $1.78 \mathrm{E}-01$ & $3.35 E-01$ & $5.85 \mathrm{E}-01$ & $8.03 E-01$ \\
\hline $.00 \mathrm{~L}-\mathrm{U}$ & $1.86 \mathrm{E}+00$ & $7.17 \mathrm{E}-02$ & $1.305-02$ & 1. $79 \mathrm{E}-01$ & $3.37 \mathrm{E}-01$ & (2. & $8.67 \mathrm{E}-01$ \\
\hline$E-06$ & $1.86 \mathrm{E}+00$ & $.21 E-02$ & $.37 \mathrm{E}-02$ & $.81 \mathrm{E}-01$ & -01 & 01 & 01 \\
\hline
\end{tabular}


RESRAD-OFFSITE, Version 2.5

Title : Offsite Resident Farmer Deterministic Run

File : RF TC99 DOESG FWD-FV2.ROF

Summary of dose at graphical times, reptition 3 (continued)

Time

Years

$4.25 E+02$

$4.25 \mathrm{E}+02$

$4.26 \mathrm{E}+02$

$4.26 \mathrm{E}+02$

$4.27 \mathrm{E}+02$

$4.27 \mathrm{E}+02$

$4.28 \mathrm{E}+02$

$4.28 \mathrm{E}+02$

$4.29 \mathrm{E}+02$

$4.29 \mathrm{E}+02$

$4.30 \mathrm{E}+02$

$4.30 \mathrm{E}+02$

4. $31 \mathrm{E}+02$

$4.31 \mathrm{E}+02$

4. $32 \mathrm{E}+02$

4. $32 \mathrm{E}+02$

4. $33 \mathrm{E}+02$

4. $33 \mathrm{E}+02$

$4.34 \mathrm{E}+02$

4. $34 \mathrm{E}+02$

$4.35 \mathrm{E}+02$

$4.35 \mathrm{E}+02$

$4.36 \mathrm{E}+02$

$4.36 \mathrm{E}+02$

$4.37 \mathrm{E}+02$

$4.37 \mathrm{E}+02$

$4.38 \mathrm{E}+02$

$4.38 \mathrm{E}+02$

$4.39 \mathrm{E}+02$

$4.39 \mathrm{E}+02$

$4.40 \mathrm{E}+02$

4. $40 \mathrm{E}+02$

$4.41 \mathrm{E}+02$

4. $41 \mathrm{E}+02$

4. $42 \mathrm{E}+02$

$4.42 \mathrm{E}+02$

$4.43 E+02$

$4.43 E+02$

4. $44 \mathrm{E}+02$

4. $45 \mathrm{E}+02$

$4.45 \mathrm{E}+02$

$4.46 \mathrm{E}+02$

$4.46 \mathrm{E}+02$

$4.47 \mathrm{E}+02$

$4.47 \mathrm{E}+02$

$4.48 \mathrm{E}+02$
Dose statistics at graphical times, mrem/yr

\begin{tabular}{|c|c|c|c|c|c|c|c|}
\hline m & $\mathrm{am}$ & Mean & 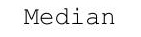 & & & $\%$ & \\
\hline 06 & $1.87 \mathrm{E}+00$ & $7.26 \mathrm{E}-02$ & 1. $39 \mathrm{E}-02$ & $1.82 \mathrm{E}-01$ & -01 & -01 & -01 \\
\hline $82 E-06$ & $1.88 \mathrm{E}+00$ & $31 E-02$ & $1.40 \mathrm{E}-02$ & $1.83 \mathrm{E}-01$ & -01 & $5.95 \mathrm{E}-01$ & -01 \\
\hline $.06 \mathrm{E}-05$ & $1.88 \mathrm{E}+00$ & $.35 E-02$ & 1. $42 \mathrm{E}-02$ & $1.84 \mathrm{E}-01$ & $.46 \mathrm{E}-01$ & -01 & $8.82 E-01$ \\
\hline $.13 E-05$ & $1.89 \mathrm{E}+00$ & $10 E-02$ & 1. $43 \mathrm{E}-02$ & $1.85 \mathrm{E}-01$ & $48 \mathrm{E}-01$ & $0 E-01$ & $8.86 \mathrm{E}-01$ \\
\hline $1 E-05$ & $1.89 \mathrm{E}+00$ & $F$ & 02 & 2. & & 01 & 01 \\
\hline $30 E-05$ & 00 & -02 & 02 & 8 & 1 & 1 & -01 \\
\hline $39 E-05$ & & & & 1 & 1 & 01 & -01 \\
\hline $48 E-05$ & & & & & & & -01 \\
\hline $.58 E-05$ & +00 & $\mathrm{~g}-02$ & -02 & 91 & 1 & -01 & $8 \mathrm{E}-01$ \\
\hline $7+400$ & $1.92 \mathrm{E}+00$ & 50 & 2 & $1.92 \mathrm{E}-01$ & $3.59 \mathrm{E}-01$ & -01 & -01 \\
\hline $78 \mathrm{E}-05$ & $1.93 \mathrm{E}+00$ & $\mathrm{~F}$ & $1.54 \mathrm{E}-02$ & $1.93 E-01$ & 1 & 1 & -01 \\
\hline $.89 \mathrm{E}-$ & & & & 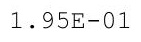 & & & -01 \\
\hline$F-05$ & $1.94 \mathrm{E}+00$ & -0 & 1. & 1 & 1 & -01 & -01 \\
\hline $.11 \mathrm{E}-05$ & $1.95 \mathrm{E}+00$ & $7.87 \mathrm{E}-02$ & $1.59 \mathrm{E}-02$ & $1.97 \mathrm{E}-01$ & $3.67 \mathrm{E}-01$ & $6.29 \mathrm{E}-01$ & $9.30 \mathrm{E}-01$ \\
\hline $23 E-05$ & $1.95 \mathrm{E}+00$ & $2 E-02$ & -02 & $99 \mathrm{E}$ & 01 & -01 & -01 \\
\hline 5 & & & & & & 01 & -01 \\
\hline * & & 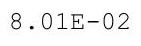 & 2 & $\perp$ & 1 & 01 & 01 \\
\hline 5 & $1.97 \mathrm{E}+$ & & 2 & & & 1 & 1 \\
\hline $75 E-05$ & $1.98 \mathrm{E}+00$ & 15 & $3 E-02$ & - & 1 & -01 & -01 \\
\hline $.88 E-05$ & $1.98 \mathrm{E}+00$ & $16 \mathrm{E}-02$ & $1.70 \mathrm{E}-02$ & $2.06 \mathrm{E}-01$ & $.79 \mathrm{E}-01$ & $.47 \mathrm{E}-01$ & $.57 \mathrm{E}-01$ \\
\hline $03 E-05$ & $1.99 \mathrm{E}+00$ & $8.21 E-02$ & $1.72 \mathrm{E}-02$ & $2.07 E-01$ & $3.81 \mathrm{E}-01$ & $6.50 \mathrm{E}-01$ & $62 E-01$ \\
\hline & & & & & & -01 & -01 \\
\hline 5 & & & & & & & -01 \\
\hline $.48 E-05$ & & $8.35 E-02$ & & & & -01 & -01 \\
\hline 5 & $.01 \mathrm{E}+$ & $8.40 \mathrm{E}-02$ & 2 & - & 1 & 1 & -01 \\
\hline$E-05$ & $.02 E+00$ & $15 \square$ & $1.81 \mathrm{E}-02$ & $15 \square$ & ת & $4 E-01$ & $85 E-01$ \\
\hline - 0 & $2.02 E+00$ & $50 F-02$ & $E-02$ & 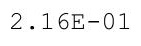 & $93 E-01$ & $E-01$ & $89 E-01$ \\
\hline 1 & & & & & & & -01 \\
\hline & & & & & & & -01 \\
\hline & &. & & 2.21 & -01 & 01 & +00 \\
\hline $.68 E-05$ & $2.05 E+00$ & . tre va & $1.88 \pm-02$ & $2.22 E-01$ & $.01 E-01$ & $6.78 \mathrm{E}-01$ & $1.01 \mathrm{E}+00$ \\
\hline 管 & $2.05 E+00$ & 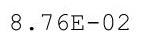 & $1.90 \mathrm{E}-02$ & 2.0 & 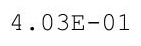 & 01 & $1.01 \mathrm{E}+00$ \\
\hline (5 & $2.06 \mathrm{E}+00$ & 015 & 2 & 2 & & & $1.02 \mathrm{E}+00$ \\
\hline F & & & & & & & $.02 E+00$ \\
\hline $5=0$ & & & 02 & 1 & 1 & & \\
\hline 5 & $2.08 E+00$ & 02 & 02 & $2.50 \mathrm{E}$ & 1 & 1 & $1.03 E+00$ \\
\hline $.00+20$ & $2.08 \mathrm{E}+00$ & 9.0 & 02 & 2.01 & 1 & & +00 \\
\hline 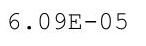 & $2.09 \mathrm{E}+00$ & & & & & & $1.04 \mathrm{E}+00$ \\
\hline 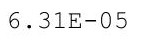 & . & 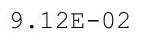 & ? & 1 & 1 & $\perp$ & $1.04 \mathrm{E}+00$ \\
\hline & $2.10 \mathrm{E}+00$ & & & & & & (5) \\
\hline 5 & & 9. & 02 & 1 & 1 & 1 & $1.05 E+00$ \\
\hline $99 \mathrm{E}-05$ & $2.11 E+00$ & $7 E-02$ & 2. & 2.3 & -01 & 01 & $1.06 \mathrm{E}+00$ \\
\hline & 0 & & & & & & \\
\hline & $2.12 \mathrm{E}+00$ & s. & 2 & 2. & & & $1.07 \mathrm{E}+00$ \\
\hline 40 & $2.13 E+00$ & . & ti & 1 & 01 & (r) & $1.07 \mathrm{E}+00$ \\
\hline $96 E-05$ & $.13 E+00$ & $8 E-02$ & $15 E-02$ & $E-01$ & $E-01$ & 1 & $.08 E+00$ \\
\hline
\end{tabular}


RESRAD-OFFSITE, Version 2.5

Title : Offsite Resident Farmer Deterministic Run

File : RF TC99 DOESG FWD-FV2.ROF

Summary of dose at graphical times, reptition 3 (continued)

Time

Years

$4.48 E+02$

$4.49 \mathrm{E}+02$

$4.49 \mathrm{E}+02$

$4.50 \mathrm{E}+02$

$4.50 \mathrm{E}+02$

$4.51 \mathrm{E}+02$

$4.51 \mathrm{E}+02$

$4.52 \mathrm{E}+02$

$4.52 \mathrm{E}+02$

$4.53 \mathrm{E}+02$

$4.53 \mathrm{E}+02$

$4.54 \mathrm{E}+02$

$4.54 \mathrm{E}+02$

$4.55 \mathrm{E}+02$

$4.55 \mathrm{E}+02$

$4.56 \mathrm{E}+02$

$4.56 \mathrm{E}+02$

$4.57 \mathrm{E}+02$

$4.57 \mathrm{E}+02$

$4.58 \mathrm{E}+02$

$4.58 \mathrm{E}+02$

$4.59 \mathrm{E}+02$

$4.59 \mathrm{E}+02$

$4.60 \mathrm{E}+02$

$4.60 \mathrm{E}+02$

$4.61 \mathrm{E}+02$

$4.61 \mathrm{E}+02$

$4.62 \mathrm{E}+02$

4. $62 \mathrm{E}+02$

4. $63 \mathrm{E}+02$

4. $63 \mathrm{E}+02$

$4.64 \mathrm{E}+02$

$4.65 \mathrm{E}+02$

$4.65 \mathrm{E}+02$

$4.66 \mathrm{E}+02$

$4.66 \mathrm{E}+02$

$4.67 \mathrm{E}+02$

$4.67 \mathrm{E}+02$

$4.68 \mathrm{E}+02$

$4.68 \mathrm{E}+02$

$4.69 \mathrm{E}+02$

$4.69 \mathrm{E}+02$

$4.70 \mathrm{E}+02$

$4.70 \mathrm{E}+02$

$4.71 \mathrm{E}+02$

$4.71 \mathrm{E}+02$
Dose statistics at graphical times, mrem/yr

\begin{tabular}{|c|c|c|c|c|c|c|c|}
\hline m & $\mathrm{m}$ & Mean & ledian & & & $\%$ & \\
\hline 05 & $.14 \mathrm{E}+00$ & $9.54 \mathrm{E}-02$ & $2.17 \mathrm{E}-02$ & $2.47 \mathrm{E}-01$ & $4.39 \mathrm{E}-01$ & -01 & $1.00 E+00$ \\
\hline $.47 E-05$ & $.14 \mathrm{E}+00$ & $9 E-02$ & $2.19 \mathrm{E}-02$ & 01 & 01 & -01 & $1.09 \mathrm{E}+00$ \\
\hline $.74 \mathrm{E}-05$ & $2.15 \mathrm{E}+00$ & $54 E-02$ & $2.21 \mathrm{E}-02$ & $2.50 \mathrm{E}-01$ & $44 E-01$ & 7. $36 \mathrm{E}-01$ & $1.09 \mathrm{E}+00$ \\
\hline $.00 E-05$ & $2.15 E+00$ & $.70 E-02$ & $2.24 \mathrm{E}-02$ & $2.52 \mathrm{E}-01$ & $4.46 \mathrm{E}-01$ & 7. $40 \mathrm{E}-01$ & $1.10 \mathrm{E}+00$ \\
\hline $7 E-05$ & $6 \mathrm{E}+00$ & $5 \mathrm{E}$ & 02 & 01 & $3 F-01$ & $3 E-01$ & -00 \\
\hline$E-05$ & 00 & -02 & 2 & 1 & 1 & -01 & +00 \\
\hline $83 E-05$ & & & & & 1 & & +00 \\
\hline-04 & & & & & & & +00 \\
\hline-04 & +00 & $E-02$ & $E-02$ & $N_{\perp}$ & $56 \mathrm{~F}-1$ & -01 & +00 \\
\hline $7 E-04$ & $2.19 \mathrm{E}+00$ & 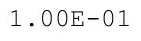 & -02 & $\perp$ & L & 1 & +00 \\
\hline $10 \mathrm{E}-04$ & $19 \mathrm{E}+00$ & 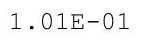 & $2.39 E-02$ & $2.64 E-01$ & $.61 E-01$ & 1 & $3 E+00$ \\
\hline 4 & $\mathrm{E}+00$ & & & $665-0$ & & 1 & +00 \\
\hline $16 F-04$ & $2.20 \mathrm{E}+00$ & $25-0$ & $3 E-02$ & 1 & 1 & 1 & +00 \\
\hline $.19 \mathrm{E}-04$ & $2.21 \mathrm{E}+00$ & $1.02 \mathrm{E}-01$ & $2.45 \mathrm{E}-02$ & $2.69 \mathrm{E}-01$ & $4.67 \mathrm{E}-01$ & $7.74 \mathrm{E}-01$ & $1.14 \mathrm{E}+00$ \\
\hline $22 \mathrm{E}-04$ & $2.21 \mathrm{E}+00$ & $3 E-01$ & $E-02$ & $\perp$ & $\perp$ & -01 & $14 \mathrm{E}+00$ \\
\hline $0^{2}$ & $.22 E+00$ & & & & & 01 & 00 \\
\hline . 2 & & $4 E-01$ & $0<$ & +1 & 1 & 1 & 00 \\
\hline $32 \mathrm{E}-$ & $2.23 E+00$ & & & $275 \mathrm{~F}-01$ & 1 & 1 & 00 \\
\hline $36 \mathrm{~F}-04$ & $2.23 E+00$ & $5 \mathrm{~F}-6$ & $6 E-02$ & $277 \mathrm{~F}$ & 1 & 1 & $1.16 \mathrm{E}+00$ \\
\hline $39 E-04$ & $2.24 \mathrm{E}+00$ & $.06 \mathrm{E}-01$ & $2.58 \mathrm{E}-02$ & $.79 \mathrm{E}-01$ & $.83 E-01$ & $E-01$ & $1.17 \mathrm{E}+00$ \\
\hline $42 E-04$ & $.24 \mathrm{E}+00$ & $.06 \mathrm{E}-0$ & -02 & $.80 \mathrm{E}$ & $.86 \mathrm{E}-01$ & $.98 E-01$ & 1. $17 \mathrm{E}+00$ \\
\hline 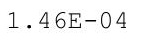 & & & & & & -01 & $.17 E+00$ \\
\hline 4 & & & & & & & 00 \\
\hline $.53 E-04$ & $2.26 \mathrm{E}+00$ & 10 & 2. & & 1 & -01 & \pm+00 \\
\hline 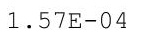 & $2.26 \mathrm{E}+00$ & 1. $09 \mathrm{E}-01$ & 2 & $\perp$ & $\perp$ & 1 & $19 \mathrm{E}+00$ \\
\hline $60=-0$ & $.27 \mathrm{E}+00$ & م & $2.72 \mathrm{E}-02$ & קרית & 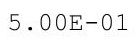 & $.16 \mathrm{E}-01$ & $1.19 \mathrm{E}+00$ \\
\hline $64 \mathrm{~F}-04$ & $2.27 \mathrm{E}+00$ & $110 F-01$ & $2.75 \mathrm{E}-02$ & תחم ק & 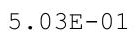 & $9 E-01$ & $1.20 \mathrm{E}+00$ \\
\hline & & & & & & & \\
\hline 4 & $2.28 \mathrm{E}+00$ & & & & & & $.21 \mathrm{E}$ \\
\hline $.75 E-04$ & $2.29 \mathrm{E}+00$ & $\perp \cdot \perp \angle \perp-\perp$ & $2.82 E-02$ & $2 \cdot 11$ & 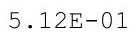 & 01 & $1.21 \mathrm{E}+00$ \\
\hline$\cdot 100-04$ & $2.30 \mathrm{E}+00$ & $\perp \cdot \perp \angle \sqcup 0$ & $2.85 E-02$ & $2.95 E-01$ & 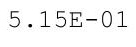 & $8.34 \mathrm{E}-01$ & $1.21 E+00$ \\
\hline .015- & $2.30 \mathrm{E}+00$ & 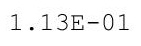 & $2.01 \mathrm{~L}-02$ & 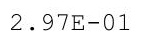 & 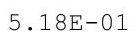 & 01 & $1.22 \mathrm{E}+00$ \\
\hline 䧄 & $2.31 \mathrm{E}+00$ & 135 & $.89 E-02$ & 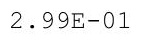 & & & $1.22 \mathrm{E}+00$ \\
\hline & & & & & & & $1.23 E+00$ \\
\hline $1 \mathrm{~F}-04$ & & & 02 & 1 & & & \\
\hline 4 & & & 02 & 3.04 & 1 & 01 & $1.24 \mathrm{E}$ \\
\hline $.98 \pm-04$ & $2.32 \mathrm{E}+00$ & & & & & & $1.24 \mathrm{E}+00$ \\
\hline 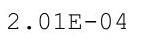 & $2.33 E+00$ & & & & & & $1.25 \mathrm{E}+00$ \\
\hline $05 \mathrm{~F}-04$ & . & $+\cdots$ & 2 & & & $\perp$ & $1.25 \mathrm{E}+00$ \\
\hline & & & & & & & $.25 \mathrm{E}-$ \\
\hline 04 & $2.34 \mathrm{E}+00$ & & 02 & 1 & 1 & 1 & $1.26 \mathrm{E}+00$ \\
\hline $16 \mathrm{E}-04$ & $2.35 E+00$ & 1.19 & 3. & -01 & -01 & & 1.2 \\
\hline & & & & & & & 00 \\
\hline & $2.36 \mathrm{E}+00$ & 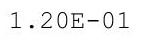 & & & & & $1.27 \mathrm{E}+00$ \\
\hline $\begin{array}{lll}2 & 0\end{array}$ & $2.36 \mathrm{E}+00$ & $\perp \cdot 20+$ & & 1 & 01 & .00 & $1.28 \mathrm{E}+00$ \\
\hline $1 E-04$ & $.37 E+00$ & $1 \mathrm{E}-01$ & $2 E-02$ & $E-01$ & $E-01$ & 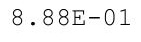 & $1.28 \mathrm{E}+00$ \\
\hline
\end{tabular}


RESRAD-OFFSITE, Version 2.5

Title : Offsite Resident Farmer Deterministic Run

File : RF TC99 DOESG FWD-FV2.ROF

Summary of dose at graphical times, reptition 3 (continued)

Time

Years

$4.72 E+02$

$4.72 \mathrm{E}+02$

$4.73 E+02$

$4.73 \mathrm{E}+02$

$4.74 \mathrm{E}+02$

$4.74 \mathrm{E}+02$

$4.75 \mathrm{E}+02$

$4.75 \mathrm{E}+02$

$4.76 \mathrm{E}+02$

$4.76 \mathrm{E}+02$

$4.77 \mathrm{E}+02$

$4.77 \mathrm{E}+02$

$4.78 \mathrm{E}+02$

$4.78 \mathrm{E}+02$

$4.79 \mathrm{E}+02$

$4.79 \mathrm{E}+02$

$4.80 \mathrm{E}+02$

$4.80 \mathrm{E}+02$

$4.81 \mathrm{E}+02$

$4.81 \mathrm{E}+02$

$4.82 \mathrm{E}+02$

$4.82 \mathrm{E}+02$

$4.83 \mathrm{E}+02$

$4.83 E+02$

$4.84 \mathrm{E}+02$

$4.84 \mathrm{E}+02$

$4.85 \mathrm{E}+02$

$4.86 \mathrm{E}+02$

$4.86 \mathrm{E}+02$

$4.87 \mathrm{E}+02$

$4.87 \mathrm{E}+02$

$4.88 \mathrm{E}+02$

$4.88 \mathrm{E}+02$

$4.89 \mathrm{E}+02$

$4.89 \mathrm{E}+02$

$4.90 \mathrm{E}+02$

$4.90 \mathrm{E}+02$

$4.91 \mathrm{E}+02$

4. $91 \mathrm{E}+02$

$4.92 E+02$

$4.92 \mathrm{E}+02$

$4.93 \mathrm{E}+02$

$4.93 \mathrm{E}+02$

$4.94 \mathrm{E}+02$

4. $94 \mathrm{E}+02$

4. $95 \mathrm{E}+02$

Dose statistics at graphical times, mrem/yr

\begin{tabular}{|c|c|c|c|c|c|c|c|}
\hline m & aximum & lea & - & & & & \\
\hline $34 \mathrm{E}-04$ & $37 \mathrm{E}+00$ & 1.22E-01 & 02 & 01 & 01 & 01 & $.20 E+00$ \\
\hline $38 E-04$ & $2.38 \mathrm{E}+00$ & $1.22 \mathrm{E}-01$ & $27 E-02$ & $3.24 \mathrm{E}-01$ & $53 E-01$ & $8.96 \mathrm{E}-01$ & $1.29 \mathrm{E}+00$ \\
\hline $42 \mathrm{E}-04$ & $38 E+00$ & $23 E-01$ & $30 E-02$ & $25 E-01$ & $56 E-01$ & $99 E-01$ & $.29 E+00$ \\
\hline $46 E-04$ & $.39 \mathrm{E}+00$ & $23 F-01$ & $32 E-02$ & $27 \mathrm{~F}-01$ & $58 F-01$ & -01 & 1. $30 \mathrm{E}+00$ \\
\hline $.50 E-04$ & $39 E+00$ & .241 & $E-02$ & 1 & 1 & 1 & +00 \\
\hline-04 & $40 E+00$ & ( & & & & & +00 \\
\hline $.58 E-04$ & $2.40 \mathrm{E}+00$ & $1.25 \mathrm{E}$ & -02 & & & & $.31 E+00$ \\
\hline-04 & $41 E+00$ & 261 & -02 & 1 & 1 & 01 & $32 \mathrm{E}+00$ \\
\hline $67 E-04$ & $41 E+00$ & $.26 E-01$ & -02 & $E-01$ & $71 E-01$ & -01 & $32 \mathrm{E}+00$ \\
\hline $.71 \mathrm{E}-04$ & $.42 \mathrm{E}+00$ & $27 \mathrm{E}-$ & $49 \mathrm{E}-02$ & $36 \pi$ & & $25-$ & $.32 E+00$ \\
\hline$E-04$ & $2.42 \mathrm{E}+00$ & - & & & & 1 & $E+00$ \\
\hline $.79 \mathrm{E}-04$ & $2.42 \mathrm{E}+00$ & $.28 \mathrm{E}$ & -02 & 1 & & 1 & +00 \\
\hline $.84 \mathrm{E}-04$ & $2.43 E+00$ & $1.29 \mathrm{E}-01$ & $3.57 \mathrm{E}-02$ & & & & $1.34 \mathrm{E}+00$ \\
\hline $88 E-04$ & $2.43 \mathrm{E}+00$ & $1.30 \mathrm{E}-01$ & $.60 \mathrm{E}-02$ & $.43 E-01$ & 1 & 1 & $1.34 \mathrm{E}+00$ \\
\hline-04 & $44 E+00$ & $.30 \mathrm{E}-0$ & -02 & $\perp$ & & $\perp$ & $35 E+00$ \\
\hline 9 & $.44 \mathrm{E}+00$ & - & 02 & 1 & 5 & $\perp$ & 00 \\
\hline 4 & 00 & 1. $31 \mathrm{E}-01$ & & & & $3 E-01$ & 00 \\
\hline$E-04$ & $245 \mathrm{~F}+0$ & 1. $32 \mathrm{E}-01$ & 2 & $\perp$ & & $5 E-01$ & 00 \\
\hline $.11 E-04$ & $2.46 \mathrm{E}+00$ & $1.33 E-01$ & $3.75 E-02$ & $3.51 \mathrm{E}-01$ & $.97 \mathrm{E}-01$ & $9.48 \mathrm{E}-0$ & $1.36 \mathrm{E}+00$ \\
\hline $16 \mathrm{E}-04$ & $2.46 \mathrm{E}+00$ & 1. $33 \mathrm{E}-01$ & $.78 E-02$ & $.52 \mathrm{E}-01$ & $99 E-01$ & $5-0$ & $1.37 \mathrm{E}+00$ \\
\hline 04 & $2.47 \mathrm{E}+00$ & 3 & & & & & +00 \\
\hline & & & & 1 & & & \\
\hline$E-04$ & & 1.0 & & $\perp$ & & & \\
\hline$E-04$ & $2.48 \mathrm{E}+00$ & $1.36 \mathrm{E}-01$ & 2 & 1 & 1 & $9.66 \mathrm{E}-01$ & $9 \mathrm{E}+00$ \\
\hline 4 & $.48 E+00$ & 375 & $2 E-02$ & (1) & 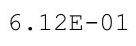 & $E-$ & $.39 E+00$ \\
\hline$E-04$ & $.49 \mathrm{E}+00$ & $1.37 \mathrm{E}-01$ & $96 E-02$ & (2) & $15 \pi$ & $.73 E-01$ & 1. $40 \mathrm{E}+00$ \\
\hline$E-04$ & $2.49 \mathrm{E}+00$ & $38 \mathrm{~F}-6 \mathrm{r}$ & $99 E-02$ & & & $5 F-01$ & L. $40 \mathrm{E}+00$ \\
\hline & & & & & & & \\
\hline & & 1.3 & & & 1 & & $1.41 \mathrm{E}+00$ \\
\hline $65 E-04$ & $2.50 \mathrm{E}+00$ & $\perp \cdot 4 U D-1$ & $4.08 E-02$ & . & • $25 E-U 1$ & .01 & $1.42 \mathrm{E}+00$ \\
\hline$E-04$ & $2.51 \mathrm{E}+00$ & $+\cdot 10+$ & $4.11 \mathrm{E}-02$ & . 120 & - & . & $1.43 E+00$ \\
\hline 4 & $2.51 \mathrm{E}+00$ & 11 & 2 & 1 & & & $1.43 \mathrm{E}+00$ \\
\hline 4 & & & & & & & $44 \mathrm{E}+00$ \\
\hline 4 & & 1 & & & & & \\
\hline 04 & & 1.4 & & 01 & & & \\
\hline $.97 E-04$ & $2.54 \mathrm{E}+00$ & $1.445-01$ & $4.27 E-02$ & 1 & 1 & & $1.45 \mathrm{E}+00$ \\
\hline $03 E-04$ & $2.55 \mathrm{E}+00$ & $\perp \cdot 110$ - & & & & & $1.46 \mathrm{E}+00$ \\
\hline 4 & $2.55 \mathrm{E}+00$ & + & 2 & & & & $1.46 \mathrm{E}+00$ \\
\hline 4 & $2.56 \mathrm{E}+00$ & 1 & - & 1 & 1 & $1.02 \mathrm{E}+00$ & $1.47 \mathrm{E}+00$ \\
\hline 4 & & & 2 & 1 & 1 & & $1.47 \mathrm{E}+00$ \\
\hline$E-04$ & $2.57 \mathrm{E}+00$ & $1.47 \mathrm{E}-01$ & $4.44 \mathrm{E}-02$ & 01 & & & $1.48 \mathrm{E}+00$ \\
\hline$E-04$ & $2.58 \mathrm{E}+00$ & $1.48 \mathrm{E}$ & & 1 & & & 1. $48 \mathrm{E}+00$ \\
\hline & 2. & $\perp$ & & & & & $1.48 \mathrm{E}+00$ \\
\hline $43 E-04$ & $2.59 \mathrm{E}+00$ & $\perp \cdot 47 \pm-01$ & $4.54 \mathrm{E}-02$ & $3.94 \mathrm{E}-01$ & $6.62 E-01$ & $1.03 E+00$ & 1. $49 \mathrm{E}+00$ \\
\hline $495-04$ & $2.60 \mathrm{E}+00$ & 1.004 & & & & $1.04 \mathrm{E}+00$ & $1.49 \mathrm{E}+00$ \\
\hline $55 E-04$ & $.61 E+00$ & $E-01$ & $.61 E-02$ & $.98 E-01$ & $.67 E-01$ & $1.04 \mathrm{E}+00$ & $1.50 \mathrm{E}+00$ \\
\hline
\end{tabular}


RESRAD-OFFSITE, Version 2.5 
RESRAD-OFFSITE, Version 2.5

Title : Offsite Resident Farmer Deterministic Run

File : RF TC99 DOESG FWD-FV2.ROF

Summary of dose at graphical times, reptition 3 (continued)

Time

Years

$5.19 \mathrm{E}+02$

$5.19 \mathrm{E}+02$

$5.20 \mathrm{E}+02$

$5.20 \mathrm{E}+02$

$5.21 \mathrm{E}+02$

$5.21 \mathrm{E}+02$

$5.22 \mathrm{E}+02$

$5.22 \mathrm{E}+02$

$5.23 \mathrm{E}+02$

$5.23 \mathrm{E}+02$

$5.24 \mathrm{E}+02$

$5.24 \mathrm{E}+02$

$5.25 \mathrm{E}+02$

$5.26 \mathrm{E}+02$

$5.26 \mathrm{E}+02$

$5.27 \mathrm{E}+02$

$5.27 \mathrm{E}+02$

$5.28 \mathrm{E}+02$

$5.28 \mathrm{E}+02$

$5.29 \mathrm{E}+02$

$5.29 \mathrm{E}+02$

$5.30 \mathrm{E}+02$

$5.30 \mathrm{E}+02$

$5.31 \mathrm{E}+02$

$5.31 \mathrm{E}+02$

$5.32 \mathrm{E}+02$

$5.32 \mathrm{E}+02$

$5.33 \mathrm{E}+02$

$5.33 \mathrm{E}+02$

$5.34 \mathrm{E}+02$

$5.34 \mathrm{E}+02$

$5.35 \mathrm{E}+02$

$5.35 \mathrm{E}+02$

$5.36 \mathrm{E}+02$

$5.36 \mathrm{E}+02$

$5.37 \mathrm{E}+02$

$5.37 \mathrm{E}+02$

$5.38 \mathrm{E}+02$

$5.38 \mathrm{E}+02$

$5.39 \mathrm{E}+02$

$5.39 \mathrm{E}+02$

$5.40 \mathrm{E}+02$

$5.40 \mathrm{E}+02$

$5.41 \mathrm{E}+02$

$5.41 \mathrm{E}+02$

$5.42 \mathrm{E}+02$
Dose statistics at graphical times, mrem/yr

\begin{tabular}{|c|c|c|c|c|c|c|c|}
\hline inimum & laximum & Mean & ledian & $\%$ & $\%$ & $97.5 \%$ & $\%$ \\
\hline 4 & -00 & 01 & 02 & 1 & 1 & 00 & +00 \\
\hline 04 & $\mathrm{E}+00$ & 1 & -02 & 1 & 1 & +00 & $1 E+00$ \\
\hline-04 & +00 & 01 & 02 & & & 00 & +00 \\
\hline $38 E-04$ & $92 E+00$ & & & & & & +00 \\
\hline $3 E-04$ & $2 E+00$ & 01 & & & $\perp$ & +00 & $72 E+00$ \\
\hline $.57 E-04$ & $2.93 E+00$ & $1.87 \mathrm{E}-01$ & $8 E-02$ & $4.92 \mathrm{E}-01$ & -01 & $E+00$ & $73 E+00$ \\
\hline 04 & $.93 E+00$ & 01 & 2 & 1 & 1 & $1 E+00$ & $73 E+00$ \\
\hline $.76 E-04$ & $.94 \mathrm{E}+00$ & 1 & 02 & S & & +00 & 00 \\
\hline $5 E-04$ & $94 \mathrm{E}+00$ & 1. & & & & +00 & $E+00$ \\
\hline $96 \mathrm{E}-04$ & $2.95 \mathrm{E}+00$ & $1.90 \mathrm{E}-01$ & $5 \mathrm{E}-02$ & $99 \mathrm{E}-$ & & & $74 \mathrm{E}+00$ \\
\hline$E-04$ & $E+00$ & 1 & -02 & 1 & 1 & +00 & $4 E+00$ \\
\hline-04 & $96 \mathrm{E}+00$ & 01 & -02 & 1 & & +00 & $75 E+00$ \\
\hline $6 E-04$ & $2.97 \mathrm{E}+00$ & 01 & -02 & $\perp$ & 1 & $\Xi+00$ & $75 E+00$ \\
\hline 04 & $97 E+00$ & 1.93E-01 & 2 & 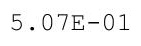 & 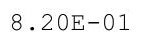 & $3 E+00$ & 765 \\
\hline 04 & $.98 E+00$ & 1. & & . & & 0 & 00 \\
\hline $.57 E-04$ & $2.98 \mathrm{E}+00$ & 1. $95 \mathrm{E}-01$ & $7.00 \mathrm{E}-02$ & & & & $1.76 \mathrm{E}+00$ \\
\hline $.67 E-04$ & $2.99 \mathrm{E}+00$ & 1. $95 \mathrm{E}-01$ & $7.04 \mathrm{E}-02$ & $.13 E-01$ & $8.27 E-01$ & $1.24 \mathrm{E}+00$ & $1.77 \mathrm{E}+00$ \\
\hline $.78 E-04$ & $3.00 \mathrm{E}+00$ & 1. $96 \mathrm{E}-01$ & $9 E-02$ & $5 E-$ & 1 & $E+00$ & $1.77 \mathrm{E}+00$ \\
\hline 04 & 00 & & & & & & $\mathrm{E}+00$ \\
\hline 4 & & 1. $98 \mathrm{E}-01$ & & 1 & & 0 & +00 \\
\hline 3 & $.01 E+00$ & 1. $98 \mathrm{E}-01$ & 2 & & & & 00 \\
\hline $2 E-03$ & $02 \mathrm{E}+00$ & 1 & 2 & . & & & $E+00$ \\
\hline $3 E-03$ & $.02 E+00$ & $20 \cap 01$ & $1 E-02$ & 65 & ח7 & $.27 E+00$ & $.79 \mathrm{E}+00$ \\
\hline$F-03$ & $.03 E+00$ & $01 E-01$ & $E-02$ & $201-3-1-1$ & 1 & $.27 E+00$ & $.79 \mathrm{E}+00$ \\
\hline$E-03$ & $03 E+00$ & & -02 & & & $7 \mathrm{E}+00$ & $.80 \mathrm{E}+00$ \\
\hline & & & & & & & \\
\hline & & & 02 & & & 00 & +00 \\
\hline $.09 E-03$ & $3.05 \mathrm{E}+00$ & 2.07 & $7.57 \mathrm{E}-02$ & . & $8.46 \mathrm{E}-01$ & 1. $29 \mathrm{E}+00$ & $1.81 \mathrm{E}+00$ \\
\hline 03 & $06 \mathrm{E}+00$ & 2.0 & 2 & . & $48 \mathrm{E}-$ & 1.29E+00 & $1.81 \mathrm{E}+00$ \\
\hline$F-03$ & $3.06 \mathrm{E}+00$ & & $5 E-02$ & & & $9 E+00$ & $1.81 \mathrm{E}+00$ \\
\hline-03 & $3.07 E+00$ & & & & & & \\
\hline 03 & & & & & & & \\
\hline 03 & & & & & & & \\
\hline $.16 \mathrm{E}-03$ & $3.08 \mathrm{E}+00$ & $2.08 E-01$ & $7.85 \mathrm{E}-02$ & $3.40 \mathrm{~L}$ & $0.00 \mathrm{E}$ & 1. $31 \mathrm{E}+00$ & $1.83 \mathrm{E}+00$ \\
\hline $17 E-03$ & $3.09 \mathrm{E}+00$ & & $7.89 \mathrm{E}-02$ & & & $1 \cdot 31 \mathrm{E}+00$ & $1.84 \mathrm{E}+00$ \\
\hline 3 & & & & & & 1. $32 \mathrm{E}+00$ & $1.84 \mathrm{E}+00$ \\
\hline 3 & & & & & & $1.32 \mathrm{E}+00$ & $.84 E+00$ \\
\hline 3 & $3.10 \mathrm{E}+00$ & & 2 & 1 & & $3 E+00$ & \\
\hline $2 E-03$ & & 2. & -02 & -01 & & $3 E+00$ & $1.85 E+00$ \\
\hline $.23 E-03$ & $3.11 \mathrm{E}+00$ & $\angle .13 E$ & 2 & 1 & 1 & 00 & $1.85 \mathrm{E}+00$ \\
\hline $24 E-03$ & . & $2 \cdot$ & & 1 & 1 & & $1.86 \mathrm{E}+00$ \\
\hline $26 E-03$ & $3.13 \mathrm{E}+00$ & $2 \cdot \perp J \pm-U \perp$ & $8.20 E-02$ & . & 1 & $1.34 \mathrm{E}+00$ & $1.86 \mathrm{E}+00$ \\
\hline $2 / 2-03$ & $3.13 \mathrm{E}+00$ & $2 . \perp 0 \perp-1$ & & & & $1.34 \mathrm{E}+00$ & $1.86 \mathrm{E}+00$ \\
\hline 3 & $3.14 \mathrm{E}+00$ & & 2 & 1 & $0.00 \mathrm{D}$ & $1.35 \mathrm{E}+00$ & $1.87 \mathrm{E}+00$ \\
\hline $30 E-03$ & $3.14 \mathrm{E}+00$ & $2.17 E-01$ & $E-02$ & $5.72 \mathrm{E}$ & $8.85 \mathrm{E}-$ & 1. $35 \mathrm{E}+00$ & $1.87 \mathrm{E}+00$ \\
\hline$E-03$ & $15 E+00$ & $18 \mathrm{E}-01$ & $.41 \mathrm{E}-02$ & $.74 \mathrm{E}-01$ & $8.88 \mathrm{E}-01$ & $1.35 \mathrm{E}+00$ & $1.87 \mathrm{E}+00$ \\
\hline
\end{tabular}


RESRAD-OFFSITE, Version 2.5

$\mathrm{T}^{1 / 2}$ Limit $=180$ days

obabilistic Dose and Risk Report

Title : Offsite Resident Farmer Deterministic Run

File : RF TC99 DOESG FWD-FV2.ROF

Summary of dose at graphical times, reptition 3 (continued)

Time

Years

$5.42 \mathrm{E}+02$

$5.43 \mathrm{E}+02$

$5.43 \mathrm{E}+02$

$5.44 \mathrm{E}+02$

$5.44 \mathrm{E}+02$

$5.45 \mathrm{E}+02$

$5.46 \mathrm{E}+02$

$5.46 \mathrm{E}+02$

$5.47 \mathrm{E}+02$

$5.47 \mathrm{E}+02$

$5.48 \mathrm{E}+02$

$5.48 \mathrm{E}+02$

$5.49 \mathrm{E}+02$

$5.49 \mathrm{E}+02$

$5.50 \mathrm{E}+02$

$5.50 \mathrm{E}+02$

$5.51 \mathrm{E}+02$

$5.51 \mathrm{E}+02$

$5.52 \mathrm{E}+02$

$5.52 \mathrm{E}+02$

$5.53 \mathrm{E}+02$

$5.53 \mathrm{E}+02$

$5.54 \mathrm{E}+02$

$5.54 \mathrm{E}+02$

$5.55 \mathrm{E}+02$

$5.55 \mathrm{E}+02$

$5.56 \mathrm{E}+02$

$5.56 \mathrm{E}+02$

$5.57 \mathrm{E}+02$

$5.57 \mathrm{E}+02$

$5.58 \mathrm{E}+02$

$5.58 \mathrm{E}+02$

$5.59 \mathrm{E}+02$

$5.59 \mathrm{E}+02$

$5.60 \mathrm{E}+02$

$5.60 \mathrm{E}+02$

$5.61 \mathrm{E}+02$

$5.61 \mathrm{E}+02$

$5.62 \mathrm{E}+02$

$5.62 \mathrm{E}+02$

$5.63 \mathrm{E}+02$

$5.63 E+02$

$5.64 \mathrm{E}+02$

$5.64 \mathrm{E}+02$

$5.65 \mathrm{E}+02$

$5.66 \mathrm{E}+02$
Dose statistics at graphical times, mrem/yr

\begin{tabular}{|c|c|c|c|c|c|c|c|}
\hline Iinimum & Maximum & Mean & Median & 900 & $90 \%$ & $97.5 \%$ & $9 \%$ \\
\hline 3 & $5 E+00$ & 01 & $6 \mathrm{~F}-02$ & -01 & 1 & $.36 \mathrm{E}+00$ & +00 \\
\hline 03 & $6 \mathrm{E}+00$ & $9 E-01$ & $51 E-02$ & 1 & 1 & $.36 E+00$ & $.88 E+00$ \\
\hline $5 E-03$ & -00 & $0 E-01$ & $6 E-02$ & 1 & 1 & Do & $88 E+00$ \\
\hline$E-03$ & $E+00$ & $E-01$ & 02 & 1 & 1 & & +00 \\
\hline $38 E-03$ & $3.17 \mathrm{E}+00$ & $.22 \mathrm{E}-01$ & & & & & $89 \mathrm{E}+00$ \\
\hline $39 E-03$ & $3.18 \mathrm{E}+00$ & $\perp$ & 02 & & & 00 & $89 E+00$ \\
\hline $.40 E-03$ & $3.18 \mathrm{E}+00$ & $2.23 E-01$ & $6 E-02$ & $9 E-01$ & $\perp$ & 0 & $90 \mathrm{E}+00$ \\
\hline $.42 E-03$ & $3.19 \mathrm{E}+00$ & $2027+01$ & $8.81 E-02$ & & $.00 \mathrm{D}-0$ & \pm+00 & 1. $90 \mathrm{E}+00$ \\
\hline$E-03$ & +00 & $E-$ & 02 & 1 & 1 & 00 & $90 E+00$ \\
\hline $4 \mathrm{E}-03$ & $E+00$ & $2.26 \mathrm{E}$ & 2 & & & $9 E+00$ & $E+00$ \\
\hline$E-03$ & & & & 1 & & & $\mathrm{E}+00$ \\
\hline-03 & 0 & 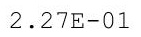 & 2 & 1 & & & $91 E+00$ \\
\hline $49 \mathrm{E}-03$ & $3.21 E+00$ & $2.20 \mathrm{x}-4$ & $5 E-02$ & & $\perp$ & +1 & $\mathrm{E}+00$ \\
\hline $.50 E-03$ & $3.22 E+00$ & $2 \cdot 2 \pi 01$ & $9.10 \mathrm{~L}-U 2$ & $0.0 \angle L-01$ & $\perp$ & 1.94 & 1. $92 \mathrm{E}+00$ \\
\hline $.52 E-03$ & $3.22 \mathrm{E}+00$ & $2 \cdot$ & 42 & & & 00 & 1. $92 \mathrm{E}+00$ \\
\hline $.53 E-03$ & $3.23 E+00$ & $2.31 \mathrm{E}-\mathrm{C}$ & $9.21 \mathrm{E}-02$ & $6.07 \mathrm{E}-$ & $9.24 \mathrm{E}-$ & $1.41 \mathrm{~F}$ & $.92 \mathrm{E}+00$ \\
\hline $.55 E-03$ & $3.23 E+00$ & $2.31 E-01$ & $9.27 \mathrm{E}-02$ & & $26 E-01$ & $1.41 E+00$ & 1. $93 \mathrm{E}+00$ \\
\hline $6 E-03$ & $3 E+00$ & ה & $E-02$ & 1 & 1 & ז & $93 E+00$ \\
\hline $.58 E-03$ & $3.24 \mathrm{E}+00$ & $2.33 E-01$ & $9.38 \mathrm{E}-02$ & 皮 & 9 & $1.42 \mathrm{E}+00$ & $3 \mathrm{E}+00$ \\
\hline $59 E-03$ & $3.24 \mathrm{E}+00$ & $2.345-01$ & $9.44 \mathrm{E}-02$ & $\perp$ & $\perp$ & 1.4 & +00 \\
\hline $.61 E-03$ & $3.25 E+00$ & $2 \cdot 004$ & 02 & & & 10.4015 & $4 \mathrm{E}+00$ \\
\hline $62 \mathrm{E}-03$ & $3.25 \mathrm{E}+00$ & 2.00 & . & . & - & $H_{1}$ & $1.94 \mathrm{E}+00$ \\
\hline $.64 E-03$ & $3.26 \mathrm{E}+00$ & $6 E-01$ & $1 E-02$ & $1 E-01$ & (0) & $1.43 E+00$ & 1.94E+00 \\
\hline $.65 E-03$ & $3.26 \mathrm{E}+00$ & $2.37 \mathrm{E}-01$ & $67 E-02$ & $23 E-$ & קבר & $1.44 \mathrm{E}+00$ & $.95 E+00$ \\
\hline$E-03$ & $.27 E+00$ & $2.38 E-01$ & $E-02$ & $\perp$ & & $1.44 \mathrm{E}+00$ & $95 \mathrm{E}+00$ \\
\hline$E-03$ & $\mathrm{E}+00$ & 2 & 2 & 1 & & 00 & \\
\hline $.70 E-03$ & $3 . \angle 8 E+00$ & $2.40 \mathrm{D}-\mathrm{c}$ & $9.83 E-02$ & ( & 年 & & $1.96 \mathrm{E}+00$ \\
\hline $.72 \mathrm{E}-03$ & $3.28 \mathrm{E}+00$ & $2.40 \mathrm{E}-01$ & $9.88 \mathrm{E}-02$ & $6.31 \mathrm{E}-01$ & $9.53 \mathrm{E}-01$ & $1.45 \mathrm{E}+00$ & $1.96 \mathrm{E}+00$ \\
\hline 03 & 0 & 2 & 2 & - & L & S & $.96 E+00$ \\
\hline 3 & $3295+0$ & 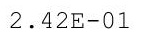 & 2 & & & 1. $45 \mathrm{E}+$ & $7 \mathrm{E}+00$ \\
\hline 3 & $3305+00$ & & & - & L & $1.46 \mathrm{E}+00$ & $1.97 \mathrm{E}+00$ \\
\hline $3 E-03$ & $3.30 \mathrm{E}+00$ & & & & & & \\
\hline $.80 E-03$ & $3.30 \mathrm{E}+00$ & 2. & $1 \mathrm{E}-01$ & 1 & 1 & 00 & $1.97 \mathrm{E}+00$ \\
\hline $.81 \mathrm{E}-03$ & $3.31 \mathrm{E}+00$ & $2.45 \mathrm{E}-01$ & 1. $02 \mathrm{E}-01$ & $0.4 \perp 5-$ & 11 & $1.4 / E+U 0$ & $1.98 \mathrm{E}+00$ \\
\hline $.83 E-03$ & $3.3 \perp E+U 0$ & & $1.02 \mathrm{E}-01$ & & & & $1.98 \mathrm{E}+00$ \\
\hline 3 & $0^{-1}$ & ${ }^{2}$ & & & & & 00 \\
\hline 3 & $5+$ & & & & & & 00 \\
\hline 3 & & 1 & 1 & 1 & 1 & 0 & 00 \\
\hline$E-03$ & 3.3 & 2 . & $E-01$ & 1 & & 00 & 00 \\
\hline $92 E-03$ & $3.34 \mathrm{E}+00$ & 2 . & & & 1 & & $1.99 \mathrm{E}+00$ \\
\hline 03 & $3.34 \mathrm{E}+00$ & 1 & & & & & $2.00 \mathrm{E}+00$ \\
\hline $20-03$ & $3.34 E+00$ & $2.52 \mathrm{E}$ & 1 & 10 & 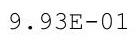 & $1.49 \mathrm{E}+00$ & $2.00 \mathrm{E}+00$ \\
\hline 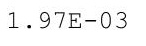 & 0 & 2.00 & & 1 & 1 & 0 & \\
\hline & & & 01 & 6 & 9 & $1.50 \mathrm{E}+00$ & $2.01 E+00$ \\
\hline$E-03$ & $3.36 \mathrm{E}+00$ & $E-01$ & 1.0 & 6 . & 1. $00 \mathrm{E}+00$ & $1.51 \mathrm{E}+00$ & $2.01 E+00$ \\
\hline $.02 E-03$ & $36 \mathrm{E}+00$ & $.55 E-01$ & $1.08 \mathrm{E}-01$ & $61 E-01$ & 1.00E+00 & $1.51 \mathrm{E}+00$ & $2.01 E+00$ \\
\hline
\end{tabular}


RESRAD-OFFSITE, Version 2.5

obabilistic Dose and Risk Report

Title : Offsite Resident Farmer Deterministic Run

File : RF TC99 DOESG FWD-FV2.ROF

Summary of dose at graphical times, reptition 3 (continued)

Time

Years

$5.66 \mathrm{E}+02$

$5.67 \mathrm{E}+02$

$5.67 \mathrm{E}+02$

$5.68 \mathrm{E}+02$

$5.68 \mathrm{E}+02$

$5.69 \mathrm{E}+02$

$5.69 \mathrm{E}+02$

$5.70 \mathrm{E}+02$

$5.70 \mathrm{E}+02$

$5.71 \mathrm{E}+02$

$5.71 \mathrm{E}+02$

$5.72 \mathrm{E}+02$

$5.72 \mathrm{E}+02$

$5.73 \mathrm{E}+02$

$5.73 \mathrm{E}+02$

$5.74 \mathrm{E}+02$

$5.74 \mathrm{E}+02$

$5.75 \mathrm{E}+02$

$5.75 \mathrm{E}+02$

$5.76 \mathrm{E}+02$

$5.76 \mathrm{E}+02$

$5.77 \mathrm{E}+02$

$5.77 \mathrm{E}+02$

$5.78 \mathrm{E}+02$

$5.78 \mathrm{E}+02$

$5.79 \mathrm{E}+02$

$5.79 \mathrm{E}+02$

$5.80 \mathrm{E}+02$

$5.80 \mathrm{E}+02$

$5.81 \mathrm{E}+02$

$5.81 \mathrm{E}+02$

$5.82 \mathrm{E}+02$

$5.82 \mathrm{E}+02$

$5.83 \mathrm{E}+02$

$5.83 \mathrm{E}+02$

$5.84 \mathrm{E}+02$

$5.84 \mathrm{E}+02$

$5.85 \mathrm{E}+02$

$5.85 \mathrm{E}+02$

$5.86 \mathrm{E}+02$

$5.87 \mathrm{E}+02$

$5.87 \mathrm{E}+02$

$5.88 \mathrm{E}+02$

$5.88 \mathrm{E}+02$

$5.89 \mathrm{E}+02$

$5.89 \mathrm{E}+02$
Dose statistics at graphical times, mrem/yr

\begin{tabular}{|c|c|c|c|c|c|c|c|}
\hline m & aximum & ea & -5 & & & $\%$ & $\%$ \\
\hline $.04 E-03$ & $.37 \mathrm{E}+00$ & $56 E-01$ & $1.09 \mathrm{E}-01$ & $6.63 \mathrm{E}-01$ & $01 E+00$ & 00 & ULE+U \\
\hline $.06 \mathrm{E}-03$ & $3.37 E+00$ & $7 E-01$ & $E-01$ & $5 E-01$ & $01 E+00$ & $1.52 \mathrm{E}+00$ & $02 E+00$ \\
\hline$E-03$ & $37 \mathrm{E}+00$ & $58 \mathrm{E}-01$ & $10 E-01$ & $67 E-01$ & $.01 E+00$ & $52 E+00$ & $2.02 E+00$ \\
\hline-03 & $38 E+00$ & $59 F-01$ & $10 F-01$ & $69 F-01$ & $01 \mathrm{~F}+00$ & $53 \mathrm{~F}+00$ & $2.02 \mathrm{E}+00$ \\
\hline $.11 \mathrm{E}-03$ & $3.38 \mathrm{E}+00$ & $2.59 \mathrm{E}-01$ & -01 & 1 & & +00 & $.03 E+00$ \\
\hline 03 & $39 \mathrm{E}+00$ & & & & & & 00 \\
\hline $15 \mathrm{E}-03$ & $39 E+00$ & & & & & & $03 E+00$ \\
\hline $.17 E-03$ & $3.40 \mathrm{E}+00$ & $\perp$ & $\perp$ & 1 & 00 & \pm+00 & $E+00$ \\
\hline $19 \mathrm{E}-03$ & $40 \mathrm{E}+00$ & $3 E-01$ & $E-01$ & $\perp$ & $03 E+00$ & $E+00$ & $04 \mathrm{E}+00$ \\
\hline $21 E-03$ & $.40 \mathrm{E}+00$ & $64 \mathrm{E}-01$ & קח & תריט & 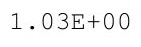 & $.55 E+00$ & $04 \mathrm{E}+00$ \\
\hline 03 & +00 & & & & 0 & -00 & $E+00$ \\
\hline $25 E-03$ & $E+00$ & F & 1 . & 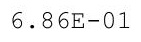 & 0 & 0 & +00 \\
\hline $27 E-03$ & $3.42 \mathrm{E}+00$ & & & . & & $1.56 \mathrm{E}+00$ & $2.05 E+00$ \\
\hline $29 E-03$ & $3.42 \mathrm{E}+00$ & $2.67 \mathrm{E}-01$ & $1.16 \mathrm{E}-01$ & $6.90 \mathrm{E}-$ & $1.04 \mathrm{E}+U \mathrm{U}$ & $1.56 \mathrm{E}+00$ & $2.05 E+00$ \\
\hline$E-03$ & $42 \mathrm{E}+00$ & $8 \mathrm{E}-01$ & $5-0$ & 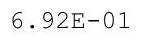 & 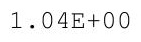 & +00 & $05 \mathrm{E}+00$ \\
\hline 3 & $.43 E+00$ & $2.69 \mathrm{E}-01$ & $\cdot$ & 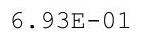 & 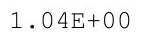 & 0 & 00 \\
\hline 3 & 0 & $2.70 \mathrm{E}-01$ & & & $05 E+00$ & 0 & 0 \\
\hline 3 & $E+00$ & $2.70 \mathrm{E}-01$ & $1.18 E-01$ & & $05 E+00$ & $58 E+00$ & 0 \\
\hline $39 E-03$ & $3.44 \mathrm{E}+00$ & $2.71 E-01$ & 1. $19 \mathrm{E}-01$ & $6.99 \mathrm{E}-$ & $1.05 \mathrm{E}+00$ & $1.58 \mathrm{E}+00$ & $2.06 \mathrm{E}+00$ \\
\hline $41 E-03$ & $.44 \mathrm{E}+00$ & $2.72 \mathrm{E}-01$ & 1.20E-01 & $1 E-01$ & $1.05 \mathrm{E}+$ & $1.58 \mathrm{E}+00$ & $2.07 \mathrm{E}+00$ \\
\hline 03 & $E+00$ & & & & & +00 & $7 \mathrm{E}+00$ \\
\hline $45 \mathrm{E}-$ & & & & & & & \\
\hline 03 & $3.46 \mathrm{E}+00$ & 2.10 & 1.2 & & $1.06 \mathrm{E}+$ & & \\
\hline 03 & $46 \mathrm{E}+00$ & $\perp$ & 1. & 7 & 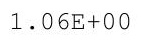 & - & 00 \\
\hline 3 & $.46 \mathrm{E}+00$ & $2.76 \mathrm{E}-01$ & , & - & $1.07 \mathrm{E}+$ & $1.60 \mathrm{E}+0$ & $.08 \mathrm{E}+$ \\
\hline $54 E-03$ & $.47 \mathrm{E}+00$ & $77 F-01$ & 1.23E-01 & 7 ד 72 & $1.07 \mathrm{E}+$ & $1.61 \mathrm{E}+00$ & $2.09 \mathrm{E}+00$ \\
\hline$E-03$ & $3.47 \mathrm{E}+00$ & & $124 \mathrm{~F}-01$ & סק & & $1.61 \mathrm{E}+00$ & $2.09 \mathrm{E}+00$ \\
\hline 03 & & & & & & & \\
\hline 03 & $3.48 \mathrm{E}+00$ & & 1.2 & & 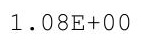 & & \\
\hline $62 E-03$ & $3.48 \mathrm{E}+00$ & $2.01+41$ & $1 . \angle 6 E-U 1$ & •.+口 & $1.08 \mathrm{E}+$ & $1.62 \mathrm{E}+00$ & $2.10 \mathrm{E}+00$ \\
\hline $64 \mathrm{E}-03$ & $3.49 \mathrm{E}+00$ & 2.02501 & म.2 & $\cdot 2+\Delta$ & $1.08 \mathrm{E}+00$ & $1.62 \mathrm{E}+00$ & $2.10 \mathrm{E}+00$ \\
\hline 3 & $3.49 \mathrm{E}+$ & er & 50 & $722 \mathrm{~F}-01$ & & & $2.10 \mathrm{E}+$ \\
\hline 6 & & & & & & & 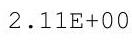 \\
\hline 03 & $3.50 \mathrm{E}+00$ & & & & & & \\
\hline $.73 E-03$ & $3.50 \mathrm{E}+00$ & 1 & 1 . & 1 & & & \\
\hline $.76 E-03$ & $3.50 \mathrm{E}+00$ & $2.86 E-01$ & $1.30 \mathrm{E}-$ & .300 & $\perp \cdot \perp U L$ & +.011 & $2.12 \mathrm{E}+00$ \\
\hline $78 E-03$ & $3.51 \mathrm{E}+00$ & $2.01 \mathrm{~L}-1$ & $\perp ・ U \perp \perp-1$ & $1 \cdot 32 \mathrm{D}$ & & & \\
\hline 03 & $3.51 \mathrm{E}+00$ & 2.00101 & I・U土L & 然 & 1. $10 \mathrm{E}+00$ & & $2.12 \mathrm{E}+00$ \\
\hline 3 & 3.5 & 2 & $+\cdots$ & 1 & & & $2.12 \mathrm{E}+00$ \\
\hline 3 & & & 1 & 1 & $1.10 \mathrm{E}+$ & & $2.13 E+00$ \\
\hline $87 E-03$ & $3.52 \mathrm{E}+00$ & $2.90 \mathrm{E}-01$ & $E-01$ & 1 & & $6 \mathrm{E}+00$ & $2.13 E+00$ \\
\hline $90 E-03$ & $3.52 \mathrm{E}+00$ & 2.9 & 1. & & & 1. & $2.13 E+00$ \\
\hline $2 E-03$ & $3.53 \mathrm{E}+00$ & & & & & & \\
\hline $94 \mathrm{E}-03$ & $3.53 \mathrm{E}+00$ & 1 & . & te & $1.11 \mathrm{E}+00$ & $1.67 \mathrm{E}+00$ & $2.14 \mathrm{E}+00$ \\
\hline $.21 \mathrm{C}-03$ & $3.54 \mathrm{E}+00$ & $2 \cdot$ & $\perp \cdot 00$ & & & $1.67 \mathrm{E}+00$ & $2.14 \mathrm{E}+00$ \\
\hline 03 & $3.54 \mathrm{E}+00$ & $E-01$ & $.37 E-01$ & $E-01$ & $1.12 \mathrm{E}+00$ & $1.67 \mathrm{E}+00$ & $.14 \mathrm{E}+00$ \\
\hline
\end{tabular}


RESRAD-OFFSITE, Version 2.5

$\mathrm{T}^{1 / 2}$ Limit $=180$ days

obabilistic Dose and Risk Report

Title : Offsite Resident Farmer Deterministic Run

File : RF TC99 DOESG FWD-FV2.ROF

Summary of dose at graphical times, reptition 3 (continued)

Time

Years

$5.90 \mathrm{E}+02$

$5.90 \mathrm{E}+02$

$5.91 \mathrm{E}+02$

$5.91 \mathrm{E}+02$

$5.92 \mathrm{E}+02$

$5.92 \mathrm{E}+02$

$5.93 \mathrm{E}+02$

$5.93 \mathrm{E}+02$

$5.94 \mathrm{E}+02$

$5.94 \mathrm{E}+02$

$5.95 \mathrm{E}+02$

$5.95 \mathrm{E}+02$

$5.96 \mathrm{E}+02$

$5.96 \mathrm{E}+02$

$5.97 \mathrm{E}+02$

$5.97 \mathrm{E}+02$

$5.98 \mathrm{E}+02$

$5.98 \mathrm{E}+02$

$5.99 \mathrm{E}+02$

$5.99 \mathrm{E}+02$

$6.00 \mathrm{E}+02$

$6.00 \mathrm{E}+02$

$6.01 \mathrm{E}+02$

$6.01 \mathrm{E}+02$

$6.02 \mathrm{E}+02$

$6.02 \mathrm{E}+02$

$6.03 E+02$

$6.03 \mathrm{E}+02$

$6.04 \mathrm{E}+02$

$6.04 \mathrm{E}+02$

$6.05 \mathrm{E}+02$

$6.05 \mathrm{E}+02$

$6.06 \mathrm{E}+02$

$6.07 \mathrm{E}+02$

$6.07 \mathrm{E}+02$

$6.08 \mathrm{E}+02$

$6.08 \mathrm{E}+02$

$6.09 \mathrm{E}+02$

$6.09 \mathrm{E}+02$

$6.10 \mathrm{E}+02$

$6.10 \mathrm{E}+02$

$6.11 \mathrm{E}+02$

$6.11 \mathrm{E}+02$

$6.12 \mathrm{E}+02$

$6.12 \mathrm{E}+02$

$6.13 \mathrm{E}+02$
Dose statistics at graphical times, mrem/yr

\begin{tabular}{|c|c|c|c|c|c|c|c|}
\hline Iinimum & Maximum & Mean & Median & 900 & $0 \%$ & $97.5 \%$ & $3 \%$ \\
\hline 3 & $4 E+00$ & $6 F-01$ & $38 E-01$ & 01 & $E+00$ & 0 & +0 \\
\hline 03 & $5 E+00$ & $6 \mathrm{E}$ & $38 E-01$ & 1 & $12 \mathrm{E}+00$ & $.68 E+00$ & $14 \mathrm{E}+00$ \\
\hline$E-03$ & 00 & $7 E-01$ & -01 & 1 & 0 & 0 & $E+00$ \\
\hline$E-03$ & +00 & $3 E-01$ & 01 & 1 & 0 & & $5 E+00$ \\
\hline $1 E-03$ & $6 E+00$ & & & & $13 E+00$ & & $15 \mathrm{E}+00$ \\
\hline $.14 \mathrm{E}-03$ & 00 & & & & 0 & 00 & $15 E+00$ \\
\hline $.17 E-03$ & $3.56 \mathrm{E}+00$ & $1 E-01$ & 1. $41 \mathrm{E}-01$ & $8 \mathrm{E}-01$ & $1.13 \mathrm{E}+00$ & 0 & $5 E+00$ \\
\hline $.19 \mathrm{E}-03$ & $3.57 \mathrm{E}+00$ & . & 1. $42 \mathrm{E}-01$ & $1.0 U \mathrm{D}-0$ & $1.13 \mathrm{E}+00$ & $1.70 \mathrm{E}+00$ & $2.15 E+00$ \\
\hline 03 & +00 & 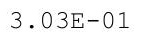 & 01 & 1 & 0 & 00 & $E+00$ \\
\hline $4 E-03$ & $E+00$ & 5 & 1. & $\perp$ & & $E+00$ & $6 \mathrm{E}+00$ \\
\hline$E-03$ & & & & 1 & & & $E+00$ \\
\hline$E-03$ & +00 & 田 & 1 & & 0 & 00 & $16 E+00$ \\
\hline $32 E-03$ & $3.58 \mathrm{E}+00$ & $3.00 \mathrm{e}-0$ & $1.45 \mathrm{E}-01$ & +4 & $1.14 \mathrm{E}+$ & 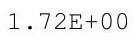 & $E+00$ \\
\hline $.35 E-03$ & $3.58 \mathrm{E}+00$ & 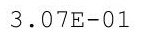 & $1.46 \mathrm{E}-01$ & $1.14 \mathrm{~L}-\mathrm{D}$ & $1.15 E+00$ & 1.72 & $\mathrm{E}+00$ \\
\hline$E-03$ & $3.59 \mathrm{E}+00$ & - & 01 & 1. 10 & $\perp \cdot \perp$ • & 00 & 00 \\
\hline $.40 \mathrm{E}-03$ & $3.59 \mathrm{E}+00$ & $9 E-C$ & $1.47 \mathrm{E}-01$ & $7.78 \mathrm{E}$ & $1.15 \mathrm{E}+00$ & $1.73 \mathrm{E}+00$ & $17 E+00$ \\
\hline $.42 E-03$ & $3.59 \mathrm{E}+00$ & $3.10 \mathrm{E}-01$ & 1. $48 \mathrm{E}-01$ & $7.80 \mathrm{E}-01$ & $1.15 \mathrm{E}+00$ & $1.74 \mathrm{E}+00$ & $2.17 \mathrm{E}+00$ \\
\hline$E-03$ & $E+00$ & 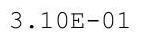 & $9 E-01$ & $2 E-01$ & $15 \Gamma_{1}$ & $.74 \mathrm{E}+00$ & $17 \mathrm{E}+00$ \\
\hline 03 & $3.60 \mathrm{E}+00$ & - & 1 & $\perp$ & $\begin{array}{lll}10 \mathrm{~T} \\
\end{array}$ & 00 & $E+00$ \\
\hline $51 E-03$ & $3.60 \mathrm{E}+00$ & $3 \cdot \perp \angle L-U \perp$ & $1.50 \mathrm{E}-01$ & OJi & $1.16 \mathrm{E}$ & 1.15 & $E+00$ \\
\hline $.53 E-03$ & $3.61 E+00$ & & 1.001 & & & + & $18 \mathrm{E}+00$ \\
\hline $.56 \mathrm{E}-03$ & $3.61 \mathrm{E}+00$ & . & 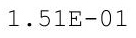 & 1.00 & $1.16 \mathrm{E}+$ & +00 & $2.18 \mathrm{E}+00$ \\
\hline $.59 E-03$ & $3.61 E+00$ & $5 E-01$ & $1.52 \mathrm{E}-01$ & $90 E-01$ & $1.16 \mathrm{E}+00$ & $1.76 \mathrm{E}+00$ & $2.18 \mathrm{E}+00$ \\
\hline $.62 E-03$ & $3.62 E+00$ & $3.16 \mathrm{E}-01$ & $1.52 \mathrm{E}-01$ & $93 \mathrm{E}-$ & $1.16 \mathrm{E}+$ & $1.76 \mathrm{E}+00$ & $2.19 \mathrm{E}+00$ \\
\hline$E-03$ & $.62 E+00$ & -01 & 1 . & & & & $.19 \mathrm{E}+00$ \\
\hline$E-03$ & +00 & 3 & 1 & $\perp$ & & 00 & 00 \\
\hline $.70 E-03$ & $3.62 \mathrm{E}+U \mathrm{U}$ & $3.10 \mathrm{x}-\mathrm{C}$ & $1.54 \mathrm{E}-$ & ( ) & $\perp \cdot \perp / D T$ & 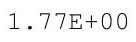 & $2.19 \mathrm{E}+00$ \\
\hline $.73 E-03$ & $3.63 \mathrm{E}+00$ & $3.19 \mathrm{E}-01$ & $1.55 \mathrm{E}-01$ & $8.01 \mathrm{E}-01$ & $1.17 \mathrm{E}+00$ & $1.78 \mathrm{E}+00$ & $2.20 \mathrm{E}+00$ \\
\hline $.76 \mathrm{E}-03$ & $3.63 E+00$ & $.2 U D-U \perp$ & $1.55 \mathrm{E}-01$ & $8.04 \mathrm{E}-01$ & $\perp . \perp O L T U$ & $1.78 \mathrm{E}+00$ & $2.20 E+00$ \\
\hline 3 & $63 F+00$ & $3.21 \mathrm{E}-01$ & 1 & . & $118 \mathrm{~F}+$ & $1.78 \mathrm{E}+00$ & $2.20 \mathrm{E}+00$ \\
\hline 3 & $.64 \mathrm{E}+00$ & 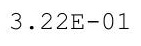 & 1 & & $118 \mathrm{~F}+$ & $8 E+00$ & $2.20 \mathrm{E}+00$ \\
\hline$E-03$ & $E+00$ & & & & & & \\
\hline $7 E-03$ & $3.64 \mathrm{E}+00$ & $3.24 \mathrm{E}-$ & 1 . & 8 & $1.19 \mathrm{E}$ & $1.18 \mathrm{E}$ & $2.21 \mathrm{E}+00$ \\
\hline $.90 \mathrm{E}-03$ & $3.64 \mathrm{E}+00$ & $3.25 E-01$ & 1. $58 \mathrm{E}-01$ & $0.10 \mathrm{E}-$ & $\perp . \perp 9 \mathrm{E}+$ & $1.19 E+U 0$ & $2.21 \mathrm{E}+00$ \\
\hline $93 E-03$ & $3.03 E+00$ & & $1.59 \mathrm{E}-01$ & & & & $2.21 \mathrm{E}+00$ \\
\hline 3 & . & & & & & & $2 \cdot 2+\Delta$ \\
\hline 3 & 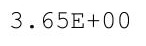 & & & & & $79 E+00$ & 00 \\
\hline $4.02 E-03$ & & & & 1 & 0 & 00 & \\
\hline$E-03$ & 3.66 & 3.2 & 1. & 01 & $1.2 C$ & 00 & $2.22 \mathrm{E}$ \\
\hline $8 E-03$ & $3.66 \mathrm{E}+00$ & 3 & 1.6 & & 1.2 & & $2.22 \mathrm{E}+00$ \\
\hline$E-03$ & $3.66 \mathrm{E}+00$ & s & & & 1.21E+ & $1.80 \mathrm{E}+00$ & $2.22 \mathrm{E}+00$ \\
\hline$-2-03$ & $3.6 / \mathrm{E}+00$ & 1 & 1 . & 1 & 1. $21 \mathrm{E}+00$ & $1.80 \mathrm{E}+00$ & $2.23 E+00$ \\
\hline $4.1 / E-03$ & $3.01 \mathrm{LT}$ & & 1 & & 0 & $1.80 \mathrm{E}+00$ & $2.23 \mathrm{E}$ \\
\hline & & 1 & 1 & 1 & $1.21 \mathrm{E}$ & $1.80 \mathrm{E}+00$ & $2.23 E+00$ \\
\hline-03 & $3.67 \mathrm{E}+00$ & $E-01$ & 1.6 & 8. & 1.22E+ & $1.81 \mathrm{E}+00$ & $2.23 E+00$ \\
\hline$E-03$ & $68 \mathrm{E}+00$ & $36 E-01$ & $1.67 \mathrm{E}-01$ & $.37 E-01$ & 1. $22 \mathrm{E}+00$ & $1.81 \mathrm{E}+00$ & $2.24 \mathrm{E}+00$ \\
\hline
\end{tabular}


RESRAD-OFFSITE, Version 2.5

$\mathrm{T}^{1 / 2}$ Limit $=180$ days

obabilistic Dose and Risk Report

Title : Offsite Resident Farmer Deterministic Run

File : RF TC99 DOESG FWD-FV2.ROF

Summary of dose at graphical times, reptition 3 (continued)

Time

Years

$6.13 \mathrm{E}+02$

$6.14 \mathrm{E}+02$

$6.14 \mathrm{E}+02$

$6.15 \mathrm{E}+02$

$6.15 \mathrm{E}+02$

$6.16 \mathrm{E}+02$

$6.16 \mathrm{E}+02$

$6.17 \mathrm{E}+02$

$6.17 \mathrm{E}+02$

$6.18 \mathrm{E}+02$

$6.18 \mathrm{E}+02$

$6.19 \mathrm{E}+02$

$6.19 \mathrm{E}+02$

$6.20 \mathrm{E}+02$

$6.20 \mathrm{E}+02$

$6.21 \mathrm{E}+02$

$6.21 \mathrm{E}+02$

$6.22 \mathrm{E}+02$

$6.22 \mathrm{E}+02$

$6.23 \mathrm{E}+02$

$6.23 \mathrm{E}+02$

$6.24 \mathrm{E}+02$

$6.24 \mathrm{E}+02$

$6.25 \mathrm{E}+02$

$6.25 \mathrm{E}+02$

$6.26 \mathrm{E}+02$

$6.27 \mathrm{E}+02$

$6.27 \mathrm{E}+02$

$6.28 \mathrm{E}+02$

$6.28 \mathrm{E}+02$

$6.29 \mathrm{E}+02$

$6.29 \mathrm{E}+02$

$6.30 \mathrm{E}+02$

$6.30 \mathrm{E}+02$

$6.31 \mathrm{E}+02$

$6.31 \mathrm{E}+02$

$6.32 \mathrm{E}+02$

$6.32 \mathrm{E}+02$

$6.33 \mathrm{E}+02$

$6.33 \mathrm{E}+02$

$6.34 \mathrm{E}+02$

$6.34 \mathrm{E}+02$

$6.35 \mathrm{E}+02$

$6.35 \mathrm{E}+02$

$6.36 \mathrm{E}+02$

$6.36 \mathrm{E}+02$

Dose statistics at graphical times, mrem/yr

\begin{tabular}{|c|c|c|c|c|c|c|c|}
\hline Minimum & Maximum & Mean & Median & $90 \%$ & $95 \%$ & $97.5 \%$ & $99 \%$ \\
\hline $4.30 E-03$ & $3.68 E+00$ & $3.36 E-01$ & $1.68 \mathrm{E}-01$ & $8.39 E-01$ & $1.22 \mathrm{E}+00$ & $1.81 E+00$ & $2.24 E+00$ \\
\hline $4.33 E-03$ & $3.68 \mathrm{E}+00$ & $3.37 E-01$ & 1. $69 \mathrm{E}-01$ & $8.41 E-01$ & $1.23 E+00$ & $1.81 \mathrm{E}+00$ & $2.24 \mathrm{E}+00$ \\
\hline $4.36 \mathrm{E}-03$ & $3.68 \mathrm{E}+00$ & $3.38 E-01$ & $1.70 \mathrm{E}-01$ & $8.43 E-01$ & $1.23 \mathrm{E}+00$ & $1.81 \mathrm{E}+00$ & $2.24 \mathrm{E}+00$ \\
\hline $4.39 \mathrm{E}-03$ & $3.69 \mathrm{E}+00$ & $3.39 \mathrm{E}-01$ & $1.70 \mathrm{E}-01$ & $8.45 \mathrm{E}-01$ & $1.23 \mathrm{E}+00$ & $1.81 \mathrm{E}+00$ & $2.24 \mathrm{E}+00$ \\
\hline $4.43 E-03$ & $3.69 \mathrm{E}+00$ & $3.40 E-01$ & 1. $71 \mathrm{E}-01$ & $8.47 \mathrm{E}-01$ & $1.23 \mathrm{E}+00$ & $1.82 \mathrm{E}+00$ & $2.25 \mathrm{E}+00$ \\
\hline $4.46 \mathrm{E}-03$ & $3.69 \mathrm{E}+00$ & $3.41 \mathrm{E}-01$ & $1.72 \mathrm{E}-01$ & $8.49 \mathrm{E}-01$ & $1.24 \mathrm{E}+00$ & $.82 \mathrm{E}+00$ & $.25 E+00$ \\
\hline $4.49 \mathrm{E}-03$ & $3.69 \mathrm{E}+00$ & $3.42 \mathrm{E}-01$ & $1.73 E-01$ & $8.51 \mathrm{E}-01$ & $1.24 \mathrm{E}+00$ & $1.82 \mathrm{E}+00$ & $2.25 \mathrm{E}+00$ \\
\hline $4.52 \mathrm{E}-03$ & $3.70 E+00$ & $3.43 E-01$ & $1.73 E-01$ & $8.54 \mathrm{E}-01$ & $1.24 \mathrm{E}+00$ & $1.82 \mathrm{E}+00$ & $2.25 E+00$ \\
\hline $4.56 \mathrm{E}-03$ & $3.70 \mathrm{E}+00$ & $3.44 \mathrm{E}-01$ & $1.74 \mathrm{E}-01$ & $8.56 \mathrm{E}-01$ & $1.24 \mathrm{E}+00$ & $1.82 \mathrm{E}+00$ & $2.25 E+00$ \\
\hline $4.59 \mathrm{E}-03$ & $3.70 \mathrm{E}+00$ & $3.45 E-01$ & $1.75 \mathrm{E}-01$ & $.58 E-01$ & $1.25 \mathrm{E}+00$ & $1.82 \mathrm{E}+00$ & $.26 E+00$ \\
\hline $4.62 \mathrm{E}-03$ & $3.70 \mathrm{E}+00$ & $3.45 E-01$ & $1.75 \mathrm{E}-01$ & $8.60 \mathrm{E}-01$ & $25 E+00$ & $.82 \mathrm{E}+00$ & $2.26 \mathrm{E}+00$ \\
\hline $4.65 E-03$ & $3.70 \mathrm{E}+00$ & $3.46 \mathrm{E}-01$ & $1.76 \mathrm{E}-01$ & $8.63 E-01$ & $1.25 \mathrm{E}+00$ & $1.83 \mathrm{E}+00$ & $2.26 \mathrm{E}+00$ \\
\hline $4.69 \mathrm{E}-03$ & $3.71 \mathrm{E}+00$ & $3.47 \mathrm{E}-01$ & $1.77 \mathrm{E}-01$ & $8.65 E-01$ & $1.26 \mathrm{E}+00$ & $1.83 \mathrm{E}+00$ & $2.26 \mathrm{E}+00$ \\
\hline $4.72 E-03$ & $3.71 \mathrm{E}+00$ & $3.48 E-01$ & $1.77 \mathrm{E}-01$ & $8.68 \mathrm{E}-01$ & $1.26 \mathrm{E}+00$ & $1.83 \mathrm{E}+00$ & $2.27 E+00$ \\
\hline $4.76 \mathrm{E}-03$ & $3.71 \mathrm{E}+00$ & $3.49 \mathrm{E}-01$ & $1.78 \mathrm{E}-01$ & $8.70 \mathrm{E}-01$ & $1.26 \mathrm{E}+00$ & $1.83 \mathrm{E}+00$ & $2.27 \mathrm{E}+00$ \\
\hline $4.79 E-03$ & $3.71 E+00$ & $3.50 E-01$ & $1.79 \mathrm{E}-01$ & $72 \mathrm{E}-01$ & $.27 E+$ & $.83 E+00$ & $.27 E+00$ \\
\hline $4.82 \mathrm{E}-03$ & $3.72 \mathrm{E}+00$ & $51 \mathrm{E}-01$ & $1.80 \mathrm{E}-01$ & $75 E-01$ & $27 E+00$ & $.83 E+00$ & $27 E+00$ \\
\hline $4.86 \mathrm{E}-03$ & $3.72 \mathrm{E}+00$ & $3.52 E-01$ & $1.80 \mathrm{E}-01$ & $8.77 \mathrm{E}-01$ & $1.27 \mathrm{E}+00$ & $1.83 \mathrm{E}+00$ & $2.27 \mathrm{E}+00$ \\
\hline $4.89 E-03$ & $3.72 \mathrm{E}+00$ & $3.53 E-01$ & $1.81 \mathrm{E}-01$ & $8.79 E-01$ & $1.27 \mathrm{E}+00$ & $1.84 \mathrm{E}+00$ & $2.28 E+00$ \\
\hline $4.93 E-03$ & $3.72 \mathrm{E}+00$ & $3.54 \mathrm{E}-01$ & $1.82 \mathrm{E}-01$ & $8.82 \mathrm{E}-01$ & $1.28 \mathrm{E}+00$ & $1.84 \mathrm{E}+00$ & $2.28 \mathrm{E}+00$ \\
\hline $4.96 \mathrm{E}-03$ & $3.72 \mathrm{E}+00$ & $3.55 E-01$ & $1.82 \mathrm{E}-01$ & $8.84 \mathrm{E}-01$ & $1.28 \mathrm{E}+00$ & $1.84 \mathrm{E}+00$ & $2.28 \mathrm{E}+00$ \\
\hline $5.00 \mathrm{E}-03$ & $3.73 E+00$ & $55 E-01$ & $1.83 E-01$ & $8.87 E-01$ & $1.28 \mathrm{E}+00$ & $1.84 \mathrm{E}+00$ & $.29 E+00$ \\
\hline $5.03 E-03$ & $3.73 E+00$ & $3.56 \mathrm{E}-01$ & $1.84 \mathrm{E}-01$ & $8.89 E-01$ & $1.29 \mathrm{E}+00$ & $1.84 \mathrm{E}+00$ & $2.29 \mathrm{E}+00$ \\
\hline $5.07 \mathrm{E}-03$ & $3.73 E+00$ & $3.57 \mathrm{E}-01$ & $1.84 \mathrm{E}-01$ & $8.91 \mathrm{E}-01$ & $1.29 \mathrm{E}+00$ & $1.84 \mathrm{E}+00$ & $2.29 \mathrm{E}+00$ \\
\hline $5.10 \mathrm{E}-03$ & $3.73 E+00$ & $3.58 E-01$ & $1.85 E-01$ & $8.94 E-01$ & $1.29 \mathrm{E}+00$ & $1.84 \mathrm{E}+00$ & $2.30 E+00$ \\
\hline $5.14 \mathrm{E}-03$ & $3.74 \mathrm{E}+00$ & $3.59 \mathrm{E}-01$ & $1.86 \mathrm{E}-01$ & $8.96 \mathrm{E}-01$ & $1.29 \mathrm{E}+00$ & $1.84 \mathrm{E}+00$ & $2.30 \mathrm{E}+00$ \\
\hline $5.18 \mathrm{E}-03$ & $3.74 \mathrm{E}+00$ & $3.60 \mathrm{E}-01$ & $1.87 \mathrm{E}-01$ & $8.98 \mathrm{E}-01$ & $1.29 \mathrm{E}+00$ & $1.85 \mathrm{E}+00$ & $2.30 \mathrm{E}+00$ \\
\hline $5.21 E-03$ & $3.74 \mathrm{E}+00$ & $3.61 E-01$ & $1.87 \mathrm{E}-01$ & $9.01 E-01$ & $1.30 \mathrm{E}+00$ & $1.85 \mathrm{E}+00$ & $2.31 E+00$ \\
\hline $5.25 E-03$ & $3.74 \mathrm{E}+00$ & $3.62 \mathrm{E}-01$ & $1.88 \mathrm{E}-01$ & $9.03 E-01$ & $1.30 \mathrm{E}+00$ & $1.85 \mathrm{E}+00$ & $2.31 E+00$ \\
\hline $5.29 \mathrm{E}-03$ & $3.74 \mathrm{E}+00$ & $3.63 E-01$ & $1.89 \mathrm{E}-01$ & $9.05 E-01$ & $1.30 \mathrm{E}+00$ & $1.85 \mathrm{E}+00$ & $2.31 E+00$ \\
\hline $5.32 \mathrm{E}-03$ & $3.75 E+00$ & $3.64 \mathrm{E}-01$ & $1.89 \mathrm{E}-01$ & $9.08 E-01$ & $1.30 \mathrm{E}+00$ & $1.85 \mathrm{E}+00$ & $2.32 \mathrm{E}+00$ \\
\hline $5.36 \mathrm{E}-03$ & $3.75 E+00$ & 3. $65 \mathrm{E}-01$ & $1.90 \mathrm{E}-01$ & $9.10 \mathrm{E}-01$ & $1.30 \mathrm{E}+00$ & $1.85 \mathrm{E}+00$ & $2.32 \mathrm{E}+00$ \\
\hline $5.40 \mathrm{E}-03$ & $.75 E+00$ & $3.66 \mathrm{E}-01$ & $1.91 \mathrm{E}-01$ & $9.13 E-01$ & $1.30 \mathrm{E}+00$ & $1.85 \mathrm{E}+00$ & $2.32 E+00$ \\
\hline $5.43 E-03$ & $3.75 \mathrm{E}+00$ & $3.66 \mathrm{E}-01$ & 1.92E-01 & $15 E-01$ & $1.31 \mathrm{E}+00$ & $1.85 \mathrm{E}+00$ & $2.32 E+00$ \\
\hline $5.47 E-03$ & $3.75 E+00$ & $3.67 E-01$ & $1.92 \mathrm{E}-01$ & $9.18 E-01$ & $1.31 \mathrm{E}+00$ & $1.86 \mathrm{E}+00$ & $2.33 E+00$ \\
\hline $5.51 \mathrm{E}-03$ & $3.75 E+00$ & $3.68 E-01$ & $1.93 E-01$ & $9.20 \mathrm{E}-01$ & $1.31 \mathrm{E}+00$ & $1.86 \mathrm{E}+00$ & $2.33 E+00$ \\
\hline $5.55 E-03$ & $3.76 \mathrm{E}+00$ & $3.69 \mathrm{E}-01$ & $1.94 \mathrm{E}-01$ & $9.23 E-01$ & $1.31 \mathrm{E}+00$ & $1.86 \mathrm{E}+00$ & $2.33 E+00$ \\
\hline $5.58 \mathrm{E}-03$ & $3.76 \mathrm{E}+00$ & $3.70 \mathrm{E}-01$ & 1. $95 \mathrm{E}-01$ & $9.25 \mathrm{E}-01$ & $1.32 \mathrm{E}+00$ & $1.86 \mathrm{E}+00$ & $2.34 \mathrm{E}+00$ \\
\hline $5.62 \mathrm{E}-03$ & $3.76 \mathrm{E}+00$ & $3.71 E-01$ & 1.95E-01 & $9.28 \mathrm{E}-01$ & $1.32 \mathrm{E}+00$ & $1.86 \mathrm{E}+00$ & $2.34 \mathrm{E}+00$ \\
\hline $5.66 \mathrm{E}-03$ & $.76 E+00$ & $3.72 \mathrm{E}-01$ & $1.96 \mathrm{E}-01$ & $9.30 \mathrm{E}-01$ & $1.32 \mathrm{E}+00$ & $1.86 \mathrm{E}+00$ & $2.34 \mathrm{E}+00$ \\
\hline $5.70 \mathrm{E}-03$ & $3.76 \mathrm{E}+00$ & $3.73 E-01$ & $1.97 \mathrm{E}-01$ & $9.33 E-01$ & $1.32 \mathrm{E}+00$ & $1.87 \mathrm{E}+00$ & $2.35 E+00$ \\
\hline $5.74 \mathrm{E}-03$ & $3.77 \mathrm{E}+00$ & $3.74 E-01$ & $1.98 \mathrm{E}-01$ & $9.35 E-01$ & $1.33 E+00$ & $1.87 \mathrm{E}+00$ & $2.35 \mathrm{E}+00$ \\
\hline $5.78 \mathrm{E}-03$ & $3.77 \mathrm{E}+00$ & $3.75 E-01$ & $1.98 \mathrm{E}-01$ & $9.38 \mathrm{E}-01$ & $1.33 \mathrm{E}+00$ & $1.87 \mathrm{E}+00$ & $2.35 \mathrm{E}+00$ \\
\hline $5.82 \mathrm{E}-03$ & $3.77 \mathrm{E}+00$ & $3.76 E-01$ & $1.99 \mathrm{E}-01$ & $9.40 \mathrm{E}-01$ & $1.33 \mathrm{E}+00$ & $1.87 \mathrm{E}+00$ & $2.36 \mathrm{E}+00$ \\
\hline $5.86 \mathrm{E}-03$ & $3.77 \mathrm{E}+00$ & $3.77 E-01$ & $2.00 E-01$ & $9.43 E-01$ & $1.33 \mathrm{E}+00$ & $1.87 \mathrm{E}+00$ & $2.36 \mathrm{E}+00$ \\
\hline $5.90 E-03$ & $3.77 \mathrm{E}+00$ & $3.78 E-01$ & $2.01 E-01$ & $9.45 E-01$ & $1.34 \mathrm{E}+00$ & $1.88 \mathrm{E}+00$ & $2.36 \mathrm{E}+00$ \\
\hline
\end{tabular}


RESRAD-OFFSITE, Version 2.5 
RESRAD-OFFSITE, Version 2.5

$\mathrm{T}^{1 / 2}$ Limit $=180$ days

Title : Offsite Resident Farmer Deterministic Run

File : RF TC99 DOESG FWD-FV2.ROF

Summary of dose at graphical times, reptition 3 (continued)

Time

Years

$6.60 \mathrm{E}+02$

$6.61 \mathrm{E}+02$

$6.61 \mathrm{E}+02$

$6.62 \mathrm{E}+02$

$6.62 \mathrm{E}+02$

$6.63 \mathrm{E}+02$

$6.63 \mathrm{E}+02$

$6.64 \mathrm{E}+02$

$6.64 \mathrm{E}+02$

$6.65 \mathrm{E}+02$

$6.65 \mathrm{E}+02$

$6.66 \mathrm{E}+02$

$6.67 \mathrm{E}+02$

$6.67 \mathrm{E}+02$

$6.68 \mathrm{E}+02$

$6.68 \mathrm{E}+02$

$6.69 \mathrm{E}+02$

$6.69 \mathrm{E}+02$

$6.70 \mathrm{E}+02$

$6.70 \mathrm{E}+02$

$6.71 \mathrm{E}+02$

$6.71 \mathrm{E}+02$

$6.72 \mathrm{E}+02$

$6.72 \mathrm{E}+02$

$6.73 \mathrm{E}+02$

$6.73 E+02$

$6.74 \mathrm{E}+02$

$6.74 \mathrm{E}+02$

$6.75 \mathrm{E}+02$

$6.75 \mathrm{E}+02$

$6.76 \mathrm{E}+02$

$6.76 \mathrm{E}+02$

$6.77 \mathrm{E}+02$

$6.77 \mathrm{E}+02$

$6.78 \mathrm{E}+02$

$6.78 \mathrm{E}+02$

$6.79 \mathrm{E}+02$

$6.79 \mathrm{E}+02$

$6.80 \mathrm{E}+02$

$6.80 \mathrm{E}+02$

$6.81 \mathrm{E}+02$

$6.81 \mathrm{E}+02$

$6.82 \mathrm{E}+02$

$6.82 \mathrm{E}+02$

$6.83 \mathrm{E}+02$

$6.83 \mathrm{E}+02$

Dose statistics at graphical times, mrem/yr

\begin{tabular}{|c|c|c|c|c|c|c|c|}
\hline Minimum & Maximum & Mean & Median & $90 \%$ & $95 \%$ & $97.5 \%$ & $99 \%$ \\
\hline $7.98 E-03$ & $3.83 \mathrm{E}+00$ & $4.21 E-01$ & $2.40 \mathrm{E}-01$ & $1.04 \mathrm{E}+00$ & $1.45 \mathrm{E}+00$ & $2.00 \mathrm{E}+00$ & $2.49 E+00$ \\
\hline $8.03 E-03$ & $3.83 E+00$ & $4.22 \mathrm{E}-01$ & $2.41 \mathrm{E}-01$ & $1.04 \mathrm{E}+00$ & $1.45 \mathrm{E}+00$ & $2.00 \mathrm{E}+00$ & $2.50 \mathrm{E}+00$ \\
\hline $8.07 E-03$ & $3.83 E+00$ & $4.23 E-01$ & $2.42 E-01$ & $1.04 \mathrm{E}+00$ & $1.46 \mathrm{E}+00$ & $2.00 \mathrm{E}+00$ & $2.50 \mathrm{E}+00$ \\
\hline $8.12 E-03$ & $3.84 \mathrm{E}+00$ & $4.24 \mathrm{E}-01$ & $2.43 \mathrm{E}-01$ & $1.05 E+00$ & $1.46 \mathrm{E}+00$ & $2.01 E+00$ & $2.50 \mathrm{E}+00$ \\
\hline $8.17 E-03$ & $3.84 \mathrm{E}+00$ & $4.25 \mathrm{E}-01$ & $2.44 \mathrm{E}-01$ & $1.05 \mathrm{E}+00$ & $1.46 \mathrm{E}+00$ & $2.01 E+00$ & $2.50 \mathrm{E}+00$ \\
\hline $8.22 E-03$ & $3.84 \mathrm{E}+00$ & $4.26 \mathrm{E}-01$ & $2.45 E-01$ & $1.05 E+00$ & $1.46 \mathrm{E}+00$ & $2.01 E+00$ & $2.51 E+00$ \\
\hline $8.27 E-03$ & $3.84 \mathrm{E}+00$ & $4.27 E-01$ & $2.46 \mathrm{E}-01$ & $1.05 \mathrm{E}+00$ & 1. $47 \mathrm{E}+00$ & $2.02 \mathrm{E}+00$ & $2.51 \mathrm{E}+00$ \\
\hline $8.32 E-03$ & $3.84 \mathrm{E}+00$ & $4.28 E-01$ & $2.47 \mathrm{E}-01$ & $1.05 E+00$ & $1.47 \mathrm{E}+00$ & $2.02 E+00$ & $2.51 E+00$ \\
\hline $8.38 E-03$ & $3.84 \mathrm{E}+00$ & $4.29 \mathrm{E}-01$ & $2.47 \mathrm{E}-01$ & $1.06 \mathrm{E}+00$ & $1.47 \mathrm{E}+00$ & $2.02 E+00$ & $2.51 E+00$ \\
\hline $8.43 E-03$ & $3.84 \mathrm{E}+00$ & $4.30 \mathrm{E}-01$ & $2.48 \mathrm{E}-01$ & $1.06 \mathrm{E}+00$ & $1.47 \mathrm{E}+00$ & $2.03 E+00$ & $2.52 E+00$ \\
\hline $8.48 E-03$ & $3.84 \mathrm{E}+00$ & $4.30 \mathrm{E}-01$ & $2.49 \mathrm{E}-01$ & $1.06 \mathrm{E}+00$ & $1.47 \mathrm{E}+00$ & $2.03 E+00$ & $2.52 E+00$ \\
\hline $8.53 E-03$ & $3.84 \mathrm{E}+00$ & $4.31 E-01$ & $2.50 \mathrm{E}-01$ & $1.06 \mathrm{E}+00$ & $1.48 \mathrm{E}+00$ & $2.03 E+00$ & $2.52 \mathrm{E}+00$ \\
\hline $8.58 E-03$ & $3.84 \mathrm{E}+00$ & 4. $32 \mathrm{E}-01$ & $2.50 \mathrm{E}-01$ & $1.07 \mathrm{E}+00$ & $1.48 \mathrm{E}+00$ & $2.03 E+00$ & $2.52 \mathrm{E}+00$ \\
\hline $8.63 E-03$ & $3.84 \mathrm{E}+00$ & $4.33 E-01$ & $2.51 \mathrm{E}-01$ & $1.07 \mathrm{E}+00$ & $1.48 \mathrm{E}+00$ & $2.04 \mathrm{E}+00$ & $2.53 E+00$ \\
\hline $8.68 E-03$ & $3.84 \mathrm{E}+00$ & $4.34 \mathrm{E}-01$ & $2.52 \mathrm{E}-01$ & $1.07 \mathrm{E}+00$ & $1.48 \mathrm{E}+00$ & $2.04 \mathrm{E}+00$ & $2.53 E+00$ \\
\hline $8.74 \mathrm{E}-03$ & $3.84 \mathrm{E}+00$ & 4. $35 \mathrm{E}-01$ & $2.53 E-01$ & $1.07 \mathrm{E}+00$ & $1.48 \mathrm{E}+00$ & $2.04 \mathrm{E}+00$ & $2.53 E+00$ \\
\hline $8.79 E-03$ & $3.85 E+00$ & $4.36 \mathrm{E}-01$ & $2.54 \mathrm{E}-01$ & $1.07 \mathrm{E}+00$ & $1.49 \mathrm{E}+00$ & $2.05 E+00$ & $2.53 E+00$ \\
\hline $8.84 E-03$ & $3.85 \mathrm{E}+00$ & $4.37 E-01$ & $2.54 \mathrm{E}-01$ & 1. $08 \mathrm{E}+00$ & $1.49 \mathrm{E}+00$ & $2.05 E+00$ & $2.53 \mathrm{E}+00$ \\
\hline $8.89 E-03$ & $3.85 \mathrm{E}+00$ & $4.38 E-01$ & $2.55 \mathrm{E}-01$ & 1. $08 \mathrm{E}+00$ & $1.49 \mathrm{E}+00$ & $2.05 \mathrm{E}+00$ & $2.54 \mathrm{E}+00$ \\
\hline $8.95 E-03$ & $3.85 \mathrm{E}+00$ & $4.39 E-01$ & $2.56 \mathrm{E}-01$ & $1.08 \mathrm{E}+00$ & $1.49 \mathrm{E}+00$ & $2.05 E+00$ & $2.54 \mathrm{E}+00$ \\
\hline $9.00 E-03$ & $3.85 \mathrm{E}+00$ & $4.40 \mathrm{E}-01$ & $2.57 \mathrm{E}-01$ & $1.08 \mathrm{E}+00$ & $1.50 \mathrm{E}+00$ & $6 \mathrm{E}+00$ & $2.54 \mathrm{E}+00$ \\
\hline $9.05 E-03$ & $3.85 \mathrm{E}+00$ & $4.41 \mathrm{E}-01$ & $2.58 \mathrm{E}-01$ & $1.08 \mathrm{E}+00$ & $1.50 \mathrm{E}+00$ & $2.06 \mathrm{E}+00$ & $2.54 \mathrm{E}+00$ \\
\hline $9.11 \mathrm{E}-03$ & $3.85 \mathrm{E}+00$ & $4.42 \mathrm{E}-01$ & $2.59 \mathrm{E}-01$ & $1.09 \mathrm{E}+00$ & 1. $50 \mathrm{E}+00$ & $2.06 \mathrm{E}+00$ & $2.54 \mathrm{E}+00$ \\
\hline $9.16 \mathrm{E}-03$ & $3.85 \mathrm{E}+00$ & $4.43 E-01$ & $2.60 \mathrm{E}-01$ & $1.09 \mathrm{E}+00$ & $1.50 \mathrm{E}+00$ & $2.07 \mathrm{E}+00$ & $2.54 \mathrm{E}+00$ \\
\hline $9.22 \mathrm{E}-03$ & $3.85 \mathrm{E}+00$ & $4.44 \mathrm{E}-01$ & $2.60 \mathrm{E}-01$ & $1.09 \mathrm{E}+00$ & $1.50 \mathrm{E}+00$ & $2.07 \mathrm{E}+00$ & $2.55 \mathrm{E}+00$ \\
\hline $9.27 E-03$ & $3.85 \mathrm{E}+00$ & $4.45 E-01$ & $2.61 \mathrm{E}-01$ & $1.09 E+00$ & $1.51 \mathrm{E}+00$ & $2.07 E+00$ & $2.55 E+00$ \\
\hline $9.33 E-03$ & $3.85 \mathrm{E}+00$ & $4.45 E-01$ & $2.62 E-01$ & $1.10 \mathrm{E}+00$ & $1.51 \mathrm{E}+00$ & $2.07 E+00$ & $2.55 \mathrm{E}+00$ \\
\hline $9.38 E-03$ & $3.85 \mathrm{E}+00$ & $4.46 \mathrm{E}-01$ & $2.62 \mathrm{E}-01$ & $1.10 \mathrm{E}+00$ & $1.51 \mathrm{E}+00$ & $2.08 \mathrm{E}+00$ & $2.55 \mathrm{E}+00$ \\
\hline $9.44 \mathrm{E}-03$ & $3.85 \mathrm{E}+00$ & $4.47 \mathrm{E}-01$ & $2.63 \mathrm{E}-01$ & 1.10E+00 & 1. $51 \mathrm{E}+00$ & $2.08 \mathrm{E}+00$ & $2.55 \mathrm{E}+00$ \\
\hline $9.49 \mathrm{E}-03$ & $3.85 \mathrm{E}+00$ & $4.48 E-01$ & $2.63 \mathrm{E}-01$ & 1.10E+00 & $1.51 \mathrm{E}+00$ & $2.08 E+00$ & $2.55 \mathrm{E}+00$ \\
\hline $9.55 E-03$ & $3.85 \mathrm{E}+00$ & $4.49 \mathrm{E}-01$ & $2.64 \mathrm{E}-01$ & $1.10 \mathrm{E}+00$ & $1.51 \mathrm{E}+00$ & $2.09 \mathrm{E}+00$ & $2.56 \mathrm{E}+00$ \\
\hline $9.60 E-03$ & $3.85 \mathrm{E}+00$ & $4.50 \mathrm{E}-01$ & $2.65 \mathrm{E}-01$ & $1.11 E+00$ & $1.52 \mathrm{E}+00$ & $2.09 E+00$ & $2.56 \mathrm{E}+00$ \\
\hline $9.66 \mathrm{E}-03$ & $3.85 \mathrm{E}+00$ & $4.51 \mathrm{E}-01$ & $2.65 \mathrm{E}-01$ & $1.11 \mathrm{E}+00$ & $1.52 \mathrm{E}+00$ & $2.09 \mathrm{E}+00$ & $2.56 \mathrm{E}+00$ \\
\hline $9.71 \mathrm{E}-03$ & $3.85 \mathrm{E}+00$ & $4.52 \mathrm{E}-01$ & $2.66 \mathrm{E}-01$ & $1.11 \mathrm{E}+00$ & $1.52 \mathrm{E}+00$ & $2.09 \mathrm{E}+00$ & $2.56 \mathrm{E}+00$ \\
\hline $9.77 E-03$ & $3.85 \mathrm{E}+00$ & $4.53 E-01$ & $2.67 \mathrm{E}-01$ & $1.11 \mathrm{E}+00$ & $1.52 \mathrm{E}+00$ & $2.10 \mathrm{E}+00$ & $2.56 \mathrm{E}+00$ \\
\hline $9.83 E-03$ & $3.85 \mathrm{E}+00$ & $4.54 \mathrm{E}-01$ & $2.67 \mathrm{E}-01$ & $1.11 \mathrm{E}+00$ & $1.52 \mathrm{E}+00$ & $2.10 \mathrm{E}+00$ & $2.56 \mathrm{E}+00$ \\
\hline $9.88 E-03$ & $3.85 \mathrm{E}$ & $55-01$ & $68 E-01$ & $1.12 \mathrm{E}+00$ & $1.53 \mathrm{E}+00$ & $2.10 E+00$ & $2.56 \mathrm{E}+00$ \\
\hline $9.94 \mathrm{E}-03$ & $3.85 \mathrm{E}+00$ & $.56 E-01$ & 01 & $1.12 \mathrm{E}+00$ & $1.53 \mathrm{E}+00$ & $2.10 \mathrm{E}+00$ & $2.57 \mathrm{E}+00$ \\
\hline $1.00 \mathrm{E}-02$ & $3.86 \mathrm{E}+00$ & $4.57 \mathrm{E}-01$ & $2.70 \mathrm{E}-01$ & $1.12 \mathrm{E}+00$ & $1.53 \mathrm{E}+00$ & $2.11 \mathrm{E}+00$ & $2.57 \mathrm{E}+00$ \\
\hline $1.01 \mathrm{E}-02$ & $3.86 \mathrm{E}+00$ & $4.58 \mathrm{E}-01$ & $2.71 \mathrm{E}-01$ & $1.12 \mathrm{E}+00$ & $1.53 \mathrm{E}+00$ & $2.11 \mathrm{E}+00$ & $2.57 \mathrm{E}+00$ \\
\hline $1.01 \mathrm{E}-02$ & $3.86 \mathrm{E}+00$ & $4.59 \mathrm{E}-01$ & $2.72 \mathrm{E}-01$ & $1.13 E+00$ & $1.53 \mathrm{E}+00$ & $2.11 \mathrm{E}+00$ & $2.57 \mathrm{E}+00$ \\
\hline $1.02 \mathrm{E}-02$ & $3.86 \mathrm{E}+00$ & $4.59 \mathrm{E}-01$ & $2.73 E-01$ & $1.13 \mathrm{E}+00$ & $1.54 \mathrm{E}+00$ & $2.12 \mathrm{E}+00$ & $2.57 \mathrm{E}+00$ \\
\hline $1.02 E-02$ & $3.86 \mathrm{E}+00$ & $4.60 \mathrm{E}-01$ & $2.73 E-01$ & $1.13 E+00$ & $1.54 \mathrm{E}+00$ & $2.12 \mathrm{E}+00$ & $2.57 \mathrm{E}+00$ \\
\hline $1.03 E-02$ & $3.86 \mathrm{E}+00$ & $4.61 \mathrm{E}-01$ & $2.74 \mathrm{E}-01$ & $1.13 E+00$ & $1.54 \mathrm{E}+00$ & $2.12 \mathrm{E}+00$ & $2.58 \mathrm{E}+00$ \\
\hline $1.03 E-02$ & $3.86 \mathrm{E}+00$ & 4. $62 \mathrm{E}-01$ & $2.75 E-01$ & $1.13 \mathrm{E}+00$ & $1.54 \mathrm{E}+00$ & $2.12 \mathrm{E}+00$ & $2.58 \mathrm{E}+00$ \\
\hline $1.04 \mathrm{E}-02$ & $3.86 \mathrm{E}+00$ & $4.63 E-01$ & $2.77 \mathrm{E}-01$ & $1.14 \mathrm{E}+00$ & $1.54 \mathrm{E}+00$ & $2.13 \mathrm{E}+00$ & $2.58 \mathrm{E}+00$ \\
\hline
\end{tabular}


RESRAD-OFFSITE, Version 2.5 
RESRAD-OFFSITE, Version 2.5

$\mathrm{T}^{1 / 2}$ Limit $=180$ days

robabilistic Dose and Risk Report

Title : Offsite Resident Farmer Deterministic Run

File : RF TC99 DOESG FWD-FV2.ROF

Summary of dose at graphical times, reptition 3 (continued)

Time

Years

7. $08 \mathrm{E}+02$

$7.08 \mathrm{E}+02$

$7.09 \mathrm{E}+02$

7. $09 \mathrm{E}+02$

$7.10 \mathrm{E}+02$

$7.10 \mathrm{E}+02$

$7.11 \mathrm{E}+02$

$7.11 \mathrm{E}+02$

$7.12 \mathrm{E}+02$

$7.12 \mathrm{E}+02$

$7.13 \mathrm{E}+02$

$7.13 \mathrm{E}+02$

$7.14 \mathrm{E}+02$

$7.14 \mathrm{E}+02$

7. $15 \mathrm{E}+02$

$7.15 \mathrm{E}+02$

$7.16 \mathrm{E}+02$

$7.16 \mathrm{E}+02$

$7.17 \mathrm{E}+02$

$7.17 \mathrm{E}+02$

$7.18 \mathrm{E}+02$

$7.18 \mathrm{E}+02$

$7.19 \mathrm{E}+02$

$7.19 \mathrm{E}+02$

$7.20 \mathrm{E}+02$

$7.20 \mathrm{E}+02$

$7.21 \mathrm{E}+02$

$7.21 \mathrm{E}+02$

7. $22 \mathrm{E}+02$

$7.22 \mathrm{E}+02$

7. $23 \mathrm{E}+02$

7. $23 \mathrm{E}+02$

$7.24 \mathrm{E}+02$

$7.24 \mathrm{E}+02$

$7.25 \mathrm{E}+02$

7. $25 \mathrm{E}+02$

7. $26 \mathrm{E}+02$

$7.26 \mathrm{E}+02$

$7.27 \mathrm{E}+02$

$7.28 \mathrm{E}+02$

$7.28 \mathrm{E}+02$

$7.29 \mathrm{E}+02$

$7.29 \mathrm{E}+02$

$7.30 \mathrm{E}+02$

7. $30 \mathrm{E}+02$

7. $31 \mathrm{E}+02$
Dose statistics at graphical times, mrem/yr

\begin{tabular}{|c|c|c|c|c|c|c|c|}
\hline m & axis & 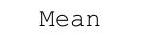 & 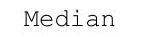 & & & & \\
\hline 02 & $.85 \mathrm{E}+00$ & $07 E-01$ & 1 & $.22 \mathrm{E}+00$ & i & -00 & . $00 \mathrm{E}+U 0$ \\
\hline $35 E-02$ & $3.85 \mathrm{E}+00$ & -01 & $3.18 \mathrm{E}-01$ & 1. $23 E+00$ & $53 E+00$ & $2.19 \mathrm{E}+00$ & $66 \mathrm{E}+00$ \\
\hline$E-02$ & $85 \mathrm{E}+00$ & $9 E-01$ & $9 E-01$ & $.23 E+00$ & $.64 \mathrm{E}+00$ & $2.19 \mathrm{E}+00$ & $2.66 \mathrm{E}+00$ \\
\hline $37 E-02$ & $.85 E+00$ & $10 \mathrm{~F}-01$ & $20 \mathrm{~F}-01$ & $.23 E+00$ & $164 \mathrm{~F}+00$ & $2.20 \mathrm{E}+00$ & $2.66 \mathrm{E}+00$ \\
\hline-02 & +00 & 01 & $E-01$ & $.23 E+$ & & $E+00$ & $E+00$ \\
\hline 02 & $85 E+00$ & & & & & & 00 \\
\hline $39 E-02$ & $3.85 \mathrm{E}+00$ & & & 00 & & & $66 E+00$ \\
\hline $39 \mathrm{E}-02$ & $3.84 \mathrm{E}+00$ & 1 & -01 & $1.24 \mathrm{E}+00$ & $E+00$ & +00 & $5 E+00$ \\
\hline $40 E-02$ & $3.84 \mathrm{E}+00$ & $5 E-01$ & $E-01$ & $1.24 \mathrm{E}+00$ & $E+00$ & $E+00$ & $6 \mathrm{E}+00$ \\
\hline$E-02$ & $.84 \mathrm{E}+00$ & $16 \mathrm{E}-01$ & 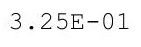 & 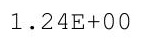 & 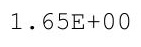 & $21 E+00$ & $.66 \mathrm{E}+00$ \\
\hline 02 & +00 & & & & & 0 & $66 \mathrm{E}+00$ \\
\hline $42 E-02$ & +00 & 1 & 㲅 & $25 \mathrm{~F}-2 \mathrm{r}$ & 0 & -00 & +00 \\
\hline $.43 E-02$ & $3.84 \mathrm{E}+00$ & & & & & $2.22 E+00$ & $2.67 \mathrm{E}+00$ \\
\hline $44 \mathrm{E}-02$ & $3.84 \mathrm{E}+00$ & $.19 \mathrm{E}-01$ & $.29 \mathrm{E}-01$ & $1.25 \mathrm{E}+00$ & & $2.22 E+00$ & $2.67 \mathrm{E}+00$ \\
\hline-02 & $E+00$ & $E-01$ & $F-0-0 \cdot 2-2$ & 0 & & +00 & $7 \mathrm{E}+00$ \\
\hline 2 & 00 & & & $\cdot 20$ & 0 & 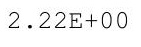 & 00 \\
\hline 2 & 00 & & & $25 \mathrm{E}$ & & 0 & 0 \\
\hline $7 E-02$ & $3.84 \mathrm{E}+00$ & $5.23 E-01$ & 3. $32 E-01$ & $26 F+$ & & 0 & 0 \\
\hline $47 E-02$ & $3.84 \mathrm{E}+00$ & $4 \mathrm{~F}-01$ & $3 F-01$ & $.26 \mathrm{E}+00$ & $67=+8010$ & $3 E+00$ & $57 E+00$ \\
\hline $48 E-02$ & $.84 E+00$ & $.25 E-01$ & $.34 \mathrm{E}-01$ & $1.26 \mathrm{E}+00$ & 1. $67 \mathrm{E}+$ & $2.23 E+00$ & $2.67 \mathrm{E}+00$ \\
\hline 02 & +00 & & & & & $.23 E+00$ & $67 E+00$ \\
\hline 2 & & & & & & & \\
\hline 2 & $.83 E+00$ & . & & $1.26 \mathrm{E}+$ & & & 00 \\
\hline$E-02$ & $83 E+00$ & $\perp$ & $3.38 \mathrm{E}-01$ & $1.26 \mathrm{E}+$ & th & 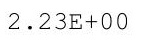 & 00 \\
\hline 2 & $.83 E+00$ & $5.29 \mathrm{E}-01$ & $3.39 \mathrm{E}-01$ & $1.26 \mathrm{E}+\mathrm{C}$ & $1.68 \mathrm{E}+$ & $2.23 E+00$ & $.67 \mathrm{E}+00$ \\
\hline $.53 E-02$ & $.83 E+00$ & $30 \mathrm{~F}-01$ & $3.40=-01$ & $1.27 \mathrm{E}+00$ & $.68 \mathrm{E}+00$ & $.23 E+00$ & $.67 E+00$ \\
\hline-02 & $3.83 E+00$ & & & & & $2.24 \mathrm{E}+00$ & $2.67 E+00$ \\
\hline 02 & & & & & & & \\
\hline 2 & $3.83 E+00$ & 3.0 & & $1.27 \mathrm{E}+$ & & & \\
\hline $56 \mathrm{E}-02$ & $3.83 E+00$ & . 3451 & 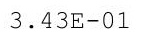 & $1.27 \mathrm{E}+00$ & $1.69 \mathrm{E}+$ & $2.24 \mathrm{E}+00$ & $2.67 \mathrm{E}+00$ \\
\hline $.57 E-02$ & $3.83 E+00$ & $5.35 E-01$ & 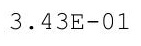 & $1.27 \mathrm{E}+00$ & $1.69 \mathrm{E}+00$ & $2.24 \mathrm{E}+00$ & $2.67 \mathrm{E}+00$ \\
\hline 2 & $3.83 E+$ & - & 1 & 1.28E+ & & & \\
\hline & & & & & & & $2.66 \mathrm{E}+00$ \\
\hline 02 & & & & & & & \\
\hline$E-02$ & & & & & & & \\
\hline $61 \mathrm{E}-02$ & $3.82 \mathrm{E}+00$ & $5.40 E-01$ & $3.40 \pm-01$ & $1.28 \mathrm{E}+00$ & $\perp \cdot 100$ & $2.25 \mathrm{E}+00$ & $2.66 \mathrm{E}+00$ \\
\hline $61 E-02$ & $3.82 \mathrm{E}+00$ & $.1+4$ & & $1.28 E+00$ & & & $2.66 \mathrm{E}+00$ \\
\hline $62 \mathrm{E}-02$ & $3.82 \mathrm{E}+00$ & 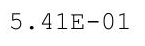 & & $1.28 \mathrm{E}+00$ & & $2.25 \mathrm{E}+00$ & $2.66 \mathrm{E}+00$ \\
\hline 2 & 0 & 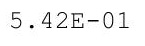 & 1 & 1.2 & 1. $70 \mathrm{E}+00$ & $2.25 E+00$ & $2.67 \mathrm{E}+00$ \\
\hline 2 & $3.82 \mathrm{E}+00$ & $5.43 E-01$ & - & $1.29 \mathrm{E}+00$ & 1 & & $7 E+00$ \\
\hline $5 E-02$ & $3.82 \mathrm{E}+00$ & 01 & -01 & 1. $29 \mathrm{E}+00$ & & $2.25 \mathrm{E}+00$ & $2.67 \mathrm{E}+00$ \\
\hline$E-02$ & $3.82 \mathrm{E}+00$ & 01 & & $1.29 \mathrm{E}+00$ & & $5+00$ & $7 E+00$ \\
\hline & 0.02 & & & & & & $0 / E+U 0$ \\
\hline $67 E-02$ & $3.81 \mathrm{E}+00$ & 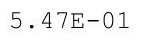 & 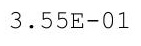 & $1.29 E+00$ & $\perp \cdot 1 \perp+100$ & $2.25 E+00$ & $2.67 \mathrm{E}+00$ \\
\hline $00 \mathrm{~L}-\mathrm{Z}$ & $3.81 E+00$ & & & $1.30 \mathrm{E}+00$ & $1.71 \mathrm{E}+00$ & $2.25 E+00$ & $2.68 \mathrm{E}+00$ \\
\hline 02 & $.81 E+00$ & $E-01$ & $E-01$ & $.30 \mathrm{E}+00$ & $1.71 \mathrm{E}+00$ & $2.25 \mathrm{E}+00$ & $2.68 \mathrm{E}+00$ \\
\hline
\end{tabular}


RESRAD-OFFSITE, Version 2.5

obabilistic Dose and Risk Report

Title : Offsite Resident Farmer Deterministic Run

File : RF TC99 DOESG FWD-FV2.ROF

Summary of dose at graphical times, reptition 3 (continued)

Time

Years

7. $31 \mathrm{E}+02$

7. $32 \mathrm{E}+02$

7. $32 \mathrm{E}+02$

7. $33 \mathrm{E}+02$

7. $33 \mathrm{E}+02$

7. $34 \mathrm{E}+02$

7. $34 \mathrm{E}+02$

7. $35 \mathrm{E}+02$

7. $35 \mathrm{E}+02$

7. $36 \mathrm{E}+02$

7. $36 \mathrm{E}+02$

7. $37 \mathrm{E}+02$

7. $37 \mathrm{E}+02$

7. $38 \mathrm{E}+02$

7. $38 \mathrm{E}+02$

7. $39 \mathrm{E}+02$

7. $39 \mathrm{E}+02$

$7.40 \mathrm{E}+02$

$7.40 \mathrm{E}+02$

7. $41 \mathrm{E}+02$

$7.41 \mathrm{E}+02$

7. $42 \mathrm{E}+02$

$7.42 \mathrm{E}+02$

$7.43 \mathrm{E}+02$

$7.43 \mathrm{E}+02$

7. $44 \mathrm{E}+02$

$7.44 \mathrm{E}+02$

$7.45 \mathrm{E}+02$

7. $45 \mathrm{E}+02$

$7.46 \mathrm{E}+02$

7. $46 \mathrm{E}+02$

7. $47 \mathrm{E}+02$

7. $48 \mathrm{E}+02$

7. $48 \mathrm{E}+02$

7. $49 \mathrm{E}+02$

$7.49 \mathrm{E}+02$

$7.50 \mathrm{E}+02$

$7.50 \mathrm{E}+02$

$7.51 \mathrm{E}+02$

$7.51 \mathrm{E}+02$

$7.52 \mathrm{E}+02$

$7.52 \mathrm{E}+02$

7. $53 \mathrm{E}+02$

$7.53 \mathrm{E}+02$

7. $54 \mathrm{E}+02$

$7.54 \mathrm{E}+02$
Dose statistics at graphical times, mrem/yr

\begin{tabular}{|c|c|c|c|c|c|c|c|}
\hline Iinimum & laximum & Mean & Median & 900 & 舟 & $97.5 \%$ & $9 \%$ \\
\hline 2 & $1 E+00$ & $0 E-01$ & $8 \mathrm{~F}-01$ & $.30 E+00$ & $72 E+00$ & $.25 E+00$ & +0 \\
\hline 02 & $81 E+00$ & $1 \mathrm{E}$ & 01 & $1.30 \mathrm{E}+00$ & $72 \mathrm{E}+00$ & $.26 \mathrm{E}+00$ & $68 E+00$ \\
\hline $1 E-02$ & +00 & $2 E-01$ & $E-01$ & 0 & 0 & 0 & $8 E+00$ \\
\hline $.72 E-02$ & $E+00$ & $E-01$ & 01 & 0 & 0 & 0 & $8 E+00$ \\
\hline $.73 E-02$ & $3.81 E+00$ & & & & & $.26 \mathrm{E}+00$ & $9 \mathrm{E}+00$ \\
\hline $.74 \mathrm{E}-02$ & 00 & & & $31 E+00$ & $72 E+00$ & 00 & $9 \mathrm{E}+00$ \\
\hline $.74 E-02$ & $3.80 \mathrm{E}+00$ & $5 E-01$ & $4 E-01$ & $1.31 \mathrm{E}+00$ & $1.73 E+00$ & $E+00$ & $9 \mathrm{E}+00$ \\
\hline $.75 E-02$ & $3.80 \mathrm{E}+00$ & $.00-4 \perp$ & $3.00-0 \perp$ & $1.31 \mathrm{E}+00$ & $1.73 E+00$ & $2.27 E+00$ & $2.69 E+00$ \\
\hline $.76 E-02$ & +00 & 1 & 01 & 0 & 0 & 00 & +00 \\
\hline $.77 E-02$ & $E+00$ & 5 & & $1.31 \mathrm{E}+00$ & 0 & 0 & +00 \\
\hline$E-02$ & & 5 & & & & & $E+00$ \\
\hline-02 & +00 & 1 & & 00 & 0 & 00 & $9 E+00$ \\
\hline $.79 E-02$ & $3.80 \mathrm{E}+00$ & 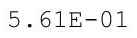 & $U E-01$ & $1 \cdot 32 \mathrm{E}+00$ & $1.74 \mathrm{ET}$ & Z. LILTU & $0 \mathrm{E}+00$ \\
\hline $.80 E-02$ & $3.80 \mathrm{E}+00$ & $3.0 \angle \mathrm{L}-01$ & $3.71 \mathrm{~L}-\mathrm{U}$ & I. . $\angle L T U O$ & . & $2 \cdot 21$ & $E+00$ \\
\hline $.81 E-02$ & $E+00$ & . & $S_{+}$ & $1.02 \mathrm{~T}$ & 1.7400 & 00 & 00 \\
\hline $.82 E-02$ & $3.79 \mathrm{E}+00$ & $5.63 E-01$ & $3.73 E-01$ & 1. $32 \mathrm{E}+00$ & & $2.27 \mathrm{E}+00$ & $0 \mathrm{E}+00$ \\
\hline $.83 E-02$ & $3.79 E+00$ & $5.64 \mathrm{E}-01$ & $3.74 \mathrm{E}-01$ & 1. $32 \mathrm{E}+00$ & $1.74 \mathrm{E}+00$ & $2.27 \mathrm{E}+00$ & $2.70 \mathrm{E}+00$ \\
\hline $4 \mathrm{E}-02$ & $E+00$ & $5-01$ & $E-01$ & ז & ( & $27 E+00$ & $0 \mathrm{E}+00$ \\
\hline $85 E-02$ & $3.79 \mathrm{E}+00$ & $5.66 \mathrm{E}-01$ & $6 \mathrm{E}-01$ & $1.33 \mathrm{E}+00$ & $1.75 \mathrm{E}+00$ & $2.27 \mathrm{E}+00$ & $70 \mathrm{E}+00$ \\
\hline $86 \mathrm{E}-02$ & $3.79 \mathrm{E}+00$ & $5.6 / E-U \perp$ & $3.7 / \mathrm{E}-\mathrm{U} \perp$ & $1.33 \mathrm{Et}$ & 1.15 & 00 & +00 \\
\hline $86 E-02$ & $3.79 E+00$ & $5.68 \mathrm{E}-01$ & & I.JUETU & I. & $2 \cdot 21$ & $\mathrm{E}+00$ \\
\hline $.87 \mathrm{E}-02$ & $3.79 \mathrm{E}+00$ & 5. & • & 1. $33 \mathrm{E}+$ & ועل & 0 & $E+00$ \\
\hline $.88 E-02$ & $3.78 \mathrm{E}+00$ & $0 E-01$ & $\mathrm{E}-01$ & $1.33 \mathrm{E}+00$ & $1.75 \mathrm{E}+00$ & $2.27 E+00$ & $70 \mathrm{E}+00$ \\
\hline $.89 E-02$ & $3.78 E+00$ & $1 E-01$ & $E-01$ & $1.33 \mathrm{E}+00$ & $1.75 \mathrm{E}+$ & $2.27 E+00$ & $70 E+00$ \\
\hline$E-02$ & $3.78 \mathrm{E}+00$ & 01 & 1 & 1. $33 \mathrm{E}+$ & & & $71 \mathrm{E}+00$ \\
\hline$E-02$ & $3 E+00$ & $3 E-01$ & 1 & $1.34 \mathrm{E}$ & 0 & 00 & -00 \\
\hline $.92 E-02$ & $3.18 \mathrm{E}+00$ & $5.73 E-01$ & $3 E-U 1$ & $1.34 \mathrm{E}$ & 1. $10 \mathrm{ET}$ & $2 \cdot 21$ & $E+00$ \\
\hline $93 \mathrm{E}-02$ & $3.78 \mathrm{E}+00$ & $5.74 \mathrm{E}-01$ & $3.84 \mathrm{E}-01$ & $1.34 \mathrm{E}+00$ & $1.76 \mathrm{E}+00$ & $2.28 \mathrm{E}+00$ & $2.71 E+00$ \\
\hline $.93 E-02$ & $3.78 \mathrm{E}+00$ & $5.75 E-01$ & $3.85 E-01$ & $1.34 \mathrm{E}+00$ & 土. & $2.28 \mathrm{E}+00$ & $2.71 E+00$ \\
\hline 2 & $3.78 \mathrm{E}+00$ & & 5 & 1. $34 \mathrm{E}+$ & & & $71 \mathrm{E}+00$ \\
\hline 02 & $3.77 \mathrm{E}+00$ & & 1 & 1 & 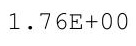 & $2.28 \mathrm{E}+00$ & $2.71 \mathrm{E}+00$ \\
\hline$E-02$ & $7 \mathrm{E}+00$ & 5 & 1 & 1. $34 \mathrm{E}+$ & $177 \mathrm{~F}$ & ( & $71 \mathrm{E}+00$ \\
\hline $.97 \mathrm{E}-02$ & $3.77 \mathrm{E}+00$ & $5.79 E-01$ & 3 & 1. $34 \mathrm{E}$ & 1 . & 2.20 & $1 \mathrm{E}+00$ \\
\hline $98 E-02$ & $3.77 \mathrm{E}+00$ & $5.80 \mathrm{E}-01$ & $3.89 \mathrm{E}-01$ & $1.34 \mathrm{E}+U \mathrm{U}$ & 1.7T+U & $2.28 E+00$ & $2.71 E+00$ \\
\hline $.99 \mathrm{E}-02$ & $3.17 \mathrm{E}+0 \mathrm{U}$ & $3.01 \mathrm{E}-$ & & $1.34 \mathrm{E}+00$ & & & $2.71 \mathrm{E}+00$ \\
\hline 2 & 1. & & & & & & - \\
\hline 2 & 3 & & & & & & \\
\hline 2 & & & & & 0 & 00 & \\
\hline$E-02$ & 3. & 5 . & -01 & $1.35 \mathrm{E}$ & 1 . & 00 & -00 \\
\hline $\mathrm{E}-02$ & $3.76 \mathrm{E}+00$ & 5.8 & & 1.35E & & & $2.71 E+00$ \\
\hline$E-02$ & $3.76 \mathrm{E}+00$ & 1 & & 1. $35 \mathrm{E}+$ & $1.78 \mathrm{E}+$ & & $2.71 \mathrm{E}+00$ \\
\hline $0 E-U 2$ & $\mathrm{E}+00$ & H & $\perp$ & 1. $35 \mathrm{E}+00$ & $78 \mathrm{E}+00$ & $2.28 \mathrm{E}+00$ & $2.71 \mathrm{E}+00$ \\
\hline $2.06 \mathrm{E}-02$ & (7) & 5 & & 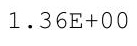 & & 0 & $2.71 \mathrm{E}$ \\
\hline 2 & & & 1 & $36 E+00$ & $1.78 \mathrm{E}+00$ & $2.29 \mathrm{E}+00$ & $2.72 \mathrm{E}+00$ \\
\hline-02 & $3.77 \mathrm{E}+00$ & $E-01$ & 3. & 1. $36 \mathrm{E}+00$ & 1. $79 \mathrm{E}+$ & $2.29 \mathrm{E}+00$ & $2.72 \mathrm{E}+00$ \\
\hline$E-02$ & $7 \mathrm{E}+00$ & $91 E-01$ & $99 E-01$ & $1.36 \mathrm{E}+00$ & 1. $79 \mathrm{E}+00$ & $2.29 \mathrm{E}+00$ & $2.72 \mathrm{E}+00$ \\
\hline
\end{tabular}


RESRAD-OFFSITE, Version 2.5

$\mathrm{T}^{1 / 2}$ Limit $=180$ days

robabilistic Dose and Risk Report

Title : Offsite Resident Farmer Deterministic Run

File : RF TC99 DOESG FWD-FV2.ROF

Summary of dose at graphical times, reptition 3 (continued)

Time

Years

7. $55 \mathrm{E}+02$

$7.55 \mathrm{E}+02$

7. $56 \mathrm{E}+02$

$7.56 \mathrm{E}+02$

$7.57 \mathrm{E}+02$

$7.57 \mathrm{E}+02$

$7.58 \mathrm{E}+02$

$7.58 \mathrm{E}+02$

$7.59 \mathrm{E}+02$

$7.59 \mathrm{E}+02$

$7.60 \mathrm{E}+02$

$7.60 \mathrm{E}+02$

7. $61 \mathrm{E}+02$

$7.61 \mathrm{E}+02$

7. $62 \mathrm{E}+02$

7. $62 \mathrm{E}+02$

7. $63 \mathrm{E}+02$

7. $63 \mathrm{E}+02$

$7.64 \mathrm{E}+02$

7. $64 \mathrm{E}+02$

$7.65 \mathrm{E}+02$

$7.65 \mathrm{E}+02$

7. $66 \mathrm{E}+02$

7. $66 \mathrm{E}+02$

$7.67 \mathrm{E}+02$

$7.68 \mathrm{E}+02$

$7.68 \mathrm{E}+02$

7. $69 \mathrm{E}+02$

$7.69 \mathrm{E}+02$

$7.70 \mathrm{E}+02$

7. $70 \mathrm{E}+02$

$7.71 \mathrm{E}+02$

7. $71 \mathrm{E}+02$

7. $72 \mathrm{E}+02$

7. $72 \mathrm{E}+02$

7. $73 \mathrm{E}+02$

$7.73 \mathrm{E}+02$

7. $74 \mathrm{E}+02$

$7.74 \mathrm{E}+02$

$7.75 \mathrm{E}+02$

$7.75 \mathrm{E}+02$

$7.76 \mathrm{E}+02$

$7.76 \mathrm{E}+02$

$7.77 \mathrm{E}+02$

$7.77 \mathrm{E}+02$

$7.78 \mathrm{E}+02$
Dose statistics at graphical times, mrem/yr

\begin{tabular}{|c|c|c|c|c|c|c|c|}
\hline m & $\mathrm{m}$ & Mean & ledian & & & $\%$ & $\%$ \\
\hline 02 & $3.77 \mathrm{E}+00$ & $5.92 \mathrm{E}-01$ & $4.00 \mathrm{E}-01$ & $1.36 \mathrm{E}+00$ & 1. $79 \mathrm{E}+00$ & $2.29 \mathrm{E}+00$ & $2.1 \angle E+U 0$ \\
\hline-02 & $3 E+00$ & 01 & 01 & 0 & 00 & +00 & $72 E+00$ \\
\hline-02 & $8 \mathrm{E}+00$ & $5.93 \mathrm{E}-01$ & $01 \mathrm{E}-01$ & $1.37 \mathrm{E}+00$ & $1.79 \mathrm{E}+00$ & $2.29 \mathrm{E}+00$ & $2.72 \mathrm{E}+00$ \\
\hline $13 E-02$ & $3.78 E+00$ & $.94 \mathrm{E}-01$ & $4.02 \mathrm{E}-01$ & 1. $37 \mathrm{E}+00$ & $1.79 \mathrm{E}+00$ & $2.29 \mathrm{E}+00$ & $2.72 \mathrm{E}+00$ \\
\hline 2 & 0 & 5. $95 \mathrm{E}-01$ & $3 \mathrm{~F}-2 \cdot r a$ & 0 & 0 & 0 & $2 E+00$ \\
\hline-02 & $E+00$ & 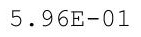 & & 0 & 0 & 0 & +00 \\
\hline-02 & & & & & & $.29 E+00$ & $1 \mathrm{E}+00$ \\
\hline-02 & & \pm & & & & & +00 \\
\hline-02 & +00 & $F-0$ & -01 & $37 \mathrm{E}+00$ & 00 & +00 & $71 E+00$ \\
\hline 02 & $\mathrm{E}+00$ & 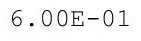 & 1 & $1.37 \mathrm{E}+00$ & 0 & $297+$ & $71 \mathrm{E}+00$ \\
\hline 02 & 0 & $6.01 \mathrm{E}-01$ & - & 0 & 0 & 0 & +00 \\
\hline 22 & $9 E+00$ & & & 0 & 0 & 0 & -00 \\
\hline $22 \mathrm{~F}-02$ & $3.79 \mathrm{E}+00$ & $25-$ & 4 & $1.38 \mathrm{E}+$ & & 0 & +00 \\
\hline $22 \mathrm{E}-02$ & $3.79 \mathrm{E}+00$ & $6.03 \mathrm{E}-01$ & $4.12 \mathrm{E}-01$ & $1.38 \mathrm{E}+00$ & $1.81 \mathrm{E}+00$ & $2.29 \mathrm{E}+00$ & $2.71 E+00$ \\
\hline $23 E-02$ & $9 E+00$ & -0 & 1 & $8 \mathrm{E}+00$ & $81 \mathrm{E}+$ & $29 E+00$ & $71 \mathrm{E}+00$ \\
\hline 2 & & & & 1.50 & 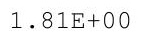 & 0 & +00 \\
\hline $25 E-02$ & $3.80 \mathrm{E}+00$ & $6.06 \mathrm{E}-01$ & & $\cdots 0$ & 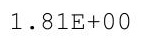 & 0 & \\
\hline 2 & 0 & & & & & & 0 \\
\hline $27 E-02$ & $3.80 \mathrm{E}+00$ & $.08 \mathrm{E}-\mathrm{C}$ & 1 & $1.39 \mathrm{E}+00$ & 1. $81 \mathrm{E}+0$ & & $2.70 \mathrm{E}+00$ \\
\hline $28 \mathrm{E}-02$ & $3.80 \mathrm{E}+00$ & $.09 \mathrm{E}-0$ & $8 E-01$ & $1.39 \mathrm{E}+00$ & $1.81 \mathrm{E}+0$ & $2.30 \mathrm{E}+00$ & $2.70 \mathrm{E}+00$ \\
\hline $29 E-02$ & $3.80 \mathrm{E}+00$ & $9 E-01$ & $4.19 \mathrm{E}-01$ & $1.39 \mathrm{E}+00$ & $1.81 \mathrm{E}+$ & $30 E+00$ & $70 \mathrm{E}+00$ \\
\hline 02 & & & & & 0 & & $70 E+00$ \\
\hline 2 & & & & $\pm \cdot 0$ & & & \\
\hline $32 E-02$ & $3.80 \mathrm{E}+00$ & & & $1.39 \mathrm{E}$ & $\perp \cdot 0<+$ & . & 00 \\
\hline 2 & 0 & $6.13 E-01$ & 1 & 30 & ใด & 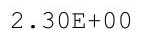 & 00 \\
\hline $34 \mathrm{~F}-02$ & $.81 E+00$ & - 100 त & $.24 \mathrm{E}-01$ & 1. $39 \mathrm{E}+00$ & 1 & $30 \mathrm{E}+0$ & $2.70 \mathrm{E}+00$ \\
\hline$F-0 ?$ & $3.81 E+00$ & $15 \mathrm{~F}-0$ & 4. $25 E-01$ & $1.39 \mathrm{E}+00$ & 1. $82 \mathrm{E}+$ & $2.30 \mathrm{E}+0$ & $2.70 \mathrm{E}+00$ \\
\hline 02 & & & & & & & \\
\hline-02 & $3.81 \mathrm{E}+00$ & & & 1.0 & & & \\
\hline $39 E-02$ & $3.01 E+U 0$ & 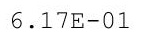 & .200 & $1.39 \mathrm{E}+00$ & I. & $2.30 \mathrm{E}+00$ & $2.69 \mathrm{E}+00$ \\
\hline $.405-02$ & J.OLLTU & $\begin{array}{lll}.10 \\
\end{array}$ & $4.29 \mathrm{E}-01$ & 1. $39 \mathrm{E}+00$ & 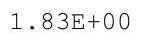 & $2.30 \mathrm{LTO}$ & $2.69 \mathrm{E}+00$ \\
\hline 20 & . & 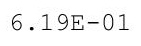 & 年 & 1. $40 \mathrm{E}+00$ & 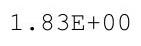 & & $2.69 \mathrm{E}+00$ \\
\hline F & $3.81 \mathrm{E}+00$ & בק & 1 & & $1.83 \mathrm{E}+$ & & $2.69 \mathrm{E}+00$ \\
\hline $.43 E-02$ & & & & & & & \\
\hline 02 & & & 1 & & & & \\
\hline $45 E-02$ & $3.82 \mathrm{E}+00$ & $6.23 E-01$ & 1.000 & $1.40 \mathrm{E}$ & $1.03 E$ & $2 \cdot$ & $2.69 \mathrm{E}+00$ \\
\hline $5-0<$ & $3.8 \angle E+U 0$ & & & 工. & & & $2.69 \mathrm{E}+00$ \\
\hline $4 / 5-02$ & $3.82 \mathrm{E}+00$ & & & $\perp .40$ पт口 & & & $2.68 \mathrm{E}+00$ \\
\hline $.48 E-02$ & 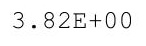 & $6.25 \mathrm{E}-01$ & & t. & $1.84 \mathrm{E}$ & & $2.68 \mathrm{E}+00$ \\
\hline & & & & $40 \mathrm{E}+00$ & & & \\
\hline 2 & $3.82 \mathrm{E}+00$ & 6 & 1 & 1. $41 \mathrm{E}+$ & $1.84 \mathrm{E}+$ & & $2.68 E+00$ \\
\hline $51 E-02$ & $3.82 \mathrm{E}+00$ & $3 E-01$ & $4 \cdot 3$ & $1.41 \mathrm{E}+00$ & $1.84 \mathrm{E}$ & 00 & 00 \\
\hline & & & & 1.4 & & & \\
\hline & $3.83 E+00$ & 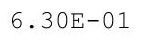 & & $1.4 \perp E+U 0$ & $1.04 D T 0$ & $2.31 \mathrm{E}+$ & $2.68 \mathrm{E}+00$ \\
\hline 02 & $3.83 E+00$ & . & & $1.41 \mathrm{E}+00$ & & $2.31 E+00$ & $2.68 \mathrm{E}+00$ \\
\hline-02 & $.83 E+00$ & $2 E-01$ & $43 E-01$ & $1.41 \mathrm{E}+00$ & $1.84 \mathrm{E}+00$ & $2.31 \mathrm{E}+00$ & $.68 E+00$ \\
\hline
\end{tabular}


RESRAD-OFFSITE, Version 2.5

$\mathrm{T}^{1 / 2}$ Limit $=180$ days

Title : Offsite Resident Farmer Deterministic Run

File : RF TC99 DOESG FWD-FV2.ROF

Summary of dose at graphical times, reptition 3 (continued)

Time

Years

$7.78 \mathrm{E}+02$

$7.79 \mathrm{E}+02$

$7.79 \mathrm{E}+02$

$7.80 \mathrm{E}+02$

$7.80 \mathrm{E}+02$

$7.81 \mathrm{E}+02$

$7.81 \mathrm{E}+02$

$7.82 \mathrm{E}+02$

$7.82 \mathrm{E}+02$

$7.83 \mathrm{E}+02$

$7.83 \mathrm{E}+02$

$7.84 \mathrm{E}+02$

$7.84 \mathrm{E}+02$

$7.85 \mathrm{E}+02$

$7.85 \mathrm{E}+02$

$7.86 \mathrm{E}+02$

$7.86 \mathrm{E}+02$

$7.87 \mathrm{E}+02$

$7.88 \mathrm{E}+02$

$7.88 \mathrm{E}+02$

$7.89 \mathrm{E}+02$

$7.89 \mathrm{E}+02$

7. $90 \mathrm{E}+02$

7. $90 \mathrm{E}+02$

7. $91 \mathrm{E}+02$

$7.91 \mathrm{E}+02$

7. $92 \mathrm{E}+02$

$7.92 \mathrm{E}+02$

$7.93 \mathrm{E}+02$

7. $93 \mathrm{E}+02$

7. $94 \mathrm{E}+02$

$7.94 \mathrm{E}+02$

$7.95 \mathrm{E}+02$

7. $95 \mathrm{E}+02$

$7.96 \mathrm{E}+02$

7. $96 \mathrm{E}+02$

$7.97 \mathrm{E}+02$

7. $97 \mathrm{E}+02$

$7.98 \mathrm{E}+02$

$7.98 \mathrm{E}+02$

$7.99 \mathrm{E}+02$

$7.99 \mathrm{E}+02$

$8.00 \mathrm{E}+02$

$8.00 \mathrm{E}+02$

$8.01 \mathrm{E}+02$

$8.01 \mathrm{E}+02$
Dose statistics at graphical times, mrem/yr

\begin{tabular}{|c|c|c|c|c|c|c|c|}
\hline m & aximum & ea & 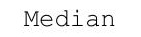 & & & & $\%$ \\
\hline $56 \mathrm{E}-02$ & $3.83 E+00$ & $6.32 \mathrm{E}$ & 1 & $41 E+00$ & 00 & -00 & . 0 OLTU \\
\hline $.57 E-02$ & $3.83 E+00$ & $6.33 E-01$ & $44 E-01$ & $41 E+00$ & $84 \mathrm{E}+00$ & $E+00$ & $58 \mathrm{E}+00$ \\
\hline $58 E-02$ & $83 E+00$ & $34 \mathrm{~F}-01$ & $44 \mathrm{E}-01$ & $.42 \mathrm{E}+00$ & $84 E+00$ & $2.31 E+00$ & $2.68 \mathrm{E}+00$ \\
\hline-02 & $83 E+00$ & $35 \mathrm{~F}-01$ & $5 \mathrm{~F}-01$ & $.42 E+00$ & $185 \mathrm{~F}+00$ & $2.31 E+00$ & $2.68 \mathrm{E}+00$ \\
\hline $.61 E-02$ & $3.83 E+00$ & $6.36 E-01$ & 4. $46 \mathrm{E}-01$ & $1.42 E+00$ & & +00 & $.68 E+00$ \\
\hline 02 & $83 E+00$ & & & & & & 00 \\
\hline $63 E-02$ & $3.83 \mathrm{E}+00$ & & & & & & $68 E+00$ \\
\hline $64 E-02$ & $3.83 E+00$ & 1 & 1 & 1. $42 \mathrm{E}+00$ & 00 & +00 & $E+00$ \\
\hline $65 E-02$ & $.84 \mathrm{E}+00$ & $E-01$ & $E-01$ & $1.42 \mathrm{E}+00$ & 00 & $1 \mathrm{E}+00$ & $7 \mathrm{E}+00$ \\
\hline $66 \mathrm{E}-02$ & $.84 \mathrm{E}+00$ & 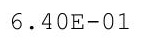 & (5 & $.42 \mathrm{E}+00$ & 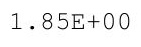 & $31 E+00$ & $67 \mathrm{E}+00$ \\
\hline 02 & +00 & & & & & 00 & -00 \\
\hline $68 E-02$ & +00 & 25 & $4.53 \mathrm{E}-01$ & $2=$ & 0 & & +00 \\
\hline $69 E-02$ & $3.84 \mathrm{E}+00$ & - & & $1.43 E+00$ & & & $2.67 \mathrm{E}+00$ \\
\hline $.70 E-02$ & $3.84 \mathrm{E}+00$ & $6.44 \mathrm{E}-01$ & $4.55 \mathrm{E}-01$ & $1.43 \mathrm{E}+00$ & $1.86 \mathrm{E}+00$ & $2.32 E+00$ & $2.67 \mathrm{E}+00$ \\
\hline$E-02$ & $E+00$ & $5 F-0$ & $\mathrm{~F}-0-0+2-2$ & 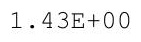 & $865+12913$ & $\mathrm{E}+00$ & $8 \mathrm{E}+00$ \\
\hline 2 & +00 & $6.46 \mathrm{E}-01$ & $4.57 \mathrm{E}-01$ & $+\cdot 1$ & 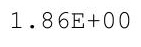 & 0 & 00 \\
\hline 2 & 0 & $6 E-01$ & & $1.43 E+00$ & & 0 & 0 \\
\hline$E-02$ & $E+00$ & $6 \quad 475-01$ & $4.59 E-01$ & 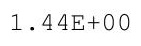 & & $32 E+00$ & 0 \\
\hline $.76 E-02$ & $3.84 \mathrm{E}+00$ & $6.48 \mathrm{E}-01$ & $4.60 \mathrm{E}-01$ & $1.44 \mathrm{E}+00$ & $1.86 \mathrm{E}+00$ & $2.32 E+00$ & $2.68 \mathrm{E}+00$ \\
\hline $.77 E-02$ & $.84 E+00$ & $.49 E-01$ & $.61 \mathrm{E}-01$ & 1. $44 \mathrm{E}+00$ & $1.86 \mathrm{E}+$ & $2.32 \mathrm{E}+00$ & $2.68 E+00$ \\
\hline-02 & +00 & & & & & $.32 E+00$ & \\
\hline 2 & & & & & & & \\
\hline 02 & $3.85 \mathrm{E}+00$ & 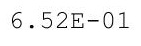 & & 1. $44 \mathrm{E}+$ & $.86 \mathrm{E}+$ & & \\
\hline $82 E-02$ & $85 E+00$ & $6.52 \mathrm{E}-01$ & $4.65 E-01$ & 土.9षण & (1) & 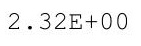 & 0 \\
\hline 2 & $.85 E+00$ & $6.53 \mathrm{E}-01$ & $\perp$ & $1.45 \mathrm{E}+$ & $1.87 \mathrm{E}+$ & $2.32 \mathrm{E}+0$ & $8 \mathrm{E}+$ \\
\hline $84 E-02$ & $.85 E+00$ & 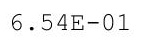 & 4. $67 \mathrm{E}-01$ & 1. $45 \mathrm{E}+00$ & $1.87 \mathrm{E}+$ & $.32 E+00$ & $2.68 \mathrm{E}+00$ \\
\hline $85 E-02$ & $85 E+00$ & $55 \pi$ & $4.68 F-01$ & 1. $45 \mathrm{E}+00$ & & $.32 E+00$ & $.68 E+00$ \\
\hline 02 & & & & & & & \\
\hline 02 & $3.85 \mathrm{E}+00$ & 0 & & $1.45 \mathrm{E}+$ & (- & & \\
\hline $89 E-02$ & $3.85 \mathrm{E}+00$ & . & $4 \cdot 1 \perp E-U \perp$ & 1. $45 \mathrm{E}+00$ & 土. & $2.31 E+00$ & $2.68 \mathrm{E}+00$ \\
\hline $90 \mathrm{E}-02$ & $3.85 \mathrm{E}+00$ & $.00 \mathrm{~L}$ & 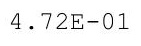 & 1. $45 \mathrm{E}+00$ & म.ÖLTU & $2.31 \mathrm{E}+00$ & $2.68 \mathrm{E}+00$ \\
\hline 2 & 3.8 & $6.59 \mathrm{E}-01$ & $4.72 E-01$ & 1. $46 \mathrm{E}+$ & & & $2.69 \mathrm{E}+$ \\
\hline 2 & & & & & & & 0 \\
\hline 02 & +00 & 1 & & $1.46 \mathrm{E}+00$ & & & \\
\hline$E-02$ & $3.85 E+00$ & 6 & 01 & 1.461 & & & \\
\hline $95 E-02$ & $3.85 \mathrm{E}+00$ & $6.63 E-U 1$ & $4.76 \mathrm{E}-01$ & $1.46 \mathrm{E}+00$ & 土.OT & 00 & $2.69 \mathrm{E}+00$ \\
\hline $97 E-02$ & $3.85 \mathrm{E}+00$ & $0.04 \mathrm{~L}$ & & $1.46 E+00$ & & & $2.69 \mathrm{E}+00$ \\
\hline $8 E-02$ & $3.85 \mathrm{E}+00$ & . & & $1.46 \mathrm{E}+00$ & & & $2.69 \mathrm{E}+00$ \\
\hline 2 & 3.8 &. & 1. & $1.46 \mathrm{E}+00$ & $1.87 \mathrm{E}+\mathrm{C}$ & & $2.69 \mathrm{E}+00$ \\
\hline 2 & & & 1 & $1.47 \mathrm{E}+00$ & $1.87 \mathrm{E}+00$ & $2.31 E+00$ & $59 \mathrm{E}+00$ \\
\hline 02 & $3.86 \mathrm{E}+00$ & $6.67 \mathrm{E}-01$ & $4.80 \mathrm{E}-01$ & 1. $47 \mathrm{E}+00$ & $1.87 \mathrm{E}$ & $31 E+00$ & $2.69 \mathrm{E}+00$ \\
\hline-02 & $3.86 \mathrm{E}+00$ & 6. & 4. & $1.47 \mathrm{E}+00$ & $1.87 \mathrm{E}+$ & 2 & $9 \mathrm{E}+00$ \\
\hline & $3.86 \mathrm{E}+00$ & & & $1.4 / E+U 0$ & & & \\
\hline $5-0<$ & $3.86 \mathrm{E}+00$ & . & 10 & $1.4 / E+00$ & $1.88 \mathrm{E}+00$ & $2.31 E+00$ & $2.69 \mathrm{E}+00$ \\
\hline$\frac{\partial-2<}{4}$ & $3.86 \mathrm{E}+00$ & & & $1.47 \mathrm{E}+00$ & $1.88 \mathrm{E}+00$ & $2.31 E+00$ & $2.69 \mathrm{E}+00$ \\
\hline 02 & $.86 \mathrm{E}+00$ & $E-01$ & $84 \mathrm{E}-01$ & $1.48 \mathrm{E}+00$ & $1.88 \mathrm{E}+00$ & $2.31 \mathrm{E}+00$ & $2.69 \mathrm{E}+00$ \\
\hline
\end{tabular}


RESRAD-OFFSITE, Version 2.5

Title : Offsite Resident Farmer Deterministic Run

File : RF TC99 DOESG FWD-FV2.ROF

Summary of dose at graphical times, reptition 3 (continued)

Time

Years

$8.02 \mathrm{E}+02$

$8.02 \mathrm{E}+02$

$8.03 \mathrm{E}+02$

$8.03 \mathrm{E}+02$

$8.04 \mathrm{E}+02$

$8.04 \mathrm{E}+02$

$8.05 \mathrm{E}+02$

$8.05 E+02$

$8.06 \mathrm{E}+02$

$8.06 \mathrm{E}+02$

$8.07 \mathrm{E}+02$

$8.07 \mathrm{E}+02$

$8.08 \mathrm{E}+02$

$8.09 \mathrm{E}+02$

$8.09 \mathrm{E}+02$

$8.10 \mathrm{E}+02$

$8.10 \mathrm{E}+02$

$8.11 \mathrm{E}+02$

$8.11 \mathrm{E}+02$

$8.12 \mathrm{E}+02$

$8.12 \mathrm{E}+02$

$8.13 \mathrm{E}+02$

$8.13 \mathrm{E}+02$

$8.14 \mathrm{E}+02$

$8.14 \mathrm{E}+02$

$8.15 \mathrm{E}+02$

$8.15 \mathrm{E}+02$

$8.16 \mathrm{E}+02$

$8.16 \mathrm{E}+02$

$8.17 \mathrm{E}+02$

$8.17 \mathrm{E}+02$

$8.18 \mathrm{E}+02$

$8.18 \mathrm{E}+02$

$8.19 \mathrm{E}+02$

$8.19 \mathrm{E}+02$

8. $20 \mathrm{E}+02$

$8.20 \mathrm{E}+02$

$8.21 E+02$

$8.21 E+02$

$8.22 \mathrm{E}+02$

$8.22 \mathrm{E}+02$

$8.23 \mathrm{E}+02$

8. $23 \mathrm{E}+02$

$8.24 \mathrm{E}+02$

$8.24 \mathrm{E}+02$

$8.25 \mathrm{E}+02$

Dose statistics at graphical times, mrem/yr

\begin{tabular}{|c|c|c|c|c|c|c|c|}
\hline Minimum & Maximum & Mean & Median & $90 \%$ & $95 \%$ & $97.5 \%$ & $99 \%$ \\
\hline $3.08 \mathrm{E}-02$ & $3.86 \mathrm{E}+00$ & $6.72 \mathrm{E}-01$ & $4.85 \mathrm{E}-01$ & 1. $48 \mathrm{E}+00$ & $1.88 \mathrm{E}+00$ & $2.31 E+00$ & $2.69 \mathrm{E}+00$ \\
\hline $3.10 \mathrm{E}-02$ & $3.86 \mathrm{E}+00$ & $6.73 E-01$ & $4.86 \mathrm{E}-01$ & $1.48 \mathrm{E}+00$ & $1.88 \mathrm{E}+00$ & $2.31 \mathrm{E}+00$ & $2.69 \mathrm{E}+00$ \\
\hline $3.11 \mathrm{E}-02$ & $3.86 \mathrm{E}+00$ & $6.74 E-01$ & $4.87 E-01$ & $1.48 \mathrm{E}+00$ & $1.88 \mathrm{E}+00$ & $2.31 E+00$ & $2.69 \mathrm{E}+00$ \\
\hline $3.12 \mathrm{E}-02$ & $3.86 \mathrm{E}+00$ & $6.75 E-01$ & $4.87 \mathrm{E}-01$ & $1.48 \mathrm{E}+00$ & $1.88 \mathrm{E}+00$ & $2.31 \mathrm{E}+00$ & $2.69 \mathrm{E}+00$ \\
\hline $3.13 \mathrm{E}-02$ & $3.86 \mathrm{E}+00$ & $6.75 E-01$ & $4.88 \mathrm{E}-01$ & $48 E+00$ & $88 E+00$ & $2.31 \mathrm{E}+00$ & $.69 \mathrm{E}+00$ \\
\hline $3.15 \mathrm{E}-02$ & $3.86 \mathrm{E}+00$ & $6.76 E-01$ & $4.89 \mathrm{E}-01$ & $48 E+00$ & $.88 \mathrm{E}+00$ & $2.31 E+00$ & $2.69 \mathrm{E}+00$ \\
\hline $3.16 \mathrm{E}-02$ & $3.86 \mathrm{E}+00$ & $6.77 E-01$ & $4.90 E-01$ & $1.48 \mathrm{E}+00$ & $1.88 \mathrm{E}+00$ & $2.31 E+00$ & $2.69 \mathrm{E}+00$ \\
\hline $3.17 \mathrm{E}-02$ & $3.86 \mathrm{E}+00$ & $6.78 E-01$ & $4.91 \mathrm{E}-01$ & $1.48 E+00$ & $1.88 \mathrm{E}+00$ & $2.31 E+00$ & $2.69 \mathrm{E}+00$ \\
\hline $3.18 \mathrm{E}-02$ & $86 \mathrm{E}+00$ & $6.79 E-01$ & $4.92 E-01$ & $.48 E+00$ & $1.88 \mathrm{E}+00$ & $2.31 E+00$ & $.69 E+00$ \\
\hline $3.19 \mathrm{E}-02$ & $.86 \mathrm{E}+00$ & $6.80 \mathrm{E}-01$ & $4.93 \mathrm{E}-01$ & $.49 \mathrm{E}+00$ & $1.89 \mathrm{E}+00$ & $2.31 \mathrm{E}+00$ & $2.69 \mathrm{E}+00$ \\
\hline $3.21 \mathrm{E}-02$ & $3.86 \mathrm{E}+00$ & $6.81 E-01$ & $4.94 \mathrm{E}-01$ & $1.49 \mathrm{E}+00$ & $1.89 \mathrm{E}+00$ & $2.31 E+00$ & $.69 \mathrm{E}+00$ \\
\hline $3.22 \mathrm{E}-02$ & $3.86 \mathrm{E}+00$ & $6.81 E-01$ & $4.94 \mathrm{E}-01$ & $1.49 \mathrm{E}+00$ & $1.89 \mathrm{E}+00$ & $2.31 E+00$ & $2.70 \mathrm{E}+00$ \\
\hline $3.23 E-02$ & $3.86 \mathrm{E}+00$ & $6.82 E-01$ & $4.95 E-01$ & $1.49 \mathrm{E}+00$ & $1.89 \mathrm{E}+00$ & $2.31 E+00$ & $2.70 \mathrm{E}+00$ \\
\hline $3.24 \mathrm{E}-02$ & $3.86 \mathrm{E}+00$ & $6.83 E-01$ & $4.96 \mathrm{E}-01$ & $1.49 \mathrm{E}+00$ & $1.89 \mathrm{E}+00$ & $2.31 E+00$ & $2.70 \mathrm{E}+00$ \\
\hline $3.26 \mathrm{E}-02$ & $3.86 \mathrm{E}+00$ & $6.84 E-01$ & $4.97 E-01$ & $1.49 E+00$ & $1.89 \mathrm{E}+00$ & $2.31 E+00$ & $.69 E+00$ \\
\hline $3.27 \mathrm{E}-02$ & $3.86 \mathrm{E}+00$ & $6.85 E-01$ & $99 \mathrm{E}-01$ & $49 \mathrm{E}+00$ & $.89 E+00$ & $2.31 E+00$ & $.69 \mathrm{E}+00$ \\
\hline $3.28 \mathrm{E}-02$ & $3.86 \mathrm{E}+00$ & $6.86 E-01$ & $4.99 E-01$ & $1.49 \mathrm{E}+00$ & $.90 \mathrm{E}+00$ & $2.31 \mathrm{E}+00$ & $2.69 \mathrm{E}+00$ \\
\hline $3.29 \mathrm{E}-02$ & $3.86 \mathrm{E}+00$ & $6.86 E-01$ & $5.00 \mathrm{E}-01$ & $1.49 \mathrm{E}+00$ & $1.90 \mathrm{E}+00$ & $2.31 E+00$ & $2.69 \mathrm{E}+00$ \\
\hline $3.31 \mathrm{E}-02$ & $3.86 \mathrm{E}+00$ & $6.87 \mathrm{E}-01$ & $5.01 \mathrm{E}-01$ & $1.49 \mathrm{E}+00$ & $1.90 \mathrm{E}+00$ & $2.31 \mathrm{E}+00$ & $2.69 \mathrm{E}+00$ \\
\hline $3.32 \mathrm{E}-02$ & $3.86 \mathrm{E}+00$ & $6.88 E-01$ & $5.02 E-01$ & $1.50 \mathrm{E}+00$ & $1.90 \mathrm{E}+00$ & $2.31 E+00$ & $2.69 \mathrm{E}+00$ \\
\hline $3.33 E-02$ & $3.86 \mathrm{E}+00$ & $6.89 \mathrm{E}-01$ & $5.03 E-01$ & $1.50 \mathrm{E}+00$ & $1.90 \mathrm{E}+00$ & $2.31 E+00$ & $2.69 \mathrm{E}+00$ \\
\hline $3.34 \mathrm{E}-02$ & $3.86 \mathrm{E}+00$ & $6.90 \mathrm{E}-01$ & $5.04 \mathrm{E}-01$ & $1.50 \mathrm{E}+00$ & $1.90 \mathrm{E}+00$ & $2.31 \mathrm{E}+00$ & $2.69 \mathrm{E}+00$ \\
\hline $3.36 \mathrm{E}-02$ & $3.86 \mathrm{E}+00$ & $6.91 E-01$ & $5.05 E-01$ & $1.50 \mathrm{E}+00$ & $1.90 \mathrm{E}+00$ & $2.32 E+00$ & $2.69 E+00$ \\
\hline $3.37 \mathrm{E}-02$ & $3.86 \mathrm{E}+00$ & $6.91 \mathrm{E}-01$ & $5.06 \mathrm{E}-01$ & $1.50 \mathrm{E}+00$ & $1.90 \mathrm{E}+00$ & $2.32 E+00$ & $2.69 \mathrm{E}+00$ \\
\hline $3.38 \mathrm{E}-02$ & $3.86 \mathrm{E}+00$ & $6.92 E-01$ & $5.07 E-01$ & $1.50 \mathrm{E}+00$ & $1.90 \mathrm{E}+00$ & $2.32 E+00$ & $2.69 \mathrm{E}+00$ \\
\hline $3.39 \mathrm{E}-02$ & $3.86 \mathrm{E}+00$ & $6.93 E-01$ & $5.08 E-01$ & $1.50 \mathrm{E}+00$ & $1.90 \mathrm{E}+00$ & $2.32 E+00$ & $2.69 \mathrm{E}+00$ \\
\hline $3.41 \mathrm{E}-02$ & $3.86 \mathrm{E}+00$ & $6.94 \mathrm{E}-01$ & $5.09 \mathrm{E}-01$ & $1.50 \mathrm{E}+00$ & $1.91 \mathrm{E}+00$ & $2.32 E+00$ & $2.69 \mathrm{E}+00$ \\
\hline $3.42 \mathrm{E}-02$ & $3.86 \mathrm{E}+00$ & $6.95 E-01$ & $5.10 \mathrm{E}-01$ & $1.50 \mathrm{E}+00$ & $1.91 \mathrm{E}+00$ & $2.32 \mathrm{E}+00$ & $2.69 \mathrm{E}+00$ \\
\hline $3.43 E-02$ & $3.86 \mathrm{E}+00$ & $6.96 \mathrm{E}-01$ & $5.11 \mathrm{E}-01$ & $1.50 \mathrm{E}+00$ & $1.91 \mathrm{E}+00$ & $2.32 E+00$ & $2.69 E+00$ \\
\hline $3.44 \mathrm{E}-02$ & $3.86 \mathrm{E}+00$ & $6.96 \mathrm{E}-01$ & $5.12 \mathrm{E}-01$ & $1.50 \mathrm{E}+00$ & $1.91 \mathrm{E}+00$ & $2.32 \mathrm{E}+00$ & $2.69 \mathrm{E}+00$ \\
\hline $3.46 \mathrm{E}-02$ & $3.86 \mathrm{E}+00$ & $6.97 \mathrm{E}-01$ & $5.13 \mathrm{E}-01$ & $1.50 \mathrm{E}+00$ & $1.91 \mathrm{E}+00$ & $2.31 E+00$ & $2.69 \mathrm{E}+00$ \\
\hline $3.47 \mathrm{E}-02$ & $3.86 \mathrm{E}+00$ & $6.98 E-01$ & $5.14 \mathrm{E}-01$ & $1.50 \mathrm{E}+00$ & $1.91 \mathrm{E}+00$ & $2.31 E+00$ & $.69 E+00$ \\
\hline $3.48 \mathrm{E}-02$ & $3.86 \mathrm{E}+00$ & $6.99 \mathrm{E}-01$ & $15 E-01$ & $1.50 \mathrm{E}+00$ & $1.91 \mathrm{E}+00$ & $2.31 \mathrm{E}+00$ & $2.69 \mathrm{E}+00$ \\
\hline $3.50 \mathrm{E}-02$ & $3.86 \mathrm{E}+00$ & $7.00 \mathrm{E}-01$ & $5.17 \mathrm{E}-01$ & $1.50 \mathrm{E}+00$ & $1.91 \mathrm{E}+00$ & $2.31 E+00$ & $2.69 \mathrm{E}+00$ \\
\hline $3.51 \mathrm{E}-02$ & $3.87 \mathrm{E}+00$ & $7.00 \mathrm{E}-01$ & $5.18 \mathrm{E}-01$ & $1.51 \mathrm{E}+00$ & $1.91 \mathrm{E}+00$ & $2.31 E+00$ & $2.69 \mathrm{E}+00$ \\
\hline $3.52 \mathrm{E}-02$ & $3.87 \mathrm{E}+00$ & $7.01 E-01$ & $5.19 \mathrm{E}-01$ & $1.51 \mathrm{E}+00$ & $1.91 \mathrm{E}+00$ & $2.32 E+00$ & $2.70 \mathrm{E}+00$ \\
\hline $3.53 E-02$ & $3.87 \mathrm{E}+00$ & $7.02 E-01$ & $5.20 \mathrm{E}-01$ & $1.51 E+00$ & $1.91 \mathrm{E}+00$ & $2.32 E+00$ & $2.70 \mathrm{E}+00$ \\
\hline $3.55 \mathrm{E}-02$ & $3.87 \mathrm{E}+00$ & $7.03 E-01$ & $5.21 \mathrm{E}-01$ & $1.51 \mathrm{E}+00$ & $1.91 \mathrm{E}+00$ & $2.32 E+00$ & $2.70 \mathrm{E}+00$ \\
\hline $3.56 \mathrm{E}-02$ & $86 \mathrm{E}+00$ & $7.04 \mathrm{E}-01$ & $5.22 \mathrm{E}-01$ & $1.51 \mathrm{E}+00$ & $1.91 \mathrm{E}+00$ & $2.32 \mathrm{E}+00$ & $2.70 \mathrm{E}+00$ \\
\hline $3.57 \mathrm{E}-02$ & $3.86 \mathrm{E}+00$ & $7.05 E-01$ & $5.23 \mathrm{E}-01$ & $1.51 \mathrm{E}+00$ & $1.91 \mathrm{E}+00$ & $2.32 \mathrm{E}+00$ & $2.70 \mathrm{E}+00$ \\
\hline $3.59 \mathrm{E}-02$ & $3.86 \mathrm{E}+00$ & $7.05 E-01$ & $5.24 \mathrm{E}-01$ & $1.51 \mathrm{E}+00$ & $1.91 \mathrm{E}+00$ & $2.32 E+00$ & $2.70 \mathrm{E}+00$ \\
\hline $3.60 \mathrm{E}-02$ & $3.86 \mathrm{E}+00$ & 7. $06 \mathrm{E}-01$ & $5.25 \mathrm{E}-01$ & $1.51 \mathrm{E}+00$ & $1.91 \mathrm{E}+00$ & $2.32 \mathrm{E}+00$ & $2.70 \mathrm{E}+00$ \\
\hline $3.61 E-02$ & $3.86 \mathrm{E}+00$ & $7.07 E-01$ & $5.27 E-01$ & $1.51 E+00$ & $1.92 \mathrm{E}+00$ & $2.32 E+00$ & $2.70 \mathrm{E}+00$ \\
\hline $3.63 E-02$ & $3.86 \mathrm{E}+00$ & $7.08 E-01$ & $5.28 \mathrm{E}-01$ & $1.51 \mathrm{E}+00$ & $1.92 \mathrm{E}+00$ & $2.32 \mathrm{E}+00$ & $2.70 \mathrm{E}+00$ \\
\hline $3.64 \mathrm{E}-02$ & $3.86 \mathrm{E}+00$ & 7.09E-01 & $5.28 \mathrm{E}-01$ & $1.52 \mathrm{E}+00$ & 1.92E+00 & $2.32 \mathrm{E}+00$ & $2.70 \mathrm{E}+00$ \\
\hline $3.65 \mathrm{E}-02$ & $3.86 \mathrm{E}+00$ & $7.09 \mathrm{E}-01$ & $5.29 \mathrm{E}-01$ & $1.52 \mathrm{E}+00$ & $1.92 \mathrm{E}+00$ & $2.32 \mathrm{E}+00$ & $2.70 \mathrm{E}+00$ \\
\hline
\end{tabular}


RESRAD-OFFSITE, Version 2.5 
RESRAD-OFFSITE, Version 2.5 
RESRAD-OFFSITE, Version 2.5 
RESRAD-OFFSITE, Version 2.5

$\mathrm{T}^{1 / 2}$ Limit $=180$ days

Title : Offsite Resident Farmer Deterministic Run

File : RF TC99 DOESG FWD-FV2.ROF

Summary of dose at graphical times, reptition 3 (continued)

Time

Years

$8.96 \mathrm{E}+02$

$8.97 \mathrm{E}+02$

$8.97 \mathrm{E}+02$

$8.98 \mathrm{E}+02$

$8.98 \mathrm{E}+02$

$8.99 \mathrm{E}+02$

$8.99 \mathrm{E}+02$

$9.00 \mathrm{E}+02$

$9.00 \mathrm{E}+02$

$9.01 \mathrm{E}+02$

$9.01 \mathrm{E}+02$

$9.02 \mathrm{E}+02$

$9.02 \mathrm{E}+02$

$9.03 \mathrm{E}+02$

$9.03 E+02$

$9.04 \mathrm{E}+02$

$9.04 \mathrm{E}+02$

$9.05 \mathrm{E}+02$

$9.05 \mathrm{E}+02$

$9.06 \mathrm{E}+02$

$9.06 \mathrm{E}+02$

$9.07 \mathrm{E}+02$

$9.07 \mathrm{E}+02$

$9.08 \mathrm{E}+02$

$9.08 \mathrm{E}+02$

$9.09 \mathrm{E}+02$

$9.10 \mathrm{E}+02$

$9.10 \mathrm{E}+02$

$9.11 \mathrm{E}+02$

$9.11 \mathrm{E}+02$

$9.12 \mathrm{E}+02$

9. $12 \mathrm{E}+02$

9. $13 \mathrm{E}+02$

9. $13 \mathrm{E}+02$

$9.14 \mathrm{E}+02$

$9.14 \mathrm{E}+02$

$9.15 \mathrm{E}+02$

$9.15 \mathrm{E}+02$

$9.16 \mathrm{E}+02$

$9.16 \mathrm{E}+02$

$9.17 \mathrm{E}+02$

$9 \cdot 17 \mathrm{E}+02$

$9.18 \mathrm{E}+02$

$9.18 \mathrm{E}+02$

$9.19 \mathrm{E}+02$

$9.19 \mathrm{E}+02$
Dose statistics at graphical times, mrem/yr

\begin{tabular}{|c|c|c|c|c|c|c|c|}
\hline$m$ & $\mathrm{~m}$ & Mean & ledian & & & $\%$ & $\%$ \\
\hline $.77 \mathrm{E}-02$ & $3.76 \mathrm{E}+00$ & $8.14 \mathrm{E}-01$ & $6.58 \mathrm{E}-01$ & $1.65 \mathrm{E}+00$ & $2.00 \mathrm{E}+00$ & $2.28 \mathrm{E}+00$ & $2.10 E+00$ \\
\hline$E-02$ & $E+00$ & 01 & 01 & 00 & 00 & $E+00$ & $0 E+00$ \\
\hline $80 \mathrm{E}-02$ & $6 \mathrm{E}+00$ & $6 E-01$ & $6.60 \mathrm{E}-01$ & $1.65 \mathrm{E}+00$ & $2.00 \mathrm{E}+00$ & $2.28 \mathrm{E}+00$ & $70 \mathrm{E}+00$ \\
\hline $82 \mathrm{E}-02$ & $3.76 \mathrm{E}+00$ & $7 E-01$ & $6.60 \mathrm{E}-01$ & 1. $65 \mathrm{E}+00$ & $2.00 \mathrm{E}+00$ & $2.28 \mathrm{E}+00$ & $70 \mathrm{E}+00$ \\
\hline 2 & 0 & (- & $1 \mathrm{~F}-2 \cdot 0$ & 0 & 0 & 0 & $\mathrm{OE}+00$ \\
\hline-02 & -00 & 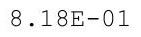 & & 0 & & & +00 \\
\hline $87 \mathrm{E}-02$ & & & & & & & $E+00$ \\
\hline-02 & & & & & & & +00 \\
\hline-02 & +00 & $F-0$ & $\perp$ & +00 & 00 & +00 & $59 \mathrm{E}+00$ \\
\hline 2 & +00 & 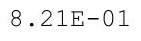 & $6.65 \mathrm{E}-01$ & 1.65 & 0 & 0 & +00 \\
\hline 02 & 0 & $8.21 E-01$ & $6.66 \mathrm{E}-01$ & 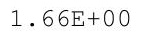 & & 0 & 00 \\
\hline 2 & -00 & & & .66 & & 0 & -00 \\
\hline $.97 \mathrm{E}-02$ & $3.75 \mathrm{E}+00$ & ل & 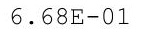 & $1.66 \mathrm{E}+00$ & & $2.29 \mathrm{E}+00$ & $59 \mathrm{E}+00$ \\
\hline $.99 \mathrm{E}-02$ & $3.74 \mathrm{E}+00$ & $8.23 \mathrm{E}-01$ & $6.69 \mathrm{E}-01$ & $1.66 \mathrm{E}+00$ & $2.01 \mathrm{E}+00$ & $2.29 \mathrm{E}+00$ & $2.68 \mathrm{E}+00$ \\
\hline-02 & $74 \mathrm{E}+00$ & 0 & 1 & 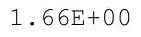 & 2 & $.29 E+00$ & $68 \mathrm{E}+00$ \\
\hline 02 & $74 \mathrm{E}+00$ & $\perp$ & $\perp$ & 1.66 & 0 & \pm+00 & +00 \\
\hline 02 & $3.74 \mathrm{E}+00$ & $8.25 E-01$ & & $\cdot 0$ & 0 & bo & 00 \\
\hline 2 & & & & & & & 0 \\
\hline $3 E-02$ & $3.74 \mathrm{E}+00$ & $.27 \mathrm{E}-\mathrm{C}$ & $6.75 \mathrm{E}-$ & $1.66 \mathrm{E}+00$ & $2.01 E+00$ & $2.29 \mathrm{E}+00$ & $\mathrm{E}+00$ \\
\hline $0 \mathrm{E}-02$ & $3.74 \mathrm{E}+00$ & $.27 \mathrm{E}-0$ & $.76 \mathrm{E}-01$ & $1.66 \mathrm{E}+00$ & $2.01 \mathrm{E}+00$ & $2.29 \mathrm{E}+00$ & $2.67 \mathrm{E}+00$ \\
\hline $11 \mathrm{E}-02$ & $3.73 E+00$ & $.28 E-01$ & $6.77 \mathrm{E}-01$ & $1.66 \mathrm{E}+00$ & & $2.29 \mathrm{E}+00$ & $.67 \mathrm{E}+00$ \\
\hline 02 & & & & & & & $67 \mathrm{E}+00$ \\
\hline 2 & & & & 1.66 & & & \\
\hline-02 & $3.73 E+00$ & $8.30 \mathrm{E}-01$ & & $\perp \cdot 00 \mathrm{H}$ & 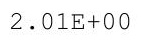 & . & 00 \\
\hline 2 & 0 & $8.31 \mathrm{E}-01$ & $\perp$ & 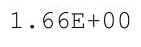 & 0. & 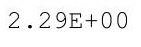 & 00 \\
\hline$F-02$ & $.73 E+00$ & $31=$ & קم & $1.66 \mathrm{E}+00$ & $.01 \mathrm{E}+$ & $.29 \mathrm{E}+00$ & $67 E+00$ \\
\hline$F-0 ?$ & $3.72 \mathrm{E}+00$ & $325-0$ & $F-01$ & $1.66 \mathrm{E}+00$ & הת1 0 & $2.29 \mathrm{E}+00$ & $2.67 \mathrm{E}+00$ \\
\hline 02 & & & & & & & \\
\hline 02 & $3.72 \mathrm{E}+00$ & & & $.66 \mathrm{E}+$ & & & \\
\hline $7 E-02$ & $3.1 \angle E+00$ & $0.04+4$ & 01 & $1.66 \mathrm{E}+00$ & $2.0<D$ & $2.29 \mathrm{E}+00$ & $2.66 \mathrm{E}+00$ \\
\hline $25-2<$ & $3.72 \mathrm{E}+00$ & . & $0.0 \mathrm{~L}-\mathrm{D}$ & $1.66 \mathrm{E}+00$ & $\angle .0 \angle \mathrm{LT} 0$ & $\angle . \angle 9 L T 00$ & $2.66 \mathrm{E}+00$ \\
\hline 年 & 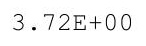 & . & 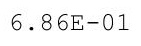 & $1.66 \mathrm{E}+00$ & $2.02 \mathrm{E}+$ & 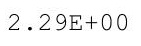 & $2.66 \mathrm{E}+00$ \\
\hline 5 & $3.72 \mathrm{E}+00$ & 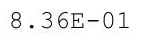 & 1 & $1.66 \mathrm{E}+00$ & & & $2.66 \mathrm{E}+00$ \\
\hline & & & & & & & \\
\hline 02 & & $8.37 \mathrm{E}-01$ & 01 & $166 \mathrm{~F}+$ & & & \\
\hline & & 0.30 & & $1.66 \mathrm{E}+00$ & $2.02 \mathrm{E}$ & $2 \cdot 201$ & +00 \\
\hline$E-02$ & $3.71 \mathrm{E}+00$ & 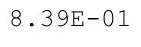 & & $1.66 \mathrm{E}+$ & & & $5 E+00$ \\
\hline पर & $3.71 \mathrm{E}+00$ & & & I.OOLTU & & & $2.65 E+00$ \\
\hline $.44 \mathrm{E}-02$ & ent & • & & t. & $2.02 \mathrm{E}$ & $2.28 \mathrm{E}$ & $2.65 E+00$ \\
\hline & & & & $66 \mathrm{E}+00$ & & & \\
\hline 2 & & 1 & 1 & $1.66 \mathrm{E}+00$ & $2.02 \mathrm{E}+$ & $2.28 \mathrm{E}+00$ & $2.65 E+00$ \\
\hline $49 \mathrm{E}-02$ & $3.70 \mathrm{E}+00$ & $8.42 E-01$ & 6.9 & 1.67 & $2.02 \mathrm{E}+$ & 00 & +00 \\
\hline & & & & & & & \\
\hline & . Tिएक & . & & $1.6 / E+00$ & $2.00 \mathrm{D} 10$ & $2.29 \mathrm{E}+00$ & 2.010100 \\
\hline 102 & $3.70 \mathrm{E}+00$ & . & & $1.67 \mathrm{E}+00$ & $2.03 E+00$ & $2.29 \mathrm{E}+00$ & $2.64 \mathrm{E}+00$ \\
\hline$E-02$ & $\mathrm{E}+00$ & $5 E-01$ & $98 E-01$ & $67 E+00$ & $.03 E+00$ & $.29 E+00$ & $.64 E+00$ \\
\hline
\end{tabular}


RESRAD-OFFSITE, Version 2.5

obabilistic Dose and Risk Report

Title : Offsite Resident Farmer Deterministic Run

File : RF TC99 DOESG FWD-FV2.ROF

Summary of dose at graphical times, reptition 3 (continued)

Time

Years

$9.20 \mathrm{E}+02$

$9.20 \mathrm{E}+02$

$9.21 \mathrm{E}+02$

$9.21 \mathrm{E}+02$

$9.22 \mathrm{E}+02$

$9.22 \mathrm{E}+02$

$9.23 \mathrm{E}+02$

$9.23 \mathrm{E}+02$

$9.24 \mathrm{E}+02$

$9.24 \mathrm{E}+02$

$9.25 \mathrm{E}+02$

$9.25 \mathrm{E}+02$

$9.26 \mathrm{E}+02$

$9.26 \mathrm{E}+02$

$9.27 \mathrm{E}+02$

$9.27 \mathrm{E}+02$

$9.28 \mathrm{E}+02$

$9.28 \mathrm{E}+02$

$9.29 \mathrm{E}+02$

$9.30 \mathrm{E}+02$

$9.30 \mathrm{E}+02$

$9.31 \mathrm{E}+02$

9. $31 \mathrm{E}+02$

9. $32 \mathrm{E}+02$

9. $32 \mathrm{E}+02$

$9.33 \mathrm{E}+02$

$9.33 \mathrm{E}+02$

$9.34 \mathrm{E}+02$

$9.34 \mathrm{E}+02$

9. $35 \mathrm{E}+02$

$9.35 \mathrm{E}+02$

$9.36 \mathrm{E}+02$

9. $36 \mathrm{E}+02$

9. $37 \mathrm{E}+02$

$9.37 \mathrm{E}+02$

$9.38 \mathrm{E}+02$

$9.38 \mathrm{E}+02$

$9.39 \mathrm{E}+02$

$9.39 \mathrm{E}+02$

$9.40 \mathrm{E}+02$

$9.40 \mathrm{E}+02$

$9.41 \mathrm{E}+02$

$9.41 \mathrm{E}+02$

$9.42 \mathrm{E}+02$

$9.42 \mathrm{E}+02$

$9.43 \mathrm{E}+02$
Dose statistics at graphical times, mrem/yr

\begin{tabular}{|c|c|c|c|c|c|c|c|}
\hline$m$ & aximum & lean & $n$ & & & & \\
\hline 02 & 0 & 01 & 1 & 0 & 00 & 00 & +00 \\
\hline $0 E-02$ & $69 \mathrm{E}+00$ & $6 E-01$ & $0 \mathrm{E}-01$ & $1.67 \mathrm{E}+00$ & $03 E+00$ & $29 E+00$ & $4 \mathrm{E}+00$ \\
\hline $62 \mathrm{~F}-02$ & $69 F+00$ & $47 E-01$ & $01 E-01$ & $.67 E+00$ & $.03 E+00$ & $2.29 \mathrm{E}+00$ & $2.64 \mathrm{E}+00$ \\
\hline $64 \mathrm{~F}-02$ & $69 F+00$ & $7 \mathrm{~F}-01$ & $02 \mathrm{~F}$ & $67 \mathrm{~F}+00$ & $.03 E+00$ & $9 F+00$ & $64 \mathrm{E}+00$ \\
\hline$E-02$ & 00 & 1 & 1 & 0 & & & +00 \\
\hline$E-02$ & 00 & $8.49 \mathrm{E}-01$ & & & & & +00 \\
\hline $69 \mathrm{E}-02$ & $68 \mathrm{E}+00$ & 1 & & $1.67 \mathrm{E}+00$ & DTo & $2.29 \mathrm{E}+00$ & $E+00$ \\
\hline $.71 E-02$ & $68 E+00$ & $O E-01$ & -01 & $1.68 \mathrm{E}+00$ & $03 E+00$ & $\mathrm{E}+00$ & $3 E+00$ \\
\hline $73 \mathrm{~F}-02$ & $.68 E+00$ & $F-(-2)-2)$ & 1 & $68 \mathrm{~F}+1$ & $03 \mathrm{~F}+$ & $.29 E+00$ & $63 E+00$ \\
\hline 2 & $68 \mathrm{~F}+0$ & $8.51 \mathrm{E}-01$ & $7.08 \mathrm{E}-01$ & $685+103$ & & 0 & 0 \\
\hline $77 \mathrm{E}-02$ & $3.68 E+00$ & 1 & 1 & $8 \mathrm{Ft}$ & 0 & +00 & $E+00$ \\
\hline $3 E-02$ & & 1 & & & & & +00 \\
\hline $.80 E-02$ & $3.67 \mathrm{E}+00$ & $8.53 E-01$ & & 1. $68 \mathrm{E}+00$ & $2.03 E+00$ & $2.29 \mathrm{E}+00$ & $2.62 \mathrm{E}+00$ \\
\hline $.82 E-02$ & $3.67 \mathrm{E}+00$ & • & 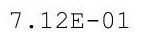 & & & $2.29 \mathrm{E}+00$ & $2.62 \mathrm{E}+00$ \\
\hline 2 & 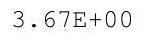 & & & 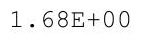 & & 0 & +00 \\
\hline 2 & & & & $168=$ & & 0 & 00 \\
\hline 2 & $67 \mathrm{~F}+00$ & $8.56 \mathrm{E}-01$ & & 叶 & & +1 & 00 \\
\hline $.90 E-02$ & $367 F+00$ & $6 \mathrm{~F}$ & $7.16 \mathrm{E}-01$ & $1.68 \mathrm{E}+00$ & & +00 & $1 E+00$ \\
\hline $.92 \mathrm{E}-02$ & $3.66 \mathrm{E}+00$ & $.57 \mathrm{E}-01$ & $7.16 \mathrm{E}-01$ & 1. $68 \mathrm{E}+00$ & $2.03 E+00$ & $2.28 \mathrm{E}+00$ & $2.61 \mathrm{E}+00$ \\
\hline $93 E-02$ & $3.66 \mathrm{E}+00$ & $.57 \mathrm{E}-01$ & $7.17 \mathrm{E}-01$ & $1.68 \mathrm{E}+00$ & $3 E+00$ & $28 \mathrm{E}+00$ & $2.61 \mathrm{E}+00$ \\
\hline & & & & & & & \\
\hline & & & & $1.68 \mathrm{E}+00$ & 0 & & $E+00$ \\
\hline $9 E-02$ & $3.66 \mathrm{E}+00$ & + & 1 & 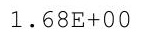 & & 0 & 0 \\
\hline 02 & $.65 \mathrm{E}+$ & 1 & $7.21 E-01$ & 1. $68 \mathrm{E}+$ & $3 \mathrm{E}+$ & 0 & $1 \mathrm{E}+00$ \\
\hline $03 \mathrm{~F}-02$ & $65 \mathrm{~F}+00$ & $61 F-01$ & $7.21 \mathrm{E}-01$ & $1.68 \mathrm{E}+00$ & $.02 \mathrm{E}+0$ & $.28 \mathrm{E}+00$ & $.60 \mathrm{E}+00$ \\
\hline$F-02$ & $.65 E+00$ & $61 F-01$ & 7. $22 \mathrm{E}-01$ & $1.68 \mathrm{E}+00$ & $2.02 E+00$ & $.28 \mathrm{E}+00$ & $2.60 \mathrm{E}+00$ \\
\hline & & & & & & & $60 \mathrm{E}+00$ \\
\hline & & & & 0 & & & \\
\hline & & . & & 1.000 & & $2.28 E+00$ & $E+00$ \\
\hline $.12 \mathrm{E}-02$ & $3.64 \mathrm{E}+00$ & . & $7.26 \mathrm{E}-01$ & 1. $69 \mathrm{E}+00$ & $2.03 E+00$ & $2.28 \mathrm{E}+00$ & $2.60 \mathrm{E}+00$ \\
\hline - & $3.64 \mathrm{E}+00$ & $=0$ & $7.27 \mathrm{E}-01$ & $1.69 \mathrm{E}+00$ & $2.03 E+00$ & $2.28 \mathrm{E}+00$ & $2.59 \mathrm{E}+00$ \\
\hline 165 & $3.64 \mathrm{E}+0$ & & & $1.69 \mathrm{E}+$ & & $2.28 E+00$ & $2.59 \mathrm{E}+00$ \\
\hline $.18 \mathrm{E}-02$ & & & & & & $2.28 \mathrm{E}+00$ & $2.59 \mathrm{E}+00$ \\
\hline 02 & $3.64 \mathrm{E}+\mathrm{C}$ & & & & & & \\
\hline $22 \mathrm{E}-02$ & $3.64 \mathrm{E}+00$ & $E-01$ & $7.30 \mathrm{E}-01$ & $1.69 \mathrm{E}+00$ & 2.000 & $E+00$ & $9 \mathrm{E}+00$ \\
\hline • $\angle 4 E-0 Z$ & $3.035+00$ & $8.67 E-01$ & $7.31 \mathrm{E}-01$ & $1.09 E+00$ & $2.03 E+00$ & $2.27 E+00$ & $2.59 \mathrm{E}+00$ \\
\hline 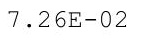 & . & & & $1.69 \mathrm{E}+00$ & & 2.210100 & $2.59 \mathrm{E}+00$ \\
\hline - & $3.63 E+0$ & 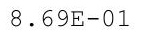 & 1 & $1.69 \mathrm{E}+00$ & $2.03 E+00$ & $2.27 \mathrm{E}+00$ & $2.58 \mathrm{E}+00$ \\
\hline $7.30 \mathrm{E}-02$ & $3.63 E+0$ & 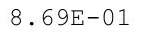 & (⿻上丨 & 1. $69 \mathrm{E}+00$ & $2.03 E+00$ & $2.27 \mathrm{E}+00$ & $2.58 \mathrm{E}+00$ \\
\hline 2 & $3.63 \mathrm{E}+00$ & 1 & 1 & $1.69 \mathrm{E}+00$ & $2.03 E+00$ & $2.27 \mathrm{E}+00$ & $2.58 \mathrm{E}+00$ \\
\hline $.33 E-02$ & $3.62 \mathrm{E}+00$ & $E-01$ & $7.35 \mathrm{E}-01$ & $1.69 \mathrm{E}+$ & $2.03 E+00$ & $E+00$ & $58 E+00$ \\
\hline$E-02$ & $3.62 \mathrm{E}+00$ & 1 & & $1.69 \mathrm{E}+$ & & & $8 \mathrm{E}+00$ \\
\hline & . & 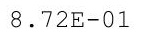 & & - & & & $2.58 \mathrm{E}+00$ \\
\hline 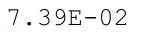 & $3.62 \mathrm{E}+00$ & $8.72 \mathrm{E}-01$ & $7.38 \mathrm{E}-01$ & $1.69 \mathrm{E}+00$ & $2.03 E+00$ & $2.26 \mathrm{E}+00$ & $2.57 \mathrm{E}+00$ \\
\hline ther & $3.62 \mathrm{E}+00$ & & & $1.70 \mathrm{E}+00$ & $2.03 E+00$ & $2.26 \mathrm{E}+00$ & $2.57 \mathrm{E}+00$ \\
\hline $43 E-02$ & $.61 E+00$ & $E-01$ & $E-01$ & $.70 \mathrm{E}+00$ & $2.02 E+00$ & $2.27 E+00$ & $.57 \mathrm{E}+00$ \\
\hline
\end{tabular}


RESRAD-OFFSITE, Version 2.5

obabilistic Dose and Risk Report

Title : Offsite Resident Farmer Deterministic Run

File : RF TC99 DOESG FWD-FV2.ROF

Summary of dose at graphical times, reptition 3 (continued)

Time

Years

$9.43 E+02$

$9.44 \mathrm{E}+02$

9. $44 \mathrm{E}+02$

$9.45 \mathrm{E}+02$

9. $45 \mathrm{E}+02$

$9.46 \mathrm{E}+02$

$9.46 \mathrm{E}+02$

$9.47 \mathrm{E}+02$

$9.47 \mathrm{E}+02$

9. $48 \mathrm{E}+02$

9. $48 \mathrm{E}+02$

9. $49 \mathrm{E}+02$

9. $50 \mathrm{E}+02$

$9.50 \mathrm{E}+02$

9. $51 \mathrm{E}+02$

9. $51 \mathrm{E}+02$

9. $52 \mathrm{E}+02$

9. $52 \mathrm{E}+02$

$9.53 \mathrm{E}+02$

$9.53 \mathrm{E}+02$

$9.54 \mathrm{E}+02$

$9.54 \mathrm{E}+02$

$9.55 \mathrm{E}+02$

9. $55 \mathrm{E}+02$

9. $56 \mathrm{E}+02$

$9.56 \mathrm{E}+02$

9. $57 \mathrm{E}+02$

9. $57 \mathrm{E}+02$

9. $58 \mathrm{E}+02$

$9.58 \mathrm{E}+02$

9. $59 \mathrm{E}+02$

$9.59 \mathrm{E}+02$

$9.60 \mathrm{E}+02$

$9.60 \mathrm{E}+02$

$9.61 \mathrm{E}+02$

$9.61 \mathrm{E}+02$

$9.62 \mathrm{E}+02$

$9.62 \mathrm{E}+02$

$9.63 \mathrm{E}+02$

$9.63 \mathrm{E}+02$

$9.64 \mathrm{E}+02$

$9.64 \mathrm{E}+02$

$9.65 \mathrm{E}+02$

$9.65 \mathrm{E}+02$

$9.66 \mathrm{E}+02$

$9.66 \mathrm{E}+02$
Dose statistics at graphical times, mrem/yr

\begin{tabular}{|c|c|c|c|c|c|c|c|}
\hline inimum & laximum & Mean & ledian & $\%$ & $5 \%$ & $97.5 \%$ & $\%$ \\
\hline $45 \mathrm{E}-02$ & $3.61 \mathrm{E}+00$ & $8.74 \mathrm{E}-01$ & $.41 \mathrm{E}-01$ & $1.70 \mathrm{E}+00$ & $2.02 E+00$ & $2.27 E+00$ & $7 \mathrm{E}+00$ \\
\hline$E-02$ & $\mathrm{E}+00$ & 1 & 1 & 0 & 0 & +00 & $\mathrm{E}+00$ \\
\hline$E-02$ & +00 & 01 & 01 & & & 00 & +00 \\
\hline 02 & $E+00$ & & & & & 00 & +00 \\
\hline $53 E-02$ & $1 \mathrm{E}+00$ & & & $E+00$ & $02 E+00$ & +00 & $E+00$ \\
\hline $.55 E-02$ & $3.60 \mathrm{E}+00$ & $7 E-01$ & $5 E-01$ & $1.70 \mathrm{E}+00$ & $02 \mathrm{E}+00$ & $2.27 E+00$ & $57 E+00$ \\
\hline 02 & $60 \mathrm{E}+00$ & -01 & 1 & 0 & 0 & $7 E+00$ & $7 \mathrm{E}+00$ \\
\hline $.59 \mathrm{E}-02$ & $3.60 \mathrm{E}+00$ & . & & & $2.02 \pm 100$ & +00 & $2.57 \mathrm{E}+00$ \\
\hline 02 & $0 \mathrm{E}+00$ & & & & & 00 & +00 \\
\hline $.63 E-02$ & $3.60 \mathrm{E}+00$ & $E-01$ & & & & & $7 \mathrm{E}+00$ \\
\hline$E-02$ & $E+00$ & $E-01$ & 1 & $E+00$ & 0 & $\mathrm{E}+00$ & $7 E+00$ \\
\hline-02 & $E+00$ & 01 & 1 & 00 & 00 & $E+00$ & $\mathrm{E}+00$ \\
\hline $69 \mathrm{E}-02$ & $3.59 \mathrm{E}+00$ & $1 E-01$ & 01 & $1.70 E+U 0$ & . $0<1$ & $E+00$ & $7 \mathrm{E}+00$ \\
\hline 02 & 0 & $8.82 \mathrm{E}-01$ & $7.53 \mathrm{E}-01$ & 0 & 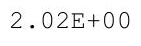 & 0 & 00 \\
\hline 2 & $.59 \mathrm{E}+00$ & $8.82 \mathrm{E}-01$ & & $\cdots$ & $02 \mathrm{E}+00$ & 0 & 0 \\
\hline $.74 \mathrm{E}-02$ & $3.58 \mathrm{E}+00$ & $8.83 E-01$ & $7.55 \mathrm{E}-01$ & & $2.02 E+00$ & $2.28 \mathrm{E}+00$ & $2.57 \mathrm{E}+00$ \\
\hline $.76 \mathrm{E}-02$ & $3.58 \mathrm{E}+00$ & $8.84 \mathrm{E}-01$ & $7.56 \mathrm{E}-01$ & $1.70 \mathrm{E}+00$ & $2.02 \mathrm{E}+00$ & $2.28 \mathrm{E}+00$ & $2.57 \mathrm{E}+00$ \\
\hline$E-02$ & $.58 E+00$ & $4 E-01$ & $7 E-01$ & $1.70 \mathrm{E}+00$ & $2.02 E+00$ & $2.28 \mathrm{E}+00$ & $57 \mathrm{E}+00$ \\
\hline 02 & $\mathrm{E}+00$ & & & & & 00 & $E+00$ \\
\hline 02 & +00 & $\perp$ & & 10 & & 00 & +00 \\
\hline 2 & $.57 E+00$ & $8.86 \mathrm{E}-01$ & & 0 & & & 00 \\
\hline$E-02$ & $7 E+00$ & 1 & $\perp$ & 1 & זרטל & 0 & $7 E+00$ \\
\hline$E-02$ & $.57 E+00$ & $387 \mathrm{~F}-01$ & 7. $61 \mathrm{E}-01$ & 1. $70 \mathrm{E}+00$ & $.02 \mathrm{E}+\mathrm{C}$ & $.28 E+00$ & $.57 E+00$ \\
\hline$E-02$ & $3.57 \mathrm{E}+00$ & $88 \mathrm{~F}-01$ & $761 \mathrm{~F}-01$ & 1. $70 \mathrm{E}+00$ & $.02 \mathrm{E}+$ & $.28 \mathrm{E}+00$ & $.57 \mathrm{E}+00$ \\
\hline$E-02$ & $57 E+00$ & & & & & $8 \mathrm{E}+00$ & $.57 \mathrm{E}+00$ \\
\hline & & & & & & & \\
\hline & & & & 1.10 & & $E+00$ & +00 \\
\hline $.98 E-02$ & $3.56 \mathrm{E}+00$ & . & . & म.Tिएक & $2.03 E+00$ & $.28 \mathrm{E}+00$ & $2.57 \mathrm{E}+00$ \\
\hline 02 & $56 \mathrm{E}+00$ & 1 & 1 & 1. $70 \mathrm{E}+00$ & $2.03 \mathrm{E}+$ & $2.28 \mathrm{E}+00$ & $2.57 E+00$ \\
\hline$F-02$ & $3.56 \mathrm{E}+00$ & $01=01$ & $7.67 \mathrm{E}-01$ & & & $228 F+00$ & $2.57 \mathrm{E}+00$ \\
\hline$E-02$ & $3.55 \mathrm{E}+00$ & & & & & & $2.56 \mathrm{E}+00$ \\
\hline 02 & & & & & & & \\
\hline & & & & & & & \\
\hline $11 \mathrm{E}-02$ & $3.55 \mathrm{E}+00$ & $8.93 E-01$ & $7.71 \mathrm{E}-01$ & $1.71 \mathrm{E}+00$ & $2.07 \pi$ & $2.28 \mathrm{E}+00$ & $.56 \mathrm{E}+00$ \\
\hline $13 E-02$ & $3.55 \mathrm{E}+00$ & & $1 \cdot 1 \angle \mathrm{L}-U \perp$ & 1. $71 \mathrm{E}+00$ & & & $2.56 \mathrm{E}+00$ \\
\hline 2 & & 1 & & $1.71 \mathrm{E}+00$ & & $2.28 \mathrm{E}+00$ & $2.56 \mathrm{E}+00$ \\
\hline 2 & & & & $1.71 \mathrm{E}+00$ & & $2.28 \mathrm{E}+00$ & $2.57 \mathrm{E}+00$ \\
\hline 2 & $3.54 \mathrm{E}+00$ & $8.96 \mathrm{E}-01$ & $7.74 \mathrm{E}-01$ & & & & $57 \mathrm{E}+00$ \\
\hline$E-02$ & & 01 & 01 & $1.71 \mathrm{E}+00$ & $2.03 E+$ & $2.28 \mathrm{E}+00$ & $7 E+00$ \\
\hline $23 E-02$ & $3.54 \mathrm{E}+00$ & 1 & 1 & $1.71 \mathrm{E}+00$ & $03 E$ & & $57 \mathrm{E}+00$ \\
\hline$E-02$ & $3.53 \mathrm{E}+00$ & $8.97 \pm-01$ & . & $1.71 \mathrm{E}+00$ & & & $2.57 \mathrm{E}+00$ \\
\hline $27 E-02$ & $3.53 \mathrm{E}+00$ & $0.90 \mathrm{~L}-\mathrm{L}$ & $0 x-4$ & $1.71 \mathrm{E}+00$ & $2.03 E+00$ & $2.28 \mathrm{E}+00$ & $2.57 \mathrm{E}+00$ \\
\hline $9 \pm-02$ & $3.53 \mathrm{E}+00$ & 0.95 & 解 & $1.71 \mathrm{E}+00$ & $2.03 E+00$ & $2.28 \mathrm{E}+00$ & $2.57 \mathrm{E}+00$ \\
\hline 2 & $3.53 E+00$ & & & $71 \mathrm{E}+00$ & & $2.28 \mathrm{E}+00$ & $2.57 \mathrm{E}+00$ \\
\hline$E-02$ & $3.53 \mathrm{E}+00$ & $E-01$ & $E-01$ & $1.71 \mathrm{E}+00$ & $2.03 E+00$ & $2.28 \mathrm{E}+00$ & $2.57 \mathrm{E}+00$ \\
\hline$E-02$ & $52 \mathrm{E}+00$ & $00 \mathrm{E}-01$ & $7.79 \mathrm{E}-01$ & $1.71 \mathrm{E}+00$ & $3 E+00$ & $.28 \mathrm{E}+00$ & $2.56 \mathrm{E}+00$ \\
\hline
\end{tabular}


RESRAD-OFFSITE, Version 2.5

obabilistic Dose and Risk Report

Title : Offsite Resident Farmer Deterministic Run

File : RF TC99 DOESG FWD-FV2.ROF

Summary of dose at graphical times, reptition 3 (continued)

Time

Years

9. $67 \mathrm{E}+02$

$9.67 \mathrm{E}+02$

9. $68 \mathrm{E}+02$

$9.68 \mathrm{E}+02$

$9.69 \mathrm{E}+02$

$9.70 \mathrm{E}+02$

$9.70 \mathrm{E}+02$

9. $71 \mathrm{E}+02$

$9.71 \mathrm{E}+02$

9. $72 \mathrm{E}+02$

$9.72 \mathrm{E}+02$

$9.73 E+02$

$9.73 E+02$

$9.74 \mathrm{E}+02$

9. $74 \mathrm{E}+02$

$9.75 \mathrm{E}+02$

$9.75 \mathrm{E}+02$

$9.76 \mathrm{E}+02$

$9.76 \mathrm{E}+02$

$9.77 \mathrm{E}+02$

$9.77 \mathrm{E}+02$

$9.78 \mathrm{E}+02$

$9.78 \mathrm{E}+02$

$9.79 \mathrm{E}+02$

$9.79 \mathrm{E}+02$

$9.80 \mathrm{E}+02$

$9.80 \mathrm{E}+02$

$9.81 \mathrm{E}+02$

$9.81 \mathrm{E}+02$

$9.82 \mathrm{E}+02$

$9.82 \mathrm{E}+02$

$9.83 E+02$

$9.83 \mathrm{E}+02$

$9.84 \mathrm{E}+02$

$9.84 \mathrm{E}+02$

$9.85 \mathrm{E}+02$

$9.85 \mathrm{E}+02$

$9.86 \mathrm{E}+02$

$9.86 \mathrm{E}+02$

$9.87 \mathrm{E}+02$

$9.87 \mathrm{E}+02$

$9.88 \mathrm{E}+02$

$9.88 \mathrm{E}+02$

$9.89 \mathrm{E}+02$

$9.90 \mathrm{E}+02$

9. $90 \mathrm{E}+02$
Dose statistics at graphical times, mrem/yr

\begin{tabular}{|c|c|c|c|c|c|c|c|}
\hline linimum & Maximum & Mean & Median & 900 & $90 \%$ & $97.5 \%$ & $9 \%$ \\
\hline 2 & $2 E+00$ & 1 & $30 E-01$ & +00 & 0 & & +00 \\
\hline-02 & $2 E+00$ & $1 E$ & $80 E-01$ & $1.71 \mathrm{E}+00$ & $04 \mathrm{E}+00$ & +00 & $56 E+00$ \\
\hline$E-02$ & 00 & $2 E-01$ & 01 & 0 & 0 & 0 & $6 \mathrm{E}+00$ \\
\hline$E-02$ & $E+00$ & $2 E-01$ & 01 & 0 & 0 & 00 & $E+00$ \\
\hline $45 E-02$ & $51 E+00$ & $3 E-01$ & 1 & & $03 E+00$ & $.28 \mathrm{E}+00$ & $56 \mathrm{E}+00$ \\
\hline $7 E-02$ & $1 \mathrm{E}+00$ & & & $\Xi+00$ & $\Xi+00$ & 00 & $56 \mathrm{E}+00$ \\
\hline $.49 E-02$ & $3.51 E+00$ & $4 E-01$ & $7.82 \mathrm{E}-01$ & $1.71 \mathrm{E}+00$ & E+ & +00 & $6 E+00$ \\
\hline $.51 E-02$ & $3.51 E+00$ & . & $7.83 E-01$ & $1.71 \mathrm{E}+00$ & $2.03 E+00$ & $2.28 \mathrm{E}+00$ & $2.56 \mathrm{E}+00$ \\
\hline$E-02$ & +00 & 1 & -01 & 1.711 & 0 & 00 & \pm+00 \\
\hline$E-02$ & $E+00$ & 9 & $\perp$ & $1 E+00$ & 0 & 00 & $E+00$ \\
\hline$E-02$ & & 9 & & & & & $E+00$ \\
\hline-02 & +00 & 田 & 1 & 1.7 & 0 & Do & $5 E+00$ \\
\hline $62 E-02$ & $3.50 \mathrm{E}+00$ & $7 \mathrm{~L}-01$ & $7.87 \mathrm{E}-01$ & $1.71 \mathrm{E}+00$ & $2.02 E+00$ & $2.28 E+00$ & $56 \mathrm{E}+00$ \\
\hline $.64 \mathrm{E}-02$ & $3.49 \mathrm{E}+00$ & . & $7.88 \mathrm{E}-01$ & $\perp \cdot T \perp E T U U$ & Z. UZLTU & 2.20 & $56 \mathrm{E}+00$ \\
\hline $5 E-02$ & $E+00$ & . & 01 & 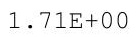 & . & 00 & 00 \\
\hline $.68 \mathrm{E}-02$ & $3.49 \mathrm{E}+00$ & $9.09 \mathrm{E}-01$ & $7.89 \mathrm{E}-01$ & $1.71 \mathrm{E}+00$ & $2.02 \mathrm{E}+00$ & $2.28 \mathrm{E}+00$ & $55 \mathrm{E}+00$ \\
\hline $.70 E-02$ & $3.49 E+00$ & $0 E-01$ & $7.90 \mathrm{E}-01$ & $1.71 \mathrm{E}+00$ & $2.02 E+00$ & $2.28 E+00$ & $5 \mathrm{E}+00$ \\
\hline$E-02$ & $8 \mathrm{E}+00$ & $E-01$ & $E-01$ & $1.71 \mathrm{E}+00$ & 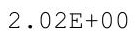 & $8 E+00$ & $5 E+00$ \\
\hline $.74 \mathrm{E}-02$ & $3.48 \mathrm{E}+00$ & $9.11 \mathrm{E}-01$ & 7. $92 \mathrm{E}-01$ & $1.71 \mathrm{E}+00$ & $2.02 \mathrm{E}+00$ & $2.28 \mathrm{E}+00$ & $5 E+00$ \\
\hline $.76 \mathrm{E}-02$ & $3.48 E+00$ & $9.11 \mathrm{E}-01$ & $7.93 E-01$ & $\perp \cdot / \perp E$ & 0 & 00 & +00 \\
\hline $.78 E-02$ & $8 E+00$ & & & I. IILTU & & 2.200 & $E+00$ \\
\hline $.80 \mathrm{E}-02$ & $3.48 \mathrm{E}+00$ & 9.7 & . & $1.71 \mathrm{E}+$ & $2.01 \mathrm{E}+$ & 00 & $\mathrm{E}+00$ \\
\hline $.82 E-02$ & $3.47 E+00$ & $3 E-01$ & $5 E-01$ & $1.72 \mathrm{E}+00$ & $2.01 \mathrm{E}+$ & $2.28 \mathrm{E}+00$ & $54 \mathrm{E}+00$ \\
\hline $84 E-02$ & $3.47 E+00$ & $3 E-01$ & $E-01$ & $1.72 \mathrm{E}+00$ & $2.01 \mathrm{E}+$ & $2.28 E+00$ & $54 E+00$ \\
\hline$E-02$ & $3.47 \mathrm{E}+00$ & 1 & 01 & $1.72 \mathrm{E}+$ & 0 & & $54 \mathrm{E}+00$ \\
\hline $3 E-02$ & $E+00$ & 1 & 1 & +00 & 0 & & \\
\hline $90 \mathrm{E}-02$ & $3.46 \mathrm{E}+00$ & $9.15 \mathrm{E}-$ & 年 & $\perp \cdot 1 \angle \mathrm{E}+$ & $2.01+1$ & .200 & $E+00$ \\
\hline $92 \mathrm{E}-02$ & $3.46 \mathrm{E}+00$ & $9.15 \mathrm{E}-01$ & $7.99 \mathrm{E}-01$ & $1.72 \mathrm{E}+00$ & $2.00 \mathrm{E}+00$ & $2.28 \mathrm{E}+00$ & $2.54 \mathrm{E}+00$ \\
\hline 02 & 0 & 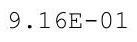 & 1 & 10 & . & 年 & $.54 \mathrm{E}+00$ \\
\hline 2 & $.46 \mathrm{E}+$ & 1 & - & $172=$ & & $238 F+00$ & $54 \mathrm{E}+00$ \\
\hline 02 & $3.46 \mathrm{~F}+00$ & 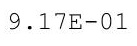 & 1 & ניתר 17 & ג תחم: & $2.28 \mathrm{E}+00$ & $4 \mathrm{E}+00$ \\
\hline$E-02$ & $5+00$ & 9 & & $72 \mathrm{~F}+$ & ג & $2.28 \mathrm{E}+00$ & $4 E+00$ \\
\hline $.02 E-02$ & $3.45 \mathrm{E}+00$ & $9.18 \mathrm{E}-01$ & $2 E-01$ & $1.72 \mathrm{E}+$ & $2.00 \mathrm{ET}$ & $2.28 \mathrm{E}$ & $4 E+00$ \\
\hline $.04 \mathrm{E}-02$ & $3.45 \mathrm{E}+00$ & $9.19 \mathrm{E}-01$ & $8.03 E-01$ & $1.1 \angle E+U 0$ & 1.99ET & $2 . \angle 8 E+00$ & $4 \mathrm{E}+00$ \\
\hline $0 E-0<$ & $3.45 E+00$ & & & $1.72 \mathrm{E}+00$ & & & $2.53 E+00$ \\
\hline & 1. & & & & & & 00 \\
\hline 2 & $3 \Delta \triangle F+$ & & & & & & 00 \\
\hline 2 & & & & 0 & 0 & 00 & \\
\hline 02 & 3.4 & 9 . & 01 & 1.72 & 1 & 00 & $3 E+00$ \\
\hline $6 E-02$ & $3.44 \mathrm{E}+$ & 9.2 & & 1.7 & $\perp \cdot 9$ & & $2.53 E+00$ \\
\hline$E-02$ & $3.43 E+00$ & 9 & & $1.72 \mathrm{E}+$ & $1.99 \mathrm{E}+$ & & $.53 E+00$ \\
\hline $5-v 2$ & $3.43 \mathrm{E}+00$ & 9 & 1 & 1. $72 \mathrm{E}+00$ & 1. $99 \mathrm{E}+00$ & $2.28 \mathrm{E}+00$ & $2.53 E+00$ \\
\hline 2 & $3.45 \mathrm{LT}$ & 9 & & 0 & $99 \mathrm{E}$ & 0 & \\
\hline & & & 01 & 1 . & 1. $98 \mathrm{E}+00$ & 2.2 & $2.53 E+00$ \\
\hline$E-02$ & $3.42 \mathrm{E}+00$ & $\mathrm{E}-01$ & 8 & 1. $72 \mathrm{E}+00$ & 1.98E+ & $2.27 \mathrm{E}+00$ & $2.53 E+00$ \\
\hline $28 E-02$ & $42 E+00$ & $25 E-01$ & $.12 \mathrm{E}-01$ & $1.72 \mathrm{E}+00$ & $1.98 \mathrm{E}+00$ & $2.27 E+00$ & $2.53 E+00$ \\
\hline
\end{tabular}


RESRAD-OFFSITE, Version 2.5

obabilistic Dose and Risk Report

Title : Offsite Resident Farmer Deterministic Run

File : RF TC99 DOESG FWD-FV2.ROF

Summary of dose at graphical times, reptition 3 (continued)

Time

Years

$9.91 \mathrm{E}+02$

$9.91 \mathrm{E}+02$

$9.92 \mathrm{E}+02$

$9.92 \mathrm{E}+02$

$9.93 \mathrm{E}+02$

$9.93 \mathrm{E}+02$

$9.94 \mathrm{E}+02$

$9.94 \mathrm{E}+02$

$9.95 \mathrm{E}+02$

$9.95 \mathrm{E}+02$

$9.96 \mathrm{E}+02$

$9.96 \mathrm{E}+02$

$9.97 \mathrm{E}+02$

$9.97 \mathrm{E}+02$

$9.98 \mathrm{E}+02$

$9.98 \mathrm{E}+02$

$9.99 \mathrm{E}+02$

$9.99 \mathrm{E}+02$

$1.00 \mathrm{E}+03$

$1.00 \mathrm{E}+03$

$1.00 \mathrm{E}+03$

$1.00 \mathrm{E}+03$

$1.00 \mathrm{E}+03$

$1.00 \mathrm{E}+03$

$1.00 \mathrm{E}+03$

$1.00 \mathrm{E}+03$

$1.00 \mathrm{E}+03$

$1.00 \mathrm{E}+03$

$1.00 \mathrm{E}+03$

$1.01 \mathrm{E}+03$

$1.01 \mathrm{E}+03$

$1.01 \mathrm{E}+03$

$1.01 \mathrm{E}+03$

$1.01 \mathrm{E}+03$

$1.01 \mathrm{E}+03$

$1.01 \mathrm{E}+03$

$1.01 \mathrm{E}+03$

$1.01 \mathrm{E}+03$

$1.01 \mathrm{E}+03$

$1.01 \mathrm{E}+03$

$1.01 \mathrm{E}+03$

$1.01 \mathrm{E}+03$

$1.01 \mathrm{E}+03$

$1.01 \mathrm{E}+03$

$1.01 \mathrm{E}+03$

$1.01 \mathrm{E}+03$
Dose statistics at graphical times, mrem/yr

\begin{tabular}{|c|c|c|c|c|c|c|c|}
\hline inimum & laximum & Mean & ledian & 年 & $\div$ & $97.5 \%$ & $\%$ \\
\hline 02 & $3.42 \mathrm{E}+00$ & $9.25 \mathrm{E}-01$ & $8.13 \mathrm{E}-01$ & $1.72 \mathrm{E}+00$ & $1.98 \mathrm{E}+00$ & $2.27 E+00$ & $3 E+00$ \\
\hline 02 & +00 & 1 & 1 & 0 & 00 & +00 & $E+00$ \\
\hline-02 & +00 & 01 & 01 & & & 00 & +00 \\
\hline 02 & $E+00$ & & & & & 00 & +00 \\
\hline$E-02$ & $1 \mathrm{E}+00$ & 1 & & $72 \mathrm{E}+00$ & & +00 & $3 E+00$ \\
\hline$E-02$ & $3.41 \mathrm{E}+00$ & $3 E-01$ & -01 & $1.73 \mathrm{E}+00$ & $97 \mathrm{E}+00$ & $\mathrm{E}+00$ & $E+00$ \\
\hline 02 & $41 E+00$ & 01 & 1 & $735+$ & 0 & $7 E+00$ & $53 E+00$ \\
\hline $45 E-02$ & $3.40 \mathrm{E}+00$ & . & & 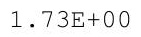 & & +00 & $\mathrm{E}+00$ \\
\hline$E-02$ & $E+00$ & & & & & +00 & +00 \\
\hline $.49 \mathrm{E}-02$ & $3.40 \mathrm{E}+00$ & $0 E-01$ & & $1.73 \mathrm{E}+00$ & & & $3 E+00$ \\
\hline-02 & $\Xi+00$ & $\perp$ & 1 & 0 & 0 & +00 & $E+00$ \\
\hline-02 & $E+00$ & 01 & & 00 & 00 & $E+00$ & $\mathrm{E}+00$ \\
\hline-02 & $3.39 \mathrm{E}+00$ & -01 & $\perp$ & $1.72 \mathrm{E}+00$ & 政 & $E+00$ & $E+00$ \\
\hline 02 & 0 & $9.32 \mathrm{E}-01$ & $8.21 \mathrm{E}-01$ & 0 & & 0 & 00 \\
\hline 2 & $.39 E+00$ & $9.32 \mathrm{E}-01$ & & 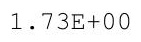 & & $E+00$ & 0 \\
\hline $.61 E-02$ & $3.39 \mathrm{E}+00$ & $9.33 E-01$ & $8.22 \mathrm{E}-01$ & $1.73 \mathrm{E}+00$ & & & $5 \mathrm{E}+00$ \\
\hline $.63 E-02$ & $3.38 \mathrm{E}+00$ & $9.33 E-01$ & $.23 E-01$ & $1.73 E+00$ & $1.96 \mathrm{E}+00$ & $2.27 \mathrm{E}+00$ & $2.53 E+00$ \\
\hline$E-02$ & $38 E+00$ & $E-01$ & $E-01$ & $1.73 E+00$ & $1.96 \mathrm{E}+00$ & $2.28 \mathrm{E}+00$ & $3 E+00$ \\
\hline 02 & +00 & & & & & & 00 \\
\hline 02 & +00 & $\perp$ & $\perp$ & 1.73 & 0 & 0 & +00 \\
\hline 2 & $.37 E+00$ & $9.35 \mathrm{E}-01$ & & 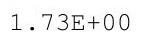 & & & 00 \\
\hline-02 & $37 E+00$ & 1 & $\perp$ & 170 & $c_{0}$ & +00 & $E+00$ \\
\hline $6 \mathrm{E}-02$ & $.37 E+00$ & $36 \mathrm{~F}-01$ & $6 \mathrm{E}-01$ & $1.73 \mathrm{E}+00$ & $96 \mathrm{E}+00$ & $.28 E+00$ & $53 E+00$ \\
\hline$E-02$ & $.37 E+00$ & $=01$ & $7 E-01$ & 1. $73 \mathrm{E}+00$ & $.96 \mathrm{E}+$ & $.27 \mathrm{E}+00$ & $.53 E+00$ \\
\hline$E-02$ & $36 E+00$ & & & 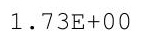 & & $7 \mathrm{E}+00$ & $5 \mathrm{E}+00$ \\
\hline & & & & & & & \\
\hline & & 1 & & $1.73 \mathrm{E}$ & (2) & 00 & +00 \\
\hline $.86 \mathrm{E}-02$ & $3.36 \mathrm{E}+00$ & . & $\cdot 0$ & $1.73 E+00$ & I. . & $.27 E+00$ & $2.53 E+00$ \\
\hline 02 & $35 E+00$ & 1 & 1 & $1.73 \mathrm{E}+00$ & 1.96E+ & $2.27 \mathrm{E}+00$ & $.53 E+00$ \\
\hline$F-02$ & $3.35 E+00$ & & & 1. $73 \mathrm{E}+00$ & & $227 \mathrm{~F}+0$ & $2.53 E+00$ \\
\hline 02 & $3.35 E+00$ & & & & & & \\
\hline 02 & & & & & & & \\
\hline 02 & & & & 1.13 & 1.96 & & \\
\hline $.99 E-02$ & $3.34 \mathrm{E}+00$ & $9.4 \angle E-U 1$ & $8.34 E-01$ & $1.73 \mathrm{E}+00$ & $1.90 \mathrm{~T}$ & $2.26 \mathrm{E}+00$ & $2.53 E+00$ \\
\hline $.00 \mathrm{E}-01$ & $3.34 \mathrm{E}+00$ & $9.425-U 1$ & & $1.13 E+00$ & & & $2.53 E+00$ \\
\hline 1 & & 1 & & $1.73 \mathrm{E}+00$ & & & $2.53 E+00$ \\
\hline 1 & & & & & & $.26 E+00$ & $2.53 E+00$ \\
\hline 01 & $3.33 E+00$ & $9.43 \mathrm{E}-01$ & 1 & & & & \\
\hline $1 E-01$ & & 01 & 01 & $1.73 \mathrm{E}+00$ & $1.96 \mathrm{E}+$ & $E+00$ & $3 E+00$ \\
\hline $.01 \mathrm{E}-01$ & $3.33 E+00$ & $9.44 \mathrm{E}$ & . & $1.73 E+00$ & $1.96 \mathrm{E}$ & $2.20 E$ & $2 E+00$ \\
\hline$E-01$ & $3.33 E+00$ & . & & $1.10 \mathrm{E}$ & $\pm \cdot 00$ & & $52 \mathrm{E}+00$ \\
\hline $.02 E-01$ & $3.32 \mathrm{E}+00$ & $.40 \pm-4 \perp$ & $0.405-0 \perp$ & $1.73 E+00$ & $1.96 \mathrm{E}+00$ & $2.26 \mathrm{E}+00$ & $2.52 \mathrm{E}+00$ \\
\hline $2 E-01$ & $3.32 \mathrm{E}+00$ & $.40 \pm-1$ & & $1.73 \mathrm{E}+00$ & $1.96 \mathrm{E}+00$ & $2.26 \mathrm{E}+00$ & $2.52 \mathrm{E}+00$ \\
\hline 1 & & & & $73 E+00$ & $1.96 \mathrm{E}+00$ & $2.26 E+00$ & $2.52 \mathrm{E}+00$ \\
\hline 01 & & 01 & 8.4 & $1.73 \mathrm{E}+00$ & $1.96 \mathrm{E}+00$ & $2.26 \mathrm{E}+00$ & $2.52 \mathrm{E}+00$ \\
\hline $02 E-01$ & $.31 E+00$ & $.47 E-01$ & $44 E-01$ & $1.73 E+00$ & $1.96 \mathrm{E}+00$ & $.26 E+00$ & $2.52 E+00$ \\
\hline
\end{tabular}


RESRAD-OFFSITE, Version 2.5

$\mathrm{T}^{1 / 2}$ Limit $=180$ days

obabilistic Dose and Risk Report

Title : Offsite Resident Farmer Deterministic Run

File : RF TC99 DOESG FWD-FV2.ROF

Summary of dose at graphical times, reptition 3 (continued)

Time

Years

1. $01 \mathrm{E}+03$

1. $01 \mathrm{E}+03$

$1.02 \mathrm{E}+03$

$1.02 \mathrm{E}+03$

1. $02 \mathrm{E}+03$

1. $02 \mathrm{E}+03$

1. $02 \mathrm{E}+03$

1. $02 \mathrm{E}+03$

1. $02 \mathrm{E}+03$

1. $02 \mathrm{E}+03$

1. $02 \mathrm{E}+03$

1. $02 \mathrm{E}+03$

1. $02 \mathrm{E}+03$

1. $02 \mathrm{E}+03$

$1.02 \mathrm{E}+03$

1. $02 \mathrm{E}+03$

$1.02 \mathrm{E}+03$

$1.02 \mathrm{E}+03$

1. $02 \mathrm{E}+03$

1. $02 \mathrm{E}+03$

$1.02 \mathrm{E}+03$

1. $02 \mathrm{E}+03$

$1.03 \mathrm{E}+03$

1. $03 \mathrm{E}+03$

$1.03 \mathrm{E}+03$

$1.03 E+03$

$1.03 E+03$

$1.03 E+03$

$1.03 \mathrm{E}+03$

$1.03 E+03$

$1.03 E+03$

$1.03 \mathrm{E}+03$

$1.03 \mathrm{E}+03$

$1.03 \mathrm{E}+03$

$1.03 E+03$

$1.03 E+03$

$1.03 \mathrm{E}+03$

$1.03 E+03$

$1.03 E+03$

$1.03 E+03$

$1.03 \mathrm{E}+03$

$1.04 \mathrm{E}+03$

$1.04 \mathrm{E}+03$

$1.04 \mathrm{E}+03$

$1.04 \mathrm{E}+03$

$1.04 \mathrm{E}+03$
Dose statistics at graphical times, mrem/yr

\begin{tabular}{|c|c|c|c|c|c|c|c|}
\hline$m$ & aximum & lean & edi & & & & \\
\hline $.03 E-01$ & $3.31 \mathrm{E}+00$ & $8 E-01$ & $4 E-01$ & 0 & 0 & 00 & +00 \\
\hline $3 E-01$ & $3.31 \mathrm{E}+00$ & $9.48 \mathrm{E}-01$ & $5 E-01$ & $1.73 E+00$ & 1. $96 \mathrm{E}+00$ & $2.26 \mathrm{E}+00$ & $2.52 \mathrm{E}+00$ \\
\hline$E-01$ & $.31 E+00$ & $49 F-01$ & $46 F-01$ & $73 E+00$ & $96 \mathrm{E}+00$ & $26 E+00$ & $2.52 \mathrm{E}+00$ \\
\hline $.03 E-01$ & $.31 E+00$ & $.49 E-01$ & $8.47 \mathrm{E}-01$ & $1.73 E+00$ & $1.96 \mathrm{E}+00$ & $2.26 \mathrm{E}+00$ & $2.52 E+00$ \\
\hline $03 E-01$ & & 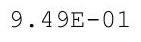 & & & & & $2 \mathrm{E}+00$ \\
\hline $04 \mathrm{E}-01$ & & 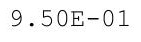 & & & & $2.26 E+00$ & $52 E+00$ \\
\hline $04 \mathrm{E}-01$ & $3.30 E+00$ & 1 & -01 & $1.73 E+00$ & $96 E+00$ & $2.26 \mathrm{E}+00$ & $52 E+00$ \\
\hline $.04 \mathrm{E}-01$ & $3.30 \mathrm{E}+00$ & $1 E-01$ & $8 \mathrm{E}-01$ & $1.73 E+00$ & $96 \mathrm{E}+00$ & $2.26 \mathrm{E}+00$ & $52 \mathrm{E}+00$ \\
\hline $4 E-01$ & $30 F+00$ & $F_{-}$ & 1 & $73 \mathrm{~F}+$ & $95 \mathrm{~F}+$ & $.26 E+00$ & $52 \mathrm{E}+00$ \\
\hline$E-01$ & $30 F+0$ & $9.52 \mathrm{E}-01$ & $8.50 \mathrm{E}-01$ & & & 0 & $52 E+00$ \\
\hline $05 E-01$ & $F+00$ & $2 F_{-}$ & 1 & 0 & 0 & +00 & $2 \mathrm{E}+00$ \\
\hline$E-01$ & & $9.53 \mathrm{E}-01$ & & & & & +00 \\
\hline $.05 E-01$ & $3.29 \mathrm{E}+00$ & $9.53 \mathrm{E}-01$ & $8.53 \mathrm{E}-01$ & $1.74 \mathrm{E}+00$ & & $2.26 \mathrm{E}+00$ & $2.52 \mathrm{E}+00$ \\
\hline$E-01$ & $3.29 \mathrm{E}+00$ & 5 & & & & +00 & $2 \mathrm{E}+00$ \\
\hline 1 & ק & & & $.74 \mathrm{E}+$ & ل & 0 & $52 E+00$ \\
\hline $.06 \mathrm{E}-01$ & 32 & $9.54 \mathrm{E}-01$ & $8.54 E-01$ & 0 & 0 & $2.25 E+00$ & 0 \\
\hline$E-01$ & $3.29 F+00$ & $9.55 \mathrm{E}-01$ & $8.54 \mathrm{E}-01$ & $174 \mathrm{~F}+$ & & $E+00$ & $1 \mathrm{E}+00$ \\
\hline $06 E-01$ & $9 F+00$ & $5 F-0$ & $5 F-01$ & $74 \mathrm{E}+00$ & 0 & $E+00$ & $1 \mathrm{E}+00$ \\
\hline$E-01$ & $.28 E+00$ & $6 \mathrm{~F}-0$ & $6 \mathrm{E}-01$ & 1. $74 \mathrm{E}+00$ & $1.96 \mathrm{E}+00$ & $2.25 E+00$ & $2.51 E+00$ \\
\hline-01 & $\mathrm{E}+00$ & -0 & -01 & 0 & & $E+00$ & $51 \mathrm{E}+00$ \\
\hline & & & & & & & \\
\hline $07 E-01$ & 3. $28 \mathrm{E}+00$ & . & & $1.74 \mathrm{E}+$ & & & 00 \\
\hline 01 & $.28 E+00$ & $9.58 \mathrm{E}-01$ & $8.59 \mathrm{E}-01$ & $1.74 \mathrm{E}+$ & ل & 0 & $1 E+00$ \\
\hline $7 E-01$ & $28 E+0$ & $2 \mathrm{~F}_{-}$ & 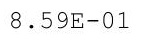 & $1.74 \mathrm{E}+\mathrm{C}$ & $1.96 \mathrm{E}+\mathrm{C}$ & $2.24 \mathrm{E}+00$ & $51 E+00$ \\
\hline $8 E-01$ & $.27 \mathrm{E}+00$ & $585-100$ & $0 \mathrm{E}-01$ & 1. $74 \mathrm{E}+00$ & $106=+0$ & $.24 \mathrm{E}+00$ & $51 E+00$ \\
\hline$E-01$ & $.27 E+00$ & & & & & $.24 \mathrm{E}+00$ & $51 E+00$ \\
\hline & & & & & & & \\
\hline & & & & $1.73 \mathrm{E}+$ & 土. & $4 \mathrm{E}+00$ & $2.51 \mathrm{E}+00$ \\
\hline $.09 \mathrm{E}-01$ & $3.27 \mathrm{E}+00$ & (.0) & $8.62 \mathrm{E}-01$ & $1.73 \mathrm{E}+00$ & 土. & $2.24 \mathrm{E}+00$ & $2.51 \mathrm{E}+00$ \\
\hline 1 & $3.27 E+00$ & - & 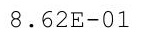 & $1.73 E+00$ & $1.96 \mathrm{E}+00$ & $2.24 \mathrm{E}+00$ & $2.51 \mathrm{E}+00$ \\
\hline $.09 \mathrm{E}-01$ & $3.27 \mathrm{E}+00$ & $.61 \mathrm{E}-$ & $.63 \mathrm{E}-$ & $1.73 E+C$ & & $2.24 \mathrm{E}+00$ & $2.51 \mathrm{E}+00$ \\
\hline$F-01$ & $.26 E+00$ & 5 & 1 & $1.73 E+$ & & & $51 E+00$ \\
\hline 1 & & & & & & & \\
\hline 01 & & & & & & $24 \mathrm{E}+00$ & $2.51 \mathrm{E}+00$ \\
\hline $.10 \mathrm{E}-01$ & $3.26 \mathrm{E}+00$ & $2.03 \mathrm{~L}-\mathrm{T}$ & $8.66 \mathrm{E}-01$ & $1.73 \mathrm{E}+00$ & 1.97E+ & $2.24 \mathrm{E}+00$ & $2.51 \mathrm{E}+00$ \\
\hline$\cdot 1 U E-U \perp$ & $3.26 \mathrm{E}+00$ & . & & $1.73 \mathrm{E}+00$ & 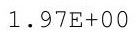 & $2.24 \mathrm{E}+00$ & $2.51 E+00$ \\
\hline 1 & - & 1 & 1 & $1.73 \mathrm{E}+$ & 1.97E+ & & $2.51 E+00$ \\
\hline $.11 \mathrm{E}-01$ & $3.25 E+0$ & 1 & 1 & $1.73 \mathrm{E}+00$ & $1.97 \mathrm{E}+00$ & $2.24 \mathrm{E}+00$ & $2.51 \mathrm{E}+00$ \\
\hline & & & & $735+$ & 0 & $2.24 \mathrm{E}+00$ & \\
\hline$E-01$ & & 01 & 01 & 1.73 & 1 & $2.24 \mathrm{E}+00$ & $1 E+00$ \\
\hline $11 \mathrm{E}-01$ & $E+00$ & 9.0 & & 1.7 & 1 & & $50 \mathrm{E}+00$ \\
\hline & 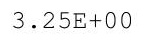 & & & $1.74 \mathrm{E}+00$ & & & $2.50 \mathrm{E}+00$ \\
\hline$\perp \angle L-U \perp$ & $3.25 \mathrm{E}+00$ & 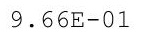 & $0.1 \angle E-U \perp$ & $1.74 \mathrm{E}+00$ & $1.97 \mathrm{E}+00$ & $2.23 E+00$ & $2.50 \mathrm{E}+00$ \\
\hline $1 \angle D-0 \perp$ & $3.24 \mathrm{E}+00$ & & & $1.74 \mathrm{E}+00$ & $1.97 \mathrm{E}+00$ & $2.23 E+00$ & $2.50 \mathrm{E}+00$ \\
\hline 1 & & & & $1.74 \mathrm{E}+$ & 1.98E+ & $2.23 E+00$ & $2.50 \mathrm{E}+00$ \\
\hline $12 E-01$ & $.24 \mathrm{E}+00$ & $E-01$ & $.74 \mathrm{E}-01$ & $1.74 \mathrm{E}+00$ & $1.98 \mathrm{E}+00$ & $2.23 E+00$ & $2.50 \mathrm{E}+00$ \\
\hline
\end{tabular}


RESRAD-OFFSITE, Version 2.5

$\mathrm{T}^{1 / 2}$ Limit $=180$ days

robabilistic Dose and Risk Report

Title : Offsite Resident Farmer Deterministic Run

File : RF TC99 DOESG FWD-FV2.ROF

Time

Years

$1.04 \mathrm{E}+03$

$1.04 \mathrm{E}+03$

$1.04 \mathrm{E}+03$

$1.04 \mathrm{E}+03$

$1.04 \mathrm{E}+03$

$1.04 \mathrm{E}+03$

$1.04 \mathrm{E}+03$

$1.04 \mathrm{E}+03$

$1.04 \mathrm{E}+03$

$1.04 \mathrm{E}+03$

$1.04 \mathrm{E}+03$

$1.04 \mathrm{E}+03$

$1.04 \mathrm{E}+03$

$1.04 \mathrm{E}+03$

$1.04 \mathrm{E}+03$

$1.05 \mathrm{E}+03$

$1.05 \mathrm{E}+03$

$1.05 \mathrm{E}+03$

$1.05 \mathrm{E}+03$

$1.05 \mathrm{E}+03$

$1.05 \mathrm{E}+03$

$1.05 \mathrm{E}+03$

$1.05 \mathrm{E}+03$

$1.05 \mathrm{E}+03$

$1.05 \mathrm{E}+03$
Summary of dose at graphical times, reptition

3 (continued)

\begin{tabular}{|c|c|c|c|c|c|c|c|}
\hline Minimum & Maximum & Mean & Median & $90 \%$ & $95 \%$ & $97.5 \%$ & $99 \%$ \\
\hline $1.12 \mathrm{E}-01$ & $3.24 \mathrm{E}+00$ & $9.68 \mathrm{E}-01$ & $8.75 \mathrm{E}-01$ & $1.74 \mathrm{E}+00$ & $1.98 \mathrm{E}+00$ & $2.23 E+00$ & $2.50 \mathrm{E}+00$ \\
\hline $1.13 \mathrm{E}-01$ & $3.24 \mathrm{E}+00$ & $9.68 \mathrm{E}-01$ & $8.76 \mathrm{E}-01$ & $1.74 \mathrm{E}+00$ & $1.97 \mathrm{E}+00$ & $2.23 \mathrm{E}+00$ & $2.50 \mathrm{E}+00$ \\
\hline $1.13 \mathrm{E}-01$ & $3.24 \mathrm{E}+00$ & $9.69 \mathrm{E}-01$ & $8.77 \mathrm{E}-01$ & $1.74 \mathrm{E}+00$ & 1.97E+00 & $2.23 E+00$ & $2.50 \mathrm{E}+00$ \\
\hline $1.13 \mathrm{E}-01$ & $3.24 \mathrm{E}+00$ & $9.69 \mathrm{E}-01$ & $8.77 \mathrm{E}-01$ & $1.74 \mathrm{E}+00$ & $1.97 \mathrm{E}+00$ & $2.23 \mathrm{E}+00$ & $2.50 \mathrm{E}+00$ \\
\hline $1.13 \mathrm{E}-01$ & $3.23 \mathrm{E}+00$ & $9.70 E-01$ & $8.78 \mathrm{E}-01$ & $1.74 \mathrm{E}+00$ & $1.97 \mathrm{E}+00$ & $2.23 \mathrm{E}+00$ & $2.49 \mathrm{E}+00$ \\
\hline $1.14 \mathrm{E}-01$ & $3.23 \mathrm{E}+00$ & $9.70 \mathrm{E}-01$ & $8.79 \mathrm{E}-01$ & $1.74 \mathrm{E}+00$ & $1.97 \mathrm{E}+00$ & $2.23 E+00$ & $2.49 \mathrm{E}+00$ \\
\hline $1.14 \mathrm{E}-01$ & $3.23 E+00$ & $9.70 E-01$ & $8.79 \mathrm{E}-01$ & $1.74 \mathrm{E}+00$ & $1.97 \mathrm{E}+00$ & $2.22 E+00$ & $2.49 \mathrm{E}+00$ \\
\hline $1.14 \mathrm{E}-01$ & $3.23 E+00$ & $9.71 E-01$ & $8.79 \mathrm{E}-01$ & $1.74 \mathrm{E}+00$ & $1.97 \mathrm{E}+00$ & $2.22 \mathrm{E}+00$ & $2.49 \mathrm{E}+00$ \\
\hline $1.14 \mathrm{E}-01$ & $3.23 E+00$ & $9.71 E-01$ & $8.80 \mathrm{E}-01$ & $1.74 \mathrm{E}+00$ & $1.97 \mathrm{E}+00$ & $2.22 \mathrm{E}+00$ & $2.49 \mathrm{E}+00$ \\
\hline $1.14 \mathrm{E}-01$ & $3.23 E+00$ & $9.72 E-01$ & $8.81 \mathrm{E}-01$ & $1.74 \mathrm{E}+00$ & $1.97 \mathrm{E}+00$ & $2.22 \mathrm{E}+00$ & $2.49 \mathrm{E}+00$ \\
\hline 1. $15 \mathrm{E}-01$ & $3.22 \mathrm{E}+00$ & $9.72 E-01$ & $8.81 E-01$ & $1.74 \mathrm{E}+00$ & $1.98 \mathrm{E}+00$ & $2.22 \mathrm{E}+00$ & $2.49 \mathrm{E}+00$ \\
\hline $1.15 \mathrm{E}-01$ & $3.22 \mathrm{E}+00$ & $9.72 \mathrm{E}-01$ & $8.82 \mathrm{E}-01$ & $1.74 \mathrm{E}+00$ & $1.98 \mathrm{E}+00$ & $2.22 \mathrm{E}+00$ & $2.49 \mathrm{E}+00$ \\
\hline 1. $15 \mathrm{E}-01$ & $3.22 \mathrm{E}+00$ & $9.73 E-01$ & $8.83 E-01$ & $1.74 \mathrm{E}+00$ & $1.98 \mathrm{E}+00$ & $2.22 \mathrm{E}+00$ & $2.49 \mathrm{E}+00$ \\
\hline $1.15 \mathrm{E}-01$ & $3.22 \mathrm{E}+00$ & $9.73 E-01$ & $8.83 E-01$ & $1.74 \mathrm{E}+00$ & $1.97 \mathrm{E}+00$ & $2.21 E+00$ & $2.49 \mathrm{E}+00$ \\
\hline $1.16 \mathrm{E}-01$ & $3.22 \mathrm{E}+00$ & $9.74 \mathrm{E}-01$ & $8.84 \mathrm{E}-01$ & $1.74 \mathrm{E}+00$ & $1.97 \mathrm{E}+00$ & $2.21 \mathrm{E}+00$ & $2.49 \mathrm{E}+00$ \\
\hline $1.16 \mathrm{E}-01$ & $3.22 \mathrm{E}+00$ & $9.74 E-01$ & $8.84 E-01$ & $1.74 \mathrm{E}+00$ & $1.97 \mathrm{E}+00$ & $2.21 E+00$ & $2.49 \mathrm{E}+00$ \\
\hline $1.16 \mathrm{E}-01$ & $3.22 \mathrm{E}+00$ & $9.74 \mathrm{E}-01$ & $8.84 \mathrm{E}-01$ & $1.74 \mathrm{E}+00$ & $1.97 \mathrm{E}+00$ & $2.21 E+00$ & $2.49 \mathrm{E}+00$ \\
\hline $1.16 \mathrm{E}-01$ & $3.22 \mathrm{E}+00$ & $9.75 E-01$ & $8.85 E-01$ & $1.74 \mathrm{E}+00$ & $1.97 \mathrm{E}+00$ & $2.21 E+00$ & $2.49 \mathrm{E}+00$ \\
\hline $1.16 \mathrm{E}-01$ & $3.22 \mathrm{E}+00$ & $9.75 E-01$ & $8.85 E-01$ & $1.74 \mathrm{E}+00$ & $1.97 \mathrm{E}+00$ & $2.21 E+00$ & $2.49 \mathrm{E}+00$ \\
\hline $1.17 \mathrm{E}-01$ & $3.22 \mathrm{E}+00$ & $9.76 \mathrm{E}-01$ & $8.86 \mathrm{E}-01$ & $1.74 \mathrm{E}+00$ & $1.97 \mathrm{E}+00$ & $2.21 E+00$ & $2.49 \mathrm{E}+00$ \\
\hline $1.17 \mathrm{E}-01$ & $3.22 \mathrm{E}+00$ & $9.76 \mathrm{E}-01$ & $8.86 \mathrm{E}-01$ & $1.74 \mathrm{E}+00$ & $1.97 \mathrm{E}+00$ & $2.21 \mathrm{E}+00$ & $2.49 \mathrm{E}+00$ \\
\hline $1.17 \mathrm{E}-01$ & $3.22 \mathrm{E}+00$ & $9.76 \mathrm{E}-01$ & $8.86 \mathrm{E}-01$ & $1.74 \mathrm{E}+00$ & $1.97 \mathrm{E}+00$ & $2.20 \mathrm{E}+00$ & $2.49 \mathrm{E}+00$ \\
\hline $1.17 \mathrm{E}-01$ & $3.22 \mathrm{E}+00$ & $9.77 E-01$ & $8.87 E-01$ & $1.74 \mathrm{E}+00$ & $1.97 \mathrm{E}+00$ & $2.20 E+00$ & $2.49 \mathrm{E}+00$ \\
\hline $1.17 \mathrm{E}-01$ & $3.22 \mathrm{E}+00$ & $9.77 \mathrm{E}-01$ & $8.87 E-01$ & $1.74 \mathrm{E}+00$ & $1.97 \mathrm{E}+00$ & $2.20 \mathrm{E}+00$ & $2.49 \mathrm{E}+00$ \\
\hline $1.18 \mathrm{E}-01$ & $3.22 \mathrm{E}+00$ & $9.77 \mathrm{E}-01$ & $8.87 E-01$ & $1.74 \mathrm{E}+00$ & $1.97 \mathrm{E}+00$ & $2.20 \mathrm{E}+00$ & $2.49 \mathrm{E}+00$ \\
\hline
\end{tabular}


RESRAD-OFFSITE, Version 2.5

Probabilistic Dose and Risk Report

Title : Offsite Resident Farmer Deterministic Run

File : RF TC99 DOESG FWD-FV2.ROF

Repetition

1

2

3

$\begin{array}{cc}\begin{array}{c}\text { Peak of the mean dose } \\ \text { Time of peak mean dose } \\ \text { Years }\end{array} & \begin{array}{c}\text { Peak mean dose } \\ \text { mrem/yr }\end{array} \\ 1.050 \mathrm{E}+03 & 9.793 \mathrm{E}-01 \\ 1.050 \mathrm{E}+03 & 9.773 \mathrm{E}-01 \\ 1.050 \mathrm{E}+03 & 9.772 \mathrm{E}-01\end{array}$




\title{
Offsite Resident Farmer
}

\author{
Parent Dose Report \\ (Deterministic Analysis Report) \\ Second Run
}

Time Horizon: 1,050 yr 
THIS PAGE INTENTIONALLY LEFT BLANK 
RESRAD-OFFSITE, Version $2.5 \quad \mathrm{~T}^{1 / 2}$ Limit $=180$ days

Parent Dose Report

Title : Offsite Resident Farmer Deterministic Run

File : RF TC99 DOESG FWD-FV2b.ROF

Table of Contents

Part I: Mixture Sums and Single Radionuclide Guidelines

Dose Conversion Factor (and Related) Parameter Summary ... 2

Site-Specific Parameter Summary ................ 4

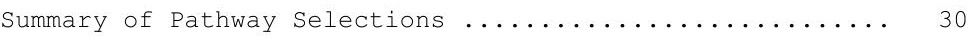

Contaminated Zone and Total Dose Summary ............ 31

Total Dose Components

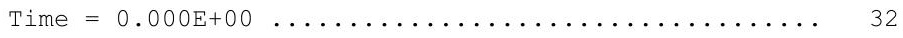

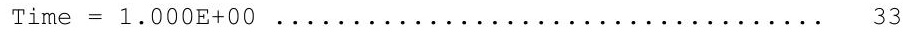

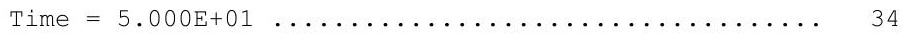

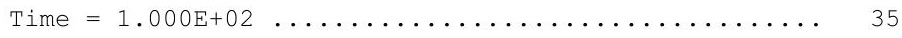

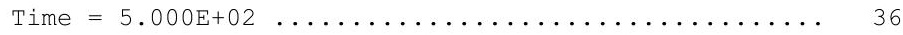

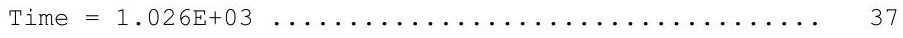

Dose/Source Ratios Summed Over All Pathways .......... 38

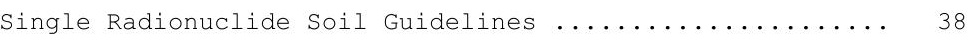

Dose Per Nuclide Summed Over All Pathways ............ 39

Soil Concentration Per Nuclide ................ 39

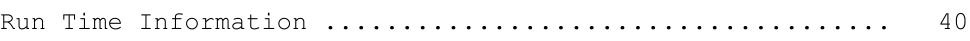


RESRAD-OFFSITE, Version 2.5

Parent Dose Report

Title : Offsite Resident Farmer Deterministic Run

File : RF TC99 DOESG FWD-FV2b.ROF

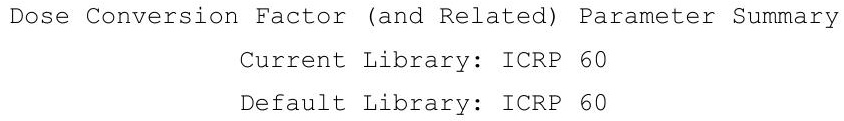

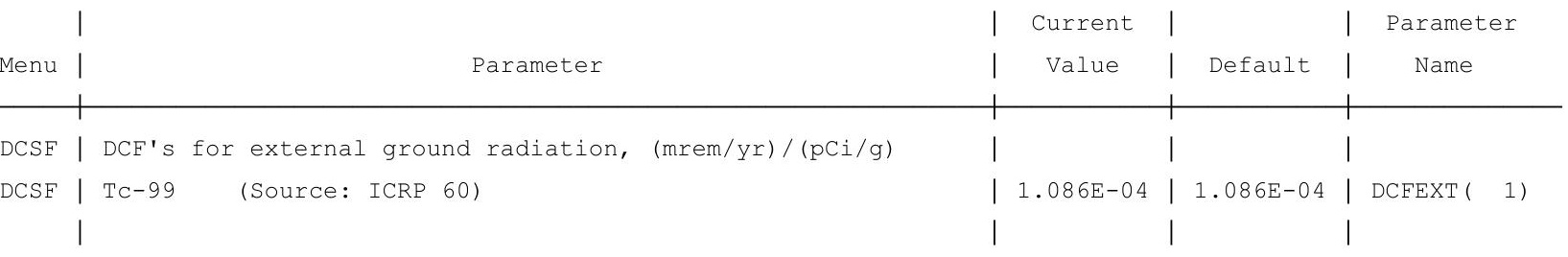

Current Library: ICRP 72 (Adult)

Default Library: ICRP 72 (Adult)

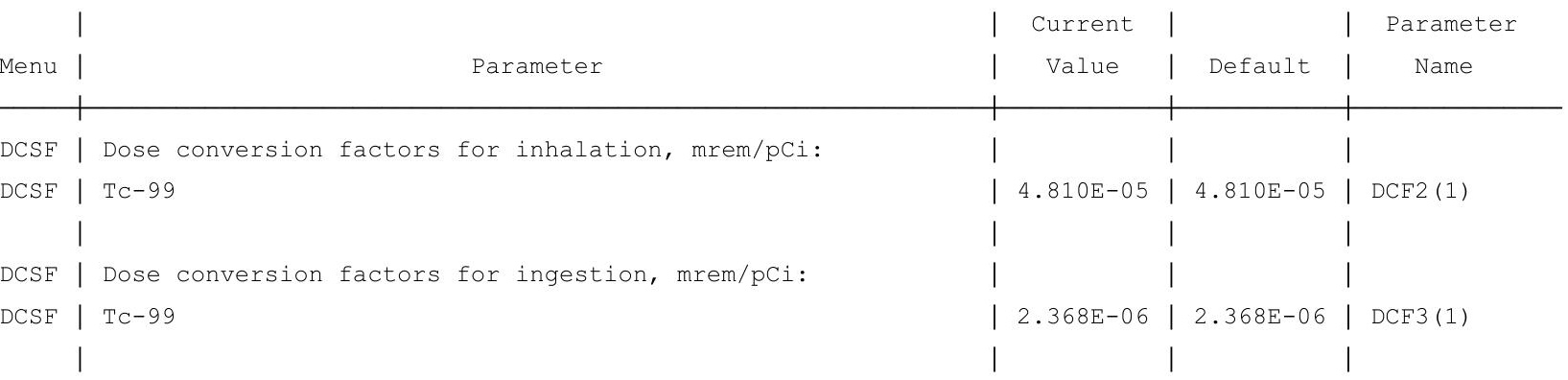


RESRAD-OFFSITE, Version 2.5

Parent Dose Report

Title : Offsite Resident Farmer Deterministic Run

File : RF TC99 DOESG FWD-FV2b.ROF

Dose Conversion Factor (and Related) Parameter Summary (continued)

Current Library: RESRAD Default Transfer factors

Default Library: RESRAD Default Transfer factors

Parameter
Menu


RESRAD-OFFSITE, Version 2.5

Parent Dose Report

Title : Offsite Resident Farmer Deterministic Run

File : RF TC99 DOESG FWD-FV2b.ROF

Site-Specific Parameter Summary

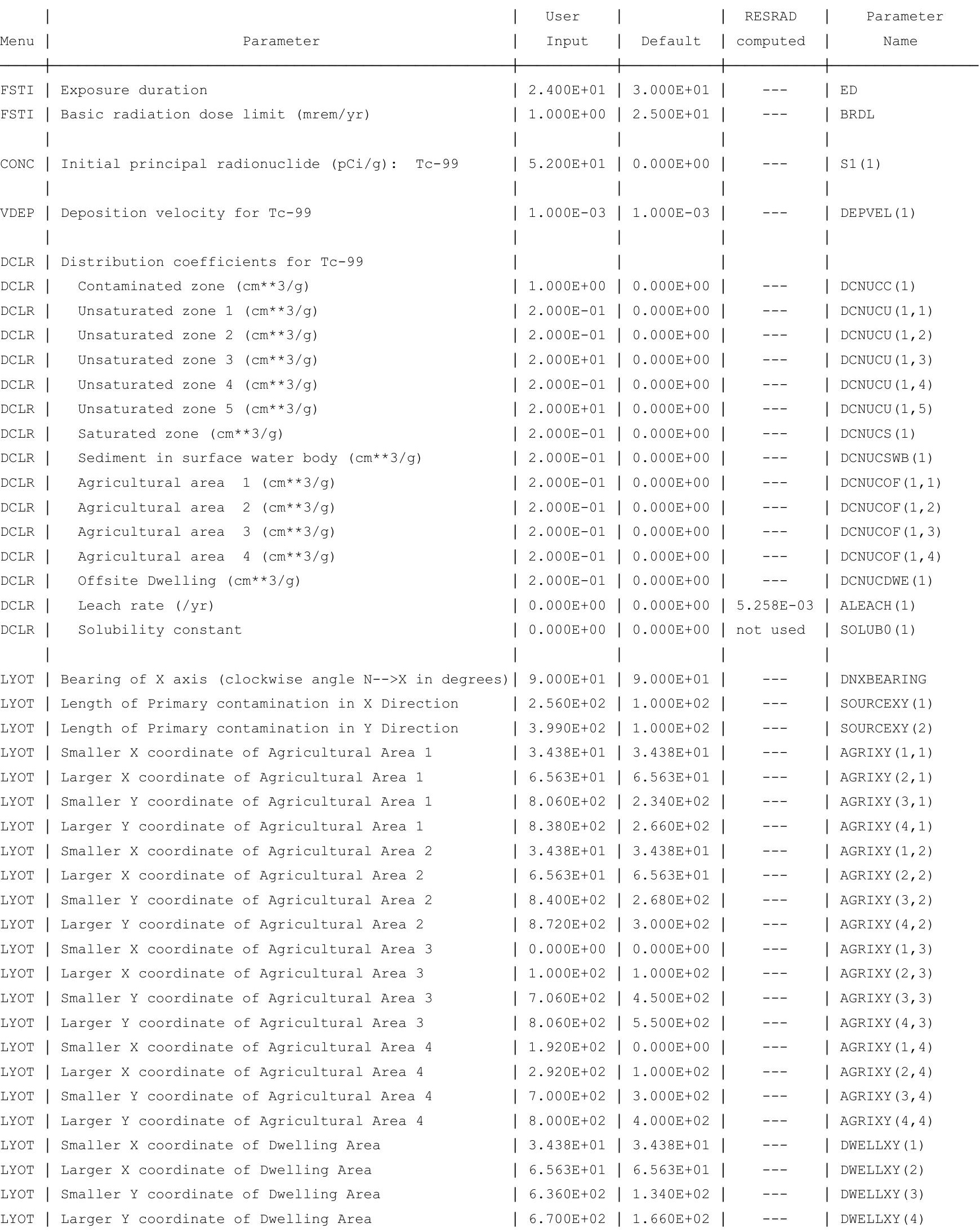


RESRAD-OFFSITE, Version 2.5

Parent Dose Report

Title : Offsite Resident Farmer Deterministic Run

File : RF TC99 DOESG FWD-FV2b.ROF

Site-Specific Parameter Summary (continued)

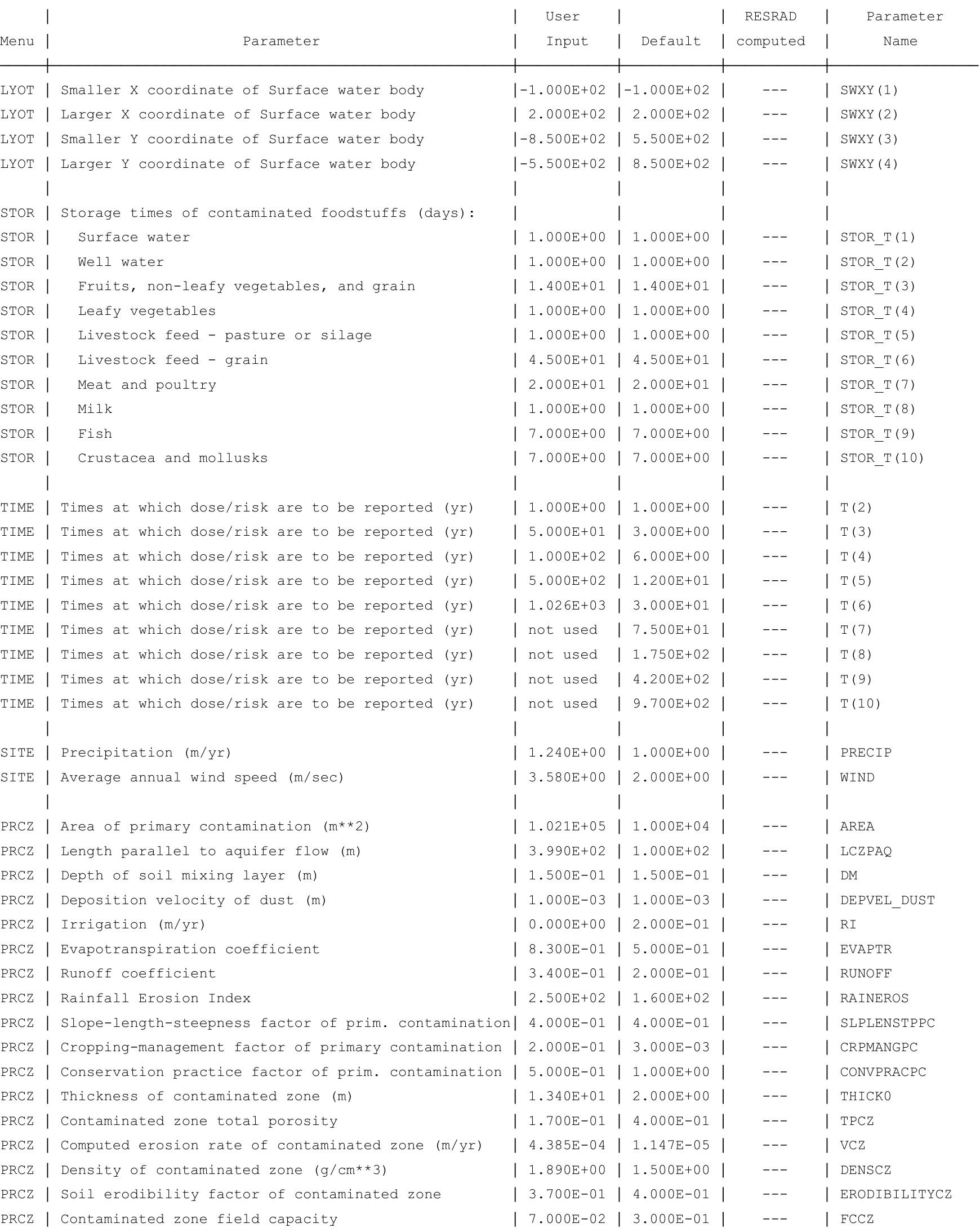


RESRAD-OFFSITE, Version 2.5

Parent Dose Report

Title : Offsite Resident Farmer Deterministic Run

File : RF TC99 DOESG FWD-FV2b.ROF

Site-Specific Parameter Summary (continued)

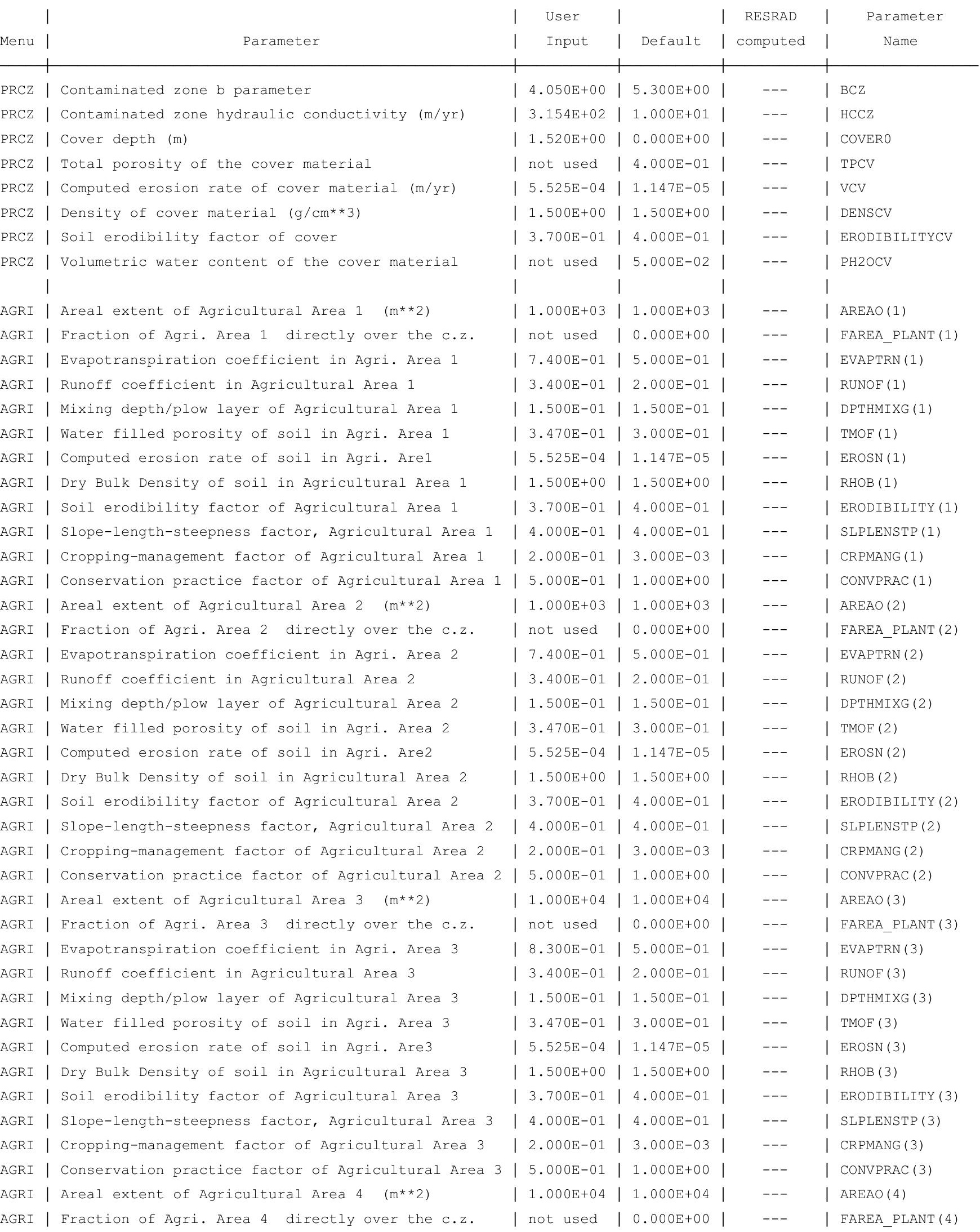


RESRAD-OFFSITE, Version 2.5

Parent Dose Report

Title : Offsite Resident Farmer Deterministic Run

File : RF TC99 DOESG FWD-FV2b.ROF

Site-Specific Parameter Summary (continued)

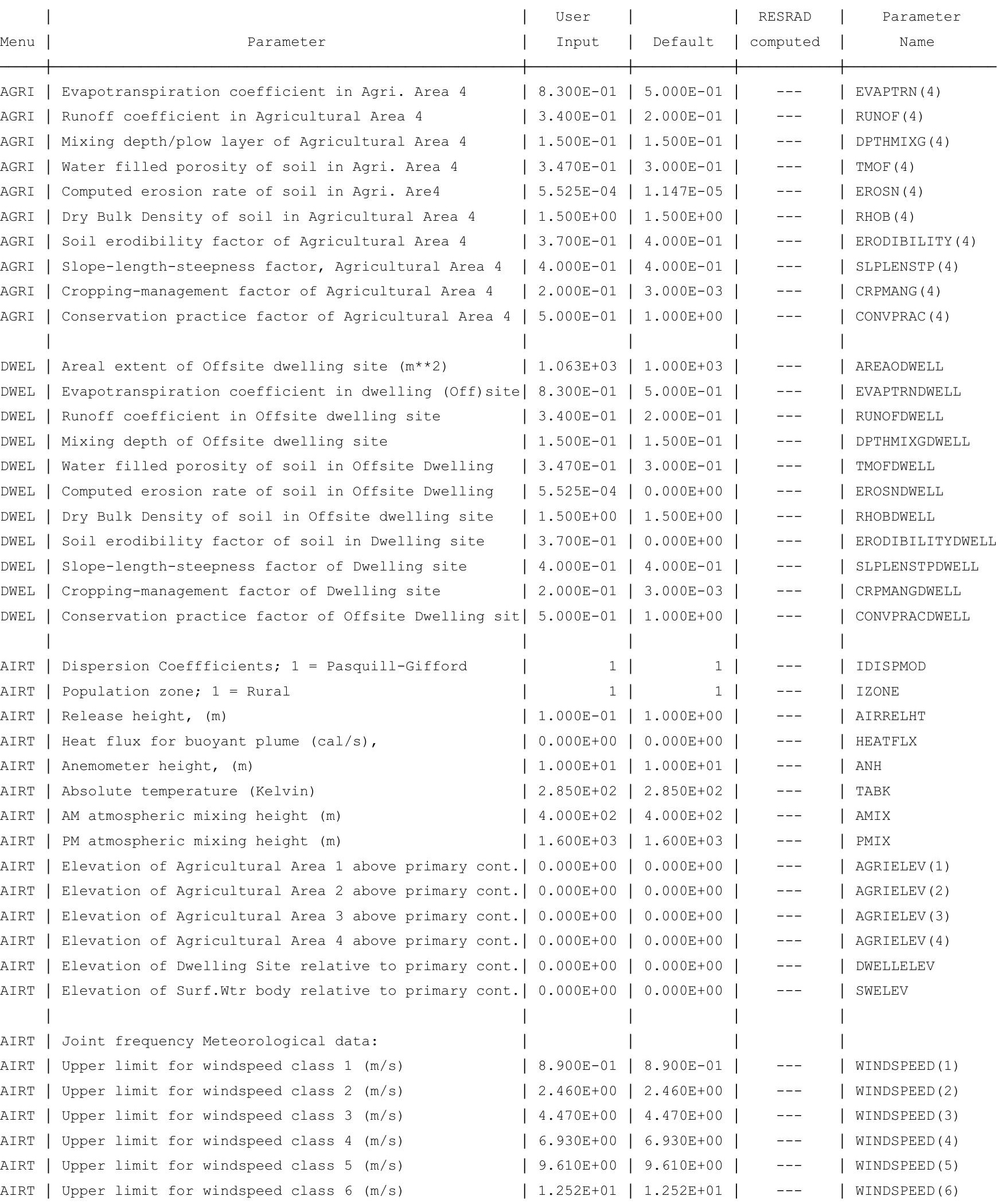


RESRAD-OFFSITE, Version 2.5

Parent Dose Report

Title : Offsite Resident Farmer Deterministic Run

File : RF TC99 DOESG FWD-FV2b.ROF

Site-Specific Parameter Summary (continued)

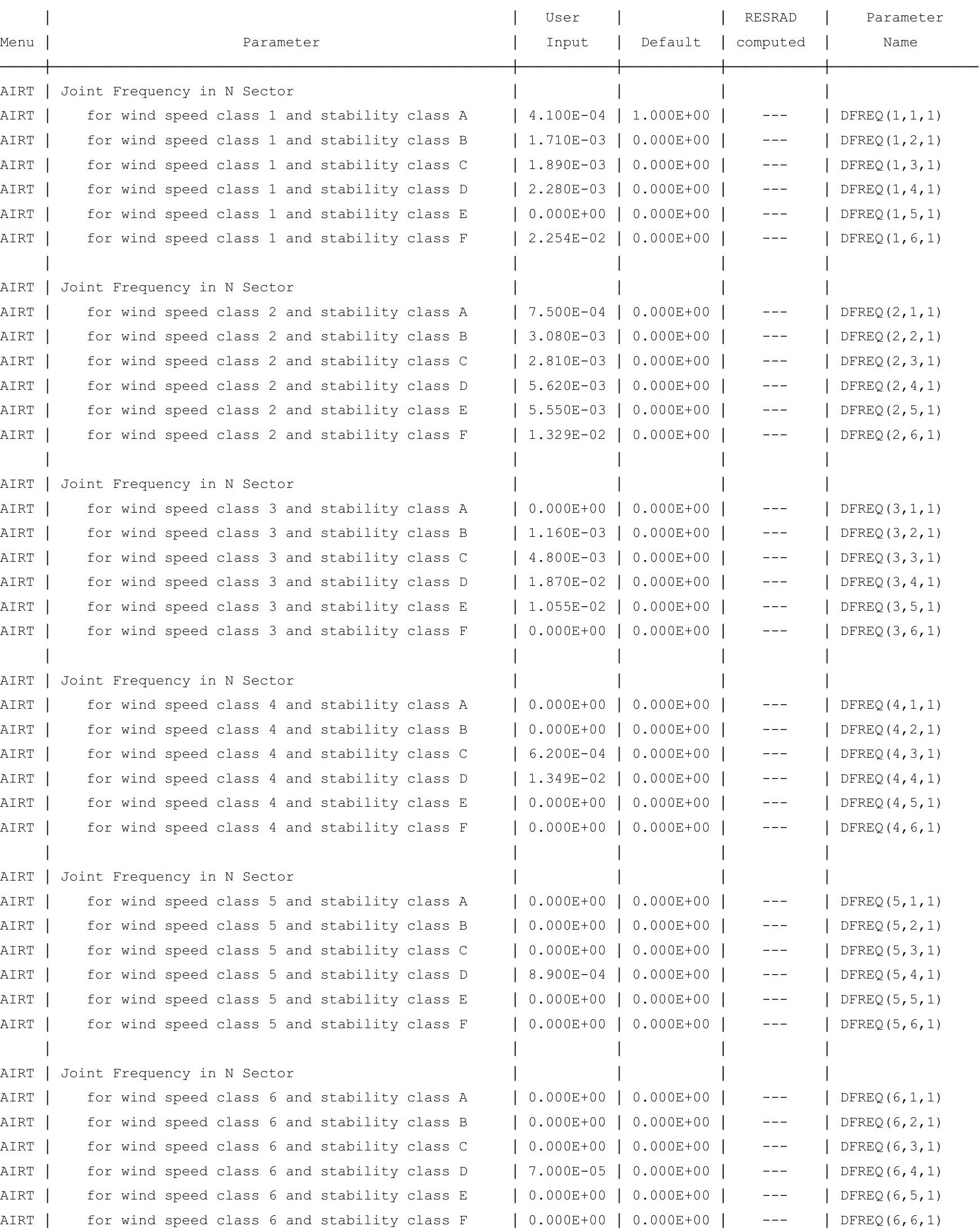


RESRAD-OFFSITE, Version 2.5

Parent Dose Report

Title : Offsite Resident Farmer Deterministic Run

File : RF TC99 DOESG FWD-FV2b.ROF

Site-Specific Parameter Summary (continued)

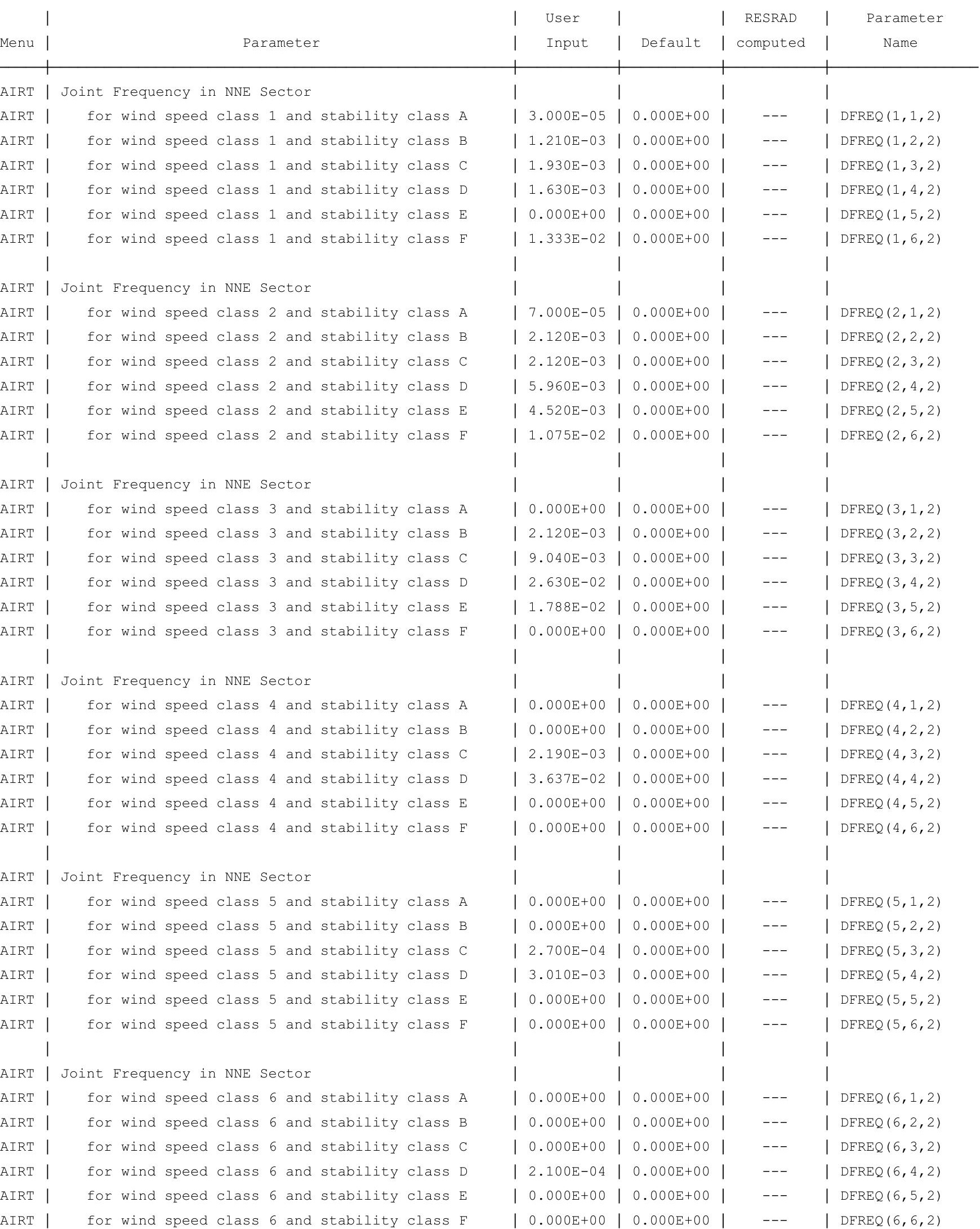


RESRAD-OFFSITE, Version 2.5

Parent Dose Report

Title : Offsite Resident Farmer Deterministic Run

File : RF TC99 DOESG FWD-FV2b.ROF

Site-Specific Parameter Summary (continued)

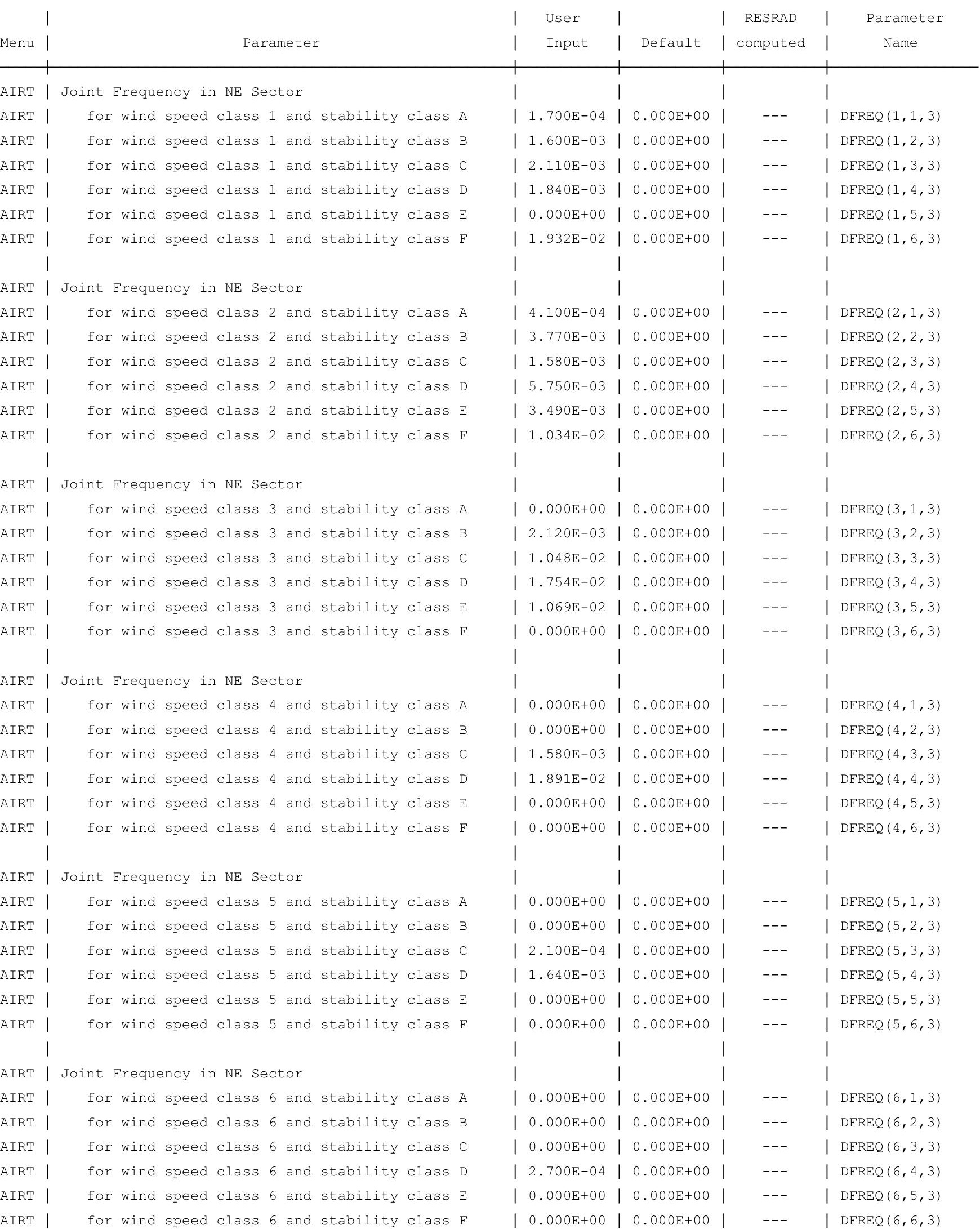


RESRAD-OFFSITE, Version 2.5

Parent Dose Report

Title : Offsite Resident Farmer Deterministic Run

File : RF TC99 DOESG FWD-FV2b.ROF

Site-Specific Parameter Summary (continued)

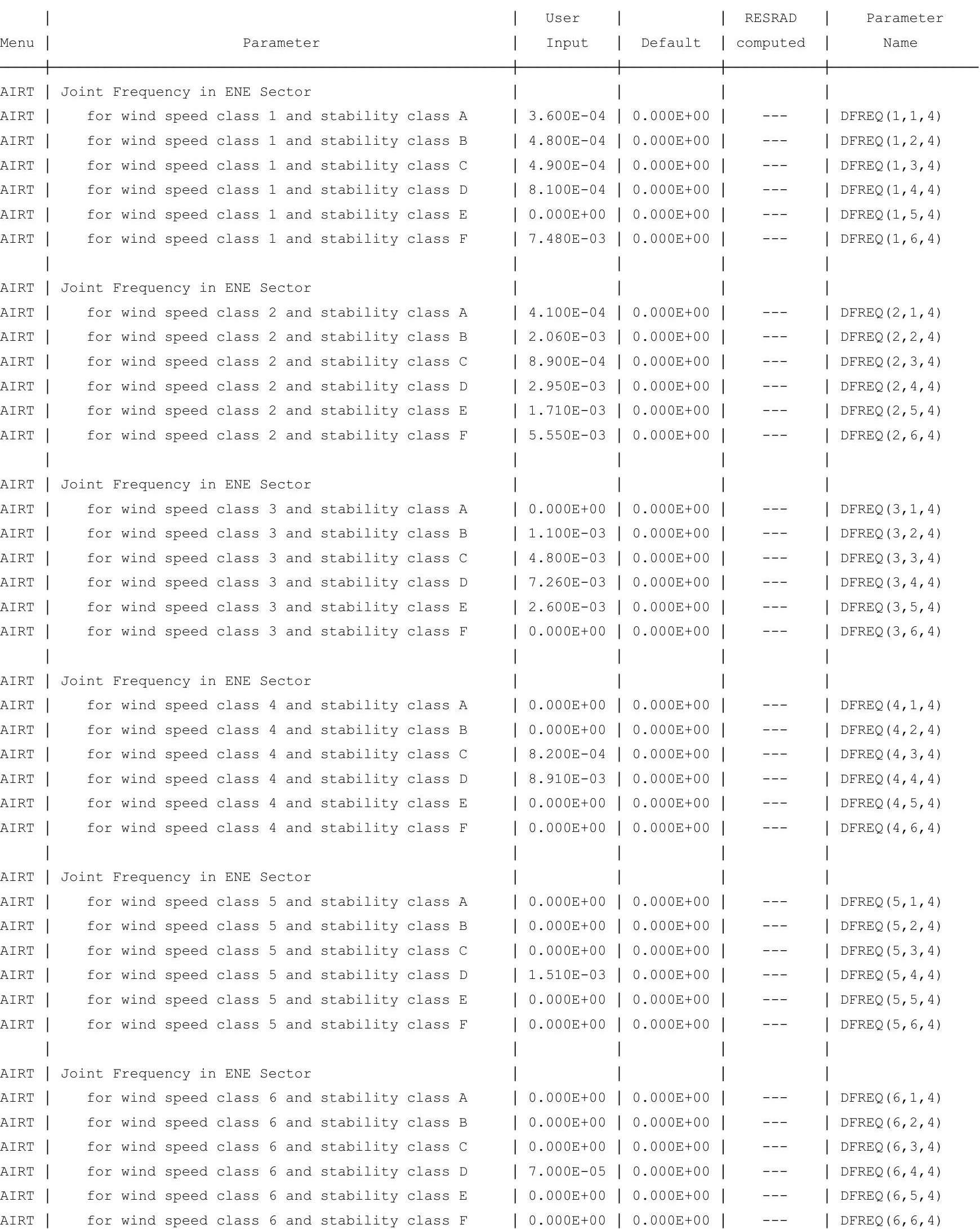


RESRAD-OFFSITE, Version 2.5

Parent Dose Report

Title : Offsite Resident Farmer Deterministic Run

File : RF TC99 DOESG FWD-FV2b.ROF

Site-Specific Parameter Summary (continued)

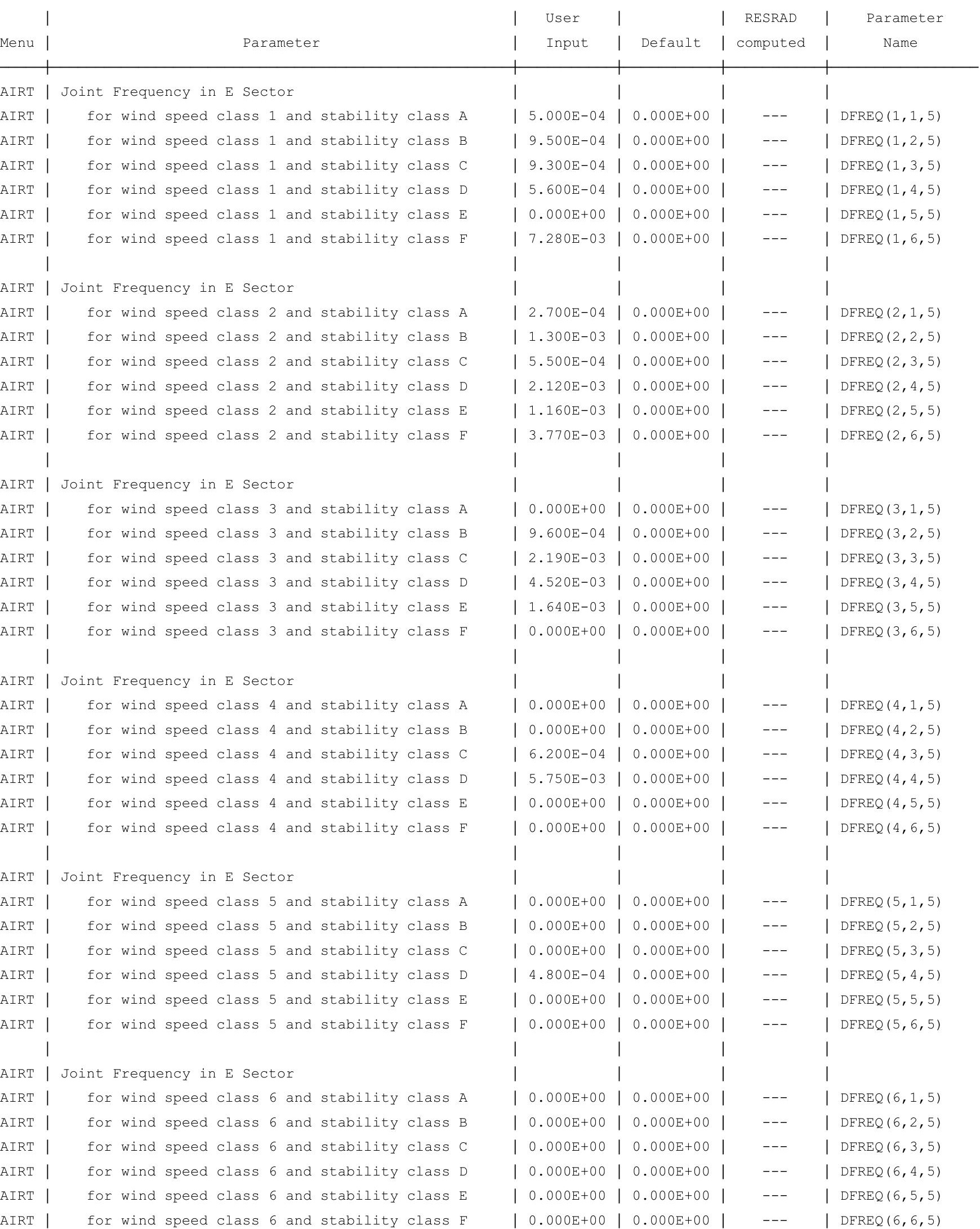


RESRAD-OFFSITE, Version 2.5

Parent Dose Report

Title : Offsite Resident Farmer Deterministic Run

File : RF TC99 DOESG FWD-FV2b.ROF

Site-Specific Parameter Summary (continued)

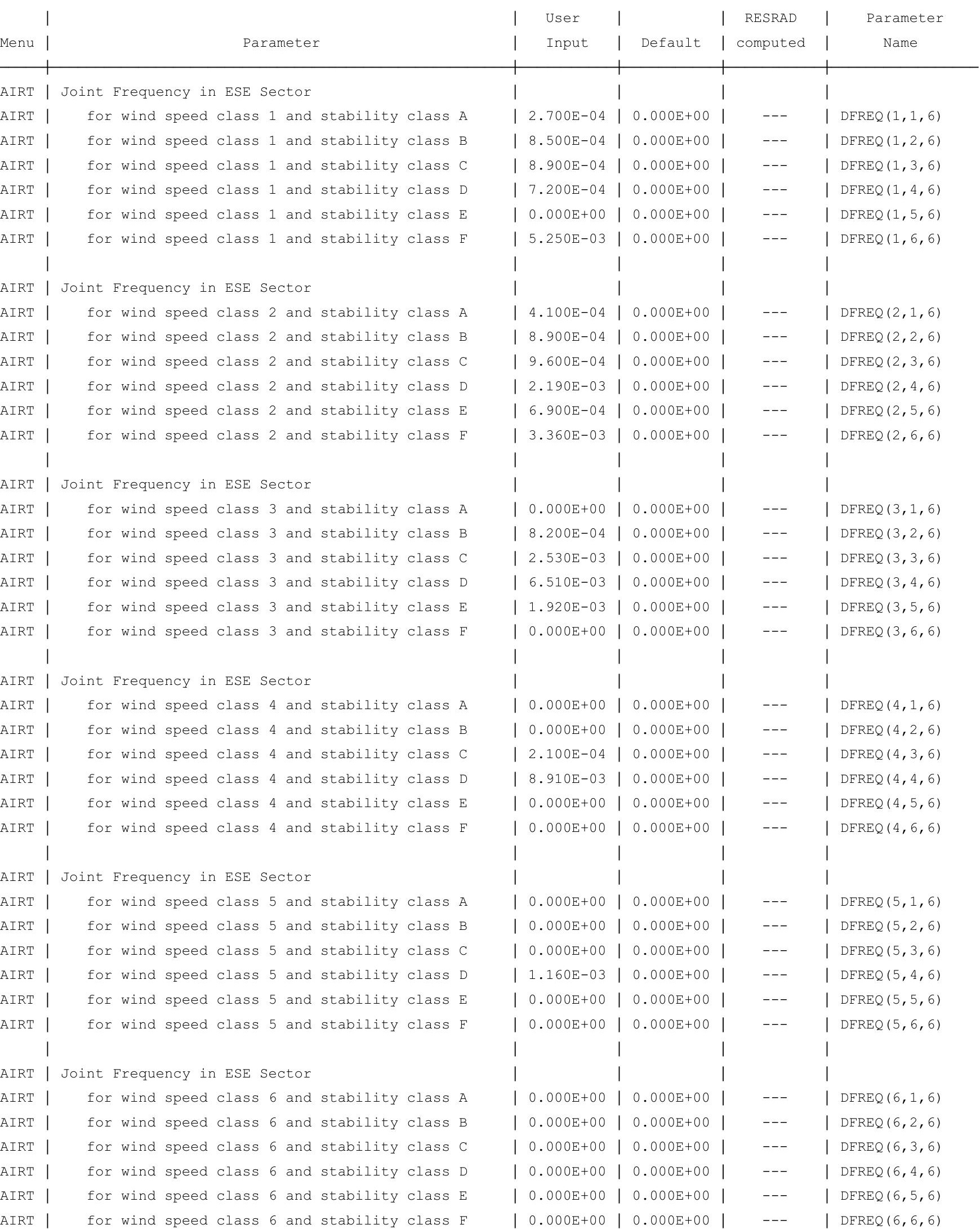


RESRAD-OFFSITE, Version 2.5

Parent Dose Report

Title : Offsite Resident Farmer Deterministic Run

File : RF TC99 DOESG FWD-FV2b.ROF

Site-Specific Parameter Summary (continued)

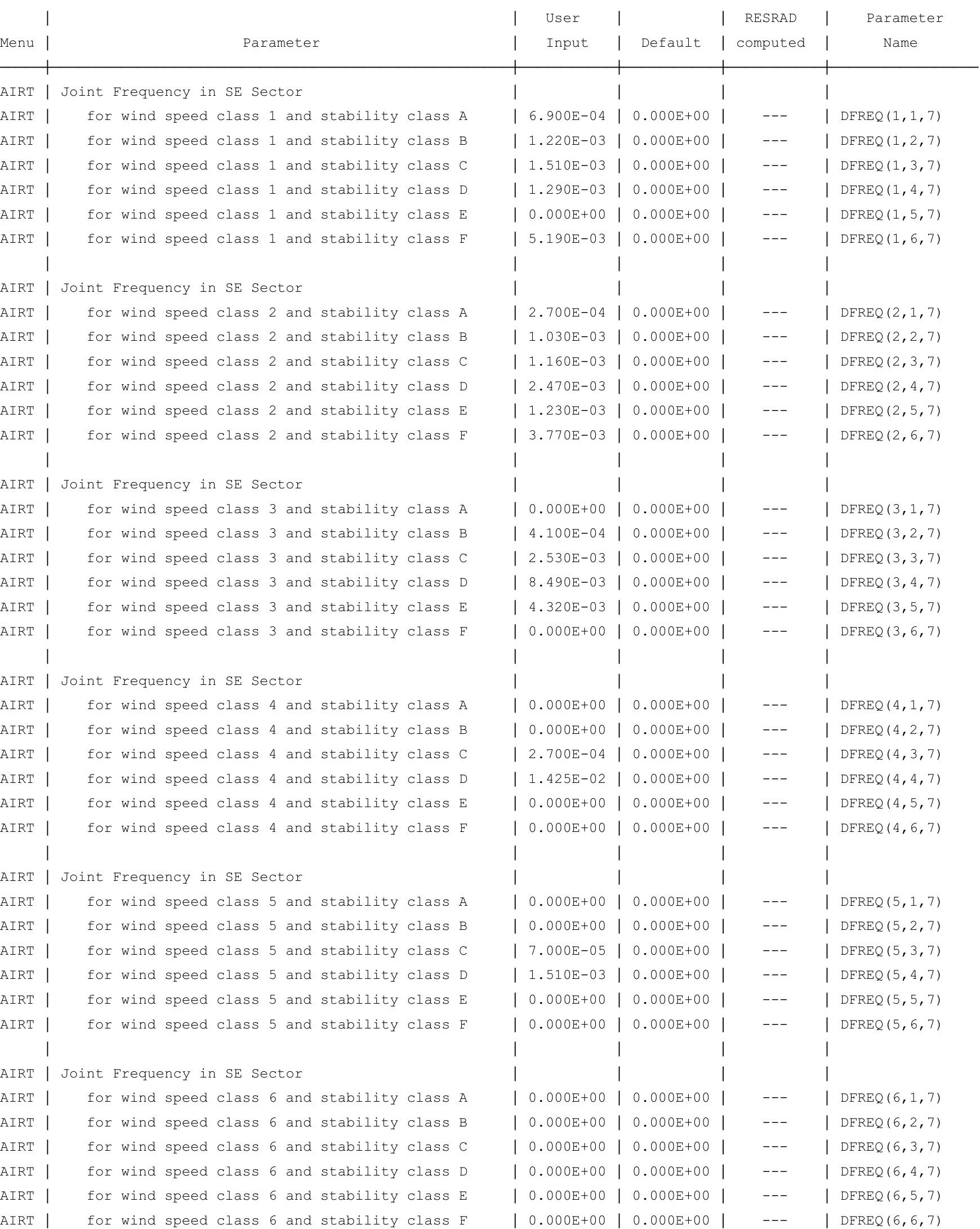


RESRAD-OFFSITE, Version 2.5

Parent Dose Report

Title : Offsite Resident Farmer Deterministic Run

File : RF TC99 DOESG FWD-FV2b.ROF

Site-Specific Parameter Summary (continued)

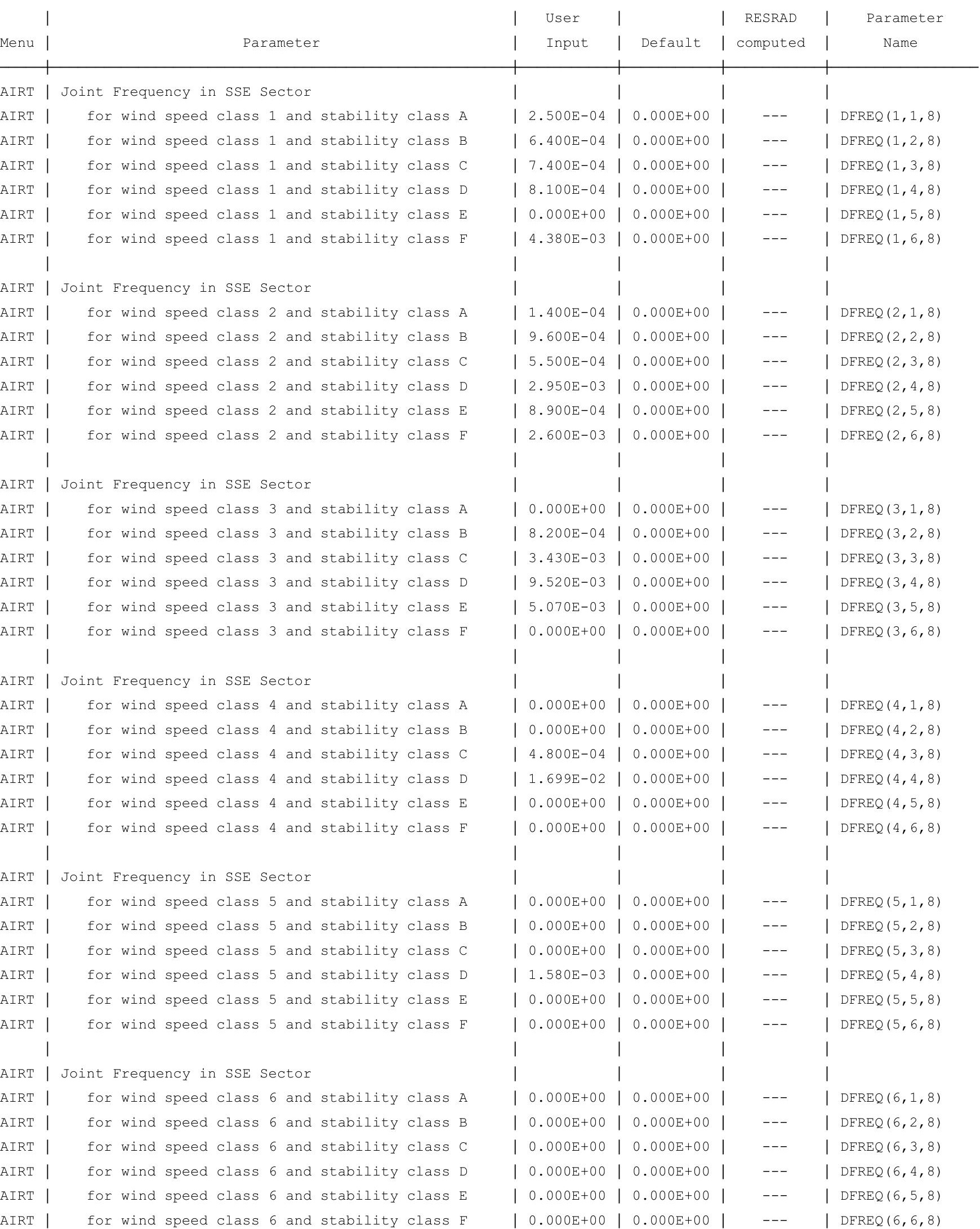


RESRAD-OFFSITE, Version 2.5

Parent Dose Report

Title : Offsite Resident Farmer Deterministic Run

File : RF TC99 DOESG FWD-FV2b.ROF

Site-Specific Parameter Summary (continued)

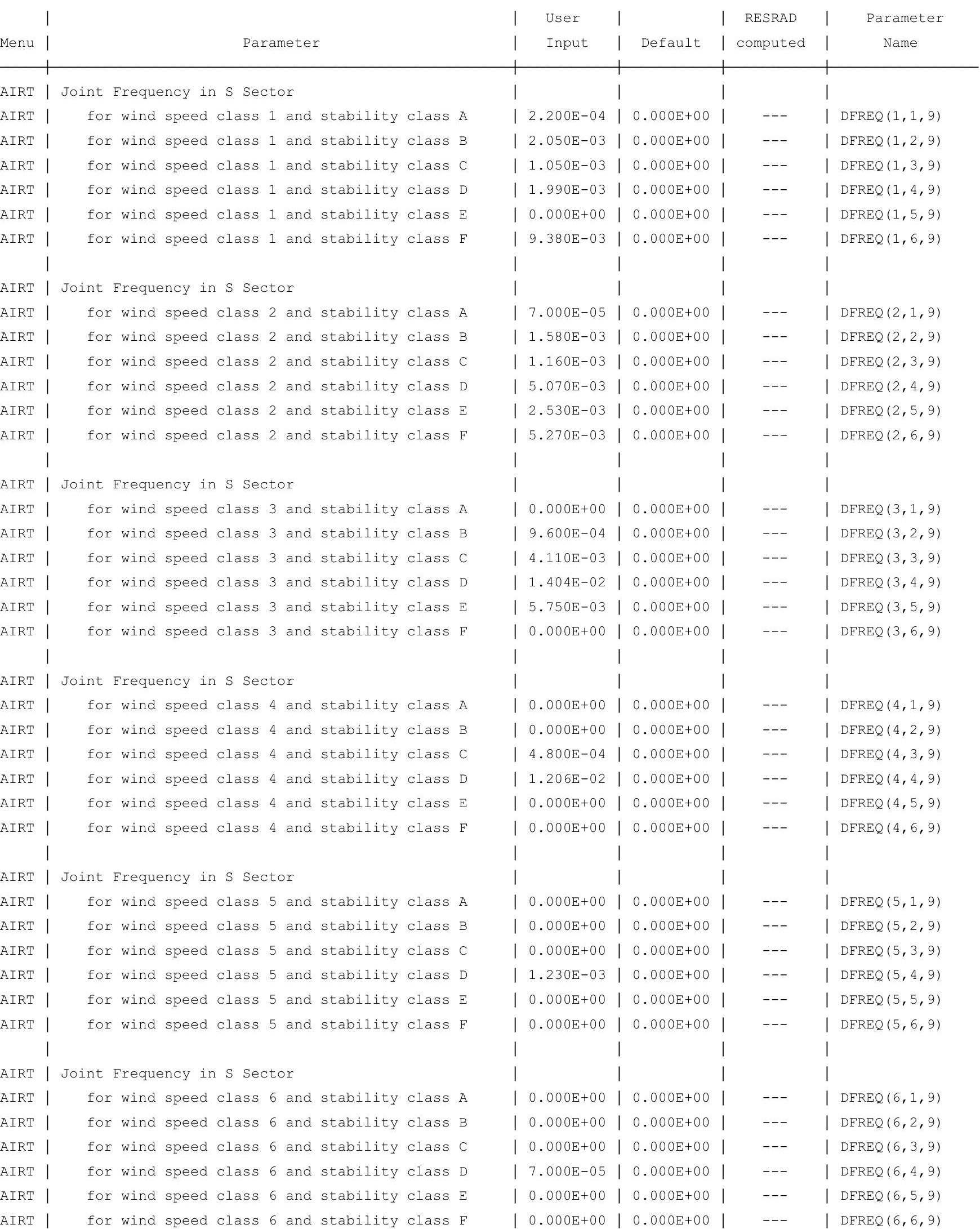


RESRAD-OFFSITE, Version 2.

Parent Dose Report

Title : Offsite Resident Farmer Deterministic Run

File : RF TC99 DOESG FWD-FV2b.ROF

Site-Specific Parameter Summary (continued)

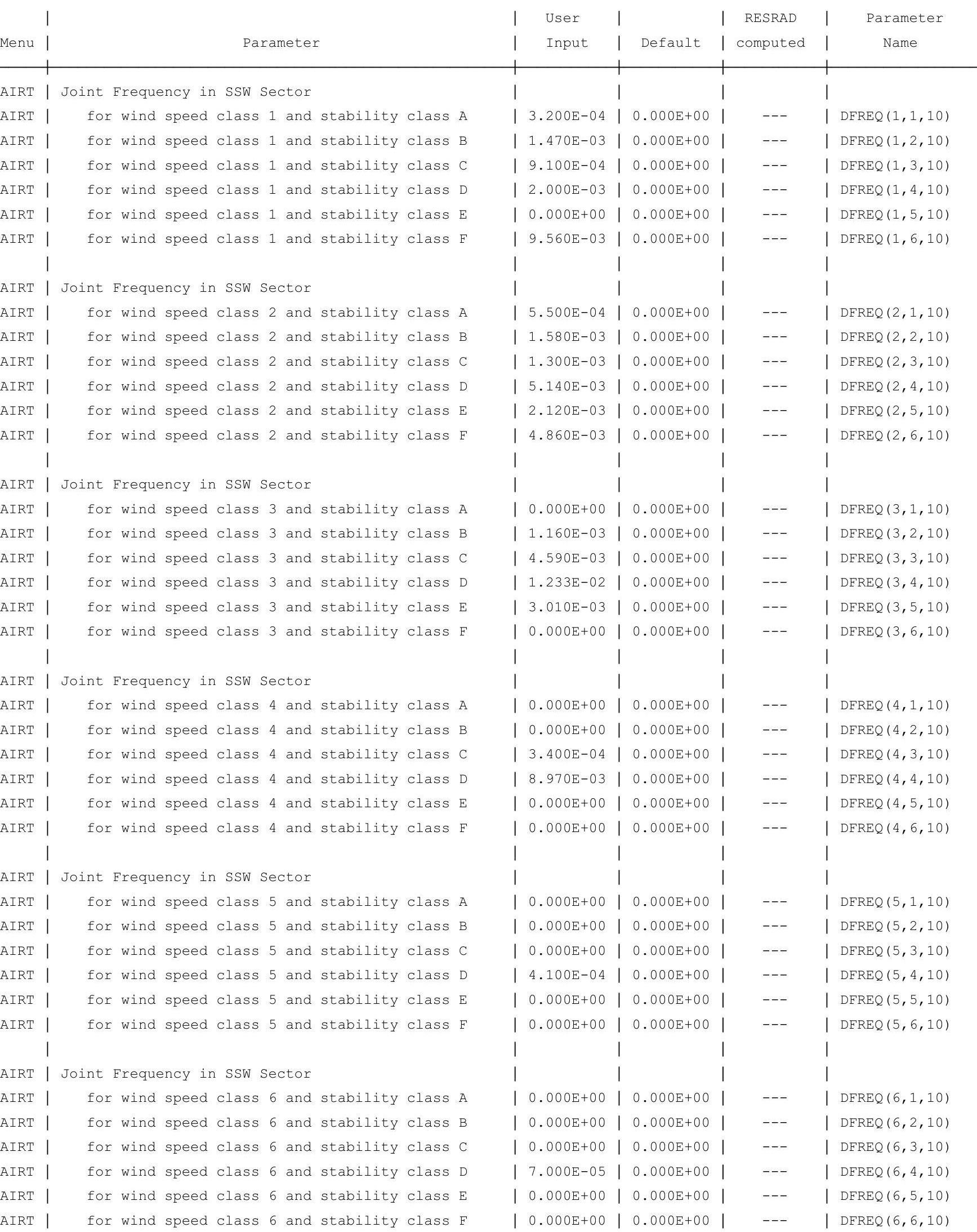


RESRAD-OFFSITE, Version 2.

Parent Dose Report

Title : Offsite Resident Farmer Deterministic Run

File : RF TC99 DOESG FWD-FV2b.ROF

Site-Specific Parameter Summary (continued)

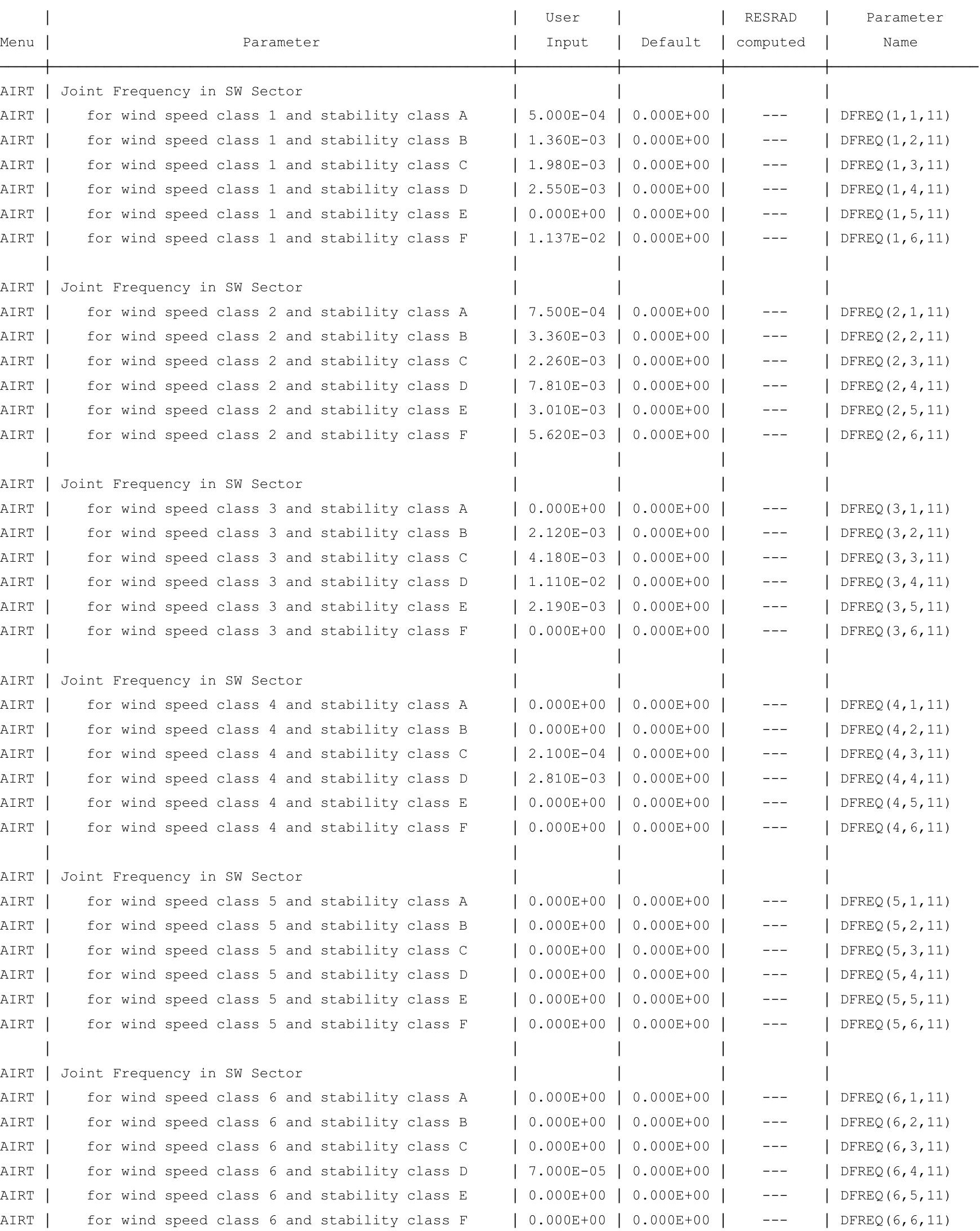


RESRAD-OFFSITE, Version 2.5

Parent Dose Report

Title : Offsite Resident Farmer Deterministic Run

File : RF TC99 DOESG FWD-FV2b.ROF

Site-Specific Parameter Summary (continued)

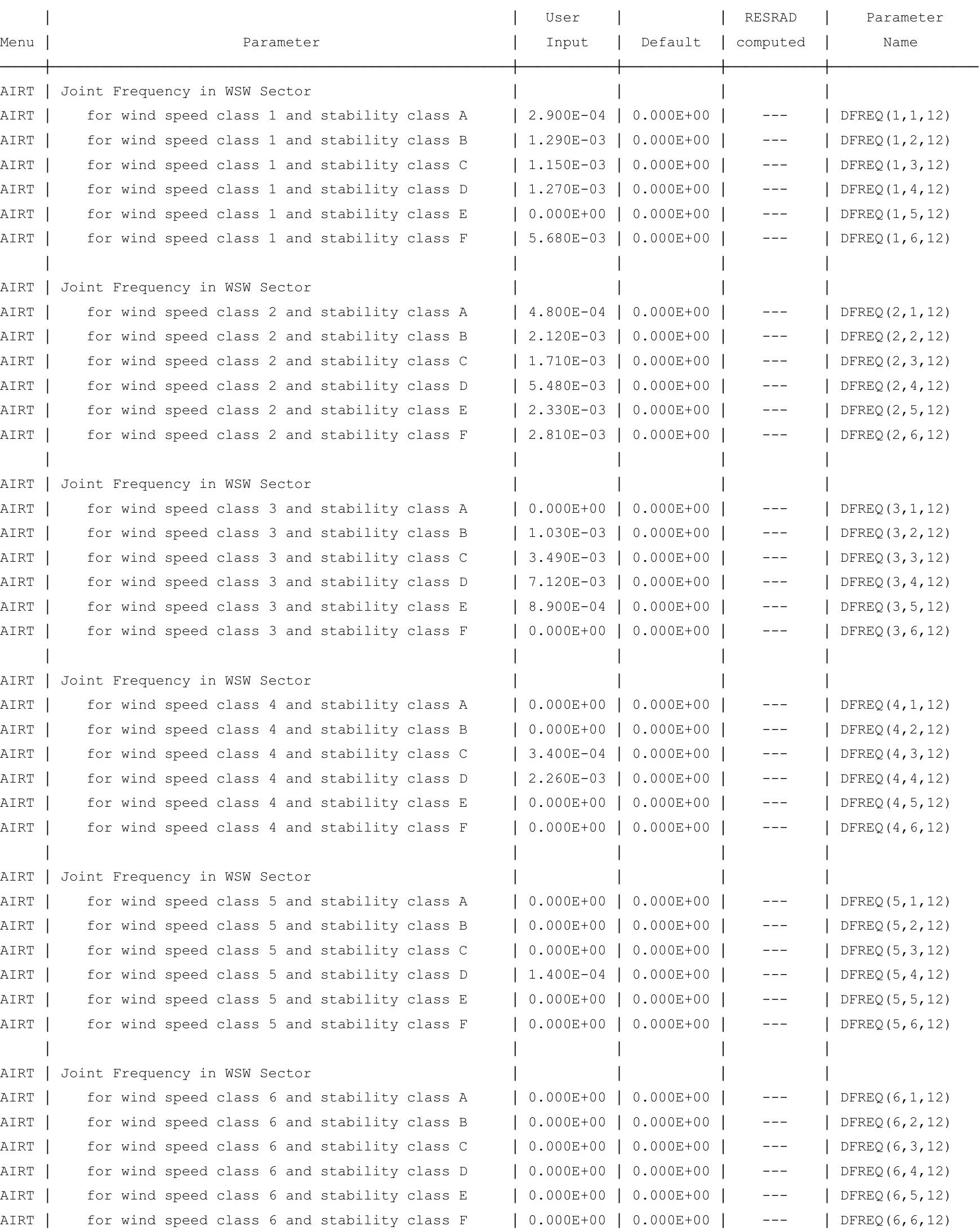


RESRAD-OFFSITE, Version 2.

Parent Dose Report

Title : Offsite Resident Farmer Deterministic Run

File : RF TC99 DOESG FWD-FV2b.ROF

Site-Specific Parameter Summary (continued)

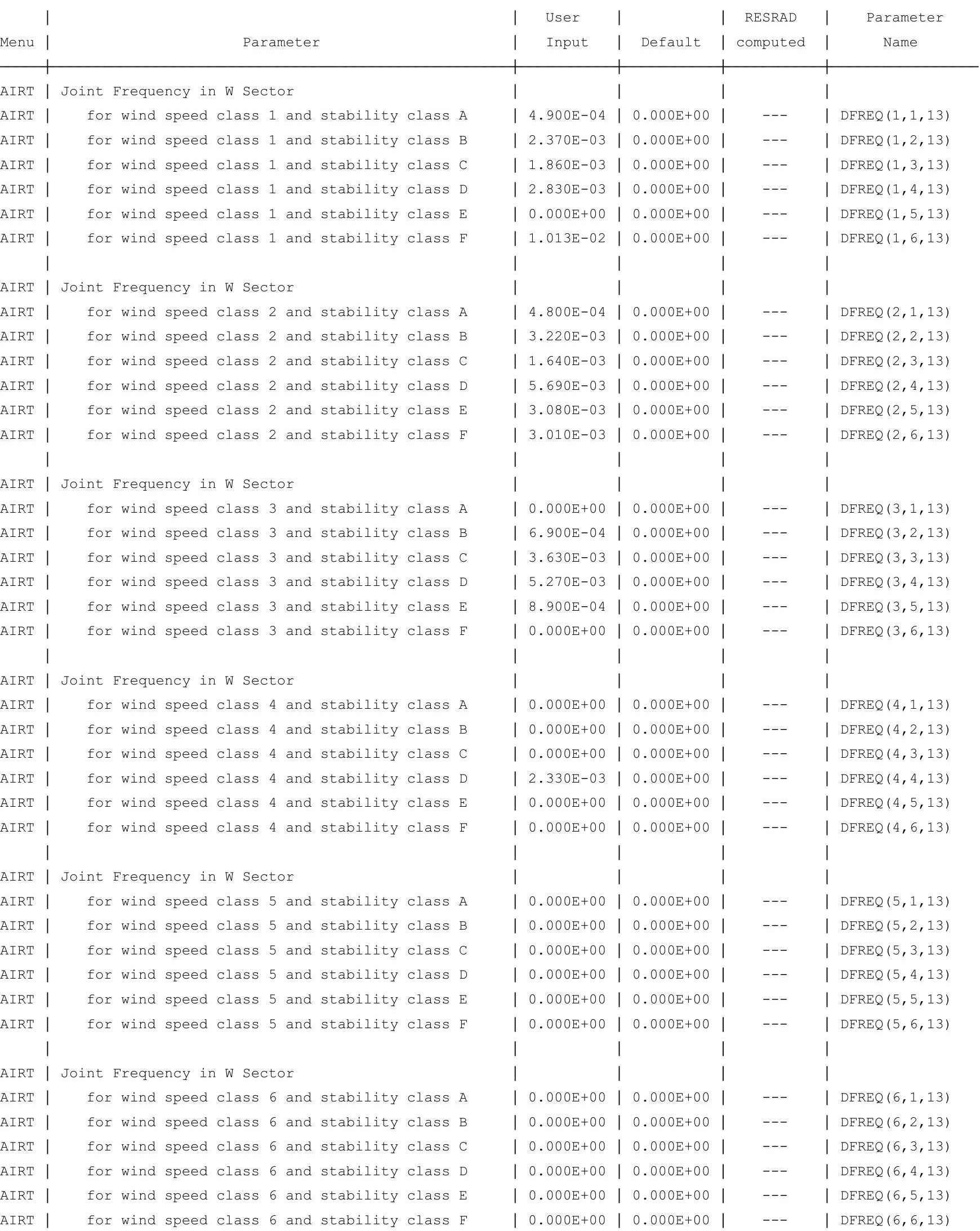


RESRAD-OFFSITE, Version 2.5

Parent Dose Report

Title : Offsite Resident Farmer Deterministic Run

File : RF TC99 DOESG FWD-FV2b.ROF

Site-Specific Parameter Summary (continued)

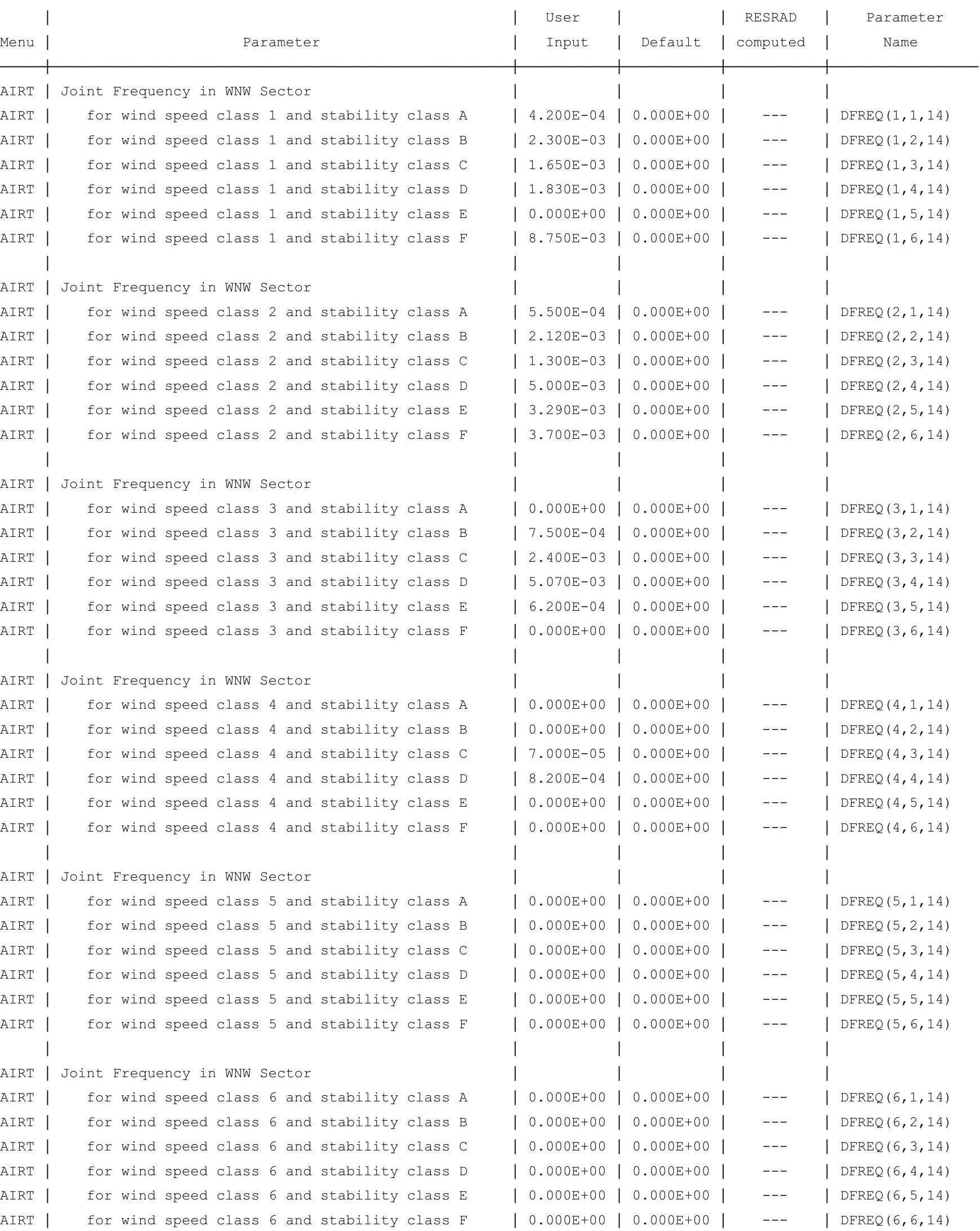


RESRAD-OFFSITE, Version 2.

Parent Dose Report

Title : Offsite Resident Farmer Deterministic Run

File : RF TC99 DOESG FWD-FV2b.ROF

Site-Specific Parameter Summary (continued)

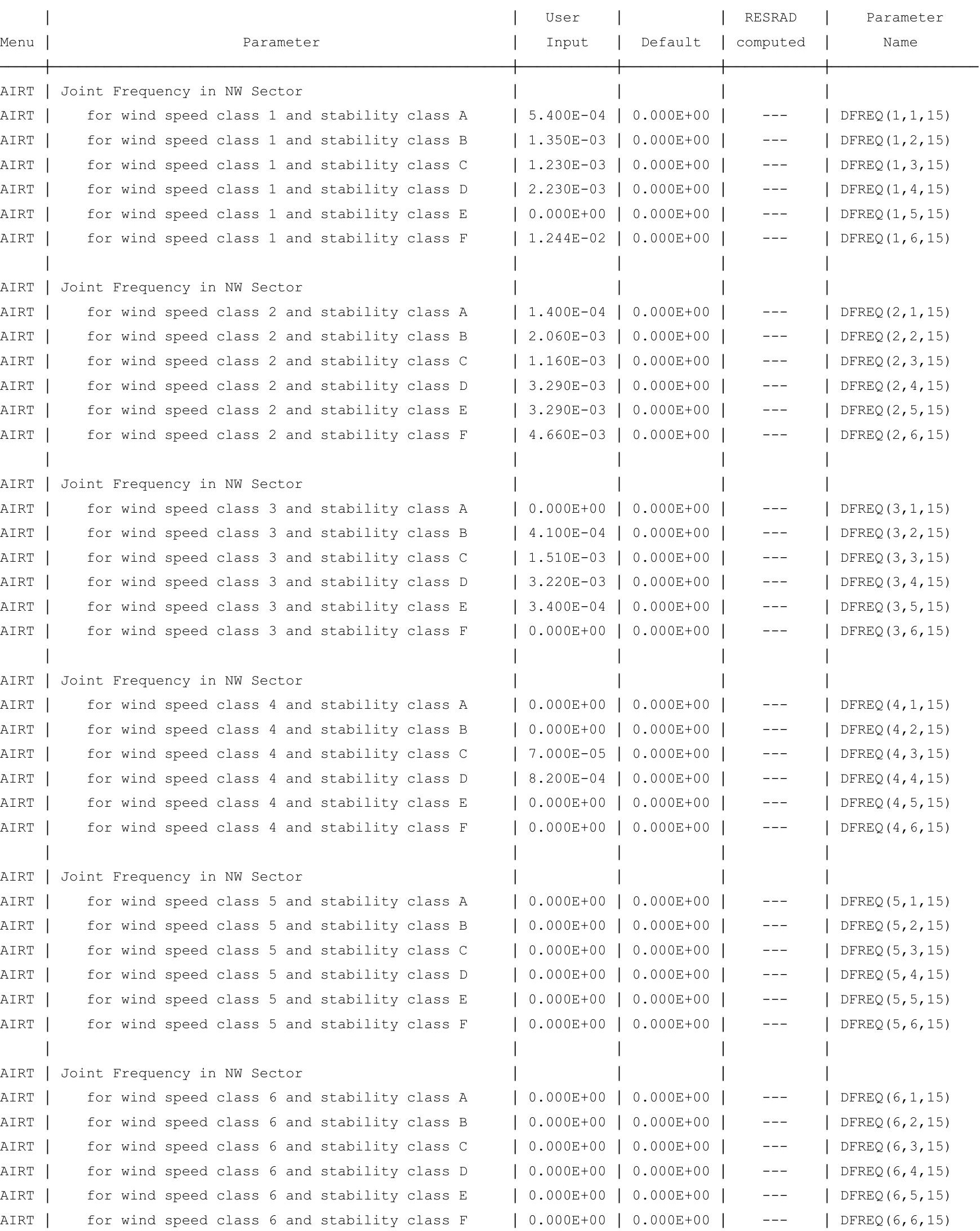


RESRAD-OFFSITE, Version 2.5

Parent Dose Report

Title : Offsite Resident Farmer Deterministic Run

File : RF TC99 DOESG FWD-FV2b.ROF

Site-Specific Parameter Summary (continued)

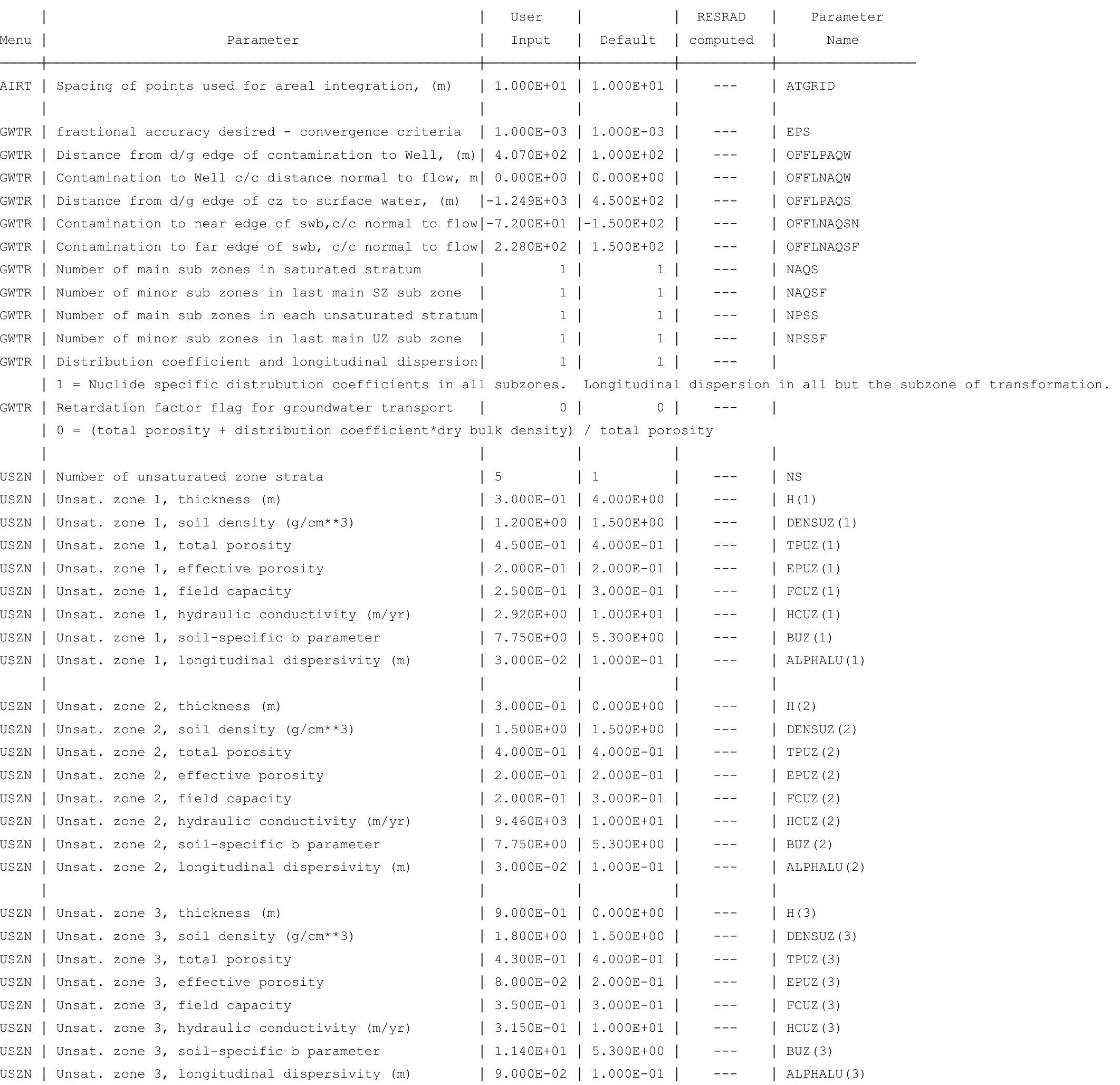


RESRAD-OFFSITE, Version 2.5

Parent Dose Report

Title : Offsite Resident Farmer Deterministic Run

File : RF TC99 DOESG FWD-FV2b.ROF

Site-Specific Parameter Summary (continued)

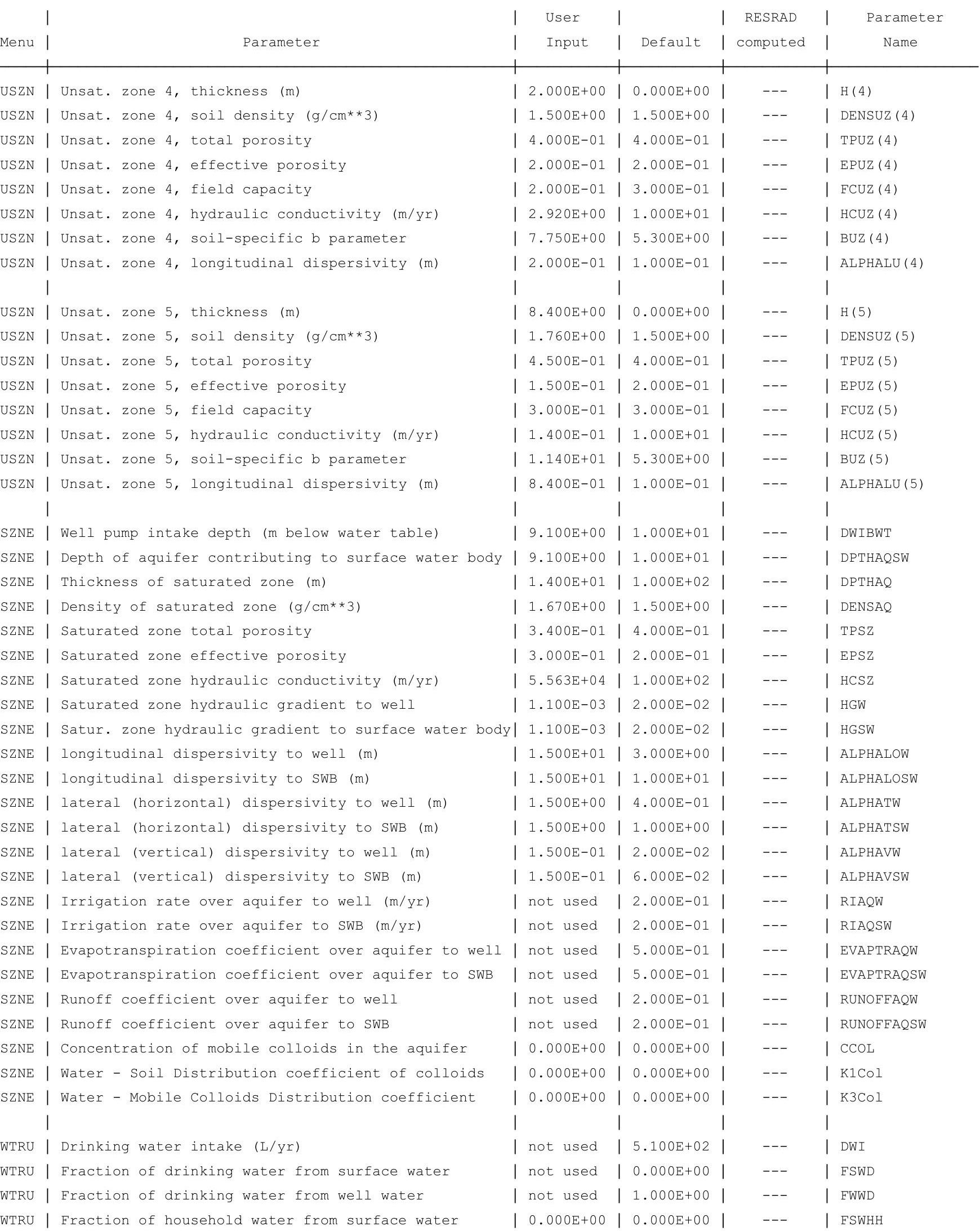


RESRAD-OFFSITE, Version 2.5

Parent Dose Report

Title : Offsite Resident Farmer Deterministic Run

File : RF TC99 DOESG FWD-FV2b.ROF

Site-Specific Parameter Summary (continued)

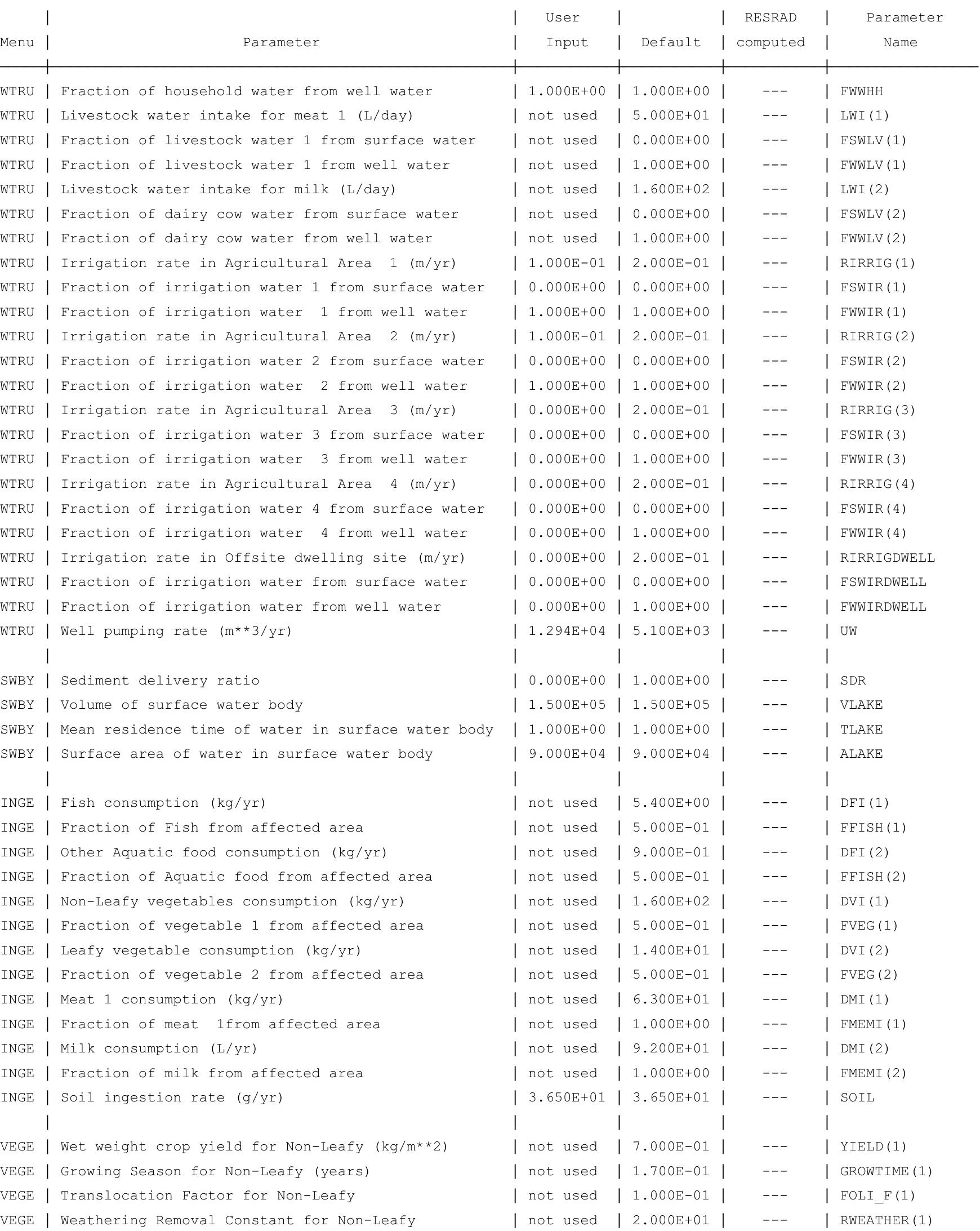


RESRAD-OFFSITE, Version 2.5

Parent Dose Report

Title : Offsite Resident Farmer Deterministic Run

File : RF TC99 DOESG FWD-FV2b.ROF

Site-Specific Parameter Summary (continued)

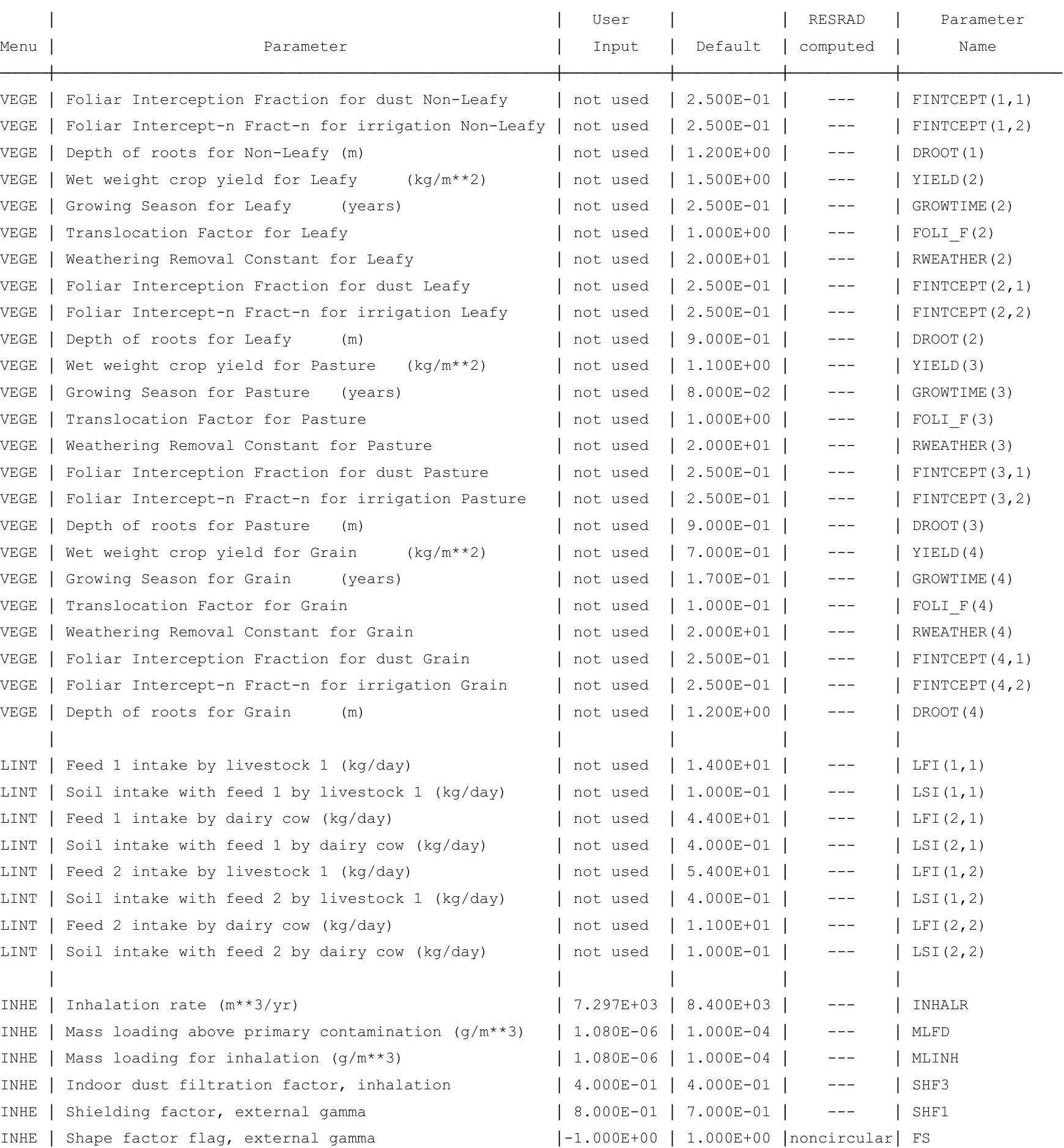


RESRAD-OFFSITE, Version $2.5 \quad \mathrm{~T}^{1 / 2}$ Limit $=180$ days

Parent Dose Report

Title : Offsite Resident Farmer Deterministic Run

File : RF TC99 DOESG FWD-FV2b.ROF

Site-Specific Parameter Summary (continued)

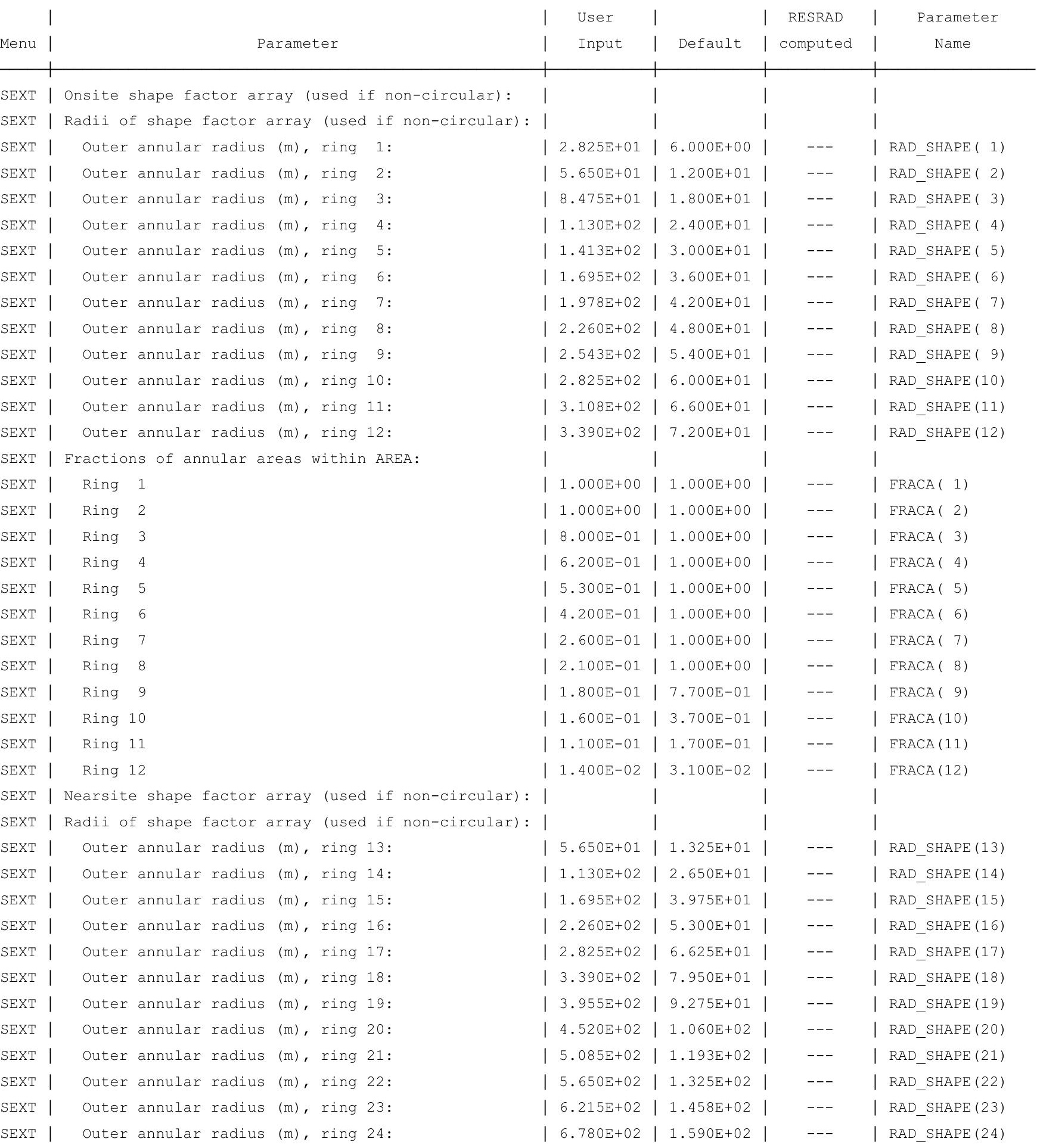


RESRAD-OFFSITE, Version 2.5

Parent Dose Report

Title : Offsite Resident Farmer Deterministic Run

File : RF TC99 DOESG FWD-FV2b.ROF

Site-Specific Parameter Summary (continued)

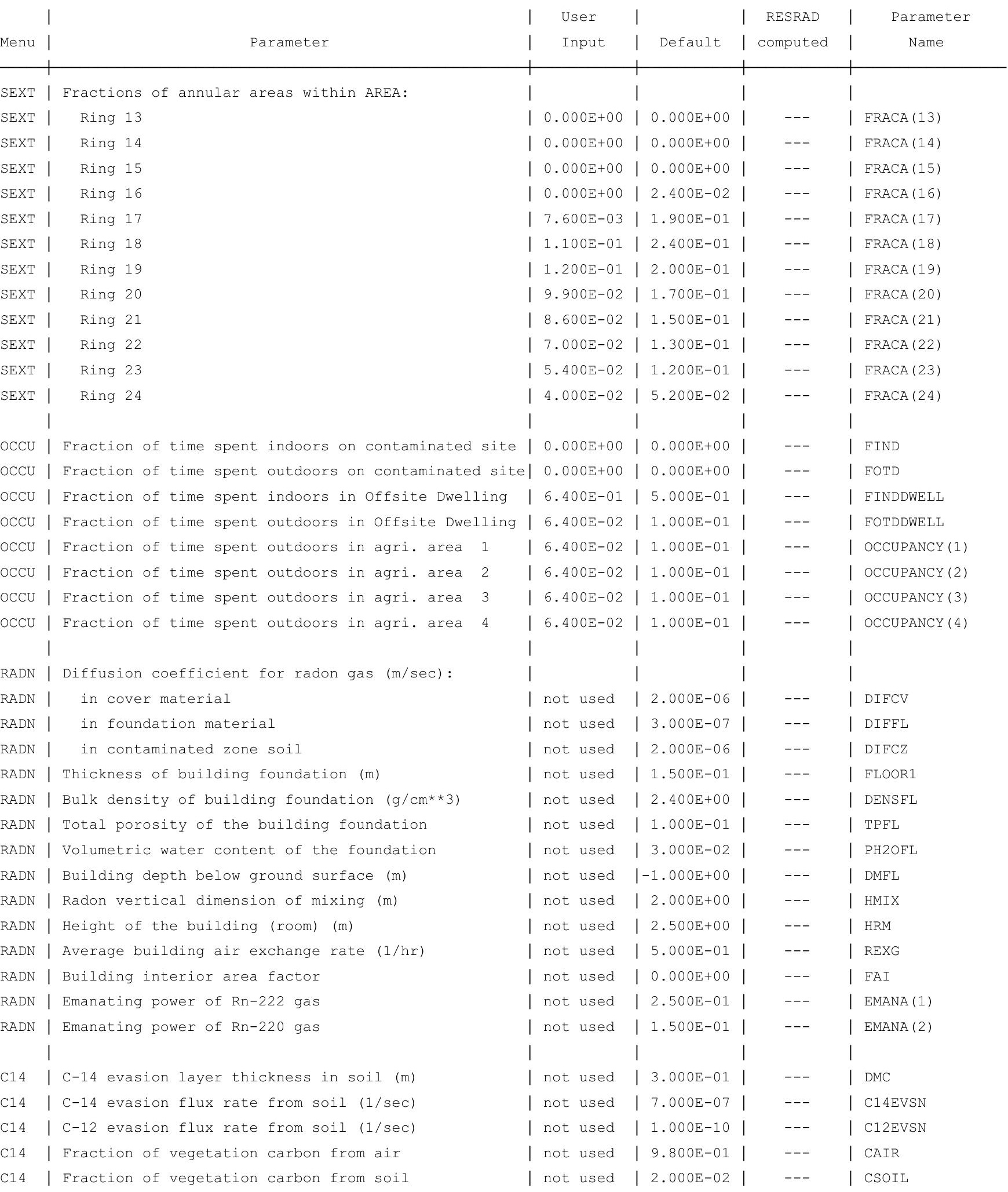


RESRAD-OFFSITE, Version 2.5

Parent Dose Report

Title : Offsite Resident Farmer Deterministic Run

File : RF TC99 DOESG FWD-FV2b.ROF

Site-Specific Parameter Summary (continued)

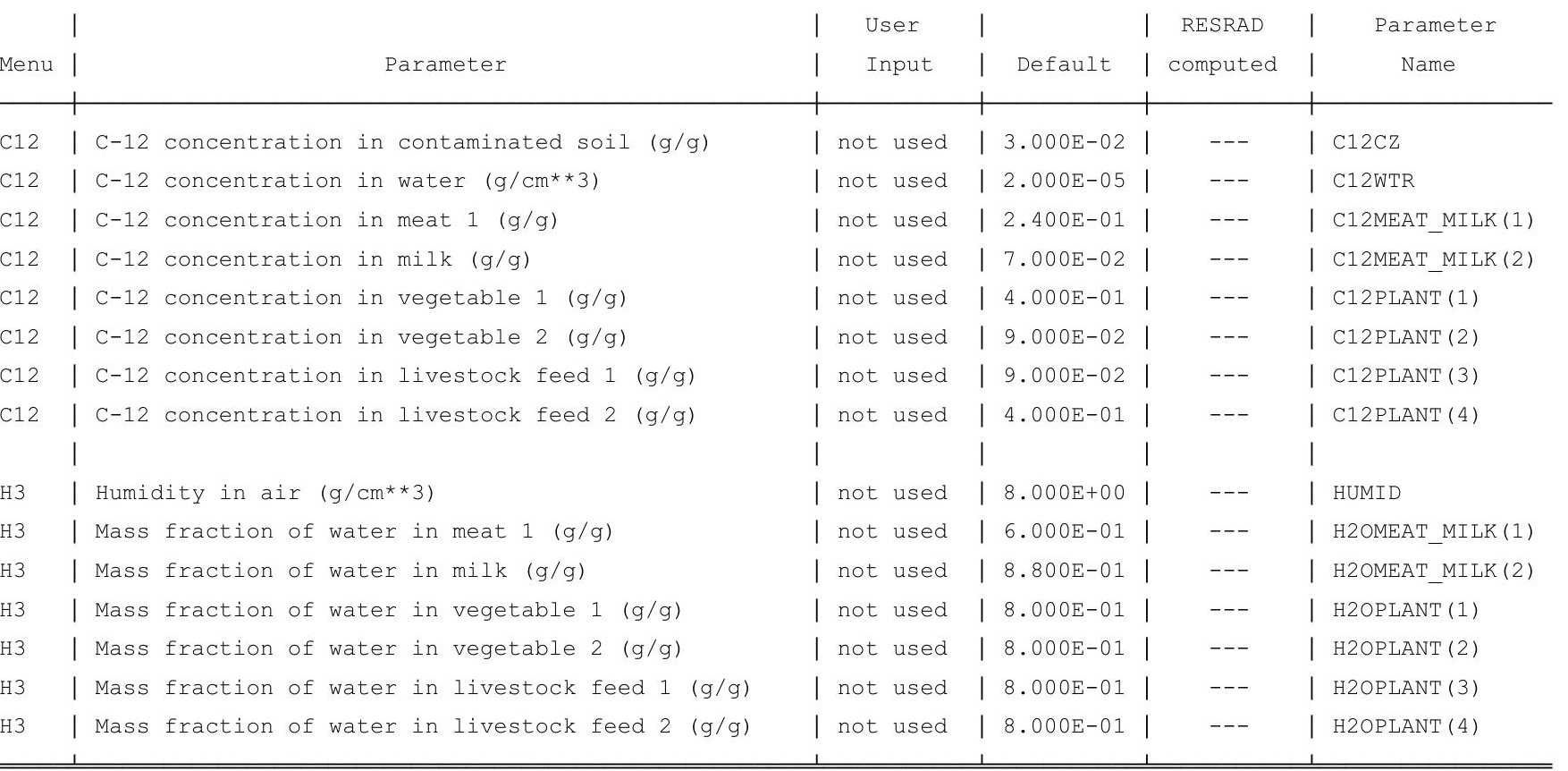

Summary of Pathway Selections

\begin{tabular}{|c|c|c|}
\hline & Pathway & | User Selection \\
\hline 1 & -- external gamma & active \\
\hline 2 & -- inhalation (w/o radon) & active \\
\hline 3 & -- plant ingestion & suppressed \\
\hline 4 & -- meat ingestion & suppressed \\
\hline 5 & -- milk ingestion & suppressed \\
\hline 6 & -- aquatic foods & suppressed \\
\hline 7 & -- drinking water & suppressed \\
\hline 8 & -- soil ingestion & active \\
\hline 9 & -- radon & suppressed \\
\hline
\end{tabular}


RESRAD-OFFSITE, Version $2.5 \quad \mathrm{~T}^{1 / 2}$ Limit $=180$ days

Parent Dose Report

Title : Offsite Resident Farmer Deterministic Run

File : RF TC99 DOESG FWD-FV2b.ROF

\section{Contaminated Zone Dimensions}

Area: 102144.00 square meters

Thickness: $\quad 13.40$ meters

Cover Depth: 1.52 meters

Total Dose TDOSE(t), mrem/yr

Basic Radiation Dose Limit $=1.000 \mathrm{E}+00 \mathrm{mrem} / \mathrm{yr}$

Total Mixture Sum $M(t)$ = Fraction of Basic Dose Limit Received at Time (t)

$\begin{array}{rllllll}t \text { (years) }: & 0.000 \mathrm{E}+00 & 1.000 \mathrm{E}+00 & 5.000 \mathrm{E}+01 & 1.000 \mathrm{E}+02 & 5.000 \mathrm{E}+02 & 1.026 \mathrm{E}+03 \\ \text { TDOSE }(\mathrm{t}): & 1.818 \mathrm{E}-32 & 1.840 \mathrm{E}-32 & 3.379 \mathrm{E}-32 & 6.282 \mathrm{E}-32 & 1.668 \mathrm{E}-06 & 2.423 \mathrm{E}-06 \\ \mathrm{M}(\mathrm{t}): & 1.818 \mathrm{E}-32 & 1.840 \mathrm{E}-32 & 3.379 \mathrm{E}-32 & 6.282 \mathrm{E}-32 & 1.668 \mathrm{E}-06 & 2.423 \mathrm{E}-06\end{array}$

Maximum TDOSE(t): $3.151 \mathrm{E}-06 \mathrm{mrem} / \mathrm{yr}$ at $t=772$ years 
RESRAD-OFFSITE, Version 2.5

Parent Dose Report

Title : Offsite Resident Farmer Deterministic Run

File : RF TC99 DOESG FWD-FV2b.ROF

Total Dose Contributions TDOSE(i,p,t) for Individual Radionuclides (i) and Pathways (p) in mrem/yr and as a Percentage of Total Dose at $t=0$ years

From releases to ground water and to surface water

\begin{tabular}{|c|c|c|c|c|c|c|c|c|c|c|c|c|c|c|c|}
\hline \multicolumn{2}{|c|}{ Ground } & \multicolumn{2}{|l|}{ Fish } & \multicolumn{2}{|c|}{ Radon } & \multicolumn{2}{|c|}{ Plant } & \multicolumn{2}{|l|}{ Meat } & \multicolumn{2}{|l|}{ Milk } & \multicolumn{2}{|l|}{ Soil } & \multicolumn{2}{|c|}{ Water } \\
\hline Dose & $\%$ & Dose & $\div$ & Dose & \% & Dose & $\%$ & Dose & $\div$ & Dose & 응 & Dose & $\%$ & Dose & 응 \\
\hline $0.00 E+00$ & 0 & $0.00 \mathrm{E}+00$ & 0 & $0.00 \mathrm{E}+00$ & 0 & $0.00 \mathrm{E}+00$ & 0 & $0.00 \mathrm{E}+00$ & 0 & $0.00 \mathrm{E}+00$ & 0 & $0.00 \mathrm{E}+00$ & 0 & $0.00 \mathrm{E}+00$ & 0 \\
\hline $0.00 \mathrm{E}+00$ & 0 & $0.00 \mathrm{E}+00$ & 0 & $0.00 \mathrm{E}+00$ & 0 & $0.00 \mathrm{E}+00$ & 0 & $0.00 \mathrm{E}+00$ & 0 & $0.00 \mathrm{E}+00$ & 0 & $0.00 \mathrm{E}+00$ & 0 & $0.00 \mathrm{E}+00$ & 0 \\
\hline
\end{tabular}

Total Dose Contributions TDOSE(i,p,t) for Individual Radionuclides (i) and Pathways (p)

in mrem/yr and as a Percentage of Total Dose at $t=0$ years

Directly from primary contamination and from release to atmosphere (Inhalation excludes radon)

\begin{tabular}{|c|c|c|c|c|c|c|c|c|c|c|c|c|c|c|c|c|}
\hline & \multicolumn{2}{|c|}{ Ground } & \multicolumn{2}{|c|}{ Inhalation } & \multicolumn{2}{|c|}{ Radon } & \multicolumn{2}{|c|}{ Plant } & \multicolumn{2}{|l|}{ Meat } & \multicolumn{2}{|l|}{ Milk } & \multicolumn{2}{|l|}{ Soil } & \multicolumn{2}{|c|}{ All Pathways* } \\
\hline uclide & Dose & $\%$ & Dose & $\%$ & Dose & $\%$ & Dose & 음 & Dose & $\%$ & Dose & \% & Dose & $\%$ & Dose & $\%$ \\
\hline-99 & $1.82 \mathrm{E}-32$ & 0 & $0.00 \mathrm{E}+00$ & 0 & $0.00 \mathrm{E}+00$ & 0 & $0.00 \mathrm{E}+00$ & 0 & $0.00 \mathrm{E}+00$ & 0 & $0.00 \mathrm{E}+00$ & 0 & $0.00 \mathrm{E}+00$ & 0 & 1. $82 \mathrm{E}-32$ & 0 \\
\hline :al & $1.82 \mathrm{E}-32$ & 0 & $0.00 \mathrm{E}+00$ & 0 & $0.00 \mathrm{E}+00$ & 0 & $0.00 \mathrm{E}+00$ & 0 & $0.00 \mathrm{E}+00$ & 0 & $0.00 \mathrm{E}+00$ & 0 & $0.00 \mathrm{E}+00$ & 0 & $1.82 \mathrm{E}-32$ & 0 \\
\hline
\end{tabular}

* Sum of dose from all releases and from primary contamination. 
RESRAD-OFFSITE, Version 2.5

Parent Dose Report

Title : Offsite Resident Farmer Deterministic Run

File : RF TC99 DOESG FWD-FV2b.ROF

Total Dose Contributions TDOSE(i,p,t) for Individual Radionuclides (i) and Pathways (p) in mrem/yr and as a Percentage of Total Dose at $t=1$ years

From releases to ground water and to surface water

\begin{tabular}{|c|c|c|c|c|c|c|c|c|c|c|c|c|c|c|c|}
\hline \multicolumn{2}{|c|}{ Ground } & \multicolumn{2}{|l|}{ Fish } & \multicolumn{2}{|c|}{ Radon } & \multicolumn{2}{|c|}{ Plant } & \multicolumn{2}{|l|}{ Meat } & \multicolumn{2}{|l|}{ Milk } & \multicolumn{2}{|l|}{ Soil } & \multicolumn{2}{|c|}{ Water } \\
\hline Dose & $\%$ & Dose & $\div$ & Dose & \% & Dose & $\%$ & Dose & $\div$ & Dose & 응 & Dose & $\%$ & Dose & 응 \\
\hline $0.00 E+00$ & 0 & $0.00 \mathrm{E}+00$ & 0 & $0.00 \mathrm{E}+00$ & 0 & $0.00 \mathrm{E}+00$ & 0 & $0.00 \mathrm{E}+00$ & 0 & $0.00 \mathrm{E}+00$ & 0 & $0.00 \mathrm{E}+00$ & 0 & $0.00 \mathrm{E}+00$ & 0 \\
\hline $0.00 \mathrm{E}+00$ & 0 & $0.00 \mathrm{E}+00$ & 0 & $0.00 \mathrm{E}+00$ & 0 & $0.00 \mathrm{E}+00$ & 0 & $0.00 \mathrm{E}+00$ & 0 & $0.00 \mathrm{E}+00$ & 0 & $0.00 \mathrm{E}+00$ & 0 & $0.00 \mathrm{E}+00$ & 0 \\
\hline
\end{tabular}

Total Dose Contributions TDOSE(i,p,t) for Individual Radionuclides (i) and Pathways (p)

in mrem/yr and as a Percentage of Total Dose at $t=1$ years

Directly from primary contamination and from release to atmosphere (Inhalation excludes radon)

\begin{tabular}{|c|c|c|c|c|c|c|c|c|c|c|c|c|c|c|c|c|}
\hline & \multicolumn{2}{|c|}{ Ground } & \multicolumn{2}{|c|}{ Inhalation } & \multicolumn{2}{|c|}{ Radon } & \multicolumn{2}{|c|}{ Plant } & \multicolumn{2}{|l|}{ Meat } & \multicolumn{2}{|l|}{ Milk } & \multicolumn{2}{|l|}{ Soil } & \multicolumn{2}{|c|}{ All Pathways* } \\
\hline uclide & Dose & $\%$ & Dose & $\%$ & Dose & $\%$ & Dose & 음 & Dose & $\%$ & Dose & \% & Dose & $\%$ & Dose & $\%$ \\
\hline-99 & $1.84 \mathrm{E}-32$ & 0 & $0.00 \mathrm{E}+00$ & 0 & $0.00 \mathrm{E}+00$ & 0 & $0.00 \mathrm{E}+00$ & 0 & $0.00 \mathrm{E}+00$ & 0 & $0.00 \mathrm{E}+00$ & 0 & $0.00 \mathrm{E}+00$ & 0 & $1.84 \mathrm{E}-32$ & 0 \\
\hline :al & $1.84 \mathrm{E}-32$ & 0 & $0.00 \mathrm{E}+00$ & 0 & $0.00 \mathrm{E}+00$ & 0 & $0.00 \mathrm{E}+00$ & 0 & $0.00 \mathrm{E}+00$ & 0 & $0.00 \mathrm{E}+00$ & 0 & $0.00 \mathrm{E}+00$ & 0 & $1.84 \mathrm{E}-32$ & 0 \\
\hline
\end{tabular}

* Sum of dose from all releases and from primary contamination. 
RESRAD-OFFSITE, Version 2.5

Parent Dose Report

Title : Offsite Resident Farmer Deterministic Run

File : RF TC99 DOESG FWD-FV2b.ROF

Total Dose Contributions TDOSE (i,p,t) for Individual Radionuclides (i) and Pathways (p) in mrem/yr and as a Percentage of Total Dose at $t=50$ years

From releases to ground water and to surface water

\begin{tabular}{|c|c|c|c|c|c|c|c|c|c|c|c|c|c|c|c|c|}
\hline & \multicolumn{2}{|c|}{ Ground } & \multicolumn{2}{|l|}{ Fish } & \multicolumn{2}{|c|}{ Radon } & \multicolumn{2}{|c|}{ Plant } & \multicolumn{2}{|l|}{ Meat } & \multicolumn{2}{|l|}{ Milk } & \multicolumn{2}{|l|}{ Soil } & \multicolumn{2}{|c|}{ Water } \\
\hline dclide & Dose & \% & Dose & $\%$ & Dose & 음 & Dose & 음 & Dose & $\%$ & Dose & 음 & Dose & $\%$ & Dose & 응 \\
\hline-99 & $0.00 \mathrm{E}+00$ & 0 & $0.00 \mathrm{E}+00$ & 0 & $0.00 \mathrm{E}+00$ & 0 & $0.00 \mathrm{E}+00$ & 0 & $0.00 \mathrm{E}+00$ & 0 & $0.00 \mathrm{E}+00$ & 0 & $0.00 \mathrm{E}+00$ & 0 & $0.00 \mathrm{E}+00$ & 0 \\
\hline ta] & $0.00 \mathrm{E}+00$ & 0 & $0.00 \mathrm{E}+00$ & 0 & $0.00 \mathrm{E}+00$ & 0 & $0.00 \mathrm{E}+00$ & 0 & $0.00 \mathrm{E}+00$ & 0 & $0.00 \mathrm{E}+00$ & 0 & $0.00 \mathrm{E}+00$ & 0 & $0.00 \mathrm{E}+00$ & 0 \\
\hline
\end{tabular}

Total Dose Contributions TDOSE(i,p,t) for Individual Radionuclides (i) and Pathways (p) in mrem/yr and as a Percentage of Total Dose at $t=50$ years

Directly from primary contamination and from release to atmosphere (Inhalation excludes radon)

\begin{tabular}{|c|c|c|c|c|c|c|c|c|c|c|c|c|c|c|c|c|}
\hline & \multicolumn{2}{|c|}{ Ground } & \multicolumn{2}{|c|}{ Inhalation } & \multicolumn{2}{|c|}{ Radon } & \multicolumn{2}{|c|}{ Plant } & \multicolumn{2}{|l|}{ Meat } & \multicolumn{2}{|l|}{ Milk } & \multicolumn{2}{|l|}{ Soil } & \multicolumn{2}{|c|}{ All Pathways* } \\
\hline dclide & Dose & \% & Dose & $\%$ & Dose & $\%$ & Dose & 음 & Dose & $\%$ & Dose & 응 & Dose & 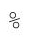 & Dose & $\%$ \\
\hline-99 & $3.38 E-32$ & 0 & $0.00 \mathrm{E}+00$ & 0 & $0.00 \mathrm{E}+00$ & 0 & $0.00 \mathrm{E}+00$ & 0 & $0.00 \mathrm{E}+00$ & 0 & $0.00 \mathrm{E}+00$ & 0 & $0.00 \mathrm{E}+00$ & 0 & $3.38 E-32$ & 0 \\
\hline tal & $3.38 E-32$ & 0 & $0.00 \mathrm{E}+00$ & 0 & $0.00 \mathrm{E}+00$ & 0 & $0.00 \mathrm{E}+00$ & 0 & $0.00 \mathrm{E}+00$ & 0 & $0.00 \mathrm{E}+00$ & 0 & $0.00 \mathrm{E}+00$ & 0 & $3.38 E-32$ & 0 \\
\hline
\end{tabular}

* Sum of dose from all releases and from primary contamination. 
RESRAD-OFFSITE, Version 2.5

Parent Dose Report

Title : Offsite Resident Farmer Deterministic Run

File : RF TC99 DOESG FWD-FV2b.ROF

Total Dose Contributions TDOSE (i,p,t) for Individual Radionuclides (i) and Pathways (p) in mrem/yr and as a Percentage of Total Dose at $t=100$ years

From releases to ground water and to surface water

\begin{tabular}{|c|c|c|c|c|c|c|c|c|c|c|c|c|c|c|c|}
\hline \multicolumn{2}{|c|}{ Ground } & \multicolumn{2}{|l|}{ Fish } & \multicolumn{2}{|c|}{ Radon } & \multicolumn{2}{|c|}{ Plant } & \multicolumn{2}{|l|}{ Meat } & \multicolumn{2}{|l|}{ Milk } & \multicolumn{2}{|l|}{ Soil } & \multicolumn{2}{|c|}{ Water } \\
\hline Dose & $\%$ & Dose & $\div$ & Dose & \% & Dose & $\%$ & Dose & $\div$ & Dose & 응 & Dose & $\%$ & Dose & 응 \\
\hline $0.00 E+00$ & 0 & $0.00 \mathrm{E}+00$ & 0 & $0.00 \mathrm{E}+00$ & 0 & $0.00 \mathrm{E}+00$ & 0 & $0.00 \mathrm{E}+00$ & 0 & $0.00 \mathrm{E}+00$ & 0 & $0.00 \mathrm{E}+00$ & 0 & $0.00 \mathrm{E}+00$ & 0 \\
\hline $0.00 \mathrm{E}+00$ & 0 & $0.00 \mathrm{E}+00$ & 0 & $0.00 \mathrm{E}+00$ & 0 & $0.00 \mathrm{E}+00$ & 0 & $0.00 \mathrm{E}+00$ & 0 & $0.00 \mathrm{E}+00$ & 0 & $0.00 \mathrm{E}+00$ & 0 & $0.00 \mathrm{E}+00$ & 0 \\
\hline
\end{tabular}

Total Dose Contributions TDOSE (i,p,t) for Individual Radionuclides (i) and Pathways (p) in mrem/yr and as a Percentage of Total Dose at $t=100$ years

Directly from primary contamination and from release to atmosphere (Inhalation excludes radon)

\begin{tabular}{|c|c|c|c|c|c|c|c|c|c|c|c|c|c|c|c|c|}
\hline & \multicolumn{2}{|c|}{ Ground } & \multicolumn{2}{|c|}{ Inhalation } & \multicolumn{2}{|c|}{ Radon } & \multicolumn{2}{|c|}{ Plant } & \multicolumn{2}{|l|}{ Meat } & \multicolumn{2}{|l|}{ Milk } & \multicolumn{2}{|l|}{ Soil } & \multicolumn{2}{|c|}{ All Pathways* } \\
\hline Juclide & Dose & \% & Dose & $\%$ & Dose & 응 & Dose & 음 & Dose & \% & Dose & \% & Dose & \% & Dose & $\frac{\circ}{0}$ \\
\hline-99 & $6.28 E-32$ & 0 & $0.00 \mathrm{E}+00$ & 0 & $0.00 E+00$ & 0 & $0.00 \mathrm{E}+00$ & 0 & $0.00 \mathrm{E}+00$ & 0 & $0.00 \mathrm{E}+00$ & 0 & $0.00 \mathrm{E}+00$ & 0 & $6.28 E-32$ & 0 \\
\hline ta & $6.28 \mathrm{E}-32$ & 0 & $0.00 \mathrm{E}+00$ & 0 & $0.00 \mathrm{E}+00$ & 0 & $0.00 \mathrm{E}+00$ & 0 & $0.00 \mathrm{E}+00$ & 0 & $0.00 \mathrm{E}+00$ & 0 & $0.00 \mathrm{E}+00$ & 0 & $6.28 E-32$ & 0 \\
\hline
\end{tabular}

* Sum of dose from all releases and from primary contamination. 
RESRAD-OFFSITE, Version 2.5

Parent Dose Report

Title : Offsite Resident Farmer Deterministic Run

File : RF TC99 DOESG FWD-FV2b.ROF

Total Dose Contributions TDOSE(i,p,t) for Individual Radionuclides (i) and Pathways (p) in mrem/yr and as a Percentage of Total Dose at $t=500$ years

From releases to ground water and to surface water

\begin{tabular}{|c|c|c|c|c|c|c|c|c|c|c|c|c|c|c|c|c|}
\hline & \multicolumn{2}{|c|}{ Ground } & \multicolumn{2}{|l|}{ Fish } & \multicolumn{2}{|c|}{ Radon } & \multicolumn{2}{|c|}{ Plant } & \multicolumn{2}{|l|}{ Meat } & \multicolumn{2}{|l|}{ Milk } & \multicolumn{2}{|l|}{ Soil } & \multicolumn{2}{|c|}{ Water } \\
\hline clide & Dose & \% & Dose & $\%$ & Dose & $\%$ & Dose & 음 & Dose & $\%$ & Dose & \% & Dose & \% & Dose & $\frac{\circ}{0}$ \\
\hline$c-99$ & $9.04 \mathrm{E}-07$ & 54 & $0.00 \mathrm{E}+00$ & 0 & $0.00 \mathrm{E}+00$ & 0 & $0.00 \mathrm{E}+00$ & 0 & $0.00 \mathrm{E}+00$ & 0 & $0.00 \mathrm{E}+00$ & 0 & $7.63 \mathrm{E}-07$ & 46 & $0.00 \mathrm{E}+00$ & 0 \\
\hline a) & $9.04 \mathrm{E}-07$ & 54 & $0.00 \mathrm{E}+00$ & 0 & $0.00 \mathrm{E}+00$ & 0 & $0.00 \mathrm{E}+00$ & 0 & $0.00 \mathrm{E}+00$ & 0 & $0.00 E+00$ & 0 & $7.63 E-07$ & 46 & $0.00 \mathrm{E}+00$ & 0 \\
\hline
\end{tabular}

Total Dose Contributions TDOSE(i,p,t) for Individual Radionuclides (i) and Pathways (p) in mrem/yr and as a Percentage of Total Dose at $t=500$ years

Directly from primary contamination and from release to atmosphere (Inhalation excludes radon)

\begin{tabular}{|c|c|c|c|c|c|c|c|c|c|c|c|c|c|c|c|c|}
\hline & \multicolumn{2}{|c|}{ Ground } & \multicolumn{2}{|c|}{ Inhalation } & \multicolumn{2}{|c|}{ Radon } & \multicolumn{2}{|c|}{ Plant } & \multicolumn{2}{|l|}{ Meat } & \multicolumn{2}{|l|}{ Milk } & \multicolumn{2}{|l|}{ Soil } & \multicolumn{2}{|c|}{ All Pathways* } \\
\hline clide & Dose & \% & Dose & $\%$ & Dose & $\%$ & Dose & 음 & Dose & $\%$ & Dose & 응 & Dose & 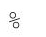 & Dose & $\%$ \\
\hline-99 & $8.96 \mathrm{E}-30$ & 0 & $0.00 \mathrm{E}+00$ & 0 & $0.00 \mathrm{E}+00$ & 0 & $0.00 \mathrm{E}+00$ & 0 & $0.00 \mathrm{E}+00$ & 0 & $0.00 \mathrm{E}+00$ & 0 & $0.00 \mathrm{E}+00$ & 0 & $1.67 \mathrm{E}-06$ & 100 \\
\hline to & $8.96 \mathrm{E}-30$ & 0 & $0.00 \mathrm{E}+00$ & 0 & $0.00 \mathrm{E}+00$ & 0 & $0.00 \mathrm{E}+00$ & 0 & $0.00 \mathrm{E}+00$ & 0 & $0.00 \mathrm{E}+00$ & 0 & $0.00 \mathrm{E}+00$ & 0 & $1.67 \mathrm{E}-06$ & 100 \\
\hline
\end{tabular}

* Sum of dose from all releases and from primary contamination. 
RESRAD-OFFSITE, Version 2.5

Parent Dose Report

Title : Offsite Resident Farmer Deterministic Run

File : RF TC99 DOESG FWD-FV2b.ROF

Total Dose Contributions TDOSE (i,p,t) for Individual Radionuclides (i) and Pathways (p) in mrem/yr and as a Percentage of Total Dose at $t=1026$ years

From releases to ground water and to surface water

\begin{tabular}{|c|c|c|c|c|c|c|c|c|c|c|c|c|c|c|c|c|}
\hline & \multicolumn{2}{|c|}{ Ground } & \multicolumn{2}{|l|}{ Fish } & \multicolumn{2}{|c|}{ Radon } & \multicolumn{2}{|c|}{ Plant } & \multicolumn{2}{|l|}{ Meat } & \multicolumn{2}{|l|}{ Milk } & \multicolumn{2}{|l|}{ Soil } & \multicolumn{2}{|c|}{ Water } \\
\hline clide & Dose & \% & Dose & $\%$ & Dose & $\%$ & Dose & 음 & Dose & $\%$ & Dose & \% & Dose & \% & Dose & $\frac{\circ}{0}$ \\
\hline$=-99$ & $1.31 \mathrm{E}-06$ & 54 & $0.00 \mathrm{E}+00$ & 0 & $0.00 \mathrm{E}+00$ & 0 & $0.00 \mathrm{E}+00$ & 0 & $0.00 \mathrm{E}+00$ & 0 & $0.00 \mathrm{E}+00$ & 0 & $1.11 \mathrm{E}-06$ & 46 & $0.00 \mathrm{E}+00$ & 0 \\
\hline a) & $1.31 \mathrm{E}-06$ & 54 & $0.00 \mathrm{E}+00$ & 0 & $0.00 \mathrm{E}+00$ & 0 & $0.00 \mathrm{E}+00$ & 0 & $0.00 \mathrm{E}+00$ & 0 & $0.00 E+00$ & 0 & $1.11 \mathrm{E}-06$ & 46 & $0.00 \mathrm{E}+00$ & 0 \\
\hline
\end{tabular}

Total Dose Contributions TDOSE(i,p,t) for Individual Radionuclides (i) and Pathways (p)

in mrem/yr and as a Percentage of Total Dose at $t=1026$ years

Directly from primary contamination and from release to atmosphere (Inhalation excludes radon)

\begin{tabular}{|c|c|c|c|c|c|c|c|c|c|c|c|c|c|c|c|c|}
\hline & \multicolumn{2}{|c|}{ Ground } & \multicolumn{2}{|c|}{ Inhalation } & \multicolumn{2}{|c|}{ Radon } & \multicolumn{2}{|c|}{ Plant } & \multicolumn{2}{|l|}{ Meat } & \multicolumn{2}{|l|}{ Milk } & \multicolumn{2}{|l|}{ Soil } & \multicolumn{2}{|c|}{ All Pathways* } \\
\hline clide & Dose & \% & Dose & $\%$ & Dose & $\%$ & Dose & 음 & Dose & $\%$ & Dose & 응 & Dose & 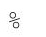 & Dose & $\%$ \\
\hline-99 & $6.10 \mathrm{E}-27$ & 0 & $0.00 \mathrm{E}+00$ & 0 & $0.00 \mathrm{E}+00$ & 0 & $0.00 \mathrm{E}+00$ & 0 & $0.00 \mathrm{E}+00$ & 0 & $0.00 \mathrm{E}+00$ & 0 & $0.00 \mathrm{E}+00$ & 0 & $2.42 E-06$ & 100 \\
\hline to & $6.10 \mathrm{E}-27$ & 0 & $0.00 \mathrm{E}+00$ & 0 & $0.00 \mathrm{E}+00$ & 0 & $0.00 \mathrm{E}+00$ & 0 & $0.00 \mathrm{E}+00$ & 0 & $0.00 \mathrm{E}+00$ & 0 & $0.00 \mathrm{E}+00$ & 0 & $2.42 E-06$ & 100 \\
\hline
\end{tabular}

* Sum of dose from all releases and from primary contamination. 
RESRAD-OFFSITE, Version $2.5 \quad \mathrm{~T}^{1 / 2}$ Limit $=180$ days

Parent Dose Report

Title : Offsite Resident Farmer Deterministic Run

File : RF TC99 DOESG FWD-FV2b.ROF

Dose/Source Ratios Summed Over All Pathways

Parent and Progeny Principal Radionuclide Contributions Indicated

\begin{tabular}{|c|c|c|c|c|c|c|c|c|}
\hline Parent & Product & Thread & & $\operatorname{DSR}(j$, & $\Rightarrow \quad(\mathrm{mrem} / \mathrm{y}$ & $\Rightarrow) /(\mathrm{pCi} / \mathrm{g})$ & & \\
\hline (i) & $(j)$ & Fraction & $0.000 \mathrm{E}+00$ & $1.000 \mathrm{E}+00$ & $5.000 \mathrm{E}+01$ & $1.000 \mathrm{E}+02$ & $5.000 \mathrm{E}+02$ & $1.026 \mathrm{E}+03$ \\
\hline$c-99$ & $\mathrm{TC}-99$ & $1.000 \mathrm{E}+00$ & $3.496 \mathrm{E}-34$ & $3.539 \mathrm{E}-34$ & $6.498 \mathrm{E}-34$ & $1.208 E-33$ & $3.207 \mathrm{E}-08$ & $4.659 \mathrm{E}-08$ \\
\hline
\end{tabular}

The DSR includes contributions from associated (half-life $\leq 180$ days) daughters.

Single Radionuclide Soil Guidelines $G(i, t)$ in $\mathrm{pCi} / \mathrm{g}$

Basic Radiation Dose Limit $=1.000 \mathrm{E}+00 \mathrm{mrem} / \mathrm{yr}$

Nuclide

\begin{tabular}{|c|c|c|c|c|c|c|c|}
\hline (i) & $t=$ & $0.000 \mathrm{E}+00$ & $1.000 \mathrm{E}+00$ & $5.000 \mathrm{E}+01$ & $1.000 \mathrm{E}+02$ & $5.000 \mathrm{E}+02$ & $1.026 \mathrm{E}+03$ \\
\hline TC-99 & & $\star 1.697 \mathrm{E}+10$ & $\star 1.697 \mathrm{E}+10$ & $\star 1.697 \mathrm{E}+10$ & $\star 1.697 \mathrm{E}+10$ & $3.118 \mathrm{E}+07$ & $2.146 \mathrm{E}+07$ \\
\hline
\end{tabular}

*At specific activity limit

Summed Dose/Source Ratios DSR (i,t) in (mrem/yr)/(pCi/g)

and Single Radionuclide Soil Guidelines G(i,t) in pCi/g

at tmin = time of minimum single radionuclide soil guideline

and at $\operatorname{tmax}=$ time of maximum total dose $=772$ years

\begin{tabular}{|c|c|c|c|c|c|c|}
\hline $\begin{array}{l}\text { Nuclide } \\
\text { (i) }\end{array}$ & $\begin{array}{l}\text { Initial } \\
(\mathrm{pCi} / \mathrm{g})\end{array}$ & $\begin{array}{c}\text { tmin } \\
\text { (years) }\end{array}$ & $\operatorname{DSR}(i, \operatorname{tmin})$ & $\begin{array}{c}\mathrm{G}(\mathrm{i}, \mathrm{tmin}) \\
(\mathrm{pCi} / \mathrm{g})\end{array}$ & $\operatorname{DSR}(i, \operatorname{tmax})$ & $\begin{array}{c}G(i, t \max ) \\
(\mathrm{pCi} / \mathrm{g})\end{array}$ \\
\hline$[c-99$ & $5.200 \mathrm{E}+01$ & 772 & $6.059 \mathrm{E}-08$ & $1.650 \mathrm{E}+07$ & $6.059 \mathrm{E}-08$ & $1.650 \mathrm{E}+07$ \\
\hline
\end{tabular}


RESRAD-OFFSITE, Version $2.5 \quad T^{1 / 2}$ Limit $=180$ days

Parent Dose Report

Title : Offsite Resident Farmer Deterministic Run

File : RF TC99 DOESG FWD-FV2b.ROF

Individual Nuclide Dose Summed Over All Pathways

Parent Nuclide and Thread Fraction Indicated

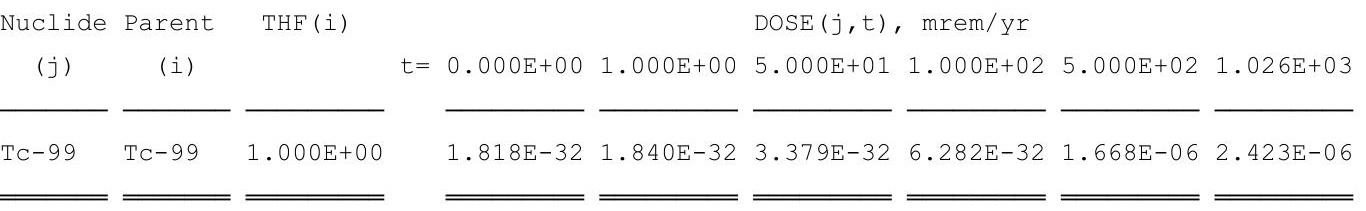

THF (i) is the thread fraction of the parent nuclide.

Individual Nuclide Soil Concentration

Parent Nuclide and Thread Fraction Indicated

\begin{tabular}{|c|c|c|c|c|c|c|c|c|c|}
\hline $\begin{array}{c}\text { Nuclide } \\
(j)\end{array}$ & $\begin{array}{c}\text { Parent } \\
\text { (i) }\end{array}$ & THF (i) & $t=$ & $0.000 \mathrm{E}+00$ & $1.000 \mathrm{E}+00$ & $\begin{array}{r}S(j, t), \\
5.000 E+01\end{array}$ & $\begin{array}{l}\mathrm{pCi} / \mathrm{g} \\
1.000 \mathrm{E}+02\end{array}$ & $5.000 \mathrm{E}+02$ & $1.026 \mathrm{E}+03$ \\
\hline 9 & TC-99 & $1.000 \mathrm{E}+00$ & & $5.200 \mathrm{E}+01$ & $5.173 \mathrm{E}+01$ & $3.997 \mathrm{E}+01$ & $3.073 E+01$ & $3.746 \mathrm{E}+00$ & $2.354 \mathrm{E}-01$ \\
\hline
\end{tabular}

THF(i) is the thread fraction of the parent nuclide. 
RESRAD-OFFSITE, Version $2.5 \quad \mathrm{~T}^{1} \frac{1}{2}$ Limit $=180$ days

Parent Dose Report

Title : Offsite Resident Farmer Deterministic Run

File : RF TC99 DOESG FWD-FV2b.ROF

Run Time Information

ResOCalc.EXE execution began at 15:32 on 07/15/2011

ResOCalc.EXE execution ended at 21:24 on 07/15/2011

ResOCalc.EXE execution time 5 hours 51 minutes 


\section{Offsite Resident Farmer}

\section{Uncertainty Analysis Report \\ Second Run}

Time Horizon: 1,050 yr 
THIS PAGE INTENTIONALLY LEFT BLANK 
RESRAD-OFFSITE, Version 2.5

Prabilistic Dose and Risk Report

Title : Offsite Resident Farmer Deterministic Run File : RF TC99 DOESG FWD-FV2b.ROF

Table of Contents

Part V: Uncertainty Analysis

RESRAD Uncertainty Analysis Results

Probabilistic Inputs .......................... 2

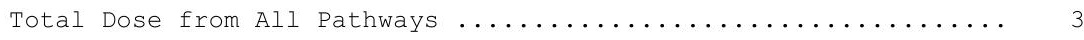

Total Risk from All Pathways ..................... 4

Ground External (water release) Pathway Dose .............. 5

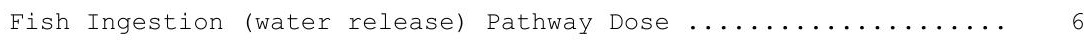

Radon Inhalation (water release) Pathway Dose ............ 7

Vegetable Ingestion (water release) Pathway Dose ............ 8

Meat Ingestion (water release) Pathway Dose .............. 9

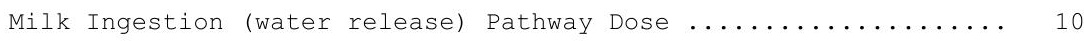

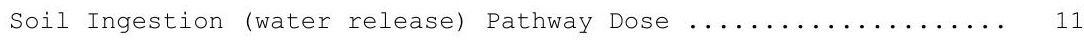

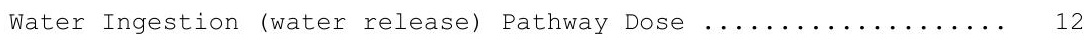

Ground External (direct \& air release) Pathway Dose .......... 13

Inhalation (w/o Radon) (direct \& air) Pathway Dose .......... 14

Radon Inhalation (direct \& air release) Pathway Dose ........ 15

Vegetable Ingestion (direct \& air release) Pathway Dose ....... 16

Meat Ingestion (direct \& air release) Pathway Dose ......... 17

Milk Ingestion (direct \& air release) Pathway Dose .......... 18

Soil Ingestion (direct \& air release) Pathway Dose .......... 19

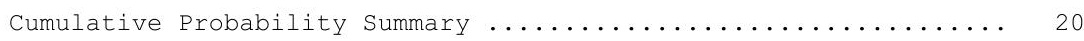

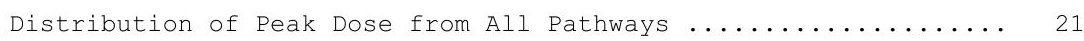

Distribution of Peak Dose from External Ground(Wreleas) ....... 22

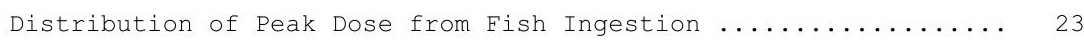

Distribution of Peak Dose from Radon (Waterrelease) ......... 24

Distribution of Peak Dose from Plant (Waterrelease) ......... 25

Distribution of Peak Dose from Meat (Waterrelease) ......... 26

Distribution of Peak Dose from Milk (Waterrelease) ......... 27

Distribution of Peak Dose from Soil Ingestion(Wrelease) ....... 28

Distribution of Peak Dose from Water Ingestion ............ 29

Distribution of Peak Dose from External Ground (CZ\&Air) ....... 30

Distribution of Peak Dose from Inhalation ExcludingRn ........ 31

Distribution of Peak Dose from Radon (CZandAir) ........... 32

Distribution of Peak Dose from Plant (CzandAir) ........... 33

Distribution of Peak Dose from Meat (CZandAir) ............ 34

Distribution of Peak Dose from Milk (CzandAir) ........... 35

Distribution of Peak Dose from Soil Ingestion(CZandAir) ...... 36

Distribution of Peak Risk from All Pathways ............. 37

Distribution of Peak Risk from External Ground(Wreleas) ...... 38

Distribution of Peak Risk from Fish Ingestion ............. 39

Distribution of Peak Risk from Radon (Waterrelease) ......... 40

Distribution of Peak Risk from Plant (Waterrelease) ......... 41

Distribution of Peak Risk from Meat (Waterrelease) ......... 42

Distribution of Peak Risk from Milk (Waterrelease) .......... 43

Distribution of Peak Risk from Soil Ingestion(Wrelease) ....... 44

Distribution of Peak Risk from Water Ingestion ............ 45

Distribution of Peak Risk from External Ground(CZ\&Air) ....... 46

Distribution of Peak Risk from Inhalation ExcludingRn ........ 47

Distribution of Peak Risk from Radon (CZandAir) ........... 48

Distribution of Peak Risk from Plant (CzandAir) ........... 49

Distribution of Peak Risk from Meat (CZandAir) ........... 50

Distribution of Peak Risk from Milk (CzandAir) ........... 51

Distribution of Peak Risk from Soil Ingestion(CZandAir) ...... $52 \quad$ DC N090-TR-02-2 
C-287

DCN 5090-TR-02-2 
C -288

DCN 5090-TR-02-2 
C -289

DCN 5090-TR-02-2 
C -290

DCN 5090-TR-02-2 
C-291

DCN 5090-TR-02-2 
C -292

DCN 5090-TR-02-2 
RESRAD-OFFSITE, Version 2.5

Probabilistic Dose and Risk Report

Title : Offsite Resident Farmer Deterministic Run

File : RF TC99 DOESG FWD-FV2b.ROF

Probabilistic Inputs

Number of Sample Runs: 6000

\begin{tabular}{lll} 
Number & Name \\
\cline { 1 - 1 } 1 & & DCACTC $(1)$ \\
2 & DENSCZ \\
3 & $\operatorname{EPUZ}(5)$ \\
4 & $\operatorname{HCSZ}$ \\
5 & $\operatorname{TPSZ}$ \\
6 & $\operatorname{EPSZ}$ \\
\hline \hline
\end{tabular}

\begin{tabular}{l} 
Distribution \\
\hline TRIANGULAR \\
TRIANGULAR \\
TRIANGULAR \\
TRIANGULAR \\
TRIANGULAR \\
TRIANGULAR \\
\hline \hline
\end{tabular}

\begin{tabular}{lll} 
Parameters & \\
\hline .1 & 1 & 10 \\
1.5 & 1.85 & 2.5 \\
.1 & .25 & .4 \\
27034 & 38938 & 67642 \\
.27 & .39 & .54 \\
.22 & .3 & .35 \\
\hline \hline
\end{tabular}

C-293

DCN 5090-TR-02-2 
RESRAD-OFFSITE, Version 2.5

Probabilistic Dose and Risk Report

Title : Offsite Resident Farmer Deterministic Run

File : RF TC99 DOESG FWD-FV2b.ROF

\begin{tabular}{|c|c|c|c|c|c|c|c|c|}
\hline Juclide & Peak & Peak & & & $\operatorname{DOSE}(j, t)$, & mrem/yr & & \\
\hline$(j)$ & Time & Dose & $t=0.00 \mathrm{E}+00$ & $1.00 \mathrm{E}+00$ & $5.00 \mathrm{E}+01$ & $1.00 \mathrm{E}+02$ & $5.00 \mathrm{E}+02$ & $1.03 E+03$ \\
\hline \multicolumn{9}{|l|}{ TC-99 } \\
\hline Min & $5.58 \mathrm{E}+02$ & $1.98 \mathrm{E}-07$ & $1.79 \mathrm{E}-32$ & $1.76 \mathrm{E}-32$ & $7.79 \mathrm{E}-33$ & $3.39 \mathrm{E}-33$ & $8.26 \mathrm{E}-10$ & $1.81 \mathrm{E}-07$ \\
\hline $\operatorname{Max}$ & $1.05 E+03$ & $7.82 \mathrm{E}-06$ & 1. $82 \mathrm{E}-32$ & $1.85 \mathrm{E}-32$ & $4.31 E-32$ & $1.02 \mathrm{E}-31$ & $6.38 E-06$ & $5.53 \mathrm{E}-06$ \\
\hline Avg & $1.03 E+03$ & $1.70 \mathrm{E}-06$ & $1.82 \mathrm{E}-32$ & $1.85 \mathrm{E}-32$ & $3.93 \mathrm{E}-32$ & $8.56 \mathrm{E}-32$ & $2.65 E-07$ & $1.62 \mathrm{E}-06$ \\
\hline Std & $6.07 \mathrm{E}+01$ & $9.96 \mathrm{E}-07$ & $0.00 \mathrm{E}+00$ & $0.00 \mathrm{E}+00$ & $0.00 \mathrm{E}+00$ & $0.00 \mathrm{E}+00$ & $5.02 E-07$ & $9.14 \mathrm{E}-07$ \\
\hline \multicolumn{9}{|l|}{$\sum$ ALL } \\
\hline Min & $5.58 \mathrm{E}+02$ & $1.98 \mathrm{E}-07$ & $1.79 \mathrm{E}-32$ & $1.76 \mathrm{E}-32$ & $7.79 \mathrm{E}-33$ & $3.39 \mathrm{E}-33$ & $8.26 \mathrm{E}-10$ & $1.81 \mathrm{E}-07$ \\
\hline Max & $1.05 E+03$ & $7.82 \mathrm{E}-06$ & $1.82 \mathrm{E}-32$ & $1.85 \mathrm{E}-32$ & $4.31 E-32$ & $1.02 \mathrm{E}-31$ & $6.38 E-06$ & $5.53 \mathrm{E}-06$ \\
\hline Avg & $1.03 \mathrm{E}+03$ & $1.70 \mathrm{E}-06$ & $1.82 \mathrm{E}-32$ & $1.85 \mathrm{E}-32$ & $3.93 E-32$ & $8.56 \mathrm{E}-32$ & $2.65 \mathrm{E}-07$ & $1.62 \mathrm{E}-06$ \\
\hline Std & $6.07 E+01$ & $9.96 \mathrm{E}-07$ & $0.00 \mathrm{E}+00$ & $0.00 \mathrm{E}+00$ & $0.00 \mathrm{E}+00$ & $0.00 \mathrm{E}+00$ & $5.02 \mathrm{E}-07$ & $9.14 \mathrm{E}-07$ \\
\hline
\end{tabular}

¿ALL is total dose summed for all nuclides. 
RESRAD-OFFSITE, Version 2.5

Probabilistic Dose and Risk Report

Title : Offsite Resident Farmer Deterministic Run

File : RF TC99 DOESG FWD-FV2b.ROF

Probabilistic Total Risk Summary

\begin{tabular}{|c|c|c|c|c|c|c|c|}
\hline \multirow{2}{*}{$\begin{array}{l}\text { Nuclide } \\
\quad(j)\end{array}$} & \multicolumn{7}{|c|}{$\operatorname{RISK}(j, t)$} \\
\hline & $t=$ & $0.00 \mathrm{E}+00$ & $1.00 \mathrm{E}+00$ & $5.00 \mathrm{E}+01$ & $1.00 \mathrm{E}+02$ & $5.00 \mathrm{E}+02$ & $1.03 \mathrm{E}+03$ \\
\hline \multicolumn{8}{|l|}{ TC-99 } \\
\hline Min & & $2.68 \mathrm{E}-37$ & $2.63 E-37$ & $1.17 \mathrm{E}-37$ & $5.07 \mathrm{E}-38$ & $3.18 \mathrm{E}-14$ & $5.36 \mathrm{E}-12$ \\
\hline $\operatorname{Max}$ & & $4.02 \mathrm{E}-37$ & $4.09 \mathrm{E}-37$ & $9.52 \mathrm{E}-37$ & $2.18 \mathrm{E}-18$ & $1.84 \mathrm{E}-10$ & $1.55 \mathrm{E}-10$ \\
\hline Avg & & $3.93 E-37$ & $3.99 \mathrm{E}-37$ & $8.50 E-37$ & $5.15 \mathrm{E}-22$ & $8.27 \mathrm{E}-12$ & $4.62 \mathrm{E}-11$ \\
\hline Std & & $0.00 \mathrm{E}+00$ & $0.00 \mathrm{E}+00$ & $0.00 \mathrm{E}+00$ & $2.86 \mathrm{E}-20$ & $1.51 \mathrm{E}-11$ & $2.56 \mathrm{E}-11$ \\
\hline \multicolumn{8}{|l|}{$\sum A L L$} \\
\hline Min & & $2.68 \mathrm{E}-37$ & $2.63 \mathrm{E}-37$ & $1.17 \mathrm{E}-37$ & $5.07 \mathrm{E}-38$ & $3.18 \mathrm{E}-14$ & $5 \cdot 36 \mathrm{E}-12$ \\
\hline $\operatorname{Max}$ & & $4.02 \mathrm{E}-37$ & $4.09 \mathrm{E}-37$ & $9.52 \mathrm{E}-37$ & $2.18 \mathrm{E}-18$ & $1.84 \mathrm{E}-10$ & $1.55 \mathrm{E}-10$ \\
\hline Avg & & $3.93 \mathrm{E}-37$ & $3.99 \mathrm{E}-37$ & $8.50 \mathrm{E}-37$ & $5.15 E-22$ & $8.27 \mathrm{E}-12$ & $4.62 \mathrm{E}-11$ \\
\hline Std & & $0.00 \mathrm{E}+00$ & $0.00 \mathrm{E}+00$ & $0.00 \mathrm{E}+00$ & $2.86 \mathrm{E}-20$ & $1.51 \mathrm{E}-11$ & $2.56 \mathrm{E}-11$ \\
\hline
\end{tabular}

¿ALL is total risk summed for all nuclides. 
RESRAD-OFFSITE, Version 2.5

Probabilistic Dose and Risk Report

Title : Offsite Resident Farmer Deterministic Run

File : RF TC99 DOESG FWD-FV2b.ROF

Probabilistic Dose vs Pathway(i): Ground External (water release)

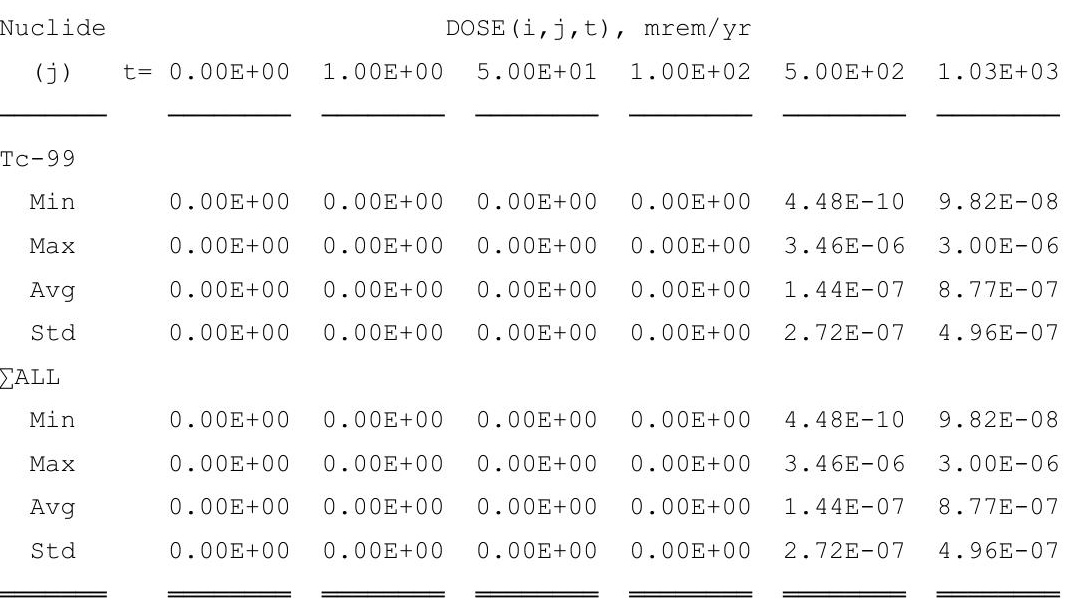

¿ALL is total pathway dose summed for all nuclides. 
RESRAD-OFFSITE, Version 2.5

Probabilistic Dose and Risk Report

Title : Offsite Resident Farmer Deterministic Run

File : RF TC99 DOESG FWD-FV2b.ROF

Probabilistic Dose vs Pathway(i): Fish Ingestion (water release)

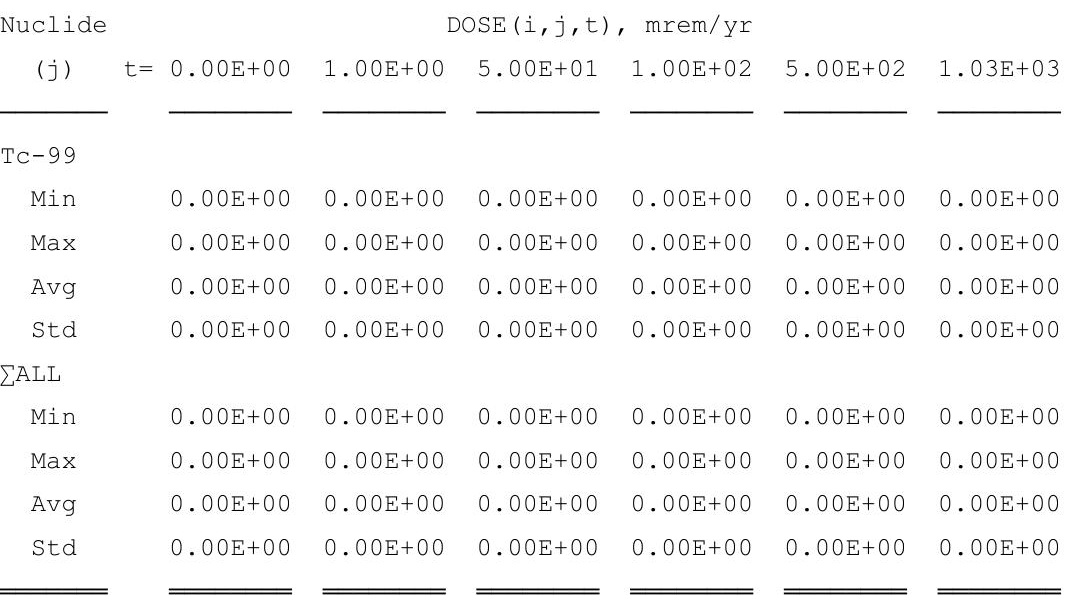

¿ALL is total pathway dose summed for all nuclides. 
RESRAD-OFFSITE, Version 2.5

Probabilistic Dose and Risk Report

Title : Offsite Resident Farmer Deterministic Run

File : RF TC99 DOESG FWD-FV2b.ROF

Probabilistic Dose vs Pathway(i): Radon Inhalation (water release)

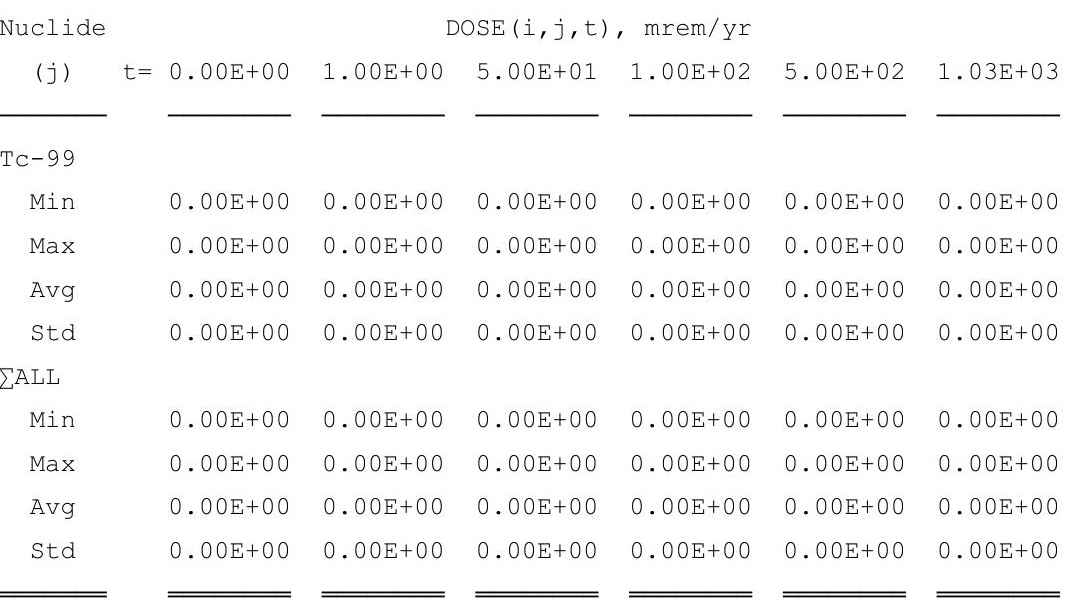

¿ALL is total pathway dose summed for all nuclides. 
RESRAD-OFFSITE, Version 2.5

Probabilistic Dose and Risk Report

Title : Offsite Resident Farmer Deterministic Run

File : RF TC99 DOESG FWD-FV2b.ROF

Probabilistic Dose vs Pathway(i): Vegetable Ingestion (water release)

\begin{tabular}{|c|c|c|c|c|c|c|c|}
\hline Juclide & & & & SE (i, & $\mathrm{mre}$ & & \\
\hline$(j)$ & $t=$ & $0.00 \mathrm{E}+00$ & $1.00 \mathrm{E}+00$ & $5.00 \mathrm{E}+01$ & $1.00 \mathrm{E}+02$ & $5.00 \mathrm{E}+02$ & $1.03 E+03$ \\
\hline-99 & & & & & & & \\
\hline Min & & $0.00 \mathrm{E}+00$ & $0.00 \mathrm{E}+00$ & $0.00 \mathrm{E}+00$ & $0.00 \mathrm{E}+00$ & $0.00 \mathrm{E}+00$ & $0.00 \mathrm{E}+00$ \\
\hline Max & & $0.00 \mathrm{E}+00$ & $0.00 \mathrm{E}+00$ & $0.00 \mathrm{E}+00$ & $0.00 \mathrm{E}+00$ & $0.00 \mathrm{E}+00$ & $0.00 \mathrm{E}+00$ \\
\hline Avg & & $0.00 \mathrm{E}+00$ & $0.00 \mathrm{E}+00$ & $0.00 \mathrm{E}+00$ & $0.00 \mathrm{E}+00$ & $0.00 \mathrm{E}+00$ & $0.00 \mathrm{E}+00$ \\
\hline Std & & $0.00 \mathrm{E}+00$ & $0.00 \mathrm{E}+00$ & $0.00 \mathrm{E}+00$ & $0.00 \mathrm{E}+00$ & $0.00 \mathrm{E}+00$ & $0.00 \mathrm{E}+00$ \\
\hline ALL & & & & & & & \\
\hline Min & & $0.00 \mathrm{E}+00$ & $0.00 \mathrm{E}+00$ & $0.00 \mathrm{E}+00$ & $0.00 \mathrm{E}+00$ & $0.00 \mathrm{E}+00$ & $0.00 \mathrm{E}+00$ \\
\hline $\operatorname{Max}$ & & $0.00 \mathrm{E}+00$ & $0.00 \mathrm{E}+00$ & $0.00 \mathrm{E}+00$ & $0.00 \mathrm{E}+00$ & $0.00 \mathrm{E}+00$ & $0.00 \mathrm{E}+00$ \\
\hline Avg & & $0.00 \mathrm{E}+00$ & $0.00 \mathrm{E}+00$ & $0.00 \mathrm{E}+00$ & $0.00 \mathrm{E}+00$ & $0.00 \mathrm{E}+00$ & $0.00 \mathrm{E}+00$ \\
\hline Std & & $0.00 \mathrm{E}+00$ & $0.00 \mathrm{E}+00$ & $0.00 \mathrm{E}+00$ & $0.00 \mathrm{E}+00$ & $0.00 \mathrm{E}+00$ & $0.00 \mathrm{E}+00$ \\
\hline
\end{tabular}

¿ALL is total pathway dose summed for all nuclides. 
RESRAD-OFFSITE, Version 2.5

Probabilistic Dose and Risk Report

Title : Offsite Resident Farmer Deterministic Run

File : RF TC99 DOESG FWD-FV2b.ROF

Probabilistic Dose vs Pathway(i): Meat Ingestion (water release)

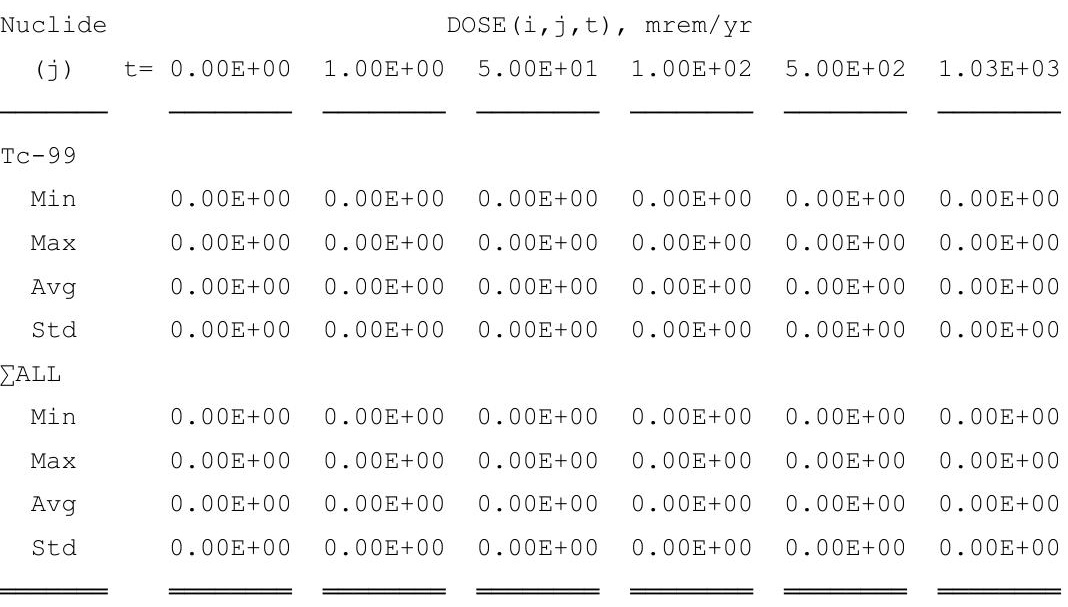

¿ALL is total pathway dose summed for all nuclides. 
RESRAD-OFFSITE, Version 2.5

Probabilistic Dose and Risk Report

Title : Offsite Resident Farmer Deterministic Run

File : RF TC99 DOESG FWD-FV2b.ROF

Probabilistic Dose vs Pathway(i): Milk Ingestion (water release)

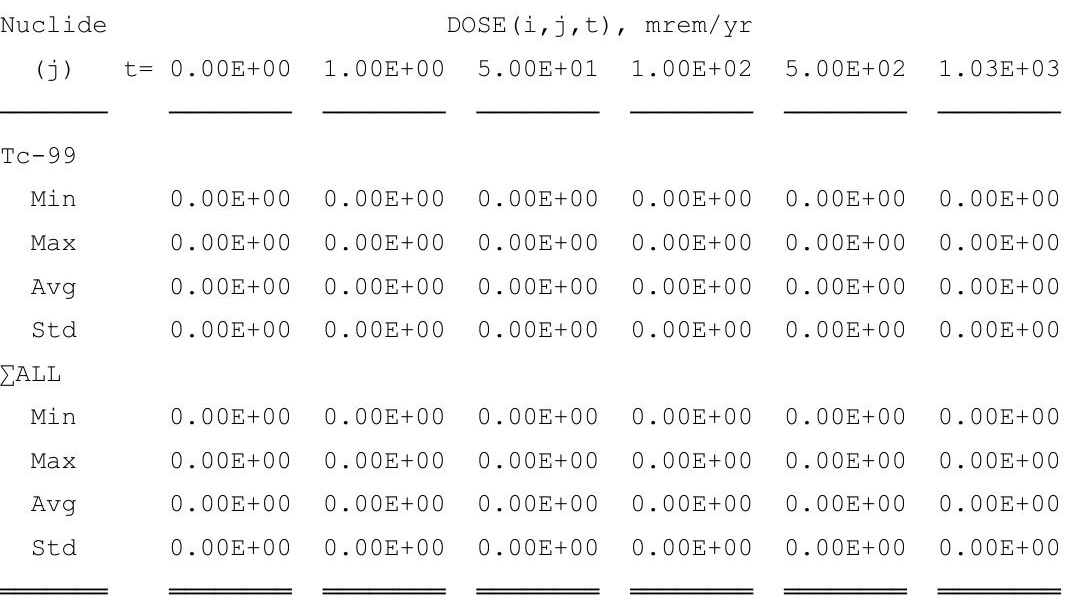

¿ALL is total pathway dose summed for all nuclides. 
RESRAD-OFFSITE, Version 2.5

Probabilistic Dose and Risk Report

Title : Offsite Resident Farmer Deterministic Run

File : RF TC99 DOESG FWD-FV2b.ROF

Probabilistic Dose vs Pathway(i): Soil Ingestion (water release)

\begin{tabular}{|c|c|c|c|c|c|c|c|}
\hline Juclide & & & & SE (i, & $\mathrm{mre}$ & & \\
\hline$(j)$ & $t=$ & $0.00 \mathrm{E}+00$ & $1.00 \mathrm{E}+00$ & $5.00 \mathrm{E}+01$ & $1.00 \mathrm{E}+02$ & $5.00 \mathrm{E}+02$ & $1.03 E+03$ \\
\hline$=-99$ & & & & & & & \\
\hline Min & & $0.00 \mathrm{E}+00$ & $0.00 \mathrm{E}+00$ & $0.00 \mathrm{E}+00$ & $0.00 \mathrm{E}+00$ & $3.78 \mathrm{E}-10$ & $8.29 \mathrm{E}-08$ \\
\hline Max & & $0.00 \mathrm{E}+00$ & $0.00 \mathrm{E}+00$ & $0.00 \mathrm{E}+00$ & $0.00 \mathrm{E}+00$ & $2.92 \mathrm{E}-06$ & $2.53 \mathrm{E}-06$ \\
\hline Avg & & $0.00 \mathrm{E}+00$ & $0.00 \mathrm{E}+00$ & $0.00 \mathrm{E}+00$ & $0.00 \mathrm{E}+00$ & $1.21 \mathrm{E}-07$ & $7.40 \mathrm{E}-07$ \\
\hline Std & & $0.00 \mathrm{E}+00$ & $0.00 \mathrm{E}+00$ & $0.00 \mathrm{E}+00$ & $0.00 \mathrm{E}+00$ & $2.30 \mathrm{E}-07$ & $4.18 \mathrm{E}-07$ \\
\hline ALL & & & & & & & \\
\hline Min & & $0.00 \mathrm{E}+00$ & $0.00 \mathrm{E}+00$ & $0.00 \mathrm{E}+00$ & $0.00 \mathrm{E}+00$ & $3.78 \mathrm{E}-10$ & $8.29 \mathrm{E}-08$ \\
\hline $\operatorname{Max}$ & & $0.00 \mathrm{E}+00$ & $0.00 \mathrm{E}+00$ & $0.00 \mathrm{E}+00$ & $0.00 \mathrm{E}+00$ & $2.92 E-06$ & $2.53 E-06$ \\
\hline Avg & & $0.00 \mathrm{E}+00$ & $0.00 \mathrm{E}+00$ & $0.00 \mathrm{E}+00$ & $0.00 \mathrm{E}+00$ & $1.21 \mathrm{E}-07$ & $7.40 \mathrm{E}-07$ \\
\hline Std & & $0.00 \mathrm{E}+00$ & $0.00 \mathrm{E}+00$ & $0.00 \mathrm{E}+00$ & $0.00 \mathrm{E}+00$ & $2.30 \mathrm{E}-07$ & $4.18 \mathrm{E}-07$ \\
\hline
\end{tabular}

¿ALL is total pathway dose summed for all nuclides. 
RESRAD-OFFSITE, Version 2.5

Probabilistic Dose and Risk Report

Title : Offsite Resident Farmer Deterministic Run

File : RF TC99 DOESG FWD-FV2b.ROF

Probabilistic Dose vs Pathway(i): Ground External (direct \& air release)

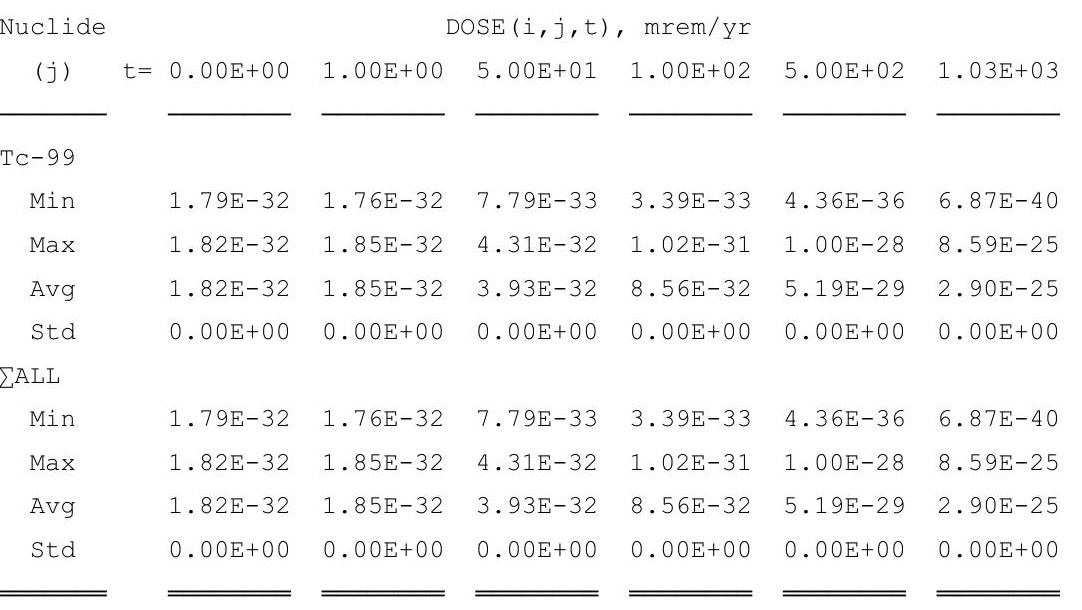

¿ALL is total pathway dose summed for all nuclides. 
RESRAD-OFFSITE, Version 2.5

Probabilistic Dose and Risk Report

Title : Offsite Resident Farmer Deterministic Run

File : RF TC99 DOESG FWD-FV2b.ROF

Probabilistic Dose vs Pathway(i): Inhalation (w/o Radon) (direct \& air)

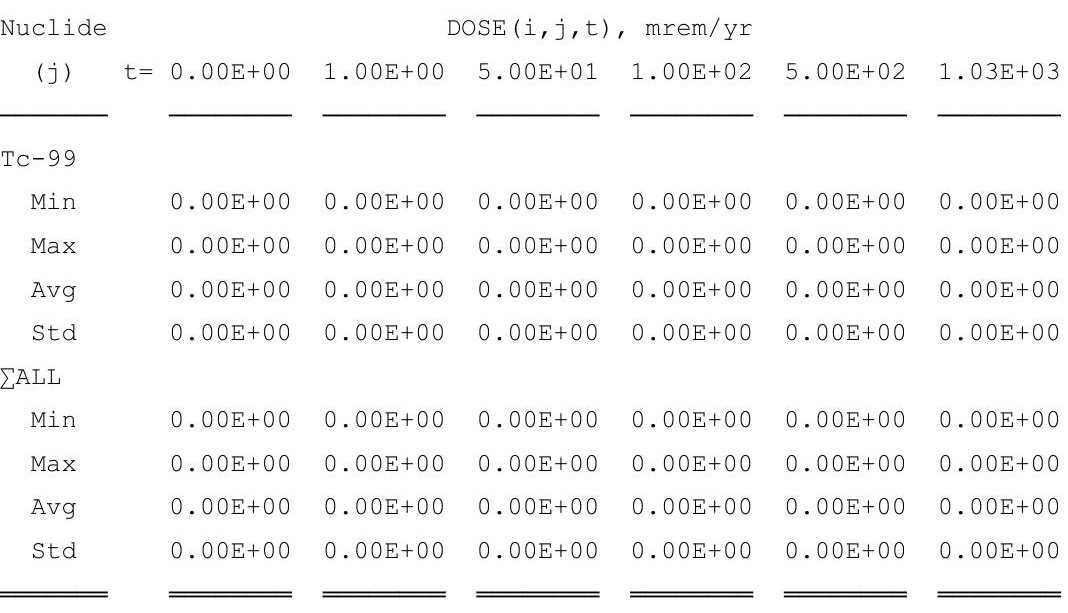

¿ALL is total pathway dose summed for all nuclides. 
RESRAD-OFFSITE, Version 2.5

Probabilistic Dose and Risk Report

Title : Offsite Resident Farmer Deterministic Run

File : RF TC99 DOESG FWD-FV2b.ROF

Probabilistic Dose vs Pathway(i): Radon Inhalation (direct \& air release)

\begin{tabular}{|c|c|c|c|c|c|c|c|}
\hline \multirow{2}{*}{$\begin{array}{c}\text { Nuclide } \\
\text { (j) }\end{array}$} & \multicolumn{7}{|c|}{$\operatorname{DOSE}(i, j, t), \mathrm{mrem} / \mathrm{yr}$} \\
\hline & $t=$ & $0.00 \mathrm{E}+00$ & $1.00 \mathrm{E}+00$ & $5.00 \mathrm{E}+01$ & $1.00 \mathrm{E}+02$ & $5.00 \mathrm{E}+02$ & $1.03 E+03$ \\
\hline \multicolumn{8}{|l|}{$\mathrm{TC}-99$} \\
\hline Min & & $0.00 \mathrm{E}+00$ & $0.00 \mathrm{E}+00$ & $0.00 \mathrm{E}+00$ & $0.00 \mathrm{E}+00$ & $0.00 \mathrm{E}+00$ & $0.00 \mathrm{E}+00$ \\
\hline Max & & $0.00 \mathrm{E}+00$ & $0.00 \mathrm{E}+00$ & $0.00 \mathrm{E}+00$ & $0.00 \mathrm{E}+00$ & $0.00 \mathrm{E}+00$ & $0.00 \mathrm{E}+00$ \\
\hline Avg & & $0.00 \mathrm{E}+00$ & $0.00 \mathrm{E}+00$ & $0.00 \mathrm{E}+00$ & $0.00 \mathrm{E}+00$ & $0.00 \mathrm{E}+00$ & $0.00 \mathrm{E}+00$ \\
\hline Std & & $0.00 \mathrm{E}+00$ & $0.00 \mathrm{E}+00$ & $0.00 \mathrm{E}+00$ & $0.00 \mathrm{E}+00$ & $0.00 \mathrm{E}+00$ & $0.00 \mathrm{E}+00$ \\
\hline \multicolumn{8}{|l|}{$\sum \mathrm{ALL}$} \\
\hline Min & & $0.00 \mathrm{E}+00$ & $0.00 \mathrm{E}+00$ & $0.00 \mathrm{E}+00$ & $0.00 \mathrm{E}+00$ & $0.00 \mathrm{E}+00$ & $0.00 \mathrm{E}+00$ \\
\hline Max & & $0.00 \mathrm{E}+00$ & $0.00 \mathrm{E}+00$ & $0.00 \mathrm{E}+00$ & $0.00 \mathrm{E}+00$ & $0.00 \mathrm{E}+00$ & $0.00 \mathrm{E}+00$ \\
\hline Avg & & $0.00 \mathrm{E}+00$ & $0.00 \mathrm{E}+00$ & $0.00 \mathrm{E}+00$ & $0.00 \mathrm{E}+00$ & $0.00 \mathrm{E}+00$ & $0.00 \mathrm{E}+00$ \\
\hline Std & & $0.00 \mathrm{E}+00$ & $0.00 \mathrm{E}+00$ & $0.00 \mathrm{E}+00$ & $0.00 \mathrm{E}+00$ & $0.00 \mathrm{E}+00$ & $0.00 \mathrm{E}+00$ \\
\hline
\end{tabular}

¿ALL is total pathway dose summed for all nuclides. 
RESRAD-OFFSITE, Version 2.5

Probabilistic Dose and Risk Report

Title : Offsite Resident Farmer Deterministic Run

File : RF TC99 DOESG FWD-FV2b.ROF

Probabilistic Dose vs Pathway(i): Vegetable Ingestion (direct \& air release)

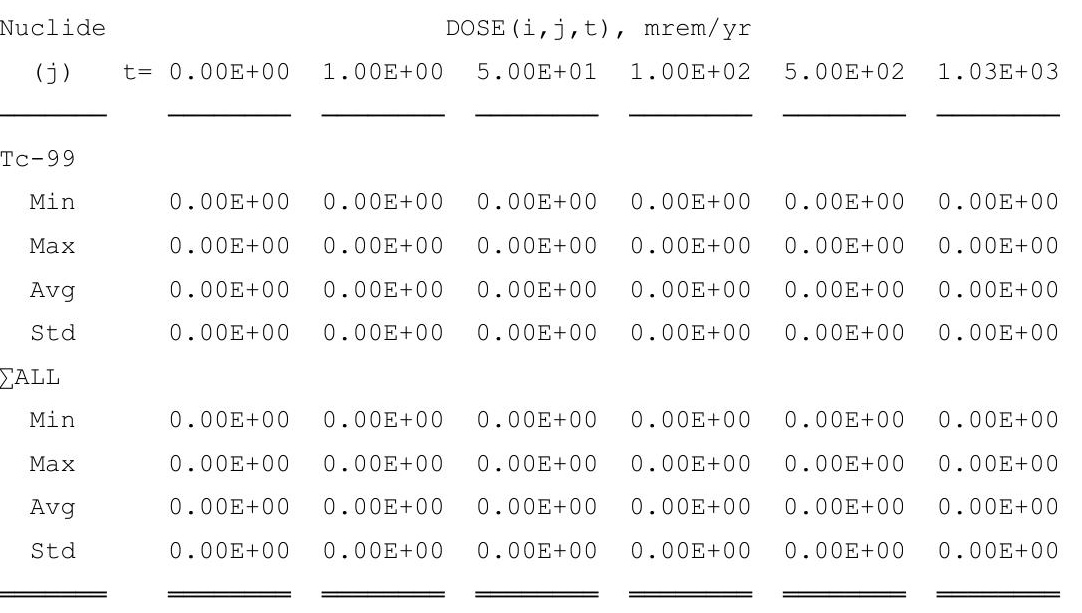

¿ALL is total pathway dose summed for all nuclides. 
RESRAD-OFFSITE, Version 2.5

Probabilistic Dose and Risk Report

Title : Offsite Resident Farmer Deterministic Run

File : RF TC99 DOESG FWD-FV2b.ROF

Probabilistic Dose vs Pathway(i): Meat Ingestion (direct \& air release)

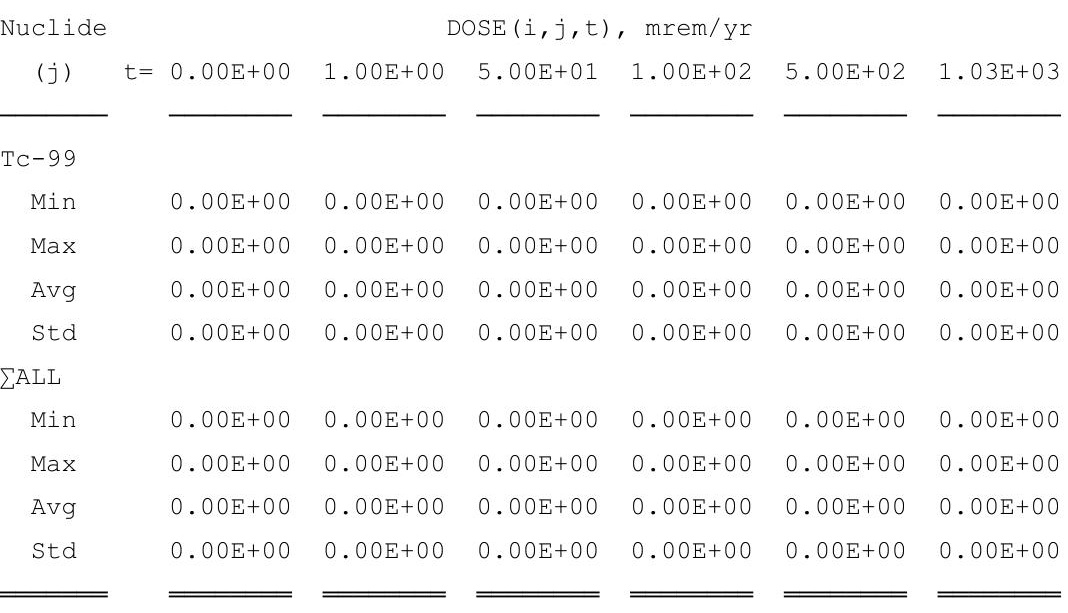

¿ALL is total pathway dose summed for all nuclides. 
RESRAD-OFFSITE, Version 2.5

Probabilistic Dose and Risk Report

Title : Offsite Resident Farmer Deterministic Run

File : RF TC99 DOESG FWD-FV2b.ROF

Probabilistic Dose vs Pathway(i): Milk Ingestion (direct \& air release)

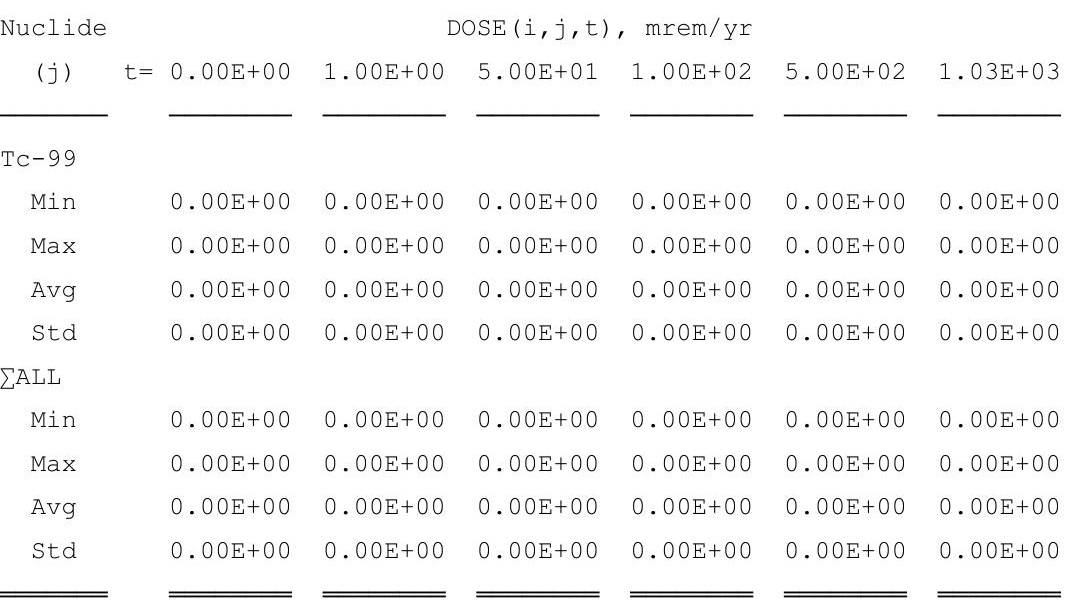

¿ALL is total pathway dose summed for all nuclides. 
RESRAD-OFFSITE, Version 2.5

Probabilistic Dose and Risk Report

Title : Offsite Resident Farmer Deterministic Run

File : RF TC99 DOESG FWD-FV2b.ROF

Probabilistic Dose vs Pathway(i): Soil Ingestion (direct \& air release)

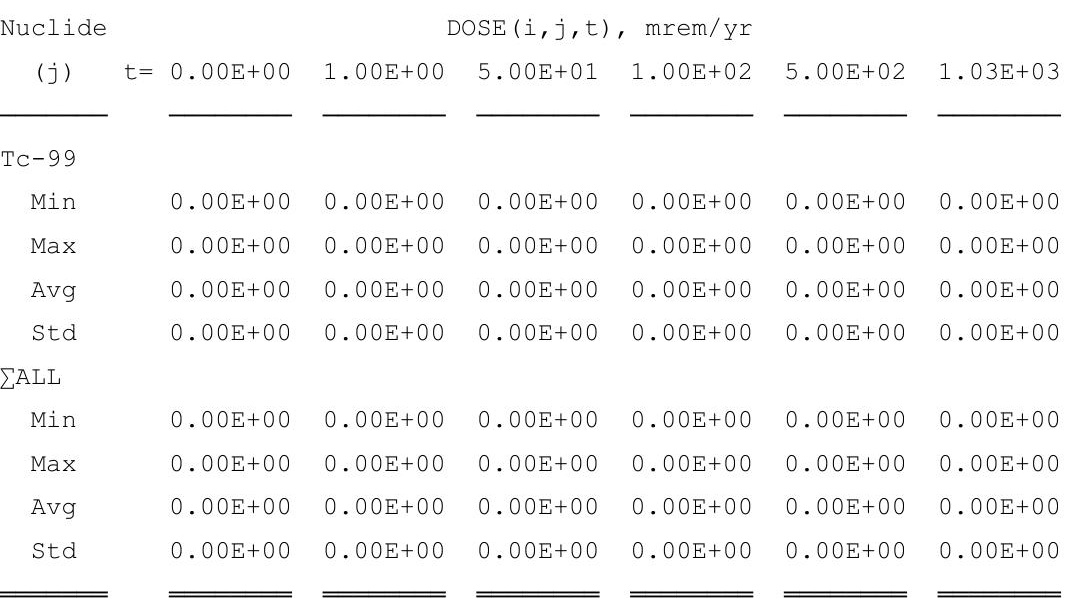

¿ALL is total pathway dose summed for all nuclides. 
RESRAD-OFFSITE, Version 2.5

$\mathrm{T}^{1 / 2}$ Limit $=180$ days

robabilistic Dose and Risk Report

Title : Offsite Resident Farmer Deterministic Run

File : RF TC99 DOESG FWD-FV2b.ROF

Cumulative Probability Summary for: Total Dose Over all Pathways

\begin{tabular}{|c|c|c|c|c|c|c|c|}
\hline \multicolumn{4}{|l|}{ Cumulative } & \multicolumn{4}{|c|}{ Dose $(t), \mathrm{mrem} / \mathrm{yr}$} \\
\hline Probability & $t=$ & $0.00 \mathrm{E}+00$ & $1.00 \mathrm{E}+00$ & $5.00 \mathrm{E}+01$ & $1.00 \mathrm{E}+02$ & $5.00 E+02$ & $1.03 E+03$ \\
\hline 0.025 & & $1.81 \mathrm{E}-32$ & $1.83 E-32$ & $2.83 E-32$ & $4.40 E-32$ & $3.08 E-09$ & $3.52 \mathrm{E}-07$ \\
\hline 0.050 & & $1.82 \mathrm{E}-32$ & $1.84 \mathrm{E}-32$ & $3.15 \mathrm{E}-32$ & $5.47 \mathrm{E}-32$ & $4.81 \mathrm{E}-09$ & $4.37 E-07$ \\
\hline 0.075 & & $1.82 \mathrm{E}-32$ & $1.84 \mathrm{E}-32$ & $3.32 E-32$ & $6.06 \mathrm{E}-32$ & $6.62 \mathrm{E}-09$ & $5.07 \mathrm{E}-07$ \\
\hline 0.100 & & $1.82 \mathrm{E}-32$ & $1.84 \mathrm{E}-32$ & $3.42 E-32$ & $6.45 E-32$ & $8.73 E-09$ & $5.83 E-07$ \\
\hline 0.125 & & $1.82 \mathrm{E}-32$ & $1.84 \mathrm{E}-32$ & $3.52 \mathrm{E}-32$ & $6.81 \mathrm{E}-32$ & $1.07 \mathrm{E}-08$ & $6.40 \mathrm{E}-07$ \\
\hline 0.150 & & $1.82 E-32$ & $1.84 E-32$ & $3.59 \mathrm{E}-32$ & $7.10 E-32$ & $1.28 E-08$ & $6.94 E-07$ \\
\hline 0.175 & & $1.82 E-32$ & $1.84 E-32$ & $3.67 E-32$ & $7.39 E-32$ & $1.54 \mathrm{E}-08$ & 7. $42 E-07$ \\
\hline 0.200 & & $1.82 \mathrm{E}-32$ & $1.85 E-32$ & $3.72 \mathrm{E}-32$ & $7.62 E-32$ & $1.84 \mathrm{E}-08$ & $7.98 E-07$ \\
\hline 0.225 & & $1.82 \mathrm{E}-32$ & $1.85 E-32$ & $3.77 \mathrm{E}-32$ & $7.81 E-32$ & $2.20 \mathrm{E}-08$ & $8.53 E-07$ \\
\hline 0.250 & & $1.82 E-32$ & $1.85 E-32$ & $3.81 E-32$ & $7.98 E-32$ & $2.52 \mathrm{E}-08$ & $9.01 E-07$ \\
\hline 0.275 & & $1.82 \mathrm{E}-32$ & $1.85 E-32$ & $3.85 E-32$ & $8.14 \mathrm{E}-32$ & $2.89 E-08$ & $9.50 \mathrm{E}-07$ \\
\hline 0.300 & & $1.82 \mathrm{E}-32$ & $1.85 \mathrm{E}-32$ & $3.88 \mathrm{E}-32$ & $8.27 E-32$ & $3.29 \mathrm{E}-08$ & $1.01 \mathrm{E}-06$ \\
\hline 0.325 & & $1.82 E-32$ & $1.85 E-32$ & $3.91 E-32$ & $8.40 E-32$ & $3.74 \mathrm{E}-08$ & $1.06 \mathrm{E}-06$ \\
\hline 0.350 & & $1.82 \mathrm{E}-32$ & $1.85 \mathrm{E}-32$ & $3.94 \mathrm{E}-32$ & $8.54 \mathrm{E}-32$ & $4.20 \mathrm{E}-08$ & $1.11 \mathrm{E}-06$ \\
\hline 0.375 & & $1.82 \mathrm{E}-32$ & $1.85 \mathrm{E}-32$ & $3.97 \mathrm{E}-32$ & $8.66 \mathrm{E}-32$ & $4.73 E-08$ & $1.17 \mathrm{E}-06$ \\
\hline 0.400 & & $1.82 E-32$ & $1.85 E-32$ & $3.99 E-32$ & $8.74 E-32$ & $5.29 E-08$ & $1.22 \mathrm{E}-06$ \\
\hline 0.425 & & $1.82 \mathrm{E}-32$ & $1.85 E-32$ & 4.01E-32 & $8.83 E-32$ & $5.87 \mathrm{E}-08$ & $1.27 \mathrm{E}-06$ \\
\hline 0.450 & & $1.82 \mathrm{E}-32$ & $1.85 \mathrm{E}-32$ & $4.03 E-32$ & $8.93 E-32$ & $6.64 \mathrm{E}-08$ & $1.33 E-06$ \\
\hline 0.475 & & $1.82 E-32$ & $1.85 E-32$ & $4.05 E-32$ & $9.01 E-32$ & $7.51 \mathrm{E}-08$ & $1.38 E-06$ \\
\hline 0.500 & & $1.82 E-32$ & $1.85 \mathrm{E}-32$ & $4.07 E-32$ & $9.08 E-32$ & $8.32 \mathrm{E}-08$ & $1.44 \mathrm{E}-06$ \\
\hline 0.525 & & $1.82 \mathrm{E}-32$ & $1.85 E-32$ & $4.08 E-32$ & $9.16 \mathrm{E}-32$ & $9.35 E-08$ & $1.50 \mathrm{E}-06$ \\
\hline 0.550 & & $1.82 E-32$ & $1.85 E-32$ & $4.10 E-32$ & $9.22 \mathrm{E}-32$ & $1.06 \mathrm{E}-07$ & $1.57 \mathrm{E}-06$ \\
\hline 0.575 & & $1.82 \mathrm{E}-32$ & $1.85 E-32$ & $4.11 \mathrm{E}-32$ & $9.28 E-32$ & $1.17 \mathrm{E}-07$ & 1. $63 \mathrm{E}-06$ \\
\hline 0.600 & & $1.82 \mathrm{E}-32$ & $1.85 E-32$ & $4.13 E-32$ & $9.35 E-32$ & $1.31 \mathrm{E}-07$ & $1.70 \mathrm{E}-06$ \\
\hline 0.625 & & $1.82 E-32$ & $1.85 E-32$ & $4.14 \mathrm{E}-32$ & $9.40 \mathrm{E}-32$ & $1.47 \mathrm{E}-07$ & $1.76 \mathrm{E}-06$ \\
\hline 0.650 & & $1.82 E-32$ & $1.85 E-32$ & $4.15 E-32$ & $9.44 E-32$ & $1.66 \mathrm{E}-07$ & $1.84 \mathrm{E}-06$ \\
\hline 0.675 & & $1.82 \mathrm{E}-32$ & $1.85 E-32$ & $4.16 \mathrm{E}-32$ & $9.49 E-32$ & $1.86 \mathrm{E}-07$ & $1.91 E-06$ \\
\hline 0.700 & & $1.82 \mathrm{E}-32$ & $1.85 \mathrm{E}-32$ & $4.17 \mathrm{E}-32$ & $9.53 E-32$ & $2.13 E-07$ & $2.00 \mathrm{E}-06$ \\
\hline 0.725 & & $1.82 E-32$ & $1.85 E-32$ & $4.18 E-32$ & $9.58 \mathrm{E}-32$ & $2.41 E-07$ & $2.08 E-06$ \\
\hline 0.750 & & $1.82 \mathrm{E}-32$ & $1.85 E-32$ & $4.19 E-32$ & $9.62 E-32$ & $2.75 E-07$ & $2.17 E-06$ \\
\hline 0.775 & & $1.82 E-32$ & $1.85 E-32$ & $4.20 E-32$ & $9.67 \mathrm{E}-32$ & $3.14 \mathrm{E}-07$ & $2.26 \mathrm{E}-06$ \\
\hline 0.800 & & $1.82 \mathrm{E}-32$ & $1.85 E-32$ & $4.21 E-32$ & $9.72 E-32$ & $3.63 E-07$ & $2.36 E-06$ \\
\hline 0.825 & & $1.82 \mathrm{E}-32$ & $1.85 E-32$ & $4.22 E-32$ & $9.75 E-32$ & $4.19 E-07$ & $2.49 E-06$ \\
\hline 0.850 & & $1.82 \mathrm{E}-32$ & $1.85 \mathrm{E}-32$ & $4.22 E-32$ & $9.79 \mathrm{E}-32$ & $4.85 E-07$ & $2.61 E-06$ \\
\hline 0.875 & & $1.82 \mathrm{E}-32$ & $1.85 E-32$ & $4.23 E-32$ & $9.83 E-32$ & $5.64 \mathrm{E}-07$ & $2.76 E-06$ \\
\hline 0.900 & & $1.82 E-32$ & $1.85 \mathrm{E}-32$ & $4.24 E-32$ & $9.88 E-32$ & $6.94 \mathrm{E}-07$ & $2.92 E-06$ \\
\hline 0.925 & & $1.82 E-32$ & $1.85 E-32$ & $4.25 E-32$ & $9.92 E-32$ & $8.81 E-07$ & $3.11 E-06$ \\
\hline 0.950 & & $1.82 \mathrm{E}-32$ & $1.85 E-32$ & $4.26 \mathrm{E}-32$ & $9.97 \mathrm{E}-32$ & $1.13 \mathrm{E}-06$ & $3.38 E-06$ \\
\hline 0.975 & & $1.82 E-32$ & $1.85 E-32$ & $4.27 \mathrm{E}-32$ & $1.00 E-31$ & $1.75 E-06$ & $3.77 E-06$ \\
\hline 1.000 & & $1.82 E-32$ & $1.85 E-32$ & $4.31 E-32$ & $1.02 E-31$ & $6.38 E-06$ & $5.53 E-06$ \\
\hline
\end{tabular}


RESRAD-OFFSITE, Version 2.5

Probabilistic Dose and Risk Report

Title : Offsite Resident Farmer Deterministic Run

File : RF TC99 DOESG FWD-FV2b.ROF

Repetition $=$

Mean

td. Dev.

Minimum

Maximum

ercentile

0.010

0.025

0.050

0.075

0.100

0.125

0.150

0.175

0.200

0.225

0.250

0.275

0.300

0.325

0.350

0.375

0.400

0.425

0.450

0.475

0.500

0.525

0.550

0.575

0.600

0.625

0.650

0.675

0.700

0.725

0.750

0.775

0.800

0.825

0.850

0.875

0.900

0.925

0.950

0.975

0.990
Statistics and Cumulative distribution function of Peak Dose from All Pathways in mrem/yr

\begin{tabular}{|c|c|c|}
\hline 1 & 2 & 3 \\
\hline $1.70 \mathrm{E}-06$ & $1.70 \mathrm{E}-06$ & $1.70 \mathrm{E}-06$ \\
\hline $9.97 \mathrm{E}-07$ & $9.98 \mathrm{E}-07$ & $9.98 \mathrm{E}-07$ \\
\hline $2.03 E-07$ & $2.03 E-07$ & $2.03 E-07$ \\
\hline $7.75 \mathrm{E}-06$ & $7.75 \mathrm{E}-06$ & 7. $75 \mathrm{E}-06$ \\
\hline
\end{tabular}

$3.25 \mathrm{E}-07 \quad 3.25 \mathrm{E}-07 \quad 3.25 \mathrm{E}-07$

$3.81 \mathrm{E}-07 \quad 3.81 \mathrm{E}-07 \quad 3.81 \mathrm{E}-07$

$4.87 \mathrm{E}-07 \quad 4.87 \mathrm{E}-07 \quad 4.87 \mathrm{E}-07$

$5.45 \mathrm{E}-07 \quad 5.45 \mathrm{E}-07 \quad 5.45 \mathrm{E}-07$

$6.16 \mathrm{E}-07 \quad 6.16 \mathrm{E}-07 \quad 6.16 \mathrm{E}-07$

$6.69 \mathrm{E}-07 \quad 6.69 \mathrm{E}-07 \quad 6.69 \mathrm{E}-07$

$7.17 \mathrm{E}-07 \quad 7.17 \mathrm{E}-07 \quad 7.17 \mathrm{E}-07$

$7.80 \mathrm{E}-07 \quad 7.80 \mathrm{E}-07 \quad 7.80 \mathrm{E}-07$

$8.28 \mathrm{E}-07 \quad 8.27 \mathrm{E}-07 \quad 8.27 \mathrm{E}-07$

$8.92 \mathrm{E}-07 \quad 8.91 \mathrm{E}-07 \quad 8.91 \mathrm{E}-07$

$9.36 \mathrm{E}-07 \quad 9.36 \mathrm{E}-07 \quad 9.36 \mathrm{E}-07$

$9.88 \mathrm{E}-07 \quad 9.88 \mathrm{E}-07 \quad 9.88 \mathrm{E}-07$

$1.04 \mathrm{E}-06 \quad 1.04 \mathrm{E}-06 \quad 1.04 \mathrm{E}-06$

1.10E-06 1.10E-06 1.10E-06

$1.16 \mathrm{E}-06 \quad 1.16 \mathrm{E}-06 \quad 1.16 \mathrm{E}-06$

$1.22 \mathrm{E}-06 \quad 1.22 \mathrm{E}-06 \quad 1.22 \mathrm{E}-06$

$1.27 \mathrm{E}-06 \quad 1.27 \mathrm{E}-06 \quad 1.27 \mathrm{E}-06$

$1.33 \mathrm{E}-06 \quad 1.33 \mathrm{E}-06 \quad 1.33 \mathrm{E}-06$

$1.38 \mathrm{E}-06 \quad 1.38 \mathrm{E}-06 \quad 1.38 \mathrm{E}-06$

$1.44 \mathrm{E}-06 \quad 1.44 \mathrm{E}-06 \quad 1.44 \mathrm{E}-06$

$1.51 \mathrm{E}-06 \quad 1.51 \mathrm{E}-06 \quad 1.51 \mathrm{E}-06$

$1.58 \mathrm{E}-06 \quad 1.58 \mathrm{E}-06 \quad 1.58 \mathrm{E}-06$

$1.63 \mathrm{E}-06 \quad 1.63 \mathrm{E}-06 \quad 1.63 \mathrm{E}-06$

$1.69 \mathrm{E}-06 \quad 1.69 \mathrm{E}-06 \quad 1.69 \mathrm{E}-06$

$1.76 \mathrm{E}-06 \quad 1.76 \mathrm{E}-06 \quad 1.76 \mathrm{E}-06$

$1.83 \mathrm{E}-06 \quad 1.83 \mathrm{E}-06 \quad 1.83 \mathrm{E}-06$

$1.90 \mathrm{E}-06 \quad 1.90 \mathrm{E}-06 \quad 1.90 \mathrm{E}-06$

$1.96 \mathrm{E}-06 \quad 1.96 \mathrm{E}-06 \quad 1.96 \mathrm{E}-06$

$2.07 \mathrm{E}-06 \quad 2.07 \mathrm{E}-06 \quad 2.07 \mathrm{E}-06$

$2.13 E-06 \quad 2.13 E-06 \quad 2.13 E-06$

2. $25 \mathrm{E}-06 \quad 2.25 \mathrm{E}-06 \quad 2.25 \mathrm{E}-06$

$2.34 \mathrm{E}-06 \quad 2.34 \mathrm{E}-06 \quad 2.34 \mathrm{E}-06$

$2.44 \mathrm{E}-06 \quad 2.44 \mathrm{E}-06 \quad 2.44 \mathrm{E}-06$

$2.55 \mathrm{E}-06 \quad 2.55 \mathrm{E}-06 \quad 2.55 \mathrm{E}-06$

$2.68 \mathrm{E}-06 \quad 2.68 \mathrm{E}-06 \quad 2.68 \mathrm{E}-06$

$2.84 \mathrm{E}-06 \quad 2.84 \mathrm{E}-06 \quad 2.84 \mathrm{E}-06$

$3.06 \mathrm{E}-06 \quad 3.06 \mathrm{E}-06 \quad 3.06 \mathrm{E}-06$

3. $32 \mathrm{E}-06 \quad 3.32 \mathrm{E}-06 \quad 3.32 \mathrm{E}-06$

$3.60 \mathrm{E}-06 \quad 3.60 \mathrm{E}-06 \quad 3.60 \mathrm{E}-06$

4.14E-06 4.14E-06 4.14E-06

4.66E-06 4.66E-06 4.66E-06 
RESRAD-OFFSITE, Version 2.5

Probabilistic Dose and Risk Report

Title : Offsite Resident Farmer Deterministic Run

File : RF TC99 DOESG FWD-FV2b.ROF

Retition $=$

Statistics and Cumulative distribution function of Peak Dose from External Ground(Wreleas) in mrem/yr

\begin{tabular}{|c|c|c|c|}
\hline Repetition = & 1 & 2 & 3 \\
\hline Mean & $9.20 \mathrm{E}-07$ & $9.20 \mathrm{E}-07$ & $9.20 \mathrm{E}-07$ \\
\hline Std. Dev. & $5.41 \mathrm{E}-07$ & $5.41 \mathrm{E}-07$ & $5.41 \mathrm{E}-07$ \\
\hline Minimum & $1.10 \mathrm{E}-07$ & $1.10 \mathrm{E}-07$ & $1.10 \mathrm{E}-07$ \\
\hline Maximum & $4.20 \mathrm{E}-06$ & $4.20 \mathrm{E}-06$ & $4.20 \mathrm{E}-06$ \\
\hline
\end{tabular}

Percentile

$0.010 \quad 1.76 \mathrm{E}-07 \quad 1.76 \mathrm{E}-07 \quad 1.76 \mathrm{E}-07$

$\begin{array}{llll}0.025 & 2.07 \mathrm{E}-07 & 2.07 \mathrm{E}-07 & 2.07 \mathrm{E}-07\end{array}$

$\begin{array}{llll}0.050 & 2.64 \mathrm{E}-07 & 2.64 \mathrm{E}-07 & 2.64 \mathrm{E}-07\end{array}$

$\begin{array}{llll}0.075 & 2.95 \mathrm{E}-07 & 2.95 \mathrm{E}-07 & 2.95 \mathrm{E}-07\end{array}$

$\begin{array}{llll}0.100 & 3.34 \mathrm{E}-07 & 3.34 \mathrm{E}-07 & 3.34 \mathrm{E}-07\end{array}$

$0.125 \quad 3.63 \mathrm{E}-07 \quad 3.63 \mathrm{E}-07 \quad 3.63 \mathrm{E}-07$

$0.150 \quad 3.89 \mathrm{E}-07 \quad 3.89 \mathrm{E}-07 \quad 3.89 \mathrm{E}-07$

$0.175 \quad 4.23 \mathrm{E}-07 \quad 4.23 \mathrm{E}-07 \quad 4.23 \mathrm{E}-07$

$0.200 \quad 4.49 \mathrm{E}-07 \quad 4.48 \mathrm{E}-07 \quad 4.48 \mathrm{E}-07$

$0.225 \quad 4.84 \mathrm{E}-07 \quad 4.83 \mathrm{E}-07 \quad 4.83 \mathrm{E}-07$

$\begin{array}{llll}0.250 \quad 5.08 \mathrm{E}-07 & 5.08 \mathrm{E}-07 \quad 5.08 \mathrm{E}-07\end{array}$

$\begin{array}{llll}0.275 & 5.36 \mathrm{E}-07 & 5.36 \mathrm{E}-07 & 5.36 \mathrm{E}-07\end{array}$

$0.300 \quad 5.64 \mathrm{E}-07 \quad 5.64 \mathrm{E}-07 \quad 5.64 \mathrm{E}-07$

$\begin{array}{llll}0.325 & 5.95 \mathrm{E}-07 & 5.95 \mathrm{E}-07 & 5.95 \mathrm{E}-07\end{array}$

$\begin{array}{llll}0.350 & 6.31 \mathrm{E}-07 & 6.30 \mathrm{E}-07 & 6.30 \mathrm{E}-07\end{array}$

$\begin{array}{llll}0.375 & 6.64 \mathrm{E}-07 & 6.63 \mathrm{E}-07 & 6.63 \mathrm{E}-07\end{array}$

$\begin{array}{llll}0.400 & 6.89 \mathrm{E}-07 & 6.88 \mathrm{E}-07 & 6.88 \mathrm{E}-07\end{array}$

$\begin{array}{llll}0.425 & 7.20 \mathrm{E}-07 & 7.19 \mathrm{E}-07 & 7.19 \mathrm{E}-07\end{array}$

$0.450 \quad 7.48 \mathrm{E}-07 \quad 7.48 \mathrm{E}-07 \quad 7.48 \mathrm{E}-07$

$0.475 \quad 7.83 \mathrm{E}-07 \quad 7.82 \mathrm{E}-07 \quad 7.83 \mathrm{E}-07$

$\begin{array}{llll}0.500 & 8.18 \mathrm{E}-07 & 8.17 \mathrm{E}-07 & 8.18 \mathrm{E}-07\end{array}$

$0.525 \quad 8.56 \mathrm{E}-07 \quad 8.54 \mathrm{E}-07 \quad 8.56 \mathrm{E}-07$
0.550

$0.550 \quad 8.84 \mathrm{E}-07 \quad 8.83 \mathrm{E}-07 \quad 8.84 \mathrm{E}-07$
0.575

$\begin{array}{llll}0.575 & 9.18 \mathrm{E}-07 & 9.17 \mathrm{E}-07 & 9.18 \mathrm{E}-07\end{array}$

$\begin{array}{llll}0.600 & 9.55 \mathrm{E}-07 & 9.55 \mathrm{E}-07 & 9.55 \mathrm{E}-07\end{array}$

$\begin{array}{llll}0.625 & 9.94 \mathrm{E}-07 & 9.91 \mathrm{E}-07 & 9.94 \mathrm{E}-07\end{array}$

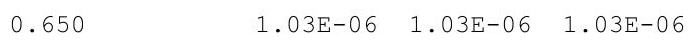

$\begin{array}{lllll}0.675 & 1.06 \mathrm{E}-06 & 1.06 \mathrm{E}-06 & 1.06 \mathrm{E}-06\end{array}$

$\begin{array}{llll}0.700 & 1.12 \mathrm{E}-06 & 1.12 \mathrm{E}-06 & 1.12 \mathrm{E}-06\end{array}$

$\begin{array}{llll}0.725 & 1.16 \mathrm{E}-06 & 1.16 \mathrm{E}-06 & 1.16 \mathrm{E}-06\end{array}$

$\begin{array}{llll}0.750 & 1.22 \mathrm{E}-06 & 1.22 \mathrm{E}-06 & 1.22 \mathrm{E}-06\end{array}$

$\begin{array}{llll}0.775 & 1.27 \mathrm{E}-06 & 1.27 \mathrm{E}-06 & 1.27 \mathrm{E}-06\end{array}$

$\begin{array}{llll}0.800 & 1.32 \mathrm{E}-06 & 1.32 \mathrm{E}-06 & 1.32 \mathrm{E}-06\end{array}$

$\begin{array}{llll}0.825 & 1.38 \mathrm{E}-06 & 1.38 \mathrm{E}-06 & 1.38 \mathrm{E}-06\end{array}$

$0.850 \quad 1.45 \mathrm{E}-06 \quad 1.45 \mathrm{E}-06 \quad 1.45 \mathrm{E}-06$

$\begin{array}{llll}0.875 & 1.54 \mathrm{E}-06 & 1.54 \mathrm{E}-06 & 1.54 \mathrm{E}-06\end{array}$

$\begin{array}{llll}0.900 & 1.66 \mathrm{E}-06 & 1.66 \mathrm{E}-06 & 1.66 \mathrm{E}-06\end{array}$

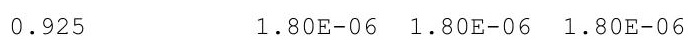

$\begin{array}{llll}0.950 & 1.95 \mathrm{E}-06 & 1.95 \mathrm{E}-06 & 1.95 \mathrm{E}-06\end{array}$

$\begin{array}{llll}0.975 & 2.24 \mathrm{E}-06 & 2.24 \mathrm{E}-06 & 2.24 \mathrm{E}-06\end{array}$

$0.990 \quad 2.53 \mathrm{E}-06 \quad 2.53 \mathrm{E}-06 \quad 2.53 \mathrm{E}-06$ 
RESRAD-OFFSITE, Version 2.5

Probabilistic Dose and Risk Report

Title : Offsite Resident Farmer Deterministic Run

File : RF TC99 DOESG FWD-FV2b.ROF

Repetition $=$

Mean

td. Dev.

Minimum

Maximum

ercentile

0.010

0.025

0.050

0.075

0.100

0.125

0.150

0.175

0.200

0.225

0.250

0.275

0.300

0.325

0.350

0.375

0.400

0.425

0.450

0.475

0.500

0.525

0.550

0.575

0.600

0.625

0.650

0.675

0.700

0.725

0.750

0.775

0.800

0.825

0.850

0.875

0.900

0.925

0.950

0.975

0.990
Statistics and Cumulative distribution function of Peak Dose from Fish Ingestion in mrem/yr

$\begin{array}{cccc}1 & 2 & 3 \\ 0.00 \mathrm{E}+00 & 0.00 \mathrm{E}+00 & 0.00 \mathrm{E}+00 \\ 0.00 \mathrm{E}+00 & 0.00 \mathrm{E}+00 & 0.00 \mathrm{E}+00 \\ 0.00 \mathrm{E}+00 & 0.00 \mathrm{E}+00 & 0.00 \mathrm{E}+00 \\ 0.00 \mathrm{E}+00 & 0.00 \mathrm{E}+00 & 0.00 \mathrm{E}+00\end{array}$

$0.00 \mathrm{E}+00 \quad 0.00 \mathrm{E}+00 \quad 0.00 \mathrm{E}+00$

$0.00 \mathrm{E}+00 \quad 0.00 \mathrm{E}+00 \quad 0.00 \mathrm{E}+00$

$0.00 \mathrm{E}+00 \quad 0.00 \mathrm{E}+00 \quad 0.00 \mathrm{E}+00$

$0.00 \mathrm{E}+00 \quad 0.00 \mathrm{E}+00 \quad 0.00 \mathrm{E}+00$

$0.00 \mathrm{E}+00 \quad 0.00 \mathrm{E}+00 \quad 0.00 \mathrm{E}+00$

$0.00 \mathrm{E}+00 \quad 0.00 \mathrm{E}+00 \quad 0.00 \mathrm{E}+00$

$0.00 \mathrm{E}+00 \quad 0.00 \mathrm{E}+00 \quad 0.00 \mathrm{E}+00$

$0.00 \mathrm{E}+00 \quad 0.00 \mathrm{E}+00 \quad 0.00 \mathrm{E}+00$

$0.00 \mathrm{E}+00 \quad 0.00 \mathrm{E}+00 \quad 0.00 \mathrm{E}+00$

$0.00 \mathrm{E}+00 \quad 0.00 \mathrm{E}+00 \quad 0.00 \mathrm{E}+00$

$0.00 \mathrm{E}+00 \quad 0.00 \mathrm{E}+00 \quad 0.00 \mathrm{E}+00$

$0.00 \mathrm{E}+00 \quad 0.00 \mathrm{E}+00 \quad 0.00 \mathrm{E}+00$

$0.00 \mathrm{E}+00 \quad 0.00 \mathrm{E}+00 \quad 0.00 \mathrm{E}+00$

$0.00 \mathrm{E}+00 \quad 0.00 \mathrm{E}+00 \quad 0.00 \mathrm{E}+00$

$0.00 \mathrm{E}+00 \quad 0.00 \mathrm{E}+00 \quad 0.00 \mathrm{E}+00$

$0.00 \mathrm{E}+00 \quad 0.00 \mathrm{E}+00 \quad 0.00 \mathrm{E}+00$

$0.00 \mathrm{E}+00 \quad 0.00 \mathrm{E}+00 \quad 0.00 \mathrm{E}+00$

$0.00 \mathrm{E}+00 \quad 0.00 \mathrm{E}+00 \quad 0.00 \mathrm{E}+00$

$0.00 \mathrm{E}+00 \quad 0.00 \mathrm{E}+00 \quad 0.00 \mathrm{E}+00$

$0.00 \mathrm{E}+00 \quad 0.00 \mathrm{E}+00 \quad 0.00 \mathrm{E}+00$

$0.00 \mathrm{E}+00 \quad 0.00 \mathrm{E}+00 \quad 0.00 \mathrm{E}+00$

$0.00 \mathrm{E}+00 \quad 0.00 \mathrm{E}+00 \quad 0.00 \mathrm{E}+00$

$0.00 \mathrm{E}+00 \quad 0.00 \mathrm{E}+00 \quad 0.00 \mathrm{E}+00$

$0.00 \mathrm{E}+00 \quad 0.00 \mathrm{E}+00 \quad 0.00 \mathrm{E}+00$

$0.00 \mathrm{E}+00 \quad 0.00 \mathrm{E}+00 \quad 0.00 \mathrm{E}+00$

$0.00 \mathrm{E}+00 \quad 0.00 \mathrm{E}+00 \quad 0.00 \mathrm{E}+00$

$0.00 \mathrm{E}+00 \quad 0.00 \mathrm{E}+00 \quad 0.00 \mathrm{E}+00$

$0.00 \mathrm{E}+00 \quad 0.00 \mathrm{E}+00 \quad 0.00 \mathrm{E}+00$

$0.00 \mathrm{E}+00 \quad 0.00 \mathrm{E}+00 \quad 0.00 \mathrm{E}+00$

$0.00 \mathrm{E}+00 \quad 0.00 \mathrm{E}+00 \quad 0.00 \mathrm{E}+00$

$\begin{array}{lll}0.00 \mathrm{E}+00 & 0.00 \mathrm{E}+00 \quad 0.00 \mathrm{E}+00\end{array}$

$0.00 \mathrm{E}+00 \quad 0.00 \mathrm{E}+00 \quad 0.00 \mathrm{E}+00$

$0.00 \mathrm{E}+00 \quad 0.00 \mathrm{E}+00 \quad 0.00 \mathrm{E}+00$

$0.00 \mathrm{E}+00 \quad 0.00 \mathrm{E}+00 \quad 0.00 \mathrm{E}+00$

$0.00 \mathrm{E}+00 \quad 0.00 \mathrm{E}+00 \quad 0.00 \mathrm{E}+00$

$0.00 \mathrm{E}+00 \quad 0.00 \mathrm{E}+00 \quad 0.00 \mathrm{E}+00$

$0.00 \mathrm{E}+00 \quad 0.00 \mathrm{E}+00 \quad 0.00 \mathrm{E}+00$

$0.00 \mathrm{E}+00 \quad 0.00 \mathrm{E}+00 \quad 0.00 \mathrm{E}+00$

$0.00 \mathrm{E}+00 \quad 0.00 \mathrm{E}+00 \quad 0.00 \mathrm{E}+00$

$0.00 \mathrm{E}+00 \quad 0.00 \mathrm{E}+00 \quad 0.00 \mathrm{E}+00$

$0.00 \mathrm{E}+00 \quad 0.00 \mathrm{E}+00 \quad 0.00 \mathrm{E}+00$ 
RESRAD-OFFSITE, Version 2.5

Probabilistic Dose and Risk Report

Title : Offsite Resident Farmer Deterministic Run

File : RF TC99 DOESG FWD-FV2b.ROF

Repetition $=$

Mean

td. Dev.

Minimum

Maximum

ercentile

0.010

0.025

0.050

0.075

0.100

0.125

0.150

0.175

0.200

0.225

0.250

0.275

0.300

0.325

0.350

0.375

0.400

0.425

0.450

0.475

0.500

0.525

0.550

0.575

0.600

0.625

0.650

0.675

0.700

0.725

0.750

0.775

0.800

0.825

0.850

0.875

0.900

0.925

0.950

0.975

0.990

Statistics and Cumulative distribution function of Peak Dose from Radon (Waterrelease) in mrem/yr

$\begin{array}{cccc}1 & 2 & 3 \\ 0.00 \mathrm{E}+00 & 0.00 \mathrm{E}+00 & 0.00 \mathrm{E}+00 \\ 0.00 \mathrm{E}+00 & 0.00 \mathrm{E}+00 & 0.00 \mathrm{E}+00 \\ 0.00 \mathrm{E}+00 & 0.00 \mathrm{E}+00 & 0.00 \mathrm{E}+00 \\ 0.00 \mathrm{E}+00 & 0.00 \mathrm{E}+00 & 0.00 \mathrm{E}+00\end{array}$

$0.00 \mathrm{E}+00 \quad 0.00 \mathrm{E}+00 \quad 0.00 \mathrm{E}+00$

$0.00 \mathrm{E}+00 \quad 0.00 \mathrm{E}+00 \quad 0.00 \mathrm{E}+00$

$0.00 \mathrm{E}+00 \quad 0.00 \mathrm{E}+00 \quad 0.00 \mathrm{E}+00$

$0.00 \mathrm{E}+00 \quad 0.00 \mathrm{E}+00 \quad 0.00 \mathrm{E}+00$

$0.00 \mathrm{E}+00 \quad 0.00 \mathrm{E}+00 \quad 0.00 \mathrm{E}+00$

$0.00 \mathrm{E}+00 \quad 0.00 \mathrm{E}+00 \quad 0.00 \mathrm{E}+00$

$0.00 \mathrm{E}+00 \quad 0.00 \mathrm{E}+00 \quad 0.00 \mathrm{E}+00$

$0.00 \mathrm{E}+00 \quad 0.00 \mathrm{E}+00 \quad 0.00 \mathrm{E}+00$

$0.00 \mathrm{E}+00 \quad 0.00 \mathrm{E}+00 \quad 0.00 \mathrm{E}+00$

$0.00 \mathrm{E}+00 \quad 0.00 \mathrm{E}+00 \quad 0.00 \mathrm{E}+00$

$0.00 \mathrm{E}+00 \quad 0.00 \mathrm{E}+00 \quad 0.00 \mathrm{E}+00$

$0.00 \mathrm{E}+00 \quad 0.00 \mathrm{E}+00 \quad 0.00 \mathrm{E}+00$

$0.00 \mathrm{E}+00 \quad 0.00 \mathrm{E}+00 \quad 0.00 \mathrm{E}+00$

$0.00 \mathrm{E}+00 \quad 0.00 \mathrm{E}+00 \quad 0.00 \mathrm{E}+00$

$0.00 \mathrm{E}+00 \quad 0.00 \mathrm{E}+00 \quad 0.00 \mathrm{E}+00$

$0.00 \mathrm{E}+00 \quad 0.00 \mathrm{E}+00 \quad 0.00 \mathrm{E}+00$

$0.00 \mathrm{E}+00 \quad 0.00 \mathrm{E}+00 \quad 0.00 \mathrm{E}+00$

$0.00 \mathrm{E}+00 \quad 0.00 \mathrm{E}+00 \quad 0.00 \mathrm{E}+00$

$0.00 \mathrm{E}+00 \quad 0.00 \mathrm{E}+00 \quad 0.00 \mathrm{E}+00$

$0.00 \mathrm{E}+00 \quad 0.00 \mathrm{E}+00 \quad 0.00 \mathrm{E}+00$

$0.00 \mathrm{E}+00 \quad 0.00 \mathrm{E}+00 \quad 0.00 \mathrm{E}+00$

$0.00 \mathrm{E}+00 \quad 0.00 \mathrm{E}+00 \quad 0.00 \mathrm{E}+00$

$0.00 \mathrm{E}+00 \quad 0.00 \mathrm{E}+00 \quad 0.00 \mathrm{E}+00$

$0.00 \mathrm{E}+00 \quad 0.00 \mathrm{E}+00 \quad 0.00 \mathrm{E}+00$

$0.00 \mathrm{E}+00 \quad 0.00 \mathrm{E}+00 \quad 0.00 \mathrm{E}+00$

$0.00 \mathrm{E}+00 \quad 0.00 \mathrm{E}+00 \quad 0.00 \mathrm{E}+00$

$0.00 \mathrm{E}+00 \quad 0.00 \mathrm{E}+00 \quad 0.00 \mathrm{E}+00$

$0.00 \mathrm{E}+00 \quad 0.00 \mathrm{E}+00 \quad 0.00 \mathrm{E}+00$

$0.00 \mathrm{E}+00 \quad 0.00 \mathrm{E}+00 \quad 0.00 \mathrm{E}+00$

$0.00 \mathrm{E}+00 \quad 0.00 \mathrm{E}+00 \quad 0.00 \mathrm{E}+00$

$\begin{array}{lll}0.00 \mathrm{E}+00 & 0.00 \mathrm{E}+00 \quad 0.00 \mathrm{E}+00\end{array}$

$0.00 \mathrm{E}+00 \quad 0.00 \mathrm{E}+00 \quad 0.00 \mathrm{E}+00$

$0.00 \mathrm{E}+00 \quad 0.00 \mathrm{E}+00 \quad 0.00 \mathrm{E}+00$

$0.00 \mathrm{E}+00 \quad 0.00 \mathrm{E}+00 \quad 0.00 \mathrm{E}+00$

$0.00 \mathrm{E}+00 \quad 0.00 \mathrm{E}+00 \quad 0.00 \mathrm{E}+00$

$0.00 \mathrm{E}+00 \quad 0.00 \mathrm{E}+00 \quad 0.00 \mathrm{E}+00$

$0.00 \mathrm{E}+00 \quad 0.00 \mathrm{E}+00 \quad 0.00 \mathrm{E}+00$

$0.00 \mathrm{E}+00 \quad 0.00 \mathrm{E}+00 \quad 0.00 \mathrm{E}+00$

$0.00 \mathrm{E}+00 \quad 0.00 \mathrm{E}+00 \quad 0.00 \mathrm{E}+00$

$0.00 \mathrm{E}+00 \quad 0.00 \mathrm{E}+00 \quad 0.00 \mathrm{E}+00$

$0.00 \mathrm{E}+00 \quad 0.00 \mathrm{E}+00 \quad 0.00 \mathrm{E}+00$

C-315

DCN 5090-TR-02-2 
RESRAD-OFFSITE, Version 2.5

Probabilistic Dose and Risk Report

Title : Offsite Resident Farmer Deterministic Run

File : RF TC99 DOESG FWD-FV2b.ROF

Repetition $=$

Mean

td. Dev.

Minimum

Maximum

ercentile

0.010

0.025

0.050

0.075

0.100

0.125

0.150

0.175

0.200

0.225

0.250

0.275

0.300

0.325

0.350

0.375

0.400

0.425

0.450

0.475

0.500

0.525

0.550

0.575

0.600

0.625

0.650

0.675

0.700

0.725

0.750

0.775

0.800

0.825

0.850

0.875

0.900

0.925

0.950

0.975

0.990

Statistics and Cumulative distribution function of Peak Dose from Plant (Waterrelease) in mrem/yr

$\begin{array}{cccc}1 & 2 & 3 \\ 0.00 \mathrm{E}+00 & 0.00 \mathrm{E}+00 & 0.00 \mathrm{E}+00 \\ 0.00 \mathrm{E}+00 & 0.00 \mathrm{E}+00 & 0.00 \mathrm{E}+00 \\ 0.00 \mathrm{E}+00 & 0.00 \mathrm{E}+00 & 0.00 \mathrm{E}+00 \\ 0.00 \mathrm{E}+00 & 0.00 \mathrm{E}+00 & 0.00 \mathrm{E}+00\end{array}$

$0.00 \mathrm{E}+00 \quad 0.00 \mathrm{E}+00 \quad 0.00 \mathrm{E}+00$

$0.00 \mathrm{E}+00 \quad 0.00 \mathrm{E}+00 \quad 0.00 \mathrm{E}+00$

$0.00 \mathrm{E}+00 \quad 0.00 \mathrm{E}+00 \quad 0.00 \mathrm{E}+00$

$0.00 \mathrm{E}+00 \quad 0.00 \mathrm{E}+00 \quad 0.00 \mathrm{E}+00$

$0.00 \mathrm{E}+00 \quad 0.00 \mathrm{E}+00 \quad 0.00 \mathrm{E}+00$

$0.00 \mathrm{E}+00 \quad 0.00 \mathrm{E}+00 \quad 0.00 \mathrm{E}+00$

$0.00 \mathrm{E}+00 \quad 0.00 \mathrm{E}+00 \quad 0.00 \mathrm{E}+00$

$0.00 \mathrm{E}+00 \quad 0.00 \mathrm{E}+00 \quad 0.00 \mathrm{E}+00$

$0.00 \mathrm{E}+00 \quad 0.00 \mathrm{E}+00 \quad 0.00 \mathrm{E}+00$

$0.00 \mathrm{E}+00 \quad 0.00 \mathrm{E}+00 \quad 0.00 \mathrm{E}+00$

$0.00 \mathrm{E}+00 \quad 0.00 \mathrm{E}+00 \quad 0.00 \mathrm{E}+00$

$0.00 \mathrm{E}+00 \quad 0.00 \mathrm{E}+00 \quad 0.00 \mathrm{E}+00$

$0.00 \mathrm{E}+00 \quad 0.00 \mathrm{E}+00 \quad 0.00 \mathrm{E}+00$

$0.00 \mathrm{E}+00 \quad 0.00 \mathrm{E}+00 \quad 0.00 \mathrm{E}+00$

$0.00 \mathrm{E}+00 \quad 0.00 \mathrm{E}+00 \quad 0.00 \mathrm{E}+00$

$0.00 \mathrm{E}+00 \quad 0.00 \mathrm{E}+00 \quad 0.00 \mathrm{E}+00$

$0.00 \mathrm{E}+00 \quad 0.00 \mathrm{E}+00 \quad 0.00 \mathrm{E}+00$

$0.00 \mathrm{E}+00 \quad 0.00 \mathrm{E}+00 \quad 0.00 \mathrm{E}+00$

$0.00 \mathrm{E}+00 \quad 0.00 \mathrm{E}+00 \quad 0.00 \mathrm{E}+00$

$0.00 \mathrm{E}+00 \quad 0.00 \mathrm{E}+00 \quad 0.00 \mathrm{E}+00$

$0.00 \mathrm{E}+00 \quad 0.00 \mathrm{E}+00 \quad 0.00 \mathrm{E}+00$

$0.00 \mathrm{E}+00 \quad 0.00 \mathrm{E}+00 \quad 0.00 \mathrm{E}+00$

$0.00 \mathrm{E}+00 \quad 0.00 \mathrm{E}+00 \quad 0.00 \mathrm{E}+00$

$0.00 \mathrm{E}+00 \quad 0.00 \mathrm{E}+00 \quad 0.00 \mathrm{E}+00$

$0.00 \mathrm{E}+00 \quad 0.00 \mathrm{E}+00 \quad 0.00 \mathrm{E}+00$

$0.00 \mathrm{E}+00 \quad 0.00 \mathrm{E}+00 \quad 0.00 \mathrm{E}+00$

$0.00 \mathrm{E}+00 \quad 0.00 \mathrm{E}+00 \quad 0.00 \mathrm{E}+00$

$0.00 \mathrm{E}+00 \quad 0.00 \mathrm{E}+00 \quad 0.00 \mathrm{E}+00$

$0.00 \mathrm{E}+00 \quad 0.00 \mathrm{E}+00 \quad 0.00 \mathrm{E}+00$

$0.00 \mathrm{E}+00 \quad 0.00 \mathrm{E}+00 \quad 0.00 \mathrm{E}+00$

$\begin{array}{lll}0.00 \mathrm{E}+00 & 0.00 \mathrm{E}+00 \quad 0.00 \mathrm{E}+00\end{array}$

$0.00 \mathrm{E}+00 \quad 0.00 \mathrm{E}+00 \quad 0.00 \mathrm{E}+00$

$0.00 \mathrm{E}+00 \quad 0.00 \mathrm{E}+00 \quad 0.00 \mathrm{E}+00$

$0.00 \mathrm{E}+00 \quad 0.00 \mathrm{E}+00 \quad 0.00 \mathrm{E}+00$

$0.00 \mathrm{E}+00 \quad 0.00 \mathrm{E}+00 \quad 0.00 \mathrm{E}+00$

$0.00 \mathrm{E}+00 \quad 0.00 \mathrm{E}+00 \quad 0.00 \mathrm{E}+00$

$0.00 \mathrm{E}+00 \quad 0.00 \mathrm{E}+00 \quad 0.00 \mathrm{E}+00$

$0.00 \mathrm{E}+00 \quad 0.00 \mathrm{E}+00 \quad 0.00 \mathrm{E}+00$

$0.00 \mathrm{E}+00 \quad 0.00 \mathrm{E}+00 \quad 0.00 \mathrm{E}+00$

$0.00 \mathrm{E}+00 \quad 0.00 \mathrm{E}+00 \quad 0.00 \mathrm{E}+00$

$\begin{array}{lll}0.00 \mathrm{E}+00 & 0.00 \mathrm{E}+00 \quad 0.00 \mathrm{E}+00\end{array}$

C-316

DCN 5090-TR-02-2 
RESRAD-OFFSITE, Version 2.5

Probabilistic Dose and Risk Report

Title : Offsite Resident Farmer Deterministic Run

File : RF TC99 DOESG FWD-FV2b.ROF

Repetition $=$

Mean

td. Dev.

Minimum

Maximum

ercentile

0.010

0.025

0.050

0.075

0.100

0.125

0.150

0.175

0.200

0.225

0.250

0.275

0.300

0.325

0.350

0.375

0.400

0.425

0.450

0.475

0.500

0.525

0.550

0.575

0.600

0.625

0.650

0.675

0.700

0.725

0.750

0.775

0.800

0.825

0.850

0.875

0.900

0.925

0.950

0.975

0.990

Statistics and Cumulative distribution function of Peak Dose from Meat (Waterrelease) in mrem/yr

$\begin{array}{cccc}1 & 2 & 3 \\ 0.00 \mathrm{E}+00 & 0.00 \mathrm{E}+00 & 0.00 \mathrm{E}+00 \\ 0.00 \mathrm{E}+00 & 0.00 \mathrm{E}+00 & 0.00 \mathrm{E}+00 \\ 0.00 \mathrm{E}+00 & 0.00 \mathrm{E}+00 & 0.00 \mathrm{E}+00 \\ 0.00 \mathrm{E}+00 & 0.00 \mathrm{E}+00 & 0.00 \mathrm{E}+00\end{array}$

$0.00 \mathrm{E}+00 \quad 0.00 \mathrm{E}+00 \quad 0.00 \mathrm{E}+00$

$0.00 \mathrm{E}+00 \quad 0.00 \mathrm{E}+00 \quad 0.00 \mathrm{E}+00$

$0.00 \mathrm{E}+00 \quad 0.00 \mathrm{E}+00 \quad 0.00 \mathrm{E}+00$

$0.00 \mathrm{E}+00 \quad 0.00 \mathrm{E}+00 \quad 0.00 \mathrm{E}+00$

$0.00 \mathrm{E}+00 \quad 0.00 \mathrm{E}+00 \quad 0.00 \mathrm{E}+00$

$0.00 \mathrm{E}+00 \quad 0.00 \mathrm{E}+00 \quad 0.00 \mathrm{E}+00$

$0.00 \mathrm{E}+00 \quad 0.00 \mathrm{E}+00 \quad 0.00 \mathrm{E}+00$

$0.00 \mathrm{E}+00 \quad 0.00 \mathrm{E}+00 \quad 0.00 \mathrm{E}+00$

$0.00 \mathrm{E}+00 \quad 0.00 \mathrm{E}+00 \quad 0.00 \mathrm{E}+00$

$0.00 \mathrm{E}+00 \quad 0.00 \mathrm{E}+00 \quad 0.00 \mathrm{E}+00$

$0.00 \mathrm{E}+00 \quad 0.00 \mathrm{E}+00 \quad 0.00 \mathrm{E}+00$

$0.00 \mathrm{E}+00 \quad 0.00 \mathrm{E}+00 \quad 0.00 \mathrm{E}+00$

$0.00 \mathrm{E}+00 \quad 0.00 \mathrm{E}+00 \quad 0.00 \mathrm{E}+00$

$0.00 \mathrm{E}+00 \quad 0.00 \mathrm{E}+00 \quad 0.00 \mathrm{E}+00$

$0.00 \mathrm{E}+00 \quad 0.00 \mathrm{E}+00 \quad 0.00 \mathrm{E}+00$

$0.00 \mathrm{E}+00 \quad 0.00 \mathrm{E}+00 \quad 0.00 \mathrm{E}+00$

$0.00 \mathrm{E}+00 \quad 0.00 \mathrm{E}+00 \quad 0.00 \mathrm{E}+00$

$0.00 \mathrm{E}+00 \quad 0.00 \mathrm{E}+00 \quad 0.00 \mathrm{E}+00$

$0.00 \mathrm{E}+00 \quad 0.00 \mathrm{E}+00 \quad 0.00 \mathrm{E}+00$

$0.00 \mathrm{E}+00 \quad 0.00 \mathrm{E}+00 \quad 0.00 \mathrm{E}+00$

$0.00 \mathrm{E}+00 \quad 0.00 \mathrm{E}+00 \quad 0.00 \mathrm{E}+00$

$0.00 \mathrm{E}+00 \quad 0.00 \mathrm{E}+00 \quad 0.00 \mathrm{E}+00$

$0.00 \mathrm{E}+00 \quad 0.00 \mathrm{E}+00 \quad 0.00 \mathrm{E}+00$

$0.00 \mathrm{E}+00 \quad 0.00 \mathrm{E}+00 \quad 0.00 \mathrm{E}+00$

$0.00 \mathrm{E}+00 \quad 0.00 \mathrm{E}+00 \quad 0.00 \mathrm{E}+00$

$0.00 \mathrm{E}+00 \quad 0.00 \mathrm{E}+00 \quad 0.00 \mathrm{E}+00$

$0.00 \mathrm{E}+00 \quad 0.00 \mathrm{E}+00 \quad 0.00 \mathrm{E}+00$

$0.00 \mathrm{E}+00 \quad 0.00 \mathrm{E}+00 \quad 0.00 \mathrm{E}+00$

$0.00 \mathrm{E}+00 \quad 0.00 \mathrm{E}+00 \quad 0.00 \mathrm{E}+00$

$0.00 \mathrm{E}+00 \quad 0.00 \mathrm{E}+00 \quad 0.00 \mathrm{E}+00$

$0.00 \mathrm{E}+00 \quad 0.00 \mathrm{E}+00 \quad 0.00 \mathrm{E}+00$

$0.00 \mathrm{E}+00 \quad 0.00 \mathrm{E}+00 \quad 0.00 \mathrm{E}+00$

$0.00 \mathrm{E}+00 \quad 0.00 \mathrm{E}+00 \quad 0.00 \mathrm{E}+00$

$0.00 \mathrm{E}+00 \quad 0.00 \mathrm{E}+00 \quad 0.00 \mathrm{E}+00$

$0.00 \mathrm{E}+00 \quad 0.00 \mathrm{E}+00 \quad 0.00 \mathrm{E}+00$

$0.00 \mathrm{E}+00 \quad 0.00 \mathrm{E}+00 \quad 0.00 \mathrm{E}+00$

$0.00 \mathrm{E}+00 \quad 0.00 \mathrm{E}+00 \quad 0.00 \mathrm{E}+00$

$0.00 \mathrm{E}+00 \quad 0.00 \mathrm{E}+00 \quad 0.00 \mathrm{E}+00$

$0.00 \mathrm{E}+00 \quad 0.00 \mathrm{E}+00 \quad 0.00 \mathrm{E}+00$

$0.00 \mathrm{E}+00 \quad 0.00 \mathrm{E}+00 \quad 0.00 \mathrm{E}+00$

$0.00 \mathrm{E}+00 \quad 0.00 \mathrm{E}+00 \quad 0.00 \mathrm{E}+00$

C-317

DCN 5090-TR-02-2 
RESRAD-OFFSITE, Version 2.5

Probabilistic Dose and Risk Report

Title : Offsite Resident Farmer Deterministic Run

File : RF TC99 DOESG FWD-FV2b.ROF

Repetition $=$

Mean

td. Dev.

Minimum

Maximum

ercentile

0.010

0.025

0.050

0.075

0.100

0.125

0.150

0.175

0.200

0.225

0.250

0.275

0.300

0.325

0.350

0.375

0.400

0.425

0.450

0.475

0.500

0.525

0.550

0.575

0.600

0.625

0.650

0.675

0.700

0.725

0.750

0.775

0.800

0.825

0.850

0.875

0.900

0.925

0.950

0.975

0.990

Statistics and Cumulative distribution function of Peak Dose from Milk (Waterrelease) in mrem/yr

$\begin{array}{cccc}1 & 2 & 3 \\ 0.00 \mathrm{E}+00 & 0.00 \mathrm{E}+00 & 0.00 \mathrm{E}+00 \\ 0.00 \mathrm{E}+00 & 0.00 \mathrm{E}+00 & 0.00 \mathrm{E}+00 \\ 0.00 \mathrm{E}+00 & 0.00 \mathrm{E}+00 & 0.00 \mathrm{E}+00 \\ 0.00 \mathrm{E}+00 & 0.00 \mathrm{E}+00 & 0.00 \mathrm{E}+00\end{array}$

$0.00 \mathrm{E}+00 \quad 0.00 \mathrm{E}+00 \quad 0.00 \mathrm{E}+00$

$0.00 \mathrm{E}+00 \quad 0.00 \mathrm{E}+00 \quad 0.00 \mathrm{E}+00$

$0.00 \mathrm{E}+00 \quad 0.00 \mathrm{E}+00 \quad 0.00 \mathrm{E}+00$

$0.00 \mathrm{E}+00 \quad 0.00 \mathrm{E}+00 \quad 0.00 \mathrm{E}+00$

$0.00 \mathrm{E}+00 \quad 0.00 \mathrm{E}+00 \quad 0.00 \mathrm{E}+00$

$0.00 \mathrm{E}+00 \quad 0.00 \mathrm{E}+00 \quad 0.00 \mathrm{E}+00$

$0.00 \mathrm{E}+00 \quad 0.00 \mathrm{E}+00 \quad 0.00 \mathrm{E}+00$

$0.00 \mathrm{E}+00 \quad 0.00 \mathrm{E}+00 \quad 0.00 \mathrm{E}+00$

$0.00 \mathrm{E}+00 \quad 0.00 \mathrm{E}+00 \quad 0.00 \mathrm{E}+00$

$0.00 \mathrm{E}+00 \quad 0.00 \mathrm{E}+00 \quad 0.00 \mathrm{E}+00$

$0.00 \mathrm{E}+00 \quad 0.00 \mathrm{E}+00 \quad 0.00 \mathrm{E}+00$

$0.00 \mathrm{E}+00 \quad 0.00 \mathrm{E}+00 \quad 0.00 \mathrm{E}+00$

$0.00 \mathrm{E}+00 \quad 0.00 \mathrm{E}+00 \quad 0.00 \mathrm{E}+00$

$0.00 \mathrm{E}+00 \quad 0.00 \mathrm{E}+00 \quad 0.00 \mathrm{E}+00$

$0.00 \mathrm{E}+00 \quad 0.00 \mathrm{E}+00 \quad 0.00 \mathrm{E}+00$

$0.00 \mathrm{E}+00 \quad 0.00 \mathrm{E}+00 \quad 0.00 \mathrm{E}+00$

$0.00 \mathrm{E}+00 \quad 0.00 \mathrm{E}+00 \quad 0.00 \mathrm{E}+00$

$0.00 \mathrm{E}+00 \quad 0.00 \mathrm{E}+00 \quad 0.00 \mathrm{E}+00$

$0.00 \mathrm{E}+00 \quad 0.00 \mathrm{E}+00 \quad 0.00 \mathrm{E}+00$

$0.00 \mathrm{E}+00 \quad 0.00 \mathrm{E}+00 \quad 0.00 \mathrm{E}+00$

$0.00 \mathrm{E}+00 \quad 0.00 \mathrm{E}+00 \quad 0.00 \mathrm{E}+00$

$0.00 \mathrm{E}+00 \quad 0.00 \mathrm{E}+00 \quad 0.00 \mathrm{E}+00$

$0.00 \mathrm{E}+00 \quad 0.00 \mathrm{E}+00 \quad 0.00 \mathrm{E}+00$

$0.00 \mathrm{E}+00 \quad 0.00 \mathrm{E}+00 \quad 0.00 \mathrm{E}+00$

$0.00 \mathrm{E}+00 \quad 0.00 \mathrm{E}+00 \quad 0.00 \mathrm{E}+00$

$0.00 \mathrm{E}+00 \quad 0.00 \mathrm{E}+00 \quad 0.00 \mathrm{E}+00$

$0.00 \mathrm{E}+00 \quad 0.00 \mathrm{E}+00 \quad 0.00 \mathrm{E}+00$

$0.00 \mathrm{E}+00 \quad 0.00 \mathrm{E}+00 \quad 0.00 \mathrm{E}+00$

$0.00 \mathrm{E}+00 \quad 0.00 \mathrm{E}+00 \quad 0.00 \mathrm{E}+00$

$0.00 \mathrm{E}+00 \quad 0.00 \mathrm{E}+00 \quad 0.00 \mathrm{E}+00$

$0.00 \mathrm{E}+00 \quad 0.00 \mathrm{E}+00 \quad 0.00 \mathrm{E}+00$

$0.00 \mathrm{E}+00 \quad 0.00 \mathrm{E}+00 \quad 0.00 \mathrm{E}+00$

$0.00 \mathrm{E}+00 \quad 0.00 \mathrm{E}+00 \quad 0.00 \mathrm{E}+00$

$0.00 \mathrm{E}+00 \quad 0.00 \mathrm{E}+00 \quad 0.00 \mathrm{E}+00$

$0.00 \mathrm{E}+00 \quad 0.00 \mathrm{E}+00 \quad 0.00 \mathrm{E}+00$

$0.00 \mathrm{E}+00 \quad 0.00 \mathrm{E}+00 \quad 0.00 \mathrm{E}+00$

$0.00 \mathrm{E}+00 \quad 0.00 \mathrm{E}+00 \quad 0.00 \mathrm{E}+00$

$0.00 \mathrm{E}+00 \quad 0.00 \mathrm{E}+00 \quad 0.00 \mathrm{E}+00$

$0.00 \mathrm{E}+00 \quad 0.00 \mathrm{E}+00 \quad 0.00 \mathrm{E}+00$

$0.00 \mathrm{E}+00 \quad 0.00 \mathrm{E}+00 \quad 0.00 \mathrm{E}+00$

$0.00 \mathrm{E}+00 \quad 0.00 \mathrm{E}+00 \quad 0.00 \mathrm{E}+00$

C-318

DCN 5090-TR-02-2 
RESRAD-OFFSITE, Version 2.5

Probabilistic Dose and Risk Report

Title : Offsite Resident Farmer Deterministic Run

File : RF TC99 DOESG FWD-FV2b.ROF

Retition $=$

Mean

Statistics and Cumulative distribution function of Peak Dose from Soil Ingestion(Wrelease) in mrem/yr

Std. Dev.

Minimum

Maximum

\begin{tabular}{|c|c|c|}
\hline 1 & 2 & 3 \\
\hline $7.77 E-07$ & $7.77 \mathrm{E}-07$ & $7.77 \mathrm{E}-07$ \\
\hline $4.57 E-07$ & $4.57 E-07$ & $4.57 \mathrm{E}-07$ \\
\hline $9.30 \mathrm{E}-08$ & $9.30 \mathrm{E}-08$ & $9.30 E-08$ \\
\hline $3.55 \mathrm{E}-06$ & $3.55 E-06$ & $3.55 E-06$ \\
\hline
\end{tabular}

Percentile

0.010

1.49E-07 1.49E-07 1.49E-07

0.025

$1.75 \mathrm{E}-07 \quad 1.75 \mathrm{E}-07 \quad 1.75 \mathrm{E}-07$

0.050

2.23E-07 2.23E-07 2.23E-07

0.075

$2.49 \mathrm{E}-07 \quad 2.49 \mathrm{E}-07 \quad 2.49 \mathrm{E}-07$

0.100

$2.82 \mathrm{E}-07 \quad 2.82 \mathrm{E}-07 \quad 2.82 \mathrm{E}-07$

0.125

$3.06 \mathrm{E}-07 \quad 3.06 \mathrm{E}-07 \quad 3.06 \mathrm{E}-07$

0.150

$3.28 \mathrm{E}-07 \quad 3.28 \mathrm{E}-07 \quad 3.28 \mathrm{E}-07$

0.175

$3.57 \mathrm{E}-07 \quad 3.57 \mathrm{E}-07 \quad 3.57 \mathrm{E}-07$

$\begin{array}{lll}3.79 \mathrm{E}-07 & 3.79 \mathrm{E}-07 & 3.79 \mathrm{E}-07\end{array}$

$4.08 \mathrm{E}-07 \quad 4.08 \mathrm{E}-07 \quad 4.08 \mathrm{E}-07$

4.29E-07 4.29E-07 4.29E-07

$4.52 \mathrm{E}-07 \quad 4.52 \mathrm{E}-07 \quad 4.52 \mathrm{E}-07$

$4.76 \mathrm{E}-07 \quad 4.76 \mathrm{E}-07 \quad 4.76 \mathrm{E}-07$

$5.02 \mathrm{E}-07 \quad 5.02 \mathrm{E}-07 \quad 5.02 \mathrm{E}-07$

$5.33 \mathrm{E}-07 \quad 5.32 \mathrm{E}-07 \quad 5.32 \mathrm{E}-07$

$5.60 \mathrm{E}-07 \quad 5.60 \mathrm{E}-07 \quad 5.60 \mathrm{E}-07$

$5.82 \mathrm{E}-07 \quad 5.81 \mathrm{E}-07 \quad 5.81 \mathrm{E}-07$

$6.08 \mathrm{E}-07 \quad 6.07 \mathrm{E}-07 \quad 6.07 \mathrm{E}-07$

$6.32 \mathrm{E}-07 \quad 6.31 \mathrm{E}-07 \quad 6.31 \mathrm{E}-07$

$6.61 \mathrm{E}-07 \quad 6.60 \mathrm{E}-07 \quad 6.61 \mathrm{E}-07$

6.90E-07 6.90E-07 6.90E-07

$7.22 \mathrm{E}-07 \quad 7.21 \mathrm{E}-07 \quad 7.23 \mathrm{E}-07$

\begin{tabular}{ll}
$7.46 \mathrm{E}-07 \quad 7.45 \mathrm{E}-07 \quad 7.47 \mathrm{E}-07$ \\
\hline
\end{tabular}

$7.75 \mathrm{E}-07 \quad 7.74 \mathrm{E}-07 \quad 7.75 \mathrm{E}-07$

$8.06 \mathrm{E}-07 \quad 8.06 \mathrm{E}-07 \quad 8.06 \mathrm{E}-07$

$8.39 \mathrm{E}-07 \quad 8.37 \mathrm{E}-07 \quad 8.39 \mathrm{E}-07$

8.69E-07 8.68E-07 8.69E-07

$8.97 \mathrm{E}-07 \quad 8.97 \mathrm{E}-07 \quad 8.97 \mathrm{E}-07$

$9.46 \mathrm{E}-07 \quad 9.45 \mathrm{E}-07 \quad 9.46 \mathrm{E}-07$

$9.76 \mathrm{E}-07 \quad 9.76 \mathrm{E}-07 \quad 9.76 \mathrm{E}-07$

$1.03 \mathrm{E}-06 \quad 1.03 \mathrm{E}-06 \quad 1.03 \mathrm{E}-06$

$1.07 \mathrm{E}-06 \quad 1.07 \mathrm{E}-06 \quad 1.07 \mathrm{E}-06$

$1.12 \mathrm{E}-06 \quad 1.12 \mathrm{E}-06 \quad 1.12 \mathrm{E}-06$

$1.17 \mathrm{E}-06 \quad 1.17 \mathrm{E}-06 \quad 1.17 \mathrm{E}-06$

$1.23 \mathrm{E}-06 \quad 1.23 \mathrm{E}-06 \quad 1.23 \mathrm{E}-06$

$1.30 \mathrm{E}-06 \quad 1.30 \mathrm{E}-06 \quad 1.30 \mathrm{E}-06$

$1.40 \mathrm{E}-06 \quad 1.40 \mathrm{E}-06 \quad 1.40 \mathrm{E}-06$

$1.52 \mathrm{E}-06 \quad 1.52 \mathrm{E}-06 \quad 1.52 \mathrm{E}-06$

$1.65 \mathrm{E}-06 \quad 1.65 \mathrm{E}-06 \quad 1.65 \mathrm{E}-06$

$1.89 \mathrm{E}-06 \quad 1.89 \mathrm{E}-06 \quad 1.89 \mathrm{E}-06$

$2.14 \mathrm{E}-06 \quad 2.14 \mathrm{E}-06 \quad 2.14 \mathrm{E}-06$ 
RESRAD-OFFSITE, Version 2.5

Probabilistic Dose and Risk Report

Title : Offsite Resident Farmer Deterministic Run

File : RF TC99 DOESG FWD-FV2b.ROF

Repetition $=$

Mean

td. Dev.

Minimum

Maximum

ercentile

0.010

0.025

0.050

0.075

0.100

0.125

0.150

0.175

0.200

0.225

0.250

0.275

0.300

0.325

0.350

0.375

0.400

0.425

0.450

0.475

0.500

0.525

0.550

0.575

0.600

0.625

0.650

0.675

0.700

0.725

0.750

0.775

0.800

0.825

0.850

0.875

0.900

0.925

0.950

0.975

0.990

Statistics and Cumulative distribution function of Peak Dose from Water Ingestion in mrem/yr

$\begin{array}{cccc}1 & 2 & 3 \\ 0.00 \mathrm{E}+00 & 0.00 \mathrm{E}+00 & 0.00 \mathrm{E}+00 \\ 0.00 \mathrm{E}+00 & 0.00 \mathrm{E}+00 & 0.00 \mathrm{E}+00 \\ 0.00 \mathrm{E}+00 & 0.00 \mathrm{E}+00 & 0.00 \mathrm{E}+00 \\ 0.00 \mathrm{E}+00 & 0.00 \mathrm{E}+00 & 0.00 \mathrm{E}+00\end{array}$

$0.00 \mathrm{E}+00 \quad 0.00 \mathrm{E}+00 \quad 0.00 \mathrm{E}+00$

$0.00 \mathrm{E}+00 \quad 0.00 \mathrm{E}+00 \quad 0.00 \mathrm{E}+00$

$0.00 \mathrm{E}+00 \quad 0.00 \mathrm{E}+00 \quad 0.00 \mathrm{E}+00$

$0.00 \mathrm{E}+00 \quad 0.00 \mathrm{E}+00 \quad 0.00 \mathrm{E}+00$

$0.00 \mathrm{E}+00 \quad 0.00 \mathrm{E}+00 \quad 0.00 \mathrm{E}+00$

$0.00 \mathrm{E}+00 \quad 0.00 \mathrm{E}+00 \quad 0.00 \mathrm{E}+00$

$0.00 \mathrm{E}+00 \quad 0.00 \mathrm{E}+00 \quad 0.00 \mathrm{E}+00$

$0.00 \mathrm{E}+00 \quad 0.00 \mathrm{E}+00 \quad 0.00 \mathrm{E}+00$

$0.00 \mathrm{E}+00 \quad 0.00 \mathrm{E}+00 \quad 0.00 \mathrm{E}+00$

$0.00 \mathrm{E}+00 \quad 0.00 \mathrm{E}+00 \quad 0.00 \mathrm{E}+00$

$0.00 \mathrm{E}+00 \quad 0.00 \mathrm{E}+00 \quad 0.00 \mathrm{E}+00$

$0.00 \mathrm{E}+00 \quad 0.00 \mathrm{E}+00 \quad 0.00 \mathrm{E}+00$

$0.00 \mathrm{E}+00 \quad 0.00 \mathrm{E}+00 \quad 0.00 \mathrm{E}+00$

$0.00 \mathrm{E}+00 \quad 0.00 \mathrm{E}+00 \quad 0.00 \mathrm{E}+00$

$0.00 \mathrm{E}+00 \quad 0.00 \mathrm{E}+00 \quad 0.00 \mathrm{E}+00$

$0.00 \mathrm{E}+00 \quad 0.00 \mathrm{E}+00 \quad 0.00 \mathrm{E}+00$

$0.00 \mathrm{E}+00 \quad 0.00 \mathrm{E}+00 \quad 0.00 \mathrm{E}+00$

$0.00 \mathrm{E}+00 \quad 0.00 \mathrm{E}+00 \quad 0.00 \mathrm{E}+00$

$0.00 \mathrm{E}+00 \quad 0.00 \mathrm{E}+00 \quad 0.00 \mathrm{E}+00$

$0.00 \mathrm{E}+00 \quad 0.00 \mathrm{E}+00 \quad 0.00 \mathrm{E}+00$

$0.00 \mathrm{E}+00 \quad 0.00 \mathrm{E}+00 \quad 0.00 \mathrm{E}+00$

$0.00 \mathrm{E}+00 \quad 0.00 \mathrm{E}+00 \quad 0.00 \mathrm{E}+00$

$0.00 \mathrm{E}+00 \quad 0.00 \mathrm{E}+00 \quad 0.00 \mathrm{E}+00$

$0.00 \mathrm{E}+00 \quad 0.00 \mathrm{E}+00 \quad 0.00 \mathrm{E}+00$

$0.00 \mathrm{E}+00 \quad 0.00 \mathrm{E}+00 \quad 0.00 \mathrm{E}+00$

$0.00 \mathrm{E}+00 \quad 0.00 \mathrm{E}+00 \quad 0.00 \mathrm{E}+00$

$0.00 \mathrm{E}+00 \quad 0.00 \mathrm{E}+00 \quad 0.00 \mathrm{E}+00$

$0.00 \mathrm{E}+00 \quad 0.00 \mathrm{E}+00 \quad 0.00 \mathrm{E}+00$

$0.00 \mathrm{E}+00 \quad 0.00 \mathrm{E}+00 \quad 0.00 \mathrm{E}+00$

$0.00 \mathrm{E}+00 \quad 0.00 \mathrm{E}+00 \quad 0.00 \mathrm{E}+00$

$0.00 \mathrm{E}+00 \quad 0.00 \mathrm{E}+00 \quad 0.00 \mathrm{E}+00$

$0.00 \mathrm{E}+00 \quad 0.00 \mathrm{E}+00 \quad 0.00 \mathrm{E}+00$

$0.00 \mathrm{E}+00 \quad 0.00 \mathrm{E}+00 \quad 0.00 \mathrm{E}+00$

$0.00 \mathrm{E}+00 \quad 0.00 \mathrm{E}+00 \quad 0.00 \mathrm{E}+00$

$0.00 \mathrm{E}+00 \quad 0.00 \mathrm{E}+00 \quad 0.00 \mathrm{E}+00$

$0.00 \mathrm{E}+00 \quad 0.00 \mathrm{E}+00 \quad 0.00 \mathrm{E}+00$

$0.00 \mathrm{E}+00 \quad 0.00 \mathrm{E}+00 \quad 0.00 \mathrm{E}+00$

$0.00 \mathrm{E}+00 \quad 0.00 \mathrm{E}+00 \quad 0.00 \mathrm{E}+00$

$0.00 \mathrm{E}+00 \quad 0.00 \mathrm{E}+00 \quad 0.00 \mathrm{E}+00$

$0.00 \mathrm{E}+00 \quad 0.00 \mathrm{E}+00 \quad 0.00 \mathrm{E}+00$

$0.00 \mathrm{E}+00 \quad 0.00 \mathrm{E}+00 \quad 0.00 \mathrm{E}+00$

C -320

DCN 5090-TR-02-2 
RESRAD-OFFSITE, Version 2.5

Probabilistic Dose and Risk Report

Title : Offsite Resident Farmer Deterministic Run

File : RF TC99 DOESG FWD-FV2b.ROF

Repetition $=$

Mean

Std. Dev.

Minimum

Maximum

ercentile

0.010

0.025

0.050

0.075

0.100

0.125

0.150

0.175

0.200

0.225

0.250

0.275

0.300

0.325

0.350

0.375

0.400

0.425

0.450

0.475

0.500

0.525

0.550

0.575

0.600

0.625

0.650

0.675

0.700

0.725

0.750

0.775

0.800

0.825

0.850

0.875

0.900

0.925

0.950

0.975

0.990
Statistics and Cumulative distribution function of Peak Dose from External Ground(Cz\&Air) in mrem/yr

\begin{tabular}{cccc}
1 & & 2 & 3 \\
\cline { 1 - 1 } & & & \\
$0.00 \mathrm{E}+00$ & $0.00 \mathrm{E}+00$ & $0.00 \mathrm{E}+00$ \\
$1.80 \mathrm{E}-32$ & $1.80 \mathrm{E}-32$ & $1.80 \mathrm{E}-32$ \\
$1.29 \mathrm{E}-24$ & $1.29 \mathrm{E}-24$ & $1.29 \mathrm{E}-24$
\end{tabular}

$3.32 \mathrm{E}-30 \quad 3.32 \mathrm{E}-30 \quad 3.32 \mathrm{E}-30$

$1.74 \mathrm{E}-28 \quad 1.74 \mathrm{E}-28 \quad 1.69 \mathrm{E}-28$

$2.01 \mathrm{E}-27 \quad 2.01 \mathrm{E}-27 \quad 1.97 \mathrm{E}-27$

$5.16 \mathrm{E}-27 \quad 5.16 \mathrm{E}-27 \quad 5.08 \mathrm{E}-27$

$1.05 \mathrm{E}-26 \quad 1.05 \mathrm{E}-26 \quad 1.05 \mathrm{E}-26$

$1.82 \mathrm{E}-26 \quad 1.84 \mathrm{E}-26 \quad 1.83 \mathrm{E}-26$

$2.80 \mathrm{E}-26 \quad 2.83 \mathrm{E}-26 \quad 2.81 \mathrm{E}-26$

4.39E-26 4.48E-26 4.48E-26

$6.28 \mathrm{E}-26 \quad 6.36 \mathrm{E}-26 \quad 6.36 \mathrm{E}-26$

$7.90 \mathrm{E}-26 \quad 7.94 \mathrm{E}-26 \quad 7.94 \mathrm{E}-26$

$9.66 \mathrm{E}-26 \quad 9.79 \mathrm{E}-26 \quad 9.79 \mathrm{E}-26$

$1.20 \mathrm{E}-25 \quad 1.21 \mathrm{E}-25 \quad 1.21 \mathrm{E}-25$

1.43E-25 1.44E-25 1.43E-25

$1.74 \mathrm{E}-25 \quad 1.75 \mathrm{E}-25 \quad 1.75 \mathrm{E}-25$

$2.01 \mathrm{E}-25 \quad 2.02 \mathrm{E}-25 \quad 2.02 \mathrm{E}-25$

$2.29 \mathrm{E}-25 \quad 2.32 \mathrm{E}-25 \quad 2.30 \mathrm{E}-25$

$2.60 \mathrm{E}-25 \quad 2.62 \mathrm{E}-25 \quad 2.61 \mathrm{E}-25$

$2.93 E-25 \quad 2.94 E-25 \quad 2.94 E-25$

$3.25 E-25 \quad 3.26 E-25 \quad 3.26 E-25$

$3.52 \mathrm{E}-25 \quad 3.53 \mathrm{E}-25 \quad 3.52 \mathrm{E}-25$

$3.84 \mathrm{E}-25 \quad 3.85 \mathrm{E}-25 \quad 3.84 \mathrm{E}-25$

$4.27 \mathrm{E}-25 \quad 4.28 \mathrm{E}-25 \quad 4.28 \mathrm{E}-25$

$4.61 \mathrm{E}-25 \quad 4.61 \mathrm{E}-25 \quad 4.61 \mathrm{E}-25$

4. $92 \mathrm{E}-25 \quad 4.94 \mathrm{E}-25 \quad 4.94 \mathrm{E}-25$

$5.20 \mathrm{E}-25 \quad 5.21 \mathrm{E}-25 \quad 5.20 \mathrm{E}-25$

$5.53 \mathrm{E}-25 \quad 5.54 \mathrm{E}-25 \quad 5.53 \mathrm{E}-25$

$5.72 \mathrm{E}-25 \quad 5.73 \mathrm{E}-25 \quad 5.73 \mathrm{E}-25$

$6.02 \mathrm{E}-25 \quad 6.02 \mathrm{E}-25 \quad 6.02 \mathrm{E}-25$

$6.31 \mathrm{E}-25 \quad 6.31 \mathrm{E}-25 \quad 6.31 \mathrm{E}-25$

$6.71 \mathrm{E}-25 \quad 6.71 \mathrm{E}-25 \quad 6.71 \mathrm{E}-25$

$7.05 \mathrm{E}-25 \quad 7.06 \mathrm{E}-25 \quad 7.06 \mathrm{E}-25$

$7.40 \mathrm{E}-25 \quad 7.41 \mathrm{E}-25 \quad 7.42 \mathrm{E}-25$

$7.82 \mathrm{E}-25 \quad 7.82 \mathrm{E}-25 \quad 7.82 \mathrm{E}-25$

$8.08 \mathrm{E}-25 \quad 8.08 \mathrm{E}-25 \quad 8.09 \mathrm{E}-25$

$8.42 \mathrm{E}-25 \quad 8.43 \mathrm{E}-25 \quad 8.43 \mathrm{E}-25$

8. $82 \mathrm{E}-25 \quad 8.82 \mathrm{E}-25 \quad 8.82 \mathrm{E}-25$

$9.18 \mathrm{E}-25 \quad 9.18 \mathrm{E}-25 \quad 9.18 \mathrm{E}-25$

$9.62 \mathrm{E}-25 \quad 9.62 \mathrm{E}-25 \quad 9.62 \mathrm{E}-25$

$1.02 \mathrm{E}-24 \quad 1.02 \mathrm{E}-24 \quad 1.02 \mathrm{E}-24$

$1.07 \mathrm{E}-24 \quad 1.07 \mathrm{E}-24 \quad 1.07 \mathrm{E}-24$

$1.14 \mathrm{E}-24 \quad 1.14 \mathrm{E}-24 \quad 1.14 \mathrm{E}-24$ 
RESRAD-OFFSITE, Version 2.5

Probabilistic Dose and Risk Report

Title : Offsite Resident Farmer Deterministic Run

File : RF TC99 DOESG FWD-FV2b.ROF

Repetition $=$

Mean

td. Dev.

Minimum

Maximum

ercentile

0.010

0.025

0.050

0.075

0.100

0.125

0.150

0.175

0.200

0.225

0.250

0.275

0.300

0.325

0.350

0.375

0.400

0.425

0.450

0.475

0.500

0.525

0.550

0.575

0.600

0.625

0.650

0.675

0.700

0.725

0.750

0.775

0.800

0.825

0.850

0.875

0.900

0.925

0.950

0.975

0.990

Statistics and Cumulative distribution function of Peak Dose from Inhalation ExcludingRn in mrem/yr

$\begin{array}{cccc}1 & 2 & 3 \\ 0.00 \mathrm{E}+00 & 0.00 \mathrm{E}+00 & 0.00 \mathrm{E}+00 \\ 0.00 \mathrm{E}+00 & 0.00 \mathrm{E}+00 & 0.00 \mathrm{E}+00 \\ 0.00 \mathrm{E}+00 & 0.00 \mathrm{E}+00 & 0.00 \mathrm{E}+00 \\ 0.00 \mathrm{E}+00 & 0.00 \mathrm{E}+00 & 0.00 \mathrm{E}+00\end{array}$

$0.00 \mathrm{E}+00 \quad 0.00 \mathrm{E}+00 \quad 0.00 \mathrm{E}+00$

$0.00 \mathrm{E}+00 \quad 0.00 \mathrm{E}+00 \quad 0.00 \mathrm{E}+00$

$0.00 \mathrm{E}+00 \quad 0.00 \mathrm{E}+00 \quad 0.00 \mathrm{E}+00$

$0.00 \mathrm{E}+00 \quad 0.00 \mathrm{E}+00 \quad 0.00 \mathrm{E}+00$

$0.00 \mathrm{E}+00 \quad 0.00 \mathrm{E}+00 \quad 0.00 \mathrm{E}+00$

$0.00 \mathrm{E}+00 \quad 0.00 \mathrm{E}+00 \quad 0.00 \mathrm{E}+00$

$0.00 \mathrm{E}+00 \quad 0.00 \mathrm{E}+00 \quad 0.00 \mathrm{E}+00$

$0.00 \mathrm{E}+00 \quad 0.00 \mathrm{E}+00 \quad 0.00 \mathrm{E}+00$

$0.00 \mathrm{E}+00 \quad 0.00 \mathrm{E}+00 \quad 0.00 \mathrm{E}+00$

$0.00 \mathrm{E}+00 \quad 0.00 \mathrm{E}+00 \quad 0.00 \mathrm{E}+00$

$0.00 \mathrm{E}+00 \quad 0.00 \mathrm{E}+00 \quad 0.00 \mathrm{E}+00$

$0.00 \mathrm{E}+00 \quad 0.00 \mathrm{E}+00 \quad 0.00 \mathrm{E}+00$

$0.00 \mathrm{E}+00 \quad 0.00 \mathrm{E}+00 \quad 0.00 \mathrm{E}+00$

$0.00 \mathrm{E}+00 \quad 0.00 \mathrm{E}+00 \quad 0.00 \mathrm{E}+00$

$0.00 \mathrm{E}+00 \quad 0.00 \mathrm{E}+00 \quad 0.00 \mathrm{E}+00$

$0.00 \mathrm{E}+00 \quad 0.00 \mathrm{E}+00 \quad 0.00 \mathrm{E}+00$

$0.00 \mathrm{E}+00 \quad 0.00 \mathrm{E}+00 \quad 0.00 \mathrm{E}+00$

$0.00 \mathrm{E}+00 \quad 0.00 \mathrm{E}+00 \quad 0.00 \mathrm{E}+00$

$0.00 \mathrm{E}+00 \quad 0.00 \mathrm{E}+00 \quad 0.00 \mathrm{E}+00$

$0.00 \mathrm{E}+00 \quad 0.00 \mathrm{E}+00 \quad 0.00 \mathrm{E}+00$

$0.00 \mathrm{E}+00 \quad 0.00 \mathrm{E}+00 \quad 0.00 \mathrm{E}+00$

$0.00 \mathrm{E}+00 \quad 0.00 \mathrm{E}+00 \quad 0.00 \mathrm{E}+00$

$0.00 \mathrm{E}+00 \quad 0.00 \mathrm{E}+00 \quad 0.00 \mathrm{E}+00$

$0.00 \mathrm{E}+00 \quad 0.00 \mathrm{E}+00 \quad 0.00 \mathrm{E}+00$

$0.00 \mathrm{E}+00 \quad 0.00 \mathrm{E}+00 \quad 0.00 \mathrm{E}+00$

$0.00 \mathrm{E}+00 \quad 0.00 \mathrm{E}+00 \quad 0.00 \mathrm{E}+00$

$0.00 \mathrm{E}+00 \quad 0.00 \mathrm{E}+00 \quad 0.00 \mathrm{E}+00$

$0.00 \mathrm{E}+00 \quad 0.00 \mathrm{E}+00 \quad 0.00 \mathrm{E}+00$

$0.00 \mathrm{E}+00 \quad 0.00 \mathrm{E}+00 \quad 0.00 \mathrm{E}+00$

$0.00 \mathrm{E}+00 \quad 0.00 \mathrm{E}+00 \quad 0.00 \mathrm{E}+00$

$0.00 \mathrm{E}+00 \quad 0.00 \mathrm{E}+00 \quad 0.00 \mathrm{E}+00$

$0.00 \mathrm{E}+00 \quad 0.00 \mathrm{E}+00 \quad 0.00 \mathrm{E}+00$

$0.00 \mathrm{E}+00 \quad 0.00 \mathrm{E}+00 \quad 0.00 \mathrm{E}+00$

$0.00 \mathrm{E}+00 \quad 0.00 \mathrm{E}+00 \quad 0.00 \mathrm{E}+00$

$0.00 \mathrm{E}+00 \quad 0.00 \mathrm{E}+00 \quad 0.00 \mathrm{E}+00$

$0.00 \mathrm{E}+00 \quad 0.00 \mathrm{E}+00 \quad 0.00 \mathrm{E}+00$

$0.00 \mathrm{E}+00 \quad 0.00 \mathrm{E}+00 \quad 0.00 \mathrm{E}+00$

$0.00 \mathrm{E}+00 \quad 0.00 \mathrm{E}+00 \quad 0.00 \mathrm{E}+00$

$0.00 \mathrm{E}+00 \quad 0.00 \mathrm{E}+00 \quad 0.00 \mathrm{E}+00$

$0.00 \mathrm{E}+00 \quad 0.00 \mathrm{E}+00 \quad 0.00 \mathrm{E}+00$

$0.00 \mathrm{E}+00 \quad 0.00 \mathrm{E}+00 \quad 0.00 \mathrm{E}+00$ 
RESRAD-OFFSITE, Version 2.5

Probabilistic Dose and Risk Report

Title : Offsite Resident Farmer Deterministic Run

File : RF TC99 DOESG FWD-FV2b.ROF

Repetition $=$

Mean

td. Dev.

Minimum

Maximum

ercentile

0.010

0.025

0.050

0.075

0.100

0.125

0.150

0.175

0.200

0.225

0.250

0.275

0.300

0.325

0.350

0.375

0.400

0.425

0.450

0.475

0.500

0.525

0.550

0.575

0.600

0.625

0.650

0.675

0.700

0.725

0.750

0.775

0.800

0.825

0.850

0.875

0.900

0.925

0.950

0.975

0.990

Statistics and Cumulative distribution function of Peak Dose from Radon (CZandAir) in mrem/yr

$\begin{array}{cccc}1 & 2 & 3 \\ 0.00 \mathrm{E}+00 & 0.00 \mathrm{E}+00 & 0.00 \mathrm{E}+00 \\ 0.00 \mathrm{E}+00 & 0.00 \mathrm{E}+00 & 0.00 \mathrm{E}+00 \\ 0.00 \mathrm{E}+00 & 0.00 \mathrm{E}+00 & 0.00 \mathrm{E}+00 \\ 0.00 \mathrm{E}+00 & 0.00 \mathrm{E}+00 & 0.00 \mathrm{E}+00\end{array}$

$0.00 \mathrm{E}+00 \quad 0.00 \mathrm{E}+00 \quad 0.00 \mathrm{E}+00$

$0.00 \mathrm{E}+00 \quad 0.00 \mathrm{E}+00 \quad 0.00 \mathrm{E}+00$

$0.00 \mathrm{E}+00 \quad 0.00 \mathrm{E}+00 \quad 0.00 \mathrm{E}+00$

$0.00 \mathrm{E}+00 \quad 0.00 \mathrm{E}+00 \quad 0.00 \mathrm{E}+00$

$0.00 \mathrm{E}+00 \quad 0.00 \mathrm{E}+00 \quad 0.00 \mathrm{E}+00$

$0.00 \mathrm{E}+00 \quad 0.00 \mathrm{E}+00 \quad 0.00 \mathrm{E}+00$

$0.00 \mathrm{E}+00 \quad 0.00 \mathrm{E}+00 \quad 0.00 \mathrm{E}+00$

$0.00 \mathrm{E}+00 \quad 0.00 \mathrm{E}+00 \quad 0.00 \mathrm{E}+00$

$0.00 \mathrm{E}+00 \quad 0.00 \mathrm{E}+00 \quad 0.00 \mathrm{E}+00$

$0.00 \mathrm{E}+00 \quad 0.00 \mathrm{E}+00 \quad 0.00 \mathrm{E}+00$

$0.00 \mathrm{E}+00 \quad 0.00 \mathrm{E}+00 \quad 0.00 \mathrm{E}+00$

$0.00 \mathrm{E}+00 \quad 0.00 \mathrm{E}+00 \quad 0.00 \mathrm{E}+00$

$0.00 \mathrm{E}+00 \quad 0.00 \mathrm{E}+00 \quad 0.00 \mathrm{E}+00$

$0.00 \mathrm{E}+00 \quad 0.00 \mathrm{E}+00 \quad 0.00 \mathrm{E}+00$

$0.00 \mathrm{E}+00 \quad 0.00 \mathrm{E}+00 \quad 0.00 \mathrm{E}+00$

$0.00 \mathrm{E}+00 \quad 0.00 \mathrm{E}+00 \quad 0.00 \mathrm{E}+00$

$0.00 \mathrm{E}+00 \quad 0.00 \mathrm{E}+00 \quad 0.00 \mathrm{E}+00$

$0.00 \mathrm{E}+00 \quad 0.00 \mathrm{E}+00 \quad 0.00 \mathrm{E}+00$

$0.00 \mathrm{E}+00 \quad 0.00 \mathrm{E}+00 \quad 0.00 \mathrm{E}+00$

$0.00 \mathrm{E}+00 \quad 0.00 \mathrm{E}+00 \quad 0.00 \mathrm{E}+00$

$0.00 \mathrm{E}+00 \quad 0.00 \mathrm{E}+00 \quad 0.00 \mathrm{E}+00$

$0.00 \mathrm{E}+00 \quad 0.00 \mathrm{E}+00 \quad 0.00 \mathrm{E}+00$

$0.00 \mathrm{E}+00 \quad 0.00 \mathrm{E}+00 \quad 0.00 \mathrm{E}+00$

$0.00 \mathrm{E}+00 \quad 0.00 \mathrm{E}+00 \quad 0.00 \mathrm{E}+00$

$0.00 \mathrm{E}+00 \quad 0.00 \mathrm{E}+00 \quad 0.00 \mathrm{E}+00$

$0.00 \mathrm{E}+00 \quad 0.00 \mathrm{E}+00 \quad 0.00 \mathrm{E}+00$

$0.00 \mathrm{E}+00 \quad 0.00 \mathrm{E}+00 \quad 0.00 \mathrm{E}+00$

$0.00 \mathrm{E}+00 \quad 0.00 \mathrm{E}+00 \quad 0.00 \mathrm{E}+00$

$0.00 \mathrm{E}+00 \quad 0.00 \mathrm{E}+00 \quad 0.00 \mathrm{E}+00$

$0.00 \mathrm{E}+00 \quad 0.00 \mathrm{E}+00 \quad 0.00 \mathrm{E}+00$

$0.00 \mathrm{E}+00 \quad 0.00 \mathrm{E}+00 \quad 0.00 \mathrm{E}+00$

$0.00 \mathrm{E}+00 \quad 0.00 \mathrm{E}+00 \quad 0.00 \mathrm{E}+00$

$0.00 \mathrm{E}+00 \quad 0.00 \mathrm{E}+00 \quad 0.00 \mathrm{E}+00$

$0.00 \mathrm{E}+00 \quad 0.00 \mathrm{E}+00 \quad 0.00 \mathrm{E}+00$

$0.00 \mathrm{E}+00 \quad 0.00 \mathrm{E}+00 \quad 0.00 \mathrm{E}+00$

$0.00 \mathrm{E}+00 \quad 0.00 \mathrm{E}+00 \quad 0.00 \mathrm{E}+00$

$0.00 \mathrm{E}+00 \quad 0.00 \mathrm{E}+00 \quad 0.00 \mathrm{E}+00$

$0.00 \mathrm{E}+00 \quad 0.00 \mathrm{E}+00 \quad 0.00 \mathrm{E}+00$

$0.00 \mathrm{E}+00 \quad 0.00 \mathrm{E}+00 \quad 0.00 \mathrm{E}+00$

$0.00 \mathrm{E}+00 \quad 0.00 \mathrm{E}+00 \quad 0.00 \mathrm{E}+00$

$0.00 \mathrm{E}+00 \quad 0.00 \mathrm{E}+00 \quad 0.00 \mathrm{E}+00$

C-323

DCN 5090-TR-02-2 
RESRAD-OFFSITE, Version 2.5

Probabilistic Dose and Risk Report

Title : Offsite Resident Farmer Deterministic Run

File : RF TC99 DOESG FWD-FV2b.ROF

Repetition $=$

Mean

td. Dev.

Minimum

Maximum

ercentile

0.010

0.025

0.050

0.075

0.100

0.125

0.150

0.175

0.200

0.225

0.250

0.275

0.300

0.325

0.350

0.375

0.400

0.425

0.450

0.475

0.500

0.525

0.550

0.575

0.600

0.625

0.650

0.675

0.700

0.725

0.750

0.775

0.800

0.825

0.850

0.875

0.900

0.925

0.950

0.975

0.990

Statistics and Cumulative distribution function of Peak Dose from Plant (CzandAir) in mrem/yr

$\begin{array}{cccc}1 & 2 & 3 \\ 0.00 \mathrm{E}+00 & 0.00 \mathrm{E}+00 & 0.00 \mathrm{E}+00 \\ 0.00 \mathrm{E}+00 & 0.00 \mathrm{E}+00 & 0.00 \mathrm{E}+00 \\ 0.00 \mathrm{E}+00 & 0.00 \mathrm{E}+00 & 0.00 \mathrm{E}+00 \\ 0.00 \mathrm{E}+00 & 0.00 \mathrm{E}+00 & 0.00 \mathrm{E}+00\end{array}$

$0.00 \mathrm{E}+00 \quad 0.00 \mathrm{E}+00 \quad 0.00 \mathrm{E}+00$

$0.00 \mathrm{E}+00 \quad 0.00 \mathrm{E}+00 \quad 0.00 \mathrm{E}+00$

$0.00 \mathrm{E}+00 \quad 0.00 \mathrm{E}+00 \quad 0.00 \mathrm{E}+00$

$0.00 \mathrm{E}+00 \quad 0.00 \mathrm{E}+00 \quad 0.00 \mathrm{E}+00$

$0.00 \mathrm{E}+00 \quad 0.00 \mathrm{E}+00 \quad 0.00 \mathrm{E}+00$

$0.00 \mathrm{E}+00 \quad 0.00 \mathrm{E}+00 \quad 0.00 \mathrm{E}+00$

$0.00 \mathrm{E}+00 \quad 0.00 \mathrm{E}+00 \quad 0.00 \mathrm{E}+00$

$0.00 \mathrm{E}+00 \quad 0.00 \mathrm{E}+00 \quad 0.00 \mathrm{E}+00$

$0.00 \mathrm{E}+00 \quad 0.00 \mathrm{E}+00 \quad 0.00 \mathrm{E}+00$

$0.00 \mathrm{E}+00 \quad 0.00 \mathrm{E}+00 \quad 0.00 \mathrm{E}+00$

$0.00 \mathrm{E}+00 \quad 0.00 \mathrm{E}+00 \quad 0.00 \mathrm{E}+00$

$0.00 \mathrm{E}+00 \quad 0.00 \mathrm{E}+00 \quad 0.00 \mathrm{E}+00$

$0.00 \mathrm{E}+00 \quad 0.00 \mathrm{E}+00 \quad 0.00 \mathrm{E}+00$

$0.00 \mathrm{E}+00 \quad 0.00 \mathrm{E}+00 \quad 0.00 \mathrm{E}+00$

$0.00 \mathrm{E}+00 \quad 0.00 \mathrm{E}+00 \quad 0.00 \mathrm{E}+00$

$0.00 \mathrm{E}+00 \quad 0.00 \mathrm{E}+00 \quad 0.00 \mathrm{E}+00$

$0.00 \mathrm{E}+00 \quad 0.00 \mathrm{E}+00 \quad 0.00 \mathrm{E}+00$

$0.00 \mathrm{E}+00 \quad 0.00 \mathrm{E}+00 \quad 0.00 \mathrm{E}+00$

$0.00 \mathrm{E}+00 \quad 0.00 \mathrm{E}+00 \quad 0.00 \mathrm{E}+00$

$0.00 \mathrm{E}+00 \quad 0.00 \mathrm{E}+00 \quad 0.00 \mathrm{E}+00$

$0.00 \mathrm{E}+00 \quad 0.00 \mathrm{E}+00 \quad 0.00 \mathrm{E}+00$

$0.00 \mathrm{E}+00 \quad 0.00 \mathrm{E}+00 \quad 0.00 \mathrm{E}+00$

$0.00 \mathrm{E}+00 \quad 0.00 \mathrm{E}+00 \quad 0.00 \mathrm{E}+00$

$0.00 \mathrm{E}+00 \quad 0.00 \mathrm{E}+00 \quad 0.00 \mathrm{E}+00$

$0.00 \mathrm{E}+00 \quad 0.00 \mathrm{E}+00 \quad 0.00 \mathrm{E}+00$

$0.00 \mathrm{E}+00 \quad 0.00 \mathrm{E}+00 \quad 0.00 \mathrm{E}+00$

$0.00 \mathrm{E}+00 \quad 0.00 \mathrm{E}+00 \quad 0.00 \mathrm{E}+00$

$0.00 \mathrm{E}+00 \quad 0.00 \mathrm{E}+00 \quad 0.00 \mathrm{E}+00$

$0.00 \mathrm{E}+00 \quad 0.00 \mathrm{E}+00 \quad 0.00 \mathrm{E}+00$

$0.00 \mathrm{E}+00 \quad 0.00 \mathrm{E}+00 \quad 0.00 \mathrm{E}+00$

$0.00 \mathrm{E}+00 \quad 0.00 \mathrm{E}+00 \quad 0.00 \mathrm{E}+00$

$0.00 \mathrm{E}+00 \quad 0.00 \mathrm{E}+00 \quad 0.00 \mathrm{E}+00$

$0.00 \mathrm{E}+00 \quad 0.00 \mathrm{E}+00 \quad 0.00 \mathrm{E}+00$

$0.00 \mathrm{E}+00 \quad 0.00 \mathrm{E}+00 \quad 0.00 \mathrm{E}+00$

$0.00 \mathrm{E}+00 \quad 0.00 \mathrm{E}+00 \quad 0.00 \mathrm{E}+00$

$0.00 \mathrm{E}+00 \quad 0.00 \mathrm{E}+00 \quad 0.00 \mathrm{E}+00$

$0.00 \mathrm{E}+00 \quad 0.00 \mathrm{E}+00 \quad 0.00 \mathrm{E}+00$

$0.00 \mathrm{E}+00 \quad 0.00 \mathrm{E}+00 \quad 0.00 \mathrm{E}+00$

$0.00 \mathrm{E}+00 \quad 0.00 \mathrm{E}+00 \quad 0.00 \mathrm{E}+00$

$0.00 \mathrm{E}+00 \quad 0.00 \mathrm{E}+00 \quad 0.00 \mathrm{E}+00$

$0.00 \mathrm{E}+00 \quad 0.00 \mathrm{E}+00 \quad 0.00 \mathrm{E}+00$

C-324

DCN 5090-TR-02-2 
RESRAD-OFFSITE, Version 2.5

Probabilistic Dose and Risk Report

Title : Offsite Resident Farmer Deterministic Run

File : RF TC99 DOESG FWD-FV2b.ROF

Repetition $=$

Mean

td. Dev.

Minimum

Maximum

ercentile

0.010

0.025

0.050

0.075

0.100

0.125

0.150

0.175

0.200

0.225

0.250

0.275

0.300

0.325

0.350

0.375

0.400

0.425

0.450

0.475

0.500

0.525

0.550

0.575

0.600

0.625

0.650

0.675

0.700

0.725

0.750

0.775

0.800

0.825

0.850

0.875

0.900

0.925

0.950

0.975

0.990

Statistics and Cumulative distribution function of Peak Dose from Meat (CZandAir) in mrem/yr

$\begin{array}{cccc}1 & 2 & 3 \\ 0.00 \mathrm{E}+00 & 0.00 \mathrm{E}+00 & 0.00 \mathrm{E}+00 \\ 0.00 \mathrm{E}+00 & 0.00 \mathrm{E}+00 & 0.00 \mathrm{E}+00 \\ 0.00 \mathrm{E}+00 & 0.00 \mathrm{E}+00 & 0.00 \mathrm{E}+00 \\ 0.00 \mathrm{E}+00 & 0.00 \mathrm{E}+00 & 0.00 \mathrm{E}+00\end{array}$

$0.00 \mathrm{E}+00 \quad 0.00 \mathrm{E}+00 \quad 0.00 \mathrm{E}+00$

$0.00 \mathrm{E}+00 \quad 0.00 \mathrm{E}+00 \quad 0.00 \mathrm{E}+00$

$0.00 \mathrm{E}+00 \quad 0.00 \mathrm{E}+00 \quad 0.00 \mathrm{E}+00$

$0.00 \mathrm{E}+00 \quad 0.00 \mathrm{E}+00 \quad 0.00 \mathrm{E}+00$

$0.00 \mathrm{E}+00 \quad 0.00 \mathrm{E}+00 \quad 0.00 \mathrm{E}+00$

$0.00 \mathrm{E}+00 \quad 0.00 \mathrm{E}+00 \quad 0.00 \mathrm{E}+00$

$0.00 \mathrm{E}+00 \quad 0.00 \mathrm{E}+00 \quad 0.00 \mathrm{E}+00$

$0.00 \mathrm{E}+00 \quad 0.00 \mathrm{E}+00 \quad 0.00 \mathrm{E}+00$

$0.00 \mathrm{E}+00 \quad 0.00 \mathrm{E}+00 \quad 0.00 \mathrm{E}+00$

$0.00 \mathrm{E}+00 \quad 0.00 \mathrm{E}+00 \quad 0.00 \mathrm{E}+00$

$0.00 \mathrm{E}+00 \quad 0.00 \mathrm{E}+00 \quad 0.00 \mathrm{E}+00$

$0.00 \mathrm{E}+00 \quad 0.00 \mathrm{E}+00 \quad 0.00 \mathrm{E}+00$

$0.00 \mathrm{E}+00 \quad 0.00 \mathrm{E}+00 \quad 0.00 \mathrm{E}+00$

$0.00 \mathrm{E}+00 \quad 0.00 \mathrm{E}+00 \quad 0.00 \mathrm{E}+00$

$0.00 \mathrm{E}+00 \quad 0.00 \mathrm{E}+00 \quad 0.00 \mathrm{E}+00$

$0.00 \mathrm{E}+00 \quad 0.00 \mathrm{E}+00 \quad 0.00 \mathrm{E}+00$

$0.00 \mathrm{E}+00 \quad 0.00 \mathrm{E}+00 \quad 0.00 \mathrm{E}+00$

$0.00 \mathrm{E}+00 \quad 0.00 \mathrm{E}+00 \quad 0.00 \mathrm{E}+00$

$0.00 \mathrm{E}+00 \quad 0.00 \mathrm{E}+00 \quad 0.00 \mathrm{E}+00$

$0.00 \mathrm{E}+00 \quad 0.00 \mathrm{E}+00 \quad 0.00 \mathrm{E}+00$

$0.00 \mathrm{E}+00 \quad 0.00 \mathrm{E}+00 \quad 0.00 \mathrm{E}+00$

$0.00 \mathrm{E}+00 \quad 0.00 \mathrm{E}+00 \quad 0.00 \mathrm{E}+00$

$0.00 \mathrm{E}+00 \quad 0.00 \mathrm{E}+00 \quad 0.00 \mathrm{E}+00$

$0.00 \mathrm{E}+00 \quad 0.00 \mathrm{E}+00 \quad 0.00 \mathrm{E}+00$

$0.00 \mathrm{E}+00 \quad 0.00 \mathrm{E}+00 \quad 0.00 \mathrm{E}+00$

$0.00 \mathrm{E}+00 \quad 0.00 \mathrm{E}+00 \quad 0.00 \mathrm{E}+00$

$0.00 \mathrm{E}+00 \quad 0.00 \mathrm{E}+00 \quad 0.00 \mathrm{E}+00$

$0.00 \mathrm{E}+00 \quad 0.00 \mathrm{E}+00 \quad 0.00 \mathrm{E}+00$

$0.00 \mathrm{E}+00 \quad 0.00 \mathrm{E}+00 \quad 0.00 \mathrm{E}+00$

$0.00 \mathrm{E}+00 \quad 0.00 \mathrm{E}+00 \quad 0.00 \mathrm{E}+00$

$0.00 \mathrm{E}+00 \quad 0.00 \mathrm{E}+00 \quad 0.00 \mathrm{E}+00$

$0.00 \mathrm{E}+00 \quad 0.00 \mathrm{E}+00 \quad 0.00 \mathrm{E}+00$

$0.00 \mathrm{E}+00 \quad 0.00 \mathrm{E}+00 \quad 0.00 \mathrm{E}+00$

$0.00 \mathrm{E}+00 \quad 0.00 \mathrm{E}+00 \quad 0.00 \mathrm{E}+00$

$0.00 \mathrm{E}+00 \quad 0.00 \mathrm{E}+00 \quad 0.00 \mathrm{E}+00$

$0.00 \mathrm{E}+00 \quad 0.00 \mathrm{E}+00 \quad 0.00 \mathrm{E}+00$

$0.00 \mathrm{E}+00 \quad 0.00 \mathrm{E}+00 \quad 0.00 \mathrm{E}+00$

$0.00 \mathrm{E}+00 \quad 0.00 \mathrm{E}+00 \quad 0.00 \mathrm{E}+00$

$0.00 \mathrm{E}+00 \quad 0.00 \mathrm{E}+00 \quad 0.00 \mathrm{E}+00$

$0.00 \mathrm{E}+00 \quad 0.00 \mathrm{E}+00 \quad 0.00 \mathrm{E}+00$

$0.00 \mathrm{E}+00 \quad 0.00 \mathrm{E}+00 \quad 0.00 \mathrm{E}+00$

C-325

DCN 5090-TR-02-2 
RESRAD-OFFSITE, Version 2.5

Probabilistic Dose and Risk Report

Title : Offsite Resident Farmer Deterministic Run

File : RF TC99 DOESG FWD-FV2b.ROF

Repetition $=$

Mean

td. Dev.

Minimum

Maximum

ercentile

0.010

0.025

0.050

0.075

0.100

0.125

0.150

0.175

0.200

0.225

0.250

0.275

0.300

0.325

0.350

0.375

0.400

0.425

0.450

0.475

0.500

0.525

0.550

0.575

0.600

0.625

0.650

0.675

0.700

0.725

0.750

0.775

0.800

0.825

0.850

0.875

0.900

0.925

0.950

0.975

0.990

Statistics and Cumulative distribution function of Peak Dose from Milk (CzandAir) in mrem/yr

$\begin{array}{cccc}1 & 2 & 3 \\ 0.00 \mathrm{E}+00 & 0.00 \mathrm{E}+00 & 0.00 \mathrm{E}+00 \\ 0.00 \mathrm{E}+00 & 0.00 \mathrm{E}+00 & 0.00 \mathrm{E}+00 \\ 0.00 \mathrm{E}+00 & 0.00 \mathrm{E}+00 & 0.00 \mathrm{E}+00 \\ 0.00 \mathrm{E}+00 & 0.00 \mathrm{E}+00 & 0.00 \mathrm{E}+00\end{array}$

$0.00 \mathrm{E}+00 \quad 0.00 \mathrm{E}+00 \quad 0.00 \mathrm{E}+00$

$0.00 \mathrm{E}+00 \quad 0.00 \mathrm{E}+00 \quad 0.00 \mathrm{E}+00$

$0.00 \mathrm{E}+00 \quad 0.00 \mathrm{E}+00 \quad 0.00 \mathrm{E}+00$

$0.00 \mathrm{E}+00 \quad 0.00 \mathrm{E}+00 \quad 0.00 \mathrm{E}+00$

$0.00 \mathrm{E}+00 \quad 0.00 \mathrm{E}+00 \quad 0.00 \mathrm{E}+00$

$0.00 \mathrm{E}+00 \quad 0.00 \mathrm{E}+00 \quad 0.00 \mathrm{E}+00$

$0.00 \mathrm{E}+00 \quad 0.00 \mathrm{E}+00 \quad 0.00 \mathrm{E}+00$

$0.00 \mathrm{E}+00 \quad 0.00 \mathrm{E}+00 \quad 0.00 \mathrm{E}+00$

$0.00 \mathrm{E}+00 \quad 0.00 \mathrm{E}+00 \quad 0.00 \mathrm{E}+00$

$0.00 \mathrm{E}+00 \quad 0.00 \mathrm{E}+00 \quad 0.00 \mathrm{E}+00$

$0.00 \mathrm{E}+00 \quad 0.00 \mathrm{E}+00 \quad 0.00 \mathrm{E}+00$

$0.00 \mathrm{E}+00 \quad 0.00 \mathrm{E}+00 \quad 0.00 \mathrm{E}+00$

$0.00 \mathrm{E}+00 \quad 0.00 \mathrm{E}+00 \quad 0.00 \mathrm{E}+00$

$0.00 \mathrm{E}+00 \quad 0.00 \mathrm{E}+00 \quad 0.00 \mathrm{E}+00$

$0.00 \mathrm{E}+00 \quad 0.00 \mathrm{E}+00 \quad 0.00 \mathrm{E}+00$

$0.00 \mathrm{E}+00 \quad 0.00 \mathrm{E}+00 \quad 0.00 \mathrm{E}+00$

$0.00 \mathrm{E}+00 \quad 0.00 \mathrm{E}+00 \quad 0.00 \mathrm{E}+00$

$0.00 \mathrm{E}+00 \quad 0.00 \mathrm{E}+00 \quad 0.00 \mathrm{E}+00$

$0.00 \mathrm{E}+00 \quad 0.00 \mathrm{E}+00 \quad 0.00 \mathrm{E}+00$

$0.00 \mathrm{E}+00 \quad 0.00 \mathrm{E}+00 \quad 0.00 \mathrm{E}+00$

$0.00 \mathrm{E}+00 \quad 0.00 \mathrm{E}+00 \quad 0.00 \mathrm{E}+00$

$0.00 \mathrm{E}+00 \quad 0.00 \mathrm{E}+00 \quad 0.00 \mathrm{E}+00$

$0.00 \mathrm{E}+00 \quad 0.00 \mathrm{E}+00 \quad 0.00 \mathrm{E}+00$

$0.00 \mathrm{E}+00 \quad 0.00 \mathrm{E}+00 \quad 0.00 \mathrm{E}+00$

$0.00 \mathrm{E}+00 \quad 0.00 \mathrm{E}+00 \quad 0.00 \mathrm{E}+00$

$0.00 \mathrm{E}+00 \quad 0.00 \mathrm{E}+00 \quad 0.00 \mathrm{E}+00$

$0.00 \mathrm{E}+00 \quad 0.00 \mathrm{E}+00 \quad 0.00 \mathrm{E}+00$

$0.00 \mathrm{E}+00 \quad 0.00 \mathrm{E}+00 \quad 0.00 \mathrm{E}+00$

$0.00 \mathrm{E}+00 \quad 0.00 \mathrm{E}+00 \quad 0.00 \mathrm{E}+00$

$0.00 \mathrm{E}+00 \quad 0.00 \mathrm{E}+00 \quad 0.00 \mathrm{E}+00$

$0.00 \mathrm{E}+00 \quad 0.00 \mathrm{E}+00 \quad 0.00 \mathrm{E}+00$

$0.00 \mathrm{E}+00 \quad 0.00 \mathrm{E}+00 \quad 0.00 \mathrm{E}+00$

$0.00 \mathrm{E}+00 \quad 0.00 \mathrm{E}+00 \quad 0.00 \mathrm{E}+00$

$0.00 \mathrm{E}+00 \quad 0.00 \mathrm{E}+00 \quad 0.00 \mathrm{E}+00$

$0.00 \mathrm{E}+00 \quad 0.00 \mathrm{E}+00 \quad 0.00 \mathrm{E}+00$

$0.00 \mathrm{E}+00 \quad 0.00 \mathrm{E}+00 \quad 0.00 \mathrm{E}+00$

$0.00 \mathrm{E}+00 \quad 0.00 \mathrm{E}+00 \quad 0.00 \mathrm{E}+00$

$0.00 \mathrm{E}+00 \quad 0.00 \mathrm{E}+00 \quad 0.00 \mathrm{E}+00$

$0.00 \mathrm{E}+00 \quad 0.00 \mathrm{E}+00 \quad 0.00 \mathrm{E}+00$

$0.00 \mathrm{E}+00 \quad 0.00 \mathrm{E}+00 \quad 0.00 \mathrm{E}+00$

$0.00 \mathrm{E}+00 \quad 0.00 \mathrm{E}+00 \quad 0.00 \mathrm{E}+00$

C -326

DCN 5090-TR-02-2 
RESRAD-OFFSITE, Version 2.5

Probabilistic Dose and Risk Report

Title : Offsite Resident Farmer Deterministic Run

File : RF TC99 DOESG FWD-FV2b.ROF

Repetition $=$

Mean

td. Dev.

Minimum

Maximum

ercentile

0.010

0.025

0.050

0.075

0.100

0.125

0.150

0.175

0.200

0.225

0.250

0.275

0.300

0.325

0.350

0.375

0.400

0.425

0.450

0.475

0.500

0.525

0.550

0.575

0.600

0.625

0.650

0.675

0.700

0.725

0.750

0.775

0.800

0.825

0.850

0.875

0.900

0.925

0.950

0.975

0.990

Statistics and Cumulative distribution function of Peak Dose from Soil Ingestion(CZandAir) in mrem/yr

$\begin{array}{cccc}1 & 2 & 3 \\ 0.00 \mathrm{E}+00 & 0.00 \mathrm{E}+00 & 0.00 \mathrm{E}+00 \\ 0.00 \mathrm{E}+00 & 0.00 \mathrm{E}+00 & 0.00 \mathrm{E}+00 \\ 0.00 \mathrm{E}+00 & 0.00 \mathrm{E}+00 & 0.00 \mathrm{E}+00 \\ 0.00 \mathrm{E}+00 & 0.00 \mathrm{E}+00 & 0.00 \mathrm{E}+00\end{array}$

$0.00 \mathrm{E}+00 \quad 0.00 \mathrm{E}+00 \quad 0.00 \mathrm{E}+00$

$0.00 \mathrm{E}+00 \quad 0.00 \mathrm{E}+00 \quad 0.00 \mathrm{E}+00$

$0.00 \mathrm{E}+00 \quad 0.00 \mathrm{E}+00 \quad 0.00 \mathrm{E}+00$

$0.00 \mathrm{E}+00 \quad 0.00 \mathrm{E}+00 \quad 0.00 \mathrm{E}+00$

$0.00 \mathrm{E}+00 \quad 0.00 \mathrm{E}+00 \quad 0.00 \mathrm{E}+00$

$0.00 \mathrm{E}+00 \quad 0.00 \mathrm{E}+00 \quad 0.00 \mathrm{E}+00$

$0.00 \mathrm{E}+00 \quad 0.00 \mathrm{E}+00 \quad 0.00 \mathrm{E}+00$

$0.00 \mathrm{E}+00 \quad 0.00 \mathrm{E}+00 \quad 0.00 \mathrm{E}+00$

$0.00 \mathrm{E}+00 \quad 0.00 \mathrm{E}+00 \quad 0.00 \mathrm{E}+00$

$0.00 \mathrm{E}+00 \quad 0.00 \mathrm{E}+00 \quad 0.00 \mathrm{E}+00$

$0.00 \mathrm{E}+00 \quad 0.00 \mathrm{E}+00 \quad 0.00 \mathrm{E}+00$

$0.00 \mathrm{E}+00 \quad 0.00 \mathrm{E}+00 \quad 0.00 \mathrm{E}+00$

$0.00 \mathrm{E}+00 \quad 0.00 \mathrm{E}+00 \quad 0.00 \mathrm{E}+00$

$0.00 \mathrm{E}+00 \quad 0.00 \mathrm{E}+00 \quad 0.00 \mathrm{E}+00$

$0.00 \mathrm{E}+00 \quad 0.00 \mathrm{E}+00 \quad 0.00 \mathrm{E}+00$

$0.00 \mathrm{E}+00 \quad 0.00 \mathrm{E}+00 \quad 0.00 \mathrm{E}+00$

$0.00 \mathrm{E}+00 \quad 0.00 \mathrm{E}+00 \quad 0.00 \mathrm{E}+00$

$0.00 \mathrm{E}+00 \quad 0.00 \mathrm{E}+00 \quad 0.00 \mathrm{E}+00$

$0.00 \mathrm{E}+00 \quad 0.00 \mathrm{E}+00 \quad 0.00 \mathrm{E}+00$

$0.00 \mathrm{E}+00 \quad 0.00 \mathrm{E}+00 \quad 0.00 \mathrm{E}+00$

$0.00 \mathrm{E}+00 \quad 0.00 \mathrm{E}+00 \quad 0.00 \mathrm{E}+00$

$0.00 \mathrm{E}+00 \quad 0.00 \mathrm{E}+00 \quad 0.00 \mathrm{E}+00$

$0.00 \mathrm{E}+00 \quad 0.00 \mathrm{E}+00 \quad 0.00 \mathrm{E}+00$

$0.00 \mathrm{E}+00 \quad 0.00 \mathrm{E}+00 \quad 0.00 \mathrm{E}+00$

$0.00 \mathrm{E}+00 \quad 0.00 \mathrm{E}+00 \quad 0.00 \mathrm{E}+00$

$0.00 \mathrm{E}+00 \quad 0.00 \mathrm{E}+00 \quad 0.00 \mathrm{E}+00$

$0.00 \mathrm{E}+00 \quad 0.00 \mathrm{E}+00 \quad 0.00 \mathrm{E}+00$

$0.00 \mathrm{E}+00 \quad 0.00 \mathrm{E}+00 \quad 0.00 \mathrm{E}+00$

$0.00 \mathrm{E}+00 \quad 0.00 \mathrm{E}+00 \quad 0.00 \mathrm{E}+00$

$0.00 \mathrm{E}+00 \quad 0.00 \mathrm{E}+00 \quad 0.00 \mathrm{E}+00$

$\begin{array}{lll}0.00 \mathrm{E}+00 & 0.00 \mathrm{E}+00 \quad 0.00 \mathrm{E}+00\end{array}$

$0.00 \mathrm{E}+00 \quad 0.00 \mathrm{E}+00 \quad 0.00 \mathrm{E}+00$

$0.00 \mathrm{E}+00 \quad 0.00 \mathrm{E}+00 \quad 0.00 \mathrm{E}+00$

$0.00 \mathrm{E}+00 \quad 0.00 \mathrm{E}+00 \quad 0.00 \mathrm{E}+00$

$0.00 \mathrm{E}+00 \quad 0.00 \mathrm{E}+00 \quad 0.00 \mathrm{E}+00$

$0.00 \mathrm{E}+00 \quad 0.00 \mathrm{E}+00 \quad 0.00 \mathrm{E}+00$

$0.00 \mathrm{E}+00 \quad 0.00 \mathrm{E}+00 \quad 0.00 \mathrm{E}+00$

$0.00 \mathrm{E}+00 \quad 0.00 \mathrm{E}+00 \quad 0.00 \mathrm{E}+00$

$0.00 \mathrm{E}+00 \quad 0.00 \mathrm{E}+00 \quad 0.00 \mathrm{E}+00$

$0.00 \mathrm{E}+00 \quad 0.00 \mathrm{E}+00 \quad 0.00 \mathrm{E}+00$

$0.00 \mathrm{E}+00 \quad 0.00 \mathrm{E}+00 \quad 0.00 \mathrm{E}+00$ 
RESRAD-OFFSITE, Version 2.5

Probabilistic Dose and Risk Report

Title : Offsite Resident Farmer Deterministic Run

File : RF TC99 DOESG FWD-FV2b.ROF

Repetition $=$

Mean

td. Dev.

Minimum

Maximum

ercentile

0.010

0.025

0.050

0.075

0.100

0.125

0.150

0.175

0.200

0.225

0.250

0.275

0.300

0.325

0.350

0.375

0.400

0.425

0.450

0.475

0.500

0.525

0.550

0.575

0.600

0.625

0.650

0.675

0.700

0.725

0.750

0.775

0.800

0.825

0.850

0.875

0.900

0.925

0.950

0.975

0.990
Statistics and Cumulative distribution function of Peak Risk from All Pathways

\begin{tabular}{|c|c|c|}
\hline 1 & 2 & 3 \\
\hline $4.81 \mathrm{E}-11$ & $4.80 \mathrm{E}-11$ & $4.81 \mathrm{E}-11$ \\
\hline $2.82 \mathrm{E}-11$ & $2.82 E-11$ & $2.82 \mathrm{E}-11$ \\
\hline $5.75 \mathrm{E}-12$ & $5.75 \mathrm{E}-12$ & $5.75 \mathrm{E}-12$ \\
\hline $2.19 \mathrm{E}-10$ & $2.19 \mathrm{E}-10$ & $2.19 \mathrm{E}-10$ \\
\hline
\end{tabular}

$9.20 \mathrm{E}-12 \quad 9.20 \mathrm{E}-12 \quad 9.20 \mathrm{E}-12$

$1.08 \mathrm{E}-11 \quad 1.08 \mathrm{E}-11 \quad 1.08 \mathrm{E}-11$

$\begin{array}{lll}1.38 \mathrm{E}-11 & 1.38 \mathrm{E}-11 & 1.38 \mathrm{E}-11\end{array}$

$1.54 \mathrm{E}-11 \quad 1.54 \mathrm{E}-11 \quad 1.54 \mathrm{E}-11$

$1.74 \mathrm{E}-11 \quad 1.74 \mathrm{E}-11 \quad 1.74 \mathrm{E}-11$

$1.90 \mathrm{E}-11 \quad 1.89 \mathrm{E}-11 \quad 1.89 \mathrm{E}-11$

$2.03 \mathrm{E}-11 \quad 2.03 \mathrm{E}-11 \quad 2.03 \mathrm{E}-11$

$2.21 \mathrm{E}-11 \quad 2.21 \mathrm{E}-11 \quad 2.21 \mathrm{E}-11$

$2.34 \mathrm{E}-11 \quad 2.34 \mathrm{E}-11 \quad 2.34 \mathrm{E}-11$

$2.53 \mathrm{E}-11 \quad 2.52 \mathrm{E}-11 \quad 2.52 \mathrm{E}-11$

$2.65 \mathrm{E}-11 \quad 2.65 \mathrm{E}-11 \quad 2.65 \mathrm{E}-11$

$2.80 \mathrm{E}-11 \quad 2.80 \mathrm{E}-11 \quad 2.80 \mathrm{E}-11$

$2.95 \mathrm{E}-11 \quad 2.94 \mathrm{E}-11 \quad 2.94 \mathrm{E}-11$

$3.11 \mathrm{E}-11 \quad 3.10 \mathrm{E}-11 \quad 3.10 \mathrm{E}-11$

$3.30 \mathrm{E}-11 \quad 3.29 \mathrm{E}-11 \quad 3.29 \mathrm{E}-11$

$3.47 \mathrm{E}-11 \quad 3.46 \mathrm{E}-11 \quad 3.46 \mathrm{E}-11$

$3.60 \mathrm{E}-11 \quad 3.59 \mathrm{E}-11 \quad 3.59 \mathrm{E}-11$

$3.76 \mathrm{E}-11 \quad 3.76 \mathrm{E}-11 \quad 3.76 \mathrm{E}-11$

$3.91 \mathrm{E}-11 \quad 3.91 \mathrm{E}-11 \quad 3.91 \mathrm{E}-11$

$4.09 \mathrm{E}-11 \quad 4.08 \mathrm{E}-11 \quad 4.09 \mathrm{E}-11$

$4.27 \mathrm{E}-11 \quad 4.27 \mathrm{E}-11 \quad 4.27 \mathrm{E}-11$

$4.47 \mathrm{E}-11 \quad 4.46 \mathrm{E}-11 \quad 4.47 \mathrm{E}-11$

$4.61 \mathrm{E}-11 \quad 4.61 \mathrm{E}-11 \quad 4.62 \mathrm{E}-11$

$4.79 \mathrm{E}-11 \quad 4.79 \mathrm{E}-11 \quad 4.79 \mathrm{E}-11$

$4.99 \mathrm{E}-11 \quad 4.99 \mathrm{E}-11 \quad 4.99 \mathrm{E}-11$

$5.19 \mathrm{E}-11 \quad 5.17 \mathrm{E}-11 \quad 5.19 \mathrm{E}-11$

$5.37 \mathrm{E}-11 \quad 5.37 \mathrm{E}-11 \quad 5.37 \mathrm{E}-11$

$5.55 \mathrm{E}-11 \quad 5.55 \mathrm{E}-11 \quad 5.55 \mathrm{E}-11$

$5.85 \mathrm{E}-11 \quad 5.85 \mathrm{E}-11 \quad 5.85 \mathrm{E}-11$

$6.04 \mathrm{E}-11 \quad 6.03 \mathrm{E}-11 \quad 6.04 \mathrm{E}-11$

$6.37 \mathrm{E}-11 \quad 6.36 \mathrm{E}-11 \quad 6.37 \mathrm{E}-11$

$6.62 \mathrm{E}-11 \quad 6.62 \mathrm{E}-11 \quad 6.62 \mathrm{E}-11$

$6.90 \mathrm{E}-11 \quad 6.90 \mathrm{E}-11 \quad 6.90 \mathrm{E}-11$

$7.21 \mathrm{E}-11 \quad 7.21 \mathrm{E}-11 \quad 7.22 \mathrm{E}-11$

$7.58 \mathrm{E}-11 \quad 7.58 \mathrm{E}-11 \quad 7.60 \mathrm{E}-11$

$8.04 \mathrm{E}-11 \quad 8.04 \mathrm{E}-11 \quad 8.05 \mathrm{E}-11$

$8.67 \mathrm{E}-11 \quad 8.67 \mathrm{E}-11 \quad 8.67 \mathrm{E}-11$

$9.40 \mathrm{E}-11 \quad 9.40 \mathrm{E}-11 \quad 9.40 \mathrm{E}-11$

$1.02 \mathrm{E}-10 \quad 1.02 \mathrm{E}-10 \quad 1.02 \mathrm{E}-10$

$1.17 \mathrm{E}-10 \quad 1.17 \mathrm{E}-10 \quad 1.17 \mathrm{E}-10$

$\begin{array}{lll}1.32 \mathrm{E}-10 & 1.32 \mathrm{E}-10 & 1.32 \mathrm{E}-10\end{array}$ 
RESRAD-OFFSITE, Version 2.5

Probabilistic Dose and Risk Report

Title : Offsite Resident Farmer Deterministic Run

File : RF TC99 DOESG FWD-FV2b.ROF

Repetition $=$

Mean

td. Dev.

Minimum

Maximum

ercentile

0.010

0.025

0.050

0.075

0.100

0.125

0.150

0.175

0.200

0.225

0.250

0.275

0.300

0.325

0.350

0.375

0.400

0.425

0.450

0.475

0.500

0.525

0.550

0.575

0.600

0.625

0.650

0.675

0.700

0.725

0.750

0.775

0.800

0.825

0.850

0.875

0.900

0.925

0.950

0.975

0.990

Statistics and Cumulative distribution function of Peak Risk from External Ground(Wreleas)

\begin{tabular}{|c|c|c|}
\hline 1 & 2 & 3 \\
\hline $1.66 \mathrm{E}-11$ & $1.65 \mathrm{E}-11$ & $1.66 \mathrm{E}-11$ \\
\hline $9.73 \mathrm{E}-12$ & $9.73 \mathrm{E}-12$ & $9.73 \mathrm{E}-12$ \\
\hline $1.98 \mathrm{E}-12$ & $1.98 \mathrm{E}-12$ & $1.98 \mathrm{E}-12$ \\
\hline $7.55 \mathrm{E}-11$ & $7.55 \mathrm{E}-11$ & $7.55 \mathrm{E}-11$ \\
\hline
\end{tabular}

$3.17 \mathrm{E}-12 \quad 3.17 \mathrm{E}-12 \quad 3.17 \mathrm{E}-12$

$3.72 \mathrm{E}-12 \quad 3.72 \mathrm{E}-12 \quad 3.72 \mathrm{E}-12$

$4.75 \mathrm{E}-12 \quad 4.75 \mathrm{E}-12 \quad 4.75 \mathrm{E}-12$

$5.31 \mathrm{E}-12 \quad 5.31 \mathrm{E}-12 \quad 5.31 \mathrm{E}-12$

$6.01 \mathrm{E}-12 \quad 6.01 \mathrm{E}-12 \quad 6.01 \mathrm{E}-12$

$6.53 \mathrm{E}-12 \quad 6.53 \mathrm{E}-12 \quad 6.53 \mathrm{E}-12$

$6.99 \mathrm{E}-12 \quad 6.99 \mathrm{E}-12 \quad 6.99 \mathrm{E}-12$

$7.61 \mathrm{E}-12 \quad 7.60 \mathrm{E}-12 \quad 7.60 \mathrm{E}-12$

$8.08 \mathrm{E}-12 \quad 8.07 \mathrm{E}-12 \quad 8.07 \mathrm{E}-12$

$8.70 \mathrm{E}-12 \quad 8.69 \mathrm{E}-12 \quad 8.69 \mathrm{E}-12$

$9.13 \mathrm{E}-12 \quad 9.13 \mathrm{E}-12 \quad 9.13 \mathrm{E}-12$

$9.64 \mathrm{E}-12 \quad 9.64 \mathrm{E}-12 \quad 9.64 \mathrm{E}-12$

$1.02 \mathrm{E}-11 \quad 1.01 \mathrm{E}-11 \quad 1.01 \mathrm{E}-11$

$1.07 \mathrm{E}-11 \quad 1.07 \mathrm{E}-11 \quad 1.07 \mathrm{E}-11$

$1.14 \mathrm{E}-11 \quad 1.13 \mathrm{E}-11 \quad 1.13 \mathrm{E}-11$

$1.19 \mathrm{E}-11 \quad 1.19 \mathrm{E}-11 \quad 1.19 \mathrm{E}-11$

$1.24 \mathrm{E}-11 \quad 1.24 \mathrm{E}-11 \quad 1.24 \mathrm{E}-11$

$1.29 \mathrm{E}-11 \quad 1.29 \mathrm{E}-11 \quad 1.29 \mathrm{E}-11$

$1.35 \mathrm{E}-11 \quad 1.35 \mathrm{E}-11 \quad 1.35 \mathrm{E}-11$

$1.41 \mathrm{E}-11 \quad 1.41 \mathrm{E}-11 \quad 1.41 \mathrm{E}-11$

$1.47 \mathrm{E}-11 \quad 1.47 \mathrm{E}-11 \quad 1.47 \mathrm{E}-11$

$1.54 \mathrm{E}-11 \quad 1.54 \mathrm{E}-11 \quad 1.54 \mathrm{E}-11$

$1.59 \mathrm{E}-11 \quad 1.59 \mathrm{E}-11 \quad 1.59 \mathrm{E}-11$

$1.65 \mathrm{E}-11 \quad 1.65 \mathrm{E}-11 \quad 1.65 \mathrm{E}-11$

$1.72 \mathrm{E}-11 \quad 1.72 \mathrm{E}-11 \quad 1.72 \mathrm{E}-11$

$1.79 \mathrm{E}-11 \quad 1.78 \mathrm{E}-11 \quad 1.79 \mathrm{E}-11$

$1.85 \mathrm{E}-11 \quad 1.85 \mathrm{E}-11 \quad 1.85 \mathrm{E}-11$

$1.91 \mathrm{E}-11 \quad 1.91 \mathrm{E}-11 \quad 1.91 \mathrm{E}-11$

$2.02 \mathrm{E}-11 \quad 2.01 \mathrm{E}-11 \quad 2.02 \mathrm{E}-11$

$2.08 \mathrm{E}-11 \quad 2.08 \mathrm{E}-11 \quad 2.08 \mathrm{E}-11$

$2.19 \mathrm{E}-11 \quad 2.19 \mathrm{E}-11 \quad 2.19 \mathrm{E}-11$

$2.28 \mathrm{E}-11 \quad 2.28 \mathrm{E}-11 \quad 2.28 \mathrm{E}-11$

$2.38 \mathrm{E}-11 \quad 2.38 \mathrm{E}-11 \quad 2.38 \mathrm{E}-11$

$2.48 \mathrm{E}-11 \quad 2.48 \mathrm{E}-11 \quad 2.49 \mathrm{E}-11$

$2.61 \mathrm{E}-11 \quad 2.61 \mathrm{E}-11 \quad 2.62 \mathrm{E}-11$

$2.77 \mathrm{E}-11 \quad 2.77 \mathrm{E}-11 \quad 2.77 \mathrm{E}-11$

$2.99 \mathrm{E}-11 \quad 2.99 \mathrm{E}-11 \quad 2.99 \mathrm{E}-11$

$3.24 \mathrm{E}-11 \quad 3.24 \mathrm{E}-11 \quad 3.24 \mathrm{E}-11$

$3.52 \mathrm{E}-11 \quad 3.52 \mathrm{E}-11 \quad 3.52 \mathrm{E}-11$

$4.04 \mathrm{E}-11 \quad 4.04 \mathrm{E}-11 \quad 4.04 \mathrm{E}-11$

$4.55 \mathrm{E}-11 \quad 4.55 \mathrm{E}-11 \quad 4.55 \mathrm{E}-11$

C -329

DCN 5090-TR-02-2 
RESRAD-OFFSITE, Version 2.5

Probabilistic Dose and Risk Report

Title : Offsite Resident Farmer Deterministic Run

File : RF TC99 DOESG FWD-FV2b.ROF

Repetition $=$

Mean

td. Dev.

Minimum

Maximum

ercentile

0.010

0.025

0.050

0.075

0.100

0.125

0.150

0.175

0.200

0.225

0.250

0.275

0.300

0.325

0.350

0.375

0.400

0.425

0.450

0.475

0.500

0.525

0.550

0.575

0.600

0.625

0.650

0.675

0.700

0.725

0.750

0.775

0.800

0.825

0.850

0.875

0.900

0.925

0.950

0.975

0.990
Statistics and Cumulative distribution function of Peak Risk from Fish Ingestion

$\begin{array}{cccc}1 & 2 & 3 \\ 0.00 \mathrm{E}+00 & 0.00 \mathrm{E}+00 & 0.00 \mathrm{E}+00 \\ 0.00 \mathrm{E}+00 & 0.00 \mathrm{E}+00 & 0.00 \mathrm{E}+00 \\ 0.00 \mathrm{E}+00 & 0.00 \mathrm{E}+00 & 0.00 \mathrm{E}+00 \\ 0.00 \mathrm{E}+00 & 0.00 \mathrm{E}+00 & 0.00 \mathrm{E}+00\end{array}$

$0.00 \mathrm{E}+00 \quad 0.00 \mathrm{E}+00 \quad 0.00 \mathrm{E}+00$

$0.00 \mathrm{E}+00 \quad 0.00 \mathrm{E}+00 \quad 0.00 \mathrm{E}+00$

$0.00 \mathrm{E}+00 \quad 0.00 \mathrm{E}+00 \quad 0.00 \mathrm{E}+00$

$0.00 \mathrm{E}+00 \quad 0.00 \mathrm{E}+00 \quad 0.00 \mathrm{E}+00$

$0.00 \mathrm{E}+00 \quad 0.00 \mathrm{E}+00 \quad 0.00 \mathrm{E}+00$

$0.00 \mathrm{E}+00 \quad 0.00 \mathrm{E}+00 \quad 0.00 \mathrm{E}+00$

$0.00 \mathrm{E}+00 \quad 0.00 \mathrm{E}+00 \quad 0.00 \mathrm{E}+00$

$0.00 \mathrm{E}+00 \quad 0.00 \mathrm{E}+00 \quad 0.00 \mathrm{E}+00$

$0.00 \mathrm{E}+00 \quad 0.00 \mathrm{E}+00 \quad 0.00 \mathrm{E}+00$

$0.00 \mathrm{E}+00 \quad 0.00 \mathrm{E}+00 \quad 0.00 \mathrm{E}+00$

$0.00 \mathrm{E}+00 \quad 0.00 \mathrm{E}+00 \quad 0.00 \mathrm{E}+00$

$0.00 \mathrm{E}+00 \quad 0.00 \mathrm{E}+00 \quad 0.00 \mathrm{E}+00$

$0.00 \mathrm{E}+00 \quad 0.00 \mathrm{E}+00 \quad 0.00 \mathrm{E}+00$

$0.00 \mathrm{E}+00 \quad 0.00 \mathrm{E}+00 \quad 0.00 \mathrm{E}+00$

$0.00 \mathrm{E}+00 \quad 0.00 \mathrm{E}+00 \quad 0.00 \mathrm{E}+00$

$0.00 \mathrm{E}+00 \quad 0.00 \mathrm{E}+00 \quad 0.00 \mathrm{E}+00$

$0.00 \mathrm{E}+00 \quad 0.00 \mathrm{E}+00 \quad 0.00 \mathrm{E}+00$

$0.00 \mathrm{E}+00 \quad 0.00 \mathrm{E}+00 \quad 0.00 \mathrm{E}+00$

$0.00 \mathrm{E}+00 \quad 0.00 \mathrm{E}+00 \quad 0.00 \mathrm{E}+00$

$0.00 \mathrm{E}+00 \quad 0.00 \mathrm{E}+00 \quad 0.00 \mathrm{E}+00$

$0.00 \mathrm{E}+00 \quad 0.00 \mathrm{E}+00 \quad 0.00 \mathrm{E}+00$

$0.00 \mathrm{E}+00 \quad 0.00 \mathrm{E}+00 \quad 0.00 \mathrm{E}+00$

$0.00 \mathrm{E}+00 \quad 0.00 \mathrm{E}+00 \quad 0.00 \mathrm{E}+00$

$0.00 \mathrm{E}+00 \quad 0.00 \mathrm{E}+00 \quad 0.00 \mathrm{E}+00$

$0.00 \mathrm{E}+00 \quad 0.00 \mathrm{E}+00 \quad 0.00 \mathrm{E}+00$

$0.00 \mathrm{E}+00 \quad 0.00 \mathrm{E}+00 \quad 0.00 \mathrm{E}+00$

$0.00 \mathrm{E}+00 \quad 0.00 \mathrm{E}+00 \quad 0.00 \mathrm{E}+00$

$0.00 \mathrm{E}+00 \quad 0.00 \mathrm{E}+00 \quad 0.00 \mathrm{E}+00$

$0.00 \mathrm{E}+00 \quad 0.00 \mathrm{E}+00 \quad 0.00 \mathrm{E}+00$

$0.00 \mathrm{E}+00 \quad 0.00 \mathrm{E}+00 \quad 0.00 \mathrm{E}+00$

$\begin{array}{lll}0.00 \mathrm{E}+00 & 0.00 \mathrm{E}+00 \quad 0.00 \mathrm{E}+00\end{array}$

$0.00 \mathrm{E}+00 \quad 0.00 \mathrm{E}+00 \quad 0.00 \mathrm{E}+00$

$0.00 \mathrm{E}+00 \quad 0.00 \mathrm{E}+00 \quad 0.00 \mathrm{E}+00$

$0.00 \mathrm{E}+00 \quad 0.00 \mathrm{E}+00 \quad 0.00 \mathrm{E}+00$

$0.00 \mathrm{E}+00 \quad 0.00 \mathrm{E}+00 \quad 0.00 \mathrm{E}+00$

$0.00 \mathrm{E}+00 \quad 0.00 \mathrm{E}+00 \quad 0.00 \mathrm{E}+00$

$0.00 \mathrm{E}+00 \quad 0.00 \mathrm{E}+00 \quad 0.00 \mathrm{E}+00$

$0.00 \mathrm{E}+00 \quad 0.00 \mathrm{E}+00 \quad 0.00 \mathrm{E}+00$

$0.00 \mathrm{E}+00 \quad 0.00 \mathrm{E}+00 \quad 0.00 \mathrm{E}+00$

$0.00 \mathrm{E}+00 \quad 0.00 \mathrm{E}+00 \quad 0.00 \mathrm{E}+00$

$0.00 \mathrm{E}+00 \quad 0.00 \mathrm{E}+00 \quad 0.00 \mathrm{E}+00$ 
RESRAD-OFFSITE, Version 2.5

Probabilistic Dose and Risk Report

Title : Offsite Resident Farmer Deterministic Run

File : RF TC99 DOESG FWD-FV2b.ROF

Repetition $=$

Mean

td. Dev.

Minimum

Maximum

ercentile

0.010

0.025

0.050

0.075

0.100

0.125

0.150

0.175

0.200

0.225

0.250

0.275

0.300

0.325

0.350

0.375

0.400

0.425

0.450

0.475

0.500

0.525

0.550

0.575

0.600

0.625

0.650

0.675

0.700

0.725

0.750

0.775

0.800

0.825

0.850

0.875

0.900

0.925

0.950

0.975

0.990
Statistics and Cumulative distribution function of Peak Risk from Radon (Waterrelease)

$\begin{array}{cccc}1 & 2 & 3 \\ 0.00 \mathrm{E}+00 & 0.00 \mathrm{E}+00 & 0.00 \mathrm{E}+00 \\ 0.00 \mathrm{E}+00 & 0.00 \mathrm{E}+00 & 0.00 \mathrm{E}+00 \\ 0.00 \mathrm{E}+00 & 0.00 \mathrm{E}+00 & 0.00 \mathrm{E}+00 \\ 0.00 \mathrm{E}+00 & 0.00 \mathrm{E}+00 & 0.00 \mathrm{E}+00\end{array}$

$0.00 \mathrm{E}+00 \quad 0.00 \mathrm{E}+00 \quad 0.00 \mathrm{E}+00$

$0.00 \mathrm{E}+00 \quad 0.00 \mathrm{E}+00 \quad 0.00 \mathrm{E}+00$

$0.00 \mathrm{E}+00 \quad 0.00 \mathrm{E}+00 \quad 0.00 \mathrm{E}+00$

$0.00 \mathrm{E}+00 \quad 0.00 \mathrm{E}+00 \quad 0.00 \mathrm{E}+00$

$0.00 \mathrm{E}+00 \quad 0.00 \mathrm{E}+00 \quad 0.00 \mathrm{E}+00$

$0.00 \mathrm{E}+00 \quad 0.00 \mathrm{E}+00 \quad 0.00 \mathrm{E}+00$

$0.00 \mathrm{E}+00 \quad 0.00 \mathrm{E}+00 \quad 0.00 \mathrm{E}+00$

$0.00 \mathrm{E}+00 \quad 0.00 \mathrm{E}+00 \quad 0.00 \mathrm{E}+00$

$0.00 \mathrm{E}+00 \quad 0.00 \mathrm{E}+00 \quad 0.00 \mathrm{E}+00$

$0.00 \mathrm{E}+00 \quad 0.00 \mathrm{E}+00 \quad 0.00 \mathrm{E}+00$

$0.00 \mathrm{E}+00 \quad 0.00 \mathrm{E}+00 \quad 0.00 \mathrm{E}+00$

$0.00 \mathrm{E}+00 \quad 0.00 \mathrm{E}+00 \quad 0.00 \mathrm{E}+00$

$0.00 \mathrm{E}+00 \quad 0.00 \mathrm{E}+00 \quad 0.00 \mathrm{E}+00$

$0.00 \mathrm{E}+00 \quad 0.00 \mathrm{E}+00 \quad 0.00 \mathrm{E}+00$

$0.00 \mathrm{E}+00 \quad 0.00 \mathrm{E}+00 \quad 0.00 \mathrm{E}+00$

$0.00 \mathrm{E}+00 \quad 0.00 \mathrm{E}+00 \quad 0.00 \mathrm{E}+00$

$0.00 \mathrm{E}+00 \quad 0.00 \mathrm{E}+00 \quad 0.00 \mathrm{E}+00$

$0.00 \mathrm{E}+00 \quad 0.00 \mathrm{E}+00 \quad 0.00 \mathrm{E}+00$

$0.00 \mathrm{E}+00 \quad 0.00 \mathrm{E}+00 \quad 0.00 \mathrm{E}+00$

$0.00 \mathrm{E}+00 \quad 0.00 \mathrm{E}+00 \quad 0.00 \mathrm{E}+00$

$0.00 \mathrm{E}+00 \quad 0.00 \mathrm{E}+00 \quad 0.00 \mathrm{E}+00$

$0.00 \mathrm{E}+00 \quad 0.00 \mathrm{E}+00 \quad 0.00 \mathrm{E}+00$

$0.00 \mathrm{E}+00 \quad 0.00 \mathrm{E}+00 \quad 0.00 \mathrm{E}+00$

$0.00 \mathrm{E}+00 \quad 0.00 \mathrm{E}+00 \quad 0.00 \mathrm{E}+00$

$0.00 \mathrm{E}+00 \quad 0.00 \mathrm{E}+00 \quad 0.00 \mathrm{E}+00$

$0.00 \mathrm{E}+00 \quad 0.00 \mathrm{E}+00 \quad 0.00 \mathrm{E}+00$

$0.00 \mathrm{E}+00 \quad 0.00 \mathrm{E}+00 \quad 0.00 \mathrm{E}+00$

$0.00 \mathrm{E}+00 \quad 0.00 \mathrm{E}+00 \quad 0.00 \mathrm{E}+00$

$0.00 \mathrm{E}+00 \quad 0.00 \mathrm{E}+00 \quad 0.00 \mathrm{E}+00$

$0.00 \mathrm{E}+00 \quad 0.00 \mathrm{E}+00 \quad 0.00 \mathrm{E}+00$

$\begin{array}{lll}0.00 \mathrm{E}+00 & 0.00 \mathrm{E}+00 \quad 0.00 \mathrm{E}+00\end{array}$

$0.00 \mathrm{E}+00 \quad 0.00 \mathrm{E}+00 \quad 0.00 \mathrm{E}+00$

$0.00 \mathrm{E}+00 \quad 0.00 \mathrm{E}+00 \quad 0.00 \mathrm{E}+00$

$0.00 \mathrm{E}+00 \quad 0.00 \mathrm{E}+00 \quad 0.00 \mathrm{E}+00$

$0.00 \mathrm{E}+00 \quad 0.00 \mathrm{E}+00 \quad 0.00 \mathrm{E}+00$

$0.00 \mathrm{E}+00 \quad 0.00 \mathrm{E}+00 \quad 0.00 \mathrm{E}+00$

$0.00 \mathrm{E}+00 \quad 0.00 \mathrm{E}+00 \quad 0.00 \mathrm{E}+00$

$0.00 \mathrm{E}+00 \quad 0.00 \mathrm{E}+00 \quad 0.00 \mathrm{E}+00$

$0.00 \mathrm{E}+00 \quad 0.00 \mathrm{E}+00 \quad 0.00 \mathrm{E}+00$

$0.00 \mathrm{E}+00 \quad 0.00 \mathrm{E}+00 \quad 0.00 \mathrm{E}+00$

$0.00 \mathrm{E}+00 \quad 0.00 \mathrm{E}+00 \quad 0.00 \mathrm{E}+00$ 
RESRAD-OFFSITE, Version 2.5

Probabilistic Dose and Risk Report

Title : Offsite Resident Farmer Deterministic Run

File : RF TC99 DOESG FWD-FV2b.ROF

Repetition $=$

Mean

td. Dev.

Minimum

Maximum

ercentile

0.010

0.025

0.050

0.075

0.100

0.125

0.150

0.175

0.200

0.225

0.250

0.275

0.300

0.325

0.350

0.375

0.400

0.425

0.450

0.475

0.500

0.525

0.550

0.575

0.600

0.625

0.650

0.675

0.700

0.725

0.750

0.775

0.800

0.825

0.850

0.875

0.900

0.925

0.950

0.975

0.990
Statistics and Cumulative distribution function of Peak Risk from Plant (Waterrelease)

$\begin{array}{cccc}1 & 2 & 3 \\ 0.00 \mathrm{E}+00 & 0.00 \mathrm{E}+00 & 0.00 \mathrm{E}+00 \\ 0.00 \mathrm{E}+00 & 0.00 \mathrm{E}+00 & 0.00 \mathrm{E}+00 \\ 0.00 \mathrm{E}+00 & 0.00 \mathrm{E}+00 & 0.00 \mathrm{E}+00 \\ 0.00 \mathrm{E}+00 & 0.00 \mathrm{E}+00 & 0.00 \mathrm{E}+00\end{array}$

$0.00 \mathrm{E}+00 \quad 0.00 \mathrm{E}+00 \quad 0.00 \mathrm{E}+00$

$0.00 \mathrm{E}+00 \quad 0.00 \mathrm{E}+00 \quad 0.00 \mathrm{E}+00$

$0.00 \mathrm{E}+00 \quad 0.00 \mathrm{E}+00 \quad 0.00 \mathrm{E}+00$

$0.00 \mathrm{E}+00 \quad 0.00 \mathrm{E}+00 \quad 0.00 \mathrm{E}+00$

$0.00 \mathrm{E}+00 \quad 0.00 \mathrm{E}+00 \quad 0.00 \mathrm{E}+00$

$0.00 \mathrm{E}+00 \quad 0.00 \mathrm{E}+00 \quad 0.00 \mathrm{E}+00$

$0.00 \mathrm{E}+00 \quad 0.00 \mathrm{E}+00 \quad 0.00 \mathrm{E}+00$

$0.00 \mathrm{E}+00 \quad 0.00 \mathrm{E}+00 \quad 0.00 \mathrm{E}+00$

$0.00 \mathrm{E}+00 \quad 0.00 \mathrm{E}+00 \quad 0.00 \mathrm{E}+00$

$0.00 \mathrm{E}+00 \quad 0.00 \mathrm{E}+00 \quad 0.00 \mathrm{E}+00$

$0.00 \mathrm{E}+00 \quad 0.00 \mathrm{E}+00 \quad 0.00 \mathrm{E}+00$

$0.00 \mathrm{E}+00 \quad 0.00 \mathrm{E}+00 \quad 0.00 \mathrm{E}+00$

$0.00 \mathrm{E}+00 \quad 0.00 \mathrm{E}+00 \quad 0.00 \mathrm{E}+00$

$0.00 \mathrm{E}+00 \quad 0.00 \mathrm{E}+00 \quad 0.00 \mathrm{E}+00$

$0.00 \mathrm{E}+00 \quad 0.00 \mathrm{E}+00 \quad 0.00 \mathrm{E}+00$

$0.00 \mathrm{E}+00 \quad 0.00 \mathrm{E}+00 \quad 0.00 \mathrm{E}+00$

$0.00 \mathrm{E}+00 \quad 0.00 \mathrm{E}+00 \quad 0.00 \mathrm{E}+00$

$0.00 \mathrm{E}+00 \quad 0.00 \mathrm{E}+00 \quad 0.00 \mathrm{E}+00$

$0.00 \mathrm{E}+00 \quad 0.00 \mathrm{E}+00 \quad 0.00 \mathrm{E}+00$

$0.00 \mathrm{E}+00 \quad 0.00 \mathrm{E}+00 \quad 0.00 \mathrm{E}+00$

$0.00 \mathrm{E}+00 \quad 0.00 \mathrm{E}+00 \quad 0.00 \mathrm{E}+00$

$0.00 \mathrm{E}+00 \quad 0.00 \mathrm{E}+00 \quad 0.00 \mathrm{E}+00$

$0.00 \mathrm{E}+00 \quad 0.00 \mathrm{E}+00 \quad 0.00 \mathrm{E}+00$

$0.00 \mathrm{E}+00 \quad 0.00 \mathrm{E}+00 \quad 0.00 \mathrm{E}+00$

$0.00 \mathrm{E}+00 \quad 0.00 \mathrm{E}+00 \quad 0.00 \mathrm{E}+00$

$0.00 \mathrm{E}+00 \quad 0.00 \mathrm{E}+00 \quad 0.00 \mathrm{E}+00$

$0.00 \mathrm{E}+00 \quad 0.00 \mathrm{E}+00 \quad 0.00 \mathrm{E}+00$

$0.00 \mathrm{E}+00 \quad 0.00 \mathrm{E}+00 \quad 0.00 \mathrm{E}+00$

$0.00 \mathrm{E}+00 \quad 0.00 \mathrm{E}+00 \quad 0.00 \mathrm{E}+00$

$0.00 \mathrm{E}+00 \quad 0.00 \mathrm{E}+00 \quad 0.00 \mathrm{E}+00$

$\begin{array}{lll}0.00 \mathrm{E}+00 & 0.00 \mathrm{E}+00 \quad 0.00 \mathrm{E}+00\end{array}$

$0.00 \mathrm{E}+00 \quad 0.00 \mathrm{E}+00 \quad 0.00 \mathrm{E}+00$

$0.00 \mathrm{E}+00 \quad 0.00 \mathrm{E}+00 \quad 0.00 \mathrm{E}+00$

$0.00 \mathrm{E}+00 \quad 0.00 \mathrm{E}+00 \quad 0.00 \mathrm{E}+00$

$0.00 \mathrm{E}+00 \quad 0.00 \mathrm{E}+00 \quad 0.00 \mathrm{E}+00$

$0.00 \mathrm{E}+00 \quad 0.00 \mathrm{E}+00 \quad 0.00 \mathrm{E}+00$

$0.00 \mathrm{E}+00 \quad 0.00 \mathrm{E}+00 \quad 0.00 \mathrm{E}+00$

$0.00 \mathrm{E}+00 \quad 0.00 \mathrm{E}+00 \quad 0.00 \mathrm{E}+00$

$0.00 \mathrm{E}+00 \quad 0.00 \mathrm{E}+00 \quad 0.00 \mathrm{E}+00$

$0.00 \mathrm{E}+00 \quad 0.00 \mathrm{E}+00 \quad 0.00 \mathrm{E}+00$

$0.00 \mathrm{E}+00 \quad 0.00 \mathrm{E}+00 \quad 0.00 \mathrm{E}+00$ 
RESRAD-OFFSITE, Version 2.5

Probabilistic Dose and Risk Report

Title : Offsite Resident Farmer Deterministic Run

File : RF TC99 DOESG FWD-FV2b.ROF

Repetition $=$

Mean

td. Dev.

Minimum

Maximum

ercentile

0.010

0.025

0.050

0.075

0.100

0.125

0.150

0.175

0.200

0.225

0.250

0.275

0.300

0.325

0.350

0.375

0.400

0.425

0.450

0.475

0.500

0.525

0.550

0.575

0.600

0.625

0.650

0.675

0.700

0.725

0.750

0.775

0.800

0.825

0.850

0.875

0.900

0.925

0.950

0.975

0.990
Statistics and Cumulative distribution function of Peak Risk from Meat (Waterrelease)

$\begin{array}{cccc}1 & 2 & 3 \\ 0.00 \mathrm{E}+00 & 0.00 \mathrm{E}+00 & 0.00 \mathrm{E}+00 \\ 0.00 \mathrm{E}+00 & 0.00 \mathrm{E}+00 & 0.00 \mathrm{E}+00 \\ 0.00 \mathrm{E}+00 & 0.00 \mathrm{E}+00 & 0.00 \mathrm{E}+00 \\ 0.00 \mathrm{E}+00 & 0.00 \mathrm{E}+00 & 0.00 \mathrm{E}+00\end{array}$

$0.00 \mathrm{E}+00 \quad 0.00 \mathrm{E}+00 \quad 0.00 \mathrm{E}+00$

$0.00 \mathrm{E}+00 \quad 0.00 \mathrm{E}+00 \quad 0.00 \mathrm{E}+00$

$0.00 \mathrm{E}+00 \quad 0.00 \mathrm{E}+00 \quad 0.00 \mathrm{E}+00$

$0.00 \mathrm{E}+00 \quad 0.00 \mathrm{E}+00 \quad 0.00 \mathrm{E}+00$

$0.00 \mathrm{E}+00 \quad 0.00 \mathrm{E}+00 \quad 0.00 \mathrm{E}+00$

$0.00 \mathrm{E}+00 \quad 0.00 \mathrm{E}+00 \quad 0.00 \mathrm{E}+00$

$0.00 \mathrm{E}+00 \quad 0.00 \mathrm{E}+00 \quad 0.00 \mathrm{E}+00$

$0.00 \mathrm{E}+00 \quad 0.00 \mathrm{E}+00 \quad 0.00 \mathrm{E}+00$

$0.00 \mathrm{E}+00 \quad 0.00 \mathrm{E}+00 \quad 0.00 \mathrm{E}+00$

$0.00 \mathrm{E}+00 \quad 0.00 \mathrm{E}+00 \quad 0.00 \mathrm{E}+00$

$0.00 \mathrm{E}+00 \quad 0.00 \mathrm{E}+00 \quad 0.00 \mathrm{E}+00$

$0.00 \mathrm{E}+00 \quad 0.00 \mathrm{E}+00 \quad 0.00 \mathrm{E}+00$

$0.00 \mathrm{E}+00 \quad 0.00 \mathrm{E}+00 \quad 0.00 \mathrm{E}+00$

$0.00 \mathrm{E}+00 \quad 0.00 \mathrm{E}+00 \quad 0.00 \mathrm{E}+00$

$0.00 \mathrm{E}+00 \quad 0.00 \mathrm{E}+00 \quad 0.00 \mathrm{E}+00$

$0.00 \mathrm{E}+00 \quad 0.00 \mathrm{E}+00 \quad 0.00 \mathrm{E}+00$

$0.00 \mathrm{E}+00 \quad 0.00 \mathrm{E}+00 \quad 0.00 \mathrm{E}+00$

$0.00 \mathrm{E}+00 \quad 0.00 \mathrm{E}+00 \quad 0.00 \mathrm{E}+00$

$0.00 \mathrm{E}+00 \quad 0.00 \mathrm{E}+00 \quad 0.00 \mathrm{E}+00$

$0.00 \mathrm{E}+00 \quad 0.00 \mathrm{E}+00 \quad 0.00 \mathrm{E}+00$

$0.00 \mathrm{E}+00 \quad 0.00 \mathrm{E}+00 \quad 0.00 \mathrm{E}+00$

$0.00 \mathrm{E}+00 \quad 0.00 \mathrm{E}+00 \quad 0.00 \mathrm{E}+00$

$0.00 \mathrm{E}+00 \quad 0.00 \mathrm{E}+00 \quad 0.00 \mathrm{E}+00$

$0.00 \mathrm{E}+00 \quad 0.00 \mathrm{E}+00 \quad 0.00 \mathrm{E}+00$

$0.00 \mathrm{E}+00 \quad 0.00 \mathrm{E}+00 \quad 0.00 \mathrm{E}+00$

$0.00 \mathrm{E}+00 \quad 0.00 \mathrm{E}+00 \quad 0.00 \mathrm{E}+00$

$0.00 \mathrm{E}+00 \quad 0.00 \mathrm{E}+00 \quad 0.00 \mathrm{E}+00$

$0.00 \mathrm{E}+00 \quad 0.00 \mathrm{E}+00 \quad 0.00 \mathrm{E}+00$

$0.00 \mathrm{E}+00 \quad 0.00 \mathrm{E}+00 \quad 0.00 \mathrm{E}+00$

$0.00 \mathrm{E}+00 \quad 0.00 \mathrm{E}+00 \quad 0.00 \mathrm{E}+00$

$\begin{array}{lll}0.00 \mathrm{E}+00 & 0.00 \mathrm{E}+00 \quad 0.00 \mathrm{E}+00\end{array}$

$0.00 \mathrm{E}+00 \quad 0.00 \mathrm{E}+00 \quad 0.00 \mathrm{E}+00$

$0.00 \mathrm{E}+00 \quad 0.00 \mathrm{E}+00 \quad 0.00 \mathrm{E}+00$

$0.00 \mathrm{E}+00 \quad 0.00 \mathrm{E}+00 \quad 0.00 \mathrm{E}+00$

$0.00 \mathrm{E}+00 \quad 0.00 \mathrm{E}+00 \quad 0.00 \mathrm{E}+00$

$0.00 \mathrm{E}+00 \quad 0.00 \mathrm{E}+00 \quad 0.00 \mathrm{E}+00$

$0.00 \mathrm{E}+00 \quad 0.00 \mathrm{E}+00 \quad 0.00 \mathrm{E}+00$

$0.00 \mathrm{E}+00 \quad 0.00 \mathrm{E}+00 \quad 0.00 \mathrm{E}+00$

$0.00 \mathrm{E}+00 \quad 0.00 \mathrm{E}+00 \quad 0.00 \mathrm{E}+00$

$0.00 \mathrm{E}+00 \quad 0.00 \mathrm{E}+00 \quad 0.00 \mathrm{E}+00$

$0.00 \mathrm{E}+00 \quad 0.00 \mathrm{E}+00 \quad 0.00 \mathrm{E}+00$ 
RESRAD-OFFSITE, Version 2.5

Probabilistic Dose and Risk Report

Title : Offsite Resident Farmer Deterministic Run

File : RF TC99 DOESG FWD-FV2b.ROF

Repetition $=$

Mean

td. Dev.

Minimum

Maximum

ercentile

0.010

0.025

0.050

0.075

0.100

0.125

0.150

0.175

0.200

0.225

0.250

0.275

0.300

0.325

0.350

0.375

0.400

0.425

0.450

0.475

0.500

0.525

0.550

0.575

0.600

0.625

0.650

0.675

0.700

0.725

0.750

0.775

0.800

0.825

0.850

0.875

0.900

0.925

0.950

0.975

0.990
Statistics and Cumulative distribution function of Peak Risk from Milk (Waterrelease)

$\begin{array}{cccc}1 & 2 & 3 \\ {+00} } & 0.00 \mathrm{E}+00 & 0.00 \mathrm{E}+00 \\ 0.00 \mathrm{E}+00 & 0.00 \mathrm{E}+00 & 0.00 \mathrm{E}+00 \\ 0.00 \mathrm{E}+00 & 0.00 \mathrm{E}+00 & 0.00 \mathrm{E}+00\end{array}$

$0.00 \mathrm{E}+00 \quad 0.00 \mathrm{E}+00 \quad 0.00 \mathrm{E}+00$

$0.00 \mathrm{E}+00 \quad 0.00 \mathrm{E}+00 \quad 0.00 \mathrm{E}+00$

$0.00 \mathrm{E}+00 \quad 0.00 \mathrm{E}+00 \quad 0.00 \mathrm{E}+00$

$0.00 \mathrm{E}+00 \quad 0.00 \mathrm{E}+00 \quad 0.00 \mathrm{E}+00$

$0.00 \mathrm{E}+00 \quad 0.00 \mathrm{E}+00 \quad 0.00 \mathrm{E}+00$

$0.00 \mathrm{E}+00 \quad 0.00 \mathrm{E}+00 \quad 0.00 \mathrm{E}+00$

$0.00 \mathrm{E}+00 \quad 0.00 \mathrm{E}+00 \quad 0.00 \mathrm{E}+00$

$0.00 \mathrm{E}+00 \quad 0.00 \mathrm{E}+00 \quad 0.00 \mathrm{E}+00$

$0.00 \mathrm{E}+00 \quad 0.00 \mathrm{E}+00 \quad 0.00 \mathrm{E}+00$

$0.00 \mathrm{E}+00 \quad 0.00 \mathrm{E}+00 \quad 0.00 \mathrm{E}+00$

$0.00 \mathrm{E}+00 \quad 0.00 \mathrm{E}+00 \quad 0.00 \mathrm{E}+00$

$0.00 \mathrm{E}+00 \quad 0.00 \mathrm{E}+00 \quad 0.00 \mathrm{E}+00$

$0.00 \mathrm{E}+00 \quad 0.00 \mathrm{E}+00 \quad 0.00 \mathrm{E}+00$

$0.00 \mathrm{E}+00 \quad 0.00 \mathrm{E}+00 \quad 0.00 \mathrm{E}+00$

$0.00 \mathrm{E}+00 \quad 0.00 \mathrm{E}+00 \quad 0.00 \mathrm{E}+00$

$0.00 \mathrm{E}+00 \quad 0.00 \mathrm{E}+00 \quad 0.00 \mathrm{E}+00$

$0.00 \mathrm{E}+00 \quad 0.00 \mathrm{E}+00 \quad 0.00 \mathrm{E}+00$

$0.00 \mathrm{E}+00 \quad 0.00 \mathrm{E}+00 \quad 0.00 \mathrm{E}+00$

$0.00 \mathrm{E}+00 \quad 0.00 \mathrm{E}+00 \quad 0.00 \mathrm{E}+00$

$0.00 \mathrm{E}+00 \quad 0.00 \mathrm{E}+00 \quad 0.00 \mathrm{E}+00$

$0.00 \mathrm{E}+00 \quad 0.00 \mathrm{E}+00 \quad 0.00 \mathrm{E}+00$

$0.00 \mathrm{E}+00 \quad 0.00 \mathrm{E}+00 \quad 0.00 \mathrm{E}+00$

$0.00 \mathrm{E}+00 \quad 0.00 \mathrm{E}+00 \quad 0.00 \mathrm{E}+00$

$0.00 \mathrm{E}+00 \quad 0.00 \mathrm{E}+00 \quad 0.00 \mathrm{E}+00$

$0.00 \mathrm{E}+00 \quad 0.00 \mathrm{E}+00 \quad 0.00 \mathrm{E}+00$

$0.00 \mathrm{E}+00 \quad 0.00 \mathrm{E}+00 \quad 0.00 \mathrm{E}+00$

$0.00 \mathrm{E}+00 \quad 0.00 \mathrm{E}+00 \quad 0.00 \mathrm{E}+00$

$0.00 \mathrm{E}+00 \quad 0.00 \mathrm{E}+00 \quad 0.00 \mathrm{E}+00$

$0.00 \mathrm{E}+00 \quad 0.00 \mathrm{E}+00 \quad 0.00 \mathrm{E}+00$

$0.00 \mathrm{E}+00 \quad 0.00 \mathrm{E}+00 \quad 0.00 \mathrm{E}+00$

$0.00 \mathrm{E}+00 \quad 0.00 \mathrm{E}+00 \quad 0.00 \mathrm{E}+00$

$0.00 \mathrm{E}+00 \quad 0.00 \mathrm{E}+00 \quad 0.00 \mathrm{E}+00$

$0.00 \mathrm{E}+00 \quad 0.00 \mathrm{E}+00 \quad 0.00 \mathrm{E}+00$

$0.00 \mathrm{E}+00 \quad 0.00 \mathrm{E}+00 \quad 0.00 \mathrm{E}+00$

$0.00 \mathrm{E}+00 \quad 0.00 \mathrm{E}+00 \quad 0.00 \mathrm{E}+00$

$0.00 \mathrm{E}+00 \quad 0.00 \mathrm{E}+00 \quad 0.00 \mathrm{E}+00$

$0.00 \mathrm{E}+00 \quad 0.00 \mathrm{E}+00 \quad 0.00 \mathrm{E}+00$

$0.00 \mathrm{E}+00 \quad 0.00 \mathrm{E}+00 \quad 0.00 \mathrm{E}+00$

$0.00 \mathrm{E}+00 \quad 0.00 \mathrm{E}+00 \quad 0.00 \mathrm{E}+00$

$0.00 \mathrm{E}+00 \quad 0.00 \mathrm{E}+00 \quad 0.00 \mathrm{E}+00$

$0.00 \mathrm{E}+00 \quad 0.00 \mathrm{E}+00 \quad 0.00 \mathrm{E}+00$ 
RESRAD-OFFSITE, Version 2.5

Probabilistic Dose and Risk Report

Title : Offsite Resident Farmer Deterministic Run

File : RF TC99 DOESG FWD-FV2b.ROF

Repetition $=$

Mean

td. Dev.

Minimum

Maximum

ercentile

0.010

0.025

0.050

0.075

0.100

0.125

0.150

0.175

0.200

0.225

0.250

0.275

0.300

0.325

0.350

0.375

0.400

0.425

0.450

0.475

0.500

0.525

0.550

0.575

0.600

0.625

0.650

0.675

0.700

0.725

0.750

0.775

0.800

0.825

0.850

0.875

0.900

0.925

0.950

0.975

0.990
Statistics and Cumulative distribution function of Peak Risk from Soil Ingestion(Wrelease)

\begin{tabular}{|c|c|c|}
\hline 1 & 2 & 3 \\
\hline $3.15 \mathrm{E}-11$ & $3.15 \mathrm{E}-11$ & $3.15 \mathrm{E}-11$ \\
\hline $1.85 \mathrm{E}-11$ & $1.85 \mathrm{E}-11$ & $1.85 \mathrm{E}-11$ \\
\hline 3. $77 \mathrm{E}-12$ & $3.77 \mathrm{E}-12$ & $3.77 \mathrm{E}-12$ \\
\hline $1.44 \mathrm{E}-10$ & $1.44 \mathrm{E}-10$ & $1.44 \mathrm{E}-10$ \\
\hline
\end{tabular}

$6.03 \mathrm{E}-12 \quad 6.03 \mathrm{E}-12 \quad 6.03 \mathrm{E}-12$

$7.08 \mathrm{E}-12 \quad 7.08 \mathrm{E}-12 \quad 7.08 \mathrm{E}-12$

$9.03 \mathrm{E}-12 \quad 9.03 \mathrm{E}-12 \quad 9.03 \mathrm{E}-12$

$\begin{array}{lll}1.01 \mathrm{E}-11 & 1.01 \mathrm{E}-11 & 1.01 \mathrm{E}-11\end{array}$

$1.14 \mathrm{E}-11 \quad 1.14 \mathrm{E}-11 \quad 1.14 \mathrm{E}-11$

$1.24 \mathrm{E}-11 \quad 1.24 \mathrm{E}-11 \quad 1.24 \mathrm{E}-11$

$\begin{array}{lll}1.33 \mathrm{E}-11 & 1.33 \mathrm{E}-11 & 1.33 \mathrm{E}-11\end{array}$

$1.45 \mathrm{E}-11 \quad 1.45 \mathrm{E}-11 \quad 1.45 \mathrm{E}-11$

$1.54 \mathrm{E}-11 \quad 1.53 \mathrm{E}-11 \quad 1.53 \mathrm{E}-11$

$1.66 \mathrm{E}-11 \quad 1.65 \mathrm{E}-11 \quad 1.65 \mathrm{E}-11$

$1.74 \mathrm{E}-11 \quad 1.74 \mathrm{E}-11 \quad 1.74 \mathrm{E}-11$

$1.83 \mathrm{E}-11 \quad 1.83 \mathrm{E}-11 \quad 1.83 \mathrm{E}-11$

$1.93 \mathrm{E}-11 \quad 1.93 \mathrm{E}-11 \quad 1.93 \mathrm{E}-11$

$2.04 \mathrm{E}-11 \quad 2.03 \mathrm{E}-11 \quad 2.03 \mathrm{E}-11$

$2.16 \mathrm{E}-11 \quad 2.16 \mathrm{E}-11 \quad 2.16 \mathrm{E}-11$

$2.27 \mathrm{E}-11 \quad 2.27 \mathrm{E}-11 \quad 2.27 \mathrm{E}-11$

$2.36 \mathrm{E}-11 \quad 2.36 \mathrm{E}-11 \quad 2.36 \mathrm{E}-11$

$2.46 \mathrm{E}-11 \quad 2.46 \mathrm{E}-11 \quad 2.46 \mathrm{E}-11$

$2.56 \mathrm{E}-11 \quad 2.56 \mathrm{E}-11 \quad 2.56 \mathrm{E}-11$

$2.68 \mathrm{E}-11 \quad 2.68 \mathrm{E}-11 \quad 2.68 \mathrm{E}-11$

$2.80 \mathrm{E}-11 \quad 2.80 \mathrm{E}-11 \quad 2.80 \mathrm{E}-11$

$2.93 \mathrm{E}-11 \quad 2.92 \mathrm{E}-11 \quad 2.93 \mathrm{E}-11$

$3.02 \mathrm{E}-11 \quad 3.02 \mathrm{E}-11 \quad 3.03 \mathrm{E}-11$

$3.14 \mathrm{E}-11 \quad 3.14 \mathrm{E}-11 \quad 3.14 \mathrm{E}-11$

$3.27 \mathrm{E}-11 \quad 3.27 \mathrm{E}-11 \quad 3.27 \mathrm{E}-11$

$3.40 \mathrm{E}-11 \quad 3.39 \mathrm{E}-11 \quad 3.40 \mathrm{E}-11$

$3.52 \mathrm{E}-11 \quad 3.52 \mathrm{E}-11 \quad 3.52 \mathrm{E}-11$

$3.64 \mathrm{E}-11 \quad 3.64 \mathrm{E}-11 \quad 3.64 \mathrm{E}-11$

$3.83 \mathrm{E}-11 \quad 3.83 \mathrm{E}-11 \quad 3.83 \mathrm{E}-11$

$3.96 \mathrm{E}-11 \quad 3.96 \mathrm{E}-11 \quad 3.96 \mathrm{E}-11$

$4.17 \mathrm{E}-11 \quad 4.17 \mathrm{E}-11 \quad 4.17 \mathrm{E}-11$

$4.34 \mathrm{E}-11 \quad 4.34 \mathrm{E}-11 \quad 4.34 \mathrm{E}-11$

$4.52 \mathrm{E}-11 \quad 4.52 \mathrm{E}-11 \quad 4.52 \mathrm{E}-11$

$4.73 \mathrm{E}-11 \quad 4.73 \mathrm{E}-11 \quad 4.73 \mathrm{E}-11$

$4.97 \mathrm{E}-11 \quad 4.97 \mathrm{E}-11 \quad 4.98 \mathrm{E}-11$

$5.27 \mathrm{E}-11 \quad 5.27 \mathrm{E}-11 \quad 5.28 \mathrm{E}-11$

$5.68 \mathrm{E}-11 \quad 5.68 \mathrm{E}-11 \quad 5.68 \mathrm{E}-11$

$6.16 \mathrm{E}-11 \quad 6.16 \mathrm{E}-11 \quad 6.16 \mathrm{E}-11$

$6.69 \mathrm{E}-11 \quad 6.69 \mathrm{E}-11 \quad 6.69 \mathrm{E}-11$

$\begin{array}{lll}7.68 \mathrm{E}-11 & 7.68 \mathrm{E}-11 & 7.68 \mathrm{E}-11\end{array}$

$8.66 \mathrm{E}-11 \quad 8.66 \mathrm{E}-11 \quad 8.66 \mathrm{E}-11$ 
RESRAD-OFFSITE, Version 2.5

Probabilistic Dose and Risk Report

Title : Offsite Resident Farmer Deterministic Run

File : RF TC99 DOESG FWD-FV2b.ROF

Repetition $=$

Mean

td. Dev.

Minimum

Maximum

ercentile

0.010

0.025

0.050

0.075

0.100

0.125

0.150

0.175

0.200

0.225

0.250

0.275

0.300

0.325

0.350

0.375

0.400

0.425

0.450

0.475

0.500

0.525

0.550

0.575

0.600

0.625

0.650

0.675

0.700

0.725

0.750

0.775

0.800

0.825

0.850

0.875

0.900

0.925

0.950

0.975

0.990
Statistics and Cumulative distribution function of Peak Risk from Water Ingestion

$\begin{array}{cccc}1 & 2 & 3 \\ 0.00 \mathrm{E}+00 & 0.00 \mathrm{E}+00 & 0.00 \mathrm{E}+00 \\ 0.00 \mathrm{E}+00 & 0.00 \mathrm{E}+00 & 0.00 \mathrm{E}+00 \\ 0.00 \mathrm{E}+00 & 0.00 \mathrm{E}+00 & 0.00 \mathrm{E}+00 \\ 0.00 \mathrm{E}+00 & 0.00 \mathrm{E}+00 & 0.00 \mathrm{E}+00\end{array}$

$0.00 \mathrm{E}+00 \quad 0.00 \mathrm{E}+00 \quad 0.00 \mathrm{E}+00$

$0.00 \mathrm{E}+00 \quad 0.00 \mathrm{E}+00 \quad 0.00 \mathrm{E}+00$

$0.00 \mathrm{E}+00 \quad 0.00 \mathrm{E}+00 \quad 0.00 \mathrm{E}+00$

$0.00 \mathrm{E}+00 \quad 0.00 \mathrm{E}+00 \quad 0.00 \mathrm{E}+00$

$0.00 \mathrm{E}+00 \quad 0.00 \mathrm{E}+00 \quad 0.00 \mathrm{E}+00$

$0.00 \mathrm{E}+00 \quad 0.00 \mathrm{E}+00 \quad 0.00 \mathrm{E}+00$

$0.00 \mathrm{E}+00 \quad 0.00 \mathrm{E}+00 \quad 0.00 \mathrm{E}+00$

$0.00 \mathrm{E}+00 \quad 0.00 \mathrm{E}+00 \quad 0.00 \mathrm{E}+00$

$0.00 \mathrm{E}+00 \quad 0.00 \mathrm{E}+00 \quad 0.00 \mathrm{E}+00$

$0.00 \mathrm{E}+00 \quad 0.00 \mathrm{E}+00 \quad 0.00 \mathrm{E}+00$

$0.00 \mathrm{E}+00 \quad 0.00 \mathrm{E}+00 \quad 0.00 \mathrm{E}+00$

$0.00 \mathrm{E}+00 \quad 0.00 \mathrm{E}+00 \quad 0.00 \mathrm{E}+00$

$0.00 \mathrm{E}+00 \quad 0.00 \mathrm{E}+00 \quad 0.00 \mathrm{E}+00$

$0.00 \mathrm{E}+00 \quad 0.00 \mathrm{E}+00 \quad 0.00 \mathrm{E}+00$

$0.00 \mathrm{E}+00 \quad 0.00 \mathrm{E}+00 \quad 0.00 \mathrm{E}+00$

$0.00 \mathrm{E}+00 \quad 0.00 \mathrm{E}+00 \quad 0.00 \mathrm{E}+00$

$0.00 \mathrm{E}+00 \quad 0.00 \mathrm{E}+00 \quad 0.00 \mathrm{E}+00$

$0.00 \mathrm{E}+00 \quad 0.00 \mathrm{E}+00 \quad 0.00 \mathrm{E}+00$

$0.00 \mathrm{E}+00 \quad 0.00 \mathrm{E}+00 \quad 0.00 \mathrm{E}+00$

$0.00 \mathrm{E}+00 \quad 0.00 \mathrm{E}+00 \quad 0.00 \mathrm{E}+00$

$0.00 \mathrm{E}+00 \quad 0.00 \mathrm{E}+00 \quad 0.00 \mathrm{E}+00$

$0.00 \mathrm{E}+00 \quad 0.00 \mathrm{E}+00 \quad 0.00 \mathrm{E}+00$

$0.00 \mathrm{E}+00 \quad 0.00 \mathrm{E}+00 \quad 0.00 \mathrm{E}+00$

$0.00 \mathrm{E}+00 \quad 0.00 \mathrm{E}+00 \quad 0.00 \mathrm{E}+00$

$0.00 \mathrm{E}+00 \quad 0.00 \mathrm{E}+00 \quad 0.00 \mathrm{E}+00$

$0.00 \mathrm{E}+00 \quad 0.00 \mathrm{E}+00 \quad 0.00 \mathrm{E}+00$

$0.00 \mathrm{E}+00 \quad 0.00 \mathrm{E}+00 \quad 0.00 \mathrm{E}+00$

$0.00 \mathrm{E}+00 \quad 0.00 \mathrm{E}+00 \quad 0.00 \mathrm{E}+00$

$0.00 \mathrm{E}+00 \quad 0.00 \mathrm{E}+00 \quad 0.00 \mathrm{E}+00$

$0.00 \mathrm{E}+00 \quad 0.00 \mathrm{E}+00 \quad 0.00 \mathrm{E}+00$

$\begin{array}{lll}0.00 \mathrm{E}+00 & 0.00 \mathrm{E}+00 \quad 0.00 \mathrm{E}+00\end{array}$

$0.00 \mathrm{E}+00 \quad 0.00 \mathrm{E}+00 \quad 0.00 \mathrm{E}+00$

$0.00 \mathrm{E}+00 \quad 0.00 \mathrm{E}+00 \quad 0.00 \mathrm{E}+00$

$0.00 \mathrm{E}+00 \quad 0.00 \mathrm{E}+00 \quad 0.00 \mathrm{E}+00$

$0.00 \mathrm{E}+00 \quad 0.00 \mathrm{E}+00 \quad 0.00 \mathrm{E}+00$

$0.00 \mathrm{E}+00 \quad 0.00 \mathrm{E}+00 \quad 0.00 \mathrm{E}+00$

$0.00 \mathrm{E}+00 \quad 0.00 \mathrm{E}+00 \quad 0.00 \mathrm{E}+00$

$0.00 \mathrm{E}+00 \quad 0.00 \mathrm{E}+00 \quad 0.00 \mathrm{E}+00$

$0.00 \mathrm{E}+00 \quad 0.00 \mathrm{E}+00 \quad 0.00 \mathrm{E}+00$

$0.00 \mathrm{E}+00 \quad 0.00 \mathrm{E}+00 \quad 0.00 \mathrm{E}+00$

$0.00 \mathrm{E}+00 \quad 0.00 \mathrm{E}+00 \quad 0.00 \mathrm{E}+00$ 
RESRAD-OFFSITE, Version 2.5

Probabilistic Dose and Risk Report

Title : Offsite Resident Farmer Deterministic Run

File : RF TC99 DOESG FWD-FV2b.ROF

Repetition $=$

Mean

td. Dev.

Minimum

Maximum

ercentile

0.010

0.025

0.050

0.075

0.100

0.125

0.150

0.175

0.200

0.225

0.250

0.275

0.300

0.325

0.350

0.375

0.400

0.425

0.450

0.475

0.500

0.525

0.550

0.575

0.600

0.625

0.650

0.675

0.700

0.725

0.750

0.775

0.800

0.825

0.850

0.875

0.900

0.925

0.950

0.975

0.990
Statistics and Cumulative distribution function of Peak Risk from External Ground(CZ\&Air)

\begin{tabular}{|c|c|c|}
\hline 1 & 2 & 3 \\
\hline $7.68 \mathrm{E}-30$ & $7.70 \mathrm{E}-30$ & 7. $69 \mathrm{E}-30$ \\
\hline $0.00 \mathrm{E}+00$ & $0.00 \mathrm{E}+00$ & $0.00 \mathrm{E}+00$ \\
\hline $2.86 \mathrm{E}-37$ & $2.86 \mathrm{E}-37$ & $2.86 \mathrm{E}-37$ \\
\hline $2.32 E-29$ & 2. $32 E-29$ & 2. $32 E-29$ \\
\hline
\end{tabular}

$5.97 \mathrm{E}-35 \quad 5.97 \mathrm{E}-35 \quad 5.97 \mathrm{E}-35$

$3.12 \mathrm{E}-33 \quad 3.12 \mathrm{E}-33 \quad 3.04 \mathrm{E}-33$

$3.62 \mathrm{E}-32 \quad 3.62 \mathrm{E}-32 \quad 3.55 \mathrm{E}-32$

$9.27 \mathrm{E}-32 \quad 9.27 \mathrm{E}-32 \quad 9.13 \mathrm{E}-32$

$1.89 \mathrm{E}-31 \quad 1.89 \mathrm{E}-31 \quad 1.89 \mathrm{E}-31$

$3.27 \mathrm{E}-31 \quad 3.31 \mathrm{E}-31 \quad 3.29 \mathrm{E}-31$

$5.04 \mathrm{E}-31 \quad 5.08 \mathrm{E}-31 \quad 5.06 \mathrm{E}-31$

$7.90 \mathrm{E}-31 \quad 8.06 \mathrm{E}-31 \quad 8.06 \mathrm{E}-31$

$1.13 \mathrm{E}-30 \quad 1.14 \mathrm{E}-30 \quad 1.14 \mathrm{E}-30$

$1.42 \mathrm{E}-30 \quad 1.43 \mathrm{E}-30 \quad 1.43 \mathrm{E}-30$

$1.74 \mathrm{E}-30 \quad 1.76 \mathrm{E}-30 \quad 1.76 \mathrm{E}-30$

$2.16 \mathrm{E}-30 \quad 2.17 \mathrm{E}-30 \quad 2.17 \mathrm{E}-30$

$2.57 \mathrm{E}-30 \quad 2.60 \mathrm{E}-30 \quad 2.58 \mathrm{E}-30$

$3.13 \mathrm{E}-30 \quad 3.15 \mathrm{E}-30 \quad 3.14 \mathrm{E}-30$

3. $62 \mathrm{E}-30 \quad 3.63 \mathrm{E}-30 \quad 3.63 \mathrm{E}-30$

$4.11 \mathrm{E}-30 \quad 4.17 \mathrm{E}-30 \quad 4.14 \mathrm{E}-30$

$4.67 \mathrm{E}-30 \quad 4.72 \mathrm{E}-30 \quad 4.70 \mathrm{E}-30$

$5.27 \mathrm{E}-30 \quad 5.29 \mathrm{E}-30 \quad 5.29 \mathrm{E}-30$

$5.85 \mathrm{E}-30 \quad 5.87 \mathrm{E}-30 \quad 5.87 \mathrm{E}-30$

$6.33 \mathrm{E}-30 \quad 6.35 \mathrm{E}-30 \quad 6.34 \mathrm{E}-30$

$6.91 \mathrm{E}-30 \quad 6.92 \mathrm{E}-30 \quad 6.91 \mathrm{E}-30$

$7.69 \mathrm{E}-30 \quad 7.70 \mathrm{E}-30 \quad 7.69 \mathrm{E}-30$

$8.29 \mathrm{E}-30 \quad 8.30 \mathrm{E}-30 \quad 8.30 \mathrm{E}-30$

$8.85 \mathrm{E}-30 \quad 8.89 \mathrm{E}-30 \quad 8.88 \mathrm{E}-30$

$9.35 \mathrm{E}-30 \quad 9.37 \mathrm{E}-30 \quad 9.36 \mathrm{E}-30$

$9.94 \mathrm{E}-30 \quad 9.96 \mathrm{E}-30 \quad 9.95 \mathrm{E}-30$

$1.03 E-29 \quad 1.03 E-29 \quad 1.03 E-29$

$1.08 \mathrm{E}-29 \quad 1.08 \mathrm{E}-29 \quad 1.08 \mathrm{E}-29$

$1.13 \mathrm{E}-29 \quad 1.14 \mathrm{E}-29 \quad 1.13 \mathrm{E}-29$

$1.21 \mathrm{E}-29 \quad 1.21 \mathrm{E}-29 \quad 1.21 \mathrm{E}-29$

$1.27 \mathrm{E}-29 \quad 1.27 \mathrm{E}-29 \quad 1.27 \mathrm{E}-29$

$1.33 \mathrm{E}-29 \quad 1.33 \mathrm{E}-29 \quad 1.33 \mathrm{E}-29$

$1.41 \mathrm{E}-29 \quad 1.41 \mathrm{E}-29 \quad 1.41 \mathrm{E}-29$

$1.45 \mathrm{E}-29 \quad 1.45 \mathrm{E}-29 \quad 1.45 \mathrm{E}-29$

$1.51 \mathrm{E}-29 \quad 1.52 \mathrm{E}-29 \quad 1.52 \mathrm{E}-29$

$1.59 \mathrm{E}-29 \quad 1.59 \mathrm{E}-29 \quad 1.59 \mathrm{E}-29$

$1.65 \mathrm{E}-29 \quad 1.65 \mathrm{E}-29 \quad 1.65 \mathrm{E}-29$

$1.73 E-29 \quad 1.73 E-29 \quad 1.73 E-29$

$1.83 \mathrm{E}-29 \quad 1.83 \mathrm{E}-29 \quad 1.83 \mathrm{E}-29$

$1.93 \mathrm{E}-29 \quad 1.93 \mathrm{E}-29 \quad 1.93 \mathrm{E}-29$

$2.05 E-29 \quad 2.05 E-29 \quad 2.05 E-29$ 
RESRAD-OFFSITE, Version 2.5

Probabilistic Dose and Risk Report

Title : Offsite Resident Farmer Deterministic Run

File : RF TC99 DOESG FWD-FV2b.ROF

Repetition $=$

Mean

td. Dev.

Minimum

Maximum

ercentile

0.010

0.025

0.050

0.075

0.100

0.125

0.150

0.175

0.200

0.225

0.250

0.275

0.300

0.325

0.350

0.375

0.400

0.425

0.450

0.475

0.500

0.525

0.550

0.575

0.600

0.625

0.650

0.675

0.700

0.725

0.750

0.775

0.800

0.825

0.850

0.875

0.900

0.925

0.950

0.975

0.990
Statistics and Cumulative distribution function of Peak Risk from Inhalation ExcludingRn

$\begin{array}{cccc}1 & 2 & 3 \\ 0.00 \mathrm{E}+00 & 0.00 \mathrm{E}+00 & 0.00 \mathrm{E}+00 \\ 0.00 \mathrm{E}+00 & 0.00 \mathrm{E}+00 & 0.00 \mathrm{E}+00 \\ 0.00 \mathrm{E}+00 & 0.00 \mathrm{E}+00 & 0.00 \mathrm{E}+00 \\ 0.00 \mathrm{E}+00 & 0.00 \mathrm{E}+00 & 0.00 \mathrm{E}+00\end{array}$

$0.00 \mathrm{E}+00 \quad 0.00 \mathrm{E}+00 \quad 0.00 \mathrm{E}+00$

$0.00 \mathrm{E}+00 \quad 0.00 \mathrm{E}+00 \quad 0.00 \mathrm{E}+00$

$0.00 \mathrm{E}+00 \quad 0.00 \mathrm{E}+00 \quad 0.00 \mathrm{E}+00$

$0.00 \mathrm{E}+00 \quad 0.00 \mathrm{E}+00 \quad 0.00 \mathrm{E}+00$

$0.00 \mathrm{E}+00 \quad 0.00 \mathrm{E}+00 \quad 0.00 \mathrm{E}+00$

$0.00 \mathrm{E}+00 \quad 0.00 \mathrm{E}+00 \quad 0.00 \mathrm{E}+00$

$0.00 \mathrm{E}+00 \quad 0.00 \mathrm{E}+00 \quad 0.00 \mathrm{E}+00$

$0.00 \mathrm{E}+00 \quad 0.00 \mathrm{E}+00 \quad 0.00 \mathrm{E}+00$

$0.00 \mathrm{E}+00 \quad 0.00 \mathrm{E}+00 \quad 0.00 \mathrm{E}+00$

$0.00 \mathrm{E}+00 \quad 0.00 \mathrm{E}+00 \quad 0.00 \mathrm{E}+00$

$0.00 \mathrm{E}+00 \quad 0.00 \mathrm{E}+00 \quad 0.00 \mathrm{E}+00$

$0.00 \mathrm{E}+00 \quad 0.00 \mathrm{E}+00 \quad 0.00 \mathrm{E}+00$

$0.00 \mathrm{E}+00 \quad 0.00 \mathrm{E}+00 \quad 0.00 \mathrm{E}+00$

$0.00 \mathrm{E}+00 \quad 0.00 \mathrm{E}+00 \quad 0.00 \mathrm{E}+00$

$0.00 \mathrm{E}+00 \quad 0.00 \mathrm{E}+00 \quad 0.00 \mathrm{E}+00$

$0.00 \mathrm{E}+00 \quad 0.00 \mathrm{E}+00 \quad 0.00 \mathrm{E}+00$

$0.00 \mathrm{E}+00 \quad 0.00 \mathrm{E}+00 \quad 0.00 \mathrm{E}+00$

$0.00 \mathrm{E}+00 \quad 0.00 \mathrm{E}+00 \quad 0.00 \mathrm{E}+00$

$0.00 \mathrm{E}+00 \quad 0.00 \mathrm{E}+00 \quad 0.00 \mathrm{E}+00$

$0.00 \mathrm{E}+00 \quad 0.00 \mathrm{E}+00 \quad 0.00 \mathrm{E}+00$

$0.00 \mathrm{E}+00 \quad 0.00 \mathrm{E}+00 \quad 0.00 \mathrm{E}+00$

$0.00 \mathrm{E}+00 \quad 0.00 \mathrm{E}+00 \quad 0.00 \mathrm{E}+00$

$0.00 \mathrm{E}+00 \quad 0.00 \mathrm{E}+00 \quad 0.00 \mathrm{E}+00$

$0.00 \mathrm{E}+00 \quad 0.00 \mathrm{E}+00 \quad 0.00 \mathrm{E}+00$

$0.00 \mathrm{E}+00 \quad 0.00 \mathrm{E}+00 \quad 0.00 \mathrm{E}+00$

$0.00 \mathrm{E}+00 \quad 0.00 \mathrm{E}+00 \quad 0.00 \mathrm{E}+00$

$0.00 \mathrm{E}+00 \quad 0.00 \mathrm{E}+00 \quad 0.00 \mathrm{E}+00$

$0.00 \mathrm{E}+00 \quad 0.00 \mathrm{E}+00 \quad 0.00 \mathrm{E}+00$

$0.00 \mathrm{E}+00 \quad 0.00 \mathrm{E}+00 \quad 0.00 \mathrm{E}+00$

$0.00 \mathrm{E}+00 \quad 0.00 \mathrm{E}+00 \quad 0.00 \mathrm{E}+00$

$0.00 \mathrm{E}+00 \quad 0.00 \mathrm{E}+00 \quad 0.00 \mathrm{E}+00$

$0.00 \mathrm{E}+00 \quad 0.00 \mathrm{E}+00 \quad 0.00 \mathrm{E}+00$

$0.00 \mathrm{E}+00 \quad 0.00 \mathrm{E}+00 \quad 0.00 \mathrm{E}+00$

$0.00 \mathrm{E}+00 \quad 0.00 \mathrm{E}+00 \quad 0.00 \mathrm{E}+00$

$0.00 \mathrm{E}+00 \quad 0.00 \mathrm{E}+00 \quad 0.00 \mathrm{E}+00$

$0.00 \mathrm{E}+00 \quad 0.00 \mathrm{E}+00 \quad 0.00 \mathrm{E}+00$

$0.00 \mathrm{E}+00 \quad 0.00 \mathrm{E}+00 \quad 0.00 \mathrm{E}+00$

$0.00 \mathrm{E}+00 \quad 0.00 \mathrm{E}+00 \quad 0.00 \mathrm{E}+00$

$0.00 \mathrm{E}+00 \quad 0.00 \mathrm{E}+00 \quad 0.00 \mathrm{E}+00$

$0.00 \mathrm{E}+00 \quad 0.00 \mathrm{E}+00 \quad 0.00 \mathrm{E}+00$

$0.00 \mathrm{E}+00 \quad 0.00 \mathrm{E}+00 \quad 0.00 \mathrm{E}+00$ 
RESRAD-OFFSITE, Version 2.5

Probabilistic Dose and Risk Report

Title : Offsite Resident Farmer Deterministic Run

File : RF TC99 DOESG FWD-FV2b.ROF

Repetition $=$

Mean

td. Dev.

Minimum

Maximum

ercentile

0.010

0.025

0.050

0.075

0.100

0.125

0.150

0.175

0.200

0.225

0.250

0.275

0.300

0.325

0.350

0.375

0.400

0.425

0.450

0.475

0.500

0.525

0.550

0.575

0.600

0.625

0.650

0.675

0.700

0.725

0.750

0.775

0.800

0.825

0.850

0.875

0.900

0.925

0.950

0.975

0.990
Statistics and Cumulative distribution function of Peak Risk from Radon (CZandAir)

$\begin{array}{cccc}1 & 2 & 3 \\ 0.00 \mathrm{E}+00 & 0.00 \mathrm{E}+00 & 0.00 \mathrm{E}+00 \\ 0.00 \mathrm{E}+00 & 0.00 \mathrm{E}+00 & 0.00 \mathrm{E}+00 \\ 0.00 \mathrm{E}+00 & 0.00 \mathrm{E}+00 & 0.00 \mathrm{E}+00 \\ 0.00 \mathrm{E}+00 & 0.00 \mathrm{E}+00 & 0.00 \mathrm{E}+00\end{array}$

$0.00 \mathrm{E}+00 \quad 0.00 \mathrm{E}+00 \quad 0.00 \mathrm{E}+00$

$0.00 \mathrm{E}+00 \quad 0.00 \mathrm{E}+00 \quad 0.00 \mathrm{E}+00$

$0.00 \mathrm{E}+00 \quad 0.00 \mathrm{E}+00 \quad 0.00 \mathrm{E}+00$

$0.00 \mathrm{E}+00 \quad 0.00 \mathrm{E}+00 \quad 0.00 \mathrm{E}+00$

$0.00 \mathrm{E}+00 \quad 0.00 \mathrm{E}+00 \quad 0.00 \mathrm{E}+00$

$0.00 \mathrm{E}+00 \quad 0.00 \mathrm{E}+00 \quad 0.00 \mathrm{E}+00$

$0.00 \mathrm{E}+00 \quad 0.00 \mathrm{E}+00 \quad 0.00 \mathrm{E}+00$

$0.00 \mathrm{E}+00 \quad 0.00 \mathrm{E}+00 \quad 0.00 \mathrm{E}+00$

$0.00 \mathrm{E}+00 \quad 0.00 \mathrm{E}+00 \quad 0.00 \mathrm{E}+00$

$0.00 \mathrm{E}+00 \quad 0.00 \mathrm{E}+00 \quad 0.00 \mathrm{E}+00$

$0.00 \mathrm{E}+00 \quad 0.00 \mathrm{E}+00 \quad 0.00 \mathrm{E}+00$

$0.00 \mathrm{E}+00 \quad 0.00 \mathrm{E}+00 \quad 0.00 \mathrm{E}+00$

$0.00 \mathrm{E}+00 \quad 0.00 \mathrm{E}+00 \quad 0.00 \mathrm{E}+00$

$0.00 \mathrm{E}+00 \quad 0.00 \mathrm{E}+00 \quad 0.00 \mathrm{E}+00$

$0.00 \mathrm{E}+00 \quad 0.00 \mathrm{E}+00 \quad 0.00 \mathrm{E}+00$

$0.00 \mathrm{E}+00 \quad 0.00 \mathrm{E}+00 \quad 0.00 \mathrm{E}+00$

$0.00 \mathrm{E}+00 \quad 0.00 \mathrm{E}+00 \quad 0.00 \mathrm{E}+00$

$0.00 \mathrm{E}+00 \quad 0.00 \mathrm{E}+00 \quad 0.00 \mathrm{E}+00$

$0.00 \mathrm{E}+00 \quad 0.00 \mathrm{E}+00 \quad 0.00 \mathrm{E}+00$

$0.00 \mathrm{E}+00 \quad 0.00 \mathrm{E}+00 \quad 0.00 \mathrm{E}+00$

$0.00 \mathrm{E}+00 \quad 0.00 \mathrm{E}+00 \quad 0.00 \mathrm{E}+00$

$0.00 \mathrm{E}+00 \quad 0.00 \mathrm{E}+00 \quad 0.00 \mathrm{E}+00$

$0.00 \mathrm{E}+00 \quad 0.00 \mathrm{E}+00 \quad 0.00 \mathrm{E}+00$

$0.00 \mathrm{E}+00 \quad 0.00 \mathrm{E}+00 \quad 0.00 \mathrm{E}+00$

$0.00 \mathrm{E}+00 \quad 0.00 \mathrm{E}+00 \quad 0.00 \mathrm{E}+00$

$0.00 \mathrm{E}+00 \quad 0.00 \mathrm{E}+00 \quad 0.00 \mathrm{E}+00$

$0.00 \mathrm{E}+00 \quad 0.00 \mathrm{E}+00 \quad 0.00 \mathrm{E}+00$

$0.00 \mathrm{E}+00 \quad 0.00 \mathrm{E}+00 \quad 0.00 \mathrm{E}+00$

$0.00 \mathrm{E}+00 \quad 0.00 \mathrm{E}+00 \quad 0.00 \mathrm{E}+00$

$0.00 \mathrm{E}+00 \quad 0.00 \mathrm{E}+00 \quad 0.00 \mathrm{E}+00$

$\begin{array}{lll}0.00 \mathrm{E}+00 & 0.00 \mathrm{E}+00 \quad 0.00 \mathrm{E}+00\end{array}$

$0.00 \mathrm{E}+00 \quad 0.00 \mathrm{E}+00 \quad 0.00 \mathrm{E}+00$

$0.00 \mathrm{E}+00 \quad 0.00 \mathrm{E}+00 \quad 0.00 \mathrm{E}+00$

$0.00 \mathrm{E}+00 \quad 0.00 \mathrm{E}+00 \quad 0.00 \mathrm{E}+00$

$0.00 \mathrm{E}+00 \quad 0.00 \mathrm{E}+00 \quad 0.00 \mathrm{E}+00$

$0.00 \mathrm{E}+00 \quad 0.00 \mathrm{E}+00 \quad 0.00 \mathrm{E}+00$

$0.00 \mathrm{E}+00 \quad 0.00 \mathrm{E}+00 \quad 0.00 \mathrm{E}+00$

$0.00 \mathrm{E}+00 \quad 0.00 \mathrm{E}+00 \quad 0.00 \mathrm{E}+00$

$0.00 \mathrm{E}+00 \quad 0.00 \mathrm{E}+00 \quad 0.00 \mathrm{E}+00$

$0.00 \mathrm{E}+00 \quad 0.00 \mathrm{E}+00 \quad 0.00 \mathrm{E}+00$

$\begin{array}{lll}0.00 \mathrm{E}+00 & 0.00 \mathrm{E}+00 \quad 0.00 \mathrm{E}+00\end{array}$ 
RESRAD-OFFSITE, Version 2.5

Probabilistic Dose and Risk Report

Title : Offsite Resident Farmer Deterministic Run

File : RF TC99 DOESG FWD-FV2b.ROF

Repetition $=$

Mean

td. Dev.

Minimum

Maximum

ercentile

0.010

0.025

0.050

0.075

0.100

0.125

0.150

0.175

0.200

0.225

0.250

0.275

0.300

0.325

0.350

0.375

0.400

0.425

0.450

0.475

0.500

0.525

0.550

0.575

0.600

0.625

0.650

0.675

0.700

0.725

0.750

0.775

0.800

0.825

0.850

0.875

0.900

0.925

0.950

0.975

0.990
Statistics and Cumulative distribution function of Peak Risk from Plant (CzandAir)

$\begin{array}{cccc}1 & 2 & 3 \\ 0.00 \mathrm{E}+00 & 0.00 \mathrm{E}+00 & 0.00 \mathrm{E}+00 \\ 0.00 \mathrm{E}+00 & 0.00 \mathrm{E}+00 & 0.00 \mathrm{E}+00 \\ 0.00 \mathrm{E}+00 & 0.00 \mathrm{E}+00 & 0.00 \mathrm{E}+00 \\ 0.00 \mathrm{E}+00 & 0.00 \mathrm{E}+00 & 0.00 \mathrm{E}+00\end{array}$

$0.00 \mathrm{E}+00 \quad 0.00 \mathrm{E}+00 \quad 0.00 \mathrm{E}+00$

$0.00 \mathrm{E}+00 \quad 0.00 \mathrm{E}+00 \quad 0.00 \mathrm{E}+00$

$0.00 \mathrm{E}+00 \quad 0.00 \mathrm{E}+00 \quad 0.00 \mathrm{E}+00$

$0.00 \mathrm{E}+00 \quad 0.00 \mathrm{E}+00 \quad 0.00 \mathrm{E}+00$

$0.00 \mathrm{E}+00 \quad 0.00 \mathrm{E}+00 \quad 0.00 \mathrm{E}+00$

$0.00 \mathrm{E}+00 \quad 0.00 \mathrm{E}+00 \quad 0.00 \mathrm{E}+00$

$0.00 \mathrm{E}+00 \quad 0.00 \mathrm{E}+00 \quad 0.00 \mathrm{E}+00$

$0.00 \mathrm{E}+00 \quad 0.00 \mathrm{E}+00 \quad 0.00 \mathrm{E}+00$

$0.00 \mathrm{E}+00 \quad 0.00 \mathrm{E}+00 \quad 0.00 \mathrm{E}+00$

$0.00 \mathrm{E}+00 \quad 0.00 \mathrm{E}+00 \quad 0.00 \mathrm{E}+00$

$0.00 \mathrm{E}+00 \quad 0.00 \mathrm{E}+00 \quad 0.00 \mathrm{E}+00$

$0.00 \mathrm{E}+00 \quad 0.00 \mathrm{E}+00 \quad 0.00 \mathrm{E}+00$

$0.00 \mathrm{E}+00 \quad 0.00 \mathrm{E}+00 \quad 0.00 \mathrm{E}+00$

$0.00 \mathrm{E}+00 \quad 0.00 \mathrm{E}+00 \quad 0.00 \mathrm{E}+00$

$0.00 \mathrm{E}+00 \quad 0.00 \mathrm{E}+00 \quad 0.00 \mathrm{E}+00$

$0.00 \mathrm{E}+00 \quad 0.00 \mathrm{E}+00 \quad 0.00 \mathrm{E}+00$

$0.00 \mathrm{E}+00 \quad 0.00 \mathrm{E}+00 \quad 0.00 \mathrm{E}+00$

$0.00 \mathrm{E}+00 \quad 0.00 \mathrm{E}+00 \quad 0.00 \mathrm{E}+00$

$0.00 \mathrm{E}+00 \quad 0.00 \mathrm{E}+00 \quad 0.00 \mathrm{E}+00$

$0.00 \mathrm{E}+00 \quad 0.00 \mathrm{E}+00 \quad 0.00 \mathrm{E}+00$

$0.00 \mathrm{E}+00 \quad 0.00 \mathrm{E}+00 \quad 0.00 \mathrm{E}+00$

$0.00 \mathrm{E}+00 \quad 0.00 \mathrm{E}+00 \quad 0.00 \mathrm{E}+00$

$0.00 \mathrm{E}+00 \quad 0.00 \mathrm{E}+00 \quad 0.00 \mathrm{E}+00$

$0.00 \mathrm{E}+00 \quad 0.00 \mathrm{E}+00 \quad 0.00 \mathrm{E}+00$

$0.00 \mathrm{E}+00 \quad 0.00 \mathrm{E}+00 \quad 0.00 \mathrm{E}+00$

$0.00 \mathrm{E}+00 \quad 0.00 \mathrm{E}+00 \quad 0.00 \mathrm{E}+00$

$0.00 \mathrm{E}+00 \quad 0.00 \mathrm{E}+00 \quad 0.00 \mathrm{E}+00$

$0.00 \mathrm{E}+00 \quad 0.00 \mathrm{E}+00 \quad 0.00 \mathrm{E}+00$

$0.00 \mathrm{E}+00 \quad 0.00 \mathrm{E}+00 \quad 0.00 \mathrm{E}+00$

$0.00 \mathrm{E}+00 \quad 0.00 \mathrm{E}+00 \quad 0.00 \mathrm{E}+00$

$\begin{array}{lll}0.00 \mathrm{E}+00 & 0.00 \mathrm{E}+00 \quad 0.00 \mathrm{E}+00\end{array}$

$0.00 \mathrm{E}+00 \quad 0.00 \mathrm{E}+00 \quad 0.00 \mathrm{E}+00$

$0.00 \mathrm{E}+00 \quad 0.00 \mathrm{E}+00 \quad 0.00 \mathrm{E}+00$

$0.00 \mathrm{E}+00 \quad 0.00 \mathrm{E}+00 \quad 0.00 \mathrm{E}+00$

$0.00 \mathrm{E}+00 \quad 0.00 \mathrm{E}+00 \quad 0.00 \mathrm{E}+00$

$0.00 \mathrm{E}+00 \quad 0.00 \mathrm{E}+00 \quad 0.00 \mathrm{E}+00$

$0.00 \mathrm{E}+00 \quad 0.00 \mathrm{E}+00 \quad 0.00 \mathrm{E}+00$

$0.00 \mathrm{E}+00 \quad 0.00 \mathrm{E}+00 \quad 0.00 \mathrm{E}+00$

$0.00 \mathrm{E}+00 \quad 0.00 \mathrm{E}+00 \quad 0.00 \mathrm{E}+00$

$0.00 \mathrm{E}+00 \quad 0.00 \mathrm{E}+00 \quad 0.00 \mathrm{E}+00$

$\begin{array}{lll}0.00 \mathrm{E}+00 & 0.00 \mathrm{E}+00 \quad 0.00 \mathrm{E}+00\end{array}$ 
RESRAD-OFFSITE, Version 2.5

Probabilistic Dose and Risk Report

Title : Offsite Resident Farmer Deterministic Run

File : RF TC99 DOESG FWD-FV2b.ROF

Repetition $=$

Mean

td. Dev.

Minimum

Maximum

ercentile

0.010

0.025

0.050

0.075

0.100

0.125

0.150

0.175

0.200

0.225

0.250

0.275

0.300

0.325

0.350

0.375

0.400

0.425

0.450

0.475

0.500

0.525

0.550

0.575

0.600

0.625

0.650

0.675

0.700

0.725

0.750

0.775

0.800

0.825

0.850

0.875

0.900

0.925

0.950

0.975

0.990
Statistics and Cumulative distribution function of Peak Risk from Meat (CZandAir)

$\begin{array}{cccc}1 & 2 & 3 \\ {+00} } & 0.00 \mathrm{E}+00 & 0.00 \mathrm{E}+00 \\ 0.00 \mathrm{E}+00 & 0.00 \mathrm{E}+00 & 0.00 \mathrm{E}+00 \\ 0.00 \mathrm{E}+00 & 0.00 \mathrm{E}+00 & 0.00 \mathrm{E}+00\end{array}$

$0.00 \mathrm{E}+00 \quad 0.00 \mathrm{E}+00 \quad 0.00 \mathrm{E}+00$

$0.00 \mathrm{E}+00 \quad 0.00 \mathrm{E}+00 \quad 0.00 \mathrm{E}+00$

$0.00 \mathrm{E}+00 \quad 0.00 \mathrm{E}+00 \quad 0.00 \mathrm{E}+00$

$0.00 \mathrm{E}+00 \quad 0.00 \mathrm{E}+00 \quad 0.00 \mathrm{E}+00$

$0.00 \mathrm{E}+00 \quad 0.00 \mathrm{E}+00 \quad 0.00 \mathrm{E}+00$

$0.00 \mathrm{E}+00 \quad 0.00 \mathrm{E}+00 \quad 0.00 \mathrm{E}+00$

$0.00 \mathrm{E}+00 \quad 0.00 \mathrm{E}+00 \quad 0.00 \mathrm{E}+00$

$0.00 \mathrm{E}+00 \quad 0.00 \mathrm{E}+00 \quad 0.00 \mathrm{E}+00$

$0.00 \mathrm{E}+00 \quad 0.00 \mathrm{E}+00 \quad 0.00 \mathrm{E}+00$

$0.00 \mathrm{E}+00 \quad 0.00 \mathrm{E}+00 \quad 0.00 \mathrm{E}+00$

$0.00 \mathrm{E}+00 \quad 0.00 \mathrm{E}+00 \quad 0.00 \mathrm{E}+00$

$0.00 \mathrm{E}+00 \quad 0.00 \mathrm{E}+00 \quad 0.00 \mathrm{E}+00$

$0.00 \mathrm{E}+00 \quad 0.00 \mathrm{E}+00 \quad 0.00 \mathrm{E}+00$

$0.00 \mathrm{E}+00 \quad 0.00 \mathrm{E}+00 \quad 0.00 \mathrm{E}+00$

$0.00 \mathrm{E}+00 \quad 0.00 \mathrm{E}+00 \quad 0.00 \mathrm{E}+00$

$0.00 \mathrm{E}+00 \quad 0.00 \mathrm{E}+00 \quad 0.00 \mathrm{E}+00$

$0.00 \mathrm{E}+00 \quad 0.00 \mathrm{E}+00 \quad 0.00 \mathrm{E}+00$

$0.00 \mathrm{E}+00 \quad 0.00 \mathrm{E}+00 \quad 0.00 \mathrm{E}+00$

$0.00 \mathrm{E}+00 \quad 0.00 \mathrm{E}+00 \quad 0.00 \mathrm{E}+00$

$0.00 \mathrm{E}+00 \quad 0.00 \mathrm{E}+00 \quad 0.00 \mathrm{E}+00$

$0.00 \mathrm{E}+00 \quad 0.00 \mathrm{E}+00 \quad 0.00 \mathrm{E}+00$

$0.00 \mathrm{E}+00 \quad 0.00 \mathrm{E}+00 \quad 0.00 \mathrm{E}+00$

$0.00 \mathrm{E}+00 \quad 0.00 \mathrm{E}+00 \quad 0.00 \mathrm{E}+00$

$0.00 \mathrm{E}+00 \quad 0.00 \mathrm{E}+00 \quad 0.00 \mathrm{E}+00$

$0.00 \mathrm{E}+00 \quad 0.00 \mathrm{E}+00 \quad 0.00 \mathrm{E}+00$

$0.00 \mathrm{E}+00 \quad 0.00 \mathrm{E}+00 \quad 0.00 \mathrm{E}+00$

$0.00 \mathrm{E}+00 \quad 0.00 \mathrm{E}+00 \quad 0.00 \mathrm{E}+00$

$0.00 \mathrm{E}+00 \quad 0.00 \mathrm{E}+00 \quad 0.00 \mathrm{E}+00$

$0.00 \mathrm{E}+00 \quad 0.00 \mathrm{E}+00 \quad 0.00 \mathrm{E}+00$

$0.00 \mathrm{E}+00 \quad 0.00 \mathrm{E}+00 \quad 0.00 \mathrm{E}+00$

$0.00 \mathrm{E}+00 \quad 0.00 \mathrm{E}+00 \quad 0.00 \mathrm{E}+00$

$0.00 \mathrm{E}+00 \quad 0.00 \mathrm{E}+00 \quad 0.00 \mathrm{E}+00$

$0.00 \mathrm{E}+00 \quad 0.00 \mathrm{E}+00 \quad 0.00 \mathrm{E}+00$

$0.00 \mathrm{E}+00 \quad 0.00 \mathrm{E}+00 \quad 0.00 \mathrm{E}+00$

$0.00 \mathrm{E}+00 \quad 0.00 \mathrm{E}+00 \quad 0.00 \mathrm{E}+00$

$0.00 \mathrm{E}+00 \quad 0.00 \mathrm{E}+00 \quad 0.00 \mathrm{E}+00$

$0.00 \mathrm{E}+00 \quad 0.00 \mathrm{E}+00 \quad 0.00 \mathrm{E}+00$

$0.00 \mathrm{E}+00 \quad 0.00 \mathrm{E}+00 \quad 0.00 \mathrm{E}+00$

$0.00 \mathrm{E}+00 \quad 0.00 \mathrm{E}+00 \quad 0.00 \mathrm{E}+00$

$0.00 \mathrm{E}+00 \quad 0.00 \mathrm{E}+00 \quad 0.00 \mathrm{E}+00$

$0.00 \mathrm{E}+00 \quad 0.00 \mathrm{E}+00 \quad 0.00 \mathrm{E}+00$ 
RESRAD-OFFSITE, Version 2.5

Probabilistic Dose and Risk Report

Title : Offsite Resident Farmer Deterministic Run

File : RF TC99 DOESG FWD-FV2b.ROF

Repetition $=$

Mean

td. Dev.

Minimum

Maximum

ercentile

0.010

0.025

0.050

0.075

0.100

0.125

0.150

0.175

0.200

0.225

0.250

0.275

0.300

0.325

0.350

0.375

0.400

0.425

0.450

0.475

0.500

0.525

0.550

0.575

0.600

0.625

0.650

0.675

0.700

0.725

0.750

0.775

0.800

0.825

0.850

0.875

0.900

0.925

0.950

0.975

0.990
Statistics and Cumulative distribution function of Peak Risk from Milk (CzandAir)

$\begin{array}{cccc}1 & 2 & 3 \\ 0.00 \mathrm{E}+00 & 0.00 \mathrm{E}+00 & 0.00 \mathrm{E}+00 \\ 0.00 \mathrm{E}+00 & 0.00 \mathrm{E}+00 & 0.00 \mathrm{E}+00 \\ 0.00 \mathrm{E}+00 & 0.00 \mathrm{E}+00 & 0.00 \mathrm{E}+00 \\ 0.00 \mathrm{E}+00 & 0.00 \mathrm{E}+00 & 0.00 \mathrm{E}+00\end{array}$

$0.00 \mathrm{E}+00 \quad 0.00 \mathrm{E}+00 \quad 0.00 \mathrm{E}+00$

$0.00 \mathrm{E}+00 \quad 0.00 \mathrm{E}+00 \quad 0.00 \mathrm{E}+00$

$0.00 \mathrm{E}+00 \quad 0.00 \mathrm{E}+00 \quad 0.00 \mathrm{E}+00$

$0.00 \mathrm{E}+00 \quad 0.00 \mathrm{E}+00 \quad 0.00 \mathrm{E}+00$

$0.00 \mathrm{E}+00 \quad 0.00 \mathrm{E}+00 \quad 0.00 \mathrm{E}+00$

$0.00 \mathrm{E}+00 \quad 0.00 \mathrm{E}+00 \quad 0.00 \mathrm{E}+00$

$0.00 \mathrm{E}+00 \quad 0.00 \mathrm{E}+00 \quad 0.00 \mathrm{E}+00$

$0.00 \mathrm{E}+00 \quad 0.00 \mathrm{E}+00 \quad 0.00 \mathrm{E}+00$

$0.00 \mathrm{E}+00 \quad 0.00 \mathrm{E}+00 \quad 0.00 \mathrm{E}+00$

$0.00 \mathrm{E}+00 \quad 0.00 \mathrm{E}+00 \quad 0.00 \mathrm{E}+00$

$0.00 \mathrm{E}+00 \quad 0.00 \mathrm{E}+00 \quad 0.00 \mathrm{E}+00$

$0.00 \mathrm{E}+00 \quad 0.00 \mathrm{E}+00 \quad 0.00 \mathrm{E}+00$

$0.00 \mathrm{E}+00 \quad 0.00 \mathrm{E}+00 \quad 0.00 \mathrm{E}+00$

$0.00 \mathrm{E}+00 \quad 0.00 \mathrm{E}+00 \quad 0.00 \mathrm{E}+00$

$0.00 \mathrm{E}+00 \quad 0.00 \mathrm{E}+00 \quad 0.00 \mathrm{E}+00$

$0.00 \mathrm{E}+00 \quad 0.00 \mathrm{E}+00 \quad 0.00 \mathrm{E}+00$

$0.00 \mathrm{E}+00 \quad 0.00 \mathrm{E}+00 \quad 0.00 \mathrm{E}+00$

$0.00 \mathrm{E}+00 \quad 0.00 \mathrm{E}+00 \quad 0.00 \mathrm{E}+00$

$0.00 \mathrm{E}+00 \quad 0.00 \mathrm{E}+00 \quad 0.00 \mathrm{E}+00$

$0.00 \mathrm{E}+00 \quad 0.00 \mathrm{E}+00 \quad 0.00 \mathrm{E}+00$

$0.00 \mathrm{E}+00 \quad 0.00 \mathrm{E}+00 \quad 0.00 \mathrm{E}+00$

$0.00 \mathrm{E}+00 \quad 0.00 \mathrm{E}+00 \quad 0.00 \mathrm{E}+00$

$0.00 \mathrm{E}+00 \quad 0.00 \mathrm{E}+00 \quad 0.00 \mathrm{E}+00$

$0.00 \mathrm{E}+00 \quad 0.00 \mathrm{E}+00 \quad 0.00 \mathrm{E}+00$

$0.00 \mathrm{E}+00 \quad 0.00 \mathrm{E}+00 \quad 0.00 \mathrm{E}+00$

$0.00 \mathrm{E}+00 \quad 0.00 \mathrm{E}+00 \quad 0.00 \mathrm{E}+00$

$0.00 \mathrm{E}+00 \quad 0.00 \mathrm{E}+00 \quad 0.00 \mathrm{E}+00$

$0.00 \mathrm{E}+00 \quad 0.00 \mathrm{E}+00 \quad 0.00 \mathrm{E}+00$

$0.00 \mathrm{E}+00 \quad 0.00 \mathrm{E}+00 \quad 0.00 \mathrm{E}+00$

$0.00 \mathrm{E}+00 \quad 0.00 \mathrm{E}+00 \quad 0.00 \mathrm{E}+00$

$0.00 \mathrm{E}+00 \quad 0.00 \mathrm{E}+00 \quad 0.00 \mathrm{E}+00$

$0.00 \mathrm{E}+00 \quad 0.00 \mathrm{E}+00 \quad 0.00 \mathrm{E}+00$

$0.00 \mathrm{E}+00 \quad 0.00 \mathrm{E}+00 \quad 0.00 \mathrm{E}+00$

$0.00 \mathrm{E}+00 \quad 0.00 \mathrm{E}+00 \quad 0.00 \mathrm{E}+00$

$0.00 \mathrm{E}+00 \quad 0.00 \mathrm{E}+00 \quad 0.00 \mathrm{E}+00$

$0.00 \mathrm{E}+00 \quad 0.00 \mathrm{E}+00 \quad 0.00 \mathrm{E}+00$

$0.00 \mathrm{E}+00 \quad 0.00 \mathrm{E}+00 \quad 0.00 \mathrm{E}+00$

$0.00 \mathrm{E}+00 \quad 0.00 \mathrm{E}+00 \quad 0.00 \mathrm{E}+00$

$0.00 \mathrm{E}+00 \quad 0.00 \mathrm{E}+00 \quad 0.00 \mathrm{E}+00$

$0.00 \mathrm{E}+00 \quad 0.00 \mathrm{E}+00 \quad 0.00 \mathrm{E}+00$

$0.00 \mathrm{E}+00 \quad 0.00 \mathrm{E}+00 \quad 0.00 \mathrm{E}+00$ 
RESRAD-OFFSITE, Version 2.5

Probabilistic Dose and Risk Report

Title : Offsite Resident Farmer Deterministic Run

File : RF TC99 DOESG FWD-FV2b.ROF

Repetition $=$

Mean

td. Dev.

Minimum

Maximum

ercentile

0.010

0.025

0.050

0.075

0.100

0.125

0.150

0.175

0.200

0.225

0.250

0.275

0.300

0.325

0.350

0.375

0.400

0.425

0.450

0.475

0.500

0.525

0.550

0.575

0.600

0.625

0.650

0.675

0.700

0.725

0.750

0.775

0.800

0.825

0.850

0.875

0.900

0.925

0.950

0.975

0.990

Statistics and Cumulative distribution function of Peak Risk from Soil Ingestion(CZandAir)

$\begin{array}{cccc}1 & 2 & 3 \\ 0.00 \mathrm{E}+00 & 0.00 \mathrm{E}+00 & 0.00 \mathrm{E}+00 \\ 0.00 \mathrm{E}+00 & 0.00 \mathrm{E}+00 & 0.00 \mathrm{E}+00 \\ 0.00 \mathrm{E}+00 & 0.00 \mathrm{E}+00 & 0.00 \mathrm{E}+00 \\ 0.00 \mathrm{E}+00 & 0.00 \mathrm{E}+00 & 0.00 \mathrm{E}+00\end{array}$

$0.00 \mathrm{E}+00 \quad 0.00 \mathrm{E}+00 \quad 0.00 \mathrm{E}+00$

$0.00 \mathrm{E}+00 \quad 0.00 \mathrm{E}+00 \quad 0.00 \mathrm{E}+00$

$0.00 \mathrm{E}+00 \quad 0.00 \mathrm{E}+00 \quad 0.00 \mathrm{E}+00$

$0.00 \mathrm{E}+00 \quad 0.00 \mathrm{E}+00 \quad 0.00 \mathrm{E}+00$

$0.00 \mathrm{E}+00 \quad 0.00 \mathrm{E}+00 \quad 0.00 \mathrm{E}+00$

$0.00 \mathrm{E}+00 \quad 0.00 \mathrm{E}+00 \quad 0.00 \mathrm{E}+00$

$0.00 \mathrm{E}+00 \quad 0.00 \mathrm{E}+00 \quad 0.00 \mathrm{E}+00$

$0.00 \mathrm{E}+00 \quad 0.00 \mathrm{E}+00 \quad 0.00 \mathrm{E}+00$

$0.00 \mathrm{E}+00 \quad 0.00 \mathrm{E}+00 \quad 0.00 \mathrm{E}+00$

$0.00 \mathrm{E}+00 \quad 0.00 \mathrm{E}+00 \quad 0.00 \mathrm{E}+00$

$0.00 \mathrm{E}+00 \quad 0.00 \mathrm{E}+00 \quad 0.00 \mathrm{E}+00$

$0.00 \mathrm{E}+00 \quad 0.00 \mathrm{E}+00 \quad 0.00 \mathrm{E}+00$

$0.00 \mathrm{E}+00 \quad 0.00 \mathrm{E}+00 \quad 0.00 \mathrm{E}+00$

$0.00 \mathrm{E}+00 \quad 0.00 \mathrm{E}+00 \quad 0.00 \mathrm{E}+00$

$0.00 \mathrm{E}+00 \quad 0.00 \mathrm{E}+00 \quad 0.00 \mathrm{E}+00$

$0.00 \mathrm{E}+00 \quad 0.00 \mathrm{E}+00 \quad 0.00 \mathrm{E}+00$

$0.00 \mathrm{E}+00 \quad 0.00 \mathrm{E}+00 \quad 0.00 \mathrm{E}+00$

$0.00 \mathrm{E}+00 \quad 0.00 \mathrm{E}+00 \quad 0.00 \mathrm{E}+00$

$0.00 \mathrm{E}+00 \quad 0.00 \mathrm{E}+00 \quad 0.00 \mathrm{E}+00$

$0.00 \mathrm{E}+00 \quad 0.00 \mathrm{E}+00 \quad 0.00 \mathrm{E}+00$

$0.00 \mathrm{E}+00 \quad 0.00 \mathrm{E}+00 \quad 0.00 \mathrm{E}+00$

$0.00 \mathrm{E}+00 \quad 0.00 \mathrm{E}+00 \quad 0.00 \mathrm{E}+00$

$0.00 \mathrm{E}+00 \quad 0.00 \mathrm{E}+00 \quad 0.00 \mathrm{E}+00$

$0.00 \mathrm{E}+00 \quad 0.00 \mathrm{E}+00 \quad 0.00 \mathrm{E}+00$

$0.00 \mathrm{E}+00 \quad 0.00 \mathrm{E}+00 \quad 0.00 \mathrm{E}+00$

$0.00 \mathrm{E}+00 \quad 0.00 \mathrm{E}+00 \quad 0.00 \mathrm{E}+00$

$0.00 \mathrm{E}+00 \quad 0.00 \mathrm{E}+00 \quad 0.00 \mathrm{E}+00$

$0.00 \mathrm{E}+00 \quad 0.00 \mathrm{E}+00 \quad 0.00 \mathrm{E}+00$

$0.00 \mathrm{E}+00 \quad 0.00 \mathrm{E}+00 \quad 0.00 \mathrm{E}+00$

$0.00 \mathrm{E}+00 \quad 0.00 \mathrm{E}+00 \quad 0.00 \mathrm{E}+00$

$0.00 \mathrm{E}+00 \quad 0.00 \mathrm{E}+00 \quad 0.00 \mathrm{E}+00$

$0.00 \mathrm{E}+00 \quad 0.00 \mathrm{E}+00 \quad 0.00 \mathrm{E}+00$

$0.00 \mathrm{E}+00 \quad 0.00 \mathrm{E}+00 \quad 0.00 \mathrm{E}+00$

$0.00 \mathrm{E}+00 \quad 0.00 \mathrm{E}+00 \quad 0.00 \mathrm{E}+00$

$0.00 \mathrm{E}+00 \quad 0.00 \mathrm{E}+00 \quad 0.00 \mathrm{E}+00$

$0.00 \mathrm{E}+00 \quad 0.00 \mathrm{E}+00 \quad 0.00 \mathrm{E}+00$

$0.00 \mathrm{E}+00 \quad 0.00 \mathrm{E}+00 \quad 0.00 \mathrm{E}+00$

$0.00 \mathrm{E}+00 \quad 0.00 \mathrm{E}+00 \quad 0.00 \mathrm{E}+00$

$0.00 \mathrm{E}+00 \quad 0.00 \mathrm{E}+00 \quad 0.00 \mathrm{E}+00$

$0.00 \mathrm{E}+00 \quad 0.00 \mathrm{E}+00 \quad 0.00 \mathrm{E}+00$

$0.00 \mathrm{E}+00 \quad 0.00 \mathrm{E}+00 \quad 0.00 \mathrm{E}+00$

C -343

DCN 5090-TR-02-2 
RESRAD-OFFSITE, Version 2.5

obabilistic Dose and Risk Report

Title : Offsite Resident Farmer Deterministic Run

File : RF TC99 DOESG FWD-FV2b.ROF

Time

Years

$0.00 \mathrm{E}+00$

$5.13 \mathrm{E}-01$

$1.03 \mathrm{E}+00$

$1.54 \mathrm{E}+00$

$2.05 \mathrm{E}+00$

$2.56 \mathrm{E}+00$

$3.08 \mathrm{E}+00$

$3.59 \mathrm{E}+00$

$4.10 \mathrm{E}+00$

$4.61 \mathrm{E}+00$

$5.13 \mathrm{E}+00$

$5.64 \mathrm{E}+00$

$6.15 \mathrm{E}+00$

$6.67 \mathrm{E}+00$

$7.18 \mathrm{E}+00$

$7.69 \mathrm{E}+00$

$8.20 \mathrm{E}+00$

$8.72 \mathrm{E}+00$

$9.23 \mathrm{E}+00$

$9.74 \mathrm{E}+00$

$1.03 \mathrm{E}+01$

$1.08 \mathrm{E}+01$

$1.13 \mathrm{E}+01$

$1.18 \mathrm{E}+01$

1. $23 \mathrm{E}+01$

$1.28 \mathrm{E}+01$

$1.33 \mathrm{E}+01$

$1.38 \mathrm{E}+01$

$1.44 \mathrm{E}+01$

$1.49 \mathrm{E}+01$

$1.54 \mathrm{E}+01$

$1.59 \mathrm{E}+01$

$1.64 \mathrm{E}+01$

$1.69 \mathrm{E}+01$

$1.74 \mathrm{E}+01$

$1.79 \mathrm{E}+01$

$1.85 \mathrm{E}+01$

$1.90 \mathrm{E}+01$

1. $95 \mathrm{E}+01$

$2.00 \mathrm{E}+01$

$2.05 \mathrm{E}+01$

$2.10 \mathrm{E}+01$

$2.15 E+01$

$2.20 \mathrm{E}+01$

$2.26 \mathrm{E}+01$

$2.31 \mathrm{E}+01$

Summary of dose at graphical times, reptition 1

Dose statistics at graphical times, mrem/yr

\begin{tabular}{|c|c|c|c|c|c|c|c|}
\hline Iinimum & Iaximum & Mean & Median & 00 & $\%$ & $97.5 \%$ & 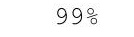 \\
\hline $80 \mathrm{E}-32$ & $1.82 \mathrm{E}-32$ & 1. $82 \mathrm{E}-32$ & $1.82 \mathrm{E}-32$ & $32 E-32$ & $82 E-32$ & 1. $82 \mathrm{E}-32$ & ז \\
\hline $79 E-32$ & 32 & $1.83 E-32$ & $1.84 \mathrm{E}-32$ & $1.84 \mathrm{E}-32$ & $1.84 \mathrm{E}-32$ & -32 & 32 \\
\hline $78 E-32$ & $35 E-32$ & 32 & -32 & $85 E-32$ & 32 & 32 & 32 \\
\hline $7 E-32$ & -32 & $6 E-32$ & -32 & $E-32$ & $7 E-$ & 32 & -32 \\
\hline $6 E-32$ & $9 E-32$ & 2 & 2 & $9 \mathrm{E}$ & $9 \mathrm{E}$ & 32 & -32 \\
\hline $.75 E-32$ & & & & & & & \\
\hline-32 & & & & 2 & 2 & 32 & $2 E-32$ \\
\hline $.73 E-32$ & 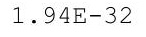 & - & - & $4 E-32$ & 2 & 32 & $94 E-32$ \\
\hline $.72 E-32$ & 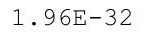 & 专 & $1.95 E-32$ & - & 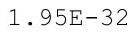 & . & 1. $95 E-32$ \\
\hline $71 \mathrm{E}-32$ & 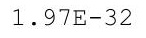 & 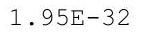 & 32 & 2 & 2 & -32 & $97 E-32$ \\
\hline $.70 E-32$ & $E-32$ & $E-32$ & 2 & 2 & 2 & 32 & -32 \\
\hline 32 & & & & & & & -32 \\
\hline 2 & & 2 & & & 2 & 2 & -32 \\
\hline $67 E-32$ & & 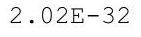 & 2 & & 2 & 82 & -32 \\
\hline $.66 E-32$ & 年 & 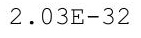 & 2.040 & . & - & 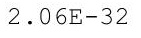 & -32 \\
\hline $.65 E-32$ & 2.0 & 舟 & & 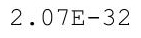 & & (2) & -32 \\
\hline $.64 E-32$ & $2.10 E-32$ & 2.06 & -32 & $9=$ & ( & 2 & -32 \\
\hline $64 \mathrm{E}-32$ & $2.12 \mathrm{E}-32$ & & $2.09 E-32$ & & $2.11 \mathrm{E}-32$ & $2.11 \mathrm{E}-32$ & $11 E-32$ \\
\hline $3 E-32$ & -3 & 2 & 2 & 2 & 2 & -32 & $3 E-32$ \\
\hline $.62 E-32$ & $2.15 E-32$ & $2.11 \mathrm{E}-3$ & $2 \cdot 13 \pm-32$ & $15 \mathrm{E}-3$ & 2 & $2.15 E-32$ & $15 E-32$ \\
\hline $61 \mathrm{E}-32$ & $2 \cdot 1 / \pm 22$ & 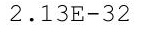 & -32 & 2 & & 32 & -32 \\
\hline $60 \mathrm{E}-32$ & 2. & 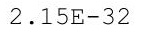 & 32 & & & & -32 \\
\hline $59 E-32$ & 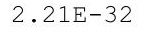 & $2 \cdot$ & 2 & 2 & 2 & $2.21 E-32$ & -32 \\
\hline $.58 E-32$ & $2.23 E-32$ & $2.18 E-32$ & -32 & $2.22 \mathrm{E}-$ & $2.23 \mathrm{E}-$ & -32 & $23 E-32$ \\
\hline $.57 E-32$ & $-6-5$ & $2.20 \mathrm{E}-32$ & $E-32$ & $2.24 \mathrm{E}-$ & $2.25 \mathrm{E}-$ & $2.25 E-32$ & $25 E-32$ \\
\hline 32 & 32 & 2 & 32 & 2 & & $.27 E-32$ & $27 E-32$ \\
\hline$E-32$ & 32 & 2 & 32 & 2 & & 32 & $E-32$ \\
\hline $.55 E-32$ & $2.315-32$ & 2.20104 & $7 E-32$ & 2 & & & -32 \\
\hline $.54 \mathrm{E}-32$ & $2.33 E-32$ & $2.27 \mathrm{E}-32$ & $2.29 E-32$ & $2.32 E-32$ & $2.33 E-32$ & $2.33 E-32$ & $2.33 E-32$ \\
\hline 2 & 2 & 管 & 2 & ? & $x^{2}$ & 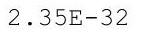 & $.35 E-32$ \\
\hline 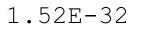 & 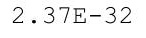 & 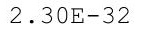 & $2.33 E-32$ & 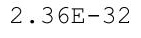 & & 32 & $E-32$ \\
\hline 2 & $2.40 E-32$ & & 2 & & & & 32 \\
\hline$E-32$ & 2 & 2 & 32 & 2 & 2 & 32 & -32 \\
\hline $0 E-32$ & $2.44 E-32$ & $2.36 \mathrm{E}-$ & 32 & 2 & & 32 & -32 \\
\hline $49 \mathrm{E}-32$ & $2.46 \mathrm{E}-32$ & $5.305-32$ & $2.41 E-32$ & $2.45 E-32$ & 2.405 & $2.45 E-32$ & $45 E-32$ \\
\hline $.405-32$ & 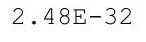 & $2.40 E-32$ & $2.43 E-32$ & $2.47 E-32$ & & & $2.48 E-32$ \\
\hline - & $2.50 E-32$ & & & & & & -32 \\
\hline $46 \mathrm{~F}-32$ & $2.53 E-32$ & & & 2 & 2 & 2 & 32 \\
\hline $.46 \mathrm{E}-32$ & $2.55 E-32$ & $2.45 E-32$ & 2 & 2 & 2 & 2 & 32 \\
\hline $.45 E-32$ & & & & 2 & 2 & -32 & 32 \\
\hline $44 E-32$ & $2.59 \mathrm{E}-$ & $2.49 \mathrm{E}$ & 32 & 2. & & 32 & -32 \\
\hline 2 & .0 & & & & & & \\
\hline 2 & 0.015 & 2 & 2 & 2 & & & -32 \\
\hline 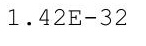 & 2 & $2 \cdot$ & 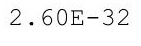 & . & 2 & 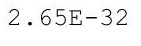 & ( \\
\hline L. $41 \mathrm{E}-32$ & $2.69 E-32$ & & & & 2.61 & 32 & 32 \\
\hline 32 & $71 E-32$ & $9 E-32$ & $64 E-32$ & 32 & 32 & 32 & 32 \\
\hline
\end{tabular}


RESRAD-OFFSITE, Version 2.5

Title : Offsite Resident Farmer Deterministic Run

File : RF TC99 DOESG FWD-FV2b.ROF

Summary of dose at graphical times, reptition 1 (continued)

Time

Years

2. $36 \mathrm{E}+01$

$2.41 \mathrm{E}+01$

2. $46 \mathrm{E}+01$

2. $51 \mathrm{E}+01$

$2.56 \mathrm{E}+01$

2. $61 \mathrm{E}+01$

$2.67 E+01$

2. $72 \mathrm{E}+01$

2. $77 \mathrm{E}+01$

2. $82 \mathrm{E}+01$

2. $87 \mathrm{E}+01$

2. $92 \mathrm{E}+01$

2. $97 \mathrm{E}+01$

3. $02 \mathrm{E}+01$

3. $08 \mathrm{E}+01$

$3.13 \mathrm{E}+01$

3. $18 \mathrm{E}+01$

3. $23 \mathrm{E}+01$

3. $28 \mathrm{E}+01$

3. $33 \mathrm{E}+01$

3. $38 \mathrm{E}+01$

3. $44 \mathrm{E}+01$

$3.49 \mathrm{E}+01$

3. $54 \mathrm{E}+01$

3. $59 \mathrm{E}+01$

3. $64 \mathrm{E}+01$

3. $69 \mathrm{E}+01$

$3.74 \mathrm{E}+01$

3. $79 \mathrm{E}+01$

3. $85 \mathrm{E}+01$

3. $90 \mathrm{E}+01$

$3.95 \mathrm{E}+01$

$4.00 \mathrm{E}+01$

$4.05 \mathrm{E}+01$

$4.10 \mathrm{E}+01$

$4.15 \mathrm{E}+01$

4. $20 \mathrm{E}+01$

$4.26 \mathrm{E}+01$

4. $31 \mathrm{E}+01$

4. $36 \mathrm{E}+01$

4. $41 \mathrm{E}+01$

$4.46 \mathrm{E}+01$

4. $51 \mathrm{E}+01$

$4.56 \mathrm{E}+01$

4. $61 \mathrm{E}+01$

$4.67 \mathrm{E}+01$

Dose statistics at graphical times, mrem/yr

\begin{tabular}{|c|c|c|c|c|c|c|c|}
\hline m & aximum & ea & 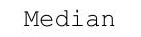 & & & & \\
\hline $39 E-32$ & $2.73 E-32$ & $2.61 E-32$ & $2.66 \mathrm{E}-32$ & $71 E-32$ & $72 E-32$ & 32 & - $13 \pm-32$ \\
\hline $39 E-32$ & $2.76 E-32$ & $2.63 E-32$ & $2.68 \mathrm{E}-32$ & $2.74 E-32$ & $2.74 E-32$ & $2.75 E-32$ & $75 E-32$ \\
\hline $38 E-32$ & $78 E-32$ & $65 E-32$ & $70 E-32$ & $76 E-32$ & $77 E-32$ & $.77 E-32$ & $78 E-32$ \\
\hline $37 E-32$ & $81 E-32$ & $68 F-32$ & $73 F-32$ & $79 F-32$ & $79 F-32$ & $80 F-32$ & $80 F-32$ \\
\hline-32 & -32 & 2 & -32 & 2 & 2 & -32 & $82 E-32$ \\
\hline 32 & 32 & & & & & & \\
\hline $35 E-32$ & $2.88 E-32$ & & & & & & $87 E-32$ \\
\hline $34 E-32$ & -32 & 2 & -32 & 2 & 32 & 32 & $0 E-32$ \\
\hline $33 E-32$ & $94 \mathrm{E}-32$ & -32 & -32 & $1 E-32$ & $92 \mathrm{E}-$ & -32 & $3 E-32$ \\
\hline$E-32$ & $96 E-32$ & ح תم00 & $86=-32$ & 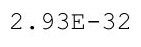 & 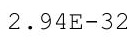 & $95 F-32$ & $95 E-32$ \\
\hline 32 & 32 & & & & & & -32 \\
\hline $31 E-32$ & $3.01 E-32$ & $285 \mathrm{~F}-32$ & -32 & 2 & 2 & 2 & -32 \\
\hline $30 E-32$ & $3.04 E-32$ & & $2.94 \mathrm{E}-32$ & & & & $3.03 E-32$ \\
\hline $30 E-32$ & -32 & $2.095-32$ & $2.96 \mathrm{E}-32$ & & & 32 & $E-32$ \\
\hline-32 & -32 & 2 & -32 & & & -32 & -32 \\
\hline 32 & 32 & 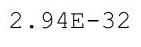 & $.01 E-32$ & & & 2 & 2 \\
\hline 2 & 2 & & & & & & 2 \\
\hline 32 & 32 & 2 & 2 & & 2 & 2 & 32 \\
\hline $26 \mathrm{E}-32$ & $3.21 E-32$ & $3.01 E-32$ & $3.09 E-32$ & $3.17 E-32$ & $3.18 E-32$ & $3.19 \mathrm{E}-32$ & $3.19 \mathrm{E}-32$ \\
\hline $25 E-32$ & $23 E-32$ & $.04 E-32$ & -32 & $0 E-32$ & & -32 & $22 E-32$ \\
\hline 32 & 32 & & & & & 2 & -32 \\
\hline 32 & -32 & & & $z$ & & -32 & -32 \\
\hline $23 E-32$ & -32 & 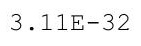 & 2 & & & 2 & 32 \\
\hline-32 & -32 & $3.13 E-32$ & $z$ & 2 & 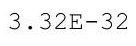 & 2 & -32 \\
\hline 2 & -32 & $3.16 \mathrm{E}-32$ & z & (1) & 5 & 2 & 32 \\
\hline $21 E-32$ & $.41 E-32$ & 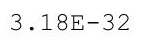 & $=-32$ & ד & חסקט & $39 E-32$ & $40 E-32$ \\
\hline-32 & $44 \mathrm{E}-32$ & & $E-32$ & 2 & & $E-32$ & $43 E-32$ \\
\hline & & & & & & & \\
\hline $19 \mathrm{E}-32$ & $3.50 \mathrm{E}-32$ & $3.20 E-32$ & -32 & $6 E-32$ & $7 E-32$ & -32 & $9 E-32$ \\
\hline $19 \mathrm{E}-32$ & $3.53 E-32$ & . & $3.38 E-32$ & $3.49 E-32$ & 80 & $1.315-22$ & $.52 E-32$ \\
\hline 32 & 32 & Pr & $E-32$ & . & - & 2 & $.55 E-32$ \\
\hline 2 & $60 E-32$ & & & & & & \\
\hline-32 & -32 & 2 & -32 & $3 E-32$ & تصט & & $1 E-32$ \\
\hline 32 & & & & & & & 32 \\
\hline $15 E-32$ & $3.69 E-32$ & $3.42 E-32$ & $2 E-32$ & 32 & 2 & 32 & $57 E-32$ \\
\hline $15 E-32$ & $3.73 E-32$ & . & $3.55 E-32$ & 3.001 & 3.00 & -32 & $.71 E-32$ \\
\hline $14 \mathrm{E}-32$ & $3.10 \mathrm{E}-32$ & $3.47 \mathrm{E}-32$ & & & & & $3.14 \pm-32$ \\
\hline 2 & 32 & . & 2 & - & & & $77 E-32$ \\
\hline 2 & $3.83 E-32$ & $3.53 E-32$ & ? & 2 & 2 & 2 & 32 \\
\hline 32 & 3 & & 2 & & & & 32 \\
\hline $2 E-32$ & $3.89 E-32$ & $3.58 E-32$ & $0 E-32$ & & 2 & -32 & -32 \\
\hline 32 & $3.93 \mathrm{E}$ & 3.015 & & 2 & & & \\
\hline & & & & & & & $\cdot 94 \mathrm{E}-32$ \\
\hline $5-32$ & $4.00 \pm-32$ & $3.67 E-32$ & $3.19 E-32$ & $3.94 \mathrm{E}-32$ & $3.96 E-32$ & $3.97 E-32$ & $3.98 E-32$ \\
\hline $09 E-32$ & $4.00 \mathrm{E}$ & $5.10 \mathrm{t}$ & & e. & 3.995 & $00 E-32$ & $1.01-$ \\
\hline $9 E-32$ & $E-32$ & $.73 E-32$ & $.85 E-32$ & $01 E-32$ & $.03 \mathrm{E}$ & -32 & 32 \\
\hline
\end{tabular}


RESRAD-OFFSITE, Version 2.5

$\mathrm{T}^{1 / 2}$ Limit $=180$ days

robabilistic Dose and Risk Report

Title : Offsite Resident Farmer Deterministic Run

File : RF TC99 DOESG FWD-FV2b.ROF

Summary of dose at graphical times, reptition 1 (continued)

Time

Years

$4.72 \mathrm{E}+01$

4. $77 \mathrm{E}+01$

4. $82 \mathrm{E}+01$

$4.87 \mathrm{E}+01$

4. $92 \mathrm{E}+01$

4. $97 \mathrm{E}+01$

$5.02 \mathrm{E}+01$

$5.08 \mathrm{E}+01$

$5.13 \mathrm{E}+01$

$5.18 \mathrm{E}+01$

$5.23 \mathrm{E}+01$

$5.28 \mathrm{E}+01$

$5.33 \mathrm{E}+01$

$5.38 \mathrm{E}+01$

$5.43 \mathrm{E}+01$

$5.49 \mathrm{E}+01$

$5.54 \mathrm{E}+01$

$5.59 \mathrm{E}+01$

$5.64 \mathrm{E}+01$

$5.69 \mathrm{E}+01$

$5.74 \mathrm{E}+01$

$5.79 \mathrm{E}+01$

$5.84 \mathrm{E}+01$

$5.90 \mathrm{E}+01$

$5.95 \mathrm{E}+01$

$6.00 \mathrm{E}+01$

$6.05 \mathrm{E}+01$

$6.10 \mathrm{E}+01$

$6.15 \mathrm{E}+01$

$6.20 \mathrm{E}+01$

$6.25 \mathrm{E}+01$

$6.31 \mathrm{E}+01$

$6.36 \mathrm{E}+01$

$6.41 \mathrm{E}+01$

$6.46 \mathrm{E}+01$

$6.51 \mathrm{E}+01$

$6.56 \mathrm{E}+01$

$6.61 \mathrm{E}+01$

$6.67 \mathrm{E}+01$

$6.72 \mathrm{E}+01$

$6.77 \mathrm{E}+01$

$6.82 \mathrm{E}+01$

$6.87 \mathrm{E}+01$

$6.92 \mathrm{E}+01$

$6.97 \mathrm{E}+01$

$7.02 \mathrm{E}+01$

Dose statistics at graphical times, mrem/yr

\begin{tabular}{|c|c|c|c|c|c|c|c|}
\hline inimum & laximum & Mean & edian & & & & \\
\hline $.08 E-32$ & $4.11 E-32$ & $3.76 \mathrm{E}-32$ & $89 E-32$ & $4 E-32$ & $6 E-32$ & $07 E-32$ & $4.08 \mathrm{E}-32$ \\
\hline $07 E-32$ & $4.14 \mathrm{E}-32$ & $3.79 E-32$ & $92 E-32$ & $4.08 E-32$ & $4.10 \mathrm{E}-32$ & -32 & $4.12 \mathrm{E}-32$ \\
\hline $7 E-32$ & $18 E-32$ & $82 F-32$ & $95 E-32$ & $11 E-32$ & $13 E-32$ & $4 E-32$ & 32 \\
\hline $06 \mathrm{E}-32$ & $4 \cdot 22 E-32$ & $85 E-32$ & $.98 E-32$ & $.15 E-32$ & $4.17 E-32$ & -32 & 32 \\
\hline $06 E-32$ & 32 & 2 & & & & & -32 \\
\hline $05 E-32$ & $4.29 E-32$ & $1 E-32$ & & 32 & & 32 & -32 \\
\hline $04 E-32$ & $4.33 E-32$ & 32 & -32 & $4.26 E-32$ & $28 E-32$ & $=32$ & $30 E-32$ \\
\hline $04 \mathrm{E}-32$ & $4.37 E-32$ & $97 E-32$ & $2 E-32$ & $4 \cdot 30 \mathrm{E}-32$ & $32 E-32$ & -32 & $34 E-32$ \\
\hline $03 E-32$ & 32 & $1 F-3$ & $15 E-32$ & $33 E-32$ & $.35 E-32$ & $.37 E-32$ & $38 E-32$ \\
\hline $3 E-32$ & 32 & $4.04 \mathrm{E}-32$ & 2 & 2 & 2 & 32 & -32 \\
\hline $02 E-32$ & 4.4 & $7 F-32$ & 2 & 2 & 2 & -32 & $6 E-32$ \\
\hline $.02 E-32$ & & & & & & & -32 \\
\hline $.01 E-32$ & $4.56 E-32$ & $4.14 E-32$ & $4.29 E-32$ & $4.49 E-32$ & $4.51 E-32$ & $4.52 E-32$ & $.54 E-32$ \\
\hline$E-32$ & -32 & -32 & & & & -32 & -32 \\
\hline 3 & & & 2 & 52 & 2 & 2 & -32 \\
\hline 33 & 4 & $4.24 \mathrm{E}-32$ & & 2 & 2 & & 32 \\
\hline 33 & 32 & 4 & 2 & 2 & 2 & 2 & -32 \\
\hline $83 E-33$ & $4.77 E-32$ & $4.30 E-32$ & $4.47 E-32$ & $4.68 E-32$ & $4.71 E-32$ & 4. $72 \mathrm{E}-32$ & $4.74 \mathrm{E}-32$ \\
\hline $.77 E-33$ & $4.81 E-32$ & $34 E-32$ & $4.51 \mathrm{E}-32$ & $4.72 E-32$ & $4.75 E-32$ & $4.77 E-32$ & 4. $78 E-32$ \\
\hline $72 E-33$ & $4.85 E-32$ & $4.37 E-32$ & $4 E-32$ & $4.77 E-32$ & & -32 & $82 E-32$ \\
\hline & & & & & & -32 & 32 \\
\hline 3 & 1.0 & & & & & & 32 \\
\hline $56 E-33$ & 32 & 2 & 2 & 2 & 2 & 32 & -32 \\
\hline$E-33$ & 035 & 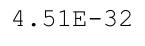 & -32 & 2 & $6 \mathrm{~F}$ & -32 & $99 E-32$ \\
\hline$E-33$ & $.07 E-32$ & $5 E-32$ & $4 E-32$ & $98 E-32$ & $01 E-32$ & $E-32$ & $04 \mathrm{E}-32$ \\
\hline 33 & $10 \mathrm{r}$ & & -32 & -32 & & -32 & $8 E-32$ \\
\hline-33 & & & & & & -32 & \\
\hline & & & & & & & \\
\hline $25 E-33$ & $5.26 \mathrm{E}-32$ & $4.70 E-32$ & $4.89 E-32$ & $5.15 \mathrm{E}-32$ & $5.18 \mathrm{E}-32$ & $5.20 \mathrm{E}-32$ & $.22 E-32$ \\
\hline 33 & 2 & 20 & 2 & 2 & 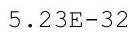 & $5-32$ & $.26 E-32$ \\
\hline 3 & 2 & $.77 \mathrm{E}-$ & $=0$ & & & $.29 E-32$ & $.31 E-32$ \\
\hline$F-33$ & $40 F-32$ & $81 F-32$ & $2 E-32$ & $29 E-32$ & 325 & $E-32$ & $36 E-32$ \\
\hline 33 & & & & & & & \\
\hline-33 & & 32 & 32 & -32 & & & \\
\hline $95 E-33$ & $5.54 \mathrm{E}-32$ & $4.93 E-32$ & $5.14 \mathrm{E}-32$ & $5.43 E-32$ & $5.46 \mathrm{E}-32$ & $5.48 E-32$ & $.50 E-32$ \\
\hline $.90 E-33$ & $3.39 E-32$ & & & $5.47 \mathrm{E}-32$ & $3.315-32$ & $2.35 E-32$ & $5.55 E-32$ \\
\hline 33 & 2 & ( & 2 & 2 & 2 & 2 & 32 \\
\hline 3 & 2 & 2 & 2 & 2 & & 2 & 32 \\
\hline 3 & 2 & & & 2 & 2 & 2 & \\
\hline$E-33$ & -32 & -32 & -32 & -32 & 5 & -32 & 32 \\
\hline $.65 E-33$ & $5.84 \mathrm{E}-32$ & & & & 2 & & -32 \\
\hline 80 & & & & & & & $.85 E-32$ \\
\hline $20 E-30$ & . & 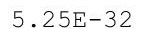 & $9 E-32$ & $5.82 E-32$ & $86 E-32$ & $38 E-32$ & $90 E-32$ \\
\hline 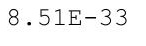 & . & & & & & & $95 E-32$ \\
\hline & 2 & & & -32 & $5.96 \mathrm{E}-32$ & $E-32$ & 32 \\
\hline-33 & -32 & $3 E-32$ & $63 E-32$ & -32 & $5.01 E-32$ & $.03 E-32$ & 32 \\
\hline
\end{tabular}


RESRAD-OFFSITE, Version 2.5

itle : Offsite Resident Farmer Deterministic Run

File : RF TC99 DOESG FWD-FV2b.ROF

Summary of dose at graphical times, reptition 1 (continued)

Time

Years

$7.08 \mathrm{E}+01$

$7.13 \mathrm{E}+01$

$7.18 \mathrm{E}+01$

$7.23 \mathrm{E}+01$

$7.28 \mathrm{E}+01$

$7.33 \mathrm{E}+01$

$7.38 \mathrm{E}+01$

$7.43 \mathrm{E}+01$

$7.49 \mathrm{E}+01$

$7.54 \mathrm{E}+01$

$7.59 \mathrm{E}+01$

$7.64 \mathrm{E}+01$

$7.69 \mathrm{E}+01$

$7.74 \mathrm{E}+01$

$7.79 \mathrm{E}+01$

$7.84 \mathrm{E}+01$

7. $90 \mathrm{E}+01$

7. $95 \mathrm{E}+01$

$8.00 \mathrm{E}+01$

$8.05 \mathrm{E}+01$

$8.10 \mathrm{E}+01$

$8.15 \mathrm{E}+01$

$8.20 \mathrm{E}+01$

$8.25 \mathrm{E}+01$

$8.31 \mathrm{E}+01$

$8.36 \mathrm{E}+01$

$8.41 E+01$

$8.46 \mathrm{E}+01$

$8.51 \mathrm{E}+01$

$8.56 \mathrm{E}+01$

8. $61 \mathrm{E}+01$

8. $66 \mathrm{E}+01$

$8.72 \mathrm{E}+01$

$8.77 \mathrm{E}+01$

$8.82 \mathrm{E}+01$

$8.87 \mathrm{E}+01$

8. $92 \mathrm{E}+01$

8. $97 \mathrm{E}+01$

$9.02 \mathrm{E}+01$

9. $07 \mathrm{E}+01$

9. $13 \mathrm{E}+01$

9. $18 \mathrm{E}+01$

9. $23 \mathrm{E}+01$

$9.28 \mathrm{E}+01$

9. $33 \mathrm{E}+01$

9. $38 \mathrm{E}+01$
Dose statistics at graphical times, mrem/yr

\begin{tabular}{|c|c|c|c|c|c|c|c|}
\hline m & um & ean & - & & & $\%$ & \\
\hline $37 E-33$ & $6.16 \mathrm{E}-32$ & $5.42 E-32$ & $5.68 E-32$ & $6.02 \mathrm{E}-32$ & $6.06 \mathrm{E}-32$ & -32 & -32 \\
\hline $32 E-33$ & $6.22 E-32$ & $7 E-32$ & $2 E-32$ & -32 & 32 & -32 & $16 E-32$ \\
\hline $28 E-33$ & $6.27 \mathrm{E}-32$ & $5.51 \mathrm{E}-32$ & $5.77 \mathrm{E}-32$ & $6.13 E-32$ & $6.17 E-32$ & $6.19 \mathrm{E}-32$ & $6.22 E-32$ \\
\hline $23 E-33$ & $6.33 E-32$ & $5.55 E-32$ & $5.82 \mathrm{E}-32$ & $6.18 \mathrm{E}-32$ & $6.23 E-32$ & -32 & $27 E-32$ \\
\hline 33 & 2 & 32 & 32 & & & -32 & -32 \\
\hline$E-33$ & -32 & $E-32$ & -32 & 2 & 32 & -32 & -32 \\
\hline $10 \mathrm{E}-33$ & 32 & & $96 \mathrm{E}-32$ & -32 & & & -32 \\
\hline $.05 E-33$ & 32 & & & 32 & & & -32 \\
\hline-33 & -32 & $E-32$ & -32 & -32 & 32 & -32 & -32 \\
\hline $96 \mathrm{E}-33$ & $6.67 \mathrm{E}-32$ & ( & -32 & 2 & 2 & 2 & 32 \\
\hline 33 & 2 & $5.87 E-32$ & $6 E-32$ & $6.57 E-32$ & -32 & 2 & 32 \\
\hline $.88 E-33$ & 32 & - & & -32 & & & -32 \\
\hline $.83 E-33$ & $5 E-32$ & $7 E-32$ & -32 & 6.6 & 32 & -32 & -32 \\
\hline$E-33$ & $E-32$ & $2 E-32$ & -32 & 2 & 2 & -32 & -32 \\
\hline-33 & -32 & $5 \mathrm{r}$ & & & & & -32 \\
\hline $.70 E-33$ & & & -32 & -32 & 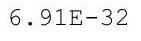 & 32 & -32 \\
\hline 33 & 32 & $6.16 \mathrm{E}-32$ & 2 & 2 & 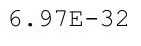 & 2 & -32 \\
\hline 33 & 2 & & & & & & \\
\hline $.58 \mathrm{E}-33$ & 7. $22 \mathrm{E}-32$ & & $6.58 E-32$ & & 32 & 32 & -32 \\
\hline $.54 E-33$ & $E-32$ & $.31 E-3$ & -32 & $0 E-32$ & $.16 \mathrm{E}-$ & -32 & -32 \\
\hline $49 E-33$ & $.35 E-32$ & $6.36 \mathrm{E}-32$ & $9 \mathrm{E}-32$ & 2 & 2 & -32 & $28 E-32$ \\
\hline & & & & & & & -32 \\
\hline & & & & & & & 32 \\
\hline & & & & 32 & & & -32 \\
\hline 3 & 2 & . & 2 & 2 & 2 & 2 & -32 \\
\hline $29 E-33$ & $.68 E-32$ & - & $6.97 E-32$ & ( & 5 & -32 & $61 E-32$ \\
\hline$F-33$ & -32 & $6-67 \mathrm{~F}-3$ & $3 E-32$ & 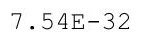 & & -32 & -32 \\
\hline-33 & -32 & $73 F-32$ & -32 & & & -32 & $74 E-32$ \\
\hline & & & & & & & -32 \\
\hline $13 E-33$ & $7.96 \mathrm{E}-32$ & $0.04 \amalg-2$ & $.01+$ & $1.17+$ & $1.0 \pm$ & 32 & -32 \\
\hline 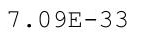 & $0.035-32$ & • & $7.27 \mathrm{E}-32$ & $7.81 \mathrm{E}-32$ & $1.00 \mathrm{E}-32$ & $7.91 E-32$ & $.95 E-32$ \\
\hline 3 & - -5 & 然 & . & & & & $8.02 E-32$ \\
\hline 3 & D & & & & & & 32 \\
\hline$F-33$ & -32 & & 2 & & & 32 & 32 \\
\hline 33 & & & & & & & 32 \\
\hline & 32 & $17 \mathrm{E}$ & 32 & 32 & 0.20 & 8 & 32 \\
\hline $86 E-33$ & $8.47 E-32$ & $7.23 \mathrm{E}$ & & & & & -32 \\
\hline $02 \mathrm{~L}-20$ & $0.345-32$ & & & & & & $8.45 E-32$ \\
\hline 3 & 2 & 2 & 2 & & 2 & 2 & 32 \\
\hline & & & & & & & 32 \\
\hline & & & 32 & 32 & 2 & 2 & \\
\hline $67 E-33$ & $8.85 E-32$ & $3 E-32$ & $7.96 \mathrm{E}$ & 32 & & -32 & -32 \\
\hline & & & & & & & 32 \\
\hline & & & & . & 2 & 0.00 & -32 \\
\hline & & & & $32 E-32$ & $90 E-32$ & -32 & 政 \\
\hline H & $E-32$ & $E-32$ & $2 E-32$ & $E-32$ & $3 E-32$ & $02 E-32$ & -32 \\
\hline
\end{tabular}


RESRAD-OFFSITE, Version 2.5

obabilistic Dose and Risk Report

Title : Offsite Resident Farmer Deterministic Run

File : RF TC99 DOESG FWD-FV2b.ROF

Summary of dose at graphical times, reptition 1 (continued)

Time

Years

$9.43 E+01$

$9.48 \mathrm{E}+01$

$9.54 \mathrm{E}+01$

$9.59 \mathrm{E}+01$

$9.64 \mathrm{E}+01$

$9.69 \mathrm{E}+01$

$9.74 \mathrm{E}+01$

$9.79 \mathrm{E}+01$

$9.84 \mathrm{E}+01$

$9.90 \mathrm{E}+01$

$9.95 \mathrm{E}+01$

$1.00 \mathrm{E}+02$

$1.00 \mathrm{E}+02$

$1.01 \mathrm{E}+02$

$1.02 \mathrm{E}+02$

$1.02 \mathrm{E}+02$

$1.03 \mathrm{E}+02$

$1.03 \mathrm{E}+02$

$1.04 \mathrm{E}+02$

$1.04 \mathrm{E}+02$

$1.05 \mathrm{E}+02$

1. $05 \mathrm{E}+02$

$1.06 \mathrm{E}+02$

$1.06 \mathrm{E}+02$

$1.07 \mathrm{E}+02$

$1.07 \mathrm{E}+02$

$1.08 \mathrm{E}+02$

$1.08 \mathrm{E}+02$

$1.09 \mathrm{E}+02$

$1.09 \mathrm{E}+02$

$1.10 \mathrm{E}+02$

$1.10 \mathrm{E}+02$

$1.11 \mathrm{E}+02$

$1.11 \mathrm{E}+02$

$1.12 \mathrm{E}+02$

$1.12 \mathrm{E}+02$

$1.13 \mathrm{E}+02$

$1.13 \mathrm{E}+02$

$1.14 \mathrm{E}+02$

$1.14 \mathrm{E}+02$

$1.15 \mathrm{E}+02$

$1.15 \mathrm{E}+02$

$1.16 \mathrm{E}+02$

$1.16 \mathrm{E}+02$

$1.17 \mathrm{E}+02$

$1.17 \mathrm{E}+02$
Dose statistics at graphical times, mrem/yr

\begin{tabular}{|c|c|c|c|c|c|c|c|}
\hline m & um & a & - & & & $\%$ & \\
\hline $49 \mathrm{E}-33$ & $9.25 \mathrm{E}-32$ & $7.83 E-32$ & $8.29 E-32$ & $8.97 E-32$ & $9.06 \mathrm{E}-32$ & $9.10 \mathrm{E}-32$ & $-2-32$ \\
\hline $45 E-33$ & $9.33 E-32$ & $7.90 E-32$ & $8.36 \mathrm{E}-32$ & $9.05 E-32$ & $9.13 E-32$ & $9.18 E-32$ & $3 E-32$ \\
\hline $42 E-33$ & $9.41 E-32$ & $7.96 \mathrm{E}-32$ & $8.43 E-32$ & $9.13 \mathrm{E}-32$ & $9.21 \mathrm{E}-32$ & $9.26 \mathrm{E}-32$ & -32 \\
\hline $38 E-33$ & $9.50 \mathrm{E}-32$ & $8.03 E-32$ & $8.50 \mathrm{E}-32$ & $9.21 \mathrm{E}-32$ & $9.29 \mathrm{E}-32$ & $34 E-32$ & -32 \\
\hline $5 E-33$ & $58 E-32$ & $09 E-32$ & $57 E-32$ & $9 F-32$ & -32 & -32 & 32 \\
\hline$E-33$ & 32 & -32 & -32 & 2 & 2 & -32 & -32 \\
\hline $.28 E-33$ & 32 & & & & & 32 & -32 \\
\hline $.24 E-33$ & & & & & & & -32 \\
\hline-33 & -32 & 2 & -32 & 32 & 32 & -32 & -32 \\
\hline$E-33$ & -31 & - & 32 & 32 & $E-32$ & -32 & -32 \\
\hline$E-33$ & $E-31$ & $F_{-1}-1-1$ & $9.00 \mathrm{E}-32$ & 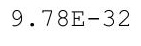 & 2 & 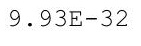 & -32 \\
\hline 3 & & & & & & & 31 \\
\hline $.07 \mathrm{E}-33$ & $3 E-31$ & $8.63 E-32$ & 2 & 2 & 1 & 1 & -31 \\
\hline $.04 \mathrm{E}-33$ & $1.04 \mathrm{E}-31$ & $8.70 \mathrm{E}-32$ & $9.23 \mathrm{E}-32$ & $1.00 \mathrm{E}-31$ & $1.01 \mathrm{E}-31$ & $1.02 \mathrm{E}-31$ & $1.03 E-31$ \\
\hline-33 & 31 & 2 & 32 & & $\perp$ & 31 & -31 \\
\hline$E-33$ & & & & & & -31 & -31 \\
\hline 33 & & & & & 1 & & -31 \\
\hline 3 & & & & & & & 31 \\
\hline $87 E-33$ & $.08 E-31$ & & 2 & 1 & 1 & 1 & 31 \\
\hline $84 \mathrm{E}-33$ & L.09E-31 & -3 & -32 & $.06 \mathrm{E}-31$ & $.07 E-31$ & $7 E-31$ & $.08 \mathrm{E}-31$ \\
\hline $81 E-33$ & -31 & 32 & -32 & 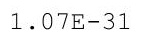 & & $.08 E-31$ & $09 E-31$ \\
\hline & & & & & & & -31 \\
\hline & & & & & & & \\
\hline 3 & & & & & & & \\
\hline - & 31 & $=$ & 1 & 1 & 1 & 1 & 31 \\
\hline$E-33$ & 1 & 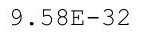 & 1 & 17. & 1 & $E-31$ & 31 \\
\hline-33 & 31 & & 1 & 110 & 110 & $E-31$ & $.15 E-31$ \\
\hline$E-33$ & 31 & 2 & & & & -31 & $16 E-31$ \\
\hline & & & & & & & \\
\hline 33 & & & & 1 & 1 & & \\
\hline $50 E-33$ & $1.05 E-28$ & 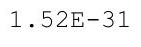 & $1.06 \mathrm{E}-31$ & $1.16 \mathrm{E}-31$ & $1.18 \mathrm{E}-31$ & $1.18 \mathrm{E}-31$ & 1. $19 \mathrm{E}-31$ \\
\hline $47 E-33$ & $1.81 \mathrm{E}-26$ & . & $1.07 \mathrm{E}-31$ & 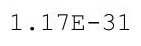 & $1.19 \mathrm{E}-31$ & $\perp \cdot \perp Y L U \perp$ & $1.20 \mathrm{E}-31$ \\
\hline $4 \mathrm{E}-$ & 8 & & & & & & L. $21 E-31$ \\
\hline$F-33$ & $F-23$ & > & $E-31$ & & & -31 & -31 \\
\hline-33 & & & & & & & \\
\hline 33 & $1.93 E-21$ & $9.03 \pm-23$ & $1.11 \mathrm{E}-31$ & $1.21 \omega$ & $1 \cdot 20$ & 31 & -31 \\
\hline $32 E-33$ & $1.30 \mathrm{E}-20$ & 0.544 & PLa &.$+<0$ & 1.2 & & -31 \\
\hline $29 \mathrm{E}-33$ & $0.905-20$ & & & $1.24 \mathrm{E}-31$ & 1. $25 \mathrm{E}-31$ & & $1.27 \mathrm{E}-31$ \\
\hline 3 & 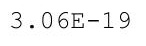 & $+\cdots$ & 1 & 1 & 1 & 1 & 31 \\
\hline & $1.14 \mathrm{E}-18$ & & & & & & 31 \\
\hline 3 & & & 31 & 1 & 1 & 1 & 31 \\
\hline$E-33$ & $1.06 \mathrm{E}-17$ & $5.87 E-21$ & 1.1 & $1.28 \mathrm{E}$ & 1.2 & -31 & 1.31 \\
\hline & 2.700 & & & & & & 31 \\
\hline & 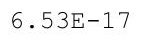 & 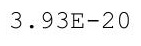 & & 土. & $1.3 \angle \mathrm{E}-$ & & $1.34 \mathrm{E}-31$ \\
\hline 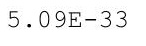 & L 10 & . & & $1.31 E-31$ & 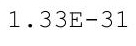 & $E-31$ & 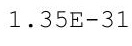 \\
\hline$E-33$ & $E-16$ & $E-19$ & $20 E-31$ & $E-31$ & $4 E-31$ & $5 E-31$ & 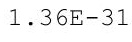 \\
\hline
\end{tabular}


RESRAD-OFFSITE, Version 2.5

$\mathrm{T}^{1 / 2}$ Limit $=180$ days

obabilistic Dose and Risk Report

Title : Offsite Resident Farmer Deterministic Run

File : RF TC99 DOESG FWD-FV2b.ROF

Summary of dose at graphical times, reptition 1 (continued)

Time

Years

$1.18 \mathrm{E}+02$

$1.18 \mathrm{E}+02$

1. $19 \mathrm{E}+02$

1. $19 \mathrm{E}+02$

1. $20 \mathrm{E}+02$

1. $20 \mathrm{E}+02$

1. $21 \mathrm{E}+02$

1. $22 \mathrm{E}+02$

1. $22 \mathrm{E}+02$

1. $23 \mathrm{E}+02$

1. $23 \mathrm{E}+02$

1. $24 \mathrm{E}+02$

1. $24 \mathrm{E}+02$

1. $25 \mathrm{E}+02$

1. $25 \mathrm{E}+02$

1. $26 \mathrm{E}+02$

1. $26 \mathrm{E}+02$

1. $27 \mathrm{E}+02$

1. $27 \mathrm{E}+02$

1. $28 \mathrm{E}+02$

1. $28 \mathrm{E}+02$

1. $29 \mathrm{E}+02$

1. $29 \mathrm{E}+02$

1. $30 \mathrm{E}+02$

1. $30 \mathrm{E}+02$

1. $31 \mathrm{E}+02$

1. $31 \mathrm{E}+02$

1. $32 \mathrm{E}+02$

1. $32 \mathrm{E}+02$

1. $33 \mathrm{E}+02$

1. $33 \mathrm{E}+02$

1. $34 \mathrm{E}+02$

1. $34 \mathrm{E}+02$

1. $35 \mathrm{E}+02$

1. $35 \mathrm{E}+02$

1. $36 \mathrm{E}+02$

1. $36 \mathrm{E}+02$

1. $37 \mathrm{E}+02$

1. $37 \mathrm{E}+02$

1. $38 \mathrm{E}+02$

1. $38 \mathrm{E}+02$

1. $39 \mathrm{E}+02$

1. $39 \mathrm{E}+02$

1. $40 \mathrm{E}+02$

1. $40 \mathrm{E}+02$

1. $41 \mathrm{E}+02$

Dose statistics at graphical times, mrem/yr

\begin{tabular}{|c|c|c|c|c|c|c|c|}
\hline Minimum & Maximum & Mean & Median & $90 \%$ & $95 \%$ & $97.5 \%$ & $99 \%$ \\
\hline $5.03 E-33$ & $5.76 \mathrm{E}-16$ & $4.03 E-19$ & $1.21 E-31$ & $1.34 E-31$ & $1.35 E-31$ & $1.36 E-31$ & $1.37 E-31$ \\
\hline $5.00 E-33$ & $1.07 E-15$ & $7.85 E-19$ & 1. $22 \mathrm{E}-31$ & $1.35 E-31$ & $1.36 \mathrm{E}-31$ & $1.38 E-31$ & 1. $39 \mathrm{E}-31$ \\
\hline $4.98 E-33$ & $1.89 \mathrm{E}-15$ & 1. $46 \mathrm{E}-18$ & $1.23 E-31$ & 1. $36 \mathrm{E}-31$ & 1. $38 \mathrm{E}-31$ & 1. $39 \mathrm{E}-31$ & $1.40 \mathrm{E}-31$ \\
\hline $4.95 E-33$ & $3.21 \mathrm{E}-15$ & $2.61 \mathrm{E}-18$ & $1.24 \mathrm{E}-31$ & $1.37 \mathrm{E}-31$ & $1.39 \mathrm{E}-31$ & $1.40 \mathrm{E}-31$ & $1.41 \mathrm{E}-31$ \\
\hline $4.92 \mathrm{E}-33$ & $5.28 \mathrm{E}-15$ & $4.50 \mathrm{E}-18$ & $1.25 \mathrm{E}-31$ & $38 E-31$ & $40 \mathrm{E}-31$ & $1.41 \mathrm{E}-31$ & $.42 E-31$ \\
\hline $4.89 E-33$ & $8.42 E-15$ & 7. $51 \mathrm{E}-18$ & $1.26 \mathrm{E}-31$ & $40 E-31$ & $41 E-31$ & $42 \mathrm{E}-31$ & $.44 E-31$ \\
\hline $4.87 E-33$ & 1. $30 \mathrm{E}-14$ & $1.22 \mathrm{E}-17$ & $1.27 \mathrm{E}-31$ & $1.41 \mathrm{E}-31$ & $1.43 E-31$ & $1.44 \mathrm{E}-31$ & $1.45 E-31$ \\
\hline $4.84 \mathrm{E}-33$ & $1.97 \mathrm{E}-14$ & $1.92 \mathrm{E}-17$ & $1.28 \mathrm{E}-31$ & $1.42 \mathrm{E}-31$ & $1.44 \mathrm{E}-31$ & $1.45 \mathrm{E}-31$ & $1.46 \mathrm{E}-31$ \\
\hline $4.81 \mathrm{E}-33$ & $2.91 E-14$ & $2.96 \mathrm{E}-17$ & $1.29 \mathrm{E}-31$ & $1.43 E-31$ & 1. $45 \mathrm{E}-31$ & $1.46 \mathrm{E}-31$ & 1. $48 E-31$ \\
\hline $4.79 E-33$ & $4.30 E-14$ & $4.45 \mathrm{E}-17$ & $1.30 \mathrm{E}-31$ & $45 E-31$ & $1.46 \mathrm{E}-31$ & $1.48 E-31$ & $.49 E-31$ \\
\hline $4.76 \mathrm{E}-33$ & $6.47 \mathrm{E}-14$ & $6.57 \mathrm{E}-17$ & 1. $32 \mathrm{E}-31$ & $46 E-31$ & $48 E-31$ & $49 \mathrm{E}-31$ & $.50 E-31$ \\
\hline $4.73 E-33$ & $9.52 \mathrm{E}-14$ & $9.52 \mathrm{E}-17$ & $1.33 \mathrm{E}-31$ & $1.47 E-31$ & $1.49 \mathrm{E}-31$ & $.50 E-31$ & $.52 E-31$ \\
\hline $4.71 \mathrm{E}-33$ & 1. $37 \mathrm{E}-13$ & $1.36 \mathrm{E}-16$ & $1.34 \mathrm{E}-31$ & 1. $48 E-31$ & $1.50 \mathrm{E}-31$ & $1.52 \mathrm{E}-31$ & $1.53 E-31$ \\
\hline $4.68 E-33$ & $1.94 \mathrm{E}-13$ & $1.90 \mathrm{E}-16$ & 1. $35 \mathrm{E}-31$ & $1.50 \mathrm{E}-31$ & $1.52 \mathrm{E}-31$ & $1.53 E-31$ & 1. $55 \mathrm{E}-31$ \\
\hline $4.66 \mathrm{E}-33$ & $2.70 E-13$ & $2.63 E-16$ & $1.36 \mathrm{E}-31$ & $.51 E-31$ & $1.53 E-31$ & 1. $54 \mathrm{E}-31$ & $1.57 \mathrm{E}-31$ \\
\hline $4.63 E-33$ & $3.69 E-13$ & $3.58 E-16$ & $37 E-31$ & $2 E-31$ & $54 E-31$ & $.56 E-31$ & $.09 E-29$ \\
\hline $4.60 \mathrm{E}-33$ & $4.97 E-13$ & $4.81 \mathrm{E}-16$ & $38 E-31$ & $54 \mathrm{E}-31$ & $56 \mathrm{E}-31$ & $.57 E-31$ & $.72 E-27$ \\
\hline $4.58 E-33$ & $6.60 \mathrm{E}-13$ & $6.40 \mathrm{E}-16$ & $1.39 \mathrm{E}-31$ & $1.55 \mathrm{E}-31$ & $1.57 \mathrm{E}-31$ & $.59 E-31$ & $3.88 \mathrm{E}-25$ \\
\hline $4.55 E-33$ & $8.65 E-13$ & $8.41 \mathrm{E}-16$ & $1.41 \mathrm{E}-31$ & $1.56 \mathrm{E}-31$ & $1.58 \mathrm{E}-31$ & $1.60 \mathrm{E}-31$ & $1.04 \mathrm{E}-23$ \\
\hline $4.53 E-33$ & $1.12 \mathrm{E}-12$ & $1.09 \mathrm{E}-15$ & $1.42 \mathrm{E}-31$ & 1. $58 \mathrm{E}-31$ & $1.60 \mathrm{E}-31$ & $1.61 \mathrm{E}-31$ & 1. $57 \mathrm{E}-22$ \\
\hline $4.50 \mathrm{E}-33$ & 1. $44 \mathrm{E}-12$ & $1.41 \mathrm{E}-15$ & $1.43 \mathrm{E}-31$ & $1.59 \mathrm{E}-31$ & $1.61 \mathrm{E}-31$ & $1.63 E-31$ & 1. $57 \mathrm{E}-21$ \\
\hline $4.48 E-33$ & $1.82 \mathrm{E}-12$ & $1.80 E-15$ & $1.44 \mathrm{E}-31$ & $61 E-31$ & $63 E-31$ & $1.64 \mathrm{E}-31$ & $.14 \mathrm{E}-20$ \\
\hline $4.45 E-33$ & $2.29 E-12$ & $2.28 E-15$ & $1.46 \mathrm{E}-31$ & $1.62 \mathrm{E}-31$ & $1.64 \mathrm{E}-31$ & $1.66 \mathrm{E}-31$ & $6.42 E-20$ \\
\hline $4.43 E-33$ & $2.84 \mathrm{E}-12$ & $2.86 \mathrm{E}-15$ & $1.47 \mathrm{E}-31$ & $1.63 E-31$ & $1.66 \mathrm{E}-31$ & $1.67 \mathrm{E}-31$ & $2.93 E-19$ \\
\hline $4.40 E-33$ & $3.51 E-12$ & $3.56 \mathrm{E}-15$ & $1.48 E-31$ & $1.65 E-31$ & $1.67 E-31$ & $1.69 \mathrm{E}-31$ & $1.12 \mathrm{E}-18$ \\
\hline $4.38 E-33$ & $4.29 E-12$ & $4.40 \mathrm{E}-15$ & $1.49 \mathrm{E}-31$ & $1.66 \mathrm{E}-31$ & $1.69 \mathrm{E}-31$ & $1.70 \mathrm{E}-31$ & $3.71 \mathrm{E}-18$ \\
\hline $4.36 \mathrm{E}-33$ & $5.20 \mathrm{E}-12$ & $5.40 \mathrm{E}-15$ & $1.51 \mathrm{E}-31$ & $1.68 \mathrm{E}-31$ & $1.70 \mathrm{E}-31$ & $1.72 \mathrm{E}-31$ & $1.08 \mathrm{E}-17$ \\
\hline $4.33 E-33$ & $6.27 \mathrm{E}-12$ & $6.59 \mathrm{E}-15$ & $1.52 \mathrm{E}-31$ & $1.69 E-31$ & $1.72 \mathrm{E}-31$ & $1.74 E-31$ & $2.85 E-17$ \\
\hline $4.31 E-33$ & $7.50 \mathrm{E}-12$ & $7.98 E-15$ & $1.53 E-31$ & $1.71 E-31$ & $1.73 E-31$ & $1.75 E-31$ & $7.02 \mathrm{E}-17$ \\
\hline $4.28 E-33$ & $8.92 E-12$ & $9.62 E-15$ & $1.55 E-31$ & $1.72 E-31$ & $1.75 E-31$ & $1.77 E-31$ & $1.60 \mathrm{E}-16$ \\
\hline $4.26 \mathrm{E}-33$ & $1.05 E-11$ & $1.15 \mathrm{E}-14$ & $1.56 \mathrm{E}-31$ & $1.74 \mathrm{E}-31$ & $1.76 \mathrm{E}-31$ & $1.79 \mathrm{E}-31$ & $3.43 E-16$ \\
\hline $4.24 \mathrm{E}-33$ & $1.24 \mathrm{E}-11$ & $1.37 \mathrm{E}-14$ & $1.57 \mathrm{E}-31$ & $1.75 E-31$ & $1.78 \mathrm{E}-31$ & $1.80 \mathrm{E}-31$ & $6.90 \mathrm{E}-16$ \\
\hline $4.21 E-33$ & $1.45 E-11$ & $1.63 E-14$ & $1.59 \mathrm{E}-31$ & $1.77 \mathrm{E}-31$ & $1.80 \mathrm{E}-31$ & $1.82 E-31$ & $1.32 E-15$ \\
\hline $4.19 \mathrm{E}-33$ & 1. $68 \mathrm{E}-11$ & $1.92 \mathrm{E}-14$ & $1.60 \mathrm{E}-31$ & $1.79 E-31$ & $1.81 \mathrm{E}-31$ & $1.84 \mathrm{E}-31$ & $2.41 E-15$ \\
\hline $4.17 E-33$ & 1. $94 \mathrm{E}-11$ & $2.26 E-14$ & $1.61 E-31$ & $1.80 E-31$ & $1.83 E-31$ & $1.85 E-31$ & $4.22 E-15$ \\
\hline $4.14 \mathrm{E}-33$ & $2.24 \mathrm{E}-11$ & $2.64 \mathrm{E}-14$ & $1.63 E-31$ & $1.82 \mathrm{E}-31$ & $1.84 \mathrm{E}-31$ & $1.88 E-31$ & $7.13 E-15$ \\
\hline $4.12 \mathrm{E}-33$ & $2.57 E-11$ & $3.08 \mathrm{E}-14$ & $1.64 \mathrm{E}-31$ & $1.83 E-31$ & $1.86 \mathrm{E}-31$ & $1.89 \mathrm{E}-31$ & $1.17 \mathrm{E}-14$ \\
\hline $4.10 \mathrm{E}-33$ & $2.93 E-11$ & $3.57 \mathrm{E}-14$ & $1.65 \mathrm{E}-31$ & $1.85 E-31$ & $1.88 \mathrm{E}-31$ & $1.92 \mathrm{E}-31$ & 1. $85 \mathrm{E}-14$ \\
\hline $4.08 E-33$ & $3.33 E-11$ & $4.13 E-14$ & $1.67 \mathrm{E}-31$ & $1.87 E-31$ & $1.89 \mathrm{E}-31$ & $2.64 E-29$ & $2.86 \mathrm{E}-14$ \\
\hline $4.05 E-33$ & $3.77 \mathrm{E}-11$ & $4.77 \mathrm{E}-14$ & $1.68 \mathrm{E}-31$ & $1.88 \mathrm{E}-31$ & 1.91E-31 & $6.46 \mathrm{E}-27$ & $4.31 \mathrm{E}-14$ \\
\hline $4.03 E-33$ & $4.25 E-11$ & $5.48 \mathrm{E}-14$ & $1.70 \mathrm{E}-31$ & $1.90 E-31$ & $1.93 E-31$ & $4.18 E-25$ & $6.15 \mathrm{E}-14$ \\
\hline $4.01 E-33$ & $4.78 E-11$ & $6.28 \mathrm{E}-14$ & $1.71 E-31$ & $1.92 E-31$ & $1.95 E-31$ & $1.14 \mathrm{E}-23$ & $8.49 \mathrm{E}-14$ \\
\hline $3.99 \mathrm{E}-33$ & $5.36 \mathrm{E}-11$ & $7.18 \mathrm{E}-14$ & $1.73 \mathrm{E}-31$ & $1.93 E-31$ & $1.97 \mathrm{E}-31$ & $1.80 \mathrm{E}-22$ & 1. $15 \mathrm{E}-13$ \\
\hline $3.97 E-33$ & $5.99 \mathrm{E}-11$ & $8.18 \mathrm{E}-14$ & $1.74 \mathrm{E}-31$ & $1.95 E-31$ & $1.98 E-31$ & $1.91 \mathrm{E}-21$ & $1.54 \mathrm{E}-13$ \\
\hline $3.94 \mathrm{E}-33$ & $6.67 \mathrm{E}-11$ & $9.30 E-14$ & $1.76 \mathrm{E}-31$ & $1.97 E-31$ & $2.00 E-31$ & $1.48 \mathrm{E}-20$ & $2.07 E-13$ \\
\hline $3.92 E-33$ & 7. $41 \mathrm{E}-11$ & $1.05 \mathrm{E}-13$ & $1.77 \mathrm{E}-31$ & $1.99 E-31$ & $2.02 E-31$ & $8.85 E-20$ & $2.75 E-13$ \\
\hline
\end{tabular}


RESRAD-OFFSITE, Version 2.5

$\mathrm{T}^{1 / 2}$ Limit $=180$ days

obabilistic Dose and Risk Report

Title : Offsite Resident Farmer Deterministic Run

File : RF TC99 DOESG FWD-FV2b.ROF

Summary of dose at graphical times, reptition 1 (continued)

Time

Years

1. $42 \mathrm{E}+02$

1. $42 \mathrm{E}+02$

1. $43 \mathrm{E}+02$

1. $43 \mathrm{E}+02$

1. $44 \mathrm{E}+02$

1. $44 \mathrm{E}+02$

1. $45 \mathrm{E}+02$

1. $45 \mathrm{E}+02$

1. $46 \mathrm{E}+02$

1. $46 \mathrm{E}+02$

1. $47 \mathrm{E}+02$

1. $47 \mathrm{E}+02$

1. $48 \mathrm{E}+02$

1. $48 \mathrm{E}+02$

1. $49 \mathrm{E}+02$

1. $49 \mathrm{E}+02$

1. $50 \mathrm{E}+02$

1. $50 \mathrm{E}+02$

1. $51 \mathrm{E}+02$

1. $51 \mathrm{E}+02$

1. $52 \mathrm{E}+02$

1. $52 \mathrm{E}+02$

1. $53 \mathrm{E}+02$

1. $53 \mathrm{E}+02$

$1.54 \mathrm{E}+02$

$1.54 \mathrm{E}+02$

1. $55 \mathrm{E}+02$

1. $55 \mathrm{E}+02$

1. $56 \mathrm{E}+02$

1. $56 \mathrm{E}+02$

1. $57 \mathrm{E}+02$

1. $57 \mathrm{E}+02$

1. $58 \mathrm{E}+02$

1. $58 \mathrm{E}+02$

1. $59 \mathrm{E}+02$

1. $59 \mathrm{E}+02$

1. $60 \mathrm{E}+02$

1. $60 \mathrm{E}+02$

1. $61 \mathrm{E}+02$

1. $61 \mathrm{E}+02$

1. $62 \mathrm{E}+02$

1. $63 \mathrm{E}+02$

1. $63 \mathrm{E}+02$

1. $64 \mathrm{E}+02$

1. $64 \mathrm{E}+02$

1. $65 \mathrm{E}+02$
Dose statistics at graphical times, mrem/yr

\begin{tabular}{|c|c|c|c|c|c|c|c|}
\hline m & aximum & ean & ledian & $0 \%$ & & $\%$ & $\%$ \\
\hline $90 \mathrm{E}-33$ & $8.21 \mathrm{E}-11$ & 1. $19 \mathrm{E}-13$ & 1. $79 \mathrm{E}-31$ & $2.00 \mathrm{E}-31$ & 2.04 & $4.30 \mathrm{E}-19$ & 0.0 \\
\hline $88 E-33$ & 11 & 13 & -31 & -31 & 31 & -18 & -13 \\
\hline $.86 \mathrm{E}-33$ & $1.00 \mathrm{E}-10$ & 1. $52 \mathrm{E}-13$ & 1. $82 \mathrm{E}-31$ & $2.04 \mathrm{E}-31$ & $2.08 \mathrm{E}-31$ & -18 & $6.04 \mathrm{E}-13$ \\
\hline $84 E-33$ & $1.10 \mathrm{E}-10$ & 1. $71 \mathrm{E}-13$ & $1.83 E-31$ & $2.06 \mathrm{E}-31$ & $2.10 \mathrm{E}-31$ & $1.88 \mathrm{E}-17$ & $68 \mathrm{E}-13$ \\
\hline 33 & & 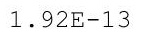 & & 1 & & 17 & 13 \\
\hline-33 & 0 & $F-13$ & 1 & 1 & -31 & 16 & -12 \\
\hline $.77 E-33$ & 0 & 2 & & & & & -12 \\
\hline-33 & 10 & 3 & & & & & -12 \\
\hline 33 & 10 & -13 & \pm & 1 & $\perp$ & 16 & -12 \\
\hline-33 & 10 & . & $1 \cdot$ & 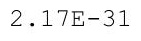 & $2.22 E-31$ & 5 & 12 \\
\hline 33 & 2.0 & - & -0 & 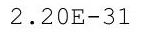 & & 15 & 12 \\
\hline 33 & 2.1 & & & & & & 12 \\
\hline $65 E-33$ & $2.36 \mathrm{E}-10$ & $4 E-13$ & 1. & $2.24 \mathrm{E}$ & $2.28 \mathrm{E}$ & -15 & -12 \\
\hline$E-33$ & $E-10$ & $E-13$ & 1 & 1 & 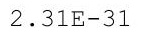 & -14 & $55 E-12$ \\
\hline 33 & 10 & 3 & & $\perp$ & & 4 & -12 \\
\hline 33 & -10 & +0 & $\perp$ & $\perp$ & $2.36 \mathrm{E}-31$ & 14 & -12 \\
\hline 33 & \pm & 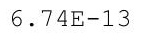 & $\perp$ & $2.32 \mathrm{E}-31$ & & & 11 \\
\hline • & 3.4 & & & & & & 11 \\
\hline $53 E-33$ & $3.66 \mathrm{E}-10$ & $8.15 E-13$ & & & & -14 & $58 E-11$ \\
\hline $51 E-33$ & -10 & $E-13$ & $D E-31$ & $2.38 \mathrm{E}-1$ & $18 \mathrm{~F}-28$ & -13 & $.85 E-11$ \\
\hline $49 \mathrm{E}-33$ & $4.19 \mathrm{E}-10$ & $9.80 \mathrm{E}-13$ & $2.12 \mathrm{E}-31$ & $2.40 E-31$ & 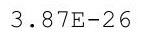 & -13 & -11 \\
\hline & & & & $\perp$ & & & $45 E-11$ \\
\hline 33 & & & & & & & \\
\hline $43 E-33$ & $3.02 \mathrm{D}-10$ & $1 \cdot 201 \quad 12$ & & & & & 11 \\
\hline 3 & 0 & $=$ & $\perp$ & $\perp$ & . & 3 & 11 \\
\hline$E-33$ & 765 & 1. $52 \mathrm{E}-12$ & $2.21 \mathrm{E}-31$ & 2 & 3 & $9 E-13$ & $09 \mathrm{E}-11$ \\
\hline-33 & 10 & 1. $66 \mathrm{E}-12$ & $2.23 \mathrm{E}-$ & $.53 \mathrm{E}-$ & & 13 & $.62 \mathrm{E}-11$ \\
\hline-33 & 10 & & & & & -12 & $20 E-11$ \\
\hline 33 & 10 & & & & & & \\
\hline $32 E-33$ & $7.30 \mathrm{E}-10$ & $\angle \cdot \perp J E-1 Z$ & $2.29 E-31$ & 2.001 & $\perp \cdot \pm 0$ & -12 & -11 \\
\hline $30 E-33$ & $1.15 \mathrm{E}-10$ & $\angle \cdot 3 \perp+-12$ & $2.31 \mathrm{~L}-3 \perp$ & $2.63 E-31$ & $0.2+1$ & $2.07 E-12$ & $.38 E-11$ \\
\hline 3 & 0 & 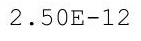 & 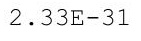 & & . & . & $0.12 \pm-11$ \\
\hline 3 & $8.65 E-10$ & & 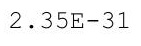 & & & & \\
\hline-33 & 0 & 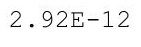 & & & & 12 & 11 \\
\hline 3 & & & & & & & \\
\hline $1 E-33$ & $1.02 \mathrm{E}-09$ & $3.41 \mathrm{E}-12$ & $2.41 E-31$ & $2 \cdot 10 \mathrm{E}$ & 5 & 12 & -10 \\
\hline$E-33$ & $1.0 / E-09$ & 12 & . & & & & \\
\hline $18 E-33$ & & $3.935-12$ & & & & & \\
\hline $.16 \mathrm{E}-33$ & 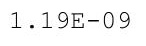 & 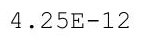 & $\perp$ & & 5 & 2 & 1. $51 \mathrm{E}-10$ \\
\hline & & & & & & & \\
\hline 3 & 09 & 4. & 31 & 1 & 1 & & \\
\hline$E-33$ & 1. 38E-09 & $7 E-12$ & 2. & 31 & 14 & 11 & 1. \\
\hline & 1.4 & & & & & & \\
\hline & $+\cdots$ & 2 & 急 & & & & . +10 \\
\hline & \pm & & & 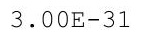 & & 11 & 2.20010 \\
\hline 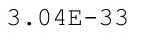 & $68 E-09$ & $2 E-12$ & $3 E-31$ & $E-31$ & $33 E-13$ & $3 E-11$ & -10 \\
\hline
\end{tabular}


RESRAD-OFFSITE, Version 2.5

obabilistic Dose and Risk Report

Title : Offsite Resident Farmer Deterministic Run

File : RF TC99 DOESG FWD-FV2b.ROF

Summary of dose at graphical times, reptition 1 (continued)

Time

Years

1. $65 \mathrm{E}+02$

$1.66 \mathrm{E}+02$

$1.66 \mathrm{E}+02$

$1.67 \mathrm{E}+02$

1. $67 \mathrm{E}+02$

1. $68 \mathrm{E}+02$

1. $68 \mathrm{E}+02$

1. $69 \mathrm{E}+02$

1. $69 \mathrm{E}+02$

1. $70 \mathrm{E}+02$

1. $70 \mathrm{E}+02$

1. $71 \mathrm{E}+02$

1. $71 \mathrm{E}+02$

1. $72 \mathrm{E}+02$

1. $72 \mathrm{E}+02$

1. $73 \mathrm{E}+02$

1. $73 \mathrm{E}+02$

1. $74 \mathrm{E}+02$

1. $74 \mathrm{E}+02$

1. $75 \mathrm{E}+02$

1. $75 \mathrm{E}+02$

$1.76 \mathrm{E}+02$

1. $76 \mathrm{E}+02$

1. $77 \mathrm{E}+02$

1. $77 \mathrm{E}+02$

$1.78 \mathrm{E}+02$

1. $78 \mathrm{E}+02$

1. $79 \mathrm{E}+02$

1. $79 \mathrm{E}+02$

1. $80 \mathrm{E}+02$

1. $80 \mathrm{E}+02$

$1.81 \mathrm{E}+02$

$1.81 \mathrm{E}+02$

$1.82 \mathrm{E}+02$

$1.83 \mathrm{E}+02$

$1.83 \mathrm{E}+02$

$1.84 \mathrm{E}+02$

$1.84 \mathrm{E}+02$

$1.85 \mathrm{E}+02$

$1.85 \mathrm{E}+02$

$1.86 \mathrm{E}+02$

$1.86 \mathrm{E}+02$

$1.87 \mathrm{E}+02$

$1.87 \mathrm{E}+02$

$1.88 \mathrm{E}+02$

1. $88 \mathrm{E}+02$
Dose statistics at graphical times, mrem/yr

\begin{tabular}{|c|c|c|c|c|c|c|c|}
\hline m & um & ean & ledian & $0 \%$ & & $\%$ & $\%$ \\
\hline $02 E-33$ & $1.76 \mathrm{E}-09$ & $7.40 \mathrm{E}-12$ & $2.65 E-31$ & $3.06 \mathrm{E}-31$ & 1. $82 \mathrm{E}-13$ & -11 & $2.57 \pm-10$ \\
\hline $01 E-33$ & -09 & 2 & -31 & 31 & 13 & -11 & -10 \\
\hline $99 E-33$ & $1.93 \mathrm{E}-09$ & $3 E-12$ & $2.70 \mathrm{E}-31$ & $3.12 \mathrm{E}-31$ & $27 E-13$ & $2.97 \mathrm{E}-11$ & $03 E-10$ \\
\hline $97 E-33$ & $2.02 E-09$ & $9 \mathrm{E}-12$ & $2.73 E-31$ & $.15 E-31$ & $4.29 \mathrm{E}-13$ & $4 \mathrm{E}-11$ & $21 E-10$ \\
\hline 3 & 9 & & 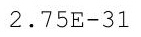 & & 3 & 5 & 10 \\
\hline$E-33$ & 09 & 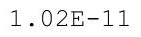 & 1 & 1 & 3 & 1 & -10 \\
\hline $92 E-33$ & 99 & & & 1 & & & -10 \\
\hline-33 & & & & & & & -10 \\
\hline-33 & -09 & -11 & \pm & 1 & -12 & -11 & -10 \\
\hline $88 \mathrm{E}-33$ & -09 & - & - & 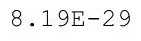 & 2 & $\perp$ & 0 \\
\hline 33 & 09 & $1+$ & \pm & 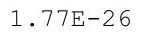 & 2 & 11 & -10 \\
\hline 33 & & & & & & & 10 \\
\hline $83 E-33$ & $2.97 \mathrm{E}-09$ & $1.55 \mathrm{E}-11$ & -31 & $2.50 \mathrm{E}-$ & $3.53 \mathrm{E}-12$ & -11 & -10 \\
\hline $81 E-33$ & $9 E-09$ & $4 \mathrm{E}-11$ & $8 E-31$ & $5 E-22$ & -12 & -11 & -10 \\
\hline-33 & -09 & -11 & & $\perp$ & 12 & 11 & -10 \\
\hline 33 & 09 & $\perp \perp$ & $\perp$ & $2.34 \mathrm{E}-20$ & 2 & 20 & 10 \\
\hline 33 & 09 & $\perp$ & & $\perp$ & 2 & & 10 \\
\hline $.75 E-33$ & $3.62 \mathrm{E}-09$ & & & & & & \\
\hline $.74 E-33$ & $3.77 \mathrm{E}-09$ & $2.16 \mathrm{E}-11$ & & & $8.74 \mathrm{E}-12$ & $E-10$ & -10 \\
\hline $72 E-33$ & $3.92 \mathrm{E}-09$ & $2.28 \mathrm{E}-11$ & $3 E-31$ & $6.24 \mathrm{E}-1$ & $.04 \mathrm{E}-11$ & \pm-10 & $46 \mathrm{E}-10$ \\
\hline $71 E-33$ & $4.07 E-09$ & $2.41 E-11$ & $3.16 \mathrm{E}-31$ & $1.76 \mathrm{E}-1$ & 1. $23 \mathrm{E}-11$ & 1. $55 \mathrm{E}-10$ & -10 \\
\hline 33 & & & & 7 & & & \\
\hline 33 & & & & & & & \\
\hline $66 \mathrm{E}-33$ & $4.50 \mathrm{~L}-09$ & $2.0 \perp \perp \quad \perp$ & & & $78 E-11$ & & 10 \\
\hline 3 & 9 & 1 & $3.28 \mathrm{E}-31$ & 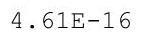 & 1 & 0 & 10 \\
\hline $63 E-33$ & تصمी & $.11 \mathrm{E}-11$ & $\Gamma_{0}$ & ק? & $20 E-11$ & 0 & 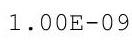 \\
\hline $62 E-33$ & 0.9 & $3.27 E-11$ & 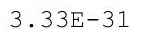 & & $45 E-11$ & $2.35 E-1$ & $.06 E-09$ \\
\hline$E-33$ & -09 & & & & $71 E-11$ & & $12 E-09$ \\
\hline 33 & 09 & & & & & & \\
\hline $57 E-33$ & $5.66 \mathrm{E}-09$ & $3.19 E-11$ & . & . 40 & 3.32 & 10 & -09 \\
\hline $56 E-33$ & $3.00 \mathrm{~L}-09$ & $3.90 \mathrm{~L}-11$ & $3.405-31$ & $1.4 / 5-14$ & $3.67 \mathrm{E}-11$ & $3.10 \mathrm{E}-10$ & $.29 E-09$ \\
\hline 3 & $6.07 E-09$ & $4.17 \mathrm{E}-11$ & 然 & - & 7. & & $1.35 E-09$ \\
\hline 3 & $6.29 E-09$ & & $3.52 \mathrm{E}-31$ & & & & \\
\hline-33 & 9 & 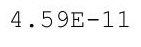 & & & 1 & & 09 \\
\hline 33 & & & & & 1 & & \\
\hline $49 E-33$ & $6.96 \mathrm{E}-09$ & $5.03 E-11$ & $3.01 \mathrm{~L}$ & $9.63 E-14$ & -11 & & -09 \\
\hline $8 E-33$ & $1.20 E-09$ & 11 & & & & & \\
\hline $46 E-33$ & $1.445-09$ & & & & & & $1.70 \mathrm{E}-0$ \\
\hline 3 & 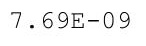 & 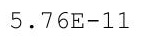 & $3.71 \mathrm{E}-31$ & 3 & & 0 & 9 \\
\hline & & & & & & & \\
\hline 3 & 09 & 11 & 1 & 3 & 1 & 0 & \\
\hline $41 E-33$ & $8.48 E-09$ & $E-11$ & $3 . \varepsilon$ & 5 & -11 & 0 & -09 \\
\hline & & & & & & & \\
\hline & & & & & & & $2.27 E-09$ \\
\hline & 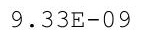 & & & $9 \pm-12$ & 0 & 10 & $2.36 E-09$ \\
\hline ت & $2 E-09$ & $9 E-11$ & $5 E-31$ & $6 \mathrm{E}-12$ & $29 E-10$ & $3 E-10$ & -09 \\
\hline
\end{tabular}


RESRAD-OFFSITE, Version 2.5

$\mathrm{T}^{1 / 2}$ Limit $=180$ days

obabilistic Dose and Risk Report

Title : Offsite Resident Farmer Deterministic Run

File : RF TC99 DOESG FWD-FV2b.ROF

Summary of dose at graphical times, reptition 1 (continued)

Time

Years

$1.89 \mathrm{E}+02$

$1.89 \mathrm{E}+02$

1. $90 \mathrm{E}+02$

1. $90 \mathrm{E}+02$

1. $91 \mathrm{E}+02$

1. $91 \mathrm{E}+02$

1. $92 \mathrm{E}+02$

1. $92 \mathrm{E}+02$

1. $93 \mathrm{E}+02$

1. $93 \mathrm{E}+02$

$1.94 \mathrm{E}+02$

1. $94 \mathrm{E}+02$

1. $95 \mathrm{E}+02$

1. $95 \mathrm{E}+02$

1. $96 \mathrm{E}+02$

1. $96 \mathrm{E}+02$

1. $97 \mathrm{E}+02$

1. $97 \mathrm{E}+02$

1. $98 \mathrm{E}+02$

1. $98 \mathrm{E}+02$

1. $99 \mathrm{E}+02$

1. $99 \mathrm{E}+02$

$2.00 \mathrm{E}+02$

$2.00 \mathrm{E}+02$

$2.01 \mathrm{E}+02$

$2.01 \mathrm{E}+02$

$2.02 \mathrm{E}+02$

$2.03 \mathrm{E}+02$

$2.03 E+02$

$2.04 \mathrm{E}+02$

$2.04 \mathrm{E}+02$

$2.05 \mathrm{E}+02$

$2.05 \mathrm{E}+02$

$2.06 \mathrm{E}+02$

$2.06 \mathrm{E}+02$

$2.07 \mathrm{E}+02$

$2.07 \mathrm{E}+02$

$2.08 \mathrm{E}+02$

$2.08 \mathrm{E}+02$

2. $09 \mathrm{E}+02$

$2.09 \mathrm{E}+02$

$2.10 \mathrm{E}+02$

$2.10 \mathrm{E}+02$

$2.11 \mathrm{E}+02$

$2.11 \mathrm{E}+02$

$2.12 \mathrm{E}+02$
Dose statistics at graphical times, mrem/yr

\begin{tabular}{|c|c|c|c|c|c|c|c|}
\hline num & aximum & ean & ledian & & & $\%$ & \\
\hline $34 \mathrm{E}-33$ & $9.93 E-09$ & $8.13 E-11$ & $3.98 E-31$ & 1. $68 \mathrm{E}-12$ & 1. $40 \mathrm{E}-10$ & -10 & $2.50 E-09$ \\
\hline $33 E-33$ & $1.02 \mathrm{E}-08$ & $7 E-11$ & $02 E-31$ & $06 \mathrm{E}-12$ & 10 & 10 & -09 \\
\hline $.32 E-33$ & $1.06 \mathrm{E}-08$ & $8.83 E-11$ & $4.06 \mathrm{E}-31$ & $2.51 \mathrm{E}-12$ & 1. $63 \mathrm{E}-10$ & $8.50 \mathrm{E}-10$ & $2.75 E-09$ \\
\hline $31 E-33$ & $1.09 \mathrm{E}-08$ & $9.19 \mathrm{E}-11$ & $4.09 E-31$ & $3.04 \mathrm{E}-12$ & $1.73 \mathrm{E}-10$ & $94 \mathrm{E}-10$ & $2.85 E-09$ \\
\hline 3 & 8 & $9.57 \mathrm{E}-11$ & & 2 & & 0 & -09 \\
\hline$E-33$ & 08 & $9.96 \mathrm{E}-11$ & 1 & 2 & 0 & 0 & -09 \\
\hline $27 E-33$ & 08 & & & & & & -09 \\
\hline-33 & 1.2 & & & & & & -09 \\
\hline-33 & -08 & -10 & \pm & -12 & 10 & 09 & $E-09$ \\
\hline $23 E-33$ & -08 & 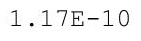 & 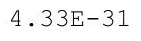 & -12 & 0 & 9 & -09 \\
\hline 33 & 1.341 & $-x_{1}+1$ & \pm & 12 & - & 09 & -09 \\
\hline 33 & $1.38 \mathrm{~F}$ & & & & 0 & & -09 \\
\hline $19 \mathrm{E}-33$ & $1.42 \mathrm{E}-08$ & 1. $31 \mathrm{E}-10$ & & $19 E-11$ & -10 & 09 & -09 \\
\hline $18 \mathrm{E}-33$ & $6 \mathrm{E}-08$ & $36 \mathrm{E}-10$ & $E-31$ & $2 E-11$ & -10 & -09 & -09 \\
\hline-33 & -08 & 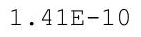 & & 1 & 0 & & -09 \\
\hline 33 & 08 & 1. & $\perp$ & $\perp$ & 0 & 9 & -09 \\
\hline 33 & 08 & $1.52 \mathrm{E}-10$ & & 1 & 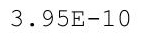 & & -09 \\
\hline $13 E-33$ & $1.63 E-08$ & & & & & & -09 \\
\hline $12 \mathrm{E}-33$ & $1.67 \mathrm{E}-08$ & & & $2.36 \mathrm{E}-11$ & & & $4 E-09$ \\
\hline $11 \mathrm{E}-33$ & $1.72 \mathrm{E}-08$ & $1.69 \mathrm{E}-1$ & $3 E-31$ & $2.71 \mathrm{E}-11$ & $4.59 \mathrm{E}-10$ & E-09 & -09 \\
\hline $10 E-33$ & $1.77 \mathrm{E}-08$ & $1.75 \mathrm{E}-10$ & $4.78 E-31$ & $3.08 E-11$ & $4.79 E-10$ & $E-09$ & -09 \\
\hline 33 & 8 & + & $\perp$ & 1 & & & -09 \\
\hline 33 & 1.8 & & & & & & 09 \\
\hline $06 \mathrm{E}-33$ & $1 \cdot 9+\mathrm{L}-00$ & I. & & $4.13 E-11$ & $405-10$ & & 09 \\
\hline 3 & 1 & $2.02 E-10$ & $\perp$ & 1 & 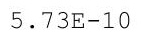 & 3 & -09 \\
\hline $04 \mathrm{E}-33$ & $.02 E-08$ & ד קחת & ד & $.88 E-11$ & 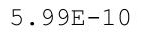 & $4 E-09$ & $09 E-09$ \\
\hline $3 E-33$ & $.07 E-08$ & $2.16 \mathrm{E}-10$ & 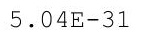 & -11 & $25 E-$ & $.32 E-0$ & $28 E-09$ \\
\hline$E-33$ & $E-08$ & & & 1 & 10 & $E-09$ & $4 \mathrm{E}-09$ \\
\hline 33 & 08 & & & & & & \\
\hline $.00 E-33$ & $2.24 \mathrm{E}-08$ & $2.07 \pm \perp 0$ &. \pm 0 & $7.00 \mathrm{E}-11$ & 10 & 09 & -09 \\
\hline $99 E-33$ & $2.295-00$ & $2 \cdot 10+10$ & $. \angle O L-31$ & $7.54 \mathrm{E}-11$ & $.40 E-10$ & -09 & $.12 E-09$ \\
\hline 3 & 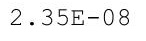 & 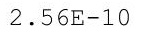 & 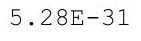 & 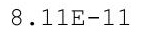 & 然 & & $7.35 E-09$ \\
\hline 3 & 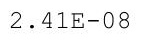 & & $5.33 E-31$ & & & & 9 \\
\hline$F-33$ & 8 & ד & & 1 & & & 09 \\
\hline 3 & & & & & & & \\
\hline 3 & 8 & & & 10 & & & \\
\hline $92 \mathrm{E}-33$ & $2.06 E-08$ & ${ }^{\circ}$ & & & & & -09 \\
\hline $91 E-33$ & $2.125-00$ & $\cdot \begin{array}{lll}\perp & \perp U\end{array}$ & & & & & $0.10 \mathrm{E}-09$ \\
\hline 3 & 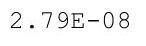 & 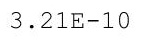 & . & 0 & 9 & 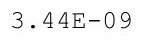 & 9 \\
\hline $.89 E-33$ & & & & & & & 9 \\
\hline & & & & 0 & 9 & 9 & \\
\hline $7 E-33$ & $3.00 \mathrm{E}-08$ & 3. & 1 & 1. & 09 & & -09 \\
\hline & 8 & & & & & & \\
\hline & 8 & 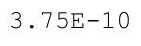 & & 0 & $+\cdot 201$ & & $1.02 \mathrm{E}-08$ \\
\hline & & & & 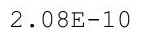 & 9 & & $05 E-08$ \\
\hline D & $9 \mathrm{E}-08$ & $3 E-10$ & $01 E-31$ & $21 E-10$ & $37 E-09$ & $3 E-09$ & -08 \\
\hline
\end{tabular}


RESRAD-OFFSITE, Version 2.5

$\mathrm{T}^{1 / 2}$ Limit $=180$ days

obabilistic Dose and Risk Report

Title : Offsite Resident Farmer Deterministic Run

File : RF TC99 DOESG FWD-FV2b.ROF

Summary of dose at graphical times, reptition 1 (continued)

Time

Years

$2.12 \mathrm{E}+02$

$2.13 \mathrm{E}+02$

$2.13 \mathrm{E}+02$

$2.14 \mathrm{E}+02$

$2.14 \mathrm{E}+02$

$2.15 \mathrm{E}+02$

$2.15 \mathrm{E}+02$

$2.16 \mathrm{E}+02$

$2.16 \mathrm{E}+02$

$2.17 \mathrm{E}+02$

$2.17 \mathrm{E}+02$

$2.18 \mathrm{E}+02$

$2.18 \mathrm{E}+02$

$2.19 \mathrm{E}+02$

$2.19 \mathrm{E}+02$

$2.20 \mathrm{E}+02$

2. $20 \mathrm{E}+02$

$2.21 E+02$

2. $21 E+02$

2. $22 \mathrm{E}+02$

$2.23 E+02$

$2.23 E+02$

$2.24 \mathrm{E}+02$

$2.24 \mathrm{E}+02$

2. $25 \mathrm{E}+02$

$2.25 \mathrm{E}+02$

2. $26 \mathrm{E}+02$

$2.26 \mathrm{E}+02$

$2.27 \mathrm{E}+02$

$2.27 \mathrm{E}+02$

2. $28 \mathrm{E}+02$

$2.28 \mathrm{E}+02$

$2.29 \mathrm{E}+02$

2. $29 \mathrm{E}+02$

2. $30 \mathrm{E}+02$

2. $30 \mathrm{E}+02$

2. $31 E+02$

2. $31 E+02$

2. $32 \mathrm{E}+02$

2. $32 E+02$

$2.33 E+02$

2. $33 E+02$

$2.34 \mathrm{E}+02$

2. $34 \mathrm{E}+02$

$2.35 \mathrm{E}+02$

$2.35 \mathrm{E}+02$
Dose statistics at graphical times, mrem/yr

\begin{tabular}{|c|c|c|c|c|c|c|c|}
\hline m & aximum & ean & 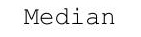 & & & $\%$ & \\
\hline $82 E-33$ & $3.36 \mathrm{E}-08$ & $4.10 \mathrm{E}-10$ & $6.07 E-31$ & $2.33 \mathrm{E}-10$ & 09 & -09 & -00 \\
\hline $81 E-33$ & $3.44 \mathrm{E}-08$ & $3 E-10$ & $6.13 \mathrm{E}-31$ & $2.46 \mathrm{E}-10$ & 9 & 09 & -08 \\
\hline $.80 E-33$ & $3.52 \mathrm{E}-08$ & $4.36 \mathrm{E}-10$ & $6.19 \mathrm{E}-31$ & $2.59 \mathrm{E}-10$ & $1.55 \mathrm{E}-09$ & $E-09$ & $1.17 \mathrm{E}-08$ \\
\hline $79 \mathrm{E}-33$ & $3.60 \mathrm{E}-08$ & $4.49 \mathrm{E}-10$ & $E-31$ & $2.72 \mathrm{E}-10$ & $1.61 \mathrm{E}-09$ & $4.87 E-09$ & $1.20 \mathrm{E}-08$ \\
\hline $.78 E-33$ & 08 & $E-10$ & $31 E-31$ & $86 \mathrm{E}-10$ & $7 E-09$ & $2 E-09$ & -08 \\
\hline $.77 E-33$ & 08 & 0 & 1 & 0 & 9 & 9 & -08 \\
\hline $.76 E-33$ & 3.85 & & & & 9 & & -08 \\
\hline $75 E-33$ & & & & & 9 & & -08 \\
\hline $.74 E-33$ & -08 & -10 & $\perp$ & -10 & 09 & -09 & $E-08$ \\
\hline $.73 E-33$ & -08 & 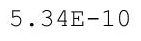 & 3 & -10 & 9 & -09 & -08 \\
\hline 33 & B & $5.49 E-10$ & $E-31$ & 0 & 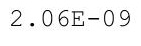 & 9 & 8 \\
\hline $.71 E-33$ & 4.2 & & & 0 & 9 & & -08 \\
\hline $.70 E-33$ & $4.38 \mathrm{E}-08$ & 5 & 1 & 0 & 9 & 9 & -08 \\
\hline$E-33$ & $7 E-08$ & $8 E-10$ & $E-31$ & $4 E-10$ & 9 & -09 & -08 \\
\hline-33 & $E-08$ & 0 & & 0 & 9 & -09 & -08 \\
\hline 33 & 08 & +0 & $\perp$ & 0 & 9 & 09 & -08 \\
\hline 33 & 08 & +0 & & 0 & & ( & 08 \\
\hline 3 & & & & & & & \\
\hline $64 E-33$ & $5.02 \mathrm{E}-08$ & $6.85 E-10$ & & $5.47 E-10$ & $2.58 \mathrm{E}$ & -09 & -08 \\
\hline $64 \mathrm{E}-33$ & $.15 E-08$ & $.04 \mathrm{E}-10$ & $.34 \mathrm{E}-31$ & $5.69 \mathrm{E}-10$ & $2.65 E-09$ & $7 E-09$ & $1.85 \mathrm{E}-08$ \\
\hline $63 E-33$ & $5.28 E-08$ & 7. $23 E-10$ & & $5.90 \mathrm{E}-10$ & $2.72 E-09$ & $E-09$ & -08 \\
\hline 33 & & & & & & & -08 \\
\hline 3 & & & & & & & \\
\hline $60 E-33$ & . & 10 & & 0 & & & 08 \\
\hline 3 & 8 & 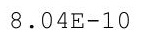 & 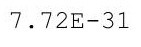 & 0 & 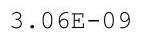 & 3 & 08 \\
\hline $58 E-33$ & F & 1 & ד & $7.30 \mathrm{E}-10$ & $15 \square$ & $5 E-09$ & $2.15 \mathrm{E}$ \\
\hline-33 & -08 & $7 F-10$ & 1 & 0 & & $E-0$ & $.20 E-08$ \\
\hline $5 E-33$ & -08 & & & & & & $25 E-08$ \\
\hline 3 & & & & & & & \\
\hline $55 E-33$ & $6.61 \mathrm{E}-08$ & $9.14 E-10$ & . & . & . & 08 & -08 \\
\hline $.54 E-33$ & $0.1 / \mathrm{E}-00$ & $9.305-10$ & $\cdot 2 U D-31$ & $8.78 \mathrm{E}-10$ & $3.67 E-09$ & $1.00 \mathrm{D}-00$ & $2.42 E-08$ \\
\hline 3 & . & 然 & 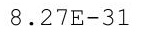 & $9.08 E-10$ & . & 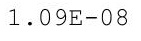 & $2.48 E-08$ \\
\hline 3 & $10 \nabla$ & 20 & 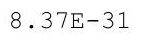 & 0 & & & 8 \\
\hline$F-33$ & 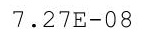 & $F-09$ & & 0 & & 8 & $E-08$ \\
\hline 3 & & & & & & & \\
\hline 3 & 8 & & 31 & $\pm \cdot 01$ & 1.02 & & 08 \\
\hline $49 \mathrm{E}-33$ & & & & & & & -08 \\
\hline $48 E-33$ & & & & & $4.025-02$ & & $2.84 \mathrm{E}-08$ \\
\hline 3 & 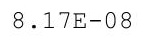 & t & & 9 & 9 & & 8 \\
\hline $.46 E-33$ & & & & & & & 8 \\
\hline & & & & 9 & 9 & 8 & -08 \\
\hline $45 E-33$ & $8.75 E-08$ & 1. & 1 & 09 & & 08 & -08 \\
\hline & & & & & & & \\
\hline & & & & $\pm \cdot 00$ & 9 & & $3.25 E-08$ \\
\hline & . & & & 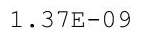 & 9 & & 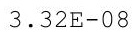 \\
\hline$E-33$ & $6 E-08$ & $5 E-09$ & $54 E-31$ & $E-09$ & $E-09$ & $1 E-08$ & -08 \\
\hline
\end{tabular}


RESRAD-OFFSITE, Version 2.5

$\mathrm{T}^{1 / 2}$ Limit $=180$ days

Title : Offsite Resident Farmer Deterministic Run

File : RF TC99 DOESG FWD-FV2b.ROF

Summary of dose at graphical times, reptition 1 (continued)

Time

Years

$2.36 \mathrm{E}+02$

$2.36 \mathrm{E}+02$

$2.37 \mathrm{E}+02$

$2.37 \mathrm{E}+02$

$2.38 \mathrm{E}+02$

$2.38 \mathrm{E}+02$

$2.39 \mathrm{E}+02$

$2.39 \mathrm{E}+02$

$2.40 \mathrm{E}+02$

$2.40 \mathrm{E}+02$

$2.41 \mathrm{E}+02$

$2.41 \mathrm{E}+02$

$2.42 \mathrm{E}+02$

2. $43 \mathrm{E}+02$

$2.43 E+02$

$2.44 \mathrm{E}+02$

$2.44 \mathrm{E}+02$

$2.45 \mathrm{E}+02$

2. $45 \mathrm{E}+02$

$2.46 \mathrm{E}+02$

$2.46 \mathrm{E}+02$

$2.47 \mathrm{E}+02$

$2.47 \mathrm{E}+02$

$2.48 \mathrm{E}+02$

$2.48 \mathrm{E}+02$

$2.49 \mathrm{E}+02$

$2.49 \mathrm{E}+02$

$2.50 \mathrm{E}+02$

$2.50 \mathrm{E}+02$

$2.51 \mathrm{E}+02$

2. $51 \mathrm{E}+02$

$2.52 \mathrm{E}+02$

$2.52 \mathrm{E}+02$

$2.53 \mathrm{E}+02$

$2.53 \mathrm{E}+02$

$2.54 \mathrm{E}+02$

$2.54 \mathrm{E}+02$

$2.55 \mathrm{E}+02$

$2.55 \mathrm{E}+02$

$2.56 \mathrm{E}+02$

$2.56 \mathrm{E}+02$

$2.57 \mathrm{E}+02$

$2.57 \mathrm{E}+02$

$2.58 \mathrm{E}+02$

$2.58 \mathrm{E}+02$

$2.59 \mathrm{E}+02$
Dose statistics at graphical times, mrem/yr

\begin{tabular}{|c|c|c|c|c|c|c|c|}
\hline m & aximum & ean & 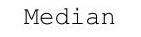 & $90 \%$ & & $\%$ & \\
\hline $41 E-33$ & $9.78 \mathrm{E}-08$ & 1. 38E-09 & $9.63 E-31$ & 1. $45 \mathrm{E}-09$ & 3.10 & -08 & -00 \\
\hline $40 E-33$ & $9.99 \mathrm{E}-08$ & $1.42 \mathrm{E}-09$ & $.73 E-31$ & 9 & 9 & 8 & -08 \\
\hline $.39 E-33$ & $1.02 \mathrm{E}-07$ & 1. $45 \mathrm{E}-09$ & $9.83 E-31$ & $1.54 \mathrm{E}-09$ & $6.11 \mathrm{E}-09$ & 1. $61 \mathrm{E}-08$ & $.62 \mathrm{E}-08$ \\
\hline $39 E-33$ & $1.04 \mathrm{E}-07$ & 1. $48 \mathrm{E}-09$ & $9.95 E-31$ & $1.59 \mathrm{E}-09$ & $6.28 \mathrm{E}-09$ & $1.64 \mathrm{E}-08$ & $.70 E-08$ \\
\hline $38 E-33$ & $07 \mathrm{E}-07$ & $2 E-09$ & $01 E-30$ & $65 E-09$ & E-09 & $3 E-08$ & .08 \\
\hline $37 E-33$ & -07 & 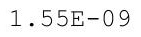 & 0 & 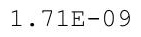 & 9 & 8 & -08 \\
\hline $36 E-33$ & & & & 9 & & & -08 \\
\hline $35 E-33$ & & & & & & & -08 \\
\hline 33 & -07 & $F-0$ & 0 & $89 \mathrm{~F}$ & 09 & -08 & -08 \\
\hline $34 \mathrm{E}-33$ & -07 & 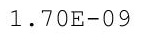 & 30 & 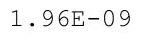 & 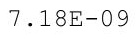 & (o & -08 \\
\hline $33 E-33$ & $F-07$ & $35-$ & 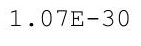 & $.02 E-09$ & & 8 & 8 \\
\hline 33 & 1.2 & 1. & & & & & 08 \\
\hline $06 \mathrm{E}-32$ & $1.26 \mathrm{E}-07$ & $1.81 \mathrm{E}-\mathrm{C}$ & $1.10 \mathrm{E}-30$ & 2 & 9 & 8 & -08 \\
\hline $.06 \mathrm{E}-32$ & $1.29 \mathrm{E}-07$ & $1.85 \mathrm{E}-09$ & $1.11 \mathrm{E}-30$ & $2.20 \mathrm{E}-09$ & $7.94 \mathrm{E}-09$ & $2.06 \mathrm{E}-08$ & $.55 E-08$ \\
\hline $06 \mathrm{E}-32$ & 07 & -09 & & 9 & & 08 & -08 \\
\hline 32 & & 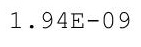 & & & & & -08 \\
\hline 32 & $\perp$ & 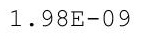 & 1. $15 \mathrm{E}-30$ & 9 & 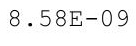 & & 08 \\
\hline 2 & 1 & 2 & & & & & 8 \\
\hline $07 E-32$ & $1.42 \mathrm{E}-07$ & $2.06 E-0$ & & $2.54 \mathrm{E}-$ & & 08 & -08 \\
\hline $.07 E-32$ & $1.45 \mathrm{E}-07$ & $2.11 \mathrm{E}-09$ & $25=3-3-3$ & $2.61 \mathrm{E}-09$ & 9 & $E-08$ & -08 \\
\hline $07 E-32$ & $1.48 E-07$ & $2.15 E-09$ & & $2.68 E-09$ & 9 & $3 E-08$ & $22 E-08$ \\
\hline 32 & & & & y & & & -08 \\
\hline 2 & 1 & & & & & & \\
\hline $07 E-32$ & $1.57 \mathrm{E}$ & 2 & 1. & - & & & -08 \\
\hline 2 & 1 . & $2.34 \mathrm{E}-09$ & 1. $28 \mathrm{E}-30$ & 9 & $1.04 \mathrm{E}-08$ & 0 & 08 \\
\hline $07 E-32$ & $163 F-0$ & סקב & 1 & 05 & 1 & $3 E-08$ & בחת \\
\hline $07 E-32$ & 1. $66 \mathrm{E}-0$ & $2.44 \mathrm{E}-0$ & $9.46 \mathrm{E}-2$ & & $1.09 \mathrm{E}-\mathrm{C}$ & $.68 E-0$ & $.85 E-08$ \\
\hline$E-32$ & 1.6 & & & & & $3 E-08$ & $96 E-08$ \\
\hline-32 & $1.72 \mathrm{E}$ & & & & & & \\
\hline $.07 E-32$ & $1.75 E-07$ & $2.07+40$ & $1.67 \mathrm{E}-23$ & (.) & 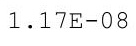 & 08 & -08 \\
\hline $07 E-32$ & $1.79 E-07$ & $2.07+0$ & $\angle \cdot \angle J 5-2 \angle$ & $3.50 \mathrm{E}-09$ & $1.20 \mathrm{E}-00$ & $2.09 \mathrm{E}-00$ & $.30 E-08$ \\
\hline 2 & $\begin{array}{ll}+02 \square \\
0\end{array}$ & 列 & e. & 0 & 土. & $2.94 \mathrm{E}-08$ & $6.42 \mathrm{E}-08$ \\
\hline $7 \mathrm{E}-$ & $1.85 \mathrm{E}-$ & & $7 \mathrm{E}-$ & & & & 8 \\
\hline $08 F-32$ & 18 & & & 9 & & 8 & 8 \\
\hline & & & & & & & \\
\hline $82 E-32$ & $1.96 \mathrm{E}-07$ & $2.9 \angle E-09$ & 1. $18 \mathrm{E}-18$ & $3.90 \mathrm{w}$ & $\perp$ & 8 & -08 \\
\hline $82 E-32$ & $1.99 \mathrm{w}$ & $2 \cdot$ & & & & & -08 \\
\hline $82 E-32$ & 2.000 t & (0) & & & & & $7.15 E-08$ \\
\hline 2 & 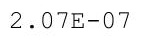 & 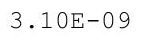 & 2 & 9 & 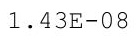 & 8 & 08 \\
\hline & & & & & & & \\
\hline 32 & 07 & 3. & 1 & & 1 & 8 & 08 \\
\hline$E-32$ & $2.18 E-07$ & 3. & 2. & 4.58 & 1.52 & -08 & -08 \\
\hline & 2.2 & & & & & & \\
\hline & 2.2 & 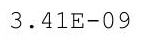 & & & $1.39 E-$ & & \\
\hline & 2.2 & & & & 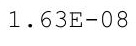 & & $\begin{array}{ll}\Delta \\
0\end{array}$ \\
\hline-32 & $33 E-07$ & $4 E-09$ & $3.10 \mathrm{E}-15$ & $E-09$ & $67 E-08$ & $6 E-08$ & -08 \\
\hline
\end{tabular}


RESRAD-OFFSITE, Version 2.5

obabilistic Dose and Risk Report

Title : Offsite Resident Farmer Deterministic Run

File : RF TC99 DOESG FWD-FV2b.ROF

Summary of dose at graphical times, reptition 1 (continued)

Time

Years

$2.59 \mathrm{E}+02$

$2.60 \mathrm{E}+02$

2. $60 \mathrm{E}+02$

2. $61 \mathrm{E}+02$

2. $61 E+02$

2. $62 \mathrm{E}+02$

$2.63 \mathrm{E}+02$

2. $63 \mathrm{E}+02$

2. $64 \mathrm{E}+02$

2. $64 \mathrm{E}+02$

2. $65 \mathrm{E}+02$

2. $65 \mathrm{E}+02$

$2.66 \mathrm{E}+02$

$2.66 \mathrm{E}+02$

$2.67 \mathrm{E}+02$

$2.67 \mathrm{E}+02$

$2.68 \mathrm{E}+02$

$2.68 \mathrm{E}+02$

$2.69 \mathrm{E}+02$

$2.69 \mathrm{E}+02$

$2.70 \mathrm{E}+02$

$2.70 \mathrm{E}+02$

$2.71 \mathrm{E}+02$

$2.71 \mathrm{E}+02$

2. $72 \mathrm{E}+02$

$2.72 \mathrm{E}+02$

$2.73 E+02$

$2.73 E+02$

$2.74 \mathrm{E}+02$

$2.74 \mathrm{E}+02$

2. $75 \mathrm{E}+02$

$2.75 \mathrm{E}+02$

2. $76 \mathrm{E}+02$

$2.76 \mathrm{E}+02$

$2.77 \mathrm{E}+02$

$2.77 \mathrm{E}+02$

$2.78 \mathrm{E}+02$

$2.78 \mathrm{E}+02$

$2.79 \mathrm{E}+02$

$2.79 \mathrm{E}+02$

$2.80 \mathrm{E}+02$

$2.80 \mathrm{E}+02$

$2.81 \mathrm{E}+02$

$2.81 \mathrm{E}+02$

$2.82 \mathrm{E}+02$

$2.82 \mathrm{E}+02$
Dose statistics at graphical times, mrem/yr

\begin{tabular}{|c|c|c|c|c|c|c|c|}
\hline $\mathrm{m}$ & aximum & lea & ed & $0 \%$ & & $\%$ & \\
\hline $84 E-32$ & $2.37 E-07$ & $3.61 E-09$ & $15 E-15$ & $13 E-09$ & $1.70 \mathrm{E}-08$ & .08 & $.30 E-00$ \\
\hline $85 E-32$ & $2.42 E-07$ & $7 E-09$ & $E-15$ & $25 E-09$ & $1.74 \mathrm{E}-08$ & $4.02 E-08$ & $0 E-08$ \\
\hline $85 E-32$ & $2.46 \mathrm{E}-07$ & $74 \mathrm{E}-09$ & 1. $26 \mathrm{E}-14$ & $36 E-09$ & $1.78 \mathrm{E}-08$ & $4.09 \mathrm{E}-08$ & $4 E-08$ \\
\hline $85 E-32$ & $50 \mathrm{~F}-07$ & $81 \mathrm{~F}-09$ & $90 \mathrm{~F}-14$ & $49 F-09$ & $82 F-08$ & $.17 \mathrm{E}-08$ & $79 E-08$ \\
\hline-32 & -07 & 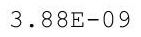 & 4 & 9 & 8 & 8 & -08 \\
\hline-32 & $2.58 \mathrm{E}-07$ & & & & & & \\
\hline $86 \mathrm{E}-32$ & $2.63 E-07$ & & & & & & \\
\hline-32 & -07 & 9 & 4 & 9 & 8 & 88 & $E-08$ \\
\hline-32 & $2.71 \mathrm{E}-07$ & $8 E-09$ & $E-13$ & 09 & 08 & -08 & $E-08$ \\
\hline $87 E-32$ & $76 E-07$ & 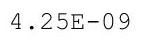 & $.53 E-13$ & תم२ & & 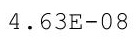 & -08 \\
\hline 32 & 07 & & & & & & 8 \\
\hline $87 E-32$ & $2.85 E-07$ & 4 & 3 & 71 & & 8 & 08 \\
\hline $.87 E-32$ & $2.89 \mathrm{E}-07$ & $4.49 E-09$ & & $6.72 E-09$ & & & $01 E-07$ \\
\hline $88 E-32$ & $2.94 \mathrm{E}-07$ & $4.57 \mathrm{E}-09$ & $4.31 \mathrm{E}-13$ & $6.87 \mathrm{E}-$ & & $E-08$ & $02 E-07$ \\
\hline-32 & $99 E-07$ & $E-09$ & $E-13$ & F & & 08 & $4 E-07$ \\
\hline-32 & 0.00 & ( & 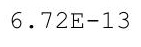 & 9 & תח & 08 & 07 \\
\hline 2 & 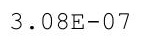 & & & & & & \\
\hline 32 & 3 & $4.90 E-09$ & 2 & & & $8 E-08$ & 7 \\
\hline $89 E-32$ & $3.18 \mathrm{E}-07$ & $4.98 E-09$ & 1. $23 \mathrm{E}-12$ & $7.66 \mathrm{E}-09$ & $2.41 \mathrm{E}-0$ & $E-08$ & $.10 E-07$ \\
\hline $89 E-32$ & $23 E-07$ & $.07 E-09$ & 1. $48 \mathrm{E}-12$ & $32 E-09$ & $2.45 \mathrm{E}-08$ & $E-08$ & $.11 \mathrm{E}-07$ \\
\hline-32 & 3 & & & & & -08 & $E-07$ \\
\hline 32 & 07 & & 2 & 9 & & 8 & -07 \\
\hline-32 & 3.3 & 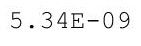 & & 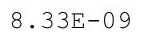 & & & \\
\hline-32 & 3. & $5.43 E-09$ & 2 & 9 & & 3 & 07 \\
\hline 2 & 7 & 9 & 2 & 9 & $2.68 E-08$ & 8 & 07 \\
\hline $91 E-32$ & $54 \mathrm{~F}-07$ & $=61=-09$ & $E-12$ & ( & $273 \pi$ & $E-C$ & $.22 \mathrm{E}-07$ \\
\hline $91 E-32$ & $359 F-07$ & $71 \mathrm{~F}-09$ & $4 \mathrm{E}-12$ & & & $5 E-08$ & $.24 \mathrm{E}-07$ \\
\hline 32 & & & & & & & \\
\hline 32 & $3.70 \mathrm{E}-07$ & $3.90 \mathrm{~L}$ & 2 & 9 & 2 & & 07 \\
\hline $92 E-32$ & $3.15 E-01$ & $0.005-09$ & $7.15 \mathrm{E}-12$ & $9.64 \mathrm{E}-09$ & 2. & $5 E-08$ & $.29 E-07$ \\
\hline $92 E-32$ & $3.81 \mathrm{E}-07$ & $6.10 \mathrm{E}-09$ & $8.28 \mathrm{E}-12$ & . & $2 \cdot 20$ & $.55 E-08$ & $.31 E-07$ \\
\hline 2 & 政 & 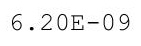 & - & 土. & 象 & . OU一 & $.33 E-07$ \\
\hline$F-32$ & $92 \mathrm{~F}-07$ & $630 \mathrm{~F}-09$ & $5-11$ & 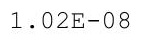 & 8 & & $.36 E-07$ \\
\hline 32 & 07 & & & & & & \\
\hline $93 E-32$ & $4.04 \mathrm{E}-07$ & 6 & 1 & 8 & & & -07 \\
\hline $93 E-32$ & $4.09 \mathrm{E}-07$ & $6.62 E-09$ & 1. $51 \mathrm{E}-11$ & $\perp \cdot 0$ - & 3.201 & 8 & $\pm \angle E-U 1$ \\
\hline $94 \mathrm{E}-32$ & 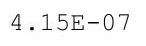 & . $12+40$ & $1.66 \mathrm{E}-11$ & $1 \cdot 11 E-08$ & & & \\
\hline $94 E-32$ & $4 \cdot 2 \perp 5$ & & & & & & \\
\hline 2 & 4 & 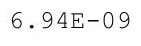 & L & 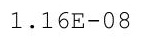 & 8 & 8 & 7 \\
\hline 2 & & & 1 & 8 & 8 & & \\
\hline$E-32$ & $4.39 E-07$ & $7 E-09$ & $E-11$ & 1 & 3 & 8 & -07 \\
\hline$E-32$ & $4.45 E-07$ & 09 & 2. & 1.22 & & & 07 \\
\hline$E-32$ & $4.52 \mathrm{E}-07$ & & & & & & \\
\hline 2 & 4.001 & (.) & ( & 20 & 8 & & $\begin{array}{ll}1.00 \\
0\end{array}$ \\
\hline $96 E-32$ & (1) & & . & 8 & 8 & & $1.0<+$ \\
\hline-32 & $E-07$ & $5 E-09$ & $69 \mathrm{E}-11$ & $33 E-08$ & $85 E-08$ & $E-08$ & -07 \\
\hline
\end{tabular}


RESRAD-OFFSITE, Version 2.5

$\mathrm{T}^{1 / 2}$ Limit $=180$ days

Title : Offsite Resident Farmer Deterministic Run

File : RF TC99 DOESG FWD-FV2b.ROF

Summary of dose at graphical times, reptition 1 (continued)

Time

Years

$2.83 \mathrm{E}+02$

$2.84 \mathrm{E}+02$

$2.84 \mathrm{E}+02$

$2.85 \mathrm{E}+02$

$2.85 \mathrm{E}+02$

2. $86 \mathrm{E}+02$

$2.86 \mathrm{E}+02$

$2.87 \mathrm{E}+02$

$2.87 \mathrm{E}+02$

$2.88 \mathrm{E}+02$

2. $88 \mathrm{E}+02$

$2.89 \mathrm{E}+02$

$2.89 \mathrm{E}+02$

2. $90 \mathrm{E}+02$

2. $90 \mathrm{E}+02$

2. $91 \mathrm{E}+02$

2. $91 \mathrm{E}+02$

2. $92 \mathrm{E}+02$

2. $92 \mathrm{E}+02$

$2.93 \mathrm{E}+02$

2. $93 \mathrm{E}+02$

2. $94 \mathrm{E}+02$

$2.94 \mathrm{E}+02$

2. $95 \mathrm{E}+02$

2. $95 \mathrm{E}+02$

2. $96 \mathrm{E}+02$

$2.96 \mathrm{E}+02$

2. $97 \mathrm{E}+02$

$2.97 \mathrm{E}+02$

2. $98 \mathrm{E}+02$

$2.98 \mathrm{E}+02$

$2.99 \mathrm{E}+02$

2. $99 \mathrm{E}+02$

$3.00 \mathrm{E}+02$

$3.00 \mathrm{E}+02$

3. $01 \mathrm{E}+02$

$3.01 \mathrm{E}+02$

$3.02 \mathrm{E}+02$

$3.02 \mathrm{E}+02$

$3.03 \mathrm{E}+02$

$3.04 \mathrm{E}+02$

$3.04 \mathrm{E}+02$

$3.05 \mathrm{E}+02$

$3.05 \mathrm{E}+02$

$3.06 \mathrm{E}+02$

$3.06 \mathrm{E}+02$
Dose statistics at graphical times, mrem/yr

\begin{tabular}{|c|c|c|c|c|c|c|c|}
\hline $\mathrm{m}$ & aximum & lean & edi & & & & \\
\hline $96 E-32$ & $4.77 E-07$ & $7.87 E-09$ & $4.05 E-11$ & $1.36 \mathrm{E}-08$ & $3.92 E-08$ & 08 & $1.00 E-01$ \\
\hline $97 E-32$ & $4.83 E-07$ & $7.99 \mathrm{E}-09$ & $4.37 \mathrm{E}-11$ & $1.38 \mathrm{E}-08$ & $98 E-08$ & $31 E-08$ & $9 E-07$ \\
\hline $97 E-32$ & $4.90 \mathrm{E}-07$ & $8.11 \mathrm{E}-09$ & $4.80 \mathrm{E}-11$ & 1. $41 \mathrm{E}-08$ & $04 \mathrm{E}-08$ & $42 E-08$ & $.71 E-07$ \\
\hline $97 E-32$ & $96 \mathrm{~F}-07$ & $24 \mathrm{~F}-09$ & $14 \mathrm{~F}-11$ & $43 E-08$ & $10 F-08$ & -08 & $74 \mathrm{~F}-07$ \\
\hline-32 & -07 & 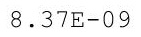 & $5.53 \mathrm{E}-11$ & 8 & & 8 & -07 \\
\hline $98 E-32$ & -07 & & & & & & 07 \\
\hline $98 E-32$ & $5.16 \mathrm{E}-07$ & & & & & & -07 \\
\hline-32 & -07 & 9 & $\perp$ & 8 & 8 & 8 & -07 \\
\hline $98 E-32$ & $5.30 \mathrm{E}-07$ & $8 E-09$ & -11 & $1.56 \mathrm{E}-08$ & $46 E-08$ & $E-08$ & $86 E-07$ \\
\hline $99 E-32$ & $37 E-07$ & 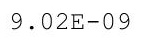 & $47 \mathrm{E}-11$ & 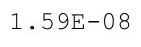 & 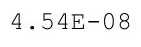 & $18 E-08$ & 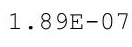 \\
\hline 32 & 07 & & & & & & 7 \\
\hline $99 E-32$ & $5.51 \mathrm{E}-07$ & 9 & & 1 . & 8 & 8 & 07 \\
\hline $99 \mathrm{E}-32$ & $5.58 \mathrm{E}-07$ & & & $1.67 E-08$ & & & $1.96 \mathrm{E}-07$ \\
\hline $00 E-32$ & $5.65 \mathrm{E}-07$ & $9.57 \mathrm{E}-09$ & $9.58 \mathrm{E}-11$ & & 8 & -08 & $1.99 \mathrm{E}-07$ \\
\hline-32 & $E-07$ & $E-09$ & & & & 0 & $E-07$ \\
\hline-32 & 0.001 & ل תזم: & & 1.70 & & 0 & 07 \\
\hline 2 & 5 & & & & & & \\
\hline 32 & 5 & 1. $01 \mathrm{E}-08$ & & $1.82 \mathrm{E}-08$ & & & 7 \\
\hline $01 \mathrm{E}-32$ & $6.02 \mathrm{E}-07$ & $1.03 E-08$ & $1.27 \mathrm{E}-10$ & $1.85 \mathrm{E}-08$ & $5.26 E-08$ & $1.02 \mathrm{E}-07$ & $2.12 \mathrm{E}-07$ \\
\hline$E-32$ & $6.09 \mathrm{E}-07$ & $.04 \mathrm{E}-08$ & 1. $33 \mathrm{E}-10$ & $1.89 \mathrm{E}-08$ & 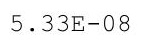 & $3 E-07$ & $2.14 \mathrm{E}-07$ \\
\hline-32 & $75-07-2-3$ & & & & & $.05 E-07$ & $17 E-07$ \\
\hline 32 & 07 & & & & & & -07 \\
\hline 32 & 6.3 & $1.09 \mathrm{E}-08$ & 1. & & 8 & & -07 \\
\hline-32 & 6 & $\perp$ & 1. $62 \mathrm{E}-10$ & 0 & $5.62 \mathrm{E}-08$ & 1 & -07 \\
\hline 2 & 7 & 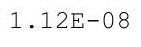 & 1. $70 \mathrm{E}-10$ & 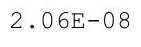 & 3 & 7 & -07 \\
\hline$E-32$ & $5.55 E-07$ & $1.14 \mathrm{E}-08$ & 170 & $10 \mathrm{E}-08$ & סרקה & $.11 \mathrm{E}-07$ & $.31 E-07$ \\
\hline-32 & $663 F-07$ & $15 E-08$ & $E-10$ & & & $1.12 \mathrm{E}-07$ & $.33 E-07$ \\
\hline & & & & & & & \\
\hline 32 & $6.79 \mathrm{E}-07$ & $1 \cdot 1$ & & 0 & & & 07 \\
\hline $04 E-32$ & $0.01 \mathrm{E}-01$ & $1.20 E-00$ & $2 \cdot 1 J \pm-10$ & $2.26 \mathrm{E}-08$ & $\cdot 100$ & $\perp \cdot 10 E-0 t$ & $2.42 E-07$ \\
\hline $04 \mathrm{E}-32$ & $6.95 E-07$ & 1. $22 \mathrm{E}-08$ & $2 \cdot 205-10$ & 2.000 & - & $\perp \cdot \perp / \mathrm{L}-U$ & $2.45 E-07$ \\
\hline 2 & 正 & 土. & 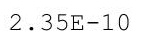 & 2.0 & 6. & 2.50 & $2.48 \mathrm{E}-07$ \\
\hline 32 & $711 \mathrm{~F}-07$ & 1 & $F-10$ & & & & $2.51 E-07$ \\
\hline 2 & & & & & & 7 & 07 \\
\hline$E-32$ & $7.28 E-07$ & 1 . & 0 & 8 & & & $E-07$ \\
\hline $06 E-32$ & $7.36 \mathrm{E}-07$ & $1.30 \mathrm{E}-08$ & $2.74 \mathrm{E}-10$ & $2.50 E-08$ & $0<1$ & -07 & $2.60 E-07$ \\
\hline $06 E-32$ & $1.40 \pm-1$ & $1 \cdot 32+40$ & $2.85 \pm-10$ & & & & $2.63 E-07$ \\
\hline-32 & . & म. & & $2.00 \mathrm{~L}-00$ & & & $2.66 \mathrm{E}-07$ \\
\hline 2 & r & t & 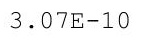 & 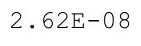 & 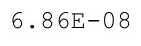 & 7 & 07 \\
\hline 2 & & & & & & & \\
\hline-32 & $7.79 E-07$ & 1.3 & $E-10$ & 2 . & 8 & 07 & -07 \\
\hline$E-32$ & $7.88 \mathrm{E}$ & $1.41 \mathrm{E}$ & 0 & & & 07 & -07 \\
\hline & & & & & & & $2.81 E-07$ \\
\hline 2 & 0.00 & 土. & . & . & $33 E-08$ & $1.37 \mathrm{E}-07$ & $2.84 \mathrm{E}-07$ \\
\hline & & म. & & 2.0 & & $1.38 \mathrm{E}-07$ & $2.87 E-07$ \\
\hline 2 & $E-07$ & $9 E-08$ & $3 E-10$ & $92 E-08$ & $E-08$ & $0 E-07$ & -07 \\
\hline
\end{tabular}


RESRAD-OFFSITE, Version 2.5

itle : Offsite Resident Farmer Deterministic Run

File : RF TC99 DOESG FWD-FV2b.ROF

Summary of dose at graphical times, reptition 1 (continued)

Time

Years

$3.07 \mathrm{E}+02$

$3.07 \mathrm{E}+02$

$3.08 \mathrm{E}+02$

$3.08 \mathrm{E}+02$

$3.09 \mathrm{E}+02$

$3.09 \mathrm{E}+02$

$3.10 \mathrm{E}+02$

$3.10 \mathrm{E}+02$

$3.11 \mathrm{E}+02$

$3.11 E+02$

$3.12 \mathrm{E}+02$

$3.12 \mathrm{E}+02$

$3.13 \mathrm{E}+02$

$3.13 \mathrm{E}+02$

$3.14 \mathrm{E}+02$

$3.14 \mathrm{E}+02$

$3.15 \mathrm{E}+02$

$3.15 \mathrm{E}+02$

$3.16 \mathrm{E}+02$

$3.16 \mathrm{E}+02$

$3.17 \mathrm{E}+02$

$3.17 \mathrm{E}+02$

$3.18 \mathrm{E}+02$

$3.18 \mathrm{E}+02$

$3.19 \mathrm{E}+02$

$3.19 \mathrm{E}+02$

$3.20 \mathrm{E}+02$

$3.20 \mathrm{E}+02$

$3.21 \mathrm{E}+02$

$3.21 \mathrm{E}+02$

$3.22 \mathrm{E}+02$

$3.22 \mathrm{E}+02$

$3.23 \mathrm{E}+02$

$3.24 \mathrm{E}+02$

$3.24 \mathrm{E}+02$

$3.25 \mathrm{E}+02$

$3.25 \mathrm{E}+02$

$3.26 \mathrm{E}+02$

$3.26 \mathrm{E}+02$

$3.27 \mathrm{E}+02$

$3.27 \mathrm{E}+02$

$3.28 \mathrm{E}+02$

$3.28 \mathrm{E}+02$

$3.29 \mathrm{E}+02$

$3.29 \mathrm{E}+02$

$3.30 \mathrm{E}+02$
Dose statistics at graphical times, mrem/yr

\begin{tabular}{|c|c|c|c|c|c|c|c|}
\hline $\mathrm{m}$ & aximum & lean & ed & & & & \\
\hline $.09 E-32$ & $8.32 \mathrm{E}-07$ & $1.51 \mathrm{E}-08$ & $4.07 \mathrm{E}-10$ & 8 & 08 & 7 & $.935-01$ \\
\hline $09 E-32$ & $8.41 E-07$ & $1.53 \mathrm{E}-08$ & $4.19 \mathrm{E}-10$ & $1 E-08$ & $75 E-08$ & $1.43 E-07$ & $96 \mathrm{E}-07$ \\
\hline-32 & $51 E-07$ & $54 \mathrm{~F}-08$ & $32 E-10$ & $06 E-08$ & $86 E-08$ & $45 E-07$ & $99 E-07$ \\
\hline-32 & -07 & $56 \mathrm{~F}-08$ & $46 \mathrm{~F}-10$ & $11 \mathrm{E}-08$ & $97 F-08$ & $47 F-07$ & $02 \mathrm{~F}-07$ \\
\hline 32 & 07 & 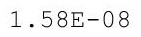 & 0 & 8 & 8 & 7 & 07 \\
\hline 32 & & & & & & & 07 \\
\hline $10 \mathrm{E}-32$ & $8.88 \mathrm{E}-07$ & & & & & & -07 \\
\hline-32 & -07 & 0 & 0 & 8 & 8 & 7 & $E-07$ \\
\hline $1 E-32$ & $9.06 \mathrm{E}-07$ & $7 E-08$ & -10 & $6 \mathrm{E}-08$ & $2 E-08$ & $E-0$ & $E-07$ \\
\hline 32 & $E-07$ & Г & $35 E-10$ & ק & & $8 \mathrm{~F}=0-3 \mathrm{C}$ & 7 \\
\hline 32 & 07 & 1 & & & & $-x_{-1}$ & 07 \\
\hline $12 E-32$ & $9.35 E-07$ & 1. & & 8 & 8 & 7 & 07 \\
\hline $12 E-32$ & $9.45 E-07$ & $1.75 \mathrm{E}-08$ & $5.93 \mathrm{E}-10$ & & & $1.63 \mathrm{E}-07$ & $E-07$ \\
\hline $12 E-32$ & $9.54 \mathrm{E}-07$ & 1. $77 \mathrm{E}-08$ & $6.14 \mathrm{E}-10$ & & & $1.65 \mathrm{E}-07$ & $.37 E-07$ \\
\hline$E-32$ & -07 & -08 & $E-10$ & & & 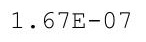 & $E-07$ \\
\hline-32 & 1 & $\pm \cdot$ & \pm 0 & 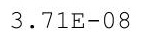 & 0 & 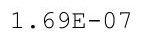 & 07 \\
\hline 2 & 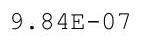 & $\perp$ & & & & & \\
\hline 2 & 7 & 1 & $6.93 E-10$ & $382 F-08$ & te & $1.73 E-07$ & 7 \\
\hline $14 \mathrm{E}-32$ & $1.00 \mathrm{E}-06$ & $1.89 \mathrm{E}-08$ & $7.13 \mathrm{E}-10$ & $3.88 E-08$ & $9.79 E-08$ & $1.75 \mathrm{E}-0$ & $.56 E-07$ \\
\hline-32 & $.01 \mathrm{E}-06$ & 1. $91 \mathrm{E}-08$ & $.34 E-10$ & $4 \mathrm{E}-08$ & 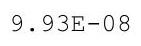 & $1.77 \mathrm{E}-07$ & $60 E-07$ \\
\hline 32 & 06 & $1.93 E-08$ & & & & $E-0$ & $E-07$ \\
\hline 32 & & & & & & & -07 \\
\hline 32 & $1 \cdot 0$ & 1.9 & & & 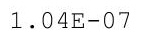 & & -07 \\
\hline-32 & 1. & 2 & 0 & 8 & 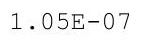 & $1.85 E-07$ & -07 \\
\hline 2 & 6 & $2.03 E-08$ & 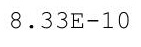 & 8 & te & 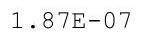 & $79 E-07$ \\
\hline$E-32$ & $.08 E-06$ & $05 \square$ & $5-10$ & כ2 קט & $.08 \mathrm{E}-$ & $1.89 \mathrm{E}-0$ & $.83 E-07$ \\
\hline-32 & $109 F-06$ & $F-08$ & $E-10$ & & & $=0$ & $.87 E-07$ \\
\hline & & & & & & & \\
\hline & 00 & $2 \cdot$ & 0 & 8 & & & -07 \\
\hline $17 E-32$ & $1 \cdot \perp \angle E-U 6$ & $2 \cdot \perp コ \pm 00$ & $9.50 \mathrm{E}-10$ & $4.59 \mathrm{E}-08$ & $\perp \cdot \pm I+$ & 土. & $.99 E-07$ \\
\hline $7 E-32$ & $1.13 E-06$ & $2 \cdot+1000$ & $.10 \mathrm{x}-10$ & $\cdot 00$ & 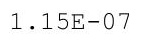 & 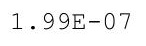 & 4.03E-07 \\
\hline 2 & $\perp \cdot \perp I$ & 20. & - & - & 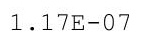 & 然 & $4.08 \mathrm{E}-07$ \\
\hline 32 & $15 \mathrm{~F}-06$ & 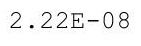 & $E-09$ & & 11 & & $.12 \mathrm{E}-07$ \\
\hline 2 & & & & & & & 07 \\
\hline-32 & & & & & & & -07 \\
\hline $9 E-32$ & $1.18 \mathrm{E}-06$ & $2.30 \pm-00$ & 1.11E-09 & $5.03 E-08$ & $\perp \cdot 2 \perp$ & $2 \cdot$ & $E-07$ \\
\hline $9 E-32$ & $\perp \cdot \perp+\operatorname{L} 00$ & 2.001 & & & res & & $.28 E-07$ \\
\hline 32 & $\pm \cdot 201$ & 2.000 b & & & $1 \cdot 245-01$ & & $4.33 E-07$ \\
\hline 2 & $\perp$ & 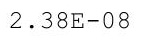 & $1.19 \mathrm{E}-09$ & 8 & 7 & 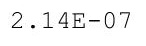 & 07 \\
\hline 2 & & & & & & & 07 \\
\hline 32 & $1.24 \mathrm{E}$ & $2.44 \mathrm{E}-08$ & 1 . & 8 & & 7 & $6 E-07$ \\
\hline$E-32$ & $1.25 E-06$ & $2.46 \mathrm{E}$ & 1.2 & & 1.2 & & -07 \\
\hline & 6 & & & & & & -07 \\
\hline & $\perp \cdot 21 \mathrm{~L}$ & . & +. & - & $\perp \cdot J \perp+$ & $2.25 E-07$ & $4.59 E-07$ \\
\hline & $\pm \cdot 2$ & $2.00=$ & & & & & $4.63 E-07$ \\
\hline 2 & $1.29 \mathrm{E}-06$ & $.58 E-08$ & $1.41 E-09$ & $E-08$ & $E-07$ & $30 E-07$ & -07 \\
\hline
\end{tabular}


RESRAD-OFFSITE, Version 2.5

$\mathrm{T}^{1 / 2}$ Limit $=180$ days

obabilistic Dose and Risk Report

Title : Offsite Resident Farmer Deterministic Run

File : RF TC99 DOESG FWD-FV2b.ROF

Summary of dose at graphical times, reptition 1 (continued)

Time

Years

$3.30 \mathrm{E}+02$

$3.31 \mathrm{E}+02$

$3.31 \mathrm{E}+02$

$3.32 \mathrm{E}+02$

$3.32 \mathrm{E}+02$

$3.33 \mathrm{E}+02$

$3.33 \mathrm{E}+02$

$3.34 \mathrm{E}+02$

$3.34 \mathrm{E}+02$

$3.35 \mathrm{E}+02$

$3.35 \mathrm{E}+02$

$3.36 \mathrm{E}+02$

3. $36 \mathrm{E}+02$

3. $37 \mathrm{E}+02$

3. $37 \mathrm{E}+02$

3. $38 \mathrm{E}+02$

$3.38 \mathrm{E}+02$

$3.39 \mathrm{E}+02$

3. $39 \mathrm{E}+02$

3. $40 \mathrm{E}+02$

$3.40 \mathrm{E}+02$

$3.41 \mathrm{E}+02$

$3.41 \mathrm{E}+02$

3. $42 \mathrm{E}+02$

$3.42 \mathrm{E}+02$

3. $43 \mathrm{E}+02$

$3.44 \mathrm{E}+02$

$3.44 \mathrm{E}+02$

$3.45 \mathrm{E}+02$

$3.45 \mathrm{E}+02$

$3.46 \mathrm{E}+02$

$3.46 \mathrm{E}+02$

$3.47 \mathrm{E}+02$

$3.47 \mathrm{E}+02$

$3.48 \mathrm{E}+02$

$3.48 \mathrm{E}+02$

$3.49 \mathrm{E}+02$

3. $49 \mathrm{E}+02$

$3.50 \mathrm{E}+02$

$3.50 \mathrm{E}+02$

$3.51 \mathrm{E}+02$

3. $51 \mathrm{E}+02$

3. $52 \mathrm{E}+02$

$3.52 \mathrm{E}+02$

3. $53 \mathrm{E}+02$

$3.53 \mathrm{E}+02$
Dose statistics at graphical times, mrem/yr

\begin{tabular}{|c|c|c|c|c|c|c|c|}
\hline $\mathrm{m}$ & aximum & lea & - & & & & \\
\hline $22 E-32$ & $1.31 \mathrm{E}-06$ & $60 E-08$ & 1. $44 \mathrm{E}-09$ & $5.80 \mathrm{E}-08$ & $1.35 \mathrm{E}-07$ & -07 & $.1 \angle E-U 1$ \\
\hline $22 E-32$ & 1. $32 E-06$ & $2.63 E-08$ & $1.47 \mathrm{E}-09$ & $38 E-08$ & $1.37 \mathrm{E}-07$ & $2.36 \mathrm{E}-07$ & $7 E-07$ \\
\hline-32 & $33 E-06$ & $66 \mathrm{E}-08$ & $50 E-09$ & $5 E-08$ & $38 E-07$ & $.38 E-07$ & $81 E-07$ \\
\hline $23 E-32$ & $34 \mathrm{E}-06$ & $69 F-08$ & $.53 E-09$ & $02 E-08$ & $39 F-07$ & $41 F-07$ & $86 \mathrm{~F}-07$ \\
\hline-32 & 06 & 8 & 9 & 8 & -07 & -07 & 07 \\
\hline 32 & 06 & & & & & & 07 \\
\hline $23 E-32$ & $1.38 \mathrm{E}-06$ & $2.78 E-08$ & & & & & $E-07$ \\
\hline-32 & 06 & 0 & 09 & 8 & 7 & -07 & -07 \\
\hline $24 E-32$ & $0 E-06$ & $84 E-0$ & 1. $71 \mathrm{E}-09$ & $39 E-08$ & $400-01$ & $E-0$ & $E-07$ \\
\hline $4 E-32$ & $1.41 \mathrm{E}-06$ & 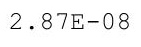 & $5 E-09$ & תר & 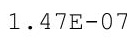 & 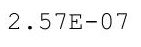 & 7 \\
\hline 32 & 06 & & 1. & & & 7 & 7 \\
\hline $25 E-32$ & $1.43 E-06$ & 8 & $1 . \varepsilon$ & 8 & 1 & 7 & -07 \\
\hline $25 E-32$ & $1.45 E-06$ & $2.96 \mathrm{E}-08$ & $1.87 \mathrm{E}-09$ & & $1.51 \mathrm{E}-07$ & $2.65 E-07$ & $28 E-07$ \\
\hline $25 E-32$ & $1.46 \mathrm{E}-06$ & $.99 \mathrm{E}-08$ & 1. $91 \mathrm{E}-09$ & $6.83 E-08$ & 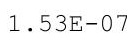 & $E-0$ & $E-07$ \\
\hline-32 & 06 & 0 & 9 & & & 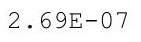 & $E-07$ \\
\hline 32 & 06 & $3.06 \mathrm{E}-08$ & - & 8 & $1.55 \mathrm{E}-07$ & 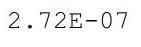 & 7 \\
\hline 32 & $\perp$ & $09 E-08$ & & & $57 E-07$ & & 7 \\
\hline 32 & 1. & $3.12 \mathrm{E}-08$ & 9 & 8 & $1.58 \mathrm{E}-07$ & $2.76 \mathrm{E}-07$ & 07 \\
\hline $50 E-32$ & $1.52 \mathrm{E}-06$ & $3.16 \mathrm{E}-08$ & $2.14 \mathrm{E}-09$ & $.26 \mathrm{E}-08$ & 1. $59 \mathrm{E}-0$ & $2.79 \mathrm{E}-0$ & $.57 E-07$ \\
\hline$E-32$ & $1.53 \mathrm{E}-06$ & $.19 \mathrm{E}-08$ & $2.19 \mathrm{E}-09$ & $7.35 E-08$ & $1.61 \mathrm{E}-$ & $2.81 E-07$ & $61 E-07$ \\
\hline 31 & 06 & & & & & $E-07$ & $E-07$ \\
\hline 31 & & & & & 7 & & 07 \\
\hline קי & $\perp$ & & & & & $2.89 E-07$ & -07 \\
\hline $23 E-31$ & 1.5 & 0 & 2. & 8 & 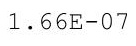 & $2.92 \mathrm{E}-07$ & -07 \\
\hline 1 & 6 & 36 & 2.4 & 8 & $.68 \mathrm{E}-$ & $2.95 E-0$ & 07 \\
\hline $24 E-31$ & $1.61 \mathrm{E}-06$ & $39 F-08$ & $2.48 \mathrm{E}-09$ & $.87 E-08$ & $1.70 \mathrm{E}-$ & $.98 E-0$ & $.89 E-07$ \\
\hline-31 & $1.62 \mathrm{E}-06$ & $42 E-08$ & $.53 E-09$ & $95 E-08$ & & 50 & $94 \mathrm{E}-07$ \\
\hline & & & & & & & \\
\hline & & & & & $t$ & 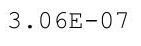 & -07 \\
\hline $26 \mathrm{E}-31$ & $1.66 \mathrm{E}-06$ & $3.35 E-00$ & $2.68 \mathrm{E}-09$ & $.26 E-08$ & 土. & . & $5.08 E-07$ \\
\hline $26 \mathrm{E}-31$ & $1.67 \mathrm{E}-06$ & $80 \mathrm{ar}-00$ & $2.73 E-09$ & $36 \mathrm{E}-08$ & $1.78 \mathrm{E}-07$ & -5 & $.13 E-07$ \\
\hline 1 & +.000 - & $3.60 \mathrm{E}-0$ & & & & & $17 \mathrm{E}-07$ \\
\hline $27 E-31$ & $170 F-06$ & $3 E-08$ & $E-09$ & $3 E-08$ & 210 & 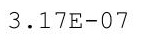 & $2 E-07$ \\
\hline 31 & & & & & & & \\
\hline 31 & & & & & 7 & & \\
\hline $28 \mathrm{E}-31$ & $1.74 \mathrm{E}-06$ & $3.14 \mathrm{E}-08$ & $3.01 E-09$ & $8.90 \mathrm{E}-08$ & 土・配 & $4 \pm-01$ & $.37 E-07$ \\
\hline $28 E-31$ & $1.75 \mathrm{E}-06$ & . $10 \mathrm{~L}$ प & & & & & $0.41 \mathrm{E}-01$ \\
\hline $29 E-31$ & $1.76 \mathrm{E}-06$ & 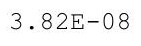 & & & & & $6.46 \mathrm{E}-07$ \\
\hline 1 & $1.78 \mathrm{E}-06$ & $3.85 \mathrm{E}-08$ & $3.18 \mathrm{E}-09$ & 8 & 7 & 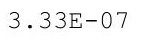 & 07 \\
\hline 31 & & & & & & & \\
\hline $30 E-31$ & $1.80 \mathrm{E}$ & 3.9 & 09 & 8 & & & 07 \\
\hline$E-31$ & $1.82 \mathrm{E}$ & 3.971 & 99 & 8 & & & -07 \\
\hline & & & & & & & $5.71 \mathrm{E}-07$ \\
\hline $31 E-31$ & $1.84 \mathrm{E}-06$ & $7.045-00$ & $3.49 E-09$ & $9.79 \mathrm{E}-08$ & $2.05 E-07$ & $3.4 / E-0 /$ & $6.76 \mathrm{E}-07$ \\
\hline $31 E-31$ & $1.00 \mathrm{~L}-0$ & .000 & $3.54 \mathrm{E}-09$ & $.00 \mathrm{E}$ & & & . 10 \\
\hline $32 E-31$ & $1.87 \mathrm{E}-06$ & $E-08$ & $.60 E-09$ & $00 \mathrm{E}-07$ & $.10 E-07$ & $3.52 \mathrm{E}-07$ & -07 \\
\hline
\end{tabular}


RESRAD-OFFSITE, Version 2.5

$\mathrm{T}^{1 / 2}$ Limit $=180$ days

Title : Offsite Resident Farmer Deterministic Run

File : RF TC99 DOESG FWD-FV2b.ROF

Summary of dose at graphical times, reptition 1 (continued)

Time

Years

$3.54 \mathrm{E}+02$

$3.54 \mathrm{E}+02$

3. $55 \mathrm{E}+02$

$3.55 \mathrm{E}+02$

$3.56 \mathrm{E}+02$

3. $56 \mathrm{E}+02$

$3.57 \mathrm{E}+02$

3. $57 \mathrm{E}+02$

$3.58 \mathrm{E}+02$

3. $58 \mathrm{E}+02$

$3.59 \mathrm{E}+02$

3. $59 \mathrm{E}+02$

$3.60 E+02$

$3.60 E+02$

$3.61 \mathrm{E}+02$

3. $61 \mathrm{E}+02$

3. $62 \mathrm{E}+02$

$3.62 \mathrm{E}+02$

$3.63 \mathrm{E}+02$

3. $64 \mathrm{E}+02$

$3.64 \mathrm{E}+02$

$3.65 \mathrm{E}+02$

$3.65 \mathrm{E}+02$

$3.66 \mathrm{E}+02$

$3.66 \mathrm{E}+02$

$3.67 \mathrm{E}+02$

3. $67 \mathrm{E}+02$

$3.68 \mathrm{E}+02$

$3.68 \mathrm{E}+02$

$3.69 \mathrm{E}+02$

3. $69 \mathrm{E}+02$

$3.70 \mathrm{E}+02$

$3.70 \mathrm{E}+02$

$3.71 \mathrm{E}+02$

$3.71 \mathrm{E}+02$

$3.72 \mathrm{E}+02$

$3.72 \mathrm{E}+02$

3. $73 \mathrm{E}+02$

$3.73 E+02$

$3.74 \mathrm{E}+02$

$3.74 \mathrm{E}+02$

$3.75 E+02$

$3.75 \mathrm{E}+02$

$3.76 \mathrm{E}+02$

$3.76 \mathrm{E}+02$

$3.77 \mathrm{E}+02$

Dose statistics at graphical times, mrem/yr

\begin{tabular}{|c|c|c|c|c|c|c|c|}
\hline m & um & ean & ledian & & & $\%$ & \\
\hline $32 E-31$ & $1.88 \mathrm{E}-06$ & $4.16 \mathrm{E}-08$ & $3.65 \mathrm{E}-09$ & $1.01 \mathrm{E}-07$ & -07 & -01 & -01 \\
\hline $32 E-31$ & $1.90 \mathrm{E}-06$ & $0 E-08$ & $1 E-09$ & $1.02 \mathrm{E}-07$ & -07 & $.56 \mathrm{E}-07$ & -07 \\
\hline $.33 E-31$ & $1.91 \mathrm{E}-06$ & $4.24 \mathrm{E}-08$ & $77 E-09$ & $1.03 E-07$ & $2.17 \mathrm{E}-07$ & $3.59 \mathrm{E}-07$ & $.04 \mathrm{E}-07$ \\
\hline $33 E-31$ & $1.92 \mathrm{E}-06$ & $4.28 E-08$ & $3.83 E-09$ & $1.04 \mathrm{E}-07$ & $2.19 \mathrm{E}-07$ & $3.62 \mathrm{E}-07$ & $7.10 \mathrm{E}-07$ \\
\hline $33 E-31$ & 06 & $2 \mathrm{~F}$ & $89 E-09$ & . & 7 & 07 & .07 \\
\hline $34 E-31$ & 06 & 4. $36 \mathrm{E}-08$ & 9 & 7 & $2.24 \mathrm{E}-07$ & 7 & -07 \\
\hline $34 \mathrm{E}-31$ & 06 & & & & 7 & 7 & -07 \\
\hline-31 & & & & & & & -07 \\
\hline 31 & -06 & $F-0$ & -09 & 7 & 7 & -07 & $E-07$ \\
\hline $35 E-31$ & $2.01 \mathrm{E}-06$ & 3 & -09 & 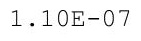 & 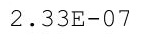 & 7 & -07 \\
\hline 31 & 6 & $4.57 \mathrm{E}-08$ & 9 & $1.11 \mathrm{E}$ & $36 \mathrm{E}-07$ & $6 \mathrm{E}-07$ & 7 \\
\hline 31 & 06 & & & & & & -07 \\
\hline $61 \mathrm{~F}-31$ & $F-06$ & $5 F-0$ & 9 & 1 & $2.41 \mathrm{E}-07$ & 7 & -07 \\
\hline $.63 E-31$ & $2.06 \mathrm{E}-06$ & $4.69 \mathrm{E}-08$ & $4.50 \mathrm{E}-09$ & $1.15 \mathrm{E}-07$ & $2.43 E-07$ & $3.97 \mathrm{E}-07$ & $7.64 \mathrm{E}-07$ \\
\hline-31 & -06 & -08 & 9 & & 7 & & -07 \\
\hline 31 & 6 & 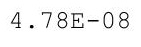 & & 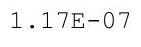 & $2.48 E-07$ & & -07 \\
\hline 31 & 06 & $4.82 \mathrm{E}-08$ & 9 & 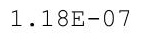 & 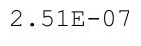 & & 07 \\
\hline 1 & 6 & & & & & & \\
\hline $71 \mathrm{E}-31$ & $2.13 \mathrm{E}-06$ & $.91 E-08$ & $.88 E-09$ & $1.21 \mathrm{E}$ & & $4.16 \mathrm{E}-07$ & -07 \\
\hline $72 E-31$ & $.15 E-06$ & $.95 E-08$ & $E-09$ & $1.22 \mathrm{E}-\mathrm{C}$ & $2.58 \mathrm{E}-$ & $E-0$ & $.96 \mathrm{E}-07$ \\
\hline $74 \mathrm{E}-31$ & $2.16 \mathrm{E}-06$ & $5.00 \mathrm{E}-08$ & $5.03 E-09$ & $1.23 E-07$ & 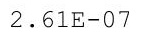 & -0 & $02 \mathrm{E}-07$ \\
\hline 31 & & & & & & & -07 \\
\hline$\perp$ & & & & & & & \\
\hline $.19 E-31$ & 2 & $5.13 E-08$ & & 1.25 & & & -07 \\
\hline 1 & 6 & $5.18 \mathrm{E}-08$ & 9 & 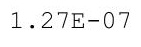 & te & 4. 38E-07 & -07 \\
\hline$E-31$ & $.23 E-06$ & : & $5 E-09$ & 1 & $274 \square$ & 田 & $30 E-07$ \\
\hline-31 & $25 E-06$ & 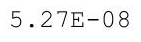 & $.53 E-09$ & 1.30E- & $2.77 \mathrm{E}-$ & $.44 \mathrm{E}-0$ & $.35 E-07$ \\
\hline-31 & & & & 3 & 7 & & $E-07$ \\
\hline-31 & 06 & & & & & & 07 \\
\hline $89 E-31$ & $2.29 E-06$ & $.4 \perp+00$ & $5.78 E-09$ & $1.34 \mathrm{E}-$ & 2.045 & $t$ & -07 \\
\hline $90 E-31$ & $2.30 E-06$ & 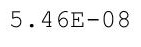 & $5.86 \mathrm{E}-09$ & $1.36 \mathrm{E}-07$ & 2.000 & 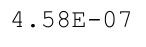 & $.58 E-07$ \\
\hline 1 & 6 & 0 & 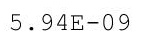 & 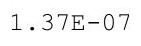 & 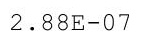 & $x^{2}=-x$ & $8.64 \mathrm{E}-07$ \\
\hline 1 & $2.33 E-06$ & & & & & & 7 \\
\hline-31 & $5-06$ & & & & & 7 & $75 E-07$ \\
\hline 1 & & & & & & & \\
\hline $.99 \mathrm{E}-31$ & $2.38 E-06$ & $5.69 \pm-08$ & $.29 E-09$ & $1.4 \angle \mathrm{E}$ & 2.905 & 7 & $87 E-07$ \\
\hline $0 E-31$ & 2.09 & . & & $+\cdot 11$ & & & -07 \\
\hline $02 E-31$ & $2.41 \mathrm{E}-06$ & & & $=-2$ & & & $8.98 E-07$ \\
\hline 1 & 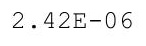 & 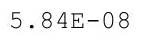 & 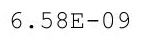 & 7 & 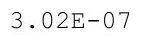 & & 07 \\
\hline & & & & & & & 7 \\
\hline 1 & & & 09 & 1 & 3 & 7 & 07 \\
\hline$E-31$ & $2.47 \mathrm{E}-06$ & $9 E-08$ & 09 & $1.50 \mathrm{E}$ & 3 & -07 & -07 \\
\hline & 6 & & & & & & \\
\hline & & & & 1.000 & & & -07 \\
\hline & 2 & & & 1 & 7 & $E-07$ & $39 E-07$ \\
\hline-31 & $52 E-06$ & $9 E-08$ & $27 E-09$ & $5-07$ & $E-07$ & $.13 E-07$ & -07 \\
\hline
\end{tabular}


RESRAD-OFFSITE, Version 2.5

Title : Offsite Resident Farmer Deterministic Run

File : RF TC99 DOESG FWD-FV2b.ROF

Summary of dose at graphical times, reptition 1 (continued)

Time

Years

$3.77 \mathrm{E}+02$

$3.78 \mathrm{E}+02$

$3.78 \mathrm{E}+02$

$3.79 \mathrm{E}+02$

$3.79 \mathrm{E}+02$

$3.80 \mathrm{E}+02$

$3.80 \mathrm{E}+02$

$3.81 \mathrm{E}+02$

$3.81 E+02$

$3.82 \mathrm{E}+02$

$3.82 \mathrm{E}+02$

$3.83 \mathrm{E}+02$

$3.83 \mathrm{E}+02$

$3.84 \mathrm{E}+02$

$3.85 \mathrm{E}+02$

$3.85 \mathrm{E}+02$

$3.86 \mathrm{E}+02$

$3.86 \mathrm{E}+02$

$3.87 \mathrm{E}+02$

$3.87 \mathrm{E}+02$

$3.88 \mathrm{E}+02$

$3.88 \mathrm{E}+02$

$3.89 \mathrm{E}+02$

$3.89 \mathrm{E}+02$

3. $90 \mathrm{E}+02$

3. $90 \mathrm{E}+02$

3. $91 \mathrm{E}+02$

3. $91 \mathrm{E}+02$

3. $92 \mathrm{E}+02$

3. $92 \mathrm{E}+02$

3. $93 \mathrm{E}+02$

3. $93 \mathrm{E}+02$

$3.94 \mathrm{E}+02$

$3.94 \mathrm{E}+02$

3. $95 \mathrm{E}+02$

$3.95 \mathrm{E}+02$

$3.96 \mathrm{E}+02$

3. $96 \mathrm{E}+02$

3. $97 \mathrm{E}+02$

3. $97 \mathrm{E}+02$

$3.98 \mathrm{E}+02$

3. $98 \mathrm{E}+02$

$3.99 \mathrm{E}+02$

$3.99 \mathrm{E}+02$

$4.00 \mathrm{E}+02$

$4.00 \mathrm{E}+02$
Dose statistics at graphical times, mrem/yr

\begin{tabular}{|c|c|c|c|c|c|c|c|}
\hline Minimum & Maximum & Mean & Median & $90 \%$ & $95 \%$ & $97.5 \%$ & $99 \%$ \\
\hline $4.18 \mathrm{E}-31$ & $2.54 \mathrm{E}-06$ & $6.24 \mathrm{E}-08$ & $7.37 \mathrm{E}-09$ & $1.57 \mathrm{E}-07$ & $3.20 \mathrm{E}-07$ & $5.16 \mathrm{E}-07$ & $9.51 \mathrm{E}-07$ \\
\hline $4.20 \mathrm{E}-31$ & $2.55 E-06$ & $6.29 \mathrm{E}-08$ & $7.48 \mathrm{E}-09$ & $1.58 \mathrm{E}-07$ & $3.23 \mathrm{E}-07$ & $5.20 \mathrm{E}-07$ & $9.57 \mathrm{E}-07$ \\
\hline $4.21 \mathrm{E}-31$ & $2.57 \mathrm{E}-06$ & $6.34 \mathrm{E}-08$ & $7.58 \mathrm{E}-09$ & $1.60 \mathrm{E}-07$ & $3.25 \mathrm{E}-07$ & $5.24 \mathrm{E}-07$ & $9.63 E-07$ \\
\hline $4.23 E-31$ & $2.58 E-06$ & $6.40 \mathrm{E}-08$ & 7. 69E-09 & $1.61 \mathrm{E}-07$ & $3.27 \mathrm{E}-07$ & $5.28 \mathrm{E}-07$ & $9.69 \mathrm{E}-07$ \\
\hline $4.25 E-31$ & $2.60 E-06$ & $6.45 \mathrm{E}-08$ & $7.80 \mathrm{E}-09$ & $1.63 E-07$ & $3.30 \mathrm{E}-07$ & $5.32 \mathrm{E}-07$ & $9.75 \mathrm{E}-07$ \\
\hline $4.27 \mathrm{E}-31$ & $2.61 E-06$ & $6.50 \mathrm{E}-08$ & $7.91 \mathrm{E}-09$ & $1.64 \mathrm{E}-07$ & $3.32 \mathrm{E}-07$ & $5.36 \mathrm{E}-07$ & $9.81 \mathrm{E}-07$ \\
\hline $4.29 E-31$ & $2.63 E-06$ & $6.55 E-08$ & $8.02 E-09$ & $1.65 \mathrm{E}-07$ & $3.35 \mathrm{E}-07$ & $5.40 \mathrm{E}-07$ & $9.87 \mathrm{E}-07$ \\
\hline $4.30 E-31$ & $2.64 E-06$ & $6.61 E-08$ & $8.14 \mathrm{E}-09$ & $1.67 \mathrm{E}-07$ & $3.37 E-07$ & $5.45 E-07$ & $9.93 E-07$ \\
\hline $4.32 E-31$ & $2.66 \mathrm{E}-06$ & $6.66 \mathrm{E}-08$ & $8.25 \mathrm{E}-09$ & $1.68 \mathrm{E}-07$ & $3.40 \mathrm{E}-07$ & $5.49 \mathrm{E}-07$ & $9.99 \mathrm{E}-07$ \\
\hline $4.34 \mathrm{E}-31$ & $2.67 \mathrm{E}-06$ & $6.71 \mathrm{E}-08$ & $8.36 \mathrm{E}-09$ & $1.70 \mathrm{E}-07$ & $3.42 \mathrm{E}-07$ & $5.53 E-07$ & $1.01 \mathrm{E}-06$ \\
\hline $4.36 \mathrm{E}-31$ & $69 E-06$ & $6.77 \mathrm{E}-08$ & $E-09$ & $.71 E-07$ & $.45 E-07$ & -07 & $.01 E-06$ \\
\hline 1. $99 \mathrm{E}-30$ & $2.71 E-06$ & $6.82 \mathrm{E}-08$ & $8.59 \mathrm{E}-09$ & $1.72 \mathrm{E}-07$ & $3.48 \mathrm{E}-07$ & $5.61 \mathrm{E}-07$ & $1.02 \mathrm{E}-06$ \\
\hline $2.00 \mathrm{E}-30$ & $2.72 E-06$ & $6.88 \mathrm{E}-08$ & $8.70 \mathrm{E}-09$ & $1.73 \mathrm{E}-07$ & $3.50 \mathrm{E}-07$ & $5.65 \mathrm{E}-07$ & $1.02 \mathrm{E}-06$ \\
\hline $2.02 E-30$ & $2.74 \mathrm{E}-06$ & $6.93 \mathrm{E}-08$ & $8.82 \mathrm{E}-09$ & $1.75 \mathrm{E}-07$ & $3.53 \mathrm{E}-07$ & $5.69 \mathrm{E}-07$ & $1.03 E-06$ \\
\hline $5.02 \mathrm{E}-30$ & $2.75 E-06$ & $6.99 \mathrm{E}-08$ & $8.94 \mathrm{E}-09$ & $1.76 \mathrm{E}-07$ & $3.55 \mathrm{E}-07$ & $5.74 \mathrm{E}-07$ & $1.04 \mathrm{E}-06$ \\
\hline $5.06 \mathrm{E}-30$ & $2.77 E-06$ & $7.04 \mathrm{E}-08$ & $9.07 \mathrm{E}-09$ & $1.78 \mathrm{E}-07$ & $3.57 \mathrm{E}-07$ & $5.78 \mathrm{E}-07$ & $1.04 \mathrm{E}-06$ \\
\hline $6.45 E-30$ & $2.78 E-06$ & $7.10 \mathrm{E}-08$ & $9.20 \mathrm{E}-09$ & $1.79 \mathrm{E}-07$ & $3.60 \mathrm{E}-07$ & $5.82 \mathrm{E}-07$ & $1.05 E-06$ \\
\hline $6.50 \mathrm{E}-30$ & $2.80 E-06$ & $7.15 E-08$ & $9.33 E-09$ & $.81 E-07$ & $.62 \mathrm{E}-$ & -07 & $5 E-06$ \\
\hline $6.55 E-30$ & $2.81 E-06$ & $7.21 \mathrm{E}-08$ & $9.46 \mathrm{E}-09$ & $1.82 \mathrm{E}-07$ & $3.65 \mathrm{E}-07$ & $5.91 \mathrm{E}-07$ & $1.06 \mathrm{E}-06$ \\
\hline $6.60 \mathrm{E}-30$ & $2.83 E-06$ & $7.26 \mathrm{E}-08$ & $9.60 \mathrm{E}-09$ & $1.83 \mathrm{E}-07$ & $3.67 \mathrm{E}-07$ & $5.95 \mathrm{E}-07$ & $1.07 \mathrm{E}-06$ \\
\hline $7.26 \mathrm{E}-30$ & $2.84 \mathrm{E}-06$ & $7.32 \mathrm{E}-08$ & $9.74 \mathrm{E}-09$ & $1.85 E-07$ & $3.70 \mathrm{E}-07$ & $5.99 E-07$ & $1.07 \mathrm{E}-06$ \\
\hline $1.19 \mathrm{E}-29$ & $2.86 E-06$ & $7.38 E-08$ & $9.87 E-09$ & $1.86 \mathrm{E}-07$ & $3.73 E-07$ & $6.03 E-07$ & $1.08 \mathrm{E}-06$ \\
\hline $4.23 E-28$ & $2.87 E-06$ & $7.43 \mathrm{E}-08$ & $1.00 \mathrm{E}-08$ & $88 \mathrm{E}-07$ & $.75 \mathrm{E}-07$ & $6.07 E-07$ & $1.09 \mathrm{E}-06$ \\
\hline $3.21 \mathrm{E}-26$ & $2.89 E-06$ & $7.49 \mathrm{E}-08$ & $1.02 \mathrm{E}-08$ & $1.89 \mathrm{E}-07$ & $3.77 \mathrm{E}-07$ & $6.12 \mathrm{E}-07$ & $1.09 \mathrm{E}-06$ \\
\hline $9.26 \mathrm{E}-25$ & $2.90 E-06$ & $7.55 \mathrm{E}-08$ & $1.03 E-08$ & $1.91 E-07$ & $3.80 \mathrm{E}-07$ & $6.16 \mathrm{E}-07$ & $1.10 \mathrm{E}-06$ \\
\hline $1.49 \mathrm{E}-23$ & $.92 E-06$ & $7.61 \mathrm{E}-08$ & $1.05 \mathrm{E}-08$ & $1.92 \mathrm{E}-07$ & $3.82 \mathrm{E}-07$ & $6.19 \mathrm{E}-07$ & 1. $10 E-06$ \\
\hline $1.60 \mathrm{E}-22$ & $2.93 E-06$ & $7.67 \mathrm{E}-08$ & $1.06 \mathrm{E}-08$ & $1.94 \mathrm{E}-07$ & $3.84 \mathrm{E}-07$ & $6.23 \mathrm{E}-07$ & $1.11 \mathrm{E}-06$ \\
\hline $1.25 \mathrm{E}-21$ & $2.95 E-06$ & $7.72 \mathrm{E}-08$ & $1.07 \mathrm{E}-08$ & $1.96 \mathrm{E}-07$ & $3.87 E-07$ & $6.27 E-07$ & $1.11 \mathrm{E}-06$ \\
\hline $7.56 \mathrm{E}-21$ & $2.97 E-06$ & $7.78 \mathrm{E}-08$ & $1.09 \mathrm{E}-08$ & $1.97 \mathrm{E}-07$ & $3.89 \mathrm{E}-07$ & $6.31 \mathrm{E}-07$ & $1.12 \mathrm{E}-06$ \\
\hline $3.71 \mathrm{E}-20$ & $2.98 E-06$ & $7.84 \mathrm{E}-08$ & $1.10 \mathrm{E}-08$ & $1.99 \mathrm{E}-07$ & $3.91 \mathrm{E}-07$ & $6.35 E-07$ & $1.13 E-06$ \\
\hline $1.52 \mathrm{E}-19$ & $3.00 E-06$ & $7.90 E-08$ & $1.11 \mathrm{E}-08$ & $2.00 E-07$ & $3.94 \mathrm{E}-07$ & $6.39 \mathrm{E}-07$ & $1.13 E-06$ \\
\hline $5.40 \mathrm{E}-19$ & $3.01 E-06$ & $7.96 \mathrm{E}-08$ & $1.13 \mathrm{E}-08$ & $2.02 E-07$ & $3.96 \mathrm{E}-07$ & $6.43 E-07$ & $1.14 \mathrm{E}-06$ \\
\hline 1. $68 \mathrm{E}-18$ & $.03 E-06$ & $8.02 E-08$ & $1.14 \mathrm{E}-08$ & $.04 \mathrm{E}-07$ & $3.98 E-07$ & $6.47 E-07$ & $1.14 \mathrm{E}-06$ \\
\hline $4.68 \mathrm{E}-18$ & $.04 \mathrm{E}-06$ & $8.08 E-08$ & $1.16 \mathrm{E}-08$ & $2.05 E-07$ & $4.01 \mathrm{E}-07$ & $6.51 \mathrm{E}-07$ & $1.15 \mathrm{E}-06$ \\
\hline $1.18 \mathrm{E}-17$ & $3.06 \mathrm{E}-06$ & $8.14 \mathrm{E}-08$ & $1.18 \mathrm{E}-08$ & $2.07 \mathrm{E}-07$ & $4.03 E-07$ & $6.55 \mathrm{E}-07$ & $1.15 \mathrm{E}-06$ \\
\hline $2.76 \mathrm{E}-17$ & $3.07 E-06$ & $8.20 E-08$ & $1.19 \mathrm{E}-08$ & $2.08 E-07$ & $4.06 \mathrm{E}-07$ & $6.59 \mathrm{E}-07$ & $1.16 \mathrm{E}-06$ \\
\hline $5.99 \mathrm{E}-17$ & $3.09 \mathrm{E}-06$ & $8.26 \mathrm{E}-08$ & 1.21E-08 & $2.10 \mathrm{E}-07$ & $4.09 \mathrm{E}-07$ & $6.63 \mathrm{E}-07$ & $1.17 \mathrm{E}-06$ \\
\hline 1. $22 \mathrm{E}-16$ & $3.11 \mathrm{E}-06$ & $8.32 \mathrm{E}-08$ & $1.22 \mathrm{E}-08$ & $2.12 \mathrm{E}-07$ & $4.12 \mathrm{E}-07$ & $6.67 \mathrm{E}-07$ & $1.17 \mathrm{E}-06$ \\
\hline $2.35 E-16$ & $3.12 \mathrm{E}$ & $8.39 E-08$ & $1.24 \mathrm{E}-08$ & $2.13 E-07$ & $4.15 E-07$ & $6.72 \mathrm{E}-07$ & $1.18 \mathrm{E}-06$ \\
\hline $4.33 E-16$ & 06 & -08 & $25 E-08$ & $2.15 \mathrm{E}-07$ & $4.18 \mathrm{E}$ & $6.76 \mathrm{E}-07$ & $1.19 \mathrm{E}-06$ \\
\hline 7. $62 \mathrm{E}-16$ & $.15 E-06$ & $8.51 E-08$ & $1.27 \mathrm{E}-08$ & $2.17 E-07$ & $4.20 E-07$ & $6.80 \mathrm{E}-07$ & $1.19 \mathrm{E}-06$ \\
\hline 1. $29 \mathrm{E}-15$ & $3.17 \mathrm{E}-06$ & $8.57 E-08$ & $1.28 E-08$ & $2.19 E-07$ & $4.23 E-07$ & $6.84 \mathrm{E}-07$ & $1.20 \mathrm{E}-06$ \\
\hline $2.12 \mathrm{E}-15$ & $3.18 \mathrm{E}-06$ & $8.64 \mathrm{E}-08$ & $1.30 \mathrm{E}-08$ & $2.20 \mathrm{E}-07$ & $4.26 \mathrm{E}-07$ & $6.88 \mathrm{E}-07$ & $1.21 \mathrm{E}-06$ \\
\hline $3.38 \mathrm{E}-15$ & $3.20 E-06$ & $8.70 \mathrm{E}-08$ & $1.31 \mathrm{E}-08$ & $2.22 \mathrm{E}-07$ & $4.29 \mathrm{E}-07$ & $6.92 E-07$ & $1.21 \mathrm{E}-06$ \\
\hline $5.23 E-15$ & $3.21 E-06$ & $8.76 E-08$ & $1.33 E-08$ & $2.24 E-07$ & $4.32 E-07$ & $6.96 \mathrm{E}-07$ & $1.22 \mathrm{E}-06$ \\
\hline 7. $90 \mathrm{E}-15$ & $.23 E-06$ & $8.83 E-08$ & $1.35 \mathrm{E}-08$ & $2.25 E-07$ & $4.35 E-07$ & $7.00 \mathrm{E}-07$ & $1.23 E-06$ \\
\hline
\end{tabular}


RESRAD-OFFSITE, Version 2.5

obabilistic Dose and Risk Report

Title : Offsite Resident Farmer Deterministic Run

File : RF TC99 DOESG FWD-FV2b.ROF

Summary of dose at graphical times, reptition 1 (continued)

Time

Years

4. $01 \mathrm{E}+02$

$4.01 \mathrm{E}+02$

$4.02 \mathrm{E}+02$

$4.02 \mathrm{E}+02$

$4.03 \mathrm{E}+02$

$4.03 E+02$

$4.04 \mathrm{E}+02$

$4.05 \mathrm{E}+02$

$4.05 \mathrm{E}+02$

$4.06 \mathrm{E}+02$

$4.06 \mathrm{E}+02$

$4.07 \mathrm{E}+02$

$4.07 \mathrm{E}+02$

$4.08 \mathrm{E}+02$

$4.08 \mathrm{E}+02$

$4.09 \mathrm{E}+02$

$4.09 \mathrm{E}+02$

$4.10 \mathrm{E}+02$

$4.10 \mathrm{E}+02$

$4.11 \mathrm{E}+02$

$4.11 \mathrm{E}+02$

$4.12 \mathrm{E}+02$

$4.12 \mathrm{E}+02$

$4.13 \mathrm{E}+02$

$4.13 \mathrm{E}+02$

$4.14 \mathrm{E}+02$

$4.14 \mathrm{E}+02$

$4.15 \mathrm{E}+02$

4. $15 \mathrm{E}+02$

$4.16 \mathrm{E}+02$

4. $16 \mathrm{E}+02$

$4.17 \mathrm{E}+02$

$4.17 \mathrm{E}+02$

4. $18 \mathrm{E}+02$

$4.18 \mathrm{E}+02$

4. $19 \mathrm{E}+02$

$4.19 \mathrm{E}+02$

$4.20 \mathrm{E}+02$

$4.20 \mathrm{E}+02$

$4.21 \mathrm{E}+02$

$4.21 \mathrm{E}+02$

$4.22 \mathrm{E}+02$

4. $22 \mathrm{E}+02$

$4.23 \mathrm{E}+02$

$4.23 E+02$

$4.24 \mathrm{E}+02$
Dose statistics at graphical times, mrem/yr

\begin{tabular}{|c|c|c|c|c|c|c|c|}
\hline Iinimum & Maximum & Mean & Median & $90 \%$ & $95 \%$ & $97.5 \%$ & 3응 \\
\hline 4 & 06 & 08 & $36 E-08$ & $27 E-07$ & 7 & 7 & -06 \\
\hline 14 & 06 & 08 & 08 & 07 & 07 & 07 & 06 \\
\hline $9 E-14$ & $8 E-06$ & $2 E-08$ & $E-08$ & $30 E-07$ & 7 & 7 & $25 E-06$ \\
\hline $34 \mathrm{E}-14$ & $9 E-06$ & $8 E-08$ & $1 E-08$ & 7 & 7 & 7 & $5 E-06$ \\
\hline $58 E-14$ & 06 & & & 7 & 7 & & -06 \\
\hline 14 & 06 & 8 & 8 & 7 & 7 & & -06 \\
\hline $4 E-14$ & $34 E-06$ & $8 E-08$ & $16 E-08$ & $.37 E-07$ & $8 E-07$ & 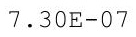 & $27 E-06$ \\
\hline $.08 E-13$ & $3.36 E-06$ & $9.34 \mathrm{E}-08$ & $1.48 \mathrm{E}-08$ & 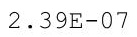 & $4.61 \mathrm{E}-07$ & & $1.28 E-06$ \\
\hline 13 & 06 & 08 & 08 & 7 & 7 & 7 & $.29 E-06$ \\
\hline $81 E-13$ & $9 E-06$ & $3 E-08$ & 08 & $2 \mathrm{E}-$ & 2 & $7.42 \mathrm{E}-$ & $30 E-06$ \\
\hline$E-13$ & 06 & & & & & & $30 E-06$ \\
\hline-13 & 06 & 8 & 8 & 7 & 7 & 7 & -06 \\
\hline $.59 E-13$ & $3 E-06$ & $8 E-08$ & $8 E-08$ & प1 & - & & $32 E-06$ \\
\hline $43 E-13$ & $3.45 E-06$ & $9.74 \mathrm{E}-08$ & $1.60 \mathrm{E}-08$ & 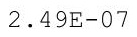 & ו & . & 1. $32 \mathrm{E}-06$ \\
\hline $43 E-13$ & $3.47 E-06$ & $1 E-08$ & 08 & $2.01+4$ & - & & -06 \\
\hline $.59 \mathrm{E}-13$ & $3.48 E-06$ & $9.88 E-08$ & 1.64 & 2.52 & 䧑 & 7 & -06 \\
\hline $.94 E-13$ & $3.50 E-06$ & & $1.66 \mathrm{E}-08$ & $2.54 \mathrm{E}-07$ & $4.88 E-07$ & 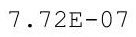 & $1.34 \mathrm{E}-06$ \\
\hline$E-13$ & $E-06$ & -07 & -08 & 7 & 7 & & $35 E-06$ \\
\hline $.13 E-12$ & $3.53 E-06$ & $1.01 \mathrm{E}-07$ & 1. $70 \mathrm{E}-08$ & 2.00 & & & -06 \\
\hline $33 E-12$ & $3.54 \mathrm{E}-06$ & $1.02 \mathrm{E}$ & $1.72 \mathrm{H}$ & 2.00 & 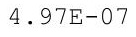 & & -06 \\
\hline $.56 E-12$ & $3.56 \mathrm{E}-06$ & $1.02 \mathrm{E}-07$ & 1. & (2) & & & $37 E-06$ \\
\hline $82 E-12$ & 3 & 1 & 1. & $2.64 \mathrm{E}-07$ & $5.01 \mathrm{E}-07$ & $7.94 \mathrm{E}-07$ & -06 \\
\hline $.11 E-12$ & $3.59 \mathrm{E}-06$ & $4 \mathrm{E}-$ & $8 E-08$ & $2.66 \mathrm{E}-$ & 7 & ז0 & $1.39 E-06$ \\
\hline $44 E-12$ & $3.61 E-06$ & 7 & 1.8 & 7 & 7 & 8 & $E-06$ \\
\hline$E-12$ & $E-06$ & 7 & 1. & 2 & & & -06 \\
\hline$E-12$ & 06 & 7 & 1 . & 2 & & & -06 \\
\hline $.64 E-12$ & $3.65 E-06$ & ( & $1.87 \mathrm{E}-08$ & 145 & t & & -06 \\
\hline $.12 \mathrm{E}-12$ & $3.67 \mathrm{E}-06$ & $1.07 \mathrm{E}-07$ & $1.89 \mathrm{E}-08$ & $2.76 \mathrm{E}-07$ & $.19 \mathrm{E}-0$ & $.20 \mathrm{E}-\mathrm{C}$ & $.42 \mathrm{E}-06$ \\
\hline $.65 \mathrm{E}$ & 0 & 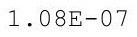 & 8 & 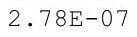 & 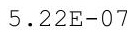 & $8.25 \mathrm{E}-07$ & $.43 \mathrm{E}$ \\
\hline 2 & 06 & 1 & 1. & $2.80 \mathrm{E}-07$ & $5.25 \mathrm{E}-07$ & $8.29 E-07$ & -06 \\
\hline 12 & 06 & 7 & 08 & 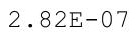 & $5.28 \mathrm{E}-$ & & -06 \\
\hline$E-12$ & $3 E-06$ & 7 & 08 & F & $5.31 \mathrm{E}-$ & 7 & $4 E-06$ \\
\hline $.26 \mathrm{E}-12$ & $3.75 \mathrm{E}-06$ & $1.11 \mathrm{E}-07$ & $2.00 \mathrm{E}-08$ & $2.86 \mathrm{E}-$ & 5 & & $16 \mathrm{E}-06$ \\
\hline $.04 \mathrm{E}-12$ & $3.76 \mathrm{E}-06$ & $1.12 \mathrm{E}-07$ & $2.02 \mathrm{E}-08$ & $2.88 \mathrm{E}-07$ & $5.37 \mathrm{E}-07$ & $8.48 \mathrm{E}-0$ & $1.46 \mathrm{E}-06$ \\
\hline $.00 \mathrm{E}-12$ & $3.78 E-06$ & & & & & & $1.47 \mathrm{E}-06$ \\
\hline$E-12$ & 6 & & 8 & 7 & & & 06 \\
\hline$E-11$ & 06 & 7 & 8 & 7 & 7 & 7 & 06 \\
\hline $.18 \mathrm{E}-11$ & $3.83 E-06$ & $1.14 \mathrm{E}$ & 2.1 & $6 \mathrm{E}$ & J & 8 . & 06 \\
\hline $.29 \mathrm{E}-11$ & $3.84 \mathrm{E}-06$ & $5 E-07$ & $E-08$ & 2 & & & $1.50 \mathrm{E}-06$ \\
\hline $.40 E-11$ & -06 & 1. & & 7 & & & -06 \\
\hline $.52 E-11$ & & & & & & & $1.51 \mathrm{E}-06$ \\
\hline $.65 E-11$ & $3.89 \mathrm{E}-06$ & $1.17 \mathrm{E}-07$ & $2.21 E-08$ & $3.04 \mathrm{E}-07$ & $5.66 \mathrm{E}-07$ & $8.85 \mathrm{E}-07$ & $1.52 \mathrm{E}-06$ \\
\hline 11 & 6 & $y$ & 8 & 7 & 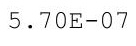 & 7 & $1.53 \mathrm{E}-06$ \\
\hline $.93 E-11$ & $3.92 \mathrm{E}-06$ & $1.19 \mathrm{E}-0$ & $2.25 \mathrm{E}-$ & 3. & 5.75 & 8.931 & 1.5 \\
\hline$E-11$ & -06 & 1. & 2. & 3 . & 5.7 & 7 & 1.5 \\
\hline $24 E-11$ & $95 E-06$ & $1.21 \mathrm{E}-07$ & $2.30 \mathrm{E}-08$ & $.13 E-07$ & $5.83 E-07$ & $9.02 \mathrm{E}-07$ & $1.55 \mathrm{E}-06$ \\
\hline
\end{tabular}


RESRAD-OFFSITE, Version 2.5

obabilistic Dose and Risk Report

Title : Offsite Resident Farmer Deterministic Run

File : RF TC99 DOESG FWD-FV2b.ROF

Summary of dose at graphical times, reptition 1 (continued)

Time

Years

$4.25 \mathrm{E}+02$

$4.25 \mathrm{E}+02$

$4.26 \mathrm{E}+02$

$4.26 \mathrm{E}+02$

$4.27 \mathrm{E}+02$

$4.27 \mathrm{E}+02$

$4.28 \mathrm{E}+02$

$4.28 \mathrm{E}+02$

$4.29 \mathrm{E}+02$

$4.29 \mathrm{E}+02$

$4.30 \mathrm{E}+02$

$4.30 \mathrm{E}+02$

4. $31 \mathrm{E}+02$

4. $31 \mathrm{E}+02$

4. $32 \mathrm{E}+02$

$4.32 \mathrm{E}+02$

$4.33 \mathrm{E}+02$

$4.33 \mathrm{E}+02$

4. $34 \mathrm{E}+02$

$4.34 \mathrm{E}+02$

4. $35 \mathrm{E}+02$

4. $35 \mathrm{E}+02$

$4.36 \mathrm{E}+02$

$4.36 \mathrm{E}+02$

$4.37 \mathrm{E}+02$

4. $37 \mathrm{E}+02$

$4.38 \mathrm{E}+02$

$4.38 \mathrm{E}+02$

$4.39 \mathrm{E}+02$

$4.39 \mathrm{E}+02$

$4.40 \mathrm{E}+02$

$4.40 \mathrm{E}+02$

$4.41 \mathrm{E}+02$

4. $41 \mathrm{E}+02$

$4.42 \mathrm{E}+02$

$4.42 \mathrm{E}+02$

$4.43 \mathrm{E}+02$

$4.43 \mathrm{E}+02$

$4.44 \mathrm{E}+02$

4. $45 \mathrm{E}+02$

$4.45 \mathrm{E}+02$

$4.46 \mathrm{E}+02$

$4.46 \mathrm{E}+02$

$4.47 \mathrm{E}+02$

$4.47 \mathrm{E}+02$

$4.48 \mathrm{E}+02$
Dose statistics at graphical times, mrem/yr

\begin{tabular}{|c|c|c|c|c|c|c|c|}
\hline m & aximum & ean & n & $90 \%$ & & $\%$ & \\
\hline 11 & $3.97 \mathrm{E}-06$ & $1.21 E-07$ & $2.33 E-08$ & $3.15 \mathrm{E}-07$ & -07 & -01 & $1.50 E-00$ \\
\hline $58 E-11$ & $8 E-06$ & $2 E-07$ & -08 & -07 & 07 & -07 & -06 \\
\hline $.76 \mathrm{E}-11$ & $4.00 \mathrm{E}-06$ & 1.23E-07 & $2.38 \mathrm{E}-08$ & $.20 \mathrm{E}-07$ & $.95 E-07$ & $9.16 \mathrm{E}-07$ & $1.57 \mathrm{E}-06$ \\
\hline $95 E-11$ & $4.01 E-06$ & $1.24 \mathrm{E}-07$ & $2.40 \mathrm{E}-08$ & $3.22 \mathrm{E}-07$ & $5.99 \mathrm{E}-07$ & $9.20 \mathrm{E}-07$ & $1.58 \mathrm{E}-06$ \\
\hline $14 \mathrm{E}-11$ & $03 E-06$ & $1.24 \mathrm{E}-07$ & $43 E-08$ & $.24 \mathrm{E}-07$ & $04=-07$ & $E-07$ & -06 \\
\hline-11 & 06 & 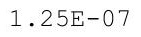 & 8 & $7 F-07$ & $08 E-07$ & 7 & -06 \\
\hline $56 \mathrm{E}-11$ & & $1.26 \mathrm{E}-\mathrm{C}$ & & 7 & & & -06 \\
\hline-11 & 06 & 1 & & & & & -06 \\
\hline-11 & -06 & $F-0$ & -08 & 7 & 7 & -07 & $61 E-06$ \\
\hline $25 E-11$ & $1 E-06$ & 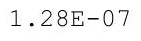 & -08 & ( & 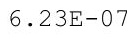 & 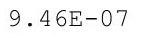 & -06 \\
\hline$F-11$ & $2 E-06$ & $F_{-1}-19-1$ & 8 & 7 & $.27 E-07$ & $50 E-07$ & -06 \\
\hline $.75 \mathrm{E}-$ & & 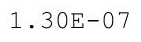 & & & & & -06 \\
\hline$E-11$ & $5-06$ & $1.31 \mathrm{E}$ & 8 & 7 & $345-0$ & 7 & -06 \\
\hline $.28 E-11$ & $4.17 \mathrm{E}-06$ & $1.32 \mathrm{E}-07$ & $2.65 \mathrm{E}-08$ & $3.45 \mathrm{E}-07$ & $6.37 \mathrm{E}-07$ & $9.64 \mathrm{E}-07$ & 1. $65 \mathrm{E}-06$ \\
\hline-11 & $E-06$ & $F-0$ & -08 & $r$ & 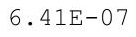 & & -06 \\
\hline $5 E-11$ & & - & 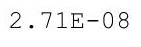 & & & & -06 \\
\hline 1 & 06 & ch & 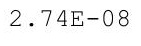 & 1 & & & -06 \\
\hline 1 & & $1.35 E-07$ & & & & & 6 \\
\hline $76 \mathrm{E}-11$ & $4.25 E-06$ & $136 \mathrm{~F}-$ & $9 E-08$ & ت & $5=$ & & -06 \\
\hline $08 \mathrm{E}-11$ & $4.26 \mathrm{E}-06$ & $1.36 \mathrm{E}-07$ & $2.82 \mathrm{E}-08$ & $.60 \mathrm{E}-07$ & $59 \mathrm{E}-\mathrm{C}$ & $E-07$ & $-.69 \mathrm{E}-06$ \\
\hline $41 \mathrm{E}-11$ & $4.28 E-06$ & $1.37 \mathrm{E}-07$ & $2.85 E-08$ & $3.0<5-01$ & & -0 & $1.70 \mathrm{E}-06$ \\
\hline 11 & & & & & & & -06 \\
\hline $\mathrm{OE}-11$ & & & & & & & 06 \\
\hline $46 \mathrm{E}-11$ & $4 \cdot 3$ & 1.1 & & & & & $72 E-06$ \\
\hline 11 & 6 & 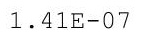 & 8 & . $10 \mathrm{~L}-1$ & 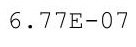 & $1.01 \mathrm{E}-06$ & -06 \\
\hline$E-11$ & $.36 E-06$ & $141 F-0$ & $.99 E-08$ & 73 & ت10 & 1 & $1.74 \mathrm{E}-06$ \\
\hline-11 & $4.37 F-06$ & $1.42 \mathrm{E}-0$ & $E-08$ & & 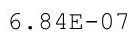 & $=0$ & $1.74 F-06$ \\
\hline-11 & $E-06$ & $1 \quad 13 F_{-1}$ & 8 & & & & \\
\hline 0 & & & & & & & \\
\hline $.08 E-10$ & $4.42 E-06$ & ×・4ป亡- & $E-08$ & . & 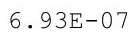 & 0 & -06 \\
\hline $12 \mathrm{E}-10$ & $4.43 E-06$ & 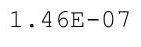 & $3.14 \mathrm{E}-08$ & $.045-01$ & . & 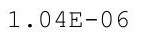 & $1.77 E-06$ \\
\hline 0 & $4.45 E-06$ & . & 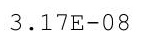 & 要 & 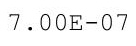 & & $1.78 \mathrm{E}-06$ \\
\hline 0 & & & 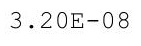 & & & & ח חת \\
\hline-10 & & $1.48 \mathrm{E}-$ & & & & & 06 \\
\hline 10 & & & & & & & \\
\hline $4 E-10$ & $4.51 E-06$ & $1.50 E-07$ & $3.29 \mathrm{E}-08$ & 10 & the & & -06 \\
\hline $8 E-10$ & $4.52 \omega$ & $1.01+$ & & & & & -06 \\
\hline $42 \mathrm{E}-10$ & & & & & & & $1.025-00$ \\
\hline 0 & 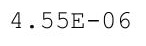 & +0 & & $t$ & 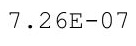 & 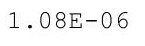 & 06 \\
\hline $.50 E-10$ & & & & & & & 06 \\
\hline & & $1.54 \mathrm{E}-07$ & 8 & 7 & 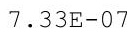 & 6 & -06 \\
\hline$E-10$ & $4.60 E-06$ & 1.55 & 08 & -07 & 7 & 06 & -06 \\
\hline & 6 & & & & & & \\
\hline & & & & & & & $1.87 \mathrm{E}-06$ \\
\hline & 6 & $+\cdots$ & 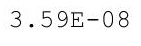 & & 1 & -06 & $1.01 \mathrm{~L}-00$ \\
\hline$E-10$ & $6 E-06$ & $9 E-07$ & $62 E-08$ & $E-07$ & $E-07$ & $.12 E-06$ & -06 \\
\hline
\end{tabular}


RESRAD-OFFSITE, Version 2.5

robabilistic Dose and Risk Report

Title : Offsite Resident Farmer Deterministic Run

File : RF TC99 DOESG FWD-FV2b.ROF

Summary of dose at graphical times, reptition 1 (continued)

Time

Years

$4.48 \mathrm{E}+02$

$4.49 \mathrm{E}+02$

$4.49 \mathrm{E}+02$

$4.50 \mathrm{E}+02$

$4.50 \mathrm{E}+02$

$4.51 \mathrm{E}+02$

$4.51 \mathrm{E}+02$

4. $52 \mathrm{E}+02$

$4.52 \mathrm{E}+02$

4. $53 \mathrm{E}+02$

$4.53 \mathrm{E}+02$

$4.54 \mathrm{E}+02$

$4.54 \mathrm{E}+02$

$4.55 \mathrm{E}+02$

$4.55 \mathrm{E}+02$

$4.56 \mathrm{E}+02$

$4.56 \mathrm{E}+02$

$4.57 \mathrm{E}+02$

$4.57 \mathrm{E}+02$

$4.58 \mathrm{E}+02$

$4.58 \mathrm{E}+02$

$4.59 \mathrm{E}+02$

$4.59 \mathrm{E}+02$

$4.60 \mathrm{E}+02$

$4.60 \mathrm{E}+02$

$4.61 E+02$

4. $61 \mathrm{E}+02$

4. $62 \mathrm{E}+02$

4. $62 \mathrm{E}+02$

4. $63 \mathrm{E}+02$

4. $63 \mathrm{E}+02$

$4.64 \mathrm{E}+02$

$4.65 \mathrm{E}+02$

$4.65 \mathrm{E}+02$

$4.66 \mathrm{E}+02$

$4.66 \mathrm{E}+02$

$4.67 \mathrm{E}+02$

$4.67 \mathrm{E}+02$

$4.68 \mathrm{E}+02$

$4.68 \mathrm{E}+02$

$4.69 \mathrm{E}+02$

$4.69 \mathrm{E}+02$

$4.70 \mathrm{E}+02$

$4.70 \mathrm{E}+02$

$4.71 \mathrm{E}+02$

$4.71 \mathrm{E}+02$
Dose statistics at graphical times, mrem/yr

\begin{tabular}{|c|c|c|c|c|c|c|c|}
\hline m & aximum & lea & -5 & & & & \\
\hline-10 & $4.67 \mathrm{E}-06$ & 1. $60 \mathrm{E}-07$ & $.66 \mathrm{E}-08$ & $E-07$ & $7.51 \mathrm{E}-07$ & 06 & $1.09 E-00$ \\
\hline $85 E-10$ & $4.69 E-06$ & $1.61 \mathrm{E}-07$ & $69 E-08$ & $8 E-07$ & $4 E-07$ & $1.13 E-06$ & $1.89 \mathrm{E}-06$ \\
\hline $89 \mathrm{E}-10$ & $4.70 \mathrm{E}-06$ & 1. $61 \mathrm{E}-07$ & $.72 E-08$ & $4.20 \mathrm{E}-07$ & $57 E-07$ & $1.14 \mathrm{E}-06$ & $.90 \mathrm{E}-06$ \\
\hline $94 \mathrm{E}-10$ & $72 E-06$ & $62 \mathrm{~F}-07$ & $75 E-08$ & $22 F-07$ & $.59 \mathrm{E}-07$ & $14 E-06$ & $90 E-06$ \\
\hline $98 \mathrm{E}-10$ & $4.73 E-06$ & $1.63 \mathrm{E}$ & 8 & 7 & 7 & -06 & -06 \\
\hline 10 & 06 & 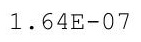 & & & & & \\
\hline $08 E-10$ & $4.76 \mathrm{E}-06$ & $1.00 \mathrm{~s}$ & & & & & -06 \\
\hline-10 & -06 & 1 & 8 & 7 & 7 & 6 & $E-06$ \\
\hline $17 \mathrm{E}-10$ & $4.79 E-06$ & $67 E-07$ & -08 & $4-4-4$ & $73 E-07$ & -06 & $E-06$ \\
\hline $22 \mathrm{E}-10$ & $81 E-06$ & $68=-07$ & $5 E-08$ & $36 \pi$ & $75 \Gamma$ & $.17 E-06$ & $E-06$ \\
\hline 10 & 06 & 1 & & & & 6 & -06 \\
\hline $32 \mathrm{E}-10$ & $4.84 \mathrm{E}-06$ & $1.70 \mathrm{E}$ & 8 & & 8150 & 6 & -06 \\
\hline $.37 E-10$ & $4.85 E-06$ & $1.71 \mathrm{E}-07$ & $4.05 E-08$ & & & $1.19 \mathrm{E}-06$ & $1.96 \mathrm{E}-06$ \\
\hline $42 \mathrm{E}-10$ & $4.87 \mathrm{E}-06$ & $1.72 \mathrm{E}-07$ & $4.09 \mathrm{E}-08$ & $4.46 \mathrm{E}-07$ & $7.87 \mathrm{E}-07$ & $1.19 \mathrm{E}-06$ & 1. $97 \mathrm{E}-06$ \\
\hline $48 E-10$ & $88 E-06$ & $73 F-0$ & -08 & 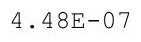 & & -06 & $E-06$ \\
\hline 0 & 4.3 & $\pm \cdot 10$ & & & & & 06 \\
\hline 5 & 6 & $1705-07$ & & 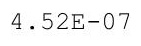 & & $E-06$ & 6 \\
\hline$E-10$ & 4 & $175 \mathrm{~F}-07$ & $4.24 E-08$ & & & $1.21 E-06$ & 6 \\
\hline $69 \mathrm{E}-10$ & 4. $94 \mathrm{E}-06$ & $1.76 \mathrm{E}-07$ & $4.27 E-08$ & $4.57 E-07$ & $8.04 \mathrm{E}-0$ & 1. $22 \mathrm{E}-06$ & $2.00 \mathrm{E}-06$ \\
\hline $75 E-10$ & $4.96 \mathrm{E}-06$ & $1.77 \mathrm{E}-07$ & $4.31 \mathrm{E}-08$ & $4.60 \mathrm{E}-07$ & $.08 E-07$ & $1.22 \mathrm{E}-06$ & $01 E-06$ \\
\hline 10 & 06 & 178 & 8 & & & -06 & $E-06$ \\
\hline 0 & & & & & & & \\
\hline 10 & 0 & 1.80 & & & & & 06 \\
\hline $98 E-10$ & 6 & 1. & 8 & 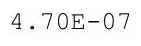 & 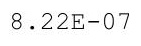 & 0 & 06 \\
\hline 0 & 6 & 8 & 0 & 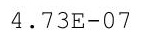 & 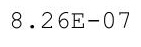 & 6 & 06 \\
\hline $10 \mathrm{E}-10$ & $.04 \mathrm{E}-06$ & 1 & $4 E-08$ & $476 \mathrm{~F}-$ & $31=0$ & $.25 E-06$ & $04 E-06$ \\
\hline$E-10$ & $06 \mathrm{E}-06$ & $184 \mathrm{~F}-10$ & $8 E-08$ & & & $6 E-06$ & $.05 E-06$ \\
\hline & & & & & & & \\
\hline 0 & 6 & 1.001 & & 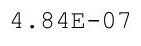 & & & 06 \\
\hline $34 E-10$ & $5.10 \mathrm{E}-06$ & 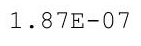 & $4.71 \mathrm{E}-08$ & $4.87 \mathrm{E}-07$ & $0.49 E-01$ & $1.27 \mathrm{E}-06$ & $2.07 E-06$ \\
\hline $41 \mathrm{E}-10$ & $5.12 \mathrm{E}-06$ & 1.000 & $4 \cdot 15 E-08$ & 1.000 & $\begin{array}{c}.320-21 \\
\end{array}$ & $1.20 \mathrm{E}-0$ & $2.08 E-06$ \\
\hline 0 & 6 & 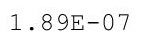 & 4. & (20. & - & I. & $2.08 \mathrm{E}-06$ \\
\hline-10 & $14 F-06$ & $1.90 \mathrm{E}-$ & & & & & $9 E-06$ \\
\hline & & & & & & & \\
\hline & & & & & & & \\
\hline $73 E-10$ & $5.19 \mathrm{E}-06$ & $1.93 E-01$ & $.96 \mathrm{E}-08$ & . U U & 10 & $1.30 \mathrm{E}-06$ & $2.11 \mathrm{E}-06$ \\
\hline $80 E-10$ & $5.20 \mathrm{E}-06$ & 土. & $3.00 \pm-08$ & $3.08 \mathrm{E}-01$ & $0.10 \mathrm{D}$ - & I・ULE & $2.11 \mathrm{E}-06$ \\
\hline$E-10$ & $21 E-06$ & . & & & & & $2.12 \mathrm{E}-06$ \\
\hline 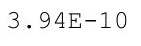 & 6 &.+ & 3 & 7 & 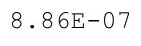 & 6 & 6 \\
\hline & $5.24 \mathrm{E}-06$ & & & & & & 6 \\
\hline $8 E-10$ & $5.26 \mathrm{E}$ & $1.98 \mathrm{E}-07$ & 8 & & 7 & 06 & $4 E-06$ \\
\hline$E-10$ & $5.27 \mathrm{E}-06$ & $1.99 \mathrm{E}$ & 8 & & & 06 & -06 \\
\hline & 6 & & & & & & \\
\hline & 6 & tra & • & . & 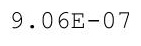 & $4 E-06$ & $2.16 \mathrm{E}-06$ \\
\hline $305-10$ & & 2.0टा & $.305-20$ & . & & $1.35 E-06$ & $2.16 \mathrm{E}-06$ \\
\hline $5 E-10$ & $.33 E-06$ & $E-07$ & $40 E-08$ & $E-07$ & $3 E-07$ & $.35 E-06$ & -06 \\
\hline
\end{tabular}


RESRAD-OFFSITE, Version 2.5

obabilistic Dose and Risk Report

Title : Offsite Resident Farmer Deterministic Run

File : RF TC99 DOESG FWD-FV2b.ROF

Summary of dose at graphical times, reptition 1 (continued)

Time

Years

$4.72 \mathrm{E}+02$

$4.72 \mathrm{E}+02$

$4.73 \mathrm{E}+02$

$4.73 \mathrm{E}+02$

$4.74 \mathrm{E}+02$

4. $74 \mathrm{E}+02$

$4.75 \mathrm{E}+02$

$4.75 \mathrm{E}+02$

$4.76 \mathrm{E}+02$

$4.76 \mathrm{E}+02$

$4.77 \mathrm{E}+02$

$4.77 \mathrm{E}+02$

$4.78 \mathrm{E}+02$

$4.78 \mathrm{E}+02$

$4.79 \mathrm{E}+02$

$4.79 \mathrm{E}+02$

$4.80 \mathrm{E}+02$

$4.80 \mathrm{E}+02$

$4.81 \mathrm{E}+02$

$4.81 \mathrm{E}+02$

$4.82 \mathrm{E}+02$

$4.82 \mathrm{E}+02$

$4.83 \mathrm{E}+02$

$4.83 \mathrm{E}+02$

$4.84 \mathrm{E}+02$

$4.84 \mathrm{E}+02$

$4.85 \mathrm{E}+02$

$4.86 \mathrm{E}+02$

$4.86 \mathrm{E}+02$

$4.87 \mathrm{E}+02$

$4.87 \mathrm{E}+02$

$4.88 \mathrm{E}+02$

$4.88 \mathrm{E}+02$

$4.89 \mathrm{E}+02$

$4.89 \mathrm{E}+02$

4. $90 \mathrm{E}+02$

$4.90 \mathrm{E}+02$

4. $91 \mathrm{E}+02$

4. $91 \mathrm{E}+02$

4. $92 \mathrm{E}+02$

$4.92 \mathrm{E}+02$

$4.93 \mathrm{E}+02$

4. $93 \mathrm{E}+02$

4. $94 \mathrm{E}+02$

4. $94 \mathrm{E}+02$

$4.95 \mathrm{E}+02$

Dose statistics at graphical times, mrem/yr

\begin{tabular}{|c|c|c|c|c|c|c|c|}
\hline m & aximum & ea & $n$ & & & & \\
\hline $.53 E-10$ & $5.34 \mathrm{E}-06$ & $4 E-07$ & $.45 E-08$ & $5.34 E-07$ & $9.16 \mathrm{E}-07$ & -06 & $10 \mathrm{E}-00$ \\
\hline $60 \mathrm{E}-10$ & $5.35 E-06$ & $2.05 E-07$ & $5.50 \mathrm{E}-08$ & $7 E-07$ & $1 E-07$ & 1. $36 \mathrm{E}-06$ & $2.18 \mathrm{E}-06$ \\
\hline $68 E-10$ & $37 E-06$ & $06 E-07$ & $55 E-08$ & $39 E-07$ & $5 E-07$ & $37 E-06$ & $19 E-06$ \\
\hline $76 \mathrm{~F}-10$ & $38 E-06$ & $07=-07$ & $.60 E-08$ & $42 F-07$ & $29 F-07$ & $.37 E-06$ & $2.20 E-06$ \\
\hline 10 & -06 & $2.08 \mathrm{E}-07$ & 8 & 7 & & -06 & -06 \\
\hline 10 & & & & & & & -06 \\
\hline $00 \mathrm{E}-10$ & 06 & & & & & & -06 \\
\hline-10 & -06 & 0 & 08 & 7 & 7 & -06 & $22 E-06$ \\
\hline $17 \mathrm{E}-10$ & $45 E-06$ & 至 & -08 & -07 & 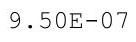 & -06 & $23 E-06$ \\
\hline $25 E-10$ & $46 E-06$ & 12 & $88 E-08$ & 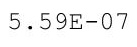 & ת & $.41 E-06$ & $.23 E-06$ \\
\hline 0 & 06 & & & & & & 06 \\
\hline $42 \mathrm{E}-10$ & 06 & & 8 & & & -06 & $E-06$ \\
\hline $.51 E-10$ & $5.50 \mathrm{E}-06$ & $2.16 \mathrm{E}-07$ & $6.03 E-08$ & & & $1.43 E-06$ & $2.25 E-06$ \\
\hline$E-10$ & -06 & $-1-0$ & -08 & & & -06 & $26 E-06$ \\
\hline 10 & 06 & & -08 & & & -06 & $26 E-06$ \\
\hline$E-10$ & 0 & $2.20 \mathrm{E}-07$ & 8 & 0 & & 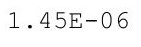 & ז7 \\
\hline 0 & 6 & & & & & & 6 \\
\hline$F-10$ & 6 & 2 & 8 & & $9.87 E-07$ & 6 & 06 \\
\hline $.05 E-10$ & $.58 E-06$ & $2.23 E-07$ & $6.30 \mathrm{E}-08$ & $5.85 E-07$ & $9.92 \mathrm{E}-07$ & $1.46 \mathrm{E}-06$ & $2.29 \mathrm{E}-06$ \\
\hline $14 \mathrm{E}-10$ & $.60 E-06$ & $.24 \mathrm{E}-07$ & $.34 E-08$ & $.88 E-07$ & $9.96 \mathrm{E}-07$ & $1.47 \mathrm{E}-06$ & $2.30 E-06$ \\
\hline 10 & & & & & & -06 & -06 \\
\hline 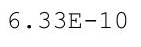 & & & & & & & \\
\hline 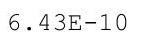 & & $2.27 \mathrm{E}-07$ & & & & & 06 \\
\hline $52 \mathrm{E}-10$ & 6 & $28-100$ & 8 & 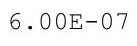 & 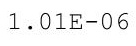 & 0 & -06 \\
\hline$E-10$ & $.66 \mathrm{E}-06$ & م- בת 2 & $E-08$ & תכ & 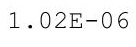 & $9 E-06$ & $2.33 E-06$ \\
\hline $72 \mathrm{E}-10$ & $68 \mathrm{~F}-06$ & $.30 E-07$ & $6.65 \mathrm{E}-08$ & $06 \mathrm{E}-\mathrm{C}$ & $1.02 \mathrm{E}-06$ & $1.50 \mathrm{E}-06$ & 2. $34 \mathrm{E}-06$ \\
\hline-10 & & & & 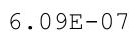 & $.03 E-06$ & $0 E-06$ & $2.35 E-06$ \\
\hline & & & & & & & \\
\hline & & & & 7 & 6 & -06 & -06 \\
\hline $.13 E-10$ & $5.73 E-06$ & $5.30 \mathrm{~L}-\mathrm{t}$ & $6.85 E-08$ & $0.1 / E-0 t$ & $1.04 E-06$ & $1.3 \angle E-06$ & $2.37 E-06$ \\
\hline 10 & $74 \mathrm{E}-06$ & $2.000-0$ & $.90 E-08$ & $\cdot 19 \mathrm{~L}-4$ & $1.04 \mathrm{E}-06$ & $1.52 \mathrm{E}-06$ & $2.38 E-06$ \\
\hline $34 \mathrm{E}-$ & 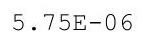 & & م & & & $E-$ & $39 \mathrm{E}-$ \\
\hline ז010 & & & & & & & 06 \\
\hline 0 & & & & & & 6 & \\
\hline & & 7 & & 7 & 6 & -06 & \\
\hline • $1 / \mathrm{E}-10$ & $5.81 \mathrm{E}-06$ & $2.4+L-1$ & $.16 \mathrm{E}-08$ & $33 E-07$ & $.06 E-06$ & $1.55 E-06$ & $2.42 E-06$ \\
\hline $.00 \mathrm{D}-10$ & & & & & & . & $2.40 \pm-00$ \\
\hline 年 & $5.83 E-06$ & $2 \cdot 100$ - & $6 E-08$ & & - & $+\cdots$ & $2.43 E-06$ \\
\hline & 6 & 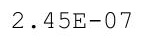 & -08 & & 6 & 6 & 06 \\
\hline 0 & 6 & & 8 & 07 & 1 & 06 & 06 \\
\hline $3 E-10$ & $5.87 \mathrm{E}-06$ & $2.47 E-07$ & $2 E-08$ & 7 & 06 & 06 & -06 \\
\hline$E-10$ & 6 & $2 \cdot$ & & & & & \\
\hline & & & & & & & $2.47 \mathrm{E}-06$ \\
\hline . & $5.91 \mathrm{E}-06$ & 2.00त & $7.60 \mathrm{E}-08$ & $6.57 \mathrm{E}-07$ & $1.10 \mathrm{E}-06$ & $1.59 \mathrm{E}-06$ & $2.48 E-06$ \\
\hline 更 & $5.92 E-06$ & $2.0+4$ & $7.66 \mathrm{E}-08$ & $6.60 \mathrm{E}-07$ & $\cdot \pm \cup-$ & $1.60 \mathrm{E}-06$ & $2.49 E-06$ \\
\hline$E-10$ & $.93 E-06$ & $52 E-07$ & $.71 \mathrm{E}-08$ & $64 \mathrm{E}-07$ & $1.11 \mathrm{E}-06$ & $E-06$ & $2.50 E-06$ \\
\hline
\end{tabular}


RESRAD-OFFSITE, Version 2.5

obabilistic Dose and Risk Report

Title : Offsite Resident Farmer Deterministic Run

File : RF TC99 DOESG FWD-FV2b.ROF

Summary of dose at graphical times, reptition 1 (continued)

Time

Years

4. $95 \mathrm{E}+02$

$4.96 \mathrm{E}+02$

$4.96 \mathrm{E}+02$

$4.97 \mathrm{E}+02$

$4.97 \mathrm{E}+02$

$4.98 \mathrm{E}+02$

$4.98 \mathrm{E}+02$

$4.99 \mathrm{E}+02$

$4.99 \mathrm{E}+02$

$5.00 \mathrm{E}+02$

$5.00 \mathrm{E}+02$

$5.01 E+02$

$5.01 \mathrm{E}+02$

$5.02 \mathrm{E}+02$

$5.02 \mathrm{E}+02$

$5.03 E+02$

$5.03 E+02$

$5.04 \mathrm{E}+02$

$5.04 \mathrm{E}+02$

$5.05 \mathrm{E}+02$

$5.06 \mathrm{E}+02$

$5.06 \mathrm{E}+02$

$5.07 \mathrm{E}+02$

$5.07 \mathrm{E}+02$

$5.08 \mathrm{E}+02$

$5.08 \mathrm{E}+02$

$5.09 \mathrm{E}+02$

$5.09 \mathrm{E}+02$

$5.10 \mathrm{E}+02$

$5.10 \mathrm{E}+02$

$5.11 \mathrm{E}+02$

$5.11 \mathrm{E}+02$

$5.12 \mathrm{E}+02$

$5.12 \mathrm{E}+02$

$5.13 \mathrm{E}+02$

$5.13 \mathrm{E}+02$

$5.14 \mathrm{E}+02$

$5.14 \mathrm{E}+02$

$5.15 \mathrm{E}+02$

$5.15 \mathrm{E}+02$

$5.16 \mathrm{E}+02$

$5.16 \mathrm{E}+02$

$5.17 \mathrm{E}+02$

$5.17 \mathrm{E}+02$

$5.18 \mathrm{E}+02$

$5.18 \mathrm{E}+02$
Dose statistics at graphical times, mrem/yr

\begin{tabular}{|c|c|c|c|c|c|c|c|}
\hline m & aximum & ea & n & & & & \\
\hline 10 & $5.94 \mathrm{E}-06$ & $54 \mathrm{E}-07$ & $7.77 \mathrm{E}-08$ & $6.67 \mathrm{E}-07$ & 06 & 06 & $U E-0$ \\
\hline $17 E-10$ & $5.96 \mathrm{E}-06$ & $2.55 E-07$ & $7.82 \mathrm{E}-08$ & $1 E-07$ & $1.11 \mathrm{E}-06$ & $1.62 \mathrm{E}-06$ & $1 E-06$ \\
\hline $29 \mathrm{E}-10$ & $97 E-06$ & $2.56 \mathrm{E}-07$ & $.88 \mathrm{E}-08$ & $6.74 \mathrm{E}-07$ & $1.12 \mathrm{E}-06$ & $1.62 \mathrm{E}-06$ & $2.52 \mathrm{E}-06$ \\
\hline-10 & -06 & $57 \mathrm{~F}-07$ & $93 E-08$ & $77 \mathrm{~F}-07$ & $12 F-06$ & -06 & $5 E-06$ \\
\hline 10 & 06 & $2.58 \mathrm{E}-07$ & 8 & 7 & 6 & 6 & -06 \\
\hline 0 & & & & & & & \\
\hline $80 \mathrm{E}-10$ & 06 & & -08 & & & & $55 E-06$ \\
\hline $93 E-10$ & -06 & 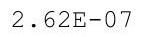 & -08 & 7 & 6 & -06 & $6 E-06$ \\
\hline $01 \mathrm{E}-09$ & -06 & - & -08 & -07 & $14 \mathrm{E}-06$ & -06 & $E-06$ \\
\hline$E-09$ & $.05 E-06$ & 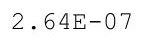 & 8 & 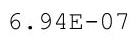 & $15 \mathrm{~F}-06$ & $6 E-06$ & $57 E-06$ \\
\hline 09 & 06 & & & & & 6 & 06 \\
\hline $.05 E-09$ & -06 & 2 & -08 & 7 & 6 & 6 & -06 \\
\hline $.06 \mathrm{E}-09$ & $6.09 E-06$ & & $8.45 E-08$ & $.04 E-07$ & $1.16 \mathrm{E}-06$ & $1.68 \mathrm{E}-06$ & $2.59 E-06$ \\
\hline-09 & -06 & $\mathrm{~F}-0$ & -08 & 1 & 6 & -06 & $E-06$ \\
\hline 09 & -06 & & -08 & & & -06 & $E-06$ \\
\hline 09 & 06 & $7=$ & 08 & & & $.69 E-06$ & 06 \\
\hline 09 & 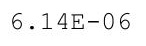 & & & & & & \\
\hline$E-09$ & 6 & 2 & 8 & & 6 & 6 & 06 \\
\hline $14 \mathrm{E}-09$ & $6.16 \mathrm{E}-06$ & $2.75 E-07$ & $.80 \mathrm{E}-08$ & $7.22 \mathrm{E}-07$ & $1.18 E-06$ & 1. $71 \mathrm{E}-06$ & $2.64 \mathrm{E}-06$ \\
\hline $16 \mathrm{E}-09$ & $.17 E-06$ & $.76 \mathrm{E}-07$ & $.86 \mathrm{E}-08$ & $.25 \mathrm{E}-\mathrm{C}$ & $1.19 \mathrm{E}-06$ & $1.71 \mathrm{E}-06$ & $2.65 E-06$ \\
\hline 09 & & & 8 & & & -06 & $E-06$ \\
\hline 09 & & & & & & 6 & \\
\hline $.20 E-09$ & & & & & & & 06 \\
\hline 09 & 06 & 2 & 8 & 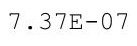 & 6 & 0 & -06 \\
\hline 9 & 6 & $2.82 \mathrm{E}-07$ & 8 & rer & $.21 \mathrm{E}-$ & $E-06$ & $.69 E-06$ \\
\hline$E-09$ & $24 E-06$ & $.83 E-0$ & $E-08$ & $42 \mathrm{E}-$ & $1.21 \mathrm{E}-06$ & $1.75 E-06$ & $.69 E-06$ \\
\hline-09 & $E-06$ & & $E-08$ & & & $5 E-06$ & $2.70 \mathrm{E}-06$ \\
\hline & & & & & & & \\
\hline & & & & & $1 \cdot 2<$ & -06 & \\
\hline $31 E-09$ & $6.28 \mathrm{E}-06$ & $2.00 \mathrm{~L}-1$ & $.47 \mathrm{E}-08$ & $.34 E-01$ & $1.22 \mathrm{E}-06$ & $1.77 \mathrm{E}-06$ & $2.72 E-06$ \\
\hline $33 E-09$ & $6.29 \mathrm{E}-06$ & 2.0. & $3 E-08$ & 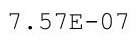 & $1 . \angle 35-00$ & म. & $2.73 E-06$ \\
\hline 年 & = & & & & & 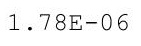 & $2.74 \mathrm{E}-06$ \\
\hline$F-09$ & $E-06$ & 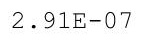 & -08 & 7 & 1 & & $5 E-06$ \\
\hline & & & & & & & \\
\hline & & & & & 06 & 6 & \\
\hline $.41 E-09$ & $6.35 \mathrm{E}-06$ & $2.30 \mathrm{~L}$ & $.86 E-08$ & $70 E-07$ & $1.25 \mathrm{E}-06$ & -06 & $2.77 E-06$ \\
\hline $.435-09$ & & & & & & & $2.18 \mathrm{E}-00$ \\
\hline & 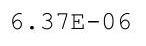 & . & $\begin{array}{c}1.00 \mathrm{~L} \\
\mathrm{~s}\end{array}$ & 然 & & $+\cdot 0+\infty$, & 06 \\
\hline$\triangle 6 F-09$ & 6 & $2.99 \mathrm{E}-07$ & 7 & 7 & 6 & 6 & 06 \\
\hline & & & & & & & \\
\hline$E-09$ & 6. & 3.0 & 07 & 89 F & 1 . & -06 & $2.80 \mathrm{E}$ \\
\hline & $6.41 \mathrm{E}$ & - & & & & & \\
\hline & & & & & & & $2.82 \mathrm{E}-06$ \\
\hline 年 & $6.44 \mathrm{E}-06$ & .0त्रा & . & $7.93 E-07$ & $1.29 \mathrm{E}-06$ & $1.85 E-06$ & $2.83 E-06$ \\
\hline $57 E-09$ & $0.4 J 5-00$ & .001 & $1.07 \pm-01$ & . & $1.29 \mathrm{E}-06$ & $1.85 E-06$ & $2.83 E-06$ \\
\hline $3 E-09$ & $.46 \mathrm{E}-06$ & $7 E-07$ & $.06 \mathrm{E}-07$ & $.00 E-07$ & 1. $30 \mathrm{E}-06$ & $E-06$ & -06 \\
\hline
\end{tabular}


RESRAD-OFFSITE, Version 2.5

obabilistic Dose and Risk Report

Title : Offsite Resident Farmer Deterministic Run

File : RF TC99 DOESG FWD-FV2b.ROF

Summary of dose at graphical times, reptition 1 (continued)

Time

Years

$5.19 \mathrm{E}+02$

$5.19 \mathrm{E}+02$

$5.20 \mathrm{E}+02$

$5.20 E+02$

$5.21 \mathrm{E}+02$

$5.21 \mathrm{E}+02$

$5.22 \mathrm{E}+02$

$5.22 \mathrm{E}+02$

$5.23 E+02$

$5.23 E+02$

$5.24 \mathrm{E}+02$

$5.24 \mathrm{E}+02$

$5.25 \mathrm{E}+02$

$5.26 \mathrm{E}+02$

$5.26 \mathrm{E}+02$

$5.27 \mathrm{E}+02$

$5.27 \mathrm{E}+02$

$5.28 \mathrm{E}+02$

$5.28 \mathrm{E}+02$

$5.29 \mathrm{E}+02$

$5.29 \mathrm{E}+02$

$5.30 \mathrm{E}+02$

$5.30 \mathrm{E}+02$

$5.31 \mathrm{E}+02$

$5.31 \mathrm{E}+02$

$5.32 \mathrm{E}+02$

$5.32 \mathrm{E}+02$

$5.33 \mathrm{E}+02$

$5.33 \mathrm{E}+02$

$5.34 \mathrm{E}+02$

$5.34 \mathrm{E}+02$

$5.35 \mathrm{E}+02$

$5.35 \mathrm{E}+02$

$5.36 \mathrm{E}+02$

$5.36 \mathrm{E}+02$

$5.37 \mathrm{E}+02$

$5.37 \mathrm{E}+02$

$5.38 \mathrm{E}+02$

$5.38 \mathrm{E}+02$

$5.39 \mathrm{E}+02$

$5.39 \mathrm{E}+02$

$5.40 \mathrm{E}+02$

$5.40 \mathrm{E}+02$

$5.41 \mathrm{E}+02$

$5.41 \mathrm{E}+02$

$5.42 \mathrm{E}+02$
Dose statistics at graphical times, mrem/yr

\begin{tabular}{|c|c|c|c|c|c|c|c|}
\hline inimum & aximum & lean & edian & & & & \\
\hline $60 E-09$ & $6.47 \mathrm{E}-06$ & $3.08 \mathrm{E}-07$ & $1.07 \mathrm{E}-07$ & $3 E-07$ & $1.30 \mathrm{E}-06$ & $1.86 E-06$ & $2.85 E-06$ \\
\hline $62 E-09$ & $.48 E-06$ & $0 E-07$ & $.08 \mathrm{E}-07$ & $8.07 \mathrm{E}-07$ & 1. $30 \mathrm{E}-06$ & $1.87 \mathrm{E}-06$ & $2.86 \mathrm{E}-06$ \\
\hline $4 E-09$ & $49 E-06$ & $11 \mathrm{~F}-07$ & $9 \mathrm{E}-07$ & $10 E-07$ & $1 E-06$ & $38 E-06$ & 06 \\
\hline $66 \mathrm{E}-09$ & 6 & $3.12 \mathrm{E}-07$ & -07 & & & 06 & 06 \\
\hline $68 E-09$ & 06 & & & & & & -06 \\
\hline $.70 E-09$ & 06 & & & & & & -06 \\
\hline 09 & 06 & 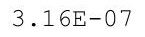 & 7 & 7 & 6 & -06 & $E-06$ \\
\hline $.74 \mathrm{E}-09$ & $54 \mathrm{E}-06$ & $7 E-07$ & $.12 \mathrm{E}-07$ & $26 \mathrm{E}-07$ & $33 E-06$ & $E-06$ & $90 E-06$ \\
\hline $76 E-09$ & 06 & F & $13 F_{-1}$ & 20 & $.33 E-06$ & $E-06$ & 06 \\
\hline 9 & 6 & $3.20 E-07$ & $4 E-07$ & 年 & 5 & 6 & 06 \\
\hline $80 \mathrm{E}-09$ & $6.57 \mathrm{E}$ & $15-8 \cdot 3-1$ & 1 . & $36 \mathrm{~F}$ & 6 & 6 & $E-06$ \\
\hline $.82 E-09$ & $6.58 E-06$ & & & & & & $2.93 E-06$ \\
\hline $.84 E-09$ & $6.59 E-06$ & $3.24 E-07$ & $1.16 \mathrm{E}-07$ & $8.43 E-07$ & $1.35 E-06$ & $1.93 E-06$ & $2.94 \mathrm{E}-06$ \\
\hline 09 & 06 & & & & & -06 & -06 \\
\hline $88 E-09$ & 06 & 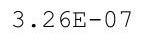 & 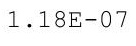 & 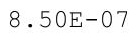 & 6 & 6 & -06 \\
\hline 9 & 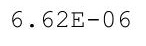 & & & & 6 & & 6 \\
\hline 9 & 6 & $3.29 \mathrm{E}-07$ & $1.20 \mathrm{E}-07$ & $8.57 \mathrm{E}-07$ & 6 & 6 & 06 \\
\hline $.94 \mathrm{E}-09$ & $6.64 \mathrm{E}-06$ & $3.30 \mathrm{E}-07$ & $1.21 \mathrm{E}-07$ & & & $1.95 E-06$ & $2.97 E-06$ \\
\hline $96 \mathrm{E}-09$ & $65 E-06$ & $.31 E-0$ & $1.21 \mathrm{E}-07$ & $\Delta F-$ & $1.37 E-06$ & $1.96 \mathrm{E}-06$ & $98 E-06$ \\
\hline $98 E-09$ & $6.66 \mathrm{E}-06$ & $3.33 E-07$ & $1.22 \mathrm{E}-07$ & 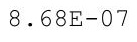 & $1.37 E-06$ & -06 & $99 E-06$ \\
\hline 09 & 06 & $4 E-07$ & & 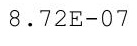 & 6 & 6 & $99 E-06$ \\
\hline $03 E-09$ & & & 1.2 & & & & 06 \\
\hline 09 & 06 & $3.36 \mathrm{E}-07$ & 1 . & $8.79 \mathrm{E}-07$ & 6 & 6 & -06 \\
\hline$E-09$ & 6 & $\mathrm{~F}$ & 1 & $82 \mathrm{~B}$ & 6 & 6 & $1 E-06$ \\
\hline $.09 \mathrm{E}-09$ & $.71 \mathrm{E}-06$ & $9=-07$ & $126=-1$ & 865 & $.39 E-06$ & $.99 E-06$ & $02 E-06$ \\
\hline $12 F-09$ & $72 F-06$ & & & & -06 & $E-06$ & $3 E-06$ \\
\hline 09 & $73 E-06$ & & & & & $E-06$ & \\
\hline & & & & & & & \\
\hline $18 \mathrm{E}-09$ & $6.74 E-06$ & 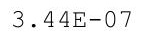 & म. & • & $1.41 \mathrm{E}-06$ & $2.01 E-06$ & $3.04 \mathrm{E}-06$ \\
\hline 09 & $75 E-06$ & 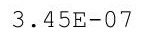 & 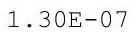 & 然 & $1.42 E-06$ & $2.02 E-06$ & $.05 E-06$ \\
\hline 9 & 6 & & $.31 \mathrm{E}-\mathrm{C}$ & & $1.42 E-06$ & 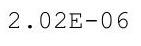 & $3.06 \mathrm{E}-06$ \\
\hline$F-09$ & $77 \mathrm{~F}-06$ & 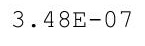 & 1325 & م7 & & $3 F-06$ & $06 E-06$ \\
\hline & & & & & & & \\
\hline & 6 & & 1 . & & 6 & 06 & -06 \\
\hline $.33 E-09$ & $6.80 \mathrm{E}-06$ & ध. & $1.34 \mathrm{E}-07$ & $9.16 \mathrm{E}-07$ & 1. $44 \mathrm{E}-06$ & $2.04 \mathrm{E}-06$ & $3.08 E-06$ \\
\hline $.35 E-09$ & $0.01 E-00$ & & I.Uतम & & $1.43 \pm-06$ & & $3.09 \mathrm{E}-06$ \\
\hline 9 & 6 & 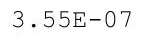 & - & 7 & 6 & & 06 \\
\hline 9 & 6 & $3.56 \mathrm{E}-07$ & 7 & 7 & 6 & 6 & 06 \\
\hline 9 & & & & & 6 & & \\
\hline $45 E-09$ & $4 E-06$ & & & & & 06 & 06 \\
\hline $3 E-09$ & $6.85 E-06$ & $3.00 \mathrm{E}$ & 1.3 & 7 & 6 & & -06 \\
\hline 9 & & & & & & & $\cdot 13 E-06$ \\
\hline $35-02$ & $0.01 \mathrm{~L}$ & ( & $1.4 \perp E-0$ & - & $1.48 \mathrm{E}-06$ & $2.09 E-06$ & $13 E-00$ \\
\hline एक & . & e. & 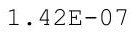 & & & $2.09 \mathrm{E}-06$ & $3.14 \mathrm{E}-06$ \\
\hline 9 & 6 & & - & 7 & -06 & 06 & 06 \\
\hline-09 & -06 & $67 E-07$ & $.44 \mathrm{E}-07$ & $45 E-07$ & $1.49 E-06$ & $2.10 \mathrm{E}-06$ & 3.1 \\
\hline
\end{tabular}


RESRAD-OFFSITE, Version 2.5

obabilistic Dose and Risk Report

Title : Offsite Resident Farmer Deterministic Run

File : RF TC99 DOESG FWD-FV2b.ROF

Summary of dose at graphical times, reptition 1 (continued)

Time

Years

$5.42 \mathrm{E}+02$

$5.43 \mathrm{E}+02$

$5.43 E+02$

$5.44 \mathrm{E}+02$

$5.44 \mathrm{E}+02$

$5.45 \mathrm{E}+02$

$5.46 \mathrm{E}+02$

$5.46 \mathrm{E}+02$

$5.47 \mathrm{E}+02$

$5.47 \mathrm{E}+02$

$5.48 \mathrm{E}+02$

$5.48 \mathrm{E}+02$

$5.49 \mathrm{E}+02$

$5.49 \mathrm{E}+02$

$5.50 \mathrm{E}+02$

$5.50 \mathrm{E}+02$

$5.51 \mathrm{E}+02$

$5.51 \mathrm{E}+02$

$5.52 \mathrm{E}+02$

$5.52 \mathrm{E}+02$

$5.53 \mathrm{E}+02$

$5.53 \mathrm{E}+02$

$5.54 \mathrm{E}+02$

$5.54 \mathrm{E}+02$

$5.55 \mathrm{E}+02$

$5.55 \mathrm{E}+02$

$5.56 \mathrm{E}+02$

$5.56 \mathrm{E}+02$

$5.57 \mathrm{E}+02$

$5.57 \mathrm{E}+02$

$5.58 \mathrm{E}+02$

$5.58 \mathrm{E}+02$

$5.59 \mathrm{E}+02$

$5.59 \mathrm{E}+02$

$5.60 \mathrm{E}+02$

$5.60 \mathrm{E}+02$

$5.61 \mathrm{E}+02$

$5.61 \mathrm{E}+02$

$5.62 \mathrm{E}+02$

$5.62 \mathrm{E}+02$

$5.63 \mathrm{E}+02$

$5.63 E+02$

$5.64 \mathrm{E}+02$

$5.64 \mathrm{E}+02$

$5.65 \mathrm{E}+02$

$5.66 \mathrm{E}+02$

Dose statistics at graphical times, mrem/yr

\begin{tabular}{|c|c|c|c|c|c|c|c|}
\hline Minimum & Maximum & Mean & Median & $90 \%$ & $95 \%$ & $97.5 \%$ & $99 \%$ \\
\hline $2.63 E-09$ & $6.90 \mathrm{E}-06$ & $3.68 E-07$ & 1. $45 E-07$ & $9.48 E-07$ & $1.49 E-06$ & $2.11 E-06$ & $3.16 \mathrm{E}-06$ \\
\hline $2.66 \mathrm{E}-09$ & $6.91 E-06$ & $3.69 \mathrm{E}-07$ & $1.46 \mathrm{E}-07$ & $9.51 \mathrm{E}-07$ & $1.50 \mathrm{E}-06$ & $2.12 \mathrm{E}-06$ & $3.16 \mathrm{E}-06$ \\
\hline $2.69 \mathrm{E}-09$ & $6.92 \mathrm{E}-06$ & $3.71 \mathrm{E}-07$ & $1.46 \mathrm{E}-07$ & $9.53 \mathrm{E}-07$ & $1.50 \mathrm{E}-06$ & $2.12 \mathrm{E}-06$ & $3.17 \mathrm{E}-06$ \\
\hline $2.71 \mathrm{E}-09$ & $6.93 E-06$ & $3.72 \mathrm{E}-07$ & $1.47 \mathrm{E}-07$ & $9.57 \mathrm{E}-07$ & $1.51 \mathrm{E}-06$ & $2.13 \mathrm{E}-06$ & $3.17 \mathrm{E}-06$ \\
\hline $2.74 E-09$ & $6.94 \mathrm{E}-06$ & $3.73 E-07$ & $1.48 E-07$ & $9.60 E-07$ & $1.51 \mathrm{E}-06$ & $2.13 E-06$ & $3.18 \mathrm{E}-06$ \\
\hline $2.77 E-09$ & $6.95 \mathrm{E}-06$ & $3.75 \mathrm{E}-07$ & 1. $49 \mathrm{E}-07$ & $9.64 \mathrm{E}-07$ & $1.52 \mathrm{E}-06$ & $2.14 \mathrm{E}-06$ & $3.19 \mathrm{E}-06$ \\
\hline $2.80 E-09$ & $6.95 \mathrm{E}-06$ & $3.76 \mathrm{E}-07$ & $1.50 \mathrm{E}-07$ & $9.68 \mathrm{E}-07$ & $1.52 \mathrm{E}-06$ & $2.14 \mathrm{E}-06$ & $3.20 E-06$ \\
\hline $2.82 \mathrm{E}-09$ & $6.96 \mathrm{E}-06$ & $3.77 \mathrm{E}-07$ & $1.51 \mathrm{E}-07$ & $9.71 \mathrm{E}-07$ & $1.53 \mathrm{E}-06$ & $2.15 \mathrm{E}-06$ & $3.20 \mathrm{E}-06$ \\
\hline $2.85 E-09$ & $6.97 \mathrm{E}-06$ & $3.79 E-07$ & $1.52 \mathrm{E}-07$ & $9.75 \mathrm{E}-07$ & $1.53 \mathrm{E}-06$ & $2.16 \mathrm{E}-06$ & $3.21 E-06$ \\
\hline $2.88 E-09$ & $6.98 \mathrm{E}-06$ & $3.80 \mathrm{E}-07$ & $1.53 E-07$ & $9.79 \mathrm{E}-07$ & $1.54 \mathrm{E}-06$ & $2.16 \mathrm{E}-06$ & $3.22 \mathrm{E}-06$ \\
\hline $2.91 \mathrm{E}-09$ & $6.99 \mathrm{E}-06$ & $3.81 \mathrm{E}-07$ & $1.54 \mathrm{E}-07$ & $9.82 \mathrm{E}-07$ & $1.54 \mathrm{E}-06$ & $2.17 \mathrm{E}-06$ & $3.22 \mathrm{E}-06$ \\
\hline $2.94 \mathrm{E}-09$ & $6.99 \mathrm{E}-06$ & $3.83 E-07$ & 1. $55 \mathrm{E}-07$ & $9.85 E-07$ & $1.54 \mathrm{E}-06$ & $2.17 \mathrm{E}-06$ & $3.23 E-06$ \\
\hline $2.97 \mathrm{E}-09$ & $7.00 \mathrm{E}-06$ & $3.84 \mathrm{E}-07$ & $1.55 \mathrm{E}-07$ & $9.87 \mathrm{E}-07$ & $1.55 \mathrm{E}-06$ & $2.18 E-06$ & $3.24 \mathrm{E}-06$ \\
\hline $3.00 E-09$ & $7.01 \mathrm{E}-06$ & $3.85 \mathrm{E}-07$ & $1.56 \mathrm{E}-07$ & $9.90 \mathrm{E}-07$ & $1.55 \mathrm{E}-06$ & $2.18 \mathrm{E}-06$ & $3.24 \mathrm{E}-06$ \\
\hline $3.02 E-09$ & $7.02 \mathrm{E}-06$ & $3.87 E-07$ & $1.57 \mathrm{E}-07$ & $9.94 \mathrm{E}-07$ & $1.56 \mathrm{E}-06$ & $2.19 E-06$ & $3.25 E-06$ \\
\hline $3.05 E-09$ & $7.03 E-06$ & $38 E-07$ & $1.58 \mathrm{E}-07$ & $9.98 E-07$ & $1.56 \mathrm{E}-06$ & $2.20 E-06$ & $3.26 E-06$ \\
\hline $3.08 E-09$ & $7.03 E-06$ & $3.90 \mathrm{E}-07$ & $1.59 \mathrm{E}-07$ & $1.00 \mathrm{E}-06$ & $.57 E-06$ & $2.20 E-06$ & $3.26 E-06$ \\
\hline $3.11 \mathrm{E}-09$ & $7.04 \mathrm{E}-06$ & $3.91 E-07$ & 1. $60 \mathrm{E}-07$ & $1.00 \mathrm{E}-06$ & $1.57 \mathrm{E}-06$ & $2.21 \mathrm{E}-06$ & $3.27 E-06$ \\
\hline $3.14 \mathrm{E}-09$ & $7.05 \mathrm{E}-06$ & $3.92 \mathrm{E}-07$ & $1.61 \mathrm{E}-07$ & $1.01 E-06$ & $1.58 \mathrm{E}-06$ & $2.21 E-06$ & $3.27 E-06$ \\
\hline $3.17 \mathrm{E}-09$ & $7.06 \mathrm{E}-06$ & $3.94 \mathrm{E}-07$ & 1. $62 \mathrm{E}-07$ & $1.01 \mathrm{E}-06$ & $1.58 \mathrm{E}-06$ & $2.22 \mathrm{E}-06$ & $3.28 \mathrm{E}-06$ \\
\hline $3.21 \mathrm{E}-09$ & $7.06 \mathrm{E}-06$ & $3.95 E-07$ & 1. $63 \mathrm{E}-07$ & $1.01 \mathrm{E}-06$ & $1.59 \mathrm{E}-06$ & $2.23 E-06$ & $3.29 \mathrm{E}-06$ \\
\hline $3.24 \mathrm{E}-09$ & $7.07 \mathrm{E}-06$ & $3.96 \mathrm{E}-07$ & $1.64 \mathrm{E}-07$ & $1.02 E-06$ & $1.59 \mathrm{E}-06$ & $2.23 E-06$ & $3.30 E-06$ \\
\hline $3.27 E-09$ & $7.08 \mathrm{E}-06$ & $3.98 \mathrm{E}-07$ & $1.65 E-07$ & $1.02 \mathrm{E}-06$ & $1.60 \mathrm{E}-06$ & $2.24 \mathrm{E}-06$ & $3.30 E-06$ \\
\hline $3.30 E-09$ & $7.09 \mathrm{E}-06$ & $3.99 \mathrm{E}-07$ & $1.66 \mathrm{E}-07$ & $1.02 \mathrm{E}-06$ & $1.60 \mathrm{E}-06$ & $2.25 E-06$ & $3.31 \mathrm{E}-06$ \\
\hline $3.33 E-09$ & $7.09 \mathrm{E}-06$ & $4.01 \mathrm{E}-07$ & $1.67 \mathrm{E}-07$ & $1.03 E-06$ & $1.61 \mathrm{E}-06$ & $2.25 E-06$ & $3.32 E-06$ \\
\hline $3.36 \mathrm{E}-09$ & $7.10 \mathrm{E}-06$ & $4.02 E-07$ & 1. $68 \mathrm{E}-07$ & $1.03 E-06$ & $1.61 \mathrm{E}-06$ & $2.26 \mathrm{E}-06$ & $3.32 \mathrm{E}-06$ \\
\hline $3.39 \mathrm{E}-09$ & $7.11 \mathrm{E}-06$ & $4.03 E-07$ & 1. $69 \mathrm{E}-07$ & $1.03 E-06$ & $1.61 \mathrm{E}-06$ & $2.27 E-06$ & $3.33 E-06$ \\
\hline $3.43 E-09$ & $7.12 \mathrm{E}-06$ & $4.05 E-07$ & $1.69 \mathrm{E}-07$ & $1.04 \mathrm{E}-06$ & $1.62 \mathrm{E}-06$ & $2.27 E-06$ & $3.34 E-06$ \\
\hline $3.46 \mathrm{E}-09$ & $7.12 \mathrm{E}-06$ & $4.06 \mathrm{E}-07$ & $1.70 \mathrm{E}-07$ & $1.04 \mathrm{E}-06$ & $1.62 \mathrm{E}-06$ & $2.28 E-06$ & $3.35 E-06$ \\
\hline $3.49 E-09$ & $7.13 E-06$ & $4.07 E-07$ & $1.71 \mathrm{E}-07$ & $1.04 E-06$ & $1.63 \mathrm{E}-06$ & $2.29 E-06$ & $3.35 E-06$ \\
\hline $3.52 E-09$ & $7.14 \mathrm{E}-06$ & $4.09 \mathrm{E}-07$ & $1.72 \mathrm{E}-07$ & $1.04 \mathrm{E}-06$ & $1.63 \mathrm{E}-06$ & $2.29 E-06$ & $3.36 E-06$ \\
\hline $3.56 \mathrm{E}-09$ & $7.15 \mathrm{E}-06$ & $4.10 \mathrm{E}-07$ & $1.73 E-07$ & $1.05 \mathrm{E}-06$ & $1.64 \mathrm{E}-06$ & $2.30 \mathrm{E}-06$ & $3.37 \mathrm{E}-06$ \\
\hline $3.59 \mathrm{E}-09$ & $7.15 \mathrm{E}-06$ & $4.12 \mathrm{E}-07$ & $1.74 \mathrm{E}-07$ & $1.05 E-06$ & $1.64 \mathrm{E}-06$ & $2.30 E-06$ & $3.37 E-06$ \\
\hline $3.62 E-09$ & $7.16 \mathrm{E}-06$ & $4.13 E-07$ & $1.75 \mathrm{E}-07$ & $1.05 E-06$ & $1.65 \mathrm{E}-06$ & $2.31 E-06$ & $.38 E-06$ \\
\hline $3.66 \mathrm{E}-09$ & $7.17 \mathrm{E}-06$ & $4.14 \mathrm{E}-07$ & $1.76 E-07$ & $1.06 \mathrm{E}-06$ & $1.65 E-06$ & $2.32 E-06$ & $3.39 E-06$ \\
\hline $3.69 \mathrm{E}-09$ & $7.17 \mathrm{E}-06$ & $4.16 \mathrm{E}-07$ & $1.77 \mathrm{E}-07$ & $1.06 E-06$ & $1.66 \mathrm{E}-06$ & $2.32 E-06$ & $3.39 E-06$ \\
\hline $3.73 E-09$ & $7.18 \mathrm{E}-06$ & $4.17 \mathrm{E}-07$ & 1. $78 \mathrm{E}-07$ & $1.07 E-06$ & $1.66 \mathrm{E}-06$ & $2.33 E-06$ & $3.40 \mathrm{E}-06$ \\
\hline $3.76 \mathrm{E}-09$ & $7.19 \mathrm{E}-06$ & $4.19 \mathrm{E}-07$ & $1.79 \mathrm{E}-07$ & $1.07 \mathrm{E}-06$ & $1.67 \mathrm{E}-06$ & $2.34 \mathrm{E}-06$ & $3.41 \mathrm{E}-06$ \\
\hline $3.80 E-09$ & $7.19 \mathrm{E}-06$ & $4.20 E-07$ & $1.80 E-07$ & $1.07 E-06$ & $1.67 \mathrm{E}-06$ & $2.34 E-06$ & $3.41 E-06$ \\
\hline $3.83 E-09$ & $7.20 \mathrm{E}-06$ & $4.21 \mathrm{E}-07$ & $1.81 \mathrm{E}$ & $1.08 \mathrm{E}-06$ & $1.68 \mathrm{E}-06$ & $2.35 E-06$ & $3.42 \mathrm{E}-06$ \\
\hline $3.87 \mathrm{E}-09$ & $7.21 \mathrm{E}-06$ & $4.23 E-07$ & $1.82 \mathrm{E}-07$ & $1.08 E-06$ & $1.68 \mathrm{E}-06$ & $2.36 E-06$ & $3.43 E-06$ \\
\hline $3.90 \mathrm{E}-09$ & $7.21 \mathrm{E}-06$ & $4.24 \mathrm{E}-07$ & $1.83 E-07$ & $1.08 E-06$ & $1.69 \mathrm{E}-06$ & $2.36 \mathrm{E}-06$ & $3.43 E-06$ \\
\hline $3.94 \mathrm{E}-09$ & $7.22 \mathrm{E}-06$ & $4.26 \mathrm{E}-07$ & $1.84 \mathrm{E}-07$ & $1.09 E-06$ & $1.69 \mathrm{E}-06$ & $2.37 E-06$ & $3.44 \mathrm{E}-06$ \\
\hline $3.97 E-09$ & $7.23 E-06$ & $4.27 E-07$ & $1.85 E-07$ & $1.09 E-06$ & $1.69 \mathrm{E}-06$ & $2.38 E-06$ & $3.45 E-06$ \\
\hline $4.01 E-09$ & $7.23 E-06$ & $4.28 E-07$ & $1.86 E-07$ & $1.10 \mathrm{E}-06$ & $1.70 \mathrm{E}-06$ & $2.38 E-06$ & $3.46 \mathrm{E}-06$ \\
\hline $4.05 E-09$ & $7.24 \mathrm{E}-06$ & $4.30 E-07$ & $1.87 \mathrm{E}-07$ & $1.10 E-06$ & $1.70 \mathrm{E}-06$ & $2.39 E-06$ & $3.46 \mathrm{E}-06$ \\
\hline
\end{tabular}


RESRAD-OFFSITE, Version 2.5

obabilistic Dose and Risk Report

Title : Offsite Resident Farmer Deterministic Run

File : RF TC99 DOESG FWD-FV2b.ROF

Summary of dose at graphical times, reptition 1 (continued)

Time

Years

$5.66 \mathrm{E}+02$

$5.67 \mathrm{E}+02$

$5.67 \mathrm{E}+02$

$5.68 \mathrm{E}+02$

$5.68 \mathrm{E}+02$

$5.69 \mathrm{E}+02$

$5.69 \mathrm{E}+02$

$5.70 \mathrm{E}+02$

$5.70 \mathrm{E}+02$

$5.71 \mathrm{E}+02$

$5.71 E+02$

$5.72 \mathrm{E}+02$

$5.72 \mathrm{E}+02$

$5.73 \mathrm{E}+02$

$5.73 \mathrm{E}+02$

$5.74 \mathrm{E}+02$

$5.74 \mathrm{E}+02$

$5.75 \mathrm{E}+02$

$5.75 \mathrm{E}+02$

$5.76 \mathrm{E}+02$

$5.76 \mathrm{E}+02$

$5.77 \mathrm{E}+02$

$5.77 \mathrm{E}+02$

$5.78 \mathrm{E}+02$

$5.78 \mathrm{E}+02$

$5.79 \mathrm{E}+02$

$5.79 \mathrm{E}+02$

$5.80 \mathrm{E}+02$

$5.80 \mathrm{E}+02$

$5.81 \mathrm{E}+02$

$5.81 \mathrm{E}+02$

$5.82 \mathrm{E}+02$

$5.82 \mathrm{E}+02$

$5.83 \mathrm{E}+02$

$5.83 \mathrm{E}+02$

$5.84 \mathrm{E}+02$

$5.84 \mathrm{E}+02$

$5.85 \mathrm{E}+02$

$5.85 \mathrm{E}+02$

$5.86 \mathrm{E}+02$

$5.87 \mathrm{E}+02$

$5.87 \mathrm{E}+02$

$5.88 \mathrm{E}+02$

$5.88 \mathrm{E}+02$

$5.89 \mathrm{E}+02$

$5.89 \mathrm{E}+02$
Dose statistics at graphical times, mrem/yr

\begin{tabular}{|c|c|c|c|c|c|c|c|}
\hline $\mathrm{m}$ & $\operatorname{axi}$ & ean & ledian & & & $\%$ & \\
\hline $.08 E-09$ & $.25 \mathrm{E}-06$ & $4.31 E-07$ & $1.88 \mathrm{E}-07$ & $1.10 \mathrm{E}-06$ & -06 & -06 & -00 \\
\hline $12 \mathrm{E}-09$ & $25 E-06$ & 然 & $1.89 \mathrm{E}-07$ & $1.11 \mathrm{E}-06$ & 06 & -06 & -06 \\
\hline $.16 \mathrm{E}-09$ & $.26 \mathrm{E}-06$ & $4.34 \mathrm{E}-07$ & 1. $90 \mathrm{E}-07$ & $1.11 \mathrm{E}-06$ & $1.71 \mathrm{E}-06$ & -06 & $3.48 \mathrm{E}-06$ \\
\hline $20 \mathrm{E}-09$ & $7.27 E-06$ & $.36 E-07$ & 1. $91 \mathrm{E}-07$ & $.11 \mathrm{E}-06$ & $1.71 \mathrm{E}-06$ & $2.41 \mathrm{E}-06$ & $3.49 \mathrm{E}-06$ \\
\hline $3 E-09$ & $7.27 E-06$ & $37 \mathrm{~F}-07$ & $92 \mathrm{~F}-07$ & $2 E-06$ & $2 F-06$ & $2 E-06$ & $3.50 E-06$ \\
\hline-09 & 06 & & & & & & -06 \\
\hline $31 E-09$ & 06 & & & 6 & & 6 & -06 \\
\hline $35 E-09$ & & & & 06 & & & -06 \\
\hline$E-09$ & 06 & -0 & 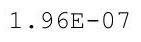 & -06 & $73 E-06$ & -06 & -06 \\
\hline $43 E-09$ & 06 & 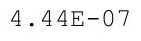 & $1.97 \mathrm{E}-07$ & 6 & 6 & -06 & -06 \\
\hline $6 E-09$ & 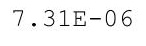 & & & 6 & & 6 & $54 E-06$ \\
\hline 9 & & & & & & 6 & 06 \\
\hline$F-09$ & $2 F-06$ & 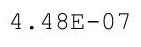 & 2 & 6 & 06 & -06 & -06 \\
\hline $.58 \mathrm{E}-09$ & $7.33 \mathrm{E}-06$ & $4.50 \mathrm{E}-07$ & $2.01 \mathrm{E}-07$ & $1.15 \mathrm{E}-06$ & $1.75 \mathrm{E}-06$ & $2.48 \mathrm{E}-06$ & $3.56 \mathrm{E}-06$ \\
\hline $62 E-09$ & $7.33 E-06$ & & & & & $2.48 E-06$ & $\Xi-06$ \\
\hline $66 \mathrm{E}-09$ & & & & & & & -06 \\
\hline 0 & & & & & & & 06 \\
\hline 9 & & & & & & & 6 \\
\hline $79 E-09$ & $7.36 \mathrm{E}-06$ & 吅 & 6 & $1.17 \mathrm{E}-06$ & 06 & 6 & -06 \\
\hline $83 E-09$ & $E-06$ & $2 F-0$ & $F=0$ & $17 E-06$ & $77 E-06$ & $E-06$ & $E-06$ \\
\hline $87 E-09$ & -06 & & 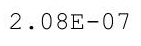 & -06 & $.77 E-06$ & $.52 E-06$ & -06 \\
\hline & & & & & & & -06 \\
\hline & & & & & & & 06 \\
\hline & & & & 6 & & & -06 \\
\hline 9 & 6 & 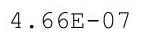 & 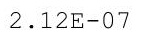 & 6 & 6 & 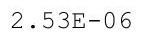 & -06 \\
\hline$E-09$ & $.40 \mathrm{E}-06$ & (1) & م 13 & $1.19 \mathrm{E}-06$ & $1.79 \mathrm{E}-06$ & $.54 \mathrm{E}-06$ & $63 E-06$ \\
\hline .09 & $40 F-06$ & $169=-0$ & & 170 & 170 & $4 F-06$ & -06 \\
\hline-09 & & & & & & & \\
\hline & & & & & & & \\
\hline $26 E-09$ & $7.42 \mathrm{E}-06$ & 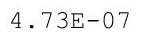 & $2 . \pm$ & 1.20E-06 & 06 & 06 & -06 \\
\hline $31 E-09$ & $7.42 \mathrm{E}-06$ & th & 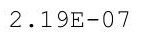 & $1.21 \mathrm{E}-06$ & $1.80 \mathrm{E}-06$ & $\angle .01 \mathrm{~L}-00$ & 3. $65 E-06$ \\
\hline 9 & $7.43 E-06$ & . & 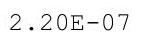 & 1. $21 \mathrm{E}-06$ & & 2. & $3.65 E-06$ \\
\hline$E-09$ & $.43 E-06$ & & 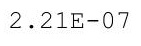 & $1.22 \mathrm{E}-06$ & & & $E-06$ \\
\hline$F-09$ & & & & $122 \mathrm{~F}$ & & & 06 \\
\hline 09 & & & & & & & \\
\hline 09 & . & $4.02 \square-01$ & $2.24 \mathrm{E}-07$ & $1 \cdot 23 \mathrm{E}$ & 1.024 & 06 & -06 \\
\hline $58 E-09$ & 1. & & & $\pm \cdot 20$ & & & -06 \\
\hline $63 E-09$ & & & & 1.23E-06 & & & $3.00 \mathrm{x}-00$ \\
\hline 9 & r & & $2.27 \mathrm{E}-07$ & 6 & 6 & 2. & 06 \\
\hline & & & & & & & 06 \\
\hline 09 & & 4 & 2 & 6 & 6 & 6 & -06 \\
\hline $81 E-09$ & $7.48 \mathrm{E}-06$ & 4.9 & $2 \cdot 3$ & $1.24 \mathrm{E}$ & 1.8 & 06 & -06 \\
\hline & & & & & & & \\
\hline & & & - & $+\cdot 201$ & $1.85 E-06$ & & $.10 E-06$ \\
\hline at & $E-06$ & & + t & 1.200 & 06 & 06 & $5-00$ \\
\hline $01 E-09$ & $E-06$ & $7 E-07$ & $35 E-07$ & $26 E-06$ & $86 E-06$ & $56 E-06$ & -06 \\
\hline
\end{tabular}


RESRAD-OFFSITE, Version 2.5

obabilistic Dose and Risk Report

Title : Offsite Resident Farmer Deterministic Run

File : RF TC99 DOESG FWD-FV2b.ROF

Summary of dose at graphical times, reptition 1 (continued)

Time

Years

$5.90 \mathrm{E}+02$

$5.90 \mathrm{E}+02$

$5.91 \mathrm{E}+02$

$5.91 \mathrm{E}+02$

$5.92 \mathrm{E}+02$

$5.92 \mathrm{E}+02$

$5.93 \mathrm{E}+02$

$5.93 \mathrm{E}+02$

$5.94 \mathrm{E}+02$

$5.94 \mathrm{E}+02$

$5.95 \mathrm{E}+02$

$5.95 \mathrm{E}+02$

$5.96 \mathrm{E}+02$

$5.96 \mathrm{E}+02$

$5.97 \mathrm{E}+02$

$5.97 \mathrm{E}+02$

$5.98 \mathrm{E}+02$

$5.98 \mathrm{E}+02$

$5.99 \mathrm{E}+02$

$5.99 \mathrm{E}+02$

$6.00 \mathrm{E}+02$

$6.00 \mathrm{E}+02$

$6.01 \mathrm{E}+02$

$6.01 \mathrm{E}+02$

$6.02 \mathrm{E}+02$

$6.02 \mathrm{E}+02$

$6.03 E+02$

$6.03 \mathrm{E}+02$

$6.04 \mathrm{E}+02$

$6.04 \mathrm{E}+02$

$6.05 \mathrm{E}+02$

$6.05 \mathrm{E}+02$

$6.06 \mathrm{E}+02$

$6.07 \mathrm{E}+02$

$6.07 \mathrm{E}+02$

$6.08 \mathrm{E}+02$

$6.08 \mathrm{E}+02$

$6.09 \mathrm{E}+02$

$6.09 \mathrm{E}+02$

$6.10 \mathrm{E}+02$

$6.10 \mathrm{E}+02$

$6.11 \mathrm{E}+02$

$6.11 \mathrm{E}+02$

$6.12 \mathrm{E}+02$

$6.12 \mathrm{E}+02$

$6.13 \mathrm{E}+02$
Dose statistics at graphical times, mrem/yr

\begin{tabular}{|c|c|c|c|c|c|c|c|}
\hline m & axis & ea & 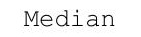 & & & & \\
\hline $.06 \mathrm{E}-09$ & $7.50 \mathrm{E}-06$ & $4.98 E-07$ & $2.36 \mathrm{E}-07$ & $1.26 \mathrm{E}-06$ & $1.87 \mathrm{E}-06$ & 06 & -00 \\
\hline $11 \mathrm{E}-09$ & $.50 E-06$ & $4.99 \mathrm{E}-07$ & $2.37 \mathrm{E}-07$ & $1.27 E-06$ & $87 E-06$ & $2.67 \mathrm{E}-06$ & $2 E-06$ \\
\hline $.16 \mathrm{E}-09$ & $.51 \mathrm{E}-06$ & $.01 E-07$ & $2.38 \mathrm{E}-07$ & 1.27E-06 & $1.88 \mathrm{E}-06$ & $2.68 \mathrm{E}-06$ & $3.72 \mathrm{E}-06$ \\
\hline$E-09$ & -06 & $02 F-07$ & $30 F-07$ & $.27 E-06$ & $88 \mathrm{~F}-06$ & $.69 \mathrm{E}-06$ & $72 E-06$ \\
\hline-09 & 06 & e & . & 6 & 6 & -06 & -06 \\
\hline 09 & & & & & & & 00 \\
\hline $.36 \mathrm{E}-09$ & $52 E-06$ & & 7 & 06 & & & $E-06$ \\
\hline-09 & 06 & 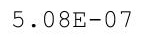 & 1 & 6 & 6 & -06 & -06 \\
\hline $.46 \mathrm{E}-09$ & $53 E-06$ & 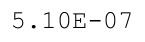 & $E-07$ & $.29 \mathrm{E}-06$ & -06 & -06 & $4 E-06$ \\
\hline$E-09$ & -06 & . & (1) & $.30 E-06$ & & $.72 E-06$ & -06 \\
\hline 09 & 06 & & & 6 & & & -06 \\
\hline $.62 E-09$ & $7.55 \mathrm{E}-06$ & $5.14 \mathrm{E}-0$ & 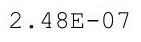 & 6 & & 6 & -06 \\
\hline $.67 E-09$ & $7.55 \mathrm{E}-06$ & & $2.49 E-07$ & $1.31 \mathrm{E}-06$ & $1.92 \mathrm{E}-06$ & $2.74 \mathrm{E}-06$ & $3.76 \mathrm{E}-06$ \\
\hline $.72 \mathrm{E}-09$ & -06 & 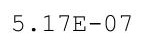 & $2.51 \mathrm{E}-07$ & $1.31 \mathrm{E}-06$ & $1.93 \mathrm{E}-06$ & $2.74 \mathrm{E}-06$ & $5 E-06$ \\
\hline$E-09$ & 06 & & 1 & 31 & & -06 & $\Xi-06$ \\
\hline 9 & 06 & 7 & קF & .02 & 6 & 6 & char \\
\hline 9 & 0 & & & & & & 6 \\
\hline 9 & 6 & $5 \quad 23 F-07$ & $2.55 \mathrm{E}-07$ & 6 & 6 & 6 & 06 \\
\hline $.00 E-09$ & $7.57 \mathrm{E}-06$ & $5.25 \mathrm{E}-07$ & $2.57 \mathrm{E}-07$ & $1.33 E-06$ & 1. $95 \mathrm{E}-06$ & $2.76 \mathrm{E}-06$ & $3.78 \mathrm{E}-06$ \\
\hline $5 E-09$ & $.58 \mathrm{E}-06$ & $.26 \mathrm{E}-0$ & $2.58 \mathrm{E}-07$ & $1.33 E-06$ & $1.96 \mathrm{E}-06$ & $2.76 \mathrm{E}-06$ & 3. $78 E-06$ \\
\hline 09 & & & & & & -06 & -06 \\
\hline 09 & & & & & & & \\
\hline 9 & & & & 6 & & & \\
\hline $27 E-09$ & 06 & $5 \quad 325-07$ & $2.62 \mathrm{E}-07$ & 6 & 6 & 0 & -06 \\
\hline 9 & 6 & (5) & קב & $35 \Gamma$ & 6 & $2.78 E-06$ & 06 \\
\hline $39 E-09$ & $7.60 \mathrm{E}-06$ & $35 E-0$ & $.64 \mathrm{E}-0$ & $1.35 \mathrm{E}-06$ & $1.99 \mathrm{E}-06$ & $2.78 \mathrm{E}-06$ & $.80 E-06$ \\
\hline$E-09$ & $.60 E-06$ & & & $.36 E-06$ & & $9 E-06$ & $80 E-06$ \\
\hline & & & & & & & \\
\hline & & & & 06 & & -06 & \\
\hline $.62 E-09$ & $7.61 \mathrm{E}-06$ & . & $2.00 \mathrm{~L}$ - & $1.37 E-06$ & $2.00 E-06$ & $2.00 E-00$ & $.81 E-06$ \\
\hline $.68 \mathrm{E}-09$ & $7.61 \mathrm{E}-06$ & . $10+4$ & 2.0 & $1.37 \mathrm{E}-06$ & $2.00 \mathrm{E}-06$ & $2.00 \mathrm{E}-00$ & 3. $81 E-06$ \\
\hline 9 & $E-06$ & & & & & 年 & \\
\hline $.79 E-09$ & $E-06$ & & 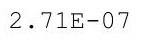 & $8 E-06$ & $01 E-06$ & & $32 F-06$ \\
\hline & & & & & & & \\
\hline & & & & 6 & 6 & & \\
\hline $.97 E-09$ & $7.63 \mathrm{E}-06$ & 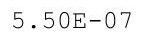 & $2 \cdot 13 \pm-01$ & $1.39 \mathrm{E}-06$ & -06 & $2.82 E-06$ & $.82 E-06$ \\
\hline $04 \mathrm{E}-09$ & $1.03 E-06$ & & & & & & $3.03 \pm-00$ \\
\hline $10 E-09$ & $7.63 E-06$ & & 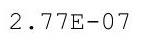 & 1. $40 \mathrm{E}-06$ & $2.02 \mathrm{E}-06$ & & $83 E-06$ \\
\hline & $7.64 \mathrm{E}-06$ & $5.55 \mathrm{E}-07$ & $2.78 \mathrm{E}-07$ & -06 & 6 & 6 & 06 \\
\hline $.22 E-09$ & $7.64 \mathrm{E}-06$ & & & & & & 06 \\
\hline E-09 & $7.64 \mathrm{E}-06$ & $5.58 E-07$ & $2.80 E-07$ & $1.41 \mathrm{E}$ & 2.03 & $2.83 E$ & -06 \\
\hline-09 & 6 & & & 1.42 & & & 06 \\
\hline & & & & & & & $.84 \mathrm{E}-06$ \\
\hline . & $7.65 \mathrm{E}-06$ & .0 & $2.04+51$ & $1.42 \mathrm{E}-06$ & $2.04 E-06$ & $2.84 E-06$ & $.84 E-06$ \\
\hline 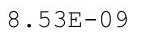 & $7.65 E-06$ & .074 & $2.00 \mathrm{H}$ & $1.43 E-06$ & $2.05 E-06$ & $E-06$ & $3.84 E-06$ \\
\hline$E-09$ & $E-06$ & $.66 E-07$ & $.86 E-07$ & $.43 E-06$ & $2.05 E-06$ & $5 E-06$ & -06 \\
\hline
\end{tabular}


RESRAD-OFFSITE, Version 2.5

obabilistic Dose and Risk Report

Title : Offsite Resident Farmer Deterministic Run

File : RF TC99 DOESG FWD-FV2b.ROF

Summary of dose at graphical times, reptition 1 (continued)

Time

Years

$6.13 \mathrm{E}+02$

$6.14 \mathrm{E}+02$

$6.14 \mathrm{E}+02$

$6.15 \mathrm{E}+02$

$6.15 \mathrm{E}+02$

$6.16 \mathrm{E}+02$

$6.16 \mathrm{E}+02$

$6.17 \mathrm{E}+02$

$6.17 \mathrm{E}+02$

$6.18 \mathrm{E}+02$

$6.18 \mathrm{E}+02$

$6.19 \mathrm{E}+02$

$6.19 \mathrm{E}+02$

$6.20 \mathrm{E}+02$

$6.20 \mathrm{E}+02$

$6.21 \mathrm{E}+02$

$6.21 \mathrm{E}+02$

$6.22 \mathrm{E}+02$

$6.22 \mathrm{E}+02$

$6.23 \mathrm{E}+02$

$6.23 \mathrm{E}+02$

$6.24 \mathrm{E}+02$

$6.24 \mathrm{E}+02$

$6.25 \mathrm{E}+02$

$6.25 \mathrm{E}+02$

$6.26 \mathrm{E}+02$

$6.27 \mathrm{E}+02$

$6.27 \mathrm{E}+02$

$6.28 \mathrm{E}+02$

$6.28 \mathrm{E}+02$

$6.29 \mathrm{E}+02$

$6.29 \mathrm{E}+02$

$6.30 \mathrm{E}+02$

$6.30 \mathrm{E}+02$

$6.31 \mathrm{E}+02$

$6.31 \mathrm{E}+02$

$6.32 \mathrm{E}+02$

$6.32 \mathrm{E}+02$

$6.33 \mathrm{E}+02$

$6.33 \mathrm{E}+02$

$6.34 \mathrm{E}+02$

$6.34 \mathrm{E}+02$

$6.35 \mathrm{E}+02$

$6.35 \mathrm{E}+02$

$6.36 \mathrm{E}+02$

$6.36 \mathrm{E}+02$

Dose statistics at graphical times, mrem/yr

\begin{tabular}{|c|c|c|c|c|c|c|c|}
\hline $\mathrm{m}$ & $\mathrm{m}$ & ea & ledian & & & $\%$ & \\
\hline $.66 \mathrm{E}-09$ & $7.66 \mathrm{E}-06$ & $5.67 \mathrm{E}-07$ & $2.87 \mathrm{E}-07$ & $1.44 \mathrm{E}-06$ & 06 & $2.85 E-06$ & $3.0 J E-06$ \\
\hline $.72 E-09$ & -06 & -07 & -07 & 06 & 06 & -06 & -06 \\
\hline $.79 E-09$ & $66 \mathrm{E}-06$ & $5.70 \mathrm{E}-07$ & $2.89 \mathrm{E}-07$ & $1.44 \mathrm{E}-06$ & $2.06 \mathrm{E}-06$ & $2.86 \mathrm{E}-06$ & $E-06$ \\
\hline $.85 E-09$ & $7.67 \mathrm{E}-06$ & $.72 E-07$ & $2.91 \mathrm{E}-07$ & $1.45 \mathrm{E}-06$ & $2.07 E-06$ & $2.86 \mathrm{E}-06$ & $3.85 E-06$ \\
\hline $2 E-09$ & $67 E-06$ & $3 E-07$ & $.92 \mathrm{E}-07$ & $.45 E-06$ & $7 E-06$ & $37 E-06$ & -06 \\
\hline$E-09$ & 06 & $5=0$ & $2.93 E-07$ & 45 & 6 & -06 & -06 \\
\hline $.05 E-09$ & 6 & & & 6 & & & -06 \\
\hline $.11 \mathrm{E}-09$ & & & & 06 & & & -06 \\
\hline$E-09$ & -06 & $E-07$ & -0 & $46 E-06$ & -06 & -06 & -06 \\
\hline$E-09$ & -06 & $5.81 \mathrm{E}-07$ & 1 & 47 & 6 & -06 & -06 \\
\hline $30 E-09$ & $685-15-10$ & $83 F_{-1}$ & - & 5 & O9F- & 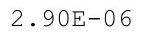 & $87 \mathrm{~F}-06$ \\
\hline 9 & & & & T & & & 06 \\
\hline$F-09$ & $F-06$ & $5.86 \mathrm{E}-07$ & $3.02 F-0$ & 6 & 06 & 6 & -06 \\
\hline $.49 \mathrm{E}-09$ & $7.69 \mathrm{E}-06$ & $5.87 \mathrm{E}-07$ & $3.03 E-07$ & $1.48 \mathrm{E}-06$ & $2.10 \mathrm{E}-06$ & $2.91 \mathrm{E}-06$ & $3.88 \mathrm{E}-06$ \\
\hline $56 E-09$ & -06 & f & & 1.48 & & -06 & -06 \\
\hline 99 & & & & & & & 06 \\
\hline 9 & 0 & & & 6 & & & -06 \\
\hline 9 & & & & 6 & & & 6 \\
\hline $82 E-09$ & $7.70 \mathrm{E}-06$ & 5 & 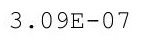 & $1.50 \mathrm{E}-06$ & 06 & 6 & -06 \\
\hline $88 \mathrm{E}-09$ & $.70 \mathrm{E}-06$ & $.96 \mathrm{E}-07$ & $3.10 \mathrm{E}-07$ & $1.50 \mathrm{E}-06$ & $2.12 \mathrm{E}-06$ & $2.94 \mathrm{E}-06$ & $E-06$ \\
\hline $.95 E-09$ & $7.70 \mathrm{E}-06$ & $5.98 E-07$ & 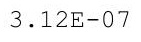 & $1.51 \mathrm{E}-06$ & $2.12 \mathrm{E}-06$ & $E-06$ & -06 \\
\hline & & & & & & & -06 \\
\hline 8 & & & & 6 & & & 06 \\
\hline $01 \mathrm{E}-08$ & 0 & & & $\perp \cdot U$ & 0 & & 06 \\
\hline 8 & 6 & or & 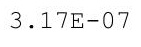 & 6 & 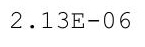 & 0 & -06 \\
\hline $03 E-08$ & $7.71 \mathrm{E}-06$ & $.06 \mathrm{E}-0$ & م & 1. $52 \mathrm{E}-06$ & $2.14 \mathrm{E}-06$ & $7 E-06$ & $91 E-06$ \\
\hline 08 & $71 \mathrm{~F}-06$ & א חדת & קט & 150 & $14 \mathrm{E}-06$ & $97 \mathrm{~F}-06$ & $7-06$ \\
\hline-08 & 06 & & & & & & 06 \\
\hline 08 & 1.1 & & & 6 & & & \\
\hline $06 \mathrm{E}-08$ & $7.72 E-06$ & 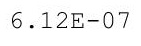 & . & $1.53 \mathrm{E}-06$ & $2.15 E-06$ & $E-06$ & -06 \\
\hline $.06 E-08$ & $7.72 \mathrm{E}-06$ & $\begin{array}{ll}. \pm 0 \\
0\end{array}$ & 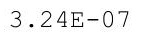 & $1.54 \mathrm{E}-06$ & $2.15 E-06$ & $2.92 \mathrm{E}-00$ & $3.93 E-06$ \\
\hline 8 & $7.72 \mathrm{E}-06$ & 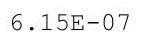 & & $1.54 \mathrm{E}-06$ & & (2. & $3.93 E-06$ \\
\hline 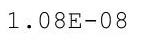 & $.72 \mathrm{E}-0$ & & & $1.54 \mathrm{E}-06$ & & & $E-06$ \\
\hline$F-08$ & $7.72 F-06$ & & & $55 E-06$ & & & 06 \\
\hline 08 & & & & 06 & 6 & & \\
\hline & 6 & 0.2 & 3.01 & $1.55 \mathrm{E}-06$ & 06 & 06 & \\
\hline $.11 \mathrm{E}-08$ & $7.73 \mathrm{E}$ & & & 1.551 & & & -06 \\
\hline $1 \mathrm{E}-08$ & & & & 1.00 & & & $4-0$ \\
\hline 8 & ( & & & 6 & 6 & 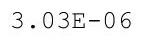 & 06 \\
\hline & & & & & & & 6 \\
\hline 8 & & & 7 & 06 & 6 & 6 & \\
\hline$E-08$ & $7.73 E-06$ & 0. & 3.4 & 1 . & 06 & 06 & -06 \\
\hline & & & & & & & \\
\hline & o & & & $\perp \cdot 00$ & & & $.96 E-06$ \\
\hline & 6 & . & & 6 & 06 & 06 & $20 \mathrm{C}-0$ \\
\hline 8 & $4 E-06$ & $7 E-07$ & $45 E-07$ & $E-06$ & $21 E-06$ & $05 E-06$ & -06 \\
\hline
\end{tabular}


RESRAD-OFFSITE, Version 2.5

itle : Offsite Resident Farmer Deterministic Run

File : RF TC99 DOESG FWD-FV2b.ROF

Summary of dose at graphical times, reptition 1 (continued)

Time

Years

$6.37 \mathrm{E}+02$

6. $37 \mathrm{E}+02$

$6.38 \mathrm{E}+02$

$6.38 \mathrm{E}+02$

$6.39 \mathrm{E}+02$

6. $39 \mathrm{E}+02$

$6.40 \mathrm{E}+02$

$6.40 \mathrm{E}+02$

$6.41 \mathrm{E}+02$

$6.41 \mathrm{E}+02$

$6.42 \mathrm{E}+02$

$6.42 \mathrm{E}+02$

$6.43 \mathrm{E}+02$

$6.43 \mathrm{E}+02$

$6.44 \mathrm{E}+02$

$6.44 \mathrm{E}+02$

$6.45 \mathrm{E}+02$

$6.45 \mathrm{E}+02$

$6.46 \mathrm{E}+02$

$6.47 \mathrm{E}+02$

$6.47 \mathrm{E}+02$

$6.48 \mathrm{E}+02$

$6.48 \mathrm{E}+02$

$6.49 \mathrm{E}+02$

$6.49 \mathrm{E}+02$

$6.50 \mathrm{E}+02$

$6.50 \mathrm{E}+02$

$6.51 \mathrm{E}+02$

$6.51 \mathrm{E}+02$

$6.52 \mathrm{E}+02$

$6.52 \mathrm{E}+02$

$6.53 \mathrm{E}+02$

$6.53 \mathrm{E}+02$

$6.54 \mathrm{E}+02$

$6.54 \mathrm{E}+02$

$6.55 \mathrm{E}+02$

$6.55 \mathrm{E}+02$

$6.56 \mathrm{E}+02$

$6.56 \mathrm{E}+02$

$6.57 \mathrm{E}+02$

$6.57 \mathrm{E}+02$

$6.58 \mathrm{E}+02$

$6.58 \mathrm{E}+02$

$6.59 \mathrm{E}+02$

$6.59 \mathrm{E}+02$

$6.60 \mathrm{E}+02$
Dose statistics at graphical times, mrem/yr

\begin{tabular}{|c|c|c|c|c|c|c|c|}
\hline inimum & aximum & lean & edic & & & & \\
\hline $.18 \mathrm{E}-08$ & $4 E-06$ & $8 E-07$ & $46 E-07$ & $D E-06$ & $1 E-06$ & $3.05 E-06$ & -06 \\
\hline $.19 \mathrm{E}-08$ & $.74 \mathrm{E}-06$ & $0 E-07$ & $47 \mathrm{E}-07$ & $1.60 \mathrm{E}-06$ & $2.22 \mathrm{E}-06$ & $3.05 E-06$ & $97 E-06$ \\
\hline $9 E-08$ & $74 E-06$ & $42 \mathrm{~F}-07$ & $48 E-07$ & $.60 E-06$ & $2.22 \mathrm{E}-06$ & $3.05 E-06$ & $97 E-06$ \\
\hline $20 \mathrm{E}-08$ & $.74 \mathrm{E}-06$ & $6.43 E-07$ & $49 E-07$ & $.60 E-06$ & $2.23 E-06$ & $6 E-06$ & $E-06$ \\
\hline $21 \mathrm{E}-08$ & 06 & & & & & & -06 \\
\hline $22 E-08$ & $74 E-06$ & & & & & & -06 \\
\hline $22 E-08$ & $7.74 \mathrm{E}-06$ & 定 & 7 & $.61 E-06$ & $2.24 E-06$ & $\Xi-06$ & $99 E-06$ \\
\hline $23 E-08$ & $74 E-06$ & $9 \mathrm{E}-07$ & $4 E-07$ & $.62 \mathrm{E}-06$ & $.24 E-06$ & $E-06$ & $99 E-06$ \\
\hline $24 \mathrm{~F}-08$ & $74 E-06$ & $51 \mathrm{~F}-0$ & $55 \mathrm{~F}-0$ & $62 \mathrm{~F}-1$ & $.25 E-06$ & $8 E-06$ & $E-06$ \\
\hline $25 \mathrm{E}-08$ & $4 E-06$ & $6.52 \mathrm{E}-07$ & $3.56 \mathrm{E}-07$ & & & $3.08 E-06$ & -06 \\
\hline $26 \mathrm{E}-08$ & $7.74 F-06$ & 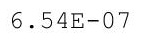 & $7 F-07$ & $63 \mathrm{~F}$ & 6 & -06 & -06 \\
\hline $26 \mathrm{E}-08$ & $7.74 \mathrm{E}-06$ & & & & & & -06 \\
\hline $.27 E-08$ & $7.74 \mathrm{E}-06$ & 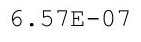 & $3.60 \mathrm{E}-07$ & $1.63 E-06$ & $2.26 E-06$ & $3.09 E-06$ & $01 E-06$ \\
\hline $28 E-08$ & $4 E-06$ & & & & & -06 & $E-06$ \\
\hline 8 & . 1 & 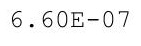 & $3.63 E-07$ & $+\infty$ & 6 & 6 & -06 \\
\hline 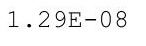 & 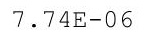 & $6.62 \mathrm{E}-07$ & $.64 \mathrm{E}-07$ & 6 & 6 & $3.10 \mathrm{E}-06$ & 06 \\
\hline $30 \mathrm{~F}$ & 6 & $6.63 \mathrm{E}-07$ & $3.65 E-07$ & 5 & 6 & 6 & -06 \\
\hline $31 \mathrm{~F}-08$ & $7.75 E-06$ & $5 F-07$ & & $5 E-06$ & $8 E-06$ & -06 & $4 E-06$ \\
\hline $32 E-08$ & $.75 E-06$ & $6.67 \mathrm{E}-07$ & $.68 \mathrm{E}-07$ & $1.65 \mathrm{E}-06$ & $2.29 \mathrm{E}-06$ & -06 & $.04 E-06$ \\
\hline-08 & $5 E-06$ & $68 \mathrm{~F}=0$ & 07 & -06 & -06 & -06 & $04 E-06$ \\
\hline 0 & & & & 6 & & & \\
\hline $34 E-08$ & & & & 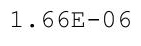 & & & 06 \\
\hline $35 E-08$ & 06 & 6735 & 35 & 6 & 6 & & -06 \\
\hline $36 \mathrm{~F}-08$ & $.75 E-06$ & $6745-0$ & 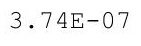 & $1.66 \mathrm{E}-06$ & $31 E-06$ & $4 E-06$ & $06 E-06$ \\
\hline $37 E-08$ & $75 \mathrm{~F}-06$ & $6.76 \mathrm{E}-07$ & $.75 \mathrm{E}-07$ & $1.67 \mathrm{E}-06$ & $2.31 \mathrm{E}-06$ & $5 E-06$ & $06 E-06$ \\
\hline$F-08$ & $.75 E-06$ & & & & & -06 & $07 E-06$ \\
\hline & & & & & & & \\
\hline & & & & 6 & & & -06 \\
\hline $.40 \mathrm{E}-08$ & $7.75 \mathrm{E}-06$ & $6.82 E-07$ & . & $1.67 \mathrm{E}-06$ & $2.33 E-06$ & $7 E-06$ & $08 E-06$ \\
\hline $41 E-$ & 6 & (1) & . & $1.67 \mathrm{E}-06$ & $.34 E-06$ & $3.17 \mathrm{E}-06$ & $.08 E-06$ \\
\hline $2 \mathrm{E}-$ & $75 E-$ & & & $1.68 \mathrm{E}-$ & & $F-06$ & $09 E-06$ \\
\hline $43 F-08$ & F- & & & 6 & & & $9 E-06$ \\
\hline 8 & & & & & & & \\
\hline 08 & 06 & & & 6 & & & -06 \\
\hline $.45 \mathrm{E}-08$ & $7.74 \mathrm{E}-06$ & $6.92 \mathrm{E}-07$ & $3.89 \mathrm{E}-07$ & $1.69 \mathrm{E}-06$ & $2.36 \mathrm{E}-06$ & $3.20 E-06$ & $.10 E-06$ \\
\hline •.70t vo & $1.145-06$ & & & $1.69 \mathrm{E}-06$ & & & $4.11 \mathrm{E}-06$ \\
\hline 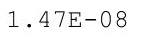 & 6 & 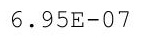 & $3.92 \mathrm{E}-07$ & 6 & & 6 & $11 E-06$ \\
\hline $.48 E-08$ & $7.74 \mathrm{E}-06$ & 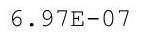 & & 6 & 6 & 6 & 06 \\
\hline $.49 \mathrm{E}-08$ & & & 7 & & 6 & 6 & \\
\hline $.50 E-08$ & & & 07 & 1. & 06 & 06 & 06 \\
\hline $.51 E-08$ & $7.74 \mathrm{E}-06$ & $7.01 E-07$ & & 6 & & & -06 \\
\hline 政 & & & & & & & $4.13 E-06$ \\
\hline ezLi vo & $\begin{array}{ll}1.74-00 \\
0\end{array}$ & . & 20 & $1.71 \mathrm{E}-06$ & $2.40 \mathrm{E}-06$ & $23 E-06$ & $4.13 E-06$ \\
\hline 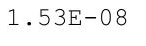 & $1.14 \mathrm{~L} 00$ & ( & & $1.72 \mathrm{E}-06$ & $2.40 \mathrm{E}-06$ & & $4.14 \mathrm{E}-06$ \\
\hline $5=0$ & 6 & & & 6 & $2.41 E-06$ & 06 & 06 \\
\hline $55 E-08$ & $.74 E-06$ & $.09 E-07$ & $07 E-07$ & -06 & $E-06$ & $.24 E-06$ & 4.1 \\
\hline
\end{tabular}


RESRAD-OFFSITE, Version 2.5

obabilistic Dose and Risk Report

Title : Offsite Resident Farmer Deterministic Run

File : RF TC99 DOESG FWD-FV2b.ROF

Summary of dose at graphical times, reptition 1 (continued)

Time

Years

$6.60 \mathrm{E}+02$

$6.61 \mathrm{E}+02$

$6.61 \mathrm{E}+02$

$6.62 \mathrm{E}+02$

$6.62 \mathrm{E}+02$

$6.63 \mathrm{E}+02$

$6.63 \mathrm{E}+02$

$6.64 \mathrm{E}+02$

$6.64 \mathrm{E}+02$

$6.65 \mathrm{E}+02$

$6.65 \mathrm{E}+02$

$6.66 \mathrm{E}+02$

$6.67 \mathrm{E}+02$

$6.67 \mathrm{E}+02$

$6.68 \mathrm{E}+02$

$6.68 \mathrm{E}+02$

$6.69 \mathrm{E}+02$

$6.69 \mathrm{E}+02$

$6.70 \mathrm{E}+02$

$6.70 \mathrm{E}+02$

$6.71 \mathrm{E}+02$

$6.71 \mathrm{E}+02$

$6.72 \mathrm{E}+02$

$6.72 \mathrm{E}+02$

$6.73 \mathrm{E}+02$

$6.73 \mathrm{E}+02$

$6.74 \mathrm{E}+02$

$6.74 \mathrm{E}+02$

$6.75 \mathrm{E}+02$

$6.75 \mathrm{E}+02$

$6.76 \mathrm{E}+02$

$6.76 \mathrm{E}+02$

$6.77 \mathrm{E}+02$

$6.77 \mathrm{E}+02$

$6.78 \mathrm{E}+02$

$6.78 \mathrm{E}+02$

$6.79 \mathrm{E}+02$

$6.79 \mathrm{E}+02$

$6.80 \mathrm{E}+02$

$6.80 \mathrm{E}+02$

$6.81 \mathrm{E}+02$

$6.81 \mathrm{E}+02$

$6.82 \mathrm{E}+02$

$6.82 \mathrm{E}+02$

$6.83 \mathrm{E}+02$

$6.83 \mathrm{E}+02$
Dose statistics at graphical times, mrem/yr

\begin{tabular}{|c|c|c|c|c|c|c|c|}
\hline num & aximum & lean & edic & & & & \\
\hline 8 & 06 & 07 & 07 & 06 & 06 & 06 & -06 \\
\hline $57 E-08$ & $.74 \mathrm{E}-06$ & $7.12 \mathrm{E}-07$ & $1 \mathrm{E}-07$ & $1.73 E-06$ & $2.42 \mathrm{E}-06$ & $3.25 E-06$ & $15 E-06$ \\
\hline $58 \mathrm{~F}-08$ & $74 E-06$ & $14 \mathrm{~F}-07$ & $12 \mathrm{~F}-07$ & $.74 E-06$ & $2.43 E-06$ & $.25 E-06$ & $.16 E-06$ \\
\hline $59 \mathrm{E}-08$ & $73 F-06$ & $16 \mathrm{~F}-0$ & $14 \mathrm{E}-07$ & $4 E-06$ & $.43 E-06$ & $.25 E-06$ & $.16 \mathrm{E}-06$ \\
\hline$E-08$ & 06 & $7.17 \mathrm{E}-07$ & & & & 6 & -06 \\
\hline $61 \mathrm{E}-08$ & $73 E-06$ & & & & & & -06 \\
\hline $62 E-08$ & $7.73 E-06$ & 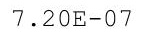 & 7 & $1.75 E-06$ & $2.45 E-06$ & $3.26 E-06$ & $.18 E-06$ \\
\hline $62 \mathrm{E}-08$ & $7.73 E-06$ & $7.22 \mathrm{E}-07$ & $20 E-07$ & $.76 \mathrm{E}-06$ & $46 E-06$ & $3.26 \mathrm{E}-06$ & $.18 E-06$ \\
\hline $63 F-08$ & $73 E-06$ & $23 F-0$ & $22 F-0$ & $.76 \mathrm{E}-06$ & $.46 E-06$ & $27 E-06$ & $19 E-06$ \\
\hline $64 \mathrm{E}-08$ & 6 & & & 6 & 6 & $27 E-06$ & -06 \\
\hline $65 F-08$ & $3 E-06$ & 7F- & 4 & 1.771 & 06 & -06 & $E-06$ \\
\hline$E-08$ & 06 & & & 6 & & & -06 \\
\hline $.67 E-08$ & $7.73 E-06$ & $7.30 E-07$ & $4.27 E-07$ & $1.77 E-06$ & $2.48 E-06$ & $3.28 E-06$ & $.20 E-06$ \\
\hline $68 E-08$ & 06 & & & & -06 & -06 & $21 E-06$ \\
\hline 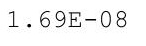 & 6 & & & 6 & & 6 & -06 \\
\hline$F$ & & $7.35 \mathrm{E}-07$ & 7 & 6 & 6 & 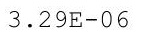 & 6 \\
\hline $71 \mathrm{~F}-08$ & $72 F-06$ & 6 & $4.33 E-07$ & 6 & 6 & 6 & -06 \\
\hline $72 \mathrm{~F}-08$ & $7.72 \mathrm{E}-06$ & $8 \mathrm{~F}$ & $\mathrm{~F}_{-1}$ & $1.79 \mathrm{E}-06$ & $0 E-06$ & -06 & $23 E-06$ \\
\hline $73 E-08$ & $.72 E-06$ & $7.39 \mathrm{E}-07$ & $4.36 \mathrm{E}-07$ & $1.79 \mathrm{E}-06$ & $2.50 \mathrm{E}-06$ & -06 & $.23 E-06$ \\
\hline$E-08$ & $72 E-06$ & & -07 & -06 & -06 & -06 & $.23 E-06$ \\
\hline - & & & & & & & \\
\hline 8 & $71 E$ & & & & 6 & & 06 \\
\hline $.77 E-08$ & $71 E-06$ & 6 & $4.42 \mathrm{E}-07$ & 6 & 6 & 6 & -06 \\
\hline $78 \mathrm{~F}-08$ & $.71 E-06$ & $47 E-0$ & $43 E-$ & $.81 E-06$ & $52 E-06$ & $E-06$ & $25 E-06$ \\
\hline $.79 E-08$ & $7.71 \mathrm{E}-06$ & 7 & $4.44 \mathrm{E}-07$ & $.81 E-06$ & $53 E-06$ & $3 E-06$ & $.26 E-06$ \\
\hline$F-08$ & $.71 F-06$ & & & -06 & -06 & -06 & $26 E-06$ \\
\hline & & & & & & & \\
\hline & & & & & & & $27 E-06$ \\
\hline $.83 E-08$ & $7.70 \mathrm{E}-06$ & . & $4.305-01$ & $1.83 \mathrm{E}-06$ & $2.54 \mathrm{E}-06$ & $3.34 \mathrm{E}-06$ & $.27 E-06$ \\
\hline 8 & $70 E-06$ & $7.57 \mathrm{E}-07$ & 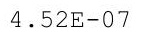 & $83 E-06$ & $2.54 \mathrm{E}-06$ & $5 E-06$ & $.28 E-06$ \\
\hline 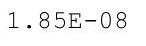 & $70 \mathrm{~F}-18$ & & 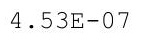 & $1.83 \mathrm{E}-$ & $55 E-$ & $E-06$ & $.28 E-06$ \\
\hline $5-08$ & & & & & & & 06 \\
\hline $.87 E-08$ & & & & & & & \\
\hline 08 & 06 & & 7 & 06 & 6 & & -06 \\
\hline $.89 \mathrm{E}-08$ & $7.69 \mathrm{E}-06$ & $1.00 \mathrm{E}-\mathrm{T}$ & $4.59 \mathrm{E}-07$ & $1.84 \mathrm{E}-06$ & $2.56 \mathrm{E}-06$ & $3.36 \mathrm{E}-06$ & $.29 E-06$ \\
\hline . & $1.095-00$ & . & & $1.84 \mathrm{E}-06$ & $2.305-06$ & $3.3 / E-00$ & $4.29 E-06$ \\
\hline 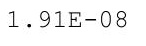 & 6 & 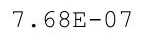 & $4.62 E-07$ & 6 & & & $29 E-06$ \\
\hline $.92 E-08$ & 6 & $7.69 \mathrm{E}-07$ & 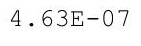 & 6 & 6 & 6 & 06 \\
\hline $.93 E-08$ & & & & 6 & & & \\
\hline $94 E-08$ & & & & 1.8 & & 06 & \\
\hline $.95 E-08$ & $7.68 \mathrm{E}-06$ & - & & 1.00 & 6 & & $30 E-06$ \\
\hline 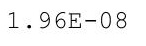 & $68 E-06$ & & & & & & $4.30 \pm-06$ \\
\hline . & $1.00 \mathrm{~L}-0$ & 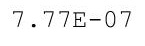 & $.70 \mathrm{E}-07$ & $1.87 \mathrm{E}-06$ & $2.59 E-06$ & $3.39 E-06$ & $4.30 E-06$ \\
\hline 年 & $7.68 \mathrm{E}-06$ & - & $4.71 \mathrm{E}-07$ & $1.87 \mathrm{E}-06$ & & $3.40 \mathrm{E}-06$ & $4.30 \mathrm{E}-06$ \\
\hline $0 E-0$ & . & & & ( & $2.60 \mathrm{E}-06$ & $E-06$ & 06 \\
\hline $.01 E-08$ & $.67 E-06$ & $.82 E-07$ & $.73 E-07$ & $E-06$ & $E-06$ & $3.41 \mathrm{E}-06$ & 4.3 \\
\hline
\end{tabular}


RESRAD-OFFSITE, Version 2.5

Title : Offsite Resident Farmer Deterministic Run

File : RF TC99 DOESG FWD-FV2b.ROF

Summary of dose at graphical times, reptition 1 (continued)

Time

Years

$6.84 \mathrm{E}+02$

$6.84 \mathrm{E}+02$

$6.85 \mathrm{E}+02$

$6.85 \mathrm{E}+02$

$6.86 \mathrm{E}+02$

$6.86 \mathrm{E}+02$

$6.87 \mathrm{E}+02$

$6.88 \mathrm{E}+02$

$6.88 \mathrm{E}+02$

$6.89 \mathrm{E}+02$

$6.89 \mathrm{E}+02$

$6.90 \mathrm{E}+02$

$6.90 \mathrm{E}+02$

$6.91 \mathrm{E}+02$

$6.91 \mathrm{E}+02$

$6.92 \mathrm{E}+02$

$6.92 \mathrm{E}+02$

$6.93 \mathrm{E}+02$

$6.93 \mathrm{E}+02$

$6.94 \mathrm{E}+02$

$6.94 \mathrm{E}+02$

$6.95 \mathrm{E}+02$

$6.95 \mathrm{E}+02$

$6.96 \mathrm{E}+02$

$6.96 \mathrm{E}+02$

$6.97 \mathrm{E}+02$

$6.97 \mathrm{E}+02$

$6.98 \mathrm{E}+02$

$6.98 \mathrm{E}+02$

$6.99 \mathrm{E}+02$

$6.99 \mathrm{E}+02$

$7.00 \mathrm{E}+02$

$7.00 \mathrm{E}+02$

$7.01 \mathrm{E}+02$

$7.01 \mathrm{E}+02$

$7.02 \mathrm{E}+02$

$7.02 \mathrm{E}+02$

$7.03 \mathrm{E}+02$

$7.03 \mathrm{E}+02$

$7.04 \mathrm{E}+02$

7. $04 \mathrm{E}+02$

$7.05 \mathrm{E}+02$

$7.05 \mathrm{E}+02$

$7.06 \mathrm{E}+02$

$7.06 \mathrm{E}+02$

$7.07 \mathrm{E}+02$
Dose statistics at graphical times, mrem/yr

\begin{tabular}{|c|c|c|c|c|c|c|c|}
\hline $\mathrm{m}$ & aximum & ea & ec & & & & \\
\hline $02 E-08$ & $7.67 \mathrm{E}-06$ & $7.84 E-07$ & $4.75 E-07$ & $1.88 \mathrm{E}-06$ & 06 & 06 & $.3 \perp E-06$ \\
\hline $.03 E-08$ & $7.67 E-06$ & $7.85 \mathrm{E}-07$ & $4.76 \mathrm{E}-07$ & $1.88 \mathrm{E}-06$ & $1 E-06$ & -06 & $31 E-06$ \\
\hline $.04 \mathrm{E}-08$ & $66 \mathrm{E}-06$ & $87 E-07$ & $.77 \mathrm{E}-07$ & $88 E-06$ & $61 E-06$ & $41 E-06$ & $1 E-06$ \\
\hline $05 E-08$ & $66 \mathrm{E}-06$ & $88 \mathrm{~F}-07$ & $.78 E-07$ & $.89 E-06$ & $62 F-06$ & $42 F-06$ & $31 E-06$ \\
\hline-08 & -06 & $7.90 \mathrm{E}-07$ & 7 & 6 & -06 & -06 & -06 \\
\hline 08 & 06 & & & & & & \\
\hline $08 \mathrm{E}-08$ & 06 & & & & & & -06 \\
\hline $10 \mathrm{E}-08$ & -06 & 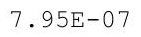 & 7 & 6 & 6 & -06 & $2 E-06$ \\
\hline-08 & -06 & 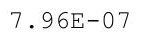 & -07 & -06 & -06 & -06 & $2 E-06$ \\
\hline $12 \mathrm{E}-08$ & $65 E-06$ & 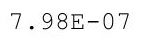 & ק תרת ת & $90 E-06$ & & $43 E-06$ & $.32 E-06$ \\
\hline$E-08$ & 7.65 & $8.00 \mathrm{E}$ & & & & 6 & $E-06$ \\
\hline $14 \mathrm{E}-08$ & $7.64 \mathrm{E}-06$ & $8.01 \mathrm{E}-07$ & 4 & & & 6 & -06 \\
\hline $15 E-08$ & $7.64 \mathrm{E}-06$ & $8.03 E-07$ & $4.91 E-07$ & $1.91 \mathrm{E}-06$ & & $E-06$ & $32 E-06$ \\
\hline $16 \mathrm{E}-08$ & $7.64 \mathrm{E}-06$ & 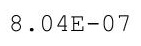 & $4.92 \mathrm{E}-07$ & $1.91 \mathrm{E}-06$ & & $3.44 \mathrm{E}-06$ & $E-06$ \\
\hline-08 & -06 & & ( & -06 & & -06 & $E-06$ \\
\hline $9 E-08$ & -06 & $8.07 E-07$ & $4.95 E-07$ & & & 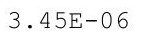 & 06 \\
\hline 8 & 6 & & & & & & 6 \\
\hline $21 \mathrm{E}-08$ & 6 & $8.11 \mathrm{E}-07$ & $4.97 \mathrm{E}-07$ & 6 & & 6 & 06 \\
\hline $22 E-08$ & $7.63 \mathrm{E}-06$ & $.12 \mathrm{E}-07$ & $4.99 \mathrm{E}-07$ & $1.93 \mathrm{E}-06$ & $2.67 E-06$ & $3.45 E-06$ & $.33 E-06$ \\
\hline $23 E-08$ & $7.62 \mathrm{E}-06$ & $.14 \mathrm{E}-07$ & $.00 E-07$ & $1.93 \mathrm{E}-06$ & $2.68 \mathrm{E}-06$ & $E-06$ & $33 E-06$ \\
\hline 08 & & & & & & 6 & -06 \\
\hline 8 & & & & 6 & & & \\
\hline 8 & 6 & & 505070 & & & & 06 \\
\hline $28 E-08$ & 06 & $8.20 \mathrm{E}-07$ & $5.07 \mathrm{E}-07$ & 6 & & 0 & -06 \\
\hline $9 E-08$ & $.61 \mathrm{E}-06$ & תרית & & 1 & $70 \mathrm{E}-$ & $.47 E-06$ & 06 \\
\hline $30 \mathrm{~F}-08$ & $7-61 \mathrm{~F}-06$ & 20 & $E-0$ & 1. $95 \mathrm{E}-06$ & $.70 E-06$ & $3.47 \mathrm{E}-06$ & $.35 E-06$ \\
\hline-08 & 6 & & & & & & $35 E-06$ \\
\hline & & & & & & & \\
\hline-08 & 1.00 & 0.2 & 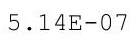 & 06 & 6 & 06 & $\Xi-06$ \\
\hline $35 E-08$ & $7.59 \mathrm{E}-06$ & ז & $\begin{array}{lll}* \\
.\end{array}$ & $1.96 \mathrm{E}-06$ & $2.72 E-06$ & $3.40 \mathrm{E}-00$ & $.36 E-06$ \\
\hline $36 \mathrm{E}$ & $7.59 \mathrm{E}-06$ & 年 & 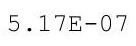 & $1.96 \mathrm{E}-06$ & $2.73 E-06$ & $3.48 \mathrm{E}-06$ & $4.36 \mathrm{E}-06$ \\
\hline - & 6 & & & & & 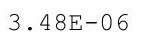 & \\
\hline-08 & & & & & & & 06 \\
\hline 8 & 06 & & & & & & \\
\hline 08 & $1.58 \mathrm{E}$ & 8.371 & -07 & $1.97 \mathrm{E}$ & 6 & 06 & \\
\hline $42 E-08$ & $7.58 \mathrm{E}-06$ & . & $.24 E-07$ & $1.97 \mathrm{E}-06$ & $2.75 E-06$ & -06 & $B E-06$ \\
\hline $44 \mathrm{E}-08$ & & & & & & & $4.500-00$ \\
\hline $45 E-08$ & . & & - & 6 & & & $E-06$ \\
\hline 8 & $7.57 \mathrm{E}-06$ & ( & 7 & 6 & 6 & 6 & 06 \\
\hline $.47 \mathrm{E}-08$ & 6 & & 07 & & & & 06 \\
\hline $48 \mathrm{E}-08$ & $7.56 \mathrm{E}-06$ & $8.47 \mathrm{E}$ & $E-07$ & 1 & & & -06 \\
\hline$E-08$ & 6 & & & & & & \\
\hline & & & & & & & $4.40 E-06$ \\
\hline $.5 \angle E-08$ & $7.55 \mathrm{E}-06$ & . & $5.39 E-01$ & $2.00 E-06$ & $2.77 E-06$ & $3.50 \mathrm{E}-06$ & $4.40 E-06$ \\
\hline L-0 & $1.03 \mathrm{C}-0$ & . & $5.41 E-07$ & & & & $4.40 E-06$ \\
\hline$E-08$ & $.54 \mathrm{E}-06$ & $.55 E-07$ & $.42 \mathrm{E}-07$ & $.01 E-06$ & $2.78 \mathrm{E}-06$ & $3.50 E-06$ & $4.40 E-06$ \\
\hline
\end{tabular}


RESRAD-OFFSITE, Version 2.5

Title : Offsite Resident Farmer Deterministic Run

File : RF TC99 DOESG FWD-FV2b.ROF

Summary of dose at graphical times, reptition 1 (continued)

Time

Years

$7.08 \mathrm{E}+02$

$7.08 \mathrm{E}+02$

7. $09 \mathrm{E}+02$

$7.09 \mathrm{E}+02$

$7.10 \mathrm{E}+02$

$7.10 \mathrm{E}+02$

7. $11 \mathrm{E}+02$

$7.11 \mathrm{E}+02$

7. $12 \mathrm{E}+02$

$7.12 \mathrm{E}+02$

$7.13 \mathrm{E}+02$

7. $13 \mathrm{E}+02$

$7.14 \mathrm{E}+02$

$7.14 \mathrm{E}+02$

$7.15 \mathrm{E}+02$

7. $15 \mathrm{E}+02$

$7.16 \mathrm{E}+02$

$7.16 \mathrm{E}+02$

$7.17 \mathrm{E}+02$

$7.17 \mathrm{E}+02$

$7.18 \mathrm{E}+02$

$7.18 \mathrm{E}+02$

7. $19 \mathrm{E}+02$

$7.19 \mathrm{E}+02$

$7.20 \mathrm{E}+02$

$7.20 \mathrm{E}+02$

$7.21 \mathrm{E}+02$

$7.21 \mathrm{E}+02$

7. $22 \mathrm{E}+02$

$7.22 \mathrm{E}+02$

$7.23 \mathrm{E}+02$

$7.23 \mathrm{E}+02$

$7.24 \mathrm{E}+02$

$7.24 \mathrm{E}+02$

$7.25 \mathrm{E}+02$

7. $25 \mathrm{E}+02$

7. $26 \mathrm{E}+02$

$7.26 \mathrm{E}+02$

$7.27 \mathrm{E}+02$

$7.28 \mathrm{E}+02$

$7.28 \mathrm{E}+02$

$7.29 \mathrm{E}+02$

$7.29 \mathrm{E}+02$

$7.30 \mathrm{E}+02$

7. $30 \mathrm{E}+02$

$7.31 \mathrm{E}+02$
Dose statistics at graphical times, mrem/yr

\begin{tabular}{|c|c|c|c|c|c|c|c|}
\hline Minimum & Maximum & Mean & Median & $90 \%$ & $95 \%$ & $97.5 \%$ & $99 \%$ \\
\hline $2.56 E-08$ & $7.54 \mathrm{E}-06$ & $8.56 \mathrm{E}-07$ & $5.44 E-07$ & $2.01 E-06$ & $2.78 E-06$ & $3.50 \mathrm{E}-06$ & $4.41 E-06$ \\
\hline $2.57 E-08$ & $7.54 \mathrm{E}-06$ & $8.58 E-07$ & $5.45 E-07$ & $2.01 E-06$ & $2.78 E-06$ & $3.50 E-06$ & $4.41 E-06$ \\
\hline $2.59 \mathrm{E}-08$ & $7.53 \mathrm{E}-06$ & $8.60 \mathrm{E}-07$ & $5.46 \mathrm{E}-07$ & $2.02 \mathrm{E}-06$ & $2.78 \mathrm{E}-06$ & $3.51 \mathrm{E}-06$ & $4.41 \mathrm{E}-06$ \\
\hline $2.60 \mathrm{E}-08$ & $7.53 \mathrm{E}-06$ & $8.61 \mathrm{E}-07$ & $5.48 \mathrm{E}-07$ & $2.02 \mathrm{E}-06$ & $2.78 \mathrm{E}-06$ & $3.51 \mathrm{E}-06$ & $4.41 \mathrm{E}-06$ \\
\hline $2.61 E-08$ & $7.53 \mathrm{E}-06$ & $8.63 E-07$ & $5.49 \mathrm{E}-07$ & $.02 \mathrm{E}-06$ & $2.79 \mathrm{E}-06$ & $3.51 E-06$ & $4.42 E-06$ \\
\hline $2.62 E-08$ & 7. $52 \mathrm{E}-06$ & $8.64 \mathrm{E}-07$ & $5.51 \mathrm{E}-07$ & $2.02 E-06$ & $2.79 E-06$ & $3.51 \mathrm{E}-06$ & $4.42 \mathrm{E}-06$ \\
\hline $2.64 \mathrm{E}-08$ & $7.52 \mathrm{E}-06$ & $8.66 \mathrm{E}-07$ & $5.52 \mathrm{E}-07$ & $2.03 E-06$ & $2.79 E-06$ & $3.51 \mathrm{E}-06$ & $4.42 E-06$ \\
\hline $2.65 \mathrm{E}-08$ & $7.52 \mathrm{E}-06$ & $8.67 \mathrm{E}-07$ & $5.54 \mathrm{E}-07$ & $2.03 E-06$ & $2.79 \mathrm{E}-06$ & $3.51 \mathrm{E}-06$ & $4.42 \mathrm{E}-06$ \\
\hline $2.66 \mathrm{E}-08$ & $7.51 \mathrm{E}-06$ & $8.69 \mathrm{E}-07$ & $5.55 \mathrm{E}-07$ & $2.03 E-06$ & $2.80 E-06$ & $3.51 \mathrm{E}-06$ & 4. $42 \mathrm{E}-06$ \\
\hline $2.68 \mathrm{E}-08$ & $.51 E-06$ & $8.71 \mathrm{E}-07$ & $5.57 \mathrm{E}-07$ & $2.03 E-06$ & $2.80 E-06$ & $3.52 E-06$ & $4.42 E-06$ \\
\hline $2.69 \mathrm{E}-08$ & $7.51 \mathrm{E}-06$ & $8.72 \mathrm{E}-07$ & $5.59 \mathrm{E}-07$ & $04 \mathrm{E}-06$ & $80 \mathrm{E}-06$ & $3.52 \mathrm{E}-06$ & $4.42 E-06$ \\
\hline $2.70 \mathrm{E}-08$ & $7.50 \mathrm{E}-06$ & $8.74 \mathrm{E}-07$ & $5.60 \mathrm{E}-07$ & $2.04 \mathrm{E}-06$ & $2.80 E-06$ & $3.52 \mathrm{E}-06$ & $4.43 E-06$ \\
\hline $2.72 \mathrm{E}-08$ & $7.50 \mathrm{E}-06$ & $8.75 E-07$ & $5.62 \mathrm{E}-07$ & $2.04 \mathrm{E}-06$ & $2.81 E-06$ & $3.52 \mathrm{E}-06$ & $4.43 E-06$ \\
\hline $2.73 E-08$ & $7.50 \mathrm{E}-06$ & $8.77 \mathrm{E}-07$ & $5.63 E-07$ & $2.04 \mathrm{E}-06$ & $2.81 E-06$ & $3.52 \mathrm{E}-06$ & $4.43 E-06$ \\
\hline $2.74 \mathrm{E}-08$ & $7.49 \mathrm{E}-06$ & $8.78 E-07$ & $5.65 E-07$ & $2.05 E-06$ & $2.81 E-06$ & $3.52 E-06$ & $4.43 E-06$ \\
\hline $2.76 \mathrm{E}-08$ & $7.49 \mathrm{E}-06$ & $8.80 E-07$ & $5.67 E-07$ & $.05 E-06$ & $2.81 E-06$ & $.52 E-06$ & $4.43 E-06$ \\
\hline $2.77 \mathrm{E}-08$ & $7.48 \mathrm{E}-06$ & $8.82 \mathrm{E}-07$ & $5.68 \mathrm{E}-07$ & $.05 E-06$ & $2.82 \mathrm{E}-06$ & $3.53 E-06$ & $4.43 E-06$ \\
\hline $2.78 \mathrm{E}-08$ & $7.48 E-06$ & $8.83 E-07$ & $5.70 \mathrm{E}-07$ & $2.05 E-06$ & $2.82 E-06$ & $3.53 E-06$ & $4.43 E-06$ \\
\hline $2.80 E-08$ & $7.48 E-06$ & $8.85 E-07$ & $5.71 \mathrm{E}-07$ & $2.06 \mathrm{E}-06$ & $2.82 E-06$ & $3.53 E-06$ & $4.43 E-06$ \\
\hline $2.81 E-08$ & $7.47 \mathrm{E}-06$ & $8.86 \mathrm{E}-07$ & $5.73 E-07$ & $2.06 \mathrm{E}-06$ & $2.83 E-06$ & $3.53 E-06$ & $4.44 \mathrm{E}-06$ \\
\hline $2.82 \mathrm{E}-08$ & $7.47 \mathrm{E}-06$ & $8.88 \mathrm{E}-07$ & $5.74 \mathrm{E}-07$ & $2.06 \mathrm{E}-06$ & $2.83 E-06$ & $3.53 E-06$ & $4.44 \mathrm{E}-06$ \\
\hline $2.84 \mathrm{E}-08$ & $7.47 E-06$ & $8.89 E-07$ & $5.76 \mathrm{E}-07$ & $2.07 E-06$ & $2.83 E-06$ & $3.53 E-06$ & $4.44 E-06$ \\
\hline $2.85 E-08$ & $7.46 \mathrm{E}-06$ & $8.91 E-07$ & $5.77 \mathrm{E}-07$ & $2.07 \mathrm{E}-06$ & $2.83 E-06$ & $3.53 E-06$ & $4.44 E-06$ \\
\hline $2.86 \mathrm{E}-08$ & $7.46 \mathrm{E}-06$ & $8.93 E-07$ & $5.79 \mathrm{E}-07$ & $2.07 \mathrm{E}-06$ & $2.83 E-06$ & $3.53 E-06$ & $4.44 \mathrm{E}-06$ \\
\hline $2.88 \mathrm{E}-08$ & $7.45 E-06$ & $8.94 \mathrm{E}-07$ & $5.81 \mathrm{E}-07$ & $2.08 E-06$ & $2.84 \mathrm{E}-06$ & $3.53 E-06$ & $4.44 \mathrm{E}-06$ \\
\hline $2.89 \mathrm{E}-08$ & $.45 E-06$ & $8.96 \mathrm{E}-07$ & $5.83 E-07$ & $2.08 \mathrm{E}-06$ & $2.84 E-06$ & $3.54 \mathrm{E}-06$ & $4.44 \mathrm{E}-06$ \\
\hline $2.90 \mathrm{E}-08$ & $7.45 E-06$ & $8.97 \mathrm{E}-07$ & $5.84 \mathrm{E}-07$ & $2.09 \mathrm{E}-06$ & $2.84 \mathrm{E}-06$ & $3.54 \mathrm{E}-06$ & $4.44 \mathrm{E}-06$ \\
\hline $2.92 \mathrm{E}-08$ & $7.44 \mathrm{E}-06$ & $8.99 E-07$ & $5.86 \mathrm{E}-07$ & $2.09 E-06$ & $2.85 E-06$ & $3.54 \mathrm{E}-06$ & $4.44 E-06$ \\
\hline $2.93 E-08$ & $7.44 \mathrm{E}-06$ & $9.00 \mathrm{E}-07$ & $5.88 E-07$ & $2.09 E-06$ & $2.85 E-06$ & $3.54 \mathrm{E}-06$ & $4.45 E-06$ \\
\hline $2.95 E-08$ & $7.43 E-06$ & $9.02 \mathrm{E}-07$ & $5.89 \mathrm{E}-07$ & $2.09 E-06$ & $2.85 E-06$ & $3.54 \mathrm{E}-06$ & $4.45 E-06$ \\
\hline $2.96 \mathrm{E}-08$ & $7.43 E-06$ & $9.04 \mathrm{E}-07$ & $5.91 \mathrm{E}-07$ & $2.10 \mathrm{E}-06$ & $2.86 \mathrm{E}-06$ & $3.54 \mathrm{E}-06$ & $4.45 E-06$ \\
\hline $2.97 \mathrm{E}-08$ & $7.43 E-06$ & $9.05 E-07$ & $5.92 \mathrm{E}-07$ & $2.10 \mathrm{E}-06$ & $2.86 \mathrm{E}-06$ & $3.54 \mathrm{E}-06$ & $4.45 E-06$ \\
\hline $2.99 E-08$ & $7.42 \mathrm{E}-06$ & $9.07 \mathrm{E}-07$ & $5.93 E-07$ & $2.10 \mathrm{E}-06$ & $2.87 E-06$ & $3.54 \mathrm{E}-06$ & $4.45 E-06$ \\
\hline $3.00 \mathrm{E}-08$ & $7.42 E-06$ & $9.08 E-07$ & $5.95 \mathrm{E}-07$ & $2.11 E-06$ & $2.87 E-06$ & $.54 E-06$ & $4.45 E-06$ \\
\hline $3.02 \mathrm{E}-08$ & $7.41 \mathrm{E}-06$ & $9.10 \mathrm{E}-07$ & $5.96 \mathrm{E}-07$ & $2.11 \mathrm{E}-06$ & $2.87 \mathrm{E}-06$ & $3.55 E-06$ & $4.45 E-06$ \\
\hline $3.03 E-08$ & $7.41 \mathrm{E}-06$ & $9.11 \mathrm{E}-07$ & $5.98 E-07$ & $2.11 \mathrm{E}-06$ & $2.87 E-06$ & $3.55 E-06$ & $4.45 E-06$ \\
\hline $3.04 \mathrm{E}-08$ & $7.41 \mathrm{E}-06$ & $9.13 E-07$ & $5.99 E-07$ & $2.12 \mathrm{E}-06$ & $2.88 E-06$ & $3.55 E-06$ & $4.45 E-06$ \\
\hline $3.06 \mathrm{E}-08$ & $7.40 \mathrm{E}-06$ & $9.15 \mathrm{E}-07$ & $6.00 \mathrm{E}-07$ & $2.12 \mathrm{E}-06$ & $2.88 \mathrm{E}-06$ & $3.55 \mathrm{E}-06$ & 4. $45 E-06$ \\
\hline $3.07 E-08$ & $7.40 \mathrm{E}$ & $9.16 \mathrm{E}-07$ & $6.02 E-07$ & $2.12 \mathrm{E}-06$ & $2.88 E-06$ & $3.55 E-06$ & $4.45 E-06$ \\
\hline $3.09 \mathrm{E}-08$ & $7.39 \mathrm{E}-06$ & $9.18 \mathrm{E}-07$ & $6.03 E-07$ & $.13 E-06$ & $2.89 E-06$ & $3.55 \mathrm{E}-06$ & $4.45 \mathrm{E}-06$ \\
\hline $3.10 \mathrm{E}-08$ & $7.39 E-06$ & $9.19 \mathrm{E}-07$ & $6.04 \mathrm{E}-07$ & $2.13 E-06$ & $2.89 \mathrm{E}-06$ & $3.55 E-06$ & $4.45 E-06$ \\
\hline $3.12 \mathrm{E}-08$ & $7.38 \mathrm{E}-06$ & $9.21 \mathrm{E}-07$ & $6.06 \mathrm{E}-07$ & $2.13 E-06$ & $2.89 \mathrm{E}-06$ & $3.55 \mathrm{E}-06$ & $4.45 E-06$ \\
\hline $3.13 \mathrm{E}-08$ & 7. $38 \mathrm{E}-06$ & $9.22 \mathrm{E}-07$ & $6.08 \mathrm{E}-07$ & $2.14 \mathrm{E}-06$ & $2.90 E-06$ & $3.55 E-06$ & $4.45 E-06$ \\
\hline $3.15 E-08$ & $7.38 E-06$ & $9.24 \mathrm{E}-07$ & $6.09 \mathrm{E}-07$ & $2.14 \mathrm{E}-06$ & $2.90 E-06$ & $3.55 E-06$ & $4.45 E-06$ \\
\hline $3.16 \mathrm{E}-08$ & $7.37 \mathrm{E}-06$ & $9.25 E-07$ & $6.11 E-07$ & $2.14 \mathrm{E}-06$ & $2.91 \mathrm{E}-06$ & $3.56 \mathrm{E}-06$ & $4.45 E-06$ \\
\hline $3.17 \mathrm{E}-08$ & $7.37 \mathrm{E}-06$ & $9.27 E-07$ & $6.13 E-07$ & $2.15 E-06$ & $2.91 E-06$ & $3.56 E-06$ & $4.45 E-06$ \\
\hline
\end{tabular}


RESRAD-OFFSITE, Version 2.5

itle : Offsite Resident Farmer Deterministic Run

File : RF TC99 DOESG FWD-FV2b.ROF

Summary of dose at graphical times, reptition 1 (continued)

Time

Years

7. $31 \mathrm{E}+02$

$7.32 \mathrm{E}+02$

$7.32 \mathrm{E}+02$

$7.33 \mathrm{E}+02$

$7.33 \mathrm{E}+02$

$7.34 \mathrm{E}+02$

$7.34 \mathrm{E}+02$

$7.35 \mathrm{E}+02$

$7.35 \mathrm{E}+02$

$7.36 \mathrm{E}+02$

$7.36 \mathrm{E}+02$

$7.37 \mathrm{E}+02$

$7.37 \mathrm{E}+02$

7. $38 \mathrm{E}+02$

7. $38 \mathrm{E}+02$

7. $39 \mathrm{E}+02$

$7.39 \mathrm{E}+02$

7. $40 \mathrm{E}+02$

$7.40 \mathrm{E}+02$

7. $41 \mathrm{E}+02$

7. $41 \mathrm{E}+02$

$7.42 \mathrm{E}+02$

7. $42 \mathrm{E}+02$

$7.43 \mathrm{E}+02$

$7.43 \mathrm{E}+02$

$7.44 \mathrm{E}+02$

7. $44 \mathrm{E}+02$

$7.45 \mathrm{E}+02$

$7.45 \mathrm{E}+02$

7. $46 \mathrm{E}+02$

$7.46 \mathrm{E}+02$

$7.47 \mathrm{E}+02$

7. $48 \mathrm{E}+02$

$7.48 \mathrm{E}+02$

7. $49 \mathrm{E}+02$

7. $49 \mathrm{E}+02$

$7.50 \mathrm{E}+02$

$7.50 \mathrm{E}+02$

$7.51 \mathrm{E}+02$

$7.51 \mathrm{E}+02$

$7.52 \mathrm{E}+02$

7. $52 \mathrm{E}+02$

$7.53 \mathrm{E}+02$

$7.53 \mathrm{E}+02$

$7.54 \mathrm{E}+02$

$7.54 \mathrm{E}+02$
Dose statistics at graphical times, mrem/yr

\begin{tabular}{|c|c|c|c|c|c|c|c|}
\hline m & aximum & lea & -5 & & & & \\
\hline 08 & $7.36 \mathrm{E}-06$ & $9.29 \mathrm{E}-07$ & $6.15 \mathrm{E}-07$ & $15 E-06$ & $91 E-06$ & 06 & $4.4 J E-06$ \\
\hline $20 E-08$ & $7.36 \mathrm{E}-06$ & $9.30 \mathrm{E}-07$ & $6.16 \mathrm{E}-07$ & $5 E-06$ & $92 E-06$ & $56 E-06$ & $5 E-06$ \\
\hline $22 E-08$ & $.35 E-06$ & $9.32 \mathrm{E}-07$ & $6.18 \mathrm{E}-07$ & $2.16 \mathrm{E}-06$ & $2.92 \mathrm{E}-06$ & $3.56 \mathrm{E}-06$ & $.45 \mathrm{E}-06$ \\
\hline-08 & -06 & $33 F-07$ & $20=-07$ & $.16 \mathrm{E}-06$ & $.92 \mathrm{E}-06$ & -06 & $.45 E-06$ \\
\hline .08 & 06 & $9.35 \mathrm{E}-07$ & 7 & 6 & 6 & 6 & -06 \\
\hline 8 & & & & & & & \\
\hline $28 \mathrm{E}-08$ & $7.34 \mathrm{E}-06$ & & $6.25 E-07$ & & & & -06 \\
\hline-08 & 06 & 1 & 1 & 6 & 6 & -06 & $E-06$ \\
\hline $31 \mathrm{E}-08$ & $7.33 E-06$ & $1 E-07$ & $E-07$ & $17 \mathrm{E}-06$ & -06 & $E-06$ & $E-06$ \\
\hline$E-08$ & 06 & 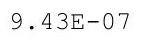 & 210 & $18 \mathrm{E}-06$ & $.94 E-06$ & $25-0$ & $45 E-06$ \\
\hline 08 & 06 & & & & & 6 & 06 \\
\hline$E-08$ & $7.31 \mathrm{E}-06$ & & $-c_{-1}$ & 6 & & 6 & -06 \\
\hline $37 E-08$ & $7.31 E-06$ & & $6.37 \mathrm{E}-07$ & $2.18 E-06$ & & $3.57 \mathrm{E}-06$ & $4.45 E-06$ \\
\hline $38 E-08$ & -06 & $9.49 \mathrm{E}-07$ & $6.38 \mathrm{E}-07$ & $2.18 \mathrm{E}-06$ & $2.95 E-06$ & -06 & $.45 E-06$ \\
\hline-08 & 06 & & 1 & 06 & & -06 & $45 E-06$ \\
\hline 08 & -06 & $9.52 \mathrm{E}-07$ & $6.41 E-07$ & 0 & $0 \Omega$ & -06 & -06 \\
\hline 8 & 6 & $9.53 E-07$ & & & & & \\
\hline 8 & 6 & $9.55 \mathrm{E}-07$ & $64 \triangle \mathrm{F}-07$ & 6 & & 6 & 06 \\
\hline $46 \mathrm{E}-08$ & $7.28 \mathrm{E}-06$ & $9.56 \mathrm{E}-07$ & $6.46 \mathrm{E}-07$ & $2.20 E-06$ & $2.97 E-06$ & $3.57 \mathrm{E}-06$ & $.45 E-06$ \\
\hline$E-08$ & $.28 \mathrm{E}-06$ & $.58 E-07$ & $6.47 \mathrm{E}-07$ & $2.20 E-06$ & $2.97 E-06$ & $E-06$ & $.45 E-06$ \\
\hline 08 & 06 & & & & & -06 & -06 \\
\hline 08 & & & & 6 & & -06 & -06 \\
\hline & & $9.63 \mathrm{E}-07$ & & 06 & & 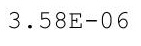 & -06 \\
\hline-08 & 06 & $9.64 \mathrm{E}-07$ & $6.52 \mathrm{E}-07$ & 6 & 6 & 0 & -06 \\
\hline 8 & 6 & $9.66 \mathrm{E}-07$ & $6.53 E-07$ & זכרכ & 6 & 6 & 06 \\
\hline$E-08$ & $7.25 \mathrm{E}-06$ & $675-10$ & 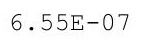 & $2.22 \mathrm{E}-06$ & $2.99 E-06$ & $9 E-06$ & $.45 E-06$ \\
\hline$E-08$ & $7.24 \mathrm{E}-06$ & & 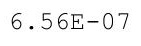 & $23 E-06$ & & $E-06$ & $.45 E-06$ \\
\hline & & & & & & & \\
\hline & & . & & 06 & 6 & -06 & -06 \\
\hline $.63 E-08$ & $7.23 E-06$ & 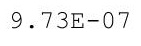 & . & $2.23 E-06$ & $3.00 \mathrm{E}-06$ & $3.00 \mathrm{E}-00$ & $.45 E-06$ \\
\hline $65 \mathrm{E}-08$ & $7.22 \mathrm{E}-06$ & (.) & coct of & $2.24 \mathrm{E}-06$ & $3.01 \mathrm{E}-06$ & $.00 \mathrm{E}-0$ & $.45 E-06$ \\
\hline 8 & 然 & & & & & ID & $.45 E-06$ \\
\hline-08 & $7.21 \mathrm{~F}-06$ & קת & 5 & $24 E-06$ & & & $45 \mathrm{~F}-06$ \\
\hline & & & & & & & \\
\hline 8 & & & 7 & 2.24 & 06 & & \\
\hline $.73 E-08$ & $7.20 E-06$ & .0उष- & 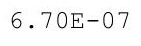 & $2.25 E-06$ & -06 & -06 & $.45 E-06$ \\
\hline $14 \mathrm{E}-08$ & & & & & & 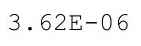 & $4.4 J \pm-00$ \\
\hline 8 & $7.19 \mathrm{E}-06$ & & ( & & & & $.45 E-06$ \\
\hline $.78 E-08$ & $7.18 \mathrm{E}-06$ & $9.87 \mathrm{E}-07$ & $6.74 \mathrm{E}-07$ & 6 & 6 & 6 & 06 \\
\hline $9 E-08$ & & & & & & & 06 \\
\hline$E-08$ & $7.17 \mathrm{E}-06$ & 9.9 - $x=1$ & 7 & 2 . & & 06 & 06 \\
\hline & $7.17 \mathrm{E}$ & 9 & & & & & -06 \\
\hline & & & & & & & $4.44 \mathrm{E}-06$ \\
\hline $80 E-08$ & . . 1 OL & . & $0.02 \mathrm{~L}$ - & $2.27 E-06$ & $3.05 E-06$ & $3.05 E-06$ & $4.44 \mathrm{E}-06$ \\
\hline$E-08$ & $7.15 \mathrm{E}-06$ & . & . & $2 \cdot 21+$ & 3.03 & & $4.44 \mathrm{E}-06$ \\
\hline-08 & $E-06$ & $98 E-07$ & $.86 \mathrm{E}-07$ & $.28 E-06$ & $E-06$ & $3.65 E-06$ & 4.4 \\
\hline
\end{tabular}


RESRAD-OFFSITE, Version 2.5

Title : Offsite Resident Farmer Deterministic Run

File : RF TC99 DOESG FWD-FV2b.ROF

Summary of dose at graphical times, reptition 1 (continued)

Time

Years

$7.55 \mathrm{E}+02$

$7.55 \mathrm{E}+02$

$7.56 \mathrm{E}+02$

7. $56 \mathrm{E}+02$

$7.57 \mathrm{E}+02$

$7.57 \mathrm{E}+02$

$7.58 \mathrm{E}+02$

$7.58 \mathrm{E}+02$

$7.59 \mathrm{E}+02$

$7.59 \mathrm{E}+02$

$7.60 \mathrm{E}+02$

$7.60 \mathrm{E}+02$

7. $61 \mathrm{E}+02$

7. $61 \mathrm{E}+02$

7. $62 \mathrm{E}+02$

7. $62 \mathrm{E}+02$

7. $63 \mathrm{E}+02$

7. $63 \mathrm{E}+02$

$7.64 \mathrm{E}+02$

$7.64 \mathrm{E}+02$

$7.65 \mathrm{E}+02$

$7.65 \mathrm{E}+02$

$7.66 \mathrm{E}+02$

$7.66 \mathrm{E}+02$

$7.67 \mathrm{E}+02$

$7.68 \mathrm{E}+02$

7. $68 \mathrm{E}+02$

7. $69 \mathrm{E}+02$

$7.69 \mathrm{E}+02$

$7.70 \mathrm{E}+02$

7. $70 \mathrm{E}+02$

$7.71 \mathrm{E}+02$

7. $71 \mathrm{E}+02$

7. $72 \mathrm{E}+02$

7. $72 \mathrm{E}+02$

7. $73 \mathrm{E}+02$

$7.73 \mathrm{E}+02$

7. $74 \mathrm{E}+02$

$7.74 \mathrm{E}+02$

$7.75 \mathrm{E}+02$

$7.75 \mathrm{E}+02$

$7.76 \mathrm{E}+02$

$7.76 \mathrm{E}+02$

$7.77 \mathrm{E}+02$

$7.77 \mathrm{E}+02$

$7.78 \mathrm{E}+02$

Dose statistics at graphical times, mrem/yr

\begin{tabular}{|c|c|c|c|c|c|c|c|}
\hline Minimum & Maximum & Mean & Median & $90 \%$ & $95 \%$ & $97.5 \%$ & $99 \%$ \\
\hline $3.91 E-08$ & $7.14 \mathrm{E}-06$ & $9.99 E-07$ & $6.88 E-07$ & $2.28 \mathrm{E}-06$ & $3.06 \mathrm{E}-06$ & $3.66 \mathrm{E}-06$ & $4.44 E-06$ \\
\hline $3.93 E-08$ & $7.14 \mathrm{E}-06$ & $1.00 \mathrm{E}-06$ & $6.89 \mathrm{E}-07$ & $2.28 E-06$ & $3.06 \mathrm{E}-06$ & $3.66 \mathrm{E}-06$ & $4.44 \mathrm{E}-06$ \\
\hline $3.94 \mathrm{E}-08$ & $7.13 \mathrm{E}-06$ & $1.00 \mathrm{E}-06$ & $6.91 \mathrm{E}-07$ & $2.28 \mathrm{E}-06$ & $3.07 E-06$ & $3.66 \mathrm{E}-06$ & $4.44 \mathrm{E}-06$ \\
\hline $3.96 \mathrm{E}-08$ & $7.13 \mathrm{E}-06$ & $1.00 \mathrm{E}-06$ & $6.92 \mathrm{E}-07$ & $2.29 \mathrm{E}-06$ & $3.07 \mathrm{E}-06$ & $3.67 \mathrm{E}-06$ & $4.44 \mathrm{E}-06$ \\
\hline $3.98 \mathrm{E}-08$ & $7.12 \mathrm{E}-06$ & $1.01 \mathrm{E}-06$ & $6.93 \mathrm{E}-07$ & $.29 E-06$ & $3.07 \mathrm{E}-06$ & $3.67 \mathrm{E}-06$ & $4.44 \mathrm{E}-06$ \\
\hline $3.99 \mathrm{E}-08$ & $7.12 \mathrm{E}-06$ & $1.01 E-06$ & $6.95 E-07$ & $2.29 E-06$ & $3.07 E-06$ & $3.67 \mathrm{E}-06$ & $4.44 E-06$ \\
\hline $4.01 E-08$ & $7.11 \mathrm{E}-06$ & $1.01 E-06$ & $6.96 \mathrm{E}-07$ & $2.30 E-06$ & $3.07 E-06$ & $3.67 \mathrm{E}-06$ & $4.44 E-06$ \\
\hline $4.03 E-08$ & $7.11 \mathrm{E}-06$ & $1.01 \mathrm{E}-06$ & $6.98 \mathrm{E}-07$ & $2.30 \mathrm{E}-06$ & $3.07 \mathrm{E}-06$ & $3.68 \mathrm{E}-06$ & $4.44 \mathrm{E}-06$ \\
\hline $4.04 \mathrm{E}-08$ & $7.10 \mathrm{E}-06$ & $1.01 \mathrm{E}-06$ & $6.99 \mathrm{E}-07$ & $.30 E-06$ & $3.08 E-06$ & $3.68 E-06$ & $4.44 E-06$ \\
\hline $4.06 \mathrm{E}-08$ & $7.10 \mathrm{E}-06$ & $.01 E-06$ & $7.00 \mathrm{E}-07$ & $2.31 \mathrm{E}-06$ & $3.08 E-06$ & $3.68 \mathrm{E}-06$ & $4.44 \mathrm{E}-06$ \\
\hline $4.08 \mathrm{E}-08$ & $7.09 E-06$ & $1.01 E-06$ & $7.02 \mathrm{E}-07$ & $31 E-06$ & $08 E-06$ & $3.68 \mathrm{E}-06$ & $4.44 \mathrm{E}-06$ \\
\hline $4.10 \mathrm{E}-08$ & $7.09 \mathrm{E}-06$ & $1.02 \mathrm{E}-06$ & $7.03 E-07$ & $2.31 \mathrm{E}-06$ & $3.08 \mathrm{E}-06$ & $3.68 \mathrm{E}-06$ & $4.44 \mathrm{E}-06$ \\
\hline $4.11 \mathrm{E}-08$ & $7.08 E-06$ & $1.02 \mathrm{E}-06$ & $7.05 E-07$ & $2.31 E-06$ & $3.09 E-06$ & $3.68 \mathrm{E}-06$ & $4.44 E-06$ \\
\hline $4.13 E-08$ & $7.07 \mathrm{E}-06$ & $1.02 \mathrm{E}-06$ & $7.06 \mathrm{E}-07$ & $2.31 E-06$ & $3.09 E-06$ & $3.68 \mathrm{E}-06$ & $4.44 \mathrm{E}-06$ \\
\hline $4.15 \mathrm{E}-08$ & $7.07 \mathrm{E}-06$ & $1.02 \mathrm{E}-06$ & $7.08 \mathrm{E}-07$ & $2.32 \mathrm{E}-06$ & $3.09 E-06$ & $3.69 E-06$ & $4.44 E-06$ \\
\hline $4.16 \mathrm{E}-08$ & $7.06 \mathrm{E}-06$ & $1.02 \mathrm{E}-06$ & $7.10 \mathrm{E}-07$ & $2.32 \mathrm{E}-06$ & $3.10 \mathrm{E}-06$ & $3.69 E-06$ & $4.44 \mathrm{E}-06$ \\
\hline $4.18 \mathrm{E}-08$ & $7.06 \mathrm{E}-06$ & $1.02 \mathrm{E}-06$ & $7.12 \mathrm{E}-07$ & $.32 E-06$ & $3.10 \mathrm{E}-06$ & $3.69 \mathrm{E}-06$ & $4.44 \mathrm{E}-06$ \\
\hline $4.20 \mathrm{E}-08$ & $7.05 E-06$ & $1.03 E-06$ & $7.13 E-07$ & $2.32 \mathrm{E}-06$ & $3.10 \mathrm{E}-06$ & $3.69 \mathrm{E}-06$ & $4.44 \mathrm{E}-06$ \\
\hline $4.22 E-08$ & $7.05 E-06$ & $1.03 E-06$ & $7.15 \mathrm{E}-07$ & $2.32 E-06$ & $3.10 \mathrm{E}-06$ & $3.69 \mathrm{E}-06$ & $4.44 E-06$ \\
\hline $4.23 E-08$ & $7.04 \mathrm{E}-06$ & $1.03 E-06$ & $7.17 \mathrm{E}-07$ & $2.32 \mathrm{E}-06$ & $3.10 \mathrm{E}-06$ & $3.69 \mathrm{E}-06$ & $4.44 E-06$ \\
\hline $4.25 \mathrm{E}-08$ & $7.04 \mathrm{E}-06$ & $1.03 E-06$ & $7.18 \mathrm{E}-07$ & $2.33 E-06$ & $3.10 \mathrm{E}-06$ & $3.69 \mathrm{E}-06$ & $4.44 \mathrm{E}-06$ \\
\hline $4.27 E-08$ & $7.03 E-06$ & $1.03 E-06$ & $7.20 \mathrm{E}-07$ & $.33 E-06$ & $.10 E-06$ & $3.70 E-06$ & $4.45 E-06$ \\
\hline $4.29 E-08$ & $7.03 E-06$ & $1.03 E-06$ & $7.21 \mathrm{E}-07$ & $2.33 E-06$ & $3.11 \mathrm{E}-06$ & $3.70 E-06$ & $4.45 E-06$ \\
\hline $4.30 \mathrm{E}-08$ & $7.02 \mathrm{E}-06$ & $1.03 E-06$ & $7.23 E-07$ & $2.33 E-06$ & $3.11 \mathrm{E}-06$ & $3.70 E-06$ & $4.45 E-06$ \\
\hline $4.32 E-08$ & $7.01 \mathrm{E}-06$ & $1.04 \mathrm{E}-06$ & $7.24 \mathrm{E}-07$ & $2.33 E-06$ & $3.11 \mathrm{E}-06$ & $3.70 E-06$ & $4.45 E-06$ \\
\hline $4.34 \mathrm{E}-08$ & $7.01 \mathrm{E}-06$ & $.04 \mathrm{E}-06$ & $7.26 \mathrm{E}-07$ & $2.33 E-06$ & $3.11 \mathrm{E}-06$ & $3.70 \mathrm{E}-06$ & $4.45 E-06$ \\
\hline $4.36 \mathrm{E}-08$ & $7.00 \mathrm{E}-06$ & $1.04 \mathrm{E}-06$ & $7.28 \mathrm{E}-07$ & $2.33 E-06$ & $3.11 \mathrm{E}-06$ & $3.70 \mathrm{E}-06$ & $4.45 E-06$ \\
\hline $4.38 E-08$ & $7.00 \mathrm{E}-06$ & $1.04 \mathrm{E}-06$ & $7.29 \mathrm{E}-07$ & $2.33 E-06$ & $3.12 \mathrm{E}-06$ & $3.70 E-06$ & $4.45 E-06$ \\
\hline $4.39 E-08$ & $6.99 \mathrm{E}-06$ & $1.04 \mathrm{E}-06$ & $7.31 E-07$ & $2.33 E-06$ & $3.12 \mathrm{E}-06$ & $3.70 E-06$ & $4.45 E-06$ \\
\hline $4.41 E-08$ & $6.99 \mathrm{E}-06$ & $1.04 \mathrm{E}-06$ & $7.33 E-07$ & $2.33 E-06$ & $3.12 E-06$ & $3.71 E-06$ & $4.46 E-06$ \\
\hline $4.43 E-08$ & $6.98 E-06$ & $1.04 \mathrm{E}-06$ & $7.34 \mathrm{E}-07$ & $2.33 E-06$ & $3.12 \mathrm{E}-06$ & $3.71 \mathrm{E}-06$ & $4.46 \mathrm{E}-06$ \\
\hline $4.45 \mathrm{E}-08$ & $6.98 E-06$ & $1.05 E-06$ & $7.36 \mathrm{E}-07$ & $2.33 E-06$ & $3.13 E-06$ & $3.71 \mathrm{E}-06$ & $4.46 \mathrm{E}-06$ \\
\hline $4.46 E-08$ & $6.97 E-06$ & $1.05 E-06$ & $7.38 E-07$ & $2.34 \mathrm{E}-06$ & $3.13 E-06$ & $3.71 E-06$ & $4.46 E-06$ \\
\hline $4.48 E-08$ & $6.96 \mathrm{E}-06$ & $1.05 E-06$ & $7.39 \mathrm{E}-07$ & $2.34 \mathrm{E}-06$ & $13 E-06$ & $3.71 E-06$ & $4.46 E-06$ \\
\hline $4.50 \mathrm{E}-08$ & $6.96 \mathrm{E}-06$ & $1.05 \mathrm{E}-06$ & $7.41 \mathrm{E}-07$ & $2.34 \mathrm{E}-06$ & $3.13 E-06$ & $3.71 \mathrm{E}-06$ & $4.46 \mathrm{E}-06$ \\
\hline $4.52 E-08$ & $6.95 E-06$ & $1.05 E-06$ & $7.43 E-07$ & $2.34 \mathrm{E}-06$ & $3.14 \mathrm{E}-06$ & $3.71 E-06$ & $4.46 E-06$ \\
\hline $4.54 \mathrm{E}-08$ & $6.95 E-06$ & $1.05 \mathrm{E}-06$ & $7.44 \mathrm{E}-07$ & $2.35 \mathrm{E}-06$ & $3.14 \mathrm{E}-06$ & $3.71 \mathrm{E}-06$ & $4.46 \mathrm{E}-06$ \\
\hline $4.56 \mathrm{E}-08$ & $6.94 \mathrm{E}-06$ & $1.06 \mathrm{E}-06$ & $7.46 \mathrm{E}-07$ & $2.35 \mathrm{E}-06$ & $3.14 \mathrm{E}-06$ & $3.72 \mathrm{E}-06$ & $4.46 \mathrm{E}-06$ \\
\hline $4.57 E-08$ & 6 & $1.06 \mathrm{E}-06$ & $7.47 \mathrm{E}-07$ & $2.35 E-06$ & $3.15 E-06$ & $3.72 E-06$ & $4.46 E-06$ \\
\hline $4.59 \mathrm{E}-08$ & $6.93 E-06$ & $1.06 \mathrm{E}-06$ & $7.49 \mathrm{E}-07$ & $.35 E-06$ & $.15 \mathrm{E}-06$ & $3.72 E-06$ & $4.47 \mathrm{E}-06$ \\
\hline $4.61 \mathrm{E}-08$ & $6.92 \mathrm{E}-06$ & $1.06 \mathrm{E}-06$ & $7.50 \mathrm{E}-07$ & $2.36 \mathrm{E}-06$ & $3.15 \mathrm{E}-06$ & $3.72 \mathrm{E}-06$ & $4.47 \mathrm{E}-06$ \\
\hline $4.63 E-08$ & $6.92 \mathrm{E}-06$ & $1.06 \mathrm{E}-06$ & $7.52 E-07$ & $2.36 \mathrm{E}-06$ & $3.16 \mathrm{E}-06$ & $3.72 E-06$ & $4.47 E-06$ \\
\hline $4.65 \mathrm{E}-08$ & $6.91 \mathrm{E}-06$ & $1.06 \mathrm{E}-06$ & $7.54 \mathrm{E}-07$ & $2.36 \mathrm{E}-06$ & $3.16 \mathrm{E}-06$ & $3.72 \mathrm{E}-06$ & $4.47 E-06$ \\
\hline $4.67 E-08$ & $6.91 \mathrm{E}-06$ & $1.06 \mathrm{E}-06$ & $7.55 \mathrm{E}-07$ & $2.36 \mathrm{E}-06$ & $3.16 \mathrm{E}-06$ & $3.72 E-06$ & $4.47 E-06$ \\
\hline $4.69 E-08$ & $6.90 \mathrm{E}-06$ & $1.07 E-06$ & $7.57 \mathrm{E}-07$ & $2.36 \mathrm{E}-06$ & $3.16 \mathrm{E}-06$ & $3.72 E-06$ & $4.47 E-06$ \\
\hline $4.70 E-08$ & $6.90 \mathrm{E}-06$ & $1.07 \mathrm{E}-06$ & $7.58 \mathrm{E}-07$ & $2.37 \mathrm{E}-06$ & $3.16 \mathrm{E}-06$ & $3.72 \mathrm{E}-06$ & $4.47 E-06$ \\
\hline
\end{tabular}


RESRAD-OFFSITE, Version 2.5

Title : Offsite Resident Farmer Deterministic Run

File : RF TC99 DOESG FWD-FV2b.ROF

Summary of dose at graphical times, reptition 1 (continued)

Time

Years

$7.78 \mathrm{E}+02$

$7.79 \mathrm{E}+02$

$7.79 \mathrm{E}+02$

$7.80 \mathrm{E}+02$

$7.80 \mathrm{E}+02$

$7.81 \mathrm{E}+02$

$7.81 \mathrm{E}+02$

$7.82 \mathrm{E}+02$

$7.82 \mathrm{E}+02$

$7.83 \mathrm{E}+02$

$7.83 \mathrm{E}+02$

$7.84 \mathrm{E}+02$

$7.84 \mathrm{E}+02$

$7.85 \mathrm{E}+02$

$7.85 \mathrm{E}+02$

$7.86 \mathrm{E}+02$

$7.86 \mathrm{E}+02$

$7.87 \mathrm{E}+02$

$7.88 \mathrm{E}+02$

$7.88 \mathrm{E}+02$

$7.89 \mathrm{E}+02$

7. $89 \mathrm{E}+02$

7. $90 \mathrm{E}+02$

$7.90 \mathrm{E}+02$

7. $91 \mathrm{E}+02$

7. $91 \mathrm{E}+02$

7. $92 \mathrm{E}+02$

7. $92 \mathrm{E}+02$

7. $93 \mathrm{E}+02$

7. $93 \mathrm{E}+02$

$7.94 \mathrm{E}+02$

7. $94 \mathrm{E}+02$

7. $95 \mathrm{E}+02$

7. $95 \mathrm{E}+02$

$7.96 \mathrm{E}+02$

7. $96 \mathrm{E}+02$

7. $97 \mathrm{E}+02$

7. $97 \mathrm{E}+02$

7. $98 \mathrm{E}+02$

7. $98 \mathrm{E}+02$

$7.99 \mathrm{E}+02$

$7.99 \mathrm{E}+02$

$8.00 \mathrm{E}+02$

$8.00 \mathrm{E}+02$

$8.01 \mathrm{E}+02$

$8.01 \mathrm{E}+02$
Dose statistics at graphical times, mrem/yr

\begin{tabular}{|c|c|c|c|c|c|c|c|}
\hline m & aximum & ea & -5 & & & & \\
\hline $.72 E-08$ & $6.89 E-06$ & $1.07 E-06$ & $7.59 \mathrm{E}-07$ & $2.37 \mathrm{E}-06$ & $3.16 \mathrm{E}-06$ & 06 & $5-00$ \\
\hline $.74 \mathrm{E}-08$ & $6.88 E-06$ & $1.07 \mathrm{E}-06$ & $.61 E-07$ & $7 E-06$ & $7 E-06$ & $3.72 E-06$ & $E-06$ \\
\hline $.76 E-08$ & $88 E-06$ & $.07 E-06$ & $62 E-07$ & $.37 E-06$ & $17 E-06$ & $72 E-06$ & $E-06$ \\
\hline $78 \mathrm{E}-08$ & $.87 E-06$ & $07 \mathrm{~F}-06$ & $64 \mathrm{E}-07$ & $.38 E-06$ & $.17 \mathrm{E}-06$ & $.72 E-06$ & $.47 E-06$ \\
\hline $80 E-08$ & -06 & -06 & $5 E-07$ & $8 E-06$ & -06 & 06 & $E-06$ \\
\hline 08 & 06 & & & & & & 06 \\
\hline $.84 \mathrm{E}-08$ & $6.85 E-06$ & & & & & & -06 \\
\hline $.85 \mathrm{E}-08$ & -06 & 0 & -07 & -06 & -06 & -06 & -06 \\
\hline $87 E-08$ & -06 & -06 & $\Xi-07$ & -06 & -06 & $E-06$ & $48 E-06$ \\
\hline $89 E-08$ & $.84 \mathrm{E}-06$ & $08=-0$ & 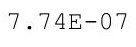 & $.40 E-06$ & & $.73 E-06$ & $48 E-06$ \\
\hline 08 & & & & & & 6 & $E-06$ \\
\hline $93 E-08$ & -06 & 1 & $7.78 \mathrm{E}-07$ & & & -06 & -06 \\
\hline $.95 E-08$ & $6.82 E-06$ & $1.09 \mathrm{E}-06$ & & & & $4 E-06$ & $E-06$ \\
\hline $.97 E-08$ & $5.81 \mathrm{E}-06$ & 1.09E-06 & $7.81 \mathrm{E}-07$ & $2.41 E-06$ & & $3.74 \mathrm{E}-06$ & 4. $47 \mathrm{E}-06$ \\
\hline-08 & -06 & 06 & & -06 & & -06 & $E-06$ \\
\hline 01 & 0 & 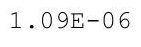 & & & & 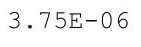 & 06 \\
\hline 8 & 0 & & & & & -06 & 6 \\
\hline 8 & 6 & $1.09 \mathrm{E}-06$ & $787 \mathrm{~F}-07$ & 6 & & 6 & 06 \\
\hline $.07 E-08$ & $6.78 E-06$ & $1.10 \mathrm{E}-06$ & $7.88 \mathrm{E}-07$ & $2.41 \mathrm{E}-06$ & $3.21 E-06$ & $3.75 E-06$ & $.46 E-06$ \\
\hline $.09 E-08$ & $.78 \mathrm{E}-06$ & $1.10 \mathrm{E}-06$ & $7.90 \mathrm{E}-07$ & $2.42 \mathrm{E}-06$ & $3.21 \mathrm{E}-06$ & $E-06$ & $.46 E-06$ \\
\hline 08 & & & & & & 0 & -06 \\
\hline 8 & & & & & & & \\
\hline 8 & 10 & $\perp$ & & & & & 06 \\
\hline $16 \mathrm{E}-08$ & 6 & 0 & $7.96 \mathrm{E}-07$ & 6 & 6 & & -06 \\
\hline $18 E-08$ & $5 E-06$ & م= & 䧑 & $.43 E-06$ & $22 E-06$ & $7 E-06$ & $45 E-$ \\
\hline$F-08$ & $74 \mathrm{~F}-06$ & $11 \mathrm{~F}-06$ & 0 & $.43 E-06$ & $22 E-06$ & $.77 E-06$ & $.44 \mathrm{E}-06$ \\
\hline 8 & & & & $2.44 \mathrm{E}-06$ & & & $.44 \mathrm{E}-06$ \\
\hline & & & & & & & \\
\hline $26 \mathrm{E}-08$ & 6.72 & $1 \cdot 1$ & 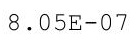 & 6 & 6 & & 06 \\
\hline $28 E-08$ & $6.72 \mathrm{E}-06$ & $\perp \cdot \perp \perp-00$ & $0.005-01$ & $2.45 E-06$ & $3.23 E-06$ & $3.17 \mathrm{E}-00$ & $.43 E-06$ \\
\hline 8 & $.71 E-06$ & $\perp \cdot \perp \perp \perp-U 0$ & 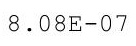 & $2.45 \mathrm{E}-06$ & $3.23 E-06$ & $7 E-06$ & $4.43 E-06$ \\
\hline 8 & 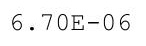 & & & & & $E-$ & 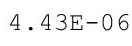 \\
\hline 3 & & & & & & & 06 \\
\hline 08 & 6 & & & & & & \\
\hline $38 E-08$ & $6.69 \mathrm{E}-06$ & 1. $12 \mathrm{E}-06$ & $E-07$ & $2.46 \mathrm{~F}$ & 06 & -06 & -06 \\
\hline $.40 E-08$ & $6.68 E-06$ & $1.12 \mathrm{E}-06$ & $8.15 E-07$ & $2.46 \mathrm{E}-06$ & $24 E-06$ & -06 & $.42 E-06$ \\
\hline $42 \mathrm{E}-08$ & & & & & & & $4.4 \angle D-00$ \\
\hline $44 \mathrm{E}-08$ & $6.67 \mathrm{E}-06$ & 1. $12 \mathrm{E}-06$ & $0.10 \mathrm{~L}-1$ & $2.46 \mathrm{E}-06$ & & & $42 E-06$ \\
\hline 8 & 6 & 1 & 7 & $47 E-06$ & 6 & 6 & 06 \\
\hline-08 & & & 07 & 6 & 06 & 6 & 06 \\
\hline $51 \mathrm{E}-08$ & $6.65 E-06$ & 1. & 07 & 2 . & & & -06 \\
\hline$E-08$ & $0.04 \mathrm{C}$ & $\perp \cdot$ & & 6 & & & 06 \\
\hline & & & & & & & $4.4 \angle E-U 6$ \\
\hline $57 E-08$ & $6.63 E-06$ & $\perp \cdot \perp \Delta \sqcup-00$ & $8.28 E-07$ & $2.48 E-06$ & $3.26 E-06$ & $3.79 E-06$ & $4.42 E-06$ \\
\hline $.59 E-08$ & $6.62 E-06$ & $\perp \cdot \pm U$ & & 2.700 & & & $4.42 E-06$ \\
\hline$E-08$ & $.62 E-06$ & $.13 E-06$ & $.32 E-07$ & $.48 E-06$ & -06 & $3.79 E-06$ & $4.42 E-06$ \\
\hline
\end{tabular}


RESRAD-OFFSITE, Version 2.5

Title : Offsite Resident Farmer Deterministic Run

File : RF TC99 DOESG FWD-FV2b.ROF

Summary of dose at graphical times, reptition 1 (continued)

Time

Years

$8.02 \mathrm{E}+02$

$8.02 \mathrm{E}+02$

$8.03 \mathrm{E}+02$

$8.03 \mathrm{E}+02$

$8.04 \mathrm{E}+02$

$8.04 \mathrm{E}+02$

$8.05 \mathrm{E}+02$

$8.05 E+02$

$8.06 \mathrm{E}+02$

$8.06 \mathrm{E}+02$

$8.07 \mathrm{E}+02$

$8.07 \mathrm{E}+02$

$8.08 \mathrm{E}+02$

$8.09 \mathrm{E}+02$

$8.09 \mathrm{E}+02$

$8.10 \mathrm{E}+02$

$8.10 \mathrm{E}+02$

8. $11 \mathrm{E}+02$

$8.11 \mathrm{E}+02$

$8.12 \mathrm{E}+02$

$8.12 \mathrm{E}+02$

$8.13 \mathrm{E}+02$

$8.13 \mathrm{E}+02$

$8.14 \mathrm{E}+02$

$8.14 \mathrm{E}+02$

$8.15 \mathrm{E}+02$

$8.15 \mathrm{E}+02$

$8.16 \mathrm{E}+02$

$8.16 \mathrm{E}+02$

$8.17 \mathrm{E}+02$

$8.17 \mathrm{E}+02$

$8.18 \mathrm{E}+02$

$8.18 \mathrm{E}+02$

$8.19 \mathrm{E}+02$

$8.19 \mathrm{E}+02$

$8.20 \mathrm{E}+02$

$8.20 \mathrm{E}+02$

$8.21 \mathrm{E}+02$

$8.21 \mathrm{E}+02$

$8.22 \mathrm{E}+02$

$8.22 \mathrm{E}+02$

$8.23 \mathrm{E}+02$

$8.23 \mathrm{E}+02$

$8.24 \mathrm{E}+02$

$8.24 \mathrm{E}+02$

$8.25 \mathrm{E}+02$
Dose statistics at graphical times, mrem/yr

\begin{tabular}{|c|c|c|c|c|c|c|c|}
\hline m & aximum & - & -5 & & & & \\
\hline $63 E-08$ & $6.61 \mathrm{E}-06$ & $1.14 \mathrm{E}-06$ & $.34 \mathrm{E}-07$ & $3 E-06$ & 06 & $3.79 \mathrm{E}-06$ & $5-00$ \\
\hline $65 E-08$ & $6.60 E-06$ & $1.14 \mathrm{E}-06$ & $8.35 E-07$ & $48 E-06$ & $7 E-06$ & $79 E-06$ & $42 E-06$ \\
\hline $67 E-08$ & $6.60 \mathrm{E}-06$ & $4 \mathrm{E}-06$ & $8.37 \mathrm{E}-07$ & $2.49 E-06$ & $3.27 E-06$ & $9 E-06$ & $.42 E-06$ \\
\hline-08 & -06 & $4 \mathrm{~F}-06$ & $30 F-07$ & $49 \mathrm{E}-06$ & $27 F-06$ & -06 & $.42 \mathrm{E}-06$ \\
\hline 08 & 06 & 6 & 7 & 6 & 6 & 6 & -06 \\
\hline 08 & 06 & & & & & & \\
\hline $.76 \mathrm{E}-08$ & 06 & & & 66 & & & -06 \\
\hline $.78 E-08$ & 06 & 0 & 1 & 6 & 6 & 6 & $42 E-06$ \\
\hline $80 \mathrm{E}-08$ & -06 & -06 & . & -06 & -06 & $E-06$ & $42 E-06$ \\
\hline$E-08$ & $55 E-06$ & $1.15 \mathrm{E}-06$ & תم & $50 \mathrm{E}-06$ & & $9 E-06$ & $42 E-06$ \\
\hline 08 & 06 & & & & & & $E-06$ \\
\hline $86 \mathrm{E}-08$ & $6.54 \mathrm{~F}$ & 1 . & $8.54 \mathrm{E}-07$ & 6 & & 6 & -06 \\
\hline $.88 \mathrm{E}-08$ & $6.53 E-06$ & $1.15 \mathrm{E}-06$ & $8.56 \mathrm{E}-07$ & $2.51 E-06$ & & $9 E-06$ & $.42 E-06$ \\
\hline $90 E-08$ & $6.53 \mathrm{E}-06$ & $1.15 \mathrm{E}-06$ & $8.57 \mathrm{E}-07$ & $2.51 E-06$ & & -06 & $.42 E-06$ \\
\hline $92 \mathrm{E}-08$ & 06 & 00 & & & & -00 & $42 E-06$ \\
\hline 8 & -06 & 0 & 701 & 06 & & -06 & $42 E-06$ \\
\hline 8 & 0 & & & & & & \\
\hline 8 & 6 & 1 & $8 \quad 65 \mathrm{~F}-07$ & 6 & & 6 & 06 \\
\hline $.01 E-08$ & $6.50 \mathrm{E}-06$ & $1.16 \mathrm{E}-06$ & $8.66 \mathrm{E}-07$ & $2.52 E-06$ & $3.29 E-06$ & $3.78 \mathrm{E}-06$ & $.42 E-06$ \\
\hline $03 E-08$ & $.49 \mathrm{E}-06$ & $1.16 \mathrm{E}-06$ & $.68 \mathrm{E}-07$ & $2.53 E-06$ & $9 E-06$ & $E-06$ & 4. $42 E-06$ \\
\hline 08 & 06 & 6 & & & & -06 & $E-06$ \\
\hline-08 & & & & 6 & 6 & 6 & 06 \\
\hline 8 & & $\perp$ & & 6 & & & 06 \\
\hline$E-08$ & 6 & $\perp$ & $8.75 E-07$ & 6 & 6 & 0 & -06 \\
\hline 8 & 6 & 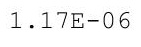 & 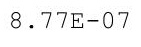 & 6 & 6 & 6 & $41 E-06$ \\
\hline $16 \mathrm{~F}-08$ & $45 E-06$ & $F-06$ & 邽 & $4 \mathrm{E}-06$ & $29 E-06$ & $8 E-06$ & $.41 E-06$ \\
\hline $18 \mathrm{E}-08$ & $44 \mathrm{E}-06$ & $E-06$ & 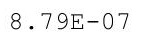 & -06 & & $E-06$ & $.41 E-06$ \\
\hline & & & & & & & \\
\hline 8 & & 06 & & 06 & & & -06 \\
\hline $25 E-08$ & $6.42 \mathrm{E}-06$ & $1 \cdot 10 \pm-U 6$ & $.045-1$ & $2.56 \mathrm{E}-06$ & $.29 E-06$ & $3.19 \mathrm{E}-00$ & $.41 E-06$ \\
\hline $27 E-08$ & $.42 E-06$ & $1 \cdot 10 \mathrm{~L}-00$ & (6) & $2.56 \mathrm{E}-06$ & $29 E-06$ & $9=-20$ & $.41 E-06$ \\
\hline $29 E-08$ & 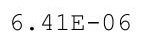 & & & & & 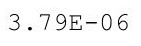 & $41 E-06$ \\
\hline-08 & $5-06$ & -06 & 7 & $E-06$ & & & 06 \\
\hline 8 & 6 & & & & & & \\
\hline 8 & 6.391 & 1. & & 6 & 06 & -06 & 06 \\
\hline $38 E-08$ & $6.39 E-06$ & $1.19 E-06$ & $.93 E-07$ & $2.01+$ & -06 & -06 & $.42 E-06$ \\
\hline $.41 E-08$ & $0.38 \mathrm{E}-00$ & & & & & & $4.4 \angle D-00$ \\
\hline $43 E-08$ & 政 & 1. $19 \mathrm{E}-06$ & 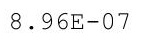 & $2.58 \mathrm{E}-06$ & & 开 & $.42 E-06$ \\
\hline $.45 E-08$ & $6.37 \mathrm{E}-06$ & $1.19 \mathrm{E}-06$ & $8.97 \mathrm{E}-07$ & 6 & 6 & 6 & 06 \\
\hline & $6.36 \mathrm{E}-06$ & & & & & & 06 \\
\hline $0 E-08$ & $6.35 E-06$ & 1. & 7 & 6 & & & -06 \\
\hline $52 E-08$ & 06 & 1.1 & & & & & -06 \\
\hline & & & & & & & $4.4 \angle E-U 6$ \\
\hline $30 E-08$ & $0.00 \mathrm{~T}$ & $1 \cdot 20+00$ & . & $2.59 \mathrm{E}-06$ & $3.31 E-06$ & $9 E-06$ & $4 \cdot 4 \angle E-U 6$ \\
\hline $.59 \mathrm{E}-08$ & 0.005 & $\perp \cdot 201$ & & 2.001 & & & $4.42 E-06$ \\
\hline$E-08$ & $.32 E-06$ & $.20 \mathrm{E}-06$ & $.08 E-07$ & $.60 \mathrm{E}-06$ & -06 & $E-06$ & $4.43 E$ \\
\hline
\end{tabular}


RESRAD-OFFSITE, Version 2.5

Title : Offsite Resident Farmer Deterministic Run

File : RF TC99 DOESG FWD-FV2b.ROF

Summary of dose at graphical times, reptition 1 (continued)

Time

Years

$8.25 \mathrm{E}+02$

$8.26 \mathrm{E}+02$

$8.26 \mathrm{E}+02$

$8.27 \mathrm{E}+02$

$8.27 \mathrm{E}+02$

$8.28 \mathrm{E}+02$

$8.29 \mathrm{E}+02$

$8.29 \mathrm{E}+02$

$8.30 \mathrm{E}+02$

$8.30 \mathrm{E}+02$

$8.31 \mathrm{E}+02$

$8.31 \mathrm{E}+02$

$8.32 \mathrm{E}+02$

$8.32 \mathrm{E}+02$

$8.33 \mathrm{E}+02$

$8.33 E+02$

$8.34 \mathrm{E}+02$

$8.34 \mathrm{E}+02$

$8.35 \mathrm{E}+02$

$8.35 \mathrm{E}+02$

$8.36 \mathrm{E}+02$

$8.36 \mathrm{E}+02$

$8.37 \mathrm{E}+02$

$8.37 \mathrm{E}+02$

$8.38 \mathrm{E}+02$

$8.38 \mathrm{E}+02$

$8.39 \mathrm{E}+02$

$8.39 \mathrm{E}+02$

$8.40 \mathrm{E}+02$

$8.40 \mathrm{E}+02$

8. $41 \mathrm{E}+02$

8. $41 \mathrm{E}+02$

$8.42 \mathrm{E}+02$

8. $42 \mathrm{E}+02$

$8.43 \mathrm{E}+02$

$8.43 \mathrm{E}+02$

$8.44 \mathrm{E}+02$

$8.44 \mathrm{E}+02$

$8.45 \mathrm{E}+02$

$8.45 \mathrm{E}+02$

$8.46 \mathrm{E}+02$

$8.46 \mathrm{E}+02$

$8.47 \mathrm{E}+02$

$8.47 \mathrm{E}+02$

8. $48 \mathrm{E}+02$

$8.49 \mathrm{E}+02$
Dose statistics at graphical times, mrem/yr

\begin{tabular}{|c|c|c|c|c|c|c|c|}
\hline m & um & lea & 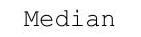 & & & & \\
\hline $63 E-08$ & $6.31 E-06$ & $1.20 \mathrm{E}-06$ & $9.09 \mathrm{E}-07$ & $2.60 \mathrm{E}-06$ & $3.31 \mathrm{E}-06$ & 06 & $4.45 E-00$ \\
\hline $65 E-08$ & $6.31 E-06$ & $1.20 \mathrm{E}-06$ & $9.11 \mathrm{E}-07$ & $0 E-06$ & $1 E-06$ & $3.79 E-06$ & $43 E-06$ \\
\hline $68 \mathrm{E}-08$ & $.30 \mathrm{E}-06$ & $1.20 \mathrm{E}-06$ & $9.13 \mathrm{E}-07$ & $2.60 \mathrm{E}-06$ & $3.31 E-06$ & $3.79 \mathrm{E}-06$ & $.43 E-06$ \\
\hline$F-08$ & -06 & $20 \mathrm{~F}-06$ & $15 \mathrm{~F}-07$ & $.60 \mathrm{E}-06$ & $\pi-06$ & -06 & $.43 E-06$ \\
\hline-08 & 06 & 6 & ${ }^{-}$ & 6 & 6 & -06 & -06 \\
\hline 08 & & & & & & & \\
\hline $.77 \mathrm{E}-08$ & 06 & $1.21 \mathrm{E}$ & & & & & -06 \\
\hline-08 & 06 & $\angle 1$ & 1 & 6 & 6 & 6 & -06 \\
\hline $.82 \mathrm{E}-08$ & -06 & $.21 \mathrm{~F}$ & -07 & -06 & $3 E-06$ & $E-06$ & $\Xi-06$ \\
\hline $4 \mathrm{E}-08$ & $25 E-06$ & $21=-06$ & (25) & $.61 E-06$ & $33 E-06$ & $8 E-06$ & $43 E-06$ \\
\hline 08 & & $.21 E-06$ & & & & & -06 \\
\hline $.89 \mathrm{E}-08$ & -06 & $1.22 \mathrm{E}$ & 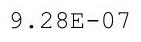 & 6 & & 6 & -06 \\
\hline $.91 E-08$ & $6.23 E-06$ & $1.22 \mathrm{E}-06$ & $9.30 E-07$ & $2.62 E-06$ & & $8 E-06$ & $E-06$ \\
\hline $.93 E-08$ & $6.23 \mathrm{E}-06$ & $1.22 \mathrm{E}-06$ & $9.32 \mathrm{E}-07$ & $2.62 \mathrm{E}-06$ & & -06 & $.44 E-06$ \\
\hline-08 & 06 & 22 & & 6 & & -06 & -06 \\
\hline $8 E-08$ & -06 & $\begin{array}{ll}0 \\
-2\end{array}$ & . & 6 & & 0 & 06 \\
\hline 8 & 0 & 1.22E-06 & & & & & 6 \\
\hline $3-08$ & 6 & 2 & a $39 F-07$ & 6 & 6 & 6 & 06 \\
\hline $.05 E-08$ & $6.19 \mathrm{E}-06$ & $1.22 \mathrm{E}-06$ & $9.40 \mathrm{E}-07$ & $2.64 \mathrm{E}-06$ & $3.34 E-06$ & $3.79 \mathrm{E}-06$ & $.44 E-06$ \\
\hline $.07 E-08$ & $.19 E-06$ & 1. $23 E-06$ & $9.42 \mathrm{E}-07$ & $2.64 \mathrm{E}-06$ & $4 E-06$ & $3.79 \mathrm{E}-06$ & 4. $44 \mathrm{E}-06$ \\
\hline 08 & & 6 & & & & 6 & $E-06$ \\
\hline 08 & & & & & & & \\
\hline 8 & & $\perp$ & & & & & 06 \\
\hline $.17 E-08$ & 06 & 0 & $9.49 \mathrm{E}-07$ & 6 & 6 & 0 & -06 \\
\hline 8 & 6 & 235 & ת & 6 & 6 & 6 & $4 \mathrm{E}-06$ \\
\hline $.22 E-08$ & $15 E-06$ & $1.23 E-06$ & $=0$ & $.65 E-06$ & $5 E-06$ & $.79 E-06$ & $.45 E-06$ \\
\hline-08 & -06 & $.24 E-06$ & $\pi$ & $65 E-06$ & & $E-06$ & $.45 E-06$ \\
\hline & & & & & & & \\
\hline & & $1.2^{2}$ & & 06 & 6 & -06 & \\
\hline $.31 E-08$ & $6.12 \mathrm{E}-06$ & $1.24 E-00$ & . & $2.66 \mathrm{E}-06$ & $.36 E-06$ & $0.00 \pm-00$ & $.45 E-06$ \\
\hline $34 \mathrm{E}-08$ & $6.11 \mathrm{E}-06$ & $1.24 \mathrm{E}-06$ & . & $2.66 \mathrm{E}-06$ & $.36 \mathrm{E}-06$ & $.00 \mathrm{~L}-00$ & $.45 E-06$ \\
\hline 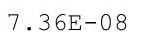 & & $1.24 \mathrm{E}-0$ & & & & $=0$ & $.45 E-06$ \\
\hline $38 E-08$ & $10 E-06$ & 1.24E-06 & 7 & $6 E-06$ & & -06 & $15 F-06$ \\
\hline & & & & & & & \\
\hline $3 E-08$ & & $1 \cdot 2$ & & 2.01 & 06 & & \\
\hline $.46 \mathrm{E}-08$ & $6.08 \mathrm{E}-06$ & $1.25 E-06$ & $9.68 E-07$ & $2.67 E-06$ & -06 & -06 & $.45 E-06$ \\
\hline $.48 \mathrm{E}-08$ & $6.07 \mathrm{E}-06$ & $1 \cdot \angle 3 E-06$ & & & & $\begin{array}{lll}.01 \mathrm{H} & 0\end{array}$ & $4.4 J \pm-00$ \\
\hline $51 \mathrm{E}-08$ & $06 E-06$ & $\begin{array}{ll}1.20 \\
0\end{array}$ & 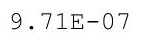 & $2.67 \mathrm{E}-06$ & & & $4.45 E-06$ \\
\hline $7.53 \mathrm{E}-08$ & $6.06 \mathrm{E}-06$ & 6 & $9.72 \mathrm{E}-07$ & 6 & 6 & 6 & 06 \\
\hline $7.55 \mathrm{E}-08$ & & & & & 6 & & 06 \\
\hline $8 E-08$ & $6.05 E-06$ & $1.25 \mathrm{E}-06$ & 7 & 2 . & & & 4.4 \\
\hline $0 E-08$ & 6 & $1.26 \mathrm{E}$ & & & & & -06 \\
\hline & & & & & & & $4.44 \mathrm{E}-06$ \\
\hline $.05 E-08$ & $6.05 E-06$ & $1.20 \mathrm{~L}-0$ & . & $2.68 \mathrm{E}-06$ & $3.37 E-06$ & $3.81 E-06$ & $4.44 \mathrm{E}-06$ \\
\hline $68 E-08$ & $0.075-20$ & 1.201 & . & $2.69 \mathrm{E}-06$ & 3.015 & & $4.44 E-06$ \\
\hline $70 \mathrm{E}-08$ & $.05 E-06$ & $E-06$ & $.82 \mathrm{E}-07$ & $.69 \mathrm{E}-06$ & -06 & $3.81 E-06$ & $4.44 \mathrm{E}-06$ \\
\hline
\end{tabular}


RESRAD-OFFSITE, Version 2.5

bilistic Dose and Risk Report

itle : Offsite Resident Farmer Deterministic Run

File : RF TC99 DOESG FWD-FV2b.ROF

Summary of dose at graphical times, reptition 1 (continued)

Time

Years

$8.49 \mathrm{E}+02$

$8.50 \mathrm{E}+02$

$8.50 \mathrm{E}+02$

$8.51 \mathrm{E}+02$

$8.51 \mathrm{E}+02$

$8.52 \mathrm{E}+02$

$8.52 \mathrm{E}+02$

8. $53 \mathrm{E}+02$

$8.53 \mathrm{E}+02$

8. $54 \mathrm{E}+02$

$8.54 \mathrm{E}+02$

8. $55 \mathrm{E}+02$

8. $55 \mathrm{E}+02$

$8.56 \mathrm{E}+02$

8. $56 \mathrm{E}+02$

$8.57 \mathrm{E}+02$

$8.57 \mathrm{E}+02$

$8.58 \mathrm{E}+02$

8. $58 \mathrm{E}+02$

$8.59 \mathrm{E}+02$

$8.59 \mathrm{E}+02$

8. $60 \mathrm{E}+02$

$8.60 \mathrm{E}+02$

$8.61 E+02$

8. $61 \mathrm{E}+02$

8. $62 \mathrm{E}+02$

8. $62 \mathrm{E}+02$

$8.63 \mathrm{E}+02$

8. $63 \mathrm{E}+02$

8. $64 \mathrm{E}+02$

8. $64 \mathrm{E}+02$

$8.65 \mathrm{E}+02$

$8.65 \mathrm{E}+02$

$8.66 \mathrm{E}+02$

$8.66 \mathrm{E}+02$

$8.67 \mathrm{E}+02$

$8.67 \mathrm{E}+02$

$8.68 \mathrm{E}+02$

8. $69 \mathrm{E}+02$

8. $69 \mathrm{E}+02$

$8.70 \mathrm{E}+02$

$8.70 \mathrm{E}+02$

$8.71 \mathrm{E}+02$

$8.71 \mathrm{E}+02$

$8.72 \mathrm{E}+02$

$8.72 \mathrm{E}+02$
Dose statistics at graphical times, mrem/yr

\begin{tabular}{|c|c|c|c|c|c|c|c|}
\hline m & aximum & lea & 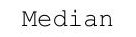 & & & & \\
\hline $.73 E-08$ & $6.05 E-06$ & $1.26 \mathrm{E}-06$ & $9.84 \mathrm{E}-07$ & $2.69 \mathrm{E}-06$ & $3.37 \mathrm{E}-06$ & 06 & $4-0$ \\
\hline $.75 E-08$ & $6.05 E-06$ & $1.26 \mathrm{E}-06$ & $9.85 \mathrm{E}-07$ & $9 E-06$ & $7 E-06$ & -06 & $4 E-06$ \\
\hline $.78 \mathrm{E}-08$ & $6.05 E-06$ & $1.26 \mathrm{E}-06$ & $9.86 \mathrm{E}-07$ & $69 E-06$ & $7 E-06$ & $3.81 E-06$ & $44 \mathrm{E}-06$ \\
\hline-08 & -06 & $.27 E-06$ & $.87 \mathrm{E}-07$ & $.70 E-06$ & $37 F-06$ & -06 & $.44 \mathrm{E}-06$ \\
\hline-08 & 06 & .27 & 7 & 6 & 6 & -06 & -06 \\
\hline 08 & 6 & 6 & & & & & \\
\hline $.88 \mathrm{E}-08$ & 06 & $1.27 \mathrm{E}$ & & & & & -06 \\
\hline-08 & 06 & 6 & 7 & 6 & 6 & 06 & -06 \\
\hline $93 E-08$ & -06 & $1.27 E-06$ & -07 & -06 & -06 & -06 & $\Xi-06$ \\
\hline$E-08$ & -06 & $7 E-06$ & תרית & 71 & & $3 F-0$ & $E-06$ \\
\hline 08 & & 6 & & & & & 06 \\
\hline$E-08$ & -06 & 1.28 & 6 & 6 & & 6 & -06 \\
\hline $.03 E-08$ & $6.04 \mathrm{E}-06$ & $1.28 \mathrm{E}-06$ & $1.00 \mathrm{E}-06$ & $2.72 E-06$ & & $3.84 \mathrm{E}-06$ & $.43 E-06$ \\
\hline $.05 E-08$ & $6.04 \mathrm{E}-06$ & -06 & $1.00 \mathrm{E}-06$ & $2.72 E-06$ & & -06 & $.43 E-06$ \\
\hline-08 & -06 & -06 & 6 & 66 & & -06 & $43 E-06$ \\
\hline 8 & -06 & .28 & $1.01 \mathrm{E}-06$ & 6 & & 0 & 06 \\
\hline 8 & 0 & 6 & & & & & \\
\hline 8 & 6 & 6 & 1. $01 \mathrm{E}-06$ & 6 & & 6 & 06 \\
\hline $18 E-08$ & $6.03 E-06$ & $1.29 \mathrm{E}-06$ & $1.01 \mathrm{E}-06$ & $2.73 E-06$ & $3.38 E-06$ & $E-06$ & $.43 E-06$ \\
\hline$E-08$ & $.03 E-06$ & 1. $29 \mathrm{E}-06$ & $2 E-06$ & $2.73 E-06$ & $9 E-06$ & -06 & $.43 E-06$ \\
\hline 08 & 06 & 06 & 6 & & & -06 & $E-06$ \\
\hline 08 & & 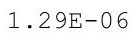 & & 6 & & 6 & -06 \\
\hline 8 & & $1 \cdot 2$ & & & & & 06 \\
\hline $31 E-08$ & 6 & 06 & 6 & 6 & 6 & 0 & -06 \\
\hline 8 & 6 & 6 & 6 & 6 & 6 & 6 & 06 \\
\hline $\mathrm{F}-08$ & $F-06$ & $.29 E-06$ & $\Xi-06$ & $.74 \mathrm{E}-06$ & $E-06$ & $E-0$ & $.43 E-06$ \\
\hline-08 & $E-06$ & 1. $30 \mathrm{E}-06$ & $E-06$ & -06 & & $E-06$ & $43 E-06$ \\
\hline 8 & & & & & & & \\
\hline 8 & & 1.30 & 06 & 06 & & & -06 \\
\hline $46 E-08$ & $6.02 \mathrm{E}-06$ & $1.30 \mathrm{E}-06$ & $1.04 \mathrm{E}-06$ & $2.74 E-06$ & $.39 E-06$ & $.045-00$ & $.43 E-06$ \\
\hline $49 \mathrm{E}-08$ & $02 E-06$ & 1.00 & $\exists-06$ & $2.74 \mathrm{E}-06$ & $9 E-06$ & $4 \mathrm{~L}-00$ & $.43 E-06$ \\
\hline 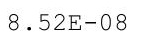 & & $30 E-06$ & & & & & \\
\hline-08 & $F-06$ & -06 & & $5 E-06$ & 6 & & $45-06$ \\
\hline 8 & & 06 & & & & & 06 \\
\hline $60 \mathrm{E}-08$ & $6.02 \mathrm{E}-06$ & 1. $31 \mathrm{E}-06$ & $4 E-06$ & 2.105 & 6 & 06 & -06 \\
\hline $62 E-08$ & $6.02 \mathrm{E}-06$ & 1. $31 \mathrm{E}-06$ & $1.05 E-06$ & $2.75 E-06$ & -06 & -06 & $.44 E-06$ \\
\hline $.05 \mathrm{E}-08$ & & 1. $31 \mathrm{E}-06$ & & & & & $4.445-00$ \\
\hline $67 \mathrm{E}-08$ & $\begin{array}{ll}-1 & 0\end{array}$ & 1. $31 \mathrm{E}-06$ & . & & & & 4. $44 \mathrm{E}-06$ \\
\hline $.70 \mathrm{E}-08$ & $6.01 \mathrm{E}-06$ & 6 & 6 & & 6 & 6 & 06 \\
\hline $.73 E-08$ & & & & & 6 & & \\
\hline$E-08$ & $6.01 E-06$ & $1.31 \mathrm{E}$ & 06 & & & & -06 \\
\hline $3 E-08$ & 06 & 1.3 & & & & & 06 \\
\hline & & & & & & & $4.44 \mathrm{E}-06$ \\
\hline . & $0.0+\mathrm{H}-0$ & $1.3 \angle E-06$ & $1.06 \mathrm{E}-06$ & $2.77 E-06$ & $3.39 E-06$ & $84 E-06$ & $4.45 E-06$ \\
\hline $86 \mathrm{E}-08$ & $6.01 E-06$ & $1.3 \angle 5$ & 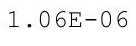 & $2 \cdot 1+1$ & . & & $4.45 E-06$ \\
\hline-08 & $6.01 \mathrm{E}-06$ & $E-06$ & $.06 \mathrm{E}-06$ & $.77 \mathrm{E}-06$ & -06 & -06 & $4.45 E-06$ \\
\hline
\end{tabular}


RESRAD-OFFSITE, Version 2.5

Title : Offsite Resident Farmer Deterministic Run

File : RF TC99 DOESG FWD-FV2b.ROF

Summary of dose at graphical times, reptition 1 (continued)

Time

Years

$8.73 \mathrm{E}+02$

$8.73 \mathrm{E}+02$

$8.74 \mathrm{E}+02$

$8.74 \mathrm{E}+02$

$8.75 \mathrm{E}+02$

$8.75 \mathrm{E}+02$

$8.76 \mathrm{E}+02$

$8.76 \mathrm{E}+02$

$8.77 \mathrm{E}+02$

$8.77 \mathrm{E}+02$

$8.78 \mathrm{E}+02$

$8.78 \mathrm{E}+02$

$8.79 \mathrm{E}+02$

$8.79 \mathrm{E}+02$

$8.80 \mathrm{E}+02$

$8.80 \mathrm{E}+02$

$8.81 \mathrm{E}+02$

$8.81 \mathrm{E}+02$

$8.82 \mathrm{E}+02$

$8.82 \mathrm{E}+02$

$8.83 \mathrm{E}+02$

$8.83 E+02$

$8.84 \mathrm{E}+02$

$8.84 \mathrm{E}+02$

$8.85 \mathrm{E}+02$

$8.85 \mathrm{E}+02$

$8.86 \mathrm{E}+02$

$8.86 \mathrm{E}+02$

$8.87 \mathrm{E}+02$

$8.87 \mathrm{E}+02$

$8.88 \mathrm{E}+02$

$8.89 \mathrm{E}+02$

$8.89 \mathrm{E}+02$

$8.90 \mathrm{E}+02$

$8.90 \mathrm{E}+02$

$8.91 \mathrm{E}+02$

$8.91 \mathrm{E}+02$

$8.92 \mathrm{E}+02$

8. $92 \mathrm{E}+02$

$8.93 \mathrm{E}+02$

$8.93 \mathrm{E}+02$

8. $94 \mathrm{E}+02$

$8.94 \mathrm{E}+02$

$8.95 \mathrm{E}+02$

8. $95 \mathrm{E}+02$

$8.96 \mathrm{E}+02$
Dose statistics at graphical times, mrem/yr

\begin{tabular}{|c|c|c|c|c|c|c|c|}
\hline m & am & a & 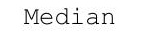 & & & $\%$ & \\
\hline 08 & 06 & 1. $32 \mathrm{E}-06$ & $1.06 \mathrm{E}-06$ & -06 & 06 & -06 & -00 \\
\hline $94 \mathrm{E}-08$ & $6.00 \mathrm{E}-06$ & $32 E-06$ & -06 & $2.77 \mathrm{E}-06$ & 06 & 06 & -06 \\
\hline $.97 E-08$ & $6.00 \mathrm{E}-06$ & 1. $32 \mathrm{E}-06$ & $1.07 \mathrm{E}-06$ & $2.78 \mathrm{E}-06$ & $3.39 \mathrm{E}-06$ & -06 & $.45 E-06$ \\
\hline $99 \mathrm{E}-08$ & $6.00 \mathrm{E}-06$ & $.32 \mathrm{E}-06$ & $1.07 \mathrm{E}-06$ & $2.78 \mathrm{E}-06$ & $3.39 \mathrm{E}-06$ & $3.84 \mathrm{E}-06$ & 4. $45 E-06$ \\
\hline $2 E-08$ & $00 E-06$ & $3 E-06$ & $7 E-06$ & $.78 E-06$ & $.39 \mathrm{E}-06$ & $.84 \mathrm{E}-06$ & -06 \\
\hline 08 & 6 & 06 & 6 & 6 & & 6 & -06 \\
\hline $07 E-08$ & & & & & & & -06 \\
\hline-08 & & & & & & & -06 \\
\hline .08 & 06 & -06 & -06 & 6 & & -06 & -06 \\
\hline 08 & -06 & 40 & -06 & -06 & 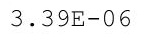 & 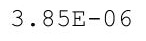 & -06 \\
\hline 8 & 6 & 6 & 06 & $79 E-06$ & $0 E-06$ & $35 E-06$ & -06 \\
\hline 8 & & & & & & & -06 \\
\hline$F-08$ & -06 & 06 & 06 & & & 6 & -06 \\
\hline $.26 \mathrm{E}-08$ & $5.99 E-06$ & $1.34 \mathrm{E}-06$ & $1.08 \mathrm{E}-06$ & $2.80 \mathrm{E}-06$ & $3.40 \mathrm{E}-06$ & $3.85 E-06$ & 4. $46 \mathrm{E}-06$ \\
\hline $29 \mathrm{E}-08$ & 06 & 06 & 06 & & & & -06 \\
\hline 8 & & 6 & 6 & & & & 06 \\
\hline 08 & 0 & 0 & 06 & & & & 06 \\
\hline 8 & & $1.34 \mathrm{E}-06$ & & & & & 6 \\
\hline $40 \mathrm{~F}-08$ & $.98 E-06$ & $34 F-06$ & $E-06$ & 6 & & 6 & -06 \\
\hline $43 E-08$ & $.98 \mathrm{E}-06$ & $1.34 \mathrm{E}-06$ & $1.09 \mathrm{E}-06$ & $.80 \mathrm{E}-06$ & -06 & $5-06$ & $.46 \mathrm{E}-06$ \\
\hline $46 \mathrm{E}-08$ & $5.98 E-06$ & 1. $35 E-06$ & $1.09 \mathrm{E}-06$ & -06 & -06 & -06 & $.46 E-06$ \\
\hline & & & & & & & -06 \\
\hline & & 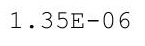 & & & & & 06 \\
\hline \pm-00 & 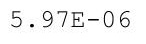 & 0 & & & & & -06 \\
\hline 8 & 6 & 6 & 6 & 6 & 6 & 0 & -06 \\
\hline$E-08$ & $.97 E-06$ & $1.35 E-06$ & $E-06$ & $81 E-06$ & $40 E-06$ & $E-06$ & $46 E-06$ \\
\hline 08 & $\mathrm{~F}-06$ & 06 & 06 & 06 & 06 & -0 & $.46 \mathrm{E}-06$ \\
\hline-08 & 06 & -06 & & -06 & & & $6 E-06$ \\
\hline & & & & & & & \\
\hline$E-08$ & $5.96 \mathrm{E}-06$ & $1.36 \mathrm{E}-06$ & $E-06$ & $2.82 \mathrm{E}-06$ & 06 & 06 & -06 \\
\hline $\begin{array}{l}-135-U 0 \\
0\end{array}$ & $3.20 \mathrm{~L}-00$ & $1.30 \mathrm{~L}-00$ & $1.10 \mathrm{E}-06$ & $2.82 E-06$ & $\cdot 41-4-00$ & $3.00 \mathrm{E}-00$ & $.46 E-06$ \\
\hline ( & 6 & . & 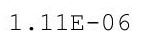 & $2.82 \mathrm{E}-06$ & 6 & & $4.47 \mathrm{E}-06$ \\
\hline 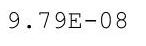 & 6 & & & תמק & & & $.46 \mathrm{E}-$ \\
\hline-08 & $5-06$ & $36 \mathrm{~F}-06$ & & 6 & & & 06 \\
\hline 8 & & & & & & & \\
\hline 08 & .9 & 06 & 06 & 2.024 & 6 & 06 & 06 \\
\hline$E-08$ & & \pm .00 & & & & & -06 \\
\hline . $95-20$ & & & & & & & $4.40 \mathrm{E}-00$ \\
\hline $.96 \mathrm{E}-08$ & & t & & 6 & & $3.86 \mathrm{E}-06$ & 06 \\
\hline & & & & & & & 06 \\
\hline & & & & 06 & 6 & 6 & \\
\hline $00 \mathrm{E}-07$ & $5.94 \mathrm{E}-06$ & 06 & 06 & 06 & 06 & 06 & 4.47 \\
\hline & & & & & & & \\
\hline & & & & & & & $4.47 E-06$ \\
\hline & & $+\cdots$ & & 6 & 06 & 06 & $4.4 / \mathrm{L}-00$ \\
\hline$E-07$ & $E-06$ & $8 E-06$ & $.13 \mathrm{E}-06$ & $E-06$ & $2 E-06$ & $7 E-06$ & -06 \\
\hline
\end{tabular}


RESRAD-OFFSITE, Version 2.5

Title : Offsite Resident Farmer Deterministic Run

File : RF TC99 DOESG FWD-FV2b.ROF

Summary of dose at graphical times, reptition 1 (continued)

Time

Years

$8.96 \mathrm{E}+02$

$8.97 \mathrm{E}+02$

$8.97 \mathrm{E}+02$

$8.98 \mathrm{E}+02$

$8.98 \mathrm{E}+02$

$8.99 \mathrm{E}+02$

$8.99 \mathrm{E}+02$

$9.00 \mathrm{E}+02$

$9.00 \mathrm{E}+02$

$9.01 \mathrm{E}+02$

$9.01 \mathrm{E}+02$

$9.02 \mathrm{E}+02$

$9.02 \mathrm{E}+02$

$9.03 \mathrm{E}+02$

$9.03 \mathrm{E}+02$

$9.04 \mathrm{E}+02$

$9.04 \mathrm{E}+02$

$9.05 \mathrm{E}+02$

$9.05 \mathrm{E}+02$

$9.06 \mathrm{E}+02$

$9.06 \mathrm{E}+02$

$9.07 \mathrm{E}+02$

$9.07 \mathrm{E}+02$

$9.08 \mathrm{E}+02$

$9.08 \mathrm{E}+02$

$9.09 \mathrm{E}+02$

$9.10 \mathrm{E}+02$

$9.10 \mathrm{E}+02$

$9.11 \mathrm{E}+02$

$9.11 \mathrm{E}+02$

$9.12 \mathrm{E}+02$

$9.12 \mathrm{E}+02$

$9.13 \mathrm{E}+02$

$9.13 \mathrm{E}+02$

$9.14 \mathrm{E}+02$

$9.14 \mathrm{E}+02$

$9.15 \mathrm{E}+02$

$9.15 \mathrm{E}+02$

$9.16 \mathrm{E}+02$

$9.16 \mathrm{E}+02$

$9.17 \mathrm{E}+02$

$9.17 \mathrm{E}+02$

$9.18 \mathrm{E}+02$

$9.18 \mathrm{E}+02$

$9.19 \mathrm{E}+02$

$9.19 \mathrm{E}+02$
Dose statistics at graphical times, mrem/yr

\begin{tabular}{|c|c|c|c|c|c|c|c|}
\hline & m & Mean & & & & & \\
\hline $02 \mathrm{E}-07$ & $94 \mathrm{E}-06$ & $1.38 \mathrm{E}-06$ & $1.13 \mathrm{E}-06$ & $82 E-06$ & $42 \mathrm{E}-06$ & $3.87 \mathrm{E}-06$ & $4.47 \mathrm{E}-06$ \\
\hline $02 \mathrm{E}-07$ & $93 E-06$ & $1.38 \mathrm{E}-06$ & $1.13 \mathrm{E}-06$ & $82 E-06$ & $42 E-06$ & $3.87 \mathrm{E}-06$ & $47 E-06$ \\
\hline $02 E-07$ & $93 E-06$ & $1.38 \mathrm{E}-06$ & $.13 E-06$ & $.82 E-06$ & $.42 \mathrm{E}-06$ & $3.87 E-06$ & $4.47 \mathrm{E}-06$ \\
\hline $.03 E-07$ & $.93 E-06$ & $1.38 \mathrm{E}-06$ & $1.13 \mathrm{E}-06$ & $2.82 \mathrm{E}-06$ & $3.41 \mathrm{E}-06$ & $3.87 \mathrm{E}-06$ & $4.47 \mathrm{E}-06$ \\
\hline $1.03 \mathrm{E}-07$ & $5.93 \mathrm{E}-06$ & $1.38 \mathrm{E}-06$ & $1.13 \mathrm{E}-06$ & $2.82 \mathrm{E}-06$ & $3.41 \mathrm{E}-06$ & $3.88 \mathrm{E}-06$ & $4.48 \mathrm{E}-06$ \\
\hline $1.03 \mathrm{E}-07$ & $5.93 \mathrm{E}-06$ & $1.38 \mathrm{E}-06$ & $1.14 \mathrm{E}-06$ & $2.83 \mathrm{E}-06$ & $.41 \mathrm{E}-06$ & $3.88 \mathrm{E}-06$ & $4.48 \mathrm{E}-06$ \\
\hline $1.04 \mathrm{E}-07$ & $5.92 \mathrm{E}-06$ & $1.38 \mathrm{E}-06$ & $1.14 \mathrm{E}-06$ & $2.83 \mathrm{E}-06$ & $3.41 \mathrm{E}-06$ & $3.88 \mathrm{E}-06$ & $4.48 \mathrm{E}-06$ \\
\hline $1.04 \mathrm{E}-07$ & $.92 E-06$ & $1.38 \mathrm{E}-06$ & $1.14 \mathrm{E}-06$ & $2.83 \mathrm{E}-06$ & $41 E-06$ & $3.88 \mathrm{E}-06$ & $48 \mathrm{E}-06$ \\
\hline $1.04 \mathrm{E}-07$ & $.92 E-06$ & $1.39 \mathrm{E}-06$ & $1.14 \mathrm{E}-06$ & $2.83 \mathrm{E}-06$ & $.41 \mathrm{E}-06$ & $3.88 \mathrm{E}-06$ & $4.48 \mathrm{E}-06$ \\
\hline $04 \mathrm{E}-07$ & $92 E-06$ & $1.39 \mathrm{E}-06$ & $1.14 \mathrm{E}-06$ & $2.83 \mathrm{E}-06$ & $.41 \mathrm{E}-06$ & $3.88 \mathrm{E}-06$ & $4.48 \mathrm{E}-06$ \\
\hline ت & $.92 \mathrm{E}-06$ & .3 & 6 & $2.83 \mathrm{E}-06$ & $3.41 \mathrm{E}-06$ & 6 & $4.48 \mathrm{E}-06$ \\
\hline $.05 \mathrm{E}-07$ & $91 E-06$ & $1.39 \mathrm{E}-06$ & $1.14 \mathrm{E}-06$ & $2.83 E-06$ & $.41 E-06$ & $3.87 \mathrm{E}-06$ & 1. 10 \\
\hline $.05 \mathrm{E}-07$ & $91 E-06$ & $1.39 \mathrm{E}-06$ & $1.15 \mathrm{E}-06$ & $2.84 \mathrm{E}-06$ & $.41 \mathrm{E}-06$ & $3.87 \mathrm{E}-06$ & 7. \\
\hline $.06 \mathrm{E}-07$ & 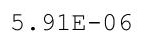 & 1.3 & $E-06$ & 6 & $41 E-06$ & $87 E-06$ & -06 \\
\hline 7 & 6 & 6 & 6 & 6 & 6 & 6 & -06 \\
\hline $1.06 \mathrm{E}-07$ & $91 \mathrm{E}-06$ & $1.39 \mathrm{E}-06$ & $1.15 \mathrm{E}-06$ & $2.84 \mathrm{E}-06$ & $3.41 \mathrm{E}-06$ & $3.87 \mathrm{E}-06$ & $4.48 \mathrm{E}-06$ \\
\hline $1.07 \mathrm{E}-07$ & $90 \mathrm{E}-06$ & $1.40 \mathrm{E}-06$ & $1.15 \mathrm{E}-06$ & $2.84 \mathrm{E}-06$ & $3.41 \mathrm{E}-06$ & $3.87 \mathrm{E}-06$ & $4.48 \mathrm{E}-06$ \\
\hline $1.07 \mathrm{E}-07$ & $5.90 \mathrm{E}-06$ & $1.40 \mathrm{E}-06$ & $1.15 \mathrm{E}-06$ & $2.84 \mathrm{E}-06$ & $3.41 \mathrm{E}-06$ & $3.87 \mathrm{E}-06$ & $4.48 \mathrm{E}-06$ \\
\hline $1.07 \mathrm{E}-07$ & $.90 E-06$ & $1.40 \mathrm{E}-06$ & $1.15 \mathrm{E}-06$ & $2.85 \mathrm{E}-06$ & $3.41 \mathrm{E}-06$ & $3.87 \mathrm{E}-06$ & $4.48 \mathrm{E}-06$ \\
\hline $1.07 \mathrm{E}-07$ & $.90 E-06$ & $1.40 \mathrm{E}-06$ & $1.15 \mathrm{E}-06$ & $2.85 \mathrm{E}-06$ & $3.41 \mathrm{E}-06$ & $3.87 \mathrm{E}-06$ & $4.48 \mathrm{E}-06$ \\
\hline $1.08 \mathrm{E}-07$ & $.90 \mathrm{E}-06$ & $1.40 \mathrm{E}-06$ & $1.16 \mathrm{E}-06$ & $2.85 E-06$ & $3.41 \mathrm{E}-06$ & $3.88 \mathrm{E}-06$ & $4.48 \mathrm{E}-06$ \\
\hline $1.08 \mathrm{E}-07$ & $.89 \mathrm{E}-06$ & $1.40 \mathrm{E}-06$ & $1.16 \mathrm{E}-06$ & $2.85 \mathrm{E}-06$ & $.42 \mathrm{E}-06$ & $3.88 \mathrm{E}-06$ & $4.48 \mathrm{E}-06$ \\
\hline 1 & 6 & $.40 \mathrm{E}$ & 6 & مᄃ & $42 \mathrm{E}$ & $3.00 \mathrm{E}-06$ & $4.48 \mathrm{E}-06$ \\
\hline 1) & 6 & $1.40 \mathrm{E}-06$ & 6 & 政 & 0 & $.88 E-06$ & $4.48 \mathrm{E}-06$ \\
\hline 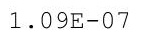 & 6 & 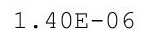 & 6 & > > & 0 & 6 & $.48 \mathrm{E}-06$ \\
\hline $.09 \mathrm{E}-07$ & $89 \mathrm{E}-06$ & $1.41 \mathrm{E}-06$ & 1.16 & $2.85 \mathrm{E}-$ & $42 \mathrm{E}$ & .881 & -06 \\
\hline $1.09 \mathrm{E}-07$ & $.88 E-06$ & $1.41 \mathrm{E}-06$ & $1.16 \mathrm{E}-06$ & $2.85 \mathrm{E}-06$ & $3.42 \mathrm{E}-06$ & $3.88 \mathrm{E}-06$ & $4.48 \mathrm{E}-06$ \\
\hline $1.10 \mathrm{E}-07$ & $.88 \mathrm{E}-06$ & $1.41 \mathrm{E}-06$ & $1.16 \mathrm{E}-06$ & $2.85 \mathrm{E}-06$ & $3.42 \mathrm{E}-06$ & $3.88 \mathrm{E}-06$ & $4.48 \mathrm{E}-06$ \\
\hline $1.10 \mathrm{E}-07$ & $5.88 \mathrm{E}-06$ & $1.41 \mathrm{E}-06$ & $1.16 \mathrm{E}-06$ & $2.86 \mathrm{E}-06$ & $3.42 \mathrm{E}-06$ & $3.89 \mathrm{E}-06$ & $4.48 \mathrm{E}-06$ \\
\hline $1.10 \mathrm{E}-07$ & $5.88 \mathrm{E}-06$ & $1.41 \mathrm{E}-06$ & $1.17 \mathrm{E}-06$ & $2.86 \mathrm{E}-06$ & $3.41 \mathrm{E}-06$ & $3.89 E-06$ & $4.48 \mathrm{E}-06$ \\
\hline $1.11 \mathrm{E}-07$ & $5.88 \mathrm{E}-06$ & $1.41 \mathrm{E}-06$ & $1.17 \mathrm{E}-06$ & $2.86 \mathrm{E}-06$ & $3.41 \mathrm{E}-06$ & $3.89 \mathrm{E}-06$ & $4.48 \mathrm{E}-06$ \\
\hline $1.11 \mathrm{E}-07$ & $5.87 E-06$ & $1.41 \mathrm{E}-06$ & $1.17 \mathrm{E}-06$ & $2.86 \mathrm{E}-06$ & $3.41 \mathrm{E}-06$ & $3.89 \mathrm{E}-06$ & $4.48 \mathrm{E}-06$ \\
\hline $1.11 \mathrm{E}-07$ & $5.87 \mathrm{E}-06$ & $1.41 \mathrm{E}-06$ & $1.17 \mathrm{E}-06$ & $2.86 \mathrm{E}-06$ & $3.41 \mathrm{E}-06$ & $.88 \mathrm{E}-06$ & $4.47 \mathrm{E}-06$ \\
\hline $1.12 \mathrm{E}-07$ & $.87 E-06$ & $1.41 \mathrm{E}-06$ & $1.1 / E-06$ & $2.86 \mathrm{E}-06$ & $3.41 \mathrm{E}-06$ & $3.88 \mathrm{E}-06$ & $4.47 \mathrm{E}-06$ \\
\hline $1.12 \mathrm{E}-07$ & 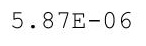 & $1.42 \mathrm{E}-06$ & $1.17 \mathrm{E}-0$ & $2.86 \mathrm{E}-0$ & $3.41 \mathrm{E}-06$ & $3.88 \mathrm{E}-06$ & $4.47 \mathrm{E}-06$ \\
\hline $.12 \mathrm{E}-07$ & $.87 \mathrm{E}-0$ & $1.42 \mathrm{E}-0$ & $1.17 \mathrm{E}-06$ & $.86 \mathrm{E}-0$ & $.41 \mathrm{E}-06$ & $3.88 \mathrm{E}-06$ & $4.47 \mathrm{E}-0$ \\
\hline $1.12 \mathrm{E}-07$ & $5.86 \mathrm{E}-06$ & $1.42 \mathrm{E}-06$ & $1.17 \mathrm{E}-06$ & $2.86 \mathrm{E}-06$ & $3.41 \mathrm{E}-06$ & $3.88 \mathrm{E}-06$ & $4.47 \mathrm{E}-06$ \\
\hline $1.13 \mathrm{E}-07$ & $5.86 \mathrm{E}-06$ & $1.42 \mathrm{E}-06$ & $1.18 \mathrm{E}-06$ & $2.86 \mathrm{E}-06$ & $3.41 \mathrm{E}-06$ & $3.88 \mathrm{E}-06$ & $4.47 \mathrm{E}-06$ \\
\hline 1.1 & 6 & 1.421 & 1. & 6 & $41 \mathrm{~F}$ & $88 E-06$ & 06 \\
\hline $1.13 \mathrm{E}-07$ & $5.86 \mathrm{E}-06$ & $1.42 \mathrm{E}-06$ & $1.18 \mathrm{E}-06$ & $2.86 \mathrm{E}-06$ & $3.41 \mathrm{E}-06$ & $3.88 \mathrm{E}-06$ & $4.47 \mathrm{E}-06$ \\
\hline $1.14 \mathrm{E}-07$ & $5.85 E-06$ & $1.42 \mathrm{E}-06$ & $1.18 \mathrm{E}-06$ & $2.86 \mathrm{E}-06$ & $3.41 \mathrm{E}-06$ & $.88 \mathrm{E}-06$ & $4.47 \mathrm{E}-06$ \\
\hline $1.14 \mathrm{E}-07$ & $5.85 \mathrm{E}-06$ & $1.42 \mathrm{E}-06$ & $1.18 \mathrm{E}$ & $2.86 \mathrm{E}-06$ & 06 & $3.88 \mathrm{E}-06$ & $4.46 \mathrm{E}-06$ \\
\hline $1.14 \mathrm{E}-07$ & $5.85 \mathrm{E}-06$ & $1.42 \mathrm{E}-06$ & $1.18 \mathrm{E}-06$ & $2.86 \mathrm{E}-06$ & $3.41 \mathrm{E}-06$ & $3.88 \mathrm{E}-06$ & $4.46 \mathrm{E}-06$ \\
\hline $1.15 \mathrm{E}-07$ & $5.85 \mathrm{E}-06$ & $1.43 \mathrm{E}-06$ & $1.19 \mathrm{E}-06$ & $2.86 \mathrm{E}-06$ & $3.41 \mathrm{E}-06$ & $3.88 \mathrm{E}-06$ & $4.46 \mathrm{E}-06$ \\
\hline $1.15 \mathrm{E}-07$ & $5.85 E-06$ & $1.43 E-06$ & $1.19 \mathrm{E}-06$ & $2.87 \mathrm{E}-06$ & $3.41 \mathrm{E}-06$ & $3.88 \mathrm{E}-06$ & $4.45 E-06$ \\
\hline $1.15 \mathrm{E}-07$ & $5.84 \mathrm{E}-06$ & $1.43 \mathrm{E}-06$ & $1.19 \mathrm{E}-06$ & $2.87 \mathrm{E}-06$ & $3.41 \mathrm{E}-06$ & $3.88 \mathrm{E}-06$ & $4.45 \mathrm{E}-06$ \\
\hline
\end{tabular}


RESRAD-OFFSITE, Version 2.5

Title : Offsite Resident Farmer Deterministic Run

File : RF TC99 DOESG FWD-FV2b.ROF

Summary of dose at graphical times, reptition 1 (continued)

Time

Years

$9.20 \mathrm{E}+02$

$9.20 \mathrm{E}+02$

$9.21 \mathrm{E}+02$

$9.21 \mathrm{E}+02$

$9.22 \mathrm{E}+02$

$9.22 \mathrm{E}+02$

$9.23 \mathrm{E}+02$

$9.23 \mathrm{E}+02$

$9.24 \mathrm{E}+02$

$9.24 \mathrm{E}+02$

$9.25 \mathrm{E}+02$

$9.25 \mathrm{E}+02$

$9.26 \mathrm{E}+02$

$9.26 \mathrm{E}+02$

$9.27 \mathrm{E}+02$

$9.27 \mathrm{E}+02$

$9.28 \mathrm{E}+02$

$9.28 \mathrm{E}+02$

$9.29 \mathrm{E}+02$

$9.30 \mathrm{E}+02$

9. $30 \mathrm{E}+02$

$9.31 \mathrm{E}+02$

$9.31 \mathrm{E}+02$

$9.32 \mathrm{E}+02$

9. $32 \mathrm{E}+02$

9. $33 \mathrm{E}+02$

9. $33 \mathrm{E}+02$

$9.34 \mathrm{E}+02$

9. $34 \mathrm{E}+02$

$9.35 \mathrm{E}+02$

9. $35 \mathrm{E}+02$

$9.36 \mathrm{E}+02$

$9 \cdot 36 \mathrm{E}+02$

$9.37 \mathrm{E}+02$

$9.37 \mathrm{E}+02$

$9.38 \mathrm{E}+02$

9. $38 \mathrm{E}+02$

$9.39 \mathrm{E}+02$

$9.39 \mathrm{E}+02$

$9.40 \mathrm{E}+02$

$9.40 \mathrm{E}+02$

$9.41 \mathrm{E}+02$

$9.41 \mathrm{E}+02$

$9.42 \mathrm{E}+02$

$9.42 \mathrm{E}+02$

$9.43 \mathrm{E}+02$
Dose statistics at graphical times, mrem/yr

\begin{tabular}{|c|c|c|c|c|c|c|c|}
\hline Minimum & Maximum & Mean & Median & $90 \%$ & $95 \%$ & $97.5 \%$ & $99 \%$ \\
\hline $1.15 \mathrm{E}-07$ & $5.84 \mathrm{E}-06$ & $1.43 \mathrm{E}-06$ & $1.19 \mathrm{E}-06$ & $2.87 E-06$ & $3.42 \mathrm{E}-06$ & $3.88 E-06$ & $4.45 E-06$ \\
\hline $1.16 \mathrm{E}-07$ & $5.84 \mathrm{E}-06$ & $1.43 \mathrm{E}-06$ & $1.19 \mathrm{E}-06$ & $2.87 \mathrm{E}-06$ & $3.42 \mathrm{E}-06$ & $3.88 \mathrm{E}-06$ & $4.45 \mathrm{E}-06$ \\
\hline $1.16 \mathrm{E}-07$ & $5.84 \mathrm{E}-06$ & $1.43 \mathrm{E}-06$ & $1.19 \mathrm{E}-06$ & $2.87 \mathrm{E}-06$ & $3.42 \mathrm{E}-06$ & $3.88 \mathrm{E}-06$ & 4. $45 \mathrm{E}-06$ \\
\hline $1.16 \mathrm{E}-07$ & $5.83 \mathrm{E}-06$ & $1.43 \mathrm{E}-06$ & $1.20 \mathrm{E}-06$ & $2.87 \mathrm{E}-06$ & $3.42 \mathrm{E}-06$ & $3.88 \mathrm{E}-06$ & $4.45 \mathrm{E}-06$ \\
\hline $1.17 \mathrm{E}-07$ & $5.83 E-06$ & $1.43 E-06$ & $1.20 E-06$ & $2.87 E-06$ & $3.42 \mathrm{E}-06$ & $3.88 E-06$ & $4.45 E-06$ \\
\hline $1.17 \mathrm{E}-07$ & $5.83 \mathrm{E}-06$ & $1.43 \mathrm{E}-06$ & $1.20 \mathrm{E}-06$ & $2.87 \mathrm{E}-06$ & $3.43 E-06$ & $3.88 \mathrm{E}-06$ & $4.44 \mathrm{E}-06$ \\
\hline $1.17 \mathrm{E}-07$ & $5.83 E-06$ & $1.44 \mathrm{E}-06$ & $1.20 \mathrm{E}-06$ & $2.88 E-06$ & $3.43 E-06$ & $3.89 \mathrm{E}-06$ & $4.44 \mathrm{E}-06$ \\
\hline $1.18 \mathrm{E}-07$ & $5.82 \mathrm{E}-06$ & $1.44 \mathrm{E}-06$ & $1.20 \mathrm{E}-06$ & $2.87 \mathrm{E}-06$ & $3.43 \mathrm{E}-06$ & $3.89 \mathrm{E}-06$ & $4.44 \mathrm{E}-06$ \\
\hline $1.18 \mathrm{E}-07$ & $5.82 \mathrm{E}-06$ & $1.44 \mathrm{E}-06$ & $1.20 \mathrm{E}-06$ & $2.87 E-06$ & $3.43 \mathrm{E}-06$ & $3.88 \mathrm{E}-06$ & $4.44 \mathrm{E}-06$ \\
\hline $1.18 \mathrm{E}-07$ & $5.82 \mathrm{E}-06$ & $1.44 \mathrm{E}-06$ & $1.21 \mathrm{E}-06$ & $2.87 \mathrm{E}-06$ & $3.44 \mathrm{E}-06$ & $3.88 \mathrm{E}-06$ & 4. $44 \mathrm{E}-06$ \\
\hline $1.19 \mathrm{E}-07$ & $5.82 \mathrm{E}-06$ & $1.44 \mathrm{E}-06$ & 1.21E-0 6 & $2.87 E-06$ & $3.44 \mathrm{E}-06$ & $3.88 \mathrm{E}-06$ & $4.44 \mathrm{E}-06$ \\
\hline $1.19 \mathrm{E}-07$ & $5.81 \mathrm{E}-06$ & $1.44 \mathrm{E}-06$ & $1.21 \mathrm{E}-06$ & $2.87 E-06$ & $3.44 \mathrm{E}-06$ & $3.88 E-06$ & $4.43 E-06$ \\
\hline $1.19 \mathrm{E}-07$ & $5.81 \mathrm{E}-06$ & $1.44 \mathrm{E}-06$ & $1.21 \mathrm{E}-06$ & $2.87 E-06$ & $3.44 \mathrm{E}-06$ & $3.88 E-06$ & $4.43 E-06$ \\
\hline $1.19 \mathrm{E}-07$ & $5.81 \mathrm{E}-06$ & $1.44 \mathrm{E}-06$ & $1.21 \mathrm{E}-06$ & $2.87 E-06$ & $3.44 \mathrm{E}-06$ & $3.88 \mathrm{E}-06$ & $4.43 E-06$ \\
\hline $1.20 \mathrm{E}-07$ & $5.81 \mathrm{E}-06$ & $1.44 \mathrm{E}-06$ & 1.21E-06 & $2.87 E-06$ & $3.44 \mathrm{E}-06$ & $3.88 \mathrm{E}-06$ & $4.42 E-06$ \\
\hline $1.20 \mathrm{E}-07$ & $5.80 \mathrm{E}-06$ & $1.45 E-06$ & $1.22 E-06$ & $2.87 E-06$ & $3.44 \mathrm{E}-06$ & $E-06$ & $4.42 E-06$ \\
\hline $1.20 \mathrm{E}-07$ & $0 E-06$ & $1.45 \mathrm{E}-06$ & 1.22E-06 & $2.87 E-06$ & $3.44 \mathrm{E}-06$ & $3.88 E-06$ & $.41 E-06$ \\
\hline $1.21 \mathrm{E}-07$ & $5.80 \mathrm{E}-06$ & $1.45 E-06$ & $1.22 E-06$ & $2.87 E-06$ & $3.44 \mathrm{E}-06$ & $3.88 E-06$ & $4.41 E-06$ \\
\hline $1.21 \mathrm{E}-07$ & $5.80 \mathrm{E}-06$ & $1.45 \mathrm{E}-06$ & $1.22 \mathrm{E}-06$ & $2.87 E-06$ & $3.44 \mathrm{E}-06$ & $3.88 E-06$ & $4.40 E-06$ \\
\hline $1.21 \mathrm{E}-07$ & $5.79 \mathrm{E}-06$ & $1.45 \mathrm{E}-06$ & $1.22 \mathrm{E}-06$ & $2.87 \mathrm{E}-06$ & $3.45 \mathrm{E}-06$ & $3.87 \mathrm{E}-06$ & $4.40 \mathrm{E}-06$ \\
\hline $1.22 \mathrm{E}-07$ & $5.79 \mathrm{E}-06$ & $1.45 \mathrm{E}-06$ & 1.22E-06 & $2.87 E-06$ & $3.45 \mathrm{E}-06$ & $3.87 \mathrm{E}-06$ & $4.40 \mathrm{E}-06$ \\
\hline $1.22 \mathrm{E}-07$ & $5.79 \mathrm{E}-06$ & $1.45 \mathrm{E}-06$ & $1.23 E-06$ & $2.87 E-06$ & $3.45 E-06$ & $3.87 E-06$ & $4.39 E-06$ \\
\hline $1.22 \mathrm{E}-07$ & $5.79 E-06$ & $1.45 \mathrm{E}-06$ & 1.23E-06 & $2.87 \mathrm{E}-06$ & $3.45 \mathrm{E}-06$ & $3.87 \mathrm{E}-06$ & $4.39 E-06$ \\
\hline $1.23 \mathrm{E}-07$ & $5.78 \mathrm{E}-06$ & $1.45 \mathrm{E}-06$ & $1.23 E-06$ & $2.87 \mathrm{E}-06$ & $3.45 \mathrm{E}-06$ & $3.87 \mathrm{E}-06$ & $4.38 E-06$ \\
\hline $1.23 \mathrm{E}-07$ & $5.78 \mathrm{E}-06$ & $1.45 \mathrm{E}-06$ & $1.23 E-06$ & $2.87 E-06$ & $3.45 E-06$ & $3.87 E-06$ & $4.38 E-06$ \\
\hline $1.23 \mathrm{E}-07$ & $5.78 \mathrm{E}-06$ & $1.46 \mathrm{E}-06$ & $1.23 E-06$ & $2.87 E-06$ & $3.45 E-06$ & $3.87 E-06$ & $4.37 E-06$ \\
\hline $1.24 \mathrm{E}-07$ & $5.78 \mathrm{E}-06$ & $1.46 \mathrm{E}-06$ & 1. $23 E-06$ & $2.88 \mathrm{E}-06$ & $3.44 \mathrm{E}-06$ & $3.87 \mathrm{E}-06$ & $4.37 \mathrm{E}-06$ \\
\hline $1.24 \mathrm{E}-07$ & $5.77 \mathrm{E}-06$ & $1.46 \mathrm{E}-06$ & $1.23 E-06$ & $2.88 E-06$ & $3.44 \mathrm{E}-06$ & $3.87 E-06$ & $4.37 E-06$ \\
\hline $1.24 \mathrm{E}-07$ & $5.77 \mathrm{E}-06$ & $1.46 \mathrm{E}-06$ & $1.23 E-06$ & $2.88 E-06$ & $3.44 \mathrm{E}-06$ & $3.88 E-06$ & $4.36 E-06$ \\
\hline $1.24 \mathrm{E}-07$ & $5.77 \mathrm{E}-06$ & $1.46 \mathrm{E}-06$ & $1.24 \mathrm{E}-06$ & $2.88 E-06$ & $3.44 \mathrm{E}-06$ & $3.88 E-06$ & $4.36 E-06$ \\
\hline $1.25 \mathrm{E}-07$ & $5.77 \mathrm{E}-06$ & $1.46 \mathrm{E}-06$ & $1.24 \mathrm{E}-06$ & $2.88 E-06$ & $3.44 \mathrm{E}-06$ & $3.88 E-06$ & $4.36 E-06$ \\
\hline $1.25 \mathrm{E}-07$ & $5.76 \mathrm{E}-06$ & $1.46 \mathrm{E}-06$ & $1.24 \mathrm{E}-06$ & $2.88 \mathrm{E}-06$ & $3.44 \mathrm{E}-06$ & $3.88 \mathrm{E}-06$ & $4.36 \mathrm{E}-06$ \\
\hline $1.25 \mathrm{E}-07$ & $5.76 \mathrm{E}-06$ & $1.46 \mathrm{E}-06$ & $1.24 \mathrm{E}-06$ & $2.88 E-06$ & $3.44 \mathrm{E}-06$ & $3.88 E-06$ & $4.36 \mathrm{E}-06$ \\
\hline $1.26 \mathrm{E}-07$ & $5.76 \mathrm{E}-06$ & $1.46 \mathrm{E}-06$ & $1.24 \mathrm{E}-06$ & $2.88 E-06$ & $3.44 \mathrm{E}-06$ & $3.88 E-06$ & $4.36 E-06$ \\
\hline $1.26 \mathrm{E}-07$ & $5.76 \mathrm{E}-06$ & $1.47 \mathrm{E}-06$ & $1.24 E-06$ & $2.88 E-06$ & $3.44 \mathrm{E}-06$ & $3.88 E-06$ & $4.36 E-06$ \\
\hline $1.26 \mathrm{E}-07$ & $5.75 \mathrm{E}-06$ & $1.47 \mathrm{E}-06$ & $1.24 \mathrm{E}-06$ & $2.88 E-06$ & $3.44 \mathrm{E}-06$ & $3.88 \mathrm{E}-06$ & $4.36 \mathrm{E}-06$ \\
\hline $1.27 \mathrm{E}-07$ & $5.75 E-06$ & $1.47 \mathrm{E}-06$ & $1.24 \mathrm{E}-06$ & $2.89 E-06$ & $3.44 \mathrm{E}-06$ & $3.88 E-06$ & $4.36 E-06$ \\
\hline $1.27 \mathrm{E}-07$ & $5.75 \mathrm{E}-06$ & $1.47 \mathrm{E}-06$ & $1.25 \mathrm{E}-06$ & $2.89 \mathrm{E}-06$ & $3.45 \mathrm{E}-06$ & $3.87 \mathrm{E}-06$ & $4.36 \mathrm{E}-06$ \\
\hline $1.27 \mathrm{E}-07$ & $5.75 \mathrm{E}-06$ & $1.47 \mathrm{E}-06$ & $1.25 E-06$ & $2.89 E-06$ & $3.45 \mathrm{E}-06$ & $3.87 \mathrm{E}-06$ & $4.36 \mathrm{E}-06$ \\
\hline $1.28 \mathrm{E}-07$ & $5.74 \mathrm{E}$ & $1.47 \mathrm{E}-06$ & $1.25 \mathrm{E}-06$ & $2.89 \mathrm{E}-06$ & $3.45 \mathrm{E}-06$ & $3.87 \mathrm{E}-06$ & $4.36 \mathrm{E}-06$ \\
\hline $1.28 \mathrm{E}-07$ & $5.74 \mathrm{E}-06$ & $1.47 \mathrm{E}-06$ & $1.25 \mathrm{E}-06$ & $2.89 E-06$ & $3.46 \mathrm{E}-06$ & $3.87 \mathrm{E}-06$ & $4.36 \mathrm{E}-06$ \\
\hline $1.28 \mathrm{E}-07$ & $5.74 \mathrm{E}-06$ & $1.47 \mathrm{E}-06$ & $1.25 E-06$ & $2.89 E-06$ & $3.46 \mathrm{E}-06$ & $3.87 \mathrm{E}-06$ & $4.36 \mathrm{E}-06$ \\
\hline $1.29 \mathrm{E}-07$ & $5.74 \mathrm{E}-06$ & $1.47 \mathrm{E}-06$ & $1.25 E-06$ & $2.89 E-06$ & $3.46 \mathrm{E}-06$ & $3.87 E-06$ & $4.36 E-06$ \\
\hline $1.29 \mathrm{E}-07$ & $5.73 E-06$ & $1.47 \mathrm{E}-06$ & $1.25 E-06$ & $2.88 E-06$ & $3.46 \mathrm{E}-06$ & $3.87 E-06$ & $4.36 E-06$ \\
\hline $1.29 \mathrm{E}-07$ & $5.73 E-06$ & $1.48 E-06$ & $1.25 E-06$ & $2.88 E-06$ & $3.45 E-06$ & $3.87 \mathrm{E}-06$ & $4.36 \mathrm{E}-06$ \\
\hline $1.30 \mathrm{E}-07$ & $5.73 E-06$ & $1.48 \mathrm{E}-06$ & $1.26 \mathrm{E}-06$ & $2.88 E-06$ & $3.45 E-06$ & $3.86 \mathrm{E}-06$ & $4.35 E-06$ \\
\hline
\end{tabular}


RESRAD-OFFSITE, Version 2.5

robabilistic Dose and Risk Report

Title : Offsite Resident Farmer Deterministic Run

File : RF TC99 DOESG FWD-FV2b.ROF

Summary of dose at graphical times, reptition 1 (continued)

Time

Years

9. $43 \mathrm{E}+02$

$9.44 \mathrm{E}+02$

$9.44 \mathrm{E}+02$

9. $45 \mathrm{E}+02$

$9.45 \mathrm{E}+02$

$9.46 \mathrm{E}+02$

$9.46 \mathrm{E}+02$

$9.47 \mathrm{E}+02$

$9.47 \mathrm{E}+02$

$9.48 \mathrm{E}+02$

$9.48 \mathrm{E}+02$

$9.49 \mathrm{E}+02$

$9.50 \mathrm{E}+02$

$9.50 \mathrm{E}+02$

$9.51 \mathrm{E}+02$

$9.51 \mathrm{E}+02$

$9.52 \mathrm{E}+02$

$9.52 \mathrm{E}+02$

$9.53 \mathrm{E}+02$

$9.53 \mathrm{E}+02$

$9.54 \mathrm{E}+02$

$9.54 \mathrm{E}+02$

$9.55 \mathrm{E}+02$

$9.55 \mathrm{E}+02$

$9.56 \mathrm{E}+02$

$9.56 \mathrm{E}+02$

$9.57 \mathrm{E}+02$

$9.57 \mathrm{E}+02$

$9.58 \mathrm{E}+02$

$9.58 \mathrm{E}+02$

$9.59 \mathrm{E}+02$

$9.59 \mathrm{E}+02$

9. $60 \mathrm{E}+02$

$9.60 \mathrm{E}+02$

$9.61 \mathrm{E}+02$

$9.61 \mathrm{E}+02$

$9.62 \mathrm{E}+02$

$9.62 \mathrm{E}+02$

$9.63 \mathrm{E}+02$

$9.63 \mathrm{E}+02$

$9.64 \mathrm{E}+02$

$9.64 \mathrm{E}+02$

$9.65 \mathrm{E}+02$

$9.65 \mathrm{E}+02$

$9.66 \mathrm{E}+02$

$9.66 \mathrm{E}+02$
Dose statistics at graphical times, mrem/yr

\begin{tabular}{|c|c|c|c|c|c|c|c|}
\hline $\mathrm{m}$ & $\operatorname{axi}$ & a & 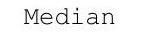 & & & $\%$ & \\
\hline 07 & 06 & $1.48 E-06$ & $1.26 \mathrm{E}-06$ & $2.88 \mathrm{E}-06$ & . 18 & $3.86 \mathrm{E}-06$ & $4.5 J E-06$ \\
\hline $30 \mathrm{E}-07$ & $5.72 \mathrm{E}-06$ & $1.48 \mathrm{E}-06$ & $26 \mathrm{E}-06$ & $2.88 E-06$ & 6 & 6 & -06 \\
\hline $.31 E-07$ & $5.72 \mathrm{E}-06$ & 1. $48 \mathrm{E}-06$ & $.26 \mathrm{E}-06$ & $2.88 \mathrm{E}-06$ & $3.45 E-06$ & $3.86 \mathrm{E}-06$ & -06 \\
\hline $31 E-07$ & $5.72 E-06$ & $.48 E-06$ & $1.26 \mathrm{E}-06$ & $2.88 \mathrm{E}-06$ & $3.45 \mathrm{E}-06$ & $3.86 \mathrm{E}-06$ & $.35 E-06$ \\
\hline $31 E-07$ & $.71 \mathrm{E}-06$ & $1.48 \mathrm{E}-06$ & $1.26 \mathrm{E}-06$ & $.88 E-06$ & $.44 \mathrm{E}-06$ & $3.86 \mathrm{E}-06$ & -06 \\
\hline $31 E-07$ & 06 & 1 & & & & 6 & -06 \\
\hline $32 E-07$ & $5.71 E-06$ & $1.48 \mathrm{E}$ & & 6 & & & -06 \\
\hline $32 E-07$ & $5.70 \mathrm{E}-06$ & & & & & & -06 \\
\hline $32 E-07$ & -06 & $E-06$ & -06 & 06 & -06 & -06 & -06 \\
\hline (2) & 06 & $1.49 \mathrm{E}-06$ & 6 & 6 & 6 & 06 & -06 \\
\hline $33 F-07$ & $5.70 \mathrm{E}-06$ & 1 & $1.27 \mathrm{E}-06$ & 6 & 6 & 6 & -06 \\
\hline $33 E-07$ & & & & 6 & & & -06 \\
\hline $34 \mathrm{E}-07$ & $5.69 \mathrm{E}-06$ & $1.49 \mathrm{E}-06$ & 1. & 6 & 6 & 6 & -06 \\
\hline $.34 \mathrm{E}-07$ & $5.69 \mathrm{E}-06$ & $1.49 \mathrm{E}-06$ & $1.27 \mathrm{E}-06$ & $2.87 \mathrm{E}-06$ & $3.44 \mathrm{E}-06$ & $3.87 \mathrm{E}-06$ & . $33 E-06$ \\
\hline $34 \mathrm{E}-07$ & $68 E-06$ & $9 E-06$ & -06 & $87 E-06$ & & & -06 \\
\hline 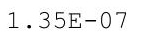 & & & & & & & -06 \\
\hline $55-07$ & & 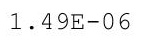 & & & & & -06 \\
\hline $35 E-$ & 6 & $1.49 \mathrm{E}-06$ & & & $44 E-06$ & & 6 \\
\hline $36 E-07$ & $.67 \mathrm{E}-06$ & $150=-0$ & $1.28 \mathrm{E}-06$ & 6 & 6 & 6 & -06 \\
\hline $36 E-07$ & $.67 E-06$ & $1.50 \mathrm{E}-06$ & $1.28 \mathrm{E}-06$ & $.87 E-06$ & $.44 \mathrm{E}-06$ & $E-06$ & -06 \\
\hline $36 E-07$ & $7 E-06$ & -06 & 06 & $.87 E-06$ & 6 & $.87 \mathrm{E}-\mathrm{C}$ & $.32 E-06$ \\
\hline & & & & & & & $.32 E-06$ \\
\hline & & 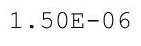 & & & & & \\
\hline $37 E-07$ & $0.00 \mathrm{E}$ & $\begin{array}{ll}1.000 \\
0\end{array}$ & 1.2 & & 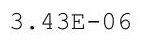 & & -06 \\
\hline 7 & 6 & 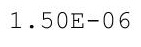 & 0 & 6 & 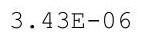 & $3.88 \mathrm{E}-06$ & -06 \\
\hline $38 F-07$ & $.65 E-06$ & $1.50 \mathrm{E}-06$ & 1. $30 \mathrm{E}-06$ & $.87 E-06$ & & $8 F-0$ & $32 E-06$ \\
\hline 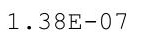 & -06 & $F-06$ & -06 & $88 E-06$ & ? & -06 & $31 \mathrm{~F}-06$ \\
\hline 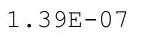 & & & & & & & 06 \\
\hline $5-01$ & & & & & & & \\
\hline $.39 E-07$ & $5.64 \mathrm{E}-06$ & $1.315-06$ & 1. $30 \mathrm{E}-06$ & $2.88 E-06$ & . & -06 & -06 \\
\hline 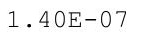 & $5.64 \mathrm{E}-06$ & $1.3 \perp[-0$ & $1.30 \mathrm{E}-06$ & $2.88 \mathrm{E}-06$ & $3.43 E-06$ & $3.00 \mathrm{E}-\mathrm{O}$ & $.31 E-06$ \\
\hline • & 年 & $5 \cdot 0$ & . & $2.88 \mathrm{E}-06$ & 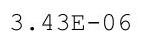 & 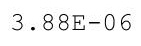 & $4.31 E-06$ \\
\hline $40 \mathrm{E}-$ & $63 F-06$ & $51 \mathrm{~F}-06$ & $F-06$ & תم:ת & & & $E-06$ \\
\hline ( & & & & & & & 06 \\
\hline 1 & 6 & & & 6 & 6 & & -06 \\
\hline $41 \mathrm{E}-07$ & $5.62 \mathrm{E}-06$ & $1.51 \mathrm{E}-06$ & 1. $31 \mathrm{E}-06$ & $2.07 \mathrm{D}$ & 6 & 06 & -06 \\
\hline • & . & $1.01+$ & 1.0 & & & & -06 \\
\hline $\begin{array}{l}* \\
\end{array}$ & & & & & & & . . $50=-00$ \\
\hline •. $4 \angle D-1$ & 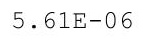 & $+\cdots$ & 6 & 6 & & 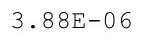 & 06 \\
\hline $.43 E-07$ & & & & & & & 6 \\
\hline 7 & 6 & 1 . & 1. & 6 & & 6 & -06 \\
\hline $3 E-07$ & $5.60 \mathrm{E}-06$ & 1.5 & $1.32 \mathrm{E}$ & 06 & 6 & 06 & -06 \\
\hline & & & & & & & \\
\hline & & t. & & & & & $4.30 E-06$ \\
\hline 列 & 06 & $+\cdots$ & 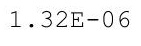 & 6 & & 0 & $4.30 E-06$ \\
\hline $5 E-07$ & $E-06$ & $2 E-06$ & $32 E-06$ & $E-06$ & $E-06$ & $88 E-06$ & -06 \\
\hline
\end{tabular}


RESRAD-OFFSITE, Version 2.5

robabilistic Dose and Risk Report

Title : Offsite Resident Farmer Deterministic Run

File : RF TC99 DOESG FWD-FV2b.ROF

Summary of dose at graphical times, reptition 1 (continued)

Time

Years

9. $67 \mathrm{E}+02$

$9.67 \mathrm{E}+02$

$9.68 \mathrm{E}+02$

$9.68 \mathrm{E}+02$

$9.69 \mathrm{E}+02$

$9.70 \mathrm{E}+02$

$9.70 \mathrm{E}+02$

$9.71 \mathrm{E}+02$

$9.71 \mathrm{E}+02$

$9.72 \mathrm{E}+02$

$9.72 \mathrm{E}+02$

$9.73 \mathrm{E}+02$

$9.73 E+02$

$9.74 \mathrm{E}+02$

$9.74 \mathrm{E}+02$

$9.75 \mathrm{E}+02$

$9.75 \mathrm{E}+02$

$9.76 \mathrm{E}+02$

$9.76 \mathrm{E}+02$

$9.77 \mathrm{E}+02$

$9.77 \mathrm{E}+02$

$9.78 \mathrm{E}+02$

$9.78 \mathrm{E}+02$

$9.79 \mathrm{E}+02$

$9.79 \mathrm{E}+02$

$9.80 \mathrm{E}+02$

$9.80 \mathrm{E}+02$

$9.81 \mathrm{E}+02$

$9.81 \mathrm{E}+02$

$9.82 \mathrm{E}+02$

$9.82 \mathrm{E}+02$

$9.83 \mathrm{E}+02$

$9.83 \mathrm{E}+02$

$9.84 \mathrm{E}+02$

$9.84 \mathrm{E}+02$

$9.85 \mathrm{E}+02$

$9.85 \mathrm{E}+02$

$9.86 \mathrm{E}+02$

$9.86 \mathrm{E}+02$

$9.87 \mathrm{E}+02$

$9.87 \mathrm{E}+02$

$9.88 \mathrm{E}+02$

$9.88 \mathrm{E}+02$

$9.89 \mathrm{E}+02$

$9.90 \mathrm{E}+02$

9. $90 \mathrm{E}+02$
Dose statistics at graphical times, mrem/yr

\begin{tabular}{|c|c|c|c|c|c|c|c|}
\hline Minimum & Maximum & Mean & Median & $90 \%$ & $95 \%$ & $97.5 \%$ & $99 \%$ \\
\hline $1.45 \mathrm{E}-07$ & $5.59 \mathrm{E}-06$ & $1.52 \mathrm{E}-06$ & 1. $32 \mathrm{E}-06$ & $2.89 \mathrm{E}-06$ & $3.45 \mathrm{E}-06$ & $3.88 E-06$ & $4.30 E-06$ \\
\hline $1.45 \mathrm{E}-07$ & $5.59 \mathrm{E}-06$ & $1.52 \mathrm{E}-06$ & $1.33 \mathrm{E}-06$ & $2.89 \mathrm{E}-06$ & $3.45 \mathrm{E}-06$ & $3.88 \mathrm{E}-06$ & $4.30 \mathrm{E}-06$ \\
\hline $1.46 \mathrm{E}-07$ & $5.58 \mathrm{E}-06$ & $1.52 \mathrm{E}-06$ & $1.33 \mathrm{E}-06$ & $2.89 \mathrm{E}-06$ & $3.45 \mathrm{E}-06$ & $3.88 \mathrm{E}-06$ & 4. $30 \mathrm{E}-06$ \\
\hline $1.46 \mathrm{E}-07$ & $5.58 \mathrm{E}-06$ & $1.53 \mathrm{E}-06$ & $1.33 \mathrm{E}-06$ & $2.89 \mathrm{E}-06$ & $3.45 \mathrm{E}-06$ & $3.88 \mathrm{E}-06$ & $4.30 \mathrm{E}-06$ \\
\hline $1.46 \mathrm{E}-07$ & $5.58 \mathrm{E}-06$ & $1.53 \mathrm{E}-06$ & $1.33 E-06$ & $2.89 E-06$ & $3.45 E-06$ & $3.88 E-06$ & $4.30 E-06$ \\
\hline $1.47 \mathrm{E}-07$ & $5.57 \mathrm{E}-06$ & $1.53 \mathrm{E}-06$ & $1.33 E-06$ & $2.89 \mathrm{E}-06$ & $3.45 \mathrm{E}-06$ & $3.89 \mathrm{E}-06$ & $4.30 E-06$ \\
\hline $1.47 \mathrm{E}-07$ & $5.57 \mathrm{E}-06$ & $1.53 \mathrm{E}-06$ & $1.33 E-06$ & $2.89 \mathrm{E}-06$ & $3.45 \mathrm{E}-06$ & $3.89 \mathrm{E}-06$ & $4.30 \mathrm{E}-06$ \\
\hline $1.47 \mathrm{E}-07$ & $5.57 \mathrm{E}-06$ & $1.53 \mathrm{E}-06$ & $1.34 \mathrm{E}-06$ & $2.89 \mathrm{E}-06$ & $3.45 \mathrm{E}-06$ & $3.89 \mathrm{E}-06$ & 4. $30 \mathrm{E}-06$ \\
\hline $1.48 \mathrm{E}-07$ & $5.56 \mathrm{E}-06$ & $1.53 \mathrm{E}-06$ & $1.34 \mathrm{E}-06$ & $2.89 \mathrm{E}-06$ & $3.45 \mathrm{E}-06$ & $3.89 \mathrm{E}-06$ & $4.30 E-06$ \\
\hline $1.48 \mathrm{E}-07$ & $5.56 \mathrm{E}-06$ & $1.53 \mathrm{E}-06$ & $1.34 \mathrm{E}-06$ & $2.89 \mathrm{E}-06$ & $3.45 \mathrm{E}-06$ & $3.89 \mathrm{E}-06$ & 4. 30E-06 \\
\hline $1.48 \mathrm{E}-07$ & $5.56 \mathrm{E}-06$ & $1.53 \mathrm{E}-06$ & $1.34 \mathrm{E}-06$ & $2.89 \mathrm{E}-06$ & $3.45 \mathrm{E}-06$ & $3.89 \mathrm{E}-06$ & $4.30 E-06$ \\
\hline $1.49 \mathrm{E}-07$ & $5.55 \mathrm{E}-06$ & $1.53 \mathrm{E}-06$ & $1.34 \mathrm{E}-06$ & $2.89 E-06$ & $3.45 E-06$ & $3.89 E-06$ & $4.30 E-06$ \\
\hline $1.49 \mathrm{E}-07$ & $5.55 \mathrm{E}-06$ & $1.53 \mathrm{E}-06$ & $1.34 \mathrm{E}-06$ & $2.89 E-06$ & $3.45 \mathrm{E}-06$ & $3.89 \mathrm{E}-06$ & $4.29 E-06$ \\
\hline $1.49 \mathrm{E}-07$ & $5.55 \mathrm{E}-06$ & $1.53 \mathrm{E}-06$ & $1.34 \mathrm{E}-06$ & $2.89 \mathrm{E}-06$ & $3.45 \mathrm{E}-06$ & $3.89 \mathrm{E}-06$ & $4.29 E-06$ \\
\hline $1.50 \mathrm{E}-07$ & $5.55 \mathrm{E}-06$ & $1.54 \mathrm{E}-06$ & $1.34 \mathrm{E}-06$ & $2.89 \mathrm{E}-06$ & $3.45 \mathrm{E}-06$ & $3.88 \mathrm{E}-06$ & $4.29 E-06$ \\
\hline $1.50 \mathrm{E}-07$ & $5.54 \mathrm{E}-06$ & $1.54 \mathrm{E}-06$ & -06 & $2.89 E-06$ & $3.45 E-06$ & $E-06$ & $4.29 E-06$ \\
\hline $1.50 \mathrm{E}-07$ & $4 E-06$ & $1.54 \mathrm{E}-06$ & $5 E-06$ & $2.89 \mathrm{E}-06$ & $3.45 \mathrm{E}-06$ & $3.88 \mathrm{E}-06$ & $.28 E-06$ \\
\hline $1.51 \mathrm{E}-07$ & $5.54 \mathrm{E}-06$ & $1.54 \mathrm{E}-06$ & $1.35 E-06$ & $2.89 E-06$ & $3.45 E-06$ & $3.88 E-06$ & $4.28 E-06$ \\
\hline $1.51 \mathrm{E}-07$ & $5.53 \mathrm{E}-06$ & $1.54 \mathrm{E}-06$ & $1.35 \mathrm{E}-06$ & $2.89 E-06$ & $3.45 E-06$ & $3.88 E-06$ & $4.28 E-06$ \\
\hline $1.51 \mathrm{E}-07$ & $5.53 \mathrm{E}-06$ & $1.54 \mathrm{E}-06$ & $1.35 \mathrm{E}-06$ & $2.89 \mathrm{E}-06$ & $3.45 \mathrm{E}-06$ & $3.88 \mathrm{E}-06$ & $4.28 E-06$ \\
\hline $1.52 \mathrm{E}-07$ & $5.53 \mathrm{E}-06$ & $1.54 \mathrm{E}-06$ & $1.35 \mathrm{E}-06$ & $2.89 \mathrm{E}-06$ & $3.45 \mathrm{E}-06$ & $3.88 E-06$ & $4.28 E-06$ \\
\hline $1.52 \mathrm{E}-07$ & $5.52 \mathrm{E}-06$ & $1.54 \mathrm{E}-06$ & $1.35 \mathrm{E}-06$ & $2.89 E-06$ & $3.45 E-06$ & $3.88 E-06$ & $4.28 E-06$ \\
\hline $1.53 \mathrm{E}-07$ & $5.52 \mathrm{E}-06$ & $1.54 \mathrm{E}-06$ & $1.35 \mathrm{E}-06$ & $2.89 \mathrm{E}-06$ & $3.45 \mathrm{E}-06$ & $3.88 \mathrm{E}-06$ & $4.28 E-06$ \\
\hline $1.53 \mathrm{E}-07$ & $5.52 \mathrm{E}-06$ & $1.54 \mathrm{E}-06$ & $1.36 \mathrm{E}-06$ & $2.90 \mathrm{E}-06$ & $3.45 \mathrm{E}-06$ & $3.88 E-06$ & $4.28 E-06$ \\
\hline $1.53 \mathrm{E}-07$ & $5.51 \mathrm{E}-06$ & $1.54 \mathrm{E}-06$ & $1.36 \mathrm{E}-06$ & $2.89 E-06$ & $3.45 E-06$ & $3.88 E-06$ & $4.27 E-06$ \\
\hline $1.54 \mathrm{E}-07$ & $5.51 \mathrm{E}-06$ & $1.55 \mathrm{E}-06$ & $1.36 \mathrm{E}-06$ & $2.89 \mathrm{E}-06$ & $3.45 \mathrm{E}-06$ & $3.88 \mathrm{E}-06$ & $4.27 E-06$ \\
\hline $1.54 \mathrm{E}-07$ & $5.51 \mathrm{E}-06$ & $1.55 \mathrm{E}-06$ & $1.36 \mathrm{E}-06$ & $2.89 \mathrm{E}-06$ & $3.44 \mathrm{E}-06$ & $3.88 E-06$ & $4.27 \mathrm{E}-06$ \\
\hline $1.54 \mathrm{E}-07$ & $5.50 \mathrm{E}-06$ & $1.55 \mathrm{E}-06$ & $1.36 \mathrm{E}-06$ & $2.89 E-06$ & $3.44 \mathrm{E}-06$ & $3.88 E-06$ & $4.26 E-06$ \\
\hline $1.55 \mathrm{E}-07$ & $5.50 \mathrm{E}-06$ & $1.55 \mathrm{E}-06$ & $1.36 \mathrm{E}-06$ & $2.89 \mathrm{E}-06$ & $3.44 \mathrm{E}-06$ & $3.88 E-06$ & $4.26 E-06$ \\
\hline $1.55 \mathrm{E}-07$ & $5.50 \mathrm{E}-06$ & $1.55 \mathrm{E}-06$ & $1.36 \mathrm{E}-06$ & $2.89 E-06$ & $3.44 \mathrm{E}-06$ & $3.88 E-06$ & $4.26 \mathrm{E}-06$ \\
\hline $1.55 \mathrm{E}-07$ & $5.49 \mathrm{E}-06$ & $1.55 \mathrm{E}-06$ & $1.36 \mathrm{E}-06$ & $2.90 \mathrm{E}-06$ & $3.44 \mathrm{E}-06$ & $3.88 E-06$ & $4.26 E-06$ \\
\hline $1.56 \mathrm{E}-07$ & $5.49 \mathrm{E}-06$ & $1.55 \mathrm{E}-06$ & $1.36 \mathrm{E}-06$ & $2.90 \mathrm{E}-06$ & $3.44 \mathrm{E}-06$ & $3.88 \mathrm{E}-06$ & $4.25 E-06$ \\
\hline $1.56 \mathrm{E}-07$ & $5.49 E-06$ & $1.55 \mathrm{E}-06$ & $1.36 \mathrm{E}-06$ & $2.90 \mathrm{E}-06$ & $3.44 \mathrm{E}-06$ & $3.88 E-06$ & $4.25 E-06$ \\
\hline $1.56 \mathrm{E}-07$ & $5.48 \mathrm{E}-06$ & $1.55 \mathrm{E}-06$ & $1.37 \mathrm{E}-06$ & $2.90 \mathrm{E}-06$ & $3.43 E-06$ & $3.88 \mathrm{E}-06$ & $4.25 E-06$ \\
\hline $1.57 \mathrm{E}-07$ & $5.48 \mathrm{E}-06$ & $1.55 \mathrm{E}-06$ & $1.37 \mathrm{E}-06$ & $2.90 \mathrm{E}-06$ & $3.43 E-06$ & $3.88 E-06$ & $4.25 E-06$ \\
\hline $1.57 \mathrm{E}-07$ & $5.48 \mathrm{E}-06$ & $1.55 E-06$ & $1.37 \mathrm{E}-06$ & $2.90 \mathrm{E}-06$ & $3.43 E-06$ & $3.88 \mathrm{E}-06$ & $4.25 E-06$ \\
\hline $1.57 \mathrm{E}-07$ & $5.47 \mathrm{E}-06$ & $1.56 \mathrm{E}-06$ & $1.37 \mathrm{E}-06$ & $2.90 \mathrm{E}-06$ & $3.43 E-06$ & $3.88 E-06$ & $4.25 E-06$ \\
\hline $1.58 \mathrm{E}-07$ & $5.47 \mathrm{E}-06$ & $1.56 \mathrm{E}-06$ & $1.37 \mathrm{E}-06$ & $2.90 \mathrm{E}-06$ & $3.43 \mathrm{E}-06$ & $3.88 \mathrm{E}-06$ & $4.25 E-06$ \\
\hline $1.58 \mathrm{E}-07$ & $5.47 \mathrm{E}-06$ & $1.56 \mathrm{E}-06$ & $1.37 \mathrm{E}-06$ & $2.90 \mathrm{E}-06$ & $3.43 E-06$ & $3.88 E-06$ & $4.25 E-06$ \\
\hline $1.58 \mathrm{E}-07$ & $5.46 \mathrm{E}-06$ & -06 & -06 & $2.90 \mathrm{E}-06$ & $3.42 \mathrm{E}-06$ & $3.88 \mathrm{E}-06$ & $4.25 E-06$ \\
\hline $1.59 \mathrm{E}-07$ & $5.46 \mathrm{E}-06$ & $1.56 \mathrm{E}-06$ & $1.37 \mathrm{E}-06$ & $2.90 \mathrm{E}-06$ & $3.42 \mathrm{E}-06$ & $3.88 E-06$ & $4.25 E-06$ \\
\hline $1.59 \mathrm{E}-07$ & $5.46 \mathrm{E}-06$ & $1.56 \mathrm{E}-06$ & $1.37 \mathrm{E}-06$ & $2.90 \mathrm{E}-06$ & $3.42 \mathrm{E}-06$ & $3.88 E-06$ & $4.25 E-06$ \\
\hline $1.59 \mathrm{E}-07$ & $5.45 E-06$ & $1.56 \mathrm{E}-06$ & $1.37 \mathrm{E}-06$ & $2.91 \mathrm{E}-06$ & $3.42 \mathrm{E}-06$ & $3.87 E-06$ & $4.25 E-06$ \\
\hline $1.60 \mathrm{E}-07$ & $5.45 E-06$ & $1.56 \mathrm{E}-06$ & $1.37 \mathrm{E}-06$ & $2.91 \mathrm{E}-06$ & $3.42 E-06$ & $3.87 E-06$ & $4.25 E-06$ \\
\hline $1.60 \mathrm{E}-07$ & $5.45 \mathrm{E}-06$ & $1.56 \mathrm{E}-06$ & $1.37 \mathrm{E}-06$ & $2.91 E-06$ & $3.42 \mathrm{E}-06$ & $3.87 \mathrm{E}-06$ & $4.25 E-06$ \\
\hline $1.61 \mathrm{E}-07$ & $5.44 \mathrm{E}-06$ & $1.56 \mathrm{E}-06$ & $1.38 \mathrm{E}-06$ & $2.91 \mathrm{E}-06$ & $3.42 E-06$ & $3.86 \mathrm{E}-06$ & $4.24 E-06$ \\
\hline
\end{tabular}


RESRAD-OFFSITE, Version 2.5

robabilistic Dose and Risk Report

Title : Offsite Resident Farmer Deterministic Run

File : RF TC99 DOESG FWD-FV2b.ROF

Summary of dose at graphical times, reptition 1 (continued)

Time

Years

$9.91 \mathrm{E}+02$

$9.91 \mathrm{E}+02$

9. $92 \mathrm{E}+02$

9. $92 \mathrm{E}+02$

$9.93 \mathrm{E}+02$

$9.93 \mathrm{E}+02$

9. $94 \mathrm{E}+02$

$9.94 \mathrm{E}+02$

$9.95 \mathrm{E}+02$

$9.95 \mathrm{E}+02$

$9.96 \mathrm{E}+02$

$9.96 \mathrm{E}+02$

$9.97 \mathrm{E}+02$

$9.97 \mathrm{E}+02$

$9.98 \mathrm{E}+02$

$9.98 \mathrm{E}+02$

$9.99 \mathrm{E}+02$

$9.99 \mathrm{E}+02$

$1.00 \mathrm{E}+03$

$1.00 \mathrm{E}+03$

$1.00 \mathrm{E}+03$

$1.00 \mathrm{E}+03$

$1.00 \mathrm{E}+03$

$1.00 \mathrm{E}+03$

$1.00 \mathrm{E}+03$

$1.00 \mathrm{E}+03$

$1.00 \mathrm{E}+03$

$1.00 \mathrm{E}+03$

$1.00 \mathrm{E}+03$

$1.01 \mathrm{E}+03$

$1.01 \mathrm{E}+03$

$1.01 \mathrm{E}+03$

$1.01 \mathrm{E}+03$

$1.01 \mathrm{E}+03$

$1.01 \mathrm{E}+03$

$1.01 \mathrm{E}+03$

$1.01 \mathrm{E}+03$

$1.01 \mathrm{E}+03$

$1.01 \mathrm{E}+03$

$1.01 E+03$

$1.01 \mathrm{E}+03$

$1.01 \mathrm{E}+03$

$1.01 \mathrm{E}+03$

$1.01 \mathrm{E}+03$

$1.01 \mathrm{E}+03$

$1.01 \mathrm{E}+03$
Dose statistics at graphical times, mrem/yr

\begin{tabular}{|c|c|c|c|c|c|c|c|}
\hline n & um & ea & - & & & & \\
\hline 07 & -06 & $1.56 \mathrm{E}-06$ & $1.38 \mathrm{E}-06$ & $1 E-06$ & . & $3.86 \mathrm{E}-06$ & $4-0$ \\
\hline $61 E-07$ & $5.44 E-06$ & $1.56 \mathrm{E}-06$ & $1.38 \mathrm{E}-06$ & $1 E-06$ & $42 E-06$ & $3.86 \mathrm{E}-06$ & $.24 E-06$ \\
\hline $62 E-07$ & $43 E-06$ & $1.57 \mathrm{E}-06$ & $1.38 \mathrm{E}-06$ & $2.91 \mathrm{E}-06$ & $3.42 E-06$ & $3.86 \mathrm{E}-06$ & $.24 \mathrm{E}-06$ \\
\hline $62 \mathrm{~F}-07$ & -06 & $57 \mathrm{~F}-06$ & $38 E-06$ & $.91 \mathrm{E}-06$ & $42 \mathrm{~F}-06$ & $36 \mathrm{~F}-06$ & $24 E-06$ \\
\hline$E-07$ & 06 & 06 & 06 & 6 & 6 & -06 & -06 \\
\hline-07 & & & & & & & \\
\hline $63 E-07$ & 06 & & & & & & -06 \\
\hline $63 E-07$ & 06 & 6 & 06 & 6 & 6 & 6 & -06 \\
\hline $64 \mathrm{E}-07$ & $5.41 \mathrm{E}-06$ & $7 E-06$ & -06 & -06 & -06 & -06 & $E-06$ \\
\hline$E-07$ & $41 E-06$ & $57 F_{-0}$ & $.39 E-06$ & $.92 E-06$ & $3 E-06$ & $E-06$ & $.22 E-06$ \\
\hline $64 E-07$ & & & & & & & $E-06$ \\
\hline $65 E-07$ & 5.401 & 1. & 1. & 6 & 6 & 6 & -06 \\
\hline $.65 E-07$ & $5.40 \mathrm{E}-06$ & $1.57 \mathrm{E}-06$ & $1.39 \mathrm{E}-06$ & & $3.43 E-06$ & $E-06$ & $.22 E-06$ \\
\hline $65 E-07$ & $5.39 \mathrm{E}-06$ & 1. $57 \mathrm{E}-06$ & 1. $39 \mathrm{E}-06$ & $2.92 \mathrm{E}-06$ & $3.43 E-06$ & -06 & $E-06$ \\
\hline-07 & 06 & 06 & -06 & 6 & 6 & -06 & $22 E-06$ \\
\hline $66 \mathrm{E}-$ & -06 & -06 & 0 & & & 0 & 06 \\
\hline 7 & 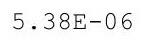 & & & & & & 6 \\
\hline $67 E-07$ & 6 & $1.58 \mathrm{E}-06$ & 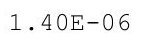 & 6 & 6 & 6 & 06 \\
\hline $.67 E-07$ & $5.38 E-06$ & $1.58 \mathrm{E}-06$ & $1.40 \mathrm{E}-06$ & $2.92 E-06$ & $3.43 E-06$ & $3.83 E-06$ & $.22 E-06$ \\
\hline $68 E-07$ & $.37 E-06$ & $1.58 \mathrm{E}-06$ & $1.40 \mathrm{E}-06$ & $2 E-06$ & $.43 E-06$ & $E-06$ & . $22 E-06$ \\
\hline 07 & & & & & & 6 & -06 \\
\hline $68 \mathrm{E}-$ & & & & & & & \\
\hline קים & & $\perp$ & & & 6 & & 06 \\
\hline $69 E-07$ & 6 & 0 & 0 & 6 & 6 & 0 & -06 \\
\hline 7 & 6 & 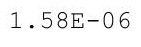 & 1 & תמת ח & $44 \mathrm{E}-$ & 6 & $21 E-$ \\
\hline $70 F-07$ & $E-06$ & $F-06$ & 1. $40 \mathrm{E}-06$ & $.92 E-06$ & $44 E-06$ & $.84 \mathrm{E}-0$ & $.21 E-06$ \\
\hline $70 \mathrm{~F}-07$ & -06 & & $.41 \mathrm{E}-06$ & $92 E-06$ & & $E-06$ & $.21 E-06$ \\
\hline .7 & & & & & & & \\
\hline 1 & & & & 06 & & & -06 \\
\hline • $11+4=1$ & $5.34 \mathrm{E}-06$ & 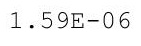 & 1. $41 \mathrm{E}-06$ & $2.92 E-06$ & $.44 E-06$ & $0.05 E-40$ & $.21 E-06$ \\
\hline $.72 \mathrm{E}-07$ & $33 E-06$ & $1.025-00$ & $1.41 \mathrm{E}-06$ & $2.92 \mathrm{E}-06$ & $.44 \mathrm{E}-06$ & $.02 \mathrm{E}-\mathrm{O}$ & $.21 E-06$ \\
\hline 管 & 6 & & 1. $41 \mathrm{E}-0$ & & Pe & 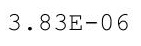 & $21 E-06$ \\
\hline-07 & -06 & -06 & & 6 & & & 06 \\
\hline 7 & & & & & & 6 & \\
\hline 7 & & & & 6 & & 06 & 06 \\
\hline $.73 E-07$ & $5.32 \mathrm{E}-06$ & $1.59 \pm-06$ & 1. $42 \mathrm{E}-06$ & $2.92 E-06$ & 0.11 & -06 & $.21 E-06$ \\
\hline $.145-1$ & & & & & & $3.00 \mathrm{H}$ & $4.21 D-00$ \\
\hline 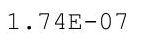 & $3 \perp 5-20$ & $1.59 \mathrm{E}-06$ & $1.42 \mathrm{E}-06$ & $2.92 \mathrm{E}-06$ & $2-2$ & & $4.21 \mathrm{E}-06$ \\
\hline $74 \mathrm{~F}-07$ & $5.30 \mathrm{E}-06$ & ; & 5 & 6 & 6 & 6 & 06 \\
\hline $.75 \mathrm{E}-07$ & & & & & & & 06 \\
\hline$E-07$ & $5.30 \mathrm{E}-06$ & 06 & 06 & 6 & & 06 & -06 \\
\hline $6 E-07$ & 5.2 & 1.6 & 1.42. & 6 & & & -06 \\
\hline & & & & & & & $4.20 E-06$ \\
\hline 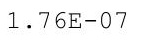 & $5.29 \mathrm{E}-06$ & $1.00 \mathrm{~L}-00$ & $1.43 E-06$ & $2.92 E-06$ & $3.44 E-06$ & $3.8 \angle E-06$ & $4 \cdot 20 E-06$ \\
\hline $77 E-07$ & . 20 D & 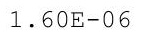 & $1.43 E-06$ & $2.92 E-06$ & & & $4.20 E-06$ \\
\hline $7 E-07$ & $.28 E-06$ & $.60 \mathrm{E}-06$ & $.43 E-06$ & $.92 \mathrm{E}-06$ & $.44 E-06$ & $2 E-06$ & $4.20 \mathrm{E}$ \\
\hline
\end{tabular}


RESRAD-OFFSITE, Version 2.5

Title : Offsite Resident Farmer Deterministic Run

File : RF TC99 DOESG FWD-FV2b.ROF

Summary of dose at graphical times, reptition 1 (continued)

Time

Years

$1.01 \mathrm{E}+03$

$1.01 \mathrm{E}+03$

$1.02 \mathrm{E}+03$

$1.02 \mathrm{E}+03$

$1.02 \mathrm{E}+03$

$1.02 \mathrm{E}+03$

$1.02 \mathrm{E}+03$

$1.02 \mathrm{E}+03$

$1.02 \mathrm{E}+03$

$1.02 \mathrm{E}+03$

$1.02 \mathrm{E}+03$

$1.02 \mathrm{E}+03$

$1.02 \mathrm{E}+03$

$1.02 \mathrm{E}+03$

$1.02 \mathrm{E}+03$

$1.02 \mathrm{E}+03$

$1.02 \mathrm{E}+03$

$1.02 \mathrm{E}+03$

$1.02 \mathrm{E}+03$

$1.02 \mathrm{E}+03$

$1.02 \mathrm{E}+03$

$1.02 \mathrm{E}+03$

$1.03 \mathrm{E}+03$

$1.03 \mathrm{E}+03$

$1.03 \mathrm{E}+03$

$1.03 \mathrm{E}+03$

$1.03 E+03$

$1.03 \mathrm{E}+03$

$1.03 \mathrm{E}+03$

$1.03 E+03$

$1.03 \mathrm{E}+03$

$1.03 \mathrm{E}+03$

$1.03 \mathrm{E}+03$

$1.03 \mathrm{E}+03$

$1.03 \mathrm{E}+03$

$1.03 E+03$

$1.03 \mathrm{E}+03$

$1.03 \mathrm{E}+03$

$1.03 E+03$

$1.03 \mathrm{E}+03$

$1.03 \mathrm{E}+03$

$1.04 \mathrm{E}+03$

$1.04 \mathrm{E}+03$

$1.04 \mathrm{E}+03$

$1.04 \mathrm{E}+03$

$1.04 \mathrm{E}+03$
Dose statistics at graphical times, mrem/yr

\begin{tabular}{|c|c|c|c|c|c|c|c|}
\hline Minimum & Maximum & Mean & Median & $90 \%$ & $95 \%$ & $97.5 \%$ & $99 \%$ \\
\hline $1.77 E-07$ & $5.28 \mathrm{E}-06$ & $1.60 E-06$ & $1.43 E-06$ & $2.92 E-06$ & $3.44 E-06$ & $3.82 E-06$ & $4.20 E-06$ \\
\hline $1.78 \mathrm{E}-07$ & $5.27 E-06$ & $1.60 \mathrm{E}-06$ & $1.43 \mathrm{E}-06$ & $2.92 E-06$ & $3.44 \mathrm{E}-06$ & $3.82 \mathrm{E}-06$ & $4.20 E-06$ \\
\hline $1.78 \mathrm{E}-07$ & $5.27 \mathrm{E}-06$ & $1.60 \mathrm{E}-06$ & 1. $43 \mathrm{E}-06$ & $2.92 \mathrm{E}-06$ & $3.43 \mathrm{E}-06$ & $3.82 \mathrm{E}-06$ & $4.20 \mathrm{E}-06$ \\
\hline $1.78 \mathrm{E}-07$ & $5.26 \mathrm{E}-06$ & $1.60 \mathrm{E}-06$ & $1.43 \mathrm{E}-06$ & $2.92 \mathrm{E}-06$ & $3.43 \mathrm{E}-06$ & $3.82 \mathrm{E}-06$ & $4.20 \mathrm{E}-06$ \\
\hline $1.79 \mathrm{E}-07$ & $5.26 \mathrm{E}-06$ & $1.60 \mathrm{E}-06$ & $1.43 \mathrm{E}-06$ & $2.92 \mathrm{E}-06$ & $3.43 \mathrm{E}-06$ & $3.81 \mathrm{E}-06$ & $4.20 \mathrm{E}-06$ \\
\hline $1.79 \mathrm{E}-07$ & $5.26 \mathrm{E}-06$ & $1.61 \mathrm{E}-06$ & $1.43 E-06$ & $2.92 \mathrm{E}-06$ & $3.43 E-06$ & $3.81 E-06$ & $4.20 E-06$ \\
\hline $1.80 \mathrm{E}-07$ & $5.25 \mathrm{E}-06$ & $1.61 \mathrm{E}-06$ & $1.44 \mathrm{E}-06$ & $2.92 \mathrm{E}-06$ & $3.43 E-06$ & $3.81 E-06$ & $4.20 E-06$ \\
\hline $1.80 \mathrm{E}-07$ & $5.25 \mathrm{E}-06$ & $1.61 \mathrm{E}-06$ & $1.44 \mathrm{E}-06$ & $2.92 \mathrm{E}-06$ & $3.43 \mathrm{E}-06$ & $3.82 \mathrm{E}-06$ & $4.20 \mathrm{E}-06$ \\
\hline $1.80 \mathrm{E}-07$ & $5.25 E-06$ & $1.61 \mathrm{E}-06$ & $1.44 \mathrm{E}-06$ & $2.92 \mathrm{E}-06$ & $3.43 E-06$ & $3.82 \mathrm{E}-06$ & $4.20 E-06$ \\
\hline $1.81 \mathrm{E}-07$ & $5.24 \mathrm{E}-06$ & $1.61 \mathrm{E}-06$ & $1.44 \mathrm{E}-06$ & $2.91 \mathrm{E}-06$ & $3.43 E-06$ & $3.82 E-06$ & $4.20 E-06$ \\
\hline $1.81 \mathrm{E}-07$ & $5.24 \mathrm{E}-06$ & $1.61 \mathrm{E}-06$ & $1.44 \mathrm{E}-06$ & $2.91 \mathrm{E}-06$ & $3.43 E-06$ & $3.82 \mathrm{E}-06$ & $4.20 \mathrm{E}-06$ \\
\hline $1.81 E-07$ & $5.24 \mathrm{E}-06$ & $1.61 \mathrm{E}-06$ & $1.44 \mathrm{E}-06$ & $2.91 \mathrm{E}-06$ & $3.42 \mathrm{E}-06$ & $3.81 \mathrm{E}-06$ & $4.19 \mathrm{E}-06$ \\
\hline $1.82 \mathrm{E}-07$ & $5.23 E-06$ & $1.61 \mathrm{E}-06$ & $1.44 \mathrm{E}-06$ & $2.91 \mathrm{E}-06$ & $3.42 \mathrm{E}-06$ & $3.81 \mathrm{E}-06$ & $4.19 \mathrm{E}-06$ \\
\hline $1.82 \mathrm{E}-07$ & $5.23 E-06$ & $1.61 \mathrm{E}-06$ & $1.45 \mathrm{E}-06$ & $2.91 \mathrm{E}-06$ & $3.42 \mathrm{E}-06$ & $3.81 E-06$ & $4.19 \mathrm{E}-06$ \\
\hline $1.82 \mathrm{E}-07$ & $5.22 \mathrm{E}-06$ & $1.61 \mathrm{E}-06$ & $1.45 \mathrm{E}-06$ & $2.91 \mathrm{E}-06$ & $3.41 \mathrm{E}-06$ & $3.80 \mathrm{E}-06$ & $4.19 \mathrm{E}-06$ \\
\hline $1.83 E-07$ & $5.22 \mathrm{E}-06$ & $1.61 \mathrm{E}-06$ & $1.45 E-06$ & $2.91 E-06$ & $3.41 E-06$ & $3.80 E-06$ & $4.19 E-06$ \\
\hline $1.83 E-07$ & $5.22 \mathrm{E}-06$ & $1.61 \mathrm{E}-06$ & $1.45 \mathrm{E}-06$ & $2.91 \mathrm{E}-06$ & $3.41 \mathrm{E}-06$ & $3.80 \mathrm{E}-06$ & $4.19 \mathrm{E}-06$ \\
\hline $1.84 \mathrm{E}-07$ & $5.21 \mathrm{E}-06$ & $1.61 \mathrm{E}-06$ & $1.45 \mathrm{E}-06$ & $2.91 \mathrm{E}-06$ & $3.41 \mathrm{E}-06$ & $3.79 E-06$ & $4.19 E-06$ \\
\hline $1.84 \mathrm{E}-07$ & $5.21 \mathrm{E}-06$ & $1.62 \mathrm{E}-06$ & $1.45 E-06$ & $2.91 E-06$ & $3.41 E-06$ & $3.79 E-06$ & $4.19 E-06$ \\
\hline $1.84 \mathrm{E}-07$ & $5.21 \mathrm{E}-06$ & $1.62 \mathrm{E}-06$ & $1.45 \mathrm{E}-06$ & $2.91 \mathrm{E}-06$ & $3.41 \mathrm{E}-06$ & $3.79 \mathrm{E}-06$ & $4.19 \mathrm{E}-06$ \\
\hline $1.85 E-07$ & $5.20 \mathrm{E}-06$ & $1.62 \mathrm{E}-06$ & $1.46 \mathrm{E}-06$ & $2.91 \mathrm{E}-06$ & $3.41 \mathrm{E}-06$ & $3.78 \mathrm{E}-06$ & $4.19 \mathrm{E}-06$ \\
\hline $1.85 E-07$ & $5.20 \mathrm{E}-06$ & $1.62 \mathrm{E}-06$ & $1.46 \mathrm{E}-06$ & $2.91 E-06$ & $3.41 \mathrm{E}-06$ & $3.78 E-06$ & $4.19 E-06$ \\
\hline $1.85 E-07$ & $5.19 \mathrm{E}-06$ & $1.62 \mathrm{E}-06$ & $1.46 \mathrm{E}-06$ & $2.91 \mathrm{E}-06$ & $3.41 \mathrm{E}-06$ & $3.78 \mathrm{E}-06$ & $4.19 E-06$ \\
\hline $1.86 \mathrm{E}-07$ & $5.19 \mathrm{E}-06$ & $1.62 \mathrm{E}-06$ & $1.46 \mathrm{E}-06$ & $2.90 \mathrm{E}-06$ & $3.41 \mathrm{E}-06$ & $3.78 \mathrm{E}-06$ & $4.19 \mathrm{E}-06$ \\
\hline $1.86 \mathrm{E}-07$ & $5.19 \mathrm{E}-06$ & $1.62 \mathrm{E}-06$ & $1.46 \mathrm{E}-06$ & $2.90 E-06$ & $3.41 \mathrm{E}-06$ & $3.78 E-06$ & $4.19 E-06$ \\
\hline $1.87 \mathrm{E}-07$ & $5.18 \mathrm{E}-06$ & $1.62 \mathrm{E}-06$ & $1.46 \mathrm{E}-06$ & $2.90 \mathrm{E}-06$ & $3.41 \mathrm{E}-06$ & $3.78 \mathrm{E}-06$ & $4.19 \mathrm{E}-06$ \\
\hline $1.87 \mathrm{E}-07$ & $5.18 \mathrm{E}-06$ & $1.62 \mathrm{E}-06$ & $1.46 \mathrm{E}-06$ & $2.90 \mathrm{E}-06$ & $3.41 \mathrm{E}-06$ & $3.78 \mathrm{E}-06$ & $4.19 \mathrm{E}-06$ \\
\hline $1.87 \mathrm{E}-07$ & $5.18 \mathrm{E}-06$ & $1.62 \mathrm{E}-06$ & $1.46 \mathrm{E}-06$ & $2.90 \mathrm{E}-06$ & $3.41 \mathrm{E}-06$ & $3.79 E-06$ & $4.19 E-06$ \\
\hline $1.88 \mathrm{E}-07$ & $5.17 \mathrm{E}-06$ & $1.62 \mathrm{E}-06$ & $1.46 \mathrm{E}-06$ & $2.90 \mathrm{E}-06$ & $3.41 \mathrm{E}-06$ & $3.79 \mathrm{E}-06$ & $4.19 E-06$ \\
\hline $1.88 E-07$ & $5.17 \mathrm{E}-06$ & $1.62 \mathrm{E}-06$ & $1.46 \mathrm{E}-06$ & $2.90 \mathrm{E}-06$ & $3.41 \mathrm{E}-06$ & $3.79 E-06$ & $4.19 E-06$ \\
\hline $1.88 \mathrm{E}-07$ & $5.16 \mathrm{E}-06$ & $1.62 \mathrm{E}-06$ & $1.46 \mathrm{E}-06$ & $2.90 \mathrm{E}-06$ & $3.41 \mathrm{E}-06$ & $3.79 \mathrm{E}-06$ & $4.19 \mathrm{E}-06$ \\
\hline $1.89 \mathrm{E}-07$ & $5.16 \mathrm{E}-06$ & $1.62 \mathrm{E}-06$ & $1.46 \mathrm{E}-06$ & $2.90 \mathrm{E}-06$ & $3.41 \mathrm{E}-06$ & $3.79 \mathrm{E}-06$ & $4.19 \mathrm{E}-06$ \\
\hline $1.89 \mathrm{E}-07$ & $5.16 \mathrm{E}-06$ & $1.63 E-06$ & $1.46 \mathrm{E}-06$ & $2.90 \mathrm{E}-06$ & $3.41 \mathrm{E}-06$ & $3.79 \mathrm{E}-06$ & $4.19 \mathrm{E}-06$ \\
\hline $1.90 \mathrm{E}-07$ & $5.15 \mathrm{E}-06$ & $1.63 \mathrm{E}-06$ & $1.46 \mathrm{E}-06$ & $2.90 \mathrm{E}-06$ & $3.41 \mathrm{E}-06$ & $3.79 \mathrm{E}-06$ & $4.19 E-06$ \\
\hline $1.90 \mathrm{E}-07$ & $5.15 \mathrm{E}-06$ & $1.63 \mathrm{E}-06$ & $1.46 \mathrm{E}-06$ & $2.90 \mathrm{E}-06$ & $3.41 \mathrm{E}-06$ & $3.79 \mathrm{E}-06$ & $4.19 \mathrm{E}-06$ \\
\hline $1.90 \mathrm{E}-07$ & $5.14 \mathrm{E}-06$ & $1.63 E-06$ & $1.47 \mathrm{E}-06$ & $2.89 \mathrm{E}-06$ & $3.40 \mathrm{E}-06$ & $3.78 \mathrm{E}-06$ & $4.19 \mathrm{E}-06$ \\
\hline $1.91 \mathrm{E}-07$ & $5.14 \mathrm{E}-06$ & $1.63 E-06$ & $1.47 \mathrm{E}-06$ & $2.89 \mathrm{E}-06$ & $3.40 \mathrm{E}-06$ & $3.78 E-06$ & $4.19 E-06$ \\
\hline $1.91 \mathrm{E}-07$ & $5.14 \mathrm{E}-06$ & $1.63 \mathrm{E}-06$ & $1.47 \mathrm{E}-06$ & $2.89 \mathrm{E}-06$ & $3.40 \mathrm{E}-06$ & $3.78 \mathrm{E}-06$ & $4.19 \mathrm{E}-06$ \\
\hline $1.91 \mathrm{E}-07$ & $5.13 \mathrm{E}-$ & $1.63 E-06$ & $1.47 \mathrm{E}-06$ & $2.89 \mathrm{E}-06$ & $3.40 \mathrm{E}-06$ & $3.78 E-06$ & $4.19 E-06$ \\
\hline $1.92 \mathrm{E}-07$ & $E-06$ & 1.6 & $1.47 \mathrm{E}-06$ & $2.89 \mathrm{E}-06$ & $3.40 \mathrm{E}-06$ & -06 & $4.19 \mathrm{E}-06$ \\
\hline $1.92 \mathrm{E}-07$ & $5.13 \mathrm{E}-06$ & $1.63 \mathrm{E}-06$ & $1.47 \mathrm{E}-06$ & $2.89 E-06$ & $3.40 \mathrm{E}-06$ & $3.77 \mathrm{E}-06$ & $4.19 E-06$ \\
\hline $1.93 E-07$ & $5.12 \mathrm{E}-06$ & $1.63 E-06$ & $1.47 \mathrm{E}-06$ & $2.89 E-06$ & $3.40 \mathrm{E}-06$ & $3.76 \mathrm{E}-06$ & $4.19 \mathrm{E}-06$ \\
\hline $1.93 E-07$ & $5.12 \mathrm{E}-06$ & $1.63 \mathrm{E}-06$ & $1.47 \mathrm{E}-06$ & $2.89 \mathrm{E}-06$ & $3.40 \mathrm{E}-06$ & $3.76 \mathrm{E}-06$ & $4.19 E-06$ \\
\hline $1.93 E-07$ & $5.11 \mathrm{E}-06$ & $1.63 E-06$ & $1.48 \mathrm{E}-06$ & $2.89 \mathrm{E}-06$ & $3.40 \mathrm{E}-06$ & $3.76 \mathrm{E}-06$ & $4.19 E-06$ \\
\hline $1.94 \mathrm{E}-07$ & $5.11 \mathrm{E}-06$ & $1.63 E-06$ & $1.48 \mathrm{E}-06$ & $2.89 E-06$ & $3.40 \mathrm{E}-06$ & $3.76 \mathrm{E}-06$ & $4.19 \mathrm{E}-06$ \\
\hline $1.94 \mathrm{E}-07$ & $5.11 \mathrm{E}-06$ & $1.63 \mathrm{E}-06$ & $1.48 \mathrm{E}-06$ & $2.89 E-06$ & $3.39 E-06$ & $3.75 \mathrm{E}-06$ & $4.19 E-06$ \\
\hline
\end{tabular}


RESRAD-OFFSITE, Version 2.5

$\mathrm{T}^{1 / 2}$ Limit $=180$ days

robabilistic Dose and Risk Report

itle : Offsite Resident Farmer Deterministic Run

File : RF TC99 DOESG FWD-FV2b.ROF

Time

Years

$1.04 \mathrm{E}+03$

$1.04 \mathrm{E}+03$

$1.04 \mathrm{E}+03$

$1.04 \mathrm{E}+03$

$1.04 \mathrm{E}+03$

$1.04 \mathrm{E}+03$

$1.04 \mathrm{E}+03$

$1.04 \mathrm{E}+03$

$1.04 \mathrm{E}+03$

$1.04 \mathrm{E}+03$

$1.04 \mathrm{E}+03$

$1.04 \mathrm{E}+03$

$1.04 \mathrm{E}+03$

$1.04 \mathrm{E}+03$

$1.04 \mathrm{E}+03$

$1.05 \mathrm{E}+03$

$1.05 \mathrm{E}+03$

$1.05 \mathrm{E}+03$

$1.05 \mathrm{E}+03$

$1.05 \mathrm{E}+03$

$1.05 \mathrm{E}+03$

1. $05 \mathrm{E}+03$

$1.05 \mathrm{E}+03$

$1.05 \mathrm{E}+03$

$1.05 \mathrm{E}+03$
Summary of dose at graphical times, reptition 1 (continued)

Dose statistics at graphical times, mrem/yr

\begin{tabular}{|c|c|c|c|c|c|c|c|}
\hline Minimum & Maximum & Mean & Median & $90 \%$ & $95 \%$ & $97.5 \%$ & $99 \%$ \\
\hline $.94 \mathrm{E}-07$ & $5.10 \mathrm{E}-06$ & $1.64 \mathrm{E}-06$ & $1.48 \mathrm{E}-06$ & $2.89 \mathrm{E}-06$ & $3.39 \mathrm{E}-06$ & $3.75 \mathrm{E}-06$ & $4.19 \mathrm{E}-06$ \\
\hline $1.95 \mathrm{E}-07$ & $5.10 \mathrm{E}-06$ & $1.64 \mathrm{E}-06$ & $1.48 \mathrm{E}-06$ & $2.89 \mathrm{E}-06$ & $3.39 \mathrm{E}-06$ & $3.76 \mathrm{E}-06$ & $4.19 \mathrm{E}-06$ \\
\hline $1.95 \mathrm{E}-07$ & $5.09 \mathrm{E}-06$ & $1.64 \mathrm{E}-06$ & 1. $48 \mathrm{E}-06$ & $2.89 \mathrm{E}-06$ & $3.39 \mathrm{E}-06$ & $3.76 \mathrm{E}-06$ & $4.18 \mathrm{E}-06$ \\
\hline $.96 \mathrm{E}-07$ & $5.09 \mathrm{E}-06$ & $1.64 \mathrm{E}-06$ & $1.48 \mathrm{E}-06$ & $2.89 \mathrm{E}-06$ & $3.39 \mathrm{E}-06$ & $3.76 E-06$ & $4.18 \mathrm{E}-06$ \\
\hline 1. $96 \mathrm{E}-07$ & $5.09 \mathrm{E}-06$ & 1. $64 \mathrm{E}-06$ & $1.49 \mathrm{E}-06$ & $2.89 \mathrm{E}-06$ & $3.39 \mathrm{E}-06$ & $3.76 \mathrm{E}-06$ & $4.18 \mathrm{E}-06$ \\
\hline $1.96 \mathrm{E}-07$ & $5.08 \mathrm{E}-06$ & $1.64 \mathrm{E}-06$ & $1.49 \mathrm{E}-06$ & $2.89 E-06$ & $3.39 E-06$ & $3.76 \mathrm{E}-06$ & $4.18 E-06$ \\
\hline $1.97 \mathrm{E}-07$ & $5.08 E-06$ & $1.64 \mathrm{E}-06$ & $1.49 \mathrm{E}-06$ & $2.89 \mathrm{E}-06$ & $3.39 \mathrm{E}-06$ & $3.76 \mathrm{E}-06$ & $4.18 \mathrm{E}-06$ \\
\hline $1.97 \mathrm{E}-07$ & $5.08 E-06$ & $1.64 \mathrm{E}-06$ & $1.49 \mathrm{E}-06$ & $2.88 E-06$ & $3.39 \mathrm{E}-06$ & $3.76 E-06$ & $4.18 \mathrm{E}-06$ \\
\hline 1. $97 \mathrm{E}-07$ & $5.07 \mathrm{E}-06$ & $1.64 \mathrm{E}-06$ & 1. $49 \mathrm{E}-06$ & $2.88 E-06$ & $3.39 \mathrm{E}-06$ & $3.76 \mathrm{E}-06$ & $4.18 E-06$ \\
\hline $1.98 \mathrm{E}-07$ & $5.07 \mathrm{E}-06$ & $1.64 \mathrm{E}-06$ & $1.49 \mathrm{E}-06$ & $2.88 \mathrm{E}-06$ & $3.39 \mathrm{E}-06$ & $6 E-06$ & $4.18 \mathrm{E}-06$ \\
\hline 1. $98 \mathrm{E}-07$ & 06 & $1.64 \mathrm{E}$ & 1. $49 \mathrm{E}-06$ & $2.88 E-06$ & $3.39 \mathrm{E}-06$ & $3.76 \mathrm{E}-06$ & $.17 \mathrm{E}-06$ \\
\hline $.99 \mathrm{E}-07$ & $5.06 \mathrm{E}-06$ & 1. $64 \mathrm{E}-06$ & 1. $49 \mathrm{E}-06$ & $2.88 \mathrm{E}-06$ & $3.39 \mathrm{E}-06$ & $3.77 \mathrm{E}-06$ & $4.17 \mathrm{E}-06$ \\
\hline $1.99 \mathrm{E}-07$ & $5.06 \mathrm{E}-06$ & $1.64 \mathrm{E}-06$ & $1.49 \mathrm{E}-06$ & $2.88 E-06$ & $3.39 \mathrm{E}-06$ & $3.77 \mathrm{E}-06$ & $4.17 E-06$ \\
\hline 1.99E-07 & $5.05 \mathrm{E}-06$ & $1.64 \mathrm{E}-06$ & $1.49 \mathrm{E}-06$ & $2.88 E-06$ & $3.39 \mathrm{E}-06$ & $3.77 \mathrm{E}-06$ & $4.17 \mathrm{E}-06$ \\
\hline $2.00 \mathrm{E}-07$ & $5.05 E-06$ & $1.64 \mathrm{E}-06$ & $1.50 \mathrm{E}-06$ & $2.88 \mathrm{E}-06$ & $3.39 \mathrm{E}-06$ & $3.76 \mathrm{E}-06$ & $4.17 \mathrm{E}-06$ \\
\hline $2.00 \mathrm{E}-07$ & $5.04 \mathrm{E}-06$ & $1.65 E-06$ & $1.50 E-06$ & $2.88 E-06$ & $3.39 \mathrm{E}-06$ & $6 E-06$ & $4.17 E-06$ \\
\hline $2.00 \mathrm{E}-07$ & $5.04 \mathrm{E}-06$ & $1.65 \mathrm{E}-06$ & $1.50 \mathrm{E}-06$ & $2.88 E-06$ & $39 E-06$ & $6 E-06$ & $4.17 \mathrm{E}-06$ \\
\hline $2.01 E-07$ & $5.04 \mathrm{E}-06$ & $1.65 E-06$ & $1.50 E-06$ & $2.89 \mathrm{E}-06$ & $3.39 \mathrm{E}-06$ & $3.76 E-06$ & $4.17 E-06$ \\
\hline $2.01 E-07$ & $5.03 E-06$ & $1.65 E-06$ & $1.50 \mathrm{E}-06$ & $2.89 E-06$ & $3.39 E-06$ & $3.76 E-06$ & $4.17 E-06$ \\
\hline $2.02 \mathrm{E}-07$ & $5.03 E-06$ & $1.65 \mathrm{E}-06$ & $1.50 \mathrm{E}-06$ & $2.89 \mathrm{E}-06$ & $3.39 \mathrm{E}-06$ & $3.75 \mathrm{E}-06$ & $4.17 \mathrm{E}-06$ \\
\hline $2.02 \mathrm{E}-07$ & $5.02 \mathrm{E}-06$ & 1. $65 \mathrm{E}-06$ & 1. $50 \mathrm{E}-06$ & $2.89 \mathrm{E}-06$ & $3.39 \mathrm{E}-06$ & $3.75 E-06$ & $4.17 \mathrm{E}-06$ \\
\hline $2.02 E-07$ & $5.02 E-06$ & $1.65 \mathrm{E}-06$ & $1.51 \mathrm{E}-06$ & $2.89 E-06$ & $3.39 \mathrm{E}-06$ & $3.75 E-06$ & $4.17 E-06$ \\
\hline $2.03 E-07$ & $5.02 \mathrm{E}-06$ & $1.65 \mathrm{E}-06$ & $1.51 \mathrm{E}-06$ & $2.89 \mathrm{E}-06$ & $3.39 \mathrm{E}$ & $3.75 \mathrm{E}-06$ & $4.17 \mathrm{E}-06$ \\
\hline $2.03 E-07$ & $5.01 E-06$ & $1.65 \mathrm{E}-06$ & $1.51 \mathrm{E}-06$ & $2.89 \mathrm{E}-06$ & $3.39 \mathrm{E}-06$ & $3.74 E-06$ & $4.17 E-06$ \\
\hline $2.03 E-07$ & $5.01 \mathrm{E}-06$ & 1. $65 \mathrm{E}-06$ & $1.51 \mathrm{E}-06$ & $2.89 E-06$ & $3.39 E-06$ & $3.74 \mathrm{E}-06$ & $4.17 E-06$ \\
\hline
\end{tabular}

C -388

DCN 5090-TR-02-2 
RESRAD-OFFSITE, Version 2.5

itle : Offsite Resident Farmer Deterministic Run

File : RF TC99 DOESG FWD-FV2b.ROF

Time

Years

$0.00 \mathrm{E}+00$

$5.13 \mathrm{E}-01$

$1.03 E+00$

$1.54 \mathrm{E}+00$

$2.05 \mathrm{E}+00$

$2.56 \mathrm{E}+00$

$3.08 \mathrm{E}+00$

$3.59 \mathrm{E}+00$

$4.10 \mathrm{E}+00$

4. $61 \mathrm{E}+00$

$5.13 \mathrm{E}+00$

$5.64 \mathrm{E}+00$

$6.15 \mathrm{E}+00$

$6.67 \mathrm{E}+00$

$7.18 \mathrm{E}+00$

$7.69 \mathrm{E}+00$

$8.20 \mathrm{E}+00$

$8.72 \mathrm{E}+00$

$9.23 \mathrm{E}+00$

$9.74 \mathrm{E}+00$

$1.03 \mathrm{E}+01$

$1.08 \mathrm{E}+01$

$1.13 \mathrm{E}+01$

1. $18 \mathrm{E}+01$

1. $23 \mathrm{E}+01$

$1.28 \mathrm{E}+01$

1. $33 \mathrm{E}+01$

1. $38 \mathrm{E}+01$

$1.44 \mathrm{E}+01$

$1.49 \mathrm{E}+01$

1. $54 \mathrm{E}+01$

$1.59 \mathrm{E}+01$

1. $64 \mathrm{E}+01$

$1.69 \mathrm{E}+01$

$1.74 \mathrm{E}+01$

$1.79 \mathrm{E}+01$

$1.85 \mathrm{E}+01$

$1.90 \mathrm{E}+01$

1. $95 \mathrm{E}+01$

$2.00 \mathrm{E}+01$

2. $05 \mathrm{E}+01$

2. $10 \mathrm{E}+01$

$2.15 E+01$

2. $20 \mathrm{E}+01$

$2.26 \mathrm{E}+01$

$2.31 \mathrm{E}+01$

Summary of dose at graphical times, reptition 2

Dose statistics at graphical times, mrem/yr

\begin{tabular}{|c|c|c|c|c|c|c|c|}
\hline Iinimum & Iaximum & Mean & Median & 00 & $\%$ & $97.5 \%$ & 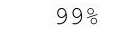 \\
\hline $80 \mathrm{E}-32$ & $1.82 \mathrm{E}-32$ & 1. $82 \mathrm{E}-32$ & $1.82 \mathrm{E}-32$ & $32 E-32$ & $82 E-32$ & 1. $82 \mathrm{E}-32$ & 2 \\
\hline $80 \mathrm{E}-32$ & $1.84 \mathrm{E}-32$ & $1.83 E-32$ & $1.84 \mathrm{E}-32$ & $1.84 \mathrm{E}-32$ & $1.84 \mathrm{E}-32$ & -32 & 32 \\
\hline $9 E-32$ & $35 E-32$ & 32 & -32 & $85 E-32$ & 32 & 32 & 32 \\
\hline $3 E-32$ & $87 E-32$ & $6 E-32$ & -32 & $E-32$ & $7 E-32$ & 32 & $7 E-32$ \\
\hline $3 E-32$ & $E-32$ & $8 E-32$ & 2 & $9 \mathrm{E}$ & 2 & 2 & -32 \\
\hline $.77 E-32$ & & & & & & & \\
\hline $.77 E-32$ & & & & 2 & 2 & 32 & $92 E-32$ \\
\hline $.76 E-32$ & 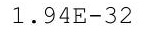 & - & $1.93 E-32$ & $4 E-32$ & 32 & 1.9 & $94 E-32$ \\
\hline $.76 \mathrm{E}-32$ & 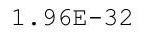 & 专 & $1.95 E-32$ & - & 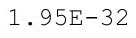 & . & 1. $95 E-32$ \\
\hline $5 E-32$ & 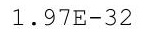 & 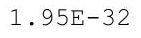 & 32 & 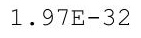 & 2 & -32 & $97 E-32$ \\
\hline $75 E-32$ & -32 & 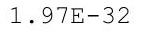 & & -32 & 2 & 32 & -32 \\
\hline-32 & 2 & & & 2 & & & -32 \\
\hline 2 & & 2 & & & 2 & 2 & -32 \\
\hline $.73 E-32$ & & 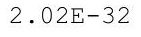 & 2 & & 2 & 82 & -32 \\
\hline $.72 E-32$ & 年 & 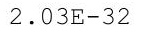 & 2.040 & . & 0.0 & 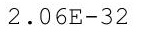 & -32 \\
\hline $.72 E-32$ & t & 2. & & - & & (2) & -32 \\
\hline $.71 E-32$ & $2.10 E-32$ & $2.06 E-3$ & -32 & FE & 2 & 32 & -32 \\
\hline $.71 \mathrm{E}-32$ & $2.12 \mathrm{E}-32$ & & $2.09 E-32$ & & $2.11 \mathrm{E}-32$ & $2.11 \mathrm{E}-32$ & $11 E-32$ \\
\hline$E-32$ & $5-3$ & 2 & 2 & 2 & 2 & -32 & $3 E-32$ \\
\hline $.70 E-32$ & $2.15 E-32$ & $2.11 \mathrm{E}-3$ & $2 \cdot 13 \pm-32$ & $15 \mathrm{E}-3$ & 2 & $2.15 E-32$ & $15 E-32$ \\
\hline $69 \mathrm{E}-32$ & $2 \cdot 1 / \pm 22$ & 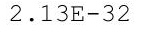 & 2 & 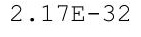 & & 32 & -32 \\
\hline $69 \mathrm{E}-32$ & 2. & 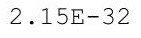 & & & & & -32 \\
\hline $68 E-32$ & 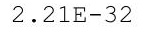 & 2. & 2 & 2 & 2 & $2.21 E-32$ & -32 \\
\hline $.68 E-32$ & $2.23 E-32$ & $2.18 E-32$ & 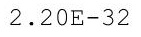 & $2.22 \mathrm{E}-$ & $2.23 \mathrm{E}$ & 2.23 & $23 E-32$ \\
\hline $.67 E-32$ & $-6-5$ & . & $E-32$ & $.24 \mathrm{E}-$ & $2.25 \mathrm{E}-$ & $2.25 \mathrm{E}-$ & $25 E-32$ \\
\hline $67 E-32$ & $2.27 E-32$ & $2.21 E-32$ & $4 E-32$ & $6 \mathrm{E}$ & & -32 & $7 E-32$ \\
\hline$E-32$ & 32 & 2 & 32 & 2 & & 32 & -32 \\
\hline $.66 E-32$ & $2.31 E-32$ & 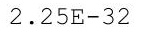 & $7 E-32$ & 2 & & 32 & -32 \\
\hline $.65 E-32$ & $2.33 E-32$ & $2.27 \mathrm{E}-32$ & $2.29 E-32$ & $2.32 E-32$ & $2.33 E-32$ & $2.33 E-32$ & $2.33 E-32$ \\
\hline 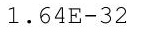 & 2 & 管 & 2 & $2.34 \mathrm{E}-32$ & $2.37 \pi 2$ & (2.0 & $2.35 E-32$ \\
\hline 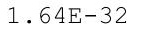 & 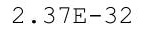 & 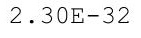 & $2.33 E-32$ & 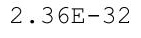 & & 32 & $E-32$ \\
\hline $.63 E-32$ & $2.39 E-32$ & & 2 & & & & 32 \\
\hline 2 & 32 & 2.3 & 32 & 2 & 2 & 32 & 32 \\
\hline $62 E-32$ & $E-32$ & $2.36 \mathrm{E}-$ & 2 & 2 & & 32 & -32 \\
\hline $62 E-32$ & $2.46 \mathrm{E}-32$ & $2.38 E-32$ & $2.41 E-32$ & $2.45 E-32$ & 2.405 & $2.45 E-32$ & $2.46 E-32$ \\
\hline . OIL-J2 & 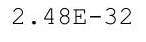 & 2. & 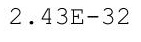 & 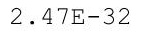 & & & $2.48 E-32$ \\
\hline $\begin{array}{lll}0 & 0\end{array}$ & $2.50 E-32$ & & & & & & -32 \\
\hline $60 F-32$ & $2.52 \mathrm{E}-32$ & & & 2 & 2 & 2 & 32 \\
\hline $.60 E-32$ & $2.55 E-32$ & $2.45 E-32$ & 2 & 2 & 2 & 2 & 32 \\
\hline 2 & & & & 2 & 2 & -32 & 32 \\
\hline $59 E-32$ & $2.59 \mathrm{E}-$ & $2.49 \mathrm{E}$ & 32 & 2. & & 32 & -32 \\
\hline 2 & .0 & & & & & & \\
\hline 2 & . & 2 & 2 & -0 & & & -32 \\
\hline 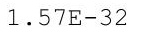 & 2 & & & . & 2 & 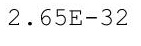 & 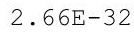 \\
\hline L. $57 \mathrm{E}-32$ & & & & & 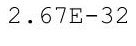 & 32 & 32 \\
\hline$E-32$ & $71 E-32$ & $9 E-32$ & 32 & 32 & 32 & 32 & 32 \\
\hline
\end{tabular}


RESRAD-OFFSITE, Version 2.5

itle : Offsite Resident Farmer Deterministic Run

File : RF TC99 DOESG FWD-FV2b.ROF

Summary of dose at graphical times, reptition 2 (continued)

Time

Years

$2.36 \mathrm{E}+01$

$2.41 \mathrm{E}+01$

2. $46 \mathrm{E}+01$

$2.51 \mathrm{E}+01$

2. $56 \mathrm{E}+01$

2. $61 \mathrm{E}+01$

$2.67 \mathrm{E}+01$

$2.72 E+01$

$2.77 \mathrm{E}+01$

$2.82 \mathrm{E}+01$

$2.87 \mathrm{E}+01$

2. $92 \mathrm{E}+01$

2. $97 \mathrm{E}+01$

3. $02 \mathrm{E}+01$

$3.08 \mathrm{E}+01$

$3.13 \mathrm{E}+01$

3. $18 \mathrm{E}+01$

3. $23 E+01$

3. $28 \mathrm{E}+01$

3. $33 E+01$

3. $38 \mathrm{E}+01$

3. $44 \mathrm{E}+01$

3. $49 \mathrm{E}+01$

$3.54 \mathrm{E}+01$

$3.59 \mathrm{E}+01$

3. $64 \mathrm{E}+01$

$3.69 \mathrm{E}+01$

$3.74 \mathrm{E}+01$

$3.79 \mathrm{E}+01$

3. $85 \mathrm{E}+01$

3. $90 \mathrm{E}+01$

$3.95 \mathrm{E}+01$

$4.00 \mathrm{E}+01$

$4.05 \mathrm{E}+01$

4. $10 \mathrm{E}+01$

4. $15 \mathrm{E}+01$

4. $20 \mathrm{E}+01$

4. $26 \mathrm{E}+01$

$4.31 \mathrm{E}+01$

4. $36 \mathrm{E}+01$

4. $41 \mathrm{E}+01$

4. $46 \mathrm{E}+01$

$4.51 \mathrm{E}+01$

$4.56 \mathrm{E}+01$

4. $61 \mathrm{E}+01$

$4.67 \mathrm{E}+01$

Dose statistics at graphical times, mrem/yr

\begin{tabular}{|c|c|c|c|c|c|c|c|}
\hline m & aximum & ea & - & & & & \\
\hline $56 \mathrm{E}-32$ & $2.73 E-32$ & $2.61 E-32$ & $2.66 \mathrm{E}-32$ & $71 E-32$ & $72 E-32$ & 32 & . $135-32$ \\
\hline $55 E-32$ & $2.76 E-32$ & $2.63 E-32$ & $2.68 \mathrm{E}-32$ & $2.74 E-32$ & $2.74 E-32$ & $2.75 E-32$ & $75 E-32$ \\
\hline-32 & $78 E-32$ & $65 E-32$ & $70 E-32$ & $76 E-32$ & $77 E-32$ & $2.77 \mathrm{E}-32$ & $78 E-32$ \\
\hline $55 E-32$ & $81 E-32$ & $68 F-32$ & $73 F-32$ & $79 F-32$ & $279 F-32$ & $80=-32$ & $80 F-32$ \\
\hline-32 & -32 & 2 & -32 & 2 & 2 & -32 & $83 E-32$ \\
\hline 32 & 32 & & & & & & -32 \\
\hline $53 E-32$ & $2.88 E-32$ & & & & & & -32 \\
\hline $53 E-32$ & -32 & 2 & -32 & 2 & 32 & -32 & $90 E-32$ \\
\hline $52 E-32$ & $93 E-32$ & $\begin{array}{lll}0 & 0\end{array}$ & $2.84 \mathrm{E}-32$ & $91 E-32$ & $92 \mathrm{E}-$ & -32 & $3 E-32$ \\
\hline$E-32$ & $96 E-32$ & ? חק00 & $865-32$ & 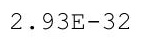 & 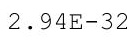 & $.95 E-32$ & $95=-32$ \\
\hline 32 & -32 & & & & & & -32 \\
\hline $51 E-32$ & $3.01 \mathrm{E}-32$ & $285 \mathrm{~F}-32$ & -32 & 2 & 2 & 2 & -32 \\
\hline $50 E-32$ & $3.04 \mathrm{E}-32$ & & $2.94 \mathrm{E}-32$ & & & & $3.03 E-32$ \\
\hline $50 E-32$ & -32 & $2.095-32$ & $2.96 \mathrm{E}-32$ & & & 32 & $E-32$ \\
\hline$E-32$ & -32 & 2 & -32 & & & -32 & $E-32$ \\
\hline $9 E-32$ & 32 & 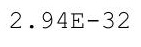 & $1 E-32$ & & & 2 & 32 \\
\hline 2 & 2 & & & & & & 32 \\
\hline$E-32$ & 32 & 2 & 2 & & & 2 & 32 \\
\hline $47 E-32$ & $3.20 \mathrm{E}-32$ & $3.01 E-32$ & $3.09 E-32$ & $3.17 E-32$ & $3.18 E-32$ & $3.19 \mathrm{E}-32$ & $3.19 E-32$ \\
\hline $47 E-32$ & $23 E-32$ & $.04 E-32$ & -32 & $0 E-32$ & 2 & -32 & $22 E-32$ \\
\hline 32 & 32 & & & & & 82 & -32 \\
\hline 32 & 32 & & & & & -32 & \\
\hline 2 & & & & & & & 32 \\
\hline $45 E-32$ & -32 & $3.13 E-32$ & $z$ & 2 & 2 & 2 & -32 \\
\hline 2 & 2 & $3.16 \mathrm{E}-32$ & 2 & 2 & 5 & 2 & 32 \\
\hline $44 \mathrm{E}-32$ & $.41 E-32$ & $18 E-32$ & $E-32$ & ד & تص8 & $.39 E-32$ & $40 E-32$ \\
\hline $44 \mathrm{E}-32$ & $44 \mathrm{E}-32$ & 2 & $E-32$ & -32 & & $E-32$ & $43 E-32$ \\
\hline & & & & & & & \\
\hline & & & & & & -32 & 32 \\
\hline $42 E-32$ & $3.53 E-32$ & . & $3.38 E-32$ & $3.49 E-32$ & $.200-28$ & $.51 \mathrm{E}-32$ & $.52 E-32$ \\
\hline $42 E-32$ & $56 \mathrm{E}-32$ & . & $E-32$ & 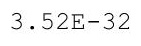 & - & $5-32$ & $.55 E-32$ \\
\hline 2 & $3.59 \mathrm{E}-32$ & & $3.43 E-32$ & & & $.57 E-32$ & \\
\hline-32 & $E-32$ & 2 & -32 & 2 & تصט & & $1 E-32$ \\
\hline 32 & & & & & & & \\
\hline 32 & & & & & 2 & -32 & \\
\hline $40 \mathrm{E}-32$ & $3.72 E-32$ & . & $3.55 E-32$ & 0.000 & 3.001 & -32 & $.71 E-32$ \\
\hline $39 E-32$ & $3.15 \mathrm{E}-32$ & $3.47 \mathrm{E}-32$ & & & & & $3.14 \mathrm{E}-32$ \\
\hline $39 E-32$ & $3.79 E-32$ & . & 然 & . 110 - & & & $77 E-32$ \\
\hline 2 & $3.82 \mathrm{E}-32$ & $3.53 E-32$ & 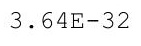 & 2 & 2 & 2 & 32 \\
\hline 32 & 2 & ? & 2 & & & & 32 \\
\hline $38 E-32$ & $3.89 E-32$ & $3.58 E-32$ & -32 & 3 . & 2 & -32 & -32 \\
\hline $37 E-32$ & $3.92 E-32$ & $3.01 \mathrm{~L}$ & & 2 & & & \\
\hline 32 & & & & & & & $\cdot 94 \mathrm{E}-32$ \\
\hline $.36 E-32$ & $3.99 E-32$ & $3.67 E-32$ & $3.19 E-32$ & $3.94 \mathrm{E}-32$ & $3.96 E-32$ & $3.97 E-32$ & $3.98 E-32$ \\
\hline $36 \mathrm{E}-32$ & $4.03 E-32$ & . & & (.) & 3.925 & $4.00 E-32$ & $4.01 \mathrm{E}-32$ \\
\hline $6 E-32$ & $E-32$ & $3 E-32$ & $.85 E-32$ & $.01 E-32$ & $.03 E-32$ & $E-32$ & $E-32$ \\
\hline
\end{tabular}


RESRAD-OFFSITE, Version 2.5

$\mathrm{T}^{1 / 2}$ Limit $=180$ days

Title : Offsite Resident Farmer Deterministic Run

File : RF TC99 DOESG FWD-FV2b.ROF

Summary of dose at graphical times, reptition 2 (continued)

Time

Years

$4.72 \mathrm{E}+01$

$4.77 \mathrm{E}+01$

4. $82 \mathrm{E}+01$

$4.87 \mathrm{E}+01$

4. $92 \mathrm{E}+01$

4. $97 \mathrm{E}+01$

$5.02 \mathrm{E}+01$

$5.08 \mathrm{E}+01$

$5.13 \mathrm{E}+01$

$5.18 \mathrm{E}+01$

$5.23 \mathrm{E}+01$

$5.28 \mathrm{E}+01$

$5.33 \mathrm{E}+01$

$5.38 \mathrm{E}+01$

$5.43 \mathrm{E}+01$

$5.49 \mathrm{E}+01$

$5.54 \mathrm{E}+01$

$5.59 \mathrm{E}+01$

$5.64 \mathrm{E}+01$

$5.69 \mathrm{E}+01$

$5.74 \mathrm{E}+01$

$5.79 \mathrm{E}+01$

$5.84 \mathrm{E}+01$

$5.90 \mathrm{E}+01$

$5.95 \mathrm{E}+01$

$6.00 \mathrm{E}+01$

$6.05 \mathrm{E}+01$

$6.10 \mathrm{E}+01$

$6.15 \mathrm{E}+01$

$6.20 \mathrm{E}+01$

$6.25 \mathrm{E}+01$

$6.31 \mathrm{E}+01$

$6.36 \mathrm{E}+01$

$6.41 \mathrm{E}+01$

$6.46 \mathrm{E}+01$

$6.51 \mathrm{E}+01$

$6.56 \mathrm{E}+01$

$6.61 \mathrm{E}+01$

$6.67 \mathrm{E}+01$

$6.72 \mathrm{E}+01$

$6.77 \mathrm{E}+01$

$6.82 \mathrm{E}+01$

$6.87 \mathrm{E}+01$

$6.92 \mathrm{E}+01$

$6.97 \mathrm{E}+01$

$7.02 \mathrm{E}+01$
Dose statistics at graphical times, mrem/yr

\begin{tabular}{|c|c|c|c|c|c|c|c|}
\hline inimum & laximum & lean & edic & & & & \\
\hline $35 E-32$ & $4.10 \mathrm{E}-32$ & $6 E-32$ & $89 E-32$ & $4 E-32$ & $6 E-32$ & $07 E-32$ & -32 \\
\hline $35 E-32$ & $4.13 E-32$ & $3.79 E-32$ & $92 E-32$ & $4.08 E-32$ & $4.10 \mathrm{E}-32$ & -32 & $4.12 E-32$ \\
\hline $4 E-32$ & $17 E-32$ & $82 E-32$ & $95 E-32$ & $11 E-32$ & $13 E-32$ & $5 E-32$ & 32 \\
\hline $34 \mathrm{E}-32$ & $4 \cdot 21 E-32$ & $85 E-32$ & $.98 E-32$ & $.15 E-32$ & $4.17 E-32$ & -32 & -32 \\
\hline $33 E-32$ & 32 & -32 & & & & & -32 \\
\hline $33 E-32$ & $4 \cdot 28 E-32$ & $1 E-32$ & $5 E-32$ & 32 & 32 & -32 & -32 \\
\hline $33 E-32$ & $4.32 E-32$ & $4+52$ & -32 & $4.26 E-32$ & $4.28 E-32$ & $E-32$ & $.30 E-32$ \\
\hline $32 E-32$ & $4 \cdot 36 E-32$ & $97 E-32$ & $2 E-32$ & $4 \cdot 30 \mathrm{E}-32$ & $32 E-32$ & -32 & $.34 E-32$ \\
\hline $32 E-32$ & 32 & $01 F-32$ & $15 E-32$ & $33 E-32$ & $36 E-32$ & $.37 E-32$ & $38 E-32$ \\
\hline $1 E-32$ & 32 & $4.04 \mathrm{E}-32$ & 2 & 32 & 2 & 32 & 32 \\
\hline $31 E-32$ & $E-32$ & $7 F-32$ & 2 & -32 & 32 & -32 & $6 E-32$ \\
\hline $31 E-32$ & & & & & & & -32 \\
\hline $30 E-32$ & $4.56 E-32$ & $4.14 E-32$ & $4.29 E-32$ & $4.49 E-32$ & $4.51 E-32$ & $3 E-32$ & $.54 E-32$ \\
\hline-32 & -32 & -32 & & & & -32 & $E-32$ \\
\hline 2 & & & 2 & 6 & 2 & 2 & -32 \\
\hline 32 & 4 & $4.24 \mathrm{E}-32$ & 2 & 2 & 2 & 2 & 32 \\
\hline $29 E-32$ & 32 & 2 & 2 & 2 & 2 & 2 & -32 \\
\hline $28 E-32$ & $4.76 E-32$ & $0 E-32$ & $7 E-32$ & $9 E-32$ & 2 & -32 & $4 E-32$ \\
\hline $28 E-32$ & $80 \mathrm{E}-32$ & $34 E-32$ & $4.51 \mathrm{E}-32$ & $4.73 E-32$ & $4.75 E-32$ & -32 & 4. $78 E-32$ \\
\hline $27 E-32$ & 4.8 & -32 & -32 & -32 & & -32 & $82 E-32$ \\
\hline 2 & & & & & & & \\
\hline & & & & & & & 32 \\
\hline $26 \mathrm{E}-32$ & 32 & 32 & 2 & 2 & 2 & 32 & -32 \\
\hline $6 E-32$ & $.02 E-32$ & $1 E-32$ & $E-32$ & $4 E-32$ & 965 & -32 & $00 E-32$ \\
\hline $25 E-32$ & $.06 \mathrm{E}-32$ & $5 E-32$ & $4.73 E-32$ & $98 E-32$ & $01 \mathrm{E}-32$ & $E-32$ & $04 \mathrm{E}-32$ \\
\hline-32 & 32 & & & -32 & & -32 & $8 E-32$ \\
\hline-32 & & & & & & & \\
\hline & & & & & & & \\
\hline $24 \mathrm{E}-32$ & $5.25 E-32$ & $4.70 E-32$ & $4.89 E-32$ & $5.15 \mathrm{E}-32$ & $5.18 \mathrm{E}-32$ & $5.20 \mathrm{E}-32$ & $.22 E-32$ \\
\hline 32 & 2 & 20. & $4.93 E-32$ & 2 & . & $5 E-32$ & $.27 E-32$ \\
\hline 2 & 2 & $.77 \mathrm{E}-$ & $.97 \mathrm{E}-3$ & & & $5.30 \mathrm{E}-32$ & $.31 E-32$ \\
\hline$F-32$ & $39 F-32$ & $81 F-32$ & $2 E-32$ & $29 E-32$ & 325 & $E-32$ & $36 E-32$ \\
\hline 32 & & & & & & & 32 \\
\hline 32 & & & 32 & -32 & & -32 & \\
\hline $21 \mathrm{E}-32$ & $5.53 E-32$ & $4.93 E-32$ & $5.14 \mathrm{E}-32$ & $5.43 E-32$ & $5.46 \mathrm{E}-32$ & $5.49 E-32$ & $.50 E-32$ \\
\hline $21 E-32$ & $3.30 \pm-32$ & & & $5.48 E-32$ & $.51 E-32$ & $.53 E-32$ & $.55 E-32$ \\
\hline 2 & 2 & $1 E-32$ & 2 & 2 & 2 & 2 & 32 \\
\hline 2 & 2 & 2 & ? & 2 & & 2 & 32 \\
\hline 2 & 2 & & & 2 & & 2 & \\
\hline$E-32$ & $E-32$ & -32 & -32 & -32 & -32 & -32 & 32 \\
\hline $19 \mathrm{E}-32$ & .035 & 2 & & & 2 & & -32 \\
\hline 32 & $3.88 E-32$ & & & & & & $.85 E-32$ \\
\hline $10 \pm-32$ & $3.93 E-32$ & 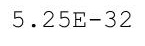 & $9 E-32$ & $5.82 E-32$ & $86 E-32$ & $38 E-32$ & $90 E-32$ \\
\hline $18 E-32$ & & & & & & $3 E-32$ & $95 E-32$ \\
\hline 2 & & & & -32 & $5.96 \mathrm{E}-32$ & $5.99 E-32$ & $5.01 E-32$ \\
\hline-32 & -32 & $E-32$ & $E-32$ & -32 & $5.01 E-32$ & $.04 E-32$ & -32 \\
\hline
\end{tabular}


RESRAD-OFFSITE, Version 2.5

itle : Offsite Resident Farmer Deterministic Run

File : RF TC99 DOESG FWD-FV2b.ROF

Summary of dose at graphical times, reptition 2 (continued)

Time

Years

7. $08 \mathrm{E}+01$

7. $13 \mathrm{E}+01$

7. $18 \mathrm{E}+01$

7. $23 \mathrm{E}+01$

7. $28 \mathrm{E}+01$

7. $33 \mathrm{E}+01$

7. $38 \mathrm{E}+01$

7. $43 \mathrm{E}+01$

7. $49 \mathrm{E}+01$

7. $54 \mathrm{E}+01$

7. $59 \mathrm{E}+01$

7. $64 \mathrm{E}+01$

7. $69 \mathrm{E}+01$

7. $74 \mathrm{E}+01$

$7.79 \mathrm{E}+01$

7. $84 \mathrm{E}+01$

7. $90 \mathrm{E}+01$

7. $95 \mathrm{E}+01$

8. $00 \mathrm{E}+01$

$8.05 \mathrm{E}+01$

$8.10 \mathrm{E}+01$

$8.15 \mathrm{E}+01$

8. $20 \mathrm{E}+01$

8. $25 \mathrm{E}+01$

8. $31 \mathrm{E}+01$

8. $36 \mathrm{E}+01$

8. $41 \mathrm{E}+01$

8. $46 \mathrm{E}+01$

8. $51 \mathrm{E}+01$

8. $56 \mathrm{E}+01$

8. $61 \mathrm{E}+01$

8. $66 \mathrm{E}+01$

$8.72 \mathrm{E}+01$

$8.77 \mathrm{E}+01$

$8.82 \mathrm{E}+01$

$8.87 \mathrm{E}+01$

$8.92 \mathrm{E}+01$

8. $97 \mathrm{E}+01$

9. $02 \mathrm{E}+01$

$9.07 \mathrm{E}+01$

$9.13 \mathrm{E}+01$

$9.18 \mathrm{E}+01$

9. $23 \mathrm{E}+01$

$9.28 \mathrm{E}+01$

$9.33 \mathrm{E}+01$

9. $38 \mathrm{E}+01$
Dose statistics at graphical times, mrem/yr

\begin{tabular}{|c|c|c|c|c|c|c|c|}
\hline $\mathrm{m}$ & aximum & lea & - & & & & \\
\hline $17 \mathrm{E}-32$ & $6.15 \mathrm{E}-32$ & $5.42 E-32$ & $5.68 E-32$ & $6.02 \mathrm{E}-32$ & $6.07 \mathrm{E}-32$ & $6.09 E-32$ & $-2-32$ \\
\hline $17 \mathrm{E}-32$ & $6.20 E-32$ & $7 E-32$ & $5.72 E-32$ & $8 E-32$ & $12 E-32$ & $E-32$ & $7 E-32$ \\
\hline $16 \mathrm{E}-32$ & $6.26 \mathrm{E}-32$ & $5.51 \mathrm{E}-32$ & $5.77 \mathrm{E}-32$ & $6.13 E-32$ & $6.17 E-32$ & -32 & $6.22 E-32$ \\
\hline-32 & $31 E-32$ & $55 F-32$ & $82 E-32$ & $18 \mathrm{E}-32$ & $23 F-32$ & -32 & $28 F-32$ \\
\hline-32 & $37 E-32$ & 32 & -32 & -32 & 2 & -32 & $33 E-32$ \\
\hline-32 & 32 & & & & & & \\
\hline $15 \mathrm{E}-32$ & $6.48 E-32$ & & $5.96 \mathrm{E}-32$ & $6.35 E-32$ & & & -32 \\
\hline $.14 \mathrm{E}-32$ & -32 & 2 & -32 & $40 E-32$ & 32 & -32 & -32 \\
\hline $14 \mathrm{E}-32$ & $6.60 \mathrm{E}-32$ & $5.78 E-32$ & $6.06 \mathrm{E}-32$ & $6.46 \mathrm{E}-32$ & $E-32$ & -32 & $E-32$ \\
\hline 32 & $65 E-32$ & תבק0 & $1 E-32$ & 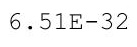 & 2 & 2 & 2 \\
\hline 32 & -32 & & & & & & 32 \\
\hline $13 E-32$ & $6.77 E-32$ & $592 \mathrm{~F}-32$ & $E-32$ & $3 E-32$ & 2 & 32 & -32 \\
\hline $13 E-32$ & $6.83 E-32$ & $5.97 E-32$ & $6.26 \mathrm{E}-32$ & $6.68 E-32$ & $6.73 E-32$ & $6.77 E-32$ & $6.79 \mathrm{E}-32$ \\
\hline $12 \mathrm{E}-32$ & $6.89 E-32$ & $6.02 \mathrm{E}-32$ & $6.32 \mathrm{E}-32$ & & 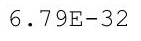 & 32 & $E-32$ \\
\hline $12 \mathrm{E}-32$ & -32 & 2 & -32 & 32 & & -32 & -32 \\
\hline 32 & 32 & & $E-32$ & 2 & (2) & 32 & 32 \\
\hline 32 & & & & & & & \\
\hline $11 \mathrm{E}-32$ & 32 & $6.21 E-32$ & 2 & 2 & 2 & 2 & 32 \\
\hline $11 E-32$ & $20 E-32$ & $26 \mathrm{~F}-32$ & $8 E-32$ & $\Delta F-$ & ק0 & $E-32$ & $16 E-32$ \\
\hline $10 \mathrm{E}-32$ & $7.27 \mathrm{E}-32$ & $.31 E-32$ & $6.64 \mathrm{E}-32$ & $0 E-32$ & $7.16 \mathrm{E}$ & -32 & $22 E-32$ \\
\hline 32 & -32 & & & & & -32 & $E-32$ \\
\hline 32 & -32 & & -32 & & & -32 & -32 \\
\hline 2 & & & & & & & \\
\hline 2 & 2 & & 2 & 2 & & & \\
\hline$E-32$ & -32 & & 2 & 2 & 2 & 2 & 32 \\
\hline$E-32$ & $66 \mathrm{E}-32$ & $62 E-32$ & $97 E-32$ & $.48 \mathrm{E}-3$ & 505 & $58 E-32$ & $.61 E-32$ \\
\hline$E-32$ & $7.73 E-32$ & & $3 E-32$ & $55 E-32$ & & $E-32$ & $68 E-32$ \\
\hline & & & & & & & \\
\hline 32 & & & & & & -32 & 32 \\
\hline $07 E-32$ & $7.94 \mathrm{E}-32$ & $0.04 \amalg-2$ & $7.21 E-32$ & $7.75 E-32$ & • & $7.85 E-32$ & $.88 E-32$ \\
\hline $7 E-32$ & -32 & . & $.27 E-32$ & 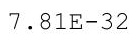 & - & $5-32$ & $95 E-32$ \\
\hline 年 & $08 E-32$ & & 7. $33 E-32$ & & & & \\
\hline-32 & $E-32$ & $E-32$ & $E-32$ & $95 E-32$ & ברטל & -32 & $9 E-32$ \\
\hline 32 & & & & & & & \\
\hline-32 & & & & & & -32 & \\
\hline $05 E-32$ & $8.37 E-32$ & ・ & $7.57 \mathrm{E}-32$ & $8.16 \mathrm{E}-32$ & 20 & -32 & $E-32$ \\
\hline $05 E-32$ & $8.44 E-32$ & & & $8 \cdot 23 E-32$ & & & $8.38 \pm-32$ \\
\hline$E-32$ & $8.52 \mathrm{E}-32$ & . & . & . & & & $46 E-32$ \\
\hline 2 & $8.59 E-32$ & 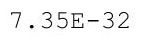 & ( & 2 & 2 & 2 & 32 \\
\hline 32 & 8 & & & & 2 & & 32 \\
\hline $3 E-32$ & $8.74 E-32$ & $7.47 E-32$ & $E-32$ & $8.52 \mathrm{E}$ & & -32 & -32 \\
\hline 32 & $8.8 \angle \mathrm{E}$ & 7.5 & & 2 & & & 32 \\
\hline & & & & & & & $.84 \mathrm{E}-32$ \\
\hline $0<E-32$ & $8.98 \pm-32$ & $7.65 E-32$ & $8.09 E-32$ & $8.74 \mathrm{E}-32$ & $8.8< \pm-32$ & $8.87 E-32$ & $8.91 \mathrm{E}-32$ \\
\hline $02 E-32$ & $9.06 \mathrm{E}-32$ & . & $8.15 E-32$ & $.0<\square$ & . & $8.95 E-32$ & 0.0 \\
\hline $2 E-32$ & $E-32$ & $E-32$ & $22 \mathrm{E}-32$ & $.90 E-32$ & $.98 E-32$ & $9.03 E-32$ & -32 \\
\hline
\end{tabular}


RESRAD-OFFSITE, Version 2.5

itle : Offsite Resident Farmer Deterministic Run

File : RF TC99 DOESG FWD-FV2b.ROF

Summary of dose at graphical times, reptition 2 (continued)

Time

Years

9. $43 \mathrm{E}+01$

9. $48 \mathrm{E}+01$

9. $54 \mathrm{E}+01$

9. $59 \mathrm{E}+01$

9. $64 \mathrm{E}+01$

9. $69 \mathrm{E}+01$

9. $74 \mathrm{E}+01$

9. $79 \mathrm{E}+01$

9. $84 \mathrm{E}+01$

9. $90 \mathrm{E}+01$

9. $95 \mathrm{E}+01$

1. $00 \mathrm{E}+02$

1. $00 \mathrm{E}+02$

1. $01 \mathrm{E}+02$

1. $02 \mathrm{E}+02$

1. $02 \mathrm{E}+02$

1. $03 \mathrm{E}+02$

$1.03 \mathrm{E}+02$

1. $04 \mathrm{E}+02$

1. $04 \mathrm{E}+02$

$1.05 \mathrm{E}+02$

1. $05 \mathrm{E}+02$

$1.06 \mathrm{E}+02$

$1.06 \mathrm{E}+02$

$1.07 \mathrm{E}+02$

1. $07 \mathrm{E}+02$

$1.08 \mathrm{E}+02$

$1.08 \mathrm{E}+02$

1. $09 \mathrm{E}+02$

1. $09 \mathrm{E}+02$

1. $10 \mathrm{E}+02$

1. $10 \mathrm{E}+02$

1. $11 \mathrm{E}+02$

1. $11 \mathrm{E}+02$

1. $12 \mathrm{E}+02$

1. $12 \mathrm{E}+02$

1. $13 \mathrm{E}+02$

1. $13 \mathrm{E}+02$

1. $14 \mathrm{E}+02$

1. $14 \mathrm{E}+02$

1. $15 \mathrm{E}+02$

1. $15 \mathrm{E}+02$

$1.16 \mathrm{E}+02$

$1.16 \mathrm{E}+02$

1. $17 \mathrm{E}+02$

1. $17 \mathrm{E}+02$

Dose statistics at graphical times, mrem/yr

\begin{tabular}{|c|c|c|c|c|c|c|c|}
\hline m & um & a & 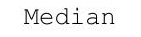 & $90 \%$ & & $\%$ & \\
\hline $01 \mathrm{E}-32$ & $9.22 \mathrm{E}-32$ & $7.84 \mathrm{E}-32$ & $8.29 E-32$ & $8.97 E-32$ & $9.06 \mathrm{E}-32$ & -32 & $-2-32$ \\
\hline $01 E-32$ & $9.30 E-32$ & $7.90 E-32$ & $8.36 \mathrm{E}-32$ & $9.05 E-32$ & $9.14 \mathrm{E}-32$ & $9.19 \mathrm{E}-32$ & $3 E-32$ \\
\hline $.01 E-32$ & $9.38 \mathrm{E}-32$ & $7.96 \mathrm{E}-32$ & $8.43 E-32$ & $9.13 \mathrm{E}-32$ & $9.22 \mathrm{E}-32$ & $9.27 \mathrm{E}-32$ & $9.31 E-32$ \\
\hline $.00 \mathrm{E}-32$ & $9.47 E-32$ & $8.03 E-32$ & $8.50 \mathrm{E}-32$ & $9.21 \mathrm{E}-32$ & $9.30 \mathrm{E}-32$ & $5 E-32$ & -32 \\
\hline $.00 \mathrm{E}$ & 32 & $9 \mathrm{E}-32$ & $57 E-32$ & -32 & -32 & 32 & 32 \\
\hline$E-33$ & -32 & -32 & -32 & 2 & 32 & -32 & -32 \\
\hline $95 E-33$ & 32 & & & -32 & & 32 & -32 \\
\hline $91 E-33$ & 32 & & & & & & -32 \\
\hline $88 E-33$ & -32 & 2 & -32 & 32 & 32 & -32 & -32 \\
\hline $85 E-33$ & -32 & - & 32 & 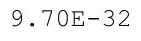 & 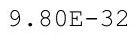 & 2 & -32 \\
\hline 33 & 1 & $E-32$ & $0 E-32$ & $79 E-32$ & ? & 2 & 32 \\
\hline 33 & & & & & & & -31 \\
\hline $5 E-33$ & $1.02 \mathrm{E}-31$ & $8.63 E-32$ & 2 & 2 & 1 & 1 & -31 \\
\hline $.73 E-33$ & $1.03 E-31$ & $8.70 \mathrm{E}-32$ & $9.23 \mathrm{E}-32$ & $1.00 \mathrm{E}-31$ & 31 & -31 & -31 \\
\hline-33 & 31 & 2 & 2 & 1 & $\perp$ & -31 & -31 \\
\hline $67 E-33$ & & & & $\perp$ & $\perp$ & -31 & -31 \\
\hline 33 & 31 & $8.91 E-32$ & 2 & $1.03 E-31$ & 1 & 1 & 31 \\
\hline 3 & & & & & & & \\
\hline $58 E-33$ & $.08 E-31$ & & 2 & 1 & 1 & 1 & 31 \\
\hline $55 E-33$ & L.09E-31 & $E-3$ & $9 E-32$ & $1.06 \mathrm{E}-31$ & $1.07 \mathrm{E}-31$ & $1.08 \mathrm{E}-31$ & $.08 \mathrm{E}-31$ \\
\hline $52 E-33$ & $1.10 \mathrm{E}-31$ & $9.20 \mathrm{E}-32$ & $9.77 \mathrm{E}-32$ & $1.07 E-31$ & & $1.09 E-31$ & $1.09 \mathrm{E}-31$ \\
\hline & & & & & & $E-31$ & -31 \\
\hline & & & & & & & \\
\hline & & & & & & & \\
\hline 3 & 1 & $=$ & 1 & 1 & 1 & 31 & 31 \\
\hline-33 & 1 & 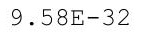 & 1 & 17 & 1 & $E-31$ & 31 \\
\hline-33 & -31 & $9.65 E-32$ & -31 & 110 & 110 & $E-31$ & $.15 E-31$ \\
\hline-33 & -31 & -32 & & 1 & 1 & -31 & $16 E-31$ \\
\hline & & & & & & & \\
\hline ת & & & & & 1 & & \\
\hline $23 E-33$ & $8.62 \mathrm{E}-27$ & •. & $1.06 \mathrm{E}-31$ & $1.16 \mathrm{E}-31$ & $1.18 \mathrm{E}-31$ & $1.19 \mathrm{E}-31$ & L. $19 \mathrm{E}-31$ \\
\hline . & $4.59 E-25$ & . & (- & म. & 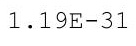 & 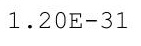 & $1.20 \mathrm{E}-31$ \\
\hline - & & & & & & & $1.21 \mathrm{E}-31$ \\
\hline-33 & $F-22$ & ת ת & $E-31$ & & & -31 & $1.22 E-31$ \\
\hline 33 & 1 & & & & & & 31 \\
\hline 33 & 20 & $.88 \mathrm{E}-24$ & $.11 \mathrm{E}-31$ & $1.2 \angle \omega$ & $1 \cdot 20$ & 31 & -31 \\
\hline $06 \mathrm{E}-33$ & $0.46 E-20$ & (. & $+\infty$ & t. & ${ }^{\perp}$ & $\perp$ & -31 \\
\hline $03 E-33$ & & & & $1.24 \mathrm{E}-31$ & 1. $25 \mathrm{E}-31$ & & $1.27 \mathrm{E}-31$ \\
\hline 3 & I & . & 1 & 1 & 1 & 1 & 31 \\
\hline & & & & & & & 31 \\
\hline 3 & & & & 1 & & 31 & \\
\hline $1 E-33$ & $3.21 \mathrm{E}-17$ & $2.90 \mathrm{E}-2$ & 31 & 1.28 & 1.3 & 31 & 1.31 \\
\hline & & & & & & & \pm \\
\hline & & & & 土. & $1.3 \angle \mathrm{E}-$ & & $\perp \cdot 0+\Delta$ \\
\hline & 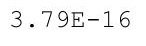 & 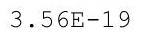 & & $1.3 \angle E-31$ & 1.305 & $E-31$ & $+.00 \pi$ a \\
\hline$E-33$ & $55 E-16$ & $6 E-19$ & $20 E-31$ & $33 E-31$ & $E-31$ & $5 E-31$ & 1.3 \\
\hline
\end{tabular}


RESRAD-OFFSITE, Version 2.5

$\mathrm{T}^{1 / 2}$ Limit $=180$ days

robabilistic Dose and Risk Report

Title : Offsite Resident Farmer Deterministic Run

File : RF TC99 DOESG FWD-FV2b.ROF

Summary of dose at graphical times, reptition 2 (continued)

Time

Years

$1.18 \mathrm{E}+02$

$1.18 \mathrm{E}+02$

1. $19 \mathrm{E}+02$

1. $19 \mathrm{E}+02$

1. $20 \mathrm{E}+02$

1. $20 \mathrm{E}+02$

1. $21 \mathrm{E}+02$

1. $22 \mathrm{E}+02$

1. $22 \mathrm{E}+02$

1. $23 \mathrm{E}+02$

1. $23 \mathrm{E}+02$

1. $24 \mathrm{E}+02$

1. $24 \mathrm{E}+02$

1. $25 \mathrm{E}+02$

1. $25 \mathrm{E}+02$

1. $26 \mathrm{E}+02$

1. $26 \mathrm{E}+02$

1. $27 \mathrm{E}+02$

1. $27 \mathrm{E}+02$

1. $28 \mathrm{E}+02$

1. $28 \mathrm{E}+02$

1. $29 \mathrm{E}+02$

1. $29 \mathrm{E}+02$

1. $30 \mathrm{E}+02$

1. $30 \mathrm{E}+02$

1. $31 \mathrm{E}+02$

1. $31 \mathrm{E}+02$

1. $32 \mathrm{E}+02$

1. $32 \mathrm{E}+02$

1. $33 \mathrm{E}+02$

1. $33 \mathrm{E}+02$

1. $34 \mathrm{E}+02$

1. $34 \mathrm{E}+02$

1. $35 \mathrm{E}+02$

1. $35 \mathrm{E}+02$

1. $36 \mathrm{E}+02$

1. $36 \mathrm{E}+02$

1. $37 \mathrm{E}+02$

1. $37 \mathrm{E}+02$

1. $38 \mathrm{E}+02$

1. $38 \mathrm{E}+02$

1. $39 \mathrm{E}+02$

1. $39 \mathrm{E}+02$

1. $40 \mathrm{E}+02$

1. $40 \mathrm{E}+02$

1. $41 \mathrm{E}+02$

Dose statistics at graphical times, mrem/yr

\begin{tabular}{|c|c|c|c|c|c|c|c|}
\hline Minimum & Maximum & Mean & Median & $90 \%$ & $95 \%$ & $97.5 \%$ & $99 \%$ \\
\hline $8.78 E-33$ & $1.43 E-15$ & $1.36 \mathrm{E}-18$ & $1.21 E-31$ & $1.34 E-31$ & $1.35 E-31$ & $1.36 E-31$ & 1. $37 E-31$ \\
\hline $8.75 E-33$ & $2.58 E-15$ & $2.48 E-18$ & 1. $22 \mathrm{E}-31$ & $1.35 E-31$ & $1.37 E-31$ & $1.38 E-31$ & 1. $39 \mathrm{E}-31$ \\
\hline $8.72 E-33$ & $4.48 E-15$ & 4. $32 \mathrm{E}-18$ & $1.23 E-31$ & 1. $36 \mathrm{E}-31$ & 1. $38 \mathrm{E}-31$ & 1. $39 \mathrm{E}-31$ & 1. $40 \mathrm{E}-31$ \\
\hline $8.69 \mathrm{E}-33$ & $7.50 \mathrm{E}-15$ & $7.27 \mathrm{E}-18$ & $1.24 \mathrm{E}-31$ & $1.37 \mathrm{E}-31$ & $1.39 \mathrm{E}-31$ & $1.40 \mathrm{E}-31$ & $1.41 \mathrm{E}-31$ \\
\hline $8.67 E-33$ & $1.22 \mathrm{E}-14$ & $1.18 \mathrm{E}-17$ & $1.25 \mathrm{E}-31$ & $39 E-31$ & $40 E-31$ & $1.41 \mathrm{E}-31$ & $.42 E-31$ \\
\hline $8.64 E-33$ & $1.91 \mathrm{E}-14$ & $1.87 \mathrm{E}-17$ & $1.26 \mathrm{E}-31$ & $40 E-31$ & $41 E-31$ & $43 E-31$ & $.44 E-31$ \\
\hline $8.61 \mathrm{E}-33$ & $2.93 E-14$ & $2.88 E-17$ & $1.27 \mathrm{E}-31$ & $1.41 \mathrm{E}-31$ & $1.43 E-31$ & $1.44 \mathrm{E}-31$ & $1.45 \mathrm{E}-31$ \\
\hline $8.59 E-33$ & $4.39 E-14$ & $4.34 \mathrm{E}-17$ & $1.28 \mathrm{E}-31$ & $1.42 E-31$ & $1.44 \mathrm{E}-31$ & $1.45 E-31$ & $1.46 \mathrm{E}-31$ \\
\hline $8.56 \mathrm{E}-33$ & $6.44 \mathrm{E}-14$ & $6.41 \mathrm{E}-17$ & $1.29 \mathrm{E}-31$ & $1.44 \mathrm{E}-31$ & 1. $45 \mathrm{E}-31$ & $1.46 \mathrm{E}-31$ & 1. $48 E-31$ \\
\hline $8.53 E-33$ & $9.24 \mathrm{E}-14$ & $9.29 \mathrm{E}-17$ & $1.31 \mathrm{E}-31$ & 1. $45 E-31$ & $1.46 \mathrm{E}-31$ & $1.48 E-31$ & 1. $49 \mathrm{E}-31$ \\
\hline $8.51 \mathrm{E}-33$ & 1. $30 \mathrm{E}-13$ & $1.32 \mathrm{E}-16$ & 1. $32 \mathrm{E}-31$ & $46 E-31$ & $48 E-31$ & $49 \mathrm{E}-31$ & $.51 E-31$ \\
\hline $8.48 E-33$ & $1.81 \mathrm{E}-13$ & $1.86 \mathrm{E}-16$ & $1.33 \mathrm{E}-31$ & $1.47 E-31$ & $1.49 \mathrm{E}-31$ & $.50 E-31$ & 1. $52 \mathrm{E}-31$ \\
\hline $8.45 E-33$ & $2.47 E-13$ & $2.58 \mathrm{E}-16$ & $1.34 \mathrm{E}-31$ & $1.49 E-31$ & $1.50 \mathrm{E}-31$ & $1.52 \mathrm{E}-31$ & $1.53 \mathrm{E}-31$ \\
\hline $8.43 E-33$ & 3. $32 \mathrm{E}-13$ & $3.53 \mathrm{E}-16$ & 1. $35 \mathrm{E}-31$ & $1.50 \mathrm{E}-31$ & $1.52 \mathrm{E}-31$ & $1.53 E-31$ & 1. $55 \mathrm{E}-31$ \\
\hline $8.40 \mathrm{E}-33$ & $4.41 E-13$ & 4. $78 \mathrm{E}-16$ & $1.36 \mathrm{E}-31$ & $.51 E-31$ & $.53 E-31$ & 1. $55 \mathrm{E}-31$ & 1. $56 \mathrm{E}-31$ \\
\hline $8.37 E-33$ & $5.78 E-13$ & $41 E-16$ & $37 E-31$ & $3 E-31$ & $54 E-31$ & $.56 E-31$ & $.61 E-29$ \\
\hline $8.35 E-33$ & 7. $48 E-13$ & $8.51 \mathrm{E}-16$ & $39 E-31$ & $54 \mathrm{E}-31$ & $56 E-31$ & -31 & 4. $32 \mathrm{E}-27$ \\
\hline $8.32 E-33$ & $9.59 E-13$ & $1.12 \mathrm{E}-15$ & $1.40 \mathrm{E}-31$ & $1.55 \mathrm{E}-31$ & $1.57 \mathrm{E}-31$ & $.59 E-31$ & $2.89 E-25$ \\
\hline $8.30 E-33$ & $1.22 \mathrm{E}-12$ & $1.46 \mathrm{E}-15$ & $1.41 \mathrm{E}-31$ & $1.57 \mathrm{E}-31$ & $1.59 \mathrm{E}-31$ & $1.60 \mathrm{E}-31$ & $7.90 \mathrm{E}-24$ \\
\hline $8.27 E-33$ & $1.53 \mathrm{E}-12$ & $1.89 \mathrm{E}-15$ & $1.42 \mathrm{E}-31$ & 1. $58 \mathrm{E}-31$ & $1.60 \mathrm{E}-31$ & $1.62 \mathrm{E}-31$ & 1. $24 \mathrm{E}-22$ \\
\hline $8.24 E-33$ & $1.90 E-12$ & $2.43 E-15$ & $1.43 \mathrm{E}-31$ & $1.59 \mathrm{E}-31$ & $1.61 \mathrm{E}-31$ & $1.63 E-31$ & 1. $31 \mathrm{E}-21$ \\
\hline $8.22 E-33$ & $2.35 E-12$ & $3.10 E-15$ & $1.44 \mathrm{E}-31$ & $61 E-31$ & $1.63 E-31$ & $.65 E-31$ & $1.01 \mathrm{E}-20$ \\
\hline $8.19 \mathrm{E}-33$ & $2.87 E-12$ & $3.93 E-15$ & $1.46 \mathrm{E}-31$ & $1.62 \mathrm{E}-31$ & $1.64 \mathrm{E}-31$ & $1.66 \mathrm{E}-31$ & $6.11 E-20$ \\
\hline $8.17 \mathrm{E}-33$ & $3.49 \mathrm{E}-12$ & $4.96 \mathrm{E}-15$ & $1.47 \mathrm{E}-31$ & $1.64 \mathrm{E}-31$ & $1.66 \mathrm{E}-31$ & $1.68 \mathrm{E}-31$ & $3.00 \mathrm{E}-19$ \\
\hline $8.14 \mathrm{E}-33$ & $4 \cdot 21 \mathrm{E}-12$ & $6.20 \mathrm{E}-15$ & $1.48 \mathrm{E}-31$ & $1.65 \mathrm{E}-31$ & $1.67 \mathrm{E}-31$ & $1.69 \mathrm{E}-31$ & 1. $23 \mathrm{E}-18$ \\
\hline $8.12 \mathrm{E}-33$ & $5.04 \mathrm{E}-12$ & $7.72 \mathrm{E}-15$ & $1.49 \mathrm{E}-31$ & $1.67 \mathrm{E}-31$ & $1.69 \mathrm{E}-31$ & $1.71 \mathrm{E}-31$ & $4.38 \mathrm{E}-18$ \\
\hline $8.09 \mathrm{E}-33$ & $6.00 \mathrm{E}-12$ & $9.55 \mathrm{E}-15$ & $1.50 \mathrm{E}-31$ & $1.68 \mathrm{E}-31$ & $1.70 \mathrm{E}-31$ & $1.72 \mathrm{E}-31$ & $1.37 \mathrm{E}-17$ \\
\hline $8.07 E-33$ & $7.09 \mathrm{E}-12$ & $1.17 \mathrm{E}-14$ & $1.52 \mathrm{E}-31$ & $1.70 E-31$ & $1.72 \mathrm{E}-31$ & $1.74 E-31$ & $3.83 E-17$ \\
\hline $8.04 \mathrm{E}-33$ & $8.34 \mathrm{E}-12$ & $1.44 \mathrm{E}-14$ & $1.53 E-31$ & $1.71 E-31$ & $1.73 E-31$ & $1.75 E-31$ & $9.75 E-17$ \\
\hline $8.02 E-33$ & $9.76 \mathrm{E}-12$ & $1.75 \mathrm{E}-14$ & $1.54 \mathrm{E}-31$ & $1.73 E-31$ & $1.75 E-31$ & $1.77 E-31$ & $2.29 E-16$ \\
\hline $7.99 \mathrm{E}-33$ & $1.14 \mathrm{E}-11$ & $2.11 \mathrm{E}-14$ & $1.56 \mathrm{E}-31$ & $1.74 \mathrm{E}-31$ & $1.77 \mathrm{E}-31$ & $1.79 \mathrm{E}-31$ & $4.99 \mathrm{E}-16$ \\
\hline $7.97 \mathrm{E}-33$ & $1.39 \mathrm{E}-11$ & $2.55 \mathrm{E}-14$ & $1.57 \mathrm{E}-31$ & $1.76 \mathrm{E}-31$ & $1.78 \mathrm{E}-31$ & $1.81 \mathrm{E}-31$ & $1.02 \mathrm{E}-15$ \\
\hline $7.94 \mathrm{E}-33$ & $1.71 \mathrm{E}-11$ & $3.05 E-14$ & $1.58 \mathrm{E}-31$ & $1.77 \mathrm{E}-31$ & $1.80 \mathrm{E}-31$ & $1.82 E-31$ & $1.86 E-15$ \\
\hline $7.92 E-33$ & $2.08 E-11$ & $3.64 \mathrm{E}-14$ & $1.60 \mathrm{E}-31$ & $1.79 E-31$ & $82 E-31$ & $1.84 \mathrm{E}-31$ & $18 E-15$ \\
\hline $7.89 \mathrm{E}-33$ & $2.53 E-11$ & $4.31 \mathrm{E}-14$ & $1.61 \mathrm{E}-31$ & $1.80 \mathrm{E}-31$ & $1.83 \mathrm{E}-31$ & $1.86 \mathrm{E}-31$ & $5.29 \mathrm{E}-15$ \\
\hline $7.87 E-33$ & $3.04 \mathrm{E}-11$ & $5.10 \mathrm{E}-14$ & $1.62 E-31$ & $1.82 \mathrm{E}-31$ & $1.85 E-31$ & $1.88 E-31$ & $8.55 E-15$ \\
\hline $7.84 \mathrm{E}-33$ & $3.64 \mathrm{E}-11$ & $5.99 \mathrm{E}-14$ & $1.64 \mathrm{E}-31$ & $1.84 \mathrm{E}-31$ & $1.86 \mathrm{E}-31$ & $1.90 \mathrm{E}-31$ & 1. $34 \mathrm{E}-14$ \\
\hline $7.82 \mathrm{E}-33$ & 4. $32 \mathrm{E}-11$ & $7.02 \mathrm{E}-14$ & $1.65 \mathrm{E}-31$ & $1.85 E-31$ & $1.88 \mathrm{E}-31$ & $1.91 \mathrm{E}-31$ & $2.06 \mathrm{E}-14$ \\
\hline $7.79 \mathrm{E}-33$ & $5.10 \mathrm{E}-11$ & $8.19 \mathrm{E}-14$ & $1.66 \mathrm{E}-31$ & $1.87 E-31$ & $1.90 \mathrm{E}-31$ & $1.93 E-31$ & $3.10 \mathrm{E}-14$ \\
\hline $7.77 \mathrm{E}-33$ & $5.98 \mathrm{E}-11$ & $9.51 \mathrm{E}-14$ & $1.68 \mathrm{E}-31$ & $1.89 \mathrm{E}-31$ & 1.92E-31 & $1.05 E-27$ & $4.57 \mathrm{E}-14$ \\
\hline $7.75 E-33$ & $6.99 \mathrm{E}-11$ & $1.10 \mathrm{E}-13$ & $1.69 \mathrm{E}-31$ & $1.90 E-31$ & $1.93 E-31$ & $1.29 \mathrm{E}-25$ & $6.60 \mathrm{E}-14$ \\
\hline $7.72 E-33$ & $8.12 \mathrm{E}-11$ & $1.27 E-13$ & $1.71 E-31$ & $1.92 E-31$ & $1.95 E-31$ & $4.42 E-24$ & $9.36 \mathrm{E}-14$ \\
\hline $7.70 \mathrm{E}-33$ & $9.38 \mathrm{E}-11$ & $1.46 \mathrm{E}-13$ & $1.72 \mathrm{E}-31$ & $1.94 \mathrm{E}-31$ & $1.97 \mathrm{E}-31$ & $7.88 \mathrm{E}-23$ & 1. $31 \mathrm{E}-13$ \\
\hline $7.67 \mathrm{E}-33$ & $1.08 E-10$ & $1.67 \mathrm{E}-13$ & $1.74 \mathrm{E}-31$ & $1.95 E-31$ & $1.99 \mathrm{E}-31$ & $9.05 E-22$ & $1.80 \mathrm{E}-13$ \\
\hline $7.65 E-33$ & 1. $24 \mathrm{E}-10$ & $1.91 E-13$ & $1.75 E-31$ & $1.97 E-31$ & $2.01 E-31$ & $7.42 E-21$ & $2.44 E-13$ \\
\hline $7.63 E-33$ & 1. $41 \mathrm{E}-10$ & $2.17 \mathrm{E}-13$ & $1.77 \mathrm{E}-31$ & $1.99 E-31$ & $2.02 E-31$ & $4.66 \mathrm{E}-20$ & $3.26 E-13$ \\
\hline
\end{tabular}


RESRAD-OFFSITE, Version 2.5

$\mathrm{T}^{1 / 2}$ Limit $=180$ days

obabilistic Dose and Risk Report

Title : Offsite Resident Farmer Deterministic Run

File : RF TC99 DOESG FWD-FV2b.ROF

Summary of dose at graphical times, reptition 2 (continued)

Time

Years

1. $42 \mathrm{E}+02$

$1.42 \mathrm{E}+02$

1. $43 \mathrm{E}+02$

1. $43 \mathrm{E}+02$

1. $44 \mathrm{E}+02$

1. $44 \mathrm{E}+02$

1. $45 \mathrm{E}+02$

1. $45 \mathrm{E}+02$

1. $46 \mathrm{E}+02$

1. $46 \mathrm{E}+02$

1. $47 \mathrm{E}+02$

1. $47 \mathrm{E}+02$

1. $48 \mathrm{E}+02$

1. $48 \mathrm{E}+02$

1. $49 \mathrm{E}+02$

1. $49 \mathrm{E}+02$

1. $50 \mathrm{E}+02$

1. $50 \mathrm{E}+02$

1. $51 \mathrm{E}+02$

1. $51 \mathrm{E}+02$

1. $52 \mathrm{E}+02$

1. $52 \mathrm{E}+02$

1. $53 \mathrm{E}+02$

1. $53 \mathrm{E}+02$

$1.54 \mathrm{E}+02$

$1.54 \mathrm{E}+02$

1. $55 \mathrm{E}+02$

1. $55 \mathrm{E}+02$

1. $56 \mathrm{E}+02$

1. $56 \mathrm{E}+02$

1. $57 \mathrm{E}+02$

1. $57 \mathrm{E}+02$

1. $58 \mathrm{E}+02$

1. $58 \mathrm{E}+02$

1. $59 \mathrm{E}+02$

1. $59 \mathrm{E}+02$

1. $60 \mathrm{E}+02$

1. $60 \mathrm{E}+02$

1. $61 \mathrm{E}+02$

1. $61 \mathrm{E}+02$

1. $62 \mathrm{E}+02$

1. $63 \mathrm{E}+02$

1. $63 \mathrm{E}+02$

$1.64 \mathrm{E}+02$

1. $64 \mathrm{E}+02$

1. $65 \mathrm{E}+02$
Dose statistics at graphical times, mrem/yr

\begin{tabular}{|c|c|c|c|c|c|c|c|}
\hline$m$ & aximum & ean & ledian & $0 \%$ & & $\%$ & $\%$ \\
\hline $60 \mathrm{E}-33$ & $1.60 \mathrm{E}-10$ & $2.46 \mathrm{E}-13$ & 1. $78 \mathrm{E}-31$ & $2.01 \mathrm{E}-31$ & $2.04 E-3 \perp$ & $2.35 E-19$ & 政 \\
\hline $58 E-33$ & 10 & 13 & -31 & 31 & 31 & 19 & -13 \\
\hline $.55 E-33$ & $2.04 \mathrm{E}-10$ & $4 E-13$ & $1.81 \mathrm{E}-31$ & $2.04 \mathrm{E}-31$ & $2.08 \mathrm{E}-31$ & -18 & $.26 \mathrm{E}-13$ \\
\hline $.53 E-33$ & $2.30 \mathrm{E}-10$ & $3.53 E-13$ & $1.83 E-31$ & $2.06 \mathrm{E}-31$ & $2.10 \mathrm{E}-31$ & -18 & $27 E-13$ \\
\hline 33 & 10 & & & -31 & & 17 & 12 \\
\hline $48 E-33$ & 10 & 3 & 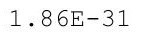 & 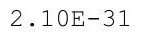 & -31 & 17 & -12 \\
\hline $46 \mathrm{E}-33$ & 10 & & & & & & -12 \\
\hline 33 & & & & & & & -12 \\
\hline-33 & 10 & -13 & \pm & 1 & 1 & -16 & -12 \\
\hline $39 E-33$ & -10 & 等 & ${ }^{\circ}$ & 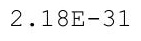 & $2.22 E-31$ & 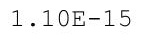 & 12 \\
\hline 33 & 4. $78 \mathrm{E}-10$ & $7.53 E-13$ & $1.94 \mathrm{E}$ & $20 E-31$ & $24 E-31$ & 年 & -12 \\
\hline 33 & 10 & & & & & & 12 \\
\hline $.32 \mathrm{E}-33$ & $5.76 \mathrm{E}-10$ & -13 & 1. & $2.24 \mathrm{E}$ & $2.29 \mathrm{E}$ & -15 & -12 \\
\hline$E-33$ & $6.30 \mathrm{E}-10$ & $1 \mathrm{E}-12$ & $E-31$ & $6 \mathrm{~F}-$ & 1 & -15 & -12 \\
\hline-33 & 10 & 2 & & $\perp$ & & & -12 \\
\hline 33 & -10 & 12 & $\perp$ & $\perp$ & $2.36 \mathrm{E}-31$ & 14 & -11 \\
\hline 33 & 10 & 2 & & $2.32 E-31$ & & & 11 \\
\hline 3 & $8.85 E-10$ & & & & & & 1 \\
\hline $.19 E-33$ & $9.59 \mathrm{E}-10$ & 1. $60 \mathrm{E}-12$ & & & 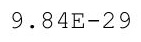 & -14 & 1. $63 \mathrm{E}-11$ \\
\hline $.16 \mathrm{E}-33$ & $.04 \mathrm{E}-09$ & $1.74 \mathrm{E}-12$ & $2.09 \mathrm{E}-31$ & $2.38 E-31$ & $2.42 \mathrm{E}-2$ & $E-14$ & $.85 E-11$ \\
\hline $.14 \mathrm{E}-33$ & $1.12 \mathrm{E}-09$ & 1. $90 \mathrm{E}-12$ & $2.11 E-31$ & $2.40 E-31$ & $1.51 \mathrm{E}-$ & -13 & $2.12 \mathrm{E}-11$ \\
\hline 33 & 09 & $8 \pi$ & $2.13 E-31$ & $\perp$ & & & $.47 E-11$ \\
\hline 3 & 9 & & & & & & \\
\hline $07 E-33$ & 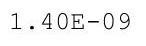 & $\perp 2$ & & & & & 11 \\
\hline 3 & 9 & $=$ & $\perp$ & $\perp$ & 4. $25 \mathrm{E}-20$ & 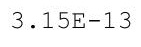 & 11 \\
\hline $03 E-33$ & $.61 E-09$ & $.85 E-12$ & $2.20 E-31$ & 2 & ה7 27 & -13 & 11 \\
\hline-33 & 1.731 & $3.08 E-12$ & $2.22 E-31$ & $.54 \mathrm{E}-$ & ק & $E-13$ & $.96 E-11$ \\
\hline-33 & 09 & 12 & & $\perp$ & & -13 & $70 E-11$ \\
\hline & 09 & 2 & & & & & 11 \\
\hline $94 E-33$ & $2.10 E-09$ & $3.00 E-12$ & 2.200 & $2 \cdot 01$ & 2.0 & 12 & $05 E-11$ \\
\hline $92 E-33$ & $2 \cdot 245-09$ & $4 \cdot 10[-12$ & $2.302-31$ & $2.63 E-31$ & . & $1 \cdot 29 \mathrm{E}-12$ & $\perp \perp$ \\
\hline $90 E-33$ & $2 \cdot 37$ & $4 \cdot 47 D \perp 2$ & 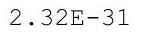 & (2. & 5.0 & & $.00 \mathrm{~L}-1$ \\
\hline 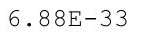 & $2.54 \mathrm{E}-09$ & & $2.34 \mathrm{E}-31$ & & & & \\
\hline$F-33$ & 9 & $5 E-12$ & & & & 2 & 10 \\
\hline 33 & & & & & & & \\
\hline $81 E-33$ & $3.04 \mathrm{E}-09$ & $5.91 \mathrm{E}-12$ & $2.40 E-31$ & $2.10 \mathrm{E}$ & 5 & 12 & -10 \\
\hline $79 E-33$ & $3.2<4$ & & $2 \cdot$ & & & & \\
\hline $.77 E-33$ & $3.4 \perp E-U 9$ & & & & & & \\
\hline 3 & - & 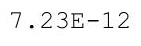 & $\perp$ & & 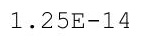 & 2 & 1. $65 \mathrm{E}-10$ \\
\hline $.73 E-33$ & & & & & & & \\
\hline 3 & & 2 & & 1 & 4 & 2 & \\
\hline $69 E-33$ & $4.25 E-09$ & $7 E-12$ & 2. & 31 & 14 & 11 & 10 \\
\hline & & & & & & & \\
\hline & 9 & & 舟 & & & & . \\
\hline & & & & 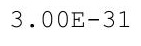 & 3 & $1+$ & $\begin{array}{l}10 \\
10\end{array}$ \\
\hline 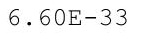 & $3 E-09$ & $2 E-11$ & $62 E-31$ & $E-31$ & $5 E-13$ & $66 E-11$ & -10 \\
\hline
\end{tabular}


RESRAD-OFFSITE, Version 2.5

$\mathrm{T}^{1 / 2}$ Limit $=180$ days

robabilistic Dose and Risk Report

Title : Offsite Resident Farmer Deterministic Run

File : RF TC99 DOESG FWD-FV2b.ROF

Summary of dose at graphical times, reptition 2 (continued)

Time

Years

$1.65 \mathrm{E}+02$

$1.66 \mathrm{E}+02$

1. $66 \mathrm{E}+02$

$1.67 \mathrm{E}+02$

1. $67 \mathrm{E}+02$

$1.68 \mathrm{E}+02$

1. $68 \mathrm{E}+02$

$1.69 \mathrm{E}+02$

$1.69 \mathrm{E}+02$

$1.70 \mathrm{E}+02$

$1.70 \mathrm{E}+02$

$1.71 \mathrm{E}+02$

$1.71 \mathrm{E}+02$

1. $72 \mathrm{E}+02$

$1.72 \mathrm{E}+02$

1. $73 \mathrm{E}+02$

$1.73 \mathrm{E}+02$

$1.74 \mathrm{E}+02$

$1.74 \mathrm{E}+02$

$1.75 \mathrm{E}+02$

$1.75 \mathrm{E}+02$

$1.76 \mathrm{E}+02$

$1.76 \mathrm{E}+02$

$1.77 \mathrm{E}+02$

$1.77 \mathrm{E}+02$

$1.78 \mathrm{E}+02$

$1.78 \mathrm{E}+02$

$1.79 \mathrm{E}+02$

$1.79 \mathrm{E}+02$

$1.80 \mathrm{E}+02$

$1.80 \mathrm{E}+02$

$1.81 \mathrm{E}+02$

$1.81 \mathrm{E}+02$

1. $82 \mathrm{E}+02$

$1.83 \mathrm{E}+02$

$1.83 E+02$

$1.84 \mathrm{E}+02$

$1.84 \mathrm{E}+02$

$1.85 \mathrm{E}+02$

$1.85 \mathrm{E}+02$

$1.86 \mathrm{E}+02$

$1.86 \mathrm{E}+02$

$1.87 \mathrm{E}+02$

$1.87 \mathrm{E}+02$

$1.88 \mathrm{E}+02$

$1.88 \mathrm{E}+02$
Dose statistics at graphical times, mrem/yr

\begin{tabular}{|c|c|c|c|c|c|c|c|}
\hline m & am & ean & ledian & & & $\%$ & \\
\hline $58 E-33$ & $5.50 \mathrm{E}-09$ & 1. $19 \mathrm{E}-11$ & $2.64 \mathrm{E}-31$ & $3.06 \mathrm{E}-31$ & -13 & -11 & -10 \\
\hline $56 \mathrm{E}-33$ & $5.78 \mathrm{E}-09$ & 1.201 & $2.66 \mathrm{E}-31$ & $9 E-31$ & -13 & -11 & -10 \\
\hline $.54 E-33$ & $6.07 \mathrm{E}-09$ & 1. $34 \mathrm{E}-11$ & $2.69 \mathrm{E}-31$ & $.12 E-31$ & $3.36 \mathrm{E}-13$ & -11 & -10 \\
\hline $52 E-33$ & $6.37 E-09$ & 1. $42 \mathrm{E}-11$ & $2.71 E-31$ & $3.15 E-31$ & $4.40 \mathrm{E}-13$ & $2.73 E-11$ & $.73 E-10$ \\
\hline $0 E-33$ & $69 \mathrm{E}-09$ & $1.51 \mathrm{E}-$ & $4 E-31$ & -31 & $E-13$ & $6 \mathrm{~F}-11$ & 10 \\
\hline$E-33$ & 09 & 1. $59 \mathrm{E}-11$ & 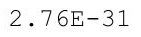 & $2 F-31$ & 3 & 1 & -10 \\
\hline $46 E-33$ & 99 & & & 1 & 3 & & -10 \\
\hline $44 E-33$ & & & & & & & -10 \\
\hline-33 & -09 & \pm & 1 & 1 & -12 & -11 & $5-10$ \\
\hline 33 & 09 & 1. $99 \mathrm{E}-11$ & 1 & 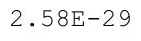 & -12 & 11 & 0 \\
\hline $8 E-33$ & $1 F-09$ & F- & $5-$ & - & -12 & $E-11$ & 0 \\
\hline 3 & & & & & & & \\
\hline$F-33$ & $F-09$ & $2.33 \mathrm{E}$ & 1 & $95 F-24$ & 2 & 1 & -10 \\
\hline $.32 E-33$ & $1.00 \mathrm{E}-08$ & $2.46 \mathrm{E}-11$ & $2.96 \mathrm{E}-31$ & $8.40 \mathrm{E}-23$ & $4.16 \mathrm{E}-12$ & -11 & -10 \\
\hline 33 & 08 & & & & & & -10 \\
\hline 33 & & + & & 12 21 & 12 & & 10 \\
\hline 33 & 00 & 2 & & 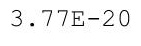 & 2 & & 0 \\
\hline 3 & & & & & & & 0 \\
\hline $22 E-33$ & $1.24 \mathrm{E}-08$ & $6 \Gamma^{1}+10$ & & 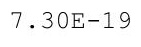 & $32 E-12$ & -10 & 10 \\
\hline $.20 \mathrm{E}-33$ & $1.29 \mathrm{E}-08$ & $3.32 \mathrm{E}-11$ & -31 & -1 & $.15 E-11$ & -10 & -09 \\
\hline $18 E-33$ & 1. $34 \mathrm{E}-08$ & $3.49 E-11$ & & & 1. $33 \mathrm{E}-11$ & $E-10$ & $E-09$ \\
\hline & & & & & & & \\
\hline & & & & & & & \\
\hline $.13 E-33$ & 1.51 & 7.0 & & 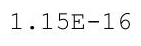 & & & 09 \\
\hline 3 & 8 & 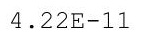 & 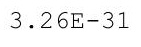 & 5 & 1 & 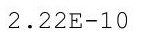 & 09 \\
\hline$E-33$ & (зг ) & 1 & F & $79 F_{-}$ & $51 \mathrm{E}-11$ & $E-10$ & $37 \mathrm{E}-$ \\
\hline$F-33$ & 1 & 4. $63 \mathrm{E}-$ & 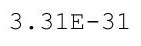 & 00 & -11 & $.55 E-1$ & $9-09$ \\
\hline$E-33$ & -08 & & & & & & $51 E-09$ \\
\hline-33 & 08 & & & & & & \\
\hline $.01 E-33$ & $1.90 \mathrm{E}-08$ & $\begin{array}{lll}U \perp \perp & \perp\end{array}$ & $\perp$ & 1.00 & 3.10 & & -09 \\
\hline $99 E-33$ & $1.91 \mathrm{E}-0$ & . & $3.44 E-31$ & $7.61 \mathrm{E}-15$ & $4.13 \mathrm{E}-11$ & $3.045-10$ & $.74 E-09$ \\
\hline 3 & $2.04 \mathrm{E}-08$ & 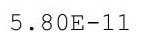 & 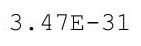 & & $4.49 \mathrm{E}-11$ & $=0$ & 1. $82 \mathrm{E}-09$ \\
\hline 3 & $.12 \mathrm{E}-$ & & & & & & \\
\hline$F-33$ & $F-08$ & & & & -11 & & \\
\hline 3 & & & & & & & \\
\hline 33 & $2.30 \mathrm{E}$ & $6.90 \mathrm{E}-11$ & . & $.45 \pm$ & 11 & 10 & 09 \\
\hline $88 E-33$ & $2.44 \mathrm{E}-08$ & 1.200 & & & & & \\
\hline $86 E-33$ & & & & & & & \\
\hline 3 & 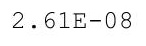 & 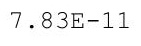 & 1 & 3 & 1 & 0 & 9 \\
\hline $.83 E-33$ & & & & & & & \\
\hline 3 & 08 & 11 & 1 & 3 & 1 & & -09 \\
\hline$E-33$ & $2.89 E-08$ & $5 E-11$ & 3.7 & 3. & -10 & 10 & -09 \\
\hline & & & & & & & \\
\hline & 8 & . & & & & & $2.92 E-09$ \\
\hline & $3-00$ & s. & & 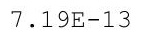 & $2 E-10$ & +0 & $3.05 E-09$ \\
\hline $72 E-33$ & $9 \mathrm{E}-08$ & $4 E-10$ & $3 E-31$ & $27 E-13$ & $33 E-10$ & $6 E-10$ & -09 \\
\hline
\end{tabular}


RESRAD-OFFSITE, Version 2.5

$\mathrm{T}^{1 / 2}$ Limit $=180$ days

obabilistic Dose and Risk Report

Title : Offsite Resident Farmer Deterministic Run

File : RF TC99 DOESG FWD-FV2b.ROF

Summary of dose at graphical times, reptition 2 (continued)

Time

Years

$1.89 \mathrm{E}+02$

$1.89 \mathrm{E}+02$

1. $90 \mathrm{E}+02$

1. $90 \mathrm{E}+02$

1. $91 \mathrm{E}+02$

1. $91 \mathrm{E}+02$

1. $92 \mathrm{E}+02$

1. $92 \mathrm{E}+02$

1. $93 \mathrm{E}+02$

1. $93 \mathrm{E}+02$

$1.94 \mathrm{E}+02$

1. $94 \mathrm{E}+02$

1. $95 \mathrm{E}+02$

1. $95 \mathrm{E}+02$

1. $96 \mathrm{E}+02$

1. $96 \mathrm{E}+02$

1. $97 \mathrm{E}+02$

1. $97 \mathrm{E}+02$

1. $98 \mathrm{E}+02$

1. $98 \mathrm{E}+02$

1. $99 \mathrm{E}+02$

$1.99 \mathrm{E}+02$

$2.00 \mathrm{E}+02$

$2.00 \mathrm{E}+02$

$2.01 \mathrm{E}+02$

$2.01 \mathrm{E}+02$

$2.02 \mathrm{E}+02$

$2.03 \mathrm{E}+02$

$2.03 E+02$

$2.04 \mathrm{E}+02$

$2.04 \mathrm{E}+02$

$2.05 \mathrm{E}+02$

$2.05 \mathrm{E}+02$

$2.06 \mathrm{E}+02$

$2.06 \mathrm{E}+02$

$2.07 \mathrm{E}+02$

$2.07 \mathrm{E}+02$

$2.08 \mathrm{E}+02$

$2.08 \mathrm{E}+02$

2. $09 \mathrm{E}+02$

$2.09 \mathrm{E}+02$

$2.10 \mathrm{E}+02$

$2.10 \mathrm{E}+02$

$2.11 \mathrm{E}+02$

$2.11 \mathrm{E}+02$

$2.12 \mathrm{E}+02$
Dose statistics at graphical times, mrem/yr

\begin{tabular}{|c|c|c|c|c|c|c|c|}
\hline m & um & ean & ledian & $0 \%$ & & $\%$ & $\%$ \\
\hline $.70 E-33$ & $3.40 \mathrm{E}-08$ & $1.08 \mathrm{E}-10$ & $3.97 E-31$ & $1.18 \mathrm{E}-12$ & -10 & -10 & -09 \\
\hline $68 E-33$ & $1 \mathrm{E}-08$ & 10 & -31 & 12 & 10 & 10 & -09 \\
\hline $.67 E-33$ & $3.62 \mathrm{E}-08$ & $1.17 \mathrm{E}-10$ & $4 E-31$ & 1. $74 \mathrm{E}-12$ & 1. $69 \mathrm{E}-10$ & $8.78 \mathrm{E}-10$ & $59 E-09$ \\
\hline $65 E-33$ & $3.74 \mathrm{E}-08$ & 1. $21 \mathrm{E}-10$ & $4.07 E-31$ & $2.06 \mathrm{E}-12$ & $1.79 \mathrm{E}-10$ & $18 E-10$ & $3.74 \mathrm{E}-09$ \\
\hline 3 & 8 & 1. $26 \mathrm{E}-10$ & & 2 & 0 & 0 & -09 \\
\hline$E-33$ & 08 & 0 & 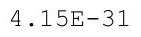 & 2 & 0 & 99 & -09 \\
\hline $60 \mathrm{E}-33$ & 8 & 1 & & & 0 & & -09 \\
\hline $58 E-33$ & & 0 & & & & & -09 \\
\hline-33 & -08 & -10 & $\perp$ & -12 & -10 & 09 & $E-09$ \\
\hline-33 & 00 & . & $J_{1}$ & 2 & 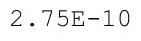 & 9 & -09 \\
\hline 33 & 08 & 10 & \pm & 12 & 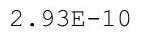 & 09 & -09 \\
\hline 33 & 4.7 & - & & & & & -09 \\
\hline $49 E-33$ & 4. $90 \mathrm{E}-08$ & 1. $69 \mathrm{E}-10$ & 4. & $09 \mathrm{E}-12$ & $3.26 \mathrm{E}-10$ & & -09 \\
\hline $48 E-33$ & $5 E-08$ & $5 E-10$ & $7 E-31$ & $8 \mathrm{E}-12$ & -10 & -09 & -09 \\
\hline-33 & -08 & -10 & & 1 & 0 & & -09 \\
\hline 33 & 08 & \pm 0 & $\perp$ & $\perp \perp$ & 0 & 9 & 09 \\
\hline 33 & 08 & \pm & & 1 & 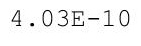 & & -09 \\
\hline $41 E-33$ & & $2.02 E-10$ & & & & & -09 \\
\hline $39 E-33$ & $5.82 \mathrm{E}-08$ & $2.09 E-10$ & 1 & $1.68 \mathrm{E}-11$ & $4.43 E-10$ & & $50 E-09$ \\
\hline $37 E-33$ & $.98 \mathrm{E}-08$ & $2.16 \mathrm{E}-10$ & $3 E-31$ & $1.87 \mathrm{E}-11$ & $4.65 E-10$ & -09 & $71 E-09$ \\
\hline $36 E-33$ & $6.15 E-08$ & $2.24 \mathrm{E}-10$ & & $2.09 E-11$ & $4.87 E-10$ & -09 & $91 \mathrm{E}-09$ \\
\hline 33 & $2 E-08$ & 0 & $\perp$ & 1 & & & -09 \\
\hline 33 & & & & & & & 09 \\
\hline $31 E-33$ & .0T & $2.17 \pm 10$ & & $86 \mathrm{E}-11$ & & & -09 \\
\hline 33 & 8 & 2 & $\perp$ & 1 & 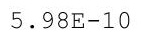 & 3 & -09 \\
\hline $7 E-33$ & 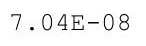 & $.64 \mathrm{E}-10$ & קم & $.63 E-11$ & $26 \mathrm{E}-10$ & $2 E-09$ & $99 E-09$ \\
\hline $6 E-33$ & -08 & $2.73 E-10$ & 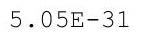 & 1 & $55 \mathrm{E}-$ & $31=0$ & $25 E-09$ \\
\hline$E-33$ & -08 & 10 & & & & $E-09$ & -09 \\
\hline 33 & 08 & & & & & & \\
\hline $21 E-33$ & $7.82 \mathrm{E}-08$ & $3.0 \perp E-10$ & $0.20 \mathrm{t}$ & $0.21+$ & 1.11 & 2.00 & -09 \\
\hline $19 \mathrm{E}-33$ & $0.05-00$ & $3.10+10$ & $.2 U D-31$ & $5.68 \mathrm{E}-11$ & $7.76 \mathrm{E}-10$ & $2.00 \mathrm{E}-09$ & $35 E-09$ \\
\hline 3 & o. & . & . & $6.12 \mathrm{E}-11$ & $.00 \mathrm{D}-10$ & (2. & $9.65 E-09$ \\
\hline 3 & $8.45 E-08$ & $3.30 \mathrm{E}-10$ & $5.35 E-31$ & & & & 9 \\
\hline-33 & -08 & 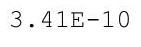 & & 1 & & 9 & 08 \\
\hline 3 & & & & & & & \\
\hline $1 E-33$ & $9.11 \mathrm{E}-08$ & $3.63 E-10$ & $.50 E-31$ & $8.56 \mathrm{E}-11$ & 0 & & -08 \\
\hline $0 E-33$ & . & $0.1+1$ & & & & & -08 \\
\hline . 0 प & & $\begin{array}{l}.00 \mathrm{~L} \\
\end{array}$ & & $9.95 \mathrm{E}-11$ & & & $1.17 \mathrm{E}-08$ \\
\hline 3 & 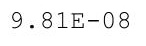 & 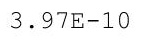 & . & 0 & 9 & & 8 \\
\hline & & & & & & & 8 \\
\hline 3 & 07 & 4. & 1 & 0 & & & \\
\hline$E-33$ & $1.05 E-07$ & $5 E-10$ & 31 & $1.30 \mathrm{E}$ & 1 & & -08 \\
\hline & & & & & & & \\
\hline & & 1. & & & & & $1.40 \mathrm{E}-08$ \\
\hline & & & & 0 & 19 & 9 & $44 E-08$ \\
\hline D & $6 \mathrm{E}-07$ & 車 10 & {$[-21$} & $E-10$ & $38 E-09$ & $8 E-09$ & -08 \\
\hline
\end{tabular}


RESRAD-OFFSITE, Version 2.5

obabilistic Dose and Risk Report

Title : Offsite Resident Farmer Deterministic Run

File : RF TC99 DOESG FWD-FV2b.ROF

Summary of dose at graphical times, reptition 2 (continued)

Time

Years

$2.12 \mathrm{E}+02$

$2.13 \mathrm{E}+02$

$2.13 \mathrm{E}+02$

$2.14 \mathrm{E}+02$

$2.14 \mathrm{E}+02$

$2.15 \mathrm{E}+02$

$2.15 \mathrm{E}+02$

$2.16 \mathrm{E}+02$

$2.16 \mathrm{E}+02$

$2.17 \mathrm{E}+02$

$2.17 \mathrm{E}+02$

$2.18 \mathrm{E}+02$

$2.18 \mathrm{E}+02$

$2.19 \mathrm{E}+02$

$2.19 \mathrm{E}+02$

2. $20 \mathrm{E}+02$

2. $20 \mathrm{E}+02$

$2.21 E+02$

2. $21 E+02$

2. $22 \mathrm{E}+02$

$2.23 E+02$

$2.23 E+02$

2. $24 \mathrm{E}+02$

$2.24 \mathrm{E}+02$

2. $25 \mathrm{E}+02$

$2.25 \mathrm{E}+02$

2. $26 \mathrm{E}+02$

$2.26 \mathrm{E}+02$

$2.27 \mathrm{E}+02$

$2.27 \mathrm{E}+02$

2. $28 \mathrm{E}+02$

$2.28 \mathrm{E}+02$

$2.29 \mathrm{E}+02$

2. $29 \mathrm{E}+02$

2. $30 E+02$

2. $30 \mathrm{E}+02$

2. $31 E+02$

2. $31 E+02$

2. $32 \mathrm{E}+02$

2. $32 E+02$

$2.33 E+02$

2. $33 E+02$

$2.34 \mathrm{E}+02$

2. $34 \mathrm{E}+02$

$2.35 E+02$

$2.35 \mathrm{E}+02$
Dose statistics at graphical times, mrem/yr

\begin{tabular}{|c|c|c|c|c|c|c|c|}
\hline $\mathrm{m}$ & aximum & ea & ed & & & & \\
\hline $94 \mathrm{E}-33$ & $1.19 \mathrm{E}-07$ & $5.03 E-10$ & $6.10 \mathrm{E}-31$ & 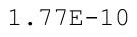 & 1. $42 \mathrm{E}-09$ & 09 & $2 \pm-00$ \\
\hline $92 E-33$ & $1.21 E-07$ & $5.17 \mathrm{E}-10$ & $6.16 \mathrm{E}-31$ & -10 & $48 E-09$ & $4.77 E-09$ & $7 E-08$ \\
\hline $91 E-33$ & $1.24 \mathrm{E}-07$ & $2 F-10$ & $2 E-31$ & $04 \mathrm{E}-10$ & $53 E-09$ & $91 E-09$ & $E-08$ \\
\hline$E-33$ & $127 \mathrm{~F}-07$ & $48 F-10$ & $29 E-31$ & $.16 \mathrm{E}-10$ & $.58 E-09$ & $7 E-09$ & $65 E-08$ \\
\hline $88 E-33$ & 1.3 & 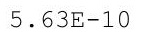 & 1 & 0 & 9 & 09 & .08 \\
\hline $86 E-33$ & $1.33 \mathrm{E}-07$ & & & & & & \\
\hline $85 E-33$ & $1.36 \mathrm{E}-07$ & & & & & & $1.79 \mathrm{E}-08$ \\
\hline-33 & 07 & $=0$ & 1 & 10 & 9 & -09 & -08 \\
\hline $82 E-33$ & $1.42 \mathrm{E}-07$ & $29 E-10$ & -31 & -10 & $1.87 \mathrm{E}-09$ & $E-09$ & $1.88 \mathrm{E}-08$ \\
\hline $80 E-33$ & $45 E-07$ & $47 \mathrm{E}-10$ & $6 \in \Gamma$ & $.02 E-10$ & 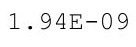 & $.07 E-09$ & $.93 E-08$ \\
\hline 33 & 1.4 & & & & & & 8 \\
\hline $.77 E-33$ & $1.52 \mathrm{E}-07$ & 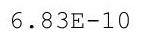 & & 0 & 9 & 9 & -08 \\
\hline $76 \mathrm{E}-33$ & $1.55 \mathrm{E}-07$ & & & & & & $2.08 E-08$ \\
\hline $.74 E-33$ & $1.58 \mathrm{E}-07$ & $7 \cdot 20 E-10$ & & & & -09 & $E-08$ \\
\hline $.73 E-33$ & 1.6 & & & & 9 & -09 & $E-08$ \\
\hline $1 E-33$ & $1 \cdot 0$ & & $\sigma_{0}$ & & & 9 & $26 E-08$ \\
\hline 3 & $\perp \cdot$ & & & & & & \\
\hline$E-33$ & 1 . & & - & 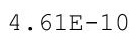 & & 9 & 08 \\
\hline $67 \mathrm{E}-33$ & $1.76 \mathrm{E}-07$ & $.22 E-10$ & 7. $28 E-31$ & $4.86 \mathrm{E}-10$ & $2.53 E-09$ & $7.80 \mathrm{E}-09$ & $2.45 E-08$ \\
\hline $65 E-33$ & $1.80 \mathrm{E}-07$ & $.43 E-10$ & $7.35 \mathrm{E}-31$ & -10 & $2.60 \mathrm{E}-09$ & -09 & $2.52 E-08$ \\
\hline 33 & 1.8 & & & & & -09 & -08 \\
\hline 33 & & & & 0 & 9 & & 08 \\
\hline 33 & & $9.10 \mathrm{E}-10$ & 1 & 0 & & & -08 \\
\hline $60 E-33$ & 1.9 & 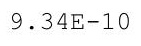 & 1 & 0 & 9 & 9 & -08 \\
\hline$E-33$ & 7 & 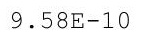 & 1 & 0 & 9 & 9 & $.87 E-$ \\
\hline $57 E-33$ & $03 \mathrm{~F}-07$ & 10 & - & $61 E-10$ & $.08 E-09$ & $E-09$ & $.94 E-08$ \\
\hline$E-33$ & $07 F-07$ & $01 E-09$ & & & & $5 E-09$ & $.02 E-08$ \\
\hline & & & & & & & \\
\hline & & & & 0 & 9 & & -08 \\
\hline $51 E-33$ & $2.19 \mathrm{E}-07$ & $1.00 \mathrm{~L}$ & & $7.67 \mathrm{E}-10$ & $.43 E-09$ & $1.05 E-00$ & $.25 E-08$ \\
\hline $50 E-33$ & $2.24 \mathrm{E}-07$ & $\perp \cdot \perp \perp \perp-U 2$ & - & $.93 E-10$ & $\cdot 0 \angle[-20$ & 1.0JE- & $.34 E-08$ \\
\hline $48 E-33$ & . & & & & & ( & $42 E-08$ \\
\hline$E-33$ & $325-07$ & & 1 & 0 & 9 & -08 & $E-08$ \\
\hline & & & & & & & \\
\hline & & & & & 9 & & \\
\hline $43 E-33$ & $2.46 \mathrm{E}-07$ & $1.25 \mathrm{E}-09$ & - OLt & . & 9 & $.19 E-08$ & $.75 E-08$ \\
\hline $41 E-33$ & (1) & & & & & & $3.83 E-08$ \\
\hline $40 E-33$ & 2. & 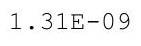 & $.78 E-31$ & $1.04 \mathrm{E}-09$ & 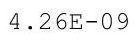 & & 8 \\
\hline 3 & $2.60 \mathrm{E}-07$ & $1.34 \mathrm{E}-09$ & 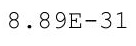 & 9 & 9 & 8 & 08 \\
\hline 33 & $2.65 E-07$ & & & 9 & & & \\
\hline$E-33$ & $2.70 \mathrm{E}-07$ & 1. & 31 & & & & -08 \\
\hline-33 & .7 & & & & & & \\
\hline & & & & & & & $4.38 E-08$ \\
\hline $.32 \pm-33$ & $2.00 \mathrm{~L}-1$ & $\perp \cdot U \perp-40$ & $9.36 \mathrm{E}-31$ & $1.33 E-09$ & $5.06 \mathrm{E}-09$ & $1.44 E-08$ & $4.48 E-08$ \\
\hline $30 E-33$ & $2.90 \mathrm{~L}-1$ & 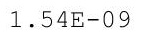 & & & $5.21 \mathrm{E}-09$ & $1.47 E-08$ & t. \\
\hline $9 E-33$ & $.95 E-07$ & $.58 E-09$ & $.54 E-31$ & $E-09$ & $5.35 E-09$ & $1.51 \mathrm{E}-08$ & $4.67 \mathrm{E}$ \\
\hline
\end{tabular}


RESRAD-OFFSITE, Version 2.5

Title : Offsite Resident Farmer Deterministic Run

File : RF TC99 DOESG FWD-FV2b.ROF

Summary of dose at graphical times, reptition 2 (continued)

Time

Years

$2.36 \mathrm{E}+02$

$2.36 \mathrm{E}+02$

2. $37 \mathrm{E}+02$

2. $37 \mathrm{E}+02$

2. $38 \mathrm{E}+02$

2. $38 \mathrm{E}+02$

$2.39 \mathrm{E}+02$

2. $39 \mathrm{E}+02$

2. $40 \mathrm{E}+02$

$2.40 \mathrm{E}+02$

$2.41 \mathrm{E}+02$

2. $41 \mathrm{E}+02$

$2.42 \mathrm{E}+02$

2. $43 \mathrm{E}+02$

$2.43 \mathrm{E}+02$

$2.44 \mathrm{E}+02$

$2.44 \mathrm{E}+02$

$2.45 \mathrm{E}+02$

$2.45 \mathrm{E}+02$

$2.46 \mathrm{E}+02$

$2.46 \mathrm{E}+02$

$2.47 \mathrm{E}+02$

$2.47 \mathrm{E}+02$

$2.48 \mathrm{E}+02$

$2.48 \mathrm{E}+02$

$2.49 \mathrm{E}+02$

$2.49 \mathrm{E}+02$

$2.50 \mathrm{E}+02$

$2.50 \mathrm{E}+02$

$2.51 \mathrm{E}+02$

$2.51 \mathrm{E}+02$

$2.52 \mathrm{E}+02$

$2.52 \mathrm{E}+02$

$2.53 \mathrm{E}+02$

$2.53 \mathrm{E}+02$

$2.54 \mathrm{E}+02$

$2.54 \mathrm{E}+02$

$2.55 \mathrm{E}+02$

$2.55 \mathrm{E}+02$

$2.56 \mathrm{E}+02$

$2.56 \mathrm{E}+02$

$2.57 \mathrm{E}+02$

$2.57 \mathrm{E}+02$

$2.58 \mathrm{E}+02$

$2.58 \mathrm{E}+02$

$2.59 \mathrm{E}+02$
Dose statistics at graphical times, mrem/yr

\begin{tabular}{|c|c|c|c|c|c|c|c|}
\hline um & aximum & ean & 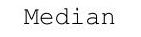 & & & $\%$ & \\
\hline $28 E-33$ & $3.00 \mathrm{E}-07$ & 1. $61 \mathrm{E}-09$ & $9.63 E-31$ & 1. $49 \mathrm{E}-09$ & 09 & -08 & -00 \\
\hline $26 \mathrm{E}-33$ & $3.05 E-07$ & $5 E-09$ & $9.73 E-31$ & 9 & 9 & $1.57 \mathrm{E}-08$ & -08 \\
\hline $.25 E-33$ & $3.11 \mathrm{E}-07$ & 1. $69 \mathrm{E}-09$ & $9.83 E-31$ & 1. $60 \mathrm{E}-09$ & $5.75 \mathrm{E}-09$ & 1. $61 \mathrm{E}-08$ & $4.98 \mathrm{E}-08$ \\
\hline $24 \mathrm{E}-33$ & $3.16 \mathrm{E}-07$ & $1.72 E-09$ & $9.95 E-31$ & $1.66 \mathrm{E}-09$ & $5.89 \mathrm{E}-09$ & $1.64 \mathrm{E}-08$ & $09 E-08$ \\
\hline $2 E-33$ & $22 F-07$ & $76 \mathrm{~F}-09$ & $01 F-30$ & $1 E-09$ & $.03 E-09$ & $3 E-08$ & $20 E-08$ \\
\hline$E-33$ & 07 & & & 9 & & & -08 \\
\hline $20 \mathrm{E}-33$ & $3.33 \mathrm{E}$ & $1.84 \mathrm{E}$ & & 9 & & & -08 \\
\hline $18 \mathrm{E}-33$ & & & & 9 & & & -08 \\
\hline-33 & -07 & $E-09$ & 0 & $96 \mathrm{E}-09$ & 09 & -08 & -08 \\
\hline $21 \mathrm{E}-33$ & 7 & 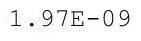 & & 9 & & 08 & -08 \\
\hline $9 E-33$ & $5-07$ & 15 & $1.07 \mathrm{E}-30$ & م्F_ & 9 & $90 E-08$ & $85 \mathrm{~F}$ \\
\hline 33 & 7 & & & & & & 8 \\
\hline$E-33$ & -07 & 2 & & 2 & 9 & 8 & -08 \\
\hline $.15 E-33$ & $3.74 \mathrm{E}-07$ & $2.14 \mathrm{E}-09$ & $1.11 \mathrm{E}-30$ & $2.32 \mathrm{E}-09$ & $7.40 \mathrm{E}-09$ & $2.02 \mathrm{E}-08$ & $9 E-08$ \\
\hline-33 & $3.80 \mathrm{E}-07$ & $8 E-09$ & & 9 & 09 & -08 & -08 \\
\hline 33 & & & & & & & 08 \\
\hline 33 & 1 & 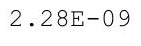 & & 9 & & & -08 \\
\hline 3 & 3 & $2.33 E-09$ & & & & & 8 \\
\hline $08 E-33$ & $4.05 E-07$ & $237 \mathrm{~F}-$ & & $268 \mathrm{~F}$ & 9 & 8 & -08 \\
\hline $.07 E-33$ & $4.11 \mathrm{E}-07$ & $2.42 \mathrm{E}-09$ & $1.20 \mathrm{E}-3$ & $2.75 E-09$ & -09 & $E-08$ & -08 \\
\hline $.06 E-33$ & $4.18 E-07$ & $2.47 E-09$ & & $2.82 E-09$ & & $E-08$ & $03 E-08$ \\
\hline & & & & & & & -08 \\
\hline 3 & & & & & & & \\
\hline $02 E-33$ & 4. & 然 & 1. & & 9 & & -08 \\
\hline 3 & 7 & $2.68 \mathrm{E}-09$ & $1.27 \mathrm{E}-30$ & 8 & 9 & 8 & -08 \\
\hline $99 E-33$ & $51 \mathrm{~F}-07$ & (2 & $13 \cap 5$ & ק1: & (2) & $5 E-08$ & $69 E-08$ \\
\hline $98 F-33$ & $58 F-07$ & $2.79 \mathrm{E}-0$ & & & & $.71 E-08$ & $83 E-08$ \\
\hline$E-33$ & $5-07$ & & & & & & $96 E-08$ \\
\hline-33 & 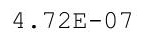 & & & & & & \\
\hline $94 E-33$ & 4. $18 \mathrm{~L}-1$ & $2.70 \mathrm{~L}-03$ & $2 \cdot 40 \pm$ & . & I. & $E-08$ & -08 \\
\hline $.93 E-33$ & 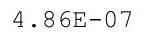 & $\begin{array}{ll}.020 \\
\end{array}$ & . & $3.65 \mathrm{E}-09$ & $1.09 \mathrm{E}-00$ & $2.90 \mathrm{~L}-00$ & $.39 E-08$ \\
\hline $91 E-33$ & 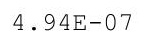 & 年 & 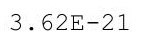 & 年 & 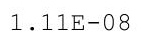 & $3.02 \mathrm{E}-08$ & $.54 \mathrm{E}-08$ \\
\hline $0 \mathrm{E}-$ & $\sigma_{0}$ & & 0 & & & & 8 \\
\hline$F-33$ & 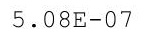 & & & & & & 08 \\
\hline 33 & & & & & & & \\
\hline $6 E-33$ & $5.23 E-07$ & $3.325-09$ & $1.00 \pm-10$ & $\cdot 12$ & $\pm \cdot 2+$ & 08 & -08 \\
\hline $5 E-33$ & $0.0+2$ & . & & & & & \\
\hline $83 E-33$ & & . 10 प vo & & & & & $9.53 E-08$ \\
\hline 3 & 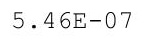 & 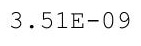 & $3.27 \mathrm{E}-17$ & 9 & 8 & 8 & 08 \\
\hline & & & & & & & \\
\hline 3 & & & 1 & ) & $B$ & 8 & -07 \\
\hline$E-33$ & $5.70 \mathrm{E}-07$ & 3.7 & 2. & 4.75 & 1 & 08 & -07 \\
\hline & & & & & & & \\
\hline & & 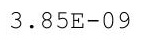 & & & $\perp ・ エ \perp \sqcup$ & & $1.06 \mathrm{E}-07$ \\
\hline (3) & & 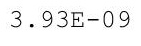 & & & 8 & & ( \\
\hline$E-33$ & $2 E-07$ & $0 E-09$ & $97 E-15$ & $22 E-09$ & $E-08$ & $3 E-08$ & -07 \\
\hline
\end{tabular}


RESRAD-OFFSITE, Version 2.5

$\mathrm{T}^{1 / 2}$ Limit $=180$ days

robabilistic Dose and Risk Report

Title : Offsite Resident Farmer Deterministic Run

File : RF TC99 DOESG FWD-FV2b.ROF

Summary of dose at graphical times, reptition 2 (continued)

Time

Years

$2.59 \mathrm{E}+02$

$2.60 \mathrm{E}+02$

$2.60 \mathrm{E}+02$

2. $61 \mathrm{E}+02$

2. $61 \mathrm{E}+02$

2. $62 \mathrm{E}+02$

$2.63 E+02$

$2.63 E+02$

$2.64 \mathrm{E}+02$

$2.64 \mathrm{E}+02$

$2.65 \mathrm{E}+02$

$2.65 E+02$

$2.66 \mathrm{E}+02$

$2.66 \mathrm{E}+02$

$2.67 \mathrm{E}+02$

$2.67 \mathrm{E}+02$

$2.68 \mathrm{E}+02$

$2.68 \mathrm{E}+02$

$2.69 \mathrm{E}+02$

$2.69 \mathrm{E}+02$

$2.70 \mathrm{E}+02$

$2.70 E+02$

$2.71 E+02$

$2.71 \mathrm{E}+02$

$2.72 \mathrm{E}+02$

$2.72 \mathrm{E}+02$

$2.73 \mathrm{E}+02$

$2.73 \mathrm{E}+02$

$2.74 \mathrm{E}+02$

$2.74 \mathrm{E}+02$

$2.75 E+02$

$2.75 \mathrm{E}+02$

2. $76 \mathrm{E}+02$

$2.76 \mathrm{E}+02$

$2.77 \mathrm{E}+02$

$2.77 \mathrm{E}+02$

$2.78 \mathrm{E}+02$

$2.78 \mathrm{E}+02$

$2.79 \mathrm{E}+02$

$2.79 \mathrm{E}+02$

$2.80 \mathrm{E}+02$

$2.80 \mathrm{E}+02$

$2.81 \mathrm{E}+02$

$2.81 \mathrm{E}+02$

$2.82 \mathrm{E}+02$

$2.82 \mathrm{E}+02$
Dose statistics at graphical times, mrem/yr

\begin{tabular}{|c|c|c|c|c|c|c|c|}
\hline am & aximum & lean & ed & & & & \\
\hline $72 E-33$ & $6.10 \mathrm{E}-07$ & $4.07 E-09$ & $.95 E-15$ & $5 E-09$ & $1.50 \mathrm{E}-08$ & -08 & $4-01$ \\
\hline $38 E-32$ & $6.18 E-07$ & $4.14 \mathrm{E}-09$ & $8.06 \mathrm{E}-15$ & $E-09$ & $53 E-08$ & $19 E-08$ & $14 E-07$ \\
\hline $38 E-32$ & $6.27 \mathrm{E}-07$ & $4.22 E-09$ & 1. $23 \mathrm{E}-14$ & $50 E-09$ & $1.56 \mathrm{E}-08$ & $4.27 E-08$ & $1.16 \mathrm{E}-07$ \\
\hline $38 E-32$ & $35 \mathrm{~F}-07$ & $30 F-09$ & $95 \mathrm{~F}-14$ & $75 \mathrm{~F}-09$ & $.59 E-08$ & $36 \mathrm{~F}-08$ & $18 \mathrm{~F}-07$ \\
\hline $.07 E-32$ & -07 & 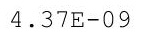 & 4 & 9 & & 08 & -07 \\
\hline $08 E-32$ & -07 & & & & & & 07 \\
\hline $08 E-32$ & $6.61 \mathrm{E}-07$ & & & & & & -07 \\
\hline-32 & -07 & 9 & 4 & 9 & 8 & 8 & $26 E-07$ \\
\hline $08 E-32$ & $3 E-07$ & $9 E-09$ & -13 & -09 & $1.75 \mathrm{E}-08$ & $E-08$ & $28 E-07$ \\
\hline $08 E-32$ & $.87 \mathrm{E}-07$ & (ס חר7 & $12 F-13$ & $.62 E-09$ & $.78 \mathrm{E}-08$ & $.85 E-08$ & $.31 E-07$ \\
\hline 32 & 07 & & & & & & 7 \\
\hline $08 E-32$ & $E-07$ & & 3 & 8 & 8 & 8 & 07 \\
\hline $08 E-32$ & $7.14 \mathrm{E}-07$ & & & & & & $1.38 \mathrm{E}-07$ \\
\hline $08 E-32$ & $7.23 E-07$ & $5.11 \mathrm{E}-09$ & $4.46 \mathrm{E}-13$ & & & -08 & $1.40 \mathrm{E}-07$ \\
\hline-32 & $E-07$ & 9 & -13 & & & 0 & $42 E-07$ \\
\hline-32 & 1 & $5.29 E-09$ & & 9 & & & 50 \\
\hline 32 & t & & & & & & 7 \\
\hline 32 & 7 & $5.47 E-09$ & 2 & & & 8 & 7 \\
\hline $08 E-32$ & $7.69 \mathrm{E}-07$ & $5.57 \mathrm{E}-09$ & 1. $38 \mathrm{E}-12$ & $8.21 E-09$ & $2.10 \mathrm{E}-08$ & $.66 E-08$ & 1. $52 \mathrm{E}-07$ \\
\hline $08 E-32$ & $7.79 \mathrm{E}-07$ & $.66 E-09$ & $E-12$ & $0 E-09$ & $2.14 \mathrm{E}-$ & $E-08$ & 1. $54 \mathrm{E}-07$ \\
\hline-32 & -07 & & & & & 8 & E-07 \\
\hline 2 & & & & & & & \\
\hline $09 E-32$ & 0.0 & 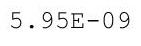 & & & & & -07 \\
\hline-32 & 8 & $6.05 E-09$ & 2 & 9 & te & 0 & -07 \\
\hline 2 & 7 & 9 & 2 & 9 & B & 8 & 07 \\
\hline $09 E-32$ & $37 \mathrm{~F}-07$ & $6-25 F-00$ & $E-12$ & (1) & $2.40 \mathrm{E}-08$ & $3 E-08$ & $.69 E-07$ \\
\hline$E-32$ & $47 \mathrm{~F}-07$ & $F-09$ & $E-12$ & & & $E-08$ & $. .71 \mathrm{E}-07$ \\
\hline & & & & & & & \\
\hline-32 & $8.6 / \mathrm{E}-0 /$ & $0.30 \mathrm{E}$ & & 8 & 0 & & 07 \\
\hline $09 E-32$ & $0.17 \mathrm{E}-01$ & $0.005-09$ & $7.48 \mathrm{E}-12$ & $1.02 \mathrm{E}-08$ & $2.60 \mathrm{E}-08$ & $9 E-08$ & $1.79 \mathrm{E}-07$ \\
\hline $09 E-32$ & $8.87 \mathrm{E}-07$ & $6.77 E-09$ & $8.52 \mathrm{E}-12$ & 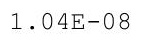 & $2.64 \mathrm{E}-08$ & $0.19 \mathrm{E}-00$ & $.81 \mathrm{E}-07$ \\
\hline 2 & 年 & 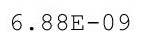 & 然 & 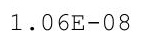 & & 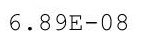 & $1.84 \mathrm{E}-07$ \\
\hline-32 & $5-07$ & $6.995-09$ & $1 \quad 12 \mathrm{~F}-11$ & $1.08 \mathrm{E}-08$ & & & $1.87 \mathrm{E}-07$ \\
\hline 32 & & & & & & & -07 \\
\hline$E-32$ & $E-07$ & 9 & 1 & & 8 & & -07 \\
\hline $09 E-32$ & $9.39 \mathrm{E}-07$ & $7.32 E-09$ & $1.58 \mathrm{E}-11$ & 1.110 & $2.01 \mathrm{~L}$ & -08 & $1.95 E-07$ \\
\hline $09 E-32$ & . & $1.445-03$ & & & & & $1.98 \mathrm{E}-07$ \\
\hline $09 \mathrm{E}-32$ & 0.0 & (. & & & & & $2.00 \mathrm{E}-07$ \\
\hline 2 & 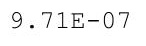 & . & 1 & 8 & 8 & 8 & 07 \\
\hline & 7 & & & 8 & 8 & & \\
\hline-32 & $9.93 E-07$ & $1 E-09$ & $4 E-11$ & 1 & & 8 & -07 \\
\hline$E-32$ & $1.00 \mathrm{E}-$ & $8 \cdot$ & 1 & & & & -07 \\
\hline & & & & & & & $2.15 \mathrm{E}-07$ \\
\hline & $1.03 E-06$ & $0.20 \mathrm{~L}-03$ & . & ז・U & 8 & & $2.18 \mathrm{E}-07$ \\
\hline$E-32$ & . & & & & . & & $2.21 \mathrm{E}$ \\
\hline$E-32$ & $1.05 E-06$ & $E-09$ & $5 E-11$ & $E-08$ & $E-08$ & $67 E-08$ & -07 \\
\hline
\end{tabular}


RESRAD-OFFSITE, Version 2.5

$\mathrm{T}^{1 / 2}$ Limit $=180$ days

Title : Offsite Resident Farmer Deterministic Run

File : RF TC99 DOESG FWD-FV2b.ROF

Summary of dose at graphical times, reptition 2 (continued)

Time

Years

$2.83 \mathrm{E}+02$

$2.84 \mathrm{E}+02$

$2.84 \mathrm{E}+02$

$2.85 \mathrm{E}+02$

$2.85 \mathrm{E}+02$

$2.86 \mathrm{E}+02$

$2.86 \mathrm{E}+02$

$2.87 \mathrm{E}+02$

$2.87 \mathrm{E}+02$

$2.88 \mathrm{E}+02$

$2.88 \mathrm{E}+02$

$2.89 \mathrm{E}+02$

$2.89 \mathrm{E}+02$

2. $90 \mathrm{E}+02$

2. $90 \mathrm{E}+02$

2. $91 \mathrm{E}+02$

2. $91 \mathrm{E}+02$

2. $92 \mathrm{E}+02$

2. $92 \mathrm{E}+02$

$2.93 \mathrm{E}+02$

2. $93 \mathrm{E}+02$

2. $94 \mathrm{E}+02$

$2.94 \mathrm{E}+02$

2. $95 \mathrm{E}+02$

2. $95 \mathrm{E}+02$

2. $96 \mathrm{E}+02$

$2.96 \mathrm{E}+02$

2. $97 \mathrm{E}+02$

2. $97 \mathrm{E}+02$

2. $98 \mathrm{E}+02$

$2.98 \mathrm{E}+02$

$2.99 \mathrm{E}+02$

2. $99 \mathrm{E}+02$

$3.00 \mathrm{E}+02$

$3.00 \mathrm{E}+02$

3. $01 \mathrm{E}+02$

3. $01 \mathrm{E}+02$

$3.02 \mathrm{E}+02$

$3.02 \mathrm{E}+02$

$3.03 \mathrm{E}+02$

$3.04 \mathrm{E}+02$

$3.04 \mathrm{E}+02$

$3.05 \mathrm{E}+02$

$3.05 \mathrm{E}+02$

$3.06 \mathrm{E}+02$

$3.06 \mathrm{E}+02$
Dose statistics at graphical times, mrem/yr

\begin{tabular}{|c|c|c|c|c|c|c|c|}
\hline $\mathrm{m}$ & aximum & lea & edi & $0 \%$ & & & \\
\hline $10 \mathrm{E}-32$ & $1.06 \mathrm{E}-06$ & $8.66 \mathrm{E}-09$ & $4.02 \mathrm{E}-11$ & $1.41 \mathrm{E}-08$ & $3.46 \mathrm{E}-08$ & 08 & 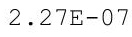 \\
\hline-32 & $1.07 E-06$ & $8.79 E-09$ & $4.31 \mathrm{E}-11$ & $1.43 E-08$ & $1 E-08$ & $94 E-08$ & $0 E-07$ \\
\hline-32 & $08 E-06$ & $92 E-09$ & $62 \mathrm{E}-11$ & $45 E-08$ & $7 E-08$ & $8 E-08$ & $3 E-07$ \\
\hline-32 & $09 E-06$ & $05 \mathrm{~F}-09$ & $97 \mathrm{~F}-11$ & $48 \mathrm{E}-08$ & $63 F-08$ & -08 & $36 \mathrm{~F}-07$ \\
\hline-32 & 06 & 9 & $5.30 \mathrm{E}-11$ & 8 & 8 & 8 & 07 \\
\hline 32 & & & & & & & 07 \\
\hline $10 \mathrm{E}-32$ & $1.13 \mathrm{E}-06$ & & & & & & $4 E-07$ \\
\hline-32 & 06 & 9 & $\perp$ & 8 & 8 & 8 & $E-07$ \\
\hline-32 & $1.15 \mathrm{E}-06$ & $4 E-09$ & -11 & 1.62 & $2 E-08$ & -08 & $E-07$ \\
\hline$E-32$ & $16 \mathrm{E}-06$ & תم תم & $14 \mathrm{~F}-11$ & 65 & 8 & 10 & 7 \\
\hline 32 & 06 & & & & & & 7 \\
\hline $11 \mathrm{E}-32$ & $1.19 \mathrm{E}-06$ & $2=$ & 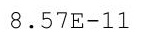 & 1 . & & 7 & 07 \\
\hline $11 \mathrm{E}-32$ & $1.20 \mathrm{E}-06$ & & & $1.73 E-08$ & & & $2 E-07$ \\
\hline $11 E-32$ & $1.21 \mathrm{E}-06$ & 1. $05 \mathrm{E}-08$ & $9.53 \mathrm{E}-11$ & $1.76 \mathrm{E}-08$ & & $1.06 \mathrm{E}-07$ & $2.65 \mathrm{E}-07$ \\
\hline-32 & 1.2 & -08 & & 0 & 0 & -07 & $9 E-07$ \\
\hline 32 & 1.201 & 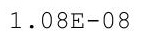 & & 1.81 & קתمת & תم: & $.72 E-07$ \\
\hline 2 & $\perp \cdot$ & & & & & & \\
\hline 32 & 1 . & 1.11E-08 & & $1.87 \mathrm{E}-08$ & $52 E-08$ & $1.12 \mathrm{E}-07$ & 7 \\
\hline $11 \mathrm{E}-32$ & $1.27 \mathrm{E}-06$ & $1.12 \mathrm{E}-08$ & $1.21 \mathrm{E}-10$ & $1.90 \mathrm{E}-08$ & $.60 \mathrm{E}-08$ & $1.13 E-07$ & $2.82 E-07$ \\
\hline $11 \mathrm{E}-32$ & $1.28 \mathrm{E}-06$ & $.14 \mathrm{E}-08$ & 1. $27 \mathrm{E}-10$ & $1.94 \mathrm{E}-08$ & $4.67 \mathrm{E}-$ & $1.15 \mathrm{E}-07$ & $2.86 \mathrm{E}-07$ \\
\hline-32 & 1.2 & & & 8 & & -07 & $9 E-07$ \\
\hline 32 & & & & & & & -07 \\
\hline-32 & 1.321 & $\cdot+$ & & 2 & 8 & & -07 \\
\hline $11 E-32$ & 1.3 & $1.20 \mathrm{E}-08$ & 1. $60 \mathrm{E}-10$ & $2.06 \mathrm{E}-08$ & $4.96 \mathrm{E}-08$ & 1 & -07 \\
\hline 2 & 6 & 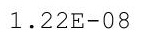 & 1. $69 \mathrm{E}-10$ & B & 3 & 7 & -07 \\
\hline $11 \mathrm{E}-32$ & $1.36 \mathrm{E}-06$ & $1.24 \mathrm{E}-08$ & 1 & 135 & 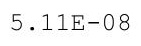 & $.24 \mathrm{E}-07$ & $07 E-07$ \\
\hline $11 \mathrm{E}-32$ & $1.37 \mathrm{E}-06$ & 1. $25 \mathrm{E}-08$ & & & & $.25 E-07$ & $.11 \mathrm{E}-07$ \\
\hline & & & & & & & \\
\hline 32 & & $1.29 E-00$ & & 0 & 8 & & -07 \\
\hline $12 E-32$ & $1.41 E-06$ & $1.30 \pm-00$ & $2 \cdot 19 E-10$ & $2.27 E-08$ & $.43 E-08$ & $\begin{array}{c}1.30 \mathrm{E}-0 t \\
\text { t }\end{array}$ & $3.22 \mathrm{E}-07$ \\
\hline $12 \mathrm{E}-32$ & $1.42 \mathrm{E}-06$ & $1 \cdot 3<5-00$ & $2 \cdot 295-10$ & 2.000 & 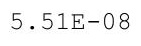 & $1 \cdot 3<\mathrm{E}-\mathrm{t}$ & $.26 E-07$ \\
\hline 2 & 6 & $5 \cdot 0$ & 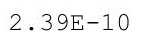 & 2.0 & & $2 \cdot 00$ & $30 E-07$ \\
\hline $12 F-32$ & $145 F-06$ & $136 \Gamma$ & 0 & & & & $4 \mathrm{E}-07$ \\
\hline 2 & & & & & & 7 & \\
\hline-32 & & & & & & -07 & \\
\hline $12 E-32$ & $1.49 \mathrm{E}-06$ & $1.41 \mathrm{E}-08$ & $2.82 E-10$ & $2 \cdot 30 \mathrm{D}$ & 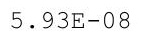 & -07 & $E-07$ \\
\hline $12 \mathrm{E}-32$ & $1.50 E-06$ & $1.40 \pm-00$ & $2 \cdot 94 \mathrm{E}-10$ & & & & $3.48 \mathrm{E}-07$ \\
\hline $12 E-32$ & $1.51 \mathrm{E}-06$ & 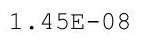 & & & & & $3.52 \mathrm{E}-07$ \\
\hline 2 & 6 & $+\cdots$ & 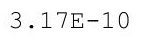 & 8 & 8 & 7 & 07 \\
\hline 2 & 1 & & & & & & 07 \\
\hline $2 E-32$ & 6 & $1.51 \mathrm{E}$ & $E-10$ & 2 . & & 07 & -07 \\
\hline $2 E-32$ & $1.57 \mathrm{E}-$ & 1.5 & -10 & 2 . & B & 07 & -07 \\
\hline & $1.58 \mathrm{E}$ & & & & & & -07 \\
\hline & 1.094 & 1. & ( & - & $52 E-08$ & $1.55 \mathrm{E}-07$ & $74 E-07$ \\
\hline $2 \pm-22$ & $1.01 \mathrm{H}$ & 土. & & & & 土.0. & $78 E-07$ \\
\hline $2 \mathrm{E}-32$ & $1.62 \mathrm{E}-06$ & $.60 E-08$ & $07 E-10$ & $E-08$ & $E-08$ & $8 E-07$ & -07 \\
\hline
\end{tabular}


RESRAD-OFFSITE, Version 2.5

$\mathrm{T}^{1 / 2}$ Limit $=180$ days

robabilistic Dose and Risk Report

Title : Offsite Resident Farmer Deterministic Run

File : RF TC99 DOESG FWD-FV2b.ROF

Summary of dose at graphical times, reptition 2 (continued)

Time

Years

$3.07 \mathrm{E}+02$

$3.07 \mathrm{E}+02$

$3.08 \mathrm{E}+02$

$3.08 \mathrm{E}+02$

$3.09 \mathrm{E}+02$

$3.09 \mathrm{E}+02$

$3.10 \mathrm{E}+02$

$3.10 \mathrm{E}+02$

$3.11 \mathrm{E}+02$

$3.11 \mathrm{E}+02$

3. $12 \mathrm{E}+02$

3. $12 \mathrm{E}+02$

$3.13 \mathrm{E}+02$

$3.13 \mathrm{E}+02$

$3.14 \mathrm{E}+02$

$3.14 \mathrm{E}+02$

$3.15 \mathrm{E}+02$

3. $15 \mathrm{E}+02$

$3.16 \mathrm{E}+02$

$3.16 \mathrm{E}+02$

$3.17 \mathrm{E}+02$

$3.17 \mathrm{E}+02$

$3.18 \mathrm{E}+02$

$3.18 \mathrm{E}+02$

$3.19 \mathrm{E}+02$

$3.19 \mathrm{E}+02$

$3.20 \mathrm{E}+02$

$3.20 \mathrm{E}+02$

$3.21 \mathrm{E}+02$

$3.21 \mathrm{E}+02$

$3.22 \mathrm{E}+02$

$3.22 \mathrm{E}+02$

$3.23 \mathrm{E}+02$

$3.24 \mathrm{E}+02$

$3.24 \mathrm{E}+02$

$3.25 \mathrm{E}+02$

$3.25 \mathrm{E}+02$

$3.26 \mathrm{E}+02$

$3.26 \mathrm{E}+02$

$3.27 \mathrm{E}+02$

$3.27 \mathrm{E}+02$

$3.28 \mathrm{E}+02$

$3.28 \mathrm{E}+02$

$3.29 \mathrm{E}+02$

$3.29 \mathrm{E}+02$

$3.30 \mathrm{E}+02$
Dose statistics at graphical times, mrem/yr

\begin{tabular}{|c|c|c|c|c|c|c|c|}
\hline um & aximum & lean & edi & & & & \\
\hline $13 E-32$ & $1.63 \mathrm{E}-06$ & 1. $62 \mathrm{E}-08$ & $4.21 \mathrm{E}-10$ & $1 E-08$ & $6.90 \mathrm{E}-08$ & $1.00 \mathrm{E}-01$ & $3.00 E-01$ \\
\hline $13 E-32$ & $1.65 E-06$ & $1.65 \mathrm{E}-08$ & $4.35 \mathrm{E}-10$ & $6 \mathrm{E}-08$ & -08 & $1.61 \mathrm{E}-07$ & $0 E-07$ \\
\hline-32 & $1.66 \mathrm{E}-06$ & 1. $67 \mathrm{E}-08$ & $4.48 \mathrm{E}-10$ & $1 E-08$ & $10 \mathrm{E}-08$ & $1.63 E-07$ & $93 E-07$ \\
\hline $13 E-32$ & $67 E-06$ & $69 F-08$ & $64 \mathrm{~F}-10$ & $E-08$ & -08 & -07 & $97 F-07$ \\
\hline-32 & 1.69 & 8 & 0 & 8 & 8 & 7 & -07 \\
\hline 32 & 1.701 & 8 & & & & & 07 \\
\hline $13 E-32$ & $1.72 \mathrm{E}-06$ & $1.75 \mathrm{E}-08$ & & & & & -07 \\
\hline-32 & $1.73 \mathrm{E}$ & 0 & 0 & 8 & 8 & 1 & $E-07$ \\
\hline $13 E-32$ & $1.74 \mathrm{E}-06$ & $1.79 \mathrm{E}-08$ & $E-10$ & $8 E-08$ & $71 E-08$ & $E-07$ & $E-07$ \\
\hline $3 E-32$ & $1.76 \mathrm{E}-06$ & $82 \mathrm{~F}-1 \mathrm{r}$ & $61 E-10$ & 8 & ברקט & $775-8$ & 7 \\
\hline 32 & 1.77 & 1 & & & & -07 & 07 \\
\hline $13 E-32$ & $1.79 \mathrm{E}-06$ & $1.86 \mathrm{E}$ & & 8 & & 7 & 07 \\
\hline $13 E-32$ & $1.80 \mathrm{E}-06$ & $1.88 \mathrm{E}-08$ & & & & $1.83 E-07$ & $E-07$ \\
\hline $13 E-32$ & $1.81 \mathrm{E}-06$ & 1. $91 \mathrm{E}-08$ & $6.45 \mathrm{E}-10$ & & & $1.85 \mathrm{E}-07$ & $.38 E-07$ \\
\hline-32 & $1.83 \mathrm{~F}$ & $.93 E-08$ & -10 & & & -07 & $E-07$ \\
\hline 32 & 1.84 & $\perp$ & 0 & 0 & 8 & 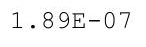 & $46 E-07$ \\
\hline 32 & $\perp \cdot c$ & 1. $98 \mathrm{E}-08$ & & & & $1.91 \mathrm{E}-07$ & 7 \\
\hline 32 & 1 . & 2 & 7. $23 E-10$ & & & 1.93E-07 & 7 \\
\hline $14 \mathrm{E}-32$ & $1.89 \mathrm{E}-06$ & $2.02 E-08$ & $7.45 \mathrm{E}-10$ & $.90 E-08$ & $8.87 E-08$ & 1. $95 \mathrm{E}-0$ & $.59 E-07$ \\
\hline $14 \mathrm{E}-32$ & $1.90 \mathrm{E}-06$ & $2.05 E-08$ & $.66 \mathrm{E}-10$ & $6 E-08$ & תمי & $E-07$ & $63 E-07$ \\
\hline-32 & $1.91 \mathrm{~F}$ & 0 & & & & $.98 \mathrm{E}-\mathrm{C}$ & $E-07$ \\
\hline 32 & 06 & & & & & & -07 \\
\hline 32 & 1.94 & $2 \cdot 1$ & & & & & -07 \\
\hline-32 & 1.9 & 2 & 0 & 0 & 0 & & -07 \\
\hline 2 & 6 & 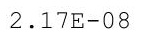 & 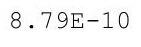 & 8 & P & 皮 & $85 E-07$ \\
\hline $14 \mathrm{E}-32$ & $1.99 \mathrm{E}-06$ & م 10 & 1 & $31=$ & ברטק & $2.08 \mathrm{E}-0$ & $.89 E-07$ \\
\hline$E-32$ & $2.00 \mathrm{E}-06$ & $2.22 E-08$ & $E-10$ & & & م תم & $93 E-07$ \\
\hline & & & & & & & \\
\hline 32 & 2.03 & 2.2 & & & 7 & & -07 \\
\hline $14 \mathrm{E}-32$ & $2.05 E-06$ & $2.00+00$ & $1.005-09$ & $4.56 \mathrm{E}-08$ & $\pm \cdot 0<+$ & $2 \cdot+10$ r & $.07 E-07$ \\
\hline $14 \mathrm{E}-32$ & $2.06 \mathrm{E}-06$ & $2.02+40$ & $.035-42$ & $1.0<1$ & 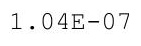 & 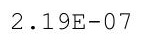 & $.11 \mathrm{E}-07$ \\
\hline 2 & 6 & 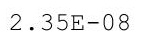 & 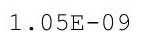 & te & 工象 & 年 & $.16 \mathrm{E}-07$ \\
\hline 32 & $90 F-06$ & $2375-08$ & $3 E-09$ & & & & $0 E-07$ \\
\hline 2 & & & & & & & \\
\hline-32 & & & & & & & \\
\hline $15 \mathrm{E}-32$ & $2.14 \mathrm{E}-06$ & $2.46 E-08$ & $1.15 \mathrm{E}-09$ & $4.20 \mathrm{~L}$ & 10 & $2.30 \mathrm{D}$ & $34 \mathrm{E}-07$ \\
\hline $15 E-32$ & $2 \cdot 15 E-06$ & $2.40 \pm-00$ & & $4.96 \mathrm{E}-08$ & & & $5.39 \mathrm{E}-07$ \\
\hline-32 & $2.17 \mathrm{E}-06$ & $\begin{array}{ccc}2.0+1 & 0\end{array}$ & & & & & $5.43 E-07$ \\
\hline 2 & 6 & 2.0 & 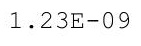 & 8 & 7 & 5 & 07 \\
\hline & 2 & & & & & & 07 \\
\hline$E-32$ & $2.21 E-06$ & $2.59 \mathrm{E}-08$ & 1 . & 8 & & 7 & -07 \\
\hline$E-32$ & $2.23 E-$ & $2.62 \mathrm{E}$ & 1.3 & & & & -07 \\
\hline & 6 & & & & & & -07 \\
\hline 2 & 2.200 & 2.00 & $1.375-09$ & $2+\infty$ & $\perp \cdot 20 \mathrm{~L}$ & 7 & $5.72 \mathrm{E}-07$ \\
\hline $35-2 Z$ & 2.210 & 2. & & & & & $76 E-07$ \\
\hline 32 & $E-06$ & $E-08$ & 1. $43 \mathrm{E}-09$ & $E-08$ & $.23 E-07$ & $.51 E-07$ & -07 \\
\hline
\end{tabular}


RESRAD-OFFSITE, Version 2.5

$\mathrm{T}^{1 / 2}$ Limit $=180$ days

Title : Offsite Resident Farmer Deterministic Run

File : RF TC99 DOESG FWD-FV2b.ROF

Summary of dose at graphical times, reptition 2 (continued)

Time

Years

$3.30 \mathrm{E}+02$

$3.31 \mathrm{E}+02$

$3.31 \mathrm{E}+02$

$3.32 \mathrm{E}+02$

$3.32 \mathrm{E}+02$

$3.33 \mathrm{E}+02$

3. $33 \mathrm{E}+02$

3. $34 \mathrm{E}+02$

3. $34 \mathrm{E}+02$

3. $35 \mathrm{E}+02$

3. $35 \mathrm{E}+02$

3. $36 \mathrm{E}+02$

3. $36 \mathrm{E}+02$

3. $37 \mathrm{E}+02$

$3.37 \mathrm{E}+02$

3. $38 \mathrm{E}+02$

$3.38 \mathrm{E}+02$

$3.39 \mathrm{E}+02$

3. $39 \mathrm{E}+02$

3. $40 \mathrm{E}+02$

$3.40 \mathrm{E}+02$

$3.41 \mathrm{E}+02$

$3.41 \mathrm{E}+02$

3. $42 \mathrm{E}+02$

$3.42 \mathrm{E}+02$

3. $43 \mathrm{E}+02$

$3.44 \mathrm{E}+02$

$3.44 \mathrm{E}+02$

$3.45 \mathrm{E}+02$

$3.45 \mathrm{E}+02$

$3.46 \mathrm{E}+02$

$3.46 \mathrm{E}+02$

$3.47 \mathrm{E}+02$

$3.47 \mathrm{E}+02$

$3.48 \mathrm{E}+02$

$3.48 \mathrm{E}+02$

$3.49 \mathrm{E}+02$

3. $49 \mathrm{E}+02$

$3.50 \mathrm{E}+02$

$3.50 \mathrm{E}+02$

$3.51 \mathrm{E}+02$

3. $51 \mathrm{E}+02$

$3.52 \mathrm{E}+02$

$3.52 \mathrm{E}+02$

3. $53 \mathrm{E}+02$

$3.53 \mathrm{E}+02$
Dose statistics at graphical times, mrem/yr

\begin{tabular}{|c|c|c|c|c|c|c|c|}
\hline $\mathrm{m}$ & aximum & lea & ec & & & $\%$ & \\
\hline $15 \mathrm{E}-32$ & $2.30 \mathrm{E}-06$ & $2.77 \mathrm{E}-08$ & 1. $47 \mathrm{E}-09$ & $E-08$ & $1.24 \mathrm{E}-07$ & $.53 E-07$ & $.00 E-01$ \\
\hline-32 & $2.32 E-06$ & $2.80 \mathrm{E}-08$ & $1.50 \mathrm{E}-09$ & $7 E-08$ & $1.26 \mathrm{E}-07$ & $2.55 E-07$ & $1 E-07$ \\
\hline-32 & $33 E-06$ & $83 E-08$ & $54 E-09$ & $4 E-08$ & $27 E-07$ & $58 E-07$ & $96 E-07$ \\
\hline$E-32$ & $35 E-06$ & $86 \mathrm{~F}-08$ & $.57 \mathrm{E}-09$ & $80 \mathrm{E}-08$ & $.29 \mathrm{E}-07$ & $605-07$ & $00=-07$ \\
\hline-32 & 06 & 8 & 9 & 8 & 7 & 7 & 07 \\
\hline 32 & & & & & & & 07 \\
\hline $16 \mathrm{E}-32$ & $2.39 \mathrm{E}-06$ & & & & & & $E-07$ \\
\hline-32 & -06 & 0 & -09 & 8 & 7 & -07 & $E-07$ \\
\hline $16 \mathrm{E}-32$ & $2.42 \mathrm{E}-06$ & -08 & $5 E-09$ & -08 & $1.36 \mathrm{E}-07$ & -07 & $5 E-07$ \\
\hline$E-32$ & $44 E-06$ & 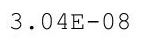 & $1.79 \mathrm{E}-$ & 8 & $37 F_{-}$ & $72 F-0$ & 7 \\
\hline 32 & 06 & & & & & 7 & 07 \\
\hline $16 \mathrm{E}-32$ & $2.47 E-06$ & $3.11 \mathrm{E}-08$ & $1.86 \mathrm{E}-09$ & 8 & Q & 7 & 07 \\
\hline $16 \mathrm{E}-32$ & $2.49 E-06$ & $3.14 \mathrm{E}-08$ & $1.90 \mathrm{E}-09$ & & $1.41 \mathrm{E}-07$ & $2.80 E-07$ & $5 E-07$ \\
\hline $16 \mathrm{E}-32$ & $2.50 \mathrm{E}-06$ & $3.17 \mathrm{E}-08$ & 1. $94 \mathrm{E}-09$ & $6.51 \mathrm{E}-08$ & $1.43 \mathrm{E}-07$ & $2.83 E-07$ & $E-07$ \\
\hline-32 & $52 \mathrm{E}-06$ & $E-08$ & -09 & 8 & 4 & $E-07$ & $E-07$ \\
\hline 32 & 2.00 & $3.24 E-08$ & $2.01 \mathrm{E}-$ & 0 & 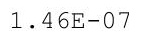 & תחק & 07 \\
\hline 2 & & & & & & & \\
\hline 32 & 2 & $3.30 E-08$ & 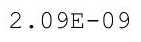 & & $1.49 \mathrm{E}-07$ & $2.94 \mathrm{E}-07$ & 7 \\
\hline $16 \mathrm{E}-32$ & $2.58 \mathrm{E}-06$ & $3.34 \mathrm{E}-08$ & $2.13 E-09$ & $6.90 \mathrm{E}-08$ & $1.50 \mathrm{E}-07$ & $2.96 \mathrm{E}-0$ & $.76 \mathrm{E}-07$ \\
\hline$E-32$ & $2.59 \mathrm{E}-06$ & $.37 E-08$ & $2.17 \mathrm{E}-09$ & $8 E-08$ & $1.52 \mathrm{E}-$ & $2.99 \mathrm{E}-07$ & $.81 E-07$ \\
\hline-32 & 06 & & 9 & & & -0 & $E-07$ \\
\hline 32 & 06 & & & & & & -07 \\
\hline-32 & $2.045-00$ & 3. & $2 \cdot 2$ & & I & & -07 \\
\hline-32 & 2.6 & $u$ & 2. & 0 & 7 & & -07 \\
\hline 2 & 6 & $3.54 \mathrm{E}-08$ & y & 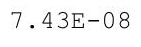 & 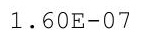 & 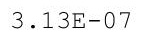 & $07 E-07$ \\
\hline $17 E-32$ & $.69 E-06$ & م 50 口 & $2.42 \mathrm{E}-09$ & 535 & $161 \pi$ & $6 E-0$ & $12 \mathrm{E}-07$ \\
\hline $17 E-32$ & $2.70 \mathrm{E}-06$ & & $2.46 \mathrm{E}-09$ & & & م ת & $17 E-07$ \\
\hline & & & & & & & \\
\hline 32 & 6 & 3.0 & & 0 & 7 & & -07 \\
\hline $17 E-32$ & $2.75 E-06$ & $\begin{array}{ll}.12+0 \\
0\end{array}$ & $2.6 \angle E-09$ & $7.92 \mathrm{E}-08$ & $\begin{array}{lll} \\
0\end{array}$ & . & $.32 E-07$ \\
\hline $17 \mathrm{E}-32$ & $2.77 E-06$ & . & $2.66 \mathrm{E}-09$ & (- & म.095- & 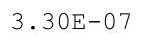 & $.36 E-07$ \\
\hline 2 & 6 & 年 & - 50 & 年 & 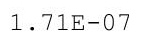 & 然 & $.41 E-07$ \\
\hline$F-32$ & $80 F-06$ & $\pi$ & $2.76 \mathrm{E}-09$ & & & & $46 E-07$ \\
\hline 2 & & & & & & & \\
\hline-32 & & & & & & & \\
\hline $17 E-32$ & $2.85 E-06$ & $3.945-00$ & $2.92 E-09$ & $0.0<\mathrm{L}$ & $\perp \cdot / \mathrm{E}$ & 1 & $61 E-07$ \\
\hline $17 E-32$ & $2.80 E-00$ & . 90 प & $2.97 \mathrm{E}-09$ & & 土. & & $7.66 \mathrm{E}-07$ \\
\hline $17 E-32$ & $2.88 E-06$ & & & & $1.00 \mathrm{~L}-\mathrm{t}$ & & $7.71 \mathrm{E}-07$ \\
\hline 2 & 6 & t & 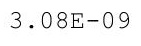 & 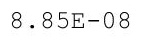 & t & 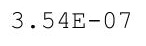 & 07 \\
\hline 2 & & & & & & & \\
\hline $8 E-32$ & $2.92 E$ & 4.1 & -09 & 9 & 1 & 7 & $7 E-07$ \\
\hline $8 E-32$ & $2.94 \mathrm{E}-$ & 4. & 3. & & 1 . & & $2 E-07$ \\
\hline & 6 & & & & & & -07 \\
\hline 2 & 2.01 & 1.200 & J- & 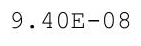 & $1.90 \mathrm{E}-07$ & 7 & $02 E-07$ \\
\hline $0 x-2 z$ & $2.99 E-06$ & & & 8 & & & $8.07 E-07$ \\
\hline$E-32$ & $3.00 \mathrm{E}-06$ & $3 E-08$ & $47 E-09$ & $E-08$ & $93 E-07$ & $5 E-07$ & -07 \\
\hline
\end{tabular}


RESRAD-OFFSITE, Version 2.5

$\mathrm{T}^{1 / 2}$ Limit $=180$ days

obabilistic Dose and Risk Report

Title : Offsite Resident Farmer Deterministic Run

File : RF TC99 DOESG FWD-FV2b.ROF

Summary of dose at graphical times, reptition 2 (continued)

Time

Years

$3.54 \mathrm{E}+02$

$3.54 \mathrm{E}+02$

$3.55 \mathrm{E}+02$

$3.55 \mathrm{E}+02$

$3.56 \mathrm{E}+02$

3. $56 \mathrm{E}+02$

$3.57 \mathrm{E}+02$

3. $57 \mathrm{E}+02$

3. $58 \mathrm{E}+02$

3. $58 \mathrm{E}+02$

$3.59 \mathrm{E}+02$

3. $59 \mathrm{E}+02$

3. $60 \mathrm{E}+02$

$3.60 E+02$

3. $61 \mathrm{E}+02$

3. $61 \mathrm{E}+02$

3. $62 \mathrm{E}+02$

3. $62 \mathrm{E}+02$

$3.63 \mathrm{E}+02$

3. $64 \mathrm{E}+02$

3. $64 \mathrm{E}+02$

$3.65 \mathrm{E}+02$

$3.65 \mathrm{E}+02$

$3.66 \mathrm{E}+02$

$3.66 \mathrm{E}+02$

$3.67 \mathrm{E}+02$

3. $67 \mathrm{E}+02$

$3.68 \mathrm{E}+02$

$3.68 \mathrm{E}+02$

$3.69 \mathrm{E}+02$

3. $69 \mathrm{E}+02$

$3.70 \mathrm{E}+02$

3. $70 \mathrm{E}+02$

$3.71 \mathrm{E}+02$

$3.71 \mathrm{E}+02$

3. $72 \mathrm{E}+02$

3. $72 \mathrm{E}+02$

$3.73 E+02$

$3.73 E+02$

$3.74 \mathrm{E}+02$

$3.74 \mathrm{E}+02$

$3.75 E+02$

$3.75 \mathrm{E}+02$

$3.76 \mathrm{E}+02$

$3.76 \mathrm{E}+02$

$3.77 \mathrm{E}+02$
Dose statistics at graphical times, mrem/yr

\begin{tabular}{|c|c|c|c|c|c|c|c|}
\hline m & um & ean & 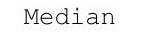 & & & $\%$ & $\%$ \\
\hline $18 \mathrm{E}-32$ & $3.02 E-06$ & $4.37 E-08$ & $3.53 E-09$ & $9.72 \mathrm{E}-08$ & $1.95 \mathrm{E}-07$ & $3.10 \mathrm{E}-01$ & -01 \\
\hline $95 E-32$ & -06 & -08 & -09 & 08 & 07 & -07 & -07 \\
\hline $96 \mathrm{E}-32$ & $3.05 \mathrm{E}-06$ & $4.45 \mathrm{E}-08$ & $54 E-09$ & $9.96 \mathrm{E}-08$ & $1.98 \mathrm{E}-07$ & $3.85 E-07$ & $8.28 \mathrm{E}-07$ \\
\hline $97 E-32$ & $3.07 E-06$ & $4.49 \mathrm{E}-08$ & $3.70 \mathrm{E}-09$ & $1.01 \mathrm{E}-07$ & $2.00 \mathrm{E}-07$ & $.88 E-07$ & $.33 E-07$ \\
\hline 2 & 6 & $4.53 E-08$ & $6 F-09$ & 7 & $2.01 \mathrm{E}-07$ & 7 & 07 \\
\hline-32 & 6 & $4.57 \mathrm{E}-08$ & 9 & in & & 7 & -07 \\
\hline $.00 E-32$ & 06 & & & & & 7 & -07 \\
\hline $.01 E-32$ & & & & & & & -07 \\
\hline-31 & -06 & $\mathrm{~g}-08$ & -09 & 7 & 7 & -07 & $E-07$ \\
\hline $3 E-31$ & -06 & 10 & -09 & ( & 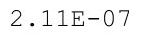 & -07 & -07 \\
\hline$E-31$ & 06 & 5 & 9 & $09 F-07$ & $13 E-07$ & $F$ & -07 \\
\hline 31 & 3 & & & & & & 07 \\
\hline$E-31$ & 3,2 & 4 & 9 & 7 & 2 & 7 & -07 \\
\hline $.90 E-31$ & $3.23 \mathrm{E}-06$ & $4.91 \mathrm{E}-08$ & $4.41 \mathrm{E}-09$ & $1.12 \mathrm{E}-07$ & $2.19 E-07$ & $4.20 \mathrm{E}-07$ & $8.85 E-07$ \\
\hline $91 E-31$ & -06 & $E-08$ & -09 & 1 & & (1) & -07 \\
\hline 31 & & & & & & & \\
\hline 1 & 06 & 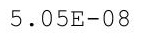 & 9 & $1.15 E-07$ & 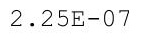 & & 07 \\
\hline 31 & 6 & & & & & & 7 \\
\hline $98 E-31$ & $3.30 \mathrm{E}-06$ & $\Gamma_{0}$ & $1 E-09$ & Г⿸厂 & $2.29 \mathrm{E}-$ & 急 & -07 \\
\hline $.00 E-31$ & $2 E-06$ & $.18 \mathrm{E}-08$ & $4.89 \mathrm{E}-09$ & $1.18 \mathrm{E}-$ & $2.31 \mathrm{E}-$ & $E-0$ & $.17 \mathrm{E}-07$ \\
\hline $.02 \mathrm{E}-31$ & $3.34 \mathrm{E}-06$ & $5.23 E-08$ & $4.97 \mathrm{E}-09$ & $1 \cdot 19 E-U 1$ & $2.33 E-0$ & $E-0$ & $22 E-07$ \\
\hline 31 & & & & & & & -07 \\
\hline 1 & & & & & & & 07 \\
\hline $.07 E-31$ & $\cdot$ & . & & $\perp \cdot 20$ & & & -07 \\
\hline $99 E-31$ & 6 & . & 9 & 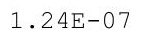 & 2 & ( & -07 \\
\hline $11 E-31$ & $.41 E-06$ & . & $4 E-09$ & $125 \pi$ & 2 & $1 E-0$ & $49 E-07$ \\
\hline$E-31$ & $3 F-06$ & $5-0$ & -09 & $126 \mathrm{~F}$ & $2.48 \mathrm{E}-$ & $.65 E-0$ & $54 \mathrm{E}-07$ \\
\hline-31 & 06 & 8 & & & & & -07 \\
\hline & 06 & & & & & & 07 \\
\hline $18 E-31$ & $3.48 E-06$ & $.04+00$ & $5.70 E-09$ & $\perp \cdot 2 y$ & $\angle .00 \mathrm{~L}$ & . & -07 \\
\hline $20 E-31$ & $3.495-00$ & . & $5.79 \mathrm{E}-09$ & $1.30 \mathrm{E}-07$ & 2.000 & 4. & $.76 E-07$ \\
\hline $21 \mathrm{E}-31$ & $3.51 \mathrm{E}-06$ & 然 & 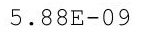 & 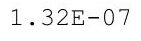 & & $x^{2}=-2$ & $9.81 \mathrm{E}-07$ \\
\hline 1 & $3.52 \mathrm{E}-06$ & & & $1.33 E-$ & & & $87 E-07$ \\
\hline-31 & $5-06$ & & $E-09$ & & & 7 & 7 \\
\hline 31 & & & & & & & \\
\hline $9 E-31$ & $3.57 \mathrm{E}-06$ & $5.93 E-08$ & 09 & $1.30 \mathrm{E}$ & 2. & & -06 \\
\hline$E-31$ & . & 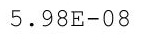 & & 1.37 & & & -06 \\
\hline $33 E-31$ & & & & & & & $1.01 \mathrm{~L}-00$ \\
\hline 1 & 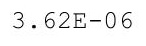 & & 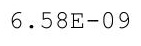 & 7 & 2 & $t$ & 06 \\
\hline $.36 E-31$ & & & & & & & 6 \\
\hline 31 & & 8 & & 1 & & 7 & \\
\hline$E-31$ & $3.67 \mathrm{E}-06$ & 6 & 09 & 1.44 & 2 & 07 & -06 \\
\hline & & & & & & & \\
\hline & & & & $\perp \cdot 100$ & & & $1.05 E-06$ \\
\hline & & 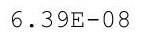 & & 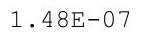 & 7 & E-07 & $1.05 E-06$ \\
\hline$E-31$ & $3 E-06$ & $4 E-08$ & $28 E-09$ & $E-07$ & $4 E-07$ & $1 E-07$ & -06 \\
\hline
\end{tabular}


RESRAD-OFFSITE, Version 2.5

$\mathrm{T}^{1 / 2}$ Limit $=180$ days

obabilistic Dose and Risk Report

Title : Offsite Resident Farmer Deterministic Run

File : RF TC99 DOESG FWD-FV2b.ROF

Summary of dose at graphical times, reptition 2 (continued)

Time

Years

$3.77 \mathrm{E}+02$

$3.78 \mathrm{E}+02$

$3.78 \mathrm{E}+02$

3. $79 \mathrm{E}+02$

$3.79 \mathrm{E}+02$

$3.80 \mathrm{E}+02$

$3.80 \mathrm{E}+02$

3. $81 \mathrm{E}+02$

3. $81 \mathrm{E}+02$

3. $82 \mathrm{E}+02$

3. $82 \mathrm{E}+02$

$3.83 E+02$

$3.83 \mathrm{E}+02$

$3.84 \mathrm{E}+02$

$3.85 \mathrm{E}+02$

$3.85 \mathrm{E}+02$

$3.86 \mathrm{E}+02$

$3.86 \mathrm{E}+02$

$3.87 \mathrm{E}+02$

$3.87 \mathrm{E}+02$

$3.88 \mathrm{E}+02$

$3.88 \mathrm{E}+02$

$3.89 \mathrm{E}+02$

$3.89 \mathrm{E}+02$

3. $90 \mathrm{E}+02$

$3.90 \mathrm{E}+02$

3. $91 \mathrm{E}+02$

3. $91 \mathrm{E}+02$

3. $92 \mathrm{E}+02$

3. $92 \mathrm{E}+02$

3. $93 \mathrm{E}+02$

$3.93 \mathrm{E}+02$

3. $94 \mathrm{E}+02$

3. $94 \mathrm{E}+02$

$3.95 \mathrm{E}+02$

3. $95 \mathrm{E}+02$

$3.96 \mathrm{E}+02$

$3.96 \mathrm{E}+02$

$3.97 \mathrm{E}+02$

$3.97 \mathrm{E}+02$

$3.98 \mathrm{E}+02$

$3.98 \mathrm{E}+02$

$3.99 \mathrm{E}+02$

3. $99 \mathrm{E}+02$

$4.00 \mathrm{E}+02$

$4.00 \mathrm{E}+02$
Dose statistics at graphical times, mrem/yr

\begin{tabular}{|c|c|c|c|c|c|c|c|}
\hline Minimum & Maximum & Mean & Median & $90 \%$ & $95 \%$ & $97.5 \%$ & $99 \%$ \\
\hline $1.27 \mathrm{E}-30$ & $3.74 \mathrm{E}-06$ & $6.49 E-08$ & $7.39 E-09$ & $1.50 \mathrm{E}-07$ & $2.96 E-07$ & $5.35 E-07$ & $1.06 \mathrm{E}-06$ \\
\hline 1. $27 \mathrm{E}-30$ & $3.76 \mathrm{E}-06$ & $6.54 \mathrm{E}-08$ & $7.49 \mathrm{E}-09$ & $1.51 \mathrm{E}-07$ & $2.99 \mathrm{E}-07$ & $5.38 E-07$ & $1.07 \mathrm{E}-06$ \\
\hline $1.28 \mathrm{E}-30$ & $3.77 \mathrm{E}-06$ & $6.59 \mathrm{E}-08$ & $7.61 \mathrm{E}-09$ & $1.53 \mathrm{E}-07$ & $3.02 \mathrm{E}-07$ & $5.42 \mathrm{E}-07$ & $1.07 \mathrm{E}-06$ \\
\hline $1.29 \mathrm{E}-30$ & $3.79 E-06$ & $6.65 E-08$ & $7.72 \mathrm{E}-09$ & $1.54 \mathrm{E}-07$ & $3.05 E-07$ & $5.46 \mathrm{E}-07$ & $1.08 E-06$ \\
\hline $1.30 \mathrm{E}-30$ & $3.81 \mathrm{E}-06$ & $6.70 \mathrm{E}-08$ & $7.83 \mathrm{E}-09$ & $1.55 \mathrm{E}-07$ & $3.08 \mathrm{E}-07$ & $5.49 \mathrm{E}-07$ & $1.09 \mathrm{E}-06$ \\
\hline 1. $30 \mathrm{E}-30$ & $3.82 \mathrm{E}-06$ & $6.75 \mathrm{E}-08$ & $7.93 E-09$ & $1.57 \mathrm{E}-07$ & $3.11 \mathrm{E}-07$ & $5.53 \mathrm{E}-07$ & $1.09 \mathrm{E}-06$ \\
\hline 1. $31 \mathrm{E}-30$ & $3.84 \mathrm{E}-06$ & $6.81 E-08$ & $8.05 E-09$ & $1.59 \mathrm{E}-07$ & $3.14 \mathrm{E}-07$ & $5.56 \mathrm{E}-07$ & $1.10 \mathrm{E}-06$ \\
\hline 1. $32 \mathrm{E}-30$ & $3.85 \mathrm{E}-06$ & $6.86 \mathrm{E}-08$ & $8.17 \mathrm{E}-09$ & $1.60 \mathrm{E}-07$ & $3.17 \mathrm{E}-07$ & $5.60 \mathrm{E}-07$ & $1.10 \mathrm{E}-06$ \\
\hline $1.33 E-30$ & $3.87 \mathrm{E}-06$ & $6.91 \mathrm{E}-08$ & $8.28 E-09$ & $1.62 \mathrm{E}-07$ & $3.20 \mathrm{E}-07$ & $5.64 \mathrm{E}-07$ & $1.11 \mathrm{E}-06$ \\
\hline $1.33 E-30$ & $3.88 \mathrm{E}-06$ & $6.97 \mathrm{E}-08$ & $8.39 E-09$ & $1.63 \mathrm{E}-07$ & $3.22 \mathrm{E}-07$ & $5.67 \mathrm{E}-07$ & $1.11 \mathrm{E}-06$ \\
\hline 1. $34 \mathrm{E}-30$ & $3.90 \mathrm{E}-06$ & $7.02 \mathrm{E}-08$ & $8.50 \mathrm{E}-09$ & $1.65 \mathrm{E}-07$ & $3.24 \mathrm{E}-07$ & $5.71 \mathrm{E}-07$ & $1.12 \mathrm{E}-06$ \\
\hline $1.35 \mathrm{E}-30$ & $3.91 E-06$ & $7.08 \mathrm{E}-08$ & $8.61 E-09$ & $1.66 \mathrm{E}-07$ & $3.26 \mathrm{E}-07$ & $5.75 E-07$ & $1.12 \mathrm{E}-06$ \\
\hline $1.36 \mathrm{E}-30$ & $3.93 E-06$ & $7.13 \mathrm{E}-08$ & $8.73 E-09$ & $1.68 \mathrm{E}-07$ & $3.29 \mathrm{E}-07$ & $5.78 \mathrm{E}-07$ & $1.13 \mathrm{E}-06$ \\
\hline 1. $36 \mathrm{E}-30$ & $3.94 \mathrm{E}-06$ & $7.19 \mathrm{E}-08$ & $8.86 \mathrm{E}-09$ & $1.69 \mathrm{E}-07$ & $3.31 E-07$ & $5.82 \mathrm{E}-07$ & $1.14 \mathrm{E}-06$ \\
\hline $1.37 \mathrm{E}-30$ & $3.96 \mathrm{E}-06$ & $7.24 \mathrm{E}-08$ & $8.98 E-09$ & $1.71 \mathrm{E}-07$ & $3.33 E-07$ & $5.86 \mathrm{E}-07$ & $1.14 \mathrm{E}-06$ \\
\hline 1. $38 \mathrm{E}-30$ & $3.97 \mathrm{E}-06$ & $7.30 \mathrm{E}-08$ & $9.10 \mathrm{E}-09$ & $1.72 \mathrm{E}-07$ & $3.35 E-07$ & $5.89 \mathrm{E}-07$ & $1.15 \mathrm{E}-06$ \\
\hline 1. $39 \mathrm{E}-30$ & $3.99 \mathrm{E}-06$ & $7.36 \mathrm{E}-08$ & $9.23 E-09$ & $1.74 \mathrm{E}-07$ & $3.37 \mathrm{E}-07$ & $5.93 E-07$ & $1.15 \mathrm{E}-06$ \\
\hline $1.40 \mathrm{E}-30$ & $4.00 E-06$ & $7.41 E-08$ & $9.37 E-09$ & $1.75 \mathrm{E}-07$ & $3.40 \mathrm{E}-07$ & $5.97 E-07$ & $1.16 \mathrm{E}-06$ \\
\hline 1. $40 \mathrm{E}-30$ & $4.02 \mathrm{E}-06$ & $7.47 \mathrm{E}-08$ & $9.51 \mathrm{E}-09$ & $1.77 \mathrm{E}-07$ & $3.42 \mathrm{E}-07$ & $6.01 \mathrm{E}-07$ & $1.16 \mathrm{E}-06$ \\
\hline $1.41 \mathrm{E}-30$ & $4.03 E-06$ & $7.53 \mathrm{E}-08$ & $9.65 \mathrm{E}-09$ & $1.78 \mathrm{E}-07$ & $3.45 \mathrm{E}-07$ & $6.04 \mathrm{E}-07$ & $1.17 \mathrm{E}-06$ \\
\hline 1. $42 \mathrm{E}-30$ & $4.05 E-06$ & $7.58 \mathrm{E}-08$ & $9.78 \mathrm{E}-09$ & $1.79 \mathrm{E}-07$ & $3.48 \mathrm{E}-07$ & $6.08 E-07$ & $1.17 \mathrm{E}-06$ \\
\hline 1. $43 \mathrm{E}-30$ & $4.06 \mathrm{E}-06$ & $7.64 \mathrm{E}-08$ & $9.91 \mathrm{E}-09$ & $1.81 \mathrm{E}-07$ & $3.51 \mathrm{E}-07$ & $6.12 \mathrm{E}-07$ & $1.18 \mathrm{E}-06$ \\
\hline $1.44 \mathrm{E}-30$ & $4.08 E-06$ & $7.70 \mathrm{E}-08$ & $1.00 \mathrm{E}-08$ & $1.83 E-07$ & $3.53 E-07$ & $6.16 \mathrm{E}-07$ & $1.19 E-06$ \\
\hline $1.56 \mathrm{E}-28$ & $4.09 E-06$ & $7.76 \mathrm{E}-08$ & $1.02 \mathrm{E}-08$ & $1.85 \mathrm{E}-07$ & $3.56 \mathrm{E}-07$ & $6.19 \mathrm{E}-07$ & $1.19 \mathrm{E}-06$ \\
\hline $2.83 E-26$ & $4.11 \mathrm{E}-06$ & $7.82 \mathrm{E}-08$ & $1.03 E-08$ & $1.87 \mathrm{E}-07$ & $3.59 \mathrm{E}-07$ & $6.23 E-07$ & $1.20 \mathrm{E}-06$ \\
\hline 1. $34 \mathrm{E}-24$ & $4.12 \mathrm{E}-06$ & $7.87 \mathrm{E}-08$ & $1.05 \mathrm{E}-08$ & $1.88 \mathrm{E}-07$ & $3.62 \mathrm{E}-07$ & $6.27 E-07$ & $1.20 \mathrm{E}-06$ \\
\hline $3.00 \mathrm{E}-23$ & $4.14 \mathrm{E}-06$ & $7.93 E-08$ & $1.06 \mathrm{E}-08$ & $1.90 \mathrm{E}-07$ & $3.64 \mathrm{E}-07$ & $6.31 E-07$ & $1.21 E-06$ \\
\hline $4.07 \mathrm{E}-22$ & $4.15 \mathrm{E}-06$ & $7.99 \mathrm{E}-08$ & $1.08 \mathrm{E}-08$ & $1.92 \mathrm{E}-07$ & $3.67 \mathrm{E}-07$ & $6.35 E-07$ & $1.21 \mathrm{E}-06$ \\
\hline $3.82 \mathrm{E}-21$ & $4.17 \mathrm{E}-06$ & $8.05 E-08$ & $1.09 \mathrm{E}-08$ & $1.93 \mathrm{E}-07$ & $3.70 \mathrm{E}-07$ & $6.38 \mathrm{E}-07$ & $1.22 E-06$ \\
\hline $2.66 \mathrm{E}-20$ & $4.18 \mathrm{E}-06$ & $8.11 \mathrm{E}-08$ & 1.11E-08 & $1.94 \mathrm{E}-07$ & $3.73 \mathrm{E}-07$ & $6.42 \mathrm{E}-07$ & 1. $22 \mathrm{E}-06$ \\
\hline 1. $46 \mathrm{E}-19$ & $4.20 E-06$ & $8.17 \mathrm{E}-08$ & $1.13 \mathrm{E}-08$ & $1.96 \mathrm{E}-07$ & $3.75 \mathrm{E}-07$ & $6.46 \mathrm{E}-07$ & $1.23 E-06$ \\
\hline $6.59 \mathrm{E}-19$ & $4.21 E-06$ & $8.23 E-08$ & $1.14 \mathrm{E}-08$ & $1.97 \mathrm{E}-07$ & $3.78 E-07$ & $6.50 \mathrm{E}-07$ & $1.24 \mathrm{E}-06$ \\
\hline $2.51 \mathrm{E}-18$ & $4.23 E-06$ & $8.29 E-08$ & $1.16 \mathrm{E}-08$ & 1.99E-07 & $3.80 \mathrm{E}-07$ & $6.53 E-07$ & $1.24 \mathrm{E}-06$ \\
\hline $8.27 \mathrm{E}-18$ & $4.24 \mathrm{E}-06$ & $8.35 \mathrm{E}-08$ & $1.17 \mathrm{E}-08$ & $2.00 \mathrm{E}-07$ & $3.83 E-07$ & $6.56 \mathrm{E}-07$ & $1.25 \mathrm{E}-06$ \\
\hline $2.41 \mathrm{E}-17$ & $4.26 \mathrm{E}-06$ & $8.41 E-08$ & $1.19 \mathrm{E}-08$ & $2.01 E-07$ & $3.85 E-07$ & $6.59 \mathrm{E}-07$ & $1.25 E-06$ \\
\hline $6.35 \mathrm{E}-17$ & $4.27 E-06$ & $8.48 E-08$ & $1.20 \mathrm{E}-08$ & $2.03 E-07$ & $3.88 \mathrm{E}-07$ & $6.62 \mathrm{E}-07$ & $1.26 \mathrm{E}-06$ \\
\hline $1.53 \mathrm{E}-16$ & $4.29 E-06$ & $8.54 \mathrm{E}-08$ & 1.21E-08 & $2.05 E-07$ & $3.90 \mathrm{E}-07$ & $6.65 E-07$ & $1.26 \mathrm{E}-06$ \\
\hline $3.01 \mathrm{E}-16$ & $4.30 \mathrm{E}-06$ & $8.60 \mathrm{E}-08$ & $1.23 \mathrm{E}-08$ & $2.06 \mathrm{E}-07$ & $3.93 E-07$ & $6.68 \mathrm{E}-07$ & $1.27 \mathrm{E}-06$ \\
\hline $5.25 \mathrm{E}-16$ & $4.32 \mathrm{E}-06$ & $8.66 \mathrm{E}-08$ & 1.24E-08 & $2.08 \mathrm{E}-07$ & $3.95 \mathrm{E}-07$ & $6.72 \mathrm{E}-07$ & 1. $28 \mathrm{E}-06$ \\
\hline $8.84 \mathrm{E}-16$ & $4.33 E-06$ & $8.72 \mathrm{E}-08$ & $1.26 \mathrm{E}-08$ & $2.10 \mathrm{E}-07$ & $3.98 \mathrm{E}-07$ & $6.75 E-07$ & $1.28 \mathrm{E}-06$ \\
\hline 1. $44 \mathrm{E}-15$ & $4.35 E-06$ & $8.79 E-08$ & $1.27 \mathrm{E}-08$ & $2.11 \mathrm{E}-07$ & $4.00 \mathrm{E}-07$ & $6.79 E-07$ & $1.29 \mathrm{E}-06$ \\
\hline $2.28 \mathrm{E}-15$ & $4.36 \mathrm{E}-06$ & $8.85 E-08$ & 1.29E-08 & $2.13 E-07$ & $4.03 E-07$ & $6.83 E-07$ & $1.29 \mathrm{E}-06$ \\
\hline $3.50 \mathrm{E}-15$ & $4.37 E-06$ & $8.91 \mathrm{E}-08$ & $1.31 \mathrm{E}-08$ & $2.15 \mathrm{E}-07$ & $4.05 E-07$ & $6.87 E-07$ & $1.30 E-06$ \\
\hline $5.26 \mathrm{E}-15$ & $4.39 E-06$ & $8.98 E-08$ & 1. $32 \mathrm{E}-08$ & $2.16 \mathrm{E}-07$ & $4.08 \mathrm{E}-07$ & $6.90 \mathrm{E}-07$ & $1.30 \mathrm{E}-06$ \\
\hline $7.72 \mathrm{E}-15$ & $4.40 E-06$ & $9.04 \mathrm{E}-08$ & $1.34 \mathrm{E}-08$ & $2.18 \mathrm{E}-07$ & $4.11 \mathrm{E}-07$ & $6.94 \mathrm{E}-07$ & 1. $31 \mathrm{E}-06$ \\
\hline $1.11 \mathrm{E}-14$ & $4.42 \mathrm{E}-06$ & $9.10 \mathrm{E}-08$ & $1.36 \mathrm{E}-08$ & $2.19 \mathrm{E}-07$ & $4.13 \mathrm{E}-07$ & $6.98 \mathrm{E}-07$ & $1.32 \mathrm{E}-06$ \\
\hline
\end{tabular}


RESRAD-OFFSITE, Version 2.5

Title : Offsite Resident Farmer Deterministic Run

File : RF TC99 DOESG FWD-FV2b.ROF

Summary of dose at graphical times, reptition 2 (continued)

Time

Years

$4.01 \mathrm{E}+02$

$4.01 \mathrm{E}+02$

$4.02 \mathrm{E}+02$

$4.02 \mathrm{E}+02$

4. $03 \mathrm{E}+02$

$4.03 E+02$

$4.04 \mathrm{E}+02$

4. $05 \mathrm{E}+02$

$4.05 \mathrm{E}+02$

4. $06 \mathrm{E}+02$

$4.06 \mathrm{E}+02$

$4.07 \mathrm{E}+02$

$4.07 \mathrm{E}+02$

$4.08 \mathrm{E}+02$

$4.08 \mathrm{E}+02$

$4.09 \mathrm{E}+02$

4. $09 \mathrm{E}+02$

$4.10 \mathrm{E}+02$

$4.10 \mathrm{E}+02$

$4.11 \mathrm{E}+02$

4. $11 \mathrm{E}+02$

$4.12 \mathrm{E}+02$

$4.12 \mathrm{E}+02$

$4.13 \mathrm{E}+02$

$4.13 \mathrm{E}+02$

$4.14 \mathrm{E}+02$

$4.14 \mathrm{E}+02$

$4.15 \mathrm{E}+02$

$4.15 \mathrm{E}+02$

$4.16 \mathrm{E}+02$

$4.16 \mathrm{E}+02$

$4.17 \mathrm{E}+02$

$4.17 \mathrm{E}+02$

$4.18 \mathrm{E}+02$

$4.18 \mathrm{E}+02$

4. $19 \mathrm{E}+02$

$4.19 \mathrm{E}+02$

$4.20 \mathrm{E}+02$

$4.20 \mathrm{E}+02$

$4.21 \mathrm{E}+02$

$4.21 \mathrm{E}+02$

$4.22 \mathrm{E}+02$

4. $22 \mathrm{E}+02$

$4.23 \mathrm{E}+02$

$4.23 E+02$

$4.24 \mathrm{E}+02$
Dose statistics at graphical times, mrem/yr

\begin{tabular}{|c|c|c|c|c|c|c|c|}
\hline$m$ & axin & ean & ${ }^{2}$ & & & $\%$ & \\
\hline-14 & 06 & $9.17 \mathrm{E}-08$ & $1.37 \mathrm{E}-08$ & -07 & $4.16 \mathrm{E}-07$ & -07 & -00 \\
\hline $18 E-14$ & $4.45 E-06$ & $9.23 E-08$ & 1. $39 \mathrm{E}-08$ & $2.23 E-07$ & 7 & -07 & -06 \\
\hline $.97 \mathrm{E}-14$ & $4.46 \mathrm{E}-06$ & $9.30 \mathrm{E}-08$ & 1. $41 \mathrm{E}-08$ & $2.24 \mathrm{E}-07$ & $21 E-07$ & $7.09 \mathrm{E}-07$ & $1.33 E-06$ \\
\hline $.00 \mathrm{E}-14$ & $4.48 E-06$ & $9.36 \mathrm{E}-08$ & $.42 \mathrm{E}-08$ & $2.26 \mathrm{E}-07$ & $4.24 \mathrm{E}-07$ & $7.13 \mathrm{E}-07$ & $1.34 \mathrm{E}-06$ \\
\hline $1 F-14$ & $49 E-06$ & $3 F-08$ & $.44 E-08$ & $28 \mathrm{~F}-07$ & $7 E-07$ & $6 \mathrm{~F}-07$ & $.34 E-06$ \\
\hline-14 & 06 & $9.49 \mathrm{E}-08$ & $1.46 \mathrm{E}-08$ & $29 F-07$ & 7 & 07 & -06 \\
\hline $00 E-14$ & 06 & & & 7 & & & -06 \\
\hline $15 E-13$ & $4.53 E-06$ & & & & & & -06 \\
\hline $5-13$ & -06 & $E-08$ & -08 & 7 & 7 & -07 & -06 \\
\hline 13 & $4.56 \mathrm{E}-06$ & 年 & -08 & 1 & 07 & 1 & -06 \\
\hline $27 \mathrm{~F}-13$ & $57 E-06$ & 835 & $E-08$ & 5 & t) & 7 & $E-06$ \\
\hline 3 & 6 & & & & & & 06 \\
\hline$E-13$ & $4.60 E-06$ & $\mathrm{ST}_{-1}$ & 1. & 7 & $4.47 \mathrm{E}-07$ & 7 & -06 \\
\hline $.12 \mathrm{E}-13$ & $4.62 E-06$ & $1.00 \mathrm{E}-07$ & $1.61 \mathrm{E}-08$ & $2.43 E-07$ & $4.49 E-07$ & $7.50 \mathrm{E}-07$ & $1.40 \mathrm{E}-06$ \\
\hline-13 & $3 E-06$ & 1 & -08 & 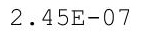 & & & -06 \\
\hline 3 & & & & & & & -06 \\
\hline 3 & & $1.02 \mathrm{E}-07$ & 8 & בת תמתמי ת & 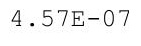 & $7.62 \mathrm{E}-07$ & -06 \\
\hline 3 & 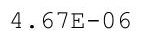 & & & & & & 6 \\
\hline $65 E-13$ & $.69 E-06$ & 原 & $0 E-08$ & 35 & 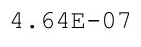 & 7 & -06 \\
\hline $12 \mathrm{E}-12$ & $4.70 \mathrm{E}-06$ & $1.04 \mathrm{E}-07$ & $1.72 \mathrm{E}-08$ & $.54 \mathrm{E}-07$ & $4.66 \mathrm{E}-07$ & $7.77 \mathrm{E}-0$ & $1.44 \mathrm{E}-06$ \\
\hline$E-12$ & $4.71 E-06$ & $.05 \mathrm{E}-0$ & -08 & .56 & 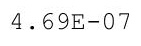 & & $.45 E-06$ \\
\hline 12 & 06 & & & & & & -06 \\
\hline & & & & & & & -06 \\
\hline & & & & & 1 & & -06 \\
\hline 2 & 6 & 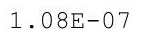 & 8 & 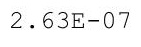 & the & $8.03 E-07$ & -06 \\
\hline $51 E-12$ & $.78 E-06$ & م & $1.84 \mathrm{E}-08$ & 655 & $85 \mathrm{D}$ & $8 \mathrm{E}-$ & $1.48 \mathrm{E}-06$ \\
\hline$E-12$ & $4.79 F-06$ & ח & $E-08$ & תר & תم: & $3 F-0$ & $.49 E-06$ \\
\hline-12 & 06 & & & & & & $49 E-06$ \\
\hline & 6 & & & & & & -06 \\
\hline $95 \mathrm{E}-12$ & $4.83 E-06$ & $\perp \cdot \perp \angle \dot{0}$ & 1.91E-08 & $2 \cdot 12+$ & 1.00 & $\cdot$ & -06 \\
\hline $39 E-12$ & $4.075-20$ & 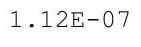 & $1.93 E-08$ & $2.74 \mathrm{E}-07$ & 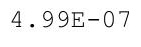 & . & $1.52 E-06$ \\
\hline $85 E-12$ & $4.86 E-06$ & 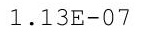 & $1.95 \pm-00$ & 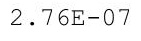 & . & & $1.52 \mathrm{E}-06$ \\
\hline 2 & $87 \mathrm{E}-$ & & & & & & -06 \\
\hline-12 & $89 F-06$ & & $E-08$ & ת קב & & 7 & 06 \\
\hline & & & & & & & \\
\hline 12 & 6 & & 08 & 2.00 & 7 & 7 & 1.35 \\
\hline $.71 \mathrm{E}-12$ & $4.93 \mathrm{E}$ & & & - 0 & 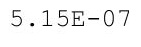 & & -06 \\
\hline $40 \mathrm{E}-12$ & $4.94 \mathrm{E}-06$ & & & & & & $1.50 \mathrm{x}-00$ \\
\hline 2 & 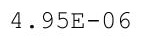 & & 8 & 7 & 7 & 7 & 06 \\
\hline & & & & & & & 6 \\
\hline & & & & & 7 & 7 & \\
\hline$E-11$ & $4.99 E-06$ & $1.20 \mathrm{E}-\mathrm{C}$ & 2.1 & $2.94 \mathrm{E}$ & 7 & 07 & 1.59 \\
\hline & & & & & & & \\
\hline & & & & & & & $1.61 \mathrm{E}-06$ \\
\hline & 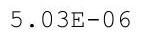 & +.2 & $2 \cdot 2$ & t & ( & $1 E-07$ & $1.01 \mathrm{~L}-00$ \\
\hline$E-11$ & $E-06$ & $4 E-07$ & $28 E-08$ & $2 E-07$ & $2 E-07$ & $.16 \mathrm{E}-07$ & -06 \\
\hline
\end{tabular}


RESRAD-OFFSITE, Version 2.5

Title : Offsite Resident Farmer Deterministic Run

File : RF TC99 DOESG FWD-FV2b.ROF

Summary of dose at graphical times, reptition 2 (continued)

Time

Years

$4.25 E+02$

$4.25 \mathrm{E}+02$

$4.26 \mathrm{E}+02$

$4.26 \mathrm{E}+02$

$4.27 \mathrm{E}+02$

$4.27 \mathrm{E}+02$

$4.28 \mathrm{E}+02$

$4.28 \mathrm{E}+02$

$4.29 \mathrm{E}+02$

$4.29 \mathrm{E}+02$

$4.30 \mathrm{E}+02$

$4.30 \mathrm{E}+02$

$4.31 \mathrm{E}+02$

$4.31 \mathrm{E}+02$

$4.32 \mathrm{E}+02$

$4.32 \mathrm{E}+02$

$4.33 \mathrm{E}+02$

$4.33 \mathrm{E}+02$

$4.34 \mathrm{E}+02$

4. $34 \mathrm{E}+02$

$4.35 \mathrm{E}+02$

$4.35 \mathrm{E}+02$

$4.36 \mathrm{E}+02$

$4.36 \mathrm{E}+02$

$4.37 \mathrm{E}+02$

$4.37 \mathrm{E}+02$

$4.38 \mathrm{E}+02$

4. $38 \mathrm{E}+02$

$4.39 \mathrm{E}+02$

$4.39 \mathrm{E}+02$

$4.40 \mathrm{E}+02$

4. $40 \mathrm{E}+02$

$4.41 \mathrm{E}+02$

4. $41 \mathrm{E}+02$

4. $42 \mathrm{E}+02$

4. $42 \mathrm{E}+02$

$4.43 E+02$

$4.43 E+02$

4. $44 \mathrm{E}+02$

4. $45 \mathrm{E}+02$

$4.45 \mathrm{E}+02$

$4.46 \mathrm{E}+02$

$4.46 \mathrm{E}+02$

$4.47 \mathrm{E}+02$

$4.47 \mathrm{E}+02$

$4.48 \mathrm{E}+02$
Dose statistics at graphical times, mrem/yr

\begin{tabular}{|c|c|c|c|c|c|c|c|}
\hline m & um & ean & n & $90 \%$ & & $\%$ & \\
\hline $64 \mathrm{E}-11$ & $5.05 \mathrm{E}-06$ & $1.24 \mathrm{E}-07$ & $2.30 \mathrm{E}-08$ & $3.03 \mathrm{E}-07$ & $3.43 \pm-01$ & -07 & -00 \\
\hline $.75 E-11$ & -06 & -07 & -08 & 7 & 07 & -07 & -06 \\
\hline $.87 E-11$ & $5.08 \mathrm{E}-06$ & $1.26 \mathrm{E}-07$ & $2.35 \mathrm{E}-08$ & $3.07 E-07$ & $.51 E-07$ & $9.33 \mathrm{E}-07$ & $1.64 \mathrm{E}-06$ \\
\hline $99 \mathrm{E}-11$ & $5.09 \mathrm{E}-06$ & $1.27 \mathrm{E}-07$ & $2.38 \mathrm{E}-08$ & $3.09 \mathrm{E}-07$ & $.55 E-07$ & $9.39 \mathrm{E}-07$ & $1.65 E-06$ \\
\hline $11 \mathrm{E}-11$ & $10 E-06$ & $1.27 \mathrm{E}-07$ & $.40 \mathrm{E}-08$ & $.11 \mathrm{E}-07$ & $.58 E-07$ & $4 \mathrm{E}-07$ & -06 \\
\hline $24 \mathrm{E}-11$ & 06 & $1.28 \mathrm{E}$ & & & & 7 & -06 \\
\hline $37 E-11$ & 06 & $1.29 \mathrm{E}$ & & 7 & & 7 & -06 \\
\hline $51 \mathrm{E}-11$ & $4 E-06$ & $1.30 \mathrm{~L}$ - & & & & & -06 \\
\hline $66 \mathrm{E}-11$ & $E-06$ & $E-07$ & -08 & $19 E-07$ & 07 & -07 & $68 E-06$ \\
\hline-11 & 06 & 3 & 8 & t & 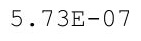 & 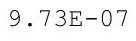 & -06 \\
\hline 1 & $5.18 \mathrm{E}-06$ & 1 & $2.57 \mathrm{E}-08$ & 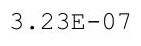 & $76 \mathrm{E}-07$ & 7 & 6 \\
\hline$F-11$ & 6 & 35 & & & $795=8$ & & -06 \\
\hline $28 \mathrm{E}-11$ & $F-06$ & $1.34 \mathrm{E}-\mathrm{C}$ & 8 & 7 & $5.83 E-07$ & 7 & -06 \\
\hline $.45 \mathrm{E}-11$ & $5.21 \mathrm{E}-06$ & $1.35 \mathrm{E}-07$ & $2.65 \mathrm{E}-08$ & $3.30 \mathrm{E}-07$ & $5.86 \mathrm{E}-07$ & $9.96 \mathrm{E}-07$ & $1.73 E-06$ \\
\hline $62 \mathrm{E}-11$ & -06 & 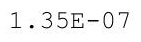 & -08 & & & 06 & -06 \\
\hline-11 & & & & & & & -06 \\
\hline 1 & & - & & 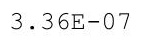 & & & 06 \\
\hline 1 & & $1.38 E-07$ & & & & & 6 \\
\hline $37 E-11$ & $5.27 E-06$ & $139 \mathrm{~F}-$ & $9 E-08$ & & & 0 & $1.77 \mathrm{E}-06$ \\
\hline $56 \mathrm{E}-11$ & $.29 E-06$ & $1.39 \mathrm{E}-07$ & $2.82 \mathrm{E}-08$ & $.42 \mathrm{E}-07$ & $6.06 \mathrm{E}-$ & $.03 E-0$ & $1.78 \mathrm{E}-06$ \\
\hline $77 E-11$ & $E-06$ & 1. $40 \mathrm{E}-0$ & $.85 E-08$ & 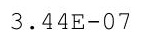 & 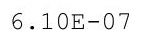 & $.04 \mathrm{E}-0$ & $.79 E-06$ \\
\hline 11 & & & & & & & $80 E-06$ \\
\hline 1 & & $+\cdot$ & & & & & 06 \\
\hline $41 \mathrm{E}-11$ & 0.0 & $1 \cdot 14$ & & & & & -06 \\
\hline 11 & 6 & 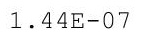 & 8 & . & $6.23 E-07$ & $1.06 \mathrm{E}-06$ & -06 \\
\hline $86 \mathrm{E}-11$ & $.36 E-06$ & 1 & $98 E-08$ & 555 & 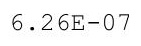 & $107 \mathrm{~F}-0$ & $1.83 E-06$ \\
\hline-11 & $F-06$ & $1.5 \mathrm{~F}-8$ & $E-08$ & & م & $E-06$ & $1.84 \mathrm{E}-06$ \\
\hline 1 & & & & & & & \\
\hline E-11 & & $\perp$ & & & & & \\
\hline $83 E-11$ & $5.40 E-06$ & $1.40 \mathrm{~L}$ & $3.10 \mathrm{E}-08$ & . & . & $1.09 E-06$ & -06 \\
\hline $09 \mathrm{E}-11$ & $5.41 E-06$ & 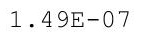 & $3.13 \mathrm{E}-08$ & $3.01 \mathrm{~L}-\mathrm{t}$ & . & $1.10 \mathrm{E}-06$ & $1.88 E-06$ \\
\hline 1 & $5.42 \mathrm{E}-06$ & 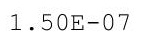 & 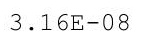 & & 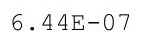 & 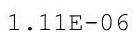 & $1.89 \mathrm{E}-06$ \\
\hline$E-11$ & $.44 E-0$ & & & & & & $1.90 \mathrm{E}-06$ \\
\hline $89 F-11$ & $5=06$ & 1 & & & & & 06 \\
\hline-11 & & & & 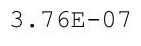 & & 6 & -06 \\
\hline $5 E-11$ & $5.47 \mathrm{E}-06$ & $1.35 E-01$ & $3.28 E-08$ & $3.10 \mathrm{D}$ & T. & $\perp \cdot \perp \circlearrowright$ & $1.92 \mathrm{E}-06$ \\
\hline $74 E-11$ & $5.48 E-06$ & 1.015 & & & & & -06 \\
\hline $03 E-11$ & & & & & & & $1.945-00$ \\
\hline 1 & ( & +0 & & & & 6 & 06 \\
\hline & $5.51 E-06$ & & & & & & 6 \\
\hline-11 & 06 & 1.5 & 8 & 7 & & 1.1 & -06 \\
\hline $3 E-10$ & $5.53 E-06$ & 1.58 & 08 & 7 & 6.77 & 1 & -06 \\
\hline & & & & & & & \\
\hline & & & & & & & $2.00 E-06$ \\
\hline 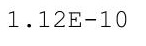 & & 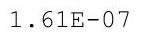 & & & 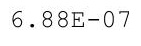 & 1.20 & $2.01 \mathrm{~L}-00$ \\
\hline-10 & $8 E-06$ & $2 E-07$ & $61 E-08$ & $E-07$ & $92 E-07$ & $20 E-06$ & -06 \\
\hline
\end{tabular}


RESRAD-OFFSITE, Version 2.5

Title : Offsite Resident Farmer Deterministic Run

File : RF TC99 DOESG FWD-FV2b.ROF

Summary of dose at graphical times, reptition 2 (continued)

Time

Years

$4.48 \mathrm{E}+02$

$4.49 \mathrm{E}+02$

$4.49 \mathrm{E}+02$

$4.50 \mathrm{E}+02$

$4.50 \mathrm{E}+02$

$4.51 \mathrm{E}+02$

$4.51 \mathrm{E}+02$

$4.52 \mathrm{E}+02$

$4.52 \mathrm{E}+02$

$4.53 \mathrm{E}+02$

$4.53 \mathrm{E}+02$

$4.54 \mathrm{E}+02$

$4.54 \mathrm{E}+02$

$4.55 \mathrm{E}+02$

$4.55 \mathrm{E}+02$

$4.56 \mathrm{E}+02$

$4.56 \mathrm{E}+02$

$4.57 \mathrm{E}+02$

$4.57 \mathrm{E}+02$

$4.58 \mathrm{E}+02$

$4.58 \mathrm{E}+02$

$4.59 \mathrm{E}+02$

$4.59 \mathrm{E}+02$

$4.60 \mathrm{E}+02$

$4.60 \mathrm{E}+02$

4. $61 \mathrm{E}+02$

4. $61 \mathrm{E}+02$

4. $62 \mathrm{E}+02$

4. $62 \mathrm{E}+02$

4. $63 \mathrm{E}+02$

4. $63 \mathrm{E}+02$

$4.64 \mathrm{E}+02$

$4.65 \mathrm{E}+02$

$4.65 \mathrm{E}+02$

$4.66 \mathrm{E}+02$

$4.66 \mathrm{E}+02$

$4.67 \mathrm{E}+02$

$4.67 \mathrm{E}+02$

$4.68 \mathrm{E}+02$

$4.68 \mathrm{E}+02$

$4.69 \mathrm{E}+02$

$4.69 \mathrm{E}+02$

$4.70 \mathrm{E}+02$

$4.70 \mathrm{E}+02$

$4.71 \mathrm{E}+02$

$4.71 \mathrm{E}+02$
Dose statistics at graphical times, mrem/yr

\begin{tabular}{|c|c|c|c|c|c|c|c|}
\hline m & axin & a & ledian & & & $\%$ & \\
\hline $19 \mathrm{E}-10$ & $5.59 \mathrm{E}-06$ & $1.63 E-07$ & $3.64 \mathrm{E}-08$ & $4.02 \mathrm{E}-07$ & 0.9 & -06 & -00 \\
\hline $23 E-10$ & $5.60 \mathrm{E}-06$ & $1.64 \mathrm{E}-07$ & $.68 \mathrm{E}-08$ & 7 & 07 & -06 & -06 \\
\hline $.26 \mathrm{E}-10$ & $5.61 \mathrm{E}-06$ & $1.65 \mathrm{E}-07$ & $1 E-08$ & $4.06 \mathrm{E}-07$ & $03 E-07$ & $1.22 \mathrm{E}-06$ & $2.04 \mathrm{E}-06$ \\
\hline $30 \mathrm{E}-10$ & $5.62 E-06$ & $1.65 \mathrm{E}-07$ & $.75 E-08$ & $4.09 \mathrm{E}-07$ & $7.07 \mathrm{E}-07$ & $1.23 E-06$ & $2.05 E-06$ \\
\hline $33 E-10$ & $63 E-06$ & $1.66 \mathrm{E}-07$ & $9 \mathrm{E}-08$ & $1 E-07$ & $15-07$ & $4 E-06$ & $2.06 \mathrm{E}-06$ \\
\hline 10 & 06 & 1.6 & & 7 & 7 & -06 & -06 \\
\hline $41 \mathrm{E}-10$ & $5.65 E-06$ & $1.68 \mathrm{E}$ & & 7 & & 6 & -06 \\
\hline $45 \mathrm{E}-10$ & & & & & & $.26 E-06$ & -06 \\
\hline $49 \mathrm{E}-10$ & -06 & -0 & -08 & 7 & 7 & -06 & $10 E-06$ \\
\hline $53 E-10$ & $3 E-06$ & 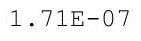 & 8 & 1 & $7.32 \mathrm{E}-07$ & -06 & -06 \\
\hline $57 \mathrm{~F}-10$ & $9 F_{-}$ & $\mathrm{F}$ & $2 \mathrm{~F}$ & $4.25 E-07$ & $37 E-07$ & 6 & -06 \\
\hline $61 \mathrm{~F}-10$ & 6 & 1 & & & & 6 & -06 \\
\hline $65 E-10$ & $E-06$ & 1. & 8 & 7 & $7.44 \mathrm{E}-07$ & 6 & -06 \\
\hline $.69 \mathrm{E}-10$ & $5.72 \mathrm{E}-06$ & $1.75 \mathrm{E}-07$ & $4.13 \mathrm{E}-08$ & $4.32 \mathrm{E}-07$ & $7.48 \mathrm{E}-07$ & $1.29 \mathrm{E}-06$ & $2.14 \mathrm{E}-06$ \\
\hline $73 E-10$ & -06 & 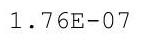 & 08 & 8 & & -06 & $15 E-06$ \\
\hline $78 E-10$ & & & & & & 6 & -06 \\
\hline 0 & & $\perp$ & & & & 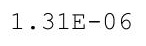 & 06 \\
\hline 0 & & 1 & & & & & 6 \\
\hline $91 E-10$ & $.77 \mathrm{E}-06$ & $1.79 \mathrm{E}-$ & $9 E-08$ & 65 & & 12 & -06 \\
\hline $95 E-10$ & $.78 \mathrm{E}-06$ & $1.80 \mathrm{E}-07$ & $4.33 E-08$ & $4.49 \mathrm{E}-07$ & $7.68 \mathrm{E}-$ & $.33 E-06$ & $2.20 E-06$ \\
\hline $00 \mathrm{E}-10$ & $5.79 \mathrm{E}-06$ & $1.81 \mathrm{E}-07$ & $4.37 E-08$ & $4 \cdot 5<5-01$ & & $E-06$ & $2.21 E-06$ \\
\hline 10 & & & & & & & $.22 E-06$ \\
\hline 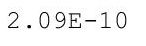 & & 1 & & & & & \\
\hline $14 \mathrm{E}-10$ & 0 & $\perp \cdot 010$ & & & 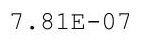 & - & $E-06$ \\
\hline 0 & 6 & 1 & 8 & $163 F-07$ & 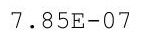 & 0 & -06 \\
\hline $24 \mathrm{E}-10$ & $.83 E-06$ & 1 & $4.57 \mathrm{E}-08$ & $06 \square^{\circ}$ & 7 & $1.37 \mathrm{E}-06$ & $.25 E-06$ \\
\hline $29 \mathrm{E}-10$ & -06 & $1.87 \mathrm{E}-$ & $L-08$ & & & $1.37 \mathrm{E}-06$ & $2.26 \mathrm{E}-06$ \\
\hline 0 & & & & & & & 06 \\
\hline 10 & 06 & & & & & & \\
\hline $44 \mathrm{E}-10$ & $5.87 \mathrm{E}-06$ & $1.90 \mathrm{E}-07$ & $4.74 \mathrm{E}-08$ & 1. & 20 & $1.39 \mathrm{E}-06$ & $2.29 E-06$ \\
\hline $50 \mathrm{E}-10$ & $5.88 E-06$ & 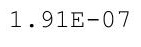 & $4.78 \mathrm{E}-08$ & $4.005-4$ & $0.0 \mathrm{CL}$ & $1.40 \mathrm{E}-00$ & $2.30 E-06$ \\
\hline 0 & 6 & $1 \cdot 22+4$ & 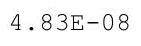 & - & 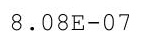 & 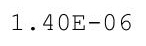 & $2.31 E-06$ \\
\hline$F-10$ & $F-06$ & & ת & & & & $2.32 E-06$ \\
\hline $66 \mathrm{~F}-10$ & & & & & & -06 & 06 \\
\hline 10 & & & & & & & \\
\hline $.77 E-10$ & $5.92 \mathrm{E}-06$ & $1.96 \mathrm{E}-07$ & $.00 E-08$ & . & 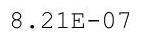 & 06 & $2.35 E-06$ \\
\hline $82 E-10$ & 06 & $+.01 \pm$ & & & & & $2.35 E-06$ \\
\hline $88 E-10$ & & & & & & & $2.50 \mathrm{x}-00$ \\
\hline 0 & e &.+ & & 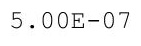 & & $+\cdots$ & 06 \\
\hline & & & & & & 6 & \\
\hline 10 & 06 & 2 & 8 & 7 & & 6 & -06 \\
\hline$E-10$ & $5.97 E-06$ & $2.02 E-07$ & 08 & 07 & & 1.4 & -06 \\
\hline & & & & & & & \\
\hline & & . & & & & & $\angle .4 \angle E-U 6$ \\
\hline+10 & & 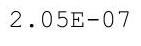 & & & & $1.47 \mathrm{E}-06$ & $2.43 E-06$ \\
\hline-10 & $E-06$ & $6 E-07$ & $4 E-08$ & $E-07$ & $2 E-07$ & $3 E-06$ & -06 \\
\hline
\end{tabular}


RESRAD-OFFSITE, Version 2.5

Title : Offsite Resident Farmer Deterministic Run

File : RF TC99 DOESG FWD-FV2b.ROF

Summary of dose at graphical times, reptition 2 (continued)

Time

Years

$4.72 \mathrm{E}+02$

$4.72 \mathrm{E}+02$

$4.73 \mathrm{E}+02$

$4.73 \mathrm{E}+02$

$4.74 \mathrm{E}+02$

$4.74 \mathrm{E}+02$

$4.75 \mathrm{E}+02$

$4.75 \mathrm{E}+02$

$4.76 \mathrm{E}+02$

$4.76 \mathrm{E}+02$

$4.77 \mathrm{E}+02$

$4.77 \mathrm{E}+02$

$4.78 \mathrm{E}+02$

$4.78 \mathrm{E}+02$

$4.79 \mathrm{E}+02$

$4.79 \mathrm{E}+02$

$4.80 \mathrm{E}+02$

$4.80 \mathrm{E}+02$

$4.81 \mathrm{E}+02$

$4.81 \mathrm{E}+02$

$4.82 \mathrm{E}+02$

$4.82 \mathrm{E}+02$

$4.83 \mathrm{E}+02$

$4.83 \mathrm{E}+02$

$4.84 \mathrm{E}+02$

$4.84 \mathrm{E}+02$

$4.85 \mathrm{E}+02$

$4.86 \mathrm{E}+02$

$4.86 \mathrm{E}+02$

$4.87 \mathrm{E}+02$

$4.87 \mathrm{E}+02$

$4.88 \mathrm{E}+02$

$4.88 \mathrm{E}+02$

$4.89 \mathrm{E}+02$

$4.89 \mathrm{E}+02$

4. $90 \mathrm{E}+02$

$4.90 \mathrm{E}+02$

$4.91 \mathrm{E}+02$

$4.91 \mathrm{E}+02$

$4.92 \mathrm{E}+02$

$4.92 \mathrm{E}+02$

$4.93 \mathrm{E}+02$

4. $93 \mathrm{E}+02$

$4.94 \mathrm{E}+02$

4. $94 \mathrm{E}+02$

$4.95 \mathrm{E}+02$
Dose statistics at graphical times, mrem/yr

\begin{tabular}{|c|c|c|c|c|c|c|c|}
\hline Minimum & Maximum & Mean & Median & $90 \%$ & $95 \%$ & $97.5 \%$ & $99 \%$ \\
\hline $3.43 E-10$ & $6.01 E-06$ & $2.07 E-07$ & $5.49 \mathrm{E}-08$ & $5.20 \mathrm{E}-07$ & $8.56 \mathrm{E}-07$ & $1.48 E-06$ & $2.45 E-06$ \\
\hline $3.49 \mathrm{E}-10$ & $6.02 E-06$ & $2.08 E-07$ & $5.53 E-08$ & $5.22 \mathrm{E}-07$ & $8.59 \mathrm{E}-07$ & $1.49 \mathrm{E}-06$ & $2.45 E-06$ \\
\hline $3.56 \mathrm{E}-10$ & $6.03 E-06$ & $2.09 \mathrm{E}-07$ & $5.57 \mathrm{E}-08$ & $5.24 \mathrm{E}-07$ & $8.62 \mathrm{E}-07$ & $1.49 \mathrm{E}-06$ & $2.46 \mathrm{E}-06$ \\
\hline $3.62 \mathrm{E}-10$ & $6.04 \mathrm{E}-06$ & $2.10 \mathrm{E}-07$ & $5.62 \mathrm{E}-08$ & $5.27 \mathrm{E}-07$ & $8.66 \mathrm{E}-07$ & $1.50 \mathrm{E}-06$ & $2.47 \mathrm{E}-06$ \\
\hline $3.69 \mathrm{E}-10$ & $6.05 E-06$ & $2.11 E-07$ & $5.67 E-08$ & $5.30 E-07$ & $8.70 \mathrm{E}-07$ & $1.50 \mathrm{E}-06$ & $.48 E-06$ \\
\hline $3.76 \mathrm{E}-10$ & $6.05 E-06$ & $2.12 \mathrm{E}-07$ & $5.71 \mathrm{E}-08$ & $5.33 E-07$ & $8.74 \mathrm{E}-07$ & $.51 \mathrm{E}-06$ & $48 E-06$ \\
\hline $3.83 E-10$ & $6.06 \mathrm{E}-06$ & $2.13 E-07$ & $5.76 \mathrm{E}-08$ & $5.36 \mathrm{E}-07$ & $8.78 \mathrm{E}-07$ & $1.51 \mathrm{E}-06$ & $2.49 \mathrm{E}-06$ \\
\hline $3.90 \mathrm{E}-10$ & $6.07 \mathrm{E}-06$ & $2.14 \mathrm{E}-07$ & $5.81 \mathrm{E}-08$ & $5.39 \mathrm{E}-07$ & $8.82 E-07$ & $1.52 \mathrm{E}-06$ & $2.50 \mathrm{E}-06$ \\
\hline $3.96 \mathrm{E}-10$ & $6.08 \mathrm{E}-06$ & $2.15 E-07$ & $5.85 \mathrm{E}-08$ & $5.42 \mathrm{E}-07$ & $8.87 \mathrm{E}-07$ & 1. $52 \mathrm{E}-06$ & $2.51 \mathrm{E}-06$ \\
\hline $4.04 \mathrm{E}-10$ & $6.09 \mathrm{E}-06$ & $2.16 \mathrm{E}-07$ & $5.90 \mathrm{E}-08$ & $.45 E-07$ & $.91 E-07$ & $1.53 E-06$ & $.51 E-06$ \\
\hline $4.11 \mathrm{E}-10$ & $6.09 \mathrm{E}-06$ & $2.17 \mathrm{E}-07$ & $5.94 \mathrm{E}-08$ & $5.48 \mathrm{E}-07$ & $95 E-07$ & $.53 E-06$ & $.52 E-06$ \\
\hline $4.18 \mathrm{E}-10$ & $6.10 \mathrm{E}-06$ & $2.18 E-07$ & $5.99 \mathrm{E}-08$ & $5.51 \mathrm{E}-07$ & $8.99 \mathrm{E}-07$ & $1.54 \mathrm{E}-06$ & $2.53 E-06$ \\
\hline $4.25 \mathrm{E}-10$ & $6.11 \mathrm{E}-06$ & $2.19 \mathrm{E}-07$ & $6.04 \mathrm{E}-08$ & $5.54 \mathrm{E}-07$ & $9.04 \mathrm{E}-07$ & $1.54 \mathrm{E}-06$ & $2.54 \mathrm{E}-06$ \\
\hline $4.33 E-10$ & $6.12 \mathrm{E}-06$ & $2.20 E-07$ & $6.08 \mathrm{E}-08$ & $5.56 \mathrm{E}-07$ & $9.08 \mathrm{E}-07$ & $1.55 \mathrm{E}-06$ & $2.54 \mathrm{E}-06$ \\
\hline 4. $40 \mathrm{E}-10$ & $6.12 \mathrm{E}-06$ & $2.21 E-07$ & $6.13 \mathrm{E}-08$ & $5.59 \mathrm{E}-07$ & $9.12 \mathrm{E}-07$ & 1. $55 \mathrm{E}-06$ & $2.55 E-06$ \\
\hline $4.48 E-10$ & $6.13 E-06$ & $2.22 E-07$ & $6.18 E-08$ & $5.61 \mathrm{E}-07$ & $.17 \mathrm{E}-07$ & $1.55 \mathrm{E}-06$ & $.56 E-06$ \\
\hline 4. $55 \mathrm{E}-10$ & $6.14 \mathrm{E}-06$ & $2.24 E-07$ & $6.22 \mathrm{E}-08$ & $5.64 \mathrm{E}-07$ & $22 E-07$ & $1.56 \mathrm{E}-06$ & $2.56 \mathrm{E}-06$ \\
\hline $4.63 \mathrm{E}-10$ & $6.15 \mathrm{E}-06$ & $2.25 E-07$ & $6.27 \mathrm{E}-08$ & $5.67 \mathrm{E}-07$ & $9.26 \mathrm{E}-07$ & $1.56 \mathrm{E}-06$ & $2.57 \mathrm{E}-06$ \\
\hline $4.71 \mathrm{E}-10$ & $6.15 \mathrm{E}-06$ & $2.26 E-07$ & $6.32 \mathrm{E}-08$ & $5.69 \mathrm{E}-07$ & $9.31 \mathrm{E}-07$ & $1.57 \mathrm{E}-06$ & $2.58 \mathrm{E}-06$ \\
\hline $4.78 \mathrm{E}-10$ & $6.16 \mathrm{E}-06$ & $2.27 E-07$ & $6.37 \mathrm{E}-08$ & $5.72 \mathrm{E}-07$ & $9.36 \mathrm{E}-07$ & $1.57 \mathrm{E}-06$ & $2.59 \mathrm{E}-06$ \\
\hline $4.86 \mathrm{E}-10$ & $6.17 \mathrm{E}-06$ & $2.28 E-07$ & $6.41 \mathrm{E}-08$ & $5.75 \mathrm{E}-07$ & $9.41 \mathrm{E}-07$ & $1.58 \mathrm{E}-06$ & $2.59 \mathrm{E}-06$ \\
\hline $4.94 \mathrm{E}-10$ & $6.17 E-06$ & $2.29 E-07$ & $6.46 \mathrm{E}-08$ & $5.78 \mathrm{E}-07$ & $9.45 E-07$ & $1.58 \mathrm{E}-06$ & $2.60 \mathrm{E}-06$ \\
\hline $5.03 E-10$ & $6.18 \mathrm{E}-06$ & $2.30 E-07$ & $6.51 \mathrm{E}-08$ & $5.81 \mathrm{E}-07$ & $9.50 \mathrm{E}-07$ & $1.59 \mathrm{E}-06$ & $2.61 E-06$ \\
\hline $5.11 \mathrm{E}-10$ & $6.19 \mathrm{E}-06$ & $2.31 E-07$ & $6.56 \mathrm{E}-08$ & $5.84 \mathrm{E}-07$ & $9.55 \mathrm{E}-07$ & $1.59 \mathrm{E}-06$ & $2.61 \mathrm{E}-06$ \\
\hline $5.19 \mathrm{E}-10$ & $6.19 \mathrm{E}-06$ & $2.32 E-07$ & $6.61 \mathrm{E}-08$ & $5.86 \mathrm{E}-07$ & $9.60 \mathrm{E}-07$ & $1.60 \mathrm{E}-06$ & $2.62 E-06$ \\
\hline $5.27 \mathrm{E}-10$ & $6.20 \mathrm{E}-06$ & $2.33 E-07$ & $6.67 \mathrm{E}-08$ & $5.88 \mathrm{E}-07$ & $9.65 \mathrm{E}-07$ & $1.60 \mathrm{E}-06$ & $2.63 E-06$ \\
\hline $5.36 \mathrm{E}-10$ & $6.21 \mathrm{E}-06$ & $2.34 E-07$ & $6.72 \mathrm{E}-08$ & $5.90 \mathrm{E}-07$ & $9.69 \mathrm{E}-07$ & $1.61 \mathrm{E}-06$ & $2.64 \mathrm{E}-06$ \\
\hline $5.45 E-10$ & $6.21 \mathrm{E}-06$ & $2.35 E-07$ & $6.77 \mathrm{E}-08$ & $5.93 E-07$ & $9.74 \mathrm{E}-07$ & $1.62 \mathrm{E}-06$ & $2.64 \mathrm{E}-06$ \\
\hline $5.53 \mathrm{E}-10$ & $6.22 \mathrm{E}-06$ & $2.36 E-07$ & $6.83 E-08$ & $5.96 \mathrm{E}-07$ & $9.79 \mathrm{E}-07$ & $1.63 E-06$ & $2.65 E-06$ \\
\hline $5.62 \mathrm{E}-10$ & $6.23 E-06$ & $2.38 E-07$ & $6.88 \mathrm{E}-08$ & $5.99 \mathrm{E}-07$ & $9.84 \mathrm{E}-07$ & $1.63 E-06$ & $2.66 \mathrm{E}-06$ \\
\hline $5.71 \mathrm{E}-10$ & $6.23 E-06$ & $2.39 E-07$ & $6.93 \mathrm{E}-08$ & $6.02 \mathrm{E}-07$ & $9.89 \mathrm{E}-07$ & $1.64 \mathrm{E}-06$ & $2.66 \mathrm{E}-06$ \\
\hline $5.80 \mathrm{E}-10$ & $6.24 \mathrm{E}-06$ & $2.40 E-07$ & $6.99 \mathrm{E}-08$ & $6.05 E-07$ & $9.94 \mathrm{E}-07$ & $1.65 E-06$ & $2.67 \mathrm{E}-06$ \\
\hline $5.89 \mathrm{E}-10$ & $6.25 E-06$ & $2.41 E-07$ & $7.04 \mathrm{E}-08$ & $6.08 \mathrm{E}-07$ & $9.98 \mathrm{E}-07$ & $1.66 \mathrm{E}-06$ & $2.68 \mathrm{E}-06$ \\
\hline $5.98 \mathrm{E}-10$ & $6.25 E-06$ & $2.42 E-07$ & $7.09 \mathrm{E}-08$ & $6.11 \mathrm{E}-07$ & $1.00 \mathrm{E}-06$ & $1.66 \mathrm{E}-06$ & $2.69 \mathrm{E}-06$ \\
\hline $6.07 \mathrm{E}-10$ & $6.26 \mathrm{E}-06$ & $2.43 E-07$ & $7.15 \mathrm{E}-08$ & $6.14 \mathrm{E}-07$ & $1.01 \mathrm{E}-06$ & $1.67 \mathrm{E}-06$ & $2.69 \mathrm{E}-06$ \\
\hline $6.16 \mathrm{E}-10$ & $6.27 E-06$ & $2.44 E-07$ & $7.20 \mathrm{E}-08$ & $6.17 \mathrm{E}-07$ & $1.01 \mathrm{E}-06$ & $1.68 \mathrm{E}-06$ & $2.70 E-06$ \\
\hline $6.26 \mathrm{E}-10$ & $6.27 \mathrm{E}-06$ & $2.45 E-07$ & $7.26 \mathrm{E}-08$ & $6.20 \mathrm{E}-07$ & $1.01 \mathrm{E}-06$ & 1. $69 \mathrm{E}-06$ & $2.70 \mathrm{E}-06$ \\
\hline $6.35 \mathrm{E}-10$ & $6.28 E-06$ & $2.46 \mathrm{E}-07$ & $7.31 \mathrm{E}-08$ & $6.23 \mathrm{E}-07$ & $1.02 \mathrm{E}-06$ & $1.69 \mathrm{E}-06$ & $2.71 \mathrm{E}-06$ \\
\hline $6.45 E-10$ & $6.29 \mathrm{E}-06$ & $2.47 E-07$ & $7.37 E-08$ & $6.25 \mathrm{E}-07$ & $1.02 E-06$ & $1.70 \mathrm{E}-06$ & $2.72 E-06$ \\
\hline $6.54 \mathrm{E}-10$ & 6.29 & $2.49 \mathrm{E}-07$ & $7.42 \mathrm{E}-08$ & $6.28 \mathrm{E}-07$ & $1.03 \mathrm{E}-06$ & -06 & $2.72 E-06$ \\
\hline $6.64 \mathrm{E}-10$ & $6.30 \mathrm{E}-06$ & $2.50 \mathrm{E}-07$ & $7.47 \mathrm{E}-08$ & $6.31 \mathrm{E}-07$ & $1.03 \mathrm{E}-06$ & $1.72 \mathrm{E}-06$ & $2.73 E-06$ \\
\hline $6.74 \mathrm{E}-10$ & $6.30 E-06$ & $2.51 E-07$ & $7.52 \mathrm{E}-08$ & $6.34 \mathrm{E}-07$ & $1.03 \mathrm{E}-06$ & $1.72 \mathrm{E}-06$ & $2.73 E-06$ \\
\hline $6.84 \mathrm{E}-10$ & $6.31 \mathrm{E}-06$ & $2.52 E-07$ & $7.58 \mathrm{E}-08$ & $6.37 \mathrm{E}-07$ & $1.04 \mathrm{E}-06$ & $1.73 E-06$ & $2.74 \mathrm{E}-06$ \\
\hline $6.94 \mathrm{E}-10$ & $6.32 E-06$ & $2.53 E-07$ & $7.63 E-08$ & $6.40 \mathrm{E}-07$ & $1.04 \mathrm{E}-06$ & $1.74 \mathrm{E}-06$ & $2.74 \mathrm{E}-06$ \\
\hline $7.04 \mathrm{E}-10$ & $6.32 E-06$ & $2.54 E-07$ & $7.68 E-08$ & $6.42 E-07$ & $1.04 \mathrm{E}-06$ & $1.75 E-06$ & $2.75 E-06$ \\
\hline $7.15 \mathrm{E}-10$ & $6.33 \mathrm{E}-06$ & $2.55 E-07$ & $7.73 E-08$ & $6.45 E-07$ & $1.05 E-06$ & $1.75 E-06$ & $2.76 \mathrm{E}-06$ \\
\hline
\end{tabular}


RESRAD-OFFSITE, Version 2.5

$\mathrm{T}^{1 / 2}$ Limit $=180$ days

Title : Offsite Resident Farmer Deterministic Run

File : RF TC99 DOESG FWD-FV2b.ROF

Summary of dose at graphical times, reptition 2 (continued)

Time

Years

$4.95 \mathrm{E}+02$

$4.96 \mathrm{E}+02$

$4.96 \mathrm{E}+02$

$4.97 \mathrm{E}+02$

$4.97 \mathrm{E}+02$

$4.98 \mathrm{E}+02$

$4.98 \mathrm{E}+02$

$4.99 \mathrm{E}+02$

$4.99 \mathrm{E}+02$

$5.00 \mathrm{E}+02$

$5.00 \mathrm{E}+02$

$5.01 \mathrm{E}+02$

$5.01 \mathrm{E}+02$

$5.02 \mathrm{E}+02$

$5.02 \mathrm{E}+02$

$5.03 E+02$

$5.03 E+02$

$5.04 \mathrm{E}+02$

$5.04 \mathrm{E}+02$

$5.05 \mathrm{E}+02$

$5.06 \mathrm{E}+02$

$5.06 \mathrm{E}+02$

$5.07 \mathrm{E}+02$

$5.07 \mathrm{E}+02$

$5.08 \mathrm{E}+02$

$5.08 \mathrm{E}+02$

$5.09 \mathrm{E}+02$

$5.09 \mathrm{E}+02$

$5.10 \mathrm{E}+02$

$5.10 \mathrm{E}+02$

$5.11 \mathrm{E}+02$

$5.11 \mathrm{E}+02$

$5.12 \mathrm{E}+02$

$5.12 \mathrm{E}+02$

$5.13 \mathrm{E}+02$

$5.13 \mathrm{E}+02$

$5.14 \mathrm{E}+02$

$5.14 \mathrm{E}+02$

$5.15 \mathrm{E}+02$

$5.15 \mathrm{E}+02$

$5.16 \mathrm{E}+02$

$5.16 \mathrm{E}+02$

$5.17 \mathrm{E}+02$

$5.17 \mathrm{E}+02$

$5.18 \mathrm{E}+02$

$5.18 \mathrm{E}+02$
Dose statistics at graphical times, mrem/yr

\begin{tabular}{|c|c|c|c|c|c|c|c|}
\hline linimum & laximum & Mean & Median & $90 \%$ & $95 \%$ & $97.5 \%$ & $9 \%$ \\
\hline 0 & $3 E-06$ & $56 \mathrm{~F}-07$ & $.78 E-08$ & 7 & 6 & 6 & -06 \\
\hline $5 E-10$ & 06 & $8 E-07$ & $E-08$ & 07 & 06 & 1.77 & -06 \\
\hline $6 \mathrm{E}-10$ & $34 E-06$ & $9 E-07$ & $38 E-08$ & 7 & 6 & 6 & $77 E-06$ \\
\hline$E-10$ & $5 E-06$ & $0 E-07$ & $3 E-08$ & 7 & 6 & 06 & $8 E-06$ \\
\hline $68 \mathrm{E}-10$ & $6 E-06$ & $1 \mathrm{E}-0$ & & & & & $78 E-06$ \\
\hline $.78 E-10$ & 06 & $\mathrm{~F}$ & 8 & & 6 & 6 & $9 E-06$ \\
\hline $.89 E-10$ & $7 E-06$ & $2.63 E-07$ & $9 E-08$ & $E-07$ & $08 E-06$ & -06 & $80 E-06$ \\
\hline $.01 E-10$ & $6.37 E-06$ & $2.64 \mathrm{E}-07$ & $8.14 \mathrm{E}-08$ & $0.00 \mathrm{~L}-1$ & $1.09 \mathrm{E}-06$ & -06 & $\Xi-06$ \\
\hline$E-10$ & 06 & $\mathrm{~F}-$ & 08 & 7 & 6 & 06 & -06 \\
\hline $23 E-10$ & $8 E-06$ & $7 \mathrm{~F}_{-}$ & 08 & 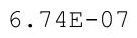 & - & 06 & $32 E-06$ \\
\hline$E-10$ & 06 & & 8 & 7 & & & $2 E-06$ \\
\hline 10 & 06 & 2 & -08 & & 6 & 6 & $\Xi-06$ \\
\hline $58 \mathrm{E}-10$ & $E-06$ & ( & $3 E-08$ & 年 & $\perp \cdot \perp \perp-00$ & -06 & $E-06$ \\
\hline $.70 E-10$ & $6.40 \mathrm{E}-06$ & $2.71 \mathrm{E}-07$ & $0.495-00$ & r & $\perp \cdot \perp \perp$ & 1.0 & $E-06$ \\
\hline $.81 E-10$ & 06 & $2.73 E-07$ & 08 & . Ot & $\perp \cdot 12$ & 06 & -06 \\
\hline $.93 E-10$ & $6.41 E-06$ & $2.74 \mathrm{E}-0$ & $.60 \mathrm{E}-08$ & $6.89 \mathrm{E}-$ & $1.12 \mathrm{E}-$ & -06 & $E-06$ \\
\hline $.06 \mathrm{E}-10$ & $6.42 E-06$ & $2.75 E-07$ & $8.66 \mathrm{E}-08$ & $6.92 \mathrm{E}-07$ & $1.13 \mathrm{E}-06$ & $1.88 \mathrm{E}-06$ & $2.86 \mathrm{E}-06$ \\
\hline$E-10$ & $2 E-06$ & 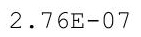 & -08 & 7 & 1 & -06 & $7 E-06$ \\
\hline $30 \mathrm{E}-10$ & $3 E-06$ & $2.77 \mathrm{E}-0$ & $9 E-08$ & 4 & $\perp$ & & $E-06$ \\
\hline $43 E-10$ & $6.43 E-06$ & $2.78 \mathrm{E}$ & -08 & 7 & 1 & 06 & -06 \\
\hline $.55 E-10$ & $E-06$ & $2.00+5$ & 08 & $2=$ & I. & 10.048 & -06 \\
\hline $68 E-10$ & o & $2.81 \mathrm{E}-$ & 8 & $7.04 \mathrm{E}-07$ & 5 & $1.91 \mathrm{E}-06$ & -06 \\
\hline $.81 E-10$ & $6.45 \mathrm{E}-06$ & $2.82 \mathrm{E}-07$ & $9.05 \mathrm{E}-08$ & $7.07 \mathrm{E}-$ & $1.16 \mathrm{E}-$ & $1.91 \mathrm{E}-06$ & $2.90 \mathrm{E}-06$ \\
\hline $.94 E-10$ & $E-06$ & 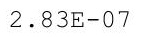 & -08 & 7 & 16 & 06 & $91 E-06$ \\
\hline $.01 E-09$ & $6.46 \mathrm{E}-06$ & $2.84 \mathrm{E}-07$ & $3 E-08$ & & $1.17 \mathrm{E}$ & -06 & $91 E-06$ \\
\hline$E-09$ & 06 & 2 & 08 & 1 & 6 & 06 & -06 \\
\hline $.03 E-09$ & $6 E-06$ & $2.01 \mathrm{~L}-01$ & 08 & H & 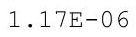 & & -06 \\
\hline $.05 E-09$ & $6.47 \mathrm{E}-06$ & $2.88 \mathrm{E}-07$ & $9.37 \mathrm{E}-08$ & $7.21 \mathrm{E}-07$ & $1.18 \mathrm{E}-06$ & $.94 \mathrm{E}-06$ & $.93 E-06$ \\
\hline $.06 \mathrm{E}-09$ & $6.47 \mathrm{E}-06$ & $2.89 \mathrm{E}-0$ & 8 & ric & 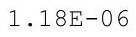 & . & $2.94 \mathrm{E}-06$ \\
\hline 09 & 6 & 2 & 8 & $7.26 \mathrm{E}-07$ & 6 & 06 & -06 \\
\hline 09 & 06 & 2 & 08 & 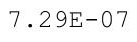 & 6 & 06 & -06 \\
\hline$E-09$ & $E-06$ & 2 & 8 & 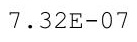 & 6 & 06 & -06 \\
\hline $.12 \mathrm{E}-09$ & $6.49 \mathrm{E}-06$ & $2.94 \mathrm{E}-0$ & $0 \mathrm{E}-08$ & . & $1.20 \mathrm{E}-$ & 1.96 & -06 \\
\hline $.13 E-09$ & $6.49 \mathrm{E}-06$ & $2.95 \mathrm{E}-07$ & $9.77 \mathrm{E}-08$ & $7.37 \mathrm{E}-07$ & $1.20 \mathrm{E}-06$ & $1.96 \mathrm{E}-06$ & $2.97 \mathrm{E}-06$ \\
\hline $.14 \mathrm{E}-09$ & & & & & & & $2.98 E-06$ \\
\hline $.16 \mathrm{E}-09$ & & & & & & & 06 \\
\hline 9 & 6 & 7 & 8 & 7 & 6 & 6 & 06 \\
\hline-09 & 06 & 3 & 7 & 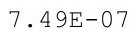 & 1 & 6 & -06 \\
\hline $.20 E-09$ & $1 \mathrm{E}-06$ & $1 E-07$ & $1 \mathrm{E}$ & $52 \mathrm{E}$ & 1.22 & 06 & -06 \\
\hline $.22 E-09$ & $2 E-06$ & 3 & & 皮 & 20 & & 06 \\
\hline 09 & 6 & & & & & & -06 \\
\hline 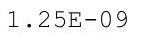 & $0.35 E-$ & $.00 \mathrm{~L}$ & . & . & $1.23 \mathrm{E}-$ & $1.99 \mathrm{E}-06$ & $3.02 E-06$ \\
\hline 9 & 6 & $3.06 \mathrm{E}-07$ & $1.04 \mathrm{E}-07$ & 7 & $\perp$ & 6 & 6 \\
\hline 9 & 6 & $3.07 E-07$ & 7 & 7 & 1 & 06 & -06 \\
\hline 09 & 06 & 3. & -07 & 7. & 1.2 & 06 & 06 \\
\hline $.31 E-09$ & $6.54 \mathrm{E}-06$ & $.10 \mathrm{E}-07$ & $1.06 \mathrm{E}-07$ & $7.77 \mathrm{E}-07$ & $1.25 \mathrm{E}-06$ & $2.00 E-06$ & $3.04 \mathrm{E}-06$ \\
\hline
\end{tabular}


RESRAD-OFFSITE, Version 2.5

obabilistic Dose and Risk Report

Title : Offsite Resident Farmer Deterministic Run

File : RF TC99 DOESG FWD-FV2b.ROF

Summary of dose at graphical times, reptition 2 (continued)

Time

Years

$5.19 \mathrm{E}+02$

$5.19 \mathrm{E}+02$

$5.20 \mathrm{E}+02$

$5.20 \mathrm{E}+02$

$5.21 \mathrm{E}+02$

$5.21 \mathrm{E}+02$

$5.22 \mathrm{E}+02$

$5.22 \mathrm{E}+02$

$5.23 \mathrm{E}+02$

$5.23 \mathrm{E}+02$

$5.24 \mathrm{E}+02$

$5.24 \mathrm{E}+02$

$5.25 \mathrm{E}+02$

$5.26 \mathrm{E}+02$

$5.26 \mathrm{E}+02$

$5.27 \mathrm{E}+02$

$5.27 \mathrm{E}+02$

$5.28 \mathrm{E}+02$

$5.28 \mathrm{E}+02$

$5.29 \mathrm{E}+02$

$5.29 \mathrm{E}+02$

$5.30 \mathrm{E}+02$

$5.30 \mathrm{E}+02$

$5.31 \mathrm{E}+02$

$5.31 \mathrm{E}+02$

$5.32 \mathrm{E}+02$

$5.32 \mathrm{E}+02$

$5.33 \mathrm{E}+02$

$5.33 \mathrm{E}+02$

$5.34 \mathrm{E}+02$

$5.34 \mathrm{E}+02$

$5.35 \mathrm{E}+02$

$5.35 \mathrm{E}+02$

$5.36 \mathrm{E}+02$

$5.36 \mathrm{E}+02$

$5.37 \mathrm{E}+02$

$5.37 \mathrm{E}+02$

$5.38 \mathrm{E}+02$

$5.38 \mathrm{E}+02$

$5.39 \mathrm{E}+02$

$5.39 \mathrm{E}+02$

$5.40 \mathrm{E}+02$

$5.40 \mathrm{E}+02$

$5.41 \mathrm{E}+02$

$5.41 \mathrm{E}+02$

$5.42 \mathrm{E}+02$
Dose statistics at graphical times, mrem/yr

\begin{tabular}{|c|c|c|c|c|c|c|c|}
\hline m & aximum & e & 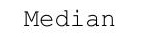 & & & & \\
\hline $33 E-09$ & $6.54 \mathrm{E}-06$ & $3.11 \mathrm{E}-07$ & $1.07 \mathrm{E}-07$ & $7.80 \mathrm{E}-07$ & $1.25 \mathrm{E}-06$ & -06 & $.03 E-06$ \\
\hline $34 E-09$ & $6.55 E-06$ & $3.12 \mathrm{E}-07$ & $1.07 \mathrm{E}-07$ & $34 E-07$ & $1.26 \mathrm{E}-06$ & $2.01 E-06$ & $5 E-06$ \\
\hline $36 \mathrm{E}-09$ & $6.55 \mathrm{E}-06$ & $4 E-07$ & $1.08 \mathrm{E}-07$ & $.87 E-07$ & $1.26 \mathrm{E}-06$ & $2.01 E-06$ & $06 \mathrm{E}-06$ \\
\hline $.37 E-09$ & -06 & $15 \mathrm{~F}-07$ & $09 F-07$ & $90 \mathrm{~F}-07$ & $27 \mathrm{~F}-06$ & $02 F-06$ & $7 E-06$ \\
\hline-09 & 06 & $6 F-07$ & 7 & 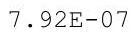 & 6 & -06 & -06 \\
\hline 09 & & & & & & & 00 \\
\hline $42 E-09$ & 06 & & & & 06 & & -06 \\
\hline $.44 E-09$ & 06 & 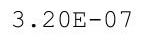 & 1 & 7 & 06 & -06 & $E-06$ \\
\hline $46 \mathrm{E}-09$ & $6.57 \mathrm{E}-06$ & 然 & 1. $12 \mathrm{E}-07$ & -07 & $29 E-06$ & -06 & $E-06$ \\
\hline $47 E-09$ & $57 E-06$ & 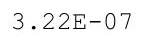 & ק ק & 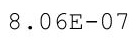 & $3 \cap 5-06$ & 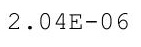 & E-06 \\
\hline $49 \mathrm{E}-09$ & 06 & & & & & & 06 \\
\hline $51 E-09$ & $E-06$ & & 1 & & 6 & 6 & -06 \\
\hline $.53 E-09$ & $6.58 E-06$ & & $1.15 \mathrm{E}-07$ & & $1.31 E-06$ & $2.05 E-06$ & $3.13 E-06$ \\
\hline $54 E-09$ & $6.58 \mathrm{E}-06$ & 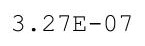 & $1.16 \mathrm{E}-07$ & & 1. $32 \mathrm{E}-06$ & $2.05 E-06$ & $E-06$ \\
\hline $56 E-09$ & 06 & & 1 & & & -06 & $E-06$ \\
\hline 99 & -06 & & 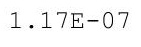 & & קבת ת2 & $E-06$ & cerar \\
\hline 9 & 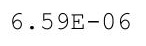 & $\begin{array}{lll}3 & 21 & 5\end{array}-07$ & & & & & 6 \\
\hline $62 E-09$ & 6 & $3.32 E-07$ & $1.18 \mathrm{E}-07$ & $8 \quad 30 \mathrm{~F}-07$ & 6 & 6 & 06 \\
\hline $64 E-09$ & $6.60 \mathrm{E}-06$ & $3.34 \mathrm{E}-07$ & $1.19 \mathrm{E}-07$ & $8.34 E-07$ & 1. $35 \mathrm{E}-06$ & $2.07 E-06$ & $3.18 \mathrm{E}-06$ \\
\hline $65 E-09$ & $.60 E-06$ & $.35 \mathrm{E}-0$ & 1.20E-07 & $8.37 \mathrm{E}-0$ & $1.35 \mathrm{E}-06$ & $2.07 \mathrm{E}-06$ & $19 E-06$ \\
\hline 09 & & & & & & -06 & -06 \\
\hline 09 & & & & 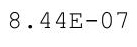 & 6 & & \\
\hline $71=0$ & & & & & & & \\
\hline $.73 E-09$ & 6 & $3 \wedge 0=-07$ & $\cdots$ & 1 & 6 & 0 & -06 \\
\hline 9 & 6 & ח & 1 & ז5 & $1.38 \mathrm{E}-$ & $.09 E-06$ & $23 E-$ \\
\hline $.77 E-09$ & $.61 \mathrm{E}-06$ & $43 E-0$ & $1.24 \mathrm{E}-0$ & 50 & $1.38 \mathrm{E}-06$ & $2.10 \mathrm{E}-06$ & $.24 \mathrm{E}-06$ \\
\hline-09 & $62 E-06$ & & ( & & & $E-06$ & $25 E-06$ \\
\hline & & & & & & & \\
\hline & & & & $t$ & 6 & -06 & -06 \\
\hline $85 E-09$ & $6.62 \mathrm{E}-06$ & . & 土.2tए & $0.09 E-4$ & $1.40 \mathrm{E}-06$ & $2 \cdot 1 \angle E-06$ & $3.27 E-06$ \\
\hline $87 E-09$ & $6.62 \mathrm{E}-06$ & $5 \cdot 100$ & 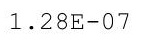 & . & $1.41 \mathrm{E}-06$ & $2 . \perp J E-00$ & $.28 E-06$ \\
\hline $89 E-09$ & 然 & & & & & 要 & \\
\hline$F-09$ & $5-06$ & 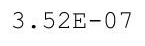 & 1 & تصم & 1 & & 06 \\
\hline & & & & & & & \\
\hline & & & & 7 & 06 & 06 & \\
\hline $98 \mathrm{E}-09$ & $6.63 \mathrm{E}-06$ & . $200 \mathrm{~L}$ & $1.3<5-01$ & $8.92 E-07$ & $1.43 E-06$ & $2.17 \mathrm{E}-06$ & $.31 E-06$ \\
\hline $00 E-09$ & $0.03 E-00$ & & 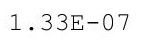 & & & & $3.32+-00$ \\
\hline $02 E-09$ & $64 E-06$ & 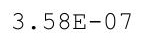 & I. & . & $1.44 \mathrm{E}-06$ & $2 \cdot+00$ - & $33 E-06$ \\
\hline 9 & 6 & 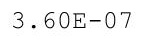 & $1.35 \mathrm{E}-07$ & 7 & 6 & 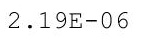 & 06 \\
\hline & & & & & & & \\
\hline $3 E-09$ & $6.64 \mathrm{E}-06$ & $3.62 E-07$ & $1.36 \mathrm{E}-07$ & & $1.45 \mathrm{E}$ & 06 & -06 \\
\hline & 06 & 3. & $1 \cdot 3$ & 7 & 1.46 & & \\
\hline & & & & & & & $.36 E-06$ \\
\hline $13 E-09$ & $6.65 E-06$ & .0 & म. & $9.23 E-07$ & $1.47 E-06$ & $2 \cdot 2 \angle E-06$ & $3.37 \mathrm{E}-06$ \\
\hline . $1 / \mathrm{L}-\mathrm{U}$ & $0.0 \mathrm{~L}-0$ & . & 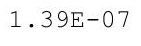 & $9.27 E-07$ & $1.47 E-06$ & & .000 \\
\hline $0 E-09$ & $6.65 E-06$ & $.69 E-07$ & $1.40 \mathrm{E}-07$ & $.31 E-07$ & 1.4 & $2.24 \mathrm{E}-06$ & 3.3 \\
\hline
\end{tabular}


RESRAD-OFFSITE, Version 2.5

itle : Offsite Resident Farmer Deterministic Run

File : RF TC99 DOESG FWD-FV2b.ROF

Summary of dose at graphical times, reptition 2 (continued)

Time

Years

$5.42 \mathrm{E}+02$

$5.43 \mathrm{E}+02$

$5.43 \mathrm{E}+02$

$5.44 \mathrm{E}+02$

$5.44 \mathrm{E}+02$

$5.45 \mathrm{E}+02$

$5.46 \mathrm{E}+02$

$5.46 \mathrm{E}+02$

$5.47 \mathrm{E}+02$

$5.47 \mathrm{E}+02$

$5.48 \mathrm{E}+02$

$5.48 \mathrm{E}+02$

$5.49 \mathrm{E}+02$

$5.49 \mathrm{E}+02$

$5.50 \mathrm{E}+02$

$5.50 \mathrm{E}+02$

$5.51 \mathrm{E}+02$

$5.51 \mathrm{E}+02$

$5.52 \mathrm{E}+02$

$5.52 \mathrm{E}+02$

$5.53 \mathrm{E}+02$

$5.53 \mathrm{E}+02$

$5.54 \mathrm{E}+02$

$5.54 \mathrm{E}+02$

$5.55 \mathrm{E}+02$

$5.55 \mathrm{E}+02$

$5.56 \mathrm{E}+02$

$5.56 \mathrm{E}+02$

$5.57 \mathrm{E}+02$

$5.57 \mathrm{E}+02$

$5.58 \mathrm{E}+02$

$5.58 \mathrm{E}+02$

$5.59 \mathrm{E}+02$

$5.59 \mathrm{E}+02$

$5.60 \mathrm{E}+02$

$5.60 \mathrm{E}+02$

$5.61 \mathrm{E}+02$

$5.61 \mathrm{E}+02$

$5.62 \mathrm{E}+02$

$5.62 \mathrm{E}+02$

$5.63 \mathrm{E}+02$

$5.63 \mathrm{E}+02$

$5.64 \mathrm{E}+02$

$5.64 \mathrm{E}+02$

$5.65 \mathrm{E}+02$

$5.66 \mathrm{E}+02$
Dose statistics at graphical times, mrem/yr

\begin{tabular}{|c|c|c|c|c|c|c|c|}
\hline m & aximum & ea & - & & & & \\
\hline-09 & $6.65 \mathrm{E}-06$ & $3.70 \mathrm{E}-07$ & $1.41 \mathrm{E}-07$ & $4 E-07$ & $1.48 \mathrm{E}-06$ & 06 & $3.39 E-00$ \\
\hline $24 E-09$ & $6.65 E-06$ & $1 E-07$ & $1.42 \mathrm{E}-07$ & $8 E-07$ & $48 E-06$ & $2.25 E-06$ & $D E-06$ \\
\hline $27 E-09$ & $.65 E-06$ & $3 E-07$ & 1. $42 \mathrm{E}-07$ & $42 E-07$ & $49 E-06$ & $2.26 \mathrm{E}-06$ & $0 E-06$ \\
\hline $29 \mathrm{E}-09$ & $65 E-06$ & $74 \mathrm{~F}-07$ & $3 \mathrm{~F}-07$ & $46 \mathrm{~F}-07$ & $49 F-06$ & $.27 E-06$ & $41 E-06$ \\
\hline-09 & 06 & $3.75 \mathrm{E}-07$ & 7 & $9.50 \mathrm{E}-07$ & 6 & 6 & $2 E-06$ \\
\hline 09 & 6 & & & & & & \\
\hline $.36 \mathrm{E}-09$ & 06 & & & & & & $E-06$ \\
\hline-09 & -06 & 1 & 1 & 7 & 6 & -06 & -06 \\
\hline $41 \mathrm{E}-09$ & $6.66 \mathrm{E}-06$ & $1 E-07$ & $1.47 E-07$ & t & $51 E-06$ & -06 & $E-06$ \\
\hline $44 \mathrm{E}-09$ & $66 \mathrm{E}-06$ & 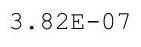 & 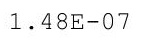 & & $.52 \mathrm{E}-06$ & $.31 E-06$ & -06 \\
\hline 09 & 06 & & & & & 6 & 06 \\
\hline $49 \mathrm{E}-09$ & 06 & 5 & 1.50 & & 6 & 6 & -06 \\
\hline $.51 E-09$ & $6.66 \mathrm{E}-06$ & & $1.51 \mathrm{E}-07$ & & $1.53 \mathrm{E}-06$ & $E-06$ & $.47 E-06$ \\
\hline $54 E-09$ & $6.66 \mathrm{E}-06$ & 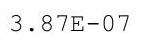 & 1. $52 \mathrm{E}-07$ & & $1.53 \mathrm{E}-06$ & $2.34 \mathrm{E}-06$ & $E-06$ \\
\hline $56 E-09$ & $66 E-06$ & $5=0$ & $\mathrm{~F}_{0}$ & & & -06 & $\Xi-06$ \\
\hline 09 & 06 & & ת & 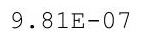 & 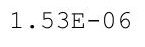 & $E-06$ & -06 \\
\hline 9 & 6 & & & & & & 6 \\
\hline 9 & 6 & & $1.55 \mathrm{E}-07$ & & 6 & & $50 E-06$ \\
\hline $67 E-09$ & $6.68 \mathrm{E}-06$ & $3.94 \mathrm{E}-07$ & $1.56 \mathrm{E}-07$ & $9.91 \mathrm{E}-0$ & 1. $55 \mathrm{E}-06$ & $E-06$ & $.51 E-06$ \\
\hline $70 E-09$ & $6.69 \mathrm{E}-06$ & $.96 E-07$ & $1.57 \mathrm{E}-07$ & $4 \mathrm{E}-$ & $1.55 \mathrm{E}-06$ & $2.39 \mathrm{E}-06$ & $52 E-06$ \\
\hline 09 & 06 & & & & & -06 & -06 \\
\hline 09 & & & & & & 0 & -06 \\
\hline 09 & 6.721 & & 1. & 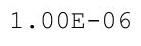 & 0 & & 06 \\
\hline $81 \mathrm{E}-09$ & 6 & \pm & 1. & 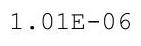 & 0 & $2.42 E-06$ & 06 \\
\hline 9 & 6 & $4.02 \mathrm{E}-07$ & 1. $61 \mathrm{E}-07$ & 5 & 6 & 6 & 06 \\
\hline $86 \mathrm{E}-09$ & $.74 \mathrm{E}-06$ & م & 1 & 1 & $1.57 \mathrm{E}-06$ & $2.43 E-06$ & $56 E-06$ \\
\hline $.89 E-09$ & $6.75 \mathrm{E}-06$ & & & 6 & & $F-06$ & $56 E-06$ \\
\hline & & & & & & & \\
\hline 9 & 06 & & 1.0 & 6 & 6 & & \\
\hline $97 E-09$ & $6.78 \mathrm{E}-06$ & . & I. & $1.03 E-06$ & $1.59 \mathrm{E}-06$ & $2.46 \mathrm{E}-06$ & $58-06$ \\
\hline $.00 \mathrm{E}-09$ & $6.79 \mathrm{E}-06$ & 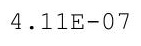 & . & . & $1.00 \mathrm{~L}-0$ & $2.405-00$ & $E-06$ \\
\hline 9 & 年 & 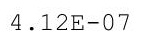 & 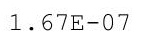 & 工象 & & 管 & \\
\hline-09 & $81 \mathrm{~F}-06$ & & 1 & & & & $E-06$ \\
\hline & & & & & & & \\
\hline 09 & & & & & & & \\
\hline $.15 \mathrm{E}-09$ & $6.84 \mathrm{E}-06$ & $4.10 \mathrm{O}-U$ & P. & 1.045 & 1.024 & -06 & $E-06$ \\
\hline $18 \mathrm{E}-09$ & $0.85 \mathrm{E}-06$ & & ×・IL & $1.05 \mathrm{E}-06$ & & & $3.0< \pm-06$ \\
\hline 09 & 6 & & & & & & $.62 E-06$ \\
\hline 9 & 6 & 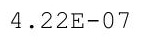 & t & 6 & 6 & 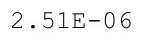 & 6 \\
\hline & & & & & & & 6 \\
\hline 09 & 6.88 & 07 & 1 & 06 & 6 & 06 & -06 \\
\hline$E-09$ & $6.89 \mathrm{E}-06$ & 4.2 & 1. & 1.00 & & 06 & -06 \\
\hline & 6 & & & & & & -06 \\
\hline y & 0.9 & 1. & I. & $1.07 \mathrm{E}-06$ & $1.66 \mathrm{E}-06$ & -06 & $65 E-06$ \\
\hline $405-03$ & $6.92 E-06$ & & 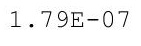 & I. & $\perp \cdot 00$ & & $65 E-06$ \\
\hline 9 & $E-06$ & $32 E-07$ & $1.80 E-07$ & $08 E-06$ & $67 E-06$ & $.55 E-06$ & -06 \\
\hline
\end{tabular}


RESRAD-OFFSITE, Version 2.5

Title : Offsite Resident Farmer Deterministic Run

File : RF TC99 DOESG FWD-FV2b.ROF

Summary of dose at graphical times, reptition 2 (continued)

Time

Years

$5.66 \mathrm{E}+02$

$5.67 \mathrm{E}+02$

$5.67 \mathrm{E}+02$

$5.68 \mathrm{E}+02$

$5.68 \mathrm{E}+02$

$5.69 \mathrm{E}+02$

$5.69 \mathrm{E}+02$

$5.70 \mathrm{E}+02$

$5.70 \mathrm{E}+02$

$5.71 \mathrm{E}+02$

$5.71 E+02$

$5.72 \mathrm{E}+02$

$5.72 \mathrm{E}+02$

$5.73 \mathrm{E}+02$

$5.73 \mathrm{E}+02$

$5.74 \mathrm{E}+02$

$5.74 \mathrm{E}+02$

$5.75 \mathrm{E}+02$

$5.75 \mathrm{E}+02$

$5.76 \mathrm{E}+02$

$5.76 \mathrm{E}+02$

$5.77 \mathrm{E}+02$

$5.77 \mathrm{E}+02$

$5.78 \mathrm{E}+02$

$5.78 \mathrm{E}+02$

$5.79 \mathrm{E}+02$

$5.79 \mathrm{E}+02$

$5.80 \mathrm{E}+02$

$5.80 \mathrm{E}+02$

$5.81 \mathrm{E}+02$

$5.81 \mathrm{E}+02$

$5.82 \mathrm{E}+02$

$5.82 \mathrm{E}+02$

$5.83 \mathrm{E}+02$

$5.83 \mathrm{E}+02$

$5.84 \mathrm{E}+02$

$5.84 \mathrm{E}+02$

$5.85 \mathrm{E}+02$

$5.85 \mathrm{E}+02$

$5.86 \mathrm{E}+02$

$5.87 \mathrm{E}+02$

$5.87 \mathrm{E}+02$

$5.88 \mathrm{E}+02$

$5.88 \mathrm{E}+02$

$5.89 \mathrm{E}+02$

$5.89 \mathrm{E}+02$
Dose statistics at graphical times, mrem/yr

\begin{tabular}{|c|c|c|c|c|c|c|c|}
\hline Iinimum & Maximum & Mean & Median & $90 \%$ & $95 \%$ & $97.5 \%$ & $9 \%$ \\
\hline 09 & 06 & $3 E-07$ & 7 & 6 & 1 & 6 & -06 \\
\hline 09 & 06 & $4 E-07$ & $82 \mathrm{E}-07$ & 06 & 06 & 06 & -06 \\
\hline $5 E-09$ & $95 E-06$ & $6 E-07$ & -07 & 6 & 6 & 06 & $5 E-06$ \\
\hline$E-09$ & $6 \mathrm{E}-06$ & $7 E-07$ & $34 \mathrm{E}-07$ & 6 & 6 & 06 & $8 E-06$ \\
\hline $3 E-09$ & 06 & & & & & & -06 \\
\hline $5 E-09$ & 06 & & & & & 6 & -06 \\
\hline $0 E-09$ & $8 E-06$ & $1 E-07$ & $1.87 \mathrm{E}-07$ & -06 & $0 E-06$ & 06 & $9 E-06$ \\
\hline $.73 E-09$ & $99 E-06$ & . & $1.88 \mathrm{E}-07$ & $1.10 \mathrm{E}-06$ & $1.70 \mathrm{E}-06$ & -06 & $70 E-06$ \\
\hline-09 & 06 & 7 & 7 & 6 & 6 & 06 & -06 \\
\hline$E-09$ & $E-06$ & S & 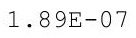 & $x_{-1}$ & 2. & 06 & -06 \\
\hline 09 & 06 & & & & 6 & & -06 \\
\hline-09 & 06 & 7 & & 6 & 6 & & $E-06$ \\
\hline $90 \mathrm{E}-09$ & $3 E-06$ & $0 E-07$ & $1.92 \mathrm{E}-07$ & $1.1 \angle E-U 6$ & $1.73 \mathrm{E}-06$ & -06 & $72 E-06$ \\
\hline $94 \mathrm{E}-09$ & $7.04 \mathrm{E}-06$ & $4.51 E-07$ & 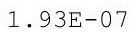 & $1 . \perp \angle L-00$ & $1.73 E-06$ & 00 & $E-06$ \\
\hline $3 E-09$ & $7.05 E-06$ & 4. & 1. & $\perp \cdot \perp L_{1}$ & 土. & 06 & -06 \\
\hline $.01 E-09$ & $7.06 \mathrm{E}-06$ & $4.54 \mathrm{E}-\mathrm{C}$ & 1.95 & 1.13 & $1.74 \mathrm{E}$ & 06 & -06 \\
\hline $.05 E-09$ & $7.06 \mathrm{E}-06$ & $4.56 \mathrm{E}-07$ & & $1.13 \mathrm{E}-06$ & $1.75 \mathrm{E}-06$ & $2.62 \mathrm{E}-06$ & $74 E-06$ \\
\hline$E-09$ & $E-06$ & $E-07$ & -07 & 6 & 1 & 6 & $4 E-06$ \\
\hline $2 E-09$ & $8 E-06$ & $9 E-07$ & & $1.14 \mathrm{E}$ & & 06 & -06 \\
\hline $.16 \mathrm{E}-09$ & $7.09 \mathrm{E}-06$ & 4. & 1.9 & $\perp$ & 1 & 06 & -06 \\
\hline $9 E-09$ & $9 E-06$ & 4. & $2 \cdot$ & 1.141 & 土. & & $75 E-06$ \\
\hline $23 E-09$ & $1.10 \pm-00$ & 4. & $\cdot$ & $\perp \cdot 1 \cup$ & 5 & 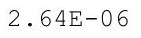 & -06 \\
\hline $.27 \mathrm{E}-09$ & $7.11 \mathrm{E}-06$ & $4.64 \mathrm{E}-07$ & $2.02 \mathrm{E}-07$ & $1.15 \mathrm{E}-06$ & $1.78 \mathrm{E}-06$ & $2.64 \mathrm{E}-06$ & $.76 E-06$ \\
\hline $.31 E-09$ & $7.12 \mathrm{E}-06$ & $4.66 \mathrm{E}-07$ & 7 & 1. & 1 & -06 & $E-06$ \\
\hline $35 E-09$ & $7.12 \mathrm{E}-06$ & $4.67 \mathrm{E}-0$ & 2. & & & -06 & $7 E-06$ \\
\hline$E-09$ & 06 & 4 & 7 & 6 & & 06 & -06 \\
\hline $2 E-09$ & $4 E-06$ & 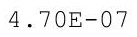 & & L & 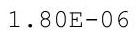 & & -06 \\
\hline $.46 \mathrm{E}-09$ & $7.15 \mathrm{E}-06$ & $4.71 E-07$ & $2.07 \mathrm{E}-07$ & $1.16 \mathrm{E}-06$ & $1.80 \mathrm{E}-06$ & $2.66 \mathrm{E}-06$ & $3.79 \mathrm{E}-06$ \\
\hline $.50 \mathrm{E}-09$ & 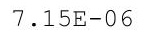 & $4.73 E-0$ & 2.001 & $\perp \cdot 1$ & 1.81 & 2.00 & $79 E-06$ \\
\hline 9 & 6 & 4. & 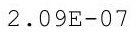 & 6 & $1.81 \mathrm{E}-06$ & 06 & 06 \\
\hline 09 & 06 & 4 & 2 & 6 & 6 & 06 & -06 \\
\hline$E-09$ & $E-06$ & 4 & 2 & 1 & 6 & 6 & -06 \\
\hline $.66 \mathrm{E}-09$ & $7.18 \mathrm{E}-06$ & $4.79 \mathrm{E}-\mathrm{C}$ & $2.12 \mathrm{E}-$ & $1.18 \mathrm{E}-$ & $1.82 \mathrm{E}-$ & & -06 \\
\hline $.70 \mathrm{E}-09$ & $7.19 \mathrm{E}-06$ & $4.80 \mathrm{E}-07$ & $2.14 \mathrm{E}-07$ & $1.18 \mathrm{E}-06$ & $1.83 \mathrm{E}-06$ & $2.68 \mathrm{E}-06$ & $3.81 E-06$ \\
\hline $.74 E-09$ & $1.20 E-06$ & $4.82 E-07$ & & & & & $81 E-06$ \\
\hline 9 & & & & & & & 06 \\
\hline 9 & 6 & 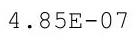 & 7 & 6 & 6 & 6 & 06 \\
\hline$E-09$ & 06 & 4 & 0 & 1 & 1 & 6 & 06 \\
\hline$E-09$ & $7.23 E-06$ & $7 E-07$ & 2 . & 1 . & 1 & & -06 \\
\hline $5 E-09$ & $7.23 \mathrm{E}$ & 4. & & 1.20 & 1 & & -06 \\
\hline 09 & & & & & 年 & & -06 \\
\hline . $35-09$ & 1.2 & 4. $92 \mathrm{E}-$ & $2 \cdot 215-$ & $1 \cdot 2$ & $1.86 \mathrm{E}-$ & $2.71 E-06$ & $3.84 \mathrm{E}-06$ \\
\hline 09 & 6 & 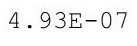 & 7 & 6 & $\perp$ & 6 & (36 \\
\hline$E-09$ & $E-06$ & $E-0$ & $3 E$ & 1 . & 1 & 06 & -06 \\
\hline $8-09$ & 7.2 & 4. & 2. & 1.2 & 1.8 & 06 & -06 \\
\hline$E-09$ & $7.27 \mathrm{E}-06$ & $.98 E-07$ & $.25 E-07$ & $1.21 \mathrm{E}-06$ & $1.88 \mathrm{E}-06$ & $2.73 E-06$ & $3.86 \mathrm{E}-06$ \\
\hline
\end{tabular}


RESRAD-OFFSITE, Version 2.5

itle : Offsite Resident Farmer Deterministic Run

File : RF TC99 DOESG FWD-FV2b.ROF

Summary of dose at graphical times, reptition 2 (continued)

Time

Years

$5.90 \mathrm{E}+02$

$5.90 \mathrm{E}+02$

$5.91 \mathrm{E}+02$

$5.91 E+02$

$5.92 \mathrm{E}+02$

$5.92 \mathrm{E}+02$

$5.93 \mathrm{E}+02$

$5.93 \mathrm{E}+02$

$5.94 \mathrm{E}+02$

$5.94 \mathrm{E}+02$

$5.95 \mathrm{E}+02$

$5.95 \mathrm{E}+02$

$5.96 \mathrm{E}+02$

$5.96 \mathrm{E}+02$

$5.97 \mathrm{E}+02$

$5.97 \mathrm{E}+02$

$5.98 \mathrm{E}+02$

$5.98 \mathrm{E}+02$

$5.99 \mathrm{E}+02$

$5.99 \mathrm{E}+02$

$6.00 \mathrm{E}+02$

$6.00 \mathrm{E}+02$

$6.01 \mathrm{E}+02$

$6.01 \mathrm{E}+02$

$6.02 \mathrm{E}+02$

$6.02 \mathrm{E}+02$

$6.03 E+02$

$6.03 \mathrm{E}+02$

$6.04 \mathrm{E}+02$

$6.04 \mathrm{E}+02$

$6.05 \mathrm{E}+02$

$6.05 \mathrm{E}+02$

$6.06 \mathrm{E}+02$

$6.07 \mathrm{E}+02$

$6.07 \mathrm{E}+02$

$6.08 \mathrm{E}+02$

$6.08 \mathrm{E}+02$

$6.09 \mathrm{E}+02$

$6.09 \mathrm{E}+02$

$6.10 \mathrm{E}+02$

$6.10 \mathrm{E}+02$

$6.11 \mathrm{E}+02$

$6.11 \mathrm{E}+02$

$6.12 \mathrm{E}+02$

$6.12 \mathrm{E}+02$

$6.13 \mathrm{E}+02$
Dose statistics at graphical times, mrem/yr

\begin{tabular}{|c|c|c|c|c|c|c|c|}
\hline inimum & laximum & Mean & ledian & $\%$ & $5 \%$ & $97.5 \%$ & $\%$ \\
\hline $25 E-09$ & $.28 E-06$ & $4.99 \mathrm{E}-07$ & $2.26 \mathrm{E}-07$ & $1.22 \mathrm{E}-06$ & $1.89 \mathrm{E}-06$ & $2.73 E-06$ & $3.86 \mathrm{E}-06$ \\
\hline 09 & $9 E-06$ & $L E-07$ & $E-07$ & 6 & 06 & 06 & -06 \\
\hline-09 & -06 & 07 & -07 & 66 & & -06 & -06 \\
\hline$E-09$ & $0 E-06$ & -07 & 07 & & & & -06 \\
\hline $43 E-09$ & $1 E-06$ & 年 & 7 & 6 & 6 & $E-06$ & -06 \\
\hline $47 E-09$ & $31 E-06$ & $E-07$ & $E-07$ & $.23 E-06$ & 0 & $E-06$ & -06 \\
\hline 09 & 06 & $5.08 E-07$ & $2.33 E-07$ & 6 & 6 & -06 & 06 \\
\hline $.57 E-09$ & $7.32 E-06$ & r & $2.01+8$ & $1.23 E-06$ & & -06 & $E-06$ \\
\hline $\mathrm{E}-09$ & -06 & e & 7 & 66 & 06 & & -06 \\
\hline $.66 \mathrm{E}-09$ & $34 \mathrm{E}-06$ & & & 1.23E- & & -06 & -06 \\
\hline-09 & -06 & 1 & 7 & 6 & 6 & -06 & -06 \\
\hline-09 & -06 & 1 & 1 & 6 & & -06 & -06 \\
\hline$E-09$ & $7.35 \mathrm{E}-06$ & I & 4 & $1 \cdot 24$ & 0 & -00 & -06 \\
\hline 9 & 6 & $5.18 E-07$ & $2.40 E-07$ & $1.24 \mathrm{E}-06$ & . & 0 & 06 \\
\hline $89 E-09$ & $7.37 E-06$ & & & & & & 06 \\
\hline $.94 \mathrm{E}-09$ & $7.37 \mathrm{E}-06$ & $5.21 \mathrm{E}-07$ & $2.43 E-07$ & $1.25 \mathrm{E}-06$ & & -06 & $2 E-06$ \\
\hline$E-09$ & $8 E-06$ & 田 & $3 E-07$ & $25 E-06$ & -06 & -06 & $E-06$ \\
\hline-09 & $E-06$ & ס & $44 E-07$ & 6 & $97 E-06$ & $1 E-06$ & $E-06$ \\
\hline 09 & -06 & $5.26 \mathrm{E}-07$ & $2.45 \mathrm{E}-01$ & 0 & & 06 & -06 \\
\hline 09 & $E-06$ & 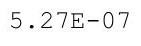 & 1 & $\cdot 20$ & 6 & -00 & -06 \\
\hline $.19 \mathrm{E}-09$ & $7.40 \mathrm{E}-06$ & & & $1 \cdot 20$ & & 0 & -06 \\
\hline $.24 \mathrm{E}-09$ & $7.41 \mathrm{E}-06$ & $O E-C$ & $E-C$ & $1.26 \mathrm{E}$ & 1. & $E-0$ & -06 \\
\hline$E-09$ & $.41 \mathrm{E}-06$ & $325=07$ & $50=-07$ & $1.26 \mathrm{E}-06$ & $1.99 \mathrm{E}-06$ & $3 E-06$ & $94 E-06$ \\
\hline 1E-09 & $7.42 \mathrm{E}-06$ & ( & 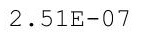 & $1.26 \mathrm{E}-$ & $1.99 \mathrm{E}-06$ & $E-06$ & $95 E-06$ \\
\hline 09 & 06 & & & 6 & & -06 & $5 E-06$ \\
\hline & & & & & & & \\
\hline $.49 E-09$ & $+4-06$ & $.004-4$ & 2 & $+\cdot 211$ & 6 & & -06 \\
\hline $.54 \mathrm{E}-09$ & $7.44 \mathrm{E}-06$ & 1 & 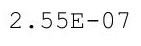 & $1.28 \mathrm{E}-06$ & 06 & $2.85 E-06$ & $96 E-06$ \\
\hline 09 & 6 & $5.41 \mathrm{E}-07$ & $2.56 \mathrm{E}-07$ & 6 & 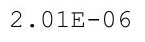 & 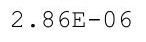 & 06 \\
\hline$F-09$ & $45 \mathrm{~F}-06$ & & & & & 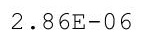 & $7 E-06$ \\
\hline$F-09$ & $F-06$ & & 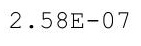 & 6 & 6 & -06 & $7 E-06$ \\
\hline 09 & & & & & & & -06 \\
\hline $.81 E-09$ & $7.47 E-06$ & 5 . & 2. & $1.30 \mathrm{E}$ & 6 & 06 & -06 \\
\hline $.86 E-09$ & $7.47 \mathrm{E}-06$ & $3.405-01$ & $2.0<2-01$ & $1.30 \mathrm{E}-06$ & $2.03 E-06$ & $8 E-06$ & $98 E-06$ \\
\hline $91 E-09$ & $7.48 E-06$ & . & & & & $2.00 \mathrm{~L}-00$ & $.99 E-06$ \\
\hline 9 & 6 & & & & & & 6 \\
\hline 9 & & $5.53 \mathrm{E}-07$ & & & & & 06 \\
\hline 9 & $7.49 \mathrm{E}-06$ & & & & & & \\
\hline$E-09$ & 06 & & 07 & 1.32 & 06 & -06 & \\
\hline $.19 \mathrm{E}-09$ & $7.50 \mathrm{E}-06$ & $7+4$ & $2 \cdot$ & $1.3 \angle \mathrm{E}$ & & 06 & -06 \\
\hline 1E-09 & $7.51 \mathrm{E}-06$ & $5.59 \mathrm{E}-$ & $2.69 \mathrm{E}-$ & $1.33 E-06$ & & & $4.02 E-06$ \\
\hline$E-09$ & $1.3 \perp E-06$ & . & 2.100 ( & $\perp \cdot 00$ & $2.07 \mathrm{E}-06$ & $2.91 \mathrm{E}-06$ & $4.02 E-06$ \\
\hline 皮 & 6 & . & - & $\pm \cdot 0$ & 2.010 & 6 & $02 E-06$ \\
\hline 9 & & & & & & & 06 \\
\hline $47 E-09$ & $7.53 E-06$ & $5.65 E-07$ & $2.74 \mathrm{E}-07$ & $1.34 \mathrm{E}-06$ & $2.08 \mathrm{E}-06$ & $2.92 \mathrm{E}-06$ & $4.03 E-06$ \\
\hline $.53 E-09$ & $.53 E-06$ & $66 \mathrm{E}-07$ & $75 E-07$ & $1.35 \mathrm{E}-06$ & $2.08 \mathrm{E}-06$ & $2.93 E-06$ & -06 \\
\hline
\end{tabular}


RESRAD-OFFSITE, Version 2.5

$\mathrm{T}^{1 / 2}$ Limit $=180$ days

Title : Offsite Resident Farmer Deterministic Run

File : RF TC99 DOESG FWD-FV2b.ROF

Summary of dose at graphical times, reptition 2 (continued)

Time

Years

$6.13 \mathrm{E}+02$

$6.14 \mathrm{E}+02$

$6.14 \mathrm{E}+02$

$6.15 \mathrm{E}+02$

$6.15 \mathrm{E}+02$

$6.16 \mathrm{E}+02$

$6.16 \mathrm{E}+02$

$6.17 \mathrm{E}+02$

$6.17 \mathrm{E}+02$

$6.18 \mathrm{E}+02$

$6.18 \mathrm{E}+02$

$6.19 \mathrm{E}+02$

$6.19 \mathrm{E}+02$

$6.20 \mathrm{E}+02$

$6.20 \mathrm{E}+02$

$6.21 \mathrm{E}+02$

$6.21 \mathrm{E}+02$

$6.22 \mathrm{E}+02$

$6.22 \mathrm{E}+02$

$6.23 \mathrm{E}+02$

$6.23 \mathrm{E}+02$

$6.24 \mathrm{E}+02$

$6.24 \mathrm{E}+02$

$6.25 \mathrm{E}+02$

$6.25 \mathrm{E}+02$

$6.26 \mathrm{E}+02$

$6.27 \mathrm{E}+02$

$6.27 \mathrm{E}+02$

$6.28 \mathrm{E}+02$

$6.28 \mathrm{E}+02$

$6.29 \mathrm{E}+02$

$6.29 \mathrm{E}+02$

$6.30 \mathrm{E}+02$

$6.30 \mathrm{E}+02$

$6.31 \mathrm{E}+02$

$6.31 \mathrm{E}+02$

$6.32 \mathrm{E}+02$

$6.32 \mathrm{E}+02$

$6.33 \mathrm{E}+02$

$6.33 \mathrm{E}+02$

$6.34 \mathrm{E}+02$

$6.34 \mathrm{E}+02$

$6.35 \mathrm{E}+02$

$6.35 \mathrm{E}+02$

$6.36 \mathrm{E}+02$

$6.36 \mathrm{E}+02$
Dose statistics at graphical times, mrem/yr

\begin{tabular}{|c|c|c|c|c|c|c|c|}
\hline m & aximum & ea & ec & & & & \\
\hline $.58 E-09$ & $7.54 \mathrm{E}-06$ & $5.68 E-07$ & $2.76 \mathrm{E}-07$ & $1.35 E-06$ & $08 E-06$ & -06 & -00 \\
\hline $64 E-09$ & $.54 E-06$ & $9 E-07$ & $2.77 \mathrm{E}-07$ & $1.36 \mathrm{E}-06$ & $09 E-06$ & $2.94 \mathrm{E}-06$ & $5 E-06$ \\
\hline $.70 E-09$ & $5 E-06$ & $71 \mathrm{~F}-07$ & $.78 E-07$ & $36 E-06$ & $09 E-06$ & $2.94 E-06$ & $05 E-06$ \\
\hline $.76 \mathrm{E}-09$ & $55 E-06$ & $72 \mathrm{~F}-07$ & $79 F-07$ & $36 F-06$ & $10 F-06$ & $2.95 E-06$ & $.05 E-06$ \\
\hline$E-09$ & -06 & 1 & 7 & 6 & 6 & 6 & $6 E-06$ \\
\hline $.88 E-09$ & & & & & & & \\
\hline $.94 \mathrm{E}-09$ & 06 & & $2.83 E-07$ & & & & -06 \\
\hline $.00 E-09$ & $7.57 \mathrm{E}-06$ & 年 & -01 & $8 \mathrm{E}-06$ & -06 & -06 & $E-06$ \\
\hline-09 & $7.57 \mathrm{E}-06$ & -07 & $E-07$ & $.38 E-06$ & -06 & -06 & $E-06$ \\
\hline $2 E-09$ & $58 E-06$ & 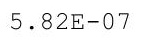 & $86=-07$ & $.38 E-06$ & $12 \mathrm{~F}-06$ & $96 \mathrm{~F}=06$ & $.07 E-06$ \\
\hline 09 & 06 & $5.83 \mathrm{E}$ & & 6 & & 6 & -06 \\
\hline $24 E-09$ & $E-06$ & $.85 \mathrm{E}$ & 2 & 6 & 6 & 6 & -06 \\
\hline $.30 E-09$ & $7.59 \mathrm{E}-06$ & $5.86 \mathrm{E}-07$ & $2.89 E-07$ & $1.39 E-06$ & $2.13 E-06$ & $2.97 E-06$ & $.08 E-06$ \\
\hline $36 E-09$ & $7.59 \mathrm{E}-06$ & 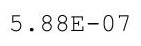 & $2.90 \mathrm{E}-07$ & $1.39 \mathrm{E}-06$ & $2.13 E-06$ & $2.97 E-06$ & $08 E-06$ \\
\hline-09 & -06 & & 1 & -06 & & -06 & $E-06$ \\
\hline $9 E-09$ & 06 & $3.91 \mathrm{~L}$ & $2.954-01$ & 0 & & 6 & 06 \\
\hline 09 & 6 & & & 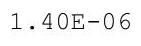 & & & 6 \\
\hline$E-09$ & 6 & $5.94 \mathrm{E}-07$ & $2.95 E-07$ & 6 & & 6 & 06 \\
\hline $68 E-09$ & $7.61 \mathrm{E}-06$ & $95 \mathrm{~F}-07$ & $6 \mathrm{~F}-07$ & $.40 \mathrm{E}-06$ & $15 E-06$ & $9 E-06$ & $10 E-06$ \\
\hline $74 \mathrm{E}-09$ & $7.62 \mathrm{E}-06$ & $7 \mathrm{~F}-07$ & $2.97 \mathrm{E}-07$ & $1.40 \mathrm{E}-06$ & $2.15 \mathrm{E}-06$ & $9 E-06$ & 1.10E-06 \\
\hline 9 & & & & & & & 06 \\
\hline & & & & & & & \\
\hline 9 & 6 & & 7 & & & & 06 \\
\hline $.00 E-09$ & 6 & ح & $3.02 \mathrm{E}-07$ & 6 & & $3.00 \mathrm{E}-06$ & -06 \\
\hline $5-09$ & $.64 \mathrm{E}-06$ & $=0$ & תבק ח & $1.42 \mathrm{E}-06$ & $17 \nabla_{1}$ & $E-06$ & $12 E-06$ \\
\hline$F-09$ & $7-64 \mathrm{~F}-06$ & 7 & 政 & 1. $42 \mathrm{E}-06$ & $2 \quad 18 \mathrm{~F}-06$ & $.01 E-06$ & $.12 \mathrm{E}-06$ \\
\hline-09 & $E-06$ & & & $42 E-06$ & & $E-06$ & $.12 E-06$ \\
\hline & & & & & & & \\
\hline 99 & 06 & o & $3.00 \mathrm{E}-01$ & $\perp \cdot$ & & -06 & -06 \\
\hline $40 E-09$ & $7.65 \mathrm{E}-06$ & 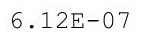 & 3.074 t & $1.43 E-06$ & $2.20 E-06$ & $3.01 E-06$ & $.13 E-06$ \\
\hline $47 E-09$ & $7.66 \mathrm{E}-06$ & 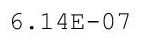 & 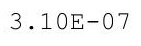 & $1.43 \mathrm{E}-06$ & $2.205-00$ & $3.0<5-00$ & $.14 \mathrm{E}-06$ \\
\hline 9 & 6 & & & $1.44 \mathrm{E}-$ & & 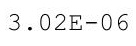 & $14 \mathrm{E}-$ \\
\hline 6 & & & & & & & 06 \\
\hline 9 & 6 & & & & & & \\
\hline $4 E-09$ & $7.67 \mathrm{E}-06$ & $0.205-4$ & 我 & $1.45 \mathrm{~F}$ & $2 \cdot 24$ & 06 & -06 \\
\hline $81 E-09$ & $7.67 \mathrm{E}-06$ & $0.2 \perp+4$ & $3.10 \pm-0 t$ & $1.45 \mathrm{E}-06$ & $2 \cdot 221$ & -06 & $.15 E-06$ \\
\hline $88 E-09$ & $7.68 \mathrm{E}-06$ & & & & & & . . \\
\hline $5 E-09$ & 1.00 D & 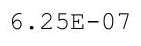 & - & $1.46 \mathrm{E}-06$ & $2 \cdot 201$ & P & 06 \\
\hline 8 & 6 & $6.26 \mathrm{E}-07$ & $3.20 \mathrm{E}-07$ & $.46 E-06$ & 6 & 6 & 06 \\
\hline & 6 & & 7 & 1 & 6 & 6 & 06 \\
\hline $2 E-08$ & $7.69 \mathrm{E}-06$ & $9 \mathrm{E}$ & 7 & $1.47 \mathrm{E}$ & 06 & & -06 \\
\hline $2 E-08$ & $1.09 \mathrm{c}$ & & & 1.47 & & & \\
\hline & & & & & & & $4.1 / \mathrm{E}-06$ \\
\hline $45-08$ & $7.70 \mathrm{E}-06$ & . & $3.20 \mathrm{~L}-1$ & $1.48 \mathrm{E}-06$ & $2.26 E-06$ & $3.05 E-06$ & $4.17 E-06$ \\
\hline $05 E-08$ & $7.70 \mathrm{E}-06$ & . & $.20=$ & $1.49 \mathrm{E}-06$ & $2.26 E-06$ & $3.05 E-06$ & . +10 \\
\hline $05 E-08$ & $.70 E-06$ & $E-07$ & $.29 \mathrm{E}-07$ & $1.49 \mathrm{E}-06$ & -06 & -06 & $4.17 \mathrm{E}$ \\
\hline
\end{tabular}


RESRAD-OFFSITE, Version 2.5

Title : Offsite Resident Farmer Deterministic Run

File : RF TC99 DOESG FWD-FV2b.ROF

Summary of dose at graphical times, reptition 2 (continued)

Time

Years

$6.37 \mathrm{E}+02$

$6.37 \mathrm{E}+02$

$6.38 \mathrm{E}+02$

$6.38 \mathrm{E}+02$

$6.39 \mathrm{E}+02$

$6.39 \mathrm{E}+02$

$6.40 \mathrm{E}+02$

$6.40 \mathrm{E}+02$

$6.41 \mathrm{E}+02$

$6.41 \mathrm{E}+02$

$6.42 \mathrm{E}+02$

$6.42 \mathrm{E}+02$

$6.43 \mathrm{E}+02$

$6.43 \mathrm{E}+02$

$6.44 \mathrm{E}+02$

$6.44 \mathrm{E}+02$

$6.45 \mathrm{E}+02$

$6.45 \mathrm{E}+02$

$6.46 \mathrm{E}+02$

$6.47 \mathrm{E}+02$

$6.47 \mathrm{E}+02$

$6.48 \mathrm{E}+02$

$6.48 \mathrm{E}+02$

$6.49 \mathrm{E}+02$

$6.49 \mathrm{E}+02$

$6.50 \mathrm{E}+02$

$6.50 \mathrm{E}+02$

$6.51 \mathrm{E}+02$

$6.51 \mathrm{E}+02$

$6.52 \mathrm{E}+02$

$6.52 \mathrm{E}+02$

$6.53 \mathrm{E}+02$

$6.53 \mathrm{E}+02$

$6.54 \mathrm{E}+02$

$6.54 \mathrm{E}+02$

$6.55 \mathrm{E}+02$

$6.55 \mathrm{E}+02$

$6.56 \mathrm{E}+02$

$6.56 \mathrm{E}+02$

$6.57 \mathrm{E}+02$

$6.57 \mathrm{E}+02$

$6.58 \mathrm{E}+02$

$6.58 \mathrm{E}+02$

$6.59 \mathrm{E}+02$

$6.59 \mathrm{E}+02$

$6.60 \mathrm{E}+02$
Dose statistics at graphical times, mrem/yr

\begin{tabular}{|c|c|c|c|c|c|c|c|}
\hline $\mathrm{m}$ & aximum & ea & 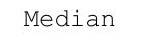 & & & & \\
\hline $.06 \mathrm{E}-08$ & $7.71 \mathrm{E}-06$ & $6.38 E-07$ & $3.30 \mathrm{E}-07$ & $1.50 \mathrm{E}-06$ & $27 E-06$ & -06 & -00 \\
\hline $.07 E-08$ & $7.71 E-06$ & $6.40 \mathrm{E}-07$ & $3.31 \mathrm{E}-07$ & $1.50 E-06$ & $2.27 E-06$ & $3.06 \mathrm{E}-06$ & $7 E-06$ \\
\hline $.07 E-08$ & $71 E-06$ & $6.42 \mathrm{E}-07$ & $3.33 \mathrm{E}-07$ & $50 \mathrm{E}-06$ & $2.28 \mathrm{E}-06$ & $3.06 \mathrm{E}-06$ & $7 E-06$ \\
\hline $.08 E-08$ & $71 \mathrm{E}-06$ & $3 F-07$ & $34 \mathrm{~F}-07$ & $.51 E-06$ & $28 \mathrm{~F}-06$ & $306 \mathrm{~F}-06$ & $17 E-06$ \\
\hline-08 & 06 & 7 & -07 & 6 & 6 & -06 & -06 \\
\hline 08 & 06 & & & & & & \\
\hline $10 \mathrm{E}-08$ & $7.72 \mathrm{E}-06$ & & & & & & -06 \\
\hline $.11 E-08$ & 06 & 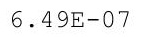 & 1 & 6 & 6 & -06 & $E-06$ \\
\hline $12 \mathrm{E}-08$ & $7.73 E-06$ & $x^{-}$ & -07 & $52 E-06$ & -06 & -06 & $E-06$ \\
\hline $13 E-08$ & $73 E-06$ & 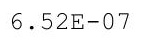 & קריט & $.53 E-06$ & $.31 E-06$ & $8 E-06$ & $17 E-06$ \\
\hline $14 \mathrm{E}-08$ & $7.731-1$ & & & & & 6 & -06 \\
\hline $14 \mathrm{E}-08$ & $7.74 \mathrm{E}-06$ & 6 & $3.45 \mathrm{E}-07$ & 6 & 6 & 6 & -06 \\
\hline $.15 \mathrm{E}-08$ & $7.74 \mathrm{E}-06$ & & $3.46 \mathrm{E}-07$ & $1.54 \mathrm{E}-06$ & & $3.09 E-06$ & $.17 E-06$ \\
\hline $16 \mathrm{E}-08$ & $7.74 \mathrm{E}-06$ & $6.59 \mathrm{E}-07$ & $.48 \mathrm{E}-07$ & $1.54 \mathrm{E}-06$ & $2.33 E-06$ & -06 & $17 E-06$ \\
\hline 08 & $74 E-06$ & 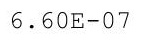 & & 6 & & 00 & $E-06$ \\
\hline $.17 E-08$ & -06 & $6-62 F-07$ & & 0 & & 0 & 06 \\
\hline 8 & 6 & & & & & & 6 \\
\hline $19 \mathrm{E}-08$ & 6 & 6 & $352 \mathrm{~F}-07$ & 6 & & 6 & 06 \\
\hline $20 E-08$ & $7.75 \mathrm{E}-06$ & $6.66 \mathrm{E}-07$ & $3.53 E-07$ & $1.56 \mathrm{E}-06$ & $2.35 E-06$ & $3.11 E-06$ & $.18 E-06$ \\
\hline $21 \mathrm{E}-08$ & $7.75 \mathrm{E}-06$ & $6.68 \mathrm{E}-07$ & $3.54 \mathrm{E}-07$ & $1.57 \mathrm{E}-06$ & $2.35 E-06$ & $3.12 \mathrm{E}-06$ & $4.18 E-06$ \\
\hline 08 & & & & & & -06 & -06 \\
\hline 0 & & & & 6 & & & \\
\hline חקרל & & $6.73 E-07$ & & 6 & & & 06 \\
\hline $24 E-08$ & 6 & $6.74 E-07$ & $3.59 \mathrm{E}-07$ & 6 & 6 & 0 & -06 \\
\hline $25 E-08$ & $.76 \mathrm{E}-06$ & 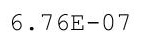 & $\Gamma$ & $150=0$ & $.37 E-06$ & $3 E-06$ & $18 \mathrm{E}-$ \\
\hline $26 \mathrm{~F}-08$ & $76 F-06$ & 6 677 - & $=0$ & $1.59 \mathrm{E}-06$ & $.37 E-06$ & $13 E-06$ & $.18 \mathrm{E}-06$ \\
\hline 08 & & & & & & & $.18 E-06$ \\
\hline 8 & & & & & & & \\
\hline-08 & 6 & & & 06 & 2.50 & -06 & -06 \\
\hline $29 \mathrm{E}-08$ & $7.77 \mathrm{E}-06$ & 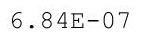 & .0t土 & $1.60 \mathrm{E}-06$ & $2.38 E-06$ & $3.14 \mathrm{E}-00$ & $.17 E-06$ \\
\hline $30 E-08$ & $7.77 \mathrm{E}-06$ & 1. & 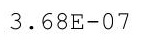 & $1.61 \mathrm{E}-06$ & $2.39 \mathrm{E}-06$ & $3.14 \mathrm{E}-0$ & 4. $17 \mathrm{E}-06$ \\
\hline 8 & תק & & & & & 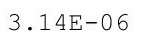 & \\
\hline $32-1-1-1$ & & & & & & & 6 \\
\hline 8 & & & & & & & 06 \\
\hline $33 E-08$ & $7.78 \mathrm{E}-06$ & $6.91 \mathrm{E}-07$ & 7 & $1.6 \angle \mathrm{F}$ & 6 & 06 & -06 \\
\hline $34 E-08$ & $7.78 E-06$ & . & . & $1.62 \mathrm{E}-06$ & 2.41 & -06 & $.18 E-06$ \\
\hline $35 E-08$ & & & & & & & $4.10 \mathrm{D}-00$ \\
\hline $36 E-08$ & $7.78 E-06$ & & - & $1.63 \mathrm{E}-06$ & & & $18 E-06$ \\
\hline 8 & 06 & 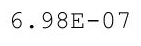 & 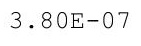 & -06 & 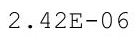 & 6 & 06 \\
\hline 08 & & & 7 & 6 & 06 & 6 & \\
\hline$E-08$ & $7.79 \mathrm{E}-06$ & $7.01 \mathrm{E}$ & 07 & 1 . & 06 & & -06 \\
\hline 8 & & & & & & & \\
\hline & & & & & & & $4 \cdot 19 \pm-06$ \\
\hline $41 E-08$ & $7.79 \mathrm{E}-06$ & t. & 3.00 म & $1.65 \mathrm{E}-06$ & $2.44 E-06$ & $3.18 \mathrm{E}-06$ & $4.20 E-06$ \\
\hline $.4 \angle 5-00$ & . & . & & $1.66 \mathrm{E}-06$ & & & $4.21 E-06$ \\
\hline $43 E-08$ & $.80 E-06$ & $.09 \mathrm{E}-07$ & $.91 \mathrm{E}-07$ & $.66 \mathrm{E}-06$ & $E-06$ & $E-06$ & $4.21 E-06$ \\
\hline
\end{tabular}


RESRAD-OFFSITE, Version 2.5

$\mathrm{T}^{1 / 2}$ Limit $=180$ days

robabilistic Dose and Risk Report

Title : Offsite Resident Farmer Deterministic Run

File : RF TC99 DOESG FWD-FV2b.ROF

Summary of dose at graphical times, reptition 2 (continued)

Time

Years

$6.60 \mathrm{E}+02$

$6.61 \mathrm{E}+02$

$6.61 \mathrm{E}+02$

$6.62 \mathrm{E}+02$

$6.62 \mathrm{E}+02$

$6.63 \mathrm{E}+02$

$6.63 \mathrm{E}+02$

$6.64 \mathrm{E}+02$

$6.64 \mathrm{E}+02$

$6.65 \mathrm{E}+02$

$6.65 \mathrm{E}+02$

$6.66 \mathrm{E}+02$

$6.67 \mathrm{E}+02$

$6.67 \mathrm{E}+02$

$6.68 \mathrm{E}+02$

$6.68 \mathrm{E}+02$

$6.69 \mathrm{E}+02$

$6.69 \mathrm{E}+02$

$6.70 \mathrm{E}+02$

$6.70 \mathrm{E}+02$

$6.71 \mathrm{E}+02$

$6.71 \mathrm{E}+02$

$6.72 \mathrm{E}+02$

$6.72 \mathrm{E}+02$

$6.73 \mathrm{E}+02$

$6.73 \mathrm{E}+02$

$6.74 \mathrm{E}+02$

$6.74 \mathrm{E}+02$

$6.75 \mathrm{E}+02$

$6.75 \mathrm{E}+02$

$6.76 \mathrm{E}+02$

$6.76 \mathrm{E}+02$

$6.77 \mathrm{E}+02$

$6.77 \mathrm{E}+02$

$6.78 \mathrm{E}+02$

$6.78 \mathrm{E}+02$

$6.79 \mathrm{E}+02$

$6.79 \mathrm{E}+02$

$6.80 \mathrm{E}+02$

$6.80 \mathrm{E}+02$

$6.81 \mathrm{E}+02$

$6.81 \mathrm{E}+02$

$6.82 \mathrm{E}+02$

$6.82 \mathrm{E}+02$

$6.83 \mathrm{E}+02$

$6.83 \mathrm{E}+02$
Dose statistics at graphical times, mrem/yr

\begin{tabular}{|c|c|c|c|c|c|c|c|}
\hline m & $\operatorname{axi}$ & e & 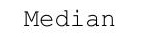 & & & & \\
\hline 08 & $7.80 \mathrm{E}-06$ & $10 E-07$ & $3.93 E-07$ & $1.66 \mathrm{E}-06$ & 06 & 06 & $4 . \angle \angle E-00$ \\
\hline $45 E-08$ & $7.80 \mathrm{E}-06$ & $7.12 \mathrm{E}-07$ & $3.94 \mathrm{E}-07$ & $1.67 E-06$ & $2.45 E-06$ & $3.20 \mathrm{E}-06$ & $.22 E-06$ \\
\hline $.46 \mathrm{E}-08$ & $.80 E-06$ & $.13 E-07$ & $.95 E-07$ & $1.67 \mathrm{E}-06$ & $2.45 \mathrm{E}-06$ & $3.20 \mathrm{E}-06$ & $.23 E-06$ \\
\hline $47 E-08$ & $80 E-06$ & $15 \mathrm{~F}-07$ & $97 \mathrm{~F}-07$ & $67 \mathrm{~F}-06$ & $245 \mathrm{~F}-06$ & -06 & $.23 E-06$ \\
\hline-08 & 06 & 07 & 7 & 6 & 6 & -06 & -06 \\
\hline-08 & & & & & & & \\
\hline $50 \mathrm{E}-08$ & -06 & & & & & & $.25 E-06$ \\
\hline $.50 E-08$ & 06 & 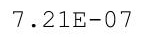 & 1 & 6 & 6 & -06 & $26 E-06$ \\
\hline $51 \mathrm{E}-08$ & -06 & ש. & $E-07$ & $69 E-06$ & $47 E-06$ & -06 & $.26 \mathrm{E}-06$ \\
\hline $52 E-08$ & $81 E-06$ & 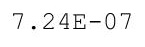 & ( & $.70 E-06$ & $.47 E-06$ & $.22 E-06$ & $.27 E-06$ \\
\hline $53 E-08$ & 06 & & & 1.70 & & 6 & -06 \\
\hline $54 \mathrm{E}-08$ & $7.81 \mathrm{E}-06$ & $7.28 \mathrm{E}-0$ & 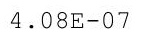 & 6 & 06 & 6 & $E-06$ \\
\hline $.55 E-08$ & $7.81 E-06$ & & $4.09 E-07$ & $1.71 E-06$ & $2.48 E-06$ & $3.23 E-06$ & $.28 E-06$ \\
\hline $56 \mathrm{E}-08$ & $7.81 \mathrm{E}-06$ & 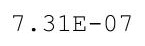 & $4.11 \mathrm{E}-07$ & $1.71 \mathrm{E}-06$ & $2.48 \mathrm{E}-06$ & -06 & $.29 E-06$ \\
\hline $57 E-08$ & -06 & & & 6 & -06 & -06 & $29 E-06$ \\
\hline $.58 \mathrm{E}-$ & 6 & $1.04+4$ & & $.72 \mathrm{E}$ & 6 & 6 & 06 \\
\hline 8 & 6 & (1. & & & & -06 & 6 \\
\hline $60 \mathrm{E}-08$ & $81 \mathrm{H}-2 \mathrm{l}$ & $7 \quad 37 \mathrm{~F}-07$ & $4.16 \mathrm{E}-07$ & 6 & 6 & 6 & 06 \\
\hline $.61 E-08$ & $7.81 \mathrm{E}-06$ & $7.39 \mathrm{E}-07$ & $4.17 \mathrm{E}-07$ & $1.73 E-06$ & $2.50 \mathrm{E}-06$ & $3.25 E-06$ & $.32 E-06$ \\
\hline $62 E-08$ & $.81 E-06$ & $7.40 \mathrm{E}-07$ & $4.18 \mathrm{E}-07$ & $1.74 \mathrm{E}-06$ & $2.51 E-06$ & $3.25 \mathrm{E}-06$ & 4. $32 E-06$ \\
\hline 08 & 06 & & & & & -06 & -06 \\
\hline 08 & & & & 6 & 6 & & \\
\hline $65 E-08$ & & & & 6 & & & -06 \\
\hline $66 \mathrm{E}-08$ & 7.811 & . & $1235-07$ & 6 & 6 & 0 & -06 \\
\hline 8 & $81 E-06$ & .4 & ב & $1.75 \mathrm{E}-06$ & 6 & $E-06$ & $35 E-$ \\
\hline $68 E-08$ & $7.81 \mathrm{E}-06$ & $50 \Gamma^{-10}$ & ก $26=0$ & 1. $75 \mathrm{E}-06$ & $.53 E-06$ & $.28 E-06$ & $.35 E-06$ \\
\hline$E-08$ & $.81 \mathrm{E}-06$ & & & $.76 \mathrm{E}-06$ & & $E-06$ & $36 E-06$ \\
\hline 8 & & & & & & & \\
\hline 8 & & & & 06 & 6 & -06 & -06 \\
\hline $72 E-08$ & $7.81 \mathrm{E}-06$ & 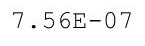 & . & $1.77 \mathrm{E}-06$ & $2.54 \mathrm{E}-06$ & $3.29 E-00$ & $.37 E-06$ \\
\hline $73 E-08$ & $7.82 \mathrm{E}-06$ & . & 1.0un & $1.77 \mathrm{E}-06$ & $2.55 \mathrm{E}-06$ & $.3 U 5-20$ & $.38 E-06$ \\
\hline 8 & 6 & & & 6 & & 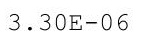 & 6 \\
\hline-08 & & & & & & & 06 \\
\hline 8 & & & & & & & \\
\hline 8 & & & & 6 & & & \\
\hline $.79 \mathrm{E}-08$ & $7.82 \mathrm{E}-06$ & . & 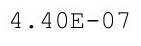 & $1.79 \mathrm{E}-06$ & $2.57 E-06$ & $4-06$ & $.40 E-06$ \\
\hline $80 \mathrm{E}-08$ & $7.82 \mathrm{E}-06$ & & & & 乙. & $\begin{array}{ll}.020 \\
\end{array}$ & $4.40 \pm-06$ \\
\hline $81 \mathrm{E}-08$ & $E-06$ & . & 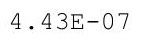 & $0 E-06$ & 6 & & $41 E-06$ \\
\hline 8 & 6 & 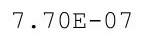 & 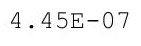 & 6 & 6 & 6 & 06 \\
\hline 8 & 6 & & & & & & \\
\hline$E-08$ & $7.81 \mathrm{E}$ & $73 E-07$ & 7 & 1.811 & 2.58 & & 4.4 \\
\hline$E-08$ & $7.81 \mathrm{E}$ & $7.75 E$ & & 1.81 & & & $4 \cdot 4$ \\
\hline & & & & & & & $4.43 E-06$ \\
\hline $.8 / E-08$ & $7.81 \mathrm{E}-06$ & t. & . & $1.82 \mathrm{E}-06$ & $2.59 E-06$ & $3.35 E-06$ & $4.43 E-06$ \\
\hline $88 E-08$ & $1.01 \mathrm{~L}-0$ & t. & $\begin{array}{lll}1 & 0\end{array}$ & $1.82 \mathrm{E}-06$ & $2.60 \mathrm{E}-06$ & & $4.44 E-06$ \\
\hline$E-08$ & $.81 E-06$ & $.81 E-07$ & $.56 \mathrm{E}-07$ & $.83 E-06$ & $2.60 \mathrm{E}-06$ & $5 E-06$ & $4.45 E-06$ \\
\hline
\end{tabular}


RESRAD-OFFSITE, Version 2.5

Title : Offsite Resident Farmer Deterministic Run

File : RF TC99 DOESG FWD-FV2b.ROF

Summary of dose at graphical times, reptition 2 (continued)

Time

Years

$6.84 \mathrm{E}+02$

$6.84 \mathrm{E}+02$

$6.85 \mathrm{E}+02$

$6.85 \mathrm{E}+02$

$6.86 \mathrm{E}+02$

$6.86 \mathrm{E}+02$

$6.87 \mathrm{E}+02$

$6.88 \mathrm{E}+02$

$6.88 \mathrm{E}+02$

$6.89 \mathrm{E}+02$

$6.89 \mathrm{E}+02$

$6.90 \mathrm{E}+02$

$6.90 \mathrm{E}+02$

$6.91 \mathrm{E}+02$

$6.91 \mathrm{E}+02$

$6.92 \mathrm{E}+02$

$6.92 \mathrm{E}+02$

$6.93 \mathrm{E}+02$

$6.93 \mathrm{E}+02$

$6.94 \mathrm{E}+02$

$6.94 \mathrm{E}+02$

$6.95 \mathrm{E}+02$

$6.95 \mathrm{E}+02$

$6.96 \mathrm{E}+02$

$6.96 \mathrm{E}+02$

$6.97 \mathrm{E}+02$

$6.97 \mathrm{E}+02$

$6.98 \mathrm{E}+02$

$6.98 \mathrm{E}+02$

$6.99 \mathrm{E}+02$

$6.99 \mathrm{E}+02$

$7.00 \mathrm{E}+02$

$7.00 \mathrm{E}+02$

$7.01 \mathrm{E}+02$

$7.01 \mathrm{E}+02$

$7.02 \mathrm{E}+02$

$7.02 \mathrm{E}+02$

7. $03 \mathrm{E}+02$

$7.03 \mathrm{E}+02$

7. $04 \mathrm{E}+02$

7. $04 \mathrm{E}+02$

$7.05 \mathrm{E}+02$

7. $05 \mathrm{E}+02$

$7.06 \mathrm{E}+02$

$7.06 \mathrm{E}+02$

$7.07 \mathrm{E}+02$
Dose statistics at graphical times, mrem/yr

\begin{tabular}{|c|c|c|c|c|c|c|c|}
\hline m & $\mathrm{m}$ & ea & ledian & & & $\%$ & \\
\hline 08 & 06 & $7.83 E-07$ & 4.57 & $1.83 \mathrm{E}-06$ & 06 & -06 & -00 \\
\hline $92 \mathrm{E}-08$ & $31 E-06$ & $4 \mathrm{E}-07$ & -07 & $83 E-06$ & 6 & 06 & -06 \\
\hline $.93 E-08$ & $81 E-06$ & $7.86 \mathrm{E}-07$ & $4.60 \mathrm{E}-07$ & $1.84 \mathrm{E}-06$ & -06 & $E-06$ & $.46 \mathrm{E}-06$ \\
\hline $94 \mathrm{E}-08$ & $7.81 E-06$ & $.87 E-07$ & $4.62 \mathrm{E}-07$ & $1.84 \mathrm{E}-06$ & $2.61 \mathrm{E}-06$ & $7 E-06$ & $.47 \mathrm{E}-06$ \\
\hline $95 E-08$ & $81 E-06$ & $7895-07$ & $463 \mathrm{~F}-07$ & $4 E-06$ & $62 F-06$ & $38 F-06$ & 4. $47 E-06$ \\
\hline-08 & 6 & & & & & 6 & -06 \\
\hline $98 \mathrm{E}-08$ & 06 & & & 6 & & 6 & -06 \\
\hline $.99 \mathrm{E}-08$ & & & & & & & -06 \\
\hline $00 \mathrm{E}-08$ & -06 & -0 & 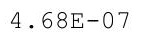 & -06 & 06 & -06 & $49 E-06$ \\
\hline$\cdot 0$ & 06 & $7.97 \mathrm{E}-07$ & & 6 & & 6 & -06 \\
\hline $2 E-08$ & 5 & & & 6 & 6 & $0 E-06$ & 6 \\
\hline $.03 E-$ & 6 & & & & & & -06 \\
\hline $04 \mathrm{~F}-08$ & $781 F-06$ & $8.01 \mathrm{E}-07$ & $4.73 E-07$ & 6 & 6 & -06 & -06 \\
\hline $.06 \mathrm{E}-08$ & $7.81 \mathrm{E}-06$ & $8.03 E-07$ & $4.75 \mathrm{E}-07$ & $1.87 \mathrm{E}-06$ & $2.65 E-06$ & $3.41 \mathrm{E}-06$ & $.51 \mathrm{E}-06$ \\
\hline $.07 E-08$ & -06 & in & 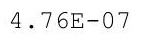 & -06 & & -06 & -06 \\
\hline $08 E-08$ & & & & & & & -06 \\
\hline 0 & & & & 6 & & & -06 \\
\hline 8 & 6 & & & & & & 6 \\
\hline $12 \mathrm{~F}-08$ & $7.80 \mathrm{E}-06$ & 15 & 泟 & 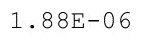 & & -06 & -06 \\
\hline $13 E-08$ & $.80 E-06$ & $.12 \mathrm{E}-07$ & $4.82 \mathrm{E}-07$ & $.88 E-06$ & $2.66 \mathrm{E}-06$ & $E-06$ & -06 \\
\hline $14 \mathrm{E}-08$ & $7.80 \mathrm{E}-06$ & $8.14 \mathrm{E}-07$ & $4.83 E-07$ & $1.89 E-06$ & $2.67 E-06$ & $E-06$ & $.55 E-06$ \\
\hline 08 & & & & & & & -06 \\
\hline 0 & & & & & & & \\
\hline $18 E-08$ & 0 & & & & & & $55 E-06$ \\
\hline 8 & 6 & $8.20 \mathrm{E}-07$ & $4.89 \mathrm{E}-07$ & 6 & 6 & 0 & -06 \\
\hline $20 \mathrm{E}-08$ & $.79 E-06$ & م & A 015 & 1. $90 \mathrm{E}-06$ & 2 & $3.44 \mathrm{E}-06$ & $56 E-06$ \\
\hline$F-08$ & $7.79 E-06$ & (2) & $4.93 \mathrm{E}-\mathrm{C}$ & $1.90 \mathrm{E}-$ & $2.68 E-06$ & $E-06$ & $.56 E-06$ \\
\hline 23 & & & & & & & 06 \\
\hline 08 & & & & & & & \\
\hline $25 E-08$ & $7.79 E-06$ & . & ter & 1.91E-06 & $2.69 \mathrm{E}-06$ & 06 & -06 \\
\hline $26 \mathrm{E}-08$ & $7.79 E-06$ & . & 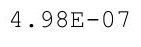 & $1.91 \mathrm{E}-06$ & $2.70 E-06$ & $3.45 \mathrm{E}-00$ & $.56 E-06$ \\
\hline 8 & (1. & 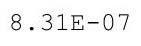 & 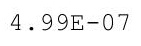 & $1.91 \mathrm{E}-06$ & & 年 & $4.56 \mathrm{E}-06$ \\
\hline $5-088-25$ & $795-06$ & ג & 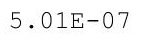 & 1 & & & $E-06$ \\
\hline 30 & & & & & & & 06 \\
\hline 08 & & $E-07$ & 7 & 6 & & 6 & -06 \\
\hline $33 E-08$ & $7.78 E-06$ & $0.00 \mathrm{~L}$ & $.00 \pm-$ & 1.930 & $2 \cdot 11$ & 06 & -06 \\
\hline $34 \mathrm{E}-08$ & 06 & & & & & & -06 \\
\hline $35 E-08$ & & & & & & & $4.31 \mathrm{E}-00$ \\
\hline 8 & . & 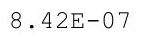 & & 6 & 6 & 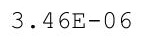 & 06 \\
\hline & & & & & & & 6 \\
\hline 08 & 06 & ( & $5.13 \mathrm{E}-0$ & 6 & 6 & 6 & -06 \\
\hline$E-08$ & $E-06$ & $7 E-07$ & 7 & $1.95 \mathrm{E}$ & 2.7 & 06 & -06 \\
\hline & & & & & & & \\
\hline & & & & & & & $4.58 E-06$ \\
\hline 車 & 06 & - & & & & 06 & $5-00$ \\
\hline$E-08$ & $E-06$ & $3 E-07$ & $21 E-07$ & $E-06$ & $E-06$ & $7 E-06$ & -06 \\
\hline
\end{tabular}


RESRAD-OFFSITE, Version 2.5

$\mathrm{T}^{1 / 2}$ Limit $=180$ days

Title : Offsite Resident Farmer Deterministic Run

File : RF TC99 DOESG FWD-FV2b.ROF

Summary of dose at graphical times, reptition 2 (continued)

Time

Years

7. $08 \mathrm{E}+02$

$7.08 \mathrm{E}+02$

7. $09 \mathrm{E}+02$

$7.09 \mathrm{E}+02$

$7.10 \mathrm{E}+02$

$7.10 \mathrm{E}+02$

7. $11 \mathrm{E}+02$

7. $11 \mathrm{E}+02$

$7.12 \mathrm{E}+02$

$7.12 \mathrm{E}+02$

$7.13 \mathrm{E}+02$

$7.13 \mathrm{E}+02$

$7.14 \mathrm{E}+02$

$7.14 \mathrm{E}+02$

$7.15 \mathrm{E}+02$

$7.15 \mathrm{E}+02$

$7.16 \mathrm{E}+02$

$7.16 \mathrm{E}+02$

$7.17 \mathrm{E}+02$

$7.17 \mathrm{E}+02$

$7.18 \mathrm{E}+02$

$7.18 \mathrm{E}+02$

7. $19 \mathrm{E}+02$

$7.19 \mathrm{E}+02$

$7.20 \mathrm{E}+02$

$7.20 \mathrm{E}+02$

$7.21 \mathrm{E}+02$

$7.21 \mathrm{E}+02$

$7.22 \mathrm{E}+02$

$7.22 \mathrm{E}+02$

7. $23 \mathrm{E}+02$

7. $23 \mathrm{E}+02$

$7.24 \mathrm{E}+02$

$7.24 \mathrm{E}+02$

$7.25 \mathrm{E}+02$

7. $25 \mathrm{E}+02$

7. $26 \mathrm{E}+02$

$7.26 \mathrm{E}+02$

$7.27 \mathrm{E}+02$

$7.28 \mathrm{E}+02$

$7.28 \mathrm{E}+02$

$7.29 \mathrm{E}+02$

$7.29 \mathrm{E}+02$

$7.30 \mathrm{E}+02$

7. $30 \mathrm{E}+02$

7. $31 \mathrm{E}+02$
Dose statistics at graphical times, mrem/yr

\begin{tabular}{|c|c|c|c|c|c|c|c|}
\hline Minimum & Maximum & Mean & Median & $90 \%$ & $95 \%$ & $97.5 \%$ & $99 \%$ \\
\hline $2.47 E-08$ & $7.77 \mathrm{E}-06$ & $8.55 E-07$ & $5.23 E-07$ & $1.96 \mathrm{E}-06$ & $2.74 E-06$ & $3.47 E-06$ & $4.59 E-06$ \\
\hline $2.49 \mathrm{E}-08$ & $7.76 \mathrm{E}-06$ & $8.56 E-07$ & $5.24 \mathrm{E}-07$ & $1.97 \mathrm{E}-06$ & $2.74 E-06$ & $3.48 E-06$ & $4.59 \mathrm{E}-06$ \\
\hline $2.50 \mathrm{E}-08$ & $7.76 \mathrm{E}-06$ & $8.58 \mathrm{E}-07$ & $5.25 \mathrm{E}-07$ & $1.97 \mathrm{E}-06$ & $2.75 E-06$ & $3.48 \mathrm{E}-06$ & $4.60 \mathrm{E}-06$ \\
\hline $2.51 \mathrm{E}-08$ & $7.76 \mathrm{E}-06$ & $8.60 \mathrm{E}-07$ & $5.26 \mathrm{E}-07$ & $1.97 \mathrm{E}-06$ & $2.75 \mathrm{E}-06$ & $3.48 \mathrm{E}-06$ & $4.60 \mathrm{E}-06$ \\
\hline $2.53 \mathrm{E}-08$ & $7.76 \mathrm{E}-06$ & $8.61 E-07$ & $5.27 \mathrm{E}-07$ & $.97 E-06$ & $2.75 \mathrm{E}-06$ & $3.48 \mathrm{E}-06$ & $4.60 \mathrm{E}-06$ \\
\hline $2.54 \mathrm{E}-08$ & $7.76 \mathrm{E}-06$ & $8.63 E-07$ & $5.29 E-07$ & $1.98 E-06$ & $2.76 \mathrm{E}-06$ & $3.48 E-06$ & $4.60 E-06$ \\
\hline $2.55 \mathrm{E}-08$ & $7.75 \mathrm{E}-06$ & $8.64 \mathrm{E}-07$ & $5.30 \mathrm{E}-07$ & $1.98 \mathrm{E}-06$ & $2.76 \mathrm{E}-06$ & $3.48 E-06$ & 4. $61 E-06$ \\
\hline $2.57 \mathrm{E}-08$ & $7.75 E-06$ & $8.66 \mathrm{E}-07$ & $5.31 \mathrm{E}-07$ & $1.98 \mathrm{E}-06$ & $2.76 \mathrm{E}-06$ & $3.49 \mathrm{E}-06$ & $4.61 \mathrm{E}-06$ \\
\hline $2.58 E-08$ & $7.75 \mathrm{E}-06$ & $8.67 E-07$ & $5.33 E-07$ & 1. $99 \mathrm{E}-06$ & $2.76 \mathrm{E}-06$ & $3.49 E-06$ & 4. $61 E-06$ \\
\hline $2.59 \mathrm{E}-08$ & $.75 E-06$ & $8.69 \mathrm{E}-07$ & $5.35 \mathrm{E}-07$ & $1.99 \mathrm{E}-06$ & $2.77 E-06$ & $3.49 \mathrm{E}-06$ & $4.61 \mathrm{E}-06$ \\
\hline $2.61 \mathrm{E}-08$ & $7.75 E-06$ & $8.71 E-07$ & $5.36 \mathrm{E}-07$ & $1.99 \mathrm{E}-06$ & $77 \mathrm{E}-06$ & $9 E-06$ & $4.61 \mathrm{E}-06$ \\
\hline $2.62 \mathrm{E}-08$ & $7.75 E-06$ & $8.72 E-07$ & $5.37 \mathrm{E}-07$ & $1.99 \mathrm{E}-06$ & $2.77 \mathrm{E}-06$ & $3.50 E-06$ & 4. $61 \mathrm{E}-06$ \\
\hline $2.64 \mathrm{E}-08$ & $7.74 \mathrm{E}-06$ & $8.74 \mathrm{E}-07$ & $5.38 \mathrm{E}-07$ & $2.00 \mathrm{E}-06$ & $2.78 E-06$ & $3.50 E-06$ & $4.61 \mathrm{E}-06$ \\
\hline $2.65 E-08$ & $7.74 \mathrm{E}-06$ & $8.75 E-07$ & $5.40 \mathrm{E}-07$ & $2.00 \mathrm{E}-06$ & $2.78 E-06$ & $3.50 \mathrm{E}-06$ & 4. $62 \mathrm{E}-06$ \\
\hline $2.66 \mathrm{E}-08$ & $7.74 \mathrm{E}-06$ & $8.77 E-07$ & $5.41 \mathrm{E}-07$ & $2.00 \mathrm{E}-06$ & $2.78 E-06$ & $3.51 E-06$ & 4. $62 E-06$ \\
\hline $2.68 \mathrm{E}-08$ & $7.74 \mathrm{E}-06$ & $8.78 E-07$ & $5.42 E-07$ & $2.01 E-06$ & $2.78 E-06$ & $.51 E-06$ & $4.62 E-06$ \\
\hline $2.69 \mathrm{E}-08$ & $7.73 E-06$ & $8.80 \mathrm{E}-07$ & $5.43 E-07$ & $2.01 \mathrm{E}-06$ & $2.79 E-06$ & $3.52 \mathrm{E}-06$ & $4.62 \mathrm{E}-06$ \\
\hline $2.71 \mathrm{E}-08$ & $7.73 E-06$ & $8.81 E-07$ & $5.44 \mathrm{E}-07$ & $2.01 E-06$ & $2.79 E-06$ & $3.52 \mathrm{E}-06$ & $4.63 E-06$ \\
\hline $2.72 E-08$ & $7.73 E-06$ & $8.83 E-07$ & $5.46 \mathrm{E}-07$ & $2.02 E-06$ & $2.79 E-06$ & $3.52 E-06$ & $4.63 E-06$ \\
\hline $2.73 E-08$ & $7.73 E-06$ & $8.85 E-07$ & $5.47 \mathrm{E}-07$ & $2.02 \mathrm{E}-06$ & $2.80 E-06$ & $3.53 E-06$ & 4. $63 E-06$ \\
\hline $2.75 \mathrm{E}-08$ & $7.73 E-06$ & $8.86 \mathrm{E}-07$ & $5.48 \mathrm{E}-07$ & $2.02 \mathrm{E}-06$ & $2.80 \mathrm{E}-06$ & $3.53 E-06$ & $4.63 E-06$ \\
\hline $2.76 \mathrm{E}-08$ & $7.72 \mathrm{E}-06$ & $8.88 E-07$ & $5.50 \mathrm{E}-07$ & $2.02 E-06$ & $2.80 E-06$ & $3.53 E-06$ & $4.64 \mathrm{E}-06$ \\
\hline $2.78 \mathrm{E}-08$ & $7.72 \mathrm{E}-06$ & $8.89 E-07$ & $5.52 \mathrm{E}-07$ & $2.03 E-06$ & $2.80 E-06$ & $3.54 \mathrm{E}-06$ & $4.64 \mathrm{E}-06$ \\
\hline $2.79 \mathrm{E}-08$ & $7.72 \mathrm{E}-06$ & $8.91 E-07$ & $5.54 \mathrm{E}-07$ & $2.03 E-06$ & $2.80 \mathrm{E}-06$ & $3.54 \mathrm{E}-06$ & $4.64 \mathrm{E}-06$ \\
\hline $2.81 E-08$ & $7.72 \mathrm{E}-06$ & $8.92 E-07$ & $5.55 E-07$ & $2.03 E-06$ & $2.80 \mathrm{E}-06$ & $3.54 \mathrm{E}-06$ & $4.64 \mathrm{E}-06$ \\
\hline $2.82 \mathrm{E}-08$ & $.71 \mathrm{E}-06$ & $8.94 \mathrm{E}-07$ & $5.57 \mathrm{E}-07$ & $2.04 \mathrm{E}-06$ & $2.80 E-06$ & $3.55 E-06$ & $4.65 E-06$ \\
\hline $2.84 \mathrm{E}-08$ & $7.71 \mathrm{E}-06$ & $8.95 E-07$ & $5.59 \mathrm{E}-07$ & $2.04 \mathrm{E}-06$ & $2.80 \mathrm{E}-06$ & $3.55 \mathrm{E}-06$ & $4.65 E-06$ \\
\hline $2.85 E-08$ & $7.71 E-06$ & $8.97 E-07$ & $5.61 \mathrm{E}-07$ & $2.04 \mathrm{E}-06$ & $2.80 E-06$ & $3.56 \mathrm{E}-06$ & $4.65 E-06$ \\
\hline $2.87 E-08$ & $7.71 \mathrm{E}-06$ & $8.99 E-07$ & $5.63 E-07$ & $2.05 E-06$ & $2.81 E-06$ & $3.56 \mathrm{E}-06$ & $4.65 E-06$ \\
\hline $2.88 E-08$ & $7.71 E-06$ & $9.00 \mathrm{E}-07$ & $5.65 E-07$ & $2.05 E-06$ & $2.81 E-06$ & $3.56 \mathrm{E}-06$ & $4.65 E-06$ \\
\hline $2.90 \mathrm{E}-08$ & $7.70 \mathrm{E}-06$ & $9.02 \mathrm{E}-07$ & $5.66 \mathrm{E}-07$ & $2.05 E-06$ & $2.81 \mathrm{E}-06$ & $3.57 \mathrm{E}-06$ & $4.66 \mathrm{E}-06$ \\
\hline $2.91 \mathrm{E}-08$ & $7.70 \mathrm{E}-06$ & $9.03 E-07$ & $5.68 \mathrm{E}-07$ & $2.05 E-06$ & $2.81 \mathrm{E}-06$ & $3.57 \mathrm{E}-06$ & $4.66 \mathrm{E}-06$ \\
\hline $2.93 E-08$ & $7.70 E-06$ & $9.05 E-07$ & $5.70 \mathrm{E}-07$ & $2.06 \mathrm{E}-06$ & $2.81 E-06$ & $3.57 E-06$ & $4.66 E-06$ \\
\hline $2.94 \mathrm{E}-08$ & $7.70 \mathrm{E}-06$ & $9.06 \mathrm{E}-07$ & $5.72 \mathrm{E}-07$ & $2.06 \mathrm{E}-06$ & $2.81 E-06$ & $3.58 \mathrm{E}-06$ & $4.66 \mathrm{E}-06$ \\
\hline $2.96 \mathrm{E}-08$ & $7.69 \mathrm{E}-06$ & $9.08 E-07$ & $5.74 \mathrm{E}-07$ & $2.06 \mathrm{E}-06$ & $2.81 \mathrm{E}-06$ & $3.58 \mathrm{E}-06$ & $4.66 \mathrm{E}-06$ \\
\hline $2.97 \mathrm{E}-08$ & $7.69 \mathrm{E}-06$ & $9.09 E-07$ & $5.76 \mathrm{E}-07$ & $2.07 \mathrm{E}-06$ & $2.82 \mathrm{E}-06$ & $3.58 \mathrm{E}-06$ & $4.67 \mathrm{E}-06$ \\
\hline $2.99 \mathrm{E}-08$ & $7.69 \mathrm{E}-06$ & $9.11 \mathrm{E}-07$ & $5.77 \mathrm{E}-07$ & $2.07 \mathrm{E}-06$ & $2.82 E-06$ & $3.59 \mathrm{E}-06$ & $4.67 \mathrm{E}-06$ \\
\hline $3.00 \mathrm{E}-08$ & $7.69 \mathrm{E}-06$ & $9.13 E-07$ & $5.79 \mathrm{E}-07$ & $2.07 \mathrm{E}-06$ & $2.82 \mathrm{E}-06$ & $3.59 \mathrm{E}-06$ & $4.67 \mathrm{E}-06$ \\
\hline $3.02 \mathrm{E}-08$ & 1.0 & $4 E-07$ & $5.80 \mathrm{E}-07$ & $2.07 \mathrm{E}-06$ & $2.82 \mathrm{E}-06$ & $3.59 \mathrm{E}-06$ & $4.67 \mathrm{E}-06$ \\
\hline $3.03 E-08$ & $7.68 \mathrm{E}-06$ & $9.16 \mathrm{E}-07$ & $5.82 \mathrm{E}-07$ & $08 E-06$ & $2.83 E-06$ & -06 & $4.67 \mathrm{E}-06$ \\
\hline $3.05 \mathrm{E}-08$ & $7.68 \mathrm{E}-06$ & $9.17 \mathrm{E}-07$ & $5.83 E-07$ & $2.08 \mathrm{E}-06$ & $2.83 E-06$ & $3.60 \mathrm{E}-06$ & $4.68 \mathrm{E}-06$ \\
\hline $3.06 \mathrm{E}-08$ & $7.67 \mathrm{E}-06$ & $9.19 \mathrm{E}-07$ & $5.85 E-07$ & $2.08 E-06$ & $2.83 E-06$ & $3.60 E-06$ & $4.68 E-06$ \\
\hline $3.08 \mathrm{E}-08$ & $7.67 \mathrm{E}-06$ & $9.20 \mathrm{E}-07$ & $5.87 \mathrm{E}-07$ & $2.08 \mathrm{E}-06$ & $2.83 E-06$ & $3.61 \mathrm{E}-06$ & $4.68 \mathrm{E}-06$ \\
\hline $3.09 \mathrm{E}-08$ & $7.67 \mathrm{E}-06$ & $9.22 \mathrm{E}-07$ & $5.88 E-07$ & $2.09 E-06$ & $2.84 E-06$ & $3.61 E-06$ & $4.68 E-06$ \\
\hline $3.11 \mathrm{E}-08$ & $7.67 \mathrm{E}-06$ & $9.23 E-07$ & $5.90 E-07$ & $2.09 E-06$ & $2.84 \mathrm{E}-06$ & $3.62 \mathrm{E}-06$ & $4.68 \mathrm{E}-06$ \\
\hline $3.13 E-08$ & $7.66 \mathrm{E}-06$ & $9.25 E-07$ & $5.92 E-07$ & $2.09 E-06$ & $2.84 E-06$ & $3.62 \mathrm{E}-06$ & $4.69 E-06$ \\
\hline
\end{tabular}


RESRAD-OFFSITE, Version 2.5

Title : Offsite Resident Farmer Deterministic Run

File : RF TC99 DOESG FWD-FV2b.ROF

Summary of dose at graphical times, reptition 2 (continued)

Time

Years

7. $31 \mathrm{E}+02$

7. $32 \mathrm{E}+02$

7. $32 \mathrm{E}+02$

7. $33 \mathrm{E}+02$

7. $33 \mathrm{E}+02$

7. $34 \mathrm{E}+02$

7. $34 \mathrm{E}+02$

$7.35 \mathrm{E}+02$

7. $35 \mathrm{E}+02$

7. $36 \mathrm{E}+02$

7. $36 \mathrm{E}+02$

$7.37 \mathrm{E}+02$

7. $37 \mathrm{E}+02$

7. $38 \mathrm{E}+02$

7. $38 \mathrm{E}+02$

7. $39 \mathrm{E}+02$

7. $39 \mathrm{E}+02$

$7.40 \mathrm{E}+02$

$7.40 \mathrm{E}+02$

$7.41 \mathrm{E}+02$

$7.41 \mathrm{E}+02$

$7.42 \mathrm{E}+02$

$7.42 \mathrm{E}+02$

$7.43 \mathrm{E}+02$

$7.43 \mathrm{E}+02$

7. $44 \mathrm{E}+02$

7. $44 \mathrm{E}+02$

7. $45 \mathrm{E}+02$

$7.45 \mathrm{E}+02$

$7.46 \mathrm{E}+02$

$7.46 \mathrm{E}+02$

$7.47 \mathrm{E}+02$

$7.48 \mathrm{E}+02$

7. $48 \mathrm{E}+02$

$7.49 \mathrm{E}+02$

7. $49 \mathrm{E}+02$

$7.50 \mathrm{E}+02$

$7.50 \mathrm{E}+02$

$7.51 \mathrm{E}+02$

$7.51 \mathrm{E}+02$

$7.52 \mathrm{E}+02$

$7.52 \mathrm{E}+02$

$7.53 \mathrm{E}+02$

$7.53 \mathrm{E}+02$

$7.54 \mathrm{E}+02$

$7.54 \mathrm{E}+02$
Dose statistics at graphical times, mrem/yr

\begin{tabular}{|c|c|c|c|c|c|c|c|}
\hline Minimum & Maximum & Mean & Median & $90 \%$ & $95 \%$ & $97.5 \%$ & $99 \%$ \\
\hline $3.14 \mathrm{E}-08$ & $7.66 \mathrm{E}-06$ & $9.27 E-07$ & $5.94 E-07$ & $2.09 \mathrm{E}-06$ & $2.85 E-06$ & $3.62 E-06$ & $4.69 E-06$ \\
\hline $3.16 \mathrm{E}-08$ & $7.66 \mathrm{E}-06$ & $9.28 E-07$ & $5.95 E-07$ & $2.09 E-06$ & $2.85 E-06$ & $3.63 E-06$ & $4.69 \mathrm{E}-06$ \\
\hline $3.17 \mathrm{E}-08$ & $7.66 \mathrm{E}-06$ & $9.30 \mathrm{E}-07$ & $5.97 \mathrm{E}-07$ & $2.10 \mathrm{E}-06$ & $2.85 E-06$ & $3.63 E-06$ & $4.69 \mathrm{E}-06$ \\
\hline $3.19 \mathrm{E}-08$ & $7.65 \mathrm{E}-06$ & $9.31 \mathrm{E}-07$ & $5.98 \mathrm{E}-07$ & $2.10 \mathrm{E}-06$ & $2.85 \mathrm{E}-06$ & $3.63 \mathrm{E}-06$ & $4.69 \mathrm{E}-06$ \\
\hline $3.20 \mathrm{E}-08$ & $7.65 \mathrm{E}-06$ & $9.33 E-07$ & $6.00 \mathrm{E}-07$ & $.10 \mathrm{E}-06$ & $2.86 \mathrm{E}-06$ & $3.64 \mathrm{E}-06$ & $4.70 \mathrm{E}-06$ \\
\hline $3.22 \mathrm{E}-08$ & $7.65 \mathrm{E}-06$ & $9.34 \mathrm{E}-07$ & $6.01 \mathrm{E}-07$ & $2.11 \mathrm{E}-06$ & $2.86 \mathrm{E}-06$ & $3.64 \mathrm{E}-06$ & $4.70 \mathrm{E}-06$ \\
\hline $3.24 \mathrm{E}-08$ & $7.64 \mathrm{E}-06$ & $9.36 \mathrm{E}-07$ & $6.03 E-07$ & $2.11 \mathrm{E}-06$ & $2.86 \mathrm{E}-06$ & $3.65 E-06$ & $4.70 \mathrm{E}-06$ \\
\hline $3.25 \mathrm{E}-08$ & $7.64 \mathrm{E}-06$ & $9.37 \mathrm{E}-07$ & $6.05 \mathrm{E}-07$ & $2.11 \mathrm{E}-06$ & $2.86 \mathrm{E}-06$ & $3.65 \mathrm{E}-06$ & $4.70 \mathrm{E}-06$ \\
\hline $3.27 E-08$ & $7.64 \mathrm{E}-06$ & $9.39 E-07$ & $6.06 \mathrm{E}-07$ & $2.11 \mathrm{E}-06$ & $2.87 E-06$ & $3.65 E-06$ & $4.70 \mathrm{E}-06$ \\
\hline $3.28 \mathrm{E}-08$ & $.63 \mathrm{E}-06$ & $9.40 \mathrm{E}-07$ & $6.08 \mathrm{E}-07$ & $2.12 \mathrm{E}-06$ & $2.87 E-06$ & $3.66 \mathrm{E}-06$ & $4.70 E-06$ \\
\hline $3.30 \mathrm{E}-08$ & $7.63 E-06$ & $9.42 \mathrm{E}-07$ & $6.10 \mathrm{E}-07$ & $2.12 \mathrm{E}-06$ & $2.87 E-06$ & $3.66 \mathrm{E}-06$ & $4.71 \mathrm{E}-06$ \\
\hline $3.32 \mathrm{E}-08$ & $7.63 E-06$ & $9.43 E-07$ & $6.12 \mathrm{E}-07$ & $2.12 \mathrm{E}-06$ & $2.88 E-06$ & $3.66 \mathrm{E}-06$ & $4.71 \mathrm{E}-06$ \\
\hline $3.33 E-08$ & $7.63 E-06$ & $9.45 E-07$ & $6.14 \mathrm{E}-07$ & $2.13 E-06$ & $2.88 E-06$ & $3.67 \mathrm{E}-06$ & $4.71 \mathrm{E}-06$ \\
\hline $3.35 \mathrm{E}-08$ & $7.62 \mathrm{E}-06$ & $9.47 \mathrm{E}-07$ & $6.15 \mathrm{E}-07$ & $2.13 E-06$ & $2.88 E-06$ & $3.67 \mathrm{E}-06$ & $4.71 E-06$ \\
\hline $3.37 E-08$ & 7. $62 \mathrm{E}-06$ & $9.48 E-07$ & $6.17 \mathrm{E}-07$ & $2.13 E-06$ & $2.88 E-06$ & $3.67 E-06$ & $4.71 \mathrm{E}-06$ \\
\hline $3.38 \mathrm{E}-08$ & $7.62 \mathrm{E}-06$ & $9.50 E-07$ & $6.18 \mathrm{E}-07$ & $2.13 E-06$ & $2.89 E-06$ & $3.68 E-06$ & $4.71 E-06$ \\
\hline $3.40 \mathrm{E}-08$ & $7.61 \mathrm{E}-06$ & $9.51 \mathrm{E}-07$ & $6.20 \mathrm{E}-07$ & $.14 \mathrm{E}-06$ & $2.89 \mathrm{E}-06$ & $3.68 \mathrm{E}-06$ & $4.72 E-06$ \\
\hline $3.42 \mathrm{E}-08$ & $7.61 \mathrm{E}-06$ & $9.53 E-07$ & $6.21 E-07$ & $2.14 \mathrm{E}-06$ & $2.89 E-06$ & $3.68 E-06$ & $4.72 E-06$ \\
\hline $3.43 E-08$ & $7.61 \mathrm{E}-06$ & $9.54 \mathrm{E}-07$ & $6.23 E-07$ & $2.14 \mathrm{E}-06$ & $2.89 E-06$ & $3.69 E-06$ & $4.72 E-06$ \\
\hline $3.45 \mathrm{E}-08$ & $7.60 \mathrm{E}-06$ & $9.56 \mathrm{E}-07$ & $6.24 \mathrm{E}-07$ & $2.15 \mathrm{E}-06$ & $2.90 E-06$ & $3.69 \mathrm{E}-06$ & $4.72 E-06$ \\
\hline $3.47 \mathrm{E}-08$ & $7.60 \mathrm{E}-06$ & $9.57 \mathrm{E}-07$ & $6.25 \mathrm{E}-07$ & $2.15 \mathrm{E}-06$ & $2.90 E-06$ & $3.69 \mathrm{E}-06$ & $4.72 E-06$ \\
\hline $3.48 \mathrm{E}-08$ & $7.60 E-06$ & $9.59 E-07$ & $6.27 \mathrm{E}-07$ & $2.15 E-06$ & $2.90 E-06$ & $3.70 E-06$ & $4.72 E-06$ \\
\hline $3.50 \mathrm{E}-08$ & $7.59 \mathrm{E}-06$ & $9.60 \mathrm{E}-07$ & $6.28 E-07$ & $2.15 E-06$ & $2.90 E-06$ & $3.70 E-06$ & $4.73 E-06$ \\
\hline $3.52 \mathrm{E}-08$ & $7.59 \mathrm{E}-06$ & $9.62 \mathrm{E}-07$ & $6.30 \mathrm{E}-07$ & $2.16 \mathrm{E}-06$ & $2.91 \mathrm{E}-06$ & $3.71 \mathrm{E}-06$ & $4.73 E-06$ \\
\hline $3.53 E-08$ & $7.59 \mathrm{E}-06$ & $9.63 E-07$ & $6.31 E-07$ & $2.16 \mathrm{E}-06$ & $2.91 \mathrm{E}-06$ & $3.71 \mathrm{E}-06$ & $4.73 E-06$ \\
\hline $3.55 \mathrm{E}-08$ & $.58 E-06$ & $9.65 E-07$ & $6.33 E-07$ & $2.16 \mathrm{E}-06$ & $2.91 E-06$ & $3.71 E-06$ & $4.73 E-06$ \\
\hline $3.57 \mathrm{E}-08$ & $7.58 \mathrm{E}-06$ & $9.67 \mathrm{E}-07$ & $6.35 \mathrm{E}-07$ & $2.16 \mathrm{E}-06$ & $2.91 \mathrm{E}-06$ & $3.72 \mathrm{E}-06$ & $4.73 E-06$ \\
\hline $3.58 \mathrm{E}-08$ & $7.58 \mathrm{E}-06$ & $9.68 E-07$ & $6.37 \mathrm{E}-07$ & $2.16 \mathrm{E}-06$ & $2.92 E-06$ & $3.72 E-06$ & $4.73 E-06$ \\
\hline $3.60 \mathrm{E}-08$ & $7.57 \mathrm{E}-06$ & $9.70 \mathrm{E}-07$ & $6.38 \mathrm{E}-07$ & $2.17 \mathrm{E}-06$ & $2.92 \mathrm{E}-06$ & $3.72 \mathrm{E}-06$ & $4.73 E-06$ \\
\hline $3.62 E-08$ & $7.57 \mathrm{E}-06$ & $9.71 E-07$ & $6.40 \mathrm{E}-07$ & $2.17 \mathrm{E}-06$ & $2.92 E-06$ & $3.72 E-06$ & $4.74 E-06$ \\
\hline $3.64 \mathrm{E}-08$ & $7.57 \mathrm{E}-06$ & $9.73 E-07$ & $6.42 \mathrm{E}-07$ & $2.17 \mathrm{E}-06$ & $2.93 E-06$ & $3.73 E-06$ & $4.74 \mathrm{E}-06$ \\
\hline $3.65 \mathrm{E}-08$ & $7.56 \mathrm{E}-06$ & $9.74 \mathrm{E}-07$ & $6.44 \mathrm{E}-07$ & $2.17 \mathrm{E}-06$ & $2.93 E-06$ & $3.73 E-06$ & $4.74 \mathrm{E}-06$ \\
\hline $3.67 E-08$ & $7.56 \mathrm{E}-06$ & $9.76 \mathrm{E}-07$ & $6.45 E-07$ & $2.17 \mathrm{E}-06$ & $2.93 E-06$ & $3.73 E-06$ & $4.74 E-06$ \\
\hline $3.69 \mathrm{E}-08$ & $7.56 \mathrm{E}-06$ & $9.77 E-07$ & $6.46 \mathrm{E}-07$ & $2.18 \mathrm{E}-06$ & $2.94 \mathrm{E}-06$ & $3.73 E-06$ & $4.74 E-06$ \\
\hline $3.71 \mathrm{E}-08$ & $7.55 \mathrm{E}-06$ & $9.79 \mathrm{E}-07$ & $6.48 \mathrm{E}-07$ & $2.18 \mathrm{E}-06$ & $2.94 \mathrm{E}-06$ & $3.73 E-06$ & $4.74 \mathrm{E}-06$ \\
\hline $3.72 E-08$ & $7.55 \mathrm{E}-06$ & $9.80 E-07$ & $6.49 \mathrm{E}-07$ & $2.18 \mathrm{E}-06$ & $2.94 E-06$ & $3.73 E-06$ & $4.74 E-06$ \\
\hline $3.74 \mathrm{E}-08$ & $7.55 \mathrm{E}-06$ & $9.82 \mathrm{E}-07$ & $6.50 \mathrm{E}-07$ & $2.19 \mathrm{E}-06$ & $2.95 E-06$ & $3.74 \mathrm{E}-06$ & $4.74 \mathrm{E}-06$ \\
\hline $3.76 \mathrm{E}-08$ & $7.54 \mathrm{E}-06$ & $9.83 E-07$ & $6.52 \mathrm{E}-07$ & $2.19 \mathrm{E}-06$ & $2.95 \mathrm{E}-06$ & $3.74 \mathrm{E}-06$ & $4.75 E-06$ \\
\hline $3.78 \mathrm{E}-08$ & .0 & 07 & $6.53 E-07$ & $2.19 \mathrm{E}-06$ & $2.95 \mathrm{E}-06$ & $3.74 \mathrm{E}-06$ & $4.75 E-06$ \\
\hline $3.80 \mathrm{E}-08$ & $7.53 \mathrm{E}-06$ & $9.86 \mathrm{E}-07$ & $6.54 \mathrm{E}-07$ & $.19 \mathrm{E}-06$ & $.95 E-06$ & $.74 \mathrm{E}-06$ & 4.75 \\
\hline $3.81 \mathrm{E}-08$ & $7.53 \mathrm{E}-06$ & $9.88 E-07$ & $6.55 \mathrm{E}-07$ & $2.19 \mathrm{E}-06$ & $2.96 \mathrm{E}-06$ & $3.74 \mathrm{E}-06$ & $4.75 E-06$ \\
\hline $3.83 E-08$ & $7.53 E-06$ & $9.89 E-07$ & $6.57 E-07$ & $2.19 E-06$ & $2.96 \mathrm{E}-06$ & $3.74 E-06$ & $4.75 E-06$ \\
\hline $3.85 \mathrm{E}-08$ & $7.52 \mathrm{E}-06$ & $9.91 \mathrm{E}-07$ & $6.58 \mathrm{E}-07$ & $2.20 \mathrm{E}-06$ & $2.96 \mathrm{E}-06$ & $3.74 \mathrm{E}-06$ & $4.75 E-06$ \\
\hline $3.87 E-08$ & $7.52 \mathrm{E}-06$ & $9.92 \mathrm{E}-07$ & $6.59 \mathrm{E}-07$ & $2.20 \mathrm{E}-06$ & $2.97 E-06$ & $3.75 E-06$ & $4.75 E-06$ \\
\hline $3.89 E-08$ & $7.52 \mathrm{E}-06$ & $9.94 E-07$ & $6.61 E-07$ & $2.20 \mathrm{E}-06$ & $2.97 E-06$ & $3.75 E-06$ & $4.75 E-06$ \\
\hline $3.90 \mathrm{E}-08$ & $7.51 \mathrm{E}-06$ & $9.95 E-07$ & $6.62 E-07$ & $2.20 \mathrm{E}-06$ & $2.97 E-06$ & $3.75 E-06$ & $4.76 E-06$ \\
\hline
\end{tabular}


RESRAD-OFFSITE, Version 2.5

Title : Offsite Resident Farmer Deterministic Run

File : RF TC99 DOESG FWD-FV2b.ROF

Summary of dose at graphical times, reptition 2 (continued)

Time

Years

$7.55 \mathrm{E}+02$

$7.55 \mathrm{E}+02$

$7.56 \mathrm{E}+02$

$7.56 \mathrm{E}+02$

$7.57 \mathrm{E}+02$

$7.57 \mathrm{E}+02$

$7.58 \mathrm{E}+02$

$7.58 \mathrm{E}+02$

$7.59 \mathrm{E}+02$

$7.59 \mathrm{E}+02$

$7.60 \mathrm{E}+02$

$7.60 \mathrm{E}+02$

7. $61 \mathrm{E}+02$

$7.61 \mathrm{E}+02$

$7.62 \mathrm{E}+02$

7. $62 \mathrm{E}+02$

$7.63 \mathrm{E}+02$

$7.63 \mathrm{E}+02$

$7.64 \mathrm{E}+02$

7. $64 \mathrm{E}+02$

$7.65 \mathrm{E}+02$

$7.65 \mathrm{E}+02$

7. $66 \mathrm{E}+02$

$7.66 \mathrm{E}+02$

$7.67 \mathrm{E}+02$

$7.68 \mathrm{E}+02$

7. $68 \mathrm{E}+02$

7. $69 \mathrm{E}+02$

$7.69 \mathrm{E}+02$

$7.70 \mathrm{E}+02$

$7.70 \mathrm{E}+02$

$7.71 \mathrm{E}+02$

$7.71 \mathrm{E}+02$

$7.72 \mathrm{E}+02$

$7.72 \mathrm{E}+02$

$7.73 \mathrm{E}+02$

$7.73 \mathrm{E}+02$

$7.74 \mathrm{E}+02$

$7.74 \mathrm{E}+02$

$7.75 \mathrm{E}+02$

$7.75 \mathrm{E}+02$

$7.76 \mathrm{E}+02$

$7.76 \mathrm{E}+02$

$7.77 \mathrm{E}+02$

$7.77 \mathrm{E}+02$

$7.78 \mathrm{E}+02$
Dose statistics at graphical times, mrem/yr

\begin{tabular}{|c|c|c|c|c|c|c|c|}
\hline Minimum & laximum & Mean & Median & $90 \%$ & $95 \%$ & $97.5 \%$ & $99 \%$ \\
\hline $3.92 \mathrm{E}-08$ & $7.51 \mathrm{E}-06$ & $9.97 E-07$ & $6.64 \mathrm{E}-07$ & $2.21 E-06$ & $2.97 E-06$ & $3.76 \mathrm{E}-06$ & $4.76 \mathrm{E}-06$ \\
\hline $3.94 \mathrm{E}-08$ & $7.51 E-06$ & $9.99 \mathrm{E}-07$ & $6.65 E-07$ & $2.21 E-06$ & $2.97 E-06$ & $3.76 \mathrm{E}-06$ & $4.76 \mathrm{E}-06$ \\
\hline $3.96 \mathrm{E}-08$ & $7.50 \mathrm{E}-06$ & $1.00 \mathrm{E}-06$ & $6.67 \mathrm{E}-07$ & $2.21 E-06$ & $2.97 E-06$ & $3.76 \mathrm{E}-06$ & $4.76 \mathrm{E}-06$ \\
\hline $3.98 \mathrm{E}-08$ & $7.50 E-06$ & $1.00 \mathrm{E}-06$ & $6.68 \mathrm{E}-07$ & $2.21 \mathrm{E}-06$ & $2.97 \mathrm{E}-06$ & $3.76 \mathrm{E}-06$ & $4.76 \mathrm{E}-06$ \\
\hline $3.99 \mathrm{E}-08$ & $7.49 \mathrm{E}-06$ & $1.00 \mathrm{E}-06$ & $6.70 \mathrm{E}-07$ & $2.22 \mathrm{E}-06$ & $2.97 \mathrm{E}-06$ & $3.77 \mathrm{E}-06$ & $4.76 \mathrm{E}-06$ \\
\hline $4.01 E-08$ & $7.49 \mathrm{E}-06$ & $1.00 \mathrm{E}-06$ & $6.71 \mathrm{E}-07$ & $2.22 E-06$ & $2.98 E-06$ & $3.77 \mathrm{E}-06$ & $4.76 \mathrm{E}-06$ \\
\hline $4.03 E-08$ & $7.49 \mathrm{E}-06$ & $1.01 E-06$ & $6.73 E-07$ & $2.22 \mathrm{E}-06$ & $2.98 E-06$ & $3.77 \mathrm{E}-06$ & $4.76 \mathrm{E}-06$ \\
\hline $4.05 \mathrm{E}-08$ & $7.48 \mathrm{E}-06$ & $1.01 \mathrm{E}-06$ & $6.74 \mathrm{E}-07$ & $2.22 \mathrm{E}-06$ & $2.98 \mathrm{E}-06$ & $3.77 \mathrm{E}-06$ & $4.75 E-06$ \\
\hline $4.07 E-08$ & $7.48 \mathrm{E}-06$ & 1. $01 E-06$ & $6.76 \mathrm{E}-07$ & $2.23 E-06$ & $2.99 \mathrm{E}-06$ & $3.77 \mathrm{E}-06$ & $4.75 E-06$ \\
\hline $4.09 \mathrm{E}-08$ & $7.47 \mathrm{E}-06$ & $1.01 \mathrm{E}-06$ & $6.77 \mathrm{E}-07$ & $2.23 E-06$ & $2.99 E-06$ & $3.77 \mathrm{E}-06$ & $4.75 E-06$ \\
\hline $4.11 \mathrm{E}-08$ & $7.47 \mathrm{E}-06$ & $1.01 \mathrm{E}-06$ & $6.79 \mathrm{E}-07$ & $23 E-06$ & $99 E-06$ & $3.77 \mathrm{E}-06$ & $4.74 \mathrm{E}-06$ \\
\hline $4.13 E-08$ & $7.47 E-06$ & $1.01 E-06$ & $6.80 \mathrm{E}-07$ & $2.24 \mathrm{E}-06$ & $2.99 \mathrm{E}-06$ & $3.78 \mathrm{E}-06$ & $4.74 \mathrm{E}-06$ \\
\hline $4.14 \mathrm{E}-08$ & $7.46 \mathrm{E}-06$ & $1.02 \mathrm{E}-06$ & $6.82 \mathrm{E}-07$ & $2.24 \mathrm{E}-06$ & $3.00 \mathrm{E}-06$ & $3.78 \mathrm{E}-06$ & $4.74 \mathrm{E}-06$ \\
\hline $4.16 \mathrm{E}-08$ & $7.46 \mathrm{E}-06$ & $1.02 \mathrm{E}-06$ & $6.84 \mathrm{E}-07$ & $2.24 \mathrm{E}-06$ & $3.00 \mathrm{E}-06$ & $3.78 \mathrm{E}-06$ & $4.73 E-06$ \\
\hline $4.18 \mathrm{E}-08$ & $7.45 E-06$ & $1.02 E-06$ & $6.85 \mathrm{E}-07$ & $2.24 E-06$ & $3.00 \mathrm{E}-06$ & $3.78 E-06$ & $4.73 E-06$ \\
\hline $4.20 E-08$ & $7.45 E-06$ & $1.02 E-06$ & $6.87 E-07$ & $.24 E-06$ & $3.01 E-06$ & $.78 E-06$ & $.73 E-06$ \\
\hline $4.22 \mathrm{E}-08$ & $7.45 E-06$ & $1.02 \mathrm{E}-06$ & $6.88 \mathrm{E}-07$ & $.25 E-06$ & $3.01 \mathrm{E}-$ & $3 E-06$ & $4.72 \mathrm{E}-06$ \\
\hline $4.24 \mathrm{E}-08$ & $7.44 \mathrm{E}-06$ & $1.02 E-06$ & $6.89 \mathrm{E}-07$ & $2.25 E-06$ & $3.01 \mathrm{E}-06$ & $3.78 \mathrm{E}-06$ & $4.72 \mathrm{E}-06$ \\
\hline $4.26 \mathrm{E}-08$ & $7.44 \mathrm{E}-06$ & $1.02 E-06$ & $6.91 \mathrm{E}-07$ & $2.25 E-06$ & $3.01 \mathrm{E}-06$ & $3.78 \mathrm{E}-06$ & $4.72 \mathrm{E}-06$ \\
\hline $4.28 E-08$ & $7.43 E-06$ & $1.03 E-06$ & $6.92 \mathrm{E}-07$ & $2.25 E-06$ & $3.01 \mathrm{E}-06$ & $3.78 \mathrm{E}-06$ & $4.71 \mathrm{E}-06$ \\
\hline $4.30 \mathrm{E}-08$ & $7.43 E-06$ & $1.03 E-06$ & $6.94 \mathrm{E}-07$ & $2.25 E-06$ & $3.01 \mathrm{E}-06$ & $3.78 \mathrm{E}-06$ & $4.71 \mathrm{E}-06$ \\
\hline $4.32 E-08$ & $7.43 E-06$ & $1.03 E-06$ & $6.95 E-07$ & $.25 E-06$ & $.02 E-06$ & $3.78 E-06$ & $4.71 \mathrm{E}-06$ \\
\hline $4.34 \mathrm{E}-08$ & $7.42 E-06$ & $1.03 E-06$ & $6.96 \mathrm{E}-07$ & $2.26 E-06$ & $3.02 E-06$ & $3.78 E-06$ & $4.70 E-06$ \\
\hline $4.36 \mathrm{E}-08$ & 7. $42 \mathrm{E}-06$ & $1.03 E-06$ & $6.98 \mathrm{E}-07$ & $2.26 \mathrm{E}-06$ & $3.02 \mathrm{E}-06$ & $3.78 \mathrm{E}-06$ & $4.70 \mathrm{E}-06$ \\
\hline $4.38 \mathrm{E}-08$ & $7.41 \mathrm{E}-06$ & $1.03 E-06$ & $6.99 \mathrm{E}-07$ & $2.26 \mathrm{E}-06$ & $3.02 \mathrm{E}-06$ & $3.78 \mathrm{E}-06$ & $4.69 \mathrm{E}-06$ \\
\hline $4.39 \mathrm{E}-08$ & $7.41 \mathrm{E}-06$ & $1.03 E-06$ & $7.00 \mathrm{E}-07$ & $2.26 \mathrm{E}-06$ & $3.02 \mathrm{E}-06$ & $3.78 \mathrm{E}-06$ & $4.69 \mathrm{E}-06$ \\
\hline $4.41 \mathrm{E}-08$ & $7.41 \mathrm{E}-06$ & $1.04 \mathrm{E}-06$ & $7.02 \mathrm{E}-07$ & $2.26 \mathrm{E}-06$ & $3.02 \mathrm{E}-06$ & $3.78 \mathrm{E}-06$ & $4.69 \mathrm{E}-06$ \\
\hline $4.43 E-08$ & $7.40 E-06$ & $1.04 \mathrm{E}-06$ & $7.03 E-07$ & $2.27 E-06$ & $3.02 E-06$ & $3.78 E-06$ & $4.68 E-06$ \\
\hline $4.45 E-08$ & $7.40 E-06$ & $1.04 \mathrm{E}-06$ & $7.05 E-07$ & $2.27 E-06$ & $3.03 E-06$ & $3.78 E-06$ & $4.68 E-06$ \\
\hline $4.47 E-08$ & $7.39 E-06$ & $1.04 \mathrm{E}-06$ & $7.07 E-07$ & $2.27 E-06$ & $3.03 E-06$ & $3.78 E-06$ & $4.68 E-06$ \\
\hline $4.49 \mathrm{E}-08$ & 7. $39 \mathrm{E}-06$ & $1.04 \mathrm{E}-06$ & $7.09 \mathrm{E}-07$ & $2.27 \mathrm{E}-06$ & $3.03 E-06$ & $3.78 \mathrm{E}-06$ & $4.67 \mathrm{E}-06$ \\
\hline $4.51 \mathrm{E}-08$ & 7. $38 E-06$ & $1.04 \mathrm{E}-06$ & $7.11 \mathrm{E}-07$ & $2.27 E-06$ & $3.03 E-06$ & $3.78 \mathrm{E}-06$ & $4.67 \mathrm{E}-06$ \\
\hline $4.53 E-08$ & $.38 E-06$ & $1.05 E-06$ & $7.13 E-07$ & $2.28 E-06$ & $3.04 \mathrm{E}-06$ & $3.78 E-06$ & $4.67 E-06$ \\
\hline $4.55 E-08$ & $7.38 E-06$ & $1.05 E-06$ & $7.15 \mathrm{E}-07$ & $2.28 E-06$ & $.04 E-06$ & $3.77 \mathrm{E}-06$ & $4.67 E-06$ \\
\hline $4.57 \mathrm{E}-08$ & $7.37 E-06$ & $1.05 E-06$ & $7.16 \mathrm{E}-07$ & $2.28 E-06$ & $3.04 \mathrm{E}-06$ & $3.77 \mathrm{E}-06$ & $4.67 \mathrm{E}-06$ \\
\hline $4.59 \mathrm{E}-08$ & $7.37 E-06$ & $1.05 E-06$ & $7.18 \mathrm{E}-07$ & $2.28 E-06$ & $3.04 \mathrm{E}-06$ & $3.77 \mathrm{E}-06$ & $4.67 \mathrm{E}-06$ \\
\hline $4.61 \mathrm{E}-08$ & 7. $36 \mathrm{E}-06$ & $1.05 E-06$ & $7.19 \mathrm{E}-07$ & $2.29 \mathrm{E}-06$ & $3.04 \mathrm{E}-06$ & $3.77 \mathrm{E}-06$ & $4.67 \mathrm{E}-06$ \\
\hline $4.63 \mathrm{E}-08$ & 7. $36 \mathrm{E}-06$ & $1.05 E-06$ & $7.21 \mathrm{E}-07$ & $2.29 \mathrm{E}-06$ & $3.05 \mathrm{E}-06$ & $3.77 \mathrm{E}-06$ & $4.68 \mathrm{E}-06$ \\
\hline $4.65 E-08$ & $7.35 E-06$ & $1.05 E-06$ & $7.22 \mathrm{E}-07$ & $2.29 E-06$ & $3.05 E-06$ & $3.77 E-06$ & $4.68 E-06$ \\
\hline $4.68 \mathrm{E}-08$ & $7.35 E-06$ & $1.06 \mathrm{E}-06$ & $7.24 \mathrm{E}-07$ & $29 E-06$ & $3.05 \mathrm{E}-06$ & -06 & $4.68 \mathrm{E}-06$ \\
\hline $4.70 E-08$ & $7.34 E-06$ & $1.06 \mathrm{E}-06$ & $7.25 \mathrm{E}-07$ & $2.30 E-06$ & $3.05 E-06$ & $3.77 \mathrm{E}-06$ & $4.68 E-06$ \\
\hline $4.72 \mathrm{E}-08$ & $7.34 E-06$ & $1.06 \mathrm{E}-06$ & $7.27 E-07$ & $2.30 E-06$ & $3.05 E-06$ & $3.77 E-06$ & $4.67 E-06$ \\
\hline $4.74 \mathrm{E}-08$ & 7. $34 \mathrm{E}-06$ & $1.06 \mathrm{E}-06$ & $7.28 \mathrm{E}-07$ & $2.30 \mathrm{E}-06$ & $3.06 \mathrm{E}-06$ & $3.77 \mathrm{E}-06$ & $4.67 \mathrm{E}-06$ \\
\hline $4.76 \mathrm{E}-08$ & $7.33 E-06$ & $1.06 E-06$ & $7.30 \mathrm{E}-07$ & $2.31 E-06$ & $3.06 \mathrm{E}-06$ & $3.77 E-06$ & $4.67 E-06$ \\
\hline $4.78 E-08$ & $7.33 E-06$ & $1.06 E-06$ & $7.31 E-07$ & $2.31 E-06$ & $3.06 \mathrm{E}-06$ & $3.77 E-06$ & $4.67 E-06$ \\
\hline $4.80 E-08$ & $7.32 \mathrm{E}-06$ & $1.06 \mathrm{E}-06$ & $7.33 E-07$ & $2.31 E-06$ & $3.06 \mathrm{E}-06$ & $3.77 E-06$ & $4.67 E-06$ \\
\hline
\end{tabular}


RESRAD-OFFSITE, Version 2.5

Title : Offsite Resident Farmer Deterministic Run

File : RF TC99 DOESG FWD-FV2b.ROF

Summary of dose at graphical times, reptition 2 (continued)

Time

Years

$7.78 \mathrm{E}+02$

$7.79 \mathrm{E}+02$

$7.79 \mathrm{E}+02$

$7.80 \mathrm{E}+02$

$7.80 \mathrm{E}+02$

$7.81 \mathrm{E}+02$

$7.81 \mathrm{E}+02$

$7.82 \mathrm{E}+02$

$7.82 \mathrm{E}+02$

$7.83 \mathrm{E}+02$

$7.83 \mathrm{E}+02$

$7.84 \mathrm{E}+02$

$7.84 \mathrm{E}+02$

$7.85 \mathrm{E}+02$

$7.85 \mathrm{E}+02$

$7.86 \mathrm{E}+02$

$7.86 \mathrm{E}+02$

$7.87 \mathrm{E}+02$

$7.88 \mathrm{E}+02$

$7.88 \mathrm{E}+02$

7. $89 \mathrm{E}+02$

$7.89 \mathrm{E}+02$

7. $90 \mathrm{E}+02$

7. $90 \mathrm{E}+02$

7. $91 \mathrm{E}+02$

7. $91 \mathrm{E}+02$

7. $92 \mathrm{E}+02$

7. $92 \mathrm{E}+02$

7. $93 \mathrm{E}+02$

7. $93 \mathrm{E}+02$

7. $94 \mathrm{E}+02$

$7.94 \mathrm{E}+02$

$7.95 \mathrm{E}+02$

7. $95 \mathrm{E}+02$

$7.96 \mathrm{E}+02$

7. $96 \mathrm{E}+02$

7. $97 \mathrm{E}+02$

7. $97 \mathrm{E}+02$

$7.98 \mathrm{E}+02$

$7.98 \mathrm{E}+02$

$7.99 \mathrm{E}+02$

$7.99 \mathrm{E}+02$

$8.00 \mathrm{E}+02$

$8.00 \mathrm{E}+02$

$8.01 \mathrm{E}+02$

$8.01 \mathrm{E}+02$
Dose statistics at graphical times, mrem/yr

\begin{tabular}{|c|c|c|c|c|c|c|c|}
\hline Minimum & aximum & Mean & edian & $90 \%$ & $95 \%$ & $.5 \%$ & $3 \%$ \\
\hline $4.82 \mathrm{E}-08$ & $7.32 \mathrm{E}-06$ & $1.07 \mathrm{E}-06$ & $7.35 \mathrm{E}-07$ & $2.32 \mathrm{E}-06$ & $3.06 \mathrm{E}-06$ & $3.77 \mathrm{E}-06$ & $4.67 \mathrm{E}-06$ \\
\hline $4.84 \mathrm{E}-08$ & $7.31 \mathrm{E}-06$ & $1.07 \mathrm{E}-06$ & $7.36 \mathrm{E}-07$ & $2.32 \mathrm{E}-06$ & $3.07 \mathrm{E}-06$ & $3.78 \mathrm{E}-06$ & $4.67 \mathrm{E}-06$ \\
\hline $4.86 \mathrm{E}-08$ & $7.31 \mathrm{E}-06$ & $1.07 \mathrm{E}-06$ & $7.38 \mathrm{E}-07$ & $2.32 \mathrm{E}-06$ & $3.07 \mathrm{E}-06$ & $3.78 \mathrm{E}-06$ & $4.67 \mathrm{E}-06$ \\
\hline $4.88 \mathrm{E}-08$ & $7.30 \mathrm{E}-06$ & $1.07 \mathrm{E}-06$ & $7.39 \mathrm{E}-07$ & $2.33 \mathrm{E}-06$ & $3.07 \mathrm{E}-06$ & $3.78 \mathrm{E}-06$ & $4.67 \mathrm{E}-06$ \\
\hline $4.90 \mathrm{E}-08$ & $7.30 \mathrm{E}-06$ & $1.07 \mathrm{E}-06$ & $7.41 \mathrm{E}-07$ & $2.33 \mathrm{E}-06$ & $3.07 \mathrm{E}-06$ & $3.78 \mathrm{E}-06$ & $4.67 \mathrm{E}-06$ \\
\hline $4.92 \mathrm{E}-08$ & $7.29 \mathrm{E}-06$ & $1.07 \mathrm{E}-06$ & $7.43 \mathrm{E}-07$ & $2.34 \mathrm{E}-06$ & $3.08 \mathrm{E}-06$ & $3.78 \mathrm{E}-06$ & $4.67 \mathrm{E}-06$ \\
\hline $4.95 \mathrm{E}-08$ & $7.29 \mathrm{E}-06$ & $1.07 \mathrm{E}-06$ & $7.44 \mathrm{E}-07$ & $2.34 \mathrm{E}-06$ & $3.08 \mathrm{E}-06$ & $3.78 \mathrm{E}-06$ & $4.67 \mathrm{E}-06$ \\
\hline $.97 \mathrm{E}-08$ & $7.29 \mathrm{E}-06$ & $1.08 \mathrm{E}-06$ & $7.46 \mathrm{E}-07$ & $2.34 \mathrm{E}-06$ & $3.08 \mathrm{E}-06$ & $3.79 \mathrm{E}-06$ & $4.67 \mathrm{E}-06$ \\
\hline $.99 \mathrm{E}-08$ & $7.28 \mathrm{E}-06$ & $1.08 \mathrm{E}-06$ & $7.47 \mathrm{E}-07$ & $2.34 \mathrm{E}-06$ & $3.08 \mathrm{E}-06$ & $3.79 \mathrm{E}-06$ & $4.67 \mathrm{E}-06$ \\
\hline $01 \mathrm{E}-08$ & $7.28 \mathrm{E}-06$ & $1.08 \mathrm{E}-06$ & $7.49 \mathrm{E}-07$ & $2.35 \mathrm{E}-06$ & $3.09 \mathrm{E}-06$ & $3.79 \mathrm{E}-06$ & $4.67 \mathrm{E}-06$ \\
\hline $.03 E-08$ & $7.27 \mathrm{E}-06$ & $1.08 \mathrm{E}-06$ & $7.51 \mathrm{E}-07$ & $2.35 \mathrm{E}-06$ & $3.09 \mathrm{E}-06$ & $3.79 \mathrm{E}-06$ & $4.67 \mathrm{E}-06$ \\
\hline $.05 \mathrm{E}-08$ & $7.27 \mathrm{E}-06$ & $1.08 \mathrm{E}-06$ & $7.52 \mathrm{E}-07$ & $2.35 \mathrm{E}-06$ & $3.09 \mathrm{E}-06$ & $3.79 \mathrm{E}-06$ & $4.67 \mathrm{E}-06$ \\
\hline $5.07 \mathrm{E}-08$ & $7.26 \mathrm{E}-06$ & $1.08 \mathrm{E}-06$ & $7.54 \mathrm{E}-07$ & $2.36 \mathrm{E}-06$ & $3.09 \mathrm{E}-06$ & $3.79 \mathrm{E}-06$ & $4.67 \mathrm{E}-06$ \\
\hline $5.09 \mathrm{E}-08$ & $7.26 \mathrm{E}-06$ & $1.08 \mathrm{E}-06$ & $7.55 \mathrm{E}-07$ & $2.36 \mathrm{E}-06$ & $3.10 \mathrm{E}-06$ & $3.79 \mathrm{E}-06$ & $4.67 \mathrm{E}-06$ \\
\hline $5.12 \mathrm{E}-08$ & $7.25 \mathrm{E}-06$ & $1.09 \mathrm{E}-06$ & $7.56 \mathrm{E}-07$ & $2.36 \mathrm{E}-06$ & $3.10 \mathrm{E}-06$ & $3.79 \mathrm{E}-06$ & $4.66 \mathrm{E}-06$ \\
\hline $5.14 \mathrm{E}-08$ & $7.25 \mathrm{E}-06$ & $1.09 \mathrm{E}-06$ & $7.57 \mathrm{E}-07$ & $2.36 \mathrm{E}-06$ & $3.10 \mathrm{E}-06$ & $3.79 \mathrm{E}-06$ & $4.66 \mathrm{E}-06$ \\
\hline $5.16 \mathrm{E}-08$ & $7.24 \mathrm{E}-06$ & $1.09 \mathrm{E}-06$ & $7.59 \mathrm{E}-07$ & $2.36 \mathrm{E}-06$ & $3.10 \mathrm{E}-06$ & $3.79 \mathrm{E}-06$ & $4.66 \mathrm{E}-06$ \\
\hline $5.18 \mathrm{E}-08$ & $7.24 \mathrm{E}-06$ & $1.09 \mathrm{E}-06$ & $7.60 \mathrm{E}-07$ & $2.37 E-06$ & $3.11 \mathrm{E}-06$ & $3.79 \mathrm{E}-06$ & $4.65 E-06$ \\
\hline $.20 \mathrm{E}-08$ & $7.23 \mathrm{E}-06$ & $1.09 \mathrm{E}-06$ & $7.62 \mathrm{E}-07$ & $2.37 \mathrm{E}-06$ & $3.11 \mathrm{E}-06$ & $3.79 \mathrm{E}-06$ & $4.65 \mathrm{E}-06$ \\
\hline $.23 \mathrm{E}-08$ & $7.23 \mathrm{E}-06$ & $1.09 \mathrm{E}-06$ & $7.63 \mathrm{E}-07$ & $2.37 E-06$ & $3.11 \mathrm{E}-06$ & $3.79 \mathrm{E}-06$ & $4.65 \mathrm{E}-06$ \\
\hline $.25 \mathrm{E}-08$ & $7.22 \mathrm{E}-06$ & $1.10 \mathrm{E}-06$ & 7 & 6 & 6 & 06 & $.64 \mathrm{E}-06$ \\
\hline 8 & & & & & & & \\
\hline $5.29 \mathrm{E}-08$ & $7.21 \mathrm{E}-06$ & $1.10 \mathrm{E}-06$ & $7.68 \mathrm{E}-07$ & $2.38 \mathrm{E}-06$ & $3.12 \mathrm{E}-06$ & $3.79 \mathrm{E}-06$ & -06 \\
\hline $5.31 E-08$ & $7.21 \mathrm{E}-06$ & $1.10 \mathrm{E}-06$ & $7.70 \mathrm{E}-07$ & $2.38 \mathrm{E}-06$ & $3.12 \mathrm{E}-06$ & $3.79 \mathrm{E}-06$ & $4.63 \mathrm{E}-06$ \\
\hline $5.34 \mathrm{E}-08$ & $7.20 \mathrm{E}-06$ & $1.10 \mathrm{E}-06$ & $7.71 \mathrm{E}-07$ & $2.38 \mathrm{E}-06$ & $3.12 \mathrm{E}-06$ & $3.79 \mathrm{E}-06$ & $4.63 \mathrm{E}-06$ \\
\hline $5.36 \mathrm{E}-08$ & $7.20 \mathrm{E}-06$ & $1.10 \mathrm{E}-06$ & $7.72 \mathrm{E}-07$ & $2.39 \mathrm{E}-06$ & $3.13 \mathrm{E}-06$ & $3.79 \mathrm{E}-06$ & $4.63 \mathrm{E}-06$ \\
\hline $5.38 \mathrm{E}-08$ & $7.19 \mathrm{E}-06$ & $1.10 \mathrm{E}-06$ & $7.73 \mathrm{E}-07$ & $2.39 \mathrm{E}-06$ & $3.13 \mathrm{E}-06$ & $3.78 \mathrm{E}-06$ & $4.62 \mathrm{E}-06$ \\
\hline $5.40 \mathrm{E}-08$ & $7.19 \mathrm{E}-06$ & $1.11 \mathrm{E}-06$ & $7.75 \mathrm{E}-07$ & $2.39 \mathrm{E}-06$ & $3.13 \mathrm{E}-06$ & $3.78 \mathrm{E}-06$ & $4.62 \mathrm{E}-06$ \\
\hline $5.43 E-08$ & $7.19 \mathrm{E}-06$ & $1.11 \mathrm{E}-06$ & $7.76 \mathrm{E}-07$ & $2.40 \mathrm{E}-06$ & $3.13 \mathrm{E}-06$ & $3.78 \mathrm{E}-06$ & $4.62 \mathrm{E}-06$ \\
\hline $5.45 \mathrm{E}-08$ & $7.18 \mathrm{E}-$ & $1.11 \mathrm{E}-06$ & $7.77 \mathrm{E}-07$ & $2.40 \mathrm{E}-06$ & $3.14 \mathrm{E}-06$ & $3.78 \mathrm{E}-06$ & $4.61 \mathrm{E}-06$ \\
\hline $5.47 \mathrm{E}-08$ & $7.18 \mathrm{E}-06$ & $1.11 \mathrm{E}-06$ & $7.79 \mathrm{E}-07$ & $2.40 \mathrm{E}-06$ & $3.14 \mathrm{E}-06$ & $3.78 \mathrm{E}-06$ & $4.61 \mathrm{E}-06$ \\
\hline $.49 E-08$ & 7. & $1.11 \mathrm{E}-06$ & 7 & $2.41 \mathrm{E}-06$ & 3.14 & $3.78 \mathrm{E}-06$ & $4.61 \mathrm{E}-06$ \\
\hline $5.51 \mathrm{E}-08$ & $7.17 \mathrm{E}-06$ & $1.11 \mathrm{E}-06$ & $7.82 \mathrm{E}-07$ & $2.41 \mathrm{E}-06$ & $3.14 \mathrm{E}-06$ & $3.78 \mathrm{E}-06$ & $4.60 \mathrm{E}-06$ \\
\hline $5.54 \mathrm{E}-08$ & $7.16 \mathrm{E}-06$ & $1.11 \mathrm{E}-06$ & $7.83 \mathrm{E}-07$ & $2.41 \mathrm{E}-06$ & $3.14 \mathrm{E}-06$ & $3.78 \mathrm{E}-06$ & $4.60 \mathrm{E}-06$ \\
\hline $5.56 \mathrm{E}-08$ & $7.16 \mathrm{E}-06$ & $1.12 \mathrm{E}-06$ & $7.84 \mathrm{E}-07$ & $2.42 \mathrm{E}-06$ & $3.15 \mathrm{E}-06$ & $3.78 \mathrm{E}-06$ & $4.60 \mathrm{E}-06$ \\
\hline $5.58 \mathrm{E}-08$ & $7.15 \mathrm{E}-06$ & $1.12 \mathrm{E}-06$ & $7.86 \mathrm{E}-07$ & $2.42 \mathrm{E}-06$ & $3.15 \mathrm{E}-06$ & $3.78 \mathrm{E}-06$ & $4.59 \mathrm{E}-06$ \\
\hline $5.60 \mathrm{E}-08$ & $7.15 \mathrm{E}-06$ & $1.12 \mathrm{E}-06$ & $7.87 \mathrm{E}-07$ & $2.42 \mathrm{E}-06$ & $3.15 \mathrm{E}-06$ & $3.78 \mathrm{E}-06$ & $4.59 \mathrm{E}-06$ \\
\hline $5.62 \mathrm{E}-08$ & $7.14 \mathrm{E}-06$ & $1.12 \mathrm{E}-06$ & $7.89 \mathrm{E}-07$ & $2.43 \mathrm{E}-06$ & $3.15 \mathrm{E}-06$ & $3.78 \mathrm{E}-06$ & $4.58 \mathrm{E}-06$ \\
\hline $5.65 \mathrm{E}-08$ & $7.14 \mathrm{E}-06$ & $1.12 \mathrm{E}-06$ & $7.90 \mathrm{E}-07$ & $2.43 \mathrm{E}-06$ & $3.15 \mathrm{E}-06$ & $3.79 \mathrm{E}-06$ & $4.58 \mathrm{E}-06$ \\
\hline $5.67 \mathrm{E}-08$ & $7.13 \mathrm{E}-06$ & $1.12 \mathrm{E}-06$ & $7.91 \mathrm{E}-07$ & $2.43 \mathrm{E}-06$ & $3.15 \mathrm{E}-06$ & $3.79 \mathrm{E}-06$ & $4.58 \mathrm{E}-06$ \\
\hline $5.69 \mathrm{E}-08$ & $7.13 \mathrm{E}-06$ & $1.12 \mathrm{E}-06$ & $7.93 \mathrm{E}-07$ & $2.43 \mathrm{E}-06$ & $3.16 \mathrm{E}-06$ & $3.79 \mathrm{E}-06$ & $4.58 \mathrm{E}-06$ \\
\hline $5.71 E-08$ & $7.12 \mathrm{E}-06$ & $1.13 \mathrm{E}-06$ & $7.94 \mathrm{E}-07$ & $2.44 \mathrm{E}-06$ & $3.16 \mathrm{E}-06$ & $3.79 \mathrm{E}-06$ & $4.58 \mathrm{E}-06$ \\
\hline $5.74 \mathrm{E}-08$ & $7.11 \mathrm{E}-06$ & $1.13 \mathrm{E}-06$ & $7.95 \mathrm{E}-07$ & $2.44 \mathrm{E}-06$ & $3.16 \mathrm{E}-06$ & $3.79 \mathrm{E}-06$ & $4.58 \mathrm{E}-06$ \\
\hline $5.76 \mathrm{E}-08$ & $7.11 \mathrm{E}-06$ & $1.13 \mathrm{E}-06$ & $7.97 \mathrm{E}-07$ & $2.44 \mathrm{E}-06$ & $3.16 \mathrm{E}-06$ & $3.80 \mathrm{E}-06$ & $4.58 \mathrm{E}-06$ \\
\hline $5.78 \mathrm{E}-08$ & $7.10 \mathrm{E}-06$ & $1.13 \mathrm{E}-06$ & $7.99 \mathrm{E}-07$ & $2.44 \mathrm{E}-06$ & $3.16 \mathrm{E}-06$ & $3.80 \mathrm{E}-06$ & $4.57 \mathrm{E}-06$ \\
\hline $5.80 \mathrm{E}-08$ & $7.10 \mathrm{E}-06$ & $1.13 \mathrm{E}-06$ & $8.01 \mathrm{E}-07$ & $2.44 \mathrm{E}-06$ & $3.16 \mathrm{E}-06$ & $3.80 \mathrm{E}-06$ & $4.57 \mathrm{E}-06$ \\
\hline
\end{tabular}


RESRAD-OFFSITE, Version 2.5

Title : Offsite Resident Farmer Deterministic Run

File : RF TC99 DOESG FWD-FV2b.ROF

Summary of dose at graphical times, reptition 2 (continued)

Time

Years

$8.02 \mathrm{E}+02$

$8.02 \mathrm{E}+02$

$8.03 \mathrm{E}+02$

$8.03 \mathrm{E}+02$

$8.04 \mathrm{E}+02$

$8.04 \mathrm{E}+02$

$8.05 \mathrm{E}+02$

$8.05 \mathrm{E}+02$

$8.06 \mathrm{E}+02$

$8.06 \mathrm{E}+02$

$8.07 \mathrm{E}+02$

$8.07 \mathrm{E}+02$

$8.08 \mathrm{E}+02$

$8.09 \mathrm{E}+02$

$8.09 \mathrm{E}+02$

$8.10 \mathrm{E}+02$

$8.10 \mathrm{E}+02$

$8.11 \mathrm{E}+02$

$8.11 \mathrm{E}+02$

$8.12 \mathrm{E}+02$

$8.12 \mathrm{E}+02$

$8.13 \mathrm{E}+02$

$8.13 \mathrm{E}+02$

$8.14 \mathrm{E}+02$

8. $14 \mathrm{E}+02$

$8.15 \mathrm{E}+02$

$8.15 \mathrm{E}+02$

$8.16 \mathrm{E}+02$

$8.16 \mathrm{E}+02$

$8.17 \mathrm{E}+02$

$8.17 \mathrm{E}+02$

$8.18 \mathrm{E}+02$

$8.18 \mathrm{E}+02$

$8.19 \mathrm{E}+02$

$8.19 \mathrm{E}+02$

8. $20 \mathrm{E}+02$

$8.20 \mathrm{E}+02$

$8.21 E+02$

$8.21 E+02$

$8.22 \mathrm{E}+02$

$8.22 \mathrm{E}+02$

$8.23 \mathrm{E}+02$

8. $23 \mathrm{E}+02$

$8.24 \mathrm{E}+02$

$8.24 \mathrm{E}+02$

$8.25 \mathrm{E}+02$
Dose statistics at graphical times, mrem/yr

\begin{tabular}{|c|c|c|c|c|c|c|c|}
\hline m & aximum & ea & -5 & & & & \\
\hline $.83 E-08$ & $7.09 \mathrm{E}-06$ & $1.13 E-06$ & $.02 \mathrm{E}-07$ & $5 E-06$ & $3.16 \mathrm{E}-06$ & 06 & $4.57 E-00$ \\
\hline $85 E-08$ & $7.09 E-06$ & $1.13 \mathrm{E}-06$ & $8.04 \mathrm{E}-07$ & $45 E-06$ & $16 E-06$ & $3.80 \mathrm{E}-06$ & $7 E-06$ \\
\hline $.87 E-08$ & $7.08 \mathrm{E}-06$ & $4 \mathrm{E}-06$ & $8.06 \mathrm{E}-07$ & $2.45 E-06$ & $3.16 \mathrm{E}-06$ & $3.81 E-06$ & $.57 \mathrm{E}-06$ \\
\hline-08 & 06 & $4 \mathrm{~F}-06$ & $08 F-07$ & $45 E-06$ & $.16 \mathrm{E}-06$ & -06 & $57 E-06$ \\
\hline-08 & 06 & 6 & r & 6 & 6 & 6 & -06 \\
\hline 08 & & & & & & & \\
\hline $97 E-08$ & $06 E-06$ & & & & & & -06 \\
\hline-08 & 06 & 0 & 1 & 6 & 6 & 6 & $E-06$ \\
\hline $.01 E-08$ & $7.05 E-06$ & $4 E-06$ & $E-07$ & -06 & $17 \mathrm{E}-06$ & $E-06$ & $E-06$ \\
\hline$E-08$ & 06 & $1.15 \mathrm{E}-06$ & 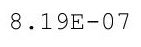 & 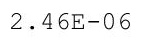 & $17 E-06$ & م & 06 \\
\hline 08 & 06 & 1. & & & & 6 & -06 \\
\hline$E-08$ & 06 & 1 . & $8.22 \mathrm{E}-07$ & 6 & & 6 & -06 \\
\hline $.11 \mathrm{E}-08$ & $7.03 E-06$ & $1.15 \mathrm{E}-06$ & $8.24 \mathrm{E}-07$ & $2.47 E-06$ & & $3.83 E-06$ & $.58 E-06$ \\
\hline $13 E-08$ & -06 & $1.15 \mathrm{E}-06$ & $8.25 \mathrm{E}-07$ & $2.47 \mathrm{E}-06$ & $3.17 \mathrm{E}-06$ & -06 & $3 E-06$ \\
\hline-08 & 06 & 06 & 1 & -06 & & -06 & $\Xi-06$ \\
\hline 08 & 06 & 0 & 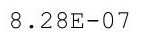 & 06 & & -06 & 06 \\
\hline 8 & 0 & $1.16 \mathrm{E}-06$ & & & & & 6 \\
\hline 8 & 6 & $1.16 \mathrm{E}-06$ & $8 \quad 31 \mathrm{~F}-07$ & 6 & 6 & 6 & 06 \\
\hline $25 E-08$ & $7.00 \mathrm{E}-06$ & $1.16 \mathrm{E}-06$ & $8.33 E-07$ & $2.47 E-06$ & $3.18 E-06$ & $3.85 E-06$ & $.59 E-06$ \\
\hline $27 E-08$ & $.99 E-06$ & $.16 \mathrm{E}-06$ & $.34 \mathrm{E}-07$ & $2.48 \mathrm{E}-06$ & $18 E-06$ & $E-06$ & $59 E-06$ \\
\hline-08 & 06 & 6 & & 6 & & -06 & -06 \\
\hline 08 & & & & & & -06 & -06 \\
\hline 8 & & $\perp$ & 7 & & & 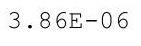 & -06 \\
\hline $7 E-08$ & 06 & $\perp$ & $8.40 \mathrm{E}-07$ & 6 & 6 & 0 & -06 \\
\hline 8 & 6 & 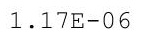 & $8.42 \mathrm{E}-07$ & 6 & 6 & 6 & 06 \\
\hline $41 E-08$ & $96 E-06$ & $17 \mathrm{~F}-06$ & 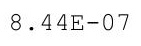 & $.49 \mathrm{E}-06$ & $19 \mathrm{E}-06$ & $.86 \mathrm{E}-0$ & $60 E-06$ \\
\hline $44 \mathrm{E}-08$ & $96 E-06$ & $1.17 \mathrm{~F}-06$ & 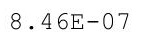 & $49 E-06$ & & $E-06$ & $60 E-06$ \\
\hline & & & & & & & \\
\hline & & & & 06 & 6 & -06 & -06 \\
\hline $.51 E-08$ & $6.94 \mathrm{E}-06$ & $1 \cdot 1 / \pm-U 6$ & $\begin{array}{lll}\cdot 3+\mathrm{L} & 1\end{array}$ & $2.50 \mathrm{E}-06$ & $.20 E-06$ & $.00 \pm-00$ & $.60 E-06$ \\
\hline $54 \mathrm{E}-08$ & $93 E-06$ & $\perp \cdot 1 / \mathrm{L}-00$ & -4 & $2.50 \mathrm{E}-06$ & $20 E-06$ & $0 \mathrm{x}-20$ & $.60 \mathrm{E}-06$ \\
\hline 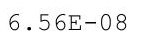 & & & & & & $=0$ & \\
\hline$E-08$ & $7-06$ & -06 & 7 & $0 E-06$ & ת & -06 & $F F-06$ \\
\hline & & & & & & & \\
\hline 08 & & 1. & & 6 & 6 & -06 & \\
\hline $.66 E-08$ & $6.91 \mathrm{E}-06$ & $1.18 \mathrm{E}-06$ & $.61 E-07$ & $2 \cdot 01$ & -06 & -06 & $E-06$ \\
\hline $.08 \mathrm{E}-08$ & & & & $2.51 \mathrm{E}-06$ & & . & $4.500-00$ \\
\hline $71 \mathrm{E}-08$ & 地 & 1. $18 \mathrm{E}-06$ & 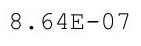 & $2.52 \mathrm{E}-06$ & & $\begin{array}{ll}7 \\
0\end{array}$ & $.58 E-06$ \\
\hline $.73 E-08$ & $6.89 \mathrm{E}-06$ & $1.19 \mathrm{E}-06$ & $8.65 E-07$ & 6 & 6 & 6 & 06 \\
\hline & & & & & & & \\
\hline $8 E-08$ & $6.88 \mathrm{E}$ & 1. & 07 & 6 & 6 & 06 & -06 \\
\hline$E-08$ & 0.011 & 1. & & & & & -06 \\
\hline & & & & & & & $4.5 / E-06$ \\
\hline $865-08$ & $.00 \mathrm{~L}$ - & $\perp \cdot \perp>-00$ & . & $2.53 E-06$ & $3.23 E-06$ & $39 E-06$ & $4.5 / E-06$ \\
\hline $88 E-08$ & $0.00 \mathrm{~L}-0$ & $\perp \cdot \perp \pi$ u & & $2 \cdot 014$ & 3.250 & & $4.57 E-06$ \\
\hline$E-08$ & $.85 E-06$ & $.20 \mathrm{E}-06$ & $.78 \mathrm{E}-07$ & $.54 \mathrm{E}-06$ & 06 & $3 E-06$ & 4.5 \\
\hline
\end{tabular}


RESRAD-OFFSITE, Version 2.5

Title : Offsite Resident Farmer Deterministic Run

File : RF TC99 DOESG FWD-FV2b.ROF

Summary of dose at graphical times, reptition 2 (continued)

Time

Years

$8.25 \mathrm{E}+02$

$8.26 \mathrm{E}+02$

$8.26 \mathrm{E}+02$

$8.27 \mathrm{E}+02$

$8.27 \mathrm{E}+02$

8. $28 \mathrm{E}+02$

$8.29 \mathrm{E}+02$

8. $29 \mathrm{E}+02$

8. $30 \mathrm{E}+02$

8. $30 \mathrm{E}+02$

8. $31 E+02$

8. $31 \mathrm{E}+02$

8. $32 \mathrm{E}+02$

8. $32 \mathrm{E}+02$

8. $33 \mathrm{E}+02$

8. $33 \mathrm{E}+02$

8. $34 \mathrm{E}+02$

8. $34 \mathrm{E}+02$

8. $35 \mathrm{E}+02$

8. $35 \mathrm{E}+02$

8. $36 \mathrm{E}+02$

8. $36 \mathrm{E}+02$

8. $37 \mathrm{E}+02$

8. $37 \mathrm{E}+02$

8. $38 \mathrm{E}+02$

8. $38 \mathrm{E}+02$

8. $39 \mathrm{E}+02$

8. $39 \mathrm{E}+02$

8. $40 \mathrm{E}+02$

8. $40 \mathrm{E}+02$

8. $41 \mathrm{E}+02$

$8.41 E+02$

$8.42 \mathrm{E}+02$

$8.42 \mathrm{E}+02$

$8.43 E+02$

$8.43 E+02$

$8.44 \mathrm{E}+02$

$8.44 \mathrm{E}+02$

$8.45 \mathrm{E}+02$

$8.45 \mathrm{E}+02$

$8.46 \mathrm{E}+02$

$8.46 \mathrm{E}+02$

$8.47 \mathrm{E}+02$

$8.47 \mathrm{E}+02$

$8.48 \mathrm{E}+02$

$8.49 \mathrm{E}+02$
Dose statistics at graphical times, mrem/yr

\begin{tabular}{|c|c|c|c|c|c|c|c|}
\hline um & aximum & lean & edi & & & & \\
\hline 8 & 06 & 06 & 07 & 06 & 06 & 06 & -06 \\
\hline $.96 \mathrm{E}-08$ & $.84 \mathrm{E}-06$ & $1.20 \mathrm{E}-06$ & $.82 \mathrm{E}-07$ & $2.54 \mathrm{E}-06$ & $3.24 \mathrm{E}-06$ & $3.88 \mathrm{E}-06$ & $.56 \mathrm{E}-06$ \\
\hline $98 E-08$ & $83 E-06$ & $20 F-06$ & $83 E-07$ & $.55 E-06$ & $.24 E-06$ & $3.87 E-06$ & $.56 E-06$ \\
\hline $1 E-08$ & $83 E-06$ & $\cap F-\cap 6$ & -07 & $.55 E-06$ & 06 & $.87 E-06$ & $.55 E-06$ \\
\hline $.04 \mathrm{E}-08$ & 06 & 6 & & & & 06 & -06 \\
\hline$E-08$ & 06 & 6 & & & & & -06 \\
\hline $.09 E-08$ & $6.81 E-06$ & - & 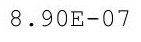 & $56 E-06$ & $24 E-06$ & $E-06$ & $55 E-06$ \\
\hline $.11 \mathrm{E}-08$ & $6.81 \mathrm{E}-06$ & $1.21 \mathrm{E}-06$ & $1 E-07$ & $56 E-06$ & $.24 \mathrm{E}-06$ & $3.87 \mathrm{E}-06$ & $55 E-06$ \\
\hline $14 \mathrm{~F}-08$ & $80 E-06$ & $21 \mathrm{~F}-06$ & $92 \mathrm{~F}-0$ & $.56 E-06$ & $24 E-06$ & $.87 E-06$ & $5 E-06$ \\
\hline $16 \mathrm{~F}-08$ & 6 & $1.21 \mathrm{E}-06$ & & 6 & 6 & $.87 E-06$ & -06 \\
\hline $19 F-08$ & $9 F-06$ & $1.21 F-06$ & $5 F-07$ & 6 & 6 & -06 & $E-06$ \\
\hline$E-08$ & $E-06$ & $121 \mathrm{~F}$ & & & & & -06 \\
\hline $.24 \mathrm{E}-08$ & $6.78 E-06$ & $1.21 E-06$ & $8.98 E-07$ & $2.57 E-06$ & $3.25 E-06$ & $3.87 E-06$ & $.55 E-06$ \\
\hline $26 E-08$ & 06 & -06 & & & & -06 & -06 \\
\hline - & 6 & 0 & & & & 6 & 06 \\
\hline 25 & & 6 & & 6 & 6 & 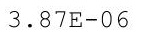 & 6 \\
\hline $34 \mathrm{~F}-08$ & $76 \mathrm{~F}$ & $1.22 \mathrm{E}-06$ & $9.05 E-07$ & 6 & 6 & 6 & -06 \\
\hline $.37 E-08$ & $5.75 E-06$ & $122 \mathrm{~F}-06$ & $7 \mathrm{~F}$ & $8 E-06$ & $26 E-06$ & $E-06$ & $5 E-06$ \\
\hline $.39 E-08$ & $.74 \mathrm{E}-06$ & $1.22 \mathrm{E}-06$ & $9.09 \mathrm{E}-07$ & $2.58 \mathrm{E}-06$ & -06 & $E-06$ & $.55 E-06$ \\
\hline $.42 \mathrm{E}-08$ & $4 E-06$ & -06 & & -06 & -06 & -06 & -06 \\
\hline & & & & & & & \\
\hline $.47 \mathrm{E}-$ & & $1.23 E-06$ & & & & & 06 \\
\hline $.50 E-08$ & 06 & 06 & 7 & 6 & 6 & 6 & -06 \\
\hline $52 E-08$ & $.71 \mathrm{E}-06$ & $.23 E-06$ & $7 F_{-}$ & $9 E-06$ & $285-$ & $E-06$ & $E-06$ \\
\hline $55 \mathrm{E}-08$ & $.71 \mathrm{E}-06$ & $1.23 E-06$ & $9.19 \mathrm{E}-07$ & $0 E-06$ & $28 E-06$ & $8 E-06$ & $55 E-06$ \\
\hline-08 & $70 F-06$ & $23 E-06$ & & & & -06 & $E-06$ \\
\hline & & & & & & & \\
\hline & & 1.23 & & & 06 & & \\
\hline $.65 E-08$ & $6.69 \mathrm{E}-06$ & $1.23 E-06$ & . & $2.61 \mathrm{E}-06$ & $3.28 E-06$ & $8 E-06$ & $.56 \mathrm{E}-06$ \\
\hline 8 & $68 E-06$ & $.24 \mathrm{E}-$ & 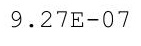 & $2.61 E-06$ & $28 E-06$ & $.88 E-06$ & $.56 E-06$ \\
\hline 5 & $67 E-06$ & $.24 \mathrm{E}-06$ & & $.61 E-06$ & & $.88 E-0$ & $4.56 E-06$ \\
\hline $73 \mathrm{~F}-08$ & $67 \mathrm{~F}-06$ & $1245-06$ & F & $.61 E-06$ & $8 E-06$ & & $6 E-06$ \\
\hline & & & & & & & \\
\hline 08 & & 1.2 & 7 & 06 & 06 & & \\
\hline $.81 \mathrm{E}-08$ & $6.65 E-06$ & $1.24 \mathrm{E}-06$ & $9.36 \mathrm{E}-07$ & $2.62 \mathrm{E}-06$ & $3.28 E-06$ & $3.87 E-06$ & $4.56 E-06$ \\
\hline .074 vo & $0.04 E-00$ & $1 \cdot 245-06$ & & $2.62 \mathrm{E}-06$ & & $3.87 E-06$ & $4.56 \mathrm{E}-06$ \\
\hline ( & . & te & $9.39 E-07$ & 6 & 6 & & 06 \\
\hline ( & $6.63 E-06$ & $1.25 \mathrm{E}-06$ & 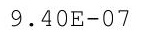 & 6 & 6 & 6 & 06 \\
\hline & & & & 6 & & & \\
\hline $94 E-08$ & -06 & 06 & & 06 & & 06 & \\
\hline $.97 \mathrm{E}-08$ & $6.61 E-06$ & $E-06$ & & 2.0 & & 06 & -06 \\
\hline 年 & & $1.25 \mathrm{E}-06$ & & & & & $4.55 E-06$ \\
\hline पL $\angle 0$ & $.00 \mathrm{D}-20$ & $\perp \cdot 2 J \pm-00$ & $.48 E-07$ & $2.64 E-06$ & $3.28 \mathrm{E}-06$ & $37 E-06$ & $4.55 E-06$ \\
\hline 年 & $0.00 \mathrm{~L}$ & $1.25 \mathrm{E}-06$ & & & & $3.87 \mathrm{E}-06$ & $4.55 E-06$ \\
\hline & & ter & & 6 & -06 & 06 & $55 E-06$ \\
\hline $10 \mathrm{E}-08$ & $.59 \mathrm{E}-06$ & $E-06$ & $52 E-07$ & -06 & -06 & $7 E-06$ & 4.5 \\
\hline
\end{tabular}


RESRAD-OFFSITE, Version 2.5

Title : Offsite Resident Farmer Deterministic Run

File : RF TC99 DOESG FWD-FV2b.ROF

Summary of dose at graphical times, reptition 2 (continued)

Time

Years

$8.49 \mathrm{E}+02$

$8.50 \mathrm{E}+02$

8. $50 \mathrm{E}+02$

$8.51 \mathrm{E}+02$

8. $51 \mathrm{E}+02$

8. $52 \mathrm{E}+02$

$8.52 \mathrm{E}+02$

$8.53 \mathrm{E}+02$

$8.53 \mathrm{E}+02$

8. $54 \mathrm{E}+02$

$8.54 \mathrm{E}+02$

$8.55 \mathrm{E}+02$

8. $55 \mathrm{E}+02$

$8.56 \mathrm{E}+02$

$8.56 \mathrm{E}+02$

$8.57 \mathrm{E}+02$

$8.57 \mathrm{E}+02$

$8.58 \mathrm{E}+02$

8. $58 \mathrm{E}+02$

$8.59 \mathrm{E}+02$

$8.59 \mathrm{E}+02$

$8.60 \mathrm{E}+02$

$8.60 \mathrm{E}+02$

$8.61 \mathrm{E}+02$

8. $61 \mathrm{E}+02$

$8.62 E+02$

$8.62 \mathrm{E}+02$

$8.63 E+02$

8. $63 \mathrm{E}+02$

8. $64 \mathrm{E}+02$

$8.64 \mathrm{E}+02$

$8.65 \mathrm{E}+02$

$8.65 \mathrm{E}+02$

$8.66 \mathrm{E}+02$

$8.66 \mathrm{E}+02$

$8.67 \mathrm{E}+02$

$8.67 \mathrm{E}+02$

$8.68 \mathrm{E}+02$

8. $69 \mathrm{E}+02$

8. $69 \mathrm{E}+02$

$8.70 \mathrm{E}+02$

$8.70 \mathrm{E}+02$

$8.71 \mathrm{E}+02$

8. $71 \mathrm{E}+02$

$8.72 \mathrm{E}+02$

$8.72 \mathrm{E}+02$

Dose statistics at graphical times, mrem/yr

\begin{tabular}{|c|c|c|c|c|c|c|c|}
\hline Minimum & Maximum & Mean & Median & $90 \%$ & $95 \%$ & $97.5 \%$ & $99 \%$ \\
\hline $8.13 \mathrm{E}-08$ & $6.58 \mathrm{E}-06$ & $1.26 \mathrm{E}-06$ & $9.54 \mathrm{E}-07$ & $2.64 \mathrm{E}-06$ & $3.28 \mathrm{E}-06$ & $3.88 E-06$ & $4.54 \mathrm{E}-06$ \\
\hline $8.16 \mathrm{E}-08$ & $6.57 \mathrm{E}-06$ & $1.26 \mathrm{E}-06$ & $9.56 \mathrm{E}-07$ & $2.65 \mathrm{E}-06$ & $3.28 \mathrm{E}-06$ & $3.88 E-06$ & $4.54 \mathrm{E}-06$ \\
\hline $8.18 E-08$ & $6.57 \mathrm{E}-06$ & $1.26 \mathrm{E}-06$ & $9.57 \mathrm{E}-07$ & $2.65 E-06$ & $3.28 E-06$ & $3.88 E-06$ & $4.54 \mathrm{E}-06$ \\
\hline $8.21 E-08$ & $6.56 \mathrm{E}-06$ & $1.26 \mathrm{E}-06$ & $9.59 \mathrm{E}-07$ & $2.65 \mathrm{E}-06$ & $3.28 \mathrm{E}-06$ & $3.88 E-06$ & $4.54 \mathrm{E}-06$ \\
\hline $8.24 \mathrm{E}-08$ & $6.56 \mathrm{E}-06$ & $1.26 \mathrm{E}-06$ & $9.60 \mathrm{E}-07$ & $2.65 E-06$ & $3.28 \mathrm{E}-06$ & $3.88 E-06$ & $4.54 \mathrm{E}-06$ \\
\hline $8.27 E-08$ & $6.55 E-06$ & $1.27 \mathrm{E}-06$ & $9.62 \mathrm{E}-07$ & $2.65 E-06$ & $3.28 E-06$ & $3.88 \mathrm{E}-06$ & $4.54 \mathrm{E}-06$ \\
\hline $8.29 \mathrm{E}-08$ & $6.54 \mathrm{E}-06$ & $1.27 \mathrm{E}-06$ & $9.63 \mathrm{E}-07$ & $2.65 \mathrm{E}-06$ & $3.28 \mathrm{E}-06$ & $3.89 E-06$ & $4.53 E-06$ \\
\hline $8.32 \mathrm{E}-08$ & $6.54 \mathrm{E}-06$ & $1.27 \mathrm{E}-06$ & $9.65 \mathrm{E}-07$ & $2.66 \mathrm{E}-06$ & $3.28 E-06$ & $3.89 \mathrm{E}-06$ & $4.53 E-06$ \\
\hline $8.35 E-08$ & $6.53 \mathrm{E}-06$ & $1.27 \mathrm{E}-06$ & $9.66 \mathrm{E}-07$ & $2.66 \mathrm{E}-06$ & $3.28 \mathrm{E}-06$ & $3.89 E-06$ & $4.53 E-06$ \\
\hline $8.38 E-08$ & $6.53 E-06$ & $1.27 \mathrm{E}-06$ & $9.68 \mathrm{E}-07$ & $2.66 \mathrm{E}-06$ & $3.28 \mathrm{E}-06$ & $3.89 \mathrm{E}-06$ & $4.53 E-06$ \\
\hline $8.40 E-08$ & $6.52 \mathrm{E}-06$ & $1.27 \mathrm{E}-06$ & $9.70 \mathrm{E}-07$ & $2.66 \mathrm{E}-06$ & $3.28 \mathrm{E}-06$ & $3.89 \mathrm{E}-06$ & $4.53 E-06$ \\
\hline $8.43 E-08$ & $6.51 E-06$ & $1.27 \mathrm{E}-06$ & $9.72 \mathrm{E}-07$ & $2.66 \mathrm{E}-06$ & $3.29 \mathrm{E}-06$ & $3.88 E-06$ & $4.53 E-06$ \\
\hline $8.46 \mathrm{E}-08$ & $6.51 E-06$ & $1.27 \mathrm{E}-06$ & $9.73 E-07$ & $2.66 \mathrm{E}-06$ & $3.29 \mathrm{E}-06$ & $3.88 E-06$ & $4.52 E-06$ \\
\hline $8.49 \mathrm{E}-08$ & $6.50 \mathrm{E}-06$ & $1.28 \mathrm{E}-06$ & $9.75 \mathrm{E}-07$ & $2.67 \mathrm{E}-06$ & $3.29 \mathrm{E}-06$ & $3.88 \mathrm{E}-06$ & $4.52 \mathrm{E}-06$ \\
\hline $8.51 E-08$ & $6.50 \mathrm{E}-06$ & $1.28 \mathrm{E}-06$ & $9.77 \mathrm{E}-07$ & $2.67 \mathrm{E}-06$ & $3.29 \mathrm{E}-06$ & $3.88 E-06$ & $4.52 E-06$ \\
\hline $8.54 \mathrm{E}-08$ & $6.49 \mathrm{E}-06$ & $1.28 \mathrm{E}-06$ & $9.78 E-07$ & $2.67 \mathrm{E}-06$ & $3.29 \mathrm{E}-06$ & $3.88 E-06$ & $4.52 \mathrm{E}-06$ \\
\hline $8.57 E-08$ & $6.48 E-06$ & $1.28 E-06$ & $9.80 \mathrm{E}-07$ & $2.67 \mathrm{E}-06$ & $3.29 E-06$ & $3.88 E-06$ & $4.52 E-06$ \\
\hline $8.60 E-08$ & $6.48 E-06$ & $1.28 E-06$ & $9.81 \mathrm{E}-07$ & $2.67 \mathrm{E}-06$ & $3.29 \mathrm{E}-06$ & $3.88 E-06$ & $4.52 \mathrm{E}-06$ \\
\hline $8.63 E-08$ & $6.47 \mathrm{E}-06$ & $1.28 E-06$ & $9.83 E-07$ & $2.67 \mathrm{E}-06$ & $3.29 \mathrm{E}-06$ & $3.88 \mathrm{E}-06$ & $4.52 E-06$ \\
\hline $8.65 E-08$ & $6.46 \mathrm{E}-06$ & $1.28 \mathrm{E}-06$ & $9.85 E-07$ & $2.67 \mathrm{E}-06$ & $3.30 \mathrm{E}-06$ & $3.88 \mathrm{E}-06$ & $4.51 E-06$ \\
\hline $8.68 E-08$ & $6.46 \mathrm{E}-06$ & $1.28 E-06$ & $9.86 \mathrm{E}-07$ & $2.67 \mathrm{E}-06$ & $3.30 \mathrm{E}-06$ & $3.88 E-06$ & $4.51 \mathrm{E}-06$ \\
\hline $8.71 E-08$ & $6.45 E-06$ & $1.29 \mathrm{E}-06$ & $9.88 \mathrm{E}-07$ & $2.68 \mathrm{E}-06$ & $3.30 \mathrm{E}-06$ & $3.88 \mathrm{E}-06$ & $4.51 \mathrm{E}-06$ \\
\hline $8.74 \mathrm{E}-08$ & $6.45 E-06$ & $1.29 \mathrm{E}-06$ & $9.89 \mathrm{E}-07$ & $2.68 E-06$ & $3.30 \mathrm{E}-06$ & $3.89 \mathrm{E}-06$ & $4.51 \mathrm{E}-06$ \\
\hline $8.77 \mathrm{E}-08$ & $6.44 \mathrm{E}-06$ & $1.29 \mathrm{E}-06$ & $9.91 \mathrm{E}-07$ & $2.68 \mathrm{E}-06$ & $3.30 \mathrm{E}-06$ & $3.89 \mathrm{E}-06$ & $4.51 \mathrm{E}-06$ \\
\hline $8.79 \mathrm{E}-08$ & $6.43 E-06$ & $1.29 \mathrm{E}-06$ & $9.92 \mathrm{E}-07$ & $2.68 \mathrm{E}-06$ & $3.30 \mathrm{E}-06$ & $3.89 \mathrm{E}-06$ & $4.51 \mathrm{E}-06$ \\
\hline $8.82 E-08$ & $6.43 E-06$ & $1.29 \mathrm{E}-06$ & $93 E-07$ & $2.68 \mathrm{E}-06$ & $3.30 E-06$ & $3.89 E-06$ & $4.50 E-06$ \\
\hline $8.85 E-08$ & $6.42 E-06$ & $1.29 \mathrm{E}-06$ & $9.95 E-07$ & $2.68 \mathrm{E}-06$ & $3.31 \mathrm{E}-06$ & $3.89 E-06$ & $4.50 E-06$ \\
\hline $8.88 E-08$ & $6.42 \mathrm{E}-06$ & $1.29 \mathrm{E}-06$ & $9.96 \mathrm{E}-07$ & $2.68 \mathrm{E}-06$ & $3.31 \mathrm{E}-06$ & $3.89 E-06$ & $4.50 E-06$ \\
\hline $8.91 \mathrm{E}-08$ & $6.41 E-06$ & $1.29 \mathrm{E}-06$ & $9.98 \mathrm{E}-07$ & $2.69 \mathrm{E}-06$ & $3.31 \mathrm{E}-06$ & $3.89 \mathrm{E}-06$ & $4.50 \mathrm{E}-06$ \\
\hline $8.94 \mathrm{E}-08$ & $6.40 \mathrm{E}-06$ & $1.30 \mathrm{E}-06$ & $9.99 \mathrm{E}-07$ & $2.69 \mathrm{E}-06$ & $3.31 \mathrm{E}-06$ & $3.89 \mathrm{E}-06$ & $4.50 \mathrm{E}-06$ \\
\hline $8.97 E-08$ & $6.40 E-06$ & $1.30 \mathrm{E}-06$ & $1.00 \mathrm{E}-06$ & $2.69 \mathrm{E}-06$ & $3.31 \mathrm{E}-06$ & $3.89 E-06$ & $4.50 E-06$ \\
\hline $8.99 E-08$ & $6.39 E-06$ & $1.30 \mathrm{E}-06$ & $1.00 \mathrm{E}-06$ & $2.69 E-06$ & $3.31 E-06$ & $3.90 E-06$ & $4.50 E-06$ \\
\hline $9.02 \mathrm{E}-08$ & $6.39 \mathrm{E}-06$ & $1.30 \mathrm{E}-06$ & $1.00 \mathrm{E}-06$ & $2.69 \mathrm{E}-06$ & $3.31 \mathrm{E}-06$ & $3.90 \mathrm{E}-06$ & $4.50 \mathrm{E}-06$ \\
\hline $9.05 E-08$ & $6.38 \mathrm{E}-06$ & $1.30 \mathrm{E}-06$ & $1.00 \mathrm{E}-06$ & $2.69 \mathrm{E}-06$ & $3.31 \mathrm{E}-06$ & $3.90 \mathrm{E}-06$ & $4.50 \mathrm{E}-06$ \\
\hline $9.08 E-08$ & $6.37 E-06$ & $1.30 E-06$ & $1.01 E-06$ & $2.70 E-06$ & $3.32 E-06$ & $3.90 E-06$ & $4.50 E-06$ \\
\hline $9.11 \mathrm{E}-08$ & $6.37 \mathrm{E}-06$ & $1.30 \mathrm{E}-06$ & $1.01 \mathrm{E}-06$ & $2.70 \mathrm{E}-06$ & $3.32 \mathrm{E}-06$ & $3.90 \mathrm{E}-06$ & $4.50 \mathrm{E}-06$ \\
\hline $9.14 \mathrm{E}-08$ & $6.36 \mathrm{E}-06$ & $1.30 \mathrm{E}-06$ & $1 E-06$ & 06 & 06 & 06 & $4.50 E-06$ \\
\hline $9.17 \mathrm{E}-08$ & $5 E-06$ & $1.31 \mathrm{E}-06$ & -06 & $2.70 \mathrm{E}-06$ & -06 & -06 & -06 \\
\hline $9.20 E-08$ & $6.35 \mathrm{E}-06$ & $1.31 \mathrm{E}-06$ & $1.01 \mathrm{E}-06$ & $2.70 \mathrm{E}-06$ & $3.32 E-06$ & $3.89 E-06$ & $4.50 E-06$ \\
\hline $9.22 \mathrm{E}-08$ & $6.34 \mathrm{E}-06$ & $1.31 \mathrm{E}-06$ & $1.01 \mathrm{E}-06$ & $2.70 \mathrm{E}-06$ & $3.32 \mathrm{E}-06$ & $3.89 \mathrm{E}-06$ & $4.50 \mathrm{E}-06$ \\
\hline $9.25 E-08$ & $6.34 \mathrm{E}-06$ & $1.31 E-06$ & $1.02 \mathrm{E}-06$ & $2.71 E-06$ & $3.32 E-06$ & $3.89 E-06$ & $4.49 E-06$ \\
\hline $9.28 E-08$ & $6.33 E-06$ & $1.31 \mathrm{E}-06$ & $1.02 \mathrm{E}-06$ & $2.71 \mathrm{E}-06$ & $3.32 \mathrm{E}-06$ & $3.89 E-06$ & $4.49 E-06$ \\
\hline $9.31 E-08$ & $6.32 \mathrm{E}-06$ & $1.31 \mathrm{E}-06$ & $1.02 \mathrm{E}-06$ & $2.71 E-06$ & $3.32 \mathrm{E}-06$ & $3.89 \mathrm{E}-06$ & $4.49 \mathrm{E}-06$ \\
\hline $9.34 \mathrm{E}-08$ & $6.32 \mathrm{E}-06$ & $31 \mathrm{E}-$ & $02 E-06$ & $71 \mathrm{E}$ & $33 E-06$ & $3.89 \mathrm{E}-06$ & $4.49 E-06$ \\
\hline $9.37 \mathrm{E}-08$ & $6.31 E-06$ & $1.31 E-06$ & $1.02 \mathrm{E}-06$ & $2.71 \mathrm{E}-06$ & $3.33 E-06$ & $3.89 \mathrm{E}-06$ & $4.48 E-06$ \\
\hline $9.40 \mathrm{E}-08$ & $6.31 \mathrm{E}-06$ & 1. $32 \mathrm{E}-06$ & 1.02E-06 & $2.71 \mathrm{E}-06$ & $3.33 \mathrm{E}-06$ & $3.89 \mathrm{E}-06$ & $4.48 E-06$ \\
\hline
\end{tabular}


RESRAD-OFFSITE, Version 2.5

Title : Offsite Resident Farmer Deterministic Run

File : RF TC99 DOESG FWD-FV2b.ROF

Summary of dose at graphical times, reptition 2 (continued)

Time

Years

$8.73 \mathrm{E}+02$

$8.73 \mathrm{E}+02$

$8.74 \mathrm{E}+02$

$8.74 \mathrm{E}+02$

$8.75 \mathrm{E}+02$

$8.75 \mathrm{E}+02$

$8.76 \mathrm{E}+02$

$8.76 \mathrm{E}+02$

$8.77 \mathrm{E}+02$

$8.77 \mathrm{E}+02$

$8.78 \mathrm{E}+02$

$8.78 \mathrm{E}+02$

$8.79 \mathrm{E}+02$

$8.79 \mathrm{E}+02$

$8.80 \mathrm{E}+02$

$8.80 \mathrm{E}+02$

$8.81 \mathrm{E}+02$

$8.81 \mathrm{E}+02$

$8.82 \mathrm{E}+02$

$8.82 \mathrm{E}+02$

$8.83 \mathrm{E}+02$

$8.83 E+02$

$8.84 \mathrm{E}+02$

$8.84 \mathrm{E}+02$

$8.85 \mathrm{E}+02$

$8.85 \mathrm{E}+02$

$8.86 \mathrm{E}+02$

$8.86 \mathrm{E}+02$

$8.87 \mathrm{E}+02$

$8.87 \mathrm{E}+02$

$8.88 \mathrm{E}+02$

$8.89 \mathrm{E}+02$

$8.89 \mathrm{E}+02$

$8.90 \mathrm{E}+02$

$8.90 \mathrm{E}+02$

$8.91 \mathrm{E}+02$

$8.91 \mathrm{E}+02$

8. $92 \mathrm{E}+02$

8. $92 \mathrm{E}+02$

$8.93 \mathrm{E}+02$

$8.93 \mathrm{E}+02$

8. $94 \mathrm{E}+02$

$8.94 \mathrm{E}+02$

$8.95 \mathrm{E}+02$

8. $95 \mathrm{E}+02$

$8.96 \mathrm{E}+02$
Dose statistics at graphical times, mrem/yr

\begin{tabular}{|c|c|c|c|c|c|c|c|}
\hline m & am & a & 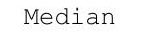 & & & $\%$ & \\
\hline 08 & 06 & 1. $32 E-06$ & $1.02 \mathrm{E}-06$ & -06 & $3.33 E-06$ & -06 & -00 \\
\hline $.46 \mathrm{E}-08$ & $6.29 \mathrm{E}-06$ & $32 E-06$ & $.03 E-06$ & $2.72 \mathrm{E}-06$ & 06 & 06 & -06 \\
\hline $.49 \mathrm{E}-08$ & $6.29 \mathrm{E}-06$ & 1. $32 \mathrm{E}-06$ & $.03 E-06$ & $2.72 \mathrm{E}-06$ & $3.34 \mathrm{E}-06$ & $E-06$ & $.48 \mathrm{E}-06$ \\
\hline $52 \mathrm{E}-08$ & $28 E-06$ & $.32 E-06$ & $1.03 E-06$ & $2.72 E-06$ & $3.34 \mathrm{E}-06$ & $3.89 \mathrm{E}-06$ & $4.48 \mathrm{E}-06$ \\
\hline $5 E-08$ & $27 E-06$ & $.32 E-06$ & $3 E-06$ & $72 E-06$ & -06 & $9 E-06$ & -06 \\
\hline-08 & 06 & $\mathrm{~F}$ & 6 & 6 & 6 & 6 & -06 \\
\hline $61 E-08$ & 06 & 6 & & 6 & & & -06 \\
\hline-08 & & & & & & & -06 \\
\hline-08 & 06 & -06 & -06 & 6 & & -06 & $48 E-06$ \\
\hline 08 & -06 & - & s & -06 & 6 & 0 & -06 \\
\hline $3 E-08$ & 6 & $1.33 E-06$ & -06 & 6 & 6 & -06 & 6 \\
\hline 08 & & & & 6 & & & -06 \\
\hline$F-08$ & -06 & $1.33 \mathrm{E}-06$ & $1.04 \mathrm{E}-06$ & 6 & & 6 & -06 \\
\hline $.81 \mathrm{E}-08$ & $6.22 \mathrm{E}-06$ & $1.33 \mathrm{E}-06$ & $1.05 \mathrm{E}-06$ & $2.74 \mathrm{E}-06$ & $3.35 \mathrm{E}-06$ & $3.88 \mathrm{E}-06$ & 4. $49 \mathrm{E}-06$ \\
\hline-08 & 06 & -06 & 6 & & & & -06 \\
\hline 8 & 6 & 0 & 6 & 6 & & & -06 \\
\hline 08 & 06 & 0 & 06 & 06 & 0 & & -06 \\
\hline$=0$ & & 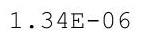 & & & & & \\
\hline $97 \mathrm{~F}-08$ & $.19 E-06$ & $3 \Delta F-0$ & -06 & 6 & & 06 & -06 \\
\hline $.00 \mathrm{E}-07$ & $.18 \mathrm{E}-06$ & $1.34 \mathrm{E}-06$ & $1.05 \mathrm{E}-06$ & $.75 E-06$ & -06 & $5-06$ & $.49 \mathrm{E}-06$ \\
\hline $.00 \mathrm{E}-07$ & $6.17 \mathrm{E}-06$ & 1. $34 \mathrm{E}-06$ & $1.06 \mathrm{E}-06$ & $2.75 E-06$ & $35 E-06$ & $E-06$ & $.49 E-06$ \\
\hline 07 & & & & & & & -06 \\
\hline 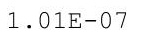 & & 0 & & & & & 06 \\
\hline $.015-U 1$ & 0 & $\perp$ & 10 & & 0 & & -06 \\
\hline 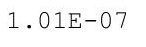 & 6 & 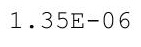 & 6 & 6 & 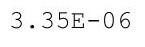 & 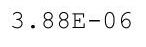 & -06 \\
\hline $02 E-07$ & $.14 \mathrm{E}-06$ & 1. $35 E-06$ & $6 E-06$ & $.77 E-06$ & $E-06$ & $E-06$ & $48 E-06$ \\
\hline 07 & $14 \mathrm{~F}-06$ & 13 & 06 & $.77 \mathrm{E}-06$ & 06 & $E-0$ & $.48 E-06$ \\
\hline $\mathrm{E}-07$ & 06 & $E-06$ & & & & & $48 E-06$ \\
\hline & & & & & & & \\
\hline $03 E-07$ & $.12 \mathrm{E}-06$ & 1. $35 \mathrm{E}-06$ & $E-06$ & $2.77 E-06$ & 06 & 06 & -06 \\
\hline $\begin{array}{l}0 \\
0\end{array}$ & $0 . \perp \perp-20$ & $1.35 E-06$ & $1.07 \mathrm{E}-06$ & $2.77 \mathrm{E}-06$ & . $32 \mathrm{~L}-00$ & $3.00 \mathrm{E}-00$ & $.47 E-06$ \\
\hline $.04 \mathrm{E}-07$ & $6.11 E-06$ & 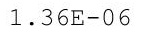 & $1.07 \mathrm{E}-06$ & $2.77 \mathrm{E}-06$ & & 年 & $4.47 \mathrm{E}-06$ \\
\hline 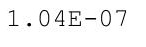 & $E-$ & & 6 & תרכ ר & & & -06 \\
\hline 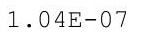 & $F-06$ & $F-06$ & -06 & 6 & & & $.46 E-06$ \\
\hline$E-07$ & & & & & & & \\
\hline & & 1.00 & & 06 & 06 & 06 & 06 \\
\hline $05 E-07$ & $6.07 \mathrm{E}-06$ & $1.36 \mathrm{E}$ & & & & & -06 \\
\hline t & & & & & & & $405-00$ \\
\hline $.06 E-07$ & & 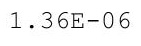 & 6 & 6 & & $3.87 \mathrm{E}-06$ & 06 \\
\hline & & & & & & & 06 \\
\hline & & & & 06 & 6 & 6 & -06 \\
\hline E-07 & $6.04 \mathrm{E}-06$ & 1.3 & 1. & 06 & 06 & 06 & -06 \\
\hline & & & & & & & \\
\hline & & & & & & & $4.45 E-06$ \\
\hline & & & & 6 & 06 & 06 & $4.4 J 5-00$ \\
\hline$E-07$ & $E-06$ & TH 00 & $9 E-06$ & $E-06$ & $E-06$ & $7 E-06$ & -06 \\
\hline
\end{tabular}


RESRAD-OFFSITE, Version 2.5

Title : Offsite Resident Farmer Deterministic Run

File : RF TC99 DOESG FWD-FV2b.ROF

Summary of dose at graphical times, reptition 2 (continued)

Time

Years

$8.96 \mathrm{E}+02$

$8.97 \mathrm{E}+02$

$8.97 \mathrm{E}+02$

$8.98 \mathrm{E}+02$

$8.98 \mathrm{E}+02$

$8.99 \mathrm{E}+02$

$8.99 \mathrm{E}+02$

$9.00 \mathrm{E}+02$

$9.00 \mathrm{E}+02$

$9.01 \mathrm{E}+02$

$9.01 \mathrm{E}+02$

$9.02 \mathrm{E}+02$

$9.02 \mathrm{E}+02$

$9.03 \mathrm{E}+02$

$9.03 \mathrm{E}+02$

$9.04 \mathrm{E}+02$

$9.04 \mathrm{E}+02$

$9.05 \mathrm{E}+02$

$9.05 \mathrm{E}+02$

$9.06 \mathrm{E}+02$

$9.06 \mathrm{E}+02$

$9.07 \mathrm{E}+02$

$9.07 \mathrm{E}+02$

$9.08 \mathrm{E}+02$

$9.08 \mathrm{E}+02$

$9.09 \mathrm{E}+02$

$9.10 \mathrm{E}+02$

$9.10 \mathrm{E}+02$

9. $11 \mathrm{E}+02$

9. $11 \mathrm{E}+02$

$9.12 \mathrm{E}+02$

9. $12 \mathrm{E}+02$

9. $13 \mathrm{E}+02$

9. $13 \mathrm{E}+02$

$9.14 \mathrm{E}+02$

$9.14 \mathrm{E}+02$

$9.15 \mathrm{E}+02$

$9.15 \mathrm{E}+02$

9. $16 \mathrm{E}+02$

$9.16 \mathrm{E}+02$

$9.17 \mathrm{E}+02$

$9.17 \mathrm{E}+02$

$9.18 \mathrm{E}+02$

$9.18 \mathrm{E}+02$

9. $19 \mathrm{E}+02$

$9.19 \mathrm{E}+02$
Dose statistics at graphical times, mrem/yr

\begin{tabular}{|c|c|c|c|c|c|c|c|}
\hline linimum & laximum & Mean & Median & $90 \%$ & $95 \%$ & $97.5 \%$ & 3응 \\
\hline 07 & 06 & $F-06$ & $.09 E-06$ & $78 E-06$ & 6 & 3.87 & -06 \\
\hline $9 E-07$ & $0 E-06$ & $37 E-06$ & -06 & $78 \mathrm{E}-$ & 6 & 87 & 06 \\
\hline $9 E-07$ & $00 E-06$ & $38 E-06$ & $E-06$ & -06 & 6 & 6 & $4 E-06$ \\
\hline$E-07$ & $9 E-06$ & $1.38 \mathrm{E}-06$ & $0 E-06$ & 6 & 6 & 06 & $4 E-06$ \\
\hline $10 \mathrm{E}-07$ & 06 & $\perp$ & & 6 & & & -06 \\
\hline-07 & 06 & 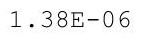 & 6 & & 6 & & $E-06$ \\
\hline $.10 E-07$ & $7 E-06$ & $1.38 \mathrm{E}-06$ & -06 & $2.79 \mathrm{E}-06$ & $3-06$ & -06 & $3 E-06$ \\
\hline $.11 E-07$ & $5.97 E-06$ & 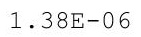 & $1.10 \mathrm{E}-06$ & $2.79 \mathrm{E}-06$ & $3.38 E-06$ & -06 & $.43 E-06$ \\
\hline $1 E-07$ & 06 & $8 E-06$ & 06 & 6 & 6 & 06 & $42 E-06$ \\
\hline $.11 \mathrm{E}-07$ & $E-06$ & $1.38 \mathrm{E}-06$ & 06 & $79 \mathrm{E}-$ & 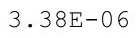 & 06 & $42 E-06$ \\
\hline$E-07$ & 06 & & & & & & $42 E-06$ \\
\hline-07 & 06 & 1 & 6 & & & 6 & $E-06$ \\
\hline $.12 \mathrm{E}-07$ & $3 E-06$ & 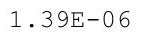 & $1.11 \mathrm{E}-06$ & $80 E-06$ & $6 \mathrm{E}-0$ & $E-06$ & $41 E-06$ \\
\hline . $\triangle \angle \mathrm{L}-U 1$ & $5.93 E-06$ & 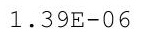 & $1.11 \mathrm{E}-06$ & $2.80 E-06$ & $10 \mathrm{~L}-0$ & -00 & $E-06$ \\
\hline $.13 E-07$ & $5.92 E-06$ & $1.39 \mathrm{E}-06$ & 06 & 2.001 & 0 & 06 & -06 \\
\hline $.13 E-07$ & $5.92 \mathrm{E}-06$ & $1.39 \mathrm{E}-0$ & 1.11 & 6 & 6 & 6 & -06 \\
\hline $.13 E-07$ & $5.91 E-06$ & $1.39 \mathrm{E}-06$ & $1.12 \mathrm{E}-06$ & $2.80 \mathrm{E}-06$ & & $36 E-06$ & $.40 E-06$ \\
\hline$E-07$ & $0 E-06$ & مص & 1. & & & & $E-06$ \\
\hline 07 & 06 & 1 & 1 & & & & -06 \\
\hline $.14 \mathrm{E}-07$ & $5.89 \mathrm{E}-06$ & $1.39 \mathrm{E}$ & 06 & 6 & 0 & 6 & -06 \\
\hline UL & $5.88 E-06$ & 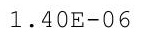 & $2 E-06$ & 0 & 正 & 0 & $39 E-06$ \\
\hline $5 E-07$ & 0 & ( & 6 & 5 & $3.38 \mathrm{E}-06$ & 6 & -06 \\
\hline $.15 E-07$ & $5.87 E-06$ & $1.40 \mathrm{E}-$ & $3 E-06$ & $2.80 \mathrm{E}-$ & 6 & $5 E-06$ & $38 E-06$ \\
\hline $.16 \mathrm{E}-07$ & $5.87 \mathrm{E}-06$ & 1. & 06 & 6 & 3 & 06 & $E-06$ \\
\hline $5-07$ & $E-06$ & $1.40 \mathrm{~F}$ & 6 & & & & -06 \\
\hline$E-07$ & 06 & 1. & 1 . & 6 & & & $\Xi-06$ \\
\hline $7 E-07$ & $35 E-06$ & $1.40 E-06$ & $3 E-06$ & $01 \mathrm{t}$ & IO & 06 & $37 E-06$ \\
\hline $.17 \mathrm{E}-07$ & $5.84 \mathrm{E}-06$ & $1.40 \mathrm{E}-06$ & $1.13 \mathrm{E}-06$ & $2.81 \mathrm{E}-06$ & $3.38 \mathrm{E}-06$ & $3.85 \mathrm{E}-06$ & $.37 \mathrm{E}-06$ \\
\hline r & 6 & 1. & 6 & 5 & $3.38 \mathrm{E}-06$ & $3.84 \mathrm{E}-06$ & $.37 E-06$ \\
\hline 7 & 06 & $1.41 \mathrm{E}$ & 1 & 5 & & 6 & 06 \\
\hline 07 & 06 & 1 . & 6 & 6 & & 6 & -06 \\
\hline $3 E-07$ & $1 E-06$ & 1.4 & 1. & 11 & 6 & 6 & $6 E-06$ \\
\hline $.19 \mathrm{E}-07$ & $5.81 \mathrm{E}-06$ & $1.41 \mathrm{E}-0$ & 1 . & $2.81 \mathrm{E}-$ & 型 & 6 & -06 \\
\hline $.19 \mathrm{E}-07$ & $5.80 \mathrm{E}-06$ & $1.41 \mathrm{E}-06$ & $1.14 \mathrm{E}-06$ & $2.81 \mathrm{E}-06$ & $3.37 \mathrm{E}-06$ & $3.83 \mathrm{E}-06$ & $4.36 \mathrm{E}-06$ \\
\hline$\cdot .9 \mathrm{E}-0$ & $5.79 E-06$ & $\perp \cdot I \perp+00$ & & & & & $.36 E-06$ \\
\hline 7 & 6 & & 6 & 5 & & & 6 \\
\hline$E-07$ & 06 & 1. & 06 & 6 & 6 & 6 & 06 \\
\hline $.20 E-07$ & $5.78 E-06$ & $1.41 \mathrm{E}$ & 1. & 2. & 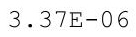 & 6 & $6 E-06$ \\
\hline $.21 \mathrm{E}-07$ & $5.77 \mathrm{E}-06$ & 1. $42 \mathrm{E}-06$ & $5 E-06$ & $2.82 \mathrm{E}$ & 3 & & $E-06$ \\
\hline $.21 E-07$ & $E-06$ & $1.42 \mathrm{E}-06$ & & 2.82 & & & \\
\hline$\cdot 2 \perp E-U 1$ & & & & & & & $4.36 \mathrm{E}-06$ \\
\hline $.22 \mathrm{E}-07$ & $5.75 E-06$ & 1. $42 \mathrm{E}-06$ & $1.15 \mathrm{E}-06$ & $2.82 \mathrm{E}-06$ & $3.36 \mathrm{E}-06$ & $3.84 \mathrm{E}-06$ & $4.36 \mathrm{E}-06$ \\
\hline 7 & 6 & 1. $42 \mathrm{E}-06$ & 6 & 5 & 5 & 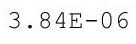 & 06 \\
\hline $.22 E-07$ & $5.74 \mathrm{E}-06$ & $1.42 \mathrm{E}-$ & 1 . & 2. & 3 & 3. & 4 \\
\hline$E-07$ & 5.7 & 1. & 1.1 & 2.8 & 3 & 3. & -06 \\
\hline $.23 E-07$ & $72 E-06$ & $1.42 \mathrm{E}-06$ & $1.16 \mathrm{E}-06$ & $2.83 E-06$ & $3.36 \mathrm{E}-06$ & $3.84 \mathrm{E}-06$ & $4.35 E-06$ \\
\hline
\end{tabular}


RESRAD-OFFSITE, Version 2.5

Title : Offsite Resident Farmer Deterministic Run

File : RF TC99 DOESG FWD-FV2b.ROF

Summary of dose at graphical times, reptition 2 (continued)

Time

Years

$9.20 \mathrm{E}+02$

$9.20 \mathrm{E}+02$

$9.21 \mathrm{E}+02$

$9.21 \mathrm{E}+02$

$9.22 \mathrm{E}+02$

$9.22 \mathrm{E}+02$

$9.23 \mathrm{E}+02$

$9.23 \mathrm{E}+02$

$9.24 \mathrm{E}+02$

$9.24 \mathrm{E}+02$

$9.25 \mathrm{E}+02$

$9.25 \mathrm{E}+02$

$9.26 \mathrm{E}+02$

$9.26 \mathrm{E}+02$

$9.27 \mathrm{E}+02$

$9.27 \mathrm{E}+02$

$9.28 \mathrm{E}+02$

$9.28 \mathrm{E}+02$

$9.29 \mathrm{E}+02$

9. $30 \mathrm{E}+02$

9. $30 \mathrm{E}+02$

9. $31 \mathrm{E}+02$

9. $31 \mathrm{E}+02$

9. $32 \mathrm{E}+02$

9. $32 \mathrm{E}+02$

$9.33 \mathrm{E}+02$

9. $33 \mathrm{E}+02$

$9.34 \mathrm{E}+02$

9. $34 \mathrm{E}+02$

9. $35 \mathrm{E}+02$

9. $35 \mathrm{E}+02$

9. $36 \mathrm{E}+02$

9. $36 \mathrm{E}+02$

9. $37 \mathrm{E}+02$

9. $37 \mathrm{E}+02$

$9.38 \mathrm{E}+02$

$9.38 \mathrm{E}+02$

$9.39 \mathrm{E}+02$

9. $39 \mathrm{E}+02$

$9.40 \mathrm{E}+02$

$9.40 \mathrm{E}+02$

$9.41 \mathrm{E}+02$

$9.41 \mathrm{E}+02$

$9.42 \mathrm{E}+02$

$9.42 \mathrm{E}+02$

$9.43 \mathrm{E}+02$
Dose statistics at graphical times, mrem/yr

\begin{tabular}{|c|c|c|c|c|c|c|c|}
\hline $\mathrm{m}$ & $\operatorname{axi}$ & a & 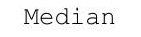 & & & $\%$ & \\
\hline 07 & $5.72 \mathrm{E}-06$ & 1. $42 \mathrm{E}-06$ & $1.16 \mathrm{E}-06$ & $2.83 \mathrm{E}-06$ & $3.36 \mathrm{E}-06$ & -06 & -06 \\
\hline $24 \mathrm{E}-07$ & $5.71 \mathrm{E}-06$ & $1.43 \mathrm{E}-06$ & $6 \mathrm{E}-06$ & 6 & 6 & 6 & -06 \\
\hline $.24 \mathrm{E}-07$ & $5.71 \mathrm{E}-06$ & $1.43 \mathrm{E}-06$ & $.16 \mathrm{E}-06$ & $2.83 E-06$ & $3.36 \mathrm{E}-06$ & $3.84 \mathrm{E}-06$ & $.34 \mathrm{E}-06$ \\
\hline $24 \mathrm{E}-07$ & $5.70 \mathrm{E}-06$ & $.43 E-06$ & $1.16 \mathrm{E}-06$ & $2.83 E-06$ & $3.36 \mathrm{E}-06$ & $3.84 \mathrm{E}-06$ & $.34 \mathrm{E}-06$ \\
\hline $25 \mathrm{E}-07$ & $69 \mathrm{E}-06$ & $1.43 \mathrm{E}-06$ & $1.16 \mathrm{E}-06$ & $.83 E-06$ & $.36 \mathrm{E}-06$ & $.84 \mathrm{E}-06$ & -06 \\
\hline $25 E-07$ & 6 & 1 & & 6 & & 6 & -06 \\
\hline $25 E-07$ & $5.68 \mathrm{E}$ & 1.43 & & 6 & & & -06 \\
\hline $26 \mathrm{E}-07$ & & 06 & & & & & -06 \\
\hline $.26 \mathrm{E}-07$ & -06 & -06 & -06 & -06 & & -06 & -06 \\
\hline $26 \mathrm{E}-0$ & 06 & 6 & 6 & 6 & 6 & 6 & -06 \\
\hline$F-07$ & $5.65 E-06$ & 1 & $1.17 \mathrm{E}-06$ & 6 & 6 & $.85 E-06$ & -06 \\
\hline $27 E-07$ & 6 & 1. & & 6 & 6 & 6 & -06 \\
\hline $27 E-07$ & $4 \mathrm{E}-06$ & $1.44 \mathrm{E}$ & 1. & 6 & 6 & 6 & -06 \\
\hline $.28 \mathrm{E}-07$ & $5.64 \mathrm{E}-06$ & $1.44 \mathrm{E}-06$ & $1.18 \mathrm{E}-06$ & $2.83 E-06$ & $3.38 \mathrm{E}-06$ & $3.85 \mathrm{E}-06$ & 4. $32 E-06$ \\
\hline $28 E-07$ & $63 E-06$ & $E-06$ & -06 & -06 & & & -06 \\
\hline 2 & & & & & & & -06 \\
\hline 2 & & 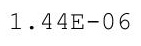 & & 6 & & & -06 \\
\hline $29 \mathrm{E}-$ & 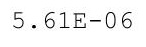 & $1.44 \mathrm{E}-06$ & & & & & 6 \\
\hline $29 E-07$ & $.60 E-06$ & $14 \triangle \mathrm{F}-0$ & $8 E-06$ & 6 & & 6 & -06 \\
\hline $30 E-07$ & $.60 E-06$ & 1. $45 \mathrm{E}-06$ & $1.18 \mathrm{E}-06$ & $.83 E-06$ & $.38 E-06$ & -06 & $31 E-06$ \\
\hline $30 E-07$ & $9 E-06$ & -06 & 06 & -06 & 6 & $.85 E-06$ & $31 E-06$ \\
\hline 3 & & & & & & & -06 \\
\hline & & & & & & & -06 \\
\hline $31 E-07$ & .0 &.+ & & & & & -06 \\
\hline 7 & 6 & 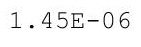 & 0 & 6 & 6 & 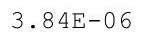 & -06 \\
\hline $32 E-07$ & $.56 E-06$ & 1. $45 \mathrm{E}-06$ & 1.19E-06 & $84 \mathrm{E}-06$ & 定 & $34 E-06$ & $31 E-06$ \\
\hline$=07-2 x-1$ & -06 & $145 \mathrm{~F}-06$ & $E-06$ & 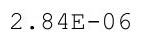 & 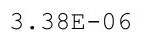 & -06 & $31 \mathrm{~F}-06$ \\
\hline $33 \mathrm{~F}-07$ & & & & & & & \\
\hline 01 & 06 & & & & & & \\
\hline . $320-01$ & $5.53 E-06$ & $1.46 \pm-06$ & 1.20E-06 & $2.84 E-06$ & $3.37 E-06$ & 06 & -06 \\
\hline 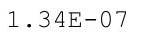 & $5.53 E-06$ & $1.40 \mathrm{E}-00$ & $1.20 \mathrm{E}-06$ & $2.84 E-06$ & $.37 E-06$ & $3.03 \mathrm{E}-\mathrm{O}$ & $.31 E-06$ \\
\hline • & $5.52 \mathrm{E}-06$ & 工象 & - & $2.84 \mathrm{E}-06$ & & $=0$ & -06 \\
\hline 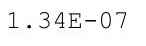 & $.51 E-06$ & $1.46 \mathrm{E}-06$ & $E-06$ & תמת ת ת & & & $E-06$ \\
\hline $355-0$ & 0 & & & & & & 06 \\
\hline 507 & & & & 6 & 6 & & -06 \\
\hline $35 E-07$ & $5.50 \mathrm{E}-06$ & $1.46 \mathrm{E}-06$ & 1.20E-06 & 2.045 & 6 & 06 & -06 \\
\hline 年 & . 1 (1) & 1.100 & & & & & -06 \\
\hline 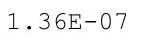 & $5.48 E-06$ & ×. & & & & & 4.J1E-U0 \\
\hline $365-07$ & . &.+ & 6 & & & 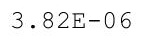 & 06 \\
\hline $37 F_{-}-07$ & & & & & & 6 & 06 \\
\hline 7 & 6 & 1 . & 6 & 6 & 6 & 6 & -06 \\
\hline $38 E-07$ & $5.46 \mathrm{E}-06$ & 1.47 & 1.2 & $2.85 \mathrm{E}$ & 06 & 06 & -06 \\
\hline & & & & & & & \\
\hline & & & & & & & $4.32 E-06$ \\
\hline 年 & $4 E-06$ & (t) & 50 & & & 06 & $4.525-00$ \\
\hline$E-07$ & $E-06$ & $7 E-06$ & $21 E-06$ & $E-06$ & $7 E-06$ & $1 E-06$ & -06 \\
\hline
\end{tabular}


RESRAD-OFFSITE, Version 2.5

Title : Offsite Resident Farmer Deterministic Run

File : RF TC99 DOESG FWD-FV2b.ROF

Summary of dose at graphical times, reptition 2 (continued)

Time

Years

9. $43 \mathrm{E}+02$

$9.44 \mathrm{E}+02$

$9.44 \mathrm{E}+02$

$9.45 \mathrm{E}+02$

$9.45 \mathrm{E}+02$

$9.46 \mathrm{E}+02$

$9.46 \mathrm{E}+02$

$9.47 \mathrm{E}+02$

$9.47 \mathrm{E}+02$

$9.48 \mathrm{E}+02$

$9.48 \mathrm{E}+02$

$9.49 \mathrm{E}+02$

$9.50 \mathrm{E}+02$

$9.50 \mathrm{E}+02$

$9.51 \mathrm{E}+02$

$9.51 \mathrm{E}+02$

$9.52 \mathrm{E}+02$

$9.52 \mathrm{E}+02$

$9.53 \mathrm{E}+02$

$9.53 \mathrm{E}+02$

$9.54 \mathrm{E}+02$

$9.54 \mathrm{E}+02$

$9.55 \mathrm{E}+02$

$9.55 \mathrm{E}+02$

$9.56 \mathrm{E}+02$

$9.56 \mathrm{E}+02$

$9.57 \mathrm{E}+02$

$9.57 \mathrm{E}+02$

$9.58 \mathrm{E}+02$

$9.58 \mathrm{E}+02$

$9.59 \mathrm{E}+02$

$9.59 \mathrm{E}+02$

$9.60 \mathrm{E}+02$

$9.60 \mathrm{E}+02$

$9.61 \mathrm{E}+02$

$9.61 \mathrm{E}+02$

$9.62 \mathrm{E}+02$

$9.62 \mathrm{E}+02$

$9.63 \mathrm{E}+02$

$9.63 \mathrm{E}+02$

$9.64 \mathrm{E}+02$

$9.64 \mathrm{E}+02$

$9.65 \mathrm{E}+02$

$9.65 \mathrm{E}+02$

$9.66 \mathrm{E}+02$

$9.66 \mathrm{E}+02$
Dose statistics at graphical times, mrem/yr

\begin{tabular}{|c|c|c|c|c|c|c|c|}
\hline m & $\mathrm{m}$ & ea & 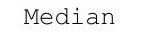 & & & $\%$ & \\
\hline 07 & 06 & $1.47 \mathrm{E}-06$ & 1. $22 \mathrm{E}-06$ & $2.85 \mathrm{E}-06$ & $3.37 \mathrm{E}-06$ & $3.80 \mathrm{E}-06$ & -06 \\
\hline $40 \mathrm{E}-07$ & $2 E-06$ & $1.47 \mathrm{E}-06$ & $22 \mathrm{E}-06$ & 6 & 6 & 06 & -06 \\
\hline $.40 \mathrm{E}-07$ & $5.42 \mathrm{E}-06$ & 1. $48 \mathrm{E}-06$ & 1.22E-06 & $2.86 \mathrm{E}-06$ & $3.37 \mathrm{E}-06$ & $3.80 \mathrm{E}-06$ & $.32 E-06$ \\
\hline $.40 \mathrm{E}-07$ & $.42 \mathrm{E}-06$ & $.48 E-06$ & 1. $22 \mathrm{E}-06$ & $2.86 \mathrm{E}-06$ & $3.37 \mathrm{E}-06$ & $3.80 \mathrm{E}-06$ & $.32 E-06$ \\
\hline $41 \mathrm{~F}-07$ & $42 E-06$ & $48 F-06$ & $2 E-06$ & $.86 E-06$ & $7 F-06$ & $30 E-06$ & $.32 E-06$ \\
\hline $41 \mathrm{E}-07$ & 06 & 6 & & 6 & & 6 & -06 \\
\hline $41 \mathrm{E}-07$ & $41 \mathrm{E}-06$ & 1.481 & & 6 & & & -06 \\
\hline $42 \mathrm{E}-07$ & & $1.48 \mathrm{E}-06$ & & & & & -06 \\
\hline $42 E-07$ & -06 & $8 E-06$ & -06 & -06 & & -06 & -06 \\
\hline $43 \mathrm{E}-0$ & 06 & 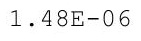 & 6 & 6 & 6 & 6 & -06 \\
\hline $43 E-07$ & 6 & $1.48 \mathrm{E}-06$ & 6 & 6 & 6 & $79 E-06$ & -06 \\
\hline $3 F-07$ & & $1.48 \mathrm{E}-06$ & & 6 & 6 & & -06 \\
\hline $44 F-07$ & $40 F-06$ & $149 F-06$ & $123 \mathrm{~F}$ & 6 & 06 & -06 & -06 \\
\hline $.44 \mathrm{E}-07$ & $5.40 \mathrm{E}-06$ & $1.49 \mathrm{E}-06$ & $1.23 \mathrm{E}-06$ & $2.87 \mathrm{E}-06$ & $3.36 \mathrm{E}-06$ & $3.79 \mathrm{E}-06$ & $4.33 E-06$ \\
\hline $44 \mathrm{E}-07$ & $.40 E-06$ & 1. $49 \mathrm{E}-06$ & 1. $23 \mathrm{E}-06$ & $2.87 \mathrm{E}-06$ & & $3.79 \mathrm{E}-06$ & $4.33 E-06$ \\
\hline 年 & & & & & & & -06 \\
\hline $5 \mathrm{~F}-\mathrm{C}-1$ & & & & & & & 06 \\
\hline 07 & 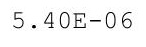 & $1.49 \mathrm{E}-06$ & & & & & 06 \\
\hline $46 E-07$ & $40 E-06$ & $1.9 F-0$ & 1. $24 \mathrm{E}-06$ & 6 & & 6 & -06 \\
\hline $46 \mathrm{E}-07$ & $.40 \mathrm{E}-06$ & $1.49 \mathrm{E}-06$ & $1.24 \mathrm{E}-06$ & $2.88 \mathrm{E}-06$ & $.36 \mathrm{E}-06$ & $E-06$ & . $33 E-06$ \\
\hline $.47 E-07$ & $9 E-06$ & $.49 E-06$ & 06 & $.88 E-06$ & 06 & $.78 E-06$ & $.33 E-06$ \\
\hline 7 & & & & & & & -06 \\
\hline & & & & & & & 06 \\
\hline & & & & & & & 06 \\
\hline $48 \mathrm{E}-07$ & 6 & 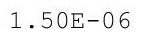 & 6 & 6 & 6 & 0 & -06 \\
\hline $48 E-07$ & $.39 E-06$ & $15 \cap \mathrm{F}-0$ & 1.25E-06 & $88 E-06$ & $36 E-06$ & $9 E-06$ & $33 E-06$ \\
\hline $.49 \mathrm{E}-0 \mathrm{~T}$ & $F-06$ & $F-06$ & $E-06$ & $8 E-06$ & 06 & $7-06$ & $.33 E-06$ \\
\hline $49 F-07$ & & & & & & & \\
\hline 1 & 6 & & & & & & -06 \\
\hline $50 \mathrm{E}-07$ & $5.38 \mathrm{E}-06$ & $1.30 \pm-06$ & $1.26 \mathrm{E}-06$ & $2.88 E-06$ & 06 & 06 & -06 \\
\hline $\begin{array}{l}0.32-01 \\
0\end{array}$ & $5.38 E-06$ & $1.50 \pm-06$ & $1.26 \mathrm{E}-06$ & $2.88 \mathrm{E}-06$ & 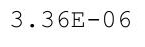 & $3.19 \mathrm{E}-00$ & $.34 E-06$ \\
\hline 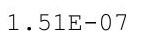 & $5.38 E-06$ & 土. & $1.26 \mathrm{E}-06$ & $2.88 \mathrm{E}-06$ & & 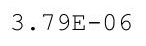 & $4.34 \mathrm{E}-06$ \\
\hline$\nabla_{0}$ & $38 F-06$ & $1.51 \mathrm{E}-06$ & $5-06$ & $.88 E-06$ & & & -06 \\
\hline مी & 0 & & & & & & 06 \\
\hline ק & & & & & & & \\
\hline 07 & $3.51 \mathrm{E}$ & $1 . J \perp$ & $1.20 \mathrm{E}$ & $2.89 \mathrm{E}-06$ & 06 & 06 & \\
\hline $52 \mathrm{E}-07$ & $5.37 \mathrm{E}-06$ & $1.51 \mathrm{E}$ & 1.2 & & & & -06 \\
\hline 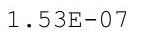 & & & & & & & A. $345-00$ \\
\hline •.720 & . & +0 & 6 & 6 & & 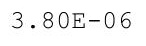 & 06 \\
\hline & & & & & & & 06 \\
\hline $.54 \mathrm{E}-07$ & 6 & & 6 & 06 & 6 & & \\
\hline$E-07$ & $5.36 \mathrm{E}-06$ & 1.51 & 1.2 & $2.89 \mathrm{E}$ & 06 & 06 & -06 \\
\hline & & & & & & & \\
\hline & & 它 & & & & & $4.34 \mathrm{E}-06$ \\
\hline 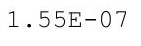 & $5.36 \mathrm{E}-06$ & ए & ti 0 & 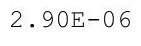 & & 06 & $4.345-00$ \\
\hline$E-07$ & $E-06$ & $2 E-06$ & $27 E-06$ & $E-06$ & $E-06$ & $0 E-06$ & -06 \\
\hline
\end{tabular}


RESRAD-OFFSITE, Version 2.5

Title : Offsite Resident Farmer Deterministic Run

File : RF TC99 DOESG FWD-FV2b.ROF

Summary of dose at graphical times, reptition 2 (continued)

Time

Years

9. $67 \mathrm{E}+02$

$9.67 \mathrm{E}+02$

$9.68 \mathrm{E}+02$

$9.68 \mathrm{E}+02$

$9.69 \mathrm{E}+02$

$9.70 \mathrm{E}+02$

$9.70 \mathrm{E}+02$

$9.71 \mathrm{E}+02$

$9.71 \mathrm{E}+02$

$9.72 \mathrm{E}+02$

$9.72 \mathrm{E}+02$

$9.73 \mathrm{E}+02$

$9.73 E+02$

$9.74 \mathrm{E}+02$

$9.74 \mathrm{E}+02$

$9.75 \mathrm{E}+02$

$9.75 \mathrm{E}+02$

$9.76 \mathrm{E}+02$

$9.76 \mathrm{E}+02$

$9.77 \mathrm{E}+02$

$9.77 \mathrm{E}+02$

$9.78 \mathrm{E}+02$

$9.78 \mathrm{E}+02$

$9.79 \mathrm{E}+02$

$9.79 \mathrm{E}+02$

$9.80 \mathrm{E}+02$

$9.80 \mathrm{E}+02$

$9.81 \mathrm{E}+02$

9. $81 \mathrm{E}+02$

9. $82 \mathrm{E}+02$

9. $82 \mathrm{E}+02$

$9.83 \mathrm{E}+02$

$9.83 \mathrm{E}+02$

$9.84 \mathrm{E}+02$

$9.84 \mathrm{E}+02$

$9.85 \mathrm{E}+02$

$9.85 \mathrm{E}+02$

$9.86 \mathrm{E}+02$

$9.86 \mathrm{E}+02$

$9.87 \mathrm{E}+02$

$9.87 \mathrm{E}+02$

$9.88 \mathrm{E}+02$

$9.88 \mathrm{E}+02$

$9.89 \mathrm{E}+02$

$9.90 \mathrm{E}+02$

$9.90 \mathrm{E}+02$
Dose statistics at graphical times, mrem/yr

\begin{tabular}{|c|c|c|c|c|c|c|c|}
\hline Minimum & Maximum & Mean & Median & $90 \%$ & $95 \%$ & $97.5 \%$ & $99 \%$ \\
\hline $1.56 \mathrm{E}-07$ & $5.35 \mathrm{E}-06$ & $1.52 \mathrm{E}-06$ & $1.27 \mathrm{E}-06$ & $2.90 \mathrm{E}-06$ & $3.35 \mathrm{E}-06$ & $3.80 \mathrm{E}-06$ & $4.34 \mathrm{E}-06$ \\
\hline $1.57 \mathrm{E}-07$ & $5.35 \mathrm{E}-06$ & $1.52 \mathrm{E}-06$ & $1.28 \mathrm{E}-06$ & $2.90 \mathrm{E}-06$ & $3.35 \mathrm{E}-06$ & $3.80 \mathrm{E}-06$ & $4.34 \mathrm{E}-06$ \\
\hline $1.57 \mathrm{E}-07$ & $5.35 E-06$ & $1.52 \mathrm{E}-06$ & $1.28 \mathrm{E}-06$ & $2.90 \mathrm{E}-06$ & $3.35 \mathrm{E}-06$ & $3.80 \mathrm{E}-06$ & $4.34 \mathrm{E}-06$ \\
\hline $1.57 \mathrm{E}-07$ & $5.35 \mathrm{E}-06$ & $1.52 \mathrm{E}-06$ & $1.28 \mathrm{E}-06$ & $2.90 \mathrm{E}-06$ & $3.35 \mathrm{E}-06$ & $3.80 \mathrm{E}-06$ & $4.34 \mathrm{E}-06$ \\
\hline $1.58 \mathrm{E}-07$ & $5.35 \mathrm{E}-06$ & $1.52 \mathrm{E}-06$ & $1.28 E-06$ & $2.90 E-06$ & $3.35 E-06$ & $3.80 E-06$ & $4.34 \mathrm{E}-06$ \\
\hline $1.58 \mathrm{E}-07$ & $5.35 \mathrm{E}-06$ & $1.52 \mathrm{E}-06$ & $1.28 \mathrm{E}-06$ & $2.91 E-06$ & $3.35 \mathrm{E}-06$ & $3.80 \mathrm{E}-06$ & $4.34 \mathrm{E}-06$ \\
\hline $1.58 \mathrm{E}-07$ & $5.34 \mathrm{E}-06$ & $1.52 \mathrm{E}-06$ & $1.28 \mathrm{E}-06$ & $2.91 \mathrm{E}-06$ & $3.35 \mathrm{E}-06$ & $3.80 \mathrm{E}-06$ & $4.34 \mathrm{E}-06$ \\
\hline $1.59 \mathrm{E}-07$ & $5.34 \mathrm{E}-06$ & $1.53 \mathrm{E}-06$ & $1.28 \mathrm{E}-06$ & $2.91 \mathrm{E}-06$ & $3.35 \mathrm{E}-06$ & $3.80 \mathrm{E}-06$ & 4. $33 E-06$ \\
\hline $1.59 \mathrm{E}-07$ & $5.34 \mathrm{E}-06$ & $1.53 \mathrm{E}-06$ & $1.28 \mathrm{E}-06$ & $2.91 \mathrm{E}-06$ & $3.35 \mathrm{E}-06$ & $3.80 \mathrm{E}-06$ & $4.33 E-06$ \\
\hline $1.60 \mathrm{E}-07$ & $5.34 \mathrm{E}-06$ & $1.53 \mathrm{E}-06$ & $1.29 \mathrm{E}-06$ & $2.91 \mathrm{E}-06$ & $3.35 \mathrm{E}-06$ & $3.80 \mathrm{E}-06$ & 4. $33 \mathrm{E}-06$ \\
\hline $1.60 \mathrm{E}-07$ & $5.34 \mathrm{E}-06$ & $1.53 \mathrm{E}-06$ & $1.29 \mathrm{E}-06$ & $2.91 \mathrm{E}-06$ & $3.35 \mathrm{E}-06$ & $3.80 E-06$ & $4.33 E-06$ \\
\hline $1.60 \mathrm{E}-07$ & $5.33 E-06$ & $1.53 \mathrm{E}-06$ & $1.29 \mathrm{E}-06$ & $2.92 E-06$ & $3.35 E-06$ & $3.79 E-06$ & $4.33 E-06$ \\
\hline $1.61 \mathrm{E}-07$ & $5.33 \mathrm{E}-06$ & $1.53 \mathrm{E}-06$ & $1.29 \mathrm{E}-06$ & $2.92 E-06$ & $3.34 \mathrm{E}-06$ & $3.79 \mathrm{E}-06$ & $4.33 E-06$ \\
\hline $1.61 \mathrm{E}-07$ & $5.33 \mathrm{E}-06$ & $1.53 \mathrm{E}-06$ & $1.29 \mathrm{E}-06$ & $2.92 \mathrm{E}-06$ & $3.34 \mathrm{E}-06$ & $3.79 \mathrm{E}-06$ & $4.33 E-06$ \\
\hline $1.62 \mathrm{E}-07$ & $5.33 E-06$ & $1.53 \mathrm{E}-06$ & $1.29 \mathrm{E}-06$ & $2.92 \mathrm{E}-06$ & $3.34 \mathrm{E}-06$ & $3.79 \mathrm{E}-06$ & $4.33 E-06$ \\
\hline $1.62 \mathrm{E}-07$ & $5.33 E-06$ & $1.53 \mathrm{E}-06$ & $1.30 E-06$ & $2.92 E-06$ & $3.35 E-06$ & $E-06$ & $4.32 E-06$ \\
\hline $1.62 \mathrm{E}-07$ & $3 E-06$ & $1.53 \mathrm{E}-06$ & $0 E-06$ & $2.92 \mathrm{E}-06$ & $5 E-06$ & $E-06$ & $.32 E-06$ \\
\hline $1.63 \mathrm{E}-07$ & $5.32 \mathrm{E}-06$ & $1.53 \mathrm{E}-06$ & $1.30 E-06$ & $2.92 E-06$ & $3.35 E-06$ & $3.80 E-06$ & $4.32 E-06$ \\
\hline $1.63 \mathrm{E}-07$ & $5.32 \mathrm{E}-06$ & $1.54 \mathrm{E}-06$ & $1.30 \mathrm{E}-06$ & $2.93 E-06$ & $3.35 E-06$ & $3.80 E-06$ & $4.32 E-06$ \\
\hline $1.63 \mathrm{E}-07$ & $5.32 \mathrm{E}-06$ & $1.54 \mathrm{E}-06$ & $1.30 \mathrm{E}-06$ & $2.93 E-06$ & $3.35 \mathrm{E}-06$ & $3.80 \mathrm{E}-06$ & 4. $32 \mathrm{E}-06$ \\
\hline $1.64 \mathrm{E}-07$ & $5.32 \mathrm{E}-06$ & $1.54 \mathrm{E}-06$ & 1. $30 \mathrm{E}-06$ & $2.93 E-06$ & $3.35 \mathrm{E}-06$ & $3.80 \mathrm{E}-06$ & $4.32 \mathrm{E}-06$ \\
\hline $1.64 \mathrm{E}-07$ & $5.32 \mathrm{E}-06$ & $1.54 \mathrm{E}-06$ & $1.31 \mathrm{E}-06$ & $2.93 E-06$ & $3.35 E-06$ & $3.80 E-06$ & $4.32 E-06$ \\
\hline $1.65 \mathrm{E}-07$ & $5.32 \mathrm{E}-06$ & $1.54 \mathrm{E}-06$ & 1. $31 \mathrm{E}-06$ & $2.93 E-06$ & $3.35 \mathrm{E}-06$ & $3.80 \mathrm{E}-06$ & $4.31 E-06$ \\
\hline $1.65 \mathrm{E}-07$ & $5.31 \mathrm{E}-06$ & $1.54 \mathrm{E}-06$ & $1.31 \mathrm{E}-06$ & $2.93 E-06$ & $3.35 \mathrm{E}-06$ & $3.80 \mathrm{E}-06$ & $4.31 \mathrm{E}-06$ \\
\hline $1.65 \mathrm{E}-07$ & $5.31 \mathrm{E}-06$ & $1.54 \mathrm{E}-06$ & $1.31 \mathrm{E}-06$ & $2.93 E-06$ & $3.35 E-06$ & $3.80 E-06$ & $4.31 E-06$ \\
\hline $1.66 \mathrm{E}-07$ & $5.31 \mathrm{E}-06$ & $1.54 \mathrm{E}-06$ & 1. $31 \mathrm{E}-06$ & $2.93 E-06$ & $3.35 \mathrm{E}-06$ & $3.79 \mathrm{E}-06$ & $4.31 \mathrm{E}-06$ \\
\hline $1.66 \mathrm{E}-07$ & $5.31 \mathrm{E}-06$ & $1.54 \mathrm{E}-06$ & 1. $31 \mathrm{E}-06$ & $2.93 E-06$ & $3.35 \mathrm{E}-06$ & $3.79 \mathrm{E}-06$ & $4.31 \mathrm{E}-06$ \\
\hline $1.67 \mathrm{E}-07$ & $5.31 \mathrm{E}-06$ & $1.54 \mathrm{E}-06$ & $1.32 \mathrm{E}-06$ & $2.93 E-06$ & $3.35 E-06$ & $3.79 E-06$ & $4.31 E-06$ \\
\hline $1.67 \mathrm{E}-07$ & $5.30 \mathrm{E}-06$ & $1.54 \mathrm{E}-06$ & $1.32 E-06$ & $2.93 E-06$ & $3.35 \mathrm{E}-06$ & $3.79 \mathrm{E}-06$ & $4.31 E-06$ \\
\hline $1.67 \mathrm{E}-07$ & $5.30 \mathrm{E}-06$ & $1.55 \mathrm{E}-06$ & 1. $32 E-06$ & $2.93 E-06$ & $3.35 E-06$ & $3.79 E-06$ & $4.31 E-06$ \\
\hline $1.68 \mathrm{E}-07$ & $5.30 \mathrm{E}-06$ & $1.55 \mathrm{E}-06$ & $1.32 \mathrm{E}-06$ & $2.93 E-06$ & $3.34 \mathrm{E}-06$ & $3.79 E-06$ & $4.31 E-06$ \\
\hline $1.68 \mathrm{E}-07$ & $5.30 \mathrm{E}-06$ & $1.55 \mathrm{E}-06$ & 1. $32 \mathrm{E}-06$ & $2.93 E-06$ & $3.34 \mathrm{E}-06$ & $3.79 \mathrm{E}-06$ & $4.31 \mathrm{E}-06$ \\
\hline $1.68 \mathrm{E}-07$ & $5.30 \mathrm{E}-06$ & $1.55 \mathrm{E}-06$ & $1.32 E-06$ & $2.94 E-06$ & $3.34 \mathrm{E}-06$ & $3.79 E-06$ & $4.31 E-06$ \\
\hline $1.69 \mathrm{E}-07$ & $5.29 \mathrm{E}-06$ & $1.55 \mathrm{E}-06$ & $1.32 \mathrm{E}-06$ & $2.94 E-06$ & $3.34 \mathrm{E}-06$ & $3.78 \mathrm{E}-06$ & $4.31 E-06$ \\
\hline $1.69 \mathrm{E}-07$ & $5.29 \mathrm{E}-06$ & $1.55 \mathrm{E}-06$ & $1.33 E-06$ & $2.94 E-06$ & $3.35 E-06$ & $3.78 E-06$ & $4.31 E-06$ \\
\hline $1.70 \mathrm{E}-07$ & $5.29 E-06$ & $1.55 E-06$ & $1.33 E-06$ & $2.94 E-06$ & $3.35 E-06$ & $3.78 E-06$ & $4.31 E-06$ \\
\hline $1.70 \mathrm{E}-07$ & $5.29 \mathrm{E}-06$ & $1.55 \mathrm{E}-06$ & $1.33 E-06$ & $2.94 \mathrm{E}-06$ & $3.34 \mathrm{E}-06$ & $3.78 E-06$ & $4.31 E-06$ \\
\hline $1.70 \mathrm{E}-07$ & $5.29 \mathrm{E}-06$ & $1.55 \mathrm{E}-06$ & $1.33 E-06$ & $2.94 \mathrm{E}-06$ & $3.34 \mathrm{E}-06$ & $3.78 \mathrm{E}-06$ & 4. $31 \mathrm{E}-06$ \\
\hline $1.71 \mathrm{E}-07$ & $5.28 \mathrm{E}-$ & $1.55 \mathrm{E}-06$ & $1.33 E-06$ & $2.94 \mathrm{E}-06$ & $3.34 \mathrm{E}-06$ & $3.78 E-06$ & $4.31 E-06$ \\
\hline $1.71 \mathrm{E}-07$ & $5.28 \mathrm{E}-06$ & -06 & -06 & $2.94 \mathrm{E}-06$ & $3.34 \mathrm{E}$ & $3.78 \mathrm{E}-06$ & $4.31 \mathrm{E}-06$ \\
\hline $1.72 \mathrm{E}-07$ & $5.28 \mathrm{E}-06$ & $1.55 \mathrm{E}-06$ & $1.34 \mathrm{E}-06$ & $2.94 E-06$ & $3.34 \mathrm{E}-06$ & $3.78 E-06$ & $4.31 E-06$ \\
\hline $1.72 \mathrm{E}-07$ & $5.28 \mathrm{E}-06$ & $1.56 \mathrm{E}-06$ & $1.34 \mathrm{E}-06$ & $2.94 E-06$ & $3.34 \mathrm{E}-06$ & $3.78 \mathrm{E}-06$ & $4.30 \mathrm{E}-06$ \\
\hline $1.72 \mathrm{E}-07$ & $5.28 E-06$ & $1.56 \mathrm{E}-06$ & 1. $34 \mathrm{E}-06$ & $2.93 E-06$ & $3.34 \mathrm{E}-06$ & $3.78 \mathrm{E}-06$ & $4.30 E-06$ \\
\hline $1.73 \mathrm{E}-07$ & $5.27 E-06$ & $1.56 \mathrm{E}-06$ & $1.34 \mathrm{E}-06$ & $2.93 E-06$ & $3.34 \mathrm{E}-06$ & $3.78 E-06$ & $4.30 E-06$ \\
\hline $1.73 \mathrm{E}-07$ & $5.27 \mathrm{E}-06$ & $1.56 \mathrm{E}-06$ & $1.34 E-06$ & $2.93 E-06$ & $3.34 \mathrm{E}-06$ & $3.78 \mathrm{E}-06$ & $4.30 \mathrm{E}-06$ \\
\hline $1.74 \mathrm{E}-07$ & $5.27 \mathrm{E}-06$ & $1.56 \mathrm{E}-06$ & $1.34 \mathrm{E}-06$ & $2.93 E-06$ & $3.34 E-06$ & $3.78 E-06$ & $4.30 E-06$ \\
\hline
\end{tabular}


RESRAD-OFFSITE, Version 2.5

Title : Offsite Resident Farmer Deterministic Run

File : RF TC99 DOESG FWD-FV2b.ROF

Summary of dose at graphical times, reptition 2 (continued)

Time

Years

$9.91 \mathrm{E}+02$

$9.91 \mathrm{E}+02$

9. $92 \mathrm{E}+02$

9. $92 \mathrm{E}+02$

$9.93 \mathrm{E}+02$

$9.93 \mathrm{E}+02$

9. $94 \mathrm{E}+02$

$9.94 \mathrm{E}+02$

$9.95 \mathrm{E}+02$

$9.95 \mathrm{E}+02$

$9.96 \mathrm{E}+02$

$9.96 \mathrm{E}+02$

$9.97 \mathrm{E}+02$

$9.97 \mathrm{E}+02$

$9.98 \mathrm{E}+02$

$9.98 \mathrm{E}+02$

$9.99 \mathrm{E}+02$

$9.99 \mathrm{E}+02$

$1.00 \mathrm{E}+03$

$1.00 \mathrm{E}+03$

$1.00 \mathrm{E}+03$

$1.00 \mathrm{E}+03$

$1.00 \mathrm{E}+03$

$1.00 \mathrm{E}+03$

$1.00 \mathrm{E}+03$

$1.00 \mathrm{E}+03$

$1.00 \mathrm{E}+03$

$1.00 \mathrm{E}+03$

$1.00 \mathrm{E}+03$

$1.01 \mathrm{E}+03$

$1.01 \mathrm{E}+03$

$1.01 \mathrm{E}+03$

$1.01 \mathrm{E}+03$

$1.01 \mathrm{E}+03$

$1.01 \mathrm{E}+03$

$1.01 \mathrm{E}+03$

$1.01 \mathrm{E}+03$

$1.01 \mathrm{E}+03$

$1.01 \mathrm{E}+03$

$1.01 \mathrm{E}+03$

$1.01 \mathrm{E}+03$

$1.01 \mathrm{E}+03$

$1.01 \mathrm{E}+03$

$1.01 \mathrm{E}+03$

$1.01 \mathrm{E}+03$

$1.01 \mathrm{E}+03$
Dose statistics at graphical times, mrem/yr

\begin{tabular}{|c|c|c|c|c|c|c|c|}
\hline m & um & ea & - & & & & \\
\hline $.74 \mathrm{E}-07$ & -06 & $1.56 \mathrm{E}-06$ & $1.34 \mathrm{E}-06$ & $93 E-06$ & $3.34 \mathrm{E}-06$ & $3.78 E-06$ & $4.29 E-00$ \\
\hline $.74 E-07$ & $5.27 E-06$ & $1.56 \mathrm{E}-06$ & $1.35 \mathrm{E}-06$ & $2.93 E-06$ & -06 & $3.78 E-06$ & $.29 \mathrm{E}-06$ \\
\hline $.75 E-07$ & $5.26 \mathrm{E}-06$ & $1.56 \mathrm{E}-06$ & $1.35 \mathrm{E}-06$ & $2.93 E-06$ & $3.34 \mathrm{E}-06$ & $3.78 \mathrm{E}-06$ & $.29 \mathrm{E}-06$ \\
\hline $75 \mathrm{~F}-07$ & $26 E-06$ & $56 \mathrm{~F}-06$ & $35 E-06$ & $.93 E-06$ & $34 F-06$ & -06 & $.29 E-06$ \\
\hline $.76 E-07$ & 06 & 06 & 6 & 6 & 6 & 06 & -06 \\
\hline 07 & 06 & & & & & & \\
\hline $.76 \mathrm{E}-07$ & $5.26 \mathrm{E}-06$ & & & & & & -06 \\
\hline $.77 E-07$ & 06 & 0 & 06 & 6 & 6 & -06 & $28 E-06$ \\
\hline $.77 E-07$ & $5.25 \mathrm{E}-06$ & $7 E-06$ & -06 & -06 & -06 & $E-06$ & $.28 E-06$ \\
\hline $.77 E-07$ & $25 E-06$ & $57 F_{-0}$ & $E-06$ & $.93 E-06$ & & $.77 E-06$ & $28 E-06$ \\
\hline $78 E-07$ & 06 & & & & & & -06 \\
\hline $78 E-07$ & $5.25 \mathrm{E}-06$ & 1. & 1. & 6 & & -06 & -06 \\
\hline $.79 \mathrm{E}-07$ & $5.24 \mathrm{E}-06$ & $1.57 \mathrm{E}-06$ & $1.36 \mathrm{E}-06$ & & & $6 E-06$ & $.28 E-06$ \\
\hline $.79 E-07$ & $5.24 \mathrm{E}-06$ & 1. $57 \mathrm{E}-06$ & 1. $36 \mathrm{E}-06$ & $2.94 \mathrm{E}-06$ & & -06 & $.27 E-06$ \\
\hline $.79 E-07$ & 06 & -06 & -06 & & & -06 & $E-06$ \\
\hline $.80 \mathrm{E}-$ & 6 & 0 & 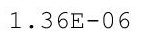 & & & 0 & char \\
\hline $80 \mathrm{E}-$ & 0 & & & & & & 6 \\
\hline $81 E-07$ & 6 & $1.57 \mathrm{E}-06$ & 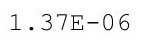 & 6 & 6 & 6 & 06 \\
\hline $81 \mathrm{E}-07$ & $5.23 E-06$ & $1.58 \mathrm{E}-06$ & $1.37 \mathrm{E}-06$ & $2.94 E-06$ & $3.33 E-06$ & $3.75 E-06$ & $.27 E-06$ \\
\hline $81 E-07$ & $.23 E-06$ & $1.58 \mathrm{E}-06$ & $1.37 \mathrm{E}-06$ & $2.94 \mathrm{E}-06$ & -06 & $E-06$ & $4.27 E-06$ \\
\hline 07 & 06 & & & & & 6 & $E-06$ \\
\hline $82 \mathrm{E}-$ & & & & & & & \\
\hline 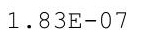 & & & & & & & -06 \\
\hline $83 E-07$ & 5.221 & 0 & 1. & 6 & & 0 & -06 \\
\hline $83 \mathrm{~F}-\mathrm{r}-\mathrm{T}$ & 6 & 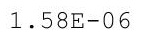 & 邽 & 泟 & 6 & 6 & $27 E-06$ \\
\hline $84 \mathrm{~F}-07$ & $22 E-06$ & $F-06$ & $1.37 \mathrm{E}-06$ & $94 E-06$ & $4 E-06$ & $.73 E-06$ & $.27 E-06$ \\
\hline $84 \mathrm{~F}-07$ & $21 E-06$ & $E-06$ & $.37 E-06$ & & & $E-06$ & $27 E-06$ \\
\hline & & & & & & & \\
\hline 1 & & & & & & 06 & -06 \\
\hline $86 \mathrm{E}-07$ & $5.21 \mathrm{E}-06$ & $1.30 \pm-06$ & 1. $38 \mathrm{E}-06$ & $2.93 E-06$ & $.34 E-06$ & $3.15 E-00$ & $.27 E-06$ \\
\hline $86 \mathrm{E}-07$ & $21 E-06$ & $1.58 \mathrm{E}-06$ & 1. $38 \mathrm{E}-06$ & $2.94 \mathrm{E}-06$ & $.34 \mathrm{E}-06$ & $3.13 \mathrm{E}-00$ & $.27 E-06$ \\
\hline 年 & & & 1.3 & & & 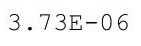 & 6 \\
\hline-07 & & & & & & & 06 \\
\hline 7 & & & & & & & \\
\hline 7 & & & & 6 & & & \\
\hline $.88 \mathrm{E}-07$ & $5.19 \mathrm{E}-06$ & $1.59 \mathrm{E}-06$ & $1.38 E-06$ & $2.93 E-06$ & -06 & $3.73 E-06$ & $.27 E-06$ \\
\hline $.000-1$ & $5.19 \mathrm{E}-06$ & & & & & $\begin{array}{ll}.10 \mathrm{~L} \\
\end{array}$ & $4.215-00$ \\
\hline 1 & & 1. $59 \mathrm{E}-06$ & 1. $39 \mathrm{E}-06$ & $2.94 \mathrm{E}-06$ & & & $27 E-06$ \\
\hline $89 F-07$ & 6 & ; & -06 & -06 & 6 & 6 & 06 \\
\hline in & & & & & & & 06 \\
\hline $90 \mathrm{E}-07$ & $5.18 E-06$ & -06 & 06 & & & & -06 \\
\hline $90 \mathrm{E}-07$ & $.18 \mathrm{E}$ & 1.5 & $1 \cdot 3$ & -06 & & & -06 \\
\hline 1 & & & & & & & $4.26 E-06$ \\
\hline . & $5.18 \mathrm{E}-06$ & $1.00 \mathrm{~L}-00$ & $1.39 E-06$ & $2.94 \mathrm{E}-06$ & $3.34 E-06$ & $3.13 E-06$ & $4 \cdot 20 E-06$ \\
\hline $.9<5-01$ & $\begin{array}{lll}-170 \\
\end{array}$ & 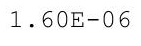 & $1.39 \mathrm{E}-06$ & & & & $4.26 E-06$ \\
\hline $92 E-07$ & $E-06$ & $.60 E-06$ & $.40 \mathrm{E}-06$ & $.94 \mathrm{E}-06$ & $E-06$ & $3 E-06$ & $4.26 \mathrm{E}-06$ \\
\hline
\end{tabular}


RESRAD-OFFSITE, Version 2.5

Title : Offsite Resident Farmer Deterministic Run

File : RF TC99 DOESG FWD-FV2b.ROF

Summary of dose at graphical times, reptition 2 (continued)

Time

Years

$1.01 \mathrm{E}+03$

$1.01 \mathrm{E}+03$

$1.02 \mathrm{E}+03$

$.02 \mathrm{E}+03$

$.02 \mathrm{E}+03$

$1.02 \mathrm{E}+03$

$.02 \mathrm{E}+03$

$1.02 \mathrm{E}+03$

. $02 \mathrm{E}+03$

$1.02 \mathrm{E}+03$

$1.02 \mathrm{E}+03$

$1.02 \mathrm{E}+03$

$1.02 \mathrm{E}+03$

$1.02 \mathrm{E}+03$

$1.02 \mathrm{E}+03$

$1.02 \mathrm{E}+03$

$1.02 \mathrm{E}+03$

$1.02 \mathrm{E}+03$

$1.02 \mathrm{E}+03$

$1.02 \mathrm{E}+03$

$1.02 \mathrm{E}+03$

$1.02 \mathrm{E}+03$

$1.03 \mathrm{E}+03$

$1.03 \mathrm{E}+03$

$1.03 E+03$

$1.03 E+03$

$1.03 E+03$

$1.03 E+03$

$1.03 \mathrm{E}+03$

$1.03 E+03$

$1.03 E+03$

$1.03 \mathrm{E}+03$

$1.03 \mathrm{E}+03$

$1.03 \mathrm{E}+03$

$1.03 \mathrm{E}+03$

$1.03 \mathrm{E}+03$

$1.03 \mathrm{E}+03$

$1.03 \mathrm{E}+03$

$1.03 E+03$

$1.03 \mathrm{E}+03$

$1.03 \mathrm{E}+03$

$1.04 \mathrm{E}+03$

$1.04 \mathrm{E}+03$

$1.04 \mathrm{E}+03$

$1.04 \mathrm{E}+03$

$1.04 \mathrm{E}+03$
Dose statistics at graphical times, mrem/yr

\begin{tabular}{|c|c|c|c|c|c|c|c|}
\hline m & aximum & lea & - & & & & \\
\hline 07 & -06 & $1.60 \mathrm{E}-06$ & $1.40 \mathrm{E}-06$ & $4 E-06$ & 06 & $3.73 E-06$ & $4.20 E-00$ \\
\hline $93 E-07$ & $5.17 E-06$ & $1.60 \mathrm{E}-06$ & $1.40 \mathrm{E}-06$ & $4 E-06$ & -06 & $E-06$ & $.26 E-06$ \\
\hline $93 E-07$ & $16 \mathrm{E}-06$ & $1.60 \mathrm{E}-06$ & 1. $40 \mathrm{E}-06$ & $2.94 \mathrm{E}-06$ & $34 E-06$ & $3 E-06$ & $.26 \mathrm{E}-06$ \\
\hline $94 \mathrm{~F}-07$ & 06 & $6 \cap 5-06$ & $.40 \mathrm{E}-06$ & $94 \mathrm{E}-06$ & -06 & -06 & $.26 E-06$ \\
\hline-07 & 06 & 60 & 06 & 06 & & -06 & $26 E-06$ \\
\hline 07 & & & & & & & 06 \\
\hline $95 E-07$ & & & & & & & $.26 E-06$ \\
\hline-07 & 06 & 6 & 6 & 6 & 6 & 6 & $26 E-06$ \\
\hline $96 \mathrm{E}-07$ & -06 & -06 & -06 & -06 & -06 & -06 & $.26 \mathrm{E}-06$ \\
\hline $96 E-07$ & -06 & $6 \cap 5-06$ & $.41 E-06$ & $94 E-06$ & & $2 E-06$ & $26 E-06$ \\
\hline-07 & & 1 & & & & & $E-06$ \\
\hline $97 E-07$ & 06 & $1.61 \mathrm{~F}$ & 1.4 & & & 6 & $E-06$ \\
\hline $.97 E-07$ & $5.14 \mathrm{E}-06$ & $1.61 \mathrm{E}-06$ & $1.41 \mathrm{E}-06$ & & & $1 E-06$ & $.25 E-06$ \\
\hline $98 E-07$ & $.14 \mathrm{E}-06$ & 1. $61 \mathrm{E}-06$ & $1.41 \mathrm{E}-06$ & $2.94 \mathrm{E}-06$ & & -06 & $25 E-06$ \\
\hline-07 & 06 & 06 & -06 & & & -06 & $E-06$ \\
\hline t & 06 & $.61 \mathrm{E}$ & $.41 \mathrm{E}-\mathrm{C}$ & 6 & & -06 & קתמת \\
\hline 7 & & 1. $61 \mathrm{E}-06$ & & & & & \\
\hline 7 & 6 & 1. $61 \mathrm{E}-06$ & 1. $41 \mathrm{E}-06$ & 6 & & $1 E-06$ & 06 \\
\hline $.00 \mathrm{E}-07$ & $5.13 \mathrm{E}-06$ & $1.61 \mathrm{E}-06$ & $1.41 \mathrm{E}-06$ & $2.94 E-06$ & $3.35 E-06$ & $3.71 \mathrm{E}-06$ & $.24 E-06$ \\
\hline $.00 E-07$ & $.12 \mathrm{E}-06$ & $1.61 \mathrm{E}-06$ & $1.41 \mathrm{E}-06$ & $4 E-06$ & -06 & $E-06$ & $.24 E-06$ \\
\hline 07 & & .61 & & & & 6 & $E-06$ \\
\hline 07 & & .6 & & & 6 & 6 & 06 \\
\hline 7 & & $1 \cdot$ & 1. & & & & -06 \\
\hline $.02 E-07$ & 6 & 0 & $1 \cdot$ & 6 & 6 & 0 & -06 \\
\hline 7 & 6 & 1605 & 1 & 6 & 6 & $1 E-$ & 06 \\
\hline $03 F-07$ & $11 E-06$ & $62 \mathrm{~F}-06$ & 1. $42 \mathrm{E}-06$ & -06 & -06 & $.71 \mathrm{E}-06$ & $.22 E-06$ \\
\hline$F-07$ & -06 & $62 E-06$ & $.42 E-06$ & $93 E-06$ & & $E-06$ & $.22 E-06$ \\
\hline & & & & & & & \\
\hline & & 1.02 & & 06 & 6 & -06 & -06 \\
\hline $.04 E-07$ & $5.10 \mathrm{E}-06$ & $1.0<5-06$ & 1. $42 \mathrm{E}-06$ & $2.93 E-06$ & $.36 E-06$ & $1 E-06$ & $.22 E-06$ \\
\hline $2-01$ & 6 & $1.0<5-00$ & 1. $42 \mathrm{E}-06$ & $2.93 E-06$ & $6 E-06$ & $.11 \mathrm{E}-00$ & $.21 E-06$ \\
\hline 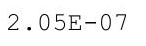 & & 1. $62 \mathrm{E}-0$ & 1. $42 \mathrm{E}-06$ & & & 象 & $.21 E-06$ \\
\hline $5-0-7+2 \cdot 2$ & -06 & $E-06$ & $1.43 E-06$ & $3 E-06$ & & & $21 E-06$ \\
\hline 7 & & 1 . & & & & 6 & \\
\hline 07 & & 1.62 & & 6 & 6 & 06 & 06 \\
\hline $.0 / E-U /$ & $5.08 E-06$ & $1.6 \angle E-06$ & $1.43 E-06$ & 2.814 & -06 & -06 & $.21 E-06$ \\
\hline . & & $1.62 \mathrm{E}-06$ & & & & $\begin{array}{ll}.10 \mathrm{~L} \\
\mathrm{~s}\end{array}$ & $4.21 D-00$ \\
\hline 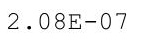 & DO & 1. $63 \mathrm{E}-06$ & $1.435-00$ & $2.94 \mathrm{E}-06$ & & 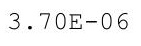 & $.21 E-06$ \\
\hline 70 & $5.08 \mathrm{E}-06$ & 6 & 6 & 6 & 6 & 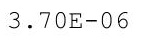 & 06 \\
\hline $.09 E-07$ & & & & & & & \\
\hline$E-07$ & $5.07 \mathrm{E}-06$ & 1. $63 \mathrm{E}-06$ & $3 E-06$ & & & & -06 \\
\hline & 06 & $1.63 \mathrm{E}$ & 1.4 & & & & -06 \\
\hline & & & & & & & $4.21 \mathrm{E}-06$ \\
\hline 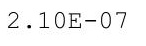 & $5.06 \mathrm{E}-06$ & $1.0 J \pm-00$ & $1.44 \mathrm{E}-06$ & $2.93 E-06$ & $3.35 E-06$ & $3.10 E-06$ & $4 \cdot \angle 1 E-06$ \\
\hline$+\mathrm{L}-\mathrm{t}$ & . & $\begin{array}{ll}.0 \\
\text {. }\end{array}$ & $1.44 \mathrm{E}-06$ & & & & $4.21 E-06$ \\
\hline $1 E-07$ & $.06 \mathrm{E}-06$ & $.63 E-06$ & $.44 E-06$ & $.93 E-06$ & $E-06$ & $E-06$ & $4.21 \mathrm{E}$ \\
\hline
\end{tabular}


RESRAD-OFFSITE, Version 2.5

$\mathrm{T}^{1 / 2}$ Limit $=180$ days

robabilistic Dose and Risk Report

Title : Offsite Resident Farmer Deterministic Run

File : RF TC99 DOESG FWD-FV2b.ROF

Time

Years

$1.04 \mathrm{E}+03$

$1.04 \mathrm{E}+03$

$1.04 \mathrm{E}+03$

$1.04 \mathrm{E}+03$

$1.04 \mathrm{E}+03$

$1.04 \mathrm{E}+03$

$1.04 \mathrm{E}+03$

$1.04 \mathrm{E}+03$

$1.04 \mathrm{E}+03$

$1.04 \mathrm{E}+03$

$1.04 \mathrm{E}+03$

$1.04 \mathrm{E}+03$

$1.04 \mathrm{E}+03$

$1.04 \mathrm{E}+03$

$1.04 \mathrm{E}+03$

$1.05 \mathrm{E}+03$

$1.05 \mathrm{E}+03$

$1.05 \mathrm{E}+03$

$1.05 \mathrm{E}+03$

$1.05 \mathrm{E}+03$

$1.05 \mathrm{E}+03$

1. $05 \mathrm{E}+03$

$1.05 \mathrm{E}+03$

$1.05 \mathrm{E}+03$

$1.05 \mathrm{E}+03$
Summary of dose at graphical times, reptition 2 (continued)

Dose statistics at graphical times, mrem/yr

\begin{tabular}{|c|c|c|c|c|c|c|c|}
\hline Minimum & Maximum & Mean & Median & $90 \%$ & $95 \%$ & $97.5 \%$ & $99 \%$ \\
\hline $2.12 \mathrm{E}-07$ & $5.06 \mathrm{E}-06$ & $1.63 E-06$ & $1.44 \mathrm{E}-06$ & $2.93 E-06$ & $3.34 E-06$ & $3.69 \mathrm{E}-06$ & $4.21 \mathrm{E}-06$ \\
\hline $2.12 \mathrm{E}-07$ & $5.05 E-06$ & $1.63 E-06$ & $1.44 \mathrm{E}-06$ & $2.94 \mathrm{E}-06$ & $3.34 \mathrm{E}-06$ & $3.69 \mathrm{E}-06$ & $4.21 \mathrm{E}-06$ \\
\hline $2.13 E-07$ & $5.05 \mathrm{E}-06$ & $1.63 \mathrm{E}-06$ & $1.45 \mathrm{E}-06$ & $2.94 \mathrm{E}-06$ & $3.34 \mathrm{E}-06$ & $3.69 \mathrm{E}-06$ & $4.21 \mathrm{E}-06$ \\
\hline $2.13 E-07$ & $5.05 E-06$ & $.63 E-06$ & $1.45 \mathrm{E}-06$ & $2.94 \mathrm{E}-06$ & $.34 \mathrm{E}-06$ & $.69 E-06$ & $.21 \mathrm{E}-06$ \\
\hline $2.13 E-07$ & $5.05 E-06$ & $1.63 E-06$ & $1.45 \mathrm{E}-06$ & $2.94 E-06$ & $34 E-06$ & $.69 E-06$ & $.21 E-06$ \\
\hline $2.14 \mathrm{E}-07$ & $5.04 \mathrm{E}-06$ & $1.64 \mathrm{E}-06$ & $1.45 \mathrm{E}-06$ & $2.94 E-06$ & $3.34 \mathrm{E}-06$ & $3.68 E-06$ & $4.21 \mathrm{E}-06$ \\
\hline $2.14 \mathrm{E}-07$ & $5.04 \mathrm{E}-06$ & $1.64 \mathrm{E}-06$ & $1.45 \mathrm{E}-06$ & $2.94 \mathrm{E}-06$ & $3.34 \mathrm{E}-06$ & $3.68 \mathrm{E}-06$ & $.21 E-06$ \\
\hline $2.15 \mathrm{E}-07$ & $5.04 \mathrm{E}-06$ & $1.64 \mathrm{E}-06$ & $1.45 \mathrm{E}-06$ & $2.94 \mathrm{E}-06$ & $3.34 \mathrm{E}-06$ & $3.68 \mathrm{E}-06$ & 4. $21 \mathrm{E}-06$ \\
\hline $2.15 \mathrm{E}-07$ & $5.03 E-06$ & $1.64 \mathrm{E}-06$ & $1.45 \mathrm{E}-06$ & $2.94 E-06$ & $3.34 \mathrm{E}-06$ & $3.68 \mathrm{E}-06$ & $4.21 \mathrm{E}-06$ \\
\hline $2.15 \mathrm{E}-07$ & $5.03 E-06$ & $1.64 \mathrm{E}-06$ & $1.46 \mathrm{E}-06$ & $2.94 \mathrm{E}-06$ & $34 E-06$ & $3.68 \mathrm{E}-06$ & $.21 E-06$ \\
\hline $2.16 \mathrm{E}-07$ & $5.03 E-06$ & $1.64 \mathrm{E}-06$ & $1.46 \mathrm{E}-06$ & $2.94 \mathrm{E}-06$ & $.34 E-06$ & $3.68 \mathrm{E}-06$ & $4.21 \mathrm{E}-06$ \\
\hline $2.16 \mathrm{E}-07$ & $5.03 E-06$ & $1.64 \mathrm{E}-06$ & $1.46 \mathrm{E}-06$ & $2.94 \mathrm{E}-06$ & $3.34 \mathrm{E}-06$ & $3.68 \mathrm{E}-06$ & $.21 E-06$ \\
\hline $2.17 \mathrm{E}-07$ & $5.02 \mathrm{E}-06$ & $1.64 \mathrm{E}-06$ & $1.46 \mathrm{E}-06$ & $2.95 E-06$ & $34 E-06$ & $3.68 \mathrm{E}-06$ & $.21 E-06$ \\
\hline $2.17 \mathrm{E}-07$ & $5.02 \mathrm{E}-06$ & $1.64 \mathrm{E}-06$ & $1.46 \mathrm{E}-06$ & $2.95 E-06$ & $3.34 \mathrm{E}-06$ & $3.68 E-06$ & $.20 E-06$ \\
\hline $2.18 \mathrm{E}-07$ & $5.02 \mathrm{E}-06$ & $1.64 \mathrm{E}-06$ & $1.46 \mathrm{E}-06$ & $2.95 E-06$ & $3.34 \mathrm{E}-06$ & $3.68 \mathrm{E}-06$ & 4. $20 \mathrm{E}-06$ \\
\hline $2.18 \mathrm{E}-07$ & $5.02 \mathrm{E}-06$ & $1.64 \mathrm{E}-06$ & $1.46 \mathrm{E}-06$ & $5 E-06$ & $4 E-06$ & $E-06$ & $20 E-06$ \\
\hline $2.18 \mathrm{E}-07$ & $5.01 \mathrm{E}-06$ & $1.64 \mathrm{E}-06$ & $1.46 \mathrm{E}-06$ & $2.95 E-06$ & $34 E-06$ & $3.68 \mathrm{E}-06$ & $.20 E-06$ \\
\hline $2.19 \mathrm{E}-07$ & $5.01 E-06$ & $1.64 \mathrm{E}-06$ & $1.46 \mathrm{E}-06$ & $2.95 E-06$ & $3.34 \mathrm{E}-06$ & $3.68 \mathrm{E}-06$ & $4.19 \mathrm{E}-06$ \\
\hline $2.19 \mathrm{E}-07$ & $5.01 \mathrm{E}-06$ & $1.64 \mathrm{E}-06$ & $1.46 \mathrm{E}-06$ & $2.95 E-06$ & $3.35 E-06$ & $3.68 \mathrm{E}-06$ & $4.19 \mathrm{E}-06$ \\
\hline $2.20 \mathrm{E}-07$ & $5.01 \mathrm{E}-06$ & $1.64 \mathrm{E}-06$ & $1.47 \mathrm{E}-06$ & $2.95 \mathrm{E}-06$ & $3.35 \mathrm{E}-06$ & $3.68 \mathrm{E}-06$ & $4.18 \mathrm{E}-06$ \\
\hline $2.20 \mathrm{E}-07$ & $5.00 \mathrm{E}-06$ & $1.65 \mathrm{E}-06$ & $1.47 \mathrm{E}-06$ & $2.95 E-06$ & $3.35 \mathrm{E}-06$ & $3.68 \mathrm{E}-06$ & $4.18 \mathrm{E}-06$ \\
\hline $2.21 \mathrm{E}-07$ & $5.00 E-06$ & $1.65 E-06$ & $1.47 \mathrm{E}-06$ & $2.95 E-06$ & $3.35 E-06$ & $3.68 \mathrm{E}-06$ & $4.17 \mathrm{E}-06$ \\
\hline $2.21 \mathrm{E}-07$ & $5.00 \mathrm{E}-06$ & $1.65 E-06$ & $1.47 \mathrm{E}-06$ & $2.95 E-06$ & $35 E-06$ & $3.68 \mathrm{E}-06$ & $4.17 E-06$ \\
\hline $2.21 \mathrm{E}-07$ & $5.00 \mathrm{E}-06$ & $1.65 \mathrm{E}-06$ & $1.47 \mathrm{E}-06$ & $2.94 \mathrm{E}-06$ & $.35 E-06$ & $3.68 \mathrm{E}-06$ & $4.17 \mathrm{E}-06$ \\
\hline $2.22 E-07$ & 4. $99 \mathrm{E}-06$ & 1. $65 \mathrm{E}-06$ & $1.47 \mathrm{E}-06$ & $2.94 E-06$ & $3.35 \mathrm{E}-06$ & $3.67 \mathrm{E}-06$ & $4.16 \mathrm{E}-06$ \\
\hline
\end{tabular}

C -433

DCN 5090-TR-02-2 
RESRAD-OFFSITE, Version 2.5

itle : Offsite Resident Farmer Deterministic Run

File : RF TC99 DOESG FWD-FV2b.ROF

Time

Years

$0.00 \mathrm{E}+00$

$5.13 \mathrm{E}-01$

$1.03 \mathrm{E}+00$

$1.54 \mathrm{E}+00$

$2.05 \mathrm{E}+00$

$2.56 \mathrm{E}+00$

$3.08 \mathrm{E}+00$

$3.59 \mathrm{E}+00$

$4.10 \mathrm{E}+00$

$4.61 \mathrm{E}+00$

$5.13 \mathrm{E}+00$

$5.64 \mathrm{E}+00$

$6.15 \mathrm{E}+00$

$6.67 \mathrm{E}+00$

$7.18 \mathrm{E}+00$

$7.69 \mathrm{E}+00$

$8.20 \mathrm{E}+00$

$8.72 \mathrm{E}+00$

$9.23 \mathrm{E}+00$

$9.74 \mathrm{E}+00$

$1.03 \mathrm{E}+01$

$1.08 \mathrm{E}+01$

$1.13 \mathrm{E}+01$

$1.18 \mathrm{E}+01$

1. $23 \mathrm{E}+01$

$1.28 \mathrm{E}+01$

$1.33 \mathrm{E}+01$

$1.38 \mathrm{E}+01$

$1.44 \mathrm{E}+01$

$1.49 \mathrm{E}+01$

$1.54 \mathrm{E}+01$

$1.59 \mathrm{E}+01$

$1.64 \mathrm{E}+01$

$1.69 \mathrm{E}+01$

$1.74 \mathrm{E}+01$

$1.79 \mathrm{E}+01$

$1.85 \mathrm{E}+01$

$1.90 \mathrm{E}+01$

1. $95 \mathrm{E}+01$

$2.00 \mathrm{E}+01$

$2.05 \mathrm{E}+01$

$2.10 \mathrm{E}+01$

$2.15 E+01$

$2.20 \mathrm{E}+01$

$2.26 \mathrm{E}+01$

$2.31 \mathrm{E}+01$

Summary of dose at graphical times, reptition 3

Dose statistics at graphical times, mrem/yr

\begin{tabular}{|c|c|c|c|c|c|c|c|}
\hline Iinimum & Iaximum & Mean & Median & 00 & $\%$ & $97.5 \%$ & 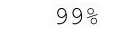 \\
\hline $.79 \mathrm{E}-32$ & $1.82 \mathrm{E}-32$ & 1. $82 \mathrm{E}-32$ & $1.82 \mathrm{E}-32$ & 1. $82 \mathrm{E}-32$ & 1. $82 \mathrm{E}-32$ & 1. $82 \mathrm{E}-32$ & $2 \mathrm{~L}-32$ \\
\hline $.78 E-32$ & $1.84 \mathrm{E}-32$ & $1.83 E-32$ & $1.84 \mathrm{E}-32$ & $1.84 \mathrm{E}-32$ & $1.84 \mathrm{E}-32$ & -32 & 32 \\
\hline $.76 E-32$ & 32 & 32 & $1.85 \mathrm{E}-32$ & $85 E-32$ & 32 & 32 & 32 \\
\hline $75 E-32$ & $87 E-32$ & $6 E-32$ & -32 & $7 E-32$ & $7 E-32$ & -32 & -32 \\
\hline$E-32$ & $9 E-32$ & $8 E-32$ & 2 & $9 \mathrm{E}$ & 2 & 32 & -32 \\
\hline $.72 E-32$ & & & & 32 & & & -32 \\
\hline-32 & & & & 32 & 2 & 32 & $2 E-32$ \\
\hline $69 E-32$ & 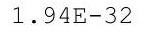 & 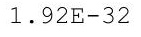 & $1.93 E-32$ & $4 E-32$ & 32 & 32 & -32 \\
\hline 要 & 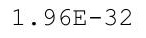 & 专 & - & 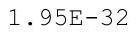 & 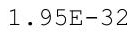 & . & 1. $95 E-32$ \\
\hline $66 \mathrm{E}-32$ & $1.97 \mathrm{~F}$ & 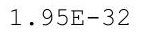 & 32 & 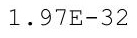 & 2 & -32 & $97 E-32$ \\
\hline $64 E-32$ & $E-32$ & -32 & -32 & -32 & 2 & 32 & -32 \\
\hline $63 E-32$ & 2 . & & & 2 & 2 & & -32 \\
\hline 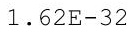 & & 2 & & & 2 & 2 & -32 \\
\hline 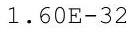 & & 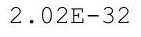 & $2 \pi-25$ & & 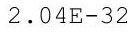 & & -32 \\
\hline (2) & 2.000 & 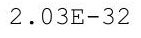 & . & 2.0042 & 0.0 & 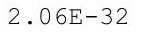 & -32 \\
\hline (1) & - & 舟 & 然 & . & & (2) & -32 \\
\hline $.56 E-32$ & $2.10 E-32$ & $2.06 \mathrm{E}-32$ & $2.08 E-32$ & $9 \mathrm{E}-$ & 2 & 32 & -32 \\
\hline $.55 E-32$ & $2.12 \mathrm{E}-32$ & $2.08 E-32$ & $2.10 \mathrm{E}-32$ & & $2.11 \mathrm{E}-32$ & $2.11 \mathrm{E}-32$ & $11 E-32$ \\
\hline-32 & 2 & ${ }^{2}$ & $E-32$ & $35-$ & 2 & -32 & $13 E-32$ \\
\hline 32 & 2 & $2.11 E-32$ & 2 & 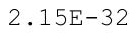 & 2 & 32 & -32 \\
\hline $51 \mathrm{E}-32$ & $2 \cdot 1 / \pm 22$ & $2 \cdot+\pi \Delta 2$ & $2.15 \mathrm{E}-32$ & 年 & & 32 & -32 \\
\hline $50 \mathrm{E}-32$ & $2.19 E-32$ & 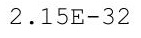 & & & & & -32 \\
\hline $48 E-32$ & 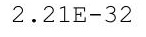 & $2 \cdot 1$ & 2 & 然 & 2 & 2 & -32 \\
\hline $.47 E-32$ & $2.23 E-32$ & $2.18 E-32$ & $2.20 \mathrm{E}-32$ & $2.22 \mathrm{E}-$ & $2.23 \mathrm{E}-$ & $2.23 E-32$ & $23 E-32$ \\
\hline $46 E-32$ & $2.25 E-32$ & $2.20 \mathrm{E}-32$ & $2.22 E-32$ & $2.24 \mathrm{E}-32$ & $2.25 \mathrm{E}-$ & $2.25 E-32$ & $25 E-32$ \\
\hline 32 & 2.2 & 2 & 2 & 2 & & $.27 E-32$ & $27 E-32$ \\
\hline-32 & 32 & 2 & 32 & & & -32 & $E-32$ \\
\hline $42 E-32$ & $2.31 E-32$ & 2.200 & (. & ( ل & & & 32 \\
\hline $41 E-32$ & 2.0 & टण्टामे & $2.29 E-32$ & $2.32 E-32$ & $2 \cdot 00$ & $2.33 E-32$ & $2.33 E-32$ \\
\hline 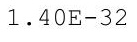 & $2.35 E-32$ & 2.2 & 2 & 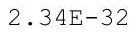 & 2.00 & 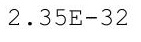 & $.35 E-32$ \\
\hline $.39 E-32$ & $2.37 E-32$ & $2.30 E-32$ & $2.33 E-32$ & 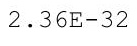 & & (e) & $.37 E-32$ \\
\hline $38 E-32$ & $2.40 E-32$ & & 2 & & & & $39 E-32$ \\
\hline 2 & 2 & 2 & 32 & 2 & 2 & 32 & -32 \\
\hline $5 E-32$ & $2.44 E-32$ & 2 & 2 . & 2 & 2 & 32 & -32 \\
\hline $34 E-32$ & $2.46 E-32$ & $2.38 E-32$ & $2.41 E-32$ & $2.45 E-32$ & $2.45 E-32$ & $2.45 E-32$ & $2.45 E-32$ \\
\hline $3 E-32$ & 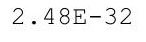 & 2. & $2.43 E-32$ & $2.47 E-32$ & & & $2.48 E-32$ \\
\hline 2 & 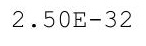 & $2.4 \perp L$ & & & & & $2.50 E-32$ \\
\hline $.31 E-32$ & $2.53 E-32$ & & 2 & 2 & 2 & 2 & 32 \\
\hline ? & $2.55 E-32$ & $2.45 E-32$ & 32 & 2 & & & 32 \\
\hline 2 & & & & 2 & 32 & -32 & 32 \\
\hline $27 E-32$ & $2.59 \mathrm{E}-$ & 2.450 & 32 & 2. & & 32 & -32 \\
\hline 2 & $-\infty$ & & & & & & \\
\hline 2 & 2.0 & . & - & 2 & $2.63 \mathrm{E}$ & & -32 \\
\hline 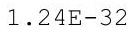 & 2 & & 5 & $-\infty$ & 2 & 2 & 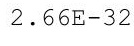 \\
\hline $.23 E-32$ & 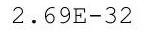 & & & 2 & $2.67 \mathrm{E}$ & 2.00 & 32 \\
\hline-32 & $71 E-32$ & $9 E-32$ & $64 E-32$ & 32 & 32 & 32 & 32 \\
\hline
\end{tabular}


RESRAD-OFFSITE, Version 2.5

itle : Offsite Resident Farmer Deterministic Run

File : RF TC99 DOESG FWD-FV2b.ROF

Summary of dose at graphical times, reptition 3 (continued)

Time

Years

$2.36 \mathrm{E}+01$

2. $41 \mathrm{E}+01$

2. $46 \mathrm{E}+01$

$2.51 \mathrm{E}+01$

2. $56 \mathrm{E}+01$

2. $61 \mathrm{E}+01$

2. $67 \mathrm{E}+01$

2. $72 \mathrm{E}+01$

$2.77 \mathrm{E}+01$

$2.82 \mathrm{E}+01$

$2.87 E+01$

2. $92 \mathrm{E}+01$

2. $97 \mathrm{E}+01$

3. $02 \mathrm{E}+01$

$3.08 \mathrm{E}+01$

$3.13 E+01$

$3.18 \mathrm{E}+01$

3. $23 E+01$

$3.28 \mathrm{E}+01$

3. $33 E+01$

3. $38 \mathrm{E}+01$

3. $44 \mathrm{E}+01$

3. $49 \mathrm{E}+01$

$3.54 \mathrm{E}+01$

3. $59 \mathrm{E}+01$

3. $64 \mathrm{E}+01$

$3.69 \mathrm{E}+01$

$3.74 \mathrm{E}+01$

$3.79 \mathrm{E}+01$

3. $85 \mathrm{E}+01$

3. $90 \mathrm{E}+01$

$3.95 \mathrm{E}+01$

$4.00 \mathrm{E}+01$

$4.05 \mathrm{E}+01$

4. $10 \mathrm{E}+01$

4. $15 \mathrm{E}+01$

4. $20 \mathrm{E}+01$

4. $26 \mathrm{E}+01$

4. $31 \mathrm{E}+01$

4. $36 \mathrm{E}+01$

4. $41 \mathrm{E}+01$

4. $46 \mathrm{E}+01$

$4.51 \mathrm{E}+01$

$4.56 \mathrm{E}+01$

4. $61 \mathrm{E}+01$

$4.67 \mathrm{E}+01$

Dose statistics at graphical times, mrem/yr

\begin{tabular}{|c|c|c|c|c|c|c|c|}
\hline m & aximum & ea & ec & & & & \\
\hline-32 & $2.73 E-32$ & $2.61 E-32$ & $2.66 \mathrm{E}-32$ & $71 E-32$ & $72 E-32$ & 32 & - $13 \pm-32$ \\
\hline $20 E-32$ & $2.76 E-32$ & $2.63 E-32$ & $2.68 \mathrm{E}-32$ & $2.74 E-32$ & $2.74 E-32$ & $2.75 E-32$ & $75 E-32$ \\
\hline-32 & $78 E-32$ & $65 E-32$ & $71 E-32$ & $76 E-32$ & $77 E-32$ & $2.77 \mathrm{E}-32$ & $78 E-32$ \\
\hline-32 & $81 E-32$ & $67 F-32$ & $73 F-32$ & $.79 E-32$ & $79 F-32$ & $80 F-32$ & $80 F-32$ \\
\hline-32 & -32 & 32 & -32 & 2 & 2 & -32 & $82 E-32$ \\
\hline 32 & 32 & & & & & & 32 \\
\hline $15 E-32$ & $2.88 E-32$ & & $2.80 E-32$ & & & & $.87 E-32$ \\
\hline $14 E-32$ & -32 & 2 & -32 & 32 & 32 & -32 & $0 E-32$ \\
\hline $13 E-32$ & $94 E-32$ & $78 \mathrm{E}-32$ & $2.84 \mathrm{E}-32$ & $91 E-32$ & $92 E-32$ & -32 & $3 E-32$ \\
\hline$E-32$ & $96 E-32$ & ? חק00 & $87 F-32$ & 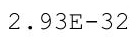 & 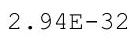 & $.95 E-32$ & $95 F-32$ \\
\hline 32 & 32 & & & & & & 32 \\
\hline $10 \mathrm{E}-32$ & $3.01 E-32$ & $285 \mathrm{~F}-32$ & $E-32$ & 2 & 2 & 32 & -32 \\
\hline $.09 E-32$ & $3.04 E-32$ & & $2.94 \mathrm{E}-32$ & & & & $3.03 E-32$ \\
\hline $08 E-32$ & -32 & $2.095-32$ & $2.96 \mathrm{E}-32$ & & 2 & 32 & $E-32$ \\
\hline$E-32$ & -32 & 2 & -32 & & & -32 & -32 \\
\hline 32 & -32 & (5) & $1 E-32$ & & & 2 & $3.11 \mathrm{E}-32$ \\
\hline 32 & 2 & & & & & & 32 \\
\hline 32 & 32 & 2 & 2 & & & 2 & 32 \\
\hline $04 \mathrm{E}-32$ & $3.21 E-32$ & $3.01 E-32$ & $3.09 E-32$ & $3.17 E-32$ & $3.18 E-32$ & $3.19 \mathrm{E}-32$ & $3.19 \mathrm{E}-32$ \\
\hline$E-32$ & $23 E-32$ & $.04 E-32$ & $E-32$ & $0 E-32$ & 1 & -32 & $22 E-32$ \\
\hline 32 & 32 & & & & & 2 & -32 \\
\hline 32 & -32 & & & & & -32 & -32 \\
\hline $.00 \mathrm{E}-32$ & 2 & & & & & 2 & -32 \\
\hline-33 & -32 & $3.13 E-32$ & 2 & 2 & L & 2 & -32 \\
\hline 3 & -32 & $3.16 \mathrm{E}-32$ & 2 & 2 & 5 & 2 & 32 \\
\hline $.77 E-33$ & $.41 E-32$ & -32 & $F-32$ & ד & 20г & $39 E-32$ & $40 E-32$ \\
\hline-33 & $44 \mathrm{E}-32$ & 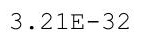 & $E-32$ & 2 & & $E-32$ & $43 E-32$ \\
\hline & & & & & & & \\
\hline & & & 32 & 2 & & -32 & \\
\hline $45 E-33$ & $3.53 E-32$ & . & $3.38 E-32$ & $3.49 E-32$ & $.200-28$ & $.51 E-32$ & $.52 E-32$ \\
\hline $37 E-33$ & 32 & Pr & $E-32$ & . & - & $5-32$ & $.55 E-32$ \\
\hline 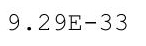 & $60 E-32$ & & $44 \mathrm{E}-32$ & & & & \\
\hline-33 & $.63 E-32$ & 2 & $E-32$ & $8 E-32$ & תח & & $1 E-32$ \\
\hline & & & & & & & \\
\hline & & & & 32 & 2 & -32 & \\
\hline $97 E-33$ & $3.73 E-32$ & $3.45 \pm-32$ & $3.55 E-32$ & 3.00 & 3.00 & -32 & $.71 E-32$ \\
\hline $90 E-33$ & $3.10 \mathrm{E}-32$ & $3.47 \mathrm{E}-32$ & & & & & $3.14 \pm-32$ \\
\hline 3 & 32 & . & 2 & . & & & $77 E-32$ \\
\hline 3 & $3.83 E-32$ & $3.53 E-32$ & 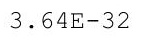 & 2 & 2 & 2 & 32 \\
\hline 33 & 2 & ? & & & & & 32 \\
\hline$E-33$ & $3.89 E-32$ & $3.58 E-32$ & $0 E-32$ & 3. & 2 & -32 & -32 \\
\hline $3 E-33$ & 3.905 & 3.015 & 2 & 2 & 2 & & \\
\hline & & & & & & & $\cdot 94 \mathrm{E}-32$ \\
\hline $.38 \pm-33$ & $4.00 \pm-32$ & $3.01 \mathrm{~L} 2 \mathrm{~L}$ & $3.19 E-32$ & $3.94 \mathrm{E}-32$ & $3.96 E-32$ & $3.97 E-32$ & $3.98 E-32$ \\
\hline ter- & $4.03 E-32$ & 5.70 & & e. & 3.995 & $4.00 E-32$ & 1. \\
\hline-33 & $E-32$ & $3 E-32$ & $.86 \mathrm{E}-32$ & $01 E-32$ & $.03 E-32$ & -32 & 4.0 \\
\hline
\end{tabular}


RESRAD-OFFSITE, Version 2.5

Title : Offsite Resident Farmer Deterministic Run

File : RF TC99 DOESG FWD-FV2b.ROF

Summary of dose at graphical times, reptition 3 (continued)

Time

Years

$4.72 \mathrm{E}+01$

$4.77 \mathrm{E}+01$

4. $82 \mathrm{E}+01$

$4.87 \mathrm{E}+01$

4. $92 \mathrm{E}+01$

4. $97 \mathrm{E}+01$

$5.02 \mathrm{E}+01$

$5.08 \mathrm{E}+01$

$5.13 \mathrm{E}+01$

$5.18 \mathrm{E}+01$

$5.23 \mathrm{E}+01$

$5.28 \mathrm{E}+01$

$5.33 \mathrm{E}+01$

5. $38 \mathrm{E}+01$

$5.43 \mathrm{E}+01$

$5.49 \mathrm{E}+01$

$5.54 \mathrm{E}+01$

$5.59 \mathrm{E}+01$

$5.64 \mathrm{E}+01$

$5.69 \mathrm{E}+01$

$5.74 \mathrm{E}+01$

$5.79 \mathrm{E}+01$

$5.84 \mathrm{E}+01$

$5.90 \mathrm{E}+01$

$5.95 \mathrm{E}+01$

$6.00 \mathrm{E}+01$

$6.05 \mathrm{E}+01$

$6.10 \mathrm{E}+01$

$6.15 \mathrm{E}+01$

$6.20 \mathrm{E}+01$

$6.25 \mathrm{E}+01$

$6.31 \mathrm{E}+01$

$6.36 \mathrm{E}+01$

$6.41 \mathrm{E}+01$

$6.46 \mathrm{E}+01$

$6.51 \mathrm{E}+01$

$6.56 \mathrm{E}+01$

$6.61 \mathrm{E}+01$

$6.67 \mathrm{E}+01$

$6.72 \mathrm{E}+01$

$6.77 \mathrm{E}+01$

$6.82 \mathrm{E}+01$

$6.87 \mathrm{E}+01$

$6.92 \mathrm{E}+01$

$6.97 \mathrm{E}+01$

$7.02 \mathrm{E}+01$
Dose statistics at graphical times, mrem/yr

\begin{tabular}{|c|c|c|c|c|c|c|c|}
\hline mum & laximum & lean & edic & & & & \\
\hline 33 & 32 & 32 & 32 & 32 & 32 & 32 & -32 \\
\hline $10 \mathrm{E}-33$ & $4.14 \mathrm{E}-32$ & $3.79 E-32$ & $92 E-32$ & $4.08 E-32$ & $4.10 \mathrm{E}-32$ & -32 & $4.12 \mathrm{E}-32$ \\
\hline$E-33$ & $18 E-32$ & $82 F-32$ & $95 E-32$ & $11 E-32$ & $.13 E-32$ & $.15 E-32$ & $16 F-32$ \\
\hline $96 \mathrm{E}-33$ & $4 \cdot 22 E-32$ & $85 E-32$ & $.99 E-32$ & $4.15 E-32$ & $4.17 E-32$ & $4.18 E-32$ & -32 \\
\hline $90 E-33$ & 32 & 2 & & & & & -32 \\
\hline $83 E-33$ & $4.29 E-32$ & $1 E-32$ & -32 & $22 E-32$ & 32 & -32 & -32 \\
\hline $.76 E-33$ & $4.33 E-32$ & 32 & -32 & $4.26 E-32$ & $28 E-32$ & \pm-32 & $30 E-32$ \\
\hline $.70 E-33$ & $4.37 E-32$ & $97 E-32$ & $2 E-32$ & $4 \cdot 30 E-32$ & $32 E-32$ & -32 & $34 E-32$ \\
\hline $63 E-33$ & $41 E-32$ & $01=-3$ & $15 E-32$ & $33 E-32$ & $.35 E-32$ & $.37 E-32$ & $38 E-32$ \\
\hline $57 E-33$ & $E-32$ & 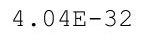 & 2 & 2 & 2 & 2 & -32 \\
\hline $50 E-33$ & $4.48 E-32$ & $7 F-32$ & 32 & -32 & 32 & -32 & $6 E-32$ \\
\hline $4 E-33$ & & & & & & & -32 \\
\hline $.38 E-33$ & $4.56 E-32$ & $4.14 E-32$ & $4.29 E-32$ & $4.49 E-32$ & $4.51 E-32$ & $4.52 E-32$ & $.54 E-32$ \\
\hline $31 E-33$ & -32 & & & & & & $E-32$ \\
\hline 3 & & & 2 & 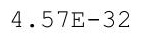 & 2 & 32 & -32 \\
\hline 3 & 4 & $4.24 \mathrm{E}-32$ & 2 & 2 & 2 & 2 & 32 \\
\hline $13 E-33$ & 32 & 2 & 2 & 2 & 2 & 2 & -32 \\
\hline $.07 E-33$ & $4.77 E-32$ & $30 E-32$ & $7 E-32$ & $9 E-32$ & $1 \mathrm{~F}$ & -32 & $7 \mathrm{E}-32$ \\
\hline $01 E-33$ & $4.81 E-32$ & $.34 E-32$ & $4.51 \mathrm{E}-32$ & $4.73 E-32$ & $4.75 E-32$ & $4.77 E-32$ & 4. $78 E-32$ \\
\hline $95 E-33$ & $E-32$ & -32 & -32 & -32 & & -32 & $82 E-32$ \\
\hline & & & & & & & \\
\hline 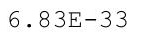 & 1. & & & & & & 32 \\
\hline $.77 E-33$ & 32 & 2 & 2 & 2 & 2 & 32 & -32 \\
\hline$E-33$ & $03 F-32$ & $1 E-32$ & $E-32$ & $4 E-32$ & 265 & -32 & $00 E-32$ \\
\hline $66 \mathrm{E}-33$ & $.07 E-32$ & $5 E-32$ & $4.74 \mathrm{E}-32$ & $98 E-32$ & $01 E-32$ & $E-32$ & $04 \mathrm{E}-32$ \\
\hline$E-33$ & 32 & & -32 & -32 & & -32 & $8 E-32$ \\
\hline & & & & & & & \\
\hline & & & & & & & \\
\hline $.43 E-33$ & $5.26 \mathrm{E}-32$ & $4.70 E-32$ & $4.90 E-32$ & $5.15 \mathrm{E}-32$ & $5.18 \mathrm{E}-32$ & $0 E-32$ & $22 E-32$ \\
\hline 3 & 2 & 20. & 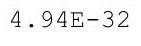 & 2 & 然 & $5 E-32$ & $.27 E-32$ \\
\hline 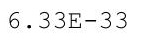 & 2 & $.77 E-3$ & $.98 \mathrm{E}-$ & & & $E-32$ & $31 E-32$ \\
\hline$E-33$ & $40 F-32$ & $81 F-32$ & $.02 E-32$ & $9 E-32$ & 325 & $E-32$ & $36 E-32$ \\
\hline & & & & & & & 32 \\
\hline-33 & & & 32 & -32 & & -32 & \\
\hline $.11 \mathrm{E}-33$ & $5.54 \mathrm{E}-32$ & $4.93 E-32$ & $5.15 \mathrm{E}-32$ & $5.43 E-32$ & $5.46 \mathrm{E}-32$ & $5.48 E-32$ & $.50 E-32$ \\
\hline $.06 \mathrm{E}-33$ & $3.39 E-32$ & & & $5.48 \mathrm{E}-32$ & - & $5.53 E-32$ & $5.55 E-32$ \\
\hline $01 E-33$ & 2 & $5.01 E-32$ & $3 E-32$ & 2 & 2 & 2 & 32 \\
\hline 5 & 2 & 5. & & 2 & & 2 & 32 \\
\hline 3 & & & 2 & 2 & & 2 & -32 \\
\hline $36 E-33$ & $5.79 E-32$ & $E-32$ & -32 & -32 & 32 & -32 & $5 E-32$ \\
\hline$E-33$ & $5.84 \mathrm{E}-32$ & 32 & & & 2 & & $30 E-32$ \\
\hline $0 \mathrm{n}-32$ & & & & & & & $.85 E-32$ \\
\hline $.115-33$ & $3.935-32$ & 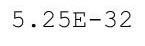 & $.50 E-32$ & $5.82 E-32$ & $5.86 E-32$ & $5.88 E-32$ & $90 E-32$ \\
\hline $66 E-33$ & $6.00 \mathrm{E}-32$ & & & & & $3 E-32$ & $5.95 E-32$ \\
\hline & & - & $E-32$ & 2 & . & $E-32$ & $.01 E-32$ \\
\hline $57 E-33$ & -32 & $E-32$ & $63 E-32$ & -32 & $6.01 E-32$ & $.04 E-32$ & $.06 E-32$ \\
\hline
\end{tabular}


RESRAD-OFFSITE, Version 2.5

itle : Offsite Resident Farmer Deterministic Run

File : RF TC99 DOESG FWD-FV2b.ROF

Summary of dose at graphical times, reptition 3 (continued)

Time

Years

$7.08 \mathrm{E}+01$

$7.13 \mathrm{E}+01$

$7.18 \mathrm{E}+01$

$7.23 \mathrm{E}+01$

$7.28 \mathrm{E}+01$

7. $33 \mathrm{E}+01$

$7.38 \mathrm{E}+01$

$7.43 \mathrm{E}+01$

$7.49 \mathrm{E}+01$

$7.54 \mathrm{E}+01$

$7.59 \mathrm{E}+01$

$7.64 \mathrm{E}+01$

$7.69 \mathrm{E}+01$

$7.74 \mathrm{E}+01$

$7.79 \mathrm{E}+01$

$7.84 \mathrm{E}+01$

7. $90 \mathrm{E}+01$

7. $95 \mathrm{E}+01$

$8.00 \mathrm{E}+01$

$8.05 \mathrm{E}+01$

$8.10 \mathrm{E}+01$

$8.15 \mathrm{E}+01$

$8.20 \mathrm{E}+01$

$8.25 \mathrm{E}+01$

$8.31 \mathrm{E}+01$

$8.36 \mathrm{E}+01$

$8.41 \mathrm{E}+01$

$8.46 \mathrm{E}+01$

$8.51 \mathrm{E}+01$

$8.56 \mathrm{E}+01$

8. $61 \mathrm{E}+01$

$8.66 \mathrm{E}+01$

$8.72 \mathrm{E}+01$

$8.77 \mathrm{E}+01$

$8.82 \mathrm{E}+01$

$8.87 \mathrm{E}+01$

8. $92 \mathrm{E}+01$

$8.97 \mathrm{E}+01$

9. $02 \mathrm{E}+01$

$9.07 \mathrm{E}+01$

9. $13 \mathrm{E}+01$

9. $18 \mathrm{E}+01$

9. $23 \mathrm{E}+01$

9. $28 \mathrm{E}+01$

9. $33 \mathrm{E}+01$

9. $38 \mathrm{E}+01$
Dose statistics at graphical times, mrem/yr

\begin{tabular}{|c|c|c|c|c|c|c|c|}
\hline m & um & ean & - & & & $\%$ & \\
\hline $52 E-33$ & $6.16 \mathrm{E}-32$ & $5.42 E-32$ & $5.68 E-32$ & $6.03 E-32$ & $6.06 \mathrm{E}-32$ & -32 & -32 \\
\hline $47 E-33$ & $2 E-32$ & -32 & -32 & -32 & 32 & -32 & -32 \\
\hline $42 E-33$ & $6.27 \mathrm{E}-32$ & $5.51 \mathrm{E}-32$ & $5.78 \mathrm{E}-32$ & $6.13 E-32$ & $6.17 E-32$ & $6.20 \mathrm{E}-32$ & $6.22 E-32$ \\
\hline $38 E-33$ & $6.33 E-32$ & $5.55 E-32$ & $5.82 \mathrm{E}-32$ & $6.18 \mathrm{E}-32$ & $6.23 E-32$ & -32 & $27 E-32$ \\
\hline 33 & 2 & 2 & 2 & & & 2 & 32 \\
\hline$E-33$ & -32 & $E-32$ & -32 & -32 & 32 & -32 & -32 \\
\hline $24 \mathrm{E}-33$ & 32 & & & -32 & & -32 & -32 \\
\hline $20 E-33$ & 32 & & & & & & -32 \\
\hline $5 E-33$ & -32 & $E-32$ & -32 & -32 & 2 & -32 & -32 \\
\hline $11 \mathrm{E}-33$ & $6.67 \mathrm{E}-32$ & 烈 & -32 & t & 2 & 2 & 32 \\
\hline $.07 E-33$ & $6.73 E-32$ & 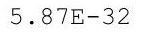 & 等 & - & r & -32 & -32 \\
\hline $02 E-33$ & 32 & & & 2 & & & \\
\hline $.98 E-33$ & $5 E-32$ & $7 E-32$ & $7 E-32$ & 6. & 32 & -32 & -32 \\
\hline$E-33$ & $E-32$ & $2 E-32$ & $E-32$ & 2 & 2 & -32 & -32 \\
\hline-33 & -32 & 2 & 2 & 2 & & & -32 \\
\hline 33 & & 2 & 32 & 2 & 2 & 32 & -32 \\
\hline 33 & 32 & 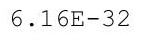 & 2 & 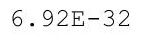 & 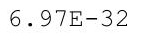 & 2 & -32 \\
\hline $.77 E-33$ & & & & & & & -32 \\
\hline $.73 E-33$ & 7. $22 \mathrm{E}-32$ & & $6.59 E-32$ & & $7.09 \mathrm{E}$ & -32 & $16 E-32$ \\
\hline $.69 \mathrm{E}-33$ & $E-32$ & $.31 E-3$ & -32 & $0 E-32$ & $6 F-32$ & -32 & -32 \\
\hline $65 E-33$ & $.35 E-32$ & $.36 E-32$ & $0 E-32$ & 2 & 2 & $6 E-32$ & $28 E-32$ \\
\hline & & & & & & & -32 \\
\hline & & & & & & & 32 \\
\hline $53 E-33$ & -32 & 0 & 2 & 2 & & & -32 \\
\hline 3 & 2 & Ut & 2 & 2 & 2 & 2 & -32 \\
\hline $46 \mathrm{E}-33$ & $.68 E-32$ & - & $6.98 \mathrm{E}-32$ & 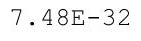 & 7 505 & $8 E-32$ & $61 E-32$ \\
\hline $2 F-33$ & -32 & $67 F-3$ & $4 E-32$ & 2 & & $E-32$ & -32 \\
\hline$F-33$ & -32 & $3 F-32$ & & & & -32 & $75 E-32$ \\
\hline & & & & & & & 32 \\
\hline $31 E-33$ & $7.96 \mathrm{E}-32$ & $0.04 \amalg-2$ & 32 & $1.10 \mathrm{x}$ & .01 & 32 & -32 \\
\hline $.27 E-33$ & $0.035-32$ & • & $7.28 E-32$ & $7.81 \mathrm{E}-32$ & . & $E-32$ & $.95 E-32$ \\
\hline $24 \mathrm{E}-33$ & - & 然 & 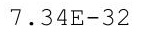 & & & $=0$ & $8.02 E-32$ \\
\hline 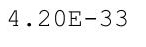 & 1 & & & & & & 32 \\
\hline-33 & .32 & & 2 & & & 2 & 32 \\
\hline 3 & & & & & & & \\
\hline & $0.39 \mathrm{E}$ & $7.17 \mathrm{E}$ & 32 & $0.10 \mathrm{~L}$ & 0.20 & & -32 \\
\hline$E-33$ & . 110 & & & & & & -32 \\
\hline$E-33$ & & & & & & & $5 E-32$ \\
\hline 3 & 2 & ? & 2 & & 2 & 2 & 32 \\
\hline & & & & & & & \\
\hline 3 & & & 32 & 2 & 2 & 32 & 32 \\
\hline $9 E-33$ & $8.85 E-32$ & -32 & 7.9 & 8 & & -32 & -32 \\
\hline & & & & & & & \\
\hline & & & & . & & & . \\
\hline & . & & & $2 E-32$ & 32 & $95 E-32$ & $E-32$ \\
\hline 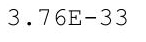 & $E-32$ & $E-32$ & $3 E-32$ & $E-32$ & $3 E-32$ & $3 E-32$ & -32 \\
\hline
\end{tabular}


RESRAD-OFFSITE, Version 2.5

itle : Offsite Resident Farmer Deterministic Run

File : RF TC99 DOESG FWD-FV2b.ROF

Summary of dose at graphical times, reptition 3 (continued)

Time

Years

9. $43 \mathrm{E}+01$

9. $48 \mathrm{E}+01$

9. $54 \mathrm{E}+01$

9. $59 \mathrm{E}+01$

9. $64 \mathrm{E}+01$

9. $69 \mathrm{E}+01$

9. $74 \mathrm{E}+01$

9. $79 \mathrm{E}+01$

9. $84 \mathrm{E}+01$

9. $90 \mathrm{E}+01$

9. $95 \mathrm{E}+01$

1. $00 \mathrm{E}+02$

1. $00 \mathrm{E}+02$

1. $01 \mathrm{E}+02$

1. $02 \mathrm{E}+02$

1. $02 \mathrm{E}+02$

1. $03 \mathrm{E}+02$

1. $03 \mathrm{E}+02$

1. $04 \mathrm{E}+02$

1. $04 \mathrm{E}+02$

$1.05 \mathrm{E}+02$

1. $05 \mathrm{E}+02$

$1.06 \mathrm{E}+02$

$1.06 \mathrm{E}+02$

$1.07 \mathrm{E}+02$

1. $07 \mathrm{E}+02$

$1.08 \mathrm{E}+02$

$1.08 \mathrm{E}+02$

1. $09 \mathrm{E}+02$

1. $09 \mathrm{E}+02$

1. $10 \mathrm{E}+02$

1. $10 \mathrm{E}+02$

1. $11 \mathrm{E}+02$

1. $11 \mathrm{E}+02$

1. $12 \mathrm{E}+02$

1. $12 \mathrm{E}+02$

1. $13 \mathrm{E}+02$

1. $13 \mathrm{E}+02$

1. $14 \mathrm{E}+02$

1. $14 \mathrm{E}+02$

1. $15 \mathrm{E}+02$

1. $15 \mathrm{E}+02$

$1.16 \mathrm{E}+02$

$1.16 \mathrm{E}+02$

1. $17 \mathrm{E}+02$

1. $17 \mathrm{E}+02$

Dose statistics at graphical times, mrem/yr

\begin{tabular}{|c|c|c|c|c|c|c|c|}
\hline m & um & ean & n & $90 \%$ & & $\%$ & \\
\hline $.73 E-33$ & $9.25 \mathrm{E}-32$ & $7.84 \mathrm{E}-32$ & $8.30 E-32$ & $8.98 E-32$ & $9.06 \mathrm{E}-32$ & -28 & $-2-32$ \\
\hline $69 \mathrm{E}-33$ & $9.33 E-32$ & $7.90 \mathrm{E}-32$ & $8.37 E-32$ & $9.06 \mathrm{E}-32$ & $9.13 \mathrm{E}-32$ & -32 & -32 \\
\hline $.66 \mathrm{E}-33$ & $9.41 E-32$ & $7.96 \mathrm{E}-32$ & $8.44 \mathrm{E}-32$ & $9.13 \mathrm{E}-32$ & $9.21 \mathrm{E}-32$ & $9.27 \mathrm{E}-32$ & $31 E-32$ \\
\hline-33 & $9.50 \mathrm{E}-32$ & $.03 E-32$ & $8.51 E-32$ & $9.21 \mathrm{E}-32$ & $9.30 \mathrm{E}-32$ & $5 E-32$ & -32 \\
\hline 33 & 2 & 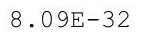 & 32 & & & -32 & -32 \\
\hline$E-33$ & 32 & -32 & -32 & -32 & 2 & -32 & -32 \\
\hline $54 \mathrm{E}-33$ & 32 & & & & & & -32 \\
\hline-33 & & & & & & & -32 \\
\hline-33 & 32 & 2 & 32 & 32 & & -32 & -32 \\
\hline-33 & -31 & - & 32 & 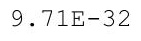 & 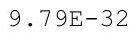 & 2 & -32 \\
\hline 33 & 1 & $9 E-32$ & $2 E-32$ & $79 E-32$ & ? & 2 & 32 \\
\hline 33 & & & & & 2 & & \\
\hline$E-33$ & $3 E-31$ & $8.63 E-32$ & 2 & 2 & & 1 & -31 \\
\hline $34 \mathrm{E}-33$ & $1.04 \mathrm{E}-31$ & $8.70 \mathrm{E}-32$ & $9.24 \mathrm{E}-32$ & $1.00 \mathrm{E}-31$ & 31 & -31 & -31 \\
\hline 33 & 31 & & & & $\perp$ & 31 & -31 \\
\hline 33 & 31 & & & $\perp$ & 1 & 31 & -31 \\
\hline 33 & 31 & $8.91 E-32$ & 32 & $\perp$ & 1 & $\perp$ & 31 \\
\hline 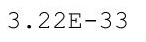 & & & & & & & 31 \\
\hline $20 E-33$ & $1.08 E-31$ & & $9.63 E-32$ & $1.05 E-31$ & & -31 & -31 \\
\hline $17 \mathrm{E}-33$ & $1.09 \mathrm{E}-31$ & -3 & -32 & $.06 \mathrm{E}-31$ & $.07 E-31$ & $E-31$ & $.08 \mathrm{E}-31$ \\
\hline $14 \mathrm{E}-33$ & $1.10 \mathrm{E}-31$ & $9.20 \mathrm{E}-32$ & $9.79 E-32$ & $1.07 E-31$ & & $1.08 E-31$ & $1.09 \mathrm{E}-31$ \\
\hline & & & & & & & $10 E-31$ \\
\hline & & & & & & & \\
\hline$E-33$ & $3 \perp$ & 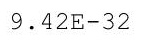 & $\perp$ & & 1 & 1 & -31 \\
\hline 3 & 1 & $9.50 \mathrm{E}-32$ & $\perp$ & 1 & 1 & 1 & -31 \\
\hline$E-33$ & $.03 E-28$ & 1 & 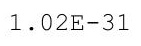 & $112=$ & 173 & $3 E-31$ & $14 \mathrm{E}-31$ \\
\hline 33 & -25 & ק & 1 & 1 & 110 & $E-31$ & $.15 E-31$ \\
\hline-33 & -24 & $2 E-27$ & 31 & 1 & 1 & $E-31$ & $16 E-31$ \\
\hline & & & & & & & \\
\hline $91 E-33$ & $6.96 \mathrm{E}-22$ & $3.40 \pm 20$ & 1. $05 \mathrm{E}-31$ & $\perp \cdot \pm J$ & 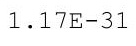 & $7 E-31$ & -31 \\
\hline $88 E-33$ & $5.74 \mathrm{E}-21$ & $2 \cdot 01024$ & $1.06 \mathrm{E}-31$ & $1.16 \mathrm{E}-31$ & $1.18 \mathrm{E}-31$ & $1.18 \mathrm{E}-31$ & $.19 \mathrm{E}-31$ \\
\hline 3 & . & 土. & 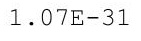 & 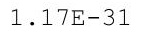 & 2.00 & 31 & $1.20 \mathrm{E}-31$ \\
\hline 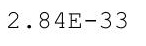 & $1.87 \mathrm{E}-19$ & ? & - & $1.18 \mathrm{E}-$ & & & 1. $21 \mathrm{E}$ \\
\hline-33 & 9 & $E-22$ & 1 & & & -31 & -31 \\
\hline 33 & & & & & & & \\
\hline $6 E-33$ & $9.4 \angle \mathrm{E}$ & 4. $71 \mathrm{E}-21$ & $\perp \cdot+\perp$ & $1.22 \mathrm{E}$ & 1.23 & & 1.24 \\
\hline $4 E-33$ & $2 \cdot 1+1$ & +.02 & & 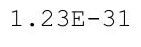 & & & -31 \\
\hline $2 E-33$ & & & & & 1. $25 \mathrm{E}-31$ & & $1.27 \mathrm{E}-31$ \\
\hline 3 & 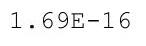 & 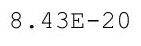 & & 1 & & 1 & 31 \\
\hline & & & & & & & 31 \\
\hline & & & & 1 & 1 & 1 & \\
\hline $3 E-33$ & $1.54 \mathrm{E}-15$ & $9 E-19$ & 1 & 1 . & 1.3 & 31 & -31 \\
\hline & & & & & & & \\
\hline & & 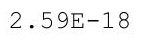 & & $\perp \cdot 00$ & & & \\
\hline & & & & म. & 1.005 & 31 & $\begin{array}{ll}1.000 \\
0\end{array}$ \\
\hline$E-33$ & $9 \mathrm{E}-14$ & $7 E-18$ & $20 E-31$ & $33 E-31$ & $34 E-31$ & $5 E-31$ & 3 \\
\hline
\end{tabular}


RESRAD-OFFSITE, Version 2.5

$\mathrm{T}^{1 / 2}$ Limit $=180$ days

robabilistic Dose and Risk Report

Title : Offsite Resident Farmer Deterministic Run

File : RF TC99 DOESG FWD-FV2b.ROF

Summary of dose at graphical times, reptition 3 (continued)

Time

Years

$1.18 \mathrm{E}+02$

$1.18 \mathrm{E}+02$

1. $19 \mathrm{E}+02$

1. $19 \mathrm{E}+02$

1. $20 \mathrm{E}+02$

1. $20 \mathrm{E}+02$

1. $21 \mathrm{E}+02$

1. $22 \mathrm{E}+02$

1. $22 \mathrm{E}+02$

1. $23 \mathrm{E}+02$

1. $23 \mathrm{E}+02$

1. $24 \mathrm{E}+02$

1. $24 \mathrm{E}+02$

1. $25 \mathrm{E}+02$

1. $25 \mathrm{E}+02$

1. $26 \mathrm{E}+02$

1. $26 \mathrm{E}+02$

1. $27 \mathrm{E}+02$

1. $27 \mathrm{E}+02$

1. $28 \mathrm{E}+02$

1. $28 \mathrm{E}+02$

1. $29 \mathrm{E}+02$

1. $29 \mathrm{E}+02$

1. $30 \mathrm{E}+02$

1. $30 \mathrm{E}+02$

1. $31 \mathrm{E}+02$

1. $31 \mathrm{E}+02$

1. $32 \mathrm{E}+02$

1. $32 \mathrm{E}+02$

1. $33 \mathrm{E}+02$

1. $33 \mathrm{E}+02$

1. $34 \mathrm{E}+02$

1. $34 \mathrm{E}+02$

1. $35 \mathrm{E}+02$

1. $35 \mathrm{E}+02$

1. $36 \mathrm{E}+02$

1. $36 \mathrm{E}+02$

1. $37 \mathrm{E}+02$

1. $37 \mathrm{E}+02$

1. $38 \mathrm{E}+02$

1. $38 \mathrm{E}+02$

1. $39 \mathrm{E}+02$

1. $39 \mathrm{E}+02$

1. $40 \mathrm{E}+02$

1. $40 \mathrm{E}+02$

1. $41 \mathrm{E}+02$

Dose statistics at graphical times, mrem/yr

\begin{tabular}{|c|c|c|c|c|c|c|c|}
\hline Minimum & Maximum & Mean & Median & $90 \%$ & $95 \%$ & $97.5 \%$ & $99 \%$ \\
\hline $2.52 E-33$ & $2.41 \mathrm{E}-14$ & $1.21 \mathrm{E}-17$ & $1.21 \mathrm{E}-31$ & $1.34 \mathrm{E}-31$ & $1.35 \mathrm{E}-31$ & $1.36 \mathrm{E}-31$ & $1.37 \mathrm{E}-31$ \\
\hline $2.50 \mathrm{E}-33$ & $3.79 \mathrm{E}-14$ & $1.90 \mathrm{E}-17$ & $1.22 \mathrm{E}-31$ & $1.35 E-31$ & $1.37 \mathrm{E}-31$ & $1.38 \mathrm{E}-31$ & $1.39 \mathrm{E}-31$ \\
\hline $2.47 E-33$ & $5.81 \mathrm{E}-14$ & $2.93 E-17$ & 1. $23 E-31$ & $1.36 \mathrm{E}-31$ & $1.38 \mathrm{E}-31$ & 1.39E-31 & 1. $40 \mathrm{E}-31$ \\
\hline $2.45 E-33$ & $8.71 E-14$ & $4.39 \mathrm{E}-17$ & $1.24 \mathrm{E}-31$ & $1.37 \mathrm{E}-31$ & $1.39 \mathrm{E}-31$ & $1.40 \mathrm{E}-31$ & $1.41 \mathrm{E}-31$ \\
\hline $2.43 E-33$ & 1. $28 E-13$ & $6.47 E-17$ & $1.25 E-31$ & $1.39 E-31$ & $1.40 \mathrm{E}-31$ & $1.41 E-31$ & $1.42 E-31$ \\
\hline $2.41 E-33$ & $1.84 \mathrm{E}-13$ & $9.34 \mathrm{E}-17$ & $1.26 \mathrm{E}-31$ & $.40 E-31$ & $.41 \mathrm{E}-31$ & $42 \mathrm{E}-31$ & $.44 \mathrm{E}-31$ \\
\hline $2.39 E-33$ & $2.60 E-13$ & $1.33 E-16$ & 1. $28 E-31$ & $1.41 \mathrm{E}-31$ & $1.43 E-31$ & $1.44 \mathrm{E}-31$ & $.45 E-31$ \\
\hline $2.37 E-33$ & $3.61 \mathrm{E}-13$ & $1.85 \mathrm{E}-16$ & $1.29 \mathrm{E}-31$ & $1.42 \mathrm{E}-31$ & $1.44 \mathrm{E}-31$ & $1.45 \mathrm{E}-31$ & $1.46 \mathrm{E}-31$ \\
\hline $2.35 E-33$ & 4. $94 \mathrm{E}-13$ & $2.55 \mathrm{E}-16$ & 1. $30 \mathrm{E}-31$ & $1.44 \mathrm{E}-31$ & $1.45 \mathrm{E}-31$ & $1.46 \mathrm{E}-31$ & $1.48 \mathrm{E}-31$ \\
\hline $2.33 E-33$ & $6.66 \mathrm{E}-13$ & $3.47 \mathrm{E}-16$ & $1.31 \mathrm{E}-31$ & $1.45 \mathrm{E}-31$ & $1.46 \mathrm{E}-31$ & $1.48 \mathrm{E}-31$ & $.49 \mathrm{E}-31$ \\
\hline $2.31 E-33$ & $8.87 E-13$ & $4.67 E-16$ & 1. $32 \mathrm{E}-31$ & $46 \mathrm{E}-31$ & $1.48 \mathrm{E}-31$ & $1.49 \mathrm{E}-31$ & $1.50 \mathrm{E}-31$ \\
\hline $2.29 E-33$ & $1.17 E-12$ & $6.20 E-16$ & $1.33 E-31$ & $47 E-31$ & $49 E-31$ & $.50 \mathrm{E}-31$ & $.52 E-31$ \\
\hline $2.27 E-33$ & $1.52 \mathrm{E}-12$ & $8.14 \mathrm{E}-16$ & 1. $34 \mathrm{E}-31$ & $1.49 E-31$ & $1.50 \mathrm{E}-31$ & $1.52 \mathrm{E}-31$ & $1.53 \mathrm{E}-31$ \\
\hline $2.25 E-33$ & $1.95 \mathrm{E}-12$ & $1.06 \mathrm{E}-15$ & $1.35 E-31$ & $1.50 \mathrm{E}-31$ & $1.52 \mathrm{E}-31$ & $1.53 \mathrm{E}-31$ & 1. $55 \mathrm{E}-31$ \\
\hline $2.23 E-33$ & $2.48 E-12$ & $1.36 \mathrm{E}-15$ & 1. $36 \mathrm{E}-31$ & $1.51 \mathrm{E}-31$ & $1.53 \mathrm{E}-31$ & $1.54 \mathrm{E}-31$ & $1.57 \mathrm{E}-31$ \\
\hline $2.21 E-33$ & $3.13 E-12$ & $1.74 E-15$ & $1.38 E-31$ & $1.53 E-31$ & $1.54 \mathrm{E}-31$ & $1.56 \mathrm{E}-31$ & 7. $45 E-28$ \\
\hline $2.20 E-33$ & $3.90 \mathrm{E}-12$ & $2.21 E-15$ & 1. $39 \mathrm{E}-31$ & $54 \mathrm{E}-31$ & $.56 \mathrm{E}-31$ & $1.57 \mathrm{E}-31$ & $.26 E-25$ \\
\hline $2.18 E-33$ & $4.84 E-12$ & $2.77 E-15$ & $1.40 E-31$ & $.55 E-31$ & $1.57 \mathrm{E}-31$ & $.58 \mathrm{E}-31$ & $.27 E-24$ \\
\hline $2.16 \mathrm{E}-33$ & $5.94 E-12$ & $3.46 E-15$ & 1. $41 E-31$ & $1.57 E-31$ & $1.59 \mathrm{E}-31$ & $1.60 \mathrm{E}-31$ & $1.08 \mathrm{E}-22$ \\
\hline $2.14 \mathrm{E}-33$ & 7. $24 \mathrm{E}-12$ & $4.29 \mathrm{E}-15$ & 1. $42 \mathrm{E}-31$ & $1.58 \mathrm{E}-31$ & $1.60 \mathrm{E}-31$ & $1.61 \mathrm{E}-31$ & 1. $38 \mathrm{E}-21$ \\
\hline $2.12 \mathrm{E}-33$ & $8.76 \mathrm{E}-12$ & $5.28 \mathrm{E}-15$ & 1. $43 E-31$ & $1.59 \mathrm{E}-31$ & $1.61 \mathrm{E}-31$ & $1.63 E-31$ & $1.23 \mathrm{E}-20$ \\
\hline $2.10 E-33$ & $1.05 E-11$ & $6.46 E-15$ & $1.45 E-31$ & $1.61 E-31$ & $1.63 E-31$ & $1.64 \mathrm{E}-31$ & $8.19 \mathrm{E}-20$ \\
\hline $2.09 E-33$ & $1.26 \mathrm{E}-11$ & $7.86 \mathrm{E}-15$ & 1. $46 \mathrm{E}-31$ & $62 \mathrm{E}-31$ & $64 \mathrm{E}-31$ & $1.66 \mathrm{E}-31$ & $4.34 \mathrm{E}-19$ \\
\hline $2.07 E-33$ & 1. $49 \mathrm{E}-11$ & $9.50 \mathrm{E}-15$ & $1.47 E-31$ & $1.64 \mathrm{E}-31$ & $1.66 \mathrm{E}-31$ & $1.67 E-31$ & $1.90 \mathrm{E}-18$ \\
\hline $2.05 E-33$ & $1.76 \mathrm{E}-11$ & $1.14 \mathrm{E}-14$ & 1. $48 E-31$ & $1.65 E-31$ & $1.67 E-31$ & $1.69 \mathrm{E}-31$ & $5.80 \mathrm{E}-18$ \\
\hline $2.03 E-33$ & $2.07 E-11$ & $1.37 \mathrm{E}-14$ & $1.50 E-31$ & $1.67 E-31$ & $1.69 \mathrm{E}-31$ & $1.71 \mathrm{E}-31$ & $.54 \mathrm{E}-17$ \\
\hline $2.02 E-33$ & $2.42 \mathrm{E}-11$ & $1.63 \mathrm{E}-14$ & $1.51 \mathrm{E}-31$ & $1.68 \mathrm{E}-31$ & $1.70 \mathrm{E}-31$ & $1.72 \mathrm{E}-31$ & $3.74 \mathrm{E}-17$ \\
\hline $2.00 E-33$ & $2.81 E-11$ & $1.93 E-14$ & $1.52 E-31$ & $1.70 E-31$ & $1.72 \mathrm{E}-31$ & $1.74 E-31$ & $8.52 E-17$ \\
\hline $1.98 \mathrm{E}-33$ & $3.24 \mathrm{E}-11$ & $2.28 \mathrm{E}-14$ & $1.53 E-31$ & $1.71 \mathrm{E}-31$ & 1. $73 \mathrm{E}-31$ & $1.75 \mathrm{E}-31$ & $1.82 \mathrm{E}-16$ \\
\hline $1.96 \mathrm{E}-33$ & $3.74 \mathrm{E}-11$ & $2.68 E-14$ & $1.55 E-31$ & $1.73 E-31$ & $1.75 E-31$ & $1.77 E-31$ & $3.71 \mathrm{E}-16$ \\
\hline $1.95 E-33$ & $4.28 E-11$ & $3.13 E-14$ & $1.56 \mathrm{E}-31$ & $1.74 E-31$ & $1.76 \mathrm{E}-31$ & $1.79 \mathrm{E}-31$ & $7.19 \mathrm{E}-16$ \\
\hline $1.93 \mathrm{E}-33$ & $4.89 \mathrm{E}-11$ & $3.65 \mathrm{E}-14$ & $1.57 \mathrm{E}-31$ & $1.76 \mathrm{E}-31$ & $1.78 \mathrm{E}-31$ & $1.80 \mathrm{E}-31$ & 1. $34 \mathrm{E}-15$ \\
\hline 1. $92 \mathrm{E}-33$ & $.56 \mathrm{E}-11$ & $4.24 \mathrm{E}-14$ & $1.59 E-31$ & $1.77 \mathrm{E}-31$ & $1.80 \mathrm{E}-31$ & $1.82 E-31$ & $2.38 E-15$ \\
\hline $1.90 \mathrm{E}-33$ & $.30 E-11$ & $4.91 \mathrm{E}-14$ & $1.60 E-31$ & $1.79 E-31$ & $1.81 \mathrm{E}-31$ & $.84 E-31$ & $4.11 \mathrm{E}-15$ \\
\hline $1.88 \mathrm{E}-33$ & $7.11 E-11$ & $5.66 \mathrm{E}-14$ & 1. $61 E-31$ & $1.80 E-31$ & $1.83 E-31$ & $1.86 E-31$ & $6.85 E-15$ \\
\hline $1.87 \mathrm{E}-33$ & $8.00 E-11$ & $6.51 \mathrm{E}-14$ & $1.63 E-31$ & $1.82 \mathrm{E}-31$ & $1.85 E-31$ & $1.87 E-31$ & $1.11 \mathrm{E}-14$ \\
\hline $1.85 E-33$ & $8.97 \mathrm{E}-11$ & $7.47 \mathrm{E}-14$ & 1. $64 \mathrm{E}-31$ & $1.84 \mathrm{E}-31$ & $1.86 \mathrm{E}-31$ & 1.89E-31 & 1. $75 \mathrm{E}-14$ \\
\hline $1.84 \mathrm{E}-33$ & $1.00 \mathrm{E}-10$ & $8.53 \mathrm{E}-14$ & $1.65 E-31$ & $1.85 E-31$ & $1.88 \mathrm{E}-31$ & $1.92 \mathrm{E}-31$ & $2.68 \mathrm{E}-14$ \\
\hline $1.82 \mathrm{E}-33$ & $1.12 \mathrm{E}-10$ & $9.73 E-14$ & 1. $67 \mathrm{E}-31$ & $1.87 E-31$ & $1.90 \mathrm{E}-31$ & $4.69 E-30$ & $4.02 E-14$ \\
\hline $1.80 \mathrm{E}-33$ & $.24 \mathrm{E}-$ & $1.11 \mathrm{E}-$ & $1.68 \mathrm{E}-31$ & $1.89 \mathrm{E}-31$ & 1.91E-31 & 1. $65 \mathrm{E}-27$ & $5.89 \mathrm{E}-14$ \\
\hline $1.79 \mathrm{E}-33$ & $1.38 E-10$ & $1.25 E-13$ & $1.70 E-31$ & $1.90 E-31$ & $1.93 E-31$ & $1.28 \mathrm{E}-25$ & $8.47 E-14$ \\
\hline $1.77 \mathrm{E}-33$ & $1.53 \mathrm{E}-10$ & $1.42 E-13$ & $1.71 E-31$ & $1.92 E-31$ & $1.95 \mathrm{E}-31$ & $3.69 \mathrm{E}-24$ & $1.20 \mathrm{E}-13$ \\
\hline $1.76 \mathrm{E}-33$ & $1.68 \mathrm{E}-10$ & $1.60 \mathrm{E}-13$ & $1.73 E-31$ & $1.94 \mathrm{E}-31$ & $1.97 \mathrm{E}-31$ & $5.98 E-23$ & $1.66 \mathrm{E}-13$ \\
\hline $1.74 \mathrm{E}-33$ & $1.85 E-10$ & $1.80 \mathrm{E}-13$ & $1.74 \mathrm{E}-31$ & $1.96 \mathrm{E}-31$ & $1.99 \mathrm{E}-31$ & $6.46 \mathrm{E}-22$ & $2.27 E-13$ \\
\hline $1.73 E-33$ & $2.04 \mathrm{E}-10$ & $2.02 E-13$ & $1.75 E-31$ & $1.97 E-31$ & $2.00 E-31$ & $5.11 \mathrm{E}-21$ & $3.06 \mathrm{E}-13$ \\
\hline $1.71 E-33$ & $2.23 E-10$ & $2.26 \mathrm{E}-13$ & $1.77 E-31$ & $1.99 E-31$ & $2.02 E-31$ & $3.15 \mathrm{E}-20$ & $4.06 \mathrm{E}-13$ \\
\hline
\end{tabular}


RESRAD-OFFSITE, Version 2.5

$\mathrm{T}^{1 / 2}$ Limit $=180$ days

obabilistic Dose and Risk Report

Title : Offsite Resident Farmer Deterministic Run

File : RF TC99 DOESG FWD-FV2b.ROF

Summary of dose at graphical times, reptition 3 (continued)

Time

Years

1. $42 \mathrm{E}+02$

1. $42 \mathrm{E}+02$

1. $43 \mathrm{E}+02$

1. $43 \mathrm{E}+02$

1. $44 \mathrm{E}+02$

1. $44 \mathrm{E}+02$

1. $45 \mathrm{E}+02$

1. $45 \mathrm{E}+02$

1. $46 \mathrm{E}+02$

1. $46 \mathrm{E}+02$

1. $47 \mathrm{E}+02$

1. $47 \mathrm{E}+02$

1. $48 \mathrm{E}+02$

1. $48 \mathrm{E}+02$

1. $49 \mathrm{E}+02$

1. $49 \mathrm{E}+02$

1. $50 \mathrm{E}+02$

1. $50 \mathrm{E}+02$

1. $51 \mathrm{E}+02$

1. $51 \mathrm{E}+02$

1. $52 \mathrm{E}+02$

1. $52 \mathrm{E}+02$

1. $53 \mathrm{E}+02$

1. $53 \mathrm{E}+02$

$1.54 \mathrm{E}+02$

$1.54 \mathrm{E}+02$

1. $55 \mathrm{E}+02$

1. $55 \mathrm{E}+02$

1. $56 \mathrm{E}+02$

1. $56 \mathrm{E}+02$

1. $57 \mathrm{E}+02$

1. $57 \mathrm{E}+02$

1. $58 \mathrm{E}+02$

1. $58 \mathrm{E}+02$

1. $59 \mathrm{E}+02$

1. $59 \mathrm{E}+02$

1. $60 \mathrm{E}+02$

1. $60 \mathrm{E}+02$

1. $61 \mathrm{E}+02$

1. $61 \mathrm{E}+02$

1. $62 \mathrm{E}+02$

1. $63 \mathrm{E}+02$

1. $63 \mathrm{E}+02$

1. $64 \mathrm{E}+02$

1. $64 \mathrm{E}+02$

1. $65 \mathrm{E}+02$
Dose statistics at graphical times, mrem/yr

\begin{tabular}{|c|c|c|c|c|c|c|c|}
\hline m & aximum & ean & ledian & & & $\%$ & $\%$ \\
\hline $.70 E-33$ & $2.44 \mathrm{E}-10$ & $2.53 E-13$ & 1. $78 \mathrm{E}-31$ & $2.01 \mathrm{E}-31$ & $2.04 \mathrm{E}-31$ & 1.57 & 15 \\
\hline $69 E-33$ & 10 & 13 & 31 & 31 & 31 & 19 & 13 \\
\hline $.67 E-33$ & $2.90 \mathrm{E}-10$ & $5 E-13$ & $1.81 \mathrm{E}-31$ & $2.04 \mathrm{E}-31$ & $2.08 \mathrm{E}-31$ & -18 & $85 E-13$ \\
\hline $66 \mathrm{E}-33$ & $3.16 \mathrm{E}-10$ & $.50 E-13$ & $1.83 E-31$ & $2.06 \mathrm{E}-31$ & $2.10 \mathrm{E}-31$ & $50 E-18$ & $12 \mathrm{E}-12$ \\
\hline 33 & 10 & 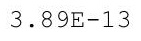 & 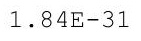 & 31 & & 17 & 12 \\
\hline $63 E-33$ & 10 & 3 & 1 & 1 & $2.14 \mathrm{E}-31$ & 17 & -12 \\
\hline $61 \mathrm{E}-33$ & $4.02 \mathrm{E}$ & & & & & & -12 \\
\hline-33 & & & & & & & -12 \\
\hline-33 & 10 & -13 & \pm & 1 & & -16 & $29 \mathrm{E}-12$ \\
\hline $57 E-33$ & -10 & - & $+{ }^{\circ}$ & 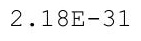 & $2.22 E-31$ & 6 & 12 \\
\hline 33 & so & -0 & -0 & -1 & & 15 & -12 \\
\hline 33 & & & & & & & 12 \\
\hline $.61 E-33$ & $6.26 \mathrm{E}-10$ & & 1. & $2.23 \mathrm{E}$ & $2.28 \mathrm{E}$ & -15 & -12 \\
\hline $58 E-33$ & $1 \mathrm{E}-10$ & $3 E-13$ & 1 & 1 & 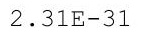 & -15 & -12 \\
\hline-33 & 10 & 2 & & $\perp$ & & & -12 \\
\hline 33 & $7.69 \mathrm{E}-10$ & 12 & $\perp$ & $\perp$ & $2.35 E-31$ & 14 & -11 \\
\hline 33 & 10 & $1.20 \mathrm{E}-12$ & $\perp$ & $32 E-31$ & 2.30 & & 11 \\
\hline 3 & 8 & & & & & & 1 \\
\hline $48 E-33$ & $9.34 \mathrm{E}-10$ & 1. $42 \mathrm{E}-12$ & & & 1.50 & -14 & -11 \\
\hline $46 \mathrm{E}-33$ & $9.94 \mathrm{E}-10$ & $4 \mathrm{E}-12$ & $D E-31$ & $.38 \mathrm{E}-3$ & $2.87 E-26$ & $E-14$ & $.80 \mathrm{E}-11$ \\
\hline $43 E-33$ & $1.06 \mathrm{E}-09$ & 1. $68 \mathrm{E}-12$ & $2.12 \mathrm{E}-31$ & $2.40 E-31$ & $1.44 \mathrm{E}$ & -13 & -11 \\
\hline 33 & & & & & & & -11 \\
\hline 3 & U. & & & & & & \\
\hline $37 E-33$ & $\perp \cdot 21$ & $\perp 2$ & & & $2.93 E-21$ & & 11 \\
\hline 3 & 9 & $=$ & $\perp$ & 1 & $1.85 \mathrm{E}-20$ & 3 & 11 \\
\hline $3 E-33$ & $.42 E-09$ & $.48 \mathrm{E}-12$ & $2.21 \mathrm{E}-31$ & $251 \mathrm{~F}-$ & & 25 & זר?6 \\
\hline $1 E-33$ & $1.50 \mathrm{E}-09$ & $2.67 \mathrm{E}-12$ & $2.23 E-31$ & $.54 \mathrm{E}-$ & $4.40 \mathrm{E}-$ & $3 E-13$ & $02 E-11$ \\
\hline-33 & 09 & $87 E-12$ & & 1 & 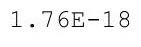 & -13 & $46 E-11$ \\
\hline-33 & $1.68 \mathrm{E}$ & & & & & & \\
\hline $25 E-33$ & $1.77 \mathrm{E}-09$ & $3.3 \angle E-12$ & $2.29 \mathrm{~L}$ & $2 \cdot 01$ & \pm .02 & 12 & -11 \\
\hline $.23 E-33$ & $1.01 \mathrm{E}-09$ & $3.012-12$ & $2.31 \mathrm{~L}-3 \perp$ & $2.63 E-31$ & 1. tor & -12 & $.19 \mathrm{E}-11$ \\
\hline $21 E-33$ & $1.97 \mathrm{E}-09$ & 年 & 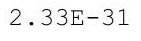 & & 年 & 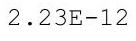 & $0.07 \pm-11$ \\
\hline $.19 E-33$ & $2.08 E-09$ & & 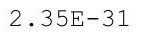 & & & & \\
\hline-33 & ( & 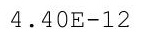 & & & & 2 & 11 \\
\hline 3 & & & & & & & \\
\hline $3 E-33$ & $2.42 E-09$ & $5.03 E-12$ & $2.41 E-31$ & $2.10 \mathrm{E}$ & $1 \cdot 47$ & 12 & -10 \\
\hline $1 E-33$ & 2.00 & $0^{\circ}$ & $2 \cdot$ & & & & 10 \\
\hline $09 E-33$ & $2.00 \mathrm{~L}-\mathrm{y}$ & & & & & & 1.22010 \\
\hline 3 & 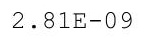 & 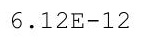 & $2.47 \mathrm{E}-31$ & 1 & 5 & 2 & 1. $33 \mathrm{E}-10$ \\
\hline & & & & & & & \\
\hline 3 & & & 31 & 1 & 4 & 1 & \\
\hline$E-33$ & $3.24 E-09$ & $E-12$ & 2. & 31 & 4 & 11 & 1. \\
\hline & & & & & & & 10 \\
\hline & & 2 & & & & & t. \\
\hline & . & 2 & & $\perp$ & 4 & 11 & मU \\
\hline 3 & $9 E-09$ & $5 E-12$ & $63 E-31$ & $E-31$ & $08 E-13$ & $4 E-11$ & -10 \\
\hline
\end{tabular}


RESRAD-OFFSITE, Version 2.5

$\mathrm{T}^{1 / 2}$ Limit $=180$ days

obabilistic Dose and Risk Report

Title : Offsite Resident Farmer Deterministic Run

File : RF TC99 DOESG FWD-FV2b.ROF

Summary of dose at graphical times, reptition 3 (continued)

Time

Years

1. $65 \mathrm{E}+02$

$1.66 \mathrm{E}+02$

1. $66 \mathrm{E}+02$

$1.67 \mathrm{E}+02$

1. $67 \mathrm{E}+02$

$1.68 \mathrm{E}+02$

1. $68 \mathrm{E}+02$

$1.69 \mathrm{E}+02$

$1.69 \mathrm{E}+02$

$1.70 \mathrm{E}+02$

$1.70 \mathrm{E}+02$

$1.71 \mathrm{E}+02$

$1.71 \mathrm{E}+02$

1. $72 \mathrm{E}+02$

1. $72 \mathrm{E}+02$

$1.73 E+02$

$1.73 \mathrm{E}+02$

$1.74 \mathrm{E}+02$

$1.74 \mathrm{E}+02$

$1.75 \mathrm{E}+02$

$1.75 \mathrm{E}+02$

$1.76 \mathrm{E}+02$

$1.76 \mathrm{E}+02$

$1.77 \mathrm{E}+02$

$1.77 \mathrm{E}+02$

$1.78 \mathrm{E}+02$

$1.78 \mathrm{E}+02$

$1.79 \mathrm{E}+02$

$1.79 \mathrm{E}+02$

$1.80 \mathrm{E}+02$

$1.80 \mathrm{E}+02$

1. $81 \mathrm{E}+02$

$1.81 \mathrm{E}+02$

1. $82 \mathrm{E}+02$

$1.83 \mathrm{E}+02$

$1.83 E+02$

$1.84 \mathrm{E}+02$

$1.84 \mathrm{E}+02$

$1.85 \mathrm{E}+02$

$1.85 \mathrm{E}+02$

$1.86 \mathrm{E}+02$

$1.86 \mathrm{E}+02$

$1.87 \mathrm{E}+02$

$1.87 \mathrm{E}+02$

$1.88 \mathrm{E}+02$

$1.88 \mathrm{E}+02$
Dose statistics at graphical times, mrem/yr

\begin{tabular}{|c|c|c|c|c|c|c|c|}
\hline$m$ & um & ean & ledian & $90 \%$ & & $\%$ & $\%$ \\
\hline $92 E-33$ & $4.07 E-09$ & $1.00 \mathrm{E}-11$ & $2.65 E-31$ & $3.06 \mathrm{E}-31$ & $1.51 \mathrm{E}-13$ & $2.76 \mathrm{E}-11$ & $2.45 E-10$ \\
\hline $90 E-33$ & -09 & 11 & 31 & 31 & 13 & -11 & -10 \\
\hline $.88 E-33$ & $4.45 E-09$ & 1. $13 \mathrm{E}-11$ & $0 \mathrm{E}-31$ & $3.12 \mathrm{E}-31$ & $2.90 \mathrm{E}-13$ & -11 & $2.78 \mathrm{E}-10$ \\
\hline $87 E-33$ & $4.64 \mathrm{E}-09$ & 1. $19 \mathrm{E}-11$ & $2.72 E-31$ & $3.15 \mathrm{E}-31$ & $3.89 \mathrm{E}-13$ & $92 \mathrm{E}-11$ & $2.96 \mathrm{E}-10$ \\
\hline $5 E-33$ & 09 & 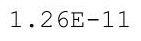 & $74 \mathrm{~F}-2-20$ & & 13 & 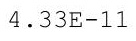 & 10 \\
\hline-33 & 09 & 1. $34 \mathrm{E}-11$ & 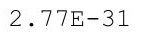 & 1 & 3 & & -10 \\
\hline $81 E-33$ & 99 & 1 & & 1 & & & -10 \\
\hline-33 & & 1 & & & & & -10 \\
\hline-33 & -09 & -1 & \pm & PI & 12 & -11 & $05 E-10$ \\
\hline $.76 \mathrm{E}-33$ & -09 & 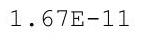 & - & - & 1. $62 \mathrm{E}-12$ & $\perp$ & 0 \\
\hline 33 & 09 & - & \pm & 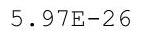 & 2 & 11 & -10 \\
\hline 33 & 6.4 & & & & & & 10 \\
\hline $.70 E-33$ & $6.73 E-09$ & $6 \mathrm{E}-11$ & 31 & $43 \mathrm{E}$ & $07 E-12$ & -11 & -10 \\
\hline$E-33$ & $E-09$ & $6 \mathrm{E}-11$ & $7 E-31$ & $30 E-22$ & -12 & -11 & -10 \\
\hline-33 & -09 & $\perp$ & 1 & & 12 & 10 & -10 \\
\hline 33 & $5 E-09$ & $\pm \perp$ & $\perp$ & 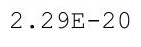 & -12 & 10 & -10 \\
\hline 33 & 09 & 2 & & -19 & 2 & & 10 \\
\hline $62 E-33$ & $8.16 \mathrm{E}$ & & & & & & 10 \\
\hline $60 E-33$ & $8.47 E-09$ & $2.66 \mathrm{E}-11$ & $3.10 \mathrm{E}-$ & $2.29 \mathrm{E}-$ & $7.54 \mathrm{E}-12$ & $E-10$ & -10 \\
\hline $58 \mathrm{E}-33$ & $8.79 E-09$ & $2.79 \mathrm{E}-11$ & $E-31$ & $7.66 \mathrm{E}-1$ & $69 \mathrm{E}-12$ & -10 & -10 \\
\hline $57 E-33$ & $9.13 E-09$ & $2.94 \mathrm{E}-11$ & $3.15 \mathrm{E}-31$ & $2.25 E-17$ & $9.88 E-12$ & 1. $72 \mathrm{E}-10$ & $85 E-10$ \\
\hline 33 & 09 & $3.08 E-11$ & & 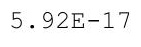 & 1 & & 10 \\
\hline 33 & 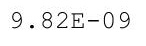 & & & & & & \\
\hline $52 E-33$ & $1.0<5-00$ & . & $3 \perp$ & & & & 10 \\
\hline 3 & 8 & $3.56 \mathrm{E}-11$ & $3.27 \mathrm{E}-31$ & 6 & 1 & 0 & 10 \\
\hline$E-33$ & 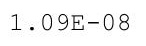 & 735 & تص & $0.35=$ & $1.83 \mathrm{E}-11$ & בקר & 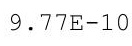 \\
\hline $47 E-33$ & 1.131 & $3.91 \mathrm{E}-11$ & 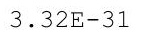 & & $2.04 \mathrm{E}-$ & $2.51 \mathrm{E}-10$ & $.04 E-09$ \\
\hline-33 & -08 & & & & $27 E-11$ & $5-10$ & $11 E-09$ \\
\hline-33 & 08 & & & & & & \\
\hline $42 E-33$ & $1.26 \mathrm{E}-08$ & $4.47 \perp \perp$ & - $1+4$ & $7.80 \mathrm{E}-15$ & 2.10 & & -09 \\
\hline $40 E-33$ & $1.30 \mathrm{~L}-00$ & (1) & $3.445-31$ & $1 \cdot 235-14$ & $3.07 E-11$ & $3.10 \mathrm{E}-10$ & $.32 E-09$ \\
\hline 3 & Le & 散 & 然 & 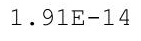 & $3.45 \mathrm{E}-11$ & . & $1.38 \mathrm{E}-09$ \\
\hline 3 & $1.39 \mathrm{E}-08$ & & $3.50 \mathrm{E}-31$ & & & & \\
\hline-33 & 8 & & & & 1 & & 09 \\
\hline 33 & & & & & & & \\
\hline $2 E-33$ & $1.53 E-08$ & $5.86 \mathrm{E}-11$ & $3.60 E-31$ & $8.82 \mathrm{E}-14$ & 11 & & -09 \\
\hline$E-33$ & $1.58 \mathrm{E}-08$ & 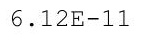 & . & 3 & 1 & & \\
\hline $9 E-33$ & $1.045-00$ & & & & & & $1.7 / 2-09$ \\
\hline 3 & I & 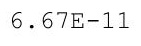 & . & B & 1 & 0 & 9 \\
\hline & & & & & & & \\
\hline 3 & & 1 & 1 & 3 & 1 & 0 & \\
\hline$E-33$ & $1.86 \mathrm{E}-08$ & $6 E-11$ & $3 . \varepsilon$ & -13 & -11 & 10 & -09 \\
\hline & 1.921 & & & & & & \\
\hline & & $\perp$ & & & & & $2.24 E-09$ \\
\hline & 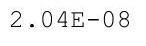 & + & & - & 0 & 10 & $2.32 E-09$ \\
\hline 3 & $0 E-08$ & $E-11$ & $4 E-31$ & $9 E-12$ & $29 E-10$ & $1 E-10$ & -09 \\
\hline
\end{tabular}


RESRAD-OFFSITE, Version 2.5

obabilistic Dose and Risk Report

Title : Offsite Resident Farmer Deterministic Run

File : RF TC99 DOESG FWD-FV2b.ROF

Summary of dose at graphical times, reptition 3 (continued)

Time

Years

$1.89 \mathrm{E}+02$

$1.89 \mathrm{E}+02$

$1.90 \mathrm{E}+02$

$1.90 \mathrm{E}+02$

$1.91 \mathrm{E}+02$

$1.91 \mathrm{E}+02$

$1.92 \mathrm{E}+02$

$1.92 \mathrm{E}+02$

$1.93 \mathrm{E}+02$

$1.93 \mathrm{E}+02$

$1.94 \mathrm{E}+02$

$1.94 \mathrm{E}+02$

$1.95 \mathrm{E}+02$

$1.95 \mathrm{E}+02$

$1.96 \mathrm{E}+02$

$1.96 \mathrm{E}+02$

$1.97 \mathrm{E}+02$

$1.97 \mathrm{E}+02$

1. $98 \mathrm{E}+02$

1. $98 \mathrm{E}+02$

1. $99 \mathrm{E}+02$

$1.99 \mathrm{E}+02$

$2.00 \mathrm{E}+02$

$2.00 \mathrm{E}+02$

$2.01 \mathrm{E}+02$

$2.01 \mathrm{E}+02$

$2.02 \mathrm{E}+02$

$2.03 \mathrm{E}+02$

$2.03 E+02$

$2.04 \mathrm{E}+02$

$2.04 \mathrm{E}+02$

$2.05 \mathrm{E}+02$

$2.05 \mathrm{E}+02$

$2.06 \mathrm{E}+02$

$2.06 \mathrm{E}+02$

$2.07 \mathrm{E}+02$

$2.07 \mathrm{E}+02$

$2.08 \mathrm{E}+02$

$2.08 \mathrm{E}+02$

2. $09 \mathrm{E}+02$

$2.09 \mathrm{E}+02$

$2.10 \mathrm{E}+02$

$2.10 \mathrm{E}+02$

$2.11 \mathrm{E}+02$

2. $11 \mathrm{E}+02$

$2.12 \mathrm{E}+02$
Dose statistics at graphical times, mrem/yr

\begin{tabular}{|c|c|c|c|c|c|c|c|}
\hline m & um & ean & ledian & & & $\%$ & \\
\hline-33 & $2.16 \mathrm{E}-08$ & $9.26 \mathrm{E}-11$ & $3.98 E-31$ & $1.50 \mathrm{E}-12$ & 1. 39E-10 & -10 & $1-09$ \\
\hline-33 & $3 E-08$ & 11 & 31 & 12 & 10 & 10 & -09 \\
\hline-33 & $2.30 \mathrm{E}-08$ & $0 E-10$ & $5 E-31$ & $2.32 \mathrm{E}-12$ & 1. $58 \mathrm{E}-10$ & $7.89 \mathrm{E}-10$ & $2.70 \mathrm{E}-09$ \\
\hline-33 & $2.37 E-08$ & $4 E-10$ & -31 & $2.80 \mathrm{E}-12$ & $1.68 \mathrm{E}-10$ & $24 \mathrm{E}-10$ & $2.82 E-09$ \\
\hline 33 & 08 & & & 12 & $2=$ & & -09 \\
\hline-33 & 8 & $1.13 \mathrm{E}-10$ & 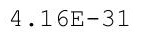 & 2 & 0 & 0 & -09 \\
\hline $.07 E-33$ & 08 & & & & 0 & & -09 \\
\hline-33 & & & & & & & -09 \\
\hline 33 & -08 & -10 & $\perp$ & -12 & 10 & 09 & $5-09$ \\
\hline-33 & 00 & 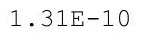 & 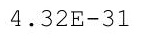 & 2 & 0 & 9 & -09 \\
\hline 33 & 08 & 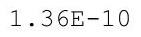 & \pm & 2 & 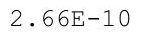 & 9 & -09 \\
\hline 33 & 2. & & & & 0 & & -09 \\
\hline $3 E-33$ & $F-08$ & $6 \mathrm{~F}$ & 4 & 1 & 0 & 9 & -09 \\
\hline$E-33$ & $E-08$ & $2 E-10$ & $3 E-31$ & $1 E-11$ & $17 \mathrm{E}-10$ & 9 & -09 \\
\hline-33 & -08 & -10 & & 1 & 0 & 09 & -09 \\
\hline 33 & 08 & \pm & $\perp$ & $\perp$ & 0 & 9 & -09 \\
\hline 33 & 08 & I & & 1 & 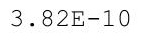 & & 09 \\
\hline $91 E-33$ & 年 & & & & & & -09 \\
\hline $.37 E-32$ & $3.59 \mathrm{E}-08$ & $1.82 \mathrm{E}-10$ & & $2.31 \mathrm{E}-11$ & & 1.58 & $3 E-09$ \\
\hline $37 E-32$ & $E-08$ & $1.88 \mathrm{E}-10$ & $3 E-31$ & $.55 E-11$ & $4.55 \mathrm{E}-10$ & -09 & -09 \\
\hline $37 E-32$ & $3.79 \mathrm{E}-08$ & 1. $95 \mathrm{E}-10$ & & $2.78 E-11$ & $4.81 \mathrm{E}-10$ & -09 & $E-09$ \\
\hline 32 & & 0 & $\perp$ & 1 & & & -09 \\
\hline $6 E-32$ & & & & & & & \\
\hline $36 E-32$ & $4.095-00$ & $2.10 \pm 16$ & & $.55 \mathrm{E}-11$ & & & 09 \\
\hline 32 & 8 & 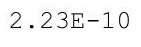 & $\perp$ & 1 & 0 & 9 & -09 \\
\hline $36 E-32$ & $31 \mathrm{~F}$ & $.31 \mathrm{E}-10$ & קم & $4.23 E-11$ & $12 \mathrm{E}-10$ & $.11 \mathrm{E}-09$ & $50 E-09$ \\
\hline $6 E-32$ & $42 E-08$ & $2.39 E-10$ & 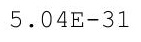 & .62 & $42 \mathrm{E}-10$ & $219 F-09$ & $69 E-09$ \\
\hline$E-32$ & -08 & & & & & $E-09$ & $88 E-09$ \\
\hline-32 & 08 & & & & & & \\
\hline $36 E-32$ & $4.76 \mathrm{E}-08$ & $2.045-10$ &.+0 & $5.83 E-11$ & . 02 & 09 & -09 \\
\hline $36 E-32$ & $4.00 \mathrm{~L}-00$ & $2 \cdot 1 \angle 2-10$ & $. \angle O L-31$ & $6.24 \mathrm{E}-11$ & $7.71 \mathrm{E}-10$ & $2.60 E-09$ & $.49 E-09$ \\
\hline 2 & 年 & 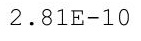 & & $6.67 \mathrm{E}-11$ & . $\perp U$ - $1 U$ & & $7.70 \mathrm{E}-09$ \\
\hline 2 & תי & & $5.34 \mathrm{E}-31$ & & & & 9 \\
\hline-32 & 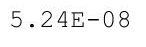 & 5. & & ح & & & 09 \\
\hline 2 & & & & & & & -09 \\
\hline $35 E-32$ & $5.50 \mathrm{E}-08$ & $3.19 \mathrm{E}-10$ & $9 E-31$ & 1 & 0.10 & 9 & -09 \\
\hline $35 E-32$ & $3.00 \mathrm{w}$ & 0 & & & & & \\
\hline $35 E-32$ & & & & & & & $9.012-09$ \\
\hline 2 & 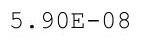 & 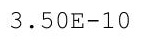 & . & 0 & & & 9 \\
\hline & & & & & & & 9 \\
\hline 32 & 08 & 10 & 1 & 0 & & 9 & -09 \\
\hline$E-32$ & $6.32 \mathrm{E}-08$ & 3. & 31 & 1.35 & 09 & & -08 \\
\hline & & & & & & & \\
\hline & & & & 0 & ז・0 & & $1.06 \mathrm{E}-08$ \\
\hline & & 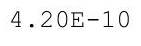 & & 0 & 9 & 9 & $09 E-08$ \\
\hline 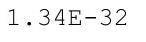 & $92 E-08$ & $3 E-10$ & $04 E-31$ & $E-10$ & $E-09$ & $2 E-09$ & -08 \\
\hline
\end{tabular}


RESRAD-OFFSITE, Version 2.5

$\mathrm{T}^{1 / 2}$ Limit $=180$ days

obabilistic Dose and Risk Report

Title : Offsite Resident Farmer Deterministic Run

File : RF TC99 DOESG FWD-FV2b.ROF

Summary of dose at graphical times, reptition 3 (continued)

Time

Years

$2.12 \mathrm{E}+02$

$2.13 \mathrm{E}+02$

$2.13 E+02$

$2.14 \mathrm{E}+02$

$2.14 \mathrm{E}+02$

$2.15 \mathrm{E}+02$

$2.15 \mathrm{E}+02$

$2.16 \mathrm{E}+02$

$2.16 \mathrm{E}+02$

$2.17 \mathrm{E}+02$

$2.17 \mathrm{E}+02$

$2.18 \mathrm{E}+02$

$2.18 \mathrm{E}+02$

$2.19 \mathrm{E}+02$

$2.19 \mathrm{E}+02$

2. $20 \mathrm{E}+02$

2. $20 \mathrm{E}+02$

$2.21 E+02$

2. $21 E+02$

2. $22 \mathrm{E}+02$

$2.23 E+02$

$2.23 E+02$

2. $24 \mathrm{E}+02$

$2.24 \mathrm{E}+02$

2. $25 \mathrm{E}+02$

$2.25 \mathrm{E}+02$

2. $26 \mathrm{E}+02$

$2.26 \mathrm{E}+02$

$2.27 \mathrm{E}+02$

$2.27 \mathrm{E}+02$

2. $28 \mathrm{E}+02$

$2.28 \mathrm{E}+02$

$2.29 \mathrm{E}+02$

2. $29 \mathrm{E}+02$

2. $30 E+02$

2. $30 \mathrm{E}+02$

2. $31 \mathrm{E}+02$

2. $31 E+02$

2. $32 \mathrm{E}+02$

2. $32 E+02$

$2.33 E+02$

2. $33 \mathrm{E}+02$

$2.34 \mathrm{E}+02$

2. $34 \mathrm{E}+02$

$2.35 \mathrm{E}+02$

$2.35 \mathrm{E}+02$
Dose statistics at graphical times, mrem/yr

\begin{tabular}{|c|c|c|c|c|c|c|c|}
\hline $\mathrm{m}$ & aximum & lea & ed & & & & \\
\hline $34 \mathrm{E}-32$ & $7.07 \mathrm{E}-08$ & $4.46 \mathrm{E}-10$ & $6.10 \mathrm{E}-31$ & 1. $90 \mathrm{E}-10$ & 1. $49 \mathrm{E}-09$ & 09 & -00 \\
\hline $34 E-32$ & $7.23 E-08$ & $4.59 \mathrm{E}-10$ & $6.15 \mathrm{E}-31$ & $2.02 E-10$ & $55 E-09$ & $4.83 E-09$ & $7 E-08$ \\
\hline $34 E-32$ & $39 E-08$ & $2 E-10$ & $E-31$ & $15 E-10$ & $62 E-09$ & $0 E-09$ & $20 E-08$ \\
\hline $34 \mathrm{E}-32$ & $55 E-08$ & $86 \mathrm{E}-10$ & $27 \mathrm{~F}-31$ & $.28 \mathrm{E}-10$ & $69 F-09$ & -09 & $.23 E-08$ \\
\hline-32 & 08 & 0 & -31 & 0 & 9 & -09 & $26 E-08$ \\
\hline 32 & 08 & & & & & & \\
\hline $34 E-32$ & $8.05 E-08$ & & & & & & $E-08$ \\
\hline $33 E-32$ & -08 & 10 & 1 & 10 & 9 & -09 & $36 E-08$ \\
\hline $33 E-32$ & $8.40 \mathrm{E}-08$ & 10 & $E-31$ & -10 & 09 & -09 & $E-08$ \\
\hline $3 E-32$ & 08 & 765 & ( & $20 \mathrm{E}-10$ & $11 \Gamma$ & $15 E-09$ & זכרי \\
\hline 32 & 08 & & & & & & 08 \\
\hline $33 E-32$ & $8.94 \mathrm{E}-08$ & 6 & 6. & 0 & 9 & 9 & -08 \\
\hline $33 E-32$ & $9.13 E-08$ & & & $3.72 \mathrm{E}-10$ & & & $1.53 \mathrm{E}-08$ \\
\hline $33 E-32$ & $9.32 \mathrm{E}-08$ & -10 & $\perp$ & -10 & 09 & -09 & $E-08$ \\
\hline-32 & -08 & & & & & -09 & -08 \\
\hline 32 & -08 & 0 & $\perp$ & 0 & ת ת & 9 & 08 \\
\hline 32 & 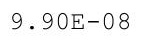 & & & & & & \\
\hline 32 & 7 & $7.16 \mathrm{E}-10$ & $7.17 \mathrm{E}-31$ & & 9 & 9 & 8 \\
\hline $32 E-32$ & $1.03 E-07$ & 7. $35 \mathrm{E}-10$ & $7.24 E-31$ & $4.71 E-10$ & $2.80 E-09$ & $.03 E-09$ & $1.76 \mathrm{E}-08$ \\
\hline $32 E-32$ & $1.05 \mathrm{E}-07$ & 7. $55 \mathrm{E}-10$ & 7. $31 \mathrm{E}-31$ & $4.90 \mathrm{E}-10$ & $2.90 \mathrm{E}-09$ & $E-09$ & $1.80 \mathrm{E}-08$ \\
\hline 32 & 07 & & & & & -09 & -08 \\
\hline 32 & & & 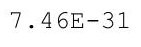 & 0 & 9 & & -08 \\
\hline $32 E-32$ & 7 & 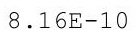 & $7.54 \mathrm{E}-31$ & & & & 08 \\
\hline-32 & 07 & 0 & 7. $61 E-31$ & 0 & 9 & 9 & -08 \\
\hline $32 \mathrm{~F}$ & $16 \Gamma$ & 0 & ת & 0 & סקר & 9 & $03 E-08$ \\
\hline $32 E-32$ & $1.18 \mathrm{E}-07$ & $81 E-10$ & 7 & $13 E-10$ & $65 E-09$ & $.66 E-09$ & $.07 E-08$ \\
\hline$E-32$ & $120 \mathrm{~F}-07$ & -10 & & $0 E-10$ & & $E-09$ & $.12 \mathrm{E}-08$ \\
\hline & & & & & & & \\
\hline 32 & & & & 0 & & -08 & 08 \\
\hline $31 E-32$ & $1.27 \mathrm{E}-07$ & $9.75 \mathrm{E}-10$ & $\cdot 1 \angle E-31$ & $7.40 \mathrm{E}-10$ & $.13 E-09$ & $1.0 / E-00$ & $2.27 E-08$ \\
\hline $31 E-32$ & $1.30 \mathrm{E}-07$ & $9.99 \mathrm{E}-10$ & 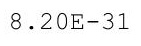 & $.75 E-10$ & $4 \cdot 245-09$ & $\perp \cdot 09 \mathrm{E}-00$ & $.33 E-08$ \\
\hline 2 & エ・コスப & & & & & 拱 & 政 \\
\hline$E-32$ & $134 \mathrm{~F}-07$ & $E-09$ & & 0 & & 1) & 8 \\
\hline 32 & 1.3 & & & & & & \\
\hline & & & & 10 & & & 08 \\
\hline $31 E-32$ & $1.42 \mathrm{E}-07$ & $1.13 E-09$ & $\cdot 1+$ & $9.64 \mathrm{E}-10$ & 09 & $.23 E-08$ & $2.60 \mathrm{E}-08$ \\
\hline $31 E-32$ & $1.44 \mathrm{E}-07$ & & & & & & $2.66 \mathrm{E}-08$ \\
\hline 2 & $1.47 \mathrm{E}-07$ & 1. $18 \mathrm{E}-09$ & & $1.04 \mathrm{E}-09$ & 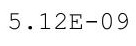 & & $2.72 E-08$ \\
\hline 2 & $1.50 \mathrm{E}-07$ & 9 & $8.87 \mathrm{E}-31$ & 9 & 9 & 8 & 08 \\
\hline 32 & 1 . & & & & 9 & & \\
\hline$E-32$ & $1.55 \mathrm{E}-07$ & 1.2 & 31 & & 9 & & $2.90 \mathrm{E}$ \\
\hline 32 & $1.58 \mathrm{E}$ & 1.3 & & & & & \\
\hline & & & & & & & $3.03 E-08$ \\
\hline $.30 E-32$ & $1.00 \mathrm{~L}-1$ & $1.30 E-09$ & $9.33 E-31$ & 1. 32E-09 & $6.01 E-09$ & $1.46 E-08$ & $3.09 \mathrm{E}-08$ \\
\hline $30 E-32$ & $1.00 \mathrm{~L}-\mathrm{t}$ & $1.40 E-09$ & & $\pm \cdot 00$ & .10 & 1. $49 \mathrm{E}-08$ & 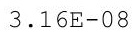 \\
\hline $0 E-32$ & $1.69 \mathrm{E}-07$ & $.43 E-09$ & $.51 E-31$ & $.45 E-09$ & -09 & $1.52 \mathrm{~F}$ & 3.2 \\
\hline
\end{tabular}


RESRAD-OFFSITE, Version 2.5

$\mathrm{T}^{1 / 2}$ Limit $=180$ days

itle : Offsite Resident Farmer Deterministic Run

File : RF TC99 DOESG FWD-FV2b.ROF

Summary of dose at graphical times, reptition 3 (continued)

Time

Years

$2.36 \mathrm{E}+02$

$2.36 \mathrm{E}+02$

$2.37 \mathrm{E}+02$

$2.37 \mathrm{E}+02$

$2.38 \mathrm{E}+02$

$2.38 \mathrm{E}+02$

$2.39 \mathrm{E}+02$

$2.39 \mathrm{E}+02$

$2.40 \mathrm{E}+02$

$2.40 \mathrm{E}+02$

$2.41 \mathrm{E}+02$

$2.41 \mathrm{E}+02$

$2.42 \mathrm{E}+02$

2. $43 \mathrm{E}+02$

$2.43 E+02$

$2.44 \mathrm{E}+02$

$2.44 \mathrm{E}+02$

$2.45 \mathrm{E}+02$

$2.45 \mathrm{E}+02$

$2.46 \mathrm{E}+02$

$2.46 \mathrm{E}+02$

$2.47 \mathrm{E}+02$

$2.47 \mathrm{E}+02$

2. $48 \mathrm{E}+02$

$2.48 \mathrm{E}+02$

2. $49 \mathrm{E}+02$

$2.49 \mathrm{E}+02$

$2.50 \mathrm{E}+02$

$2.50 \mathrm{E}+02$

$2.51 \mathrm{E}+02$

$2.51 \mathrm{E}+02$

$2.52 \mathrm{E}+02$

$2.52 \mathrm{E}+02$

$2.53 \mathrm{E}+02$

$2.53 \mathrm{E}+02$

$2.54 \mathrm{E}+02$

$2.54 \mathrm{E}+02$

$2.55 \mathrm{E}+02$

$2.55 \mathrm{E}+02$

$2.56 \mathrm{E}+02$

$2.56 \mathrm{E}+02$

$2.57 \mathrm{E}+02$

$2.57 \mathrm{E}+02$

$2.58 \mathrm{E}+02$

$2.58 \mathrm{E}+02$

$2.59 \mathrm{E}+02$
Dose statistics at graphical times, mrem/yr

\begin{tabular}{|c|c|c|c|c|c|c|c|}
\hline um & aximum & ean & 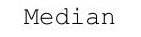 & & & $\%$ & \\
\hline $30 \mathrm{E}-32$ & $1.72 \mathrm{E}-07$ & $1.46 \mathrm{E}-09$ & $9.60 \mathrm{E}-31$ & $1.51 \mathrm{E}-09$ & 0.401 & -08 & -08 \\
\hline $30 E-32$ & $1.75 \mathrm{E}-07$ & $1.50 \mathrm{E}-09$ & $9.70 \mathrm{E}-31$ & 9 & 9 & 8 & -08 \\
\hline $30 \mathrm{E}-32$ & $1.78 \mathrm{E}-07$ & $1.53 \mathrm{E}-09$ & $9.81 \mathrm{E}-31$ & 1. $61 \mathrm{E}-09$ & $6.80 \mathrm{E}-09$ & 1. $62 \mathrm{E}-08$ & $.43 E-08$ \\
\hline $30 E-32$ & $1.81 \mathrm{E}-07$ & $1.56 \mathrm{E}-09$ & $9.90 \mathrm{E}-31$ & $1.67 \mathrm{E}-09$ & $6.97 \mathrm{E}-09$ & $1.65 \mathrm{E}-08$ & $.51 \mathrm{E}-08$ \\
\hline $29 E-32$ & $184 \mathrm{~F}-07$ & $160 \mathrm{~F}-09$ & $99 F-31$ & $72 \mathrm{~F}-09$ & $3 F-09$ & $9 F-08$ & -08 \\
\hline 32 & 1.8 & 1 & & 9 & & & -08 \\
\hline $29 \mathrm{E}-32$ & 07 & $1.67 \mathrm{E}-$ & & 9 & & & -08 \\
\hline $29 \mathrm{E}-32$ & & 1. & & & & & -08 \\
\hline $29 E-32$ & $1.96 \mathrm{E}-07$ & $5 E-09$ & 0 & $97 E-09$ & -09 & -08 & $90 E-08$ \\
\hline $29 \mathrm{E}-32$ & 7 & $1.79 \mathrm{E}-09$ & $1.06 \mathrm{E}-30$ & 9 & 9 & 8 & -08 \\
\hline $9 E-32$ & 7 & 1 & & 9 & 9 & 8 & 8 \\
\hline $29 E-32$ & $205 \mathrm{~F}$ & & & 9 & & & 08 \\
\hline $29 E-32$ & $9 F-07$ & 1. & 1 & 2015101 & 9 & 8 & $3 E-08$ \\
\hline $.29 \mathrm{E}-32$ & $2.12 \mathrm{E}-07$ & $1.95 \mathrm{E}-09$ & $1.10 \mathrm{E}-30$ & $2.28 \mathrm{E}-09$ & $9.00 \mathrm{E}-09$ & $2.03 E-08$ & $4.32 E-08$ \\
\hline $29 E-32$ & $2.15 \mathrm{E}-07$ & 1.99E-09 & & $2.35 \mathrm{E}-09$ & & $2.07 E-08$ & $4.40 \mathrm{E}-08$ \\
\hline $28 E-32$ & & & & & & & -08 \\
\hline 32 & & & & ) & & & 08 \\
\hline 2 & 00 & $2.12 E-09$ & & & & & 8 \\
\hline $28 E-32$ & $2.29 \mathrm{E}-07$ & $217 \mathrm{~F}-8$ & & $65 \square$ & ז? & $F-08$ & -08 \\
\hline $28 E-32$ & $2.33 \mathrm{E}-07$ & $2.21 \mathrm{E}-0$ & $9 E-3$ & $2.73 E-09$ & $.04 E-08$ & $2.28 \mathrm{E}-08$ & $.87 E-08$ \\
\hline $28 E-32$ & $.36 \mathrm{E}-07$ & $.26 \mathrm{E}-0$ & & 9 & 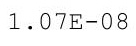 & $.32 E-08$ & $.97 \mathrm{E}-08$ \\
\hline 32 & & & & & & & $08 E-08$ \\
\hline & & & & & & & -08 \\
\hline $28 E-32$ & $2.47 E-07$ & - - & 1. & & 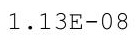 & & 08 \\
\hline 2 & 2 & 2 & $1.26 \mathrm{E}-30$ & 9 & $1.16 \mathrm{E}-08$ & 0 & -08 \\
\hline $27 E-32$ & $54 \mathrm{~F}-07$ & $250 \mathrm{~F}-0$ & 1 & $18=$ & $1.18 \mathrm{E}-08$ & $5 E-08$ & $50 E-08$ \\
\hline $27 F-32$ & $258 F-07$ & $255 F-0$ & & & & $F-08$ & -08 \\
\hline-32 & $262 \mathrm{~F}-07$ & ק & & & & & \\
\hline 32 & 2.0 & & & & & & 08 \\
\hline $.27 E-32$ & $2.69 \mathrm{E}-07$ & $2 \cdot 1+\mathrm{L}-0$ & $1.38 \mathrm{E}-23$ & . & $\pm \cdot 201$ & $2.75 E-08$ & -08 \\
\hline $27 E-32$ & $2.10 \mathrm{E}-1$ & 2. & $1.00 \mathrm{E}-22$ & $3.62 E-09$ & $1 \cdot 3 \perp-00$ & $2.00 \mathrm{E}-00$ & $.02 E-08$ \\
\hline $27 E-32$ & 2. & e. & - & 年 & 2000 & & $6.14 \mathrm{E}-08$ \\
\hline $27 E-32$ & $.81 E-0$ & $2.88 \mathrm{E}-$ & $1.22 \mathrm{E}-$ & & & & $25 E-08$ \\
\hline $27 F-32$ & $285 \mathrm{~F}-07$ & ע & & & & & 08 \\
\hline $7 E-32$ & & & & & & & \\
\hline $27 E-32$ & $2.95 \mathrm{E}$ & -09 & 1. $13 \mathrm{E}-18$ & 9 & $\perp$ & 8 & -08 \\
\hline $26 E-32$ & 2. $31 \mathrm{~L}-\mathrm{T}$ & $\cdot$ & & & & & \\
\hline $26 E-32$ & $\begin{array}{lll}0 & 0\end{array}$ & $\begin{array}{cc}-1 & -1\end{array}$ & & & ×. & & \\
\hline 2 & 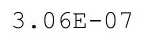 & s. & 2. & 9 & 8 & 8 & 0 \\
\hline 2 & $3.10 \mathrm{E}-07$ & & & & 8 & & \\
\hline 32 & 7 & 3. & 1 & & & & -08 \\
\hline $26 \mathrm{E}-32$ & $3.18 \mathrm{E}-07$ & 3. & 2. & 9 & & & .08 \\
\hline & 0.2 & & & & & & \\
\hline & - & 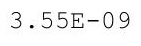 & & & & & \\
\hline & $\begin{array}{lll} & 0\end{array}$ & ( & & & & & . \\
\hline$E-32$ & $36 \mathrm{E}-07$ & $8 E-09$ & $95 E-15$ & $E-09$ & $5 E-08$ & $2 E-08$ & -08 \\
\hline
\end{tabular}


RESRAD-OFFSITE, Version 2.5

$\mathrm{T}^{1 / 2}$ Limit $=180$ days

robabilistic Dose and Risk Report

Title : Offsite Resident Farmer Deterministic Run

File : RF TC99 DOESG FWD-FV2b.ROF

Summary of dose at graphical times, reptition 3 (continued)

Time

Years

$2.59 \mathrm{E}+02$

$2.60 \mathrm{E}+02$

$2.60 E+02$

2. $61 \mathrm{E}+02$

2. $61 E+02$

2. $62 \mathrm{E}+02$

$2.63 \mathrm{E}+02$

2. $63 \mathrm{E}+02$

2. $64 \mathrm{E}+02$

2. $64 \mathrm{E}+02$

2. $65 \mathrm{E}+02$

2. $65 \mathrm{E}+02$

$2.66 \mathrm{E}+02$

$2.66 \mathrm{E}+02$

$2.67 \mathrm{E}+02$

$2.67 \mathrm{E}+02$

$2.68 \mathrm{E}+02$

$2.68 \mathrm{E}+02$

$2.69 \mathrm{E}+02$

$2.69 \mathrm{E}+02$

$2.70 \mathrm{E}+02$

$2.70 \mathrm{E}+02$

$2.71 \mathrm{E}+02$

$2.71 \mathrm{E}+02$

$2.72 \mathrm{E}+02$

$2.72 \mathrm{E}+02$

$2.73 \mathrm{E}+02$

$2.73 \mathrm{E}+02$

$2.74 \mathrm{E}+02$

$2.74 \mathrm{E}+02$

$2.75 E+02$

$2.75 \mathrm{E}+02$

2. $76 \mathrm{E}+02$

$2.76 \mathrm{E}+02$

$2.77 \mathrm{E}+02$

$2.77 \mathrm{E}+02$

$2.78 \mathrm{E}+02$

$2.78 \mathrm{E}+02$

$2.79 \mathrm{E}+02$

$2.79 \mathrm{E}+02$

$2.80 \mathrm{E}+02$

$2.80 \mathrm{E}+02$

$2.81 \mathrm{E}+02$

$2.81 \mathrm{E}+02$

$2.82 \mathrm{E}+02$

$2.82 \mathrm{E}+02$
Dose statistics at graphical times, mrem/yr

\begin{tabular}{|c|c|c|c|c|c|c|c|}
\hline m & $\operatorname{axin}$ & ea & 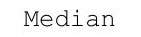 & & & & \\
\hline $26 \mathrm{E}-32$ & $3.40 \mathrm{E}-07$ & $3.75 E-09$ & $4.94 \mathrm{E}-15$ & 9 & $1.79 \mathrm{E}-08$ & 08 & $0 E-00$ \\
\hline $26 E-32$ & $3.45 E-07$ & $32 E-09$ & $8.00 \mathrm{E}-15$ & $6 E-09$ & $1.82 \mathrm{E}-08$ & $E-08$ & $9 E-08$ \\
\hline-32 & $49 E-07$ & $39 E-09$ & -14 & $59-09$ & $85 E-08$ & $95 E-08$ & $2 E-08$ \\
\hline $25 E-32$ & $54 \mathrm{E}-07$ & $96 \mathrm{~F}-09$ & $83 F-14$ & $83 E-09$ & $.89 \mathrm{E}-08$ & -08 & $34 \mathrm{E}-08$ \\
\hline-32 & 07 & 09 & 14 & 09 & 08 & -08 & -08 \\
\hline 32 & & & & & & & \\
\hline $25 E-32$ & $3.67 \mathrm{E}-07$ & & & & & & -08 \\
\hline-32 & 07 & 9 & 4 & 9 & 8 & 8 & $E-08$ \\
\hline $25 E-32$ & $3.77 \mathrm{E}-07$ & $4 E-09$ & -13 & $57 E-09$ & $06 \mathrm{E}-08$ & -08 & $E-08$ \\
\hline $25 E-32$ & $82 E-07$ & $42 E-09$ & $45 \mathrm{E}-13$ & $.74 \mathrm{E}-09$ & $.10 \mathrm{E}-08$ & $.54 \mathrm{E}-08$ & $2 E-08$ \\
\hline 32 & 07 & & & & & & 8 \\
\hline $25 E-32$ & $E-07$ & 09 & 3 & 9 & 8 & 8 & 08 \\
\hline $25 E-32$ & $3.96 \mathrm{E}-07$ & & & $.27 E-09$ & & & $E-08$ \\
\hline $24 \mathrm{E}-32$ & $4.01 E-07$ & $4.74 \mathrm{E}-09$ & $4.22 \mathrm{E}-13$ & $7.46 \mathrm{E}-09$ & & 4. $91 \mathrm{E}-08$ & $E-08$ \\
\hline $24 E-32$ & $E-07$ & $2 E-09$ & -13 & & & -08 & $E-08$ \\
\hline-32 & $11 E-07$ & 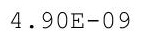 & 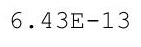 & حك & ק־5 & 0 & -08 \\
\hline 32 & 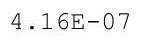 & & & & & & \\
\hline 32 & 4 & $5.07 \mathrm{E}-09$ & $9.64 \mathrm{E}-13$ & 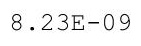 & & 8 & 7 \\
\hline $24 E-32$ & $4.26 \mathrm{E}-07$ & $5.16 \mathrm{E}-09$ & 1. $18 \mathrm{E}-12$ & $8.42 E-09$ & $2.49 E-08$ & $E-08$ & $1.04 \mathrm{E}-07$ \\
\hline $24 E-32$ & $4.31 E-07$ & $.25 E-09$ & 1. $43 \mathrm{E}-12$ & $8.59 \mathrm{E}-09$ & $2.54 \mathrm{E}-$ & $E-08$ & $.05 E-07$ \\
\hline 32 & 4 & & & & & -08 & $E-07$ \\
\hline 32 & & & & & & 0 & 07 \\
\hline 2 & $4.46 \mathrm{E}$ & 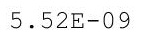 & & & & & 07 \\
\hline $24 E-32$ & 4. & 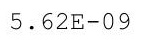 & 2 & 9 & 0 & 0 & 07 \\
\hline 2 & 7 & 9 & $\angle$ & 9 & B & 8 & 07 \\
\hline $23 E-32$ & $4.62 \mathrm{E}-07$ & $.81 E-09$ & $3.71 \mathrm{E}-12$ & $72 E-09$ & $2.84 \mathrm{E}-08$ & $99-08$ & $.14 \mathrm{E}-07$ \\
\hline-32 & $4.68 \mathrm{E}-07$ & $90 F-09$ & $E-12$ & & & $3 E-08$ & $.16 \mathrm{E}-07$ \\
\hline 32 & & & & & & & \\
\hline 32 & & & & 8 & & & -07 \\
\hline $23 E-32$ & $4.84 \mathrm{E}-07$ & $6.20 E-09$ & $6.03 E-12$ & $1.06 \mathrm{E}-08$ & $3.05 E-08$ & $5 E-08$ & $.21 E-07$ \\
\hline $23 E-32$ & $4.89 E-07$ & $6.30 E-09$ & $6.84 \mathrm{E}-12$ & $.08 E-08$ & . & 0 & $.23 E-07$ \\
\hline 2 & (. & $\begin{array}{lll}1+\square & 0\end{array}$ & $.69 \mathrm{E}-12$ & 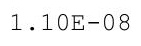 & & 0.04500 & $1.25 \mathrm{E}-07$ \\
\hline 32 & $=00 F-07$ & $51 \mathrm{~F}-0 \mathrm{~g}$ & $E-12$ & 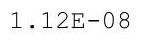 & & & $.27 E-07$ \\
\hline 2 & & & & & & & \\
\hline $23 E-32$ & & & & & & & \\
\hline $22 \mathrm{E}-32$ & $5.17 \mathrm{E}-07$ & $6.83 E-09$ & 1. $22 \mathrm{E}-11$ & $\perp ・ \perp ン$ & . & -08 & $1.33 E-07$ \\
\hline $22 E-32$ & . $200-4$ & $6.94 \mathrm{E}-09$ & +.000 & ots & en & & $.35 E-07$ \\
\hline $22 E-32$ & . 200 i & $7.05 E-09$ & 1. $49 \mathrm{E}-11$ & $1.24 \mathrm{E}-08$ & & & $1.36 \mathrm{E}-07$ \\
\hline 2 & 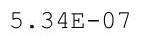 & 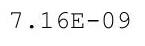 & 1 & 8 & 8 & 8 & 7 \\
\hline 32 & 7 & & & & & & \\
\hline $2 E-32$ & $5.46 \mathrm{E}$ & 09 & 2. & -08 & & 08 & -07 \\
\hline $22 E-32$ & $5.52 \mathrm{E}-07$ & 09 & 2. & $1.34 \mathrm{E}$ & & 08 & -07 \\
\hline 32 & . & & & & & & \\
\hline 2 & . & 3 & . & $1.38 \mathrm{E}-08$ & $5 E-08$ & $9 E-08$ & $1.49 \mathrm{E}-07$ \\
\hline $22 E-32$ & . & .00स & & & & & $1.51 \mathrm{E}-07$ \\
\hline $22 E-32$ & $.75 E-07$ & $8 E-09$ & $12 \mathrm{E}-11$ & $44 E-08$ & $07 E-08$ & $0 E-08$ & -07 \\
\hline
\end{tabular}


RESRAD-OFFSITE, Version 2.5

$\mathrm{T}^{1 / 2}$ Limit $=180$ days

Title : Offsite Resident Farmer Deterministic Run

File : RF TC99 DOESG FWD-FV2b.ROF

Summary of dose at graphical times, reptition 3 (continued)

Time

Years

$2.83 \mathrm{E}+02$

$2.84 \mathrm{E}+02$

$2.84 \mathrm{E}+02$

$2.85 \mathrm{E}+02$

$2.85 \mathrm{E}+02$

$2.86 \mathrm{E}+02$

$2.86 \mathrm{E}+02$

$2.87 \mathrm{E}+02$

$2.87 \mathrm{E}+02$

$2.88 \mathrm{E}+02$

$2.88 \mathrm{E}+02$

$2.89 \mathrm{E}+02$

$2.89 \mathrm{E}+02$

$2.90 \mathrm{E}+02$

$2.90 \mathrm{E}+02$

$2.91 \mathrm{E}+02$

$2.91 \mathrm{E}+02$

$2.92 \mathrm{E}+02$

$2.92 \mathrm{E}+02$

$2.93 \mathrm{E}+02$

2. $93 \mathrm{E}+02$

2. $94 \mathrm{E}+02$

$2.94 \mathrm{E}+02$

2. $95 \mathrm{E}+02$

$2.95 \mathrm{E}+02$

2. $96 \mathrm{E}+02$

$2.96 \mathrm{E}+02$

$2.97 \mathrm{E}+02$

$2.97 \mathrm{E}+02$

$2.98 \mathrm{E}+02$

$2.98 \mathrm{E}+02$

$2.99 \mathrm{E}+02$

2. $99 \mathrm{E}+02$

$3.00 \mathrm{E}+02$

$3.00 \mathrm{E}+02$

3. $01 \mathrm{E}+02$

$3.01 \mathrm{E}+02$

$3.02 \mathrm{E}+02$

$3.02 \mathrm{E}+02$

$3.03 \mathrm{E}+02$

$3.04 \mathrm{E}+02$

$3.04 \mathrm{E}+02$

$3.05 \mathrm{E}+02$

$3.05 \mathrm{E}+02$

$3.06 \mathrm{E}+02$

$3.06 \mathrm{E}+02$
Dose statistics at graphical times, mrem/yr

\begin{tabular}{|c|c|c|c|c|c|c|c|}
\hline m & aximum & ea & ec & & & & \\
\hline-32 & $5.81 \mathrm{E}-07$ & $8.10 \mathrm{E}-09$ & $3.37 \mathrm{E}-11$ & $1.47 \mathrm{E}-08$ & $4.14 \mathrm{E}-08$ & 08 & - $-305-01$ \\
\hline-32 & $5.87 E-07$ & $8.23 E-09$ & 3. $61 \mathrm{E}-11$ & $1.50 \mathrm{E}-08$ & $20 E-08$ & $8.32 E-08$ & $7 E-07$ \\
\hline $21 E-32$ & $93 E-07$ & $5 E-09$ & $89 E-11$ & $53 E-08$ & $28 E-08$ & $43 E-08$ & $9 E-07$ \\
\hline $21 E-32$ & -07 & $8 F-09$ & $20 \mathrm{~F}-11$ & $56 \mathrm{E}-08$ & $35 F-08$ & -08 & $61 F-07$ \\
\hline-32 & -07 & 9 & 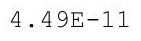 & 8 & 8 & -08 & -07 \\
\hline 32 & & & & & & & 07 \\
\hline $21 \mathrm{E}-32$ & $6.18 \mathrm{E}-07$ & & & & & & $E-07$ \\
\hline-32 & -07 & 9 & 1 & 8 & 8 & 8 & $E-07$ \\
\hline $21 E-32$ & $6.30 \mathrm{E}-07$ & $E-09$ & -11 & $1.70 \mathrm{E}-08$ & $75 E-08$ & -08 & $3 E-07$ \\
\hline $21 E-32$ & $37 E-07$ & ת7ר & $36 \mathrm{~F}-11$ & $173=$ & קح० קט & $4 E-08$ & 7 \\
\hline $21 E-32$ & 07 & & & & & & 7 \\
\hline $21 E-32$ & $6.49 \mathrm{E}-07$ & P & $7.38 \mathrm{E}-11$ & 1.79 & 8 & 8 & 07 \\
\hline $20 E-32$ & $6.56 \mathrm{E}-07$ & $9.68 E-09$ & & $1.82 E-08$ & & & $1.81 \mathrm{E}-07$ \\
\hline $20 \mathrm{E}-32$ & $6.62 \mathrm{E}-07$ & $9.83 \mathrm{E}-09$ & $8.30 \mathrm{E}-11$ & $1.85 \mathrm{E}-08$ & & -08 & $1.84 \mathrm{E}-07$ \\
\hline-32 & $E-07$ & $E-09$ & 1 & 8 & & -08 & $5 E-07$ \\
\hline $20 E-32$ & $75 E-07$ & קח & & תר: ת) & 0 & 0 & 07 \\
\hline$E-32$ & 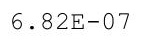 & & & & & & \\
\hline 32 & $6.88 \mathrm{E}-07$ & $1.04 \mathrm{E}-08$ & & & & $1.02 \mathrm{E}-07$ & 7 \\
\hline $20 E-32$ & $6.95 E-07$ & $1.06 \mathrm{E}-08$ & $1.14 \mathrm{E}-10$ & $2.02 E-08$ & $5.50 \mathrm{E}-08$ & $1.03 E-07$ & $1.96 \mathrm{E}-07$ \\
\hline $20 E-32$ & $.01 E-07$ & $.07 \mathrm{E}-08$ & $.20 \mathrm{E}-10$ & $2.06 \mathrm{E}-08$ & 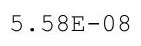 & $.05 E-07$ & 1. $99 E-07$ \\
\hline 32 & 07 & & & & & -07 & $E-07$ \\
\hline 32 & & & & & & & -07 \\
\hline 2 & & & & & & & -07 \\
\hline $20 E-32$ & 7 & $\perp$ & $1.44 \mathrm{E}-10$ & 0 & & 7 & -07 \\
\hline 2 & 7 & 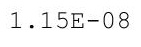 & 1. $50 \mathrm{E}-10$ & 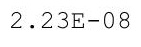 & 3 & 7 & $2 E-07$ \\
\hline $19 E-32$ & $7.42 \mathrm{E}-07$ & $1165-0$ & $156 \mathrm{~F}-10$ & $.27 E-08$ & $08 \mathrm{E}-$ & $.13 E-07$ & $2.15 \mathrm{E}-07$ \\
\hline$E-32$ & $748 \mathrm{~F}-07$ & 1. $18 \mathrm{E}-08$ & & & & $1.14 \mathrm{E}-07$ & $.18 E-07$ \\
\hline 32 & & & & & & & \\
\hline 32 & 7 & $1 \cdot 2$ & & & & & -07 \\
\hline $19 \mathrm{E}-32$ & $7.69 \mathrm{E}-07$ & $1 \cdot 23 E-00$ & $1.00 \mathrm{E}-10$ & $2.41 E-00$ & $.44 \mathrm{E}-08$ & I. & $2.26 \mathrm{E}-07$ \\
\hline $19 \mathrm{E}-32$ & $7.76 \mathrm{E}-07$ & $1 \cdot 205-00$ & $1 \cdot 945-10$ & $2.45 \mathrm{E}-08$ & (4) & $\perp \cdot \perp Y$ E- & $2.29 \mathrm{E}-07$ \\
\hline 2 & . & 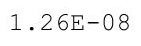 & 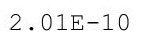 & 年 & & 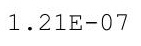 & $2.32 E-07$ \\
\hline$E-32$ & 7 90F-07 & 1 & $F-10$ & & & & $5 E-07$ \\
\hline 32 & & & & & & & \\
\hline$E-32$ & & & & & & -07 & \\
\hline $19 \mathrm{E}-32$ & $8.11 \mathrm{E}-07$ & $1.33 E-08$ & $2.38 E-10$ & $2.66 \mathrm{E}-08$ & 25 & $6 E-07$ & $3 E-07$ \\
\hline $18 E-32$ & $0.10 \mathrm{~L}-1$ & $1.03 \pm-20$ & & & & & $2.45 E-07$ \\
\hline $18 E-32$ & $.20 \pm$ & 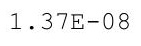 & & & & & $2.48 \mathrm{E}-07$ \\
\hline 2 & 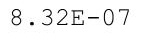 & + & 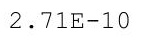 & 2 & . & 7 & 07 \\
\hline & 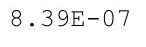 & & & & & & 07 \\
\hline-32 & 7 & 1.4 & 2.9 & 2. & & 07 & $7 E-07$ \\
\hline $18 \mathrm{E}-32$ & $8.54 \mathrm{E}-07$ & $1.44 \mathrm{E}-08$ & $E-10$ & 2 . & B & 07 & $0 E-07$ \\
\hline & $0.01 \mathrm{~L}$ & & & & & & -07 \\
\hline 2 & 0.0 & \pm & . & . & $7.81 \mathrm{E}-08$ & $1.38 E-07$ & $2.66 \mathrm{E}-07$ \\
\hline $18 E-32$ & . & $\begin{array}{lll} \\
\text {. }\end{array}$ & & ( & 1.00 & & $2.69 \mathrm{E}-07$ \\
\hline $8 E-32$ & $.83 E-07$ & $1.52 \mathrm{E}-08$ & $9 E-10$ & $E-08$ & $00 E-08$ & $1 E-07$ & .721 \\
\hline
\end{tabular}


RESRAD-OFFSITE, Version 2.5

$\mathrm{T}^{1 / 2}$ Limit $=180$ days

obabilistic Dose and Risk Report

Title : Offsite Resident Farmer Deterministic Run

File : RF TC99 DOESG FWD-FV2b.ROF

Summary of dose at graphical times, reptition 3 (continued)

Time

Years

$3.07 \mathrm{E}+02$

$3.07 \mathrm{E}+02$

$3.08 \mathrm{E}+02$

$3.08 \mathrm{E}+02$

$3.09 \mathrm{E}+02$

$3.09 \mathrm{E}+02$

$3.10 \mathrm{E}+02$

$3.10 \mathrm{E}+02$

$3.11 \mathrm{E}+02$

$3.11 \mathrm{E}+02$

$3.12 \mathrm{E}+02$

$3.12 \mathrm{E}+02$

$3.13 \mathrm{E}+02$

$3.13 \mathrm{E}+02$

$3.14 \mathrm{E}+02$

$3.14 \mathrm{E}+02$

$3.15 \mathrm{E}+02$

$3.15 \mathrm{E}+02$

$3.16 \mathrm{E}+02$

$3.16 \mathrm{E}+02$

$3.17 \mathrm{E}+02$

$3.17 \mathrm{E}+02$

$3.18 \mathrm{E}+02$

$3.18 \mathrm{E}+02$

$3.19 \mathrm{E}+02$

$3.19 \mathrm{E}+02$

$3.20 \mathrm{E}+02$

$3.20 \mathrm{E}+02$

$3.21 \mathrm{E}+02$

$3.21 \mathrm{E}+02$

$3.22 \mathrm{E}+02$

3. $22 \mathrm{E}+02$

$3.23 \mathrm{E}+02$

$3.24 \mathrm{E}+02$

$3.24 \mathrm{E}+02$

$3.25 \mathrm{E}+02$

$3.25 \mathrm{E}+02$

$3.26 \mathrm{E}+02$

$3.26 \mathrm{E}+02$

$3.27 \mathrm{E}+02$

$3.27 \mathrm{E}+02$

$3.28 \mathrm{E}+02$

$3.28 \mathrm{E}+02$

$3.29 \mathrm{E}+02$

$3.29 \mathrm{E}+02$

$3.30 \mathrm{E}+02$
Dose statistics at graphical times, mrem/yr

\begin{tabular}{|c|c|c|c|c|c|c|c|}
\hline $\mathrm{m}$ & aximum & ea & ed & & & $\%$ & \\
\hline $18 \mathrm{E}-32$ & $8.90 \mathrm{E}-07$ & $1.54 \mathrm{E}-08$ & $E-10$ & $6 \mathrm{E}-08$ & $8.09 \mathrm{E}-08$ & 7 & . $130-01$ \\
\hline-32 & $8.98 E-07$ & $1.56 \mathrm{E}-08$ & $3.75 \mathrm{E}-10$ & $20 E-08$ & $19 E-08$ & $1.44 \mathrm{E}-07$ & $8 E-07$ \\
\hline $17 E-32$ & $05 E-07$ & $58 \mathrm{~F}-08$ & $89 E-10$ & $6 E-08$ & $8 E-08$ & $1.46 \mathrm{E}-07$ & $81 E-07$ \\
\hline $17 E-32$ & $13 E-07$ & $6 \cap F-08$ & $03 F-10$ & $31 E-08$ & $38 F-08$ & $48 \mathrm{~F}-07$ & $85 \mathrm{~F}-07$ \\
\hline-32 & 07 & $=0$ & 10 & 8 & 08 & -07 & $38 E-07$ \\
\hline 32 & 07 & & & & & & 07 \\
\hline $17 \mathrm{E}-32$ & $9.35 \mathrm{E}-07$ & & & & & & $E-07$ \\
\hline-32 & -07 & 0 & 10 & 8 & 8 & -07 & $E-07$ \\
\hline $17 E-32$ & $9.50 \mathrm{E}-07$ & $0 E-08$ & -10 & $6 E-08$ & 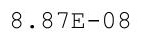 & $E-07$ & $1 E-07$ \\
\hline$E-32$ & -07 & גרקר & $98 \mathrm{E}-10$ & 8 & & $8 \mathrm{~F}-\mathrm{s}-1-1$ & 7 \\
\hline$E-32$ & 07 & 1 & & & & -07 & 7 \\
\hline $17 E-32$ & $9.73 E-07$ & $1.77 \mathrm{E}$ & 0 & 8 & 8 & 7 & -07 \\
\hline $17 E-32$ & $9.81 \mathrm{E}-07$ & $1.79 E-08$ & & & & $E-07$ & $E-07$ \\
\hline $16 \mathrm{E}-32$ & $9.88 \mathrm{E}-07$ & $1.81 \mathrm{E}-08$ & $5.70 \mathrm{E}-10$ & 8 & & $1.66 \mathrm{E}-07$ & $E-07$ \\
\hline-32 & -07 & -08 & -10 & 8 & & 年 & $E-07$ \\
\hline 32 & -06 & \pm & 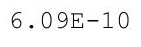 & 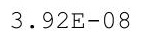 & 0 & 70 & 07 \\
\hline-32 & & & & & & & \\
\hline 32 & 6 & 1 & $6.51 E-10$ & $03 F-08$ & & $1.75 E-07$ & 7 \\
\hline $16 \mathrm{E}-32$ & $1.03 E-06$ & $1.92 \mathrm{E}-08$ & $6.73 E-10$ & 4.09E-08 & $9.91 E-08$ & $1.77 \mathrm{E}-0$ & $.33 E-07$ \\
\hline$E-32$ & $1.04 \mathrm{E}-06$ & 1. $95 \mathrm{E}-08$ & $6 \mathrm{E}-10$ & $.15 E-08$ & תחת & $1.79 \mathrm{E}-07$ & $36 E-07$ \\
\hline 32 & 06 & 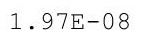 & & & & 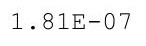 & -07 \\
\hline 32 & & & & & & & -07 \\
\hline 2 & 0 & 2.0 & & & 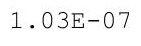 & & -07 \\
\hline-32 & 1. & 2 & 0 & 0 & 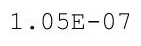 & 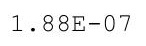 & -07 \\
\hline 2 & 6 & $2.06 E-08$ & 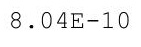 & 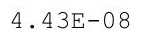 & 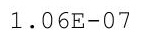 & 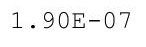 & -07 \\
\hline$E-32$ & $.08 E-06$ & $2.09 \mathrm{E}-0$ & $6 \Gamma_{1}$ & 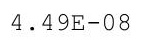 & $1.07 \mathrm{E}-07$ & 1. $92 \mathrm{E}-0$ & $56 E-07$ \\
\hline$E-32$ & $109 F-06$ & $211 \mathrm{~F}-08$ & -10 & 8 & & م ח ח & $59 E-07$ \\
\hline 32 & & & & & & & \\
\hline 32 & & & & & & & $E-07$ \\
\hline $15 E-32$ & $1 \cdot 1 \perp E-U 6$ & $2 \cdot \perp>-00$ & $9.14 \mathrm{E}-10$ & $4.73 \mathrm{E}-08$ & $\perp \cdot \pm 2 D$ & $2 \cdot 0+4$ t & $.69 E-07$ \\
\hline $5 E-32$ & $1.12 \mathrm{E}-06$ & $2 \cdot 2+\perp 00$ & $.29 \mathrm{n}-10$ & . & - & 2.010 or & $.72 \mathrm{E}-07$ \\
\hline 2 & $\perp ・ \perp U \sqcup$ & eve & . & - & 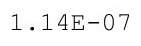 & 年 & $.76 E-07$ \\
\hline 32 & $114 \mathrm{~F}-06$ & 20 & $5-10$ & & 1 & & $79 E-07$ \\
\hline 32 & & & & & & & -07 \\
\hline$E-32$ & $1.16 \mathrm{E}-06$ & 2 & 9 & 8 & & & -07 \\
\hline $5 E-32$ & $1.16 \mathrm{E}-06$ & $2.345-00$ & 1.07E-09 & - & $\perp \cdot \pm 0$ & $2 \cdot$ & $39 E-07$ \\
\hline $15 E-32$ & $\perp \cdot \perp T L U$ & ट. & & & $\perp \cdot 2 \perp+4 t$ & & $3.93 E-07$ \\
\hline $14 \mathrm{E}-32$ & & $2.70 \pm 00$ & & & & & 3. $96 \mathrm{E}-07$ \\
\hline 2 & $\perp$ & 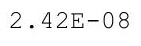 & $1.15 \mathrm{E}-09$ & 3 & 7 & 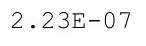 & 07 \\
\hline & 1 . & & & & & & 7 \\
\hline-32 & 1.20 & $2.48 E-08$ & 1 . & 8 & 7 & 2 & -07 \\
\hline$E-32$ & $1.21 E-06$ & 2.5 & & & 1.2 & & -07 \\
\hline & $1 \cdot 2$ & & & & & & \\
\hline & 6 & - & $1.31 E-09$ & 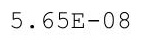 & $\perp \cdot 30 \mathrm{~L}$ & $2.35 E-07$ & $4.17 \mathrm{E}-07$ \\
\hline $\begin{array}{c}-32 \\
\end{array}$ & म.टनि & 2.0 & & & & & $4.21 E-07$ \\
\hline-32 & $1.25 E-06$ & $62 E-08$ & $.37 E-09$ & $E-08$ & $33 E-07$ & $.40 \mathrm{E}-07$ & -07 \\
\hline
\end{tabular}


RESRAD-OFFSITE, Version 2.5

Title : Offsite Resident Farmer Deterministic Run

File : RF TC99 DOESG FWD-FV2b.ROF

Summary of dose at graphical times, reptition 3 (continued)

Time

Years

$3.30 \mathrm{E}+02$

$3.31 \mathrm{E}+02$

$3.31 \mathrm{E}+02$

$3.32 \mathrm{E}+02$

$3.32 \mathrm{E}+02$

$3.33 \mathrm{E}+02$

$3.33 \mathrm{E}+02$

$3.34 \mathrm{E}+02$

$3.34 \mathrm{E}+02$

$3.35 \mathrm{E}+02$

$3.35 \mathrm{E}+02$

$3.36 \mathrm{E}+02$

$3.36 \mathrm{E}+02$

3. $37 \mathrm{E}+02$

3. $37 \mathrm{E}+02$

3. $38 \mathrm{E}+02$

3. $38 \mathrm{E}+02$

3. $39 \mathrm{E}+02$

3. $39 \mathrm{E}+02$

3. $40 \mathrm{E}+02$

$3.40 \mathrm{E}+02$

$3.41 \mathrm{E}+02$

$3.41 \mathrm{E}+02$

3. $42 \mathrm{E}+02$

$3.42 \mathrm{E}+02$

3. $43 \mathrm{E}+02$

$3.44 \mathrm{E}+02$

$3.44 \mathrm{E}+02$

$3.45 \mathrm{E}+02$

$3.45 \mathrm{E}+02$

$3.46 \mathrm{E}+02$

$3.46 \mathrm{E}+02$

$3.47 \mathrm{E}+02$

$3.47 \mathrm{E}+02$

$3.48 \mathrm{E}+02$

$3.48 \mathrm{E}+02$

$3.49 \mathrm{E}+02$

$3.49 \mathrm{E}+02$

$3.50 \mathrm{E}+02$

$3.50 \mathrm{E}+02$

$3.51 \mathrm{E}+02$

3. $51 \mathrm{E}+02$

$3.52 \mathrm{E}+02$

$3.52 \mathrm{E}+02$

3. $53 \mathrm{E}+02$

$3.53 \mathrm{E}+02$
Dose statistics at graphical times, mrem/yr

\begin{tabular}{|c|c|c|c|c|c|c|c|}
\hline m & aximum & ean & 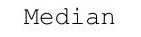 & & & $\%$ & \\
\hline $14 \mathrm{E}-32$ & $1.25 \mathrm{E}-06$ & $2.65 E-08$ & 1. $40 \mathrm{E}-09$ & $5.86 \mathrm{E}-08$ & -07 & -01 & -01 \\
\hline $14 \mathrm{E}-32$ & $1.26 \mathrm{E}-06$ & $8 E-08$ & $1.44 \mathrm{E}-09$ & $3 E-08$ & 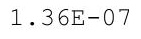 & -07 & -07 \\
\hline $14 \mathrm{E}-32$ & $1.27 \mathrm{E}-06$ & $2.70 \mathrm{E}-08$ & 1. $47 \mathrm{E}-09$ & $6.00 \mathrm{E}-08$ & $1.38 \mathrm{E}-07$ & $2.48 \mathrm{E}-07$ & $.36 \mathrm{E}-07$ \\
\hline $14 \mathrm{E}-32$ & $1.28 \mathrm{E}-06$ & $2.73 E-08$ & $1.50 \mathrm{E}-09$ & $6.07 \mathrm{E}-08$ & $1.39 \mathrm{E}-07$ & $2.51 \mathrm{E}-07$ & $4.40 \mathrm{E}-07$ \\
\hline $3 E-32$ & 06 & $6 \mathrm{E}-$ & $3 E-09$ & 08 & $1=-07$ & $4 E-07$ & .07 \\
\hline$E-32$ & -06 & $9 F-08$ & 9 & 8 & 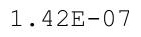 & 7 & -07 \\
\hline $13 E-32$ & 1.311 & & & & 7 & 7 & -07 \\
\hline-32 & & & & & 7 & & -07 \\
\hline-32 & -06 & -08 & -09 & 8 & 46 & -07 & -07 \\
\hline-32 & -06 & 年 & 4 & -08 & $1.48 \mathrm{E}-07$ & 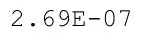 & -07 \\
\hline 32 & 6 & $2.95 E-08$ & $6 E-09$ & 8 & $49 E-07$ & -07 & 7 \\
\hline 32 & 1.351 & & & & 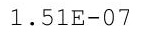 & 2.7 & -07 \\
\hline $3 E-32$ & $1.36 \mathrm{E}-06$ & -0 & 1. & 8 & 50 & 7 & -07 \\
\hline$E-32$ & $7 E-06$ & $E-08$ & $E-09$ & $9 E-08$ & 51 & 7 & $83 E-07$ \\
\hline 32 & -06 & $7 F-0$ & 9 & 8 & 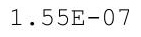 & 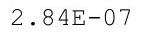 & -07 \\
\hline 32 & 06 & $3.10 \mathrm{E}-08$ & s & -08 & $t$ & 1 & -07 \\
\hline 32 & 06 & $3.14 \mathrm{E}-08$ & 9 & 8 & 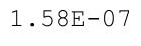 & $.91 E-07$ & 07 \\
\hline 2 & 6 & & & & & & \\
\hline $12 E-32$ & $1.41 \mathrm{E}-06$ & F & 9 & 8 & 1.61 & 2.9 & -07 \\
\hline $12 \mathrm{E}-32$ & $1.42 \mathrm{E}-06$ & $.23 E-08$ & $4 E-09$ & $.27 \mathrm{E}-08$ & $1.63 \mathrm{E}-$ & $3.01 \mathrm{E}-0$ & $.10 \mathrm{E}-07$ \\
\hline $12 \mathrm{E}-32$ & $1.43 E-06$ & $3.27 E-08$ & $2.18 E-09$ & $.35 E-08$ & 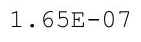 & $4 \mathrm{E}-0$ & -07 \\
\hline 32 & & & & & & & -07 \\
\hline 2 & & & & & & & 07 \\
\hline $12 E-32$ & $\perp \cdot$ & . & 9 & & & & -07 \\
\hline 2 & 6 & $3.40 \mathrm{E}-08$ & (9) & 8 & 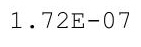 & $3.18 \mathrm{E}-07$ & -07 \\
\hline $12 E-32$ & $.47 E-06$ & 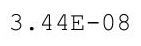 & $2.39 \mathrm{E}-09$ & $.78 E-08$ & $17 \cap 5$ & 2015 & $37 E-07$ \\
\hline$F-32$ & $148 F-06$ & $=17 F-0$ & $.43 E-09$ & 8 & 176 & קחת & $42 E-07$ \\
\hline-32 & 06 & & & 8 & 785 & 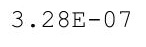 & 07 \\
\hline 32 & 06 & & & & & & 07 \\
\hline $11 \mathrm{E}-32$ & $1.50 \mathrm{E}-06$ & . & $2.58 \mathrm{E}-09$ & $8.13 E-08$ & $\pm \cdot 0<D$ & 2.01 & -07 \\
\hline $11 \mathrm{E}-32$ & $1.51 E-06$ & $\begin{array}{ll}.01+0 \\
0\end{array}$ & $2.64 \mathrm{E}-09$ & $8.22 \mathrm{E}-08$ & $1.045-01$ & . & $.61 E-07$ \\
\hline 2 & $1.52 \mathrm{E}-06$ & 年 & 然 & 年 & . & & $5.66 \mathrm{E}-07$ \\
\hline$\Gamma$ & 5 & & 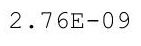 & & & & 7 \\
\hline-32 & $5-06$ & & & 8 & & 7 & 7 \\
\hline 32 & & & & & & & \\
\hline $11 E-32$ & $1.56 \mathrm{E}-06$ & $3.79 E-08$ & $2.93 E-09$ & $8.67 \mathrm{E}-08$ & $1.94 \mathrm{~B}$ & & $85 E-07$ \\
\hline $11 \mathrm{E}-32$ & $1.57 \mathrm{E}-06$ & .00 & & & & & -07 \\
\hline $11 \mathrm{E}-32$ & $1.58 \mathrm{E}-06$ & & & & & & $.95 E-07$ \\
\hline 2 & $\perp$ & & & & 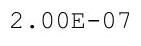 & & 07 \\
\hline & $\perp$ & & & & & & 7 \\
\hline 2 & & & & 8 & 2 & 7 & \\
\hline$D E-32$ & $1.62 \mathrm{E}-$ & 4.0 & 3. & -08 & 2 & 07 & -07 \\
\hline & 1.6 & & & & & & \\
\hline & 1.0 & & & & & & $.25 E-07$ \\
\hline & $\perp$ & & & 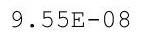 & & $E-07$ & $30 E-07$ \\
\hline$t$ & $6 E-06$ & (15 00 & $6 E-09$ & $E-08$ & $11 E-07$ & -07 & -07 \\
\hline
\end{tabular}


RESRAD-OFFSITE, Version 2.5

$\mathrm{T}^{1 / 2}$ Limit $=180$ days

Title : Offsite Resident Farmer Deterministic Run

File : RF TC99 DOESG FWD-FV2b.ROF

Summary of dose at graphical times, reptition 3 (continued)

Time

Years

$3.54 \mathrm{E}+02$

$3.54 \mathrm{E}+02$

$3.55 \mathrm{E}+02$

$3.55 \mathrm{E}+02$

$3.56 \mathrm{E}+02$

$3.56 \mathrm{E}+02$

$3.57 \mathrm{E}+02$

$3.57 \mathrm{E}+02$

$3.58 \mathrm{E}+02$

$3.58 \mathrm{E}+02$

$3.59 \mathrm{E}+02$

$3.59 \mathrm{E}+02$

$3.60 \mathrm{E}+02$

3. $60 \mathrm{E}+02$

$3.61 \mathrm{E}+02$

$3.61 \mathrm{E}+02$

3. $62 \mathrm{E}+02$

$3.62 \mathrm{E}+02$

$3.63 \mathrm{E}+02$

3. $64 \mathrm{E}+02$

$3.64 \mathrm{E}+02$

3. $65 \mathrm{E}+02$

$3.65 \mathrm{E}+02$

$3.66 \mathrm{E}+02$

$3.66 \mathrm{E}+02$

$3.67 \mathrm{E}+02$

3. $67 \mathrm{E}+02$

$3.68 \mathrm{E}+02$

$3.68 \mathrm{E}+02$

3. $69 \mathrm{E}+02$

$3.69 \mathrm{E}+02$

$3.70 \mathrm{E}+02$

$3.70 \mathrm{E}+02$

$3.71 \mathrm{E}+02$

$3.71 \mathrm{E}+02$

$3.72 \mathrm{E}+02$

$3.72 \mathrm{E}+02$

$3.73 \mathrm{E}+02$

$3.73 \mathrm{E}+02$

$3.74 \mathrm{E}+02$

$3.74 \mathrm{E}+02$

$3.75 \mathrm{E}+02$

$3.75 \mathrm{E}+02$

$3.76 \mathrm{E}+02$

$3.76 \mathrm{E}+02$

$3.77 \mathrm{E}+02$
Dose statistics at graphical times, mrem/yr

\begin{tabular}{|c|c|c|c|c|c|c|c|}
\hline Minimum & Maximum & Mean & Median & $90 \%$ & $95 \%$ & $97.5 \%$ & $99 \%$ \\
\hline $1.10 \mathrm{E}-32$ & $1.67 \mathrm{E}-06$ & $4.21 E-08$ & $3.52 E-09$ & $9.77 E-08$ & $2.13 E-07$ & $3.88 E-07$ & $6.40 \mathrm{E}-07$ \\
\hline $1.10 \mathrm{E}-32$ & $1.68 \mathrm{E}-06$ & $4.25 E-08$ & $3.58 E-09$ & $9.88 E-08$ & $2.15 \mathrm{E}-07$ & $3.91 \mathrm{E}-07$ & $6.45 E-07$ \\
\hline $1.10 \mathrm{E}-32$ & $1.69 \mathrm{E}-06$ & $4.29 \mathrm{E}-08$ & $3.64 \mathrm{E}-09$ & $9.99 \mathrm{E}-08$ & $2.17 \mathrm{E}-07$ & $3.94 \mathrm{E}-07$ & $6.50 \mathrm{E}-07$ \\
\hline $1.10 \mathrm{E}-32$ & $1.70 \mathrm{E}-06$ & $4.33 E-08$ & $3.70 \mathrm{E}-09$ & $1.01 \mathrm{E}-07$ & $2.18 \mathrm{E}-07$ & $3.97 \mathrm{E}-07$ & $6.56 \mathrm{E}-07$ \\
\hline $1.10 \mathrm{E}-32$ & $1.71 \mathrm{E}-06$ & $4.37 E-08$ & $3.76 \mathrm{E}-09$ & $1.02 \mathrm{E}-07$ & $2.20 \mathrm{E}-07$ & $4.01 \mathrm{E}-07$ & $6.61 \mathrm{E}-07$ \\
\hline $1.10 \mathrm{E}-32$ & $1.72 \mathrm{E}-06$ & $4.41 E-08$ & $3.84 \mathrm{E}-09$ & $1.03 E-07$ & $2.22 E-07$ & $4.05 E-07$ & $6.66 \mathrm{E}-07$ \\
\hline $1.10 \mathrm{E}-32$ & $1.73 E-06$ & $4.45 E-08$ & $3.91 E-09$ & $1.04 \mathrm{E}-07$ & $2.23 E-07$ & $4.09 E-07$ & $6.71 E-07$ \\
\hline $1.10 \mathrm{E}-32$ & $1.74 \mathrm{E}-06$ & $4.50 \mathrm{E}-08$ & $3.99 \mathrm{E}-09$ & $1.06 \mathrm{E}-07$ & $2.25 \mathrm{E}-07$ & $4.13 \mathrm{E}-07$ & $6.77 \mathrm{E}-07$ \\
\hline 1.09E-32 & $1.75 \mathrm{E}-06$ & $4.54 \mathrm{E}-08$ & $4.07 E-09$ & $1.07 \mathrm{E}-07$ & $2.27 E-07$ & $4.17 E-07$ & $6.82 \mathrm{E}-07$ \\
\hline $1.09 \mathrm{E}-32$ & $1.76 \mathrm{E}-06$ & $4.58 E-08$ & $4.13 E-09$ & $1.08 \mathrm{E}-07$ & $2.29 E-07$ & $4.21 E-07$ & $6.87 \mathrm{E}-07$ \\
\hline $1.09 \mathrm{E}-32$ & $1.77 \mathrm{E}-06$ & $4.62 \mathrm{E}-08$ & $4.21 \mathrm{E}-09$ & $1.09 \mathrm{E}-07$ & $2.30 \mathrm{E}-07$ & $4.25 \mathrm{E}-07$ & $6.92 \mathrm{E}-07$ \\
\hline $1.09 \mathrm{E}-32$ & $1.78 E-06$ & $4.66 \mathrm{E}-08$ & 4. $28 E-09$ & $1.10 \mathrm{E}-07$ & $2.32 \mathrm{E}-07$ & $4.28 E-07$ & $6.98 E-07$ \\
\hline $1.09 \mathrm{E}-32$ & $1.79 \mathrm{E}-06$ & $4.70 \mathrm{E}-08$ & $4.36 \mathrm{E}-09$ & $1.11 \mathrm{E}-07$ & $2.34 \mathrm{E}-07$ & $4.31 \mathrm{E}-07$ & $7.03 E-07$ \\
\hline $1.09 E-32$ & $1.80 \mathrm{E}-06$ & 4. $75 E-08$ & 4. $44 \mathrm{E}-09$ & $1.12 \mathrm{E}-07$ & $2.36 \mathrm{E}-07$ & $4.35 \mathrm{E}-07$ & $7.08 \mathrm{E}-07$ \\
\hline 1.09E-32 & $1.82 \mathrm{E}-06$ & $4.79 E-08$ & $4.52 E-09$ & $1.14 \mathrm{E}-07$ & $2.38 E-07$ & $4.38 E-07$ & $7.14 \mathrm{E}-07$ \\
\hline $1.09 E-32$ & $1.83 \mathrm{E}-06$ & $4.83 E-08$ & $4.61 E-09$ & $1.15 E-07$ & $2.39 E-07$ & $4.42 E-07$ & $7.19 E-07$ \\
\hline $1.09 \mathrm{E}-32$ & $1.84 \mathrm{E}-06$ & $4.88 E-08$ & 4. 69E-09 & $1.16 \mathrm{E}-07$ & $2.41 \mathrm{E}-07$ & $4.45 \mathrm{E}-07$ & $7.25 \mathrm{E}-07$ \\
\hline $1.09 \mathrm{E}-32$ & $1.85 \mathrm{E}-06$ & 4. $92 E-08$ & $4.77 E-09$ & $1.17 \mathrm{E}-07$ & $2.43 E-07$ & $4.49 \mathrm{E}-07$ & $7.30 \mathrm{E}-07$ \\
\hline $1.09 E-32$ & $1.86 \mathrm{E}-06$ & $4.96 E-08$ & $4.85 E-09$ & $1.18 \mathrm{E}-07$ & $2.45 E-07$ & $4.52 E-07$ & $7.35 E-07$ \\
\hline $1.09 E-32$ & $1.87 \mathrm{E}-06$ & $5.01 \mathrm{E}-08$ & 4. $93 E-09$ & $1.19 \mathrm{E}-07$ & $2.47 \mathrm{E}-07$ & $4.56 \mathrm{E}-07$ & $7.41 \mathrm{E}-07$ \\
\hline $1.09 \mathrm{E}-32$ & $1.88 \mathrm{E}-06$ & $5.05 E-08$ & $5.01 \mathrm{E}-09$ & $1.21 \mathrm{E}-07$ & $2.50 \mathrm{E}-07$ & $4.60 \mathrm{E}-07$ & $7.46 \mathrm{E}-07$ \\
\hline $1.08 E-32$ & $1.89 \mathrm{E}-06$ & $5.10 \mathrm{E}-08$ & $5.09 \mathrm{E}-09$ & $1.22 E-07$ & $2.52 E-07$ & $4.63 E-07$ & $7.52 \mathrm{E}-07$ \\
\hline $1.08 \mathrm{E}-32$ & $1.90 \mathrm{E}-06$ & $5.14 \mathrm{E}-08$ & $5.17 \mathrm{E}-09$ & $1.23 E-07$ & $2.55 \mathrm{E}-07$ & $4.67 \mathrm{E}-07$ & $7.57 \mathrm{E}-07$ \\
\hline $1.08 E-32$ & $1.91 \mathrm{E}-06$ & $5.19 \mathrm{E}-08$ & $5.25 E-09$ & $1.24 \mathrm{E}-07$ & $2.57 \mathrm{E}-07$ & $4.71 E-07$ & $7.63 E-07$ \\
\hline $1.08 E-32$ & $1.92 \mathrm{E}-06$ & $5.23 E-08$ & $5.34 \mathrm{E}-09$ & $1.25 E-07$ & $2.60 \mathrm{E}-07$ & $4.75 E-07$ & $7.69 E-07$ \\
\hline $1.08 \mathrm{E}-32$ & $1.93 E-06$ & $5.28 \mathrm{E}-08$ & $5.42 E-09$ & $1.26 \mathrm{E}-07$ & $2.62 \mathrm{E}-07$ & $4.79 \mathrm{E}-07$ & $7.74 \mathrm{E}-07$ \\
\hline $1.08 \mathrm{E}-32$ & $1.94 \mathrm{E}-06$ & $5.32 \mathrm{E}-08$ & $5.52 \mathrm{E}-09$ & $1.28 \mathrm{E}-07$ & $2.64 \mathrm{E}-07$ & $4.84 \mathrm{E}-07$ & $7.80 \mathrm{E}-07$ \\
\hline $1.08 E-32$ & $1.95 \mathrm{E}-06$ & $5.37 E-08$ & $5.60 \mathrm{E}-09$ & $1.29 \mathrm{E}-07$ & $2.66 \mathrm{E}-07$ & $4.88 E-07$ & $.86 E-07$ \\
\hline $1.08 E-32$ & $1.97 \mathrm{E}-06$ & $5.42 E-08$ & $5.69 E-09$ & $1.30 E-07$ & $2.68 \mathrm{E}-07$ & $4.92 \mathrm{E}-07$ & $7.91 \mathrm{E}-07$ \\
\hline $1.08 E-32$ & $1.98 \mathrm{E}-06$ & $5.46 E-08$ & $5.77 E-09$ & $1.31 E-07$ & $2.71 \mathrm{E}-07$ & $4.97 E-07$ & $7.97 E-07$ \\
\hline $1.08 \mathrm{E}-32$ & $1.99 \mathrm{E}-06$ & $5.51 \mathrm{E}-08$ & $5.86 \mathrm{E}-09$ & $1.33 E-07$ & $2.73 E-07$ & $5.01 \mathrm{E}-07$ & $8.03 E-07$ \\
\hline $1.08 \mathrm{E}-32$ & $2.00 \mathrm{E}-06$ & $5.56 \mathrm{E}-08$ & $5.95 E-09$ & $1.34 \mathrm{E}-07$ & $2.75 \mathrm{E}-07$ & $5.06 \mathrm{E}-07$ & $8.09 E-07$ \\
\hline $1.08 E-32$ & $2.01 E-06$ & $5.61 E-08$ & $6.04 E-09$ & $1.35 E-07$ & $2.78 \mathrm{E}-07$ & $5.10 \mathrm{E}-07$ & $8.15 E-07$ \\
\hline $1.07 E-32$ & $2.02 \mathrm{E}-06$ & $5.65 E-08$ & $6.13 E-09$ & $1.36 \mathrm{E}-07$ & $2.80 \mathrm{E}-07$ & $5.15 \mathrm{E}-07$ & $8.21 E-07$ \\
\hline $1.07 \mathrm{E}-32$ & $2.03 E-06$ & $5.70 E-08$ & $6.23 E-09$ & 1. $38 \mathrm{E}-07$ & $2.83 E-07$ & $5.19 \mathrm{E}-07$ & $8.27 \mathrm{E}-07$ \\
\hline $1.07 E-32$ & $2.04 \mathrm{E}-06$ & $5.75 E-08$ & $6.32 E-09$ & $1.39 \mathrm{E}-07$ & $2.85 E-07$ & $5.24 \mathrm{E}-07$ & $8.33 E-07$ \\
\hline $1.07 \mathrm{E}-32$ & $2.05 E-06$ & $5.80 E-08$ & $6.42 E-09$ & 1. $40 \mathrm{E}-07$ & $2.87 \mathrm{E}-07$ & $5.28 \mathrm{E}-07$ & $8.39 E-07$ \\
\hline $1.07 \mathrm{E}-32$ & $2.06 \mathrm{E}-06$ & $5.85 E-08$ & $6.52 \mathrm{E}-09$ & 1. $41 \mathrm{E}-07$ & $2.90 \mathrm{E}-07$ & $5.33 \mathrm{E}-07$ & $8.45 E-07$ \\
\hline $1.07 E-32$ & $2.07 E-06$ & $5.90 \mathrm{E}$ & $6.62 E-09$ & 1. $42 \mathrm{E}-07$ & $2.92 E-07$ & $5.37 E-07$ & $8.51 \mathrm{E}-07$ \\
\hline $1.07 E-32$ & $2.08 E-06$ & $5.95 E-08$ & $6.73 E-09$ & $1.44 \mathrm{E}-07$ & $2.95 \mathrm{E}-07$ & $5.42 \mathrm{E}-07$ & $8.57 \mathrm{E}-07$ \\
\hline $1.07 \mathrm{E}-32$ & $2.09 E-06$ & $6.00 \mathrm{E}-08$ & $6.83 E-09$ & $1.45 E-07$ & $2.97 \mathrm{E}-07$ & $5.46 \mathrm{E}-07$ & $8.63 E-07$ \\
\hline $1.07 E-32$ & $2.11 E-06$ & $6.05 E-08$ & $6.92 E-09$ & $1.46 E-07$ & $3.00 \mathrm{E}-07$ & $5.51 E-07$ & $8.69 E-07$ \\
\hline $1.07 E-32$ & $2.12 \mathrm{E}-06$ & $6.10 \mathrm{E}-08$ & $7.02 E-09$ & 1. $47 \mathrm{E}-07$ & $3.02 \mathrm{E}-07$ & $5.55 \mathrm{E}-07$ & $8.75 E-07$ \\
\hline $1.07 E-32$ & $2.13 E-06$ & $6.15 E-08$ & $7.13 E-09$ & 1. $48 \mathrm{E}-07$ & $3.05 E-07$ & $5.59 \mathrm{E}-07$ & $8.80 E-07$ \\
\hline $1.07 E-32$ & $2.14 \mathrm{E}-06$ & $6.20 E-08$ & $7.23 E-09$ & $1.50 \mathrm{E}-07$ & $3.07 E-07$ & $5.63 E-07$ & $8.85 E-07$ \\
\hline $1.07 E-32$ & $2.15 \mathrm{E}-06$ & $6.25 E-08$ & $7.34 \mathrm{E}-09$ & $1.51 E-07$ & $3.09 E-07$ & $5.67 \mathrm{E}-07$ & $8.91 E-07$ \\
\hline
\end{tabular}


RESRAD-OFFSITE, Version 2.5

$\mathrm{T}^{1 / 2}$ Limit $=180$ days

Title : Offsite Resident Farmer Deterministic Run

File : RF TC99 DOESG FWD-FV2b.ROF

Summary of dose at graphical times, reptition 3 (continued)

Time

Years

$3.77 \mathrm{E}+02$

$3.78 \mathrm{E}+02$

$3.78 \mathrm{E}+02$

$3.79 \mathrm{E}+02$

$3.79 \mathrm{E}+02$

$3.80 \mathrm{E}+02$

$3.80 \mathrm{E}+02$

$3.81 \mathrm{E}+02$

$3.81 \mathrm{E}+02$

$3.82 \mathrm{E}+02$

$3.82 \mathrm{E}+02$

$3.83 \mathrm{E}+02$

$3.83 E+02$

$3.84 \mathrm{E}+02$

$3.85 \mathrm{E}+02$

$3.85 \mathrm{E}+02$

$3.86 \mathrm{E}+02$

$3.86 \mathrm{E}+02$

$3.87 \mathrm{E}+02$

$3.87 \mathrm{E}+02$

$3.88 \mathrm{E}+02$

3. $88 \mathrm{E}+02$

$3.89 \mathrm{E}+02$

$3.89 \mathrm{E}+02$

3. $90 \mathrm{E}+02$

$3.90 \mathrm{E}+02$

3. $91 \mathrm{E}+02$

3. $91 \mathrm{E}+02$

3. $92 \mathrm{E}+02$

3. $92 \mathrm{E}+02$

3. $93 \mathrm{E}+02$

3. $93 \mathrm{E}+02$

$3.94 \mathrm{E}+02$

$3.94 \mathrm{E}+02$

$3.95 \mathrm{E}+02$

$3.95 \mathrm{E}+02$

$3.96 \mathrm{E}+02$

$3.96 \mathrm{E}+02$

3. $97 \mathrm{E}+02$

3. $97 \mathrm{E}+02$

$3.98 \mathrm{E}+02$

3. $98 \mathrm{E}+02$

$3.99 \mathrm{E}+02$

$3.99 \mathrm{E}+02$

4. $00 \mathrm{E}+02$

$4.00 \mathrm{E}+02$
Dose statistics at graphical times, mrem/yr

\begin{tabular}{|c|c|c|c|c|c|c|c|}
\hline m & aximum & ean & 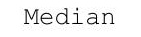 & & & $\%$ & \\
\hline $.06 \mathrm{E}-32$ & $2.16 \mathrm{E}-06$ & $6.30 \mathrm{E}-08$ & $7.45 \mathrm{E}-09$ & $1.52 \mathrm{E}-07$ & -07 & -07 & -01 \\
\hline-32 & -06 & -08 & -09 & 7 & 07 & -07 & -07 \\
\hline $.06 \mathrm{E}-32$ & $2.18 \mathrm{E}-06$ & $6.40 \mathrm{E}-08$ & $7.66 \mathrm{E}-09$ & $1.55 \mathrm{E}-07$ & $3.17 \mathrm{E}-07$ & $5.78 \mathrm{E}-07$ & $E-07$ \\
\hline $06 \mathrm{E}-32$ & $2.19 E-06$ & $6.45 E-08$ & $7.77 \mathrm{E}-09$ & $1.56 \mathrm{E}-07$ & $3.19 \mathrm{E}-07$ & $5.82 \mathrm{E}-07$ & $13 E-07$ \\
\hline $06 \mathrm{E}-32$ & 06 & . & 09 & $=0$ & 07 & $6 E-07$ & 07 \\
\hline $06 \mathrm{E}-32$ & 06 & $6.56 \mathrm{E}-08$ & 9 & $1.59 \mathrm{E}-07$ & 7 & 7 & -07 \\
\hline $06 \mathrm{E}-32$ & $2.23 \mathrm{E}$ & & & & 7 & 7 & -07 \\
\hline-32 & & & & & & & -07 \\
\hline-32 & $E-06$ & $F-0$ & -09 & 7 & 7 & -07 & -07 \\
\hline $06 \mathrm{E}-32$ & -06 & 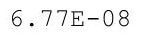 & -09 & 2.0 & $3.34 \mathrm{E}-07$ & $6.01 \mathrm{E}-07$ & 07 \\
\hline$E-30$ & 6 & $6.83 E-08$ & 9 & $1.66 \mathrm{E}-07$ & -07 & -07 & 7 \\
\hline 30 & 2.2 & & & 1.67 & & & -07 \\
\hline $02 F-30$ & $229 F-06$ & $3 F-0$ & 9 & $695-1201$ & 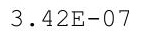 & $11 E-07$ & -07 \\
\hline $.08 \mathrm{E}-30$ & $2.30 \mathrm{E}-06$ & $6.99 \mathrm{E}-08$ & $8.96 \mathrm{E}-09$ & $1.70 \mathrm{E}-07$ & $3.45 \mathrm{E}-07$ & $6.14 \mathrm{E}-07$ & -07 \\
\hline-30 & -06 & -08 & -09 & 7 & & & -07 \\
\hline 30 & -06 & - & -09 & $\perp$ & 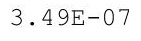 & $2 E-07$ & -07 \\
\hline 30 & 06 & $.16 \mathrm{E}-08$ & 9 & $\pm \cdot T$ & 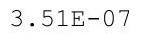 & & 07 \\
\hline 0 & 6 & & & & & & \\
\hline $09 E-30$ & $2.36 \mathrm{E}-06$ & $7.27 \mathrm{E}-08$ & $9.58 \mathrm{E}-09$ & $1.77 E-07$ & $55 \mathrm{E}$ & & -06 \\
\hline $09 E-29$ & $2.37 \mathrm{E}-06$ & $.32 E-08$ & -09 & $1.79 \mathrm{E}-0$ & $.57 \mathrm{E}-$ & $3 E-0$ & $.01 E-06$ \\
\hline $09 E-29$ & $2.38 E-06$ & 7. $38 E-08$ & $9.86 \mathrm{E}-09$ & $1.81 \mathrm{E}-07$ & $.005-01$ & $E-0^{\prime}$ & $1.01 \mathrm{E}-06$ \\
\hline 29 & & & & & & & -06 \\
\hline 9 & & & & & & & 06 \\
\hline $12 \mathrm{E}-29$ & 0 & & 8 & 1. & & & 06 \\
\hline 9 & 6 & 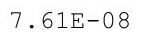 & 8 & 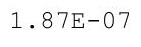 & 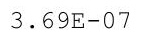 & $6.60 \mathrm{E}-07$ & -06 \\
\hline $27 E-27$ & $.43 E-06$ & 167 & $.05 E-08$ & 1 & ק? & 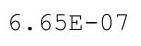 & $1.04 \mathrm{E}-06$ \\
\hline$F-25$ & $44 F-06$ & $73 F-08$ & -08 & & תЕ & 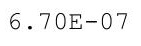 & $.05 E-06$ \\
\hline$E-24$ & 06 & F & 8 & 01 & & & $06 E-06$ \\
\hline & & & & & & & \\
\hline $03 E-22$ & $2.48 E-06$ & . & $1 E-08$ & $1 \cdot 34$ & 5.00 & $t$ & -06 \\
\hline $99 \mathrm{E}-21$ & $2.495-00$ & . & $1.12 \mathrm{E}-08$ & $1.96 \mathrm{E}-07$ & $3.03 \mathrm{~L}-\mathrm{t}$ & $\begin{array}{l}.000 \\
0\end{array}$ & $.07 E-06$ \\
\hline 0 & $2.50 \mathrm{E}-06$ & 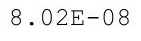 & 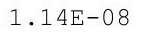 & 工象 & 然 & & $1.08 \mathrm{E}-06$ \\
\hline $.61 \mathrm{E}-20$ & 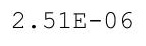 & & & & & & 6 \\
\hline$F-19$ & $E-06$ & & 8 & & & $E-07$ & 6 \\
\hline 9 & & & & & & & \\
\hline 18 & $2.34 \mathrm{E}$ & 0.20 & 1.201 & 2.05 & 7 & & 06 \\
\hline $39 \mathrm{E}-18$ & 2.00 & & & & & & -06 \\
\hline $07 E-17$ & 2.0 & & & & & & $1.1 \angle D-00$ \\
\hline 7 & 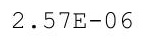 & 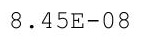 & $1.24 \mathrm{E}-08$ & 2 & $t$ & & 06 \\
\hline & & & & & & & 6 \\
\hline & & 8 & 8 & 7 & 7 & 7 & -06 \\
\hline$E-16$ & $2.61 E-06$ & -08 & 1.2 & & 7 & 07 & 1.1 \\
\hline & 6 & & & & & & \\
\hline & 2. & - & & & & & $1.15 E-06$ \\
\hline & & & & - & 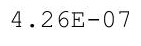 & $E-07$ & $1.10 \mathrm{D}-00$ \\
\hline$E-15$ & $5 E-06$ & $9 E-08$ & $1.35 E-08$ & $21 E-07$ & $9 E-07$ & $0 E-07$ & -06 \\
\hline
\end{tabular}


RESRAD-OFFSITE, Version 2.5

Title : Offsite Resident Farmer Deterministic Run

File : RF TC99 DOESG FWD-FV2b.ROF

Summary of dose at graphical times, reptition 3 (continued)

Time

Years

4. $01 \mathrm{E}+02$

$4.01 \mathrm{E}+02$

$4.02 \mathrm{E}+02$

$4.02 \mathrm{E}+02$

$4.03 E+02$

$4.03 \mathrm{E}+02$

4. $04 \mathrm{E}+02$

$4.05 \mathrm{E}+02$

$4.05 \mathrm{E}+02$

$4.06 \mathrm{E}+02$

$4.06 \mathrm{E}+02$

$4.07 \mathrm{E}+02$

$4.07 \mathrm{E}+02$

$4.08 \mathrm{E}+02$

$4.08 \mathrm{E}+02$

$4.09 \mathrm{E}+02$

4. $09 \mathrm{E}+02$

$4.10 \mathrm{E}+02$

$4.10 \mathrm{E}+02$

$4.11 \mathrm{E}+02$

$4.11 \mathrm{E}+02$

$4.12 \mathrm{E}+02$

$4.12 \mathrm{E}+02$

$4.13 \mathrm{E}+02$

$4.13 \mathrm{E}+02$

$4.14 \mathrm{E}+02$

$4.14 \mathrm{E}+02$

$4.15 \mathrm{E}+02$

$4.15 \mathrm{E}+02$

$4.16 \mathrm{E}+02$

$4.16 \mathrm{E}+02$

$4.17 \mathrm{E}+02$

$4.17 \mathrm{E}+02$

$4.18 \mathrm{E}+02$

$4.18 \mathrm{E}+02$

4. $19 \mathrm{E}+02$

$4.19 \mathrm{E}+02$

$4.20 \mathrm{E}+02$

$4.20 \mathrm{E}+02$

$4.21 \mathrm{E}+02$

$4.21 \mathrm{E}+02$

$4.22 \mathrm{E}+02$

4. $22 \mathrm{E}+02$

$4.23 \mathrm{E}+02$

$4.23 E+02$

$4.24 \mathrm{E}+02$
Dose statistics at graphical times, mrem/yr

\begin{tabular}{|c|c|c|c|c|c|c|c|}
\hline m & aximum & ean & 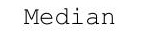 & & & $\%$ & \\
\hline $56 \mathrm{E}-15$ & $2.66 \mathrm{E}-06$ & $8.95 E-08$ & $1.37 \mathrm{E}-08$ & $2.23 \mathrm{E}-07$ & -07 & -07 & $\perp \cdot 1$ \\
\hline-15 & 06 & -08 & -08 & 7 & 07 & -07 & -06 \\
\hline $92 E-15$ & $2.68 \mathrm{E}-06$ & $9.08 \mathrm{E}-08$ & 1. $40 \mathrm{E}-08$ & $2.27 E-07$ & $4.37 \mathrm{E}-07$ & $7.75 \mathrm{E}-07$ & $1.19 \mathrm{E}-06$ \\
\hline $69 \mathrm{E}-15$ & $2.69 \mathrm{E}-06$ & $9.14 \mathrm{E}-08$ & $.42 \mathrm{E}-08$ & $2.28 \mathrm{E}-07$ & $4.39 \mathrm{E}-07$ & $7.80 \mathrm{E}-07$ & $1.19 \mathrm{E}-06$ \\
\hline $25 \mathrm{~F}-14$ & $.70 E-06$ & $21 \mathrm{~F}-08$ & $1.43 E-08$ & $30 F-07$ & $2 E-07$ & $785 F-07$ & 1. $20 E-06$ \\
\hline-14 & 06 & 0 & -08 & 7 & & & -06 \\
\hline $46 \mathrm{E}-14$ & $2.73 \mathrm{E}$ & 8 & & 7 & & 7 & -06 \\
\hline $37 E-14$ & $2.74 \mathrm{E}-06$ & & & & 07 & & $1.22 \mathrm{E}-06$ \\
\hline $54 \mathrm{E}-14$ & -06 & $7 E-08$ & $0 E-08$ & $38 E-07$ & 07 & -07 & -06 \\
\hline $04 \mathrm{E}-14$ & 06 & $9.54 \mathrm{E}-08$ & 8 & 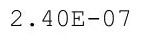 & 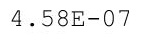 & t & -06 \\
\hline $4 E-14$ & 5 & $9.60 \mathrm{E}-08$ & $1.54 \mathrm{E}-08$ & & $.60 \mathrm{E}-07$ & 7 & 6 \\
\hline 3 & 6 & & & & & & 06 \\
\hline $32 \mathrm{E}-13$ & $9 F-06$ & 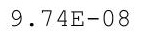 & 1. & $5 \mathrm{~F}$ & $4.66 \mathrm{E}-07$ & 7 & $25 E-06$ \\
\hline $.68 \mathrm{E}-13$ & $2.80 \mathrm{E}-06$ & $9.80 \mathrm{E}-08$ & $1.60 \mathrm{E}-08$ & $2.47 \mathrm{E}-07$ & $4.69 \mathrm{E}-07$ & $8.31 E-07$ & $1.26 \mathrm{E}-06$ \\
\hline $11 \mathrm{E}-13$ & $2.81 \mathrm{E}-06$ & $E-08$ & -08 & $49 E-07$ & & & -06 \\
\hline$E-13$ & & & & 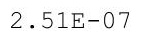 & & & -06 \\
\hline $5 E-13$ & & & & 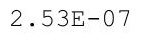 & & & 06 \\
\hline 3 & 6 & & & & & & 06 \\
\hline $83 E-13$ & $.85 E-06$ & $15-6$ & $1.70 \mathrm{E}-08$ & ت & $4.84 E-07$ & & -06 \\
\hline $82 E-13$ & $.86 E-06$ & $.02 \mathrm{E}-07$ & $1.71 \mathrm{E}-08$ & $.59 E-07$ & $4.87 E-07$ & $E-07$ & $.29 E-06$ \\
\hline $97 E-13$ & $87 E-06$ & 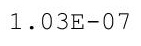 & -08 & 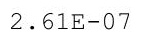 & 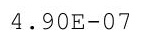 & $.65 E-c$ & $.30 E-06$ \\
\hline & & & & & & & -06 \\
\hline$E-13$ & & & & & & & -06 \\
\hline 2 & & & & & & & -06 \\
\hline $4 \mathrm{E}-12$ & 6 & $1.06 \mathrm{E}-07$ & 8 & 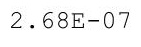 & 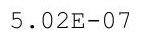 & $8.85 E-07$ & -06 \\
\hline $56 \mathrm{E}-12$ & $.93 E-06$ & 1 & $1.84 \mathrm{E}-08$ & تصم & 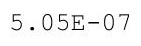 & م= & $1.33 E-06$ \\
\hline-12 & $94 \mathrm{~F}-06$ & 1. & $1.86 \mathrm{E}-08$ & 710 & & $F-0$ & $1.34 \mathrm{E}-06$ \\
\hline-12 & & & & & & & 06 \\
\hline & & & & & & & 06 \\
\hline $70 \mathrm{E}-12$ & $2.97 E-06$ & 土.णें & $1.93 \mathrm{E}-08$ & $2 \cdot 100$ & 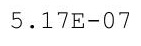 & & -06 \\
\hline $06 \mathrm{E}-12$ & $2.98 E-06$ & 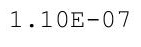 & $1.95 E-08$ & $2.77 \mathrm{E}-07$ & $.2 U 5-U 1$ & $\begin{array}{ccc}\text {. } & 0 \\
\end{array}$ & $1.37 E-06$ \\
\hline 2 & $2.99 E-06$ & 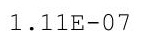 & 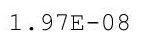 & 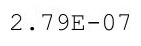 & & & $1.37 \mathrm{E}-06$ \\
\hline-12 & E- & & $1.99 \mathrm{E}-\mathrm{C}$ & & & & $1.38 \mathrm{E}-06$ \\
\hline-12 & & & & קת & & & $38 E-06$ \\
\hline 2 & & & & & & & \\
\hline 12 & 6 & $1 \cdot 141$ & $2.06 \mathrm{E}-08$ & $2.00 \mathrm{~L}$ & 7 & & 1.4 \\
\hline$E-12$ & $3.04 \mathrm{E}-06$ & & & & & & -06 \\
\hline $65 \mathrm{E}-12$ & $3.05 E-06$ & & & & & & $1.41 \mathrm{~L}-00$ \\
\hline 2 & 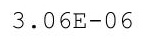 & & $2.13 E-08$ & 7 & 7 & 7 & 06 \\
\hline & & & & & & & 06 \\
\hline & & & 8 & 7 & 7 & 7 & -06 \\
\hline$E-12$ & $3.10 \mathrm{E}-06$ & 1.18 & 2. & 2.96 & 5.5 & 07 & 1.4 \\
\hline & 06 & & & & & & 1.4 \\
\hline & & & (2) & & & & $1.45 E-06$ \\
\hline 1 & & & (2) & $\begin{array}{lll}1 & 1\end{array}$ & & $9.87 \mathrm{E}-07$ & $1.40 \mathrm{D}-00$ \\
\hline$E-11$ & $E-06$ & $1 E-07$ & $30 E-08$ & $3 E-07$ & $E-07$ & $92 E-07$ & -06 \\
\hline
\end{tabular}


RESRAD-OFFSITE, Version 2.5

Title : Offsite Resident Farmer Deterministic Run

File : RF TC99 DOESG FWD-FV2b.ROF

Summary of dose at graphical times, reptition 3 (continued)

Time

Years

$4.25 \mathrm{E}+02$

$4.25 \mathrm{E}+02$

$4.26 \mathrm{E}+02$

$4.26 \mathrm{E}+02$

$4.27 \mathrm{E}+02$

$4.27 \mathrm{E}+02$

$4.28 \mathrm{E}+02$

4. $28 \mathrm{E}+02$

$4.29 \mathrm{E}+02$

4. $29 \mathrm{E}+02$

4. $30 \mathrm{E}+02$

$4.30 E+02$

$4.31 \mathrm{E}+02$

4. $31 \mathrm{E}+02$

4. $32 \mathrm{E}+02$

4. $32 \mathrm{E}+02$

$4.33 \mathrm{E}+02$

4. $33 \mathrm{E}+02$

$4.34 \mathrm{E}+02$

$4.34 \mathrm{E}+02$

4. $35 \mathrm{E}+02$

$4.35 \mathrm{E}+02$

$4.36 \mathrm{E}+02$

$4.36 \mathrm{E}+02$

$4.37 \mathrm{E}+02$

$4.37 \mathrm{E}+02$

$4.38 \mathrm{E}+02$

$4.38 \mathrm{E}+02$

$4.39 \mathrm{E}+02$

$4.39 \mathrm{E}+02$

$4.40 \mathrm{E}+02$

4. $40 \mathrm{E}+02$

$4.41 \mathrm{E}+02$

4. $41 \mathrm{E}+02$

$4.42 \mathrm{E}+02$

4. $42 \mathrm{E}+02$

4. $43 \mathrm{E}+02$

$4.43 \mathrm{E}+02$

4. $44 \mathrm{E}+02$

4. $45 \mathrm{E}+02$

$4.45 \mathrm{E}+02$

$4.46 \mathrm{E}+02$

$4.46 \mathrm{E}+02$

$4.47 \mathrm{E}+02$

$4.47 \mathrm{E}+02$

$4.48 \mathrm{E}+02$
Dose statistics at graphical times, mrem/yr

\begin{tabular}{|c|c|c|c|c|c|c|c|}
\hline m & $\operatorname{axi}$ & ea & 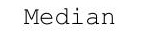 & & & $\%$ & \\
\hline $46 \mathrm{E}-11$ & $.15 \mathrm{E}-06$ & 1.22E-07 & $2.32 \mathrm{E}-08$ & $3.05 \mathrm{E}-07$ & $5.73 E-07$ & -07 & $1.4 / E-06$ \\
\hline $57 \mathrm{E}-11$ & $.16 \mathrm{E}-06$ & 1.23E-07 & $2.35 \mathrm{E}-08$ & $E-07$ & 07 & -06 & $1.48 \mathrm{E}-06$ \\
\hline $.69 \mathrm{E}-11$ & $3.17 \mathrm{E}-06$ & 1.23E-07 & $2.37 \mathrm{E}-08$ & $09 E-07$ & $80 \mathrm{E}-07$ & -06 & $1.48 \mathrm{E}-06$ \\
\hline $82 \mathrm{E}-11$ & $3.18 E-06$ & $.24 \mathrm{E}-07$ & $2.40 \mathrm{E}-08$ & $.10 \mathrm{E}-07$ & $5.84 \mathrm{E}-07$ & $1.01 \mathrm{E}-06$ & $1.49 \mathrm{E}-06$ \\
\hline $95 E-11$ & $.19 E-06$ & $25 \mathrm{~F}-07$ & $.43 E-08$ & $12 \mathrm{~F}-07$ & $87 \mathrm{~F}-07$ & $1 \mathrm{~F}-06$ & $50 E-06$ \\
\hline 0 & 06 & 1 & & & & 6 & -06 \\
\hline $24 \mathrm{E}-11$ & $3.21 \mathrm{E}-06$ & $1.27 \mathrm{E}-$ & & 7 & & 6 & -06 \\
\hline $39 \mathrm{E}-11$ & $3.22 \mathrm{E}-06$ & -0. & & & & & -06 \\
\hline $.55 \mathrm{E}-11$ & -06 & $8 E-07$ & -08 & 7 & 07 & -06 & $53 E-06$ \\
\hline-11 & 06 & $1.29 \mathrm{E}-07$ & 8 & 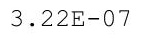 & 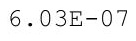 & -06 & -06 \\
\hline 1 & $3.25 E-06$ & 1. $30 \mathrm{E}-07$ & $2.58 E-08$ & $25 \mathrm{~F}-07$ & $07 E-07$ & 6 & 6 \\
\hline$F-11$ & 6 & 1 & & 7 & & & -06 \\
\hline$E-11$ & $F-06$ & $131 \mathrm{~F}-$ & 8 & 7 & $13 E-07$ & -06 & -06 \\
\hline $43 E-11$ & $3.28 \mathrm{E}-06$ & 1. $32 \mathrm{E}-07$ & $2.66 \mathrm{E}-08$ & $3.31 E-07$ & $6.17 \mathrm{E}-07$ & $1.06 \mathrm{E}-06$ & $1.56 \mathrm{E}-06$ \\
\hline $62 \mathrm{E}-11$ & -06 & 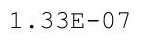 & -08 & , & & 06 & -06 \\
\hline 1 & & & & & & & -06 \\
\hline$E-11$ & & & & & & & 06 \\
\hline 1 & & $1.35 E-07$ & & & & & 06 \\
\hline $47 E-11$ & $3.33 E-06$ & $136 \mathrm{~F}-$ & $2.81 E-08$ & & $25=$ & $E-06$ & -06 \\
\hline $70 \mathrm{E}-11$ & $4 E-06$ & $137 F_{-0}$ & $4 \mathrm{E}-08$ & $5 \mathrm{~F}-07$ & $8 \mathrm{~F}-\mathrm{C}-3 \mathrm{r}$ & $F-06$ & $.61 E-06$ \\
\hline $94 \mathrm{E}-11$ & $E-06$ & 1. $38 \mathrm{E}-0$ & $.87 E-08$ & 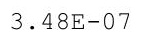 & 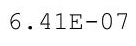 & $1.09 E-06$ & $.62 \mathrm{E}-06$ \\
\hline 11 & & & & & & & -06 \\
\hline 1 & & $1.39 \mathrm{E}-07$ & & & & & -06 \\
\hline $69 \mathrm{E}-11$ & 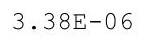 & 1.90 & & & & & -06 \\
\hline 11 & 6 & 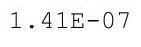 & 8 & 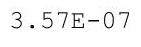 & $6.54 \mathrm{E}-07$ & 0 & -06 \\
\hline $22 \mathrm{E}-11$ & $.40 E-06$ & 1 & $3 E-08$ & 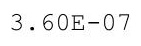 & 57 Г & $1.12 \mathrm{E}-06$ & $1.66 \mathrm{E}-06$ \\
\hline $50 \mathrm{E}-11$ & $41 \mathrm{~F}-06$ & 1 & $E-08$ & & & $F-06$ & $1.66 \mathrm{E}-06$ \\
\hline 11 & & & & & & & 06 \\
\hline-11 & & $\perp$ & & & & & \\
\hline $38 E-11$ & $3.44 \mathrm{E}-06$ & ×・4ป亡- & $3.13 E-08$ & . & $+\infty$ & $\perp \cdot \pm 1$ & -06 \\
\hline $.68 \mathrm{E}-11$ & $3.45 E-06$ & 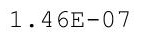 & $3.15 \mathrm{E}-08$ & $3.13 \mathrm{E}-\mathrm{t}$ & . & $1 \cdot 14 \mathrm{E}-00$ & $1.69 E-06$ \\
\hline 1 & $3.45 E-06$ & 然 & 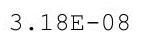 & 年 & 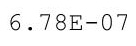 & $\perp \cdot 14 \pm-00$ & $1.70 \mathrm{E}-06$ \\
\hline $32 E-11$ & $46 \mathrm{~F}-06$ & $1.48 \mathrm{E}-$ & $F-08$ & & & & $1.71 \mathrm{E}-06$ \\
\hline $64 \mathrm{~F}-11$ & & & & & & & 06 \\
\hline-11 & & & & 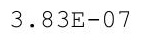 & 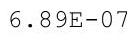 & 6 & \\
\hline $32 \mathrm{E}-11$ & $3.49 \mathrm{E}-06$ & I. $3 \perp E-U$ & $3.29 E-08$ & . & the & 06 & $1.73 E-06$ \\
\hline $67 E-11$ & $3.50 \mathrm{E}-06$ & $1.01+$ & & & & & -06 \\
\hline $00 \mathrm{E}-10$ & & & & & & & $1.70 \mathrm{E}-00$ \\
\hline 0 & $3.52 \mathrm{E}-06$ & +0 & 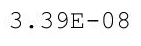 & & $t$ & $+0^{\circ}$ & 06 \\
\hline & & & & & & & 06 \\
\hline-10 & & 1.5 & 8 & 7 & & 6 & -06 \\
\hline$E-10$ & $3.55 \mathrm{E}-06$ & 1.56 & 08 & 7 & 7 & 06 & -06 \\
\hline & & & & & & & \\
\hline & & & & & & & $1.79 E-06$ \\
\hline 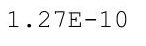 & 06 & t & & & & 06 & $1.00 \mathrm{E}-00$ \\
\hline $1 E-10$ & $9 E-06$ & $9 \mathrm{E}-07$ & $61 E-08$ & $E-07$ & $3 E-07$ & $.22 E-06$ & -06 \\
\hline
\end{tabular}


RESRAD-OFFSITE, Version 2.5

Title : Offsite Resident Farmer Deterministic Run

File : RF TC99 DOESG FWD-FV2b.ROF

Summary of dose at graphical times, reptition 3 (continued)

Time

Years

$4.48 \mathrm{E}+02$

$4.49 \mathrm{E}+02$

$4.49 \mathrm{E}+02$

$4.50 \mathrm{E}+02$

$4.50 \mathrm{E}+02$

$4.51 \mathrm{E}+02$

$4.51 \mathrm{E}+02$

4. $52 \mathrm{E}+02$

$4.52 \mathrm{E}+02$

4. $53 \mathrm{E}+02$

$4.53 \mathrm{E}+02$

$4.54 \mathrm{E}+02$

$4.54 \mathrm{E}+02$

$4.55 \mathrm{E}+02$

$4.55 \mathrm{E}+02$

$4.56 \mathrm{E}+02$

$4.56 \mathrm{E}+02$

$4.57 \mathrm{E}+02$

$4.57 \mathrm{E}+02$

$4.58 \mathrm{E}+02$

$4.58 \mathrm{E}+02$

$4.59 \mathrm{E}+02$

$4.59 \mathrm{E}+02$

$4.60 \mathrm{E}+02$

$4.60 \mathrm{E}+02$

4. $61 \mathrm{E}+02$

$4.61 \mathrm{E}+02$

$4.62 \mathrm{E}+02$

$4.62 \mathrm{E}+02$

$4.63 \mathrm{E}+02$

4. $63 \mathrm{E}+02$

$4.64 \mathrm{E}+02$

$4.65 \mathrm{E}+02$

4. $65 \mathrm{E}+02$

$4.66 \mathrm{E}+02$

$4.66 \mathrm{E}+02$

$4.67 \mathrm{E}+02$

$4.67 \mathrm{E}+02$

$4.68 \mathrm{E}+02$

$4.68 \mathrm{E}+02$

$4.69 \mathrm{E}+02$

$4.69 \mathrm{E}+02$

$4.70 \mathrm{E}+02$

$4.70 \mathrm{E}+02$

$4.71 \mathrm{E}+02$

$4.71 \mathrm{E}+02$
Dose statistics at graphical times, mrem/yr

\begin{tabular}{|c|c|c|c|c|c|c|c|}
\hline $\mathrm{m}$ & aximum & lea & - & & & & \\
\hline $36 \mathrm{E}-10$ & $3.60 \mathrm{E}-06$ & 1. $60 \mathrm{E}-07$ & $.64 \mathrm{E}-08$ & $5 E-07$ & $7.37 \mathrm{E}-07$ & 06 & $1.0<E-00$ \\
\hline $40 E-10$ & $3.61 E-06$ & $1.61 \mathrm{E}-07$ & $3.67 \mathrm{E}-08$ & $8 E-07$ & $\Xi-07$ & $1.23 E-06$ & $1.83 E-06$ \\
\hline $44 \mathrm{E}-10$ & $.62 E-06$ & 1. $62 \mathrm{E}-07$ & $.70 \mathrm{E}-08$ & $4.20 \mathrm{E}-07$ & $45 E-07$ & $1.24 \mathrm{E}-06$ & $1.83 E-06$ \\
\hline $49 F-10$ & $62 E-06$ & $63 F-07$ & $74 \mathrm{E}-08$ & $23 F-07$ & $.49 \mathrm{E}-07$ & -06 & $84 E-06$ \\
\hline 10 & 06 & 7 & -08 & 7 & 7 & -06 & $.85 E-06$ \\
\hline 10 & & 1. $65 \mathrm{E}-07$ & & & & & \\
\hline $62 \mathrm{E}-10$ & $3.65 \mathrm{E}-06$ & 1.001 & & & & & -06 \\
\hline-10 & 06 & 1 & 8 & 7 & 7 & 6 & -06 \\
\hline $72 \mathrm{E}-10$ & $67 E-06$ & $67 E-07$ & -08 & $7 E-07$ & -07 & -06 & $88 E-06$ \\
\hline $.77 \mathrm{E}-10$ & $68 E-06$ & 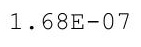 & 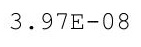 & 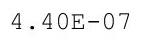 & & $.28 E-06$ & $.89 E-06$ \\
\hline 0 & 06 & 1 & & & & 6 & 06 \\
\hline $87 E-10$ & $3.70 \mathrm{E}-06$ & $1.70 \mathrm{E}$ & 8 & 6 & $78 F-8$ & 6 & -06 \\
\hline $92 \mathrm{E}-10$ & $3.71 E-06$ & $1.71 \mathrm{E}-07$ & $4.07 E-08$ & & & $1.30 \mathrm{E}-06$ & $1.91 \mathrm{E}-06$ \\
\hline $97 \mathrm{E}-10$ & $.72 E-06$ & $1.72 \mathrm{E}-07$ & $4.10 \mathrm{E}-08$ & $4.52 \mathrm{E}-07$ & $7.85 \mathrm{E}-07$ & 1. $30 \mathrm{E}-06$ & $E-06$ \\
\hline $03 E-10$ & $72 E-06$ & $.73 E-0$ & -08 & & 1 & -06 & $E-06$ \\
\hline 0 & 06 & +. & 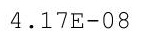 & 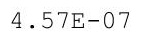 & קב? م & 6 & $93 E-06$ \\
\hline 0 & 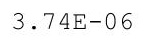 & $175 \mathrm{~F}-07$ & & & & & 6 \\
\hline 0 & 6 & 1 & $4.25 E-08$ & & & 1. $32 \mathrm{E}-06$ & 6 \\
\hline $25 E-10$ & $3.76 \mathrm{E}-06$ & $1.77 E-07$ & $4.29 E-08$ & $4.65 E-07$ & $8.07 \mathrm{E}-0$ & $1.33 E-06$ & $1.95 \mathrm{E}-06$ \\
\hline $30 \mathrm{E}-10$ & $.77 \mathrm{E}-06$ & $1.78 \mathrm{E}-07$ & $4.33 E-08$ & $4.68 \mathrm{E}-07$ & $.12 \mathrm{E}-07$ & $E-06$ & 1. $96 \mathrm{E}-06$ \\
\hline 10 & 06 & 1.79 & 8 & & & -06 & $E-06$ \\
\hline 10 & & & & & & -06 & -06 \\
\hline 0 & 06 & 1.01 & & & & & 06 \\
\hline $4 E-10$ & 6 & $\perp$ & 8 & 7 & & $1.36 \mathrm{E}-06$ & 06 \\
\hline 0 & 6 & $1.83 \mathrm{E}-07$ & 0 & 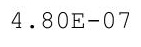 & 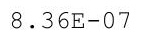 & 6 & 06 \\
\hline $66 \mathrm{~F}-10$ & $.82 E-06$ & 1 & $4.56 \mathrm{E}-08$ & $82 F-$ & $=17=0$ & $.37 E-06$ & $.01 \mathrm{E}-06$ \\
\hline$F-10$ & $83 E-06$ & $184 \mathrm{~F}-10$ & $E-08$ & & & $38 F-06$ & $.01 E-06$ \\
\hline & & & & & & & \\
\hline 0 & $3.00 \mathrm{t}$ & $1.00 \mathrm{~L}$ & & & 7 & & 06 \\
\hline $91 E-10$ & $3.86 \mathrm{E}-06$ & 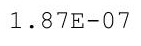 & $4.735-00$ & . & . & $1.40 \mathrm{E}-06$ & $2.04 E-06$ \\
\hline $96 \mathrm{E}-10$ & $3.86 \mathrm{E}-06$ & 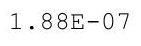 & $4.1 / E-08$ & 1.000 & - & $1.40 \mathrm{~L}-00$ & $2.04 \mathrm{E}-06$ \\
\hline $.02 E-10$ & 6 & 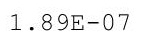 & $4.01+20$ & - & & 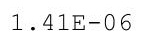 & $2.05 E-06$ \\
\hline 1 & $88 \mathrm{~F}-06$ & 1 & & קת & & & $6 E-06$ \\
\hline & & & & & & & \\
\hline & & & & & & & \\
\hline $24 \mathrm{E}-10$ & $3.91 \mathrm{E}-06$ & $1.93 E-01$ & $4.97 E-08$ & $\cdot \perp \perp$ & $0.00 \mathrm{~L}$ & -06 & $2.08 E-06$ \\
\hline $30 E-10$ & $3.91 E-06$ & I.0tम & $3.01 E-08$ & $0 .+15$ & & $1.445-00$ & $2.09 \pm-06$ \\
\hline+0 & 6 & . & & & & & $2.09 \mathrm{E}-06$ \\
\hline $41 F-10$ & 6 &.+ & & 7 & 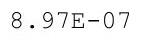 & 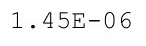 & 6 \\
\hline & & & & & & & 6 \\
\hline$E-10$ & 3.95 & $1.98 \mathrm{E}$ & 8 & 5 & 7 & 06 & -06 \\
\hline$E-10$ & $3.96 \mathrm{E}-06$ & 1.9 & 08 & & & 06 & -06 \\
\hline & & 2.000 & & & & & \\
\hline $.72 \mathrm{E}-10$ & 10 & 2.0.t & 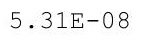 & (- & $9.16 \mathrm{E}-07$ & $1.48 \mathrm{E}-06$ & $2.14 \mathrm{E}-06$ \\
\hline & & 2.0टा & 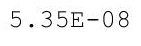 & & $20 \mathrm{E}-$ & $1.49 E-06$ & $2.15 E-06$ \\
\hline$F-1$ & $E-06$ & $E-07$ & $40 E-08$ & $E-07$ & $3 E-07$ & $.49 E-06$ & -06 \\
\hline
\end{tabular}


RESRAD-OFFSITE, Version 2.5

Title : Offsite Resident Farmer Deterministic Run

File : RF TC99 DOESG FWD-FV2b.ROF

Summary of dose at graphical times, reptition 3 (continued)

Time

Years

$4.72 \mathrm{E}+02$

$4.72 \mathrm{E}+02$

$4.73 \mathrm{E}+02$

$4.73 \mathrm{E}+02$

$4.74 \mathrm{E}+02$

$4.74 \mathrm{E}+02$

$4.75 \mathrm{E}+02$

$4.75 \mathrm{E}+02$

$4.76 \mathrm{E}+02$

$4.76 \mathrm{E}+02$

$4.77 \mathrm{E}+02$

$4.77 \mathrm{E}+02$

$4.78 \mathrm{E}+02$

$4.78 \mathrm{E}+02$

$4.79 \mathrm{E}+02$

$4.79 \mathrm{E}+02$

$4.80 \mathrm{E}+02$

$4.80 \mathrm{E}+02$

$4.81 \mathrm{E}+02$

$4.81 \mathrm{E}+02$

$4.82 \mathrm{E}+02$

$4.82 \mathrm{E}+02$

$4.83 \mathrm{E}+02$

$4.83 \mathrm{E}+02$

$4.84 \mathrm{E}+02$

$4.84 \mathrm{E}+02$

$4.85 \mathrm{E}+02$

$4.86 \mathrm{E}+02$

$4.86 \mathrm{E}+02$

$4.87 \mathrm{E}+02$

$4.87 \mathrm{E}+02$

$4.88 \mathrm{E}+02$

$4.88 \mathrm{E}+02$

$4.89 \mathrm{E}+02$

$4.89 \mathrm{E}+02$

4. $90 \mathrm{E}+02$

$4.90 \mathrm{E}+02$

$4.91 \mathrm{E}+02$

$4.91 \mathrm{E}+02$

$4.92 \mathrm{E}+02$

$4.92 \mathrm{E}+02$

$4.93 \mathrm{E}+02$

4. $93 \mathrm{E}+02$

$4.94 \mathrm{E}+02$

4. $94 \mathrm{E}+02$

$4.95 \mathrm{E}+02$
Dose statistics at graphical times, mrem/yr

\begin{tabular}{|c|c|c|c|c|c|c|c|}
\hline m & aximum & ea & $n$ & & & & \\
\hline 10 & $4.00 \mathrm{E}-06$ & $4 E-07$ & $.44 \mathrm{E}-08$ & $E-07$ & $9.27 \mathrm{E}-07$ & 06 & $5-00$ \\
\hline $97 E-10$ & $4.00 E-06$ & $2.05 E-07$ & $5.48 \mathrm{E}-08$ & $4 E-07$ & $1 \mathrm{E}-07$ & $51 E-06$ & $7 E-06$ \\
\hline-10 & $4.01 E-06$ & $2.06 \mathrm{E}-07$ & $5.53 \mathrm{E}-08$ & $47 E-07$ & $9.34 \mathrm{E}-07$ & $1.51 \mathrm{E}-06$ & $2.18 \mathrm{E}-06$ \\
\hline $1 F-10$ & $02 E-06$ & $07 \mathrm{~F}-07$ & $.57 \mathrm{E}-08$ & $49 F-07$ & $39 F-07$ & -06 & $18 E-06$ \\
\hline $7 E-10$ & 06 & 07 & 08 & 然 & 7 & -06 & -06 \\
\hline 10 & & & & & & & \\
\hline $31 E-10$ & $04 \mathrm{E}-06$ & & & & & & $1 E-06$ \\
\hline-10 & -06 & 1 & 8 & 7 & 1 & 6 & $E-06$ \\
\hline $.45 E-10$ & -06 & -07 & -08 & ( & 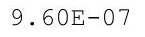 & -06 & $2.22 E-06$ \\
\hline$E-10$ & $07 E-06$ & 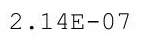 & 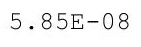 & 6 & & $E-06$ & $.23 E-06$ \\
\hline 0 & 06 & & & & & 6 & 06 \\
\hline $66 \mathrm{E}-10$ & $E-06$ & 2 & & $71 \mathrm{~F} 0 \mathrm{O}$ & $73 E-07$ & 6 & $E-06$ \\
\hline $.73 E-10$ & $4.09 E-06$ & & $5.99 \mathrm{E}-08$ & $5.74 E-07$ & & $1.57 \mathrm{E}-06$ & $2.25 E-06$ \\
\hline $.81 E-10$ & $4.10 \mathrm{E}-06$ & $2.18 \mathrm{E}-07$ & $6.04 \mathrm{E}-08$ & $5.76 \mathrm{E}-07$ & $.015-U 1$ & $1.57 \mathrm{E}-06$ & $5 E-06$ \\
\hline$E-10$ & $E-06$ & $E-07$ & $E-08$ & & 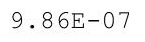 & -06 & $E-06$ \\
\hline 0 & -06 & ti & 0 & 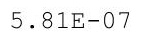 & PO & $E-06$ & $27 E-06$ \\
\hline 10 & & & & & & & \\
\hline 0 & 6 & 2 & & & & & 6 \\
\hline $19 \mathrm{E}-10$ & $4.14 \mathrm{E}-06$ & $2.23 E-07$ & $6.28 E-08$ & $5.89 E-07$ & $1.00 \mathrm{E}-06$ & $E-06$ & $2.30 \mathrm{E}-06$ \\
\hline $27 E-10$ & $.14 \mathrm{E}-06$ & $2.24 \mathrm{E}-07$ & $.33 E-08$ & ד קר & 1010 & $1.60 \mathrm{E}-06$ & $2.30 \mathrm{E}-06$ \\
\hline $35 E-10$ & $4.15 E-06$ & & & & & -06 & $E-06$ \\
\hline & & & & & & -06 & -06 \\
\hline 0 & & 2.2 & & & 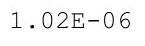 & & 06 \\
\hline $9 \mathrm{E}-10$ & 6 & 2 & 8 & 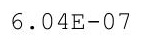 & $1.02 \mathrm{E}-06$ & $1.62 \mathrm{E}-06$ & 06 \\
\hline 0 & 6 & $2.30 \mathrm{E}-07$ & 0 & 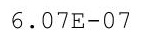 & $1.03 E-06$ & 6 & 06 \\
\hline$E-10$ & $.19 \mathrm{E}-06$ & $.31 E-07$ & 田 & 100 & 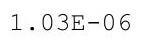 & $4 E-06$ & $.35 E-06$ \\
\hline$E-10$ & $4.20 \mathrm{E}-06$ & & $E-08$ & & & $5-06$ & $.36 E-06$ \\
\hline & & & & & & & \\
\hline & & & & & & & 06 \\
\hline $.10 \mathrm{E}-10$ & $4.22 \mathrm{E}-06$ & $2.005-1$ & $6.84 \mathrm{E}-08$ & $\cdot 2<+$ & $1.07 \mathrm{~L}-0$ & $1.66 \mathrm{E}-06$ & $2.39 E-06$ \\
\hline $8 E-10$ & $4.22 E-06$ & . & $90 E-08$ & $\cdot 200$ & - & - & $2.40 E-06$ \\
\hline $27 E-10$ & 1.200 & (2) & $.95 E-08$ & 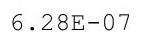 & 2.00 & 土. & $2.41 E-06$ \\
\hline$F-10$ & $24 F-06$ & 305 & $E-08$ & & & & $2.42 E-06$ \\
\hline & & & & & & & \\
\hline$E-10$ & & & & & & & \\
\hline 10 & $4.2 O 5$ & 2.424 & 08 & $39 E-07$ & \pm .00 & -06 & 06 \\
\hline $.73 E-10$ & $4.29 \mathrm{E}-06$ & $2.43 E$ & & & . & 0 & $5 E-06$ \\
\hline $32 E-10$ & $1.00 \mathrm{D}$ & & & & & & $2.46 \mathrm{E}-06$ \\
\hline 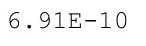 & 6 & 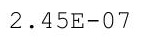 & 3 & 7 & 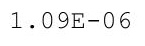 & 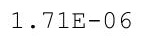 & 06 \\
\hline & & & & & & & 6 \\
\hline $11 E-10$ & & 2.4 & -08 & 7 & 6 & 06 & $E-06$ \\
\hline$E-10$ & $4.34 \mathrm{E}-06$ & $2.40 \mathrm{~L}$ & 08 & & & 06 & -06 \\
\hline & 6 & & & & & & \\
\hline & 4.0 & 1 & $2+$ & . & $1.11 \mathrm{E}-06$ & $1.74 \mathrm{E}-06$ & $2.51 E-06$ \\
\hline 年 & $4.38 E-06$ & $2.025-01$ & & $05 E-U 1$ & $+\cdot \pm<+$ & $4 E-06$ & $2 . J 1 \mathrm{~L}-00$ \\
\hline 10 & $4.39 E-06$ & $3 E-07$ & $E-08$ & $E-07$ & $12 E-06$ & $.75 E-06$ & -06 \\
\hline
\end{tabular}


RESRAD-OFFSITE, Version 2.5

Title : Offsite Resident Farmer Deterministic Run

File : RF TC99 DOESG FWD-FV2b.ROF

Summary of dose at graphical times, reptition 3 (continued)

Time

Years

$4.95 \mathrm{E}+02$

$4.96 \mathrm{E}+02$

$4.96 \mathrm{E}+02$

4. $97 \mathrm{E}+02$

$4.97 \mathrm{E}+02$

$4.98 \mathrm{E}+02$

$4 \cdot 98 \mathrm{E}+02$

$4.99 \mathrm{E}+02$

$4.99 \mathrm{E}+02$

$5.00 \mathrm{E}+02$

$5.00 \mathrm{E}+02$

$5.01 \mathrm{E}+02$

$5.01 \mathrm{E}+02$

$5.02 \mathrm{E}+02$

$5.02 \mathrm{E}+02$

$5.03 E+02$

$5.03 E+02$

$5.04 \mathrm{E}+02$

$5.04 \mathrm{E}+02$

$5.05 \mathrm{E}+02$

$5.06 \mathrm{E}+02$

$5.06 \mathrm{E}+02$

$5.07 \mathrm{E}+02$

$5.07 \mathrm{E}+02$

$5.08 \mathrm{E}+02$

$5.08 \mathrm{E}+02$

$5.09 \mathrm{E}+02$

$5.09 \mathrm{E}+02$

$5.10 \mathrm{E}+02$

$5.10 \mathrm{E}+02$

$5.11 \mathrm{E}+02$

$5.11 \mathrm{E}+02$

$5.12 \mathrm{E}+02$

$5.12 \mathrm{E}+02$

$5.13 \mathrm{E}+02$

$5.13 \mathrm{E}+02$

$5.14 \mathrm{E}+02$

$5.14 \mathrm{E}+02$

$5.15 \mathrm{E}+02$

$5.15 \mathrm{E}+02$

$5.16 \mathrm{E}+02$

$5.16 \mathrm{E}+02$

$5.17 \mathrm{E}+02$

$5.17 \mathrm{E}+02$

$5.18 \mathrm{E}+02$

$5.18 \mathrm{E}+02$
Dose statistics at graphical times, mrem/yr

\begin{tabular}{|c|c|c|c|c|c|c|c|}
\hline inimum & laximum & Mean & Median & $90 \%$ & $95 \%$ & $97.5 \%$ & 3응 \\
\hline 0 & $0 E-06$ & $54 \mathrm{~F}-07$ & $.80 E-08$ & 07 & 6 & 6 & -06 \\
\hline$E-10$ & $E-06$ & $5 E-07$ & $36 E-08$ & $75 E-$ & 6 & .76 & 06 \\
\hline $1 E-10$ & $2 E-06$ & $6 E-07$ & $E-08$ & -07 & 6 & 6 & -06 \\
\hline $2 E-10$ & $3 E-06$ & $7 E-07$ & $7 E-08$ & 7 & 6 & 06 & $5 E-06$ \\
\hline $12 \mathrm{E}-10$ & -06 & & & 7 & & & $56 \mathrm{E}-06$ \\
\hline $3 E-10$ & 06 & 2 & 8 & & 6 & 06 & $6 E-06$ \\
\hline $34 E-10$ & $6 E-06$ & $1 E-07$ & -08 & $2 E-07$ & -06 & -06 & $E-06$ \\
\hline $45 E-10$ & $4.48 E-06$ & 2. & $8.21 E-08$ & 1 & $1.16 \mathrm{E}-06$ & -06 & $\Xi-06$ \\
\hline$E-10$ & 06 & $\mathrm{~F}$ & 08 & 7 & 6 & 06 & $8 E-06$ \\
\hline $7 E-10$ & $4.50 \mathrm{E}-06$ & 5 & 08 & 5 & 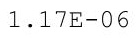 & & $9 E-06$ \\
\hline-10 & 06 & & & & & 6 & $E-06$ \\
\hline-10 & 06 & 2 & 8 & & 6 & 6 & $E-06$ \\
\hline $01 \mathrm{E}-10$ & $3 E-06$ & 年 & $1 \mathrm{E}-08$ & L & $10 \mathrm{E}-00$ & -06 & $E-06$ \\
\hline $12 \mathrm{E}-10$ & $4.54 \mathrm{E}-06$ & $2.69 \mathrm{E}-07$ & $0.00 \mathrm{~L}-0$ & 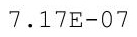 & 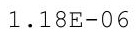 & 1.0 & $E-06$ \\
\hline $.24 E-10$ & $4.55 E-06$ & 2 . & 08 & -0 & $\perp \cdot U^{\prime}$ & 06 & -06 \\
\hline $36 \mathrm{E}-10$ & $4.56 \mathrm{E}-06$ & $2.71 \mathrm{E}-\mathrm{C}$ & -08 & $7.23 \mathrm{E}-$ & $1.19 \mathrm{E}-$ & 06 & $3 E-06$ \\
\hline $.47 E-10$ & $4.57 E-06$ & $2.72 E-07$ & $8.75 E-08$ & $26 E-07$ & $1.19 \mathrm{E}-06$ & $1.84 \mathrm{E}-06$ & $54 \mathrm{E}-06$ \\
\hline$E-10$ & $8 E-06$ & 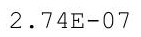 & -08 & 7 & 6 & 6 & $55 E-06$ \\
\hline$E-10$ & 06 & 2 & 8 & $1.30 \mathrm{E}-01$ & $\perp$ & & -06 \\
\hline $84 \mathrm{E}-10$ & 4. $60 \mathrm{E}-06$ & $2.76 \mathrm{E}$ & 08 & נר & 0 & 6 & -06 \\
\hline $96 \mathrm{E}-10$ & $4.61 E-06$ & 2. & $9 E-08$ & 年 & $\perp \cdot 2 \perp+$ & 06 & $7 E-06$ \\
\hline $.01 E-09$ & 0 & 2 & 8 & $7 \quad 375-07$ & $1.21 \mathrm{E}-06$ & 6 & -06 \\
\hline $.02 E-09$ & $4.64 \mathrm{E}-06$ & $9 E-C$ & $E-08$ & 7 & 1.21 & -06 & $59 E-06$ \\
\hline $.03 E-09$ & $4.65 E-06$ & 7 & -08 & 7 & $1.22 \mathrm{E}-$ & 06 & $0 E-06$ \\
\hline$E-09$ & $E-06$ & 2 & 08 & $7.45 \mathrm{E}-0$ & & & $70 \mathrm{E}-06$ \\
\hline$E-09$ & 06 & 2 & 08 & 7 & & & -06 \\
\hline $7 E-09$ & $4.68 E-06$ & $2.07 \pm 0$ & $E-08$ & $1 \mathrm{~L}$ & $23 \mathrm{E}$ & & $2 E-06$ \\
\hline $.08 E-09$ & $4.69 \mathrm{E}-06$ & $2.85 \mathrm{E}-07$ & $9.42 \mathrm{E}-08$ & $7.53 \mathrm{E}-07$ & $1.24 \mathrm{E}-06$ & $1.90 \mathrm{E}-06$ & $.73 E-06$ \\
\hline $.10 \mathrm{E}-09$ & $4.70 E-06$ & $2.87 E-07$ & $9.48 \mathrm{E}-08$ & $7.56 \mathrm{E}-07$ & $1.24 D-00$ & $\perp e^{\prime}$ & $2.73 E-06$ \\
\hline a & 6 & tha & 8 & $750 F-07$ & 1 & 06 & $E-06$ \\
\hline 09 & 06 & 7 & 08 & $62 E-07$ & 5 & 06 & $E-06$ \\
\hline $4 E-09$ & $3 E-06$ & 2 & 08 & $5 \mathrm{E}$ & 1 & 6 & -06 \\
\hline $.15 \mathrm{E}-09$ & $4.74 \mathrm{E}-06$ & $2.91 \mathrm{E}-07$ & $9.73 \mathrm{E}-08$ & $1.00 \mathrm{D}$ & $1.26 \mathrm{E}-$ & 1.931 & $E-06$ \\
\hline $.17 \mathrm{E}-09$ & $4.75 E-06$ & $2.93 E-07$ & $9.80 \mathrm{E}-08$ & $7.71 \mathrm{E}-07$ & $1.26 \mathrm{E}-06$ & $1.94 \mathrm{E}-06$ & $2.77 \mathrm{E}-06$ \\
\hline . $10 \mathrm{E}-09$ & $4.10 E-00$ & & & & & & $78 E-06$ \\
\hline 0 & 6 & & & On & 1 & 6 & $79 E-06$ \\
\hline 09 & 4. & 2 & 7 & 7 & 6 & 6 & 06 \\
\hline $.22 E-09$ & $4.79 E-06$ & $2.98 \mathrm{E}-$ & 7 & $1.00 \mathrm{D}$ & 1 . & 6 & 06 \\
\hline $4 E-09$ & $4.80 \mathrm{E}-06$ & $9 \mathrm{E}$ & $2 \mathrm{E}$ & $9 \mathrm{E}$ & 1 . & 06 & \\
\hline $5 E-09$ & 4. & & & 7 & & & \\
\hline 9 & & & & & & & \\
\hline 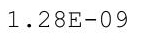 & $4.05 E-00$ & . पर & . & 年 & $1.30 \mathrm{E}-$ & $1.99 E-06$ & $2.84 \mathrm{E}-06$ \\
\hline 09 & 6 & $3.04 \mathrm{E}-07$ & $1.04 \mathrm{E}-07$ & 7 & 1 & 6 & $2.84 E-06$ \\
\hline$E-09$ & 6 & 3 & 1 . & 8 & 1 & 06 & 2 \\
\hline-09 & 4.8 & 3 & $E-07$ & 8 & 1 . & 06 & 2 . \\
\hline$E-09$ & $4.87 E-06$ & $07 E-07$ & $1.06 \mathrm{E}-07$ & $8.11 \mathrm{E}-07$ & 1. $32 \mathrm{E}-06$ & $2.01 E-06$ & $2.87 E-06$ \\
\hline
\end{tabular}


RESRAD-OFFSITE, Version 2.5

$\mathrm{T}^{1 / 2}$ Limit $=180$ days

Title : Offsite Resident Farmer Deterministic Run

File : RF TC99 DOESG FWD-FV2b.ROF

Summary of dose at graphical times, reptition 3 (continued)

Time

Years

$5.19 \mathrm{E}+02$

$5.19 \mathrm{E}+02$

$5.20 \mathrm{E}+02$

$5.20 \mathrm{E}+02$

$5.21 \mathrm{E}+02$

$5.21 \mathrm{E}+02$

$5.22 \mathrm{E}+02$

$5.22 \mathrm{E}+02$

$5.23 \mathrm{E}+02$

$5.23 \mathrm{E}+02$

$5.24 \mathrm{E}+02$

$5.24 \mathrm{E}+02$

$5.25 \mathrm{E}+02$

$5.26 \mathrm{E}+02$

$5.26 \mathrm{E}+02$

$5.27 \mathrm{E}+02$

$5.27 \mathrm{E}+02$

$5.28 \mathrm{E}+02$

$5.28 \mathrm{E}+02$

$5.29 \mathrm{E}+02$

$5.29 \mathrm{E}+02$

$5.30 \mathrm{E}+02$

$5.30 \mathrm{E}+02$

$5.31 \mathrm{E}+02$

$5.31 \mathrm{E}+02$

$5.32 \mathrm{E}+02$

$5.32 \mathrm{E}+02$

$5.33 \mathrm{E}+02$

$5.33 \mathrm{E}+02$

$5.34 \mathrm{E}+02$

$5.34 \mathrm{E}+02$

$5.35 \mathrm{E}+02$

$5.35 \mathrm{E}+02$

$5.36 \mathrm{E}+02$

$5.36 \mathrm{E}+02$

$5.37 \mathrm{E}+02$

$5.37 \mathrm{E}+02$

$5.38 \mathrm{E}+02$

$5.38 \mathrm{E}+02$

$5.39 \mathrm{E}+02$

$5.39 \mathrm{E}+02$

$5.40 \mathrm{E}+02$

$5.40 \mathrm{E}+02$

$5.41 \mathrm{E}+02$

$5.41 \mathrm{E}+02$

$5.42 \mathrm{E}+02$
Dose statistics at graphical times, mrem/yr

\begin{tabular}{|c|c|c|c|c|c|c|c|}
\hline Minimum & Maximum & Mean & ledian & $90 \%$ & $95 \%$ & $97.5 \%$ & $99 \%$ \\
\hline $1.36 \mathrm{E}-09$ & $4.88 \mathrm{E}-06$ & $3.09 \mathrm{E}-07$ & $1.07 \mathrm{E}-07$ & $8.14 \mathrm{E}-07$ & $1.32 \mathrm{E}-06$ & $2.01 E-06$ & $2.87 E-06$ \\
\hline $1.37 \mathrm{E}-09$ & $4.89 \mathrm{E}-06$ & $3.10 \mathrm{E}-07$ & $1.07 \mathrm{E}-07$ & $8.17 \mathrm{E}-07$ & $1.32 \mathrm{E}-06$ & $2.02 \mathrm{E}-06$ & $2.88 \mathrm{E}-06$ \\
\hline $1.39 \mathrm{E}-09$ & $4.90 \mathrm{E}-06$ & $3.11 \mathrm{E}-07$ & $1.08 \mathrm{E}-07$ & $8.19 \mathrm{E}-07$ & $1.33 \mathrm{E}-06$ & $2.02 \mathrm{E}-06$ & $2.89 \mathrm{E}-06$ \\
\hline $1.40 \mathrm{E}-09$ & $4.91 \mathrm{E}-06$ & $3.12 \mathrm{E}-07$ & $1.09 \mathrm{E}-07$ & $8.22 \mathrm{E}-07$ & $1.33 \mathrm{E}-06$ & $2.03 E-06$ & $2.89 \mathrm{E}-06$ \\
\hline $1.42 E-09$ & $4.92 E-06$ & $3.14 \mathrm{E}-07$ & $1.10 \mathrm{E}-07$ & $8.25 E-07$ & $1.34 \mathrm{E}-06$ & $2.03 E-06$ & $2.90 E-06$ \\
\hline $1.43 E-09$ & $4.93 E-06$ & $3.15 \mathrm{E}-07$ & $1.10 \mathrm{E}-07$ & $8.28 E-07$ & $1.34 \mathrm{E}-06$ & $2.04 E-06$ & $2.91 E-06$ \\
\hline $1.45 E-09$ & $4.94 \mathrm{E}-06$ & $3.16 \mathrm{E}-07$ & $1.11 \mathrm{E}-07$ & $8.31 \mathrm{E}-07$ & $1.35 \mathrm{E}-06$ & $2.04 \mathrm{E}-06$ & $2.91 \mathrm{E}-06$ \\
\hline $1.47 \mathrm{E}-09$ & $4.95 E-06$ & $3.17 \mathrm{E}-07$ & $1.12 \mathrm{E}-07$ & $8.34 \mathrm{E}-07$ & $1.35 \mathrm{E}-06$ & $2.05 E-06$ & $2.92 \mathrm{E}-06$ \\
\hline $1.48 \mathrm{E}-09$ & $4.96 \mathrm{E}-06$ & $3.19 \mathrm{E}-07$ & $1.13 E-07$ & $8.36 \mathrm{E}-07$ & $1.36 \mathrm{E}-06$ & $2.05 E-06$ & $2.93 E-06$ \\
\hline $1.50 \mathrm{E}-09$ & $4.97 \mathrm{E}-06$ & $3.20 \mathrm{E}-07$ & $1.13 \mathrm{E}-07$ & $8.39 \mathrm{E}-07$ & $1.36 \mathrm{E}-06$ & $2.06 \mathrm{E}-06$ & $2.93 \mathrm{E}-06$ \\
\hline $1.52 \mathrm{E}-09$ & $4.98 E-06$ & $3.21 \mathrm{E}-07$ & $1.14 \mathrm{E}-07$ & $8.42 \mathrm{E}-07$ & $1.37 \mathrm{E}-06$ & $2.06 \mathrm{E}-06$ & $2.94 \mathrm{E}-06$ \\
\hline $1.53 E-09$ & $4.99 \mathrm{E}-06$ & $3.22 E-07$ & $1.15 \mathrm{E}-07$ & $8.45 E-07$ & $1.37 \mathrm{E}-06$ & $2.07 E-06$ & $2.94 E-06$ \\
\hline $1.55 \mathrm{E}-09$ & $5.00 \mathrm{E}-06$ & $3.24 \mathrm{E}-07$ & $1.15 \mathrm{E}-07$ & $8.48 E-07$ & $1.38 \mathrm{E}-06$ & $2.07 E-06$ & $2.95 E-06$ \\
\hline $1.57 \mathrm{E}-09$ & $5.01 \mathrm{E}-06$ & $3.25 \mathrm{E}-07$ & $1.16 \mathrm{E}-07$ & $8.52 \mathrm{E}-07$ & $1.38 \mathrm{E}-06$ & $2.08 \mathrm{E}-06$ & $2.96 \mathrm{E}-06$ \\
\hline $1.58 \mathrm{E}-09$ & $5.02 \mathrm{E}-06$ & $3.26 E-07$ & $1.17 \mathrm{E}-07$ & $8.56 \mathrm{E}-07$ & $1.38 \mathrm{E}-06$ & $2.08 \mathrm{E}-06$ & $2.96 \mathrm{E}-06$ \\
\hline $1.60 E-09$ & $5.03 E-06$ & $3.27 E-07$ & $1.17 \mathrm{E}-07$ & $8.59 E-07$ & $1.39 \mathrm{E}-06$ & $E-06$ & $2.97 E-06$ \\
\hline $1.62 \mathrm{E}-09$ & $E-06$ & $3.29 E-07$ & $1.18 \mathrm{E}-07$ & $8.63 E-07$ & $1.39 \mathrm{E}-06$ & $.09 E-06$ & $.97 E-06$ \\
\hline $1.64 E-09$ & $5.04 \mathrm{E}-06$ & $3.30 E-07$ & $1.19 \mathrm{E}-07$ & $8.67 E-07$ & $1.40 \mathrm{E}-06$ & $2.10 E-06$ & $2.98 E-06$ \\
\hline $1.65 E-09$ & $5.05 E-06$ & $3.31 E-07$ & $1.20 \mathrm{E}-07$ & $8.70 E-07$ & $1.40 \mathrm{E}-06$ & $2.10 E-06$ & $2.99 E-06$ \\
\hline $1.67 \mathrm{E}-09$ & $5.06 \mathrm{E}-06$ & $3.33 E-07$ & $1.21 \mathrm{E}-07$ & $8.74 \mathrm{E}-07$ & $1.40 \mathrm{E}-06$ & $2.11 \mathrm{E}-06$ & $2.99 E-06$ \\
\hline $1.69 \mathrm{E}-09$ & $5.07 \mathrm{E}-06$ & $3.34 \mathrm{E}-07$ & $1.21 \mathrm{E}-07$ & $8.78 \mathrm{E}-07$ & $1.40 \mathrm{E}-06$ & $2.12 \mathrm{E}-06$ & $3.00 \mathrm{E}-06$ \\
\hline $1.71 \mathrm{E}-09$ & $5.08 \mathrm{E}-06$ & $3.35 E-07$ & $1.22 \mathrm{E}-07$ & $8.82 E-07$ & $1.41 \mathrm{E}-06$ & $2.12 E-06$ & $3.01 E-06$ \\
\hline $1.73 E-09$ & $5.09 \mathrm{E}-06$ & $3.36 E-07$ & 1.23E-07 & $8.85 E-07$ & $1.41 \mathrm{E}-06$ & $2.13 \mathrm{E}-06$ & $3.01 \mathrm{E}-06$ \\
\hline $1.75 \mathrm{E}-09$ & $5.10 \mathrm{E}-06$ & $3.38 E-07$ & $1.24 \mathrm{E}-07$ & $8.89 \mathrm{E}-07$ & $1.41 \mathrm{E}-06$ & $2.14 \mathrm{E}-06$ & $3.02 \mathrm{E}-06$ \\
\hline $1.76 \mathrm{E}-09$ & $5.11 \mathrm{E}-06$ & $3.39 E-07$ & $1.24 \mathrm{E}-07$ & $8.92 E-07$ & $1.42 \mathrm{E}-06$ & $2.14 \mathrm{E}-06$ & $3.02 E-06$ \\
\hline $1.78 E-09$ & $5.12 \mathrm{E}-06$ & $3.40 E-07$ & $1.25 E-07$ & $8.95 E-07$ & $1.42 \mathrm{E}-06$ & $2.15 E-06$ & $3.03 E-06$ \\
\hline $1.80 \mathrm{E}-09$ & $5.13 \mathrm{E}-06$ & $3.42 \mathrm{E}-07$ & $1.26 \mathrm{E}-07$ & $8.98 \mathrm{E}-07$ & $1.42 \mathrm{E}-06$ & $2.16 \mathrm{E}-06$ & $3.04 \mathrm{E}-06$ \\
\hline $1.82 E-09$ & $5.14 \mathrm{E}-06$ & $3.43 E-07$ & $1.27 \mathrm{E}-07$ & $9.01 \mathrm{E}-07$ & $1.42 \mathrm{E}-06$ & $2.16 \mathrm{E}-06$ & $3.04 E-06$ \\
\hline $1.84 \mathrm{E}-09$ & $5.15 \mathrm{E}-06$ & $3.44 \mathrm{E}-07$ & $1.28 \mathrm{E}-07$ & $9.04 \mathrm{E}-07$ & $1.43 \mathrm{E}-06$ & $2.17 \mathrm{E}-06$ & $3.05 E-06$ \\
\hline $1.86 \mathrm{E}-09$ & $5.16 \mathrm{E}-06$ & $3.45 E-07$ & 1.29E-07 & $9.08 E-07$ & $1.43 \mathrm{E}-06$ & $2.18 \mathrm{E}-06$ & $3.05 E-06$ \\
\hline $1.88 \mathrm{E}-09$ & $5.17 \mathrm{E}-06$ & $3.47 E-07$ & $1.29 \mathrm{E}-07$ & $9.11 \mathrm{E}-07$ & $1.44 \mathrm{E}-06$ & $2.18 E-06$ & $3.06 \mathrm{E}-06$ \\
\hline $1.90 \mathrm{E}-09$ & $5.17 \mathrm{E}-06$ & $3.48 E-07$ & 1. $30 \mathrm{E}-07$ & $9.15 \mathrm{E}-07$ & $1.44 \mathrm{E}-06$ & $2.19 \mathrm{E}-06$ & $3.07 E-06$ \\
\hline $1.92 \mathrm{E}-09$ & $5.18 E-06$ & $3.49 E-07$ & $1.31 \mathrm{E}-07$ & $9.18 \mathrm{E}-07$ & $1.44 \mathrm{E}-06$ & $2.20 E-06$ & $3.08 E-06$ \\
\hline $1.94 \mathrm{E}-09$ & $5.19 \mathrm{E}-06$ & $3.51 \mathrm{E}-07$ & $1.32 \mathrm{E}-07$ & $9.22 \mathrm{E}-07$ & $1.45 \mathrm{E}-06$ & $2.20 E-06$ & $3.08 E-06$ \\
\hline $1.96 \mathrm{E}-09$ & $5.20 \mathrm{E}-06$ & $3.52 E-07$ & $1.33 E-07$ & $9.25 E-07$ & $1.45 E-06$ & $2.21 E-06$ & $3.09 E-06$ \\
\hline $1.98 \mathrm{E}-09$ & $5.21 \mathrm{E}-06$ & $3.53 E-07$ & $1.33 E-07$ & $9.29 \mathrm{E}-07$ & $1.46 \mathrm{E}-06$ & $2.22 \mathrm{E}-06$ & $3.10 \mathrm{E}-06$ \\
\hline $2.00 E-09$ & $5.22 \mathrm{E}-06$ & $3.55 E-07$ & $1.34 \mathrm{E}-07$ & $9.32 \mathrm{E}-07$ & $1.46 \mathrm{E}-06$ & $2.22 E-06$ & $3.10 \mathrm{E}-06$ \\
\hline $2.02 \mathrm{E}-09$ & $5.23 E-06$ & $3.56 \mathrm{E}-07$ & $1.35 E-07$ & $9.36 \mathrm{E}-07$ & $1.46 \mathrm{E}-06$ & $2.23 E-06$ & $3.11 \mathrm{E}-06$ \\
\hline $2.04 \mathrm{E}-09$ & $5.24 \mathrm{E}-06$ & $3.57 E-07$ & $1.35 E-07$ & $9.39 E-07$ & $1.47 \mathrm{E}-06$ & $2.24 E-06$ & $3.12 \mathrm{E}-06$ \\
\hline $2.06 \mathrm{E}-09$ & $5.25 \mathrm{E}-06$ & $.59 \mathrm{E}$ & $1.36 \mathrm{E}$ & $9.43 \mathrm{E}$ & $1.47 \mathrm{E}-06$ & $2.25 E-06$ & $3.12 \mathrm{E}-06$ \\
\hline $2.08 E-09$ & $5.25 \mathrm{E}-06$ & $3.60 \mathrm{E}-07$ & $1.37 \mathrm{E}-07$ & $9.46 E-07$ & $1.48 \mathrm{E}-06$ & $2.25 E-06$ & $3.13 E-06$ \\
\hline $2.10 E-09$ & $5.26 \mathrm{E}-06$ & $3.61 E-07$ & $1.38 E-07$ & $9.50 E-07$ & $1.48 \mathrm{E}-06$ & $2.26 \mathrm{E}-06$ & $3.13 E-06$ \\
\hline $2.13 E-09$ & $5.27 \mathrm{E}-06$ & $3.62 \mathrm{E}-07$ & $1.39 \mathrm{E}-07$ & $9.54 \mathrm{E}-07$ & $1.48 \mathrm{E}-06$ & $2.26 \mathrm{E}-06$ & $3.14 \mathrm{E}-06$ \\
\hline $2.15 E-09$ & $5.28 E-06$ & $3.64 E-07$ & $1.39 E-07$ & $9.58 \mathrm{E}-07$ & $1.49 \mathrm{E}-06$ & $2.27 E-06$ & $3.14 \mathrm{E}-06$ \\
\hline $2.17 E-09$ & $5.29 E-06$ & $3.65 E-07$ & $1.40 E-07$ & $9.62 E-07$ & $1.49 \mathrm{E}-06$ & $2.27 E-06$ & $3.15 E-06$ \\
\hline $2.19 E-09$ & $5.30 E-06$ & $3.66 E-07$ & $1.41 E-07$ & $9.66 \mathrm{E}-07$ & $1.49 \mathrm{E}-06$ & $2.28 E-06$ & $3.16 \mathrm{E}-06$ \\
\hline
\end{tabular}


RESRAD-OFFSITE, Version 2.5

itle : Offsite Resident Farmer Deterministic Run

File : RF TC99 DOESG FWD-FV2b.ROF

Summary of dose at graphical times, reptition 3 (continued)

Time

Years

$5.42 \mathrm{E}+02$

$5.43 \mathrm{E}+02$

$5.43 \mathrm{E}+02$

$5.44 \mathrm{E}+02$

$5.44 \mathrm{E}+02$

$5.45 \mathrm{E}+02$

$5.46 \mathrm{E}+02$

$5.46 \mathrm{E}+02$

$5.47 \mathrm{E}+02$

$5.47 \mathrm{E}+02$

$5.48 \mathrm{E}+02$

$5.48 \mathrm{E}+02$

$5.49 \mathrm{E}+02$

$5.49 \mathrm{E}+02$

$5.50 \mathrm{E}+02$

$5.50 \mathrm{E}+02$

$5.51 \mathrm{E}+02$

$5.51 \mathrm{E}+02$

$5.52 \mathrm{E}+02$

$5.52 \mathrm{E}+02$

$5.53 \mathrm{E}+02$

$5.53 \mathrm{E}+02$

$5.54 \mathrm{E}+02$

$5.54 \mathrm{E}+02$

$5.55 \mathrm{E}+02$

$5.55 \mathrm{E}+02$

$5.56 \mathrm{E}+02$

$5.56 \mathrm{E}+02$

$5.57 \mathrm{E}+02$

$5.57 \mathrm{E}+02$

$5.58 \mathrm{E}+02$

$5.58 \mathrm{E}+02$

$5.59 \mathrm{E}+02$

$5.59 \mathrm{E}+02$

$5.60 \mathrm{E}+02$

$5.60 \mathrm{E}+02$

$5.61 \mathrm{E}+02$

$5.61 \mathrm{E}+02$

$5.62 \mathrm{E}+02$

$5.62 \mathrm{E}+02$

$5.63 E+02$

$5.63 E+02$

$5.64 \mathrm{E}+02$

$5.64 \mathrm{E}+02$

$5.65 \mathrm{E}+02$

$5.66 \mathrm{E}+02$
Dose statistics at graphical times, mrem/yr

\begin{tabular}{|c|c|c|c|c|c|c|c|}
\hline m & um & ean & $x^{-1}$ & & & $\%$ & \\
\hline 09 & $5.31 E-06$ & $3.68 E-07$ & 1. $42 \mathrm{E}-07$ & $9.70 \mathrm{E}-07$ & 06 & -06 & -00 \\
\hline $24 \mathrm{E}-09$ & $5.32 \mathrm{E}-06$ & $9 E-07$ & $43 E-07$ & 7 & $50 E-06$ & -06 & -06 \\
\hline $.26 \mathrm{E}-09$ & $5.32 \mathrm{E}-06$ & $0 E-07$ & $44 \mathrm{E}-07$ & $9.77 \mathrm{E}-07$ & $1.51 \mathrm{E}-06$ & $2.30 \mathrm{E}-06$ & $3.17 \mathrm{E}-06$ \\
\hline $28 E-09$ & $.33 E-06$ & $.72 E-07$ & $.45 \mathrm{E}-07$ & $9.81 \mathrm{E}-07$ & $1.51 \mathrm{E}-06$ & $2.30 \mathrm{E}-06$ & $18 E-06$ \\
\hline $30 E-09$ & 06 & $3 \mathrm{E}$ & $x^{-}$ & $84 \mathrm{~F}-2-2-1$ & 06 & $1 E-06$ & -06 \\
\hline $.33 E-09$ & 06 & $4 F-07$ & $1.46 \mathrm{E}-07$ & ? & 6 & 6 & -06 \\
\hline $.35 E-09$ & & & & & & 6 & -06 \\
\hline-09 & & & & & & & -06 \\
\hline-09 & -06 & $F-0$ & -0 & 7 & -06 & -06 & -06 \\
\hline $42 E-09$ & -06 & ( & - & 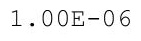 & 06 & 06 & -06 \\
\hline 09 & 06 & 1. & $1.50 \mathrm{E}-07$ & $\cap \cap F-\cap 6$ & 6 & 6 & 6 \\
\hline $47 \mathrm{E}-$ & & & & & & & 06 \\
\hline $49 F-09$ & -06 & $3.84 \mathrm{E}-07$ & 1. & $101 F-06$ & 6 & 6 & -06 \\
\hline $.52 \mathrm{E}-09$ & $5.42 \mathrm{E}-06$ & $3.85 \mathrm{E}-07$ & $1.53 \mathrm{E}-07$ & $1.01 \mathrm{E}-06$ & $1.55 \mathrm{E}-06$ & $2.36 \mathrm{E}-06$ & $3.23 E-06$ \\
\hline-09 & $E-06$ & $F_{-}$ & & 6 & & 6 & -06 \\
\hline$E-09$ & 6 & & $1.55 \mathrm{E}-07$ & 0 & 0 & & -06 \\
\hline 09 & 06 & 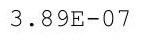 & $1.56 \mathrm{E}-07$ & 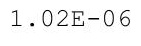 & 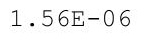 & & 06 \\
\hline 9 & & & & & & & 6 \\
\hline $64 E-09$ & $5.46 \mathrm{E}-06$ & $3.92 \mathrm{E}-0$ & 1. $58 \mathrm{E}-0$ & $1.03 \mathrm{E}$ & & 2 . & -06 \\
\hline $67 E-09$ & $.47 \mathrm{E}-06$ & $.93 E-07$ & $1.58 \mathrm{E}-07$ & $.03 E-06$ & $1.57 \mathrm{E}-06$ & $2.39 \mathrm{E}-06$ & $.26 \mathrm{E}-06$ \\
\hline $69 \mathrm{E}-09$ & $5.47 \mathrm{E}-06$ & $3.95 E-07$ & 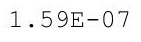 & $1.04 \mathrm{E}-06$ & $1.57 \mathrm{E}-06$ & $E-06$ & $E-06$ \\
\hline 09 & & & & & & & -06 \\
\hline 9 & & & & & & & 06 \\
\hline $.77 E-09$ & .00 & & 1. & & 1.0 & & 06 \\
\hline 9 & 6 & $\triangle \cap \cap \cap-\cap 7$ & $1.00 \mathrm{~L}-\mathrm{t}$ & 5 & 6 & 0 & -06 \\
\hline $82 E-09$ & $51 E-06$ & קחת ח & $16 \cap 5$ & 105 & $1.59 \mathrm{E}-06$ & $2.43 E-06$ & $29 E-06$ \\
\hline-09 & 06 & 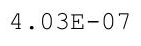 & $1.65 \mathrm{E}-$ & & -06 & $2.43 E-0$ & $30 F-06$ \\
\hline-09 & 06 & 5 & $10 \Omega$ & & & & $E-06$ \\
\hline 99 & & & & & & & \\
\hline $93 E-09$ & $5.54 \mathrm{E}-06$ & 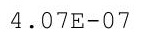 & $1.00 \mathrm{~L}$ & $\perp$ & 06 & 06 & -06 \\
\hline $96 \mathrm{E}-09$ & $3.075-20$ & 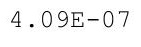 & 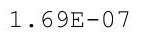 & $1.07 \mathrm{E}-06$ & $1.62 \mathrm{E}-06$ & $2.45 \mathrm{E}-00$ & $32 E-06$ \\
\hline (2) & 6 & tes & -0.000 & 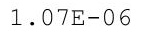 & $1.62 \mathrm{E}-06$ & 告 & $3.32 E-06$ \\
\hline 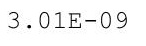 & $5.57 \mathrm{E}-06$ & & & 1 & & & 6 \\
\hline-09 & $5-06$ & & & & 6 & & 06 \\
\hline & & & & & & & \\
\hline $10 \mathrm{E}-09$ & $5.59 \mathrm{E}-06$ & $4 \cdot 13 E-U$ & $1.73 \mathrm{E}-$ & 1.090 & 06 & 06 & -06 \\
\hline $12 \mathrm{E}-09$ & $5.60 \mathrm{E}-06$ & & \pm & & & & -06 \\
\hline $10 \mathrm{~T}-29$ & & & & & & & $3.325-0$ \\
\hline $.18 \mathrm{E}-09$ & ( & & $\perp$ & 6 & 6 & 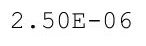 & 06 \\
\hline & & & & & & & 6 \\
\hline & & & 7 & 6 & 6 & 6 & \\
\hline$E-09$ & $5.63 E-06$ & 4. & 1. & 1.1 & -06 & 06 & -06 \\
\hline & & & & & & & \\
\hline & & & & & $1.00 \mathrm{~L}$ & & $38 E-06$ \\
\hline 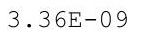 & 0 & & & & 1.00 & 06 & PL- \\
\hline 5 & $6 E-06$ & $9 E-07$ & $1.81 \mathrm{E}-07$ & $1 E-06$ & $69 E-06$ & $4 E-06$ & -06 \\
\hline
\end{tabular}


RESRAD-OFFSITE, Version 2.5

itle : Offsite Resident Farmer Deterministic Run

File : RF TC99 DOESG FWD-FV2b.ROF

Summary of dose at graphical times, reptition 3 (continued)

Time

Years

$5.66 \mathrm{E}+02$

$5.67 \mathrm{E}+02$

$5.67 \mathrm{E}+02$

$5.68 \mathrm{E}+02$

$5.68 \mathrm{E}+02$

$5.69 \mathrm{E}+02$

$5.69 \mathrm{E}+02$

$5.70 \mathrm{E}+02$

$5.70 \mathrm{E}+02$

$5.71 \mathrm{E}+02$

$5.71 \mathrm{E}+02$

$5.72 \mathrm{E}+02$

$5.72 \mathrm{E}+02$

$5.73 \mathrm{E}+02$

$5.73 \mathrm{E}+02$

$5.74 \mathrm{E}+02$

$5.74 \mathrm{E}+02$

$5.75 \mathrm{E}+02$

$5.75 \mathrm{E}+02$

$5.76 \mathrm{E}+02$

$5.76 \mathrm{E}+02$

$5.77 \mathrm{E}+02$

$5.77 \mathrm{E}+02$

$5.78 \mathrm{E}+02$

$5.78 \mathrm{E}+02$

$5.79 \mathrm{E}+02$

$5.79 \mathrm{E}+02$

$5.80 \mathrm{E}+02$

$5.80 \mathrm{E}+02$

$5.81 \mathrm{E}+02$

$5.81 \mathrm{E}+02$

$5.82 \mathrm{E}+02$

$5.82 \mathrm{E}+02$

$5.83 \mathrm{E}+02$

$5.83 \mathrm{E}+02$

$5.84 \mathrm{E}+02$

$5.84 \mathrm{E}+02$

$5.85 \mathrm{E}+02$

$5.85 \mathrm{E}+02$

$5.86 \mathrm{E}+02$

$5.87 \mathrm{E}+02$

$5.87 \mathrm{E}+02$

$5.88 \mathrm{E}+02$

$5.88 \mathrm{E}+02$

$5.89 \mathrm{E}+02$

$5.89 \mathrm{E}+02$
Dose statistics at graphical times, mrem/yr

\begin{tabular}{|c|c|c|c|c|c|c|c|}
\hline$m$ & aximum & ean & ${ }^{2}$ & & & $\%$ & \\
\hline 09 & 06 & $4.31 E-07$ & $1.82 \mathrm{E}-07$ & $1.12 \mathrm{E}-06$ & 06 & -06 & -00 \\
\hline $45 E-09$ & $5.68 E-06$ & $32 E-07$ & $1.83 \mathrm{E}-07$ & $1.12 \mathrm{E}-06$ & $1.70 \mathrm{E}-06$ & -06 & -06 \\
\hline$E-09$ & $5.69 \mathrm{E}-06$ & $4.34 \mathrm{E}-07$ & $1.84 \mathrm{E}-07$ & $1.12 \mathrm{E}-06$ & $1.70 \mathrm{E}-06$ & $2.56 \mathrm{E}-06$ & $3.40 \mathrm{E}-06$ \\
\hline-09 & $.69 \mathrm{E}-06$ & $.35 E-07$ & $1.85 \mathrm{E}-07$ & $1.13 E-06$ & $1.71 \mathrm{E}-06$ & $7 E-06$ & $.41 E-06$ \\
\hline $4 \mathrm{E}-09$ & $70 E-06$ & $7 E-07$ & $1.86 \mathrm{E}-07$ & $1.13 \mathrm{E}-06$ & $1.71 \mathrm{E}-06$ & $8 E-06$ & -06 \\
\hline-09 & 6 & 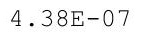 & $1.87 \mathrm{E}-07$ & 6 & 6 & 6 & -06 \\
\hline $61 E-09$ & 06 & & & & & 6 & -06 \\
\hline $.64 E-09$ & $5.72 E-06$ & & & & & & -06 \\
\hline-09 & -06 & $F-0$ & 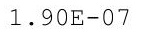 & 6 & 06 & -06 & -06 \\
\hline-09 & -06 & . & 列 & -06 & -06 & -06 & -06 \\
\hline $4 E-09$ & $4 E-06$ & 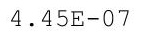 & > & 6 & 6 & $15-$ & -06 \\
\hline 99 & 6 & & & & & & 06 \\
\hline$F-09$ & $6 F-06$ & - & 1 . & 6 & 6 & 6 & -06 \\
\hline $.84 \mathrm{E}-09$ & $5.76 \mathrm{E}-06$ & $4.49 \mathrm{E}-07$ & $1.95 \mathrm{E}-07$ & $1.16 \mathrm{E}-06$ & $1.75 \mathrm{E}-06$ & $2.63 E-06$ & $3.45 E-06$ \\
\hline $87 E-09$ & $77 E-06$ & 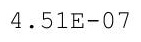 & 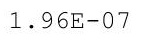 & 06 & & 06 & -06 \\
\hline 09 & & & & & & & -06 \\
\hline 9 & 06 & & & 06 & & & c \\
\hline 9 & 6 & & & & & & 6 \\
\hline $01 E-09$ & $.80 E-06$ & ק & F & 6 & 06 & 6 & -06 \\
\hline $.04 E-09$ & $.80 \mathrm{E}-06$ & $4.58 \mathrm{E}-07$ & $2.01 \mathrm{E}-07$ & $1.18 \mathrm{E}-06$ & $1.77 \mathrm{E}-06$ & $E-06$ & $.48 \mathrm{E}-06$ \\
\hline $.07 \mathrm{E}-09$ & $5.81 \mathrm{E}-06$ & $4.59 \mathrm{E}-07$ & 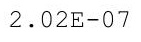 & $1.18 E-06$ & $1.78 \mathrm{E}-06$ & $7 E-06$ & $E-06$ \\
\hline & & & & & & & -06 \\
\hline & & & & & & & 06 \\
\hline 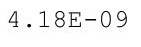 & . & & & 6 & & & -06 \\
\hline 9 & 6 & 象 & 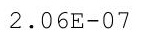 & 6 & 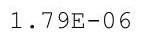 & 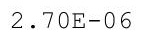 & -06 \\
\hline $5 E-09$ & $84 E-06$ & $.67 \mathrm{E}-0$ & & 1. $20 \mathrm{E}-06$ & $1.80 \mathrm{E}-06$ & $0 E-06$ & $51 E-06$ \\
\hline$F-09$ & -06 & $468=0$ & תחمח ק & 1.20 & $80 E-06$ & $1 E-06$ & $52 E-06$ \\
\hline$E-09$ & 06 & & & & & & $52 E-06$ \\
\hline & 06 & & & & & & \\
\hline $40 E-09$ & $5.87 \mathrm{E}-06$ & 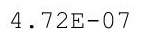 & $2 \cdot \pm 2+$ & 1.21E-06 & $1.82 \mathrm{E}-06$ & 06 & -06 \\
\hline$\cdot 435-09$ & $3.01 \mathrm{E}-00$ & th & 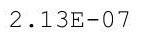 & $1.21 \mathrm{E}-06$ & $1.0<\mathrm{L}-00$ & $2.15 \mathrm{E}-00$ & $.54 E-06$ \\
\hline $.47 E-09$ & $.88 E-06$ & - & 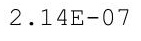 & $1.22 \mathrm{E}-06$ & $1.83 \mathrm{E}-06$ & 然 & $3.54 \mathrm{E}-06$ \\
\hline 5 & $5.89 \mathrm{E}-06$ & & $2.15 \mathrm{E}-$ & & & & 6 \\
\hline$F-09$ & & & & $102 \pi$ & & -06 & 6 \\
\hline 9 & & & & & & & \\
\hline $2 E-09$ & $5.90 E-06$ & $4.81 E-07$ & $2.18 \mathrm{E}-$ & $1.25 \mathrm{E}$ & 1.005 & 06 & -06 \\
\hline $5-09$ & 0 & 1.00 & & 1.23 & & & -06 \\
\hline $70 E-09$ & & & & 1.23E-06 & & & $3.31 \mathrm{E}-00$ \\
\hline 9 & 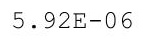 & & 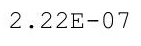 & 6 & 6 & 2 & 06 \\
\hline & & & & & & & 6 \\
\hline & & & 2 & 1 & 6 & & -06 \\
\hline $6 \mathrm{E}-09$ & $5.94 \mathrm{E}-06$ & 07 & 2. & 1.25 & 06 & 06 & -06 \\
\hline & & & & & & & \\
\hline & & & & $\pm \cdot 20$ & & & $E-06$ \\
\hline & 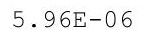 & & + t & +0.20 & 06 & 06 & $00 \mathrm{~L}-0$ \\
\hline 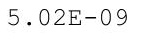 & $E-06$ & $5 E-07$ & $30 E-07$ & $26 E-06$ & $3 E-06$ & $82 E-06$ & -06 \\
\hline
\end{tabular}


RESRAD-OFFSITE, Version 2.5

itle : Offsite Resident Farmer Deterministic Run

File : RF TC99 DOESG FWD-FV2b.ROF

Summary of dose at graphical times, reptition 3 (continued)

Time

Years

$5.90 \mathrm{E}+02$

$5.90 \mathrm{E}+02$

$5.91 \mathrm{E}+02$

5. $91 \mathrm{E}+02$

$5.92 \mathrm{E}+02$

$5.92 \mathrm{E}+02$

$5.93 \mathrm{E}+02$

$5.93 \mathrm{E}+02$

$5.94 \mathrm{E}+02$

$5.94 \mathrm{E}+02$

$5.95 \mathrm{E}+02$

$5.95 \mathrm{E}+02$

$5.96 \mathrm{E}+02$

$5.96 \mathrm{E}+02$

$5.97 \mathrm{E}+02$

$5.97 \mathrm{E}+02$

$5.98 \mathrm{E}+02$

$5.98 \mathrm{E}+02$

$5.99 \mathrm{E}+02$

$5.99 \mathrm{E}+02$

$6.00 \mathrm{E}+02$

$6.00 \mathrm{E}+02$

$6.01 \mathrm{E}+02$

$6.01 \mathrm{E}+02$

$6.02 \mathrm{E}+02$

$6.02 \mathrm{E}+02$

$6.03 E+02$

$6.03 \mathrm{E}+02$

$6.04 \mathrm{E}+02$

$6.04 \mathrm{E}+02$

$6.05 \mathrm{E}+02$

$6.05 \mathrm{E}+02$

$6.06 \mathrm{E}+02$

$6.07 \mathrm{E}+02$

$6.07 \mathrm{E}+02$

$6.08 \mathrm{E}+02$

$6.08 \mathrm{E}+02$

$6.09 \mathrm{E}+02$

$6.09 \mathrm{E}+02$

$6.10 \mathrm{E}+02$

$6.10 \mathrm{E}+02$

$6.11 \mathrm{E}+02$

$6.11 \mathrm{E}+02$

$6.12 \mathrm{E}+02$

$6.12 \mathrm{E}+02$

$6.13 \mathrm{E}+02$
Dose statistics at graphical times, mrem/yr

\begin{tabular}{|c|c|c|c|c|c|c|c|}
\hline m & aximum & ea & -5 & & & & \\
\hline $.06 \mathrm{E}-09$ & -06 & $4.97 \mathrm{E}-07$ & $2.31 \mathrm{E}-07$ & $1.26 \mathrm{E}-06$ & $1.88 \mathrm{E}-06$ & -06 & -00 \\
\hline $10 \mathrm{E}-09$ & $5.97 E-06$ & $4.99 \mathrm{E}-07$ & $2.32 \mathrm{E}-07$ & $1.26 E-06$ & $1.89 \mathrm{E}-06$ & $2.83 E-06$ & $1 E-06$ \\
\hline-09 & $98 E-06$ & $.00 E-07$ & $2.33 E-07$ & $1.27 \mathrm{E}-06$ & $1.89 \mathrm{E}-06$ & $2.84 \mathrm{E}-06$ & $1 E-06$ \\
\hline-09 & 06 & $02 F-07$ & $35 \mathrm{~F}-07$ & $27 \mathrm{~F}-06$ & $89 F-06$ & -06 & $52 \mathrm{E}-06$ \\
\hline-09 & 06 & $5.03 E-07$ & 7 & 6 & 6 & 6 & -06 \\
\hline 09 & 06 & & & & & & \\
\hline $31 E-09$ & 06 & & 7 & 66 & & & $E-06$ \\
\hline-09 & 06 & 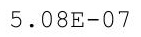 & 1 & 6 & 06 & -06 & $3 E-06$ \\
\hline $39 E-09$ & -06 & 然 & -07 & $28 \mathrm{E}-06$ & -06 & -06 & $E-06$ \\
\hline$E-09$ & 06 & 15 & 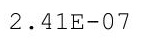 & $9 E-06$ & $92 F-06$ & $.88 E-06$ & -06 \\
\hline 09 & 06 & & & & & & 06 \\
\hline $52 E-09$ & -06 & & 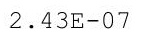 & .29 & & 6 & -06 \\
\hline $57 E-09$ & $6.04 \mathrm{E}-06$ & & $2.44 \mathrm{E}-07$ & $1.30 E-06$ & $1.93 E-06$ & $2.90 E-06$ & $65 E-06$ \\
\hline $61 E-09$ & $5.04 \mathrm{E}-06$ & 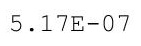 & $2.45 \mathrm{E}-07$ & -06 & -06 & -06 & $E-06$ \\
\hline$E-09$ & -06 & & 1 & 06 & & -06 & -06 \\
\hline 99 & 06 & 7 & $48 E-C$ & $.31 E-$ & & $E-06$ & -06 \\
\hline 9 & 0 & & & & & & 6 \\
\hline 9 & 6 & $5.23 E-07$ & $2.50 \mathrm{E}-07$ & 6 & & 6 & 06 \\
\hline $83 E-09$ & $6.07 \mathrm{E}-06$ & $5.24 E-07$ & $2.51 \mathrm{E}-07$ & 1. $32 E-06$ & $1.94 \mathrm{E}-06$ & $2.94 \mathrm{E}-06$ & $3.66 \mathrm{E}-06$ \\
\hline $88 E-09$ & $.07 E-06$ & $.25 E-0$ & $2.52 \mathrm{E}-07$ & 1. $32 \mathrm{E}-06$ & $1.95 \mathrm{E}-06$ & $E-06$ & $67 E-06$ \\
\hline 09 & & & & & & -06 & -06 \\
\hline 09 & & & & 6 & & -06 & -06 \\
\hline 9 & & 7 5 & $2.55 \mathrm{E}-07$ & 1.0 & & & 06 \\
\hline $6 E-09$ & 06 & $5.31 \mathrm{E}-07$ & $2.56 \mathrm{E}-07$ & 6 & 6 & 0 & -06 \\
\hline 9 & 6 & $5.33 E-07$ & 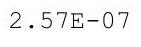 & 6 & 6 & $E-06$ & 06 \\
\hline $5-09$ & $10 \mathrm{E}-06$ & $\pi$ & 50 & $1.34 \mathrm{E}-06$ & $1.97 \mathrm{E}-06$ & $.98 \mathrm{E}-06$ & $.69 E-06$ \\
\hline-09 & -06 & & $F-07$ & $34 \mathrm{E}-06$ & & $E-06$ & $70 E-06$ \\
\hline & & & & & & & \\
\hline & & & & 1.00 & 6 & -06 & -06 \\
\hline $35 E-09$ & $6.12 \mathrm{E}-06$ & . & $2.0 \angle \mathrm{L}-1$ & $1.36 \mathrm{E}-06$ & $1.99 \mathrm{E}-06$ & $3.00 E-06$ & $.71 E-06$ \\
\hline $0 E-09$ & $13 E-06$ & - 1 क्ष & 2.000 r & $1.36 \mathrm{E}-06$ & $.99 E-06$ & $U-20$ & $71 E-06$ \\
\hline $45 E-09$ & & & 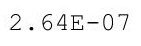 & & & 0 & $71 E-06$ \\
\hline$E-09$ & $F-06$ & 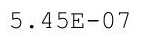 & F & $E-06$ & $0 E-06$ & & $2 F-06$ \\
\hline 9 & & & & & & 6 & \\
\hline 9 & & & 2.0 & 1.38 & 06 & 06 & \\
\hline $.64 \mathrm{E}-09$ & $6.15 E-06$ & . 20 प & $2.69 \mathrm{E}-01$ & $1.38 \mathrm{E}-06$ & 2.01 & -06 & $73 E-06$ \\
\hline $.09 \pm-09$ & & & & & & & $3.130-00$ \\
\hline $74 \mathrm{E}-09$ & $16 E-06$ & ( & - & $1.38 \mathrm{E}-06$ & $2.02 \mathrm{E}-06$ & & $.74 \mathrm{E}-06$ \\
\hline 9 & $6.16 \mathrm{E}-06$ & $5.54 \mathrm{E}-07$ & $2.72 \mathrm{E}-07$ & 6 & 6 & 6 & 06 \\
\hline & & & & & & & \\
\hline$E-09$ & $E-06$ & $5 \cdot 5$ & 2 . & 1 . & & 06 & -06 \\
\hline$E-09$ & 6 & 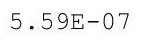 & & 1.40 & & & 06 \\
\hline & & & & & & & $3.16 E-06$ \\
\hline Litor & $0.17 \mathrm{~L}-0$ & . & $2.12 \mathrm{~L}-1$ & $1.40 \mathrm{E}-06$ & $2.05 E-06$ & $3.04 E-06$ & $3.10 \mathrm{E}-06$ \\
\hline$\perp U E-02$ & $6.19 E-06$ & . & $2.00 \mathrm{E}-1$ & $1.41 \mathrm{E}-06$ & 2.05 & & $3.76 E-06$ \\
\hline $6 E-09$ & $.19 \mathrm{E}-06$ & $.65 E-07$ & $.81 \mathrm{E}-07$ & $.41 \mathrm{E}-06$ & $E-06$ & $3.05 \mathrm{~F}$ & -06 \\
\hline
\end{tabular}


RESRAD-OFFSITE, Version 2.5

$\mathrm{T}^{1 / 2}$ Limit $=180$ days

Title : Offsite Resident Farmer Deterministic Run

File : RF TC99 DOESG FWD-FV2b.ROF

Summary of dose at graphical times, reptition 3 (continued)

Time

Years

$6.13 \mathrm{E}+02$

$6.14 \mathrm{E}+02$

$6.14 \mathrm{E}+02$

$6.15 \mathrm{E}+02$

$6.15 \mathrm{E}+02$

$6.16 \mathrm{E}+02$

$6.16 \mathrm{E}+02$

$6.17 \mathrm{E}+02$

$6.17 \mathrm{E}+02$

$6.18 \mathrm{E}+02$

$6.18 \mathrm{E}+02$

$6.19 \mathrm{E}+02$

$6.19 \mathrm{E}+02$

$6.20 \mathrm{E}+02$

$6.20 \mathrm{E}+02$

$6.21 \mathrm{E}+02$

$6.21 \mathrm{E}+02$

$6.22 \mathrm{E}+02$

$6.22 \mathrm{E}+02$

$6.23 \mathrm{E}+02$

$6.23 \mathrm{E}+02$

$6.24 \mathrm{E}+02$

$6.24 \mathrm{E}+02$

$6.25 \mathrm{E}+02$

$6.25 \mathrm{E}+02$

$6.26 \mathrm{E}+02$

$6.27 \mathrm{E}+02$

$6.27 \mathrm{E}+02$

$6.28 \mathrm{E}+02$

$6.28 \mathrm{E}+02$

$6.29 \mathrm{E}+02$

$6.29 \mathrm{E}+02$

$6.30 \mathrm{E}+02$

$6.30 \mathrm{E}+02$

$6.31 \mathrm{E}+02$

$6.31 \mathrm{E}+02$

$6.32 \mathrm{E}+02$

$6.32 \mathrm{E}+02$

$6.33 \mathrm{E}+02$

$6.33 \mathrm{E}+02$

$6.34 \mathrm{E}+02$

$6.34 \mathrm{E}+02$

$6.35 \mathrm{E}+02$

$6.35 \mathrm{E}+02$

$6.36 \mathrm{E}+02$

$6.36 \mathrm{E}+02$
Dose statistics at graphical times, mrem/yr

\begin{tabular}{|c|c|c|c|c|c|c|c|}
\hline$m$ & aximum & lea & ec & & & $\%$ & \\
\hline 09 & $6.20 \mathrm{E}-06$ & $5.66 \mathrm{E}-07$ & $2.83 E-07$ & $1.41 \mathrm{E}-06$ & $06 E-06$ & 06 & $5-00$ \\
\hline $.26 E-09$ & $6.20 E-06$ & $8 E-07$ & $2.84 \mathrm{E}-07$ & $1.42 \mathrm{E}-06$ & $06 E-06$ & $E-06$ & $7 E-06$ \\
\hline $.32 E-09$ & $6.21 E-06$ & $69 E-07$ & $2.85 \mathrm{E}-07$ & $1.42 \mathrm{E}-06$ & $2.07 E-06$ & $05 E-06$ & $8 E-06$ \\
\hline $37 E-09$ & $21 \mathrm{E}-06$ & $71 \mathrm{~F}-07$ & $87 \mathrm{~F}-07$ & $42 \mathrm{E}-06$ & $07 \mathrm{~F}-06$ & -06 & $78 E-06$ \\
\hline-09 & 06 & 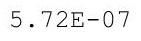 & -07 & 06 & 06 & -06 & -06 \\
\hline 09 & 06 & & & & & & \\
\hline $.53 E-09$ & $6.22 \mathrm{E}-06$ & & & & & & $79 E-06$ \\
\hline-09 & -06 & 1 & 7 & 6 & 6 & 6 & -06 \\
\hline $64 \mathrm{E}-09$ & $6.23 E-06$ & $8 E-07$ & $E-07$ & -06 & -06 & -06 & $E-06$ \\
\hline$E-09$ & $24 E-06$ & תمחم & 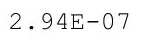 & $44 \mathrm{E}-06$ & $.10 \mathrm{E}-06$ & 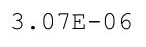 & -06 \\
\hline 09 & 6 & & & & & 6 & 06 \\
\hline $.81 \mathrm{E}-09$ & $6.24 \mathrm{E}-06$ & $.83 \mathrm{E}$ & $2.96 \mathrm{E}-07$ & 6 & & 6 & -06 \\
\hline $.87 E-09$ & $6.25 E-06$ & $5.85 E-07$ & & $1.46 \mathrm{E}-06$ & $2.11 E-06$ & $3.08 E-06$ & $81 E-06$ \\
\hline $.92 E-09$ & $6.25 E-06$ & $5.86 \mathrm{E}-07$ & $2.98 \mathrm{E}-07$ & $1.46 \mathrm{E}-06$ & $2.12 \mathrm{E}-06$ & -06 & $E-06$ \\
\hline $98 E-09$ & $26 E-06$ & 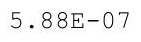 & ( & -06 & -06 & -06 & $E-06$ \\
\hline 09 & 06 & 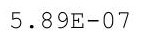 & ${ }_{0}$ & $.47 E-$ & $10=$ & $E-06$ & 06 \\
\hline 9 & 0 & & & & & & \\
\hline 9 & 6 & $5 \quad 92 F-07$ & & 6 & & & 6 \\
\hline $21 E-09$ & $6.27 \mathrm{E}-06$ & $5.94 \mathrm{E}-07$ & $3.04 \mathrm{E}-07$ & $1.48 E-06$ & $2.15 \mathrm{E}-06$ & $E-06$ & $.83 E-06$ \\
\hline $27 E-09$ & $.27 E-06$ & $.95 E-07$ & $.05 E-07$ & $1.48 \mathrm{E}-06$ & $2.15 \mathrm{E}-06$ & $E-06$ & $84 E-06$ \\
\hline-09 & $6.28 E-06$ & & & $1.49 \mathrm{E}-06$ & & -06 & -06 \\
\hline 09 & 06 & & & & & 0 & -06 \\
\hline 09 & 0.23 & & & $\pm \cdot 0$ & & & 06 \\
\hline-09 & 6 & $6.01 \mathrm{E}-07$ & $3.10 E-07$ & 6 & & 0 & -06 \\
\hline 9 & 6 & $6.03 \mathrm{E}-07$ & $3.11 \mathrm{E}-07$ & 6 & 6 & 6 & 06 \\
\hline$E-09$ & $.30 E-06$ & 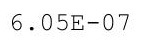 & 䧑 & $1.51 \mathrm{E}-06$ & $2.18 \mathrm{E}-06$ & $1 E-06$ & $87 E-06$ \\
\hline$E-09$ & $30 E-06$ & & & -06 & & $F-06$ & $38 E-06$ \\
\hline & & & & & & & \\
\hline 09 & 6.315 & $0.095-01$ & (2) & $\perp \cdot 321$ & & & 06 \\
\hline $87 E-09$ & $6.31 E-06$ & 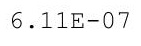 & $\begin{array}{lll} \\
0\end{array}$ & $1.52 \mathrm{E}-06$ & $2.19 \mathrm{E}-06$ & $3.12 \mathrm{E}-06$ & $89 E-06$ \\
\hline $93 E-09$ & $6.31 E-06$ & . & 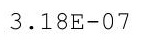 & 1. 53E-06 & $2 \cdot 19 \bar{L}-0$ & दL- & $90 E-06$ \\
\hline 9 & 6 & . & 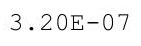 & 1. $53 \mathrm{E}-06$ & $2.19 \mathrm{E}-06$ & 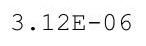 & $91 E-06$ \\
\hline$F-09$ & $32 F-06$ & 15 & & $1.54 \mathrm{E}-06$ & & & $1 E-06$ \\
\hline 9 & & & & & & & \\
\hline 09 & & & & 6 & & & \\
\hline $24 \mathrm{E}-09$ & $6.33 E-06$ & $0.20 E-01$ & $3.235-01$ & $1.55 \mathrm{E}-06$ & $2.21 \mathrm{E}-06$ & $3 E-06$ & $93 E-06$ \\
\hline $31 E-09$ & $0.33 E-06$ & . $220 \quad 01$ & & 1. $55 \mathrm{E}-06$ & $2 \cdot 2 \perp+00$ & . & $3.93 \pm-06$ \\
\hline$E-09$ & 6 & & & $1.56 \mathrm{E}-06$ & & & $945-00$ \\
\hline 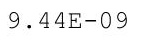 & 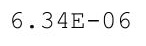 & $6.25 \mathrm{E}-07$ & 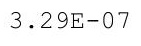 & 6 & 6 & 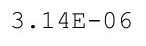 & 6 \\
\hline & & & & 6 & & & 06 \\
\hline-09 & 6.35 & $6.28 \mathrm{E}$ & 3. & 1 . & 6 & 06 & -06 \\
\hline$E-09$ & $6.35 E-06$ &. & 5 & 1.57 & 6 & 06 & $6 E-06$ \\
\hline & & & & & & & $3.96 \mathrm{E}-06$ \\
\hline & 0.05 & $\cdot 0<4$ & 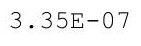 & \pm .00 & & $5 E-06$ & $3.97 E-06$ \\
\hline 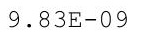 & $6.36 \mathrm{E}-06$ & -5 & & 1.000 & & 0 & $21 \mathrm{~L}-0$ \\
\hline 9 & $E-06$ & $E-07$ & $3 E-07$ & $59 E-06$ & $E-06$ & 06 & -06 \\
\hline
\end{tabular}


RESRAD-OFFSITE, Version 2.5

Title : Offsite Resident Farmer Deterministic Run

File : RF TC99 DOESG FWD-FV2b.ROF

Summary of dose at graphical times, reptition 3 (continued)

Time

Years

$6.37 \mathrm{E}+02$

$6.37 \mathrm{E}+02$

$6.38 \mathrm{E}+02$

$6.38 \mathrm{E}+02$

$6.39 \mathrm{E}+02$

6. $39 \mathrm{E}+02$

$6.40 \mathrm{E}+02$

$6.40 \mathrm{E}+02$

$6.41 \mathrm{E}+02$

$6.41 \mathrm{E}+02$

$6.42 \mathrm{E}+02$

$6.42 \mathrm{E}+02$

$6.43 \mathrm{E}+02$

$6.43 \mathrm{E}+02$

$6.44 \mathrm{E}+02$

$6.44 \mathrm{E}+02$

$6.45 \mathrm{E}+02$

$6.45 \mathrm{E}+02$

$6.46 \mathrm{E}+02$

$6.47 \mathrm{E}+02$

$6.47 \mathrm{E}+02$

$6.48 \mathrm{E}+02$

$6.48 \mathrm{E}+02$

$6.49 \mathrm{E}+02$

$6.49 \mathrm{E}+02$

$6.50 \mathrm{E}+02$

$6.50 \mathrm{E}+02$

$6.51 \mathrm{E}+02$

$6.51 \mathrm{E}+02$

$6.52 \mathrm{E}+02$

$6.52 \mathrm{E}+02$

$6.53 \mathrm{E}+02$

$6.53 \mathrm{E}+02$

$6.54 \mathrm{E}+02$

$6.54 \mathrm{E}+02$

$6.55 \mathrm{E}+02$

$6.55 \mathrm{E}+02$

$6.56 \mathrm{E}+02$

$6.56 \mathrm{E}+02$

$6.57 \mathrm{E}+02$

$6.57 \mathrm{E}+02$

$6.58 \mathrm{E}+02$

$6.58 \mathrm{E}+02$

$6.59 \mathrm{E}+02$

$6.59 \mathrm{E}+02$

$6.60 \mathrm{E}+02$

Dose statistics at graphical times, mrem/yr

\begin{tabular}{|c|c|c|c|c|c|c|c|}
\hline lum & aximum & lean & edi & & & & \\
\hline 09 & 06 & 07 & 07 & 06 & 06 & 06 & -06 \\
\hline $.00 \mathrm{E}-08$ & $.37 E-06$ & $9 E-07$ & $40 E-07$ & $1.60 \mathrm{E}-06$ & $2.26 \mathrm{E}-06$ & $3.17 \mathrm{E}-06$ & $99 E-06$ \\
\hline $01 E-08$ & $.37 E-06$ & $40 F-07$ & $42 E-07$ & $.60 E-06$ & $.26 E-06$ & $3.17 E-06$ & $99 E-06$ \\
\hline $02 \mathrm{E}-08$ & $37 \mathrm{~F}-06$ & $42 \mathrm{~F}-0$ & $.43 E-07$ & $.61 E-06$ & $27 E-06$ & $3.18 \mathrm{E}-06$ & $.00 E-06$ \\
\hline$E-08$ & 06 & $6.43 E-07$ & & & & 6 & -06 \\
\hline $03 E-08$ & $5.38 E-06$ & 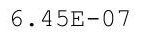 & & & & & -06 \\
\hline $04 E-08$ & $6.38 E-06$ & - & 7 & $1.62 E-06$ & $2.28 E-06$ & $3.19 E-06$ & $01 E-06$ \\
\hline $04 \mathrm{E}-08$ & $6.38 E-06$ & $8 E-07$ & $48 E-07$ & $.62 \mathrm{E}-06$ & $2.28 \mathrm{E}-06$ & $E-06$ & $.02 E-06$ \\
\hline $05 \mathrm{~F}-08$ & $38 E-06$ & $50 F-0$ & $50 \mathrm{~F}-0-\mathrm{C}$ & $.63 E-06$ & $.29 E-06$ & $0 E-06$ & $02 E-06$ \\
\hline $6 F-08$ & 6 & & & 5 & 6 & 6 & -06 \\
\hline $06 \mathrm{E}-08$ & $639 F-06$ & $3 \mathrm{~F}-8 \cdot-2$ & $2 F-07$ & 6 & 06 & -06 & $E-06$ \\
\hline$E-08$ & 06 & & & & & & -06 \\
\hline $.08 E-08$ & $6.39 E-06$ & $6.56 \mathrm{E}-07$ & $3.54 \mathrm{E}-07$ & $1.64 E-06$ & $2.31 E-06$ & $3.22 E-06$ & $04 E-06$ \\
\hline$E-08$ & 06 & & & & & -06 & -06 \\
\hline - & 6 & & & 6 & & 6 & 06 \\
\hline$F$ & & & & 6 & 6 & 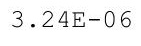 & 6 \\
\hline$F-08$ & 001 t & $6.62 \mathrm{E}-07$ & $3.59 E-07$ & 6 & 6 & 6 & -06 \\
\hline $.11 \mathrm{E}-08$ & $.41 E-06$ & $4 F-07$ & & 6 & $3 E-06$ & $5 E-06$ & $7 E-06$ \\
\hline $12 \mathrm{E}-08$ & $.41 \mathrm{E}-06$ & $6.65 E-07$ & $.62 \mathrm{E}-07$ & $1.66 \mathrm{E}-06$ & $2.33 E-06$ & $3.25 E-06$ & $.07 E-06$ \\
\hline $.13 E-08$ & $41 E-06$ & $67 E-07$ & -07 & -06 & $E-06$ & -06 & $E-06$ \\
\hline & & & & & & & \\
\hline 8 & & & & & & & 06 \\
\hline $15 E-08$ & 06 & 6.711 & $3.67 \mathrm{E}-07$ & 6 & 6 & & -06 \\
\hline $16 \mathrm{E}-08$ & $.42 E-06$ & $5.73 E-C$ & $68 \mathrm{E}-$ & $1.68 \mathrm{E}-06$ & $35 E-06$ & $3 E-06$ & $10 E-06$ \\
\hline $17 \mathrm{E}-08$ & $.42 \mathrm{E}-06$ & $6.75 E-07$ & $70 \mathrm{E}-07$ & $1.68 \mathrm{E}-06$ & $.36 \mathrm{E}-06$ & $8 E-06$ & $10 E-06$ \\
\hline$F-08$ & $42 F-06$ & & & -06 & & $E-06$ & $11 E-06$ \\
\hline & & & & & & & \\
\hline & & & & 1.6 & & & \\
\hline $.20 E-08$ & $6.43 E-06$ & $6.81 E-07$ & $3.13 \pm-01$ & $1.69 \mathrm{E}-06$ & $2.38 E-06$ & $0 E-06$ & $.12 \mathrm{E}-06$ \\
\hline 8 & $43 E-06$ & (c) & $.77 E-07$ & $1.69 \mathrm{E}-06$ & $.38 E-06$ & $.30 E-06$ & $.12 E-06$ \\
\hline 5 & $43 E-06$ & & & $1.69 \mathrm{E}-06$ & $38 E-06$ & $31 E-06$ & $4.12 \mathrm{E}-06$ \\
\hline$F-08$ & $44 F-06$ & & $F_{-1}$ & $17 \mathrm{~F}$ & 6 & & $4.13 E-06$ \\
\hline $.23 E-08$ & & & & & & & \\
\hline 08 & & & & 06 & 6 & & \\
\hline $.24 \mathrm{E}-08$ & $6.44 \mathrm{E}-06$ & $6.90 \mathrm{E}-07$ & $3.85 \mathrm{E}-07$ & $1.71 \mathrm{E}-06$ & $2.40 E-06$ & $3.32 E-06$ & $.14 \mathrm{E}-06$ \\
\hline$\cdot 20 \mathrm{E}-00$ & $0.445-00$ & & & $1.71 \mathrm{E}-06$ & $2.40=-06$ & $3.32 E-06$ & $4.15 E-06$ \\
\hline 8 & - & $6.93 E-07$ & $3.88 E-07$ & 6 & 6 & & $15 E-06$ \\
\hline 8 & $6.45 \mathrm{E}-06$ & 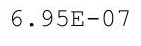 & & 6 & 6 & 6 & 06 \\
\hline $.27 E-08$ & & & & 6 & & & \\
\hline $28 \mathrm{E}-08$ & $6.45 E-06$ & & & 1 . & 2 & 06 & $4.17 \mathrm{E}$ \\
\hline $.29 E-08$ & $6.45 \mathrm{E}-06$ & 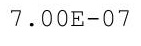 & & 6 & & 06 & -06 \\
\hline 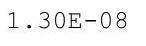 & & & & & & & $4.18 E-06$ \\
\hline . & $.40 \mathrm{~L}-0$ & . & $.98 E-07$ & $1.74 \mathrm{E}-06$ & $2.43 E-06$ & $3.35 E-06$ & $4 \cdot 10 \mathrm{E}-00$ \\
\hline 迸 & $0.40 \mathrm{~L} 0$ & ( & & & & $3.36 \mathrm{E}-06$ & $4.19 \mathrm{E}-06$ \\
\hline$E-$ & - & & & & -06 & -06 & $4.19 E-06$ \\
\hline $.33 E-08$ & $.46 \mathrm{E}-06$ & $.07 E-07$ & $2 E-07$ & $.75 E-06$ & $E-06$ & $E-06$ & 4.2 \\
\hline
\end{tabular}


RESRAD-OFFSITE, Version 2.5

robabilistic Dose and Risk Report

Title : Offsite Resident Farmer Deterministic Run

File : RF TC99 DOESG FWD-FV2b.ROF

Summary of dose at graphical times, reptition 3 (continued)

Time

Years

$6.60 \mathrm{E}+02$

$6.61 \mathrm{E}+02$

$6.61 \mathrm{E}+02$

$6.62 \mathrm{E}+02$

$6.62 \mathrm{E}+02$

$6.63 \mathrm{E}+02$

$6.63 \mathrm{E}+02$

$6.64 \mathrm{E}+02$

$6.64 \mathrm{E}+02$

$6.65 \mathrm{E}+02$

$6.65 \mathrm{E}+02$

$6.66 \mathrm{E}+02$

$6.67 \mathrm{E}+02$

$6.67 \mathrm{E}+02$

$6.68 \mathrm{E}+02$

$6.68 \mathrm{E}+02$

$6.69 \mathrm{E}+02$

$6.69 \mathrm{E}+02$

$6.70 \mathrm{E}+02$

$6.70 \mathrm{E}+02$

$6.71 \mathrm{E}+02$

$6.71 \mathrm{E}+02$

$6.72 \mathrm{E}+02$

$6.72 \mathrm{E}+02$

$6.73 \mathrm{E}+02$

$6.73 \mathrm{E}+02$

$6.74 \mathrm{E}+02$

$6.74 \mathrm{E}+02$

$6.75 \mathrm{E}+02$

$6.75 \mathrm{E}+02$

$6.76 \mathrm{E}+02$

$6.76 \mathrm{E}+02$

$6.77 \mathrm{E}+02$

$6.77 \mathrm{E}+02$

$6.78 \mathrm{E}+02$

$6.78 \mathrm{E}+02$

$6.79 \mathrm{E}+02$

$6.79 \mathrm{E}+02$

$6.80 \mathrm{E}+02$

$6.80 \mathrm{E}+02$

$6.81 \mathrm{E}+02$

$6.81 \mathrm{E}+02$

$6.82 \mathrm{E}+02$

$6.82 \mathrm{E}+02$

$6.83 \mathrm{E}+02$

$6.83 \mathrm{E}+02$
Dose statistics at graphical times, mrem/yr

\begin{tabular}{|c|c|c|c|c|c|c|c|}
\hline m & axis & e & 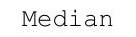 & & & & \\
\hline $34 \mathrm{E}-08$ & $6.46 \mathrm{E}-06$ & $.09 E-07$ & $4.04 \mathrm{E}-07$ & $1.75 \mathrm{E}-06$ & $.44 E-06$ & 06 & $.20 E-00$ \\
\hline $35 E-08$ & $6.46 \mathrm{E}-06$ & $7.11 \mathrm{E}-07$ & $4.05 E-07$ & $1.75 E-06$ & $45 E-06$ & $37 E-06$ & $21 E-06$ \\
\hline $36 \mathrm{E}-08$ & $.47 \mathrm{E}-06$ & $.12 \mathrm{E}-07$ & $4.07 \mathrm{E}-07$ & $1.76 \mathrm{E}-06$ & $2.45 \mathrm{E}-06$ & $3.38 \mathrm{E}-06$ & $.21 E-06$ \\
\hline $36 \mathrm{E}-08$ & $47 E-06$ & $14 \mathrm{~F}-07$ & $.09 \mathrm{E}-07$ & $.76 \mathrm{E}-06$ & $46 \mathrm{~F}-06$ & $8 F-06$ & $.21 E-06$ \\
\hline-08 & 06 & $7.15 \mathrm{E}-07$ & 7 & 06 & 6 & 06 & -06 \\
\hline $38 E-08$ & 06 & & & & & & \\
\hline $39 E-08$ & -06 & & & 66 & & & -06 \\
\hline $40 E-08$ & -06 & 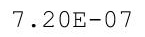 & 7 & 6 & 6 & 6 & $23 E-06$ \\
\hline $41 \mathrm{E}-08$ & $6.47 \mathrm{E}-06$ & 至 & -07 & 1. $78 \mathrm{E}-06$ & $48 E-06$ & -06 & $.23 E-06$ \\
\hline $41 \mathrm{E}-08$ & $48 E-06$ & 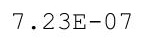 & 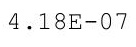 & $.78 E-06$ & $.48 E-06$ & $1 E-06$ & $.24 \mathrm{E}-06$ \\
\hline $42 \mathrm{E}-08$ & 06 & & & & & 6 & -06 \\
\hline $43 E-08$ & $6.48 \mathrm{E}-06$ & $7.26 \mathrm{E}-07$ & $4.20 \mathrm{E}-07$ & 6 & 6 & -06 & $25 E-06$ \\
\hline $.44 \mathrm{E}-08$ & $6.48 E-06$ & & & $1.79 E-06$ & $2.49 E-06$ & $3 E-06$ & $.25 E-06$ \\
\hline $45 E-08$ & $6.48 \mathrm{E}-06$ & 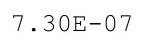 & $4.23 E-07$ & $1.80 \mathrm{E}-06$ & $2.49 \mathrm{E}-06$ & $3.43 \mathrm{E}-06$ & $.26 E-06$ \\
\hline-08 & -06 & & & 6 & -06 & -06 & $26 E-06$ \\
\hline $47 E-08$ & 06 & 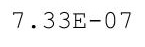 & & 0 & & & 06 \\
\hline 8 & 6 & & & & 5 & $5 E-06$ & 6 \\
\hline $48 E-08$ & 6 & $736 \mathrm{~F}-07$ & $4.28 E-07$ & 6 & 6 & 6 & 06 \\
\hline $49 E-08$ & $6.49 \mathrm{E}-06$ & 7 & 西 & $1.81 \mathrm{E}-06$ & $51 E-06$ & $E-06$ & $27 E-06$ \\
\hline $50 E-08$ & $.49 E-06$ & $7.39 \mathrm{E}-07$ & $4.31 E-07$ & $1.82 \mathrm{E}-06$ & $2.52 E-06$ & $3.46 \mathrm{E}-06$ & . $28 E-06$ \\
\hline 08 & 06 & & & & & 6 & -06 \\
\hline 0 & & & & 6 & 6 & & \\
\hline $53 E-08$ & 60 & & & & 6 & & 06 \\
\hline $4 E-08$ & 6 & 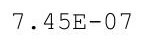 & $4.37 \mathrm{E}-07$ & 6 & 6 & 0 & -06 \\
\hline $5 E-08$ & $.49 \mathrm{E}-06$ & $7.47 \mathrm{E}-$ & חק & $.84 E-06$ & 5 & 6 & $29 E-06$ \\
\hline$E-08$ & $.49 E-06$ & & ח & $1.84 \mathrm{E}-06$ & $.54 \mathrm{E}-06$ & $.49 E-06$ & $.29 E-06$ \\
\hline-08 & $49 \mathrm{E}-06$ & & & & & $E-06$ & $30 E-06$ \\
\hline & & & & & & & \\
\hline & 0.4 & & & 1.00 & 6 & -06 & -06 \\
\hline $59 E-08$ & $6.49 \mathrm{E}-06$ & 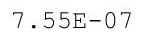 & $4.445-01$ & $1.86 \mathrm{E}-06$ & $2.55 E-06$ & $2.315-40$ & $.30 E-06$ \\
\hline $60 \mathrm{E}-08$ & $6.50 \mathrm{E}-06$ & . & . & $1.86 \mathrm{E}-06$ & $2.55 \mathrm{E}-06$ & $2.3 \perp E-U R$ & $.31 E-06$ \\
\hline $61 \mathrm{E}-$ & 6 & & & & & 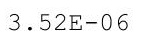 & 6 \\
\hline-08 & & & & & & & 06 \\
\hline 8 & & & & & & & \\
\hline 08 & & & & 06 & 6 & -06 & 06 \\
\hline $.65 E-08$ & $6.50 E-06$ & $1.045-1$ & $4.50 E-07$ & $1.88 \mathrm{E}-06$ & 2.01 & -06 & $.32 E-06$ \\
\hline $66 \mathrm{E}-08$ & $6.50 \mathrm{E}-06$ & & & & & & $4.525-00$ \\
\hline $67 E-08$ & $6.50 \mathrm{E}-06$ & & $4.305-4$ & $1.88 \mathrm{E}-06$ & & & 06 \\
\hline 8 & 6 & $7.69 \mathrm{E}-07$ & 7 & -06 & 6 & 6 & 06 \\
\hline 08 & 6 & & 7 & & 06 & 6 & 06 \\
\hline$E-08$ & $6.50 \mathrm{E}-06$ & 7.72 & 07 & 1 . & 06 & & -06 \\
\hline & 6.5 & & & & & & \\
\hline & & & & & & & $4.34 \mathrm{E}-06$ \\
\hline $.13 E-08$ & $6.50 E-06$ & 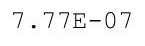 & $4.62 E-07$ & $1.91 \mathrm{E}-06$ & $2.60 \mathrm{E}-06$ & $3.51 E-06$ & $4.34 \mathrm{E}-06$ \\
\hline $74 \mathrm{E}-08$ & $0.30 \mathrm{~L}-0$ & 1. & & $1.91 \mathrm{E}-06$ & 2.60 & & $4.34 E-06$ \\
\hline $75 E-08$ & $.50 \mathrm{E}-06$ & $.80 E-07$ & $.65 E-07$ & $.91 \mathrm{E}-06$ & $2.60 \mathrm{E}-06$ & $3 E-06$ & $4.35 E-06$ \\
\hline
\end{tabular}


RESRAD-OFFSITE, Version 2.5

Title : Offsite Resident Farmer Deterministic Run

File : RF TC99 DOESG FWD-FV2b.ROF

Summary of dose at graphical times, reptition 3 (continued)

Time

Years

$6.84 \mathrm{E}+02$

$6.84 \mathrm{E}+02$

$6.85 \mathrm{E}+02$

$6.85 \mathrm{E}+02$

$6.86 \mathrm{E}+02$

$6.86 \mathrm{E}+02$

$6.87 \mathrm{E}+02$

$6.88 \mathrm{E}+02$

$6.88 \mathrm{E}+02$

$6.89 \mathrm{E}+02$

$6.89 \mathrm{E}+02$

$6.90 \mathrm{E}+02$

$6.90 \mathrm{E}+02$

$6.91 \mathrm{E}+02$

$6.91 \mathrm{E}+02$

$6.92 \mathrm{E}+02$

$6.92 \mathrm{E}+02$

$6.93 \mathrm{E}+02$

$6.93 \mathrm{E}+02$

$6.94 \mathrm{E}+02$

$6.94 \mathrm{E}+02$

$6.95 \mathrm{E}+02$

$6.95 \mathrm{E}+02$

$6.96 \mathrm{E}+02$

$6.96 \mathrm{E}+02$

$6.97 \mathrm{E}+02$

$6.97 \mathrm{E}+02$

$6.98 \mathrm{E}+02$

$6.98 \mathrm{E}+02$

$6.99 \mathrm{E}+02$

$6.99 \mathrm{E}+02$

$7.00 \mathrm{E}+02$

$7.00 \mathrm{E}+02$

$7.01 \mathrm{E}+02$

$7.01 \mathrm{E}+02$

$7.02 \mathrm{E}+02$

$7.02 \mathrm{E}+02$

$7.03 \mathrm{E}+02$

$7.03 \mathrm{E}+02$

7. $04 \mathrm{E}+02$

7. $04 \mathrm{E}+02$

$7.05 \mathrm{E}+02$

7. $05 \mathrm{E}+02$

$7.06 \mathrm{E}+02$

$7.06 \mathrm{E}+02$

$7.07 \mathrm{E}+02$
Dose statistics at graphical times, mrem/yr

\begin{tabular}{|c|c|c|c|c|c|c|c|}
\hline $\mathrm{m}$ & aximum & lea & ed & & & & \\
\hline $.76 \mathrm{E}-08$ & $6.50 \mathrm{E}-06$ & $7.82 \mathrm{E}-07$ & $4.67 \mathrm{E}-07$ & $1.91 \mathrm{E}-06$ & $2.00 \mathrm{H}$ & 06 & $4.5 J E-06$ \\
\hline $.77 E-08$ & $6.50 E-06$ & $7.83 E-07$ & $4.69 \mathrm{E}-07$ & $1.92 \mathrm{E}-06$ & $1 E-06$ & $E-06$ & $5 E-06$ \\
\hline $.78 \mathrm{E}-08$ & $.50 \mathrm{E}-06$ & $.85 E-07$ & $4.70 \mathrm{E}-07$ & 1. $92 \mathrm{E}-06$ & $2.61 \mathrm{E}-06$ & $3.59 \mathrm{E}-06$ & $.35 E-06$ \\
\hline $.79 E-08$ & $50 E-06$ & $86 \mathrm{~F}-07$ & $72 \mathrm{~F}-07$ & $93 E-06$ & $61 \mathrm{~F}-06$ & -06 & $.36 E-06$ \\
\hline $80 \mathrm{E}-08$ & -06 & 西 & -07 & 6 & 6 & -06 & -06 \\
\hline 08 & & & & & & & \\
\hline $82 E-08$ & $6.50 \mathrm{E}-06$ & & & & & & -06 \\
\hline $.83 E-08$ & -06 & 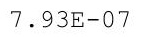 & 7 & 6 & 6 & 6 & $E-06$ \\
\hline $84 \mathrm{E}-08$ & $6.50 \mathrm{E}-06$ & - -5 & $4.77 E-07$ & $1.94 \mathrm{E}-06$ & $53 E-06$ & -06 & $E-06$ \\
\hline $85 E-08$ & -06 & 问 & 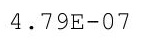 & $94 E-06$ & & $2 E-06$ & $38 E-06$ \\
\hline 08 & 06 & & & & & & -06 \\
\hline $87 E-08$ & $6.50 E-06$ & 7 & 4 & 6 & & 6 & -06 \\
\hline $.88 \mathrm{E}-08$ & $6.50 \mathrm{E}-06$ & $8.01 E-07$ & $4.83 E-07$ & $1.95 \mathrm{E}-06$ & & $3.63 E-06$ & $E-06$ \\
\hline $89 E-08$ & $6.50 \mathrm{E}-06$ & 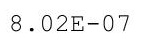 & $4.84 \mathrm{E}-07$ & $1.95 \mathrm{E}-06$ & & -06 & $E-06$ \\
\hline-08 & -06 & & 1 & & & -06 & $\Xi-06$ \\
\hline$E-08$ & -06 & & $4.87 \mathrm{E}-07$ & ل & 6 & 6 & 06 \\
\hline 8 & 0 & & & & & & \\
\hline $93 E-08$ & 6 & $8.08 E-07$ & 4. $90 \mathrm{E}-07$ & 6 & & 6 & 06 \\
\hline $94 \mathrm{E}-08$ & $6.50 \mathrm{E}-06$ & $.10 \mathrm{E}-07$ & $4.91 \mathrm{E}-07$ & $1.96 \mathrm{E}-06$ & $2.66 \mathrm{E}-06$ & $3.64 \mathrm{E}-06$ & $.41 E-06$ \\
\hline $95 E-08$ & $.50 \mathrm{E}-06$ & $.12 \mathrm{E}-07$ & $4.93 E-07$ & $1.96 \mathrm{E}-06$ & $2.66 \mathrm{E}-06$ & -06 & 4. $41 E-06$ \\
\hline 08 & & & & & & 0 & -06 \\
\hline 08 & & & & 6 & & & \\
\hline 8 & & & & & & & 06 \\
\hline $.00 \mathrm{E}-08$ & 06 & $8.18 \mathrm{E}-07$ & $4.99 \mathrm{E}-07$ & 6 & & 0 & -06 \\
\hline$E-08$ & $E-06$ & חת & 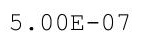 & דיم 1 & $67 \mathrm{E}-$ & 6 & 06 \\
\hline $02 \mathrm{~F}-08$ & $F-06$ & $21 \Gamma^{2}$ & קח & $1.98 \mathrm{E}-06$ & $.68 E-06$ & $65 E-06$ & $.43 E-06$ \\
\hline$E-08$ & $E-06$ & 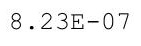 & ( & $99 E-06$ & & $E-06$ & $43 E-06$ \\
\hline & & & & & & & \\
\hline-08 & 6 & 0.2 & 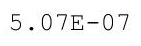 & 06 & 6 & -06 & -06 \\
\hline $06 E-08$ & $6.50 E-06$ & 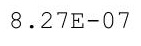 & . & $2.00 E-06$ & $2.69 \mathrm{E}-06$ & $3.03 E-00$ & $.43 E-06$ \\
\hline $07 E-08$ & $50 E-06$ & 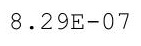 & 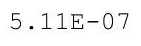 & $2.00 \mathrm{E}-06$ & $2.69 \mathrm{E}-06$ & $3.65 E-06$ & $.43 E-06$ \\
\hline - & & & & & & 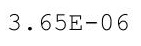 & $43 E-06$ \\
\hline-08 & & & & 1. & & & 06 \\
\hline 8 & & & & & & & \\
\hline 8 & 6.500 & $8.35 \mathrm{~F}$ & 07 & $2.0 \angle \mathrm{F}$ & 2.11 & -06 & \\
\hline $13 E-08$ & $6.50 E-06$ & 0.01 & 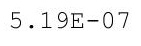 & $2.03 E-06$ & 2.11 & -06 & $.45 E-06$ \\
\hline $14 \mathrm{E}-08$ & & & & & & & $4.4 J \pm-00$ \\
\hline $15 E-08$ & -06 & & 它 & 6 & 6 & & $46 E-06$ \\
\hline $.17 \mathrm{E}-08$ & 6 & $8.42 E-07$ & 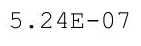 & 6 & 6 & 6 & 06 \\
\hline $8 E-08$ & 6 & & 07 & & & & \\
\hline$E-08$ & $6.49 \mathrm{E}-06$ & $8.45 \mathrm{E}$ & 07 & & 6 & & -06 \\
\hline & 6 & 0. & & & & & -06 \\
\hline & & & & & & & $4.4 / \mathrm{E}-\mathrm{U} 6$ \\
\hline $.2 \angle E-08$ & $6.49 \mathrm{E}-06$ & 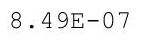 & 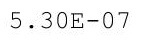 & $2.05 E-06$ & $2.74 E-06$ & $3.08 E-06$ & $4.48 \mathrm{E}-06$ \\
\hline$\cdot 245-00$ & $0.495-00$ & . & & $2 \cdot 00$ & & & $4.48 E-06$ \\
\hline $5 E-08$ & $.49 \mathrm{E}-06$ & $.53 E-07$ & $.33 E-07$ & $.06 \mathrm{E}-06$ & $2.74 \mathrm{E}-06$ & $E-06$ & $4.48 E-06$ \\
\hline
\end{tabular}


RESRAD-OFFSITE, Version 2.5

itle : Offsite Resident Farmer Deterministic Run

File : RF TC99 DOESG FWD-FV2b.ROF

Summary of dose at graphical times, reptition 3 (continued)

Time

Years

$7.08 \mathrm{E}+02$

$7.08 \mathrm{E}+02$

$7.09 \mathrm{E}+02$

$7.09 \mathrm{E}+02$

$7.10 \mathrm{E}+02$

7. $10 \mathrm{E}+02$

7. $11 \mathrm{E}+02$

7. $11 \mathrm{E}+02$

$7.12 \mathrm{E}+02$

$7.12 \mathrm{E}+02$

7. $13 \mathrm{E}+02$

7. $13 \mathrm{E}+02$

$7.14 \mathrm{E}+02$

$7.14 \mathrm{E}+02$

$7.15 \mathrm{E}+02$

$7.15 \mathrm{E}+02$

$7.16 \mathrm{E}+02$

7. $16 \mathrm{E}+02$

$7.17 \mathrm{E}+02$

7. $17 \mathrm{E}+02$

7. $18 \mathrm{E}+02$

$7.18 \mathrm{E}+02$

7. $19 \mathrm{E}+02$

$7.19 \mathrm{E}+02$

$7.20 \mathrm{E}+02$

$7.20 \mathrm{E}+02$

$7.21 \mathrm{E}+02$

$7.21 \mathrm{E}+02$

$7.22 \mathrm{E}+02$

7. $22 \mathrm{E}+02$

7. $23 \mathrm{E}+02$

7. $23 \mathrm{E}+02$

$7.24 \mathrm{E}+02$

$7.24 \mathrm{E}+02$

$7.25 \mathrm{E}+02$

7. $25 \mathrm{E}+02$

7. $26 \mathrm{E}+02$

$7.26 \mathrm{E}+02$

$7.27 \mathrm{E}+02$

$7.28 \mathrm{E}+02$

$7.28 \mathrm{E}+02$

$7.29 \mathrm{E}+02$

$7.29 \mathrm{E}+02$

$7.30 \mathrm{E}+02$

7. $30 \mathrm{E}+02$

7. $31 \mathrm{E}+02$
Dose statistics at graphical times, mrem/yr

\begin{tabular}{|c|c|c|c|c|c|c|c|}
\hline Minimum & Maximum & Mean & Median & $90 \%$ & $95 \%$ & $97.5 \%$ & $99 \%$ \\
\hline $2.26 \mathrm{E}-08$ & $6.49 \mathrm{E}-06$ & $8.54 \mathrm{E}-07$ & $5.34 \mathrm{E}-07$ & $2.06 \mathrm{E}-06$ & $2.75 E-06$ & $3.69 E-06$ & $4.48 E-06$ \\
\hline $2.27 E-08$ & $6.49 \mathrm{E}-06$ & $8.56 \mathrm{E}-07$ & $5.36 \mathrm{E}-07$ & $2.06 E-06$ & $2.75 E-06$ & $3.69 \mathrm{E}-06$ & $4.48 E-06$ \\
\hline $2.28 \mathrm{E}-08$ & $6.49 \mathrm{E}-06$ & $8.57 \mathrm{E}-07$ & $5.37 \mathrm{E}-07$ & $2.07 E-06$ & $2.75 \mathrm{E}-06$ & $3.70 \mathrm{E}-06$ & $4.48 \mathrm{E}-06$ \\
\hline $2.29 \mathrm{E}-08$ & $6.49 \mathrm{E}-06$ & $8.59 \mathrm{E}-07$ & $5.38 \mathrm{E}-07$ & $2.07 \mathrm{E}-06$ & $2.76 \mathrm{E}-06$ & $3.70 \mathrm{E}-06$ & $4.48 \mathrm{E}-06$ \\
\hline $2.31 \mathrm{E}-08$ & $6.49 \mathrm{E}-06$ & $8.60 \mathrm{E}-07$ & $5.40 \mathrm{E}-07$ & $2.07 \mathrm{E}-06$ & $2.76 \mathrm{E}-06$ & $3.70 \mathrm{E}-06$ & $4.48 \mathrm{E}-06$ \\
\hline $2.32 E-08$ & $6.49 E-06$ & $8.62 \mathrm{E}-07$ & $5.41 E-07$ & $2.08 E-06$ & $2.77 E-06$ & $3.71 \mathrm{E}-06$ & $4.48 E-06$ \\
\hline $2.33 E-08$ & $6.48 E-06$ & $8.63 E-07$ & $5.43 E-07$ & $2.08 E-06$ & $2.77 E-06$ & $3.71 \mathrm{E}-06$ & $4.48 E-06$ \\
\hline $2.34 \mathrm{E}-08$ & $6.48 \mathrm{E}-06$ & $8.65 E-07$ & $5.44 \mathrm{E}-07$ & $2.08 \mathrm{E}-06$ & $2.77 \mathrm{E}-06$ & $3.72 \mathrm{E}-06$ & $4.48 \mathrm{E}-06$ \\
\hline $2.35 E-08$ & $6.48 E-06$ & $8.67 \mathrm{E}-07$ & $5.46 E-07$ & $2.09 E-06$ & $2.77 E-06$ & $3.72 \mathrm{E}-06$ & 4. $49 \mathrm{E}-06$ \\
\hline $2.37 E-08$ & $6.48 \mathrm{E}-06$ & $8.68 \mathrm{E}-07$ & $5.48 E-07$ & $2.09 E-06$ & $2.78 E-06$ & $3.72 E-06$ & $4.49 \mathrm{E}-06$ \\
\hline $2.38 E-08$ & $6.48 E-06$ & $8.70 \mathrm{E}-07$ & $5.49 \mathrm{E}-07$ & $2.09 E-06$ & $2.78 \mathrm{E}-06$ & $3.73 E-06$ & $4.49 E-06$ \\
\hline $2.39 E-08$ & $6.48 E-06$ & $8.71 \mathrm{E}-07$ & $5.51 \mathrm{E}-07$ & $2.10 \mathrm{E}-06$ & $2.78 \mathrm{E}-06$ & $3.73 E-06$ & $4.49 E-06$ \\
\hline $2.40 E-08$ & $6.48 E-06$ & $8.73 E-07$ & $5.52 \mathrm{E}-07$ & $2.10 \mathrm{E}-06$ & $2.79 E-06$ & $3.73 E-06$ & $4.49 E-06$ \\
\hline $2.42 \mathrm{E}-08$ & $6.48 \mathrm{E}-06$ & $8.74 \mathrm{E}-07$ & $5.54 \mathrm{E}-07$ & $2.10 \mathrm{E}-06$ & $2.79 \mathrm{E}-06$ & $3.74 \mathrm{E}-06$ & $4.50 \mathrm{E}-06$ \\
\hline $2.43 E-08$ & $6.48 E-06$ & $8.76 \mathrm{E}-07$ & $5.55 E-07$ & $2.11 \mathrm{E}-06$ & $2.79 E-06$ & $3.74 \mathrm{E}-06$ & $4.50 \mathrm{E}-06$ \\
\hline $2.44 E-08$ & $6.47 \mathrm{E}-06$ & $8.78 E-07$ & $5.57 \mathrm{E}-07$ & $2.11 E-06$ & $2.80 E-06$ & $3.74 \mathrm{E}-06$ & $4.50 E-06$ \\
\hline $2.45 E-08$ & $6.47 \mathrm{E}-06$ & $8.79 \mathrm{E}-07$ & $5.58 \mathrm{E}-07$ & $2.11 \mathrm{E}-06$ & $2.80 \mathrm{E}-06$ & $3.75 \mathrm{E}-06$ & $4.50 \mathrm{E}-06$ \\
\hline $2.47 \mathrm{E}-08$ & $6.47 \mathrm{E}-06$ & $8.81 E-07$ & $5.59 \mathrm{E}-07$ & $2.12 \mathrm{E}-06$ & $2.80 \mathrm{E}-06$ & $3.75 \mathrm{E}-06$ & $4.50 \mathrm{E}-06$ \\
\hline $2.48 E-08$ & $6.47 \mathrm{E}-06$ & $8.82 \mathrm{E}-07$ & $5.61 E-07$ & $2.12 \mathrm{E}-06$ & $2.81 E-06$ & $3.75 \mathrm{E}-06$ & $4.50 \mathrm{E}-06$ \\
\hline $2.49 \mathrm{E}-08$ & $6.47 \mathrm{E}-06$ & $8.84 \mathrm{E}-07$ & $5.62 E-07$ & $2.12 \mathrm{E}-06$ & $2.81 \mathrm{E}-06$ & $3.75 \mathrm{E}-06$ & $4.51 \mathrm{E}-06$ \\
\hline $2.50 \mathrm{E}-08$ & $6.47 \mathrm{E}-06$ & $8.85 E-07$ & $5.64 \mathrm{E}-07$ & $2.12 \mathrm{E}-06$ & $2.81 \mathrm{E}-06$ & $3.76 \mathrm{E}-06$ & $4.51 \mathrm{E}-06$ \\
\hline $2.52 E-08$ & $6.47 \mathrm{E}-06$ & $8.87 \mathrm{E}-07$ & $5.65 E-07$ & $2.12 E-06$ & $2.81 E-06$ & $3.76 E-06$ & $4.51 E-06$ \\
\hline $2.53 E-08$ & $6.47 \mathrm{E}-06$ & $8.89 \mathrm{E}-07$ & $5.67 \mathrm{E}-07$ & $2.13 E-06$ & $2.82 E-06$ & $3.76 \mathrm{E}-06$ & $4.51 E-06$ \\
\hline $2.54 \mathrm{E}-08$ & $6.46 \mathrm{E}-06$ & $8.90 \mathrm{E}-07$ & $5.68 \mathrm{E}-07$ & $2.13 E-06$ & $2.82 \mathrm{E}-06$ & $3.76 \mathrm{E}-06$ & $4.51 \mathrm{E}-06$ \\
\hline $2.55 E-08$ & $6.46 \mathrm{E}-06$ & $8.92 \mathrm{E}-07$ & $5.70 \mathrm{E}-07$ & $2.13 E-06$ & $2.82 E-06$ & $3.76 \mathrm{E}-06$ & $4.51 E-06$ \\
\hline $2.57 \mathrm{E}-08$ & $6.46 \mathrm{E}-06$ & $8.93 E-07$ & $5.71 E-07$ & $2.13 E-06$ & $2.83 E-06$ & $3.76 \mathrm{E}-06$ & $4.51 \mathrm{E}-06$ \\
\hline $2.58 \mathrm{E}-08$ & $6.46 \mathrm{E}-06$ & $8.95 E-07$ & $5.73 E-07$ & $2.13 E-06$ & $2.83 E-06$ & $3.77 \mathrm{E}-06$ & $4.51 \mathrm{E}-06$ \\
\hline $2.59 \mathrm{E}-08$ & $6.46 \mathrm{E}-06$ & $8.96 \mathrm{E}-07$ & $5.75 \mathrm{E}-07$ & $2.14 \mathrm{E}-06$ & $2.83 E-06$ & $3.77 E-06$ & $4.50 E-06$ \\
\hline $2.61 \mathrm{E}-08$ & $6.46 \mathrm{E}-06$ & $8.98 E-07$ & $5.76 \mathrm{E}-07$ & $2.14 \mathrm{E}-06$ & $2.84 \mathrm{E}-06$ & $3.77 \mathrm{E}-06$ & $4.50 \mathrm{E}-06$ \\
\hline $2.62 E-08$ & $6.46 \mathrm{E}-06$ & $8.99 E-07$ & $5.77 \mathrm{E}-07$ & $2.14 \mathrm{E}-06$ & $2.84 \mathrm{E}-06$ & $3.78 E-06$ & $4.50 E-06$ \\
\hline $2.63 E-08$ & $6.45 \mathrm{E}-06$ & $9.01 \mathrm{E}-07$ & $5.78 \mathrm{E}-07$ & $2.15 E-06$ & $2.84 \mathrm{E}-06$ & $3.78 \mathrm{E}-06$ & $4.50 \mathrm{E}-06$ \\
\hline $65 E-08$ & $.45 E-06$ & $9.03 E-07$ & $5.80 E-07$ & $2.15 E-06$ & $2.85 \mathrm{E}-06$ & $3.78 \mathrm{E}-06$ & $4.50 \mathrm{E}-06$ \\
\hline $2.66 \mathrm{E}-08$ & $6.45 E-06$ & $9.04 \mathrm{E}-07$ & $5.81 E-07$ & $2.15 E-06$ & $2.85 E-06$ & $3.78 E-06$ & $4.49 E-06$ \\
\hline $2.67 E-08$ & $6.45 \mathrm{E}-06$ & $9.06 \mathrm{E}-07$ & $5.83 E-07$ & $2.15 E-06$ & $2.85 E-06$ & $3.79 \mathrm{E}-06$ & $4.49 E-06$ \\
\hline $2.69 E-08$ & $6.45 \mathrm{E}-06$ & $9.07 \mathrm{E}-07$ & $5.84 \mathrm{E}-07$ & $2.16 \mathrm{E}-06$ & $2.85 E-06$ & $3.79 \mathrm{E}-06$ & $4.49 E-06$ \\
\hline $2.70 E-08$ & $6.45 E-06$ & $9.09 E-07$ & $5.86 E-07$ & $2.16 E-06$ & $2.86 \mathrm{E}-06$ & $3.79 \mathrm{E}-06$ & $4.49 E-06$ \\
\hline $2.71 E-08$ & $6.45 \mathrm{E}-06$ & $9.10 \mathrm{E}-07$ & $5.87 \mathrm{E}-07$ & $2.16 \mathrm{E}-06$ & $2.86 \mathrm{E}-06$ & $3.79 \mathrm{E}-06$ & $4.49 E-06$ \\
\hline $2.73 E-08$ & $6.44 \mathrm{E}-06$ & $9.12 \mathrm{E}-07$ & $5.89 \mathrm{E}-07$ & $2.16 \mathrm{E}-06$ & $2.86 \mathrm{E}-06$ & $3.79 \mathrm{E}-06$ & $4.49 \mathrm{E}-06$ \\
\hline 08 & 6 & $9.13 \mathrm{E}$ & $5.91 \mathrm{E}$ & $2.17 E-06$ & $2.87 E-06$ & $3.79 E-06$ & $4.49 E-06$ \\
\hline $2.75 \mathrm{E}-08$ & $6.44 \mathrm{E}-06$ & $9.15 \mathrm{E}-07$ & $5.92 \mathrm{E}-07$ & $2.17 \mathrm{E}-06$ & $2.87 \mathrm{E}-06$ & $3.80 \mathrm{E}-06$ & $4.50 \mathrm{E}-06$ \\
\hline $2.77 \mathrm{E}-08$ & $6.44 \mathrm{E}-06$ & $9.17 \mathrm{E}-07$ & $5.94 \mathrm{E}-07$ & $2.17 \mathrm{E}-06$ & $2.87 \mathrm{E}-06$ & $3.80 \mathrm{E}-06$ & $4.50 \mathrm{E}-06$ \\
\hline $2.78 \mathrm{E}-08$ & $6.44 \mathrm{E}-06$ & $9.18 \mathrm{E}-07$ & $5.95 E-07$ & $2.17 \mathrm{E}-06$ & $2.88 E-06$ & $3.80 \mathrm{E}-06$ & $4.50 \mathrm{E}-06$ \\
\hline $2.79 \mathrm{E}-08$ & $6.44 \mathrm{E}-06$ & $9.20 \mathrm{E}-07$ & $5.96 \mathrm{E}-07$ & $2.18 \mathrm{E}-06$ & $2.88 \mathrm{E}-06$ & $3.80 \mathrm{E}-06$ & $4.50 \mathrm{E}-06$ \\
\hline $2.81 \mathrm{E}-08$ & $6.43 E-06$ & $9.21 \mathrm{E}-07$ & $5.98 E-07$ & $2.18 E-06$ & $2.88 E-06$ & $3.80 \mathrm{E}-06$ & $4.51 \mathrm{E}-06$ \\
\hline $2.82 E-08$ & $6.43 E-06$ & $9.23 E-07$ & $5.99 E-07$ & $2.18 E-06$ & $2.88 E-06$ & $3.80 E-06$ & $4.51 E-06$ \\
\hline $2.83 E-08$ & $6.43 E-06$ & $9.24 \mathrm{E}-07$ & $6.01 \mathrm{E}-07$ & $2.19 \mathrm{E}-06$ & $2.89 \mathrm{E}-06$ & $3.80 E-06$ & $4.51 \mathrm{E}-06$ \\
\hline
\end{tabular}


RESRAD-OFFSITE, Version 2.5

itle : Offsite Resident Farmer Deterministic Run

File : RF TC99 DOESG FWD-FV2b.ROF

Summary of dose at graphical times, reptition 3 (continued)

Time

Years

7. $31 \mathrm{E}+02$

7. $32 \mathrm{E}+02$

7. $32 \mathrm{E}+02$

7. $33 \mathrm{E}+02$

7. $33 \mathrm{E}+02$

7. $34 \mathrm{E}+02$

7. $34 \mathrm{E}+02$

7. $35 \mathrm{E}+02$

7. $35 \mathrm{E}+02$

7. $36 \mathrm{E}+02$

7. $36 \mathrm{E}+02$

7. $37 \mathrm{E}+02$

7. $37 \mathrm{E}+02$

7. $38 \mathrm{E}+02$

7. $38 \mathrm{E}+02$

7. $39 \mathrm{E}+02$

7. $39 \mathrm{E}+02$

7. $40 \mathrm{E}+02$

$7.40 \mathrm{E}+02$

7. $41 \mathrm{E}+02$

$7.41 \mathrm{E}+02$

7. $42 \mathrm{E}+02$

$7.42 \mathrm{E}+02$

$7.43 \mathrm{E}+02$

$7.43 \mathrm{E}+02$

7. $44 \mathrm{E}+02$

$7.44 \mathrm{E}+02$

$7.45 \mathrm{E}+02$

7. $45 \mathrm{E}+02$

$7.46 \mathrm{E}+02$

7. $46 \mathrm{E}+02$

$7.47 \mathrm{E}+02$

7. $48 \mathrm{E}+02$

7. $48 \mathrm{E}+02$

$7.49 \mathrm{E}+02$

7. $49 \mathrm{E}+02$

$7.50 \mathrm{E}+02$

$7.50 \mathrm{E}+02$

$7.51 \mathrm{E}+02$

$7.51 \mathrm{E}+02$

$7.52 \mathrm{E}+02$

$7.52 \mathrm{E}+02$

7. $53 \mathrm{E}+02$

$7.53 \mathrm{E}+02$

$7.54 \mathrm{E}+02$

$7.54 \mathrm{E}+02$
Dose statistics at graphical times, mrem/yr

\begin{tabular}{|c|c|c|c|c|c|c|c|}
\hline m & aximum & lea & - & & & & \\
\hline $.85 E-08$ & $6.43 E-06$ & $9.26 \mathrm{E}-07$ & $6.03 E-07$ & $2.19 \mathrm{E}-06$ & $89 E-06$ & 06 & $4.3<E-00$ \\
\hline $86 E-08$ & $6.43 E-06$ & $9.27 \mathrm{E}-07$ & $6.04 \mathrm{E}-07$ & $2.19 \mathrm{E}-06$ & $89 E-06$ & $3.80 \mathrm{E}-06$ & $52 E-06$ \\
\hline $88 \mathrm{E}-08$ & $.42 \mathrm{E}-06$ & $9.29 \mathrm{E}-07$ & $6.06 \mathrm{E}-07$ & $2.19 \mathrm{E}-06$ & $2.90 \mathrm{E}-06$ & $3.81 E-06$ & $.52 E-06$ \\
\hline-08 & -06 & $31 \mathrm{~F}-07$ & $.08 \mathrm{E}-07$ & $.20 E-06$ & $90 F-06$ & -06 & $52 E-06$ \\
\hline-08 & 06 & 7 & 7 & 6 & 6 & 6 & -06 \\
\hline 08 & 06 & & & & & & \\
\hline $.93 E-08$ & 06 & & & & & & -06 \\
\hline $.95 E-08$ & -06 & 7 & 7 & 6 & 6 & -06 & -06 \\
\hline $96 \mathrm{E}-08$ & $6.41 \mathrm{E}-06$ & $8 E-07$ & $\Xi-07$ & -06 & $91 E-06$ & -06 & $E-06$ \\
\hline$E-08$ & $41 E-06$ & תחת תמו & 10 & $.21 E-06$ & $.92 E-06$ & م & $E-06$ \\
\hline$E-08$ & 6.41 & & & & & 6 & 06 \\
\hline $.00 \mathrm{E}-08$ & $6.41 E-06$ & 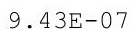 & $6.22 \mathrm{E}-07$ & 6 & & 6 & -06 \\
\hline $.02 \mathrm{E}-08$ & $6.41 E-06$ & $9.44 \mathrm{E}-07$ & $6.23 E-07$ & $2.22 E-06$ & & $3.82 E-06$ & $E-06$ \\
\hline-08 & $6.40 \mathrm{E}-06$ & $9.46 \mathrm{E}-07$ & $6.25 \mathrm{E}-07$ & $2.22 E-06$ & & -06 & $E-06$ \\
\hline-08 & -06 & & & 06 & & -06 & $\Xi-06$ \\
\hline 8 & 401 & 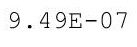 & 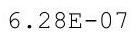 & 6 & & -06 & 06 \\
\hline 8 & 6 & & & & & & \\
\hline 8 & 6 & 9 & $6 \quad 315-07$ & 6 & & 6 & 06 \\
\hline $10 \mathrm{E}-08$ & $6.39 E-06$ & $9.54 \mathrm{E}-07$ & $6.33 E-07$ & $2.23 E-06$ & $2.94 E-06$ & $3.82 \mathrm{E}-06$ & $.55 E-06$ \\
\hline$E-08$ & $.39 E-06$ & $9.55 \mathrm{E}-07$ & $6.34 \mathrm{E}-07$ & $2.24 E-06$ & $2.95 E-06$ & $E-06$ & $.55 E-06$ \\
\hline 08 & 06 & & & & & 6 & -06 \\
\hline 08 & & & & 6 & 06 & -06 & -06 \\
\hline & & 9 & & & & 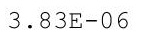 & -06 \\
\hline 08 & 06 & 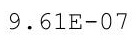 & 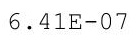 & 6 & 6 & 0 & -06 \\
\hline 8 & 6 & 7 & 7 & 6 & 6 & 6 & 06 \\
\hline-08 & $38 E-06$ & $6 \cap 5$ & 6 & $25 E-06$ & $2.96 \mathrm{E}-06$ & $.83 E-06$ & $6 F-06$ \\
\hline-08 & $37 E-06$ & & T & $25 E-06$ & & $E-06$ & $56 E-06$ \\
\hline & & & & & & & \\
\hline & & & & & 06 & -06 & -06 \\
\hline $27 E-08$ & $6.37 E-06$ & $9 . t \perp E-U$ & $6.49 \mathrm{E}-07$ & $2.26 \mathrm{E}-06$ & $2.97 E-06$ & $.045-00$ & $.57 E-06$ \\
\hline 08 & $6.37 E-06$ & $9.12 \mathrm{~L}-\mathrm{t}$ & $0.3+5-4$ & $2.26 \mathrm{E}-06$ & $2.97 \mathrm{E}-06$ & $.04 \mathrm{~L}-\mathrm{U}$ & $.57 E-06$ \\
\hline 8 & 6 & & & & & 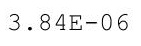 & $.57 E-06$ \\
\hline-08 & $36 \mathrm{~F}-06$ & $75=$ & ת & & $98 E-06$ & & $7 F-06$ \\
\hline 8 & 6 & & & & & 6 & \\
\hline 8 & 6.361 & 9.78 & 7 & 2.21 & 06 & -06 & \\
\hline $36 E-08$ & $6.35 E-06$ & $9.80 E-07$ & $6.58 E-07$ & $2.27 E-06$ & 2.99 & -06 & $57 E-06$ \\
\hline $.375-08$ & $0.35 E-06$ & & & & & $3.00 \mathrm{H}$ & $4.5 / E-06$ \\
\hline 8 & 6 & 年 & 年 & & & & $.57 E-06$ \\
\hline $.40 \mathrm{E}-08$ & $6.35 E-06$ & 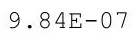 & 7 & 6 & 6 & 6 & 06 \\
\hline $.42 \mathrm{E}-08$ & 6 & & & & & & 06 \\
\hline$E-08$ & $6.35 E-06$ & $9.8 / \mathrm{E}-$ & 7 & 2 . & 6 & 06 & -06 \\
\hline & 6 & 3 & & & & & 06 \\
\hline & & & & & & & $4.58 E-06$ \\
\hline $48 \pm-08$ & $0.35 E-06$ & $9.9<E-01$ & $6.68 \mathrm{E}-07$ & $2.29 \mathrm{E}-06$ & $3.01 E-06$ & $3.85 E-06$ & $4.58 \mathrm{E}-06$ \\
\hline$E-08$ & 0.30 & $9.935-0$ & ( & 2.201 & 3.01 & & 1.000 \\
\hline$E-08$ & $.36 \mathrm{E}-06$ & $E-07$ & $.72 \mathrm{E}-07$ & $.29 E-06$ & $.01 E-06$ & $5 E-06$ & $E-06$ \\
\hline
\end{tabular}


RESRAD-OFFSITE, Version 2.5

Title : Offsite Resident Farmer Deterministic Run

File : RF TC99 DOESG FWD-FV2b.ROF

Summary of dose at graphical times, reptition 3 (continued)

Time

Years

$7.55 \mathrm{E}+02$

$7.55 \mathrm{E}+02$

$7.56 \mathrm{E}+02$

$7.56 \mathrm{E}+02$

$7.57 \mathrm{E}+02$

7. $57 \mathrm{E}+02$

$7.58 \mathrm{E}+02$

$7.58 \mathrm{E}+02$

$7.59 \mathrm{E}+02$

$7.59 \mathrm{E}+02$

$7.60 \mathrm{E}+02$

$7.60 \mathrm{E}+02$

7. $61 \mathrm{E}+02$

$7.61 \mathrm{E}+02$

$7.62 \mathrm{E}+02$

7. $62 \mathrm{E}+02$

$7.63 \mathrm{E}+02$

7. $63 \mathrm{E}+02$

$7.64 \mathrm{E}+02$

7. $64 \mathrm{E}+02$

$7.65 \mathrm{E}+02$

$7.65 \mathrm{E}+02$

7. $66 \mathrm{E}+02$

$7.66 \mathrm{E}+02$

$7.67 \mathrm{E}+02$

$7.68 \mathrm{E}+02$

$7.68 \mathrm{E}+02$

7. $69 \mathrm{E}+02$

7. $69 \mathrm{E}+02$

$7.70 \mathrm{E}+02$

$7.70 \mathrm{E}+02$

$7.71 \mathrm{E}+02$

$7.71 \mathrm{E}+02$

$7.72 \mathrm{E}+02$

$7.72 \mathrm{E}+02$

$7.73 \mathrm{E}+02$

$7.73 \mathrm{E}+02$

$7.74 \mathrm{E}+02$

$7.74 \mathrm{E}+02$

$7.75 \mathrm{E}+02$

$7.75 \mathrm{E}+02$

$7.76 \mathrm{E}+02$

$7.76 \mathrm{E}+02$

$7.77 \mathrm{E}+02$

$7.77 \mathrm{E}+02$

$7.78 \mathrm{E}+02$
Dose statistics at graphical times, mrem/yr

\begin{tabular}{|c|c|c|c|c|c|c|c|}
\hline Minimum & Maximum & Mean & Median & $90 \%$ & $95 \%$ & $97.5 \%$ & $99 \%$ \\
\hline $3.53 E-08$ & $6.36 \mathrm{E}-06$ & $9.97 \mathrm{E}-07$ & $6.73 E-07$ & $2.30 E-06$ & $3.01 E-06$ & $3.86 \mathrm{E}-06$ & $4.58 E-06$ \\
\hline $3.55 E-08$ & $6.36 \mathrm{E}-06$ & $9.98 \mathrm{E}-07$ & $6.75 E-07$ & $2.30 E-06$ & $3.02 E-06$ & $3.86 \mathrm{E}-06$ & $4.58 E-06$ \\
\hline $3.56 \mathrm{E}-08$ & $6.37 \mathrm{E}-06$ & $1.00 \mathrm{E}-06$ & $6.76 \mathrm{E}-07$ & $2.30 \mathrm{E}-06$ & $3.02 \mathrm{E}-06$ & $3.86 \mathrm{E}-06$ & $4.58 \mathrm{E}-06$ \\
\hline $3.58 \mathrm{E}-08$ & $6.37 \mathrm{E}-06$ & $1.00 \mathrm{E}-06$ & $6.77 \mathrm{E}-07$ & $2.31 \mathrm{E}-06$ & $3.02 \mathrm{E}-06$ & $3.86 \mathrm{E}-06$ & $4.58 \mathrm{E}-06$ \\
\hline $3.59 \mathrm{E}-08$ & $6.37 \mathrm{E}-06$ & $1.00 \mathrm{E}-06$ & $6.79 \mathrm{E}-07$ & $2.31 \mathrm{E}-06$ & $3.03 E-06$ & $3.86 \mathrm{E}-06$ & $4.58 \mathrm{E}-06$ \\
\hline $3.61 \mathrm{E}-08$ & $6.37 \mathrm{E}-06$ & $1.00 \mathrm{E}-06$ & $6.80 \mathrm{E}-07$ & $2.31 E-06$ & $3.03 E-06$ & $3.86 \mathrm{E}-06$ & $4.58 \mathrm{E}-06$ \\
\hline $3.63 E-08$ & $6.38 E-06$ & $1.01 \mathrm{E}-06$ & $6.82 \mathrm{E}-07$ & $2.31 E-06$ & $3.03 E-06$ & $3.86 \mathrm{E}-06$ & $4.58 E-06$ \\
\hline $3.64 \mathrm{E}-08$ & $6.38 \mathrm{E}-06$ & $1.01 \mathrm{E}-06$ & $6.84 \mathrm{E}-07$ & $2.31 \mathrm{E}-06$ & $3.04 \mathrm{E}-06$ & $3.86 \mathrm{E}-06$ & $4.57 \mathrm{E}-06$ \\
\hline $3.66 \mathrm{E}-08$ & $6.38 E-06$ & $1.01 \mathrm{E}-06$ & $6.85 E-07$ & $2.31 \mathrm{E}-06$ & $3.04 \mathrm{E}-06$ & $3.86 \mathrm{E}-06$ & $4.57 E-06$ \\
\hline $3.67 \mathrm{E}-08$ & $6.38 \mathrm{E}-06$ & $1.01 \mathrm{E}-06$ & $6.87 \mathrm{E}-07$ & $2.32 \mathrm{E}-06$ & $3.04 \mathrm{E}-06$ & $3.86 \mathrm{E}-06$ & $4.57 \mathrm{E}-06$ \\
\hline $3.69 \mathrm{E}-08$ & $6.39 \mathrm{E}-06$ & $1.01 \mathrm{E}-06$ & $6.88 \mathrm{E}-07$ & $2.32 \mathrm{E}-06$ & $3.04 \mathrm{E}-06$ & $3.87 \mathrm{E}-06$ & $.57 \mathrm{E}-06$ \\
\hline $3.71 \mathrm{E}-08$ & $6.39 E-06$ & $1.01 \mathrm{E}-06$ & $6.90 \mathrm{E}-07$ & $2.32 \mathrm{E}-06$ & $3.04 \mathrm{E}-06$ & $3.87 \mathrm{E}-06$ & $4.57 \mathrm{E}-06$ \\
\hline $3.72 \mathrm{E}-08$ & $6.39 \mathrm{E}-06$ & $1.01 \mathrm{E}-06$ & $6.92 \mathrm{E}-07$ & $2.33 E-06$ & $3.05 E-06$ & $3.87 \mathrm{E}-06$ & $4.57 \mathrm{E}-06$ \\
\hline $3.74 \mathrm{E}-08$ & $6.39 \mathrm{E}-06$ & $1.02 \mathrm{E}-06$ & $6.93 E-07$ & $2.33 E-06$ & $3.05 \mathrm{E}-06$ & $3.87 \mathrm{E}-06$ & $4.57 \mathrm{E}-06$ \\
\hline $3.76 \mathrm{E}-08$ & $6.39 E-06$ & $1.02 \mathrm{E}-06$ & $6.95 E-07$ & $2.33 E-06$ & $3.05 \mathrm{E}-06$ & $3.87 E-06$ & $4.56 \mathrm{E}-06$ \\
\hline $3.77 \mathrm{E}-08$ & $6.40 \mathrm{E}-06$ & $1.02 \mathrm{E}-06$ & $6.96 \mathrm{E}-07$ & $2.33 E-06$ & $3.05 E-06$ & $3.87 E-06$ & $.56 E-06$ \\
\hline $3.79 \mathrm{E}-08$ & $6.40 \mathrm{E}-06$ & $1.02 \mathrm{E}-06$ & $6.98 E-07$ & $2.33 E-06$ & $3.05 E-06$ & $3.87 \mathrm{E}-06$ & $4.56 \mathrm{E}-06$ \\
\hline $3.81 E-08$ & $6.40 \mathrm{E}-06$ & $1.02 \mathrm{E}-06$ & $7.00 \mathrm{E}-07$ & $2.33 E-06$ & $3.05 \mathrm{E}-06$ & $3.87 E-06$ & $4.56 E-06$ \\
\hline $3.82 E-08$ & $6.40 \mathrm{E}-06$ & $1.02 \mathrm{E}-06$ & $7.02 \mathrm{E}-07$ & $2.34 E-06$ & $3.06 \mathrm{E}-06$ & $3.87 E-06$ & $4.56 E-06$ \\
\hline $3.84 \mathrm{E}-08$ & $6.41 E-06$ & $1.03 E-06$ & $7.03 E-07$ & $2.34 \mathrm{E}-06$ & $3.06 \mathrm{E}-06$ & $3.87 \mathrm{E}-06$ & $4.56 \mathrm{E}-06$ \\
\hline $3.86 \mathrm{E}-08$ & $6.41 \mathrm{E}-06$ & $1.03 E-06$ & $7.05 E-07$ & $2.34 \mathrm{E}-06$ & $3.06 \mathrm{E}-06$ & $3.87 \mathrm{E}-06$ & $4.56 \mathrm{E}-06$ \\
\hline $3.87 \mathrm{E}-08$ & $6.41 \mathrm{E}-06$ & $1.03 E-06$ & $7.07 \mathrm{E}-07$ & $2.34 E-06$ & $3.06 \mathrm{E}-06$ & $3.87 E-06$ & $4.55 E-06$ \\
\hline $3.89 \mathrm{E}-08$ & $6.41 \mathrm{E}-06$ & $1.03 E-06$ & $7.09 E-07$ & $2.34 E-06$ & $3.06 \mathrm{E}-06$ & $3.87 E-06$ & $4.55 E-06$ \\
\hline $3.91 \mathrm{E}-08$ & $6.41 \mathrm{E}-06$ & $1.03 E-06$ & $7.11 \mathrm{E}-07$ & $2.34 \mathrm{E}-06$ & $3.06 \mathrm{E}-06$ & $3.88 \mathrm{E}-06$ & $4.55 E-06$ \\
\hline $3.92 E-08$ & $6.42 \mathrm{E}-06$ & $1.03 \mathrm{E}-06$ & $7.12 \mathrm{E}-07$ & $2.34 E-06$ & $3.07 E-06$ & $3.88 E-06$ & $4.55 E-06$ \\
\hline $3.94 \mathrm{E}-08$ & $6.42 \mathrm{E}-06$ & $1.03 E-06$ & $7.14 \mathrm{E}-07$ & $2.34 \mathrm{E}-06$ & $3.07 E-06$ & $3.88 \mathrm{E}-06$ & $4.55 E-06$ \\
\hline $3.96 \mathrm{E}-08$ & $6.42 \mathrm{E}-06$ & $1.04 \mathrm{E}-06$ & $7.15 \mathrm{E}-07$ & $2.34 \mathrm{E}-06$ & $3.07 \mathrm{E}-06$ & $3.88 E-06$ & $4.55 \mathrm{E}-06$ \\
\hline $3.98 E-08$ & $6.42 \mathrm{E}-06$ & $1.04 \mathrm{E}-06$ & $7.17 \mathrm{E}-07$ & $2.34 E-06$ & $3.07 \mathrm{E}-06$ & $3.88 E-06$ & $4.54 E-06$ \\
\hline $3.99 \mathrm{E}-08$ & $6.42 \mathrm{E}-06$ & $1.04 \mathrm{E}-06$ & $7.19 \mathrm{E}-07$ & $2.35 E-06$ & $3.08 \mathrm{E}-06$ & $3.88 E-06$ & $4.54 \mathrm{E}-06$ \\
\hline $4.01 E-08$ & $6.43 E-06$ & $1.04 \mathrm{E}-06$ & $7.20 E-07$ & $2.35 E-06$ & $3.08 E-06$ & $3.88 E-06$ & $4.54 \mathrm{E}-06$ \\
\hline $4.03 E-08$ & $6.43 E-06$ & $1.04 \mathrm{E}-06$ & $7.22 \mathrm{E}-07$ & $2.35 E-06$ & $3.08 E-06$ & $3.88 \mathrm{E}-06$ & $4.54 \mathrm{E}-06$ \\
\hline $4.04 \mathrm{E}-08$ & $6.43 E-06$ & $1.04 \mathrm{E}-06$ & $7.24 \mathrm{E}-07$ & $2.35 E-06$ & $3.08 \mathrm{E}-06$ & $3.88 \mathrm{E}-06$ & $4.54 \mathrm{E}-06$ \\
\hline $4.06 E-08$ & $6.43 E-06$ & $1.04 \mathrm{E}-06$ & $7.25 E-07$ & $2.35 E-06$ & $3.08 E-06$ & $3.88 E-06$ & $4.54 \mathrm{E}-06$ \\
\hline $4.08 E-08$ & $6.43 \mathrm{E}-06$ & $1.05 \mathrm{E}-06$ & $7.27 \mathrm{E}-07$ & $2.35 E-06$ & $3.08 \mathrm{E}-06$ & $3.88 \mathrm{E}-06$ & $4.54 \mathrm{E}-06$ \\
\hline $4.10 \mathrm{E}-08$ & $6.44 \mathrm{E}-06$ & $1.05 \mathrm{E}-06$ & $7.28 E-07$ & $2.36 \mathrm{E}-06$ & $3.09 E-06$ & $3.88 E-06$ & $4.53 E-06$ \\
\hline $4.11 E-08$ & $6.44 \mathrm{E}-06$ & $1.05 E-06$ & $7.30 E-07$ & $2.36 E-06$ & $3.09 E-06$ & $3.88 E-06$ & $4.53 E-06$ \\
\hline $4.13 E-08$ & $6.44 \mathrm{E}-06$ & $1.05 E-06$ & $7.31 \mathrm{E}-07$ & $2.36 \mathrm{E}-06$ & $3.09 \mathrm{E}-06$ & $3.88 \mathrm{E}-06$ & $4.53 E-06$ \\
\hline $4.15 \mathrm{E}-08$ & $6.44 \mathrm{E}-06$ & $1.05 \mathrm{E}-06$ & $7.33 E-07$ & $2.36 \mathrm{E}-06$ & $3.09 \mathrm{E}-06$ & $3.88 \mathrm{E}-06$ & $4.53 E-06$ \\
\hline $4.17 E-08$ & $6.44 \mathrm{E}-06$ & $1.05 E-06$ & $7.35 E-07$ & $2.37 E-06$ & $3.09 E-06$ & $3.89 E-06$ & $4.53 E-06$ \\
\hline $4.18 \mathrm{E}-08$ & $6.44 \mathrm{E}-06$ & $1.06 \mathrm{E}-06$ & $7.36 \mathrm{E}-07$ & $2.37 E-06$ & $.10 \mathrm{E}-06$ & $.89 E-06$ & $4.53 E-06$ \\
\hline $4.20 E-08$ & $6.45 \mathrm{E}-06$ & $1.06 \mathrm{E}-06$ & $7.38 \mathrm{E}-07$ & $2.37 E-06$ & $3.10 \mathrm{E}-06$ & $3.89 E-06$ & $4.52 \mathrm{E}-06$ \\
\hline $4.22 E-08$ & $6.45 E-06$ & $1.06 \mathrm{E}-06$ & $7.40 E-07$ & $2.37 E-06$ & $3.10 \mathrm{E}-06$ & $3.89 E-06$ & $4.52 E-06$ \\
\hline $4.24 E-08$ & $6.45 E-06$ & $1.06 \mathrm{E}-06$ & $7.41 \mathrm{E}-07$ & $2.37 E-06$ & $3.10 \mathrm{E}-06$ & $3.89 \mathrm{E}-06$ & $4.52 \mathrm{E}-06$ \\
\hline $4.26 \mathrm{E}-08$ & $6.45 E-06$ & $1.06 \mathrm{E}-06$ & $7.43 E-07$ & $2.38 E-06$ & $3.10 \mathrm{E}-06$ & $3.89 \mathrm{E}-06$ & $4.52 E-06$ \\
\hline $4.27 E-08$ & $6.45 E-06$ & $1.06 \mathrm{E}-06$ & $7.44 E-07$ & $2.38 E-06$ & $3.10 \mathrm{E}-06$ & $3.89 E-06$ & $4.52 E-06$ \\
\hline $4.29 E-08$ & $6.45 \mathrm{E}-06$ & $1.06 \mathrm{E}-06$ & $7.45 E-07$ & $2.38 E-06$ & $3.11 \mathrm{E}-06$ & $3.89 E-06$ & $4.52 E-06$ \\
\hline
\end{tabular}


RESRAD-OFFSITE, Version 2.5

Title : Offsite Resident Farmer Deterministic Run

File : RF TC99 DOESG FWD-FV2b.ROF

Summary of dose at graphical times, reptition 3 (continued)

Time

Years

$7.78 \mathrm{E}+02$

$7.79 \mathrm{E}+02$

$7.79 \mathrm{E}+02$

$7.80 \mathrm{E}+02$

$7.80 \mathrm{E}+02$

$7.81 \mathrm{E}+02$

$7.81 \mathrm{E}+02$

$7.82 \mathrm{E}+02$

$7.82 \mathrm{E}+02$

$7.83 E+02$

$7.83 \mathrm{E}+02$

$7.84 \mathrm{E}+02$

$7.84 \mathrm{E}+02$

$7.85 \mathrm{E}+02$

$7.85 \mathrm{E}+02$

$7.86 \mathrm{E}+02$

$7.86 \mathrm{E}+02$

$7.87 \mathrm{E}+02$

$7.88 \mathrm{E}+02$

$7.88 \mathrm{E}+02$

7. $89 \mathrm{E}+02$

7. $89 \mathrm{E}+02$

7. $90 \mathrm{E}+02$

$7.90 \mathrm{E}+02$

7. $91 \mathrm{E}+02$

7. $91 \mathrm{E}+02$

7. $92 \mathrm{E}+02$

7. $92 \mathrm{E}+02$

7. $93 \mathrm{E}+02$

7. $93 \mathrm{E}+02$

$7.94 \mathrm{E}+02$

7. $94 \mathrm{E}+02$

7. $95 \mathrm{E}+02$

7. $95 \mathrm{E}+02$

$7.96 \mathrm{E}+02$

$7.96 \mathrm{E}+02$

7. $97 \mathrm{E}+02$

7. $97 \mathrm{E}+02$

7. $98 \mathrm{E}+02$

7. $98 \mathrm{E}+02$

$7.99 \mathrm{E}+02$

7. $99 \mathrm{E}+02$

$8.00 \mathrm{E}+02$

$8.00 \mathrm{E}+02$

$8.01 \mathrm{E}+02$

$8.01 \mathrm{E}+02$
Dose statistics at graphical times, mrem/yr

\begin{tabular}{|c|c|c|c|c|c|c|c|}
\hline Minimum & Maximum & Mean & Median & $90 \%$ & $95 \%$ & $97.5 \%$ & $99 \%$ \\
\hline $4.31 E-08$ & $6.46 \mathrm{E}-06$ & $1.07 E-06$ & $7.47 \mathrm{E}-07$ & $2.38 E-06$ & $3.11 E-06$ & $3.89 E-06$ & $4.52 \mathrm{E}-06$ \\
\hline $4.33 E-08$ & $6.46 \mathrm{E}-06$ & $1.07 \mathrm{E}-06$ & $7.48 \mathrm{E}-07$ & $2.38 \mathrm{E}-06$ & $3.11 \mathrm{E}-06$ & $3.89 \mathrm{E}-06$ & $4.52 E-06$ \\
\hline $4.35 \mathrm{E}-08$ & $6.46 \mathrm{E}-06$ & $1.07 \mathrm{E}-06$ & $7.49 \mathrm{E}-07$ & $2.39 \mathrm{E}-06$ & $3.11 \mathrm{E}-06$ & $3.89 \mathrm{E}-06$ & $4.52 \mathrm{E}-06$ \\
\hline $4.36 \mathrm{E}-08$ & $6.46 \mathrm{E}-06$ & $1.07 \mathrm{E}-06$ & $7.50 \mathrm{E}-07$ & $2.39 \mathrm{E}-06$ & $3.11 \mathrm{E}-06$ & $3.89 \mathrm{E}-06$ & 4. 52E-06 \\
\hline $4.38 E-08$ & $6.46 \mathrm{E}-06$ & $1.07 \mathrm{E}-06$ & $7.51 \mathrm{E}-07$ & $2.39 E-06$ & $3.11 \mathrm{E}-06$ & $3.90 E-06$ & $4.51 E-06$ \\
\hline 4. $40 \mathrm{E}-08$ & $6.46 \mathrm{E}-06$ & $1.07 \mathrm{E}-06$ & $7.53 \mathrm{E}-07$ & $2.39 \mathrm{E}-06$ & $3.11 \mathrm{E}-06$ & $3.90 \mathrm{E}-06$ & $4.51 \mathrm{E}-06$ \\
\hline 4. $42 E-08$ & $6.46 \mathrm{E}-06$ & $1.07 \mathrm{E}-06$ & $7.54 \mathrm{E}-07$ & $2.39 \mathrm{E}-06$ & $3.12 \mathrm{E}-06$ & $3.90 \mathrm{E}-06$ & $4.51 E-06$ \\
\hline $4.44 \mathrm{E}-08$ & $6.47 \mathrm{E}-06$ & $1.08 \mathrm{E}-06$ & $7.56 \mathrm{E}-07$ & $2.39 \mathrm{E}-06$ & $3.12 \mathrm{E}-06$ & $3.90 \mathrm{E}-06$ & $4.51 \mathrm{E}-06$ \\
\hline 4. $45 \mathrm{E}-08$ & $6.47 \mathrm{E}-06$ & $1.08 E-06$ & $7.57 \mathrm{E}-07$ & $2.40 \mathrm{E}-06$ & $3.12 \mathrm{E}-06$ & $3.90 \mathrm{E}-06$ & $4.51 \mathrm{E}-06$ \\
\hline $4.47 \mathrm{E}-08$ & $6.47 \mathrm{E}-06$ & $1.08 \mathrm{E}-06$ & $7.59 \mathrm{E}-07$ & $2.40 \mathrm{E}-06$ & $3.12 \mathrm{E}-06$ & $3.90 \mathrm{E}-06$ & $4.51 \mathrm{E}-06$ \\
\hline $4.49 \mathrm{E}-08$ & $6.47 \mathrm{E}-06$ & $1.08 \mathrm{E}-06$ & $7.61 \mathrm{E}-07$ & $2.40 \mathrm{E}-06$ & $3.13 E-06$ & $3.90 \mathrm{E}-06$ & $4.51 \mathrm{E}-06$ \\
\hline $4.51 \mathrm{E}-08$ & $6.47 \mathrm{E}-06$ & $1.08 \mathrm{E}-06$ & $7.62 \mathrm{E}-07$ & $2.40 \mathrm{E}-06$ & $3.13 \mathrm{E}-06$ & $3.90 \mathrm{E}-06$ & $4.51 \mathrm{E}-06$ \\
\hline $4.53 E-08$ & $6.47 \mathrm{E}-06$ & $1.08 \mathrm{E}-06$ & $7.64 \mathrm{E}-07$ & $2.41 \mathrm{E}-06$ & $3.13 E-06$ & $3.90 \mathrm{E}-06$ & $4.51 \mathrm{E}-06$ \\
\hline $4.55 E-08$ & $6.47 \mathrm{E}-06$ & $1.08 \mathrm{E}-06$ & $7.66 \mathrm{E}-07$ & $2.41 \mathrm{E}-06$ & $3.13 \mathrm{E}-06$ & $3.91 \mathrm{E}-06$ & $4.51 \mathrm{E}-06$ \\
\hline 4. $57 \mathrm{E}-08$ & $6.48 E-06$ & $1.09 \mathrm{E}-06$ & $7.67 \mathrm{E}-07$ & $2.41 \mathrm{E}-06$ & $3.13 \mathrm{E}-06$ & $3.91 \mathrm{E}-06$ & $4.51 \mathrm{E}-06$ \\
\hline $4.58 \mathrm{E}-08$ & $6.48 \mathrm{E}-06$ & $1.09 \mathrm{E}-06$ & $7.69 \mathrm{E}$ & $41 E-06$ & $.13 E-06$ & $91 E-06$ & $51 E-06$ \\
\hline $4.60 \mathrm{E}-08$ & $6.48 \mathrm{E}-06$ & $1.09 \mathrm{E}-06$ & $7.71 \mathrm{E}-07$ & $2.42 \mathrm{E}-06$ & $3.13 E-06$ & $3.91 \mathrm{E}-06$ & $4.51 \mathrm{E}-06$ \\
\hline $4.62 \mathrm{E}-08$ & $6.48 E-06$ & $1.09 E-06$ & $7.72 \mathrm{E}-07$ & $2.42 \mathrm{E}-06$ & $3.14 \mathrm{E}-06$ & $3.91 \mathrm{E}-06$ & $4.51 \mathrm{E}-06$ \\
\hline $4.64 \mathrm{E}-08$ & $6.48 \mathrm{E}-06$ & $1.09 E-06$ & $7.74 \mathrm{E}-07$ & $2.42 \mathrm{E}-06$ & $3.14 \mathrm{E}-06$ & $3.91 \mathrm{E}-06$ & $4.51 \mathrm{E}-06$ \\
\hline $4.66 \mathrm{E}-08$ & $6.48 \mathrm{E}-06$ & $1.09 \mathrm{E}-06$ & $7.76 \mathrm{E}-07$ & $2.42 \mathrm{E}-06$ & $3.14 \mathrm{E}-06$ & $3.91 \mathrm{E}-06$ & $4.52 \mathrm{E}-06$ \\
\hline $4.68 \mathrm{E}-08$ & $6.48 \mathrm{E}-06$ & $1.09 \mathrm{E}-06$ & $7.78 \mathrm{E}-07$ & $2.43 E-06$ & $3.14 \mathrm{E}-06$ & $3.91 \mathrm{E}-06$ & $.52 E-06$ \\
\hline $4.70 \mathrm{E}-08$ & $6.48 \mathrm{E}-06$ & $1.10 \mathrm{E}-06$ & $7.80 \mathrm{E}-07$ & $2.43 E-06$ & $3.14 \mathrm{E}-06$ & $3.91 E-06$ & $.52 E-06$ \\
\hline $4.72 \mathrm{E}-08$ & $6.48 E-06$ & $1.10 \mathrm{E}-06$ & $7.81 \mathrm{E}-07$ & $2.43 E-06$ & $3.14 \mathrm{E}-06$ & $3.91 \mathrm{E}-06$ & $4.52 \mathrm{E}-06$ \\
\hline $4.74 \mathrm{E}-08$ & $6.49 \mathrm{E}-06$ & $1.10 \mathrm{E}-06$ & $7.83 E-07$ & $2.43 E-06$ & $3.15 \mathrm{E}-06$ & $3.91 \mathrm{E}-06$ & $4.52 \mathrm{E}-06$ \\
\hline $4.76 \mathrm{E}-08$ & $6.49 \mathrm{E}-06$ & $1.10 \mathrm{E}-06$ & $7.85 \mathrm{E}-07$ & $2.44 \mathrm{E}-06$ & $3.15 \mathrm{E}-06$ & $3.91 \mathrm{E}-06$ & $4.52 \mathrm{E}-06$ \\
\hline $4.77 \mathrm{E}-08$ & $6.49 \mathrm{E}-06$ & $1.10 \mathrm{E}-06$ & $7.86 \mathrm{E}-07$ & $2.44 \mathrm{E}-06$ & $3.15 \mathrm{E}-06$ & $3.91 \mathrm{E}-06$ & $4.52 \mathrm{E}-06$ \\
\hline $4.79 \mathrm{E}-08$ & $6.49 \mathrm{E}-06$ & $1.10 \mathrm{E}-06$ & $7.88 \mathrm{E}-07$ & $2.44 \mathrm{E}-06$ & $3.15 \mathrm{E}-06$ & $3.91 \mathrm{E}-06$ & $4.52 \mathrm{E}-06$ \\
\hline $4.81 \mathrm{E}-08$ & $6.49 \mathrm{E}-06$ & 1.10E-06 & $7.90 \mathrm{E}-07$ & $2.44 \mathrm{E}-06$ & $3.15 \mathrm{E}-06$ & $3.91 \mathrm{E}-06$ & $4.52 \mathrm{E}-06$ \\
\hline $4.83 E-08$ & $6.49 \mathrm{E}-06$ & $1.11 \mathrm{E}-06$ & $7.91 \mathrm{E}-07$ & $2.45 \mathrm{E}-06$ & $3.15 \mathrm{E}-06$ & $3.91 \mathrm{E}-06$ & $4.52 \mathrm{E}-06$ \\
\hline $4.85 E-08$ & $6.49 E-06$ & $1.11 \mathrm{E}-06$ & $7.93 E-07$ & $2.45 E-06$ & $3.15 \mathrm{E}-06$ & $3.90 E-06$ & $4.53 E-06$ \\
\hline $4.87 \mathrm{E}-08$ & $6.49 \mathrm{E}-06$ & $1.11 \mathrm{E}-06$ & $7.94 \mathrm{E}-07$ & $2.45 \mathrm{E}-06$ & $3.15 \mathrm{E}-06$ & $3.90 \mathrm{E}-06$ & $4.53 E-06$ \\
\hline $4.89 \mathrm{E}-08$ & $6.49 \mathrm{E}-06$ & $1.11 \mathrm{E}-06$ & $7.96 \mathrm{E}-07$ & $2.45 \mathrm{E}-06$ & $3.15 \mathrm{E}-06$ & $3.90 \mathrm{E}-06$ & $4.53 E-06$ \\
\hline $4.91 E-08$ & $6.49 E-06$ & $1.11 \mathrm{E}-06$ & $7.97 \mathrm{E}-07$ & $2.45 E-06$ & $3.15 \mathrm{E}-06$ & $3.90 E-06$ & $4.53 E-06$ \\
\hline $4.93 E-08$ & $6.50 \mathrm{E}-06$ & $1.11 \mathrm{E}-06$ & $7.99 \mathrm{E}-07$ & $2.46 \mathrm{E}-06$ & $3.15 \mathrm{E}-06$ & $3.90 \mathrm{E}-06$ & $4.53 E-06$ \\
\hline $4.95 E-08$ & $6.50 \mathrm{E}-06$ & $1.12 \mathrm{E}-06$ & $8.00 \mathrm{E}-07$ & $2.46 \mathrm{E}-06$ & $3.15 \mathrm{E}-06$ & $3.90 \mathrm{E}-06$ & $4.53 E-06$ \\
\hline $4.97 \mathrm{E}-08$ & $6.50 \mathrm{E}-06$ & $1.12 \mathrm{E}-06$ & $8.02 E-07$ & $2.46 \mathrm{E}-06$ & $3.15 \mathrm{E}-06$ & $3.90 \mathrm{E}-06$ & $4.53 E-06$ \\
\hline $4.99 \mathrm{E}-08$ & $6.50 \mathrm{E}-06$ & $1.12 \mathrm{E}-06$ & $8.03 E-07$ & $2.46 \mathrm{E}-06$ & $3.15 \mathrm{E}-06$ & $3.90 \mathrm{E}-06$ & $4.53 E-06$ \\
\hline $5.01 \mathrm{E}-08$ & $6.50 \mathrm{E}-06$ & $1.12 \mathrm{E}-06$ & $8.05 \mathrm{E}-07$ & $2.46 \mathrm{E}-06$ & $3.15 \mathrm{E}-06$ & $3.90 \mathrm{E}-06$ & $4.53 E-06$ \\
\hline $03 E-08$ & $50 \mathrm{E}$ & $1.12 \mathrm{E}-06$ & $8.06 \mathrm{E}-07$ & $2.47 E-06$ & $3.16 \mathrm{E}-06$ & $3.90 \mathrm{E}-06$ & $4.53 E-06$ \\
\hline $5.05 \mathrm{E}-08$ & $6.50 \mathrm{E}-06$ & $1.12 \mathrm{E}-06$ & $8.08 \mathrm{E}-07$ & $2.47 \mathrm{E}-06$ & $3.16 \mathrm{E}-06$ & $3.90 \mathrm{E}-06$ & $4.53 E-06$ \\
\hline $5.07 \mathrm{E}-08$ & $6.50 \mathrm{E}-06$ & $1.12 \mathrm{E}-06$ & $8.09 \mathrm{E}-07$ & $2.47 \mathrm{E}-06$ & $3.16 \mathrm{E}-06$ & $3.90 \mathrm{E}-06$ & $4.53 E-06$ \\
\hline $5.09 \mathrm{E}-08$ & $6.50 \mathrm{E}-06$ & $1.13 \mathrm{E}-06$ & $8.10 \mathrm{E}-07$ & $2.47 \mathrm{E}-06$ & $3.16 \mathrm{E}-06$ & $3.90 \mathrm{E}-06$ & $4.53 E-06$ \\
\hline $5.11 \mathrm{E}-08$ & $6.50 \mathrm{E}-06$ & $1.13 \mathrm{E}-06$ & $8.12 \mathrm{E}-07$ & $2.48 \mathrm{E}-06$ & $3.16 \mathrm{E}-06$ & $3.90 \mathrm{E}-06$ & $4.53 E-06$ \\
\hline $5.13 \mathrm{E}-08$ & $6.50 \mathrm{E}-06$ & $1.13 \mathrm{E}-06$ & $8.13 E-07$ & $2.48 E-06$ & $3.16 \mathrm{E}-06$ & $3.90 \mathrm{E}-06$ & $4.53 E-06$ \\
\hline $5.15 \mathrm{E}-08$ & $6.50 \mathrm{E}-06$ & $1.13 E-06$ & $8.14 \mathrm{E}-07$ & $2.48 E-06$ & $3.16 \mathrm{E}-06$ & $3.90 E-06$ & $4.53 E-06$ \\
\hline $5.17 \mathrm{E}-08$ & $6.51 \mathrm{E}-06$ & $1.13 \mathrm{E}-06$ & $8.15 \mathrm{E}-07$ & $2.49 \mathrm{E}-06$ & $3.16 \mathrm{E}-06$ & $3.90 E-06$ & $4.53 E-06$ \\
\hline
\end{tabular}


RESRAD-OFFSITE, Version 2.5

Title : Offsite Resident Farmer Deterministic Run

File : RF TC99 DOESG FWD-FV2b.ROF

Summary of dose at graphical times, reptition 3 (continued)

Time

Years

$8.02 \mathrm{E}+02$

$8.02 \mathrm{E}+02$

$8.03 E+02$

$8.03 \mathrm{E}+02$

$8.04 \mathrm{E}+02$

$8.04 \mathrm{E}+02$

$8.05 \mathrm{E}+02$

$8.05 \mathrm{E}+02$

$8.06 \mathrm{E}+02$

$8.06 \mathrm{E}+02$

$8.07 \mathrm{E}+02$

$8.07 \mathrm{E}+02$

$8.08 \mathrm{E}+02$

$8.09 \mathrm{E}+02$

$8.09 \mathrm{E}+02$

$8.10 \mathrm{E}+02$

$8.10 \mathrm{E}+02$

$8.11 \mathrm{E}+02$

$8.11 \mathrm{E}+02$

$8.12 \mathrm{E}+02$

$8.12 \mathrm{E}+02$

$8.13 E+02$

$8.13 \mathrm{E}+02$

$8.14 \mathrm{E}+02$

$8.14 \mathrm{E}+02$

$8.15 \mathrm{E}+02$

$8.15 \mathrm{E}+02$

$8.16 \mathrm{E}+02$

$8.16 \mathrm{E}+02$

$8.17 \mathrm{E}+02$

$8.17 \mathrm{E}+02$

$8.18 \mathrm{E}+02$

$8.18 \mathrm{E}+02$

$8.19 \mathrm{E}+02$

$8.19 \mathrm{E}+02$

$8.20 \mathrm{E}+02$

$8.20 \mathrm{E}+02$

$8.21 \mathrm{E}+02$

$8.21 \mathrm{E}+02$

$8.22 \mathrm{E}+02$

$8.22 \mathrm{E}+02$

8. $23 \mathrm{E}+02$

$8.23 \mathrm{E}+02$

$8.24 \mathrm{E}+02$

$8.24 \mathrm{E}+02$

$8.25 \mathrm{E}+02$
Dose statistics at graphical times, mrem/yr

\begin{tabular}{|c|c|c|c|c|c|c|c|}
\hline m & aximum & ea & ec & & & & \\
\hline 08 & $6.51 \mathrm{E}-06$ & $1.13 E-06$ & $.16 \mathrm{E}-07$ & $2.49 \mathrm{E}-06$ & $3.16 \mathrm{E}-06$ & $3.90 \mathrm{E}-06$ & $4.53 E-06$ \\
\hline $21 E-08$ & $6.51 E-06$ & $1.13 \mathrm{E}-06$ & $8.18 \mathrm{E}-07$ & $2.49 \mathrm{E}-06$ & $17 E-06$ & $3.90 \mathrm{E}-06$ & $3 E-06$ \\
\hline $23 E-08$ & $6.51 E-06$ & $4 \mathrm{E}-06$ & $8.19 \mathrm{E}-07$ & $2.49 \mathrm{E}-06$ & $3.17 \mathrm{E}-06$ & $3.90 \mathrm{E}-06$ & $.53 E-06$ \\
\hline-08 & 06 & $\Delta F-06$ & $21 \mathrm{~F}-07$ & $49 \mathrm{E}-06$ & $17 \mathrm{~F}-06$ & -06 & $5 E-06$ \\
\hline-08 & 06 & 6 & 7 & 6 & 6 & 6 & -06 \\
\hline 08 & 06 & & & & & & \\
\hline $31 E-08$ & 06 & & 7 & & & & -06 \\
\hline-08 & -06 & 0 & 1 & 6 & 6 & 6 & -06 \\
\hline$E-08$ & -06 & $4 E-06$ & $E-07$ & -06 & -06 & -06 & $\Xi-06$ \\
\hline $7 E-08$ & $51 E-06$ & ת & תم२ תم & $50 \mathrm{E}-06$ & & $5-06$ & -06 \\
\hline$E-08$ & 06 & & & & & & 06 \\
\hline$E-08$ & $6.51 E-06$ & 1. & $8.33 E-07$ & 6 & & 6 & -06 \\
\hline $43 E-08$ & $6.51 E-06$ & $1.15 \mathrm{E}-06$ & $8.34 \mathrm{E}-07$ & $2.51 E-06$ & & $3.90 E-06$ & $.55 E-06$ \\
\hline $45 E-08$ & $6.51 \mathrm{E}-06$ & $1.15 \mathrm{E}-06$ & $8.36 \mathrm{E}-07$ & $2.51 E-06$ & 06 & -06 & $E-06$ \\
\hline-08 & -06 & 06 & & & & -06 & -06 \\
\hline 08 & 06 & 0 & $839 F-07$ & 06 & & 0 & ce \\
\hline 8 & 0 & & & & & & \\
\hline 8 & 6 & $1.16 \mathrm{E}-06$ & $8 \quad 43 F-07$ & 6 & & $E-06$ & 06 \\
\hline $56 \mathrm{E}-08$ & $6.51 \mathrm{E}-06$ & $1.16 \mathrm{E}-06$ & $8.44 E-07$ & $2.52 E-06$ & $3.20 E-06$ & $E-06$ & $.54 E-06$ \\
\hline $58 E-08$ & $.51 \mathrm{E}-06$ & $1.16 \mathrm{E}-06$ & $.45 \mathrm{E}-07$ & $2.52 E-06$ & $.20 E-06$ & $E-06$ & $4 E-06$ \\
\hline 08 & & & & & & 6 & -06 \\
\hline 08 & & & & 6 & 6 & 06 & -06 \\
\hline 08 & & $\perp$ & 7 & 6 & & & 06 \\
\hline $66 \mathrm{E}-08$ & 06 & 0 & $8.52 \mathrm{E}-07$ & 6 & 6 & 0 & -06 \\
\hline 8 & 6 & 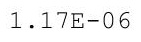 & $8.54 \mathrm{E}-07$ & 6 & 6 & 6 & 06 \\
\hline $71 \mathrm{~F}-08$ & $52 E-06$ & $117 \mathrm{~F}-06$ & م & -06 & $21 E-06$ & $.91 \mathrm{E}-06$ & $4 F-06$ \\
\hline $.73 E-08$ & $2 E-06$ & $1.17 \mathrm{E}-06$ & 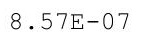 & $3 E-06$ & & $E-06$ & $4 E-06$ \\
\hline 8 & & & & & & & \\
\hline$E-08$ & & $\perp \cdot$ & & 06 & 6 & & -06 \\
\hline $.79 E-08$ & $6.52 \mathrm{E}-06$ & $1 \cdot 1 / \pm-U 6$ & $.02+51$ & $2.53 E-06$ & $.22 E-06$ & $3.91 \mathrm{~L}-00$ & $.54 E-06$ \\
\hline $81 E-08$ & $52 E-06$ & $\perp \cdot 1 / \mathrm{L}-00$ & 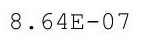 & $2.53 E-06$ & $22 E-06$ & $2-20$ & $.54 E-06$ \\
\hline 皮 & 6 & $=0$ & & & & 然 & \\
\hline $86 F-08$ & $5-06$ & $E-06$ & $F-07$ & $3 E-06$ & $22 E-06$ & & $4 F-06$ \\
\hline 8 & & & & & & & \\
\hline 8 & & 1. & 07 & 06 & 06 & 06 & \\
\hline $92 E-08$ & $6.52 \mathrm{E}-06$ & $1.18 \mathrm{E}-06$ & $8.73 E-07$ & 2.045 & -06 & -06 & $5 \mathrm{E}-06$ \\
\hline $.935-08$ & & & & & & & . . \\
\hline $97 E-08$ & $52 E-06$ & 1. $18 \mathrm{E}-06$ & 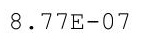 & $2.54 \mathrm{E}-06$ & & & $.55 E-06$ \\
\hline $.99 E-08$ & $6.52 \mathrm{E}-06$ & $1.19 \mathrm{E}-06$ & $8.79 \mathrm{E}-07$ & 6 & 6 & 6 & 06 \\
\hline & $6.52 E-06$ & & 7 & 6 & 6 & & \\
\hline $3 E-08$ & $6.52 \mathrm{E}-06$ & $9 E-06$ & $3 E-07$ & 06 & 06 & & -06 \\
\hline$E-08$ & 6 & 1. & & & & & 06 \\
\hline & & & & & & & $5 E-06$ \\
\hline $10 \pm-08$ & $0.025-00$ & $\perp \cdot \perp>-00$ & $.00 \pm-1$ & $2.55 \mathrm{E}-06$ & $3.23 E-06$ & $9 \perp E-06$ & $4.55 E-06$ \\
\hline $12 \mathrm{E}-08$ & $0.0 \angle D-20$ & $\perp \cdot \perp \pi$ u & & 2.001 & & & $4.55 E-06$ \\
\hline$E-08$ & $.52 \mathrm{E}-06$ & $.20 \mathrm{E}-06$ & $92 \mathrm{E}-07$ & $.56 \mathrm{E}-06$ & -06 & -06 & $4.56 \mathrm{E}$ \\
\hline
\end{tabular}


RESRAD-OFFSITE, Version 2.5

Title : Offsite Resident Farmer Deterministic Run

File : RF TC99 DOESG FWD-FV2b.ROF

Summary of dose at graphical times, reptition 3 (continued)

Time

Years

$8.25 E+02$

$8.26 \mathrm{E}+02$

$8.26 \mathrm{E}+02$

$8.27 \mathrm{E}+02$

$8.27 \mathrm{E}+02$

$8.28 \mathrm{E}+02$

$8.29 \mathrm{E}+02$

$8.29 \mathrm{E}+02$

$8.30 \mathrm{E}+02$

$8.30 \mathrm{E}+02$

$8.31 \mathrm{E}+02$

$8.31 \mathrm{E}+02$

$8.32 \mathrm{E}+02$

$8.32 \mathrm{E}+02$

$8.33 E+02$

$8.33 \mathrm{E}+02$

$8.34 \mathrm{E}+02$

8. $34 \mathrm{E}+02$

$8.35 \mathrm{E}+02$

$8.35 \mathrm{E}+02$

$8.36 \mathrm{E}+02$

$8.36 \mathrm{E}+02$

$8.37 \mathrm{E}+02$

$8.37 \mathrm{E}+02$

$8.38 \mathrm{E}+02$

$8.38 \mathrm{E}+02$

$8.39 \mathrm{E}+02$

$8.39 \mathrm{E}+02$

$8.40 \mathrm{E}+02$

$8.40 \mathrm{E}+02$

$8.41 \mathrm{E}+02$

$8.41 \mathrm{E}+02$

$8.42 \mathrm{E}+02$

$8.42 \mathrm{E}+02$

$8.43 \mathrm{E}+02$

$8.43 \mathrm{E}+02$

$8.44 \mathrm{E}+02$

$8.44 \mathrm{E}+02$

$8.45 \mathrm{E}+02$

$8.45 \mathrm{E}+02$

$8.46 \mathrm{E}+02$

$8.46 \mathrm{E}+02$

$8.47 \mathrm{E}+02$

$8.47 \mathrm{E}+02$

$8.48 \mathrm{E}+02$

$8.49 \mathrm{E}+02$
Dose statistics at graphical times, mrem/yr

\begin{tabular}{|c|c|c|c|c|c|c|c|}
\hline lum & aximum & lean & edi & & & & \\
\hline 8 & 06 & 06 & 07 & 06 & 06 & 06 & -06 \\
\hline $.19 \mathrm{E}-08$ & $.52 \mathrm{E}-06$ & $1.20 \mathrm{E}-06$ & $.94 \mathrm{E}-07$ & $2.56 \mathrm{E}-06$ & $3.24 \mathrm{E}-06$ & $3.91 \mathrm{E}-06$ & $.56 \mathrm{E}-06$ \\
\hline $21 E-08$ & $52 E-06$ & $20 F-06$ & $96 \mathrm{E}-07$ & $56 E-06$ & $.24 E-06$ & $.91 E-06$ & $.56 E-06$ \\
\hline $3 E-08$ & $52 \mathrm{~F}-06$ & $0 \mathrm{~F}-06$ & $97 E-07$ & $57 \mathrm{~F}$ & 06 & $E-06$ & $.56 \mathrm{E}-06$ \\
\hline$E-08$ & 06 & 6 & & & & 6 & -06 \\
\hline$E-08$ & 06 & 6 & & & & & -06 \\
\hline $30 E-08$ & -06 & 0 & . & $7 E-06$ & $24 E-06$ & $2 E-06$ & $56 E-06$ \\
\hline $32 E-08$ & $51 E-06$ & $.21 E-06$ & $4 E-07$ & $57 E-06$ & $.24 \mathrm{E}-06$ & $3.92 E-06$ & $56 E-06$ \\
\hline $35 F-08$ & $.51 E-06$ & $21 \mathrm{~F}-06$ & $06 \mathrm{~F}-0$ & $.58 E-06$ & $24 E-06$ & $E-06$ & $56 E-06$ \\
\hline 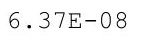 & 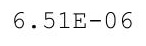 & $1.21 \mathrm{E}-06$ & & 6 & 6 & $92 E-06$ & 06 \\
\hline $39 F-08$ & $6.51 E-06$ & $1.21 F-06$ & $9.10 F-0$ & 6 & 6 & -06 & $E-06$ \\
\hline$E-08$ & $E-06$ & 6 & & & & & -06 \\
\hline $.44 E-08$ & $6.51 E-06$ & $1.21 E-06$ & $9.13 E-07$ & $2.59 E-06$ & $3.24 E-06$ & $3 E-06$ & $57 E-06$ \\
\hline $46 \mathrm{E}-08$ & 06 & -06 & & & & -06 & $E-06$ \\
\hline $48 \mathrm{E}-$ & & $1.22 \mathrm{E}-06$ & & & & 6 & 06 \\
\hline $51 \mathrm{~F}$ & & 5 & 7 & 6 & 6 & 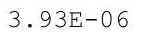 & 6 \\
\hline $53 \mathrm{~F}-08$ & $51 \mathrm{r}^{2}$ & $1.22 E-06$ & $9.20 E-07$ & 6 & 6 & 6 & -06 \\
\hline $.55 E-08$ & $.51 E-06$ & $1.22 F-06$ & 15 & & 6 & -06 & $7 E-06$ \\
\hline $58 E-08$ & $.51 \mathrm{E}-06$ & 1. $22 \mathrm{E}-06$ & $9.22 \mathrm{E}-07$ & $.60 E-06$ & -06 & -06 & $.57 E-06$ \\
\hline-08 & $E-06$ & -06 & & & 06 & -06 & $E-06$ \\
\hline & & & & & & & \\
\hline $65 E-08$ & & 1.200 & & & & & 06 \\
\hline$E-08$ & 06 & 06 & a & 6 & 6 & & -06 \\
\hline $9 E-08$ & $.51 E-06$ & $.23 E-06$ & בת & $1 E-06$ & 6 & $E-06$ & $6 E-06$ \\
\hline $72 \mathrm{E}-08$ & $.51 \mathrm{E}-06$ & $.23 E-06$ & $34 \mathrm{E}-07$ & $61 E-06$ & $25 E-06$ & $E-06$ & $56 E-06$ \\
\hline $74 \mathrm{~F}-08$ & $F-06$ & $23 E-06$ & & & & -06 & $6 E-06$ \\
\hline & & & & & & & \\
\hline & & 1.23 & & & 06 & & -06 \\
\hline $.81 \mathrm{E}-08$ & $6.51 \mathrm{E}-06$ & $1.23 E-06$ & . & $2.61 \mathrm{E}-06$ & $3.25 E-06$ & $3.92 \mathrm{E}-06$ & $56 E-06$ \\
\hline $.84 E-08$ & $50 E-06$ & $.24 \mathrm{E}-06$ & 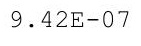 & $2.61 E-06$ & $25 E-06$ & $3.92 E-06$ & $.56 E-06$ \\
\hline $86 \mathrm{E}-0$ & $50 E-06$ & $.24 \mathrm{E}-0$ & & $.61 E-06$ & & $3.92 E-0$ & 7. $56 \mathrm{E}-06$ \\
\hline $8 F-08$ & $50 F-06$ & & 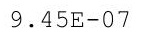 & $.61 E-06$ & & $F-06$ & $6 E-06$ \\
\hline & & & & & & & \\
\hline $3 E-08$ & & 1.2 & 7 & 06 & 6 & & \\
\hline $.96 \mathrm{E}-08$ & $6.50 \mathrm{E}-06$ & $1.24 \mathrm{E}-06$ & $9.49 \mathrm{E}-07$ & $2.62 \mathrm{E}-06$ & $3.25 E-06$ & $3.92 E-06$ & $4.56 E-06$ \\
\hline $.90 \pm-00$ & $0.30 \pm-06$ & $1 \cdot 245-06$ & & $2.62 \mathrm{E}-06$ & $3.235-06$ & $3.92 E-06$ & $4.56 \mathrm{E}-06$ \\
\hline $00 E-08$ & 6 & . & $9.52 \mathrm{E}-07$ & 6 & & & $56 E-06$ \\
\hline $7.03 E-08$ & $6.50 \mathrm{E}-06$ & $1.25 \mathrm{E}-06$ & 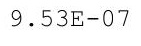 & 6 & 6 & 6 & 06 \\
\hline $7.05 E-08$ & & & & 6 & & & \\
\hline $.08 E-08$ & & & & 2.6 & & 06 & \\
\hline $.10 \mathrm{E}-08$ & $0 E-06$ & $5 E-06$ & & 2.0 & 6 & 06 & $6 E-06$ \\
\hline 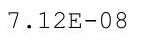 & & $1.25 \mathrm{E}-06$ & & & & & $4.50 E-06$ \\
\hline •. & $0.45 \mathrm{~L}-0$ & $\perp \cdot 2 J \pm-00$ & $.59 \mathrm{E}-07$ & $2.64 E-06$ & $3.25 E-06$ & $1 E-06$ & $4.56 E-06$ \\
\hline 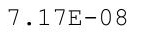 & & $1.25 \mathrm{E}-06$ & $9.60 \mathrm{E}-07$ & $2.64 \mathrm{E}-06$ & & $91 E-06$ & $4.56 \mathrm{E}-06$ \\
\hline$E-0$ & & tevor & & & & $E-06$ & $.56 \mathrm{E}-06$ \\
\hline $22 \mathrm{E}-08$ & $E-06$ & $E-06$ & $.63 E-07$ & $.64 \mathrm{E}-06$ & -06 & $.91 E-06$ & $5 E-06$ \\
\hline
\end{tabular}


RESRAD-OFFSITE, Version 2.5

Title : Offsite Resident Farmer Deterministic Run

File : RF TC99 DOESG FWD-FV2b.ROF

Summary of dose at graphical times, reptition 3 (continued)

Time

Years

$8.49 \mathrm{E}+02$

$8.50 \mathrm{E}+02$

8. $50 \mathrm{E}+02$

$8.51 \mathrm{E}+02$

8. $51 \mathrm{E}+02$

8. $52 \mathrm{E}+02$

$8.52 \mathrm{E}+02$

$8.53 \mathrm{E}+02$

$8.53 \mathrm{E}+02$

8. $54 \mathrm{E}+02$

$8.54 \mathrm{E}+02$

$8.55 \mathrm{E}+02$

8. $55 \mathrm{E}+02$

$8.56 \mathrm{E}+02$

$8.56 \mathrm{E}+02$

$8.57 \mathrm{E}+02$

$8.57 \mathrm{E}+02$

$8.58 \mathrm{E}+02$

8. $58 \mathrm{E}+02$

$8.59 \mathrm{E}+02$

$8.59 \mathrm{E}+02$

$8.60 \mathrm{E}+02$

$8.60 \mathrm{E}+02$

$8.61 E+02$

8. $61 \mathrm{E}+02$

8. $62 \mathrm{E}+02$

$8.62 \mathrm{E}+02$

$8.63 \mathrm{E}+02$

8. $63 \mathrm{E}+02$

8. $64 \mathrm{E}+02$

$8.64 \mathrm{E}+02$

$8.65 \mathrm{E}+02$

$8.65 \mathrm{E}+02$

$8.66 \mathrm{E}+02$

$8.66 \mathrm{E}+02$

$8.67 \mathrm{E}+02$

$8.67 \mathrm{E}+02$

$8.68 \mathrm{E}+02$

8. $69 \mathrm{E}+02$

8. $69 \mathrm{E}+02$

$8.70 \mathrm{E}+02$

$8.70 \mathrm{E}+02$

$8.71 \mathrm{E}+02$

8. $71 \mathrm{E}+02$

$8.72 \mathrm{E}+02$

$8.72 \mathrm{E}+02$
Dose statistics at graphical times, mrem/yr

\begin{tabular}{|c|c|c|c|c|c|c|c|}
\hline m & aximum & lea & - & & & & \\
\hline 08 & $6.49 \mathrm{E}-06$ & $1.26 \mathrm{E}-06$ & $9.64 \mathrm{E}-07$ & $4 E-06$ & $3.26 \mathrm{E}-06$ & 06 & $4.50 E-00$ \\
\hline $.27 E-08$ & $6.49 E-06$ & $1.26 \mathrm{E}-06$ & $9.66 \mathrm{E}-07$ & $4 E-06$ & $3.26 \mathrm{E}-06$ & $3.91 E-06$ & $6 E-06$ \\
\hline $30 E-08$ & $.49 E-06$ & $1.26 \mathrm{E}-06$ & $9.68 \mathrm{E}-07$ & $64 E-06$ & $3.27 E-06$ & $3.91 \mathrm{E}-06$ & $56 E-06$ \\
\hline-08 & -06 & $26 \mathrm{E}-06$ & $60 F-07$ & $.65 E-06$ & $27 F-06$ & -06 & $56 E-06$ \\
\hline-08 & 06 & 6 & . & 6 & 6 & -06 & -06 \\
\hline 08 & 06 & 6 & & & & & 06 \\
\hline $.40 \mathrm{E}-08$ & $6.48 E-06$ & $1.27 \mathrm{E}$ & & & & & $56 E-06$ \\
\hline $.42 E-08$ & -06 & 6 & 7 & 6 & 6 & 6 & $5 E-06$ \\
\hline $44 \mathrm{E}-08$ & -06 & $1.27 E-06$ & $E-07$ & -06 & $27 E-06$ & -06 & $E-06$ \\
\hline $47 \mathrm{E}-08$ & $48 E-06$ & $7 E-06$ & 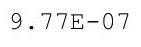 & $.66 E-06$ & $27 E-06$ & $15-0$ & $E-06$ \\
\hline 08 & 06 & 6 & & & & & $E-06$ \\
\hline $.52 \mathrm{E}-08$ & $6.48 E-06$ & $1.27 \mathrm{E}$ & 0 & 6 & 6 & 6 & $\Xi-06$ \\
\hline $.55 E-08$ & $6.48 E-06$ & $1.27 \mathrm{E}-06$ & $9.82 \mathrm{E}-07$ & & & $3.92 E-06$ & $.57 E-06$ \\
\hline $.57 E-08$ & $6.48 \mathrm{E}-06$ & 1. $28 \mathrm{E}-06$ & $9.83 \mathrm{E}-07$ & $2.67 \mathrm{E}-06$ & & -06 & $57 E-06$ \\
\hline-08 & -06 & -06 & & 06 & & -06 & $E-06$ \\
\hline 8 & -06 & .28 & 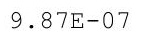 & 06 & & -06 & 06 \\
\hline 8 & 0 & 6 & & & & & \\
\hline$E-08$ & 6 & 6 & a $91 \mathrm{~F}-07$ & 6 & 6 & 6 & 06 \\
\hline $.70 \mathrm{E}-08$ & $6.47 \mathrm{E}-06$ & $1.28 E-06$ & $9.93 E-07$ & $2.67 E-06$ & $3.27 E-06$ & $3.93 E-06$ & $.58 E-06$ \\
\hline $.72 E-08$ & $6.47 \mathrm{E}-06$ & 1. $28 \mathrm{E}-06$ & $.94 \mathrm{E}-07$ & $2.68 \mathrm{E}-06$ & $.27 E-06$ & $E-06$ & $.59 E-06$ \\
\hline 08 & 06 & 6 & & & & 6 & -06 \\
\hline 08 & & & & & & & -06 \\
\hline$a_{0}$ & & 6 & & & & & -06 \\
\hline $82 E-08$ & 06 & 06 & 0 & 6 & 6 & 0 & -06 \\
\hline 8 & 6 & 201 & $p$ & 6 & 6 & 6 & 06 \\
\hline $88 \mathrm{~F}-08$ & $.46 \mathrm{E}-06$ & 1. $29 \mathrm{E}-06$ & $F-06$ & $E-06$ & $28 E-06$ & $.93 E-06$ & $.60 \mathrm{E}-06$ \\
\hline$E-08$ & $46 \mathrm{E}-06$ & 1. $29 \mathrm{E}-06$ & $01 E-06$ & $69 \mathrm{E}-06$ & & $E-06$ & $50 \mathrm{E}-06$ \\
\hline & & & & & & & \\
\hline & & $1 \cdot 2$ & & & 6 & -06 & -06 \\
\hline $.98 E-08$ & $6.46 \mathrm{E}-06$ & $1.30 \mathrm{E}-06$ & 1.01E-06 & $2.70 E-06$ & $.29 E-06$ & $3.92 \mathrm{E}-00$ & $.61 E-06$ \\
\hline $00 \mathrm{E}-08$ & $6.46 \mathrm{E}-06$ & 1. $30 \mathrm{E}-06$ & $L E-06$ & $2.70 \mathrm{E}-06$ & $29 E-06$ & $25-00$ & $.61 \mathrm{E}-06$ \\
\hline $03 E-08$ & $45 E-06$ & $.30 E-06$ & & & & 年 & \\
\hline$E-08$ & $E-06$ & 1. $30 E-06$ & & -06 & 6 & & $1 \mathrm{~F}-06$ \\
\hline & & & & & & & \\
\hline & & 1.30 & & 6 & 06 & & \\
\hline $.14 \mathrm{E}-08$ & $6.45 \mathrm{E}-06$ & $1.30 E-06$ & $1.02 \mathrm{E}-06$ & $2 \cdot 1 \perp$ & -06 & -06 & $.62 E-06$ \\
\hline 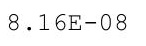 & $0.45 E-00$ & 1. $30 \mathrm{E}-06$ & & & & & $4.0<5-00$ \\
\hline $19 \mathrm{E}-08$ & $6.45 E-06$ & 1. $31 \mathrm{E}-06$ & 200 & $2.71 \mathrm{E}-06$ & & & $62 E-06$ \\
\hline $.21 E-08$ & $6.44 \mathrm{E}-06$ & 6 & $1.03 E-06$ & 6 & 6 & 6 & 06 \\
\hline $.24 E-08$ & & & & & & & \\
\hline$E-08$ & $6.44 \mathrm{E}-06$ & 1. $31 E-06$ & 06 & 2 . & & & -06 \\
\hline$E-08$ & 6 & 1.31 & & 6 & 6 & & 06 \\
\hline & & & & & & & $4.61 \mathrm{E}-06$ \\
\hline 年 & $6.44 \mathrm{E}-06$ & $1.31 E-06$ & $1.04 E-06$ & $2.72 E-06$ & $3.31 E-06$ & $3.90 E-06$ & $4.01 \mathrm{E}-06$ \\
\hline $37 E-08$ & $0.445-00$ & $\perp \cdot 3 \perp+-00$ & $+\cdot 0+1$ & $2 \cdot 121$ & 3.32 & & . \\
\hline$E-08$ & $.43 E-06$ & $E-06$ & $.04 \mathrm{E}-06$ & $.72 \mathrm{E}-06$ & -06 & $E-06$ & -06 \\
\hline
\end{tabular}


RESRAD-OFFSITE, Version 2.5

Title : Offsite Resident Farmer Deterministic Run

File : RF TC99 DOESG FWD-FV2b.ROF

Summary of dose at graphical times, reptition 3 (continued)

Time

Years

$8.73 \mathrm{E}+02$

$8.73 \mathrm{E}+02$

$8.74 \mathrm{E}+02$

$8.74 \mathrm{E}+02$

$8.75 \mathrm{E}+02$

$8.75 \mathrm{E}+02$

$8.76 \mathrm{E}+02$

$8.76 \mathrm{E}+02$

$8.77 \mathrm{E}+02$

$8.77 \mathrm{E}+02$

$8.78 \mathrm{E}+02$

$8.78 \mathrm{E}+02$

$8.79 \mathrm{E}+02$

$8.79 \mathrm{E}+02$

$8.80 \mathrm{E}+02$

$8.80 \mathrm{E}+02$

$8.81 \mathrm{E}+02$

$8.81 \mathrm{E}+02$

$8.82 \mathrm{E}+02$

$8.82 \mathrm{E}+02$

$8.83 \mathrm{E}+02$

$8.83 E+02$

$8.84 \mathrm{E}+02$

$8.84 \mathrm{E}+02$

$8.85 \mathrm{E}+02$

$8.85 \mathrm{E}+02$

$8.86 \mathrm{E}+02$

$8.86 \mathrm{E}+02$

$8.87 \mathrm{E}+02$

$8.87 \mathrm{E}+02$

$8.88 \mathrm{E}+02$

$8.89 \mathrm{E}+02$

$8.89 \mathrm{E}+02$

$8.90 \mathrm{E}+02$

$8.90 \mathrm{E}+02$

$8.91 \mathrm{E}+02$

$8.91 \mathrm{E}+02$

$8.92 \mathrm{E}+02$

8. $92 \mathrm{E}+02$

$8.93 E+02$

$8.93 \mathrm{E}+02$

8. $94 \mathrm{E}+02$

$8.94 \mathrm{E}+02$

$8.95 \mathrm{E}+02$

$8.95 \mathrm{E}+02$

8. $96 \mathrm{E}+02$
Dose statistics at graphical times, mrem/yr

\begin{tabular}{|c|c|c|c|c|c|c|c|}
\hline Iinimum & laximum & Mean & Median & $90 \%$ & $95 \%$ & $97.5 \%$ & $9 \%$ \\
\hline 08 & 06 & 6 & 6 & 06 & 6 & 6 & -06 \\
\hline 08 & 06 & 06 & 06 & 06 & 06 & 06 & -06 \\
\hline $8 E-08$ & $E-06$ & $32 E-06$ & -06 & 6 & 6 & 06 & -06 \\
\hline $51 E-08$ & $3 E-06$ & 1. $32 \mathrm{E}-06$ & $5 E-06$ & 6 & 6 & 06 & $1 E-06$ \\
\hline $.53 E-08$ & 06 & 1 & & 6 & & & -06 \\
\hline 08 & 06 & 6 & 6 & 6 & 6 & 6 & $1 E-06$ \\
\hline $.59 E-08$ & $2 E-06$ & $1.32 \mathrm{E}-06$ & $5 E-06$ & $3 E-06$ & $E-06$ & 06 & $61 E-06$ \\
\hline $61 E-08$ & $6.42 E-06$ & $1.33 E-06$ & $1.05 E-06$ & $2.73 E-06$ & 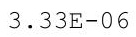 & -06 & $\Xi-06$ \\
\hline$E-08$ & 06 & $1.33 E-06$ & 06 & 6 & 6 & 06 & $51 E-06$ \\
\hline $67 E-08$ & $6.42 \mathrm{E}-06$ & $1.33 \mathrm{E}-06$ & 06 & $3 E-$ & 66 & 06 & $1 E-06$ \\
\hline$E-08$ & 06 & 1 & & & & & $1 E-06$ \\
\hline-08 & -06 & 6 & 6 & 6 & & & 06 \\
\hline $.75 E-08$ & $1 E-06$ & $3 E-06$ & $1.06 \mathrm{E}-06$ & $3 E-06$ & $+\Delta$ & -06 & $E-06$ \\
\hline $.78 E-08$ & $6.41 E-06$ & $1.33 E-06$ & $1.06 \mathrm{E}-06$ & $2.14 \mathrm{E}-00$ & $2 \pi-0$ & 06 & -06 \\
\hline $.81 E-08$ & 06 & $1.33 E-06$ & 06 & 2.711 & (.) & 06 & -06 \\
\hline $83 E-08$ & $6.41 E-06$ & $1.34 \mathrm{E}-06$ & 1.07 & 6 & 6 & 06 & -06 \\
\hline $.86 E-08$ & $6.40 E-06$ & $1.34 \mathrm{E}-06$ & 1.07 & & & -06 & $.60 E-06$ \\
\hline$E-08$ & $E-06$ & $4 E-06$ & -06 & 6 & & & $E-06$ \\
\hline $.91 E-08$ & $0 E-06$ & $1.34 \mathrm{E}-06$ & $1.07 \mathrm{E}-06$ & & & & -06 \\
\hline $94 \mathrm{E}-08$ & $6.40 E-06$ & $1.34 \mathrm{E}$ & 1. & 6 & 6 & 0 & -06 \\
\hline $.97 E-08$ & $6.40 E-06$ & $1.34 \mathrm{E}-06$ & $1.07 \mathrm{E}-06$ & 政 & & & $60 E-06$ \\
\hline $.00 \mathrm{E}-08$ & 6 & 1.3 & 6 & 5 & 5 & $3.90 \mathrm{E}-06$ & -06 \\
\hline $.03 E-08$ & $6.39 \mathrm{E}-06$ & $1.34 \mathrm{E}-06$ & $1.07 \mathrm{E}-06$ & $2.76 \mathrm{E}-06$ & $3.36 \mathrm{E}-$ & $0 E-06$ & $.60 \mathrm{E}-06$ \\
\hline $.05 E-08$ & $6.39 E-06$ & 1.3 & -06 & 6 & 0 & 06 & $E-06$ \\
\hline $.08 \mathrm{E}-08$ & $6.39 E-06$ & $1.35 \mathrm{E}-06$ & $8 E-06$ & & & & $E-06$ \\
\hline$E-08$ & 06 & 1. & 06 & & & 06 & -06 \\
\hline $4 E-08$ & $6.39 E-06$ & $1.35 E-06$ & $1.08 \mathrm{E}-06$ & 等 & 更 & & $9 E-06$ \\
\hline $16 \mathrm{E}-08$ & $6.38 E-06$ & $1.35 \mathrm{E}-06$ & $1.08 \mathrm{E}-06$ & $2.77 \mathrm{E}-06$ & $3.36 \mathrm{E}-06$ & $3.91 E-06$ & $.59 E-06$ \\
\hline 08 & 6.38 & 1.3 & 6 & $2 \cdot 7$ & $3.36 \mathrm{E}-06$ & $3.91 E-06$ & $.59 \mathrm{E}-06$ \\
\hline 8 & 6 & 1. $35 \mathrm{E}$ & 1 & 6 & 6 & 06 & -06 \\
\hline 08 & 06 & 06 & 06 & 6 & & 06 & -06 \\
\hline$E-08$ & $6.38 E-06$ & $1.35 E-06$ & 1. & $7 \mathrm{E}$ & & 06 & $\Xi-06$ \\
\hline $.31 E-08$ & $6.37 E-06$ & $1.36 \mathrm{E}-06$ & $1.09 \mathrm{E}-06$ & 2. & 3. & 06 & $E-06$ \\
\hline $.33 E-08$ & $6.37 E-06$ & $1.36 \mathrm{E}-06$ & $1.09 \mathrm{E}-06$ & $2.78 \mathrm{E}-06$ & $3.37 \mathrm{E}-06$ & $3.90 \mathrm{E}-06$ & $.58 \mathrm{E}-06$ \\
\hline $.30 E-00$ & $6.3 / \mathrm{E}-06$ & $1.36 \mathrm{E}-06$ & & & & & $.57 E-06$ \\
\hline 88 & 6 & 6 & 6 & 6 & & & 06 \\
\hline$E-08$ & 06 & 1. & 06 & 6 & 6 & 06 & 06 \\
\hline $.45 E-08$ & $6.36 E-06$ & $1.36 \mathrm{E}$ & $1.09 \mathrm{E}$ & $2.78 \mathrm{E}$ & 6 & 06 & 06 \\
\hline $.48 \mathrm{E}-08$ & $6.36 \mathrm{E}-06$ & $1.36 \mathrm{E}-06$ & $E-06$ & $2.79 \mathrm{E}-06$ & & 06 & $7 E-06$ \\
\hline$E-08$ & $6.36 \mathrm{E}-06$ & 1 & & & & & $56 E-06$ \\
\hline $.53 E-08$ & & $1.37 \mathrm{E}-$ & & & & & $4.56 \mathrm{E}-06$ \\
\hline $.56 \mathrm{E}-08$ & $6.35 E-06$ & $1.37 \mathrm{E}-06$ & $1.10 \mathrm{E}-06$ & $2.78 \mathrm{E}-06$ & $3.37 \mathrm{E}-06$ & $3.88 E-06$ & $4.56 \mathrm{E}-06$ \\
\hline 8 & 6 & 1 & 6 & 6 & 6 & 6 & 06 \\
\hline$E-08$ & $6.35 E-06$ & $1.37 \mathrm{E}-$ & 1.10 & 2 . & 3.38 & 06 & -06 \\
\hline $65 E-08$ & -06 & 1.3 & 1.1 & 2. & 3 & -06 & -06 \\
\hline $68 \mathrm{E}-08$ & $6.35 \mathrm{E}-06$ & $1.37 \mathrm{E}-06$ & 1.11E-06 & $2.78 \mathrm{E}-06$ & $3.38 \mathrm{E}-06$ & $3.86 \mathrm{E}-06$ & $4.56 \mathrm{E}-06$ \\
\hline
\end{tabular}


RESRAD-OFFSITE, Version 2.5

Title : Offsite Resident Farmer Deterministic Run

File : RF TC99 DOESG FWD-FV2b.ROF

Summary of dose at graphical times, reptition 3 (continued)

Time

Years

$8.96 \mathrm{E}+02$

8. $97 \mathrm{E}+02$

$8.97 \mathrm{E}+02$

$8.98 \mathrm{E}+02$

$8.98 \mathrm{E}+02$

8. $99 \mathrm{E}+02$

$8.99 \mathrm{E}+02$

$9.00 \mathrm{E}+02$

$9.00 \mathrm{E}+02$

$9.01 \mathrm{E}+02$

9. $01 \mathrm{E}+02$

$9.02 \mathrm{E}+02$

$9.02 \mathrm{E}+02$

$9.03 \mathrm{E}+02$

$9.03 \mathrm{E}+02$

$9.04 \mathrm{E}+02$

$9.04 \mathrm{E}+02$

$9.05 \mathrm{E}+02$

$9.05 \mathrm{E}+02$

$9.06 \mathrm{E}+02$

$9.06 \mathrm{E}+02$

$9.07 \mathrm{E}+02$

$9.07 \mathrm{E}+02$

$9.08 \mathrm{E}+02$

$9.08 \mathrm{E}+02$

$9.09 \mathrm{E}+02$

$9.10 \mathrm{E}+02$

$9.10 \mathrm{E}+02$

9. $11 \mathrm{E}+02$

9. $11 \mathrm{E}+02$

$9.12 \mathrm{E}+02$

9. $12 \mathrm{E}+02$

9. $13 \mathrm{E}+02$

9. $13 \mathrm{E}+02$

$9.14 \mathrm{E}+02$

$9.14 \mathrm{E}+02$

$9.15 \mathrm{E}+02$

$9.15 \mathrm{E}+02$

9. $16 \mathrm{E}+02$

$9.16 \mathrm{E}+02$

$9.17 \mathrm{E}+02$

$9.17 \mathrm{E}+02$

$9.18 \mathrm{E}+02$

$9.18 \mathrm{E}+02$

9. $19 \mathrm{E}+02$

$9.19 \mathrm{E}+02$
Dose statistics at graphical times, mrem/yr

\begin{tabular}{|c|c|c|c|c|c|c|c|}
\hline lum & aximum & lean & n & & & & \\
\hline 8 & 06 & 06 & 06 & 06 & 06 & 06 & -06 \\
\hline $73 E-08$ & 06 & $37 E-06$ & $1 E-06$ & $78 E-06$ & $7 E-06$ & $85 E-06$ & $6 E-06$ \\
\hline $76 \mathrm{E}-08$ & $34 E-06$ & $37 E-06$ & $11 E-06$ & $.78 E-06$ & $.37 E-06$ & $3.85 E-06$ & $.55 E-06$ \\
\hline $79 \mathrm{~F}-08$ & $34 \mathrm{~F}-06$ & $38 \mathrm{~F}-06$ & $11 \mathrm{E}-06$ & $78 E-06$ & $77 F-06$ & $5-06$ & $5 E-06$ \\
\hline $82 \mathrm{E}-08$ & 06 & $1.38 \mathrm{E}-06$ & 06 & 6 & 6 & 06 & -06 \\
\hline$E-08$ & 06 & 6 & & & & & -06 \\
\hline $88 E-08$ & $6.33 \mathrm{E}-06$ & $1.38 \mathrm{E}-06$ & $.12 \mathrm{E}-06$ & $2.78 \mathrm{E}-06$ & $37 E-06$ & $E-06$ & $E-06$ \\
\hline $91 E-08$ & $33 E-06$ & $8 E-06$ & $.12 \mathrm{E}-06$ & $79 E-06$ & $37 E-06$ & -06 & $54 E-06$ \\
\hline $94 \mathrm{~F}-$ & $6.33 E-06$ & 1. $38 \mathrm{E}-06$ & & $79 \mathrm{~F}$ & & 6 & $54 \mathrm{E}-06$ \\
\hline$F-08$ & 6 & $1.38 E-06$ & 6 & 6 & 6 & 6 & -06 \\
\hline $99 F-08$ & $6.32 F-06$ & $138 F-06$ & $1.12 \mathrm{E}-06$ & $9 E-06$ & $8 E-06$ & $E-06$ & $E-06$ \\
\hline $.00 \mathrm{E}-07$ & $2 E-06$ & 6 & & & & & -06 \\
\hline $.01 \mathrm{E}-07$ & $6.32 \mathrm{E}-06$ & $1.39 \mathrm{E}-06$ & 1. $13 \mathrm{E}-06$ & $2.79 E-06$ & $3.38 \mathrm{E}-06$ & $3.86 \mathrm{E}-06$ & $53 E-06$ \\
\hline $.01 E-07$ & 06 & -06 & 06 & & & -06 & $E-06$ \\
\hline 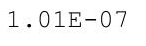 & & & & & & & 06 \\
\hline 015 & & 6 & 6 & 6 & 6 & $3.86 E-06$ & -06 \\
\hline $02 F-07$ & $31 \mathrm{~F}$ & -0 & $3 E-06$ & 6 & 6 & 6 & -06 \\
\hline $02 \mathrm{E}-07$ & $.30 \mathrm{E}-06$ & 1. $39 F-06$ & $3 E-06$ & $0 E-06$ & -06 & -06 & $2 E-06$ \\
\hline $.02 E-07$ & $.30 \mathrm{E}-06$ & $1.39 \mathrm{E}-06$ & $1.14 \mathrm{E}-06$ & $.80 \mathrm{E}-06$ & $.39 E-06$ & -06 & $.51 E-06$ \\
\hline $3 E-07$ & 06 & -06 & 06 & -06 & -06 & -06 & $E-06$ \\
\hline & & & & & & & \\
\hline $03 E-07$ & & 1. $40 E-06$ & & & & & 06 \\
\hline $03 E-07$ & 06 & $.40 \mathrm{E}-06$ & $110 \mathrm{~B}$ - & 6 & 6 & & -06 \\
\hline $04 \mathrm{~F}-07$ & $.29 E-06$ & $1.40 E-06$ & $1.14 \mathrm{E}-06$ & $30 E-06$ & $9 E-06$ & $7 E-06$ & $0 E-06$ \\
\hline $4=-07$ & $.29 E-06$ & $1.40 \mathrm{E}-06$ & 1. $15 \mathrm{E}-06$ & $80 E-06$ & $39 E-06$ & $7 E-06$ & $50 E-06$ \\
\hline$F-07$ & $6.29 F-06$ & & & & & & $0 E-06$ \\
\hline & & & & & & & \\
\hline & & & & & & & $.50 E-06$ \\
\hline $.05 E-07$ & $6.28 E-06$ & $1.40 \mathrm{E}-06$ & $1.15 \mathrm{E}-06$ & $2.80 \mathrm{E}-06$ & $3.40 \mathrm{E}-06$ & $6 E-06$ & $4 \mathrm{E}-06$ \\
\hline 7 & $28 E-06$ & $1.41 E-06$ & $1.15 \mathrm{E}-06$ & $.80 E-06$ & $.40 E-06$ & $3.86 \mathrm{E}-06$ & $.49 E-06$ \\
\hline 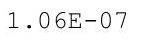 & $.27 E-06$ & $1.41 \mathrm{E}-06$ & $1.15 \mathrm{E}-06$ & $.80 E-06$ & & $6 E-06$ & $.49 E-06$ \\
\hline 0 & & & & & & & $E-06$ \\
\hline $.06 E-07$ & 6 & & & & & & \\
\hline & 06 & 1.41 & & 6 & & & -06 \\
\hline . $01 \mathrm{~L}-\mathrm{T}$ & $6.26 \mathrm{E}-06$ & $1.41 \mathrm{E}-06$ & $1.16 \mathrm{E}-06$ & $2.80 \mathrm{E}-06$ & $3.40 \mathrm{E}-06$ & $3.86 \mathrm{E}-06$ & $4.48 E-06$ \\
\hline .010 & $6.26 \mathrm{E}-06$ & $1.4 \perp E-06$ & $1.16 \mathrm{E}-06$ & & & $3.85 E-06$ & $4.48 E-06$ \\
\hline 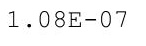 & 6 & 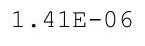 & 6 & 6 & & 6 & $48 E-06$ \\
\hline $.08 E-07$ & $6.25 E-06$ & $1.41 \mathrm{E}-06$ & 5 & 6 & 6 & 6 & 06 \\
\hline $.08 E-07$ & & 6 & & 6 & 6 & 6 & \\
\hline $9 F-07$ & $25 E-06$ & 1 . & & -06 & -06 & -06 & $4.47 E-06$ \\
\hline $.09 \mathrm{E}-07$ & $25 E-06$ & $1.42 \mathrm{E}$ & 06 & 6 & & 06 & $47 E-06$ \\
\hline 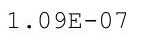 & & $1.42 \mathrm{E}-06$ & & & & & $4.47 E-06$ \\
\hline 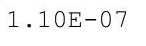 & $0.24+00$ & $\perp \cdot 4 \angle \dot{1}-00$ & $1.17 \mathrm{E}-06$ & $2.81 E-06$ & $3.41 E-06$ & $5 E-06$ & $4.40 \pm-00$ \\
\hline 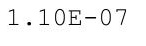 & & म. & $1.17 \mathrm{E}-06$ & & & $3.85 E-06$ & $4.46 E-06$ \\
\hline & & & & & $.42 E-06$ & & $4.46 \mathrm{E}-06$ \\
\hline-07 & -06 & $.42 E-06$ & $E-06$ & -06 & -06 & $E-06$ & $4.46 E-06$ \\
\hline
\end{tabular}


RESRAD-OFFSITE, Version 2.5

Title : Offsite Resident Farmer Deterministic Run

File : RF TC99 DOESG FWD-FV2b.ROF

Summary of dose at graphical times, reptition 3 (continued)

Time

Years

$9.20 \mathrm{E}+02$

$9.20 \mathrm{E}+02$

$9.21 \mathrm{E}+02$

$9.21 \mathrm{E}+02$

$9.22 \mathrm{E}+02$

$9.22 \mathrm{E}+02$

$9.23 \mathrm{E}+02$

$9.23 \mathrm{E}+02$

$9.24 \mathrm{E}+02$

$9.24 \mathrm{E}+02$

$9.25 \mathrm{E}+02$

$9.25 \mathrm{E}+02$

$9.26 \mathrm{E}+02$

$9.26 \mathrm{E}+02$

$9.27 \mathrm{E}+02$

$9.27 \mathrm{E}+02$

$9.28 \mathrm{E}+02$

$9.28 \mathrm{E}+02$

$9.29 \mathrm{E}+02$

9. $30 \mathrm{E}+02$

$9.30 \mathrm{E}+02$

9. $31 \mathrm{E}+02$

9. $31 \mathrm{E}+02$

9. $32 \mathrm{E}+02$

9. $32 \mathrm{E}+02$

$9.33 \mathrm{E}+02$

9. $33 \mathrm{E}+02$

$9.34 \mathrm{E}+02$

9. $34 \mathrm{E}+02$

9. $35 \mathrm{E}+02$

9. $35 \mathrm{E}+02$

9. $36 \mathrm{E}+02$

9. $36 \mathrm{E}+02$

9. $37 \mathrm{E}+02$

9. $37 \mathrm{E}+02$

$9.38 \mathrm{E}+02$

$9.38 \mathrm{E}+02$

$9.39 \mathrm{E}+02$

9. $39 \mathrm{E}+02$

$9.40 \mathrm{E}+02$

$9.40 \mathrm{E}+02$

$9.41 \mathrm{E}+02$

$9.41 \mathrm{E}+02$

$9.42 \mathrm{E}+02$

9. $42 \mathrm{E}+02$

$9.43 \mathrm{E}+02$
Dose statistics at graphical times, mrem/yr

\begin{tabular}{|c|c|c|c|c|c|c|c|}
\hline m & aximum & ea & 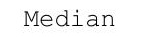 & & & & \\
\hline 07 & $6.23 E-06$ & 1. $42 \mathrm{E}-06$ & $1.18 \mathrm{E}-06$ & $82 E-06$ & . & $3.86 \mathrm{E}-06$ & $4.4 J E-06$ \\
\hline $.11 \mathrm{E}-07$ & $6.23 E-06$ & $1.43 \mathrm{E}-06$ & $1.18 \mathrm{E}-06$ & $2.82 E-06$ & $42 E-06$ & $3.86 \mathrm{E}-06$ & $5 E-06$ \\
\hline $.11 \mathrm{E}-07$ & $6.22 \mathrm{E}-06$ & 1. $43 \mathrm{E}-06$ & $1.18 \mathrm{E}-06$ & $2.82 \mathrm{E}-06$ & $3.43 E-06$ & $3.86 \mathrm{E}-06$ & $.45 E-06$ \\
\hline $12 \mathrm{~F}-07$ & $22 E-06$ & $3 F-06$ & $18 \mathrm{E}-06$ & $.82 \mathrm{E}-06$ & $43 F-06$ & $86 F-06$ & $.45 E-06$ \\
\hline $12 F-07$ & $22 E-06$ & 6 & -06 & 6 & 6 & -06 & -06 \\
\hline 07 & $6.22 \mathrm{E}$ & & & & & & \\
\hline $13 E-07$ & $6.21 E-06$ & 6 & & & & & -06 \\
\hline $.13 E-07$ & 06 & 6 & 06 & 6 & 6 & -06 & -06 \\
\hline $.13 E-07$ & -06 & $.43 E-06$ & -06 & $83 E-06$ & -06 & -06 & $E-06$ \\
\hline $4 E-07$ & $21 E-06$ & $3 F-06$ & $19 E-06$ & $83 E-06$ & קכ & م5 & $43 E-06$ \\
\hline $14 \mathrm{E}-07$ & & 1 & & & & 6 & $E-06$ \\
\hline $14 \mathrm{E}-07$ & $6.20 E-06$ & $1.44 \mathrm{~F}$ & 1 . & 6 & 6 & 6 & -06 \\
\hline $.15 \mathrm{E}-07$ & $6.20 E-06$ & $1.44 \mathrm{E}-06$ & $1.20 \mathrm{E}-06$ & & $3.42 E-06$ & $3.86 \mathrm{E}-06$ & $.42 E-06$ \\
\hline $15 E-07$ & $6.19 \mathrm{E}-06$ & $1.44 \mathrm{E}-06$ & 1.20E-06 & $2.83 E-06$ & $3.42 \mathrm{E}-06$ & -06 & $E-06$ \\
\hline-07 & -06 & 06 & 6 & -06 & 10 & -06 & $42 E-06$ \\
\hline 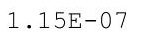 & -06 & - & 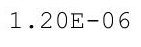 & 0 & & 0 & 06 \\
\hline 7 & 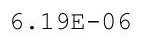 & & & & & & 6 \\
\hline $16 \mathrm{E}-07$ & 6 & $1.44 \mathrm{E}-06$ & 1.21E-06 & 6 & 6 & 6 & 06 \\
\hline $.16 E-07$ & $6.18 \mathrm{E}-06$ & $1.44 \mathrm{E}-06$ & $1.21 \mathrm{E}-06$ & $2.83 E-06$ & $3.42 E-06$ & $3.85 E-06$ & $.41 E-06$ \\
\hline $17 E-07$ & $.18 E-06$ & $1.45 \mathrm{E}-06$ & 1.21E-06 & $2.83 E-06$ & $.42 E-06$ & $E-06$ & 4. $41 E-06$ \\
\hline 07 & 06 & & & & & 6 & -06 \\
\hline 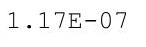 & & & & 6 & 6 & 6 & \\
\hline 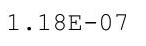 & & $\perp$ & & & 6 & & 06 \\
\hline $8 E-07$ & 6 & 0 & 1. & 6 & 6 & 0 & -06 \\
\hline בת & $16 \mathrm{E}-06$ & 5 & 1 & 䧄 & $42 \mathrm{E}-$ & 6 & 06 \\
\hline $19 F-07$ & $16 F-06$ & $F-06$ & $E-06$ & $84 \mathrm{E}-06$ & $41 E-06$ & $.85 E-06$ & $.39 E-06$ \\
\hline-07 & $6.16 \mathrm{E}-06$ & -06 & & & $41 E-06$ & $E-06$ & $39 E-06$ \\
\hline & & & & & & & \\
\hline & & 1.4 & 06 & 06 & 6 & 06 & -06 \\
\hline $.200-01$ & $6.15 E-06$ & $1.40 \pm-00$ & $1.22 \mathrm{E}-06$ & $2.84 E-06$ & $3.42 E-06$ & $3.04 E-00$ & $4.38 E-06$ \\
\hline $20 E-07$ & $6.14 \mathrm{E}-06$ & $1.405-00$ & 1. $22 \mathrm{E}-06$ & $2.84 \mathrm{E}-06$ & $.42 \mathrm{E}-06$ & $.045-00$ & $.38 E-06$ \\
\hline $21 E-0$ & & 1. & & & חרקו & 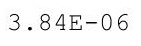 & 6 \\
\hline 07 & & & & & & & 6 \\
\hline 7 & & & & & & & \\
\hline $22 \mathrm{E}-07$ & $6.13 E-06$ & $1.46 \mathrm{E}-06$ & 1. $23 \mathrm{E}-06$ & 2.005 & 6 & 06 & -06 \\
\hline • $2 \angle E-U 1$ & $6.13 E-06$ & $1.46 \mathrm{E}-06$ & 1.23E-06 & $2.85 E-06$ & -06 & -06 & $.36 E-06$ \\
\hline $\begin{array}{ll}2 \\
1\end{array}$ & & $1.46 \mathrm{E}-06$ & & & $3.4 \angle D-00$ & $3.00 \mathrm{H}$ & $4.500-00$ \\
\hline $22-401$ & 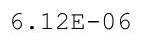 & $1.46 \mathrm{E}-06$ & $1.23 \mathrm{E}-06$ & & 6 & 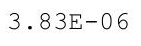 & $36 E-06$ \\
\hline 7 & 6 & $1.47 \mathrm{E}-06$ & 5 & 6 & 6 & 6 & 06 \\
\hline $.23 E-07$ & & & & & 6 & 6 & 06 \\
\hline $3 E-07$ & $6.11 E-06$ & 1. & 06 & & 6 & 06 & -06 \\
\hline $4 \mathrm{E}-07$ & 6 & $1 \cdot$ & & & 6 & & \\
\hline & & & & & & & $4.35 E-06$ \\
\hline $245-1$ & $6.10 \mathrm{E}-06$ & $1.4 / \mathrm{L}-00$ & $1.24 E-06$ & $2.86 \mathrm{E}-06$ & $3.42 E-06$ & $3.8 \angle E-06$ & $4.34 \mathrm{E}-06$ \\
\hline $25 E-07$ & $0.10 \mathrm{~L}-0$ & $1.4 / 2-00$ & $1.25 E-00$ & $2.86 \mathrm{E}-06$ & 3.924 & & 1.010 \\
\hline $25 E-07$ & $.10 E-06$ & $.47 \mathrm{E}-06$ & $.25 E-06$ & $.86 \mathrm{E}-06$ & .411 & $2 E-06$ & $4.34 \mathrm{E}-06$ \\
\hline
\end{tabular}


RESRAD-OFFSITE, Version 2.5

Title : Offsite Resident Farmer Deterministic Run

File : RF TC99 DOESG FWD-FV2b.ROF

Summary of dose at graphical times, reptition 3 (continued)

Time

Years

$9.43 \mathrm{E}+02$

$9.44 \mathrm{E}+02$

$9.44 \mathrm{E}+02$

9. $45 \mathrm{E}+02$

$9.45 \mathrm{E}+02$

$9.46 \mathrm{E}+02$

$9.46 \mathrm{E}+02$

$9.47 \mathrm{E}+02$

$9.47 \mathrm{E}+02$

$9.48 \mathrm{E}+02$

$9.48 \mathrm{E}+02$

$9.49 \mathrm{E}+02$

$9.50 \mathrm{E}+02$

$9.50 \mathrm{E}+02$

$9.51 \mathrm{E}+02$

$9.51 \mathrm{E}+02$

$9.52 \mathrm{E}+02$

9. $52 \mathrm{E}+02$

$9.53 \mathrm{E}+02$

$9.53 \mathrm{E}+02$

$9.54 \mathrm{E}+02$

$9.54 \mathrm{E}+02$

$9.55 \mathrm{E}+02$

$9.55 \mathrm{E}+02$

$9.56 \mathrm{E}+02$

$9.56 \mathrm{E}+02$

$9.57 \mathrm{E}+02$

$9.57 \mathrm{E}+02$

$9.58 \mathrm{E}+02$

$9.58 \mathrm{E}+02$

$9.59 \mathrm{E}+02$

$9.59 \mathrm{E}+02$

9. $60 \mathrm{E}+02$

$9.60 \mathrm{E}+02$

9. $61 \mathrm{E}+02$

$9.61 \mathrm{E}+02$

9. $62 \mathrm{E}+02$

$9.62 \mathrm{E}+02$

$9.63 \mathrm{E}+02$

$9.63 \mathrm{E}+02$

$9.64 \mathrm{E}+02$

$9.64 \mathrm{E}+02$

$9.65 \mathrm{E}+02$

$9.65 \mathrm{E}+02$

$9.66 \mathrm{E}+02$

$9.66 \mathrm{E}+02$
Dose statistics at graphical times, mrem/yr

\begin{tabular}{|c|c|c|c|c|c|c|c|}
\hline m & am & a & 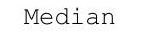 & & & $\%$ & \\
\hline 07 & 06 & $1.47 \mathrm{E}-06$ & $1.25 \mathrm{E}-06$ & $2.86 \mathrm{E}-06$ & -06 & -06 & -00 \\
\hline $26 \mathrm{E}-07$ & $6.09 \mathrm{E}-06$ & $E-06$ & $25 E-06$ & 6 & 6 & 6 & -06 \\
\hline $.26 \mathrm{E}-07$ & $6.09 \mathrm{E}-06$ & 1. $48 \mathrm{E}-06$ & $.25 E-06$ & $2.86 \mathrm{E}-06$ & $3.41 \mathrm{E}-06$ & $3.82 \mathrm{E}-06$ & $.34 \mathrm{E}-06$ \\
\hline $26 \mathrm{E}-07$ & $6.08 E-06$ & $.48 E-06$ & $1.25 \mathrm{E}-06$ & $2.86 \mathrm{E}-06$ & $3.41 \mathrm{E}-06$ & $3.82 \mathrm{E}-06$ & $.34 \mathrm{E}-06$ \\
\hline $27 E-07$ & $08 E-06$ & $1.48 \mathrm{E}-06$ & $1.25 \mathrm{E}-06$ & $.86 \mathrm{E}-06$ & $41 \mathrm{E}-06$ & $3.83 E-06$ & -06 \\
\hline $27 E-07$ & -06 & 1 & -06 & 6 & 6 & 6 & -06 \\
\hline $27 E-07$ & 06 & $1.48 \mathrm{E}$ & & 6 & & & -06 \\
\hline $.28 E-07$ & & 06 & & & & & -06 \\
\hline $.28 E-07$ & -06 & -06 & -06 & 06 & -06 & -06 & -06 \\
\hline $28 \mathrm{E}-0$ & 06 & $1.48 \mathrm{E}-06$ & 6 & 6 & 6 & 6 & -06 \\
\hline$F-07$ & 6 & 1 & $1.26 \mathrm{E}-06$ & 6 & 6 & 6 & -06 \\
\hline $29 \mathrm{E}-07$ & 6 & 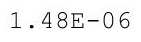 & & 6 & & & -06 \\
\hline $29 \mathrm{E}-07$ & $E-06$ & $1.49 \mathrm{E}-06$ & 1. & 6 & 6 & 6 & -06 \\
\hline $.30 \mathrm{E}-07$ & $6.05 E-06$ & $1.49 \mathrm{E}-06$ & $1.27 \mathrm{E}-06$ & $2.87 \mathrm{E}-06$ & $3.41 \mathrm{E}-06$ & $3.84 \mathrm{E}-06$ & . $33 E-06$ \\
\hline $30 E-07$ & -06 & $9 E-06$ & $E-06$ & $87 E-06$ & 06 & -06 & -06 \\
\hline 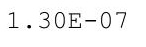 & & $1.49 \mathrm{E}-06$ & & & & & -06 \\
\hline 31 & & 0 & 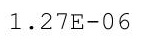 & & & & -06 \\
\hline $31 \mathrm{E}-$ & & 1. $49 \mathrm{E}-06$ & & & $41 E-06$ & & 6 \\
\hline $31 E-07$ & $6.04 \mathrm{E}-06$ & $1.9 F-0$ & $1.28 \mathrm{E}-06$ & 6 & 6 & 6 & -06 \\
\hline $32 E-07$ & $6.03 E-06$ & 1. $49 \mathrm{E}-06$ & $8 E-06$ & $.87 E-06$ & $.41 E-06$ & -06 & $.33 E-06$ \\
\hline $32 E-07$ & $.03 E-06$ & 1. $49 \mathrm{E}-06$ & -06 & $.87 E-06$ & 6 & -8 & $.33 E-06$ \\
\hline 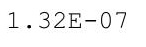 & & & & & & & -06 \\
\hline & & 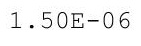 & & & & & \\
\hline $33 E-07$ & 0 & 1.00 & 1.2 & & 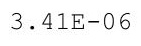 & & -06 \\
\hline 7 & 6 & 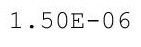 & 0 & 6 & 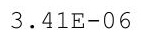 & $3.84 \mathrm{E}-06$ & -06 \\
\hline $34 E-07$ & $.01 E-06$ & $1.50 \mathrm{E}-06$ & 1.29E-06 & $.87 E-06$ & $15=$ & $\Delta F-0$ & $33 E-06$ \\
\hline $5-07-1-2 \cdot$ & $01 F-06$ & $F-06$ & $E-06$ & $.87 E-06$ & 11 & $5-06$ & $F-06$ \\
\hline-07 & & & & & & & 06 \\
\hline $.350-01$ & & 0 & & & & & \\
\hline $.220-01$ & $6.00 E-06$ & $1.30 \pm-06$ & 1.29E-06 & $2.87 E-06$ & 0.12 & 06 & -06 \\
\hline e. & $6.00 E-06$ & $1.30 \mathrm{~m}-0$ & $1.29 \mathrm{E}-06$ & $2.87 \mathrm{E}-06$ & $3.42 E-06$ & $3.04 \mathrm{E}-0 \mathrm{O}$ & $.33 E-06$ \\
\hline 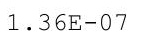 & 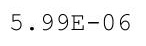 & 土. & . & $2.01 \mathrm{~L}-0$ & . & 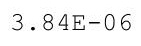 & $4.32 E-06$ \\
\hline 365 & $E-06$ & $1.50 \mathrm{E}-06$ & 1.3 & תרת ת & & & $E-06$ \\
\hline$F=0$ & 0 & & & & & & 06 \\
\hline 7 & & & & 6 & 6 & & -06 \\
\hline $37 E-07$ & $5.98 \mathrm{E}-06$ & $1.51 \mathrm{E}-06$ & $1.30 \mathrm{E}-06$ & $2.00 \mathrm{~L}$ & 3.421 & 06 & -06 \\
\hline 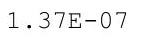 & 06 & 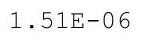 & $1 \cdots$ & & & & -06 \\
\hline (1) & & & & & & & . $.35=-00$ \\
\hline $38 F-07$ & & + & 6 & 6 & 6 & 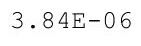 & 06 \\
\hline $.38 E-07$ & & & & & & & 6 \\
\hline 7 & 6 & 1 . & 1. & 6 & 6 & 6 & -06 \\
\hline $9 E-07$ & $5.96 \mathrm{E}-06$ & 1.5 & $1 \cdot 3$ & 06 & 6 & 06 & -06 \\
\hline & & & & & & & \\
\hline & & & & & & & $4.33 E-06$ \\
\hline 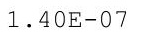 & & $+\cdots$ & $+\cdots$ & 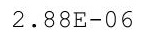 & 6 & & $20-20$ \\
\hline$E-07$ & $4 E-06$ & $2 E-06$ & $31 E-06$ & $3-06$ & $E-06$ & $4 E-06$ & -06 \\
\hline
\end{tabular}


RESRAD-OFFSITE, Version 2.5

Title : Offsite Resident Farmer Deterministic Run

File : RF TC99 DOESG FWD-FV2b.ROF

Summary of dose at graphical times, reptition 3 (continued)

Time

Years

$9.67 \mathrm{E}+02$

$9.67 \mathrm{E}+02$

$9.68 \mathrm{E}+02$

$9.68 \mathrm{E}+02$

$9.69 \mathrm{E}+02$

$9.70 \mathrm{E}+02$

$9.70 \mathrm{E}+02$

$9.71 \mathrm{E}+02$

$9.71 \mathrm{E}+02$

$9.72 \mathrm{E}+02$

$9.72 \mathrm{E}+02$

$9.73 \mathrm{E}+02$

$9.73 \mathrm{E}+02$

$9.74 \mathrm{E}+02$

$9.74 \mathrm{E}+02$

$9.75 \mathrm{E}+02$

$9.75 \mathrm{E}+02$

$9.76 \mathrm{E}+02$

$9.76 \mathrm{E}+02$

$9.77 \mathrm{E}+02$

$9.77 \mathrm{E}+02$

$9.78 \mathrm{E}+02$

9. $78 \mathrm{E}+02$

$9.79 \mathrm{E}+02$

$9.79 \mathrm{E}+02$

$9.80 \mathrm{E}+02$

$9.80 \mathrm{E}+02$

$9.81 \mathrm{E}+02$

9. $81 \mathrm{E}+02$

9. $82 \mathrm{E}+02$

9. $82 \mathrm{E}+02$

$9.83 \mathrm{E}+02$

$9.83 \mathrm{E}+02$

$9.84 \mathrm{E}+02$

$9.84 \mathrm{E}+02$

$9.85 \mathrm{E}+02$

$9.85 \mathrm{E}+02$

$9.86 \mathrm{E}+02$

$9.86 \mathrm{E}+02$

$9.87 \mathrm{E}+02$

$9.87 \mathrm{E}+02$

$9.88 \mathrm{E}+02$

$9.88 \mathrm{E}+02$

$9.89 \mathrm{E}+02$

$9.90 \mathrm{E}+02$

$9.90 \mathrm{E}+02$
Dose statistics at graphical times, mrem/yr

\begin{tabular}{|c|c|c|c|c|c|c|c|}
\hline Minimum & Maximum & Mean & Median & $90 \%$ & $95 \%$ & $97.5 \%$ & $99 \%$ \\
\hline $1.41 \mathrm{E}-07$ & $5.94 \mathrm{E}-06$ & $1.52 E-06$ & $1.31 \mathrm{E}-06$ & $2.88 E-06$ & $3.43 E-06$ & $3.84 E-06$ & $4.32 E-06$ \\
\hline $1.41 \mathrm{E}-07$ & $5.94 \mathrm{E}-06$ & $1.52 \mathrm{E}-06$ & $1.31 \mathrm{E}-06$ & $2.88 \mathrm{E}-06$ & $3.43 E-06$ & $3.84 \mathrm{E}-06$ & $4.32 E-06$ \\
\hline 1. $42 \mathrm{E}-07$ & $5.93 E-06$ & $1.52 \mathrm{E}-06$ & 1. $32 \mathrm{E}-06$ & $2.88 \mathrm{E}-06$ & $3.43 E-06$ & $3.84 \mathrm{E}-06$ & $4.32 \mathrm{E}-06$ \\
\hline $1.42 \mathrm{E}-07$ & $5.93 \mathrm{E}-06$ & $1.52 \mathrm{E}-06$ & $1.32 \mathrm{E}-06$ & $2.88 \mathrm{E}-06$ & $3.43 E-06$ & $3.84 \mathrm{E}-06$ & $4.32 \mathrm{E}-06$ \\
\hline $1.42 \mathrm{E}-07$ & $5.93 E-06$ & $1.52 \mathrm{E}-06$ & $1.32 \mathrm{E}-06$ & $2.88 \mathrm{E}-06$ & $3.43 E-06$ & $3.84 \mathrm{E}-06$ & $4.32 E-06$ \\
\hline $1.43 E-07$ & $5.92 \mathrm{E}-06$ & $1.52 \mathrm{E}-06$ & $1.32 \mathrm{E}-06$ & $2.88 \mathrm{E}-06$ & $3.43 E-06$ & $3.84 \mathrm{E}-06$ & $.32 E-06$ \\
\hline $1.43 E-07$ & $5.92 \mathrm{E}-06$ & $1.52 \mathrm{E}-06$ & $1.32 \mathrm{E}-06$ & $2.88 \mathrm{E}-06$ & $3.43 E-06$ & $3.84 \mathrm{E}-06$ & $4.32 E-06$ \\
\hline $1.43 \mathrm{E}-07$ & $5.91 \mathrm{E}-06$ & $1.52 \mathrm{E}-06$ & $1.32 \mathrm{E}-06$ & $2.89 \mathrm{E}-06$ & $3.42 \mathrm{E}-06$ & $3.84 \mathrm{E}-06$ & 4. $32 \mathrm{E}-06$ \\
\hline 1. $44 \mathrm{E}-07$ & $5.91 \mathrm{E}-06$ & $1.53 E-06$ & $1.32 \mathrm{E}-06$ & $2.89 \mathrm{E}-06$ & $3.42 \mathrm{E}-06$ & $3.84 \mathrm{E}-06$ & $.32 E-06$ \\
\hline $1.44 \mathrm{E}-07$ & $5.91 \mathrm{E}-06$ & $1.53 E-06$ & 1. $32 \mathrm{E}-06$ & $2.89 \mathrm{E}-06$ & $3.42 E-06$ & $3.84 \mathrm{E}-06$ & $.32 E-06$ \\
\hline $1.44 \mathrm{E}-07$ & $5.90 \mathrm{E}-06$ & $1.53 \mathrm{E}-06$ & $1.32 \mathrm{E}-06$ & $2.89 E-06$ & $3.42 \mathrm{E}-06$ & $3.84 \mathrm{E}-06$ & $.32 E-06$ \\
\hline 1. $45 \mathrm{E}-07$ & $5.90 \mathrm{E}-06$ & $1.53 E-06$ & $1.33 E-06$ & $2.89 E-06$ & $3.41 \mathrm{E}-06$ & $3.84 \mathrm{E}-06$ & $4.31 \mathrm{E}-06$ \\
\hline $1.45 E-07$ & $5.90 \mathrm{E}-06$ & $1.53 E-06$ & $1.33 E-06$ & $2.88 E-06$ & $3.41 E-06$ & $3.84 \mathrm{E}-06$ & $4.31 \mathrm{E}-06$ \\
\hline $1.45 \mathrm{E}-07$ & $5.89 \mathrm{E}-06$ & $1.53 \mathrm{E}-06$ & $1.33 \mathrm{E}-06$ & $2.88 \mathrm{E}-06$ & $3.41 \mathrm{E}-06$ & $3.84 \mathrm{E}-06$ & 4. $31 E-06$ \\
\hline 1. $46 \mathrm{E}-07$ & $5.89 \mathrm{E}-06$ & $1.53 E-06$ & $1.33 E-06$ & $2.88 E-06$ & $3.41 \mathrm{E}-06$ & $3.84 \mathrm{E}-06$ & 4. $31 \mathrm{E}-06$ \\
\hline $1.46 \mathrm{E}-07$ & $5.89 \mathrm{E}-06$ & $1.53 E-06$ & $1.33 E-06$ & $2.89 E-06$ & $3.41 E-06$ & $3.84 \mathrm{E}-06$ & $.31 E-06$ \\
\hline $1.46 \mathrm{E}-07$ & $5.88 \mathrm{E}-06$ & $1.53 E-06$ & $1.33 \mathrm{E}-06$ & $2.89 \mathrm{E}-06$ & $3.41 \mathrm{E}-06$ & $3.85 \mathrm{E}-06$ & $.30 E-06$ \\
\hline $1.47 \mathrm{E}-07$ & $5.88 E-06$ & $1.53 E-06$ & $1.33 E-06$ & $2.89 \mathrm{E}-06$ & $3.41 \mathrm{E}-06$ & $3.85 E-06$ & $.30 E-06$ \\
\hline 1. $47 \mathrm{E}-07$ & $5.87 \mathrm{E}-06$ & $1.53 E-06$ & $1.33 E-06$ & $2.89 E-06$ & $3.41 \mathrm{E}-06$ & $3.85 \mathrm{E}-06$ & $4.30 \mathrm{E}-06$ \\
\hline 1. $48 \mathrm{E}-07$ & $5.87 \mathrm{E}-06$ & $1.54 \mathrm{E}-06$ & $1.34 \mathrm{E}-06$ & $2.89 \mathrm{E}-06$ & $3.40 \mathrm{E}-06$ & $3.85 \mathrm{E}-06$ & $4.30 \mathrm{E}-06$ \\
\hline $1.48 \mathrm{E}-07$ & $5.87 \mathrm{E}-06$ & $1.54 \mathrm{E}-06$ & $1.34 \mathrm{E}-06$ & $2.89 \mathrm{E}-06$ & $3.40 \mathrm{E}-06$ & $3.85 E-06$ & $4.29 \mathrm{E}-06$ \\
\hline $1.48 \mathrm{E}-07$ & $5.86 \mathrm{E}-06$ & $1.54 \mathrm{E}-06$ & $1.34 \mathrm{E}-06$ & $2.89 E-06$ & $3.40 E-06$ & $3.85 E-06$ & $.29 E-06$ \\
\hline $1.49 \mathrm{E}-07$ & $5.86 \mathrm{E}-06$ & $1.54 \mathrm{E}-06$ & $1.34 \mathrm{E}-06$ & $2.89 \mathrm{E}-06$ & $3.39 E-06$ & $3.85 E-06$ & $4.29 E-06$ \\
\hline $1.49 \mathrm{E}-07$ & $5.86 \mathrm{E}-06$ & $1.54 \mathrm{E}-06$ & $1.34 \mathrm{E}-06$ & $2.89 \mathrm{E}-06$ & $3.39 \mathrm{E}-06$ & $3.85 \mathrm{E}-06$ & $4.29 \mathrm{E}-06$ \\
\hline $1.49 \mathrm{E}-07$ & $5.85 E-06$ & $1.54 \mathrm{E}-06$ & $1.34 \mathrm{E}-06$ & $2.89 E-06$ & $3.39 E-06$ & $3.85 E-06$ & $.29 E-06$ \\
\hline $1.50 \mathrm{E}-07$ & $5.85 \mathrm{E}-06$ & $1.54 \mathrm{E}-06$ & $1.34 \mathrm{E}-06$ & $2.89 \mathrm{E}-06$ & $3.39 \mathrm{E}-06$ & $3.85 \mathrm{E}-06$ & $4.29 E-06$ \\
\hline $1.50 \mathrm{E}-07$ & $5.84 \mathrm{E}-06$ & $1.54 \mathrm{E}-06$ & $1.35 \mathrm{E}-06$ & $2.90 \mathrm{E}-06$ & $3.38 \mathrm{E}-06$ & $3.85 \mathrm{E}-06$ & $4.29 \mathrm{E}-06$ \\
\hline $1.50 \mathrm{E}-07$ & $5.84 \mathrm{E}-06$ & $1.54 \mathrm{E}-06$ & $1.35 \mathrm{E}-06$ & $2.90 \mathrm{E}-06$ & $3.38 E-06$ & $3.85 E-06$ & $4.29 E-06$ \\
\hline $1.51 \mathrm{E}-07$ & $5.84 \mathrm{E}-06$ & $1.54 \mathrm{E}-06$ & $1.35 \mathrm{E}-06$ & $2.90 \mathrm{E}-06$ & $3.38 \mathrm{E}-06$ & $3.85 \mathrm{E}-06$ & $4.29 \mathrm{E}-06$ \\
\hline $1.51 \mathrm{E}-07$ & $5.83 E-06$ & $1.54 \mathrm{E}-06$ & $1.35 \mathrm{E}-06$ & $2.90 \mathrm{E}-06$ & $3.37 E-06$ & $3.85 E-06$ & $4.28 E-06$ \\
\hline $1.51 \mathrm{E}-07$ & $5.83 E-06$ & $1.55 E-06$ & $1.35 \mathrm{E}-06$ & $2.90 \mathrm{E}-06$ & $3.37 \mathrm{E}-06$ & $3.85 \mathrm{E}-06$ & $4.28 \mathrm{E}-06$ \\
\hline $1.52 \mathrm{E}-07$ & $5.83 E-06$ & 1. $55 \mathrm{E}-06$ & $1.35 \mathrm{E}-06$ & $2.90 \mathrm{E}-06$ & $3.37 E-06$ & $3.85 E-06$ & $4.28 \mathrm{E}-06$ \\
\hline $1.52 \mathrm{E}-07$ & $5.82 E-06$ & $1.55 E-06$ & $1.35 \mathrm{E}-06$ & $2.90 \mathrm{E}-06$ & $3.37 E-06$ & $3.85 E-06$ & $4.28 E-06$ \\
\hline $1.52 \mathrm{E}-07$ & $5.82 \mathrm{E}-06$ & $1.55 \mathrm{E}-06$ & $1.35 \mathrm{E}-06$ & $2.90 \mathrm{E}-06$ & $3.36 E-06$ & $3.85 E-06$ & $4.28 E-06$ \\
\hline $1.53 \mathrm{E}-07$ & $5.81 \mathrm{E}-06$ & $1.55 E-06$ & $1.35 \mathrm{E}-06$ & $2.90 \mathrm{E}-06$ & $3.36 \mathrm{E}-06$ & $3.84 \mathrm{E}-06$ & $4.27 E-06$ \\
\hline $1.53 \mathrm{E}-07$ & $5.81 \mathrm{E}-06$ & 1. $55 E-06$ & $1.36 \mathrm{E}-06$ & $2.90 \mathrm{E}-06$ & $3.36 E-06$ & $3.84 \mathrm{E}-06$ & $4.27 E-06$ \\
\hline $1.53 \mathrm{E}-07$ & $5.81 \mathrm{E}-06$ & 1. 55E-06 & $1.36 \mathrm{E}-06$ & $2.90 \mathrm{E}-06$ & $3.36 \mathrm{E}-06$ & $3.84 \mathrm{E}-06$ & $4.27 E-06$ \\
\hline $1.54 \mathrm{E}-07$ & $5.80 \mathrm{E}-06$ & $1.55 \mathrm{E}-06$ & $1.36 \mathrm{E}-06$ & $2.90 \mathrm{E}-06$ & $3.35 E-06$ & $3.84 \mathrm{E}-06$ & $4.27 \mathrm{E}-06$ \\
\hline $4 E-07$ & 6 & 6 & $1.36 \mathrm{E}$ & $2.90 \mathrm{E}-06$ & $3.35 E-06$ & $3.84 \mathrm{E}-06$ & $4.27 E-06$ \\
\hline $1.54 \mathrm{E}-07$ & $5.80 \mathrm{E}-06$ & $1.55 \mathrm{E}-06$ & $1.36 \mathrm{E}-06$ & $2.90 \mathrm{E}-06$ & $3.35 E-06$ & $3.84 \mathrm{E}-06$ & $4.27 E-06$ \\
\hline $1.55 \mathrm{E}-07$ & $5.79 \mathrm{E}-06$ & $1.55 E-06$ & $1.36 \mathrm{E}-06$ & $2.90 \mathrm{E}-06$ & $3.35 E-06$ & $3.84 \mathrm{E}-06$ & $4.27 \mathrm{E}-06$ \\
\hline $1.55 \mathrm{E}-07$ & $5.79 E-06$ & $1.56 \mathrm{E}-06$ & $1.36 \mathrm{E}-06$ & $2.90 \mathrm{E}-06$ & $3.35 E-06$ & $3.84 E-06$ & $4.27 E-06$ \\
\hline 1. $55 \mathrm{E}-07$ & $5.78 \mathrm{E}-06$ & $1.56 \mathrm{E}-06$ & $1.37 \mathrm{E}-06$ & $2.90 \mathrm{E}-06$ & $3.35 E-06$ & $3.84 \mathrm{E}-06$ & $4.27 E-06$ \\
\hline $1.56 \mathrm{E}-07$ & $5.78 E-06$ & $1.56 E-06$ & $1.37 \mathrm{E}-06$ & $2.90 \mathrm{E}-06$ & $3.35 E-06$ & $3.84 \mathrm{E}-06$ & $4.27 E-06$ \\
\hline $1.56 \mathrm{E}-07$ & $5.78 E-06$ & $1.56 E-06$ & $1.37 \mathrm{E}-06$ & $2.90 \mathrm{E}-06$ & $3.35 E-06$ & $3.83 E-06$ & $4.27 E-06$ \\
\hline $1.56 \mathrm{E}-07$ & $5.77 \mathrm{E}-06$ & $1.56 \mathrm{E}-06$ & $1.37 \mathrm{E}-06$ & $2.90 \mathrm{E}-06$ & $3.34 \mathrm{E}-06$ & $3.83 E-06$ & $4.27 \mathrm{E}-06$ \\
\hline
\end{tabular}


RESRAD-OFFSITE, Version 2.5

Title : Offsite Resident Farmer Deterministic Run

File : RF TC99 DOESG FWD-FV2b.ROF

Summary of dose at graphical times, reptition 3 (continued)

Time

Years

$9.91 \mathrm{E}+02$

$9.91 \mathrm{E}+02$

9. $92 \mathrm{E}+02$

9. $92 \mathrm{E}+02$

$9.93 \mathrm{E}+02$

$9.93 \mathrm{E}+02$

$9.94 \mathrm{E}+02$

$9.94 \mathrm{E}+02$

$9.95 \mathrm{E}+02$

$9.95 \mathrm{E}+02$

$9.96 \mathrm{E}+02$

$9.96 \mathrm{E}+02$

$9.97 \mathrm{E}+02$

$9.97 \mathrm{E}+02$

$9.98 \mathrm{E}+02$

$9.98 \mathrm{E}+02$

$9.99 \mathrm{E}+02$

$9.99 \mathrm{E}+02$

$1.00 \mathrm{E}+03$

$1.00 \mathrm{E}+03$

$1.00 \mathrm{E}+03$

$1.00 \mathrm{E}+03$

$1.00 \mathrm{E}+03$

$1.00 \mathrm{E}+03$

$1.00 \mathrm{E}+03$

$1.00 \mathrm{E}+03$

$1.00 \mathrm{E}+03$

$1.00 \mathrm{E}+03$

$1.00 \mathrm{E}+03$

$1.01 \mathrm{E}+03$

$1.01 \mathrm{E}+03$

$1.01 \mathrm{E}+03$

$1.01 \mathrm{E}+03$

$1.01 \mathrm{E}+03$

$1.01 \mathrm{E}+03$

$1.01 \mathrm{E}+03$

$1.01 \mathrm{E}+03$

$1.01 \mathrm{E}+03$

$1.01 \mathrm{E}+03$

$1.01 E+03$

$1.01 \mathrm{E}+03$

$1.01 \mathrm{E}+03$

$1.01 \mathrm{E}+03$

$1.01 \mathrm{E}+03$

$1.01 \mathrm{E}+03$

$1.01 \mathrm{E}+03$
Dose statistics at graphical times, mrem/yr

\begin{tabular}{|c|c|c|c|c|c|c|c|}
\hline m & um & ea & - & & & & \\
\hline 07 & $5.77 \mathrm{E}-06$ & $1.56 \mathrm{E}-06$ & $1.37 \mathrm{E}-06$ & $D E-06$ & 06 & $3.83 E-06$ & $4-0$ \\
\hline $.57 E-07$ & $5.77 E-06$ & $1.56 \mathrm{E}-06$ & $1.37 \mathrm{E}-06$ & $0 E-06$ & $4 E-06$ & $3.83 E-06$ & $7 E-06$ \\
\hline $.57 E-07$ & $76 \mathrm{E}-06$ & $1.56 \mathrm{E}-06$ & $1.37 \mathrm{E}-06$ & $2.90 \mathrm{E}-06$ & $3.33 E-06$ & $3.83 E-06$ & $.27 E-06$ \\
\hline $58 \mathrm{~F}-07$ & $76 \mathrm{E}-06$ & $56 \mathrm{~F}-06$ & $37 \mathrm{~F}-06$ & $.91 \mathrm{E}-06$ & $33 F-06$ & -06 & $.27 \mathrm{E}-06$ \\
\hline-07 & 06 & 06 & 6 & 6 & 6 & -06 & $.27 E-06$ \\
\hline 07 & & & & & & & \\
\hline $59 E-07$ & $5.75 \mathrm{E}-06$ & & & & & & -06 \\
\hline-07 & 06 & 0 & -06 & 6 & 6 & 06 & $E-06$ \\
\hline $.59 E-07$ & $5.74 \mathrm{E}-06$ & $7 E-06$ & $E-06$ & -06 & -06 & -06 & $E-06$ \\
\hline $60 E-07$ & $73 E-06$ & $57 F_{-0}$ & $.38 E-06$ & $.91 E-06$ & & $3 E-06$ & $27 E-06$ \\
\hline $60 \mathrm{E}-07$ & 06 & & & & & 6 & -06 \\
\hline $60 \mathrm{E}-07$ & $5.73 E-06$ & 1. & -06 & 6 & & 6 & $27 E-06$ \\
\hline $.61 E-07$ & $5.72 \mathrm{E}-06$ & $1.57 \mathrm{E}-06$ & $1.38 \mathrm{E}-06$ & & & $3.83 E-06$ & $.27 E-06$ \\
\hline $61 E-07$ & $.72 \mathrm{E}-06$ & 1. $57 \mathrm{E}-06$ & 1. $38 \mathrm{E}-06$ & $2.91 E-06$ & & -06 & $.27 E-06$ \\
\hline$E-07$ & 06 & 0 & -06 & & & -06 & $E-06$ \\
\hline $62 \mathrm{E}-$ & -06 & 0 & 0 & 6 & & 0 & cerar \\
\hline 7 & 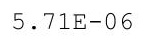 & & & & & & \\
\hline $63 E-07$ & 6 & $1.57 \mathrm{E}-06$ & 1. 39E-06 & 6 & 6 & 6 & 06 \\
\hline $.63 E-07$ & $5.70 \mathrm{E}-06$ & $1.57 \mathrm{E}-06$ & $1.39 \mathrm{E}-06$ & $2.91 E-06$ & $3.31 E-06$ & $E-06$ & $.27 E-06$ \\
\hline $63 E-07$ & $.69 \mathrm{E}-06$ & $1.58 \mathrm{E}-06$ & 1. $39 \mathrm{E}-06$ & $2.91 \mathrm{E}-06$ & -06 & -06 & . $27 E-06$ \\
\hline 07 & & & & & & 6 & $E-06$ \\
\hline 1 & & & & & & & \\
\hline c & & $1.58 \mathrm{E}-06$ & & & & & 06 \\
\hline $5 E-07$ & 6 & 0 & 6 & 6 & & 0 & -06 \\
\hline 7 & 6 & 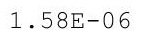 & 1 & תמת ח & 6 & 6 & $27 E-$ \\
\hline $65 \mathrm{~F}-07$ & $67 E-06$ & $F-06$ & 1. $40 \mathrm{E}-06$ & $.92 E-06$ & $31 E-06$ & $.83 E-06$ & $.27 E-06$ \\
\hline$F-07$ & $67 E-06$ & -06 & $E-06$ & $92 E-06$ & & $E-06$ & $27 E-06$ \\
\hline & & & & & & & \\
\hline & & & & 06 & & 06 & -06 \\
\hline $67 E-07$ & $5.66 \mathrm{E}-06$ & $1.30 \pm-06$ & 1. $40 \mathrm{E}-06$ & $2.92 E-06$ & $.31 E-06$ & $3.0<E-00$ & $.27 E-06$ \\
\hline $67 \mathrm{E}-07$ & $65 E-06$ & $1.20 \mathrm{~L}-00$ & $1.40 \mathrm{E}-06$ & $2.92 \mathrm{E}-06$ & $.31 E-06$ & $25-00$ & $.27 E-06$ \\
\hline 年 & & & 1. $40 \mathrm{E}-0$ & & & 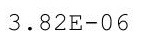 & \\
\hline $68 \mathrm{~F}-07$ & $\mathrm{~F}-06$ & -06 & & 6 & & & 06 \\
\hline 7 & 6 & & & & & & \\
\hline & & & & 6 & & -06 & 06 \\
\hline $.69 \mathrm{E}-07$ & $5.63 \mathrm{E}-06$ & $1.59 \mathrm{E}-06$ & $1.41 \mathrm{E}-06$ & $2.92 E-06$ & -06 & -06 & $.26 E-06$ \\
\hline . & $5.63 \mathrm{E}-06$ & & $1.41 \mathrm{E}-06$ & & & $\begin{array}{ll}.0 \angle L \\
0\end{array}$ & $4.200-00$ \\
\hline 10世 & -00 & 1.0म & $1.41 \mathrm{E}-06$ & & & & $26 E-06$ \\
\hline $705-07$ & 6 & 5 & 6 & 6 & 6 & 6 & 06 \\
\hline ( & & & & & & & 06 \\
\hline$E-07$ & $5.61 \mathrm{E}$ & 06 & $1.41 \mathrm{E}$ & & & & -06 \\
\hline $1 \mathrm{E}-07$ & 61 & 1.5 & 1.42 & 6 & & & -06 \\
\hline & & & & & & & $4.25 E-06$ \\
\hline $\begin{array}{l}-1< \pm-01 \\
0\end{array}$ & $5.60 \mathrm{E}-06$ & $1.00 \mathrm{~L}-00$ & $1.4 \angle E-06$ & $2.91 \mathrm{E}-06$ & $3.30 E-06$ & $3.81 E-06$ & $4 \cdot 25 E-06$ \\
\hline $72 E-07$ & . & 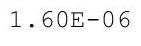 & $1.42 \mathrm{E}-06$ & $2.92 E-06$ & & & $4.25 E-06$ \\
\hline $72 E-07$ & $.59 E-06$ & $.60 E-06$ & $.42 \mathrm{E}-06$ & $.92 E-06$ & $E-06$ & $1 E-06$ & $4.25 E-06$ \\
\hline
\end{tabular}


RESRAD-OFFSITE, Version 2.5

itle : Offsite Resident Farmer Deterministic Run

File : RF TC99 DOESG FWD-FV2b.ROF

Summary of dose at graphical times, reptition 3 (continued)

Time

Years

1. $01 \mathrm{E}+03$

1. $01 \mathrm{E}+03$

1. $02 \mathrm{E}+03$

1. $02 \mathrm{E}+03$

1. $02 \mathrm{E}+03$

1. $02 \mathrm{E}+03$

1. $02 \mathrm{E}+03$

1. $02 \mathrm{E}+03$

1. $02 \mathrm{E}+03$

1. $02 \mathrm{E}+03$

1. $02 \mathrm{E}+03$

1. $02 \mathrm{E}+03$

1. $02 \mathrm{E}+03$

1. $02 \mathrm{E}+03$

$1.02 \mathrm{E}+03$

1. $02 \mathrm{E}+03$

$1.02 \mathrm{E}+03$

$1.02 \mathrm{E}+03$

1. $02 \mathrm{E}+03$

1. $02 \mathrm{E}+03$

$1.02 \mathrm{E}+03$

1. $02 \mathrm{E}+03$

$1.03 \mathrm{E}+03$

1. $03 \mathrm{E}+03$

$1.03 \mathrm{E}+03$

$1.03 E+03$

$1.03 E+03$

$1.03 E+03$

$1.03 \mathrm{E}+03$

$1.03 E+03$

1. $03 \mathrm{E}+03$

$1.03 E+03$

$1.03 E+03$

$1.03 E+03$

1. $03 \mathrm{E}+03$

$1.03 \mathrm{E}+03$

$1.03 E+03$

$1.03 E+03$

$1.03 E+03$

$1.03 E+03$

$1.03 E+03$

$1.04 \mathrm{E}+03$

$1.04 \mathrm{E}+03$

$1.04 \mathrm{E}+03$

$1.04 \mathrm{E}+03$

$1.04 \mathrm{E}+03$

Dose statistics at graphical times, mrem/yr

\begin{tabular}{|c|c|c|c|c|c|c|c|}
\hline Minimum & Maximum & Mean & Median & $90 \%$ & $95 \%$ & $97.5 \%$ & $99 \%$ \\
\hline $1.73 E-07$ & $5.59 \mathrm{E}-06$ & $1.60 E-06$ & $1.42 \mathrm{E}-06$ & $2.92 E-06$ & $3.30 E-06$ & $3.81 E-06$ & $4.25 E-06$ \\
\hline $1.73 E-07$ & $5.58 \mathrm{E}-06$ & $1.60 \mathrm{E}-06$ & 1. $42 \mathrm{E}-06$ & $2.92 E-06$ & $3.30 \mathrm{E}-06$ & $3.81 \mathrm{E}-06$ & $4.25 E-06$ \\
\hline $1.73 E-07$ & $5.58 \mathrm{E}-06$ & $1.60 \mathrm{E}-06$ & $1.43 \mathrm{E}-06$ & $2.92 \mathrm{E}-06$ & $3.30 \mathrm{E}-06$ & $3.81 E-06$ & $4.25 E-06$ \\
\hline $1.74 \mathrm{E}-07$ & $5.58 \mathrm{E}-06$ & $1.60 \mathrm{E}-06$ & $1.43 E-06$ & $2.92 E-06$ & $3.30 E-06$ & $3.81 \mathrm{E}-06$ & $4.25 E-06$ \\
\hline $1.74 \mathrm{E}-07$ & $5.57 \mathrm{E}-06$ & $1.60 \mathrm{E}-06$ & $1.43 \mathrm{E}-06$ & $2.92 E-06$ & $3.30 \mathrm{E}-06$ & $3.81 \mathrm{E}-06$ & $4.25 E-06$ \\
\hline $1.75 \mathrm{E}-07$ & $5.57 \mathrm{E}-06$ & $1.60 \mathrm{E}-06$ & $1.43 \mathrm{E}-06$ & $2.92 \mathrm{E}-06$ & $3.30 \mathrm{E}-06$ & $3.81 \mathrm{E}-06$ & $4.25 E-06$ \\
\hline $1.75 \mathrm{E}-07$ & $5.57 \mathrm{E}-06$ & $1.60 \mathrm{E}-06$ & $1.43 \mathrm{E}-06$ & $2.92 E-06$ & $3.30 E-06$ & $3.81 E-06$ & $4.25 E-06$ \\
\hline $1.75 \mathrm{E}-07$ & $5.57 \mathrm{E}-06$ & $1.60 \mathrm{E}-06$ & $1.43 E-06$ & $2.92 E-06$ & $3.30 E-06$ & $3.81 E-06$ & $4.25 E-06$ \\
\hline $1.76 \mathrm{E}-07$ & $5.56 \mathrm{E}-06$ & $1.60 \mathrm{E}-06$ & $1.43 E-06$ & $2.92 E-06$ & $3.30 \mathrm{E}-06$ & $3.81 \mathrm{E}-06$ & $4.24 E-06$ \\
\hline $1.76 \mathrm{E}-07$ & $5.56 \mathrm{E}-06$ & $1.60 \mathrm{E}-06$ & $1.43 E-06$ & $2.92 \mathrm{E}-06$ & $3.30 \mathrm{E}-06$ & $3.81 E-06$ & $4.24 \mathrm{E}-06$ \\
\hline $1.76 \mathrm{E}-07$ & $5.56 \mathrm{E}-06$ & $1.61 \mathrm{E}-06$ & $1.43 \mathrm{E}-06$ & $2.92 E-06$ & $3.29 \mathrm{E}-06$ & $3.81 \mathrm{E}-06$ & $4.24 E-06$ \\
\hline $1.77 \mathrm{E}-07$ & $5.56 \mathrm{E}-06$ & 1. $61 \mathrm{E}-06$ & $1.44 \mathrm{E}-06$ & $2.92 E-06$ & $3.29 \mathrm{E}-06$ & $3.81 E-06$ & $4.24 E-06$ \\
\hline $1.77 \mathrm{E}-07$ & $5.55 \mathrm{E}-06$ & $1.61 \mathrm{E}-06$ & $1.44 \mathrm{E}-06$ & $2.93 \mathrm{E}-06$ & $3.29 \mathrm{E}-06$ & $3.81 \mathrm{E}-06$ & $4.24 \mathrm{E}-06$ \\
\hline $1.77 \mathrm{E}-07$ & $5.55 \mathrm{E}-06$ & $1.61 E-06$ & $1.44 \mathrm{E}-06$ & $2.93 E-06$ & $3.29 \mathrm{E}-06$ & $3.80 \mathrm{E}-06$ & $4.24 E-06$ \\
\hline $1.78 \mathrm{E}-07$ & $5.55 E-06$ & $1.61 \mathrm{E}-06$ & $1.44 \mathrm{E}-06$ & $2.93 E-06$ & $3.29 \mathrm{E}-06$ & $3.80 E-06$ & $4.24 E-06$ \\
\hline $1.78 \mathrm{E}-07$ & $5.55 \mathrm{E}-06$ & 1. $61 \mathrm{E}-06$ & $1.44 \mathrm{E}-06$ & $2.93 E-06$ & $3.29 \mathrm{E}-06$ & $3.80 E-06$ & $4.24 \mathrm{E}-06$ \\
\hline $1.78 \mathrm{E}-07$ & $5.54 \mathrm{E}-06$ & $1.61 \mathrm{E}-06$ & $1.44 \mathrm{E}-06$ & $2.93 E-06$ & $3.30 \mathrm{E}-06$ & $3.80 \mathrm{E}-06$ & $4.24 \mathrm{E}-06$ \\
\hline $1.79 \mathrm{E}-07$ & $5.54 \mathrm{E}-06$ & 1. $61 \mathrm{E}-06$ & $1.44 \mathrm{E}-06$ & $2.93 E-06$ & $3.30 E-06$ & $3.80 E-06$ & $4.24 E-06$ \\
\hline $1.79 \mathrm{E}-07$ & $5.54 \mathrm{E}-06$ & 1. $61 \mathrm{E}-06$ & $1.44 \mathrm{E}-06$ & $2.93 E-06$ & $3.30 \mathrm{E}-06$ & $3.80 E-06$ & $4.24 \mathrm{E}-06$ \\
\hline $1.80 \mathrm{E}-07$ & $5.54 \mathrm{E}-06$ & $1.61 \mathrm{E}-06$ & $1.44 \mathrm{E}-06$ & $2.93 E-06$ & $3.30 \mathrm{E}-06$ & $3.79 \mathrm{E}-06$ & $4.24 \mathrm{E}-06$ \\
\hline $1.80 \mathrm{E}-07$ & $5.53 E-06$ & $1.61 E-06$ & $1.45 \mathrm{E}-06$ & $2.93 E-06$ & $3.30 \mathrm{E}-06$ & $3.79 E-06$ & $4.24 E-06$ \\
\hline $1.80 \mathrm{E}-07$ & $5.53 \mathrm{E}-06$ & $1.61 \mathrm{E}-06$ & $1.45 \mathrm{E}-06$ & $2.93 E-06$ & $3.30 \mathrm{E}-06$ & $3.79 E-06$ & $4.24 \mathrm{E}-06$ \\
\hline $1.81 \mathrm{E}-07$ & $5.53 \mathrm{E}-06$ & 1. $61 \mathrm{E}-06$ & $1.45 \mathrm{E}-06$ & $2.93 \mathrm{E}-06$ & $3.30 \mathrm{E}-06$ & $3.78 \mathrm{E}-06$ & $4.24 \mathrm{E}-06$ \\
\hline $1.81 \mathrm{E}-07$ & $5.53 E-06$ & $1.61 E-06$ & $1.45 \mathrm{E}-06$ & $2.93 E-06$ & $3.30 \mathrm{E}-06$ & $3.78 \mathrm{E}-06$ & $4.24 E-06$ \\
\hline $1.81 \mathrm{E}-07$ & $5.52 \mathrm{E}-06$ & 1. $62 \mathrm{E}-06$ & $1.45 \mathrm{E}-06$ & $2.93 E-06$ & $3.30 \mathrm{E}-06$ & $3.78 \mathrm{E}-06$ & $4.24 \mathrm{E}-06$ \\
\hline 1. $82 \mathrm{E}-07$ & $5.52 \mathrm{E}-06$ & $1.62 \mathrm{E}-06$ & $1.45 \mathrm{E}-06$ & $2.93 E-06$ & $3.30 \mathrm{E}-06$ & $3.78 E-06$ & $4.23 E-06$ \\
\hline $1.82 \mathrm{E}-07$ & $5.52 \mathrm{E}-06$ & $1.62 \mathrm{E}-06$ & $1.45 \mathrm{E}-06$ & $2.93 E-06$ & $3.31 E-06$ & $3.78 E-06$ & $4.23 E-06$ \\
\hline $1.82 \mathrm{E}-07$ & $5.52 \mathrm{E}-06$ & $1.62 \mathrm{E}-06$ & $1.45 \mathrm{E}-06$ & $2.93 E-06$ & $3.31 E-06$ & $3.78 E-06$ & $4.23 E-06$ \\
\hline $1.83 \mathrm{E}-07$ & $5.51 \mathrm{E}-06$ & $1.62 \mathrm{E}-06$ & $1.45 \mathrm{E}-06$ & $2.92 \mathrm{E}-06$ & $3.31 \mathrm{E}-06$ & $3.78 \mathrm{E}-06$ & 4. $23 E-06$ \\
\hline $1.83 \mathrm{E}-07$ & $5.51 \mathrm{E}-06$ & 1. $62 \mathrm{E}-06$ & 1. $45 \mathrm{E}-06$ & $2.92 \mathrm{E}-06$ & $3.31 \mathrm{E}-06$ & $3.78 \mathrm{E}-06$ & $4.23 E-06$ \\
\hline $1.84 \mathrm{E}-07$ & $5.51 E-06$ & $1.62 \mathrm{E}-06$ & $1.45 \mathrm{E}-06$ & $2.92 \mathrm{E}-06$ & $3.31 \mathrm{E}-06$ & $3.78 E-06$ & $4.23 E-06$ \\
\hline $1.84 \mathrm{E}-07$ & $5.51 \mathrm{E}-06$ & 1. $62 \mathrm{E}-06$ & $1.46 \mathrm{E}-06$ & $2.92 E-06$ & $3.31 E-06$ & $3.78 E-06$ & $4.23 E-06$ \\
\hline $1.84 \mathrm{E}-07$ & $5.50 \mathrm{E}-06$ & $1.62 \mathrm{E}-06$ & $1.46 \mathrm{E}-06$ & $2.92 \mathrm{E}-06$ & $3.31 \mathrm{E}-06$ & $3.78 \mathrm{E}-06$ & $4.23 E-06$ \\
\hline $1.85 \mathrm{E}-07$ & $5.50 \mathrm{E}-06$ & $1.62 \mathrm{E}-06$ & $1.46 \mathrm{E}-06$ & $2.92 \mathrm{E}-06$ & $3.32 \mathrm{E}-06$ & $3.78 E-06$ & $4.23 E-06$ \\
\hline $1.85 \mathrm{E}-07$ & $5.50 \mathrm{E}-06$ & $1.62 \mathrm{E}-06$ & $1.46 \mathrm{E}-06$ & $2.92 E-06$ & $3.32 E-06$ & $3.78 \mathrm{E}-06$ & $4.23 E-06$ \\
\hline $1.85 \mathrm{E}-07$ & $5.50 \mathrm{E}-06$ & 1. $62 \mathrm{E}-06$ & $1.46 \mathrm{E}-06$ & $2.92 \mathrm{E}-06$ & $3.32 E-06$ & $3.78 \mathrm{E}-06$ & $4.23 E-06$ \\
\hline 1. $86 \mathrm{E}-07$ & $5.49 \mathrm{E}-06$ & $1.62 \mathrm{E}-06$ & $1.46 \mathrm{E}-06$ & $2.92 \mathrm{E}-06$ & $3.32 E-06$ & $3.78 E-06$ & $4.23 E-06$ \\
\hline $1.86 \mathrm{E}-07$ & $5.49 \mathrm{E}-06$ & $1.63 \mathrm{E}-06$ & $1.46 \mathrm{E}-06$ & $2.92 E-06$ & $3.32 E-06$ & $3.78 \mathrm{E}-06$ & 4. $23 E-06$ \\
\hline $1.86 \mathrm{E}-07$ & $5.49 \mathrm{E}-06$ & $1.63 \mathrm{E}-06$ & $1.46 \mathrm{E}-06$ & $2.92 \mathrm{E}-06$ & $3.32 \mathrm{E}-06$ & $3.78 \mathrm{E}-06$ & $4.23 E-06$ \\
\hline $1.87 \mathrm{E}-07$ & $5.48 E-06$ & $1.63 \mathrm{E}-06$ & $1.47 \mathrm{E}-06$ & $2.92 \mathrm{E}-06$ & $3.32 E-06$ & $3.78 \mathrm{E}-06$ & $4.22 \mathrm{E}-06$ \\
\hline $1.87 \mathrm{E}-07$ & $5.48 E-06$ & $1.63 E-06$ & $1.47 \mathrm{E}-06$ & $2.93 E-06$ & $3.33 \mathrm{E}-06$ & $3.77 E-06$ & $4.22 \mathrm{E}-06$ \\
\hline $1.88 \mathrm{E}-07$ & $5.48 \mathrm{E}-06$ & $1.63 \mathrm{E}-06$ & $1.47 \mathrm{E}-06$ & $2.93 E-06$ & $3.33 E-06$ & $3.77 \mathrm{E}-06$ & $4.22 E-06$ \\
\hline $1.88 \mathrm{E}-07$ & $5.48 \mathrm{E}-06$ & $1.63 \mathrm{E}-06$ & $1.47 \mathrm{E}-06$ & $2.93 \mathrm{E}-06$ & $3.33 E-06$ & $3.77 \mathrm{E}-06$ & 4. $22 \mathrm{E}-06$ \\
\hline $1.88 \mathrm{E}-07$ & $5.47 \mathrm{E}-06$ & $1.63 \mathrm{E}-06$ & $1.47 \mathrm{E}-06$ & $2.93 \mathrm{E}-06$ & $3.33 \mathrm{E}-06$ & $3.77 \mathrm{E}-06$ & $4.22 E-06$ \\
\hline $1.89 \mathrm{E}-07$ & $5.47 E-06$ & $1.63 E-06$ & $1.47 \mathrm{E}-06$ & $2.93 E-06$ & $3.33 E-06$ & $3.76 \mathrm{E}-06$ & 4. $22 \mathrm{E}-06$ \\
\hline $1.89 \mathrm{E}-07$ & $5.47 \mathrm{E}-06$ & $1.63 E-06$ & $1.47 \mathrm{E}-06$ & $2.93 \mathrm{E}-06$ & $3.33 \mathrm{E}-06$ & $3.76 \mathrm{E}-06$ & $4.22 \mathrm{E}-06$ \\
\hline
\end{tabular}


RESRAD-OFFSITE, Version 2.5

$\mathrm{T}^{1 / 2}$ Limit $=180$ days

robabilistic Dose and Risk Report

itle : Offsite Resident Farmer Deterministic Run

File : RF TC99 DOESG FWD-FV2b.ROF

Time

Years

$1.04 \mathrm{E}+03$

$1.04 \mathrm{E}+03$

$1.04 \mathrm{E}+03$

$1.04 \mathrm{E}+03$

$1.04 \mathrm{E}+03$

$1.04 \mathrm{E}+03$

$1.04 \mathrm{E}+03$

$1.04 \mathrm{E}+03$

$1.04 \mathrm{E}+03$

$1.04 \mathrm{E}+03$

$1.04 \mathrm{E}+03$

$1.04 \mathrm{E}+03$

$1.04 \mathrm{E}+03$

$1.04 \mathrm{E}+03$

$1.04 \mathrm{E}+03$

$1.05 \mathrm{E}+03$

$1.05 \mathrm{E}+03$

$1.05 \mathrm{E}+03$

$1.05 \mathrm{E}+03$

$1.05 \mathrm{E}+03$

$1.05 \mathrm{E}+03$

$1.05 \mathrm{E}+03$

$1.05 \mathrm{E}+03$

$1.05 \mathrm{E}+03$

$1.05 \mathrm{E}+03$

Summary of dose at graphical times, reptition 3 (continued)

Dose statistics at graphical times, mrem/yr

\begin{tabular}{|c|c|c|c|c|c|c|c|}
\hline Minimum & Maximum & Mean & Median & $90 \%$ & $95 \%$ & $97.5 \%$ & $99 \%$ \\
\hline 1. $89 \mathrm{E}-07$ & $5.47 \mathrm{E}-06$ & $1.63 E-06$ & $1.47 \mathrm{E}-06$ & $2.93 \mathrm{E}-06$ & $3.33 E-06$ & $3.76 \mathrm{E}-06$ & $4.22 \mathrm{E}-06$ \\
\hline $1.90 \mathrm{E}-07$ & $5.46 \mathrm{E}-06$ & $1.63 \mathrm{E}-06$ & $1.48 \mathrm{E}-06$ & $2.93 E-06$ & $3.33 E-06$ & $3.76 \mathrm{E}-06$ & $4.21 \mathrm{E}-06$ \\
\hline $1.90 \mathrm{E}-07$ & $5.46 \mathrm{E}-06$ & $1.63 \mathrm{E}-06$ & 1. $48 \mathrm{E}-06$ & $2.93 E-06$ & $3.33 E-06$ & $3.76 \mathrm{E}-06$ & $4.21 \mathrm{E}-06$ \\
\hline $.90 E-07$ & $5.46 \mathrm{E}-06$ & $1.63 \mathrm{E}-06$ & $1.48 \mathrm{E}-06$ & $2.93 E-06$ & $3.33 E-06$ & $3.76 E-06$ & $4.21 \mathrm{E}-06$ \\
\hline 1. $91 \mathrm{E}-07$ & $5.45 \mathrm{E}-06$ & 1. $63 \mathrm{E}-06$ & $1.48 \mathrm{E}-06$ & $2.93 E-06$ & $3.33 E-06$ & $3.75 \mathrm{E}-06$ & $.21 E-06$ \\
\hline 1. $91 \mathrm{E}-07$ & $5.45 E-06$ & $1.64 \mathrm{E}-06$ & $1.48 \mathrm{E}-06$ & $2.93 E-06$ & $3.33 E-06$ & $3.75 \mathrm{E}-06$ & $4.21 \mathrm{E}-06$ \\
\hline $1.92 \mathrm{E}-07$ & $5.45 E-06$ & $1.64 \mathrm{E}-06$ & $1.48 \mathrm{E}-06$ & $2.93 E-06$ & $3.33 E-06$ & $3.75 E-06$ & $4.20 \mathrm{E}-06$ \\
\hline $1.92 \mathrm{E}-07$ & $5.45 E-06$ & $1.64 \mathrm{E}-06$ & $1.48 \mathrm{E}-06$ & $2.93 E-06$ & $3.33 E-06$ & $3.75 E-06$ & $4.20 \mathrm{E}-06$ \\
\hline 1. $92 \mathrm{E}-07$ & $5.44 \mathrm{E}-06$ & $1.64 \mathrm{E}-06$ & 1. $48 \mathrm{E}-06$ & $2.93 E-06$ & $3.33 E-06$ & $3.75 E-06$ & $4.20 \mathrm{E}-06$ \\
\hline $1.93 E-07$ & $5.44 \mathrm{E}-06$ & $1.64 \mathrm{E}-06$ & $1.48 \mathrm{E}-06$ & $2.93 E-06$ & $3.33 E-06$ & $5 E-06$ & $4.20 \mathrm{E}-06$ \\
\hline 1.93E-07 & $5.44 \mathrm{E}-06$ & 1.641 & 1. $49 \mathrm{E}-06$ & $2.93 E-06$ & $3.33 E-06$ & $3.74 \mathrm{E}-06$ & $.20 E-06$ \\
\hline $.93 \mathrm{E}-07$ & $5.44 \mathrm{E}-06$ & $1.64 \mathrm{E}-06$ & 1. $49 \mathrm{E}-06$ & $2.93 E-06$ & $3.33 E-06$ & $3.74 \mathrm{E}-06$ & $4.19 \mathrm{E}-06$ \\
\hline $1.94 \mathrm{E}-07$ & $5.43 E-06$ & $1.64 \mathrm{E}-06$ & $1.49 \mathrm{E}-06$ & $2.93 E-06$ & $3.33 E-06$ & $3.74 \mathrm{E}-06$ & $4.19 \mathrm{E}-06$ \\
\hline $1.94 \mathrm{E}-07$ & $5.43 E-06$ & $1.64 \mathrm{E}-06$ & $1.49 \mathrm{E}-06$ & $2.93 E-06$ & $3.33 E-06$ & $3.74 \mathrm{E}-06$ & $4.19 \mathrm{E}-06$ \\
\hline $.95 \mathrm{E}-07$ & $5.43 E-06$ & $1.64 \mathrm{E}-06$ & 1. $49 \mathrm{E}-06$ & $2.93 E-06$ & $3.33 E-06$ & $3.73 E-06$ & $4.19 \mathrm{E}-06$ \\
\hline $1.95 \mathrm{E}-07$ & $5.43 E-06$ & $1.64 \mathrm{E}-06$ & $1.49 E-06$ & $2.93 E-06$ & $3.33 E-06$ & $3 E-06$ & $4.19 \mathrm{E}-06$ \\
\hline $1.95 \mathrm{E}-07$ & $5.43 E-06$ & $1.64 \mathrm{E}-06$ & $1.49 \mathrm{E}-06$ & $2.93 E-06$ & $3.33 E-06$ & $.73 E-06$ & $4.19 E-06$ \\
\hline $1.96 \mathrm{E}-07$ & $5.43 E-06$ & $1.64 \mathrm{E}-06$ & $1.49 E-06$ & $2.93 E-06$ & $3.33 E-06$ & $3.73 E-06$ & $4.19 \mathrm{E}-06$ \\
\hline $1.96 \mathrm{E}-07$ & $5.43 E-06$ & $1.64 \mathrm{E}-06$ & $1.49 E-06$ & $2.93 E-06$ & $3.33 E-06$ & $3.73 E-06$ & $4.19 \mathrm{E}-06$ \\
\hline $1.96 \mathrm{E}-07$ & $5.43 E-06$ & $1.64 \mathrm{E}-06$ & 1. $49 \mathrm{E}-06$ & $2.93 E-06$ & $3.33 E-06$ & $3.72 \mathrm{E}-06$ & $4.19 \mathrm{E}-06$ \\
\hline 1.97E-07 & $5.43 E-06$ & 1. $65 \mathrm{E}-06$ & 1. $49 \mathrm{E}-06$ & $2.93 E-06$ & $3.33 E-06$ & $3.72 \mathrm{E}-06$ & $4.19 \mathrm{E}-06$ \\
\hline $1.97 \mathrm{E}-07$ & $5.43 E-06$ & $1.65 \mathrm{E}-06$ & $1.49 \mathrm{E}-06$ & $2.93 E-06$ & $3.32 E-06$ & $3.72 E-06$ & $4.19 \mathrm{E}-06$ \\
\hline $1.98 \mathrm{E}-07$ & $5.43 E-06$ & $1.65 \mathrm{E}-06$ & 1. $49 \mathrm{E}-06$ & $2.93 E$ & $3.32 \mathrm{E}$ & $3.72 \mathrm{E}-06$ & $4.19 \mathrm{E}-06$ \\
\hline $1.98 \mathrm{E}-07$ & $5.42 E-06$ & $1.65 \mathrm{E}-06$ & $1.50 \mathrm{E}-06$ & $2.93 E-06$ & $3.32 \mathrm{E}-06$ & $3.72 E-06$ & $4.19 \mathrm{E}-06$ \\
\hline $1.98 \mathrm{E}-07$ & $5.42 \mathrm{E}-06$ & $1.65 \mathrm{E}-06$ & $1.50 \mathrm{E}-06$ & $2.93 E-06$ & $3.32 E-06$ & $3.72 \mathrm{E}-06$ & $4.19 \mathrm{E}-06$ \\
\hline
\end{tabular}


RESRAD-OFFSITE, Version 2.5

Probabilistic Dose and Risk Report

Title : Offsite Resident Farmer Deterministic Run

File : RF TC99 DOESG FWD-FV2b.ROF

Repetition

1

2

3

$\begin{array}{cc}\begin{array}{c}\text { Peak of the mean dose } \\ \text { Time of peak mean dose } \\ \text { Years }\end{array} & \begin{array}{c}\text { Peak mean dose } \\ \text { mrem/yr }\end{array} \\ 1.050 \mathrm{E}+03 & 1.651 \mathrm{E}-06 \\ 1.050 \mathrm{E}+03 & 1.648 \mathrm{E}-06 \\ 1.050 \mathrm{E}+03 & 1.647 \mathrm{E}-06\end{array}$




\section{Offsite Resident Farmer}

\section{Parent Dose Report \\ (Deterministic Analysis Report)}

Third Run

Time Horizon: 1,050 yr 
THIS PAGE INTENTIONALLY LEFT BLANK 
RESRAD-OFFSITE, Version 2.5

Parent Dose Report

Title : Offsite Resident Farmer

File : RF TC99 DOESG FWD-FV2all.ROF

Table of Contents

Part I: Mixture Sums and Single Radionuclide Guidelines

Dose Conversion Factor (and Related) Parameter Summary ... 2

Site-Specific Parameter Summary ................. 4

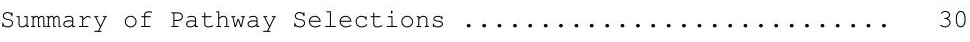

Contaminated Zone and Total Dose Summary ............ 31

Total Dose Components

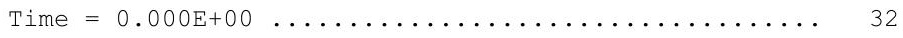

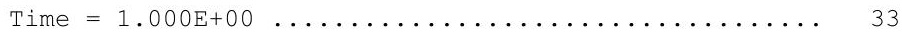

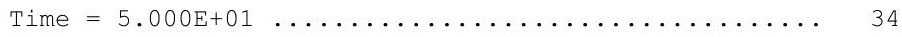

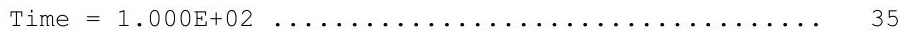

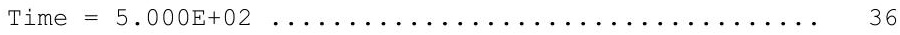

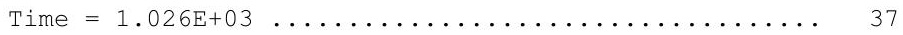

Dose/Source Ratios Summed Over All Pathways .......... 38

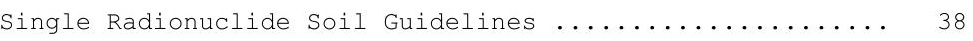

Dose Per Nuclide Summed Over All Pathways ............ 39

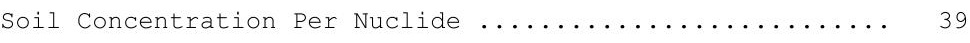

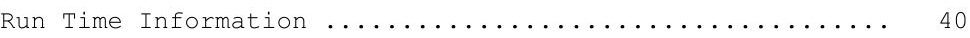


RESRAD-OFFSITE, Version 2.5

Parent Dose Report

Title : Offsite Resident Farmer

File : RF TC99 DOESG FWD-FV2all.ROF

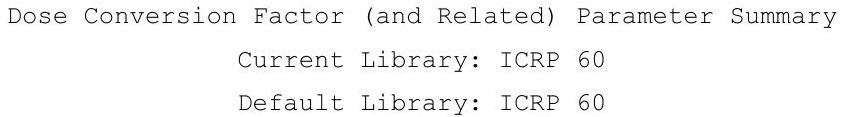

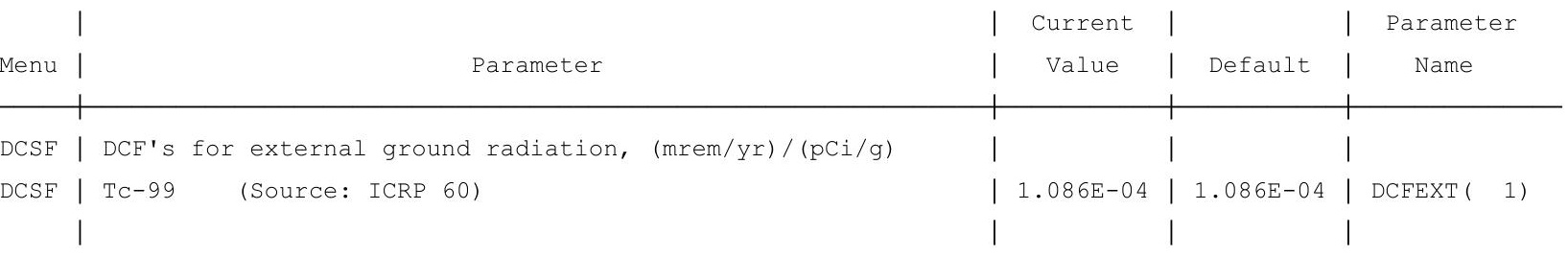

Current Library: ICRP 72 (Adult)

Default Library: ICRP 72 (Adult)

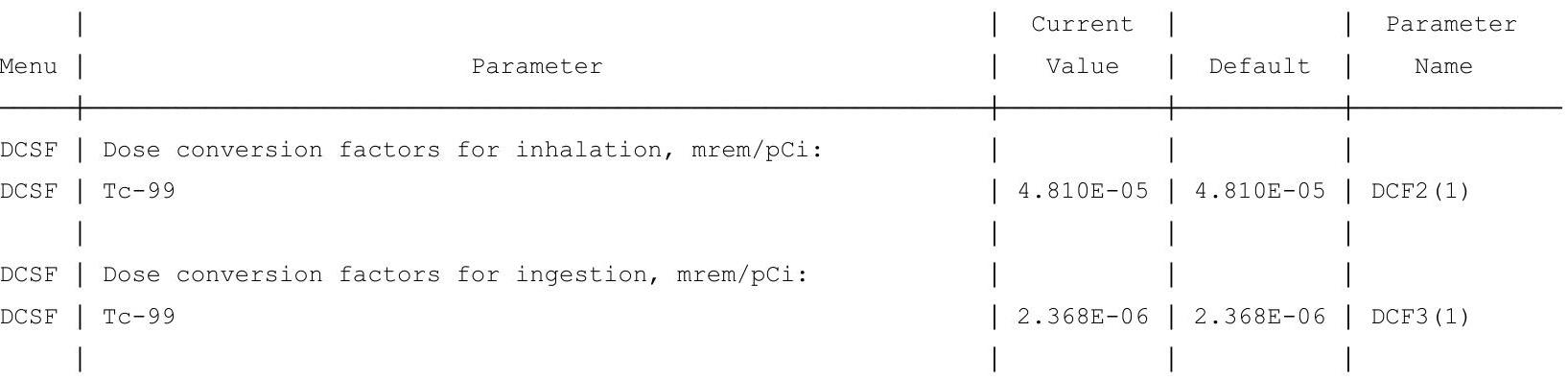


RESRAD-OFFSITE, Version 2.5

Parent Dose Report

Title : Offsite Resident Farmer

File : RF TC99 DOESG FWD-FV2all.ROF

Dose Conversion Factor (and Related) Parameter Summary (continued)

Current Library: RESRAD Default Transfer factors

Default Library: RESRAD Default Transfer factors

Menu $\quad$ Parameter
M


RESRAD-OFFSITE, Version 2.5

Parent Dose Report

Title : Offsite Resident Farmer

File : RF TC99 DOESG FWD-FV2all.ROF

Site-Specific Parameter Summary

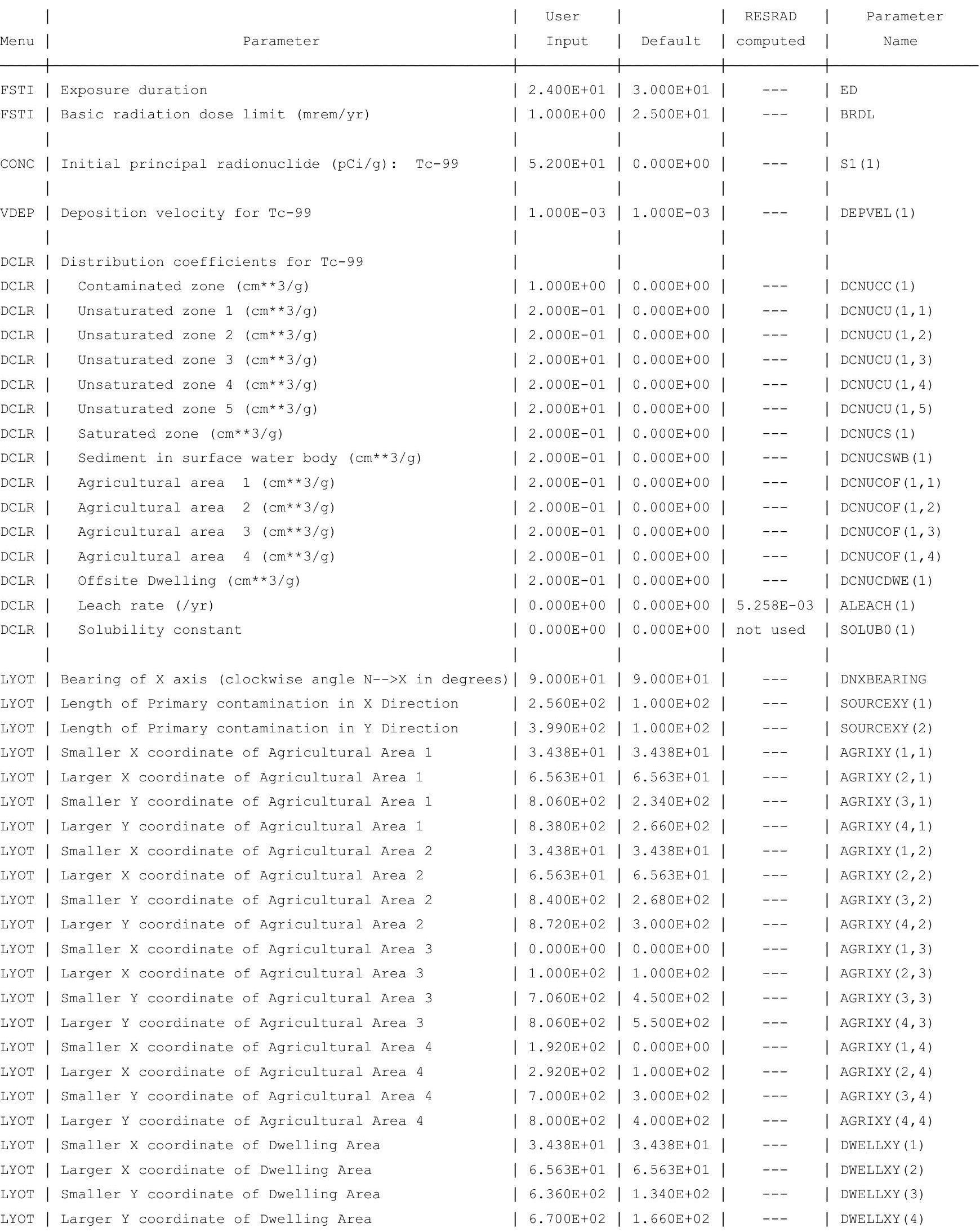


RESRAD-OFFSITE, Version 2.5

Parent Dose Report

Title : Offsite Resident Farmer

File : RF TC99 DOESG FWD-FV2all.ROF

Site-Specific Parameter Summary (continued)

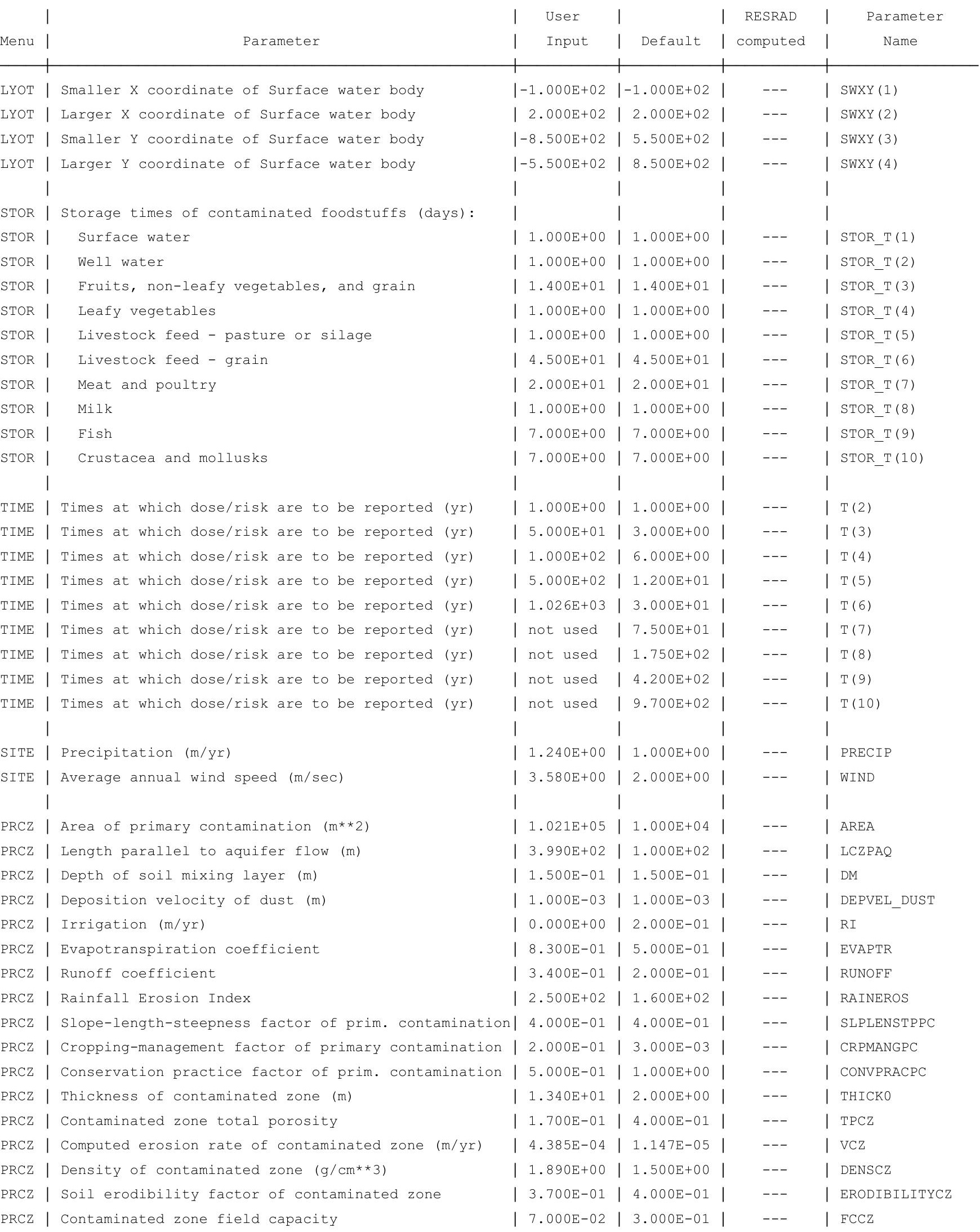


RESRAD-OFFSITE, Version 2.5

Parent Dose Report

Title : Offsite Resident Farmer

File : RF TC99 DOESG FWD-FV2all.ROF

Site-Specific Parameter Summary (continued)

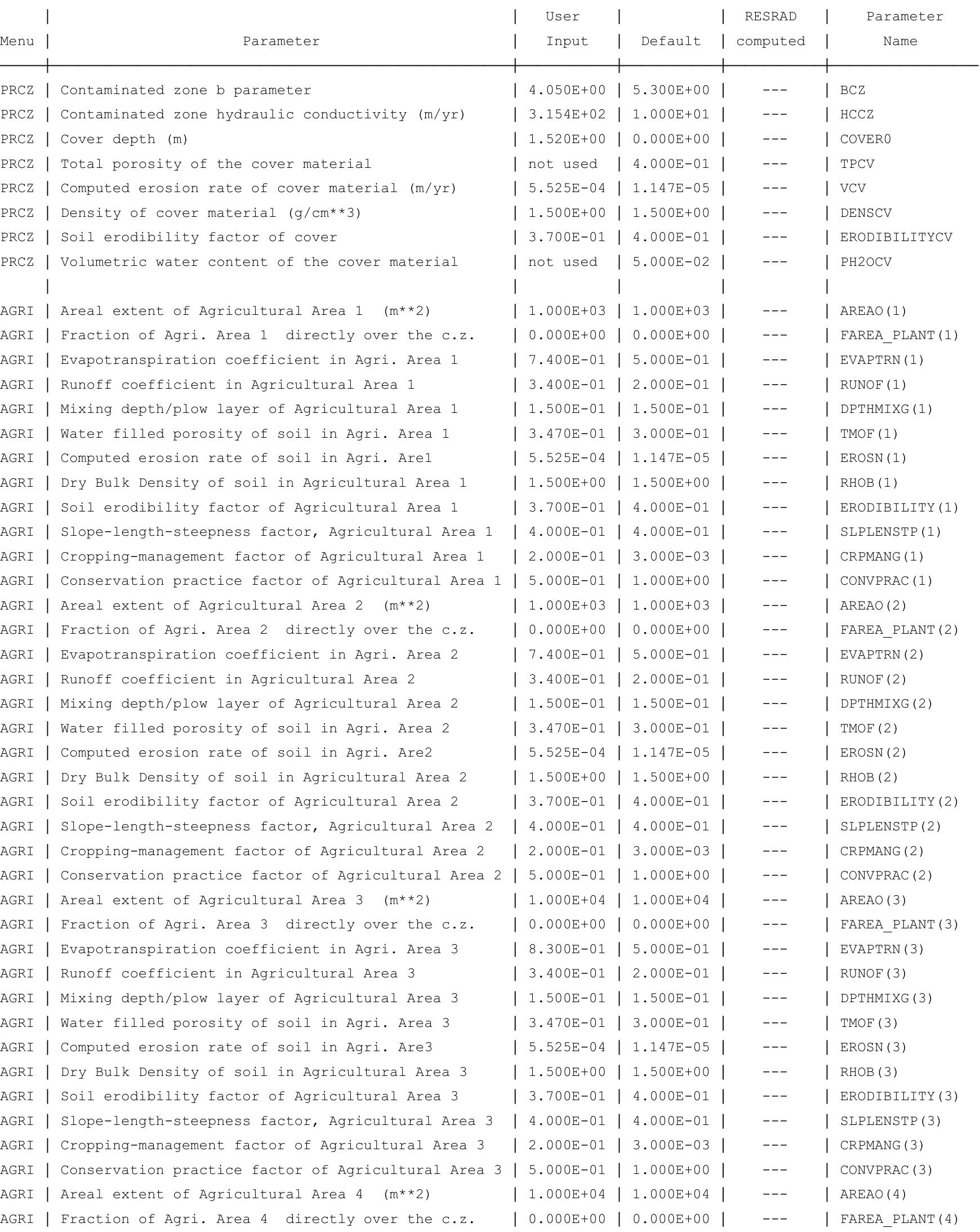


RESRAD-OFFSITE, Version 2.5

Parent Dose Report

Title : Offsite Resident Farmer

File : RF TC99 DOESG FWD-FV2all.ROF

Site-Specific Parameter Summary (continued)

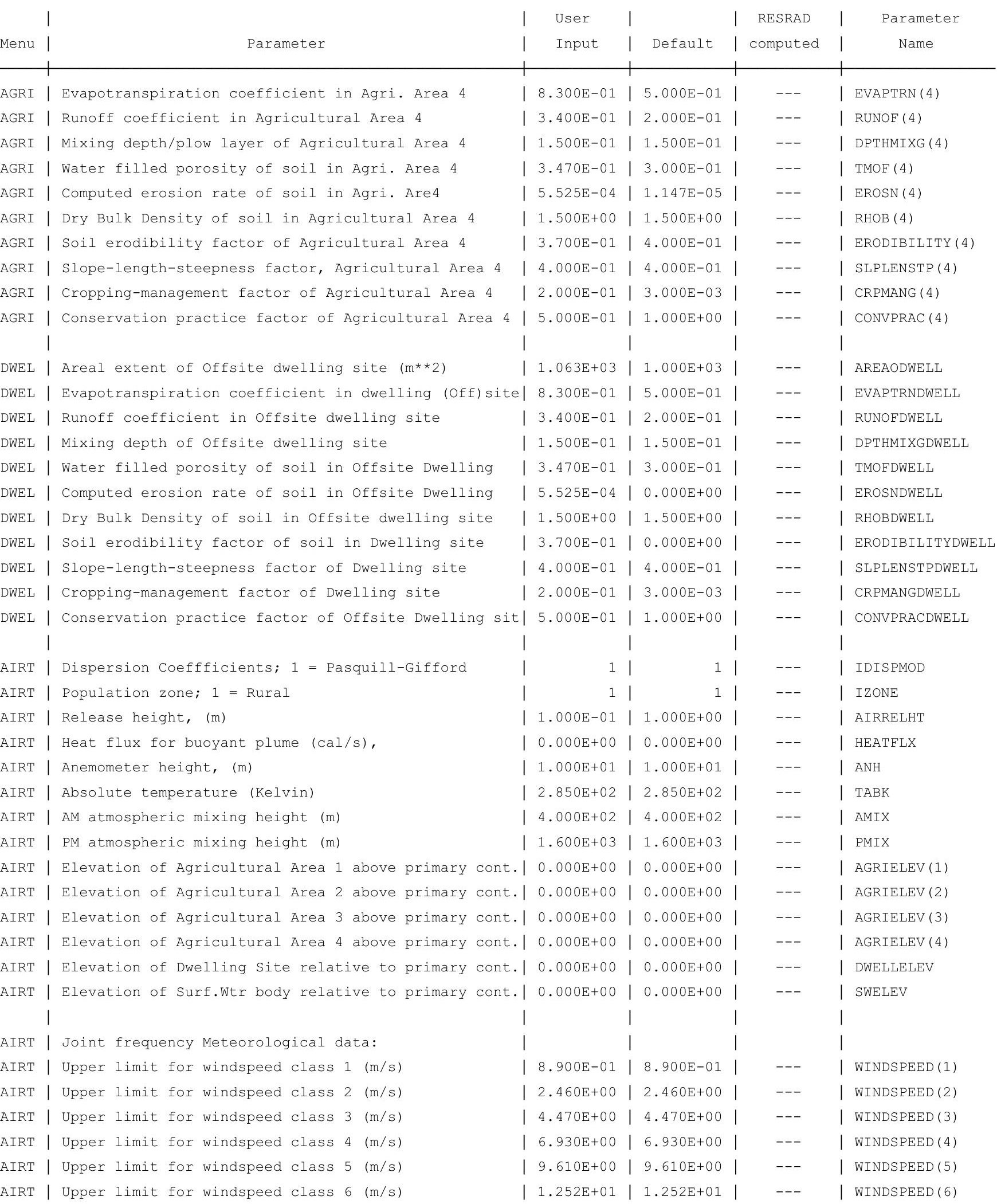


RESRAD-OFFSITE, Version 2.5

Site-Specific Parameter Summary (continued)

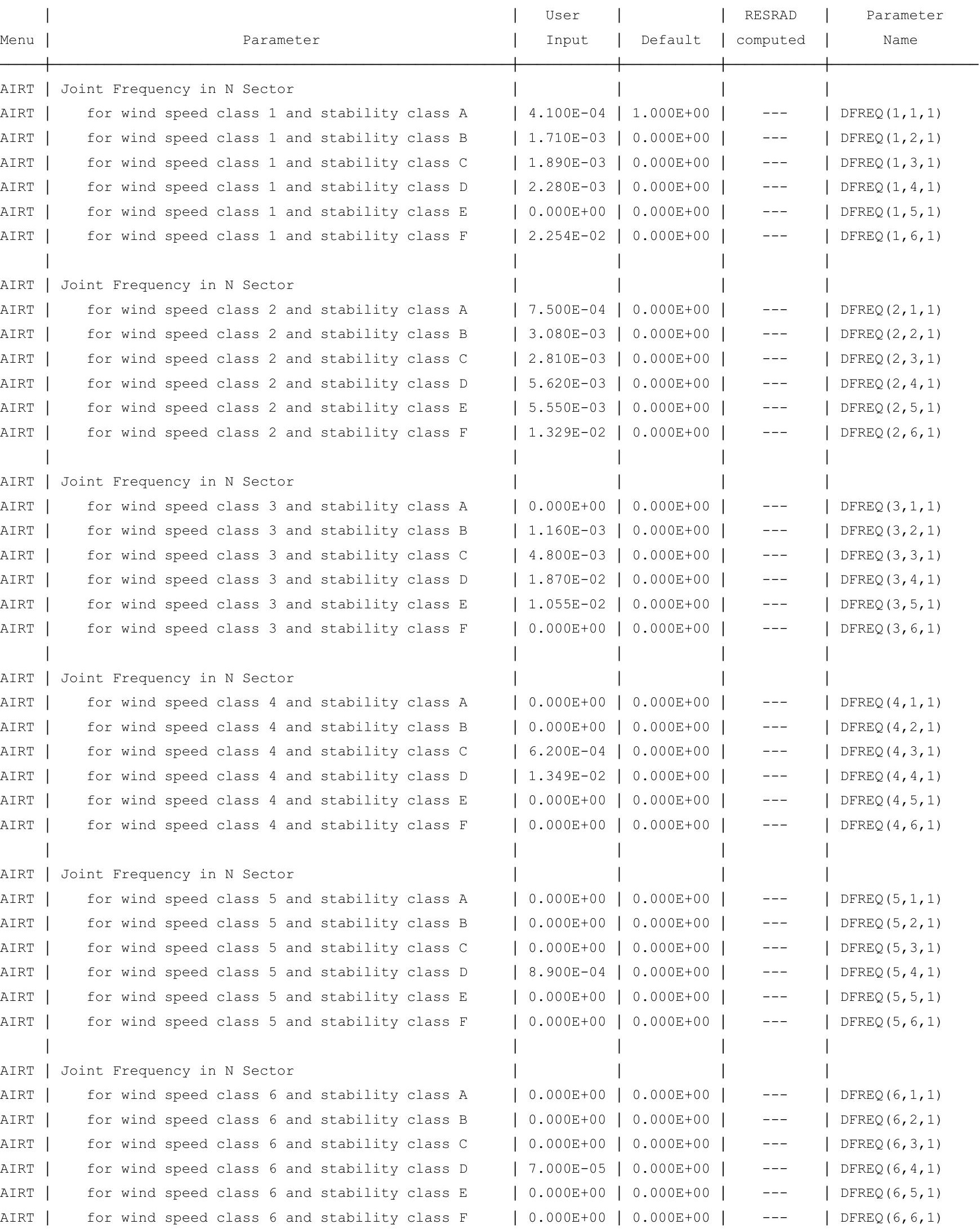

for wind speed class 1 and stability class A wind speed class 1 and stability class for wind speed class 1 and stability class D for wind speed class 1 and stability class E

for wind speed class 2 and stability class B for wind speed class 2 and stability class E
$\operatorname{DFREQ}(6,6,1)$ 
RESRAD-OFFSITE, Version 2.5

Parent Dose Report

Title : Offsite Resident Farmer

File : RF TC99 DOESG FWD-FV2all.ROF

Site-Specific Parameter Summary (continued)

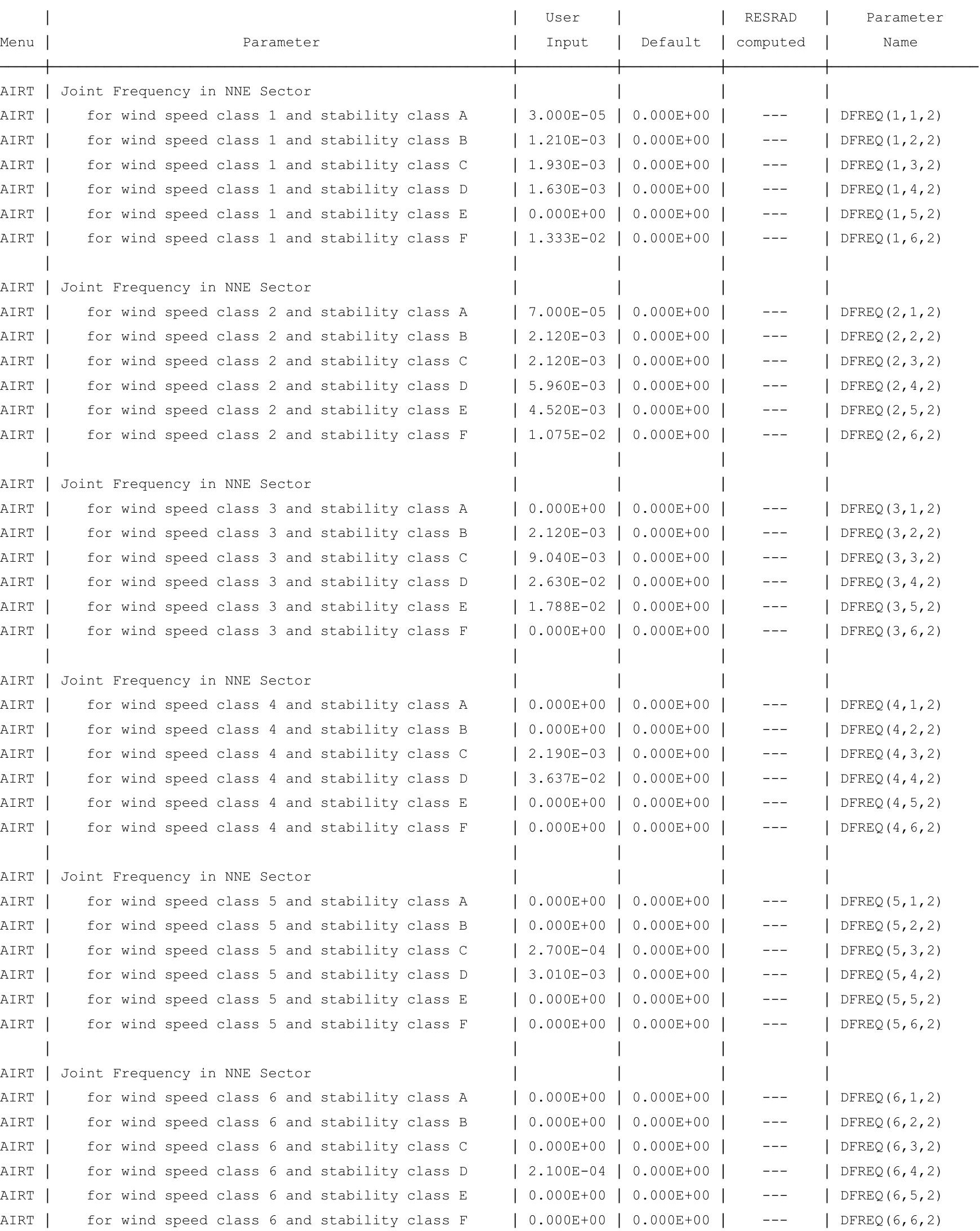


RESRAD-OFFSITE, Version 2.5

itle : Offsite Resident Farmer

File : RF TC99 DOESG FWD-FV2all.ROF

Site-Specific Parameter Summary (continued)

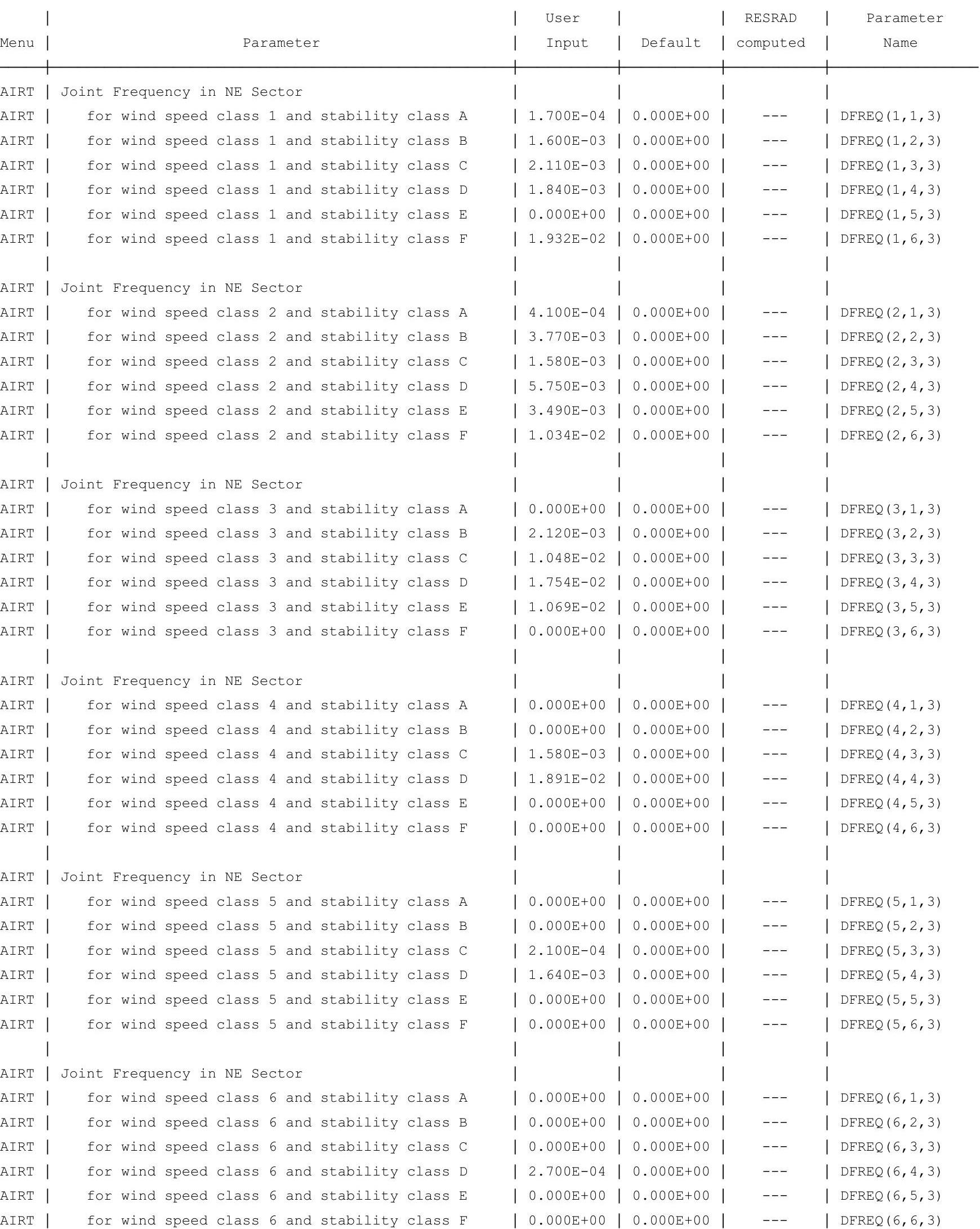


RESRAD-OFFSITE, Version 2.5

Site-Specific Parameter Summary (continued)

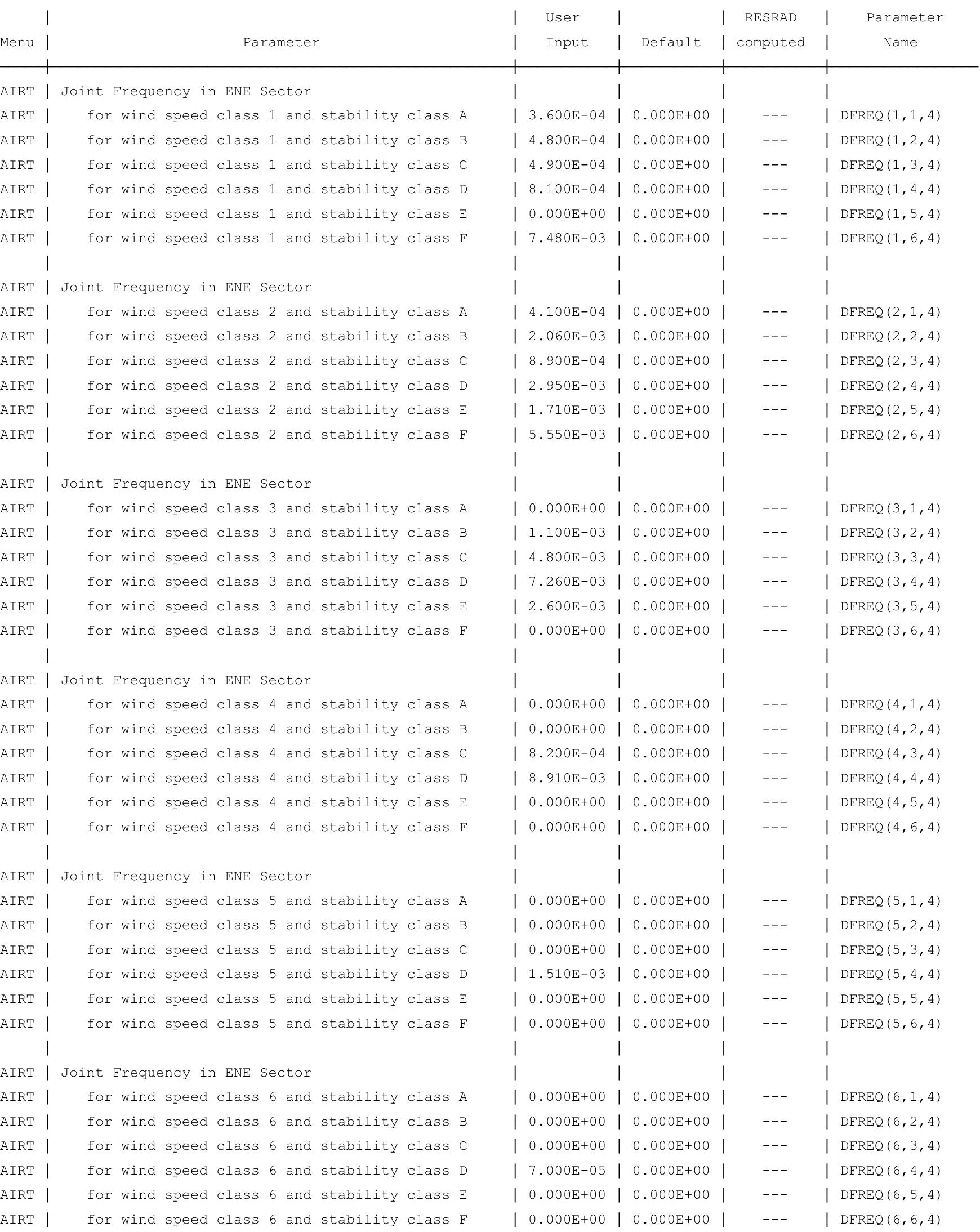


RESRAD-OFFSITE, Version 2.5

Site-Specific Parameter Summary (continued)

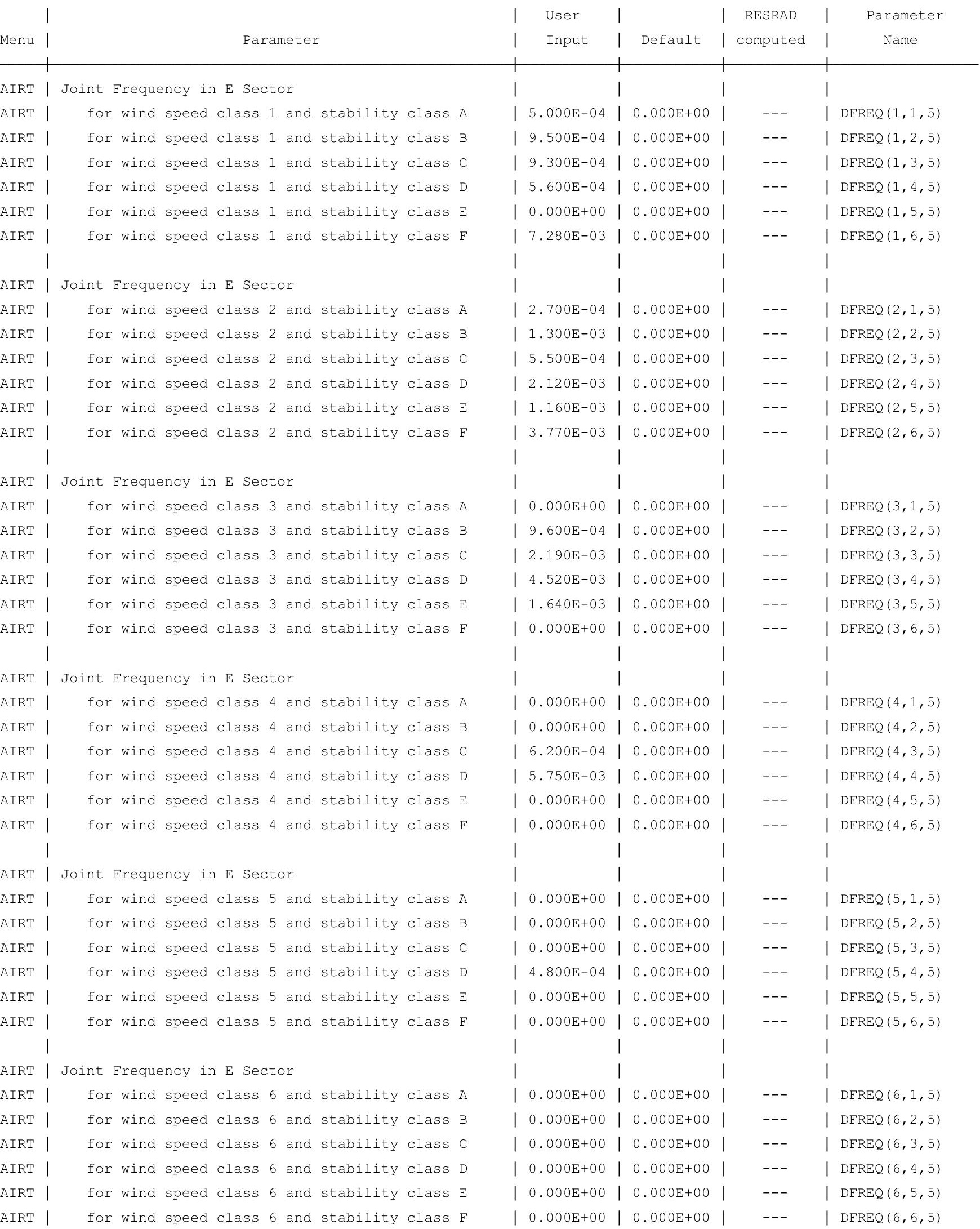


RESRAD-OFFSITE, Version 2.5

Site-Specific Parameter Summary (continued)

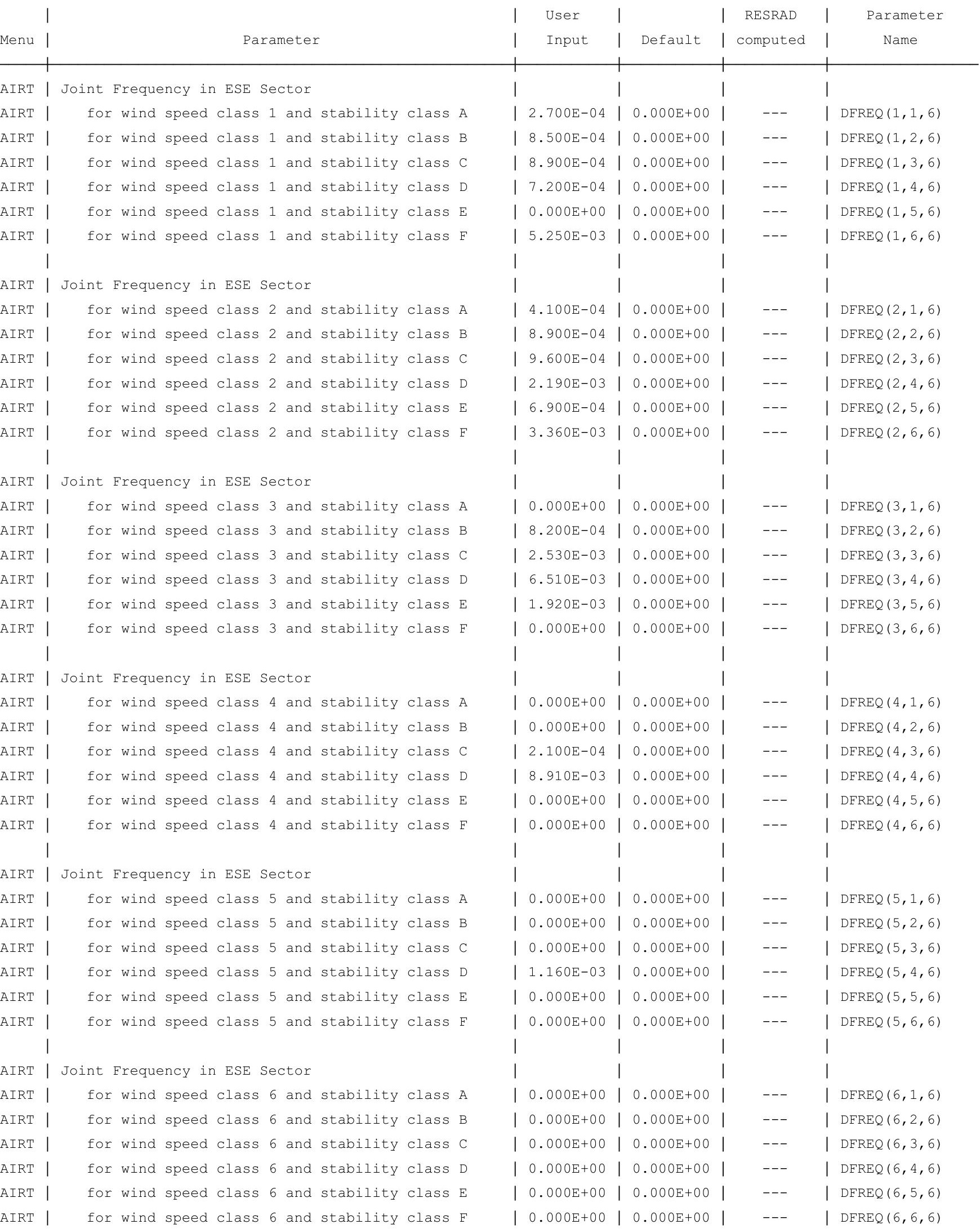


RESRAD-OFFSITE, Version 2.5

arent Dose Report

Title : Offsite Resident Farmer

File : RF TC99 DOESG FWD-FV2all.ROF

Site-Specific Parameter Summary (continued)

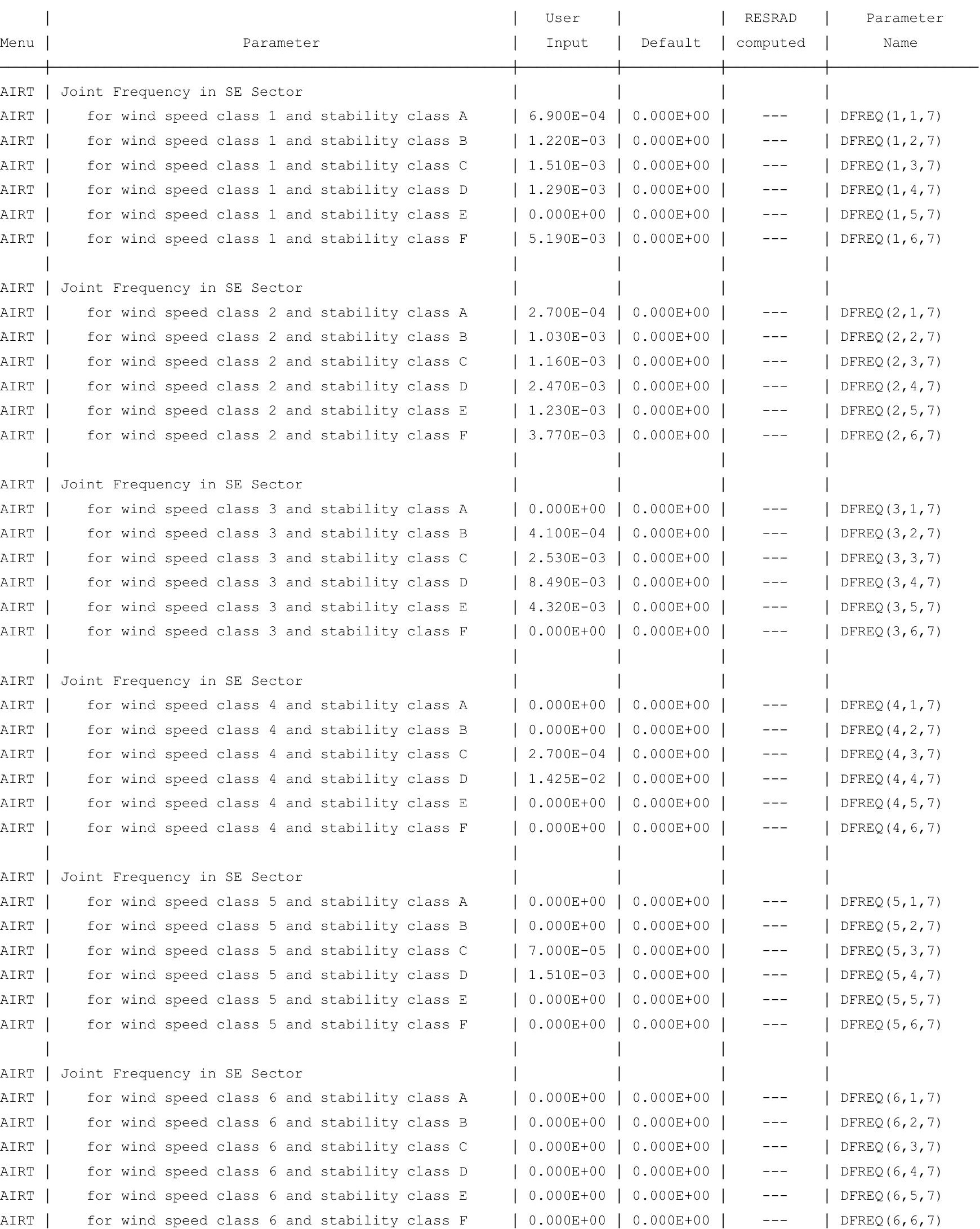


RESRAD-OFFSITE, Version 2.5

itle : Offsite Resident Farmer

File : RF TC99 DOESG FWD-FV2all.ROF

Site-Specific Parameter Summary (continued)

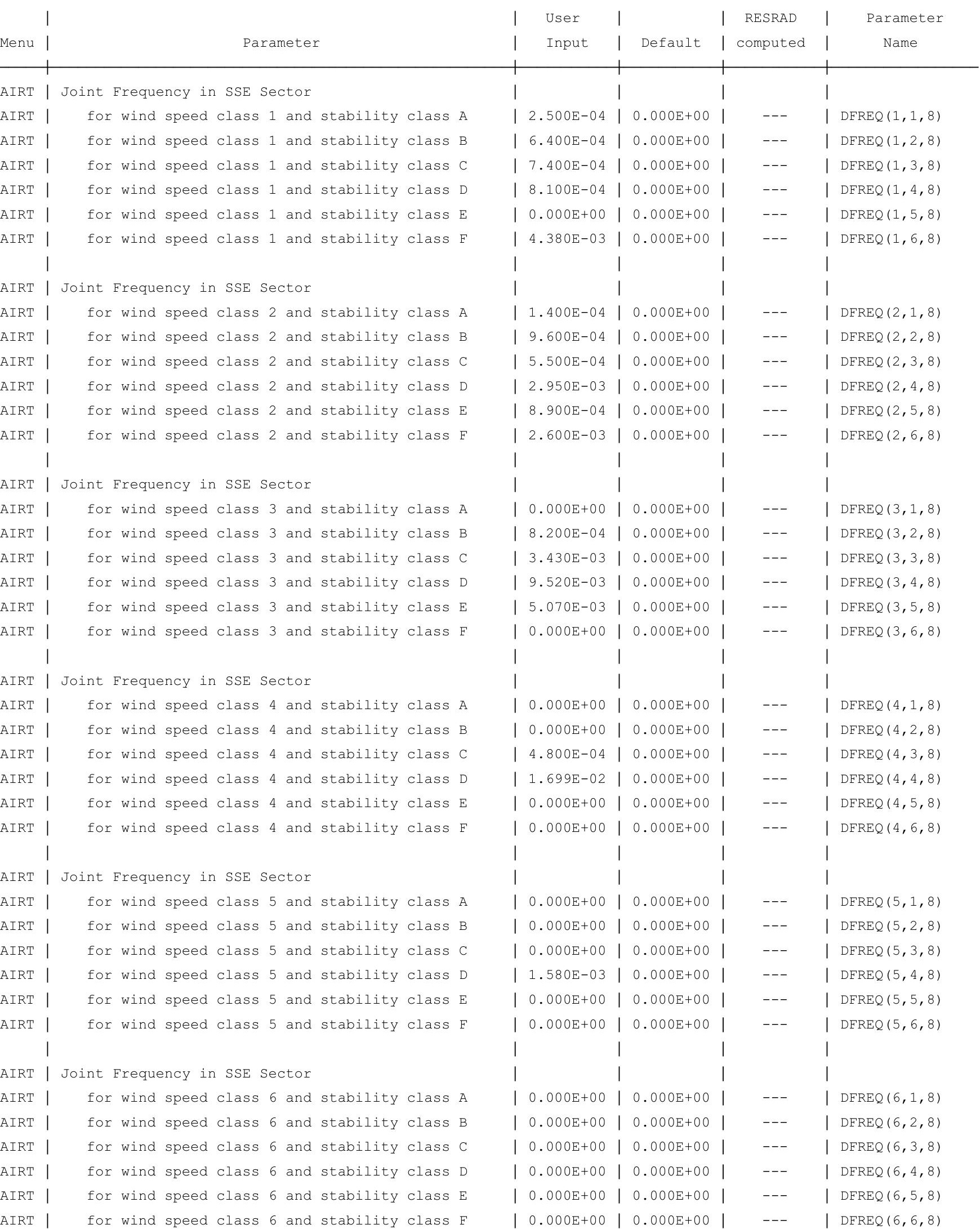


RESRAD-OFFSITE, Version 2.5

itle : Offsite Resident Farmer

File : RF TC99 DOESG FWD-FV2all.ROF

Site-Specific Parameter Summary (continued)

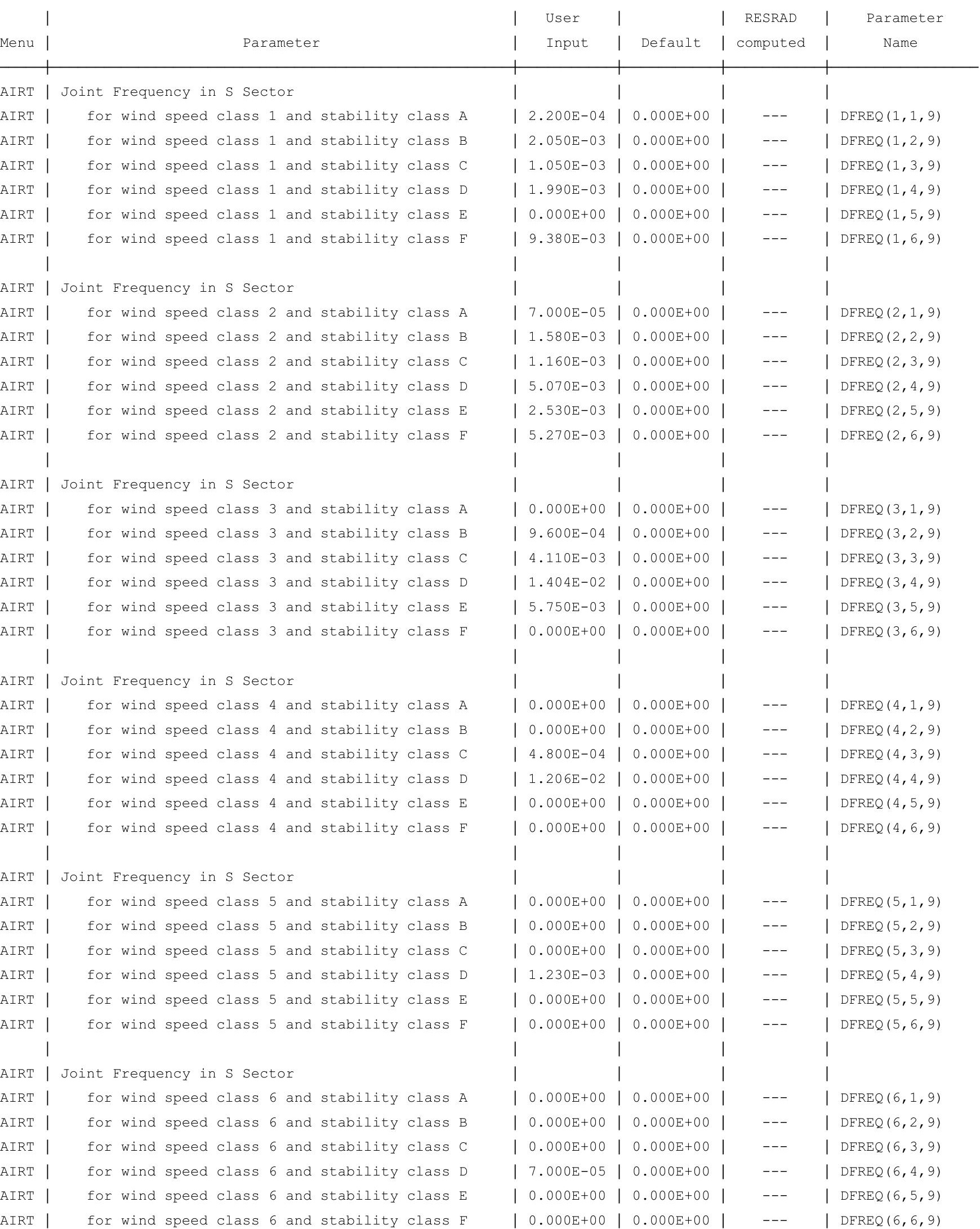


RESRAD-OFFSITE, Version 2.5

rent Dose Report

Title : Offsite Resident Farmer

File : RF TC99 DOESG FWD-FV2all.ROF

Site-Specific Parameter Summary (continued)

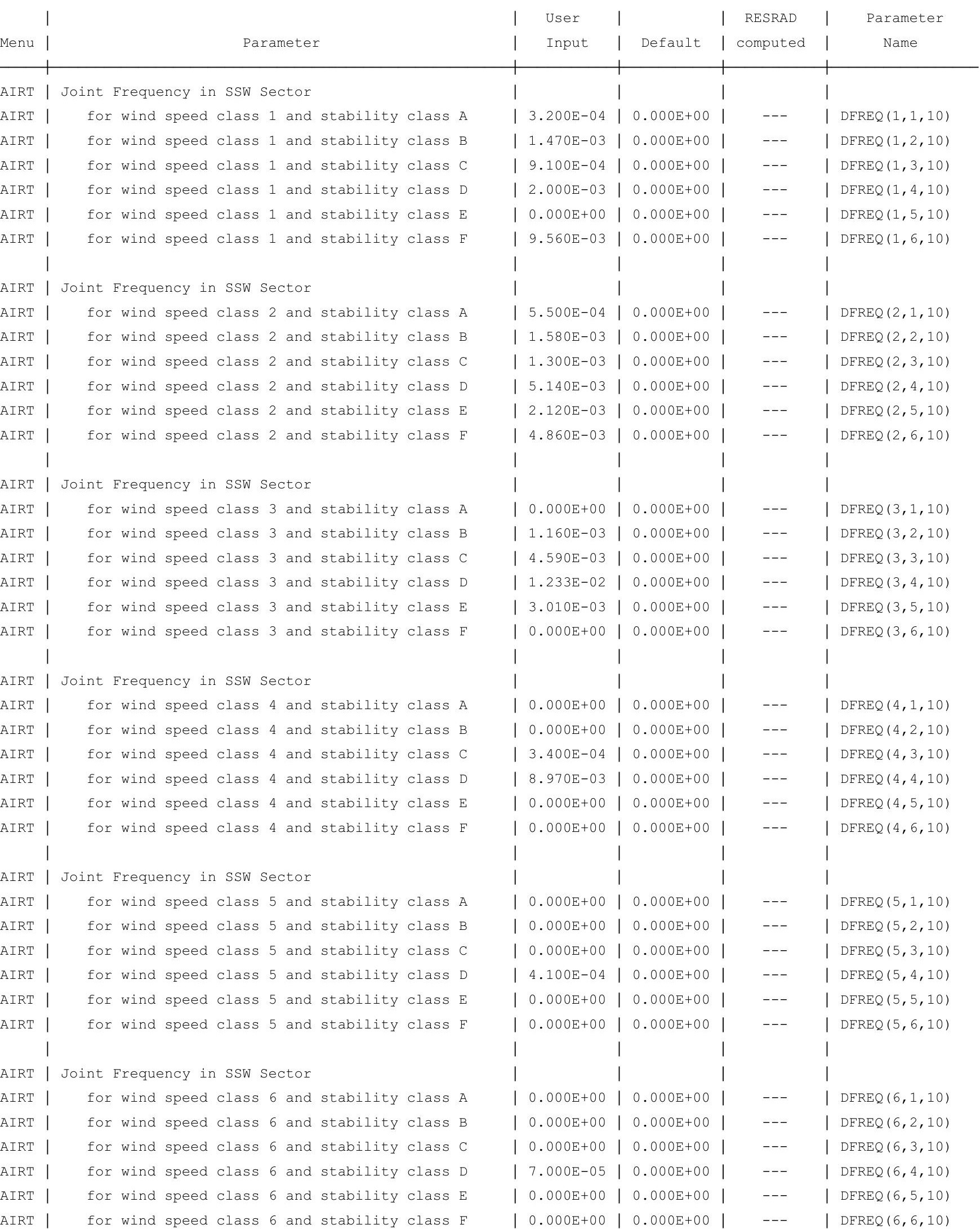


RESRAD-OFFSITE, Version 2.5

Site-Specific Parameter Summary (continued)

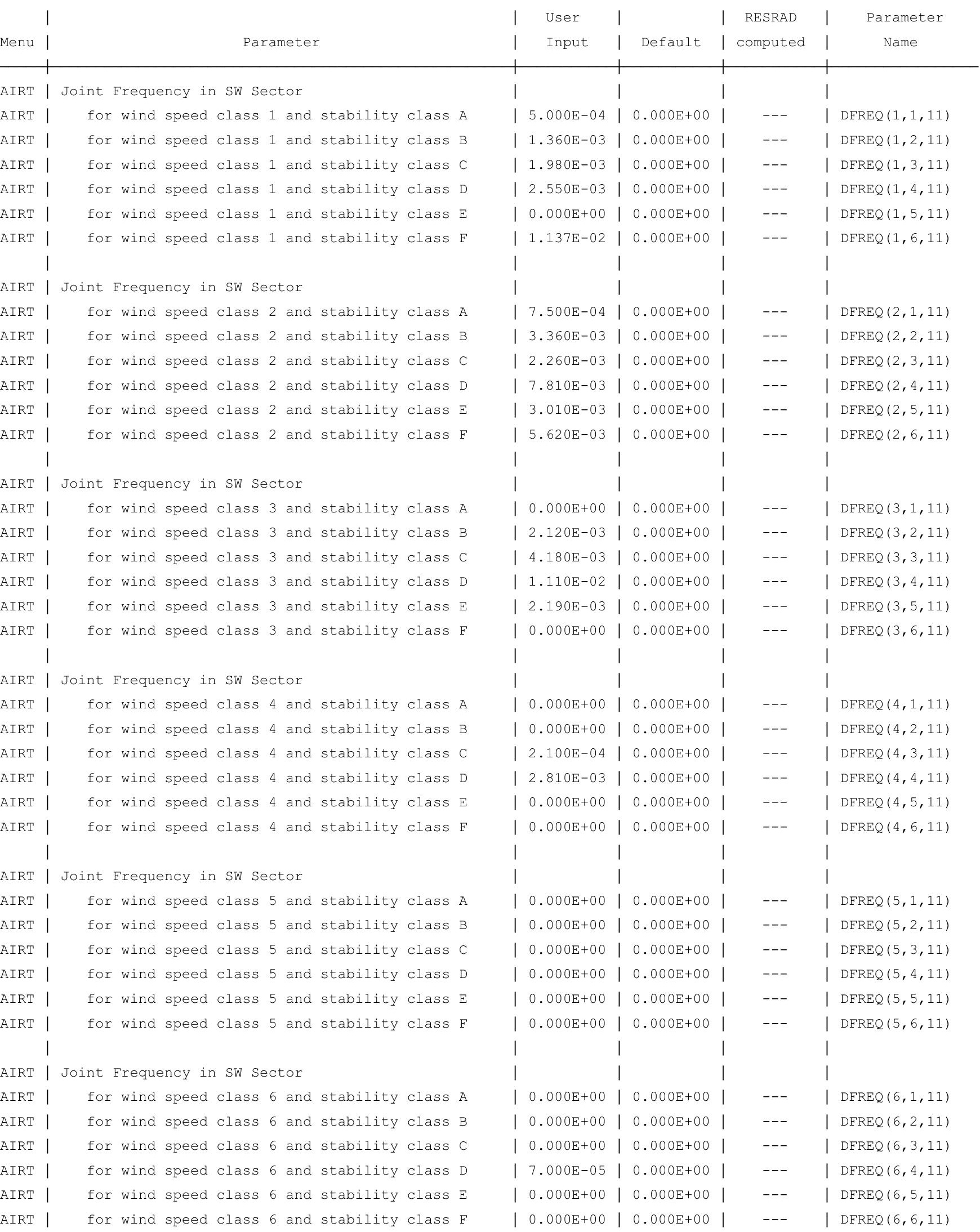


RESRAD-OFFSITE, Version 2.5

itle : Offsite Resident Farmer

File : RF TC99 DOESG FWD-FV2all.ROF

Site-Specific Parameter Summary (continued)

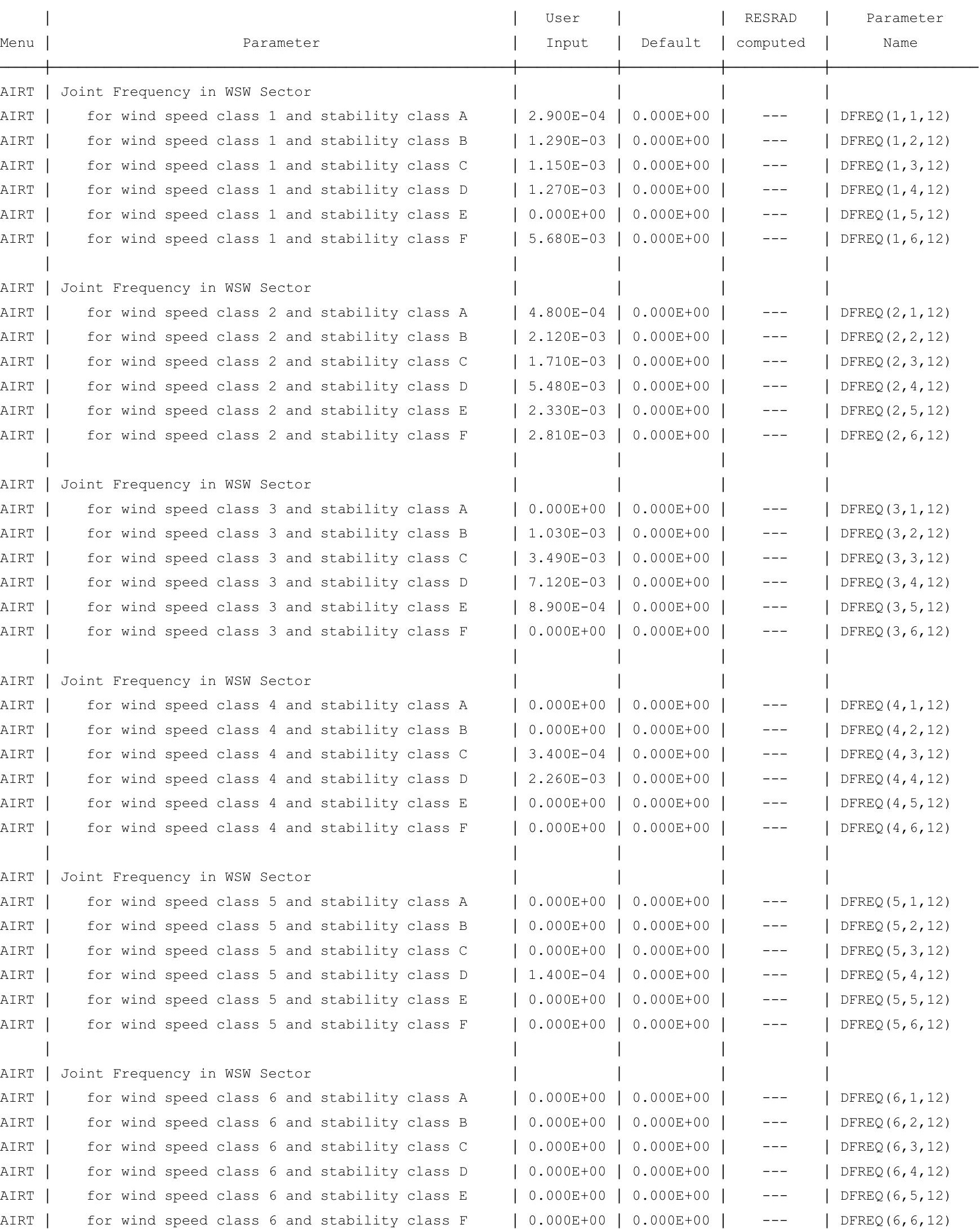


RESRAD-OFFSITE, Version 2.5

rent Dose Report

Title : Offsite Resident Farmer

File : RF TC99 DOESG FWD-FV2all.ROF

Site-Specific Parameter Summary (continued)

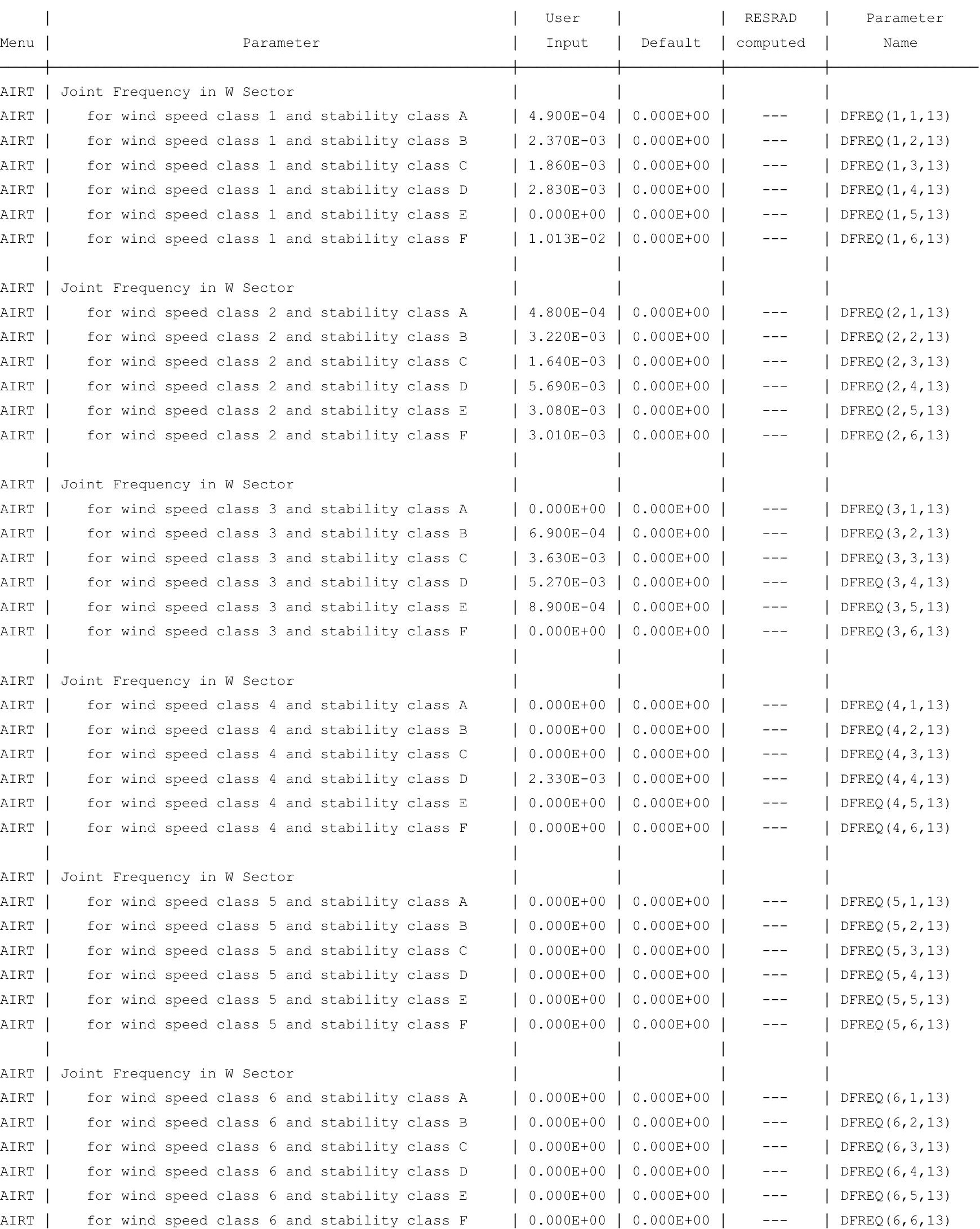


RESRAD-OFFSITE, Version 2.5

Site-Specific Parameter Summary (continued)

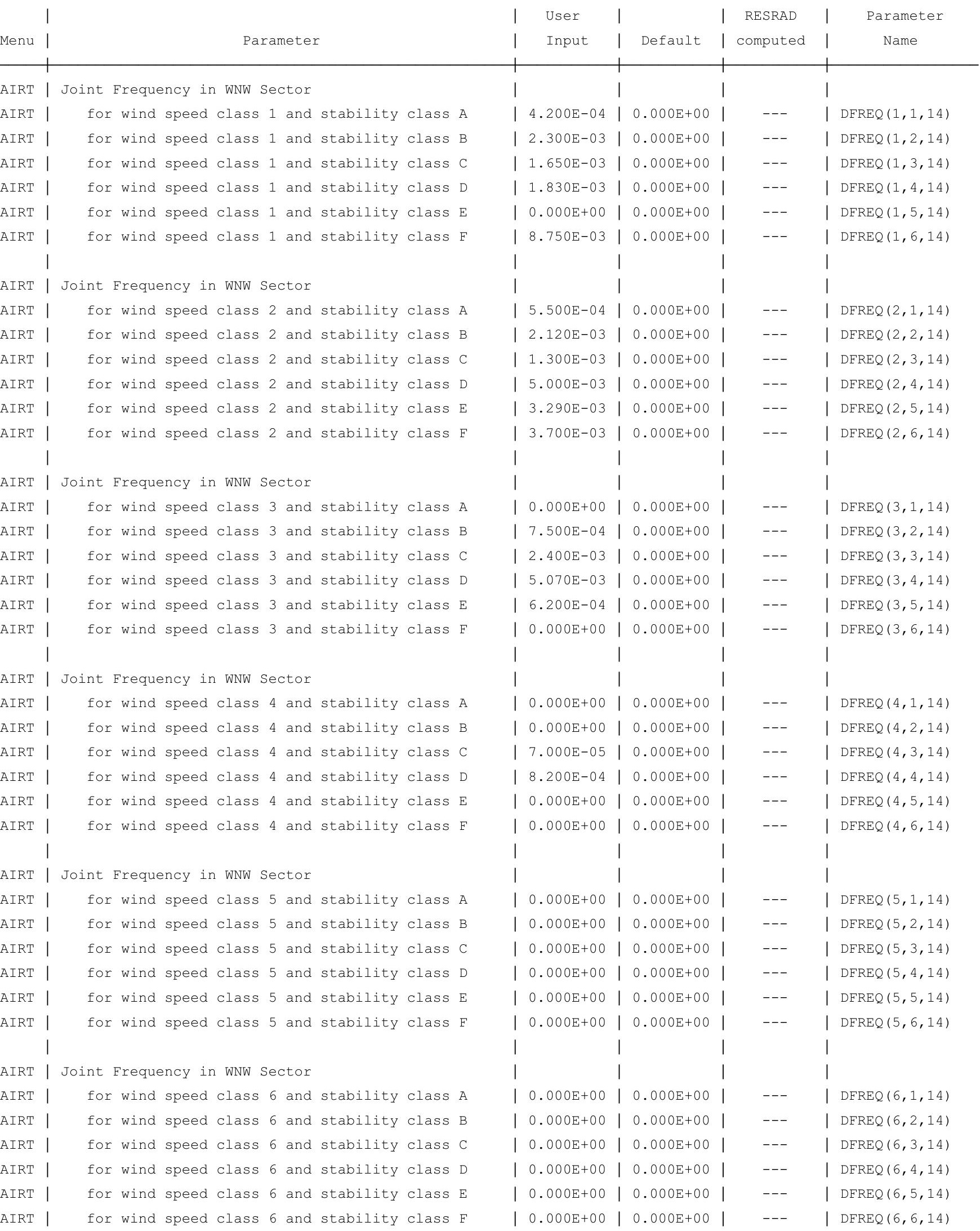


RESRAD-OFFSITE, Version 2.5

Site-Specific Parameter Summary (continued)

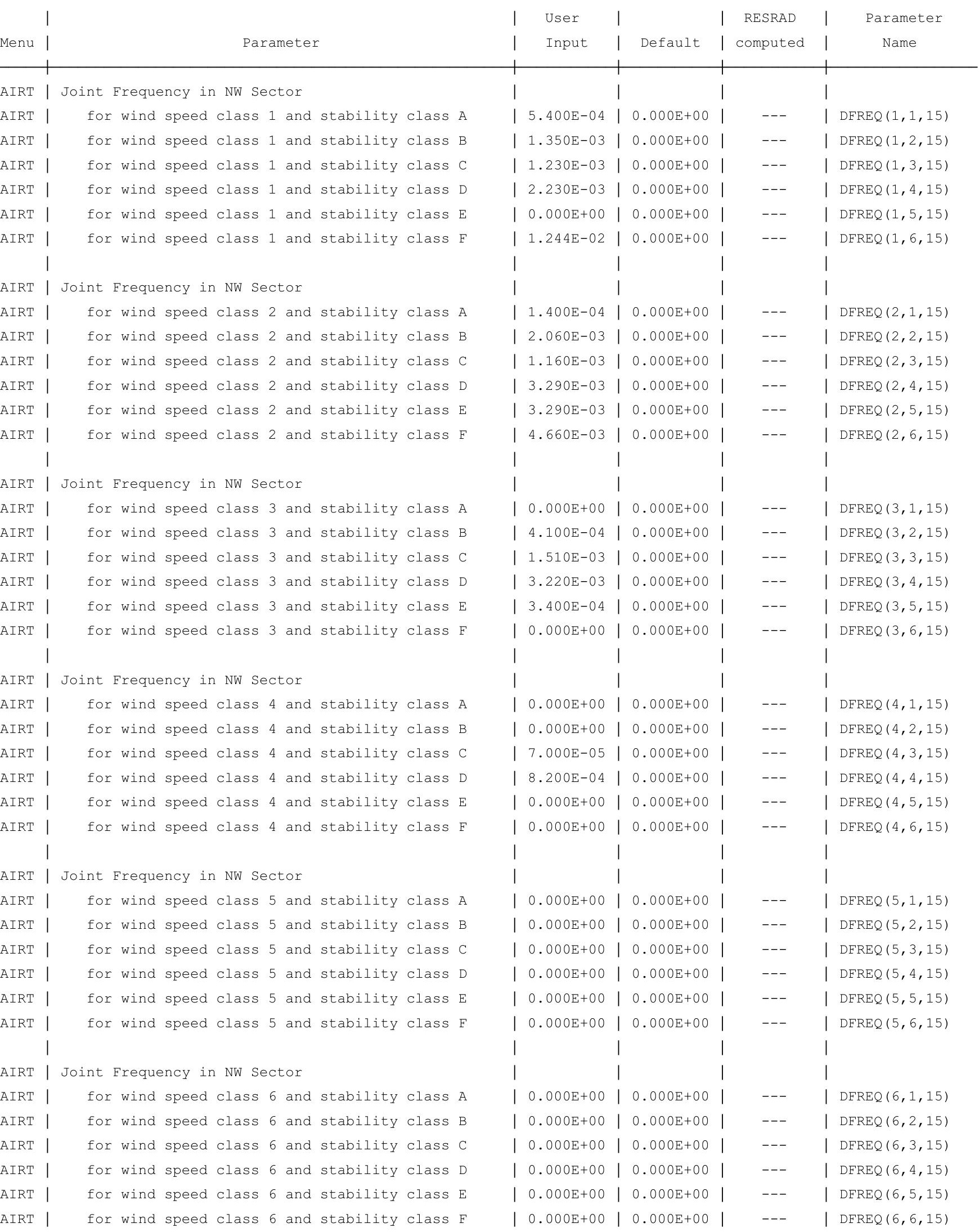


RESRAD-OFFSITE, Version 2.5

rent Dose Report

Title : Offsite Resident Farmer

File : RF TC99 DOESG FWD-FV2all.ROF

Site-Specific Parameter Summary (continued)

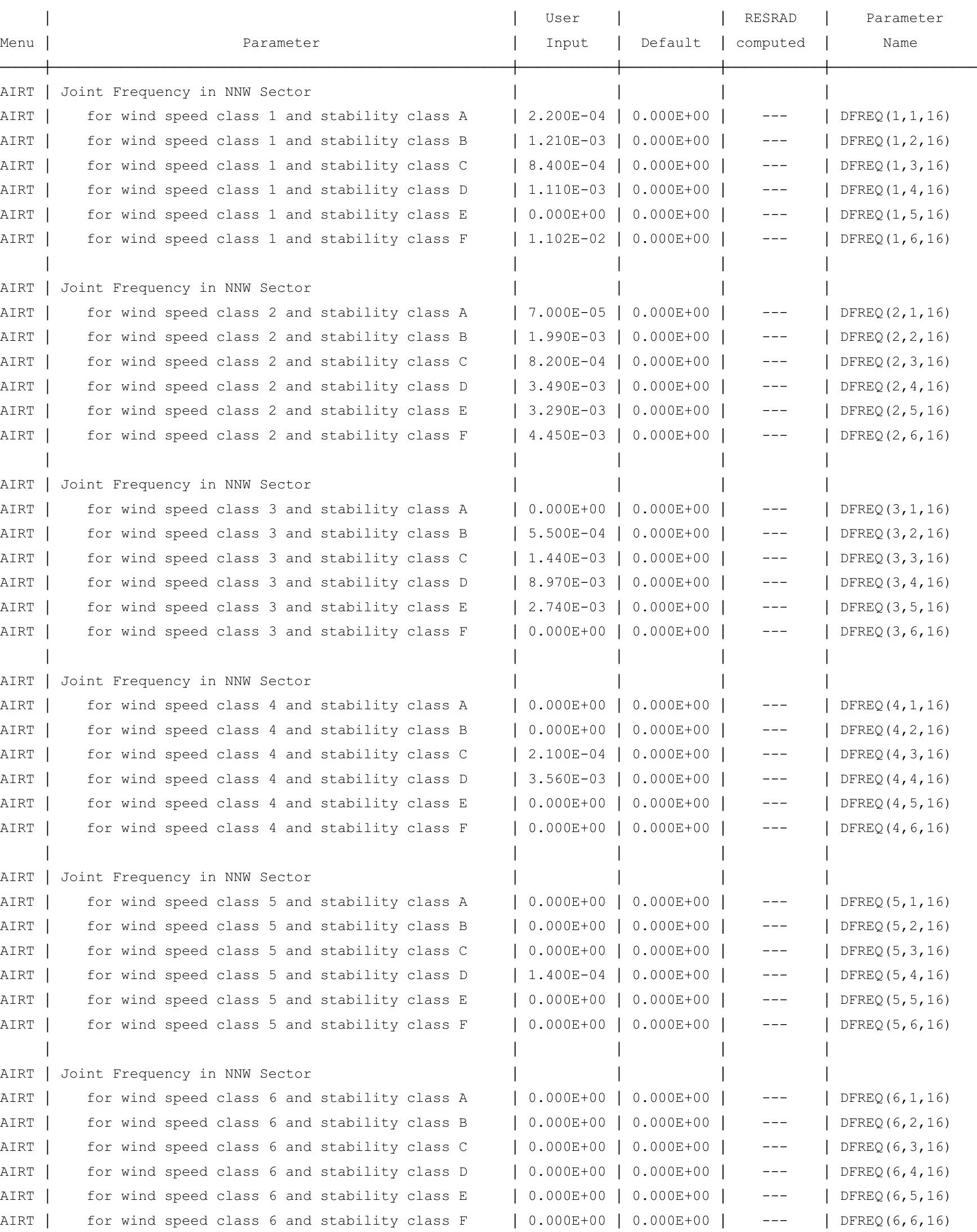


RESRAD-OFFSITE, Version 2.5

Parent Dose Report

Title : Offsite Resident Farmer

File : RF TC99 DOESG FWD-FV2all.ROF

Site-Specific Parameter Summary (continued)

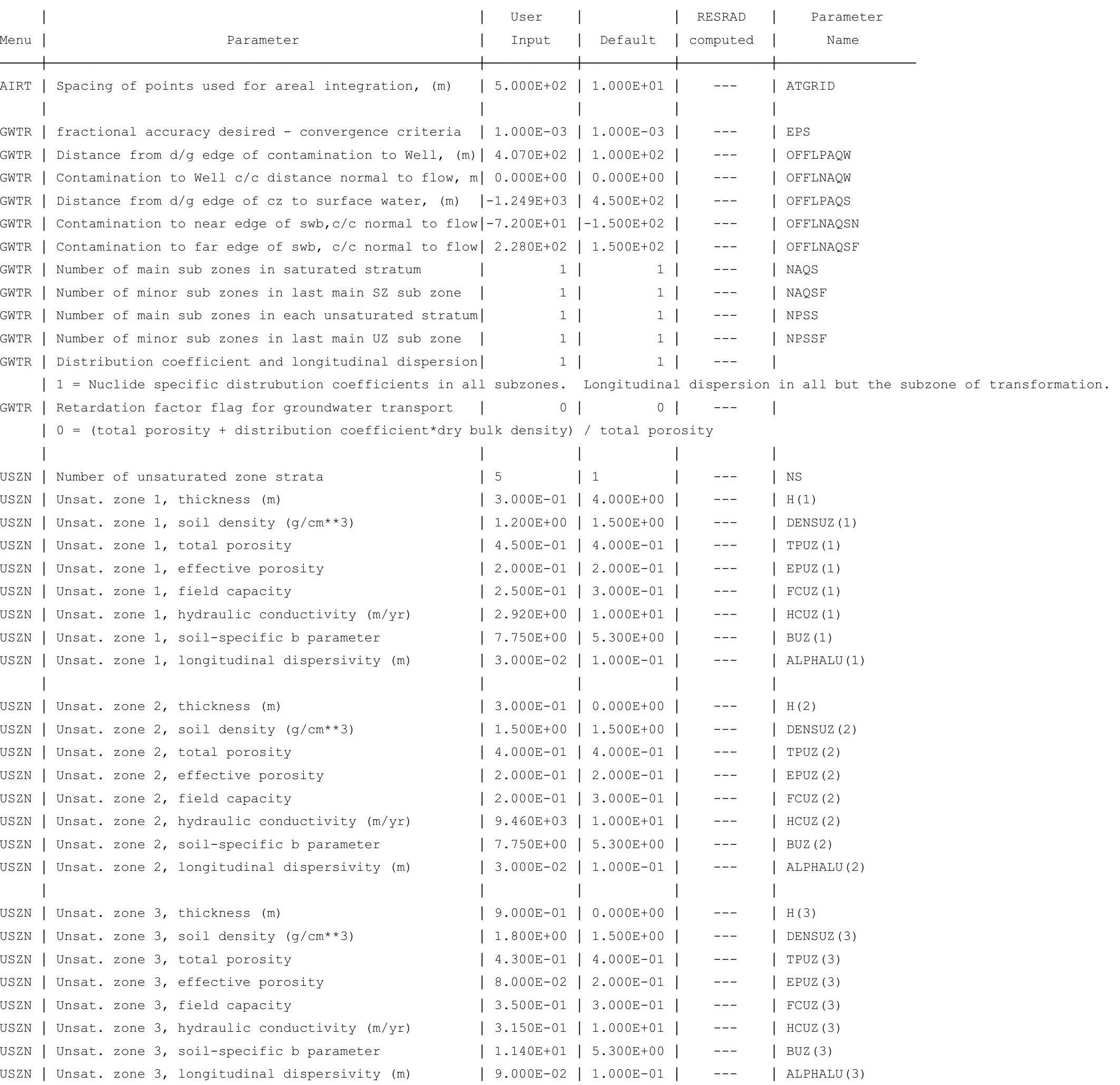


RESRAD-OFFSITE, Version 2.5

$\mathrm{T}^{1 / 2}$ Limit $=180$ days

Parent Dose Report

Title : Offsite Resident Farmer

File : RF TC99 DOESG FWD-FV2all.ROF

Site-Specific Parameter Summary (continued)

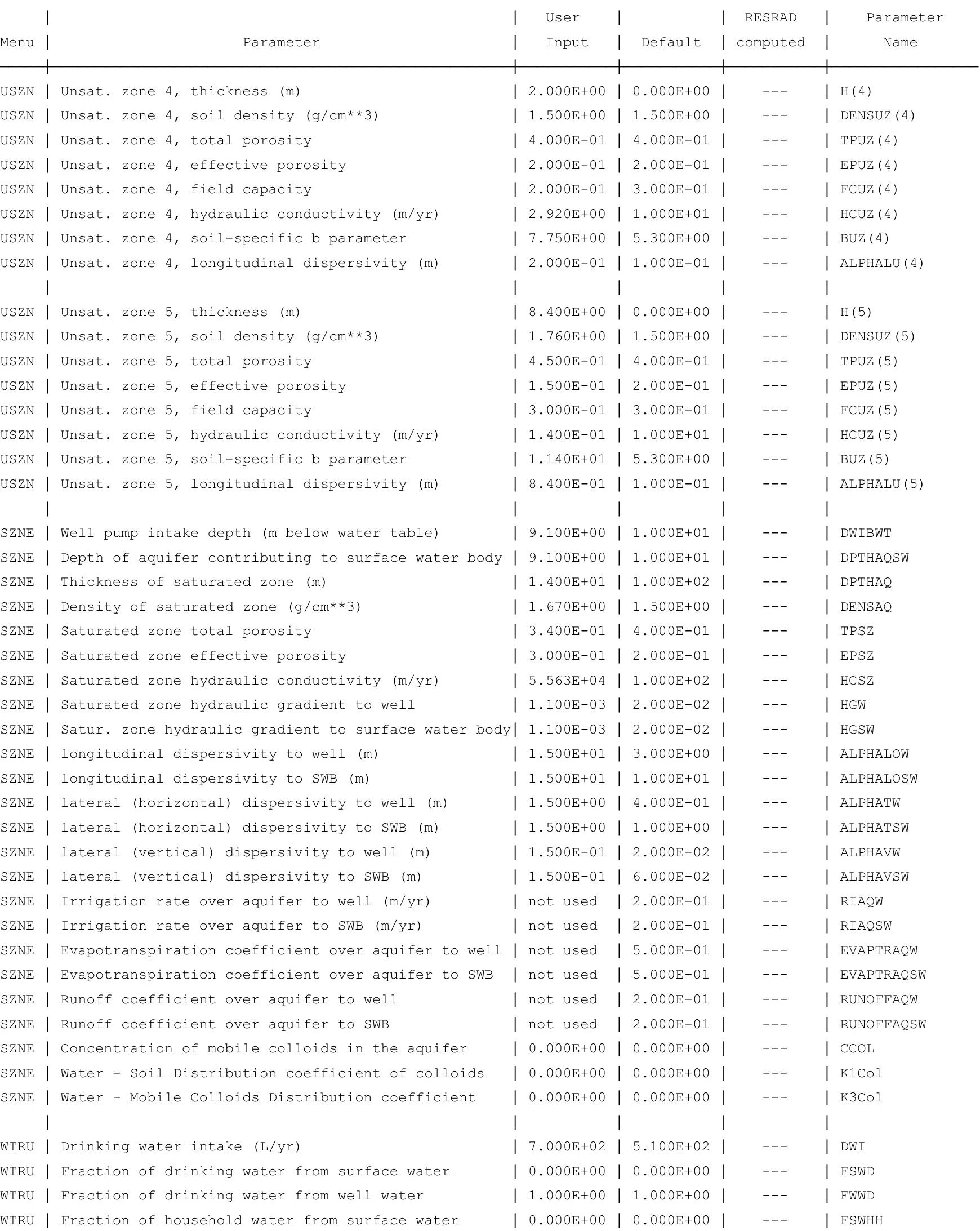


RESRAD-OFFSITE, Version 2.5

$\mathrm{T}^{1 / 2}$ Limit $=180$ days

Parent Dose Report

Title : Offsite Resident Farmer

File : RF TC99 DOESG FWD-FV2all.ROF

Site-Specific Parameter Summary (continued)

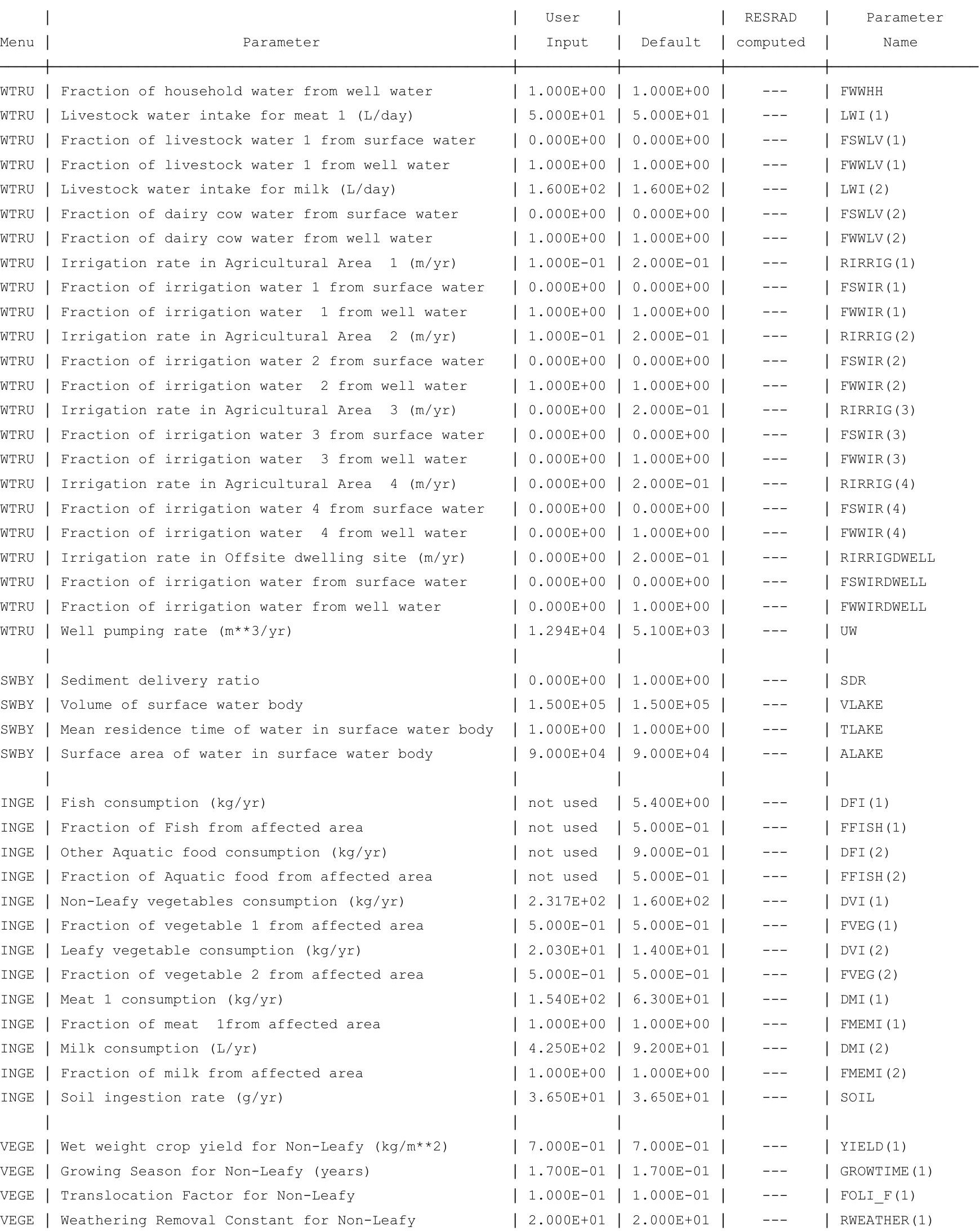


RESRAD-OFFSITE, Version 2.5

Parent Dose Report

Title : Offsite Resident Farmer

File : RF TC99 DOESG FWD-FV2all.ROF

Site-Specific Parameter Summary (continued)

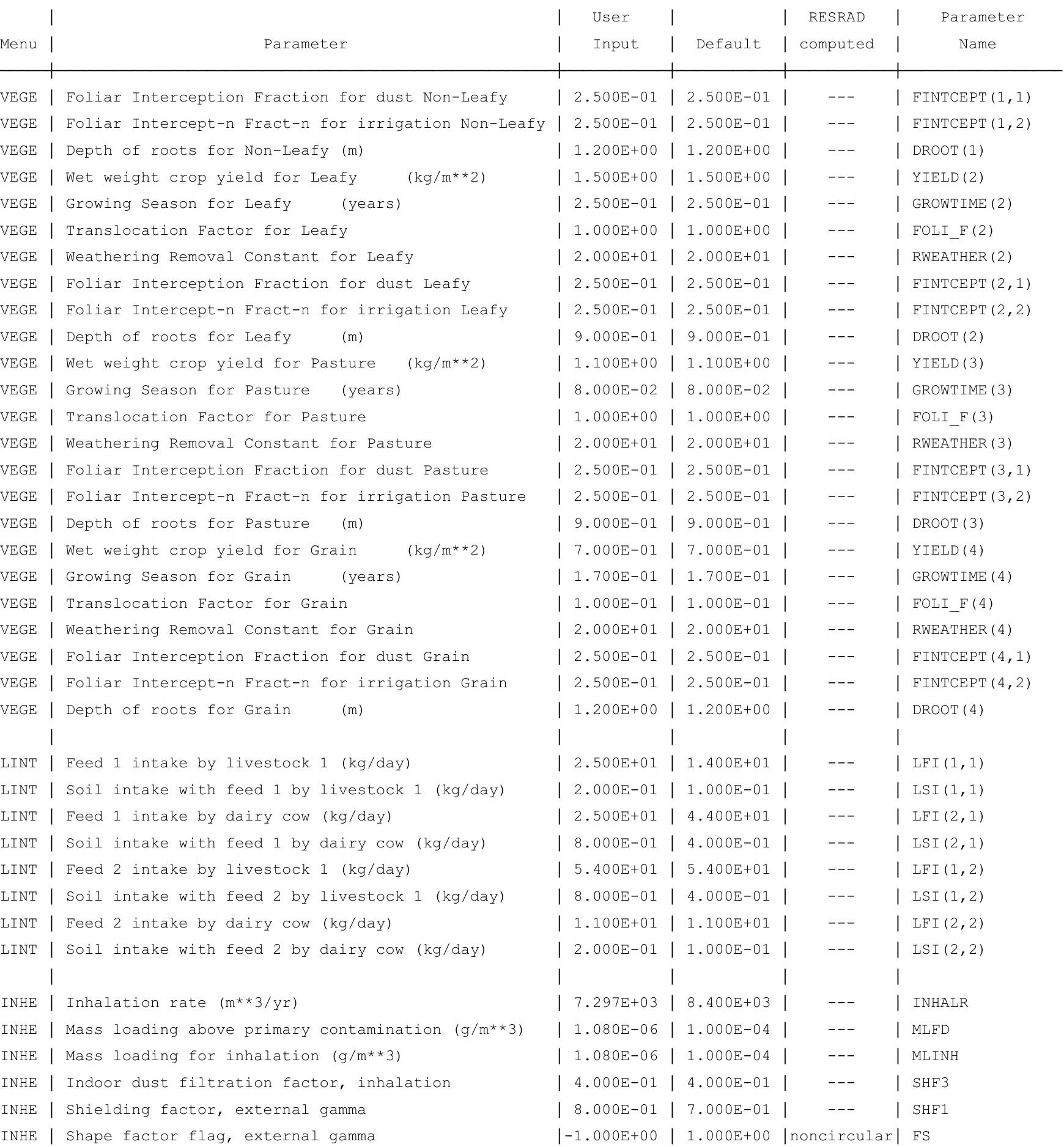


RESRAD-OFFSITE, Version 2.5

Parent Dose Report

Title : Offsite Resident Farmer

File : RF TC99 DOESG FWD-FV2all.ROF

Site-Specific Parameter Summary (continued)

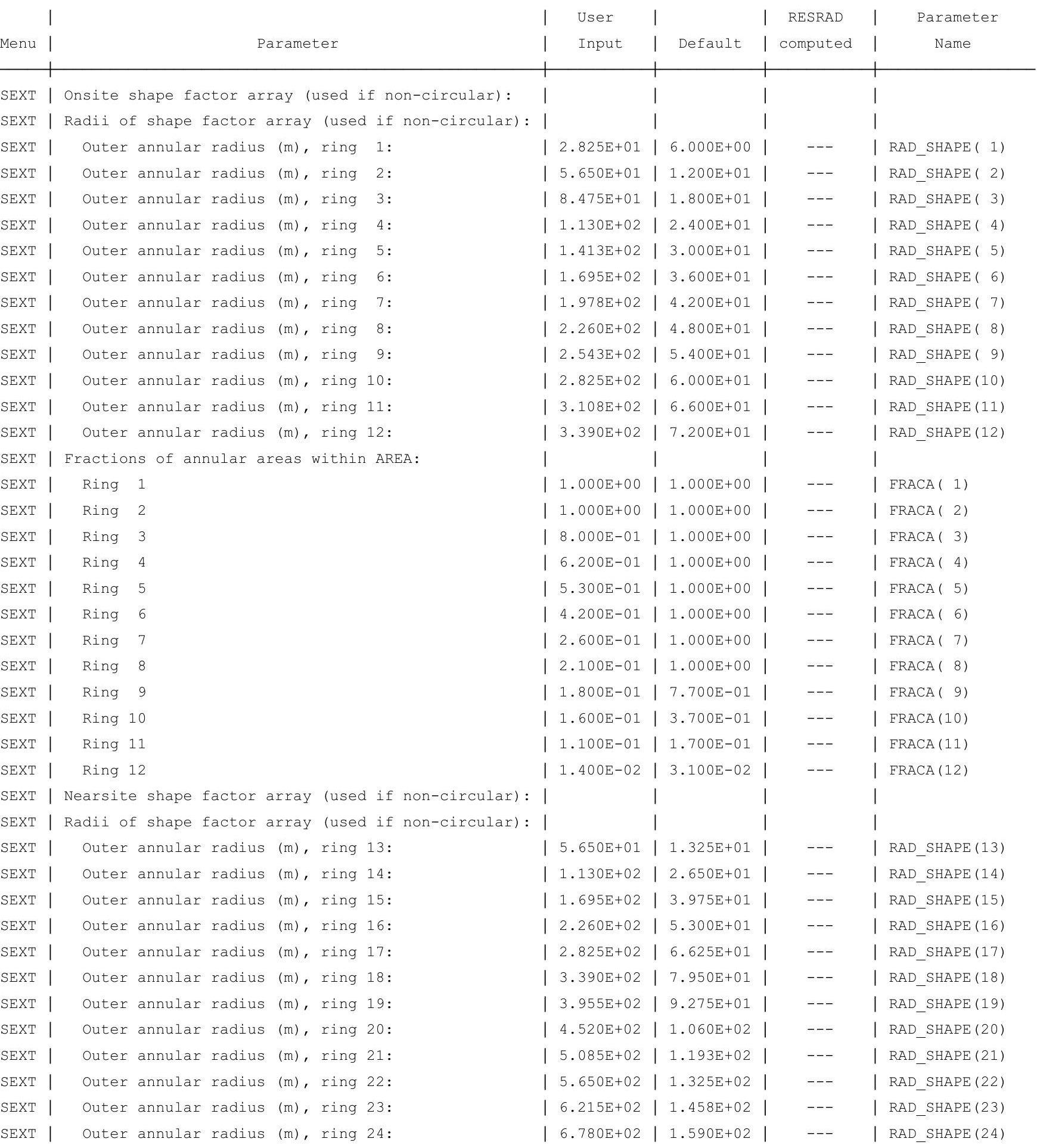


RESRAD-OFFSITE, Version 2.5

Parent Dose Report

Title : Offsite Resident Farmer

File : RF TC99 DOESG FWD-FV2all.ROF

\section{Contaminated Zone Dimensions}

Area: 102144.00 square meters

Thickness: $\quad 13.40$ meters

Cover Depth: $\quad 1.52$ meters

Total Dose TDOSE(t), mrem/yr

Basic Radiation Dose Limit $=1.000 \mathrm{E}+00 \mathrm{mrem} / \mathrm{yr}$

Total Mixture Sum $M(t)$ = Fraction of Basic Dose Limit Received at Time (t)

$\begin{array}{rllllll}t \text { (years) }: & 0.000 \mathrm{E}+00 & 1.000 \mathrm{E}+00 & 5.000 \mathrm{E}+01 & 1.000 \mathrm{E}+02 & 5.000 \mathrm{E}+02 & 1.026 \mathrm{E}+03 \\ \text { TDOSE }(\mathrm{t}): & 1.818 \mathrm{E}-32 & 1.840 \mathrm{E}-32 & 3.379 \mathrm{E}-32 & 6.282 \mathrm{E}-32 & 9.910 \mathrm{E}-01 & 1.436 \mathrm{E}+00 \\ \mathrm{M}(\mathrm{t}): & 1.818 \mathrm{E}-32 & 1.840 \mathrm{E}-32 & 3.379 \mathrm{E}-32 & 6.282 \mathrm{E}-32 & 9.910 \mathrm{E}-01 & 1.436 \mathrm{E}+00\end{array}$

Maximum TDOSE $(\mathrm{t}): \quad 1.868 \mathrm{E}+00 \mathrm{mrem} / \mathrm{yr}$ at $t=772$ years 
RESRAD-OFFSITE, Version 2.5

Parent Dose Report

Title : Offsite Resident Farmer

File : RF TC99 DOESG FWD-FV2all.ROF

Total Dose Contributions TDOSE(i,p,t) for Individual Radionuclides (i) and Pathways (p) in mrem/yr and as a Percentage of Total Dose at $t=0$ years

From releases to ground water and to surface water

\begin{tabular}{|c|c|c|c|c|c|c|c|c|c|c|c|c|c|c|c|c|}
\hline & \multicolumn{2}{|c|}{ Ground } & \multicolumn{2}{|l|}{ Fish } & \multicolumn{2}{|c|}{ Radon } & \multicolumn{2}{|c|}{ Plant } & \multicolumn{2}{|l|}{ Meat } & \multicolumn{2}{|l|}{ Milk } & \multicolumn{2}{|l|}{ Soil } & \multicolumn{2}{|c|}{ Water } \\
\hline dclide & Dose & \% & Dose & $\%$ & Dose & 음 & Dose & 음 & Dose & $\%$ & Dose & 음 & Dose & $\%$ & Dose & 응 \\
\hline-99 & $0.00 \mathrm{E}+00$ & 0 & $0.00 \mathrm{E}+00$ & 0 & $0.00 \mathrm{E}+00$ & 0 & $0.00 \mathrm{E}+00$ & 0 & $0.00 \mathrm{E}+00$ & 0 & $0.00 \mathrm{E}+00$ & 0 & $0.00 \mathrm{E}+00$ & 0 & $0.00 \mathrm{E}+00$ & 0 \\
\hline ta] & $0.00 \mathrm{E}+00$ & 0 & $0.00 \mathrm{E}+00$ & 0 & $0.00 \mathrm{E}+00$ & 0 & $0.00 \mathrm{E}+00$ & 0 & $0.00 \mathrm{E}+00$ & 0 & $0.00 \mathrm{E}+00$ & 0 & $0.00 \mathrm{E}+00$ & 0 & $0.00 \mathrm{E}+00$ & 0 \\
\hline
\end{tabular}

Total Dose Contributions TDOSE(i,p,t) for Individual Radionuclides (i) and Pathways (p) in mrem/yr and as a Percentage of Total Dose at $t=0$ years

Directly from primary contamination and from release to atmosphere (Inhalation excludes radon)

\begin{tabular}{|c|c|c|c|c|c|c|c|c|c|c|c|c|c|c|c|c|}
\hline & \multicolumn{2}{|c|}{ Ground } & \multicolumn{2}{|c|}{ Inhalation } & \multicolumn{2}{|c|}{ Radon } & \multicolumn{2}{|c|}{ Plant } & \multicolumn{2}{|l|}{ Meat } & \multicolumn{2}{|l|}{ Milk } & \multicolumn{2}{|l|}{ Soil } & \multicolumn{2}{|c|}{ All Pathways* } \\
\hline dclide & Dose & \% & Dose & $\%$ & Dose & $\%$ & Dose & 음 & Dose & $\%$ & Dose & 응 & Dose & 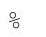 & Dose & $\%$ \\
\hline-99 & $1.82 \mathrm{E}-32$ & 0 & $0.00 \mathrm{E}+00$ & 0 & $0.00 \mathrm{E}+00$ & 0 & $0.00 \mathrm{E}+00$ & 0 & $0.00 \mathrm{E}+00$ & 0 & $0.00 \mathrm{E}+00$ & 0 & $0.00 \mathrm{E}+00$ & 0 & $1.82 E-32$ & 0 \\
\hline to & $1.82 \mathrm{E}-32$ & 0 & $0.00 \mathrm{E}+00$ & 0 & $0.00 \mathrm{E}+00$ & 0 & $0.00 \mathrm{E}+00$ & 0 & $0.00 \mathrm{E}+00$ & 0 & $0.00 \mathrm{E}+00$ & 0 & $0.00 \mathrm{E}+00$ & 0 & $1.82 \mathrm{E}-32$ & 0 \\
\hline
\end{tabular}

* Sum of dose from all releases and from primary contamination. 
RESRAD-OFFSITE, Version 2.5

Parent Dose Report

Title : Offsite Resident Farmer

File : RF TC99 DOESG FWD-FV2all.ROF

Total Dose Contributions TDOSE(i,p,t) for Individual Radionuclides (i) and Pathways (p) in mrem/yr and as a Percentage of Total Dose at $t=1$ years

From releases to ground water and to surface water

\begin{tabular}{|c|c|c|c|c|c|c|c|c|c|c|c|c|c|c|c|c|}
\hline & \multicolumn{2}{|c|}{ Ground } & \multicolumn{2}{|l|}{ Fish } & \multicolumn{2}{|c|}{ Radon } & \multicolumn{2}{|c|}{ Plant } & \multicolumn{2}{|l|}{ Meat } & \multicolumn{2}{|l|}{ Milk } & \multicolumn{2}{|l|}{ Soil } & \multicolumn{2}{|c|}{ Water } \\
\hline dclide & Dose & \% & Dose & $\%$ & Dose & 음 & Dose & 음 & Dose & $\%$ & Dose & 음 & Dose & $\%$ & Dose & 응 \\
\hline-99 & $0.00 \mathrm{E}+00$ & 0 & $0.00 \mathrm{E}+00$ & 0 & $0.00 \mathrm{E}+00$ & 0 & $0.00 \mathrm{E}+00$ & 0 & $0.00 \mathrm{E}+00$ & 0 & $0.00 \mathrm{E}+00$ & 0 & $0.00 \mathrm{E}+00$ & 0 & $0.00 \mathrm{E}+00$ & 0 \\
\hline ta] & $0.00 \mathrm{E}+00$ & 0 & $0.00 \mathrm{E}+00$ & 0 & $0.00 \mathrm{E}+00$ & 0 & $0.00 \mathrm{E}+00$ & 0 & $0.00 \mathrm{E}+00$ & 0 & $0.00 \mathrm{E}+00$ & 0 & $0.00 \mathrm{E}+00$ & 0 & $0.00 \mathrm{E}+00$ & 0 \\
\hline
\end{tabular}

Total Dose Contributions TDOSE(i,p,t) for Individual Radionuclides (i) and Pathways (p) in mrem/yr and as a Percentage of Total Dose at $t=1$ years

Directly from primary contamination and from release to atmosphere (Inhalation excludes radon)

\begin{tabular}{|c|c|c|c|c|c|c|c|c|c|c|c|c|c|c|c|c|}
\hline & \multicolumn{2}{|c|}{ Ground } & \multicolumn{2}{|c|}{ Inhalation } & \multicolumn{2}{|c|}{ Radon } & \multicolumn{2}{|c|}{ Plant } & \multicolumn{2}{|l|}{ Meat } & \multicolumn{2}{|l|}{ Milk } & \multicolumn{2}{|l|}{ Soil } & \multicolumn{2}{|c|}{ All Pathways* } \\
\hline dclide & Dose & \% & Dose & $\%$ & Dose & $\%$ & Dose & 음 & Dose & $\%$ & Dose & 응 & Dose & 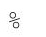 & Dose & $\%$ \\
\hline-99 & $1.84 \mathrm{E}-32$ & 0 & $0.00 \mathrm{E}+00$ & 0 & $0.00 \mathrm{E}+00$ & 0 & $0.00 \mathrm{E}+00$ & 0 & $0.00 \mathrm{E}+00$ & 0 & $0.00 \mathrm{E}+00$ & 0 & $0.00 \mathrm{E}+00$ & 0 & $1.84 E-32$ & 0 \\
\hline to & $1.84 \mathrm{E}-32$ & 0 & $0.00 \mathrm{E}+00$ & 0 & $0.00 \mathrm{E}+00$ & 0 & $0.00 \mathrm{E}+00$ & 0 & $0.00 \mathrm{E}+00$ & 0 & $0.00 \mathrm{E}+00$ & 0 & $0.00 \mathrm{E}+00$ & 0 & $1.84 \mathrm{E}-32$ & 0 \\
\hline
\end{tabular}

* Sum of dose from all releases and from primary contamination. 
RESRAD-OFFSITE, Version 2.5

Parent Dose Report

Title : Offsite Resident Farmer

File : RF TC99 DOESG FWD-FV2all.ROF

Total Dose Contributions TDOSE(i,p,t) for Individual Radionuclides (i) and Pathways (p) in mrem/yr and as a Percentage of Total Dose at $t=50$ years

From releases to ground water and to surface water

\begin{tabular}{|c|c|c|c|c|c|c|c|c|c|c|c|c|c|c|c|c|}
\hline & \multicolumn{2}{|c|}{ Ground } & \multicolumn{2}{|l|}{ Fish } & \multicolumn{2}{|c|}{ Radon } & \multicolumn{2}{|c|}{ Plant } & \multicolumn{2}{|l|}{ Meat } & \multicolumn{2}{|l|}{ Milk } & \multicolumn{2}{|l|}{ Soil } & \multicolumn{2}{|c|}{ Water } \\
\hline dclide & Dose & \% & Dose & $\%$ & Dose & 음 & Dose & 음 & Dose & $\%$ & Dose & 음 & Dose & $\%$ & Dose & 응 \\
\hline-99 & $0.00 \mathrm{E}+00$ & 0 & $0.00 \mathrm{E}+00$ & 0 & $0.00 \mathrm{E}+00$ & 0 & $0.00 \mathrm{E}+00$ & 0 & $0.00 \mathrm{E}+00$ & 0 & $0.00 \mathrm{E}+00$ & 0 & $0.00 \mathrm{E}+00$ & 0 & $0.00 \mathrm{E}+00$ & 0 \\
\hline ta] & $0.00 \mathrm{E}+00$ & 0 & $0.00 \mathrm{E}+00$ & 0 & $0.00 \mathrm{E}+00$ & 0 & $0.00 \mathrm{E}+00$ & 0 & $0.00 \mathrm{E}+00$ & 0 & $0.00 \mathrm{E}+00$ & 0 & $0.00 \mathrm{E}+00$ & 0 & $0.00 \mathrm{E}+00$ & 0 \\
\hline
\end{tabular}

Total Dose Contributions TDOSE(i,p,t) for Individual Radionuclides (i) and Pathways (p) in mrem/yr and as a Percentage of Total Dose at $t=50$ years

Directly from primary contamination and from release to atmosphere (Inhalation excludes radon)

\begin{tabular}{|c|c|c|c|c|c|c|c|c|c|c|c|c|c|c|c|c|}
\hline & \multicolumn{2}{|c|}{ Ground } & \multicolumn{2}{|c|}{ Inhalation } & \multicolumn{2}{|c|}{ Radon } & \multicolumn{2}{|c|}{ Plant } & \multicolumn{2}{|l|}{ Meat } & \multicolumn{2}{|l|}{ Milk } & \multicolumn{2}{|l|}{ Soil } & \multicolumn{2}{|c|}{ All Pathways* } \\
\hline dclide & Dose & \% & Dose & $\%$ & Dose & $\%$ & Dose & 음 & Dose & $\%$ & Dose & 응 & Dose & 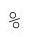 & Dose & $\%$ \\
\hline-99 & $3.38 E-32$ & 0 & $0.00 \mathrm{E}+00$ & 0 & $0.00 \mathrm{E}+00$ & 0 & $0.00 \mathrm{E}+00$ & 0 & $0.00 \mathrm{E}+00$ & 0 & $0.00 \mathrm{E}+00$ & 0 & $0.00 \mathrm{E}+00$ & 0 & $3.38 E-32$ & 0 \\
\hline tal & $3.38 E-32$ & 0 & $0.00 \mathrm{E}+00$ & 0 & $0.00 \mathrm{E}+00$ & 0 & $0.00 \mathrm{E}+00$ & 0 & $0.00 \mathrm{E}+00$ & 0 & $0.00 \mathrm{E}+00$ & 0 & $0.00 \mathrm{E}+00$ & 0 & $3.38 E-32$ & 0 \\
\hline
\end{tabular}

* Sum of dose from all releases and from primary contamination. 
RESRAD-OFFSITE, Version 2.5

Parent Dose Report

Title : Offsite Resident Farmer

File : RF TC99 DOESG FWD-FV2all.ROF

Total Dose Contributions TDOSE(i,p,t) for Individual Radionuclides (i) and Pathways (p) in mrem/yr and as a Percentage of Total Dose at $t=100$ years

From releases to ground water and to surface water

\begin{tabular}{|c|c|c|c|c|c|c|c|c|c|c|c|c|c|c|c|c|}
\hline & \multicolumn{2}{|c|}{ Ground } & \multicolumn{2}{|l|}{ Fish } & \multicolumn{2}{|c|}{ Radon } & \multicolumn{2}{|c|}{ Plant } & \multicolumn{2}{|l|}{ Meat } & \multicolumn{2}{|l|}{ Milk } & \multicolumn{2}{|l|}{ Soil } & \multicolumn{2}{|c|}{ Water } \\
\hline uclide & Dose & $\frac{\circ}{0}$ & Dose & $\%$ & Dose & \% & Dose & \% & Dose & $\%$ & Dose & $\%$ & Dose & \% & Dose & $\%$ \\
\hline-99 & $0.00 \mathrm{E}+00$ & 0 & $0.00 \mathrm{E}+00$ & 0 & $0.00 \mathrm{E}+00$ & 0 & $0.00 \mathrm{E}+00$ & 0 & $0.00 \mathrm{E}+00$ & 0 & $0.00 \mathrm{E}+00$ & 0 & $0.00 \mathrm{E}+00$ & 0 & $0.00 \mathrm{E}+00$ & 0 \\
\hline tal & $0.00 \mathrm{E}+00$ & 0 & $0.00 \mathrm{E}+00$ & 0 & $0.00 \mathrm{E}+00$ & 0 & $0.00 \mathrm{E}+00$ & 0 & $0.00 \mathrm{E}+00$ & 0 & $0.00 \mathrm{E}+00$ & 0 & $0.00 \mathrm{E}+00$ & 0 & $0.00 \mathrm{E}+00$ & 0 \\
\hline
\end{tabular}

Total Dose Contributions TDOSE(i,p,t) for Individual Radionuclides (i) and Pathways (p) in mrem/yr and as a Percentage of Total Dose at $t=100$ years

Directly from primary contamination and from release to atmosphere (Inhalation excludes radon)

\begin{tabular}{|c|c|c|c|c|c|c|c|c|c|c|c|c|c|c|c|c|}
\hline & \multicolumn{2}{|c|}{ Ground } & \multicolumn{2}{|c|}{ Inhalation } & \multicolumn{2}{|c|}{ Radon } & \multicolumn{2}{|c|}{ Plant } & \multicolumn{2}{|l|}{ Meat } & \multicolumn{2}{|l|}{ Milk } & \multicolumn{2}{|l|}{ Soil } & \multicolumn{2}{|c|}{ All Pathways* } \\
\hline uclide & Dose & \% & Dose & $\%$ & Dose & $\%$ & Dose & $\frac{\circ}{0}$ & Dose & $\%$ & Dose & \% & Dose & \% & Dose & $\%$ \\
\hline-99 & $6.28 \mathrm{E}-32$ & 0 & $0.00 \mathrm{E}+00$ & 0 & $0.00 \mathrm{E}+00$ & 0 & $0.00 \mathrm{E}+00$ & 0 & $0.00 \mathrm{E}+00$ & 0 & $0.00 \mathrm{E}+00$ & 0 & $0.00 \mathrm{E}+00$ & 0 & $6.28 \mathrm{E}-32$ & 0 \\
\hline al & $6.28 \mathrm{E}-32$ & 0 & $0.00 \mathrm{E}+00$ & 0 & $0.00 \mathrm{E}+00$ & 0 & $0.00 \mathrm{E}+00$ & 0 & $0.00 \mathrm{E}+00$ & 0 & $0.00 \mathrm{E}+00$ & 0 & $0.00 \mathrm{E}+00$ & 0 & $6.28 E-32$ & 0 \\
\hline
\end{tabular}

* Sum of dose from all releases and from primary contamination. 
RESRAD-OFFSITE, Version 2.5

Parent Dose Report

Title : Offsite Resident Farmer

File : RF TC99 DOESG FWD-FV2all.ROF

Total Dose Contributions TDOSE(i,p,t) for Individual Radionuclides (i) and Pathways (p) in mrem/yr and as a Percentage of Total Dose at $t=500$ years

From releases to ground water and to surface water

\begin{tabular}{|c|c|c|c|c|c|c|c|c|c|c|c|c|c|c|c|c|}
\hline & \multicolumn{2}{|c|}{ Ground } & \multicolumn{2}{|l|}{ Fish } & \multicolumn{2}{|c|}{ Radon } & \multicolumn{2}{|c|}{ Plant } & \multicolumn{2}{|l|}{ Meat } & \multicolumn{2}{|l|}{ Milk } & \multicolumn{2}{|l|}{ Soil } & \multicolumn{2}{|c|}{ Water } \\
\hline clide & Dose & \% & Dose & $\%$ & Dose & $\%$ & Dose & 음 & Dose & $\%$ & Dose & \% & Dose & \% & Dose & $\frac{\circ}{0}$ \\
\hline$c-99$ & $9.04 \mathrm{E}-07$ & 0 & $0.00 \mathrm{E}+00$ & 0 & $0.00 \mathrm{E}+00$ & 0 & $2.48 \mathrm{E}-01$ & 25 & $7.44 \mathrm{E}-04$ & 0 & $6.57 \mathrm{E}-02$ & 7 & $7.63 \mathrm{E}-07$ & 0 & $6.76 \mathrm{E}-01$ & 68 \\
\hline a) & $9.04 \mathrm{E}-07$ & 0 & $0.00 \mathrm{E}+00$ & 0 & $0.00 \mathrm{E}+00$ & 0 & $2.48 \mathrm{E}-01$ & 25 & $7.44 \mathrm{E}-04$ & 0 & $6.57 E-02$ & 7 & $7.63 E-07$ & 0 & $6.76 \mathrm{E}-01$ & 68 \\
\hline
\end{tabular}

Total Dose Contributions TDOSE(i,p,t) for Individual Radionuclides (i) and Pathways (p) in mrem/yr and as a Percentage of Total Dose at $t=500$ years

Directly from primary contamination and from release to atmosphere (Inhalation excludes radon)

\begin{tabular}{|c|c|c|c|c|c|c|c|c|c|c|c|c|c|c|c|c|}
\hline & \multicolumn{2}{|c|}{ Ground } & \multicolumn{2}{|c|}{ Inhalation } & \multicolumn{2}{|c|}{ Radon } & \multicolumn{2}{|c|}{ Plant } & \multicolumn{2}{|l|}{ Meat } & \multicolumn{2}{|l|}{ Milk } & \multicolumn{2}{|l|}{ Soil } & \multicolumn{2}{|c|}{ All Pathways* } \\
\hline dclide & Dose & \% & Dose & $\%$ & Dose & $\%$ & Dose & 음 & Dose & $\%$ & Dose & 응 & Dose & 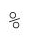 & Dose & $\%$ \\
\hline-99 & $8.96 \mathrm{E}-30$ & 0 & $0.00 \mathrm{E}+00$ & 0 & $0.00 \mathrm{E}+00$ & 0 & $0.00 \mathrm{E}+00$ & 0 & $0.00 \mathrm{E}+00$ & 0 & $0.00 \mathrm{E}+00$ & 0 & $0.00 \mathrm{E}+00$ & 0 & $9.91 \mathrm{E}-01$ & 100 \\
\hline to & $8.96 \mathrm{E}-30$ & 0 & $0.00 \mathrm{E}+00$ & 0 & $0.00 \mathrm{E}+00$ & 0 & $0.00 \mathrm{E}+00$ & 0 & $0.00 \mathrm{E}+00$ & 0 & $0.00 \mathrm{E}+00$ & 0 & $0.00 \mathrm{E}+00$ & 0 & $9.91 \mathrm{E}-01$ & 100 \\
\hline
\end{tabular}

* Sum of dose from all releases and from primary contamination. 
RESRAD-OFFSITE, Version 2.5

Parent Dose Report

Title : Offsite Resident Farmer

File : RF TC99 DOESG FWD-FV2all.ROF

Total Dose Contributions TDOSE(i,p,t) for Individual Radionuclides (i) and Pathways (p) in mrem/yr and as a Percentage of Total Dose at $t=1026$ years

From releases to ground water and to surface water

\begin{tabular}{|c|c|c|c|c|c|c|c|c|c|c|c|c|c|c|c|c|}
\hline & \multicolumn{2}{|c|}{ Ground } & \multicolumn{2}{|l|}{ Fish } & \multicolumn{2}{|c|}{ Radon } & \multicolumn{2}{|c|}{ Plant } & \multicolumn{2}{|l|}{ Meat } & \multicolumn{2}{|l|}{ Milk } & \multicolumn{2}{|l|}{ Soil } & \multicolumn{2}{|c|}{ Water } \\
\hline clide & Dose & \% & Dose & $\%$ & Dose & $\%$ & Dose & 음 & Dose & $\%$ & Dose & \% & Dose & \% & Dose & $\frac{\circ}{0}$ \\
\hline$=-99$ & $1.31 \mathrm{E}-06$ & 0 & $0.00 \mathrm{E}+00$ & 0 & $0.00 \mathrm{E}+00$ & 0 & $3.60 \mathrm{E}-01$ & 25 & $1.08 \mathrm{E}-03$ & 0 & $9.52 \mathrm{E}-02$ & 7 & $1.11 \mathrm{E}-06$ & 0 & $9.80 \mathrm{E}-01$ & 68 \\
\hline a) & $1.31 \mathrm{E}-06$ & 0 & $0.00 \mathrm{E}+00$ & 0 & $0.00 \mathrm{E}+00$ & 0 & $3.60 \mathrm{E}-01$ & 25 & $1.08 \mathrm{E}-03$ & 0 & $9.52 E-02$ & 7 & $1.11 \mathrm{E}-06$ & 0 & $9.80 \mathrm{E}-01$ & 68 \\
\hline
\end{tabular}

Total Dose Contributions TDOSE(i,p,t) for Individual Radionuclides (i) and Pathways (p)

in mrem/yr and as a Percentage of Total Dose at $t=1026$ years

Directly from primary contamination and from release to atmosphere (Inhalation excludes radon)

\begin{tabular}{|c|c|c|c|c|c|c|c|c|c|c|c|c|c|c|c|c|}
\hline & \multicolumn{2}{|c|}{ Ground } & \multicolumn{2}{|c|}{ Inhalation } & \multicolumn{2}{|c|}{ Radon } & \multicolumn{2}{|c|}{ Plant } & \multicolumn{2}{|l|}{ Meat } & \multicolumn{2}{|l|}{ Milk } & \multicolumn{2}{|l|}{ Soil } & \multicolumn{2}{|c|}{ All Pathways* } \\
\hline clide & Dose & \% & Dose & $\%$ & Dose & $\%$ & Dose & 음 & Dose & $\%$ & Dose & 응 & Dose & 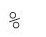 & Dose & $\%$ \\
\hline-99 & $6.10 \mathrm{E}-27$ & 0 & $0.00 \mathrm{E}+00$ & 0 & $0.00 \mathrm{E}+00$ & 0 & $0.00 \mathrm{E}+00$ & 0 & $0.00 \mathrm{E}+00$ & 0 & $0.00 \mathrm{E}+00$ & 0 & $0.00 \mathrm{E}+00$ & 0 & $1.44 \mathrm{E}+00$ & 100 \\
\hline to & $6.10 \mathrm{E}-27$ & 0 & $0.00 \mathrm{E}+00$ & 0 & $0.00 \mathrm{E}+00$ & 0 & $0.00 \mathrm{E}+00$ & 0 & $0.00 \mathrm{E}+00$ & 0 & $0.00 \mathrm{E}+00$ & 0 & $0.00 \mathrm{E}+00$ & 0 & $1.44 \mathrm{E}+00$ & 100 \\
\hline
\end{tabular}

* Sum of dose from all releases and from primary contamination. 
RESRAD-OFFSITE, Version 2.5

Parent Dose Report

Title : Offsite Resident Farmer

File : RF TC99 DOESG FWD-FV2all.ROF

Dose/Source Ratios Summed Over All Pathways

Parent and Progeny Principal Radionuclide Contributions Indicated

\begin{tabular}{|c|c|c|c|c|c|c|c|c|}
\hline Parent & Product & Thread & & $\operatorname{DSR}(j$, & $\Rightarrow \quad(\mathrm{mrem} / \mathrm{y}$ & $\Rightarrow) /(\mathrm{pCi} / \mathrm{g})$ & & \\
\hline (i) & $(j)$ & Fraction & $0.000 \mathrm{E}+00$ & $1.000 \mathrm{E}+00$ & $5.000 \mathrm{E}+01$ & $1.000 \mathrm{E}+02$ & $5.000 \mathrm{E}+02$ & $1.026 \mathrm{E}+03$ \\
\hline$c-99$ & $\mathrm{TC}-99$ & $1.000 \mathrm{E}+00$ & $3.496 \mathrm{E}-34$ & $3.539 \mathrm{E}-34$ & $6.498 \mathrm{E}-34$ & $1.208 E-33$ & $1.906 \mathrm{E}-02$ & $2.761 \mathrm{E}-02$ \\
\hline
\end{tabular}

The DSR includes contributions from associated (half-life $\leq 180$ days) daughters.

Single Radionuclide Soil Guidelines $G(i, t)$ in pCi/g

Basic Radiation Dose Limit $=1.000 \mathrm{E}+00 \mathrm{mrem} / \mathrm{yr}$

Nuclide

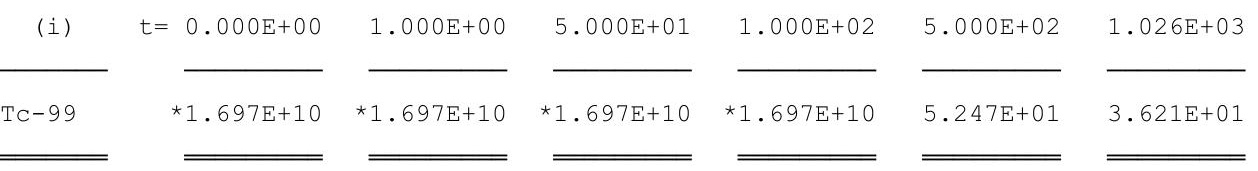

*At specific activity limit

Summed Dose/Source Ratios DSR (i,t) in (mrem/yr)/(pCi/g)

and Single Radionuclide Soil Guidelines G(i,t) in pCi/g

at tmin = time of minimum single radionuclide soil guideline

and at $\operatorname{tmax}=$ time of maximum total dose $=772$ years

\begin{tabular}{|c|c|c|c|c|c|c|}
\hline $\begin{array}{c}\text { Nuclide } \\
\text { (i) }\end{array}$ & $\begin{array}{l}\text { Initial } \\
(\mathrm{pCi} / \mathrm{g})\end{array}$ & $\begin{array}{c}\text { tmin } \\
\text { (years) }\end{array}$ & $\operatorname{DSR}(i, \operatorname{tmin})$ & $\begin{array}{c}G(i, \operatorname{tmin}) \\
(\mathrm{pCi} / \mathrm{g})\end{array}$ & $\operatorname{DSR}(i, \operatorname{tmax})$ & $\begin{array}{c}G(i, t \max ) \\
(\mathrm{pCi} / \mathrm{g})\end{array}$ \\
\hline$[c-99$ & $5.200 \mathrm{E}+01$ & 772 & $3.593 E-02$ & $2.783 \mathrm{E}+01$ & $3.593 E-02$ & $2.783 \mathrm{E}+01$ \\
\hline
\end{tabular}


RESRAD-OFFSITE, Version 2.5

Parent Dose Report

Title : Offsite Resident Farmer

File : RF TC99 DOESG FWD-FV2all.ROF

Individual Nuclide Dose Summed Over All Pathways

Parent Nuclide and Thread Fraction Indicated

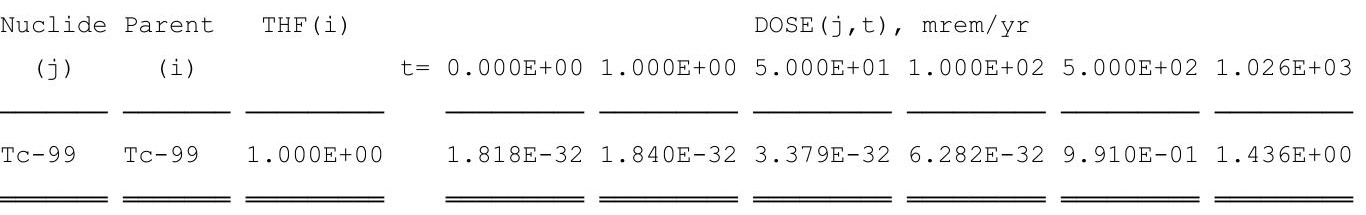

THF(i) is the thread fraction of the parent nuclide.

Individual Nuclide Soil Concentration

Parent Nuclide and Thread Fraction Indicated

\begin{tabular}{|c|c|c|c|c|c|c|c|c|c|}
\hline $\begin{array}{c}\text { Nuclide } \\
(j)\end{array}$ & $\begin{array}{c}\text { Parent } \\
\text { (i) }\end{array}$ & THF (i) & $t=$ & $0.000 \mathrm{E}+00$ & $1.000 \mathrm{E}+00$ & $\begin{array}{r}S(j, t), \\
5.000 E+01\end{array}$ & $\begin{array}{l}\mathrm{pCi} / \mathrm{g} \\
1.000 \mathrm{E}+02\end{array}$ & $5.000 \mathrm{E}+02$ & $1.026 \mathrm{E}+03$ \\
\hline CC-99 & TC-99 & $1.000 \mathrm{E}+00$ & & $5.200 \mathrm{E}+01$ & $5.173 E+01$ & $3.997 \mathrm{E}+01$ & $3.073 E+01$ & $3.746 \mathrm{E}+00$ & $2.354 \mathrm{E}-01$ \\
\hline
\end{tabular}

THF(i) is the thread fraction of the parent nuclide. 
RESRAD-OFFSITE, Version $2.5 \quad \mathrm{~T}^{1 / 2}$ Limit $=180$ days

Parent Dose Report

Title : Offsite Resident Farmer

File : RF TC99 DOESG FWD-FV2all.ROF

Run Time Information

ResOCalc.EXE execution began at 15:45 on 07/19/2011

ResOCalc.EXE execution ended at 16:25 on 07/19/2011

ResOCalc.EXE execution time 40 minutes 2 seconds 


\title{
Offsite Resident Farmer
}

\section{Uncertainty Analysis Report}

\author{
Third Run
}

Time Horizon: 1,050 yr 
THIS PAGE INTENTIONALLY LEFT BLANK 
RESRAD-OFFSITE, Version 2.5

robabilistic Dose and Risk Report

Title : Offsite Resident Farmer

File : RF TC99 DOESG FWD-FV2all.ROF

Table of Contents

Part V: Uncertainty Analysis

RESRAD Uncertainty Analysis Results

Probabilistic Inputs ......................... 2

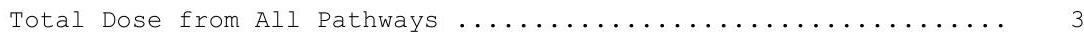

Total Risk from All Pathways ..................... 4

Ground External (water release) Pathway Dose ............. 5

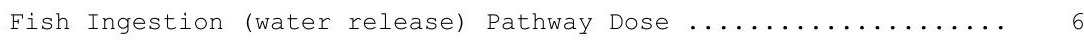

Radon Inhalation (water release) Pathway Dose ............ 7

Vegetable Ingestion (water release) Pathway Dose ........... 8

Meat Ingestion (water release) Pathway Dose .............. 9

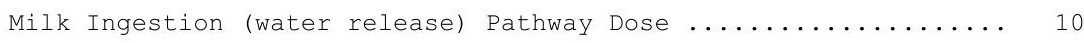

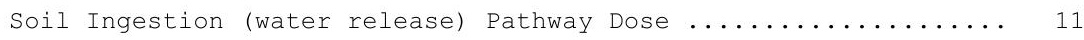

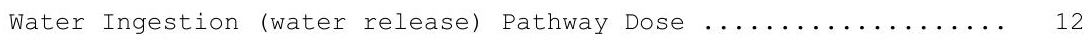

Ground External (direct \& air release) Pathway Dose .......... 13

Inhalation (w/o Radon) (direct \& air) Pathway Dose .......... 14

Radon Inhalation (direct \& air release) Pathway Dose ........ 15

Vegetable Ingestion (direct \& air release) Pathway Dose ....... 16

Meat Ingestion (direct \& air release) Pathway Dose ......... 17

Milk Ingestion (direct \& air release) Pathway Dose .......... 18

Soil Ingestion (direct \& air release) Pathway Dose .......... 19

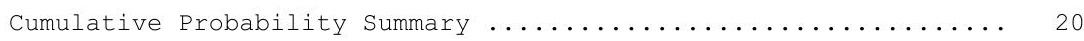

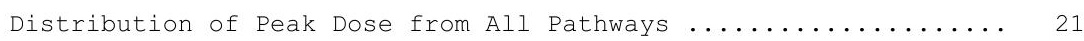

Distribution of Peak Dose from External Ground(Wreleas) ....... 22

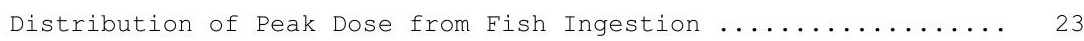

Distribution of Peak Dose from Radon (Waterrelease) ......... 24

Distribution of Peak Dose from Plant (Waterrelease) ......... 25

Distribution of Peak Dose from Meat (Waterrelease) ......... 26

Distribution of Peak Dose from Milk (Waterrelease) ......... 27

Distribution of Peak Dose from Soil Ingestion(Wrelease) ....... 28

Distribution of Peak Dose from Water Ingestion ............ 29

Distribution of Peak Dose from External Ground(CZ\&Air) ....... 30

Distribution of Peak Dose from Inhalation ExcludingRn ........ 31

Distribution of Peak Dose from Radon (CZandAir) ........... 32

Distribution of Peak Dose from Plant (CzandAir) ........... 33

Distribution of Peak Dose from Meat (CZandAir) ............ 34

Distribution of Peak Dose from Milk (CzandAir) ........... 35

Distribution of Peak Dose from Soil Ingestion(CZandAir) ...... 36

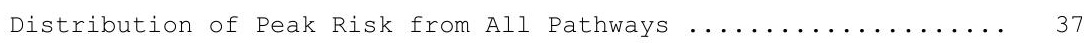

Distribution of Peak Risk from External Ground(Wreleas) ....... 38

Distribution of Peak Risk from Fish Ingestion ............. 39

Distribution of Peak Risk from Radon (Waterrelease) ......... 40

Distribution of Peak Risk from Plant (Waterrelease) ......... 41

Distribution of Peak Risk from Meat (Waterrelease) ......... 42

Distribution of Peak Risk from Milk (Waterrelease) ......... 43

Distribution of Peak Risk from Soil Ingestion(Wrelease) ....... 44

Distribution of Peak Risk from Water Ingestion ........... 45

Distribution of Peak Risk from External Ground(CZ\&Air) ....... 46

Distribution of Peak Risk from Inhalation ExcludingRn ........ 47

Distribution of Peak Risk from Radon (CZandAir) ........... 48

Distribution of Peak Risk from Plant (CzandAir) ........... 49

Distribution of Peak Risk from Meat (CZandAir) ........... 50

Distribution of Peak Risk from Milk (CzandAir) ........... 51

Distribution of Peak Risk from soil Ingestion(CZandAir) ....... $52 \quad$ DC N $90-T R-02-2$ 
C -526

DCN 5090-TR-02-2 
C -527

DCN 5090-TR-02-2 
C -528

DCN 5090-TR-02-2 
C -529

DCN 5090-TR-02-2 
C-531

DCN 5090-TR-02-2 
RESRAD-OFFSITE, Version 2.5

Probabilistic Dose and Risk Report

Title : Offsite Resident Farmer

File : RF TC99 DOESG FWD-FV2all.ROF

Probabilistic Inputs

Number of Sample Runs: 6000

\begin{tabular}{rll}
\cline { 1 - 1 } & & Number \\
\cline { 1 - 1 } 1 & & DCACTC (1) \\
2 & DENSCZ \\
3 & $\operatorname{EPUZ~(5)~}$ \\
4 & $\operatorname{HCSZ}$ \\
5 & $\operatorname{TPSZ}$ \\
6 & EPSZ \\
\hline \hline
\end{tabular}

\begin{tabular}{l} 
Distribution \\
\hline TRIANGULAR \\
TRIANGULAR \\
TRIANGULAR \\
TRIANGULAR \\
TRIANGULAR \\
TRIANGULAR \\
\hline \hline
\end{tabular}

\begin{tabular}{lll} 
Parameters \\
\hline .1 & 1 & 10 \\
1.5 & 1.85 & 2.5 \\
.1 & .25 & .4 \\
27034 & 38938 & 67642 \\
.27 & .39 & .54 \\
.22 & .3 & .35 \\
\hline \hline
\end{tabular}

C -532

DCN 5090-TR-02-2 
RESRAD-OFFSITE, Version 2.5

Probabilistic Dose and Risk Report

Title : Offsite Resident Farmer

File : RF TC99 DOESG FWD-FV2all.ROF

\begin{tabular}{|c|c|c|c|c|c|c|c|c|}
\hline Juclide & Peak & Peak & & & $\operatorname{DOSE}(j, t)$, & $\mathrm{mrem} / \mathrm{yr}$ & & \\
\hline (j) & Time & Dose & $\mathrm{t}=0.00 \mathrm{E}+00$ & $1.00 \mathrm{E}+00$ & $5.00 \mathrm{E}+01$ & $1.00 \mathrm{E}+02$ & $5.00 \mathrm{E}+02$ & $1.03 E+03$ \\
\hline \multicolumn{9}{|l|}{$c-9 s$} \\
\hline Min & $5.57 \mathrm{E}+02$ & $1.18 \mathrm{E}-01$ & $1.79 \mathrm{E}-32$ & $1.76 \mathrm{E}-32$ & $7.79 \mathrm{E}-33$ & $3.39 \mathrm{E}-33$ & $4.94 \mathrm{E}-04$ & $1.08 \mathrm{E}-01$ \\
\hline Max & $1.05 E+03$ & $4.63 \mathrm{E}+00$ & $1.82 \mathrm{E}-32$ & $1.85 \mathrm{E}-32$ & $4.31 \mathrm{E}-32$ & $1.02 \mathrm{E}-31$ & $3.79 \mathrm{E}+00$ & $3.28 \mathrm{E}+00$ \\
\hline Avg & $1.03 E+03$ & $1.01 \mathrm{E}+00$ & $1.82 \mathrm{E}-32$ & $1.85 \mathrm{E}-32$ & $3.93 E-32$ & $8.56 \mathrm{E}-32$ & $1.58 \mathrm{E}-01$ & $9.59 \mathrm{E}-01$ \\
\hline Std & $6.08 \mathrm{E}+01$ & $5.91 \mathrm{E}-01$ & $0.00 \mathrm{E}+00$ & $0.00 \mathrm{E}+00$ & $0.00 \mathrm{E}+00$ & $0.00 \mathrm{E}+00$ & $2.98 \mathrm{E}-01$ & $5.42 \mathrm{E}-01$ \\
\hline \multicolumn{9}{|l|}{$\sum$ ALL } \\
\hline Min & $5.57 \mathrm{E}+02$ & $1.18 \mathrm{E}-01$ & $1.79 \mathrm{E}-32$ & $1.76 \mathrm{E}-32$ & $7.79 \mathrm{E}-33$ & $3.39 \mathrm{E}-33$ & $4.94 \mathrm{E}-04$ & $1.08 \mathrm{E}-01$ \\
\hline $\operatorname{Max}$ & $1.05 \mathrm{E}+03$ & $4.63 \mathrm{E}+00$ & $1.82 \mathrm{E}-32$ & $1.85 \mathrm{E}-32$ & $4.31 E-32$ & $1.02 \mathrm{E}-31$ & $3.79 \mathrm{E}+00$ & $3.28 \mathrm{E}+00$ \\
\hline Avg & $1.03 E+03$ & $1.01 \mathrm{E}+00$ & $1.82 \mathrm{E}-32$ & $1.85 \mathrm{E}-32$ & $3.93 E-32$ & $8.56 \mathrm{E}-32$ & $1.58 \mathrm{E}-01$ & $9.59 \mathrm{E}-01$ \\
\hline Std & $6.08 \mathrm{E}+01$ & $5.91 \mathrm{E}-01$ & $0.00 \mathrm{E}+00$ & $0.00 \mathrm{E}+00$ & $0.00 \mathrm{E}+00$ & $0.00 \mathrm{E}+00$ & $2.98 \mathrm{E}-01$ & $5.42 \mathrm{E}-01$ \\
\hline
\end{tabular}

¿ALL is total dose summed for all nuclides. 
RESRAD-OFFSITE, Version 2.5

Probabilistic Dose and Risk Report

Title : Offsite Resident Farmer

File : RF TC99 DOESG FWD-FV2all.ROF

Probabilistic Total Risk Summary

\begin{tabular}{|c|c|c|c|c|c|c|c|}
\hline \multirow{2}{*}{$\begin{array}{c}\text { Nuclide } \\
\text { (j) }\end{array}$} & \multicolumn{7}{|c|}{$\operatorname{RISK}(j, t)$} \\
\hline & $t=$ & $0.00 \mathrm{E}+00$ & $1.00 \mathrm{E}+00$ & $5.00 \mathrm{E}+01$ & $1.00 \mathrm{E}+02$ & $5.00 \mathrm{E}+02$ & $1.03 \mathrm{E}+03$ \\
\hline \multicolumn{8}{|l|}{ TC-99 } \\
\hline Min & & $2.68 \mathrm{E}-37$ & $2.63 E-37$ & $1.17 \mathrm{E}-37$ & $5.07 \mathrm{E}-38$ & $2.14 \mathrm{E}-08$ & $3.58 \mathrm{E}-06$ \\
\hline $\operatorname{Max}$ & & $4.02 \mathrm{E}-37$ & $4.09 \mathrm{E}-37$ & $9.52 \mathrm{E}-37$ & $1.75 \mathrm{E}-12$ & $1.23 \mathrm{E}-04$ & $1.03 \mathrm{E}-04$ \\
\hline Avg & & $3.93 \mathrm{E}-37$ & $3.99 \mathrm{E}-37$ & $8.50 \mathrm{E}-37$ & $4.18 \mathrm{E}-16$ & $5.54 \mathrm{E}-06$ & $3.09 \mathrm{E}-05$ \\
\hline Std & & $0.00 \mathrm{E}+00$ & $0.00 \mathrm{E}+00$ & $0.00 \mathrm{E}+00$ & $2.30 \mathrm{E}-14$ & $1.01 \mathrm{E}-05$ & $1.71 \mathrm{E}-05$ \\
\hline \multicolumn{8}{|l|}{$\sum \mathrm{ALL}$} \\
\hline Min & & $2.68 \mathrm{E}-37$ & $2.63 E-37$ & $1.17 \mathrm{E}-37$ & $5.07 \mathrm{E}-38$ & $2.14 \mathrm{E}-08$ & $3.58 \mathrm{E}-06$ \\
\hline $\operatorname{Max}$ & & $4.02 \mathrm{E}-37$ & $4.09 \mathrm{E}-37$ & $9.52 \mathrm{E}-37$ & $1.75 \mathrm{E}-12$ & $1.23 \mathrm{E}-04$ & $1.03 E-04$ \\
\hline Avg & & $3.93 \mathrm{E}-37$ & $3.99 \mathrm{E}-37$ & $8.50 E-37$ & $4.18 \mathrm{E}-16$ & $5.54 \mathrm{E}-06$ & $3.09 \mathrm{E}-05$ \\
\hline Std & & $0.00 \mathrm{E}+00$ & $0.00 \mathrm{E}+00$ & $0.00 \mathrm{E}+00$ & $2.30 \mathrm{E}-14$ & $1.01 \mathrm{E}-05$ & $1.71 \mathrm{E}-05$ \\
\hline
\end{tabular}

¿ALL is total risk summed for all nuclides. 
RESRAD-OFFSITE, Version 2.5

Probabilistic Dose and Risk Report

Title : Offsite Resident Farmer

File : RF TC99 DOESG FWD-FV2all.ROF

Probabilistic Dose vs Pathway(i): Ground External (water release)

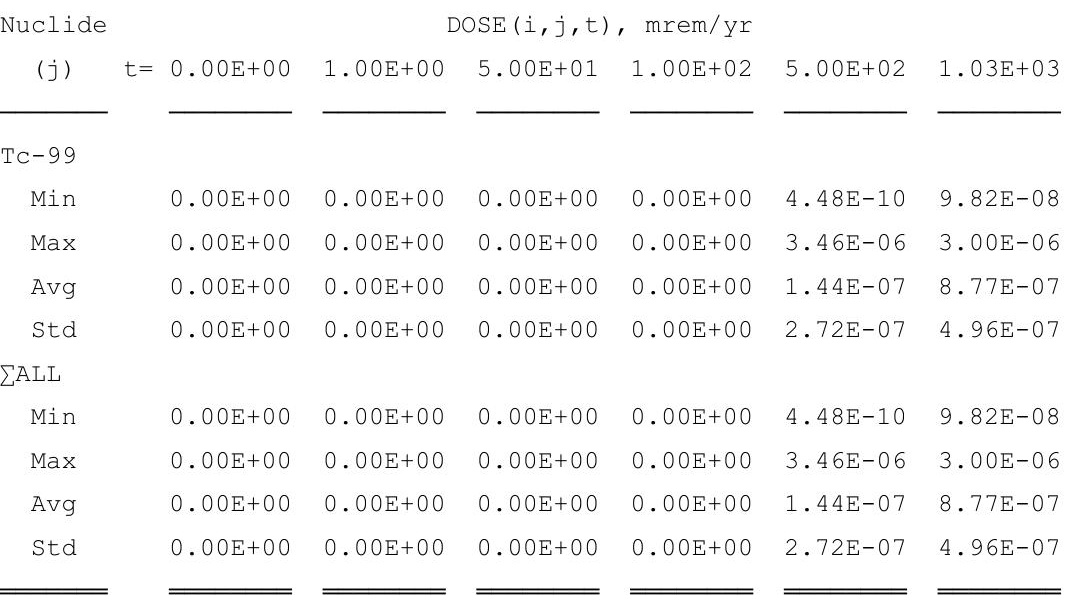

¿ALL is total pathway dose summed for all nuclides. 
RESRAD-OFFSITE, Version 2.5

Probabilistic Dose and Risk Report

Title : Offsite Resident Farmer

File : RF TC99 DOESG FWD-FV2all.ROF

Probabilistic Dose vs Pathway(i): Fish Ingestion (water release)

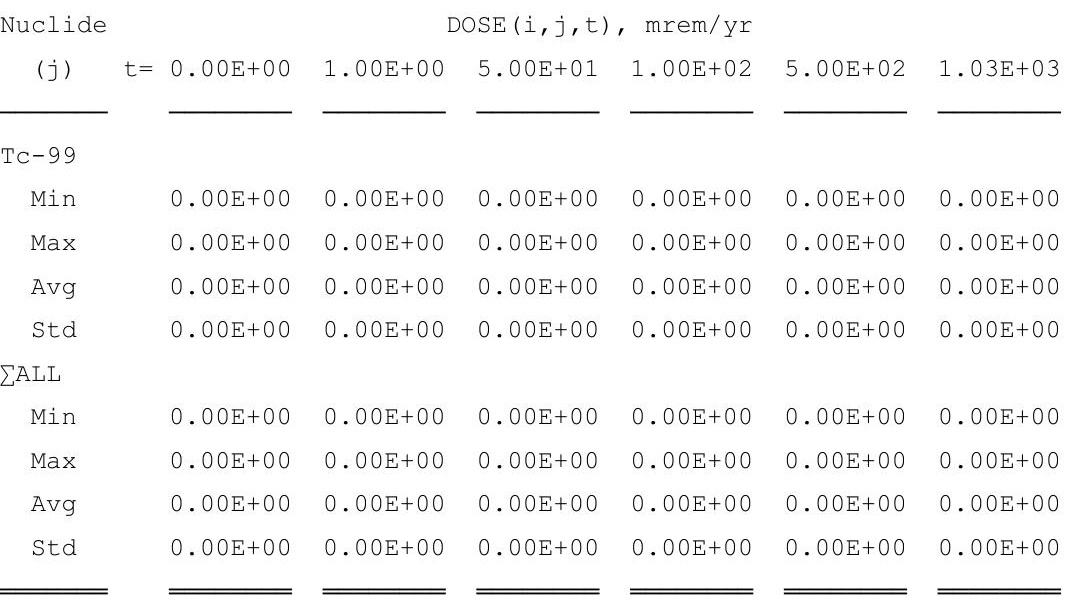

¿ALL is total pathway dose summed for all nuclides. 
RESRAD-OFFSITE, Version 2.5

Probabilistic Dose and Risk Report

Title : Offsite Resident Farmer

File : RF TC99 DOESG FWD-FV2all.ROF

Probabilistic Dose vs Pathway(i): Radon Inhalation (water release)

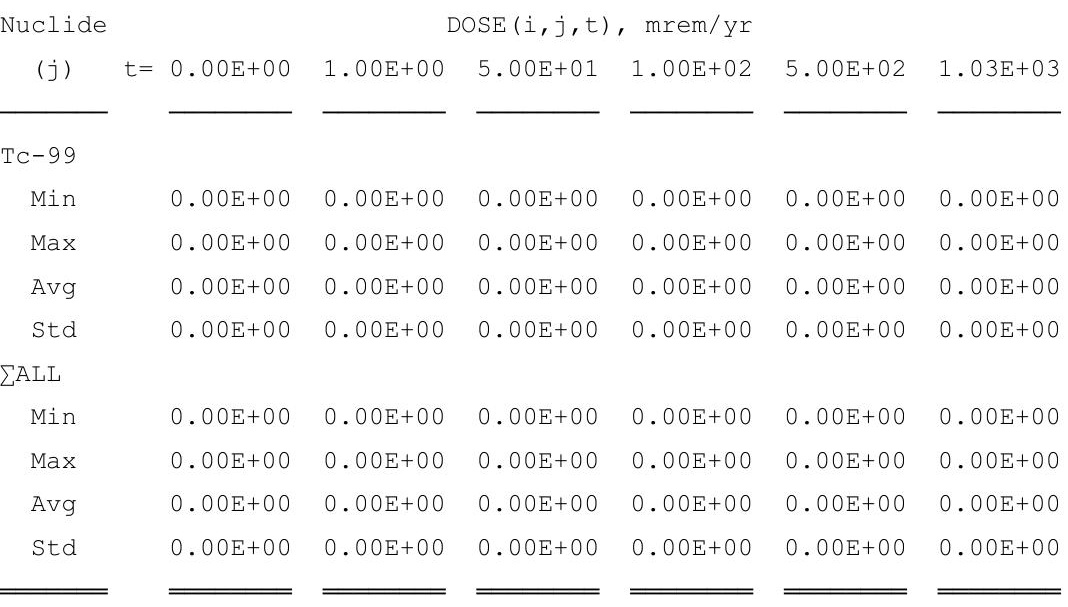

¿ALL is total pathway dose summed for all nuclides. 
RESRAD-OFFSITE, Version 2.5

Probabilistic Dose and Risk Report

Title : Offsite Resident Farmer

File : RF TC99 DOESG FWD-FV2all.ROF

Probabilistic Dose vs Pathway(i): Vegetable Ingestion (water release)

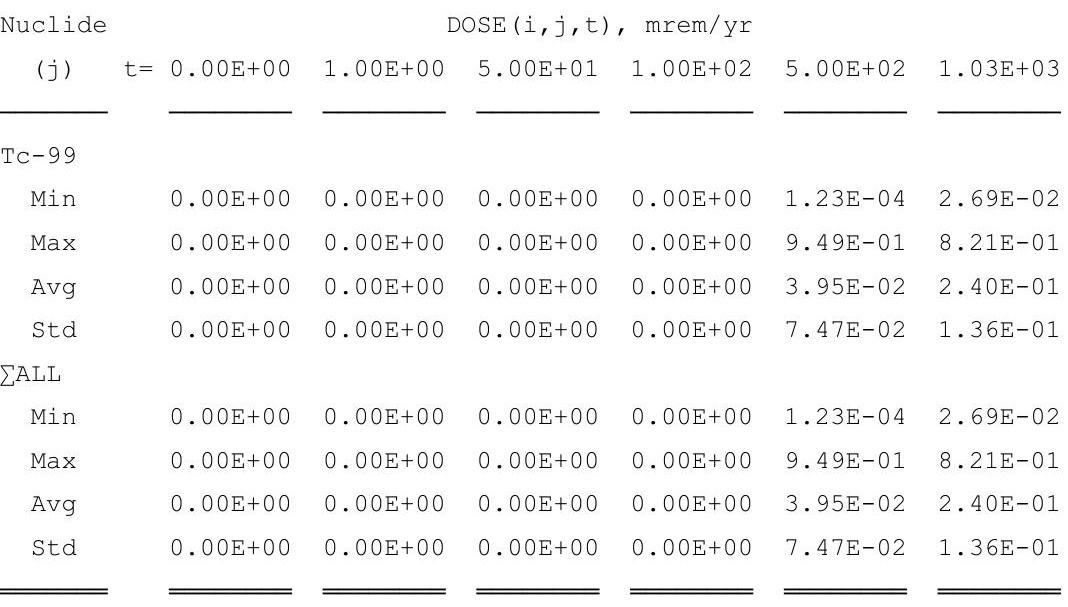

¿ALL is total pathway dose summed for all nuclides. 
RESRAD-OFFSITE, Version 2.5

Probabilistic Dose and Risk Report

Title : Offsite Resident Farmer

File : RF TC99 DOESG FWD-FV2all.ROF

Probabilistic Dose vs Pathway(i): Meat Ingestion (water release)

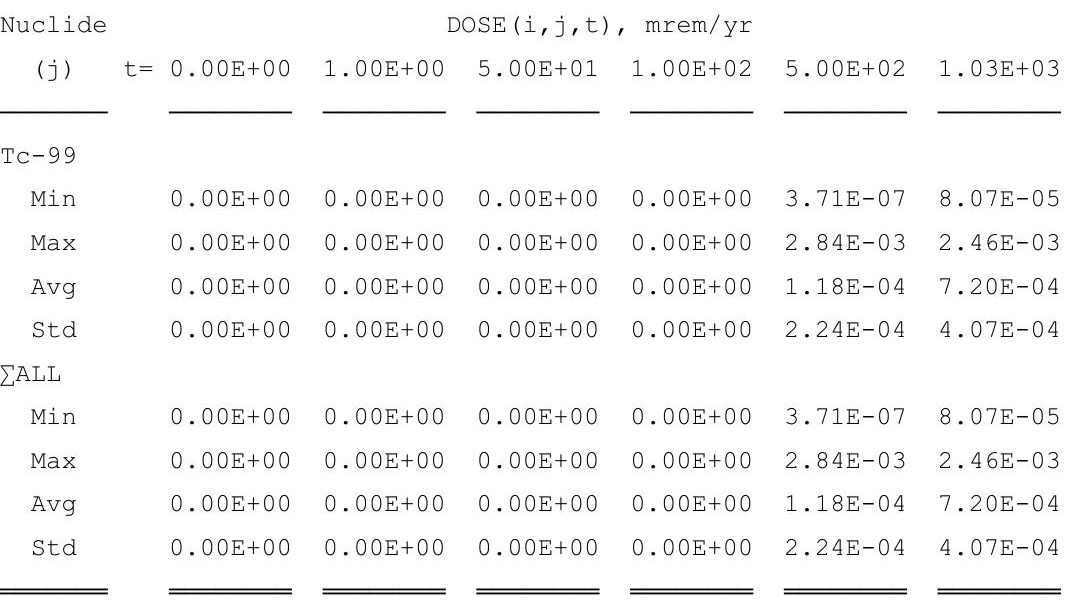

¿ALL is total pathway dose summed for all nuclides. 
RESRAD-OFFSITE, Version 2.5

Probabilistic Dose and Risk Report

Title : Offsite Resident Farmer

File : RF TC99 DOESG FWD-FV2all.ROF

Probabilistic Dose vs Pathway(i): Milk Ingestion (water release)

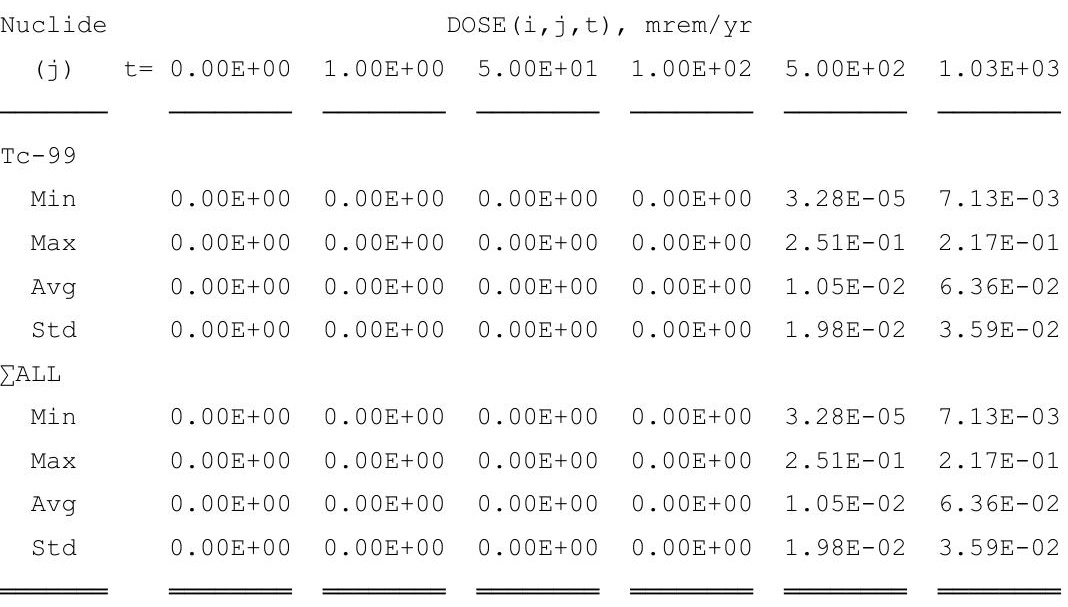

¿ALL is total pathway dose summed for all nuclides. 
RESRAD-OFFSITE, Version 2.5

Probabilistic Dose and Risk Report

Title : Offsite Resident Farmer

File : RF TC99 DOESG FWD-FV2all.ROF

Probabilistic Dose vs Pathway(i): Soil Ingestion (water release)

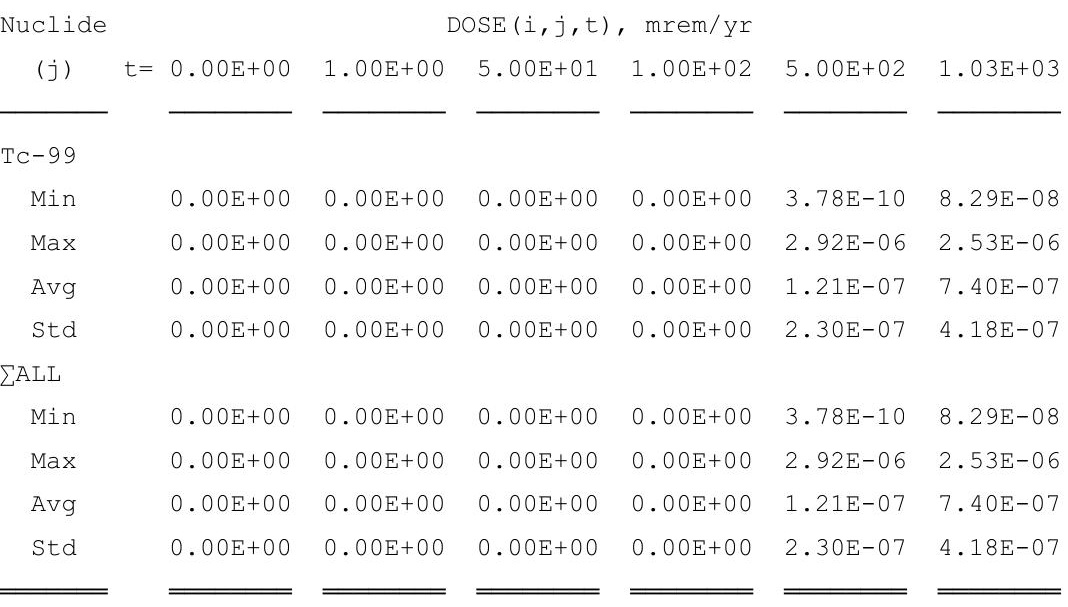

¿ALL is total pathway dose summed for all nuclides. 
RESRAD-OFFSITE, Version 2.5

Probabilistic Dose and Risk Report

Title : Offsite Resident Farmer

File : RF TC99 DOESG FWD-FV2all.ROF

Probabilistic Dose vs Pathway(i): Water Ingestion (water release)

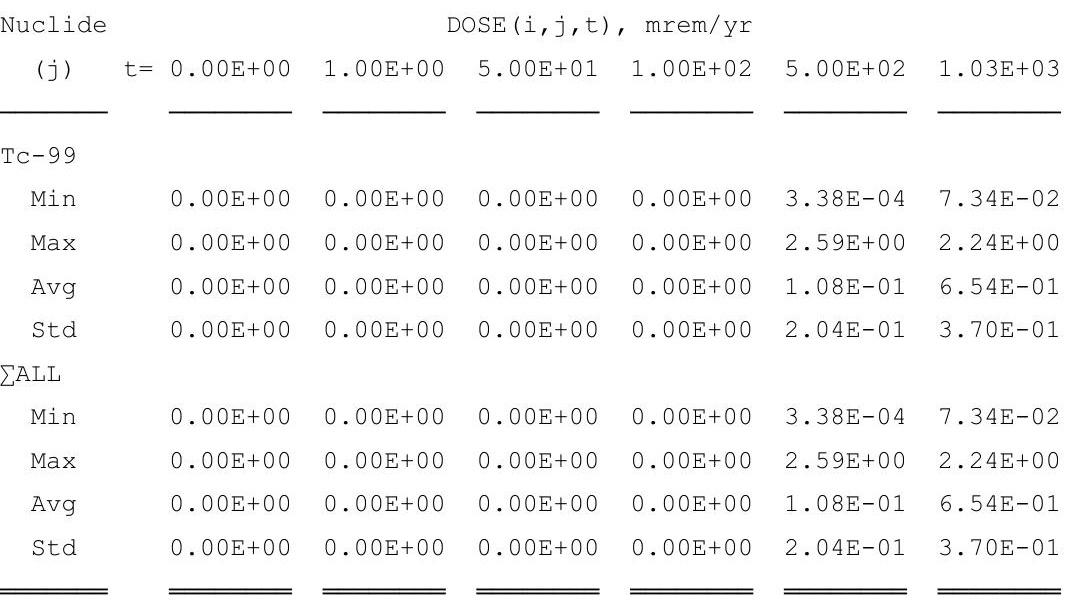

¿ALL is total pathway dose summed for all nuclides. 
RESRAD-OFFSITE, Version 2.5

Probabilistic Dose and Risk Report

Title : Offsite Resident Farmer

File : RF TC99 DOESG FWD-FV2all.ROF

Probabilistic Dose vs Pathway(i): Ground External (direct \& air release)

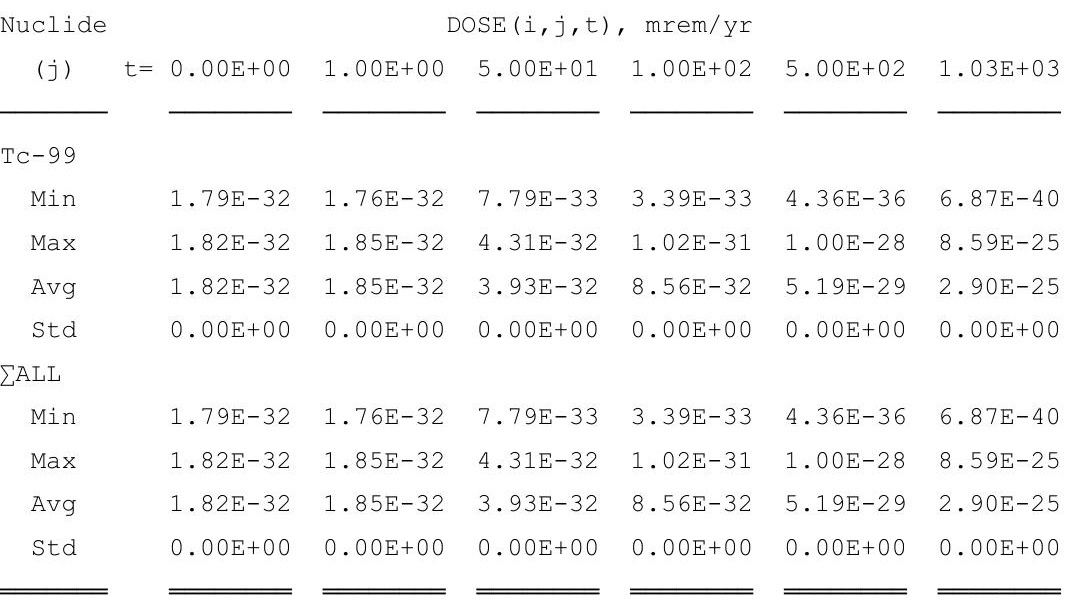

¿ALL is total pathway dose summed for all nuclides. 
RESRAD-OFFSITE, Version 2.5

Probabilistic Dose and Risk Report

Title : Offsite Resident Farmer

File : RF TC99 DOESG FWD-FV2all.ROF

Probabilistic Dose vs Pathway(i): Inhalation (w/o Radon) (direct \& air)

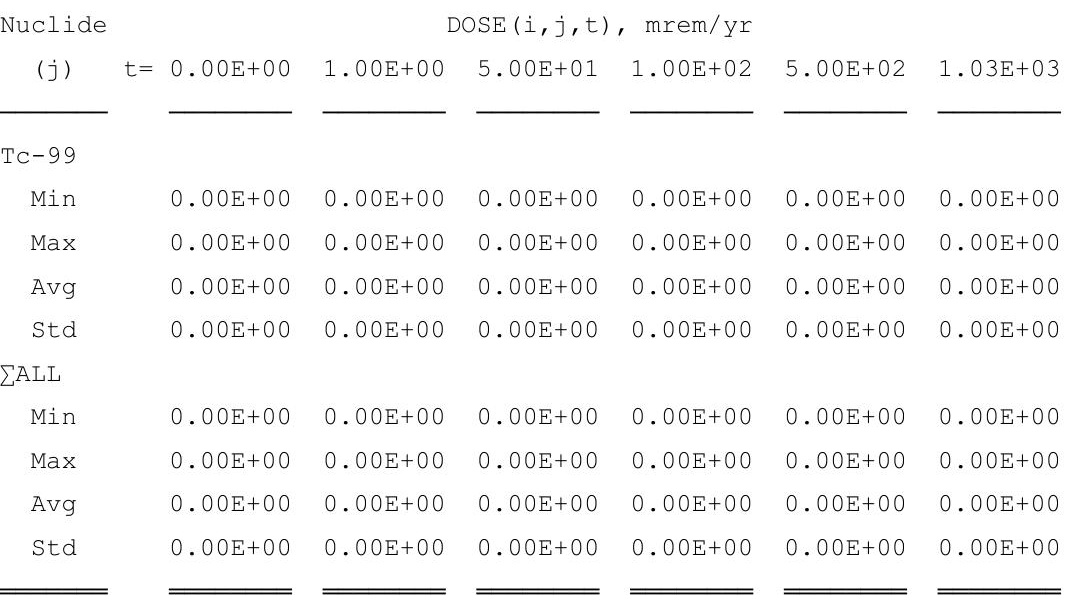

¿ALL is total pathway dose summed for all nuclides. 
RESRAD-OFFSITE, Version 2.5

Probabilistic Dose and Risk Report

Title : Offsite Resident Farmer

File : RF TC99 DOESG FWD-FV2all.ROF

Probabilistic Dose vs Pathway(i): Radon Inhalation (direct \& air release)

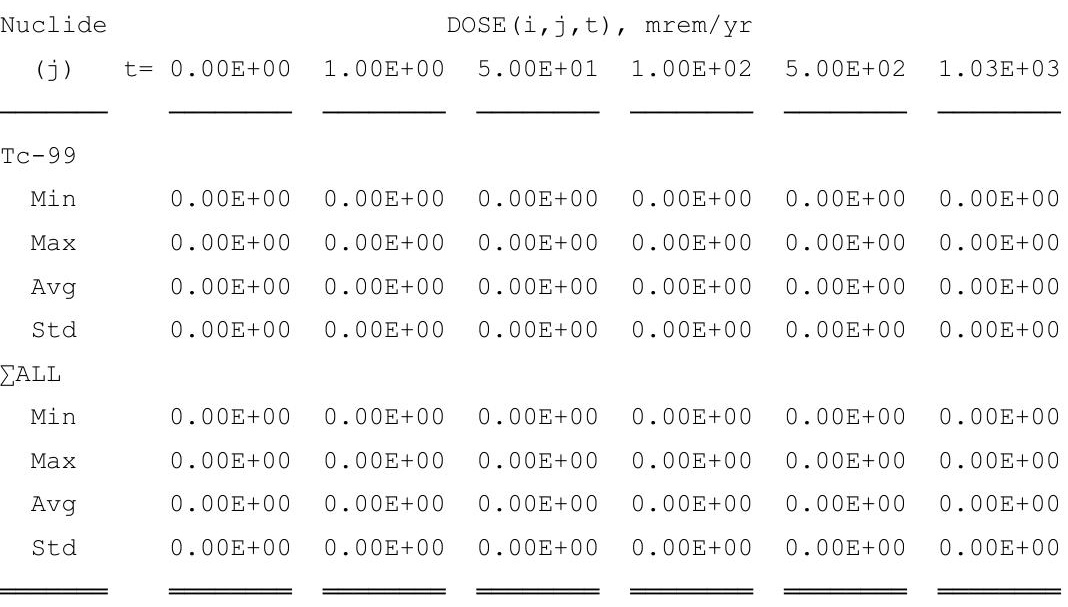

¿ALL is total pathway dose summed for all nuclides. 
RESRAD-OFFSITE, Version 2.5

Probabilistic Dose and Risk Report

Title : Offsite Resident Farmer

File : RF TC99 DOESG FWD-FV2all.ROF

Probabilistic Dose vs Pathway(i): Vegetable Ingestion (direct \& air release)

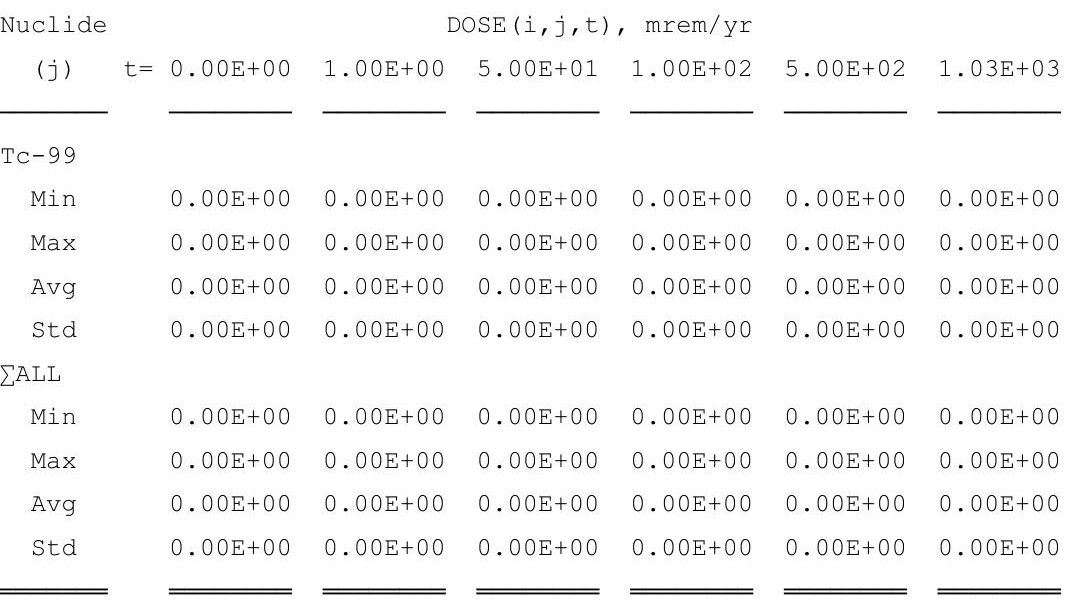

¿ALL is total pathway dose summed for all nuclides. 
RESRAD-OFFSITE, Version 2.5

Probabilistic Dose and Risk Report

Title : Offsite Resident Farmer

File : RF TC99 DOESG FWD-FV2all.ROF

Probabilistic Dose vs Pathway(i): Meat Ingestion (direct \& air release)

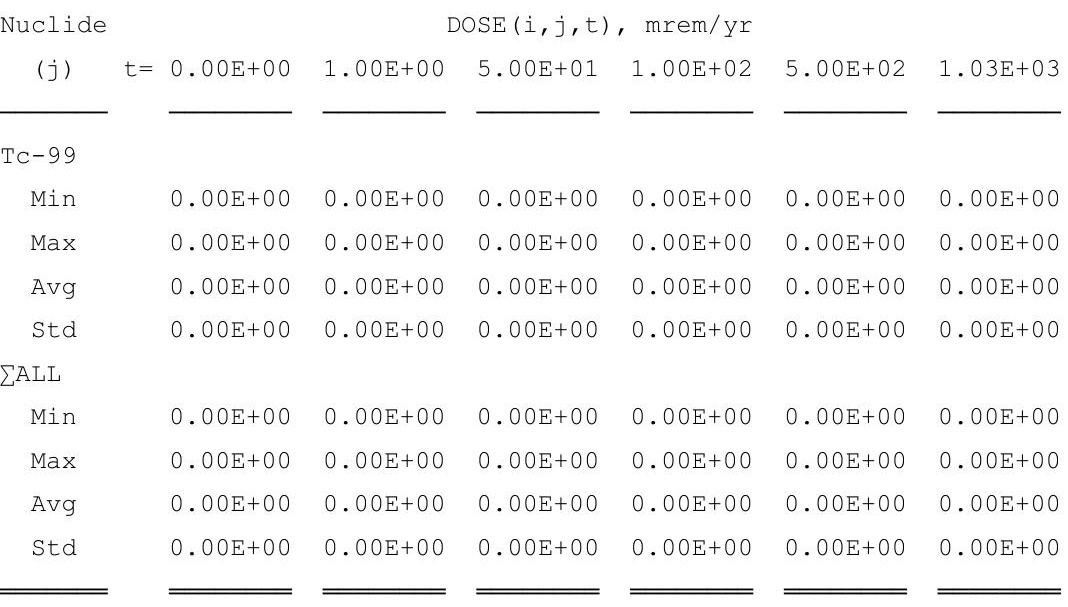

¿ALL is total pathway dose summed for all nuclides. 
RESRAD-OFFSITE, Version 2.5

Probabilistic Dose and Risk Report

Title : Offsite Resident Farmer

File : RF TC99 DOESG FWD-FV2all.ROF

Probabilistic Dose vs Pathway(i): Milk Ingestion (direct \& air release)

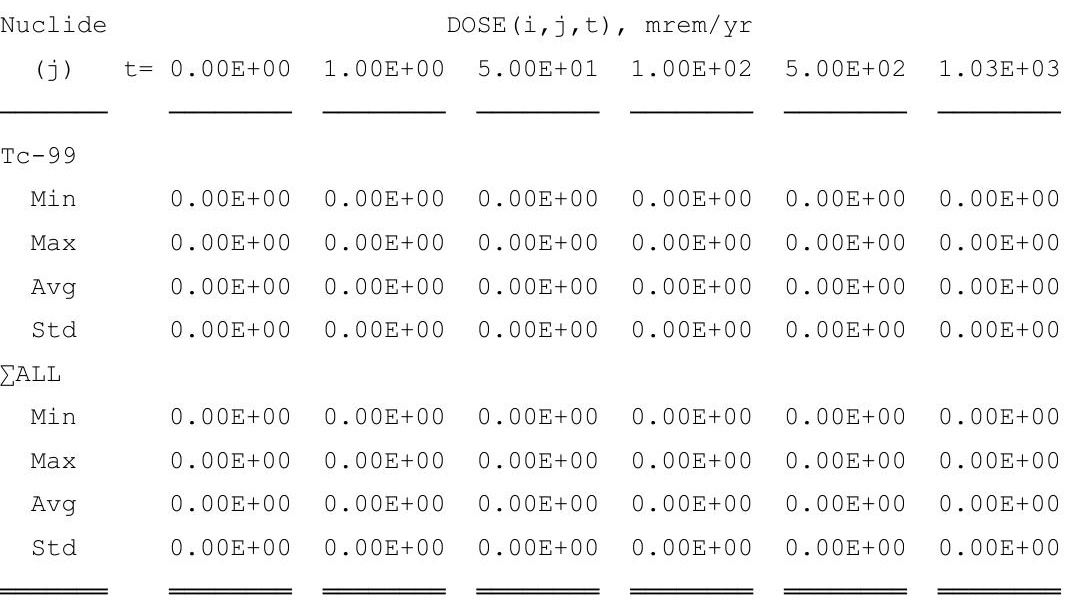

¿ALL is total pathway dose summed for all nuclides. 
RESRAD-OFFSITE, Version 2.5

Probabilistic Dose and Risk Report

Title : Offsite Resident Farmer

File : RF TC99 DOESG FWD-FV2all.ROF

Probabilistic Dose vs Pathway(i): Soil Ingestion (direct \& air release)

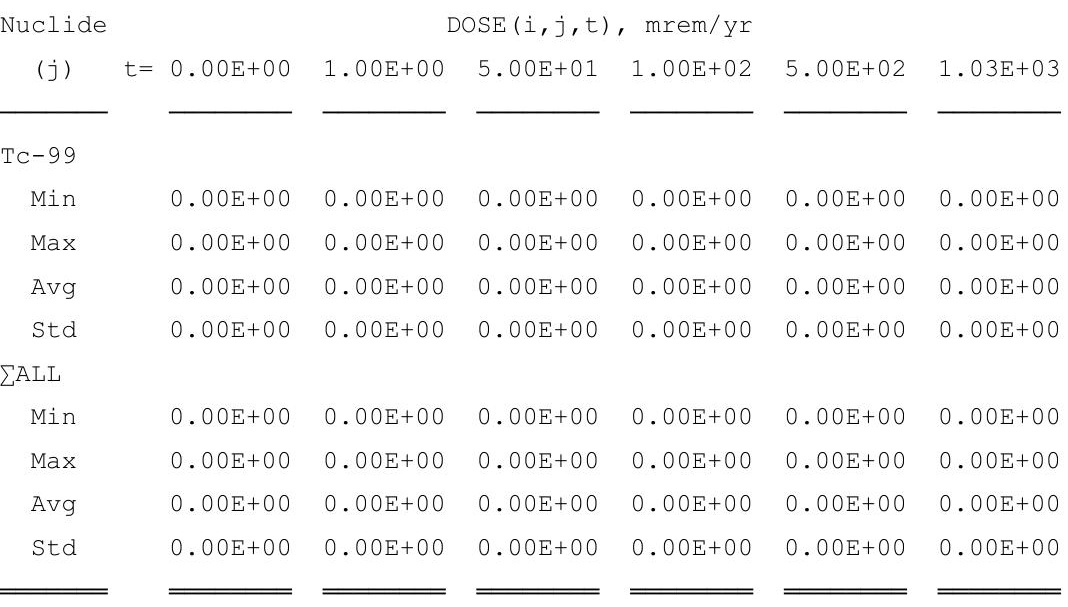

¿ALL is total pathway dose summed for all nuclides. 
RESRAD-OFFSITE, Version 2.5

$\mathrm{T}^{1 / 2}$ Limit $=180$ days

robabilistic Dose and Risk Report

Title : Offsite Resident Farmer

File : RF TC99 DOESG FWD-FV2all.ROF

Cumulative Probability Summary for: Total Dose Over all Pathways

\begin{tabular}{|c|c|c|c|c|c|c|c|}
\hline \multicolumn{4}{|l|}{ Cumulative } & \multicolumn{4}{|c|}{ Dose $(t)$, mrem/yr } \\
\hline Probability & $t=$ & $0.00 \mathrm{E}+00$ & $1.00 \mathrm{E}+00$ & $5.00 \mathrm{E}+01$ & $1.00 \mathrm{E}+02$ & $5.00 \mathrm{E}+02$ & $1.03 E+03$ \\
\hline 0.025 & & $1.81 E-32$ & $1.83 E-32$ & $2.83 E-32$ & $4.40 E-32$ & $1.84 \mathrm{E}-03$ & $2.09 \mathrm{E}-01$ \\
\hline 0.050 & & $1.82 E-32$ & $1.84 \mathrm{E}-32$ & $3.15 E-32$ & $5.47 E-32$ & $2.88 E-03$ & $2.60 \mathrm{E}-01$ \\
\hline 0.075 & & $1.82 \mathrm{E}-32$ & $1.84 \mathrm{E}-32$ & $3.32 E-32$ & $6.06 \mathrm{E}-32$ & $3.95 E-03$ & $3.01 \mathrm{E}-01$ \\
\hline 0.100 & & $1.82 \mathrm{E}-32$ & $1.84 \mathrm{E}-32$ & $3.42 E-32$ & $6.45 E-32$ & $5.21 \mathrm{E}-03$ & $3.46 \mathrm{E}-01$ \\
\hline 0.125 & & $1.82 \mathrm{E}-32$ & $1.84 \mathrm{E}-32$ & $3.52 \mathrm{E}-32$ & $6.81 \mathrm{E}-32$ & $6.42 \mathrm{E}-03$ & $3.80 \mathrm{E}-01$ \\
\hline 0.150 & & $1.82 E-32$ & $1.84 \mathrm{E}-32$ & $3.59 \mathrm{E}-32$ & $7.10 \mathrm{E}-32$ & $7.65 E-03$ & $4.12 \mathrm{E}-01$ \\
\hline 0.175 & & $1.82 E-32$ & $1.84 \mathrm{E}-32$ & $3.67 E-32$ & 7. $39 E-32$ & $9.20 E-03$ & $4.40 \mathrm{E}-01$ \\
\hline 0.200 & & $1.82 E-32$ & $1.85 E-32$ & $3.72 E-32$ & 7. $62 E-32$ & 1.10E-02 & $4.74 \mathrm{E}-01$ \\
\hline 0.225 & & $1.82 \mathrm{E}-32$ & $1.85 \mathrm{E}-32$ & $3.77 \mathrm{E}-32$ & $7.81 \mathrm{E}-32$ & 1. $31 \mathrm{E}-02$ & $5.06 \mathrm{E}-01$ \\
\hline 0.250 & & $1.82 \mathrm{E}-32$ & $1.85 E-32$ & $3.81 \mathrm{E}-32$ & $7.98 \mathrm{E}-32$ & 1. $50 \mathrm{E}-02$ & $5.34 \mathrm{E}-01$ \\
\hline 0.275 & & $1.82 E-32$ & $1.85 E-32$ & $3.85 E-32$ & $8.14 \mathrm{E}-32$ & 1. $72 \mathrm{E}-02$ & $5.64 \mathrm{E}-01$ \\
\hline 0.300 & & $1.82 \mathrm{E}-32$ & $1.85 E-32$ & $3.88 E-32$ & $8.27 \mathrm{E}-32$ & 1. $96 \mathrm{E}-02$ & $5.98 \mathrm{E}-01$ \\
\hline 0.325 & & $1.82 \mathrm{E}-32$ & $1.85 \mathrm{E}-32$ & $3.91 \mathrm{E}-32$ & $8.40 \mathrm{E}-32$ & $2.23 E-02$ & $6.30 \mathrm{E}-01$ \\
\hline 0.350 & & $1.82 E-32$ & $1.85 E-32$ & $3.94 \mathrm{E}-32$ & $8.54 \mathrm{E}-32$ & $2.50 \mathrm{E}-02$ & $6.60 \mathrm{E}-01$ \\
\hline 0.375 & & $1.82 \mathrm{E}-32$ & $1.85 \mathrm{E}-32$ & $3.97 \mathrm{E}-32$ & $8.66 \mathrm{E}-32$ & $2.82 \mathrm{E}-02$ & $6.94 \mathrm{E}-01$ \\
\hline 0.400 & & $1.82 \mathrm{E}-32$ & $1.85 \mathrm{E}-32$ & $3.99 \mathrm{E}-32$ & $8.74 E-32$ & $3.15 \mathrm{E}-02$ & $7.26 \mathrm{E}-01$ \\
\hline 0.425 & & $1.82 \mathrm{E}-32$ & $1.85 E-32$ & $4.01 E-32$ & $8.83 E-32$ & $3.50 E-02$ & $7.54 \mathrm{E}-01$ \\
\hline 0.450 & & $1.82 \mathrm{E}-32$ & $1.85 \mathrm{E}-32$ & $4.03 E-32$ & $8.93 E-32$ & $3.96 \mathrm{E}-02$ & $7.87 \mathrm{E}-01$ \\
\hline 0.475 & & $1.82 E-32$ & $1.85 E-32$ & $4.05 E-32$ & $9.01 E-32$ & 4. $48 E-02$ & $8.19 \mathrm{E}-01$ \\
\hline 0.500 & & $1.82 E-32$ & $1.85 E-32$ & $4.07 E-32$ & $9.08 E-32$ & 4. $96 \mathrm{E}-02$ & $8.55 \mathrm{E}-01$ \\
\hline 0.525 & & $1.82 \mathrm{E}-32$ & $1.85 \mathrm{E}-32$ & $4.08 E-32$ & $9.16 \mathrm{E}-32$ & $5.57 \mathrm{E}-02$ & $8.92 \mathrm{E}-01$ \\
\hline 0.550 & & $1.82 E-32$ & $1.85 E-32$ & $4.10 E-32$ & $9.22 \mathrm{E}-32$ & $6.30 \mathrm{E}-02$ & $9.30 \mathrm{E}-01$ \\
\hline 0.575 & & 1. $82 \mathrm{E}-32$ & $1.85 \mathrm{E}-32$ & 4.11E-32 & $9.28 \mathrm{E}-32$ & $7.00 \mathrm{E}-02$ & $9.68 \mathrm{E}-01$ \\
\hline 0.600 & & $1.82 \mathrm{E}-32$ & $1.85 \mathrm{E}-32$ & $4.13 \mathrm{E}-32$ & $9.35 E-32$ & $7.78 \mathrm{E}-02$ & $1.01 \mathrm{E}+00$ \\
\hline 0.625 & & $1.82 E-32$ & $1.85 \mathrm{E}-32$ & $4.14 \mathrm{E}-32$ & $9.40 \mathrm{E}-32$ & $8.75 E-02$ & $1.05 \mathrm{E}+00$ \\
\hline 0.650 & & $1.82 \mathrm{E}-32$ & $1.85 \mathrm{E}-32$ & $4.15 E-32$ & $9.44 \mathrm{E}-32$ & $9.87 \mathrm{E}-02$ & $1.09 \mathrm{E}+0 \mathrm{C}$ \\
\hline 0.675 & & $1.82 \mathrm{E}-32$ & $1.85 \mathrm{E}-32$ & $4.16 \mathrm{E}-32$ & $9.49 \mathrm{E}-32$ & 1.10E-01 & $1.13 \mathrm{E}+00$ \\
\hline 0.700 & & $1.82 E-32$ & $1.85 E-32$ & $4.17 E-32$ & $9.53 E-32$ & $1.27 \mathrm{E}-01$ & $1.19 \mathrm{E}+0 \mathrm{C}$ \\
\hline 0.725 & & $1.82 \mathrm{E}-32$ & $1.85 E-32$ & $4.18 E-32$ & $9.58 \mathrm{E}-32$ & 1. $44 \mathrm{E}-01$ & $1.24 \mathrm{E}+0 \mathrm{C}$ \\
\hline 0.750 & & $1.82 E-32$ & $1.85 E-32$ & $4.19 E-32$ & $9.62 E-32$ & $1.64 E-01$ & $1.29 \mathrm{E}+00$ \\
\hline 0.775 & & $1.82 E-32$ & $1.85 E-32$ & $4.20 E-32$ & $9.67 \mathrm{E}-32$ & $1.87 \mathrm{E}-01$ & $1.34 \mathrm{E}+0 \mathrm{C}$ \\
\hline 0.800 & & $1.82 \mathrm{E}-32$ & $1.85 E-32$ & $4.21 E-32$ & $9.72 \mathrm{E}-32$ & $2.16 \mathrm{E}-01$ & $1.40 \mathrm{E}+0 \mathrm{C}$ \\
\hline 0.825 & & $1.82 \mathrm{E}-32$ & $1.85 \mathrm{E}-32$ & $4 \cdot 22 \mathrm{E}-32$ & $9.75 E-32$ & $2.50 \mathrm{E}-01$ & $1.47 \mathrm{E}+00$ \\
\hline 0.850 & & $1.82 E-32$ & $1.85 \mathrm{E}-32$ & $4.22 E-32$ & $9.79 \mathrm{E}-32$ & $2.88 E-01$ & $1.55 \mathrm{E}+0 \mathrm{C}$ \\
\hline 0.875 & & $1.82 \mathrm{E}-32$ & $1.85 E-32$ & $4.23 E-32$ & $9.83 E-32$ & $3.35 E-01$ & $1.64 \mathrm{E}+0 \mathrm{C}$ \\
\hline 0.900 & & $1.82 E-32$ & $1.85 E-32$ & $4.24 E-32$ & $9.88 E-32$ & $4.13 E-01$ & $1.73 E+00$ \\
\hline 0.925 & & $1.82 E-32$ & $1.85 E-32$ & $4.25 E-32$ & $9.92 E-32$ & $5.23 E-01$ & $1.84 \mathrm{E}+0 \mathrm{C}$ \\
\hline 0.950 & & $1.82 E-32$ & $1.85 E-32$ & $4.26 E-32$ & $9.97 \mathrm{E}-32$ & $6.74 \mathrm{E}-01$ & $2.00 \mathrm{E}+0 \mathrm{C}$ \\
\hline 0.975 & & $1.82 E-32$ & $1.85 E-32$ & $4.27 E-32$ & $1.00 E-31$ & $1.04 \mathrm{E}+00$ & $2.24 \mathrm{E}+0 \mathrm{C}$ \\
\hline 1.000 & & $1.82 \mathrm{E}-32$ & $1.85 \mathrm{E}-32$ & 4. $31 \mathrm{E}-32$ & 1. $02 \mathrm{E}-31$ & $3.79 \mathrm{E}+00$ & $3.28 \mathrm{E}+0 \mathrm{C}$ \\
\hline
\end{tabular}


RESRAD-OFFSITE, Version 2.5

Probabilistic Dose and Risk Report

Title : Offsite Resident Farmer

File : RF TC99 DOESG FWD-FV2all.ROF

Retition

Statistics and Cumulative distribution function of Peak Dose from All Pathways in mrem/yr

$\begin{array}{ccccc}\text { Repetition }= & 1 & 2 & 3 \\ \text { Mean } & 1.01 \mathrm{E}+00 & 1.01 \mathrm{E}+00 & 1.01 \mathrm{E}+00 \\ \text { Std. Dev. } & 5.91 \mathrm{E}-01 & 5.91 \mathrm{E}-01 & 5.92 \mathrm{E}-01 \\ \text { Minimum } & 1.21 \mathrm{E}-01 & 1.21 \mathrm{E}-01 & 1.21 \mathrm{E}-01 \\ \text { Maximum } & 4.59 \mathrm{E}+00 & 4.59 \mathrm{E}+00 & 4.59 \mathrm{E}+00\end{array}$

Percentile

$0.010 \quad 1.93 \mathrm{E}-01 \quad 1.93 \mathrm{E}-01 \quad 1.93 \mathrm{E}-01$

$0.025 \quad 2.26 \mathrm{E}-01 \quad 2.26 \mathrm{E}-01 \quad 2.26 \mathrm{E}-01$

\begin{tabular}{l}
$0.050 \quad 2.89 \mathrm{E}-01 \quad 2.89 \mathrm{E}-01 \quad 2.89 \mathrm{E}-01$ \\
\hline
\end{tabular}

$0.075 \quad 3.23 \mathrm{E}-01 \quad 3.23 \mathrm{E}-01 \quad 3.23 \mathrm{E}-01$

$0.100 \quad 3.66 \mathrm{E}-01 \quad 3.66 \mathrm{E}-01 \quad 3.66 \mathrm{E}-01$

$0.125 \quad 3.97 \mathrm{E}-01 \quad 3.97 \mathrm{E}-01 \quad 3.97 \mathrm{E}-01$

$0.1504 .25 \mathrm{E}-01 \quad 4.25 \mathrm{E}-01 \quad 4.25 \mathrm{E}-01$

$0.175 \quad 4.63 \mathrm{E}-01 \quad 4.63 \mathrm{E}-01 \quad 4.63 \mathrm{E}-01$

$0.200 \quad 4.91 \mathrm{E}-01 \quad 4.91 \mathrm{E}-01 \quad 4.91 \mathrm{E}-01$

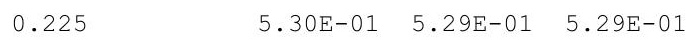

$0.250 \quad 5.55 \mathrm{E}-01 \quad 5.55 \mathrm{E}-01 \quad 5.55 \mathrm{E}-01$

$0.275 \quad 5.86 \mathrm{E}-01 \quad 5.86 \mathrm{E}-01 \quad 5.86 \mathrm{E}-01$
0.301

$\begin{array}{llll}0.300 & 6.17 \mathrm{E}-01 & 6.17 \mathrm{E}-01 & 6.17 \mathrm{E}-01\end{array}$

$\begin{array}{llll}0.325 & 6.52 \mathrm{E}-01 & 6.51 \mathrm{E}-01 & 6.51 \mathrm{E}-01\end{array}$

$\begin{array}{llll}0.350 & 6.91 \mathrm{E}-01 & 6.90 \mathrm{E}-01 & 6.90 \mathrm{E}-01\end{array}$

$\begin{array}{llll}0.375 & 7.27 \mathrm{E}-01 & 7.26 \mathrm{E}-01 & 7.26 \mathrm{E}-01\end{array}$

$0.400 \quad 7.54 \mathrm{E}-01 \quad 7.53 \mathrm{E}-01 \quad 7.53 \mathrm{E}-01$

$\begin{array}{llll}0.425 & 7.88 \mathrm{E}-01 & 7.87 \mathrm{E}-01 & 7.87 \mathrm{E}-01\end{array}$

$0.450 \quad 8.19 \mathrm{E}-01 \quad 8.19 \mathrm{E}-01 \quad 8.19 \mathrm{E}-01$
0.475

$0.475 \quad 8.57 \mathrm{E}-01 \quad 8.55 \mathrm{E}-01 \quad 8.57 \mathrm{E}-01$
0.500

$0.500 \quad 8.95 \mathrm{E}-01 \quad 8.94 \mathrm{E}-01 \quad 8.95 \mathrm{E}-01$
0.525

$\begin{array}{llll}0.525 & 9.36 \mathrm{E}-01 & 9.35 \mathrm{E}-01 & 9.36 \mathrm{E}-01\end{array}$

$\begin{array}{llll}0.550 \quad 9.67 \mathrm{E}-01 & 9.66 \mathrm{E}-01 & 9.68 \mathrm{E}-01\end{array}$

$\begin{array}{llll}0.575 & 1.00 \mathrm{E}+00 & 1.00 \mathrm{E}+00 & 1.00 \mathrm{E}+00\end{array}$

$\begin{array}{llll}0.600 & 1.05 \mathrm{E}+00 & 1.04 \mathrm{E}+00 & 1.05 \mathrm{E}+00\end{array}$

$\begin{array}{llll}0.625 & 1.09 \mathrm{E}+00 & 1.08 \mathrm{E}+00 & 1.09 \mathrm{E}+00\end{array}$

$\begin{array}{llll}0.650 & 1.13 \mathrm{E}+00 & 1.12 \mathrm{E}+00 & 1.13 \mathrm{E}+00\end{array}$

$\begin{array}{llll}0.675 & 1.16 \mathrm{E}+00 & 1.16 \mathrm{E}+00 & 1.16 \mathrm{E}+00\end{array}$

$\begin{array}{llll}0.700 & 1.23 \mathrm{E}+00 & 1.23 \mathrm{E}+00 & 1.23 \mathrm{E}+00\end{array}$

$\begin{array}{llll}0.725 & 1.26 \mathrm{E}+00 & 1.26 \mathrm{E}+00 & 1.26 \mathrm{E}+00\end{array}$

$\begin{array}{llll}0.750 & 1.33 \mathrm{E}+00 & 1.33 \mathrm{E}+00 & 1.33 \mathrm{E}+00\end{array}$

$\begin{array}{llll}0.775 & 1.39 \mathrm{E}+00 & 1.39 \mathrm{E}+00 & 1.39 \mathrm{E}+00\end{array}$

$\begin{array}{llll}0.800 & 1.45 \mathrm{E}+00 & 1.44 \mathrm{E}+00 & 1.45 \mathrm{E}+00\end{array}$

$\begin{array}{llll}0.825 & 1.51 \mathrm{E}+00 & 1.51 \mathrm{E}+00 & 1.51 \mathrm{E}+00\end{array}$

$\begin{array}{llll}0.850 & 1.59 \mathrm{E}+00 & 1.59 \mathrm{E}+00 & 1.59 \mathrm{E}+00\end{array}$

$\begin{array}{llll}0.875 & 1.68 \mathrm{E}+00 & 1.68 \mathrm{E}+00 & 1.69 \mathrm{E}+00\end{array}$

$\begin{array}{llll}0.900 & 1.82 \mathrm{E}+00 & 1.82 \mathrm{E}+00 & 1.82 \mathrm{E}+00\end{array}$

$\begin{array}{llll}0.925 & 1.97 \mathrm{E}+00 & 1.97 \mathrm{E}+00 & 1.97 \mathrm{E}+00\end{array}$

$\begin{array}{llll}0.950 & 2.14 \mathrm{E}+00 \quad 2.14 \mathrm{E}+00 \quad 2.14 \mathrm{E}+00\end{array}$

$\begin{array}{lll}0.975 & 2.45 \mathrm{E}+00 \quad 2.45 \mathrm{E}+00 \quad 2.45 \mathrm{E}+00\end{array}$

$\begin{array}{llll}0.990 & 2.77 \mathrm{E}+00 \quad 2.77 \mathrm{E}+00 \quad 2.77 \mathrm{E}+00\end{array}$

C-551

DCN 5090-TR-02-2 
RESRAD-OFFSITE, Version 2.5

$\mathrm{T}^{1 / 2}$ Limit $=180$ days

robabilistic Dose and Risk Report

Title : Offsite Resident Farmer

File : RF TC99 DOESG FWD-FV2all.ROF

Repetition

Mean

Statistics and Cumulative distribution function of Peak Dose from External Ground(Wreleas) in mrem/yr

Std. Dev.

Minimum

Maximum

\begin{tabular}{|c|c|c|}
\hline 1 & 2 & 3 \\
\hline $9.20 \mathrm{E}-07$ & $9.20 \mathrm{E}-07$ & $9.20 \mathrm{E}-07$ \\
\hline $5.41 \mathrm{E}-07$ & $5.41 E-07$ & $5.41 \mathrm{E}-07$ \\
\hline $1.10 \mathrm{E}-07$ & $1.10 \mathrm{E}-07$ & $1.10 \mathrm{E}-07$ \\
\hline $4.20 E-06$ & $4.20 E-06$ & $4.20 E-06$ \\
\hline
\end{tabular}

ercentile

0.010

$1.76 \mathrm{E}-07 \quad 1.76 \mathrm{E}-07 \quad 1.76 \mathrm{E}-07$

0.025

2.07E-07 2.07E-07 2.07E-07

0.050

$2.64 \mathrm{E}-07 \quad 2.64 \mathrm{E}-07 \quad 2.64 \mathrm{E}-07$

0.075

$2.95 \mathrm{E}-07 \quad 2.95 \mathrm{E}-07 \quad 2.95 \mathrm{E}-07$

0.100

$3.34 \mathrm{E}-07 \quad 3.34 \mathrm{E}-07 \quad 3.34 \mathrm{E}-07$

0.125

$3.63 \mathrm{E}-07 \quad 3.63 \mathrm{E}-07 \quad 3.63 \mathrm{E}-07$

0.150

$\begin{array}{lll}3.89 \mathrm{E}-07 \quad 3.89 \mathrm{E}-07 \quad 3.89 \mathrm{E}-07 & 07\end{array}$

0.175

4.23E-07 4.23E-07 4.23E-07

4.49E-07 4.48E-07 4.48E-07

4.84E-07 4.83E-07 4.83E-07

$5.08 \mathrm{E}-07 \quad 5.08 \mathrm{E}-07 \quad 5.08 \mathrm{E}-07$

$5.36 \mathrm{E}-07 \quad 5.36 \mathrm{E}-07 \quad 5.36 \mathrm{E}-07$

$5.64 \mathrm{E}-07 \quad 5.64 \mathrm{E}-07 \quad 5.64 \mathrm{E}-07$

$5.95 \mathrm{E}-07 \quad 5.95 \mathrm{E}-07 \quad 5.95 \mathrm{E}-07$

$6.31 \mathrm{E}-07 \quad 6.30 \mathrm{E}-07 \quad 6.30 \mathrm{E}-07$

$6.64 \mathrm{E}-07 \quad 6.63 \mathrm{E}-07 \quad 6.63 \mathrm{E}-07$

$6.89 \mathrm{E}-07 \quad 6.88 \mathrm{E}-07 \quad 6.88 \mathrm{E}-07$

$7.20 \mathrm{E}-07 \quad 7.19 \mathrm{E}-07 \quad 7.19 \mathrm{E}-07$

$7.48 \mathrm{E}-07 \quad 7.48 \mathrm{E}-07 \quad 7.48 \mathrm{E}-07$

$7.83 \mathrm{E}-07 \quad 7.82 \mathrm{E}-07 \quad 7.83 \mathrm{E}-07$

8.18E-07 8.17E-07 8.18E-07

$8.56 \mathrm{E}-07 \quad 8.54 \mathrm{E}-07 \quad 8.56 \mathrm{E}-07$

8.84E-07 8.83E-07 8.84E-07

$9.18 \mathrm{E}-07 \quad 9.17 \mathrm{E}-07 \quad 9.18 \mathrm{E}-07$

9.55E-07 9.55E-07 9.55E-07

9.94E-07 9.91E-07 9.94E-07

$1.03 \mathrm{E}-06 \quad 1.03 \mathrm{E}-06 \quad 1.03 \mathrm{E}-06$

$1.06 \mathrm{E}-06 \quad 1.06 \mathrm{E}-06 \quad 1.06 \mathrm{E}-06$

$1.12 \mathrm{E}-06 \quad 1.12 \mathrm{E}-06 \quad 1.12 \mathrm{E}-06$

$1.16 \mathrm{E}-06 \quad 1.16 \mathrm{E}-06 \quad 1.16 \mathrm{E}-06$

$1.22 \mathrm{E}-06 \quad 1.22 \mathrm{E}-06 \quad 1.22 \mathrm{E}-06$

$1.27 \mathrm{E}-06 \quad 1.27 \mathrm{E}-06 \quad 1.27 \mathrm{E}-06$

$1.32 \mathrm{E}-06 \quad 1.32 \mathrm{E}-06 \quad 1.32 \mathrm{E}-06$

$1.38 \mathrm{E}-06 \quad 1.38 \mathrm{E}-06 \quad 1.38 \mathrm{E}-06$

$1.45 \mathrm{E}-06 \quad 1.45 \mathrm{E}-06 \quad 1.45 \mathrm{E}-06$

$1.54 \mathrm{E}-06 \quad 1.54 \mathrm{E}-06 \quad 1.54 \mathrm{E}-06$

$1.66 \mathrm{E}-06 \quad 1.66 \mathrm{E}-06 \quad 1.66 \mathrm{E}-06$

$1.80 \mathrm{E}-06 \quad 1.80 \mathrm{E}-06 \quad 1.80 \mathrm{E}-06$

$1.95 \mathrm{E}-06 \quad 1.95 \mathrm{E}-06 \quad 1.95 \mathrm{E}-06$

$2.24 \mathrm{E}-06 \quad 2.24 \mathrm{E}-06 \quad 2.24 \mathrm{E}-06$

2.53E-06 2.53E-06 2.53E-06 
RESRAD-OFFSITE, Version 2.5

Probabilistic Dose and Risk Report

Title : Offsite Resident Farmer

File : RF TC99 DOESG FWD-FV2all.ROF

Statistics and Cumulative distribution function of Peak Dose from Fish Ingestion in mrem/yr

$\begin{array}{ccccc}\text { Repetition }= & 1 & 2 & 3 \\ \begin{array}{c}\text { Mean } \\ \text { Std. Dev. }\end{array} & 0.00 \mathrm{E}+00 & 0.00 \mathrm{E}+00 & 0.00 \mathrm{E}+00 \\ \text { Minimum } & 0.00 \mathrm{E}+00 & 0.00 \mathrm{E}+00 & 0.00 \mathrm{E}+00 \\ \text { Maximum } & 0.00 \mathrm{E}+00 & 0.00 \mathrm{E}+00 & 0.00 \mathrm{E}+00 \\ & 0.00 \mathrm{E}+00 & 0.00 \mathrm{E}+00 & 0.00 \mathrm{E}+00\end{array}$

Percentile

$\begin{array}{llll}0.010 & 0.00 \mathrm{E}+00 & 0.00 \mathrm{E}+00 & 0.00 \mathrm{E}+00\end{array}$

$\begin{array}{llll}0.025 & 0.00 \mathrm{E}+00 & 0.00 \mathrm{E}+00 & 0.00 \mathrm{E}+00\end{array}$

$\begin{array}{lllll}0.050 & 0.00 \mathrm{E}+00 & 0.00 \mathrm{E}+00 & 0.00 \mathrm{E}+00\end{array}$

$\begin{array}{llll}0.075 & 0.00 \mathrm{E}+00 & 0.00 \mathrm{E}+00 & 0.00 \mathrm{E}+00\end{array}$

$\begin{array}{llll}0.100 & 0.00 \mathrm{E}+00 & 0.00 \mathrm{E}+00 & 0.00 \mathrm{E}+00\end{array}$

$\begin{array}{llll}0.125 & 0.00 \mathrm{E}+00 & 0.00 \mathrm{E}+00 & 0.00 \mathrm{E}+00\end{array}$

$\begin{array}{llll}0.150 & 0.00 \mathrm{E}+00 & 0.00 \mathrm{E}+00 & 0.00 \mathrm{E}+00\end{array}$

$\begin{array}{llll}0.175 & 0.00 \mathrm{E}+00 & 0.00 \mathrm{E}+00 & 0.00 \mathrm{E}+00\end{array}$

$\begin{array}{llll}0.200 & 0.00 \mathrm{E}+00 & 0.00 \mathrm{E}+00 & 0.00 \mathrm{E}+00\end{array}$

$\begin{array}{lllll}0.225 & 0.00 \mathrm{E}+00 & 0.00 \mathrm{E}+00 & 0.00 \mathrm{E}+00\end{array}$

$\begin{array}{llll}0.250 & 0.00 \mathrm{E}+00 & 0.00 \mathrm{E}+00 & 0.00 \mathrm{E}+00\end{array}$

$\begin{array}{llll}0.275 & 0.00 \mathrm{E}+00 & 0.00 \mathrm{E}+00 & 0.00 \mathrm{E}+00\end{array}$

$\begin{array}{lllll}0.300 & 0.00 \mathrm{E}+00 & 0.00 \mathrm{E}+00 & 0.00 \mathrm{E}+00\end{array}$

$\begin{array}{lllll}0.325 & 0.00 \mathrm{E}+00 & 0.00 \mathrm{E}+00 & 0.00 \mathrm{E}+00\end{array}$

$\begin{array}{lllll}0.350 & 0.00 \mathrm{E}+00 & 0.00 \mathrm{E}+00 & 0.00 \mathrm{E}+00\end{array}$

$\begin{array}{lllll}0.375 & 0.00 \mathrm{E}+00 & 0.00 \mathrm{E}+00 & 0.00 \mathrm{E}+00\end{array}$

$\begin{array}{lllll}0.400 & 0.00 \mathrm{E}+00 & 0.00 \mathrm{E}+00 & 0.00 \mathrm{E}+00\end{array}$

$\begin{array}{lllll}0.425 & 0.00 \mathrm{E}+00 & 0.00 \mathrm{E}+00 & 0.00 \mathrm{E}+00\end{array}$

$\begin{array}{lllll}0.450 & 0.00 \mathrm{E}+00 & 0.00 \mathrm{E}+00 & 0.00 \mathrm{E}+00\end{array}$

$\begin{array}{lllll}0.475 & 0.00 \mathrm{E}+00 & 0.00 \mathrm{E}+00 & 0.00 \mathrm{E}+00\end{array}$

$\begin{array}{lllll}0.500 & 0.00 \mathrm{E}+00 & 0.00 \mathrm{E}+00 & 0.00 \mathrm{E}+00\end{array}$

$\begin{array}{lllll}0.525 & 0.00 \mathrm{E}+00 & 0.00 \mathrm{E}+00 & 0.00 \mathrm{E}+00\end{array}$

$\begin{array}{llll}0.550 & 0.00 \mathrm{E}+00 & 0.00 \mathrm{E}+00 & 0.00 \mathrm{E}+00\end{array}$

$\begin{array}{lllll}0.575 & 0.00 \mathrm{E}+00 & 0.00 \mathrm{E}+00 & 0.00 \mathrm{E}+00\end{array}$

$\begin{array}{lllll}0.600 & 0.00 \mathrm{E}+00 & 0.00 \mathrm{E}+00 & 0.00 \mathrm{E}+00\end{array}$

$\begin{array}{lllll}0.625 & 0.00 \mathrm{E}+00 & 0.00 \mathrm{E}+00 & 0.00 \mathrm{E}+00\end{array}$

$\begin{array}{lllll}0.650 & 0.00 \mathrm{E}+00 & 0.00 \mathrm{E}+00 & 0.00 \mathrm{E}+00\end{array}$

$\begin{array}{lllll}0.675 & 0.00 \mathrm{E}+00 & 0.00 \mathrm{E}+00 & 0.00 \mathrm{E}+00\end{array}$

$\begin{array}{lllll}0.700 & 0.00 \mathrm{E}+00 & 0.00 \mathrm{E}+00 & 0.00 \mathrm{E}+00\end{array}$

$\begin{array}{lllll}0.725 & 0.00 \mathrm{E}+00 & 0.00 \mathrm{E}+00 & 0.00 \mathrm{E}+00\end{array}$

$\begin{array}{lllll}0.750 & 0.00 \mathrm{E}+00 & 0.00 \mathrm{E}+00 & 0.00 \mathrm{E}+00\end{array}$

$\begin{array}{lllll}0.775 & 0.00 \mathrm{E}+00 & 0.00 \mathrm{E}+00 & 0.00 \mathrm{E}+00\end{array}$

$\begin{array}{lllll}0.800 & 0.00 \mathrm{E}+00 & 0.00 \mathrm{E}+00 & 0.00 \mathrm{E}+00\end{array}$

$\begin{array}{lllll}0.825 & 0.00 \mathrm{E}+00 & 0.00 \mathrm{E}+00 & 0.00 \mathrm{E}+00\end{array}$

$\begin{array}{lllll}0.850 & 0.00 \mathrm{E}+00 & 0.00 \mathrm{E}+00 & 0.00 \mathrm{E}+00\end{array}$

$\begin{array}{lllll}0.875 & 0.00 \mathrm{E}+00 & 0.00 \mathrm{E}+00 & 0.00 \mathrm{E}+00\end{array}$

$\begin{array}{lllll}0.900 & 0.00 \mathrm{E}+00 & 0.00 \mathrm{E}+00 & 0.00 \mathrm{E}+00\end{array}$

$\begin{array}{llll}0.925 & 0.00 \mathrm{E}+00 & 0.00 \mathrm{E}+00 & 0.00 \mathrm{E}+00\end{array}$

$\begin{array}{lllll}0.950 & 0.00 \mathrm{E}+00 & 0.00 \mathrm{E}+00 & 0.00 \mathrm{E}+00\end{array}$

$\begin{array}{lllll}0.975 & 0.00 \mathrm{E}+00 & 0.00 \mathrm{E}+00 & 0.00 \mathrm{E}+00\end{array}$

$\begin{array}{lllll}0.990 & 0.00 \mathrm{E}+00 & 0.00 \mathrm{E}+00 & 0.00 \mathrm{E}+00\end{array}$ 
RESRAD-OFFSITE, Version 2.5

Probabilistic Dose and Risk Report

Title : Offsite Resident Farmer

File : RF TC99 DOESG FWD-FV2all.ROF

Statistics and Cumulative distribution function of Peak Dose from Radon (Waterrelease) in mrem/yr

$\begin{array}{ccccc}\text { Repetition }= & 1 & 2 & 3 \\ \begin{array}{c}\text { Mean } \\ \text { Std. Dev. }\end{array} & 0.00 \mathrm{E}+00 & 0.00 \mathrm{E}+00 & 0.00 \mathrm{E}+00 \\ \text { Minimum } & 0.00 \mathrm{E}+00 & 0.00 \mathrm{E}+00 & 0.00 \mathrm{E}+00 \\ \text { Maximum } & 0.00 \mathrm{E}+00 & 0.00 \mathrm{E}+00 & 0.00 \mathrm{E}+00 \\ & 0.00 \mathrm{E}+00 & 0.00 \mathrm{E}+00 & 0.00 \mathrm{E}+00\end{array}$

Percentile

$\begin{array}{llll}0.010 & 0.00 \mathrm{E}+00 & 0.00 \mathrm{E}+00 & 0.00 \mathrm{E}+00\end{array}$

$\begin{array}{llll}0.025 & 0.00 \mathrm{E}+00 & 0.00 \mathrm{E}+00 & 0.00 \mathrm{E}+00\end{array}$

$\begin{array}{lllll}0.050 & 0.00 \mathrm{E}+00 & 0.00 \mathrm{E}+00 & 0.00 \mathrm{E}+00\end{array}$

$\begin{array}{lllll}0.075 & 0.00 \mathrm{E}+00 & 0.00 \mathrm{E}+00 & 0.00 \mathrm{E}+00\end{array}$

$\begin{array}{llll}0.100 & 0.00 \mathrm{E}+00 & 0.00 \mathrm{E}+00 & 0.00 \mathrm{E}+00\end{array}$

$\begin{array}{llll}0.125 & 0.00 \mathrm{E}+00 & 0.00 \mathrm{E}+00 & 0.00 \mathrm{E}+00\end{array}$

$\begin{array}{llll}0.150 & 0.00 \mathrm{E}+00 & 0.00 \mathrm{E}+00 & 0.00 \mathrm{E}+00\end{array}$

$\begin{array}{llll}0.175 & 0.00 \mathrm{E}+00 & 0.00 \mathrm{E}+00 & 0.00 \mathrm{E}+00\end{array}$

$\begin{array}{llll}0.200 & 0.00 \mathrm{E}+00 & 0.00 \mathrm{E}+00 & 0.00 \mathrm{E}+00\end{array}$

$\begin{array}{lllll}0.225 & 0.00 \mathrm{E}+00 & 0.00 \mathrm{E}+00 & 0.00 \mathrm{E}+00\end{array}$

$\begin{array}{llll}0.250 & 0.00 \mathrm{E}+00 & 0.00 \mathrm{E}+00 & 0.00 \mathrm{E}+00\end{array}$

$\begin{array}{llll}0.275 & 0.00 \mathrm{E}+00 & 0.00 \mathrm{E}+00 & 0.00 \mathrm{E}+00\end{array}$

$\begin{array}{lllll}0.300 & 0.00 \mathrm{E}+00 & 0.00 \mathrm{E}+00 & 0.00 \mathrm{E}+00\end{array}$

$\begin{array}{lllll}0.325 & 0.00 \mathrm{E}+00 & 0.00 \mathrm{E}+00 & 0.00 \mathrm{E}+00\end{array}$

$\begin{array}{lllll}0.350 & 0.00 \mathrm{E}+00 & 0.00 \mathrm{E}+00 & 0.00 \mathrm{E}+00\end{array}$

$\begin{array}{lllll}0.375 & 0.00 \mathrm{E}+00 & 0.00 \mathrm{E}+00 & 0.00 \mathrm{E}+00\end{array}$

$\begin{array}{lllll}0.400 & 0.00 \mathrm{E}+00 & 0.00 \mathrm{E}+00 & 0.00 \mathrm{E}+00\end{array}$

$\begin{array}{lllll}0.425 & 0.00 \mathrm{E}+00 & 0.00 \mathrm{E}+00 & 0.00 \mathrm{E}+00\end{array}$

$\begin{array}{lllll}0.450 & 0.00 \mathrm{E}+00 & 0.00 \mathrm{E}+00 & 0.00 \mathrm{E}+00\end{array}$

$\begin{array}{lllll}0.475 & 0.00 \mathrm{E}+00 & 0.00 \mathrm{E}+00 & 0.00 \mathrm{E}+00\end{array}$

$\begin{array}{lllll}0.500 & 0.00 \mathrm{E}+00 & 0.00 \mathrm{E}+00 & 0.00 \mathrm{E}+00\end{array}$

$\begin{array}{lllll}0.525 & 0.00 \mathrm{E}+00 & 0.00 \mathrm{E}+00 & 0.00 \mathrm{E}+00\end{array}$

$\begin{array}{llll}0.550 & 0.00 \mathrm{E}+00 & 0.00 \mathrm{E}+00 & 0.00 \mathrm{E}+00\end{array}$

$\begin{array}{lllll}0.575 & 0.00 \mathrm{E}+00 & 0.00 \mathrm{E}+00 & 0.00 \mathrm{E}+00\end{array}$

$\begin{array}{lllll}0.600 & 0.00 \mathrm{E}+00 & 0.00 \mathrm{E}+00 & 0.00 \mathrm{E}+00\end{array}$

$\begin{array}{lllll}0.625 & 0.00 \mathrm{E}+00 & 0.00 \mathrm{E}+00 & 0.00 \mathrm{E}+00\end{array}$

$\begin{array}{lllll}0.650 & 0.00 \mathrm{E}+00 & 0.00 \mathrm{E}+00 & 0.00 \mathrm{E}+00\end{array}$

$\begin{array}{lllll}0.675 & 0.00 \mathrm{E}+00 & 0.00 \mathrm{E}+00 & 0.00 \mathrm{E}+00\end{array}$

$\begin{array}{lllll}0.700 & 0.00 \mathrm{E}+00 & 0.00 \mathrm{E}+00 & 0.00 \mathrm{E}+00\end{array}$

$\begin{array}{lllll}0.725 & 0.00 \mathrm{E}+00 & 0.00 \mathrm{E}+00 & 0.00 \mathrm{E}+00\end{array}$

$\begin{array}{lllll}0.750 & 0.00 \mathrm{E}+00 & 0.00 \mathrm{E}+00 & 0.00 \mathrm{E}+00\end{array}$

$\begin{array}{lllll}0.775 & 0.00 \mathrm{E}+00 & 0.00 \mathrm{E}+00 & 0.00 \mathrm{E}+00\end{array}$

$\begin{array}{lllll}0.800 & 0.00 \mathrm{E}+00 & 0.00 \mathrm{E}+00 & 0.00 \mathrm{E}+00\end{array}$

$\begin{array}{lllll}0.825 & 0.00 \mathrm{E}+00 & 0.00 \mathrm{E}+00 & 0.00 \mathrm{E}+00\end{array}$

$\begin{array}{lllll}0.850 & 0.00 \mathrm{E}+00 & 0.00 \mathrm{E}+00 & 0.00 \mathrm{E}+00\end{array}$

$\begin{array}{lllll}0.875 & 0.00 \mathrm{E}+00 & 0.00 \mathrm{E}+00 & 0.00 \mathrm{E}+00\end{array}$

$\begin{array}{lllll}0.900 & 0.00 \mathrm{E}+00 & 0.00 \mathrm{E}+00 & 0.00 \mathrm{E}+00\end{array}$

$\begin{array}{llll}0.925 & 0.00 \mathrm{E}+00 & 0.00 \mathrm{E}+00 & 0.00 \mathrm{E}+00\end{array}$

$\begin{array}{lllll}0.950 & 0.00 \mathrm{E}+00 & 0.00 \mathrm{E}+00 & 0.00 \mathrm{E}+00\end{array}$

$\begin{array}{lllll}0.975 & 0.00 \mathrm{E}+00 & 0.00 \mathrm{E}+00 & 0.00 \mathrm{E}+00\end{array}$

$\begin{array}{lllll}0.990 & 0.00 \mathrm{E}+00 & 0.00 \mathrm{E}+00 & 0.00 \mathrm{E}+00\end{array}$ 
RESRAD-OFFSITE, Version 2.5

robabilistic Dose and Risk Report

Title : Offsite Resident Farmer

File : RF TC99 DOESG FWD-FV2all.ROF

Repetition

Mean

Std. Dev.

Minimum

Maximum

Statistics and Cumulative distribution function of Peak Dose from Plant (Waterrelease) in mrem/yr

Percentile

0.010

4.83E-02 4.83E-02 4.83E-02

0.025

$5.67 \mathrm{E}-02 \quad 5.67 \mathrm{E}-02 \quad 5.67 \mathrm{E}-02$

0.050

$7.24 \mathrm{E}-02 \quad 7.24 \mathrm{E}-02 \quad 7.24 \mathrm{E}-02$

0.075

8.10E-02

8.10E-02 8.10E-02

0.100

$9.16 \mathrm{E}-02$

$9.16 \mathrm{E}-02$

9. 16E-02

0.125

9. $95 \mathrm{E}-02$

9.95E-02 9.95E-02

0.150

$1.07 \mathrm{E}-01 \quad 1.07 \mathrm{E}-01 \quad 1.07 \mathrm{E}-01$

0.175

$1.16 \mathrm{E}-01 \quad 1.16 \mathrm{E}-01 \quad 1.16 \mathrm{E}-01$

0.200

$1.23 \mathrm{E}-01 \quad 1.23 \mathrm{E}-01 \quad 1.23 \mathrm{E}-01$

0.225

$1.33 \mathrm{E}-01 \quad 1.32 \mathrm{E}-01 \quad 1.32 \mathrm{E}-01$

0.250

$1.39 \mathrm{E}-01 \quad 1.39 \mathrm{E}-01 \quad 1.39 \mathrm{E}-01$

0.275

1.47E-01 1.47E-01 1.47E-01

0.300

$1.55 \mathrm{E}-01 \quad 1.55 \mathrm{E}-01 \quad 1.54 \mathrm{E}-01$

0.325

$1.63 \mathrm{E}-01 \quad 1.63 \mathrm{E}-01 \quad 1.63 \mathrm{E}-01$

0.350

$1.73 \mathrm{E}-01 \quad 1.73 \mathrm{E}-01 \quad 1.73 \mathrm{E}-01$

0.375

$1.82 \mathrm{E}-01 \quad 1.82 \mathrm{E}-01 \quad 1.82 \mathrm{E}-01$

0.400

$1.89 \mathrm{E}-01 \quad 1.89 \mathrm{E}-01 \quad 1.89 \mathrm{E}-01$

0.425

$1.97 \mathrm{E}-01 \quad 1.97 \mathrm{E}-01 \quad 1.97 \mathrm{E}-01$

0.450

2.05E-01 2.05E-01 2.05E-01

0.475

$2.15 \mathrm{E}-01 \quad 2.14 \mathrm{E}-01 \quad 2.15 \mathrm{E}-01$

0.500

$2.24 \mathrm{E}-01 \quad 2.24 \mathrm{E}-01 \quad 2.24 \mathrm{E}-01$

0.525

2.34E-01 2.34E-01 2.35E-01

0.550

$2.42 \mathrm{E}-01 \quad 2.42 \mathrm{E}-01 \quad 2.42 \mathrm{E}-01$

0.575

2.51E-01 2.51E-01 2.51E-01

0.600

2. $62 \mathrm{E}-01 \quad 2.62 \mathrm{E}-01 \quad 2.62 \mathrm{E}-01$

0.625

0.650

$2.72 \mathrm{E}-01 \quad 2.72 \mathrm{E}-01 \quad 2.72 \mathrm{E}-01$

$2.82 \mathrm{E}-01 \quad 2.82 \mathrm{E}-01 \quad 2.82 \mathrm{E}-01$

0.675

0.700

0.725

0.750

0.775

0.800

0.825

0.850

0.875

0.900

0.925

0.950

0.975

0.990

$2.91 \mathrm{E}-01 \quad 2.91 \mathrm{E}-01 \quad 2.91 \mathrm{E}-01$

$3.07 \mathrm{E}-01 \quad 3.07 \mathrm{E}-01 \quad 3.07 \mathrm{E}-01$

$3.17 \mathrm{E}-01 \quad 3.17 \mathrm{E}-01 \quad 3.17 \mathrm{E}-01$

$3.34 \mathrm{E}-01 \quad 3.34 \mathrm{E}-01 \quad 3.34 \mathrm{E}-01$

$3.47 \mathrm{E}-01 \quad 3.47 \mathrm{E}-01 \quad 3.47 \mathrm{E}-01$

$3.62 \mathrm{E}-01 \quad 3.62 \mathrm{E}-01 \quad 3.62 \mathrm{E}-01$

$3.78 \mathrm{E}-01 \quad 3.78 \mathrm{E}-01 \quad 3.79 \mathrm{E}-01$

$3.98 \mathrm{E}-01 \quad 3.98 \mathrm{E}-01 \quad 3.99 \mathrm{E}-01$

4.22E-01 4.22E-01 4.23E-01

4.55E-01 4.55E-01 4.55E-01

4.93E-01 4.93E-01 4.93E-01

$5.36 \mathrm{E}-01 \quad 5.36 \mathrm{E}-01 \quad 5.36 \mathrm{E}-01$

$6.15 \mathrm{E}-01 \quad 6.15 \mathrm{E}-01 \quad 6.15 \mathrm{E}-01$

$6.93 \mathrm{E}-01 \quad 6.93 \mathrm{E}-01 \quad 6.93 \mathrm{E}-01$ 
RESRAD-OFFSITE, Version 2.5

robabilistic Dose and Risk Report

Title : Offsite Resident Farmer

File : RF TC99 DOESG FWD-FV2all.ROF

Repetition

Mean

Std. Dev.

Minimum

Maximum

Statistics and Cumulative distribution function of Peak Dose from Meat (Waterrelease) in mrem/yr

Percentile

0.010

1.45E-04 1.45E-04 1.45E-04

0.025

1.70E-04 1.70E-04 1.70E-04

0.050

2.17E-04 2.17E-04 2.17E-04

0.075

2.43E-04 2.43E-04 2.43E-04

0.100

2.75E-04 2.75E-04 2.75E-04

2.98E-04 2.98E-04 2.98E-04

3.19E-04 3.19E-04 3.19E-04

3. $48 \mathrm{E}-04 \quad 3.47 \mathrm{E}-04 \quad 3.47 \mathrm{E}-04$

3. $69 \mathrm{E}-04 \quad 3.68 \mathrm{E}-04 \quad 3.68 \mathrm{E}-04$

$3.98 \mathrm{E}-04 \quad 3.97 \mathrm{E}-04 \quad 3.97 \mathrm{E}-04$

4.17E-04 4.17E-04 4.17E-04

4.40E-04 4.40E-04 4.40E-04

4.63E-04 4.63E-04 4.63E-04

4.89E-04 4.88E-04 4.88E-04

$5.19 \mathrm{E}-04 \quad 5.18 \mathrm{E}-04 \quad 5.18 \mathrm{E}-04$

$5.45 \mathrm{E}-04 \quad 5.45 \mathrm{E}-04 \quad 5.45 \mathrm{E}-04$

$5.66 \mathrm{E}-04 \quad 5.65 \mathrm{E}-04 \quad 5.65 \mathrm{E}-04$

5.91E-04 5.91E-04 5.91E-04

6.15E-04 6.14E-04 6.14E-04

$6.43 \mathrm{E}-04 \quad 6.42 \mathrm{E}-04 \quad 6.43 \mathrm{E}-04$

$6.72 \mathrm{E}-04 \quad 6.71 \mathrm{E}-04 \quad 6.72 \mathrm{E}-04$

$7.02 \mathrm{E}-04 \quad 7.02 \mathrm{E}-04 \quad 7.03 \mathrm{E}-04$

$7.26 \mathrm{E}-04 \quad 7.25 \mathrm{E}-04 \quad 7.26 \mathrm{E}-04$

$7.54 \mathrm{E}-04 \quad 7.53 \mathrm{E}-04 \quad 7.54 \mathrm{E}-04$

$7.84 \mathrm{E}-04 \quad 7.84 \mathrm{E}-04 \quad 7.84 \mathrm{E}-04$

$8.16 \mathrm{E}-04 \quad 8.14 \mathrm{E}-04 \quad 8.16 \mathrm{E}-04$

$8.45 \mathrm{E}-04 \quad 8.44 \mathrm{E}-04 \quad 8.45 \mathrm{E}-04$

$8.73 \mathrm{E}-04 \quad 8.73 \mathrm{E}-04 \quad 8.73 \mathrm{E}-04$

9.20E-04 9.20E-04 9.20E-04

9.49E-04 9.49E-04 9.49E-04

$1.00 \mathrm{E}-03 \quad 1.00 \mathrm{E}-03 \quad 1.00 \mathrm{E}-03$

$1.04 \mathrm{E}-03 \quad 1.04 \mathrm{E}-03 \quad 1.04 \mathrm{E}-03$

$1.08 \mathrm{E}-03 \quad 1.08 \mathrm{E}-03 \quad 1.08 \mathrm{E}-03$

$1.13 \mathrm{E}-03 \quad 1.13 \mathrm{E}-03 \quad 1.14 \mathrm{E}-03$

$1.19 \mathrm{E}-03 \quad 1.19 \mathrm{E}-03 \quad 1.19 \mathrm{E}-03$

$1.26 \mathrm{E}-03 \quad 1.26 \mathrm{E}-03 \quad 1.27 \mathrm{E}-03$

$1.36 \mathrm{E}-03 \quad 1.36 \mathrm{E}-03 \quad 1.36 \mathrm{E}-03$

$1.48 \mathrm{E}-03 \quad 1.48 \mathrm{E}-03 \quad 1.48 \mathrm{E}-03$

$1.60 \mathrm{E}-03 \quad 1.60 \mathrm{E}-03 \quad 1.60 \mathrm{E}-03$

$1.84 \mathrm{E}-03 \quad 1.84 \mathrm{E}-03 \quad 1.84 \mathrm{E}-03$

$2.08 \mathrm{E}-03 \quad 2.08 \mathrm{E}-03 \quad 2.08 \mathrm{E}-03$ 
RESRAD-OFFSITE, Version 2.5

robabilistic Dose and Risk Report

Title : Offsite Resident Farmer

File : RF TC99 DOESG FWD-FV2all.ROF

Repetition

Mean

Statistics and Cumulative distribution function of Peak Dose from Milk (Waterrelease) in mrem/yr

Std. Dev.

Minimum

Maximum

\begin{tabular}{|c|c|c|}
\hline 1 & 2 & 3 \\
\hline $6.68 \mathrm{E}-02$ & $6.67 \mathrm{E}-02$ & $6.68 \mathrm{E}-02$ \\
\hline $3.92 \mathrm{E}-02$ & $3.92 E-02$ & $3.92 \mathrm{E}-02$ \\
\hline $8.00 \mathrm{E}-03$ & $8.00 \mathrm{E}-03$ & $8.00 E-03$ \\
\hline $3.05 E-01$ & $3.05 E-01$ & $3.05 E-01$ \\
\hline
\end{tabular}

ercentile

0.010

$1.28 \mathrm{E}-02 \quad 1.28 \mathrm{E}-02 \quad 1.28 \mathrm{E}-02$

0.025

1.50E-02 1.50E-02 1.50E-02

0.050

1.92E-02 1.92E-02 1.92E-02

0.075

$2.14 \mathrm{E}-02 \quad 2.14 \mathrm{E}-02 \quad 2.14 \mathrm{E}-02$

0.100

2.43E-02 2.43E-02 2.43E-02

0.125

2.64E-02 2.63E-02 2.63E-02

0.150

2.82E-02 2.82E-02 2.82E-02

0.175

$3.07 \mathrm{E}-02 \quad 3.07 \mathrm{E}-02 \quad 3.07 \mathrm{E}-02$

0.200

3.26E-02 3.25E-02 3.25E-02

0.225

3.51E-02 3.50E-02 3.50E-02

3. $68 \mathrm{E}-02 \quad 3.68 \mathrm{E}-02 \quad 3.68 \mathrm{E}-02$

$3.89 \mathrm{E}-02 \quad 3.89 \mathrm{E}-02 \quad 3.89 \mathrm{E}-02$

4.09E-02 4.09E-02 4.09E-02

4.32E-02 4.31E-02 4.31E-02

$4.58 \mathrm{E}-02 \quad 4.57 \mathrm{E}-02 \quad 4.57 \mathrm{E}-02$

4.82E-02 4.81E-02 4.81E-02

$5.00 \mathrm{E}-02 \quad 4.99 \mathrm{E}-02 \quad 4.99 \mathrm{E}-02$

$5.22 \mathrm{E}-02 \quad 5.22 \mathrm{E}-02 \quad 5.22 \mathrm{E}-02$

$5.43 \mathrm{E}-02 \quad 5.43 \mathrm{E}-02 \quad 5.43 \mathrm{E}-02$

$5.68 \mathrm{E}-02 \quad 5.67 \mathrm{E}-02 \quad 5.68 \mathrm{E}-02$

5.93E-02 5.93E-02 5.93E-02

6.20E-02 6.20E-02 6.21E-02

$6.41 \mathrm{E}-02 \quad 6.40 \mathrm{E}-02 \quad 6.42 \mathrm{E}-02$

$6.65 \mathrm{E}-02 \quad 6.65 \mathrm{E}-02 \quad 6.65 \mathrm{E}-02$

6.93E-02 6.93E-02 6.93E-02

$7.21 \mathrm{E}-02 \quad 7.19 \mathrm{E}-02 \quad 7.21 \mathrm{E}-02$

$7.46 \mathrm{E}-02 \quad 7.46 \mathrm{E}-02 \quad 7.46 \mathrm{E}-02$

$7.71 \mathrm{E}-02 \quad 7.71 \mathrm{E}-02 \quad 7.71 \mathrm{E}-02$

$8.13 \mathrm{E}-02 \quad 8.12 \mathrm{E}-02 \quad 8.13 \mathrm{E}-02$

$8.38 \mathrm{E}-02 \quad 8.38 \mathrm{E}-02 \quad 8.38 \mathrm{E}-02$

8.84E-02 8.83E-02 8.84E-02

$9.19 \mathrm{E}-02 \quad 9.19 \mathrm{E}-02 \quad 9.19 \mathrm{E}-02$

9.58E-02 9.58E-02 9.58E-02

$1.00 \mathrm{E}-01 \quad 1.00 \mathrm{E}-01 \quad 1.00 \mathrm{E}-01$

$1.05 \mathrm{E}-01 \quad 1.05 \mathrm{E}-01 \quad 1.05 \mathrm{E}-01$

$1.12 \mathrm{E}-01 \quad 1.12 \mathrm{E}-01 \quad 1.12 \mathrm{E}-01$

$1.20 \mathrm{E}-01 \quad 1.20 \mathrm{E}-01 \quad 1.20 \mathrm{E}-01$

1.31E-01 1.31E-01 1.31E-01

1. $42 \mathrm{E}-01 \quad 1.42 \mathrm{E}-01 \quad 1.42 \mathrm{E}-01$

$1.63 E-01 \quad 1.63 E-01 \quad 1.63 E-01$

$1.83 \mathrm{E}-01 \quad 1.83 \mathrm{E}-01 \quad 1.83 \mathrm{E}-01$ 
RESRAD-OFFSITE, Version 2.5

$\mathrm{T}^{1} \frac{1}{2}$ Limit $=180$ days

robabilistic Dose and Risk Report

Title : Offsite Resident Farmer

File : RF TC99 DOESG FWD-FV2all.ROF

epetition $=$

Mean

Statistics and Cumulative distribution function of Peak Dose from Soil Ingestion(Wrelease) in mrem/yr

Std. Dev.

Minimum

Maximum

\begin{tabular}{|c|c|c|}
\hline 1 & 2 & 3 \\
\hline $7.77 E-07$ & $7.77 E-07$ & $7.77 \mathrm{E}-07$ \\
\hline $4.57 E-07$ & $4.57 E-07$ & $4.57 \mathrm{E}-07$ \\
\hline $9.30 \mathrm{E}-08$ & $9.30 \mathrm{E}-08$ & $9.30 \mathrm{E}-08$ \\
\hline $3.55 E-06$ & $3.55 E-06$ & $3.55 E-06$ \\
\hline
\end{tabular}

ercentile

0.010

1.49E-07 1.49E-07 1.49E-07

0.025

$1.75 \mathrm{E}-07 \quad 1.75 \mathrm{E}-07 \quad 1.75 \mathrm{E}-07$

0.050

2.23E-07 2.23E-07 2.23E-07

0.075

$2.49 \mathrm{E}-07 \quad 2.49 \mathrm{E}-07 \quad 2.49 \mathrm{E}-07$

0.100

2.82E-07 2.82E-07 2.82E-07

0.125

$3.06 \mathrm{E}-07 \quad 3.06 \mathrm{E}-07 \quad 3.06 \mathrm{E}-07$

0.150

$3.28 \mathrm{E}-07 \quad 3.28 \mathrm{E}-07 \quad 3.28 \mathrm{E}-07$

0.175

$3.57 \mathrm{E}-07 \quad 3.57 \mathrm{E}-07 \quad 3.57 \mathrm{E}-07$

$\begin{array}{lll}3.79 \mathrm{E}-07 & 3.79 \mathrm{E}-07 & 3.79 \mathrm{E}-07\end{array}$

4.08E-07 4.08E-07 4.08E-07

4.29E-07 4.29E-07 4.29E-07

4.52E-07 4.52E-07 4.52E-07

$4.76 \mathrm{E}-07 \quad 4.76 \mathrm{E}-07 \quad 4.76 \mathrm{E}-07$

$5.02 \mathrm{E}-07 \quad 5.02 \mathrm{E}-07 \quad 5.02 \mathrm{E}-07$

$5.33 \mathrm{E}-07 \quad 5.32 \mathrm{E}-07 \quad 5.32 \mathrm{E}-07$

$5.60 \mathrm{E}-07 \quad 5.60 \mathrm{E}-07 \quad 5.60 \mathrm{E}-07$

$5.82 \mathrm{E}-07 \quad 5.81 \mathrm{E}-07 \quad 5.81 \mathrm{E}-07$

$6.08 \mathrm{E}-07 \quad 6.07 \mathrm{E}-07 \quad 6.07 \mathrm{E}-07$

$6.32 \mathrm{E}-07 \quad 6.31 \mathrm{E}-07 \quad 6.31 \mathrm{E}-07$

$6.61 \mathrm{E}-07 \quad 6.60 \mathrm{E}-07 \quad 6.61 \mathrm{E}-07$

6.90E-07 6.90E-07 6.90E-07

$7.22 \mathrm{E}-07 \quad 7.21 \mathrm{E}-07 \quad 7.23 \mathrm{E}-07$

$7.46 \mathrm{E}-07 \quad 7.45 \mathrm{E}-07 \quad 7.47 \mathrm{E}-07$

$7.75 \mathrm{E}-07 \quad 7.74 \mathrm{E}-07 \quad 7.75 \mathrm{E}-07$

$8.06 \mathrm{E}-07 \quad 8.06 \mathrm{E}-07 \quad 8.06 \mathrm{E}-07$

$8.39 \mathrm{E}-07 \quad 8.37 \mathrm{E}-07 \quad 8.39 \mathrm{E}-07$

8.69E-07 8.68E-07 8.69E-07

$8.97 \mathrm{E}-07 \quad 8.97 \mathrm{E}-07 \quad 8.97 \mathrm{E}-07$

$9.46 \mathrm{E}-07 \quad 9.45 \mathrm{E}-07 \quad 9.46 \mathrm{E}-07$

$9.76 \mathrm{E}-07 \quad 9.76 \mathrm{E}-07 \quad 9.76 \mathrm{E}-07$

$1.03 \mathrm{E}-06 \quad 1.03 \mathrm{E}-06 \quad 1.03 \mathrm{E}-06$

$1.07 \mathrm{E}-06 \quad 1.07 \mathrm{E}-06 \quad 1.07 \mathrm{E}-06$

$1.12 \mathrm{E}-06 \quad 1.12 \mathrm{E}-06 \quad 1.12 \mathrm{E}-06$

$1.17 \mathrm{E}-06 \quad 1.17 \mathrm{E}-06 \quad 1.17 \mathrm{E}-06$

$1.23 \mathrm{E}-06 \quad 1.23 \mathrm{E}-06 \quad 1.23 \mathrm{E}-06$

$1.30 \mathrm{E}-06 \quad 1.30 \mathrm{E}-06 \quad 1.30 \mathrm{E}-06$

$1.40 \mathrm{E}-06 \quad 1.40 \mathrm{E}-06 \quad 1.40 \mathrm{E}-06$

$1.52 \mathrm{E}-06 \quad 1.52 \mathrm{E}-06 \quad 1.52 \mathrm{E}-06$

$1.65 \mathrm{E}-06 \quad 1.65 \mathrm{E}-06 \quad 1.65 \mathrm{E}-06$

$1.89 \mathrm{E}-06 \quad 1.89 \mathrm{E}-06 \quad 1.89 \mathrm{E}-06$

$2.14 \mathrm{E}-06 \quad 2.14 \mathrm{E}-06 \quad 2.14 \mathrm{E}-06$ 
RESRAD-OFFSITE, Version 2.5

$\mathrm{T}^{1} \frac{1}{2}$ Limit $=180$ days

robabilistic Dose and Risk Report

Title : Offsite Resident Farmer

File : RF TC99 DOESG FWD-FV2all.ROF

epetition

Mean

Std. Dev.

Minimum

Maximum

Statistics and Cumulative distribution function of Peak Dose from Water Ingestion in mrem/yr

Percentile

0.010

1.32E-01 1.32E-01 1.32E-01

0.025

1.55E-01 1.55E-01 1.55E-01

0.050

1.97E-01 1.97E-01 1.97E-01

0.075

2.21E-01 2.21E-01 2.21E-01

0.100

2.50E-01 2.50E-01 2.50E-01

0.125

2.71E-01 2.71E-01 2.71E-01

0.150

2. $90 \mathrm{E}-01 \quad 2.90 \mathrm{E}-01 \quad 2.90 \mathrm{E}-01$

0.175

$3.16 \mathrm{E}-01 \quad 3.16 \mathrm{E}-01 \quad 3.16 \mathrm{E}-01$

0.200

3. 35E-01 3.35E-01 3.35E-01

0.225

3.61E-01 3.61E-01 3.61E-01

$3.79 \mathrm{E}-01 \quad 3.79 \mathrm{E}-01 \quad 3.79 \mathrm{E}-01$

4.00E-01 4.00E-01 4.00E-01

4.21E-01 4.21E-01 4.21E-01

4. 45E-01 4.44E-01 4.44E-01

4.71E-01 4.71E-01 4.71E-01

$4.96 \mathrm{E}-01 \quad 4.96 \mathrm{E}-01 \quad 4.96 \mathrm{E}-01$

$5.14 \mathrm{E}-01 \quad 5.14 \mathrm{E}-01 \quad 5.14 \mathrm{E}-01$

$5.38 \mathrm{E}-01 \quad 5.37 \mathrm{E}-01 \quad 5.37 \mathrm{E}-01$

$5.59 \mathrm{E}-01 \quad 5.59 \mathrm{E}-01 \quad 5.59 \mathrm{E}-01$

$5.85 \mathrm{E}-01 \quad 5.84 \mathrm{E}-01 \quad 5.85 \mathrm{E}-01$

6.11E-01 6.10E-01 6.11E-01

$6.39 \mathrm{E}-01 \quad 6.38 \mathrm{E}-01 \quad 6.39 \mathrm{E}-01$

$6.60 \mathrm{E}-01 \quad 6.59 \mathrm{E}-01 \quad 6.60 \mathrm{E}-01$

$6.85 \mathrm{E}-01 \quad 6.85 \mathrm{E}-01 \quad 6.85 \mathrm{E}-01$

$7.13 \mathrm{E}-01 \quad 7.13 \mathrm{E}-01 \quad 7.13 \mathrm{E}-01$

$7.42 \mathrm{E}-01 \quad 7.40 \mathrm{E}-01 \quad 7.42 \mathrm{E}-01$

$7.68 \mathrm{E}-01 \quad 7.67 \mathrm{E}-01 \quad 7.68 \mathrm{E}-01$

$7.93 \mathrm{E}-01 \quad 7.93 \mathrm{E}-01 \quad 7.93 \mathrm{E}-01$

$8.37 \mathrm{E}-01 \quad 8.36 \mathrm{E}-01 \quad 8.37 \mathrm{E}-01$

8.63E-01 8.63E-01 8.63E-01

$9.10 \mathrm{E}-01 \quad 9.09 \mathrm{E}-01 \quad 9.10 \mathrm{E}-01$

$9.46 \mathrm{E}-01 \quad 9.46 \mathrm{E}-01 \quad 9.46 \mathrm{E}-01$

$9.86 \mathrm{E}-01 \quad 9.86 \mathrm{E}-01 \quad 9.86 \mathrm{E}-01$

$1.03 \mathrm{E}+00 \quad 1.03 \mathrm{E}+00 \quad 1.03 \mathrm{E}+00$

$1.08 \mathrm{E}+00 \quad 1.08 \mathrm{E}+00 \quad 1.09 \mathrm{E}+00$

$1.15 \mathrm{E}+00 \quad 1.15 \mathrm{E}+00 \quad 1.15 \mathrm{E}+00$

$1.24 \mathrm{E}+00 \quad 1.24 \mathrm{E}+00 \quad 1.24 \mathrm{E}+00$

$1.34 \mathrm{E}+00 \quad 1.34 \mathrm{E}+00 \quad 1.34 \mathrm{E}+00$

$1.46 \mathrm{E}+00 \quad 1.46 \mathrm{E}+00 \quad 1.46 \mathrm{E}+00$

$1.67 \mathrm{E}+00 \quad 1.67 \mathrm{E}+00 \quad 1.67 \mathrm{E}+00$

$1.89 \mathrm{E}+00 \quad 1.89 \mathrm{E}+00 \quad 1.89 \mathrm{E}+00$

0.990

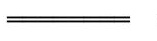

$.89 \mathrm{E}+00$ 
RESRAD-OFFSITE, Version 2.5

Probabilistic Dose and Risk Report

Title : Offsite Resident Farmer

File : RF TC99 DOESG FWD-FV2all.ROF

petition

Statistics and Cumulative distribution function of Peak Dose from External Ground(Cz\&Air) in mrem/yr

$\begin{array}{rcccc}\text { Repetition }= & 1 & 2 & 3 \\ \text { Mean } & 4.27 \mathrm{E}-25 & 4.28 \mathrm{E}-25 & 4.28 \mathrm{E}-25 \\ \text { Std. Dev. } & 0.00 \mathrm{E}+00 & 0.00 \mathrm{E}+00 & 0.00 \mathrm{E}+00 \\ \text { Minimum } & 1.80 \mathrm{E}-32 & 1.80 \mathrm{E}-32 & 1.80 \mathrm{E}-32 \\ \text { Maximum } & 1.29 \mathrm{E}-24 & 1.29 \mathrm{E}-24 & 1.29 \mathrm{E}-24\end{array}$

Percentile

0.010

3. $32 \mathrm{E}-30 \quad 3.32 \mathrm{E}-30 \quad 3.32 \mathrm{E}-30$

0.025

$1.74 \mathrm{E}-28 \quad 1.74 \mathrm{E}-28 \quad 1.69 \mathrm{E}-28$

0.050

$2.01 \mathrm{E}-27 \quad 2.01 \mathrm{E}-27 \quad 1.97 \mathrm{E}-27$

0.075

$5.16 \mathrm{E}-27 \quad 5.16 \mathrm{E}-27 \quad 5.08 \mathrm{E}-27$

0.100

$1.05 \mathrm{E}-26 \quad 1.05 \mathrm{E}-26 \quad 1.05 \mathrm{E}-26$

0.125

$1.82 \mathrm{E}-26 \quad 1.84 \mathrm{E}-26 \quad 1.83 \mathrm{E}-26$

0.150

$2.80 \mathrm{E}-26 \quad 2.83 \mathrm{E}-26 \quad 2.81 \mathrm{E}-26$

0.175

4.39E-26 4.48E-26 4.48E-26

$6.28 \mathrm{E}-26 \quad 6.36 \mathrm{E}-26 \quad 6.36 \mathrm{E}-26$

$7.90 \mathrm{E}-26 \quad 7.94 \mathrm{E}-26 \quad 7.94 \mathrm{E}-26$

$9.66 \mathrm{E}-26 \quad 9.79 \mathrm{E}-26 \quad 9.79 \mathrm{E}-26$

$1.20 \mathrm{E}-25 \quad 1.21 \mathrm{E}-25 \quad 1.21 \mathrm{E}-25$

1.43E-25 1.44E-25 1.43E-25

$1.74 \mathrm{E}-25 \quad 1.75 \mathrm{E}-25 \quad 1.75 \mathrm{E}-25$

$2.01 \mathrm{E}-25 \quad 2.02 \mathrm{E}-25 \quad 2.02 \mathrm{E}-25$

$2.29 \mathrm{E}-25 \quad 2.32 \mathrm{E}-25 \quad 2.30 \mathrm{E}-25$

$2.60 \mathrm{E}-25 \quad 2.62 \mathrm{E}-25 \quad 2.61 \mathrm{E}-25$

$2.93 E-25 \quad 2.94 E-25 \quad 2.94 E-25$

$3.25 \mathrm{E}-25 \quad 3.26 \mathrm{E}-25 \quad 3.26 \mathrm{E}-25$

$3.52 \mathrm{E}-25 \quad 3.53 \mathrm{E}-25 \quad 3.52 \mathrm{E}-25$

$3.84 \mathrm{E}-25 \quad 3.85 \mathrm{E}-25 \quad 3.84 \mathrm{E}-25$

$4.27 \mathrm{E}-25 \quad 4.28 \mathrm{E}-25 \quad 4.28 \mathrm{E}-25$

4.61E-25 4.61E-25 4.61E-25

4.92E-25 4.94E-25 4.94E-25

$5.20 \mathrm{E}-25 \quad 5.21 \mathrm{E}-25 \quad 5.20 \mathrm{E}-25$

$5.53 \mathrm{E}-25 \quad 5.54 \mathrm{E}-25 \quad 5.53 \mathrm{E}-25$

$5.72 \mathrm{E}-25 \quad 5.73 \mathrm{E}-25 \quad 5.73 \mathrm{E}-25$

$6.02 \mathrm{E}-25 \quad 6.02 \mathrm{E}-25 \quad 6.02 \mathrm{E}-25$

$6.31 \mathrm{E}-25 \quad 6.31 \mathrm{E}-25 \quad 6.31 \mathrm{E}-25$

$6.71 \mathrm{E}-25 \quad 6.71 \mathrm{E}-25 \quad 6.71 \mathrm{E}-25$

$7.05 \mathrm{E}-25 \quad 7.06 \mathrm{E}-25 \quad 7.06 \mathrm{E}-25$

$7.40 \mathrm{E}-25 \quad 7.41 \mathrm{E}-25 \quad 7.42 \mathrm{E}-25$

$7.82 \mathrm{E}-25 \quad 7.82 \mathrm{E}-25 \quad 7.82 \mathrm{E}-25$

$8.08 \mathrm{E}-25 \quad 8.08 \mathrm{E}-25 \quad 8.09 \mathrm{E}-25$

$8.42 \mathrm{E}-25 \quad 8.43 \mathrm{E}-25 \quad 8.43 \mathrm{E}-25$

$8.82 \mathrm{E}-25 \quad 8.82 \mathrm{E}-25 \quad 8.82 \mathrm{E}-25$

$9.18 \mathrm{E}-25 \quad 9.18 \mathrm{E}-25 \quad 9.18 \mathrm{E}-25$

$9.62 \mathrm{E}-25 \quad 9.62 \mathrm{E}-25 \quad 9.62 \mathrm{E}-25$

$1.02 \mathrm{E}-24 \quad 1.02 \mathrm{E}-24 \quad 1.02 \mathrm{E}-24$

$1.07 \mathrm{E}-24 \quad 1.07 \mathrm{E}-24 \quad 1.07 \mathrm{E}-24$

$1.14 \mathrm{E}-24 \quad 1.14 \mathrm{E}-24 \quad 1.14 \mathrm{E}-24$ 
RESRAD-OFFSITE, Version 2.5

Probabilistic Dose and Risk Report

Title : Offsite Resident Farmer

File : RF TC99 DOESG FWD-FV2all.ROF

Statistics and Cumulative distribution function of Peak Dose from Inhalation ExcludingRn in mrem/yr

$\begin{array}{rcccc}\text { Repetition }= & 1 & 2 & 3 \\ \text { Mean } & 0.00 \mathrm{E}+00 & 0.00 \mathrm{E}+00 & 0.00 \mathrm{E}+00 \\ \text { Std. Dev. } & 0.00 \mathrm{E}+00 & 0.00 \mathrm{E}+00 & 0.00 \mathrm{E}+00 \\ \text { Minimum } & 0.00 \mathrm{E}+00 & 0.00 \mathrm{E}+00 & 0.00 \mathrm{E}+00 \\ \text { Maximum } & 0.00 \mathrm{E}+00 & 0.00 \mathrm{E}+00 & 0.00 \mathrm{E}+00\end{array}$

Percentile

$\begin{array}{llll}0.010 & 0.00 \mathrm{E}+00 & 0.00 \mathrm{E}+00 & 0.00 \mathrm{E}+00\end{array}$

$\begin{array}{llll}0.025 & 0.00 \mathrm{E}+00 & 0.00 \mathrm{E}+00 & 0.00 \mathrm{E}+00\end{array}$

$\begin{array}{lllll}0.050 & 0.00 \mathrm{E}+00 & 0.00 \mathrm{E}+00 & 0.00 \mathrm{E}+00\end{array}$

$\begin{array}{llll}0.075 & 0.00 \mathrm{E}+00 & 0.00 \mathrm{E}+00 & 0.00 \mathrm{E}+00\end{array}$

$\begin{array}{llll}0.100 & 0.00 \mathrm{E}+00 & 0.00 \mathrm{E}+00 & 0.00 \mathrm{E}+00\end{array}$

$\begin{array}{llll}0.125 & 0.00 \mathrm{E}+00 & 0.00 \mathrm{E}+00 & 0.00 \mathrm{E}+00\end{array}$

$\begin{array}{llll}0.150 & 0.00 \mathrm{E}+00 & 0.00 \mathrm{E}+00 & 0.00 \mathrm{E}+00\end{array}$

$\begin{array}{llll}0.175 & 0.00 \mathrm{E}+00 & 0.00 \mathrm{E}+00 & 0.00 \mathrm{E}+00\end{array}$

$\begin{array}{llll}0.200 & 0.00 \mathrm{E}+00 & 0.00 \mathrm{E}+00 & 0.00 \mathrm{E}+00\end{array}$

$\begin{array}{lllll}0.225 & 0.00 \mathrm{E}+00 & 0.00 \mathrm{E}+00 & 0.00 \mathrm{E}+00\end{array}$

$\begin{array}{llll}0.250 & 0.00 \mathrm{E}+00 & 0.00 \mathrm{E}+00 & 0.00 \mathrm{E}+00\end{array}$

$\begin{array}{llll}0.275 & 0.00 \mathrm{E}+00 & 0.00 \mathrm{E}+00 & 0.00 \mathrm{E}+00\end{array}$

$\begin{array}{lllll}0.300 & 0.00 \mathrm{E}+00 & 0.00 \mathrm{E}+00 & 0.00 \mathrm{E}+00\end{array}$

$\begin{array}{lllll}0.325 & 0.00 \mathrm{E}+00 & 0.00 \mathrm{E}+00 & 0.00 \mathrm{E}+00\end{array}$

$\begin{array}{lllll}0.350 & 0.00 \mathrm{E}+00 & 0.00 \mathrm{E}+00 & 0.00 \mathrm{E}+00\end{array}$

$\begin{array}{lllll}0.375 & 0.00 \mathrm{E}+00 & 0.00 \mathrm{E}+00 & 0.00 \mathrm{E}+00\end{array}$

$\begin{array}{lllll}0.400 & 0.00 \mathrm{E}+00 & 0.00 \mathrm{E}+00 & 0.00 \mathrm{E}+00\end{array}$

$\begin{array}{lllll}0.425 & 0.00 \mathrm{E}+00 & 0.00 \mathrm{E}+00 & 0.00 \mathrm{E}+00\end{array}$

$\begin{array}{lllll}0.450 & 0.00 \mathrm{E}+00 & 0.00 \mathrm{E}+00 & 0.00 \mathrm{E}+00\end{array}$

$\begin{array}{lllll}0.475 & 0.00 \mathrm{E}+00 & 0.00 \mathrm{E}+00 & 0.00 \mathrm{E}+00\end{array}$

$\begin{array}{lllll}0.500 & 0.00 \mathrm{E}+00 & 0.00 \mathrm{E}+00 & 0.00 \mathrm{E}+00\end{array}$

$\begin{array}{lllll}0.525 & 0.00 \mathrm{E}+00 & 0.00 \mathrm{E}+00 & 0.00 \mathrm{E}+00\end{array}$

$\begin{array}{lllll}0.550 & 0.00 \mathrm{E}+00 & 0.00 \mathrm{E}+00 & 0.00 \mathrm{E}+00\end{array}$

$\begin{array}{lllll}0.575 & 0.00 \mathrm{E}+00 & 0.00 \mathrm{E}+00 & 0.00 \mathrm{E}+00\end{array}$

$\begin{array}{lllll}0.600 & 0.00 \mathrm{E}+00 & 0.00 \mathrm{E}+00 & 0.00 \mathrm{E}+00\end{array}$

$\begin{array}{lllll}0.625 & 0.00 \mathrm{E}+00 & 0.00 \mathrm{E}+00 & 0.00 \mathrm{E}+00\end{array}$

$\begin{array}{lllll}0.650 & 0.00 \mathrm{E}+00 & 0.00 \mathrm{E}+00 & 0.00 \mathrm{E}+00\end{array}$

$\begin{array}{lllll}0.675 & 0.00 \mathrm{E}+00 & 0.00 \mathrm{E}+00 & 0.00 \mathrm{E}+00\end{array}$

$\begin{array}{lllll}0.700 & 0.00 \mathrm{E}+00 & 0.00 \mathrm{E}+00 & 0.00 \mathrm{E}+00\end{array}$

$\begin{array}{lllll}0.725 & 0.00 \mathrm{E}+00 & 0.00 \mathrm{E}+00 & 0.00 \mathrm{E}+00\end{array}$

$\begin{array}{lllll}0.750 & 0.00 \mathrm{E}+00 & 0.00 \mathrm{E}+00 & 0.00 \mathrm{E}+00\end{array}$

$\begin{array}{llll}0.775 & 0.00 \mathrm{E}+00 & 0.00 \mathrm{E}+00 & 0.00 \mathrm{E}+00\end{array}$

$\begin{array}{lllll}0.800 & 0.00 \mathrm{E}+00 & 0.00 \mathrm{E}+00 & 0.00 \mathrm{E}+00\end{array}$

$\begin{array}{lllll}0.825 & 0.00 \mathrm{E}+00 & 0.00 \mathrm{E}+00 & 0.00 \mathrm{E}+00\end{array}$

$\begin{array}{lllll}0.850 & 0.00 \mathrm{E}+00 & 0.00 \mathrm{E}+00 & 0.00 \mathrm{E}+00\end{array}$

$\begin{array}{llll}0.875 & 0.00 \mathrm{E}+00 & 0.00 \mathrm{E}+00 & 0.00 \mathrm{E}+00\end{array}$

$\begin{array}{lllll}0.900 & 0.00 \mathrm{E}+00 & 0.00 \mathrm{E}+00 & 0.00 \mathrm{E}+00\end{array}$

$\begin{array}{llll}0.925 & 0.00 \mathrm{E}+00 & 0.00 \mathrm{E}+00 & 0.00 \mathrm{E}+00\end{array}$

$\begin{array}{lllll}0.950 & 0.00 \mathrm{E}+00 & 0.00 \mathrm{E}+00 & 0.00 \mathrm{E}+00\end{array}$

$\begin{array}{lllll}0.975 & 0.00 \mathrm{E}+00 & 0.00 \mathrm{E}+00 & 0.00 \mathrm{E}+00\end{array}$

$\begin{array}{lllll}0.990 & 0.00 \mathrm{E}+00 & 0.00 \mathrm{E}+00 & 0.00 \mathrm{E}+00\end{array}$ 
RESRAD-OFFSITE, Version 2.5

Probabilistic Dose and Risk Report

Title : Offsite Resident Farmer

File : RF TC99 DOESG FWD-FV2all.ROF

Statistics and Cumulative distribution function of Peak Dose from Radon (CZandAir) in mrem/yr

$\begin{array}{ccccc}\text { Repetition }= & 1 & 2 & 3 \\ \begin{array}{c}\text { Mean } \\ \text { Std. Dev. }\end{array} & 0.00 \mathrm{E}+00 & 0.00 \mathrm{E}+00 & 0.00 \mathrm{E}+00 \\ \text { Minimum } & 0.00 \mathrm{E}+00 & 0.00 \mathrm{E}+00 & 0.00 \mathrm{E}+00 \\ \text { Maximum } & 0.00 \mathrm{E}+00 & 0.00 \mathrm{E}+00 & 0.00 \mathrm{E}+00 \\ & 0.00 \mathrm{E}+00 & 0.00 \mathrm{E}+00 & 0.00 \mathrm{E}+00\end{array}$

Percentile

$\begin{array}{llll}0.010 & 0.00 \mathrm{E}+00 & 0.00 \mathrm{E}+00 & 0.00 \mathrm{E}+00\end{array}$

$\begin{array}{llll}0.025 & 0.00 \mathrm{E}+00 & 0.00 \mathrm{E}+00 & 0.00 \mathrm{E}+00\end{array}$

$\begin{array}{lllll}0.050 & 0.00 \mathrm{E}+00 & 0.00 \mathrm{E}+00 & 0.00 \mathrm{E}+00\end{array}$

$\begin{array}{llll}0.075 & 0.00 \mathrm{E}+00 & 0.00 \mathrm{E}+00 & 0.00 \mathrm{E}+00\end{array}$

$\begin{array}{llll}0.100 & 0.00 \mathrm{E}+00 & 0.00 \mathrm{E}+00 & 0.00 \mathrm{E}+00\end{array}$

$\begin{array}{llll}0.125 & 0.00 \mathrm{E}+00 & 0.00 \mathrm{E}+00 & 0.00 \mathrm{E}+00\end{array}$

$\begin{array}{llll}0.150 & 0.00 \mathrm{E}+00 & 0.00 \mathrm{E}+00 & 0.00 \mathrm{E}+00\end{array}$

$\begin{array}{llll}0.175 & 0.00 \mathrm{E}+00 & 0.00 \mathrm{E}+00 & 0.00 \mathrm{E}+00\end{array}$

$\begin{array}{llll}0.200 & 0.00 \mathrm{E}+00 & 0.00 \mathrm{E}+00 & 0.00 \mathrm{E}+00\end{array}$

$\begin{array}{lllll}0.225 & 0.00 \mathrm{E}+00 & 0.00 \mathrm{E}+00 & 0.00 \mathrm{E}+00\end{array}$

$\begin{array}{llll}0.250 & 0.00 \mathrm{E}+00 & 0.00 \mathrm{E}+00 & 0.00 \mathrm{E}+00\end{array}$

$\begin{array}{llll}0.275 & 0.00 \mathrm{E}+00 & 0.00 \mathrm{E}+00 & 0.00 \mathrm{E}+00\end{array}$

$\begin{array}{lllll}0.300 & 0.00 \mathrm{E}+00 & 0.00 \mathrm{E}+00 & 0.00 \mathrm{E}+00\end{array}$

$\begin{array}{lllll}0.325 & 0.00 \mathrm{E}+00 & 0.00 \mathrm{E}+00 & 0.00 \mathrm{E}+00\end{array}$

$\begin{array}{lllll}0.350 & 0.00 \mathrm{E}+00 & 0.00 \mathrm{E}+00 & 0.00 \mathrm{E}+00\end{array}$

$\begin{array}{lllll}0.375 & 0.00 \mathrm{E}+00 & 0.00 \mathrm{E}+00 & 0.00 \mathrm{E}+00\end{array}$

$\begin{array}{lllll}0.400 & 0.00 \mathrm{E}+00 & 0.00 \mathrm{E}+00 & 0.00 \mathrm{E}+00\end{array}$

$\begin{array}{lllll}0.425 & 0.00 \mathrm{E}+00 & 0.00 \mathrm{E}+00 & 0.00 \mathrm{E}+00\end{array}$

$\begin{array}{lllll}0.450 & 0.00 \mathrm{E}+00 & 0.00 \mathrm{E}+00 & 0.00 \mathrm{E}+00\end{array}$

$\begin{array}{lllll}0.475 & 0.00 \mathrm{E}+00 & 0.00 \mathrm{E}+00 & 0.00 \mathrm{E}+00\end{array}$

$\begin{array}{lllll}0.500 & 0.00 \mathrm{E}+00 & 0.00 \mathrm{E}+00 & 0.00 \mathrm{E}+00\end{array}$

$\begin{array}{lllll}0.525 & 0.00 \mathrm{E}+00 & 0.00 \mathrm{E}+00 & 0.00 \mathrm{E}+00\end{array}$

$\begin{array}{llll}0.550 & 0.00 \mathrm{E}+00 & 0.00 \mathrm{E}+00 & 0.00 \mathrm{E}+00\end{array}$

$\begin{array}{lllll}0.575 & 0.00 \mathrm{E}+00 & 0.00 \mathrm{E}+00 & 0.00 \mathrm{E}+00\end{array}$

$\begin{array}{lllll}0.600 & 0.00 \mathrm{E}+00 & 0.00 \mathrm{E}+00 & 0.00 \mathrm{E}+00\end{array}$

$\begin{array}{lllll}0.625 & 0.00 \mathrm{E}+00 & 0.00 \mathrm{E}+00 & 0.00 \mathrm{E}+00\end{array}$

$\begin{array}{lllll}0.650 & 0.00 \mathrm{E}+00 & 0.00 \mathrm{E}+00 & 0.00 \mathrm{E}+00\end{array}$

$\begin{array}{lllll}0.675 & 0.00 \mathrm{E}+00 & 0.00 \mathrm{E}+00 & 0.00 \mathrm{E}+00\end{array}$

$\begin{array}{lllll}0.700 & 0.00 \mathrm{E}+00 & 0.00 \mathrm{E}+00 & 0.00 \mathrm{E}+00\end{array}$

$\begin{array}{lllll}0.725 & 0.00 \mathrm{E}+00 & 0.00 \mathrm{E}+00 & 0.00 \mathrm{E}+00\end{array}$

$\begin{array}{lllll}0.750 & 0.00 \mathrm{E}+00 & 0.00 \mathrm{E}+00 & 0.00 \mathrm{E}+00\end{array}$

$\begin{array}{lllll}0.775 & 0.00 \mathrm{E}+00 & 0.00 \mathrm{E}+00 & 0.00 \mathrm{E}+00\end{array}$

$\begin{array}{lllll}0.800 & 0.00 \mathrm{E}+00 & 0.00 \mathrm{E}+00 & 0.00 \mathrm{E}+00\end{array}$

$\begin{array}{lllll}0.825 & 0.00 \mathrm{E}+00 & 0.00 \mathrm{E}+00 & 0.00 \mathrm{E}+00\end{array}$

$\begin{array}{lllll}0.850 & 0.00 \mathrm{E}+00 & 0.00 \mathrm{E}+00 & 0.00 \mathrm{E}+00\end{array}$

$\begin{array}{llll}0.875 & 0.00 \mathrm{E}+00 & 0.00 \mathrm{E}+00 & 0.00 \mathrm{E}+00\end{array}$

$\begin{array}{lllll}0.900 & 0.00 \mathrm{E}+00 & 0.00 \mathrm{E}+00 & 0.00 \mathrm{E}+00\end{array}$

$\begin{array}{llll}0.925 & 0.00 \mathrm{E}+00 & 0.00 \mathrm{E}+00 & 0.00 \mathrm{E}+00\end{array}$

$\begin{array}{lllll}0.950 & 0.00 \mathrm{E}+00 & 0.00 \mathrm{E}+00 & 0.00 \mathrm{E}+00\end{array}$

$\begin{array}{lllll}0.975 & 0.00 \mathrm{E}+00 & 0.00 \mathrm{E}+00 & 0.00 \mathrm{E}+00\end{array}$

$\begin{array}{lllll}0.990 & 0.00 \mathrm{E}+00 & 0.00 \mathrm{E}+00 & 0.00 \mathrm{E}+00\end{array}$ 
RESRAD-OFFSITE, Version 2.5

Probabilistic Dose and Risk Report

Title : Offsite Resident Farmer

File : RF TC99 DOESG FWD-FV2all.ROF

Statistics and Cumulative distribution function of Peak Dose from Plant (CzandAir) in mrem/yr

$\begin{array}{ccccc}\text { Repetition }= & 1 & 2 & 3 \\ \begin{array}{c}\text { Mean } \\ \text { Std. Dev. }\end{array} & 0.00 \mathrm{E}+00 & 0.00 \mathrm{E}+00 & 0.00 \mathrm{E}+00 \\ \text { Minimum } & 0.00 \mathrm{E}+00 & 0.00 \mathrm{E}+00 & 0.00 \mathrm{E}+00 \\ \text { Maximum } & 0.00 \mathrm{E}+00 & 0.00 \mathrm{E}+00 & 0.00 \mathrm{E}+00 \\ & 0.00 \mathrm{E}+00 & 0.00 \mathrm{E}+00 & 0.00 \mathrm{E}+00\end{array}$

Percentile

$\begin{array}{llll}0.010 & 0.00 \mathrm{E}+00 & 0.00 \mathrm{E}+00 & 0.00 \mathrm{E}+00\end{array}$

$\begin{array}{llll}0.025 & 0.00 \mathrm{E}+00 & 0.00 \mathrm{E}+00 & 0.00 \mathrm{E}+00\end{array}$

$\begin{array}{lllll}0.050 & 0.00 \mathrm{E}+00 & 0.00 \mathrm{E}+00 & 0.00 \mathrm{E}+00\end{array}$

$\begin{array}{llll}0.075 & 0.00 \mathrm{E}+00 & 0.00 \mathrm{E}+00 & 0.00 \mathrm{E}+00\end{array}$

$\begin{array}{llll}0.100 & 0.00 \mathrm{E}+00 & 0.00 \mathrm{E}+00 & 0.00 \mathrm{E}+00\end{array}$

$\begin{array}{llll}0.125 & 0.00 \mathrm{E}+00 & 0.00 \mathrm{E}+00 & 0.00 \mathrm{E}+00\end{array}$

$\begin{array}{llll}0.150 & 0.00 \mathrm{E}+00 & 0.00 \mathrm{E}+00 & 0.00 \mathrm{E}+00\end{array}$

$\begin{array}{llll}0.175 & 0.00 \mathrm{E}+00 & 0.00 \mathrm{E}+00 & 0.00 \mathrm{E}+00\end{array}$

$\begin{array}{llll}0.200 & 0.00 \mathrm{E}+00 & 0.00 \mathrm{E}+00 & 0.00 \mathrm{E}+00\end{array}$

$\begin{array}{lllll}0.225 & 0.00 \mathrm{E}+00 & 0.00 \mathrm{E}+00 & 0.00 \mathrm{E}+00\end{array}$

$\begin{array}{llll}0.250 & 0.00 \mathrm{E}+00 & 0.00 \mathrm{E}+00 & 0.00 \mathrm{E}+00\end{array}$

$\begin{array}{llll}0.275 & 0.00 \mathrm{E}+00 & 0.00 \mathrm{E}+00 & 0.00 \mathrm{E}+00\end{array}$

$\begin{array}{lllll}0.300 & 0.00 \mathrm{E}+00 & 0.00 \mathrm{E}+00 & 0.00 \mathrm{E}+00\end{array}$

$\begin{array}{lllll}0.325 & 0.00 \mathrm{E}+00 & 0.00 \mathrm{E}+00 & 0.00 \mathrm{E}+00\end{array}$

$\begin{array}{lllll}0.350 & 0.00 \mathrm{E}+00 & 0.00 \mathrm{E}+00 & 0.00 \mathrm{E}+00\end{array}$

$\begin{array}{lllll}0.375 & 0.00 \mathrm{E}+00 & 0.00 \mathrm{E}+00 & 0.00 \mathrm{E}+00\end{array}$

$\begin{array}{lllll}0.400 & 0.00 \mathrm{E}+00 & 0.00 \mathrm{E}+00 & 0.00 \mathrm{E}+00\end{array}$

$\begin{array}{lllll}0.425 & 0.00 \mathrm{E}+00 & 0.00 \mathrm{E}+00 & 0.00 \mathrm{E}+00\end{array}$

$\begin{array}{lllll}0.450 & 0.00 \mathrm{E}+00 & 0.00 \mathrm{E}+00 & 0.00 \mathrm{E}+00\end{array}$

$\begin{array}{lllll}0.475 & 0.00 \mathrm{E}+00 & 0.00 \mathrm{E}+00 & 0.00 \mathrm{E}+00\end{array}$

$\begin{array}{lllll}0.500 & 0.00 \mathrm{E}+00 & 0.00 \mathrm{E}+00 & 0.00 \mathrm{E}+00\end{array}$

$\begin{array}{lllll}0.525 & 0.00 \mathrm{E}+00 & 0.00 \mathrm{E}+00 & 0.00 \mathrm{E}+00\end{array}$

$\begin{array}{llll}0.550 & 0.00 \mathrm{E}+00 & 0.00 \mathrm{E}+00 & 0.00 \mathrm{E}+00\end{array}$

$\begin{array}{lllll}0.575 & 0.00 \mathrm{E}+00 & 0.00 \mathrm{E}+00 & 0.00 \mathrm{E}+00\end{array}$

$\begin{array}{lllll}0.600 & 0.00 \mathrm{E}+00 & 0.00 \mathrm{E}+00 & 0.00 \mathrm{E}+00\end{array}$

$\begin{array}{lllll}0.625 & 0.00 \mathrm{E}+00 & 0.00 \mathrm{E}+00 & 0.00 \mathrm{E}+00\end{array}$

$\begin{array}{lllll}0.650 & 0.00 \mathrm{E}+00 & 0.00 \mathrm{E}+00 & 0.00 \mathrm{E}+00\end{array}$

$\begin{array}{lllll}0.675 & 0.00 \mathrm{E}+00 & 0.00 \mathrm{E}+00 & 0.00 \mathrm{E}+00\end{array}$

$\begin{array}{lllll}0.700 & 0.00 \mathrm{E}+00 & 0.00 \mathrm{E}+00 & 0.00 \mathrm{E}+00\end{array}$

$\begin{array}{lllll}0.725 & 0.00 \mathrm{E}+00 & 0.00 \mathrm{E}+00 & 0.00 \mathrm{E}+00\end{array}$

$\begin{array}{lllll}0.750 & 0.00 \mathrm{E}+00 & 0.00 \mathrm{E}+00 & 0.00 \mathrm{E}+00\end{array}$

$\begin{array}{lllll}0.775 & 0.00 \mathrm{E}+00 & 0.00 \mathrm{E}+00 & 0.00 \mathrm{E}+00\end{array}$

$\begin{array}{lllll}0.800 & 0.00 \mathrm{E}+00 & 0.00 \mathrm{E}+00 & 0.00 \mathrm{E}+00\end{array}$

$\begin{array}{lllll}0.825 & 0.00 \mathrm{E}+00 & 0.00 \mathrm{E}+00 & 0.00 \mathrm{E}+00\end{array}$

$\begin{array}{lllll}0.850 & 0.00 \mathrm{E}+00 & 0.00 \mathrm{E}+00 & 0.00 \mathrm{E}+00\end{array}$

$\begin{array}{llll}0.875 & 0.00 \mathrm{E}+00 & 0.00 \mathrm{E}+00 & 0.00 \mathrm{E}+00\end{array}$

$\begin{array}{lllll}0.900 & 0.00 \mathrm{E}+00 & 0.00 \mathrm{E}+00 & 0.00 \mathrm{E}+00\end{array}$

$\begin{array}{llll}0.925 & 0.00 \mathrm{E}+00 & 0.00 \mathrm{E}+00 & 0.00 \mathrm{E}+00\end{array}$

$\begin{array}{lllll}0.950 & 0.00 \mathrm{E}+00 & 0.00 \mathrm{E}+00 & 0.00 \mathrm{E}+00\end{array}$

$\begin{array}{lllll}0.975 & 0.00 \mathrm{E}+00 & 0.00 \mathrm{E}+00 & 0.00 \mathrm{E}+00\end{array}$

$\begin{array}{lllll}0.990 & 0.00 \mathrm{E}+00 & 0.00 \mathrm{E}+00 & 0.00 \mathrm{E}+00\end{array}$ 
RESRAD-OFFSITE, Version 2.5

Probabilistic Dose and Risk Report

Title : Offsite Resident Farmer

File : RF TC99 DOESG FWD-FV2all.ROF

Statistics and Cumulative distribution function of Peak Dose from Meat (CZandAir) in mrem/yr

$\begin{array}{ccccc}\text { Repetition }= & 1 & 2 & 3 \\ \begin{array}{c}\text { Mean } \\ \text { Std. Dev. }\end{array} & 0.00 \mathrm{E}+00 & 0.00 \mathrm{E}+00 & 0.00 \mathrm{E}+00 \\ \text { Minimum } & 0.00 \mathrm{E}+00 & 0.00 \mathrm{E}+00 & 0.00 \mathrm{E}+00 \\ \text { Maximum } & 0.00 \mathrm{E}+00 & 0.00 \mathrm{E}+00 & 0.00 \mathrm{E}+00 \\ & 0.00 \mathrm{E}+00 & 0.00 \mathrm{E}+00 & 0.00 \mathrm{E}+00\end{array}$

Percentile

$\begin{array}{llll}0.010 & 0.00 \mathrm{E}+00 & 0.00 \mathrm{E}+00 & 0.00 \mathrm{E}+00\end{array}$

$\begin{array}{llll}0.025 & 0.00 \mathrm{E}+00 & 0.00 \mathrm{E}+00 & 0.00 \mathrm{E}+00\end{array}$

$\begin{array}{lllll}0.050 & 0.00 \mathrm{E}+00 & 0.00 \mathrm{E}+00 & 0.00 \mathrm{E}+00\end{array}$

$\begin{array}{llll}0.075 & 0.00 \mathrm{E}+00 & 0.00 \mathrm{E}+00 & 0.00 \mathrm{E}+00\end{array}$

$\begin{array}{llll}0.100 & 0.00 \mathrm{E}+00 & 0.00 \mathrm{E}+00 & 0.00 \mathrm{E}+00\end{array}$

$\begin{array}{llll}0.125 & 0.00 \mathrm{E}+00 & 0.00 \mathrm{E}+00 & 0.00 \mathrm{E}+00\end{array}$

$\begin{array}{llll}0.150 & 0.00 \mathrm{E}+00 & 0.00 \mathrm{E}+00 & 0.00 \mathrm{E}+00\end{array}$

$\begin{array}{llll}0.175 & 0.00 \mathrm{E}+00 & 0.00 \mathrm{E}+00 & 0.00 \mathrm{E}+00\end{array}$

$\begin{array}{llll}0.200 & 0.00 \mathrm{E}+00 & 0.00 \mathrm{E}+00 & 0.00 \mathrm{E}+00\end{array}$

$\begin{array}{lllll}0.225 & 0.00 \mathrm{E}+00 & 0.00 \mathrm{E}+00 & 0.00 \mathrm{E}+00\end{array}$

$\begin{array}{llll}0.250 & 0.00 \mathrm{E}+00 & 0.00 \mathrm{E}+00 & 0.00 \mathrm{E}+00\end{array}$

$\begin{array}{llll}0.275 & 0.00 \mathrm{E}+00 & 0.00 \mathrm{E}+00 & 0.00 \mathrm{E}+00\end{array}$

$\begin{array}{lllll}0.300 & 0.00 \mathrm{E}+00 & 0.00 \mathrm{E}+00 & 0.00 \mathrm{E}+00\end{array}$

$\begin{array}{lllll}0.325 & 0.00 \mathrm{E}+00 & 0.00 \mathrm{E}+00 & 0.00 \mathrm{E}+00\end{array}$

$\begin{array}{lllll}0.350 & 0.00 \mathrm{E}+00 & 0.00 \mathrm{E}+00 & 0.00 \mathrm{E}+00\end{array}$

$\begin{array}{lllll}0.375 & 0.00 \mathrm{E}+00 & 0.00 \mathrm{E}+00 & 0.00 \mathrm{E}+00\end{array}$

$\begin{array}{lllll}0.400 & 0.00 \mathrm{E}+00 & 0.00 \mathrm{E}+00 & 0.00 \mathrm{E}+00\end{array}$

$\begin{array}{lllll}0.425 & 0.00 \mathrm{E}+00 & 0.00 \mathrm{E}+00 & 0.00 \mathrm{E}+00\end{array}$

$\begin{array}{lllll}0.450 & 0.00 \mathrm{E}+00 & 0.00 \mathrm{E}+00 & 0.00 \mathrm{E}+00\end{array}$

$\begin{array}{lllll}0.475 & 0.00 \mathrm{E}+00 & 0.00 \mathrm{E}+00 & 0.00 \mathrm{E}+00\end{array}$

$\begin{array}{lllll}0.500 & 0.00 \mathrm{E}+00 & 0.00 \mathrm{E}+00 & 0.00 \mathrm{E}+00\end{array}$

$\begin{array}{lllll}0.525 & 0.00 \mathrm{E}+00 & 0.00 \mathrm{E}+00 & 0.00 \mathrm{E}+00\end{array}$

$\begin{array}{lllll}0.550 & 0.00 \mathrm{E}+00 & 0.00 \mathrm{E}+00 & 0.00 \mathrm{E}+00\end{array}$

$\begin{array}{lllll}0.575 & 0.00 \mathrm{E}+00 & 0.00 \mathrm{E}+00 & 0.00 \mathrm{E}+00\end{array}$

$\begin{array}{lllll}0.600 & 0.00 \mathrm{E}+00 & 0.00 \mathrm{E}+00 & 0.00 \mathrm{E}+00\end{array}$

$\begin{array}{lllll}0.625 & 0.00 \mathrm{E}+00 & 0.00 \mathrm{E}+00 & 0.00 \mathrm{E}+00\end{array}$

$\begin{array}{lllll}0.650 & 0.00 \mathrm{E}+00 & 0.00 \mathrm{E}+00 & 0.00 \mathrm{E}+00\end{array}$

$\begin{array}{lllll}0.675 & 0.00 \mathrm{E}+00 & 0.00 \mathrm{E}+00 & 0.00 \mathrm{E}+00\end{array}$

$\begin{array}{lllll}0.700 & 0.00 \mathrm{E}+00 & 0.00 \mathrm{E}+00 & 0.00 \mathrm{E}+00\end{array}$

$\begin{array}{lllll}0.725 & 0.00 \mathrm{E}+00 & 0.00 \mathrm{E}+00 & 0.00 \mathrm{E}+00\end{array}$

$\begin{array}{lllll}0.750 & 0.00 \mathrm{E}+00 & 0.00 \mathrm{E}+00 & 0.00 \mathrm{E}+00\end{array}$

$\begin{array}{llll}0.775 & 0.00 \mathrm{E}+00 & 0.00 \mathrm{E}+00 & 0.00 \mathrm{E}+00\end{array}$

$\begin{array}{lllll}0.800 & 0.00 \mathrm{E}+00 & 0.00 \mathrm{E}+00 & 0.00 \mathrm{E}+00\end{array}$

$\begin{array}{lllll}0.825 & 0.00 \mathrm{E}+00 & 0.00 \mathrm{E}+00 & 0.00 \mathrm{E}+00\end{array}$

$\begin{array}{lllll}0.850 & 0.00 \mathrm{E}+00 & 0.00 \mathrm{E}+00 & 0.00 \mathrm{E}+00\end{array}$

$\begin{array}{llll}0.875 & 0.00 \mathrm{E}+00 & 0.00 \mathrm{E}+00 & 0.00 \mathrm{E}+00\end{array}$

$\begin{array}{lllll}0.900 & 0.00 \mathrm{E}+00 & 0.00 \mathrm{E}+00 & 0.00 \mathrm{E}+00\end{array}$

$\begin{array}{llll}0.925 & 0.00 \mathrm{E}+00 & 0.00 \mathrm{E}+00 & 0.00 \mathrm{E}+00\end{array}$

$\begin{array}{lllll}0.950 & 0.00 \mathrm{E}+00 & 0.00 \mathrm{E}+00 & 0.00 \mathrm{E}+00\end{array}$

$\begin{array}{lllll}0.975 & 0.00 \mathrm{E}+00 & 0.00 \mathrm{E}+00 & 0.00 \mathrm{E}+00\end{array}$

$\begin{array}{lllll}0.990 & 0.00 \mathrm{E}+00 & 0.00 \mathrm{E}+00 & 0.00 \mathrm{E}+00\end{array}$ 
RESRAD-OFFSITE, Version 2.5

Probabilistic Dose and Risk Report

Title : Offsite Resident Farmer

File : RF TC99 DOESG FWD-FV2all.ROF

Statistics and Cumulative distribution function of Peak Dose from Milk (CzandAir) in mrem/yr

$\begin{array}{ccccc}\text { Repetition }= & 1 & 2 & 3 \\ \begin{array}{c}\text { Mean } \\ \text { Std. Dev. }\end{array} & 0.00 \mathrm{E}+00 & 0.00 \mathrm{E}+00 & 0.00 \mathrm{E}+00 \\ \text { Minimum } & 0.00 \mathrm{E}+00 & 0.00 \mathrm{E}+00 & 0.00 \mathrm{E}+00 \\ \text { Maximum } & 0.00 \mathrm{E}+00 & 0.00 \mathrm{E}+00 & 0.00 \mathrm{E}+00 \\ & 0.00 \mathrm{E}+00 & 0.00 \mathrm{E}+00 & 0.00 \mathrm{E}+00\end{array}$

Percentile

$\begin{array}{llll}0.010 & 0.00 \mathrm{E}+00 & 0.00 \mathrm{E}+00 & 0.00 \mathrm{E}+00\end{array}$

$\begin{array}{llll}0.025 & 0.00 \mathrm{E}+00 & 0.00 \mathrm{E}+00 & 0.00 \mathrm{E}+00\end{array}$

$\begin{array}{lllll}0.050 & 0.00 \mathrm{E}+00 & 0.00 \mathrm{E}+00 & 0.00 \mathrm{E}+00\end{array}$

$\begin{array}{llll}0.075 & 0.00 \mathrm{E}+00 & 0.00 \mathrm{E}+00 & 0.00 \mathrm{E}+00\end{array}$

$\begin{array}{llll}0.100 & 0.00 \mathrm{E}+00 & 0.00 \mathrm{E}+00 & 0.00 \mathrm{E}+00\end{array}$

$\begin{array}{llll}0.125 & 0.00 \mathrm{E}+00 & 0.00 \mathrm{E}+00 & 0.00 \mathrm{E}+00\end{array}$

$\begin{array}{llll}0.150 & 0.00 \mathrm{E}+00 & 0.00 \mathrm{E}+00 & 0.00 \mathrm{E}+00\end{array}$

$\begin{array}{llll}0.175 & 0.00 \mathrm{E}+00 & 0.00 \mathrm{E}+00 & 0.00 \mathrm{E}+00\end{array}$

$\begin{array}{llll}0.200 & 0.00 \mathrm{E}+00 & 0.00 \mathrm{E}+00 & 0.00 \mathrm{E}+00\end{array}$

$\begin{array}{lllll}0.225 & 0.00 \mathrm{E}+00 & 0.00 \mathrm{E}+00 & 0.00 \mathrm{E}+00\end{array}$

$\begin{array}{llll}0.250 & 0.00 \mathrm{E}+00 & 0.00 \mathrm{E}+00 & 0.00 \mathrm{E}+00\end{array}$

$\begin{array}{llll}0.275 & 0.00 \mathrm{E}+00 & 0.00 \mathrm{E}+00 & 0.00 \mathrm{E}+00\end{array}$

$\begin{array}{lllll}0.300 & 0.00 \mathrm{E}+00 & 0.00 \mathrm{E}+00 & 0.00 \mathrm{E}+00\end{array}$

$\begin{array}{lllll}0.325 & 0.00 \mathrm{E}+00 & 0.00 \mathrm{E}+00 & 0.00 \mathrm{E}+00\end{array}$

$\begin{array}{lllll}0.350 & 0.00 \mathrm{E}+00 & 0.00 \mathrm{E}+00 & 0.00 \mathrm{E}+00\end{array}$

$\begin{array}{lllll}0.375 & 0.00 \mathrm{E}+00 & 0.00 \mathrm{E}+00 & 0.00 \mathrm{E}+00\end{array}$

$\begin{array}{lllll}0.400 & 0.00 \mathrm{E}+00 & 0.00 \mathrm{E}+00 & 0.00 \mathrm{E}+00\end{array}$

$\begin{array}{lllll}0.425 & 0.00 \mathrm{E}+00 & 0.00 \mathrm{E}+00 & 0.00 \mathrm{E}+00\end{array}$

$\begin{array}{lllll}0.450 & 0.00 \mathrm{E}+00 & 0.00 \mathrm{E}+00 & 0.00 \mathrm{E}+00\end{array}$

$\begin{array}{lllll}0.475 & 0.00 \mathrm{E}+00 & 0.00 \mathrm{E}+00 & 0.00 \mathrm{E}+00\end{array}$

$\begin{array}{lllll}0.500 & 0.00 \mathrm{E}+00 & 0.00 \mathrm{E}+00 & 0.00 \mathrm{E}+00\end{array}$

$\begin{array}{lllll}0.525 & 0.00 \mathrm{E}+00 & 0.00 \mathrm{E}+00 & 0.00 \mathrm{E}+00\end{array}$

$\begin{array}{lllll}0.550 & 0.00 \mathrm{E}+00 & 0.00 \mathrm{E}+00 & 0.00 \mathrm{E}+00\end{array}$

$\begin{array}{lllll}0.575 & 0.00 \mathrm{E}+00 & 0.00 \mathrm{E}+00 & 0.00 \mathrm{E}+00\end{array}$

$\begin{array}{lllll}0.600 & 0.00 \mathrm{E}+00 & 0.00 \mathrm{E}+00 & 0.00 \mathrm{E}+00\end{array}$

$\begin{array}{lllll}0.625 & 0.00 \mathrm{E}+00 & 0.00 \mathrm{E}+00 & 0.00 \mathrm{E}+00\end{array}$

$\begin{array}{lllll}0.650 & 0.00 \mathrm{E}+00 & 0.00 \mathrm{E}+00 & 0.00 \mathrm{E}+00\end{array}$

$\begin{array}{lllll}0.675 & 0.00 \mathrm{E}+00 & 0.00 \mathrm{E}+00 & 0.00 \mathrm{E}+00\end{array}$

$\begin{array}{lllll}0.700 & 0.00 \mathrm{E}+00 & 0.00 \mathrm{E}+00 & 0.00 \mathrm{E}+00\end{array}$

$\begin{array}{lllll}0.725 & 0.00 \mathrm{E}+00 & 0.00 \mathrm{E}+00 & 0.00 \mathrm{E}+00\end{array}$

$\begin{array}{lllll}0.750 & 0.00 \mathrm{E}+00 & 0.00 \mathrm{E}+00 & 0.00 \mathrm{E}+00\end{array}$

$\begin{array}{llll}0.775 & 0.00 \mathrm{E}+00 & 0.00 \mathrm{E}+00 & 0.00 \mathrm{E}+00\end{array}$

$\begin{array}{lllll}0.800 & 0.00 \mathrm{E}+00 & 0.00 \mathrm{E}+00 & 0.00 \mathrm{E}+00\end{array}$

$\begin{array}{lllll}0.825 & 0.00 \mathrm{E}+00 & 0.00 \mathrm{E}+00 & 0.00 \mathrm{E}+00\end{array}$

$\begin{array}{lllll}0.850 & 0.00 \mathrm{E}+00 & 0.00 \mathrm{E}+00 & 0.00 \mathrm{E}+00\end{array}$

$\begin{array}{llll}0.875 & 0.00 \mathrm{E}+00 & 0.00 \mathrm{E}+00 & 0.00 \mathrm{E}+00\end{array}$

$\begin{array}{lllll}0.900 & 0.00 \mathrm{E}+00 & 0.00 \mathrm{E}+00 & 0.00 \mathrm{E}+00\end{array}$

$\begin{array}{llll}0.925 & 0.00 \mathrm{E}+00 & 0.00 \mathrm{E}+00 & 0.00 \mathrm{E}+00\end{array}$

$\begin{array}{lllll}0.950 & 0.00 \mathrm{E}+00 & 0.00 \mathrm{E}+00 & 0.00 \mathrm{E}+00\end{array}$

$\begin{array}{lllll}0.975 & 0.00 \mathrm{E}+00 & 0.00 \mathrm{E}+00 & 0.00 \mathrm{E}+00\end{array}$

$\begin{array}{lllll}0.990 & 0.00 \mathrm{E}+00 & 0.00 \mathrm{E}+00 & 0.00 \mathrm{E}+00\end{array}$ 
RESRAD-OFFSITE, Version 2.5

Probabilistic Dose and Risk Report

Title : Offsite Resident Farmer

File : RF TC99 DOESG FWD-FV2all.ROF

Statistics and Cumulative distribution function of Peak Dose from Soil Ingestion(CZandAir) in mrem/yr

$\begin{array}{ccccc}\text { Repetition }= & 1 & 2 & 3 \\ \begin{array}{c}\text { Mean } \\ \text { Std. Dev. }\end{array} & 0.00 \mathrm{E}+00 & 0.00 \mathrm{E}+00 & 0.00 \mathrm{E}+00 \\ \text { Minimum } & 0.00 \mathrm{E}+00 & 0.00 \mathrm{E}+00 & 0.00 \mathrm{E}+00 \\ \text { Maximum } & 0.00 \mathrm{E}+00 & 0.00 \mathrm{E}+00 & 0.00 \mathrm{E}+00 \\ & 0.00 \mathrm{E}+00 & 0.00 \mathrm{E}+00 & 0.00 \mathrm{E}+00\end{array}$

Percentile

$\begin{array}{llll}0.010 & 0.00 \mathrm{E}+00 & 0.00 \mathrm{E}+00 & 0.00 \mathrm{E}+00\end{array}$

$\begin{array}{llll}0.025 & 0.00 \mathrm{E}+00 & 0.00 \mathrm{E}+00 & 0.00 \mathrm{E}+00\end{array}$

$\begin{array}{lllll}0.050 & 0.00 \mathrm{E}+00 & 0.00 \mathrm{E}+00 & 0.00 \mathrm{E}+00\end{array}$

$\begin{array}{lllll}0.075 & 0.00 \mathrm{E}+00 & 0.00 \mathrm{E}+00 & 0.00 \mathrm{E}+00\end{array}$

$\begin{array}{llll}0.100 & 0.00 \mathrm{E}+00 & 0.00 \mathrm{E}+00 & 0.00 \mathrm{E}+00\end{array}$

$\begin{array}{llll}0.125 & 0.00 \mathrm{E}+00 & 0.00 \mathrm{E}+00 & 0.00 \mathrm{E}+00\end{array}$

$\begin{array}{llll}0.150 & 0.00 \mathrm{E}+00 & 0.00 \mathrm{E}+00 & 0.00 \mathrm{E}+00\end{array}$

$\begin{array}{llll}0.175 & 0.00 \mathrm{E}+00 & 0.00 \mathrm{E}+00 & 0.00 \mathrm{E}+00\end{array}$

$\begin{array}{llll}0.200 & 0.00 \mathrm{E}+00 & 0.00 \mathrm{E}+00 & 0.00 \mathrm{E}+00\end{array}$

$\begin{array}{lllll}0.225 & 0.00 \mathrm{E}+00 & 0.00 \mathrm{E}+00 & 0.00 \mathrm{E}+00\end{array}$

$\begin{array}{llll}0.250 & 0.00 \mathrm{E}+00 & 0.00 \mathrm{E}+00 & 0.00 \mathrm{E}+00\end{array}$

$\begin{array}{llll}0.275 & 0.00 \mathrm{E}+00 & 0.00 \mathrm{E}+00 & 0.00 \mathrm{E}+00\end{array}$

$\begin{array}{lllll}0.300 & 0.00 \mathrm{E}+00 & 0.00 \mathrm{E}+00 & 0.00 \mathrm{E}+00\end{array}$

$\begin{array}{lllll}0.325 & 0.00 \mathrm{E}+00 & 0.00 \mathrm{E}+00 & 0.00 \mathrm{E}+00\end{array}$

$\begin{array}{lllll}0.350 & 0.00 \mathrm{E}+00 & 0.00 \mathrm{E}+00 & 0.00 \mathrm{E}+00\end{array}$

$\begin{array}{lllll}0.375 & 0.00 \mathrm{E}+00 & 0.00 \mathrm{E}+00 & 0.00 \mathrm{E}+00\end{array}$

$\begin{array}{lllll}0.400 & 0.00 \mathrm{E}+00 & 0.00 \mathrm{E}+00 & 0.00 \mathrm{E}+00\end{array}$

$\begin{array}{lllll}0.425 & 0.00 \mathrm{E}+00 & 0.00 \mathrm{E}+00 & 0.00 \mathrm{E}+00\end{array}$

$\begin{array}{lllll}0.450 & 0.00 \mathrm{E}+00 & 0.00 \mathrm{E}+00 & 0.00 \mathrm{E}+00\end{array}$

$\begin{array}{lllll}0.475 & 0.00 \mathrm{E}+00 & 0.00 \mathrm{E}+00 & 0.00 \mathrm{E}+00\end{array}$

$\begin{array}{lllll}0.500 & 0.00 \mathrm{E}+00 & 0.00 \mathrm{E}+00 & 0.00 \mathrm{E}+00\end{array}$

$\begin{array}{lllll}0.525 & 0.00 \mathrm{E}+00 & 0.00 \mathrm{E}+00 & 0.00 \mathrm{E}+00\end{array}$

$\begin{array}{llll}0.550 & 0.00 \mathrm{E}+00 & 0.00 \mathrm{E}+00 & 0.00 \mathrm{E}+00\end{array}$

$\begin{array}{lllll}0.575 & 0.00 \mathrm{E}+00 & 0.00 \mathrm{E}+00 & 0.00 \mathrm{E}+00\end{array}$

$\begin{array}{lllll}0.600 & 0.00 \mathrm{E}+00 & 0.00 \mathrm{E}+00 & 0.00 \mathrm{E}+00\end{array}$

$\begin{array}{lllll}0.625 & 0.00 \mathrm{E}+00 & 0.00 \mathrm{E}+00 & 0.00 \mathrm{E}+00\end{array}$

$\begin{array}{lllll}0.650 & 0.00 \mathrm{E}+00 & 0.00 \mathrm{E}+00 & 0.00 \mathrm{E}+00\end{array}$

$\begin{array}{lllll}0.675 & 0.00 \mathrm{E}+00 & 0.00 \mathrm{E}+00 & 0.00 \mathrm{E}+00\end{array}$

$\begin{array}{lllll}0.700 & 0.00 \mathrm{E}+00 & 0.00 \mathrm{E}+00 & 0.00 \mathrm{E}+00\end{array}$

$\begin{array}{lllll}0.725 & 0.00 \mathrm{E}+00 & 0.00 \mathrm{E}+00 & 0.00 \mathrm{E}+00\end{array}$

$\begin{array}{lllll}0.750 & 0.00 \mathrm{E}+00 & 0.00 \mathrm{E}+00 & 0.00 \mathrm{E}+00\end{array}$

$\begin{array}{lllll}0.775 & 0.00 \mathrm{E}+00 & 0.00 \mathrm{E}+00 & 0.00 \mathrm{E}+00\end{array}$

$\begin{array}{lllll}0.800 & 0.00 \mathrm{E}+00 & 0.00 \mathrm{E}+00 & 0.00 \mathrm{E}+00\end{array}$

$\begin{array}{lllll}0.825 & 0.00 \mathrm{E}+00 & 0.00 \mathrm{E}+00 & 0.00 \mathrm{E}+00\end{array}$

$\begin{array}{lllll}0.850 & 0.00 \mathrm{E}+00 & 0.00 \mathrm{E}+00 & 0.00 \mathrm{E}+00\end{array}$

$\begin{array}{lllll}0.875 & 0.00 \mathrm{E}+00 & 0.00 \mathrm{E}+00 & 0.00 \mathrm{E}+00\end{array}$

$\begin{array}{lllll}0.900 & 0.00 \mathrm{E}+00 & 0.00 \mathrm{E}+00 & 0.00 \mathrm{E}+00\end{array}$

$\begin{array}{llll}0.925 & 0.00 \mathrm{E}+00 & 0.00 \mathrm{E}+00 & 0.00 \mathrm{E}+00\end{array}$

$\begin{array}{lllll}0.950 & 0.00 \mathrm{E}+00 & 0.00 \mathrm{E}+00 & 0.00 \mathrm{E}+00\end{array}$

$\begin{array}{lllll}0.975 & 0.00 \mathrm{E}+00 & 0.00 \mathrm{E}+00 & 0.00 \mathrm{E}+00\end{array}$

$\begin{array}{lllll}0.990 & 0.00 \mathrm{E}+00 & 0.00 \mathrm{E}+00 & 0.00 \mathrm{E}+00\end{array}$ 
RESRAD-OFFSITE, Version 2.5

Probabilistic Dose and Risk Report

Title : Offsite Resident Farmer

File : RF TC99 DOESG FWD-FV2all.ROF

petition $=$

Statistics and Cumulative distribution function of Peak Risk from All Pathways

\begin{tabular}{ccccc} 
Repetition $=$ & 1 & 2 & 3 \\
\cline { 5 - 5 } Mean & $3.21 \mathrm{E}-05$ & $3.21 \mathrm{E}-05$ & $3.21 \mathrm{E}-05$ \\
Std. Dev. & $1.89 \mathrm{E}-05$ & $1.89 \mathrm{E}-05$ & $1.89 \mathrm{E}-05$ \\
Minimum & $3.85 \mathrm{E}-06$ & $3.85 \mathrm{E}-06$ & $3.85 \mathrm{E}-06$ \\
Maximum & $1.46 \mathrm{E}-04$ & $1.46 \mathrm{E}-04$ & $1.46 \mathrm{E}-04$
\end{tabular}

Percentile

0.010

$6.15 \mathrm{E}-06 \quad 6.15 \mathrm{E}-06 \quad 6.15 \mathrm{E}-06$

0.025

7.22 $-06 \quad 7.22 \mathrm{E}-06 \quad 7.22 \mathrm{E}-06$

0.050

$9.22 \mathrm{E}-06 \quad 9.22 \mathrm{E}-06 \quad 9.22 \mathrm{E}-06$

0.075

$1.03 \mathrm{E}-05 \quad 1.03 \mathrm{E}-05 \quad 1.03 \mathrm{E}-05$

0.100

$1.17 \mathrm{E}-05 \quad 1.17 \mathrm{E}-05 \quad 1.17 \mathrm{E}-05$

0.125

$1.27 \mathrm{E}-05 \quad 1.27 \mathrm{E}-05 \quad 1.27 \mathrm{E}-05$

0.150

$1.36 \mathrm{E}-05 \quad 1.36 \mathrm{E}-05 \quad 1.36 \mathrm{E}-05$

0.175

$1.48 \mathrm{E}-05 \quad 1.48 \mathrm{E}-05 \quad 1.48 \mathrm{E}-05$

0.200

$1.57 \mathrm{E}-05 \quad 1.57 \mathrm{E}-05 \quad 1.57 \mathrm{E}-05$

0.225

$1.69 \mathrm{E}-05 \quad 1.69 \mathrm{E}-05 \quad 1.69 \mathrm{E}-05$

0.250

$1.77 \mathrm{E}-05 \quad 1.77 \mathrm{E}-05 \quad 1.77 \mathrm{E}-05$

0.275

$1.87 \mathrm{E}-05 \quad 1.87 \mathrm{E}-05 \quad 1.87 \mathrm{E}-05$

0.300

$1.97 \mathrm{E}-05 \quad 1.97 \mathrm{E}-05 \quad 1.97 \mathrm{E}-05$

0.325

2.08E-05 2.08E-05 2.08E-05

$2.20 E-05 \quad 2.20 E-05 \quad 2.20 E-05$

$2.32 E-05 \quad 2.32 E-05 \quad 2.32 E-05$

0.375

$2.40 E-05 \quad 2.40 E-05 \quad 2.40 E-05$

0.400

$2.51 \mathrm{E}-05 \quad 2.51 \mathrm{E}-05 \quad 2.51 \mathrm{E}-05$

$2.61 \mathrm{E}-05 \quad 2.61 \mathrm{E}-05 \quad 2.61 \mathrm{E}-05$

$2.73 \mathrm{E}-05 \quad 2.73 \mathrm{E}-05 \quad 2.73 \mathrm{E}-05$

$2.85 \mathrm{E}-05 \quad 2.85 \mathrm{E}-05 \quad 2.85 \mathrm{E}-05$

$2.98 \mathrm{E}-05 \quad 2.98 \mathrm{E}-05 \quad 2.99 \mathrm{E}-05$

$3.08 \mathrm{E}-05 \quad 3.08 \mathrm{E}-05 \quad 3.09 \mathrm{E}-05$

$3.20 \mathrm{E}-05 \quad 3.20 \mathrm{E}-05 \quad 3.20 \mathrm{E}-05$

3.33E-05 3.33E-05 3.33E-05

$3.47 \mathrm{E}-05 \quad 3.46 \mathrm{E}-05 \quad 3.47 \mathrm{E}-05$

$3.59 \mathrm{E}-05 \quad 3.59 \mathrm{E}-05 \quad 3.59 \mathrm{E}-05$

$3.71 \mathrm{E}-05 \quad 3.71 \mathrm{E}-05 \quad 3.71 \mathrm{E}-05$

$3.91 \mathrm{E}-05 \quad 3.91 \mathrm{E}-05 \quad 3.91 \mathrm{E}-05$

4.03E-05 4.03E-05 4.03E-05

4.26E-05 4.25E-05 4.26E-05

4.42E-05 4.42E-05 4.42E-05

4.61E-05 4.61E-05 4.61E-05

4.82E-05 4.82E-05 4.83E-05

$5.07 \mathrm{E}-05 \quad 5.07 \mathrm{E}-05 \quad 5.08 \mathrm{E}-05$

$5.37 \mathrm{E}-05 \quad 5.37 \mathrm{E}-05 \quad 5.38 \mathrm{E}-05$

$5.79 \mathrm{E}-05 \quad 5.79 \mathrm{E}-05 \quad 5.79 \mathrm{E}-05$

$6.28 \mathrm{E}-05 \quad 6.28 \mathrm{E}-05 \quad 6.28 \mathrm{E}-05$

$6.82 \mathrm{E}-05 \quad 6.82 \mathrm{E}-05 \quad 6.82 \mathrm{E}-05$

$7.82 \mathrm{E}-05 \quad 7.82 \mathrm{E}-05 \quad 7.82 \mathrm{E}-05$

8.82E-05 8.82E-05 8.82E-05 
RESRAD-OFFSITE, Version 2.5

$\mathrm{T}^{1} \frac{1}{2}$ Limit $=180$ days

robabilistic Dose and Risk Report

Title : Offsite Resident Farmer

File : RF TC99 DOESG FWD-FV2all.ROF

epetition =

Mean

Statistics and Cumulative distribution function of Peak Risk from External Ground(Wreleas)

Std. Dev.

Minimum

Maximum

\begin{tabular}{|c|c|c|}
\hline 1 & 2 & 3 \\
\hline $1.66 \mathrm{E}-11$ & $1.65 \mathrm{E}-11$ & 1. $66 \mathrm{E}-11$ \\
\hline $9.73 E-12$ & $9.73 E-12$ & $9.73 \mathrm{E}-12$ \\
\hline 1. $98 \mathrm{E}-12$ & 1. $98 \mathrm{E}-12$ & 1. $98 \mathrm{E}-12$ \\
\hline 7. $55 \mathrm{E}-11$ & 7. $55 \mathrm{E}-11$ & 7. $55 \mathrm{E}-11$ \\
\hline
\end{tabular}

Percentile

0.010

$3.17 \mathrm{E}-12 \quad 3.17 \mathrm{E}-12 \quad 3.17 \mathrm{E}-12$

0.025

3. $72 \mathrm{E}-12 \quad 3.72 \mathrm{E}-12 \quad 3.72 \mathrm{E}-12$

0.050

4.75E-12 4.75E-12 4.75E-12

0.075

5.31E-12 5.31E-12 5.31E-12

0.100

$6.01 \mathrm{E}-12 \quad 6.01 \mathrm{E}-12 \quad 6.01 \mathrm{E}-12$

0.125

6.53E-12 6.53E-12 6.53E-12

0.150

6.99E-12 6.99E-12 6.99E-12

0.175

7.61E-12 7.60E-12 7.60E-12

0.200

8.08E-12 8.07E-12 8.07E-12

0.225

8.70E-12 8.69E-12 8.69E-12

$9.13 \mathrm{E}-12 \quad 9.13 \mathrm{E}-12 \quad 9.13 \mathrm{E}-12$

9.64E-12 9.64E-12 9.64E-12

0.275

0.300

$1.02 \mathrm{E}-11 \quad 1.01 \mathrm{E}-11 \quad 1.01 \mathrm{E}-11$

0.325

$1.07 \mathrm{E}-11 \quad 1.07 \mathrm{E}-11 \quad 1.07 \mathrm{E}-11$

0.350

$1.14 \mathrm{E}-11 \quad 1.13 \mathrm{E}-11 \quad 1.13 \mathrm{E}-11$

$1.19 \mathrm{E}-11 \quad 1.19 \mathrm{E}-11 \quad 1.19 \mathrm{E}-11$

1.24E-11 1.24E-11 1.24E-11

0.400

$1.29 \mathrm{E}-11 \quad 1.29 \mathrm{E}-11 \quad 1.29 \mathrm{E}-11$

1.35E-11 1.35E-11 1.35E-11

1. $41 \mathrm{E}-11 \quad 1.41 \mathrm{E}-11 \quad 1.41 \mathrm{E}-11$

$1.47 \mathrm{E}-11 \quad 1.47 \mathrm{E}-11 \quad 1.47 \mathrm{E}-11$

$1.54 \mathrm{E}-11 \quad 1.54 \mathrm{E}-11 \quad 1.54 \mathrm{E}-11$

$1.59 \mathrm{E}-11 \quad 1.59 \mathrm{E}-11 \quad 1.59 \mathrm{E}-11$

$1.65 \mathrm{E}-11 \quad 1.65 \mathrm{E}-11 \quad 1.65 \mathrm{E}-11$

$1.72 \mathrm{E}-11 \quad 1.72 \mathrm{E}-11 \quad 1.72 \mathrm{E}-11$

$1.79 \mathrm{E}-11 \quad 1.78 \mathrm{E}-11 \quad 1.79 \mathrm{E}-11$

1.85E-11 1.85E-11 1.85E-11

$1.91 \mathrm{E}-11 \quad 1.91 \mathrm{E}-11 \quad 1.91 \mathrm{E}-11$

$2.02 \mathrm{E}-11 \quad 2.01 \mathrm{E}-11 \quad 2.02 \mathrm{E}-11$

$2.08 \mathrm{E}-11 \quad 2.08 \mathrm{E}-11 \quad 2.08 \mathrm{E}-11$

$2.19 \mathrm{E}-11 \quad 2.19 \mathrm{E}-11 \quad 2.19 \mathrm{E}-11$

2. $28 \mathrm{E}-11 \quad 2.28 \mathrm{E}-11 \quad 2.28 \mathrm{E}-11$

2. $38 \mathrm{E}-11 \quad 2.38 \mathrm{E}-11 \quad 2.38 \mathrm{E}-11$

2. $48 \mathrm{E}-11 \quad 2.48 \mathrm{E}-11 \quad 2.49 \mathrm{E}-11$

2. $61 \mathrm{E}-11 \quad 2.61 \mathrm{E}-11 \quad 2.62 \mathrm{E}-11$

$2.77 \mathrm{E}-11 \quad 2.77 \mathrm{E}-11 \quad 2.77 \mathrm{E}-11$

$2.99 \mathrm{E}-11 \quad 2.99 \mathrm{E}-11 \quad 2.99 \mathrm{E}-11$

3. $24 \mathrm{E}-11 \quad 3.24 \mathrm{E}-11 \quad 3.24 \mathrm{E}-11$

$3.52 \mathrm{E}-11 \quad 3.52 \mathrm{E}-11 \quad 3.52 \mathrm{E}-11$

4.04E-11 4.04E-11 4.04E-11

4.55E-11 4.55E-11 4.55E-11 
RESRAD-OFFSITE, Version 2.5

Probabilistic Dose and Risk Report

Title : Offsite Resident Farmer

File : RF TC99 DOESG FWD-FV2all.ROF

Statistics and Cumulative distribution function of Peak Risk from Fish Ingestion

$\begin{array}{rcccc}\text { Repetition }= & 1 & 2 & 3 \\ \begin{array}{rlll}\text { Mean } \\ \text { Std. Dev. }\end{array} & 0.00 \mathrm{E}+00 & 0.00 \mathrm{E}+00 & 0.00 \mathrm{E}+00 \\ \text { Minimum } & 0.00 \mathrm{E}+00 & 0.00 \mathrm{E}+00 & 0.00 \mathrm{E}+00 \\ \text { Maximum } & 0.00 \mathrm{E}+00 & 0.00 \mathrm{E}+00 & 0.00 \mathrm{E}+00 \\ & 0.00 \mathrm{E}+00 & 0.00 \mathrm{E}+00 & 0.00 \mathrm{E}+00\end{array}$

Percentile

$\begin{array}{llll}0.010 & 0.00 \mathrm{E}+00 & 0.00 \mathrm{E}+00 & 0.00 \mathrm{E}+00\end{array}$

$\begin{array}{llll}0.025 & 0.00 \mathrm{E}+00 & 0.00 \mathrm{E}+00 & 0.00 \mathrm{E}+00\end{array}$

$\begin{array}{llll}0.050 & 0.00 \mathrm{E}+00 & 0.00 \mathrm{E}+00 & 0.00 \mathrm{E}+00\end{array}$

$\begin{array}{llll}0.075 & 0.00 \mathrm{E}+00 & 0.00 \mathrm{E}+00 & 0.00 \mathrm{E}+00\end{array}$

$\begin{array}{llll}0.100 & 0.00 \mathrm{E}+00 & 0.00 \mathrm{E}+00 & 0.00 \mathrm{E}+00\end{array}$

$\begin{array}{llll}0.125 & 0.00 \mathrm{E}+00 & 0.00 \mathrm{E}+00 & 0.00 \mathrm{E}+00\end{array}$

$\begin{array}{llll}0.150 & 0.00 \mathrm{E}+00 & 0.00 \mathrm{E}+00 & 0.00 \mathrm{E}+00\end{array}$

$\begin{array}{llll}0.175 & 0.00 \mathrm{E}+00 & 0.00 \mathrm{E}+00 & 0.00 \mathrm{E}+00\end{array}$

$\begin{array}{llll}0.200 & 0.00 \mathrm{E}+00 & 0.00 \mathrm{E}+00 & 0.00 \mathrm{E}+00\end{array}$

$\begin{array}{lllll}0.225 & 0.00 \mathrm{E}+00 & 0.00 \mathrm{E}+00 & 0.00 \mathrm{E}+00\end{array}$

$\begin{array}{llll}0.250 & 0.00 \mathrm{E}+00 & 0.00 \mathrm{E}+00 & 0.00 \mathrm{E}+00\end{array}$

$\begin{array}{llll}0.275 & 0.00 \mathrm{E}+00 & 0.00 \mathrm{E}+00 & 0.00 \mathrm{E}+00\end{array}$

$\begin{array}{lllll}0.300 & 0.00 \mathrm{E}+00 & 0.00 \mathrm{E}+00 & 0.00 \mathrm{E}+00\end{array}$

$\begin{array}{lllll}0.325 & 0.00 \mathrm{E}+00 & 0.00 \mathrm{E}+00 & 0.00 \mathrm{E}+00\end{array}$

$\begin{array}{lllll}0.350 & 0.00 \mathrm{E}+00 & 0.00 \mathrm{E}+00 & 0.00 \mathrm{E}+00\end{array}$

$\begin{array}{lllll}0.375 & 0.00 \mathrm{E}+00 & 0.00 \mathrm{E}+00 & 0.00 \mathrm{E}+00\end{array}$

$\begin{array}{lllll}0.400 & 0.00 \mathrm{E}+00 & 0.00 \mathrm{E}+00 & 0.00 \mathrm{E}+00\end{array}$

$\begin{array}{lllll}0.425 & 0.00 \mathrm{E}+00 & 0.00 \mathrm{E}+00 & 0.00 \mathrm{E}+00\end{array}$

$\begin{array}{lllll}0.450 & 0.00 \mathrm{E}+00 & 0.00 \mathrm{E}+00 & 0.00 \mathrm{E}+00\end{array}$

$\begin{array}{lllll}0.475 & 0.00 \mathrm{E}+00 & 0.00 \mathrm{E}+00 & 0.00 \mathrm{E}+00\end{array}$

$\begin{array}{lllll}0.500 & 0.00 \mathrm{E}+00 & 0.00 \mathrm{E}+00 & 0.00 \mathrm{E}+00\end{array}$

$\begin{array}{lllll}0.525 & 0.00 \mathrm{E}+00 & 0.00 \mathrm{E}+00 & 0.00 \mathrm{E}+00\end{array}$

$\begin{array}{lllll}0.550 & 0.00 \mathrm{E}+00 & 0.00 \mathrm{E}+00 & 0.00 \mathrm{E}+00\end{array}$

$\begin{array}{lllll}0.575 & 0.00 \mathrm{E}+00 & 0.00 \mathrm{E}+00 & 0.00 \mathrm{E}+00\end{array}$

$\begin{array}{lllll}0.600 & 0.00 \mathrm{E}+00 & 0.00 \mathrm{E}+00 & 0.00 \mathrm{E}+00\end{array}$

$\begin{array}{lllll}0.625 & 0.00 \mathrm{E}+00 & 0.00 \mathrm{E}+00 & 0.00 \mathrm{E}+00\end{array}$

$\begin{array}{lllll}0.650 & 0.00 \mathrm{E}+00 & 0.00 \mathrm{E}+00 & 0.00 \mathrm{E}+00\end{array}$

$\begin{array}{lllll}0.675 & 0.00 \mathrm{E}+00 & 0.00 \mathrm{E}+00 & 0.00 \mathrm{E}+00\end{array}$

$\begin{array}{lllll}0.700 & 0.00 \mathrm{E}+00 & 0.00 \mathrm{E}+00 & 0.00 \mathrm{E}+00\end{array}$

$\begin{array}{lllll}0.725 & 0.00 \mathrm{E}+00 & 0.00 \mathrm{E}+00 & 0.00 \mathrm{E}+00\end{array}$

$\begin{array}{lllll}0.750 & 0.00 \mathrm{E}+00 & 0.00 \mathrm{E}+00 & 0.00 \mathrm{E}+00\end{array}$

$\begin{array}{lllll}0.775 & 0.00 \mathrm{E}+00 & 0.00 \mathrm{E}+00 & 0.00 \mathrm{E}+00\end{array}$

$\begin{array}{lllll}0.800 & 0.00 \mathrm{E}+00 & 0.00 \mathrm{E}+00 & 0.00 \mathrm{E}+00\end{array}$

$\begin{array}{lllll}0.825 & 0.00 \mathrm{E}+00 & 0.00 \mathrm{E}+00 & 0.00 \mathrm{E}+00\end{array}$

$\begin{array}{lllll}0.850 & 0.00 \mathrm{E}+00 & 0.00 \mathrm{E}+00 & 0.00 \mathrm{E}+00\end{array}$

$\begin{array}{llll}0.875 & 0.00 \mathrm{E}+00 & 0.00 \mathrm{E}+00 & 0.00 \mathrm{E}+00\end{array}$

$\begin{array}{lllll}0.900 & 0.00 \mathrm{E}+00 & 0.00 \mathrm{E}+00 & 0.00 \mathrm{E}+00\end{array}$

$\begin{array}{llll}0.925 & 0.00 \mathrm{E}+00 & 0.00 \mathrm{E}+00 & 0.00 \mathrm{E}+00\end{array}$

$\begin{array}{lllll}0.950 & 0.00 \mathrm{E}+00 & 0.00 \mathrm{E}+00 & 0.00 \mathrm{E}+00\end{array}$

$\begin{array}{lllll}0.975 & 0.00 \mathrm{E}+00 & 0.00 \mathrm{E}+00 & 0.00 \mathrm{E}+00\end{array}$

$\begin{array}{llll}0.990 & 0.00 \mathrm{E}+00 & 0.00 \mathrm{E}+00 & 0.00 \mathrm{E}+00\end{array}$ 
RESRAD-OFFSITE, Version 2.5

Probabilistic Dose and Risk Report

Title : Offsite Resident Farmer

File : RF TC99 DOESG FWD-FV2all.ROF

Statistics and Cumulative distribution function of Peak Risk from Radon (Waterrelease)

$\begin{array}{rcccc}\text { Repetition }= & 1 & 2 & 3 \\ \text { Mean } & 0.00 \mathrm{E}+00 & 0.00 \mathrm{E}+00 & 0.00 \mathrm{E}+00 \\ \text { Std. Dev. } & 0.00 \mathrm{E}+00 & 0.00 \mathrm{E}+00 & 0.00 \mathrm{E}+00 \\ \text { Minimum } & 0.00 \mathrm{E}+00 & 0.00 \mathrm{E}+00 & 0.00 \mathrm{E}+00 \\ \text { Maximum } & 0.00 \mathrm{E}+00 & 0.00 \mathrm{E}+00 & 0.00 \mathrm{E}+00\end{array}$

Percentile

$\begin{array}{llll}0.010 & 0.00 \mathrm{E}+00 & 0.00 \mathrm{E}+00 & 0.00 \mathrm{E}+00\end{array}$

$\begin{array}{llll}0.025 & 0.00 \mathrm{E}+00 & 0.00 \mathrm{E}+00 & 0.00 \mathrm{E}+00\end{array}$

$\begin{array}{llll}0.050 & 0.00 \mathrm{E}+00 & 0.00 \mathrm{E}+00 & 0.00 \mathrm{E}+00\end{array}$

$\begin{array}{llll}0.075 & 0.00 \mathrm{E}+00 & 0.00 \mathrm{E}+00 & 0.00 \mathrm{E}+00\end{array}$

$\begin{array}{llll}0.100 & 0.00 \mathrm{E}+00 & 0.00 \mathrm{E}+00 & 0.00 \mathrm{E}+00\end{array}$

$\begin{array}{llll}0.125 & 0.00 \mathrm{E}+00 & 0.00 \mathrm{E}+00 & 0.00 \mathrm{E}+00\end{array}$

$\begin{array}{llll}0.150 & 0.00 \mathrm{E}+00 & 0.00 \mathrm{E}+00 & 0.00 \mathrm{E}+00\end{array}$

$\begin{array}{llll}0.175 & 0.00 \mathrm{E}+00 & 0.00 \mathrm{E}+00 & 0.00 \mathrm{E}+00\end{array}$

$\begin{array}{llll}0.200 & 0.00 \mathrm{E}+00 & 0.00 \mathrm{E}+00 & 0.00 \mathrm{E}+00\end{array}$

$\begin{array}{lllll}0.225 & 0.00 \mathrm{E}+00 & 0.00 \mathrm{E}+00 & 0.00 \mathrm{E}+00\end{array}$

$\begin{array}{llll}0.250 & 0.00 \mathrm{E}+00 & 0.00 \mathrm{E}+00 & 0.00 \mathrm{E}+00\end{array}$

$\begin{array}{llll}0.275 & 0.00 \mathrm{E}+00 & 0.00 \mathrm{E}+00 & 0.00 \mathrm{E}+00\end{array}$

$\begin{array}{lllll}0.300 & 0.00 \mathrm{E}+00 & 0.00 \mathrm{E}+00 & 0.00 \mathrm{E}+00\end{array}$

$\begin{array}{llll}0.325 & 0.00 \mathrm{E}+00 & 0.00 \mathrm{E}+00 & 0.00 \mathrm{E}+00\end{array}$

$\begin{array}{lllll}0.350 & 0.00 \mathrm{E}+00 & 0.00 \mathrm{E}+00 & 0.00 \mathrm{E}+00\end{array}$

$\begin{array}{lllll}0.375 & 0.00 \mathrm{E}+00 & 0.00 \mathrm{E}+00 & 0.00 \mathrm{E}+00\end{array}$

$\begin{array}{lllll}0.400 & 0.00 \mathrm{E}+00 & 0.00 \mathrm{E}+00 & 0.00 \mathrm{E}+00\end{array}$

$\begin{array}{lllll}0.425 & 0.00 \mathrm{E}+00 & 0.00 \mathrm{E}+00 & 0.00 \mathrm{E}+00\end{array}$

$\begin{array}{lllll}0.450 & 0.00 \mathrm{E}+00 & 0.00 \mathrm{E}+00 & 0.00 \mathrm{E}+00\end{array}$

$\begin{array}{lllll}0.475 & 0.00 \mathrm{E}+00 & 0.00 \mathrm{E}+00 & 0.00 \mathrm{E}+00\end{array}$

$\begin{array}{lllll}0.500 & 0.00 \mathrm{E}+00 & 0.00 \mathrm{E}+00 & 0.00 \mathrm{E}+00\end{array}$

$\begin{array}{lllll}0.525 & 0.00 \mathrm{E}+00 & 0.00 \mathrm{E}+00 & 0.00 \mathrm{E}+00\end{array}$

$\begin{array}{lllll}0.550 & 0.00 \mathrm{E}+00 & 0.00 \mathrm{E}+00 & 0.00 \mathrm{E}+00\end{array}$

$\begin{array}{lllll}0.575 & 0.00 \mathrm{E}+00 & 0.00 \mathrm{E}+00 & 0.00 \mathrm{E}+00\end{array}$

$\begin{array}{lllll}0.600 & 0.00 \mathrm{E}+00 & 0.00 \mathrm{E}+00 & 0.00 \mathrm{E}+00\end{array}$

$\begin{array}{lllll}0.625 & 0.00 \mathrm{E}+00 & 0.00 \mathrm{E}+00 & 0.00 \mathrm{E}+00\end{array}$

$\begin{array}{lllll}0.650 & 0.00 \mathrm{E}+00 & 0.00 \mathrm{E}+00 & 0.00 \mathrm{E}+00\end{array}$

$\begin{array}{lllll}0.675 & 0.00 \mathrm{E}+00 & 0.00 \mathrm{E}+00 & 0.00 \mathrm{E}+00\end{array}$

$\begin{array}{lllll}0.700 & 0.00 \mathrm{E}+00 & 0.00 \mathrm{E}+00 & 0.00 \mathrm{E}+00\end{array}$

$\begin{array}{lllll}0.725 & 0.00 \mathrm{E}+00 & 0.00 \mathrm{E}+00 & 0.00 \mathrm{E}+00\end{array}$

$\begin{array}{lllll}0.750 & 0.00 \mathrm{E}+00 & 0.00 \mathrm{E}+00 & 0.00 \mathrm{E}+00\end{array}$

$\begin{array}{llll}0.775 & 0.00 \mathrm{E}+00 & 0.00 \mathrm{E}+00 & 0.00 \mathrm{E}+00\end{array}$

$\begin{array}{lllll}0.800 & 0.00 \mathrm{E}+00 & 0.00 \mathrm{E}+00 & 0.00 \mathrm{E}+00\end{array}$

$\begin{array}{lllll}0.825 & 0.00 \mathrm{E}+00 & 0.00 \mathrm{E}+00 & 0.00 \mathrm{E}+00\end{array}$

$\begin{array}{lllll}0.850 & 0.00 \mathrm{E}+00 & 0.00 \mathrm{E}+00 & 0.00 \mathrm{E}+00\end{array}$

$\begin{array}{llll}0.875 & 0.00 \mathrm{E}+00 & 0.00 \mathrm{E}+00 & 0.00 \mathrm{E}+00\end{array}$

$\begin{array}{lllll}0.900 & 0.00 \mathrm{E}+00 & 0.00 \mathrm{E}+00 & 0.00 \mathrm{E}+00\end{array}$

$\begin{array}{llll}0.925 & 0.00 \mathrm{E}+00 & 0.00 \mathrm{E}+00 & 0.00 \mathrm{E}+00\end{array}$

$\begin{array}{lllll}0.950 & 0.00 \mathrm{E}+00 & 0.00 \mathrm{E}+00 & 0.00 \mathrm{E}+00\end{array}$

$\begin{array}{lllll}0.975 & 0.00 \mathrm{E}+00 & 0.00 \mathrm{E}+00 & 0.00 \mathrm{E}+00\end{array}$

$\begin{array}{llll}0.990 & 0.00 \mathrm{E}+00 & 0.00 \mathrm{E}+00 & 0.00 \mathrm{E}+00\end{array}$ 
RESRAD-OFFSITE, Version 2.5

Probabilistic Dose and Risk Report

Title : Offsite Resident Farmer

File : RF TC99 DOESG FWD-FV2all.ROF

Statistics and Cumulative distribution function of Peak Risk from Plant (Waterrelease)

$\begin{array}{ccccc}\text { Repetition }= & 1 & 2 & 3 \\ \text { Mean } & 1.02 \mathrm{E}-05 & 1.02 \mathrm{E}-05 & 1.02 \mathrm{E}-05 \\ \text { Std. Dev. } & 6.01 \mathrm{E}-06 & 6.01 \mathrm{E}-06 & 6.01 \mathrm{E}-06 \\ \text { Minimum } & 1.22 \mathrm{E}-06 & 1.22 \mathrm{E}-06 & 1.22 \mathrm{E}-06 \\ \text { Maximum } & 4.66 \mathrm{E}-05 & 4.66 \mathrm{E}-05 & 4.66 \mathrm{E}-05\end{array}$

Percentile

$0.010 \quad 1.96 \mathrm{E}-06 \quad 1.96 \mathrm{E}-06 \quad 1.96 \mathrm{E}-06$

$0.025 \quad 2.30 \mathrm{E}-06 \quad 2.30 \mathrm{E}-06 \quad 2.30 \mathrm{E}-06$

$0.050 \quad 2.93 E-06 \quad 2.93 E-06 \quad 2.93 E-06$

$0.075 \quad 3.28 \mathrm{E}-06 \quad 3.28 \mathrm{E}-06 \quad 3.28 \mathrm{E}-06$

$0.100 \quad 3.71 \mathrm{E}-06 \quad 3.71 \mathrm{E}-06 \quad 3.71 \mathrm{E}-06$

$0.125 \quad 4.04 \mathrm{E}-06 \quad 4.03 \mathrm{E}-06 \quad 4.03 \mathrm{E}-06$

$0.150 \quad 4.32 \mathrm{E}-06 \quad 4.32 \mathrm{E}-06 \quad 4.32 \mathrm{E}-06$

$0.1754 .70 \mathrm{E}-06 \quad 4.70 \mathrm{E}-06 \quad 4.70 \mathrm{E}-06$

$0.200 \quad 4.99 \mathrm{E}-06 \quad 4.98 \mathrm{E}-06 \quad 4.98 \mathrm{E}-06$

$0.225 \quad 5.38 \mathrm{E}-06 \quad 5.37 \mathrm{E}-06 \quad 5.37 \mathrm{E}-06$

$0.250 \quad 5.64 \mathrm{E}-06 \quad 5.64 \mathrm{E}-06 \quad 5.64 \mathrm{E}-06$

$0.275 \quad 5.95 \mathrm{E}-06 \quad 5.95 \mathrm{E}-06 \quad 5.95 \mathrm{E}-06$

$0.300 \quad 6.27 \mathrm{E}-06 \quad 6.26 \mathrm{E}-06 \quad 6.26 \mathrm{E}-06$

$0.325 \quad 6.62 \mathrm{E}-06 \quad 6.61 \mathrm{E}-06 \quad 6.61 \mathrm{E}-06$

$0.350 \quad 7.01 \mathrm{E}-06 \quad 7.01 \mathrm{E}-06 \quad 7.01 \mathrm{E}-06$

$\begin{array}{llll}0.375 & 7.38 \mathrm{E}-06 \quad 7.37 \mathrm{E}-06 \quad 7.37 \mathrm{E}-06\end{array}$

$0.400 \quad 7.65 \mathrm{E}-06 \quad 7.65 \mathrm{E}-06 \quad 7.65 \mathrm{E}-06$

$\begin{array}{llll}0.425 & 8.00 \mathrm{E}-06 \quad 7.99 \mathrm{E}-06 \quad 7.99 \mathrm{E}-06\end{array}$

$0.450 \quad 8.32 \mathrm{E}-06 \quad 8.31 \mathrm{E}-06 \quad 8.31 \mathrm{E}-06$
0.475

$\begin{array}{llll}0.475 & 8.70 \mathrm{E}-06 & 8.68 \mathrm{E}-06 & 8.70 \mathrm{E}-06\end{array}$

$0.500 \quad 9.09 \mathrm{E}-06 \quad 9.08 \mathrm{E}-06 \quad 9.09 \mathrm{E}-06$

$0.5259 .50 \mathrm{E}-06 \quad 9.49 \mathrm{E}-06 \quad 9.51 \mathrm{E}-06$

$0.550 \quad 9.82 \mathrm{E}-06 \quad 9.81 \mathrm{E}-06 \quad 9.83 \mathrm{E}-06$

$0.575 \quad 1.02 \mathrm{E}-05 \quad 1.02 \mathrm{E}-05 \quad 1.02 \mathrm{E}-05$

$0.600 \quad 1.06 \mathrm{E}-05 \quad 1.06 \mathrm{E}-05 \quad 1.06 \mathrm{E}-05$

$0.625 \quad 1.10 \mathrm{E}-05 \quad 1.10 \mathrm{E}-05 \quad 1.10 \mathrm{E}-05$

$0.650 \quad 1.14 \mathrm{E}-05 \quad 1.14 \mathrm{E}-05 \quad 1.14 \mathrm{E}-05$

$0.675 \quad 1.18 \mathrm{E}-05 \quad 1.18 \mathrm{E}-05 \quad 1.18 \mathrm{E}-05$

$0.700 \quad 1.24 \mathrm{E}-05 \quad 1.24 \mathrm{E}-05 \quad 1.24 \mathrm{E}-05$

$0.725 \quad 1.28 \mathrm{E}-05 \quad 1.28 \mathrm{E}-05 \quad 1.28 \mathrm{E}-05$

$0.750 \quad 1.35 \mathrm{E}-05 \quad 1.35 \mathrm{E}-05 \quad 1.35 \mathrm{E}-05$

$0.775 \quad 1.41 \mathrm{E}-05 \quad 1.41 \mathrm{E}-05 \quad 1.41 \mathrm{E}-05$

$0.800 \quad 1.47 \mathrm{E}-05 \quad 1.47 \mathrm{E}-05 \quad 1.47 \mathrm{E}-05$

$0.825 \quad 1.53 \mathrm{E}-05 \quad 1.53 \mathrm{E}-05 \quad 1.54 \mathrm{E}-05$

$0.850 \quad 1.61 \mathrm{E}-05 \quad 1.61 \mathrm{E}-05 \quad 1.62 \mathrm{E}-05$

$0.875 \quad 1.71 \mathrm{E}-05 \quad 1.71 \mathrm{E}-05 \quad 1.71 \mathrm{E}-05$

$0.900 \quad 1.84 \mathrm{E}-05 \quad 1.84 \mathrm{E}-05 \quad 1.84 \mathrm{E}-05$

$0.925 \quad 2.00 \mathrm{E}-05 \quad 2.00 \mathrm{E}-05 \quad 2.00 \mathrm{E}-05$

$0.950 \quad 2.17 \mathrm{E}-05 \quad 2.17 \mathrm{E}-05 \quad 2.17 \mathrm{E}-05$

$\begin{array}{llll}0.975 & 2.49 \mathrm{E}-05 & 2.49 \mathrm{E}-05 & 2.49 \mathrm{E}-05\end{array}$

$0.990 \quad 2.81 \mathrm{E}-05 \quad 2.81 \mathrm{E}-05 \quad 2.81 \mathrm{E}-05$ 
RESRAD-OFFSITE, Version 2.5

Probabilistic Dose and Risk Report

Title : Offsite Resident Farmer

File : RF TC99 DOESG FWD-FV2all.ROF

Retition

Statistics and Cumulative distribution function of Peak Risk from Meat (Waterrelease)

$\begin{array}{ccccc}\text { Repetition }= & 1 & 2 & 3 \\ \text { Mean } & 3.06 \mathrm{E}-08 & 3.06 \mathrm{E}-08 & 3.06 \mathrm{E}-08 \\ \text { Std. Dev. } & 1.80 \mathrm{E}-08 & 1.80 \mathrm{E}-08 & 1.80 \mathrm{E}-08 \\ \text { Minimum } & 3.67 \mathrm{E}-09 & 3.67 \mathrm{E}-09 & 3.67 \mathrm{E}-09 \\ \text { Maximum } & 1.40 \mathrm{E}-07 & 1.40 \mathrm{E}-07 & 1.40 \mathrm{E}-07\end{array}$

Percentile

0.010

$5.87 \mathrm{E}-09 \quad 5.87 \mathrm{E}-09 \quad 5.87 \mathrm{E}-09$

0.025

$6.89 \mathrm{E}-09 \quad 6.89 \mathrm{E}-09 \quad 6.89 \mathrm{E}-09$

0.050

$8.80 \mathrm{E}-09 \quad 8.80 \mathrm{E}-09 \quad 8.80 \mathrm{E}-09$

0.075

$9.84 \mathrm{E}-09 \quad 9.84 \mathrm{E}-09 \quad 9.84 \mathrm{E}-09$

0.100

1.11E-08 1.11E-08 1.11E-08

0.125

$1.21 \mathrm{E}-08 \quad 1.21 \mathrm{E}-08 \quad 1.21 \mathrm{E}-08$

0.150

$\begin{array}{lll}1.29 \mathrm{E}-08 & 1.29 \mathrm{E}-08 & 1.29 \mathrm{E}-08\end{array}$

0.175

$1.41 \mathrm{E}-08 \quad 1.41 \mathrm{E}-08 \quad 1.41 \mathrm{E}-08$

0.200

$1.50 \mathrm{E}-08 \quad 1.49 \mathrm{E}-08 \quad 1.49 \mathrm{E}-08$

0.225

$1.61 \mathrm{E}-08 \quad 1.61 \mathrm{E}-08 \quad 1.61 \mathrm{E}-08$

0.250

$\begin{array}{lll}1.69 \mathrm{E}-08 & 1.69 \mathrm{E}-08 & 1.69 \mathrm{E}-08\end{array}$

0.275

$1.78 \mathrm{E}-08 \quad 1.78 \mathrm{E}-08 \quad 1.78 \mathrm{E}-08$

0.300

$1.88 \mathrm{E}-08 \quad 1.88 \mathrm{E}-08 \quad 1.88 \mathrm{E}-08$

0.325

$1.98 \mathrm{E}-08 \quad 1.98 \mathrm{E}-08 \quad 1.98 \mathrm{E}-08$

0.350

$2.10 \mathrm{E}-08 \quad 2.10 \mathrm{E}-08 \quad 2.10 \mathrm{E}-08$

0.375

$2.21 \mathrm{E}-08 \quad 2.21 \mathrm{E}-08 \quad 2.21 \mathrm{E}-08$

0.400

$2.29 \mathrm{E}-08 \quad 2.29 \mathrm{E}-08 \quad 2.29 \mathrm{E}-08$

0.425

$2.40 \mathrm{E}-08 \quad 2.40 \mathrm{E}-08 \quad 2.40 \mathrm{E}-08$

0.450

2. $49 \mathrm{E}-08 \quad 2.49 \mathrm{E}-08 \quad 2.49 \mathrm{E}-08$

0.475

$2.61 \mathrm{E}-08 \quad 2.60 \mathrm{E}-08 \quad 2.61 \mathrm{E}-08$

0.500

$\begin{array}{lll}2.72 \mathrm{E}-08 & 2.72 \mathrm{E}-08 \quad 2.72 \mathrm{E}-08\end{array}$

$2.85 \mathrm{E}-08 \quad 2.84 \mathrm{E}-08 \quad 2.85 \mathrm{E}-08$

$2.94 \mathrm{E}-08 \quad 2.94 \mathrm{E}-08 \quad 2.94 \mathrm{E}-08$

$3.05 \mathrm{E}-08 \quad 3.05 \mathrm{E}-08 \quad 3.05 \mathrm{E}-08$

$3.18 \mathrm{E}-08 \quad 3.18 \mathrm{E}-08 \quad 3.18 \mathrm{E}-08$

$\begin{array}{lll}3.31 E-08 & 3.30 E-08 & 3.31 E-08\end{array}$

$3.43 \mathrm{E}-08 \quad 3.42 \mathrm{E}-08 \quad 3.43 \mathrm{E}-08$

$3.54 \mathrm{E}-08 \quad 3.54 \mathrm{E}-08 \quad 3.54 \mathrm{E}-08$

$3.73 \mathrm{E}-08 \quad 3.73 \mathrm{E}-08 \quad 3.73 \mathrm{E}-08$

$3.85 \mathrm{E}-08 \quad 3.85 \mathrm{E}-08 \quad 3.85 \mathrm{E}-08$

$4.06 \mathrm{E}-08 \quad 4.06 \mathrm{E}-08 \quad 4.06 \mathrm{E}-08$

4.22 E-08 4.22E-08 4.22E-08

$4.40 \mathrm{E}-08 \quad 4.40 \mathrm{E}-08 \quad 4.40 \mathrm{E}-08$

4. $60 \mathrm{E}-08 \quad 4.60 \mathrm{E}-08 \quad 4.60 \mathrm{E}-08$

$4.84 \mathrm{E}-08 \quad 4.84 \mathrm{E}-08 \quad 4.84 \mathrm{E}-08$

$5.13 \mathrm{E}-08 \quad 5.13 \mathrm{E}-08 \quad 5.13 \mathrm{E}-08$

$5.53 \mathrm{E}-08 \quad 5.53 \mathrm{E}-08 \quad 5.53 \mathrm{E}-08$

$5.99 \mathrm{E}-08 \quad 5.99 \mathrm{E}-08 \quad 5.99 \mathrm{E}-08$

$6.51 \mathrm{E}-08 \quad 6.51 \mathrm{E}-08 \quad 6.51 \mathrm{E}-08$

$\begin{array}{lll}7.47 \mathrm{E}-08 \quad 7.47 \mathrm{E}-08 \quad 7.47 \mathrm{E}-08 & 8.48\end{array}$

$8.42 \mathrm{E}-08 \quad 8.42 \mathrm{E}-08 \quad 8.42 \mathrm{E}-08$ 
RESRAD-OFFSITE, Version 2.5

Probabilistic Dose and Risk Report

Title : Offsite Resident Farmer

File : RF TC99 DOESG FWD-FV2all.ROF

petition

Statistics and Cumulative distribution function of Peak Risk from Milk (Waterrelease)

$\begin{array}{rcccc}\text { Repetition }= & 1 & 2 & 3 \\ \text { Mean } & 2.71 \mathrm{E}-06 & 2.70 \mathrm{E}-06 & 2.71 \mathrm{E}-06 \\ \text { Std. Dev. } & 1.59 \mathrm{E}-06 & 1.59 \mathrm{E}-06 & 1.59 \mathrm{E}-06 \\ \text { Minimum } & 3.24 \mathrm{E}-07 & 3.24 \mathrm{E}-07 & 3.24 \mathrm{E}-07 \\ \text { Maximum } & 1.23 \mathrm{E}-05 & 1.23 \mathrm{E}-05 & 1.23 \mathrm{E}-05\end{array}$

Percentile

0.010

5.18E-07 5.18E-07 5.18E-07

0.025

6.09E-07 6.09E-07 6.09E-07

0.050

$7.77 \mathrm{E}-07 \quad 7.77 \mathrm{E}-07 \quad 7.77 \mathrm{E}-07$

0.075

$8.69 \mathrm{E}-07 \quad 8.69 \mathrm{E}-07 \quad 8.69 \mathrm{E}-07$

0.100

9.83E-07 9.83E-07 9.83E-07

0.125

$1.07 \mathrm{E}-06 \quad 1.07 \mathrm{E}-06 \quad 1.07 \mathrm{E}-06$

0.150

$1.14 \mathrm{E}-06 \quad 1.14 \mathrm{E}-06 \quad 1.14 \mathrm{E}-06$

0.175

$1.25 \mathrm{E}-06 \quad 1.24 \mathrm{E}-06 \quad 1.24 \mathrm{E}-06$

0.200

$1.32 \mathrm{E}-06 \quad 1.32 \mathrm{E}-06 \quad 1.32 \mathrm{E}-06$

0.225

1. $42 \mathrm{E}-06 \quad 1.42 \mathrm{E}-06 \quad 1.42 \mathrm{E}-06$

0.250

$1.49 \mathrm{E}-06 \quad 1.49 \mathrm{E}-06 \quad 1.49 \mathrm{E}-06$

$1.58 \mathrm{E}-06 \quad 1.58 \mathrm{E}-06 \quad 1.58 \mathrm{E}-06$

$1.66 \mathrm{E}-06 \quad 1.66 \mathrm{E}-06 \quad 1.66 \mathrm{E}-06$

$1.75 \mathrm{E}-06 \quad 1.75 \mathrm{E}-06 \quad 1.75 \mathrm{E}-06$

$1.86 \mathrm{E}-06 \quad 1.85 \mathrm{E}-06 \quad 1.85 \mathrm{E}-06$

$1.95 \mathrm{E}-06 \quad 1.95 \mathrm{E}-06 \quad 1.95 \mathrm{E}-06$

$2.03 E-06 \quad 2.02 E-06 \quad 2.02 E-06$

$2.12 \mathrm{E}-06 \quad 2.12 \mathrm{E}-06 \quad 2.12 \mathrm{E}-06$

$2.20 \mathrm{E}-06 \quad 2.20 \mathrm{E}-06 \quad 2.20 \mathrm{E}-06$

$\begin{array}{lll}2.30 \mathrm{E}-06 & 2.30 \mathrm{E}-06 & 2.30 \mathrm{E}-06\end{array}$

$2.40 \mathrm{E}-06 \quad 2.40 \mathrm{E}-06 \quad 2.40 \mathrm{E}-06$

$2.51 \mathrm{E}-06 \quad 2.51 \mathrm{E}-06 \quad 2.52 \mathrm{E}-06$

$2.60 \mathrm{E}-06 \quad 2.60 \mathrm{E}-06 \quad 2.60 \mathrm{E}-06$

$2.70 \mathrm{E}-06 \quad 2.70 \mathrm{E}-06 \quad 2.70 \mathrm{E}-06$

$2.81 \mathrm{E}-06 \quad 2.81 \mathrm{E}-06 \quad 2.81 \mathrm{E}-06$

2.92E-06 2.91E-06 2.92E-06

$3.03 E-06 \quad 3.02 E-06 \quad 3.03 E-06$

$3.12 \mathrm{E}-06 \quad 3.12 \mathrm{E}-06 \quad 3.12 \mathrm{E}-06$

$3.29 \mathrm{E}-06 \quad 3.29 \mathrm{E}-06 \quad 3.29 \mathrm{E}-06$

$3.40 \mathrm{E}-06 \quad 3.40 \mathrm{E}-06 \quad 3.40 \mathrm{E}-06$

$3.59 \mathrm{E}-06 \quad 3.58 \mathrm{E}-06 \quad 3.59 \mathrm{E}-06$

$3.73 E-06 \quad 3.73 E-06 \quad 3.73 E-06$

$3.88 \mathrm{E}-06 \quad 3.88 \mathrm{E}-06 \quad 3.88 \mathrm{E}-06$

$4.06 \mathrm{E}-06 \quad 4.06 \mathrm{E}-06 \quad 4.07 \mathrm{E}-06$

$4.27 \mathrm{E}-06 \quad 4.27 \mathrm{E}-06 \quad 4.28 \mathrm{E}-06$

4.53E-06 4.53E-06 4.53E-06

4.88E-06 4.88E-06 4.88E-06

$5.29 \mathrm{E}-06 \quad 5.29 \mathrm{E}-06 \quad 5.29 \mathrm{E}-06$

$5.74 \mathrm{E}-06 \quad 5.74 \mathrm{E}-06 \quad 5.74 \mathrm{E}-06$

$6.59 \mathrm{E}-06 \quad 6.59 \mathrm{E}-06 \quad 6.59 \mathrm{E}-06$

$7.43 \mathrm{E}-06 \quad 7.43 \mathrm{E}-06 \quad 7.43 \mathrm{E}-06$ 
RESRAD-OFFSITE, Version 2.5

$\mathrm{T}^{1 / 2}$ Limit $=180$ days

robabilistic Dose and Risk Report

Title : Offsite Resident Farmer

File : RF TC99 DOESG FWD-FV2all.ROF

Repetition

Std. Dev.

Minimum

Maximum

Statistics and Cumulative distribution function of Peak Risk from Soil Ingestion(Wrelease)

Percentile

0.010

6.03E-12 6.03E-12 6.03E-12

0.025

$7.08 \mathrm{E}-12 \quad 7.08 \mathrm{E}-12 \quad 7.08 \mathrm{E}-12$

0.050

9.03E-12 9.03E-12 9.03E-12

0.075

1.01E-11 1.01E-11 1.01E-11

0.100

$1.14 \mathrm{E}-11 \quad 1.14 \mathrm{E}-11 \quad 1.14 \mathrm{E}-11$

0.125

1.24E-11 1.24E-11 1.24E-11

0.150

1.33E-11 1.33E-11 1.33E-11

0.175

$1.45 \mathrm{E}-11 \quad 1.45 \mathrm{E}-11 \quad 1.45 \mathrm{E}-11$

0.200

1.54E-11 1.53E-11 1.53E-11

0.225

$1.66 \mathrm{E}-11 \quad 1.65 \mathrm{E}-11 \quad 1.65 \mathrm{E}-11$

0.250

$1.74 \mathrm{E}-11 \quad 1.74 \mathrm{E}-11 \quad 1.74 \mathrm{E}-11$

0.275

$1.83 \mathrm{E}-11 \quad 1.83 \mathrm{E}-11 \quad 1.83 \mathrm{E}-11$

0.300

1.93E-11 1.93E-11 1.93E-11

0.325

0.350

0.375

0.400

0.425

0.450

0.475

0.500

0.525

0.550

0.575

0.600

0.625

0.650

$2.04 \mathrm{E}-11 \quad 2.03 \mathrm{E}-11 \quad 2.03 \mathrm{E}-11$

$2.16 \mathrm{E}-11 \quad 2.16 \mathrm{E}-11 \quad 2.16 \mathrm{E}-11$

$2.27 \mathrm{E}-11 \quad 2.27 \mathrm{E}-11 \quad 2.27 \mathrm{E}-11$

$2.36 \mathrm{E}-11 \quad 2.36 \mathrm{E}-11 \quad 2.36 \mathrm{E}-11$

$2.46 \mathrm{E}-11 \quad 2.46 \mathrm{E}-11 \quad 2.46 \mathrm{E}-11$

$2.56 \mathrm{E}-11 \quad 2.56 \mathrm{E}-11 \quad 2.56 \mathrm{E}-11$

$2.68 \mathrm{E}-11 \quad 2.68 \mathrm{E}-11 \quad 2.68 \mathrm{E}-11$

$2.80 \mathrm{E}-11 \quad 2.80 \mathrm{E}-11 \quad 2.80 \mathrm{E}-11$

$2.93 \mathrm{E}-11 \quad 2.92 \mathrm{E}-11 \quad 2.93 \mathrm{E}-11$

$3.02 \mathrm{E}-11 \quad 3.02 \mathrm{E}-11 \quad 3.03 \mathrm{E}-11$

$3.14 \mathrm{E}-11 \quad 3.14 \mathrm{E}-11 \quad 3.14 \mathrm{E}-11$

$3.27 \mathrm{E}-11 \quad 3.27 \mathrm{E}-11 \quad 3.27 \mathrm{E}-11$

$3.40 \mathrm{E}-11 \quad 3.39 \mathrm{E}-11 \quad 3.40 \mathrm{E}-11$

$3.52 \mathrm{E}-11 \quad 3.52 \mathrm{E}-11 \quad 3.52 \mathrm{E}-11$

$3.64 \mathrm{E}-11 \quad 3.64 \mathrm{E}-11 \quad 3.64 \mathrm{E}-11$

$3.83 \mathrm{E}-11 \quad 3.83 \mathrm{E}-11 \quad 3.83 \mathrm{E}-11$

$3.96 \mathrm{E}-11 \quad 3.96 \mathrm{E}-11 \quad 3.96 \mathrm{E}-11$

$4.17 \mathrm{E}-11 \quad 4.17 \mathrm{E}-11 \quad 4.17 \mathrm{E}-11$

4.34E-11 4.34E-11 4.34E-11

4.52E-11 4.52E-11 4.52E-11

4.73E-11 4.73E-11 4.73E-11

$4.97 \mathrm{E}-11 \quad 4.97 \mathrm{E}-11 \quad 4.98 \mathrm{E}-11$

$5.27 \mathrm{E}-11 \quad 5.27 \mathrm{E}-11 \quad 5.28 \mathrm{E}-11$

$5.68 \mathrm{E}-11 \quad 5.68 \mathrm{E}-11 \quad 5.68 \mathrm{E}-11$

$6.16 \mathrm{E}-11 \quad 6.16 \mathrm{E}-11 \quad 6.16 \mathrm{E}-11$

$6.69 \mathrm{E}-11 \quad 6.69 \mathrm{E}-11 \quad 6.69 \mathrm{E}-11$

$7.68 \mathrm{E}-11 \quad 7.68 \mathrm{E}-11 \quad 7.68 \mathrm{E}-11$

$8.66 \mathrm{E}-11 \quad 8.66 \mathrm{E}-11 \quad 8.66 \mathrm{E}-11$ 
RESRAD-OFFSITE, Version 2.5

$\mathrm{T}^{1} \frac{1}{2}$ Limit $=180$ days

robabilistic Dose and Risk Report

Title : Offsite Resident Farmer

File : RF TC99 DOESG FWD-FV2all.ROF

epetition =

Mean

Std. Dev.

Minimum

Maximum

Percentile

0.010

0.025

0.050

0.075

0.100

0.125

0.150

0.175

0.200

0.225

0.250

0.275

0.300

0.325

0.350

0.375

0.400

0.425

0.450

0.475

0.500

0.525

0.550

0.575

0.600

0.625

0.650

0.675

0.700

0.725

0.750

0.775

0.800

0.825

0.850

0.875

0.900

0.925

0.950

0.975

0.990

Statistics and Cumulative distribution function of Peak Risk from Water Ingestion

\begin{tabular}{|c|c|c|}
\hline $3.67 \mathrm{E}-06$ & $3.67 \mathrm{E}-06$ & $3.67 \mathrm{E}-06$ \\
\hline $4.31 \mathrm{E}-06$ & $4.31 \mathrm{E}-06$ & $4.31 \mathrm{E}-06$ \\
\hline $5.50 \mathrm{E}-06$ & $5.50 \mathrm{E}-06$ & $5.50 \mathrm{E}-06$ \\
\hline $6.15 \mathrm{E}-06$ & $6.15 E-06$ & $6.15 E-06$ \\
\hline $6.96 \mathrm{E}-06$ & $6.96 \mathrm{E}-06$ & $6.96 \mathrm{E}-06$ \\
\hline $7.56 \mathrm{E}-06$ & $7.56 \mathrm{E}-06$ & $7.56 \mathrm{E}-06$ \\
\hline $8.09 \mathrm{E}-06$ & $8.09 \mathrm{E}-06$ & $8.09 \mathrm{E}-06$ \\
\hline $8.81 \mathrm{E}-06$ & $8.80 \mathrm{E}-06$ & $8.80 E-06$ \\
\hline $9.35 \mathrm{E}-06$ & $9.34 \mathrm{E}-06$ & $9.34 \mathrm{E}-06$ \\
\hline $1.01 \mathrm{E}-05$ & $1.01 \mathrm{E}-05$ & $1.01 \mathrm{E}-05$ \\
\hline $1.06 \mathrm{E}-05$ & $1.06 \mathrm{E}-05$ & $1.06 \mathrm{E}-05$ \\
\hline $1.12 \mathrm{E}-05$ & $1.12 \mathrm{E}-05$ & $1.12 \mathrm{E}-05$ \\
\hline $1.17 \mathrm{E}-05$ & $1.17 \mathrm{E}-05$ & $1.17 \mathrm{E}-05$ \\
\hline $1.24 \mathrm{E}-05$ & $1.24 \mathrm{E}-05$ & $1.24 \mathrm{E}-05$ \\
\hline $1.31 \mathrm{E}-05$ & $1.31 \mathrm{E}-05$ & 1. $31 \mathrm{E}-05$ \\
\hline $1.38 \mathrm{E}-05$ & $1.38 E-05$ & $1.38 \mathrm{E}-05$ \\
\hline $1.43 E-05$ & $1.43 E-05$ & $1.43 E-05$ \\
\hline $1.50 \mathrm{E}-05$ & $1.50 \mathrm{E}-05$ & $1.50 \mathrm{E}-05$ \\
\hline $1.56 \mathrm{E}-05$ & $1.56 \mathrm{E}-05$ & $1.56 \mathrm{E}-05$ \\
\hline $1.63 \mathrm{E}-05$ & $1.63 \mathrm{E}-05$ & $1.63 E-05$ \\
\hline $1.70 \mathrm{E}-05$ & $1.70 E-05$ & $1.70 E-05$ \\
\hline $1.78 \mathrm{E}-05$ & $1.78 \mathrm{E}-05$ & $1.78 E-05$ \\
\hline $1.84 \mathrm{E}-05$ & $1.84 \mathrm{E}-05$ & $1.84 \mathrm{E}-05$ \\
\hline $1.91 \mathrm{E}-05$ & $1.91 \mathrm{E}-05$ & $1.91 E-05$ \\
\hline $1.99 \mathrm{E}-05$ & $1.99 \mathrm{E}-05$ & $1.99 \mathrm{E}-05$ \\
\hline $2.07 E-05$ & $2.06 \mathrm{E}-05$ & $2.07 E-05$ \\
\hline $2.14 \mathrm{E}-05$ & $2.14 E-05$ & $2.14 E-05$ \\
\hline $2.21 E-05$ & $2.21 \mathrm{E}-05$ & $2.21 \mathrm{E}-05$ \\
\hline $2.33 E-05$ & $2.33 E-05$ & $2.33 E-05$ \\
\hline $2.41 E-05$ & $2.40 E-05$ & $2.41 E-05$ \\
\hline $2.54 \mathrm{E}-05$ & $2.53 E-05$ & $2.54 \mathrm{E}-05$ \\
\hline $2.64 \mathrm{E}-05$ & $2.64 \mathrm{E}-05$ & $2.64 \mathrm{E}-05$ \\
\hline $2.75 E-05$ & $2.75 E-05$ & $2.75 E-05$ \\
\hline $2.87 \mathrm{E}-05$ & $2.87 E-05$ & $2.88 E-05$ \\
\hline $3.02 \mathrm{E}-05$ & $3.02 E-05$ & $3.03 E-05$ \\
\hline $3.20 \mathrm{E}-05$ & $3.20 E-05$ & $3.21 E-05$ \\
\hline $3.45 E-05$ & $3.45 \mathrm{E}-05$ & $3.45 E-05$ \\
\hline $3.74 \mathrm{E}-05$ & $3.74 E-05$ & $3.74 \mathrm{E}-05$ \\
\hline $4.07 E-05$ & $4.07 \mathrm{E}-05$ & $4.07 E-05$ \\
\hline $4.67 \mathrm{E}-05$ & $4.67 \mathrm{E}-05$ & $4.67 E-05$ \\
\hline $5.26 \mathrm{E}-05$ & $5.26 \mathrm{E}-05$ & $5.26 \mathrm{E}-05$ \\
\hline
\end{tabular}

\begin{tabular}{|c|c|c|}
\hline 1 & 2 & 3 \\
\hline $1.92 \mathrm{E}-05$ & $1.91 \mathrm{E}-05$ & 1.92E-05 \\
\hline $1.12 \mathrm{E}-05$ & $1.12 \mathrm{E}-05$ & $1.13 \mathrm{E}-05$ \\
\hline $2.29 \mathrm{E}-06$ & $2.29 \mathrm{E}-06$ & $2.29 \mathrm{E}-06$ \\
\hline $8.73 E-05$ & $8.73 E-05$ & $8.73 E-05$ \\
\hline
\end{tabular}

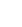

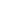

(1)

6


RESRAD-OFFSITE, Version 2.5

Probabilistic Dose and Risk Report

Title : Offsite Resident Farmer

File : RF TC99 DOESG FWD-FV2all.ROF

epetition

Statistics and Cumulative distribution function of Peak Risk from External Ground(CZ\&Air)

$\begin{array}{cccc}\text { Mean } & 7.68 \mathrm{E}-30 & 7.70 \mathrm{E}-30 & 7.69 \mathrm{E}-30 \\ \text { Minimum } & 0.00 \mathrm{E}+00 & 0.00 \mathrm{E}+00 & 0.00 \mathrm{E}+00 \\ \text { Maximum } & 2.86 \mathrm{E}-37 & 2.86 \mathrm{E}-37 & 2.86 \mathrm{E}-37 \\ & 2.32 \mathrm{E}-29 & 2.32 \mathrm{E}-29 & 2.32 \mathrm{E}-29\end{array}$

Percentile

0.010

$5.97 \mathrm{E}-35 \quad 5.97 \mathrm{E}-35 \quad 5.97 \mathrm{E}-35$

0.025

3.12E-33 3.12E-33 3.04E-33

0.050

3. $62 E-32 \quad 3.62 E-32 \quad 3.55 E-32$

$9.27 \mathrm{E}-32 \quad 9.27 \mathrm{E}-32 \quad 9.13 \mathrm{E}-32$

$1.89 \mathrm{E}-31 \quad 1.89 \mathrm{E}-31 \quad 1.89 \mathrm{E}-31$

$3.27 E-31 \quad 3.31 E-31 \quad 3.29 E-31$

$5.04 \mathrm{E}-31 \quad 5.08 \mathrm{E}-31 \quad 5.06 \mathrm{E}-31$

$7.90 \mathrm{E}-31 \quad 8.06 \mathrm{E}-31 \quad 8.06 \mathrm{E}-31$

$1.13 \mathrm{E}-30 \quad 1.14 \mathrm{E}-30 \quad 1.14 \mathrm{E}-30$

$1.42 \mathrm{E}-30 \quad 1.43 \mathrm{E}-30 \quad 1.43 \mathrm{E}-30$

$1.74 \mathrm{E}-30 \quad 1.76 \mathrm{E}-30 \quad 1.76 \mathrm{E}-30$

$2.16 \mathrm{E}-30 \quad 2.17 \mathrm{E}-30 \quad 2.17 \mathrm{E}-30$

$2.57 \mathrm{E}-30 \quad 2.60 \mathrm{E}-30 \quad 2.58 \mathrm{E}-30$

$3.13 \mathrm{E}-30 \quad 3.15 \mathrm{E}-30 \quad 3.14 \mathrm{E}-30$

3. $62 \mathrm{E}-30 \quad 3.63 \mathrm{E}-30 \quad 3.63 \mathrm{E}-30$

$4.11 \mathrm{E}-30 \quad 4.17 \mathrm{E}-30 \quad 4.14 \mathrm{E}-30$

$4.67 \mathrm{E}-30 \quad 4.72 \mathrm{E}-30 \quad 4.70 \mathrm{E}-30$

$5.27 \mathrm{E}-30 \quad 5.29 \mathrm{E}-30 \quad 5.29 \mathrm{E}-30$

$5.85 \mathrm{E}-30 \quad 5.87 \mathrm{E}-30 \quad 5.87 \mathrm{E}-30$

$6.33 \mathrm{E}-30 \quad 6.35 \mathrm{E}-30 \quad 6.34 \mathrm{E}-30$

$6.91 \mathrm{E}-30 \quad 6.92 \mathrm{E}-30 \quad 6.91 \mathrm{E}-30$

$\begin{array}{lll}7.69 \mathrm{E}-30 \quad 7.70 \mathrm{E}-30 \quad 7.69 \mathrm{E}-30 & 0\end{array}$

$8.29 \mathrm{E}-30 \quad 8.30 \mathrm{E}-30 \quad 8.30 \mathrm{E}-30$

$8.85 \mathrm{E}-30 \quad 8.89 \mathrm{E}-30 \quad 8.88 \mathrm{E}-30$

$9.35 \mathrm{E}-30 \quad 9.37 \mathrm{E}-30 \quad 9.36 \mathrm{E}-30$

$9.94 \mathrm{E}-30 \quad 9.96 \mathrm{E}-30 \quad 9.95 \mathrm{E}-30$

$1.03 \mathrm{E}-29 \quad 1.03 \mathrm{E}-29 \quad 1.03 \mathrm{E}-29$

$1.08 \mathrm{E}-29 \quad 1.08 \mathrm{E}-29 \quad 1.08 \mathrm{E}-29$

$1.13 \mathrm{E}-29 \quad 1.14 \mathrm{E}-29 \quad 1.13 \mathrm{E}-29$

$1.21 E-29 \quad 1.21 E-29 \quad 1.21 E-29$

$1.27 \mathrm{E}-29 \quad 1.27 \mathrm{E}-29 \quad 1.27 \mathrm{E}-29$

$1.33 E-29 \quad 1.33 E-29 \quad 1.33 E-29$

$1.41 \mathrm{E}-29 \quad 1.41 \mathrm{E}-29 \quad 1.41 \mathrm{E}-29$

$1.45 \mathrm{E}-29 \quad 1.45 \mathrm{E}-29 \quad 1.45 \mathrm{E}-29$

$1.51 \mathrm{E}-29 \quad 1.52 \mathrm{E}-29 \quad 1.52 \mathrm{E}-29$

$1.59 \mathrm{E}-29 \quad 1.59 \mathrm{E}-29 \quad 1.59 \mathrm{E}-29$

$1.65 \mathrm{E}-29 \quad 1.65 \mathrm{E}-29 \quad 1.65 \mathrm{E}-29$

$1.73 \mathrm{E}-29 \quad 1.73 \mathrm{E}-29 \quad 1.73 \mathrm{E}-29$

$1.83 \mathrm{E}-29 \quad 1.83 \mathrm{E}-29 \quad 1.83 \mathrm{E}-29$

$1.93 \mathrm{E}-29 \quad 1.93 \mathrm{E}-29 \quad 1.93 \mathrm{E}-29$

$2.05 E-29 \quad 2.05 E-29 \quad 2.05 E-29$ 
RESRAD-OFFSITE, Version 2.5

Probabilistic Dose and Risk Report

Title : Offsite Resident Farmer

File : RF TC99 DOESG FWD-FV2all.ROF

Statistics and Cumulative distribution function of Peak Risk from Inhalation ExcludingRn

$\begin{array}{ccccc}\text { Repetition }= & 1 & 2 & 3 \\ \begin{array}{c}\text { Mean } \\ \text { Std. Dev. }\end{array} & 0.00 \mathrm{E}+00 & 0.00 \mathrm{E}+00 & 0.00 \mathrm{E}+00 \\ \text { Minimum } & 0.00 \mathrm{E}+00 & 0.00 \mathrm{E}+00 & 0.00 \mathrm{E}+00 \\ \text { Maximum } & 0.00 \mathrm{E}+00 & 0.00 \mathrm{E}+00 & 0.00 \mathrm{E}+00 \\ & 0.00 \mathrm{E}+00 & 0.00 \mathrm{E}+00 & 0.00 \mathrm{E}+00\end{array}$

Percentile

$\begin{array}{llll}0.010 & 0.00 \mathrm{E}+00 & 0.00 \mathrm{E}+00 & 0.00 \mathrm{E}+00\end{array}$

$\begin{array}{llll}0.025 & 0.00 \mathrm{E}+00 & 0.00 \mathrm{E}+00 & 0.00 \mathrm{E}+00\end{array}$

$\begin{array}{lllll}0.050 & 0.00 \mathrm{E}+00 & 0.00 \mathrm{E}+00 & 0.00 \mathrm{E}+00\end{array}$

$\begin{array}{llll}0.075 & 0.00 \mathrm{E}+00 & 0.00 \mathrm{E}+00 & 0.00 \mathrm{E}+00\end{array}$

$\begin{array}{llll}0.100 & 0.00 \mathrm{E}+00 & 0.00 \mathrm{E}+00 & 0.00 \mathrm{E}+00\end{array}$

$\begin{array}{llll}0.125 & 0.00 \mathrm{E}+00 & 0.00 \mathrm{E}+00 & 0.00 \mathrm{E}+00\end{array}$

$\begin{array}{llll}0.150 & 0.00 \mathrm{E}+00 & 0.00 \mathrm{E}+00 & 0.00 \mathrm{E}+00\end{array}$

$\begin{array}{llll}0.175 & 0.00 \mathrm{E}+00 & 0.00 \mathrm{E}+00 & 0.00 \mathrm{E}+00\end{array}$

$\begin{array}{lllll}0.200 & 0.00 \mathrm{E}+00 & 0.00 \mathrm{E}+00 & 0.00 \mathrm{E}+00\end{array}$

$\begin{array}{lllll}0.225 & 0.00 \mathrm{E}+00 & 0.00 \mathrm{E}+00 & 0.00 \mathrm{E}+00\end{array}$

$\begin{array}{llll}0.250 & 0.00 \mathrm{E}+00 & 0.00 \mathrm{E}+00 & 0.00 \mathrm{E}+00\end{array}$

$\begin{array}{llll}0.275 & 0.00 \mathrm{E}+00 & 0.00 \mathrm{E}+00 & 0.00 \mathrm{E}+00\end{array}$

$\begin{array}{lllll}0.300 & 0.00 \mathrm{E}+00 & 0.00 \mathrm{E}+00 & 0.00 \mathrm{E}+00\end{array}$

$\begin{array}{lllll}0.325 & 0.00 \mathrm{E}+00 & 0.00 \mathrm{E}+00 & 0.00 \mathrm{E}+00\end{array}$

$\begin{array}{lllll}0.350 & 0.00 \mathrm{E}+00 & 0.00 \mathrm{E}+00 & 0.00 \mathrm{E}+00\end{array}$

$\begin{array}{lllll}0.375 & 0.00 \mathrm{E}+00 & 0.00 \mathrm{E}+00 & 0.00 \mathrm{E}+00\end{array}$

$\begin{array}{lllll}0.400 & 0.00 \mathrm{E}+00 & 0.00 \mathrm{E}+00 & 0.00 \mathrm{E}+00\end{array}$

$\begin{array}{lllll}0.425 & 0.00 \mathrm{E}+00 & 0.00 \mathrm{E}+00 & 0.00 \mathrm{E}+00\end{array}$

$\begin{array}{lllll}0.450 & 0.00 \mathrm{E}+00 & 0.00 \mathrm{E}+00 & 0.00 \mathrm{E}+00\end{array}$

$\begin{array}{lllll}0.475 & 0.00 \mathrm{E}+00 & 0.00 \mathrm{E}+00 & 0.00 \mathrm{E}+00\end{array}$

$\begin{array}{lllll}0.500 & 0.00 \mathrm{E}+00 & 0.00 \mathrm{E}+00 & 0.00 \mathrm{E}+00\end{array}$

$\begin{array}{lllll}0.525 & 0.00 \mathrm{E}+00 & 0.00 \mathrm{E}+00 & 0.00 \mathrm{E}+00\end{array}$

$\begin{array}{llll}0.550 & 0.00 \mathrm{E}+00 & 0.00 \mathrm{E}+00 & 0.00 \mathrm{E}+00\end{array}$

$\begin{array}{lllll}0.575 & 0.00 \mathrm{E}+00 & 0.00 \mathrm{E}+00 & 0.00 \mathrm{E}+00\end{array}$

$\begin{array}{lllll}0.600 & 0.00 \mathrm{E}+00 & 0.00 \mathrm{E}+00 & 0.00 \mathrm{E}+00\end{array}$

$\begin{array}{lllll}0.625 & 0.00 \mathrm{E}+00 & 0.00 \mathrm{E}+00 & 0.00 \mathrm{E}+00\end{array}$

$\begin{array}{lllll}0.650 & 0.00 \mathrm{E}+00 & 0.00 \mathrm{E}+00 & 0.00 \mathrm{E}+00\end{array}$

$\begin{array}{lllll}0.675 & 0.00 \mathrm{E}+00 & 0.00 \mathrm{E}+00 & 0.00 \mathrm{E}+00\end{array}$

$\begin{array}{lllll}0.700 & 0.00 \mathrm{E}+00 & 0.00 \mathrm{E}+00 & 0.00 \mathrm{E}+00\end{array}$

$\begin{array}{lllll}0.725 & 0.00 \mathrm{E}+00 & 0.00 \mathrm{E}+00 & 0.00 \mathrm{E}+00\end{array}$

$\begin{array}{lllll}0.750 & 0.00 \mathrm{E}+00 & 0.00 \mathrm{E}+00 & 0.00 \mathrm{E}+00\end{array}$

$\begin{array}{lllll}0.775 & 0.00 \mathrm{E}+00 & 0.00 \mathrm{E}+00 & 0.00 \mathrm{E}+00\end{array}$

$\begin{array}{lllll}0.800 & 0.00 \mathrm{E}+00 & 0.00 \mathrm{E}+00 & 0.00 \mathrm{E}+00\end{array}$

$\begin{array}{lllll}0.825 & 0.00 \mathrm{E}+00 & 0.00 \mathrm{E}+00 & 0.00 \mathrm{E}+00\end{array}$

$\begin{array}{lllll}0.850 & 0.00 \mathrm{E}+00 & 0.00 \mathrm{E}+00 & 0.00 \mathrm{E}+00\end{array}$

$\begin{array}{lllll}0.875 & 0.00 \mathrm{E}+00 & 0.00 \mathrm{E}+00 & 0.00 \mathrm{E}+00\end{array}$

$\begin{array}{lllll}0.900 & 0.00 \mathrm{E}+00 & 0.00 \mathrm{E}+00 & 0.00 \mathrm{E}+00\end{array}$

$\begin{array}{llll}0.925 & 0.00 \mathrm{E}+00 & 0.00 \mathrm{E}+00 & 0.00 \mathrm{E}+00\end{array}$

$\begin{array}{lllll}0.950 & 0.00 \mathrm{E}+00 & 0.00 \mathrm{E}+00 & 0.00 \mathrm{E}+00\end{array}$

$\begin{array}{lllll}0.975 & 0.00 \mathrm{E}+00 & 0.00 \mathrm{E}+00 & 0.00 \mathrm{E}+00\end{array}$

$\begin{array}{lllll}0.990 & 0.00 \mathrm{E}+00 & 0.00 \mathrm{E}+00 & 0.00 \mathrm{E}+00\end{array}$ 
RESRAD-OFFSITE, Version 2.5

Probabilistic Dose and Risk Report

Title : Offsite Resident Farmer

File : RF TC99 DOESG FWD-FV2all.ROF

Statistics and Cumulative distribution function of Peak Risk from Radon (CZandAir)

$\begin{array}{ccccc}\text { Repetition }= & 1 & 2 & 3 \\ \text { Mean } & 0.00 \mathrm{E}+00 & 0.00 \mathrm{E}+00 & 0.00 \mathrm{E}+00 \\ \text { Std. Dev. } & 0.00 \mathrm{E}+00 & 0.00 \mathrm{E}+00 & 0.00 \mathrm{E}+00 \\ \text { Minimum } & 0.00 \mathrm{E}+00 & 0.00 \mathrm{E}+00 & 0.00 \mathrm{E}+00 \\ \text { Maximum } & 0.00 \mathrm{E}+00 & 0.00 \mathrm{E}+00 & 0.00 \mathrm{E}+00\end{array}$

Percentile

$\begin{array}{llll}0.010 & 0.00 \mathrm{E}+00 & 0.00 \mathrm{E}+00 & 0.00 \mathrm{E}+00\end{array}$

$\begin{array}{llll}0.025 & 0.00 \mathrm{E}+00 & 0.00 \mathrm{E}+00 & 0.00 \mathrm{E}+00\end{array}$

$\begin{array}{llll}0.050 & 0.00 \mathrm{E}+00 & 0.00 \mathrm{E}+00 & 0.00 \mathrm{E}+00\end{array}$

$\begin{array}{llll}0.075 & 0.00 \mathrm{E}+00 & 0.00 \mathrm{E}+00 & 0.00 \mathrm{E}+00\end{array}$

$\begin{array}{llll}0.100 & 0.00 \mathrm{E}+00 & 0.00 \mathrm{E}+00 & 0.00 \mathrm{E}+00\end{array}$

$\begin{array}{llll}0.125 & 0.00 \mathrm{E}+00 & 0.00 \mathrm{E}+00 & 0.00 \mathrm{E}+00\end{array}$

$\begin{array}{llll}0.150 & 0.00 \mathrm{E}+00 & 0.00 \mathrm{E}+00 & 0.00 \mathrm{E}+00\end{array}$

$\begin{array}{llll}0.175 & 0.00 \mathrm{E}+00 & 0.00 \mathrm{E}+00 & 0.00 \mathrm{E}+00\end{array}$

$\begin{array}{llll}0.200 & 0.00 \mathrm{E}+00 & 0.00 \mathrm{E}+00 & 0.00 \mathrm{E}+00\end{array}$

$\begin{array}{lllll}0.225 & 0.00 \mathrm{E}+00 & 0.00 \mathrm{E}+00 & 0.00 \mathrm{E}+00\end{array}$

$\begin{array}{llll}0.250 & 0.00 \mathrm{E}+00 & 0.00 \mathrm{E}+00 & 0.00 \mathrm{E}+00\end{array}$

$\begin{array}{llll}0.275 & 0.00 \mathrm{E}+00 & 0.00 \mathrm{E}+00 & 0.00 \mathrm{E}+00\end{array}$

$\begin{array}{lllll}0.300 & 0.00 \mathrm{E}+00 & 0.00 \mathrm{E}+00 & 0.00 \mathrm{E}+00\end{array}$

$\begin{array}{lllll}0.325 & 0.00 \mathrm{E}+00 & 0.00 \mathrm{E}+00 & 0.00 \mathrm{E}+00\end{array}$

$\begin{array}{lllll}0.350 & 0.00 \mathrm{E}+00 & 0.00 \mathrm{E}+00 & 0.00 \mathrm{E}+00\end{array}$

$\begin{array}{lllll}0.375 & 0.00 \mathrm{E}+00 & 0.00 \mathrm{E}+00 & 0.00 \mathrm{E}+00\end{array}$

$\begin{array}{lllll}0.400 & 0.00 \mathrm{E}+00 & 0.00 \mathrm{E}+00 & 0.00 \mathrm{E}+00\end{array}$

$\begin{array}{lllll}0.425 & 0.00 \mathrm{E}+00 & 0.00 \mathrm{E}+00 & 0.00 \mathrm{E}+00\end{array}$

$\begin{array}{lllll}0.450 & 0.00 \mathrm{E}+00 & 0.00 \mathrm{E}+00 & 0.00 \mathrm{E}+00\end{array}$

$\begin{array}{lllll}0.475 & 0.00 \mathrm{E}+00 & 0.00 \mathrm{E}+00 & 0.00 \mathrm{E}+00\end{array}$

$\begin{array}{lllll}0.500 & 0.00 \mathrm{E}+00 & 0.00 \mathrm{E}+00 & 0.00 \mathrm{E}+00\end{array}$

$\begin{array}{lllll}0.525 & 0.00 \mathrm{E}+00 & 0.00 \mathrm{E}+00 & 0.00 \mathrm{E}+00\end{array}$

$\begin{array}{lllll}0.550 & 0.00 \mathrm{E}+00 & 0.00 \mathrm{E}+00 & 0.00 \mathrm{E}+00\end{array}$

$\begin{array}{lllll}0.575 & 0.00 \mathrm{E}+00 & 0.00 \mathrm{E}+00 & 0.00 \mathrm{E}+00\end{array}$

$\begin{array}{lllll}0.600 & 0.00 \mathrm{E}+00 & 0.00 \mathrm{E}+00 & 0.00 \mathrm{E}+00\end{array}$

$\begin{array}{lllll}0.625 & 0.00 \mathrm{E}+00 & 0.00 \mathrm{E}+00 & 0.00 \mathrm{E}+00\end{array}$

$\begin{array}{lllll}0.650 & 0.00 \mathrm{E}+00 & 0.00 \mathrm{E}+00 & 0.00 \mathrm{E}+00\end{array}$

$\begin{array}{lllll}0.675 & 0.00 \mathrm{E}+00 & 0.00 \mathrm{E}+00 & 0.00 \mathrm{E}+00\end{array}$

$\begin{array}{lllll}0.700 & 0.00 \mathrm{E}+00 & 0.00 \mathrm{E}+00 & 0.00 \mathrm{E}+00\end{array}$

$\begin{array}{lllll}0.725 & 0.00 \mathrm{E}+00 & 0.00 \mathrm{E}+00 & 0.00 \mathrm{E}+00\end{array}$

$\begin{array}{lllll}0.750 & 0.00 \mathrm{E}+00 & 0.00 \mathrm{E}+00 & 0.00 \mathrm{E}+00\end{array}$

$\begin{array}{lllll}0.775 & 0.00 \mathrm{E}+00 & 0.00 \mathrm{E}+00 & 0.00 \mathrm{E}+00\end{array}$

$\begin{array}{lllll}0.800 & 0.00 \mathrm{E}+00 & 0.00 \mathrm{E}+00 & 0.00 \mathrm{E}+00\end{array}$

$\begin{array}{lllll}0.825 & 0.00 \mathrm{E}+00 & 0.00 \mathrm{E}+00 & 0.00 \mathrm{E}+00\end{array}$

$\begin{array}{lllll}0.850 & 0.00 \mathrm{E}+00 & 0.00 \mathrm{E}+00 & 0.00 \mathrm{E}+00\end{array}$

$\begin{array}{llll}0.875 & 0.00 \mathrm{E}+00 & 0.00 \mathrm{E}+00 & 0.00 \mathrm{E}+00\end{array}$

$\begin{array}{lllll}0.900 & 0.00 \mathrm{E}+00 & 0.00 \mathrm{E}+00 & 0.00 \mathrm{E}+00\end{array}$

$\begin{array}{llll}0.925 & 0.00 \mathrm{E}+00 & 0.00 \mathrm{E}+00 & 0.00 \mathrm{E}+00\end{array}$

$\begin{array}{lllll}0.950 & 0.00 \mathrm{E}+00 & 0.00 \mathrm{E}+00 & 0.00 \mathrm{E}+00\end{array}$

$\begin{array}{lllll}0.975 & 0.00 \mathrm{E}+00 & 0.00 \mathrm{E}+00 & 0.00 \mathrm{E}+00\end{array}$

$\begin{array}{lllll}0.990 & 0.00 \mathrm{E}+00 & 0.00 \mathrm{E}+00 & 0.00 \mathrm{E}+00\end{array}$ 
RESRAD-OFFSITE, Version 2.5

Probabilistic Dose and Risk Report

Title : Offsite Resident Farmer

File : RF TC99 DOESG FWD-FV2all.ROF

Statistics and Cumulative distribution function of Peak Risk from Plant (CzandAir)

$\begin{array}{ccccc}\text { Repetition }= & 1 & 2 & 3 \\ \text { Mean } & 0.00 \mathrm{E}+00 & 0.00 \mathrm{E}+00 & 0.00 \mathrm{E}+00 \\ \text { Std. Dev. } & 0.00 \mathrm{E}+00 & 0.00 \mathrm{E}+00 & 0.00 \mathrm{E}+00 \\ \text { Minimum } & 0.00 \mathrm{E}+00 & 0.00 \mathrm{E}+00 & 0.00 \mathrm{E}+00 \\ \text { Maximum } & 0.00 \mathrm{E}+00 & 0.00 \mathrm{E}+00 & 0.00 \mathrm{E}+00\end{array}$

Percentile

$\begin{array}{llll}0.010 & 0.00 \mathrm{E}+00 & 0.00 \mathrm{E}+00 & 0.00 \mathrm{E}+00\end{array}$

$\begin{array}{llll}0.025 & 0.00 \mathrm{E}+00 & 0.00 \mathrm{E}+00 & 0.00 \mathrm{E}+00\end{array}$

$\begin{array}{llll}0.050 & 0.00 \mathrm{E}+00 & 0.00 \mathrm{E}+00 & 0.00 \mathrm{E}+00\end{array}$

$\begin{array}{llll}0.075 & 0.00 \mathrm{E}+00 & 0.00 \mathrm{E}+00 & 0.00 \mathrm{E}+00\end{array}$

$\begin{array}{llll}0.100 & 0.00 \mathrm{E}+00 & 0.00 \mathrm{E}+00 & 0.00 \mathrm{E}+00\end{array}$

$\begin{array}{llll}0.125 & 0.00 \mathrm{E}+00 & 0.00 \mathrm{E}+00 & 0.00 \mathrm{E}+00\end{array}$

$\begin{array}{llll}0.150 & 0.00 \mathrm{E}+00 & 0.00 \mathrm{E}+00 & 0.00 \mathrm{E}+00\end{array}$

$\begin{array}{llll}0.175 & 0.00 \mathrm{E}+00 & 0.00 \mathrm{E}+00 & 0.00 \mathrm{E}+00\end{array}$

$\begin{array}{llll}0.200 & 0.00 \mathrm{E}+00 & 0.00 \mathrm{E}+00 & 0.00 \mathrm{E}+00\end{array}$

$\begin{array}{lllll}0.225 & 0.00 \mathrm{E}+00 & 0.00 \mathrm{E}+00 & 0.00 \mathrm{E}+00\end{array}$

$\begin{array}{llll}0.250 & 0.00 \mathrm{E}+00 & 0.00 \mathrm{E}+00 & 0.00 \mathrm{E}+00\end{array}$

$\begin{array}{llll}0.275 & 0.00 \mathrm{E}+00 & 0.00 \mathrm{E}+00 & 0.00 \mathrm{E}+00\end{array}$

$\begin{array}{lllll}0.300 & 0.00 \mathrm{E}+00 & 0.00 \mathrm{E}+00 & 0.00 \mathrm{E}+00\end{array}$

$\begin{array}{lllll}0.325 & 0.00 \mathrm{E}+00 & 0.00 \mathrm{E}+00 & 0.00 \mathrm{E}+00\end{array}$

$\begin{array}{lllll}0.350 & 0.00 \mathrm{E}+00 & 0.00 \mathrm{E}+00 & 0.00 \mathrm{E}+00\end{array}$

$\begin{array}{lllll}0.375 & 0.00 \mathrm{E}+00 & 0.00 \mathrm{E}+00 & 0.00 \mathrm{E}+00\end{array}$

$\begin{array}{lllll}0.400 & 0.00 \mathrm{E}+00 & 0.00 \mathrm{E}+00 & 0.00 \mathrm{E}+00\end{array}$

$\begin{array}{lllll}0.425 & 0.00 \mathrm{E}+00 & 0.00 \mathrm{E}+00 & 0.00 \mathrm{E}+00\end{array}$

$\begin{array}{lllll}0.450 & 0.00 \mathrm{E}+00 & 0.00 \mathrm{E}+00 & 0.00 \mathrm{E}+00\end{array}$

$\begin{array}{lllll}0.475 & 0.00 \mathrm{E}+00 & 0.00 \mathrm{E}+00 & 0.00 \mathrm{E}+00\end{array}$

$\begin{array}{lllll}0.500 & 0.00 \mathrm{E}+00 & 0.00 \mathrm{E}+00 & 0.00 \mathrm{E}+00\end{array}$

$\begin{array}{lllll}0.525 & 0.00 \mathrm{E}+00 & 0.00 \mathrm{E}+00 & 0.00 \mathrm{E}+00\end{array}$

$\begin{array}{lllll}0.550 & 0.00 \mathrm{E}+00 & 0.00 \mathrm{E}+00 & 0.00 \mathrm{E}+00\end{array}$

$\begin{array}{lllll}0.575 & 0.00 \mathrm{E}+00 & 0.00 \mathrm{E}+00 & 0.00 \mathrm{E}+00\end{array}$

$\begin{array}{lllll}0.600 & 0.00 \mathrm{E}+00 & 0.00 \mathrm{E}+00 & 0.00 \mathrm{E}+00\end{array}$

$\begin{array}{lllll}0.625 & 0.00 \mathrm{E}+00 & 0.00 \mathrm{E}+00 & 0.00 \mathrm{E}+00\end{array}$

$\begin{array}{lllll}0.650 & 0.00 \mathrm{E}+00 & 0.00 \mathrm{E}+00 & 0.00 \mathrm{E}+00\end{array}$

$\begin{array}{lllll}0.675 & 0.00 \mathrm{E}+00 & 0.00 \mathrm{E}+00 & 0.00 \mathrm{E}+00\end{array}$

$\begin{array}{lllll}0.700 & 0.00 \mathrm{E}+00 & 0.00 \mathrm{E}+00 & 0.00 \mathrm{E}+00\end{array}$

$\begin{array}{lllll}0.725 & 0.00 \mathrm{E}+00 & 0.00 \mathrm{E}+00 & 0.00 \mathrm{E}+00\end{array}$

$\begin{array}{lllll}0.750 & 0.00 \mathrm{E}+00 & 0.00 \mathrm{E}+00 & 0.00 \mathrm{E}+00\end{array}$

$\begin{array}{llll}0.775 & 0.00 \mathrm{E}+00 & 0.00 \mathrm{E}+00 & 0.00 \mathrm{E}+00\end{array}$

$\begin{array}{lllll}0.800 & 0.00 \mathrm{E}+00 & 0.00 \mathrm{E}+00 & 0.00 \mathrm{E}+00\end{array}$

$\begin{array}{lllll}0.825 & 0.00 \mathrm{E}+00 & 0.00 \mathrm{E}+00 & 0.00 \mathrm{E}+00\end{array}$

$\begin{array}{lllll}0.850 & 0.00 \mathrm{E}+00 & 0.00 \mathrm{E}+00 & 0.00 \mathrm{E}+00\end{array}$

$\begin{array}{llll}0.875 & 0.00 \mathrm{E}+00 & 0.00 \mathrm{E}+00 & 0.00 \mathrm{E}+00\end{array}$

$\begin{array}{lllll}0.900 & 0.00 \mathrm{E}+00 & 0.00 \mathrm{E}+00 & 0.00 \mathrm{E}+00\end{array}$

$\begin{array}{llll}0.925 & 0.00 \mathrm{E}+00 & 0.00 \mathrm{E}+00 & 0.00 \mathrm{E}+00\end{array}$

$\begin{array}{lllll}0.950 & 0.00 \mathrm{E}+00 & 0.00 \mathrm{E}+00 & 0.00 \mathrm{E}+00\end{array}$

$\begin{array}{lllll}0.975 & 0.00 \mathrm{E}+00 & 0.00 \mathrm{E}+00 & 0.00 \mathrm{E}+00\end{array}$

$\begin{array}{lllll}0.990 & 0.00 \mathrm{E}+00 & 0.00 \mathrm{E}+00 & 0.00 \mathrm{E}+00\end{array}$ 
RESRAD-OFFSITE, Version 2.5

Probabilistic Dose and Risk Report

Title : Offsite Resident Farmer

File : RF TC99 DOESG FWD-FV2all.ROF

Statistics and Cumulative distribution function of Peak Risk from Meat (CZandAir)

$\begin{array}{ccccc}\text { Repetition }= & 1 & 2 & 3 \\ \begin{array}{c}\text { Mean } \\ \text { Std. Dev. }\end{array} & 0.00 \mathrm{E}+00 & 0.00 \mathrm{E}+00 & 0.00 \mathrm{E}+00 \\ \text { Minimum } & 0.00 \mathrm{E}+00 & 0.00 \mathrm{E}+00 & 0.00 \mathrm{E}+00 \\ \text { Maximum } & 0.00 \mathrm{E}+00 & 0.00 \mathrm{E}+00 & 0.00 \mathrm{E}+00 \\ & 0.00 \mathrm{E}+00 & 0.00 \mathrm{E}+00 & 0.00 \mathrm{E}+00\end{array}$

Percentile

$\begin{array}{llll}0.010 & 0.00 \mathrm{E}+00 & 0.00 \mathrm{E}+00 & 0.00 \mathrm{E}+00\end{array}$

$\begin{array}{llll}0.025 & 0.00 \mathrm{E}+00 & 0.00 \mathrm{E}+00 & 0.00 \mathrm{E}+00\end{array}$

$\begin{array}{llll}0.050 & 0.00 \mathrm{E}+00 & 0.00 \mathrm{E}+00 & 0.00 \mathrm{E}+00\end{array}$

$\begin{array}{llll}0.075 & 0.00 \mathrm{E}+00 & 0.00 \mathrm{E}+00 & 0.00 \mathrm{E}+00\end{array}$

$\begin{array}{llll}0.100 & 0.00 \mathrm{E}+00 & 0.00 \mathrm{E}+00 & 0.00 \mathrm{E}+00\end{array}$

$\begin{array}{llll}0.125 & 0.00 \mathrm{E}+00 & 0.00 \mathrm{E}+00 & 0.00 \mathrm{E}+00\end{array}$

$\begin{array}{llll}0.150 & 0.00 \mathrm{E}+00 & 0.00 \mathrm{E}+00 & 0.00 \mathrm{E}+00\end{array}$

$\begin{array}{llll}0.175 & 0.00 \mathrm{E}+00 & 0.00 \mathrm{E}+00 & 0.00 \mathrm{E}+00\end{array}$

$\begin{array}{llll}0.200 & 0.00 \mathrm{E}+00 & 0.00 \mathrm{E}+00 & 0.00 \mathrm{E}+00\end{array}$

$\begin{array}{lllll}0.225 & 0.00 \mathrm{E}+00 & 0.00 \mathrm{E}+00 & 0.00 \mathrm{E}+00\end{array}$

$\begin{array}{llll}0.250 & 0.00 \mathrm{E}+00 & 0.00 \mathrm{E}+00 & 0.00 \mathrm{E}+00\end{array}$

$\begin{array}{llll}0.275 & 0.00 \mathrm{E}+00 & 0.00 \mathrm{E}+00 & 0.00 \mathrm{E}+00\end{array}$

$\begin{array}{lllll}0.300 & 0.00 \mathrm{E}+00 & 0.00 \mathrm{E}+00 & 0.00 \mathrm{E}+00\end{array}$

$\begin{array}{lllll}0.325 & 0.00 \mathrm{E}+00 & 0.00 \mathrm{E}+00 & 0.00 \mathrm{E}+00\end{array}$

$\begin{array}{lllll}0.350 & 0.00 \mathrm{E}+00 & 0.00 \mathrm{E}+00 & 0.00 \mathrm{E}+00\end{array}$

$\begin{array}{lllll}0.375 & 0.00 \mathrm{E}+00 & 0.00 \mathrm{E}+00 & 0.00 \mathrm{E}+00\end{array}$

$\begin{array}{lllll}0.400 & 0.00 \mathrm{E}+00 & 0.00 \mathrm{E}+00 & 0.00 \mathrm{E}+00\end{array}$

$\begin{array}{lllll}0.425 & 0.00 \mathrm{E}+00 & 0.00 \mathrm{E}+00 & 0.00 \mathrm{E}+00\end{array}$

$\begin{array}{lllll}0.450 & 0.00 \mathrm{E}+00 & 0.00 \mathrm{E}+00 & 0.00 \mathrm{E}+00\end{array}$

$\begin{array}{lllll}0.475 & 0.00 \mathrm{E}+00 & 0.00 \mathrm{E}+00 & 0.00 \mathrm{E}+00\end{array}$

$\begin{array}{lllll}0.500 & 0.00 \mathrm{E}+00 & 0.00 \mathrm{E}+00 & 0.00 \mathrm{E}+00\end{array}$

$\begin{array}{lllll}0.525 & 0.00 \mathrm{E}+00 & 0.00 \mathrm{E}+00 & 0.00 \mathrm{E}+00\end{array}$

$\begin{array}{lllll}0.550 & 0.00 \mathrm{E}+00 & 0.00 \mathrm{E}+00 & 0.00 \mathrm{E}+00\end{array}$

$\begin{array}{lllll}0.575 & 0.00 \mathrm{E}+00 & 0.00 \mathrm{E}+00 & 0.00 \mathrm{E}+00\end{array}$

$\begin{array}{lllll}0.600 & 0.00 \mathrm{E}+00 & 0.00 \mathrm{E}+00 & 0.00 \mathrm{E}+00\end{array}$

$\begin{array}{lllll}0.625 & 0.00 \mathrm{E}+00 & 0.00 \mathrm{E}+00 & 0.00 \mathrm{E}+00\end{array}$

$\begin{array}{lllll}0.650 & 0.00 \mathrm{E}+00 & 0.00 \mathrm{E}+00 & 0.00 \mathrm{E}+00\end{array}$

$\begin{array}{lllll}0.675 & 0.00 \mathrm{E}+00 & 0.00 \mathrm{E}+00 & 0.00 \mathrm{E}+00\end{array}$

$\begin{array}{lllll}0.700 & 0.00 \mathrm{E}+00 & 0.00 \mathrm{E}+00 & 0.00 \mathrm{E}+00\end{array}$

$\begin{array}{lllll}0.725 & 0.00 \mathrm{E}+00 & 0.00 \mathrm{E}+00 & 0.00 \mathrm{E}+00\end{array}$

$\begin{array}{lllll}0.750 & 0.00 \mathrm{E}+00 & 0.00 \mathrm{E}+00 & 0.00 \mathrm{E}+00\end{array}$

$\begin{array}{llll}0.775 & 0.00 \mathrm{E}+00 & 0.00 \mathrm{E}+00 & 0.00 \mathrm{E}+00\end{array}$

$\begin{array}{lllll}0.800 & 0.00 \mathrm{E}+00 & 0.00 \mathrm{E}+00 & 0.00 \mathrm{E}+00\end{array}$

$\begin{array}{lllll}0.825 & 0.00 \mathrm{E}+00 & 0.00 \mathrm{E}+00 & 0.00 \mathrm{E}+00\end{array}$

$\begin{array}{lllll}0.850 & 0.00 \mathrm{E}+00 & 0.00 \mathrm{E}+00 & 0.00 \mathrm{E}+00\end{array}$

$\begin{array}{llll}0.875 & 0.00 \mathrm{E}+00 & 0.00 \mathrm{E}+00 & 0.00 \mathrm{E}+00\end{array}$

$\begin{array}{lllll}0.900 & 0.00 \mathrm{E}+00 & 0.00 \mathrm{E}+00 & 0.00 \mathrm{E}+00\end{array}$

$\begin{array}{llll}0.925 & 0.00 \mathrm{E}+00 & 0.00 \mathrm{E}+00 & 0.00 \mathrm{E}+00\end{array}$

$\begin{array}{lllll}0.950 & 0.00 \mathrm{E}+00 & 0.00 \mathrm{E}+00 & 0.00 \mathrm{E}+00\end{array}$

$\begin{array}{lllll}0.975 & 0.00 \mathrm{E}+00 & 0.00 \mathrm{E}+00 & 0.00 \mathrm{E}+00\end{array}$

$\begin{array}{lllll}0.990 & 0.00 \mathrm{E}+00 & 0.00 \mathrm{E}+00 & 0.00 \mathrm{E}+00\end{array}$ 
RESRAD-OFFSITE, Version 2.5

Probabilistic Dose and Risk Report

Title : Offsite Resident Farmer

File : RF TC99 DOESG FWD-FV2all.ROF

Statistics and Cumulative distribution function of Peak Risk from Milk (CzandAir)

$\begin{array}{ccccc}\text { Repetition }= & 1 & 2 & 3 \\ \begin{array}{c}\text { Mean } \\ \text { Std. Dev. }\end{array} & 0.00 \mathrm{E}+00 & 0.00 \mathrm{E}+00 & 0.00 \mathrm{E}+00 \\ \text { Minimum } & 0.00 \mathrm{E}+00 & 0.00 \mathrm{E}+00 & 0.00 \mathrm{E}+00 \\ \text { Maximum } & 0.00 \mathrm{E}+00 & 0.00 \mathrm{E}+00 & 0.00 \mathrm{E}+00 \\ & 0.00 \mathrm{E}+00 & 0.00 \mathrm{E}+00 & 0.00 \mathrm{E}+00\end{array}$

Percentile

$\begin{array}{llll}0.010 & 0.00 \mathrm{E}+00 & 0.00 \mathrm{E}+00 & 0.00 \mathrm{E}+00\end{array}$

$\begin{array}{llll}0.025 & 0.00 \mathrm{E}+00 & 0.00 \mathrm{E}+00 & 0.00 \mathrm{E}+00\end{array}$

$\begin{array}{lllll}0.050 & 0.00 \mathrm{E}+00 & 0.00 \mathrm{E}+00 & 0.00 \mathrm{E}+00\end{array}$

$\begin{array}{llll}0.075 & 0.00 \mathrm{E}+00 & 0.00 \mathrm{E}+00 & 0.00 \mathrm{E}+00\end{array}$

$\begin{array}{llll}0.100 & 0.00 \mathrm{E}+00 & 0.00 \mathrm{E}+00 & 0.00 \mathrm{E}+00\end{array}$

$\begin{array}{llll}0.125 & 0.00 \mathrm{E}+00 & 0.00 \mathrm{E}+00 & 0.00 \mathrm{E}+00\end{array}$

$\begin{array}{llll}0.150 & 0.00 \mathrm{E}+00 & 0.00 \mathrm{E}+00 & 0.00 \mathrm{E}+00\end{array}$

$\begin{array}{llll}0.175 & 0.00 \mathrm{E}+00 & 0.00 \mathrm{E}+00 & 0.00 \mathrm{E}+00\end{array}$

$\begin{array}{llll}0.200 & 0.00 \mathrm{E}+00 & 0.00 \mathrm{E}+00 & 0.00 \mathrm{E}+00\end{array}$

$\begin{array}{lllll}0.225 & 0.00 \mathrm{E}+00 & 0.00 \mathrm{E}+00 & 0.00 \mathrm{E}+00\end{array}$

$\begin{array}{llll}0.250 & 0.00 \mathrm{E}+00 & 0.00 \mathrm{E}+00 & 0.00 \mathrm{E}+00\end{array}$

$\begin{array}{llll}0.275 & 0.00 \mathrm{E}+00 & 0.00 \mathrm{E}+00 & 0.00 \mathrm{E}+00\end{array}$

$\begin{array}{lllll}0.300 & 0.00 \mathrm{E}+00 & 0.00 \mathrm{E}+00 & 0.00 \mathrm{E}+00\end{array}$

$\begin{array}{lllll}0.325 & 0.00 \mathrm{E}+00 & 0.00 \mathrm{E}+00 & 0.00 \mathrm{E}+00\end{array}$

$\begin{array}{lllll}0.350 & 0.00 \mathrm{E}+00 & 0.00 \mathrm{E}+00 & 0.00 \mathrm{E}+00\end{array}$

$\begin{array}{lllll}0.375 & 0.00 \mathrm{E}+00 & 0.00 \mathrm{E}+00 & 0.00 \mathrm{E}+00\end{array}$

$\begin{array}{lllll}0.400 & 0.00 \mathrm{E}+00 & 0.00 \mathrm{E}+00 & 0.00 \mathrm{E}+00\end{array}$

$\begin{array}{lllll}0.425 & 0.00 \mathrm{E}+00 & 0.00 \mathrm{E}+00 & 0.00 \mathrm{E}+00\end{array}$

$\begin{array}{lllll}0.450 & 0.00 \mathrm{E}+00 & 0.00 \mathrm{E}+00 & 0.00 \mathrm{E}+00\end{array}$

$\begin{array}{lllll}0.475 & 0.00 \mathrm{E}+00 & 0.00 \mathrm{E}+00 & 0.00 \mathrm{E}+00\end{array}$

$\begin{array}{lllll}0.500 & 0.00 \mathrm{E}+00 & 0.00 \mathrm{E}+00 & 0.00 \mathrm{E}+00\end{array}$

$\begin{array}{lllll}0.525 & 0.00 \mathrm{E}+00 & 0.00 \mathrm{E}+00 & 0.00 \mathrm{E}+00\end{array}$

$\begin{array}{lllll}0.550 & 0.00 \mathrm{E}+00 & 0.00 \mathrm{E}+00 & 0.00 \mathrm{E}+00\end{array}$

$\begin{array}{lllll}0.575 & 0.00 \mathrm{E}+00 & 0.00 \mathrm{E}+00 & 0.00 \mathrm{E}+00\end{array}$

$\begin{array}{lllll}0.600 & 0.00 \mathrm{E}+00 & 0.00 \mathrm{E}+00 & 0.00 \mathrm{E}+00\end{array}$

$\begin{array}{lllll}0.625 & 0.00 \mathrm{E}+00 & 0.00 \mathrm{E}+00 & 0.00 \mathrm{E}+00\end{array}$

$\begin{array}{lllll}0.650 & 0.00 \mathrm{E}+00 & 0.00 \mathrm{E}+00 & 0.00 \mathrm{E}+00\end{array}$

$\begin{array}{lllll}0.675 & 0.00 \mathrm{E}+00 & 0.00 \mathrm{E}+00 & 0.00 \mathrm{E}+00\end{array}$

$\begin{array}{lllll}0.700 & 0.00 \mathrm{E}+00 & 0.00 \mathrm{E}+00 & 0.00 \mathrm{E}+00\end{array}$

$\begin{array}{lllll}0.725 & 0.00 \mathrm{E}+00 & 0.00 \mathrm{E}+00 & 0.00 \mathrm{E}+00\end{array}$

$\begin{array}{lllll}0.750 & 0.00 \mathrm{E}+00 & 0.00 \mathrm{E}+00 & 0.00 \mathrm{E}+00\end{array}$

$\begin{array}{llll}0.775 & 0.00 \mathrm{E}+00 & 0.00 \mathrm{E}+00 & 0.00 \mathrm{E}+00\end{array}$

$\begin{array}{lllll}0.800 & 0.00 \mathrm{E}+00 & 0.00 \mathrm{E}+00 & 0.00 \mathrm{E}+00\end{array}$

$\begin{array}{lllll}0.825 & 0.00 \mathrm{E}+00 & 0.00 \mathrm{E}+00 & 0.00 \mathrm{E}+00\end{array}$

$\begin{array}{lllll}0.850 & 0.00 \mathrm{E}+00 & 0.00 \mathrm{E}+00 & 0.00 \mathrm{E}+00\end{array}$

$\begin{array}{llll}0.875 & 0.00 \mathrm{E}+00 & 0.00 \mathrm{E}+00 & 0.00 \mathrm{E}+00\end{array}$

$\begin{array}{lllll}0.900 & 0.00 \mathrm{E}+00 & 0.00 \mathrm{E}+00 & 0.00 \mathrm{E}+00\end{array}$

$\begin{array}{llll}0.925 & 0.00 \mathrm{E}+00 & 0.00 \mathrm{E}+00 & 0.00 \mathrm{E}+00\end{array}$

$\begin{array}{lllll}0.950 & 0.00 \mathrm{E}+00 & 0.00 \mathrm{E}+00 & 0.00 \mathrm{E}+00\end{array}$

$\begin{array}{lllll}0.975 & 0.00 \mathrm{E}+00 & 0.00 \mathrm{E}+00 & 0.00 \mathrm{E}+00\end{array}$

$\begin{array}{llll}0.990 & 0.00 \mathrm{E}+00 & 0.00 \mathrm{E}+00 & 0.00 \mathrm{E}+00\end{array}$

C-581

DCN 5090-TR-02-2 
RESRAD-OFFSITE, Version 2.5

Probabilistic Dose and Risk Report

Title : Offsite Resident Farmer

File : RF TC99 DOESG FWD-FV2all.ROF

Statistics and Cumulative distribution function of Peak Risk from Soil Ingestion(CZandAir)

$\begin{array}{ccccc}\text { Repetition }= & 1 & 2 & 3 \\ \begin{array}{c}\text { Mean } \\ \text { Std. Dev. }\end{array} & 0.00 \mathrm{E}+00 & 0.00 \mathrm{E}+00 & 0.00 \mathrm{E}+00 \\ \text { Minimum } & 0.00 \mathrm{E}+00 & 0.00 \mathrm{E}+00 & 0.00 \mathrm{E}+00 \\ \text { Maximum } & 0.00 \mathrm{E}+00 & 0.00 \mathrm{E}+00 & 0.00 \mathrm{E}+00 \\ & 0.00 \mathrm{E}+00 & 0.00 \mathrm{E}+00 & 0.00 \mathrm{E}+00\end{array}$

Percentile

$\begin{array}{llll}0.010 & 0.00 \mathrm{E}+00 & 0.00 \mathrm{E}+00 & 0.00 \mathrm{E}+00\end{array}$

$\begin{array}{llll}0.025 & 0.00 \mathrm{E}+00 & 0.00 \mathrm{E}+00 & 0.00 \mathrm{E}+00\end{array}$

$\begin{array}{llll}0.050 & 0.00 \mathrm{E}+00 & 0.00 \mathrm{E}+00 & 0.00 \mathrm{E}+00\end{array}$

$\begin{array}{llll}0.075 & 0.00 \mathrm{E}+00 & 0.00 \mathrm{E}+00 & 0.00 \mathrm{E}+00\end{array}$

$\begin{array}{llll}0.100 & 0.00 \mathrm{E}+00 & 0.00 \mathrm{E}+00 & 0.00 \mathrm{E}+00\end{array}$

$\begin{array}{llll}0.125 & 0.00 \mathrm{E}+00 & 0.00 \mathrm{E}+00 & 0.00 \mathrm{E}+00\end{array}$

$\begin{array}{llll}0.150 & 0.00 \mathrm{E}+00 & 0.00 \mathrm{E}+00 & 0.00 \mathrm{E}+00\end{array}$

$\begin{array}{llll}0.175 & 0.00 \mathrm{E}+00 & 0.00 \mathrm{E}+00 & 0.00 \mathrm{E}+00\end{array}$

$\begin{array}{llll}0.200 & 0.00 \mathrm{E}+00 & 0.00 \mathrm{E}+00 & 0.00 \mathrm{E}+00\end{array}$

$\begin{array}{lllll}0.225 & 0.00 \mathrm{E}+00 & 0.00 \mathrm{E}+00 & 0.00 \mathrm{E}+00\end{array}$

$\begin{array}{llll}0.250 & 0.00 \mathrm{E}+00 & 0.00 \mathrm{E}+00 & 0.00 \mathrm{E}+00\end{array}$

$\begin{array}{llll}0.275 & 0.00 \mathrm{E}+00 & 0.00 \mathrm{E}+00 & 0.00 \mathrm{E}+00\end{array}$

$\begin{array}{lllll}0.300 & 0.00 \mathrm{E}+00 & 0.00 \mathrm{E}+00 & 0.00 \mathrm{E}+00\end{array}$

$\begin{array}{lllll}0.325 & 0.00 \mathrm{E}+00 & 0.00 \mathrm{E}+00 & 0.00 \mathrm{E}+00\end{array}$

$\begin{array}{lllll}0.350 & 0.00 \mathrm{E}+00 & 0.00 \mathrm{E}+00 & 0.00 \mathrm{E}+00\end{array}$

$\begin{array}{lllll}0.375 & 0.00 \mathrm{E}+00 & 0.00 \mathrm{E}+00 & 0.00 \mathrm{E}+00\end{array}$

$\begin{array}{lllll}0.400 & 0.00 \mathrm{E}+00 & 0.00 \mathrm{E}+00 & 0.00 \mathrm{E}+00\end{array}$

$\begin{array}{lllll}0.425 & 0.00 \mathrm{E}+00 & 0.00 \mathrm{E}+00 & 0.00 \mathrm{E}+00\end{array}$

$\begin{array}{lllll}0.450 & 0.00 \mathrm{E}+00 & 0.00 \mathrm{E}+00 & 0.00 \mathrm{E}+00\end{array}$

$\begin{array}{lllll}0.475 & 0.00 \mathrm{E}+00 & 0.00 \mathrm{E}+00 & 0.00 \mathrm{E}+00\end{array}$

$\begin{array}{lllll}0.500 & 0.00 \mathrm{E}+00 & 0.00 \mathrm{E}+00 & 0.00 \mathrm{E}+00\end{array}$

$\begin{array}{lllll}0.525 & 0.00 \mathrm{E}+00 & 0.00 \mathrm{E}+00 & 0.00 \mathrm{E}+00\end{array}$

$\begin{array}{llll}0.550 & 0.00 \mathrm{E}+00 & 0.00 \mathrm{E}+00 & 0.00 \mathrm{E}+00\end{array}$

$\begin{array}{lllll}0.575 & 0.00 \mathrm{E}+00 & 0.00 \mathrm{E}+00 & 0.00 \mathrm{E}+00\end{array}$

$\begin{array}{lllll}0.600 & 0.00 \mathrm{E}+00 & 0.00 \mathrm{E}+00 & 0.00 \mathrm{E}+00\end{array}$

$\begin{array}{lllll}0.625 & 0.00 \mathrm{E}+00 & 0.00 \mathrm{E}+00 & 0.00 \mathrm{E}+00\end{array}$

$\begin{array}{lllll}0.650 & 0.00 \mathrm{E}+00 & 0.00 \mathrm{E}+00 & 0.00 \mathrm{E}+00\end{array}$

$\begin{array}{lllll}0.675 & 0.00 \mathrm{E}+00 & 0.00 \mathrm{E}+00 & 0.00 \mathrm{E}+00\end{array}$

$\begin{array}{lllll}0.700 & 0.00 \mathrm{E}+00 & 0.00 \mathrm{E}+00 & 0.00 \mathrm{E}+00\end{array}$

$\begin{array}{lllll}0.725 & 0.00 \mathrm{E}+00 & 0.00 \mathrm{E}+00 & 0.00 \mathrm{E}+00\end{array}$

$\begin{array}{lllll}0.750 & 0.00 \mathrm{E}+00 & 0.00 \mathrm{E}+00 & 0.00 \mathrm{E}+00\end{array}$

$\begin{array}{lllll}0.775 & 0.00 \mathrm{E}+00 & 0.00 \mathrm{E}+00 & 0.00 \mathrm{E}+00\end{array}$

$\begin{array}{lllll}0.800 & 0.00 \mathrm{E}+00 & 0.00 \mathrm{E}+00 & 0.00 \mathrm{E}+00\end{array}$

$\begin{array}{lllll}0.825 & 0.00 \mathrm{E}+00 & 0.00 \mathrm{E}+00 & 0.00 \mathrm{E}+00\end{array}$

$\begin{array}{lllll}0.850 & 0.00 \mathrm{E}+00 & 0.00 \mathrm{E}+00 & 0.00 \mathrm{E}+00\end{array}$

$\begin{array}{lllll}0.875 & 0.00 \mathrm{E}+00 & 0.00 \mathrm{E}+00 & 0.00 \mathrm{E}+00\end{array}$

$\begin{array}{lllll}0.900 & 0.00 \mathrm{E}+00 & 0.00 \mathrm{E}+00 & 0.00 \mathrm{E}+00\end{array}$

$\begin{array}{llll}0.925 & 0.00 \mathrm{E}+00 & 0.00 \mathrm{E}+00 & 0.00 \mathrm{E}+00\end{array}$

$\begin{array}{lllll}0.950 & 0.00 \mathrm{E}+00 & 0.00 \mathrm{E}+00 & 0.00 \mathrm{E}+00\end{array}$

$\begin{array}{lllll}0.975 & 0.00 \mathrm{E}+00 & 0.00 \mathrm{E}+00 & 0.00 \mathrm{E}+00\end{array}$

$\begin{array}{lllll}0.990 & 0.00 \mathrm{E}+00 & 0.00 \mathrm{E}+00 & 0.00 \mathrm{E}+00\end{array}$ 
RESRAD-OFFSITE, Version 2.5

Title : Offsite Resident Farmer

File : RF TC99 DOESG FWD-FV2all.ROF

Time

Years

$0.00 \mathrm{E}+00$

$5.13 \mathrm{E}-01$

$1.03 \mathrm{E}+00$

$1.54 \mathrm{E}+00$

$2.05 \mathrm{E}+00$

$2.56 \mathrm{E}+00$

$3.08 \mathrm{E}+00$

$3.59 \mathrm{E}+00$

$4.10 \mathrm{E}+00$

$4.61 \mathrm{E}+00$

$5.13 \mathrm{E}+00$

$5.64 \mathrm{E}+00$

$6.15 \mathrm{E}+00$

$6.67 \mathrm{E}+00$

$7.18 \mathrm{E}+00$

$7.69 \mathrm{E}+00$

$8.20 \mathrm{E}+00$

$8.72 \mathrm{E}+00$

$9.23 \mathrm{E}+00$

$9.74 \mathrm{E}+00$

$1.03 E+01$

$1.08 \mathrm{E}+01$

$1.13 \mathrm{E}+01$

$1.18 \mathrm{E}+01$

$1.23 E+01$

$1.28 \mathrm{E}+01$

$1.33 \mathrm{E}+01$

$1.38 \mathrm{E}+01$

$1.44 \mathrm{E}+01$

$1.49 \mathrm{E}+01$

$1.54 \mathrm{E}+01$

$1.59 \mathrm{E}+01$

$1.64 \mathrm{E}+01$

$1.69 \mathrm{E}+01$

$1.74 \mathrm{E}+01$

$1.79 \mathrm{E}+01$

$1.85 \mathrm{E}+01$

$1.90 \mathrm{E}+01$

1. $95 \mathrm{E}+01$

$2.00 \mathrm{E}+01$

$2.05 \mathrm{E}+01$

$2.10 \mathrm{E}+01$

$2.15 E+01$

$2.20 \mathrm{E}+01$

$2.26 \mathrm{E}+01$

$2.31 \mathrm{E}+01$
Summary of dose at graphical times, reptition 1

Dose statistics at graphical times, mrem/yr

\begin{tabular}{|c|c|c|c|c|c|c|c|}
\hline Iinimum & Iaximum & Mean & Median & 00 & $\%$ & $97.5 \%$ & 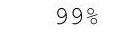 \\
\hline $80 \mathrm{E}-32$ & $1.82 \mathrm{E}-32$ & 1. $82 \mathrm{E}-32$ & $1.82 \mathrm{E}-32$ & $32 E-32$ & $82 E-32$ & 1. $82 \mathrm{E}-32$ & ז \\
\hline $79 E-32$ & 32 & $1.83 E-32$ & $1.84 \mathrm{E}-32$ & $1.84 \mathrm{E}-32$ & $1.84 \mathrm{E}-32$ & -32 & 32 \\
\hline $78 E-32$ & $35 E-32$ & 32 & -32 & $85 E-32$ & 32 & 32 & 32 \\
\hline $7 E-32$ & -32 & $6 E-32$ & -32 & $E-32$ & $7 E-$ & 32 & -32 \\
\hline $6 E-32$ & $9 E-32$ & 2 & 2 & $9 \mathrm{E}$ & $9 \mathrm{E}$ & 32 & -32 \\
\hline $.75 E-32$ & & & & & & & \\
\hline-32 & & & & 2 & 2 & 32 & $2 E-32$ \\
\hline $.73 E-32$ & 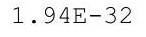 & - & - & $4 E-32$ & 2 & 32 & $94 E-32$ \\
\hline $.72 E-32$ & 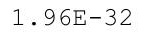 & 专 & $1.95 E-32$ & - & 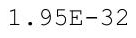 & . & 1. $95 E-32$ \\
\hline $71 \mathrm{E}-32$ & 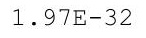 & 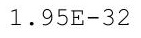 & 32 & 2 & 2 & -32 & $97 E-32$ \\
\hline $.70 E-32$ & $E-32$ & $E-32$ & 2 & 2 & 2 & 32 & -32 \\
\hline 32 & & & & & & & -32 \\
\hline 2 & & 2 & & & 2 & 2 & -32 \\
\hline $67 E-32$ & & 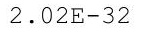 & 2 & & 2 & 82 & -32 \\
\hline $.66 E-32$ & 年 & 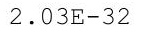 & 2.040 & . & - & 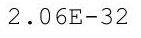 & -32 \\
\hline $.65 E-32$ & 2.0 & 舟 & & 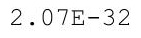 & & (2) & -32 \\
\hline $.64 E-32$ & $2.10 E-32$ & 2.06 & -32 & $9=$ & ( & 2 & -32 \\
\hline $64 \mathrm{E}-32$ & $2.12 \mathrm{E}-32$ & & $2.09 E-32$ & & $2.11 \mathrm{E}-32$ & $2.11 \mathrm{E}-32$ & $11 E-32$ \\
\hline $3 E-32$ & -3 & 2 & 2 & 2 & 2 & -32 & $3 E-32$ \\
\hline $.62 E-32$ & $2.15 E-32$ & $2.11 \mathrm{E}-3$ & $2 \cdot 13 \pm-32$ & $15 \mathrm{E}-3$ & 2 & $2.15 E-32$ & $15 E-32$ \\
\hline $61 \mathrm{E}-32$ & $2 \cdot 1 / \pm 22$ & 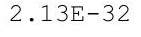 & -32 & 2 & & 32 & -32 \\
\hline $60 \mathrm{E}-32$ & 2. & 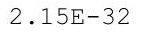 & 32 & & & & -32 \\
\hline $59 E-32$ & 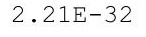 & $2 \cdot$ & 2 & 2 & 2 & $2.21 E-32$ & -32 \\
\hline $.58 E-32$ & $2.23 E-32$ & $2.18 E-32$ & -32 & $2.22 \mathrm{E}-$ & $2.23 \mathrm{E}-$ & -32 & $23 E-32$ \\
\hline $.57 E-32$ & $-6-5$ & $2.20 \mathrm{E}-32$ & $E-32$ & $2.24 \mathrm{E}-$ & $2.25 \mathrm{E}-$ & $2.25 E-32$ & $25 E-32$ \\
\hline 32 & 32 & 2 & 32 & 2 & & $.27 E-32$ & $27 E-32$ \\
\hline$E-32$ & 32 & 2 & 32 & 2 & & 32 & $E-32$ \\
\hline $.55 E-32$ & $2.315-32$ & 2.20104 & $7 E-32$ & 2 & & & -32 \\
\hline $.54 \mathrm{E}-32$ & $2.33 E-32$ & $2.27 \mathrm{E}-32$ & $2.29 E-32$ & $2.32 E-32$ & $2.33 E-32$ & $2.33 E-32$ & $2.33 E-32$ \\
\hline 2 & 2 & 管 & 2 & ? & $x^{2}$ & 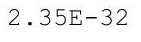 & $.35 E-32$ \\
\hline 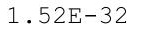 & 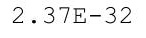 & 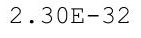 & $2.33 E-32$ & 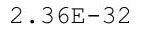 & & 32 & $E-32$ \\
\hline 2 & $2.40 E-32$ & & 2 & & & & 32 \\
\hline$E-32$ & 2 & 2 & 32 & 2 & 2 & 32 & -32 \\
\hline $0 E-32$ & $2.44 E-32$ & $2.36 \mathrm{E}-$ & 32 & 2 & & 32 & -32 \\
\hline $49 \mathrm{E}-32$ & $2.46 \mathrm{E}-32$ & $5.305-32$ & $2.41 E-32$ & $2.45 E-32$ & 2.405 & $2.45 E-32$ & $45 E-32$ \\
\hline $.405-32$ & 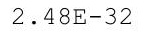 & $2.40 E-32$ & $2.43 E-32$ & $2.47 E-32$ & & & $2.48 E-32$ \\
\hline - & $2.50 E-32$ & & & & & & -32 \\
\hline $46 \mathrm{~F}-32$ & $2.53 E-32$ & & & 2 & 2 & 2 & 32 \\
\hline $.46 \mathrm{E}-32$ & $2.55 E-32$ & $2.45 E-32$ & 2 & 2 & 2 & 2 & 32 \\
\hline $.45 E-32$ & & & & 2 & 2 & -32 & 32 \\
\hline $44 E-32$ & $2.59 \mathrm{E}-$ & $2.49 \mathrm{E}$ & 32 & 2. & & 32 & -32 \\
\hline 2 & .0 & & & & & & \\
\hline 2 & 0.015 & 2 & 2 & 2 & & & -32 \\
\hline 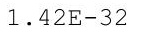 & 2 & $2 \cdot$ & 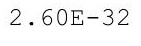 & . & 2 & 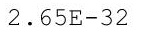 & ( \\
\hline L. $41 \mathrm{E}-32$ & $2.69 E-32$ & & & & 2.61 & 32 & 32 \\
\hline 32 & $71 E-32$ & $9 E-32$ & $64 E-32$ & 32 & 32 & 32 & 32 \\
\hline
\end{tabular}

C -583

DCN 5090-TR-02-2 
RESRAD-OFFSITE, Version 2.5

Title : Offsite Resident Farmer

File : RF TC99 DOESG FWD-FV2all.ROF

Summary of dose at graphical times, reptition 1 (continued)

Time

Years

$2.36 \mathrm{E}+01$

$2.41 \mathrm{E}+01$

2. $46 \mathrm{E}+01$

$2.51 \mathrm{E}+01$

$2.56 \mathrm{E}+01$

2. $61 \mathrm{E}+01$

$2.67 \mathrm{E}+01$

2. $72 \mathrm{E}+01$

$2.77 \mathrm{E}+01$

2. $82 \mathrm{E}+01$

$2.87 E+01$

2. $92 \mathrm{E}+01$

2. $97 \mathrm{E}+01$

3. $02 \mathrm{E}+01$

$3.08 \mathrm{E}+01$

$3.13 E+01$

$3.18 \mathrm{E}+01$

3. $23 E+01$

3. $28 \mathrm{E}+01$

3. $33 E+01$

3. $38 \mathrm{E}+01$

3. $44 \mathrm{E}+01$

3. $49 \mathrm{E}+01$

$3.54 \mathrm{E}+01$

3. $59 \mathrm{E}+01$

3. $64 \mathrm{E}+01$

$3.69 \mathrm{E}+01$

$3.74 \mathrm{E}+01$

$3.79 \mathrm{E}+01$

3. $85 \mathrm{E}+01$

$3.90 \mathrm{E}+01$

$3.95 \mathrm{E}+01$

$4.00 \mathrm{E}+01$

4. $05 \mathrm{E}+01$

4. $10 \mathrm{E}+01$

4. $15 \mathrm{E}+01$

4. $20 \mathrm{E}+01$

4. $26 \mathrm{E}+01$

$4.31 \mathrm{E}+01$

$4.36 \mathrm{E}+01$

4. $41 \mathrm{E}+01$

$4.46 \mathrm{E}+01$

4. $51 \mathrm{E}+01$

$4.56 \mathrm{E}+01$

4. $61 \mathrm{E}+01$

$4.67 \mathrm{E}+01$

Dose statistics at graphical times, mrem/yr

\begin{tabular}{|c|c|c|c|c|c|c|c|}
\hline m & aximum & ea & 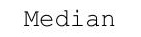 & & & & \\
\hline $39 E-32$ & $2.73 E-32$ & $2.61 E-32$ & $2.66 \mathrm{E}-32$ & $71 E-32$ & $72 E-32$ & 32 & - $13 \pm-32$ \\
\hline $39 E-32$ & $2.76 E-32$ & $2.63 E-32$ & $2.68 \mathrm{E}-32$ & $2.74 E-32$ & $2.74 E-32$ & $2.75 E-32$ & $75 E-32$ \\
\hline $38 E-32$ & $78 E-32$ & $65 E-32$ & $70 E-32$ & $76 E-32$ & $77 E-32$ & $.77 E-32$ & $78 E-32$ \\
\hline $37 E-32$ & $81 E-32$ & $68 F-32$ & $73 F-32$ & $79 F-32$ & $79 F-32$ & $80 F-32$ & $80 F-32$ \\
\hline-32 & -32 & 2 & -32 & 2 & 2 & -32 & $82 E-32$ \\
\hline 32 & 32 & & & & & & \\
\hline $35 E-32$ & $2.88 E-32$ & & & & & & $87 E-32$ \\
\hline $34 E-32$ & -32 & 2 & -32 & 2 & 32 & 32 & $0 E-32$ \\
\hline $33 E-32$ & $94 \mathrm{E}-32$ & -32 & -32 & $1 E-32$ & $92 \mathrm{E}-$ & -32 & $3 E-32$ \\
\hline$E-32$ & $96 E-32$ & ح תم00 & $86=-32$ & 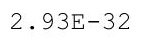 & 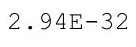 & $95 F-32$ & $95 E-32$ \\
\hline 32 & 32 & & & & & & -32 \\
\hline $31 E-32$ & $3.01 E-32$ & $285 \mathrm{~F}-32$ & -32 & 2 & 2 & 2 & -32 \\
\hline $30 E-32$ & $3.04 E-32$ & & $2.94 \mathrm{E}-32$ & & & & $3.03 E-32$ \\
\hline $30 E-32$ & -32 & $2.095-32$ & $2.96 \mathrm{E}-32$ & & & 32 & $E-32$ \\
\hline-32 & -32 & 2 & -32 & & & -32 & -32 \\
\hline 32 & 32 & 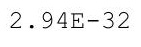 & $.01 E-32$ & & & 2 & 2 \\
\hline 2 & 2 & & & & & & 2 \\
\hline 32 & 32 & 2 & 2 & & 2 & 2 & 32 \\
\hline $26 \mathrm{E}-32$ & $3.21 E-32$ & $3.01 E-32$ & $3.09 E-32$ & $3.17 E-32$ & $3.18 E-32$ & $3.19 \mathrm{E}-32$ & $3.19 \mathrm{E}-32$ \\
\hline $25 E-32$ & $23 E-32$ & $.04 E-32$ & -32 & $0 E-32$ & & -32 & $22 E-32$ \\
\hline 32 & 32 & & & & & 2 & -32 \\
\hline 32 & -32 & & & $z$ & & -32 & -32 \\
\hline $23 E-32$ & -32 & 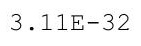 & 2 & & & 2 & 32 \\
\hline-32 & -32 & $3.13 E-32$ & $z$ & 2 & 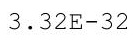 & 2 & -32 \\
\hline 2 & -32 & $3.16 \mathrm{E}-32$ & z & (1) & 5 & 2 & 32 \\
\hline $21 E-32$ & $.41 E-32$ & 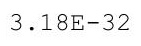 & $=-32$ & ד & חסקט & $39 E-32$ & $40 E-32$ \\
\hline-32 & $44 \mathrm{E}-32$ & & $E-32$ & 2 & & $E-32$ & $43 E-32$ \\
\hline & & & & & & & \\
\hline $19 \mathrm{E}-32$ & $3.50 \mathrm{E}-32$ & $3.20 E-32$ & -32 & $6 E-32$ & $7 E-32$ & -32 & $9 E-32$ \\
\hline $19 \mathrm{E}-32$ & $3.53 E-32$ & . & $3.38 E-32$ & $3.49 E-32$ & 80 & $1.315-22$ & $.52 E-32$ \\
\hline 32 & 32 & Pr & $E-32$ & . & - & 2 & $.55 E-32$ \\
\hline 2 & $60 E-32$ & & & & & & \\
\hline-32 & -32 & 2 & -32 & $3 E-32$ & تصט & & $1 E-32$ \\
\hline 32 & & & & & & & 32 \\
\hline $15 E-32$ & $3.69 E-32$ & $3.42 E-32$ & $2 E-32$ & 32 & 2 & 32 & $57 E-32$ \\
\hline $15 E-32$ & $3.73 E-32$ & . & $3.55 E-32$ & 3.001 & 3.00 & -32 & $.71 E-32$ \\
\hline $14 \mathrm{E}-32$ & $3.10 \mathrm{E}-32$ & $3.47 \mathrm{E}-32$ & & & & & $3.14 \pm-32$ \\
\hline 2 & 32 & . & 2 & - & & & $77 E-32$ \\
\hline 2 & $3.83 E-32$ & $3.53 E-32$ & ? & 2 & 2 & 2 & 32 \\
\hline 32 & 3 & & 2 & & & & 32 \\
\hline $2 E-32$ & $3.89 E-32$ & $3.58 E-32$ & $0 E-32$ & & 2 & -32 & -32 \\
\hline 32 & $3.93 \mathrm{E}$ & 3.015 & & 2 & & & \\
\hline & & & & & & & $\cdot 94 \mathrm{E}-32$ \\
\hline $5-32$ & $4.00 \pm-32$ & $3.67 E-32$ & $3.19 E-32$ & $3.94 \mathrm{E}-32$ & $3.96 E-32$ & $3.97 E-32$ & $3.98 E-32$ \\
\hline $09 E-32$ & $4.00 \mathrm{E}$ & $5.10 \mathrm{t}$ & & e. & 3.995 & $00 E-32$ & $1.01-$ \\
\hline $9 E-32$ & $E-32$ & $.73 E-32$ & $.85 E-32$ & $01 E-32$ & $.03 \mathrm{E}$ & -32 & 32 \\
\hline
\end{tabular}


RESRAD-OFFSITE, Version 2.5

$\mathrm{T}^{1 / 2}$ Limit $=180$ days

obabilistic Dose and Risk Report

Title : Offsite Resident Farmer

File : RF TC99 DOESG FWD-FV2all.ROF

Summary of dose at graphical times, reptition 1 (continued)

Time

Years

4. $72 \mathrm{E}+01$

$4.77 \mathrm{E}+01$

$4.82 \mathrm{E}+01$

$4.87 \mathrm{E}+01$

4. $92 \mathrm{E}+01$

$4.97 \mathrm{E}+01$

$5.02 \mathrm{E}+01$

$5.08 \mathrm{E}+01$

$5.13 \mathrm{E}+01$

$5.18 \mathrm{E}+01$

$5.23 \mathrm{E}+01$

$5.28 \mathrm{E}+01$

$5.33 E+01$

$5.38 \mathrm{E}+01$

$5.43 \mathrm{E}+01$

$5.49 \mathrm{E}+01$

$5.54 \mathrm{E}+01$

$5.59 \mathrm{E}+01$

$5.64 \mathrm{E}+01$

$5.69 \mathrm{E}+01$

$5.74 \mathrm{E}+01$

$5.79 \mathrm{E}+01$

$5.84 \mathrm{E}+01$

$5.90 \mathrm{E}+01$

$5.95 \mathrm{E}+01$

$6.00 \mathrm{E}+01$

$6.05 \mathrm{E}+01$

$6.10 \mathrm{E}+01$

$6.15 \mathrm{E}+01$

$6.20 \mathrm{E}+01$

$6.25 \mathrm{E}+01$

$6.31 \mathrm{E}+01$

$6.36 \mathrm{E}+01$

$6.41 \mathrm{E}+01$

$6.46 \mathrm{E}+01$

$6.51 \mathrm{E}+01$

$6.56 \mathrm{E}+01$

$6.61 \mathrm{E}+01$

$6.67 \mathrm{E}+01$

$6.72 \mathrm{E}+01$

$6.77 \mathrm{E}+01$

$6.82 \mathrm{E}+01$

$6.87 \mathrm{E}+01$

$6.92 \mathrm{E}+01$

$6.97 \mathrm{E}+01$

$7.02 \mathrm{E}+01$
Dose statistics at graphical times, mrem/yr

\begin{tabular}{|c|c|c|c|c|c|c|c|}
\hline $\mathrm{m}$ & aximum & lea & ed & & & & \\
\hline $.08 E-32$ & $4.11 E-32$ & $3.76 E-32$ & $3.89 \mathrm{E}-32$ & 32 & $4.06 \mathrm{E}-32$ & -32 & $4.00 E-32$ \\
\hline $.07 E-32$ & $4.14 E-32$ & $9 E-32$ & $3.92 \mathrm{E}-32$ & $8 E-32$ & $10 E-32$ & -32 & $12 E-32$ \\
\hline $07 E-32$ & $18 E-32$ & $32 E-32$ & $95 E-32$ & $11 E-32$ & $13 F_{-1}$ & -32 & $15 E-32$ \\
\hline $06 \mathrm{E}-32$ & -32 & $85 E-32$ & $98 F-32$ & $15 \mathrm{~F}-32$ & $17 F-32$ & $18 \mathrm{~F}-32$ & $19 \mathrm{E}-32$ \\
\hline-32 & -32 & 32 & -32 & 2 & 2 & -32 & $23 E-32$ \\
\hline 32 & & & & & & & \\
\hline $04 E-32$ & $4.33 E-32$ & & & & & & -32 \\
\hline-32 & -32 & 2 & 32 & 2 & 32 & -32 & -32 \\
\hline $03 E-32$ & -32 & -32 & -32 & 32 & $35 E-32$ & -32 & $38 E-32$ \\
\hline $03 E-32$ & 32 & Г & $8 E-32$ & 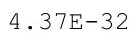 & 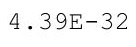 & $E-32$ & $42 E-32$ \\
\hline-32 & 32 & & & & & & -32 \\
\hline $02 E-32$ & $4.52 E-32$ & -32 & $E-32$ & 2 & 2 & -32 & -32 \\
\hline $01 \mathrm{E}-32$ & $4.56 E-32$ & & $4.29 E-32$ & $4.49 E-32$ & $4.51 E-32$ & & $4.54 \mathrm{E}-32$ \\
\hline-32 & -32 & 2 & -32 & 2 & 2 & 32 & $E-32$ \\
\hline-33 & -32 & 2 & -32 & 32 & & -32 & $E-32$ \\
\hline 33 & -32 & & 32 & 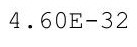 & r & 2 & 32 \\
\hline-33 & 2 & & & & & & 32 \\
\hline 33 & 32 & 4 & 2 & & & 2 & 32 \\
\hline $.77 E-33$ & $4.81 E-32$ & $4.34 E-32$ & $4.51 E-32$ & $4.72 E-32$ & $4.75 E-32$ & $4.77 E-32$ & $4.78 E-32$ \\
\hline $72 E-33$ & $4.85 E-32$ & $4.37 E-32$ & $4.54 \mathrm{E}-32$ & $4.77 E-32$ & $4.79 \mathrm{E}-$ & -32 & 4. $82 E-32$ \\
\hline 33 & 32 & & & & & 2 & $E-32$ \\
\hline 33 & -32 & & & 2 & 2 & -32 & -32 \\
\hline $56 E-33$ & 4.9 & 4 & $25<$ & & & 2 & 32 \\
\hline 33 & 32 & 4 & 2 & 2 & 2 & 2 & -32 \\
\hline$E-33$ & -32 & 4 & 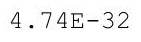 & קم & 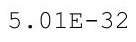 & 2 & 32 \\
\hline $40 E-33$ & $5.12 \mathrm{E}-32$ & $4.59 E-32$ & $4.77 E-32$ & $5.02 \mathrm{E}-$ & $.05 E-32$ & $5.07 E-32$ & $5.08 E-32$ \\
\hline$E-33$ & $16 \mathrm{E}-32$ & & $E-32$ & 2 & & $E-32$ & $13 E-32$ \\
\hline & & & & & & & \\
\hline $25 E-33$ & $5.26 E-32$ & $4.70 E-32$ & $E-32$ & 2 & 2 & & $2 E-32$ \\
\hline $20 E-33$ & $5.30 E-32$ & $4.73 E-32$ & $4.93 E-32$ & $.20 E-32$ & $.23 E-32$ & $.25 E-32$ & $.26 E-32$ \\
\hline $15 E-33$ & 32 & $4.77 E-32$ & $E-32$ & - & . & $\cdot .295-22$ & $.31 E-32$ \\
\hline 3 & 2 & & . & & & & \\
\hline-33 & $E-32$ & $85 F-32$ & $E-32$ & $3 E-32$ & 27 & -32 & $D E-32$ \\
\hline & 32 & & & & & & -32 \\
\hline $95 E-33$ & $5.54 E-32$ & $4 \cdot 93 E-32$ & $4 E-32$ & $3.40 \mathrm{E}$ & 2 & -32 & $50 E-32$ \\
\hline $90 E-33$ & $5.59 E-32$ & $4.97 E-32$ & $E-32$ & . 11 & 2 & -32 & $55 E-32$ \\
\hline $.85 E-33$ & $5.04 E-32$ & & & & & & $3.60 \pm-32$ \\
\hline 3 & 32 & .025 & 列 & . & & & $.65 E-32$ \\
\hline 3 & $5.74 \mathrm{E}-32$ & 5 & ? & & 2 & 2 & 32 \\
\hline 33 & 2 & & & 32 & & -32 & 32 \\
\hline $65 E-33$ & $5.84 \mathrm{E}-32$ & $5.17 \mathrm{E}$ & $E-32$ & 5. & 2 & -32 & -32 \\
\hline $61 E-33$ & 32 & & & 2 & & & \\
\hline 3 & & & & & & & $.90 \pm-32$ \\
\hline $315-33$ & $6.00 \pm-32$ & $3.29 E-32$ & $\cdot 34 \mathrm{E}-32$ & $5.87 E-32$ & $5.91 E-32$ & $5.93 E-32$ & $5.95 E-32$ \\
\hline 3 & . & 3.345 & & 20 & . & $5.98 E-32$ & .00 \\
\hline-33 & $.11 \mathrm{E}-32$ & $38 E-32$ & $63 E-32$ & $.97 E-32$ & 6.0 & -32 & -32 \\
\hline
\end{tabular}


RESRAD-OFFSITE, Version 2.5

$\mathrm{T}^{1 / 2}$ Limit $=180$ days

obabilistic Dose and Risk Report

Title : Offsite Resident Farmer

File : RF TC99 DOESG FWD-FV2all.ROF

Summary of dose at graphical times, reptition 1 (continued)

Time

Years

7. $08 \mathrm{E}+01$

7. $13 \mathrm{E}+01$

7. $18 \mathrm{E}+01$

$7.23 \mathrm{E}+01$

7. $28 \mathrm{E}+01$

7. $33 \mathrm{E}+01$

7. $38 \mathrm{E}+01$

7. $43 \mathrm{E}+01$

7. $49 \mathrm{E}+01$

$7.54 \mathrm{E}+01$

7. $59 \mathrm{E}+01$

7. $64 \mathrm{E}+01$

7. $69 \mathrm{E}+01$

$7.74 \mathrm{E}+01$

7. $79 \mathrm{E}+01$

$7.84 \mathrm{E}+01$

7. $90 \mathrm{E}+01$

7. $95 \mathrm{E}+01$

8. $00 \mathrm{E}+01$

$8.05 \mathrm{E}+01$

8. $10 \mathrm{E}+01$

$8.15 \mathrm{E}+01$

8. $20 \mathrm{E}+01$

8. $25 \mathrm{E}+01$

8. $31 \mathrm{E}+01$

8. $36 \mathrm{E}+01$

8. $41 \mathrm{E}+01$

8. $46 \mathrm{E}+01$

8. $51 \mathrm{E}+01$

8. $56 \mathrm{E}+01$

8. $61 \mathrm{E}+01$

8. $66 \mathrm{E}+01$

$8.72 \mathrm{E}+01$

8. $77 \mathrm{E}+01$

$8.82 \mathrm{E}+01$

8. $87 \mathrm{E}+01$

8. $92 \mathrm{E}+01$

8. $97 \mathrm{E}+01$

9. $02 \mathrm{E}+01$

$9.07 \mathrm{E}+01$

9. $13 \mathrm{E}+01$

9. $18 \mathrm{E}+01$

$9.23 \mathrm{E}+01$

$9.28 \mathrm{E}+01$

$9.33 \mathrm{E}+01$

9. $38 \mathrm{E}+01$
Dose statistics at graphical times, mrem/yr

\begin{tabular}{|c|c|c|c|c|c|c|c|}
\hline m & aximum & lea & - & & & & \\
\hline $37 E-33$ & $6.16 \mathrm{E}-32$ & $5.42 E-32$ & $5.68 E-32$ & $6.02 \mathrm{E}-32$ & $6.06 \mathrm{E}-32$ & 32 & -25 \\
\hline $32 E-33$ & $6.22 E-32$ & $5.47 E-32$ & $5.72 E-32$ & $6.07 E-32$ & $6.12 E-32$ & $6.14 \mathrm{E}-32$ & $6.16 \mathrm{E}-32$ \\
\hline $28 \mathrm{E}-33$ & $6.27 E-32$ & $5.51 \mathrm{E}-32$ & $5.77 \mathrm{E}-32$ & $6.13 E-32$ & $6.17 E-32$ & $6.19 \mathrm{E}-32$ & $6.22 E-32$ \\
\hline-33 & $33 E-32$ & $55 E-32$ & $82 E-32$ & $18 \mathrm{E}-32$ & $23 F-32$ & -32 & $27 F-32$ \\
\hline $19 E-33$ & $38 E-32$ & 32 & -32 & 2 & 2 & -32 & $33 E-32$ \\
\hline 33 & 32 & & & & & & \\
\hline $10 \mathrm{E}-33$ & $6.50 E-32$ & & $5.96 \mathrm{E}-32$ & $6.34 \mathrm{E}-32$ & & & -32 \\
\hline $.05 E-33$ & -32 & 32 & -32 & $0 E-32$ & $E-32$ & -32 & -32 \\
\hline $.01 E-33$ & $6.61 E-32$ & $5.78 E-32$ & $6.06 \mathrm{E}-32$ & $6.45 \mathrm{E}-32$ & $E-32$ & -32 & $E-32$ \\
\hline $96 E-33$ & $67 E-32$ & תקטי & $1 E-32$ & 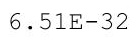 & 2 & 2 & 2 \\
\hline-33 & 32 & & & & & & 32 \\
\hline $.88 E-33$ & $6.79 E-32$ & $92 E-32$ & $E-32$ & $62 E-32$ & 2 & 32 & -32 \\
\hline $.83 E-33$ & $6.85 E-32$ & $5.97 E-32$ & $6.27 E-32$ & $6.68 E-32$ & $6.73 E-32$ & $6.76 E-32$ & $6.79 \mathrm{E}-32$ \\
\hline $.79 E-33$ & $6.91 E-32$ & $6.02 \mathrm{E}-32$ & $6.32 \mathrm{E}-32$ & & 2 & 32 & $E-32$ \\
\hline $.75 E-33$ & -32 & & -32 & 32 & & -32 & -32 \\
\hline 33 & $03 E-32$ & & $E-32$ & 2 & (2) & 2 & $E-32$ \\
\hline-33 & & & 2 & & & $E-32$ & 32 \\
\hline $62 E-33$ & 2 & ( & 2 & $z$ & 2 & 2 & 32 \\
\hline $58 E-33$ & $7.22 \mathrm{E}-32$ & $6.26 \mathrm{E}-32$ & $6.58 E-32$ & $7.04 \mathrm{E}-32$ & $7.09 \mathrm{E}-32$ & $E-32$ & $.16 \mathrm{E}-32$ \\
\hline $54 E-33$ & 7. $29 \mathrm{E}-32$ & $6.31 E-32$ & $6.64 \mathrm{E}-32$ & 7. $10 \mathrm{E}-32$ & $7.16 \mathrm{E}-$ & -32 & 7. $22 E-32$ \\
\hline 33 & -32 & & & & & -32 & $E-32$ \\
\hline-33 & -32 & & 2 & & & -32 & -32 \\
\hline $41 E-33$ & & & & & & & \\
\hline $37 E-33$ & 2 & & 2 & 2 & & & \\
\hline$E-33$ & 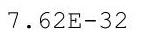 & & 2 & 2 & 2 & 2 & 32 \\
\hline $29 E-33$ & $.68 E-32$ & $6.62 E-32$ & $6.97 E-32$ & $48 \mathrm{E}-3$ & $50 \nabla^{2}$ & $.57 E-32$ & $.61 E-32$ \\
\hline-33 & $7.75 E-32$ & & $3 E-32$ & $54 \mathrm{E}-32$ & & $E-32$ & $68 E-32$ \\
\hline & & & & & & & \\
\hline & & & & & & & \\
\hline $.13 E-33$ & $7.96 \mathrm{E}-32$ & $6.84 \mathrm{E}-32$ & $7.21 E-32$ & $7.74 \mathrm{E}-32$ & $1.01 \mathrm{H} z 2$ & $7.84 \mathrm{E}-32$ & $.88 E-32$ \\
\hline $.09 E-33$ & $0.0 \mathrm{~T}$ & $0.025-32$ & $E-32$ & . & - & $\begin{array}{c}-32 \\
252\end{array}$ & $95 E-32$ \\
\hline 3 & $10 E-32$ & & 7. $33 E-32$ & & & & \\
\hline$F-33$ & $E-32$ & $E-32$ & $E-32$ & $95 E-32$ & 田 & -32 & $9 E-32$ \\
\hline 33 & 32 & & & & & & \\
\hline & & & & & 2 & & \\
\hline $.90 E-33$ & $8.39 E-32$ & $7.17 E-32$ & $7.57 E-32$ & $8.16 \mathrm{E}-32$ & 20 & -32 & $.31 E-32$ \\
\hline $.805-33$ & $8.4 / E-32$ & & & $8 \cdot 23 E-32$ & & & $8.38 \pm-32$ \\
\hline $82 E-33$ & $8.54 \mathrm{E}-32$ & . & . & . & $8.37 \mathrm{E}-32$ & & $45 E-32$ \\
\hline 3 & 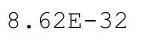 & 2 & 2 & 2 & 2 & 2 & 32 \\
\hline 33 & 2 & 2 & & 2 & & & 32 \\
\hline $71 \mathrm{E}-33$ & $8.77 E-32$ & $7.47 \mathrm{E}-32$ & $7.89 \mathrm{E}-32$ & $8.52 E-32$ & 2 & -32 & 32 \\
\hline $67 E-33$ & $8.85 \mathrm{~F}$ & 2 & & 2 & & & \\
\hline & & & & & & & $.83 E-32$ \\
\hline $.00 \pm-33$ & $9.01 E-32$ & $1.05 E-32$ & $8.09 E-32$ & $8.74 \mathrm{E}-32$ & $8.8< \pm-32$ & $8.86 E-32$ & $8.91 E-32$ \\
\hline$E-33$ & $9.09 \mathrm{E}-$ & . & $E-32$ & $.0<1$ & $0.90 \mathrm{~L}$ & 32 & . \\
\hline-33 & $E-32$ & $E-32$ & $.22 E-32$ & $.89 E-32$ & $.98 E-32$ & $9.02 E-32$ & -32 \\
\hline
\end{tabular}


RESRAD-OFFSITE, Version 2.5

$\mathrm{T}^{1 / 2}$ Limit $=180$ days

obabilistic Dose and Risk Report

Title : Offsite Resident Farmer

File : RF TC99 DOESG FWD-FV2all.ROF

Summary of dose at graphical times, reptition 1 (continued)

Time

Years

9. $43 \mathrm{E}+01$

$9.48 \mathrm{E}+01$

$9.54 \mathrm{E}+01$

$9.59 \mathrm{E}+01$

9. $64 \mathrm{E}+01$

$9.69 \mathrm{E}+01$

$9.74 \mathrm{E}+01$

$9.79 \mathrm{E}+01$

$9.84 \mathrm{E}+01$

$9.90 \mathrm{E}+01$

$9.95 \mathrm{E}+01$

$1.00 \mathrm{E}+02$

$1.00 \mathrm{E}+02$

$1.01 \mathrm{E}+02$

$1.02 \mathrm{E}+02$

$1.02 \mathrm{E}+02$

$1.03 \mathrm{E}+02$

$1.03 \mathrm{E}+02$

$1.04 \mathrm{E}+02$

1. $04 \mathrm{E}+02$

$1.05 \mathrm{E}+02$

$1.05 \mathrm{E}+02$

$1.06 \mathrm{E}+02$

$1.06 \mathrm{E}+02$

$1.07 \mathrm{E}+02$

$1.07 \mathrm{E}+02$

$1.08 \mathrm{E}+02$

$1.08 \mathrm{E}+02$

$1.09 \mathrm{E}+02$

$1.09 \mathrm{E}+02$

$1.10 \mathrm{E}+02$

1. $10 \mathrm{E}+02$

$1.11 \mathrm{E}+02$

1. $11 \mathrm{E}+02$

$1.12 \mathrm{E}+02$

$1.12 \mathrm{E}+02$

1. $13 \mathrm{E}+02$

1. $13 \mathrm{E}+02$

$1.14 \mathrm{E}+02$

1. $14 \mathrm{E}+02$

1. $15 \mathrm{E}+02$

1. $15 \mathrm{E}+02$

$1.16 \mathrm{E}+02$

$1.16 \mathrm{E}+02$

$1.17 \mathrm{E}+02$

1. $17 \mathrm{E}+02$
Dose statistics at graphical times, mrem/yr

\begin{tabular}{|c|c|c|c|c|c|c|c|}
\hline m & um & a & - & & & $\%$ & \\
\hline $49 \mathrm{E}-33$ & $9.25 \mathrm{E}-32$ & $7.83 E-32$ & $8.29 E-32$ & $8.97 E-32$ & $9.06 \mathrm{E}-32$ & $9.10 \mathrm{E}-32$ & $-2-32$ \\
\hline $45 E-33$ & $9.33 E-32$ & $7.90 E-32$ & $8.36 \mathrm{E}-32$ & $9.05 E-32$ & $9.13 E-32$ & $9.18 E-32$ & $3 E-32$ \\
\hline $42 E-33$ & $E-32$ & $6 E-32$ & $3 E-32$ & $9.13 E-32$ & $9.21 \mathrm{E}-32$ & $9.26 \mathrm{E}-32$ & -32 \\
\hline $38 E-33$ & $9.50 \mathrm{E}-32$ & $8.03 E-32$ & $8.50 \mathrm{E}-32$ & $9.21 \mathrm{E}-32$ & $9.29 \mathrm{E}-32$ & $34 E-32$ & -32 \\
\hline $5 E-33$ & $58 E-32$ & $09 E-32$ & $57 E-32$ & $9 F-32$ & -32 & -32 & 32 \\
\hline$E-33$ & 32 & -32 & -32 & 2 & 2 & -32 & -32 \\
\hline $.28 E-33$ & 32 & & & & & 32 & -32 \\
\hline $.24 E-33$ & & & & & & & -32 \\
\hline-33 & -32 & 2 & -32 & 32 & 32 & -32 & -32 \\
\hline$E-33$ & -31 & - & 32 & 32 & $E-32$ & -32 & -32 \\
\hline$E-33$ & $E-31$ & $F_{-1}-1-1$ & $9.00 E-32$ & 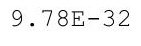 & 2 & 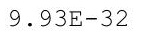 & -32 \\
\hline 3 & & & & & & & 31 \\
\hline $.07 \mathrm{E}-33$ & $3 E-31$ & $8.63 E-32$ & 2 & 2 & 1 & 1 & -31 \\
\hline $.04 \mathrm{E}-33$ & $1.04 \mathrm{E}-31$ & $8.70 \mathrm{E}-32$ & $9.23 \mathrm{E}-32$ & $1.00 \mathrm{E}-31$ & $1.01 \mathrm{E}-31$ & $1.02 \mathrm{E}-31$ & $1.03 E-31$ \\
\hline-33 & 31 & 2 & 32 & & $\perp$ & 31 & -31 \\
\hline$E-33$ & & & & & & -31 & -31 \\
\hline 33 & & & & & 1 & & -31 \\
\hline 3 & & & & & & & 31 \\
\hline $87 E-33$ & $.08 E-31$ & & 2 & 1 & 1 & 1 & 31 \\
\hline $84 \mathrm{E}-33$ & L.09E-31 & -3 & -32 & $.06 \mathrm{E}-31$ & $.07 E-31$ & $7 E-31$ & $.08 \mathrm{E}-31$ \\
\hline $81 E-33$ & -31 & 32 & -32 & 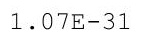 & & $.08 E-31$ & $09 E-31$ \\
\hline & & & & & & & -31 \\
\hline & & & & & & & \\
\hline 3 & & & & & & & \\
\hline - & 31 & $=$ & 1 & 1 & 1 & 1 & 31 \\
\hline$E-33$ & 1 & 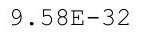 & 1 & 17. & 1 & $E-31$ & 31 \\
\hline-33 & 31 & $9.65 E-32$ & 1 & 110 & 110 & $E-31$ & $.15 E-31$ \\
\hline$E-33$ & & 2 & & & & -31 & $16 E-31$ \\
\hline & & & & & & & \\
\hline 33 & & & & 1 & 1 & & \\
\hline $50 E-33$ & $1.07 E-22$ & . & $1.06 \mathrm{E}-31$ & $1.16 \mathrm{E}-31$ & I. & $1.18 \mathrm{E}-31$ & $1.19 E-31$ \\
\hline $47 E-33$ & $1.91 \mathrm{E}-20$ & 舟 & $1.07 \mathrm{E}-31$ & 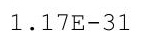 & $1.19 \mathrm{E}-31$ & $\perp \cdot \perp Y L U \perp$ & $1.20 \mathrm{E}-31$ \\
\hline 3 & 9 & & & & & & $1.21 \mathrm{E}-31$ \\
\hline$F-33$ & $5-17$ & - & $E-31$ & & & -31 & -31 \\
\hline-33 & & & & & & & \\
\hline 33 & 15 & 1. $08 \mathrm{E}-18$ & $1.11 \mathrm{E}-31$ & $1.21 \omega$ & $1 \cdot 20$ & 31 & -31 \\
\hline $32 E-33$ & $1.43 E-14$ & $1 . \pm$ & N &.$+<0$ & 1.2 & & -31 \\
\hline $29 \mathrm{E}-33$ & 7. $42 \mathrm{E}-14$ & $.76 \mathrm{E}-17$ & & $1.24 \mathrm{E}-31$ & 1. $25 \mathrm{E}-31$ & & $1.27 \mathrm{E}-31$ \\
\hline 3 & 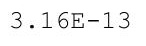 & 5 & & 1 & 1 & 1 & 31 \\
\hline & & & & & & & 31 \\
\hline 3 & & & 31 & 1 & 1 & 1 & 31 \\
\hline$E-33$ & $1.00 \mathrm{E}-11$ & $9 E-15$ & 1.1 & $1.28 \mathrm{E}$ & 1.2 & -31 & -31 \\
\hline & 2.324 & & & & & & 31 \\
\hline &. & . & & 土. & $1.3 \angle \mathrm{E}-$ & $1.33 E-31$ & $1.34 \mathrm{E}-31$ \\
\hline 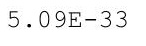 & $\perp \cdot 2 J \pm-10$ & 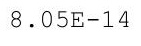 & & $1.31 E-31$ & 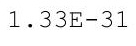 & $E-31$ & $1.20 \mathrm{JT}-21$ \\
\hline$E-33$ & $52 E-10$ & $1 E-13$ & $20 E-31$ & $E-31$ & $E-31$ & $5 E-31$ & 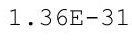 \\
\hline
\end{tabular}


RESRAD-OFFSITE, Version 2.5 
RESRAD-OFFSITE, Version 2.5 
RESRAD-OFFSITE, Version 2.5 
RESRAD-OFFSITE, Version 2.5

$\mathrm{T}^{1 / 2}$ Limit $=180$ days

obabilistic Dose and Risk Report

Title : Offsite Resident Farmer

File : RF TC99 DOESG FWD-FV2all.ROF

Summary of dose at graphical times, reptition 1 (continued)

Time

Years

$1.89 \mathrm{E}+02$

$1.89 \mathrm{E}+02$

$1.90 \mathrm{E}+02$

$1.90 \mathrm{E}+02$

$1.91 \mathrm{E}+02$

$1.91 \mathrm{E}+02$

$1.92 \mathrm{E}+02$

$1.92 \mathrm{E}+02$

$1.93 \mathrm{E}+02$

$1.93 \mathrm{E}+02$

$1.94 \mathrm{E}+02$

$1.94 \mathrm{E}+02$

$1.95 \mathrm{E}+02$

$1.95 \mathrm{E}+02$

$1.96 \mathrm{E}+02$

$1.96 \mathrm{E}+02$

$1.97 \mathrm{E}+02$

$1.97 \mathrm{E}+02$

1. $98 \mathrm{E}+02$

$1.98 \mathrm{E}+02$

1. $99 \mathrm{E}+02$

$1.99 \mathrm{E}+02$

$2.00 \mathrm{E}+02$

$2.00 \mathrm{E}+02$

$2.01 \mathrm{E}+02$

$2.01 \mathrm{E}+02$

$2.02 \mathrm{E}+02$

$2.03 \mathrm{E}+02$

$2.03 E+02$

$2.04 \mathrm{E}+02$

$2.04 \mathrm{E}+02$

$2.05 \mathrm{E}+02$

$2.05 \mathrm{E}+02$

$2.06 \mathrm{E}+02$

$2.06 \mathrm{E}+02$

$2.07 \mathrm{E}+02$

$2.07 \mathrm{E}+02$

$2.08 \mathrm{E}+02$

$2.08 \mathrm{E}+02$

$2.09 \mathrm{E}+02$

$2.09 \mathrm{E}+02$

$2.10 \mathrm{E}+02$

$2.10 \mathrm{E}+02$

$2.11 \mathrm{E}+02$

2. $11 \mathrm{E}+02$

$2.12 \mathrm{E}+02$
Dose statistics at graphical times, mrem/yr

\begin{tabular}{|c|c|c|c|c|c|c|c|}
\hline um & aximum & ean & 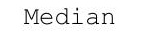 & & & $\%$ & \\
\hline $34 \mathrm{E}-33$ & $6.01 E-03$ & $4.96 \mathrm{E}-05$ & $3.98 E-31$ & $1.14 \mathrm{E}-06$ & -05 & -04 & $1-03$ \\
\hline $33 E-33$ & $0 E-03$ & -05 & 31 & 06 & 05 & -04 & -03 \\
\hline $.32 E-33$ & $6.39 \mathrm{E}-03$ & $5.38 \mathrm{E}-05$ & $4.06 \mathrm{E}-31$ & $1.69 \mathrm{E}-06$ & $1.01 \mathrm{E}-04$ & $5.22 \mathrm{E}-04$ & $1.67 \mathrm{E}-03$ \\
\hline $31 E-33$ & $6.59 \mathrm{E}-03$ & $5.60 \mathrm{E}-05$ & $4.09 E-31$ & $2.03 E-06$ & $1.07 \mathrm{E}-04$ & $48 E-04$ & $1.73 E-03$ \\
\hline $9 \mathrm{E}-33$ & $79 E-03$ & $3 \mathrm{E}$ & $3 E-31$ & $1 E-06$ & $3 F-04$ & $5 E-04$ & 03 \\
\hline$E-33$ & -03 & $6.07 E-05$ & 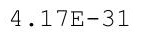 & 6 & 4 & 04 & -03 \\
\hline $27 E-33$ & 03 & 6 & & 6 & & 4 & -03 \\
\hline-33 & & & & & & 04 & -03 \\
\hline-33 & $E-03$ & -6 & \pm & -06 & 50 & -04 & $08 E-03$ \\
\hline-33 & 03 & & $\perp$ & -06 & $1.60 \mathrm{E}-04$ & 4 & -03 \\
\hline 33 & $E-03$ & 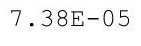 & $4.36 \mathrm{E}-31$ & 6 & & -04 & 3 \\
\hline $21 \mathrm{E}$ & 8.331 & & & & & & -03 \\
\hline$E-33$ & $857 F-03$ & $7.96 \mathrm{E}-05$ & & 6 & 1.93E-04 & 4 & -03 \\
\hline $.18 E-33$ & $8.81 E-03$ & $8.26 \mathrm{E}-05$ & $4.49 \mathrm{E}-31$ & $8.45 E-06$ & $2.06 \mathrm{E}-04$ & $8.58 \mathrm{E}-04$ & $2.48 \mathrm{E}-03$ \\
\hline-33 & $E-03$ & 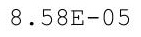 & & 6 & 4 & -04 & -03 \\
\hline 33 & & & & 5 & 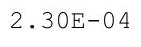 & & \\
\hline 33 & 03 & 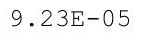 & & 5 & & 7 & 03 \\
\hline 3 & 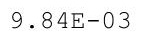 & & & & & & 3 \\
\hline $12 E-33$ & $1.01 \mathrm{E}-02$ & $9.93 E-0$ & & $1.53 E-05$ & & 03 & -03 \\
\hline $11 \mathrm{E}-33$ & $.04 \mathrm{E}-02$ & $1.03 \mathrm{E}-0$ & $4.73 E-31$ & $1.75 \mathrm{E}-05$ & $2.80 \mathrm{E}-$ & $E-03$ & -03 \\
\hline $10 E-33$ & $1.07 \mathrm{E}-02$ & $1.07 E-04$ & $4.78 E-31$ & $1.96 \mathrm{E}-05$ & 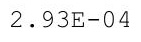 & $E-03$ & $14 \mathrm{E}-03$ \\
\hline 33 & & & & & & & -03 \\
\hline 3 & & & & & & & 03 \\
\hline $06 E-33$ & 02 & 1. & & 5 & $3.35 \mathrm{E}-04$ & & 03 \\
\hline 3 & 2 & 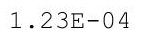 & $\perp$ & 5 & 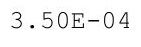 & 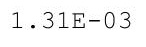 & 03 \\
\hline $4 E-33$ & $.22 \mathrm{E}-02$ & 1 & קח & $.09 E-05$ & $66 \Gamma$ & $1.36 \mathrm{E}-03$ & $69 E-03$ \\
\hline$F-33$ & -02 & $1.31 \mathrm{E}-$ & 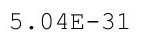 & 5 & & $.41 \mathrm{E}-0$ & $81 F-03$ \\
\hline$E-33$ & $E-02$ & $136=$ & & & & & $93 E-03$ \\
\hline 3 & 02 & & & & & & \\
\hline $.00 E-33$ & $1.35 E-02$ & $1.45 E-04$ & $\cdot \pm 0$ & (. & 1.00 & 03 & -03 \\
\hline $99 E-33$ & $1.38 E-02$ & 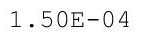 & $.235-31$ & $4.70 E-05$ & 1.0टा & $7.00 \mathrm{~m}-20$ & $.32 E-03$ \\
\hline $97 E-33$ & $1.42 \mathrm{E}-02$ & 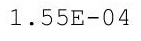 & (2) & 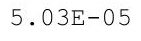 & 然 & 50 & $4.45 E-03$ \\
\hline 3 & A & & 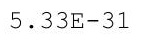 & 5 & & & . \\
\hline$F-33$ & $F-02$ & & & 5 & & 3 & 3 \\
\hline 33 & 1. & & & & & & \\
\hline 33 & $1.56 \mathrm{E}$ & 1.77 & 31 & .00 & $3.00 \mathrm{~L}$ & 03 & 03 \\
\hline $92 \mathrm{E}-33$ & $1.60 \mathrm{E}-02$ & $1.0<\Delta$ & & ( & & & \\
\hline $1 E-33$ & $1.64 \mathrm{E}-02$ & & & & & & o \\
\hline 3 & $+\cdots$ & \pm & . & 5 & & 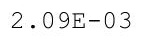 & 3 \\
\hline $.89 E-33$ & 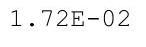 & & & & & & 3 \\
\hline & & $2.07 \mathrm{E}-04$ & & & & & -03 \\
\hline $7 E-33$ & $1.81 \mathrm{E}-02$ & 2.1 & 1 & -04 & & 03 & -03 \\
\hline & 1.8 & & & & & & \\
\hline & $+\cdots$ & 2.2. & & $\perp \cdot 2+\infty$ & & & -03 \\
\hline & & & & - & 4 & 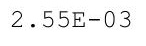 & $0.32 \mathrm{E}-\mathrm{S}$ \\
\hline 5 & $E-02$ & $1 E-04$ & $01 E-31$ & $36 E-04$ & $6 E-04$ & $2 E-03$ & -03 \\
\hline
\end{tabular}


RESRAD-OFFSITE, Version 2.5 
RESRAD-OFFSITE, Version 2.5

$\mathrm{T}^{1 / 2}$ Limit $=180$ days

obabilistic Dose and Risk Report

Title : Offsite Resident Farmer

File : RF TC99 DOESG FWD-FV2all.ROF

Summary of dose at graphical times, reptition 1 (continued)

Time

Years

$2.36 \mathrm{E}+02$

2. $36 \mathrm{E}+02$

2. $37 \mathrm{E}+02$

2. $37 \mathrm{E}+02$

2. $38 \mathrm{E}+02$

2. $38 \mathrm{E}+02$

$2.39 \mathrm{E}+02$

2. $39 \mathrm{E}+02$

$2.40 \mathrm{E}+02$

$2.40 E+02$

2. $41 \mathrm{E}+02$

2. $41 \mathrm{E}+02$

2. $42 \mathrm{E}+02$

$2.43 \mathrm{E}+02$

2. $43 \mathrm{E}+02$

2. $44 \mathrm{E}+02$

2. $44 \mathrm{E}+02$

$2.45 \mathrm{E}+02$

2. $45 \mathrm{E}+02$

$2.46 \mathrm{E}+02$

$2.46 \mathrm{E}+02$

$2.47 \mathrm{E}+02$

$2.47 \mathrm{E}+02$

$2.48 \mathrm{E}+02$

$2.48 \mathrm{E}+02$

$2.49 \mathrm{E}+02$

$2.49 \mathrm{E}+02$

$2.50 \mathrm{E}+02$

$2.50 \mathrm{E}+02$

2. $51 \mathrm{E}+02$

2. $51 \mathrm{E}+02$

2. $52 \mathrm{E}+02$

$2.52 \mathrm{E}+02$

$2.53 E+02$

$2.53 \mathrm{E}+02$

2. $54 \mathrm{E}+02$

$2.54 \mathrm{E}+02$

2. $55 \mathrm{E}+02$

2. $55 \mathrm{E}+02$

$2.56 \mathrm{E}+02$

$2.56 \mathrm{E}+02$

$2.57 \mathrm{E}+02$

$2.57 \mathrm{E}+02$

$2.58 \mathrm{E}+02$

$2.58 \mathrm{E}+02$

$2.59 \mathrm{E}+02$
Dose statistics at graphical times, mrem/yr

\begin{tabular}{|c|c|c|c|c|c|c|c|}
\hline m & aximum & ean & 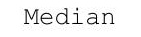 & $90 \%$ & & $\%$ & \\
\hline $41 E-33$ & $5.89 \mathrm{E}-02$ & $8.33 E-04$ & $9.63 E-31$ & $8.79 \mathrm{E}-04$ & $3.49 \mathrm{E}-03$ & -03 & $-0<$ \\
\hline $40 E-33$ & $6.02 \mathrm{E}-02$ & $3 E-04$ & $9.74 \mathrm{E}-31$ & - & 3 & -03 & -02 \\
\hline $.39 E-33$ & $6.15 \mathrm{E}-02$ & $3 E-04$ & $9.83 E-31$ & $9.35 \mathrm{E}-04$ & $3.69 \mathrm{E}-03$ & $9.69 \mathrm{E}-03$ & $2.18 \mathrm{E}-02$ \\
\hline $39 E-33$ & $6.28 \mathrm{E}-02$ & $3 E-04$ & $9.95 E-31$ & $9.68 \mathrm{E}-04$ & $3.79 \mathrm{E}-03$ & $9.90 \mathrm{E}-03$ & $2.23 E-02$ \\
\hline $38 E-33$ & 2 & $9.13 \mathrm{E}-04$ & 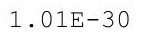 & & & -02 & -02 \\
\hline $37 E-33$ & 02 & $9.34 \mathrm{E}-04$ & 0 & 3 & & 2 & -02 \\
\hline $36 E-33$ & 2 & & & & & & -02 \\
\hline 33 & & & & & & & -02 \\
\hline 33 & 02 & -0 & & 3 & 3 & -02 & $E-02$ \\
\hline $34 \mathrm{E}-33$ & -02 & 年 & 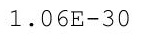 & 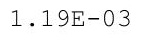 & 3 & 2 & -02 \\
\hline 33 & 2 & $1.04 \mathrm{E}-03$ & 7E-30 & $1.22 \mathrm{E}$ & & 2 & 2 \\
\hline 33 & 02 & & & & & & -02 \\
\hline $06 \mathrm{E}-32$ & $8 F-02$ & 1 & & 20 & 3 & 2 & -02 \\
\hline$E-32$ & $3 E-02$ & $2 E-03$ & 0 & $33 F$ & 3 & -02 & $73 E-02$ \\
\hline-32 & -02 & 3 & & 3 & & -02 & -02 \\
\hline 32 & 02 & $1.16 \mathrm{E}-03$ & $1.13 \mathrm{E}-30$ & 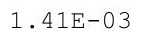 & 3 & 02 & -02 \\
\hline 32 & 02 & $1.19 \mathrm{E}-03$ & 1.15 & 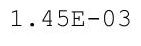 & & & -02 \\
\hline 2 & & & & & & & 2 \\
\hline $07 E-32$ & $8.54 \mathrm{E}-02$ & $1.24 \mathrm{E}-0$ & & $1.53 E-03$ & 42 & 02 & -02 \\
\hline $07 E-32$ & $1 \mathrm{E}-02$ & $1.27 \mathrm{E}-03$ & 1.1 & $1.57 \mathrm{E}-\mathrm{C}$ & .54 & -02 & $E-02$ \\
\hline $07 E-32$ & $8.89 \mathrm{E}-02$ & $1.30 \mathrm{E}-03$ & & $1.62 \mathrm{E}-03$ & & $E-02$ & -02 \\
\hline 32 & & & & 3 & & & -02 \\
\hline 32 & & $\perp$ & & 3 & & & 02 \\
\hline $07 E-32$ & $9.4 \angle L-U \angle$ & 1.000 & $1 \cdot 200$ & $\perp ・ 10 \amalg$ & & & -02 \\
\hline 2 & 2 & 1 & 1. $28 \mathrm{E}-30$ & 3 & P & 2 & -02 \\
\hline $07 E-32$ & $8 E-02$ & 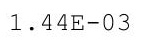 & $13 \cap 5$ & $184 \mathrm{~F}-$ & & $E-02$ & $45 E-02$ \\
\hline $07 E-32$ & -05 & $1.47 \mathrm{E}-$ & & 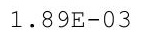 & קח & $E-02$ & $52 E-02$ \\
\hline$E-32$ & $E-01$ & 3 & & 3 & & -02 & -02 \\
\hline 32 & 01 & $\perp$ & & & & & 02 \\
\hline $07 E-32$ & $1.05 E-01$ & $1.30 E-43$ & 1. & 2.00 & 3 & 02 & -02 \\
\hline $07 E-32$ & $\perp \cdot 0 / L-01$ & 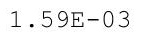 & ट. & $2.12 \mathrm{E}-03$ & $\cdot 2 \angle \mathrm{E}-\mathrm{U}$ & $1 \cdot 74 \mathrm{~L}-02$ & $.79 E-02$ \\
\hline 然 & 土. & $1 \cdot 0<\square$ & 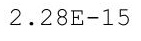 & 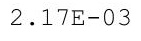 & . & 土.Tाए人 & $.86 \mathrm{E}-02$ \\
\hline $7 E-$ & 1 & $E-$ & & २ २२ & & & 02 \\
\hline$F-32$ & 1 & & & & & 02 & 02 \\
\hline & & & & & & & \\
\hline $82 E-32$ & $1.18 \mathrm{E}-01$ & $1.76 E-03$ & $1.18 \mathrm{E}-12$ & $2.40 \mathrm{E}$ & 3 & 2 & -02 \\
\hline $82 E-32$ & 1.200 & 1. & . & & 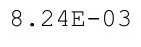 & & -02 \\
\hline $82 E-32$ & $\perp \cdot \angle \angle L-U \perp$ & & & & & & $4.295-U 2$ \\
\hline 2 & 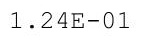 & 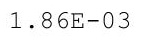 & 2 & 2 & 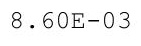 & 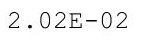 & 02 \\
\hline & & & & & & & 2 \\
\hline & & & & & & 2 & \\
\hline $3 E-32$ & 1.31E-01 & 1. & 2. & 2 . & 3 & 02 & -02 \\
\hline & 1.3 & & & & & & \\
\hline & $\perp$ & 2. & 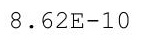 & & 3 & & $4.76 E-02$ \\
\hline & $\perp$ & & & & 3 & 2 & $85 E-02$ \\
\hline 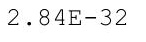 & $E-01$ & 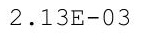 & $45 E-09$ & $2 E-03$ & $D E-02$ & $32 E-02$ & -02 \\
\hline
\end{tabular}


RESRAD-OFFSITE, Version 2.5 
RESRAD-OFFSITE, Version 2.5 
RESRAD-OFFSITE, Version 2.5 
RESRAD-OFFSITE, Version 2.5

$\mathrm{T}^{1 / 2}$ Limit $=180$ days

obabilistic Dose and Risk Report

Title : Offsite Resident Farmer

File : RF TC99 DOESG FWD-FV2all.ROF

Summary of dose at graphical times, reptition 1 (continued)

Time

Years

$3.30 \mathrm{E}+02$

$3.31 \mathrm{E}+02$

$3.31 \mathrm{E}+02$

$3.32 \mathrm{E}+02$

$3.32 \mathrm{E}+02$

$3.33 \mathrm{E}+02$

$3.33 \mathrm{E}+02$

$3.34 \mathrm{E}+02$

$3.34 \mathrm{E}+02$

$3.35 \mathrm{E}+02$

$3.35 \mathrm{E}+02$

$3.36 \mathrm{E}+02$

$3.36 \mathrm{E}+02$

$3.37 \mathrm{E}+02$

$3.37 \mathrm{E}+02$

$3.38 \mathrm{E}+02$

$3.38 \mathrm{E}+02$

$3.39 \mathrm{E}+02$

$3.39 \mathrm{E}+02$

3. $40 \mathrm{E}+02$

$3.40 \mathrm{E}+02$

$3.41 \mathrm{E}+02$

$3.41 \mathrm{E}+02$

$3.42 \mathrm{E}+02$

$3.42 \mathrm{E}+02$

$3.43 \mathrm{E}+02$

$3.44 \mathrm{E}+02$

$3.44 \mathrm{E}+02$

$3.45 \mathrm{E}+02$

$3.45 \mathrm{E}+02$

$3.46 \mathrm{E}+02$

$3.46 \mathrm{E}+02$

$3.47 \mathrm{E}+02$

$3.47 \mathrm{E}+02$

$3.48 \mathrm{E}+02$

$3.48 \mathrm{E}+02$

$3.49 \mathrm{E}+02$

$3.49 \mathrm{E}+02$

$3.50 \mathrm{E}+02$

$3.50 \mathrm{E}+02$

$3.51 \mathrm{E}+02$

$3.51 \mathrm{E}+02$

$3.52 \mathrm{E}+02$

$3.52 \mathrm{E}+02$

3. $53 \mathrm{E}+02$

$3.53 \mathrm{E}+02$
Dose statistics at graphical times, mrem/yr

\begin{tabular}{|c|c|c|c|c|c|c|c|}
\hline m & aximum & ean & ledian & & & $\%$ & \\
\hline 32 & $7.79 \mathrm{E}-01$ & $1.56 \mathrm{E}-02$ & $8.67 \mathrm{E}-04$ & $3.47 \mathrm{E}-02$ & $8.08 \mathrm{E}-02$ & -01 & -01 \\
\hline $22 E-32$ & -01 & 02 & -04 & 02 & 02 & -01 & -01 \\
\hline-32 & $7.93 \mathrm{E}-01$ & 1. 59E-02 & $9.03 \mathrm{E}-04$ & $.56 \mathrm{E}-02$ & $8.23 \mathrm{E}-02$ & 1. $42 \mathrm{E}-01$ & $2.87 \mathrm{E}-01$ \\
\hline $23 E-32$ & $7.99 \mathrm{E}-01$ & 1. $61 \mathrm{E}-02$ & -04 & $.60 \mathrm{E}-02$ & $1 E-02$ & $1.44 \mathrm{E}-01$ & $2.90 \mathrm{E}-01$ \\
\hline 32 & 01 & 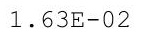 & 4 & & & 01 & 01 \\
\hline-32 & 1 & 2 & 4 & 2 & 2 & 1 & -01 \\
\hline $23 E-32$ & 01 & & & & & 1 & -01 \\
\hline-32 & & & & & & 01 & -01 \\
\hline-32 & -01 & -02 & -03 & -02 & -02 & -01 & -01 \\
\hline-32 & -01 & - & 0 & 2 & 2 & 1 & -01 \\
\hline 32 & $8.49 E-01$ & $1.73 \mathrm{E}-02$ & $8 E-03$ & $93 E-02$ & 2 & 1 & 1 \\
\hline 32 & & & & 2 & & 01 & -01 \\
\hline$E-32$ & -01 & 1. & 3 & 2 & 2 & 1 & -01 \\
\hline$E-32$ & $0 E-01$ & $9 E-02$ & $5 E-03$ & $8 E-02$ & 2 & -01 & -01 \\
\hline-32 & -01 & 2 & 3 & 2 & & -01 & -01 \\
\hline 32 & 1 & 2 & -03 & -02 & 2 & 01 & -01 \\
\hline 32 & 01 & $\perp \cdot$ & 3 & 2 & 2 & 1 & -01 \\
\hline 32 & & & & & & & 1 \\
\hline $50 E-32$ & $9.06 \mathrm{E}-01$ & $1.88 \mathrm{E}-02$ & $1.29 \mathrm{E}-03$ & $4.34 E-02$ & -02 & -01 & -01 \\
\hline $52 E-32$ & $.14 \mathrm{E}-01$ & $1.90 \mathrm{E}-02$ & $1.31 \mathrm{E}-03$ & $.40 \mathrm{E}-02$ & -02 & $.68 \mathrm{E}-01$ & $.35 E-01$ \\
\hline $22 E-31$ & $9.21 \mathrm{E}-01$ & 1. $92 \mathrm{E}-02$ & $1.34 \mathrm{E}-03$ & $4.45 E-02$ & $57 E-02$ & $E-01$ & $3.37 E-01$ \\
\hline & & & & & & $E-01$ & -01 \\
\hline & & & & & & & 01 \\
\hline $23 E-31$ & . & $\perp$ & 3 & & & 1 & -01 \\
\hline $24 E-31$ & 1 & $2 \cdot 0$ & 3 & 2 & 1 & 1 & -01 \\
\hline $24 E-31$ & $500^{2}$ & م & 1 & $.70 E-02$ & 1.01E-01 & $1.78 \mathrm{E}-01$ & $51 E-01$ \\
\hline$E-31$ & 1 & $20 \triangle \mathrm{F}=0$ & -03 & -02 & -01 & $9 E-01$ & -01 \\
\hline-31 & & ק ק & & -02 & $3 E-01$ & -01 & -01 \\
\hline & & & & & & & 01 \\
\hline $26 \mathrm{E}-31$ & $9.09 E-U 1$ & $2 \cdot \perp \perp+0<$ & 1. $61 \mathrm{E}-03$ & $.94 E-02$ & $1.05 \mathrm{E}-01$ & $.84 \mathrm{E}-01$ & -01 \\
\hline $26 E-31$ & $9.90 \mathrm{~L}-\mathrm{C}$ & ¿. & $1.64 \mathrm{E}-03$ & $.00 E-02$ & $1.06 \mathrm{E}-01$ & $1.86 \mathrm{E}-01$ & 3. $65 E-01$ \\
\hline $26 \mathrm{E}-31$ & $1.00 \mathrm{E}+00$ & $2 \cdot=0$ & $1.67 \mathrm{E}-03$ & $x^{2}$ & $1.07 \mathrm{E}-01$ & $\perp$ & $3.68 \mathrm{E}-01$ \\
\hline 1 & $1.01 \mathrm{E}+$ & & 1 & & & & 01 \\
\hline 31 & 1. $02 \mathrm{E}+0$ & & & & & & \\
\hline $27 E-31$ & & 2 & 3 & 2 & 1 & & 01 \\
\hline$E-31$ & & 2 & & 02 & 01 & 01 & 01 \\
\hline $28 E-31$ & $1.04 \mathrm{E}+00$ & $2 \cdot 2$ & 33 & & 1 & & -01 \\
\hline $9 E-31$ & 土. & - & & & & & OUL-U \\
\hline 1 & t. & 2 & 3 & 2 & 1 & & 01 \\
\hline 1 & 1. & & & & & & 1 \\
\hline 31 & & & 3 & 2 & 1 & & \\
\hline $30 E-31$ & $1.08 \mathrm{E}+00$ & -02 & 2. & -02 & 1.2 & 01 & -01 \\
\hline & & & & & & & \\
\hline & ×. & . & 2. & 2 & 1 & & $03 E-01$ \\
\hline $31 E-31$ & $\perp \cdot \perp \perp \mathrm{T} T U$ & +402 & 3 & $1 E-02$ & 1.2 & 2.0 & $06 E-01$ \\
\hline$E-31$ & $1.11 \mathrm{E}+00$ & $6 \mathrm{E}-02$ & $16 E-03$ & $E-02$ & $25 E-01$ & 01 & -01 \\
\hline
\end{tabular}


RESRAD-OFFSITE, Version 2.5

$\mathrm{T}^{1 / 2}$ Limit $=180$ days

obabilistic Dose and Risk Report

Title : Offsite Resident Farmer

File : RF TC99 DOESG FWD-FV2all.ROF

Summary of dose at graphical times, reptition 1 (continued)

Time

Years

$3.54 \mathrm{E}+02$

$3.54 \mathrm{E}+02$

$3.55 \mathrm{E}+02$

$3.55 \mathrm{E}+02$

$3.56 \mathrm{E}+02$

$3.56 \mathrm{E}+02$

$3.57 \mathrm{E}+02$

$3.57 \mathrm{E}+02$

$3.58 \mathrm{E}+02$

$3.58 \mathrm{E}+02$

$3.59 \mathrm{E}+02$

$3.59 \mathrm{E}+02$

$3.60 \mathrm{E}+02$

3. $60 \mathrm{E}+02$

$3.61 \mathrm{E}+02$

$3.61 \mathrm{E}+02$

$3.62 \mathrm{E}+02$

3. $62 \mathrm{E}+02$

$3.63 \mathrm{E}+02$

3. $64 \mathrm{E}+02$

$3.64 \mathrm{E}+02$

$3.65 \mathrm{E}+02$

$3.65 \mathrm{E}+02$

$3.66 \mathrm{E}+02$

$3.66 \mathrm{E}+02$

$3.67 \mathrm{E}+02$

$3.67 \mathrm{E}+02$

$3.68 \mathrm{E}+02$

$3.68 \mathrm{E}+02$

$3.69 \mathrm{E}+02$

$3.69 \mathrm{E}+02$

$3.70 \mathrm{E}+02$

$3.70 \mathrm{E}+02$

$3.71 \mathrm{E}+02$

$3.71 \mathrm{E}+02$

$3.72 \mathrm{E}+02$

$3.72 \mathrm{E}+02$

$3.73 E+02$

$3.73 E+02$

$3.74 \mathrm{E}+02$

$3.74 \mathrm{E}+02$

$3.75 \mathrm{E}+02$

$3.75 \mathrm{E}+02$

$3.76 \mathrm{E}+02$

$3.76 \mathrm{E}+02$

$3.77 \mathrm{E}+02$
Dose statistics at graphical times, mrem/yr

\begin{tabular}{|c|c|c|c|c|c|c|c|}
\hline m & aximum & ea & ec & & & & \\
\hline $32 E-31$ & $.12 \mathrm{E}+00$ & $48 E-02$ & 3 & 2 & 01 & 01 & $.13 E-U 1$ \\
\hline $32 E-31$ & $1.13 E+00$ & $2.51 E-02$ & $2.22 \mathrm{E}-03$ & $8 E-02$ & 1. $28 \mathrm{E}-01$ & $2.12 \mathrm{E}-01$ & $16 E-01$ \\
\hline $33 E-31$ & $.14 \mathrm{E}+00$ & $53 E-02$ & $26 E-03$ & $14 E-02$ & $29 E-01$ & $14 \mathrm{E}-01$ & $20 E-01$ \\
\hline $33 E-31$ & $1.15 \mathrm{E}+00$ & $56 \mathrm{~F}-02$ & $30 \mathrm{~F}-03$ & $19 F-02$ & $31 \mathrm{~F}-01$ & $2 \quad 16 \mathrm{~F}-01$ & $.23 E-01$ \\
\hline $33 E-31$ & $.15 \mathrm{E}+00$ & -02 & $\mathrm{~F}-03$ & 2 & $32 \mathrm{r}$ & 1 & -01 \\
\hline 31 & $.16 \mathrm{E}+00$ & & & & & & -01 \\
\hline $34 E-31$ & $1.17 \mathrm{E}+00$ & & 03 & & & & -01 \\
\hline $.35 E-31$ & $1.18 \mathrm{E}+00$ & $-0<$ & -03 & -02 & -01 & -01 & $36 \mathrm{E}-01$ \\
\hline $35 E-31$ & $1.19 \mathrm{E}+00$ & $8 E-02$ & $.49 E-03$ & -02 & 1. $38 \mathrm{E}-01$ & -01 & $39 E-01$ \\
\hline$E-31$ & $.20 E+00$ & $70=-0 ?$ & $.53 E-03$ & ת7 - & 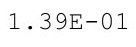 & $28 \mathrm{~F}$ & $.42 E-01$ \\
\hline-31 & $1.20 \mathrm{E}+00$ & & & & & 1 & $E-01$ \\
\hline $36 E-31$ & $1.21 \mathrm{E}+00$ & $5 F-02$ & $E-03$ & 2 & 1 & 1 & $E-01$ \\
\hline $61 E-31$ & $1.22 \mathrm{E}+00$ & $2.78 E-02$ & $2.65 E-03$ & $6.78 E-02$ & & $E-01$ & $.52 E-01$ \\
\hline $63 E-31$ & $1.23 E+00$ & $.80 \mathrm{E}-02$ & $2.70 \mathrm{E}-03$ & $6.85 \mathrm{E}-02$ & 1. $45 \mathrm{E}-01$ & $E-01$ & $55 E-01$ \\
\hline-31 & +00 & $\angle$ & -03 & 2 & $\perp$ & -01 & $E-01$ \\
\hline 1 & $1.24 \mathrm{E}+00$ & $2.85 E-02$ & 3 & 2 & L & 1 & 01 \\
\hline 31 & 0 & & & & $50 E-01$ & & 1 \\
\hline$E-31$ & $1.26 \mathrm{E}+00$ & $2.90 \mathrm{E}-02$ & 3 & 2 & 1 & 1 & 01 \\
\hline $71 E-31$ & $1.27 \mathrm{E}+00$ & $3 F-02$ & $2 E-03$ & $20 E-02$ & $53 F-$ & $8 E-01$ & $71 E-01$ \\
\hline $72 E-31$ & $1.28 \mathrm{E}+00$ & $.96 \mathrm{E}-02$ & $2.97 \mathrm{E}-03$ & $7.26 \mathrm{E}-02$ & $1.54 \mathrm{E}-$ & $2.50 \mathrm{E}-01$ & $4.75 E-01$ \\
\hline 1 & $1.29 \mathrm{E}+00$ & & & & & 1 & $E-01$ \\
\hline 1 & & & & & 1 & & 01 \\
\hline 1 & $1.30 \mathrm{E}+00$ & ¿ & 3 & & $\perp$ & & 01 \\
\hline $9 E-31$ & $1.31 E+00$ & $=$ & 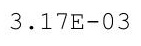 & 2 & L & L & -01 \\
\hline$E-31$ & $1.32 \mathrm{E}+00$ & م & 吅 & $1 \mathrm{E}-02$ & (20 & $E-$ & $91 \mathrm{E}-01$ \\
\hline$E-31$ & $1.33 E+00$ & $12 \mathrm{~F}-02$ & $.26 \mathrm{E}-03$ & $68 E-02$ & $1.64 \mathrm{E}-$ & $.63 E-01$ & $94 E-01$ \\
\hline-31 & $1.34 \mathrm{E}+00$ & & & & 1 & & $98 E-01$ \\
\hline & & & & & & & 01 \\
\hline & & 02 & & -02 & +.00 & 1 & 01 \\
\hline $89 E-31$ & $1.36 \mathrm{E}+00$ & . & $3.46 \mathrm{E}-03$ & $8.01 \mathrm{E}-02$ & $1.09 E-01$ & $2.71 \mathrm{E}-01$ & $.08 E-01$ \\
\hline 31 & $1.37 \mathrm{E}+00$ & $3.25 E-02$ & $.51 \mathrm{E}-03$ & $.09 \mathrm{E}-02$ & 土. & $2.75 \mathrm{~L}-\mathrm{L}$ & $.11 \mathrm{E}-01$ \\
\hline 1 & $1.38 \mathrm{E}+00$ & תחת ת & ת & & & & $15 E-01$ \\
\hline-31 & & & & & & & $8 E-01$ \\
\hline 31 & & 02 & 03 & 2 & & & 01 \\
\hline-31 & & 02 & 03 & 02 & 1.15 & 1 & 01 \\
\hline $99 E-31$ & $1.42 \mathrm{E}+00$ & $3.40 \pm-02$ & $3.77 \mathrm{E}-03$ & $8.49 \mathrm{E}-02$ & D.T1 & -01 & $.28 E-01$ \\
\hline $00 E-31$ & $1.42 \mathrm{E}+00$ & $3.43 E-02$ & & & & & $3.3 \angle E-01$ \\
\hline 1 & $1.43 E+00$ & 2 & 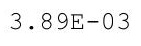 & & 1. $79 \mathrm{E}-01$ & & $35 E-01$ \\
\hline 1 & $1.44 \mathrm{E}+00$ & 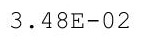 & 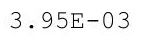 & 2 & 1 & $2 \cdot$ & 01 \\
\hline 31 & $1.45 E+00$ & & 3 & 02 & 1 & & 01 \\
\hline$E-31$ & $1.46 \mathrm{E}+00$ & $3.54 \mathrm{E}-02$ & $E-03$ & 02 & $1.82 \mathrm{E}$ & $2.95 E-01$ & $45 E-01$ \\
\hline-31 & $1.47 \mathrm{E}+00$ & $3.57 \mathrm{E}-02$ & & & 1.84 & & $E-01$ \\
\hline$E-31$ & $1.48 \mathrm{E}+00$ & & & & & & $.5 \angle E-U \perp$ \\
\hline $12 \mathrm{E}-31$ & $1.49 \mathrm{E}+00$ & $3.00 \mathrm{~L}-02$ & $4.24 \mathrm{E}-03$ & $9.12 \mathrm{E}-02$ & $1.87 \mathrm{E}-01$ & $3.01 \mathrm{E}-01$ & $5.56 \mathrm{E}-01$ \\
\hline $14 \mathrm{E}-31$ & $1.49 \mathrm{E}+00$ & 3.00042 & $\pi .52 \pi-42$ & $9.20 \mathrm{E}-02$ & $1.88 \mathrm{E}-01$ & . & $5.59 \mathrm{E}-01$ \\
\hline$E-31$ & $1.50 \mathrm{E}+00$ & $9 E-02$ & $.35 E-03$ & $E-02$ & -01 & 01 & $5.63 E-01$ \\
\hline
\end{tabular}


RESRAD-OFFSITE, Version 2.5

obabilistic Dose and Risk Report

Title : Offsite Resident Farmer

File : RF TC99 DOESG FWD-FV2all.ROF

Summary of dose at graphical times, reptition 1 (continued)

Time

Years

$3.77 \mathrm{E}+02$

$3.78 \mathrm{E}+02$

$3.78 \mathrm{E}+02$

$3.79 \mathrm{E}+02$

$3.79 \mathrm{E}+02$

$3.80 \mathrm{E}+02$

$3.80 \mathrm{E}+02$

3. $81 \mathrm{E}+02$

$3.81 \mathrm{E}+02$

3. $82 \mathrm{E}+02$

3. $82 \mathrm{E}+02$

$3.83 \mathrm{E}+02$

$3.83 \mathrm{E}+02$

$3.84 \mathrm{E}+02$

$3.85 \mathrm{E}+02$

$3.85 \mathrm{E}+02$

$3.86 \mathrm{E}+02$

$3.86 \mathrm{E}+02$

$3.87 \mathrm{E}+02$

$3.87 \mathrm{E}+02$

$3.88 \mathrm{E}+02$

$3.88 \mathrm{E}+02$

$3.89 \mathrm{E}+02$

$3.89 \mathrm{E}+02$

3. $90 \mathrm{E}+02$

$3.90 E+02$

3. $91 \mathrm{E}+02$

3. $91 \mathrm{E}+02$

3. $92 \mathrm{E}+02$

3. $92 \mathrm{E}+02$

3. $93 \mathrm{E}+02$

3. $93 \mathrm{E}+02$

$3.94 \mathrm{E}+02$

$3.94 \mathrm{E}+02$

3. $95 \mathrm{E}+02$

$3.95 \mathrm{E}+02$

$3.96 \mathrm{E}+02$

$3.96 \mathrm{E}+02$

$3.97 \mathrm{E}+02$

$3.97 \mathrm{E}+02$

$3.98 \mathrm{E}+02$

$3.98 \mathrm{E}+02$

$3.99 \mathrm{E}+02$

3. $99 \mathrm{E}+02$

$4.00 \mathrm{E}+02$

$4.00 \mathrm{E}+02$
Dose statistics at graphical times, mrem/yr

\begin{tabular}{|c|c|c|c|c|c|c|c|}
\hline Minimum & Maximum & Mean & Median & $90 \%$ & $95 \%$ & $97.5 \%$ & $99 \%$ \\
\hline $4.18 E-31$ & $1.51 \mathrm{E}+00$ & $3.72 E-02$ & $4.41 E-03$ & $9.36 \mathrm{E}-02$ & $1.91 E-01$ & $3.08 E-01$ & $5.66 \mathrm{E}-01$ \\
\hline $4.20 E-31$ & $1.52 \mathrm{E}+00$ & $3.75 E-02$ & $4.48 \mathrm{E}-03$ & $9.45 \mathrm{E}-02$ & 1.92E-01 & $3.10 \mathrm{E}-01$ & $5.70 \mathrm{E}-01$ \\
\hline $4.21 E-31$ & $1.53 \mathrm{E}+00$ & $3.78 \mathrm{E}-02$ & $4.54 \mathrm{E}-03$ & $9.53 \mathrm{E}-02$ & 1.94E-01 & $3.13 \mathrm{E}-01$ & $5.73 E-01$ \\
\hline $4.23 E-31$ & $1.54 \mathrm{E}+00$ & $3.81 \mathrm{E}-02$ & $4.61 \mathrm{E}-03$ & $9.61 \mathrm{E}-02$ & $1.95 \mathrm{E}-01$ & $3.15 \mathrm{E}-01$ & $5.77 \mathrm{E}-01$ \\
\hline $4.25 E-31$ & $1.55 \mathrm{E}+00$ & $3.85 \mathrm{E}-02$ & $4.67 \mathrm{E}-03$ & $9.69 \mathrm{E}-02$ & $1.97 \mathrm{E}-01$ & $3.17 \mathrm{E}-01$ & $5.81 \mathrm{E}-01$ \\
\hline $4.27 E-31$ & $1.56 \mathrm{E}+00$ & $3.88 \mathrm{E}-02$ & $4.74 E-03$ & $9.78 \mathrm{E}-02$ & $1.98 \mathrm{E}-01$ & $3.20 \mathrm{E}-01$ & $5.84 \mathrm{E}-01$ \\
\hline 4. $29 E-31$ & $1.57 \mathrm{E}+00$ & $3.91 \mathrm{E}-02$ & $4.80 E-03$ & $9.86 \mathrm{E}-02$ & $1.99 \mathrm{E}-01$ & $3.22 \mathrm{E}-01$ & $5.88 E-01$ \\
\hline $4.30 \mathrm{E}-31$ & $1.57 \mathrm{E}+00$ & $3.94 \mathrm{E}-02$ & $4.87 \mathrm{E}-03$ & $9.95 \mathrm{E}-02$ & $2.01 \mathrm{E}-01$ & $3.25 \mathrm{E}-01$ & $5.91 \mathrm{E}-01$ \\
\hline 4. $32 \mathrm{E}-31$ & $1.58 \mathrm{E}+00$ & $3.97 \mathrm{E}-02$ & $4.94 \mathrm{E}-03$ & $1.00 \mathrm{E}-01$ & $2.03 E-01$ & $3.27 E-01$ & $5.95 E-01$ \\
\hline $4.34 \mathrm{E}-31$ & $1.59 \mathrm{E}+00$ & $4.00 \mathrm{E}-02$ & $5.00 \mathrm{E}-03$ & $1.01 \mathrm{E}-01$ & $2.04 \mathrm{E}-01$ & $3.29 \mathrm{E}-01$ & $5.99 \mathrm{E}-01$ \\
\hline $4.36 \mathrm{E}-31$ & $1.60 \mathrm{E}+00$ & $4.04 \mathrm{E}-02$ & $5.07 \mathrm{E}-03$ & $1.02 \mathrm{E}-01$ & $2.06 \mathrm{E}-01$ & $3.32 \mathrm{E}-01$ & $6.02 \mathrm{E}-01$ \\
\hline $1.99 \mathrm{E}-30$ & 1. $61 \mathrm{E}+00$ & $4.07 E-02$ & $5.14 \mathrm{E}-03$ & $1.03 \mathrm{E}-01$ & $2.07 \mathrm{E}-01$ & $3.34 \mathrm{E}-01$ & $6.06 \mathrm{E}-01$ \\
\hline $2.00 E-30$ & $1.62 \mathrm{E}+00$ & $4.10 \mathrm{E}-02$ & $5.21 E-03$ & $1.03 E-01$ & $2.09 E-01$ & $3.37 E-01$ & $6.09 \mathrm{E}-01$ \\
\hline $2.02 E-30$ & $1.63 \mathrm{E}+00$ & $4.13 \mathrm{E}-02$ & $5.28 \mathrm{E}-03$ & $1.04 \mathrm{E}-01$ & $2.10 \mathrm{E}-01$ & $3.39 \mathrm{E}-01$ & $6.13 \mathrm{E}-01$ \\
\hline $5.02 \mathrm{E}-30$ & $1.64 \mathrm{E}+00$ & $4.17 E-02$ & $5.36 \mathrm{E}-03$ & $1.05 \mathrm{E}-01$ & $2.11 \mathrm{E}-01$ & $3.42 \mathrm{E}-01$ & $6.17 \mathrm{E}-01$ \\
\hline $5.06 \mathrm{E}-30$ & $1.65 \mathrm{E}+00$ & $4.20 E-02$ & $5.43 E-03$ & $1.06 \mathrm{E}-01$ & $2.13 E-01$ & $3.44 \mathrm{E}-01$ & $20 E-01$ \\
\hline $6.45 \mathrm{E}-30$ & $1.66 \mathrm{E}+00$ & $4.23 E-02$ & $5.51 \mathrm{E}-03$ & $1.07 \mathrm{E}-01$ & $2.14 \mathrm{E}-01$ & $3.47 \mathrm{E}-01$ & $6.24 \mathrm{E}-01$ \\
\hline $6.50 \mathrm{E}-30$ & $1.66 \mathrm{E}+00$ & $4.26 E-02$ & $5.58 \mathrm{E}-03$ & $1.08 \mathrm{E}-01$ & $2.16 \mathrm{E}-01$ & $3.49 \mathrm{E}-01$ & $6.28 E-01$ \\
\hline $6.55 E-30$ & $1.67 \mathrm{E}+00$ & $4.30 \mathrm{E}-02$ & $5.67 \mathrm{E}-03$ & $1.09 \mathrm{E}-01$ & $2.17 \mathrm{E}-01$ & $3.52 E-01$ & $6.31 E-01$ \\
\hline $6.60 \mathrm{E}-30$ & 1. $68 \mathrm{E}+00$ & $4.33 E-02$ & $5.75 \mathrm{E}-03$ & $1.09 \mathrm{E}-01$ & $2.19 \mathrm{E}-01$ & $3.55 \mathrm{E}-01$ & $6.35 E-01$ \\
\hline $1.07 \mathrm{E}-29$ & 1. $69 \mathrm{E}+00$ & $4.36 \mathrm{E}-02$ & $5.83 E-03$ & 1.10E-01 & $2.20 \mathrm{E}-01$ & $3.57 \mathrm{E}-01$ & $6.39 \mathrm{E}-01$ \\
\hline $1.04 \mathrm{E}-24$ & $1.70 \mathrm{E}+00$ & $4.40 \mathrm{E}-02$ & $5.91 E-03$ & $1.11 \mathrm{E}-01$ & $2.22 E-01$ & $3.59 \mathrm{E}-01$ & $6.42 E-01$ \\
\hline $4.31 E-22$ & $1.71 \mathrm{E}+00$ & $4.43 E-02$ & $6.00 \mathrm{E}-03$ & $1.12 \mathrm{E}-01$ & $2.23 E-01$ & $3.62 \mathrm{E}-01$ & $6.46 \mathrm{E}-01$ \\
\hline $3.42 \mathrm{E}-20$ & 1. $72 \mathrm{E}+00$ & $4.47 \mathrm{E}-02$ & $6.09 \mathrm{E}-03$ & $1.13 \mathrm{E}-01$ & $2.25 \mathrm{E}-01$ & $3.64 \mathrm{E}-01$ & $6.49 \mathrm{E}-01$ \\
\hline $1.05 \mathrm{E}-18$ & 1. $73 \mathrm{E}+00$ & $4.50 \mathrm{E}-02$ & $6.17 \mathrm{E}-03$ & $1.14 \mathrm{E}-01$ & $2.26 \mathrm{E}-01$ & $3.67 \mathrm{E}-01$ & $6.53 \mathrm{E}-01$ \\
\hline $1.71 \mathrm{E}-17$ & 1. $74 \mathrm{E}+00$ & $4.54 \mathrm{E}-02$ & $6.26 \mathrm{E}-03$ & $1.15 \mathrm{E}-01$ & $2.27 E-01$ & $3.69 \mathrm{E}-01$ & $6.56 \mathrm{E}-01$ \\
\hline $1.81 \mathrm{E}-16$ & $1.75 \mathrm{E}+00$ & $4.57 \mathrm{E}-02$ & $6.34 \mathrm{E}-03$ & $1.16 \mathrm{E}-01$ & $2.29 \mathrm{E}-01$ & $3.71 \mathrm{E}-01$ & $6.60 \mathrm{E}-01$ \\
\hline $1.38 \mathrm{E}-15$ & $1.76 \mathrm{E}+00$ & $4.60 \mathrm{E}-02$ & $6.42 \mathrm{E}-03$ & $1.17 \mathrm{E}-01$ & $2.30 \mathrm{E}-01$ & $3.74 \mathrm{E}-01$ & $6.63 E-01$ \\
\hline $8.18 \mathrm{E}-15$ & $1.77 \mathrm{E}+00$ & $4.64 \mathrm{E}-02$ & $6.50 \mathrm{E}-03$ & $1.18 \mathrm{E}-01$ & $2.32 \mathrm{E}-01$ & $3.76 \mathrm{E}-01$ & $6.67 \mathrm{E}-01$ \\
\hline $3.90 \mathrm{E}-14$ & $1.77 \mathrm{E}+00$ & $4.68 E-02$ & $6.59 \mathrm{E}-03$ & $1.19 \mathrm{E}-01$ & $2.33 E-01$ & $3.78 \mathrm{E}-01$ & $6.70 \mathrm{E}-01$ \\
\hline 1. $56 \mathrm{E}-13$ & $1.78 \mathrm{E}+00$ & $4.71 E-02$ & $6.67 \mathrm{E}-03$ & $1.19 \mathrm{E}-01$ & $2.34 \mathrm{E}-01$ & $3.81 \mathrm{E}-01$ & $6.73 E-01$ \\
\hline $5.35 \mathrm{E}-13$ & 1. $79 \mathrm{E}+00$ & $4.75 E-02$ & $6.76 \mathrm{E}-03$ & 1.20E-01 & $2.36 \mathrm{E}-01$ & $3.83 \mathrm{E}-01$ & $6.77 \mathrm{E}-01$ \\
\hline 1. $62 \mathrm{E}-12$ & $1.80 \mathrm{E}+00$ & $.78 E-02$ & $6.86 \mathrm{E}-03$ & $1.21 \mathrm{E}-01$ & $2.37 E-01$ & $3.86 \mathrm{E}-01$ & $6.80 \mathrm{E}-01$ \\
\hline 4. $38 \mathrm{E}-12$ & $1.81 \mathrm{E}+00$ & $4.82 \mathrm{E}-02$ & $6.95 \mathrm{E}-03$ & 1.22E-01 & $2.39 \mathrm{E}-01$ & $3.88 \mathrm{E}-01$ & $6.84 \mathrm{E}-01$ \\
\hline $1.08 \mathrm{E}-11$ & $1.82 \mathrm{E}+00$ & $4.85 E-02$ & $7.04 \mathrm{E}-03$ & 1.23E-01 & $2.40 \mathrm{E}-01$ & $3.90 \mathrm{E}-01$ & $6.87 \mathrm{E}-01$ \\
\hline $2.45 \mathrm{E}-11$ & $1.83 \mathrm{E}+00$ & $4.89 E-02$ & $7.13 E-03$ & $1.24 \mathrm{E}-01$ & $2.42 \mathrm{E}-01$ & $3.93 \mathrm{E}-01$ & $6.91 \mathrm{E}-01$ \\
\hline $5.19 \mathrm{E}-11$ & $1.84 \mathrm{E}+00$ & $4.93 E-02$ & $7.22 \mathrm{E}-03$ & $1.25 \mathrm{E}-01$ & $2.44 \mathrm{E}-01$ & $3.95 \mathrm{E}-01$ & $6.95 E-01$ \\
\hline $1.04 \mathrm{E}-10$ & $1.85 \mathrm{E}+00$ & $4.96 \mathrm{E}-02$ & $7.31 \mathrm{E}-03$ & $1.26 \mathrm{E}-01$ & $2.45 \mathrm{E}-01$ & $3.98 \mathrm{E}-01$ & $6.99 \mathrm{E}-01$ \\
\hline $96 E-10$ & $1.86 \mathrm{E}+00$ & $5.00 \mathrm{E}-02$ & $7.40 \mathrm{E}-03$ & $1.27 \mathrm{E}-01$ & $2.47 E-01$ & $4.00 \mathrm{E}-01$ & $7.03 E-01$ \\
\hline $3.53 \mathrm{E}-10$ & $1.87 \mathrm{E}+00$ & $5.04 \mathrm{E}-02$ & $7.49 \mathrm{E}-03$ & $1.28 \mathrm{E}-01$ & $2.49 \mathrm{E}-01$ & $4.02 E-01$ & $7.07 \mathrm{E}-01$ \\
\hline $6.12 \mathrm{E}-10$ & $1.88 \mathrm{E}+00$ & $5.07 \mathrm{E}-02$ & $7.58 \mathrm{E}-03$ & $1.29 \mathrm{E}-01$ & $2.50 \mathrm{E}-01$ & $4.05 E-01$ & $7.11 \mathrm{E}-01$ \\
\hline $1.02 \mathrm{E}-09$ & $1.88 \mathrm{E}+00$ & $5.11 \mathrm{E}-02$ & $7.67 \mathrm{E}-03$ & $1.30 \mathrm{E}-01$ & $2.52 \mathrm{E}-01$ & $4.07 E-01$ & $7.15 E-01$ \\
\hline $1.65 \mathrm{E}-09$ & $1.89 \mathrm{E}+00$ & $5.15 \mathrm{E}-02$ & $7.76 \mathrm{E}-03$ & $1.31 \mathrm{E}-01$ & $2.54 \mathrm{E}-01$ & $4.10 \mathrm{E}-01$ & $7.19 \mathrm{E}-01$ \\
\hline $2.59 \mathrm{E}-09$ & $1.90 \mathrm{E}+00$ & $5.18 \mathrm{E}-02$ & $7.86 \mathrm{E}-03$ & $1.32 \mathrm{E}-01$ & $2.56 \mathrm{E}-01$ & $4.12 \mathrm{E}-01$ & $7.23 E-01$ \\
\hline $3.97 \mathrm{E}-09$ & $1.91 \mathrm{E}+00$ & $5.22 E-02$ & $7.96 \mathrm{E}-03$ & $1.33 \mathrm{E}-01$ & $2.57 E-01$ & $4.15 E-01$ & $7.27 E-01$ \\
\hline $5.92 \mathrm{E}-09$ & $1.92 \mathrm{E}+00$ & $5.26 \mathrm{E}-02$ & $8.06 \mathrm{E}-03$ & 1. $34 \mathrm{E}-01$ & $2.59 \mathrm{E}-01$ & $4.17 \mathrm{E}-01$ & 7. $31 \mathrm{E}-01$ \\
\hline
\end{tabular}


RESRAD-OFFSITE, Version 2.5 
RESRAD-OFFSITE, Version 2.5 
RESRAD-OFFSITE, Version 2.5

$\mathrm{T}^{1 / 2}$ Limit $=180$ days

robabilistic Dose and Risk Report

Title : Offsite Resident Farmer

File : RF TC99 DOESG FWD-FV2all.ROF

Summary of dose at graphical times, reptition 1 (continued)

Time

Years

$4.48 \mathrm{E}+02$

$4.49 \mathrm{E}+02$

$4.49 \mathrm{E}+02$

$4.50 \mathrm{E}+02$

$4.50 \mathrm{E}+02$

$4.51 \mathrm{E}+02$

$4.51 \mathrm{E}+02$

$4.52 \mathrm{E}+02$

$4.52 \mathrm{E}+02$

$4.53 E+02$

$4.53 \mathrm{E}+02$

$4.54 \mathrm{E}+02$

$4.54 \mathrm{E}+02$

$4.55 \mathrm{E}+02$

$4.55 \mathrm{E}+02$

$4.56 \mathrm{E}+02$

$4.56 \mathrm{E}+02$

$4.57 \mathrm{E}+02$

$4.57 \mathrm{E}+02$

$4.58 \mathrm{E}+02$

$4.58 \mathrm{E}+02$

$4.59 \mathrm{E}+02$

$4.59 \mathrm{E}+02$

$4.60 \mathrm{E}+02$

$4.60 \mathrm{E}+02$

$4.61 \mathrm{E}+02$

4. $61 \mathrm{E}+02$

$4.62 \mathrm{E}+02$

4. $62 \mathrm{E}+02$

4. $63 \mathrm{E}+02$

4. $63 \mathrm{E}+02$

$4.64 \mathrm{E}+02$

$4.65 \mathrm{E}+02$

4. $65 \mathrm{E}+02$

$4.66 \mathrm{E}+02$

$4.66 \mathrm{E}+02$

$4.67 \mathrm{E}+02$

$4.67 \mathrm{E}+02$

$4.68 \mathrm{E}+02$

$4.68 \mathrm{E}+02$

$4.69 \mathrm{E}+02$

$4.69 \mathrm{E}+02$

$4.70 \mathrm{E}+02$

$4.70 \mathrm{E}+02$

$4.71 \mathrm{E}+02$

$4.71 \mathrm{E}+02$
Dose statistics at graphical times, mrem/yr

\begin{tabular}{|c|c|c|c|c|c|c|c|}
\hline$m$ & $\mathrm{~m}$ & ea & ledian & & & $\%$ & \\
\hline $.09 \mathrm{E}-04$ & $.78 \mathrm{E}+00$ & $9.51 \mathrm{E}-02$ & $2.18 \mathrm{E}-02$ & $2.47 \mathrm{E}-01$ & $4.46 \mathrm{E}-01$ & -01 & +00 \\
\hline $.11 \mathrm{E}-04$ & $2.79 \mathrm{E}+00$ & $.56 \mathrm{E}-02$ & $2.20 \mathrm{E}-02$ & 01 & 01 & -01 & $1.12 \mathrm{E}+00$ \\
\hline $.14 \mathrm{E}-04$ & $2.80 \mathrm{E}+00$ & $9.61 \mathrm{E}-02$ & $2.22 \mathrm{E}-02$ & $2.50 \mathrm{E}-01$ & $4.50 \mathrm{E}-01$ & $6.75 \mathrm{E}-01$ & $1.13 \mathrm{E}+00$ \\
\hline $17 \mathrm{E}-04$ & $2.81 E+00$ & $9.67 \mathrm{E}-02$ & $2.24 \mathrm{E}-02$ & $2.51 \mathrm{E}-01$ & $4.51 \mathrm{E}-01$ & $6.78 \mathrm{E}-01$ & $1.13 \mathrm{E}+00$ \\
\hline $9 E-04$ & $.81 E+00$ & $2 \mathrm{E}-02$ & $2.26 \mathrm{E}$ & $53 E-01$ & $53 E-01$ & $31 E-01$ & $1.14 \mathrm{E}+00$ \\
\hline $22 \mathrm{E}-04$ & $82 \mathrm{E}+00$ & 2 & 2 & 1 & 1 & 1 & +00 \\
\hline $25 E-04$ & $2.83 \mathrm{E}+00$ & 2 & 2 & 1 & 1 & & +00 \\
\hline $28 \mathrm{E}-04$ & & & & $\perp$ & & & $15 E+00$ \\
\hline $.31 E-04$ & $2.85 \mathrm{E}+00$ & -02 & $E-02$ & $58 E-01$ & $59 E-01$ & -01 & $15 E+00$ \\
\hline 3 & $86 \mathrm{E}+00$ & $9.99 \mathrm{E}-02$ & -02 & $\perp$ & 1 & -01 & +00 \\
\hline 4 & $.87 \mathrm{E}+00$ & 1.00E-01 & 2 & 1 & 1 & 1 & $.16 \mathrm{E}+00$ \\
\hline$\triangle \cap F-04$ & $E+00$ & & & & & & +00 \\
\hline $43 F-04$ & $3 E+00$ & $25-0$ & $E-02$ & 1 & 1 & -01 & +00 \\
\hline $.46 \mathrm{E}-04$ & $2.89 \mathrm{E}+00$ & $1.02 \mathrm{E}-01$ & $2.44 \mathrm{E}-02$ & $2.65 \mathrm{E}-01$ & $4.68 \mathrm{E}-01$ & $7.09 \mathrm{E}-01$ & $1.17 \mathrm{E}+00$ \\
\hline $49 E-04$ & $2.90 \mathrm{E}+00$ & $3 E-01$ & $6 E-02$ & 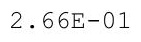 & 01 & -01 & $17 \mathrm{E}+00$ \\
\hline 4 & & & & & & 1 & 00 \\
\hline $5 E-04$ & & $4 E-01$ & & - & 5 & & 00 \\
\hline $59 \mathrm{E}-$ & & & & & $.76 \mathrm{E}-01$ & & 00 \\
\hline $62 E-04$ & $2.94 \mathrm{E}+00$ & $5 \mathrm{~F}-1$ & $5 E-02$ & $272 \mathrm{~F}$ & 1 & -01 & $19 \mathrm{E}+00$ \\
\hline $65 E-04$ & $2.95 \mathrm{E}+00$ & 1. $05 \mathrm{E}-01$ & $2.57 \mathrm{E}-02$ & $2.74 \mathrm{E}-01$ & $.81 E-01$ & $E-01$ & $1.19 \mathrm{E}+00$ \\
\hline$F-04$ & $.95 E+00$ & $.06 \mathrm{E}-0$ & -02 & $.75 \mathrm{E}-01$ & $.83 E-01$ & $.29 \mathrm{E}-01$ & L. $20 \mathrm{E}+00$ \\
\hline 04 & & & & & & -01 & \\
\hline & & & & & & & 00 \\
\hline $.79 E-04$ & $2.98 \mathrm{E}+00$ & +.000 & 2 & & & 01 & 00 \\
\hline 4 & $2.99 \mathrm{E}+00$ & 1. $08 \mathrm{E}-01$ & 2 & $\perp$ & $\perp$ & 1 & $21 E+00$ \\
\hline $86 E-04$ & $.00 \mathrm{E}+00$ & م & $2.71 \mathrm{E}-02$ & م२ & $.94 E-01$ & $7.44 \mathrm{E}-01$ & $1.22 \mathrm{E}+00$ \\
\hline-04 & $3.01 \mathrm{E}+00$ & $=01$ & $2.74 \mathrm{E}-02$ & $85 F_{-}$ & $4.97 \mathrm{E}-01$ & $.47 E-01$ & $1.22 \mathrm{E}+00$ \\
\hline 4 & & & & & & & \\
\hline-04 & $3.02 \mathrm{E}+00$ & & & & & & 00 \\
\hline$\cdot 01 E-04$ & $3.03 E+00$ & $\perp \cdot \perp \perp \perp-$ & $2.81 E-02$ & $2 \cdot 20$ & $5.05 E-01$ & -01 & $1.23 E+00$ \\
\hline $.035-4$ & $3.04 \mathrm{E}+00$ & $\perp \cdot \perp \angle \dot{0}$ & $2.84 \mathrm{E}-02$ & $2.92 E-01$ & $3.01 \mathrm{~L}-0 \perp$ & $7.59 \mathrm{E}-01$ & $1.23 \mathrm{E}+00$ \\
\hline 然 & $3.05 \mathrm{E}+00$ & 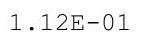 & 年 & (2) & 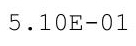 & $=0$ & $1.24 \mathrm{E}+00$ \\
\hline 10 & $3.06 \mathrm{E}+00$ & 135 & תم: תم & $0.5 \Gamma$ & & & $1.24 \mathrm{E}+00$ \\
\hline & & & & & & & $.25 \mathrm{E}+00$ \\
\hline$E-04$ & $3.07 E+00$ & & 02 & 1 & 1 & & $1.25 \mathrm{E}+00$ \\
\hline $24 E-04$ & $3.08 \mathrm{E}+00$ & $1.15 \mathrm{E}-01$ & $2.96 \mathrm{E}-02$ & 3.014 & 1 & 01 & $1.25 \mathrm{E}+00$ \\
\hline $5-04$ & $3.09 \mathrm{E}+00$ & & & & & & $1.26 \mathrm{E}+00$ \\
\hline $\begin{array}{ll}04 \\
4\end{array}$ & & & & & & & $1.26 \mathrm{E}+00$ \\
\hline $37 F-04$ & ent & $+\cdots$ & 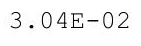 & $\perp$ & & 1 & $1.26 \mathrm{E}+00$ \\
\hline & & & & & & & $.27 E+00$ \\
\hline 04 & $3.12 \mathrm{E}+00$ & & 02 & 1 & 1 & 1 & $1.27 E+00$ \\
\hline$E-04$ & $3.13 \mathrm{E}+00$ & 1.1 & 3. & 01 & 01 & 1 & $1.27 \mathrm{E}+00$ \\
\hline & & & & & & & 00 \\
\hline & $3.15 \mathrm{E}+00$ & 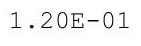 & & & & & $1.28 \mathrm{E}+00$ \\
\hline 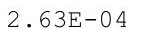 & $3.16 \mathrm{E}+00$ & $\perp \cdot 20+$ & & 1 & & 0.025 & $1.29 \mathrm{E}+00$ \\
\hline-04 & $.16 \mathrm{E}+00$ & $1 \mathrm{E}-01$ & $2 E-02$ & $E-01$ & $E-01$ & 1 & $1.29 \mathrm{E}+00$ \\
\hline
\end{tabular}


RESRAD-OFFSITE, Version 2.5

robabilistic Dose and Risk Report

Title : Offsite Resident Farmer

File : RF TC99 DOESG FWD-FV2all.ROF

Summary of dose at graphical times, reptition 1 (continued)

Time

Years

$4.72 \mathrm{E}+02$

$4.72 \mathrm{E}+02$

$4.73 E+02$

4. $73 \mathrm{E}+02$

$4.74 \mathrm{E}+02$

4. $74 \mathrm{E}+02$

$4.75 \mathrm{E}+02$

4. $75 \mathrm{E}+02$

$4.76 \mathrm{E}+02$

4. $76 \mathrm{E}+02$

$4.77 \mathrm{E}+02$

$4.77 \mathrm{E}+02$

$4.78 \mathrm{E}+02$

$4.78 \mathrm{E}+02$

$4.79 \mathrm{E}+02$

$4.79 \mathrm{E}+02$

$4.80 \mathrm{E}+02$

$4.80 \mathrm{E}+02$

$4.81 \mathrm{E}+02$

$4.81 \mathrm{E}+02$

$4.82 \mathrm{E}+02$

$4.82 \mathrm{E}+02$

$4.83 \mathrm{E}+02$

$4.83 \mathrm{E}+02$

$4.84 \mathrm{E}+02$

$4.84 \mathrm{E}+02$

$4.85 \mathrm{E}+02$

$4.86 \mathrm{E}+02$

4. $86 \mathrm{E}+02$

$4.87 \mathrm{E}+02$

$4.87 \mathrm{E}+02$

$4.88 \mathrm{E}+02$

$4.88 \mathrm{E}+02$

4. $89 \mathrm{E}+02$

$4.89 \mathrm{E}+02$

4. $90 \mathrm{E}+02$

$4.90 \mathrm{E}+02$

4. $91 \mathrm{E}+02$

4. $91 \mathrm{E}+02$

4. $92 \mathrm{E}+02$

4. $92 \mathrm{E}+02$

$4.93 \mathrm{E}+02$

$4.93 \mathrm{E}+02$

4. $94 \mathrm{E}+02$

4. $94 \mathrm{E}+02$

4. $95 \mathrm{E}+02$
Dose statistics at graphical times, mrem/yr

\begin{tabular}{|c|c|c|c|c|c|c|c|}
\hline $\mathrm{m}$ & aximum & lea & ec & & & & $\%$ \\
\hline $.72 E-04$ & $.17 \mathrm{E}+00$ & 1.21E-01 & $.25 E-02$ & $3.18 \mathrm{E}-01$ & 01 & 01 & $.29 E+00$ \\
\hline $.76 E-04$ & $3.18 \mathrm{E}+00$ & $1.22 \mathrm{E}-01$ & $3.28 \mathrm{E}-02$ & $19 E-01$ & $8 E-01$ & $8.11 \mathrm{E}-01$ & $1.30 \mathrm{E}+00$ \\
\hline $81 E-04$ & $19 \mathrm{E}+00$ & $23 E-01$ & $31 E-02$ & $21 E-01$ & $50 E-01$ & $14 \mathrm{E}-01$ & $30 E+00$ \\
\hline $86 E-04$ & $.20 E+00$ & $23 F-01$ & $34 \mathrm{E}-02$ & $23 F-01$ & $53 F-01$ & $17 \mathrm{~F}-01$ & 1. $30 \mathrm{E}+00$ \\
\hline $90 E-04$ & $\mathrm{E}+00$ & 4 & -02 & 1 & 1 & 1 & $E+00$ \\
\hline 04 & $21 E+00$ & 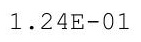 & 2 & & & & +00 \\
\hline $.00 E-04$ & $3.22 \mathrm{E}+00$ & $1.25 \mathrm{E}$ & -02 & & & & $.32 E+00$ \\
\hline-04 & +00 & $\perp$ & -02 & 1 & 1 & 01 & $\mathrm{E}+00$ \\
\hline $10 E-04$ & $3.24 \mathrm{E}+00$ & $.26 \mathrm{E}-0$. & $\Xi-02$ & $31 E-01$ & - & $E-01$ & $2 \mathrm{E}+00$ \\
\hline$E-04$ & $.25 E+00$ & $27 \mathrm{~F}-1$ & $1 E-02$ & & & קטק & $.33 E+00$ \\
\hline 04 & $3.25 \mathrm{E}+00$ & .27 & 2 & & & & +00 \\
\hline $25 E-04$ & +00 & $1.28 \mathrm{E}$ & $E-02$ & 6 & 1 & 1 & +00 \\
\hline $30 E-04$ & $3.27 \mathrm{E}+00$ & $1.29 \mathrm{E}-01$ & $3.59 \mathrm{E}-02$ & $3.38 \mathrm{E}-01$ & $5.75 \mathrm{E}-01$ & & $1.34 \mathrm{E}+00$ \\
\hline $35 E-04$ & $3.28 \mathrm{E}+00$ & 1.29E-01 & $.62 E-02$ & 1 & 1 & 1 & $1.34 \mathrm{E}+00$ \\
\hline-04 & +00 & $30 \mathrm{~F}-1$ & $E-02$ & & & 1 & $\mathrm{E}+00$ \\
\hline 4 & $.29 \mathrm{E}+00$ & - e & -02 & & 1 & $\perp$ & 00 \\
\hline 4 & 0 & 1. $31 \mathrm{E}-01$ & 2 & & $85 E-01$ & 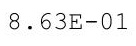 & 0 \\
\hline 4 & $3315+0$ & 1. $32 \mathrm{E}-01$ & 2 & $\perp$ & 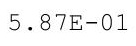 & 1 & 00 \\
\hline $62 E-04$ & $3.32 \mathrm{E}+00$ & $1.33 E-01$ & $3.75 E-02$ & $3.48 \mathrm{E}-01$ & $.90 E-01$ & $8.69 \mathrm{E}-01$ & $1.36 \mathrm{E}+00$ \\
\hline $68 E-04$ & $.33 E+00$ & $.33 E-01$ & $.78 E-02$ & $0 E-01$ & $92 \mathrm{E}-01$ & 8. $72 \mathrm{E}-01$ & $1.36 \mathrm{E}+00$ \\
\hline 04 & $33 E+00$ & 3 & 2 & & & & $\mathrm{E}+00$ \\
\hline 4 & & 1 & & 1 & & & \\
\hline 04 & & $1 \cdot 0$ & 2 & & & & $1.38 \mathrm{E}$ \\
\hline $1 E-04$ & $36 \mathrm{E}+00$ & $1.36 \mathrm{E}-01$ & 2 & 1 & 1 & - & +00 \\
\hline 4 & $.36 \mathrm{E}+00$ & 365 & $3 E-02$ & תח & $5 E-$ & $E-$ & $1.39 \mathrm{E}+00$ \\
\hline $.03 E-04$ & $37 \mathrm{E}+00$ & $1.37 \mathrm{E}-01$ & $5 E-02$ & תח & 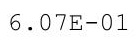 & $.90 E-01$ & $1.39 \mathrm{E}+00$ \\
\hline$E-04$ & $38 E+00$ & $38=-01$ & $99 E-02$ & & & $3 E-01$ & L. $40 \mathrm{E}+00$ \\
\hline & & & & & & & \\
\hline 4 & & 1.3 & 02 & & 1 & & $1.41 \mathrm{E}+00$ \\
\hline $.27 E-04$ & $3.40 \mathrm{E}+00$ & $\perp \cdot 4 U D-1$ & $4.08 E-02$ & $3.67 \mathrm{E}-01$ & $\cdot \perp / E-U \perp$ & $2 E-U 1$ & 1. $41 \mathrm{E}+00$ \\
\hline $33 E-04$ & $3.41 \mathrm{E}+00$ & $+\cdot 10+$ & $.11 \mathrm{E}-02$ & ( & - & .0 & $1.42 \mathrm{E}+00$ \\
\hline 4 & $3.42 \mathrm{E}+00$ & 1.41 & 2 & 1 & & & $1.42 \mathrm{E}+00$ \\
\hline & & & & & & & $42 E+00$ \\
\hline 4 & & & 02 & & & 1 & $1.43 E+00$ \\
\hline $9 E-04$ & $3.44 \mathrm{E}+00$ & $1.43 \mathrm{E}$ & 02 & 1 & 1 & & $1.43 \mathrm{E}+00$ \\
\hline $.65 E-04$ & $3.45 \mathrm{E}+00$ & $1.445-01$ & $7 E-02$ & 18 & $\perp$ & & $1.44 \mathrm{E}+00$ \\
\hline $72 E-04$ & $3.46 \mathrm{E}+00$ & $\perp \cdot 110$ - & & & & & $1.44 \mathrm{E}+00$ \\
\hline 4 & $3.46 \mathrm{E}+00$ & 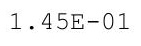 & 2 & & & & $1.45 \mathrm{E}+00$ \\
\hline 4 & $3.47 \mathrm{E}+00$ & 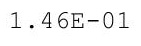 & 2 & 1 & & 1 & 1. $45 \mathrm{E}+00$ \\
\hline 4 & & & 2 & 1 & & 1 & \\
\hline $9 E-04$ & $3.49 \mathrm{E}+00$ & $1.47 \mathrm{E}-01$ & $2 E-02$ & & 01 & & $1.46 \mathrm{E}+00$ \\
\hline$E-04$ & $3.49 \pm+00$ & $1.40 \mathrm{I}$ & & & & & $1.47 \mathrm{E}+00$ \\
\hline $13 E-04$ & . & $1 \cdot$ & & & & & $1.47 \mathrm{E}+00$ \\
\hline $20 E-04$ & $3.51 \mathrm{E}+00$ & $\perp \cdot 47 \pm-01$ & $4.53 E-02$ & $3.91 \mathrm{E}-01$ & $6.53 E-01$ & $9.48 \mathrm{E}-01$ & $1.47 \mathrm{E}+00$ \\
\hline $27 E-04$ & $3.51 \mathrm{E}+00$ & $1.30 \mathrm{~L}-0$ & $4.57 \mathrm{E}-02$ & $3.93 \mathrm{E}-01$ & & $9.51 \mathrm{E}-01$ & $1.48 \mathrm{E}+00$ \\
\hline$E-04$ & $.52 \mathrm{E}+00$ & $E-01$ & $.60 \mathrm{E}-02$ & $95 E-01$ & $.58 E-01$ & 01 & $1.48 \mathrm{E}+00$ \\
\hline
\end{tabular}


RESRAD-OFFSITE, Version 2.5

$\mathrm{T}^{1 / 2}$ Limit $=180$ days

obabilistic Dose and Risk Report

Title : Offsite Resident Farmer

File : RF TC99 DOESG FWD-FV2all.ROF

Summary of dose at graphical times, reptition 1 (continued)

Time

Years

$4.95 \mathrm{E}+02$

$4.96 \mathrm{E}+02$

$4.96 \mathrm{E}+02$

$4.97 \mathrm{E}+02$

$4.97 \mathrm{E}+02$

$4.98 \mathrm{E}+02$

$4.98 \mathrm{E}+02$

$4.99 \mathrm{E}+02$

$4.99 \mathrm{E}+02$

$5.00 \mathrm{E}+02$

$5.00 \mathrm{E}+02$

$5.01 \mathrm{E}+02$

$5.01 \mathrm{E}+02$

$5.02 \mathrm{E}+02$

$5.02 \mathrm{E}+02$

$5.03 E+02$

$5.03 \mathrm{E}+02$

$5.04 \mathrm{E}+02$

$5.04 \mathrm{E}+02$

$5.05 \mathrm{E}+02$

$5.06 \mathrm{E}+02$

$5.06 \mathrm{E}+02$

$5.07 \mathrm{E}+02$

$5.07 \mathrm{E}+02$

$5.08 \mathrm{E}+02$

$5.08 \mathrm{E}+02$

$5.09 \mathrm{E}+02$

$5.09 \mathrm{E}+02$

$5.10 \mathrm{E}+02$

$5.10 \mathrm{E}+02$

$5.11 \mathrm{E}+02$

$5.11 \mathrm{E}+02$

$5.12 \mathrm{E}+02$

$5.12 \mathrm{E}+02$

$5.13 \mathrm{E}+02$

$5.13 \mathrm{E}+02$

$5.14 \mathrm{E}+02$

$5.14 \mathrm{E}+02$

$5.15 \mathrm{E}+02$

$5.15 \mathrm{E}+02$

$5.16 \mathrm{E}+02$

$5.16 \mathrm{E}+02$

$5.17 \mathrm{E}+02$

$5.17 \mathrm{E}+02$

$5.18 \mathrm{E}+02$

$5.18 \mathrm{E}+02$
Dose statistics at graphical times, mrem/yr

\begin{tabular}{|c|c|c|c|c|c|c|c|}
\hline m & aximum & ean & 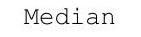 & & & $\%$ & \\
\hline $41 \mathrm{E}-04$ & $3.53 \mathrm{E}+00$ & $1.51 \mathrm{E}-01$ & $4.63 E-02$ & $3.97 \mathrm{E}-01$ & $6.60 \mathrm{E}-01$ & $9.58 \mathrm{E}-01$ & $1.49 \mathrm{E}+00$ \\
\hline $49 \mathrm{E}-04$ & $3.54 \mathrm{E}+00$ & $2 E-01$ & $4.66 \mathrm{E}-02$ & 01 & 01 & -01 & $1.49 \mathrm{E}+00$ \\
\hline $.56 \mathrm{E}-04$ & $3.54 \mathrm{E}+00$ & 1. $52 \mathrm{E}-01$ & $4.69 \mathrm{E}-02$ & $.01 E-01$ & $6.65 \mathrm{E}-01$ & -01 & $1.50 \mathrm{E}+00$ \\
\hline $64 \mathrm{E}-04$ & $3.55 \mathrm{E}+00$ & $1.53 \mathrm{E}-01$ & $4.73 E-02$ & $4.02 \mathrm{E}-01$ & $6.67 \mathrm{E}-01$ & $7 E-01$ & $1.50 \mathrm{E}+00$ \\
\hline $1 \mathrm{E}-04$ & $3.56 \mathrm{E}+00$ & $.54 \mathrm{E}-01$ & $4.77 \mathrm{E}-02$ & $4 \mathrm{E}-01$ & $0 E-01$ & $1 E-01$ & $1 \mathrm{E}+00$ \\
\hline$E-04$ & +00 & 1 & 2 & 1 & 1 & 1 & +00 \\
\hline $.86 \mathrm{E}-04$ & & 1 & & & & & $1 \mathrm{E}+00$ \\
\hline $.94 \mathrm{E}-04$ & & & & & & & $.52 \mathrm{E}+00$ \\
\hline $.02 \mathrm{E}-04$ & $3.59 \mathrm{E}+00$ & $6 E-01$ & -02 & $1 E-01$ & $0 \mathrm{E}-01$ & -01 & +00 \\
\hline 04 & $59 \mathrm{E}+00$ & $1.57 \mathrm{E}-01$ & -02 & $\perp$ & 1 & -01 & +00 \\
\hline 4 & $.60 \mathrm{E}+00$ & 1. $58 \mathrm{E}-01$ & 2 & $4.15 \mathrm{E}-01$ & 1 & -01 & $53 E+00$ \\
\hline$E-04$ & $E+00$ & & & & & & +00 \\
\hline $34 \mathrm{~F}-04$ & $E+00$ & 1 & 2 & $4.18 \mathrm{E}-01$ & 1 & 1 & +00 \\
\hline $.42 \mathrm{E}-04$ & $3.62 \mathrm{E}+00$ & $1.60 \mathrm{E}-01$ & $5.07 \mathrm{E}-02$ & $4.20 \mathrm{E}-01$ & $6.91 \mathrm{E}-01$ & $9.99 \mathrm{E}-01$ & $1.55 \mathrm{E}+00$ \\
\hline $.51 \mathrm{E}-04$ & $3 E+00$ & $2=-0$ & $E-02$ & $\perp$ & $\perp$ & +00 & $55 E+00$ \\
\hline 4 & & & & & & & 00 \\
\hline$\cdot$ & & & & & 5 & & 00 \\
\hline 4 & (2) & $1.63 \mathrm{E}-01$ & & & & 0 & 00 \\
\hline $84 F-04$ & $.66 \mathrm{E}+00$ & $163 \mathrm{~F}-$ & $4 E-02$ & $9 \mathrm{~F}$ & 1 & & $7 E+00$ \\
\hline $93 E-04$ & $3.66 \mathrm{E}+00$ & 1. $64 \mathrm{E}-01$ & $.28 \mathrm{E}-02$ & $4.31 \mathrm{E}-01$ & $.05 E-01$ & $.02 \mathrm{E}+00$ & $1.57 \mathrm{E}+00$ \\
\hline$E-04$ & $.67 \mathrm{E}+00$ & 1. $65 \mathrm{E}-0$ & -02 & .331 & $.07 \mathrm{E}-\mathrm{C}$ & L. $02 \mathrm{E}+00$ & L. $58 \mathrm{E}+00$ \\
\hline 04 & & & & & & & $58 E+00$ \\
\hline ( & & & & & & & $1.59 \mathrm{E}+00$ \\
\hline $29 \mathrm{E}-04$ & $3.69 \mathrm{E}+00$ & $\perp \cdot 010$ & & & & & 00 \\
\hline 4 & $.70 \mathrm{E}+00$ & 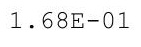 & 2 & $\perp$ & 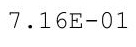 & 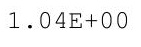 & $.60 \mathrm{E}+00$ \\
\hline $47 E-04$ & $.70 \mathrm{E}+00$ & م & $5.49 \mathrm{E}-02$ & 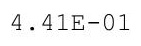 & 7 & $1.04 \mathrm{E}+00$ & 1. $60 \mathrm{E}+00$ \\
\hline $56 \mathrm{~F}-04$ & $3.71 \mathrm{E}+00$ & $169 F-01$ & $3 E-02$ & $13 F$ & $21=0$ & $1.04 \mathrm{E}+00$ & $1.60 \mathrm{E}+00$ \\
\hline 4 & & & & & & & \\
\hline $5 E-04$ & $3.72 \mathrm{E}+00$ & & & & & & \\
\hline $84 \mathrm{E}-04$ & $3.73 E+00$ & $\perp \cdot T \perp-\perp$ & $5.64 \mathrm{E}-02$ & $1.10 \mathrm{D}$ & $\cdot 201$ & $1.05 \mathrm{E}+00$ & $1.62 \mathrm{E}+00$ \\
\hline •945- & $3.74 \mathrm{E}+00$ & $\perp \cdot 12+0 \perp$ & $3.00 \mathrm{E}-02$ & $4.50 \mathrm{E}-01$ & $.3 \perp \mathrm{L}-\mathrm{D}$ & 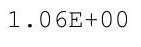 & $1.62 E+00$ \\
\hline 年 & $3.74 \mathrm{E}+00$ & 工象 & 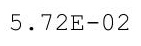 & (10.0 & . & $1.06 \mathrm{E}+00$ & $1.63 \mathrm{E}+00$ \\
\hline F & $3.75 \mathrm{E}+00$ & 735 & 2 & 535 & & & $1.63 E+00$ \\
\hline 5 & & & & & & & \\
\hline$E-04$ & & 1 & 02 & & & & \\
\hline $3 E-04$ & $3.77 \mathrm{E}+00$ & $1 . T O E$ & $5.88 E-02$ & 1 & & & $1.64 \mathrm{E}$ \\
\hline $3 E-04$ & $3.78 \mathrm{E}+00$ & 1.60 & & & & & $1.65 E+00$ \\
\hline (1) & & & & & & & $1.65 \mathrm{E}+00$ \\
\hline $73 F-04$ & 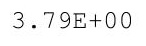 & $+\cdots$ & & & & $1.08 \mathrm{E}+00$ & $1.66 \mathrm{E}+00$ \\
\hline & & & & & & & $.66 \mathrm{E}+00$ \\
\hline 4 & $3.80 \mathrm{E}+00$ & & 02 & 01 & 1 & $\mathrm{E}+00$ & $1.67 \mathrm{E}+00$ \\
\hline$E-04$ & $3.81 E+00$ & $1.80 \mathrm{E}-01$ & -02 & 4.6 & 7.60 & $1.09 \mathrm{E}+00$ & $1.67 \mathrm{E}+00$ \\
\hline & & & & & & & \\
\hline & $3.82 \mathrm{E}+00$ & $+0^{\circ}$ a & & & & $1.10 \mathrm{E}+00$ & 1.000100 \\
\hline 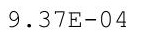 & $3.83 E+00$ & $+\cdot 0<\Delta$ & & & 1 & $1.10 \mathrm{E}+00$ & $1.68 \mathrm{E}+00$ \\
\hline$E-04$ & $.83 E+00$ & $E-01$ & $33 E-02$ & $E-01$ & $E-01$ & $.10 \mathrm{E}+00$ & $1.69 \mathrm{E}+00$ \\
\hline
\end{tabular}


RESRAD-OFFSITE, Version 2.5

obabilistic Dose and Risk Report

Title : Offsite Resident Farmer

File : RF TC99 DOESG FWD-FV2all.ROF

Summary of dose at graphical times, reptition 1 (continued)

Time

Years

$5.19 \mathrm{E}+02$

$5.19 \mathrm{E}+02$

$5.20 \mathrm{E}+02$

$5.20 \mathrm{E}+02$

$5.21 \mathrm{E}+02$

$5.21 \mathrm{E}+02$

$5.22 \mathrm{E}+02$

$5.22 \mathrm{E}+02$

$5.23 \mathrm{E}+02$

$5.23 \mathrm{E}+02$

$5.24 \mathrm{E}+02$

$5.24 \mathrm{E}+02$

$5.25 \mathrm{E}+02$

$5.26 \mathrm{E}+02$

$5.26 \mathrm{E}+02$

$5.27 \mathrm{E}+02$

$5.27 \mathrm{E}+02$

$5.28 \mathrm{E}+02$

$5.28 \mathrm{E}+02$

$5.29 \mathrm{E}+02$

$5.29 \mathrm{E}+02$

$5.30 \mathrm{E}+02$

$5.30 \mathrm{E}+02$

$5.31 \mathrm{E}+02$

$5.31 \mathrm{E}+02$

$5.32 \mathrm{E}+02$

$5.32 \mathrm{E}+02$

$5.33 \mathrm{E}+02$

$5.33 \mathrm{E}+02$

$5.34 \mathrm{E}+02$

$5.34 \mathrm{E}+02$

$5.35 \mathrm{E}+02$

$5.35 \mathrm{E}+02$

$5.36 \mathrm{E}+02$

$5.36 \mathrm{E}+02$

$5.37 \mathrm{E}+02$

$5.37 \mathrm{E}+02$

$5.38 \mathrm{E}+02$

$5.38 \mathrm{E}+02$

$5.39 \mathrm{E}+02$

$5.39 \mathrm{E}+02$

$5.40 \mathrm{E}+02$

$5.40 \mathrm{E}+02$

$5.41 \mathrm{E}+02$

$5.41 \mathrm{E}+02$

$5.42 \mathrm{E}+02$
Dose statistics at graphical times, mrem/yr

\begin{tabular}{|c|c|c|c|c|c|c|c|}
\hline Minimum & Maximum & Mean & Median & $90 \%$ & $95 \%$ & $97.5 \%$ & $99 \%$ \\
\hline $9.58 E-04$ & $3.84 \mathrm{E}+00$ & $1.83 E-01$ & $6.38 E-02$ & $4.78 E-01$ & $7.73 E-01$ & $1.11 E+00$ & 1. $69 \mathrm{E}+00$ \\
\hline $9.69 \mathrm{E}-04$ & $3.85 E+00$ & $1.84 \mathrm{E}-01$ & $6.42 E-02$ & $4.80 E-01$ & $7.75 E-01$ & $1.11 \mathrm{E}+00$ & $1.70 \mathrm{E}+00$ \\
\hline $9.81 \mathrm{E}-04$ & $3.85 \mathrm{E}+00$ & $1.85 \mathrm{E}-01$ & $6.47 \mathrm{E}-02$ & $4.82 \mathrm{E}-01$ & $7.78 \mathrm{E}-01$ & $1.11 \mathrm{E}+00$ & $1.70 \mathrm{E}+00$ \\
\hline $9.92 \mathrm{E}-04$ & $3.86 \mathrm{E}+00$ & $1.86 \mathrm{E}-01$ & $6.52 \mathrm{E}-02$ & $4.84 \mathrm{E}-01$ & $7.80 \mathrm{E}-01$ & $1.12 \mathrm{E}+00$ & $1.71 \mathrm{E}+00$ \\
\hline $1.00 E-03$ & $3.86 \mathrm{E}+00$ & $1.86 \mathrm{E}-01$ & $6.57 E-02$ & $4.86 E-01$ & $7.83 E-01$ & $1.12 \mathrm{E}+00$ & $1.71 \mathrm{E}+00$ \\
\hline $1.01 \mathrm{E}-03$ & $3.87 \mathrm{E}+00$ & $1.87 \mathrm{E}-01$ & $6.61 \mathrm{E}-02$ & $4.88 E-01$ & $7.85 E-01$ & $1.12 \mathrm{E}+00$ & $1.71 \mathrm{E}+00$ \\
\hline $1.03 E-03$ & $3.88 E+00$ & $1.88 \mathrm{E}-01$ & $6.65 E-02$ & $4.89 E-01$ & $7.87 \mathrm{E}-01$ & $1.13 E+00$ & $1.72 \mathrm{E}+00$ \\
\hline $1.04 \mathrm{E}-03$ & $3.88 \mathrm{E}+00$ & $1.89 \mathrm{E}-01$ & $6.70 \mathrm{E}-02$ & $4.91 \mathrm{E}-01$ & $7.89 \mathrm{E}-01$ & $1.13 \mathrm{E}+00$ & $1.72 \mathrm{E}+00$ \\
\hline $1.05 \mathrm{E}-03$ & $3.89 \mathrm{E}+00$ & $1.89 \mathrm{E}-01$ & $6.75 E-02$ & 4. $93 E-01$ & 7. $91 \mathrm{E}-01$ & $1.13 \mathrm{E}+00$ & $1.73 E+00$ \\
\hline $1.06 \mathrm{E}-03$ & $3.89 \mathrm{E}+00$ & $1.90 \mathrm{E}-01$ & $6.79 \mathrm{E}-02$ & $4.95 \mathrm{E}-01$ & $7.93 \mathrm{E}-01$ & $1.14 \mathrm{E}+00$ & $1.73 E+00$ \\
\hline $1.07 \mathrm{E}-03$ & $3.90 \mathrm{E}+00$ & $1.91 \mathrm{E}-01$ & $6.84 \mathrm{E}-02$ & $4.97 \mathrm{E}-01$ & $7.96 \mathrm{E}-01$ & $1.14 \mathrm{E}+00$ & $.74 \mathrm{E}+00$ \\
\hline $1.09 \mathrm{E}-03$ & $3.91 \mathrm{E}+00$ & $1.92 \mathrm{E}-01$ & $6.89 \mathrm{E}-02$ & $4.99 \mathrm{E}-01$ & $7.98 \mathrm{E}-01$ & $1.14 \mathrm{E}+00$ & $1.74 \mathrm{E}+00$ \\
\hline $1.10 \mathrm{E}-03$ & $3.91 E+00$ & $1.92 \mathrm{E}-01$ & $6.94 \mathrm{E}-02$ & $5.01 \mathrm{E}-01$ & $8.00 \mathrm{E}-01$ & $1.15 \mathrm{E}+00$ & $1.74 \mathrm{E}+00$ \\
\hline $1.11 \mathrm{E}-03$ & $3.92 \mathrm{E}+00$ & $1.93 \mathrm{E}-01$ & $6.98 E-02$ & $5.03 E-01$ & $8.02 E-01$ & $1.15 \mathrm{E}+00$ & $1.75 \mathrm{E}+00$ \\
\hline 1. 12E-03 & $3.92 \mathrm{E}+00$ & $1.94 \mathrm{E}-01$ & $7.03 E-02$ & $5.05 E-01$ & $8.04 \mathrm{E}-01$ & $1.15 \mathrm{E}+00$ & $1.75 \mathrm{E}+00$ \\
\hline $1.13 E-03$ & $3.93 E+00$ & $1.95 E-01$ & $7.08 E-02$ & $.07 E-01$ & $.06 E-01$ & $.15 E+00$ & $.76 \mathrm{E}+00$ \\
\hline $1.15 \mathrm{E}-03$ & $3.94 \mathrm{E}+00$ & $95 E-01$ & $7.13 E-02$ & $10 \mathrm{E}-01$ & $8.08 \mathrm{E}-01$ & $1.16 \mathrm{E}+00$ & $1.76 \mathrm{E}+00$ \\
\hline $1.16 \mathrm{E}-03$ & $3.94 \mathrm{E}+00$ & $1.96 \mathrm{E}-01$ & $7.18 \mathrm{E}-02$ & $5.12 \mathrm{E}-01$ & $8.11 \mathrm{E}-01$ & $1.16 \mathrm{E}+00$ & $1.77 \mathrm{E}+00$ \\
\hline $1.17 E-03$ & $3.95 \mathrm{E}+00$ & $1.97 \mathrm{E}-01$ & $7.24 \mathrm{E}-02$ & $5.14 \mathrm{E}-01$ & $8.13 E-01$ & $1.16 \mathrm{E}+00$ & $1.77 \mathrm{E}+00$ \\
\hline $1.18 \mathrm{E}-03$ & $3.95 \mathrm{E}+00$ & $1.98 \mathrm{E}-01$ & $7.28 E-02$ & $5.16 \mathrm{E}-01$ & $8.16 \mathrm{E}-01$ & $1.17 \mathrm{E}+00$ & $1.77 \mathrm{E}+00$ \\
\hline $1.20 E-03$ & $3.96 \mathrm{E}+00$ & $1.98 \mathrm{E}-01$ & $7.33 E-02$ & $5.19 \mathrm{E}-01$ & $8.18 \mathrm{E}-01$ & $1.17 \mathrm{E}+00$ & $1.78 \mathrm{E}+00$ \\
\hline $1.21 \mathrm{E}-03$ & $3.96 \mathrm{E}+00$ & $1.99 \mathrm{E}-01$ & $7.37 \mathrm{E}-02$ & $21 E-01$ & $8.21 \mathrm{E}-01$ & $1.17 \mathrm{E}+00$ & $1.78 \mathrm{E}+00$ \\
\hline $1.22 \mathrm{E}-03$ & $3.97 \mathrm{E}+00$ & $2.00 \mathrm{E}-01$ & $7.42 E-02$ & $5.23 E-01$ & $8.23 E-01$ & $1.18 \mathrm{E}+00$ & $1.79 \mathrm{E}+00$ \\
\hline $1.24 \mathrm{E}-03$ & $3.98 \mathrm{E}+00$ & $2.01 E-01$ & $7.47 \mathrm{E}-02$ & $5.25 \mathrm{E}-01$ & $8.26 \mathrm{E}-01$ & $1.18 \mathrm{E}+00$ & $1.79 \mathrm{E}+00$ \\
\hline $1.25 E-03$ & $3.98 \mathrm{E}+00$ & $2.02 E-01$ & $7.52 \mathrm{E}-02$ & $5.27 \mathrm{E}-01$ & $8.28 \mathrm{E}-01$ & $1.18 \mathrm{E}+00$ & $1.79 \mathrm{E}+00$ \\
\hline $1.26 \mathrm{E}-03$ & $.99 E+00$ & $2.02 \mathrm{E}-01$ & $7.57 \mathrm{E}-02$ & $5.28 \mathrm{E}-01$ & $8.31 \mathrm{E}-01$ & $1.19 \mathrm{E}+00$ & $1.80 \mathrm{E}+00$ \\
\hline $1.28 \mathrm{E}-03$ & $3.99 \mathrm{E}+00$ & $2.03 E-01$ & $7.62 \mathrm{E}-02$ & $5.30 \mathrm{E}-01$ & $8.34 \mathrm{E}-01$ & $1.19 \mathrm{E}+00$ & $1.80 \mathrm{E}+00$ \\
\hline $1.29 \mathrm{E}-03$ & $4.00 \mathrm{E}+00$ & $2.04 \mathrm{E}-01$ & $7.66 \mathrm{E}-02$ & $5.31 \mathrm{E}-01$ & $8.37 E-01$ & $1.19 \mathrm{E}+00$ & $1.80 \mathrm{E}+00$ \\
\hline $1.30 \mathrm{E}-03$ & $4.00 \mathrm{E}+00$ & $2.05 E-01$ & $7.71 \mathrm{E}-02$ & $5.33 E-01$ & $8.41 \mathrm{E}-01$ & $1.19 \mathrm{E}+00$ & $1.81 \mathrm{E}+00$ \\
\hline $1.32 E-03$ & $4.01 E+00$ & $2.05 E-01$ & $7.76 \mathrm{E}-02$ & $5.35 E-01$ & $8.44 E-01$ & $1.20 \mathrm{E}+00$ & $1.81 \mathrm{E}+00$ \\
\hline $1.33 E-03$ & $4.01 E+00$ & $2.06 \mathrm{E}-01$ & $7.80 \mathrm{E}-02$ & $5.37 \mathrm{E}-01$ & $8.47 E-01$ & $1.20 \mathrm{E}+00$ & $1.82 E+00$ \\
\hline $1.35 \mathrm{E}-03$ & $4.02 \mathrm{E}+00$ & $2.07 \mathrm{E}-01$ & $7.85 E-02$ & $5.39 \mathrm{E}-01$ & $8.50 \mathrm{E}-01$ & $1.20 \mathrm{E}+00$ & $.82 \mathrm{E}+00$ \\
\hline $1.36 \mathrm{E}-03$ & $4.02 E+00$ & $2.08 \mathrm{E}-01$ & $7.90 \mathrm{E}-02$ & $5.41 \mathrm{E}-01$ & $8.53 E-01$ & $1.21 \mathrm{E}+00$ & $1.82 \mathrm{E}+00$ \\
\hline $1.38 \mathrm{E}-03$ & $4.03 E+00$ & $2.09 E-01$ & $7.95 \mathrm{E}-02$ & $5.43 E-01$ & $8.56 \mathrm{E}-01$ & $1.21 \mathrm{E}+00$ & $1.83 E+00$ \\
\hline $1.39 E-03$ & $4.04 \mathrm{E}+00$ & $2.09 E-01$ & $8.00 E-02$ & $5.44 E-01$ & $8.59 E-01$ & $1.21 E+00$ & $1.83 E+00$ \\
\hline $1.40 \mathrm{E}-03$ & $4.04 \mathrm{E}+00$ & $2.10 \mathrm{E}-01$ & $8.05 E-02$ & $5.46 \mathrm{E}-01$ & $8.61 \mathrm{E}-01$ & $1.22 \mathrm{E}+00$ & $1.83 E+00$ \\
\hline $1.42 E-03$ & $4.05 E+00$ & $2.11 \mathrm{E}-01$ & $8.10 \mathrm{E}-02$ & $5.48 E-01$ & $8.63 E-01$ & $1.22 \mathrm{E}+00$ & $1.84 \mathrm{E}+00$ \\
\hline $1.43 E-03$ & $4.05 E+00$ & $2.12 \mathrm{E}-01$ & $8.15 \mathrm{E}-02$ & $5.49 \mathrm{E}-01$ & $8.66 \mathrm{E}-01$ & $1.22 \mathrm{E}+00$ & $1.84 \mathrm{E}+00$ \\
\hline $1.45 E-03$ & $4.06 \mathrm{E}+00$ & $2.12 \mathrm{E}-01$ & $8.20 \mathrm{E}-02$ & $5.51 \mathrm{E}-01$ & $8.68 E-01$ & $1.23 E+00$ & $1.85 E+00$ \\
\hline $1.46 \mathrm{E}-03$ & $4.06 \mathrm{E}+00$ & $2.13 \mathrm{E}-01$ & $8.25 \mathrm{E}-02$ & $5.52 \mathrm{E}-01$ & $8.70 \mathrm{E}-01$ & $1.23 \mathrm{E}+00$ & $1.85 \mathrm{E}+00$ \\
\hline $1.48 \mathrm{E}-03$ & $4.07 E+00$ & $2.14 \mathrm{E}-01$ & $8.30 \mathrm{E}-02$ & $5.54 \mathrm{E}-01$ & $8.73 E-01$ & $1.23 \mathrm{E}+00$ & $1.85 E+00$ \\
\hline $1.49 \mathrm{E}-03$ & $4.07 \mathrm{E}+00$ & $2.15 \mathrm{E}-01$ & $8.35 E-02$ & $5.55 E-01$ & $8.75 E-01$ & $1.24 \mathrm{E}+00$ & $1.86 \mathrm{E}+00$ \\
\hline $1.51 \mathrm{E}-03$ & $4.08 \mathrm{E}+00$ & $2.16 \mathrm{E}-01$ & $8.40 \mathrm{E}-02$ & $5.57 \mathrm{E}-01$ & $8.77 \mathrm{E}-01$ & $1.24 \mathrm{E}+00$ & $1.86 \mathrm{E}+00$ \\
\hline $1.52 \mathrm{E}-03$ & $4.08 \mathrm{E}+00$ & $2.16 \mathrm{E}-01$ & $8.45 E-02$ & $5.58 E-01$ & $8.80 E-01$ & $1.24 \mathrm{E}+00$ & $1.86 \mathrm{E}+00$ \\
\hline $1.54 \mathrm{E}-03$ & $4.09 E+00$ & $2.17 \mathrm{E}-01$ & $8.51 E-02$ & $5.60 \mathrm{E}-01$ & $8.82 E-01$ & $1.25 E+00$ & $1.87 \mathrm{E}+00$ \\
\hline $1.56 \mathrm{E}-03$ & $4.09 \mathrm{E}+00$ & $2.18 \mathrm{E}-01$ & $8.56 \mathrm{E}-02$ & $5.61 \mathrm{E}-01$ & $8.84 E-01$ & $1.25 \mathrm{E}+00$ & $1.87 \mathrm{E}+00$ \\
\hline
\end{tabular}


RESRAD-OFFSITE, Version 2.5 
RESRAD-OFFSITE, Version 2.5

robabilistic Dose and Risk Report

Title : Offsite Resident Farmer

File : RF TC99 DOESG FWD-FV2all.ROF

Summary of dose at graphical times, reptition 1 (continued)

Time

Years

$5.66 \mathrm{E}+02$

$5.67 \mathrm{E}+02$

$5.67 \mathrm{E}+02$

$5.68 \mathrm{E}+02$

$5.68 \mathrm{E}+02$

$5.69 \mathrm{E}+02$

$5.69 \mathrm{E}+02$

$5.70 \mathrm{E}+02$

$5.70 \mathrm{E}+02$

$5.71 \mathrm{E}+02$

$5.71 \mathrm{E}+02$

$5.72 \mathrm{E}+02$

$5.72 \mathrm{E}+02$

$5.73 \mathrm{E}+02$

$5.73 \mathrm{E}+02$

$5.74 \mathrm{E}+02$

$5.74 \mathrm{E}+02$

$5.75 \mathrm{E}+02$

$5.75 \mathrm{E}+02$

$5.76 \mathrm{E}+02$

$5.76 \mathrm{E}+02$

$5.77 \mathrm{E}+02$

$5.77 \mathrm{E}+02$

$5.78 \mathrm{E}+02$

$5.78 \mathrm{E}+02$

$5.79 \mathrm{E}+02$

$5.79 \mathrm{E}+02$

$5.80 \mathrm{E}+02$

$5.80 \mathrm{E}+02$

$5.81 \mathrm{E}+02$

$5.81 \mathrm{E}+02$

$5.82 \mathrm{E}+02$

$5.82 \mathrm{E}+02$

$5.83 \mathrm{E}+02$

$5.83 \mathrm{E}+02$

$5.84 \mathrm{E}+02$

$5.84 \mathrm{E}+02$

$5.85 \mathrm{E}+02$

$5.85 \mathrm{E}+02$

$5.86 \mathrm{E}+02$

$5.87 \mathrm{E}+02$

$5.87 \mathrm{E}+02$

$5.88 \mathrm{E}+02$

$5.88 \mathrm{E}+02$

$5.89 \mathrm{E}+02$

$5.89 \mathrm{E}+02$
Dose statistics at graphical times, mrem/yr

\begin{tabular}{|c|c|c|c|c|c|c|c|}
\hline Minimum & Maximum & Mean & Median & $90 \%$ & $95 \%$ & $97.5 \%$ & $99 \%$ \\
\hline $2.44 E-03$ & $4.30 \mathrm{E}+00$ & $2.56 \mathrm{E}-01$ & 1. $12 \mathrm{E}-01$ & $6.56 \mathrm{E}-01$ & 1.01E+00 & $1.42 \mathrm{E}+00$ & $2.06 \mathrm{E}+00$ \\
\hline $2.46 \mathrm{E}-03$ & $4.30 \mathrm{E}+00$ & $2.57 \mathrm{E}-01$ & $1.13 \mathrm{E}-01$ & $6.58 E-01$ & $1.01 \mathrm{E}+00$ & 1. $43 \mathrm{E}+00$ & $2.06 \mathrm{E}+00$ \\
\hline $2.48 E-03$ & $4.31 E+00$ & $2.58 \mathrm{E}-01$ & 1. $13 \mathrm{E}-01$ & $6.60 \mathrm{E}-01$ & $1.02 \mathrm{E}+00$ & $1.43 E+00$ & $2.07 E+00$ \\
\hline $2.50 \mathrm{E}-03$ & $4.31 E+00$ & $2.59 \mathrm{E}-01$ & $1.14 \mathrm{E}-01$ & $6.62 \mathrm{E}-01$ & $1.02 \mathrm{E}+00$ & $1.43 \mathrm{E}+00$ & $2.07 \mathrm{E}+00$ \\
\hline $2.53 E-03$ & $4.32 \mathrm{E}+00$ & $2.60 \mathrm{E}-01$ & $1.14 \mathrm{E}-01$ & $6.64 \mathrm{E}-01$ & $1.02 \mathrm{E}+00$ & $1.44 \mathrm{E}+00$ & $2.08 \mathrm{E}+00$ \\
\hline $2.55 E-03$ & $4.32 \mathrm{E}+00$ & $2.61 \mathrm{E}-01$ & 1. $15 \mathrm{E}-01$ & $6.66 \mathrm{E}-01$ & $1.02 \mathrm{E}+00$ & 1. $44 \mathrm{E}+00$ & $2.08 \mathrm{E}+00$ \\
\hline $2.57 \mathrm{E}-03$ & $4.32 \mathrm{E}+00$ & $2.61 \mathrm{E}-01$ & $1.15 \mathrm{E}-01$ & $6.67 \mathrm{E}-01$ & $1.02 \mathrm{E}+00$ & $1.45 \mathrm{E}+00$ & $2.08 E+00$ \\
\hline $2.59 \mathrm{E}-03$ & $4.33 E+00$ & $2.62 \mathrm{E}-01$ & $1.16 \mathrm{E}-01$ & $6.69 \mathrm{E}-01$ & $1.03 E+00$ & $1.45 \mathrm{E}+00$ & $2.09 \mathrm{E}+00$ \\
\hline $2.62 E-03$ & 4. $33 E+00$ & $2.63 E-01$ & 1. $16 \mathrm{E}-01$ & $6.71 \mathrm{E}-01$ & 1. $03 \mathrm{E}+00$ & $1.45 \mathrm{E}+00$ & $2.09 E+00$ \\
\hline $2.64 \mathrm{E}-03$ & $4.33 \mathrm{E}+00$ & $2.64 \mathrm{E}-01$ & 1.17E-01 & $6.73 E-01$ & $1.03 E+00$ & $1.46 \mathrm{E}+00$ & $2.10 \mathrm{E}+00$ \\
\hline $2.66 \mathrm{E}-03$ & $4.34 \mathrm{E}+00$ & $2.65 \mathrm{E}-01$ & 1. $18 \mathrm{E}-01$ & $6.75 E-01$ & $1.03 E+00$ & $1.46 \mathrm{E}+00$ & $2.10 \mathrm{E}+00$ \\
\hline $2.69 \mathrm{E}-03$ & $4.34 \mathrm{E}+00$ & $2.66 \mathrm{E}-01$ & 1. $18 \mathrm{E}-01$ & $6.78 \mathrm{E}-01$ & $1.03 \mathrm{E}+00$ & $1.46 \mathrm{E}+00$ & $2.10 \mathrm{E}+00$ \\
\hline $2.71 \mathrm{E}-03$ & $4.34 \mathrm{E}+00$ & $2.67 \mathrm{E}-01$ & 1.19E-01 & $6.80 \mathrm{E}-01$ & $1.03 E+00$ & $1.47 \mathrm{E}+00$ & $2.11 \mathrm{E}+00$ \\
\hline $2.73 E-03$ & $4.35 \mathrm{E}+00$ & $2.67 \mathrm{E}-01$ & 1. $20 \mathrm{E}-01$ & $6.82 \mathrm{E}-01$ & $1.04 \mathrm{E}+00$ & $1.47 \mathrm{E}+00$ & $2.11 \mathrm{E}+00$ \\
\hline $2.76 \mathrm{E}-03$ & $4.35 \mathrm{E}+00$ & $2.68 \mathrm{E}-01$ & 1.20E-01 & $6.85 \mathrm{E}-01$ & $1.04 \mathrm{E}+00$ & 1. $48 \mathrm{E}+00$ & $2.11 \mathrm{E}+00$ \\
\hline $2.78 E-03$ & $4.35 \mathrm{E}+00$ & $2.69 \mathrm{E}-01$ & $1.21 \mathrm{E}-01$ & $6.87 E-01$ & $1.04 \mathrm{E}+00$ & $.48 E+00$ & $.12 \mathrm{E}+00$ \\
\hline $2.81 \mathrm{E}-03$ & $4.36 \mathrm{E}+00$ & $2.70 \mathrm{E}-01$ & 1.21E-01 & $6.89 \mathrm{E}-01$ & $1.04 \mathrm{E}+00$ & $1.48 \mathrm{E}+00$ & $2.12 \mathrm{E}+00$ \\
\hline $2.83 E-03$ & $4.36 \mathrm{E}+00$ & $2.71 E-01$ & 1. $22 \mathrm{E}-01$ & $6.91 \mathrm{E}-01$ & $1.05 \mathrm{E}+00$ & 1. $49 \mathrm{E}+00$ & $2.13 \mathrm{E}+00$ \\
\hline $2.86 E-03$ & $4.37 \mathrm{E}+00$ & $2.72 \mathrm{E}-01$ & $1.22 \mathrm{E}-01$ & $6.94 \mathrm{E}-01$ & $1.05 E+00$ & $1.49 \mathrm{E}+00$ & $2.13 E+00$ \\
\hline $2.88 E-03$ & $4.37 \mathrm{E}+00$ & $2.72 \mathrm{E}-01$ & 1. $23 \mathrm{E}-01$ & $6.96 \mathrm{E}-01$ & $1.05 \mathrm{E}+00$ & $1.49 \mathrm{E}+00$ & $2.13 \mathrm{E}+00$ \\
\hline $2.91 \mathrm{E}-03$ & $4.37 \mathrm{E}+00$ & $2.73 E-01$ & 1. $24 \mathrm{E}-01$ & $6.97 \mathrm{E}-01$ & $1.05 \mathrm{E}+00$ & $1.49 \mathrm{E}+00$ & $2.14 \mathrm{E}+00$ \\
\hline $2.93 E-03$ & $4.37 \mathrm{E}+00$ & $2.74 \mathrm{E}-01$ & $1.24 \mathrm{E}-01$ & $6.99 E-01$ & $1.05 E+00$ & $1.50 \mathrm{E}+00$ & $2.14 \mathrm{E}+00$ \\
\hline $2.96 E-03$ & $4.38 \mathrm{E}+00$ & $2.75 \mathrm{E}-01$ & $1.25 E-01$ & $7.00 \mathrm{E}-01$ & $1.06 \mathrm{E}+00$ & $1.50 \mathrm{E}+00$ & $2.14 \mathrm{E}+00$ \\
\hline $2.98 E-03$ & $4.38 \mathrm{E}+00$ & $2.76 \mathrm{E}-01$ & $1.26 \mathrm{E}-01$ & $7.02 \mathrm{E}-01$ & $1.06 \mathrm{E}+00$ & $1.50 \mathrm{E}+00$ & $2.15 \mathrm{E}+00$ \\
\hline $3.01 \mathrm{E}-03$ & $4.38 \mathrm{E}+00$ & $2.77 \mathrm{E}-01$ & 1. $26 \mathrm{E}-01$ & $7.04 \mathrm{E}-01$ & $1.06 \mathrm{E}+00$ & $1.50 \mathrm{E}+00$ & $2.15 \mathrm{E}+00$ \\
\hline $3.03 E-03$ & $4.39 \mathrm{E}+00$ & $2.78 \mathrm{E}-01$ & $1.27 \mathrm{E}-01$ & $7.06 \mathrm{E}-01$ & $1.06 \mathrm{E}+00$ & $1.51 \mathrm{E}+00$ & $2.15 \mathrm{E}+00$ \\
\hline $3.06 \mathrm{E}-03$ & $4.39 \mathrm{E}+00$ & $2.79 \mathrm{E}-01$ & $1.27 \mathrm{E}-01$ & $7.07 \mathrm{E}-01$ & $1.06 \mathrm{E}+00$ & $1.51 \mathrm{E}+00$ & $2.15 \mathrm{E}+00$ \\
\hline $3.09 E-03$ & $4.39 \mathrm{E}+00$ & $2.79 \mathrm{E}-01$ & 1.28E-01 & $7.09 \mathrm{E}-01$ & $1.06 \mathrm{E}+00$ & $1.51 E+00$ & $2.16 \mathrm{E}+00$ \\
\hline $3.11 \mathrm{E}-03$ & $4.40 \mathrm{E}+00$ & $2.80 \mathrm{E}-01$ & 1.29E-01 & $7.12 \mathrm{E}-01$ & $1.07 \mathrm{E}+00$ & $1.52 \mathrm{E}+00$ & $2.16 \mathrm{E}+00$ \\
\hline $3.14 \mathrm{E}-03$ & $4.40 \mathrm{E}+00$ & $2.81 \mathrm{E}-01$ & 1.29E-01 & $7.15 E-01$ & $1.07 \mathrm{E}+00$ & $1.52 \mathrm{E}+00$ & $2.16 \mathrm{E}+00$ \\
\hline $3.16 \mathrm{E}-03$ & $4.40 \mathrm{E}+00$ & $2.82 \mathrm{E}-01$ & 1. $30 \mathrm{E}-01$ & $7.17 \mathrm{E}-01$ & $1.07 \mathrm{E}+00$ & $1.52 \mathrm{E}+00$ & $2.16 \mathrm{E}+00$ \\
\hline $3.19 \mathrm{E}-03$ & $4.41 \mathrm{E}+00$ & $2.83 E-01$ & 1. $31 \mathrm{E}-01$ & 7. $20 \mathrm{E}-01$ & $1.07 \mathrm{E}+00$ & $1.53 \mathrm{E}+00$ & $2.17 \mathrm{E}+00$ \\
\hline $3.22 E-03$ & $4.41 \mathrm{E}+00$ & $2.84 \mathrm{E}-01$ & $1.31 \mathrm{E}-01$ & $7.22 \mathrm{E}-01$ & $1.08 \mathrm{E}+00$ & $1.53 \mathrm{E}+00$ & $2.17 \mathrm{E}+00$ \\
\hline $3.25 E-03$ & $4.41 E+00$ & $2.85 \mathrm{E}-01$ & 1. 32E-01 & $7.24 \mathrm{E}-01$ & $1.08 \mathrm{E}+00$ & $1.54 \mathrm{E}+00$ & $2.17 E+00$ \\
\hline $3.27 \mathrm{E}-03$ & $4.42 \mathrm{E}+00$ & $2.85 \mathrm{E}-01$ & 1. $33 \mathrm{E}-01$ & $7.27 \mathrm{E}-01$ & $1.08 \mathrm{E}+00$ & $1.54 \mathrm{E}+00$ & $2.17 \mathrm{E}+00$ \\
\hline $3.30 E-03$ & $4.42 \mathrm{E}+00$ & $2.86 \mathrm{E}-01$ & $1.33 E-01$ & $7.29 \mathrm{E}-01$ & $1.08 \mathrm{E}+00$ & $1.54 \mathrm{E}+00$ & $2.18 \mathrm{E}+00$ \\
\hline $3.33 E-03$ & $4.42 \mathrm{E}+00$ & $2.87 \mathrm{E}-01$ & 1. $34 \mathrm{E}-01$ & 7. $31 \mathrm{E}-01$ & $1.09 \mathrm{E}+00$ & $1.55 \mathrm{E}+00$ & $2.18 \mathrm{E}+00$ \\
\hline $3.36 \mathrm{E}-03$ & $4.42 \mathrm{E}+00$ & $2.88 \mathrm{E}-01$ & 1. $34 \mathrm{E}-01$ & 7. $32 \mathrm{E}-01$ & $1.09 \mathrm{E}+00$ & $1.55 \mathrm{E}+00$ & $2.18 \mathrm{E}+00$ \\
\hline $38 E-03$ & $4.43 E+00$ & $2.89 \mathrm{E}-01$ & 1. $35 E-01$ & $7.34 \mathrm{E}-01$ & $1.09 \mathrm{E}+00$ & $1.55 \mathrm{E}+00$ & $2.18 \mathrm{E}+00$ \\
\hline $3.41 \mathrm{E}-03$ & $4.43 E+00$ & $2.90 \mathrm{E}-01$ & $1.36 \mathrm{E}-01$ & 7. $36 \mathrm{E}-01$ & $1.09 \mathrm{E}+00$ & $1.56 \mathrm{E}+00$ & $2.19 \mathrm{E}+00$ \\
\hline $3.44 \mathrm{E}-03$ & $4.43 E+00$ & $2.91 \mathrm{E}-01$ & 1. $36 \mathrm{E}-01$ & $7.37 \mathrm{E}-01$ & $1.09 \mathrm{E}+00$ & $1.56 \mathrm{E}+00$ & $2.19 \mathrm{E}+00$ \\
\hline $3.47 E-03$ & $4.44 \mathrm{E}+00$ & $2.92 \mathrm{E}-01$ & $1.37 E-01$ & 7. 39E-01 & $1.10 \mathrm{E}+00$ & $1.57 \mathrm{E}+00$ & $2.19 \mathrm{E}+00$ \\
\hline $3.50 E-03$ & $4.44 \mathrm{E}+00$ & $2.92 \mathrm{E}-01$ & 1. $38 \mathrm{E}-01$ & 7. $41 \mathrm{E}-01$ & $1.10 \mathrm{E}+00$ & $1.57 \mathrm{E}+00$ & $2.19 \mathrm{E}+00$ \\
\hline $3.53 E-03$ & $4.44 \mathrm{E}+00$ & $2.93 E-01$ & 1. 38E-01 & $7.43 E-01$ & $1.10 \mathrm{E}+00$ & $1.57 \mathrm{E}+00$ & $2.20 \mathrm{E}+00$ \\
\hline $3.55 E-03$ & $4.44 \mathrm{E}+00$ & $2.94 \mathrm{E}-01$ & $1.39 E-01$ & $7.46 \mathrm{E}-01$ & $1.10 \mathrm{E}+00$ & $1.58 \mathrm{E}+00$ & $2.20 \mathrm{E}+00$ \\
\hline $3.58 E-03$ & $4.45 \mathrm{E}+00$ & $2.95 \mathrm{E}-01$ & 1. $40 \mathrm{E}-01$ & $7.48 E-01$ & $1.11 \mathrm{E}+00$ & $1.58 \mathrm{E}+00$ & $2.20 \mathrm{E}+00$ \\
\hline
\end{tabular}


RESRAD-OFFSITE, Version 2.5

robabilistic Dose and Risk Report

Title : Offsite Resident Farmer

File : RF TC99 DOESG FWD-FV2all.ROF

Summary of dose at graphical times, reptition 1 (continued)

Time

Years

$5.90 \mathrm{E}+02$

$5.90 \mathrm{E}+02$

$5.91 \mathrm{E}+02$

$5.91 \mathrm{E}+02$

$5.92 \mathrm{E}+02$

$5.92 \mathrm{E}+02$

$5.93 \mathrm{E}+02$

$5.93 \mathrm{E}+02$

$5.94 \mathrm{E}+02$

$5.94 \mathrm{E}+02$

$5.95 \mathrm{E}+02$

$5.95 \mathrm{E}+02$

$5.96 \mathrm{E}+02$

$5.96 \mathrm{E}+02$

$5.97 \mathrm{E}+02$

$5.97 \mathrm{E}+02$

$5.98 \mathrm{E}+02$

$5.98 \mathrm{E}+02$

$5.99 \mathrm{E}+02$

$5.99 \mathrm{E}+02$

$6.00 \mathrm{E}+02$

$6.00 \mathrm{E}+02$

$6.01 \mathrm{E}+02$

$6.01 \mathrm{E}+02$

$6.02 \mathrm{E}+02$

$6.02 \mathrm{E}+02$

$6.03 \mathrm{E}+02$

$6.03 \mathrm{E}+02$

$6.04 \mathrm{E}+02$

$6.04 \mathrm{E}+02$

$6.05 \mathrm{E}+02$

$6.05 \mathrm{E}+02$

$6.06 \mathrm{E}+02$

$6.07 \mathrm{E}+02$

$6.07 \mathrm{E}+02$

$6.08 \mathrm{E}+02$

$6.08 \mathrm{E}+02$

$6.09 \mathrm{E}+02$

$6.09 \mathrm{E}+02$

$6.10 \mathrm{E}+02$

$6.10 \mathrm{E}+02$

$6.11 \mathrm{E}+02$

$6.11 \mathrm{E}+02$

$6.12 \mathrm{E}+02$

$6.12 \mathrm{E}+02$

$6.13 \mathrm{E}+02$
Dose statistics at graphical times, mrem/yr

\begin{tabular}{|c|c|c|c|c|c|c|c|}
\hline Minimum & Maximum & Mean & Median & $90 \%$ & $95 \%$ & $97.5 \%$ & $99 \%$ \\
\hline $3.61 \mathrm{E}-03$ & $4.45 E+00$ & $2.96 \mathrm{E}-01$ & $1.40 \mathrm{E}-01$ & $7.50 \mathrm{E}-01$ & $1.11 \mathrm{E}+00$ & $1.58 \mathrm{E}+00$ & $2.20 \mathrm{E}+00$ \\
\hline $3.64 \mathrm{E}-03$ & $4.45 E+00$ & $2.97 E-01$ & $1.41 \mathrm{E}-01$ & $7.52 \mathrm{E}-01$ & $1.11 \mathrm{E}+00$ & $1.59 \mathrm{E}+00$ & $2.21 \mathrm{E}+00$ \\
\hline $3.67 \mathrm{E}-03$ & $4.45 \mathrm{E}+00$ & $2.98 \mathrm{E}-01$ & 1. $42 \mathrm{E}-01$ & $7.54 \mathrm{E}-01$ & $1.12 \mathrm{E}+00$ & $1.59 \mathrm{E}+00$ & $2.21 \mathrm{E}+00$ \\
\hline $3.70 \mathrm{E}-03$ & $4.46 \mathrm{E}+00$ & $2.99 \mathrm{E}-01$ & $1.42 \mathrm{E}-01$ & $7.55 \mathrm{E}-01$ & $1.12 \mathrm{E}+00$ & $1.60 \mathrm{E}+00$ & $2.21 \mathrm{E}+00$ \\
\hline $3.73 E-03$ & $4.46 \mathrm{E}+00$ & $2.99 \mathrm{E}-01$ & $1.43 \mathrm{E}-01$ & 7. $58 \mathrm{E}-01$ & $1.12 \mathrm{E}+00$ & $1.60 \mathrm{E}+00$ & $2.21 \mathrm{E}+00$ \\
\hline $3.76 \mathrm{E}-03$ & $4.46 \mathrm{E}+00$ & $3.00 \mathrm{E}-01$ & $1.44 \mathrm{E}-01$ & 7. $60 \mathrm{E}-01$ & $.12 \mathrm{E}+00$ & $1.60 \mathrm{E}+00$ & $2.21 E+00$ \\
\hline $3.79 \mathrm{E}-03$ & $4.46 \mathrm{E}+00$ & $3.01 \mathrm{E}-01$ & $1.44 \mathrm{E}-01$ & $7.63 E-01$ & $1.13 \mathrm{E}+00$ & $1.61 \mathrm{E}+00$ & $2.22 \mathrm{E}+00$ \\
\hline $3.82 \mathrm{E}-03$ & $4.47 \mathrm{E}+00$ & $3.02 \mathrm{E}-01$ & $1.45 \mathrm{E}-01$ & $7.65 \mathrm{E}-01$ & $1.13 \mathrm{E}+00$ & $1.61 \mathrm{E}+00$ & $2.22 \mathrm{E}+00$ \\
\hline $3.85 \mathrm{E}-03$ & $4.47 \mathrm{E}+00$ & $3.03 E-01$ & $1.46 \mathrm{E}-01$ & 7. $68 \mathrm{E}-01$ & $1.13 \mathrm{E}+00$ & $1.61 \mathrm{E}+00$ & $2.22 E+00$ \\
\hline $3.88 E-03$ & $4.47 \mathrm{E}+00$ & $3.04 \mathrm{E}-01$ & $1.46 \mathrm{E}-01$ & $.70 \mathrm{E}-01$ & $1.13 \mathrm{E}+00$ & $1.62 \mathrm{E}+00$ & $.22 \mathrm{E}+00$ \\
\hline $3.92 \mathrm{E}-03$ & $4.47 \mathrm{E}+00$ & $3.05 E-01$ & $1.47 \mathrm{E}-01$ & $7.72 \mathrm{E}-01$ & $14 \mathrm{E}+00$ & $1.62 \mathrm{E}+00$ & $2.23 E+00$ \\
\hline $3.95 E-03$ & $4.48 \mathrm{E}+00$ & $3.06 \mathrm{E}-01$ & $1.48 \mathrm{E}-01$ & $7.74 \mathrm{E}-01$ & $1.14 \mathrm{E}+00$ & $1.62 \mathrm{E}+00$ & $2.23 E+00$ \\
\hline $3.98 E-03$ & $4.48 E+00$ & $3.07 \mathrm{E}-01$ & $1.48 \mathrm{E}-01$ & $7.76 \mathrm{E}-01$ & $1.14 \mathrm{E}+00$ & $1.62 \mathrm{E}+00$ & $2.23 E+00$ \\
\hline $4.01 E-03$ & $4.48 \mathrm{E}+00$ & $3.07 \mathrm{E}-01$ & $1.49 \mathrm{E}-01$ & 7. $79 \mathrm{E}-01$ & $1.15 \mathrm{E}+00$ & $1.63 \mathrm{E}+00$ & $2.23 E+00$ \\
\hline $4.04 \mathrm{E}-03$ & $4.48 \mathrm{E}+00$ & $3.08 \mathrm{E}-01$ & $1.50 \mathrm{E}-01$ & $7.81 \mathrm{E}-01$ & $1.15 \mathrm{E}+00$ & $1.63 \mathrm{E}+00$ & $2.23 E+00$ \\
\hline $4.07 E-03$ & $4.49 \mathrm{E}+00$ & $3.09 E-01$ & $.51 E-01$ & $84 E-01$ & $.15 \mathrm{E}+$ & $.63 E+00$ & $.24 E+00$ \\
\hline $4.11 \mathrm{E}-03$ & $4.49 \mathrm{E}+00$ & $10 \mathrm{E}-01$ & $1.51 \mathrm{E}-01$ & $86 E-01$ & $15 \mathrm{E}+00$ & $.63 E+00$ & $.24 \mathrm{E}+00$ \\
\hline $4.14 \mathrm{E}-03$ & $4.49 \mathrm{E}+00$ & $3.11 \mathrm{E}-01$ & $1.52 \mathrm{E}-01$ & $7.88 \mathrm{E}-01$ & $1.16 \mathrm{E}+00$ & $1.64 \mathrm{E}+00$ & $2.24 \mathrm{E}+00$ \\
\hline $4.17 E-03$ & $4.49 \mathrm{E}+00$ & $3.12 \mathrm{E}-01$ & $1.53 E-01$ & $7.90 E-01$ & $1.16 \mathrm{E}+00$ & $1.64 \mathrm{E}+00$ & $2.24 \mathrm{E}+00$ \\
\hline $4.20 E-03$ & $4.49 \mathrm{E}+00$ & $3.13 \mathrm{E}-01$ & $1.53 \mathrm{E}-01$ & 7. $92 \mathrm{E}-01$ & $1.16 \mathrm{E}+00$ & $1.64 \mathrm{E}+00$ & $2.25 \mathrm{E}+00$ \\
\hline $4.24 \mathrm{E}-03$ & $4.50 \mathrm{E}+00$ & $3.14 \mathrm{E}-01$ & $1.54 \mathrm{E}-01$ & 7. $93 \mathrm{E}-01$ & $1.17 \mathrm{E}+00$ & $1.64 \mathrm{E}+00$ & $2.25 \mathrm{E}+00$ \\
\hline $4.27 E-03$ & $4.50 \mathrm{E}+00$ & $3.15 E-01$ & $55 E-01$ & $95 E-01$ & $1.17 \mathrm{E}+00$ & $1.64 \mathrm{E}+00$ & $.25 E+00$ \\
\hline $4.30 E-03$ & $4.50 \mathrm{E}+00$ & $3.15 \mathrm{E}-01$ & $1.55 \mathrm{E}-01$ & $7.97 \mathrm{E}-01$ & $1.17 \mathrm{E}+00$ & $1.65 \mathrm{E}+00$ & $2.25 E+00$ \\
\hline $4.34 \mathrm{E}-03$ & $4.50 \mathrm{E}+00$ & $3.16 \mathrm{E}-01$ & $1.56 \mathrm{E}-01$ & $7.99 \mathrm{E}-01$ & $1.17 \mathrm{E}+00$ & $1.65 \mathrm{E}+00$ & $2.25 \mathrm{E}+00$ \\
\hline $4.37 E-03$ & $4.50 \mathrm{E}+00$ & $3.17 \mathrm{E}-01$ & $1.56 \mathrm{E}-01$ & $8.01 E-01$ & $1.18 \mathrm{E}+00$ & $1.65 \mathrm{E}+00$ & $2.25 E+00$ \\
\hline $4.40 E-03$ & $4.51 \mathrm{E}+00$ & $3.18 \mathrm{E}-01$ & $1.57 \mathrm{E}-01$ & $8.04 \mathrm{E}-01$ & $1.18 \mathrm{E}+00$ & $1.65 \mathrm{E}+00$ & $2.26 \mathrm{E}+00$ \\
\hline $4.44 \mathrm{E}-03$ & $4.51 \mathrm{E}+00$ & $3.19 \mathrm{E}-01$ & $1.57 \mathrm{E}-01$ & $8.06 \mathrm{E}-01$ & $1.18 \mathrm{E}+00$ & $1.65 \mathrm{E}+00$ & $2.26 \mathrm{E}+00$ \\
\hline $4.47 E-03$ & $4.51 \mathrm{E}+00$ & $3.20 E-01$ & $1.58 \mathrm{E}-01$ & $8.08 E-01$ & $1.18 \mathrm{E}+00$ & $1.66 \mathrm{E}+00$ & $2.26 \mathrm{E}+00$ \\
\hline $4.51 \mathrm{E}-03$ & $4.51 \mathrm{E}+00$ & $3.21 \mathrm{E}-01$ & $1.59 \mathrm{E}-01$ & $10 \mathrm{E}-01$ & $1.18 \mathrm{E}+00$ & $1.66 \mathrm{E}+00$ & $2.26 \mathrm{E}+00$ \\
\hline $4.54 \mathrm{E}-03$ & $4.51 \mathrm{E}+00$ & $3.22 E-01$ & $1.59 \mathrm{E}-01$ & $8.13 E-01$ & $1.19 \mathrm{E}+00$ & $1.66 \mathrm{E}+00$ & $2.26 \mathrm{E}+00$ \\
\hline $4.58 E-03$ & $4.52 \mathrm{E}+00$ & $3.23 E-01$ & $1.60 \mathrm{E}-01$ & $8.15 E-01$ & $1.19 \mathrm{E}+00$ & $1.66 \mathrm{E}+00$ & $2.26 \mathrm{E}+00$ \\
\hline $4.61 \mathrm{E}-03$ & $4.52 \mathrm{E}+00$ & $3.23 \mathrm{E}-01$ & $1.61 \mathrm{E}-01$ & $8.17 \mathrm{E}-01$ & $1.19 \mathrm{E}+00$ & $1.66 \mathrm{E}+00$ & $2.26 \mathrm{E}+00$ \\
\hline $4.65 E-03$ & $4.52 \mathrm{E}+00$ & $3.24 \mathrm{E}-01$ & $1.61 \mathrm{E}-01$ & $3.19 \mathrm{E}-01$ & $1.19 \mathrm{E}+00$ & $1.67 \mathrm{E}+00$ & $2.27 E+00$ \\
\hline $4.68 E-03$ & $4.52 \mathrm{E}+00$ & $3.25 E-01$ & 1. $62 \mathrm{E}-01$ & $.21 E-01$ & $1.19 \mathrm{E}+00$ & $1.67 \mathrm{E}+00$ & $2.27 E+00$ \\
\hline $4.72 E-03$ & $4.52 \mathrm{E}+00$ & $3.26 E-01$ & $1.63 E-01$ & $8.24 E-01$ & $1.20 \mathrm{E}+00$ & $1.67 \mathrm{E}+00$ & $2.27 E+00$ \\
\hline $4.75 E-03$ & $4.53 E+00$ & $3.27 E-01$ & $1.63 E-01$ & $8.26 \mathrm{E}-01$ & $1.20 \mathrm{E}+00$ & $1.67 \mathrm{E}+00$ & $2.27 \mathrm{E}+00$ \\
\hline $4.79 E-03$ & $4.53 E+00$ & $3.28 \mathrm{E}-01$ & $1.64 \mathrm{E}-01$ & $8.29 E-01$ & $1.20 \mathrm{E}+00$ & $1.67 \mathrm{E}+00$ & $2.27 E+00$ \\
\hline $4.83 E-03$ & $4.53 \mathrm{E}+00$ & $3.29 \mathrm{E}-01$ & $1.65 \mathrm{E}-01$ & $8.32 \mathrm{E}-01$ & $1.20 \mathrm{E}+00$ & $1.68 \mathrm{E}+00$ & $2.27 \mathrm{E}+00$ \\
\hline $4.86 \mathrm{E}-03$ & $4.53 E+00$ & $3.30 E-01$ & $1.65 \mathrm{E}-01$ & $8.34 \mathrm{E}-01$ & $1.20 \mathrm{E}+00$ & $1.68 \mathrm{E}+00$ & $2.27 E+00$ \\
\hline $4.90 \mathrm{E}-03$ & $4.53 E+00$ & $3.31 \mathrm{E}-01$ & $1.66 \mathrm{E}-01$ & $8.37 \mathrm{E}-01$ & $1.21 \mathrm{E}+00$ & $1.68 \mathrm{E}+00$ & $2.27 \mathrm{E}+00$ \\
\hline $4.94 E-03$ & $4.53 E+00$ & $3.32 \mathrm{E}-01$ & $1.67 \mathrm{E}-01$ & $8.39 E-01$ & $1.21 \mathrm{E}+00$ & $1.68 \mathrm{E}+00$ & $2.28 \mathrm{E}+00$ \\
\hline $4.97 \mathrm{E}-03$ & $4.54 \mathrm{E}+00$ & $3.32 E-01$ & $1.67 \mathrm{E}-01$ & $8.42 E-01$ & $1.21 \mathrm{E}+00$ & $1.68 \mathrm{E}+00$ & $2.28 \mathrm{E}+00$ \\
\hline $5.01 \mathrm{E}-03$ & $4.54 \mathrm{E}+00$ & $3.33 \mathrm{E}-01$ & $1.68 \mathrm{E}-01$ & $8.44 \mathrm{E}-01$ & $1.21 \mathrm{E}+00$ & $1.68 \mathrm{E}+00$ & $2.28 \mathrm{E}+00$ \\
\hline $5.05 E-03$ & $4.54 \mathrm{E}+00$ & $3.34 \mathrm{E}-01$ & $1.69 \mathrm{E}-01$ & $8.47 E-01$ & $1.21 \mathrm{E}+00$ & $1.69 \mathrm{E}+00$ & $2.28 \mathrm{E}+00$ \\
\hline $5.09 \mathrm{E}-03$ & $4.54 \mathrm{E}+00$ & $3.35 E-01$ & $1.69 \mathrm{E}-01$ & $8.49 E-01$ & $1.22 \mathrm{E}+00$ & $1.69 \mathrm{E}+00$ & $2.28 \mathrm{E}+00$ \\
\hline $5.12 \mathrm{E}-03$ & $4.54 \mathrm{E}+00$ & $3.36 \mathrm{E}-01$ & 1. $70 \mathrm{E}-01$ & $8.51 E-01$ & $1.22 \mathrm{E}+00$ & $1.69 \mathrm{E}+00$ & $2.28 \mathrm{E}+00$ \\
\hline
\end{tabular}


RESRAD-OFFSITE, Version 2.5 
RESRAD-OFFSITE, Version 2.5

obabilistic Dose and Risk Report

Title : Offsite Resident Farmer

File : RF TC99 DOESG FWD-FV2all.ROF

Summary of dose at graphical times, reptition 1 (continued)

Time

Years

$6.37 \mathrm{E}+02$

$6.37 \mathrm{E}+02$

$6.38 \mathrm{E}+02$

$6.38 \mathrm{E}+02$

$6.39 \mathrm{E}+02$

$6.39 \mathrm{E}+02$

$6.40 \mathrm{E}+02$

$6.40 \mathrm{E}+02$

$6.41 \mathrm{E}+02$

$6.41 \mathrm{E}+02$

$6.42 \mathrm{E}+02$

$6.42 \mathrm{E}+02$

$6.43 \mathrm{E}+02$

$6.43 \mathrm{E}+02$

$6.44 \mathrm{E}+02$

$6.44 \mathrm{E}+02$

$6.45 \mathrm{E}+02$

$6.45 \mathrm{E}+02$

$6.46 \mathrm{E}+02$

$6.47 \mathrm{E}+02$

$6.47 \mathrm{E}+02$

$6.48 \mathrm{E}+02$

$6.48 \mathrm{E}+02$

$6.49 \mathrm{E}+02$

$6.49 \mathrm{E}+02$

$6.50 \mathrm{E}+02$

$6.50 \mathrm{E}+02$

$6.51 \mathrm{E}+02$

$6.51 \mathrm{E}+02$

$6.52 \mathrm{E}+02$

$6.52 \mathrm{E}+02$

$6.53 \mathrm{E}+02$

$6.53 \mathrm{E}+02$

$6.54 \mathrm{E}+02$

$6.54 \mathrm{E}+02$

$6.55 \mathrm{E}+02$

$6.55 \mathrm{E}+02$

$6.56 \mathrm{E}+02$

$6.56 \mathrm{E}+02$

$6.57 \mathrm{E}+02$

$6.57 \mathrm{E}+02$

$6.58 \mathrm{E}+02$

$6.58 \mathrm{E}+02$

$6.59 \mathrm{E}+02$

$6.59 \mathrm{E}+02$

$6.60 \mathrm{E}+02$

Dose statistics at graphical times, mrem/yr

\begin{tabular}{|c|c|c|c|c|c|c|c|}
\hline Minimum & Maximum & Mean & Median & $90 \%$ & $95 \%$ & $97.5 \%$ & $99 \%$ \\
\hline $7.02 \mathrm{E}-03$ & $4.59 \mathrm{E}+00$ & $3.79 \mathrm{E}-01$ & $2.06 \mathrm{E}-01$ & $9.48 \mathrm{E}-01$ & $1.31 E+00$ & $1.81 E+00$ & $2.35 E+00$ \\
\hline $7.07 E-03$ & $4.59 \mathrm{E}+00$ & $3.80 \mathrm{E}-01$ & $2.06 \mathrm{E}-01$ & $9.49 \mathrm{E}-01$ & $1.32 \mathrm{E}+00$ & $1.81 \mathrm{E}+00$ & $2.35 \mathrm{E}+00$ \\
\hline $7.11 \mathrm{E}-03$ & $4.59 \mathrm{E}+00$ & $3.81 \mathrm{E}-01$ & $2.07 E-01$ & $9.51 \mathrm{E}-01$ & $1.32 \mathrm{E}+00$ & $1.81 \mathrm{E}+00$ & $2.36 \mathrm{E}+00$ \\
\hline $7.16 \mathrm{E}-03$ & $4.59 \mathrm{E}+00$ & $3.82 \mathrm{E}-01$ & $2.08 \mathrm{E}-01$ & $9.53 \mathrm{E}-01$ & $1.32 \mathrm{E}+00$ & $1.81 \mathrm{E}+00$ & $2.36 \mathrm{E}+00$ \\
\hline $7.20 \mathrm{E}-03$ & $4.59 \mathrm{E}+00$ & $3.83 \mathrm{E}-01$ & $2.08 \mathrm{E}-01$ & $9.54 \mathrm{E}-01$ & $1.33 \mathrm{E}+00$ & $1.82 \mathrm{E}+00$ & $2.36 \mathrm{E}+00$ \\
\hline $7.25 E-03$ & $4.59 \mathrm{E}+00$ & $3.84 \mathrm{E}-01$ & $2.09 \mathrm{E}-01$ & $9.56 \mathrm{E}-01$ & $33 E+00$ & $.82 \mathrm{E}+00$ & $.36 E+00$ \\
\hline $7.29 \mathrm{E}-03$ & $4.59 \mathrm{E}+00$ & $3.85 E-01$ & $2.10 \mathrm{E}-01$ & $9.58 \mathrm{E}-01$ & $1.33 \mathrm{E}+00$ & $1.82 \mathrm{E}+00$ & $2.37 \mathrm{E}+00$ \\
\hline $7.34 \mathrm{E}-03$ & $4.59 \mathrm{E}+00$ & $3.86 \mathrm{E}-01$ & $2.10 \mathrm{E}-01$ & $9.60 \mathrm{E}-01$ & $1.33 \mathrm{E}+00$ & $1.82 \mathrm{E}+00$ & $2.37 \mathrm{E}+00$ \\
\hline 7. $38 \mathrm{E}-03$ & $4.59 \mathrm{E}+00$ & $3.87 \mathrm{E}-01$ & $2.11 \mathrm{E}-01$ & $9.62 \mathrm{E}-01$ & 1. $33 \mathrm{E}+00$ & $1.83 \mathrm{E}+00$ & $2.37 \mathrm{E}+00$ \\
\hline $7.43 E-03$ & $4.59 \mathrm{E}+00$ & $3.88 \mathrm{E}-01$ & $2.12 \mathrm{E}-01$ & $.64 \mathrm{E}-01$ & $1.34 \mathrm{E}+00$ & $1.83 \mathrm{E}+00$ & $.38 E+00$ \\
\hline $7.48 \mathrm{E}-03$ & $4.59 \mathrm{E}+00$ & $3.89 \mathrm{E}-01$ & $2.12 \mathrm{E}-01$ & $9.66 \mathrm{E}-01$ & $1.34 \mathrm{E}+00$ & $.83 E+00$ & $38 E+00$ \\
\hline $7.52 \mathrm{E}-03$ & $4.59 \mathrm{E}+00$ & $3.89 \mathrm{E}-01$ & $2.13 \mathrm{E}-01$ & $9.68 \mathrm{E}-01$ & $1.34 \mathrm{E}+00$ & $1.83 \mathrm{E}+00$ & $2.38 \mathrm{E}+00$ \\
\hline $7.57 \mathrm{E}-03$ & $4.59 \mathrm{E}+00$ & $3.90 \mathrm{E}-01$ & $2.14 \mathrm{E}-01$ & $9.70 \mathrm{E}-01$ & $1.34 \mathrm{E}+00$ & $1.83 \mathrm{E}+00$ & $2.38 \mathrm{E}+00$ \\
\hline $7.62 \mathrm{E}-03$ & $4.59 \mathrm{E}+00$ & $3.91 \mathrm{E}-01$ & $2.15 \mathrm{E}-01$ & $9.72 \mathrm{E}-01$ & $1.34 \mathrm{E}+00$ & $1.84 \mathrm{E}+00$ & $2.39 \mathrm{E}+00$ \\
\hline $7.66 \mathrm{E}-03$ & $4.59 \mathrm{E}+00$ & $3.92 \mathrm{E}-01$ & $2.16 \mathrm{E}-01$ & $9.74 \mathrm{E}-01$ & $1.35 \mathrm{E}+00$ & $1.84 \mathrm{E}+00$ & $2.39 \mathrm{E}+00$ \\
\hline $7.71 E-03$ & $4.59 \mathrm{E}+00$ & $3.93 E-01$ & $2.16 E-01$ & $76 E-01$ & $.35 E+$ & $.84 E+00$ & $.39 E+00$ \\
\hline $7.76 \mathrm{E}-03$ & $4.59 \mathrm{E}+00$ & $94 \mathrm{E}-01$ & $.17 \mathrm{E}-01$ & $.77 \mathrm{E}-01$ & $35 E+00$ & $.85 E+00$ & $.39 E+00$ \\
\hline $7.81 \mathrm{E}-03$ & $4.59 \mathrm{E}+00$ & $3.95 E-01$ & $2.18 \mathrm{E}-01$ & $9.79 \mathrm{E}-01$ & $1.36 \mathrm{E}+00$ & $1.85 \mathrm{E}+00$ & $2.39 \mathrm{E}+00$ \\
\hline $7.86 \mathrm{E}-03$ & $4.59 \mathrm{E}+00$ & $3.96 \mathrm{E}-01$ & $2.19 \mathrm{E}-01$ & $9.81 \mathrm{E}-01$ & $1.36 \mathrm{E}+00$ & $1.85 \mathrm{E}+00$ & $2.40 \mathrm{E}+00$ \\
\hline $7.90 \mathrm{E}-03$ & $4.59 \mathrm{E}+00$ & $3.97 \mathrm{E}-01$ & $2.19 \mathrm{E}-01$ & $9.82 \mathrm{E}-01$ & $1.36 \mathrm{E}+00$ & $1.86 \mathrm{E}+00$ & $2.40 \mathrm{E}+00$ \\
\hline $7.95 \mathrm{E}-03$ & $4.59 \mathrm{E}+00$ & $3.98 \mathrm{E}-01$ & $2.20 \mathrm{E}-01$ & $9.84 \mathrm{E}-01$ & $1.36 \mathrm{E}+00$ & $1.86 \mathrm{E}+00$ & $2.40 \mathrm{E}+00$ \\
\hline $8.00 E-03$ & $4.59 \mathrm{E}+00$ & $3.99 E-01$ & $2.21 E-01$ & $86 E-01$ & $1.37 \mathrm{E}+00$ & $1.86 \mathrm{E}+00$ & $.40 E+00$ \\
\hline $8.05 E-03$ & $4.59 \mathrm{E}+00$ & $4.00 \mathrm{E}-01$ & $2.22 E-01$ & $9.87 \mathrm{E}-01$ & $1.37 \mathrm{E}+00$ & $1.86 \mathrm{E}+00$ & $2.41 E+00$ \\
\hline $8.10 \mathrm{E}-03$ & $4.59 \mathrm{E}+00$ & $4.01 \mathrm{E}-01$ & $2.22 \mathrm{E}-01$ & $9.88 \mathrm{E}-01$ & $1.37 \mathrm{E}+00$ & $1.87 \mathrm{E}+00$ & $2.41 \mathrm{E}+00$ \\
\hline $8.15 E-03$ & $4.59 \mathrm{E}+00$ & $4.02 E-01$ & $2.23 E-01$ & $9.89 \mathrm{E}-01$ & $1.37 \mathrm{E}+00$ & $1.87 \mathrm{E}+00$ & $2.41 \mathrm{E}+00$ \\
\hline $8.20 \mathrm{E}-03$ & $4.59 \mathrm{E}+00$ & $4.02 \mathrm{E}-01$ & $2.24 \mathrm{E}-01$ & $9.90 \mathrm{E}-01$ & $1.38 \mathrm{E}+00$ & $1.87 \mathrm{E}+00$ & $2.41 \mathrm{E}+00$ \\
\hline $8.25 \mathrm{E}-03$ & $4.59 \mathrm{E}+00$ & $4.03 E-01$ & $2.25 \mathrm{E}-01$ & $9.91 \mathrm{E}-01$ & $1.38 \mathrm{E}+00$ & $1.88 \mathrm{E}+00$ & $2.42 \mathrm{E}+00$ \\
\hline $8.30 E-03$ & $4.59 \mathrm{E}+00$ & $4.04 \mathrm{E}-01$ & $2.26 \mathrm{E}-01$ & $9.92 \mathrm{E}-01$ & $1.38 \mathrm{E}+00$ & $1.88 \mathrm{E}+00$ & $2.42 \mathrm{E}+00$ \\
\hline $8.35 E-03$ & $4.59 \mathrm{E}+00$ & $4.05 E-01$ & $2.27 E-01$ & $9.93 E-01$ & $1.39 \mathrm{E}+00$ & $1.88 \mathrm{E}+00$ & $2.42 \mathrm{E}+00$ \\
\hline $8.40 E-03$ & $4.59 \mathrm{E}+00$ & $4.06 \mathrm{E}-01$ & $2.27 E-01$ & $9.94 \mathrm{E}-01$ & $1.39 \mathrm{E}+00$ & $1.88 \mathrm{E}+00$ & $2.42 \mathrm{E}+00$ \\
\hline $8.45 E-03$ & $4.59 \mathrm{E}+00$ & $4.07 E-01$ & $2.28 \mathrm{E}-01$ & $9.95 \mathrm{E}-01$ & $1.39 \mathrm{E}+00$ & $1.89 \mathrm{E}+00$ & $2.43 E+00$ \\
\hline $8.50 \mathrm{E}-03$ & $4.59 \mathrm{E}+00$ & $4.08 \mathrm{E}-01$ & $2.29 \mathrm{E}-01$ & $9.97 \mathrm{E}-01$ & $1.39 \mathrm{E}+00$ & $1.89 \mathrm{E}+00$ & $2.43 E+00$ \\
\hline $8.55 E-03$ & $4.59 \mathrm{E}+00$ & $4.09 \mathrm{E}-01$ & $2.30 \mathrm{E}-01$ & $9.99 \mathrm{E}-01$ & $1.40 \mathrm{E}+00$ & $1.89 \mathrm{E}+00$ & $2.43 E+00$ \\
\hline $8.60 \mathrm{E}-03$ & $4.59 \mathrm{E}+00$ & $4.10 \mathrm{E}-01$ & $2.30 E-01$ & $1.00 \mathrm{E}+00$ & $1.40 \mathrm{E}+00$ & $1.90 \mathrm{E}+00$ & $2.43 E+00$ \\
\hline $8.65 E-03$ & $4.59 \mathrm{E}+00$ & $4.11 E-01$ & $2.31 E-01$ & $1.00 \mathrm{E}+00$ & $1.40 \mathrm{E}+00$ & $1.90 \mathrm{E}+00$ & $2.44 \mathrm{E}+00$ \\
\hline $8.71 E-03$ & $4.59 \mathrm{E}+00$ & $4.12 \mathrm{E}-01$ & $2.32 E-01$ & $1.00 \mathrm{E}+00$ & $1.40 \mathrm{E}+00$ & $1.90 \mathrm{E}+00$ & $2.44 \mathrm{E}+00$ \\
\hline $8.76 \mathrm{E}-03$ & $4.59 \mathrm{E}+00$ & $4.13 E-01$ & $2.33 E-01$ & $1.01 \mathrm{E}+00$ & $1.41 \mathrm{E}+00$ & $1.90 \mathrm{E}+00$ & $2.44 \mathrm{E}+00$ \\
\hline $8.81 \mathrm{E}-03$ & $4.59 \mathrm{E}+00$ & $4.14 \mathrm{E}-01$ & $2.34 \mathrm{E}-01$ & $1.01 \mathrm{E}+00$ & $1.41 \mathrm{E}+00$ & $1.91 \mathrm{E}+00$ & $2.44 \mathrm{E}+00$ \\
\hline $8.86 \mathrm{E}-03$ & $4.59 \mathrm{E}+00$ & $4.15 \mathrm{E}-01$ & $2.35 E-01$ & $1.01 \mathrm{E}+00$ & $1.41 \mathrm{E}+00$ & $1.91 \mathrm{E}+00$ & $2.44 \mathrm{E}+00$ \\
\hline $8.91 \mathrm{E}-03$ & $4.59 \mathrm{E}+00$ & $4.16 \mathrm{E}-01$ & $2.36 \mathrm{E}-01$ & $1.01 \mathrm{E}+00$ & $1.41 \mathrm{E}+00$ & $1.91 \mathrm{E}+00$ & $2.45 \mathrm{E}+00$ \\
\hline $8.97 E-03$ & $4.59 \mathrm{E}+00$ & $4.17 \mathrm{E}-01$ & $2.37 E-01$ & $1.01 \mathrm{E}+00$ & $1.42 \mathrm{E}+00$ & $1.91 \mathrm{E}+00$ & $2.45 \mathrm{E}+00$ \\
\hline $9.02 \mathrm{E}-03$ & $4.59 \mathrm{E}+00$ & $4.17 E-01$ & $2.38 E-01$ & $1.01 \mathrm{E}+00$ & $1.42 \mathrm{E}+00$ & $1.92 \mathrm{E}+00$ & $2.45 \mathrm{E}+00$ \\
\hline $9.07 E-03$ & $4.59 \mathrm{E}+00$ & $4.18 \mathrm{E}-01$ & $2.39 \mathrm{E}-01$ & $1.02 \mathrm{E}+00$ & $1.42 \mathrm{E}+00$ & $1.92 \mathrm{E}+00$ & $2.45 E+00$ \\
\hline $9.13 E-03$ & $4.59 \mathrm{E}+00$ & $4.19 \mathrm{E}-01$ & $2.40 E-01$ & $1.02 \mathrm{E}+00$ & $1.43 \mathrm{E}+00$ & $1.92 \mathrm{E}+00$ & $2.46 \mathrm{E}+00$ \\
\hline $9.18 \mathrm{E}-03$ & $4.59 \mathrm{E}+00$ & $4.20 E-01$ & $2.41 E-01$ & $1.02 \mathrm{E}+00$ & $1.43 E+00$ & $1.92 \mathrm{E}+00$ & $2.46 \mathrm{E}+00$ \\
\hline $9.23 \mathrm{E}-03$ & $4.59 \mathrm{E}+00$ & $4.21 E-01$ & $2.42 \mathrm{E}-01$ & $1.02 \mathrm{E}+00$ & $1.43 E+00$ & $1.92 \mathrm{E}+00$ & $2.46 \mathrm{E}+00$ \\
\hline
\end{tabular}


RESRAD-OFFSITE, Version 2.5

$\mathrm{T}^{1 / 2}$ Limit $=180$ days

obabilistic Dose and Risk Report

Title : Offsite Resident Farmer

File : RF TC99 DOESG FWD-FV2all.ROF

Summary of dose at graphical times, reptition 1 (continued)

Time

Years

$6.60 \mathrm{E}+02$

$6.61 \mathrm{E}+02$

$6.61 \mathrm{E}+02$

$6.62 \mathrm{E}+02$

$6.62 \mathrm{E}+02$

$6.63 \mathrm{E}+02$

$6.63 \mathrm{E}+02$

$6.64 \mathrm{E}+02$

$6.64 \mathrm{E}+02$

$6.65 \mathrm{E}+02$

$6.65 \mathrm{E}+02$

$6.66 \mathrm{E}+02$

$6.67 \mathrm{E}+02$

$6.67 \mathrm{E}+02$

$6.68 \mathrm{E}+02$

$6.68 \mathrm{E}+02$

$6.69 \mathrm{E}+02$

$6.69 \mathrm{E}+02$

$6.70 \mathrm{E}+02$

$6.70 \mathrm{E}+02$

$6.71 \mathrm{E}+02$

$6.71 \mathrm{E}+02$

$6.72 \mathrm{E}+02$

$6.72 \mathrm{E}+02$

$6.73 \mathrm{E}+02$

$6.73 \mathrm{E}+02$

$6.74 \mathrm{E}+02$

$6.74 \mathrm{E}+02$

$6.75 \mathrm{E}+02$

$6.75 \mathrm{E}+02$

$6.76 \mathrm{E}+02$

$6.76 \mathrm{E}+02$

$6.77 \mathrm{E}+02$

$6.77 \mathrm{E}+02$

$6.78 \mathrm{E}+02$

$6.78 \mathrm{E}+02$

$6.79 \mathrm{E}+02$

$6.79 \mathrm{E}+02$

$6.80 \mathrm{E}+02$

$6.80 \mathrm{E}+02$

$6.81 \mathrm{E}+02$

$6.81 \mathrm{E}+02$

$6.82 \mathrm{E}+02$

$6.82 \mathrm{E}+02$

$6.83 \mathrm{E}+02$

$6.83 \mathrm{E}+02$
Dose statistics at graphical times, mrem/yr

\begin{tabular}{|c|c|c|c|c|c|c|c|}
\hline linimum & laximum & Mean & Median & 900 & $0 \%$ & $97.5 \%$ & $3 \%$ \\
\hline 3 & $9 \mathrm{E}+00$ & $22 E-01$ & $43 E-01$ & $03 E+00$ & $44 E+00$ & $32 \mathrm{E}+00$ & +00 \\
\hline 03 & $9 \mathrm{E}+00$ & $3 E-$ & 1 & $03 E$ & $44 \mathrm{E}+00$ & $.93 E+00$ & $47 E+00$ \\
\hline$E-03$ & $E+00$ & $4 E-01$ & $E-01$ & 0 & 0 & 00 & $7 E+00$ \\
\hline$E-03$ & +00 & $E-01$ & 01 & 0 & 0 & 0 & $7 E+00$ \\
\hline $.51 E-03$ & $9 E+00$ & & & & & & $47 \mathrm{E}+00$ \\
\hline $5 E-03$ & 00 & & & $\Xi+00$ & 0 & 00 & $48 E+00$ \\
\hline $62 E-03$ & $4.58 E+00$ & 4. $28 E-01$ & $2.49 \mathrm{E}-01$ & $1.04 \mathrm{E}+00$ & 1. $45 \mathrm{E}+$ & 0 & $48 E+00$ \\
\hline $.67 E-03$ & $4.58 E+00$ & 4.25- & $2.50 \mathrm{E}-01$ & $1.04 \mathrm{E}+00$ & $1.46 \mathrm{E}+00$ & +00 & $2.48 E+00$ \\
\hline 03 & 00 & 1 & 01 & 0 & 0 & 00 & \pm+00 \\
\hline$E-03$ & $E+00$ & 4 & 1 & & 年 & & $9 \mathrm{E}+00$ \\
\hline$E-03$ & $E+00$ & 4 & 1 & & & & $E+00$ \\
\hline-03 & +00 & 田 & 1 & 0 & 0 & & $9 E+00$ \\
\hline $95 E-03$ & $4.58 E+00$ & $4.33 E-0$ & $2.54 \mathrm{E}-01$ & $1.05 E+00$ & I. & 0 & $E+00$ \\
\hline $.00 E-02$ & $4.58 E+00$ & $4.345-01$ & $2.55 \mathrm{E}-01$ & $1.00 \mathrm{LT}$ U & 1.4 OLTU & $+e^{-1}$ & $E+00$ \\
\hline $.01 E-02$ & $4.58 E+00$ & 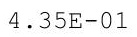 & 01 & 1.00 प & 1.70 & 00 & 00 \\
\hline $.01 \mathrm{E}-02$ & $4.58 \mathrm{E}+00$ & $4.36 \mathrm{E}-0$ & $2.56 \mathrm{E}-01$ & $1.06 \mathrm{E}+00$ & $1.48 \mathrm{E}+00$ & $1.95 \mathrm{E}+00$ & $50 \mathrm{E}+00$ \\
\hline $.02 E-02$ & $4.58 E+00$ & $4.37 \mathrm{E}-01$ & $2.57 \mathrm{E}-01$ & $1.06 \mathrm{E}+00$ & 1. $48 \mathrm{E}+00$ & $1.96 \mathrm{E}+00$ & $2.51 \mathrm{E}+00$ \\
\hline$E-02$ & $3 E+00$ & $8 E-01$ & $8 E-01$ & $06 \Gamma+$ & + & $6 E+00$ & $51 E+00$ \\
\hline$E-02$ & $4.58 \mathrm{E}+00$ & 4 & 1 & $E+00$ & 1 & 00 & $E+00$ \\
\hline $.04 \mathrm{E}-02$ & $4.58 E+00$ & $4.40 \mathrm{E}-01$ & $0 E-01$ & $1.0 / E+00$ & $1.495 T 00$ & +00 & $51 E+00$ \\
\hline $4 E-02$ & $4.57 E+00$ & & & & ו & & $E+00$ \\
\hline $.05 E-02$ & $4.57 \mathrm{E}+00$ & 4.4 & 1 & $1.07 \mathrm{E}+$ & $1.49 \mathrm{E}$ & 1. & 00 \\
\hline $.05 E-02$ & $4.57 E+00$ & $4.43 E-01$ & $2 E-01$ & $1.07 \mathrm{E}+00$ & 1. $49 \mathrm{E}+00$ & $1.97 \mathrm{E}+00$ & $.52 E+00$ \\
\hline $.06 E-02$ & $4.57 E+00$ & $4.44 \mathrm{E}-01$ & $2.63 \mathrm{E}-01$ & $1.08 \mathrm{E}+00$ & $1.50 \mathrm{E}+$ & $1.97 \mathrm{E}+00$ & $.52 E+00$ \\
\hline$E-02$ & $4.57 \mathrm{E}+00$ & $5 E-01$ & 1 & $1.08 \mathrm{E}+$ & 1. $50 \mathrm{E}+$ & & $.53 E+00$ \\
\hline$E-02$ & $7 E+00$ & 1 & 1 & 0 & 0 & 00 & \\
\hline $08 E-02$ & $4.57 \mathrm{E}+00$ & $4.47 \mathrm{E}-\mathrm{C}$ & 2.004 & $1.00 \mathrm{LT}$ & $\perp . J U L T$ & & $5 \mathrm{E}+00$ \\
\hline $.08 E-02$ & $4.57 \mathrm{E}+00$ & $4.48 \mathrm{E}-01$ & $2.67 \mathrm{E}-01$ & $1.08 \mathrm{E}+00$ & $1.51 \mathrm{E}+00$ & $1.98 \mathrm{E}+00$ & $2.53 E+00$ \\
\hline $.09 \mathrm{E}-02$ & $4.57 E+00$ & $4.48 E-01$ & $2.68 \mathrm{E}-01$ & $1.08 \mathrm{E}+00$ & 土. & $1.98 \mathrm{E}+00$ & $2.54 \mathrm{E}+00$ \\
\hline 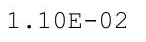 & $57 \mathrm{~F}+$ & 50 म & 1 & & $151=$ & & $.54 \mathrm{E}+00$ \\
\hline 02 & $4.57 \mathrm{E}+00$ & 1 & 1 & נ בתחم 1 & 1 & $\mathrm{E}+00$ & $.54 \mathrm{E}+00$ \\
\hline$E-02$ & 4.5 & & & & & & \\
\hline $1 E-02$ & $4.56 \mathrm{E}+00$ & 4. & 1 & $1.09 \mathrm{E}$ & $1.5 \angle \mathrm{E}$ & 00 & $4 \mathrm{E}+00$ \\
\hline $12 \mathrm{E}-02$ & $4.56 \mathrm{E}+00$ & $4.53 \mathrm{E}-01$ & $2.72 \mathrm{E}-01$ & $1.09 E+00$ & $1 . J \angle E+$ & $1.99 E+U 0$ & $2.54 \mathrm{E}+00$ \\
\hline IJE-UZ & $4.30 E+U 0$ & $4.54 \mathrm{E}-01$ & & & エ・Uட山 & & $2.55 E+00$ \\
\hline 2 & 4.5 & & & & 0 & & 00 \\
\hline 2 & & & & & & $0 E+00$ & ב \\
\hline 2 & 00 & 1 & 1 & 0 & 1.53 & & 00 \\
\hline$E-02$ & $4.56 \mathrm{E}+00$ & $8 E-01$ & $5 E-01$ & 1 . & 1.53 & & $5 E+00$ \\
\hline $6 E-02$ & $4.56 \mathrm{E}$ & 4 & & 1 & 1.5 & & 00 \\
\hline 2 & $4.55 E+00$ & & & & $1.54 \mathrm{E}+$ & & $2.55 E+00$ \\
\hline 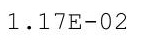 & $4.55 E+00$ & 4. & 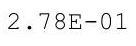 & $\perp \cdot \perp \perp \amalg \uparrow$ & 1. $54 \mathrm{E}+00$ & $2.01 \mathrm{E}+00$ & $2.05 E+00$ \\
\hline 2 & 0 & 4.6 & $2.19 E-$ & 0 & $54 \mathrm{E}+00$ & $1 E+00$ & $55 \mathrm{E}$ \\
\hline & & & 1 & $1.11 \mathrm{E}$ & $1.54 \mathrm{E}$ & $2 \mathrm{E}+00$ & $2.55 E+00$ \\
\hline-02 & $4.55 E+00$ & 4.6 & 2.8 & $1.11 \mathrm{E}+00$ & 1. $54 \mathrm{E}+$ & $2.02 E+00$ & $2.55 \mathrm{E}+00$ \\
\hline $20 E-02$ & $4.55 E+00$ & $.64 \mathrm{E}-01$ & $.81 E-01$ & $1.11 \mathrm{E}+00$ & 1. $55 \mathrm{E}+00$ & $2.02 E+00$ & $2.56 \mathrm{E}+00$ \\
\hline
\end{tabular}


RESRAD-OFFSITE, Version 2.5

$\mathrm{T}^{1 / 2}$ Limit $=180$ days

obabilistic Dose and Risk Report

Title : Offsite Resident Farmer

File : RF TC99 DOESG FWD-FV2all.ROF

Summary of dose at graphical times, reptition 1 (continued)

Time

Years

$6.84 \mathrm{E}+02$

$6.84 \mathrm{E}+02$

$6.85 \mathrm{E}+02$

$6.85 \mathrm{E}+02$

$6.86 \mathrm{E}+02$

$6.86 \mathrm{E}+02$

$6.87 \mathrm{E}+02$

$6.88 \mathrm{E}+02$

$6.88 \mathrm{E}+02$

$6.89 \mathrm{E}+02$

$6.89 \mathrm{E}+02$

$6.90 \mathrm{E}+02$

$6.90 \mathrm{E}+02$

$6.91 E+02$

$6.91 \mathrm{E}+02$

$6.92 \mathrm{E}+02$

$6.92 \mathrm{E}+02$

$6.93 \mathrm{E}+02$

$6.93 \mathrm{E}+02$

$6.94 \mathrm{E}+02$

$6.94 \mathrm{E}+02$

$6.95 \mathrm{E}+02$

$6.95 \mathrm{E}+02$

$6.96 \mathrm{E}+02$

$6.96 \mathrm{E}+02$

$6.97 \mathrm{E}+02$

$6.97 \mathrm{E}+02$

$6.98 \mathrm{E}+02$

$6.98 \mathrm{E}+02$

$6.99 \mathrm{E}+02$

$6.99 \mathrm{E}+02$

$7.00 \mathrm{E}+02$

$7.00 \mathrm{E}+02$

$7.01 \mathrm{E}+02$

$7.01 \mathrm{E}+02$

$7.02 \mathrm{E}+02$

$7.02 \mathrm{E}+02$

$7.03 \mathrm{E}+02$

$7.03 E+02$

$7.04 \mathrm{E}+02$

$7.04 \mathrm{E}+02$

$7.05 \mathrm{E}+02$

$7.05 \mathrm{E}+02$

$7.06 \mathrm{E}+02$

$7.06 \mathrm{E}+02$

$7.07 \mathrm{E}+02$
Dose statistics at graphical times, mrem/yr

\begin{tabular}{|c|c|c|c|c|c|c|c|}
\hline Minimum & Maximum & Mean & Median & $90 \%$ & $95 \%$ & $97.5 \%$ & $99 \%$ \\
\hline $1.20 \mathrm{E}-02$ & $4.55 \mathrm{E}+00$ & $4.65 E-01$ & $2.82 E-01$ & 1.11E+00 & $1.55 \mathrm{E}+00$ & $2.02 E+00$ & $2.56 \mathrm{E}+00$ \\
\hline $1.21 E-02$ & $4.55 \mathrm{E}+00$ & 4. $66 \mathrm{E}-01$ & $2.83 E-01$ & $1.12 \mathrm{E}+00$ & $1.55 \mathrm{E}+00$ & $2.02 E+00$ & $2.56 \mathrm{E}+00$ \\
\hline $1.21 \mathrm{E}-02$ & $4.54 \mathrm{E}+00$ & $4.67 \mathrm{E}-01$ & $2.83 E-01$ & $1.12 \mathrm{E}+00$ & $1.55 \mathrm{E}+00$ & $2.03 E+00$ & $2.56 \mathrm{E}+00$ \\
\hline $1.22 \mathrm{E}-02$ & $4.54 \mathrm{E}+00$ & $4.68 \mathrm{E}-01$ & $2.84 \mathrm{E}-01$ & $1.12 \mathrm{E}+00$ & $1.55 \mathrm{E}+00$ & $2.03 E+00$ & $2.56 \mathrm{E}+00$ \\
\hline $1.23 E-02$ & $4.54 \mathrm{E}+00$ & $4.69 \mathrm{E}-01$ & $2.85 E-01$ & $1.12 \mathrm{E}+00$ & $1.56 \mathrm{E}+00$ & $2.03 E+00$ & $2.56 \mathrm{E}+00$ \\
\hline $1.23 E-02$ & $4.54 \mathrm{E}+00$ & $4.70 \mathrm{E}-01$ & $2.86 \mathrm{E}-01$ & 1. $12 \mathrm{E}+00$ & $1.56 \mathrm{E}+00$ & $2.03 E+00$ & $2.56 \mathrm{E}+00$ \\
\hline $1.24 \mathrm{E}-02$ & $4.54 \mathrm{E}+00$ & 4. $71 \mathrm{E}-01$ & $2.87 E-01$ & $1.12 \mathrm{E}+00$ & $1.56 \mathrm{E}+00$ & $2.03 E+00$ & $2.56 \mathrm{E}+00$ \\
\hline $1.25 E-02$ & $4.54 \mathrm{E}+00$ & $4.72 \mathrm{E}-01$ & $2.88 E-01$ & $1.13 E+00$ & $1.56 \mathrm{E}+00$ & $2.03 E+00$ & $2.56 \mathrm{E}+00$ \\
\hline 1. $25 \mathrm{E}-02$ & $4.54 \mathrm{E}+00$ & $4.73 E-01$ & $2.88 E-01$ & $1.13 \mathrm{E}+00$ & $1.56 \mathrm{E}+00$ & $2.03 E+00$ & $2.56 \mathrm{E}+00$ \\
\hline $1.26 \mathrm{E}-02$ & $4.53 \mathrm{E}+00$ & $4.74 \mathrm{E}-01$ & $2.89 \mathrm{E}-01$ & $1.13 \mathrm{E}+00$ & $1.57 \mathrm{E}+00$ & $2.04 \mathrm{E}+00$ & $2.56 \mathrm{E}+00$ \\
\hline $1.27 \mathrm{E}-02$ & $4.53 \mathrm{E}+00$ & $4.75 E-01$ & $2.90 \mathrm{E}-01$ & $1.13 \mathrm{E}+00$ & $1.57 \mathrm{E}+00$ & $2.04 \mathrm{E}+00$ & $2.56 \mathrm{E}+00$ \\
\hline $1.27 \mathrm{E}-02$ & $4.53 \mathrm{E}+00$ & $4.76 \mathrm{E}-01$ & $2.91 \mathrm{E}-01$ & $1.13 \mathrm{E}+00$ & $1.57 \mathrm{E}+00$ & $2.04 \mathrm{E}+00$ & $2.56 \mathrm{E}+00$ \\
\hline $1.28 \mathrm{E}-02$ & $4.53 \mathrm{E}+00$ & $4.77 \mathrm{E}-01$ & $2.92 \mathrm{E}-01$ & $1.13 \mathrm{E}+00$ & $1.57 \mathrm{E}+00$ & $2.04 \mathrm{E}+00$ & $2.56 \mathrm{E}+00$ \\
\hline $1.29 \mathrm{E}-02$ & $4.53 \mathrm{E}+00$ & $4.78 \mathrm{E}-01$ & $2.93 E-01$ & $1.13 \mathrm{E}+00$ & $1.58 \mathrm{E}+00$ & $2.04 \mathrm{E}+00$ & $2.57 \mathrm{E}+00$ \\
\hline $1.29 \mathrm{E}-02$ & $4.53 \mathrm{E}+00$ & $4.79 E-01$ & $2.93 E-01$ & $1.14 \mathrm{E}+00$ & $1.58 \mathrm{E}+00$ & $2.04 \mathrm{E}+00$ & $2.57 \mathrm{E}+00$ \\
\hline $1.30 \mathrm{E}-02$ & $4.53 \mathrm{E}+00$ & $4.79 \mathrm{E}-01$ & $2.94 \mathrm{E}-01$ & $1.14 \mathrm{E}+00$ & $1.58 \mathrm{E}+00$ & $.04 E+00$ & $57 E+00$ \\
\hline $1.31 \mathrm{E}-02$ & $4.52 \mathrm{E}+00$ & $4.80 \mathrm{E}-01$ & $2.95 E-01$ & $1.14 \mathrm{E}+00$ & $1.58 \mathrm{E}+00$ & $2.05 \mathrm{E}+00$ & $2.57 \mathrm{E}+00$ \\
\hline $1.31 \mathrm{E}-02$ & $4.52 \mathrm{E}+00$ & $4.81 E-01$ & $2.96 \mathrm{E}-01$ & $1.14 \mathrm{E}+00$ & $1.58 \mathrm{E}+00$ & $2.05 \mathrm{E}+00$ & $2.57 \mathrm{E}+00$ \\
\hline $1.32 \mathrm{E}-02$ & $4.52 \mathrm{E}+00$ & $4.82 \mathrm{E}-01$ & $2.97 \mathrm{E}-01$ & $1.14 \mathrm{E}+00$ & $1.59 \mathrm{E}+00$ & $2.05 E+00$ & $2.57 \mathrm{E}+00$ \\
\hline $1.33 E-02$ & $4.52 \mathrm{E}+00$ & $4.83 E-01$ & $2.97 E-01$ & $1.15 \mathrm{E}+00$ & $1.59 \mathrm{E}+00$ & $2.05 \mathrm{E}+00$ & $2.57 \mathrm{E}+00$ \\
\hline $1.34 \mathrm{E}-02$ & $4.52 \mathrm{E}+00$ & $4.84 \mathrm{E}-01$ & $2.98 \mathrm{E}-01$ & $1.15 \mathrm{E}+00$ & $1.59 \mathrm{E}+00$ & $2.05 E+00$ & $2.57 \mathrm{E}+00$ \\
\hline $1.34 \mathrm{E}-02$ & $4.52 \mathrm{E}+00$ & $4.85 \mathrm{E}-01$ & $2.99 \mathrm{E}-01$ & $1.15 \mathrm{E}+00$ & $1.59 \mathrm{E}+00$ & $2.05 E+00$ & $2.57 \mathrm{E}+00$ \\
\hline $1.35 E-02$ & $4.51 \mathrm{E}+00$ & $4.86 \mathrm{E}-01$ & $3.00 E-01$ & $1.15 \mathrm{E}+00$ & $1.60 \mathrm{E}+00$ & $2.05 E+00$ & $2.57 \mathrm{E}+00$ \\
\hline $1.36 \mathrm{E}-02$ & $4.51 \mathrm{E}+00$ & $4.87 \mathrm{E}-01$ & $3.01 \mathrm{E}-01$ & $1.15 \mathrm{E}+00$ & $1.60 \mathrm{E}+00$ & $2.06 \mathrm{E}+00$ & $2.57 \mathrm{E}+00$ \\
\hline $1.36 \mathrm{E}-02$ & $4.51 \mathrm{E}+00$ & $4.88 \mathrm{E}-01$ & $3.02 \mathrm{E}-01$ & $1.16 \mathrm{E}+00$ & $1.60 \mathrm{E}+00$ & $2.06 \mathrm{E}+00$ & $2.58 \mathrm{E}+00$ \\
\hline $1.37 \mathrm{E}-02$ & $4.51 \mathrm{E}+00$ & $4.89 \mathrm{E}-01$ & $3.03 E-01$ & $1.16 \mathrm{E}+00$ & $1.61 \mathrm{E}+00$ & $2.06 \mathrm{E}+00$ & $2.58 \mathrm{E}+00$ \\
\hline $1.38 \mathrm{E}-02$ & $4.51 \mathrm{E}+00$ & $4.90 \mathrm{E}-01$ & $3.04 \mathrm{E}-01$ & $1.16 \mathrm{E}+00$ & $1.61 \mathrm{E}+00$ & $2.06 \mathrm{E}+00$ & $2.58 \mathrm{E}+00$ \\
\hline $1.38 E-02$ & $4.51 \mathrm{E}+00$ & $4.91 \mathrm{E}-01$ & $3.05 E-01$ & $1.16 \mathrm{E}+00$ & $1.61 \mathrm{E}+00$ & $2.06 \mathrm{E}+00$ & $2.58 \mathrm{E}+00$ \\
\hline $1.39 \mathrm{E}-02$ & $4.50 \mathrm{E}+00$ & $4.92 \mathrm{E}-01$ & $3.06 E-01$ & $1.16 \mathrm{E}+00$ & $1.61 \mathrm{E}+00$ & $2.06 \mathrm{E}+00$ & $2.59 \mathrm{E}+00$ \\
\hline $1.40 \mathrm{E}-02$ & $4.50 \mathrm{E}+00$ & $4.93 E-01$ & $3.06 \mathrm{E}-01$ & $1.16 \mathrm{E}+00$ & $1.62 \mathrm{E}+00$ & $2.06 \mathrm{E}+00$ & $2.59 \mathrm{E}+00$ \\
\hline $1.41 \mathrm{E}-02$ & $4.50 \mathrm{E}+00$ & $4.94 \mathrm{E}-01$ & $3.07 \mathrm{E}-01$ & $1.16 \mathrm{E}+00$ & $1.62 \mathrm{E}+00$ & $2.06 \mathrm{E}+00$ & $2.59 \mathrm{E}+00$ \\
\hline $1.41 \mathrm{E}-02$ & $4.50 \mathrm{E}+00$ & $4.94 \mathrm{E}-01$ & $3.08 \mathrm{E}-01$ & $1.17 \mathrm{E}+00$ & $1.62 \mathrm{E}+00$ & $2.06 \mathrm{E}+00$ & $2.59 \mathrm{E}+00$ \\
\hline $1.42 E-02$ & $4.50 \mathrm{E}+00$ & $4.95 E-01$ & $3.09 E-01$ & $1.17 \mathrm{E}+00$ & $1.62 \mathrm{E}+00$ & $2.07 E+00$ & $2.59 \mathrm{E}+00$ \\
\hline $1.43 E-02$ & $4.50 \mathrm{E}+00$ & $4.96 \mathrm{E}-01$ & $3.10 \mathrm{E}-01$ & $1.17 \mathrm{E}+00$ & $1.63 \mathrm{E}+00$ & $2.07 E+00$ & $2.59 E+00$ \\
\hline $1.43 E-02$ & $4.49 \mathrm{E}+00$ & $4.97 \mathrm{E}-01$ & $3.11 \mathrm{E}-01$ & $1.17 \mathrm{E}+00$ & $1.63 \mathrm{E}+00$ & $2.07 \mathrm{E}+00$ & $2.60 \mathrm{E}+00$ \\
\hline $1.44 \mathrm{E}-02$ & $4.49 \mathrm{E}+00$ & 4. $98 \mathrm{E}-01$ & $3.12 E-01$ & $1.17 \mathrm{E}+00$ & $1.63 \mathrm{E}+00$ & $2.07 E+00$ & $2.60 \mathrm{E}+00$ \\
\hline $1.45 E-02$ & $4.49 \mathrm{E}+00$ & $4.99 \mathrm{E}-01$ & $3.13 E-01$ & $1.17 \mathrm{E}+00$ & $1.63 \mathrm{E}+00$ & $2.07 E+00$ & $2.60 \mathrm{E}+00$ \\
\hline $1.46 \mathrm{E}-02$ & $4.49 \mathrm{E}+00$ & $5.00 \mathrm{E}-01$ & $3.14 \mathrm{E}-01$ & $1.18 \mathrm{E}+00$ & $1.63 \mathrm{E}+00$ & $2.07 \mathrm{E}+00$ & $2.60 \mathrm{E}+00$ \\
\hline $1.46 \mathrm{E}-02$ & $4.49 \mathrm{E}+00$ & $5.01 \mathrm{E}-01$ & $3.15 E-01$ & $1.18 \mathrm{E}+00$ & $1.64 \mathrm{E}+00$ & $2.07 E+00$ & $2.60 \mathrm{E}+00$ \\
\hline $1.47 \mathrm{E}-02$ & $4.48 \mathrm{E}+00$ & $5.02 \mathrm{E}-01$ & $3.16 \mathrm{E}-01$ & $1.18 \mathrm{E}+00$ & $1.64 \mathrm{E}+00$ & $2.07 E+00$ & $2.60 \mathrm{E}+00$ \\
\hline $1.48 \mathrm{E}-02$ & $4.48 \mathrm{E}+00$ & $5.03 E-01$ & $3.17 \mathrm{E}-01$ & $1.18 \mathrm{E}+00$ & $1.64 \mathrm{E}+00$ & $2.07 \mathrm{E}+00$ & $2.61 \mathrm{E}+00$ \\
\hline 1. $49 \mathrm{E}-02$ & $4.48 \mathrm{E}+00$ & $5.04 \mathrm{E}-01$ & $3.18 \mathrm{E}-01$ & $1.18 \mathrm{E}+00$ & $1.64 \mathrm{E}+00$ & $2.07 E+00$ & $2.61 \mathrm{E}+00$ \\
\hline $1.49 \mathrm{E}-02$ & $4.48 \mathrm{E}+00$ & $5.05 \mathrm{E}-01$ & $3.19 \mathrm{E}-01$ & $1.19 \mathrm{E}+00$ & $1.64 \mathrm{E}+00$ & $2.07 E+00$ & $2.61 E+00$ \\
\hline $1.50 \mathrm{E}-02$ & $4.48 \mathrm{E}+00$ & $5.06 \mathrm{E}-01$ & $3.20 E-01$ & $1.19 \mathrm{E}+00$ & $1.64 \mathrm{E}+00$ & $2.08 \mathrm{E}+00$ & $2.61 E+00$ \\
\hline $1.51 \mathrm{E}-02$ & $4.47 \mathrm{E}+00$ & $5.07 E-01$ & $3.21 E-01$ & $1.19 \mathrm{E}+00$ & $1.65 \mathrm{E}+00$ & $2.08 E+00$ & $2.61 E+00$ \\
\hline $1.52 \mathrm{E}-02$ & $4.47 \mathrm{E}+00$ & $5.08 \mathrm{E}-01$ & $3.22 \mathrm{E}-01$ & $1.19 \mathrm{E}+00$ & $1.65 \mathrm{E}+00$ & $2.08 E+00$ & $2.61 \mathrm{E}+00$ \\
\hline
\end{tabular}


RESRAD-OFFSITE, Version 2.5

$\mathrm{T}^{1 / 2}$ Limit $=180$ days

obabilistic Dose and Risk Report

Title : Offsite Resident Farmer

File : RF TC99 DOESG FWD-FV2all.ROF

Summary of dose at graphical times, reptition 1 (continued)

Time

Years

7. $08 \mathrm{E}+02$

7. $08 \mathrm{E}+02$

$7.09 \mathrm{E}+02$

$7.09 \mathrm{E}+02$

$7.10 \mathrm{E}+02$

7. $10 \mathrm{E}+02$

$7.11 \mathrm{E}+02$

$7.11 \mathrm{E}+02$

$7.12 \mathrm{E}+02$

$7.12 \mathrm{E}+02$

$7.13 \mathrm{E}+02$

$7.13 \mathrm{E}+02$

$7.14 \mathrm{E}+02$

$7.14 \mathrm{E}+02$

7. $15 \mathrm{E}+02$

7. $15 \mathrm{E}+02$

$7.16 \mathrm{E}+02$

$7.16 \mathrm{E}+02$

$7.17 \mathrm{E}+02$

$7.17 \mathrm{E}+02$

$7.18 \mathrm{E}+02$

$7.18 \mathrm{E}+02$

$7.19 \mathrm{E}+02$

$7.19 \mathrm{E}+02$

$7.20 \mathrm{E}+02$

$7.20 \mathrm{E}+02$

$7.21 \mathrm{E}+02$

$7.21 \mathrm{E}+02$

7. $22 \mathrm{E}+02$

$7.22 \mathrm{E}+02$

7. $23 \mathrm{E}+02$

7. $23 \mathrm{E}+02$

$7.24 \mathrm{E}+02$

$7.24 \mathrm{E}+02$

$7.25 \mathrm{E}+02$

7. $25 \mathrm{E}+02$

7. $26 \mathrm{E}+02$

$7.26 \mathrm{E}+02$

$7.27 \mathrm{E}+02$

$7.28 \mathrm{E}+02$

$7.28 \mathrm{E}+02$

$7.29 \mathrm{E}+02$

$7.29 \mathrm{E}+02$

$7.30 \mathrm{E}+02$

7. $30 \mathrm{E}+02$

7. $31 \mathrm{E}+02$
Dose statistics at graphical times, mrem/yr

\begin{tabular}{|c|c|c|c|c|c|c|c|}
\hline m & um & ea & 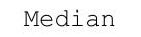 & & & $\%$ & \\
\hline 02 & $4.47 \mathrm{E}+00$ & $09 E-01$ & 1 & $19 \mathrm{E}+00$ & $.65 E+00$ & $08 E+00$ & . $01 \mathrm{E}+U 0$ \\
\hline $.53 E-02$ & $4.47 E+00$ & -01 & $3.24 \mathrm{E}-01$ & $20 E+00$ & $5 E+00$ & $2.08 \mathrm{E}+00$ & $62 E+00$ \\
\hline $54 E-02$ & $47 \mathrm{E}+00$ & $0 E-01$ & $5 E-01$ & $.20 \mathrm{E}+00$ & $.65 E+00$ & $2.08 E+00$ & $2.62 \mathrm{E}+00$ \\
\hline $5 E-02$ & $4.46 E+00$ & $11 \mathrm{~F}-01$ & $25 \mathrm{~F}-01$ & $.20 \mathrm{E}+00$ & $165 \mathrm{~F}+00$ & $2.08 E+00$ & $2.62 \mathrm{E}+00$ \\
\hline$E-02$ & $E+00$ & 1 & -01 & & & $E+00$ & $2 \mathrm{E}+00$ \\
\hline 02 & $4.46 E+00$ & & & & & & 00 \\
\hline $.57 E-02$ & +00 & & & & & & $62 \mathrm{E}+00$ \\
\hline $58 \mathrm{E}-02$ & $6 \mathrm{E}+00$ & 1 & $\perp$ & $1.20 \mathrm{E}+00$ & $E+00$ & +00 & $52 \mathrm{E}+00$ \\
\hline $58 E-02$ & $4.45 E+00$ & -01 & -01 & $1.21 \mathrm{E}+00$ & $66 \mathrm{E}+00$ & $E+00$ & $62 E+00$ \\
\hline$E-02$ & $.45 E+00$ & $17 E-01$ & 210 & $1215+$ & 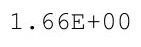 & $.09 E+00$ & $.62 E+00$ \\
\hline 02 & $E+00$ & & & & & 00 & $62 E+00$ \\
\hline $61 E-02$ & $E+00$ & 1 & $3.33 \mathrm{E}-01$ & $.21 \mathrm{E}+$ & & & $52 \mathrm{E}+00$ \\
\hline $.62 E-02$ & $4.45 E+00$ & & & $1.21 \mathrm{E}+00$ & & & $2.63 E+00$ \\
\hline $62 E-02$ & $4.44 \mathrm{E}+00$ & $.21 \mathrm{E}-01$ & $.35 E-01$ & $1.21 \mathrm{E}+00$ & & $2.09 E+00$ & $2.63 E+00$ \\
\hline-02 & $E+00$ & $2 E-01$ & -0 & 21 & & +00 & $53 \mathrm{E}+00$ \\
\hline 2 & $E+00$ & & $\perp$ & .22 & $.67 E+00$ & 0 & 00 \\
\hline 2 & 00 & & & 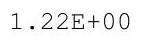 & 0 & 0 & 0 \\
\hline $6 \mathrm{E}-02$ & $4.43 E+00$ & $5.24 \mathrm{E}-01$ & 3. 39E-01 & $20 \mathrm{~F}+1$ & & 0 & 0 \\
\hline $66 \mathrm{E}-02$ & $4.43 E+00$ & $5 F-01$ & $9 F-01$ & 1 & 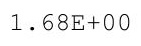 & $E+00$ & $63 E+00$ \\
\hline $67 E-02$ & $4.43 E+00$ & $.26 \mathrm{E}-01$ & $E-01$ & $1.22 \mathrm{E}+00$ & 1. $68 \mathrm{E}+$ & $2.09 \mathrm{E}+00$ & $2.63 E+00$ \\
\hline 02 & $4.43 E+00$ & & & 0 & & +00 & $E+00$ \\
\hline & & & & & & & \\
\hline 02 & $4.42 \mathrm{E}+00$ & .2 & & 1.23E+ & & & \\
\hline$E-02$ & $4.42 \mathrm{E}+00$ & 1 & & 1.23E+ & - & 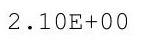 & 00 \\
\hline 2 & $4.42 \mathrm{E}+00$ & $5.31 \mathrm{E}-01$ & $\perp$ & $1.23 \mathrm{E}+\mathrm{C}$ & & $\mathrm{E}+\mathrm{C}$ & $63 E+00$ \\
\hline $.72 E-02$ & $4.42 \mathrm{E}+00$ & $32 \mathrm{~F}-01$ & $46 \mathrm{~F}-01$ & 1. $24 \mathrm{E}+00$ & $1.68 \mathrm{E}+\mathrm{C}$ & $10 \mathrm{E}+00$ & $.64 \mathrm{E}+00$ \\
\hline $.73 E-02$ & $4.41 E+00$ & & & & & $2.10 \mathrm{E}+00$ & 2. $64 \mathrm{E}+00$ \\
\hline 02 & & & & & & & \\
\hline 2 & $4.41 E+00$ & 0 & & $1.24 \mathrm{E}+$ & & & \\
\hline $75 E-02$ & $4.41 E+00$ & . & . & $1.24 \mathrm{E}+00$ & $1.69 \mathrm{E}+00$ & $2.10 \mathrm{E}+00$ & $2.64 \mathrm{E}+00$ \\
\hline $76 \mathrm{E}-02$ & $4.40 \mathrm{E}+00$ & $5.36 \mathrm{E}-01$ & 然 & $1.25 \mathrm{E}+00$ & 1. $70 \mathrm{E}+00$ & $2.10 \mathrm{E}+00$ & $2.64 \mathrm{E}+00$ \\
\hline 2 & $4.40 \mathrm{E}+00$ & - & $3.52 \mathrm{E}-01$ & 1.25E+ & & & $2.64 \mathrm{E}+$ \\
\hline $.78 E-02$ & & & & & & & \\
\hline 02 & & & & & & & \\
\hline$E-02$ & $4.39 E+00$ & & & 1 . & & & \\
\hline $80 E-02$ & $4.39 \mathrm{E}+00$ & $5.41 E-01$ & $3.35 \pm-01$ & $1.25 \mathrm{E}+00$ & $\perp \cdot 1 \perp$ & $2.10 \mathrm{U}$ & $2.64 \mathrm{E}+00$ \\
\hline $81 \mathrm{E}-02$ & $4.39 \mathrm{E}+00$ & $.4 \angle L-4$ & & $1.26 E+00$ & & & $2.64 \mathrm{E}+00$ \\
\hline $82 E-02$ & $4.39 \mathrm{E}+00$ & .尹U士 U & & $1.26 \mathrm{E}+00$ & $1.71 \mathrm{E}+$ & & $2.64 \mathrm{E}+00$ \\
\hline 2 & $4.38 \mathrm{E}+00$ & 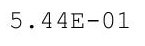 & 1 & $1.26 \mathrm{E}+00$ & $1.71 \mathrm{E}+$ & & $2.64 \mathrm{E}+00$ \\
\hline 2 & $4.38 E+00$ & 1 & 1 & $1.26 \mathrm{E}+00$ & $171=$ & & $54 \mathrm{E}+00$ \\
\hline $5 E-02$ & $4.38 E+00$ & -01 & $E-01$ & $E+00$ & $1.72 \mathrm{E}$ & $11 E+00$ & $54 \mathrm{E}+00$ \\
\hline$E-02$ & $4.38 E+00$ & 5.4 & & $1.27 \mathrm{E}+00$ & & 2. & $2.64 \mathrm{E}+00$ \\
\hline & $4 \cdot 3$ & & & & & & $2.64 \mathrm{E}+00$ \\
\hline$E-02$ & $4.37 \mathrm{E}+00$ & . & $2+$ & $1.27 E+00$ & $1.72 \mathrm{E}+00$ & $2.11 \mathrm{E}+00$ & $2.64 \mathrm{E}+00$ \\
\hline $88 E-02$ & $4.37 E+00$ & & & $1.27 \mathrm{E}+00$ & $1.72 \mathrm{E}+00$ & $2.11 \mathrm{E}+00$ & $2.64 \mathrm{E}+00$ \\
\hline$E-02$ & $4.37 E+00$ & $E-01$ & $4 E-01$ & $.27 \mathrm{E}+00$ & $1.73 E+00$ & $2.11 \mathrm{E}+00$ & $.64 E+00$ \\
\hline
\end{tabular}


RESRAD-OFFSITE, Version 2.5

$\mathrm{T}^{1 / 2}$ Limit $=180$ days

obabilistic Dose and Risk Report

Title : Offsite Resident Farmer

File : RF TC99 DOESG FWD-FV2all.ROF

Summary of dose at graphical times, reptition 1 (continued)

Time

Years

7. $31 \mathrm{E}+02$

$7.32 \mathrm{E}+02$

7. $32 \mathrm{E}+02$

7. $33 \mathrm{E}+02$

7. $33 \mathrm{E}+02$

7. $34 \mathrm{E}+02$

7. $34 \mathrm{E}+02$

$7.35 \mathrm{E}+02$

$7.35 \mathrm{E}+02$

$7.36 \mathrm{E}+02$

$7.36 \mathrm{E}+02$

$7.37 \mathrm{E}+02$

$7.37 \mathrm{E}+02$

$7.38 \mathrm{E}+02$

7. $38 \mathrm{E}+02$

$7.39 \mathrm{E}+02$

$7.39 \mathrm{E}+02$

$7.40 \mathrm{E}+02$

$7.40 \mathrm{E}+02$

$7.41 \mathrm{E}+02$

$7.41 \mathrm{E}+02$

$7.42 \mathrm{E}+02$

$7.42 \mathrm{E}+02$

$7.43 \mathrm{E}+02$

$7.43 \mathrm{E}+02$

$7.44 \mathrm{E}+02$

7. $44 \mathrm{E}+02$

7. $45 \mathrm{E}+02$

$7.45 \mathrm{E}+02$

$7.46 \mathrm{E}+02$

$7.46 \mathrm{E}+02$

$7.47 \mathrm{E}+02$

$7.48 \mathrm{E}+02$

7. $48 \mathrm{E}+02$

$7.49 \mathrm{E}+02$

7. $49 \mathrm{E}+02$

$7.50 \mathrm{E}+02$

$7.50 \mathrm{E}+02$

$7.51 \mathrm{E}+02$

$7.51 \mathrm{E}+02$

$7.52 \mathrm{E}+02$

$7.52 \mathrm{E}+02$

$7.53 \mathrm{E}+02$

$7.53 \mathrm{E}+02$

$7.54 \mathrm{E}+02$

$7.54 \mathrm{E}+02$
Dose statistics at graphical times, mrem/yr

\begin{tabular}{|c|c|c|c|c|c|c|c|}
\hline m & $\operatorname{axi}$ & 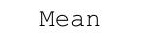 & 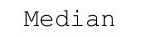 & & & & \\
\hline 02 & $4.36 E+00$ & 01 & 1 & $.28 E+00$ & $1.73 \mathrm{E}+00$ & -00 & . $04 \mathrm{E}+U \mathrm{U}$ \\
\hline $91 E-02$ & $4.36 E+00$ & $2 E-01$ & $3.66 \mathrm{E}-01$ & $.28 E+00$ & $73 E+00$ & $E+00$ & $4 E+00$ \\
\hline $91 E-02$ & $4.36 \mathrm{E}+00$ & $53 E-01$ & $3.67 \mathrm{E}-01$ & $.28 \mathrm{E}+00$ & $.73 E+00$ & $11 E+00$ & $64 \mathrm{E}+00$ \\
\hline $92 E-02$ & $4.36 E+00$ & $54 \mathrm{~F}-01$ & $68 \mathrm{~F}-01$ & $.28 \mathrm{E}+00$ & $73 F+00$ & $.11 \mathrm{E}+00$ & $2.64 \mathrm{E}+00$ \\
\hline $93 E-02$ & $4.35 E+00$ & 01 & 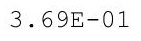 & $.28 \mathrm{E}+$ & & $E+00$ & +00 \\
\hline 02 & $35 E+00$ & & & & & & 00 \\
\hline $95 E-02$ & $4.35 E+00$ & & & 00 & & & +00 \\
\hline $96 \mathrm{E}-02$ & $4.35 E+00$ & 1 & $\perp$ & $1.29 \mathrm{E}+00$ & & +00 & +00 \\
\hline $97 E-02$ & $4.34 \mathrm{E}+00$ & $9 E-01$ & $E-01$ & $1.29 \mathrm{E}+00$ & $74 \mathrm{E}+00$ & $E+00$ & $\Xi+00$ \\
\hline $3 E-02$ & $34 \mathrm{E}+00$ & $60 E-01$ & $75 \Gamma$ & $297+$ & ו & $11 E+00$ & $64 \mathrm{E}+00$ \\
\hline 02 & +00 & & & & & 0 & +00 \\
\hline $99 E-02$ & $4.34 \mathrm{E}+00$ & $1 \mathrm{~F}-2010$ & $3.77 \mathrm{E}-01$ & $.29 \mathrm{E}+$ & & -00 & +00 \\
\hline $.00 E-02$ & $4.33 E+00$ & & & & & $2.12 \mathrm{E}+00$ & $E+00$ \\
\hline $01 E-02$ & $4.33 E+00$ & $.63 E-01$ & $.79 \mathrm{E}-01$ & $1.30 \mathrm{E}+00$ & & $2.12 \mathrm{E}+00$ & $2.64 \mathrm{E}+00$ \\
\hline-02 & 4. $33 E+00$ & $E-01$ & -0 & 0 & & $\mathrm{E}+00$ & $\mathrm{E}+00$ \\
\hline 2 & 0 & & & $+\cdots$ & $76 E+00$ & 0 & 00 \\
\hline 2 & $32 \mathrm{E}+00$ & & & 1. $30 \mathrm{E}+00$ & & 0 & 0 \\
\hline 2 & $4.32 \mathrm{E}+00$ & $5.67 \mathrm{E}-01$ & $3.83 E-01$ & $1.30 \mathrm{E}+00$ & & 0 & 0 \\
\hline $.06 E-02$ & $4.32 E+00$ & $8 \mathrm{~F}-01$ & $3 F-01$ & $.31 E+00$ & $765+8 x-10$ & $2 E+00$ & $E+00$ \\
\hline $.07 E-02$ & $4.31 E+00$ & $.69 \mathrm{E}-01$ & $4 E-01$ & $1.31 \mathrm{E}+00$ & $1.76 \mathrm{E}+$ & $2.12 \mathrm{E}+00$ & $2.64 \mathrm{E}+00$ \\
\hline-02 & $4.31 E+00$ & & & & & $.12 \mathrm{E}+00$ & $4 E+00$ \\
\hline 2 & & & & & & & \\
\hline 2 & $4.30 \mathrm{E}+00$ & \pm & & 1.31E+ & & & \\
\hline$E-02$ & $4 \cdot 3$ & 1 & $3.87 \mathrm{E}-01$ & 1. $32 \mathrm{E}+$ & 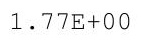 & 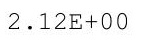 & 00 \\
\hline 2 & $.30 \mathrm{E}+00$ & $5.73 \mathrm{E}-01$ & $\perp$ & 1. $32 \mathrm{E}+$ & & $2.13 \mathrm{E}+0$ & $64 \mathrm{E}+00$ \\
\hline $12 \mathrm{E}-02$ & $4.30 \mathrm{E}+00$ & $74 \mathrm{~F}-01$ & $89 F-01$ & 1. $32 \mathrm{E}+00$ & 1 & $.13 E+00$ & $2.64 \mathrm{E}+00$ \\
\hline$E-02$ & $4.29 \mathrm{E}+00$ & $5 \mathrm{~F}-01$ & & & & $2.13 E+00$ & $2.64 \mathrm{E}+00$ \\
\hline 02 & & & & & & & \\
\hline 02 & $4.29 \mathrm{E}+00$ & . & & 1.32E+ & & & \\
\hline $16 \mathrm{E}-02$ & $4.28 \mathrm{E}+00$ & . $10 \pm 01$ & . & $1.33 \mathrm{E}+00$ & 土. & $2.14 \mathrm{E}+00$ & $2.64 \mathrm{E}+00$ \\
\hline $17 \mathrm{E}-02$ & $4.28 \mathrm{E}+00$ & $.79 E-01$ & - & $1.33 \mathrm{E}+00$ & 1. $78 \mathrm{E}+00$ & $2.14 \mathrm{E}+00$ & $2.64 \mathrm{E}+00$ \\
\hline 2 & $4.28 \mathrm{E}+00$ & $5.80 \mathrm{E}-01$ & $3.94 \mathrm{E}-01$ & 1.33E+ & & & \\
\hline 2 & & & & & & & \\
\hline & & & & $1.33 \mathrm{E}+00$ & & & \\
\hline 02 & & & & & & & \\
\hline $22 \mathrm{E}-02$ & $4.27 E+00$ & $5.83 E-01$ & $3.98 \mathrm{E}-01$ & $1.33 \mathrm{E}+00$ & $1.19 E+$ & $2.15 \mathrm{E}+00$ & $2.64 \mathrm{E}+00$ \\
\hline $23 E-02$ & $4.26 \mathrm{E}+00$ & $.045-1$ & & $1.33 E+00$ & & & \\
\hline$E-02$ & $4.26 \mathrm{E}+00$ & $.0 J \Delta$ U & & $1.34 \mathrm{E}+00$ & 1. $80 \mathrm{E}+00$ & & $2.64 \mathrm{E}+00$ \\
\hline 2 & 4. $26 \mathrm{E}+$ & 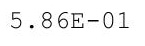 & 1 & $1.34 \mathrm{E}+00$ & $1.80 \mathrm{E}+00$ & $2.15 E+00$ & $2.64 \mathrm{E}+00$ \\
\hline & & & 1 & $1.34 \mathrm{E}+00$ & & & $64 E+00$ \\
\hline $7 E-02$ & $4.25 E+00$ & $5.88 E-01$ & $4.02 \mathrm{E}-01$ & 1. $34 \mathrm{E}+00$ & $1.80 \mathrm{E}$ & $2.16 \mathrm{E}+00$ & $2.64 \mathrm{E}+00$ \\
\hline$E-02$ & $4.25 E+00$ & 01 & 4. & $1.34 \mathrm{E}+00$ & $1.81 \mathrm{E}+$ & $E+00$ & $4 E+00$ \\
\hline & $4.25 \mathrm{E}+00$ & & & & & & \\
\hline$E-02$ & $4.24 \mathrm{E}+00$ & . & 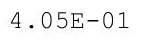 & $1.35 E+00$ & $1.81 \mathrm{E}+00$ & $2.16 \mathrm{E}+00$ & $2.64 \mathrm{E}+00$ \\
\hline $3 \perp+-02$ & $4.24 \mathrm{E}+00$ & & & $1.35 \mathrm{E}+00$ & $1.81 \mathrm{E}+00$ & $2.17 E+00$ & $2.63 E+00$ \\
\hline 02 & $4.24 \mathrm{E}+00$ & $2 E-01$ & $07 E-01$ & 1. $35 \mathrm{E}+00$ & $1.81 \mathrm{E}+00$ & $2.17 \mathrm{E}+00$ & $2.63 E+00$ \\
\hline
\end{tabular}


RESRAD-OFFSITE, Version 2.5

robabilistic Dose and Risk Report

Title : Offsite Resident Farmer

File : RF TC99 DOESG FWD-FV2all.ROF

Summary of dose at graphical times, reptition 1 (continued)

Time

Years

$7.55 \mathrm{E}+02$

$7.55 \mathrm{E}+02$

7. $56 \mathrm{E}+02$

7. $56 \mathrm{E}+02$

$7.57 \mathrm{E}+02$

$7.57 \mathrm{E}+02$

$7.58 \mathrm{E}+02$

7. $58 \mathrm{E}+02$

$7.59 \mathrm{E}+02$

$7.59 \mathrm{E}+02$

$7.60 \mathrm{E}+02$

$7.60 \mathrm{E}+02$

7. $61 \mathrm{E}+02$

7. $61 \mathrm{E}+02$

7. $62 \mathrm{E}+02$

7. $62 \mathrm{E}+02$

7. $63 \mathrm{E}+02$

7. $63 \mathrm{E}+02$

$7.64 \mathrm{E}+02$

$7.64 \mathrm{E}+02$

$7.65 \mathrm{E}+02$

$7.65 \mathrm{E}+02$

$7.66 \mathrm{E}+02$

$7.66 \mathrm{E}+02$

7. $67 \mathrm{E}+02$

$7.68 \mathrm{E}+02$

$7.68 \mathrm{E}+02$

7. $69 \mathrm{E}+02$

$7.69 \mathrm{E}+02$

$7.70 \mathrm{E}+02$

7. $70 \mathrm{E}+02$

$7.71 \mathrm{E}+02$

7. $71 \mathrm{E}+02$

7. $72 \mathrm{E}+02$

7. $72 \mathrm{E}+02$

7. $73 \mathrm{E}+02$

$7.73 \mathrm{E}+02$

7. $74 \mathrm{E}+02$

$7.74 \mathrm{E}+02$

$7.75 \mathrm{E}+02$

$7.75 \mathrm{E}+02$

$7.76 \mathrm{E}+02$

$7.76 \mathrm{E}+02$

$7.77 \mathrm{E}+02$

$7.77 \mathrm{E}+02$

$7.78 \mathrm{E}+02$

Dose statistics at graphical times, mrem/yr

\begin{tabular}{|c|c|c|c|c|c|c|c|}
\hline Minimum & Maximum & Mean & Median & $90 \%$ & $95 \%$ & $97.5 \%$ & $99 \%$ \\
\hline $2.33 E-02$ & $4.23 E+00$ & $5.93 E-01$ & $4.08 E-01$ & $1.35 \mathrm{E}+00$ & $1.82 \mathrm{E}+00$ & $2.17 E+00$ & $2.63 E+00$ \\
\hline $2.34 \mathrm{E}-02$ & $4.23 E+00$ & $5.94 \mathrm{E}-01$ & $4.09 \mathrm{E}-01$ & $1.35 \mathrm{E}+00$ & $1.82 \mathrm{E}+00$ & $2.17 \mathrm{E}+00$ & $2.63 E+00$ \\
\hline $2.34 \mathrm{E}-02$ & $4.23 E+00$ & $5.95 \mathrm{E}-01$ & $4.10 \mathrm{E}-01$ & $1.36 \mathrm{E}+00$ & $1.82 \mathrm{E}+00$ & $2.17 \mathrm{E}+00$ & $2.63 E+00$ \\
\hline $2.35 \mathrm{E}-02$ & $4.22 \mathrm{E}+00$ & $5.96 \mathrm{E}-01$ & $4.11 \mathrm{E}-01$ & $1.36 \mathrm{E}+00$ & $1.82 \mathrm{E}+00$ & $2.18 \mathrm{E}+00$ & $2.63 \mathrm{E}+00$ \\
\hline $2.36 E-02$ & $4.22 E+00$ & $5.97 E-01$ & $4.12 E-01$ & $1.36 \mathrm{E}+00$ & $1.82 \mathrm{E}+00$ & $2.18 \mathrm{E}+00$ & $2.63 E+00$ \\
\hline $2.37 E-02$ & $4.22 \mathrm{E}+00$ & $5.98 \mathrm{E}-01$ & $4.13 E-01$ & $.36 \mathrm{E}+00$ & $82 E+00$ & $2.18 \mathrm{E}+00$ & $.63 E+00$ \\
\hline $2.38 \mathrm{E}-02$ & $4.22 \mathrm{E}+00$ & $5.99 \mathrm{E}-01$ & $4.13 E-01$ & $1.36 \mathrm{E}+00$ & $1.82 \mathrm{E}+00$ & $2.18 \mathrm{E}+00$ & $2.63 E+00$ \\
\hline $2.40 \mathrm{E}-02$ & $4.21 \mathrm{E}+00$ & $6.00 \mathrm{E}-01$ & $4.14 \mathrm{E}-01$ & $1.36 \mathrm{E}+00$ & $1.82 \mathrm{E}+00$ & $2.18 \mathrm{E}+00$ & $2.63 \mathrm{E}+00$ \\
\hline $2.41 \mathrm{E}-02$ & $4.21 \mathrm{E}+00$ & $6.01 \mathrm{E}-01$ & $4.15 \mathrm{E}-01$ & $1.37 \mathrm{E}+00$ & $1.83 \mathrm{E}+00$ & $2.18 \mathrm{E}+00$ & $2.63 E+00$ \\
\hline $2.42 \mathrm{E}-02$ & $4.21 \mathrm{E}+00$ & $6.01 \mathrm{E}-01$ & $4.16 \mathrm{E}-01$ & $1.37 \mathrm{E}+00$ & $1.83 \mathrm{E}+00$ & $2.18 \mathrm{E}+00$ & $2.63 E+00$ \\
\hline $2.43 E-02$ & $4.20 \mathrm{E}+00$ & $6.02 \mathrm{E}-01$ & $4.17 \mathrm{E}-01$ & $.37 \mathrm{E}+00$ & $1.83 \mathrm{E}+00$ & $2.18 \mathrm{E}+00$ & $2.63 \mathrm{E}+00$ \\
\hline $2.44 \mathrm{E}-02$ & $4.20 \mathrm{E}+00$ & $6.03 E-01$ & $4.18 \mathrm{E}-01$ & $1.37 \mathrm{E}+00$ & $1.83 \mathrm{E}+00$ & $2.18 \mathrm{E}+00$ & $2.63 E+00$ \\
\hline $2.45 \mathrm{E}-02$ & $4.20 \mathrm{E}+00$ & $6.04 \mathrm{E}-01$ & $4.19 \mathrm{E}-01$ & $1.37 \mathrm{E}+00$ & $1.83 \mathrm{E}+00$ & $2.18 \mathrm{E}+00$ & $2.63 E+00$ \\
\hline $2.46 \mathrm{E}-02$ & $4.19 \mathrm{E}+00$ & $6.05 E-01$ & $4.20 \mathrm{E}-01$ & $1.37 \mathrm{E}+00$ & $1.83 E+00$ & $2.19 \mathrm{E}+00$ & $2.63 E+00$ \\
\hline $2.47 E-02$ & $4.19 \mathrm{E}+00$ & $6.06 \mathrm{E}-01$ & $4.21 \mathrm{E}-01$ & $1.37 \mathrm{E}+00$ & $1.83 \mathrm{E}+00$ & $2.19 \mathrm{E}+00$ & $2.63 E+00$ \\
\hline $2.48 E-02$ & $4.19 \mathrm{E}+00$ & $6.07 E-01$ & $22 E-01$ & $.38 \mathrm{E}+00$ & $.84 \mathrm{E}+$ & $.19 \mathrm{E}+00$ & $.63 E+00$ \\
\hline $2.49 \mathrm{E}-02$ & $4.18 \mathrm{E}+00$ & $6.08 \mathrm{E}-01$ & $4.23 E-01$ & $38 \mathrm{E}+00$ & $84 \mathrm{E}+00$ & $2.19 \mathrm{E}+00$ & $.63 E+00$ \\
\hline $2.50 \mathrm{E}-02$ & $4.18 \mathrm{E}+00$ & $6.09 \mathrm{E}-01$ & $4.24 \mathrm{E}-01$ & $1.38 \mathrm{E}+00$ & $1.84 \mathrm{E}+00$ & $2.19 \mathrm{E}+00$ & $2.63 E+00$ \\
\hline $2.51 E-02$ & $4.18 \mathrm{E}+00$ & $6.10 \mathrm{E}-01$ & $4.25 E-01$ & $1.38 \mathrm{E}+00$ & $1.84 \mathrm{E}+00$ & $2.19 \mathrm{E}+00$ & $2.63 E+00$ \\
\hline $2.52 E-02$ & $4.17 \mathrm{E}+00$ & $6.10 \mathrm{E}-01$ & $4.26 \mathrm{E}-01$ & $1.38 \mathrm{E}+00$ & $1.84 \mathrm{E}+00$ & $2.19 \mathrm{E}+00$ & $2.64 \mathrm{E}+00$ \\
\hline $2.53 \mathrm{E}-02$ & $4.17 \mathrm{E}+00$ & $6.11 \mathrm{E}-01$ & $4.27 \mathrm{E}-01$ & $1.38 \mathrm{E}+00$ & $1.84 \mathrm{E}+00$ & $2.19 \mathrm{E}+00$ & $2.64 \mathrm{E}+00$ \\
\hline $2.54 \mathrm{E}-02$ & $4.17 E+00$ & $6.12 \mathrm{E}-01$ & $4.27 \mathrm{E}-01$ & $.38 E+00$ & $1.84 \mathrm{E}+00$ & $2.19 \mathrm{E}+00$ & $2.64 \mathrm{E}+00$ \\
\hline $2.55 E-02$ & $4.16 \mathrm{E}+00$ & $6.13 E-01$ & $4.28 E-01$ & $1.38 \mathrm{E}+00$ & $1.84 \mathrm{E}+00$ & $2.19 \mathrm{E}+00$ & $2.64 \mathrm{E}+00$ \\
\hline $2.56 \mathrm{E}-02$ & $4.16 \mathrm{E}+00$ & $6.14 \mathrm{E}-01$ & $4.29 \mathrm{E}-01$ & $1.38 \mathrm{E}+00$ & $1.84 \mathrm{E}+00$ & $2.19 \mathrm{E}+00$ & $2.64 \mathrm{E}+00$ \\
\hline $2.57 E-02$ & $4.16 \mathrm{E}+00$ & $6.15 E-01$ & $4.30 E-01$ & $1.38 \mathrm{E}+00$ & $1.84 \mathrm{E}+00$ & $2.19 \mathrm{E}+00$ & $2.64 \mathrm{E}+00$ \\
\hline $2.58 \mathrm{E}-02$ & $4.15 \mathrm{E}+00$ & $6.16 \mathrm{E}-01$ & 4. $31 \mathrm{E}-01$ & $1.38 \mathrm{E}+00$ & $1.85 \mathrm{E}+00$ & $2.20 \mathrm{E}+00$ & $2.64 \mathrm{E}+00$ \\
\hline $2.59 \mathrm{E}-02$ & $4.15 \mathrm{E}+00$ & $6.17 \mathrm{E}-01$ & $4.32 \mathrm{E}-01$ & $1.38 \mathrm{E}+00$ & $1.85 \mathrm{E}+00$ & $2.20 E+00$ & $2.64 \mathrm{E}+00$ \\
\hline $2.60 \mathrm{E}-02$ & $4.15 \mathrm{E}+00$ & $6.18 \mathrm{E}-01$ & $4.33 E-01$ & $1.38 \mathrm{E}+00$ & $1.85 \mathrm{E}+00$ & $2.20 \mathrm{E}+00$ & $2.64 \mathrm{E}+00$ \\
\hline $2.61 E-02$ & $4.14 \mathrm{E}+00$ & $6.18 E-01$ & $4.34 \mathrm{E}-01$ & $1.38 \mathrm{E}+00$ & $1.85 \mathrm{E}+00$ & $2.20 \mathrm{E}+00$ & $2.64 \mathrm{E}+00$ \\
\hline $2.62 E-02$ & $4.14 \mathrm{E}+00$ & $6.19 \mathrm{E}-01$ & $4.35 E-01$ & $1.38 \mathrm{E}+00$ & $1.85 \mathrm{E}+00$ & $2.20 E+00$ & $2.64 \mathrm{E}+00$ \\
\hline $2.63 E-02$ & $4.14 \mathrm{E}+00$ & $6.20 \mathrm{E}-01$ & $4.36 \mathrm{E}-01$ & $1.38 \mathrm{E}+00$ & $1.85 \mathrm{E}+00$ & $2.20 \mathrm{E}+00$ & $2.64 \mathrm{E}+00$ \\
\hline $2.64 \mathrm{E}-02$ & $4.13 \mathrm{E}+00$ & $6.21 \mathrm{E}-01$ & $4.37 \mathrm{E}-01$ & $1.38 \mathrm{E}+00$ & $1.85 \mathrm{E}+00$ & $2.20 \mathrm{E}+00$ & $2.64 \mathrm{E}+00$ \\
\hline $2.66 \mathrm{E}-02$ & $4.13 E+00$ & $6.22 E-01$ & $4.38 E-01$ & $1.39 \mathrm{E}+00$ & $1.86 \mathrm{E}+00$ & $2.20 E+00$ & $2.64 \mathrm{E}+00$ \\
\hline $2.67 E-02$ & $4.13 E+00$ & $6.23 E-01$ & $4.39 \mathrm{E}-01$ & $1.39 \mathrm{E}+00$ & $1.86 \mathrm{E}+00$ & $2.20 \mathrm{E}+00$ & $2.64 \mathrm{E}+00$ \\
\hline $2.68 E-02$ & $4.12 \mathrm{E}+00$ & $6.24 E-01$ & $4.40 E-01$ & $1.39 \mathrm{E}+00$ & $1.86 \mathrm{E}+00$ & $2.20 E+00$ & $2.65 E+00$ \\
\hline $2.69 \mathrm{E}-02$ & $4.12 \mathrm{E}+00$ & $6.25 E-01$ & $4.41 \mathrm{E}-01$ & $1.39 \mathrm{E}+00$ & $1.86 \mathrm{E}+00$ & $2.20 E+00$ & $2.65 E+00$ \\
\hline $2.70 \mathrm{E}-02$ & $4.12 \mathrm{E}+00$ & $6.26 \mathrm{E}-01$ & $4.42 E-01$ & $1.39 \mathrm{E}+00$ & $1.86 \mathrm{E}+00$ & $2.20 E+00$ & $2.65 \mathrm{E}+00$ \\
\hline $2.71 \mathrm{E}-02$ & $4.11 \mathrm{E}+00$ & $6.26 \mathrm{E}-01$ & $4.43 E-01$ & $1.39 \mathrm{E}+00$ & $1.86 \mathrm{E}+00$ & $2.20 \mathrm{E}+00$ & $2.65 E+00$ \\
\hline $2.72 E-02$ & $4.11 \mathrm{E}+00$ & $6.27 E-01$ & $4.44 \mathrm{E}-01$ & $1.40 \mathrm{E}+00$ & $1.87 \mathrm{E}+00$ & $2.20 E+00$ & $2.65 E+00$ \\
\hline $2.73 E-02$ & $4.11 \mathrm{E}+00$ & $6.28 \mathrm{E}-01$ & $4.45 \mathrm{E}-01$ & $1.40 \mathrm{E}+00$ & $1.87 \mathrm{E}+00$ & $2.21 \mathrm{E}+00$ & $2.65 \mathrm{E}+00$ \\
\hline $2.74 \mathrm{E}-02$ & $4.10 \mathrm{E}+00$ & $6.29 \mathrm{E}-01$ & $4.46 \mathrm{E}-01$ & $1.40 \mathrm{E}+00$ & $1.87 \mathrm{E}+00$ & $2.21 E+00$ & $2.65 \mathrm{E}+00$ \\
\hline $2.75 \mathrm{E}-02$ & $4.10 \mathrm{E}+00$ & $6.30 \mathrm{E}-01$ & $4.47 E-01$ & $1.40 \mathrm{E}+00$ & $1.87 \mathrm{E}+00$ & $2.21 \mathrm{E}+00$ & $2.65 \mathrm{E}+00$ \\
\hline $2.76 \mathrm{E}-02$ & $4.10 \mathrm{E}+00$ & $6.31 E-01$ & $4.48 E-01$ & $1.40 \mathrm{E}+00$ & $1.87 \mathrm{E}+00$ & $2.21 \mathrm{E}+00$ & $2.65 \mathrm{E}+00$ \\
\hline $2.77 E-02$ & $4.09 \mathrm{E}+00$ & $6.32 E-01$ & $4.48 E-01$ & $1.40 \mathrm{E}+00$ & $1.87 \mathrm{E}+00$ & $2.21 E+00$ & $2.65 E+00$ \\
\hline $2.79 E-02$ & $4.09 \mathrm{E}+00$ & $6.33 E-01$ & $4.49 E-01$ & $1.40 \mathrm{E}+00$ & $1.88 \mathrm{E}+00$ & $2.21 E+00$ & $2.65 E+00$ \\
\hline $2.80 \mathrm{E}-02$ & $4.09 \mathrm{E}+00$ & $6.33 E-01$ & $4.50 \mathrm{E}-01$ & $1.40 \mathrm{E}+00$ & $1.88 \mathrm{E}+00$ & $2.21 E+00$ & $2.65 E+00$ \\
\hline
\end{tabular}


RESRAD-OFFSITE, Version 2.5

obabilistic Dose and Risk Report

Title : Offsite Resident Farmer

File : RF TC99 DOESG FWD-FV2all.ROF

Summary of dose at graphical times, reptition 1 (continued)

Time

Years

$7.78 \mathrm{E}+02$

$7.79 \mathrm{E}+02$

$7.79 \mathrm{E}+02$

$7.80 \mathrm{E}+02$

$7.80 \mathrm{E}+02$

$7.81 \mathrm{E}+02$

$7.81 \mathrm{E}+02$

7. $82 \mathrm{E}+02$

7. $82 \mathrm{E}+02$

$7.83 \mathrm{E}+02$

$7.83 \mathrm{E}+02$

$7.84 \mathrm{E}+02$

$7.84 \mathrm{E}+02$

$7.85 \mathrm{E}+02$

$7.85 \mathrm{E}+02$

$7.86 \mathrm{E}+02$

$7.86 \mathrm{E}+02$

$7.87 \mathrm{E}+02$

$7.88 \mathrm{E}+02$

$7.88 \mathrm{E}+02$

$7.89 \mathrm{E}+02$

$7.89 \mathrm{E}+02$

$7.90 \mathrm{E}+02$

$7.90 \mathrm{E}+02$

7. $91 \mathrm{E}+02$

$7.91 \mathrm{E}+02$

7. $92 \mathrm{E}+02$

7. $92 \mathrm{E}+02$

7. $93 \mathrm{E}+02$

7. $93 \mathrm{E}+02$

7. $94 \mathrm{E}+02$

7. $94 \mathrm{E}+02$

7. $95 \mathrm{E}+02$

7. $95 \mathrm{E}+02$

7. $96 \mathrm{E}+02$

7. $96 \mathrm{E}+02$

$7.97 \mathrm{E}+02$

7. $97 \mathrm{E}+02$

$7.98 \mathrm{E}+02$

$7.98 \mathrm{E}+02$

7. $99 \mathrm{E}+02$

$7.99 \mathrm{E}+02$

8. $00 \mathrm{E}+02$

$8.00 \mathrm{E}+02$

$8.01 \mathrm{E}+02$

8. $01 \mathrm{E}+02$

Dose statistics at graphical times, mrem/yr

\begin{tabular}{|c|c|c|c|c|c|c|c|}
\hline Minimum & Maximum & Mean & Median & $90 \%$ & $95 \%$ & $97.5 \%$ & $99 \%$ \\
\hline $2.81 E-02$ & $4.08 \mathrm{E}+00$ & $6.34 \mathrm{E}-01$ & $4.51 \mathrm{E}-01$ & $1.41 E+00$ & $1.88 \mathrm{E}+00$ & $2.21 E+00$ & $2.65 E+00$ \\
\hline $2.82 \mathrm{E}-02$ & $4.08 E+00$ & $6.35 E-01$ & $4.52 \mathrm{E}-01$ & $1.41 E+00$ & $1.88 \mathrm{E}+00$ & $2.21 E+00$ & $2.65 \mathrm{E}+00$ \\
\hline $2.83 E-02$ & $4.08 \mathrm{E}+00$ & $6.36 \mathrm{E}-01$ & $4.53 E-01$ & $1.41 E+00$ & $1.88 \mathrm{E}+00$ & $2.21 E+00$ & $2.65 \mathrm{E}+00$ \\
\hline $2.84 \mathrm{E}-02$ & $4.07 E+00$ & $6.37 \mathrm{E}-01$ & $4.53 \mathrm{E}-01$ & $1.41 \mathrm{E}+00$ & $1.88 \mathrm{E}+00$ & $2.21 \mathrm{E}+00$ & $2.65 \mathrm{E}+00$ \\
\hline $2.85 E-02$ & $4.07 \mathrm{E}+00$ & $6.38 \mathrm{E}-01$ & $4.55 \mathrm{E}-01$ & $1.41 \mathrm{E}+00$ & $.88 \mathrm{E}+00$ & $2.21 \mathrm{E}+00$ & $2.65 \mathrm{E}+00$ \\
\hline $2.86 \mathrm{E}-02$ & $4.07 \mathrm{E}+00$ & $6.39 \mathrm{E}-01$ & $4.56 \mathrm{E}-01$ & $.42 E+00$ & $89 E+00$ & $2.21 \mathrm{E}+00$ & $.66 \mathrm{E}+00$ \\
\hline $2.88 E-02$ & $4.06 \mathrm{E}+00$ & $6.40 \mathrm{E}-01$ & $4.57 \mathrm{E}-01$ & $1.42 \mathrm{E}+00$ & $1.89 \mathrm{E}+00$ & $2.21 \mathrm{E}+00$ & $2.66 \mathrm{E}+00$ \\
\hline $2.89 E-02$ & $4.06 \mathrm{E}+00$ & $6.41 E-01$ & $4.58 \mathrm{E}-01$ & $1.42 E+00$ & $1.89 \mathrm{E}+00$ & $2.21 E+00$ & $2.66 \mathrm{E}+00$ \\
\hline $2.90 \mathrm{E}-02$ & $4.06 \mathrm{E}+00$ & $6.41 \mathrm{E}-01$ & $4.59 \mathrm{E}-01$ & $1.42 \mathrm{E}+00$ & $1.89 \mathrm{E}+00$ & $2.21 \mathrm{E}+00$ & $2.66 \mathrm{E}+00$ \\
\hline $2.91 \mathrm{E}-02$ & $4.05 E+00$ & $6.42 \mathrm{E}-01$ & $4.60 \mathrm{E}-01$ & $1.42 \mathrm{E}+00$ & $1.89 \mathrm{E}+00$ & $.21 E+00$ & $.66 E+00$ \\
\hline $2.92 \mathrm{E}-02$ & $4.05 E+00$ & $6.43 E-01$ & $4.61 \mathrm{E}-01$ & $43 E+00$ & $1.89 \mathrm{E}+00$ & $2.21 \mathrm{E}+00$ & $2.66 \mathrm{E}+00$ \\
\hline $2.93 E-02$ & $4.05 E+00$ & $6.44 \mathrm{E}-01$ & $4.62 \mathrm{E}-01$ & $1.43 E+00$ & $1.89 \mathrm{E}+00$ & $2.22 \mathrm{E}+00$ & $2.65 \mathrm{E}+00$ \\
\hline $2.94 \mathrm{E}-02$ & $4.04 \mathrm{E}+00$ & $6.45 \mathrm{E}-01$ & $4.63 \mathrm{E}-01$ & $1.43 E+00$ & $1.90 \mathrm{E}+00$ & $2.22 \mathrm{E}+00$ & $2.65 \mathrm{E}+00$ \\
\hline $2.95 E-02$ & $4.04 \mathrm{E}+00$ & $6.46 \mathrm{E}-01$ & $4.64 \mathrm{E}-01$ & $1.43 E+00$ & $1.90 \mathrm{E}+00$ & $2.22 \mathrm{E}+00$ & $2.65 \mathrm{E}+00$ \\
\hline $2.97 E-02$ & $4.03 E+00$ & $6.47 \mathrm{E}-01$ & $4.65 \mathrm{E}-01$ & $1.43 E+00$ & $1.90 \mathrm{E}+00$ & $2.22 \mathrm{E}+00$ & $2.65 \mathrm{E}+00$ \\
\hline $2.98 E-02$ & $4.03 E+00$ & $6.47 E-01$ & $4.66 E-01$ & $43 E+00$ & $90 \mathrm{E}+$ & $.22 E+00$ & $65 E+00$ \\
\hline $2.99 \mathrm{E}-02$ & $4.03 E+00$ & $6.48 \mathrm{E}-01$ & $4.66 \mathrm{E}-01$ & $43 E+00$ & $90 \mathrm{E}+00$ & $2.22 \mathrm{E}+00$ & $.65 E+00$ \\
\hline $3.00 \mathrm{E}-02$ & $4.02 \mathrm{E}+00$ & $6.49 \mathrm{E}-01$ & $4.67 \mathrm{E}-01$ & $1.43 \mathrm{E}+00$ & $1.90 \mathrm{E}+00$ & $2.23 E+00$ & $2.65 \mathrm{E}+00$ \\
\hline $3.01 E-02$ & $4.02 \mathrm{E}+00$ & $6.50 \mathrm{E}-01$ & $4.68 E-01$ & $1.43 E+00$ & $1.90 \mathrm{E}+00$ & $2.23 E+00$ & $2.64 \mathrm{E}+00$ \\
\hline $3.02 \mathrm{E}-02$ & $4.02 \mathrm{E}+00$ & $6.51 \mathrm{E}-01$ & $4.69 \mathrm{E}-01$ & $1.43 E+00$ & $1.91 \mathrm{E}+00$ & $2.23 E+00$ & $2.64 \mathrm{E}+00$ \\
\hline $3.04 \mathrm{E}-02$ & $4.01 \mathrm{E}+00$ & $6.52 \mathrm{E}-01$ & $4.70 \mathrm{E}-01$ & $1.44 \mathrm{E}+00$ & $1.91 \mathrm{E}+00$ & $2.23 \mathrm{E}+00$ & $2.64 \mathrm{E}+00$ \\
\hline $3.05 E-02$ & $4.01 E+00$ & $6.53 E-01$ & $4.71 E-01$ & $.44 \mathrm{E}+00$ & $1.91 \mathrm{E}+00$ & $2.23 E+00$ & $2.64 \mathrm{E}+00$ \\
\hline $3.06 \mathrm{E}-02$ & $4.01 \mathrm{E}+00$ & $6.54 \mathrm{E}-01$ & $4.72 \mathrm{E}-01$ & $1.44 \mathrm{E}+00$ & $1.91 \mathrm{E}+00$ & $2.23 E+00$ & $2.64 \mathrm{E}+00$ \\
\hline $3.07 \mathrm{E}-02$ & $4.00 \mathrm{E}+00$ & $6.54 \mathrm{E}-01$ & $4.73 E-01$ & $1.44 \mathrm{E}+00$ & $1.91 \mathrm{E}+00$ & $2.24 \mathrm{E}+00$ & $2.64 \mathrm{E}+00$ \\
\hline $3.08 \mathrm{E}-02$ & $4.00 \mathrm{E}+00$ & $6.55 E-01$ & $4.74 \mathrm{E}-01$ & $1.44 \mathrm{E}+00$ & $1.91 \mathrm{E}+00$ & $2.24 \mathrm{E}+00$ & $2.64 \mathrm{E}+00$ \\
\hline $3.09 \mathrm{E}-02$ & $4.00 \mathrm{E}+00$ & $6.56 \mathrm{E}-01$ & $4.75 \mathrm{E}-01$ & $1.44 \mathrm{E}+00$ & $1.91 \mathrm{E}+00$ & $2.24 \mathrm{E}+00$ & $2.63 \mathrm{E}+00$ \\
\hline $3.11 \mathrm{E}-02$ & $3.99 \mathrm{E}+00$ & $6.57 \mathrm{E}-01$ & $4.76 \mathrm{E}-01$ & $1.45 \mathrm{E}+00$ & $1.91 \mathrm{E}+00$ & $2.24 \mathrm{E}+00$ & $2.63 E+00$ \\
\hline $3.12 \mathrm{E}-02$ & $3.99 \mathrm{E}+00$ & $6.58 \mathrm{E}-01$ & $4.77 \mathrm{E}-01$ & $1.45 \mathrm{E}+00$ & $1.91 \mathrm{E}+00$ & $2.24 E+00$ & $2.63 E+00$ \\
\hline $3.13 \mathrm{E}-02$ & $3.98 \mathrm{E}+00$ & $6.59 \mathrm{E}-01$ & $4.78 \mathrm{E}-01$ & $1.45 \mathrm{E}+00$ & $1.91 \mathrm{E}+00$ & $2.24 \mathrm{E}+00$ & $2.63 E+00$ \\
\hline $3.14 \mathrm{E}-02$ & $3.98 \mathrm{E}+00$ & $6.60 \mathrm{E}-01$ & $4.79 \mathrm{E}-01$ & $1.45 E+00$ & $1.91 \mathrm{E}+00$ & $2.24 \mathrm{E}+00$ & $2.63 E+00$ \\
\hline $3.15 \mathrm{E}-02$ & $3.98 \mathrm{E}+00$ & $6.60 \mathrm{E}-01$ & $4.80 \mathrm{E}-01$ & $1.45 \mathrm{E}+00$ & $1.91 \mathrm{E}+00$ & $2.24 \mathrm{E}+00$ & $2.63 \mathrm{E}+00$ \\
\hline $3.17 \mathrm{E}-02$ & $3.97 \mathrm{E}+00$ & $6.61 \mathrm{E}-01$ & $4.81 \mathrm{E}-01$ & $1.45 \mathrm{E}+00$ & $1.91 \mathrm{E}+00$ & $2.24 \mathrm{E}+00$ & $2.62 \mathrm{E}+00$ \\
\hline $3.18 \mathrm{E}-02$ & $3.97 \mathrm{E}+00$ & $6.62 E-01$ & $4.82 E-01$ & $1.45 \mathrm{E}+00$ & $1.92 \mathrm{E}+00$ & $2.24 \mathrm{E}+00$ & $2.62 E+00$ \\
\hline $3.19 \mathrm{E}-02$ & $3.97 \mathrm{E}+00$ & $6.63 E-01$ & $4.82 \mathrm{E}-01$ & $1.46 \mathrm{E}+00$ & $1.92 \mathrm{E}+00$ & $2.24 \mathrm{E}+00$ & $2.62 \mathrm{E}+00$ \\
\hline $3.20 \mathrm{E}-02$ & $3.96 \mathrm{E}+00$ & $6.64 E-01$ & $4.83 E-01$ & $1.46 \mathrm{E}+00$ & $1.92 \mathrm{E}+00$ & $2.24 E+00$ & $2.62 \mathrm{E}+00$ \\
\hline $3.21 \mathrm{E}-02$ & $3.96 \mathrm{E}+00$ & $6.65 E-01$ & $4.84 \mathrm{E}-01$ & $1.46 \mathrm{E}+00$ & $1.92 \mathrm{E}+00$ & $2.24 \mathrm{E}+00$ & $2.62 \mathrm{E}+00$ \\
\hline $3.23 E-02$ & $3.95 \mathrm{E}+00$ & $6.66 \mathrm{E}-01$ & $4.85 E-01$ & $1.46 \mathrm{E}+00$ & $1.92 \mathrm{E}+00$ & $2.24 \mathrm{E}+00$ & $2.62 E+00$ \\
\hline $3.24 \mathrm{E}-02$ & $3.95 \mathrm{E}+00$ & $6.66 \mathrm{E}-01$ & $4.86 \mathrm{E}-01$ & $1.46 \mathrm{E}+00$ & $1.92 \mathrm{E}+00$ & $2.24 \mathrm{E}+00$ & $2.62 \mathrm{E}+00$ \\
\hline $3.25 \mathrm{E}-02$ & $3.95 \mathrm{E}+00$ & $6.67 \mathrm{E}-01$ & $4.87 E-01$ & $1.46 \mathrm{E}+00$ & $1.92 \mathrm{E}+00$ & $2.24 \mathrm{E}+00$ & $2.62 E+00$ \\
\hline $3.26 \mathrm{E}-02$ & $3.94 \mathrm{E}+00$ & $6.68 \mathrm{E}-01$ & $4.88 \mathrm{E}-01$ & $1.46 \mathrm{E}+00$ & $1.93 \mathrm{E}+00$ & $2.25 \mathrm{E}+00$ & $2.62 \mathrm{E}+00$ \\
\hline $3.27 \mathrm{E}-02$ & $3.94 \mathrm{E}+00$ & $6.69 \mathrm{E}-01$ & $4.89 \mathrm{E}-01$ & $1.47 \mathrm{E}+00$ & $1.93 \mathrm{E}+00$ & $2.25 \mathrm{E}+00$ & $2.62 \mathrm{E}+00$ \\
\hline $3.29 \mathrm{E}-02$ & $3.94 \mathrm{E}+00$ & $6.70 E-01$ & $4.90 \mathrm{E}-01$ & $1.47 \mathrm{E}+00$ & $1.93 \mathrm{E}+00$ & $2.25 \mathrm{E}+00$ & $2.62 \mathrm{E}+00$ \\
\hline $3.30 \mathrm{E}-02$ & $3.93 E+00$ & $6.71 \mathrm{E}-01$ & $4.91 \mathrm{E}-01$ & $1.47 \mathrm{E}+00$ & $1.93 \mathrm{E}+00$ & $2.25 \mathrm{E}+00$ & $2.62 E+00$ \\
\hline $3.31 \mathrm{E}-02$ & $3.93 E+00$ & $6.72 E-01$ & $4.92 E-01$ & $1.47 \mathrm{E}+00$ & $1.93 \mathrm{E}+00$ & $2.25 \mathrm{E}+00$ & $2.62 \mathrm{E}+00$ \\
\hline $3.32 \mathrm{E}-02$ & $3.93 E+00$ & $6.72 E-01$ & $4.93 E-01$ & $1.47 \mathrm{E}+00$ & $1.93 \mathrm{E}+00$ & $2.25 E+00$ & $2.62 E+00$ \\
\hline $3.33 E-02$ & $3.92 \mathrm{E}+00$ & $6.73 E-01$ & $4.94 \mathrm{E}-01$ & $1.47 E+00$ & $1.94 \mathrm{E}+00$ & $2.25 \mathrm{E}+00$ & $2.62 \mathrm{E}+00$ \\
\hline
\end{tabular}


RESRAD-OFFSITE, Version 2.5

$\mathrm{T}^{1 / 2}$ Limit $=180$ days

obabilistic Dose and Risk Report

Title : Offsite Resident Farmer

File : RF TC99 DOESG FWD-FV2all.ROF

Summary of dose at graphical times, reptition 1 (continued)

Time

Years

$8.02 \mathrm{E}+02$

$8.02 \mathrm{E}+02$

$8.03 \mathrm{E}+02$

$8.03 \mathrm{E}+02$

$8.04 \mathrm{E}+02$

$8.04 \mathrm{E}+02$

$8.05 \mathrm{E}+02$

$8.05 \mathrm{E}+02$

$8.06 \mathrm{E}+02$

$8.06 \mathrm{E}+02$

$8.07 \mathrm{E}+02$

$8.07 \mathrm{E}+02$

$8.08 \mathrm{E}+02$

8.09E+02

$8.09 \mathrm{E}+02$

$8.10 \mathrm{E}+02$

$8.10 \mathrm{E}+02$

$8.11 \mathrm{E}+02$

$8.11 \mathrm{E}+02$

$8.12 \mathrm{E}+02$

8. $12 \mathrm{E}+02$

$8.13 \mathrm{E}+02$

$8.13 \mathrm{E}+02$

$8.14 \mathrm{E}+02$

$8.14 \mathrm{E}+02$

$8.15 \mathrm{E}+02$

$8.15 \mathrm{E}+02$

$8.16 \mathrm{E}+02$

$8.16 \mathrm{E}+02$

$8.17 \mathrm{E}+02$

$8.17 \mathrm{E}+02$

$8.18 \mathrm{E}+02$

$8.18 \mathrm{E}+02$

$8.19 \mathrm{E}+02$

$8.19 \mathrm{E}+02$

$8.20 \mathrm{E}+02$

$8.20 \mathrm{E}+02$

$8.21 \mathrm{E}+02$

$8.21 \mathrm{E}+02$

$8.22 \mathrm{E}+02$

$8.22 \mathrm{E}+02$

8. $23 \mathrm{E}+02$

$8.23 \mathrm{E}+02$

$8.24 \mathrm{E}+02$

$8.24 \mathrm{E}+02$

$8.25 \mathrm{E}+02$
Dose statistics at graphical times, mrem/yr

\begin{tabular}{|c|c|c|c|c|c|c|c|}
\hline m & aximum & lea & - & & & & \\
\hline 02 & $3.92 \mathrm{E}+00$ & $6.74 \mathrm{E}-01$ & (4) & $.47 \mathrm{E}+00$ & 00 & -00 & $.0 \angle E+U 0$ \\
\hline $36 E-02$ & $3.91 E+00$ & $6.75 E-01$ & $4.96 \mathrm{E}-01$ & 1. $47 \mathrm{E}+00$ & $94 \mathrm{E}+00$ & $2.25 \mathrm{E}+00$ & $62 E+00$ \\
\hline$E-02$ & $91 E+00$ & $76 \mathrm{E}-01$ & $97 E-01$ & $.48 \mathrm{E}+00$ & $.94 E+00$ & $2.25 E+00$ & $2.62 \mathrm{E}+00$ \\
\hline-02 & $91 E+00$ & $77 \mathrm{~F}-01$ & $98 \mathrm{~F}-01$ & $.48 E+00$ & $9 \triangle F+00$ & $2.25 \mathrm{E}+00$ & $2.62 \mathrm{E}+00$ \\
\hline $\mathrm{E}-02$ & $E+00$ & $8 E-01$ & 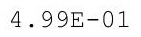 & 0 & & +00 & $2 E+00$ \\
\hline 02 & $90 \mathrm{E}+00$ & & & & & & 00 \\
\hline $42 \mathrm{E}-02$ & $3.90 \mathrm{E}+00$ & 1 & & & & +00 & $2.62 \mathrm{E}+00$ \\
\hline $43 E-02$ & $3.89 \mathrm{E}+00$ & 1 & $\perp$ & $48 E+00$ & 00 & +00 & $2 \mathrm{E}+00$ \\
\hline$E-02$ & $.89 \mathrm{E}+00$ & $6.81 E-01$ & -01 & $1.48 \mathrm{E}+00$ & $94 \mathrm{E}+00$ & $E+00$ & $62 \mathrm{E}+00$ \\
\hline$E-02$ & $.88 \mathrm{E}+00$ & $82 E-01$ & 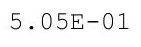 & $.49 \mathrm{E}+00$ & 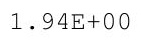 & $.25 E+00$ & $.62 E+00$ \\
\hline 02 & +00 & $83 E-01$ & & & & 0 & $2 E+00$ \\
\hline $48 E-02$ & +00 & 6 & $E-01$ & $x^{2}+$ & & -00 & +00 \\
\hline $50 E-02$ & $3.87 \mathrm{E}+00$ & $6.84 \mathrm{E}-01$ & & $1.49 \mathrm{E}+00$ & & $2.25 E+00$ & $2.62 \mathrm{E}+00$ \\
\hline $51 E-02$ & $3.87 \mathrm{E}+00$ & $6.85 \mathrm{E}-01$ & $.09 \mathrm{E}-01$ & 1. $49 \mathrm{E}+00$ & & $2.24 \mathrm{E}+00$ & $2.62 \mathrm{E}+00$ \\
\hline-02 & $\mathrm{E}+00$ & -01 & 0 & 0 & & +00 & $62 \mathrm{E}+00$ \\
\hline 2 & 00 & 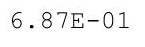 & & 0 & & 0 & 00 \\
\hline 2 & 00 & $6.88 \mathrm{E}-01$ & & 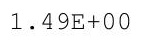 & & 0 & 0 \\
\hline 2 & $85 E+00$ & $6.88 \mathrm{E}-01$ & $5.14 \mathrm{E}-01$ & קח & & & 0 \\
\hline$E-02$ & $.85 \mathrm{E}+00$ & $6895-01$ & $4 E-01$ & 50 - & $5=+8010$ & $E+00$ & $62 \mathrm{E}+00$ \\
\hline$E-02$ & $.85 E+00$ & $0 E-01$ & $.16 \mathrm{E}-01$ & $1.50 \mathrm{E}+00$ & $1.95 \mathrm{E}+$ & $2.24 \mathrm{E}+00$ & $2.62 \mathrm{E}+00$ \\
\hline 02 & +00 & & & & & +00 & $2 E+00$ \\
\hline & & & & & & & \\
\hline 02 & $3.83 E+00$ & \pm & & $1.50 \mathrm{E}+$ & & & \\
\hline 02 & $83 E+00$ & $\perp$ & $5.20 E-01$ & エ・ル上 & . & 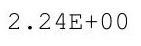 & 00 \\
\hline 2 & $.83 E+00$ & $6.94 \mathrm{E}-01$ & $5.20 \mathrm{E}-01$ & $1.51 \mathrm{E}+$ & $1.95 \mathrm{E}+$ & $4 \mathrm{E}+00$ & $.62 \mathrm{E}+00$ \\
\hline$E-02$ & $.82 \mathrm{E}+00$ & $695-01$ & $5-21 \mathrm{~F}-01$ & 1. $51 \mathrm{E}+00$ & $.95 E+00$ & $.24 \mathrm{E}+00$ & $.62 E+00$ \\
\hline$E-02$ & $3.82 \mathrm{E}+00$ & $96 \mathrm{~F}-01$ & & & & $2.25 E+00$ & $2.62 \mathrm{E}+00$ \\
\hline 02 & & & & & & & \\
\hline & $3.81 \mathrm{E}+00$ & $\perp$ & & $1.52 \mathrm{E}+$ & $-x_{-1}$ & & \\
\hline $.72 E-02$ & $3.81 \mathrm{E}+00$ & $0.90 \mathrm{~L}$ & . $2 U \Delta-1$ & $1.3 \angle E+00$ & 1. & $2.25 E+00$ & $2.62 \mathrm{E}+00$ \\
\hline $3 E-02$ & $3.80 \mathrm{E}+00$ & $.99 E-01$ & 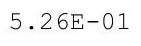 & 1. $52 \mathrm{E}+00$ & 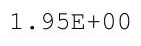 & $2.25 \mathrm{E}+00$ & $2.62 \mathrm{E}+00$ \\
\hline 2 & $3.80 \mathrm{E}+00$ & $\theta^{\circ}$ & . & 1. $52 \mathrm{E}+$ & & & \\
\hline$E-02$ & $3.80 \mathrm{E}+00$ & & & & & & $2.62 \mathrm{E}+00$ \\
\hline 02 & & & & 1. $52 \mathrm{E}+00$ & & & \\
\hline$E-02$ & & & & & & & \\
\hline $9 \mathrm{E}-02$ & $3.78 \mathrm{E}+00$ & $.03 E-01$ & $5.30 E-01$ & $1.53 \mathrm{E}+00$ & $\perp \cdot 20 \amalg$ & $2.25 \mathrm{E}+00$ & $2.62 \mathrm{E}+00$ \\
\hline $81 \mathrm{E}-02$ & $3.78 \mathrm{E}+00$ & $1.045-1$ & & $1.33 E+00$ & 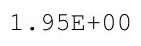 & & $2.62 E+00$ \\
\hline 02 & $3.78 \mathrm{E}+00$ & 年 & & $1.53 \mathrm{E}+00$ & 1. $96 \mathrm{E}+00$ & & $2.62 \mathrm{E}+00$ \\
\hline 2 & . & .0 & 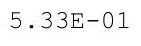 & $1.53 \mathrm{E}+$ & $1.96 \mathrm{E}+$ & $2.25 E+00$ & $2.62 E+00$ \\
\hline 2 & $3.77 \mathrm{E}+00$ & & 1 & $1.53 \mathrm{E}+00$ & & & $2.62 \mathrm{E}+00$ \\
\hline-02 & $3.76 \mathrm{E}+00$ & $7.08 \mathrm{E}-01$ & $5.34 \mathrm{E}-01$ & 1. $53 \mathrm{E}+00$ & & $2.25 \mathrm{E}+00$ & $2.62 \mathrm{E}+00$ \\
\hline$E-02$ & $3.76 \mathrm{E}+00$ & 01 & 1 & $1.54 \mathrm{E}+00$ & $1.96 \mathrm{E}+$ & $E+00$ & $2.62 \mathrm{E}+00$ \\
\hline & 0 & & & & & & \\
\hline $5-0<$ & $3.75 \mathrm{E}+00$ & 1 & + & $1.34 E+00$ & $1.96 E+00$ & $2.25 E+00$ & $2.62 \mathrm{E}+00$ \\
\hline & $3.75 \mathrm{E}+00$ & 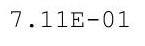 & & $1.54 \mathrm{E}+00$ & $1.96 \mathrm{E}+00$ & $2.25 E+00$ & $2.62 \mathrm{E}+00$ \\
\hline 02 & $.75 E+00$ & $E-01$ & $9 E-01$ & $.54 \mathrm{E}+00$ & $1.96 \mathrm{E}+00$ & $2.25 \mathrm{E}+00$ & $2.62 E+00$ \\
\hline
\end{tabular}


RESRAD-OFFSITE, Version 2.5

$\mathrm{T}^{1 / 2}$ Limit $=180$ days

obabilistic Dose and Risk Report

Title : Offsite Resident Farmer

File : RF TC99 DOESG FWD-FV2all.ROF

Summary of dose at graphical times, reptition 1 (continued)

Time

Years

$8.25 \mathrm{E}+02$

$8.26 \mathrm{E}+02$

$8.26 \mathrm{E}+02$

$8.27 \mathrm{E}+02$

$8.27 \mathrm{E}+02$

$8.28 \mathrm{E}+02$

$8.29 \mathrm{E}+02$

$8.29 \mathrm{E}+02$

$8.30 \mathrm{E}+02$

$8.30 \mathrm{E}+02$

$8.31 \mathrm{E}+02$

$8.31 \mathrm{E}+02$

$8.32 \mathrm{E}+02$

8. $32 \mathrm{E}+02$

$8.33 \mathrm{E}+02$

$8.33 \mathrm{E}+02$

$8.34 \mathrm{E}+02$

$8.34 \mathrm{E}+02$

$8.35 \mathrm{E}+02$

$8.35 \mathrm{E}+02$

$8.36 \mathrm{E}+02$

$8.36 \mathrm{E}+02$

$8.37 \mathrm{E}+02$

$8.37 \mathrm{E}+02$

$8.38 \mathrm{E}+02$

$8.38 \mathrm{E}+02$

$8.39 \mathrm{E}+02$

$8.39 \mathrm{E}+02$

$8.40 \mathrm{E}+02$

$8.40 \mathrm{E}+02$

$8.41 \mathrm{E}+02$

$8.41 \mathrm{E}+02$

$8.42 \mathrm{E}+02$

$8.42 \mathrm{E}+02$

$8.43 \mathrm{E}+02$

$8.43 E+02$

$8.44 \mathrm{E}+02$

$8.44 \mathrm{E}+02$

$8.45 \mathrm{E}+02$

$8.45 \mathrm{E}+02$

$8.46 \mathrm{E}+02$

$8.46 \mathrm{E}+02$

$8.47 \mathrm{E}+02$

$8.47 \mathrm{E}+02$

$8.48 \mathrm{E}+02$

8. $49 \mathrm{E}+02$
Dose statistics at graphical times, mrem/yr

\begin{tabular}{|c|c|c|c|c|c|c|c|}
\hline$m$ & $\mathrm{am}$ & e & ledian & & & & \\
\hline 02 & $.74 \mathrm{E}+00$ & 01 & 01 & $.54 \mathrm{E}+00$ & $96 \mathrm{E}+00$ & 00 & . OJETU \\
\hline $96 \mathrm{E}-02$ & $3.74 \mathrm{E}+00$ & $3 E-01$ & $5.41 \mathrm{E}-01$ & $4 E+00$ & $97 \mathrm{E}+00$ & $E+00$ & $3 E+00$ \\
\hline$E-02$ & $73 E+00$ & $4 E-01$ & $43 E-01$ & $54 E+00$ & $.97 \mathrm{E}+00$ & $2.25 E+00$ & $2.63 E+00$ \\
\hline$E-02$ & $73 E+00$ & $15 \mathrm{~F}-01$ & $44 \mathrm{~F}-01$ & $.55 E+00$ & $97 \mathrm{~F}+00$ & $.24 \mathrm{E}+00$ & $2.63 E+00$ \\
\hline-02 & $3.73 E+00$ & 01 & 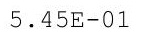 & & & +00 & +00 \\
\hline 02 & $72 \mathrm{E}+00$ & & & & & & 00 \\
\hline $02 E-02$ & $3.72 \mathrm{E}+00$ & & & & & & $53 E+00$ \\
\hline $.04 \mathrm{E}-02$ & $3.71 \mathrm{E}+00$ & 1 & $\perp$ & $E+00$ & $97 \mathrm{E}+00$ & +00 & $E+00$ \\
\hline $05 E-02$ & $71 \mathrm{E}+00$ & $9 E-01$ & $E-01$ & $5 \mathrm{E}+00$ & $97 E+00$ & +00 & $3 E+00$ \\
\hline $7 E-02$ & $.71 E+00$ & $0 E-01$ & 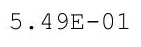 & 1 & 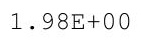 & $.24 E+00$ & $.63 E+00$ \\
\hline-02 & $70 \mathrm{E}+00$ & $21 E-01$ & & ז5 & & 0 & $63 E+00$ \\
\hline $.09 \mathrm{E}-02$ & $3.70 \mathrm{E}+00$ & 15 & 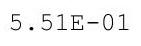 & & & -00 & +00 \\
\hline $.11 \mathrm{E}-02$ & $3.69 \mathrm{E}+00$ & 7. $22 \mathrm{E}-01$ & & & & $2.24 \mathrm{E}+00$ & $2.63 E+00$ \\
\hline $12 \mathrm{E}-02$ & $3.69 \mathrm{E}+00$ & $7.23 E-01$ & $.53 E-01$ & & $1.98 \mathrm{E}+00$ & $2.24 \mathrm{E}+00$ & $2.63 E+00$ \\
\hline-02 & $69 \mathrm{E}+00$ & $4 E-01$ & $F-0-0 \cdot 2-2$ & 0 & & +00 & $3 E+00$ \\
\hline 2 & 0 & & & & & 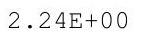 & 00 \\
\hline 2 & & & & & & 0 & 0 \\
\hline 2 & $3.67 \mathrm{E}+00$ & $7.26 \mathrm{E}-01$ & $5.57 \mathrm{E}-01$ & & & 0 & 0 \\
\hline $19 \mathrm{E}-02$ & $.67 \mathrm{E}+00$ & $7 \mathrm{~F}-01$ & $8 \mathrm{~F}-01$ & $565+0$ & 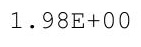 & $E+00$ & $53 E+00$ \\
\hline$E-02$ & $.67 E+00$ & $.28 E-01$ & $.59 E-01$ & $1.57 \mathrm{E}+00$ & $1.98 \mathrm{E}+$ & $2.25 \mathrm{E}+00$ & $2.63 E+00$ \\
\hline-02 & $66 \mathrm{E}+00$ & & & & & +00 & $E+00$ \\
\hline & & & & & & & \\
\hline 2 & $3.65 \mathrm{E}+00$ & + & & $1.57 \mathrm{E}+$ & & & \\
\hline$E-02$ & $3.65 \mathrm{E}+00$ & $\perp$ & $5.63 E-01$ & म.UILTU & 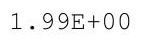 & 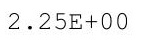 & 0 \\
\hline 2 & $.65 E+00$ & 7. $32 \mathrm{E}-01$ & $5.64 \mathrm{E}-01$ & 1. $57 \mathrm{E}+00$ & & $2.25 E+00$ & $54 \mathrm{E}+00$ \\
\hline $29 \mathrm{E}-02$ & $.64 E+00$ & $73 F-01$ & $65 \mathrm{~F}-01$ & 1. $57 \mathrm{E}+00$ & $.99 \mathrm{E}+00$ & $2.25 E+00$ & $.64 \mathrm{E}+00$ \\
\hline$E-02$ & $3.64 \mathrm{E}+00$ & & & & & $2.25 E+00$ & $2.64 \mathrm{E}+00$ \\
\hline-02 & & & & & & & \\
\hline & $3.63 \mathrm{E}+00$ & 然 & & $1.58 \mathrm{E}+$ & & & \\
\hline $.35 E-02$ & $3.63 E+00$ & . & 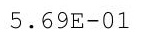 & $1.58 \mathrm{E}+00$ & 1.99E+ & $2.25 E+00$ & $2.64 \mathrm{E}+00$ \\
\hline $6 E-02$ & $3.62 \mathrm{E}+00$ & $7.37 \mathrm{E}-01$ & . & 1. $58 \mathrm{E}+00$ & $2.00 \mathrm{E}+00$ & $2.26 \mathrm{E}+00$ & $2.64 \mathrm{E}+00$ \\
\hline 2 & $3.62 \mathrm{E}+$ & . & - & 1. $58 \mathrm{E}+$ & & & \\
\hline 2 & & & & & & & \\
\hline 02 & $3.61 \mathrm{E}+00$ & & & & & & \\
\hline$E-02$ & 3.6 & & & & & & \\
\hline $43 E-02$ & $3.60 \mathrm{E}+00$ & $7.41 \mathrm{E}-01$ & $4 E-01$ & $1.58 \mathrm{E}+00$ & 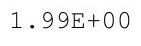 & $2.26 \mathrm{E}+00$ & $2.64 \mathrm{E}+00$ \\
\hline $45 E-02$ & $3.60 \mathrm{E}+00$ & $1.4 \perp L-1$ & & $1.38 E+00$ & & & \\
\hline & $3.59 \mathrm{E}+00$ & & & 1. $59 \mathrm{E}+00$ & 1. $99 \mathrm{E}+00$ & & $2.64 \mathrm{E}+00$ \\
\hline 2 & $3.59 \mathrm{E}+$ & 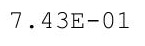 & 1 & $1.59 \mathrm{E}+00$ & $1.99 \mathrm{E}+$ & $2.26 \mathrm{E}+00$ & $2.64 \mathrm{E}+00$ \\
\hline & $3.59 \mathrm{E}+00$ & & - & $1.59 \mathrm{E}+00$ & & & $64 \mathrm{E}+00$ \\
\hline$E-02$ & $3.59 \mathrm{E}+00$ & $7.44 \mathrm{E}-01$ & $5.79 \mathrm{E}-01$ & 1. $59 \mathrm{E}+00$ & & $2.26 \mathrm{E}+00$ & $2.64 \mathrm{E}+00$ \\
\hline$E-02$ & $3.59 \mathrm{E}+00$ & 01 & & $1.59 \mathrm{E}+00$ & & $E+00$ & $4 E+00$ \\
\hline & 3.0 & & & & & & \\
\hline $5-02$ & $3.59 \mathrm{E}+00$ & 1. & $+\infty$ & $1.39 E+00$ & $2.00 \mathrm{E}+00$ & $2.26 \mathrm{E}+00$ & $2.63 E+00$ \\
\hline $5-02$ & $3.59 \mathrm{E}+00$ & . & & $1.59 \mathrm{E}+00$ & $2.00 \mathrm{E}+00$ & $2.26 \mathrm{E}+00$ & $2.63 E+00$ \\
\hline 02 & $.59 \mathrm{E}+00$ & $E-01$ & $83 E-01$ & $.59 \mathrm{E}+00$ & $.00 \mathrm{E}+00$ & $2.26 \mathrm{E}+00$ & $2.63 E+00$ \\
\hline
\end{tabular}


RESRAD-OFFSITE, Version 2.5 
RESRAD-OFFSITE, Version 2.5

$\mathrm{T}^{1 / 2}$ Limit $=180$ days

obabilistic Dose and Risk Report

Title : Offsite Resident Farmer

File : RF TC99 DOESG FWD-FV2all.ROF

Summary of dose at graphical times, reptition 1 (continued)

Time

Years

$8.73 E+02$

$8.73 \mathrm{E}+02$

$8.74 \mathrm{E}+02$

$8.74 \mathrm{E}+02$

$8.75 \mathrm{E}+02$

$8.75 \mathrm{E}+02$

$8.76 \mathrm{E}+02$

$8.76 \mathrm{E}+02$

$8.77 \mathrm{E}+02$

$8.77 \mathrm{E}+02$

$8.78 \mathrm{E}+02$

$8.78 \mathrm{E}+02$

$8.79 \mathrm{E}+02$

$8.79 \mathrm{E}+02$

$8.80 \mathrm{E}+02$

$8.80 \mathrm{E}+02$

$8.81 \mathrm{E}+02$

$8.81 \mathrm{E}+02$

$8.82 \mathrm{E}+02$

$8.82 \mathrm{E}+02$

$8.83 \mathrm{E}+02$

$8.83 E+02$

$8.84 \mathrm{E}+02$

$8.84 \mathrm{E}+02$

$8.85 \mathrm{E}+02$

$8.85 \mathrm{E}+02$

$8.86 \mathrm{E}+02$

$8.86 \mathrm{E}+02$

$8.87 \mathrm{E}+02$

$8.87 \mathrm{E}+02$

$8.88 \mathrm{E}+02$

$8.89 \mathrm{E}+02$

$8.89 \mathrm{E}+02$

$8.90 \mathrm{E}+02$

$8.90 \mathrm{E}+02$

$8.91 \mathrm{E}+02$

$8.91 \mathrm{E}+02$

$8.92 \mathrm{E}+02$

8. $92 \mathrm{E}+02$

8. $93 \mathrm{E}+02$

$8.93 E+02$

8. $94 \mathrm{E}+02$

8. $94 \mathrm{E}+02$

$8.95 \mathrm{E}+02$

$8.95 \mathrm{E}+02$

$8.96 \mathrm{E}+02$
Dose statistics at graphical times, mrem/yr

\begin{tabular}{|c|c|c|c|c|c|c|c|}
\hline m & $\mathrm{m}$ & Mean & ledian & & & $\%$ & $\%$ \\
\hline $30 \mathrm{E}-02$ & $3.56 \mathrm{E}+00$ & $7.84 \mathrm{E}-01$ & $6.32 \mathrm{E}-01$ & $1.64 \mathrm{E}+00$ & $2.01 E+00$ & $2.28 \mathrm{E}+00$ & \pm+00 \\
\hline-02 & +00 & 01 & -01 & 00 & 00 & $E+00$ & $\Xi+00$ \\
\hline $33 E-02$ & $3.56 \mathrm{E}+00$ & $.85 E-01$ & $6.33 \mathrm{E}-01$ & $1.65 \mathrm{E}+00$ & $2.01 E+00$ & $2.28 \mathrm{E}+00$ & $2.64 \mathrm{E}+00$ \\
\hline $34 \mathrm{E}-02$ & $3.56 \mathrm{E}+00$ & $.86 \mathrm{E}-01$ & $4 \mathrm{E}-01$ & $1.65 \mathrm{E}+00$ & $2.01 \mathrm{E}+00$ & $2.28 \mathrm{E}+00$ & $2.64 \mathrm{E}+00$ \\
\hline 02 & $6 \mathrm{E}+00$ & $7 \mathrm{E}$ & 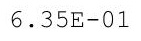 & $1.65 \mathrm{E}+00$ & 0 & 00 & $4 E+00$ \\
\hline-02 & -00 & - & & 0 & & 0 & +00 \\
\hline $39 \mathrm{E}-02$ & & & & & & & $4 \mathrm{E}+00$ \\
\hline-02 & & & & & & 00 & +00 \\
\hline-02 & +00 & $F-0$ & $\perp$ & $E+00$ & 00 & +00 & $\Xi+00$ \\
\hline 02 & $E+00$ & $\perp$ & $\perp$ & $1.65 \mathrm{E}+00$ & $01 \mathrm{~F}+\mathrm{t}$ & 0 & +00 \\
\hline 02 & $E+00$ & 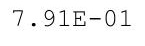 & $6.39 \mathrm{E}-01$ & 0 & 0 & 00 & -00 \\
\hline $7 E-02$ & -00 & & & .66 & 0 & 0 & -00 \\
\hline$F-02$ & $3.55 \mathrm{E}+00$ & $7.93 \mathrm{E}-01$ & $6.40 \mathrm{E}-01$ & $1.66 \mathrm{E}+$ & & 0 & +00 \\
\hline $.51 \mathrm{E}-02$ & $3.55 \mathrm{E}+00$ & $7.93 \mathrm{E}-01$ & $6.41 \mathrm{E}-01$ & $1.66 \mathrm{E}+00$ & $2.02 \mathrm{E}+00$ & $2.28 \mathrm{E}+00$ & $2.64 \mathrm{E}+00$ \\
\hline$E-02$ & $5 \mathrm{E}+00$ & $F-0$ & 1 & $1.66 \mathrm{E}+00$ & $02 \mathrm{E}+$ & $E+00$ & $4 \mathrm{E}+00$ \\
\hline 2 & & & & .66 & & 0 & -00 \\
\hline 2 & $\mathrm{E}+00$ & $7.96 \mathrm{E}-01$ & $\perp$ & $\cdot 0$ & קח & 0 & \\
\hline 2 & 0 & & & & & & 0 \\
\hline $59 F-02$ & $5 \mathrm{E}+00$ & 吅 & F & $1.66 \mathrm{E}+00$ & 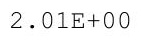 & +00 & $5 E+00$ \\
\hline$F-02$ & $.55 \mathrm{E}+00$ & $8 E-0$ & $.45 E-01$ & $1.66 \mathrm{E}+00$ & $2.01 \mathrm{E}+0$ & $2.28 \mathrm{E}+00$ & $2.65 \mathrm{E}+00$ \\
\hline $62 \mathrm{E}-02$ & $3.54 \mathrm{E}+00$ & $7.99 \mathrm{E}-01$ & $E-01$ & $1.66 \mathrm{E}+00$ & נת 01 & $2.28 \mathrm{E}+00$ & $.65 \mathrm{E}+00$ \\
\hline 02 & & & & & & & $65 E+00$ \\
\hline 2 & & & & $1.66 \mathrm{E}$ & & & 00 \\
\hline $5-2<$ & $3.54 \mathrm{E}+00$ & & & $\perp \cdot 010$ & - & .200 & 00 \\
\hline 2 & 0 & $8.01 \mathrm{E}-01$ & $\perp$ & 0 & $.02 \mathrm{E}$ & 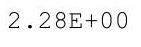 & 00 \\
\hline$F-02$ & $.54 \mathrm{E}+00$ & م & $6 \quad 51 \mathrm{~F}-01$ & $1.67 \mathrm{E}+00$ & $2.02 \mathrm{E}+0$ & $2.29 \mathrm{E}+00$ & $2.64 \mathrm{E}+00$ \\
\hline$F-0 ?$ & $3.54 \mathrm{E}+00$ & $F=0$ & $53 \mathrm{~F}-01$ & $1.67 \mathrm{E}+00$ & קתמת מ & $2.29 \mathrm{E}+00$ & $2.65 E+00$ \\
\hline 2 & & & & & & & \\
\hline 02 & & & & $.67 \mathrm{E}+$ & & & \\
\hline $7 E-02$ & $3.54 \mathrm{E}+00$ & $0.0 U \mathrm{~L}$ & $6.55 \mathrm{E}-01$ & $1.67 \mathrm{E}+00$ & $2.0<D$ & $2.29 \mathrm{E}+00$ & $2.65 E+00$ \\
\hline OL- & $3.54 \mathrm{E}+00$ & . OU U & $0.03 \mathrm{~L}-\mathrm{C}$ & $1.67 \mathrm{E}+00$ & $\angle .0 \angle \mathrm{LT} 0$ & $\angle . \angle 9 L T 00$ & $2.65 E+00$ \\
\hline 2 & . & 然定 & 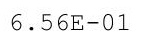 & म. ОTि & $2.02 \mathrm{E}+$ & $2.29 \mathrm{E}+0$ & $2.65 \mathrm{E}+00$ \\
\hline 5 & $3.53 \mathrm{E}+00$ & & 1 & $1.67 \mathrm{E}+00$ & & & $2.65 E+00$ \\
\hline & & & & & & & \\
\hline$E-02$ & & & 01 & 1.67E+ & & & \\
\hline 02 & 3.531 & 01 & 01 & $1.0 / \mathrm{ET}$ & $2.02 \mathrm{E}$ & 2.291 & $2.65 E+00$ \\
\hline $3-0<$ & $3.53 E+00$ & & & $1.67 \mathrm{E}+00$ & & & $2.65 E+00$ \\
\hline $.905-02$ & $3.53 \mathrm{E}+00$ & & & 1.OILTU & & & $2.65 E+00$ \\
\hline $.92 E-02$ & (.) & $8.11 \mathrm{E}-01$ & & t. & $2.02 \mathrm{E}$ & $2.29 \mathrm{E}$ & $2.65 E+00$ \\
\hline $.94 \mathrm{E}-02$ & & & & $7 \mathrm{E}+00$ & & & $65 F+00$ \\
\hline 2 & $3.53 \mathrm{E}+00$ & 8 & 1 & $1.67 \mathrm{E}+$ & $2.03 \mathrm{E}+$ & $2.29 \mathrm{E}+00$ & $5 E+00$ \\
\hline$E-02$ & $3.52 \mathrm{E}+00$ & $E-01$ & 6. & $1.67 \mathrm{E}+00$ & & $2.30 \mathrm{E}+00$ & $E+00$ \\
\hline 2 & & & & & & & \\
\hline & $3.52 \mathrm{E}+00$ & 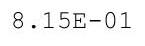 & & $1.6 / E+00$ & $2.03 E+00$ & $2.30 \mathrm{E}+00$ & $2.65 E+00$ \\
\hline 42 & $3.52 \mathrm{E}+00$ & & & $1.67 \mathrm{E}+00$ & $2.03 E+00$ & $2.30 \mathrm{E}+00$ & $2.65 E+00$ \\
\hline$E-02$ & $.52 E+00$ & $6 E-01$ & $69 E-01$ & $67 E+00$ & $.03 E+00$ & $30 E+00$ & $65 E+00$ \\
\hline
\end{tabular}


RESRAD-OFFSITE, Version 2.5

$\mathrm{T}^{1 / 2}$ Limit $=180$ days

obabilistic Dose and Risk Report

Title : Offsite Resident Farmer

File : RF TC99 DOESG FWD-FV2all.ROF

Summary of dose at graphical times, reptition 1 (continued)

Time

Years

$8.96 \mathrm{E}+02$

$8.97 \mathrm{E}+02$

$8.97 \mathrm{E}+02$

$8.98 \mathrm{E}+02$

$8.98 \mathrm{E}+02$

8. $99 \mathrm{E}+02$

$8.99 \mathrm{E}+02$

$9.00 \mathrm{E}+02$

$9.00 \mathrm{E}+02$

$9.01 \mathrm{E}+02$

$9.01 \mathrm{E}+02$

$9.02 \mathrm{E}+02$

$9.02 \mathrm{E}+02$

$9.03 \mathrm{E}+02$

$9.03 \mathrm{E}+02$

$9.04 \mathrm{E}+02$

$9.04 \mathrm{E}+02$

$9.05 \mathrm{E}+02$

$9.05 \mathrm{E}+02$

$9.06 \mathrm{E}+02$

$9.06 \mathrm{E}+02$

$9.07 \mathrm{E}+02$

$9.07 \mathrm{E}+02$

$9.08 \mathrm{E}+02$

$9.08 \mathrm{E}+02$

$9.09 \mathrm{E}+02$

$9.10 \mathrm{E}+02$

$9.10 \mathrm{E}+02$

$9.11 \mathrm{E}+02$

$9.11 \mathrm{E}+02$

$9.12 \mathrm{E}+02$

9. $12 \mathrm{E}+02$

9. $13 \mathrm{E}+02$

9. $13 \mathrm{E}+02$

$9.14 \mathrm{E}+02$

$9.14 \mathrm{E}+02$

9. $15 \mathrm{E}+02$

$9.15 \mathrm{E}+02$

$9.16 \mathrm{E}+02$

$9.16 \mathrm{E}+02$

$9.17 \mathrm{E}+02$

$9.17 \mathrm{E}+02$

$9.18 \mathrm{E}+02$

$9.18 \mathrm{E}+02$

$9.19 \mathrm{E}+02$

$9.19 \mathrm{E}+02$
Dose statistics at graphical times, mrem/yr

\begin{tabular}{|c|c|c|c|c|c|c|c|}
\hline m & m & Mean & ledian & & & $\%$ & \\
\hline 02 & $3.52 \mathrm{E}+00$ & $8.17 \mathrm{E}-01$ & $6.70 \mathrm{E}-01$ & $1.67 \mathrm{E}+00$ & $2.03 E+00$ & $2.30 \mathrm{E}+00$ & $2.65 E+00$ \\
\hline $.07 E-02$ & $2 E+00$ & 01 & -01 & $7 \mathrm{E}+00$ & $2.03 E+00$ & $2.30 \mathrm{E}+00$ & $5 \mathrm{E}+00$ \\
\hline $.09 \mathrm{E}-02$ & $3.52 \mathrm{E}+00$ & $18 E-01$ & $6.72 \mathrm{E}-01$ & $1.67 \mathrm{E}+00$ & $2.03 E+00$ & $2.30 \mathrm{E}+00$ & $55 E+00$ \\
\hline $10 \mathrm{E}-02$ & $3.52 \mathrm{E}+00$ & $9 E-01$ & $6.73 E-01$ & $1.67 \mathrm{E}+00$ & $2.02 E+00$ & $2.30 \mathrm{E}+00$ & $2.65 E+00$ \\
\hline 2 & 0 & 1 & 3 & 0 & 0 & 0 & $2.65 E+00$ \\
\hline-02 & -00 & 1 & & 0 & & & +00 \\
\hline $16 \mathrm{E}-02$ & & 1 & & & & & $E+00$ \\
\hline $.17 \mathrm{E}-02$ & & & & & 00 & & +00 \\
\hline$E-02$ & +00 & $E-01$ & $\perp$ & $68 E+00$ & 00 & +00 & $E+00$ \\
\hline 2 & $51 E+00$ & 1 & $\perp$ & $.68 \mathrm{E}+$ & $0 ? \mathrm{~F}+$ & $E+00$ & $65 \mathrm{E}+00$ \\
\hline 02 & $3.51 \mathrm{E}+00$ & $8.24 \mathrm{E}-01$ & $6.78 \mathrm{E}-01$ & $168=+$ & ค2F+ & $\mathrm{E}+00$ & $66 E+00$ \\
\hline 2 & -00 & & & 0 & 0 & 0 & -00 \\
\hline $5-02$ & $\mathrm{~F}+00$ & 5 & 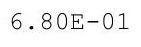 & 0 & 0 & 0 & +00 \\
\hline $.28 \mathrm{E}-02$ & $3.50 \mathrm{E}+00$ & $8.26 \mathrm{E}-01$ & $6.80 \mathrm{E}-01$ & $1.68 \mathrm{E}+00$ & $2.02 \mathrm{E}+00$ & $2.30 \mathrm{E}+00$ & $2.66 \mathrm{E}+00$ \\
\hline $29 \mathrm{E}-02$ & $E+00$ & $E-01$ & 1 & $1.68 \mathrm{E}+00$ & $02 \mathrm{E}+$ & $\mathrm{E}+00$ & $56 \mathrm{E}+00$ \\
\hline 2 & & & & & & 0 & 00 \\
\hline $.33 E-02$ & & & & 0 & 0 & & 00 \\
\hline 2 & & $8.29 \mathrm{E}-01$ & & 0 & & & 0 \\
\hline $36 E-02$ & $0 \mathrm{E}+00$ & $9 F-01$ & 5 & $1.69 \mathrm{E}+00$ & 0 & +00 & $6 E+00$ \\
\hline $38 E-02$ & $3.50 \mathrm{E}+00$ & $30 E-01$ & $.85 E-01$ & $1.69 \mathrm{E}+00$ & $2.02 \mathrm{E}+00$ & $2.30 \mathrm{E}+00$ & $2.66 \mathrm{E}+00$ \\
\hline $10 \mathrm{E}-02$ & $.50 \mathrm{E}+00$ & $E-01$ & -01 & 1. $69 \mathrm{E}+00$ & 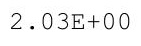 & $.30 E+00$ & $.66 \mathrm{E}+00$ \\
\hline 02 & & & & & & & $.66 \mathrm{E}+00$ \\
\hline & & & & $.69 \mathrm{E}$ & & & -00 \\
\hline-02 & $3.49 \mathrm{E}+00$ & $\perp$ & & $\perp \cdot 0,1$ & $03 \mathrm{E}+$ & & 00 \\
\hline 2 & $.49 \mathrm{E}+00$ & $8.33 \mathrm{E}-01$ & $6.88 \mathrm{E}-01$ & 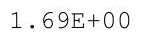 & 03 & 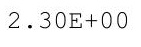 & 00 \\
\hline $9 E-02$ & $.49 \mathrm{E}+00$ & $34 \mathrm{~F}-01$ & تص & 1. $69 \mathrm{E}+00$ & $.03 E+C$ & $30 E+00$ & $66 \mathrm{E}+00$ \\
\hline$F-02$ & $3.49 \mathrm{E}+00$ & $5=01$ & $0 F-01$ & $1.69 \mathrm{E}+00$ & 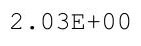 & $30 E+00$ & $2.66 \mathrm{E}+00$ \\
\hline 02 & & & & & & & \\
\hline 02 & & & & $.69 \mathrm{E}+$ & & & \\
\hline $6 E-02$ & $3.49 \mathrm{E}+00$ & $0.01+4$ & . & $1.69 \mathrm{E}+00$ & $2.0<D$ & $2.30 \mathrm{E}+00$ & $2.65 E+00$ \\
\hline . & $3.48 \mathrm{E}+00$ & . & $\cdot 9 \angle L-U 1$ & $1.70 \mathrm{E}+00$ & $\angle .0 \angle \mathrm{LT} 0$ & $\angle .30 \mathrm{LT} 0$ & $2.65 E+00$ \\
\hline 年 & . & 管 & & 1. $70 \mathrm{E}+00$ & $2.02 \mathrm{E}+$ & & $2.65 \mathrm{E}+00$ \\
\hline 5 & $3.48 \mathrm{E}+00$ & 1 & $3 E-01$ & $1.70 \mathrm{E}+00$ & & & $2.65 E+00$ \\
\hline & & & & & & & \\
\hline 02 & & & & & & & \\
\hline 02 & $3.48 \mathrm{E}+$ & 1 & & $1.10 E T$ & $2.02 \mathrm{E}$ & $2.30 \mathrm{E}$ & $2.65 E+00$ \\
\hline $5-0<$ & & 1 & & 1.70E+ & & & $5 E+00$ \\
\hline . 100 2 & & & & & & & $2.65 E+00$ \\
\hline 2 & 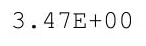 & * & & ter & $2.02 \mathrm{E}+$ & & $2.65 E+00$ \\
\hline & & & & $70 \mathrm{E}+00$ & & & \\
\hline 2 & & 1 & & $1.70 \mathrm{E}+00$ & $2.02 E+00$ & $\mathrm{E}+00$ & $5 E+00$ \\
\hline $.77 E-02$ & $3.47 \mathrm{E}+00$ & $4 E-01$ & 01 & $1.70 \mathrm{E}+00$ & $2.02 \mathrm{E}+$ & 00 & +00 \\
\hline & & & & & & & \\
\hline & & . & & $1.10 E+U 0$ & $2.02 E+00$ & $2.30 \mathrm{E}+00$ & $2.64 \mathrm{E}+00$ \\
\hline 02 & & . & & $1.70 \mathrm{E}+00$ & $2.02 E+00$ & $2.30 \mathrm{E}+00$ & $2.64 \mathrm{E}+00$ \\
\hline $4 E-02$ & $.46 E+00$ & $E-01$ & $6 E-01$ & $.70 E+00$ & $.03 E+00$ & $.30 E+00$ & $.64 E+00$ \\
\hline
\end{tabular}


RESRAD-OFFSITE, Version 2.5

$\mathrm{T}^{1 / 2}$ Limit $=180$ days

obabilistic Dose and Risk Report

Title : Offsite Resident Farmer

File : RF TC99 DOESG FWD-FV2all.ROF

Summary of dose at graphical times, reptition 1 (continued)

Time

Years

$9.20 \mathrm{E}+02$

$9.20 \mathrm{E}+02$

$9.21 \mathrm{E}+02$

9. $21 \mathrm{E}+02$

$9.22 \mathrm{E}+02$

9. $22 \mathrm{E}+02$

$9.23 \mathrm{E}+02$

$9.23 \mathrm{E}+02$

$9.24 \mathrm{E}+02$

$9.24 \mathrm{E}+02$

$9.25 \mathrm{E}+02$

$9.25 \mathrm{E}+02$

$9.26 \mathrm{E}+02$

$9.26 \mathrm{E}+02$

$9.27 \mathrm{E}+02$

$9.27 \mathrm{E}+02$

$9.28 \mathrm{E}+02$

$9.28 \mathrm{E}+02$

$9.29 \mathrm{E}+02$

9. $30 \mathrm{E}+02$

$9.30 \mathrm{E}+02$

$9.31 \mathrm{E}+02$

9. $31 \mathrm{E}+02$

$9.32 \mathrm{E}+02$

9. $32 \mathrm{E}+02$

$9.33 \mathrm{E}+02$

$9.33 \mathrm{E}+02$

$9.34 \mathrm{E}+02$

$9.34 \mathrm{E}+02$

9. $35 \mathrm{E}+02$

$9.35 \mathrm{E}+02$

$9.36 \mathrm{E}+02$

$9 \cdot 36 \mathrm{E}+02$

9. $37 \mathrm{E}+02$

$9.37 \mathrm{E}+02$

$9.38 \mathrm{E}+02$

$9.38 \mathrm{E}+02$

$9.39 \mathrm{E}+02$

$9.39 \mathrm{E}+02$

$9.40 \mathrm{E}+02$

$9.40 \mathrm{E}+02$

$9.41 \mathrm{E}+02$

$9.41 \mathrm{E}+02$

$9.42 \mathrm{E}+02$

$9.42 \mathrm{E}+02$

$9.43 \mathrm{E}+02$
Dose statistics at graphical times, mrem/yr

\begin{tabular}{|c|c|c|c|c|c|c|c|}
\hline m & $\mathrm{m}$ & Mean & ledian & & & & \\
\hline $86 \mathrm{E}-02$ & $.46 \mathrm{E}+00$ & 01 & $7.07 \mathrm{E}-01$ & $1.70 \mathrm{E}+00$ & $03 E+00$ & -00 & $.04 \mathrm{E}+U \mathrm{U}$ \\
\hline $88 E-02$ & $3.46 \mathrm{E}+00$ & $8.48 E-01$ & $08 E-01$ & $1.70 \mathrm{E}+00$ & $03 E+00$ & $2.30 \mathrm{E}+00$ & $64 E+00$ \\
\hline$E-02$ & $46 \mathrm{E}+00$ & $9 E-01$ & $9 \mathrm{E}-01$ & $1.70 \mathrm{E}+00$ & $.03 E+00$ & $2.30 \mathrm{E}+00$ & $2.64 \mathrm{E}+00$ \\
\hline $91 E-02$ & $46 E+00$ & $50 \mathrm{~F}-01$ & $10 \mathrm{~F}-01$ & $.70 \mathrm{E}+00$ & $.03 E+00$ & $2.30 \mathrm{E}+00$ & $2.64 \mathrm{E}+00$ \\
\hline $93 E-02$ & $\mathrm{E}+00$ & $0 \mathrm{~F}-01$ & -01 & $F+00$ & $3 F+00$ & $E+00$ & $64 \mathrm{E}+00$ \\
\hline 02 & +00 & & & & & & +00 \\
\hline $97 E-02$ & $3.45 \mathrm{E}+00$ & 1 & & & & +00 & $2.63 \mathrm{E}+00$ \\
\hline $.99 E-02$ & $5 E+00$ & 01 & -01 & $1.70 \mathrm{E}+00$ & 00 & $E+00$ & \pm+00 \\
\hline $01 E-02$ & $45 E+00$ & $3 E-01$ & $E-01$ & $0 \mathrm{E}+00$ & $04 \mathrm{E}+$ & $E+00$ & $E+00$ \\
\hline $.02 E-02$ & $.45 E+00$ & $4 \mathrm{E}-01$ & $16 F_{-1}-01$ & $.70 \mathrm{E}+00$ & 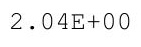 & $30 E+00$ & $.63 E+00$ \\
\hline 02 & $E+00$ & $4 E-01$ & $17 E-01$ & 0 & 0 & 0 & $63 E+00$ \\
\hline $06 E-02$ & $E+00$ & 5 & $7.18 \mathrm{E}-01$ & & & -00 & +00 \\
\hline $.08 E-02$ & $3.45 \mathrm{E}+00$ & $8.55 E-01$ & & & & $2.30 \mathrm{E}+00$ & $2.62 \mathrm{E}+00$ \\
\hline $.10 \mathrm{E}-02$ & $3.44 \mathrm{E}+00$ & $3.56 \mathrm{E}-01$ & 7. $20 \mathrm{E}-01$ & 1. $70 \mathrm{E}+00$ & & $2.30 \mathrm{E}+00$ & $2.62 \mathrm{E}+00$ \\
\hline-02 & $E+00$ & $E-01$ & -0 & 0 & & +00 & $52 \mathrm{E}+00$ \\
\hline 2 & 0 & & & & & 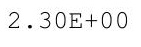 & 00 \\
\hline 2 & & & & & & & 0 \\
\hline $7 E-02$ & $3.44 \mathrm{E}+00$ & $8.59 \mathrm{E}-01$ & D. & & & T & 0 \\
\hline $.19 \mathrm{E}-02$ & $.44 \mathrm{E}+00$ & -01 & $725 \mathrm{~F}-0$ & $70 E+00$ & 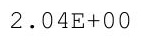 & $E+00$ & $1 \mathrm{E}+00$ \\
\hline $.21 E-02$ & $.44 \mathrm{E}+00$ & $60 \mathrm{E}-01$ & $7.26 \mathrm{E}-01$ & 1. $70 \mathrm{E}+00$ & $2.04 \mathrm{E}+$ & $2.30 \mathrm{E}+00$ & $2.61 \mathrm{E}+00$ \\
\hline 02 & $3.43 E+00$ & & & & & +00 & $0 E+00$ \\
\hline 2 & & & & & & & \\
\hline 2 & $.43 E+00$ & 1 & & $1.70 \mathrm{E}+$ & & & \\
\hline 02 & $3.43 E+00$ & $\perp$ & $7.29 \mathrm{E}-01$ & म. & 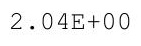 & 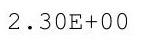 & 0 \\
\hline 2 & $.43 E+00$ & $8.63 E-01$ & $7.30 \mathrm{E}-01$ & 1. $70 \mathrm{E}+00$ & $.04 \mathrm{E}+$ & $.30 \mathrm{E}+00$ & $59 \mathrm{E}+00$ \\
\hline $32 E-02$ & $.43 E+00$ & $6 \Delta \mathrm{F}-01$ & $7 \quad 31 \mathrm{~F}-01$ & 1. $70 \mathrm{E}+00$ & $.04 \mathrm{E}+00$ & $30 E+00$ & $.59 \mathrm{E}+00$ \\
\hline $.34 \mathrm{E}-02$ & $3.42 \mathrm{E}+00$ & & & & & $\mathrm{E}+00$ & $59 \mathrm{E}+00$ \\
\hline 02 & & & & & & & \\
\hline 2 & $3.42 \mathrm{E}+00$ & 0.0 & & 1.71E+ & & & \\
\hline $.39 E-02$ & $3.42 \mathrm{E}+00$ & $0.00 \mathrm{~L}-1$ & . $34 \mathrm{~L}$ & $1.71 \mathrm{E}+00$ & $2.04 \pm 100$ & $2.30 \mathrm{E}+00$ & $2.59 \mathrm{E}+00$ \\
\hline $.41 \mathrm{E}-02$ & $3.42 \mathrm{E}+00$ & $8.67 E-01$ & . & 1. $71 \mathrm{E}+00$ & $2.04 \mathrm{E}+00$ & $2.30 \mathrm{E}+00$ & $2.58 \mathrm{E}+00$ \\
\hline 2 & $3.42 \mathrm{E}+00$ & . & $7.35 E-01$ & 1. $71 \mathrm{E}+$ & & & \\
\hline (1) & & & & & & & $2.58 \mathrm{E}+00$ \\
\hline 02 & & & & & & & \\
\hline $9 E-02$ & & & 01 & & & & \\
\hline $.51 \mathrm{E}-02$ & $3.41 \mathrm{E}+00$ & $8.70 E-01$ & $7.38 E-01$ & $1.71 \mathrm{E}+00$ & $2.04 \mathrm{E}+$ & $2.30 \mathrm{E}+00$ & $58 \mathrm{E}+00$ \\
\hline $53 E-02$ & $3.41 \mathrm{E}+00$ & $0.10 \pm-4$ & $7.39 \mathrm{E}-01$ & $1.11 E+00$ & & & $2.58 \mathrm{E}+00$ \\
\hline $54 \mathrm{E}-02$ & $3.41 \mathrm{E}+00$ & $8.71 E-01$ & 7. $39 \mathrm{E}-01$ & 1. $71 \mathrm{E}+00$ & & & $2.58 \mathrm{E}+00$ \\
\hline 2 & $.1 \pm$ & 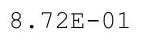 & 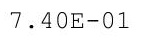 & $1.71 \mathrm{E}+00$ & $2.05 E+00$ & $2.29 \mathrm{E}+00$ & $2.58 \mathrm{E}+00$ \\
\hline 2 & $3.40 \mathrm{E}+00$ & 1 & . & $1.71 \mathrm{E}+00$ & & & $B E+00$ \\
\hline $60 \mathrm{E}-02$ & $3.40 \mathrm{E}+00$ & $8.73 E-01$ & $7.42 \mathrm{E}-01$ & 1. $71 \mathrm{E}+00$ & $2.05 \mathrm{E}+$ & $2.29 \mathrm{E}+00$ & $2.58 \mathrm{E}+00$ \\
\hline$E-02$ & $3.40 \mathrm{E}+00$ & 01 & 7.4 & $1.71 \mathrm{E}+00$ & & $E+00$ & $E+00$ \\
\hline & $3.40 \mathrm{E}+00$ & & & & & & \\
\hline $66 \mathrm{E}-02$ & $3.40 \mathrm{E}+00$ & $8.75 E-01$ & (ent & $1.1 \perp E+U 0$ & $2.05 E+00$ & $2.29 \mathrm{E}+00$ & $2.58 \mathrm{E}+00$ \\
\hline $.00 \mathrm{~L}-\mathrm{C}$ & $3.40 \mathrm{E}+00$ & $0.10 \pm-0 \perp$ & & $1.71 \mathrm{E}+00$ & $2.05 E+00$ & $2.29 \mathrm{E}+00$ & $2.58 \mathrm{E}+00$ \\
\hline 02 & $.40 E+00$ & $5 E-01$ & $E-01$ & 1. $71 \mathrm{E}+00$ & $.05 E+00$ & $2.29 \mathrm{E}+00$ & $.58 \mathrm{E}+00$ \\
\hline
\end{tabular}


RESRAD-OFFSITE, Version 2.5

$\mathrm{T}^{1 / 2}$ Limit $=180$ days

robabilistic Dose and Risk Report

Title : Offsite Resident Farmer

File : RF TC99 DOESG FWD-FV2all.ROF

Summary of dose at graphical times, reptition 1 (continued)

Time

Years

9. $43 \mathrm{E}+02$

$9.44 \mathrm{E}+02$

$9.44 \mathrm{E}+02$

9. $45 \mathrm{E}+02$

$9.45 \mathrm{E}+02$

$9.46 \mathrm{E}+02$

$9.46 \mathrm{E}+02$

$9.47 \mathrm{E}+02$

$9.47 \mathrm{E}+02$

$9.48 \mathrm{E}+02$

$9.48 \mathrm{E}+02$

$9.49 \mathrm{E}+02$

$9.50 \mathrm{E}+02$

$9.50 \mathrm{E}+02$

$9.51 \mathrm{E}+02$

$9.51 \mathrm{E}+02$

$9.52 \mathrm{E}+02$

$9.52 \mathrm{E}+02$

$9.53 \mathrm{E}+02$

$9.53 \mathrm{E}+02$

$9.54 \mathrm{E}+02$

$9.54 \mathrm{E}+02$

$9.55 \mathrm{E}+02$

$9.55 \mathrm{E}+02$

$9.56 \mathrm{E}+02$

$9.56 \mathrm{E}+02$

$9.57 \mathrm{E}+02$

$9.57 \mathrm{E}+02$

$9.58 \mathrm{E}+02$

$9.58 \mathrm{E}+02$

$9.59 \mathrm{E}+02$

$9.59 \mathrm{E}+02$

$9.60 \mathrm{E}+02$

$9.60 \mathrm{E}+02$

$9.61 \mathrm{E}+02$

$9.61 \mathrm{E}+02$

$9.62 \mathrm{E}+02$

$9.62 \mathrm{E}+02$

$9.63 \mathrm{E}+02$

$9.63 \mathrm{E}+02$

$9.64 \mathrm{E}+02$

$9.64 \mathrm{E}+02$

$9.65 \mathrm{E}+02$

$9.65 \mathrm{E}+02$

$9.66 \mathrm{E}+02$

$9.66 \mathrm{E}+02$
Dose statistics at graphical times, mrem/yr

\begin{tabular}{|c|c|c|c|c|c|c|c|}
\hline m & aximum & ea & 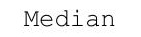 & & & $\%$ & $\%$ \\
\hline 02 & $3.39 \mathrm{E}+00$ & 01 & 1 & $1.71 E+00$ & 00 & -00 & $30 \mathrm{E}+00$ \\
\hline $.73 E-02$ & $3.39 E+00$ & $8.77 E-01$ & $7.46 \mathrm{E}-01$ & $1.71 \mathrm{E}+00$ & +00 & $2.29 \mathrm{E}+00$ & $8 E+00$ \\
\hline $.75 E-02$ & $39 E+00$ & $78 E-01$ & $47 E-01$ & $.71 E+00$ & $2.04 \mathrm{E}+00$ & $2.29 \mathrm{E}+00$ & $58 E+00$ \\
\hline $.77 E-02$ & $.39 \mathrm{E}+00$ & $78 \mathrm{~F}-01$ & $48 F-01$ & $1.71 \mathrm{E}+00$ & $04 \mathrm{~F}+0 \cap$ & $2.29 \mathrm{E}+00$ & $2.58 \mathrm{E}+00$ \\
\hline $.79 E-02$ & $3.39 \mathrm{E}+00$ & 01 & 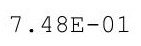 & & & +00 & $E+00$ \\
\hline 02 & $39 E+00$ & & & & & & 00 \\
\hline $.83 E-02$ & $3.38 \mathrm{E}+00$ & & & & & +00 & $E+00$ \\
\hline $.85 E-02$ & $3.38 E+00$ & $\perp$ & $\perp$ & $E+00$ & 00 & +00 & $E+00$ \\
\hline $.87 E-02$ & $38 E+00$ & $1 E-01$ & $E-01$ & $0 \mathrm{E}+00$ & 00 & $E+00$ & $7 \mathrm{E}+00$ \\
\hline$E-02$ & $38 E+00$ & $82 E-01$ & 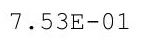 & $.70 \mathrm{E}+00$ & $.04 \mathrm{E}+00$ & $29 F+00$ & $7 \mathrm{E}+00$ \\
\hline 02 & $E+00$ & & & & & 00 & $E+00$ \\
\hline $93 E-02$ & $.38 E+00$ & $\mathrm{~F}$ & 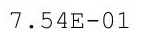 & & & & +00 \\
\hline $.95 E-02$ & $3.37 E+00$ & $8.84 \mathrm{E}-01$ & $7.55 \mathrm{E}-01$ & & & & $2.57 \mathrm{E}+00$ \\
\hline-02 & $3.37 \mathrm{E}+00$ & $8.84 \mathrm{E}-01$ & 7. $56 \mathrm{E}-01$ & 1. $70 \mathrm{E}+00$ & & $2.30 \mathrm{E}+00$ & $57 \mathrm{E}+00$ \\
\hline-02 & $37 E+00$ & $E-01$ & $5-0$ & 0 & & +00 & $7 \mathrm{E}+00$ \\
\hline-02 & +00 & $8.85 E-01$ & 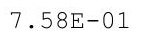 & $\cdot$ & 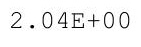 & o & 00 \\
\hline 2 & 00 & $6 E-01$ & & & & 0 & 0 \\
\hline 2 & $7 \mathrm{E}+00$ & $8.87 \mathrm{E}-01$ & 7. $60 \mathrm{E}-01$ & & & & 0 \\
\hline $.06 \mathrm{E}-02$ & $36 \mathrm{E}+00$ & $3875-01$ & $1 F-01$ & 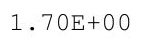 & 的 & $\mathrm{F}+0 \Omega$ & $6 \mathrm{E}+00$ \\
\hline$E-02$ & $.36 E+00$ & $88 E-01$ & 7. $62 \mathrm{E}-01$ & 1. $70 \mathrm{E}+00$ & $2.04 \mathrm{E}+$ & $2.30 E+00$ & $6 E+00$ \\
\hline-02 & $E+00$ & & & & & 0 & $5 E+00$ \\
\hline 2 & & & & & & & \\
\hline 02 & $3.36 \mathrm{E}+00$ & & & $1.71 \mathrm{E}+$ & & & \\
\hline-02 & +00 & $\perp$ & $7.67 \mathrm{E}-01$ & $1.71 \mathrm{E}+$ & & 0 & 00 \\
\hline 2 & $35 \mathrm{E}+00$ & $8.91 \mathrm{E}-01$ & $\perp$ & $1.71 \mathrm{E}+\mathrm{C}$ & $.03 E+$ & 2. $30 \mathrm{E}+$ & $6 \mathrm{E}+$ \\
\hline$E-02$ & $35 E+00$ & $91 F-01$ & $760 F-01$ & 1. $70 \mathrm{E}+00$ & $2.04 \mathrm{E}+$ & $30 \mathrm{E}+0$ & $56 \mathrm{E}+00$ \\
\hline$E-02$ & $3.35 \mathrm{E}+00$ & & & & & $30 E+00$ & $.56 E+00$ \\
\hline-02 & & & & & & & \\
\hline $26 \mathrm{E}-02$ & $3.35 \mathrm{E}+00$ & 0.3 & 1. & & & & 00 \\
\hline $28 E-02$ & $3.34 \mathrm{E}+00$ & $0.94 \square-1$ & $.735-U \perp$ & 1. $71 \mathrm{E}+00$ & $2.04 \mathrm{E}+00$ & $2.30 \mathrm{E}+00$ & $2.55 \mathrm{E}+00$ \\
\hline $30 \mathrm{E}-02$ & $3.34 \mathrm{E}+00$ & $8.94 \mathrm{E}-01$ & . & 1. $71 \mathrm{E}+00$ & $2.04 \mathrm{E}+00$ & $2.30 \mathrm{E}+00$ & $2.55 E+00$ \\
\hline 2 & $3.34 \mathrm{E}+$ & $8.95 E-01$ & $7.74 \mathrm{E}-01$ & $1.71 \mathrm{E}+$ & & & $5 \mathrm{E}+$ \\
\hline 2 & & & & & & & 0 \\
\hline-02 & $3.34 \mathrm{E}+00$ & & 1 & & & & \\
\hline$E-02$ & $3.34 \mathrm{E}+00$ & & 7 & 1. & & & 00 \\
\hline $40 E-02$ & $3.33 E+00$ & $8.97 \mathrm{E}-01$ & $7.77 \mathrm{E}-01$ & $1.71 \mathrm{E}+00$ & $2.01+1$ & $2.00 \mathrm{~L}$ & $5 \mathrm{E}+00$ \\
\hline $41 \mathrm{E}-02$ & $3.33 E+00$ & & & $1.11 E+00$ & & & $2.55 \mathrm{E}+00$ \\
\hline 02 & $3.33 E+00$ & . & & 1. $71 \mathrm{E}+00$ & & & $55 \mathrm{E}+00$ \\
\hline 2 & 3.3 & $8.99 E-01$ & 1 & $1.71 \mathrm{E}+00$ & $2.04 \mathrm{E}+$ & 2 & $5 E+00$ \\
\hline 2 & +00 & 1 & 1 & $1.71 \mathrm{E}+00$ & $2.05 \mathrm{E}+$ & $E+00$ & $5 \mathrm{E}+00$ \\
\hline$E-02$ & $3.32 \mathrm{E}+00$ & $E-01$ & $7.81 \mathrm{E}-01$ & 1.71 & & 00 & $55 E+00$ \\
\hline$E-02$ & $3.32 \mathrm{E}+00$ & 01 & 7. & $1.71 \mathrm{E}+00$ & & 2. & $E+00$ \\
\hline & $3.32 \mathrm{E}+00$ & & & & & & \\
\hline $5 E-02$ & $3.32 \mathrm{E}+00$ & . & . & $1.71 \mathrm{E}+00$ & $2.05 E+00$ & $2.30 \mathrm{E}+00$ & $2.55 E+00$ \\
\hline 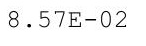 & $3.32 \mathrm{E}+00$ & & & $1.71 \mathrm{E}+00$ & $2.05 E+00$ & $2.30 \mathrm{E}+00$ & $2.55 E+00$ \\
\hline 02 & $.32 E+00$ & $E-01$ & $E-01$ & 1. $71 \mathrm{E}+00$ & $.05 E+00$ & $2.30 \mathrm{E}+00$ & $.55 E+00$ \\
\hline
\end{tabular}


RESRAD-OFFSITE, Version 2.5

$\mathrm{T}^{1 / 2}$ Limit $=180$ days

robabilistic Dose and Risk Report

Title : Offsite Resident Farmer

File : RF TC99 DOESG FWD-FV2all.ROF

Summary of dose at graphical times, reptition 1 (continued)

Time

Years

9. $67 \mathrm{E}+02$

$9.67 \mathrm{E}+02$

9. $68 \mathrm{E}+02$

$9.68 \mathrm{E}+02$

$9.69 \mathrm{E}+02$

$9.70 \mathrm{E}+02$

$9.70 \mathrm{E}+02$

$9.71 \mathrm{E}+02$

$9.71 \mathrm{E}+02$

9. $72 \mathrm{E}+02$

$9.72 \mathrm{E}+02$

$9.73 E+02$

$9.73 \mathrm{E}+02$

$9.74 \mathrm{E}+02$

$9.74 \mathrm{E}+02$

$9.75 \mathrm{E}+02$

$9.75 \mathrm{E}+02$

$9.76 \mathrm{E}+02$

$9.76 \mathrm{E}+02$

$9.77 \mathrm{E}+02$

$9.77 \mathrm{E}+02$

$9.78 \mathrm{E}+02$

$9.78 \mathrm{E}+02$

$9.79 \mathrm{E}+02$

$9.79 \mathrm{E}+02$

$9.80 \mathrm{E}+02$

$9.80 \mathrm{E}+02$

$9.81 \mathrm{E}+02$

$9.81 \mathrm{E}+02$

$9.82 \mathrm{E}+02$

9. $82 \mathrm{E}+02$

$9.83 \mathrm{E}+02$

$9.83 \mathrm{E}+02$

$9.84 \mathrm{E}+02$

$9.84 \mathrm{E}+02$

$9.85 \mathrm{E}+02$

$9.85 \mathrm{E}+02$

$9.86 \mathrm{E}+02$

$9.86 \mathrm{E}+02$

$9.87 \mathrm{E}+02$

$9.87 \mathrm{E}+02$

$9.88 \mathrm{E}+02$

$9.88 \mathrm{E}+02$

$9.89 \mathrm{E}+02$

$9.90 \mathrm{E}+02$

9. $90 \mathrm{E}+02$
Dose statistics at graphical times, mrem/yr

\begin{tabular}{|c|c|c|c|c|c|c|c|}
\hline linimum & Maximum & Mean & Median & 900 & $95 \%$ & $97.5 \%$ & $9 \%$ \\
\hline 2 & $31 E+00$ & 1 & $36 E-01$ & $71 E+00$ & 055 & 2.30 & +00 \\
\hline-02 & $1 \mathrm{E}+00$ & $4 E-01$ & $87 E-01$ & $1.71 \mathrm{E}+00$ & $05 E+00$ & +00 & $55 E+00$ \\
\hline$E-02$ & -00 & $4 E-01$ & $88 E-01$ & 0 & 0 & Do & $5 E+00$ \\
\hline$E-02$ & +00 & $E-01$ & 01 & 0 & & Do & $\mathrm{E}+00$ \\
\hline $69 \mathrm{E}-02$ & $3.31 E+00$ & & & & $05 E+00$ & $E+00$ & $55 E+00$ \\
\hline $.71 \mathrm{E}-02$ & 00 & 1 & & & & 00 & $5 E+00$ \\
\hline $.73 E-02$ & $3.30 \mathrm{E}+00$ & $6 E-01$ & $92 E-01$ & $1.71 \mathrm{E}+00$ & $4 \mathrm{E}+$ & +00 & $5 E+00$ \\
\hline $.75 E-02$ & $3.30 E+00$ & . & $7.92 \mathrm{E}-01$ & $1.71 \mathrm{E}+00$ & $2.04 \mathrm{E}+00$ & \pm+00 & $2.55 E+00$ \\
\hline$E-02$ & +00 & $E-01$ & 01 & $1.71 \mathrm{E}$ & 0 & 00 & 00 \\
\hline $9 E-02$ & $3.30 \mathrm{E}+00$ & 9 & & $1.71 \mathrm{I}$ & $\mathrm{S}^{-1}$ & 00 & $E+00$ \\
\hline$E-02$ & & 9 & & & & & $\mathrm{E}+00$ \\
\hline-02 & +00 & 1 & 1 & $71=$ & 0 & Do & $E+00$ \\
\hline $.86 \mathrm{E}-02$ & $3.29 \mathrm{E}+00$ & $9.1 U E-U 1$ & $7.95 \mathrm{E}-01$ & $1.11 E+00$ & ИБT & $2.3 \perp E+U 0$ & $5 E+00$ \\
\hline $.88 E-02$ & $3.29 \mathrm{E}+00$ & $. \perp U E-U \perp$ & $7.96 \mathrm{E}-01$ & $\perp \cdot T \perp E T U U$ & $2.045 T 00$ & 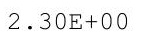 & $E+00$ \\
\hline$E-02$ & $3.29 \mathrm{E}+00$ & . & & 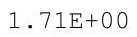 & $2.01+4$ & 00 & -00 \\
\hline $.92 \mathrm{E}-02$ & $3.29 \mathrm{E}+00$ & $9.11 \mathrm{E}-01$ & $7.98 \mathrm{E}-01$ & $1.71 \mathrm{E}+00$ & $2.04 \mathrm{E}+00$ & $2.30 \mathrm{E}+00$ & $4 \mathrm{E}+00$ \\
\hline $.94 E-02$ & $3.28 E+00$ & $9.12 \mathrm{E}-01$ & $7.99 \mathrm{E}-01$ & & & $\mathrm{DE}+00$ & $4 E+00$ \\
\hline $6 E-02$ & $\mathrm{E}+00$ & $2 E-01$ & $E-01$ & 17 & 0 & 0 & $4 E+00$ \\
\hline $.98 \mathrm{E}-02$ & $3.28 \mathrm{E}+00$ & $9.13 \mathrm{E}-01$ & $8.00 \mathrm{E}-01$ & $1.71 \mathrm{E}+00$ & $2.04 \mathrm{E}+00$ & 2 . & $4 \mathrm{E}+00$ \\
\hline $.00 E-02$ & $3.28 \mathrm{E}+00$ & $4+-U 1$ & 01 & $1.1 \angle \mathrm{E}$ & 0 & 00 & +00 \\
\hline $.02 E-02$ & $3.28 E+00$ & $9.14 \mathrm{E}-01$ & & I. ILLTU & & 0 & +00 \\
\hline $.04 \mathrm{E}-02$ & $3.27 E+00$ & $9.15 \mathrm{E}-$ & 1 & $1 \cdot 7 \angle \mathrm{D}$ & 2.040 & 00 & $\mathrm{E}+00$ \\
\hline $.06 E-02$ & $3.27 E+00$ & $5 E-$ & $4 E-01$ & $1.72 \mathrm{E}+00$ & $2.04 \mathrm{E}+$ & $0 E+00$ & $4 \mathrm{E}+00$ \\
\hline $.08 E-02$ & $3.27 E+00$ & $E-01$ & $4 E-01$ & $1.72 \mathrm{E}+$ & $2.04 \mathrm{E}+$ & $2.30 E+00$ & $3 E+00$ \\
\hline$E-02$ & $3.27 \mathrm{E}+00$ & $E-01$ & 01 & $1.72 \mathrm{E}+$ & 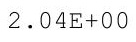 & & $3 E+00$ \\
\hline$E-02$ & $E+00$ & 1 & 1 & 1.72 & U & 00 & +00 \\
\hline$E-02$ & $3.26 \mathrm{E}+00$ & $7 \pm-01$ & $.05 E-01$ & $1.72 \mathrm{E}+00$ & 1 & & $3 E+00$ \\
\hline $16 \mathrm{E}-02$ & $3.26 \mathrm{E}+00$ & $9.18 \mathrm{E}-01$ & $8.06 \mathrm{E}-01$ & $1.72 \mathrm{E}+00$ & $2.04 \mathrm{E}+00$ & $2.30 \mathrm{E}+00$ & $2.53 E+00$ \\
\hline $.18 E-02$ & . 20 स & $9.18 \mathrm{E}-01$ & $8.06 \mathrm{E}-01$ & $1.72 \mathrm{E}+00$ & 2.04010 & $2.00 \mathrm{~L}$ & $2.53 E+00$ \\
\hline 2 & $3.26 \mathrm{E}+00$ & & 1 & 1. $72 \mathrm{E}+$ & $2.04 \mathrm{E}$ & 2 . & $2 \mathrm{E}+00$ \\
\hline 02 & $3.26 \mathrm{E}+00$ & 1 & 1 & $172 \mathrm{~F}+$ & 0 & $0 E+00$ & $2 E+00$ \\
\hline$E-02$ & $\mathrm{E}+00$ & 9 & 1 & $1.72 \mathrm{E}$ & U & $E+00$ & -00 \\
\hline $26 \mathrm{E}-02$ & $3.25 \mathrm{E}+00$ & $9.20 \mathrm{E}-01$ & $0 E-01$ & $1.72 \mathrm{E}+$ & 2. & 00 & $2 \mathrm{E}+00$ \\
\hline $.28 \mathrm{E}-02$ & $3.25 \mathrm{E}+00$ & $9.21 \mathrm{E}-01$ & $8.10 \mathrm{E}-01$ & $1.72 \mathrm{E}+00$ & $2.04 \mathrm{E}+00$ & $2.30 \mathrm{E}+00$ & $2.52 \mathrm{E}+00$ \\
\hline $31 \mathrm{E}-02$ & $3 . \angle 3 E+U 0$ & $9.21 \mathrm{E}-$ & & $1.72 \mathrm{E}+00$ & $2.03 E+00$ & & $2.52 E+00$ \\
\hline $.33 E-02$ & & & & & 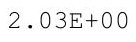 & & 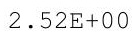 \\
\hline 2 & 只 & 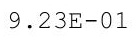 & . & גיתר & (2) & $0 \mathrm{E}+00$ & $2 \mathrm{E}+00$ \\
\hline 2 & $.24 \mathrm{E}+00$ & 1 & & 0 & 0 & 00 & \\
\hline 2 & & 9. & & 1.7 & 2.03 & & $2 \mathrm{E}+00$ \\
\hline $41 \mathrm{E}-02$ & $3.24 \mathrm{E}+00$ & 9. & & 1.72 & 0 & & $2.52 \mathrm{E}+00$ \\
\hline$E-02$ & $3.24 \mathrm{E}+00$ & 1 & & 1. $72 \mathrm{E}+$ & $2.03 E+$ & & $2.52 \mathrm{E}+00$ \\
\hline $5 E-02$ & $3.23 E+00$ & 1 & 1 & 1. $72 \mathrm{E}+00$ & 2.035 & $2.30 \mathrm{E}+00$ & $2.52 E+00$ \\
\hline$Z$ & $\mathrm{~s}$ & 9 & 1 & 0 & $2.03 \mathrm{E}$ & $2.50 \mathrm{E}$ & 2.025 \\
\hline 2 & & & & 00 & 2. & $2.29 \mathrm{E}$ & $2.52 \mathrm{E}$ \\
\hline-02 & $E+00$ & $E-01$ & 8.1 & 1. $72 \mathrm{E}+00$ & $2.03 \mathrm{E}$ & $E+00$ & $2.52 \mathrm{E}+00$ \\
\hline $.53 E-02$ & $23 E+00$ & $27 E-01$ & $.16 \mathrm{E}-01$ & $1.73 \mathrm{E}+00$ & $E+00$ & $2.29 E+00$ & $2.52 \mathrm{E}+00$ \\
\hline
\end{tabular}


RESRAD-OFFSITE, Version 2.5

$\mathrm{T}^{1 / 2}$ Limit $=180$ days

robabilistic Dose and Risk Report

Title : Offsite Resident Farmer

File : RF TC99 DOESG FWD-FV2all.ROF

Summary of dose at graphical times, reptition 1 (continued)

Time

Years

9. $91 \mathrm{E}+02$

9. $91 \mathrm{E}+02$

9. $92 \mathrm{E}+02$

9. $92 \mathrm{E}+02$

9. $93 \mathrm{E}+02$

$9.93 \mathrm{E}+02$

9. $94 \mathrm{E}+02$

$9.94 \mathrm{E}+02$

9. $95 \mathrm{E}+02$

$9.95 \mathrm{E}+02$

$9.96 \mathrm{E}+02$

$9.96 \mathrm{E}+02$

$9.97 \mathrm{E}+02$

$9.97 \mathrm{E}+02$

9. $98 \mathrm{E}+02$

$9.98 \mathrm{E}+02$

$9.99 \mathrm{E}+02$

9. $99 \mathrm{E}+02$

$1.00 \mathrm{E}+03$

$1.00 \mathrm{E}+03$

$1.00 \mathrm{E}+03$

$1.00 \mathrm{E}+03$

$1.00 \mathrm{E}+03$

$1.00 \mathrm{E}+03$

$1.00 \mathrm{E}+03$

$1.00 \mathrm{E}+03$

$1.00 \mathrm{E}+03$

$1.00 \mathrm{E}+03$

$1.00 \mathrm{E}+03$

$1.01 \mathrm{E}+03$

$1.01 \mathrm{E}+03$

$1.01 \mathrm{E}+03$

$1.01 \mathrm{E}+03$

$1.01 \mathrm{E}+03$

$1.01 \mathrm{E}+03$

$1.01 \mathrm{E}+03$

$1.01 \mathrm{E}+03$

$1.01 \mathrm{E}+03$

$1.01 \mathrm{E}+03$

$1.01 \mathrm{E}+03$

$1.01 \mathrm{E}+03$

$1.01 \mathrm{E}+03$

$1.01 \mathrm{E}+03$

$1.01 \mathrm{E}+03$

$1.01 \mathrm{E}+03$

$1.01 \mathrm{E}+03$
Dose statistics at graphical times, mrem/yr

\begin{tabular}{|c|c|c|c|c|c|c|c|}
\hline m & m & Mean & ledian & & & $\%$ & \\
\hline 02 & $3.22 \mathrm{E}+00$ & $9.28 \mathrm{E}-01$ & $8.16 \mathrm{E}-01$ & $1.73 \mathrm{E}+00$ & $2.03 E+00$ & $2.29 \mathrm{E}+00$ & $2.52 \mathrm{E}+00$ \\
\hline-02 & +00 & 01 & 01 & 00 & 00 & +00 & $\Xi+00$ \\
\hline $60 \mathrm{E}-02$ & $3.22 \mathrm{E}+00$ & $9 E-01$ & $8.17 \mathrm{E}-01$ & $1.73 \mathrm{E}+00$ & $2.03 E+00$ & $2.29 \mathrm{E}+00$ & $2.51 \mathrm{E}+00$ \\
\hline $62 \mathrm{E}-02$ & $3.22 E+00$ & $.29 \mathrm{E}-01$ & $3.18 \mathrm{E}-01$ & $1.73 \mathrm{E}+00$ & $2.03 E+00$ & $2.29 \mathrm{E}+00$ & $51 E+00$ \\
\hline 02 & $3.22 \mathrm{E}+00$ & 01 & 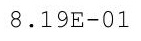 & $1.73 \mathrm{E}+00$ & $2.03 \mathrm{E}$ & $2.28 \mathrm{E}+00$ & $1 \mathrm{E}+00$ \\
\hline 02 & $E+00$ & -1 & & & & & +00 \\
\hline $68 \mathrm{E}-02$ & $3.21 \mathrm{E}+$ & 1 & & & & & +00 \\
\hline $.70 \mathrm{E}-02$ & $3.21 \mathrm{E}+00$ & & & & & +00 & +00 \\
\hline $72 \mathrm{E}-02$ & +00 & $E-01$ & $\perp$ & $73 E+00$ & 00 & +00 & +00 \\
\hline 2 & $3.21 \mathrm{E}+00$ & 1 & $\perp$ & 0 & $3=$ & $E+00$ & $E+00$ \\
\hline 2 & $3.20 \mathrm{E}+00$ & $9.33 \mathrm{E}-01$ & $8.25 E-01$ & 0 & גבת קט & $3 E+00$ & $50 \mathrm{E}+00$ \\
\hline$E-02$ & $E+00$ & & & 0 & 0 & -00 & +00 \\
\hline$F-02$ & $0 F+00$ & $F_{-}$ & 1 & 0 & & 0 & +00 \\
\hline $.83 E-02$ & $3.20 \mathrm{E}+00$ & $9.34 \mathrm{E}-01$ & $8.27 \mathrm{E}-01$ & $1.73 \mathrm{E}+00$ & $2.03 E+00$ & $2.28 \mathrm{E}+00$ & $2.50 \mathrm{E}+00$ \\
\hline $85 E-02$ & $3.20 \mathrm{E}+00$ & $E-01$ & 1 & $73 E+00$ & 00 & $\mathrm{E}+00$ & $\mathrm{E}+00$ \\
\hline 2 & & & & & & 00 & 00 \\
\hline $9 E-02$ & & $9.36 \mathrm{E}-01$ & $8.30 E-01$ & 1.73 & 0 & 0 & 00 \\
\hline 2 & & $9.36 \mathrm{E}-01$ & & & & & 0 \\
\hline $93 \mathrm{~F}-02$ & $.19 \mathrm{E}+00$ & $75-01$ & קט & $1.73 \mathrm{E}+00$ & (2) & +00 & +00 \\
\hline $95 E-02$ & $.18 \mathrm{E}+00$ & $.37 E-01$ & $.32 E-01$ & $1.73 \mathrm{E}+00$ & $2.04 \mathrm{E}+00$ & $2.27 \mathrm{E}+00$ & $2.50 \mathrm{E}+00$ \\
\hline $98 E-02$ & $3.18 \mathrm{E}+00$ & $9.38 E-01$ & $32 \mathrm{E}-01$ & $1.73 E+00$ & 0 & $2.27 \mathrm{E}+00$ & $50 \mathrm{E}+00$ \\
\hline & & & & & & & $50 E+00$ \\
\hline & & & & $.73 \mathrm{E}$ & & & \\
\hline 年 & $.18 \mathrm{E}+00$ & $\perp$ & & $\perp \cdot 10 \mathrm{D}$ & & ( & 00 \\
\hline 1 & $.17 \mathrm{E}$ & $9.40 \mathrm{E}-01$ & $\perp$ & $1.73 \mathrm{E}+00$ & $04 \mathrm{E}+$ & קית ת & 00 \\
\hline $01 \mathrm{E}-01$ & $.17 \mathrm{E}+00$ & $40 F-01$ & כ & 1. $73 \mathrm{E}+00$ & $.04 \mathrm{E}+0$ & $.28 E+00$ & $50 \mathrm{E}+00$ \\
\hline-01 & $3.17 \mathrm{E}+00$ & $11 \mathrm{~F}-01$ & $E-01$ & $1.73 E+00$ & $2.04 \mathrm{E}+00$ & $2.28 E+00$ & $2.50 \mathrm{E}+00$ \\
\hline 1 & & & & & & & \\
\hline 01 & $17 \mathrm{E}+00$ & & & & & & \\
\hline $.02 E-01$ & $3.16 \mathrm{E}+00$ & $.4 \angle D-1$ & 01 & $1.73 E+00$ & $2.04 \mathrm{E}+$ & $2.27 \mathrm{E}+00$ & $2.50 \mathrm{E}+00$ \\
\hline$\cdot 0 \angle \mathrm{L}-U \perp$ & $3.16 \mathrm{E}+00$ & . & $0.3 / 2-01$ & $1.73 E+00$ & $2.04 \mathrm{LT} 0$ & $\angle . \angle I L T O 0$ & $2.50 E+00$ \\
\hline 然 & $3.16 \mathrm{E}+00$ & . & & 1. $73 \mathrm{E}+00$ & $2.04 \mathrm{E}+$ & & $2.50 \mathrm{E}+00$ \\
\hline$F-01$ & $3.16 \mathrm{E}+00$ & 13न & $E-01$ & $1.73 E+00$ & & & $2.50 \mathrm{E}+00$ \\
\hline $.03 E-01$ & & & & & & & \\
\hline$E-01$ & & & & & & & \\
\hline & $15 \mathrm{E}+$ & 01 & 1 & $1 . / 3 E T$ & 2.010 & 2.214 & $2.50 \mathrm{E}+00$ \\
\hline $03 E-01$ & $3.15 \mathrm{E}+00$ & . & & 1.73E+ & & & $0 \mathrm{E}+00$ \\
\hline $2-0 \perp$ & & & & 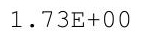 & & & \\
\hline $0 \triangle F-01$ & 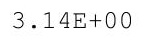 & 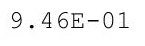 & & ter & & & $2.49 \mathrm{E}+00$ \\
\hline & & & & $73 E+00$ & & & \\
\hline 1 & $3.14 \mathrm{E}+00$ & 9.4 & 1 & $1.73 E+00$ & & $2.27 \mathrm{E}+00$ & $2.49 \mathrm{E}+00$ \\
\hline E-01 & $3.14 \mathrm{E}+00$ & $9.48 E-01$ & 01 & $1.73 \mathrm{E}+00$ & & 00 & $9 \mathrm{E}+00$ \\
\hline & & & & & & & \\
\hline & $3.13 \mathrm{E}+00$ & $\perp$ & $\perp$ & $1.13 E+00$ & $2.04 \mathrm{E}+00$ & $2.27 E+00$ & $2.49 \mathrm{E}+00$ \\
\hline & & . & & $1.73 E+00$ & & $2.27 E+00$ & $2.49 \mathrm{E}+00$ \\
\hline $05 E-01$ & $.13 E+00$ & $E-01$ & $8 E-01$ & $.73 E+00$ & $.04 E+00$ & $.27 E+00$ & $.49 E+00$ \\
\hline
\end{tabular}


RESRAD-OFFSITE, Version 2.5

$\mathrm{T}^{1 / 2}$ Limit $=180$ days

obabilistic Dose and Risk Report

Title : Offsite Resident Farmer

File : RF TC99 DOESG FWD-FV2all.ROF

Summary of dose at graphical times, reptition 1 (continued)

Time

Years

1. $01 \mathrm{E}+03$

$1.01 \mathrm{E}+03$

1. $02 \mathrm{E}+03$

1. $02 \mathrm{E}+03$

1. $02 \mathrm{E}+03$

$1.02 \mathrm{E}+03$

$1.02 \mathrm{E}+03$

1. $02 \mathrm{E}+03$

1. $02 \mathrm{E}+03$

1. $02 \mathrm{E}+03$

1. $02 \mathrm{E}+03$

1. $02 \mathrm{E}+03$

1. $02 \mathrm{E}+03$

1. $02 \mathrm{E}+03$

$1.02 \mathrm{E}+03$

1. $02 \mathrm{E}+03$

$1.02 \mathrm{E}+03$

$1.02 \mathrm{E}+03$

1. $02 \mathrm{E}+03$

1. $02 \mathrm{E}+03$

$1.02 \mathrm{E}+03$

1. $02 \mathrm{E}+03$

$1.03 \mathrm{E}+03$

1. $03 \mathrm{E}+03$

$1.03 \mathrm{E}+03$

$1.03 E+03$

$1.03 E+03$

$1.03 E+03$

$1.03 \mathrm{E}+03$

1. $03 \mathrm{E}+03$

1. $03 \mathrm{E}+03$

$1.03 E+03$

$1.03 E+03$

$1.03 E+03$

$1.03 E+03$

$1.03 \mathrm{E}+03$

$1.03 E+03$

1. $03 \mathrm{E}+03$

$1.03 E+03$

$1.03 E+03$

$1.03 E+03$

$1.04 \mathrm{E}+03$

$1.04 \mathrm{E}+03$

$1.04 \mathrm{E}+03$

$1.04 \mathrm{E}+03$

$1.04 \mathrm{E}+03$

Dose statistics at graphical times, mrem/yr

\begin{tabular}{|c|c|c|c|c|c|c|c|}
\hline inimum & laximum & Mean & ledian & $\%$ & $5 \%$ & $97.5 \%$ & $\%$ \\
\hline $5 E-01$ & $3.13 \mathrm{E}+00$ & $9.50 \mathrm{E}-01$ & $.49 \mathrm{E}-01$ & $1.73 \mathrm{E}+00$ & $2.04 \mathrm{E}+00$ & $2.27 E+00$ & $2.49 \mathrm{E}+00$ \\
\hline$E-01$ & +00 & 1 & 1 & 0 & 00 & +00 & $9 E+00$ \\
\hline$E-01$ & +00 & 01 & 01 & & & 00 & +00 \\
\hline 01 & $E+00$ & & & & & 00 & +00 \\
\hline-01 & +00 & 1 & & $73 E+00$ & & +00 & $49 E+00$ \\
\hline $.06 \mathrm{E}-01$ & $3.12 \mathrm{E}+00$ & $2 E-01$ & -01 & $1.73 \mathrm{E}+00$ & $4 \mathrm{E}+00$ & $E+00$ & $49 E+00$ \\
\hline 01 & $11 \mathrm{E}+00$ & 01 & 1 & 0 & 0 & $6 \mathrm{E}+00$ & $49 E+00$ \\
\hline $.07 E-01$ & $3.11 E+00$ & . & & 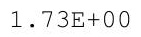 & 2.00100 & +00 & +00 \\
\hline $.07 E-01$ & $E+00$ & & & & & +00 & \pm+00 \\
\hline $.07 \mathrm{E}-01$ & $3.11 \mathrm{E}+00$ & $4 E-01$ & & & & & $49 E+00$ \\
\hline$E-01$ & $E+00$ & $E-01$ & 1 & 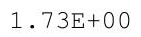 & 0 & $E+00$ & $9 E+00$ \\
\hline-01 & $10 \mathrm{E}+00$ & -01 & & 00 & 0 & $E+00$ & $49 E+00$ \\
\hline $08 \mathrm{E}-01$ & $3.10 \mathrm{E}+00$ & $\perp$ & 01 & $1.13 \mathrm{E}+00$ & . & +00 & $\mathrm{E}+00$ \\
\hline 01 & 0 & $9.56 \mathrm{E}-01$ & $8.58 \mathrm{E}-01$ & 0 & 0 & 0 & 00 \\
\hline 01 & $E+00$ & & & $\cdots 1$ & & 0 & 00 \\
\hline $.09 \mathrm{E}-01$ & $\mathrm{E}+00$ & 1 & & 0 & 0 & +00 & $9 \mathrm{E}+00$ \\
\hline $09 E-01$ & $3.09 \mathrm{E}+00$ & $9.57 \mathrm{E}-01$ & $8.61 \mathrm{E}-01$ & $1.72 \mathrm{E}+00$ & $2.02 \mathrm{E}+00$ & $2.25 \mathrm{E}+00$ & $2.49 \mathrm{E}+00$ \\
\hline-01 & $.09 E+00$ & $3 E-01$ & $E-01$ & $1.72 \mathrm{E}+00$ & 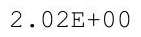 & $2.25 E+00$ & $2.49 \mathrm{E}+00$ \\
\hline 01 & +00 & & & & & 0 & -00 \\
\hline 01 & $E+00$ & $\perp$ & $0 \perp$ & $1.72 \mathrm{E}+00$ & 0 & 0 & +00 \\
\hline 1 & 0 & $9.59 \mathrm{E}-01$ & & 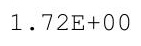 & & & 00 \\
\hline$E-01$ & $.08 E+00$ & 1 & $\perp$ & 1 & & & $E+00$ \\
\hline$E-01$ & $.08 E+00$ & $0 F-01$ & $.65 E-01$ & $1.72 \mathrm{E}+00$ & $02 E+00$ & $.24 \mathrm{E}+00$ & $.49 E+00$ \\
\hline-01 & $.08 E+00$ & $=01$ & $=01$ & 1. $72 \mathrm{E}+00$ & $.02 \mathrm{E}+00$ & $.24 \mathrm{E}+00$ & $.49 E+00$ \\
\hline 01 & $07 E+00$ & & & 0 & & $4 \mathrm{E}+00$ & $.49 \mathrm{E}+00$ \\
\hline & & & & & & & 00 \\
\hline & & & & $1.72 \mathrm{E}+00$ & & 00 & +00 \\
\hline $11 \mathrm{E}-01$ & $3.07 \mathrm{E}+00$ & $\cdot 0<+$ & .00 & $1.72 \mathrm{E}+00$ & $2.02 E+00$ & $.25 E+00$ & $2.49 \mathrm{E}+00$ \\
\hline 1 & $3.07 \mathrm{E}+00$ & 1 & 1 & $1.72 \mathrm{E}+00$ & $2.02 \mathrm{E}+$ & $2.25 \mathrm{E}+00$ & $.49 E+00$ \\
\hline $2 \mathrm{~F}-01$ & $3.06 \mathrm{E}+00$ & $=01$ & & 1. $72 \mathrm{E}+00$ & & $25 F+00$ & $2.49 \mathrm{E}+00$ \\
\hline 01 & $3.06 \mathrm{E}+00$ & & & & & & \\
\hline 01 & & & & & & & $2.49 \mathrm{E}+00$ \\
\hline 01 & & & & $1 \cdot 12$ & $2.0<1$ & $E+00$ & +00 \\
\hline $.13 E-01$ & $3.05 \mathrm{E}+00$ & $9.05 E-U 1$ & $8.68 \mathrm{E}-01$ & $1.72 \mathrm{E}+00$ & $2.0<D 1$ & $2.25 \mathrm{E}+00$ & $2.49 \mathrm{E}+00$ \\
\hline $13 E-01$ & $3.05 \mathrm{E}+00$ & $9.035-U 1$ & & $1.1 \angle E+U 0$ & & & $2.49 \mathrm{E}+00$ \\
\hline 1 & $3.05 \mathrm{E}+$ & 1 & 1 & & & & $2.49 \mathrm{E}+00$ \\
\hline 1 & & & & & & & $2.49 \mathrm{E}+00$ \\
\hline 1 & & $9.66 \mathrm{E}-01$ & 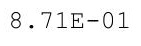 & & & & \\
\hline$E-01$ & & 01 & 01 & $1 \mathrm{E}+00$ & $2.02 \mathrm{E}$ & $2.24 \mathrm{E}+00$ & $2.49 \mathrm{E}+00$ \\
\hline $14 \mathrm{E}-01$ & $3.04 \mathrm{E}+00$ & $9.01 \mathrm{E}$ & 1 & $1.71 \mathrm{E}+00$ & - & & $2.49 \mathrm{E}+00$ \\
\hline $4 E-01$ & $3.04 \mathrm{E}+00$ & .000 & $\perp$ & $1.1 \perp \mathrm{E}$ & & & $2.49 \mathrm{E}+00$ \\
\hline $4 E-01$ & $3.04 \mathrm{E}+00$ & $9.00 \mathrm{~L}-\mathrm{L}$ & $45-01$ & $1.71 \mathrm{E}+00$ & $2.02 \mathrm{E}+00$ & $2.23 E+00$ & $2.49 \mathrm{E}+00$ \\
\hline 1 & $3.03 E+00$ & $9.00 \mathrm{~L}$ & & $1.71 \mathrm{E}+00$ & $2.01 E+00$ & $2.23 E+00$ & $2.49 \mathrm{E}+00$ \\
\hline 1 & $3.03 E+00$ & & 1 & $71 \mathrm{E}+00$ & $01 E+00$ & $2.23 E+00$ & $2.48 \mathrm{E}+00$ \\
\hline $5 E-01$ & $3.03 E+00$ & $E-01$ & $E-01$ & $1.71 \mathrm{E}+00$ & $2.01 E+00$ & $2.23 \mathrm{E}+00$ & $2.48 \mathrm{E}+00$ \\
\hline$E-01$ & $03 E+00$ & $0 \mathrm{E}-01$ & $77 \mathrm{E}-01$ & $1.71 \mathrm{E}+00$ & $01 E+00$ & $.23 E+00$ & $2.48 \mathrm{E}+00$ \\
\hline
\end{tabular}


RESRAD-OFFSITE, Version 2.5

$\mathrm{T}^{1 / 2}$ Limit $=180$ days

robabilistic Dose and Risk Report

Title : Offsite Resident Farmer

File : RF TC99 DOESG FWD-FV2all. ROF

Time

Years

$1.04 \mathrm{E}+03$

$1.04 \mathrm{E}+03$

$1.04 \mathrm{E}+03$

$1.04 \mathrm{E}+03$

$1.04 \mathrm{E}+03$

$1.04 \mathrm{E}+03$

$1.04 \mathrm{E}+03$

$1.04 \mathrm{E}+03$

$1.04 \mathrm{E}+03$

1. $04 \mathrm{E}+03$

$1.04 \mathrm{E}+03$

1. $04 \mathrm{E}+03$

1. $04 \mathrm{E}+03$

1. $04 \mathrm{E}+03$

$1.04 \mathrm{E}+03$

1. $05 \mathrm{E}+03$

1. $05 \mathrm{E}+03$

1. $05 \mathrm{E}+03$

1. $05 \mathrm{E}+03$

1. $05 \mathrm{E}+03$

1. $05 \mathrm{E}+03$

1. $05 \mathrm{E}+03$

1. $05 \mathrm{E}+03$

1. $05 \mathrm{E}+03$

1. $05 \mathrm{E}+03$

Summary of dose at graphical times, reptition 1 (continued)

Dose statistics at graphical times, mrem/yr

\begin{tabular}{|c|c|c|c|c|c|c|c|}
\hline Minimum & Maximum & Mean & Median & $90 \%$ & $95 \%$ & $97.5 \%$ & $99 \%$ \\
\hline $.15 \mathrm{E}-01$ & $3.02 \mathrm{E}+00$ & $9.70 E-01$ & $8.78 E-01$ & $1.71 \mathrm{E}+00$ & $2.01 E+00$ & $2.23 E+00$ & $2.48 \mathrm{E}+00$ \\
\hline $1.16 \mathrm{E}-01$ & $3.02 E+00$ & $9.70 \mathrm{E}-01$ & $8.79 \mathrm{E}-01$ & $1.71 \mathrm{E}+00$ & $2.01 \mathrm{E}+00$ & $2.23 E+00$ & $2.48 \mathrm{E}+00$ \\
\hline 1. $16 \mathrm{E}-01$ & $3.02 \mathrm{E}+00$ & $9.71 \mathrm{E}-01$ & $8.80 \mathrm{E}-01$ & $1.71 \mathrm{E}+00$ & $2.01 \mathrm{E}+00$ & $2.23 \mathrm{E}+00$ & $2.48 \mathrm{E}+00$ \\
\hline $.16 \mathrm{E}-01$ & $3.02 \mathrm{E}+00$ & $9.71 \mathrm{E}-01$ & $8.81 \mathrm{E}-01$ & $1.71 \mathrm{E}+00$ & $2.01 \mathrm{E}+00$ & $2.23 E+00$ & $2.48 \mathrm{E}+00$ \\
\hline $1.16 \mathrm{E}-01$ & $3.02 \mathrm{E}+00$ & $9.72 \mathrm{E}-01$ & $8.81 E-01$ & $1.71 \mathrm{E}+00$ & $2.01 E+00$ & $2.23 E+00$ & $2.48 \mathrm{E}+00$ \\
\hline $1.17 \mathrm{E}-01$ & $3.01 \mathrm{E}+00$ & $9.72 \mathrm{E}-01$ & $8.82 \mathrm{E}-01$ & $1.71 \mathrm{E}+00$ & $2.01 E+00$ & $2.23 E+00$ & $2.48 \mathrm{E}+00$ \\
\hline $1.17 \mathrm{E}-01$ & $3.01 \mathrm{E}+00$ & $9.73 E-01$ & $8.82 E-01$ & $1.71 \mathrm{E}+00$ & $2.01 E+00$ & $2.23 E+00$ & $2.48 \mathrm{E}+00$ \\
\hline $1.17 \mathrm{E}-01$ & $3.01 \mathrm{E}+00$ & $9.73 \mathrm{E}-01$ & $8.83 \mathrm{E}-01$ & $1.71 \mathrm{E}+00$ & $2.01 \mathrm{E}+00$ & $2.23 E+00$ & $2.48 \mathrm{E}+00$ \\
\hline $1.17 \mathrm{E}-01$ & $3.01 \mathrm{E}+00$ & $9.73 E-01$ & $8.84 \mathrm{E}-01$ & $1.71 \mathrm{E}+00$ & $2.01 \mathrm{E}+00$ & $2.23 E+00$ & $2.48 \mathrm{E}+00$ \\
\hline $1.17 \mathrm{E}-01$ & $3.00 \mathrm{E}+00$ & $9.74 \mathrm{E}-01$ & $8.84 \mathrm{E}-01$ & $1.71 \mathrm{E}+00$ & $2.01 \mathrm{E}+00$ & $2.23 E+00$ & $2.48 \mathrm{E}+00$ \\
\hline $.18 \mathrm{E}-01$ & $3.00 \mathrm{E}+00$ & $9.74 \mathrm{E}-01$ & $8.85 \mathrm{E}-01$ & 1. $71 \mathrm{E}+00$ & $2.01 \mathrm{E}+00$ & $2.23 E+00$ & $2.48 \mathrm{E}+00$ \\
\hline $.18 \mathrm{E}-01$ & $3.00 \mathrm{E}+00$ & $9.75 \mathrm{E}-01$ & $8.85 \mathrm{E}-01$ & 1. $71 \mathrm{E}+00$ & $2.01 \mathrm{E}+00$ & $2.23 E+00$ & $2.47 \mathrm{E}+00$ \\
\hline $.18 \mathrm{E}-01$ & $3.00 \mathrm{E}+00$ & $9.75 \mathrm{E}-01$ & $8.86 \mathrm{E}-01$ & $1.71 \mathrm{E}+00$ & $2.01 \mathrm{E}+00$ & $2.23 E+00$ & $2.47 \mathrm{E}+00$ \\
\hline $.18 \mathrm{E}-01$ & $2.99 \mathrm{E}+00$ & $9.75 \mathrm{E}-01$ & $8.87 \mathrm{E}-01$ & $1.71 \mathrm{E}+00$ & $2.01 \mathrm{E}+00$ & $2.23 E+00$ & $2.47 \mathrm{E}+00$ \\
\hline $.19 \mathrm{E}-01$ & $2.99 \mathrm{E}+00$ & $9.76 \mathrm{E}-01$ & $8.88 \mathrm{E}-01$ & 1. $71 \mathrm{E}+00$ & $2.01 \mathrm{E}+00$ & $2.23 E+00$ & $2.47 \mathrm{E}+00$ \\
\hline $1.19 \mathrm{E}-01$ & $2.99 \mathrm{E}+00$ & $9.76 \mathrm{E}-01$ & $E-01$ & $1.71 \mathrm{E}+00$ & $2.01 \mathrm{E}+00$ & $2.23 E+00$ & $2.47 \mathrm{E}+00$ \\
\hline $1.19 \mathrm{E}-01$ & $2.99 \mathrm{E}+00$ & $9.77 \mathrm{E}-01$ & $8.90 \mathrm{E}-01$ & 1. $71 \mathrm{E}+00$ & $2.01 \mathrm{E}+00$ & $2.23 E+00$ & $2.47 \mathrm{E}+00$ \\
\hline $.19 \mathrm{E}-01$ & $2.99 \mathrm{E}+00$ & $9.77 E-01$ & $8.91 E-01$ & $1.71 \mathrm{E}+00$ & $2.01 \mathrm{E}+00$ & $2.23 E+00$ & $2.47 \mathrm{E}+00$ \\
\hline $1.19 \mathrm{E}-01$ & $2.98 \mathrm{E}+00$ & $9.77 \mathrm{E}-01$ & $8.91 E-01$ & $1.71 \mathrm{E}+00$ & $2.01 \mathrm{E}+00$ & $2.23 E+00$ & $2.47 \mathrm{E}+00$ \\
\hline $1.20 \mathrm{E}-01$ & $2.98 \mathrm{E}+00$ & $9.78 \mathrm{E}-01$ & $8.92 \mathrm{E}-01$ & 1. $71 \mathrm{E}+00$ & $2.01 \mathrm{E}+00$ & $2.22 \mathrm{E}+00$ & $2.47 \mathrm{E}+00$ \\
\hline 1. $20 \mathrm{E}-01$ & $2.98 E+00$ & $9.78 \mathrm{E}-01$ & $8.93 E-01$ & 1. $71 \mathrm{E}+00$ & $2.01 \mathrm{E}+00$ & $2.22 \mathrm{E}+00$ & $2.47 \mathrm{E}+00$ \\
\hline 1. $20 \mathrm{E}-01$ & $2.98 \mathrm{E}+00$ & $9.79 \mathrm{E}-$ & $8.94 \mathrm{E}-01$ & $1.71 \mathrm{E}+00$ & $2.01 \mathrm{E}+00$ & $2.22 \mathrm{E}+00$ & $2.47 \mathrm{E}+00$ \\
\hline $.20 E-01$ & $2.97 \mathrm{E}+00$ & $9.79 \mathrm{E}-01$ & $8.94 \mathrm{E}-01$ & $1.72 \mathrm{E}+00$ & $2.01 \mathrm{E}+00$ & $2.22 E+00$ & $2.47 \mathrm{E}+00$ \\
\hline 1. $21 \mathrm{E}-01$ & $2.97 \mathrm{E}+00$ & $9.79 \mathrm{E}-01$ & $8.95 \mathrm{E}-01$ & $1.72 \mathrm{E}+00$ & $2.01 \mathrm{E}+00$ & $2.22 E+00$ & $2.47 \mathrm{E}+00$ \\
\hline $1.21 \mathrm{E}-01$ & $2.97 \mathrm{E}+00$ & $9.79 \mathrm{E}-01$ & $8.95 E-01$ & $1.72 \mathrm{E}+00$ & $2.01 \mathrm{E}+00$ & $2.22 \mathrm{E}+00$ & $2.47 \mathrm{E}+00$ \\
\hline
\end{tabular}


RESRAD-OFFSITE, Version 2.5

Title : Offsite Resident Farmer

File : RF TC99 DOESG FWD-FV2all.ROF

Time

Years

$0.00 \mathrm{E}+00$

$5.13 \mathrm{E}-01$

$1.03 \mathrm{E}+00$

$1.54 \mathrm{E}+00$

$2.05 \mathrm{E}+00$

$2.56 \mathrm{E}+00$

$3.08 \mathrm{E}+00$

$3.59 \mathrm{E}+00$

$4.10 \mathrm{E}+00$

$4.61 \mathrm{E}+00$

$5.13 \mathrm{E}+00$

$5.64 \mathrm{E}+00$

$6.15 \mathrm{E}+00$

$6.67 \mathrm{E}+00$

$7.18 \mathrm{E}+00$

$7.69 \mathrm{E}+00$

$8.20 \mathrm{E}+00$

$8.72 \mathrm{E}+00$

$9.23 \mathrm{E}+00$

$9.74 \mathrm{E}+00$

$1.03 E+01$

$1.08 \mathrm{E}+01$

$1.13 \mathrm{E}+01$

$1.18 \mathrm{E}+01$

$1.23 \mathrm{E}+01$

$1.28 \mathrm{E}+01$

$1.33 \mathrm{E}+01$

$1.38 \mathrm{E}+01$

$1.44 \mathrm{E}+01$

$1.49 \mathrm{E}+01$

$1.54 \mathrm{E}+01$

$1.59 \mathrm{E}+01$

$1.64 \mathrm{E}+01$

$1.69 \mathrm{E}+01$

$1.74 \mathrm{E}+01$

$1.79 \mathrm{E}+01$

$1.85 \mathrm{E}+01$

$1.90 \mathrm{E}+01$

1. $95 \mathrm{E}+01$

$2.00 \mathrm{E}+01$

2. $05 E+01$

$2.10 \mathrm{E}+01$

$2.15 E+01$

$2.20 \mathrm{E}+01$

2. $26 \mathrm{E}+01$

$2.31 E+01$

Summary of dose at graphical times, reptition 2

Dose statistics at graphical times, mrem/yr

\begin{tabular}{|c|c|c|c|c|c|c|c|}
\hline Iinimum & Iaximum & Mean & Median & 00 & $\%$ & $97.5 \%$ & 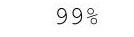 \\
\hline $80 \mathrm{E}-32$ & $1.82 \mathrm{E}-32$ & 1. $82 \mathrm{E}-32$ & $1.82 \mathrm{E}-32$ & $32 E-32$ & $82 E-32$ & 1. $82 \mathrm{E}-32$ & 2 \\
\hline $80 \mathrm{E}-32$ & $1.84 \mathrm{E}-32$ & $1.83 E-32$ & $1.84 \mathrm{E}-32$ & $1.84 \mathrm{E}-32$ & $1.84 \mathrm{E}-32$ & -32 & 32 \\
\hline $9 E-32$ & $35 E-32$ & 32 & -32 & $85 E-32$ & 32 & 32 & 32 \\
\hline $3 E-32$ & $87 E-32$ & $6 E-32$ & -32 & $E-32$ & $7 E-32$ & 32 & $7 E-32$ \\
\hline $3 E-32$ & $E-32$ & $8 E-32$ & 2 & $9 \mathrm{E}$ & 2 & 2 & -32 \\
\hline $.77 E-32$ & & & & & & & \\
\hline $.77 E-32$ & & & & 2 & 2 & 32 & $92 E-32$ \\
\hline $.76 E-32$ & 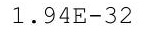 & - & $1.93 E-32$ & $4 E-32$ & 32 & 1.9 & $94 E-32$ \\
\hline $.76 \mathrm{E}-32$ & 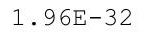 & 专 & $1.95 E-32$ & - & 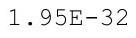 & . & 1. $95 E-32$ \\
\hline $5 E-32$ & 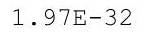 & 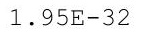 & 32 & 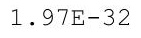 & 2 & -32 & $97 E-32$ \\
\hline $75 E-32$ & -32 & 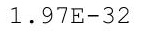 & & -32 & 2 & 32 & -32 \\
\hline-32 & 2 & & & 2 & & & -32 \\
\hline 2 & & 2 & & & 2 & 2 & -32 \\
\hline $.73 E-32$ & & 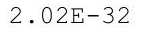 & 2 & & 2 & 82 & -32 \\
\hline $.72 E-32$ & 年 & 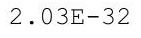 & 2.040 & . & 0.0 & 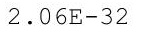 & -32 \\
\hline $.72 E-32$ & t & 2. & & - & & (2) & -32 \\
\hline $.71 E-32$ & $2.10 E-32$ & $2.06 E-3$ & -32 & FE & 2 & 32 & -32 \\
\hline $.71 \mathrm{E}-32$ & $2.12 \mathrm{E}-32$ & & $2.09 E-32$ & & $2.11 \mathrm{E}-32$ & $2.11 \mathrm{E}-32$ & $11 E-32$ \\
\hline$E-32$ & $5-3$ & 2 & 2 & 2 & 2 & -32 & $3 E-32$ \\
\hline $.70 E-32$ & $2.15 E-32$ & $2.11 \mathrm{E}-3$ & $2 \cdot 13 \pm-32$ & $15 \mathrm{E}-3$ & 2 & $2.15 E-32$ & $15 E-32$ \\
\hline $69 \mathrm{E}-32$ & $2 \cdot 1 / \pm 22$ & 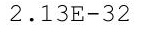 & 2 & 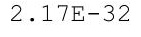 & & 32 & -32 \\
\hline $69 \mathrm{E}-32$ & 2. & 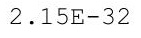 & & & & & -32 \\
\hline $68 E-32$ & 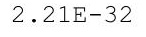 & 2. & 2 & 2 & 2 & $2.21 E-32$ & -32 \\
\hline $.68 E-32$ & $2.23 E-32$ & $2.18 E-32$ & 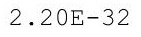 & $2.22 \mathrm{E}-$ & $2.23 \mathrm{E}$ & 2.23 & $23 E-32$ \\
\hline $.67 E-32$ & $-6-5$ & . & $E-32$ & $.24 \mathrm{E}-$ & $2.25 \mathrm{E}-$ & $2.25 \mathrm{E}-$ & $25 E-32$ \\
\hline $67 E-32$ & $2.27 E-32$ & $2.21 E-32$ & $4 E-32$ & $6 \mathrm{E}$ & & -32 & $7 E-32$ \\
\hline$E-32$ & 32 & 2 & 32 & 2 & & 32 & -32 \\
\hline $.66 E-32$ & $2.31 E-32$ & 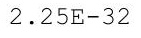 & $7 E-32$ & 2 & & 32 & -32 \\
\hline $.65 E-32$ & $2.33 E-32$ & $2.27 \mathrm{E}-32$ & $2.29 E-32$ & $2.32 E-32$ & $2.33 E-32$ & $2.33 E-32$ & $2.33 E-32$ \\
\hline 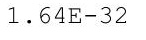 & 2 & 管 & 2 & $2.34 \mathrm{E}-32$ & $2.37 \pi 2$ & (2.0 & $2.35 E-32$ \\
\hline 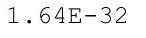 & 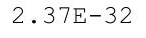 & 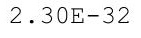 & $2.33 E-32$ & 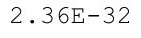 & & 32 & $E-32$ \\
\hline $.63 E-32$ & $2.39 E-32$ & & 2 & & & & 32 \\
\hline 2 & 32 & 2.3 & 32 & 2 & 2 & 32 & 32 \\
\hline $62 E-32$ & $E-32$ & $2.36 \mathrm{E}-$ & 2 & 2 & & 32 & -32 \\
\hline $62 E-32$ & $2.46 \mathrm{E}-32$ & $2.38 E-32$ & $2.41 E-32$ & $2.45 E-32$ & 2.405 & $2.45 E-32$ & $2.46 E-32$ \\
\hline . OIL-J2 & 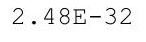 & 2. & 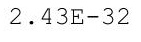 & 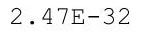 & & & $2.48 E-32$ \\
\hline $\begin{array}{lll}0 & 0\end{array}$ & $2.50 E-32$ & & & & & & -32 \\
\hline $60 F-32$ & $2.52 \mathrm{E}-32$ & & & 2 & 2 & 2 & 32 \\
\hline $.60 E-32$ & $2.55 E-32$ & $2.45 E-32$ & 2 & 2 & 2 & 2 & 32 \\
\hline 2 & & & & 2 & 2 & -32 & 32 \\
\hline $59 E-32$ & $2.59 \mathrm{E}-$ & $2.49 \mathrm{E}$ & 32 & 2. & & 32 & -32 \\
\hline 2 & .0 & & & & & & \\
\hline 2 & . & 2 & 2 & -0 & & & -32 \\
\hline 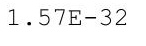 & 2 & & & . & 2 & 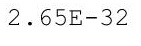 & 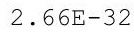 \\
\hline L. $57 \mathrm{E}-32$ & & & & & 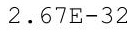 & 32 & 32 \\
\hline$E-32$ & $71 E-32$ & $9 E-32$ & 32 & 32 & 32 & 32 & 32 \\
\hline
\end{tabular}


RESRAD-OFFSITE, Version 2.5

$\mathrm{T}^{1 / 2}$ Limit $=180$ days

obabilistic Dose and Risk Report

Title : Offsite Resident Farmer

File : RF TC99 DOESG FWD-FV2all.ROF

Summary of dose at graphical times, reptition 2 (continued)

Time

Years

$2.36 \mathrm{E}+01$

$2.41 \mathrm{E}+01$

2. $46 \mathrm{E}+01$

2. $51 \mathrm{E}+01$

2. $56 \mathrm{E}+01$

2. $61 \mathrm{E}+01$

2. $67 \mathrm{E}+01$

2. $72 \mathrm{E}+01$

$2.77 \mathrm{E}+01$

2. $82 \mathrm{E}+01$

$2.87 \mathrm{E}+01$

2. $92 \mathrm{E}+01$

2. $97 \mathrm{E}+01$

3. $02 \mathrm{E}+01$

$3.08 \mathrm{E}+01$

$3.13 E+01$

$3.18 \mathrm{E}+01$

3. $23 E+01$

$3.28 \mathrm{E}+01$

3. $33 E+01$

3. $38 \mathrm{E}+01$

$3.44 \mathrm{E}+01$

$3.49 \mathrm{E}+01$

$3.54 \mathrm{E}+01$

$3.59 \mathrm{E}+01$

3. $64 \mathrm{E}+01$

$3.69 \mathrm{E}+01$

$3.74 \mathrm{E}+01$

$3.79 \mathrm{E}+01$

3. $85 \mathrm{E}+01$

$3.90 \mathrm{E}+01$

$3.95 \mathrm{E}+01$

$4.00 \mathrm{E}+01$

4. $05 \mathrm{E}+01$

4. $10 \mathrm{E}+01$

4. $15 \mathrm{E}+01$

4. $20 \mathrm{E}+01$

4. $26 \mathrm{E}+01$

4. $31 \mathrm{E}+01$

4. $36 \mathrm{E}+01$

4. $41 \mathrm{E}+01$

4. $46 \mathrm{E}+01$

4. $51 \mathrm{E}+01$

4. $56 \mathrm{E}+01$

4. $61 \mathrm{E}+01$

$4.67 \mathrm{E}+01$
Dose statistics at graphical times, mrem/yr

\begin{tabular}{|c|c|c|c|c|c|c|c|}
\hline m & aximum & ea & - & & & & \\
\hline $56 \mathrm{E}-32$ & $2.73 E-32$ & $2.61 E-32$ & $2.66 \mathrm{E}-32$ & $71 E-32$ & $72 E-32$ & 32 & . $135-32$ \\
\hline $55 E-32$ & $2.76 E-32$ & $2.63 E-32$ & $2.68 \mathrm{E}-32$ & $2.74 E-32$ & $2.74 E-32$ & $2.75 E-32$ & $75 E-32$ \\
\hline-32 & $78 E-32$ & $65 E-32$ & $70 E-32$ & $76 E-32$ & $77 E-32$ & $2.77 \mathrm{E}-32$ & $78 E-32$ \\
\hline $55 E-32$ & $81 E-32$ & $68 F-32$ & $73 F-32$ & $79 F-32$ & $279 F-32$ & $80=-32$ & $80 F-32$ \\
\hline-32 & -32 & 2 & -32 & 2 & 2 & -32 & $83 E-32$ \\
\hline 32 & 32 & & & & & & -32 \\
\hline $53 E-32$ & $2.88 E-32$ & & & & & & -32 \\
\hline $53 E-32$ & -32 & 2 & -32 & 2 & 32 & -32 & $90 E-32$ \\
\hline $52 E-32$ & $93 E-32$ & $\begin{array}{lll}0 & 0\end{array}$ & $2.84 \mathrm{E}-32$ & $91 E-32$ & $92 \mathrm{E}-$ & -32 & $3 E-32$ \\
\hline$E-32$ & $96 E-32$ & ? חק00 & $865-32$ & 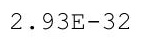 & 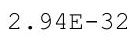 & $.95 E-32$ & $95=-32$ \\
\hline 32 & -32 & & & & & & -32 \\
\hline $51 E-32$ & $3.01 \mathrm{E}-32$ & $285 \mathrm{~F}-32$ & -32 & 2 & 2 & 2 & -32 \\
\hline $50 E-32$ & $3.04 \mathrm{E}-32$ & & $2.94 \mathrm{E}-32$ & & & & $3.03 E-32$ \\
\hline $50 E-32$ & -32 & $2.095-32$ & $2.96 \mathrm{E}-32$ & & & 32 & $E-32$ \\
\hline$E-32$ & -32 & 2 & -32 & & & -32 & $E-32$ \\
\hline $9 E-32$ & 32 & 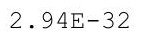 & $1 E-32$ & & & 2 & 32 \\
\hline 2 & 2 & & & & & & 32 \\
\hline$E-32$ & 32 & 2 & 2 & & & 2 & 32 \\
\hline $47 E-32$ & $3.20 \mathrm{E}-32$ & $3.01 E-32$ & $3.09 E-32$ & $3.17 E-32$ & $3.18 E-32$ & $3.19 \mathrm{E}-32$ & $3.19 E-32$ \\
\hline $47 E-32$ & $23 E-32$ & $.04 E-32$ & -32 & $0 E-32$ & 2 & -32 & $22 E-32$ \\
\hline 32 & 32 & & & & & 82 & -32 \\
\hline 32 & 32 & & & & & -32 & \\
\hline 2 & & & & & & & 32 \\
\hline $45 E-32$ & -32 & $3.13 E-32$ & $z$ & 2 & 2 & 2 & -32 \\
\hline 2 & 2 & $3.16 \mathrm{E}-32$ & 2 & 2 & 5 & 2 & 32 \\
\hline $44 \mathrm{E}-32$ & $.41 E-32$ & $18 E-32$ & $E-32$ & ד & تص8 & $.39 E-32$ & $40 E-32$ \\
\hline $44 \mathrm{E}-32$ & $44 \mathrm{E}-32$ & 2 & $E-32$ & -32 & & $E-32$ & $43 E-32$ \\
\hline & & & & & & & \\
\hline & & & & & & -32 & 32 \\
\hline $42 E-32$ & $3.53 E-32$ & . & $3.38 E-32$ & $3.49 E-32$ & $.200-28$ & $.51 \mathrm{E}-32$ & $.52 E-32$ \\
\hline $42 E-32$ & $56 \mathrm{E}-32$ & . & $E-32$ & 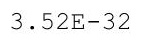 & - & $5-32$ & $.55 E-32$ \\
\hline 2 & $3.59 \mathrm{E}-32$ & & $3.43 E-32$ & & & $.57 E-32$ & \\
\hline-32 & $E-32$ & 2 & -32 & 2 & تصט & & $1 E-32$ \\
\hline 32 & & & & & & & \\
\hline 32 & & & & & 2 & -32 & \\
\hline $40 \mathrm{E}-32$ & $3.72 E-32$ & . & $3.55 E-32$ & 0.000 & 3.001 & -32 & $.71 E-32$ \\
\hline $39 E-32$ & $3.15 \mathrm{E}-32$ & $3.47 \mathrm{E}-32$ & & & & & $3.14 \mathrm{E}-32$ \\
\hline $39 E-32$ & $3.79 E-32$ & . & 然 & . 110 - & & & $77 E-32$ \\
\hline 2 & $3.82 \mathrm{E}-32$ & $3.53 E-32$ & 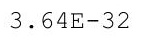 & 2 & 2 & 2 & 32 \\
\hline 32 & 2 & ? & 2 & & & & 32 \\
\hline $38 E-32$ & $3.89 E-32$ & $3.58 E-32$ & -32 & 3 . & 2 & -32 & -32 \\
\hline $37 E-32$ & $3.92 E-32$ & $3.01 \mathrm{~L}$ & & 2 & & & \\
\hline 32 & & & & & & & $\cdot 94 \mathrm{E}-32$ \\
\hline $.36 E-32$ & $3.99 E-32$ & $3.67 E-32$ & $3.19 E-32$ & $3.94 \mathrm{E}-32$ & $3.96 E-32$ & $3.97 E-32$ & $3.98 E-32$ \\
\hline $36 \mathrm{E}-32$ & $4.03 E-32$ & . & & (.) & 3.925 & $4.00 E-32$ & $4.01 \mathrm{E}-32$ \\
\hline $6 E-32$ & $E-32$ & $3 E-32$ & $.85 E-32$ & $.01 E-32$ & $.03 E-32$ & $E-32$ & $E-32$ \\
\hline
\end{tabular}


RESRAD-OFFSITE, Version 2.5

$\mathrm{T}^{1 / 2}$ Limit $=180$ days

Title : Offsite Resident Farmer

File : RF TC99 DOESG FWD-FV2all.ROF

Summary of dose at graphical times, reptition 2 (continued)

Time

Years

$4.72 \mathrm{E}+01$

4. $77 \mathrm{E}+01$

4. $82 \mathrm{E}+01$

4. $87 \mathrm{E}+01$

4. $92 \mathrm{E}+01$

4. $97 \mathrm{E}+01$

$5.02 \mathrm{E}+01$

$5.08 \mathrm{E}+01$

$5.13 \mathrm{E}+01$

$5.18 \mathrm{E}+01$

$5.23 \mathrm{E}+01$

$5.28 \mathrm{E}+01$

$5.33 \mathrm{E}+01$

$5.38 \mathrm{E}+01$

$5.43 \mathrm{E}+01$

$5.49 \mathrm{E}+01$

$5.54 \mathrm{E}+01$

$5.59 \mathrm{E}+01$

$5.64 \mathrm{E}+01$

$5.69 \mathrm{E}+01$

$5.74 \mathrm{E}+01$

$5.79 \mathrm{E}+01$

$5.84 \mathrm{E}+01$

$5.90 \mathrm{E}+01$

$5.95 \mathrm{E}+01$

$6.00 \mathrm{E}+01$

$6.05 \mathrm{E}+01$

$6.10 \mathrm{E}+01$

$6.15 \mathrm{E}+01$

$6.20 \mathrm{E}+01$

$6.25 \mathrm{E}+01$

$6.31 \mathrm{E}+01$

$6.36 \mathrm{E}+01$

$6.41 \mathrm{E}+01$

$6.46 \mathrm{E}+01$

$6.51 \mathrm{E}+01$

$6.56 \mathrm{E}+01$

$6.61 \mathrm{E}+01$

$6.67 \mathrm{E}+01$

$6.72 \mathrm{E}+01$

$6.77 \mathrm{E}+01$

$6.82 \mathrm{E}+01$

$6.87 \mathrm{E}+01$

$6.92 \mathrm{E}+01$

$6.97 \mathrm{E}+01$

$7.02 \mathrm{E}+01$
Dose statistics at graphical times, mrem/yr

\begin{tabular}{|c|c|c|c|c|c|c|c|}
\hline $\mathrm{m}$ & aximum & ea & 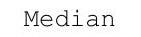 & & & & \\
\hline $35 E-32$ & $4.10 \mathrm{E}-32$ & $3.76 \mathrm{E}-32$ & $3.89 \mathrm{E}-32$ & 32 & $4.06 \mathrm{E}-32$ & -32 & $4.00 E-32$ \\
\hline $35 E-32$ & $4.13 E-32$ & $9 E-32$ & $3.92 \mathrm{E}-32$ & $8 E-32$ & $10 E-32$ & $4.11 E-32$ & $12 E-32$ \\
\hline-32 & $17 E-32$ & $32 E-32$ & $95 E-32$ & 1 & 32 & -32 & $16 E-32$ \\
\hline $34 \mathrm{E}-32$ & $4.21 E-32$ & $85 F-32$ & $98 F-32$ & $15 F-32$ & $17 F-32$ & $18 \mathrm{~F}-32$ & $19 F-32$ \\
\hline-32 & -32 & 32 & -32 & 2 & 2 & -32 & $23 E-32$ \\
\hline 32 & & & & & & & \\
\hline $33 E-32$ & $4.32 E-32$ & & & & & & -32 \\
\hline $32 E-32$ & -32 & 2 & -32 & 2 & 32 & -32 & -32 \\
\hline $32 E-32$ & $4.40 E-32$ & 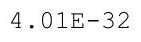 & $E-32$ & $4.33 E-32$ & 4. $36 \mathrm{E}-32$ & -32 & $38 E-32$ \\
\hline$E-32$ & 32 & Г & $8=-32$ & 27 & 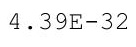 & $41 E-32$ & $42 F-32$ \\
\hline 32 & 32 & & & & & & -32 \\
\hline $31 E-32$ & $4.52 E-32$ & $5-32$ & $E-32$ & 2 & 2 & -32 & -32 \\
\hline $30 E-32$ & $4.56 E-32$ & & $4.29 E-32$ & & $4.51 E-32$ & & $4.54 \mathrm{E}-32$ \\
\hline-32 & -32 & 2 & -32 & 2 & 2 & 32 & $E-32$ \\
\hline $29 E-32$ & -32 & & -32 & & & -32 & $E-32$ \\
\hline 32 & -32 & $4.24 E-32$ & -32 & 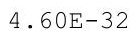 & 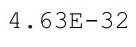 & 2 & 32 \\
\hline-32 & 2 & & & & & & \\
\hline 32 & 32 & 4 & 2 & & & 2 & 32 \\
\hline $28 E-32$ & $4.80 E-32$ & $4.34 E-32$ & $4.51 E-32$ & $4.73 E-32$ & $4.75 E-32$ & $4.77 E-32$ & $4.78 E-32$ \\
\hline $27 E-32$ & $4.85 E-32$ & $.37 E-32$ & $4.54 \mathrm{E}-32$ & $4.77 E-32$ & $4.79 \mathrm{E}-$ & $4.81 E-32$ & $4.82 E-32$ \\
\hline 32 & -32 & & & & & -32 & $E-32$ \\
\hline 32 & -32 & & 2 & $z$ & 2 & -32 & -32 \\
\hline $26 E-32$ & 4.9 & 1 & -32 & & & 2 & 32 \\
\hline-32 & -32 & $4.51 E-32$ & 2 & 2 & 2 & 2 & -32 \\
\hline 2 & $E-32$ & $4.55 \mathrm{E}-32$ & 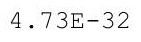 & 2 & 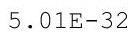 & 2 & 32 \\
\hline $25 E-32$ & $11 \mathrm{E}-32$ & 5 & $E-32$ & קת קח & $05 \mathrm{E}-$ & $.07 E-32$ & $.08 E-32$ \\
\hline-32 & $E-32$ & & $E-32$ & ת7 - 201 - & & $E-32$ & $13 E-32$ \\
\hline & & & & & & & \\
\hline 32 & & & 32 & & & 32 & 32 \\
\hline $23 E-32$ & $5.29 \mathrm{E}-32$ & 月. & $4.93 E-32$ & $.20 E-32$ & $\cdot 235-32$ & $.25 E-32$ & $.27 E-32$ \\
\hline $23 E-32$ & $5.34 \mathrm{E}-32$ & $4.77 E-32$ & $4.97 \mathrm{E}-32$ & - & $.28 E-32$ & $0 E-32$ & $.31 E-32$ \\
\hline 2 & $39 E-32$ & & $5.02 \mathrm{E}-32$ & & & & $36 E-32$ \\
\hline$E-32$ & -32 & $E-32$ & $E-32$ & 2 & ז7ר & -32 & $E-32$ \\
\hline 32 & & & & & & & \\
\hline 32 & & & & & 2 & -32 & \\
\hline $21 E-32$ & $5.58 \mathrm{E}-32$ & $4.97 \mathrm{E}-32$ & $.18 E-32$ & .10 & 2 & -32 & $.55 E-32$ \\
\hline $21 E-32$ & $5.03 E-32$ & & & & $3.36 \pm-32$ & & $3.60 \pm-32$ \\
\hline 32 & -32 & . & (1) & . & $5.61 \mathrm{E}-32$ & & $.65 E-32$ \\
\hline 2 & $5.73 E-32$ & 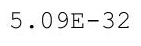 & ? & 2 & 2 & 2 & 32 \\
\hline 32 & 5 & & & & & & 32 \\
\hline $9 E-32$ & $5.83 E-32$ & $5.17 E-32$ & $0 E-32$ & 32 & 2 & -32 & -32 \\
\hline 32 & $5.88 \mathrm{E}$ & 2 & & 5.77 & & & \\
\hline & & & & & & & $.90 \pm-32$ \\
\hline $4-32$ & $3.99 E-32$ & $5.29 E-32$ & $5.54 \mathrm{E}-32$ & $5.87 E-32$ & $5.91 E-32$ & $5.93 E-32$ & $5.95 E-32$ \\
\hline $18 E-32$ & $6.04 E-32$ & 0.07 & . & $\begin{array}{ll}0 \\
0\end{array}$ & . & $5.99 E-32$ & .01 \\
\hline$E-32$ & $.09 \mathrm{E}-32$ & $38 E-32$ & $63 E-32$ & $.97 E-32$ & $6.01 \mathrm{E}-32$ & $4 E-32$ & -32 \\
\hline
\end{tabular}


RESRAD-OFFSITE, Version 2.5

$\mathrm{T}^{1 / 2}$ Limit $=180$ days

Title : Offsite Resident Farmer

File : RF TC99 DOESG FWD-FV2all.ROF

Summary of dose at graphical times, reptition 2 (continued)

Time

Years

7. $08 \mathrm{E}+01$

7. $13 \mathrm{E}+01$

7. $18 \mathrm{E}+01$

7. $23 \mathrm{E}+01$

7. $28 \mathrm{E}+01$

7. $33 \mathrm{E}+01$

7. $38 \mathrm{E}+01$

7. $43 \mathrm{E}+01$

7. $49 \mathrm{E}+01$

7. $54 \mathrm{E}+01$

7. $59 \mathrm{E}+01$

7. $64 \mathrm{E}+01$

7. $69 \mathrm{E}+01$

7. $74 \mathrm{E}+01$

$7.79 \mathrm{E}+01$

7. $84 \mathrm{E}+01$

7. $90 \mathrm{E}+01$

7. $95 \mathrm{E}+01$

8. $00 \mathrm{E}+01$

$8.05 \mathrm{E}+01$

$8.10 \mathrm{E}+01$

$8.15 \mathrm{E}+01$

8. $20 \mathrm{E}+01$

8. $25 \mathrm{E}+01$

8. $31 \mathrm{E}+01$

8. $36 \mathrm{E}+01$

8. $41 \mathrm{E}+01$

8. $46 \mathrm{E}+01$

8. $51 \mathrm{E}+01$

8. $56 \mathrm{E}+01$

8. $61 \mathrm{E}+01$

8. $66 \mathrm{E}+01$

$8.72 \mathrm{E}+01$

$8.77 \mathrm{E}+01$

$8.82 \mathrm{E}+01$

$8.87 \mathrm{E}+01$

$8.92 \mathrm{E}+01$

8. $97 \mathrm{E}+01$

9. $02 \mathrm{E}+01$

$9.07 \mathrm{E}+01$

$9.13 \mathrm{E}+01$

$9.18 \mathrm{E}+01$

9. $23 \mathrm{E}+01$

$9.28 \mathrm{E}+01$

$9.33 \mathrm{E}+01$

9. $38 \mathrm{E}+01$
Dose statistics at graphical times, mrem/yr

\begin{tabular}{|c|c|c|c|c|c|c|c|}
\hline $\mathrm{m}$ & aximum & lea & - & & & & \\
\hline $17 \mathrm{E}-32$ & $6.15 \mathrm{E}-32$ & $5.42 E-32$ & $5.68 E-32$ & $6.02 \mathrm{E}-32$ & $6.07 \mathrm{E}-32$ & $6.09 E-32$ & $-2-32$ \\
\hline $17 \mathrm{E}-32$ & $6.20 E-32$ & $7 E-32$ & $5.72 E-32$ & $8 E-32$ & $12 E-32$ & $E-32$ & $7 E-32$ \\
\hline $16 \mathrm{E}-32$ & $6.26 \mathrm{E}-32$ & $5.51 \mathrm{E}-32$ & $5.77 \mathrm{E}-32$ & $6.13 E-32$ & $6.17 E-32$ & -32 & $6.22 E-32$ \\
\hline-32 & $31 E-32$ & $55 F-32$ & $82 E-32$ & $18 \mathrm{E}-32$ & $23 F-32$ & -32 & $28 F-32$ \\
\hline-32 & $37 E-32$ & 32 & -32 & -32 & 2 & -32 & $33 E-32$ \\
\hline-32 & 32 & & & & & & \\
\hline $15 \mathrm{E}-32$ & $6.48 E-32$ & & $5.96 \mathrm{E}-32$ & $6.35 E-32$ & & & -32 \\
\hline $.14 \mathrm{E}-32$ & -32 & 2 & -32 & $40 E-32$ & 32 & -32 & -32 \\
\hline $14 \mathrm{E}-32$ & $6.60 \mathrm{E}-32$ & $5.78 E-32$ & $6.06 \mathrm{E}-32$ & $6.46 \mathrm{E}-32$ & $E-32$ & -32 & $E-32$ \\
\hline 32 & $65 E-32$ & תבק0 & $1 E-32$ & 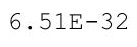 & 2 & 2 & 2 \\
\hline 32 & -32 & & & & & & 32 \\
\hline $13 E-32$ & $6.77 E-32$ & $592 \mathrm{~F}-32$ & $E-32$ & $3 E-32$ & 2 & 32 & -32 \\
\hline $13 E-32$ & $6.83 E-32$ & $5.97 E-32$ & $6.26 \mathrm{E}-32$ & $6.68 E-32$ & $6.73 E-32$ & $6.77 E-32$ & $6.79 \mathrm{E}-32$ \\
\hline $12 \mathrm{E}-32$ & $6.89 E-32$ & $6.02 \mathrm{E}-32$ & $6.32 \mathrm{E}-32$ & & 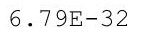 & 32 & $E-32$ \\
\hline $12 \mathrm{E}-32$ & -32 & 2 & -32 & 32 & & -32 & -32 \\
\hline 32 & 32 & & $E-32$ & 2 & (2) & 32 & 32 \\
\hline 32 & & & & & & & \\
\hline $11 \mathrm{E}-32$ & 32 & $6.21 E-32$ & 2 & 2 & 2 & 2 & 32 \\
\hline $11 E-32$ & $20 E-32$ & $26 \mathrm{~F}-32$ & $8 E-32$ & $\Delta F-$ & ק0 & $E-32$ & $16 E-32$ \\
\hline $10 \mathrm{E}-32$ & $7.27 \mathrm{E}-32$ & $.31 E-32$ & $6.64 \mathrm{E}-32$ & $0 E-32$ & $7.16 \mathrm{E}$ & -32 & $22 E-32$ \\
\hline 32 & -32 & & & & & -32 & $E-32$ \\
\hline 32 & -32 & & -32 & & & -32 & -32 \\
\hline 2 & & & & & & & \\
\hline 2 & 2 & & 2 & 2 & & & \\
\hline$E-32$ & -32 & & 2 & 2 & 2 & 2 & 32 \\
\hline$E-32$ & $66 \mathrm{E}-32$ & $62 E-32$ & $97 E-32$ & $.48 \mathrm{E}-3$ & 505 & $58 E-32$ & $.61 E-32$ \\
\hline$E-32$ & $7.73 E-32$ & & $3 E-32$ & $55 E-32$ & & $E-32$ & $68 E-32$ \\
\hline & & & & & & & \\
\hline 32 & & & & & & -32 & 32 \\
\hline $07 E-32$ & $7.94 \mathrm{E}-32$ & $0.04 \amalg-2$ & $7.21 E-32$ & $7.75 E-32$ & • & $7.85 E-32$ & $.88 E-32$ \\
\hline $7 E-32$ & -32 & . & $.27 E-32$ & 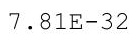 & - & $5-32$ & $95 E-32$ \\
\hline 年 & $08 E-32$ & & 7. $33 E-32$ & & & & \\
\hline-32 & $E-32$ & $E-32$ & $E-32$ & $95 E-32$ & ברטל & -32 & $9 E-32$ \\
\hline 32 & & & & & & & \\
\hline-32 & & & & & & -32 & \\
\hline $05 E-32$ & $8.37 E-32$ & ・ & $7.57 \mathrm{E}-32$ & $8.16 \mathrm{E}-32$ & 20 & -32 & $E-32$ \\
\hline $05 E-32$ & $8.44 E-32$ & & & $8 \cdot 23 E-32$ & & & $8.38 \pm-32$ \\
\hline$E-32$ & $8.52 \mathrm{E}-32$ & . & . & . & & & $46 E-32$ \\
\hline 2 & $8.59 E-32$ & 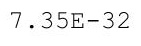 & ( & 2 & 2 & 2 & 32 \\
\hline 32 & 8 & & & & 2 & & 32 \\
\hline $3 E-32$ & $8.74 E-32$ & $7.47 E-32$ & $E-32$ & $8.52 \mathrm{E}$ & & -32 & -32 \\
\hline 32 & $8.8 \angle \mathrm{E}$ & 7.5 & & 2 & & & 32 \\
\hline & & & & & & & $.84 \mathrm{E}-32$ \\
\hline $0<E-32$ & $8.98 \pm-32$ & $7.65 E-32$ & $8.09 E-32$ & $8.74 \mathrm{E}-32$ & $8.8< \pm-32$ & $8.87 E-32$ & $8.91 \mathrm{E}-32$ \\
\hline $02 E-32$ & $9.06 \mathrm{E}-32$ & . & $8.15 E-32$ & $.0<\square$ & . & $8.95 E-32$ & 0.0 \\
\hline $2 E-32$ & $E-32$ & $E-32$ & $22 \mathrm{E}-32$ & $.90 E-32$ & $.98 E-32$ & $9.03 E-32$ & -32 \\
\hline
\end{tabular}


RESRAD-OFFSITE, Version 2.5

$\mathrm{T}^{1 / 2}$ Limit $=180$ days

robabilistic Dose and Risk Report

Title : Offsite Resident Farmer

File : RF TC99 DOESG FWD-FV2all.ROF

Summary of dose at graphical times, reptition 2 (continued)

Time

Years

$9.43 \mathrm{E}+01$

$9.48 \mathrm{E}+01$

$9.54 \mathrm{E}+01$

$9.59 \mathrm{E}+01$

$9.64 \mathrm{E}+01$

$9.69 \mathrm{E}+01$

$9.74 \mathrm{E}+01$

$9.79 \mathrm{E}+01$

$9.84 \mathrm{E}+01$

$9.90 \mathrm{E}+01$

9. $95 \mathrm{E}+01$

$1.00 \mathrm{E}+02$

$1.00 \mathrm{E}+02$

$1.01 \mathrm{E}+02$

$1.02 \mathrm{E}+02$

$1.02 \mathrm{E}+02$

$1.03 \mathrm{E}+02$

$1.03 \mathrm{E}+02$

$1.04 \mathrm{E}+02$

$1.04 \mathrm{E}+02$

$1.05 \mathrm{E}+02$

$1.05 \mathrm{E}+02$

$1.06 \mathrm{E}+02$

$1.06 \mathrm{E}+02$

$1.07 \mathrm{E}+02$

$1.07 \mathrm{E}+02$

$1.08 \mathrm{E}+02$

$1.08 \mathrm{E}+02$

$1.09 \mathrm{E}+02$

$1.09 \mathrm{E}+02$

$1.10 \mathrm{E}+02$

1. $10 \mathrm{E}+02$

$1.11 \mathrm{E}+02$

1. $11 \mathrm{E}+02$

$1.12 \mathrm{E}+02$

1. $12 \mathrm{E}+02$

1. $13 \mathrm{E}+02$

$1.13 \mathrm{E}+02$

1. $14 \mathrm{E}+02$

1. $14 \mathrm{E}+02$

$1.15 \mathrm{E}+02$

1. $15 \mathrm{E}+02$

$1.16 \mathrm{E}+02$

$1.16 \mathrm{E}+02$

$1.17 \mathrm{E}+02$

1. $17 \mathrm{E}+02$
Dose statistics at graphical times, mrem/yr

\begin{tabular}{|c|c|c|c|c|c|c|c|}
\hline m & aximum & ea & 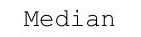 & & & & \\
\hline $01 \mathrm{E}-32$ & $9.22 \mathrm{E}-32$ & $7.84 \mathrm{E}-32$ & $8.29 \mathrm{E}-32$ & $8.97 E-32$ & $9.06 \mathrm{E}-32$ & -32 & $0 \pm-32$ \\
\hline $01 \mathrm{E}-32$ & $9.30 E-32$ & $0 E-32$ & $8 \cdot 36 \mathrm{E}-32$ & $5 E-32$ & -32 & -32 & $3 E-32$ \\
\hline $01 \mathrm{E}-32$ & $9.38 \mathrm{E}-32$ & $7.96 \mathrm{E}-32$ & $8.43 E-32$ & $9.13 \mathrm{E}-32$ & $9.22 \mathrm{E}-32$ & -32 & -32 \\
\hline $00 \mathrm{E}-32$ & $47 E-32$ & $03 E-32$ & $50 \mathrm{E}-32$ & $21 E-32$ & $30 E-32$ & $5 E-32$ & $40 F-32$ \\
\hline $.00 E-32$ & $9.55 E-32$ & $9 E-32$ & $57 E-32$ & $29 \mathrm{E}-32$ & -32 & -32 & -32 \\
\hline $98 E-33$ & $9.64 \mathrm{E}-32$ & & & & & & \\
\hline $95 E-33$ & $9.72 \mathrm{E}-32$ & & $8.71 E-32$ & & & & -32 \\
\hline $91 E-33$ & $9.81 E-32$ & -32 & $8.78 E-32$ & $9.54 \mathrm{E}-32$ & $53 E-32$ & -32 & $73 E-32$ \\
\hline $88 E-33$ & $89 E-32$ & $E-32$ & $E-32$ & $2 \pm-2 z$ & $71 E-32$ & $E-32$ & $E-32$ \\
\hline$E-33$ & $98 E-32$ & -32 & $E-32$ & $0 E-32$ & $30 E-32$ & $86 E-32$ & $E-32$ \\
\hline 33 & 31 & $9 E-32$ & & 2 & & 2 & 32 \\
\hline $79 E-33$ & $1.02 \mathrm{E}-31$ & 32 & -32 & 2 & 2 & 1 & -31 \\
\hline $76 \mathrm{E}-33$ & $1.02 \mathrm{E}-31$ & & $9.15 \mathrm{E}-32$ & & & -31 & $02 E-31$ \\
\hline $73 E-33$ & $.03 E-31$ & $.70 E-32$ & $9.23 E-32$ & $1.00 \mathrm{E}-31$ & $-01 E-31$ & $1.02 \mathrm{E}-31$ & $3 E-31$ \\
\hline-33 & -31 & & -32 & $\perp$ & $S \perp$ & -31 & $3 E-31$ \\
\hline 3 & 1 & & & 1 & & & 31 \\
\hline 3 & & & & & & & 31 \\
\hline$E-33$ & 31 & $8.98 E-32$ & 2 & 1 & $.05 E-31$ & 1 & -31 \\
\hline $58 E-33$ & $.08 E-31$ & -32 & -32 & $5 \mathrm{~F}-$ & 25 & $E-31$ & $7 E-31$ \\
\hline $55 E-33$ & $.09 E-31$ & $.13 E-32$ & $9.69 \mathrm{E}-32$ & $.06 \mathrm{E}-31$ & $.07 E-31$ & $E-31$ & $08 E-31$ \\
\hline 33 & -31 & & & & & $.09 E-31$ & -31 \\
\hline 33 & & & & & & -31 & -31 \\
\hline & & & & & & & 31 \\
\hline 3 & 1 & & & & & & \\
\hline $40 E-33$ & $14 \mathrm{E}-31$ & ד & -31 & 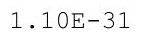 & 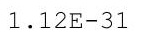 & $E-31$ & $13 E-31$ \\
\hline $37 E-33$ & $.15 E-31$ & $58 F-32$ & $1.02 \mathrm{E}-31$ & $111=1$ & $1.13 \mathrm{E}-$ & $.13 E-31$ & $.14 \mathrm{E}-31$ \\
\hline-33 & $.16 \mathrm{E}-31$ & & $E-31$ & 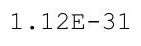 & & $E-31$ & $.15 \mathrm{E}-31$ \\
\hline & & & & & & & \\
\hline & & & & & & & \\
\hline 3 & 23 & & 31 & $\perp \cdot \pm 0$ & $\perp ・ \perp / E-3 \perp$ & $E-31$ & 1.10 \\
\hline $23 E-33$ & $9.08 E-21$ & . & $1.06 \mathrm{E}-31$ & $1.16 \mathrm{E}-31$ & $1.18 \mathrm{E}-$ & $E-31$ & $.19 \mathrm{E}-31$ \\
\hline 3 & $5.02 \mathrm{E}-19$ & $2.0+12=2$ & $1.07 \mathrm{E}-31$ & & 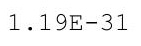 & 1. $20 \mathrm{E}-31$ & $1.20 \mathrm{E}-31$ \\
\hline$F-33$ & $26 \mathrm{~F}-17$ & $96 F-21$ & & & & $E-31$ & $1.21 \mathrm{E}-31$ \\
\hline 33 & & & & & & & \\
\hline-33 & & & & & & & \\
\hline 33 & -14 & $0.10 \mathrm{~L}$ & 31 & $\perp \cdot 2<\amalg$ & $\perp \cdot 2 \circlearrowright \amalg$ & -31 & $1.25 \mathrm{E}$ \\
\hline $06 E-33$ & $6.94 \mathrm{E}-14$ & $\cdot 17 \pm-1$ & 1. $12 \mathrm{E}-31$ & t. & $1 \cdot 2+1$ & & $1.26 \mathrm{E}-31$ \\
\hline 33 & $13 E-13$ & & & $1.24 \mathrm{E}-31$ & 1. $25 \mathrm{E}-31$ & & $1.27 \mathrm{E}-31$ \\
\hline 3 & 2 & $9.89 \mathrm{E}-16$ & 1 & +.0 & 1 & -31 & 31 \\
\hline & & & & & & & 31 \\
\hline$E-33$ & $1.14 \mathrm{E}-11$ & $E-14$ & $E-31$ & 31 & $128 \mathrm{~F}$ & $E-31$ & 31 \\
\hline$E-33$ & $2.98 E-11$ & 2.7 & 31 & 1.2 & 1 & & -31 \\
\hline & 1 & & & & & & \\
\hline 3 & 10 & 3 & $1.18 E-31$ & $1.30 \mathrm{E}-31$ & $\perp \cdot 3<\dot{1}$ & $1.33 E-31$ & $1.34 \mathrm{E}-31$ \\
\hline $83 E-33$ & $3.20 D^{-10}$ & & & $+0<1$ & $1.33 \mathrm{E}-$ & $1.34 E-31$ & $1.35 E-31$ \\
\hline-33 & $E-10$ & $E-13$ & $20 E-31$ & $33 E-31$ & $34 E-31$ & $5 E-31$ & -31 \\
\hline
\end{tabular}


RESRAD-OFFSITE, Version 2.5

File : RF TC99 DOESG FWD-FV2all.ROF

Summary of dose at graphical times, reptition 2 (continued)

Time

Years

$1.18 \mathrm{E}+02$

$1.18 \mathrm{E}+02$

1. $19 \mathrm{E}+02$

$1.19 \mathrm{E}+02$

1. $20 \mathrm{E}+02$

1. $20 \mathrm{E}+02$

1. $21 \mathrm{E}+02$

1. $22 \mathrm{E}+02$

1. $22 \mathrm{E}+02$

1. $23 \mathrm{E}+02$

1. $23 \mathrm{E}+02$

1. $24 \mathrm{E}+02$

1. $24 \mathrm{E}+02$

1. $25 \mathrm{E}+02$

1. $25 \mathrm{E}+02$

1. $26 \mathrm{E}+02$

1. $26 \mathrm{E}+02$

1. $27 \mathrm{E}+02$

1. $27 \mathrm{E}+02$

1. $28 \mathrm{E}+02$

1. $28 \mathrm{E}+02$

1. $29 \mathrm{E}+02$

1. $29 \mathrm{E}+02$

1. $30 \mathrm{E}+02$

1. $30 \mathrm{E}+02$

1. $31 \mathrm{E}+02$

1. $31 \mathrm{E}+02$

1. $32 \mathrm{E}+02$

1. $32 \mathrm{E}+02$

1. $33 \mathrm{E}+02$

1. $33 \mathrm{E}+02$

1. $34 \mathrm{E}+02$

1. $34 \mathrm{E}+02$

1. $35 \mathrm{E}+02$

1. $35 \mathrm{E}+02$

1. $36 \mathrm{E}+02$

1. $36 \mathrm{E}+02$

1. $37 \mathrm{E}+02$

1. $37 \mathrm{E}+02$

1. $38 \mathrm{E}+02$

1. $38 \mathrm{E}+02$

1. $39 \mathrm{E}+02$

1. $39 \mathrm{E}+02$

1. $40 \mathrm{E}+02$

1. $40 \mathrm{E}+02$

1. $41 \mathrm{E}+02$
Dose statistics at graphical times, mrem/yr

\begin{tabular}{|c|c|c|c|c|c|c|c|}
\hline m & aximum & ea & ec & & & $\%$ & \\
\hline $.78 E-33$ & $1.18 \mathrm{E}-09$ & 1. $13 \mathrm{E}-12$ & 31 & 31 & 31 & 31 & $-3 / E-31$ \\
\hline $.75 E-33$ & $2.09 E-09$ & $1 E-12$ & $1.22 \mathrm{E}-31$ & $1.35 E-31$ & $7 E-31$ & 1. $38 E-31$ & $39 E-31$ \\
\hline $72 E-33$ & $3.57 \mathrm{E}-09$ & $5 E-12$ & 1. $23 \mathrm{E}-31$ & $1.36 \mathrm{E}-31$ & $1.38 \mathrm{E}-31$ & 1.39E-31 & $1.40 \mathrm{E}-31$ \\
\hline $69 E-33$ & $89 E-09$ & $72 F-12$ & $24 \mathrm{~F}-31$ & $37 F-31$ & $39 F-31$ & -31 & $41 F-31$ \\
\hline $67 E-33$ & -09 & 2 & -31 & 1 & 31 & -31 & -31 \\
\hline $64 E-33$ & & & & & & & \\
\hline $61 E-33$ & $2.22 \mathrm{E}-08$ & & & & & & \\
\hline $59 \mathrm{E}-33$ & $3.28 \mathrm{E}-08$ & $\perp \perp$ & $4-21$ & 8 & $P \perp$ & 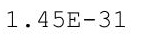 & $E-31$ \\
\hline $56 E-33$ & $4.76 \mathrm{E}-08$ & $6 E-11$ & $1.23 \pm-3$ & $-0-2$ & $\perp$ & -31 & $3 E-31$ \\
\hline $3 E-33$ & $77 \mathrm{E}-08$ & $83 E-11$ & . & $5 F$ & 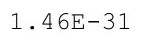 & $18 F-31$ & $49 F-31$ \\
\hline 33 & 08 & & & & & & 31 \\
\hline $48 E-33$ & $1.30 \mathrm{E}-07$ & $5 \mathrm{~F}$ & 1.3 & 7 & & 1 & -31 \\
\hline $45 E-33$ & $1.76 \mathrm{E}-07$ & & & $1.49 E-31$ & & & $1.53 E-31$ \\
\hline $43 E-33$ & $2.35 \mathrm{E}-07$ & $2.53 \mathrm{E}-10$ & I.3U一⿻上丨 & $1.50 \mathrm{E}-31$ & I.JZL-JI & 1 & 1. $55 \mathrm{E}-31$ \\
\hline-33 & -07 & 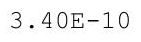 & 3 & $\perp$ & & $\perp$ & $E-31$ \\
\hline 3 & -07 & 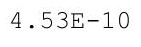 & ${ }^{\perp}$ & . & & 1 & 565 \\
\hline 3 & 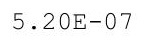 & & & & & & 1 \\
\hline 3 & 7 & $7.84 \mathrm{E}-10$ & 1. $40 E-31$ & 1. $55 \mathrm{E}-31$ & & $59-31$ & 9 \\
\hline $30 E-33$ & $35 E-07$ & $2 F-00$ & 1 & 7 & 吅 & 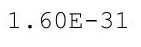 & $4 E-18$ \\
\hline $27 E-33$ & $.04 \mathrm{E}-06$ & $.31 E-09$ & 1. $42 \mathrm{E}-31$ & $1.58 \mathrm{E}-31$ & $1.60 \mathrm{E}-$ & -31 & $42 E-16$ \\
\hline-33 & 06 & & & & & & $E-15$ \\
\hline 33 & & & & & & & -14 \\
\hline 3 & & (2) & & \pm & & & 14 \\
\hline-33 & 2.3 & $3.39 \mathrm{E}-09$ & 1. & 1 & $\perp$ & & 3 \\
\hline 3 & 6 & 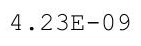 & 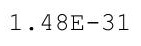 & - & L & - & 12 \\
\hline $12 \mathrm{E}-33$ & $.35 E-06$ & $5.25 E-09$ & 1. $49 \mathrm{E}-31$ & 1 & $1.69 \mathrm{E}-$ & $.71 E-31$ & $4.34 \mathrm{E}-12$ \\
\hline-33 & $E-06$ & & & & & & $.32 E-11$ \\
\hline & & & & & & & \\
\hline 33 & 06 & & 1. & $\perp$ & 1 & & \\
\hline $.02 E-33$ & $6.40 \mathrm{E}-06$ & $1 \cdot 1 / E-00$ & $1.345-31$ & $1.73 E-31$ & $1.75 \mathrm{E}-31$ & $1 \cdot 7 / E-31$ & $.03 E-10$ \\
\hline $99 E-33$ & $7.61 \mathrm{E}-06$ & $1 \cdot 4 \perp \perp-00$ & $+\cdot 00$ & 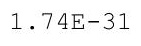 & 土. & ×・Tिए & $4.34 \mathrm{E}-10$ \\
\hline 3 & $40 E-06$ & 土e & - & 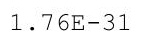 & 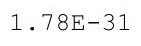 & 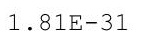 & $.56 \mathrm{E}-10$ \\
\hline$F-33$ & $15 \mathrm{~F}-0.5$ & $035-08$ & 1 & 177 & & & $0 E-09$ \\
\hline & & & & & & & \\
\hline$E-33$ & & 08 & & & & & \\
\hline $.87 E-33$ & $2.03 E-05$ & $3.36 \mathrm{E}-08$ & $1.62 \mathrm{E}-31$ & $1.0 \angle \mathrm{E}$ & 1.001 & 31 & -09 \\
\hline $84 E-33$ & $2.4 \perp E-05$ & . & $1.64 \mathrm{E}-31$ & $1.84 E-31$ & & & $1.03 E-08$ \\
\hline $82 E-33$ & 2.00 & & $1.65 \mathrm{E}-31$ & $1.85 \mathrm{E}-31$ & & & $1.56 \mathrm{E}-08$ \\
\hline 3 & $3.36 \mathrm{E}-05$ & 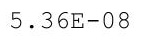 & t & 1 & 1 & & 8 \\
\hline & & & & & & & 8 \\
\hline $5 E-33$ & 4.5 & -08 & 1 . & 1 & 1 & 9 & -08 \\
\hline $2 E-33$ & $5.30 \mathrm{E}$ & 8.2 & 1. & 1.92 & & & -08 \\
\hline & & & & & & & \\
\hline 3 & 5 & . & 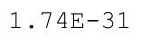 & $1.95 \mathrm{E}-31$ & $1.99 \mathrm{E}-31$ & $1.03 E-15$ & $1.29 \mathrm{E}-07$ \\
\hline $65 E-33$ & 5 & 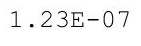 & 舟, & 土. & $2.01 \mathrm{E}$ & $8.27 \mathrm{E}-$ & $1.73 E-07$ \\
\hline$B E-33$ & $.10 \mathrm{E}-05$ & $0 E-07$ & $77 E-31$ & $99 E-31$ & $02 E-31$ & $7 E-14$ & -07 \\
\hline
\end{tabular}


RESRAD-OFFSITE, Version 2.5 
RESRAD-OFFSITE, Version 2.5 
RESRAD-OFFSITE, Version 2.5 
RESRAD-OFFSITE, Version 2.5 
RESRAD-OFFSITE, Version 2.5

$\mathrm{T}^{1 / 2}$ Limit $=180$ days

obabilistic Dose and Risk Report

Title : Offsite Resident Farmer

File : RF TC99 DOESG FWD-FV2all.ROF

Summary of dose at graphical times, reptition 2 (continued)

Time

Years

$2.36 \mathrm{E}+02$

$2.36 \mathrm{E}+02$

$2.37 \mathrm{E}+02$

$2.37 \mathrm{E}+02$

$2.38 \mathrm{E}+02$

2. $38 \mathrm{E}+02$

2. $39 \mathrm{E}+02$

$2.39 \mathrm{E}+02$

$2.40 \mathrm{E}+02$

$2.40 \mathrm{E}+02$

$2.41 E+02$

$2.41 \mathrm{E}+02$

$2.42 \mathrm{E}+02$

$2.43 \mathrm{E}+02$

$2.43 \mathrm{E}+02$

$2.44 \mathrm{E}+02$

$2.44 \mathrm{E}+02$

$2.45 \mathrm{E}+02$

$2.45 \mathrm{E}+02$

$2.46 \mathrm{E}+02$

$2.46 \mathrm{E}+02$

$2.47 \mathrm{E}+02$

$2.47 \mathrm{E}+02$

$2.48 \mathrm{E}+02$

$2.48 \mathrm{E}+02$

$2.49 \mathrm{E}+02$

$2.49 \mathrm{E}+02$

$2.50 \mathrm{E}+02$

$2.50 \mathrm{E}+02$

$2.51 \mathrm{E}+02$

$2.51 \mathrm{E}+02$

$2.52 \mathrm{E}+02$

$2.52 \mathrm{E}+02$

$2.53 \mathrm{E}+02$

$2.53 \mathrm{E}+02$

$2.54 \mathrm{E}+02$

$2.54 \mathrm{E}+02$

$2.55 \mathrm{E}+02$

$2.55 \mathrm{E}+02$

$2.56 \mathrm{E}+02$

$2.56 \mathrm{E}+02$

$2.57 \mathrm{E}+02$

$2.57 \mathrm{E}+02$

$2.58 \mathrm{E}+02$

$2.58 \mathrm{E}+02$

$2.59 \mathrm{E}+02$
Dose statistics at graphical times, mrem/yr

\begin{tabular}{|c|c|c|c|c|c|c|c|}
\hline lum & aximum & ean & 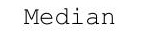 & $90 \%$ & & $\%$ & \\
\hline $28 E-33$ & $1.80 \mathrm{E}-01$ & $9.72 E-04$ & $9.63 E-31$ & $9.06 \mathrm{E}-04$ & $3.31 E-03$ & -03 & $-0<$ \\
\hline $26 \mathrm{E}-33$ & $1.83 \mathrm{E}-01$ & $4 \mathrm{E}-04$ & $9.73 E-31$ & - & 3 & -03 & -02 \\
\hline $.25 E-33$ & $1.86 \mathrm{E}-01$ & $2 E-03$ & $9.83 E-31$ & $9.71 \mathrm{E}-04$ & $47 E-03$ & $9.66 \mathrm{E}-03$ & $3.00 \mathrm{E}-02$ \\
\hline $24 \mathrm{E}-33$ & $1.90 \mathrm{E}-01$ & $1.04 \mathrm{E}-03$ & $9.95 E-31$ & $1.01 \mathrm{E}-03$ & $3.55 E-03$ & $9.87 \mathrm{E}-03$ & $3.06 \mathrm{E}-02$ \\
\hline $2 E-33$ & 01 & $6 \mathrm{E}$ & $01 E-30$ & $E-03$ & -03 & $1 E-02$ & -02 \\
\hline$E-33$ & 1 & 1. $08 \mathrm{E}-03$ & 0 & 3 & & -02 & -02 \\
\hline $20 E-33$ & 2.001 & & & & & & -02 \\
\hline $18 E-33$ & & & & & & & -02 \\
\hline-33 & -01 & -0 & & 3 & 3 & -02 & $E-02$ \\
\hline $21 \mathrm{E}-33$ & -01 & t & 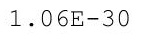 & 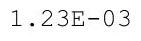 & $4.07 \mathrm{E}-03$ & 2 & -02 \\
\hline $9 E-33$ & -01 & 1 & -30 & $1.27 \mathrm{E}$ & & -02 & 2 \\
\hline 33 & 2.1 & & & & & & -02 \\
\hline$E-33$ & -01 & 1 & & 36 & 3 & -02 & -02 \\
\hline $.15 E-33$ & $2.24 \mathrm{E}-01$ & $1.29 \mathrm{E}-03$ & $1.11 \mathrm{E}-30$ & $1.41 \mathrm{E}-03$ & $4.47 \mathrm{E}-03$ & $1.21 \mathrm{E}-02$ & $.72 E-02$ \\
\hline 33 & $E-01$ & 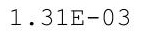 & & 3 & 3 & -02 & -02 \\
\hline 33 & 1 & $\perp$ & 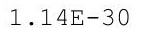 & 3 & & 2 & -02 \\
\hline 33 & 1 & 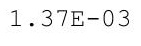 & & 3 & 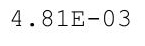 & & 02 \\
\hline 3 & $2.39 \mathrm{E}-01$ & & & & & & 2 \\
\hline $.08 E-33$ & $2.43 E-01$ & 1. $43 \mathrm{E}-0$ & & & $03 \mathrm{E}$ & 1.35 & -02 \\
\hline $.07 E-33$ & $.47 \mathrm{E}-01$ & $1.46 \mathrm{E}-0$ & ( & $1.66 \mathrm{E}-03$ & 03 & $1.38 \mathrm{E}-02$ & $.15 E-02$ \\
\hline $.06 E-33$ & $2.50 \mathrm{E}-01$ & 1. $49 \mathrm{E}-03$ & & & & $E-02$ & $22 E-02$ \\
\hline 33 & & & & & & & -02 \\
\hline 3 & & 1 . & & & & & 02 \\
\hline $02 E-33$ & $2 \cdot$ & $\perp$ & 1. & & & & -02 \\
\hline 3 & 1 & 1 & $1.27 \mathrm{E}-30$ & 3 & $5.76 \mathrm{E}-03$ & 2 & -02 \\
\hline $99 E-33$ & $.70 \mathrm{E}-01$ & 1 & $13 \cap 5$ & 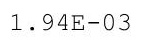 & تصم0 & $0 \mathrm{E}-02$ & $62 E-02$ \\
\hline $98 F-33$ & -01 & 10 & & 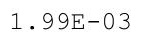 & & $.63 E-02$ & $.70 \mathrm{E}-02$ \\
\hline$E-33$ & -01 & & & & & $\mathrm{E}-02$ & $78 E-02$ \\
\hline & & & & & & & \\
\hline $94 E-33$ & $2.015-01$ & $1.78 E-03$ & $2.10 \mathrm{~L}$ & $2 \cdot \perp \circlearrowleft \amalg$ & $1<0$ & 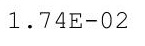 & -02 \\
\hline $.93 E-33$ & $2.91 \mathrm{~L}-0 \perp$ & $\begin{array}{ll}1.010 \\
0\end{array}$ & $\begin{array}{l}+10 \\
0\end{array}$ & 2.201 & . & $1.10 \mathrm{E}-\mathrm{U} 2$ & $04 E-02$ \\
\hline $91 E-33$ & 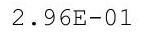 & $\perp \cdot 0)$ & tes & & - & 2.00 & $13 E-02$ \\
\hline 3 & $3.00 \mathrm{E}-01$ & 1.88 & & & & & 02 \\
\hline$F-33$ & 1 & & & & & -02 & 02 \\
\hline 3 & & & & & & & \\
\hline 33 & $3.13 E$ & $1.99 \mathrm{E}$ & 1. $62 \mathrm{E}-12$ & $2.40 \mathrm{E}$ & 21 & 02 & -02 \\
\hline $5 E-33$ & $\cdot .00$ & 2. & 1. & & & & -02 \\
\hline $83 E-33$ & $0.2<$ & & & & & & $72 E-02$ \\
\hline 3 & 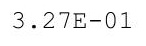 & 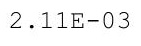 & . & & $7.71 \mathrm{E}-03$ & 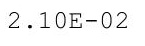 & 02 \\
\hline & & & & & & & 02 \\
\hline 3 & & & & 3 & & 2 & \\
\hline$E-33$ & $3.41 \mathrm{E}-01$ & $3 E-03$ & 2.2 & $2 \cdot$ & 3 & 02 & -02 \\
\hline & 1 & & & & & & \\
\hline & 1 & 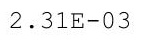 & & 3 & & & $0.30 \mathrm{E}-\mathrm{U} 2$ \\
\hline & 0 & 2.00 & 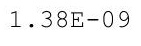 & & 3 & $2 \cdot 010$ & $E-02$ \\
\hline$E-33$ & $E-01$ & $0 E-03$ & $37 E-09$ & $E-03$ & $2 E-03$ & $2 E-02$ & -02 \\
\hline
\end{tabular}


RESRAD-OFFSITE, Version 2.5 
RESRAD-OFFSITE, Version 2.5 
RESRAD-OFFSITE, Version 2.5

robabilistic Dose and Risk Report

Title : Offsite Resident Farmer

File : RF TC99 DOESG FWD-FV2all.ROF

Summary of dose at graphical times, reptition 2 (continued)

Time

Years

$3.07 \mathrm{E}+02$

$3.07 \mathrm{E}+02$

$3.08 \mathrm{E}+02$

$3.08 \mathrm{E}+02$

$3.09 \mathrm{E}+02$

3. $09 \mathrm{E}+02$

$3.10 \mathrm{E}+02$

$3.10 \mathrm{E}+02$

3. $11 \mathrm{E}+02$

$3.11 \mathrm{E}+02$

$3.12 \mathrm{E}+02$

$3.12 \mathrm{E}+02$

$3.13 \mathrm{E}+02$

$3.13 \mathrm{E}+02$

$3.14 \mathrm{E}+02$

$3.14 \mathrm{E}+02$

$3.15 \mathrm{E}+02$

$3.15 \mathrm{E}+02$

$3.16 \mathrm{E}+02$

$3.16 \mathrm{E}+02$

$3.17 \mathrm{E}+02$

$3.17 \mathrm{E}+02$

$3.18 \mathrm{E}+02$

$3.18 \mathrm{E}+02$

$3.19 \mathrm{E}+02$

$3.19 \mathrm{E}+02$

$3.20 \mathrm{E}+02$

$3.20 \mathrm{E}+02$

$3.21 \mathrm{E}+02$

$3.21 \mathrm{E}+02$

$3.22 \mathrm{E}+02$

$3.22 \mathrm{E}+02$

$3.23 \mathrm{E}+02$

$3.24 \mathrm{E}+02$

$3.24 \mathrm{E}+02$

$3.25 \mathrm{E}+02$

$3.25 \mathrm{E}+02$

$3.26 \mathrm{E}+02$

$3.26 \mathrm{E}+02$

$3.27 \mathrm{E}+02$

$3.27 \mathrm{E}+02$

$3.28 \mathrm{E}+02$

$3.28 \mathrm{E}+02$

$3.29 \mathrm{E}+02$

$3.29 \mathrm{E}+02$

$3.30 \mathrm{E}+02$
Dose statistics at graphical times, mrem/yr

\begin{tabular}{|c|c|c|c|c|c|c|c|}
\hline Minimum & Maximum & Mean & Median & $90 \%$ & $95 \%$ & $97.5 \%$ & $99 \%$ \\
\hline $2.13 E-32$ & $9.74 \mathrm{E}-01$ & $9.72 E-03$ & $2.55 E-04$ & $1.81 E-02$ & $4.13 E-02$ & $9.54 \mathrm{E}-02$ & $2.30 E-01$ \\
\hline $2.13 E-32$ & $9.82 \mathrm{E}-01$ & $9.84 \mathrm{E}-03$ & $2.63 E-04$ & $1.83 E-02$ & $4.19 \mathrm{E}-02$ & $9.64 \mathrm{E}-02$ & $2.33 E-01$ \\
\hline $2.13 E-32$ & $9.91 \mathrm{E}-01$ & $9.97 \mathrm{E}-03$ & $2.72 \mathrm{E}-04$ & $1.86 \mathrm{E}-02$ & $4.25 \mathrm{E}-02$ & $9.76 \mathrm{E}-02$ & $2.35 \mathrm{E}-01$ \\
\hline $2.13 E-32$ & $9.99 \mathrm{E}-01$ & $1.01 \mathrm{E}-02$ & $2.81 \mathrm{E}-04$ & $1.88 \mathrm{E}-02$ & $4.31 \mathrm{E}-02$ & $9.87 \mathrm{E}-02$ & $2.37 \mathrm{E}-01$ \\
\hline $2.13 E-32$ & $1.01 \mathrm{E}+00$ & $1.02 \mathrm{E}-02$ & $2.89 E-04$ & $1.91 E-02$ & $4.37 E-02$ & $9.98 \mathrm{E}-02$ & $2.40 E-01$ \\
\hline $2.13 E-32$ & $1.02 \mathrm{E}+00$ & $1.03 E-02$ & $2.97 E-04$ & $1.94 \mathrm{E}-02$ & $4.43 E-02$ & 1.01E-01 & $2.42 \mathrm{E}-01$ \\
\hline $2.13 E-32$ & $1.02 \mathrm{E}+00$ & $1.05 \mathrm{E}-02$ & $3.09 E-04$ & 1.97E-02 & $4.49 E-02$ & $1.02 \mathrm{E}-01$ & $2.44 E-01$ \\
\hline $2.13 E-32$ & $1.03 \mathrm{E}+00$ & $1.06 \mathrm{E}-02$ & $3.21 \mathrm{E}-04$ & $1.99 \mathrm{E}-02$ & $4.56 \mathrm{E}-02$ & $1.03 \mathrm{E}-01$ & $2.47 \mathrm{E}-01$ \\
\hline $2.13 E-32$ & $1.04 \mathrm{E}+00$ & $1.07 \mathrm{E}-02$ & $3.30 E-04$ & $2.02 \mathrm{E}-02$ & $4.62 \mathrm{E}-02$ & $1.05 \mathrm{E}-01$ & $2.49 E-01$ \\
\hline $2.13 E-32$ & $1.05 \mathrm{E}+00$ & $1.09 \mathrm{E}-02$ & $3.39 \mathrm{E}-04$ & $2.05 E-02$ & $4.68 \mathrm{E}-02$ & $1.06 \mathrm{E}-01$ & $2.52 \mathrm{E}-01$ \\
\hline $2.13 \mathrm{E}-32$ & $1.06 \mathrm{E}+00$ & $1.10 \mathrm{E}-02$ & $3.53 E-04$ & $2.09 E-02$ & $4.75 \mathrm{E}-02$ & $1.07 \mathrm{E}-01$ & $2.54 \mathrm{E}-01$ \\
\hline $2.13 E-32$ & $1.07 \mathrm{E}+00$ & $1.11 \mathrm{E}-02$ & $3.66 \mathrm{E}-04$ & $2.12 \mathrm{E}-02$ & $4.83 \mathrm{E}-02$ & $1.08 \mathrm{E}-01$ & $2.56 \mathrm{E}-01$ \\
\hline $2.13 E-32$ & $1.07 \mathrm{E}+00$ & $1.13 \mathrm{E}-02$ & $3.78 \mathrm{E}-04$ & $2.15 E-02$ & $4.90 \mathrm{E}-02$ & $1.09 \mathrm{E}-01$ & $2.59 \mathrm{E}-01$ \\
\hline $2.13 E-32$ & $1.08 \mathrm{E}+00$ & $1.14 \mathrm{E}-02$ & $3.90 \mathrm{E}-04$ & $2.18 \mathrm{E}-02$ & $4.97 \mathrm{E}-02$ & $1.11 \mathrm{E}-01$ & $2.61 \mathrm{E}-01$ \\
\hline $2.13 E-32$ & $1.09 \mathrm{E}+00$ & $1.15 \mathrm{E}-02$ & $4.01 E-04$ & $2.21 \mathrm{E}-02$ & $5.04 \mathrm{E}-02$ & $1.12 \mathrm{E}-01$ & $2.64 \mathrm{E}-01$ \\
\hline $2.13 E-32$ & $1.10 \mathrm{E}+00$ & $1.17 \mathrm{E}-02$ & $4.14 \mathrm{E}-04$ & $2.24 E-02$ & $5.10 \mathrm{E}-02$ & $1.13 E-01$ & $2.66 \mathrm{E}-01$ \\
\hline $2.13 E-32$ & $1.11 \mathrm{E}+00$ & $1.18 \mathrm{E}-02$ & $4.25 E-04$ & $2.27 E-02$ & $5.17 \mathrm{E}-02$ & $1.14 \mathrm{E}-01$ & $2.69 \mathrm{E}-01$ \\
\hline $2.13 E-32$ & $1.12 \mathrm{E}+00$ & $1.19 \mathrm{E}-02$ & $4.37 E-04$ & $2.30 \mathrm{E}-02$ & $5.24 \mathrm{E}-02$ & $1.15 \mathrm{E}-01$ & $2.71 \mathrm{E}-01$ \\
\hline $2.14 \mathrm{E}-32$ & $1.12 \mathrm{E}+00$ & $1.21 \mathrm{E}-02$ & $4.50 E-04$ & $2.34 \mathrm{E}-02$ & $5.31 \mathrm{E}-02$ & $1.16 \mathrm{E}-01$ & $2.74 \mathrm{E}-01$ \\
\hline $2.14 \mathrm{E}-32$ & $1.13 \mathrm{E}+00$ & $1.22 \mathrm{E}-02$ & 4. $62 \mathrm{E}-04$ & $2.37 E-02$ & $5.38 \mathrm{E}-02$ & $1.17 \mathrm{E}-01$ & $2.76 \mathrm{E}-01$ \\
\hline $2.14 \mathrm{E}-32$ & $1.14 \mathrm{E}+00$ & $1.24 \mathrm{E}-02$ & $4.76 \mathrm{E}-04$ & $2.40 \mathrm{E}-02$ & $5.45 \mathrm{E}-02$ & $1.18 \mathrm{E}-01$ & $2.79 \mathrm{E}-01$ \\
\hline $2.14 \mathrm{E}-32$ & $1.15 \mathrm{E}+00$ & $1.25 \mathrm{E}-02$ & $4.89 \mathrm{E}-04$ & $2.44 E-02$ & $.52 E-02$ & $1.20 \mathrm{E}-01$ & $2.81 E-01$ \\
\hline $2.14 \mathrm{E}-32$ & $1.16 \mathrm{E}+00$ & $1.27 \mathrm{E}-02$ & $5.04 \mathrm{E}-04$ & $2.47 E-02$ & $5.60 \mathrm{E}-02$ & $1.21 \mathrm{E}-01$ & $2.84 \mathrm{E}-01$ \\
\hline $2.14 \mathrm{E}-32$ & $1.17 \mathrm{E}+00$ & $1.28 \mathrm{E}-02$ & $5.17 \mathrm{E}-04$ & $2.51 \mathrm{E}-02$ & $5.67 \mathrm{E}-02$ & $1.22 \mathrm{E}-01$ & $2.87 \mathrm{E}-01$ \\
\hline $2.14 \mathrm{E}-32$ & $1.18 \mathrm{E}+00$ & 1. $30 \mathrm{E}-02$ & $5.30 E-04$ & $2.54 \mathrm{E}-02$ & $5.74 \mathrm{E}-02$ & $1.23 \mathrm{E}-01$ & $2.89 E-01$ \\
\hline $2.14 \mathrm{E}-32$ & $1.18 \mathrm{E}+00$ & $1.31 \mathrm{E}-02$ & $5.44 \mathrm{E}-04$ & $2.58 \mathrm{E}-02$ & $5.82 \mathrm{E}-02$ & 1. $24 \mathrm{E}-01$ & $2.92 \mathrm{E}-01$ \\
\hline $2.14 \mathrm{E}-32$ & $1.19 \mathrm{E}+00$ & $1.33 E-02$ & $5.60 \mathrm{E}-04$ & $2.62 \mathrm{E}-02$ & $5.89 \mathrm{E}-02$ & $1.25 \mathrm{E}-01$ & $2.94 \mathrm{E}-01$ \\
\hline $2.14 \mathrm{E}-32$ & $1.20 \mathrm{E}+00$ & $1.34 \mathrm{E}-02$ & $5.77 \mathrm{E}-04$ & $2.65 E-02$ & $5.97 \mathrm{E}-02$ & $1.27 \mathrm{E}-01$ & $2.97 E-01$ \\
\hline $2.14 \mathrm{E}-32$ & $1.21 \mathrm{E}+00$ & $1.36 \mathrm{E}-02$ & $5.90 E-04$ & $2.69 E-02$ & $6.04 \mathrm{E}-02$ & $1.28 \mathrm{E}-01$ & $3.00 E-01$ \\
\hline $2.14 \mathrm{E}-32$ & $1.22 \mathrm{E}+00$ & $1.37 \mathrm{E}-02$ & $6.04 \mathrm{E}-04$ & $2.73 E-02$ & $6.12 \mathrm{E}-02$ & $1.29 \mathrm{E}-01$ & $3.02 E-01$ \\
\hline $2.14 \mathrm{E}-32$ & $1.23 \mathrm{E}+00$ & $1.39 \mathrm{E}-02$ & $6.19 \mathrm{E}-04$ & $2.76 \mathrm{E}-02$ & $6.20 \mathrm{E}-02$ & $1.31 \mathrm{E}-01$ & $3.05 E-01$ \\
\hline $2.14 \mathrm{E}-32$ & $1.24 \mathrm{E}+00$ & $1.40 \mathrm{E}-02$ & $6.34 \mathrm{E}-04$ & $2.79 \mathrm{E}-02$ & $6.27 \mathrm{E}-02$ & 1. $32 \mathrm{E}-01$ & $3.08 \mathrm{E}-01$ \\
\hline $2.14 \mathrm{E}-32$ & $1.25 \mathrm{E}+00$ & $1.42 \mathrm{E}-02$ & $6.48 E-04$ & $2.83 E-02$ & $6.35 E-02$ & $1.33 \mathrm{E}-01$ & $3.10 \mathrm{E}-01$ \\
\hline $2.14 \mathrm{E}-32$ & $1.25 \mathrm{E}+00$ & $1.44 \mathrm{E}-02$ & $6.62 \mathrm{E}-04$ & $2.86 E-02$ & $6.42 \mathrm{E}-02$ & $1.35 \mathrm{E}-01$ & $3.13 E-01$ \\
\hline $2.14 \mathrm{E}-32$ & $1.26 \mathrm{E}+00$ & $1.45 \mathrm{E}-02$ & $6.77 \mathrm{E}-04$ & $2.89 \mathrm{E}-02$ & $6.49 \mathrm{E}-02$ & $1.36 \mathrm{E}-01$ & $3.16 \mathrm{E}-01$ \\
\hline $2.15 E-32$ & $1.27 \mathrm{E}+00$ & $1.47 \mathrm{E}-02$ & $6.93 E-04$ & $2.93 E-02$ & $6.56 \mathrm{E}-02$ & $1.37 \mathrm{E}-01$ & $3.19 \mathrm{E}-01$ \\
\hline $2.15 E-32$ & $1.28 \mathrm{E}+00$ & $1.48 \mathrm{E}-02$ & $7.09 E-04$ & $2.97 E-02$ & $6.64 \mathrm{E}-02$ & $1.39 \mathrm{E}-01$ & $3.21 \mathrm{E}-01$ \\
\hline $2.15 \mathrm{E}-32$ & $1.29 \mathrm{E}+00$ & $1.50 \mathrm{E}-02$ & $7.25 E-04$ & $3.00 \mathrm{E}-02$ & $6.71 \mathrm{E}-02$ & $1.40 \mathrm{E}-01$ & $3.24 \mathrm{E}-01$ \\
\hline$E-32$ & $1.30 \mathrm{E}+00$ & $1.52 \mathrm{E}-$ & $7.42 \mathrm{E}-04$ & $3.04 \mathrm{E}-02$ & $6.79 \mathrm{E}-02$ & $1.41 \mathrm{E}-01$ & $3.27 E-01$ \\
\hline $2.15 \mathrm{E}-32$ & $1.31 \mathrm{E}+00$ & $1.53 \mathrm{E}-02$ & $7.59 \mathrm{E}-04$ & $3.08 \mathrm{E}-02$ & $6.86 \mathrm{E}-02$ & $1.43 \mathrm{E}-01$ & $3.30 \mathrm{E}-01$ \\
\hline $2.15 \mathrm{E}-32$ & $1.32 \mathrm{E}+00$ & $1.55 \mathrm{E}-02$ & $7.75 \mathrm{E}-04$ & $3.12 \mathrm{E}-02$ & $6.94 \mathrm{E}-02$ & $1.44 \mathrm{E}-01$ & $3.32 \mathrm{E}-01$ \\
\hline $2.15 E-32$ & $1.33 \mathrm{E}+00$ & $1.57 \mathrm{E}-02$ & $7.92 E-04$ & $3.16 \mathrm{E}-02$ & $7.02 \mathrm{E}-02$ & $1.45 \mathrm{E}-01$ & $3.35 E-01$ \\
\hline $2.15 E-32$ & $1.33 \mathrm{E}+00$ & $1.58 \mathrm{E}-02$ & $8.09 E-04$ & $3.20 \mathrm{E}-02$ & $7.10 \mathrm{E}-02$ & $1.46 \mathrm{E}-01$ & $3.38 \mathrm{E}-01$ \\
\hline $2.15 E-32$ & $1.34 \mathrm{E}+00$ & $1.60 \mathrm{E}-02$ & $8.26 E-04$ & $3.24 \mathrm{E}-02$ & $7.18 \mathrm{E}-02$ & $1.47 \mathrm{E}-01$ & $3.41 \mathrm{E}-01$ \\
\hline $2.15 E-32$ & $1.35 \mathrm{E}+00$ & $1.62 \mathrm{E}-02$ & $8.43 E-04$ & $3.28 E-02$ & $7.27 E-02$ & $1.49 \mathrm{E}-01$ & $3.44 \mathrm{E}-01$ \\
\hline $2.15 E-32$ & $1.36 \mathrm{E}+00$ & $1.64 \mathrm{E}-02$ & $8.64 \mathrm{E}-04$ & $3.32 E-02$ & $7.35 \mathrm{E}-02$ & $1.50 \mathrm{E}-01$ & $3.47 E-01$ \\
\hline
\end{tabular}


RESRAD-OFFSITE, Version 2.5

$\mathrm{T}^{1 / 2}$ Limit $=180$ days

obabilistic Dose and Risk Report

Title : Offsite Resident Farmer

File : RF TC99 DOESG FWD-FV2all.ROF

Summary of dose at graphical times, reptition 2 (continued)

Time

Years

$3.30 \mathrm{E}+02$

$3.31 \mathrm{E}+02$

$3.31 \mathrm{E}+02$

$3.32 \mathrm{E}+02$

$3.32 \mathrm{E}+02$

$3.33 \mathrm{E}+02$

$3.33 \mathrm{E}+02$

$3.34 \mathrm{E}+02$

$3.34 \mathrm{E}+02$

$3.35 \mathrm{E}+02$

$3.35 \mathrm{E}+02$

$3.36 \mathrm{E}+02$

$3.36 \mathrm{E}+02$

$3.37 \mathrm{E}+02$

$3.37 \mathrm{E}+02$

$3.38 \mathrm{E}+02$

$3.38 \mathrm{E}+02$

$3.39 \mathrm{E}+02$

$3.39 \mathrm{E}+02$

3. $40 \mathrm{E}+02$

$3.40 \mathrm{E}+02$

$3.41 \mathrm{E}+02$

$3.41 \mathrm{E}+02$

$3.42 \mathrm{E}+02$

$3.42 \mathrm{E}+02$

$3.43 \mathrm{E}+02$

$3.44 \mathrm{E}+02$

$3.44 \mathrm{E}+02$

$3.45 \mathrm{E}+02$

$3.45 \mathrm{E}+02$

$3.46 \mathrm{E}+02$

$3.46 \mathrm{E}+02$

3. $47 \mathrm{E}+02$

$3.47 \mathrm{E}+02$

$3.48 \mathrm{E}+02$

$3.48 \mathrm{E}+02$

$3.49 \mathrm{E}+02$

$3.49 \mathrm{E}+02$

$3.50 \mathrm{E}+02$

$3.50 \mathrm{E}+02$

$3.51 \mathrm{E}+02$

$3.51 \mathrm{E}+02$

$3.52 \mathrm{E}+02$

$3.52 \mathrm{E}+02$

$3.53 \mathrm{E}+02$

$3.53 \mathrm{E}+02$
Dose statistics at graphical times, mrem/yr

\begin{tabular}{|c|c|c|c|c|c|c|c|}
\hline $\mathrm{m}$ & aximum & ea & - & & & & \\
\hline $15 \mathrm{E}-32$ & $1.37 \mathrm{E}+00$ & 1. $65 \mathrm{E}-02$ & $8.83 E-04$ & $3.35 E-02$ & $7.44 \mathrm{E}-02$ & 01 & $9 \pm-U 1$ \\
\hline-32 & $1.38 \mathrm{E}+00$ & $1.67 \mathrm{E}-02$ & $9.04 \mathrm{E}-04$ & $9 E-02$ & $52 E-02$ & $1.52 \mathrm{E}-01$ & $2 E-01$ \\
\hline-32 & $1.39 \mathrm{E}+00$ & 1. $69 \mathrm{E}-02$ & $9.26 \mathrm{E}-04$ & $43 E-02$ & $61 E-02$ & $1.54 \mathrm{E}-01$ & $55 E-01$ \\
\hline$E-32$ & $40 E+00$ & $71 \mathrm{~F}-02$ & $50 \mathrm{E}-04$ & $47 \mathrm{~F}-02$ & $59 E-02$ & -01 & $58 \mathrm{~F}-01$ \\
\hline-32 & +00 & 2 & 4 & 2 & 2 & -01 & -01 \\
\hline 32 & $1.42 \mathrm{E}+00$ & & & & & & 01 \\
\hline $16 \mathrm{E}-32$ & $1.43 E+00$ & $1.76 \mathrm{E}$ & & & & & -01 \\
\hline-32 & $1.43 E+00$ & 2 & 3 & 2 & 2 & 1 & -01 \\
\hline-32 & $1.44 \mathrm{E}+00$ & $1.80 \mathrm{E}-02$ & -03 & $9 E-02$ & -02 & -01 & $73 E-01$ \\
\hline $16 E-32$ & $.45 E+00$ & ת חרים & 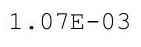 & 2 & 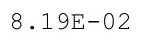 & $.63 E-01$ & $E-01$ \\
\hline 32 & $1.46 E+00$ & 1.84 & & & & 1 & 01 \\
\hline $16 \mathrm{E}-32$ & $1.47 \mathrm{E}+00$ & $1 . \varepsilon$ & 3 & 2 & 2 & 1 & -01 \\
\hline $16 \mathrm{E}-32$ & $1.48 E+00$ & $1.87 \mathrm{E}-02$ & & $.85 E-02$ & & & $85 E-01$ \\
\hline $16 \mathrm{E}-32$ & $1.49 \mathrm{E}+00$ & $1.89 \mathrm{E}-02$ & $1.16 \mathrm{E}-03$ & 2 & 2 & $1.69 \mathrm{E}-01$ & $88 E-01$ \\
\hline-32 & $1.50 \mathrm{E}+00$ & $F-0$ & -03 & 2 & 02 & 1 & $E-01$ \\
\hline 2 & $1.51 \mathrm{E}+00$ & $\perp$ & 3 & 2 & 2 & $\perp$ & -01 \\
\hline 2 & 0 & 1. $95 \mathrm{E}-02$ & & & 2 & & 1 \\
\hline$E-32$ & $.53 E+00$ & 1.97E-02 & 3 & & 2 & $1.75 \mathrm{E}-01$ & 01 \\
\hline $16 \mathrm{E}-32$ & $1.54 \mathrm{E}+00$ & $1.99 \mathrm{E}-02$ & $1.28 E-03$ & $.13 E-02$ & $8.98 E-02$ & 1. $77 \mathrm{E}-01$ & $.03 E-01$ \\
\hline$E-32$ & $1.54 \mathrm{E}+00$ & $2.01 \mathrm{E}-02$ & 1. $30 \mathrm{E}-03$ & $4.17 \mathrm{E}-02$ & $9.07 \mathrm{E}-02$ & $1.79 \mathrm{E}-01$ & $.06 E-01$ \\
\hline-32 & $1.55 \mathrm{E}+00$ & $\angle$ & & & & $\perp$ & $E-01$ \\
\hline & & & & & & & \\
\hline-32 & $1.57 \mathrm{E}+00$ & $2 \cdot 0$ & 03 & 2 & & & -01 \\
\hline$E-32$ & $1.58 \mathrm{E}+00$ & 2 & 3 & 2 & & & -01 \\
\hline 32 & $1.59 \mathrm{E}+00$ & $2.12 \mathrm{E}-02$ & o & 2 & 2 & 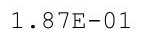 & $21 E-01$ \\
\hline $17 E-32$ & $1.60 \mathrm{E}+00$ & $.14 \mathrm{E}-0$ & $1.45 \mathrm{E}-03$ & 50 ת - & $62 E-02$ & $1.88 \mathrm{E}-01$ & $24 \mathrm{E}-01$ \\
\hline $17 E-32$ & $1.61 \mathrm{E}+00$ & $216 \mathrm{~F}-02$ & $.48 E-03$ & & & $\mathrm{DE}-01$ & $27 E-01$ \\
\hline-32 & & & & & & & $E-01$ \\
\hline-32 & $1.63 \mathrm{E}+00$ & 2.2 & & & & & -01 \\
\hline $17 E-32$ & $1.64 \mathrm{E}+00$ & $2 \cdot 2 \angle \dot{0} 02$ & $1.57 \mathrm{E}-03$ & $4.74 \mathrm{E}-02$ & $1.00 \mathrm{E}-01$ & $1.90 E-01$ & $.36 E-01$ \\
\hline $17 \mathrm{E}-32$ & $1.65 \mathrm{E}+00$ & $2.215-02$ & $1.60 \mathrm{E}-03$ & 1. & $1.01 \mathrm{E}-01$ & 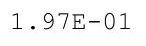 & $.39 E-01$ \\
\hline 2 & $1.66 \mathrm{E}+00$ & . & 3 & 2 & 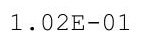 & 土. & $42 E-01$ \\
\hline 2 & $1.67 \mathrm{E}+00$ & & & & & & 01 \\
\hline 32 & & & & & & & $8 \mathrm{E}-01$ \\
\hline-32 & & & & & & & \\
\hline $17 E-32$ & $1.69 \mathrm{E}+00$ & $2.35 E-02$ & $1.7 O E$ & 2 & 1 & -01 & -01 \\
\hline $17 E-32$ & $1.70 \mathrm{E}+00$ & 2.00 & 1.100 & 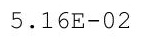 & & & $.57 E-01$ \\
\hline $17 E-32$ & $1.71 \mathrm{E}+00$ & $2.40 \mathrm{E}-02$ & & & & & $60 \mathrm{E}-01$ \\
\hline 2 & $\begin{array}{ll}0 \\
0\end{array}$ & 2. & 3 & 2 & - & & 01 \\
\hline & $1.73 E+00$ & & & 2 & & & 01 \\
\hline $8 E-32$ & $1.74 \mathrm{E}+00$ & $2.47 E-02$ & $1.91 \mathrm{E}-03$ & 2 & 1 & $5 E-01$ & $9 E-01$ \\
\hline $3 E-32$ & $1.75 E+00$ & 2. & 1. & & & & -01 \\
\hline & $1 \cdot 7$ & & & & & & -01 \\
\hline $5-32$ & $1.77 \mathrm{E}+00$ & $2.34 E-02$ & $2.01 E-03$ & - & 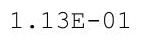 & $2.20 \mathrm{E}-01$ & $4.78 E-01$ \\
\hline $0 \mathrm{x}-32$ & $1.78 \mathrm{E}+00$ & $2.00+02$ & 2.001 & & & & $4.81 E-01$ \\
\hline 32 & $1.79 \mathrm{E}+00$ & $3 E-02$ & $08 E-03$ & $E-02$ & $.15 E-01$ & $.24 \mathrm{E}-01$ & -01 \\
\hline
\end{tabular}


RESRAD-OFFSITE, Version 2.5

$\mathrm{T}^{1 / 2}$ Limit $=180$ days

obabilistic Dose and Risk Report

Title : Offsite Resident Farmer

File : RF TC99 DOESG FWD-FV2all.ROF

Summary of dose at graphical times, reptition 2 (continued)

Time

Years

$3.54 \mathrm{E}+02$

$3.54 \mathrm{E}+02$

$3.55 \mathrm{E}+02$

$3.55 \mathrm{E}+02$

$3.56 \mathrm{E}+02$

$3.56 \mathrm{E}+02$

$3.57 \mathrm{E}+02$

$3.57 \mathrm{E}+02$

$3.58 \mathrm{E}+02$

$3.58 \mathrm{E}+02$

$3.59 \mathrm{E}+02$

$3.59 \mathrm{E}+02$

$3.60 \mathrm{E}+02$

$3.60 \mathrm{E}+02$

$3.61 \mathrm{E}+02$

$3.61 \mathrm{E}+02$

$3.62 \mathrm{E}+02$

3. $62 \mathrm{E}+02$

$3.63 \mathrm{E}+02$

3. $64 \mathrm{E}+02$

$3.64 \mathrm{E}+02$

$3.65 \mathrm{E}+02$

$3.65 \mathrm{E}+02$

$3.66 \mathrm{E}+02$

$3.66 \mathrm{E}+02$

$3.67 \mathrm{E}+02$

$3.67 \mathrm{E}+02$

$3.68 \mathrm{E}+02$

$3.68 \mathrm{E}+02$

$3.69 \mathrm{E}+02$

$3.69 \mathrm{E}+02$

$3.70 \mathrm{E}+02$

$3.70 \mathrm{E}+02$

$3.71 \mathrm{E}+02$

$3.71 \mathrm{E}+02$

$3.72 \mathrm{E}+02$

$3.72 \mathrm{E}+02$

$3.73 \mathrm{E}+02$

$3.73 E+02$

$3.74 \mathrm{E}+02$

$3.74 \mathrm{E}+02$

$3.75 \mathrm{E}+02$

$3.75 \mathrm{E}+02$

$3.76 \mathrm{E}+02$

$3.76 \mathrm{E}+02$

$3.77 \mathrm{E}+02$
Dose statistics at graphical times, mrem/yr

\begin{tabular}{|c|c|c|c|c|c|c|c|}
\hline $\mathrm{m}$ & aximum & e & 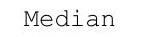 & & & & \\
\hline $18 \mathrm{E}-32$ & $1.80 \mathrm{E}+00$ & $61 E-02$ & $2.12 \mathrm{E}-03$ & $5.81 \mathrm{E}-02$ & $1.16 \mathrm{E}-01$ & 01 & $.07 \mathrm{E}-U 1$ \\
\hline $95 E-32$ & $1.81 \mathrm{E}+00$ & $2.63 E-02$ & $2.15 \mathrm{E}-03$ & $9 E-02$ & $17 E-01$ & $2.28 \mathrm{E}-01$ & $D E-01$ \\
\hline $96 \mathrm{E}-32$ & $1.82 \mathrm{E}+00$ & $66 E-02$ & $18 E-03$ & $6 \mathrm{E}-02$ & $18 E-01$ & $29 E-01$ & $93 E-01$ \\
\hline $97 E-32$ & $1.83 \mathrm{E}+00$ & $68 \mathrm{~F}-02$ & $22 \mathrm{~F}-03$ & $03 F-02$ & $19 F-01$ & $31 \mathrm{~F}-01$ & $96 F-01$ \\
\hline $98 E-32$ & $1.83 \mathrm{E}+00$ & 2 & $E-03$ & 2 & 1 & 1 & -01 \\
\hline $99 E-32$ & $1.84 \mathrm{E}+00$ & & & & & & $U \perp$ \\
\hline $.00 E-32$ & $1.85 \mathrm{E}+00$ & & 03 & & & & $05 E-01$ \\
\hline $.01 E-32$ & $1.86 \mathrm{E}+00$ & 2 & -03 & 2 & 1 & 01 & $E-01$ \\
\hline $81 E-31$ & $1.87 \mathrm{E}+00$ & $80 \mathrm{E}-0$ & $E-03$ & -02 & $24 E-01$ & -01 & $E-01$ \\
\hline $3 E-31$ & $.88 \mathrm{E}+00$ & $83 F-0 ?$ & $.46 \mathrm{E}-03$ & 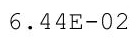 & 26 & 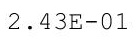 & $F-01$ \\
\hline 31 & $E+00$ & & & & & & 01 \\
\hline $86 \mathrm{E}-31$ & 1.90 & -02 & $E-03$ & 2 & 1 & 1 & -01 \\
\hline $88 E-31$ & $1.91 \mathrm{E}+00$ & $2.91 E-02$ & $2.60 E-03$ & & $1.29 \mathrm{E}-01$ & $2.49 E-01$ & $.24 E-01$ \\
\hline $90 E-31$ & 1. $92 \mathrm{E}+00$ & $.93 E-02$ & $2.65 \mathrm{E}-03$ & $6.69 \mathrm{E}-02$ & $1.31 \mathrm{E}-01$ & $2.51 \mathrm{E}-01$ & $7 E-01$ \\
\hline-31 & +00 & $\angle$ & -03 & 2 & & 1 & $E-01$ \\
\hline 1 & $1.94 \mathrm{E}+00$ & $2.98 E-02$ & 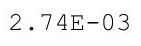 & 2 & & 1 & -01 \\
\hline 31 & $1.95 \mathrm{E}$ & & & & & L & 1 \\
\hline$E-31$ & $1.96 \mathrm{E}+00$ & $3.04 \mathrm{E}-02$ & $2.84 \mathrm{E}-03$ & 2 & 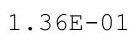 & 1 & 01 \\
\hline $98 E-31$ & $1.97 \mathrm{E}+00$ & $3.06 \mathrm{E}-02$ & $2.88 E-03$ & $.00 \mathrm{E}-02$ & $1.37 E-01$ & $2.60 \mathrm{E}-01$ & $.43 E-01$ \\
\hline $0 E-31$ & $1.98 \mathrm{E}+00$ & $.09 E-02$ & $2.93 E-03$ & $.06 \mathrm{E}-02$ & $1.38 \mathrm{E}-01$ & $2.63 E-01$ & $46 E-01$ \\
\hline-31 & $1.98 \mathrm{E}+00$ & & & & & 1 & $E-01$ \\
\hline 31 & & & & & & & 01 \\
\hline-31 & & ¿ & & 2 & & & 01 \\
\hline $7 E-31$ & $2.01 E+00$ & $=$ & 3 & 2 & 1 & 1 & -01 \\
\hline$E-31$ & $.02 \mathrm{E}+00$ & ח & 5 & $38 E-02$ & $.45 \mathrm{E}-$ & $.73 E-$ & $62 E-01$ \\
\hline $11 \mathrm{E}-31$ & $2.03 E+00$ & $.25 E-02$ & $E-03$ & $.45 E-02$ & $1.47 \mathrm{E}-$ & $2.75 E-0$ & $65 E-01$ \\
\hline$E-31$ & $2.04 \mathrm{E}+00$ & $8 E-02$ & & $52 \mathrm{E}-02$ & & $7 E-01$ & $68 E-01$ \\
\hline & & & & & & & 01 \\
\hline & & 3.04 & 03 & -02 & 1 & 1 & 01 \\
\hline $.18 E-31$ & $2.07 \mathrm{E}+00$ & . & $3.42 \mathrm{E}-03$ & $7.71 \mathrm{E}-02$ & $1.35 E-01$ & $2.84 \mathrm{E}-01$ & $.78 E-01$ \\
\hline $20 E-31$ & $2.08 E+00$ & $3.39 \mathrm{E}-02$ & $.47 E-03$ & $7.78 \mathrm{E}-02$ & $\perp \cdot 345-0 \perp$ & $2.00 \mathrm{~L}-0 \perp$ & $.81 E-01$ \\
\hline 1 & $2.09 \mathrm{E}+0$ & 2 & ק) & & & & $84 \mathrm{E}-01$ \\
\hline-31 & & & & & & & 01 \\
\hline 31 & & & & 2 & & & 01 \\
\hline-31 & & 02 & 03 & 02 & 1 & 1 & \\
\hline $29 E-31$ & $2.12 \mathrm{E}+00$ & $3.345-02$ & $3.75 E-03$ & -02 & $\perp \cdot 0$ & 01 & $97 E-01$ \\
\hline $31 E-31$ & $2.13 \mathrm{E}+00$ & $3.57 \mathrm{E}-02$ & & & & & $0.00 \pm-01$ \\
\hline 1 & $2.14 \mathrm{E}+00$ & 2 & $3.88 E-03$ & 2 & & & $03 E-01$ \\
\hline 1 & $2.15 \mathrm{E}+00$ & 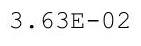 & 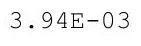 & 2 & 1 & . & 01 \\
\hline 31 & & 2 & 3 & 02 & 1 & & 01 \\
\hline$E-31$ & $2.17 \mathrm{E}+00$ & $3.69 \mathrm{E}-02$ & $E-03$ & 02 & & 1 & $13 E-01$ \\
\hline$E-31$ & $2.18 \mathrm{E}+00$ & $.72 E-0$ & & -02 & & & \\
\hline $42 E-31$ & $2.19 \mathrm{E}+00$ & ¿ & & & & & $20 E-U 1$ \\
\hline $44 E-31$ & $2.20 \mathrm{E}+00$ & . $10 \mathrm{~L}$ - & $4.24 \mathrm{E}-03$ & $8.73 E-02$ & $1.72 \mathrm{E}-01$ & $3.12 \mathrm{E}-01$ & $0.23 E-U 1$ \\
\hline $46 \mathrm{E}-31$ & $2.21 E+00$ & . & & & $1.74 \mathrm{E}-01$ & & $6.26 \mathrm{E}-01$ \\
\hline$E-31$ & $.22 E+00$ & $.84 \mathrm{E}-02$ & $.36 E-03$ & $.87 E-02$ & 1. $75 \mathrm{E}-01$ & 3. & $5.29 \mathrm{E}-01$ \\
\hline
\end{tabular}


RESRAD-OFFSITE, Version 2.5

$\mathrm{T}^{1 / 2}$ Limit $=180$ days

obabilistic Dose and Risk Report

Title : Offsite Resident Farmer

File : RF TC99 DOESG FWD-FV2all.ROF

Summary of dose at graphical times, reptition 2 (continued)

Time

Years

$3.77 \mathrm{E}+02$

$3.78 \mathrm{E}+02$

$3.78 \mathrm{E}+02$

$3.79 \mathrm{E}+02$

$3.79 \mathrm{E}+02$

$3.80 \mathrm{E}+02$

$3.80 \mathrm{E}+02$

3. $81 \mathrm{E}+02$

3. $81 \mathrm{E}+02$

3. $82 \mathrm{E}+02$

3. $82 \mathrm{E}+02$

$3.83 E+02$

$3.83 \mathrm{E}+02$

$3.84 \mathrm{E}+02$

$3.85 \mathrm{E}+02$

$3.85 \mathrm{E}+02$

$3.86 \mathrm{E}+02$

$3.86 \mathrm{E}+02$

$3.87 \mathrm{E}+02$

$3.87 \mathrm{E}+02$

$3.88 \mathrm{E}+02$

$3.88 \mathrm{E}+02$

$3.89 \mathrm{E}+02$

$3.89 \mathrm{E}+02$

3. $90 \mathrm{E}+02$

$3.90 \mathrm{E}+02$

3. $91 \mathrm{E}+02$

3. $91 \mathrm{E}+02$

3. $92 \mathrm{E}+02$

3. $92 \mathrm{E}+02$

3. $93 \mathrm{E}+02$

$3.93 \mathrm{E}+02$

3. $94 \mathrm{E}+02$

3. $94 \mathrm{E}+02$

$3.95 \mathrm{E}+02$

3. $95 \mathrm{E}+02$

$3.96 \mathrm{E}+02$

$3.96 \mathrm{E}+02$

$3.97 \mathrm{E}+02$

$3.97 \mathrm{E}+02$

$3.98 \mathrm{E}+02$

$3.98 \mathrm{E}+02$

$3.99 \mathrm{E}+02$

$3.99 \mathrm{E}+02$

$4.00 \mathrm{E}+02$

$4.00 \mathrm{E}+02$
Dose statistics at graphical times, mrem/yr

\begin{tabular}{|c|c|c|c|c|c|c|c|}
\hline Minimum & Maximum & Mean & Median & $90 \%$ & $95 \%$ & $97.5 \%$ & $99 \%$ \\
\hline $1.27 \mathrm{E}-30$ & $2.23 E+00$ & $3.87 E-02$ & 4. $42 E-03$ & $8.95 E-02$ & $1.77 E-01$ & $3.19 \mathrm{E}-01$ & $6.33 E-01$ \\
\hline $1.27 \mathrm{E}-30$ & $2.24 \mathrm{E}+00$ & $3.90 \mathrm{E}-02$ & $4.49 \mathrm{E}-03$ & $9.03 E-02$ & $1.79 \mathrm{E}-01$ & $3.21 \mathrm{E}-01$ & $6.36 \mathrm{E}-01$ \\
\hline 1. $28 \mathrm{E}-30$ & $2.24 \mathrm{E}+00$ & $3.93 E-02$ & $4.56 \mathrm{E}-03$ & $9.11 \mathrm{E}-02$ & $1.80 \mathrm{E}-01$ & $3.23 \mathrm{E}-01$ & $6.39 \mathrm{E}-01$ \\
\hline $1.29 \mathrm{E}-30$ & $2.25 \mathrm{E}+00$ & $3.96 \mathrm{E}-02$ & $4.62 \mathrm{E}-03$ & $9.19 \mathrm{E}-02$ & $1.82 \mathrm{E}-01$ & $3.25 \mathrm{E}-01$ & $6.43 \mathrm{E}-01$ \\
\hline $1.30 \mathrm{E}-30$ & $2.26 \mathrm{E}+00$ & $3.99 \mathrm{E}-02$ & $4.69 \mathrm{E}-03$ & $9.27 \mathrm{E}-02$ & $1.84 \mathrm{E}-01$ & $3.27 \mathrm{E}-01$ & $6.46 \mathrm{E}-01$ \\
\hline 1. $30 \mathrm{E}-30$ & $2.27 E+00$ & $4.03 E-02$ & $4.75 E-03$ & $9.37 \mathrm{E}-02$ & $1.86 \mathrm{E}-01$ & $3.29 \mathrm{E}-01$ & $6.49 \mathrm{E}-01$ \\
\hline $1.31 \mathrm{E}-30$ & $2.28 \mathrm{E}+00$ & $4.06 \mathrm{E}-02$ & $4.82 E-03$ & $9.47 \mathrm{E}-02$ & $1.87 \mathrm{E}-01$ & $3.31 E-01$ & $6.52 \mathrm{E}-01$ \\
\hline 1. $32 \mathrm{E}-30$ & $2.29 \mathrm{E}+00$ & $4.09 \mathrm{E}-02$ & $4.89 \mathrm{E}-03$ & $9.56 \mathrm{E}-02$ & $1.89 \mathrm{E}-01$ & $3.34 \mathrm{E}-01$ & $6.56 \mathrm{E}-01$ \\
\hline 1. $33 \mathrm{E}-30$ & $2.30 \mathrm{E}+00$ & $4.12 \mathrm{E}-02$ & $4.95 E-03$ & $9.65 \mathrm{E}-02$ & $1.91 \mathrm{E}-01$ & $3.36 \mathrm{E}-01$ & $6.59 \mathrm{E}-01$ \\
\hline 1. $33 \mathrm{E}-30$ & $2.31 \mathrm{E}+00$ & $4.15 \mathrm{E}-02$ & $5.02 \mathrm{E}-03$ & $9.74 \mathrm{E}-02$ & $1.92 \mathrm{E}-01$ & $3.38 E-01$ & $6.62 \mathrm{E}-01$ \\
\hline 1. $34 \mathrm{E}-30$ & $2.32 E+00$ & $4.19 \mathrm{E}-02$ & $5.09 \mathrm{E}-03$ & $9.83 \mathrm{E}-02$ & $1.93 \mathrm{E}-01$ & $3.40 \mathrm{E}-01$ & $6.66 \mathrm{E}-01$ \\
\hline 1. $35 \mathrm{E}-30$ & $2.33 \mathrm{E}+00$ & $4.22 E-02$ & $5.16 \mathrm{E}-03$ & $9.92 \mathrm{E}-02$ & $1.94 \mathrm{E}-01$ & $3.42 \mathrm{E}-01$ & $6.69 \mathrm{E}-01$ \\
\hline $1.36 \mathrm{E}-30$ & $2.34 \mathrm{E}+00$ & $4.25 \mathrm{E}-02$ & $5.23 E-03$ & $1.00 \mathrm{E}-01$ & $1.96 \mathrm{E}-01$ & $3.44 \mathrm{E}-01$ & $6.72 \mathrm{E}-01$ \\
\hline 1. $36 \mathrm{E}-30$ & $2.34 \mathrm{E}+00$ & $4.29 \mathrm{E}-02$ & $5.30 \mathrm{E}-03$ & $1.01 \mathrm{E}-01$ & $1.97 \mathrm{E}-01$ & $3.47 \mathrm{E}-01$ & $6.75 \mathrm{E}-01$ \\
\hline 1. $37 \mathrm{E}-30$ & $2.35 \mathrm{E}+00$ & $4.32 E-02$ & $5.38 E-03$ & $1.02 \mathrm{E}-01$ & $1.98 \mathrm{E}-01$ & $3.49 \mathrm{E}-01$ & $6.79 \mathrm{E}-01$ \\
\hline $1.38 \mathrm{E}-30$ & $2.36 \mathrm{E}+00$ & $4.35 E-02$ & $5.45 E-03$ & $1.03 E-01$ & $2.00 E-01$ & $3.51 \mathrm{E}-01$ & $6.82 E-01$ \\
\hline 1. $39 \mathrm{E}-30$ & $2.37 \mathrm{E}+00$ & $4.39 E-02$ & $5.53 \mathrm{E}-03$ & $1.04 \mathrm{E}-01$ & $2.01 \mathrm{E}-01$ & $3.53 \mathrm{E}-01$ & $6.85 E-01$ \\
\hline $1.40 \mathrm{E}-30$ & $2.38 \mathrm{E}+00$ & $4.42 E-02$ & $5.61 \mathrm{E}-03$ & $1.04 \mathrm{E}-01$ & $2.03 \mathrm{E}-01$ & $3.55 \mathrm{E}-01$ & $6.89 E-01$ \\
\hline 1. $40 \mathrm{E}-30$ & $2.39 \mathrm{E}+00$ & $4.45 E-02$ & $5.70 \mathrm{E}-03$ & $1.05 \mathrm{E}-01$ & $2.04 \mathrm{E}-01$ & $3.58 \mathrm{E}-01$ & $6.92 \mathrm{E}-01$ \\
\hline 1. $41 \mathrm{E}-30$ & $2.40 \mathrm{E}+00$ & $4.49 \mathrm{E}-02$ & $5.78 \mathrm{E}-03$ & $1.06 \mathrm{E}-01$ & $2.06 \mathrm{E}-01$ & $3.60 \mathrm{E}-01$ & $6.95 E-01$ \\
\hline $1.42 \mathrm{E}-30$ & $2.41 \mathrm{E}+00$ & $4.52 \mathrm{E}-02$ & $5.86 \mathrm{E}-03$ & $1.07 \mathrm{E}-01$ & $2.07 \mathrm{E}-01$ & $3.62 \mathrm{E}-01$ & $6.99 \mathrm{E}-01$ \\
\hline $1.43 E-30$ & $2.42 \mathrm{E}+00$ & $4.56 \mathrm{E}-02$ & $5.93 E-03$ & $1.08 \mathrm{E}-01$ & $2.09 E-01$ & $3.64 \mathrm{E}-01$ & $7.02 E-01$ \\
\hline $1.44 \mathrm{E}-30$ & $2.43 E+00$ & $4.59 \mathrm{E}-02$ & $6.01 \mathrm{E}-03$ & $1.09 \mathrm{E}-01$ & $2.11 \mathrm{E}-01$ & $3.67 \mathrm{E}-01$ & $7.05 E-01$ \\
\hline $1.56 \mathrm{E}-22$ & $2.43 E+00$ & $4.62 \mathrm{E}-02$ & $6.10 \mathrm{E}-03$ & $1.10 \mathrm{E}-01$ & $2.12 \mathrm{E}-01$ & $3.69 \mathrm{E}-01$ & $7.09 \mathrm{E}-01$ \\
\hline $2.99 \mathrm{E}-20$ & $2.44 \mathrm{E}+00$ & $4.66 \mathrm{E}-02$ & $6.18 \mathrm{E}-03$ & 1.11E-01 & $2.14 \mathrm{E}-01$ & $3.71 \mathrm{E}-01$ & $7.12 \mathrm{E}-01$ \\
\hline 1. $48 \mathrm{E}-18$ & $2.45 \mathrm{E}+00$ & $4.69 \mathrm{E}-02$ & $6.26 \mathrm{E}-03$ & 1.12E-01 & $2.16 \mathrm{E}-01$ & $3.73 \mathrm{E}-01$ & $7.15 \mathrm{E}-01$ \\
\hline $3.42 \mathrm{E}-17$ & $2.46 \mathrm{E}+00$ & $4.73 E-02$ & $6.36 \mathrm{E}-03$ & $1.13 \mathrm{E}-01$ & $2.17 \mathrm{E}-01$ & $3.76 \mathrm{E}-01$ & $7.19 \mathrm{E}-01$ \\
\hline $4.65 E-16$ & $2.47 \mathrm{E}+00$ & $4.76 \mathrm{E}-02$ & $6.45 \mathrm{E}-03$ & $1.14 \mathrm{E}-01$ & $2.19 \mathrm{E}-01$ & $3.78 \mathrm{E}-01$ & $7.22 \mathrm{E}-01$ \\
\hline $4.29 \mathrm{E}-15$ & $2.48 \mathrm{E}+00$ & $4.80 \mathrm{E}-02$ & $6.55 \mathrm{E}-03$ & $1.15 \mathrm{E}-01$ & $2.21 \mathrm{E}-01$ & $3.80 \mathrm{E}-01$ & 7. $25 \mathrm{E}-01$ \\
\hline $2.93 E-14$ & $2.49 \mathrm{E}+00$ & $4.83 E-02$ & $6.64 \mathrm{E}-03$ & $1.16 \mathrm{E}-01$ & $2.22 \mathrm{E}-01$ & $3.82 \mathrm{E}-01$ & $7.29 \mathrm{E}-01$ \\
\hline $1.57 \mathrm{E}-13$ & $2.50 \mathrm{E}+00$ & $4.87 \mathrm{E}-02$ & $6.74 \mathrm{E}-03$ & $1.17 \mathrm{E}-01$ & $2.23 E-01$ & $3.85 \mathrm{E}-01$ & 7. $32 \mathrm{E}-01$ \\
\hline $6.84 \mathrm{E}-13$ & $2.51 \mathrm{E}+00$ & $4.91 \mathrm{E}-02$ & $6.84 \mathrm{E}-03$ & 1.17E-01 & $2.25 \mathrm{E}-01$ & $3.87 \mathrm{E}-01$ & 7. $35 \mathrm{E}-01$ \\
\hline $2.52 \mathrm{E}-12$ & $2.51 \mathrm{E}+00$ & $.94 \mathrm{E}-02$ & $6.92 E-03$ & $1.18 \mathrm{E}-01$ & $2.26 \mathrm{E}-01$ & $3.88 E-01$ & $7.39 \mathrm{E}-01$ \\
\hline $8.07 \mathrm{E}-12$ & $2.52 \mathrm{E}+00$ & $4.98 \mathrm{E}-02$ & $7.01 \mathrm{E}-03$ & $1.19 \mathrm{E}-01$ & $2.28 \mathrm{E}-01$ & $3.90 \mathrm{E}-01$ & $7.42 \mathrm{E}-01$ \\
\hline $2.29 \mathrm{E}-11$ & $2.53 \mathrm{E}+00$ & $5.01 \mathrm{E}-02$ & $7.09 \mathrm{E}-03$ & 1.20E-01 & $2.29 \mathrm{E}-01$ & $3.92 \mathrm{E}-01$ & $7.45 \mathrm{E}-01$ \\
\hline $5.85 E-11$ & $2.54 \mathrm{E}+00$ & $5.05 E-02$ & $7.18 \mathrm{E}-03$ & $1.21 \mathrm{E}-01$ & $2.31 \mathrm{E}-01$ & $3.94 \mathrm{E}-01$ & $7.49 \mathrm{E}-01$ \\
\hline 1. $37 \mathrm{E}-10$ & $2.55 \mathrm{E}+00$ & $5.09 E-02$ & $7.26 \mathrm{E}-03$ & 1.22E-01 & $2.32 \mathrm{E}-01$ & $3.96 \mathrm{E}-01$ & $7.52 \mathrm{E}-01$ \\
\hline $2.45 \mathrm{E}-10$ & $2.56 \mathrm{E}+00$ & $5.12 \mathrm{E}-02$ & $7.34 \mathrm{E}-03$ & $1.23 \mathrm{E}-01$ & $2.34 \mathrm{E}-01$ & $3.98 \mathrm{E}-01$ & 7. $55 \mathrm{E}-01$ \\
\hline 4. $20 \mathrm{E}-10$ & $2.57 \mathrm{E}+00$ & $5.16 \mathrm{E}-02$ & $7.43 E-03$ & $1.24 \mathrm{E}-01$ & $2.35 \mathrm{E}-01$ & $4.00 \mathrm{E}-01$ & $7.59 \mathrm{E}-01$ \\
\hline $6.96 \mathrm{E}-10$ & $2.57 \mathrm{E}+00$ & $5.20 \mathrm{E}-02$ & $7.52 \mathrm{E}-03$ & $1.25 \mathrm{E}-01$ & $2.37 \mathrm{E}-01$ & $4.02 E-01$ & $7.62 \mathrm{E}-01$ \\
\hline $1.12 \mathrm{E}-09$ & $2.58 \mathrm{E}+00$ & $5.24 \mathrm{E}-02$ & $7.61 \mathrm{E}-03$ & $1.26 \mathrm{E}-01$ & $2.38 \mathrm{E}-01$ & $4.04 \mathrm{E}-01$ & 7. $65 \mathrm{E}-01$ \\
\hline $1.74 \mathrm{E}-09$ & $2.59 \mathrm{E}+00$ & $5.27 \mathrm{E}-02$ & $7.71 \mathrm{E}-03$ & $1.27 \mathrm{E}-01$ & $2.40 \mathrm{E}-01$ & $4.06 \mathrm{E}-01$ & $7.69 \mathrm{E}-01$ \\
\hline $2.65 \mathrm{E}-09$ & $2.60 \mathrm{E}+00$ & $5.31 \mathrm{E}-02$ & $7.82 \mathrm{E}-03$ & $1.28 \mathrm{E}-01$ & $2.41 \mathrm{E}-01$ & $4.09 \mathrm{E}-01$ & 7. $72 \mathrm{E}-01$ \\
\hline $3.93 \mathrm{E}-09$ & $2.61 \mathrm{E}+00$ & $5.35 E-02$ & $7.92 \mathrm{E}-03$ & $1.29 \mathrm{E}-01$ & $2.43 E-01$ & $4.11 \mathrm{E}-01$ & 7. $76 \mathrm{E}-01$ \\
\hline $5.72 \mathrm{E}-09$ & $2.62 E+00$ & $5.39 E-02$ & $8.02 E-03$ & $1.30 \mathrm{E}-01$ & $2.45 E-01$ & $4.13 E-01$ & $7.79 E-01$ \\
\hline $8.14 \mathrm{E}-09$ & $2.63 E+00$ & $5.43 E-02$ & $8.11 \mathrm{E}-03$ & 1. $31 \mathrm{E}-01$ & $2.46 \mathrm{E}-01$ & $4.15 \mathrm{E}-01$ & $7.82 \mathrm{E}-01$ \\
\hline
\end{tabular}


RESRAD-OFFSITE, Version 2.5 
RESRAD-OFFSITE, Version 2.5 
RESRAD-OFFSITE, Version 2.5

robabilistic Dose and Risk Report

Title : Offsite Resident Farmer

File : RF TC99 DOESG FWD-FV2all.ROF

Summary of dose at graphical times, reptition 2 (continued)

Time

Years

$4.48 \mathrm{E}+02$

$4.49 \mathrm{E}+02$

$4.49 \mathrm{E}+02$

$4.50 \mathrm{E}+02$

$4.50 \mathrm{E}+02$

$4.51 \mathrm{E}+02$

$4.51 \mathrm{E}+02$

4. $52 \mathrm{E}+02$

$4.52 \mathrm{E}+02$

4. $53 \mathrm{E}+02$

$4.53 \mathrm{E}+02$

$4.54 \mathrm{E}+02$

$4.54 \mathrm{E}+02$

$4.55 \mathrm{E}+02$

$4.55 \mathrm{E}+02$

$4.56 \mathrm{E}+02$

$4.56 \mathrm{E}+02$

$4.57 \mathrm{E}+02$

$4.57 \mathrm{E}+02$

$4.58 \mathrm{E}+02$

$4.58 \mathrm{E}+02$

$4.59 \mathrm{E}+02$

$4.59 \mathrm{E}+02$

$4.60 \mathrm{E}+02$

$4.60 \mathrm{E}+02$

$4.61 \mathrm{E}+02$

$4.61 \mathrm{E}+02$

$4.62 \mathrm{E}+02$

$4.62 \mathrm{E}+02$

$4.63 \mathrm{E}+02$

4. $63 \mathrm{E}+02$

$4.64 \mathrm{E}+02$

$4.65 \mathrm{E}+02$

4. $65 \mathrm{E}+02$

$4.66 \mathrm{E}+02$

$4.66 \mathrm{E}+02$

$4.67 \mathrm{E}+02$

$4.67 \mathrm{E}+02$

$4.68 \mathrm{E}+02$

$4.68 \mathrm{E}+02$

$4.69 \mathrm{E}+02$

$4.69 \mathrm{E}+02$

$4.70 \mathrm{E}+02$

$4.70 \mathrm{E}+02$

$4.71 \mathrm{E}+02$

$4.71 \mathrm{E}+02$
Dose statistics at graphical times, mrem/yr

\begin{tabular}{|c|c|c|c|c|c|c|c|}
\hline $\mathrm{m}$ & aximum & ea & 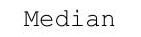 & & & & \\
\hline 05 & $32 \mathrm{E}+00$ & $9.69 \mathrm{E}-02$ & $2.17 \mathrm{E}-02$ & $2.39 \mathrm{E}-01$ & $4.14 \mathrm{E}-01$ & 01 & $-.20 E+00$ \\
\hline $.42 E-05$ & $3.32 E+00$ & $4 E-02$ & $2.19 \mathrm{E}-02$ & $0 E-01$ & $16 \mathrm{E}-01$ & -01 & $1.21 \mathrm{E}+00$ \\
\hline $.63 E-05$ & $33 E+00$ & $9.79 \mathrm{E}-02$ & $2.22 \mathrm{E}-02$ & $2.42 \mathrm{E}-01$ & $19 \mathrm{E}-01$ & 7. $28 \mathrm{E}-01$ & $1.21 \mathrm{E}+00$ \\
\hline $85 \mathrm{~F}-05$ & $34 \mathrm{E}+00$ & $85 \mathrm{~F}-02$ & $.24 \mathrm{E}-02$ & $43 \mathrm{~F}-01$ & $21 \mathrm{~F}-01$ & -01 & 1. $22 \mathrm{E}+00$ \\
\hline$E-05$ & $3.34 \mathrm{E}+00$ & 02 & -02 & 1 & 1 & 1 & +00 \\
\hline 05 & $35 E+00$ & & & & & & +00 \\
\hline $51 E-05$ & $3.35 \mathrm{E}+00$ & & -02 & & & & $.24 E+00$ \\
\hline $.74 \mathrm{E}-05$ & $3.36 \mathrm{E}+00$ & 01 & -02 & 1 & 1 & -01 & $1.24 \mathrm{E}+00$ \\
\hline $98 E-05$ & $.37 E+00$ & $1 E-01$ & -02 & 1 & $4 E-01$ & -01 & $1.25 \mathrm{E}+00$ \\
\hline $21 E-05$ & $37 E+00$ & $02 E-01$ & $.38 E-02$ & 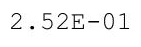 & $36 \Gamma$ & $4 \mathrm{E}-01$ & $.25 E+00$ \\
\hline 05 & $E+00$ & & & & & 1 & $E+00$ \\
\hline $.70 E-05$ & $3.38 \mathrm{E}+00$ & 01 & $E-02$ & 1 & 1 & & +00 \\
\hline $94 E-05$ & $3.39 \mathrm{E}+00$ & $1.03 E-01$ & $2.44 \mathrm{E}-02$ & $2.56 \mathrm{E}-01$ & & & $1.27 \mathrm{E}+00$ \\
\hline $.02 E-04$ & $3.40 \mathrm{E}+00$ & $1.04 \mathrm{E}-01$ & $2.46 \mathrm{E}-02$ & $2.57 \mathrm{E}-01$ & 4. $45 \mathrm{E}-01$ & 7. $69 \mathrm{E}-01$ & $1.27 \mathrm{E}+00$ \\
\hline$E-04$ & $40 E+00$ & $E-01$ & $E-02$ & (9F- & 1 & 1 & $.28 E+00$ \\
\hline$\cdot 0$ & 0 & $.05 E-01$ & & & & 1 & 00 \\
\hline${ }_{0}$ & & & & & & 1 & -00 \\
\hline $2 E-04$ & $3.42 \mathrm{E}+00$ & $1.06 \mathrm{E}-01$ & $2.54 \mathrm{E}-02$ & $2 \quad 6 \triangle \mathrm{F}-01$ & L & $7.83 \mathrm{E}-01$ & 0 \\
\hline $15 E-04$ & $.42 \mathrm{E}+00$ & $7 F-01$ & $6 \mathrm{E}-02$ & $266 \mathrm{~F}=$ & $55 \mathrm{~F}$ & 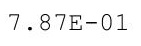 & $30 \mathrm{E}+00$ \\
\hline $18 E-04$ & $.43 E+00$ & $1.07 \mathrm{E}-01$ & $2.59 \mathrm{E}-02$ & $2.67 \mathrm{E}-01$ & $4.57 \mathrm{E}-\mathrm{C}$ & $F-01$ & $1.31 \mathrm{E}+00$ \\
\hline 04 & $.44 \mathrm{E}+00$ & & & & & 1 & $31 E+00$ \\
\hline 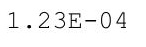 & & & & & & & \\
\hline 4 & $3.45 \mathrm{E}+00$ & \pm & & $2 \cdot 12$ & 1 & & (200 \\
\hline $29 E-04$ & $3.45 \mathrm{E}+00$ & $\perp$ & 2 & 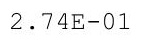 & $\perp$ & & 00 \\
\hline 4 & $3.46 \mathrm{E}+00$ & 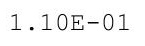 & 2 & - & L & $8.09 \mathrm{E}-01$ & $.33 E+$ \\
\hline $35 E-04$ & $.46 \mathrm{E}+00$ & $1.11 \mathrm{E}-01$ & $2.72 \mathrm{E}-02$ & م & $4.69 \mathrm{E}-$ & $.12 \mathrm{E}-01$ & $1.34 \mathrm{E}+00$ \\
\hline$F-04$ & $3.47 \mathrm{E}+00$ & & $2.75 \mathrm{E}-02$ & & & $.16 \mathrm{E}-01$ & $1.35 \mathrm{E}+00$ \\
\hline & & & & & & & \\
\hline 04 & $3.48 \mathrm{E}+00$ & $1 . \pm$ & & $\perp$ & 1 & & L. $36 E+00$ \\
\hline $.47 E-04$ & $3.48 \mathrm{E}+00$ & $\perp \cdot \perp J \amalg$ & $2.035-02$ & $2.84 \mathrm{E}-01$ & $4.77 \mathrm{E}-01$ & $0.2 / E-01$ & $1.36 \mathrm{E}+00$ \\
\hline $50 \mathrm{E}-04$ & $3.49 \mathrm{E}+00$ & $1.14 \mathrm{E}-01$ & $2.86 \mathrm{E}-02$ & 2.001 & 1. & $\begin{array}{lll}0 & 0\end{array}$ & $1.37 \mathrm{E}+00$ \\
\hline 4 & $3.49 \mathrm{E}+00$ & 1.1 & 2 & c & 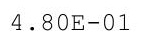 & 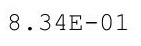 & \\
\hline $.57 E-04$ & & & & & & & 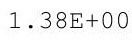 \\
\hline 4 & $3.51 \mathrm{E}+00$ & & 2 & 1 & & & $.38 E+00$ \\
\hline $3 E-04$ & $3.51 E+00$ & 1 & & 1 & & & 00 \\
\hline $66 \mathrm{E}-04$ & $3.52 \mathrm{E}+00$ & $1.17 \mathrm{E}-01$ & $2.98 E-02$ & $2.30 \mathrm{~L}$ & 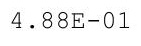 & -01 & $1.39 \mathrm{E}+00$ \\
\hline $.10 E-04$ & $3.52 \mathrm{E}+00$ & & & $2.95 \pm-0 \perp$ & & & 1. $40 \mathrm{E}+00$ \\
\hline $73 E-04$ & $3.53 \mathrm{E}+00$ & & & & & & $1.41 \mathrm{E}+00$ \\
\hline • $175-4$ & $3.53 \mathrm{E}+00$ & $+\cdots$ & 2 & 1 & 1 & & 1. $41 \mathrm{E}+00$ \\
\hline & & & & & 1 & & $.42 \mathrm{E}+00$ \\
\hline $84 \mathrm{E}-04$ & $3.54 \mathrm{E}+00$ & $1.19 \mathrm{E}-01$ & 02 & 30 F & & 1 & $1.42 \mathrm{E}+00$ \\
\hline $7 E-04$ & $3.55 \mathrm{E}+00$ & $1.20 \mathrm{E}$ & 2 & & & 01 & $1.43 E+00$ \\
\hline & & & & & & & \\
\hline $5 E-04$ & $3.56 \mathrm{E}+00$ & $\perp \cdot 2+\square$ & s. & 0.00 & 1 & & $1.44 \mathrm{E}+00$ \\
\hline $98 E-04$ & $3.56 \mathrm{E}+00$ & $\perp \cdot 2<\amalg$ & & ( & 0.00 & & $1.44 \mathrm{E}+00$ \\
\hline 04 & $.57 \mathrm{E}+00$ & $3 E-01$ & $E-02$ & $E-01$ & $07 E-01$ & $78 E-01$ & $1.45 \mathrm{E}+00$ \\
\hline
\end{tabular}


RESRAD-OFFSITE, Version 2.5

robabilistic Dose and Risk Report

Title : Offsite Resident Farmer

File : RF TC99 DOESG FWD-FV2all.ROF

Summary of dose at graphical times, reptition 2 (continued)

Time

Years

$4.72 \mathrm{E}+02$

$4.72 \mathrm{E}+02$

$4.73 E+02$

$4.73 E+02$

$4.74 \mathrm{E}+02$

4. $74 \mathrm{E}+02$

$4.75 \mathrm{E}+02$

4. $75 \mathrm{E}+02$

$4.76 \mathrm{E}+02$

4. $76 \mathrm{E}+02$

$4.77 \mathrm{E}+02$

$4.77 \mathrm{E}+02$

$4.78 \mathrm{E}+02$

$4.78 \mathrm{E}+02$

$4.79 \mathrm{E}+02$

$4.79 \mathrm{E}+02$

$4.80 \mathrm{E}+02$

$4.80 \mathrm{E}+02$

$4.81 \mathrm{E}+02$

$4.81 \mathrm{E}+02$

$4.82 \mathrm{E}+02$

$4.82 \mathrm{E}+02$

$4.83 \mathrm{E}+02$

$4.83 \mathrm{E}+02$

$4.84 \mathrm{E}+02$

$4.84 \mathrm{E}+02$

$4.85 \mathrm{E}+02$

$4.86 \mathrm{E}+02$

4. $86 \mathrm{E}+02$

$4.87 \mathrm{E}+02$

$4.87 \mathrm{E}+02$

$4.88 \mathrm{E}+02$

$4.88 \mathrm{E}+02$

4. $89 \mathrm{E}+02$

4. $89 \mathrm{E}+02$

4. $90 \mathrm{E}+02$

$4.90 \mathrm{E}+02$

4. $91 \mathrm{E}+02$

4. $91 \mathrm{E}+02$

4. $92 \mathrm{E}+02$

4. $92 \mathrm{E}+02$

$4.93 \mathrm{E}+02$

$4.93 \mathrm{E}+02$

4. $94 \mathrm{E}+02$

4. $94 \mathrm{E}+02$

4. $95 \mathrm{E}+02$
Dose statistics at graphical times, mrem/yr

\begin{tabular}{|c|c|c|c|c|c|c|c|}
\hline $\mathrm{m}$ & aximum & lea & ec & & & & $\%$ \\
\hline $.06 E-04$ & $3.57 \mathrm{E}+00$ & $1.23 E-01$ & $.27 E-02$ & (- & 01 & 01 & $.45 E+00$ \\
\hline $10 \mathrm{E}-04$ & $3.57 \mathrm{E}+00$ & $1.24 \mathrm{E}-01$ & $3.30 \mathrm{E}-02$ & $1 E-01$ & $11 E-01$ & $2-01$ & $46 E+00$ \\
\hline $.14 \mathrm{E}-04$ & $58 E+00$ & $24 E-01$ & $32 E-02$ & $12 \mathrm{E}-01$ & $13 E-01$ & $87 E-01$ & $46 \mathrm{E}+00$ \\
\hline $18 E-04$ & $58 F+00$ & $25 \mathrm{~F}-01$ & $35 E-02$ & $14 \mathrm{~F}-01$ & $15 \mathrm{~F}-01$ & $0 \cap F-01$ & $1.47 \mathrm{E}+00$ \\
\hline $.22 E-04$ & $3.59 \mathrm{E}+00$ & $1.26 \mathrm{E}-01$ & $3.38 E-02$ & 1 & 1 & -01 & $.47 E+00$ \\
\hline $26 E-04$ & $59 E+00$ & & & & & & $48 E+00$ \\
\hline $.30 E-04$ & $3.60 \mathrm{E}+00$ & - & -02 & 1 & & & $48 E+00$ \\
\hline $34 E-04$ & $3.60 \mathrm{E}+00$ & 1 & -02 & 1 & 01 & -01 & $49 E+00$ \\
\hline $38 E-04$ & $3.61 \mathrm{E}+00$ & $.28 \mathrm{E}-0$ & $9 \mathrm{E}-02$ & 22 & 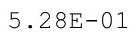 & -01 & $49 E+00$ \\
\hline $42 \mathrm{E}-04$ & $.61 E+00$ & $29=$ & $52 E-02$ & קח קח & תחק & חבר & $49 \mathrm{E}+00$ \\
\hline$E-04$ & $3.62 \mathrm{E}+00$ & .29 & 2 & & & & +00 \\
\hline $51 E-04$ & +00 & 1. $30 \mathrm{E}$ & $E-02$ & $3.28 \mathrm{E}-01$ & 1 & 1 & +00 \\
\hline $55 E-04$ & $3.63 \mathrm{E}+00$ & $1.30 \mathrm{E}-01$ & $3.60 \mathrm{E}-02$ & $3.29 \mathrm{E}-01$ & & & $1.51 \mathrm{E}+00$ \\
\hline $60 E-04$ & $3.63 \mathrm{E}+00$ & 1. $31 \mathrm{E}-01$ & $.63 E-02$ & 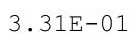 & 1 & -01 & $1.51 \mathrm{E}+00$ \\
\hline-04 & +00 & $32 F-0$ & $E-02$ & $\perp$ & $\perp$ & 1 & $52 \mathrm{E}+00$ \\
\hline .6 & $3.64 \mathrm{E}+00$ & - 0 - & -02 & $\perp$ & & $\perp$ & 00 \\
\hline 04 & 0 & 1. $33 E-01$ & 2 & . & & L & 0 \\
\hline $3 E-04$ & $3655+00$ & 1. $34 \mathrm{E}-01$ & 2 & & $51 E-01$ & 1 & 00 \\
\hline $82 E-04$ & $3.65 \mathrm{E}+00$ & $1.34 \mathrm{E}-01$ & $3.77 \mathrm{E}-02$ & $3.39 \mathrm{E}-01$ & $.54 \mathrm{E}-01$ & $E-01$ & $1.53 E+00$ \\
\hline $87 E-04$ & $3.66 \mathrm{E}+00$ & $1.35 \mathrm{E}-01$ & $.80 E-02$ & $3.40 \mathrm{E}-01$ & $.57 \mathrm{E}-01$ & $9.35 E-0$ & $1.54 \mathrm{E}+00$ \\
\hline$E-04$ & $3.66 \mathrm{E}+00$ & & 2 & & & & +00 \\
\hline $97 \mathrm{E}-$ & & .00 & & & & & \\
\hline $01 E-04$ & $3.67 \mathrm{E}+00$ & 1.0 & 2 & & $\perp$ & & T5 \\
\hline $.06 \mathrm{E}-04$ & $.67 E+00$ & $1.37 \mathrm{E}-01$ & 2 & 1 & $\perp$ & - & +00 \\
\hline$E-04$ & $.68 \mathrm{E}+00$ & & $4 \mathrm{E}-02$ & ת0 & חק & 1 & $56 \mathrm{E}+00$ \\
\hline $16 \mathrm{E}-04$ & $3.68 \mathrm{E}+00$ & $1.39 \mathrm{E}-01$ & $98 E-02$ & 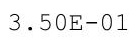 & 70 & $E-01$ & $1.56 \mathrm{E}+00$ \\
\hline $21 E-04$ & $3.68 \mathrm{E}+00$ & & & & & & $.57 \mathrm{E}+00$ \\
\hline 4 & & & & & & & \\
\hline 04 & & 1.41 & & $\perp$ & $\perp$ & 1 & $1.57 \mathrm{E}+00$ \\
\hline $.37 E-04$ & $3.70 \mathrm{E}+00$ & $\perp \cdot 4 \perp-0 \perp$ & $.10 \mathrm{E}-02$ & 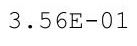 & $.0 J E-01$ & $.72 E-01$ & $1.58 \mathrm{E}+00$ \\
\hline $42 E-04$ & $3.70 \mathrm{E}+00$ & $+\cdot 12+$ & $.13 E-02$ & - & - & 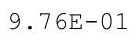 & $1.58 \mathrm{E}+00$ \\
\hline 4 & $3.70 \mathrm{E}+00$ & 1 & 2 & 1 & & & $1.59 \mathrm{E}+00$ \\
\hline 04 & & & & & & & $.59 \mathrm{E}+00$ \\
\hline 4 & $3.71 \mathrm{E}+00$ & & 2 & & & & $.60 \mathrm{E}+00$ \\
\hline $64 \mathrm{E}-04$ & $3.72 \mathrm{E}+00$ & $1.45 \mathrm{E}-01$ & $6 E-02$ & 1 & 1 & & $1.60 \mathrm{E}+00$ \\
\hline $.69 E-04$ & $3.72 \mathrm{E}+00$ & $1.4 J E-U \perp$ & $4.29 \mathrm{E}-02$ & . & • & $9.98 \mathrm{E}-01$ & 1. $60 \mathrm{E}+00$ \\
\hline $.75 E-04$ & $3.72 \mathrm{E}+00$ & $1 \cdot 100$ - & & & & & $1.01 \mathrm{E}+00$ \\
\hline 4 & $3.73 E+00$ & $1 \cdot 1$ & 2 & 1 & 1 & & $1.61 \mathrm{E}+00$ \\
\hline$t$ & $3.73 E+00$ & 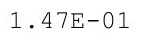 & 2 & 1 & 1 & $1.01 \mathrm{E}+00$ & 1. $61 \mathrm{E}+00$ \\
\hline 04 & & 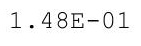 & 2 & 1 & 1 & & $1.62 \mathrm{E}+00$ \\
\hline $3 E-04$ & $3.74 \mathrm{E}+00$ & 1. $49 \mathrm{E}-01$ & $5 E-02$ & 01 & & & $1.62 \mathrm{E}+00$ \\
\hline$E-04$ & $3.14 \mathrm{E}+0 \mathrm{U}$ & $\perp \cdot$ & & & & & -00 \\
\hline $10 E-04$ & . & & & & & & $1.63 \mathrm{E}+00$ \\
\hline $16 \mathrm{E}-04$ & $3.75 \mathrm{E}+00$ & $\perp \cdot U \perp-\Delta \perp$ & $4.54 \mathrm{E}-02$ & $3.80 \mathrm{E}-01$ & $6.19 \mathrm{E}-01$ & $1.03 E+00$ & $1.63 E+00$ \\
\hline $22 E-04$ & $3.75 \mathrm{E}+00$ & $\begin{array}{lll}1.010 & 0\end{array}$ & & & & $1.04 \mathrm{E}+00$ & $1.63 \mathrm{E}+00$ \\
\hline $8 E-04$ & $.75 \mathrm{E}+00$ & $E-01$ & $.61 \mathrm{E}-02$ & $.84 \mathrm{E}-01$ & $E-01$ & 1. $04 \mathrm{E}+00$ & $1.64 \mathrm{E}+00$ \\
\hline
\end{tabular}


RESRAD-OFFSITE, Version 2.5

robabilistic Dose and Risk Report

Title : Offsite Resident Farmer

File : RF TC99 DOESG FWD-FV2all.ROF

Summary of dose at graphical times, reptition 2 (continued)

Time

Years

$4.95 \mathrm{E}+02$

$4.96 \mathrm{E}+02$

$4.96 \mathrm{E}+02$

4. $97 \mathrm{E}+02$

4. $97 \mathrm{E}+02$

$4.98 \mathrm{E}+02$

$4.98 \mathrm{E}+02$

$4.99 \mathrm{E}+02$

$4.99 \mathrm{E}+02$

$5.00 \mathrm{E}+02$

$5.00 \mathrm{E}+02$

$5.01 \mathrm{E}+02$

$5.01 \mathrm{E}+02$

$5.02 \mathrm{E}+02$

$5.02 \mathrm{E}+02$

$5.03 \mathrm{E}+02$

$5.03 \mathrm{E}+02$

$5.04 \mathrm{E}+02$

$5.04 \mathrm{E}+02$

$5.05 \mathrm{E}+02$

$5.06 \mathrm{E}+02$

$5.06 \mathrm{E}+02$

$5.07 \mathrm{E}+02$

$5.07 \mathrm{E}+02$

$5.08 \mathrm{E}+02$

$5.08 \mathrm{E}+02$

$5.09 \mathrm{E}+02$

$5.09 \mathrm{E}+02$

$5.10 \mathrm{E}+02$

$5.10 \mathrm{E}+02$

$5.11 \mathrm{E}+02$

$5.11 \mathrm{E}+02$

$5.12 \mathrm{E}+02$

$5.12 \mathrm{E}+02$

$5.13 \mathrm{E}+02$

$5.13 \mathrm{E}+02$

$5.14 \mathrm{E}+02$

$5.14 \mathrm{E}+02$

$5.15 \mathrm{E}+02$

$5.15 \mathrm{E}+02$

$5.16 \mathrm{E}+02$

$5.16 \mathrm{E}+02$

$5.17 \mathrm{E}+02$

$5.17 \mathrm{E}+02$

$5.18 \mathrm{E}+02$

$5.18 \mathrm{E}+02$
Dose statistics at graphical times, mrem/yr

\begin{tabular}{|c|c|c|c|c|c|c|c|}
\hline Iinimum & Maximum & Mean & Median & 900 & $90 \%$ & $97.5 \%$ & $9 \%$ \\
\hline-04 & $6 E+00$ & $3 E-01$ & $64 E-02$ & $85 E-01$ & 1 & $1.05 \mathrm{E}+00$ & +00 \\
\hline$E-04$ & $6 \mathrm{E}+00$ & $3 E-01$ & $67 E-02$ & $3.87 \mathrm{E}$ & 1 & $.05 E+00$ & $64 \mathrm{E}+00$ \\
\hline $7 E-04$ & $76 \mathrm{E}+00$ & $4 \mathrm{E}-01$ & $0 \mathrm{E}-02$ & 1 & $6.32 \mathrm{E}$ & -00 & $55 \mathrm{E}+00$ \\
\hline $3 E-04$ & $E+00$ & $5 E-01$ & $3 E-02$ & 1 & $5 \mathrm{E}$ & 0 & $5 E+00$ \\
\hline$O E-04$ & $3.77 \mathrm{E}+00$ & & -02 & & & & $65 E+00$ \\
\hline $66 \mathrm{E}-04$ & 00 & 1 & -02 & & & 00 & $66 \mathrm{E}+00$ \\
\hline $.73 E-04$ & $3.78 \mathrm{E}+00$ & $1.57 \mathrm{E}-01$ & $4.82 \mathrm{E}-02$ & $6 E-01$ & 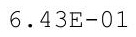 & +00 & $66 \mathrm{E}+00$ \\
\hline $.79 E-04$ & $3.78 \mathrm{E}+00$ & $\perp$. U一 & $4.85 E-02$ & 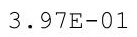 & $0.4 J-4 \perp$ & +00 & $1.66 \mathrm{E}+00$ \\
\hline $5-04$ & +00 & $8 E-01$ & 02 & 1 & 1 & 00 & $57 \mathrm{E}+00$ \\
\hline $3 E-04$ & $9 \mathrm{E}+00$ & $1.59 \mathrm{E}$ & 2 & & & & $E+00$ \\
\hline$E-04$ & 3. & 1 & 2 & 1 & 1 & & $3 E+00$ \\
\hline-04 & +00 & 1 & 2 & 1 & 1 & & $E+00$ \\
\hline $.13 E-04$ & $3.80 \mathrm{E}+00$ & 1. $61 \mathrm{E}-01$ & $2 E-02$ & UE-U工 & $9 \bar{L}-01$ & $4+00$ & $9 E+00$ \\
\hline $.21 E-04$ & $3.80 \mathrm{E}+00$ & 1. $61 \mathrm{E}-01$ & $5.06 \mathrm{E}-02$ & $4.07 \mathrm{E}-01$ & $0.0 \angle L-01$ & 1.1 & $9 \mathrm{E}+00$ \\
\hline $28 E-04$ & $3.80 \mathrm{E}+00$ & $1.62 \mathrm{E}-01$ & 02 & 1 & $\perp$ & 00 & $9 \mathrm{E}+00$ \\
\hline $35 E-04$ & $3.81 E+00$ & $1.63 E-0$ & -02 & - & $67 \mathrm{E}-$ & $1.11 \mathrm{E}+00$ & $\mathrm{OE}+00$ \\
\hline $.42 E-04$ & $3.81 E+00$ & $1.64 \mathrm{E}-01$ & $5.16 \mathrm{E}-02$ & $4.11 \mathrm{E}-01$ & $6.70 \mathrm{E}-01$ & $1.12 \mathrm{E}+00$ & $1.70 \mathrm{E}+00$ \\
\hline $9 E-04$ & $1 \mathrm{E}+00$ & $E-01$ & -02 & 1 & 1 & 0 & $70 E+00$ \\
\hline $.57 E-04$ & $3.81 \mathrm{E}+00$ & $1.65 \mathrm{E}-01$ & $4 E-02$ & +1 & & $1.1 \angle \mathrm{B}$ & $71 \mathrm{E}+00$ \\
\hline $64 \mathrm{E}-04$ & $3.82 \mathrm{E}+00$ & $1.66 \mathrm{E}-01$ & 02 & $\perp$ & $\perp$ & 1 & +00 \\
\hline $.72 E-04$ & $3.82 E+00$ & $1.66 \mathrm{E}-01$ & 02 & S. & 我 & & $.72 \mathrm{E}+00$ \\
\hline $.79 E-04$ & $3.82 \mathrm{E}+00$ & $1.67 \mathrm{E}-0$ & 2 & $1 .+0$ & 0 & 00 & $.72 E+00$ \\
\hline $.87 E-04$ & $3.82 \mathrm{E}+00$ & $8 E-$ & $0 E-02$ & 䟚 & ت7 & $4 \mathrm{E}+00$ & $1.72 E+00$ \\
\hline $.95 E-04$ & $3.83 E+00$ & $1.68 \mathrm{E}-01$ & -02 & 4.22 & קח תمמ & $1.14 \mathrm{E}+$ & $73 E+00$ \\
\hline$E-04$ & $.83 E+00$ & 1 . & 02 & & & & $73 E+00$ \\
\hline$E-04$ & $3.83 E+00$ & $1.70 \mathrm{E}$ & 02 & 1 & & $1.15 \mathrm{H}$ & +00 \\
\hline $8 E-04$ & $3.84 \mathrm{E}+00$ & $1.71 \mathrm{E}-01$ & $5 E-02$ & CIL & $\perp$ & 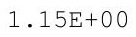 & $74 \mathrm{E}+00$ \\
\hline $.26 \mathrm{E}-04$ & $3.84 \mathrm{E}+00$ & $1.71 \mathrm{E}-01$ & $5.58 \mathrm{E}-02$ & $4.28 \mathrm{E}-01$ & $7.00 \mathrm{E}-01$ & $1.15 \mathrm{E}+00$ & $1.74 \mathrm{E}+00$ \\
\hline $.345-4$ & .045 & $1.72 \mathrm{E}-01$ & $5.62 E-02$ & $1.00-8$ & P. & $1.15 \mathrm{E}+00$ & $1.75 E+00$ \\
\hline $2 E-04$ & $3.84 \mathrm{E}+00$ & $1.73 \mathrm{E}$ & 2 & & $.04 \mathrm{E}-01$ & 0 & $1.75 \mathrm{E}+00$ \\
\hline 04 & $.85 E+00$ & 1 . & 2 & 1 & L & $E+00$ & $5 E+00$ \\
\hline $9 E-04$ & $3.85 E+00$ & $1.74 \mathrm{E}-$ & 02 & 1 & 1 & 1. & 00 \\
\hline $.67 E-04$ & $3.85 \mathrm{E}+00$ & $1.75 \mathrm{E}-01$ & $5.78 \mathrm{E}-02$ & $4.37 \mathrm{E}-$ &.$\perp \perp \mathrm{L}$ & $1.16 \mathrm{E}+00$ & $1.76 \mathrm{E}+00$ \\
\hline $.76 \mathrm{E}-04$ & $3.85 \mathrm{E}+00$ & $1.76 \mathrm{E}-01$ & $5.82 \mathrm{E}-02$ & $4.38 \mathrm{E}-01$ & $7.14 \mathrm{E}-01$ & $1.16 \mathrm{E}+00$ & $1.76 \mathrm{E}+00$ \\
\hline $.84 \mathrm{E}-04$ & $3.00 \mathrm{E}+00$ & $1.76 \mathrm{E}-01$ & & & & & $1.77 \mathrm{E}+00$ \\
\hline 年 & & $7 E-01$ & & & & & $1.77 \mathrm{E}+00$ \\
\hline 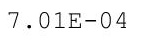 & 0 & 1 & 2 & 1 & 1 & $7 \mathrm{E}+00$ & ג גר ג \\
\hline 4 & $E+00$ & 1 & 02 & 1 & 1 & 0 & $8 \mathrm{E}+00$ \\
\hline $9 E-04$ & $3.86 \mathrm{E}+00$ & 1. $79 \mathrm{E}-01$ & $3 E-02$ & $47 \mathrm{E}$ & 1 & 00 & 00 \\
\hline $3 E-04$ & $3.87 \mathrm{E}$ & 1. & & & & & $9 E+00$ \\
\hline$E-04$ & $7 \mathrm{E}+00$ & 1 & & 1 & & & $1.79 \mathrm{E}+00$ \\
\hline $6 E-04$ & $3.01 E+00$ & $+\infty$ & 2 & 1 & 1 & $1.18 \mathrm{E}$ & $1.79 \mathrm{E}+00$ \\
\hline 4 & 3.0 & 1 & 2 & 1 & 1 & +0 & 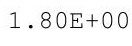 \\
\hline 4 & & & & & & & \\
\hline-04 & $E+00$ & $3 E-01$ & 6.2 & 4. & 7. & 1 . & $1.80 \mathrm{E}+00$ \\
\hline $.83 E-04$ & $88 E+00$ & $1.84 \mathrm{E}-01$ & $.31 E-02$ & $4.62 \mathrm{E}-01$ & $7.41 \mathrm{E}-01$ & 1.19E+00 & $1.81 \mathrm{E}+00$ \\
\hline
\end{tabular}


RESRAD-OFFSITE, Version 2.5 
RESRAD-OFFSITE, Version 2.5

obabilistic Dose and Risk Report

Title : Offsite Resident Farmer

File : RF TC99 DOESG FWD-FV2all.ROF

Summary of dose at graphical times, reptition 2 (continued)

Time

Years

$5.42 \mathrm{E}+02$

$5.43 E+02$

$5.43 \mathrm{E}+02$

$5.44 \mathrm{E}+02$

$5.44 \mathrm{E}+02$

$5.45 \mathrm{E}+02$

$5.46 \mathrm{E}+02$

$5.46 \mathrm{E}+02$

$5.47 \mathrm{E}+02$

$5.47 \mathrm{E}+02$

$5.48 \mathrm{E}+02$

$5.48 \mathrm{E}+02$

$5.49 \mathrm{E}+02$

$5.49 \mathrm{E}+02$

$5.50 \mathrm{E}+02$

$5.50 \mathrm{E}+02$

$5.51 \mathrm{E}+02$

$5.51 \mathrm{E}+02$

$5.52 \mathrm{E}+02$

$5.52 \mathrm{E}+02$

$5.53 \mathrm{E}+02$

$5.53 \mathrm{E}+02$

$5.54 \mathrm{E}+02$

$5.54 \mathrm{E}+02$

$5.55 \mathrm{E}+02$

$5.55 \mathrm{E}+02$

$5.56 \mathrm{E}+02$

$5.56 \mathrm{E}+02$

$5.57 \mathrm{E}+02$

$5.57 \mathrm{E}+02$

$5.58 \mathrm{E}+02$

$5.58 \mathrm{E}+02$

$5.59 \mathrm{E}+02$

$5.59 \mathrm{E}+02$

$5.60 \mathrm{E}+02$

$5.60 \mathrm{E}+02$

$5.61 \mathrm{E}+02$

$5.61 \mathrm{E}+02$

$5.62 \mathrm{E}+02$

$5.62 \mathrm{E}+02$

$5.63 E+02$

$5.63 \mathrm{E}+02$

$5.64 \mathrm{E}+02$

$5.64 \mathrm{E}+02$

$5.65 \mathrm{E}+02$

$5.66 \mathrm{E}+02$
Dose statistics at graphical times, mrem/yr

\begin{tabular}{|c|c|c|c|c|c|c|c|}
\hline Minimum & Maximum & Mean & Median & $90 \%$ & $95 \%$ & $97.5 \%$ & $99 \%$ \\
\hline $1.33 E-03$ & $3.94 \mathrm{E}+00$ & $2.20 E-01$ & $8.39 E-02$ & $5.56 \mathrm{E}-01$ & $8.79 E-01$ & $1.34 \mathrm{E}+00$ & $2.01 E+00$ \\
\hline $1.34 E-03$ & $3.94 \mathrm{E}+00$ & $2.21 E-01$ & $8.44 E-02$ & $5.58 \mathrm{E}-01$ & $8.81 \mathrm{E}-01$ & $1.34 \mathrm{E}+00$ & $2.02 E+00$ \\
\hline $1.35 E-03$ & $3.95 \mathrm{E}+00$ & 2. $22 \mathrm{E}-01$ & $8.48 \mathrm{E}-02$ & $5.60 \mathrm{E}-01$ & $8.83 \mathrm{E}-01$ & $1.34 \mathrm{E}+00$ & $2.02 \mathrm{E}+00$ \\
\hline $1.37 \mathrm{E}-03$ & $3.95 \mathrm{E}+00$ & $2.22 \mathrm{E}-01$ & $8.53 \mathrm{E}-02$ & $5.62 \mathrm{E}-01$ & $8.86 \mathrm{E}-01$ & $1.35 \mathrm{E}+00$ & $2.03 E+00$ \\
\hline $1.38 \mathrm{E}-03$ & $3.95 \mathrm{E}+00$ & $2.23 \mathrm{E}-01$ & $8.58 \mathrm{E}-02$ & $5.65 \mathrm{E}-01$ & $8.89 \mathrm{E}-01$ & $1.35 \mathrm{E}+00$ & $2.03 E+00$ \\
\hline $1.40 \mathrm{E}-03$ & $3.95 \mathrm{E}+00$ & $2.24 E-01$ & $8.62 \mathrm{E}-02$ & $5.66 \mathrm{E}-01$ & $8.91 \mathrm{E}-01$ & $1.36 \mathrm{E}+00$ & $2.03 E+00$ \\
\hline $1.41 E-03$ & $3.95 \mathrm{E}+00$ & $2.25 E-01$ & $8.68 E-02$ & $5.68 \mathrm{E}-01$ & $8.94 \mathrm{E}-01$ & $1.36 \mathrm{E}+00$ & $2.04 \mathrm{E}+00$ \\
\hline $1.43 \mathrm{E}-03$ & $3.95 \mathrm{E}+00$ & $2.26 \mathrm{E}-01$ & $8.73 \mathrm{E}-02$ & $5.70 \mathrm{E}-01$ & $8.97 \mathrm{E}-01$ & $1.37 \mathrm{E}+00$ & $2.04 \mathrm{E}+00$ \\
\hline 1. $44 \mathrm{E}-03$ & $3.95 \mathrm{E}+00$ & $2.26 E-01$ & $8.78 E-02$ & $5.71 \mathrm{E}-01$ & $8.99 \mathrm{E}-01$ & $1.37 \mathrm{E}+00$ & $2.05 E+00$ \\
\hline $1.46 \mathrm{E}-03$ & $3.95 \mathrm{E}+00$ & $2.27 \mathrm{E}-01$ & $8.83 E-02$ & $5.73 E-01$ & $9.01 \mathrm{E}-01$ & $1 \cdot 38 \mathrm{E}+00$ & $2.05 E+00$ \\
\hline $1.47 \mathrm{E}-03$ & $3.95 \mathrm{E}+00$ & $2.28 E-01$ & $8.88 E-02$ & $5.75 E-01$ & $9.03 E-01$ & $1.38 \mathrm{E}+00$ & $2.05 E+00$ \\
\hline $1.49 \mathrm{E}-03$ & $3.95 \mathrm{E}+00$ & $2.29 \mathrm{E}-01$ & $8.93 E-02$ & $5.76 \mathrm{E}-01$ & $9.04 \mathrm{E}-01$ & $1.38 \mathrm{E}+00$ & $2.06 \mathrm{E}+00$ \\
\hline $1.50 \mathrm{E}-03$ & $3.95 \mathrm{E}+00$ & $2.30 \mathrm{E}-01$ & $8.98 E-02$ & $5.78 E-01$ & $9.06 \mathrm{E}-01$ & $1 \cdot 39 \mathrm{E}+00$ & $2.06 \mathrm{E}+00$ \\
\hline $1.52 \mathrm{E}-03$ & $3.95 \mathrm{E}+00$ & $2.30 \mathrm{E}-01$ & $9.03 E-02$ & $5.79 \mathrm{E}-01$ & $9.07 \mathrm{E}-01$ & $1.39 \mathrm{E}+00$ & $2.07 \mathrm{E}+00$ \\
\hline 1. $53 E-03$ & $3.95 \mathrm{E}+00$ & $2.31 E-01$ & $9.08 E-02$ & $5.81 \mathrm{E}-01$ & $9.09 \mathrm{E}-01$ & $1.40 \mathrm{E}+00$ & $2.07 E+00$ \\
\hline $1.55 E-03$ & $3.95 \mathrm{E}+00$ & $2.32 E-01$ & $9.12 \mathrm{E}-02$ & $3 E-01$ & $11 E-01$ & $1.40 \mathrm{E}+00$ & $.07 E+00$ \\
\hline $1.56 \mathrm{E}-03$ & $3.95 \mathrm{E}+00$ & $2.33 E-01$ & $9.17 \mathrm{E}-02$ & $5.85 E-01$ & $9.13 \mathrm{E}-01$ & $1.41 \mathrm{E}+00$ & $2.08 \mathrm{E}+00$ \\
\hline $1.58 \mathrm{E}-03$ & $3.96 \mathrm{E}+00$ & $2.34 \mathrm{E}-01$ & $9.22 \mathrm{E}-02$ & $5.87 \mathrm{E}-01$ & $9.16 \mathrm{E}-01$ & $1.41 \mathrm{E}+00$ & $2.08 \mathrm{E}+00$ \\
\hline $1.59 \mathrm{E}-03$ & $3.96 \mathrm{E}+00$ & $2.34 \mathrm{E}-01$ & $9.27 \mathrm{E}-02$ & $5.89 \mathrm{E}-01$ & $9.18 \mathrm{E}-01$ & 1. $42 \mathrm{E}+00$ & $2.09 \mathrm{E}+00$ \\
\hline $1.61 \mathrm{E}-03$ & $3.97 \mathrm{E}+00$ & $2.35 E-01$ & $9.32 E-02$ & $5.91 \mathrm{E}-01$ & $9.21 \mathrm{E}-01$ & $1.42 \mathrm{E}+00$ & $2.09 \mathrm{E}+00$ \\
\hline $1.63 E-03$ & $3.98 \mathrm{E}+00$ & $2.36 \mathrm{E}-01$ & $9.37 \mathrm{E}-02$ & $5.93 E-01$ & $9.23 \mathrm{E}-01$ & $1.42 \mathrm{E}+00$ & $2.09 \mathrm{E}+00$ \\
\hline $1.64 \mathrm{E}-03$ & $3.98 \mathrm{E}+00$ & $2.37 E-01$ & $9.42 \mathrm{E}-02$ & $5.95 E-01$ & $9.26 \mathrm{E}-01$ & $1.43 E+00$ & $2.10 \mathrm{E}+00$ \\
\hline $1.66 \mathrm{E}-03$ & $3.99 \mathrm{E}+00$ & $2.38 E-01$ & $9.47 E-02$ & $5.97 \mathrm{E}-01$ & $9.28 \mathrm{E}-01$ & $1.43 \mathrm{E}+00$ & $2.10 \mathrm{E}+00$ \\
\hline $1.67 \mathrm{E}-03$ & $3.99 \mathrm{E}+00$ & $2.38 E-01$ & $9.52 \mathrm{E}-02$ & $5.99 \mathrm{E}-01$ & $9.30 \mathrm{E}-01$ & $1.44 \mathrm{E}+00$ & $2.10 \mathrm{E}+00$ \\
\hline $1.69 \mathrm{E}-03$ & $4.00 \mathrm{E}+00$ & $2.39 E-01$ & $9.57 \mathrm{E}-02$ & $6.00 \mathrm{E}-01$ & $9.33 \mathrm{E}-01$ & $1.44 \mathrm{E}+00$ & $2.11 \mathrm{E}+00$ \\
\hline $1.71 \mathrm{E}-03$ & $4.00 \mathrm{E}+00$ & $2.40 E-01$ & $9.62 E-02$ & $6.02 \mathrm{E}-01$ & $9.35 \mathrm{E}-01$ & 1. $45 \mathrm{E}+00$ & $2.11 \mathrm{E}+00$ \\
\hline $1.72 \mathrm{E}-03$ & $4.01 \mathrm{E}+00$ & $2.41 E-01$ & $9.67 \mathrm{E}-02$ & $6.04 \mathrm{E}-01$ & $9.38 \mathrm{E}-01$ & $1.45 \mathrm{E}+00$ & $2.12 \mathrm{E}+00$ \\
\hline $1.74 \mathrm{E}-03$ & $4.01 \mathrm{E}+00$ & $2.42 E-01$ & $9.72 \mathrm{E}-02$ & $6.06 \mathrm{E}-01$ & $9.41 \mathrm{E}-01$ & $1.45 \mathrm{E}+00$ & $2.12 \mathrm{E}+00$ \\
\hline $1.76 \mathrm{E}-03$ & $4.02 \mathrm{E}+00$ & $2.42 E-01$ & $9.77 E-02$ & $6.08 E-01$ & $9.44 \mathrm{E}-01$ & $1.46 \mathrm{E}+00$ & $2.12 \mathrm{E}+00$ \\
\hline $1.78 E-03$ & $4.03 E+00$ & $2.43 E-01$ & $9.82 E-02$ & $6.10 \mathrm{E}-01$ & $9.47 \mathrm{E}-01$ & $1.46 \mathrm{E}+00$ & $2.13 E+00$ \\
\hline $1.79 \mathrm{E}-03$ & $4.03 E+00$ & $2.44 \mathrm{E}-01$ & $9.88 \mathrm{E}-02$ & $6.12 \mathrm{E}-01$ & $9.50 \mathrm{E}-01$ & $1.46 \mathrm{E}+00$ & $2.13 E+00$ \\
\hline $1.81 \mathrm{E}-03$ & $4.04 \mathrm{E}+00$ & $2.45 E-01$ & $9.93 E-02$ & $6.13 \mathrm{E}-01$ & $9.52 \mathrm{E}-01$ & $1.47 \mathrm{E}+00$ & $2.13 \mathrm{E}+00$ \\
\hline $1.83 E-03$ & $4.04 \mathrm{E}+00$ & $2.46 E-01$ & $9.99 E-02$ & $6.15 E-01$ & $9.55 \mathrm{E}-01$ & $1.47 \mathrm{E}+00$ & $2.13 E+00$ \\
\hline $1.85 E-03$ & $4.05 \mathrm{E}+00$ & $2.47 E-01$ & 1.00E-01 & $6.17 E-01$ & $9.58 \mathrm{E}-01$ & $1.47 \mathrm{E}+00$ & $2.14 \mathrm{E}+00$ \\
\hline $1.86 \mathrm{E}-03$ & $4.05 E+00$ & $2.47 E-01$ & 1.01E-01 & $6.19 \mathrm{E}-01$ & $9.61 \mathrm{E}-01$ & $1.48 \mathrm{E}+00$ & $2.14 \mathrm{E}+00$ \\
\hline $1.88 E-03$ & $4.06 \mathrm{E}+00$ & $2.48 E-01$ & $1.02 \mathrm{E}-01$ & $6.21 \mathrm{E}-01$ & $9.64 \mathrm{E}-01$ & $1.48 \mathrm{E}+00$ & $2.14 \mathrm{E}+00$ \\
\hline $1.90 \mathrm{E}-03$ & $4.06 \mathrm{E}+00$ & $2.49 E-01$ & $1.02 \mathrm{E}-01$ & $6.23 E-01$ & $9.66 \mathrm{E}-01$ & $1.48 \mathrm{E}+00$ & $2.15 \mathrm{E}+00$ \\
\hline $1.92 \mathrm{E}-03$ & $4.07 \mathrm{E}+00$ & $2.50 \mathrm{E}-01$ & 1.03E-01 & $6.25 E-01$ & $9.69 \mathrm{E}-01$ & $1.49 \mathrm{E}+00$ & $2.15 \mathrm{E}+00$ \\
\hline $1.94 \mathrm{E}-03$ & $4.07 \mathrm{E}+00$ & $2.51 \mathrm{E}-01$ & 1.03E-01 & $6.26 \mathrm{E}-01$ & $9.72 \mathrm{E}-01$ & 1. $49 \mathrm{E}+00$ & $2.15 \mathrm{E}+00$ \\
\hline $1.95 \mathrm{E}-03$ & $4.08 \mathrm{E}+00$ & $2.52 \mathrm{E}-01$ & $1.04 \mathrm{E}$ & $6.28 \mathrm{E}-01$ & $9.75 \mathrm{E}-01$ & 1. $49 \mathrm{E}+00$ & $2.16 \mathrm{E}+00$ \\
\hline $1.97 \mathrm{E}-03$ & $4.08 \mathrm{E}+00$ & $2.52 \mathrm{E}-01$ & $1.04 \mathrm{E}-01$ & $6.30 \mathrm{E}-01$ & $9.77 \mathrm{E}-01$ & $1.50 \mathrm{E}+00$ & $2.16 \mathrm{E}+00$ \\
\hline 1.99E-03 & $4.09 \mathrm{E}+00$ & $2.53 E-01$ & $1.05 E-01$ & $6.32 E-01$ & $9.80 \mathrm{E}-01$ & $1.50 \mathrm{E}+00$ & $2.16 \mathrm{E}+00$ \\
\hline $2.01 E-03$ & $4.09 \mathrm{E}+00$ & $2.54 \mathrm{E}-01$ & $1.05 E-01$ & $6.34 \mathrm{E}-01$ & $9.82 \mathrm{E}-01$ & $1.50 \mathrm{E}+00$ & $2.16 \mathrm{E}+00$ \\
\hline $2.03 E-03$ & $4.10 \mathrm{E}+00$ & $2.55 E-01$ & $1.06 \mathrm{E}-01$ & $6.36 \mathrm{E}-01$ & $9.85 E-01$ & $1.51 \mathrm{E}+00$ & $2.17 \mathrm{E}+00$ \\
\hline $2.05 E-03$ & $4.10 \mathrm{E}+00$ & $2.56 E-01$ & $1.06 \mathrm{E}-01$ & $6.38 E-01$ & $9.87 \mathrm{E}-01$ & $1.51 \mathrm{E}+00$ & $2.17 \mathrm{E}+00$ \\
\hline $2.07 E-03$ & $4.11 \mathrm{E}+00$ & $2.57 E-01$ & $1.07 \mathrm{E}-01$ & $6.39 E-01$ & $9.90 \mathrm{E}-01$ & $1.51 \mathrm{E}+00$ & $2.17 \mathrm{E}+00$ \\
\hline
\end{tabular}


RESRAD-OFFSITE, Version 2.5 
RESRAD-OFFSITE, Version 2.5

$\mathrm{T}^{1 / 2}$ Limit $=180$ days

obabilistic Dose and Risk Report

Title : Offsite Resident Farmer

File : RF TC99 DOESG FWD-FV2all.ROF

Summary of dose at graphical times, reptition 2 (continued)

Time

Years

$5.90 \mathrm{E}+02$

$5.90 \mathrm{E}+02$

$5.91 \mathrm{E}+02$

$5.91 \mathrm{E}+02$

$5.92 \mathrm{E}+02$

$5.92 \mathrm{E}+02$

$5.93 \mathrm{E}+02$

$5.93 \mathrm{E}+02$

$5.94 \mathrm{E}+02$

$5.94 \mathrm{E}+02$

$5.95 \mathrm{E}+02$

$5.95 \mathrm{E}+02$

$5.96 \mathrm{E}+02$

$5.96 \mathrm{E}+02$

$5.97 \mathrm{E}+02$

$5.97 \mathrm{E}+02$

$5.98 \mathrm{E}+02$

$5.98 \mathrm{E}+02$

$5.99 \mathrm{E}+02$

$5.99 \mathrm{E}+02$

$6.00 \mathrm{E}+02$

$6.00 \mathrm{E}+02$

$6.01 \mathrm{E}+02$

$6.01 \mathrm{E}+02$

$6.02 \mathrm{E}+02$

$6.02 \mathrm{E}+02$

$6.03 E+02$

$6.03 \mathrm{E}+02$

$6.04 \mathrm{E}+02$

$6.04 \mathrm{E}+02$

$6.05 \mathrm{E}+02$

$6.05 \mathrm{E}+02$

$6.06 \mathrm{E}+02$

$6.07 \mathrm{E}+02$

$6.07 \mathrm{E}+02$

$6.08 \mathrm{E}+02$

$6.08 \mathrm{E}+02$

$6.09 \mathrm{E}+02$

$6.09 \mathrm{E}+02$

$6.10 \mathrm{E}+02$

$6.10 \mathrm{E}+02$

$6.11 \mathrm{E}+02$

$6.11 \mathrm{E}+02$

$6.12 \mathrm{E}+02$

$6.12 \mathrm{E}+02$

$6.13 \mathrm{E}+02$
Dose statistics at graphical times, mrem/yr

\begin{tabular}{|c|c|c|c|c|c|c|c|}
\hline$m$ & m & Mean & ledian & & & $\%$ & \\
\hline 03 & $4.32 \mathrm{E}+00$ & $2.97 \mathrm{E}-01$ & 1. $34 \mathrm{E}-01$ & $7.22 \mathrm{E}-01$ & $1.12 \mathrm{E}+00$ & 1. $62 \mathrm{E}+00$ & $2.29 \mathrm{E}+00$ \\
\hline-03 & +00 & 01 & 01 & 01 & 00 & +00 & $E+00$ \\
\hline$E-03$ & $4.33 E+00$ & $2.98 \mathrm{E}-01$ & 1. $36 \mathrm{E}-01$ & $.24 \mathrm{E}-01$ & $1.12 \mathrm{E}+00$ & $1.63 \mathrm{E}+00$ & $2.30 \mathrm{E}+00$ \\
\hline $21 E-03$ & $4.33 E+00$ & $.99 E-01$ & $1.36 \mathrm{E}-01$ & 7. 25E-01 & $1.13 \mathrm{E}+00$ & $1.63 E+00$ & $2.30 \mathrm{E}+00$ \\
\hline $4 E-03$ & $33 \mathrm{E}+00$ & $.00 \mathrm{E}-01$ & -01 & $.27 E-01$ & $1.13 \mathrm{E}+00$ & $1.63 \mathrm{E}+00$ & $2.30 \mathrm{E}+00$ \\
\hline$E-03$ & +00 & 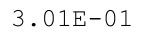 & 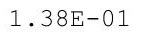 & 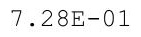 & & 00 & +00 \\
\hline $29 \mathrm{E}-03$ & & & & .29 & & & +00 \\
\hline $32 E-03$ & & 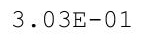 & & $.30 E-01$ & & & +00 \\
\hline $35 E-03$ & 4. $35 E+00$ & -0 & $\perp$ & 01 & $14 \mathrm{E}+00$ & $.64 \mathrm{E}+00$ & +00 \\
\hline 03 & $4.35 E+00$ & $3.04 \mathrm{E}-01$ & $\perp$ & $\perp$ & $14 \mathrm{~F}$ & $E+00$ & +00 \\
\hline 03 & $4.36 \mathrm{E}+00$ & $3.05 E-01$ & 1. $41 \mathrm{E}-01$ & $734 \mathrm{~F}-01$ & 15Г & $.65 E+00$ & $.31 E+00$ \\
\hline 33 & 00 & & & 年 & 0 & -00 & +00 \\
\hline $5-03$ & $E+00$ & $3.07 \mathrm{E}-01$ & 1 & 36 & 0 & 0 & +00 \\
\hline $.49 \mathrm{E}-03$ & $4.37 \mathrm{E}+00$ & $3.08 \mathrm{E}-01$ & $1.43 \mathrm{E}-01$ & $7.37 \mathrm{E}-01$ & $1.16 \mathrm{E}+00$ & $1.66 \mathrm{E}+00$ & $2.32 \mathrm{E}+00$ \\
\hline $52 E-03$ & $4.37 E+00$ & $E-01$ & 1 & $39 \mathrm{E}$ & $16 \mathrm{E}+$ & $.66 E+00$ & $\mathrm{E}+00$ \\
\hline & $37 E+00$ & & & & & 00 & -00 \\
\hline B & & & & & & 0 & 00 \\
\hline 3 & $38 E+00$ & & & & & 0 & 00 \\
\hline $3 E-03$ & $.39 \mathrm{E}+00$ & בת & 6 & $3 F-$ & & $1.67 \mathrm{E}+00$ & $3 E+00$ \\
\hline $66 E-03$ & $4.39 E+00$ & $.13 E-01$ & 1. $47 \mathrm{E}-01$ & $.45 \mathrm{E}-0$ & 1.17E+00 & $1.67 \mathrm{E}+00$ & $2.33 E+00$ \\
\hline$E-03$ & $4.39 \mathrm{E}+00$ & $5=0$ & -01 & -01 & 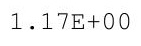 & L. $68 \mathrm{E}+00$ & 2. $34 \mathrm{E}+00$ \\
\hline & & & & & & & $.34 E+00$ \\
\hline & & & & & & $1.68 \mathrm{E}+$ & +00 \\
\hline $.78 E-03$ & & & & $\perp$ & & 1.0 & 00 \\
\hline 3 & $4.41 \mathrm{E}+00$ & $3.18 \mathrm{E}-01$ & $\perp$ & . & $1.18 \mathrm{E}+$ & $.69 \mathrm{E}+00$ & $.34 \mathrm{E}+00$ \\
\hline$E-03$ & $.41 E+00$ & 10 & $151 \mathrm{~F}^{2}$ & $55 \Gamma^{2}$ & $1.19 \mathrm{E}+0$ & $1.69 \mathrm{E}+00$ & $2.35 E+00$ \\
\hline$F-03$ & $4.41 E+00$ & $=01$ & 1. $51 \mathrm{E}-01$ & תר & 1.19E+ & $1.69 \mathrm{E}+00$ & $2.35 E+00$ \\
\hline 03 & & & & & & & \\
\hline & & & & & & & \\
\hline $6 E-03$ & $4.42 \mathrm{E}+00$ & . & $\perp \cdot U 兀 \mathrm{~L}$ & 1.00 & 1.20E+ & $1.70 \mathrm{E}+00$ & $2.36 \mathrm{E}+00$ \\
\hline $.00 \mathrm{E}-03$ & $4.42 \mathrm{E}+00$ & 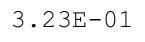 & $1.54 \mathrm{E}-U \perp$ & $7.65 \mathrm{E}-01$ & $1 . \angle U D T U U$ & I. TUETU & $2.36 \mathrm{E}+00$ \\
\hline $.03 E-03$ & $4.43 E+00$ & (6. & $2 \cdot 0-1$ & 年 & 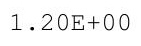 & $1.70 \mathrm{E}+00$ & $2.36 \mathrm{E}+00$ \\
\hline$F-03$ & $4.43 E+00$ & 25 & 1. $55 \mathrm{E}-01$ & תחק & & & $2.36 \mathrm{E}+00$ \\
\hline & & & & & & & \\
\hline$E-03$ & & $7 E-01$ & & 1 & & & \\
\hline 03 & 4.44 & 3.201 & 01 & . & $1.21 \mathrm{E}$ & $1.71 \mathrm{E}$ & $2.37 \mathrm{E}+00$ \\
\hline$E-03$ & $4.44 \mathrm{E}+00$ & & 1.5 & & 1.22E+ & & +00 \\
\hline $22 E-03$ & $4.45 E+00$ & & & & $\begin{array}{ll}0 \\
\text {. }\end{array}$ & & $2.38 E+00$ \\
\hline 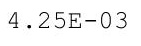 & . & $3.30 \mathrm{E}-01$ & 10 & 1 & $1 \cdot 0<+1$ & $1.72 \mathrm{E}+00$ & $2.38 \mathrm{E}+00$ \\
\hline & & & & & & & \\
\hline 3 & & 1 & 1 & 1 & 1.22E+ & $1.73 E+00$ & $2.38 E+00$ \\
\hline$E-03$ & $4.46 \mathrm{E}+00$ & $E-01$ & 1.6 & 7.91 & 1.23E+ & 00 & +00 \\
\hline & $4.46 \mathrm{E}+00$ & & & & & & \\
\hline & $4.46 \mathrm{E}+00$ & $3.35 E-01$ & \pm & $\perp$ & 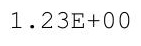 & $1.73 E+00$ & $2.39 E+00$ \\
\hline 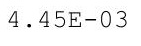 & $4.47 E+00$ & . & $+00 \pi$ & 1 & $1.23 \mathrm{E}+00$ & $1.74 \mathrm{E}+00$ & $2.39 \mathrm{E}+00$ \\
\hline $9 E-03$ & $4.47 E+00$ & $6 E-01$ & $64 \mathrm{E}-01$ & $E-01$ & $1.24 \mathrm{E}+00$ & $1.74 \mathrm{E}+00$ & $.40 E+00$ \\
\hline
\end{tabular}


RESRAD-OFFSITE, Version 2.5

obabilistic Dose and Risk Report

Title : Offsite Resident Farmer

File : RF TC99 DOESG FWD-FV2all.ROF

Summary of dose at graphical times, reptition 2 (continued)

Time

Years

$6.13 \mathrm{E}+02$

$6.14 \mathrm{E}+02$

$6.14 \mathrm{E}+02$

$6.15 \mathrm{E}+02$

$6.15 \mathrm{E}+02$

$6.16 \mathrm{E}+02$

$6.16 \mathrm{E}+02$

$6.17 \mathrm{E}+02$

$6.17 \mathrm{E}+02$

$6.18 \mathrm{E}+02$

$6.18 \mathrm{E}+02$

$6.19 \mathrm{E}+02$

$6.19 \mathrm{E}+02$

$6.20 \mathrm{E}+02$

$6.20 \mathrm{E}+02$

$6.21 \mathrm{E}+02$

$6.21 \mathrm{E}+02$

$6.22 \mathrm{E}+02$

$6.22 \mathrm{E}+02$

$6.23 \mathrm{E}+02$

$6.23 \mathrm{E}+02$

$6.24 \mathrm{E}+02$

$6.24 \mathrm{E}+02$

$6.25 \mathrm{E}+02$

$6.25 \mathrm{E}+02$

$6.26 \mathrm{E}+02$

$6.27 \mathrm{E}+02$

$6.27 \mathrm{E}+02$

$6.28 \mathrm{E}+02$

$6.28 \mathrm{E}+02$

$6.29 \mathrm{E}+02$

$6.29 \mathrm{E}+02$

$6.30 \mathrm{E}+02$

$6.30 \mathrm{E}+02$

$6.31 \mathrm{E}+02$

$6.31 \mathrm{E}+02$

$6.32 \mathrm{E}+02$

$6.32 \mathrm{E}+02$

$6.33 \mathrm{E}+02$

$6.33 \mathrm{E}+02$

$6.34 \mathrm{E}+02$

$6.34 \mathrm{E}+02$

$6.35 \mathrm{E}+02$

$6.35 \mathrm{E}+02$

$6.36 \mathrm{E}+02$

$6.36 \mathrm{E}+02$

Dose statistics at graphical times, mrem/yr

\begin{tabular}{|c|c|c|c|c|c|c|c|}
\hline Minimum & Maximum & Mean & Median & $90 \%$ & $95 \%$ & $97.5 \%$ & $99 \%$ \\
\hline $4.52 E-03$ & $4.47 \mathrm{E}+00$ & $3.37 E-01$ & 1. $64 \mathrm{E}-01$ & $8.04 E-01$ & $1.24 E+00$ & $1.74 \mathrm{E}+00$ & $2.40 E+00$ \\
\hline $4.56 E-03$ & $4.47 E+00$ & $3.38 E-01$ & $1.65 \mathrm{E}-01$ & $8.06 \mathrm{E}-01$ & $1.24 \mathrm{E}+00$ & $1.74 \mathrm{E}+00$ & $2.40 E+00$ \\
\hline $4.59 E-03$ & $4.48 E+00$ & $3.39 E-01$ & $1.65 \mathrm{E}-01$ & $8.08 E-01$ & $1.24 \mathrm{E}+00$ & $1.75 \mathrm{E}+00$ & $2.40 E+00$ \\
\hline $4.63 \mathrm{E}-03$ & $4.48 \mathrm{E}+00$ & $3.40 \mathrm{E}-01$ & $1.66 \mathrm{E}-01$ & $8.10 \mathrm{E}-01$ & $1.24 \mathrm{E}+00$ & $1.75 \mathrm{E}+00$ & $2.40 \mathrm{E}+00$ \\
\hline $4.66 \mathrm{E}-03$ & $4.48 \mathrm{E}+00$ & $3.41 \mathrm{E}-01$ & 1. $67 \mathrm{E}-01$ & $8.12 \mathrm{E}-01$ & $1.25 \mathrm{E}+00$ & $1.75 \mathrm{E}+00$ & $2.41 \mathrm{E}+00$ \\
\hline $4.70 E-03$ & $4.48 \mathrm{E}+00$ & $3.42 \mathrm{E}-01$ & $1.67 \mathrm{E}-01$ & $8.14 \mathrm{E}-01$ & $1.25 \mathrm{E}+00$ & $1.75 \mathrm{E}+00$ & $2.41 \mathrm{E}+00$ \\
\hline $4.73 E-03$ & $4.49 \mathrm{E}+00$ & $3.43 E-01$ & $1.68 \mathrm{E}-01$ & $8.16 \mathrm{E}-01$ & $1.25 \mathrm{E}+00$ & $1.75 \mathrm{E}+00$ & $2.41 \mathrm{E}+00$ \\
\hline $4.77 E-03$ & $4.49 \mathrm{E}+00$ & $3.44 E-01$ & 1. $69 \mathrm{E}-01$ & $8.18 E-01$ & $1.25 \mathrm{E}+00$ & $1.75 \mathrm{E}+00$ & $2.41 E+00$ \\
\hline $4.80 E-03$ & $4.49 E+00$ & $3.45 E-01$ & 1. $69 \mathrm{E}-01$ & $8.19 \mathrm{E}-01$ & $1.26 \mathrm{E}+00$ & $1.76 \mathrm{E}+00$ & $2.41 E+00$ \\
\hline $4.84 \mathrm{E}-03$ & $4.49 \mathrm{E}+00$ & $3.46 \mathrm{E}-01$ & 1. $70 \mathrm{E}-01$ & $8.21 \mathrm{E}-01$ & $1.26 \mathrm{E}+00$ & $1.76 \mathrm{E}+00$ & $2.42 E+00$ \\
\hline $4.87 \mathrm{E}-03$ & $4.50 \mathrm{E}+00$ & $3.46 \mathrm{E}-01$ & 1. $71 \mathrm{E}-01$ & $8.22 \mathrm{E}-01$ & $1.26 \mathrm{E}+00$ & $1.76 \mathrm{E}+00$ & $2.42 \mathrm{E}+00$ \\
\hline 4. $91 \mathrm{E}-03$ & $4.50 \mathrm{E}+00$ & $3.47 E-01$ & 1. $71 \mathrm{E}-01$ & $8.23 E-01$ & $1.26 \mathrm{E}+00$ & $1.76 \mathrm{E}+00$ & $2.42 \mathrm{E}+00$ \\
\hline $4.95 E-03$ & $4.50 \mathrm{E}+00$ & $3.48 E-01$ & $1.72 \mathrm{E}-01$ & $8.24 \mathrm{E}-01$ & $1.26 \mathrm{E}+00$ & $1.76 \mathrm{E}+00$ & $2.42 E+00$ \\
\hline $4.98 E-03$ & $4.50 \mathrm{E}+00$ & $3.49 \mathrm{E}-01$ & 1. $73 \mathrm{E}-01$ & $8.26 \mathrm{E}-01$ & $1.27 \mathrm{E}+00$ & $1.76 \mathrm{E}+00$ & $2.42 \mathrm{E}+00$ \\
\hline $5.02 E-03$ & $4.51 E+00$ & $3.50 \mathrm{E}-01$ & 1. $73 E-01$ & $8.27 E-01$ & $1.27 \mathrm{E}+00$ & $1.77 \mathrm{E}+00$ & $2.43 E+00$ \\
\hline $5.06 \mathrm{E}-03$ & $4.51 \mathrm{E}+00$ & $3.51 \mathrm{E}-01$ & $1.74 \mathrm{E}-01$ & $8.28 E-01$ & $1.27 \mathrm{E}+00$ & $.77 E+00$ & $.43 E+00$ \\
\hline $5.10 \mathrm{E}-03$ & $4.51 \mathrm{E}+00$ & $3.52 \mathrm{E}-01$ & 1. $75 \mathrm{E}-01$ & $8.30 E-01$ & $1.27 \mathrm{E}+00$ & $1.77 \mathrm{E}+00$ & $2.43 E+00$ \\
\hline $5.13 E-03$ & $4.51 \mathrm{E}+00$ & $3.53 E-01$ & 1. $75 \mathrm{E}-01$ & $8.31 \mathrm{E}-01$ & $1.28 \mathrm{E}+00$ & $1.77 \mathrm{E}+00$ & $2.43 E+00$ \\
\hline $5.17 \mathrm{E}-03$ & $4.52 \mathrm{E}+00$ & $3.54 \mathrm{E}-01$ & 1. $76 \mathrm{E}-01$ & $8.32 \mathrm{E}-01$ & $1.28 \mathrm{E}+00$ & 1. $77 \mathrm{E}+00$ & $2.43 E+00$ \\
\hline $5.21 E-03$ & $4.52 \mathrm{E}+00$ & $3.55 \mathrm{E}-01$ & 1. $77 \mathrm{E}-01$ & $8.33 E-01$ & $1.28 \mathrm{E}+00$ & $1.77 \mathrm{E}+00$ & $2.43 E+00$ \\
\hline $5.25 E-03$ & $4.52 \mathrm{E}+00$ & $3.55 E-01$ & $1.77 \mathrm{E}-01$ & $8.35 E-01$ & $1.28 \mathrm{E}+00$ & $1.78 \mathrm{E}+00$ & $2.44 \mathrm{E}+00$ \\
\hline $5.29 \mathrm{E}-03$ & $4.52 \mathrm{E}+00$ & $3.56 \mathrm{E}-01$ & $1.78 \mathrm{E}-01$ & $8.37 E-01$ & $1.28 \mathrm{E}+00$ & $1.78 \mathrm{E}+00$ & $2.44 \mathrm{E}+00$ \\
\hline $5.32 E-03$ & $4.53 \mathrm{E}+00$ & $3.57 \mathrm{E}-01$ & 1. $79 \mathrm{E}-01$ & $8.39 E-01$ & $1.29 \mathrm{E}+00$ & $1.78 \mathrm{E}+00$ & $2.44 \mathrm{E}+00$ \\
\hline $5.36 \mathrm{E}-03$ & $4.53 \mathrm{E}+00$ & $3.58 \mathrm{E}-01$ & 1. $79 \mathrm{E}-01$ & $8.40 \mathrm{E}-01$ & $1.29 \mathrm{E}+00$ & $1.78 \mathrm{E}+00$ & $2.44 \mathrm{E}+00$ \\
\hline $5.40 E-03$ & $4.53 \mathrm{E}+00$ & $3.59 \mathrm{E}-01$ & 1. $80 \mathrm{E}-01$ & $8.42 \mathrm{E}-01$ & $1.29 \mathrm{E}+00$ & $1.78 \mathrm{E}+00$ & $2.44 \mathrm{E}+00$ \\
\hline $5.44 \mathrm{E}-03$ & $4.53 E+00$ & $3.60 \mathrm{E}-01$ & $1.81 \mathrm{E}-01$ & $8.43 E-01$ & $1.29 \mathrm{E}+00$ & 1. $78 \mathrm{E}+00$ & $2.44 \mathrm{E}+00$ \\
\hline $5.48 E-03$ & $4.53 \mathrm{E}+00$ & 3. $61 \mathrm{E}-01$ & $1.81 \mathrm{E}-01$ & $8.45 E-01$ & $1.30 \mathrm{E}+00$ & 1. $78 \mathrm{E}+00$ & $2.45 \mathrm{E}+00$ \\
\hline $5.52 E-03$ & $4.54 \mathrm{E}+00$ & $3.62 E-01$ & $1.82 \mathrm{E}-01$ & $8.46 \mathrm{E}-01$ & $1.30 \mathrm{E}+00$ & $1.79 \mathrm{E}+00$ & $2.45 E+00$ \\
\hline $5.56 \mathrm{E}-03$ & $4.54 \mathrm{E}+00$ & $3.63 E-01$ & $1.83 E-01$ & $8.47 E-01$ & $1.30 \mathrm{E}+00$ & $1.79 \mathrm{E}+00$ & $2.45 E+00$ \\
\hline $5.60 E-03$ & $4.54 \mathrm{E}+00$ & $3.64 \mathrm{E}-01$ & 1. $84 \mathrm{E}-01$ & $8.49 E-01$ & $1.30 \mathrm{E}+00$ & $1.79 \mathrm{E}+00$ & $2.45 E+00$ \\
\hline $5.64 \mathrm{E}-03$ & $4.54 \mathrm{E}+00$ & $3.65 E-01$ & $1.84 \mathrm{E}-01$ & $8.51 \mathrm{E}-01$ & $1.31 \mathrm{E}+00$ & $1.79 \mathrm{E}+00$ & $2.45 E+00$ \\
\hline $5.68 \mathrm{E}-03$ & $4.54 \mathrm{E}+00$ & $3.66 \mathrm{E}-01$ & $1.85 \mathrm{E}-01$ & $8.53 E-01$ & $1.31 \mathrm{E}+00$ & 1. $79 \mathrm{E}+00$ & $2.46 \mathrm{E}+00$ \\
\hline $5.72 E-03$ & $4.55 \mathrm{E}+00$ & $3.66 \mathrm{E}-01$ & $1.86 \mathrm{E}-01$ & $8.55 E-01$ & $1.31 \mathrm{E}+00$ & $1.79 \mathrm{E}+00$ & $2.46 \mathrm{E}+00$ \\
\hline $5.76 \mathrm{E}-03$ & $4.55 \mathrm{E}+00$ & $3.67 \mathrm{E}-01$ & $1.87 \mathrm{E}-01$ & $8.57 \mathrm{E}-01$ & $1.31 \mathrm{E}+00$ & $1.79 \mathrm{E}+00$ & $2.46 \mathrm{E}+00$ \\
\hline $5.80 \mathrm{E}-03$ & $4.55 \mathrm{E}+00$ & $3.68 \mathrm{E}-01$ & $1.87 \mathrm{E}-01$ & $8.59 \mathrm{E}-01$ & $1.32 \mathrm{E}+00$ & $1.80 \mathrm{E}+00$ & $2.46 \mathrm{E}+00$ \\
\hline $5.85 \mathrm{E}-03$ & $4.55 \mathrm{E}+00$ & $3.69 E-01$ & $1.88 E-01$ & $8.61 E-01$ & $1.32 \mathrm{E}+00$ & $1.80 \mathrm{E}+00$ & $2.46 \mathrm{E}+00$ \\
\hline $5.89 \mathrm{E}-03$ & $4.55 \mathrm{E}+00$ & $3.70 E-01$ & $1.89 \mathrm{E}-01$ & $8.64 \mathrm{E}-01$ & $1.32 \mathrm{E}+00$ & $1.80 \mathrm{E}+00$ & $2.46 \mathrm{E}+00$ \\
\hline $5.93 E-03$ & $4.56 \mathrm{E}+00$ & $3.71 \mathrm{E}-01$ & 1. $89 \mathrm{E}-01$ & $8.66 \mathrm{E}-01$ & $1.32 \mathrm{E}+00$ & $1.80 \mathrm{E}+00$ & $2.46 \mathrm{E}+00$ \\
\hline $5.97 \mathrm{E}-03$ & $4.56 \mathrm{E}+00$ & $3.72 \mathrm{E}-01$ & $1.90 \mathrm{E}-01$ & $8.69 E-01$ & $1.33 \mathrm{E}+00$ & $1.80 \mathrm{E}+00$ & $2.47 \mathrm{E}+00$ \\
\hline $6.01 E-03$ & $4.56 \mathrm{E}+00$ & $3.73 E-01$ & 1.91E-01 & $8.71 E-01$ & $1.33 \mathrm{E}+00$ & $1.80 \mathrm{E}+00$ & $2.47 \mathrm{E}+00$ \\
\hline $6.06 \mathrm{E}-03$ & $4.56 \mathrm{E}+00$ & $3.74 \mathrm{E}-01$ & 1. $92 \mathrm{E}-01$ & $8.74 \mathrm{E}-01$ & $1.33 \mathrm{E}+00$ & $1.80 \mathrm{E}+00$ & $2.47 \mathrm{E}+00$ \\
\hline $6.10 E-03$ & $4.56 \mathrm{E}+00$ & $3.75 E-01$ & $1.92 \mathrm{E}-01$ & $8.76 E-01$ & $1.33 \mathrm{E}+00$ & $1.81 \mathrm{E}+00$ & $2.47 E+00$ \\
\hline $6.14 \mathrm{E}-03$ & $4.56 \mathrm{E}+00$ & $3.76 E-01$ & $1.93 E-01$ & $8.78 E-01$ & $1.34 \mathrm{E}+00$ & $1.81 \mathrm{E}+00$ & $2.47 \mathrm{E}+00$ \\
\hline $6.18 E-03$ & $4.57 \mathrm{E}+00$ & $3.77 E-01$ & $1.94 \mathrm{E}-01$ & $8.81 E-01$ & $1.34 \mathrm{E}+00$ & $1.81 \mathrm{E}+00$ & $2.47 \mathrm{E}+00$ \\
\hline $6.23 E-03$ & $4.57 \mathrm{E}+00$ & $3.77 E-01$ & $1.95 E-01$ & $8.84 E-01$ & $1.34 \mathrm{E}+00$ & $1.81 \mathrm{E}+00$ & $2.47 \mathrm{E}+00$ \\
\hline $6.27 \mathrm{E}-03$ & $4.57 \mathrm{E}+00$ & $3.78 \mathrm{E}-01$ & 1. $96 \mathrm{E}-01$ & $8.86 \mathrm{E}-01$ & $1.35 \mathrm{E}+00$ & $1.81 \mathrm{E}+00$ & $2.47 \mathrm{E}+00$ \\
\hline
\end{tabular}


RESRAD-OFFSITE, Version 2.5

robabilistic Dose and Risk Report

Title : Offsite Resident Farmer

File : RF TC99 DOESG FWD-FV2all.ROF

Summary of dose at graphical times, reptition 2 (continued)

Time

Years

$6.37 \mathrm{E}+02$

$6.37 \mathrm{E}+02$

$6.38 \mathrm{E}+02$

$6.38 \mathrm{E}+02$

$6.39 \mathrm{E}+02$

$6.39 \mathrm{E}+02$

$6.40 \mathrm{E}+02$

$6.40 \mathrm{E}+02$

$6.41 \mathrm{E}+02$

$6.41 \mathrm{E}+02$

$6.42 \mathrm{E}+02$

$6.42 \mathrm{E}+02$

$6.43 \mathrm{E}+02$

$6.43 \mathrm{E}+02$

$6.44 \mathrm{E}+02$

$6.44 \mathrm{E}+02$

$6.45 \mathrm{E}+02$

$6.45 \mathrm{E}+02$

$6.46 \mathrm{E}+02$

$6.47 \mathrm{E}+02$

$6.47 \mathrm{E}+02$

$6.48 \mathrm{E}+02$

$6.48 \mathrm{E}+02$

$6.49 \mathrm{E}+02$

$6.49 \mathrm{E}+02$

$6.50 \mathrm{E}+02$

$6.50 \mathrm{E}+02$

$6.51 \mathrm{E}+02$

$6.51 \mathrm{E}+02$

$6.52 \mathrm{E}+02$

$6.52 \mathrm{E}+02$

$6.53 \mathrm{E}+02$

$6.53 \mathrm{E}+02$

$6.54 \mathrm{E}+02$

$6.54 \mathrm{E}+02$

$6.55 \mathrm{E}+02$

$6.55 \mathrm{E}+02$

$6.56 \mathrm{E}+02$

$6.56 \mathrm{E}+02$

$6.57 \mathrm{E}+02$

$6.57 \mathrm{E}+02$

$6.58 \mathrm{E}+02$

$6.58 \mathrm{E}+02$

$6.59 \mathrm{E}+02$

$6.59 \mathrm{E}+02$

$6.60 \mathrm{E}+02$
Dose statistics at graphical times, mrem/yr

\begin{tabular}{|c|c|c|c|c|c|c|c|}
\hline Minimum & laximum & Mean & Median & 900 & $5 \%$ & $97.5 \%$ & $9 \%$ \\
\hline 3 & $7 E+00$ & 1 & 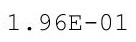 & 1 & 355 & 01 & +00 \\
\hline 3 & $57 E+00$ & OE- & 01 & 01 & $35 E+00$ & $1.82 \mathrm{E}+$ & $7 E+00$ \\
\hline $\mathrm{DE}-03$ & $7 \mathrm{E}+00$ & $1 \mathrm{E}$ & $98 E-01$ & 1 & $35 \mathrm{E}$ & 0 & $7 E+00$ \\
\hline $5 E-03$ & $8 E+00$ & $82 E-01$ & $98 \mathrm{E}-01$ & 1 & 0 & 0 & $7 \mathrm{E}+00$ \\
\hline $49 \mathrm{E}-03$ & $8 \mathrm{E}+00$ & 1 & & & $36 \mathrm{E}+00$ & & $47 \mathrm{E}+00$ \\
\hline-03 & 0 & & & 1 & 0 & 00 & $7 \mathrm{E}+00$ \\
\hline $.58 E-03$ & $4.58 E+00$ & $85 E-01$ & -01 & -01 & $1.36 \mathrm{E}+$ & 0 & $47 \mathrm{E}+00$ \\
\hline $.63 E-03$ & $4.58 E+00$ & $3.00 \mathrm{~L}-01$ & $2.02 \mathrm{E}-01$ & 每 & $1 \cdot 37 \mathrm{E}+00$ & $1.82 \mathrm{E}+00$ & $2.47 \mathrm{E}+00$ \\
\hline$E-03$ & +00 & 1 & 01 & 1 & $1.37 \mathrm{E}$ & 00 & $48 E+00$ \\
\hline $.72 E-03$ & $E+00$ & $38 E-01$ & $\perp$ & & $1 \cdot 37 \mathrm{E}+00$ & 00 & $\mathrm{E}+00$ \\
\hline$E-03$ & & 3 & & & & & $48 E+00$ \\
\hline-03 & +00 & 1 & 1 & & 0 & & $48 E+00$ \\
\hline $.86 E-03$ & $4.59 \mathrm{E}+00$ & 90E-01 & $2.06 \mathrm{E}-01$ & $\perp$ LU & $1.38 \mathrm{E}+00$ & $1.84 \mathrm{E}+0 \mathrm{U}$ & $2.48 \mathrm{E}+00$ \\
\hline $.90 E-03$ & $4.59 E+00$ & $3.91 \mathrm{~L}-1$ & $2.07 \mathrm{E}-01$ & • & $1.38 \mathrm{E}+00$ & $1.04 \mathrm{~s}-\mathrm{s}$ & $2.48 \mathrm{E}+00$ \\
\hline $5 E-03$ & $4.59 \mathrm{E}+00$ & 3 & 01 & 0.20 & 工. & 00 & $2.48 E+00$ \\
\hline $.00 \mathrm{E}-03$ & $4.59 \mathrm{E}+00$ & $3.93 \mathrm{E}-\mathrm{C}$ & 2.00 & 舟 & 1. $39 \mathrm{E}+$ & 1. & $2.48 \mathrm{E}+00$ \\
\hline $.05 E-03$ & $4.59 E+00$ & $3.94 \mathrm{E}-01$ & 2.0 & Sorte & 1. 39E+00 & $1.84 \mathrm{E}+00$ & $2.48 \mathrm{E}+00$ \\
\hline$E-03$ & $\mathrm{E}+00$ & $5 E-01$ & -01 & 1 & 0 & 0 & $48 E+00$ \\
\hline $.14 \mathrm{E}-03$ & $4.60 \mathrm{E}+00$ & $6 E-01$ & $0 E-01$ & ت & 1. $39 \mathrm{E}+00$ & $1.85 \mathrm{E}+00$ & $2.48 \mathrm{E}+00$ \\
\hline $.19 \mathrm{E}-03$ & $4.60 \mathrm{E}+00$ & 3 . & 1 & ( & 1. & 00 & $\mathrm{~s}+00$ \\
\hline $.24 E-03$ & $4.60 E+00$ & & & (15 & & 1.01 & $48 E+00$ \\
\hline $.29 \mathrm{E}-03$ & $4.00 \mathrm{E}+00$ & $3.99 \mathrm{E}-$ & 1 & 0.00 & $1.40 \mathrm{U}$ & 00 & $48 \mathrm{E}+00$ \\
\hline $.33 E-03$ & $4.60 \mathrm{E}+00$ & F & 1 & $9.37 \mathrm{E}-$ & 1. $40 \mathrm{E}+$ & $5 E+00$ & $2.48 E+00$ \\
\hline $.38 E-03$ & $4.60 \mathrm{E}+00$ & -01 & 01 & 1 & 1. $40 \mathrm{E}+$ & $1.85 \mathrm{E}+$ & $.48 E+00$ \\
\hline 03 & $4.60 \mathrm{E}+00$ & 1 & 1 & & & $E+00$ & $.48 E+00$ \\
\hline$E-03$ & $4.61 E+00$ & 1 & & $\perp$ & 1 & 00 & -00 \\
\hline $3 E-03$ & $4.61 E+00$ & $3 E-U 1$ & & $\perp$ & $\perp .4 \perp E$ & 1.00 & $2.48 E+00$ \\
\hline $.58 \mathrm{E}-03$ & $4.61 \mathrm{E}+00$ & $4.04 \mathrm{E}-01$ & $2.17 \mathrm{E}-01$ & $9.48 \mathrm{E}-01$ & 1. $41 \mathrm{E}+00$ & $1.86 \mathrm{E}+00$ & $2.48 \mathrm{E}+00$ \\
\hline $.63 E-03$ & $4.61 \mathrm{E}+00$ & $4.05 \mathrm{E}-$ & $2 \cdot 1,+4$ & (. & 1. $41 \mathrm{E}+$ & $1.80 \mathrm{E}+00$ & 2. $48 \mathrm{E}+00$ \\
\hline 3 & $4.61 E+00$ & & 1 & & $1.42 \mathrm{E}$ & 1. & $48 E+00$ \\
\hline 03 & $4.61 E+00$ & 1 & 1 & 1 & 1. $42 \mathrm{E}+$ & $E+00$ & $.48 E+00$ \\
\hline$E-03$ & $4.61 E+00$ & 4 & 1 & 1 & 1 & 0 & 00 \\
\hline $.83 E-03$ & $4.61 \mathrm{E}+00$ & $4.09 \mathrm{E}-01$ & $2.21 \mathrm{E}-01$ & $9.57 \mathrm{E}-$ & 1. $42 \mathrm{E}+$ & $1.87 \mathrm{E}+00$ & $2.48 \mathrm{E}+00$ \\
\hline $.89 \mathrm{E}-03$ & $4.61 E+00$ & $4.10 \mathrm{E}-01$ & $2.22 \mathrm{E}-01$ & $9.59 \mathrm{E}-01$ & 1. $43 \mathrm{E}+00$ & $1.87 \mathrm{E}+00$ & $2.48 \mathrm{E}+00$ \\
\hline $.94 E-03$ & $4.01 E+00$ & & & & 1. $43 \mathrm{E}+$ & & $2.48 \mathrm{E}+00$ \\
\hline $7.99 \mathrm{E}-03$ & $4.62 \mathrm{E}+00$ & & & & $1.43 \mathrm{E}$ & & $2.48 \mathrm{E}+00$ \\
\hline 3 & קת & 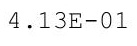 & 1 & - & 0 & $7 E+00$ & $48 E+00$ \\
\hline $9 \mathrm{E}-03$ & $62 \mathrm{E}+00$ & 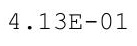 & 1 & 1 & 0 & 0 & 30 \\
\hline 3 & & & -01 & 9 & 1. & 00 & $2.48 \mathrm{E}$ \\
\hline$E-03$ & 4. $62 \mathrm{E}+$ & 4 & & & $1.44 \mathrm{E}+$ & & $2.48 \mathrm{E}+00$ \\
\hline$E-03$ & 4. $62 \mathrm{E}+00$ & 4 & & & 1. $44 \mathrm{E}+$ & $1.88 \mathrm{E}+$ & $2.49 \mathrm{E}+00$ \\
\hline 3 & $4.0 \angle E+00$ & 4 . & 1 & 1 & $1.44 \mathrm{E}$ & $1.88 \mathrm{E}+00$ & $2.49 \mathrm{E}+00$ \\
\hline 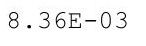 & 4.02 & 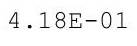 & 2. & 1 & 0 & 1.00 & 2.150 \\
\hline & 4 & & & & 1 . & & \\
\hline-03 & $4.62 \mathrm{E}+00$ & $E-01$ & 2.3 & 9. & 1.4 & 1 . & $\mathrm{E}+00$ \\
\hline $.52 E-03$ & $4.62 E+00$ & $.21 E-01$ & $.33 E-01$ & $9.86 \mathrm{E}-01$ & 1. $45 \mathrm{E}+00$ & $1.89 \mathrm{E}+00$ & $2.50 \mathrm{E}+00$ \\
\hline
\end{tabular}


RESRAD-OFFSITE, Version 2.5 
RESRAD-OFFSITE, Version 2.5

robabilistic Dose and Risk Report

Title : Offsite Resident Farmer

File : RF TC99 DOESG FWD-FV2all.ROF

Summary of dose at graphical times, reptition 2 (continued)

Time

Years

$6.84 \mathrm{E}+02$

$6.84 \mathrm{E}+02$

$6.85 \mathrm{E}+02$

$6.85 \mathrm{E}+02$

$6.86 \mathrm{E}+02$

$6.86 \mathrm{E}+02$

$6.87 \mathrm{E}+02$

$6.88 \mathrm{E}+02$

$6.88 \mathrm{E}+02$

$6.89 \mathrm{E}+02$

$6.89 \mathrm{E}+02$

$6.90 \mathrm{E}+02$

$6.90 \mathrm{E}+02$

$6.91 \mathrm{E}+02$

$6.91 \mathrm{E}+02$

$6.92 \mathrm{E}+02$

$6.92 \mathrm{E}+02$

$6.93 \mathrm{E}+02$

$6.93 \mathrm{E}+02$

$6.94 \mathrm{E}+02$

$6.94 \mathrm{E}+02$

$6.95 \mathrm{E}+02$

$6.95 \mathrm{E}+02$

$6.96 \mathrm{E}+02$

$6.96 \mathrm{E}+02$

$6.97 \mathrm{E}+02$

$6.97 \mathrm{E}+02$

$6.98 \mathrm{E}+02$

$6.98 \mathrm{E}+02$

$6.99 \mathrm{E}+02$

$6.99 \mathrm{E}+02$

$7.00 \mathrm{E}+02$

$7.00 \mathrm{E}+02$

$7.01 \mathrm{E}+02$

$7.01 \mathrm{E}+02$

$7.02 \mathrm{E}+02$

$7.02 \mathrm{E}+02$

$7.03 \mathrm{E}+02$

$7.03 E+02$

$7.04 \mathrm{E}+02$

$7.04 \mathrm{E}+02$

$7.05 \mathrm{E}+02$

$7.05 \mathrm{E}+02$

$7.06 \mathrm{E}+02$

$7.06 \mathrm{E}+02$

$7.07 \mathrm{E}+02$
Dose statistics at graphical times, mrem/yr

\begin{tabular}{|c|c|c|c|c|c|c|c|}
\hline m & $a x$ & Mean & ledian & & & $\circ$ & $\%$ \\
\hline 02 & $4.63 E+00$ & $4.65 \mathrm{E}-01$ & $2.72 \mathrm{E}-01$ & $1.09 \mathrm{E}+00$ & $1.55 \mathrm{E}+00$ & $2.00 \mathrm{E}+00$ & $2.64 \mathrm{E}+00$ \\
\hline $.14 \mathrm{E}-02$ & $.63 E+00$ & $6 \mathrm{E}-01$ & $2.73 E-01$ & 0 & 0 & 0 & $4 \mathrm{E}+00$ \\
\hline $15 \mathrm{E}-02$ & $4.63 \mathrm{E}+00$ & $4.67 \mathrm{E}-01$ & $2.73 E-01$ & 1.09E+00 & $1.55 \mathrm{E}+00$ & $\Xi+00$ & $2.65 \mathrm{E}+00$ \\
\hline $16 \mathrm{E}-02$ & $4.63 E+00$ & $.68 E-01$ & $2.74 \mathrm{E}-01$ & $1.09 \mathrm{E}+00$ & $1.55 \mathrm{E}+00$ & $2.00 \mathrm{E}+00$ & $2.65 \mathrm{E}+00$ \\
\hline $6 \mathrm{E}-02$ & $4.63 E+00$ & $8 \mathrm{E}$ & $.75 \mathrm{E}-01$ & $1.09 \mathrm{E}+00$ & $.55 \mathrm{E}+00$ & $1 E+00$ & $2.65 \mathrm{E}+00$ \\
\hline 02 & $63 E+00$ & 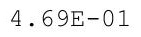 & - & & & & +00 \\
\hline $18 \mathrm{E}-02$ & & 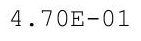 & & 0 & & & +00 \\
\hline $18 \mathrm{E}-02$ & & & & & & & $E+00$ \\
\hline$E-02$ & +00 & $2 E-01$ & $3 E-01$ & $10 \mathrm{E}+00$ & $56 \mathrm{E}+00$ & +00 & $66 \mathrm{E}+00$ \\
\hline 2 & $4.63 E+0$ & - & $\perp$ & $10 \mathrm{~F}$ & $56 \mathrm{~F}+$ & $E+00$ & $67 \mathrm{E}+00$ \\
\hline 02 & $463 F+00$ & $4.74 E-01$ & $2.80 E-01$ & $110=+$ & & $.02 E+00$ & $.67 \mathrm{E}+00$ \\
\hline $21 E-02$ & $4 \quad 63 F+00$ & & & 0 & 0 & 0 & مी \\
\hline $22 \mathrm{~F}-02$ & $3 F+00$ & $6 \mathrm{~F}-0$ & $F_{-}$ & 0 & 0 & 0 & +00 \\
\hline $.22 E-02$ & $4.63 \mathrm{E}+00$ & $4.77 \mathrm{E}-01$ & $2.82 \mathrm{E}-01$ & $1.11 \mathrm{E}+00$ & 1. $57 \mathrm{E}+00$ & $2.03 E+00$ & $2.68 \mathrm{E}+00$ \\
\hline $23 E-02$ & $4.63 E+00$ & $8 E-01$ & $3 E-01$ & $1.11 \mathrm{E}+00$ & & $E+00$ & $68 \mathrm{E}+00$ \\
\hline 2 & קת תקו & & & 0 & & & \\
\hline $5 E-02$ & & & & & 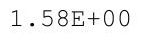 & & 00 \\
\hline 2 & 4. $63 \mathrm{E}+$ & & & 0 & & & -0 \\
\hline $26 \mathrm{~F}-02$ & 4 63F+0 & (1) & $\sigma_{\Gamma}$ & $1.12 \mathrm{E}+00$ & ג䧄 & $E+00$ & $9 \mathrm{E}+00$ \\
\hline $27 E-02$ & 4. $63 \mathrm{E}+00$ & $.82 E-01$ & $.86 \mathrm{E}-01$ & $1.12 \mathrm{E}+00$ & 1. $58 \mathrm{E}+00$ & $2.03 E+00$ & $2.70 \mathrm{E}+00$ \\
\hline $7 E-02$ & $4.63 E+00$ & $4.83 E-0$ & $87 \mathrm{E}-01$ & 1. $12 \mathrm{E}+00$ & & $.04 E+00$ & $.70 \mathrm{E}+00$ \\
\hline 2 & & & & & & & \\
\hline & & & & $.12 \mathrm{E}$ & & & \\
\hline . $20 \mathrm{n}-\mathrm{z}$ & $4.62 \mathrm{E}+00$ & & & $1.12 \mathrm{E}+$ & 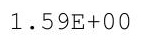 & & $2.70 \mathrm{E}+00$ \\
\hline 2 & (2) & $4.87 \mathrm{E}-01$ & $\perp$ & $1.12 \mathrm{E}+$ & $9 \mathrm{E}+$ & תח & 00 \\
\hline $31 \mathrm{~F}-02$ & $462 F+00$ & $88 F-0$ & $2.92 \mathrm{E}-01$ & $1.13 \mathrm{E}+00$ & 1 & $2.04 \mathrm{E}+00$ & $70 E+00$ \\
\hline$F-0 ?$ & $4.62 \mathrm{E}+00$ & $4.89 E-01$ & $293 \mathrm{~F}-01$ & $1.13 \mathrm{E}+00$ & & $2.04 \mathrm{E}+00$ & $2.70 \mathrm{E}+00$ \\
\hline 02 & & & & & & & \\
\hline 02 & $4.62 \mathrm{E}+00$ & & & & & & \\
\hline $34 \mathrm{E}-02$ & 4.021100 & $\begin{array}{ll}1.02 \square & -1\end{array}$ & $2.95 \mathrm{E}-01$ & $1.13 \mathrm{E}+00$ & 土. & $2.04 \mathrm{E}+00$ & $2.71 \mathrm{E}+00$ \\
\hline 82 & 4. $0 \angle 5 T 00$ & . & $2 \cdot 90 \mathrm{~L}-01$ & $1.13 \mathrm{E}+00$ & 土. & $2.00 \mathrm{D}$ & 2.1 LTU \\
\hline . & ४. & 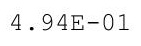 & 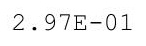 & $1.14 \mathrm{E}+00$ & & & $2.71 \mathrm{E}+00$ \\
\hline 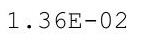 & $4.62 \mathrm{E}+00$ & 05 & $297 \mathrm{~F}-01$ & $1.14 \mathrm{E}+00$ & & & $2.71 \mathrm{E}+00$ \\
\hline 2 & & & & & & & \\
\hline$E-02$ & $4.62 E+C$ & & 01 & & & & $71 E+00$ \\
\hline $39 \mathrm{E}-02$ & $4.61 \mathrm{E}+00$ & $4.97 E-01$ & $3.00 \mathrm{E}-01$ & $\perp \cdot 14 \mathrm{ET}$ & 1.014 & $2.03 E+00$ & $2.71 \mathrm{E}+00$ \\
\hline $.39 E-02$ & 7. & & & $1 \cdot 1 J E+U 0$ & & & \\
\hline • & 7. & & & & & & \\
\hline $.41 E-02$ & 4. $61 \mathrm{E}+$ & 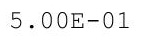 & & $1.15 \mathrm{E}+$ & 1. $61 \mathrm{E}+$ & & $2.71 \mathrm{E}+00$ \\
\hline & & & & $15 E+00$ & 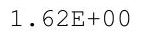 & & $.71 \mathrm{E}+00$ \\
\hline $42 \mathrm{E}-02$ & $4.61 E+00$ & 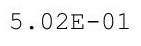 & 1 & $1.15 \mathrm{E}+$ & $1.62 \mathrm{E}$ & & \\
\hline $43 E-02$ & $4.61 E+00$ & $5.03 E-01$ & 3. & $1.16 \mathrm{E}+00$ & 1. $62 \mathrm{E}+$ & & $2.72 \mathrm{E}+00$ \\
\hline & $4.0 \perp E+U 0$ & & & & & & \\
\hline & $4.61 \mathrm{E}+00$ & + & & $1.16 \mathrm{E}+00$ & $1.62 \mathrm{E}+00$ & $2.06 \mathrm{E}+00$ & $2.72 \mathrm{E}+00$ \\
\hline $.405-02$ & $4.61 E+00$ & & & $1.16 \mathrm{E}+00$ & $1.62 \mathrm{E}+00$ & $2.06 \mathrm{E}+00$ & $2.72 \mathrm{E}+00$ \\
\hline $46 \mathrm{E}-02$ & $4.61 \mathrm{E}+00$ & $7 E-01$ & $0 E-01$ & $1.16 \mathrm{E}+00$ & $1.63 \mathrm{E}+00$ & $2.06 \mathrm{E}+00$ & $.72 \mathrm{E}+00$ \\
\hline
\end{tabular}


RESRAD-OFFSITE, Version 2.5

$\mathrm{T}^{1 / 2}$ Limit $=180$ days

robabilistic Dose and Risk Report

Title : Offsite Resident Farmer

File : RF TC99 DOESG FWD-FV2all.ROF

Summary of dose at graphical times, reptition 2 (continued)

Time

Years

7. $08 \mathrm{E}+02$

$7.08 \mathrm{E}+02$

7. $09 \mathrm{E}+02$

7. $09 \mathrm{E}+02$

$7.10 \mathrm{E}+02$

$7.10 \mathrm{E}+02$

$7.11 \mathrm{E}+02$

$7.11 \mathrm{E}+02$

$7.12 \mathrm{E}+02$

$7.12 \mathrm{E}+02$

$7.13 \mathrm{E}+02$

$7.13 \mathrm{E}+02$

$7.14 \mathrm{E}+02$

$7.14 \mathrm{E}+02$

7. $15 \mathrm{E}+02$

7. $15 \mathrm{E}+02$

$7.16 \mathrm{E}+02$

$7.16 \mathrm{E}+02$

$7.17 \mathrm{E}+02$

$7.17 \mathrm{E}+02$

$7.18 \mathrm{E}+02$

$7.18 \mathrm{E}+02$

7. $19 \mathrm{E}+02$

$7.19 \mathrm{E}+02$

$7.20 \mathrm{E}+02$

$7.20 \mathrm{E}+02$

$7.21 \mathrm{E}+02$

$7.21 \mathrm{E}+02$

7. $22 \mathrm{E}+02$

$7.22 \mathrm{E}+02$

7. $23 \mathrm{E}+02$

7. $23 \mathrm{E}+02$

$7.24 \mathrm{E}+02$

$7.24 \mathrm{E}+02$

$7.25 \mathrm{E}+02$

7. $25 \mathrm{E}+02$

7. $26 \mathrm{E}+02$

$7.26 \mathrm{E}+02$

$7.27 \mathrm{E}+02$

$7.28 \mathrm{E}+02$

$7.28 \mathrm{E}+02$

$7.29 \mathrm{E}+02$

$7.29 \mathrm{E}+02$

$7.30 \mathrm{E}+02$

7. $30 \mathrm{E}+02$

7. $31 \mathrm{E}+02$
Dose statistics at graphical times, mrem/yr

\begin{tabular}{|c|c|c|c|c|c|c|c|}
\hline m & um & e & ledian & & & $\%$ & \\
\hline 02 & $4.60 \mathrm{E}+00$ & $08 E-01$ & 1 & $17 E+00$ & $.63 E+00$ & -00 & - $12 \mathrm{E}+U \mathrm{U}$ \\
\hline $48 E-02$ & $4.60 E+00$ & $9 E-01$ & $3.11 \mathrm{E}-01$ & $17 E+00$ & $63 E+00$ & $2.06 \mathrm{E}+00$ & $3 E+00$ \\
\hline $49 E-02$ & $60 \mathrm{E}+00$ & $9 E-01$ & $2 E-01$ & $.17 E+00$ & $.63 E+00$ & $2.06 \mathrm{E}+00$ & $73 E+00$ \\
\hline $50 \mathrm{E}-02$ & $4.60 \mathrm{E}+00$ & $10 \mathrm{~F}-01$ & $13 F-01$ & $.17 \mathrm{E}+00$ & $163 E+00$ & $2.06 \mathrm{E}+00$ & $2.73 E+00$ \\
\hline-02 & $4.60 \mathrm{E}+00$ & 01 & $3.13 \mathrm{E}-01$ & & & $E+00$ & +00 \\
\hline 02 & $4.60 \mathrm{E}+00$ & & & & & & 00 \\
\hline $52 E-02$ & $60 \mathrm{E}+00$ & & & & & & $73 E+00$ \\
\hline $53 E-02$ & $4.60 \mathrm{E}+00$ & 1 & $\perp$ & $1.18 \mathrm{E}+00$ & 00 & +00 & $E+00$ \\
\hline $54 \mathrm{E}-02$ & $4.60 \mathrm{E}+00$ & $5 E-01$ & $E-01$ & $18 \mathrm{E}+00$ & $64 \mathrm{E}+00$ & $.07 \mathrm{E}+00$ & $3 E+00$ \\
\hline$E-02$ & $.59 \mathrm{E}+00$ & $16 \mathrm{E}-01$ & 10 & $.18 \mathrm{E}+00$ & 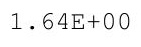 & $.07 E+00$ & $.73 E+00$ \\
\hline 2 & $9 \mathrm{E}+00$ & $7 E-01$ & & & & -00 & $3 E+00$ \\
\hline $56 \mathrm{E}-02$ & $4.59 \mathrm{E}+00$ & 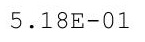 & & 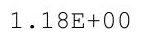 & 0 & 0 & +00 \\
\hline $.57 E-02$ & $4.59 \mathrm{E}+00$ & & & & & $2.08 E+00$ & $2.74 \mathrm{E}+00$ \\
\hline $58 E-02$ & $4.59 \mathrm{E}+00$ & $.20 \mathrm{E}-01$ & $.20 \mathrm{E}-01$ & $1.19 \mathrm{E}+00$ & & $2.08 E+00$ & $2.74 \mathrm{E}+00$ \\
\hline-02 & $59 \mathrm{E}+00$ & $\Xi-01$ & 制 & 0 & & $E+00$ & $4 \mathrm{E}+00$ \\
\hline .5 & 0 & & & & & 0 & 00 \\
\hline 2 & $9 E+00$ & & & 100 & & 0 & 0 \\
\hline $61 E-02$ & $4.58 \mathrm{E}+00$ & $5.23 E-01$ & $3235-01$ & ניחק & & 0 & 0 \\
\hline $62 E-02$ & $4.58 \mathrm{E}+00$ & $24 F-01$ & $\Delta F-01$ & 1 & $66 \sigma^{\circ}$ & $F+00$ & $5 E+00$ \\
\hline $63 E-02$ & $4.58 \mathrm{E}+00$ & $.25 E-01$ & $.25 \mathrm{E}-01$ & $1.20 \mathrm{E}+00$ & $1.66 \mathrm{E}+$ & $2.09 \mathrm{E}+00$ & $2.75 E+00$ \\
\hline 02 & $58 E+00$ & & & & & +00 & $5 \mathrm{E}+00$ \\
\hline 2 & & & & & & & \\
\hline 02 & $4.58 \mathrm{E}+00$ & .2 & & 1.20E+ & & & \\
\hline 02 & $4.58 \mathrm{E}+00$ & $\perp$ & $3.29 \mathrm{E}-01$ & 1.2 & - & $0 E+00$ & 00 \\
\hline 2 & $4.58 \mathrm{E}+00$ & $5.30 \mathrm{E}-01$ & $\perp$ & $1.21 \mathrm{E}+\mathrm{C}$ & $1.66 \mathrm{E}+$ & $2.10 \mathrm{E}+\mathrm{C}$ & $75 E+00$ \\
\hline $68 E-02$ & $4.57 \mathrm{E}+00$ & $31 \mathrm{~F}-01$ & $3 \quad 31 F-01$ & 1. $21 \mathrm{E}+00$ & $.66 \mathrm{E}+\mathrm{C}$ & $.11 \mathrm{E}+00$ & $76 E+00$ \\
\hline$E-02$ & $4.57 \mathrm{E}+00$ & זרכי & & 1. $21 \mathrm{E}+00$ & & $2.11 E+00$ & $.76 \mathrm{E}+00$ \\
\hline 02 & & & & & & & \\
\hline 2 & $4.57 \mathrm{E}+00$ & & & 1.21E+ & $0+\sigma_{0}$ & & $.76 \mathrm{E}+00$ \\
\hline $.71 E-02$ & $4.57 \mathrm{E}+00$ & . 3451 & $\begin{array}{lll}30 \mathrm{~L} \\
\end{array}$ & $1.22 \mathrm{E}+00$ & $1.66 \mathrm{E}+00$ & $2.11 \mathrm{E}+00$ & $2.76 \mathrm{E}+00$ \\
\hline $72 \mathrm{E}-02$ & $4.57 \mathrm{E}+00$ & $5.35 E-01$ & . & 1. $22 \mathrm{E}+00$ & $1.67 \mathrm{E}+00$ & $2.12 \mathrm{E}+00$ & $2.76 \mathrm{E}+00$ \\
\hline 2 & $4.57 \mathrm{E}+00$ & ? & 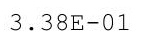 & 1.22E+ & & & $2.76 \mathrm{E}+$ \\
\hline 7 & & & & & & & 0 \\
\hline $\mathrm{E}-02$ & $4.56 \mathrm{E}+00$ & & 1 & & & & \\
\hline$E-02$ & $4.56 \mathrm{E}+00$ & 1 & & $1.22 \mathrm{E}$ & & & 00 \\
\hline $.77 E-02$ & $4.56 \mathrm{E}+00$ & $5.40 \mathrm{E}-01$ & $3.4 \angle E-01$ & $1.23 \mathrm{E}+00$ & 土.OTH & $2.13 E+00$ & $2.77 \mathrm{E}+00$ \\
\hline $78 E-02$ & $4.56 \mathrm{E}+00$ & $.4 \perp L-4$ & & $1.23 E+00$ & & & $2.77 \mathrm{E}+00$ \\
\hline 02 & $4.56 \mathrm{E}+00$ & 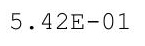 & & $1.23 \mathrm{E}+00$ & $1.67 \mathrm{E}+$ & & $2.77 \mathrm{E}+00$ \\
\hline 2 & 4. $55 \mathrm{E}+$ & $u$ & 1 & $1.23 \mathrm{E}+00$ & $1.68 \mathrm{E}+$ & $2.13 \mathrm{E}+$ & $2.77 \mathrm{E}+00$ \\
\hline 2 & $4.55 E+00$ & 1 & 1 & $1.23 \mathrm{E}+00$ & $1.68 \mathrm{E}+$ & $2.13 E+00$ & $2.77 \mathrm{E}+00$ \\
\hline $81 \mathrm{E}-02$ & $4.55 E+00$ & $5.45 E-01$ & $5 E-01$ & 1. $23 \mathrm{E}+00$ & 1 . & $4 \mathrm{E}+00$ & $2.77 \mathrm{E}+00$ \\
\hline $82 E-02$ & $4.55 E+00$ & 01 & & $1.23 \mathrm{E}+00$ & & 2 & $2.78 \mathrm{E}+00$ \\
\hline & 0 & & & & & & \\
\hline$E-02$ & $4.55 E+00$ & 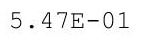 & 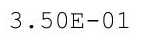 & $1.24 E+U 0$ & $1.68 \mathrm{E}+00$ & $2.14 \mathrm{E}+00$ & $2.78 \mathrm{E}+00$ \\
\hline $85 E-02$ & $4.55 E+00$ & & & $1.24 \mathrm{E}+00$ & $1.69 \mathrm{E}+00$ & $2.15 E+00$ & $2.78 \mathrm{E}+00$ \\
\hline 02 & $4.54 \mathrm{E}+00$ & $E-01$ & $E-01$ & $.24 \mathrm{E}+00$ & $1.69 \mathrm{E}+00$ & $2.15 \mathrm{E}+00$ & $.78 E+00$ \\
\hline
\end{tabular}


RESRAD-OFFSITE, Version 2.5 
RESRAD-OFFSITE, Version 2.5

obabilistic Dose and Risk Report

Title : Offsite Resident Farmer

File : RF TC99 DOESG FWD-FV2all.ROF

Summary of dose at graphical times, reptition 2 (continued)

Time

Years

$7.55 \mathrm{E}+02$

$7.55 \mathrm{E}+02$

$7.56 \mathrm{E}+02$

7. $56 \mathrm{E}+02$

$7.57 \mathrm{E}+02$

$7.57 \mathrm{E}+02$

$7.58 \mathrm{E}+02$

7. $58 \mathrm{E}+02$

$7.59 \mathrm{E}+02$

$7.59 \mathrm{E}+02$

$7.60 \mathrm{E}+02$

$7.60 \mathrm{E}+02$

7. $61 \mathrm{E}+02$

7. $61 \mathrm{E}+02$

7. $62 \mathrm{E}+02$

7. $62 \mathrm{E}+02$

7. $63 \mathrm{E}+02$

7. $63 \mathrm{E}+02$

$7.64 \mathrm{E}+02$

$7.64 \mathrm{E}+02$

$7.65 \mathrm{E}+02$

$7.65 \mathrm{E}+02$

$7.66 \mathrm{E}+02$

$7.66 \mathrm{E}+02$

7. $67 \mathrm{E}+02$

$7.68 \mathrm{E}+02$

$7.68 \mathrm{E}+02$

7. $69 \mathrm{E}+02$

$7.69 \mathrm{E}+02$

$7.70 \mathrm{E}+02$

7. $70 \mathrm{E}+02$

$7.71 \mathrm{E}+02$

7. $71 \mathrm{E}+02$

7. $72 \mathrm{E}+02$

7. $72 \mathrm{E}+02$

7. $73 \mathrm{E}+02$

$7.73 \mathrm{E}+02$

7. $74 \mathrm{E}+02$

$7.74 \mathrm{E}+02$

$7.75 \mathrm{E}+02$

$7.75 \mathrm{E}+02$

$7.76 \mathrm{E}+02$

$7.76 \mathrm{E}+02$

$7.77 \mathrm{E}+02$

$7.77 \mathrm{E}+02$

$7.78 \mathrm{E}+02$

Dose statistics at graphical times, mrem/yr

\begin{tabular}{|c|c|c|c|c|c|c|c|}
\hline Minimum & Maximum & Mean & Median & $90 \%$ & $95 \%$ & $97.5 \%$ & $99 \%$ \\
\hline $2.33 E-02$ & $4.45 E+00$ & $5.92 \mathrm{E}-01$ & $3.94 E-01$ & $1.31 \mathrm{E}+00$ & $1.76 \mathrm{E}+00$ & $2.23 E+00$ & $2.82 E+00$ \\
\hline $2.34 \mathrm{E}-02$ & $4.45 E+00$ & $5.93 E-01$ & $3.95 \mathrm{E}-01$ & $1.31 E+00$ & $1.76 \mathrm{E}+00$ & $2.23 E+00$ & $2.82 \mathrm{E}+00$ \\
\hline $2.35 \mathrm{E}-02$ & $4.45 \mathrm{E}+00$ & $5.94 \mathrm{E}-01$ & $3.96 \mathrm{E}-01$ & $1.31 \mathrm{E}+00$ & $1.76 \mathrm{E}+00$ & $2.23 E+00$ & $2.82 \mathrm{E}+00$ \\
\hline $2.37 \mathrm{E}-02$ & $4.44 \mathrm{E}+00$ & $5.95 \mathrm{E}-01$ & $3.97 \mathrm{E}-01$ & $1.31 \mathrm{E}+00$ & $1.76 \mathrm{E}+00$ & $2.23 E+00$ & $2.82 \mathrm{E}+00$ \\
\hline $2.38 \mathrm{E}-02$ & $4.44 \mathrm{E}+00$ & $5.95 E-01$ & $3.98 \mathrm{E}-01$ & $1.32 \mathrm{E}+00$ & $1.76 \mathrm{E}+00$ & $2.23 E+00$ & $2.82 \mathrm{E}+00$ \\
\hline $2.39 E-02$ & $4.44 \mathrm{E}+00$ & $5.96 \mathrm{E}-01$ & $3.99 E-01$ & $.32 E+00$ & $.77 \mathrm{E}+00$ & $2.24 \mathrm{E}+00$ & $.82 E+00$ \\
\hline $2.40 \mathrm{E}-02$ & $4.44 \mathrm{E}+00$ & $5.97 E-01$ & $4.00 \mathrm{E}-01$ & $1.32 \mathrm{E}+00$ & $1.77 \mathrm{E}+00$ & $2.24 \mathrm{E}+00$ & $2.82 \mathrm{E}+00$ \\
\hline $2.41 \mathrm{E}-02$ & $4.44 \mathrm{E}+00$ & $5.98 \mathrm{E}-01$ & $4.00 \mathrm{E}-01$ & $1.32 \mathrm{E}+00$ & $1.77 \mathrm{E}+00$ & $2.24 \mathrm{E}+00$ & $2.82 \mathrm{E}+00$ \\
\hline $2.42 \mathrm{E}-02$ & $4.43 E+00$ & $5.99 \mathrm{E}-01$ & $4.01 \mathrm{E}-01$ & $1.32 \mathrm{E}+00$ & $1.77 \mathrm{E}+00$ & $2.24 \mathrm{E}+00$ & $2.82 E+00$ \\
\hline $2.43 E-02$ & $4.43 E+00$ & $6.00 \mathrm{E}-01$ & $4.02 E-01$ & $.32 \mathrm{E}+00$ & $1.77 \mathrm{E}+00$ & $2.24 \mathrm{E}+00$ & $.81 E+00$ \\
\hline $2.44 \mathrm{E}-02$ & $4.43 E+00$ & $6.01 \mathrm{E}-01$ & $4.03 E-01$ & $1.33 E+00$ & $1.78 \mathrm{E}+00$ & $2.24 \mathrm{E}+00$ & $2.81 \mathrm{E}+00$ \\
\hline $2.45 \mathrm{E}-02$ & $4.43 E+00$ & $6.02 \mathrm{E}-01$ & $4.04 \mathrm{E}-01$ & $1.33 E+00$ & $1.78 \mathrm{E}+00$ & $2.24 \mathrm{E}+00$ & $2.81 \mathrm{E}+00$ \\
\hline $2.47 \mathrm{E}-02$ & $4.42 E+00$ & $6.03 E-01$ & $4.05 E-01$ & $1.33 E+00$ & $1.78 \mathrm{E}+00$ & $2.24 \mathrm{E}+00$ & $2.81 \mathrm{E}+00$ \\
\hline $2.48 E-02$ & $4.42 \mathrm{E}+00$ & $6.04 \mathrm{E}-01$ & $4.06 \mathrm{E}-01$ & $1.33 \mathrm{E}+00$ & $1.78 \mathrm{E}+00$ & $2.24 \mathrm{E}+00$ & $2.81 E+00$ \\
\hline $2.49 \mathrm{E}-02$ & $4.42 \mathrm{E}+00$ & $6.04 \mathrm{E}-01$ & $4.07 \mathrm{E}-01$ & $1.33 E+00$ & $1.78 \mathrm{E}+00$ & $2.24 \mathrm{E}+00$ & $2.80 \mathrm{E}+00$ \\
\hline $2.50 \mathrm{E}-02$ & $4.42 E+00$ & $6.05 E-01$ & $.08 E-01$ & $.33 E+00$ & $.78 \mathrm{E}+00$ & $.24 E+00$ & $.80 E+00$ \\
\hline $2.51 \mathrm{E}-02$ & $4.41 \mathrm{E}+00$ & $6.06 \mathrm{E}-01$ & $4.09 \mathrm{E}-01$ & $.33 E+00$ & $.78 E+00$ & $2.24 \mathrm{E}+00$ & $.80 \mathrm{E}+00$ \\
\hline $2.52 E-02$ & $4.41 \mathrm{E}+00$ & $6.07 E-01$ & $4.09 E-01$ & $1.33 \mathrm{E}+00$ & $1.79 \mathrm{E}+00$ & $2.24 \mathrm{E}+00$ & $2.80 \mathrm{E}+00$ \\
\hline $2.53 E-02$ & $4.41 \mathrm{E}+00$ & $6.08 E-01$ & $4.10 \mathrm{E}-01$ & $1.33 \mathrm{E}+00$ & $1.79 \mathrm{E}+00$ & $2.24 \mathrm{E}+00$ & $2.80 \mathrm{E}+00$ \\
\hline $2.54 \mathrm{E}-02$ & $4.41 \mathrm{E}+00$ & $6.09 \mathrm{E}-01$ & $4.11 \mathrm{E}-01$ & $1.33 \mathrm{E}+00$ & $1.79 \mathrm{E}+00$ & $2.24 \mathrm{E}+00$ & $2.79 E+00$ \\
\hline $2.56 \mathrm{E}-02$ & $4.40 \mathrm{E}+00$ & $6.10 \mathrm{E}-01$ & $4.12 \mathrm{E}-01$ & $1.34 \mathrm{E}+00$ & $1.79 \mathrm{E}+00$ & $2.24 \mathrm{E}+00$ & $2.79 \mathrm{E}+00$ \\
\hline $2.57 E-02$ & $4.40 \mathrm{E}+00$ & $6.11 \mathrm{E}-01$ & $4.13 E-01$ & $34 \mathrm{E}+00$ & $.79 \mathrm{E}+00$ & $2.24 \mathrm{E}+00$ & $2.79 \mathrm{E}+00$ \\
\hline $2.58 \mathrm{E}-02$ & $4.40 \mathrm{E}+00$ & $6.12 \mathrm{E}-01$ & $4.13 E-01$ & $34 \mathrm{E}+00$ & $1.79 \mathrm{E}+00$ & $2.24 \mathrm{E}+00$ & $2.79 E+00$ \\
\hline $2.59 \mathrm{E}-02$ & $4.40 \mathrm{E}+00$ & $6.12 \mathrm{E}-01$ & $4.14 \mathrm{E}-01$ & $1.34 \mathrm{E}+00$ & $1.79 \mathrm{E}+00$ & $2.24 \mathrm{E}+00$ & $2.78 \mathrm{E}+00$ \\
\hline $2.60 \mathrm{E}-02$ & $4.39 \mathrm{E}+00$ & $6.13 E-01$ & $4.15 E-01$ & $1.34 \mathrm{E}+00$ & $1.79 \mathrm{E}+00$ & $2.24 \mathrm{E}+00$ & $2.78 \mathrm{E}+00$ \\
\hline $2.61 \mathrm{E}-02$ & $4.39 \mathrm{E}+00$ & $6.14 \mathrm{E}-01$ & $4.16 \mathrm{E}-01$ & $1.34 \mathrm{E}+00$ & $1.79 \mathrm{E}+00$ & $2.24 \mathrm{E}+00$ & $2.78 \mathrm{E}+00$ \\
\hline $2.63 E-02$ & $4.39 \mathrm{E}+00$ & $6.15 \mathrm{E}-01$ & $4.17 \mathrm{E}-01$ & $1.34 \mathrm{E}+00$ & $1.79 \mathrm{E}+00$ & $2.24 \mathrm{E}+00$ & $2.78 \mathrm{E}+00$ \\
\hline $2.64 \mathrm{E}-02$ & $4.39 \mathrm{E}+00$ & $6.16 \mathrm{E}-01$ & $4.18 \mathrm{E}-01$ & $1.34 \mathrm{E}+00$ & $1.79 \mathrm{E}+00$ & $2.24 \mathrm{E}+00$ & $2.78 \mathrm{E}+00$ \\
\hline $2.65 E-02$ & $4.38 \mathrm{E}+00$ & $6.17 E-01$ & $4.19 \mathrm{E}-01$ & $1.35 \mathrm{E}+00$ & $1.80 \mathrm{E}+00$ & $2.24 \mathrm{E}+00$ & $2.77 \mathrm{E}+00$ \\
\hline $2.66 \mathrm{E}-02$ & $4.38 \mathrm{E}+00$ & $6.18 \mathrm{E}-01$ & $4.20 \mathrm{E}-01$ & $1.35 \mathrm{E}+00$ & $1.80 \mathrm{E}+00$ & $2.24 \mathrm{E}+00$ & $2.77 \mathrm{E}+00$ \\
\hline $2.67 E-02$ & $4.38 E+00$ & $6.19 \mathrm{E}-01$ & $4.21 \mathrm{E}-01$ & $1.35 \mathrm{E}+00$ & $1.80 \mathrm{E}+00$ & $2.24 \mathrm{E}+00$ & $2.77 \mathrm{E}+00$ \\
\hline $2.68 \mathrm{E}-02$ & $4.38 \mathrm{E}+00$ & $6.19 \mathrm{E}-01$ & $4.22 \mathrm{E}-01$ & $1.35 \mathrm{E}+00$ & $1.80 \mathrm{E}+00$ & $2.24 \mathrm{E}+00$ & $2.77 \mathrm{E}+00$ \\
\hline $2.70 \mathrm{E}-02$ & $4.37 E+00$ & $6.20 \mathrm{E}-01$ & $4.23 E-01$ & $1.35 \mathrm{E}+00$ & $1.80 \mathrm{E}+00$ & $2.24 \mathrm{E}+00$ & $2.77 \mathrm{E}+00$ \\
\hline $2.71 E-02$ & $4.37 E+00$ & $6.21 E-01$ & $4.24 \mathrm{E}-01$ & $1.35 \mathrm{E}+00$ & $1.80 \mathrm{E}+00$ & $2.24 \mathrm{E}+00$ & $2.77 \mathrm{E}+00$ \\
\hline $2.72 E-02$ & $4.37 E+00$ & $6.22 E-01$ & $4.25 E-01$ & $1.35 \mathrm{E}+00$ & $1.80 \mathrm{E}+00$ & $2.24 \mathrm{E}+00$ & $2.77 \mathrm{E}+00$ \\
\hline $2.73 E-02$ & $4.37 E+00$ & $6.23 E-01$ & $4.26 \mathrm{E}-01$ & $1.35 \mathrm{E}+00$ & $1.81 \mathrm{E}+00$ & $2.24 \mathrm{E}+00$ & $2.77 \mathrm{E}+00$ \\
\hline $2.74 \mathrm{E}-02$ & $4.36 \mathrm{E}+00$ & $6.24 \mathrm{E}-01$ & $4.27 E-01$ & $1.36 \mathrm{E}+00$ & $1.81 \mathrm{E}+00$ & $2.24 \mathrm{E}+00$ & $2.77 E+00$ \\
\hline $2.76 \mathrm{E}-02$ & $4.36 \mathrm{E}+00$ & $6.25 \mathrm{E}-01$ & $4.28 \mathrm{E}-01$ & $1.36 \mathrm{E}+00$ & $1.81 \mathrm{E}+00$ & $2.24 \mathrm{E}+00$ & $2.77 \mathrm{E}+00$ \\
\hline $2.77 E-02$ & $4.36 \mathrm{E}+00$ & $6.26 \mathrm{E}-01$ & $4.29 \mathrm{E}-01$ & $1.36 \mathrm{E}+00$ & $1.81 \mathrm{E}+00$ & $2.23 E+00$ & $2.77 E+00$ \\
\hline $2.78 \mathrm{E}-02$ & $4.36 \mathrm{E}+00$ & $6.27 E-01$ & $4.30 \mathrm{E}-01$ & $1.36 \mathrm{E}+00$ & $1.81 \mathrm{E}+00$ & $2.23 E+00$ & $2.77 \mathrm{E}+00$ \\
\hline $2.79 \mathrm{E}-02$ & $4.35 E+00$ & $6.27 E-01$ & $4.31 E-01$ & $1.36 \mathrm{E}+00$ & $1.81 \mathrm{E}+00$ & $2.24 \mathrm{E}+00$ & $2.77 \mathrm{E}+00$ \\
\hline $2.81 \mathrm{E}-02$ & $4.35 \mathrm{E}+00$ & $6.28 E-01$ & $4.32 E-01$ & $1.36 \mathrm{E}+00$ & $1.81 \mathrm{E}+00$ & $2.24 \mathrm{E}+00$ & $2.77 \mathrm{E}+00$ \\
\hline $2.82 \mathrm{E}-02$ & $4.35 \mathrm{E}+00$ & $6.29 \mathrm{E}-01$ & $4.32 E-01$ & $1.37 \mathrm{E}+00$ & $1.81 \mathrm{E}+00$ & $2.24 \mathrm{E}+00$ & $2.77 \mathrm{E}+00$ \\
\hline $2.83 E-02$ & $4.35 \mathrm{E}+00$ & $6.30 \mathrm{E}-01$ & $4.33 E-01$ & $1.37 \mathrm{E}+00$ & $1.81 \mathrm{E}+00$ & $2.24 \mathrm{E}+00$ & $2.77 \mathrm{E}+00$ \\
\hline $2.84 E-02$ & $4.34 E+00$ & $6.31 E-01$ & $4.34 E-01$ & $1.37 \mathrm{E}+00$ & $1.82 \mathrm{E}+00$ & $2.24 \mathrm{E}+00$ & $2.77 \mathrm{E}+00$ \\
\hline $2.85 E-02$ & $4.34 \mathrm{E}+00$ & $6.32 E-01$ & $4.35 E-01$ & $1.37 \mathrm{E}+00$ & $1.82 \mathrm{E}+00$ & $2.24 \mathrm{E}+00$ & $2.77 \mathrm{E}+00$ \\
\hline
\end{tabular}


RESRAD-OFFSITE, Version 2.5

$\mathrm{T}^{1 / 2}$ Limit $=180$ days

obabilistic Dose and Risk Report

Title : Offsite Resident Farmer

File : RF TC99 DOESG FWD-FV2all.ROF

Summary of dose at graphical times, reptition 2 (continued)

Time

Years

$7.78 \mathrm{E}+02$

$7.79 \mathrm{E}+02$

$7.79 \mathrm{E}+02$

$7.80 \mathrm{E}+02$

$7.80 \mathrm{E}+02$

$7.81 \mathrm{E}+02$

$7.81 \mathrm{E}+02$

$7.82 \mathrm{E}+02$

$7.82 \mathrm{E}+02$

$7.83 \mathrm{E}+02$

$7.83 \mathrm{E}+02$

$7.84 \mathrm{E}+02$

$7.84 \mathrm{E}+02$

$7.85 \mathrm{E}+02$

$7.85 \mathrm{E}+02$

$7.86 \mathrm{E}+02$

$7.86 \mathrm{E}+02$

$7.87 \mathrm{E}+02$

$7.88 \mathrm{E}+02$

$7.88 \mathrm{E}+02$

$7.89 \mathrm{E}+02$

$7.89 \mathrm{E}+02$

7. $90 \mathrm{E}+02$

$7.90 \mathrm{E}+02$

7. $91 \mathrm{E}+02$

$7.91 \mathrm{E}+02$

7. $92 \mathrm{E}+02$

$7.92 \mathrm{E}+02$

7. $93 \mathrm{E}+02$

7. $93 \mathrm{E}+02$

7. $94 \mathrm{E}+02$

$7.94 \mathrm{E}+02$

$7.95 \mathrm{E}+02$

7. $95 \mathrm{E}+02$

$7.96 \mathrm{E}+02$

7. $96 \mathrm{E}+02$

$7.97 \mathrm{E}+02$

7. $97 \mathrm{E}+02$

$7.98 \mathrm{E}+02$

$7.98 \mathrm{E}+02$

$7.99 \mathrm{E}+02$

$7.99 \mathrm{E}+02$

$8.00 \mathrm{E}+02$

$8.00 \mathrm{E}+02$

$8.01 \mathrm{E}+02$

$8.01 \mathrm{E}+02$
Dose statistics at graphical times, mrem/yr

\begin{tabular}{|c|c|c|c|c|c|c|c|}
\hline m & num & ea & 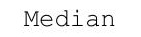 & & & & $\%$ \\
\hline 02 & $4.34 \mathrm{E}+00$ & $0.35 E$ & 1 & $.38 E+00$ & 00 & -00 & • 17 t +00 \\
\hline $88 E-02$ & $4.34 E+00$ & $6.34 \mathrm{E}-01$ & $37 E-01$ & 1. $38 \mathrm{E}+00$ & $82 E+00$ & $2.24 \mathrm{E}+00$ & $7 E+00$ \\
\hline $89 E-02$ & $33 E+00$ & $34 E-01$ & $38 E-01$ & $.38 E+00$ & $.82 \mathrm{E}+00$ & $.24 \mathrm{E}+00$ & $77 \mathrm{E}+00$ \\
\hline $90 F-02$ & $4.33 E+00$ & $35 F-01$ & $39 F-01$ & $.38 E+00$ & $1.82 \mathrm{E}+00$ & $2.24 \mathrm{E}+00$ & $2.77 \mathrm{E}+00$ \\
\hline $92 E-02$ & $4.33 E+00$ & $36 \mathrm{~F}-01$ & -6 & $.38 \mathrm{E}+00$ & $32 \mathrm{~F}+00$ & $E+00$ & $E+00$ \\
\hline 02 & 4. $32 E+00$ & & & & & & 00 \\
\hline $94 E-02$ & $4.32 E+00$ & & & & & & $E+00$ \\
\hline $95 E-02$ & $4.32 E+00$ & 1 & 01 & $39 E+00$ & $83 E+00$ & \pm+00 & $E+00$ \\
\hline $97 E-02$ & 4. $32 \mathrm{E}+00$ & $E-01$ & $E-01$ & $39 \mathrm{E}+00$ & $83 E+00$ & $E+00$ & $7 E+00$ \\
\hline $98 E-02$ & $.31 E+00$ & ק & 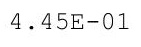 & L. $39 E+00$ & קבר0 & $.25 E+00$ & $77 \mathrm{E}+00$ \\
\hline 02 & $\mathrm{E}+00$ & & & & & -00 & $\mathrm{E}+00$ \\
\hline $.00 \mathrm{E}-02$ & $4.31 E+00$ & p & & & 0 & 0 & +00 \\
\hline $02 E-02$ & $4.30 E+00$ & - & & & & $2.25 E+00$ & $2.77 \mathrm{E}+00$ \\
\hline-02 & $4.30 \mathrm{E}+00$ & $6.44 \mathrm{E}-01$ & $4.48 \mathrm{E}-01$ & 1. $40 \mathrm{E}+00$ & & $2.25 E+00$ & $2.77 \mathrm{E}+00$ \\
\hline-02 & $\Xi+00$ & $=0$ & $F-0$ & 0 & 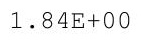 & $E+00$ & $6 E+00$ \\
\hline 2 & 00 & $6.46 \mathrm{E}-01$ & $4.50 E-01$ & $\cdot$ & 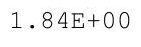 & 0 & 00 \\
\hline 2 & 00 & & & & & 0 & 00 \\
\hline 2 & $4.29 E+00$ & $6 \quad 475-01$ & $4.51 E-01$ & & & $2.25 E+00$ & 0 \\
\hline $.09 E-02$ & $4.29 \mathrm{E}+00$ & 涫 & $2 F-01$ & $1+1=0$ & 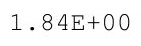 & $\mathrm{F}+00$ & $6 \mathrm{E}+00$ \\
\hline$E-02$ & $4.28 \mathrm{E}+00$ & $.49 E-01$ & $.53 E-01$ & 1. $41 \mathrm{E}+00$ & $1.85 \mathrm{E}+$ & $2.25 \mathrm{E}+00$ & $2.75 \mathrm{E}+00$ \\
\hline 02 & $E+00$ & & & & & +00 & $5 \mathrm{E}+00$ \\
\hline 2 & & & & & & & \\
\hline 02 & $4.28 \mathrm{E}+00$ & & & $1.41 \mathrm{E}$ & .85 & & \\
\hline-02 & $4.27 E+00$ & $6.53 \mathrm{E}-01$ & $4.57 E-01$ & エ・IL & 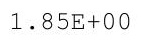 & 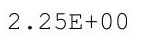 & 00 \\
\hline 2 & $4.27 \mathrm{E}+00$ & $6.53 \mathrm{E}-01$ & $\perp$ & 1. $42 \mathrm{E}+$ & $1.85 \mathrm{E}+$ & $2.25 \mathrm{E}+$ & $74 \mathrm{E}+00$ \\
\hline$E-02$ & $4.27 E+00$ & 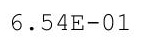 & $58 \mathrm{~F}-01$ & 1. $42 \mathrm{E}+00$ & $1.85 \mathrm{E}+$ & $2.24 \mathrm{E}+00$ & $74 \mathrm{E}+00$ \\
\hline-02 & $4.26 \mathrm{E}+00$ & 5 & & 1. $42 \mathrm{E}+00$ & & $.24 E+00$ & $.74 \mathrm{E}+00$ \\
\hline 02 & & & & & & & \\
\hline 02 & $4.26 \mathrm{E}+00$ & 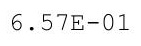 & & $1.42 \mathrm{E}$ & (- & & \\
\hline $24 E-02$ & $4.26 \mathrm{E}+00$ & . & . & $1.43 \mathrm{E}+00$ & $1.86 \mathrm{E}+00$ & $2.24 \mathrm{E}+00$ & $2.73 E+00$ \\
\hline $5 E-02$ & $4.25 E+00$ & . & 1.00 & 1. $43 \mathrm{E}+00$ & $1.86 \mathrm{E}+00$ & $2.24 \mathrm{E}+00$ & $2.73 E+00$ \\
\hline 2 & $4.25 \mathrm{E}+$ & 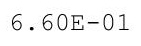 & $4.63 E-01$ & 1. $43 \mathrm{E}+$ & & & $.73 E+$ \\
\hline $.28 \mathrm{E}-02$ & & & & & & & 0 \\
\hline 2 & $4.24 \mathrm{E}+00$ & & 1 & & & & \\
\hline$E-02$ & $4.24 E+00$ & 6 & & 1 . & & & 00 \\
\hline $32 E-02$ & $4.24 \mathrm{E}+00$ & $6.63 E-U 1$ & $4.67 \mathrm{E}-01$ & $1.44 \mathrm{E}+00$ & 土.OT & $2.24 \mathrm{E}+00$ & $2.72 \mathrm{E}+00$ \\
\hline $33 E-02$ & $4.24 \mathrm{E}+00$ & $0.04 \mathrm{~L}$ & & $1.44 \mathrm{E}+0 \mathrm{U}$ & 土.OTए & & $2.72 \mathrm{E}+00$ \\
\hline 02 & $4.23 E+00$ & . & & $1.44 \mathrm{E}+00$ & & & $2.72 \mathrm{E}+00$ \\
\hline 2 & 1.25 & $6.65 \mathrm{E}-01$ & 1. & 1. $44 \mathrm{E}+$ & $1.87 \mathrm{E}+$ & $2.25 E+00$ & $2.72 E+00$ \\
\hline 2 & & & 1 & $1.44 \mathrm{E}+00$ & 1 & & $2.72 \mathrm{E}+00$ \\
\hline-02 & $4.22 \mathrm{E}+00$ & $6.67 \mathrm{E}-01$ & $4.71 \mathrm{E}-01$ & 1. $44 \mathrm{E}+00$ & $1.87 \mathrm{E}$ & $2.25 \mathrm{E}+00$ & $2.72 \mathrm{E}+00$ \\
\hline$E-02$ & $4.22 \mathrm{E}+00$ & 6. & 4.7 & $1.45 \mathrm{E}+00$ & $1.87 \mathrm{E}+$ & 2.2 & $2.71 \mathrm{E}+00$ \\
\hline & $4.22 \mathrm{E}+00$ & & & & & & \\
\hline$E-02$ & $4.21 \mathrm{E}+00$ & 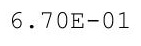 & 10 & $1.45 E+U 0$ & $1.87 \mathrm{E}+00$ & $2.25 E+00$ & $2.71 E+00$ \\
\hline & $4.21 E+00$ & & & $1.45 \mathrm{E}+00$ & $1.87 \mathrm{E}+00$ & $2.25 E+00$ & $2.71 \mathrm{E}+00$ \\
\hline 02 & $4.21 E+00$ & $E-01$ & $6 \mathrm{E}-01$ & $.45 \mathrm{E}+00$ & $1.87 \mathrm{E}+00$ & $2.25 \mathrm{E}+00$ & $2.71 E+00$ \\
\hline
\end{tabular}


RESRAD-OFFSITE, Version 2.5

$\mathrm{T}^{1 / 2}$ Limit $=180$ days

obabilistic Dose and Risk Report

Title : Offsite Resident Farmer

File : RF TC99 DOESG FWD-FV2all.ROF

Summary of dose at graphical times, reptition 2 (continued)

Time

Years

$8.02 \mathrm{E}+02$

$8.02 \mathrm{E}+02$

$8.03 \mathrm{E}+02$

$8.03 \mathrm{E}+02$

$8.04 \mathrm{E}+02$

$8.04 \mathrm{E}+02$

$8.05 \mathrm{E}+02$

$8.05 \mathrm{E}+02$

$8.06 \mathrm{E}+02$

$8.06 \mathrm{E}+02$

$8.07 \mathrm{E}+02$

$8.07 \mathrm{E}+02$

$8.08 \mathrm{E}+02$

8.09E+02

8. $09 \mathrm{E}+02$

$8.10 \mathrm{E}+02$

$8.10 \mathrm{E}+02$

$8.11 \mathrm{E}+02$

$8.11 \mathrm{E}+02$

$8.12 \mathrm{E}+02$

8. $12 \mathrm{E}+02$

$8.13 \mathrm{E}+02$

$8.13 \mathrm{E}+02$

$8.14 \mathrm{E}+02$

$8.14 \mathrm{E}+02$

$8.15 \mathrm{E}+02$

$8.15 \mathrm{E}+02$

$8.16 \mathrm{E}+02$

$8.16 \mathrm{E}+02$

$8.17 \mathrm{E}+02$

$8.17 \mathrm{E}+02$

$8.18 \mathrm{E}+02$

$8.18 \mathrm{E}+02$

$8.19 \mathrm{E}+02$

$8.19 \mathrm{E}+02$

$8.20 \mathrm{E}+02$

$8.20 \mathrm{E}+02$

$8.21 E+02$

$8.21 \mathrm{E}+02$

$8.22 \mathrm{E}+02$

$8.22 \mathrm{E}+02$

8. $23 \mathrm{E}+02$

$8.23 \mathrm{E}+02$

$8.24 \mathrm{E}+02$

$8.24 \mathrm{E}+02$

$8.25 \mathrm{E}+02$
Dose statistics at graphical times, mrem/yr

\begin{tabular}{|c|c|c|c|c|c|c|c|}
\hline m & aximum & lea & 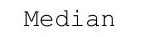 & & & & \\
\hline 02 & $4.21 E+00$ & $6.72 E-01$ & $4.77 \mathrm{E}-01$ & $.45 E+00$ & $87 \mathrm{E}+00$ & -00 & • TIE+U \\
\hline $48 E-02$ & $4.20 E+00$ & $6.73 E-01$ & $4.78 \mathrm{E}-01$ & 1. $45 \mathrm{E}+00$ & $88 \mathrm{E}+00$ & $2.26 \mathrm{E}+00$ & $71 E+00$ \\
\hline-02 & $20 E+00$ & $74 \mathrm{E}-01$ & $79 E-01$ & $.45 E+00$ & $.88 E+00$ & $2.26 \mathrm{E}+00$ & $2.71 E+00$ \\
\hline-02 & $4.20 E+00$ & $75 \mathrm{~F}-01$ & $80 \mathrm{E}-01$ & $.45 E+00$ & $187 \mathrm{~F}+00$ & $.26 \mathrm{E}+00$ & $2.71 \mathrm{E}+00$ \\
\hline$E-02$ & $4.19 \mathrm{E}+00$ & $6 \mathrm{E}-01$ & -01 & 0 & 0 & +00 & +00 \\
\hline 02 & $4.19 \mathrm{E}+00$ & & & & & & +00 \\
\hline $.55 E-02$ & $4.19 \mathrm{E}+00$ & 1 & & & & +00 & $71 \mathrm{E}+00$ \\
\hline $56 \mathrm{E}-02$ & $4.18 \mathrm{E}+00$ & 01 & -01 & $1.46 \mathrm{E}+00$ & $88 \mathrm{E}+00$ & +00 & $71 \mathrm{E}+00$ \\
\hline $57 E-02$ & $4.18 \mathrm{E}+00$ & $6.79 E-01$ & $E-01$ & $1.46 \mathrm{E}+00$ & $88 E+00$ & $E+00$ & $1 \mathrm{E}+00$ \\
\hline$E-02$ & $18 E+00$ & $80 E-01$ & (5) & $.46 \mathrm{E}+00$ & 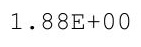 & $.27 E+00$ & $71 E+00$ \\
\hline 02 & $17 E+00$ & $.81 E-01$ & & & & 0 & $E+00$ \\
\hline $62 \mathrm{E}-02$ & $4.17 \mathrm{E}+00$ & $6.82 \mathrm{E}$ & 4 & ( & & -00 & +00 \\
\hline $63 E-02$ & $4.17 E+00$ & $6.82 \mathrm{E}-01$ & $4.89 E-01$ & $1.46 \mathrm{E}+00$ & & $2.27 E+00$ & $2.72 \mathrm{E}+00$ \\
\hline $64 \mathrm{E}-02$ & $4.16 \mathrm{E}+00$ & $6.83 E-01$ & $4.90 \mathrm{E}-01$ & $1.46 \mathrm{E}+00$ & $1.88 \mathrm{E}+00$ & $2.28 \mathrm{E}+00$ & $2.72 \mathrm{E}+00$ \\
\hline$E-02$ & $16 \mathrm{E}+00$ & $4 \mathrm{E}-01$ & $\mathrm{~F}-0-0+2-2$ & $605+$ & & $E+00$ & $72 \mathrm{E}+00$ \\
\hline 2 & 0 & & & & 0 & 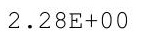 & 00 \\
\hline 2 & & $\perp$ & & (1) & & 0 & 0 \\
\hline 2 & $4.15 \mathrm{E}+00$ & $6.87 \mathrm{E}-01$ & $4.94 \mathrm{E}-01$ & 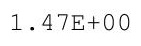 & & 0 & 0 \\
\hline$E-02$ & $4.15 E+00$ & $6875-01$ & $5 E-01$ & $17=0$ & 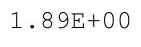 & $E+00$ & $2 \mathrm{E}+00$ \\
\hline $3 E-02$ & $4.15 E+00$ & $.88 E-01$ & $4.95 \mathrm{E}-01$ & $1.47 \mathrm{E}+00$ & $1.89 \mathrm{E}+$ & $2.29 \mathrm{E}+00$ & $2.72 \mathrm{E}+00$ \\
\hline-02 & $4.14 \mathrm{E}+00$ & & & 0 & & $.29 E+00$ & $72 \mathrm{E}+00$ \\
\hline 2 & & & & & & & \\
\hline 2 & & \pm & & 1. $47 \mathrm{E}+$ & & & \\
\hline 2 & $.13 \mathrm{E}+00$ & 1 & & $\perp$ & (2) & 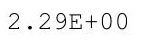 & \\
\hline$E-02$ & $4.13 E+00$ & $6.92 \mathrm{E}-01$ & $5.00 \mathrm{E}-01$ & $1.48 \mathrm{E}+00$ & $1.89 \mathrm{E}+$ & $2.29 \mathrm{E}+00$ & $73 E+00$ \\
\hline$E-02$ & $4.13 E+00$ & $=93 \mathrm{~F}-01$ & $.01 E-01$ & 1. $48 \mathrm{E}+00$ & $1.89 \mathrm{E}+00$ & $2.29 \mathrm{E}+00$ & $.73 E+00$ \\
\hline$E-02$ & $4.12 \mathrm{E}+00$ & $94 \mathrm{~F}-01$ & & $1.48 \mathrm{E}+00$ & & $2.29 \mathrm{E}+00$ & $2.73 E+00$ \\
\hline 02 & & & & & & & \\
\hline & & & & 1. $48 \mathrm{E}+$ & & & \\
\hline $.87 E-02$ & $4.11 E+00$ & $0.70 \pm$ L & . U UL & $1.40 E+U 0$ & 土. • & $2.29 \mathrm{E}+00$ & $2.73 E+00$ \\
\hline $89 E-02$ & $4.11 \mathrm{E}+00$ & . & $.07 E-01$ & 1. $48 \mathrm{E}+00$ & 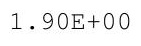 & $2.29 \mathrm{E}+00$ & $2.73 E+00$ \\
\hline 2 & $4.11 \mathrm{E}+00$ & 年 & . & 1. $49 \mathrm{E}+$ & & & \\
\hline 02 & $4.10 \mathrm{E}+00$ & & & & & & $2.72 \mathrm{E}+00$ \\
\hline 02 & & & & & & & \\
\hline-02 & & & & & & & \\
\hline 02 & $09 E+00$ & 01 & 01 & $1.49 \mathrm{E}+00$ & $1.91 \mathrm{E}+$ & $E+00$ & $2.72 \mathrm{E}+00$ \\
\hline $7 E-02$ & $4.09 \mathrm{E}+00$ & $.02 E-01$ & & 1. $49 \mathrm{E}+$ & & & $.72 \mathrm{E}+00$ \\
\hline & $4.09 \mathrm{E}+00$ & & & 1. $49 \mathrm{E}+00$ & & & $2.72 \mathrm{E}+00$ \\
\hline 2 & 1. & . & . & 1. $49 \mathrm{E}+00$ & 1.91E+ & $2.30 \mathrm{E}+00$ & $2.71 E+00$ \\
\hline & & 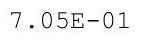 & 1 & $1.50 \mathrm{E}+00$ & & & $2.71 E+00$ \\
\hline $3 E-02$ & $4.08 E+00$ & $7.06 \mathrm{E}-01$ & $6 E-01$ & $1.50 \mathrm{E}+00$ & & $2.31 \mathrm{E}+00$ & $2.71 E+00$ \\
\hline$E-02$ & $4.07 E+00$ & 01 & & $1.50 \mathrm{E}+00$ & $1.91 \mathrm{E}+$ & $E+00$ & $2.71 \mathrm{E}+00$ \\
\hline & 0 & & & & & & $2.71 E+00$ \\
\hline$-2-02$ & $4.07 \mathrm{E}+00$ & 年 & $U E-01$ & $1.50 E+00$ & $1.9 \angle E+00$ & $2.30 \mathrm{E}+00$ & $2.71 E+00$ \\
\hline & $4.06 \mathrm{E}+00$ & & & $1.50 \mathrm{E}+00$ & $1.92 \mathrm{E}+00$ & $2.30 \mathrm{E}+00$ & $2.71 \mathrm{E}+00$ \\
\hline 02 & $4.06 \mathrm{E}+00$ & $E-01$ & $E-01$ & $.51 \mathrm{E}+00$ & 1. $92 \mathrm{E}+00$ & $2.30 \mathrm{E}+00$ & $2.71 \mathrm{E}+00$ \\
\hline
\end{tabular}


RESRAD-OFFSITE, Version 2.5

$\mathrm{T}^{1 / 2}$ Limit $=180$ days

obabilistic Dose and Risk Report

Title : Offsite Resident Farmer

File : RF TC99 DOESG FWD-FV2all.ROF

Summary of dose at graphical times, reptition 2 (continued)

Time

Years

$8.25 \mathrm{E}+02$

$8.26 \mathrm{E}+02$

$8.26 \mathrm{E}+02$

$8.27 \mathrm{E}+02$

$8.27 \mathrm{E}+02$

$8.28 \mathrm{E}+02$

$8.29 \mathrm{E}+02$

$8.29 \mathrm{E}+02$

8. $30 \mathrm{E}+02$

$8.30 \mathrm{E}+02$

$8.31 \mathrm{E}+02$

$8.31 \mathrm{E}+02$

$8.32 \mathrm{E}+02$

8. $32 \mathrm{E}+02$

$8.33 \mathrm{E}+02$

8. $33 \mathrm{E}+02$

$8.34 \mathrm{E}+02$

8. $34 \mathrm{E}+02$

$8.35 \mathrm{E}+02$

$8.35 \mathrm{E}+02$

$8.36 \mathrm{E}+02$

$8.36 \mathrm{E}+02$

$8.37 \mathrm{E}+02$

$8.37 \mathrm{E}+02$

$8.38 \mathrm{E}+02$

$8.38 \mathrm{E}+02$

$8.39 \mathrm{E}+02$

$8.39 \mathrm{E}+02$

$8.40 \mathrm{E}+02$

$8.40 \mathrm{E}+02$

$8.41 \mathrm{E}+02$

8. $41 \mathrm{E}+02$

$8.42 \mathrm{E}+02$

$8.42 \mathrm{E}+02$

$8.43 \mathrm{E}+02$

$8.43 E+02$

$8.44 \mathrm{E}+02$

$8.44 \mathrm{E}+02$

$8.45 \mathrm{E}+02$

$8.45 \mathrm{E}+02$

$8.46 \mathrm{E}+02$

$8.46 \mathrm{E}+02$

$8.47 \mathrm{E}+02$

$8.47 \mathrm{E}+02$

$8.48 \mathrm{E}+02$

8. $49 \mathrm{E}+02$
Dose statistics at graphical times, mrem/yr

\begin{tabular}{|c|c|c|c|c|c|c|c|}
\hline m & $\mathrm{m}$ & Mean & ledian & & & $\%$ & \\
\hline 02 & $4.06 \mathrm{E}+00$ & $7.10 \mathrm{E}-01$ & $5.23 E-01$ & $1.51 \mathrm{E}+00$ & 1. $92 \mathrm{E}+00$ & $2.30 \mathrm{E}+00$ & $2.70 \mathrm{E}+00$ \\
\hline $.14 \mathrm{E}-02$ & $4.05 E+00$ & $1 E-01$ & $5.24 \mathrm{E}-01$ & 0 & 0 & 0 & $0 \mathrm{E}+00$ \\
\hline$E-02$ & $4.05 \mathrm{E}+00$ & $.12 \mathrm{E}-01$ & $5 E-01$ & 1. $51 \mathrm{E}+00$ & 1. $92 \mathrm{E}+00$ & $2.30 \mathrm{E}+00$ & $0 \mathrm{E}+00$ \\
\hline $.17 \mathrm{E}-02$ & $4.05 E+00$ & $.13 E-01$ & $5.26 \mathrm{E}-01$ & $1.51 \mathrm{E}+00$ & 1. $92 \mathrm{E}+00$ & $2.30 \mathrm{E}+00$ & $2.70 \mathrm{E}+00$ \\
\hline $3 E-02$ & $4.04 \mathrm{E}+00$ & $4 E-01$ & $.27 E-01$ & $1.52 \mathrm{E}+00$ & 1. $92 \mathrm{E}+00$ & $2.30 \mathrm{E}+00$ & $2.70 \mathrm{E}+00$ \\
\hline 02 & & & & & & & +00 \\
\hline $21 E-02$ & & & & & & & +00 \\
\hline $23 E-02$ & & & & & & & +00 \\
\hline-02 & +00 & $E-01$ & $\perp$ & $52 \mathrm{E}+00$ & +00 & +00 & $\mathrm{E}+00$ \\
\hline$E-02$ & $4.03 E+00$ & $\perp$ & $\perp$ & $.52 \mathrm{E}+$ & $935+$ & $E+00$ & $70 \mathrm{E}+00$ \\
\hline-02 & $4.02 E+00$ & $7.19 \mathrm{E}-01$ & $5.31 E-01$ & $152 \mathrm{~F}+1$ & $23 F+$ & $\mathrm{E}+00$ & $0 E+00$ \\
\hline$E-02$ & 00 & & & 0 & 0 & 0 & +00 \\
\hline$F-02$ & $2 E+00$ & $7.20 \mathrm{E}-01$ & $5.33 E-01$ & 0 & & & +00 \\
\hline $.32 E-02$ & $4.01 \mathrm{E}+00$ & $7.21 \mathrm{E}-01$ & $5.34 \mathrm{E}-01$ & $1.53 \mathrm{E}+00$ & 1.93E+00 & $2.30 \mathrm{E}+00$ & $2.70 \mathrm{E}+00$ \\
\hline $33 E-02$ & $4.01 \mathrm{E}+00$ & $2 E-01$ & 1 & $53 E+00$ & 0 & $\mathrm{E}+00$ & $\mathrm{E}+00$ \\
\hline 2 & & & & & & & -00 \\
\hline $6 \mathrm{E}-02$ & & & & T & & & 00 \\
\hline 2 & & 7. $24 \mathrm{E}-01$ & & & & & 0 \\
\hline $39 E-02$ & $4.00 \mathrm{E}+00$ & $5 F-01$ & 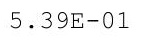 & $1.53 \mathrm{E}+00$ & & +00 & $E+00$ \\
\hline $41 \mathrm{E}-02$ & $3.99 \mathrm{E}+00$ & $.26 \mathrm{E}-01$ & $E-01$ & $1.53 \mathrm{E}+00$ & $1.94 \mathrm{E}+00$ & $2.30 \mathrm{E}+00$ & $2.70 \mathrm{E}+00$ \\
\hline $42 E-02$ & $.99 E+00$ & $27 E-01$ & -01 & 1. $53 \mathrm{E}+00$ & 0 & $.30 E+00$ & $70 \mathrm{E}+00$ \\
\hline 02 & & & & & & & $70 \mathrm{E}+00$ \\
\hline & & & & & & & \\
\hline $4 / E-02$ & $.98 E+00$ & $\perp$ & & 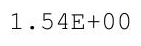 & & & 00 \\
\hline 2 & $.98 \mathrm{E}$ & 1 & $\perp$ & th & 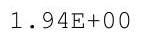 & 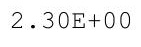 & 00 \\
\hline $50 \mathrm{~F}-02$ & $.97 E+00$ & $30=-01$ & $7 \mathrm{~F}-01$ & 1. $54 \mathrm{E}+00$ & 1 & $30 E+00$ & $70 \mathrm{E}+00$ \\
\hline$F-02$ & $3.97 \mathrm{E}+00$ & $31 \mathrm{~F}=01$ & $3 F-01$ & & 1 & $30 E+00$ & $.70 E+00$ \\
\hline 2 & & & & & & & \\
\hline$E-02$ & $3.96 \mathrm{E}+00$ & & & 0 & & & \\
\hline $56 \mathrm{E}-02$ & $3.96 \mathrm{E}+00$ & $1.34-4$ & $5.51 \mathrm{E}-01$ & $1.55 \mathrm{E}+00$ & $1.95 \mathrm{E}+00$ & $2.30 \mathrm{E}+00$ & $2.70 \mathrm{E}+00$ \\
\hline $.00 \mathrm{~L}-\mathrm{Lz}$ & $3.96 \mathrm{E}+00$ & $1.345-01$ & $3.3 \angle 5-U \perp$ & 1. $55 \mathrm{E}+00$ & 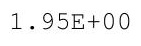 & $2.30 \mathrm{LTO}$ & $2.70 \mathrm{E}+00$ \\
\hline 年 & . & 年 & 然 & 1. $55 \mathrm{E}+00$ & 1.95E+ & & $.70 \mathrm{E}+00$ \\
\hline$\nabla_{0}$ & $3.95 \mathrm{E}+00$ & $7365-01$ & $E-01$ & $1.55 \mathrm{E}+00$ & & & $2.70 \mathrm{E}+00$ \\
\hline 6 & & & & & & & \\
\hline & & & & & & & $0 E+00$ \\
\hline $66 \mathrm{E}-02$ & $3.94 \mathrm{E}+00$ & $7.38 E-01$ & $.56 \mathrm{E}-01$ & $1.56 \mathrm{E}+00$ & $1.9 J E T$ & $2.30 \mathrm{E}+00$ & $2.70 \mathrm{E}+00$ \\
\hline $.018-02$ & $3.93 E+00$ & 1.0 & & 土. & t. & & $2.70 \mathrm{E}+00$ \\
\hline • & $3.93 \mathrm{E}+00$ & & & 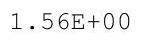 & 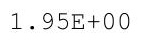 & & $2.70 \mathrm{E}+00$ \\
\hline 2 & . & $\bullet$ & & $1.56 \mathrm{E}+$ & $1.95 \mathrm{E}+$ & & $2.70 \mathrm{E}+00$ \\
\hline & & & & $56 \mathrm{E}+00$ & 1.95E+ & & \\
\hline 2 & $3.92 \mathrm{E}+00$ & 1 & 1 & $1.56 \mathrm{E}+00$ & $1.95 \mathrm{E}+00$ & $2.30 \mathrm{E}+00$ & $0 E+00$ \\
\hline $.75 E-02$ & $3.92 \mathrm{E}+00$ & $3 E-01$ & 01 & $1.56 \mathrm{E}+00$ & 1.95E+ & 00 & 00 \\
\hline & & & & & & & \\
\hline & $3.91 \mathrm{E}+00$ & 1 & & $1.5 / E+00$ & $1.95 E+00$ & & $2.70 \mathrm{E}+00$ \\
\hline एᄂ口 & & & & $1.57 \mathrm{E}+00$ & $1.95 \mathrm{E}+00$ & & $2.70 \mathrm{E}+$ \\
\hline $82 E-02$ & $.90 E+00$ & $5 E-01$ & $5 E-01$ & $1.57 \mathrm{E}+00$ & $1.95 \mathrm{E}+00$ & $2.30 \mathrm{E}+00$ & $.69 E+00$ \\
\hline
\end{tabular}


RESRAD-OFFSITE, Version 2.5

$\mathrm{T}^{1 / 2}$ Limit $=180$ days

obabilistic Dose and Risk Report

Title : Offsite Resident Farmer

File : RF TC99 DOESG FWD-FV2all.ROF

Summary of dose at graphical times, reptition 2 (continued)

Time

Years

$8.49 \mathrm{E}+02$

$8.50 \mathrm{E}+02$

$8.50 \mathrm{E}+02$

$8.51 \mathrm{E}+02$

8. $51 \mathrm{E}+02$

8. $52 \mathrm{E}+02$

8. $52 \mathrm{E}+02$

$8.53 \mathrm{E}+02$

$8.53 \mathrm{E}+02$

8. $54 \mathrm{E}+02$

$8.54 \mathrm{E}+02$

$8.55 \mathrm{E}+02$

$8.55 \mathrm{E}+02$

$8.56 \mathrm{E}+02$

$8.56 \mathrm{E}+02$

$8.57 \mathrm{E}+02$

$8.57 \mathrm{E}+02$

$8.58 \mathrm{E}+02$

8. $58 \mathrm{E}+02$

$8.59 \mathrm{E}+02$

$8.59 \mathrm{E}+02$

$8.60 \mathrm{E}+02$

$8.60 \mathrm{E}+02$

$8.61 E+02$

8. $61 \mathrm{E}+02$

8. $62 \mathrm{E}+02$

8. $62 \mathrm{E}+02$

$8.63 \mathrm{E}+02$

8. $63 \mathrm{E}+02$

8. $64 \mathrm{E}+02$

$8.64 \mathrm{E}+02$

8. $65 \mathrm{E}+02$

$8.65 \mathrm{E}+02$

$8.66 \mathrm{E}+02$

$8.66 \mathrm{E}+02$

$8.67 \mathrm{E}+02$

$8.67 \mathrm{E}+02$

$8.68 \mathrm{E}+02$

8. $69 \mathrm{E}+02$

8. $69 \mathrm{E}+02$

$8.70 \mathrm{E}+02$

$8.70 \mathrm{E}+02$

$8.71 \mathrm{E}+02$

8. $71 \mathrm{E}+02$

$8.72 \mathrm{E}+02$

$8.72 \mathrm{E}+02$
Dose statistics at graphical times, mrem/yr

\begin{tabular}{|c|c|c|c|c|c|c|c|}
\hline Iinimum & Maximum & Mean & Median & $90 \%$ & $95 \%$ & $97.5 \%$ & $9 \%$ \\
\hline 02 & $0 \mathrm{E}+00$ & $7 E-01$ & $66 E-01$ & $57 E+00$ & $95 E+00$ & $2.30 \mathrm{E}+$ & + \\
\hline-02 & $90 \mathrm{E}+00$ & $8 E-$ & 01 & $1.57 \mathrm{E}+00$ & $95 \mathrm{E}+00$ & $\mathrm{E}+00$ & $9 \mathrm{E}+00$ \\
\hline $6 \mathrm{E}-02$ & $E+00$ & $8 E-01$ & $8 E-01$ & 0 & 0 & 0 & $9 \mathrm{E}+00$ \\
\hline $8 E-02$ & $9 \mathrm{E}+00$ & $9 \mathrm{E}-01$ & $9 E-01$ & 0 & & 0 & $9 \mathrm{E}+00$ \\
\hline $\mathrm{OE}-02$ & $3.89 \mathrm{E}+00$ & & & & & & $69 \mathrm{E}+00$ \\
\hline-02 & 0 & & & & 0 & 00 & $9 \mathrm{E}+00$ \\
\hline $93 E-02$ & $3.88 \mathrm{E}+00$ & $2 E-01$ & $72 E-01$ & $1.57 \mathrm{E}+00$ & $95 \mathrm{E}+$ & +00 & $69 \mathrm{E}+00$ \\
\hline $.95 E-02$ & $3.87 E+00$ & 由 由 & $5.73 E-01$ & $1.58 \mathrm{E}+00$ & $1.95 \mathrm{E}+00$ & +00 & $2.69 E+00$ \\
\hline$E-02$ & +00 & 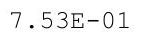 & 01 & $1.58 \mathrm{E}$ & 0 & 00 & +00 \\
\hline $8 \mathrm{E}-02$ & $7 \mathrm{E}+00$ & $4 E-01$ & $5 \mathrm{E}$ & $8 \mathrm{E}+00$ & $5 \mathrm{E}+$ & 00 & $9 \mathrm{E}+00$ \\
\hline$E-02$ & & 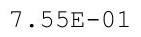 & & & & & $3 E+00$ \\
\hline-02 & +00 & r & 1 & 0 & & & $3 E+00$ \\
\hline $.03 E-02$ & $3.86 \mathrm{E}+00$ & $\begin{array}{llll} & 0\end{array}$ & $8 E-01$ & $1.58 E+00$ & $1.90 \mathrm{C}$ & & $68 E+00$ \\
\hline $.04 E-02$ & $3.85 \mathrm{E}+00$ & ( & $5.79 \mathrm{E}-01$ & I.JOLTU & $\perp$. & 0 & $\mathrm{E}+00$ \\
\hline $.06 E-02$ & $3.85 E+00$ & $\begin{array}{lll}-1 & -1\end{array}$ & . & 土. & 1. & 00 & 00 \\
\hline $.08 \mathrm{E}-02$ & $3.85 \mathrm{E}+00$ & $7.58 \mathrm{E}-\mathrm{C}$ & - & $1.58 \mathrm{E}+00$ & & 2 . & $8 \mathrm{E}+00$ \\
\hline $.09 E-02$ & $3.84 \mathrm{E}+00$ & & $5.82 \mathrm{E}-01$ & & 1. $95 \mathrm{E}+00$ & $E+00$ & $2.68 \mathrm{E}+00$ \\
\hline$E-02$ & $E+00$ & $E-01$ & 1 & 1 & 0 & 0 & $3 E+00$ \\
\hline$E-02$ & $3 E+00$ & $\perp$ & 1 & $E+00$ & 0 & 00 & $\mathrm{E}+00$ \\
\hline $4 \mathrm{E}-02$ & $3.83 E+00$ & $7.62 \mathrm{E}-01$ & 01 & 1.59 & 1 & & $\Xi+00$ \\
\hline $5 E-02$ & $3.83 E+00$ & 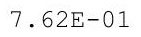 & & $1.59 \mathrm{E}$ & & & 00 \\
\hline $3 E-02$ & $3.82 \mathrm{E}+00$ & S & 1 & 1.03 & 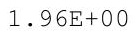 & 0 & +00 \\
\hline $.19 \mathrm{E}-02$ & $3.82 \mathrm{E}+00$ & $7.64 \mathrm{E}-01$ & $.87 \mathrm{E}-01$ & $1.59 \mathrm{E}+00$ & $1.96 \mathrm{E}+00$ & $2.31 \mathrm{E}+00$ & $2.67 \mathrm{E}+00$ \\
\hline $.21 E-02$ & $3.82 \mathrm{E}+00$ & + & 1 & $1.59 \mathrm{E}+$ & $1.96 \mathrm{E}+$ & $2.31 \mathrm{E}+$ & $67 E+00$ \\
\hline$E-02$ & $E+00$ & 1 & 1 & & & & $67 \mathrm{E}+00$ \\
\hline$E-02$ & $1 E+00$ & 1 & 1 & $1.59 \mathrm{E}$ & 0 & & -00 \\
\hline $6 \mathrm{E}-02$ & $3.81 E+00$ & $1.07 \mathrm{~L}-\mathrm{D}$ & & $1.59 \mathrm{E}$ & 皮 & & $E+00$ \\
\hline $28 \mathrm{E}-02$ & $3.80 \mathrm{E}+00$ & $7.68 \mathrm{E}-01$ & $5.91 \mathrm{E}-01$ & $1.59 \mathrm{E}+00$ & $1.96 \mathrm{E}+00$ & $2.31 E+00$ & $.67 \mathrm{E}+00$ \\
\hline $.29 \mathrm{E}-02$ & .0 & $1.00 \mathrm{~L}-\mathrm{C}$ & $5.92 \mathrm{E}-01$ & $1.59 \mathrm{E}+00$ & 土. & +00 & $2.67 E+00$ \\
\hline 2 & $3.80 \mathrm{E}+00$ & & 1 & $1.59 \mathrm{E}$ & 1 & $E+00$ & -00 \\
\hline 02 & $E+00$ & 1 & 1 & $16 \cap 5+$ & 0 & $E+00$ & $\mathrm{E}+00$ \\
\hline$E-02$ & $E+00$ & 1 & 1 & 1 & 1 & & 00 \\
\hline $.36 \mathrm{E}-02$ & $3.78 \mathrm{E}+00$ & $7.71 \mathrm{E}-01$ & $5.96 \mathrm{E}-01$ & $1.60 \mathrm{E}+00$ & $1.96 \mathrm{E}+$ & $2.31 \mathrm{E}+00$ & $2.67 \mathrm{E}+00$ \\
\hline $.38 E-02$ & $3.78 \mathrm{E}+00$ & $7.72 \mathrm{E}-01$ & $5.96 \mathrm{E}-01$ & $1.60 \mathrm{E}+00$ & $1.97 \mathrm{E}+00$ & $2.31 \mathrm{E}+00$ & $2.67 \mathrm{E}+00$ \\
\hline $.40 \mathrm{E}-02$ & $3.10 \mathrm{E}+00$ & . & & $1.00 \mathrm{E}$ & & & $67 \mathrm{E}+00$ \\
\hline D & & & & & & & $7 \mathrm{E}+00$ \\
\hline 2 & 0 & 7 & 1 & 0 & 0 & $1 E+00$ & $7 E+00$ \\
\hline-02 & $\mathrm{E}+00$ & $F^{2}$ & 1 & $1.60 \mathrm{E}$ & 1 . & 0 & 00 \\
\hline $.47 \mathrm{E}-02$ & $3.76 \mathrm{E}+00$ & $6 E-01$ & $1 E-01$ & $1.60 \mathrm{E}$ & 1.97 & & 00 \\
\hline $3 E-02$ & $3.76 \mathrm{E}+00$ & 1 & & 1. $60 \mathrm{E}+$ & 1.9/E+ & & $2.67 \mathrm{E}+00$ \\
\hline 02 & & 1 & & 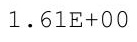 & 年 & & $2.66 \mathrm{E}+00$ \\
\hline 02 & $3.75 E+00$ & 1. 100 & 1 & 1. $61 \mathrm{E}+$ & $1.97 \mathrm{E}+$ & $2.31 E+00$ & $2.66 \mathrm{E}+00$ \\
\hline-02 & 00 & $\perp$ & 1 & 00 & 1 & 00 & 0 \\
\hline$E-02$ & $E+00$ & 01 & 6 & 1. & 1 . & 2 . & 2 . \\
\hline-02 & $E+00$ & $\mathrm{E}-01$ & $\Xi-01$ & $1.61 \mathrm{E}+00$ & 1.9 & 00 & $2.66 \mathrm{E}+00$ \\
\hline $.59 E-02$ & $74 \mathrm{E}+00$ & $7.81 \mathrm{E}-01$ & $07 E-01$ & $1.61 \mathrm{E}+00$ & $1.98 \mathrm{E}+00$ & $2.31 \mathrm{E}+00$ & $2.66 \mathrm{E}+00$ \\
\hline
\end{tabular}


RESRAD-OFFSITE, Version 2.5

$\mathrm{T}^{1 / 2}$ Limit $=180$ days

obabilistic Dose and Risk Report

Title : Offsite Resident Farmer

File : RF TC99 DOESG FWD-FV2all.ROF

Summary of dose at graphical times, reptition 2 (continued)

Time

Years

$8.73 E+02$

$8.73 \mathrm{E}+02$

$8.74 \mathrm{E}+02$

$8.74 \mathrm{E}+02$

$8.75 \mathrm{E}+02$

$8.75 \mathrm{E}+02$

$8.76 \mathrm{E}+02$

$8.76 \mathrm{E}+02$

$8.77 \mathrm{E}+02$

$8.77 \mathrm{E}+02$

$8.78 \mathrm{E}+02$

$8.78 \mathrm{E}+02$

$8.79 \mathrm{E}+02$

$8.79 \mathrm{E}+02$

$8.80 \mathrm{E}+02$

$8.80 \mathrm{E}+02$

$8.81 \mathrm{E}+02$

$8.81 \mathrm{E}+02$

$8.82 \mathrm{E}+02$

$8.82 \mathrm{E}+02$

$8.83 \mathrm{E}+02$

$8.83 E+02$

$8.84 \mathrm{E}+02$

$8.84 \mathrm{E}+02$

$8.85 \mathrm{E}+02$

$8.85 \mathrm{E}+02$

$8.86 \mathrm{E}+02$

$8.86 \mathrm{E}+02$

$8.87 \mathrm{E}+02$

$8.87 \mathrm{E}+02$

$8.88 \mathrm{E}+02$

$8.89 \mathrm{E}+02$

$8.89 \mathrm{E}+02$

$8.90 \mathrm{E}+02$

$8.90 \mathrm{E}+02$

$8.91 \mathrm{E}+02$

$8.91 \mathrm{E}+02$

$8.92 \mathrm{E}+02$

8. $92 \mathrm{E}+02$

8. $93 \mathrm{E}+02$

$8.93 \mathrm{E}+02$

8. $94 \mathrm{E}+02$

8. $94 \mathrm{E}+02$

$8.95 \mathrm{E}+02$

$8.95 \mathrm{E}+02$

$8.96 \mathrm{E}+02$
Dose statistics at graphical times, mrem/yr

\begin{tabular}{|c|c|c|c|c|c|c|c|}
\hline$m$ & $\mathrm{~m}$ & Mean & ledian & & & $\%$ & $\%$ \\
\hline $60 \mathrm{E}-02$ & $3.73 \mathrm{E}+00$ & $7.82 \mathrm{E}-01$ & $6.08 \mathrm{E}-01$ & $1.61 \mathrm{E}+00$ & $1.98 \mathrm{E}+00$ & +00 & $2.00 E+00$ \\
\hline$E-02$ & $3 E+00$ & 01 & 01 & 0 & 00 & +00 & $5 E+00$ \\
\hline $64 \mathrm{E}-02$ & $3.73 \mathrm{E}+00$ & $.83 E-01$ & $6.10 \mathrm{E}-01$ & 1. $61 \mathrm{E}+00$ & $1.98 \mathrm{E}+00$ & $2.31 E+00$ & $2.66 \mathrm{E}+00$ \\
\hline $66 \mathrm{E}-02$ & $3.72 E+00$ & $.84 \mathrm{E}-01$ & $1 E-01$ & 1. $61 \mathrm{E}+00$ & 1. $98 \mathrm{E}+00$ & $2.31 E+00$ & $66 \mathrm{E}+00$ \\
\hline 02 & $2 E+00$ & $5 \mathrm{E}$ & 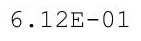 & $1.62 \mathrm{E}$ & 0 & 00 & $2.66 \mathrm{E}+00$ \\
\hline-02 & 00 & & & .6 & 0 & & +00 \\
\hline $.71 \mathrm{E}-02$ & & & & $.62 \mathrm{E}+00$ & & & $6 \mathrm{E}+00$ \\
\hline$E-02$ & 0 & & & & & & $E+00$ \\
\hline-02 & +00 & $F-0$ & $\perp$ & $62 \mathrm{E}+00$ & 00 & +00 & $66 E+00$ \\
\hline$E-02$ & $0 \mathrm{E}+00$ & $7.88 \mathrm{E}-01$ & $\perp$ & 1. $62 \mathrm{E}+$ & 0 & 0 & $66 \mathrm{E}+00$ \\
\hline$E-02$ & 00 & 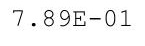 & $6.18 \mathrm{E}-01$ & $1625+$ & 0 & 0 & $6 E+00$ \\
\hline 2 & $3.69 \mathrm{E}+00$ & & & .62 & & & -00 \\
\hline$F-02$ & +00 & $7.90 \mathrm{E}-01$ & $6.20 \mathrm{E}-01$ & 0 & & & +00 \\
\hline $.83 E-02$ & $3.69 \mathrm{E}+00$ & $7.91 \mathrm{E}-01$ & $6.21 \mathrm{E}-01$ & $1.62 \mathrm{E}+00$ & $1.99 \mathrm{E}+00$ & $2.30 \mathrm{E}+00$ & $2.66 \mathrm{E}+00$ \\
\hline$E-02$ & $3.68 \mathrm{E}+00$ & $2 E-01$ & 1 & $1.63 \mathrm{E}+00$ & 00 & $E+00$ & $66 \mathrm{E}+00$ \\
\hline 2 & 0 & & & & & 0 & -00 \\
\hline $9 \mathrm{E}-02$ & 0 & & $6.23 E-01$ & .6 & & 0 & 00 \\
\hline 2 & $3675+12-1$ & & & 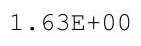 & & & 0 \\
\hline$F-0 ?$ & $.67 \mathrm{E}+00$ & $5 F_{-}$ & 5 & $1.63 \mathrm{E}+00$ & 原 & & $6 \mathrm{E}+00$ \\
\hline $94 \mathrm{E}-02$ & $3.66 \mathrm{E}+00$ & $6 E-0$ & $6.26 \mathrm{E}-01$ & $1.63 \mathrm{E}+00$ & 1. $99 \mathrm{E}+0$ & $2.30 \mathrm{E}+00$ & $2.66 \mathrm{E}+00$ \\
\hline $96 \mathrm{E}-02$ & $3.66 \mathrm{E}+00$ & $7.96 \mathrm{E}-01$ & $6.26 \mathrm{E}-01$ & $1.63 \mathrm{E}+00$ & & $30 \mathrm{E}+00$ & $.66 \mathrm{E}+00$ \\
\hline 02 & & & & & & & $66 E+00$ \\
\hline 2 & 3. $65 \mathrm{E}-$ & & & $1.64 \mathrm{E}$ & & & 00 \\
\hline$E-02$ & $3.65 \mathrm{E}+00$ & $7.98 \mathrm{E}-01$ & & $\perp \cdot 0$ I & 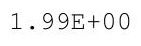 & & 00 \\
\hline 2 & 0 & 7. $99 \mathrm{E}-01$ & $\perp$ & 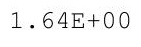 & 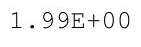 & 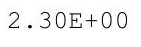 & 00 \\
\hline$F-02$ & $.64 E+00$ & (סחم & $630 \mathrm{~F}-01$ & 1. $64 \mathrm{E}+00$ & 1 & $.30 E+00$ & $.66 \mathrm{E}+00$ \\
\hline $07 E-02$ & $3.64 \mathrm{E}+00$ & مी & $31 \mathrm{~F}-01$ & $1.64 \mathrm{E}+00$ & בתחמ 1 & $2.30 \mathrm{E}+00$ & $2.66 \mathrm{E}+00$ \\
\hline 02 & & & & & & & \\
\hline 02 & $3.63 \mathrm{E}+00$ & & & $.64 \mathrm{E}+$ & & & \\
\hline$E-02$ & $3.63 E+00$ & $0.0 \mathrm{~L}$ & 01 & $1.64 \mathrm{E}+00$ & 土. & $2.30 \mathrm{E}+00$ & $2.65 E+00$ \\
\hline $75-2<$ & $3.62 \mathrm{E}+00$ & $.00 \mathrm{~L}$ & $0.35-21$ & $1.64 \mathrm{E}+00$ & I. & $\angle .30 \mathrm{LT} 0$ & $2.65 E+00$ \\
\hline 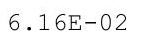 & 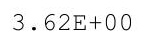 & 然 & 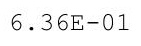 & 1. $64 \mathrm{E}+00$ & 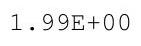 & & $2.65 \mathrm{E}+00$ \\
\hline$F_{-1}$ & $3.61 \mathrm{E}+00$ & F & $E-01$ & $1.64 \mathrm{E}+00$ & & & $2.65 E+00$ \\
\hline $.19 \mathrm{E}-02$ & & & & & & & \\
\hline 02 & & & 1 & $165 \mathrm{~F}+$ & & & \\
\hline 02 & $3.60 \mathrm{E}$ & 1 & 01 & $1.0 J E T$ & $1.99 \mathrm{E}$ & 00 & +00 \\
\hline$\pm-U<$ & $3.60 \mathrm{E}+00$ & & & 工. & & & $2.64 \mathrm{E}+00$ \\
\hline काष & & & & I.OJ上TU & & & \\
\hline $.29 E-02$ & $3.59 \mathrm{E}+$ & $8.09 \mathrm{E}-01$ & 1 & t. & $2.00 \mathrm{E}$ & & $2.64 \mathrm{E}+00$ \\
\hline & & & & $5 E+00$ & 2. & & \\
\hline 2 & $3.58 \mathrm{E}+00$ & 8 & 1 & 1. $65 \mathrm{E}+$ & $2.00 \mathrm{E}+$ & $2.29 \mathrm{E}+00$ & $2.64 \mathrm{E}+00$ \\
\hline $4 E-02$ & $3.58 \mathrm{E}+00$ & $8.11 E$ & 6 & $1.65 \mathrm{E}+00$ & & 00 & $E+00$ \\
\hline & & & & & & & $64 \mathrm{E}+00$ \\
\hline & $3.57 \mathrm{E}+00$ & & & $1.05 E+00$ & $2.00 \mathrm{E}+00$ & $2.29 \mathrm{E}+00$ & $2.64 \mathrm{E}+00$ \\
\hline & $3.57 \mathrm{E}+00$ & . & & $1.65 \mathrm{E}+00$ & $2.00 \mathrm{E}+00$ & $2.29 \mathrm{E}+00$ & $2.64 \mathrm{E}+00$ \\
\hline$E-02$ & $.57 E+00$ & $4 E-01$ & $47 E-01$ & $.65 E+00$ & $.00 \mathrm{E}+00$ & $2.29 \mathrm{E}+00$ & $.64 E+00$ \\
\hline
\end{tabular}


RESRAD-OFFSITE, Version 2.5

$\mathrm{T}^{1 / 2}$ Limit $=180$ days

obabilistic Dose and Risk Report

Title : Offsite Resident Farmer

File : RF TC99 DOESG FWD-FV2all.ROF

Summary of dose at graphical times, reptition 2 (continued)

Time

Years

$8.96 \mathrm{E}+02$

$8.97 \mathrm{E}+02$

$8.97 \mathrm{E}+02$

$8.98 \mathrm{E}+02$

$8.98 \mathrm{E}+02$

8. $99 \mathrm{E}+02$

$8.99 \mathrm{E}+02$

$9.00 \mathrm{E}+02$

$9.00 \mathrm{E}+02$

$9.01 \mathrm{E}+02$

$9.01 \mathrm{E}+02$

$9.02 \mathrm{E}+02$

$9.02 \mathrm{E}+02$

$9.03 \mathrm{E}+02$

$9.03 \mathrm{E}+02$

$9.04 \mathrm{E}+02$

$9.04 \mathrm{E}+02$

$9.05 \mathrm{E}+02$

$9.05 \mathrm{E}+02$

$9.06 \mathrm{E}+02$

$9.06 \mathrm{E}+02$

$9.07 \mathrm{E}+02$

$9.07 \mathrm{E}+02$

$9.08 \mathrm{E}+02$

$9.08 \mathrm{E}+02$

$9.09 \mathrm{E}+02$

$9.10 \mathrm{E}+02$

$9.10 \mathrm{E}+02$

$9.11 \mathrm{E}+02$

$9.11 \mathrm{E}+02$

$9.12 \mathrm{E}+02$

$9.12 \mathrm{E}+02$

$9.13 \mathrm{E}+02$

$9.13 \mathrm{E}+02$

$9.14 \mathrm{E}+02$

$9.14 \mathrm{E}+02$

$9.15 \mathrm{E}+02$

$9.15 \mathrm{E}+02$

$9.16 \mathrm{E}+02$

$9.16 \mathrm{E}+02$

$9.17 \mathrm{E}+02$

$9.17 \mathrm{E}+02$

$9.18 \mathrm{E}+02$

$9.18 \mathrm{E}+02$

$9.19 \mathrm{E}+02$

$9.19 \mathrm{E}+02$
Dose statistics at graphical times, mrem/yr

\begin{tabular}{|c|c|c|c|c|c|c|c|}
\hline m & axis & ea & 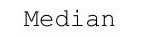 & & & $\%$ & \\
\hline 02 & $3.56 \mathrm{E}+00$ & 01 & $6.48 \mathrm{E}-01$ & $.65 E+00$ & 00 & -00 & . OJETU \\
\hline $46 E-02$ & $3.56 \mathrm{E}+00$ & -01 & $E-01$ & 1. $65 \mathrm{E}+00$ & $0 E+00$ & $2.29 \mathrm{E}+00$ & $53 \mathrm{E}+00$ \\
\hline $47 \mathrm{E}-02$ & $55 \mathrm{E}+00$ & $6 E-01$ & $50 E-01$ & $.65 E+00$ & $.00 \mathrm{E}+00$ & $2.29 \mathrm{E}+00$ & $2.63 E+00$ \\
\hline $49 E-02$ & $.55 E+00$ & $17 \mathrm{~F}-01$ & $50 \mathrm{~F}-01$ & $.65 E+00$ & $01 F+00$ & $.29 \mathrm{E}+00$ & $2.63 E+00$ \\
\hline $51 E-02$ & $3.55 \mathrm{E}+00$ & 01 & $6.51 \mathrm{E}-01$ & & & +00 & $.63 E+00$ \\
\hline 02 & $4 \mathrm{E}+00$ & & & & & & 00 \\
\hline $55 E-02$ & $4 \mathrm{E}+00$ & & & & & +00 & $\mathrm{E}+00$ \\
\hline $.57 \mathrm{E}-02$ & +00 & 1 & $\perp$ & $66 \mathrm{E}+00$ & 00 & +00 & $E+00$ \\
\hline $59 E-02$ & $.53 E+00$ & -01 & $E-01$ & $1.66 \mathrm{E}+00$ & 00 & $E+00$ & $2 \mathrm{E}+00$ \\
\hline$E-02$ & $.53 E+00$ & $21 E-01$ & 56 & $.66 \mathrm{E}+00$ & 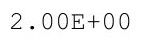 & $.29 E+00$ & $.62 \mathrm{E}+00$ \\
\hline 02 & +00 & & & & & 00 & +00 \\
\hline $64 \mathrm{E}-02$ & $.52 E+00$ & 2 & 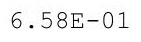 & 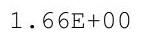 & & -00 & +00 \\
\hline $.66 \mathrm{E}-02$ & $3.52 \mathrm{E}+00$ & $8.23 E-01$ & & & & & $2.62 \mathrm{E}+00$ \\
\hline $68 E-02$ & $3.51 \mathrm{E}+00$ & $3.23 \mathrm{E}-01$ & $6.60 \mathrm{E}-01$ & & & $2.30 \mathrm{E}+00$ & $2.61 E+00$ \\
\hline-02 & $E+00$ & $E-01$ & $F-0-0$ & 0 & & +00 & $1 \mathrm{E}+00$ \\
\hline 2 & +00 & $8.25 E-01$ & 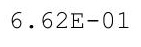 & $.66 \mathrm{E}$ & & 0 & 00 \\
\hline 2 & 00 & $8.26 \mathrm{E}-01$ & & & & 0 & 0 \\
\hline 2 & $0 \mathrm{E}+00$ & $8.26 \mathrm{E}-01$ & $6.63 E-01$ & & & 0 & 0 \\
\hline $.78 E-02$ & $.49 \mathrm{E}+00$ & $27 \mathrm{~F}-01$ & $6-6 \Delta \mathrm{F}_{-0}-1$ & $6 \in \Gamma+0$ & 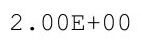 & $E+00$ & $0 \mathrm{E}+00$ \\
\hline$E-02$ & $.49 E+00$ & $8 E-01$ & $6.65 \mathrm{E}-01$ & $1.66 \mathrm{E}+00$ & & $2.29 \mathrm{E}+00$ & $2.60 E+00$ \\
\hline 02 & +00 & & & & & +00 & \\
\hline 2 & & & & & & & \\
\hline 02 & $3.48 \mathrm{E}+00$ & - & & $1.66 \mathrm{E}+$ & & & \\
\hline$E-02$ & $48 E+00$ & $\perp$ & $6.70 \mathrm{E}-01$ & (1) & 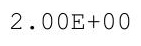 & 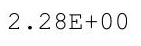 & 00 \\
\hline 2 & $.47 \mathrm{E}+00$ & $8.31 \mathrm{E}-01$ & $\perp$ & $1.66 \mathrm{E}+\mathrm{C}$ & $.00 \mathrm{E}+$ & $2.28 \mathrm{E}+00$ & $9 \mathrm{E}+$ \\
\hline $91 E-02$ & $.47 \mathrm{E}+00$ & $32 \mathrm{~F}-01$ & $671 \mathrm{~F}-01$ & $1.67 \mathrm{E}+00$ & $.00 \mathrm{E}+$ & $.28 E+00$ & $59 E+00$ \\
\hline $.93 E-02$ & $3.46 \mathrm{E}+00$ & & & & & $.28 E+00$ & $59 \mathrm{E}+00$ \\
\hline 02 & & & & & & & \\
\hline 02 & $3.46 \mathrm{E}+00$ & 1 & & $1.66 \mathrm{E}+$ & & & \\
\hline $.99 E-02$ & $3.45 \mathrm{E}+00$ & 0.0451 & $.14 \mathrm{~L}$ & $1.66 \mathrm{E}+00$ & $2.00 \mathrm{E}+$ & $2.28 \mathrm{E}+00$ & $2.59 \mathrm{E}+00$ \\
\hline $01 E-02$ & $3.45 \mathrm{E}+00$ & $8.35 E-01$ & . & $1.67 \mathrm{E}+00$ & $2.00 \mathrm{E}+00$ & $2.27 \mathrm{E}+00$ & $2.59 \mathrm{E}+00$ \\
\hline 2 & $3.45 \mathrm{E}+$ & 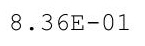 & . & 1. $67 \mathrm{E}+$ & & & $9 \mathrm{E}+$ \\
\hline 0 & & & & & & & \\
\hline 02 & & & & & & & \\
\hline$E-02$ & $3.43 E+00$ & 1 & 1 & 1. & & & 00 \\
\hline $.11 \mathrm{E}-02$ & $3.43 E+00$ & $8.38 E-01$ & $6.19 E-01$ & $1.67 \mathrm{E}+00$ & 2.001 & $\mathrm{E}+00$ & $59 \mathrm{E}+00$ \\
\hline $13 E-02$ & $3.43 \mathrm{E}+00$ & $0.07-4$ & & $1.0 / E+00$ & & & \\
\hline 02 & $3.42 \mathrm{E}+00$ & . & & $1.67 \mathrm{E}+00$ & & & $2.59 \mathrm{E}+00$ \\
\hline 2 & 3.42 & 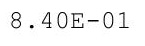 & 1 & $1.67 \mathrm{E}+00$ & $2.00 \mathrm{E}+$ & $2.27 E+00$ & $2.58 \mathrm{E}+00$ \\
\hline 2 & & 1 & 1 & $1.67 \mathrm{E}+00$ & & $E+00$ & $58 \mathrm{E}+00$ \\
\hline $1 E-02$ & $3.41 \mathrm{E}+00$ & $8.42 \mathrm{E}-01$ & $6.83 \mathrm{E}-01$ & $1.67 \mathrm{E}+00$ & & $2.28 \mathrm{E}+00$ & $2.58 \mathrm{E}+00$ \\
\hline-02 & $3.41 \mathrm{E}+00$ & 01 & & $1.68 \mathrm{E}+00$ & & $E+00$ & $8 E+00$ \\
\hline & & & & & & & $2.58 \mathrm{E}+00$ \\
\hline$E-02$ & $3.40 \mathrm{E}+00$ & . & ( & $1.68 E+00$ & $1.99 \mathrm{E}+00$ & $2.28 E+00$ & $2.58 \mathrm{E}+00$ \\
\hline & $3.40 \mathrm{E}+00$ & $4 E-01$ & & $1.68 \mathrm{E}+00$ & $1.99 \mathrm{E}+00$ & $2.28 E+00$ & $2.58 \mathrm{E}+00$ \\
\hline 02 & $.39 E+00$ & $E-01$ & $E-01$ & $.68 \mathrm{E}+00$ & $1.99 \mathrm{E}+00$ & $2.27 \mathrm{E}+00$ & $2.58 \mathrm{E}+00$ \\
\hline
\end{tabular}


RESRAD-OFFSITE, Version 2.5

$\mathrm{T}^{1 / 2}$ Limit $=180$ days

obabilistic Dose and Risk Report

Title : Offsite Resident Farmer

File : RF TC99 DOESG FWD-FV2all.ROF

Summary of dose at graphical times, reptition 2 (continued)

Time

Years

9. $20 \mathrm{E}+02$

$9.20 \mathrm{E}+02$

$9.21 \mathrm{E}+02$

9. $21 \mathrm{E}+02$

$9.22 \mathrm{E}+02$

$9.22 \mathrm{E}+02$

$9.23 \mathrm{E}+02$

$9.23 \mathrm{E}+02$

$9.24 \mathrm{E}+02$

$9.24 \mathrm{E}+02$

$9.25 \mathrm{E}+02$

$9.25 \mathrm{E}+02$

$9.26 \mathrm{E}+02$

$9.26 \mathrm{E}+02$

$9.27 \mathrm{E}+02$

$9.27 \mathrm{E}+02$

$9.28 \mathrm{E}+02$

$9.28 \mathrm{E}+02$

$9.29 \mathrm{E}+02$

9. $30 \mathrm{E}+02$

$9.30 \mathrm{E}+02$

$9.31 \mathrm{E}+02$

9. $31 \mathrm{E}+02$

$9.32 \mathrm{E}+02$

$9.32 \mathrm{E}+02$

$9.33 \mathrm{E}+02$

$9.33 \mathrm{E}+02$

$9.34 \mathrm{E}+02$

$9.34 \mathrm{E}+02$

9. $35 \mathrm{E}+02$

$9.35 \mathrm{E}+02$

$9.36 \mathrm{E}+02$

$9 \cdot 36 \mathrm{E}+02$

9. $37 \mathrm{E}+02$

$9.37 \mathrm{E}+02$

$9.38 \mathrm{E}+02$

9. $38 \mathrm{E}+02$

$9.39 \mathrm{E}+02$

$9.39 \mathrm{E}+02$

$9.40 \mathrm{E}+02$

$9.40 \mathrm{E}+02$

$9.41 \mathrm{E}+02$

$9.41 \mathrm{E}+02$

$9.42 \mathrm{E}+02$

$9.42 \mathrm{E}+02$

$9.43 \mathrm{E}+02$
Dose statistics at graphical times, mrem/yr

\begin{tabular}{|c|c|c|c|c|c|c|c|}
\hline$m$ & aximum & ea & - & & & & \\
\hline $33 E-02$ & $3.39 \mathrm{E}+00$ & 01 & $6.88 \mathrm{E}-01$ & 1. $68 \mathrm{E}+00$ & $99 \mathrm{E}+00$ & $27 E+00$ & . $50 \mathrm{E}+\mathrm{T}$ \\
\hline $35 E-02$ & $3.38 \mathrm{E}+00$ & $8.46 E-01$ & $6.89 \mathrm{E}-01$ & $1.68 \mathrm{E}+00$ & $1.99 \mathrm{E}+00$ & $2.27 E+00$ & $8 \mathrm{E}+00$ \\
\hline $37 E-02$ & $38 E+00$ & $47 E-01$ & $90 E-01$ & $.68 E+00$ & L. $99 \mathrm{E}+00$ & $.28 \mathrm{E}+00$ & $57 E+00$ \\
\hline$E-02$ & $38 E+00$ & $47 F-01$ & $90 F-01$ & $.68 \mathrm{E}+00$ & $199 F+00$ & $2.28 \mathrm{E}+00$ & $2.57 \mathrm{E}+00$ \\
\hline-02 & $3.37 \mathrm{E}+00$ & $8 \mathrm{E}-01$ & -01 & 0 & & +00 & +00 \\
\hline 02 & $37 E+00$ & & & & & & 00 \\
\hline $45 E-02$ & $3.37 \mathrm{E}+00$ & & & & & +00 & $7 \mathrm{E}+00$ \\
\hline $.47 \mathrm{E}-02$ & $3.36 \mathrm{E}+00$ & 01 & -01 & $1.68 \mathrm{E}+00$ & $00 \mathrm{E}+00$ & $E+00$ & $56 \mathrm{E}+00$ \\
\hline $49 \mathrm{E}-02$ & $3.36 \mathrm{E}+00$ & $1 \mathrm{E}-01$ & $E-01$ & $1.68 \mathrm{E}+00$ & $00 \mathrm{E}+00$ & $E+00$ & $5 \mathrm{E}+00$ \\
\hline$E-02$ & $35 E+00$ & $51 E-01$ & 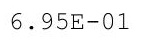 & $.68 E+00$ & 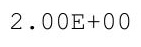 & $.28 E+00$ & $6 E+00$ \\
\hline 02 & $\mathrm{E}+00$ & & & & & 0 & $\mathrm{E}+00$ \\
\hline $55 E-02$ & +00 & F & 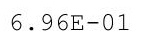 & 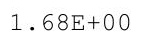 & & -00 & 00 \\
\hline $.57 \mathrm{E}-02$ & $3.34 \mathrm{E}+00$ & $8.53 E-01$ & $6.97 \mathrm{E}-01$ & & & $2.29 \mathrm{E}+00$ & $2.56 \mathrm{E}+00$ \\
\hline $.59 E-02$ & $3.34 \mathrm{E}+00$ & $8.54 \mathrm{E}-01$ & $6.98 \mathrm{E}-01$ & $1.68 \mathrm{E}+00$ & & $2.29 E+00$ & $2.56 \mathrm{E}+00$ \\
\hline-02 & $34 \mathrm{E}+00$ & $E-01$ & $\mathrm{~F}-0-0+2-2$ & & & +00 & $6 E+00$ \\
\hline 2 & 0 & & & 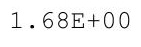 & & 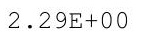 & 00 \\
\hline 2 & & & & 0 & & & 0 \\
\hline$E-02$ & $.32 E+00$ & $8.56 \mathrm{E}-01$ & $7.01 E-01$ & & & T & 0 \\
\hline $69 \mathrm{E}-02$ & $3.32 \mathrm{E}+00$ & -01 & $2 F-01$ & $605+100$ & 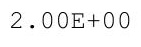 & $E+00$ & $6 \mathrm{E}+00$ \\
\hline $71 \mathrm{E}-02$ & $.32 E+00$ & $.58 \mathrm{E}-01$ & $.03 E-01$ & $1.68 \mathrm{E}+00$ & & $2.28 \mathrm{E}+00$ & $2.56 \mathrm{E}+00$ \\
\hline 02 & $3.31 E+00$ & & & & & +00 & $5 E+00$ \\
\hline 2 & & & & & & & \\
\hline 2 & & $8.59 \mathrm{E}-01$ & & $1.68 \mathrm{E}+$ & & & \\
\hline$E-02$ & $.30 \mathrm{E}+00$ & 1 & & 1. & & 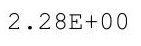 & \\
\hline $2 E-02$ & $30 \mathrm{E}+00$ & $8.61 \mathrm{E}-01$ & $\perp$ & $1.68 \mathrm{E}+00$ & & $2.28 E+00$ & $56 \mathrm{E}+00$ \\
\hline $84 E-02$ & $.29 \mathrm{E}+00$ & $61 \mathrm{~F}-01$ & $70075-01$ & 1. $68 \mathrm{E}+00$ & $.00 \mathrm{E}+00$ & $2.28 \mathrm{E}+00$ & $.56 \mathrm{E}+00$ \\
\hline$E-02$ & $3.29 \mathrm{E}+00$ & & $.07 E-01$ & & & $2.27 \mathrm{E}+00$ & $56 \mathrm{E}+00$ \\
\hline 02 & & & & & & & \\
\hline & & & & $.68 \mathrm{E}+$ & & & \\
\hline $92 \mathrm{E}-02$ & $3.28 \mathrm{E}+00$ & $0.045-1$ & $\cdot \perp U \perp$ U & $1.68 \mathrm{E}+00$ & $2.00 \mathrm{E}+00$ & $2.27 \mathrm{E}+00$ & $2.56 \mathrm{E}+00$ \\
\hline $94 \mathrm{E}-02$ & $3.28 E+00$ & $8.64 \mathrm{E}-01$ & (2- & $1.68 \mathrm{E}+00$ & $2.00 \mathrm{E}+00$ & Z. $21 \mathrm{ET} U 0$ & $2.56 \mathrm{E}+00$ \\
\hline 2 & $3.27 \mathrm{E}+00$ & - & 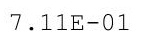 & 1. $68 \mathrm{E}+00$ & & & \\
\hline 02 & $3.27 \mathrm{E}+00$ & & & $1.68 \mathrm{E}+00$ & & & $2.56 \mathrm{E}+00$ \\
\hline 2 & & & & & & & \\
\hline$E-02$ & & & 1 & & & & \\
\hline 02 & $3.26 \mathrm{E}+00$ & 01 & 01 & $1.68 \mathrm{E}+00$ & $2.00 \mathrm{E}+$ & $2.27 E+00$ & $6 \mathrm{E}+00$ \\
\hline $07 E-02$ & $3.25 \mathrm{E}+00$ & $0.00 \mathrm{~L}-\mathrm{L}$ & & $1.08 E+00$ & & & $2.56 \mathrm{E}+00$ \\
\hline 02 & $3.25 \mathrm{E}+00$ & . & & 1. $69 \mathrm{E}+00$ & & $2.27 \mathrm{E}+00$ & $2.56 \mathrm{E}+00$ \\
\hline 2 & . & 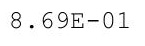 & 1 & $1.69 \mathrm{E}+00$ & $2.00 \mathrm{E}+00$ & $2.26 \mathrm{E}+00$ & $2.56 \mathrm{E}+00$ \\
\hline & $3.24 \mathrm{E}+00$ & 1 & & $1.69 \mathrm{E}+00$ & & & $.56 \mathrm{E}+00$ \\
\hline$E-02$ & $3.24 \mathrm{E}+00$ & $8.71 E-01$ & $7.17 \mathrm{E}-01$ & 1. $69 \mathrm{E}+00$ & $2.00 \mathrm{E}+$ & $2.26 \mathrm{E}+00$ & $2.56 \mathrm{E}+00$ \\
\hline$E-02$ & $3.23 E+00$ & 01 & 1 & $1.69 \mathrm{E}+00$ & & $E+00$ & $6 E+00$ \\
\hline & $3.23 \mathrm{E}+00$ & $8.72 \mathrm{E}-01$ & & $1.09 E+00$ & & & $2.56 \mathrm{E}+00$ \\
\hline $2+E-02$ & $3.23 E+00$ & $8.72 \mathrm{E}-01$ & . & $1.09 E+00$ & $2.00 \mathrm{E}+00$ & $2.26 \mathrm{E}+00$ & $2.56 \mathrm{E}+00$ \\
\hline . $235-02$ & $3.22 \mathrm{E}+00$ & •. & & $1.69 \mathrm{E}+00$ & $2.00 \mathrm{E}+00$ & $2.26 \mathrm{E}+00$ & $2.56 \mathrm{E}+00$ \\
\hline$E-02$ & $.22 E+00$ & $E-01$ & $E-01$ & $.69 \mathrm{E}+00$ & $.00 E+00$ & $2.26 \mathrm{E}+00$ & $2.56 \mathrm{E}+00$ \\
\hline
\end{tabular}


RESRAD-OFFSITE, Version 2.5

$\mathrm{T}^{1 / 2}$ Limit $=180$ days

obabilistic Dose and Risk Report

Title : Offsite Resident Farmer

File : RF TC99 DOESG FWD-FV2all.ROF

Summary of dose at graphical times, reptition 2 (continued)

Time

Years

9. $43 \mathrm{E}+02$

$9.44 \mathrm{E}+02$

$9.44 \mathrm{E}+02$

$9.45 \mathrm{E}+02$

$9.45 \mathrm{E}+02$

$9.46 \mathrm{E}+02$

$9.46 \mathrm{E}+02$

$9.47 \mathrm{E}+02$

$9.47 \mathrm{E}+02$

$9.48 \mathrm{E}+02$

$9.48 \mathrm{E}+02$

$9.49 \mathrm{E}+02$

$9.50 \mathrm{E}+02$

$9.50 \mathrm{E}+02$

$9.51 \mathrm{E}+02$

$9.51 \mathrm{E}+02$

$9.52 \mathrm{E}+02$

$9.52 \mathrm{E}+02$

$9.53 \mathrm{E}+02$

$9.53 \mathrm{E}+02$

$9.54 \mathrm{E}+02$

$9.54 \mathrm{E}+02$

$9.55 \mathrm{E}+02$

$9.55 \mathrm{E}+02$

$9.56 \mathrm{E}+02$

$9.56 \mathrm{E}+02$

$9.57 \mathrm{E}+02$

$9.57 \mathrm{E}+02$

$9.58 \mathrm{E}+02$

$9.58 \mathrm{E}+02$

$9.59 \mathrm{E}+02$

$9.59 \mathrm{E}+02$

$9.60 \mathrm{E}+02$

$9.60 \mathrm{E}+02$

$9.61 \mathrm{E}+02$

$9.61 \mathrm{E}+02$

$9.62 \mathrm{E}+02$

$9.62 \mathrm{E}+02$

$9.63 \mathrm{E}+02$

$9.63 \mathrm{E}+02$

$9.64 \mathrm{E}+02$

$9.64 \mathrm{E}+02$

$9.65 \mathrm{E}+02$

$9.65 \mathrm{E}+02$

$9.66 \mathrm{E}+02$

$9.66 \mathrm{E}+02$
Dose statistics at graphical times, mrem/yr

\begin{tabular}{|c|c|c|c|c|c|c|c|}
\hline m & um & ea & ec & & & $\%$ & $\%$ \\
\hline 02 & +00 & 01 & 1 & $.69 \mathrm{E}+00$ & 00 & $.26 \mathrm{E}+00$ & $.30 E+U 0$ \\
\hline $30 E-02$ & +00 & $8.75 E-01$ & $7.22 \mathrm{E}-01$ & $9 \mathrm{E}+00$ & $00 E+00$ & $2.25 \mathrm{E}+00$ & $6 E+00$ \\
\hline $32 E-02$ & $21 E+00$ & $5 E-01$ & $23 E-01$ & $.69 \mathrm{E}+00$ & $.00 \mathrm{E}+00$ & $2.25 E+00$ & $56 \mathrm{E}+00$ \\
\hline $34 E-02$ & $21 E+00$ & $76 \mathrm{~F}-01$ & $24 \mathrm{~F}-01$ & $.69 \mathrm{E}+00$ & $O \cap F+0 \cap$ & $2.25 \mathrm{E}+00$ & $2.56 \mathrm{E}+00$ \\
\hline $36 \mathrm{E}-02$ & $3.21 E+00$ & 01 & 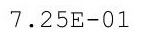 & & & $E+00$ & +00 \\
\hline $38 E-02$ & +00 & & & & & & 00 \\
\hline $40 E-02$ & $3.21 \mathrm{E}+00$ & & & & & $E+00$ & $6 \mathrm{E}+00$ \\
\hline $43 E-02$ & $3.21 \mathrm{E}+00$ & $\perp$ & $\perp$ & $E+00$ & 00 & +00 & $E+00$ \\
\hline $45 E-02$ & $21 E+00$ & $79 E-01$ & $E-01$ & $O E+00$ & 00 & $E+00$ & $5 \mathrm{E}+00$ \\
\hline $7 E-02$ & $.21 E+00$ & $80 E-01$ & תחק & $.70 \mathrm{E}+00$ & 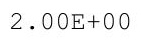 & $.25 E+00$ & $56 \mathrm{E}+00$ \\
\hline 02 & \pm 00 & & & & & -00 & $E+00$ \\
\hline $51 E-02$ & $.21 E+00$ & 1 & 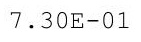 & & & 0 & +00 \\
\hline $.53 E-02$ & $3.20 \mathrm{E}+00$ & $8.81 E-01$ & & & & $2.25 E+00$ & $2.57 \mathrm{E}+00$ \\
\hline-02 & $3.20 \mathrm{E}+00$ & $.82 \mathrm{E}-01$ & 7. $31 \mathrm{E}-01$ & & $1.99 E+00$ & $2.25 E+00$ & $2.57 \mathrm{E}+00$ \\
\hline-02 & $E+00$ & $83 E-01$ & 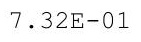 & & 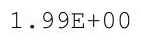 & +00 & $7 \mathrm{E}+00$ \\
\hline 2 & +00 & $8.83 E-01$ & . & $+\cdots$ & & 0 & 00 \\
\hline 2 & 00 & $8.84 \mathrm{E}-01$ & $7.34 \mathrm{E}-01$ & 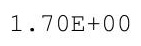 & & 0 & 0 \\
\hline 2 & $20 \mathrm{E}+00$ & $8.84 \mathrm{E}-01$ & 7. $35 E-01$ & & & $E+00$ & 0 \\
\hline $66 \mathrm{E}-02$ & $.20 \mathrm{E}+00$ & $5 F-01$ & $36 \mathrm{~F}-01$ & 政 & 㧒 & $F+00$ & $7 E+00$ \\
\hline $3 E-02$ & $.20 E+00$ & $85 E-01$ & 7. $37 \mathrm{E}-01$ & $1.71 \mathrm{E}+00$ & $1.99 \mathrm{E}+$ & $2.24 \mathrm{E}+00$ & $2.57 \mathrm{E}+00$ \\
\hline 02 & $E+00$ & & & & & +00 & $7 \mathrm{E}+00$ \\
\hline 2 & & & & & & & \\
\hline 02 & $3.20 \mathrm{E}+00$ & \pm & & $1.71 \mathrm{E}+$ & & & \\
\hline$E-02$ & $20 E+00$ & $\perp$ & $7.40 \mathrm{E}-01$ & $1.71 \mathrm{E}+$ & ( & 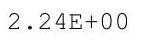 & 0 \\
\hline 2 & $.19 \mathrm{E}+00$ & $8.88 \mathrm{E}-01$ & $\perp$ & $1.71 \mathrm{E}+$ & $1.99 \mathrm{E}+$ & $4 \mathrm{E}+$ & $57 \mathrm{E}+$ \\
\hline$E-02$ & $.19 \mathrm{E}+00$ & $89 F-01$ & $7 \quad 41 F-01$ & 1. $71 \mathrm{E}+00$ & $.99 \mathrm{E}+$ & $2.25 E+00$ & $57 \mathrm{E}+00$ \\
\hline$E-02$ & $3.19 \mathrm{E}+00$ & & & & & $2.25 E+00$ & $57 E+00$ \\
\hline 02 & & & & & & & \\
\hline 02 & $19 \mathrm{E}+00$ & & & $1.71 \mathrm{E}$ & & & \\
\hline $.90 E-02$ & $3.19 \mathrm{E}+00$ & $0.9+\mathrm{L}$ & . & 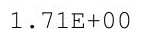 & 1.99E+ & $2.25 E+00$ & $2.57 \mathrm{E}+00$ \\
\hline $92 \mathrm{E}-02$ & $3.19 \mathrm{E}+00$ & $8.92 E-01$ & . 10 & 1. $71 \mathrm{E}+00$ & 1. $99 \mathrm{E}+00$ & $2.25 \mathrm{E}+00$ & $2.57 \mathrm{E}+00$ \\
\hline 2 & $3.19 \mathrm{E}+$ & . & $7.47 \mathrm{E}-01$ & 1. $71 \mathrm{E}+$ & & & $7 \mathrm{E}+$ \\
\hline 2 & & & & & & & 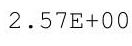 \\
\hline 02 & $3.19 \mathrm{E}+00$ & 1 & 1 & & & & \\
\hline$E-02$ & $3.19 \mathrm{E}+00$ & 1 & & 1 . & & & 00 \\
\hline $.03 E-02$ & $3.18 \mathrm{E}+00$ & $8.95 E-01$ & $.5 U E-01$ & $1.71 \mathrm{E}+00$ & 土. & $2 \cdot 2 J \pm$ & $57 \mathrm{E}+00$ \\
\hline $06 \mathrm{E}-02$ & $3.18 \mathrm{E}+00$ & $0.90 \mathrm{H}-\mathrm{L}$ & & $1.11 E+00$ & म. & & $2.57 \mathrm{E}+00$ \\
\hline 02 & $3.18 \mathrm{E}+00$ & . & & 1. $71 \mathrm{E}+00$ & 1. $99 \mathrm{E}+00$ & & $2.57 \mathrm{E}+00$ \\
\hline $.10 \mathrm{E}-02$ & 3.18 & $8.96 \mathrm{E}-01$ & 1 & $1.71 \mathrm{E}+00$ & 1.99E+ & $2.26 \mathrm{E}+00$ & $2.57 \mathrm{E}+00$ \\
\hline 2 & & & - & $1.72 \mathrm{E}+00$ & $1.99 \mathrm{E}+00$ & $5 E+00$ & $57 \mathrm{E}+00$ \\
\hline$E-02$ & $3.18 \mathrm{E}+00$ & $98 E-01$ & $7.53 \mathrm{E}-01$ & 1. $72 \mathrm{E}+00$ & $1.99 \mathrm{E}$ & $2.26 \mathrm{E}+00$ & $2.57 \mathrm{E}+00$ \\
\hline$E-02$ & $3.18 \mathrm{E}+00$ & 01 & 7.5 & $1.72 \mathrm{E}+00$ & & $2.26 \mathrm{~B}$ & $7 \mathrm{E}+00$ \\
\hline & $3.18 \mathrm{E}+00$ & & & & & & $2.58 \mathrm{E}+00$ \\
\hline$E-02$ & $3.18 \mathrm{E}+00$ & . & 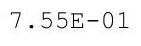 & $1.1 \angle E+U 0$ & $1.99 \mathrm{E}+00$ & $2.26 \mathrm{E}+00$ & $2.58 \mathrm{E}+00$ \\
\hline $235-02$ & & $.00-$ & $5 E-01$ & $1.72 \mathrm{E}+00$ & $1.99 \mathrm{E}+00$ & $2.26 \mathrm{E}+00$ & $2.58 \mathrm{E}+00$ \\
\hline 02 & $.18 \mathrm{E}+00$ & $E-01$ & $6 E-01$ & $1.72 \mathrm{E}+00$ & $1.99 \mathrm{E}+00$ & $2.26 \mathrm{E}+00$ & $2.58 \mathrm{E}+00$ \\
\hline
\end{tabular}


RESRAD-OFFSITE, Version 2.5

$\mathrm{T}^{1 / 2}$ Limit $=180$ days

obabilistic Dose and Risk Report

Title : Offsite Resident Farmer

File : RF TC99 DOESG FWD-FV2all.ROF

Summary of dose at graphical times, reptition 2 (continued)

Time

Years

9. $67 \mathrm{E}+02$

$9.67 \mathrm{E}+02$

$9.68 \mathrm{E}+02$

$9.68 \mathrm{E}+02$

$9.69 \mathrm{E}+02$

$9.70 \mathrm{E}+02$

$9.70 \mathrm{E}+02$

$9.71 \mathrm{E}+02$

$9.71 \mathrm{E}+02$

$9.72 \mathrm{E}+02$

$9.72 \mathrm{E}+02$

$9.73 E+02$

$9.73 E+02$

$9.74 \mathrm{E}+02$

$9.74 \mathrm{E}+02$

$9.75 \mathrm{E}+02$

$9.75 \mathrm{E}+02$

$9.76 \mathrm{E}+02$

$9.76 \mathrm{E}+02$

$9.77 \mathrm{E}+02$

$9.77 \mathrm{E}+02$

$9.78 \mathrm{E}+02$

$9.78 \mathrm{E}+02$

$9.79 \mathrm{E}+02$

$9.79 \mathrm{E}+02$

$9.80 \mathrm{E}+02$

$9.80 \mathrm{E}+02$

$9.81 \mathrm{E}+02$

$9.81 \mathrm{E}+02$

$9.82 \mathrm{E}+02$

$9.82 \mathrm{E}+02$

$9.83 \mathrm{E}+02$

$9.83 \mathrm{E}+02$

$9.84 \mathrm{E}+02$

$9.84 \mathrm{E}+02$

$9.85 \mathrm{E}+02$

$9.85 \mathrm{E}+02$

$9.86 \mathrm{E}+02$

$9.86 \mathrm{E}+02$

$9.87 \mathrm{E}+02$

$9.87 \mathrm{E}+02$

$9.88 \mathrm{E}+02$

$9.88 \mathrm{E}+02$

$9.89 \mathrm{E}+02$

$9.90 \mathrm{E}+02$

9. $90 \mathrm{E}+02$
Dose statistics at graphical times, mrem/yr

\begin{tabular}{|c|c|c|c|c|c|c|c|}
\hline$m$ & um & e & ledian & & & $\%$ & \\
\hline 02 & +00 & 01 & $7.57 \mathrm{E}-01$ & $1.72 \mathrm{E}+00$ & 0 & $.26 \mathrm{E}+00$ & $0 \pm+00$ \\
\hline $30 E-02$ & $3.17 E+00$ & $9.01 E-01$ & $57 E-01$ & $1.72 E+00$ & $98 E+00$ & $2.25 \mathrm{E}+00$ & $7 E+00$ \\
\hline$E-02$ & $17 \mathrm{E}+00$ & $02 E-01$ & $57 E-01$ & $.72 \mathrm{E}+00$ & $.98 E+00$ & $2.25 E+00$ & $57 E+00$ \\
\hline-02 & $17 E+00$ & $03 F-01$ & $58 \mathrm{~F}-01$ & $1.72 \mathrm{E}+00$ & $98 F+00$ & $.25 E+00$ & $2.57 E+00$ \\
\hline $37 E-02$ & $\mathrm{E}+00$ & $3 E-01$ & -6 & $.72 \mathrm{E}+$ & & $E+00$ & +00 \\
\hline 02 & +00 & & & & & & 00 \\
\hline $41 E-02$ & +00 & & & & & $E+00$ & $7 \mathrm{E}+00$ \\
\hline $.44 \mathrm{E}-02$ & $3.17 \mathrm{E}+00$ & $\perp$ & -01 & $1.73 \mathrm{E}+00$ & $99 \mathrm{E}+00$ & $E+00$ & $\mathrm{E}+00$ \\
\hline $46 E-02$ & $17 \mathrm{E}+00$ & -01 & $2 E-01$ & $1.73 \mathrm{E}+00$ & $99 \mathrm{E}+00$ & $E+00$ & $7 \mathrm{E}+00$ \\
\hline$E-02$ & $.17 \mathrm{E}+00$ & $06 E-01$ & ת? & $.73 E+00$ & 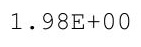 & $.25 E+00$ & $7 \mathrm{E}+00$ \\
\hline 02 & $E+00$ & & & & & -00 & $7 E+00$ \\
\hline $53 E-02$ & $3.16 \mathrm{E}+00$ & 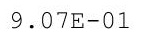 & 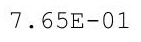 & 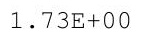 & & -00 & +00 \\
\hline $55 E-02$ & $3.16 \mathrm{E}+00$ & & $7.66 \mathrm{E}-01$ & & & $2.25 E+00$ & $2.57 \mathrm{E}+00$ \\
\hline $57 E-02$ & $3.16 \mathrm{E}+00$ & $9.08 \mathrm{E}-01$ & 7. $67 \mathrm{E}-01$ & $1.73 \mathrm{E}+00$ & $1.98 \mathrm{E}+00$ & $2.25 E+00$ & $2.57 \mathrm{E}+00$ \\
\hline-02 & $E+00$ & $E-01$ & $\mathrm{~F}-0-0+2-2$ & $73=+1010$ & & $E+00$ & $6 E+00$ \\
\hline 2 & +00 & & & 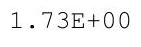 & & 0 & 00 \\
\hline 2 & 00 & & & & & 0 & 0 \\
\hline 2 & $.16 \mathrm{E}+00$ & $9.10 \mathrm{E}-01$ & $7.71 E-01$ & 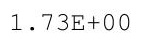 & & 0 & 0 \\
\hline $68 \mathrm{E}-02$ & $.16 \mathrm{E}+00$ & $1=-01$ & $2 F-01$ & $74 \mathrm{E}+00$ & (8) & $E+00$ & $6 \mathrm{E}+00$ \\
\hline$E-02$ & $.15 E+00$ & $.11 \mathrm{E}-01$ & $7.73 \mathrm{E}-01$ & $1.74 \mathrm{E}+00$ & $1.98 \mathrm{E}+$ & $2.25 \mathrm{E}+00$ & $2.56 \mathrm{E}+00$ \\
\hline-02 & $E+00$ & & & & & +00 & $5 E+00$ \\
\hline & & & & & & & \\
\hline 2 & $.15 \mathrm{E}+00$ & \pm & & $1.74 \mathrm{E}+$ & & & \\
\hline$E-02$ & $.15 E+00$ & $\perp$ & - & 1. & - & 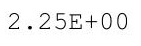 & 0 \\
\hline 2 & $.15 \mathrm{E}+00$ & $9.14 \mathrm{E}-01$ & $\perp$ & 1. $74 \mathrm{E}+00$ & & $2.25 E+00$ & $56 \mathrm{E}+00$ \\
\hline $84 \mathrm{E}-02$ & $.15 E+00$ & $14 \mathrm{~F}-01$ & $779 F-01$ & 1. $74 \mathrm{E}+00$ & $1.99 \mathrm{E}+$ & $2.25 E+00$ & $56 \mathrm{E}+00$ \\
\hline$E-02$ & $3.15 \mathrm{E}+00$ & $5 F-01$ & & & & $.25 E+00$ & $5 E+00$ \\
\hline 02 & & & & & & & \\
\hline & $3.14 \mathrm{E}+00$ & & & $1.74 \mathrm{E}+$ & & & 00 \\
\hline $94 \mathrm{E}-02$ & $3.14 \mathrm{E}+00$ & $\cdot 1 / \mathrm{L}$ & $.02 \mathrm{~L}$ & $1.74 \mathrm{E}+00$ & $1.98 \mathrm{E}+00$ & $2.25 E+00$ & $2.55 E+00$ \\
\hline $96 \mathrm{E}-02$ & $3.14 \mathrm{E}+00$ & $9.17 \mathrm{E}-01$ & . & 1. $74 \mathrm{E}+00$ & $1 \cdot 98 \mathrm{E}+00$ & $2.25 \mathrm{E}+00$ & $2.55 E+00$ \\
\hline 2 & $3.14 \mathrm{E}+00$ & . & 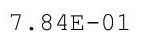 & $1.74 \mathrm{E}+$ & & $2.25 \mathrm{E}+0$ & \\
\hline 1 & $3.14 \mathrm{E}+0$ & & & & & & $5 E+00$ \\
\hline 01 & & & & 1. $74 \mathrm{E}+00$ & & & \\
\hline$E-01$ & & & 01 & & & & \\
\hline $.01 \mathrm{E}-01$ & $3.14 \mathrm{E}+00$ & $9.20 E-01$ & $7.88 E-01$ & $1.74 \mathrm{E}+00$ & $\perp \cdot 700$ & $2.24 \mathrm{E}+00$ & $2.55 \mathrm{E}+00$ \\
\hline $.01 \mathrm{E}-01$ & $3.14 \mathrm{E}+00$ & & & $1.14 \mathrm{E}+0 \mathrm{U}$ & & & $2.56 \mathrm{E}+00$ \\
\hline $01 E-01$ & $3.13 \mathrm{E}+00$ & 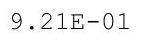 & & 1. $74 \mathrm{E}+00$ & 1. $98 \mathrm{E}+00$ & & $2.55 E+00$ \\
\hline 1 & $3.13 \mathrm{E}+$ & $9.21 \mathrm{E}-01$ & 1 & $1.74 \mathrm{E}+00$ & $1.98 \mathrm{E}+00$ & $2.24 \mathrm{E}+00$ & $2.55 E+00$ \\
\hline 1 & $3.13 \mathrm{E}+00$ & 1 & & $1.74 \mathrm{E}+00$ & & & $55 E+00$ \\
\hline $2 E-01$ & $3.13 E+00$ & -01 & $7.93 \mathrm{E}-01$ & 1. $74 \mathrm{E}+00$ & $1.98 \mathrm{E}$ & $2.24 \mathrm{E}+00$ & $2.55 E+00$ \\
\hline$E-01$ & $3.13 \mathrm{E}+00$ & 01 & 7. & $1.74 \mathrm{E}+00$ & & $E+00$ & $E+00$ \\
\hline & & & & & & & $55 E+00$ \\
\hline $03 E-01$ & $3.13 \mathrm{E}+00$ & . & . & $1.14 E+00$ & 土. & $2.24 \mathrm{E}+00$ & $2.55 E+00$ \\
\hline OSL- 1 & $3.13 \mathrm{E}+00$ & & & $1.74 \mathrm{E}+00$ & $1.98 \mathrm{E}+00$ & $2.24 \mathrm{E}+00$ & $2.55 E+00$ \\
\hline 01 & $.12 \mathrm{E}+00$ & $E-01$ & $E-01$ & $.74 \mathrm{E}+00$ & $1.98 \mathrm{E}+00$ & $2.24 \mathrm{E}+00$ & $.55 E+00$ \\
\hline
\end{tabular}


RESRAD-OFFSITE, Version 2.5

$\mathrm{T}^{1 / 2}$ Limit $=180$ days

robabilistic Dose and Risk Report

Title : Offsite Resident Farmer

File : RF TC99 DOESG FWD-FV2all.ROF

Summary of dose at graphical times, reptition 2 (continued)

Time

Years

9. $91 \mathrm{E}+02$

9. $91 \mathrm{E}+02$

9. $92 \mathrm{E}+02$

$9.92 \mathrm{E}+02$

9. $93 \mathrm{E}+02$

$9.93 \mathrm{E}+02$

9. $94 \mathrm{E}+02$

$9.94 \mathrm{E}+02$

9. $95 \mathrm{E}+02$

$9.95 \mathrm{E}+02$

$9.96 \mathrm{E}+02$

$9.96 \mathrm{E}+02$

$9.97 \mathrm{E}+02$

$9.97 \mathrm{E}+02$

9. $98 \mathrm{E}+02$

$9.98 \mathrm{E}+02$

$9.99 \mathrm{E}+02$

9. $99 \mathrm{E}+02$

$1.00 \mathrm{E}+03$

$1.00 \mathrm{E}+03$

$1.00 \mathrm{E}+03$

$1.00 \mathrm{E}+03$

$1.00 \mathrm{E}+03$

$1.00 \mathrm{E}+03$

$1.00 \mathrm{E}+03$

$1.00 \mathrm{E}+03$

$1.00 \mathrm{E}+03$

$1.00 \mathrm{E}+03$

$1.00 \mathrm{E}+03$

$1.01 \mathrm{E}+03$

$1.01 \mathrm{E}+03$

$1.01 \mathrm{E}+03$

$1.01 \mathrm{E}+03$

$1.01 \mathrm{E}+03$

$1.01 \mathrm{E}+03$

$1.01 \mathrm{E}+03$

$1.01 \mathrm{E}+03$

$1.01 \mathrm{E}+03$

$1.01 \mathrm{E}+03$

$1.01 \mathrm{E}+03$

$1.01 \mathrm{E}+03$

$1.01 \mathrm{E}+03$

$1.01 \mathrm{E}+03$

$1.01 \mathrm{E}+03$

$1.01 \mathrm{E}+03$

$1.01 \mathrm{E}+03$
Dose statistics at graphical times, mrem/yr

\begin{tabular}{|c|c|c|c|c|c|c|c|}
\hline m & $\mathrm{am}$ & ea & 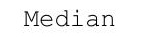 & & & & \\
\hline 01 & $.12 \mathrm{E}+00$ & 01 & 7. $98 \mathrm{E}-01$ & $1.74 \mathrm{E}+00$ & $98 \mathrm{E}+00$ & -00 & . 34 E +U \\
\hline $.04 E-01$ & $3.12 \mathrm{E}+00$ & $9.26 \mathrm{E}-01$ & $7.98 \mathrm{E}-01$ & $1.74 \mathrm{E}+00$ & $98 E+00$ & $2.24 \mathrm{E}+00$ & $4 \mathrm{E}+00$ \\
\hline $04 \mathrm{E}-01$ & $12 \mathrm{E}+00$ & $26 E-01$ & $99 E-01$ & $.74 E+00$ & $.98 \mathrm{E}+00$ & $.24 \mathrm{E}+00$ & $54 \mathrm{E}+00$ \\
\hline $04 \mathrm{~F}-01$ & $.12 \mathrm{E}+00$ & $27 \mathrm{~F}-01$ & $0 \cap=-01$ & $.74 \mathrm{E}+00$ & $98 \mathrm{~F}+00$ & $.24 \mathrm{E}+00$ & $2.54 \mathrm{E}+00$ \\
\hline-01 & $3.12 \mathrm{E}+00$ & -01 & 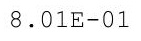 & & & $E+00$ & +00 \\
\hline 01 & +00 & & & & & & 00 \\
\hline $05 E-01$ & +00 & & & & & & +00 \\
\hline $.05 \mathrm{E}-01$ & $3.12 \mathrm{E}+00$ & $\perp$ & $\perp$ & $1.74 \mathrm{E}+00$ & $E+00$ & +00 & +00 \\
\hline $05 E-01$ & $3.11 \mathrm{E}+00$ & $9 E-01$ & -01 & $1.74 \mathrm{E}+00$ & $98 \mathrm{E}+00$ & $E+00$ & $\mathrm{\Xi}+00$ \\
\hline-01 & $.11 \mathrm{E}+00$ & $30 E-01$ & 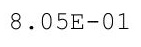 & $.74 \mathrm{E}+00$ & & $.23 E+00$ & $4 \mathrm{E}+00$ \\
\hline 1 & $E+00$ & & & & & -00 & +00 \\
\hline $06 \mathrm{E}-01$ & $3.11 \mathrm{E}+00$ & $F$ & $6 \mathrm{E}-01$ & & & 0 & +00 \\
\hline $.06 \mathrm{E}-01$ & $3.11 \mathrm{E}+00$ & & & & & $2.23 E+00$ & $54 \mathrm{E}+00$ \\
\hline $06 \mathrm{E}-01$ & $3.11 \mathrm{E}+00$ & $9.32 \mathrm{E}-01$ & $8.08 \mathrm{E}-01$ & $1.74 \mathrm{E}+00$ & $1.98 \mathrm{E}+00$ & $2.23 E+00$ & $2.53 E+00$ \\
\hline-01 & $1 \mathrm{E}+00$ & $E-01$ & 制 & $70=$ & & +00 & $\mathrm{E}+00$ \\
\hline 0 & $E+00$ & & & 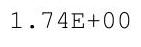 & & 0 & 00 \\
\hline 1 & 00 & $\perp$ & & 1. $74 \mathrm{E}+00$ & & 0 & 0 \\
\hline 1 & $10 \mathrm{E}+00$ & $9.34 \mathrm{E}-01$ & $8 \quad 115-01$ & 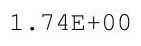 & & 0 & 0 \\
\hline $08 E-01$ & $.10 \mathrm{E}+00$ & $\Delta F-01$ & 10 & 1. $74 \mathrm{E}+00$ & 䧄 & $2.22 \mathrm{~F}+00$ & $3 E+00$ \\
\hline $08 E-01$ & $.10 \mathrm{E}+00$ & $.35 E-01$ & $.12 \mathrm{E}-01$ & $1.74 \mathrm{E}+00$ & $1.98 \mathrm{E}+$ & $2.22 \mathrm{E}+00$ & $2.53 E+00$ \\
\hline 01 & $\mathrm{E}+00$ & & & & & $22 \mathrm{E}+00$ & +00 \\
\hline 1 & & & & & & & \\
\hline 1 & $3.10 \mathrm{E}+00$ & $\cdot$ & & $1.74 \mathrm{E}+$ & & & \\
\hline-01 & $3.10 \mathrm{E}+00$ & $\perp$ & & 1. & 年 & 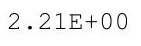 & 00 \\
\hline 1 & $3.09 \mathrm{E}+00$ & $9.37 \mathrm{E}-01$ & $\perp$ & 1. $74 \mathrm{E}+00$ & $1.98 \mathrm{E}+$ & $2.21 \mathrm{E}+\mathrm{C}$ & $5 \mathrm{E}+00$ \\
\hline $09 \mathrm{E}-01$ & $.09 \mathrm{E}+00$ & $38 F-01$ & (15 & 1. $74 \mathrm{E}+00$ & $.98 \mathrm{E}+$ & $.21 E+00$ & $53 E+00$ \\
\hline-01 & $3.09 \mathrm{E}+00$ & $38 F-01$ & & & & $2.21 E+00$ & $.53 E+00$ \\
\hline 1 & & & & & & & \\
\hline 1 & $3.09 \mathrm{E}+00$ & 3.0 & & $1.74 \mathrm{E}+$ & & & \\
\hline $10 \mathrm{E}-01$ & $3.09 \mathrm{E}+00$ & $.40 \pm-1$ & $\begin{array}{lll} \\
0\end{array}$ & $1.74 \mathrm{E}+00$ & 1.98E+ & $2.21 \mathrm{E}+00$ & $2.53 E+00$ \\
\hline $10 \mathrm{E}-01$ & $3.09 \mathrm{E}+00$ & $9.40 \mathrm{E}-01$ & 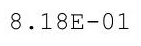 & 1. $74 \mathrm{E}+00$ & $1 \cdot 98 \mathrm{E}+00$ & $2.21 \mathrm{E}+00$ & $2.53 E+00$ \\
\hline 1 & $3.08 \mathrm{E}+$ & 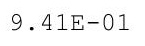 & $8.19 \mathrm{E}-01$ & 1. $74 \mathrm{E}+$ & & $2.21 \mathrm{E}+\mathrm{C}$ & \\
\hline 1 & & & & & & & \\
\hline 1 & & & 1 & & & & $3 E+00$ \\
\hline$E-01$ & $3.08 E+00$ & 1 & 01 & 1. & & & \\
\hline $12 \mathrm{E}-01$ & $3.08 \mathrm{E}+00$ & $9.43 E-01$ & $8.2 \angle E-U 1$ & $1.74 \mathrm{E}+00$ & 土.9 & $2.21 \mathrm{E}+00$ & $2.53 E+00$ \\
\hline $12 \mathrm{E}-01$ & $3.08 \mathrm{E}+00$ & $9.45 \pm-4$ & & $1.14 \mathrm{E}+0 \mathrm{U}$ & & & $2.53 E+00$ \\
\hline $12 \mathrm{E}-01$ & $3.08 \mathrm{E}+00$ & . & $8.23 E-01$ & 1. $74 \mathrm{E}+00$ & 1. $98 \mathrm{E}+00$ & $2.21 \mathrm{E}+00$ & $2.53 E+00$ \\
\hline 1 & 3.0 & 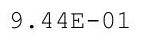 & 1 & $1.74 \mathrm{E}+00$ & $1.98 \mathrm{E}+00$ & $2.21 \mathrm{E}+00$ & $2.53 E+00$ \\
\hline 1 & & 1 & 1 & $1.74 \mathrm{E}+00$ & 1 & $2.21 \mathrm{E}+00$ & $3 E+00$ \\
\hline $3 E-01$ & $3.07 \mathrm{E}+00$ & -01 & $E-01$ & 1. $74 \mathrm{E}+00$ & 1 & $2.21 \mathrm{E}+00$ & $2.53 E+00$ \\
\hline $13 E-01$ & $3.07 \mathrm{E}+00$ & 01 & & $1.74 \mathrm{E}+00$ & & $2.21 \mathrm{~F}$ & +00 \\
\hline & 3.0 & & & & & & \\
\hline$E-01$ & $3.07 \mathrm{E}+00$ & $9.46 \mathrm{E}-01$ & . & $1.15 E+U 0$ & $1 \cdot 98 \mathrm{E}+00$ & $2.21 \mathrm{E}+00$ & $2.53 E+00$ \\
\hline $4 E-01$ & $3.07 E+00$ & . & & $1.75 \mathrm{E}+00$ & $1.98 \mathrm{E}+00$ & $2.21 E+00$ & $2.53 E+00$ \\
\hline 01 & $.07 \mathrm{E}+00$ & $E-01$ & $28 E-01$ & $.74 \mathrm{E}+00$ & 1. $98 \mathrm{E}+00$ & $2.21 \mathrm{E}+00$ & $.53 E+00$ \\
\hline
\end{tabular}


RESRAD-OFFSITE, Version 2.5

$\mathrm{T}^{1 / 2}$ Limit $=180$ days

obabilistic Dose and Risk Report

Title : Offsite Resident Farmer

File : RF TC99 DOESG FWD-FV2all.ROF

Summary of dose at graphical times, reptition 2 (continued)

Time

Years

1. $01 \mathrm{E}+03$

$1.01 \mathrm{E}+03$

$1.02 \mathrm{E}+03$

1. $02 \mathrm{E}+03$

1. $02 \mathrm{E}+03$

$1.02 \mathrm{E}+03$

$1.02 \mathrm{E}+03$

$1.02 \mathrm{E}+03$

$1.02 \mathrm{E}+03$

1. $02 \mathrm{E}+03$

$1.02 \mathrm{E}+03$

$1.02 \mathrm{E}+03$

$1.02 \mathrm{E}+03$

$1.02 \mathrm{E}+03$

$1.02 \mathrm{E}+03$

$1.02 \mathrm{E}+03$

$1.02 \mathrm{E}+03$

$1.02 \mathrm{E}+03$

$1.02 \mathrm{E}+03$

$1.02 \mathrm{E}+03$

$1.02 \mathrm{E}+03$

$1.02 \mathrm{E}+03$

$1.03 \mathrm{E}+03$

$1.03 \mathrm{E}+03$

$1.03 \mathrm{E}+03$

$1.03 E+03$

$1.03 \mathrm{E}+03$

$1.03 E+03$

$1.03 \mathrm{E}+03$

$1.03 E+03$

$1.03 \mathrm{E}+03$

$1.03 E+03$

$1.03 \mathrm{E}+03$

1. $03 \mathrm{E}+03$

$1.03 E+03$

$1.03 \mathrm{E}+03$

1. $03 \mathrm{E}+03$

1. $03 \mathrm{E}+03$

$1.03 E+03$

$1.03 \mathrm{E}+03$

$1.03 E+03$

$1.04 \mathrm{E}+03$

$1.04 \mathrm{E}+03$

$1.04 \mathrm{E}+03$

$1.04 \mathrm{E}+03$

$1.04 \mathrm{E}+03$
Dose statistics at graphical times, mrem/yr

\begin{tabular}{|c|c|c|c|c|c|c|c|}
\hline$m$ & aximum & lean & edi & & & & \\
\hline 1 & 00 & 01 & 01 & 0 & 0 & +00 & +00 \\
\hline $15 E-01$ & $06 \mathrm{E}+00$ & $8 E-01$ & $9 \mathrm{E}-01$ & $1.74 \mathrm{E}+00$ & $1.98 \mathrm{E}+00$ & $1 E+00$ & $3 E+00$ \\
\hline $15 E-01$ & $06 F+00$ & $49 F-01$ & $30 F-01$ & $1.74 \mathrm{E}+00$ & $1.98 \mathrm{E}+00$ & $2.21 \mathrm{E}+00$ & $2.53 E+00$ \\
\hline $5 F-01$ & $06 F+00$ & $9 F-0-2-2-5$ & -01 & $74 \mathrm{~F}+00$ & $98 \mathrm{~F}+00$ & $\mathrm{~F}+00$ & $53 E+00$ \\
\hline$E-01$ & 00 & $9.50 \mathrm{E}-01$ & & & & & +00 \\
\hline$E-01$ & & & & & & 0 & +00 \\
\hline $16 \mathrm{E}-01$ & $3.06 \mathrm{E}+00$ & 1 & -01 & 1. $74 \mathrm{E}+00$ & $98 \mathrm{E}+00$ & $2.21 \mathrm{E}+00$ & $52 \mathrm{E}+00$ \\
\hline $16 \mathrm{E}-01$ & $3.05 \mathrm{E}+00$ & $.51 \mathrm{E}-0$ & $33 E-01$ & $1.74 \mathrm{E}+00$ & $98 E+00$ & $.21 E+00$ & $52 \mathrm{E}+00$ \\
\hline $16 \mathrm{~F}-01$ & $05 \mathrm{~F}+0$ & $1 \mathrm{~F}$ & $3 \mathrm{~F}$ & $74 \mathrm{~F}+$ & $98 \mathrm{F+}$ & $.21 E+00$ & $52 E+00$ \\
\hline 1 & $305 \mathrm{~F}+00$ & $9.52 \mathrm{E}-01$ & 1 & $74 \mathrm{~F}+00$ & & $F+0$ & $52 \mathrm{E}+00$ \\
\hline $17 E-01$ & $F+00$ & $25-8$ & 1 & 0 & 0 & +00 & $2 \mathrm{E}+00$ \\
\hline$E-01$ & & 2F & & 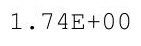 & & & $\mathrm{E}+00$ \\
\hline $.17 \mathrm{E}-01$ & $3.05 E+00$ & $9.53 \mathrm{E}-01$ & $8.35 \mathrm{E}-01$ & 1. $74 \mathrm{E}+00$ & $1.99 E+00$ & $2.20 \mathrm{E}+00$ & $2.52 \mathrm{E}+00$ \\
\hline $17 E-01$ & +00 & -0 & & $74 \mathrm{~F}$ & & +00 & $2 \mathrm{E}+00$ \\
\hline ( & & & & ת & & & 00 \\
\hline $.18 \mathrm{E}-01$ & & $9.55 \mathrm{E}-01$ & $8.37 E-01$ & $171 \mathrm{~F}+$ & 0 & 0 & 0 \\
\hline $18 \mathrm{~F}-01$ & $304 F+00$ & $9.55 \mathrm{E}-01$ & $8.38 E-01$ & $17 \Delta \mathrm{F}+$ & & +00 & $1 E+00$ \\
\hline $18 \mathrm{E}-01$ & $A E+00$ & $6 \mathrm{~F}-0$ & $8 \mathrm{~F}-01$ & $1.74 \mathrm{E}+00$ & $9 \mathrm{E}+00$ & $E+00$ & $1 \mathrm{E}+00$ \\
\hline $19 \mathrm{E}-01$ & $.04 \mathrm{E}+00$ & $6=-01$ & $9 \mathrm{E}-01$ & 1. $74 \mathrm{E}+00$ & 1. $99 \mathrm{E}+00$ & $2.20 \mathrm{E}+00$ & $2.51 E+00$ \\
\hline$E-01$ & $3.04 \mathrm{E}+00$ & -0 & -01 & 0 & & $E+00$ & $51 \mathrm{E}+00$ \\
\hline & & & & & & & \\
\hline $19 \mathrm{E}-01$ & & (c) & & 1. $74 \mathrm{E}+$ & & & \\
\hline 01 & $.03 E+00$ & $9.58 \mathrm{E}-01$ & 1 & $1.74 \mathrm{E}+$ & + & $E+00$ & $1 \mathrm{E}+00$ \\
\hline $20 E-01$ & $.03 E+00$ & $8 F-0$ & 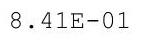 & $1.74 \mathrm{E}+00$ & $.99 \mathrm{E}+0$ & $2.20 E+00$ & $.51 E+00$ \\
\hline $20 E-01$ & $.03 E+00$ & $59 F-01$ & $42 \mathrm{E}-01$ & 1. $74 \mathrm{E}+00$ & 1. $99 \mathrm{E}+0$ & $20 \mathrm{E}+00$ & $.51 E+00$ \\
\hline$E-01$ & & & & & & & $50 \mathrm{E}+00$ \\
\hline & & & & & & & \\
\hline 1 & & & & 1. & $1.99 \mathrm{E}+00$ & $2.20 E+00$ & $2.50 \mathrm{E}+00$ \\
\hline $21 \mathrm{E}-01$ & $3.02 \mathrm{E}+00$ & (.) & $8.44 \mathrm{E}-01$ & $1.74 \mathrm{E}+00$ & $1.99 \mathrm{E}+00$ & $2.20 \mathrm{E}+00$ & $2.50 \mathrm{E}+00$ \\
\hline 1 & $3.02 E+00$ & 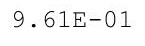 & 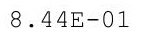 & $1.74 \mathrm{E}+00$ & $1.99 \mathrm{E}+00$ & $2.20 \mathrm{E}+00$ & $2.50 \mathrm{E}+00$ \\
\hline $22 E-$ & $3.02 \mathrm{E}+00$ & $9.61 \mathrm{E}-$ & $45 E-01$ & $1.74 \mathrm{E}+00$ & & $2.20 \mathrm{E}+00$ & $2.50 \mathrm{E}+00$ \\
\hline $205-0$ & 2 & & & $1.74 \mathrm{E}+$ & & & \\
\hline 1 & & 1 & & & & & \\
\hline $2 E-01$ & & 01 & 01 & & & $20 E+00$ & $2.50 \mathrm{E}+00$ \\
\hline $.23 E-01$ & $3.02 \mathrm{E}+00$ & $9.03 \mathrm{E}-\mathrm{D}$ & $8.47 \mathrm{E}-01$ & $1.74 \mathrm{E}+00$ & 1.99E+ & $2.20 \mathrm{E}+00$ & $2.50 \mathrm{E}+00$ \\
\hline •.2JE-U1 & $3.01 \mathrm{E}+00$ & . & & $1.14 E+00$ & 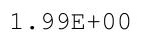 & & $2.50 \mathrm{E}+00$ \\
\hline 1 & $3.01 \mathrm{E}+$ & 1 & 1 & $1.74 \mathrm{E}+\mathrm{C}$ & 1.99E+ & & $2.50 E+00$ \\
\hline $.23 E-01$ & $3.01 \mathrm{E}+0$ & 1 & & $1.74 \mathrm{E}+00$ & 1.99E+00 & $2.20 \mathrm{E}+00$ & $2.50 \mathrm{E}+00$ \\
\hline $.24 E-01$ & & & & $1.74 \mathrm{E}+00$ & $1.99 \mathrm{E}+00$ & $E+00$ & \\
\hline $24 E-01$ & & & 01 & 1.74 & 1. & $2.20 \mathrm{E}+00$ & $50 \mathrm{E}+00$ \\
\hline $24 \mathrm{E}-01$ & $3.01 \mathrm{E}+00$ & $9.00 \mathrm{E}$ & & $1.74 \mathrm{E}+$ & & & $50 \mathrm{E}+00$ \\
\hline & כ. U Оटт & & & 1. & & & $2.50 \mathrm{E}+00$ \\
\hline . $20 \pm-4$ & $3.00 \mathrm{E}+00$ & . & $0.35-01$ & $1.74 \mathrm{E}+00$ & $1.99 \mathrm{E}+00$ & $2.19 E+00$ & $2.50 \mathrm{E}+00$ \\
\hline 㛡 & $3.00 \mathrm{E}+00$ & . & & & & $2.19 E+00$ & $2.50 \mathrm{E}+00$ \\
\hline $5 \mathrm{E}-$ & & & & $1.74 \mathrm{E}+00$ & $1.98 \mathrm{E}+$ & $2.19 E+00$ & $2.50 \mathrm{E}+00$ \\
\hline $25 E-01$ & $.00 \mathrm{E}+00$ & $E-01$ & $.55 E-01$ & $1.74 \mathrm{E}+00$ & $1.98 \mathrm{E}+00$ & $2.19 \mathrm{E}+00$ & $2.50 \mathrm{E}+00$ \\
\hline
\end{tabular}


RESRAD-OFFSITE, Version 2.5

$\mathrm{T}^{1 / 2}$ Limit $=180$ days

robabilistic Dose and Risk Report

Title : Offsite Resident Farmer

File : RF TC99 DOESG FWD-FV2all.ROF

Time

Years

$1.04 \mathrm{E}+03$

$1.04 \mathrm{E}+03$

$1.04 \mathrm{E}+03$

$1.04 \mathrm{E}+03$

$1.04 \mathrm{E}+03$

$1.04 \mathrm{E}+03$

$1.04 \mathrm{E}+03$

$1.04 \mathrm{E}+03$

1. $04 \mathrm{E}+03$

$1.04 \mathrm{E}+03$

$1.04 \mathrm{E}+03$

1. $04 \mathrm{E}+03$

1. $04 \mathrm{E}+03$

1. $04 \mathrm{E}+03$

1. $04 \mathrm{E}+03$

1. $05 \mathrm{E}+03$

1. $05 \mathrm{E}+03$

1. $05 \mathrm{E}+03$

1. $05 \mathrm{E}+03$

1. $05 \mathrm{E}+03$

1. $05 \mathrm{E}+03$

1. $05 \mathrm{E}+03$

$1.05 \mathrm{E}+03$

1. $05 \mathrm{E}+03$

1. $05 \mathrm{E}+03$

Summary of dose at graphical times, reptition 2 (continued)

Dose statistics at graphical times, mrem/yr

\begin{tabular}{|c|c|c|c|c|c|c|c|}
\hline Iini & laximum & lean & ledian & & & $\%$ & $\%$ \\
\hline $26 \mathrm{E}-01$ & $.00 \mathrm{E}+00$ & $68 E-01$ & $.56 \mathrm{E}-01$ & $.74 \mathrm{E}+00$ & 1. $98 \mathrm{E}+00$ & $19 E+00$ & $E+00$ \\
\hline $26 \mathrm{E}-01$ & $.00 E+00$ & $8 E-01$ & $7 E-01$ & $1.74 \mathrm{E}+00$ & $1.98 \mathrm{E}+00$ & $2.19 \mathrm{E}+00$ & $0 \mathrm{E}+00$ \\
\hline $26 \mathrm{~F}-01$ & 2 & $69=-01$ & $.58 E-01$ & $1.74 \mathrm{E}+00$ & 1. $98 \mathrm{E}+00$ & $2.19 \mathrm{E}+00$ & $2507+00$ \\
\hline 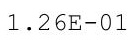 & 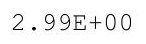 & $9.69 \mathrm{E}-01$ & $8.59 \mathrm{E}-01$ & $1.74 \mathrm{E}+$ & 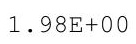 & $E+00$ & 政 \\
\hline $27 F_{1}$ & $F+00$ & 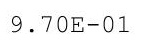 & 1 & 0 & & & $E+00$ \\
\hline $27 \mathrm{~F}-01$ & & 0 & 1 & 西 & & & $\mathrm{E}+00$ \\
\hline $.27 E-01$ & $2.99 \mathrm{E}+00$ & $9.71 \mathrm{E}-01$ & $8.61 \mathrm{E}-01$ & $1.74 \mathrm{E}+00$ & 1. $98 \mathrm{E}+00$ & $2.18 \mathrm{E}+00$ & $2.50 \mathrm{E}+00$ \\
\hline-01 & 䧄 & م 10 & $E-01$ & $70 F+$ & תم & & $0 E+00$ \\
\hline 28 & & & & 1.7 & & & 00 \\
\hline $.200-0$ & & 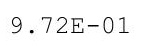 & & $1.74 \mathrm{E}+$ & & & 00 \\
\hline $.28 E-01$ & (2007 & $9.72 \mathrm{E}-01$ & & 1750 & & & 0 \\
\hline $.28 E-01$ & 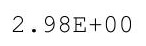 & ח תרת & 01 & $1.75 E+00$ & $1.98 \mathrm{E}+$ & $2.18 \mathrm{E}+00$ & $9 \mathrm{E}+00$ \\
\hline $29=-01$ & مח ניתمח & م & $8.65 E-01$ & $1.75 E+00$ & $1.98 \mathrm{E}+00$ & $2.18 \mathrm{E}+00$ & $.49 \mathrm{E}+00$ \\
\hline $29=-01$ & $2.98 \mathrm{E}+00$ & & 0 & $1.75 \mathrm{E}+00$ & 1. $98 \mathrm{E}+00$ & $218 F+00$ & $.49 \mathrm{E}+00$ \\
\hline 0 & & & & & & & \\
\hline & & & & & & & \\
\hline $30 E-01$ & $2.97 \mathrm{E}+00$ & $9.15 \mathrm{E}-\mathrm{C}$ & & $1.75 \mathrm{E}+$ & $1.98 \mathrm{E}+$ & & $9 \mathrm{E}+00$ \\
\hline $.30 E-01$ & $2.97 \mathrm{t}+00$ & $9.15 \mathrm{E}-\mathrm{U} \perp$ & $8.69 \mathrm{E}-01$ & $1.75 E+00$ & $1.98 \mathrm{E}+00$ & $2.18 \mathrm{E}+00$ & $2.49 \mathrm{E}+00$ \\
\hline $.30 E-01$ & $2.97 \mathrm{E}+00$ & $9.75 E-01$ & & $1.75 E+00$ & $1.98 \mathrm{E}+00$ & & $2.48 \mathrm{E}+00$ \\
\hline $31 \mathrm{E}-\mathrm{C}$ & $2.97 \mathrm{E}+00$ & - & & $1.75 \mathrm{E}+00$ & 1. $98 \mathrm{E}+00$ & $2.18 \mathrm{E}+00$ & $2.48 \mathrm{E}+00$ \\
\hline 1. $31 \mathrm{E}-01$ & & & & & & & $2.48 \mathrm{E}+00$ \\
\hline $31 E-01$ & $2.96 \mathrm{E}+00$ & $9.77 \mathrm{E}-\mathrm{C}$ & $8.71 \mathrm{E}-$ & $1.75 \mathrm{E}+00$ & 1. $99 \mathrm{E}+00$ & $2.18 \mathrm{E}+00$ & $2.47 \mathrm{E}+00$ \\
\hline $31 E-01$ & $2.96 \mathrm{E}+00$ & $9.77 \mathrm{E}-01$ & $8.71 \mathrm{E}-01$ & $1.75 \mathrm{E}+00$ & 1. $99 \mathrm{E}+00$ & $2.18 \mathrm{E}+00$ & $2.47 \mathrm{E}+00$ \\
\hline-01 & 2.96 & $E-01$ & $8.72 \mathrm{E}-0$ & 1.7 & 1.99 & $2.18 \mathrm{E}+00$ & $2.47 \mathrm{E}+00$ \\
\hline 1 & $.96 \mathrm{E}+00$ & -01 & -01 & 1.7 & $1.99 \mathrm{E}+00$ & $E+00$ & $2.47 \mathrm{E}$ \\
\hline
\end{tabular}


RESRAD-OFFSITE, Version 2.5

Title : Offsite Resident Farmer

File : RF TC99 DOESG FWD-FV2all.ROF

Time

Years

$0.00 \mathrm{E}+00$

$5.13 \mathrm{E}-01$

$1.03 \mathrm{E}+00$

$1.54 \mathrm{E}+00$

$2.05 \mathrm{E}+00$

$2.56 \mathrm{E}+00$

$3.08 \mathrm{E}+00$

$3.59 \mathrm{E}+00$

$4.10 \mathrm{E}+00$

$4.61 \mathrm{E}+00$

$5.13 E+00$

$5.64 \mathrm{E}+00$

$6.15 \mathrm{E}+00$

$6.67 \mathrm{E}+00$

$7.18 \mathrm{E}+00$

$7.69 \mathrm{E}+00$

$8.20 \mathrm{E}+00$

$8.72 \mathrm{E}+00$

$9.23 \mathrm{E}+00$

$9.74 \mathrm{E}+00$

$1.03 \mathrm{E}+01$

$1.08 \mathrm{E}+01$

$1.13 \mathrm{E}+01$

$1.18 \mathrm{E}+01$

$1.23 \mathrm{E}+01$

$1.28 \mathrm{E}+01$

$1.33 \mathrm{E}+01$

$1.38 \mathrm{E}+01$

$1.44 \mathrm{E}+01$

$1.49 \mathrm{E}+01$

$1.54 \mathrm{E}+01$

$1.59 \mathrm{E}+01$

$1.64 \mathrm{E}+01$

$1.69 \mathrm{E}+01$

$1.74 \mathrm{E}+01$

$1.79 \mathrm{E}+01$

$1.85 \mathrm{E}+01$

1. $90 \mathrm{E}+01$

1. $95 \mathrm{E}+01$

$2.00 \mathrm{E}+01$

$2.05 \mathrm{E}+01$

$2.10 \mathrm{E}+01$

$2.15 E+01$

$2.20 \mathrm{E}+01$

$2.26 \mathrm{E}+01$

$2.31 \mathrm{E}+01$

Summary of dose at graphical times, reptition 3

Dose statistics at graphical times, mrem/yr

\begin{tabular}{|c|c|c|c|c|c|c|c|}
\hline Iinimum & Iaximum & Mean & Median & 00 & $\%$ & $97.5 \%$ & 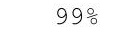 \\
\hline $.79 \mathrm{E}-32$ & $1.82 \mathrm{E}-32$ & 1. $82 \mathrm{E}-32$ & $1.82 \mathrm{E}-32$ & 1. $82 \mathrm{E}-32$ & 1. $82 \mathrm{E}-32$ & 1. $82 \mathrm{E}-32$ & $2 \mathrm{~L}-32$ \\
\hline $.78 E-32$ & $1.84 \mathrm{E}-32$ & $1.83 E-32$ & $1.84 \mathrm{E}-32$ & $1.84 \mathrm{E}-32$ & $1.84 \mathrm{E}-32$ & -32 & 32 \\
\hline $.76 E-32$ & 32 & 32 & $1.85 \mathrm{E}-32$ & $85 E-32$ & 32 & 32 & 32 \\
\hline $75 E-32$ & $87 E-32$ & $6 E-32$ & -32 & $7 E-32$ & $7 E-32$ & -32 & -32 \\
\hline$E-32$ & $9 E-32$ & $8 E-32$ & 2 & $9 \mathrm{E}$ & 2 & 32 & -32 \\
\hline $.72 E-32$ & & & & 32 & & & -32 \\
\hline-32 & & & & 32 & 2 & 32 & $2 E-32$ \\
\hline $69 E-32$ & 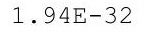 & 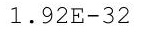 & $1.93 E-32$ & $4 E-32$ & 32 & 32 & -32 \\
\hline 要 & 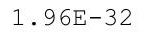 & 专 & - & 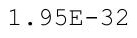 & 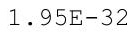 & . & 1. $95 E-32$ \\
\hline $66 \mathrm{E}-32$ & $1.97 \mathrm{~F}$ & 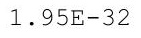 & 32 & 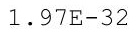 & 2 & -32 & $97 E-32$ \\
\hline $64 E-32$ & $E-32$ & -32 & -32 & -32 & 2 & 32 & -32 \\
\hline $63 E-32$ & 2 . & & & 2 & 2 & & -32 \\
\hline 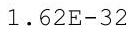 & & 2 & & & 2 & 2 & -32 \\
\hline 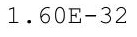 & & 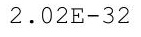 & $2 \pi-25$ & & 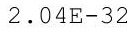 & & -32 \\
\hline (2) & 2.000 & 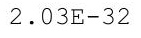 & . & 2.0042 & 0.0 & 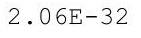 & -32 \\
\hline (1) & - & 舟 & 然 & . & & (2) & -32 \\
\hline $.56 E-32$ & $2.10 E-32$ & $2.06 \mathrm{E}-32$ & $2.08 E-32$ & $9 \mathrm{E}-$ & 2 & 32 & -32 \\
\hline $.55 E-32$ & $2.12 \mathrm{E}-32$ & $2.08 E-32$ & $2.10 \mathrm{E}-32$ & & $2.11 \mathrm{E}-32$ & $2.11 \mathrm{E}-32$ & $11 E-32$ \\
\hline-32 & 2 & ${ }^{2}$ & $E-32$ & $35-$ & 2 & -32 & $13 E-32$ \\
\hline 32 & 2 & $2.11 E-32$ & 2 & 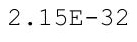 & 2 & 32 & -32 \\
\hline $51 \mathrm{E}-32$ & $2 \cdot 1 / \pm 22$ & $2 \cdot+\pi \Delta 2$ & $2.15 \mathrm{E}-32$ & 年 & & 32 & -32 \\
\hline $50 \mathrm{E}-32$ & $2.19 E-32$ & 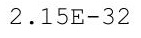 & & & & & -32 \\
\hline $48 E-32$ & 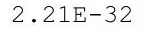 & $2 \cdot 1$ & 2 & 然 & 2 & 2 & -32 \\
\hline $.47 E-32$ & $2.23 E-32$ & $2.18 E-32$ & $2.20 \mathrm{E}-32$ & $2.22 \mathrm{E}-$ & $2.23 \mathrm{E}-$ & $2.23 E-32$ & $23 E-32$ \\
\hline $46 E-32$ & $2.25 E-32$ & $2.20 \mathrm{E}-32$ & $2.22 E-32$ & $2.24 \mathrm{E}-32$ & $2.25 \mathrm{E}-$ & $2.25 E-32$ & $25 E-32$ \\
\hline 32 & 2.2 & 2 & 2 & 2 & & $.27 E-32$ & $27 E-32$ \\
\hline-32 & 32 & 2 & 32 & & & -32 & $E-32$ \\
\hline $42 E-32$ & $2.31 E-32$ & 2.200 & (. & ( ل & & & 32 \\
\hline $41 E-32$ & 2.0 & टण्टामे & $2.29 E-32$ & $2.32 E-32$ & $2 \cdot 00$ & $2.33 E-32$ & $2.33 E-32$ \\
\hline 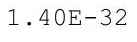 & $2.35 E-32$ & 2.2 & 2 & 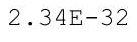 & 2.00 & 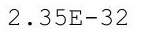 & $.35 E-32$ \\
\hline $.39 E-32$ & $2.37 E-32$ & $2.30 E-32$ & $2.33 E-32$ & 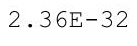 & & (e) & $.37 E-32$ \\
\hline $38 E-32$ & $2.40 E-32$ & & 2 & & & & $39 E-32$ \\
\hline 2 & 2 & 2 & 32 & 2 & 2 & 32 & -32 \\
\hline $5 E-32$ & $2.44 E-32$ & 2 & 2 . & 2 & 2 & 32 & -32 \\
\hline $34 E-32$ & $2.46 E-32$ & $2.38 E-32$ & $2.41 E-32$ & $2.45 E-32$ & $2.45 E-32$ & $2.45 E-32$ & $2.45 E-32$ \\
\hline $3 E-32$ & 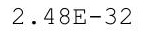 & 2. & $2.43 E-32$ & $2.47 E-32$ & & & $2.48 E-32$ \\
\hline 2 & 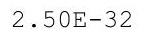 & $2.4 \perp L$ & & & & & $2.50 E-32$ \\
\hline $.31 E-32$ & $2.53 E-32$ & & 2 & 2 & 2 & 2 & 32 \\
\hline ? & $2.55 E-32$ & $2.45 E-32$ & 32 & 2 & & & 32 \\
\hline 2 & & & & 2 & 32 & -32 & 32 \\
\hline $27 E-32$ & $2.59 \mathrm{E}-$ & 2.450 & 32 & 2. & & 32 & -32 \\
\hline 2 & $-\infty$ & & & & & & \\
\hline 2 & 2.0 & . & - & 2 & $2.63 \mathrm{E}$ & & -32 \\
\hline 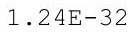 & 2 & & 5 & $-\infty$ & 2 & 2 & 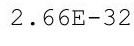 \\
\hline $.23 E-32$ & 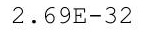 & & & 2 & $2.67 \mathrm{E}$ & 2.00 & 32 \\
\hline-32 & $71 E-32$ & $9 E-32$ & $64 E-32$ & 32 & 32 & 32 & 32 \\
\hline
\end{tabular}


RESRAD-OFFSITE, Version 2.5

$\mathrm{T}^{1 / 2}$ Limit $=180$ days

Title : Offsite Resident Farmer

File : RF TC99 DOESG FWD-FV2all.ROF

Summary of dose at graphical times, reptition 3 (continued)

Time

Years

$2.36 \mathrm{E}+01$

$2.41 \mathrm{E}+01$

$2.46 \mathrm{E}+01$

$2.51 \mathrm{E}+01$

2. $56 \mathrm{E}+01$

2. $61 \mathrm{E}+01$

$2.67 \mathrm{E}+01$

2. $72 \mathrm{E}+01$

$2.77 \mathrm{E}+01$

2. $82 \mathrm{E}+01$

$2.87 E+01$

2. $92 \mathrm{E}+01$

2. $97 \mathrm{E}+01$

3. $02 \mathrm{E}+01$

$3.08 \mathrm{E}+01$

$3.13 E+01$

$3.18 \mathrm{E}+01$

3. $23 E+01$

3. $28 \mathrm{E}+01$

3. $33 E+01$

3. $38 \mathrm{E}+01$

3. $44 \mathrm{E}+01$

3. $49 \mathrm{E}+01$

$3.54 \mathrm{E}+01$

$3.59 \mathrm{E}+01$

$3.64 \mathrm{E}+01$

$3.69 \mathrm{E}+01$

$3.74 \mathrm{E}+01$

$3.79 \mathrm{E}+01$

3. $85 \mathrm{E}+01$

3. $90 \mathrm{E}+01$

$3.95 \mathrm{E}+01$

$4.00 \mathrm{E}+01$

$4.05 \mathrm{E}+01$

4. $10 \mathrm{E}+01$

4. $15 \mathrm{E}+01$

4. $20 \mathrm{E}+01$

4. $26 \mathrm{E}+01$

4. $31 \mathrm{E}+01$

4. $36 \mathrm{E}+01$

$4.41 \mathrm{E}+01$

4. $46 \mathrm{E}+01$

$4.51 \mathrm{E}+01$

$4.56 \mathrm{E}+01$

4. $61 \mathrm{E}+01$

$4.67 \mathrm{E}+01$
Dose statistics at graphical times, mrem/yr

\begin{tabular}{|c|c|c|c|c|c|c|c|}
\hline m & aximum & ea & ec & & & & \\
\hline-32 & $2.73 E-32$ & $2.61 E-32$ & $2.66 \mathrm{E}-32$ & $71 E-32$ & $72 E-32$ & 32 & - $13 \pm-32$ \\
\hline $20 E-32$ & $2.76 E-32$ & $2.63 E-32$ & $2.68 \mathrm{E}-32$ & $2.74 E-32$ & $2.74 E-32$ & $2.75 E-32$ & $75 E-32$ \\
\hline-32 & $78 E-32$ & $65 E-32$ & $71 E-32$ & $76 E-32$ & $77 E-32$ & $2.77 \mathrm{E}-32$ & $78 E-32$ \\
\hline-32 & $81 E-32$ & $67 F-32$ & $73 F-32$ & $.79 E-32$ & $79 F-32$ & $80 F-32$ & $80 F-32$ \\
\hline-32 & -32 & 32 & -32 & 2 & 2 & -32 & $82 E-32$ \\
\hline 32 & 32 & & & & & & 32 \\
\hline $15 E-32$ & $2.88 E-32$ & & $2.80 E-32$ & & & & $.87 E-32$ \\
\hline $14 E-32$ & -32 & 2 & -32 & 32 & 32 & -32 & $0 E-32$ \\
\hline $13 E-32$ & $94 E-32$ & $78 \mathrm{E}-32$ & $2.84 \mathrm{E}-32$ & $91 E-32$ & $92 E-32$ & -32 & $3 E-32$ \\
\hline$E-32$ & $96 E-32$ & ? חק00 & $87 F-32$ & 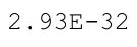 & 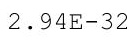 & $.95 E-32$ & $95 F-32$ \\
\hline 32 & 32 & & & & & & 32 \\
\hline $10 \mathrm{E}-32$ & $3.01 E-32$ & $285 \mathrm{~F}-32$ & $E-32$ & 2 & 2 & 32 & -32 \\
\hline $.09 E-32$ & $3.04 E-32$ & & $2.94 \mathrm{E}-32$ & & & & $3.03 E-32$ \\
\hline $08 E-32$ & -32 & $2.095-32$ & $2.96 \mathrm{E}-32$ & & 2 & 32 & $E-32$ \\
\hline$E-32$ & -32 & 2 & -32 & & & -32 & -32 \\
\hline 32 & -32 & (5) & $1 E-32$ & & & 2 & $3.11 \mathrm{E}-32$ \\
\hline 32 & 2 & & & & & & 32 \\
\hline 32 & 32 & 2 & 2 & & & 2 & 32 \\
\hline $04 \mathrm{E}-32$ & $3.21 E-32$ & $3.01 E-32$ & $3.09 E-32$ & $3.17 E-32$ & $3.18 E-32$ & $3.19 \mathrm{E}-32$ & $3.19 \mathrm{E}-32$ \\
\hline$E-32$ & $23 E-32$ & $.04 E-32$ & $E-32$ & $0 E-32$ & 1 & -32 & $22 E-32$ \\
\hline 32 & 32 & & & & & 2 & -32 \\
\hline 32 & -32 & & & & & -32 & -32 \\
\hline $.00 \mathrm{E}-32$ & 2 & & & & & 2 & -32 \\
\hline-33 & -32 & $3.13 E-32$ & 2 & 2 & L & 2 & -32 \\
\hline 3 & -32 & $3.16 \mathrm{E}-32$ & 2 & 2 & 5 & 2 & 32 \\
\hline $.77 E-33$ & $.41 E-32$ & -32 & $F-32$ & ד & 20г & $39 E-32$ & $40 E-32$ \\
\hline-33 & $44 \mathrm{E}-32$ & 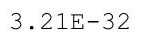 & $E-32$ & 2 & & $E-32$ & $43 E-32$ \\
\hline & & & & & & & \\
\hline & & & 32 & 2 & & -32 & \\
\hline $45 E-33$ & $3.53 E-32$ & . & $3.38 E-32$ & $3.49 E-32$ & $.200-28$ & $.51 E-32$ & $.52 E-32$ \\
\hline $37 E-33$ & 32 & Pr & $E-32$ & . & - & $5-32$ & $.55 E-32$ \\
\hline 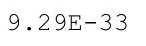 & $60 E-32$ & & $44 \mathrm{E}-32$ & & & & \\
\hline-33 & $.63 E-32$ & 2 & $E-32$ & $8 E-32$ & תח & & $1 E-32$ \\
\hline & & & & & & & \\
\hline & & & & 32 & 2 & -32 & \\
\hline $97 E-33$ & $3.73 E-32$ & $3.45 \pm-32$ & $3.55 E-32$ & 3.00 & 3.00 & -32 & $.71 E-32$ \\
\hline $90 E-33$ & $3.10 \mathrm{E}-32$ & $3.47 \mathrm{E}-32$ & & & & & $3.14 \pm-32$ \\
\hline 3 & 32 & . & 2 & . & & & $77 E-32$ \\
\hline 3 & $3.83 E-32$ & $3.53 E-32$ & 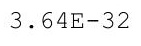 & 2 & 2 & 2 & 32 \\
\hline 33 & 2 & ? & & & & & 32 \\
\hline$E-33$ & $3.89 E-32$ & $3.58 E-32$ & $0 E-32$ & 3. & 2 & -32 & -32 \\
\hline $3 E-33$ & 3.905 & 3.015 & 2 & 2 & 2 & & \\
\hline & & & & & & & $\cdot 94 \mathrm{E}-32$ \\
\hline $.38 \pm-33$ & $4.00 \pm-32$ & $3.01 \mathrm{~L} 2 \mathrm{~L}$ & $3.19 E-32$ & $3.94 \mathrm{E}-32$ & $3.96 E-32$ & $3.97 E-32$ & $3.98 E-32$ \\
\hline ter- & $4.03 E-32$ & 5.70 & & e. & 3.995 & $4.00 E-32$ & 1. \\
\hline-33 & $E-32$ & $3 E-32$ & $.86 \mathrm{E}-32$ & $01 E-32$ & $.03 E-32$ & -32 & 4.0 \\
\hline
\end{tabular}


RESRAD-OFFSITE, Version 2.5

$\mathrm{T}^{1 / 2}$ Limit $=180$ days

obabilistic Dose and Risk Report

Title : Offsite Resident Farmer

File : RF TC99 DOESG FWD-FV2all.ROF

Summary of dose at graphical times, reptition 3 (continued)

Time

Years

4. $72 \mathrm{E}+01$

$4.77 \mathrm{E}+01$

4. $82 \mathrm{E}+01$

$4.87 \mathrm{E}+01$

4. $92 \mathrm{E}+01$

$4.97 \mathrm{E}+01$

$5.02 \mathrm{E}+01$

$5.08 \mathrm{E}+01$

$5.13 \mathrm{E}+01$

$5.18 \mathrm{E}+01$

$5.23 \mathrm{E}+01$

$5.28 \mathrm{E}+01$

$5.33 E+01$

$5.38 \mathrm{E}+01$

$5.43 \mathrm{E}+01$

$5.49 \mathrm{E}+01$

$5.54 \mathrm{E}+01$

$5.59 \mathrm{E}+01$

$5.64 \mathrm{E}+01$

$5.69 \mathrm{E}+01$

$5.74 \mathrm{E}+01$

$5.79 \mathrm{E}+01$

$5.84 \mathrm{E}+01$

$5.90 \mathrm{E}+01$

$5.95 \mathrm{E}+01$

$6.00 \mathrm{E}+01$

$6.05 \mathrm{E}+01$

$6.10 \mathrm{E}+01$

$6.15 \mathrm{E}+01$

$6.20 \mathrm{E}+01$

$6.25 \mathrm{E}+01$

$6.31 \mathrm{E}+01$

$6.36 \mathrm{E}+01$

$6.41 \mathrm{E}+01$

$6.46 \mathrm{E}+01$

$6.51 \mathrm{E}+01$

$6.56 \mathrm{E}+01$

$6.61 \mathrm{E}+01$

$6.67 \mathrm{E}+01$

$6.72 \mathrm{E}+01$

$6.77 \mathrm{E}+01$

$6.82 \mathrm{E}+01$

$6.87 \mathrm{E}+01$

$6.92 \mathrm{E}+01$

$6.97 \mathrm{E}+01$

$7.02 \mathrm{E}+01$
Dose statistics at graphical times, mrem/yr

\begin{tabular}{|c|c|c|c|c|c|c|c|}
\hline $\mathrm{m}$ & aximum & lea & ec & & & & \\
\hline $17 \mathrm{E}-33$ & $4.11 E-32$ & $3.76 E-32$ & $3.89 \mathrm{E}-32$ & 32 & $4.06 \mathrm{E}-32$ & -32 & $4.00 E-32$ \\
\hline $10 \mathrm{E}-33$ & $4.14 E-32$ & $9 E-32$ & $3.92 \mathrm{E}-32$ & $8 E-32$ & $10 E-32$ & $4.11 E-32$ & $4.12 \mathrm{E}-32$ \\
\hline 33 & -32 & $2 E-32$ & $95 E-32$ & 1 & 2 & -32 & $16 E-32$ \\
\hline-33 & -32 & $85 E-32$ & $99 F-32$ & $15 F-32$ & $17 F-32$ & $18 \mathrm{~F}-32$ & $19 F-32$ \\
\hline-33 & -32 & 32 & -32 & 2 & 2 & -32 & $23 E-32$ \\
\hline 33 & & & & & & & \\
\hline $.76 \mathrm{E}-33$ & $4.33 E-32$ & & & & & & -32 \\
\hline $.70 E-33$ & -32 & 2 & 32 & 2 & 32 & -32 & -32 \\
\hline $.63 E-33$ & -32 & 32 & -32 & 32 & $35 E-32$ & -32 & $38 E-32$ \\
\hline $57 E-33$ & -32 & קים & 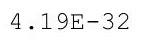 & חק & תم & 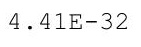 & -32 \\
\hline$E-33$ & 32 & & & & & & -32 \\
\hline $44 \mathrm{E}-33$ & $4.52 E-32$ & $F-32$ & $E-32$ & 2 & 2 & -32 & -32 \\
\hline $38 E-33$ & $4.56 E-32$ & & $4.29 E-32$ & $4.49 E-32$ & $4.51 E-32$ & $4.52 E-32$ & $4.54 \mathrm{E}-32$ \\
\hline $.31 E-33$ & $4.60 \mathrm{E}-32$ & $4.17 \mathrm{E}-32$ & $4.33 E-32$ & $4.53 E-32$ & 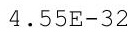 & 32 & $E-32$ \\
\hline$E-33$ & -32 & & -32 & & & -32 & $E-32$ \\
\hline 33 & -32 & 4 & -32 & 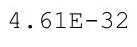 & 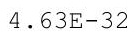 & 2 & 32 \\
\hline-33 & 2 & & & & & & \\
\hline$E-33$ & 32 & 4 & 2 & & & 2 & 32 \\
\hline $.01 \mathrm{E}-33$ & $4.81 E-32$ & $4.34 E-32$ & $4.51 E-32$ & $4.73 E-32$ & $4.75 E-32$ & $4.77 E-32$ & $4.78 E-32$ \\
\hline $95 E-33$ & $4.85 E-32$ & $4.37 \mathrm{E}-32$ & $4.55 \mathrm{E}-32$ & $4.77 E-32$ & $4.79 \mathrm{E}-$ & $4.81 E-32$ & 4. $82 \mathrm{E}-32$ \\
\hline 33 & -32 & & & & & -32 & $E-32$ \\
\hline-33 & -32 & & 2 & & & -32 & -32 \\
\hline $.77 E-33$ & 4.9 & 4 & $25<$ & & & 2 & 32 \\
\hline$E-33$ & 32 & 4 & 2 & 2 & 2 & 2 & -32 \\
\hline 3 & $E-32$ & 4 & 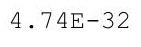 & 2 & 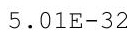 & 2 & 32 \\
\hline $60 E-33$ & $12 E-32$ & $E-32$ & $E-32$ & 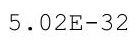 & $05 \mathrm{E}-$ & $.07 E-32$ & $08 E-32$ \\
\hline $54 E-33$ & $E-32$ & & $2 E-32$ & & & $E-32$ & $13 E-32$ \\
\hline & & & & & & & \\
\hline & & & 32 & 2 & & 32 & \\
\hline $.38 \mathrm{E}-33$ & $5.30 E-32$ & $4.73 E-32$ & $4.94 \mathrm{E}-32$ & $.20 E-32$ & $\cdot 235-32$ & $.25 E-32$ & $.27 E-32$ \\
\hline $3 E-33$ & 32 & $4.77 E-32$ & $E-32$ & - & - & 2 & $.31 E-32$ \\
\hline 年 & 2 & & 年 & & & & $36 E-32$ \\
\hline$F-33$ & $5-32$ & -32 & $E-32$ & 2 & م7 & -32 & $E-32$ \\
\hline 3 & & & 32 & & & & \\
\hline 33 & & & 32 & 32 & 2 & 32 & \\
\hline $.06 E-33$ & $5.59 E-32$ & $4.97 E-32$ & $E-32$ & .10 & 2 & -32 & $55 E-32$ \\
\hline $01 E-33$ & $5.04 E-32$ & & & & & & $.00 E-32$ \\
\hline $6 E-33$ & $E-32$ & .025 & 年 & . & $5.61 \mathrm{E}-32$ & & $.65 E-32$ \\
\hline 3 & $5.74 \mathrm{E}-32$ & 5 & ? & & 2 & 2 & 32 \\
\hline 33 & 2 & & & & & & 32 \\
\hline $1 E-33$ & $5.84 \mathrm{E}-32$ & $5.17 \mathrm{E}-32$ & $1 E-32$ & 5. & 5 & -32 & -32 \\
\hline$E-33$ & 32 & $5 \cdot 2$ & & - 11 & 2 & & \\
\hline & & & & & & & $.90 E-32$ \\
\hline $60 E-33$ & $6.00 \pm-32$ & $3.29 E-32$ & $5.34 E-32$ & $5.87 E-32$ & $5.91 E-32$ & $5.93 E-32$ & $5.95 E-32$ \\
\hline • & $6.05 E-32$ & 3.345 & $5.59 \pm-32$ & $\begin{array}{ll}0 \\
0\end{array}$ & . & $5.99 E-32$ & . \\
\hline-33 & $.11 \mathrm{E}-32$ & $38 E-32$ & $.63 E-32$ & $.97 E-32$ & $6.01 \mathrm{E}-32$ & $6.04 \mathrm{E}-32$ & 6.0 \\
\hline
\end{tabular}


RESRAD-OFFSITE, Version 2.5

$\mathrm{T}^{1 / 2}$ Limit $=180$ days

itle : Offsite Resident Farmer

File : RF TC99 DOESG FWD-FV2all.ROF

Summary of dose at graphical times, reptition 3 (continued)

Time

Years

7. $08 \mathrm{E}+01$

7. $13 \mathrm{E}+01$

7. $18 \mathrm{E}+01$

7. $23 \mathrm{E}+01$

7. $28 \mathrm{E}+01$

7. $33 \mathrm{E}+01$

7. $38 \mathrm{E}+01$

7. $43 \mathrm{E}+01$

7. $49 \mathrm{E}+01$

7. $54 \mathrm{E}+01$

7. $59 \mathrm{E}+01$

7. $64 \mathrm{E}+01$

7. $69 \mathrm{E}+01$

7. $74 \mathrm{E}+01$

$7.79 \mathrm{E}+01$

7. $84 \mathrm{E}+01$

7. $90 \mathrm{E}+01$

7. $95 \mathrm{E}+01$

8. $00 \mathrm{E}+01$

$8.05 \mathrm{E}+01$

$8.10 \mathrm{E}+01$

$8.15 \mathrm{E}+01$

8. $20 \mathrm{E}+01$

8. $25 \mathrm{E}+01$

8. $31 \mathrm{E}+01$

8. $36 \mathrm{E}+01$

8. $41 \mathrm{E}+01$

8. $46 \mathrm{E}+01$

8. $51 \mathrm{E}+01$

8. $56 \mathrm{E}+01$

8. $61 \mathrm{E}+01$

$8.66 \mathrm{E}+01$

$8.72 \mathrm{E}+01$

$8.77 \mathrm{E}+01$

$8.82 \mathrm{E}+01$

$8.87 \mathrm{E}+01$

$8.92 \mathrm{E}+01$

$8.97 \mathrm{E}+01$

9. $02 \mathrm{E}+01$

$9.07 \mathrm{E}+01$

$9.13 \mathrm{E}+01$

$9.18 \mathrm{E}+01$

9. $23 \mathrm{E}+01$

$9.28 \mathrm{E}+01$

$9.33 \mathrm{E}+01$

9. $38 \mathrm{E}+01$
Dose statistics at graphical times, mrem/yr

\begin{tabular}{|c|c|c|c|c|c|c|c|}
\hline $\mathrm{m}$ & aximum & lea & - & & & & \\
\hline $52 E-33$ & $6.16 \mathrm{E}-32$ & $5.42 E-32$ & $5.68 E-32$ & $6.03 E-32$ & $6.06 \mathrm{E}-32$ & $6.09 E-32$ & $-2-32$ \\
\hline $47 E-33$ & $6.22 E-32$ & $5.47 E-32$ & $5.73 E-32$ & $6.08 E-32$ & $6.12 E-32$ & $6.14 \mathrm{E}-32$ & $7 E-32$ \\
\hline $42 E-33$ & $6.27 \mathrm{E}-32$ & $5.51 \mathrm{E}-32$ & $5.78 \mathrm{E}-32$ & $6.13 E-32$ & $6.17 E-32$ & $6.20 \mathrm{E}-32$ & $6.22 E-32$ \\
\hline $38 E-33$ & $33 E-32$ & $55 E-32$ & $82 E-32$ & $18 E-32$ & $23 F-32$ & -32 & $27 F-32$ \\
\hline $33 E-33$ & $6.38 E-32$ & 32 & -32 & 2 & 2 & 32 & 32 \\
\hline 33 & 32 & & & & & & \\
\hline $24 \mathrm{E}-33$ & $6.50 \mathrm{E}-32$ & & $5.97 E-32$ & $6.35 E-32$ & & & -32 \\
\hline $20 E-33$ & -32 & 32 & -32 & 32 & $E-32$ & -32 & -32 \\
\hline $15 \mathrm{E}-33$ & $6.61 E-32$ & $5.78 E-32$ & $6.07 E-32$ & $6.46 \mathrm{E}-32$ & $50 E-32$ & -32 & $E-32$ \\
\hline$E-33$ & $67 E-32$ & תכיט & $2 E-32$ & קח & (6 & 2 & $6.61 \mathrm{E}-32$ \\
\hline-33 & 32 & & & & & & 32 \\
\hline $02 E-33$ & $6.79 E-32$ & $2 E-32$ & -32 & $3 E-32$ & 2 & -32 & -32 \\
\hline $98 \mathrm{E}-33$ & $6.85 E-32$ & $5.97 E-32$ & $6.27 \mathrm{E}-32$ & $6.69 \mathrm{E}-32$ & $6.73 E-32$ & $6.77 E-32$ & $6.79 \mathrm{E}-32$ \\
\hline $.94 \mathrm{E}-33$ & $6.91 E-32$ & $6.02 \mathrm{E}-32$ & $6.32 \mathrm{E}-32$ & & 6.791 & 32 & $35 E-32$ \\
\hline$E-33$ & $97 E-32$ & $06 E-32$ & $E-32$ & 32 & 2 & -32 & -32 \\
\hline $6 E-33$ & $03 E-32$ & & $E-32$ & 2 & (2) & 32 & 32 \\
\hline-33 & 32 & & & & & -32 & 32 \\
\hline $7 E-33$ & 32 & 6 & 2 & 2 & $7.03 E-32$ & 2 & 32 \\
\hline $73 E-33$ & $22 E-32$ & $.26 E-32$ & $9 E-32$ & $0 \Delta F_{-}$ & $295-$ & $E-32$ & $16 E-32$ \\
\hline $69 \mathrm{E}-33$ & $.29 \mathrm{E}-32$ & $6.31 \mathrm{E}-32$ & $6.64 \mathrm{E}-32$ & $0 E-32$ & $.16 \mathrm{E}-$ & $E-32$ & $22 E-32$ \\
\hline 33 & -32 & & & & & -32 & $E-32$ \\
\hline 33 & -32 & & -32 & & & -32 & -32 \\
\hline 3 & & & & & & & \\
\hline $35-33$ & 2 & & 2 & 2 & & & \\
\hline$E-33$ & -32 & & 2 & 2 & 2 & 2 & 32 \\
\hline $46 \mathrm{E}-33$ & $68 E-32$ & $62 E-32$ & $E-32$ & $.48 \mathrm{E}-3$ & $50 \nabla^{2}$ & $.58 E-32$ & $.61 E-32$ \\
\hline $2 E-33$ & $75 E-32$ & & $4 E-32$ & $55 E-32$ & & $E-32$ & $68 E-32$ \\
\hline & & & & & & & \\
\hline & & & & & & -32 & \\
\hline $.31 E-33$ & $7.96 \mathrm{E}-32$ & $6.84 \mathrm{E}-32$ & $7.22 E-32$ & $7.75 E-32$ & $1.01 \mathrm{H} z 2$ & $7.85 E-32$ & $.88 E-32$ \\
\hline $27 E-33$ & . & $.025-32$ & $E-32$ & 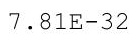 & - & $5-32$ & $95 E-32$ \\
\hline $24 E-33$ & $10 E-32$ & & . & & & & \\
\hline$F-33$ & $5-32$ & $E-32$ & $E-32$ & م5 & תרקט & & $9 E-32$ \\
\hline & & & & & & & \\
\hline & & & & & & & \\
\hline $.09 \mathrm{E}-33$ & $8.39 E-32$ & $7.17 E-32$ & $.58 E-32$ & +0 & 20 & -32 & $.31 E-32$ \\
\hline .0. & $8.4 / E-32$ & & & & & & $8.38 \pm-32$ \\
\hline & $E-32$ & . & $0.2=$ & . & 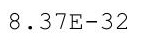 & & $45 E-32$ \\
\hline & $8.62 E-32$ & 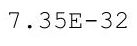 & ( & 2 & 2 & 2 & 32 \\
\hline 33 & 2 & & & & & & 32 \\
\hline$E-33$ & $8.77 E-32$ & $7.47 E-32$ & $E-32$ & 32 & 2 & -32 & -32 \\
\hline$E-33$ & 32 & 2 & & & & & \\
\hline & & & & & & & $.83 E-32$ \\
\hline $8<E-33$ & $9.01 E-32$ & $1.05 E-32$ & $8 \cdot 10 \pm-32$ & $8.75 E-32$ & $8.8< \pm-32$ & $8.87 E-32$ & $8.91 E-32$ \\
\hline$E-33$ & $9.09 E-32$ & $\cdot 1 \perp \mathrm{L}$ & $0.1 / 2-32$ & $0.0<\mathrm{L}$ & . & $8.95 E-32$ & . \\
\hline$E-33$ & $E-32$ & $E-32$ & $.23 E-32$ & $.90 E-32$ & $.98 E-32$ & $9.03 E-32$ & 9.0 \\
\hline
\end{tabular}


RESRAD-OFFSITE, Version 2.5

$\mathrm{T}^{1 / 2}$ Limit $=180$ days

robabilistic Dose and Risk Report

Title : Offsite Resident Farmer

File : RF TC99 DOESG FWD-FV2all.ROF

Summary of dose at graphical times, reptition 3 (continued)

Time

Years

9. $43 \mathrm{E}+01$

9. $48 \mathrm{E}+01$

9. $54 \mathrm{E}+01$

$9.59 \mathrm{E}+01$

$9.64 \mathrm{E}+01$

9. $69 \mathrm{E}+01$

$9.74 \mathrm{E}+01$

9. $79 \mathrm{E}+01$

9. $84 \mathrm{E}+01$

9. $90 \mathrm{E}+01$

9. $95 \mathrm{E}+01$

1. $00 \mathrm{E}+02$

1. $00 \mathrm{E}+02$

1. $01 \mathrm{E}+02$

1. $02 \mathrm{E}+02$

1. $02 \mathrm{E}+02$

1. $03 \mathrm{E}+02$

$1.03 \mathrm{E}+02$

1. $04 \mathrm{E}+02$

1. $04 \mathrm{E}+02$

$1.05 \mathrm{E}+02$

1. $05 \mathrm{E}+02$

$1.06 \mathrm{E}+02$

$1.06 \mathrm{E}+02$

$1.07 \mathrm{E}+02$

$1.07 \mathrm{E}+02$

$1.08 \mathrm{E}+02$

$1.08 \mathrm{E}+02$

1. $09 \mathrm{E}+02$

$1.09 \mathrm{E}+02$

$1.10 \mathrm{E}+02$

1. $10 \mathrm{E}+02$

1. $11 \mathrm{E}+02$

1. $11 \mathrm{E}+02$

1. $12 \mathrm{E}+02$

1. $12 \mathrm{E}+02$

1. $13 \mathrm{E}+02$

1. $13 \mathrm{E}+02$

1. $14 \mathrm{E}+02$

1. $14 \mathrm{E}+02$

1. $15 \mathrm{E}+02$

1. $15 \mathrm{E}+02$

$1.16 \mathrm{E}+02$

$1.16 \mathrm{E}+02$

$1.17 \mathrm{E}+02$

1. $17 \mathrm{E}+02$
Dose statistics at graphical times, mrem/yr

\begin{tabular}{|c|c|c|c|c|c|c|c|}
\hline m & um & ean & n & $90 \%$ & & $\%$ & \\
\hline $.73 E-33$ & $9.25 \mathrm{E}-32$ & $7.84 \mathrm{E}-32$ & $8.30 E-32$ & $8.98 E-32$ & $9.06 \mathrm{E}-32$ & -28 & $-2-32$ \\
\hline $69 \mathrm{E}-33$ & $9.33 E-32$ & $7.90 \mathrm{E}-32$ & $8.37 E-32$ & $9.06 \mathrm{E}-32$ & $9.13 \mathrm{E}-32$ & -32 & -32 \\
\hline $.66 \mathrm{E}-33$ & $9.41 E-32$ & $7.96 \mathrm{E}-32$ & $8.44 \mathrm{E}-32$ & $9.13 \mathrm{E}-32$ & $9.21 \mathrm{E}-32$ & $9.27 \mathrm{E}-32$ & $31 E-32$ \\
\hline-33 & $9.50 \mathrm{E}-32$ & $8.03 E-32$ & $8.51 E-32$ & $9.21 \mathrm{E}-32$ & $9.30 \mathrm{E}-32$ & $5 E-32$ & -32 \\
\hline 33 & 32 & 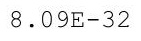 & 32 & $9.29 \mathrm{E}-32$ & & -32 & -32 \\
\hline$E-33$ & 32 & -32 & -32 & -32 & 2 & -32 & -32 \\
\hline $54 \mathrm{E}-33$ & 32 & & & & & & -32 \\
\hline-33 & & & & & & & -32 \\
\hline-33 & 32 & 2 & 32 & 32 & & -32 & -32 \\
\hline-33 & -31 & - & 32 & 2 & 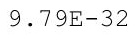 & 2 & -32 \\
\hline 33 & 1 & $9 E-32$ & $2 E-32$ & $79 E-32$ & $88 E-32$ & 2 & 32 \\
\hline 33 & & & & & 2 & & \\
\hline$E-33$ & $3 E-31$ & $8.63 E-32$ & 2 & 2 & & 1 & -31 \\
\hline$E-33$ & $E-31$ & $E-32$ & -32 & - & 17 & -31 & -31 \\
\hline 33 & 31 & 2 & & $\perp$ & 1 & 31 & -31 \\
\hline 33 & 31 & & & $\perp$ & $\perp$ & 31 & -31 \\
\hline 33 & 31 & $8.91 E-32$ & 32 & $\perp$ & 1 & $\perp$ & 31 \\
\hline 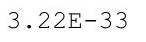 & & & & & & & 31 \\
\hline $20 E-33$ & $1.08 E-31$ & & $9.63 E-32$ & $1.05 E-31$ & & -31 & -31 \\
\hline $17 E-33$ & $1.09 \mathrm{E}-31$ & -3 & -32 & $.06 \mathrm{E}-31$ & $.07 E-31$ & $E-31$ & $.08 \mathrm{E}-31$ \\
\hline $14 \mathrm{E}-33$ & $1.10 \mathrm{E}-31$ & $9.20 \mathrm{E}-32$ & $9.79 E-32$ & $1.07 E-31$ & & $1.08 E-31$ & $1.09 \mathrm{E}-31$ \\
\hline & & & & & & & $.10 E-31$ \\
\hline & & & & & & & \\
\hline$E-33$ & $3 \perp$ & 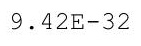 & $\perp$ & & 1 & 1 & -31 \\
\hline 3 & 1 & $9.50 \mathrm{E}-32$ & $\perp$ & 1 & 1 & 1 & -31 \\
\hline$E-33$ & $.27 E-22$ & $10 \mathrm{~s}$ & $.02 E-31$ & $112=$ & 173 & $3 E-31$ & $.14 \mathrm{E}-31$ \\
\hline 33 & 19 & F & 1 & 1 & 114 & $E-31$ & $.15 E-31$ \\
\hline-33 & 18 & 5 & 31 & 1 & 1 & -31 & $16 E-31$ \\
\hline & & & & & & & \\
\hline $91 E-33$ & $1.90 \pm-16$ & . & 1. $05 \mathrm{E}-31$ & $\perp \cdot \pm J$ & I. & $7 E-31$ & -31 \\
\hline $88 E-33$ & $0.405-10$ & $.20+10$ & $1.06 \mathrm{E}-31$ & $1.16 \mathrm{E}-31$ & $1.18 \mathrm{E}-31$ & $1.18 \mathrm{E}-31$ & $.19 \mathrm{E}-31$ \\
\hline 年 & $3.97 \mathrm{E}-14$ & & - & 土. & 20.0 & $2+$ & $1.20 \mathrm{E}-31$ \\
\hline 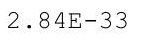 & $1.98 E-13$ & & & & & & 1. $21 \mathrm{E}$ \\
\hline-33 & 3 & & -31 & & & -31 & -31 \\
\hline 33 & & & & & & & \\
\hline 33 & $9.1 \mathrm{U}$ & 4.375 & 31 & $1.2 \angle \amalg$ & $1 \cdot 20$ & 31 & -31 \\
\hline $4 E-33$ & 2.000 & & & 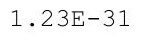 & & & -31 \\
\hline $2 E-33$ & & & & & $\perp \cdot 2 U \Delta-3 \perp$ & & $1.27 \mathrm{E}-31$ \\
\hline 3 & 0 & 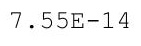 & & 1 & & 1 & 31 \\
\hline & & & & & & & 31 \\
\hline & & & & 1 & 1 & 31 & \\
\hline $3 E-33$ & $E-09$ & $E-13$ & 1 & $1.2 \varepsilon$ & 1.3 & 31 & -31 \\
\hline & 9 & & & & & & \\
\hline & & & & 土. & & & $\perp \cdot 0+\Delta$ \\
\hline & & 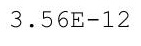 & & . & 1.505 & 31 & $\begin{array}{ll}1.000 \\
0\end{array}$ \\
\hline 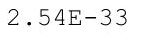 & $E-08$ & $6 E-12$ & $20 E-31$ & $33 E-31$ & $34 E-31$ & $5 E-31$ & 3 \\
\hline
\end{tabular}


RESRAD-OFFSITE, Version 2.5

obabilistic Dose and Risk Report

Title : Offsite Resident Farmer

File : RF TC99 DOESG FWD-FV2all.ROF

Summary of dose at graphical times, reptition 3 (continued)

Time

Years

$1.18 \mathrm{E}+02$

$1.18 \mathrm{E}+02$

$1.19 \mathrm{E}+02$

$1.19 \mathrm{E}+02$

1. $20 \mathrm{E}+02$

$1.20 \mathrm{E}+02$

1. $21 \mathrm{E}+02$

1. $22 \mathrm{E}+02$

$1.22 \mathrm{E}+02$

1. $23 \mathrm{E}+02$

1. $23 \mathrm{E}+02$

$1.24 \mathrm{E}+02$

1. $24 \mathrm{E}+02$

$1.25 \mathrm{E}+02$

1. $25 \mathrm{E}+02$

1. $26 \mathrm{E}+02$

$1.26 \mathrm{E}+02$

1. $27 \mathrm{E}+02$

$1.27 \mathrm{E}+02$

1. $28 \mathrm{E}+02$

1. $28 \mathrm{E}+02$

$1.29 \mathrm{E}+02$

1. $29 \mathrm{E}+02$

1. $30 \mathrm{E}+02$

1. $30 \mathrm{E}+02$

1. $31 \mathrm{E}+02$

1. $31 \mathrm{E}+02$

1. $32 \mathrm{E}+02$

1. $32 \mathrm{E}+02$

1. $33 \mathrm{E}+02$

1. $33 \mathrm{E}+02$

1. $34 \mathrm{E}+02$

$1.34 \mathrm{E}+02$

1. $35 \mathrm{E}+02$

1. $35 \mathrm{E}+02$

1. $36 \mathrm{E}+02$

1. $36 \mathrm{E}+02$

$1.37 \mathrm{E}+02$

1. $37 \mathrm{E}+02$

1. $38 \mathrm{E}+02$

1. $38 \mathrm{E}+02$

1. $39 \mathrm{E}+02$

1. $39 \mathrm{E}+02$

$1.40 \mathrm{E}+02$

1. $40 \mathrm{E}+02$

1. $41 \mathrm{E}+02$
Dose statistics at graphical times, mrem/yr

\begin{tabular}{|c|c|c|c|c|c|c|c|}
\hline um & Maximum & Mean & Median & $90 \%$ & & & \\
\hline $.52 \mathrm{E}-33$ & $1.87 \mathrm{E}-08$ & $9.36 \mathrm{E}-12$ & $1.21 \mathrm{E}-31$ & $1.34 \mathrm{E}-31$ & $1.35 E-31$ & $1.36 \mathrm{E}-31$ & $1.37 \mathrm{E}-31$ \\
\hline $2.50 \mathrm{E}-33$ & $2.90 \mathrm{E}-08$ & $1.46 \mathrm{E}-11$ & $1.22 \mathrm{E}-31$ & $1.35 \mathrm{E}-31$ & $1.37 \mathrm{E}-31$ & $1.38 \mathrm{E}-31$ & $1.39 \mathrm{E}-31$ \\
\hline $2.47 E-33$ & $4.39 \mathrm{E}-08$ & $2.21 \mathrm{E}-11$ & $1.23 E-31$ & $1.36 \mathrm{E}-31$ & $1.38 \mathrm{E}-31$ & $1.39 \mathrm{E}-31$ & $1.40 \mathrm{E}-31$ \\
\hline $2.45 E-33$ & $6.51 \mathrm{E}-08$ & $3.29 \mathrm{E}-11$ & $1.24 \mathrm{E}-31$ & $1.37 \mathrm{E}-31$ & $1.39 \mathrm{E}-31$ & $1.40 \mathrm{E}-31$ & $1.41 E-31$ \\
\hline $2.43 E-33$ & $9.45 \mathrm{E}-08$ & $4.79 \mathrm{E}-11$ & $1.25 \mathrm{E}-31$ & $1.39 \mathrm{E}-31$ & $1.40 \mathrm{E}-31$ & $1.41 \mathrm{E}-31$ & $1.42 \mathrm{E}-31$ \\
\hline $2.41 \mathrm{E}-33$ & $1.35 \mathrm{E}-07$ & $6.86 \mathrm{E}-11$ & $1.26 \mathrm{E}-31$ & $1.40 \mathrm{E}-31$ & $1.41 \mathrm{E}-31$ & $1.42 \mathrm{E}-31$ & $1.44 \mathrm{E}-31$ \\
\hline $2.39 \mathrm{E}-33$ & $1.89 \mathrm{E}-07$ & $9.66 \mathrm{E}-11$ & $1.28 \mathrm{E}-31$ & $1.41 \mathrm{E}-31$ & $1.43 \mathrm{E}-31$ & $1.44 \mathrm{E}-31$ & $1.45 \mathrm{E}-31$ \\
\hline $2.37 \mathrm{E}-33$ & $2.60 \mathrm{E}-07$ & $1.34 \mathrm{E}-10$ & $1.29 \mathrm{E}-31$ & $1.42 \mathrm{E}-31$ & $1.44 \mathrm{E}-31$ & $1.45 E-31$ & $1.46 \mathrm{E}-31$ \\
\hline $2.35 \mathrm{E}-33$ & $3.53 \mathrm{E}-07$ & $1.83 \mathrm{E}-10$ & $1.30 \mathrm{E}-31$ & $1.44 \mathrm{E}-31$ & $1.45 \mathrm{E}-31$ & $1.46 \mathrm{E}-31$ & $1.48 \mathrm{E}-31$ \\
\hline $2.33 E-33$ & $4.73 E-07$ & $2.48 \mathrm{E}-10$ & $1.31 \mathrm{E}-31$ & $1.45 \mathrm{E}-31$ & $1.46 \mathrm{E}-31$ & $1.48 \mathrm{E}-31$ & $1.49 \mathrm{E}-31$ \\
\hline $2.31 \mathrm{E}-33$ & $6.25 \mathrm{E}-07$ & $3.30 \mathrm{E}-10$ & $1.32 \mathrm{E}-31$ & $1.46 \mathrm{E}-31$ & $1.48 \mathrm{E}-31$ & $1.49 \mathrm{E}-31$ & $1.50 \mathrm{E}-31$ \\
\hline $2.29 \mathrm{E}-33$ & $8.17 E-07$ & $4.36 \mathrm{E}-10$ & $1.33 \mathrm{E}-31$ & $1.47 \mathrm{E}-31$ & $1.49 \mathrm{E}-31$ & $1.50 \mathrm{E}-31$ & $1.52 \mathrm{E}-31$ \\
\hline $2.27 E-33$ & $1.05 E-06$ & $5.70 \mathrm{E}-10$ & $1.34 \mathrm{E}-31$ & $1.49 \mathrm{E}-31$ & $1.50 \mathrm{E}-31$ & $1.52 \mathrm{E}-31$ & $1.53 \mathrm{E}-31$ \\
\hline $2.25 E-33$ & $1.35 \mathrm{E}-06$ & $7.37 \mathrm{E}-10$ & $1.35 \mathrm{E}-31$ & $1.50 \mathrm{E}-31$ & $1.52 \mathrm{E}-31$ & $1.53 E-31$ & $1.55 \mathrm{E}-31$ \\
\hline $2.23 E-33$ & $1.71 \mathrm{E}-06$ & $9.45 \mathrm{E}-10$ & $1.36 \mathrm{E}-31$ & $1.51 \mathrm{E}-31$ & $1.53 \mathrm{E}-31$ & $1.54 \mathrm{E}-31$ & $.57 E-31$ \\
\hline $2.21 \mathrm{E}-33$ & $2.14 \mathrm{E}-06$ & $1.20 \mathrm{E}-09$ & $1.38 \mathrm{E}$ & $1.53 \mathrm{E}-31$ & 1.54 & $1.56 \mathrm{E}-31$ & -22 \\
\hline $2.20 \mathrm{E}-33$ & $2.66 \mathrm{E}-06$ & $1.51 \mathrm{E}-09$ & $1.39 \mathrm{E}-31$ & $1.54 \mathrm{E}-31$ & $1.56 \mathrm{E}-31$ & $1.57 \mathrm{E}-31$ & $1.33 \mathrm{E}-19$ \\
\hline $2.18 \mathrm{E}-33$ & $3.28 \mathrm{E}-06$ & $1.90 \mathrm{E}-09$ & $1.40 \mathrm{E}-31$ & $1.55 \mathrm{E}-31$ & $1.57 \mathrm{E}-31$ & $1.58 \mathrm{E}-31$ & $5.86 \mathrm{E}-18$ \\
\hline $2.16 \mathrm{E}-33$ & $4.01 \mathrm{E}-06$ & $2.36 \mathrm{E}-09$ & $1.41 \mathrm{E}-31$ & $1.57 \mathrm{E}-31$ & $1.59 \mathrm{E}-31$ & $1.60 \mathrm{E}-31$ & $1.24 \mathrm{E}-16$ \\
\hline $2.14 \mathrm{E}-33$ & $4.86 \mathrm{E}-06$ & $2.91 \mathrm{E}-09$ & $1.42 \mathrm{E}-31$ & $1.58 \mathrm{E}-31$ & $1.60 \mathrm{E}-31$ & $1.61 \mathrm{E}-31$ & $1.57 \mathrm{E}-15$ \\
\hline $2.12 \mathrm{E}-33$ & $5.86 \mathrm{E}-06$ & $3.57 \mathrm{E}-09$ & $1.43 E-31$ & $1.59 \mathrm{E}-31$ & $1.61 \mathrm{E}-31$ & $1.63 E-31$ & $1.37 \mathrm{E}-14$ \\
\hline $2.10 \mathrm{E}-33$ & $7.02 \mathrm{E}-06$ & $4.35 E-09$ & $1.45 \mathrm{E}-31$ & $1.61 \mathrm{E}-31$ & $1.63 \mathrm{E}-31$ & $1.64 \mathrm{E}-31$ & $8.97 \mathrm{E}-14$ \\
\hline $2.09 \mathrm{E}-33$ & $8.35 E-06$ & $5.27 \mathrm{E}-$ & $1.46 \mathrm{E}-31$ & $1.62 \mathrm{E}-31$ & $1.64 \mathrm{E}-31$ & $1.66 \mathrm{E}-31$ & $4.62 \mathrm{E}-13$ \\
\hline $2.07 \mathrm{E}-33$ & $9.88 \mathrm{E}-06$ & $6.35 \mathrm{E}$ & $1.47 \mathrm{E}-31$ & 1 & 1 & $1.67 E-31$ & $1.945-12$ \\
\hline $2.05 E-3$ & 1 & I & $\perp$ & 1 & 1 & 31 & 12 \\
\hline $2.03 E-33$ & $1.36 \mathrm{E}-05$ & $9.09 \mathrm{E}-09$ & $1.50 \mathrm{E}-31$ & $1.67 \mathrm{E}-31$ & $1.69 \mathrm{E}-31$ & $1.71 \mathrm{E}-31$ & $1.42 \mathrm{E}-11$ \\
\hline $2.02 \mathrm{E}-33$ & $1.58 \mathrm{E}-05$ & $1.08 \mathrm{E}-08$ & $1.51 \mathrm{E}-31$ & $1.68 \mathrm{E}-31$ & $1.70 \mathrm{E}-31$ & $1.72 \mathrm{E}-31$ & $3.37 \mathrm{E}-11$ \\
\hline $2.00 \mathrm{E}-33$ & $1.83 \mathrm{E}-05$ & $1.28 \mathrm{E}-08$ & $1.52 \mathrm{E}-31$ & $1.70 \mathrm{E}-31$ & $1.72 \mathrm{E}-31$ & $1.74 \mathrm{E}-31$ & $7.51 \mathrm{E}-11$ \\
\hline $1.98 \mathrm{E}-33$ & $2.11 E-05$ & $1.50 \mathrm{E}-08$ & $1.53 \mathrm{E}-31$ & $1.71 \mathrm{E}-31$ & $1.73 \mathrm{E}-31$ & $1.75 \mathrm{E}-31$ & $1.58 \mathrm{E}-10$ \\
\hline $1.96 \mathrm{E}-33$ & $2.43 E-05$ & $1.76 \mathrm{E}-08$ & $1.55 E-31$ & $1.73 \mathrm{E}-31$ & $1.75 \mathrm{E}-31$ & $1.77 \mathrm{E}-31$ & $3.15 \mathrm{E}-10$ \\
\hline $1.95 \mathrm{E}-33$ & $2.77 E-05$ & $2.05 E-08$ & $1.56 \mathrm{E}-31$ & $1.74 \mathrm{E}-31$ & $1.76 \mathrm{E}-31$ & $1.79 \mathrm{E}-31$ & $5.99 \mathrm{E}-10$ \\
\hline $1.93 \mathrm{E}-33$ & $3.16 \mathrm{E}-05$ & $2.39 \mathrm{E}-08$ & $1.57 \mathrm{E}-31$ & $1.76 \mathrm{E}-31$ & $1.78 \mathrm{E}-31$ & $1.80 \mathrm{E}-31$ & $1.09 \mathrm{E}-09$ \\
\hline $1.92 \mathrm{E}-33$ & $3.58 \mathrm{E}-05$ & $2.77 \mathrm{E}-08$ & $1.59 \mathrm{E}-31$ & $1.77 \mathrm{E}-31$ & $1.80 \mathrm{E}-31$ & $1.82 \mathrm{E}-31$ & $1.92 \mathrm{E}-09$ \\
\hline $1.90 \mathrm{E}-33$ & $4.05 E-05$ & $3.20 \mathrm{E}-08$ & $1.60 \mathrm{E}-31$ & $1.79 \mathrm{E}-31$ & $1.81 \mathrm{E}-31$ & $1.84 \mathrm{E}-31$ & $3.27 \mathrm{E}-09$ \\
\hline $1.88 \mathrm{E}-33$ & $4.56 \mathrm{E}-05$ & $3.68 \mathrm{E}-08$ & $1.61 \mathrm{E}-31$ & $1.80 \mathrm{E}-31$ & $1.83 \mathrm{E}-31$ & $1.86 \mathrm{E}-31$ & $5.37 \mathrm{E}-09$ \\
\hline $1.87 \mathrm{E}-33$ & $5.12 \mathrm{E}-05$ & $4.23 E-08$ & $1.63 \mathrm{E}-31$ & $1.82 \mathrm{E}-31$ & $1.85 \mathrm{E}-31$ & $1.87 \mathrm{E}-31$ & $8.58 \mathrm{E}-09$ \\
\hline $1.85 \mathrm{E}-33$ & $5.74 \mathrm{E}-05$ & $4.84 \mathrm{E}-08$ & $1.64 \mathrm{E}-31$ & $1.84 \mathrm{E}-31$ & $1.86 \mathrm{E}-31$ & $1.89 \mathrm{E}-31$ & $1.33 \mathrm{E}-08$ \\
\hline $1.84 \mathrm{E}-33$ & $6.40 \mathrm{E}-05$ & $5.52 \mathrm{E}-08$ & $1.65 \mathrm{E}-31$ & $1.85 \mathrm{E}-31$ & $1.88 \mathrm{E}-31$ & $1.92 \mathrm{E}-31$ & $2.02 \mathrm{E}-08$ \\
\hline $1.82 \mathrm{E}-33$ & $7.12 \mathrm{E}-05$ & $6.28 \mathrm{E}-08$ & $1.67 \mathrm{E}-31$ & $1.87 \mathrm{E}-31$ & $1.90 \mathrm{E}-31$ & $4.26 \mathrm{E}-24$ & $3.00 \mathrm{E}-08$ \\
\hline $1.80 \mathrm{E}-33$ & $7.91 \mathrm{E}-05$ & $7.12 \mathrm{E}-08$ & $1.68 \mathrm{E}-31$ & $1.89 \mathrm{E}-31$ & $1.91 \mathrm{E}-31$ & $1.73 E-21$ & $4.36 \mathrm{E}-08$ \\
\hline $1.79 \mathrm{E}-33$ & $8.75 E-05$ & $8.06 \mathrm{E}-08$ & $1.70 \mathrm{E}-31$ & $1.90 \mathrm{E}-31$ & $1.93 \mathrm{E}-31$ & $1.36 \mathrm{E}-19$ & $6.21 \mathrm{E}-08$ \\
\hline $1.77 \mathrm{E}-33$ & $9.67 \mathrm{E}-05$ & $9.11 \mathrm{E}-08$ & $1.71 \mathrm{E}-31$ & $1.92 \mathrm{E}-31$ & $1.95 \mathrm{E}-31$ & $4.17 \mathrm{E}-18$ & $8.69 \mathrm{E}-08$ \\
\hline $1.76 \mathrm{E}-33$ & $1.07 \mathrm{E}-04$ & $1.03 \mathrm{E}-07$ & $1.73 \mathrm{E}-31$ & $1.94 \mathrm{E}-31$ & $1.97 \mathrm{E}-31$ & $6.83 \mathrm{E}-17$ & $1.20 \mathrm{E}-07$ \\
\hline $1.74 \mathrm{E}-33$ & $1.17 \mathrm{E}-04$ & $1.15 \mathrm{E}-07$ & $1.74 \mathrm{E}-31$ & $1.96 \mathrm{E}-31$ & $1.99 \mathrm{E}-31$ & 7. $31 E-16$ & $1.62 \mathrm{E}-07$ \\
\hline $1.73 \mathrm{E}-33$ & $1.28 \mathrm{E}-04$ & $1.29 \mathrm{E}-07$ & $1.75 \mathrm{E}-31$ & $1.97 \mathrm{E}-31$ & $2.00 \mathrm{E}-31$ & $5.68 \mathrm{E}-15$ & $2.17 \mathrm{E}-07$ \\
\hline $1.71 \mathrm{E}-33$ & $1.41 \mathrm{E}-04$ & $1.45 \mathrm{E}-07$ & $1.77 \mathrm{E}-31$ & $1.99 \mathrm{E}-31$ & $2.02 E-31$ & $3.41 E-14$ & $2.86 \mathrm{E}-07$ \\
\hline
\end{tabular}


RESRAD-OFFSITE, Version 2.5 
RESRAD-OFFSITE, Version 2.5

robabilistic Dose and Risk Report

Title : Offsite Resident Farmer

File : RF TC99 DOESG FWD-FV2all.ROF

Summary of dose at graphical times, reptition 3 (continued)

Time

Years

$1.65 \mathrm{E}+02$

$1.66 \mathrm{E}+02$

1. $66 \mathrm{E}+02$

1. $67 \mathrm{E}+02$

1. $67 \mathrm{E}+02$

1. $68 \mathrm{E}+02$

1. $68 \mathrm{E}+02$

1. $69 \mathrm{E}+02$

1. $69 \mathrm{E}+02$

1. $70 \mathrm{E}+02$

1. $70 \mathrm{E}+02$

1. $71 \mathrm{E}+02$

1. $71 \mathrm{E}+02$

1. $72 \mathrm{E}+02$

$1.72 \mathrm{E}+02$

1. $73 \mathrm{E}+02$

1. $73 \mathrm{E}+02$

1. $74 \mathrm{E}+02$

1. $74 \mathrm{E}+02$

1. $75 \mathrm{E}+02$

1. $75 \mathrm{E}+02$

$1.76 \mathrm{E}+02$

$1.76 \mathrm{E}+02$

$1.77 \mathrm{E}+02$

$1.77 \mathrm{E}+02$

$1.78 \mathrm{E}+02$

$1.78 \mathrm{E}+02$

$1.79 \mathrm{E}+02$

$1.79 \mathrm{E}+02$

$1.80 \mathrm{E}+02$

$1.80 \mathrm{E}+02$

1. $81 \mathrm{E}+02$

1. $81 \mathrm{E}+02$

1. $82 \mathrm{E}+02$

1. $83 \mathrm{E}+02$

1. $83 \mathrm{E}+02$

1. $84 \mathrm{E}+02$

1. $84 \mathrm{E}+02$

1. $85 \mathrm{E}+02$

$1.85 \mathrm{E}+02$

$1.86 \mathrm{E}+02$

$1.86 \mathrm{E}+02$

$1.87 \mathrm{E}+02$

$1.87 \mathrm{E}+02$

$1.88 \mathrm{E}+02$

$1.88 \mathrm{E}+02$
Dose statistics at graphical times, mrem/yr

\begin{tabular}{|c|c|c|c|c|c|c|c|}
\hline $\mathrm{m}$ & aximum & lea & ed & $0 \%$ & & $\%$ & \\
\hline $92 E-33$ & $2.49 \mathrm{E}-03$ & $6.19 \mathrm{E}-06$ & $2.65 E-31$ & $3.06 \mathrm{E}-31$ & $1.10 \mathrm{E}-07$ & $.77 E-05$ & $4-04$ \\
\hline $90 E-33$ & $2.60 E-03$ & $6.56 \mathrm{E}-06$ & $2.67 \mathrm{E}-31$ & $8 E-31$ & $1.52 \mathrm{E}-07$ & $1.99 \mathrm{E}-05$ & $51 E-04$ \\
\hline $88 E-33$ & $2.72 \mathrm{E}-03$ & $6.95 \mathrm{E}-06$ & $2.70 \mathrm{E}-31$ & $12 E-31$ & $2.08 \mathrm{E}-07$ & $2.24 \mathrm{E}-05$ & $1.72 \mathrm{E}-04$ \\
\hline-33 & $84 E-03$ & $36 \mathrm{~F}-06$ & $72 F-31$ & $15 E-31$ & $68 \mathrm{~F}-07$ & $50 \mathrm{~F}-0.5$ & $.84 E-04$ \\
\hline-33 & 03 & 6 & 1 & 1 & $36 E-07$ & 5 & -04 \\
\hline 33 & 03 & & & & & & 04 \\
\hline $81 E-33$ & $3.22 \mathrm{E}-03$ & & & & & & -04 \\
\hline-33 & 03 & 0 & $\perp$ & 1 & 7 & 5 & $36 E-04$ \\
\hline $8 E-33$ & $3.49 E-03$ & $1 E-06$ & -31 & $34 E-31$ & 年 & -05 & $E-04$ \\
\hline$E-33$ & 03 & $03 E-05$ & . & & $11 \Gamma$ & תקר & 685 \\
\hline 33 & 3 & & & & & & 04 \\
\hline $72 E-33$ & -03 & & $2.91 E-31$ & $2.68 \mathrm{E}-18$ & 6 & 5 & -04 \\
\hline $70 E-33$ & $4.10 E-03$ & $1.20 \mathrm{E}-05$ & & & $2.03 E-06$ & & $3.25 E-04$ \\
\hline $69 E-33$ & -03 & $1.27 \mathrm{E}-05$ & $2.97 \mathrm{E}-31$ & $4.29 \mathrm{E}-16$ & & -05 & $E-04$ \\
\hline$E-33$ & 03 & 05 & $\perp$ & & & J & $E-04$ \\
\hline-33 & s & 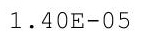 & 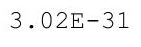 & 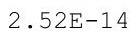 & & 5 & 04 \\
\hline 3 & 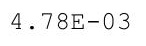 & & & & & & 4 \\
\hline 33 & 4 & $1.55 \mathrm{E}-05$ & $3.07 E-31$ & & $4.27 E-06$ & 5 & -04 \\
\hline $60 E-33$ & $5.15 E-03$ & $1.63 E-05$ & $3.10 \mathrm{E}-31$ & $2 \cdot 32 E-12$ & $4.87 E-06$ & $7 E-05$ & $4.39 E-04$ \\
\hline $58 E-33$ & $5.35 E-03$ & $1.71 \mathrm{E}-05$ & $3.13 E-31$ & $7.50 \mathrm{E}-12$ & $5.61 \mathrm{E}-06$ & $9.94 \mathrm{E}-05$ & $4.59 \mathrm{E}-04$ \\
\hline 33 & & & & & & -04 & -04 \\
\hline 33 & & & $\perp$ & 10 & 0 & -04 & -04 \\
\hline $53 E-33$ & 5.9 & $\perp \cdot$ & $3.21 E-31$ & 年 & & -04 & 04 \\
\hline-33 & 3 & 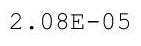 & $3.24 \mathrm{E}-31$ & 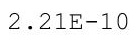 & $9.16 \mathrm{E}-06$ & 4 & -04 \\
\hline 3 & 3 & 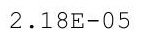 & 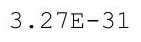 & Fח & 5 & 4 & $E-04$ \\
\hline $48 E-33$ & $6.64 \mathrm{E}-03$ & $2.28 E-05$ & $3.29 E-31$ & $7.66 \mathrm{E}-$ & $1.17 \mathrm{E}-$ & $1.46 \mathrm{E}-04$ & $6.06 \mathrm{E}-04$ \\
\hline$E-33$ & $E-03$ & $39 F-05$ & 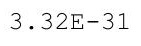 & 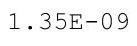 & & $E-04$ & $46 E-04$ \\
\hline & & & & & & & \\
\hline $3 E-33$ & $7.37 E-03$ & -03 & $E-31$ & $3 \cdot 1+1$ & 1. & & $E-04$ \\
\hline $42 E-33$ & $1.02 \mathrm{E}-03$ & $2 \cdot 10 \pm-0 丁$ & $3.41 E-31$ & . & 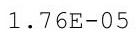 & $1.015-04$ & $.74 E-04$ \\
\hline $40 E-33$ & 3 & $2.87 E-05$ & $3.44 \mathrm{E}-31$ & $9.46 \mathrm{E}-09$ & म. & म. & $.09 E-04$ \\
\hline 3 & $8.15 E-03$ & & 然 & & & $D E-04$ & $45 E-04$ \\
\hline-33 & -03 & $F-05$ & $E-31$ & $6 \pi$ & 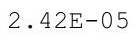 & -04 & $82 E-04$ \\
\hline-33 & 3 & & & & & & \\
\hline $4 E-33$ & $9.00 \mathrm{E}-03$ & $3.43 E-05$ & $E-31$ & 配 & 5 & 4 & $57 E-04$ \\
\hline $32 E-33$ & $9.30 E-03$ & $3.58 E-05$ & $3.60 \mathrm{E}-31$ & 0.025 & 3.20 & & $97 E-04$ \\
\hline $31 E-33$ & . & $3.145-05$ & & & & & $1.04 \mathrm{E}-03$ \\
\hline 3 & 3 & (.) & (2) & $=0$ & & & $1.08 \mathrm{E}-03$ \\
\hline & $1.02 \mathrm{E}-02$ & 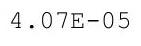 & 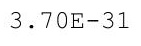 & 7 & & & 03 \\
\hline 3 & & & & & & & \\
\hline$E-33$ & $1.09 \mathrm{E}-02$ & 4. & $E-31$ & 2 . & 5 & & -03 \\
\hline & $1.13 \mathrm{E}$ & & & 7 & & & 03 \\
\hline & & & & & & & $1.31 \mathrm{E}-03$ \\
\hline $20 \pm-33$ & $1 \cdot \angle 0 E-0 \angle$ & . & $3.87 \mathrm{E}-31$ & $5.03 E-07$ & $6.83 E-05$ & $3.86 \mathrm{E}-04$ & $1.30 \mathrm{E}-03$ \\
\hline 3 & $1.23 E-02$ & 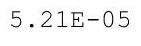 & $.0+4$ & . & $1.40 \mathrm{D}$ & & $1.41 \mathrm{E}-03$ \\
\hline-33 & $1.27 \mathrm{E}-02$ & $.42 E-05$ & $94 \mathrm{E}-31$ & -07 & -05 & 4. & 1.4 \\
\hline
\end{tabular}


RESRAD-OFFSITE, Version 2.5

$\mathrm{T}^{1 / 2}$ Limit $=180$ days

obabilistic Dose and Risk Report

Title : Offsite Resident Farmer

File : RF TC99 DOESG FWD-FV2all.ROF

Summary of dose at graphical times, reptition 3 (continued)

Time

Years

$1.89 \mathrm{E}+02$

$1.89 \mathrm{E}+02$

$1.90 \mathrm{E}+02$

$1.90 \mathrm{E}+02$

$1.91 \mathrm{E}+02$

$1.91 \mathrm{E}+02$

$1.92 \mathrm{E}+02$

$1.92 \mathrm{E}+02$

$1.93 \mathrm{E}+02$

$1.93 \mathrm{E}+02$

$1.94 \mathrm{E}+02$

$1.94 \mathrm{E}+02$

$1.95 \mathrm{E}+02$

$1.95 \mathrm{E}+02$

$1.96 \mathrm{E}+02$

$1.96 \mathrm{E}+02$

$1.97 \mathrm{E}+02$

$1.97 \mathrm{E}+02$

1. $98 \mathrm{E}+02$

$1.98 \mathrm{E}+02$

$1.99 \mathrm{E}+02$

$1.99 \mathrm{E}+02$

$2.00 \mathrm{E}+02$

$2.00 \mathrm{E}+02$

$2.01 \mathrm{E}+02$

$2.01 \mathrm{E}+02$

$2.02 \mathrm{E}+02$

$2.03 \mathrm{E}+02$

$2.03 E+02$

$2.04 \mathrm{E}+02$

$2.04 \mathrm{E}+02$

$2.05 \mathrm{E}+02$

$2.05 \mathrm{E}+02$

$2.06 \mathrm{E}+02$

$2.06 \mathrm{E}+02$

$2.07 \mathrm{E}+02$

$2.07 \mathrm{E}+02$

$2.08 \mathrm{E}+02$

$2.08 \mathrm{E}+02$

$2.09 \mathrm{E}+02$

$2.09 \mathrm{E}+02$

$2.10 \mathrm{E}+02$

$2.10 \mathrm{E}+02$

$2.11 \mathrm{E}+02$

2. $11 \mathrm{E}+02$

$2.12 \mathrm{E}+02$
Dose statistics at graphical times, mrem/yr

\begin{tabular}{|c|c|c|c|c|c|c|c|}
\hline $\mathrm{m}$ & aximum & lea & ed & & & & \\
\hline $15 E-33$ & 1. $31 \mathrm{E}-02$ & $5.64 \mathrm{E}-05$ & $3.98 E-31$ & $1.03 \mathrm{E}-06$ & $8.66 \mathrm{E}-05$ & -04 & $-.325-03$ \\
\hline $14 \mathrm{E}-33$ & $1.35 E-02$ & $5.87 \mathrm{E}-05$ & $4.02 \mathrm{E}-31$ & $1.28 \mathrm{E}-06$ & $20 E-05$ & $4.61 E-04$ & $8 E-03$ \\
\hline $12 \mathrm{E}-33$ & 1. 39E-02 & $6.11 \mathrm{E}-05$ & $4.05 E-31$ & $1.56 \mathrm{E}-06$ & $9.76 \mathrm{E}-05$ & $4.82 \mathrm{E}-04$ & $.65 E-03$ \\
\hline $11 \mathrm{E}-33$ & $43 E-02$ & $35 \mathrm{~F}-05$ & $09-31$ & $86 \mathrm{E}-06$ & $04 \mathrm{~F}-04$ & $05 \mathrm{~F}-04$ & $72 \mathrm{~F}-03$ \\
\hline $0 E-33$ & -02 & $6.60 \mathrm{E}-05$ & $4.12 \mathrm{E}-31$ & 66 & 4 & 04 & 03 \\
\hline 33 & 02 & & & & & & \\
\hline $.07 E-33$ & $1.56 \mathrm{E}-02$ & & & & $.29 E-04$ & & \\
\hline-33 & -02 & 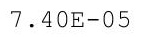 & $\perp$ & 6 & 4 & -04 & -03 \\
\hline $04 E-33$ & $1.65 \mathrm{E}-02$ & $8 E-05$ & $4.28 E-31$ & -06 & $46 E-04$ & $E-04$ & $2 E-03$ \\
\hline$E-33$ & $.70 \mathrm{E}-02$ & תم & $325-31$ & $.19 E-06$ & 5 & $.53 E-04$ & $21 \mathrm{~F}-03$ \\
\hline 33 & 02 & & & & & 4 & 3 \\
\hline $99 E-33$ & $1.80 \mathrm{E}-02$ & 8 & & 6 & 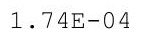 & 4 & 03 \\
\hline $98 E-33$ & $1.85 \mathrm{E}-02$ & & & & & $7.49 E-04$ & $9 E-03$ \\
\hline $97 E-33$ & -02 & $9.24 \mathrm{E}-05$ & $4.48 \mathrm{E}-31$ & $8.37 \mathrm{E}-06$ & $1.96 \mathrm{E}-$ & $7.91 \mathrm{E}-04$ & $2.59 \mathrm{E}-03$ \\
\hline $95 E-33$ & -02 & (c) & $\perp$ & -06 & T & -04 & $E-03$ \\
\hline 33 & -02 & $9.92 E-05$ & & 5 & (2) & $E-04$ & $79 E-03$ \\
\hline 3 & 2 & & & & & & 3 \\
\hline 3 & 2 & $107 \mathrm{~F}-04$ & & 5 & $2.50 \mathrm{E}-04$ & $9.28 E-04$ & 3 \\
\hline $37 E-32$ & $2.17 \mathrm{E}-02$ & $1.10 \mathrm{E}-04$ & $4.69 E-31$ & $1.47 E-05$ & $2.65 E-0$ & $9.67 \mathrm{E}-04$ & $.12 \mathrm{E}-03$ \\
\hline $37 E-32$ & $2.23 \mathrm{E}-02$ & $1.14 \mathrm{E}-0$ & $4.73 E-31$ & $1.60 \mathrm{E}-05$ & $2.80 \mathrm{E}-$ & $E-03$ & $24 E-03$ \\
\hline-32 & 02 & & & & & -03 & $E-03$ \\
\hline 32 & 02 & & & & & -03 & 03 \\
\hline 32 & $2 \cdot 4$ & $1 \cdot 2 t$ & & & & & \\
\hline $36 E-32$ & $2.47 \mathrm{E}-02$ & $1.01+$ & $4.91 E-31$ & 5 & & $1.19 \mathrm{E}-03$ & 3 \\
\hline 2 & 2 & 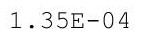 & $4.95 E-31$ & 5 & $3.59 \mathrm{E}-04$ & 3 & 3 \\
\hline $36 E-32$ & $.60 E-02$ & 1 & $E-31$ & $267=0$ & 70 & $.28 E-03$ & $93 F-03$ \\
\hline$E-32$ & $2.66 \mathrm{E}-02$ & & & & & $1 F-03$ & $05 E-03$ \\
\hline & & & & & & & \\
\hline 32 & $2.80 \mathrm{E}-02$ & $1.00 \mathrm{~L}$ & & 3 & 年 & & \\
\hline $36 E-32$ & $2.87 E-02$ & $\perp .00 \amalg-4$ & $3.10 \pm-31$ & $3.62 E-05$ & 1.120 & $1.52 \mathrm{E}-03$ & $.40 E-03$ \\
\hline $36 \mathrm{E}-32$ & $2.94 \mathrm{E}-02$ & 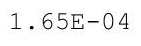 & 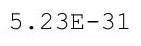 & $3.87 \mathrm{E}-05$ & 1. & $1.02 \mathrm{E}-0$ & $.53 E-03$ \\
\hline 年 & $.0+\square$ & 20 & (5) & 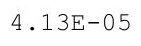 & 年 & 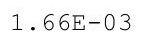 & \\
\hline 32 & $3.09 F-02$ & $1.76 \mathrm{E}-$ & & & & & $79 F-03$ \\
\hline 32 & & & & & & & \\
\hline$E-32$ & & & & 05 & & 03 & -03 \\
\hline $35 E-32$ & $3.32 \mathrm{E}-02$ & $1.95 E-04$ & $.49 E-31$ & 0.04 & . & -03 & $9 E-03$ \\
\hline $35 E-32$ & $3.39 E-02$ & 2.000 & & .00 & & & 0 \\
\hline $35 E-32$ & $3.47 \mathrm{E}-02$ & & & $.56 \mathrm{E}-05$ & & & $.48 E-03$ \\
\hline 2 & 2 & 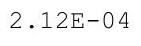 & 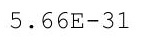 & 5 & & 3 & $5.62 \mathrm{E}-03$ \\
\hline 2 & 3 & & & & 4 & & 3 \\
\hline$E-32$ & $3.72 \mathrm{E}-02$ & $2.26 \mathrm{E}-04$ & 1 & 7 & 4 & 03 & 03 \\
\hline$E-32$ & $3.81 E-02$ & $2.32 \mathrm{E}$ & & & 4 & 03 & 03 \\
\hline & 2 & & & & & & \\
\hline & $.90 \mathrm{~L}$ & . & ( & 5 & $\cdot \pm \perp$ & $6 E-03$ & $40 E-03$ \\
\hline 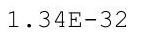 & $4.07 E-02$ & 2.0 & & 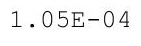 & & & 03 \\
\hline $4 E-32$ & $.17 \mathrm{E}-02$ & $2 E-04$ & $04 E-31$ & $E-04$ & $3 E-04$ & $.74 E-03$ & 03 \\
\hline
\end{tabular}


RESRAD-OFFSITE, Version 2.5 
RESRAD-OFFSITE, Version 2.5

$\mathrm{T}^{1 / 2}$ Limit $=180$ days

obabilistic Dose and Risk Report

Title : Offsite Resident Farmer

File : RF TC99 DOESG FWD-FV2all.ROF

Summary of dose at graphical times, reptition 3 (continued)

Time

Years

$2.36 \mathrm{E}+02$

2. $36 \mathrm{E}+02$

$2.37 \mathrm{E}+02$

$2.37 \mathrm{E}+02$

$2.38 \mathrm{E}+02$

2. $38 \mathrm{E}+02$

$2.39 \mathrm{E}+02$

$2.39 \mathrm{E}+02$

$2.40 \mathrm{E}+02$

$2.40 \mathrm{E}+02$

$2.41 \mathrm{E}+02$

$2.41 \mathrm{E}+02$

$2.42 \mathrm{E}+02$

$2.43 \mathrm{E}+02$

$2.43 \mathrm{E}+02$

$2.44 \mathrm{E}+02$

$2.44 \mathrm{E}+02$

$2.45 \mathrm{E}+02$

$2.45 \mathrm{E}+02$

$2.46 \mathrm{E}+02$

$2.46 \mathrm{E}+02$

$2.47 \mathrm{E}+02$

$2.47 \mathrm{E}+02$

$2.48 \mathrm{E}+02$

$2.48 \mathrm{E}+02$

$2.49 \mathrm{E}+02$

$2.49 \mathrm{E}+02$

$2.50 \mathrm{E}+02$

$2.50 \mathrm{E}+02$

$2.51 \mathrm{E}+02$

$2.51 \mathrm{E}+02$

$2.52 \mathrm{E}+02$

$2.52 \mathrm{E}+02$

$2.53 \mathrm{E}+02$

$2.53 \mathrm{E}+02$

$2.54 \mathrm{E}+02$

$2.54 \mathrm{E}+02$

$2.55 \mathrm{E}+02$

$2.55 \mathrm{E}+02$

$2.56 \mathrm{E}+02$

$2.56 \mathrm{E}+02$

$2.57 \mathrm{E}+02$

$2.57 \mathrm{E}+02$

$2.58 \mathrm{E}+02$

$2.58 \mathrm{E}+02$

$2.59 \mathrm{E}+02$
Dose statistics at graphical times, mrem/yr

\begin{tabular}{|c|c|c|c|c|c|c|c|}
\hline m & aximum & ean & 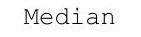 & & & $\%$ & \\
\hline $30 E-32$ & $1.03 \mathrm{E}-01$ & $8.81 E-04$ & $9.60 \mathrm{E}-31$ & $9.14 \mathrm{E}-04$ & $3.91 E-03$ & -03 & $-0<$ \\
\hline $30 E-32$ & $1.05 \mathrm{E}-01$ & $1 E-04$ & $9.70 \mathrm{E}-31$ & -2 & 3 & 3 & -02 \\
\hline $.30 E-32$ & $1.07 \mathrm{E}-01$ & $1 E-04$ & $9.81 \mathrm{E}-31$ & $9.79 \mathrm{E}-04$ & $10 \mathrm{E}-03$ & $9.73 E-03$ & $2.06 \mathrm{E}-02$ \\
\hline $30 E-32$ & $1.08 \mathrm{E}-01$ & $9.42 \mathrm{E}-04$ & $9.90 \mathrm{E}-31$ & $1.01 \mathrm{E}-03$ & $4.20 E-03$ & $94 \mathrm{E}-03$ & $2.11 \mathrm{E}-02$ \\
\hline $9 \mathrm{E}-32$ & $0 \mathrm{E}-01$ & $\Delta \mathrm{F}-202-1$ & $99 \mathrm{E}-31$ & 3 & & 02 & -02 \\
\hline-32 & 1 & $E_{-1}(-3)$ & 0 & 3 & & -02 & -02 \\
\hline $29 \mathrm{E}-32$ & & & & & & & -02 \\
\hline $29 E-32$ & & & & & & & -02 \\
\hline-32 & 01 & -0 & & 3 & 3 & -02 & -02 \\
\hline $29 \mathrm{E}-32$ & -01 & - & 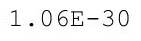 & 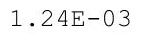 & $4.87 \mathrm{E}-03$ & 2 & -02 \\
\hline$E-32$ & 1 & $1.10 \mathrm{E}-03$ & 7E-30 & $1.27 E-03$ & & 2 & 2 \\
\hline 32 & 1 & & & & & & -02 \\
\hline $29 \mathrm{E}-32$ & $1.25 E-01$ & $5 \mathrm{~F}-\ell(2)-1$ & & 34 & 3 & -02 & -02 \\
\hline $.29 \mathrm{E}-32$ & $1.27 \mathrm{E}-01$ & $1.17 \mathrm{E}-03$ & $1.10 \mathrm{E}-30$ & $1.38 \mathrm{E}-03$ & $5.43 \mathrm{E}-03$ & $1.22 \mathrm{E}-02$ & $2.60 \mathrm{E}-02$ \\
\hline 32 & $E-01$ & 3 & & 3 & & -02 & -02 \\
\hline 32 & 1 & 1. $22 \mathrm{E}-03$ & 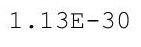 & 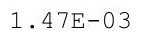 & 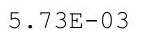 & 02 & -02 \\
\hline 32 & 01 & $1.25 \mathrm{E}-03$ & & 3 & 03 & 2 & 02 \\
\hline 32 & 1 & & & & & & 2 \\
\hline $28 \mathrm{E}-32$ & $1.37 \mathrm{E}-01$ & $130 \mathrm{~F}-$ & & & & & -02 \\
\hline $28 \mathrm{E}-32$ & $1.39 \mathrm{E}-01$ & $1.33 \mathrm{E}-0$ & -3 & $1.65 \mathrm{E}-03$ & $.28 \mathrm{E}-03$ & $1.37 \mathrm{E}-02$ & $.93 E-02$ \\
\hline $28 E-32$ & $1.41 \mathrm{E}-01$ & $1.36 \mathrm{E}-03$ & & $1.70 \mathrm{E}-03$ & & $E-02$ & $99 E-02$ \\
\hline 32 & & & & & & & $06 E-02$ \\
\hline 2 & & & & & & & 02 \\
\hline $28 E-32$ & $1 \cdot 4$ & $\perp$ & 1. & & & & -02 \\
\hline 2 & 1 & $\perp \cdot 1$ & $1.26 \mathrm{E}-30$ & 3 & $6.97 \mathrm{E}-03$ & 2 & 02 \\
\hline $27 E-32$ & $.52 \mathrm{E}-01$ & $150 \square$ & 1 & 1 & 117 & $3 E-02$ & $30 E-02$ \\
\hline-32 & 15 & 1 & & 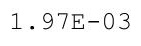 & & $E-02$ & $E-02$ \\
\hline-32 & 1 & & & & & -02 & $42 E-02$ \\
\hline & & & & & & & \\
\hline $27 E-32$ & 1. $61 \mathrm{E}-01$ & $\perp \cdot 0 J \pm-0 J$ & $\perp \cdot 00$ & $2 \cdot \perp 01$ & . 1 & & -02 \\
\hline $27 E-32$ & $1.045-01$ & 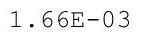 & $\measuredangle \cdot \perp \angle \sqcup \perp 0$ & $2.18 \mathrm{E}-03$ & $.00 \mathrm{E}$ & $1.00 \mathrm{~L}-\mathrm{Z}$ & $.62 E-02$ \\
\hline $27 E-32$ & 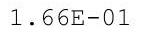 & 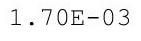 & & & & 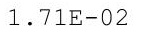 & $3.69 \mathrm{E}-02$ \\
\hline 2 & $B E-$ & $B E-$ & 1 & & & & -02 \\
\hline$F-32$ & 17 & & & & & -02 & 02 \\
\hline 32 & 1 & & & & & & \\
\hline & & 1.8 & 2 & 2.41 & 3 & 02 & 02 \\
\hline $26 E-32$ & 1. 78E-01 & 1.8 & & & & & -02 \\
\hline $26 E-32$ & \pm .000 & & & & & & 02 \\
\hline 2 & 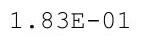 & 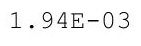 & $2.43 E-11$ & & & 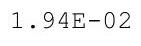 & 02 \\
\hline $26 \mathrm{E}-32$ & & & & & & & 2 \\
\hline 2 & & & & 3 & 3 & 2 & \\
\hline $6 E-32$ & 1.90E-01 & 2. & 2. & 2 . & & & -02 \\
\hline & 1 & & & & & & \\
\hline & $1 \cdot 3$ & . & . & & $\pm \cdot 0+\square$ & & $4.54 \mathrm{E}-\mathrm{U}<$ \\
\hline & \pm & & & 3 & 2 & & $62 E-02$ \\
\hline 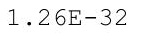 & $E-01$ & It 00 & $35 E-09$ & $E-03$ & $E-02$ & $4 E-02$ & -02 \\
\hline
\end{tabular}


RESRAD-OFFSITE, Version 2.5

$\mathrm{T}^{1 / 2}$ Limit $=180$ days

Title : Offsite Resident Farmer

File : RF TC99 DOESG FWD-FV2all.ROF

Summary of dose at graphical times, reptition 3 (continued)

Time

Years

$2.59 \mathrm{E}+02$

$2.60 \mathrm{E}+02$

$2.60 \mathrm{E}+02$

$2.61 \mathrm{E}+02$

$2.61 \mathrm{E}+02$

2. $62 \mathrm{E}+02$

2. $63 \mathrm{E}+02$

$2.63 \mathrm{E}+02$

2. $64 \mathrm{E}+02$

$2.64 \mathrm{E}+02$

$2.65 \mathrm{E}+02$

$2.65 \mathrm{E}+02$

$2.66 \mathrm{E}+02$

$2.66 \mathrm{E}+02$

$2.67 \mathrm{E}+02$

$2.67 \mathrm{E}+02$

$2.68 \mathrm{E}+02$

$2.68 \mathrm{E}+02$

$2.69 \mathrm{E}+02$

$2.69 \mathrm{E}+02$

$2.70 \mathrm{E}+02$

$2.70 \mathrm{E}+02$

$2.71 \mathrm{E}+02$

$2.71 \mathrm{E}+02$

2. $72 \mathrm{E}+02$

$2.72 \mathrm{E}+02$

$2.73 E+02$

$2.73 \mathrm{E}+02$

$2.74 \mathrm{E}+02$

$2.74 \mathrm{E}+02$

$2.75 \mathrm{E}+02$

$2.75 \mathrm{E}+02$

$2.76 \mathrm{E}+02$

$2.76 \mathrm{E}+02$

$2.77 \mathrm{E}+02$

$2.77 \mathrm{E}+02$

$2.78 \mathrm{E}+02$

$2.78 \mathrm{E}+02$

$2.79 \mathrm{E}+02$

$2.79 \mathrm{E}+02$

$2.80 \mathrm{E}+02$

$2.80 \mathrm{E}+02$

$2.81 \mathrm{E}+02$

$2.81 \mathrm{E}+02$

$2.82 \mathrm{E}+02$

$2.82 \mathrm{E}+02$
Dose statistics at graphical times, mrem/yr

\begin{tabular}{|c|c|c|c|c|c|c|c|}
\hline m & aximum & ea & 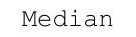 & & & & \\
\hline $26 \mathrm{E}-32$ & $E-01$ & 3 & $3.88 E-09$ & 3 & $07 E-02$ & -02 & $4.10 \pm-02$ \\
\hline $26 E-32$ & $2.06 \mathrm{E}-01$ & $2.30 E-03$ & $6.14 \mathrm{E}-09$ & $35 E-03$ & $09 E-02$ & $2.33 E-02$ & $4.85 E-02$ \\
\hline-32 & $09 E-01$ & $34 E-03$ & $6 E-09$ & $3 E-03$ & $11 E-02$ & $38 E-02$ & $92 E-02$ \\
\hline $25 E-32$ & $12 \mathrm{E}-01$ & $38 \mathrm{~F}-03$ & $36 \mathrm{E}-08$ & $51 \mathrm{~F}-03$ & $13 F-02$ & $43 F-02$ & $00 E-02$ \\
\hline-32 & 01 & 3 & 08 & 3 & 2 & -02 & -02 \\
\hline-32 & & & & & & & -02 \\
\hline $25 E-32$ & $2.20 \mathrm{E}-01$ & 3 & & & 02 & & -02 \\
\hline $.25 E-32$ & -01 & 3 & -08 & 3 & -02 & -02 & -02 \\
\hline $25 E-32$ & $.25 E-01$ & $60 \mathrm{E}-03$ & $\Xi-08$ & $97 E-03$ & $.24 \mathrm{E}-02$ & -02 & $E-02$ \\
\hline $25 E-32$ & $28 \mathrm{E}-01$ & (65 & $.02 E-07$ & ( & $26 \sigma^{2}$ & $.73 E-02$ & $5-0 ?$ \\
\hline 32 & 01 & & & & & & -02 \\
\hline $25 E-32$ & $2.34 \mathrm{E}-01$ & 2 & -07 & 3 & 2 & -02 & -02 \\
\hline $25 E-32$ & $2.37 \mathrm{E}-01$ & & $2.30 E-07$ & $4.39 E-03$ & $1.34 \mathrm{E}-02$ & $2.89 E-02$ & $.71 E-02$ \\
\hline $24 E-32$ & $2.40 \mathrm{E}-01$ & $2.84 \mathrm{E}-03$ & $2.89 \mathrm{E}-07$ & $4.50 \mathrm{E}-03$ & $1.36 \mathrm{E}-02$ & $2.95 E-02$ & $79 E-02$ \\
\hline $24 E-32$ & -01 & $2.89 \mathrm{E}-03$ & -07 & & & -02 & $E-02$ \\
\hline $24 E-32$ & 1 & $2.94 E-03$ & & 7 & 2 & 2 & 02 \\
\hline $24 \mathrm{H}$ & & & & & & 2 & 2 \\
\hline $24 E-32$ & $2.52 \mathrm{E}$ & $3.05 E-03$ & 7 & 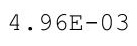 & 2 & 2 & -02 \\
\hline $24 E-32$ & $2.55 \mathrm{E}-01$ & م & $7 E-07$ & 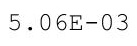 & $50 E-02$ & $E-02$ & $21 E-02$ \\
\hline $24 E-32$ & $2.58 \mathrm{E}-01$ & $3.15 \mathrm{E}-03$ & $9.48 \mathrm{E}-07$ & $5.17 \mathrm{E}-03$ & 1. 53E-02 & $3.28 \mathrm{E}-02$ & $.30 E-02$ \\
\hline .24 & & & & & & 2 & -02 \\
\hline 2 & & & & & & & \\
\hline 2 & & & & & & & 02 \\
\hline $24 E-32$ & 1 & $3.37 \mathrm{E}-03$ & 6 & ? & 2 & 2 & -02 \\
\hline $23 \mathrm{E}$ & $.73 E-01$ & $.43 \mathrm{E}-$ & 涫 & תכו & $1.67 \mathrm{E}-$ & 2 & $75 E-02$ \\
\hline $23 E-32$ & $76 \mathrm{E}-01$ & $.48 E-0$ & $2.40 \mathrm{E}-06$ & $.85 \mathrm{E}-$ & 1. $70 \mathrm{E}-02$ & $.65 E-02$ & $.84 E-02$ \\
\hline 32 & & & & & $1.73 \mathrm{E}-02$ & $E-02$ & $94 E-02$ \\
\hline 32 & & & & & & & \\
\hline 32 & & & & & 02 & -02 & 02 \\
\hline $23 E-32$ & $2.89 E-01$ & $3.12 \pm-00$ & $3.88 E-06$ & $0.30 E-43$ & $1.83 E-02$ & $3.87 E-02$ & $.27 E-02$ \\
\hline $23 E-32$ & $92 \mathrm{E}-01$ & . & $4.40 \mathrm{E}-06$ & $.495-00$ & $1.87 \mathrm{E}-02$ & $3.92 \mathrm{E}-02$ & $.38 E-02$ \\
\hline 2 & 1 & & 6 & & & 2 & $49 E-02$ \\
\hline-32 & & & & & & & 02 \\
\hline 32 & & & & & & & \\
\hline-32 & & & & & 2 & & \\
\hline $22 \mathrm{E}-32$ & $3.09 \mathrm{E}-01$ & $4.09 E-03$ & $7.75 E-06$ & $14 \mathrm{E}-03$ & 2.001 & -02 & $.94 \mathrm{E}-02$ \\
\hline $22 E-32$ & $3.12 \mathrm{E}-01$ & & $8.58 \mathrm{E}-06$ & & & & $8.00 E-02$ \\
\hline $22 E-32$ & $3.16 \mathrm{E}-01$ & 1.20 & $6 E-06$ & - $-2=0$ & $2.12 \mathrm{E}-02$ & - & E-02 \\
\hline 2 & 1 & $4.29 E-03$ & -05 & 3 & $1<\pi$ & 2 & 02 \\
\hline 32 & 1 & & 5 & & & & \\
\hline $22 E-32$ & $3.26 \mathrm{E}$ & 4. & 1 . & $88 \mathrm{E}$ & & & 02 \\
\hline $22 E-32$ & $3.30 \mathrm{~L}$ & $4.50 \mathrm{E}$ & $1 \cdot 3$ & & & & -02 \\
\hline & 3.031 & & & & & & . $17 E-U \angle$ \\
\hline $22 E-32$ & $3.37 \mathrm{E}-01$ & $4.04 E-03$ & $1.64 \mathrm{E}-05$ & $8.33 E-03$ & $2.37 E-02$ & $4.72 \mathrm{E}-02$ & $8.90 \pm-02$ \\
\hline $22 E-32$ & $3.40 \mathrm{E}-01$ & . & $1.80 E-05$ & & $2.40 \mathrm{E}-02$ & $4.79 E-02$ & $9.02 E-02$ \\
\hline $22 \mathrm{E}-32$ & $E-01$ & $.78 E-03$ & $.96 \mathrm{E}-05$ & $.66 E-03$ & $E-02$ & $4.85 E-02$ & $9.15 E-02$ \\
\hline
\end{tabular}


RESRAD-OFFSITE, Version 2.5 
RESRAD-OFFSITE, Version 2.5 
RESRAD-OFFSITE, Version 2.5

robabilistic Dose and Risk Report

Title : Offsite Resident Farmer

File : RF TC99 DOESG FWD-FV2all.ROF

Summary of dose at graphical times, reptition 3 (continued)

Time

Years

3. $30 \mathrm{E}+02$

$3.31 \mathrm{E}+02$

$3.31 \mathrm{E}+02$

3. $32 \mathrm{E}+02$

3. $32 \mathrm{E}+02$

3. $33 \mathrm{E}+02$

3. $33 \mathrm{E}+02$

3. $34 \mathrm{E}+02$

3. $34 \mathrm{E}+02$

$3.35 \mathrm{E}+02$

$3.35 \mathrm{E}+02$

$3.36 \mathrm{E}+02$

$3.36 \mathrm{E}+02$

$3.37 \mathrm{E}+02$

$3.37 \mathrm{E}+02$

$3.38 \mathrm{E}+02$

$3.38 \mathrm{E}+02$

$3.39 \mathrm{E}+02$

$3.39 \mathrm{E}+02$

3. $40 \mathrm{E}+02$

$3.40 \mathrm{E}+02$

$3.41 \mathrm{E}+02$

$3.41 \mathrm{E}+02$

$3.42 \mathrm{E}+02$

$3.42 \mathrm{E}+02$

$3.43 E+02$

$3.44 \mathrm{E}+02$

$3.44 \mathrm{E}+02$

$3.45 \mathrm{E}+02$

$3.45 \mathrm{E}+02$

$3.46 \mathrm{E}+02$

$3.46 \mathrm{E}+02$

$3.47 \mathrm{E}+02$

$3.47 \mathrm{E}+02$

$3.48 \mathrm{E}+02$

$3.48 \mathrm{E}+02$

$3.49 \mathrm{E}+02$

$3.49 \mathrm{E}+02$

$3.50 \mathrm{E}+02$

$3.50 \mathrm{E}+02$

$3.51 \mathrm{E}+02$

$3.51 \mathrm{E}+02$

$3.52 \mathrm{E}+02$

$3.52 \mathrm{E}+02$

$3.53 \mathrm{E}+02$

$3.53 \mathrm{E}+02$
Dose statistics at graphical times, mrem/yr

\begin{tabular}{|c|c|c|c|c|c|c|c|}
\hline m & aximum & ean & ledian & & & $\%$ & \\
\hline $14 \mathrm{E}-32$ & 01 & $1.58 \mathrm{E}-02$ & $8.46 \mathrm{E}-04$ & $3.51 \mathrm{E}-02$ & -02 & -01 & -01 \\
\hline $14 \mathrm{E}-32$ & $7.52 \mathrm{E}-01$ & $0 \mathrm{E}-02$ & $8.64 \mathrm{E}-04$ & $55 E-02$ & 02 & -01 & -01 \\
\hline $14 \mathrm{E}-32$ & $7.57 \mathrm{E}-01$ & 1. $62 \mathrm{E}-02$ & $8.84 \mathrm{E}-04$ & $.59 \mathrm{E}-02$ & $8.23 \mathrm{E}-02$ & $1.48 \mathrm{E}-01$ & 2. $60 \mathrm{E}-01$ \\
\hline $14 \mathrm{E}-32$ & $7.62 \mathrm{E}-01$ & 1. $63 \mathrm{E}-02$ & $9.03 E-04$ & $.63 E-02$ & $8.31 \mathrm{E}-02$ & $1.50 \mathrm{E}-01$ & $63 E-01$ \\
\hline 32 & 01 & 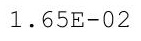 & 04 & & & 01 & 01 \\
\hline-32 & 01 & 2 & 4 & 2 & 2 & -01 & -01 \\
\hline $13 E-32$ & 01 & & & & & 01 & -01 \\
\hline-32 & & & & & & & -01 \\
\hline-32 & -01 & -02 & -03 & -02 & -02 & -01 & $2.75 E-01$ \\
\hline $13 E-32$ & $7.93 \mathrm{E}-01$ & 等 & ( & 2 & 2 & 1 & -01 \\
\hline 32 & 1 & $1.76 \mathrm{E}-02$ & $6 \mathrm{E}-03$ & 2 & 2 & 1 & 01 \\
\hline 32 & & & & 2 & & & -01 \\
\hline $13 E-32$ & $3 F-01$ & 1. & 3 & 2 & 2 & -01 & -01 \\
\hline$E-32$ & $3 E-01$ & $2 E-02$ & $4 E-03$ & $6 E-02$ & 2 & $68 \mathrm{E}-01$ & $38 E-01$ \\
\hline 32 & $3-01$ & 2 & -03 & 22 & 2 & -01 & -01 \\
\hline 32 & & 2 & -03 & 22 & 2 & 1 & -01 \\
\hline 32 & 01 & $\perp \cdot$ & 3 & 2 & & 1 & 01 \\
\hline 32 & 8 & & & & & & 1 \\
\hline $12 \mathrm{E}-32$ & $8.39 E-01$ & $1.91 \mathrm{E}-$ & ( & 2 & & -01 & -01 \\
\hline $12 \mathrm{E}-32$ & $.44 \mathrm{E}-01$ & $1.93 \mathrm{E}-02$ & $1.29 \mathrm{E}-03$ & $.35 E-02$ & $.73 E-02$ & $E-01$ & $3.04 \mathrm{E}-01$ \\
\hline $12 \mathrm{E}-32$ & $8.49 \mathrm{E}-01$ & $1.95 \mathrm{E}-02$ & $1.31 \mathrm{E}-03$ & $4.40 E-02$ & $83 E-02$ & $E-01$ & $07 E-01$ \\
\hline 32 & & & & & & -01 & -01 \\
\hline & & & & & & & 01 \\
\hline $12 \mathrm{E}-32$ & $\perp$ & 2.0 & 1. & 2 & 1 & & 01 \\
\hline 2 & 1 & $2.03 E-02$ & o & 2 & 1 & 1 & -01 \\
\hline $12 E-32$ & $75 \Gamma^{2}$ & ( & 1 & $65 E-02$ & $1.04 \mathrm{E}-01$ & 1. $92 \mathrm{E}-01$ & $21 E-01$ \\
\hline$F-32$ & 1 & $207 F_{-1}=0$ & 03 & -02 & $.05 \mathrm{E}-01$ & $.94 E-01$ & $23 E-01$ \\
\hline-32 & 1 & ק & & -02 & $06 E-01$ & $E-01$ & $26 E-01$ \\
\hline & & & & & & & -01 \\
\hline $11 \mathrm{E}-32$ & $8.96 \mathrm{E}-01$ & $2 \cdot 14+02$ & $1.55 \mathrm{E}-03$ & -02 & 1.09E-01 & $2.00 \mathrm{E}-01$ & -01 \\
\hline $11 \mathrm{E}-32$ & $9.0 \perp-01$ & द. & $1.59 E-03$ & $.91 \mathrm{E}-02$ & $1.10 \mathrm{E}-01$ & $2.02 \mathrm{E}-01$ & $3.35 E-01$ \\
\hline 2 & .00 & 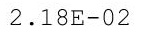 & - & $4.97 \mathrm{E}-02$ & $1.11 \mathrm{E}-01$ & $2.045-1$ & $3.38 E-01$ \\
\hline$\Gamma$ & זיר & & 1.6 & & & & -01 \\
\hline-32 & 1 & T & $E-03$ & 2 & & -01 & -01 \\
\hline 32 & & & & & & & \\
\hline & & 02 & & 02 & 01 & 01 & \\
\hline $11 E-32$ & $9.33 E-01$ & $2 \cdot 2$ & & & & & -01 \\
\hline $1 E-32$ & & $2.01+$ & & & & & $55 E-01$ \\
\hline 2 & 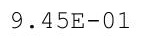 & 2 & 3 & & 1 & & 01 \\
\hline $.11 E-32$ & & & & & & & 1 \\
\hline 2 & & & & 02 & 1 & & \\
\hline$E-32$ & $9.63 E-01$ & 2. & 1 . & -02 & 1.2 & & -01 \\
\hline & & & & & & & \\
\hline & $\perp$ & 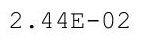 & & & & & $3.13 \mathrm{E}-01$ \\
\hline & 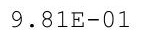 & 2 & & & $+\cdot 201$ & 2.210 & $105-21$ \\
\hline 2 & $E-01$ & $9 E-02$ & $08 E-03$ & $E-02$ & $26 E-01$ & 01 & -01 \\
\hline
\end{tabular}


RESRAD-OFFSITE, Version 2.5

$\mathrm{T}^{1 / 2}$ Limit $=180$ days

obabilistic Dose and Risk Report

Title : Offsite Resident Farmer

File : RF TC99 DOESG FWD-FV2all.ROF

Summary of dose at graphical times, reptition 3 (continued)

Time

Years

$3.54 \mathrm{E}+02$

$3.54 \mathrm{E}+02$

$3.55 \mathrm{E}+02$

$3.55 \mathrm{E}+02$

$3.56 \mathrm{E}+02$

$3.56 \mathrm{E}+02$

$3.57 \mathrm{E}+02$

$3.57 \mathrm{E}+02$

$3.58 \mathrm{E}+02$

$3.58 \mathrm{E}+02$

$3.59 \mathrm{E}+02$

$3.59 \mathrm{E}+02$

$3.60 \mathrm{E}+02$

$3.60 \mathrm{E}+02$

$3.61 \mathrm{E}+02$

$3.61 \mathrm{E}+02$

$3.62 \mathrm{E}+02$

$3.62 \mathrm{E}+02$

$3.63 \mathrm{E}+02$

3. $64 \mathrm{E}+02$

$3.64 \mathrm{E}+02$

$3.65 \mathrm{E}+02$

$3.65 \mathrm{E}+02$

$3.66 \mathrm{E}+02$

$3.66 \mathrm{E}+02$

$3.67 \mathrm{E}+02$

$3.67 \mathrm{E}+02$

$3.68 \mathrm{E}+02$

$3.68 \mathrm{E}+02$

$3.69 \mathrm{E}+02$

$3.69 \mathrm{E}+02$

$3.70 \mathrm{E}+02$

$3.70 \mathrm{E}+02$

$3.71 \mathrm{E}+02$

$3.71 \mathrm{E}+02$

$3.72 \mathrm{E}+02$

$3.72 \mathrm{E}+02$

$3.73 \mathrm{E}+02$

$3.73 E+02$

$3.74 \mathrm{E}+02$

$3.74 \mathrm{E}+02$

$3.75 \mathrm{E}+02$

$3.75 \mathrm{E}+02$

$3.76 \mathrm{E}+02$

$3.76 \mathrm{E}+02$

$3.77 \mathrm{E}+02$
Dose statistics at graphical times, mrem/yr

\begin{tabular}{|c|c|c|c|c|c|c|c|}
\hline m & aximum & e & 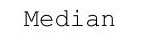 & & & & \\
\hline 32 & $94 \mathrm{E}-01$ & $51 E-02$ & $2.11 \mathrm{E}-03$ & 22 & $1.27 \mathrm{E}-01$ & 01 & $4-01$ \\
\hline $10 \mathrm{E}-32$ & $1.00 \mathrm{E}+00$ & $4 E-02$ & $2.15 E-03$ & $D E-02$ & $1.28 \mathrm{E}-01$ & $33 E-01$ & $85 E-01$ \\
\hline $10 \mathrm{E}-32$ & $1.01 \mathrm{E}+00$ & $2.56 \mathrm{E}-02$ & $2.18 \mathrm{E}-03$ & $97 E-02$ & $1.29 \mathrm{E}-01$ & $2.35 \mathrm{E}-01$ & $.88 \mathrm{E}-01$ \\
\hline $10 \mathrm{E}-32$ & $.01 E+00$ & $59 F-02$ & $22 \mathrm{E}-03$ & $04 \mathrm{E}-02$ & $.30 \mathrm{E}-01$ & $37 F-01$ & $91 \mathrm{~F}-01$ \\
\hline $10 \mathrm{E}-32$ & $1.02 \mathrm{E}+00$ & $E-02$ & $E-03$ & 2 & 1 & -01 & -01 \\
\hline 32 & $1.02 \mathrm{E}+00$ & & & & & & -01 \\
\hline $10 \mathrm{E}-32$ & $1.03 E+00$ & & & & & & -01 \\
\hline $10 \mathrm{E}-32$ & $1.04 \mathrm{E}+00$ & 02 & -03 & -02 & 1 & -01 & $E-01$ \\
\hline $09 E-32$ & $1.04 \mathrm{E}+00$ & $1 E-02$ & -03 & $8 E-02$ & $1.3 J E-U \perp$ & -01 & $06 E-01$ \\
\hline-32 & $.05 E+00$ & $.73 E-02$ & $.48 E-03$ & (5) & $.36 E-01$ & $.51 E-01$ & $10 E-01$ \\
\hline 32 & $E+00$ & & & & & 1 & -01 \\
\hline $09 E-32$ & $E+00$ & $8 \mathrm{~F}-02$ & $E-03$ & 2 & 1 & 1 & $6 E-01$ \\
\hline $.09 E-32$ & $1.07 E+00$ & & $2.62 E-03$ & & & & $.19 \mathrm{E}-01$ \\
\hline $09 E-32$ & $1.07 \mathrm{E}+00$ & $2.83 E-02$ & $2.67 \mathrm{E}-03$ & & $1.41 E-U 1$ & $2.59 \mathrm{E}-01$ & $.22 E-01$ \\
\hline-32 & $E+00$ & $6 \mathrm{E}-02$ & $E-03$ & 2 & 01 & -01 & $26 E-01$ \\
\hline 2 & $1.09 \mathrm{E}+$ & 2 & 3 & & 1 & $\perp$ & 01 \\
\hline 32 & $1.09 \mathrm{E}+00$ & & & & & \pm & 1 \\
\hline$E-32$ & $1.10 \mathrm{E}+00$ & 的 & B & 2 & 1 & $2.68 \mathrm{E}-01$ & 01 \\
\hline $09 E-32$ & $1.11 \mathrm{E}+00$ & $6 E-02$ & $1 E-03$ & $6 E-02$ & 0 & $E-01$ & $8 E-01$ \\
\hline$E-32$ & $1.11 \mathrm{E}+00$ & $.99 E-02$ & $2.96 \mathrm{E}-03$ & $3 E-02$ & 1. $48 \mathrm{E}-01$ & $2.72 \mathrm{E}-01$ & 4. $42 \mathrm{E}-01$ \\
\hline-32 & $1.12 \mathrm{E}+00$ & & 3 & & & -01 & $5 E-01$ \\
\hline 32 & & & & & & & $\Xi-01$ \\
\hline 32 & $1.13 \mathrm{E}+00$ & 2 & & & 1 & & -01 \\
\hline$E-32$ & $1.14 \mathrm{E}+00$ & 2 & 3 & & 1 & & -01 \\
\hline$E-32$ & $1.14 \mathrm{E}+00$ & . & 3 & 2 & 1 & $E-$ & $58 E-01$ \\
\hline$E-32$ & $1.15 \mathrm{E}+00$ & $15 \mathrm{~F}-02$ & $.25 E-03$ & $55 E-02$ & 1. $56 \mathrm{E}-01$ & $2.86 \mathrm{E}-01$ & $61 E-01$ \\
\hline$E-32$ & $1.16 \mathrm{E}+00$ & $F-02$ & $E-03$ & & & $E-01$ & $.65 E-01$ \\
\hline-32 & & & & & & & $68 E-01$ \\
\hline-32 & & & & & & & $.72 E-01$ \\
\hline $.08 E-32$ & $1.18 \mathrm{E}+00$ & $3.26 \mathrm{E}-02$ & $3.46 \mathrm{E}-03$ & $7.84 \mathrm{E}-02$ & $1.61 \mathrm{E}-01$ & $2.96 \mathrm{E}-01$ & $.75 E-01$ \\
\hline $08 E-32$ & $1.18 \mathrm{E}+00$ & . & $.51 E-03$ & $7.91 \mathrm{E}-02$ & $1.63 \mathrm{E}-01$ & $2 \cdot 30 \mathrm{D}$ & $4.79 \mathrm{E}-01$ \\
\hline 2 & $1.19 \mathrm{E}+00$ & . & 3 & & & $3.02 \mathrm{E}-$ & $.82 E-01$ \\
\hline 2 & $1.20 \mathrm{E}+00$ & & & & & & 01 \\
\hline 32 & & & & & & & 01 \\
\hline$E-32$ & & & & & & & 01 \\
\hline 32 & $1.21 \mathrm{E}+00$ & 02 & 03 & $8.27 E-02$ & 土. & & $96 E-01$ \\
\hline $07 E-32$ & $1.22 \mathrm{E}+00$ & $0.40 \pm-2<$ & & & & & $.00 E-01$ \\
\hline $07 E-32$ & $1.23 E+00$ & .尹णम Uट & & & & & $03 E-01$ \\
\hline 2 & म・ट & - & 3 & & & & 01 \\
\hline & $1.24 \mathrm{E}+00$ & & & 2 & 1 & & 01 \\
\hline $7 E-32$ & $1.25 \mathrm{E}+00$ & $3.58 E-02$ & $E-03$ & 2 & 1.77 & 1 & -01 \\
\hline $7 E-32$ & $1.25 E+00$ & 02 & & & 1.7 & & -01 \\
\hline & 1.26 & & & & & & 01 \\
\hline $4-32$ & $1.27 \mathrm{E}+00$ & $0.01 \mathrm{~L}-\mathrm{Z}$ & to & . & $\perp \cdot 0<\dot{1}$ & & $0.24 \mathrm{E}-U 1$ \\
\hline U1-32 & $1.27 \mathrm{E}+00$ & $5-2<$ & & - & 土. & & $27 E-01$ \\
\hline 32 & $1.28 \mathrm{E}+00$ & $E-02$ & $40 E-03$ & $E-02$ & $84 E-01$ & $8 E-01$ & -01 \\
\hline
\end{tabular}


RESRAD-OFFSITE, Version 2.5

robabilistic Dose and Risk Report

Title : Offsite Resident Farmer

File : RF TC99 DOESG FWD-FV2all.ROF

Summary of dose at graphical times, reptition 3 (continued)

Time

Years

$3.77 \mathrm{E}+02$

$3.78 \mathrm{E}+02$

$3.78 \mathrm{E}+02$

$3.79 \mathrm{E}+02$

$3.79 \mathrm{E}+02$

$3.80 \mathrm{E}+02$

$3.80 \mathrm{E}+02$

3. $81 \mathrm{E}+02$

$3.81 \mathrm{E}+02$

3. $82 \mathrm{E}+02$

3. $82 \mathrm{E}+02$

$3.83 \mathrm{E}+02$

$3.83 \mathrm{E}+02$

$3.84 \mathrm{E}+02$

$3.85 \mathrm{E}+02$

$3.85 \mathrm{E}+02$

$3.86 \mathrm{E}+02$

$3.86 \mathrm{E}+02$

$3.87 \mathrm{E}+02$

$3.87 \mathrm{E}+02$

$3.88 \mathrm{E}+02$

$3.88 \mathrm{E}+02$

$3.89 \mathrm{E}+02$

$3.89 \mathrm{E}+02$

3. $90 \mathrm{E}+02$

$3.90 E+02$

3. $91 \mathrm{E}+02$

3. $91 \mathrm{E}+02$

3. $92 \mathrm{E}+02$

3. $92 \mathrm{E}+02$

3. $93 \mathrm{E}+02$

3. $93 \mathrm{E}+02$

3. $94 \mathrm{E}+02$

$3.94 \mathrm{E}+02$

3. $95 \mathrm{E}+02$

$3.95 \mathrm{E}+02$

$3.96 \mathrm{E}+02$

$3.96 \mathrm{E}+02$

$3.97 \mathrm{E}+02$

$3.97 \mathrm{E}+02$

$3.98 \mathrm{E}+02$

$3.98 \mathrm{E}+02$

$3.99 \mathrm{E}+02$

3. $99 \mathrm{E}+02$

$4.00 \mathrm{E}+02$

$4.00 \mathrm{E}+02$
Dose statistics at graphical times, mrem/yr

\begin{tabular}{|c|c|c|c|c|c|c|c|}
\hline Minimum & Maximum & Mean & Median & $90 \%$ & $95 \%$ & $97.5 \%$ & $99 \%$ \\
\hline $1.06 \mathrm{E}-32$ & $1.29 \mathrm{E}+00$ & $3.76 \mathrm{E}-02$ & $4.46 \mathrm{E}-03$ & $9.08 \mathrm{E}-02$ & $1.86 \mathrm{E}-01$ & $3.40 \mathrm{E}-01$ & $5.34 \mathrm{E}-01$ \\
\hline $1.06 \mathrm{E}-32$ & $1.29 \mathrm{E}+00$ & $3.79 \mathrm{E}-02$ & $4.52 \mathrm{E}-03$ & $9.17 \mathrm{E}-02$ & $1.87 \mathrm{E}-01$ & $3.42 \mathrm{E}-01$ & $5.37 \mathrm{E}-01$ \\
\hline $1.06 \mathrm{E}-32$ & $1.30 \mathrm{E}+00$ & $3.82 \mathrm{E}-02$ & $4.59 \mathrm{E}-03$ & $9.25 \mathrm{E}-02$ & $1.89 \mathrm{E}-01$ & $3.44 \mathrm{E}-01$ & $5.40 \mathrm{E}-01$ \\
\hline $1.06 \mathrm{E}-32$ & $1.30 \mathrm{E}+00$ & $3.85 \mathrm{E}-02$ & $4.65 \mathrm{E}-03$ & $9.33 \mathrm{E}-02$ & $1.90 \mathrm{E}-01$ & $3.47 \mathrm{E}-01$ & $5.44 \mathrm{E}-01$ \\
\hline $1.06 \mathrm{E}-32$ & $1.31 \mathrm{E}+00$ & $3.88 E-02$ & $4.71 E-03$ & $9.41 E-02$ & $1.92 \mathrm{E}-01$ & $3.49 \mathrm{E}-01$ & $5.47 E-01$ \\
\hline $1.06 \mathrm{E}-32$ & $1.32 \mathrm{E}+00$ & $3.91 \mathrm{E}-02$ & $4.78 E-03$ & $9.50 \mathrm{E}-02$ & $1.93 \mathrm{E}-01$ & $3.51 \mathrm{E}-01$ & $5.51 \mathrm{E}-01$ \\
\hline $1.06 \mathrm{E}-32$ & $1.32 \mathrm{E}+00$ & $3.94 \mathrm{E}-02$ & $4.85 E-03$ & $9.58 \mathrm{E}-02$ & $1.95 \mathrm{E}-01$ & $3.53 E-01$ & $5.54 \mathrm{E}-01$ \\
\hline $1.06 \mathrm{E}-32$ & $1.33 \mathrm{E}+00$ & $3.97 \mathrm{E}-02$ & $4.92 \mathrm{E}-03$ & $9.66 \mathrm{E}-02$ & $1.96 \mathrm{E}-01$ & $3.54 \mathrm{E}-01$ & $5.58 \mathrm{E}-01$ \\
\hline $1.06 \mathrm{E}-32$ & $1.34 \mathrm{E}+00$ & $4.01 \mathrm{E}-02$ & $4.99 E-03$ & $9.74 \mathrm{E}-02$ & $1.98 \mathrm{E}-01$ & $3.56 \mathrm{E}-01$ & $5.61 \mathrm{E}-01$ \\
\hline $1.06 \mathrm{E}-32$ & $1.34 \mathrm{E}+00$ & $4.04 \mathrm{E}-02$ & $5.06 \mathrm{E}-03$ & $9.82 \mathrm{E}-02$ & $1.99 \mathrm{E}-01$ & $3.58 \mathrm{E}-01$ & $5.65 \mathrm{E}-01$ \\
\hline $6.91 E-30$ & $1.35 \mathrm{E}+00$ & $4.07 E-02$ & $5.14 \mathrm{E}-03$ & $9.90 \mathrm{E}-02$ & $2.01 \mathrm{E}-01$ & $3.60 \mathrm{E}-01$ & $.68 E-01$ \\
\hline $6.97 \mathrm{E}-30$ & $1.36 \mathrm{E}+00$ & $4.10 \mathrm{E}-02$ & $5.22 E-03$ & $9.98 \mathrm{E}-02$ & $2.02 \mathrm{E}-01$ & $3.61 \mathrm{E}-01$ & $5.72 \mathrm{E}-01$ \\
\hline $7.02 \mathrm{E}-30$ & $1.36 \mathrm{E}+00$ & $4.13 E-02$ & $5.29 \mathrm{E}-03$ & $1.01 \mathrm{E}-01$ & $2.04 \mathrm{E}-01$ & $3.64 \mathrm{E}-01$ & $5.75 \mathrm{E}-01$ \\
\hline $7.08 E-30$ & $1.37 \mathrm{E}+00$ & $4.17 \mathrm{E}-02$ & $5.37 E-03$ & $1.01 \mathrm{E}-01$ & $2.05 \mathrm{E}-01$ & $3.66 \mathrm{E}-01$ & $5.79 \mathrm{E}-01$ \\
\hline $7.14 \mathrm{E}-30$ & $1.38 \mathrm{E}+00$ & 4. $20 \mathrm{E}-02$ & $5.44 \mathrm{E}-03$ & $1.02 \mathrm{E}-01$ & $2.07 \mathrm{E}-01$ & $3.68 \mathrm{E}-01$ & $5.82 \mathrm{E}-01$ \\
\hline $7.89 E-30$ & $1.38 \mathrm{E}+00$ & $4.23 E-02$ & $2 E-03$ & $1.03 E-01$ & $2.08 E-01$ & $3.70 E-01$ & $.86 E-01$ \\
\hline $7.96 \mathrm{E}-30$ & $1.39 \mathrm{E}+00$ & $4.27 E-02$ & $5.59 \mathrm{E}-03$ & $1.04 \mathrm{E}-01$ & $2.09 \mathrm{E}-01$ & $.73 E-01$ & $.89 E-01$ \\
\hline $8.02 E-30$ & $1.40 \mathrm{E}+00$ & $4.30 E-02$ & $5.66 \mathrm{E}-03$ & $1.05 E-01$ & $2.10 \mathrm{E}-01$ & $3.75 E-01$ & $5.93 E-01$ \\
\hline $8.09 E-30$ & $1.40 \mathrm{E}+00$ & $4.33 E-02$ & $5.74 \mathrm{E}-03$ & $1.06 \mathrm{E}-01$ & $2.11 E-01$ & $3.77 E-01$ & $5.96 \mathrm{E}-01$ \\
\hline $1.09 \mathrm{E}-29$ & $1.41 \mathrm{E}+00$ & $4.37 E-02$ & $5.82 \mathrm{E}-03$ & $1.07 \mathrm{E}-01$ & $2.13 \mathrm{E}-01$ & $3.80 \mathrm{E}-01$ & $6.00 \mathrm{E}-01$ \\
\hline $1.09 \mathrm{E}-29$ & $1.41 \mathrm{E}+00$ & $4.40 E-02$ & $5.90 \mathrm{E}-03$ & $1.08 \mathrm{E}-01$ & $2.14 \mathrm{E}-01$ & $3.83 E-01$ & $6.03 E-01$ \\
\hline $1.10 \mathrm{E}-29$ & $1.42 \mathrm{E}+00$ & $4.43 E-02$ & $5.97 \mathrm{E}-03$ & $1.09 E-01$ & $2.16 \mathrm{E}-01$ & $3.85 E-01$ & $6.07 E-01$ \\
\hline $1.11 \mathrm{E}-29$ & $1.43 \mathrm{E}+00$ & $4.47 E-02$ & $6.05 E-03$ & 1.09E-01 & $2.17 \mathrm{E}-01$ & $3.88 \mathrm{E}-01$ & $6.10 \mathrm{E}-01$ \\
\hline $1.12 \mathrm{E}-29$ & $1.43 \mathrm{E}+00$ & $4.50 E-02$ & $6.13 E-03$ & 1.10E-01 & $2.19 \mathrm{E}-01$ & $3.91 \mathrm{E}-01$ & $6.14 \mathrm{E}-01$ \\
\hline $2.80 E-23$ & $1.44 \mathrm{E}+00$ & $4.54 \mathrm{E}-02$ & $6.21 \mathrm{E}-03$ & $1.11 \mathrm{E}-01$ & $2.20 \mathrm{E}-01$ & $3.94 \mathrm{E}-01$ & $6.18 \mathrm{E}-01$ \\
\hline $4.50 E-21$ & $1.45 \mathrm{E}+00$ & $4.57 E-02$ & $6.29 E-03$ & $1.12 \mathrm{E}-01$ & $2.22 \mathrm{E}-01$ & $3.96 \mathrm{E}-01$ & $6.21 \mathrm{E}-01$ \\
\hline $1.75 \mathrm{E}-19$ & $1.45 \mathrm{E}+00$ & 4. $61 \mathrm{E}-02$ & $6.37 \mathrm{E}-03$ & $1.13 \mathrm{E}-01$ & $2.23 E-01$ & $3.99 \mathrm{E}-01$ & $6.25 \mathrm{E}-01$ \\
\hline $3.34 \mathrm{E}-18$ & $1.46 \mathrm{E}+00$ & $4.64 \mathrm{E}-02$ & $6.45 E-03$ & $1.14 \mathrm{E}-01$ & $2.25 E-01$ & $4.02 E-01$ & $6.28 E-01$ \\
\hline $4.00 \mathrm{E}-17$ & $1.47 \mathrm{E}+00$ & $4.68 E-02$ & $6.54 \mathrm{E}-03$ & $1.15 \mathrm{E}-01$ & $2.26 \mathrm{E}-01$ & $4.05 E-01$ & $6.32 E-01$ \\
\hline $3.38 E-16$ & $1.47 \mathrm{E}+00$ & $4.71 E-02$ & $6.62 E-03$ & $1.16 \mathrm{E}-01$ & $2.28 E-01$ & $4.07 E-01$ & $6.36 \mathrm{E}-01$ \\
\hline $2.17 E-15$ & $1.48 \mathrm{E}+00$ & $4.75 E-02$ & $6.71 \mathrm{E}-03$ & $1.17 \mathrm{E}-01$ & $2.30 \mathrm{E}-01$ & $4.10 \mathrm{E}-01$ & $6.39 E-01$ \\
\hline $1.12 \mathrm{E}-14$ & $1.49 \mathrm{E}+00$ & $4.78 E-02$ & $6.79 E-03$ & 1. $18 \mathrm{E}-01$ & $2.31 \mathrm{E}-01$ & $4.13 \mathrm{E}-01$ & $6.43 E-01$ \\
\hline $4.77 E-14$ & $1.49 \mathrm{E}+00$ & $4.82 E-02$ & $6.88 E-03$ & $1.19 \mathrm{E}-01$ & $2.33 E-01$ & $4.16 \mathrm{E}-01$ & $6.47 E-01$ \\
\hline $1.74 \mathrm{E}-13$ & $1.50 \mathrm{E}+00$ & $.85 E-02$ & $6.97 \mathrm{E}-03$ & 1.19E-01 & $2.35 E-01$ & $4.18 \mathrm{E}-01$ & $6.50 \mathrm{E}-01$ \\
\hline $5.54 \mathrm{E}-13$ & $1.51 \mathrm{E}+00$ & $4.89 E-02$ & $7.06 E-03$ & 1.20E-01 & $2.37 E-01$ & $4.21 E-01$ & $6.54 \mathrm{E}-01$ \\
\hline $1.57 \mathrm{E}-12$ & $1.51 \mathrm{E}+00$ & $4.93 E-02$ & $7.15 E-03$ & $1.21 \mathrm{E}-01$ & $2.38 \mathrm{E}-01$ & $4.24 \mathrm{E}-01$ & $6.57 \mathrm{E}-01$ \\
\hline $4.05 E-12$ & $1.52 \mathrm{E}+00$ & $4.96 E-02$ & $7.25 E-03$ & 1.22E-01 & $2.40 \mathrm{E}-01$ & $4.27 E-01$ & $6.61 \mathrm{E}-01$ \\
\hline $9.59 \mathrm{E}-12$ & $1.52 \mathrm{E}+00$ & $5.00 \mathrm{E}-02$ & $7.35 E-03$ & $1.23 E-01$ & $2.42 \mathrm{E}-01$ & $4.30 \mathrm{E}-01$ & $6.65 E-01$ \\
\hline $2.11 \mathrm{E}-11$ & $1.53 \mathrm{E}+00$ & $5.03 E-02$ & $7.45 E-03$ & $1.24 \mathrm{E}-01$ & $2.44 \mathrm{E}-01$ & $4.33 E-01$ & $6.68 \mathrm{E}-01$ \\
\hline $4.34 \mathrm{E}-11$ & $1.54 \mathrm{E}+00$ & $5.07 \mathrm{E}-02$ & $7.53 \mathrm{E}-03$ & $1.25 \mathrm{E}-01$ & $2.45 \mathrm{E}-01$ & $4.35 \mathrm{E}-01$ & $6.72 \mathrm{E}-01$ \\
\hline $8.46 \mathrm{E}-11$ & $1.54 \mathrm{E}+00$ & $5.11 \mathrm{E}-02$ & $7.62 \mathrm{E}-03$ & $1.26 E-01$ & $2.47 \mathrm{E}-01$ & $4.38 E-01$ & $6.76 \mathrm{E}-01$ \\
\hline $1.57 \mathrm{E}-10$ & $1.55 \mathrm{E}+00$ & $5.15 E-02$ & $7.72 E-03$ & $1.27 E-01$ & $2.49 \mathrm{E}-01$ & $4.41 E-01$ & $6.80 E-01$ \\
\hline $2.79 \mathrm{E}-10$ & $1.56 \mathrm{E}+00$ & $5.18 \mathrm{E}-02$ & $7.81 \mathrm{E}-03$ & 1.29E-01 & $2.51 \mathrm{E}-01$ & $4.44 \mathrm{E}-01$ & $6.83 E-01$ \\
\hline $4.76 \mathrm{E}-10$ & $1.56 \mathrm{E}+00$ & $5.22 E-02$ & $7.90 E-03$ & $1.30 \mathrm{E}-01$ & $2.52 \mathrm{E}-01$ & $4.47 E-01$ & $6.87 \mathrm{E}-01$ \\
\hline $7.86 \mathrm{E}-10$ & $1.57 \mathrm{E}+00$ & $5.26 E-02$ & $7.99 E-03$ & $1.31 E-01$ & $2.54 \mathrm{E}-01$ & $4.50 E-01$ & $6.91 E-01$ \\
\hline $1.26 \mathrm{E}-09$ & $1.58 \mathrm{E}+00$ & $5.30 E-02$ & $8.08 E-03$ & $1.32 E-01$ & $2.55 \mathrm{E}-01$ & $4.53 E-01$ & $6.94 \mathrm{E}-01$ \\
\hline
\end{tabular}


RESRAD-OFFSITE, Version 2.5 
RESRAD-OFFSITE, Version 2.5

robabilistic Dose and Risk Report

Title : Offsite Resident Farmer

File : RF TC99 DOESG FWD-FV2all.ROF

Summary of dose at graphical times, reptition 3 (continued)

Time

Years

4. $25 \mathrm{E}+02$

$4.25 \mathrm{E}+02$

$4.26 \mathrm{E}+02$

$4.26 \mathrm{E}+02$

$4.27 \mathrm{E}+02$

$4.27 \mathrm{E}+02$

$4.28 \mathrm{E}+02$

$4.28 \mathrm{E}+02$

$4.29 \mathrm{E}+02$

$4.29 \mathrm{E}+02$

4. $30 \mathrm{E}+02$

$4.30 \mathrm{E}+02$

4. $31 \mathrm{E}+02$

$4.31 \mathrm{E}+02$

4. $32 \mathrm{E}+02$

4. $32 \mathrm{E}+02$

$4.33 E+02$

4. $33 \mathrm{E}+02$

$4.34 \mathrm{E}+02$

4. $34 \mathrm{E}+02$

$4.35 \mathrm{E}+02$

$4.35 \mathrm{E}+02$

$4.36 \mathrm{E}+02$

$4.36 \mathrm{E}+02$

$4.37 \mathrm{E}+02$

$4.37 \mathrm{E}+02$

$4.38 \mathrm{E}+02$

$4.38 \mathrm{E}+02$

$4.39 \mathrm{E}+02$

$4.39 \mathrm{E}+02$

$4.40 \mathrm{E}+02$

4. $40 \mathrm{E}+02$

$4.41 \mathrm{E}+02$

$4.41 \mathrm{E}+02$

4. $42 \mathrm{E}+02$

4. $42 \mathrm{E}+02$

$4.43 E+02$

$4.43 E+02$

4. $44 \mathrm{E}+02$

4. $45 \mathrm{E}+02$

$4.45 E+02$

$4.46 \mathrm{E}+02$

$4.46 \mathrm{E}+02$

$4.47 \mathrm{E}+02$

$4.47 \mathrm{E}+02$

$4.48 \mathrm{E}+02$
Dose statistics at graphical times, mrem/yr

\begin{tabular}{|c|c|c|c|c|c|c|c|}
\hline m & $\mathrm{am}$ & Mean & 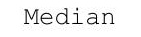 & & & $\%$ & \\
\hline 06 & $1.87 \mathrm{E}+00$ & $7.26 \mathrm{E}-02$ & 1. $39 \mathrm{E}-02$ & $1.82 \mathrm{E}-01$ & -01 & -01 & -01 \\
\hline $82 E-06$ & $1.88 \mathrm{E}+00$ & $.31 E-02$ & $1.40 \mathrm{E}-02$ & $1.83 \mathrm{E}-01$ & $\Xi-01$ & $5.95 \mathrm{E}-01$ & -01 \\
\hline $.06 \mathrm{E}-05$ & $1.88 \mathrm{E}+00$ & $.35 E-02$ & 1. $42 \mathrm{E}-02$ & $1.84 \mathrm{E}-01$ & $.46 \mathrm{E}-01$ & $5.98 \mathrm{E}-01$ & $8.82 E-01$ \\
\hline $.13 E-05$ & $1.89 \mathrm{E}+00$ & $.40 E-02$ & 1. $43 \mathrm{E}-02$ & $1.85 \mathrm{E}-01$ & $48 \mathrm{E}-01$ & $0 E-01$ & $8.86 \mathrm{E}-01$ \\
\hline $1 E-05$ & $1.89 \mathrm{E}+00$ & $F$ & 02 & 2. & & 01 & 01 \\
\hline $30 E-05$ & 00 & -02 & 02 & 8 & 1 & 01 & -01 \\
\hline $39 E-05$ & & & & 1 & 1 & 01 & -01 \\
\hline $48 E-05$ & & & & & & & -01 \\
\hline $.58 E-05$ & +00 & $\mathrm{~g}-02$ & -02 & 91 & 1 & -01 & $8 \mathrm{E}-01$ \\
\hline $7+400$ & $1.92 \mathrm{E}+00$ & tr 02 & -02 & $\perp$ & $3.59 \mathrm{E}-01$ & -01 & -01 \\
\hline $78 \mathrm{E}-05$ & $1.93 \mathrm{E}+00$ & 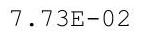 & 2 & $1.93 E-01$ & 1 & 1 & -01 \\
\hline $.89 \mathrm{E}-$ & & & & & - & 01 & -01 \\
\hline$F-05$ & $1.94 \mathrm{E}+00$ & -0 & 1. & 1 & 1 & -01 & -01 \\
\hline $.11 \mathrm{E}-05$ & $1.95 \mathrm{E}+00$ & $7.87 \mathrm{E}-02$ & $1.59 \mathrm{E}-02$ & $1.97 \mathrm{E}-01$ & $3.67 \mathrm{E}-01$ & $6.29 \mathrm{E}-01$ & $9.30 \mathrm{E}-01$ \\
\hline $23 E-05$ & $1.95 \mathrm{E}+00$ & $2 E-02$ & -02 & $99 \mathrm{E}-\mathrm{C}$ & 01 & -01 & -01 \\
\hline 5 & & & & & & 01 & -01 \\
\hline * & & 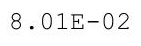 & 2 & $\perp$ & 1 & 01 & -01 \\
\hline 5 & $1.97 \mathrm{E}+00$ & & 2 & & & 1 & 1 \\
\hline $75 E-05$ & $1.98 \mathrm{E}+00$ & 15 & $3 E-02$ & - & 1 & -01 & -01 \\
\hline $.88 E-05$ & $1.98 \mathrm{E}+00$ & $.16 \mathrm{E}-02$ & $1.70 \mathrm{E}-02$ & $2.06 \mathrm{E}-01$ & $.79 \mathrm{E}-01$ & $.47 \mathrm{E}-01$ & $.57 \mathrm{E}-01$ \\
\hline$F-05$ & $.99 E+00$ & $F-02$ & -02 & 1 & -0 & $.50 E-01$ & -01 \\
\hline & & & & & & -01 & -01 \\
\hline & & & & & & & 01 \\
\hline 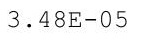 & & $8.36 \mathrm{E}-02$ & & & & & 01 \\
\hline 5 & $.01 \mathrm{E}+00$ & ter & 2 & - & 1 & 1 & 01 \\
\hline$E-05$ & $.02 E+00$ & 2 & $1.81 \mathrm{E}-02$ & $215 \square$ & ת & $4 E-01$ & $85 E-01$ \\
\hline - 0 & $2.02 E+00$ & $50 F-02$ & $E-02$ & 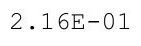 & $93 E-01$ & $E-01$ & $89 E-01$ \\
\hline 1 & & & & & & & -01 \\
\hline & & & & & & & -01 \\
\hline & &. & & 2.21 & 1 & 01 & +00 \\
\hline $.68 E-05$ & $2.05 E+00$ & . tre va & $1.88 \pm-02$ & $2.22 E-01$ & $.01 E-01$ & $6.78 \mathrm{E}-01$ & $1.01 \mathrm{E}+00$ \\
\hline 管 & $2.05 E+00$ & 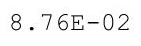 & $1.90 \mathrm{E}-02$ & 2.0 & 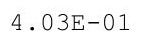 & 01 & $1.01 \mathrm{E}+00$ \\
\hline (5 & $2.06 \mathrm{E}+00$ & م1 & 2 & 2 & & & $1.02 \mathrm{E}+00$ \\
\hline 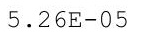 & & & & & & & $.02 E+00$ \\
\hline & & & 02 & 1 & 1 & & \\
\hline 05 & $2.08 E+00$ & 02 & 02 & 2.30 & 1 & 1 & $1.03 E+00$ \\
\hline $.00+20$ & $2.08 \mathrm{E}+00$ & 9.0 & t. & 2.01 & 1 & & $.04 \mathrm{E}+00$ \\
\hline 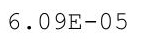 & $2.09 \mathrm{E}+00$ & & & & & & $1.04 \mathrm{E}+00$ \\
\hline 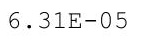 & . & 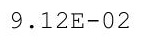 & 2 & 1 & 1 & $\perp$ & $1.04 \mathrm{E}+00$ \\
\hline & $2.10 \mathrm{E}+00$ & & & & & & 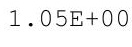 \\
\hline 5 & & 9. & 02 & 1 & 1 & 1 & $1.05 E+00$ \\
\hline $99 \mathrm{E}-05$ & $2.11 E+00$ & $7 E-02$ & 2. & 2.3 & -01 & 01 & $1.06 \mathrm{E}+00$ \\
\hline & 0 & & & & & & \\
\hline & $2.12 \mathrm{E}+00$ & (.) & 2 & 2. & 1 & & $1.07 \mathrm{E}+00$ \\
\hline 40 & $2.13 E+00$ & 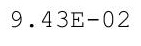 & $5-0<$ & 1 & 01 & (r) & $1.07 \mathrm{E}+00$ \\
\hline $96 E-05$ & $.13 E+00$ & $8 E-02$ & $15 E-02$ & $E-01$ & $E-01$ & 1 & $.08 E+00$ \\
\hline
\end{tabular}


RESRAD-OFFSITE, Version 2.5

$\mathrm{T}^{1 / 2}$ Limit $=180$ days

robabilistic Dose and Risk Report

Title : Offsite Resident Farmer

File : RF TC99 DOESG FWD-FV2all.ROF

Summary of dose at graphical times, reptition 3 (continued)

Time

Years

$4.48 \mathrm{E}+02$

$4.49 \mathrm{E}+02$

$4.49 \mathrm{E}+02$

$4.50 \mathrm{E}+02$

$4.50 \mathrm{E}+02$

$4.51 \mathrm{E}+02$

$4.51 \mathrm{E}+02$

$4.52 \mathrm{E}+02$

$4.52 \mathrm{E}+02$

$4.53 \mathrm{E}+02$

$4.53 \mathrm{E}+02$

$4.54 \mathrm{E}+02$

$4.54 \mathrm{E}+02$

$4.55 \mathrm{E}+02$

$4.55 \mathrm{E}+02$

$4.56 \mathrm{E}+02$

$4.56 \mathrm{E}+02$

$4.57 \mathrm{E}+02$

$4.57 \mathrm{E}+02$

$4.58 \mathrm{E}+02$

$4.58 \mathrm{E}+02$

$4.59 \mathrm{E}+02$

$4.59 \mathrm{E}+02$

$4.60 \mathrm{E}+02$

$4.60 \mathrm{E}+02$

$4.61 \mathrm{E}+02$

4. $61 \mathrm{E}+02$

$4.62 \mathrm{E}+02$

4. $62 \mathrm{E}+02$

4. $63 \mathrm{E}+02$

4. $63 \mathrm{E}+02$

$4.64 \mathrm{E}+02$

$4.65 \mathrm{E}+02$

4. $65 \mathrm{E}+02$

$4.66 \mathrm{E}+02$

$4.66 \mathrm{E}+02$

$4.67 \mathrm{E}+02$

$4.67 \mathrm{E}+02$

$4.68 \mathrm{E}+02$

$4.68 \mathrm{E}+02$

$4.69 \mathrm{E}+02$

$4.69 \mathrm{E}+02$

$4.70 \mathrm{E}+02$

$4.70 \mathrm{E}+02$

$4.71 \mathrm{E}+02$

$4.71 \mathrm{E}+02$
Dose statistics at graphical times, mrem/yr

\begin{tabular}{|c|c|c|c|c|c|c|c|}
\hline m & $\mathrm{m}$ & Mean & ledian & & & $\%$ & \\
\hline 05 & $.14 \mathrm{E}+00$ & $9.54 \mathrm{E}-02$ & $2.17 \mathrm{E}-02$ & $2.47 \mathrm{E}-01$ & $4.39 \mathrm{E}-01$ & -01 & $1.00 E+00$ \\
\hline $.47 E-05$ & $.14 \mathrm{E}+00$ & $9 E-02$ & $2.19 \mathrm{E}-02$ & 01 & 01 & -01 & $1.09 \mathrm{E}+00$ \\
\hline $.74 \mathrm{E}-05$ & $2.15 \mathrm{E}+00$ & $54 E-02$ & $2.21 \mathrm{E}-02$ & $2.50 \mathrm{E}-01$ & $44 E-01$ & 7. $36 \mathrm{E}-01$ & $1.09 \mathrm{E}+00$ \\
\hline $.00 E-05$ & $2.15 E+00$ & $.70 E-02$ & $2.24 \mathrm{E}-02$ & $2.52 \mathrm{E}-01$ & $4.46 \mathrm{E}-01$ & 7. $40 \mathrm{E}-01$ & $1.10 \mathrm{E}+00$ \\
\hline $7 E-05$ & $6 \mathrm{E}+00$ & $5 \mathrm{E}$ & 02 & 01 & $3 F-01$ & $3 E-01$ & -00 \\
\hline$E-05$ & 00 & -02 & 2 & 1 & 1 & -01 & +00 \\
\hline $83 E-05$ & & & & & 1 & & +00 \\
\hline-04 & & & & & & & +00 \\
\hline-04 & +00 & $E-02$ & $E-02$ & $N_{\perp}$ & $56 \mathrm{~F}-1$ & -01 & +00 \\
\hline $7 E-04$ & $2.19 \mathrm{E}+00$ & 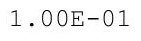 & -02 & $\perp$ & L & 1 & +00 \\
\hline $10 \mathrm{E}-04$ & $19 \mathrm{E}+00$ & 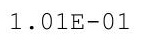 & $2.39 E-02$ & $2.64 E-01$ & $.61 E-01$ & 1 & $3 E+00$ \\
\hline 4 & $\mathrm{E}+00$ & & & $665-0$ & & 1 & +00 \\
\hline $16 F-04$ & $2.20 \mathrm{E}+00$ & $25-0$ & $3 E-02$ & 1 & 1 & 1 & +00 \\
\hline $.19 \mathrm{E}-04$ & $2.21 \mathrm{E}+00$ & $1.02 \mathrm{E}-01$ & $2.45 \mathrm{E}-02$ & $2.69 \mathrm{E}-01$ & $4.67 \mathrm{E}-01$ & $7.74 \mathrm{E}-01$ & $1.14 \mathrm{E}+00$ \\
\hline $22 \mathrm{E}-04$ & $2.21 \mathrm{E}+00$ & $3 E-01$ & $E-02$ & $\perp$ & $\perp$ & -01 & $14 \mathrm{E}+00$ \\
\hline $0^{2}$ & $.22 E+00$ & & & & & 01 & 00 \\
\hline . 2 & & $4 E-01$ & $0<$ & +1 & 1 & 1 & 00 \\
\hline $32 \mathrm{E}-$ & $2.23 E+00$ & & & $275 \mathrm{~F}-01$ & 1 & 1 & 00 \\
\hline $36 \mathrm{~F}-04$ & $2.23 E+00$ & $5 \mathrm{~F}-6$ & $6 E-02$ & $277 \mathrm{~F}$ & 1 & 1 & $1.16 \mathrm{E}+00$ \\
\hline $39 E-04$ & $2.24 \mathrm{E}+00$ & $.06 \mathrm{E}-01$ & $2.58 \mathrm{E}-02$ & $.79 \mathrm{E}-01$ & $.83 E-01$ & $E-01$ & $1.17 \mathrm{E}+00$ \\
\hline $42 E-04$ & $.24 \mathrm{E}+00$ & $.06 \mathrm{E}-0$ & -02 & $.80 \mathrm{E}$ & $.86 \mathrm{E}-01$ & $.98 E-01$ & 1. $17 \mathrm{E}+00$ \\
\hline 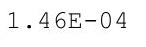 & & & & & & -01 & $.17 E+00$ \\
\hline 4 & & & & & & & 00 \\
\hline $.53 E-04$ & $2.26 \mathrm{E}+00$ & 10 & 2. & & 1 & -01 & \pm+00 \\
\hline 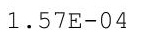 & $2.26 \mathrm{E}+00$ & 1. $09 \mathrm{E}-01$ & 2 & $\perp$ & $\perp$ & 1 & $19 \mathrm{E}+00$ \\
\hline $60=-0$ & $.27 \mathrm{E}+00$ & م & $2.72 \mathrm{E}-02$ & קרית & 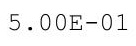 & $.16 \mathrm{E}-01$ & $1.19 \mathrm{E}+00$ \\
\hline $64 \mathrm{~F}-04$ & $2.27 \mathrm{E}+00$ & $110 F-01$ & $2.75 \mathrm{E}-02$ & תחم ק & 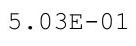 & $9 E-01$ & $1.20 \mathrm{E}+00$ \\
\hline & & & & & & & \\
\hline 4 & $2.28 \mathrm{E}+00$ & & & & & & $.21 \mathrm{E}$ \\
\hline $.75 E-04$ & $2.29 \mathrm{E}+00$ & $\perp \cdot \perp \angle \perp-\perp$ & $2.82 E-02$ & $2 \cdot 11$ & 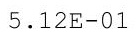 & 01 & $1.21 \mathrm{E}+00$ \\
\hline$\cdot 100-04$ & $2.30 \mathrm{E}+00$ & $\perp \cdot \perp \angle \sqcup 0$ & $2.85 E-02$ & $2.95 E-01$ & 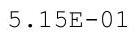 & $8.34 \mathrm{E}-01$ & $1.21 E+00$ \\
\hline .015- & $2.30 \mathrm{E}+00$ & 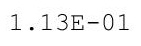 & $2.01 \mathrm{~L}-02$ & 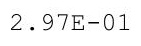 & 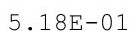 & 01 & $1.22 \mathrm{E}+00$ \\
\hline 䧄 & $2.31 \mathrm{E}+00$ & 135 & $.89 E-02$ & 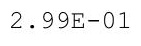 & & & $1.22 \mathrm{E}+00$ \\
\hline & & & & & & & $1.23 E+00$ \\
\hline $1 \mathrm{~F}-04$ & & & 02 & 1 & & & \\
\hline 4 & & & 02 & 3.04 & 1 & 01 & $1.24 \mathrm{E}$ \\
\hline $.98 \pm-04$ & $2.32 \mathrm{E}+00$ & & & & & & $1.24 \mathrm{E}+00$ \\
\hline 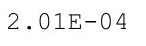 & $2.33 E+00$ & & & & & & $1.25 \mathrm{E}+00$ \\
\hline $05 \mathrm{~F}-04$ & . & $+\cdots$ & 2 & & & $\perp$ & $1.25 \mathrm{E}+00$ \\
\hline & & & & & & & $.25 \mathrm{E}-$ \\
\hline 04 & $2.34 \mathrm{E}+00$ & & 02 & 1 & 1 & 1 & $1.26 \mathrm{E}+00$ \\
\hline $16 \mathrm{E}-04$ & $2.35 E+00$ & 1.19 & 3. & -01 & -01 & & 1.2 \\
\hline & & & & & & & 00 \\
\hline & $2.36 \mathrm{E}+00$ & 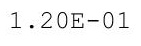 & & & & & $1.27 \mathrm{E}+00$ \\
\hline $\begin{array}{lll}2 & 0\end{array}$ & $2.36 \mathrm{E}+00$ & $\perp \cdot 20+$ & & 1 & 01 & .00 & $1.28 \mathrm{E}+00$ \\
\hline $1 E-04$ & $.37 E+00$ & $1 \mathrm{E}-01$ & $2 E-02$ & $E-01$ & $E-01$ & 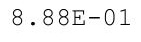 & $1.28 \mathrm{E}+00$ \\
\hline
\end{tabular}


RESRAD-OFFSITE, Version 2.5

robabilistic Dose and Risk Report

Title : Offsite Resident Farmer

File : RF TC99 DOESG FWD-FV2all.ROF

Summary of dose at graphical times, reptition 3 (continued)

Time

Years

$4.72 \mathrm{E}+02$

$4.72 \mathrm{E}+02$

$4.73 E+02$

4. $73 \mathrm{E}+02$

$4.74 \mathrm{E}+02$

4. $74 \mathrm{E}+02$

$4.75 \mathrm{E}+02$

4. $75 \mathrm{E}+02$

$4.76 \mathrm{E}+02$

4. $76 \mathrm{E}+02$

$4.77 \mathrm{E}+02$

$4.77 \mathrm{E}+02$

$4.78 \mathrm{E}+02$

$4.78 \mathrm{E}+02$

$4.79 \mathrm{E}+02$

$4.79 \mathrm{E}+02$

$4.80 \mathrm{E}+02$

$4.80 \mathrm{E}+02$

$4.81 \mathrm{E}+02$

$4.81 \mathrm{E}+02$

$4.82 \mathrm{E}+02$

$4.82 \mathrm{E}+02$

$4.83 \mathrm{E}+02$

$4.83 \mathrm{E}+02$

$4.84 \mathrm{E}+02$

$4.84 \mathrm{E}+02$

$4.85 \mathrm{E}+02$

$4.86 \mathrm{E}+02$

$4.86 \mathrm{E}+02$

$4.87 \mathrm{E}+02$

$4.87 \mathrm{E}+02$

$4.88 \mathrm{E}+02$

$4.88 \mathrm{E}+02$

4. $89 \mathrm{E}+02$

$4.89 \mathrm{E}+02$

4. $90 \mathrm{E}+02$

$4.90 \mathrm{E}+02$

4. $91 \mathrm{E}+02$

4. $91 \mathrm{E}+02$

4. $92 \mathrm{E}+02$

4. $92 \mathrm{E}+02$

$4.93 \mathrm{E}+02$

$4.93 \mathrm{E}+02$

4. $94 \mathrm{E}+02$

4. $94 \mathrm{E}+02$

4. $95 \mathrm{E}+02$
Dose statistics at graphical times, mrem/yr

\begin{tabular}{|c|c|c|c|c|c|c|c|}
\hline m & aximum & lea & - & & & & \\
\hline $34 \mathrm{E}-04$ & $37 \mathrm{E}+00$ & 1.22E-01 & 02 & 01 & 01 & 01 & $.20 E+00$ \\
\hline $38 E-04$ & $2.38 \mathrm{E}+00$ & $1.22 \mathrm{E}-01$ & $27 E-02$ & $3.24 \mathrm{E}-01$ & $53 E-01$ & $8.96 \mathrm{E}-01$ & $1.29 \mathrm{E}+00$ \\
\hline $42 \mathrm{E}-04$ & $38 E+00$ & $23 E-01$ & $30 E-02$ & $25 E-01$ & $56 E-01$ & $99 E-01$ & $.29 E+00$ \\
\hline $46 E-04$ & $.39 \mathrm{E}+00$ & $23 F-01$ & $32 E-02$ & $27 \mathrm{~F}-01$ & $58 F-01$ & -01 & 1. $30 \mathrm{E}+00$ \\
\hline $.50 E-04$ & $39 E+00$ & .241 & $E-02$ & 1 & 1 & 1 & +00 \\
\hline-04 & $40 E+00$ & ( & & & & & +00 \\
\hline $.58 E-04$ & $2.40 \mathrm{E}+00$ & $1.25 \mathrm{E}$ & -02 & & & & $.31 E+00$ \\
\hline-04 & $41 E+00$ & 261 & -02 & 1 & 1 & 01 & $32 \mathrm{E}+00$ \\
\hline $67 E-04$ & $41 E+00$ & $.26 E-01$ & -02 & $E-01$ & $71 E-01$ & -01 & $32 \mathrm{E}+00$ \\
\hline $.71 \mathrm{E}-04$ & $.42 \mathrm{E}+00$ & $27 \mathrm{E}-$ & $49 \mathrm{E}-02$ & $36 \pi$ & & $25-$ & $.32 E+00$ \\
\hline$E-04$ & $2.42 \mathrm{E}+00$ & - & & & & 1 & $E+00$ \\
\hline $.79 \mathrm{E}-04$ & $2.42 \mathrm{E}+00$ & $.28 \mathrm{E}$ & -02 & 1 & & 1 & +00 \\
\hline $.84 \mathrm{E}-04$ & $2.43 E+00$ & $1.29 \mathrm{E}-01$ & $3.57 \mathrm{E}-02$ & & & & $1.34 \mathrm{E}+00$ \\
\hline $88 E-04$ & $2.43 \mathrm{E}+00$ & $1.30 \mathrm{E}-01$ & $.60 \mathrm{E}-02$ & $.43 E-01$ & 1 & 1 & $1.34 \mathrm{E}+00$ \\
\hline-04 & $44 E+00$ & $.30 \mathrm{E}-0$ & -02 & $\perp$ & & $\perp$ & $35 E+00$ \\
\hline 9 & $.44 \mathrm{E}+00$ & - & 02 & 1 & 5 & $\perp$ & 00 \\
\hline 4 & 00 & 1. $31 \mathrm{E}-01$ & & & & $3 E-01$ & 00 \\
\hline$E-04$ & $245 \mathrm{~F}+0$ & 1. $32 \mathrm{E}-01$ & 2 & $\perp$ & & $5 E-01$ & 00 \\
\hline $.11 E-04$ & $2.46 \mathrm{E}+00$ & $1.33 E-01$ & $3.75 E-02$ & $3.51 \mathrm{E}-01$ & $.97 \mathrm{E}-01$ & $9.48 \mathrm{E}-0$ & $1.36 \mathrm{E}+00$ \\
\hline $16 \mathrm{E}-04$ & $2.46 \mathrm{E}+00$ & 1. $33 \mathrm{E}-01$ & $.78 E-02$ & $.52 \mathrm{E}-01$ & $99 E-01$ & $5-0$ & $1.37 \mathrm{E}+00$ \\
\hline 04 & $2.47 \mathrm{E}+00$ & 3 & & & & & +00 \\
\hline & & & & 1 & & & \\
\hline$E-04$ & & 1.0 & & $\perp$ & & & \\
\hline$E-04$ & $2.48 \mathrm{E}+00$ & $1.36 \mathrm{E}-01$ & 2 & 1 & 1 & $9.66 \mathrm{E}-01$ & $9 \mathrm{E}+00$ \\
\hline 4 & $.48 E+00$ & 375 & $2 E-02$ & (1) & 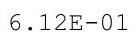 & $E-$ & $.39 E+00$ \\
\hline$E-04$ & $.49 \mathrm{E}+00$ & $1.37 \mathrm{E}-01$ & $96 E-02$ & (2) & $15 \pi$ & $.73 E-01$ & 1. $40 \mathrm{E}+00$ \\
\hline$E-04$ & $2.49 \mathrm{E}+00$ & $38 \mathrm{~F}-6 \mathrm{r}$ & $99 E-02$ & & & $5 F-01$ & L. $40 \mathrm{E}+00$ \\
\hline & & & & & & & \\
\hline & & 1.3 & & & 1 & & $1.41 \mathrm{E}+00$ \\
\hline $65 E-04$ & $2.50 \mathrm{E}+00$ & $\perp \cdot 4 U D-1$ & $4.08 E-02$ & . & • $25 E-U 1$ & .01 & $1.42 \mathrm{E}+00$ \\
\hline$E-04$ & $2.51 \mathrm{E}+00$ & $+\cdot 10+$ & $4.11 \mathrm{E}-02$ & . 120 & - & . & $1.43 E+00$ \\
\hline 4 & $2.51 \mathrm{E}+00$ & 11 & 2 & 1 & & & $1.43 \mathrm{E}+00$ \\
\hline 4 & & & & & & & $44 \mathrm{E}+00$ \\
\hline 4 & & 1 & & & & & \\
\hline 04 & & 1.4 & & 01 & & & \\
\hline $.97 E-04$ & $2.54 \mathrm{E}+00$ & $1.445-01$ & $4.27 E-02$ & 1 & 1 & & $1.45 \mathrm{E}+00$ \\
\hline $03 E-04$ & $2.55 \mathrm{E}+00$ & $\perp \cdot 110$ - & & & & & $1.46 \mathrm{E}+00$ \\
\hline 4 & $2.55 \mathrm{E}+00$ & + & 2 & & & & $1.46 \mathrm{E}+00$ \\
\hline 4 & $2.56 \mathrm{E}+00$ & 1 & - & 1 & 1 & $1.02 \mathrm{E}+00$ & $1.47 \mathrm{E}+00$ \\
\hline 4 & & & 2 & 1 & 1 & & $1.47 \mathrm{E}+00$ \\
\hline$E-04$ & $2.57 \mathrm{E}+00$ & $1.47 \mathrm{E}-01$ & $4.44 \mathrm{E}-02$ & 01 & & & $1.48 \mathrm{E}+00$ \\
\hline$E-04$ & $2.58 \mathrm{E}+00$ & $1.48 \mathrm{E}$ & & 1 & & & 1. $48 \mathrm{E}+00$ \\
\hline & 2. & $\perp$ & & & & & $1.48 \mathrm{E}+00$ \\
\hline $43 E-04$ & $2.59 \mathrm{E}+00$ & $\perp \cdot 47 \pm-01$ & $4.54 \mathrm{E}-02$ & $3.94 \mathrm{E}-01$ & $6.62 E-01$ & $1.03 E+00$ & 1. $49 \mathrm{E}+00$ \\
\hline $495-04$ & $2.60 \mathrm{E}+00$ & 1.004 & & & & $1.04 \mathrm{E}+00$ & $1.49 \mathrm{E}+00$ \\
\hline $55 E-04$ & $.61 E+00$ & $E-01$ & $.61 E-02$ & $.98 E-01$ & $.67 E-01$ & $1.04 \mathrm{E}+00$ & $1.50 \mathrm{E}+00$ \\
\hline
\end{tabular}


RESRAD-OFFSITE, Version 2.5

$\mathrm{T}^{1 / 2}$ Limit $=180$ days

obabilistic Dose and Risk Report

Title : Offsite Resident Farmer

File : RF TC99 DOESG FWD-FV2all.ROF

Summary of dose at graphical times, reptition 3 (continued)

Time

Years

$4.95 \mathrm{E}+02$

$4.96 \mathrm{E}+02$

$4.96 \mathrm{E}+02$

$4.97 \mathrm{E}+02$

$4.97 \mathrm{E}+02$

$4.98 \mathrm{E}+02$

$4.98 \mathrm{E}+02$

$4.99 \mathrm{E}+02$

$4.99 \mathrm{E}+02$

$5.00 \mathrm{E}+02$

$5.00 \mathrm{E}+02$

$5.01 \mathrm{E}+02$

$5.01 \mathrm{E}+02$

$5.02 \mathrm{E}+02$

$5.02 \mathrm{E}+02$

$5.03 \mathrm{E}+02$

$5.03 \mathrm{E}+02$

$5.04 \mathrm{E}+02$

$5.04 \mathrm{E}+02$

$5.05 \mathrm{E}+02$

$5.06 \mathrm{E}+02$

$5.06 \mathrm{E}+02$

$5.07 \mathrm{E}+02$

$5.07 \mathrm{E}+02$

$5.08 \mathrm{E}+02$

$5.08 \mathrm{E}+02$

$5.09 \mathrm{E}+02$

$5.09 \mathrm{E}+02$

$5.10 \mathrm{E}+02$

$5.10 \mathrm{E}+02$

$5.11 \mathrm{E}+02$

$5.11 \mathrm{E}+02$

$5.12 \mathrm{E}+02$

$5.12 \mathrm{E}+02$

$5.13 \mathrm{E}+02$

$5.13 \mathrm{E}+02$

$5.14 \mathrm{E}+02$

$5.14 \mathrm{E}+02$

$5.15 \mathrm{E}+02$

$5.15 \mathrm{E}+02$

$5.16 \mathrm{E}+02$

$5.16 \mathrm{E}+02$

$5.17 \mathrm{E}+02$

$5.17 \mathrm{E}+02$

$5.18 \mathrm{E}+02$

$5.18 \mathrm{E}+02$
Dose statistics at graphical times, mrem/yr

\begin{tabular}{|c|c|c|c|c|c|c|c|}
\hline m & um & ean & ledian & & & $\%$ & \\
\hline 04 & $.61 E+00$ & $1.51 \mathrm{E}-01$ & $4.65 E-02$ & $3.99 \mathrm{E}-01$ & -01 & $1.04 \mathrm{E}+00$ & $1.50 \mathrm{E}+00$ \\
\hline $67 E-04$ & $.62 \mathrm{E}+00$ & $2 E-01$ & $58 \mathrm{E}-02$ & 01 & 1 & 0 & +00 \\
\hline $.73 E-04$ & $2.63 \mathrm{E}+00$ & 1. $52 \mathrm{E}-01$ & $4.71 \mathrm{E}-02$ & $4.03 E-01$ & $6.75 \mathrm{E}-01$ & $1.05 \mathrm{E}+00$ & $1.51 \mathrm{E}+00$ \\
\hline $.80 E-04$ & $2.63 E+00$ & $1.53 \mathrm{E}-01$ & $4.75 \mathrm{E}-02$ & $4.05 \mathrm{E}-01$ & $6.77 \mathrm{E}-01$ & $1.05 \mathrm{E}+00$ & $1.51 \mathrm{E}+00$ \\
\hline $86 E-04$ & $.64 \mathrm{E}+00$ & $1.54 \mathrm{E}-01$ & $4.79 \mathrm{E}-02$ & $.08 \mathrm{E}-01$ & $.80 \mathrm{E}-01$ & $1.06 \mathrm{E}+00$ & $.52 \mathrm{E}+00$ \\
\hline 04 & $65 E+00$ & 1 & 2 & 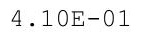 & 1 & & +00 \\
\hline $99 \mathrm{E}-04$ & & $1.55 \mathrm{E}$ & 2 & 1 & 1 & & +00 \\
\hline $.05 E-04$ & & & & 1 & & & $53 E+00$ \\
\hline-04 & +00 & $F-0$ & $E-02$ & $6 \mathrm{~F}-0$ & 01 & +00 & +00 \\
\hline 4 & $67 \mathrm{E}+00$ & $1.57 \mathrm{E}-01$ & 2 & $\perp$ & $\perp$ & 0 & +00 \\
\hline 4 & $2.68 \mathrm{E}+00$ & 1. $58 \mathrm{E}-01$ & $5.00 E-02$ & 4. $21 \mathrm{E}-01$ & 1 & $8 \mathrm{E}+00$ & $E+00$ \\
\hline$E-04$ & $3 E+00$ & & & & 1 & 0 & +00 \\
\hline $39 F-04$ & $E+00$ & $9 F-8 \cdot s-3$ & 2 & $5 \mathrm{t}-2-10$ & 1 & 0 & +00 \\
\hline $.46 \mathrm{E}-04$ & $2.70 \mathrm{E}+00$ & 1. $60 \mathrm{E}-01$ & $5.11 \mathrm{E}-02$ & $4.27 \mathrm{E}-01$ & $02 E-01$ & $1.09 \mathrm{E}+00$ & $1.56 \mathrm{E}+00$ \\
\hline $.53 E-04$ & $0 \mathrm{E}+00$ & $\mathrm{~F}_{-1}$ & -02 & $8 F$ & $\perp$ & $E+00$ & $5 \mathrm{E}+00$ \\
\hline 4 & & & & & & & 00 \\
\hline $7 E-04$ & & & & & & 0 & 00 \\
\hline 4 & $2.72 \mathrm{E}+00$ & & & & & & 0 \\
\hline $81 \mathrm{~F}-04$ & $2.73 E+00$ & $163 \mathrm{~F}-$ & $9 \mathrm{E}-02$ & 酒 & ת5 & +00 & $3 E+00$ \\
\hline $88 E-04$ & $2.73 \mathrm{E}+00$ & 1. $64 \mathrm{E}-01$ & $2 E-02$ & $4.35 \mathrm{E}-01$ & $14 \mathrm{E}-0$ & $1.10 \mathrm{E}+00$ & 1. $58 \mathrm{E}+00$ \\
\hline $96 \mathrm{E}-04$ & $.74 \mathrm{E}+00$ & $.65 E-0$ & -02 & 1 & $\perp$ & 0 & +00 \\
\hline-04 & & & & & & & +00 \\
\hline 4 & & & & & & & 00 \\
\hline $.18 E-04$ & $2.76 \mathrm{E}+00$ & $\perp$ & 2 & & & & 00 \\
\hline 4 & $.77 \mathrm{E}+$ & 1. $68 \mathrm{E}-01$ & 2 & $4 \quad 4 F-01$ & 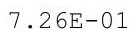 & 1 & 00 \\
\hline $33 E-04$ & $.77 \mathrm{E}+00$ & $168 F-0$ & $5.54 \mathrm{E}-02$ & $45 F_{-}$ & 7 & 1. $12 \mathrm{E}+00$ & 1. $61 \mathrm{E}+00$ \\
\hline$F-04$ & $2.78 \mathrm{E}+00$ & $169 F-01$ & $.58 E-02$ & $016 \sigma^{\circ}$ & $32 \mathrm{E}-01$ & $1.13 \mathrm{E}+0$ & $1.62 \mathrm{E}+00$ \\
\hline 1 & & & & & & & \\
\hline-04 & $2.79 \mathrm{E}+$ & $\perp \cdot$ & & & & & \\
\hline $.64 E-04$ & $2.80 \mathrm{E}+00$ & $\perp \cdot 1 \perp-1$ & $5.69 \mathrm{E}-02$ & ・UD & 10 & $1.14 \mathrm{E}+00$ & $1.63 E+00$ \\
\hline • $12 \mathrm{~L}-04$ & $2.80 \mathrm{E}+00$ & $\perp \cdot T<\perp<\perp$ & $5.72 \mathrm{E}-02$ & $4.53 E-01$ & $1.4 \angle D-0 \perp$ & $\perp \cdot \perp$ पा & $1.63 \mathrm{E}+00$ \\
\hline .015- & $2.81 E+00$ & 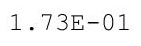 & 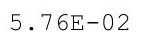 & (20) & . & & $1.64 \mathrm{E}+00$ \\
\hline 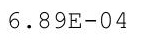 & $2.81 \mathrm{E}+00$ & 13 & ת & בתרז5 & & & 1. $64 \mathrm{E}+$ \\
\hline$F$ & & & & & & & \\
\hline$E-04$ & $2.83 E+00$ & & 02 & & & $E+00$ & $1.65 \mathrm{E}+00$ \\
\hline $.13 E-04$ & $2.83 E+00$ & $1.75 \mathrm{E}-01$ & $5.92 \mathrm{E}-02$ & 1 & 1 & $1 \cdot 10 \mathrm{r}$ & $1.66 \mathrm{E}+00$ \\
\hline$\cdot 2 \angle E-04$ & $2.84 \mathrm{E}+00$ & 1.60 & & & & & $1.00 \pm 100$ \\
\hline 年 & $2.84 \mathrm{E}+00$ & & & & & & 1.07 \\
\hline $39 F-04$ & $2.85 \mathrm{E}+$ & t & 2 & & & & tent \\
\hline & & & & & & & \\
\hline 04 & $2.86 \mathrm{E}+00$ & 1 . & 02 & 1 & 1 & & $1.68 \mathrm{E}+00$ \\
\hline $65 E-04$ & $2.87 \mathrm{E}+00$ & $1.80 \mathrm{E}-01$ & -02 & $4.75 E-01$ & 7.72 & 1 . & $B E+00$ \\
\hline & 0 & & & & & & \\
\hline & $2.88 \mathrm{E}+00$ & $1.01+$ & & & & $1.19 \mathrm{E}+00$ & 1.000100 \\
\hline 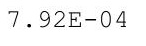 & $2.89 \mathrm{E}+00$ & $1.0<2$ & & 1 & 1 & & $1.70 \mathrm{E}+00$ \\
\hline $01 E-04$ & $.89 \mathrm{E}+00$ & $E-01$ & $32 E-02$ & $E-01$ & $E-01$ & $.19 \mathrm{E}+00$ & $1.70 \mathrm{E}+00$ \\
\hline
\end{tabular}


RESRAD-OFFSITE, Version 2.5

$\mathrm{T}^{1 / 2}$ Limit $=180$ days

obabilistic Dose and Risk Report

Title : Offsite Resident Farmer

File : RF TC99 DOESG FWD-FV2all.ROF

Summary of dose at graphical times, reptition 3 (continued)

Time

Years

$5.19 \mathrm{E}+02$

$5.19 \mathrm{E}+02$

$5.20 \mathrm{E}+02$

$5.20 \mathrm{E}+02$

$5.21 \mathrm{E}+02$

$5.21 \mathrm{E}+02$

$5.22 \mathrm{E}+02$

$5.22 \mathrm{E}+02$

$5.23 \mathrm{E}+02$

$5.23 \mathrm{E}+02$

$5.24 \mathrm{E}+02$

$5.24 \mathrm{E}+02$

$5.25 \mathrm{E}+02$

$5.26 \mathrm{E}+02$

$5.26 \mathrm{E}+02$

$5.27 \mathrm{E}+02$

$5.27 \mathrm{E}+02$

$5.28 \mathrm{E}+02$

$5.28 \mathrm{E}+02$

$5.29 \mathrm{E}+02$

$5.29 \mathrm{E}+02$

$5.30 \mathrm{E}+02$

$5.30 \mathrm{E}+02$

$5.31 \mathrm{E}+02$

$5.31 \mathrm{E}+02$

$5.32 \mathrm{E}+02$

$5.32 \mathrm{E}+02$

$5.33 \mathrm{E}+02$

$5.33 \mathrm{E}+02$

$5.34 \mathrm{E}+02$

$5.34 \mathrm{E}+02$

$5.35 \mathrm{E}+02$

$5.35 \mathrm{E}+02$

$5.36 \mathrm{E}+02$

$5.36 \mathrm{E}+02$

$5.37 \mathrm{E}+02$

$5.37 \mathrm{E}+02$

$5.38 \mathrm{E}+02$

$5.38 \mathrm{E}+02$

$5.39 \mathrm{E}+02$

$5.39 \mathrm{E}+02$

$5.40 \mathrm{E}+02$

$5.40 \mathrm{E}+02$

$5.41 \mathrm{E}+02$

$5.41 \mathrm{E}+02$

$5.42 \mathrm{E}+02$
Dose statistics at graphical times, mrem/yr

\begin{tabular}{|c|c|c|c|c|c|c|c|}
\hline $\mathrm{m}$ & aximum & ea & ec & & & & \\
\hline $10 \mathrm{E}-04$ & $.90 \mathrm{E}+00$ & $1.84 \mathrm{E}-01$ & $6.36 \mathrm{E}-02$ & $E-01$ & $7.84 \mathrm{E}-01$ & 00 & $\therefore / 1 E+U 0$ \\
\hline $.19 \mathrm{E}-04$ & $2.90 \mathrm{E}+00$ & $1.84 \mathrm{E}-01$ & $6.40 \mathrm{E}-02$ & $85 E-01$ & $37 E-01$ & $1.20 \mathrm{E}+00$ & $1.71 \mathrm{E}+00$ \\
\hline $.29 \mathrm{E}-04$ & 2. $91 \mathrm{E}+00$ & $1.85 \mathrm{E}-01$ & $6.45 \mathrm{E}-02$ & $4.87 \mathrm{E}-01$ & $7.89 \mathrm{E}-01$ & $1.20 \mathrm{E}+00$ & $.71 E+00$ \\
\hline $38 E-04$ & $.92 E+00$ & $86 E-01$ & $49 \mathrm{E}-02$ & $89 F-01$ & $.92 \mathrm{E}-01$ & $.20 \mathrm{E}+00$ & $.72 \mathrm{E}+00$ \\
\hline $48 E-04$ & $.92 \mathrm{E}+00$ & $1.86 \mathrm{E}-01$ & -02 & 1 & 1 & +00 & +00 \\
\hline 04 & $2.93 \mathrm{E}+00$ & & & & & & $3 E+00$ \\
\hline $67 E-04$ & $2.93 \mathrm{E}+00$ & & & & & +00 & $73 E+00$ \\
\hline $.76 \mathrm{E}-04$ & $2.94 \mathrm{E}+00$ & 01 & -02 & $\perp$ & 1 & +00 & $1.73 E+00$ \\
\hline $.86 E-04$ & $2.94 \mathrm{E}+00$ & 1. $89 \mathrm{E}-01$ & $1 \mathrm{E}-02$ & $1 \mathrm{-}-\mathrm{U}$ & 1 & $E+00$ & $74 \mathrm{E}+00$ \\
\hline $96 E-04$ & $.95 E+00$ & $90 E-01$ & $.75 E-02$ & $99 E-01$ & & $.22 E+00$ & $.74 \mathrm{E}+00$ \\
\hline$E-04$ & $2.96 \mathrm{E}+00$ & 1 & $E-02$ & 1 & 1 & $E+00$ & $.74 \mathrm{E}+00$ \\
\hline $16 \mathrm{E}-04$ & $2.96 \mathrm{E}+00$ & 25 & -02 & . & & -00 & $5 \mathrm{E}+00$ \\
\hline $.26 \mathrm{E}-04$ & $2.97 \mathrm{E}+00$ & 1. $92 \mathrm{E}-01$ & $6.87 \mathrm{E}-02$ & & & $1.23 E+00$ & $1.75 \mathrm{E}+00$ \\
\hline $36 E-04$ & $2.97 \mathrm{E}+00$ & $1.93 \mathrm{E}-01$ & $6.91 \mathrm{E}-02$ & $.07 \mathrm{E}-01$ & & $1.23 E+00$ & $1.76 \mathrm{E}+00$ \\
\hline$E-04$ & $98 \mathrm{E}+00$ & $E-01$ & $E-02$ & & \pm & +00 & $76 \mathrm{E}+00$ \\
\hline 4 & 0 & & & & & 0 & 00 \\
\hline 4 & & & & & & 0 & 00 \\
\hline $3 E-04$ & $3.00 \mathrm{E}+00$ & $1.96 \mathrm{E}-01$ & 2 & & 1 & 0 & 0 \\
\hline $89 E-04$ & $3.00 \mathrm{E}+00$ & $107 F-01$ & $3 E-02$ & ت م & 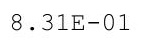 & $.25 E+00$ & $7 E+00$ \\
\hline $99 E-04$ & $3.01 \mathrm{E}+00$ & $1.98 \mathrm{E}-01$ & $7.18 \mathrm{E}-02$ & זم ז & $32 E-01$ & $1.25 \mathrm{E}+00$ & $1.78 \mathrm{E}+00$ \\
\hline 03 & $.01 E+00$ & & 02 & & & +00 & $E+00$ \\
\hline & & & & & & & \\
\hline 3 & $.02 \mathrm{E}+00$ & 2.0 & & & & 1.2 & תח \\
\hline $04 \mathrm{E}-03$ & $.03 E+00$ & 2 & . & - & 1 & 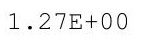 & $79 E+00$ \\
\hline 3 & $.03 E+00$ & 2. & . & - & 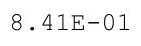 & $1.27 \mathrm{E}+00$ & $80 \mathrm{E}+00$ \\
\hline $.07 E-03$ & $.04 E+00$ & $2.02 \mathrm{E}-01$ & $7.47 \mathrm{E}-02$ & 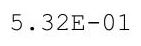 & $42 \mathrm{E}-01$ & $1.28 \mathrm{E}+00$ & $1.80 \mathrm{E}+00$ \\
\hline $5-03$ & $3.05 E+00$ & $203 F-01$ & $7.52 \mathrm{E}-02$ & & & $1.28 \mathrm{E}+00$ & $1.80 \mathrm{E}+00$ \\
\hline 03 & & & & & & & \\
\hline 3 & $.06 \mathrm{E}+00$ & & 02 & & & & \\
\hline $.11 \mathrm{E}-03$ & $3.06 \mathrm{E}+00$ & $2.00 \pm-1$ & $7.65 \mathrm{E}-02$ & $5.40 \mathrm{E}-01$ & $8.50 \mathrm{E}-01$ & $1.29 \mathrm{E}+00$ & $1.81 \mathrm{E}+00$ \\
\hline $12 \mathrm{E}-03$ & $3.07 E+00$ & $2.06 E-01$ & $E-02$ & - & - & 1. $30 \mathrm{E}+00$ & $1.82 \mathrm{E}+00$ \\
\hline 3 & $3.07 \mathrm{E}+00$ & . & 2 & & & & \\
\hline & & & & & & & $1.83 E+00$ \\
\hline 03 & & & & & & & \\
\hline$E-03$ & & & 02 & & & & \\
\hline $18 \mathrm{E}-03$ & $3.09 \mathrm{E}+00$ & $2.10 E-01$ & $7.93 E-02$ & 1 & 1 & 1. $32 \mathrm{E}+00$ & $1.84 \mathrm{E}+00$ \\
\hline $19 \mathrm{E}-03$ & $3.10 \mathrm{E}+00$ & $\cdot+1$ & & or & & & $1.84 \mathrm{E}+00$ \\
\hline $21 \mathrm{E}-03$ & $3.10 \mathrm{E}+00$ & $\angle \cdot \perp \angle D U \perp$ & & & & & $1.85 \mathrm{E}+00$ \\
\hline 3 & . & ${ }^{2}$ & 2 & 1 & 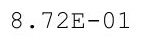 & $1.33 E+00$ & $1.85 E+00$ \\
\hline 3 & $3.11 \mathrm{E}+00$ & & & 1 & & $3 E+00$ & $.85 E+00$ \\
\hline $4 E-03$ & $3.12 \mathrm{E}+00$ & $2.14 \mathrm{E}-01$ & $.16 \mathrm{E}-02$ & 01 & $8.77 \mathrm{E}$ & $1.34 \mathrm{E}+00$ & $1.86 \mathrm{E}+00$ \\
\hline $6 \mathrm{E}-03$ & $3.13 \mathrm{E}+00$ & 1 & 2 & & 8.7 & $E+00$ & $6 \mathrm{E}+00$ \\
\hline &. & & & & & & $1.80 E+00$ \\
\hline $3 E-03$ & $3.14 \mathrm{E}+00$ & 1 & $8.31 \mathrm{E}-02$ & . & 1 & $1.35 \mathrm{E}+00$ & $1.87 \mathrm{E}+00$ \\
\hline $30 \mathrm{n}-20$ & $3.14 \mathrm{E}+00$ & $2 \cdot \perp / L-0 \perp$ & & & & $1.35 E+00$ & $1.87 \mathrm{E}+00$ \\
\hline 03 & $.15 E+00$ & $E-01$ & $E-02$ & $E-01$ & $E-01$ & $1.35 \mathrm{E}+00$ & $1.87 \mathrm{E}+00$ \\
\hline
\end{tabular}


RESRAD-OFFSITE, Version 2.5

Title : Offsite Resident Farmer

File : RF TC99 DOESG FWD-FV2all.ROF

Summary of dose at graphical times, reptition 3 (continued)

Time

Years

$5.42 \mathrm{E}+02$

$5.43 \mathrm{E}+02$

$5.43 \mathrm{E}+02$

$5.44 \mathrm{E}+02$

$5.44 \mathrm{E}+02$

$5.45 \mathrm{E}+02$

$5.46 \mathrm{E}+02$

$5.46 \mathrm{E}+02$

$5.47 \mathrm{E}+02$

$5.47 \mathrm{E}+02$

$5.48 \mathrm{E}+02$

$5.48 \mathrm{E}+02$

$5.49 \mathrm{E}+02$

$5.49 \mathrm{E}+02$

$5.50 \mathrm{E}+02$

$5.50 \mathrm{E}+02$

$5.51 \mathrm{E}+02$

$5.51 \mathrm{E}+02$

$5.52 \mathrm{E}+02$

$5.52 \mathrm{E}+02$

$5.53 \mathrm{E}+02$

$5.53 \mathrm{E}+02$

$5.54 \mathrm{E}+02$

$5.54 \mathrm{E}+02$

$5.55 \mathrm{E}+02$

$5.55 \mathrm{E}+02$

$5.56 \mathrm{E}+02$

$5.56 \mathrm{E}+02$

$5.57 \mathrm{E}+02$

$5.57 \mathrm{E}+02$

$5.58 \mathrm{E}+02$

$5.58 \mathrm{E}+02$

$5.59 \mathrm{E}+02$

$5.59 \mathrm{E}+02$

$5.60 \mathrm{E}+02$

$5.60 \mathrm{E}+02$

$5.61 \mathrm{E}+02$

$5.61 \mathrm{E}+02$

$5.62 \mathrm{E}+02$

$5.62 \mathrm{E}+02$

$5.63 \mathrm{E}+02$

$5.63 \mathrm{E}+02$

$5.64 \mathrm{E}+02$

$5.64 \mathrm{E}+02$

$5.65 \mathrm{E}+02$

$5.66 \mathrm{E}+02$
Dose statistics at graphical times, mrem/yr

\begin{tabular}{|c|c|c|c|c|c|c|c|}
\hline Iinimum & Maximum & Mean & Median & 900 & $90 \%$ & $97.5 \%$ & $9 \%$ \\
\hline 3 & $5 E+00$ & 01 & $6 \mathrm{~F}-02$ & -01 & 1 & $.36 \mathrm{E}+00$ & +00 \\
\hline 03 & $6 \mathrm{E}+00$ & $9 E-01$ & $51 E-02$ & 1 & 1 & $.36 E+00$ & $.88 E+00$ \\
\hline $5 E-03$ & -00 & $0 E-01$ & $6 E-02$ & 1 & 1 & Do & $88 E+00$ \\
\hline$E-03$ & $E+00$ & $E-01$ & 02 & 1 & 1 & & +00 \\
\hline $38 E-03$ & $3.17 \mathrm{E}+00$ & $.22 \mathrm{E}-01$ & & & & & $89 \mathrm{E}+00$ \\
\hline $39 E-03$ & $3.18 \mathrm{E}+00$ & $\perp$ & 02 & & & 00 & $89 E+00$ \\
\hline $.40 E-03$ & $3.18 \mathrm{E}+00$ & $2.23 E-01$ & $6 E-02$ & $9 E-01$ & $\perp$ & 0 & $90 \mathrm{E}+00$ \\
\hline $.42 E-03$ & $3.19 \mathrm{E}+00$ & $2027+01$ & $8.81 E-02$ & & $.00 \mathrm{D}-0$ & \pm+00 & 1. $90 \mathrm{E}+00$ \\
\hline$E-03$ & +00 & $E-$ & 02 & 1 & 1 & 00 & $90 E+00$ \\
\hline $4 \mathrm{E}-03$ & $E+00$ & $2.26 \mathrm{E}$ & 2 & & & $9 E+00$ & $E+00$ \\
\hline$E-03$ & & & & 1 & & & $\mathrm{E}+00$ \\
\hline-03 & 0 & 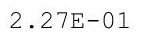 & 2 & 1 & & & $91 E+00$ \\
\hline $49 \mathrm{E}-03$ & $3.21 E+00$ & $2.20 \mathrm{x}-4$ & $5 E-02$ & & $\perp$ & +1 & $\mathrm{E}+00$ \\
\hline $.50 E-03$ & $3.22 E+00$ & $2 \cdot 2 \pi 01$ & $9.10 \mathrm{~L}-U 2$ & $0.0 \angle L-01$ & $\perp$ & 1.94 & 1. $92 \mathrm{E}+00$ \\
\hline $.52 E-03$ & $3.22 \mathrm{E}+00$ & $2 \cdot$ & 42 & & & 00 & 1. $92 \mathrm{E}+00$ \\
\hline $.53 E-03$ & $3.23 E+00$ & $2.31 \mathrm{E}-\mathrm{C}$ & $9.21 \mathrm{E}-02$ & $6.07 \mathrm{E}-$ & $9.24 \mathrm{E}-$ & $1.41 \mathrm{~F}$ & $.92 \mathrm{E}+00$ \\
\hline $.55 E-03$ & $3.23 E+00$ & $2.31 E-01$ & $9.27 \mathrm{E}-02$ & & $26 E-01$ & $1.41 E+00$ & 1. $93 \mathrm{E}+00$ \\
\hline $6 E-03$ & $3 E+00$ & ה & $E-02$ & 1 & 1 & ז & $93 E+00$ \\
\hline $.58 E-03$ & $3.24 \mathrm{E}+00$ & $2.33 E-01$ & $9.38 \mathrm{E}-02$ & 皮 & 9 & $1.42 \mathrm{E}+00$ & $3 \mathrm{E}+00$ \\
\hline $59 E-03$ & $3.24 \mathrm{E}+00$ & $2.345-01$ & $9.44 \mathrm{E}-02$ & $\perp$ & $\perp$ & 1.4 & +00 \\
\hline $.61 E-03$ & $3.25 E+00$ & $2 \cdot 004$ & 02 & & & 10.4015 & $4 \mathrm{E}+00$ \\
\hline $62 \mathrm{E}-03$ & $3.25 \mathrm{E}+00$ & 2.00 & . & . & - & $H_{1}$ & $1.94 \mathrm{E}+00$ \\
\hline $.64 E-03$ & $3.26 \mathrm{E}+00$ & $6 E-01$ & $1 E-02$ & $1 E-01$ & (0) & $1.43 E+00$ & 1.94E+00 \\
\hline $.65 E-03$ & $3.26 \mathrm{E}+00$ & $2.37 \mathrm{E}-01$ & $67 E-02$ & $23 E-$ & קבר & $1.44 \mathrm{E}+00$ & $.95 E+00$ \\
\hline$E-03$ & $.27 E+00$ & $2.38 E-01$ & $E-02$ & $\perp$ & & $1.44 \mathrm{E}+00$ & $95 \mathrm{E}+00$ \\
\hline$E-03$ & $\mathrm{E}+00$ & 2 & 2 & 1 & & 00 & \\
\hline $.70 E-03$ & $3 . \angle 8 E+00$ & $2.40 \mathrm{D}-\mathrm{c}$ & $9.83 E-02$ & ( & 年 & & $1.96 \mathrm{E}+00$ \\
\hline $.72 \mathrm{E}-03$ & $3.28 \mathrm{E}+00$ & $2.40 \mathrm{E}-01$ & $9.88 \mathrm{E}-02$ & $6.31 \mathrm{E}-01$ & $9.53 \mathrm{E}-01$ & $1.45 \mathrm{E}+00$ & $1.96 \mathrm{E}+00$ \\
\hline 03 & 0 & 2 & 2 & - & L & S & $.96 E+00$ \\
\hline 3 & $3295+0$ & 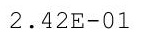 & 2 & & & 1. $45 \mathrm{E}+$ & $7 \mathrm{E}+00$ \\
\hline 3 & $3305+00$ & & & - & L & $1.46 \mathrm{E}+00$ & $1.97 \mathrm{E}+00$ \\
\hline $3 E-03$ & $3.30 \mathrm{E}+00$ & & & & & & \\
\hline $.80 E-03$ & $3.30 \mathrm{E}+00$ & 2. & $1 \mathrm{E}-01$ & 1 & 1 & 00 & $1.97 \mathrm{E}+00$ \\
\hline $.81 \mathrm{E}-03$ & $3.31 \mathrm{E}+00$ & $2.45 \mathrm{E}-01$ & 1. $02 \mathrm{E}-01$ & $0.4 \perp 5-$ & 11 & $1.4 / E+U 0$ & $1.98 \mathrm{E}+00$ \\
\hline $.83 E-03$ & $3.3 \perp E+U 0$ & & $1.02 \mathrm{E}-01$ & & & & $1.98 \mathrm{E}+00$ \\
\hline 3 & $0^{-1}$ & ${ }^{2}$ & & & & & 00 \\
\hline 3 & $5+$ & & & & & & 00 \\
\hline 3 & & 1 & 1 & 1 & 1 & 0 & 00 \\
\hline$E-03$ & 3.3 & 2 . & $E-01$ & 1 & & 00 & 00 \\
\hline $92 E-03$ & $3.34 \mathrm{E}+00$ & 2 . & & & 1 & & $1.99 \mathrm{E}+00$ \\
\hline 03 & $3.34 \mathrm{E}+00$ & 1 & & & & & $2.00 \mathrm{E}+00$ \\
\hline $20-03$ & $3.34 E+00$ & $2.52 \mathrm{E}$ & 1 & 10 & 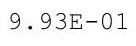 & $1.49 \mathrm{E}+00$ & $2.00 \mathrm{E}+00$ \\
\hline 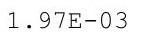 & 0 & 2.00 & & 1 & 1 & 0 & \\
\hline & & & 01 & 6 & 9 & $1.50 \mathrm{E}+00$ & $2.01 E+00$ \\
\hline$E-03$ & $3.36 \mathrm{E}+00$ & $E-01$ & 1.0 & 6 . & 1. $00 \mathrm{E}+00$ & $1.51 \mathrm{E}+00$ & $2.01 E+00$ \\
\hline $.02 E-03$ & $36 \mathrm{E}+00$ & $.55 E-01$ & $1.08 \mathrm{E}-01$ & $61 E-01$ & 1.00E+00 & $1.51 \mathrm{E}+00$ & $2.01 E+00$ \\
\hline
\end{tabular}


RESRAD-OFFSITE, Version 2.5

$\mathrm{T}^{1 / 2}$ Limit $=180$ days

obabilistic Dose and Risk Report

Title : Offsite Resident Farmer

File : RF TC99 DOESG FWD-FV2all.ROF

Summary of dose at graphical times, reptition 3 (continued)

Time

Years

$5.66 \mathrm{E}+02$

$5.67 \mathrm{E}+02$

$5.67 \mathrm{E}+02$

$5.68 \mathrm{E}+02$

$5.68 \mathrm{E}+02$

$5.69 \mathrm{E}+02$

$5.69 \mathrm{E}+02$

$5.70 \mathrm{E}+02$

$5.70 \mathrm{E}+02$

$5.71 \mathrm{E}+02$

$5.71 \mathrm{E}+02$

$5.72 \mathrm{E}+02$

$5.72 \mathrm{E}+02$

$5.73 \mathrm{E}+02$

$5.73 \mathrm{E}+02$

$5.74 \mathrm{E}+02$

$5.74 \mathrm{E}+02$

$5.75 \mathrm{E}+02$

$5.75 \mathrm{E}+02$

$5.76 \mathrm{E}+02$

$5.76 \mathrm{E}+02$

$5.77 \mathrm{E}+02$

$5.77 \mathrm{E}+02$

$5.78 \mathrm{E}+02$

$5.78 \mathrm{E}+02$

$5.79 \mathrm{E}+02$

$5.79 \mathrm{E}+02$

$5.80 \mathrm{E}+02$

$5.80 \mathrm{E}+02$

$5.81 \mathrm{E}+02$

$5.81 \mathrm{E}+02$

$5.82 \mathrm{E}+02$

$5.82 \mathrm{E}+02$

$5.83 \mathrm{E}+02$

$5.83 \mathrm{E}+02$

$5.84 \mathrm{E}+02$

$5.84 \mathrm{E}+02$

$5.85 \mathrm{E}+02$

$5.85 \mathrm{E}+02$

$5.86 \mathrm{E}+02$

$5.87 \mathrm{E}+02$

$5.87 \mathrm{E}+02$

$5.88 \mathrm{E}+02$

$5.88 \mathrm{E}+02$

$5.89 \mathrm{E}+02$

$5.89 \mathrm{E}+02$
Dose statistics at graphical times, mrem/yr

\begin{tabular}{|c|c|c|c|c|c|c|c|}
\hline inimum & laximum & Mean & ledian & $\%$ & $\div$ & $97.5 \%$ & $\%$ \\
\hline $4 E-03$ & $3.37 \mathrm{E}+00$ & $2.56 \mathrm{E}-01$ & $.09 \mathrm{E}-01$ & $6.63 \mathrm{E}-01$ & $1.01 \mathrm{E}+00$ & $1.51 \mathrm{E}+00$ & $E+00$ \\
\hline 03 & $\mathrm{E}+00$ & 1 & 1 & 1 & 0 & +00 & $2 \mathrm{E}+00$ \\
\hline$E-03$ & +00 & 01 & & & & +00 & +00 \\
\hline 03 & $E+00$ & & & & & & +00 \\
\hline-03 & $\mathrm{E}+00$ & & & & 00 & $E+00$ & $03 E+00$ \\
\hline $.13 E-03$ & $9 \mathrm{E}+00$ & $D E-01$ & -01 & $74 \mathrm{E}-01$ & $1.02 \mathrm{E}+00$ & $3 E+00$ & $E+00$ \\
\hline 03 & $.39 \mathrm{E}+00$ & 01 & 01 & . & 0 & $4 \mathrm{E}+00$ & $03 E+00$ \\
\hline $.17 E-03$ & $3.40 \mathrm{E}+00$ & 2.02501 & & $0.70 \mathrm{U}$ & $1 \cdot 0<+10$ & +00 & $2.03 E+00$ \\
\hline 03 & $E+00$ & & & & & +00 & +00 \\
\hline $.21 E-03$ & $3.40 \mathrm{E}+00$ & $4 \mathrm{E}-01$ & & & & & $4 \mathrm{E}+00$ \\
\hline-03 & +00 & $E-01$ & 1 & 1 & 0 & +00 & $E+00$ \\
\hline-03 & $41 E+00$ & $E-01$ & 1 & 1 & 00 & +00 & $04 \mathrm{E}+00$ \\
\hline $27 E-03$ & $3.42 \mathrm{E}+00$ & -01 & 01 & $\perp$ & 0 & $E+00$ & $05 E+00$ \\
\hline 3 & $.42 E+00$ & $2.67 \mathrm{E}-01$ & $\perp$ & - & 0 & 0 & م5 \\
\hline 3 & $E+00$ & 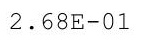 & & & & 0 & 00 \\
\hline $33 E-03$ & $3.43 E+00$ & $2.69 \mathrm{E}-01$ & $1.17 \mathrm{E}-01$ & $6.93 E-01$ & $1.04 \mathrm{E}+00$ & $1.57 \mathrm{E}+00$ & $2.06 \mathrm{E}+00$ \\
\hline $35 E-03$ & $3.43 E+00$ & $2.70 \mathrm{E}-01$ & 1. $18 \mathrm{E}-01$ & $6.95 \mathrm{E}-01$ & $1.05 \mathrm{E}+00$ & $1.57 \mathrm{E}+00$ & $2.06 \mathrm{E}+00$ \\
\hline $37 E-03$ & $3.44 \mathrm{E}+00$ & $2.70 \mathrm{E}-01$ & $1.18 \mathrm{E}-01$ & $97 E-01$ & $1.05 \mathrm{E}+00$ & $E+00$ & $06 E+00$ \\
\hline 03 & 00 & & & & & & $E+00$ \\
\hline 3 & $.44 \mathrm{E}+00$ & $\perp$ & $\perp$ & 1 & 0 & 0 & +00 \\
\hline 3 & 0 & & $\perp$ & & & & 00 \\
\hline-03 & $E+00$ & 1 & 1 & . & & & $7 E+00$ \\
\hline $47 E-03$ & $.46 \mathrm{E}+00$ & $75 \mathrm{~F}-01$ & 1. $22 \mathrm{E}-01$ & $07 E-01$ & $1.06 \mathrm{E}+\mathrm{C}$ & $.60 E+00$ & $.08 E+00$ \\
\hline $49 F-03$ & $.46 \mathrm{E}+00$ & $76 E-01$ & $1.22 \mathrm{E}-01$ & $8 E-01$ & $1.06 \mathrm{E}+$ & $.60 \mathrm{E}+00$ & $.08 E+00$ \\
\hline$E-03$ & $.46 \mathrm{E}+00$ & & & & & & $.08 \mathrm{E}+00$ \\
\hline & & & & & & & $09 E+00$ \\
\hline 3 & & $2 \cdot 1$ & $1 \cdot 2$ & & & 00 & +00 \\
\hline $58 E-03$ & $3.47 \mathrm{E}+00$ & $2 \cdot 120$ & $1 \cdot 20$ & $\cdot+0=$ & म. UIDTU & $1.61 \mathrm{E}+00$ & $2.09 \mathrm{E}+00$ \\
\hline 33 & $48 E+00$ & 1 & 1 & ז7 & 1.08E+ & 1. $62 \mathrm{E}+00$ & $2.09 \mathrm{E}+00$ \\
\hline $5=03$ & $3.48 \mathrm{E}+00$ & & & & & 1. $62 \mathrm{E}+00$ & $2.10 \mathrm{E}+00$ \\
\hline$F-03$ & $3.49 \mathrm{E}+00$ & & & & & & \\
\hline & & & & & & & $2.10 \mathrm{E}+00$ \\
\hline 3 & & & & 1 & & $E+00$ & +00 \\
\hline $.71 E-03$ & $3.50 \mathrm{E}+00$ & $2.84 E-U 1$ & $1.29 \mathrm{E}-01$ & $\cdot 205$ & $\perp .0 Y L T$ & 1. $63 \mathrm{E}+00$ & $2.11 \mathrm{E}+00$ \\
\hline $\begin{array}{l}1 \\
.\end{array}$ & $3.50 \mathrm{E}+00$ & & $1.295-U 1$ & & & I.OयLTU & $2.11 \mathrm{E}+00$ \\
\hline 3 & $3.50 \mathrm{E}+00$ & & & & & & $2.12 \mathrm{E}+00$ \\
\hline $.78 E-03$ & & & & & & & $2.12 \mathrm{E}+00$ \\
\hline 3 & & $2.88 \mathrm{E}-01$ & 1 & 1 & & & \\
\hline $3 E-03$ & $3.51 E+00$ & 01 & 01 & 01 & & $E+00$ & $2.12 \mathrm{E}+00$ \\
\hline $85 E-03$ & $3.52 \mathrm{E}+00$ & 1 & 1.3 & 1 & $1.10 \mathrm{E}$ & & $2.13 E+00$ \\
\hline$E-03$ & $3.52 \mathrm{E}+00$ & $2.90 \pm-01$ & $1.33 E-01$ & . 100 & & & $2.13 \mathrm{E}+00$ \\
\hline $2-42$ & $3.52 \mathrm{E}+00$ & $2.9 \perp \perp-U \perp$ & $1.345-U \perp$ & - tra & $1.11 \mathrm{E}+00$ & $1.66 \mathrm{E}+00$ & $2.13 E+00$ \\
\hline 20 & $3.53 \mathrm{E}+00$ & $2.02+0=$ & $1.00 \mathrm{~L}$ & & & $1.66 \mathrm{E}+00$ & $2.13 E+00$ \\
\hline $2.94 \mathrm{E}-03$ & $3.53 E+00$ & & & 1 & $1.11 \mathrm{E}+00$ & $1.67 \mathrm{E}+00$ & $.14 \mathrm{E}+00$ \\
\hline $97 E-03$ & $3.54 \mathrm{E}+00$ & $2.94 E-01$ & $E-01$ & $7.46 \mathrm{E}-$ & $1.12 \mathrm{E}+00$ & $1.67 \mathrm{E}+00$ & $2.14 \mathrm{E}+00$ \\
\hline $9 E-03$ & $54 \mathrm{E}+00$ & $95 \mathrm{E}-01$ & $1.37 \mathrm{E}-01$ & $7.47 \mathrm{E}-01$ & $1.12 \mathrm{E}+00$ & $1.67 \mathrm{E}+00$ & +00 \\
\hline
\end{tabular}


RESRAD-OFFSITE, Version 2.5

$\mathrm{T}^{1 / 2}$ Limit $=180$ days

obabilistic Dose and Risk Report

Title : Offsite Resident Farmer

File : RF TC99 DOESG FWD-FV2all.ROF

Summary of dose at graphical times, reptition 3 (continued)

Time

Years

$5.90 \mathrm{E}+02$

$5.90 \mathrm{E}+02$

$5.91 \mathrm{E}+02$

$5.91 \mathrm{E}+02$

$5.92 \mathrm{E}+02$

$5.92 \mathrm{E}+02$

$5.93 \mathrm{E}+02$

$5.93 \mathrm{E}+02$

$5.94 \mathrm{E}+02$

$5.94 \mathrm{E}+02$

$5.95 \mathrm{E}+02$

$5.95 \mathrm{E}+02$

$5.96 \mathrm{E}+02$

$5.96 \mathrm{E}+02$

$5.97 \mathrm{E}+02$

$5.97 \mathrm{E}+02$

$5.98 \mathrm{E}+02$

$5.98 \mathrm{E}+02$

$5.99 \mathrm{E}+02$

$5.99 \mathrm{E}+02$

$6.00 \mathrm{E}+02$

$6.00 \mathrm{E}+02$

$6.01 \mathrm{E}+02$

$6.01 \mathrm{E}+02$

$6.02 \mathrm{E}+02$

$6.02 \mathrm{E}+02$

$6.03 E+02$

$6.03 \mathrm{E}+02$

$6.04 \mathrm{E}+02$

$6.04 \mathrm{E}+02$

$6.05 \mathrm{E}+02$

$6.05 \mathrm{E}+02$

$6.06 \mathrm{E}+02$

$6.07 \mathrm{E}+02$

$6.07 \mathrm{E}+02$

$6.08 \mathrm{E}+02$

$6.08 \mathrm{E}+02$

$6.09 \mathrm{E}+02$

$6.09 \mathrm{E}+02$

$6.10 \mathrm{E}+02$

$6.10 \mathrm{E}+02$

$6.11 \mathrm{E}+02$

$6.11 \mathrm{E}+02$

$6.12 \mathrm{E}+02$

$6.12 \mathrm{E}+02$

$6.13 \mathrm{E}+02$
Dose statistics at graphical times, mrem/yr

\begin{tabular}{|c|c|c|c|c|c|c|c|}
\hline m & $\mathrm{m}$ & Mean & ${ }^{2}$ & & & $\%$ & $\%$ \\
\hline 03 & $3.54 \mathrm{E}+00$ & $2.96 \mathrm{E}-01$ & 1. $38 \mathrm{E}-01$ & $7.48 \mathrm{E}-01$ & $1.12 \mathrm{E}+00$ & 1. $68 \mathrm{E}+00$ & $2.14 \mathrm{E}+00$ \\
\hline-03 & $5 E+00$ & 01 & -01 & 01 & 00 & +00 & $14 \mathrm{E}+00$ \\
\hline $.07 E-03$ & $5 \mathrm{E}+00$ & $2.97 \mathrm{E}-01$ & $39 E-01$ & $51 \mathrm{E}-01$ & $1.12 \mathrm{E}+00$ & 1. $68 \mathrm{E}+00$ & $2.14 \mathrm{E}+00$ \\
\hline$E-03$ & $.55 E+00$ & $98 F-01$ & $40 E-01$ & $53 E-01$ & $13 E+00$ & $.69 \mathrm{E}+00$ & $15 E+00$ \\
\hline$E-03$ & $3.56 \mathrm{E}+00$ & $99 F-01$ & $140 \mathrm{~F}-01$ & $55 \mathrm{~F}-01$ & $1.13 \mathrm{E}+00$ & $69 E+00$ & $2.15 E+00$ \\
\hline-03 & & 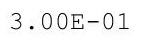 & ( & 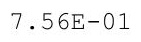 & & & +00 \\
\hline $.17 \mathrm{E}-03$ & & & & & & & +00 \\
\hline $.19 \mathrm{E}-03$ & & & & & & & $2.15 E+00$ \\
\hline $22 E-03$ & $3.57 \mathrm{E}+00$ & $E-01$ & -01 & $35-6(-2)-1$ & $14 \mathrm{E}+00$ & $E+00$ & $16 \mathrm{E}+00$ \\
\hline 03 & $57 \mathrm{E}+00$ & $3.03 E-01$ & $\perp$ & $\perp$ & $14 \mathrm{~F}$ & $.71 \mathrm{E}+$ & $16 \mathrm{E}+00$ \\
\hline 03 & $.58 \mathrm{E}+00$ & $3.04 \mathrm{E}-01$ & 1 & $7.67 \mathrm{E}-01$ & 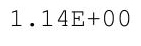 & $.71 E+00$ & $.16 \mathrm{E}+00$ \\
\hline$E-03$ & $3 E+00$ & & & & & 0 & +00 \\
\hline$E-03$ & +00 & -8 & 1 & $7.71 F-01$ & & 0 & +00 \\
\hline $.35 E-03$ & $3.58 \mathrm{E}+00$ & $3.07 \mathrm{E}-01$ & 1. $46 \mathrm{E}-01$ & $7.74 \mathrm{E}-01$ & $1.15 \mathrm{E}+00$ & 1. $72 \mathrm{E}+00$ & $2.17 \mathrm{E}+00$ \\
\hline $37 E-03$ & $.59 \mathrm{E}+00$ & $.08 \mathrm{E}-01$ & 1. $47 \mathrm{E}-01$ & $7.76 \mathrm{E}-$ & $1.15 \mathrm{E}+00$ & 1. $73 \mathrm{E}+00$ & $2.17 \mathrm{E}+00$ \\
\hline & 0 & & & & & 0 & $17 E+00$ \\
\hline B & & & & & & 0 & 00 \\
\hline 3 & $.60 \mathrm{E}+00$ & & & & & & 00 \\
\hline$E-03$ & $.60 \mathrm{E}+00$ & 15 & בم & & & $1.74 \mathrm{E}+00$ & $17 E+00$ \\
\hline $51 E-03$ & $3.60 \mathrm{E}+00$ & $.12 \mathrm{E}-01$ & 1. $50 \mathrm{E}-01$ & $.85 E-0$ & $1.16 \mathrm{E}+00$ & $1.75 \mathrm{E}+00$ & $2.18 \mathrm{E}+00$ \\
\hline$E-03$ & $.61 E+00$ & $13 \mathrm{E}-0$ & -01 & $\perp$ & $1.16 \mathrm{E}+$ & $1.75 \mathrm{E}+00$ & $2.18 \mathrm{E}+00$ \\
\hline & & & & & & & $.18 \mathrm{E}+00$ \\
\hline & & & & & & $1.76 \mathrm{E}+$ & 00 \\
\hline-03 & $3.62 \mathrm{E}+00$ & & 1. & & $1.16 \mathrm{E}$ & +00 & 2.1 \\
\hline 3 & +00 & $3.17 \mathrm{E}-01$ & - & (1) & $1.17 \mathrm{E}+$ & - & $19 E+00$ \\
\hline$E-03$ & $.62 E+00$ & $3-18 F-0$ & 1. $54 \mathrm{E}-01$ & 7 ברת 7 & $1.17 \mathrm{E}+\mathrm{C}$ & 1. $77 \mathrm{E}+00$ & $2.19 \mathrm{E}+00$ \\
\hline$F-03$ & $3.62 \mathrm{E}+00$ & $18 F-01$ & $154 \mathrm{~F}-01$ & 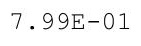 & 1.17E+ & 1. $77 \mathrm{E}+00$ & $2.19 \mathrm{E}+00$ \\
\hline 03 & & & & & & & \\
\hline 03 & $3.63 \mathrm{E}+00$ & & & & & & \\
\hline $.79 E-03$ & $3.63 E+00$ & $3 . \angle \perp \amalg-U 1$ & $1.56 \mathrm{E}-01$ & . & $1.18 \mathrm{E}+00$ & $1.78 \mathrm{E}+00$ & $2.20 \mathrm{E}+00$ \\
\hline $81 E-03$ & $3.64 \mathrm{E}+00$ & 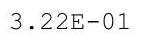 & $\perp \cdot U / \mathrm{L}-U$ & $0.095-0 \perp$ & 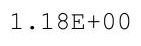 & म.TOLTU & $2.20 \mathrm{ETOU}$ \\
\hline 3 & $3.64 \mathrm{E}+00$ & 年 & 200 & 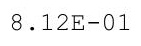 & 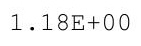 & 土. & $2.20 \mathrm{E}+00$ \\
\hline$F-03$ & $3.64 \mathrm{E}+00$ & ת & 150 & ת ת 1 & & & $2.21 \mathrm{E}+$ \\
\hline & & & & & & & \\
\hline 03 & & & 1 & 1 & & & \\
\hline $6 E-03$ & $3.65 \mathrm{E}+00$ & $3.27 E-01$ & $1.60 \mathrm{E}-01$ & 1 & $1.19 \mathrm{E}$ & $1.79 \mathrm{E}$ & $2.21 \mathrm{E}$ \\
\hline$E-03$ & $3.65 \mathrm{E}+00$ & & 1. & & $1 \cdot 20 \mathrm{~L}$ & & $2.22 \pm 100$ \\
\hline $.02 E-03$ & $3.65 \mathrm{E}+00$ & & & & 土. & & $2.22 \mathrm{E}+00$ \\
\hline 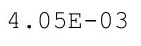 & e. & $3.29 \mathrm{E}-01$ & +0 & 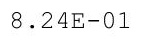 & $+\cdot 20$ & & $2.22 \mathrm{E}+$ \\
\hline & & & & & $20 \mathrm{E}+$ & & $2.22 \mathrm{E}+$ \\
\hline 3 & $3.66 \mathrm{E}+00$ & 3 & 1 . & 1 & 1.21E+ & & $2.22 E+00$ \\
\hline-03 & $3.67 \mathrm{E}+00$ & $3.32 E-01$ & 1. & -01 & 1.21E+ & & $2.23 E+00$ \\
\hline & & & & & & & \\
\hline & $3.67 \mathrm{E}+00$ & $3.34 \mathrm{E}-01$ & \pm & & $\perp \cdot 2 \perp+100$ & $1.80 \mathrm{E}+00$ & $2.23 E+00$ \\
\hline$E-03$ & $3.67 \mathrm{E}+00$ & . & $1.6 / \mathrm{E}-01$ & ( & $1.22 \mathrm{E}+00$ & & $2.23 E+00$ \\
\hline$E-03$ & $.68 E+00$ & $6 E-01$ & $67 E-01$ & $E-01$ & $1.22 \mathrm{E}+00$ & $1.81 \mathrm{E}+00$ & $.24 E+00$ \\
\hline
\end{tabular}


RESRAD-OFFSITE, Version 2.5

robabilistic Dose and Risk Report

Title : Offsite Resident Farmer

File : RF TC99 DOESG FWD-FV2all.ROF

Summary of dose at graphical times, reptition 3 (continued)

Time

Years

$6.13 \mathrm{E}+02$

$6.14 \mathrm{E}+02$

$6.14 \mathrm{E}+02$

$6.15 \mathrm{E}+02$

$6.15 \mathrm{E}+02$

$6.16 \mathrm{E}+02$

$6.16 \mathrm{E}+02$

$6.17 \mathrm{E}+02$

$6.17 \mathrm{E}+02$

$6.18 \mathrm{E}+02$

$6.18 \mathrm{E}+02$

$6.19 \mathrm{E}+02$

$6.19 \mathrm{E}+02$

$6.20 \mathrm{E}+02$

$6.20 \mathrm{E}+02$

$6.21 \mathrm{E}+02$

$6.21 \mathrm{E}+02$

$6.22 \mathrm{E}+02$

$6.22 \mathrm{E}+02$

$6.23 \mathrm{E}+02$

$6.23 \mathrm{E}+02$

$6.24 \mathrm{E}+02$

$6.24 \mathrm{E}+02$

$6.25 \mathrm{E}+02$

$6.25 \mathrm{E}+02$

$6.26 \mathrm{E}+02$

$6.27 \mathrm{E}+02$

$6.27 \mathrm{E}+02$

$6.28 \mathrm{E}+02$

$6.28 \mathrm{E}+02$

$6.29 \mathrm{E}+02$

$6.29 \mathrm{E}+02$

$6.30 \mathrm{E}+02$

$6.30 \mathrm{E}+02$

$6.31 \mathrm{E}+02$

$6.31 \mathrm{E}+02$

$6.32 \mathrm{E}+02$

$6.32 \mathrm{E}+02$

$6.33 \mathrm{E}+02$

$6.33 \mathrm{E}+02$

$6.34 \mathrm{E}+02$

$6.34 \mathrm{E}+02$

$6.35 \mathrm{E}+02$

$6.35 \mathrm{E}+02$

$6.36 \mathrm{E}+02$

$6.36 \mathrm{E}+02$

Dose statistics at graphical times, mrem/yr

\begin{tabular}{|c|c|c|c|c|c|c|c|}
\hline Minimum & Maximum & Mean & Median & $90 \%$ & $95 \%$ & $97.5 \%$ & $99 \%$ \\
\hline $4.30 \mathrm{E}-03$ & $3.68 \mathrm{E}+00$ & $3.36 \mathrm{E}-01$ & 1. $68 \mathrm{E}-01$ & $8.39 E-01$ & $1.22 \mathrm{E}+00$ & $1.81 \mathrm{E}+00$ & $2.24 E+00$ \\
\hline $4.33 E-03$ & $3.68 \mathrm{E}+00$ & $3.37 E-01$ & $1.69 \mathrm{E}-01$ & $8.41 E-01$ & $1.23 \mathrm{E}+00$ & $1.81 \mathrm{E}+00$ & $2.24 E+00$ \\
\hline $4.36 \mathrm{E}-03$ & $3.68 \mathrm{E}+00$ & $3.38 \mathrm{E}-01$ & 1. $70 \mathrm{E}-01$ & $8.43 E-01$ & $1.23 \mathrm{E}+00$ & $1.81 \mathrm{E}+00$ & $2.24 \mathrm{E}+00$ \\
\hline $4.39 \mathrm{E}-03$ & $3.69 \mathrm{E}+00$ & $3.39 \mathrm{E}-01$ & $1.70 \mathrm{E}-01$ & $8.45 \mathrm{E}-01$ & $1.23 \mathrm{E}+00$ & $1.81 \mathrm{E}+00$ & $2.24 \mathrm{E}+00$ \\
\hline $4.43 E-03$ & $3.69 \mathrm{E}+00$ & $3.40 \mathrm{E}-01$ & 1. $71 \mathrm{E}-01$ & $8.47 \mathrm{E}-01$ & $1.23 \mathrm{E}+00$ & $1.82 \mathrm{E}+00$ & $2.25 \mathrm{E}+00$ \\
\hline $4.46 E-03$ & $3.69 \mathrm{E}+00$ & $3.41 \mathrm{E}-01$ & 1. $72 \mathrm{E}-01$ & $8.49 \mathrm{E}-01$ & $1.24 \mathrm{E}+00$ & $1.82 \mathrm{E}+00$ & $2.25 \mathrm{E}+00$ \\
\hline $4.49 \mathrm{E}-03$ & $3.69 \mathrm{E}+00$ & $3.42 \mathrm{E}-01$ & $1.73 E-01$ & $8.51 \mathrm{E}-01$ & $1.24 \mathrm{E}+00$ & $1.82 \mathrm{E}+00$ & $2.25 \mathrm{E}+00$ \\
\hline $4.52 E-03$ & $3.70 \mathrm{E}+00$ & $3.43 E-01$ & 1. $73 E-01$ & $8.54 E-01$ & $1.24 \mathrm{E}+00$ & $1.82 \mathrm{E}+00$ & $2.25 E+00$ \\
\hline $4.56 \mathrm{E}-03$ & $3.70 \mathrm{E}+00$ & $3.44 \mathrm{E}-01$ & 1. $74 \mathrm{E}-01$ & $8.56 \mathrm{E}-01$ & $1.24 \mathrm{E}+00$ & $1.82 \mathrm{E}+00$ & $2.25 E+00$ \\
\hline $4.59 \mathrm{E}-03$ & $3.70 \mathrm{E}+00$ & $3.45 \mathrm{E}-01$ & 1. $75 \mathrm{E}-01$ & $8.58 \mathrm{E}-01$ & $1.25 \mathrm{E}+00$ & $1.82 \mathrm{E}+00$ & $2.26 \mathrm{E}+00$ \\
\hline $4.62 \mathrm{E}-03$ & $3.70 \mathrm{E}+00$ & $3.45 \mathrm{E}-01$ & 1. $75 \mathrm{E}-01$ & $8.60 \mathrm{E}-01$ & $1.25 \mathrm{E}+00$ & $1.82 \mathrm{E}+00$ & $2.26 \mathrm{E}+00$ \\
\hline 4. $65 \mathrm{E}-03$ & $3.70 \mathrm{E}+00$ & $3.46 \mathrm{E}-01$ & 1. $76 \mathrm{E}-01$ & $8.63 E-01$ & $1.25 \mathrm{E}+00$ & $1.83 \mathrm{E}+00$ & $2.26 \mathrm{E}+00$ \\
\hline $4.69 \mathrm{E}-03$ & $3.71 \mathrm{E}+00$ & $3.47 \mathrm{E}-01$ & $1.77 \mathrm{E}-01$ & $8.65 E-01$ & $1.26 \mathrm{E}+00$ & $1.83 \mathrm{E}+00$ & $2.26 \mathrm{E}+00$ \\
\hline $4.72 E-03$ & $3.71 \mathrm{E}+00$ & $3.48 \mathrm{E}-01$ & 1. $77 \mathrm{E}-01$ & $8.68 \mathrm{E}-01$ & $1.26 \mathrm{E}+00$ & $1.83 \mathrm{E}+00$ & $2.27 \mathrm{E}+00$ \\
\hline $4.76 E-03$ & $3.71 \mathrm{E}+00$ & $3.49 \mathrm{E}-01$ & 1. $78 \mathrm{E}-01$ & $8.70 \mathrm{E}-01$ & $1.26 \mathrm{E}+00$ & $1.83 \mathrm{E}+00$ & $2.27 \mathrm{E}+00$ \\
\hline $4.79 E-03$ & $3.71 \mathrm{E}+00$ & $3.50 \mathrm{E}-01$ & $1.79 \mathrm{E}-01$ & $2 E-01$ & $1.27 \mathrm{E}+00$ & $.83 E+00$ & $.27 E+00$ \\
\hline $4.82 \mathrm{E}-03$ & $3.72 \mathrm{E}+00$ & $3.51 \mathrm{E}-01$ & 1. $80 \mathrm{E}-01$ & $8.75 E-01$ & $1.27 \mathrm{E}+00$ & $1.83 \mathrm{E}+00$ & $2.27 \mathrm{E}+00$ \\
\hline $4.86 \mathrm{E}-03$ & $3.72 \mathrm{E}+00$ & $3.52 \mathrm{E}-01$ & 1. $80 \mathrm{E}-01$ & $8.77 \mathrm{E}-01$ & $1.27 \mathrm{E}+00$ & $1.83 \mathrm{E}+00$ & $2.27 \mathrm{E}+00$ \\
\hline $4.89 E-03$ & $3.72 \mathrm{E}+00$ & $3.53 E-01$ & 1. $81 \mathrm{E}-01$ & $8.79 \mathrm{E}-01$ & $1.27 \mathrm{E}+00$ & $1.84 \mathrm{E}+00$ & $2.28 \mathrm{E}+00$ \\
\hline $4.93 E-03$ & $3.72 \mathrm{E}+00$ & $3.54 \mathrm{E}-01$ & 1. $82 \mathrm{E}-01$ & $8.82 \mathrm{E}-01$ & $1.28 \mathrm{E}+00$ & $1.84 \mathrm{E}+00$ & $2.28 \mathrm{E}+00$ \\
\hline $4.96 \mathrm{E}-03$ & $3.72 \mathrm{E}+00$ & $3.55 \mathrm{E}-01$ & 1. $82 \mathrm{E}-01$ & $8.84 \mathrm{E}-01$ & $1.28 \mathrm{E}+00$ & $1.84 \mathrm{E}+00$ & $2.28 \mathrm{E}+00$ \\
\hline $5.00 E-03$ & $3.73 \mathrm{E}+00$ & $3.55 \mathrm{E}-01$ & $1.83 E-01$ & $8.87 E-01$ & $1.28 \mathrm{E}+00$ & $1.84 \mathrm{E}+00$ & $2.29 \mathrm{E}+00$ \\
\hline $5.03 E-03$ & $3.73 \mathrm{E}+00$ & $3.56 \mathrm{E}-01$ & $1.84 \mathrm{E}-01$ & $8.89 E-01$ & $1.29 \mathrm{E}+00$ & $1.84 \mathrm{E}+00$ & $2.29 \mathrm{E}+00$ \\
\hline $5.07 \mathrm{E}-03$ & $3.73 \mathrm{E}+00$ & $3.57 \mathrm{E}-01$ & $1.84 \mathrm{E}-01$ & $8.91 \mathrm{E}-01$ & $1.29 \mathrm{E}+00$ & $1.84 \mathrm{E}+00$ & $2.29 \mathrm{E}+00$ \\
\hline $5.10 \mathrm{E}-03$ & $3.73 E+00$ & $3.58 \mathrm{E}-01$ & $1.85 \mathrm{E}-01$ & $8.94 \mathrm{E}-01$ & $1.29 \mathrm{E}+00$ & $1.84 \mathrm{E}+00$ & $2.30 \mathrm{E}+00$ \\
\hline $5.14 \mathrm{E}-03$ & $3.74 \mathrm{E}+00$ & $3.59 \mathrm{E}-01$ & $1.86 \mathrm{E}-01$ & $8.96 \mathrm{E}-01$ & $1.29 \mathrm{E}+00$ & $1.84 \mathrm{E}+00$ & $2.30 \mathrm{E}+00$ \\
\hline $5.18 \mathrm{E}-03$ & $3.74 \mathrm{E}+00$ & $3.60 \mathrm{E}-01$ & $1.87 \mathrm{E}-01$ & $8.98 \mathrm{E}-01$ & $1.29 \mathrm{E}+00$ & $1.85 \mathrm{E}+00$ & $2.30 \mathrm{E}+00$ \\
\hline $5.21 \mathrm{E}-03$ & $3.74 \mathrm{E}+00$ & $3.61 \mathrm{E}-01$ & $1.87 \mathrm{E}-01$ & $9.01 \mathrm{E}-01$ & $1.30 \mathrm{E}+00$ & $1.85 \mathrm{E}+00$ & $2.31 E+00$ \\
\hline $5.25 E-03$ & $3.74 \mathrm{E}+00$ & $3.62 \mathrm{E}-01$ & $1.88 E-01$ & $9.03 E-01$ & $1.30 \mathrm{E}+00$ & $1.85 \mathrm{E}+00$ & $2.31 E+00$ \\
\hline $5.29 E-03$ & $3.74 \mathrm{E}+00$ & $3.63 E-01$ & 1. 89E-01 & $9.05 E-01$ & $1.30 \mathrm{E}+00$ & $1.85 \mathrm{E}+00$ & $2.31 E+00$ \\
\hline $5.32 \mathrm{E}-03$ & $3.75 \mathrm{E}+00$ & $3.64 \mathrm{E}-01$ & 1. $89 \mathrm{E}-01$ & $9.08 \mathrm{E}-01$ & $1.30 \mathrm{E}+00$ & $1.85 \mathrm{E}+00$ & $2.32 \mathrm{E}+00$ \\
\hline $5.36 \mathrm{E}-03$ & $3.75 \mathrm{E}+00$ & $3.65 \mathrm{E}-01$ & 1. $90 \mathrm{E}-01$ & $9.10 \mathrm{E}-01$ & $1.30 \mathrm{E}+00$ & $1.85 \mathrm{E}+00$ & $2.32 \mathrm{E}+00$ \\
\hline $5.40 E-03$ & $3.75 \mathrm{E}+00$ & $3.66 \mathrm{E}-01$ & 1.91E-01 & $3 E-01$ & $1.30 \mathrm{E}+00$ & $1.85 \mathrm{E}+00$ & $2.32 \mathrm{E}+00$ \\
\hline $5.43 E-03$ & $3.75 \mathrm{E}+00$ & $3.66 \mathrm{E}-01$ & 1. $92 \mathrm{E}-01$ & $9.15 \mathrm{E}-01$ & $1.31 \mathrm{E}+00$ & $1.85 \mathrm{E}+00$ & $2.32 \mathrm{E}+00$ \\
\hline $5.47 \mathrm{E}-03$ & $3.75 \mathrm{E}+00$ & $3.67 \mathrm{E}-01$ & 1.92E-01 & $9.18 \mathrm{E}-01$ & $1.31 \mathrm{E}+00$ & $1.86 \mathrm{E}+00$ & $2.33 E+00$ \\
\hline $5.51 E-03$ & $3.75 \mathrm{E}+00$ & $3.68 E-01$ & $1.93 E-01$ & $9.20 \mathrm{E}-01$ & $1.31 \mathrm{E}+00$ & $1.86 \mathrm{E}+00$ & $2.33 E+00$ \\
\hline $5.55 E-03$ & $3.76 \mathrm{E}+00$ & $3.69 \mathrm{E}-01$ & 1. $94 \mathrm{E}-01$ & $9.23 \mathrm{E}-01$ & $1.31 \mathrm{E}+00$ & $1.86 \mathrm{E}+00$ & $2.33 E+00$ \\
\hline $5.58 \mathrm{E}-03$ & $3.76 \mathrm{E}+00$ & $3.70 \mathrm{E}-01$ & 1. $95 \mathrm{E}-01$ & $9.25 \mathrm{E}-01$ & $1.32 \mathrm{E}+00$ & $1.86 \mathrm{E}+00$ & $2.34 \mathrm{E}+00$ \\
\hline $5.62 \mathrm{E}-03$ & $3.76 \mathrm{E}+00$ & $3.71 \mathrm{E}-01$ & 1.95E-01 & $9.28 \mathrm{E}-01$ & $1.32 \mathrm{E}+00$ & $1.86 \mathrm{E}+00$ & $2.34 \mathrm{E}+00$ \\
\hline $5.66 \mathrm{E}-03$ & $3.76 \mathrm{E}+00$ & $3.72 \mathrm{E}-01$ & $1.96 \mathrm{E}-01$ & $9.30 \mathrm{E}-01$ & $1.32 \mathrm{E}+00$ & $1.86 \mathrm{E}+00$ & $2.34 \mathrm{E}+00$ \\
\hline $5.70 \mathrm{E}-03$ & $3.76 \mathrm{E}+00$ & $3.73 E-01$ & $1.97 \mathrm{E}-01$ & $9.33 E-01$ & $1.32 \mathrm{E}+00$ & $1.87 \mathrm{E}+00$ & $2.35 \mathrm{E}+00$ \\
\hline $5.74 E-03$ & $3.77 \mathrm{E}+00$ & $3.74 \mathrm{E}-01$ & $1.98 \mathrm{E}-01$ & $9.35 E-01$ & $1.33 \mathrm{E}+00$ & $1.87 \mathrm{E}+00$ & $2.35 E+00$ \\
\hline $5.78 \mathrm{E}-03$ & $3.77 \mathrm{E}+00$ & $3.75 \mathrm{E}-01$ & 1. $98 \mathrm{E}-01$ & $9.38 \mathrm{E}-01$ & $1.33 \mathrm{E}+00$ & $1.87 \mathrm{E}+00$ & $2.35 \mathrm{E}+00$ \\
\hline $5.82 E-03$ & $3.77 \mathrm{E}+00$ & $3.76 \mathrm{E}-01$ & 1.99E-01 & $9.40 \mathrm{E}-01$ & $1.33 \mathrm{E}+00$ & $1.87 \mathrm{E}+00$ & $2.36 \mathrm{E}+00$ \\
\hline $5.86 \mathrm{E}-03$ & $3.77 \mathrm{E}+00$ & $3.77 E-01$ & $2.00 E-01$ & $9.43 E-01$ & $1.33 \mathrm{E}+00$ & $1.87 \mathrm{E}+00$ & $2.36 \mathrm{E}+00$ \\
\hline $5.90 E-03$ & $3.77 \mathrm{E}+00$ & $3.78 \mathrm{E}-01$ & $2.01 E-01$ & $9.45 E-01$ & $1.34 \mathrm{E}+00$ & $1.88 \mathrm{E}+00$ & $2.36 \mathrm{E}+00$ \\
\hline
\end{tabular}


RESRAD-OFFSITE, Version 2.5

robabilistic Dose and Risk Report

Title : Offsite Resident Farmer

File : RF TC99 DOESG FWD-FV2all.ROF

Summary of dose at graphical times, reptition 3 (continued)

Time

Years

$6.37 \mathrm{E}+02$

$6.37 \mathrm{E}+02$

$6.38 \mathrm{E}+02$

$6.38 \mathrm{E}+02$

$6.39 \mathrm{E}+02$

$6.39 \mathrm{E}+02$

$6.40 \mathrm{E}+02$

$6.40 \mathrm{E}+02$

$6.41 \mathrm{E}+02$

$6.41 \mathrm{E}+02$

$6.42 \mathrm{E}+02$

$6.42 \mathrm{E}+02$

$6.43 \mathrm{E}+02$

$6.43 \mathrm{E}+02$

$6.44 \mathrm{E}+02$

$6.44 \mathrm{E}+02$

$6.45 \mathrm{E}+02$

$6.45 \mathrm{E}+02$

$6.46 \mathrm{E}+02$

$6.47 \mathrm{E}+02$

$6.47 \mathrm{E}+02$

$6.48 \mathrm{E}+02$

$6.48 \mathrm{E}+02$

$6.49 \mathrm{E}+02$

$6.49 \mathrm{E}+02$

$6.50 \mathrm{E}+02$

$6.50 \mathrm{E}+02$

$6.51 \mathrm{E}+02$

$6.51 \mathrm{E}+02$

$6.52 \mathrm{E}+02$

$6.52 \mathrm{E}+02$

$6.53 \mathrm{E}+02$

$6.53 \mathrm{E}+02$

$6.54 \mathrm{E}+02$

$6.54 \mathrm{E}+02$

$6.55 \mathrm{E}+02$

$6.55 \mathrm{E}+02$

$6.56 \mathrm{E}+02$

$6.56 \mathrm{E}+02$

$6.57 \mathrm{E}+02$

$6.57 \mathrm{E}+02$

$6.58 \mathrm{E}+02$

$6.58 \mathrm{E}+02$

$6.59 \mathrm{E}+02$

$6.59 \mathrm{E}+02$

$6.60 \mathrm{E}+02$

Dose statistics at graphical times, mrem/yr

\begin{tabular}{|c|c|c|c|c|c|c|c|}
\hline Minimum & Maximum & Mean & Median & $90 \%$ & $95 \%$ & $97.5 \%$ & $99 \%$ \\
\hline $5.94 E-03$ & $3.77 \mathrm{E}+00$ & $3.78 E-01$ & $2.01 E-01$ & $9.48 E-01$ & $1.34 \mathrm{E}+00$ & $1.88 \mathrm{E}+00$ & $2.36 \mathrm{E}+00$ \\
\hline $5.97 E-03$ & $3.78 \mathrm{E}+00$ & $3.79 \mathrm{E}-01$ & $2.02 E-01$ & $9.50 \mathrm{E}-01$ & $1.34 \mathrm{E}+00$ & $1.88 \mathrm{E}+00$ & $2.37 \mathrm{E}+00$ \\
\hline $6.02 E-03$ & $3.78 \mathrm{E}+00$ & $3.80 \mathrm{E}-01$ & $2.03 E-01$ & $9.53 E-01$ & $1.34 \mathrm{E}+00$ & $1.88 \mathrm{E}+00$ & $2.37 E+00$ \\
\hline $6.06 \mathrm{E}-03$ & $3.78 \mathrm{E}+00$ & $3.81 \mathrm{E}-01$ & $2.04 \mathrm{E}-01$ & $9.55 \mathrm{E}-01$ & $1.35 \mathrm{E}+00$ & $1.89 \mathrm{E}+00$ & $2.37 \mathrm{E}+00$ \\
\hline $6.10 \mathrm{E}-03$ & $3.78 \mathrm{E}+00$ & $3.82 \mathrm{E}-01$ & $2.05 E-01$ & $9.58 \mathrm{E}-01$ & 1. $35 \mathrm{E}+00$ & $1.89 \mathrm{E}+00$ & $2.38 \mathrm{E}+00$ \\
\hline $6.14 \mathrm{E}-03$ & $3.78 \mathrm{E}+00$ & $3.83 \mathrm{E}-01$ & $2.06 \mathrm{E}-01$ & $9.60 \mathrm{E}-01$ & $1.35 \mathrm{E}+00$ & $1.89 \mathrm{E}+00$ & $2.38 \mathrm{E}+00$ \\
\hline $6.18 \mathrm{E}-03$ & $3.78 \mathrm{E}+00$ & $3.84 \mathrm{E}-01$ & $2.06 \mathrm{E}-01$ & $9.63 E-01$ & 1. $35 \mathrm{E}+00$ & $1.89 \mathrm{E}+00$ & $2.38 E+00$ \\
\hline $6.22 E-03$ & $3.79 \mathrm{E}+00$ & $3.85 E-01$ & $2.07 E-01$ & $9.65 E-01$ & $1.36 \mathrm{E}+00$ & $1.90 \mathrm{E}+00$ & $2.39 E+00$ \\
\hline $6.26 \mathrm{E}-03$ & $3.79 \mathrm{E}+00$ & $3.86 \mathrm{E}-01$ & $2.08 E-01$ & $9.67 \mathrm{E}-01$ & $1.36 \mathrm{E}+00$ & $1.90 \mathrm{E}+00$ & $2.39 \mathrm{E}+00$ \\
\hline $6.30 E-03$ & $3.79 \mathrm{E}+00$ & $3.87 \mathrm{E}-01$ & $2.09 \mathrm{E}-01$ & $9.69 \mathrm{E}-01$ & $1.36 \mathrm{E}+00$ & $1.90 \mathrm{E}+00$ & $2.39 \mathrm{E}+00$ \\
\hline $6.34 \mathrm{E}-03$ & $3.79 \mathrm{E}+00$ & $3.88 \mathrm{E}-01$ & $2.09 \mathrm{E}-01$ & $9.71 \mathrm{E}-01$ & $1.36 \mathrm{E}+00$ & $1.91 \mathrm{E}+00$ & $2.39 \mathrm{E}+00$ \\
\hline $6.38 E-03$ & $3.79 \mathrm{E}+00$ & $3.89 \mathrm{E}-01$ & $2.10 \mathrm{E}-01$ & $9.73 E-01$ & $1.37 \mathrm{E}+00$ & $1.91 \mathrm{E}+00$ & $2.40 \mathrm{E}+00$ \\
\hline $6.43 E-03$ & $3.79 \mathrm{E}+00$ & $3.90 \mathrm{E}-01$ & $2.11 \mathrm{E}-01$ & $9.75 E-01$ & $1.37 \mathrm{E}+00$ & $1.91 \mathrm{E}+00$ & $2.40 \mathrm{E}+00$ \\
\hline $6.47 E-03$ & $3.79 \mathrm{E}+00$ & $3.90 \mathrm{E}-01$ & $2.11 \mathrm{E}-01$ & $9.78 \mathrm{E}-01$ & $1.37 \mathrm{E}+00$ & 1.92E+00 & $2.40 \mathrm{E}+00$ \\
\hline $6.51 E-03$ & $3.80 \mathrm{E}+00$ & $3.91 \mathrm{E}-01$ & $2.12 \mathrm{E}-01$ & $9.80 \mathrm{E}-01$ & $1.37 \mathrm{E}+00$ & $1.92 \mathrm{E}+00$ & $2.41 \mathrm{E}+00$ \\
\hline $6.55 E-03$ & $3.80 \mathrm{E}+00$ & $3.92 \mathrm{E}-01$ & $2.13 E-01$ & $32 E-01$ & $1.38 \mathrm{E}+00$ & $.92 E+00$ & $.41 E+00$ \\
\hline $6.60 \mathrm{E}-03$ & $3.80 \mathrm{E}+00$ & $3.93 E-01$ & $2.14 \mathrm{E}-01$ & $9.84 \mathrm{E}-01$ & 1. $38 \mathrm{E}+00$ & $1.93 \mathrm{E}+00$ & $2.41 \mathrm{E}+00$ \\
\hline $6.64 \mathrm{E}-03$ & $3.80 \mathrm{E}+00$ & $3.94 \mathrm{E}-01$ & $2.14 \mathrm{E}-01$ & $9.86 \mathrm{E}-01$ & $1.38 \mathrm{E}+00$ & $1.93 \mathrm{E}+00$ & $2.41 \mathrm{E}+00$ \\
\hline $6.68 E-03$ & $3.80 \mathrm{E}+00$ & $3.95 \mathrm{E}-01$ & $2.15 \mathrm{E}-01$ & $9.88 \mathrm{E}-01$ & $1.38 \mathrm{E}+00$ & $1.93 \mathrm{E}+00$ & $2.42 \mathrm{E}+00$ \\
\hline $6.73 E-03$ & $3.80 \mathrm{E}+00$ & $3.96 \mathrm{E}-01$ & $2.16 \mathrm{E}-01$ & $9.90 \mathrm{E}-01$ & 1. $39 \mathrm{E}+00$ & $1.93 \mathrm{E}+00$ & $2.42 \mathrm{E}+00$ \\
\hline $6.77 E-03$ & $3.80 \mathrm{E}+00$ & $3.97 \mathrm{E}-01$ & $2.17 \mathrm{E}-01$ & $9.91 \mathrm{E}-01$ & 1. $39 \mathrm{E}+00$ & $1.94 \mathrm{E}+00$ & $2.42 \mathrm{E}+00$ \\
\hline $6.81 E-03$ & $3.81 \mathrm{E}+00$ & $3.98 \mathrm{E}-01$ & $2.17 \mathrm{E}-01$ & $9.92 E-01$ & $1.39 \mathrm{E}+00$ & $1.94 \mathrm{E}+00$ & $2.43 E+00$ \\
\hline $6.86 E-03$ & $3.81 \mathrm{E}+00$ & $3.99 \mathrm{E}-01$ & $2.18 E-01$ & $9.94 \mathrm{E}-01$ & 1. $40 \mathrm{E}+00$ & $1.94 \mathrm{E}+00$ & $2.43 E+00$ \\
\hline $6.90 \mathrm{E}-03$ & $3.81 \mathrm{E}+00$ & $4.00 \mathrm{E}-01$ & $2.19 \mathrm{E}-01$ & $9.95 \mathrm{E}-01$ & 1. $40 \mathrm{E}+00$ & $1.95 \mathrm{E}+00$ & $2.43 E+00$ \\
\hline $6.95 E-03$ & $3.81 \mathrm{E}+00$ & $4.01 \mathrm{E}-01$ & $2.20 E-01$ & $9.96 \mathrm{E}-01$ & 1. $40 \mathrm{E}+00$ & $1.95 \mathrm{E}+00$ & $2.43 E+00$ \\
\hline $6.99 \mathrm{E}-03$ & $3.81 \mathrm{E}+00$ & $4.02 \mathrm{E}-01$ & $2.21 E-01$ & $9.97 \mathrm{E}-01$ & 1. $40 \mathrm{E}+00$ & 1.95E+00 & $2.44 \mathrm{E}+00$ \\
\hline $7.04 \mathrm{E}-03$ & $3.81 \mathrm{E}+00$ & $4.03 E-01$ & $2.22 \mathrm{E}-01$ & $9.99 \mathrm{E}-01$ & 1. $41 \mathrm{E}+00$ & $1.95 \mathrm{E}+00$ & $2.44 \mathrm{E}+00$ \\
\hline $7.08 E-03$ & $3.81 \mathrm{E}+00$ & $4.03 E-01$ & $2.22 \mathrm{E}-01$ & $1.00 \mathrm{E}+00$ & 1. $41 \mathrm{E}+00$ & $1.95 \mathrm{E}+00$ & $2.44 \mathrm{E}+00$ \\
\hline $7.13 E-03$ & $3.81 \mathrm{E}+00$ & $4.04 \mathrm{E}-01$ & $2.23 E-01$ & $1.00 \mathrm{E}+00$ & 1. $41 \mathrm{E}+00$ & $1.96 \mathrm{E}+00$ & $2.44 \mathrm{E}+00$ \\
\hline $7.17 E-03$ & $3.82 \mathrm{E}+00$ & $4.05 E-01$ & $2.24 \mathrm{E}-01$ & $1.00 \mathrm{E}+00$ & 1. $41 \mathrm{E}+00$ & $1.96 \mathrm{E}+00$ & $2.44 \mathrm{E}+00$ \\
\hline $7.22 \mathrm{E}-03$ & $3.82 \mathrm{E}+00$ & $4.06 \mathrm{E}-01$ & $2.25 E-01$ & $1.01 \mathrm{E}+00$ & 1. $42 \mathrm{E}+00$ & $1.96 \mathrm{E}+00$ & $2.45 E+00$ \\
\hline 7. $26 \mathrm{E}-03$ & $3.82 \mathrm{E}+00$ & $4.07 \mathrm{E}-01$ & $2.26 \mathrm{E}-01$ & $1.01 \mathrm{E}+00$ & $1.42 \mathrm{E}+00$ & $1.96 \mathrm{E}+00$ & $2.45 \mathrm{E}+00$ \\
\hline-03 & $3.82 \mathrm{E}+00$ & $4.08 E-01$ & $2.27 E-01$ & $1.01 \mathrm{E}+00$ & $1.42 \mathrm{E}+00$ & $1.97 \mathrm{E}+00$ & $2.45 E+00$ \\
\hline $7.36 \mathrm{E}-03$ & $3.82 \mathrm{E}+00$ & $4.09 \mathrm{E}-01$ & $2.28 \mathrm{E}-01$ & $1.01 \mathrm{E}+00$ & 1. $42 \mathrm{E}+00$ & $1.97 \mathrm{E}+00$ & $2.46 \mathrm{E}+00$ \\
\hline $7.40 \mathrm{E}-03$ & $3.82 \mathrm{E}+00$ & $4.10 \mathrm{E}-01$ & $2.29 \mathrm{E}-01$ & $1.02 \mathrm{E}+00$ & 1. $42 \mathrm{E}+00$ & $1.97 \mathrm{E}+00$ & $2.46 \mathrm{E}+00$ \\
\hline $7.45 E-03$ & $3.82 \mathrm{E}+00$ & $4.11 \mathrm{E}-01$ & $2.30 E-01$ & $1.02 \mathrm{E}+00$ & $1.43 E+00$ & $1.97 \mathrm{E}+00$ & $2.46 \mathrm{E}+00$ \\
\hline $7.50 \mathrm{E}-03$ & $3.82 \mathrm{E}+00$ & $4.12 \mathrm{E}-01$ & $2.31 \mathrm{E}-01$ & $1.02 \mathrm{E}+00$ & $1.43 \mathrm{E}+00$ & $1.98 \mathrm{E}+00$ & $2.46 \mathrm{E}+00$ \\
\hline $7.54 \mathrm{E}-03$ & $3.82 \mathrm{E}+00$ & $4.13 \mathrm{E}-01$ & $2.32 \mathrm{E}-01$ & $1.02 \mathrm{E}+00$ & 1. $43 \mathrm{E}+00$ & $1.98 \mathrm{E}+00$ & $2.47 \mathrm{E}+00$ \\
\hline $7.59 \mathrm{E}-03$ & $3.83 \mathrm{E}+00$ & $4.14 \mathrm{E}-01$ & $2.33 E-01$ & $1.02 \mathrm{E}+00$ & $1.43 E+00$ & $1.98 \mathrm{E}+00$ & $2.47 \mathrm{E}+00$ \\
\hline $7.64 \mathrm{E}-03$ & $3.83 E+00$ & $4.15 \mathrm{E}-01$ & $2.34 \mathrm{E}-01$ & $1.03 E+00$ & $1.43 E+00$ & $1.98 \mathrm{E}+00$ & $2.47 \mathrm{E}+00$ \\
\hline $7.69 \mathrm{E}-03$ & $3.83 \mathrm{E}+00$ & $4.16 \mathrm{E}-01$ & $2.35 E-01$ & $1.03 E+00$ & 1. $44 \mathrm{E}+00$ & $1.98 \mathrm{E}+00$ & $2.48 \mathrm{E}+00$ \\
\hline $7.73 E-03$ & $3.83 \mathrm{E}+00$ & $4.16 \mathrm{E}-01$ & $2.36 E-01$ & $1.03 E+00$ & 1. $44 \mathrm{E}+00$ & $1.99 \mathrm{E}+00$ & $2.48 \mathrm{E}+00$ \\
\hline $7.78 \mathrm{E}-03$ & $3.83 E+00$ & $4.17 \mathrm{E}-01$ & $2.36 \mathrm{E}-01$ & $1.03 E+00$ & $1.44 \mathrm{E}+00$ & $1.99 \mathrm{E}+00$ & $2.48 \mathrm{E}+00$ \\
\hline $7.83 E-03$ & $3.83 E+00$ & $4.18 \mathrm{E}-01$ & $2.37 E-01$ & $1.03 E+00$ & 1. $44 \mathrm{E}+00$ & $1.99 \mathrm{E}+00$ & $2.48 \mathrm{E}+00$ \\
\hline $7.88 E-03$ & $3.83 E+00$ & $4.19 \mathrm{E}-01$ & $2.38 E-01$ & $1.04 \mathrm{E}+00$ & 1. $45 E+00$ & $1.99 \mathrm{E}+00$ & $2.49 \mathrm{E}+00$ \\
\hline $7.93 E-03$ & $3.83 \mathrm{E}+00$ & $4.20 E-01$ & $2.39 E-01$ & $1.04 \mathrm{E}+00$ & 1. $45 E+00$ & $2.00 \mathrm{E}+00$ & $2.49 \mathrm{E}+00$ \\
\hline
\end{tabular}


RESRAD-OFFSITE, Version 2.5

robabilistic Dose and Risk Report

Title : Offsite Resident Farmer

File : RF TC99 DOESG FWD-FV2all.ROF

Summary of dose at graphical times, reptition 3 (continued)

Time

Years

$6.60 \mathrm{E}+02$

$6.61 \mathrm{E}+02$

$6.61 \mathrm{E}+02$

$6.62 \mathrm{E}+02$

$6.62 \mathrm{E}+02$

$6.63 \mathrm{E}+02$

$6.63 \mathrm{E}+02$

$6.64 \mathrm{E}+02$

$6.64 \mathrm{E}+02$

$6.65 \mathrm{E}+02$

$6.65 \mathrm{E}+02$

$6.66 \mathrm{E}+02$

$6.67 \mathrm{E}+02$

$6.67 \mathrm{E}+02$

$6.68 \mathrm{E}+02$

$6.68 \mathrm{E}+02$

$6.69 \mathrm{E}+02$

$6.69 \mathrm{E}+02$

$6.70 \mathrm{E}+02$

$6.70 \mathrm{E}+02$

$6.71 \mathrm{E}+02$

$6.71 \mathrm{E}+02$

$6.72 \mathrm{E}+02$

$6.72 \mathrm{E}+02$

$6.73 \mathrm{E}+02$

$6.73 \mathrm{E}+02$

$6.74 \mathrm{E}+02$

$6.74 \mathrm{E}+02$

$6.75 \mathrm{E}+02$

$6.75 \mathrm{E}+02$

$6.76 \mathrm{E}+02$

$6.76 \mathrm{E}+02$

$6.77 \mathrm{E}+02$

$6.77 \mathrm{E}+02$

$6.78 \mathrm{E}+02$

$6.78 \mathrm{E}+02$

$6.79 \mathrm{E}+02$

$6.79 \mathrm{E}+02$

$6.80 \mathrm{E}+02$

$6.80 \mathrm{E}+02$

$6.81 \mathrm{E}+02$

$6.81 \mathrm{E}+02$

$6.82 \mathrm{E}+02$

$6.82 \mathrm{E}+02$

$6.83 \mathrm{E}+02$

$6.83 \mathrm{E}+02$
Dose statistics at graphical times, mrem/yr

\begin{tabular}{|c|c|c|c|c|c|c|c|}
\hline inimum & Maximum & Mean & Median & 900 & $90 \%$ & $97.5 \%$ & $9 \%$ \\
\hline 3 & $33 E+00$ & 1 & $.40 E-01$ & $04 E+00$ & $45 E+00$ & 0 & +0 \\
\hline 03 & $3 E+00$ & $2 \mathrm{E}$ & 01 & $04 \mathrm{E}+$ & $45 E+00$ & 00 & $50 \mathrm{E}+00$ \\
\hline$E-03$ & -00 & $3 E-01$ & $E-01$ & 0 & 0 & Do & $E+00$ \\
\hline$E-03$ & +00 & $E-01$ & $E-01$ & 0 & 0 & Do & +00 \\
\hline $.17 \mathrm{E}-03$ & $3.84 \mathrm{E}+00$ & $5 E-01$ & & & $46 \mathrm{E}+00$ & & $50 \mathrm{E}+00$ \\
\hline $22 E-03$ & $4 \mathrm{E}+00$ & 1 & 1 & & $46 \mathrm{E}+$ & 00 & $51 E+00$ \\
\hline $.27 E-03$ & $3.84 \mathrm{E}+00$ & $4.27 E-01$ & $E-01$ & $1.05 \mathrm{E}+00$ & $1.47 \mathrm{E}+00$ & $2 E+00$ & $51 \mathrm{E}+00$ \\
\hline $.32 E-03$ & $3.84 \mathrm{E}+00$ & $4.201-01$ & $2.47 E-01$ & $1.05 \mathrm{E}+00$ & $1.47 \mathrm{E}+00$ & $2.02 \mathrm{E}+00$ & $2.51 E+00$ \\
\hline$E-03$ & +00 & 1 & 01 & 0 & $1.47 \mathrm{E}$ & 00 & \pm+00 \\
\hline $3-03$ & +00 & 4 & 1 & $1.06 \mathrm{E}+00$ & $47 \mathrm{E}+$ & & $E+00$ \\
\hline$E-03$ & & 4 & 1 & & 0 & & $2 E+00$ \\
\hline-03 & +00 & $\sigma_{0}$ & -01 & 0 & 0 & & $2 E+00$ \\
\hline $.58 E-03$ & $3.84 \mathrm{E}+00$ & $\angle D-0 \perp$ & $0 \mathrm{E}-01$ & $1.07 \mathrm{t}+00$ & $1.40 \mathrm{LT}$ U & ET & $52 \mathrm{E}+00$ \\
\hline $.63 E-03$ & $3.84 \mathrm{E}+00$ & $4.33 E-01$ & $2.51 \mathrm{E}-01$ & D.UILTUO & 1.4 OLTU & 0 & $\mathrm{E}+00$ \\
\hline$E-03$ & $3.84 \mathrm{E}+00$ & 4 & 01 & 土. & $1.40 \mathrm{CO}$ & 00 & 00 \\
\hline $.74 \mathrm{E}-03$ & $3.84 \mathrm{E}+00$ & $4.35 E-01$ & $2.53 \mathrm{E}-01$ & $1.07 \mathrm{E}+00$ & $1.48 \mathrm{E}+00$ & 2.04 & $3 E+00$ \\
\hline $.79 E-03$ & $3.85 E+00$ & $4.36 \mathrm{E}-01$ & $2.54 \mathrm{E}-01$ & $1.07 \mathrm{E}+00$ & 1. $49 \mathrm{E}+00$ & $2.05 E+00$ & $53 E+00$ \\
\hline$E-03$ & $\mathrm{E}+00$ & $7 E-01$ & $4 E-01$ & 1 & म & 0 & $3 E+00$ \\
\hline $.89 \mathrm{E}-03$ & $3.85 \mathrm{E}+00$ & $4.38 E-01$ & $2.55 \mathrm{E}-01$ & $1.08 \mathrm{E}+00$ & 1. $49 \mathrm{E}+00$ & $2.05 E+00$ & $54 \mathrm{E}+00$ \\
\hline $95 E-03$ & $3.85 E+00$ & $4.39 E-01$ & -01 & I. VOLT & 1.49 & 00 & +00 \\
\hline$E-03$ & $3.85 E+00$ & $4.40 \mathrm{E}-01$ & & I. OOLTU & I.JULT & & $E+00$ \\
\hline $.05 E-03$ & . & $4.41 \mathrm{E}-0$ & $2 \cdot 0$ & $1.08 \mathrm{E}+$ & 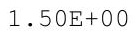 & 0 & $\mathrm{E}+00$ \\
\hline $.11 E-03$ & $3.85 \mathrm{E}+00$ & $2 E-0$ & $9 E-01$ & $1.09 \mathrm{E}+00$ & $1.50 \mathrm{E}+00$ & $2.06 \mathrm{E}+00$ & $54 \mathrm{E}+00$ \\
\hline $.16 \mathrm{E}-03$ & $3.85 E+00$ & $4.43 E-01$ & -01 & $1.09 \mathrm{E}+$ & $1.50 \mathrm{E}+$ & $2.07 E+00$ & $54 E+00$ \\
\hline$E-03$ & $E+00$ & $4 E-01$ & 2 . & 0 & 1. $50 \mathrm{E}+$ & & $55 \mathrm{E}+00$ \\
\hline$E-03$ & $5 E+00$ & 1 & 1 & $1.09 \mathrm{E}$ & of & 00 & -00 \\
\hline $3 E-03$ & $3.85 \mathrm{E}+00$ & 4. $45 E-01$ & $2.62 \mathrm{E}-01$ & $\perp \cdot \perp U \mathrm{~L}$ & $\perp \cdot U \perp L$ & & $5 \mathrm{E}+00$ \\
\hline $.38 E-03$ & $3.85 \mathrm{E}+00$ & $4.46 \mathrm{E}-01$ & $2.62 \mathrm{E}-01$ & $1.10 \mathrm{E}+00$ & $1.51 \mathrm{E}+00$ & $2.08 \mathrm{E}+00$ & $2.55 E+00$ \\
\hline $.44 \mathrm{E}-03$ & . & $4.47 E-01$ & $2.63 E-01$ & $1.10 \mathrm{E}+00$ & 土. & $2.00 \mathrm{LT}$ & $2.55 E+00$ \\
\hline 3 & $3.85 \mathrm{E}+00$ & $4.48 \mathrm{E}$ & $2.00 \mathrm{t}-\mathrm{s}$ & & $1.51 \mathrm{E}+$ & & $55 \mathrm{E}+00$ \\
\hline 3 & $\mathrm{E}+00$ & & 1 & 0 & 1 & $2.09 \mathrm{E}+00$ & $6 \mathrm{E}+00$ \\
\hline$E-03$ & $\mathrm{E}+00$ & 4 & 1 & 0 & $152 \mathrm{~F}+$ & & $6 \mathrm{E}+00$ \\
\hline $.66 \mathrm{E}-03$ & $3.85 \mathrm{E}+00$ & $4.51 \mathrm{E}-01$ & 2 . & 1.11E+ & $1.5 \angle \mathrm{E}$ & 00 & $56 \mathrm{E}+00$ \\
\hline $.71 \mathrm{E}-03$ & $3.85 \mathrm{E}+00$ & $4.52 \mathrm{E}-01$ & $2.66 \mathrm{E}-01$ & $1.11 \mathrm{E}+00$ & $1.52 \mathrm{E}+00$ & $2.09 \mathrm{E}+00$ & $2.56 \mathrm{E}+00$ \\
\hline $.77 E-03$ & $3.03 E+00$ & $4.53 E-01$ & & & エ・Uட山1 & & $2.56 \mathrm{E}+00$ \\
\hline $9.83 E-03$ & & & & " & 政 & & 0 \\
\hline 3 & $5+$ & 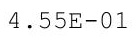 & 1 & 10 & $5=$ & > & $6 \mathrm{E}+00$ \\
\hline 3 & $E+00$ & & & & 0 & 0 & \\
\hline$E-02$ & & 01 & 2 . & 1.12 & 1.5 & & $7 \mathrm{E}+00$ \\
\hline $.01 E-02$ & $3.86 \mathrm{E}+00$ & 4 & 2 . & 1.12 & 1.5 & & 00 \\
\hline$E-02$ & $3.86 \mathrm{E}+00$ & 4 & & $1.13 \mathrm{E}+$ & $1.53 \mathrm{E}+$ & & $2.57 \mathrm{E}+00$ \\
\hline $2 \mathrm{E}-02$ & $3.00 E+00$ & $4.59 \mathrm{E}$ & 2 . & $\perp \cdot \perp$ ऽ & $1.54 \mathrm{E}$ & $2.12 \mathrm{E}+00$ & $2.57 \mathrm{E}+00$ \\
\hline $1.02 \mathrm{E}-02$ & 3.0 & 4. & $\angle \cdot 10 \mathrm{E}$ & 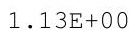 & 0 & 0 & \\
\hline & & & & $13 E+00$ & 1 . & 00 & $2.58 \mathrm{E}$ \\
\hline-02 & $E+00$ & $E-01$ & 2 . & 1. $13 \mathrm{E}+00$ & $1.54 \mathrm{E}$ & $2.12 \mathrm{E}$ & $2.58 \mathrm{E}+00$ \\
\hline $4 E-02$ & $86 \mathrm{E}+00$ & $.63 E-01$ & $.77 E-01$ & $1.14 \mathrm{E}+00$ & $1.54 \mathrm{E}+00$ & $2.13 E+00$ & $2.58 \mathrm{E}+00$ \\
\hline
\end{tabular}


RESRAD-OFFSITE, Version 2.5

$\mathrm{T}^{1 / 2}$ Limit $=180$ days

obabilistic Dose and Risk Report

Title : Offsite Resident Farmer

File : RF TC99 DOESG FWD-FV2all.ROF

Summary of dose at graphical times, reptition 3 (continued)

Time

Years

$6.84 \mathrm{E}+02$

$6.84 \mathrm{E}+02$

$6.85 \mathrm{E}+02$

$6.85 \mathrm{E}+02$

$6.86 \mathrm{E}+02$

$6.86 \mathrm{E}+02$

$6.87 \mathrm{E}+02$

$6.88 \mathrm{E}+02$

$6.88 \mathrm{E}+02$

$6.89 \mathrm{E}+02$

$6.89 \mathrm{E}+02$

$6.90 \mathrm{E}+02$

$6.90 \mathrm{E}+02$

$6.91 E+02$

$6.91 \mathrm{E}+02$

$6.92 \mathrm{E}+02$

$6.92 \mathrm{E}+02$

$6.93 E+02$

$6.93 \mathrm{E}+02$

$6.94 \mathrm{E}+02$

$6.94 \mathrm{E}+02$

$6.95 \mathrm{E}+02$

$6.95 \mathrm{E}+02$

$6.96 \mathrm{E}+02$

$6.96 \mathrm{E}+02$

$6.97 \mathrm{E}+02$

$6.97 \mathrm{E}+02$

$6.98 \mathrm{E}+02$

$6.98 \mathrm{E}+02$

$6.99 \mathrm{E}+02$

$6.99 \mathrm{E}+02$

$7.00 \mathrm{E}+02$

$7.00 \mathrm{E}+02$

$7.01 \mathrm{E}+02$

$7.01 \mathrm{E}+02$

$7.02 \mathrm{E}+02$

$7.02 \mathrm{E}+02$

$7.03 \mathrm{E}+02$

$7.03 E+02$

$7.04 \mathrm{E}+02$

$7.04 \mathrm{E}+02$

$7.05 \mathrm{E}+02$

$7.05 \mathrm{E}+02$

$7.06 \mathrm{E}+02$

$7.06 \mathrm{E}+02$

$7.07 \mathrm{E}+02$
Dose statistics at graphical times, mrem/yr

\begin{tabular}{|c|c|c|c|c|c|c|c|}
\hline m & $\operatorname{axi}$ & 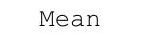 & 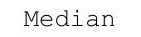 & & & & $\%$ \\
\hline $.05 E-02$ & $3.86 \mathrm{E}+00$ & $4.64 \mathrm{E}-01$ & 1 & $14 \mathrm{E}+00$ & 1. $55 \mathrm{E}+00$ & 00 & $.50 \mathrm{E}+\mathrm{U}$ \\
\hline $.05 E-02$ & $3.86 \mathrm{E}+00$ & 4. $65 \mathrm{E}-01$ & $2.79 \mathrm{E}-01$ & $14 \mathrm{E}+00$ & $55 E+00$ & $2.13 E+00$ & $8 E+00$ \\
\hline-02 & $86 E+00$ & $66 E-01$ & $.79 E-01$ & $14 \mathrm{E}+00$ & $55 \mathrm{E}+00$ & $13 E+00$ & $58 \mathrm{E}+00$ \\
\hline-02 & $86 \mathrm{~F}+00$ & $67 \mathrm{~F}-01$ & $80 \mathrm{~F}-01$ & $.14 \mathrm{E}+00$ & $155 F+0$ & $13 F+00$ & 2. $59 \mathrm{E}+00$ \\
\hline $.07 E-02$ & $3.86 \mathrm{E}+00$ & $8 F-0$ & -01 & & & +00 & +00 \\
\hline $08 E-02$ & $86 \mathrm{E}+00$ & & & & & & +00 \\
\hline $08 E-02$ & $3.86 \mathrm{E}+00$ & & & & & +00 & $9 \mathrm{E}+00$ \\
\hline-02 & +00 & 1 & 1 & 00 & 0 & +00 & $\mathrm{E}+00$ \\
\hline $09 \mathrm{E}-02$ & $3.86 \mathrm{E}+00$ & $.72 \mathrm{E}-01$ & -01 & $1.15 \mathrm{E}+00$ & $56 \mathrm{E}+$ & $4 \mathrm{E}+00$ & $\mathrm{E}+00$ \\
\hline$E-02$ & $.86 E+00$ & $73=-01$ & $84 \mathrm{~F}-01$ & $.15 E+00$ & $.56 E+00$ & $15 \mathrm{~F}+00$ & $60 E+00$ \\
\hline 02 & +00 & & & & & 0 & $E+00$ \\
\hline $11 \mathrm{E}-02$ & +00 & 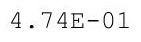 & - 0 & 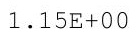 & & 0 & +00 \\
\hline $.12 \mathrm{E}-02$ & $3.86 \mathrm{E}+00$ & $4.75 E-01$ & $2.87 \mathrm{E}-01$ & & & $2.15 E+00$ & $2.60 \mathrm{E}+00$ \\
\hline $13 E-02$ & $3.86 \mathrm{E}+00$ & $4.76 \mathrm{E}-01$ & $2.88 \mathrm{E}-01$ & $1.16 \mathrm{E}+00$ & & $2.15 E+00$ & $2.61 E+00$ \\
\hline-02 & +00 & 7 & 0 & 0 & & +00 & $1 \mathrm{E}+00$ \\
\hline 2 & $.86 E+00$ & 4. $78 \mathrm{E}-01$ & $2.89 E-01$ & & & 0 & 00 \\
\hline 2 & $86 E+00$ & 4. $79 \mathrm{E}-01$ & & & & 0 & 00 \\
\hline $5-02$ & $386 \mathrm{~F}+00$ & $4.80 \mathrm{E}-01$ & $2.91 \mathrm{E}-01$ & 1 & & 0 & 00 \\
\hline $16 \mathrm{E}-02$ & $3.86 \mathrm{~F}+00$ & $81 F-01$ & $2.92 \mathrm{E}-01$ & $16 \mathrm{E}+00$ & $58 E+00$ & $16 \mathrm{E}+00$ & $62 \mathrm{E}+00$ \\
\hline $16 \mathrm{E}-02$ & $.86 \mathrm{E}+00$ & $.82 E-01$ & $2.93 \mathrm{E}-01$ & $1.16 \mathrm{E}+00$ & 1. $58 \mathrm{E}+00$ & $2.16 \mathrm{E}+00$ & $2.62 E+00$ \\
\hline 02 & +00 & & & & & 0 & $\mathrm{E}+00$ \\
\hline 2 & & & & & & & \\
\hline 2 & & $4.85 E-01$ & & 1.17E+ & & & \\
\hline 02 & $3.86 \mathrm{E}+00$ & $4.86 \mathrm{E}-01$ & $2.96 \mathrm{E}-01$ & $1.17 \mathrm{E}+00$ & 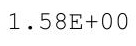 & & $3 E+00$ \\
\hline 2 & $.86 \mathrm{E}+00$ & חק & 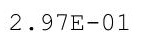 & $1.17 \mathrm{E}+00$ & 1. $59 \mathrm{E}+$ & $.16 \mathrm{E}+00$ & $.63 E+00$ \\
\hline $20 F-02$ & $.86 \mathrm{E}+00$ & $4.88 \mathrm{E}-0$ & $2.98 \mathrm{E}-01$ & $1.18 \mathrm{E}+00$ & 1. $59 \mathrm{E}+00$ & $2.16 \mathrm{E}+00$ & . $63 \mathrm{E}+00$ \\
\hline$E-02$ & $.86 \mathrm{E}+00$ & & & $1.18 \mathrm{E}+00$ & & & $2.63 E+00$ \\
\hline 2 & & & & & & & \\
\hline 02 & & & & & $1.59 \mathrm{E}$ & $2.17 \mathrm{E}+00$ & $2.63 E+00$ \\
\hline $23 E-02$ & $3.85 \mathrm{E}+00$ & $\begin{array}{lll}-2+\square & 0\end{array}$ & $3.035-01$ & $1.19 \mathrm{E}+00$ & $1.60 \mathrm{E}+00$ & $2.17 \mathrm{E}+00$ & $2.63 E+00$ \\
\hline $24 E-02$ & $3.85 \mathrm{E}+00$ & 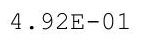 & - & 1. $19 \mathrm{E}+00$ & $1.60 \mathrm{E}+00$ & $2.17 \mathrm{E}+00$ & $2.63 E+00$ \\
\hline 2 & $3.85 \mathrm{E}+00$ & & & 1. $19 \mathrm{E}+00$ & & $2.17 \mathrm{E}+0$ & $2.63 E+00$ \\
\hline 02 & $3.85 \mathrm{E}+00$ & & & & & $\mathrm{E}+00$ & $2.63 E+00$ \\
\hline 02 & & & & & & & \\
\hline 2 & & 1 & & 1.20 & 00 & $E+00$ & \\
\hline $.27 E-02$ & $3.85 \mathrm{E}+00$ & $4.975-01$ & $3.09 E-01$ & $1.20 \mathrm{E}+00$ & $1.61 \mathrm{E}+00$ & $2.17 \mathrm{E}+00$ & $2.64 \mathrm{E}+00$ \\
\hline $.201-22$ & $3.85 \mathrm{E}+00$ & & & $1.20 \mathrm{E}+00$ & & & $2.64 \mathrm{E}+00$ \\
\hline 2 & $3.85 \mathrm{E}+00$ & 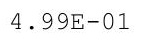 & & 1. $21 \mathrm{E}+00$ & 1. $61 \mathrm{E}+00$ & $2.17 \mathrm{E}+00$ & $2.64 \mathrm{E}+00$ \\
\hline $.29 \mathrm{E}-02$ & $3.85 \mathrm{E}+00$ & 1 & 1 & $1.21 \mathrm{E}+00$ & $1.62 \mathrm{E}+00$ & $2.17 \mathrm{E}+00$ & $2.65 E+00$ \\
\hline $.30 E-02$ & & 0 & 1 & $1.21 \mathrm{E}+00$ & & & \\
\hline $30 E-02$ & $3.85 \mathrm{E}+00$ & $5.02 \mathrm{E}-01$ & -01 & $1.21 \mathrm{E}+$ & & & $2.65 E+00$ \\
\hline$E-02$ & $3.85 \mathrm{E}+00$ & & & 1.21 & & & $55 \mathrm{E}+00$ \\
\hline 02 & .0工力 & & & $1.21 \mathrm{E}+00$ & 1. $62 \mathrm{E}+00$ & $2.18 \mathrm{E}+00$ & $2.65 \mathrm{E}+00$ \\
\hline $32 E-02$ & $3.85 \mathrm{E}+00$ & $.04+01$ & $3.15 E-01$ & 1. $22 \mathrm{E}+00$ & $1.62 \mathrm{E}+00$ & $2.18 \mathrm{E}+00$ & $2.66 \mathrm{E}+00$ \\
\hline 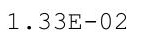 & $3.85 \mathrm{E}+00$ & (.) & & 1. $22 \mathrm{E}+00$ & $1.63 \mathrm{E}+00$ & $2.19 \mathrm{E}+00$ & $2.66 \mathrm{E}+00$ \\
\hline $4 E-02$ & $.85 E+00$ & $6 E-01$ & $.17 \mathrm{E}-01$ & 1. $22 \mathrm{E}+00$ & 1. $63 \mathrm{E}+00$ & $2.19 \mathrm{E}+00$ & $2.66 \mathrm{E}+00$ \\
\hline
\end{tabular}


RESRAD-OFFSITE, Version 2.5

$\mathrm{T}^{1 / 2}$ Limit $=180$ days

obabilistic Dose and Risk Report

Title : Offsite Resident Farmer

File : RF TC99 DOESG FWD-FV2all.ROF

Summary of dose at graphical times, reptition 3 (continued)

Time

Years

7. $08 \mathrm{E}+02$

$7.08 \mathrm{E}+02$

7. $09 \mathrm{E}+02$

7. $09 \mathrm{E}+02$

$7.10 \mathrm{E}+02$

$7.10 \mathrm{E}+02$

$7.11 \mathrm{E}+02$

$7.11 \mathrm{E}+02$

$7.12 \mathrm{E}+02$

$7.12 \mathrm{E}+02$

$7.13 \mathrm{E}+02$

$7.13 \mathrm{E}+02$

$7.14 \mathrm{E}+02$

$7.14 \mathrm{E}+02$

$7.15 \mathrm{E}+02$

$7.15 \mathrm{E}+02$

$7.16 \mathrm{E}+02$

$7.16 \mathrm{E}+02$

$7.17 \mathrm{E}+02$

$7.17 \mathrm{E}+02$

$7.18 \mathrm{E}+02$

$7.18 \mathrm{E}+02$

$7.19 \mathrm{E}+02$

$7.19 \mathrm{E}+02$

$7.20 \mathrm{E}+02$

$7.20 \mathrm{E}+02$

$7.21 \mathrm{E}+02$

$7.21 \mathrm{E}+02$

7. $22 \mathrm{E}+02$

$7.22 \mathrm{E}+02$

$7.23 \mathrm{E}+02$

$7.23 \mathrm{E}+02$

$7.24 \mathrm{E}+02$

$7.24 \mathrm{E}+02$

$7.25 \mathrm{E}+02$

7. $25 \mathrm{E}+02$

7. $26 \mathrm{E}+02$

$7.26 \mathrm{E}+02$

$7.27 \mathrm{E}+02$

$7.28 \mathrm{E}+02$

$7.28 \mathrm{E}+02$

$7.29 \mathrm{E}+02$

$7.29 \mathrm{E}+02$

$7.30 \mathrm{E}+02$

7. $30 \mathrm{E}+02$

7. $31 \mathrm{E}+02$
Dose statistics at graphical times, mrem/yr

\begin{tabular}{|c|c|c|c|c|c|c|c|}
\hline m & axis & 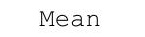 & 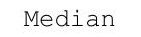 & & & & \\
\hline 02 & $.85 \mathrm{E}+00$ & $07 E-01$ & 1 & $.22 \mathrm{E}+00$ & i & -00 & . $00 \mathrm{E}+U 0$ \\
\hline $35 E-02$ & $3.85 \mathrm{E}+00$ & -01 & $3.18 \mathrm{E}-01$ & 1. $23 E+00$ & $53 E+00$ & $2.19 \mathrm{E}+00$ & $66 \mathrm{E}+00$ \\
\hline$E-02$ & $85 \mathrm{E}+00$ & $9 E-01$ & $9 E-01$ & $.23 E+00$ & $.64 \mathrm{E}+00$ & $2.19 \mathrm{E}+00$ & $2.66 \mathrm{E}+00$ \\
\hline $37 E-02$ & $.85 E+00$ & $10 \mathrm{~F}-01$ & $20 \mathrm{~F}-01$ & $.23 E+00$ & $164 \mathrm{~F}+00$ & $2.20 \mathrm{E}+00$ & $2.66 \mathrm{E}+00$ \\
\hline-02 & +00 & 01 & $E-01$ & $.23 E+$ & & $E+00$ & $E+00$ \\
\hline 02 & $85 E+00$ & & & & & & 00 \\
\hline $39 E-02$ & $3.85 \mathrm{E}+00$ & & & 00 & & & $66 E+00$ \\
\hline $39 \mathrm{E}-02$ & $3.84 \mathrm{E}+00$ & 1 & -01 & $1.24 \mathrm{E}+00$ & $E+00$ & +00 & $5 E+00$ \\
\hline $40 E-02$ & $3.84 \mathrm{E}+00$ & $5 E-01$ & $E-01$ & $1.24 \mathrm{E}+00$ & $E+00$ & $E+00$ & $6 \mathrm{E}+00$ \\
\hline$E-02$ & $.84 \mathrm{E}+00$ & $16 \mathrm{E}-01$ & 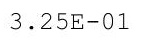 & 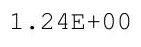 & 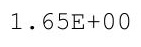 & $21 E+00$ & $.66 \mathrm{E}+00$ \\
\hline 02 & +00 & & & & & 0 & $66 \mathrm{E}+00$ \\
\hline $42 E-02$ & +00 & 1 & 㲅 & $25 \mathrm{~F}-2 \mathrm{r}$ & 0 & -00 & +00 \\
\hline $.43 E-02$ & $3.84 \mathrm{E}+00$ & & & & & $2.22 E+00$ & $2.67 \mathrm{E}+00$ \\
\hline $44 \mathrm{E}-02$ & $3.84 \mathrm{E}+00$ & $.19 \mathrm{E}-01$ & $.29 \mathrm{E}-01$ & $1.25 \mathrm{E}+00$ & & $2.22 E+00$ & $2.67 \mathrm{E}+00$ \\
\hline-02 & $E+00$ & $E-01$ & $F-0-0 \cdot 2-2$ & 0 & & +00 & $7 \mathrm{E}+00$ \\
\hline 2 & 00 & & & $\cdot 20$ & 0 & 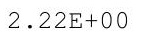 & 00 \\
\hline 2 & 00 & & & $25 \mathrm{E}$ & & 0 & 0 \\
\hline $7 E-02$ & $3.84 \mathrm{E}+00$ & $5.23 E-01$ & 3. $32 E-01$ & $26 F+$ & & 0 & 0 \\
\hline $47 E-02$ & $3.84 \mathrm{E}+00$ & $4 \mathrm{~F}-01$ & $3 F-01$ & $.26 \mathrm{E}+00$ & $67=+8010$ & $3 E+00$ & $57 E+00$ \\
\hline $48 E-02$ & $.84 E+00$ & $.25 E-01$ & $.34 \mathrm{E}-01$ & $1.26 \mathrm{E}+00$ & 1. $67 \mathrm{E}+$ & $2.23 E+00$ & $2.67 \mathrm{E}+00$ \\
\hline 02 & +00 & & & & & $.23 E+00$ & $67 E+00$ \\
\hline 2 & & & & & & & \\
\hline 2 & $.83 E+00$ & . & & $1.26 \mathrm{E}+$ & & & 00 \\
\hline$E-02$ & $83 E+00$ & $\perp$ & $3.38 \mathrm{E}-01$ & $1.26 \mathrm{E}+$ & th & 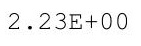 & 00 \\
\hline 2 & $.83 E+00$ & $5.29 \mathrm{E}-01$ & $3.39 \mathrm{E}-01$ & $1.26 \mathrm{E}+\mathrm{C}$ & $1.68 \mathrm{E}+$ & $2.23 E+00$ & $.67 \mathrm{E}+00$ \\
\hline $.53 E-02$ & $.83 E+00$ & $30 \mathrm{~F}-01$ & $3.40=-01$ & $1.27 \mathrm{E}+00$ & $.68 \mathrm{E}+00$ & $.23 E+00$ & $.67 E+00$ \\
\hline-02 & $3.83 E+00$ & & & & & $2.24 \mathrm{E}+00$ & $2.67 E+00$ \\
\hline 02 & & & & & & & \\
\hline 2 & $3.83 E+00$ & 3.0 & & $1.27 \mathrm{E}+$ & & & \\
\hline $56 \mathrm{E}-02$ & $3.83 E+00$ & . 3451 & 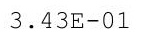 & $1.27 \mathrm{E}+00$ & $1.69 \mathrm{E}+$ & $2.24 \mathrm{E}+00$ & $2.67 \mathrm{E}+00$ \\
\hline $.57 E-02$ & $3.83 E+00$ & $5.35 E-01$ & 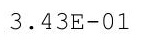 & $1.27 \mathrm{E}+00$ & $1.69 \mathrm{E}+00$ & $2.24 \mathrm{E}+00$ & $2.67 \mathrm{E}+00$ \\
\hline 2 & $3.83 E+$ & - & 1 & 1.28E+ & & & \\
\hline & & & & & & & $2.66 \mathrm{E}+00$ \\
\hline 02 & & & & & & & \\
\hline$E-02$ & & & & & & & \\
\hline $61 \mathrm{E}-02$ & $3.82 \mathrm{E}+00$ & $5.40 E-01$ & $3.40 \pm-01$ & $1.28 \mathrm{E}+00$ & $\perp \cdot 100$ & $2.25 \mathrm{E}+00$ & $2.66 \mathrm{E}+00$ \\
\hline $61 E-02$ & $3.82 \mathrm{E}+00$ & $.1+4$ & & $1.28 E+00$ & & & $2.66 \mathrm{E}+00$ \\
\hline $62 \mathrm{E}-02$ & $3.82 \mathrm{E}+00$ & 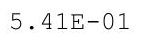 & & $1.28 \mathrm{E}+00$ & & $2.25 \mathrm{E}+00$ & $2.66 \mathrm{E}+00$ \\
\hline 2 & 0 & 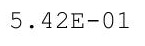 & 1 & 1.2 & 1. $70 \mathrm{E}+00$ & $2.25 E+00$ & $2.67 \mathrm{E}+00$ \\
\hline 2 & $3.82 \mathrm{E}+00$ & $5.43 E-01$ & - & $1.29 \mathrm{E}+00$ & 1 & & $7 E+00$ \\
\hline $5 E-02$ & $3.82 \mathrm{E}+00$ & 01 & -01 & 1. $29 \mathrm{E}+00$ & & $2.25 \mathrm{E}+00$ & $2.67 \mathrm{E}+00$ \\
\hline$E-02$ & $3.82 \mathrm{E}+00$ & 01 & & $1.29 \mathrm{E}+00$ & & $5+00$ & $7 E+00$ \\
\hline & 0.02 & & & & & & $0 / E+U 0$ \\
\hline $67 E-02$ & $3.81 \mathrm{E}+00$ & 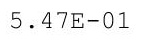 & 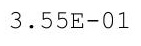 & $1.29 E+00$ & $\perp \cdot 1 \perp+100$ & $2.25 E+00$ & $2.67 \mathrm{E}+00$ \\
\hline $00 \mathrm{~L}-\mathrm{Z}$ & $3.81 E+00$ & & & $1.30 \mathrm{E}+00$ & $1.71 \mathrm{E}+00$ & $2.25 E+00$ & $2.68 \mathrm{E}+00$ \\
\hline 02 & $.81 E+00$ & $E-01$ & $E-01$ & $.30 \mathrm{E}+00$ & $1.71 \mathrm{E}+00$ & $2.25 \mathrm{E}+00$ & $2.68 \mathrm{E}+00$ \\
\hline
\end{tabular}


RESRAD-OFFSITE, Version 2.5

$\mathrm{T}^{1 / 2}$ Limit $=180$ days

obabilistic Dose and Risk Report

Title : Offsite Resident Farmer

File : RF TC99 DOESG FWD-FV2all.ROF

Summary of dose at graphical times, reptition 3 (continued)

Time

Years

7. $31 \mathrm{E}+02$

7. $32 \mathrm{E}+02$

7. $32 \mathrm{E}+02$

7. $33 \mathrm{E}+02$

7. $33 \mathrm{E}+02$

7. $34 \mathrm{E}+02$

7. $34 \mathrm{E}+02$

$7.35 \mathrm{E}+02$

$7.35 \mathrm{E}+02$

$7.36 \mathrm{E}+02$

7. $36 \mathrm{E}+02$

$7.37 \mathrm{E}+02$

$7.37 \mathrm{E}+02$

$7.38 \mathrm{E}+02$

7. $38 \mathrm{E}+02$

$7.39 \mathrm{E}+02$

$7.39 \mathrm{E}+02$

$7.40 \mathrm{E}+02$

$7.40 \mathrm{E}+02$

$7.41 \mathrm{E}+02$

$7.41 \mathrm{E}+02$

$7.42 \mathrm{E}+02$

$7.42 \mathrm{E}+02$

$7.43 \mathrm{E}+02$

$7.43 \mathrm{E}+02$

$7.44 \mathrm{E}+02$

$7.44 \mathrm{E}+02$

7. $45 \mathrm{E}+02$

$7.45 \mathrm{E}+02$

$7.46 \mathrm{E}+02$

$7.46 \mathrm{E}+02$

$7.47 \mathrm{E}+02$

$7.48 \mathrm{E}+02$

7. $48 \mathrm{E}+02$

$7.49 \mathrm{E}+02$

7. $49 \mathrm{E}+02$

$7.50 \mathrm{E}+02$

$7.50 \mathrm{E}+02$

$7.51 \mathrm{E}+02$

$7.51 \mathrm{E}+02$

$7.52 \mathrm{E}+02$

$7.52 \mathrm{E}+02$

$7.53 \mathrm{E}+02$

$7.53 \mathrm{E}+02$

$7.54 \mathrm{E}+02$

$7.54 \mathrm{E}+02$
Dose statistics at graphical times, mrem/yr

\begin{tabular}{|c|c|c|c|c|c|c|c|}
\hline m & um & ea & - & & & & \\
\hline 02 & $3.81 \mathrm{E}+00$ & 01 & $.58 E-01$ & $1.30 \mathrm{E}+00$ & $1.72 \mathrm{E}+00$ & -00 & $.00 \mathrm{E}+00$ \\
\hline $.70 E-02$ & $3.81 E+00$ & $1 E-01$ & $3.59 \mathrm{E}-01$ & $30 E+00$ & $72 E+00$ & $2.26 \mathrm{E}+00$ & $8 \mathrm{E}+00$ \\
\hline $.71 E-02$ & $81 E+00$ & $2 E-01$ & $0 \mathrm{E}-01$ & $.30 E+00$ & $.72 E+00$ & $2.26 \mathrm{E}+00$ & $2.68 \mathrm{E}+00$ \\
\hline $72 E-02$ & $81 E+00$ & $52 \mathrm{~F}-01$ & $61 \mathrm{~F}-01$ & $.30 E+00$ & $72 F+00$ & $2.26 \mathrm{E}+00$ & $2.68 \mathrm{E}+00$ \\
\hline $.73 E-02$ & $E+00$ & 01 & 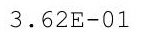 & & & $E+00$ & +00 \\
\hline 02 & $E+00$ & & & & & & 00 \\
\hline $74 \mathrm{E}-02$ & $3.80 \mathrm{E}+00$ & & & & & +00 & $9 \mathrm{E}+00$ \\
\hline $.75 E-02$ & +00 & 1 & 1 & 0 & 0 & +00 & $E+00$ \\
\hline $76 \mathrm{E}-02$ & $3.80 \mathrm{E}+00$ & $7 E-01$ & -01 & $1.31 \mathrm{E}+00$ & $73 E+00$ & $27 E+00$ & $9 \mathrm{E}+00$ \\
\hline $.77 \mathrm{E}-02$ & $.80 \mathrm{E}+00$ & $8 E-01$ & 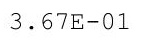 & 12 & וקבר & $.27 E+00$ & $9 \mathrm{E}+00$ \\
\hline 02 & $E+00$ & & & & & -00 & $9 \mathrm{E}+00$ \\
\hline $.79 \mathrm{E}-02$ & $\Xi+00$ & 厚 & $3.69 \mathrm{E}-01$ & $325+130$ & & 0 & +00 \\
\hline $.79 \mathrm{E}-02$ & $3.80 E+00$ & & & & & & $70 \mathrm{E}+00$ \\
\hline $80 E-02$ & $3.80 \mathrm{E}+00$ & $.62 \mathrm{E}-01$ & $.71 \mathrm{E}-01$ & & & $E+00$ & $2.70 \mathrm{E}+00$ \\
\hline $81 \mathrm{E}-02$ & +00 & $E-01$ & $2 \mathrm{~F}-0+2-\mathrm{C}$ & 325 & . & $E+00$ & $\mathrm{E}+00$ \\
\hline 8 & 00 & $.63 E-01$ & & 1.32 & & 0 & 00 \\
\hline 2 & 00 & & & קח & & 0 & 0 \\
\hline $84 E-02$ & $79 \mathrm{E}+00$ & $5.65 E-01$ & $3.75 E-01$ & קתרק & & 0 & 0 \\
\hline $85 E-02$ & $9 \mathrm{E}+00$ & $66 \mathrm{~F}-01$ & $6 \mathrm{~F}-0.1$ & $133 \nabla+0$ & $75=+8=010$ & $\mathrm{~F}+00$ & $0 \mathrm{E}+00$ \\
\hline $86 \mathrm{E}-02$ & $.79 E+00$ & $.67 \mathrm{E}-01$ & $.77 \mathrm{E}-01$ & $1.33 \mathrm{E}+00$ & 1. $75 \mathrm{E}+$ & $2.27 \mathrm{E}+00$ & $2.70 \mathrm{E}+00$ \\
\hline 02 & +00 & & & & & $.27 E+00$ & $\Xi+00$ \\
\hline 2 & & & & & & & \\
\hline 2 & $3.78 \mathrm{E}+00$ & & & 1.33E+ & & & \\
\hline $89 \mathrm{E}-02$ & $3.78 \mathrm{E}+00$ & $\perp$ & & 1. $33 \mathrm{E}+$ & ( & 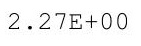 & 00 \\
\hline 2 & $.78 E+00$ & $5.72 \mathrm{E}-01$ & $\perp$ & $1.33 \mathrm{E}+\mathrm{C}$ & & $2.27 \mathrm{E}+\mathrm{C}$ & $71 \mathrm{E}+00$ \\
\hline $91 E-02$ & $.78 E+00$ & $73 \mathrm{~F}-01$ & 3 & 1. $34 \mathrm{E}+00$ & $1.76 \mathrm{E}+$ & $.27 E+00$ & $.71 E+00$ \\
\hline $92 \mathrm{E}-02$ & $3.78 \mathrm{E}+00$ & $3 F-01$ & & & & $2.27 \mathrm{E}+00$ & $.71 E+00$ \\
\hline 02 & & & & & & & \\
\hline 02 & $3.78 \mathrm{E}+00$ & . & & $\perp \cdot 345$ & & & \\
\hline $94 E-02$ & $3.78 \mathrm{E}+00$ & . $10 \pm 01$ & $3.00 \mathrm{~L}-\mathrm{L}$ & $1.34 \mathrm{E}+00$ & $1.76 \mathrm{E}+$ & $2.28 \mathrm{E}+00$ & $2.71 E+00$ \\
\hline $95 E-02$ & $3.77 \mathrm{E}+00$ & $5.77 \mathrm{E}-01$ & - & $1.34 \mathrm{E}+00$ & $1.76 \mathrm{E}+00$ & $2.28 \mathrm{E}+00$ & $2.71 \mathrm{E}+00$ \\
\hline 2 & $3.77 \mathrm{E}+$ & $5.78 \mathrm{E}-01$ & $3.88 \mathrm{E}-01$ & 1. $34 \mathrm{E}+$ & & & $2.71 \mathrm{E}+$ \\
\hline 9 & & & & & & & 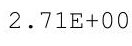 \\
\hline 02 & $3.77 \mathrm{E}+00$ & & 1 & & & & \\
\hline$E-02$ & $3.77 \mathrm{E}+00$ & 1 & & & & & \\
\hline $00 E-02$ & $3.77 \mathrm{E}+00$ & $5.82 \mathrm{E}-01$ & $3.915-01$ & $1.35 \mathrm{E}+00$ & 土. & $2.28 \mathrm{E}+00$ & $2.71 E+00$ \\
\hline $01 \mathrm{E}-02$ & $3.76 \mathrm{E}+00$ & $.00 \pm-1$ & . & $1.35 E+00$ & & & $2.71 E+00$ \\
\hline $02 E-02$ & $3.76 \mathrm{E}+00$ & $.00 \begin{array}{l}0 \\
\end{array}$ & & $1.35 \mathrm{E}+00$ & & & $2.71 \mathrm{E}+00$ \\
\hline 2 & $3.76 \mathrm{E}+$ & 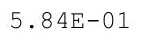 & 1 & $1.35 \mathrm{E}+00$ & $1.78 \mathrm{E}+$ & 2.2 & $2.71 E+00$ \\
\hline & & 1 & 1 & $1.35 \mathrm{E}+00$ & 1 & $E+00$ & $2.71 E+00$ \\
\hline $04 \mathrm{E}-02$ & $3.76 \mathrm{E}+00$ & $5 E-01$ & $E-01$ & 1. $35 \mathrm{E}+00$ & 1 . & $2.28 \mathrm{E}+00$ & $2.71 \mathrm{E}+00$ \\
\hline $.05 E-02$ & $3.77 \mathrm{E}+00$ & 01 & 1 & $1.35 \mathrm{E}+00$ & & 2.2 & $2.71 \mathrm{E}+00$ \\
\hline & $3.77 \mathrm{E}+00$ & $5.88 \mathrm{E}-01$ & & $1.36 E+U 0$ & & & $2.71 \mathrm{E}+00$ \\
\hline $7 E-02$ & $3.77 \mathrm{E}+00$ & $5.89 \mathrm{E}-01$ & + & $1.36 E+00$ & $1.78 \mathrm{E}+00$ & $2.29 \mathrm{E}+00$ & $2.72 \mathrm{E}+00$ \\
\hline OL-U< & $3.77 \mathrm{E}+00$ & & & $1.36 \mathrm{E}+00$ & $1.79 \mathrm{E}+00$ & $2.29 \mathrm{E}+00$ & $2.72 \mathrm{E}+00$ \\
\hline 02 & $3.77 \mathrm{E}+00$ & $E-01$ & $9 E-01$ & $1.36 \mathrm{E}+00$ & $1.79 \mathrm{E}+00$ & $2.29 \mathrm{E}+00$ & $2.72 \mathrm{E}+00$ \\
\hline
\end{tabular}


RESRAD-OFFSITE, Version 2.5

robabilistic Dose and Risk Report

Title : Offsite Resident Farmer

File : RF TC99 DOESG FWD-FV2all.ROF

Summary of dose at graphical times, reptition 3 (continued)

Time

Years

$7.55 \mathrm{E}+02$

$7.55 \mathrm{E}+02$

$7.56 \mathrm{E}+02$

7. $56 \mathrm{E}+02$

$7.57 \mathrm{E}+02$

$7.57 \mathrm{E}+02$

$7.58 \mathrm{E}+02$

7. $58 \mathrm{E}+02$

$7.59 \mathrm{E}+02$

$7.59 \mathrm{E}+02$

$7.60 \mathrm{E}+02$

$7.60 \mathrm{E}+02$

7. $61 \mathrm{E}+02$

7. $61 \mathrm{E}+02$

7. $62 \mathrm{E}+02$

7. $62 \mathrm{E}+02$

7. $63 \mathrm{E}+02$

7. $63 \mathrm{E}+02$

$7.64 \mathrm{E}+02$

$7.64 \mathrm{E}+02$

$7.65 \mathrm{E}+02$

$7.65 \mathrm{E}+02$

$7.66 \mathrm{E}+02$

$7.66 \mathrm{E}+02$

7. $67 \mathrm{E}+02$

$7.68 \mathrm{E}+02$

$7.68 \mathrm{E}+02$

7. $69 \mathrm{E}+02$

$7.69 \mathrm{E}+02$

$7.70 \mathrm{E}+02$

7. $70 \mathrm{E}+02$

$7.71 \mathrm{E}+02$

7. $71 \mathrm{E}+02$

7. $72 \mathrm{E}+02$

7. $72 \mathrm{E}+02$

7. $73 \mathrm{E}+02$

$7.73 \mathrm{E}+02$

7. $74 \mathrm{E}+02$

$7.74 \mathrm{E}+02$

$7.75 \mathrm{E}+02$

$7.75 \mathrm{E}+02$

$7.76 \mathrm{E}+02$

$7.76 \mathrm{E}+02$

$7.77 \mathrm{E}+02$

$7.77 \mathrm{E}+02$

$7.78 \mathrm{E}+02$
Dose statistics at graphical times, mrem/yr

\begin{tabular}{|c|c|c|c|c|c|c|c|}
\hline m & aximum & ea & 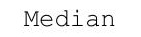 & & & $\%$ & \\
\hline 02 & $.77 E+00$ & 01 & 1 & $.36 \mathrm{E}+00$ & $79 E+00$ & -00 & $.12 E+U U$ \\
\hline-02 & $3.78 E+00$ & $5.92 \mathrm{E}-01$ & $01 E-01$ & $37 E+00$ & $79 E+00$ & $2.29 \mathrm{E}+00$ & $72 \mathrm{E}+00$ \\
\hline $12 E-02$ & $78 E+00$ & $3 \mathrm{~F}-01$ & $01 E-01$ & $.37 E+00$ & $.79 E+00$ & $2.29 \mathrm{E}+00$ & $2.72 \mathrm{E}+00$ \\
\hline $13 E-02$ & $78 \mathrm{E}+00$ & $94 \mathrm{~F}-01$ & $02 \mathrm{~F}-01$ & $.37 E+00$ & $1795+00$ & $2.29 \mathrm{E}+00$ & $2.72 E+00$ \\
\hline $14 \mathrm{E}-02$ & $3.78 \mathrm{E}+00$ & ( & $4.03 E-01$ & & & +00 & $72 \mathrm{E}+00$ \\
\hline 02 & $78 \mathrm{E}+00$ & & & & & & 00 \\
\hline $16 \mathrm{E}-02$ & $3.78 \mathrm{E}+00$ & & & & & & $71 E+00$ \\
\hline $.17 E-02$ & $3.78 E+00$ & 1 & $\perp$ & $37 E+00$ & 00 & +00 & $1 E+00$ \\
\hline $18 \mathrm{E}-02$ & $79 E+00$ & $9 E-01$ & $E-01$ & $1.37 \mathrm{E}+00$ & 00 & $E+00$ & $71 \mathrm{E}+00$ \\
\hline $19 \mathrm{E}-02$ & $.79 E+00$ & 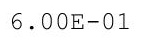 & תمת ת & $.37 E+00$ & 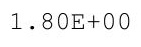 & $.29 E+00$ & م7 \\
\hline 02 & $3.79 \mathrm{E}+00$ & & & & & 00 & $\mathrm{E}+00$ \\
\hline $21 E-02$ & $3.79 \mathrm{E}+00$ & $1 \mathrm{~F}$ & $4.10 \mathrm{E}-01$ & 列 & & 0 & +00 \\
\hline $22 \mathrm{E}-02$ & $3.79 \mathrm{E}+00$ & $6.02 \mathrm{E}-01$ & & & & & $2.71 E+00$ \\
\hline $22 E-02$ & $3.79 \mathrm{E}+00$ & $6.03 \mathrm{E}-01$ & $4.12 \mathrm{E}-01$ & $1.38 \mathrm{E}+00$ & & $2.29 E+00$ & $2.71 E+00$ \\
\hline$E-02$ & $79 \mathrm{E}+00$ & $F-0$ & $5-0$ & 0 & & $E+00$ & $71 \mathrm{E}+00$ \\
\hline 2 & +00 & $6.05 E-01$ & & $+\cdots$ & 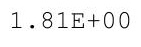 & 0 & 00 \\
\hline 2 & 0 & $6 E-01$ & & 1. $38 \mathrm{E}+00$ & & 0 & 0 \\
\hline 2 & $80 \mathrm{E}+00$ & $6 \quad 075-01$ & $4.16 E-01$ & 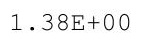 & & & 0 \\
\hline $27 E-02$ & $3.80 \mathrm{E}+00$ & $6.08 \mathrm{E}-01$ & $4.17 \mathrm{E}-01$ & $1.39 \mathrm{E}+00$ & $1.81 \mathrm{E}+00$ & $2.30 \mathrm{E}+00$ & $2.70 E+00$ \\
\hline $28 E-02$ & $.80 E+00$ & $.09 E-01$ & $.18 \mathrm{E}-01$ & $1.39 \mathrm{E}+00$ & $1.81 \mathrm{E}+$ & $2.30 \mathrm{E}+00$ & $2.70 E+00$ \\
\hline 02 & $80 \mathrm{E}+00$ & & & & & +00 & $E+00$ \\
\hline 2 & & & & & & & \\
\hline 02 & $3.80 \mathrm{E}+00$ & & & 1.39E+ & $1.82 \mathrm{E}+$ & & \\
\hline 02 & $80 \mathrm{E}+00$ & & $4.22 E-01$ & $\perp \cdot 01$ & 20 & 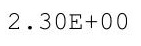 & 00 \\
\hline 2 & $.81 E+00$ & $6.13 \mathrm{E}-01$ & $\perp$ & $1.39 \mathrm{E}+$ & $1.82 \mathrm{E}+$ & $0 \mathrm{E}+\mathrm{C}$ & $70 \mathrm{E}+00$ \\
\hline $34 E-02$ & $.81 E+00$ & - 1 & $4.24 \mathrm{E}-01$ & 1. $39 \mathrm{E}+00$ & $1.82 \mathrm{E}+$ & $30 E+00$ & $70 E+00$ \\
\hline $35 E-02$ & $3.81 \mathrm{E}+00$ & $15 \pi$ & & & & $30 E+00$ & $.70 \mathrm{E}+00$ \\
\hline 02 & & & & & & & \\
\hline 02 & $3.81 \mathrm{E}+00$ & & & $1.39 \mathrm{E}+$ & I. & & \\
\hline $39 E-02$ & $3.81 \mathrm{E}+00$ & 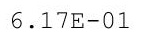 & $4.2 O L-U$ & 1. $39 \mathrm{E}+00$ & $1.83 \mathrm{E}+00$ & $2.30 \mathrm{E}+00$ & $2.69 \mathrm{E}+00$ \\
\hline $40 \mathrm{E}-02$ & $3.81 \mathrm{E}+00$ & 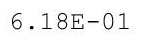 & $1 \cdot 201$ & 1. $39 \mathrm{E}+00$ & $1.83 \mathrm{E}+00$ & $2.30 \mathrm{E}+00$ & $2.69 \mathrm{E}+00$ \\
\hline 2 & $3.81 \mathrm{E}+$ & $6.19 \mathrm{E}-01$ & 4. $30 \mathrm{E}-01$ & 1. $40 \mathrm{E}+$ & & & $2.69 \mathrm{E}+$ \\
\hline 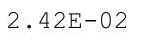 & & & & & & & 0 \\
\hline 02 & $3.82 \mathrm{E}+00$ & 1 & 1 & & & & \\
\hline$E-02$ & $3.82 \mathrm{E}+00$ & 1 & 4. & 1 . & & & 00 \\
\hline $45 E-02$ & $3.82 \mathrm{E}+00$ & $0.25 E-01$ & $4.33 E-01$ & $1.40 \mathrm{E}+00$ & 土.0 & 00 & $59 \mathrm{E}+00$ \\
\hline $46 \mathrm{E}-02$ & $3.82 \mathrm{E}+00$ & & & $1.40 E+00$ & & & \\
\hline $47 E-02$ & $3.82 \mathrm{E}+00$ & 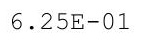 & & 1. $40 \mathrm{E}+00$ & $1.83 \mathrm{E}+00$ & & $2.68 \mathrm{E}+00$ \\
\hline 2 & 3.821 & 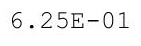 & 1. & $1.40 \mathrm{E}+00$ & $1.84 \mathrm{E}+$ & & $2.68 \mathrm{E}+00$ \\
\hline 2 & $3.82 \mathrm{E}+00$ & $6.26 \mathrm{E}-01$ & 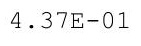 & $1.40 \mathrm{E}+00$ & 1 & $E+00$ & $.68 \mathrm{E}+00$ \\
\hline $50 \mathrm{E}-02$ & $3.82 \mathrm{E}+00$ & $7 E-01$ & $4.38 \mathrm{E}-01$ & 1. $41 \mathrm{E}+00$ & 1 & $2.31 E$ & $2.68 \mathrm{E}+00$ \\
\hline$E-02$ & $3.82 \mathrm{E}+00$ & 6 & 4. & $1.41 \mathrm{E}+00$ & $1.84 \mathrm{E}+$ & 2. & $2.68 \mathrm{E}+00$ \\
\hline $2 E-02$ & $3.83 \mathrm{E}+00$ & & & & & & \\
\hline $.53 E-02$ & $3.83 E+00$ & . & te & $1.41 \mathrm{E}+00$ & $1.84 \mathrm{E}+00$ & $2.31 E+00$ & $2.68 \mathrm{E}+00$ \\
\hline $44-02$ & $3.83 E+00$ & . & & $1.41 \mathrm{E}+00$ & $1.84 \mathrm{E}+00$ & & $2.68 \mathrm{E}+00$ \\
\hline 02 & $3.83 \mathrm{E}+00$ & $E-01$ & $43 E-01$ & $1.41 \mathrm{E}+00$ & $1.84 \mathrm{E}+00$ & $2.31 \mathrm{E}+00$ & $2.68 \mathrm{E}+00$ \\
\hline
\end{tabular}


RESRAD-OFFSITE, Version 2.5

$\mathrm{T}^{1 / 2}$ Limit $=180$ days

obabilistic Dose and Risk Report

Title : Offsite Resident Farmer

File : RF TC99 DOESG FWD-FV2all.ROF

Summary of dose at graphical times, reptition 3 (continued)

Time

Years

$7.78 \mathrm{E}+02$

$7.79 \mathrm{E}+02$

$7.79 \mathrm{E}+02$

$7.80 \mathrm{E}+02$

$7.80 \mathrm{E}+02$

$7.81 \mathrm{E}+02$

$7.81 \mathrm{E}+02$

$7.82 \mathrm{E}+02$

$7.82 \mathrm{E}+02$

$7.83 \mathrm{E}+02$

$7.83 \mathrm{E}+02$

$7.84 \mathrm{E}+02$

$7.84 \mathrm{E}+02$

$7.85 \mathrm{E}+02$

$7.85 \mathrm{E}+02$

$7.86 \mathrm{E}+02$

$7.86 \mathrm{E}+02$

$7.87 \mathrm{E}+02$

$7.88 \mathrm{E}+02$

$7.88 \mathrm{E}+02$

$7.89 \mathrm{E}+02$

$7.89 \mathrm{E}+02$

7. $90 \mathrm{E}+02$

7. $90 \mathrm{E}+02$

7. $91 \mathrm{E}+02$

$7.91 \mathrm{E}+02$

7. $92 \mathrm{E}+02$

$7.92 \mathrm{E}+02$

7. $93 \mathrm{E}+02$

7. $93 \mathrm{E}+02$

7. $94 \mathrm{E}+02$

$7.94 \mathrm{E}+02$

$7.95 \mathrm{E}+02$

$7.95 \mathrm{E}+02$

$7.96 \mathrm{E}+02$

7. $96 \mathrm{E}+02$

$7.97 \mathrm{E}+02$

7. $97 \mathrm{E}+02$

$7.98 \mathrm{E}+02$

$7.98 \mathrm{E}+02$

$7.99 \mathrm{E}+02$

$7.99 \mathrm{E}+02$

$8.00 \mathrm{E}+02$

$8.00 \mathrm{E}+02$

$8.01 \mathrm{E}+02$

$8.01 \mathrm{E}+02$
Dose statistics at graphical times, mrem/yr

\begin{tabular}{|c|c|c|c|c|c|c|c|}
\hline m & aximum & ea & 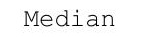 & & & & $\%$ \\
\hline $56 \mathrm{E}-02$ & $3.83 E+00$ & $6.32 \mathrm{E}$ & 1 & $41 E+00$ & 00 & -00 & . 0 OLTU \\
\hline $.57 E-02$ & $3.83 E+00$ & $6.33 E-01$ & $44 E-01$ & $41 E+00$ & $84 \mathrm{E}+00$ & $E+00$ & $58 \mathrm{E}+00$ \\
\hline $58 E-02$ & $83 E+00$ & $34 \mathrm{~F}-01$ & $44 \mathrm{E}-01$ & $.42 \mathrm{E}+00$ & $84 E+00$ & $2.31 E+00$ & $2.68 \mathrm{E}+00$ \\
\hline-02 & $83 E+00$ & $35 \mathrm{~F}-01$ & $5 \mathrm{~F}-01$ & $.42 E+00$ & $185 \mathrm{~F}+00$ & $2.31 E+00$ & $2.68 \mathrm{E}+00$ \\
\hline $.61 E-02$ & $3.83 E+00$ & $6.36 E-01$ & 4. $46 \mathrm{E}-01$ & $1.42 E+00$ & & +00 & $.68 E+00$ \\
\hline 02 & $83 E+00$ & & & & & & 00 \\
\hline $63 E-02$ & $3.83 \mathrm{E}+00$ & & & & & & $68 E+00$ \\
\hline $64 E-02$ & $3.83 E+00$ & 1 & 1 & 1. $42 \mathrm{E}+00$ & 00 & +00 & $E+00$ \\
\hline $65 E-02$ & $.84 \mathrm{E}+00$ & $E-01$ & $E-01$ & $1.42 \mathrm{E}+00$ & 00 & $1 \mathrm{E}+00$ & $7 \mathrm{E}+00$ \\
\hline $66 \mathrm{E}-02$ & $.84 \mathrm{E}+00$ & 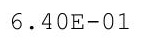 & (5 & $.42 \mathrm{E}+00$ & 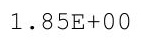 & $31 E+00$ & $67 \mathrm{E}+00$ \\
\hline 02 & +00 & & & & & 00 & -00 \\
\hline $68 E-02$ & +00 & 25 & $4.53 \mathrm{E}-01$ & $2=$ & 0 & & +00 \\
\hline $69 E-02$ & $3.84 \mathrm{E}+00$ & - & & $1.43 E+00$ & & & $2.67 \mathrm{E}+00$ \\
\hline $.70 E-02$ & $3.84 \mathrm{E}+00$ & $6.44 \mathrm{E}-01$ & $4.55 \mathrm{E}-01$ & $1.43 \mathrm{E}+00$ & $1.86 \mathrm{E}+00$ & $2.32 E+00$ & $2.67 \mathrm{E}+00$ \\
\hline$E-02$ & $E+00$ & $5 F-0$ & $\mathrm{~F}-0-0+2-2$ & 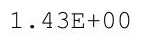 & $865+12913$ & $\mathrm{E}+00$ & $8 \mathrm{E}+00$ \\
\hline 2 & +00 & $6.46 \mathrm{E}-01$ & $4.57 \mathrm{E}-01$ & $+\cdot 1$ & 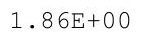 & 0 & 00 \\
\hline 2 & 0 & $6 E-01$ & & $1.43 E+00$ & & 0 & 0 \\
\hline$E-02$ & $E+00$ & $6 \quad 475-01$ & $4.59 E-01$ & 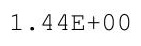 & & $32 E+00$ & 0 \\
\hline $.76 E-02$ & $3.84 \mathrm{E}+00$ & $6.48 \mathrm{E}-01$ & $4.60 \mathrm{E}-01$ & $1.44 \mathrm{E}+00$ & $1.86 \mathrm{E}+00$ & $2.32 E+00$ & $2.68 \mathrm{E}+00$ \\
\hline $.77 E-02$ & $.84 E+00$ & $.49 E-01$ & $.61 \mathrm{E}-01$ & 1. $44 \mathrm{E}+00$ & $1.86 \mathrm{E}+$ & $2.32 \mathrm{E}+00$ & $2.68 E+00$ \\
\hline-02 & +00 & & & & & $.32 E+00$ & \\
\hline 2 & & & & & & & \\
\hline 02 & $3.85 \mathrm{E}+00$ & 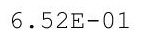 & & 1. $44 \mathrm{E}+$ & $.86 \mathrm{E}+$ & & \\
\hline $82 E-02$ & $85 E+00$ & $6.52 \mathrm{E}-01$ & $4.65 E-01$ & 土.9षण & (1) & 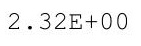 & 0 \\
\hline 2 & $.85 E+00$ & $6.53 \mathrm{E}-01$ & $\perp$ & $1.45 \mathrm{E}+$ & $1.87 \mathrm{E}+$ & $2.32 \mathrm{E}+0$ & $8 \mathrm{E}+$ \\
\hline $84 E-02$ & $.85 E+00$ & 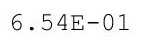 & 4. $67 \mathrm{E}-01$ & 1. $45 \mathrm{E}+00$ & $1.87 \mathrm{E}+$ & $.32 E+00$ & $2.68 \mathrm{E}+00$ \\
\hline $85 E-02$ & $85 E+00$ & $55 \pi$ & $4.68 F-01$ & 1. $45 \mathrm{E}+00$ & & $.32 E+00$ & $.68 E+00$ \\
\hline 02 & & & & & & & \\
\hline 02 & $3.85 \mathrm{E}+00$ & 0 & & $1.45 \mathrm{E}+$ & (- & & \\
\hline $89 E-02$ & $3.85 \mathrm{E}+00$ & . & $4 \cdot 1 \perp E-U \perp$ & 1. $45 \mathrm{E}+00$ & 土. & $2.31 E+00$ & $2.68 \mathrm{E}+00$ \\
\hline $90 \mathrm{E}-02$ & $3.85 \mathrm{E}+00$ & $.00 \mathrm{~L}$ & 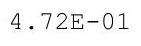 & 1. $45 \mathrm{E}+00$ & म.ÖLTU & $2.31 \mathrm{E}+00$ & $2.68 \mathrm{E}+00$ \\
\hline 2 & 3.8 & $6.59 \mathrm{E}-01$ & $4.72 E-01$ & 1. $46 \mathrm{E}+$ & & & $2.69 \mathrm{E}+$ \\
\hline 2 & & & & & & & 0 \\
\hline 02 & +00 & 1 & & $1.46 \mathrm{E}+00$ & & & \\
\hline$E-02$ & $3.85 E+00$ & 6 & 01 & 1.461 & & & \\
\hline $95 E-02$ & $3.85 \mathrm{E}+00$ & $6.63 E-U 1$ & $4.76 \mathrm{E}-01$ & $1.46 \mathrm{E}+00$ & 土.OT & 00 & $2.69 \mathrm{E}+00$ \\
\hline $97 E-02$ & $3.85 \mathrm{E}+00$ & $0.04 \mathrm{~L}$ & & $1.46 E+00$ & & & $2.69 \mathrm{E}+00$ \\
\hline $8 E-02$ & $3.85 \mathrm{E}+00$ & . & & $1.46 \mathrm{E}+00$ & & & $2.69 \mathrm{E}+00$ \\
\hline 2 & 3.8 &. & 1. & $1.46 \mathrm{E}+00$ & $1.87 \mathrm{E}+\mathrm{C}$ & & $2.69 \mathrm{E}+00$ \\
\hline 2 & & & 1 & $1.47 \mathrm{E}+00$ & $1.87 \mathrm{E}+00$ & $2.31 E+00$ & $59 \mathrm{E}+00$ \\
\hline 02 & $3.86 \mathrm{E}+00$ & $6.67 \mathrm{E}-01$ & $4.80 \mathrm{E}-01$ & 1. $47 \mathrm{E}+00$ & $1.87 \mathrm{E}$ & $31 E+00$ & $2.69 \mathrm{E}+00$ \\
\hline-02 & $3.86 \mathrm{E}+00$ & 6. & 4. & $1.47 \mathrm{E}+00$ & $1.87 \mathrm{E}+$ & 2 & $9 \mathrm{E}+00$ \\
\hline & $3.86 \mathrm{E}+00$ & & & $1.4 / E+U 0$ & & & \\
\hline $5-0<$ & $3.86 \mathrm{E}+00$ & . & 10 & $1.4 / E+00$ & $1.88 \mathrm{E}+00$ & $2.31 E+00$ & $2.69 \mathrm{E}+00$ \\
\hline$\frac{\partial-2<}{4}$ & $3.86 \mathrm{E}+00$ & & & $1.47 \mathrm{E}+00$ & $1.88 \mathrm{E}+00$ & $2.31 E+00$ & $2.69 \mathrm{E}+00$ \\
\hline 02 & $.86 \mathrm{E}+00$ & $E-01$ & $84 \mathrm{E}-01$ & $1.48 \mathrm{E}+00$ & $1.88 \mathrm{E}+00$ & $2.31 \mathrm{E}+00$ & $2.69 \mathrm{E}+00$ \\
\hline
\end{tabular}


RESRAD-OFFSITE, Version 2.5

$\mathrm{T}^{1 / 2}$ Limit $=180$ days

obabilistic Dose and Risk Report

Title : Offsite Resident Farmer

File : RF TC99 DOESG FWD-FV2all.ROF

Summary of dose at graphical times, reptition 3 (continued)

Time

Years

$8.02 \mathrm{E}+02$

$8.02 \mathrm{E}+02$

$8.03 \mathrm{E}+02$

$8.03 \mathrm{E}+02$

$8.04 \mathrm{E}+02$

$8.04 \mathrm{E}+02$

$8.05 \mathrm{E}+02$

$8.05 \mathrm{E}+02$

$8.06 \mathrm{E}+02$

$8.06 \mathrm{E}+02$

$8.07 \mathrm{E}+02$

$8.07 \mathrm{E}+02$

$8.08 \mathrm{E}+02$

8.09E+02

$8.09 \mathrm{E}+02$

$8.10 \mathrm{E}+02$

$8.10 \mathrm{E}+02$

$8.11 \mathrm{E}+02$

$8.11 \mathrm{E}+02$

$8.12 \mathrm{E}+02$

8. $12 \mathrm{E}+02$

$8.13 \mathrm{E}+02$

$8.13 \mathrm{E}+02$

$8.14 \mathrm{E}+02$

$8.14 \mathrm{E}+02$

$8.15 \mathrm{E}+02$

$8.15 \mathrm{E}+02$

$8.16 \mathrm{E}+02$

$8.16 \mathrm{E}+02$

$8.17 \mathrm{E}+02$

$8.17 \mathrm{E}+02$

$8.18 \mathrm{E}+02$

$8.18 \mathrm{E}+02$

$8.19 \mathrm{E}+02$

$8.19 \mathrm{E}+02$

$8.20 \mathrm{E}+02$

$8.20 \mathrm{E}+02$

$8.21 \mathrm{E}+02$

$8.21 \mathrm{E}+02$

$8.22 \mathrm{E}+02$

$8.22 \mathrm{E}+02$

8. $23 \mathrm{E}+02$

$8.23 \mathrm{E}+02$

$8.24 \mathrm{E}+02$

$8.24 \mathrm{E}+02$

$8.25 \mathrm{E}+02$
Dose statistics at graphical times, mrem/yr

\begin{tabular}{|c|c|c|c|c|c|c|c|}
\hline m & aximum & lea & 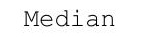 & & & & \\
\hline 02 & $3.86 \mathrm{E}+00$ & $6.72 E-01$ & $4.85 \mathrm{E}$ & $1.48 \mathrm{E}+00$ & $1.88 \mathrm{E}+00$ & -00 & . 09 E+U \\
\hline $10 \mathrm{E}-02$ & $3.86 \mathrm{E}+00$ & $6.73 E-01$ & $4.86 \mathrm{E}-01$ & 1. $48 \mathrm{E}+00$ & $88 \mathrm{E}+00$ & $2.31 E+00$ & $59 \mathrm{E}+00$ \\
\hline-02 & $86 \mathrm{E}+00$ & $74 \mathrm{E}-01$ & $87 E-01$ & $.48 E+00$ & $.88 E+00$ & $2.31 E+00$ & $2.69 \mathrm{E}+00$ \\
\hline-02 & $86 E+00$ & $75 \mathrm{~F}-01$ & $87 E-01$ & $.48 E+00$ & $188 \mathrm{~F}+00$ & $2.31 \mathrm{E}+00$ & $2.69 \mathrm{E}+00$ \\
\hline $.13 \mathrm{E}-02$ & $3.86 \mathrm{E}+00$ & $5 E-01$ & $88 E-01$ & 0 & 0 & \pm+00 & $2.69 \mathrm{E}+00$ \\
\hline 02 & $86 E+00$ & & & & & & 00 \\
\hline $16 \mathrm{E}-02$ & $3.86 \mathrm{E}+00$ & 1 & & & & +00 & $9 E+00$ \\
\hline $.17 \mathrm{E}-02$ & $3.86 \mathrm{E}+00$ & 01 & -01 & $1.48 \mathrm{E}+00$ & $88 \mathrm{E}+00$ & +00 & $E+00$ \\
\hline $18 E-02$ & $3.86 \mathrm{E}+00$ & $6.79 E-01$ & 4. $92 \mathrm{E}-01$ & $1.48 \mathrm{E}+00$ & $88 E+00$ & $E+00$ & $9 E+00$ \\
\hline-02 & $.86 \mathrm{E}+00$ & $80 E-01$ & בכיטי & $.49 \mathrm{E}+00$ & $.89 E+00$ & $31 E+00$ & $.69 E+00$ \\
\hline 02 & $86 \mathrm{E}+00$ & $6.81 E-01$ & & & & 0 & $69 \mathrm{E}+00$ \\
\hline $22 E-02$ & +00 & $681 \mathrm{~F}$ & 4 & 1. $49 \mathrm{E}+00$ & & 0 & 00 \\
\hline $23 E-02$ & $3.86 \mathrm{E}+00$ & $6.82 \mathrm{E}-01$ & 4. $95 \mathrm{E}-01$ & $1.49 \mathrm{E}+00$ & & $2.31 E+00$ & $2.70 \mathrm{E}+00$ \\
\hline $24 E-02$ & $.86 \mathrm{E}+00$ & $6.83 E-01$ & $4.96 \mathrm{E}-01$ & 1. $49 \mathrm{E}+00$ & $1.89 \mathrm{E}+00$ & $2.31 E+00$ & $2.70 \mathrm{E}+00$ \\
\hline-02 & +00 & $4 E-01$ & $5-0$ & $49 \mathrm{E}+$ & & $E+00$ & $9 \mathrm{E}+00$ \\
\hline 2 & 0 & & & & & 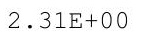 & 00 \\
\hline 2 & & & & & & & 00 \\
\hline 2 & $86 E+00$ & $6.86 \mathrm{E}-01$ & $5.00 E-01$ & 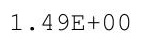 & & 0 & 0 \\
\hline$E-02$ & $3.86 \mathrm{E}+00$ & $6875-01$ & $F-0$ & (1) & Fम & $E+00$ & $9 E+00$ \\
\hline$E-02$ & $.86 E+00$ & $.88 E-01$ & $2 E-01$ & $1.50 \mathrm{E}+00$ & 1. $90 \mathrm{E}+$ & $2.31 \mathrm{E}+00$ & $2.69 E+00$ \\
\hline 02 & +00 & & & & & $.31 E+00$ & $9 \mathrm{E}+00$ \\
\hline & & & & & & & \\
\hline & $.86 \mathrm{E}+00$ & . & & $1.50 \mathrm{E}+$ & & & \\
\hline-02 & $86 \mathrm{E}+00$ & 1 & $5.06 \mathrm{E}-01$ & . & - & - & 0 \\
\hline 2 & $.86 \mathrm{E}+00$ & $6.92 \mathrm{E}-01$ & $5.07 E-01$ & $1.50 \mathrm{E}+00$ & $1.90 \mathrm{E}+$ & $2.32 E+00$ & $.69 \mathrm{E}+00$ \\
\hline$E-02$ & $.86 \mathrm{E}+00$ & $603 \mathrm{E}-01$ & $5.08 \mathrm{E}-01$ & 1. $50 \mathrm{E}+00$ & $1.90 \mathrm{E}+00$ & $32 \mathrm{E}+00$ & $.69 E+00$ \\
\hline$E-02$ & $3.86 \mathrm{E}+00$ & $94 \mathrm{~F}-01$ & & & & $2.32 \mathrm{E}+00$ & $2.69 \mathrm{E}+00$ \\
\hline 02 & & & & & & & \\
\hline & & & & $1.50 \mathrm{E}+$ & & & \\
\hline $.44 \mathrm{E}-02$ & $3.86 \mathrm{E}+00$ & $0.70 \pm$ L & $\cdot \perp \angle \perp-\perp$ & $1.30 E+00$ & म. & $2.32 \mathrm{E}+00$ & $2.69 \mathrm{E}+00$ \\
\hline $6 E-02$ & $3.86 \mathrm{E}+00$ & . & - & 1. $50 \mathrm{E}+00$ & $\perp \cdot 9 \perp$ पTU & $2.31 \mathrm{E}+00$ & $2.69 \mathrm{E}+00$ \\
\hline 2 & $3.86 \mathrm{E}+00$ & . & . & 1. $50 \mathrm{E}+$ & & & \\
\hline$E-02$ & $3.86 \mathrm{E}+00$ & & & & & & $2.69 \mathrm{E}+00$ \\
\hline 02 & & & & & & & \\
\hline 02 & & & 01 & & & & \\
\hline $.52 E-02$ & $3.87 \mathrm{E}+00$ & 01 & 01 & $1.51 \mathrm{E}+00$ & $1.91 \mathrm{E}$ & $2.32 \mathrm{E}+$ & $0 E+00$ \\
\hline $3 E-02$ & $3.87 \mathrm{E}+00$ & $.02 \mathrm{E}$ & & $1.51 \mathrm{E}+00$ & & & $.70 \mathrm{E}+00$ \\
\hline 02 & $3.87 \mathrm{E}+00$ & & & 1. $51 \mathrm{E}+00$ & 1. $91 \mathrm{E}+00$ & & $2.70 \mathrm{E}+00$ \\
\hline 2 & . & . & $5.22 \mathrm{E}-01$ & $1 \cdot 0+5$ & 1.91E+ & $2.32 E+00$ & $2.70 E+00$ \\
\hline 2 & $3.86 \mathrm{E}+00$ & 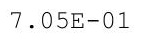 & 1 & $1.51 \mathrm{E}+00$ & & & $2.70 E+00$ \\
\hline-02 & $3.86 \mathrm{E}+00$ & $7.05 E-01$ & $5 \quad 24 \mathrm{~F}-$ & 1. $51 \mathrm{E}+00$ & $1.91 \mathrm{E}$ & $2.32 \mathrm{E}+00$ & $2.70 \mathrm{E}+00$ \\
\hline$E-02$ & $3.86 \mathrm{E}+00$ & 01 & & $1.51 \mathrm{E}+00$ & $1.91 \mathrm{E}+$ & $\mathrm{E}+00$ & $D E+00$ \\
\hline & 3.0 & & & & & & \\
\hline $5-0<$ & $3.86 \mathrm{E}+00$ & $.08 E-01$ & . & $1.3 \perp E+U 0$ & $1.9 \angle E+00$ & $2.32 E+00$ & $2.70 \mathrm{E}+00$ \\
\hline & $3.86 \mathrm{E}+00$ & ( & & $1.52 \mathrm{E}+00$ & $1.92 \mathrm{E}+00$ & $2.32 E+00$ & $2.70 \mathrm{E}+00$ \\
\hline$E-02$ & $3.86 \mathrm{E}+00$ & $E-01$ & $29 E-01$ & $.52 E+00$ & $1.92 \mathrm{E}+00$ & $2.32 \mathrm{E}+00$ & $2.70 \mathrm{E}+00$ \\
\hline
\end{tabular}


RESRAD-OFFSITE, Version 2.5

$\mathrm{T}^{1 / 2}$ Limit $=180$ days

obabilistic Dose and Risk Report

Title : Offsite Resident Farmer

File : RF TC99 DOESG FWD-FV2all.ROF

Summary of dose at graphical times, reptition 3 (continued)

Time

Years

$8.25 \mathrm{E}+02$

$8.26 \mathrm{E}+02$

$8.26 \mathrm{E}+02$

$8.27 \mathrm{E}+02$

$8.27 \mathrm{E}+02$

$8.28 \mathrm{E}+02$

$8.29 \mathrm{E}+02$

$8.29 \mathrm{E}+02$

8. $30 \mathrm{E}+02$

$8.30 \mathrm{E}+02$

8. $31 \mathrm{E}+02$

$8.31 E+02$

$8.32 \mathrm{E}+02$

8. $32 \mathrm{E}+02$

$8.33 \mathrm{E}+02$

8. $33 \mathrm{E}+02$

$8.34 \mathrm{E}+02$

$8.34 \mathrm{E}+02$

$8.35 \mathrm{E}+02$

$8.35 \mathrm{E}+02$

$8.36 \mathrm{E}+02$

$8.36 \mathrm{E}+02$

$8.37 \mathrm{E}+02$

$8.37 \mathrm{E}+02$

$8.38 \mathrm{E}+02$

$8.38 \mathrm{E}+02$

$8.39 \mathrm{E}+02$

$8.39 \mathrm{E}+02$

$8.40 \mathrm{E}+02$

$8.40 \mathrm{E}+02$

$8.41 \mathrm{E}+02$

$8.41 \mathrm{E}+02$

$8.42 \mathrm{E}+02$

$8.42 \mathrm{E}+02$

$8.43 \mathrm{E}+02$

$8.43 E+02$

$8.44 \mathrm{E}+02$

$8.44 \mathrm{E}+02$

$8.45 \mathrm{E}+02$

$8.45 \mathrm{E}+02$

$8.46 \mathrm{E}+02$

$8.46 \mathrm{E}+02$

$8.47 \mathrm{E}+02$

$8.47 \mathrm{E}+02$

$8.48 \mathrm{E}+02$

8. $49 \mathrm{E}+02$
Dose statistics at graphical times, mrem/yr

\begin{tabular}{|c|c|c|c|c|c|c|c|}
\hline m & $\operatorname{axi}$ & 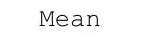 & 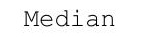 & & & $\%$ & \\
\hline 02 & $.86 \mathrm{E}+00$ & 01 & 01 & L. $52 \mathrm{E}+00$ & $92 \mathrm{E}+00$ & -00 & - TUE+U \\
\hline $68 \mathrm{E}-02$ & $3.86 \mathrm{E}+00$ & $1 E-01$ & $5.31 \mathrm{E}-01$ & $52 \mathrm{E}+00$ & $92 \mathrm{E}+00$ & $2.32 E+00$ & $0 E+00$ \\
\hline$E-02$ & $86 \mathrm{E}+00$ & $2 E-01$ & $32 E-01$ & $.52 \mathrm{E}+00$ & $.92 E+00$ & $2.32 E+00$ & $2.70 \mathrm{E}+00$ \\
\hline$E-02$ & $86 E+00$ & $3 F-01$ & $33 F-01$ & $.52 E+00$ & $92 F+00$ & $2.32 E+00$ & $2.71 E+00$ \\
\hline $.72 E-02$ & +00 & 1 & 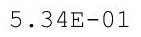 & & & +00 & +00 \\
\hline 02 & $86 \mathrm{E}+00$ & & & & & & 00 \\
\hline $.75 E-02$ & $3.86 \mathrm{E}+00$ & & & & 00 & +00 & $1 \mathrm{E}+00$ \\
\hline $.76 \mathrm{E}-02$ & $3.86 \mathrm{E}+00$ & 1 & $\perp$ & $3 E+00$ & $9 \angle 5+00$ & $E+00$ & $\mathrm{E}+00$ \\
\hline $.77 E-02$ & $.86 \mathrm{E}+00$ & $7 \mathrm{E}-01$ & -01 & $53 E+00$ & $92 \mathrm{E}+00$ & $E+00$ & $1 \mathrm{E}+00$ \\
\hline $9 E-02$ & $.86 \mathrm{E}+00$ & $8 E-01$ & תمת ת & $.53 E+00$ & 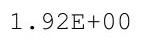 & $33 E+00$ & $.71 \mathrm{E}+00$ \\
\hline 02 & $E+00$ & & & & & 0 & $E+00$ \\
\hline $81 E-02$ & $.86 E+00$ & & & ent & 0 & -00 & +00 \\
\hline $83 E-02$ & $3.86 \mathrm{E}+00$ & & & & $1.92 \mathrm{E}+00$ & $2.33 E+00$ & $2.71 E+00$ \\
\hline$E-02$ & $.86 \mathrm{E}+00$ & 7. $21 \mathrm{E}-01$ & $.43 E-01$ & $1.53 \mathrm{E}+00$ & 1. $92 \mathrm{E}+00$ & $2.33 E+00$ & $2.71 E+00$ \\
\hline-02 & +00 & $2 E-01$ & F- 0 & 0 & $92 \mathrm{Ft}+2 \mathrm{C}$ & $E+00$ & $71 \mathrm{E}+00$ \\
\hline 2 & 00 & & & 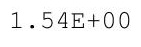 & $92 E+00$ & 0 & 00 \\
\hline 2 & 00 & $7.23 E-01$ & $5.46 \mathrm{E}-01$ & & 0 & 0 & 0 \\
\hline 2 & $86 E+00$ & $7.24 \mathrm{E}-01$ & $5.47 E-01$ & & תק & 0 & 0 \\
\hline $91 E-02$ & $.86 \mathrm{E}+00$ & $5 F-01$ & $8 F-01$ & 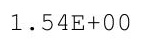 & $92 \mathrm{~F}+\varepsilon \mathrm{C}$ & $3 E+00$ & $1 \mathrm{E}+00$ \\
\hline $92 E-02$ & $.86 E+00$ & $.26 \mathrm{E}-01$ & $9 E-01$ & $1.54 \mathrm{E}+00$ & 1.92E+ & $2.33 E+00$ & $2.71 E+00$ \\
\hline-02 & +00 & & & & 0 & +00 & $71 \mathrm{E}+00$ \\
\hline & & & & & & & \\
\hline 2 & $3.86 \mathrm{E}+00$ & $7.28 \mathrm{E}-01$ & & $1.55 \mathrm{E}+$ & $1.92 \mathrm{E}+$ & & \\
\hline$E-02$ & $86 \mathrm{E}+00$ & $\perp$ & $5.53 \mathrm{E}-01$ & 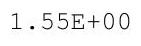 & 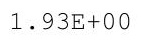 & 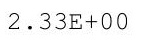 & 0 \\
\hline 2 & $.86 \mathrm{E}+00$ & $7.30 \mathrm{E}-01$ & $\perp$ & $1.55 \mathrm{E}+$ & $1.93 \mathrm{E}+$ & $.33 E+00$ & $71 \mathrm{E}+00$ \\
\hline $.01 E-02$ & $.86 \mathrm{E}+00$ & $30 F-01$ & $5 \mathrm{~F}-01$ & 1. $55 \mathrm{E}+00$ & $.93 E+$ & $33 E+00$ & $71 E+00$ \\
\hline $2 E-02$ & $3.86 \mathrm{E}+00$ & & & & & $2.32 \mathrm{E}+00$ & $2.71 \mathrm{E}+00$ \\
\hline 02 & & & & & & & \\
\hline 2 & $3.86 \mathrm{E}+00$ & . & & $1.55 \mathrm{E}+$ & & & \\
\hline $.06 E-02$ & $3.86 \mathrm{E}+00$ & 1.0451 & 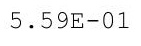 & $1.55 \mathrm{E}+00$ & 1.93E+ & $2.32 \mathrm{E}+00$ & $2.71 E+00$ \\
\hline $8 E-02$ & $3.86 \mathrm{E}+00$ & 7. $34 \mathrm{E}-01$ & . & 1. $55 \mathrm{E}+00$ & $1.93 \mathrm{E}+00$ & $2.32 \mathrm{E}+00$ & $2.71 \mathrm{E}+00$ \\
\hline 2 & $3.86 \mathrm{E}+$ & . & $5.61 \mathrm{E}-01$ & 1. $55 \mathrm{E}+$ & $1.93 \mathrm{E}+$ & & \\
\hline & & & & & & & $2.71 E+00$ \\
\hline 02 & & & & 1. $55 \mathrm{E}+00$ & & & \\
\hline$E-02$ & & 01 & & & & & \\
\hline $5 E-02$ & $3.85 \mathrm{E}+00$ & $7.38 E-01$ & $3.045-01$ & $1.55 \mathrm{E}+00$ & 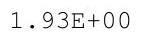 & 2.524 & $2.71 E+00$ \\
\hline $16 \mathrm{E}-02$ & $3.85 \mathrm{E}+00$ & 1.0401 & & $1.30 E+00$ & 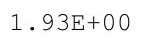 & & \\
\hline 2 & $3.85 \mathrm{E}+00$ & & & $1.56 \mathrm{E}+00$ & 1. $92 \mathrm{E}+00$ & & $2.71 \mathrm{E}+00$ \\
\hline $.19 \mathrm{E}-02$ & 0 & $\cdot$ & 1 & $1.56 \mathrm{E}+00$ & $1.93 \mathrm{E}+$ & $2.32 E+00$ & $2.71 E+00$ \\
\hline & $E+00$ & & - & $1.56 \mathrm{E}+00$ & & & $2.71 E+00$ \\
\hline $2 E-02$ & $3.85 \mathrm{E}+00$ & $7.42 \mathrm{E}-01$ & $5.68 \mathrm{E}-01$ & $1.56 \mathrm{E}+00$ & $1.93 \mathrm{E}$ & $2.32 \mathrm{E}+00$ & $2.71 \mathrm{E}+00$ \\
\hline $24 E-02$ & $3.85 \mathrm{E}+00$ & 01 & & & 1.93E+ & $\mathrm{E}+00$ & $2.71 \mathrm{E}+00$ \\
\hline & $3.85 \mathrm{E}+00$ & & & & & & \\
\hline $6 E-02$ & $3.85 \mathrm{E}+00$ & 1 & (7) & $1.36 E+00$ & $1.93 \mathrm{E}+00$ & $2.32 E+00$ & $2.70 \mathrm{E}+00$ \\
\hline $6+2-02$ & $3.85 \mathrm{E}+00$ & .尹UШ & & $1.57 \mathrm{E}+00$ & $1.93 \mathrm{E}+00$ & $2.32 E+00$ & $2.70 \mathrm{E}+00$ \\
\hline 02 & $.85 E+00$ & $5-01$ & $2 E-01$ & $.57 \mathrm{E}+00$ & $1.93 \mathrm{E}+00$ & $2.32 \mathrm{E}+00$ & $2.70 \mathrm{E}+00$ \\
\hline
\end{tabular}


RESRAD-OFFSITE, Version 2.5

$\mathrm{T}^{1 / 2}$ Limit $=180$ days

obabilistic Dose and Risk Report

Title : Offsite Resident Farmer

File : RF TC99 DOESG FWD-FV2all.ROF

Summary of dose at graphical times, reptition 3 (continued)

Time

Years

$8.49 \mathrm{E}+02$

$8.50 \mathrm{E}+02$

$8.50 \mathrm{E}+02$

$8.51 \mathrm{E}+02$

8. $51 \mathrm{E}+02$

8. $52 \mathrm{E}+02$

8. $52 \mathrm{E}+02$

$8.53 \mathrm{E}+02$

$8.53 \mathrm{E}+02$

8. $54 \mathrm{E}+02$

$8.54 \mathrm{E}+02$

$8.55 \mathrm{E}+02$

8. $55 \mathrm{E}+02$

$8.56 \mathrm{E}+02$

$8.56 \mathrm{E}+02$

$8.57 \mathrm{E}+02$

$8.57 \mathrm{E}+02$

$8.58 \mathrm{E}+02$

8. $58 \mathrm{E}+02$

$8.59 \mathrm{E}+02$

$8.59 \mathrm{E}+02$

$8.60 \mathrm{E}+02$

$8.60 \mathrm{E}+02$

$8.61 \mathrm{E}+02$

8. $61 \mathrm{E}+02$

$8.62 \mathrm{E}+02$

$8.62 \mathrm{E}+02$

$8.63 \mathrm{E}+02$

8. $63 \mathrm{E}+02$

8. $64 \mathrm{E}+02$

$8.64 \mathrm{E}+02$

8. $65 \mathrm{E}+02$

$8.65 \mathrm{E}+02$

$8.66 \mathrm{E}+02$

$8.66 \mathrm{E}+02$

$8.67 \mathrm{E}+02$

$8.67 \mathrm{E}+02$

$8.68 \mathrm{E}+02$

8. $69 \mathrm{E}+02$

8. $69 \mathrm{E}+02$

$8.70 \mathrm{E}+02$

$8.70 \mathrm{E}+02$

$8.71 \mathrm{E}+02$

8. $71 \mathrm{E}+02$

$8.72 \mathrm{E}+02$

$8.72 \mathrm{E}+02$
Dose statistics at graphical times, mrem/yr

\begin{tabular}{|c|c|c|c|c|c|c|c|}
\hline m & axis & 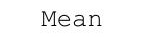 & 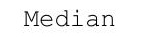 & & & & \\
\hline 02 & $.85 E+00$ & $7.47 E-01$ & $.73 E-01$ & $1.57 E+00$ & $94 E+00$ & $.32 E+00$ & . TUETU \\
\hline $32 E-02$ & $3.85 \mathrm{E}+00$ & $8 E-01$ & $74 E-01$ & $7 E+00$ & $94 \mathrm{E}+00$ & $2.32 E+00$ & $0 E+00$ \\
\hline $34 \mathrm{E}-02$ & $85 E+00$ & $.48 \mathrm{E}-01$ & $.75 \mathrm{E}-01$ & $.57 E+00$ & $.94 \mathrm{E}+00$ & $2.32 \mathrm{E}+00$ & $2.70 \mathrm{E}+00$ \\
\hline $35 E-02$ & $.85 E+00$ & $49 F-01$ & $75 \mathrm{~F}-01$ & $1.57 \mathrm{E}+00$ & $.94 \mathrm{E}+00$ & $2.32 E+00$ & $2.70 \mathrm{E}+00$ \\
\hline $37 E-02$ & $3.85 \mathrm{E}+00$ & $0 E-01$ & 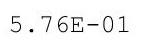 & $.57 \mathrm{E}+00$ & 0 & $32 E+00$ & $0 E+00$ \\
\hline 02 & $85 E+00$ & & & & & 00 & 00 \\
\hline$E-02$ & $3.85 \mathrm{E}+00$ & & & & & +00 & $\mathrm{E}+00$ \\
\hline-02 & $84 \mathrm{E}+00$ & 1 & $\perp$ & $8 \mathrm{E}+00$ & 00 & +00 & $E+00$ \\
\hline $43 E-02$ & $.84 \mathrm{E}+00$ & $3 E-01$ & $E-01$ & $58 \mathrm{E}+00$ & $\Xi+00$ & $E+00$ & $1 \mathrm{E}+00$ \\
\hline $4 E-02$ & $.84 \mathrm{E}+00$ & $4 E-01$ & תחم: & 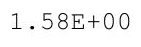 & 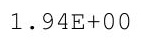 & $32 E+00$ & $71 \mathrm{E}+00$ \\
\hline 02 & +00 & & & & & +00 & $E+00$ \\
\hline $47 E-02$ & +00 & 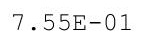 & $5.82 \mathrm{E}-01$ & 1. $58 \mathrm{E}+00$ & & -00 & +00 \\
\hline $48 \mathrm{E}-02$ & $3.84 \mathrm{E}+00$ & & & & & $2.33 E+00$ & $2.71 E+00$ \\
\hline $50 E-02$ & $3.84 \mathrm{E}+00$ & $7.57 \mathrm{E}-01$ & $.84 \mathrm{E}-01$ & $1.58 \mathrm{E}+00$ & $1.94 \mathrm{E}+U \mathrm{U}$ & $3 E+00$ & $2.71 E+00$ \\
\hline-02 & $E+00$ & $E-01$ & $5-0$ & 0 & 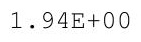 & $E+00$ & $1 \mathrm{E}+00$ \\
\hline 2 & 0 & & & & & 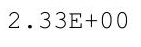 & 00 \\
\hline 2 & $E+00$ & $7.59 \mathrm{E}-01$ & & 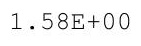 & & 0 & 0 \\
\hline 2 & $84 E+00$ & 7. $60 \mathrm{E}-01$ & $5.88 E-01$ & & & 0 & 0 \\
\hline $.57 E-02$ & $.84 \mathrm{E}+00$ & $1 \mathrm{~F}-01$ & Гم & $50=0$ & 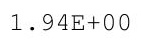 & $3 E+00$ & $72 \mathrm{E}+00$ \\
\hline $59 E-02$ & $.84 E+00$ & $.61 E-01$ & $0 E-01$ & $1.59 \mathrm{E}+00$ & $1.94 \mathrm{E}+$ & $2.33 E+00$ & $2.72 \mathrm{E}+00$ \\
\hline 02 & +00 & & & & & +00 & $2 E+00$ \\
\hline & & & & & & & \\
\hline $64 \mathrm{E}-02$ & $3.83 \mathrm{E}+00$ & & & 1. $59 \mathrm{E}+$ & & & \\
\hline 02 & $83 E+00$ & $\perp$ & & I・UL & 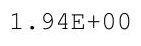 & - & 00 \\
\hline 2 & $.83 E+00$ & $7.65 \mathrm{E}-01$ & $\perp$ & $1.60 \mathrm{E}+\mathrm{C}$ & $1.94 \mathrm{E}+$ & $2.33 E+00$ & $73 E+00$ \\
\hline $68 E-02$ & $.83 E+00$ & $7-665-01$ & $6 \sigma^{-1} 0$ & 1. $60 \mathrm{E}+00$ & $.95 \mathrm{E}+$ & $33 E+00$ & $73 E+00$ \\
\hline $.70 \mathrm{E}-02$ & $83 E+00$ & & & & & $33 E+00$ & $.73 E+00$ \\
\hline 02 & & & & & & & \\
\hline 02 & $3.83 \mathrm{E}+00$ & $\cdot 0$ & & $\perp .00 \mathrm{~L}$ & 年 & & \\
\hline $.74 \mathrm{E}-02$ & $3.83 E+00$ & $1.07 \mathrm{~L}-\mathrm{L}$ & . & $1.60 \mathrm{E}+00$ & 1.95E+ & $2.32 \mathrm{E}+00$ & $2.73 E+00$ \\
\hline $6 E-02$ & $3.83 E+00$ & . & . & $1.60 \mathrm{E}+00$ & $1.95 \mathrm{E}+00$ & $2.32 \mathrm{E}+00$ & $2.73 E+00$ \\
\hline 2 & $3.83 E+$ & & 1 & 1. $60 \mathrm{E}+$ & & & $2.73 \mathrm{E}+$ \\
\hline 7 & & & & & & & \\
\hline & & & 1 & $1.60 \mathrm{E}+00$ & & & \\
\hline$E-02$ & $3.82 \mathrm{E}+00$ & 1 & & 1. & & & \\
\hline $4 E-02$ & $3.82 \mathrm{E}+00$ & $7.73 E-01$ & $0 \pm-01$ & $1.61 \mathrm{E}+00$ & $\perp \cdot 201$ & 2.324 & $2.74 \mathrm{E}+00$ \\
\hline $85 E-02$ & $3.82 \mathrm{E}+00$ & & & $1.01 E+00$ & & & \\
\hline $87 E-02$ & $3.82 \mathrm{E}+00$ & & & $1.61 \mathrm{E}+00$ & 1. $96 \mathrm{E}+00$ & & $2.74 \mathrm{E}+00$ \\
\hline 2 & ( & 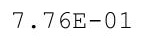 & 1 & $1.61 \mathrm{E}+00$ & $1.96 \mathrm{E}+$ & & $2.74 \mathrm{E}+00$ \\
\hline 2 & $3.82 \mathrm{E}+00$ & & - & $1.61 \mathrm{E}+00$ & 1 & & $2.74 \mathrm{E}+00$ \\
\hline $1 E-02$ & $3.82 \mathrm{E}+00$ & $7.77 \mathrm{E}-01$ & $2 \mathrm{E}-01$ & 1. $61 \mathrm{E}+00$ & & $2.31 \mathrm{E}+00$ & $2.74 \mathrm{E}+00$ \\
\hline$E-02$ & $3.82 \mathrm{E}+00$ & 01 & & $1.61 \mathrm{E}+00$ & & $E+00$ & $2.74 \mathrm{E}+00$ \\
\hline & $3.82 \mathrm{E}+00$ & & & $1.6 \perp E+U 0$ & & & \\
\hline $5-02$ & $3.82 \mathrm{E}+00$ & 1 & 1 & $1.0 \perp E+U 0$ & $1.97 \mathrm{E}+00$ & $2.31 E+00$ & $2.74 \mathrm{E}+00$ \\
\hline $5-0<$ & $3.82 E+00$ & & & $1.61 \mathrm{E}+00$ & $1.97 \mathrm{E}+00$ & $2.31 E+00$ & $2.73 E+00$ \\
\hline$E-02$ & $.81 E+00$ & $E-01$ & $E-01$ & $.61 \mathrm{E}+00$ & $1.97 \mathrm{E}+00$ & $2.31 E+00$ & $2.73 E+00$ \\
\hline
\end{tabular}


RESRAD-OFFSITE, Version 2.5

$\mathrm{T}^{1 / 2}$ Limit $=180$ days

obabilistic Dose and Risk Report

Title : Offsite Resident Farmer

File : RF TC99 DOESG FWD-FV2all.ROF

Summary of dose at graphical times, reptition 3 (continued)

Time

Years

$8.73 E+02$

$8.73 \mathrm{E}+02$

$8.74 \mathrm{E}+02$

$8.74 \mathrm{E}+02$

$8.75 \mathrm{E}+02$

$8.75 \mathrm{E}+02$

$8.76 \mathrm{E}+02$

$8.76 \mathrm{E}+02$

$8.77 \mathrm{E}+02$

$8.77 \mathrm{E}+02$

$8.78 \mathrm{E}+02$

$8.78 \mathrm{E}+02$

$8.79 \mathrm{E}+02$

$8.79 \mathrm{E}+02$

$8.80 \mathrm{E}+02$

$8.80 \mathrm{E}+02$

$8.81 \mathrm{E}+02$

$8.81 \mathrm{E}+02$

$8.82 \mathrm{E}+02$

$8.82 \mathrm{E}+02$

$8.83 \mathrm{E}+02$

$8.83 E+02$

$8.84 \mathrm{E}+02$

$8.84 \mathrm{E}+02$

$8.85 \mathrm{E}+02$

$8.85 \mathrm{E}+02$

$8.86 \mathrm{E}+02$

$8.86 \mathrm{E}+02$

$8.87 \mathrm{E}+02$

$8.87 \mathrm{E}+02$

$8.88 \mathrm{E}+02$

$8.89 \mathrm{E}+02$

$8.89 \mathrm{E}+02$

$8.90 \mathrm{E}+02$

$8.90 \mathrm{E}+02$

$8.91 \mathrm{E}+02$

$8.91 \mathrm{E}+02$

$8.92 \mathrm{E}+02$

8. $92 \mathrm{E}+02$

8. $93 \mathrm{E}+02$

$8.93 E+02$

8. $94 \mathrm{E}+02$

8. $94 \mathrm{E}+02$

$8.95 \mathrm{E}+02$

$8.95 \mathrm{E}+02$

8. $96 \mathrm{E}+02$
Dose statistics at graphical times, mrem/yr

\begin{tabular}{|c|c|c|c|c|c|c|c|}
\hline m & $\mathrm{m}$ & Mean & ledian & & & $\%$ & $\%$ \\
\hline $01 \mathrm{E}-02$ & $3.81 \mathrm{E}+00$ & $7.82 \mathrm{E}-01$ & $6.19 \mathrm{E}-01$ & $1.61 \mathrm{E}+00$ & $1.97 \mathrm{E}+00$ & +00 & 2.15E+U \\
\hline $02 E-02$ & +00 & 01 & 01 & 0 & 00 & +00 & $3 E+00$ \\
\hline $04 \mathrm{E}-02$ & $3.81 \mathrm{E}+00$ & $83 E-01$ & $6.20 \mathrm{E}-01$ & 1. $61 \mathrm{E}+00$ & $1.97 \mathrm{E}+00$ & +00 & $2.73 E+00$ \\
\hline $06 \mathrm{E}-02$ & $3.81 E+00$ & $.84 \mathrm{E}-01$ & $6.21 \mathrm{E}-01$ & 1. $61 \mathrm{E}+00$ & 1. $97 \mathrm{E}+00$ & $2.31 E+00$ & $73 E+00$ \\
\hline 02 & $E+00$ & $5 \mathrm{E}$ & 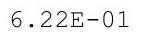 & $1.62 \mathrm{E}$ & 0 & 00 & $3 E+00$ \\
\hline-02 & 00 & & & .6 & 0 & 00 & +00 \\
\hline $10 \mathrm{E}-02$ & & & & $.62 \mathrm{E}+00$ & & & $3 E+00$ \\
\hline-02 & & & & & & & +00 \\
\hline-02 & +00 & -0 & $\perp$ & $62 \mathrm{E}+00$ & 00 & +00 & $73 E+00$ \\
\hline 02 & $E+00$ & 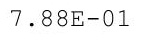 & $6.27 \mathrm{E}-01$ & $1.62 \mathrm{E}+$ & 0 & 0 & +00 \\
\hline 02 & 0 & $7.89 E-01$ & $6.28 \mathrm{E}-01$ & 1.6 & & 0 & 00 \\
\hline 2 & +00 & & & .62 & & & -00 \\
\hline $.20 \mathrm{E}-02$ & $3.80 \mathrm{E}+00$ & ل & קم: & $1.62 \mathrm{E}+00$ & & & $3 E+00$ \\
\hline $22 \mathrm{E}-02$ & $3.80 \mathrm{E}+00$ & $7.91 \mathrm{E}-01$ & $6.31 \mathrm{E}-01$ & $1.62 \mathrm{E}+00$ & $1.98 \mathrm{E}+00$ & $2.31 \mathrm{E}+00$ & $2.73 E+00$ \\
\hline-02 & $80 E+00$ & $2 F-0$ & 1 & $1.63 \mathrm{E}+00$ & 1 & $2.31 E+00$ & $73 E+00$ \\
\hline 2 & 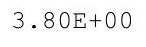 & $\perp$ & & $\pm \cdot 00$ & 0 & 00 & +00 \\
\hline 02 & $3.80 \mathrm{E}+00$ & $7.93 \mathrm{E}-01$ & $\perp$ & . & 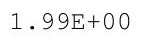 & 0 & \\
\hline 2 & & & & & & & 00 \\
\hline $30 E-02$ & $3.80 \mathrm{E}+00$ & $7.95 \mathrm{E}-$ & 泬 & $1.63 \mathrm{E}+00$ & 1. $99 \mathrm{E}+0$ & $2.31 \mathrm{E}+00$ & $73 E+00$ \\
\hline $31 \mathrm{E}-02$ & $3.79 \mathrm{E}+00$ & $5 E-0$ & $.35 \mathrm{E}-01$ & $1.63 \mathrm{E}+00$ & $1.99 \mathrm{E}+0$ & $2.31 \mathrm{E}+00$ & $2.73 E+00$ \\
\hline $33 E-02$ & $3.79 \mathrm{E}+00$ & $7.96 \mathrm{E}-01$ & $E-01$ & $1.63 \mathrm{E}+00$ & & $.31 E+00$ & $73 E+00$ \\
\hline 02 & & & & 0 & & & $7 \mathrm{E}+00$ \\
\hline 2 & & & & 1.014 & & & \\
\hline-02 & $3.79 \mathrm{E}+00$ & & & $\perp \cdot 0 \pm \perp$ & 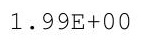 & & 00 \\
\hline 2 & $3.79 \mathrm{E}+00$ & o & $\perp$ & 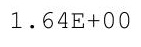 & 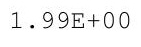 & 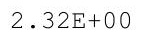 & 00 \\
\hline $41 F-02$ & $79 F+00$ & (סחم & 6 & 1. $64 \mathrm{E}+00$ & 1.99E+00 & $2.32 E+00$ & $2.72 \mathrm{E}+00$ \\
\hline $3 F-02$ & $3.79 \mathrm{E}+00$ & $F=0$ & $40 \mathrm{~F}-01$ & $1.64 \mathrm{E}+00$ & 1 & $2.32 \mathrm{E}+00$ & $2.72 \mathrm{E}+00$ \\
\hline 2 & & & & & & & \\
\hline 02 & $78 E+00$ & & & $.64 \mathrm{E}$ & & & \\
\hline $48 E-02$ & . & $0.0 J \pm-4$ & $6.43 E-01$ & $1.64 \mathrm{E}+00$ & 2.001 & $2.3 \angle E+00$ & $2.72 \mathrm{E}+00$ \\
\hline . $30 \mathrm{D}-02$ & . & 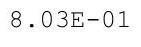 & $0.445-01$ & $1.64 \mathrm{E}+00$ & 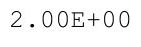 & Z. ОСЕТО & $2.72 E+00$ \\
\hline 2 & 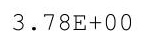 & 然 & 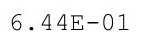 & म. & . & & $2.72 \mathrm{E}+00$ \\
\hline 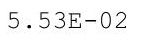 & $3.78 \mathrm{E}+00$ & 5 & F & $1.65 \mathrm{E}+00$ & & & $2.71 E+00$ \\
\hline 2 & & & & & & & \\
\hline 02 & & & 1 & $1.65 \mathrm{E}+$ & & & \\
\hline $8 E-02$ & $3.78 \mathrm{E}+00$ & $8.07 E-01$ & 1 & $1.0 J E T$ & $2.00 \mathrm{w}$ & $2 \cdot$ & +00 \\
\hline $60 E-02$ & 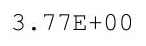 & & & $1.65 \mathrm{E}+00$ & & & $2.71 \mathrm{E}+00$ \\
\hline . & & & & I.OJ上TU & & & $2.71 \mathrm{E}+00$ \\
\hline $.63 E-02$ & . & 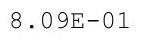 & & +.00 & $2.00 \mathrm{E}$ & & $2.71 E+00$ \\
\hline $.65 E-02$ & & & & $5 \mathrm{E}+00$ & & & \\
\hline 2 & $3.77 \mathrm{E}+00$ & 8 & 01 & $1.65 \mathrm{E}+$ & $2.00 \mathrm{E}+$ & & $2.70 E+00$ \\
\hline$E-02$ & 3.771 & 8.1 & -01 & $1.65 \mathrm{E}+00$ & & $2.30 \mathrm{E}+00$ & $2.70 \mathrm{E}+00$ \\
\hline & & & & & & & \\
\hline & 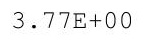 & $8.12 E-01$ & & $1.05 E+00$ & $2.00 \mathrm{E}+00$ & & $2.70 \mathrm{E}+00$ \\
\hline D & & & & $1.65 \mathrm{E}+00$ & & & $2.70 \mathrm{E}+$ \\
\hline$E-02$ & $3.76 \mathrm{E}+00$ & $4 E-01$ & $57 E-01$ & $1.65 \mathrm{E}+00$ & $.00 E+00$ & $2.29 \mathrm{E}+00$ & $.70 E+00$ \\
\hline
\end{tabular}


RESRAD-OFFSITE, Version 2.5

$\mathrm{T}^{1 / 2}$ Limit $=180$ days

obabilistic Dose and Risk Report

Title : Offsite Resident Farmer

File : RF TC99 DOESG FWD-FV2all.ROF

Summary of dose at graphical times, reptition 3 (continued)

Time

Years

$8.96 \mathrm{E}+02$

$8.97 \mathrm{E}+02$

$8.97 \mathrm{E}+02$

$8.98 \mathrm{E}+02$

$8.98 \mathrm{E}+02$

8. $99 \mathrm{E}+02$

$8.99 \mathrm{E}+02$

$9.00 \mathrm{E}+02$

$9.00 \mathrm{E}+02$

$9.01 \mathrm{E}+02$

$9.01 \mathrm{E}+02$

$9.02 \mathrm{E}+02$

$9.02 \mathrm{E}+02$

$9.03 E+02$

$9.03 \mathrm{E}+02$

$9.04 \mathrm{E}+02$

$9.04 \mathrm{E}+02$

$9.05 \mathrm{E}+02$

$9.05 \mathrm{E}+02$

$9.06 \mathrm{E}+02$

$9.06 \mathrm{E}+02$

$9.07 \mathrm{E}+02$

$9.07 \mathrm{E}+02$

$9.08 \mathrm{E}+02$

$9.08 \mathrm{E}+02$

$9.09 \mathrm{E}+02$

$9.10 \mathrm{E}+02$

$9.10 \mathrm{E}+02$

$9.11 \mathrm{E}+02$

$9.11 \mathrm{E}+02$

9. $12 \mathrm{E}+02$

$9.12 \mathrm{E}+02$

$9.13 \mathrm{E}+02$

$9.13 \mathrm{E}+02$

$9.14 \mathrm{E}+02$

$9.14 \mathrm{E}+02$

$9.15 \mathrm{E}+02$

$9.15 \mathrm{E}+02$

$9.16 \mathrm{E}+02$

$9.16 \mathrm{E}+02$

$9.17 \mathrm{E}+02$

$9.17 \mathrm{E}+02$

$9.18 \mathrm{E}+02$

$9.18 \mathrm{E}+02$

$9.19 \mathrm{E}+02$

$9.19 \mathrm{E}+02$
Dose statistics at graphical times, mrem/yr

\begin{tabular}{|c|c|c|c|c|c|c|c|}
\hline$m$ & $\mathrm{~m}$ & Mean & ledian & & & $\%$ & $\%$ \\
\hline $.77 \mathrm{E}-02$ & $3.76 \mathrm{E}+00$ & $8.14 \mathrm{E}-01$ & $6.58 \mathrm{E}-01$ & $1.65 \mathrm{E}+00$ & $2.00 \mathrm{E}+00$ & $2.28 \mathrm{E}+00$ & $2.10 E+00$ \\
\hline$E-02$ & $E+00$ & 01 & 01 & 00 & 00 & $E+00$ & $0 E+00$ \\
\hline $80 \mathrm{E}-02$ & $6 \mathrm{E}+00$ & $6 E-01$ & $6.60 \mathrm{E}-01$ & $1.65 \mathrm{E}+00$ & $2.00 \mathrm{E}+00$ & $2.28 \mathrm{E}+00$ & $70 \mathrm{E}+00$ \\
\hline $82 \mathrm{E}-02$ & $3.76 \mathrm{E}+00$ & $7 E-01$ & $6.60 \mathrm{E}-01$ & 1. $65 \mathrm{E}+00$ & $2.00 \mathrm{E}+00$ & $2.28 \mathrm{E}+00$ & $70 \mathrm{E}+00$ \\
\hline 2 & 0 & (- & $1 \mathrm{~F}-2 \cdot 0$ & 0 & 0 & 0 & $\mathrm{OE}+00$ \\
\hline-02 & -00 & 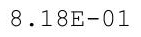 & & 0 & & & +00 \\
\hline $87 \mathrm{E}-02$ & & & & & & & $E+00$ \\
\hline-02 & & & & & & & +00 \\
\hline-02 & +00 & $F-0$ & $\perp$ & +00 & 00 & +00 & $59 \mathrm{E}+00$ \\
\hline 2 & +00 & 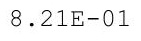 & $6.65 \mathrm{E}-01$ & 1.65 & 0 & 0 & +00 \\
\hline 02 & 0 & $8.21 E-01$ & $6.66 \mathrm{E}-01$ & 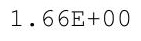 & & 0 & 00 \\
\hline 2 & -00 & & & .66 & & 0 & -00 \\
\hline $.97 \mathrm{E}-02$ & $3.75 \mathrm{E}+00$ & ل & 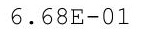 & $1.66 \mathrm{E}+00$ & & $2.29 \mathrm{E}+00$ & $59 \mathrm{E}+00$ \\
\hline $.99 \mathrm{E}-02$ & $3.74 \mathrm{E}+00$ & $8.23 \mathrm{E}-01$ & $6.69 \mathrm{E}-01$ & $1.66 \mathrm{E}+00$ & $2.01 \mathrm{E}+00$ & $2.29 \mathrm{E}+00$ & $2.68 \mathrm{E}+00$ \\
\hline-02 & $74 \mathrm{E}+00$ & -0 & 1 & 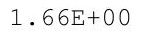 & 2 & $.29 E+00$ & $68 \mathrm{E}+00$ \\
\hline 02 & $74 \mathrm{E}+00$ & $\perp$ & $\perp$ & 1.66 & 0 & \pm+00 & +00 \\
\hline 02 & $3.74 \mathrm{E}+00$ & $8.25 E-01$ & & $\cdot 0$ & 0 & bo & 00 \\
\hline 2 & & & & & & & 0 \\
\hline $3 E-02$ & $3.74 \mathrm{E}+00$ & $.27 \mathrm{E}-\mathrm{C}$ & $6.75 \mathrm{E}-$ & $1.66 \mathrm{E}+00$ & $2.01 E+00$ & $2.29 \mathrm{E}+00$ & $\mathrm{E}+00$ \\
\hline $0 \mathrm{E}-02$ & $3.74 \mathrm{E}+00$ & $.27 \mathrm{E}-0$ & $.76 \mathrm{E}-01$ & $1.66 \mathrm{E}+00$ & $2.01 \mathrm{E}+00$ & $2.29 \mathrm{E}+00$ & $2.67 \mathrm{E}+00$ \\
\hline $11 \mathrm{E}-02$ & $3.73 E+00$ & $.28 E-01$ & $6.77 \mathrm{E}-01$ & $1.66 \mathrm{E}+00$ & & $2.29 \mathrm{E}+00$ & $.67 \mathrm{E}+00$ \\
\hline 02 & & & & & & & $67 \mathrm{E}+00$ \\
\hline 2 & & & & 1.66 & & & \\
\hline-02 & $3.73 E+00$ & $8.30 \mathrm{E}-01$ & & $\perp \cdot 00 \mathrm{H}$ & 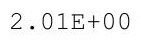 & . & 00 \\
\hline 2 & 0 & $8.31 \mathrm{E}-01$ & $\perp$ & 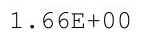 & 0. & 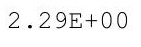 & 00 \\
\hline$F-02$ & $.73 E+00$ & 20 & קم & $1.66 \mathrm{E}+00$ & $.01 \mathrm{E}+$ & $2.29 E+00$ & $67 E+00$ \\
\hline$F-0 ?$ & $3.72 \mathrm{E}+00$ & $F-0$ & $F-01$ & $1.66 \mathrm{E}+00$ & הת1 0 & $2.29 \mathrm{E}+00$ & $2.67 \mathrm{E}+00$ \\
\hline 02 & & & & & & & \\
\hline 02 & $3.72 \mathrm{E}+00$ & & & $.66 \mathrm{E}+$ & & & \\
\hline $7 E-02$ & $3.1 \angle E+00$ & $0.04+4$ & 01 & $1.66 \mathrm{E}+00$ & $2.0<D$ & $2.29 \mathrm{E}+00$ & $2.66 \mathrm{E}+00$ \\
\hline $25-2<$ & $3.72 \mathrm{E}+00$ & . & $0.0 \mathrm{~L}-\mathrm{D}$ & $1.66 \mathrm{E}+00$ & $\angle .0 \angle \mathrm{LT} 0$ & $\angle . \angle 9 L T 00$ & $2.66 \mathrm{E}+00$ \\
\hline 年 & 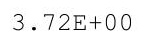 & . & 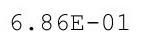 & $1.66 \mathrm{E}+00$ & $2.02 \mathrm{E}+$ & 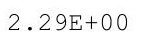 & $2.66 \mathrm{E}+00$ \\
\hline 5 & $3.72 \mathrm{E}+00$ & 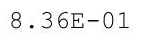 & 1 & $1.66 \mathrm{E}+00$ & & & $2.66 \mathrm{E}+00$ \\
\hline & & & & & & & \\
\hline 02 & & $8.37 \mathrm{E}-01$ & 01 & $166 \mathrm{~F}+$ & & & \\
\hline & & 0.30 & & $1.66 \mathrm{E}+00$ & $2.02 \mathrm{E}$ & $2 \cdot 201$ & +00 \\
\hline$E-02$ & $3.71 \mathrm{E}+00$ & 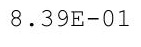 & & $1.66 \mathrm{E}+$ & & & $5 E+00$ \\
\hline पर & $3.71 \mathrm{E}+00$ & & & I.OOLTU & & & $2.65 E+00$ \\
\hline $.44 \mathrm{E}-02$ & ent & • & & t. & $2.02 \mathrm{E}$ & $2.28 \mathrm{E}$ & $2.65 E+00$ \\
\hline & & & & $66 \mathrm{E}+00$ & & & \\
\hline 2 & & 1 & 1 & $1.66 \mathrm{E}+00$ & $2.02 \mathrm{E}+$ & $2.28 \mathrm{E}+00$ & $2.65 E+00$ \\
\hline $49 \mathrm{E}-02$ & $3.70 \mathrm{E}+00$ & $8.42 E-01$ & 6.9 & 1.67 & $2.02 \mathrm{E}+$ & 00 & +00 \\
\hline & & & & & & & \\
\hline & . Tिएक & . & & $1.6 / E+00$ & $2.00 \mathrm{D} 10$ & $2.29 \mathrm{E}+00$ & 2.010100 \\
\hline 102 & $3.70 \mathrm{E}+00$ & . & & $1.67 \mathrm{E}+00$ & $2.03 E+00$ & $2.29 \mathrm{E}+00$ & $2.64 \mathrm{E}+00$ \\
\hline$E-02$ & $\mathrm{E}+00$ & $5 E-01$ & $98 E-01$ & $67 E+00$ & $.03 E+00$ & $.29 E+00$ & $.64 E+00$ \\
\hline
\end{tabular}


RESRAD-OFFSITE, Version 2.5

$\mathrm{T}^{1 / 2}$ Limit $=180$ days

obabilistic Dose and Risk Report

Title : Offsite Resident Farmer

File : RF TC99 DOESG FWD-FV2all.ROF

Summary of dose at graphical times, reptition 3 (continued)

Time

Years

9. $20 \mathrm{E}+02$

$9.20 \mathrm{E}+02$

$9.21 \mathrm{E}+02$

9. $21 \mathrm{E}+02$

$9.22 \mathrm{E}+02$

9. $22 \mathrm{E}+02$

$9.23 \mathrm{E}+02$

$9.23 \mathrm{E}+02$

$9.24 \mathrm{E}+02$

$9.24 \mathrm{E}+02$

$9.25 \mathrm{E}+02$

$9.25 \mathrm{E}+02$

$9.26 \mathrm{E}+02$

$9.26 \mathrm{E}+02$

$9.27 \mathrm{E}+02$

$9.27 \mathrm{E}+02$

$9.28 \mathrm{E}+02$

$9.28 \mathrm{E}+02$

$9.29 \mathrm{E}+02$

9. $30 \mathrm{E}+02$

$9.30 \mathrm{E}+02$

$9.31 \mathrm{E}+02$

9. $31 \mathrm{E}+02$

$9.32 \mathrm{E}+02$

$9.32 \mathrm{E}+02$

$9.33 \mathrm{E}+02$

$9.33 \mathrm{E}+02$

$9.34 \mathrm{E}+02$

$9.34 \mathrm{E}+02$

9. $35 \mathrm{E}+02$

$9.35 \mathrm{E}+02$

$9.36 \mathrm{E}+02$

$9 \cdot 36 \mathrm{E}+02$

9. $37 \mathrm{E}+02$

$9.37 \mathrm{E}+02$

$9.38 \mathrm{E}+02$

9. $38 \mathrm{E}+02$

$9.39 \mathrm{E}+02$

$9.39 \mathrm{E}+02$

$9.40 \mathrm{E}+02$

$9.40 \mathrm{E}+02$

$9.41 \mathrm{E}+02$

$9.41 \mathrm{E}+02$

$9.42 \mathrm{E}+02$

$9.42 \mathrm{E}+02$

$9.43 \mathrm{E}+02$
Dose statistics at graphical times, mrem/yr

\begin{tabular}{|c|c|c|c|c|c|c|c|}
\hline m & $\operatorname{axi}$ & ea & 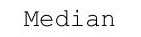 & & & $\%$ & \\
\hline $.58 \mathrm{E}-02$ & $3.69 \mathrm{E}+00$ & 01 & $6.99 \mathrm{E}-01$ & $.67 \mathrm{E}+00$ & $03 E+00$ & -00 & . $04 \mathrm{E}+U \mathrm{U}$ \\
\hline $60 \mathrm{E}-02$ & $3.69 \mathrm{E}+00$ & $6 E-01$ & $7.00 \mathrm{E}-01$ & $7 E+00$ & $03 E+00$ & $2.29 \mathrm{E}+00$ & $4 E+00$ \\
\hline $62 E-02$ & $69 \mathrm{E}+00$ & $47 E-01$ & $.01 E-01$ & $.67 E+00$ & $.03 E+00$ & $2.29 \mathrm{E}+00$ & $2.64 \mathrm{E}+00$ \\
\hline $4 E-02$ & $69 E+00$ & $\Delta 7 \mathrm{~F}-01$ & $02 F-01$ & $.67 E+00$ & $03 F+00$ & $.29 \mathrm{E}+00$ & $.64 \mathrm{E}+00$ \\
\hline-02 & $3.69 \mathrm{E}+00$ & 01 & $7.03 \mathrm{E}-01$ & . & & +00 & $3 E+00$ \\
\hline 02 & $69 \mathrm{E}+00$ & & & 0 & & & 00 \\
\hline $69 \mathrm{E}-02$ & $3.68 \mathrm{E}+00$ & & & & & +00 & $\mathrm{E}+00$ \\
\hline $.71 E-02$ & $3.68 \mathrm{E}+00$ & $\perp$ & $\perp$ & $1.68 \mathrm{E}+00$ & 00 & +00 & +00 \\
\hline $.73 E-02$ & $68 E+00$ & -01 & $E-01$ & $1.68 \mathrm{E}+00$ & $03 E+00$ & $E+00$ & $E+00$ \\
\hline$E-02$ & $.68 E+00$ & $51 E-01$ & 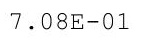 & $.68 E+00$ & 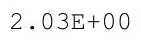 & $.29 E+00$ & $.63 E+00$ \\
\hline 02 & $E+00$ & & & 0 & & 0 & +00 \\
\hline $.78 \mathrm{E}-02$ & $.68 \mathrm{E}+00$ & 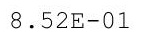 & & .68 & & -00 & +00 \\
\hline $.80 E-02$ & $3.67 \mathrm{E}+00$ & & & & & $2.29 \mathrm{E}+00$ & $2.62 \mathrm{E}+00$ \\
\hline $.82 E-02$ & $3.67 \mathrm{E}+00$ & $.54 \mathrm{E}-01$ & 7. $12 \mathrm{E}-01$ & $1.68 \mathrm{E}+00$ & & $2.29 E+00$ & $2.62 \mathrm{E}+00$ \\
\hline-02 & $67 E+00$ & $E-01$ & 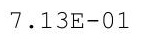 & $685+120$ & & +00 & $52 \mathrm{E}+00$ \\
\hline 2 & $3.67 \mathrm{E}+00$ & $8.55 \mathrm{E}$ & & . & & 0 & 00 \\
\hline 2 & 00 & & & 1. $68 \mathrm{E}+00$ & 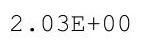 & 0 & 0 \\
\hline 2 & -00 & $8.56 \mathrm{E}-01$ & & & & 0 & 0 \\
\hline $.92 E-02$ & $.66 \mathrm{E}+00$ & $7 F-01$ & $\Gamma^{2}$ & $605+0$ & $5=5+8 x-5$ & $E+00$ & $1 \mathrm{E}+00$ \\
\hline $3 E-02$ & $.66 \mathrm{E}+00$ & $.57 \mathrm{E}-01$ & $7.17 \mathrm{E}-01$ & $1.68 \mathrm{E}+00$ & $2.03 \mathrm{E}+$ & $2.28 \mathrm{E}+00$ & $2.61 E+00$ \\
\hline-02 & $E+00$ & & & & & +00 & $E+00$ \\
\hline & & & & & & & \\
\hline 2 & $.66 \mathrm{E}+00$ & & & $1.68 \mathrm{E}+$ & & & \\
\hline$E-02$ & $65 E+00$ & $\perp$ & $7.21 E-01$ & $1.00 \mathrm{1}$ & 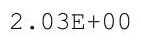 & 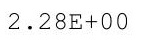 & 0 \\
\hline 2 & $.65 E+00$ & $8.61 \mathrm{E}-01$ & $\perp$ & $1.68 \mathrm{E}+$ & $02 \mathrm{E}+$ & $8 \mathrm{E}+00$ & $.60 \mathrm{E}+00$ \\
\hline $.05 E-02$ & $.65 \mathrm{E}+00$ & $61 F-01$ & 7 ח & 1. $68 \mathrm{E}+00$ & $.02 \mathrm{E}+\mathrm{C}$ & $.28 E+00$ & $.60 \mathrm{E}+00$ \\
\hline$E-02$ & $3.65 \mathrm{E}+00$ & & & & & $2.28 \mathrm{E}+00$ & $2.60 \mathrm{E}+00$ \\
\hline & & & & & & & \\
\hline & $3.65 \mathrm{E}+00$ & 0.0 & & $1.69 \mathrm{E}+$ & & & \\
\hline $.12 \mathrm{E}-02$ & $3.64 \mathrm{E}+00$ & $0.045-1$ & . $20 \mathrm{~L}-\mathrm{L}$ & $1.69 \mathrm{E}+00$ & $2.07 \mathrm{~L} 100$ & $2.28 \mathrm{E}+00$ & $2.60 \mathrm{E}+00$ \\
\hline $14 \mathrm{E}-02$ & $3.64 \mathrm{E}+00$ & $8.64 \mathrm{E}-01$ & . 210 & 1. $69 \mathrm{E}+00$ & $2.03 E+00$ & $2.28 \mathrm{E}+00$ & $2.59 \mathrm{E}+00$ \\
\hline 2 & $3.64 \mathrm{E}+$ & . & 7. $28 \mathrm{E}-01$ & $1.69 \mathrm{E}+$ & & & \\
\hline 2 & & & & & & & 00 \\
\hline 02 & $3.64 \mathrm{E}+00$ & & & $1.69 \mathrm{E}+00$ & & & \\
\hline$E-02$ & 3.6 & & & 1.6 & & & \\
\hline $24 \mathrm{E}-02$ & $3.63 \mathrm{E}+00$ & $8.67 E-01$ & $.3 \perp E-U \perp$ & $1.69 \mathrm{E}+00$ & $2.03 E+$ & $2.27 \mathrm{E}+00$ & $2.59 \mathrm{E}+00$ \\
\hline $26 \mathrm{E}-02$ & $3.63 \mathrm{E}+00$ & $0.001-1$ & $7.32 \mathrm{E}-01$ & $1.09 E+00$ & 2.00 पा & & $2.59 \mathrm{E}+00$ \\
\hline $28 E-02$ & $3.63 \mathrm{E}+00$ & . & 7. $33 \mathrm{E}-01$ & 1. $69 \mathrm{E}+00$ & & & $2.58 \mathrm{E}+00$ \\
\hline 2 & 3.631 & 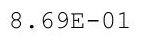 & 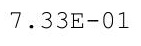 & $1.69 \mathrm{E}+00$ & $2.03 E+00$ & $2.27 E+00$ & $2.58 \mathrm{E}+00$ \\
\hline 2 & $3.63 E+00$ & $8.70 E-01$ & - & $1.69 \mathrm{E}+00$ & & & $B E+00$ \\
\hline $33 E-02$ & $3.62 \mathrm{E}+00$ & -01 & $7.35 \mathrm{E}-01$ & 1. $69 \mathrm{E}+00$ & $2.03 \mathrm{E}$ & $2.27 \mathrm{E}+00$ & $2.58 \mathrm{E}+00$ \\
\hline$E-02$ & $3.62 \mathrm{E}+00$ & 01 & 1 & $1.69 \mathrm{E}+00$ & & 00 & $B E+00$ \\
\hline & $3.62 \mathrm{E}+00$ & & & & & & $2.58 \mathrm{E}+00$ \\
\hline$E-02$ & $3.62 \mathrm{E}+00$ & 1 & 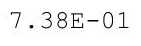 & $1.09 E+00$ & $2.03 E+00$ & $2.26 \mathrm{E}+00$ & $2.57 \mathrm{E}+00$ \\
\hline $\pm L-U 2$ & $3.62 \mathrm{E}+00$ & . & & $1.70 \mathrm{E}+00$ & $2.03 E+00$ & $2.26 \mathrm{E}+00$ & $2.57 \mathrm{E}+00$ \\
\hline 02 & $.61 E+00$ & $E-01$ & $0 E-01$ & $.70 \mathrm{E}+00$ & $.02 E+00$ & $2.27 \mathrm{E}+00$ & $2.57 \mathrm{E}+00$ \\
\hline
\end{tabular}


RESRAD-OFFSITE, Version 2.5

$\mathrm{T}^{1 / 2}$ Limit $=180$ days

obabilistic Dose and Risk Report

Title : Offsite Resident Farmer

File : RF TC99 DOESG FWD-FV2all.ROF

Summary of dose at graphical times, reptition 3 (continued)

Time

Years

9. $43 \mathrm{E}+02$

$9.44 \mathrm{E}+02$

$9.44 \mathrm{E}+02$

9. $45 \mathrm{E}+02$

$9.45 \mathrm{E}+02$

$9.46 \mathrm{E}+02$

$9.46 \mathrm{E}+02$

$9.47 \mathrm{E}+02$

$9.47 \mathrm{E}+02$

$9.48 \mathrm{E}+02$

$9.48 \mathrm{E}+02$

$9.49 \mathrm{E}+02$

$9.50 \mathrm{E}+02$

$9.50 \mathrm{E}+02$

$9.51 \mathrm{E}+02$

$9.51 \mathrm{E}+02$

$9.52 \mathrm{E}+02$

$9.52 \mathrm{E}+02$

$9.53 \mathrm{E}+02$

$9.53 \mathrm{E}+02$

$9.54 \mathrm{E}+02$

$9.54 \mathrm{E}+02$

$9.55 \mathrm{E}+02$

$9.55 \mathrm{E}+02$

$9.56 \mathrm{E}+02$

$9.56 \mathrm{E}+02$

$9.57 \mathrm{E}+02$

$9.57 \mathrm{E}+02$

$9.58 \mathrm{E}+02$

$9.58 \mathrm{E}+02$

$9.59 \mathrm{E}+02$

$9.59 \mathrm{E}+02$

$9.60 \mathrm{E}+02$

$9.60 \mathrm{E}+02$

$9.61 \mathrm{E}+02$

$9.61 \mathrm{E}+02$

$9.62 \mathrm{E}+02$

$9.62 \mathrm{E}+02$

$9.63 \mathrm{E}+02$

$9.63 \mathrm{E}+02$

$9.64 \mathrm{E}+02$

$9.64 \mathrm{E}+02$

$9.65 \mathrm{E}+02$

$9.65 \mathrm{E}+02$

$9.66 \mathrm{E}+02$

$9.66 \mathrm{E}+02$
Dose statistics at graphical times, mrem/yr

\begin{tabular}{|c|c|c|c|c|c|c|c|}
\hline m & um & ea & ledian & & & & \\
\hline 02 & $.61 \mathrm{E}+00$ & 01 & 1 & $1.70 E+00$ & 00 & $27 E+00$ & $10+00$ \\
\hline $.47 E-02$ & $3.61 E+00$ & $8.75 E-01$ & $7.42 \mathrm{E}-01$ & $0 \mathrm{E}+00$ & $02 E+00$ & $E+00$ & $7 E+00$ \\
\hline $49 E-02$ & $61 E+00$ & $5 E-01$ & $43 E-01$ & $.70 E+00$ & $.02 E+00$ & $2.27 E+00$ & $57 \mathrm{E}+00$ \\
\hline $51 E-02$ & $61 E+00$ & $76 \mathrm{~F}-01$ & $44 \mathrm{~F}-01$ & $1.70 \mathrm{E}+00$ & $02 F+0 \cap$ & $2.27 \mathrm{E}+00$ & $2.57 \mathrm{E}+00$ \\
\hline $53 E-02$ & $3.61 \mathrm{E}+00$ & 01 & 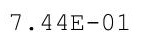 & & & +00 & $7 E+00$ \\
\hline 02 & $60 \mathrm{E}+00$ & & & & & & 00 \\
\hline $.57 \mathrm{E}-02$ & $3.60 \mathrm{E}+00$ & & & & 00 & & $7 \mathrm{E}+00$ \\
\hline $.59 \mathrm{E}-02$ & $3.60 \mathrm{E}+00$ & $\perp$ & $\perp$ & $E+00$ & $02 E+00$ & +00 & $E+00$ \\
\hline $61 \mathrm{E}-02$ & $3.60 \mathrm{E}+00$ & $79 E-01$ & $E-01$ & $\mathrm{OE}+00$ & $02 \mathrm{E}+00$ & $E+00$ & $7 \mathrm{E}+00$ \\
\hline $3 E-02$ & $.60 E+00$ & $80 E-01$ & 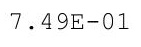 & $.70 \mathrm{E}+00$ & ניתרת & $.27 E+00$ & $57 \mathrm{E}+00$ \\
\hline 02 & $E+00$ & & & & & 00 & $7 E+00$ \\
\hline $.67 \mathrm{E}-02$ & $3.59 \mathrm{E}+00$ & $81=$ & - & & 0 & -00 & +00 \\
\hline $.69 \mathrm{E}-02$ & $3.59 \mathrm{E}+00$ & $8.81 E-01$ & & & & $2.28 E+00$ & $2.57 \mathrm{E}+00$ \\
\hline $.71 E-02$ & $3.59 \mathrm{E}+00$ & $8.82 \mathrm{E}-01$ & 7. $53 \mathrm{E}-01$ & 1. $70 \mathrm{E}+00$ & $\angle .0 \angle E+U 0$ & $2.28 \mathrm{E}+00$ & $2.57 \mathrm{E}+00$ \\
\hline-02 & $E+00$ & $82 E-01$ & -0 & 0 & & +00 & $7 \mathrm{E}+00$ \\
\hline 2 & 00 & $8.83 E-01$ & & $+\cdots$ & & 0 & 00 \\
\hline 2 & 00 & & & & > & 0 & 0 \\
\hline$E-02$ & $3.58 \mathrm{E}+00$ & $8.84 \mathrm{E}-01$ & $7.57 \mathrm{E}-01$ & & 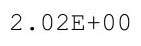 & 0 & 0 \\
\hline $80 E-02$ & $.58 \mathrm{E}+00$ & $85 \mathrm{~F}-01$ & $8 F-01$ & 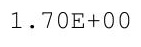 & (8) & $E+00$ & $7 E+00$ \\
\hline$E-02$ & $.58 E+00$ & $85 E-01$ & $7.58 \mathrm{E}-01$ & 1. $70 \mathrm{E}+00$ & $2.02 \mathrm{E}+$ & $2.28 \mathrm{E}+00$ & $2.57 E+00$ \\
\hline 02 & $57 E+00$ & & & & & +00 & $7 \mathrm{E}+00$ \\
\hline 2 & & & & & & & \\
\hline 2 & $3.57 \mathrm{E}+00$ & + & & $1.70 \mathrm{E}+$ & $.02 \mathrm{E}+$ & & \\
\hline-02 & $3.57 \mathrm{E}+00$ & $\perp$ & 7. $61 \mathrm{E}-01$ & 土. & 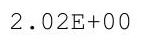 & 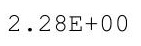 & 0 \\
\hline 2 & $.57 \mathrm{E}+00$ & $8.88 \mathrm{E}-01$ & $\perp$ & $1.70 \mathrm{E}+$ & $.02 \mathrm{E}+$ & $.28 E+00$ & $57 \mathrm{E}+00$ \\
\hline $94 E-02$ & $.56 \mathrm{E}+00$ & $89 F-01$ & 7 63F-01 & 1. $70 \mathrm{E}+00$ & $.02 \mathrm{E}+\mathrm{C}$ & $.28 E+00$ & $.57 \mathrm{E}+00$ \\
\hline$E-02$ & $3.56 \mathrm{E}+00$ & & & & & $.28 E+00$ & $.57 E+00$ \\
\hline 02 & & & & & & & \\
\hline 2 & $3.56 \mathrm{E}+00$ & $\perp$ & & 1.70E+ & & & 00 \\
\hline $02 \mathrm{E}-02$ & $3.56 \mathrm{E}+00$ & $0.9 \perp-1$ & $1.07 \pm-U \perp$ & $1.7 U E+U 0$ & $2.00 \mathrm{x} 100$ & $2.28 \mathrm{E}+00$ & $2.57 \mathrm{E}+00$ \\
\hline $.04 \mathrm{E}-02$ & $3.55 \mathrm{E}+00$ & $8.92 E-01$ & . & 1. $70 \mathrm{E}+00$ & $2.02 \mathrm{E}+00$ & $2.28 \mathrm{E}+00$ & $2.56 \mathrm{E}+00$ \\
\hline 2 & $3.55 \mathrm{E}+$ & . & $7.69 \mathrm{E}-01$ & 1. $70 \mathrm{E}+$ & & & $56 \mathrm{E}+$ \\
\hline 2 & & & & & & & 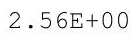 \\
\hline 2 & & & & 1. $71 \mathrm{E}+00$ & & & \\
\hline$E-02$ & & & 01 & & & & \\
\hline $15 E-02$ & $3.54 \mathrm{E}+00$ & $8.95 E-01$ & $7.73 E-01$ & $1.71 \mathrm{E}+00$ & $2.03 E+$ & 2.201 & $2.56 \mathrm{E}+00$ \\
\hline $17 E-02$ & $3.54 \mathrm{E}+00$ & . & & $1.11 E+00$ & & & $2.57 \mathrm{E}+00$ \\
\hline 02 & $3.54 \mathrm{E}+00$ & . & & 1. $71 \mathrm{E}+00$ & & & $2.57 \mathrm{E}+00$ \\
\hline 2 & $3.54 \mathrm{E}+$ & 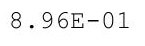 & 1 & $1.71 \mathrm{E}+00$ & $2.03 E+$ & $8 E+00$ & $2.57 \mathrm{E}+00$ \\
\hline 2 & $3.54 \mathrm{E}+00$ & 1 & 1 & $1.71 \mathrm{E}+00$ & & & $57 E+00$ \\
\hline $\mathrm{E}-02$ & $3.53 \mathrm{E}+00$ & $97 E-01$ & $7.76 \mathrm{E}-01$ & 1. $71 \mathrm{E}+00$ & $2.03 \mathrm{E}+$ & $2.28 \mathrm{E}+00$ & $2.57 \mathrm{E}+00$ \\
\hline$E-02$ & $3.53 E+00$ & 01 & 7. & $1.71 \mathrm{E}+00$ & & $E+00$ & $7 \mathrm{E}+00$ \\
\hline & $3.53 \mathrm{E}+00$ & & & & & & $2.5 / \mathrm{E}+00$ \\
\hline$E-02$ & $3.53 \mathrm{E}+00$ & . & + & $1.1 \perp E+U 0$ & $2.03 E+00$ & $2.28 E+00$ & $2.57 \mathrm{E}+00$ \\
\hline 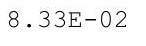 & $3.53 E+00$ & .0 & & $1.71 \mathrm{E}+00$ & $2.03 E+00$ & $2.28 E+00$ & $2.57 \mathrm{E}+00$ \\
\hline 02 & $.52 E+00$ & $E-01$ & $E-01$ & 1. $71 \mathrm{E}+00$ & $.03 E+00$ & $2.28 \mathrm{E}+00$ & $.56 \mathrm{E}+00$ \\
\hline
\end{tabular}


RESRAD-OFFSITE, Version 2.5

$\mathrm{T}^{1 / 2}$ Limit $=180$ days

obabilistic Dose and Risk Report

Title : Offsite Resident Farmer

File : RF TC99 DOESG FWD-FV2all.ROF

Summary of dose at graphical times, reptition 3 (continued)

Time

Years

9. $67 \mathrm{E}+02$

$9.67 \mathrm{E}+02$

9. $68 \mathrm{E}+02$

$9.68 \mathrm{E}+02$

$9.69 \mathrm{E}+02$

$9.70 \mathrm{E}+02$

$9.70 \mathrm{E}+02$

$9.71 \mathrm{E}+02$

$9.71 \mathrm{E}+02$

9. $72 \mathrm{E}+02$

$9.72 \mathrm{E}+02$

$9.73 \mathrm{E}+02$

$9.73 \mathrm{E}+02$

$9.74 \mathrm{E}+02$

$9.74 \mathrm{E}+02$

$9.75 \mathrm{E}+02$

$9.75 \mathrm{E}+02$

$9.76 \mathrm{E}+02$

$9.76 \mathrm{E}+02$

$9.77 \mathrm{E}+02$

$9.77 \mathrm{E}+02$

$9.78 \mathrm{E}+02$

$9.78 \mathrm{E}+02$

$9.79 \mathrm{E}+02$

$9.79 \mathrm{E}+02$

$9.80 \mathrm{E}+02$

$9.80 \mathrm{E}+02$

$9.81 \mathrm{E}+02$

$9.81 \mathrm{E}+02$

$9.82 \mathrm{E}+02$

9. $82 \mathrm{E}+02$

$9.83 \mathrm{E}+02$

$9.83 \mathrm{E}+02$

$9.84 \mathrm{E}+02$

$9.84 \mathrm{E}+02$

$9.85 \mathrm{E}+02$

$9.85 \mathrm{E}+02$

$9.86 \mathrm{E}+02$

$9.86 \mathrm{E}+02$

$9.87 \mathrm{E}+02$

$9.87 \mathrm{E}+02$

$9.88 \mathrm{E}+02$

$9.88 \mathrm{E}+02$

$9.89 \mathrm{E}+02$

$9.90 \mathrm{E}+02$

9. $90 \mathrm{E}+02$
Dose statistics at graphical times, mrem/yr

\begin{tabular}{|c|c|c|c|c|c|c|c|}
\hline linimum & Maximum & Mean & Median & 900 & $90 \%$ & $97.5 \%$ & $9 \%$ \\
\hline 2 & $2 E+00$ & 1 & $30 E-01$ & +00 & 0 & & +00 \\
\hline-02 & $2 E+00$ & $1 E$ & $80 E-01$ & $1.71 \mathrm{E}+00$ & $04 \mathrm{E}+00$ & +00 & $56 E+00$ \\
\hline$E-02$ & 00 & $2 E-01$ & 01 & 0 & 0 & 0 & $6 \mathrm{E}+00$ \\
\hline$E-02$ & $E+00$ & $2 E-01$ & 01 & 0 & 0 & 00 & $E+00$ \\
\hline $45 E-02$ & $51 E+00$ & $3 E-01$ & 1 & & $03 E+00$ & $.28 \mathrm{E}+00$ & $56 \mathrm{E}+00$ \\
\hline $7 E-02$ & $1 \mathrm{E}+00$ & & & $\Xi+00$ & $\Xi+00$ & 00 & $56 \mathrm{E}+00$ \\
\hline $.49 E-02$ & $3.51 E+00$ & $4 E-01$ & $7.82 \mathrm{E}-01$ & $1.71 \mathrm{E}+00$ & E+ & +00 & $6 E+00$ \\
\hline $.51 E-02$ & $3.51 E+00$ & . & $7.83 E-01$ & $1.71 \mathrm{E}+00$ & $2.03 E+00$ & $2.28 \mathrm{E}+00$ & $2.56 \mathrm{E}+00$ \\
\hline$E-02$ & +00 & 1 & -01 & 1.711 & 0 & 00 & \pm+00 \\
\hline$E-02$ & $E+00$ & 9 & $\perp$ & $1 E+00$ & 0 & 00 & $E+00$ \\
\hline$E-02$ & & 9 & & & & & $E+00$ \\
\hline-02 & +00 & 田 & 1 & 1.7 & 0 & Do & $5 E+00$ \\
\hline $62 E-02$ & $3.50 \mathrm{E}+00$ & $7 \mathrm{~L}-01$ & $7.87 \mathrm{E}-01$ & $1.71 \mathrm{E}+00$ & $2.02 E+00$ & $2.28 E+00$ & $56 \mathrm{E}+00$ \\
\hline $.64 \mathrm{E}-02$ & $3.49 \mathrm{E}+00$ & . & $7.88 \mathrm{E}-01$ & $\perp \cdot T \perp E T U U$ & Z. UZLTU & 2.20 & $56 \mathrm{E}+00$ \\
\hline $5 E-02$ & $E+00$ & . & 01 & 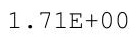 & . & 00 & 00 \\
\hline $.68 \mathrm{E}-02$ & $3.49 \mathrm{E}+00$ & $9.09 \mathrm{E}-01$ & $7.89 \mathrm{E}-01$ & $1.71 \mathrm{E}+00$ & $2.02 \mathrm{E}+00$ & $2.28 \mathrm{E}+00$ & $55 \mathrm{E}+00$ \\
\hline $.70 E-02$ & $3.49 E+00$ & $0 E-01$ & $7.90 \mathrm{E}-01$ & $1.71 \mathrm{E}+00$ & $2.02 E+00$ & $2.28 E+00$ & $5 \mathrm{E}+00$ \\
\hline$E-02$ & $8 \mathrm{E}+00$ & $E-01$ & $E-01$ & $1.71 \mathrm{E}+00$ & 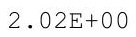 & $8 E+00$ & $5 E+00$ \\
\hline $.74 \mathrm{E}-02$ & $3.48 \mathrm{E}+00$ & $9.11 \mathrm{E}-01$ & 7. $92 \mathrm{E}-01$ & $1.71 \mathrm{E}+00$ & $2.02 \mathrm{E}+00$ & $2.28 \mathrm{E}+00$ & $5 E+00$ \\
\hline $.76 \mathrm{E}-02$ & $3.48 E+00$ & $9.11 \mathrm{E}-01$ & $7.93 E-01$ & $\perp \cdot / \perp E$ & 0 & 00 & +00 \\
\hline $.78 E-02$ & $8 E+00$ & & & I. IILTU & & 2.200 & $E+00$ \\
\hline $.80 \mathrm{E}-02$ & $3.48 \mathrm{E}+00$ & 9.7 & . & $1.71 \mathrm{E}+$ & $2.01 \mathrm{E}+$ & 00 & $\mathrm{E}+00$ \\
\hline $.82 E-02$ & $3.47 E+00$ & $3 E-01$ & $5 E-01$ & $1.72 \mathrm{E}+00$ & $2.01 \mathrm{E}+$ & $2.28 \mathrm{E}+00$ & $54 \mathrm{E}+00$ \\
\hline $84 E-02$ & $3.47 E+00$ & $3 E-01$ & $E-01$ & $1.72 \mathrm{E}+00$ & $2.01 \mathrm{E}+$ & $2.28 E+00$ & $54 E+00$ \\
\hline$E-02$ & $3.47 \mathrm{E}+00$ & 1 & 01 & $1.72 \mathrm{E}+$ & 0 & & $54 \mathrm{E}+00$ \\
\hline $3 E-02$ & $E+00$ & 1 & 1 & +00 & 0 & & \\
\hline $90 \mathrm{E}-02$ & $3.46 \mathrm{E}+00$ & $9.15 \mathrm{E}-$ & 年 & $\perp \cdot 1 \angle \mathrm{E}+$ & $2.01+1$ & .200 & $E+00$ \\
\hline $92 \mathrm{E}-02$ & $3.46 \mathrm{E}+00$ & $9.15 \mathrm{E}-01$ & $7.99 \mathrm{E}-01$ & $1.72 \mathrm{E}+00$ & $2.00 \mathrm{E}+00$ & $2.28 \mathrm{E}+00$ & $2.54 \mathrm{E}+00$ \\
\hline 02 & 0 & 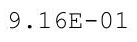 & 1 & 10 & . & 年 & $.54 \mathrm{E}+00$ \\
\hline 2 & $.46 \mathrm{E}+$ & 1 & - & $172=$ & & $238 F+00$ & $54 \mathrm{E}+00$ \\
\hline 02 & $3.46 \mathrm{~F}+00$ & 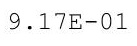 & 1 & ניתר 17 & ג תחم: & $2.28 \mathrm{E}+00$ & $4 \mathrm{E}+00$ \\
\hline$E-02$ & $5+00$ & 9 & & $72 \mathrm{~F}+$ & ג & $2.28 \mathrm{E}+00$ & $4 E+00$ \\
\hline $.02 E-02$ & $3.45 \mathrm{E}+00$ & $9.18 \mathrm{E}-01$ & $2 E-01$ & $1.72 \mathrm{E}+$ & $2.00 \mathrm{ET}$ & $2.28 \mathrm{E}$ & $4 E+00$ \\
\hline $.04 \mathrm{E}-02$ & $3.45 \mathrm{E}+00$ & $9.19 \mathrm{E}-01$ & $8.03 E-01$ & $1.1 \angle E+U 0$ & 1.99ET & $2 . \angle 8 E+00$ & $4 \mathrm{E}+00$ \\
\hline $0 E-0<$ & $3.45 E+00$ & & & $1.72 \mathrm{E}+00$ & & & $2.53 E+00$ \\
\hline & 1. & & & & & & 00 \\
\hline 2 & $3 \Delta \triangle F+$ & & & & & & 00 \\
\hline 2 & & & & 0 & 0 & 00 & \\
\hline 02 & 3.4 & 9 . & 01 & 1.72 & 1 & 00 & $3 E+00$ \\
\hline $6 E-02$ & $3.44 \mathrm{E}+$ & 9.2 & & 1.7 & $\perp \cdot 9$ & & $2.53 E+00$ \\
\hline$E-02$ & $3.43 E+00$ & 9 & & $1.72 \mathrm{E}+$ & $1.99 \mathrm{E}+$ & & $.53 E+00$ \\
\hline $5-v 2$ & $3.43 \mathrm{E}+00$ & 9 & 1 & 1. $72 \mathrm{E}+00$ & 1. $99 \mathrm{E}+00$ & $2.28 \mathrm{E}+00$ & $2.53 E+00$ \\
\hline 2 & $3.45 \mathrm{LT}$ & 9 & & 0 & $99 \mathrm{E}$ & 0 & \\
\hline & & & 01 & 1 . & 1. $98 \mathrm{E}+00$ & 2.2 & $2.53 E+00$ \\
\hline$E-02$ & $3.42 \mathrm{E}+00$ & $\mathrm{E}-01$ & 8 & 1. $72 \mathrm{E}+00$ & 1.98E+ & $2.27 \mathrm{E}+00$ & $2.53 E+00$ \\
\hline $28 E-02$ & $42 E+00$ & $25 E-01$ & $.12 \mathrm{E}-01$ & $1.72 \mathrm{E}+00$ & $1.98 \mathrm{E}+00$ & $2.27 E+00$ & $2.53 E+00$ \\
\hline
\end{tabular}


RESRAD-OFFSITE, Version 2.5

$\mathrm{T}^{1 / 2}$ Limit $=180$ days

robabilistic Dose and Risk Report

Title : Offsite Resident Farmer

File : RF TC99 DOESG FWD-FV2all.ROF

Summary of dose at graphical times, reptition 3 (continued)

Time

Years

9. $91 \mathrm{E}+02$

9. $91 \mathrm{E}+02$

9. $92 \mathrm{E}+02$

$9.92 \mathrm{E}+02$

9. $93 \mathrm{E}+02$

$9.93 \mathrm{E}+02$

9. $94 \mathrm{E}+02$

$9.94 \mathrm{E}+02$

$9.95 \mathrm{E}+02$

$9.95 \mathrm{E}+02$

$9.96 \mathrm{E}+02$

$9.96 \mathrm{E}+02$

$9.97 \mathrm{E}+02$

$9.97 \mathrm{E}+02$

$9.98 \mathrm{E}+02$

$9.98 \mathrm{E}+02$

$9.99 \mathrm{E}+02$

$9.99 \mathrm{E}+02$

$1.00 \mathrm{E}+03$

$1.00 \mathrm{E}+03$

$1.00 \mathrm{E}+03$

$1.00 \mathrm{E}+03$

$1.00 \mathrm{E}+03$

$1.00 \mathrm{E}+03$

$1.00 \mathrm{E}+03$

$1.00 \mathrm{E}+03$

$1.00 \mathrm{E}+03$

$1.00 \mathrm{E}+03$

$1.00 \mathrm{E}+03$

$1.01 \mathrm{E}+03$

$1.01 \mathrm{E}+03$

$1.01 \mathrm{E}+03$

$1.01 \mathrm{E}+03$

$1.01 \mathrm{E}+03$

$1.01 \mathrm{E}+03$

$1.01 \mathrm{E}+03$

$1.01 \mathrm{E}+03$

$1.01 \mathrm{E}+03$

$1.01 \mathrm{E}+03$

$1.01 \mathrm{E}+03$

$1.01 \mathrm{E}+03$

$1.01 \mathrm{E}+03$

$1.01 \mathrm{E}+03$

$1.01 \mathrm{E}+03$

$1.01 \mathrm{E}+03$

$1.01 \mathrm{E}+03$
Dose statistics at graphical times, mrem/yr

\begin{tabular}{|c|c|c|c|c|c|c|c|}
\hline$m$ & $\mathrm{am}$ & ea & ledian & & & & $\%$ \\
\hline 02 & $3.42 \mathrm{E}+00$ & 01 & 1 & $1.72 \mathrm{E}+00$ & 0 & $27 E+00$ & SEtu \\
\hline $32 E-02$ & $3.42 E+00$ & $9.26 \mathrm{E}-01$ & $8.13 \mathrm{E}-01$ & $1.72 E+00$ & $98 E+00$ & $E+00$ & $3 E+00$ \\
\hline$E-02$ & $42 E+00$ & $6 E-01$ & $4 E-01$ & $.72 E+00$ & $.97 \mathrm{E}+00$ & $2.27 E+00$ & $3 E+00$ \\
\hline-02 & $41 E+00$ & $27 \mathrm{~F}-01$ & $14 \mathrm{~F}-01$ & $1.72 \mathrm{E}+00$ & $97 \mathrm{~F}+00$ & $.27 \mathrm{E}+00$ & $2.53 E+00$ \\
\hline-02 & $41 E+00$ & 01 & 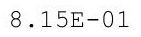 & $.72 \mathrm{E}+$ & & $E+00$ & +00 \\
\hline 02 & $41 E+00$ & & & & & & 00 \\
\hline $43 E-02$ & $3.41 E+00$ & & & & & & $3 E+00$ \\
\hline-02 & $O E+00$ & 1 & $\perp$ & 0 & 0 & +00 & $\mathrm{E}+00$ \\
\hline $47 E-02$ & $40 \mathrm{E}+00$ & $9 E-01$ & -01 & $1.73 \mathrm{E}+00$ & $97 E+00$ & $E+00$ & $E+00$ \\
\hline$E-02$ & $.40 \mathrm{E}+00$ & $30 E-01$ & תח & $.73 E+00$ & & $.27 E+00$ & $3 E+00$ \\
\hline 02 & $E+00$ & & & & & 0 & +00 \\
\hline $53 E-02$ & $3.39 \mathrm{E}+00$ & $F$ & $8.20 \mathrm{E}-01$ & 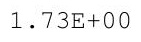 & & -00 & +00 \\
\hline $.55 E-02$ & $3.39 \mathrm{E}+00$ & & & & & $2.27 E+00$ & $2.53 E+00$ \\
\hline $57 E-02$ & $3.39 \mathrm{E}+00$ & $9.32 \mathrm{E}-01$ & $8.21 \mathrm{E}-01$ & $1.72 \mathrm{E}+00$ & $1.96 \mathrm{E}+00$ & $2.27 \mathrm{E}+00$ & $2.53 E+00$ \\
\hline-02 & $39 E+00$ & $E-01$ & $F-0-0 \cdot 2-2$ & $735+1010$ & & +00 & $3 E+00$ \\
\hline 2 & -00 & & & $x^{\prime}$ & & 0 & 00 \\
\hline 2 & 00 & $\perp$ & & & & 0 & 0 \\
\hline 2 & $3.38 \mathrm{E}+00$ & $9.34 \mathrm{E}-01$ & $8.23 E-01$ & ( & & 0 & 0 \\
\hline $67 E-02$ & $38 \mathrm{E}+00$ & $\Delta F-01$ & F & مै & 原 & $.28 E+00$ & $3 E+00$ \\
\hline$E-02$ & $.38 E+00$ & $.35 E-01$ & $4 E-01$ & $1.73 \mathrm{E}+00$ & $1.96 \mathrm{E}+$ & $2.28 \mathrm{E}+00$ & $2.53 E+00$ \\
\hline$E-02$ & +00 & & & & & +00 & $E+00$ \\
\hline & & & & & & & \\
\hline 2 & $37 \mathrm{E}+00$ & $\cdot$ & $\perp$ & $1.73 \mathrm{E}+$ & & & \\
\hline 02 & $3.37 \mathrm{E}+00$ & $\perp$ & $8.27 \mathrm{E}-01$ & أt & t & 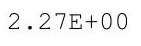 & 0 \\
\hline 2 & $.36 \mathrm{E}+00$ & $9.37 \mathrm{E}-01$ & $\perp$ & $1.73 \mathrm{E}+\mathrm{C}$ & $1.96 \mathrm{E}+$ & $2.27 \mathrm{E}+00$ & $5 \mathrm{E}+00$ \\
\hline$E-02$ & $.36 \mathrm{E}+00$ & $38 F-01$ & $328 \mathrm{~F}-01$ & 1. $73 \mathrm{E}+00$ & $.96 \mathrm{E}+$ & $.27 E+00$ & $.53 E+00$ \\
\hline$E-02$ & $3.36 \mathrm{E}+00$ & $38 F-01$ & & & & $2.27 \mathrm{E}+00$ & $.53 E+00$ \\
\hline 02 & & & & & & & \\
\hline & $3.35 E+00$ & $\perp$ & & & 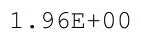 & & \\
\hline $90 E-02$ & $3.35 E+00$ & $.40 \pm-1$ & . $3 \perp+C \perp$ & $1 \cdot 13 \pm+U 0$ & $1.96 \mathrm{E}+00$ & $2 \cdot 21 E+00$ & $2.53 E+00$ \\
\hline $92 \mathrm{E}-02$ & $3.35 \mathrm{E}+00$ & $9.40 \mathrm{E}-01$ & 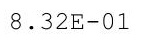 & 1. $73 \mathrm{E}+00$ & $1.96 \mathrm{E}+00$ & $2.27 \mathrm{E}+00$ & $2.53 E+00$ \\
\hline 2 & $3.35 \mathrm{E}+00$ & . & . & 1. $73 \mathrm{E}+$ & & & \\
\hline 2 & $3.34 \mathrm{E}+00$ & & & & & & $3 E+00$ \\
\hline 02 & & & & & & & \\
\hline$E-01$ & & & 01 & & & & \\
\hline $.00 \mathrm{E}-01$ & $3.34 \mathrm{E}+00$ & $9.43 E-01$ & $8.36 E-01$ & $1.73 \mathrm{E}+00$ & 土. & $2.26 \mathrm{E}+00$ & $2.53 E+00$ \\
\hline $.00 \mathrm{E}-01$ & $3.34 \mathrm{E}+00$ & $9.45 \pm-4$ & & $1.13 E+00$ & & & \\
\hline $01 E-01$ & $3.33 E+00$ & 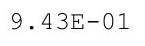 & & 1. $73 \mathrm{E}+00$ & 1. $96 \mathrm{E}+00$ & & $2.53 E+00$ \\
\hline 1 & 3.33 & $9.44 \mathrm{E}-01$ & 1 & $1.73 E+00$ & $1.96 \mathrm{E}+$ & $2.26 \mathrm{E}+00$ & $2.53 E+00$ \\
\hline 1 & $3.33 E+00$ & & - & $1.73 E+00$ & $1.96 \mathrm{E}+$ & & $2 \mathrm{E}+00$ \\
\hline $1 \mathrm{E}-01$ & $3.33 E+00$ & -01 & -01 & 1. $73 \mathrm{E}+00$ & & $2.26 \mathrm{E}+00$ & $2.52 \mathrm{E}+00$ \\
\hline $02 E-01$ & $3.32 \mathrm{E}+00$ & 01 & 1 & $1.73 \mathrm{E}+00$ & $1.96 \mathrm{E}+$ & 00 & $2 \mathrm{E}+00$ \\
\hline & 3.0 & & & & & & \\
\hline $02 E-01$ & $3.32 \mathrm{E}+00$ & . & 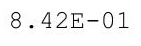 & $1.13 E+00$ & $1.96 \mathrm{E}+00$ & $2.26 \mathrm{E}+00$ & $2.52 \mathrm{E}+00$ \\
\hline $2 \angle-O \perp$ & $3.32 E+00$ & $.475-01$ & & $1.73 E+00$ & $1.96 \mathrm{E}+00$ & $2.26 \mathrm{E}+00$ & $2.52 \mathrm{E}+00$ \\
\hline 01 & $.31 E+00$ & $E-01$ & $4 E-01$ & $.73 E+00$ & $1.96 \mathrm{E}+00$ & $2.26 \mathrm{E}+00$ & $2.52 \mathrm{E}+00$ \\
\hline
\end{tabular}


RESRAD-OFFSITE, Version 2.5

$\mathrm{T}^{1 / 2}$ Limit $=180$ days

obabilistic Dose and Risk Report

Title : Offsite Resident Farmer

File : RF TC99 DOESG FWD-FV2all.ROF

Summary of dose at graphical times, reptition 3 (continued)

Time

Years

1. $01 \mathrm{E}+03$

$1.01 \mathrm{E}+03$

$1.02 \mathrm{E}+03$

1. $02 \mathrm{E}+03$

1. $02 \mathrm{E}+03$

1. $02 \mathrm{E}+03$

$1.02 \mathrm{E}+03$

1. $02 \mathrm{E}+03$

1. $02 \mathrm{E}+03$

1. $02 \mathrm{E}+03$

$1.02 \mathrm{E}+03$

$1.02 \mathrm{E}+03$

1. $02 \mathrm{E}+03$

$1.02 \mathrm{E}+03$

$1.02 \mathrm{E}+03$

$1.02 \mathrm{E}+03$

$1.02 \mathrm{E}+03$

$1.02 \mathrm{E}+03$

$1.02 \mathrm{E}+03$

$1.02 \mathrm{E}+03$

$1.02 \mathrm{E}+03$

$1.02 \mathrm{E}+03$

$1.03 \mathrm{E}+03$

$1.03 \mathrm{E}+03$

$1.03 \mathrm{E}+03$

$1.03 E+03$

$1.03 \mathrm{E}+03$

$1.03 E+03$

$1.03 \mathrm{E}+03$

$1.03 E+03$

$1.03 \mathrm{E}+03$

$1.03 E+03$

$1.03 \mathrm{E}+03$

1. $03 \mathrm{E}+03$

$1.03 E+03$

$1.03 \mathrm{E}+03$

1. $03 \mathrm{E}+03$

1. $03 \mathrm{E}+03$

$1.03 E+03$

$1.03 \mathrm{E}+03$

$1.03 E+03$

$1.04 \mathrm{E}+03$

$1.04 \mathrm{E}+03$

$1.04 \mathrm{E}+03$

$1.04 \mathrm{E}+03$

$1.04 \mathrm{E}+03$

Dose statistics at graphical times, mrem/yr

\begin{tabular}{|c|c|c|c|c|c|c|c|}
\hline Minimum & Maximum & Mean & Median & $90 \%$ & $95 \%$ & $97.5 \%$ & $99 \%$ \\
\hline $1.03 E-01$ & $3.31 E+00$ & $9.48 E-01$ & $8.44 E-01$ & 1. $73 \mathrm{E}+00$ & $1.96 \mathrm{E}+00$ & $2.26 \mathrm{E}+00$ & $2.52 \mathrm{E}+00$ \\
\hline $1.03 E-01$ & $3.31 E+00$ & $9.48 \mathrm{E}-01$ & $8.45 E-01$ & $1.73 E+00$ & $1.96 \mathrm{E}+00$ & $2.26 \mathrm{E}+00$ & $2.52 E+00$ \\
\hline $1.03 E-01$ & $3.31 E+00$ & $9.49 \mathrm{E}-01$ & $8.46 \mathrm{E}-01$ & $1.73 E+00$ & $1.96 \mathrm{E}+00$ & $2.26 \mathrm{E}+00$ & $2.52 \mathrm{E}+00$ \\
\hline $1.03 \mathrm{E}-01$ & $3.31 \mathrm{E}+00$ & $9.49 \mathrm{E}-01$ & $8.47 \mathrm{E}-01$ & $1.73 \mathrm{E}+00$ & $1.96 \mathrm{E}+00$ & $2.26 \mathrm{E}+00$ & $2.52 \mathrm{E}+00$ \\
\hline $1.03 E-01$ & $3.30 \mathrm{E}+00$ & $9.49 \mathrm{E}-01$ & $8.47 E-01$ & $1.73 E+00$ & $1.96 \mathrm{E}+00$ & $2.26 \mathrm{E}+00$ & $2.52 \mathrm{E}+00$ \\
\hline $1.04 \mathrm{E}-01$ & $3.30 \mathrm{E}+00$ & $9.50 \mathrm{E}-01$ & $8.48 E-01$ & $1.73 \mathrm{E}+00$ & $1.96 \mathrm{E}+00$ & $2.26 \mathrm{E}+00$ & $2.52 \mathrm{E}+00$ \\
\hline $1.04 \mathrm{E}-01$ & $3.30 \mathrm{E}+00$ & $9.50 \mathrm{E}-01$ & $8.48 E-01$ & $1.73 \mathrm{E}+00$ & $1.96 \mathrm{E}+00$ & $2.26 \mathrm{E}+00$ & $2.52 \mathrm{E}+00$ \\
\hline $1.04 \mathrm{E}-01$ & $3.30 \mathrm{E}+00$ & $9.51 \mathrm{E}-01$ & $8.48 E-01$ & $1.73 E+00$ & $1.96 \mathrm{E}+00$ & $2.26 \mathrm{E}+00$ & $2.52 \mathrm{E}+00$ \\
\hline 1. $04 \mathrm{E}-01$ & $3.30 \mathrm{E}+00$ & $9.51 \mathrm{E}-01$ & $8.49 E-01$ & $1.73 \mathrm{E}+00$ & $1.95 \mathrm{E}+00$ & $2.26 \mathrm{E}+00$ & $2.52 \mathrm{E}+00$ \\
\hline $1.04 \mathrm{E}-01$ & $3.30 \mathrm{E}+00$ & $9.52 \mathrm{E}-01$ & $8.50 \mathrm{E}-01$ & $1.73 \mathrm{E}+00$ & $1.95 \mathrm{E}+00$ & $2.26 \mathrm{E}+00$ & $2.52 \mathrm{E}+00$ \\
\hline $1.05 \mathrm{E}-01$ & $3.30 \mathrm{E}+00$ & $9.52 \mathrm{E}-01$ & $8.51 \mathrm{E}-01$ & $1.73 E+00$ & $1.95 \mathrm{E}+00$ & $2.26 \mathrm{E}+00$ & $2.52 \mathrm{E}+00$ \\
\hline $1.05 \mathrm{E}-01$ & $3.29 \mathrm{E}+00$ & $9.53 \mathrm{E}-01$ & $8.52 E-01$ & $1.73 \mathrm{E}+00$ & $1.95 \mathrm{E}+00$ & $2.26 \mathrm{E}+00$ & $2.52 \mathrm{E}+00$ \\
\hline $1.05 \mathrm{E}-01$ & $3.29 \mathrm{E}+00$ & $9.53 \mathrm{E}-01$ & $8.53 E-01$ & $1.74 \mathrm{E}+00$ & $1.95 \mathrm{E}+00$ & $2.26 \mathrm{E}+00$ & $2.52 \mathrm{E}+00$ \\
\hline $1.05 E-01$ & $3.29 \mathrm{E}+00$ & $9.54 \mathrm{E}-01$ & $8.53 E-01$ & $1.74 \mathrm{E}+00$ & 1. $95 \mathrm{E}+00$ & $2.26 \mathrm{E}+00$ & $2.52 \mathrm{E}+00$ \\
\hline $1.06 \mathrm{E}-01$ & $3.29 \mathrm{E}+00$ & $9.54 \mathrm{E}-01$ & $8.54 \mathrm{E}-01$ & $1.74 \mathrm{E}+00$ & $1.95 \mathrm{E}+00$ & $2.25 \mathrm{E}+00$ & $2.52 \mathrm{E}+00$ \\
\hline $1.06 \mathrm{E}-01$ & $3.29 \mathrm{E}+00$ & $9.54 \mathrm{E}-01$ & $8.54 \mathrm{E}-01$ & $1.74 \mathrm{E}+00$ & $1.95 \mathrm{E}+00$ & $.25 E+00$ & $51 E+00$ \\
\hline $1.06 \mathrm{E}-01$ & $3.29 \mathrm{E}+00$ & $9.55 \mathrm{E}-01$ & $8.54 \mathrm{E}-01$ & $1.74 \mathrm{E}+00$ & $1.95 \mathrm{E}+00$ & $2.25 \mathrm{E}+00$ & $2.51 \mathrm{E}+00$ \\
\hline $1.06 \mathrm{E}-01$ & $3.29 \mathrm{E}+00$ & $9.55 \mathrm{E}-01$ & $8.55 E-01$ & $1.74 \mathrm{E}+00$ & $1.96 \mathrm{E}+00$ & $2.25 \mathrm{E}+00$ & $2.51 \mathrm{E}+00$ \\
\hline $1.06 \mathrm{E}-01$ & $3.28 \mathrm{E}+00$ & $9.56 \mathrm{E}-01$ & $8.56 \mathrm{E}-01$ & $1.74 \mathrm{E}+00$ & $1.96 \mathrm{E}+00$ & $2.25 \mathrm{E}+00$ & $2.51 \mathrm{E}+00$ \\
\hline $1.07 \mathrm{E}-01$ & $3.28 \mathrm{E}+00$ & $9.56 \mathrm{E}-01$ & $8.57 \mathrm{E}-01$ & $1.74 \mathrm{E}+00$ & $1.96 \mathrm{E}+00$ & $2.25 \mathrm{E}+00$ & $2.51 \mathrm{E}+00$ \\
\hline $1.07 \mathrm{E}-01$ & $3.28 \mathrm{E}+00$ & $9.57 \mathrm{E}-01$ & $8.58 \mathrm{E}-01$ & $1.74 \mathrm{E}+00$ & $1.96 \mathrm{E}+00$ & $2.25 \mathrm{E}+00$ & $2.51 \mathrm{E}+00$ \\
\hline $1.07 \mathrm{E}-01$ & $3.28 \mathrm{E}+00$ & $9.57 \mathrm{E}-01$ & $8.58 E-01$ & $1.74 \mathrm{E}+00$ & $1.96 \mathrm{E}+00$ & $2.24 \mathrm{E}+00$ & $2.51 E+00$ \\
\hline $1.07 E-01$ & $3.28 \mathrm{E}+00$ & $9.58 \mathrm{E}-01$ & $8.59 E-01$ & $1.74 \mathrm{E}+00$ & $1.96 \mathrm{E}+00$ & $2.24 \mathrm{E}+00$ & $2.51 \mathrm{E}+00$ \\
\hline $1.07 \mathrm{E}-01$ & $3.28 \mathrm{E}+00$ & $9.58 \mathrm{E}-01$ & $8.59 \mathrm{E}-01$ & $1.74 \mathrm{E}+00$ & $1.96 \mathrm{E}+00$ & $2.24 \mathrm{E}+00$ & $2.51 \mathrm{E}+00$ \\
\hline $1.08 \mathrm{E}-01$ & $3.27 \mathrm{E}+00$ & $9.58 \mathrm{E}-01$ & $8.60 \mathrm{E}-01$ & $1.74 \mathrm{E}+00$ & $1.96 \mathrm{E}+00$ & $2.24 \mathrm{E}+00$ & $2.51 \mathrm{E}+00$ \\
\hline $1.08 \mathrm{E}-01$ & $3.27 \mathrm{E}+00$ & $9.59 \mathrm{E}-01$ & $8.60 E-01$ & $1.74 \mathrm{E}+00$ & $1.96 \mathrm{E}+00$ & $2.24 \mathrm{E}+00$ & $2.51 \mathrm{E}+00$ \\
\hline $1.08 \mathrm{E}-01$ & $3.27 \mathrm{E}+00$ & $9.59 \mathrm{E}-01$ & $8.61 \mathrm{E}-01$ & $1.74 \mathrm{E}+00$ & $1.96 \mathrm{E}+00$ & $2.24 \mathrm{E}+00$ & $2.51 \mathrm{E}+00$ \\
\hline $1.08 \mathrm{E}-01$ & $3.27 \mathrm{E}+00$ & $9.60 \mathrm{E}-01$ & $8.61 \mathrm{E}-01$ & $1.73 E+00$ & $1.96 \mathrm{E}+00$ & $2.24 E+00$ & $2.51 E+00$ \\
\hline $1.09 \mathrm{E}-01$ & $3.27 \mathrm{E}+00$ & $9.60 \mathrm{E}-01$ & $8.62 E-01$ & $1.73 E+00$ & $1.96 \mathrm{E}+00$ & $2.24 \mathrm{E}+00$ & $2.51 \mathrm{E}+00$ \\
\hline $1.09 \mathrm{E}-01$ & $3.27 \mathrm{E}+00$ & $9.61 \mathrm{E}-01$ & $8.62 E-01$ & $1.73 E+00$ & $1.96 \mathrm{E}+00$ & $2.24 \mathrm{E}+00$ & $2.51 \mathrm{E}+00$ \\
\hline $1.09 \mathrm{E}-01$ & $3.27 \mathrm{E}+00$ & $9.61 \mathrm{E}-01$ & $8.63 E-01$ & $1.73 E+00$ & $1.96 \mathrm{E}+00$ & $2.24 \mathrm{E}+00$ & $2.51 \mathrm{E}+00$ \\
\hline $1.09 \mathrm{E}-01$ & $3.26 \mathrm{E}+00$ & $9.62 \mathrm{E}-01$ & $8.64 \mathrm{E}-01$ & $1.73 \mathrm{E}+00$ & $1.97 \mathrm{E}+00$ & $2.24 \mathrm{E}+00$ & $2.51 \mathrm{E}+00$ \\
\hline $1.09 \mathrm{E}-01$ & $3.26 \mathrm{E}+00$ & $9.62 \mathrm{E}-01$ & $8.65 E-01$ & $1.73 E+00$ & $1.97 \mathrm{E}+00$ & $2.24 \mathrm{E}+00$ & $2.51 \mathrm{E}+00$ \\
\hline $1.10 \mathrm{E}-01$ & $3.26 \mathrm{E}+00$ & $9.62 \mathrm{E}-01$ & $8.66 \mathrm{E}-01$ & $1.73 E+00$ & $1.97 \mathrm{E}+00$ & $2.24 \mathrm{E}+00$ & $2.51 E+00$ \\
\hline $1.10 \mathrm{E}-01$ & $3.26 \mathrm{E}+00$ & $9.63 \mathrm{E}-01$ & $8.66 \mathrm{E}-01$ & $1.73 E+00$ & $1.97 \mathrm{E}+00$ & $2.24 \mathrm{E}+00$ & $2.51 \mathrm{E}+00$ \\
\hline $1.10 \mathrm{E}-01$ & $3.26 \mathrm{E}+00$ & $9.63 E-01$ & $8.67 E-01$ & $1.73 E+00$ & $1.97 \mathrm{E}+00$ & $2.24 \mathrm{E}+00$ & $2.51 \mathrm{E}+00$ \\
\hline $1.10 \mathrm{E}-01$ & $3.26 \mathrm{E}+00$ & $9.64 \mathrm{E}-01$ & $8.68 E-01$ & $1.73 E+00$ & $1.97 \mathrm{E}+00$ & $2.24 \mathrm{E}+00$ & $2.51 \mathrm{E}+00$ \\
\hline $1.11 \mathrm{E}-01$ & $3.25 \mathrm{E}+00$ & $9.64 \mathrm{E}-01$ & $8.68 \mathrm{E}-01$ & $1.73 \mathrm{E}+00$ & $1.97 \mathrm{E}+00$ & $2.24 \mathrm{E}+00$ & $2.51 \mathrm{E}+00$ \\
\hline $1.11 \mathrm{E}-01$ & $3.25 \mathrm{E}+00$ & $9.64 \mathrm{E}-01$ & $8.69 \mathrm{E}-01$ & $1.73 E+00$ & $1.97 \mathrm{E}+00$ & $2.24 \mathrm{E}+00$ & $2.51 \mathrm{E}+00$ \\
\hline $1.11 \mathrm{E}-01$ & $3.25 \mathrm{E}+00$ & $9.65 \mathrm{E}-01$ & $8.70 E-01$ & $1.73 E+00$ & $1.97 \mathrm{E}+00$ & $2.24 \mathrm{E}+00$ & $2.51 \mathrm{E}+00$ \\
\hline $1.11 \mathrm{E}-01$ & $3.25 \mathrm{E}+00$ & $9.65 \mathrm{E}-01$ & $8.71 \mathrm{E}-01$ & $1.74 \mathrm{E}+00$ & $1.97 \mathrm{E}+00$ & $2.24 \mathrm{E}+00$ & $2.50 \mathrm{E}+00$ \\
\hline 1.11E-01 & $3.25 \mathrm{E}+00$ & $9.66 \mathrm{E}-01$ & $8.71 E-01$ & $1.74 \mathrm{E}+00$ & $1.97 \mathrm{E}+00$ & $2.24 \mathrm{E}+00$ & $2.50 \mathrm{E}+00$ \\
\hline $1.12 \mathrm{E}-01$ & $3.25 \mathrm{E}+00$ & $9.66 \mathrm{E}-01$ & $8.72 E-01$ & $1.74 \mathrm{E}+00$ & $1.97 \mathrm{E}+00$ & $2.23 E+00$ & $2.50 \mathrm{E}+00$ \\
\hline $1.12 \mathrm{E}-01$ & $3.24 \mathrm{E}+00$ & $9.67 \mathrm{E}-01$ & $8.73 E-01$ & $1.74 \mathrm{E}+00$ & $1.97 \mathrm{E}+00$ & $2.23 E+00$ & $2.50 \mathrm{E}+00$ \\
\hline $1.12 \mathrm{E}-01$ & $3.24 \mathrm{E}+00$ & $9.67 \mathrm{E}-01$ & $8.74 E-01$ & $1.74 \mathrm{E}+00$ & $1.98 \mathrm{E}+00$ & $2.23 E+00$ & $2.50 \mathrm{E}+00$ \\
\hline $1.12 \mathrm{E}-01$ & $3.24 \mathrm{E}+00$ & $9.67 \mathrm{E}-01$ & $8.74 \mathrm{E}-01$ & 1. $74 \mathrm{E}+00$ & $1.98 \mathrm{E}+00$ & $2.23 E+00$ & $2.50 \mathrm{E}+00$ \\
\hline
\end{tabular}


RESRAD-OFFSITE, Version 2.5

$\mathrm{T}^{1 / 2}$ Limit $=180$ days

robabilistic Dose and Risk Report

Title : Offsite Resident Farmer

File : RF TC99 DOESG FWD-FV2all. ROF

Time

Years

$1.04 \mathrm{E}+03$

$1.04 \mathrm{E}+03$

$1.04 \mathrm{E}+03$

$1.04 \mathrm{E}+03$

$1.04 \mathrm{E}+03$

$1.04 \mathrm{E}+03$

$1.04 \mathrm{E}+03$

$1.04 \mathrm{E}+03$

$1.04 \mathrm{E}+03$

$1.04 \mathrm{E}+03$

$1.04 \mathrm{E}+03$

1. $04 \mathrm{E}+03$

1. $04 \mathrm{E}+03$

1. $04 \mathrm{E}+03$

1. $04 \mathrm{E}+03$

1. $05 \mathrm{E}+03$

1. $05 \mathrm{E}+03$

1. $05 \mathrm{E}+03$

1. $05 \mathrm{E}+03$

1. $05 \mathrm{E}+03$

1. $05 \mathrm{E}+03$

1. $05 \mathrm{E}+03$

$1.05 \mathrm{E}+03$

1. $05 \mathrm{E}+03$

1. $05 \mathrm{E}+03$

Summary of dose at graphical times, reptition 3 (continued)

Dose statistics at graphical times, mrem/yr

\begin{tabular}{|c|c|c|c|c|c|c|c|}
\hline Minimum & Maximum & Mean & Median & $90 \%$ & $95 \%$ & $97.5 \%$ & $99 \%$ \\
\hline $.12 \mathrm{E}-01$ & $3.24 \mathrm{E}+00$ & $9.68 E-01$ & $8.75 E-01$ & $1.74 \mathrm{E}+00$ & $1.98 \mathrm{E}+00$ & $2.23 E+00$ & $2.50 \mathrm{E}+00$ \\
\hline $1.13 \mathrm{E}-01$ & $3.24 \mathrm{E}+00$ & $9.68 \mathrm{E}-01$ & $8.76 \mathrm{E}-01$ & $1.74 \mathrm{E}+00$ & $1.97 \mathrm{E}+00$ & $2.23 E+00$ & $2.50 \mathrm{E}+00$ \\
\hline $1.13 \mathrm{E}-01$ & $3.24 \mathrm{E}+00$ & $9.69 \mathrm{E}-01$ & $8.77 \mathrm{E}-01$ & 1. $74 \mathrm{E}+00$ & $1.97 \mathrm{E}+00$ & $2.23 \mathrm{E}+00$ & $2.50 \mathrm{E}+00$ \\
\hline $.13 E-01$ & $3.24 \mathrm{E}+00$ & $9.69 \mathrm{E}-01$ & $8.77 \mathrm{E}-01$ & $1.74 \mathrm{E}+00$ & $1.97 \mathrm{E}+00$ & $2.23 E+00$ & $2.50 \mathrm{E}+00$ \\
\hline $1.13 \mathrm{E}-01$ & $3.23 E+00$ & $9.70 \mathrm{E}-01$ & $8.78 \mathrm{E}-01$ & $1.74 \mathrm{E}+00$ & $1.97 \mathrm{E}+00$ & $2.23 E+00$ & $2.49 \mathrm{E}+00$ \\
\hline $.14 \mathrm{E}-01$ & $3.23 \mathrm{E}+00$ & $9.70 \mathrm{E}-01$ & $8.79 E-01$ & $1.74 \mathrm{E}+00$ & $1.97 \mathrm{E}+00$ & $2.23 E+00$ & $2.49 \mathrm{E}+00$ \\
\hline $1.14 \mathrm{E}-01$ & $3.23 E+00$ & $9.70 \mathrm{E}-01$ & $8.79 \mathrm{E}-01$ & $1.74 \mathrm{E}+00$ & $1.97 \mathrm{E}+00$ & $2.22 E+00$ & $2.49 \mathrm{E}+00$ \\
\hline $1.14 \mathrm{E}-01$ & $3.23 \mathrm{E}+00$ & $9.71 \mathrm{E}-01$ & $8.79 \mathrm{E}-01$ & $1.74 \mathrm{E}+00$ & $1.97 \mathrm{E}+00$ & $2.22 \mathrm{E}+00$ & $2.49 \mathrm{E}+00$ \\
\hline $1.14 \mathrm{E}-01$ & $3.23 \mathrm{E}+00$ & $9.71 \mathrm{E}-01$ & $8.80 \mathrm{E}-01$ & $1.74 \mathrm{E}+00$ & $1.97 \mathrm{E}+00$ & $2.22 \mathrm{E}+00$ & $2.49 \mathrm{E}+00$ \\
\hline $1.14 \mathrm{E}-01$ & $3.23 \mathrm{E}+00$ & $9.72 \mathrm{E}-01$ & $8.81 \mathrm{E}-01$ & $1.74 \mathrm{E}+00$ & $1.97 \mathrm{E}+00$ & $2.22 \mathrm{E}+00$ & $2.49 \mathrm{E}+00$ \\
\hline $.15 \mathrm{E}-01$ & $3.22 \mathrm{E}+00$ & $9.72 \mathrm{E}-01$ & $8.81 \mathrm{E}-01$ & 1. $74 \mathrm{E}+00$ & $1.98 \mathrm{E}+00$ & $2.22 \mathrm{E}+00$ & $2.49 \mathrm{E}+00$ \\
\hline $.15 \mathrm{E}-01$ & $3.22 \mathrm{E}+00$ & $9.72 \mathrm{E}-01$ & $8.82 \mathrm{E}-01$ & 1. $74 \mathrm{E}+00$ & 1. $98 \mathrm{E}+00$ & $2.22 \mathrm{E}+00$ & $2.49 \mathrm{E}+00$ \\
\hline $1.15 \mathrm{E}-01$ & $3.22 \mathrm{E}+00$ & $9.73 E-01$ & $8.83 E-01$ & $1.74 \mathrm{E}+00$ & $1.98 \mathrm{E}+00$ & $2.22 \mathrm{E}+00$ & $2.49 \mathrm{E}+00$ \\
\hline $.15 \mathrm{E}-01$ & $3.22 \mathrm{E}+00$ & $9.73 \mathrm{E}-01$ & $8.83 \mathrm{E}-01$ & $1.74 \mathrm{E}+00$ & 1.97E+00 & $2.21 \mathrm{E}+00$ & $2.49 \mathrm{E}+00$ \\
\hline $.16 \mathrm{E}-01$ & $3.22 \mathrm{E}+00$ & $9.74 \mathrm{E}-01$ & $8.84 \mathrm{E}-01$ & 1. $74 \mathrm{E}+00$ & $1.97 \mathrm{E}+00$ & $2.21 \mathrm{E}+00$ & $2.49 \mathrm{E}+00$ \\
\hline $1.16 \mathrm{E}-01$ & $3.22 \mathrm{E}+00$ & $9.74 \mathrm{E}-01$ & $8.84 E-01$ & $1.74 \mathrm{E}+00$ & $1.97 \mathrm{E}+00$ & $2.21 \mathrm{E}+00$ & $2.49 \mathrm{E}+00$ \\
\hline $1.16 \mathrm{E}-01$ & $3.22 \mathrm{E}+00$ & $9.74 \mathrm{E}-01$ & $8.84 \mathrm{E}-01$ & 1. $74 \mathrm{E}+00$ & $1.97 \mathrm{E}+00$ & $2.21 \mathrm{E}+00$ & $2.49 \mathrm{E}+00$ \\
\hline $.16 \mathrm{E}-01$ & $3.22 \mathrm{E}+00$ & $9.75 E-01$ & $8.85 E-01$ & $1.74 \mathrm{E}+00$ & $1.97 \mathrm{E}+00$ & $2.21 \mathrm{E}+00$ & $2.49 \mathrm{E}+00$ \\
\hline $1.16 \mathrm{E}-01$ & $3.22 \mathrm{E}+00$ & $9.75 E-01$ & $8.85 E-01$ & $1.74 \mathrm{E}+00$ & $1.97 \mathrm{E}+00$ & $2.21 \mathrm{E}+00$ & $2.49 \mathrm{E}+00$ \\
\hline $1.17 \mathrm{E}-01$ & $3.22 \mathrm{E}+00$ & $9.76 \mathrm{E}-01$ & $8.86 \mathrm{E}-01$ & 1. $74 \mathrm{E}+00$ & 1. $97 \mathrm{E}+00$ & $2.21 \mathrm{E}+00$ & $2.49 \mathrm{E}+00$ \\
\hline $1.17 \mathrm{E}-01$ & $3.22 \mathrm{E}+00$ & $9.76 \mathrm{E}-01$ & $8.86 \mathrm{E}-01$ & 1. $74 \mathrm{E}+00$ & $1.97 \mathrm{E}+00$ & $2.21 \mathrm{E}+00$ & $2.49 \mathrm{E}+00$ \\
\hline $1.17 \mathrm{E}-01$ & 3.221 & $9.76 \mathrm{E}-01$ & $8.86 \mathrm{E}-$ & $1.74 \mathrm{E}+00$ & $1.97 \mathrm{E}+00$ & $2.20 \mathrm{E}+00$ & $2.49 \mathrm{E}+00$ \\
\hline $.17 E-01$ & $3.22 \mathrm{E}+00$ & $9.77 \mathrm{E}-01$ & $8.87 \mathrm{E}-01$ & $1.74 \mathrm{E}+00$ & $1.97 \mathrm{E}+00$ & $2.20 \mathrm{E}+00$ & $2.49 \mathrm{E}+00$ \\
\hline $1.17 \mathrm{E}-01$ & $3.22 \mathrm{E}+00$ & $9.77 \mathrm{E}-01$ & $8.87 \mathrm{E}-01$ & $1.74 \mathrm{E}+00$ & $1.97 \mathrm{E}+00$ & $2.20 E+00$ & $2.49 \mathrm{E}+00$ \\
\hline 1. $18 \mathrm{E}-01$ & $3.22 \mathrm{E}+00$ & $9.77 \mathrm{E}-01$ & $8.87 \mathrm{E}-01$ & $1.74 \mathrm{E}+00$ & $1.97 \mathrm{E}+00$ & $2.20 \mathrm{E}+00$ & $2.49 \mathrm{E}+00$ \\
\hline
\end{tabular}


RESRAD-OFFSITE, Version 2.5

Probabilistic Dose and Risk Report

Title : Offsite Resident Farmer

File : RF TC99 DOESG FWD-FV2all.ROF

Repetition

Peak of the mean dose
Time of peak mean dose
Years
1.050E+03
$1.050 \mathrm{E}+03$
$1.050 \mathrm{E}+03$

(averaged over observations) at graphical times

Peak mean dose

mrem/yr

$9.794 \mathrm{E}-01$

9.773E-01

$9.772 \mathrm{E}-01$ 


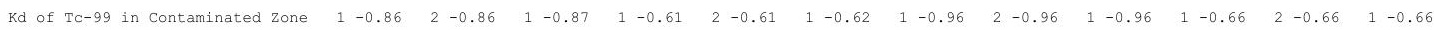

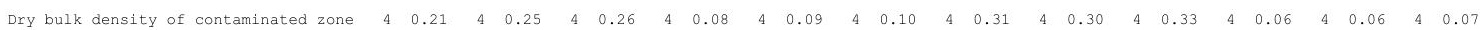
Effective Porosity of Unsaturated zone $\begin{array}{ccccccccccccccccccccccccc}5 & 2 & -0.86 & 1 & -0.86 & 2 & -0.87 & 2 & -0.61 & 1 & -0.62 & 2 & -0.62 & 2 & -0.96 & 1 & -0.96 & 2 & -0.96 & 2 & -0.65 & 1 & -0.66 & 2 & -0.65\end{array}$

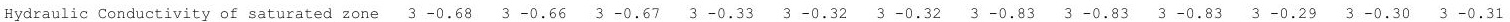
Total porosity of saturated zone $\quad \begin{array}{rlllllllllllllllllllllll}-0.01 & 6 & 0.03 & 5 & 0.01 & 5 & -0.01 & 6 & 0.03 & 5 & 0.01 & 5 & 0.04 & 6 & 0.02 & 6 & -0.02 & 5 & 0.02 & 6 & 0.01 & 6 & -0.01\end{array}$

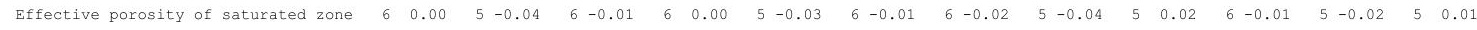

-Sig is set to zero if the dose or risk is zero or the correlation matrix is singular.

-R-SQUARE varies between 0 and 1 and is called the coefficient of determination; it provides a measure of the variation in the dependent variable (Dose) explained by regression on the independent variables. 


\title{
Evaluation of the Potential for Pooled Leachate to Rise above Ground Surface at $U$-Landfill as a Result of Synthetic Liner Failure
}

\author{
By \\ A. D. Laase, S. M. Stoller Corporation, \\ 105 Technology Dr., Suite 190 \\ Broomfield, CO 80021
}


THIS PAGE INTENTIONALLY LEFT BLANK 


\title{
Evaluation of the Potential for Pooled Leachate to Rise above Ground Surface at U- Landfill as a Result of Synthetic Liner Failure
}

\author{
A. D. Laase, S. M. Stoller Corporation, 105 Technology Dr., Suite 190 \\ Broomfield, CO 80021
}

The potential for pooled U-Landfill leachate to breach ground surface due to synthetic liner failure and cause contaminated surface runoff was evaluated using a combination of Hydrologic Evaluation of Landfill Performance (HELP) modeling, Darcy's Law calculations, evaluation of expected U-Landfill operations and expected synthetic liner performance. The calculations showed that for pooled leachate to breach land surface requires complete upper synthetic liner and minimal lower synthetic liner degradation. Operation of the U-Landfill will result in significant more leachate contact time with the lower synthetic liner than the upper synthetic liner. Contact with leachate accelerates synthetic liner degradation. Thus, the lower synthetic liner is expected to degrade at a faster rate than the upper synthetic liner. This synthetic liner degradation relationship is opposite that required to develop a pooled leachate height within the U-Landfill waste sufficient to breach ground surface. Therefore, is unlikely that conditions will ever exist at the U-Landfill to cause contaminated surface runoff.

\section{HYDROLOGIC EVALUATION OF LANDFILL PERFORMANCE (HELP) MODELING}

Hydrologic Evaluation of Landfill Performance (HELP) modeling was performed as part of the ULandfill assessment to determine if upper and lower synthetic liner failure would result in precipitation infiltration collecting on top of the lower synthetic liner and pooling to a height sufficient to breach ground surface resulting in contaminated surface water runoff. The starting point for the modeling effort was the HELP model used to evaluate the Institutional Control Period (ICP) for the U-Landfill (DOE 2003). The ICP corresponds to when the U-Landfill is no longer receiving waste material, the upper synthetic liner has been emplaced and the leachate collection system is operational. The ICP HELP model, summarized in Table 1, consists of 15 alternating layers of soil (brown), synthetic liner (purple), soil liner (pink) waste (yellow) and lateral drainage material (green) all having different hydrologic properties. Note that the synthetic liners have assigned hydraulic conductivities approximately six orders of magnitude less than the next lowest assigned hydraulic conductivities (soil liner - pink) and that distance from the top of the lower synthetic liner to ground surface is approximately 540.5 inches.

ICP modeling results predict that when the U-Landfill leachate collection system is operational, 10.19 inches of infiltrating water (resulting from precipitation infiltration) will pool on top of the upper model liner and no leachate will pool on top of the lower synthetic liner. These results are as expected because the landfill is designed to stop precipitation infiltration and to collect leachate generated by waste decomposition.

Another HELP modeling simulation (Post-ICP Period) was performed to determine the expected hydrologic response within the U-Landfill if both the upper and lower synthetic liners fail simultaneously. To facilitate the simulation the ICP HELP model was modified by combining the 
Table 1.Comparison of Institutional Control Period and Post-Institutional Control Period.

\begin{tabular}{|c|c|c|c|c|c|c|c|c|c|}
\hline \multicolumn{5}{|c|}{ INSTITUTIONAL CONTROL PERIOD } & \multicolumn{5}{|c|}{ POST-INSTITUTIONAL CONTROL PERIOD } \\
\hline $\begin{array}{c}\text { Layer } \\
\text { Description }\end{array}$ & $\begin{array}{l}\text { Layer } \\
\text { Number }\end{array}$ & $\begin{array}{c}\text { Hydraulic } \\
\text { Conductivity, } \\
\mathrm{cm} / \mathrm{s}\end{array}$ & $\begin{array}{c}\text { Layer } \\
\text { Thickness, } \\
\text { in }\end{array}$ & $\begin{array}{c}\text { Cumulative } \\
\text { Layer } \\
\text { Thickness, } \\
\text { in }\end{array}$ & $\begin{array}{c}\text { Layer } \\
\text { Description }\end{array}$ & $\begin{array}{l}\text { Layer } \\
\text { Number }\end{array}$ & $\begin{array}{c}\text { Hydraulic } \\
\text { Conductivity, } \\
\mathrm{cm} / \mathrm{s}\end{array}$ & $\begin{array}{c}\text { Layer } \\
\text { Thickness, } \\
\text { in }\end{array}$ & $\begin{array}{c}\text { Cumulative } \\
\text { Layer } \\
\text { Thickness, } \\
\text { in } \\
\end{array}$ \\
\hline Soil & 1 & $5 e-4$ & 13 & 13 & Soil & 1 & $5 e-4$ & 13 & 13 \\
\hline Soil & 2 & $1 e-4$ & 23 & 36 & Soil & 2 & $1 \mathrm{e}-4$ & 23 & 36 \\
\hline Soil & 3 & $1 \mathrm{e} 1$ & 0.24 & 36.24 & \multirow{3}{*}{ Soil Liner } & \multirow{3}{*}{3} & \multirow{3}{*}{$1 e-5$} & \multirow{3}{*}{7} & \multirow{3}{*}{42} \\
\hline $\begin{array}{c}\text { Synthetic } \\
\text { Liner }\end{array}$ & 4 & $4 e-11$ & 0.004 & 36.244 & & & & & \\
\hline Soil Liner & 5 & $1 e-5$ & 6 & 42.244 & & & & & \\
\hline Soil & 6 & $1 e-4$ & 6 & 48.244 & Soil & 4 & $1 e-4$ & 6 & 48 \\
\hline Soil & 7 & $6 e-1$ & 12 & 60.244 & Soil & 5 & $6 e-1$ & 12 & 60 \\
\hline Waste & 8 & $1 e-1$ & 456 & 516.244 & Waste & 6 & $1 e-1$ & 456 & 516 \\
\hline Soil & 9 & $5 e-3$ & 12 & 528.244 & Soil & 7 & $5 e-3$ & 12 & 528 \\
\hline $\begin{array}{l}\text { Lateral } \\
\text { Drainage }\end{array}$ & 10 & $1 \mathrm{e} 1$ & 0.24 & 528.484 & \multirow{2}{*}{ Soil } & \multirow{2}{*}{8} & \multirow{2}{*}{$3 e 0$} & \multirow{2}{*}{12.24} & \multirow{2}{*}{540.24} \\
\hline $\begin{array}{c}\text { Lateral } \\
\text { Drainage }\end{array}$ & 11 & $3 e-1$ & 12 & 540.484 & & & & & \\
\hline Soil Liner & 13 & $1 e-5$ & 36 & 576.491 & Soil Liner & 9 & $1 e-5$ & 37.07 & 577.31 \\
\hline Soil & 14 & $9 e-4$ & 78 & 654.491 & Soil & 10 & $9 e-4$ & 78 & 655.31 \\
\hline Soil & 15 & $4 e-5$ & 162 & 816.491 & Soil & 11 & $4 e-5$ & 162 & 817.31 \\
\hline
\end{tabular}

synthetic liner model layers (yellow) with the underlying soil liner layers (pink) and assigning the composite layer a hydraulic conductivity corresponding to the soil liner layers (Table 1).

Conceptually this makes sense as the synthetic liners are assumed to have completely failed (i.e. offer no resistance to flow) and the synthetic liner thickness is much less than the soil liner thickness. Additionally the thin soil layer above the upper synthetic liner was also combined with the composite soil and synthetic liner layers. Another POST-ICP HELP model modification was the combining of the two lateral drainage layers (green) into a single soil layer (brown) of equal thickness. The new soil layer was assigned a hydraulic conductivity corresponding to the weighted average hydraulic conductivity of the two drainage layers. This model modification was performed because HELP drainage layers remove water or leachate from the model domain and in the POST-ICP simulation the leachate collection system is no longer active.

Post-ICP HELP model results predict that given the same climatic regime, 0.0011 inches and 0.003 inches of water will pond on top of the upper and lower synthetic liner layers, respectively. As stated previously, the distance from the top of the upper synthetic model layer and ground surface is approximately 540.5 inches, which represents the required pool height for surface flow of contaminated groundwater to occur. The simulated pool height of 0.003 inches is significantly less than 540.5 inches which shows for expected climatic conditions that pooled leachate is not expected to breach ground surface.

\section{DARCY'S LAW HYDROLOGIC EVALUATION}

While the HELP model results demonstrate that pooled leachate is not expected to breach ground surface when both liners fail simultaneously, the evaluation does not predict what happens when differential synthetic liner failure occurs, specifically what if the upper synthetic liner fails completely and allows maximum precipitation infiltration while the lower synthetic liner maintains partial competency which results in leachate pooling on top of the lower synthetic liner? Conceptually, this situation is not problematic as long as the leachate pooled on top of 
the lower synthetic model layer is less than 540.5 inches high, the distance from the top of the synthetic liner to ground surface (Figure 1). Leachate pool heights of more than 540.5 inches will result in contaminated surface water runoff. Of interest is how much does the lower synthetic liner need to degrade (quantified as an increase in synthetic liner hydraulic conductivity) for the leachate pool height to be equal or less than 540.5 inches.

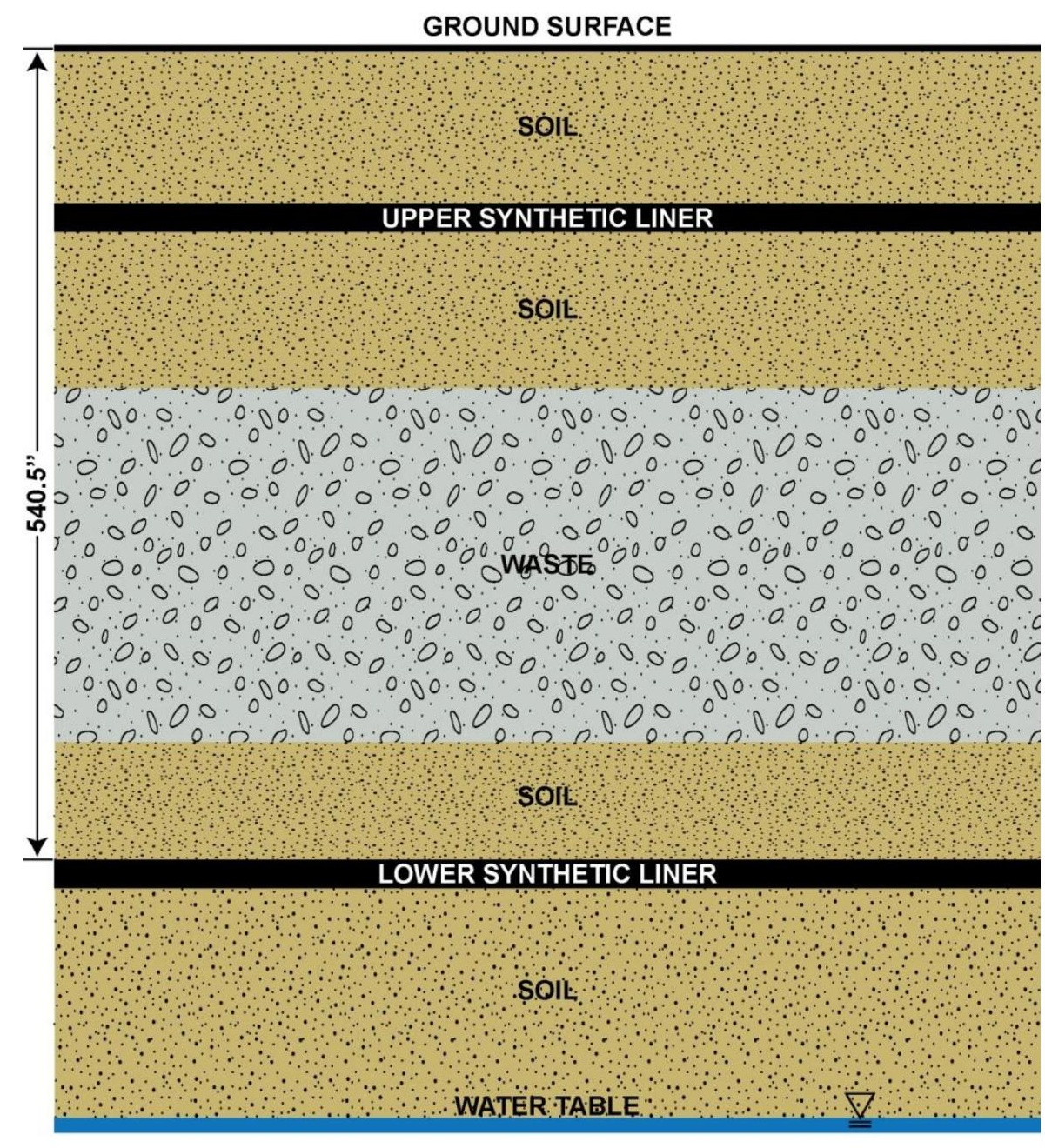

$$
\begin{aligned}
& \text { Relative Hydraulic Conductivity Relationship } \\
& \mathrm{K}_{\text {soil }} \cong \mathrm{K}_{\text {waste }} \gg \mathrm{K}_{\text {synthetic Liners }}
\end{aligned}
$$

Figure 1. U-Landfill schematic.

The required synthetic liner hydraulic conductivity to maintain a leachate pool height of 540 inches, 0.5 inches below ground surface, was determined using Darcy's Law. Calculation assumptions include that the waste and the soil above the lower synthetic liner have sufficiently high hydraulic conductivities relative to the synthetic liner (Table 1) such that these materials offer minimal resistance to leachate migration relative to the synthetic liner. Also, because the synthetic liner hydraulic conductivity is much less than the underlying soil hydraulic conductivity, 
unsaturated flow conditions exists between the bottom of the lower synthetic liner and the water table (Figure 1). Lastly, the precipitation infiltration rate and the flux across the lower synthetic liner are equal.

Darcy's Law is:

$$
q=K h / b
$$

where:

$$
\begin{aligned}
& \mathrm{q}=\text { flux rate across the lower synthetic liner, equal to the precipitation infiltration rate }(\mathrm{L} / \mathrm{t}) \\
& \mathrm{K}=\text { hydraulic conductivity of the lower synthetic liner }(\mathrm{L} / \mathrm{t}) \\
& \mathrm{H}=\text { height of the pooled leachate }(\mathrm{L}) \\
& \mathrm{b}=\text { thickness of the lower synthetic liner }
\end{aligned}
$$

Rearranging Darcy's Law to solve for K yields:

$$
\mathrm{K}=\mathrm{qb} / \mathrm{H}
$$

Calculation inputs are:

$$
\begin{aligned}
& \mathrm{q}=\text { calibrated regional model precipitation infiltration rate }=7.44 \mathrm{in} / \mathrm{yr}(\mathrm{DOE} 2008) \\
& \mathrm{H}=\text { maximum allowable leachate pooling height }=540 \text { inches } \\
& \mathrm{b}=\text { thickness of the lower synthetic liner }=0.07 \text { inches (Table } 1)
\end{aligned}
$$

Calculation results show that to maintain a leachate pool height of 540 inches under "typical" precipitation infiltration conditions requires a lower synthetic liner hydraulic conductivity of $7.78 \times 10^{-11} \mathrm{~cm} / \mathrm{s}\left(9.64 \times 10^{-4} \mathrm{in} / \mathrm{yr}\right)$, which is approximately four times higher than the hydraulic conductivity of the uncompromised synthetic lower liner (Table 1). In other words, the only way for leachate pooling to breach land surface is for the upper synthetic liner to completely degrade while the lower synthetic liner minimally degrades such that the liner hydraulic conductivity increases, due to degradation, by less than a factor of four.

\section{UNCERTAINTY EVALUATION}

While the Darcy's Law evaluation shows that excessive leachate pool height can only occur if lower synthetic liner hydraulic conductivity increases due to degradation are less than a factor of four, the results are specific to "typical" precipitation infiltration conditions and are not applicable to extreme precipitation events. Fortunately, while historical precipitation rates vary widely, precipitation infiltration variation is less extreme. This is because soil has a maximum infiltration capacity and when that capacity is exceeded surface runoff occurs. Calculation associated with the Paducah Gaseous Diffusion Plant regional model update show that precipitation infiltration cannot exceed 115 inches/year (DOE 2008). Repeating the Darcy's Law calculations with 115 inches/year as the maximum possible precipitation infiltration rate yields a synthetic liner 
hydraulic conductivity of $1.20 \times 10^{-9} \mathrm{~cm} / \mathrm{s}\left(1.49 \times 10^{-2} \mathrm{in} / \mathrm{yr}\right)$, which is approximately 60 times higher than the hydraulic conductivity of the uncompromised synthetic lower liner (Table 1). The only way for leachate pooling to breach land surface under maximum precipitation infiltration conditions is for the upper synthetic liner to completely degrade while the lower synthetic liner degrades such that the liner hydraulic conductivity increases, due to degradation, by less than a factor of 60 .

\section{LANDFILL OPERATION AND EXPECTED SYNTHETIC LINER PERFORMANCE}

While calculations quantify the degree of lower synthetic liner degradation, reported as an increase in hydraulic conductivity required to avoid excessive leachate pooling, the calculations reveal nothing about expected U-Landfill synthetic liner performance. Expected U-Landfill synthetic liner performance was evaluated by examining expected U-Landfill operation and literature specific to synthetic liner performance.

When U-Landfill waste is being emplaced only the lower synthetic liner is present. There is no upper synthetic liner to restrict precipitation infiltration. While there is no restriction on precipitation infiltration, a leachate collection system prevents leachate pooling. Thus, as the ULandfill is being filled, only the upper surface of the lower synthetic liner comes into contact with leachate.

When U-Landfill capacity is reached, or the landfill is no longer needed, the top synthetic liner is added to prevent precipitation infiltration. Isolated from precipitation infiltration, the entombed waste decomposes and generates leachate which is captured by the leachate collection system located above the lower synthetic liner. During leachate generation the upper surface of the lower synthetic liner is in constant contact with leachate. Different than the lower synthetic liner, because of the leachate collection system minimizes pooling, the bottom surface of the top synthetic liner is expected to minimally, if at all, contact leachate. The top surface of the upper synthetic liner is in contact with clean infiltrating water.

After awhile leachate generation is expected to cease, at which time active operation of the leachate collection system will be halted. Because there is no longer leachate generation, leachate exposure to the top surface and bottom surface of the bottom and top synthetic liners, respectively, is minimized. Considerably later, the upper synthetic liner begins to degrade allowing precipitation infiltration which causes renewed leachate generation. As before, the top surface of the bottom synthetic liner is in direct contact with the leachate while the upper synthetic liner minimally contacts leachate.

In summary, during operational and post-operational activities at the U-Landfill, the lower synthetic liner is expected to have significantly more contact with leachate than the upper synthetic liner. The ramifications of increased leachate exposure are increased synthetic liner degradation rates. A study by Sangam and Rowe (2002) determined that synthetic liners exposed to leachate degraded four times as fast as those exposed to air and 1.6 to 3.2 times as fast as those exposed water alone. 


\section{CONCLUSIONS}

Calculations show that for leachate pooling to reach sufficient height to breach ground surface and cause contaminated surface runoff requires complete degradation of the upper synthetic liner while the lower synthetic liner minimally degrades such that the liner hydraulic conductivity increases by less than a factor of four for typical precipitation infiltration conditions and by less than a factor of 60 for maximum precipitation infiltration conditions. Evaluation of expected Ulandfill operations suggests that leachate will be in extensive contact with the lower synthetic liner and minimally in contact with the upper synthetic liner. Leachate contact accelerates synthetic liner degradation. Thus, it is likely that the lower synthetic liner will preferentially degrade relative to the upper synthetic liner, conditions exactly opposite of those required to achieve a leachate pool height of sufficient thickness to breach ground surface. In summary, it is unlikely that conditions will ever exist at the $U$-Landfill to cause contaminated surface runoff.

\section{REFERENCES}

DOE (Department of Energy) 2003. Institutional Control Period (ICP) in Risk and Performance Evaluation of the C-746-U Landfill, DOE/OR/07-2041\&D2R1; November 2003.

DOE 2008. 2008 Update of the Paducah Gaseous Diffusion Plant Sitewide Groundwater Flow Model, PRS/ENR/0028.

Sangam and Rowe 2002. Effects of exposure conditions on the depletion ofantioxidants from high-density polyethylene(HDPE) geomembranes. Can. Geotech. J. 39. 1221-1230. 
Probabilistic Risk Assessment Analysis for Establishing the Technetium-99 Single Radionuclide Soil Guideline from the Drinking Water Pathway for the Offsite Resident Farmer for the C-746-U Landfill at the Paducah Gaseous Diffusion Plant, Paducah Kentucky

\author{
By \\ Birhanu Mengistu* \\ Department of Energy \\ And \\ John A. Volpe, Ph.D. \\ Performance Results Corporation
}

* Summer Intern, U.S. Department of Energy Portsmouth/Paducah Project Office

Disclaimer-This document was not developed by ORISE; it is included as an appendix per the request of DOE - PPPO as additional documentation in support of the DOE-PPPO Authorized Limits Request for the C - 746 - U Landfill at the Paducah Gaseous Diffusion Plant. 
THIS PAGE INTENTIONALLY LEFT BLANK 


\title{
Probabilistic Risk Assessment Analysis for Establishing the Technetium-99 Single Radionuclide Soil Guideline from the Drinking Water Pathway for the Offsite Resident Farmer for the C-746-U Landfill at the Paducah Gaseous Diffusion Plant, Paducah Kentucky
}

\author{
Prepared by \\ Birhanu Mengistu* \\ Department of Energy \\ And \\ John A Volpe, Ph.D. \\ Performance Results Corporation
}

For the

U.S. Department of Energy Portsmouth/Paducah Project Office

July 2011

* Summer Intern, U.S. Department of Energy Portsmouth/Paducah Project Office 
Probabilistic Risk Assessment Analysis for Establishing the Technetium-99 Single Radionuclide Soil Guideline from the Drinking Water Pathway for the Offsite Resident Farmer for the C-746-U Landfill at the Paducah Gaseous Diffusion Plant, Paducah Kentucky

Acknowledgments

The authors acknowledge the assistance and support of Richard Bonczek, Ph.D and Donald Dihel, CHMM of the U.S. Department of Energy Portsmouth/Paducah Project Office, Orville Cypret, CHP (technical support consultant to DOE through Radiation Physics Solutions, LLC), A. J. Boerner, CHP, and D. G. Maldonado, Health Physicist, Independent Environmental Assessment and Verification Program, Oak Ridge Institute for Science and Education, and Dr. J.-J. Cheng, Argonne National Laboratory 
Probabilistic Risk Assessment Analysis for Establishing the Technetium-99 Single Radionuclide Soil Guideline from the Drinking Water Pathway for the Offsite Resident Farmer for the C-746-U Landfill at the Paducah Gaseous Diffusion Plant, Paducah Kentucky

\section{Table of Contents}

List of Tables, Figures, and Appendix iii

Terms, Acronyms, and Abbreviations $\mathrm{V}$

Abstract vi

1.0: Introduction 1

2.0: Materials and Methods 1

2.1 Radionuclide selection, dose, and concentration 2

2.2 Target Dose Constraint ___ 2

2.3 Computer Code _ 2

2.4 Probabilistic Analysis __ 3

2.4.1 Parameters Used for Probabilistic Analysis __ 4

2.4.2 Probabilistic Analysis Using a Triangular Distribution ___ 5

2.4.3 Approaches _ 7

3.0: Results and Discussion ___ 7

3.1 Results __ 7

3.2 Single Radionuclide Soil Guideline___ 9

4.0: Conclusion____ 11

5.0: References ____ A 
Lists of Tables, Figures and Appendix

Table 2-1. Parameters varied for the offsite resident farmer using RESRAD-OFFSITE

Table 3-1. Summary statistics for the mean of the means of the repetitions for Approach 2

Figure 3-1. Peak radiation dose summary for the ten repetitions from the drinking water pathway 8

Appendix A. Statistics and Cumulative distribution function of Peak Dose from Drinking Water Pathway in mrem/yr at 1 pCi/g for Approach 1

Appendix B. Statistics and Cumulative distribution function of Peak Dose from Drinking Water Pathway in mrem/yr at 1 pCi/g for Approach 2 $\boldsymbol{E}$

Appendix C. Statistics and Cumulative distribution function of Peak Dose from all Pathways in mrem/yr at 1 pCi/g for Approach 1 
Terms, Acronyms, and Abbreviations

ALs

ANL

CG

KAR

KDWM

LHS

$\mathrm{mrem} / \mathrm{yr}$

ORISE

PGDP

$\mathrm{pCi} / \mathrm{g}$

PCB

PPPO

PRA

RCRA

SME

SRSG

${ }^{99} \mathrm{Tc}$

TSCA

UCRS

$\mathrm{yr}$

NRC

DOE

RG

USEPA

VSP
Authorized Limits

Argonne National Laboratory

Correlated/Uncorrelated Grouping

Kentucky Administrative Regulations

Kentucky Division of Waste Management

Latin Hypercube Sampling

millirem per year

Oak Ridge Institute for Science and Education

Paducah Gaseous Diffusion Plant

Picocuries per gram

Polychlorinated Biphenyl

Portsmouth/Paducah Project Office

Probabilistic Risk Assessment

Resource Conservation and Recovery Act

Subject Matter Expert

Single Radionuclide Soil Guideline

Technetium-99

Toxic Substances Control Act

Upper Continental Recharge System

year(s)

U. S. Nuclear Regulatory Commission

U.S. Department of Energy

Random Grouping

U.S. Environmental Protection Agency

Visual Sampling Plan 
Probabilistic Risk Assessment Analysis for Establishing the Technetium-99 Single Radionuclide Soil Guideline from the Drinking Water Pathway for the Offsite Resident Farmer for the C-746-U Landfill at the Paducah Gaseous Diffusion Plant, Paducah Kentucky

\section{ABSTRACT}

At the request of the U.S. Department of Energy Portsmouth/Paducah Project Office a probabilistic risk assessment (PRA) was conducted to establish a single radionuclide soil guideline (SRSG) for technetium-99 $\left({ }^{99} \mathrm{Tc}\right)$ from the drinking water pathway for the resident farmer at the Department of Energy (DOE) property boundary for the C-746-U Landfill at the Paducah Gaseous Diffusion Plant (PGDP). The Oak Ridge Institute for Science and Education (ORISE) carried out a deterministic analysis for 13 radionuclides and determined that ${ }^{99} \mathrm{Tc}$ contributed the majority of the radiation dose within the 1,050 years (yr) time frame (ORISE, 2011) to the offsite resident farmer at the DOE property boundary for the C-746-U Landfill.

Based on ORISE's deterministic analysis, ${ }^{99} \mathrm{Tc}$ was demonstrated to be the limiting radionuclide for the offsite resident farmer. The deterministic analysis conducted by ORISE was based on a target radiation dose constraint of $1 \mathrm{mrem} / \mathrm{yr}$ (ORISE, 2011). The $1 \mathrm{mrem} / \mathrm{yr}$ (above background) radiation dose constraint is referred to as a "walk-away" dose, and it is both a DOE field element and a Commonwealth of Kentucky Radiation Health Branch constraint. ORISE used RESRADOFFSITE (Version 2.5) computer code for the deterministic analysis. The ${ }^{99}$ Tc SRSG was 28 $\mathrm{pCi} / \mathrm{g}$ for the C-746-U Landfill as determined by ORISE using the radiation dose to the offsite resident farmer at the DOE property boundary.

The PRA analysis was also performed using the RESRAD-OFFSITE (Version 2.5) computer code, which has the capability of performing deterministic and probabilistic analyses. A deterministic analysis assumes that all input parameters are known and have a single input value, which results in a single output value. A probabilistic approach assigns parameter value ranges and the code randomly selects the values for each variable from the given range each time it calculates the radiation dose (NRC, 2006). Parameter inputs previously used by ORISE (ORISE, 2011) for the deterministic analysis were used for the PRA analysis, except six parameters were varied. The PRA analysis used the same receptor scenario, computer code, target radiation dose constraint, and parameter input file previously used by ORISE. In the previous deterministic analysis (ORISE, 2011), it was determined that the drinking water pathway for the offsite resident farmer accounts for approximately sixty eight percent (68\%) of the total radiation dose. Therefore, the PRA analysis considered only the radiation dose from the drinking water pathway for ${ }^{99} \mathrm{Tc}$. To account for radiation dose from other possible exposure pathways, an adjustment 
Probabilistic Risk Assessment Analysis for Establishing the Technetium-99 Single Radionuclide Soil Guideline from the Drinking Water Pathway for the Offsite Resident Farmer for the C-746-U Landfill at the Paducah Gaseous Diffusion Plant, Paducah Kentucky

was made for the ${ }^{99} \mathrm{Tc}$ SRSG and verified by performing a PRA analysis for ${ }^{99} \mathrm{Tc}$ for all the pathways used by ORISE in the deterministic analysis for the offsite resident farmer.

A deterministic and probabilistic sensitivity analysis performed by Argonne National Laboratory (ANL) (Cheng and Yu, 2011) was used as a starting point for the PRA analysis for the C-746-U Landfill. The ANL analyses incorporated deterministic input parameters used by ORISE (ORISE, 2011). ANL expanded ORISE's input parameters to include a range of input parameter that would potentially address other sites within the DOE complex. Therefore, ANL's analyses used values and distribution functions that could potentially permit assessment of ${ }^{99} \mathrm{Tc}$ disposal impacts across the DOE complex.

The present PRA analysis of the drinking water pathway for the offsite resident farmer at the DOE property boundary resulted in a ${ }^{99} \mathrm{Tc}$ SRSG of $76 \mathrm{pCi} / \mathrm{g}$ for the C-746-U Landfill. In order to account for all potential pathways the ${ }^{99}$ Tc SRSG value was adjusted for the consumable pathways (plant, milk and meat pathways). The adjusted ${ }^{99} \mathrm{Tc}$ SRSG was $52 \mathrm{pCi} / \mathrm{g}$ for the C-746U Landfill which accounts for all potential pathways. 
Probabilistic Risk Assessment Analysis for Establishing the Technetium-99 Single Radionuclide Soil Guideline from the Drinking Water Pathway for the Offsite Resident Farmer for the C-746-U Landfill at the Paducah Gaseous Diffusion Plant, Paducah Kentucky

\section{0: INTRODUCTION}

DOE constructed the C-746-U Landfill at the Paducah Gaseous Diffusion Plant (PGDP) from 1995 to 1997 . Disposal of solid wastes that are not regulated as hazardous waste under the Resource Conservation and Recovery Act (RCRA) Subtitle C or as waste containing Polychlorinated Biphenyls (PCBs) under the Toxic Substances Control Act (TSCA) are permitted. The Landfill was needed to continue onsite disposal of certain wastes generated at the PGDP after an older landfill at the PDGP was filled to capacity and closed in accordance with Commonwealth of Kentucky requirements.

The C-746-U Landfill is permitted by the Commonwealth of Kentucky Energy and Environment Cabinet, Department for Environmental Protection, Division of Waste Management (DWM) in accordance with the requirements of its solid waste regulations-401 Kentucky Administrative Regulations (KAR) 48, Standards for Solid Waste Facilities - and Subtitle D of RCRA. The landfill is located north of PGDP.

The PRA analysis presented in this report varies certain parameters that are considered to have an influence on the peak radiation dose. The mean radiation dose for the drinking water pathway for the offsite resident farmer from the PRA analysis is used in the calculation of a ${ }^{99} \mathrm{Tc}$ SRSG for the C-746-U Landfill. The analysis is performed using an initial unit activity for ${ }^{99} \mathrm{Tc}$. The RESRAD-OFFSITE (Version 2.5) computer code is used for the PRA analysis.

\section{0: MATERIALS AND METHODS}

The PRA analysis for the C-746-U Landfill discussed in this report is for the ${ }^{99} \mathrm{Tc}$ radiation dose to the offsite resident farmer at DOE property. The analysis considers only the drinking water pathway for the offsite resident farmer withdrawing groundwater from a well completed at the PGDP DOE property boundary. The SRSG for the C-746-U Landfill from the drinking water pathway is adjusted using ratios derived from ORISE's deterministic analysis (ORISE, 2011). This adjustment is made to incorporate impacts from other pathways on the final SRSG value. A PRA analysis with all pathways was completed to confirm the SRSG from the above approach. The input parameters and relevant assumptions for the analysis presented in this report are included in this section. 
Probabilistic Risk Assessment Analysis for Establishing the Technetium-99 Single Radionuclide Soil Guideline from the Drinking Water Pathway for the Offsite Resident Farmer for the C-746-U Landfill at the Paducah Gaseous Diffusion Plant, Paducah Kentucky

\subsection{RADIONUCLIDE SELECTION, DOSE, AND CONCENTRATION}

Although ORISE evaluated 13 radionuclides (ORISE, 2011) for the offsite resident farmer at the DOE property, ${ }^{99} \mathrm{Tc}$ is the only radionuclide included in the PRA because it was shown to contribute $100 \%$ of the total radiation dose to the offsite resident farmer. Consistent with the earlier deterministic analysis, a unit activity (i.e., $1 \mathrm{pCi} / \mathrm{g}$ ) was used for the PRA.

\section{$2.2 \quad$ TARGET RADIATION DOSE CONSTRAINT}

One mrem/yr (above background) was used in the PRA analysis as the target dose constraint. The $1 \mathrm{mrem} / \mathrm{yr}$ constraint represents a "walk-away" dose level for the site. The term "walk-away dose" was cited in the 2001 memorandum Risk versus Dose Cleanup Levels issued by the Kentucky Radiation Health and Toxic Agents Branch to the PGDP (Volpe, 2001). The memorandum states the following: "It is the position of the Radiation Health and Toxic Agents Branch that dose assessments must be conducted and considered for all pathways and radionuclides," and that "regardless of the pathway, it is the position of the Radiation Health and Toxic Agents Branch that a $1 \mathrm{mrem} / \mathrm{yr}$ dose should be used as a walk-away requirement where no further action is required to reduce the dose."

Additionally, a $1 \mathrm{mrem} / \mathrm{yr}$ dose meets DOE's preference in Order 458.1 as a level of exposure for Authorized Limits (ALs) that can be approved by the PPPO Manager. The DOE primary standard radiation dose limit to members of the public in a year from all sources is $100 \mathrm{mrem}$ (DOE, 2011).

\subsection{COMPUTER CODE}

One of the RESRAD family of codes, RESRAD-OFFSITE (Version 2.5), developed by ANL, was used for the PRA analysis presented in this report. This computer code was not available during the 2003 development of the ALs for the C-746-U Landfill, but was used in the current PRA analysis and by ORISE (ORISE, 2011) to provide SRSG that can be used by DOE for setting ALs.

RESRAD-OFFSITE uses models such as a three-dimensional dispersion groundwater flow and radionuclide transport model, a Gaussian plume model for atmospheric dispersion, and a deposition model used to estimate the accumulation of radionuclides in offsite locations and in 
Probabilistic Risk Assessment Analysis for Establishing the Technetium-99 Single Radionuclide Soil Guideline from the Drinking Water Pathway for the Offsite Resident Farmer for the C-746-U Landfill at the Paducah Gaseous Diffusion Plant, Paducah Kentucky

foods (Yu et al., 2007).

The RESRAD-OFFSITE code is capable of evaluating the radiation dose and excess cancer risk to an individual who is exposed while located within or outside the area of initial (primary) contamination. The releases of contaminants from the primary contamination to the atmosphere, to surface water, and to groundwater are considered. RESRAD-OFFSITE can model both onsite and offsite receptors.

The RESRAD-OFFSITE code was used to analyze the drinking water pathway for the offsite resident farmer at the PGDP DOE property boundary. In this scenario, the offsite resident farmer is assumed to place a well 407 meters north from the down gradient edge of the contaminated zone at the C-746-U Landfill and build a house, grow crops, and raise livestock near the DOE property boundary. This particular location was selected for consistency with previously conducted analyses (DOE, 2003 and ORISE, 2011).

\subsection{PROBABILISTIC ANALYSIS}

PRA is an approach that can be applied to address both variability and uncertainty in data sets. PRA analysis can be used to support environmental risk-based decision making. Also, the results of uncertainty analysis can be used as a basis for determining if it would be advantageous to obtain additional information or data on input variables (Yu et al., 2001). This last point was important in addressing the input parameters included in the PRA analysis for the C-746-U Landfill.

ORISE used RESRAD-OFFSITE (Version 2.5) to model deterministically the dose to the offsite resident farmer at the PGDP DOE property boundary from radionuclide contaminants that could be released from the C-746-U Landfill. In this modeling, which included 13 radionuclides, ${ }^{99} \mathrm{Tc}$ was found to account for $100 \%$ of the radiation dose within the $1,050 \mathrm{yr}$ time period modeled.

Of the above radiation dose from ${ }^{99} \mathrm{Tc}, 68 \%$ resulted from the drinking water pathway (ORISE, 2011). Consequently, the drinking water pathway was selected for this PRA analysis. The deterministic analysis input parameters used by ORISE were chosen as the starting point for the present PRA analysis. 
Probabilistic Risk Assessment Analysis for Establishing the Technetium-99 Single Radionuclide Soil Guideline from the Drinking Water Pathway for the Offsite Resident Farmer for the C-746-U Landfill at the Paducah Gaseous Diffusion Plant, Paducah Kentucky

\subsubsection{PARAMETERS USED FOR PROBABILISTIC ANALYSIS}

ANL (NUREG/CR-6697, Attachment B) established three priority levels for two hundred (200) input parameters in RESRAD and RESRAD-BUILD (Yu et al. 2000). Attachment B of NUREG/CR-6697 lists four criteria used to prioritize the parameters. Based on the analysis, ten (10) parameters were listed as Priority 1 in Table 4.2 of Attachment B of NUREG/CR-6697. In general, Priority 1 input parameters have the greater potential to impact the radiation dose.

ANL's draft paper (Cheng and Yu, 2011) was used to select parameters that may be varied for the present PRA. Tables 9 and 14 of the ANL analysis were reviewed to determine if the parameters listed in those tables should be included in a site-specific PRA for the C-746-U Landfill at PGDP. A review of the parameters in the ANL report was undertaken in regards to available PGDP data and information for these parameters. This assessment also included discussions with Subject Matter Experts (SME) at PGDP. Based on review of the parameters, it was determined that four parameters had sufficient data to be included in a PGDP site-specific PRA analysis. The distribution coefficient for the contaminated zone was included based on literature review and the unsaturated zone 5 effective porosity was included based on discussions with SME at PGDP. The ranges and most likely values for each of the six parameters are provided in Table 2-1.

Table 2-1. Parameters varied for the Offsite Resident Farmer using RESRAD-OFFSITE

\begin{tabular}{|l|c|c|c|c|c|}
\hline \multicolumn{1}{|c|}{ Parameter } & $\begin{array}{c}\text { Type of } \\
\text { Distribution }\end{array}$ & $\begin{array}{c}\text { Minimum } \\
\text { Value }\end{array}$ & Mode & $\begin{array}{c}\text { ORISE } \\
\text { Maximum } \\
\text { Value }\end{array}$ & $\begin{array}{c}\text { Deterministic } \\
\text { Value }\end{array}$ \\
\hline $\begin{array}{l}\text { Saturated Zone Hydraulic } \\
\text { Conductivity (m/yr) }\end{array}$ & Triangular & 27034 & 38938 & 67642 & 55630 \\
\hline Total Porosity of Saturated Zone ${ }^{\mathrm{a}}$ & Triangular & 0.27 & 0.39 & 0.54 & 0.34 \\
\hline $\begin{array}{l}\text { Effective Porosity of Saturated } \\
\text { Zone }\end{array}$ & Triangular & 0.22 & 0.3 & 0.35 & 0.30 \\
\hline $\begin{array}{l}\text { Distribution Coefficient }\left(\mathrm{K}_{\mathrm{d}} \text { ) of }\right. \\
\text { Contaminated zone }\left(\mathrm{cm}^{3} / \mathrm{g}\right)^{\mathrm{c}, \mathrm{d}, \mathrm{e}, \mathrm{f}, \mathrm{g}}\end{array}$ & Triangular & 0.1 & 1 & 10 & 1 \\
\hline $\begin{array}{l}\text { Dry Bulk Density of Contaminated } \\
\text { Zone }\left(\mathrm{g} / \mathrm{cm}^{3}\right)^{\mathrm{h}}\end{array}$ & Triangular & 1.5 & 1.85 & 2.5 & 1.89 \\
\hline $\begin{array}{l}\text { Unsaturated Zone 5 Effective } \\
\text { Porosity }\end{array}$ & Triangular & 0.1 & 0.25 & 0.4 & 0.15 \\
\hline
\end{tabular}

a - Methods for Conducting Risk Assessments and Risk Evaluations at the Paducah Gaseous Diffusion Plant Paducah, Kentucky Volume 1. Human Health, DOE/LX/07-0107\&D2/R1/V1, February 2011

b- Site Investigation Report for the C-746-S\&T Landfills at the Paducah Gaseous Diffusion Plant, Paducah, Kentucky, DOE/OR/07-2212\&DISECONDARY DOCUMENT, September 2005 c - Risk and Performance Evaluation of the C-746-U Landfill at the Paducah Gaseous Diffusion Plant, Paducah, Kentucky, DOE/OR/07-2041\&D2R1, November 2003 
Probabilistic Risk Assessment Analysis for Establishing the Technetium-99 Single Radionuclide Soil Guideline from the Drinking Water Pathway for the Offsite Resident Farmer for the C-746-U Landfill at the Paducah Gaseous Diffusion Plant, Paducah Kentucky

d - Patrick V. Brady ${ }^{1}$ and James E. Amonette ${ }^{2}$, Technetium, ${ }^{1}$ Geochemistry Department (MS-0750), Sandia National Laboratories, Albuquerque, New Mexico $87185 ;{ }^{2}$ Environmental Molecular Sciences Laboratory, Pacific Northwest National Laboratory, Richland, Washington 99352, October 17, 2002, http://prod.sandia.gov/techlib/accesscontrol.cgi/2004/041849p.pdf e - United States Environmental Protection Agency, Office of Air and Radiation, UNDERSTANDING VARIATION IN PARTITION COEFFICIENT, Kd, VALUES Volume III: Review of Geochemistry and Available Kd Values for Americium, Arsenic, Curium, Iodine, Neptunium, Radium, and Technetium, EPA 402-R-04-002C, July 2004

f - K. M. Krupka and R. J. Serne, Geochemical Factors Affecting the Behavior of Antimony, Cobalt, Europium, Technetium, and Uranium in Vadose Sediments, PNNL-14126, December 2002

$\mathrm{g}-\mathrm{QH} \mathrm{Hu}, \mathrm{M}$ Zavarin and TP Rose, Effect of reducing groundwater on the retardation of redox sensitive radionuclides, http://www.geochemicaltransactions.com/content/9/1/12

h - Email, ${ }^{99}$ Tc run - Bulk density issue, Bonczek, Rich [Rich.Bonczek@lex.doe.gov], Thu 6/16/2011 2:23 PM

$\mathrm{i}$ - ANL draft paper "Examination of Technetium-99 Dose Assessment Modeling with RESRAD (onsite) and RESRAD-OFFSITE (January 2011)"

$j$ - Several parameter distributions were considered when selecting the distribution for the varied input parameters. Chen and Yu (June 2011(note j)) and the DOE Risk Methods Document (DOE, February 2011 [note a]) were used to aid in the selection process.

$\mathrm{k}$ - ORISE's deterministic values for the parameters in the table were not used in the present PRA analysis, but were within the ranges of used in the PRA. ORISE, 2011. Dose Modeling Evaluations and Technical Support Document for the Authorized Limits Request for the C-746-U Landfill at the Paducah Gaseous Diffusion Plant, Paducah, Kentucky (May 2011).

Priority 1 parameters not used in the analysis were root depth, transfer factor for plants, unsaturated zone thickness, density of cover material, density of contaminated zone, and density of unsaturated zone. The root depth and transfer factor for plants were not used because the sitespecific PRA was limited to the drinking water pathway for the offsite resident farmer. Other Priority 1 parameters not varied were the unsaturated zone thickness, density of cover material, and density of unsaturated zone. The unsaturated zone thickness and density were not varied because site specific data are available setting these parameters. The density of the cover material was not varied because it is set by design.

\subsubsection{PROBABILISTIC ANALYSIS USING A TRIANGULAR DISTRIBUTION}

An evaluation of several available distributions and ultimate selection of the distribution(s) used in the analysis is required for a PRA analysis. Also, likely correlations between selected input parameters need to be addressed to guarantee appropriate results. A triangular distribution is typically used to describe a population for which there is only limited sample data. It is based on data for a minimum, maximum and an informed selection of the most likely value. Minimum, maximum and most likely values were available for the saturated zone hydraulic conductivity, total porosity of the saturated zone, effective porosity of the saturated zone, distribution coefficient of contaminated zone, density of contaminated zone, and unsaturated zone 5 effective porosity: thus, a triangular distribution was chosen for these parameters. (See: Methods for Conducting Risk Assessments and Risk Evaluations at the Paducah Gaseous Diffusion Plant 
Probabilistic Risk Assessment Analysis for Establishing the Technetium-99 Single Radionuclide Soil Guideline from the Drinking Water Pathway for the Offsite Resident Farmer for the C-746-U Landfill at the Paducah Gaseous Diffusion Plant, Paducah Kentucky

Paducah, Kentucky, Volume 1. Human Health, February 2011, Appendix E, Attachment 3, Input Parameters for Probabilistic Modeling.)

Sampling parameters were specified for the RESRAD-OFFSITE code after the parameters and distributions were selected. The RESRAD-OFFSITE sampling parameters are the random seed, the number of observations, and the number of repetitions. The series of random numbers that are generated are determined by the random seed. The number of observations is the number of sample values to be generated for each input variable. The number of repetitions is the number of times the analysis is repeated and along with the number of observations is used to assess the convergence and the stability of the probabilistic analysis.

A sampling technique was also specified. Two sampling techniques are available in the code: Latin hypercube sampling (LHS) and simple random sampling (SRS). LHS is the default sampling technique and was selected. It comprises a constrained sampling scheme developed by McKay, et al. (1979) as referenced in Yu et al. (2000). Latin Hypercube sampling divides the cumulative curve for each input variable into equal nonoverlapping intervals on the cumulative probability scale. A sample is randomly selected from each interval of the input variable distribution.

The final step in the probabilistic analysis is combining the samples. The code allows two methods of grouping (or combining): Random Grouping (RG) and Correlated/Uncorrelated Grouping (CG). Under RG, the samples generated for each of the variables are combined randomly to produce the required number of probabilistic inputs, and it is possible that some pairs of variables may be correlated to some degree in the randomly selected grouping. Under $\mathrm{CG}$, the user specifies the degree of correlation between each correlated variable by inputting the correlation coefficients between the ranks of the variables. CG was used and correlations were set for input parameters. It was documented in ATTACHMENT C of NUREG/CR-6697 (Yu et al., 2000) that a strong correlation exists between total and effective porosity. Therefore, a rank correlation value of 0.9 was chosen for the saturated zone total and effective porosities. Setting this correlation minimizes the selection of values from the cumulative probability distribution for the effective porosity that would be greater than the total porosity. 
Probabilistic Risk Assessment Analysis for Establishing the Technetium-99 Single Radionuclide Soil Guideline from the Drinking Water Pathway for the Offsite Resident Farmer for the C-746-U Landfill at the Paducah Gaseous Diffusion Plant, Paducah Kentucky

\subsubsection{APPROACHES}

The present PRA analysis used two different approaches to evaluate the mean radiation dose from the drinking water pathway for the offsite resident farmer using RESRAD-OFFSITE PRA analyses. The following runs were conducted using sample specifications for the RESRADOFFSITE probabilistic module to assess the radiation dose from ${ }^{99} \mathrm{Tc}$ :

○ Approach 1: 2000 observations and 3 repetitions, and

○ Approach 2: 2000 observations and 10 repetitions

The number of observations and repetitions in Approach 1 is consistent with the observations and repetitions used in ANL's ${ }^{99}$ Tc dose assessment modeling (Cheng and Yu, 2011). Approach 2 was included as a result of a recommendation by DOE PPPO staff.

\section{0: RESULTS AND DISCUSSION}

This section provides results and discussion of the PRA analysis used for determination of the ${ }^{99} \mathrm{Tc}$ SRSG for the U-Landfill. The ${ }^{99} \mathrm{Tc}$ SRSG can be used by DOE to develop a ${ }^{99} \mathrm{Tc}$ AL for the C-746-U Landfill.

\subsection{RESULTS}

The PRA analysis used the parameters, distributions, and ranges listed in Table 2-1 and ORISE's deterministic parameter values (ORISE, 2011) for the parameters that are not listed in Table 2-1. The RESRAD-OFFSITE code provides uncertainty analysis results as an output. Included in the uncertainty analysis results are tables for the Cumulative Probability Summary for Total Dose Over all Pathways and Statistics and Cumulative Distribution Function of Peak Dose from All Pathways. The Statistic and Cumulative Distribution Function of Peak Dose from All Pathways Table includes the mean and other descriptive statistics for the repetitions and the percentiles for the repetitions. The Statistic and Cumulative Distribution Function of Peak Dose for All Pathways Table can be used to compare radiation dose at various percentiles. Commonly cited percentile values include the $50^{\text {th }}$ (the median), $75^{\text {th }}, 90^{\text {th }}$, and $95^{\text {th }}$ percentiles.

Approach 1 and 2 yielded essentially the same ${ }^{99}$ Tc radiation dose from the drinking water pathway for the offsite resident farmer at the DOE property boundary. Appendices A and B provide the RESRAD-OFFSITE Statistic and Cumulative Distribution Function of the Peak 
Probabilistic Risk Assessment Analysis for Establishing the Technetium-99 Single Radionuclide Soil Guideline from the Drinking Water Pathway for the Offsite Resident Farmer for the C-746-U Landfill at the Paducah Gaseous Diffusion Plant, Paducah Kentucky

Dose from the Drinking Water Pathway Table for Approaches 1 and 2. Appendix C provides the Statistic and Cumulative Distribution Function of the Peak Dose from All Pathways Table.

Although the results from Approach 2 were used to calculate the mean dose from the drinking water pathway for the offsite resident farmer and the resulting SRSG for the C-746-U Landfill, both approaches yield identical mean dose and SRSG. At the recommendation of DOE PPPO staff the mean for the means of the repetitions from Approach 2 was calculated using the statistical analysis package in VISUAL SAMPLING PLAN Version 5.0 (Battelle Memorial Institute, 2007). Results from Approach 2 are discussed in detail in this section and are used to calculate the SRSG for the C-746-U Landfill.

The radiation dose determined for the ten repetitions is graphed against the percentile in Figure 3-1. The graph demonstrates that the output distributions for the ten runs are stable. Therefore, additional observations and repetitions would not markedly change the shape or statistics of the sampled distribution.

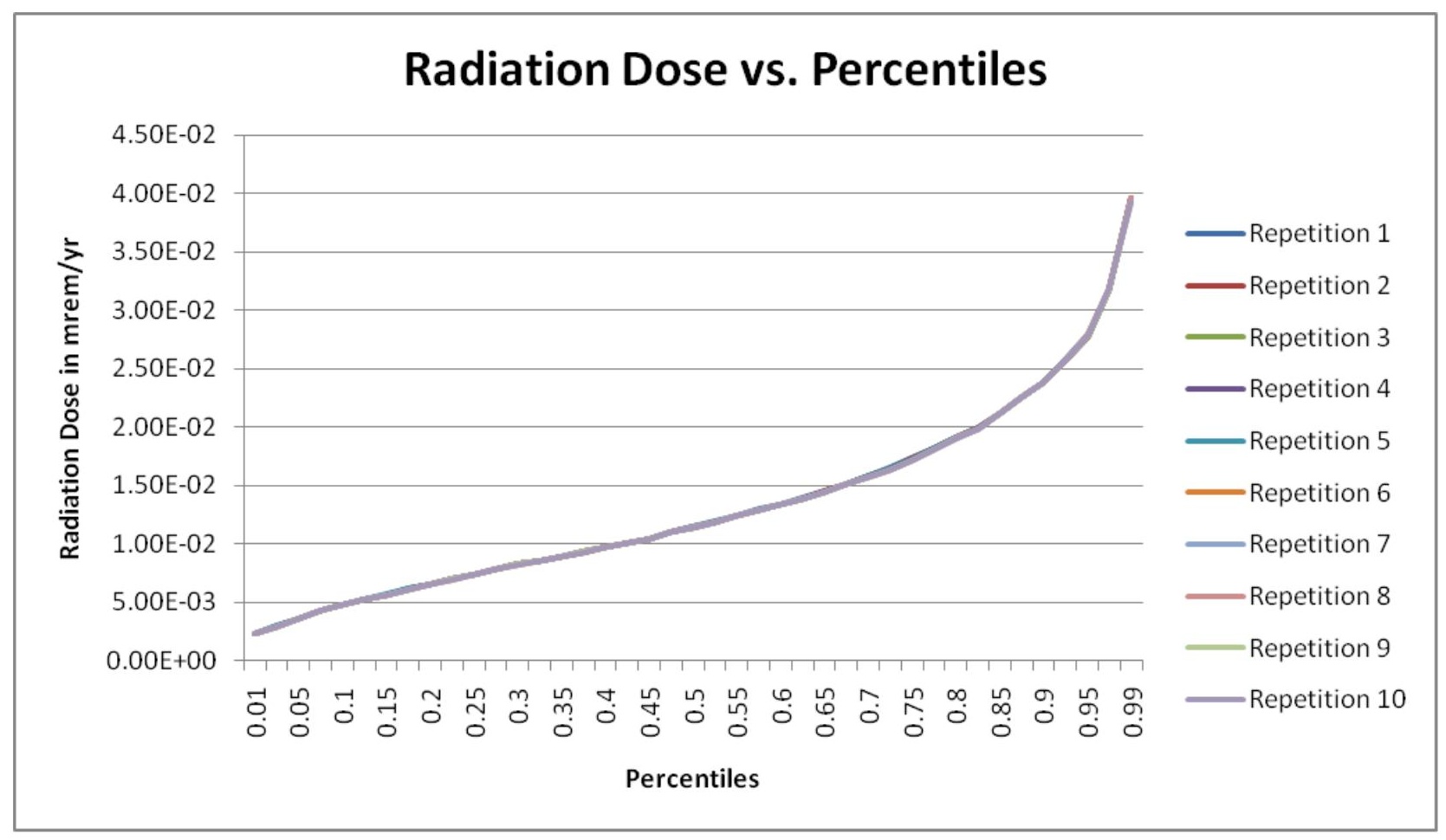

Figure 3-1. Radiation dose summary for the ten repetitions from the drinking water pathway 
Probabilistic Risk Assessment Analysis for Establishing the Technetium-99 Single Radionuclide Soil Guideline from the Drinking Water Pathway for the Offsite Resident Farmer for the C-746-U Landfill at the Paducah Gaseous Diffusion Plant, Paducah Kentucky

Also, as shown in Table 3-1, the repetitions means of the ten repetitions, which range from $1.31 \mathrm{E}-02 \mathrm{mrem} / \mathrm{yr}$ to $1.32 \mathrm{mrem} / \mathrm{yr}$ and the mean of the means of the repetitions (which is $1.32 \mathrm{E}$ $02 \mathrm{mrem} / \mathrm{yr}$ ) are essentially the same (another indicator of convergence).

Table 3-1. Summary statistics for the means of the repetitions for Approach 2

\begin{tabular}{|l|c|}
\hline $\mathrm{N}$ & 10 \\
\hline Minimum & $1.31 \mathrm{E}-02$ \\
\hline Maximum & $1.32 \mathrm{E}-02$ \\
\hline Range & $1.00 \mathrm{E}-04$ \\
\hline Mean $^{\text {a }}$ & $1.32 \mathrm{E}-02$ \\
\hline Median & $1.32 \mathrm{E}-02$ \\
\hline Variance & $2.67 \mathrm{E}-09$ \\
\hline Standard Deviation & $5.16 \mathrm{E}-05$ \\
\hline Standard Error & $1.63 \mathrm{E}-05$ \\
\hline Skewness & $-4.84 \mathrm{E}-01$ \\
\hline Interquartile Range & $1.00 \mathrm{E}-04$ \\
\hline
\end{tabular}

$\mathrm{a}-$ It is the mean of the means of the ten repetitions. Each repetition has 2000 observations. For each repetition the repetition mean is calculated based on the 2000 observations for the repetition. The mean is then computed based on the means of the 10 repetitions.

\subsection{SINGL RADIONUCLIDE SOIL GUIDELINE}

In addition to using PRA analysis to identify sensitive parameters as demonstrated by Chen and $\mathrm{Yu}$ (Chen and $\mathrm{Yu}, 2011$ ), the results of probabilistic analysis have been used by NRC licensees to demonstrate compliance with dose standards (NRC, 2006). The following is taken from NUREG 1727, Section 8.3.2.2 (NRC, 2000), “Although bounding analyses are a good starting point for determining regulatory compliance, the demonstration that a single, deterministic result is bounding may be too difficult to prove. For site-specific probabilistic analysis, it is only necessary to demonstrate that the mean dose does not exceed the regulatory criterion. A single deterministic calculation using the mean values of parameters is unlikely to result in the mean dose." NRC indicates the peak of the mean dose is currently used to show compliance with dose criteria when utilizing PRA analysis (Abu-Eid, 2004). Based on this guidance, the mean for the means of the repetitions was used to calculate the ${ }^{99}$ Tc SRSG for the C-746-U Landfill. 
The SRSG calculation was performed as follows:

$$
S R S G=\frac{\text { Target dose in mrem } / y r}{\frac{\text { Peak of mean dose in } \mathrm{mrem} / \mathrm{yr}}{\text { Initial radionuclid concentrat ion in } \mathrm{pCi} / \mathrm{g}}}
$$

The unit for SRSG is $\mathrm{pCi} / \mathrm{g}$. In this PRA analysis the target radiation dose is $1 \mathrm{mrem} / \mathrm{yr}$ and the initial radionuclide concentration is $1 \mathrm{pCi} / \mathrm{g}$

The mean for the means of the repetitions specified in Table 3-1 was utilized to calculate the ${ }^{99}$ Tc SRSG for the C-746-U Landfill.

$$
\begin{aligned}
& S R S G=\frac{1 \mathrm{mrem} / \mathrm{yr}}{\frac{1.32 E-2 \mathrm{mrem} / \mathrm{yr}}{1 \mathrm{pCi} / \mathrm{g}}} \\
& \mathrm{SRSG}=76 \mathrm{pCi} / \mathrm{g}
\end{aligned}
$$

The calculated ${ }^{99} \mathrm{Tc}$ SRSG is for the offsite resident farmer drinking water pathway at the DOE property boundary. Based on ORISE's deterministic analysis of impacts of ${ }^{99} \mathrm{Tc}$ from the C-746U Landfill (ORISE, 2011), the drinking water pathway makes up approximately $68 \%$ of the radiation dose to the offsite resident farmer at the PGDP DOE property boundary. To include contribution from consumables (plant ingestion, milk, meat, etc.) to the total radiation dose, the SRSG for drinking water pathway was multiplied by 0.68. Adjusting for the consumable pathways the ${ }^{99}$ Tc SRSG would be $52 \mathrm{pCi} / \mathrm{g}$ for the C-746-U Landfill.

Appendix C provides the Statistic and Cumulative Distribution Function of the Peak Dose from All Pathways Table using 2000 observations and 3 repetitions. Using the mean dose of 0.0193 $\mathrm{mrem} / \mathrm{yr}$, unit activity, and the above equation, the ${ }^{99} \mathrm{Tc}$ SRSG is $52 \mathrm{pCi} / \mathrm{g}$ for the C-746-U Landfill. This value is identical to the ${ }^{99} \mathrm{Tc}$ SRSG calculated from analysis of the drinking water pathway for the offsite resident farmer at the DOE property boundary and corrected for the consumables. The approach using only the drinking water pathway for the PRA analysis was selected because of the following two issues: (1) The run time with all pathways is over five hours, and (2) Random Access Memory (8 GB RAM) issues for the available computers. 


\section{0: CONCLUSION}

Based on the present PRA analysis using unit activity and a target radiation dose of $1 \mathrm{mrem} / \mathrm{yr}$ for the offsite resident farmer at the DOE property boundary, the ${ }^{99} \mathrm{Tc}$ SRSG is $52 \mathrm{pCi} / \mathrm{g}$ for the C-746-U Landfill. Although Approach 1 and 2 yield identical results, Approach 2 using the mean for the means of the repetitions was used to calculate the ${ }^{99} \mathrm{Tc}$ SRSG for the C-746-U Landfill. Based on the present PRA analysis, it is recommended that DOE use $52 \mathrm{pCi} / \mathrm{g}$ for the ${ }^{99} \mathrm{Tc}$ SRSG for the C-746-U Landfill. 


\section{0: REFERENCES}

1. Abu-Eid R., 2004. Probabilistic Versus Deterministic Analysis for Demonstration of Compliance with the Dose Criteria in 10 CFR Part 20, Subpart E, U.S. Nuclear Regulatory Commission, Waste Management Conference, Tucson, AZ (February 29 - March 4, 2004)

2. Battelle Memorial Institute, Visual Sampling Plan Version 5.0, 2007

3. Brady, Patrick V. ${ }^{1}$ and Amonette, James E. ${ }^{2}$, Technetium, ${ }^{1}$ Geochemistry Department (MS-0750), Sandia National Laboratories, Albuquerque, New Mexico $87185 ;{ }^{2}$ Environmental Molecular Sciences Laboratory, Pacific Northwest National Laboratory, Richland, Washington 99352, October 17, 2002, http://prod.sandia.gov/techlib/access-control.cgi/2004/041849p.pdf

4. Cheng J-J., and Yu C., 2011. Examination of Technetium-99 Dose Assessment Modeling with RESRAD (onsite) and RESRAD-OFFSITE, Draft by Argonne National Laboratory

5. DOE, 2003. Risk and Performance Evaluation of the C-746-U Landfill at the Paducah Gaseous Diffusion Plant, Paducah, Kentucky, DOE/OR/07-2041\&D2R1 (2003).

6. DOE, 2005. Site Investigation Report for the C-746-S\&T Landfills at the Paducah Gaseous Diffusion Plant, Paducah, Kentucky, DOE/OR/07-2212\&DISECONDARY DOCUMENT, September 2005

7. DOE, 2011, Methods for Conducting Risk Assessments and Risk Evaluations at the Paducah Gaseous Diffusion Plant Paducah, Kentucky Volume 1. Human Health, DOE/LX/07-0107\&D2/R1/V1, February 2011

8. DOE-PPPO, 2011. Authorized Limits Request for Solid Waste Disposal at Landfill C-746-U at the Paducah Gaseous Diffusion Plant.

9. $\mathrm{Hu}, \mathrm{QH}, \mathrm{Zavarin}, \mathrm{M}$ and Rose, $\mathrm{TP}$, Effect of reducing groundwater on the retardation of redox sensitive radionuclides, http://www.geochemicaltransactions.com/content/9/1/12

10. Kentucky Administrative Regulations, 401 KAR Chapter 48, Standards for Solid Waste Facilities, http://www.lrc.ky.gov/kar/401/048/005.htm

11. Krupka, K. M. and Serne, R. J., Geochemical Factors Affecting the Behavior of Antimony, Cobalt, Europium, Technetium, and Uranium in Vadose Sediments, PNNL-14126, December 2002

12. ORISE, 2011. Dose Modeling Evaluations and Technical Support Document for the Authorized Limits Request for the C-746-U Landfill at the Paducah Gaseous Diffusion Plant, Paducah, Kentucky (May 2011).

13. NRC, 2000. NNMS Decommissioning Standard Review Plan, NUREG 1727, (September 2000).

14. NRC, 2006. Consolidated Decommissioning Guidance Characterization, Survey, and Determination of Radiological Criteria, NUREG-1757 Vol. 2, Rev. 1 (September 2006).

15. USEPA, 2004. United States Environmental Protection Agency, Office of Air and Radiation, UNDERSTANDING VARIATION IN PARTITION COEFFICIENT, Kd, VALUES Volume III: Review of Geochemistry and Available Kd Values for Americium, Arsenic, Curium, Iodine, Neptunium, Radium, and Technetium, EPA 402-R-04-002C, July 2004

16. Volpe J., 2001. Risk versus Dose Cleanup Levels (Memorandum), Kentucky Radiation Health and Toxic Agents Branch. 
17. Yu C., et al, 2000. Development of Probabilistic RESRAD 6.0 and RESRAD-BUILD 3.0 Computer Codes, NUREG/CR-6697 (ANL/EAD/TM-98), prepared for the USNRC by the Argonne National Laboratory, Washington, D.C.

18. Yu C., et al, 2001. User's Manual for RESRAD Version 6, Argonne National Laboratory, ANL/EAD4.

19. Yu C., et al, 2007. User's Manual for RESRAD-OFFSITE Version 2, Argonne National Laboratory, ANL/EVS/TM/07-1 (NUREG/CR-6937). 


\section{Appendix A}

\section{Statistics and Cumulative distribution function of Peak Dose from Drinking Water Pathway in mrem/yr at $1 \mathrm{pCi} / \mathrm{g}$ for Approach 1}

\begin{tabular}{|c|c|c|c|}
\hline Repetition & 1 & 2 & 3 \\
\hline Mean & $1.32 \mathrm{E}-02$ & $1.32 \mathrm{E}-02$ & $1.32 \mathrm{E}-02$ \\
\hline Std. Dev. & $7.87 \mathrm{E}-03$ & $7.86 \mathrm{E}-03$ & $7.87 \mathrm{E}-03$ \\
\hline Minimum & $1.59 \mathrm{E}-03$ & $1.59 \mathrm{E}-03$ & $1.59 \mathrm{E}-03$ \\
\hline Maximum & $7.48 \mathrm{E}-02$ & $7.48 \mathrm{E}-02$ & $7.48 \mathrm{E}-02$ \\
\hline \multicolumn{4}{|l|}{ Percentiles } \\
\hline 0.01 & $2.28 \mathrm{E}-03$ & $2.28 \mathrm{E}-03$ & $2.28 \mathrm{E}-03$ \\
\hline 0.025 & $2.97 \mathrm{E}-03$ & $2.97 \mathrm{E}-03$ & $2.97 \mathrm{E}-03$ \\
\hline 0.05 & $3.64 \mathrm{E}-03$ & $3.64 \mathrm{E}-03$ & $3.64 \mathrm{E}-03$ \\
\hline 0.075 & $4.30 \mathrm{E}-03$ & $4.30 \mathrm{E}-03$ & $4.30 \mathrm{E}-03$ \\
\hline 0.1 & $4.77 \mathrm{E}-03$ & $4.77 \mathrm{E}-03$ & $4.77 \mathrm{E}-03$ \\
\hline 0.125 & $5.26 \mathrm{E}-03$ & $5.26 \mathrm{E}-03$ & $5.26 \mathrm{E}-03$ \\
\hline 0.15 & $5.68 \mathrm{E}-03$ & $5.68 \mathrm{E}-03$ & $5.68 \mathrm{E}-03$ \\
\hline 0.175 & $6.16 \mathrm{E}-03$ & $6.16 \mathrm{E}-03$ & $6.16 \mathrm{E}-03$ \\
\hline 0.2 & $6.54 \mathrm{E}-03$ & $6.54 \mathrm{E}-03$ & $6.54 \mathrm{E}-03$ \\
\hline 0.225 & $6.99 \mathrm{E}-03$ & $6.98 \mathrm{E}-03$ & $6.98 \mathrm{E}-03$ \\
\hline 0.25 & $7.43 \mathrm{E}-03$ & $7.42 \mathrm{E}-03$ & $7.42 \mathrm{E}-03$ \\
\hline 0.275 & $7.87 \mathrm{E}-03$ & $7.86 \mathrm{E}-03$ & $7.86 \mathrm{E}-03$ \\
\hline 0.3 & $8.29 \mathrm{E}-03$ & $8.28 \mathrm{E}-03$ & $8.28 \mathrm{E}-03$ \\
\hline 0.325 & 8.61E-03 & $8.61 \mathrm{E}-03$ & $8.61 \mathrm{E}-03$ \\
\hline 0.35 & $8.95 \mathrm{E}-03$ & $8.95 \mathrm{E}-03$ & $8.95 \mathrm{E}-03$ \\
\hline 0.375 & $9.34 \mathrm{E}-03$ & $9.33 \mathrm{E}-03$ & $9.34 \mathrm{E}-03$ \\
\hline 0.4 & $9.76 \mathrm{E}-03$ & $9.75 \mathrm{E}-03$ & $9.76 \mathrm{E}-03$ \\
\hline 0.425 & $1.01 \mathrm{E}-02$ & $1.01 \mathrm{E}-02$ & $1.01 \mathrm{E}-02$ \\
\hline 0.45 & $1.05 \mathrm{E}-02$ & $1.05 \mathrm{E}-02$ & $1.05 \mathrm{E}-02$ \\
\hline 0.475 & $1.10 \mathrm{E}-02$ & $1.10 \mathrm{E}-02$ & $1.10 \mathrm{E}-02$ \\
\hline 0.5 & $1.15 \mathrm{E}-02$ & $1.15 \mathrm{E}-02$ & $1.15 \mathrm{E}-02$ \\
\hline 0.525 & $1.20 \mathrm{E}-02$ & $1.19 \mathrm{E}-02$ & $1.19 \mathrm{E}-02$ \\
\hline 0.55 & $1.25 \mathrm{E}-02$ & $1.25 \mathrm{E}-02$ & $1.25 \mathrm{E}-02$ \\
\hline 0.575 & $1.30 \mathrm{E}-02$ & $1.29 \mathrm{E}-02$ & $1.29 \mathrm{E}-02$ \\
\hline 0.6 & $1.34 \mathrm{E}-02$ & $1.34 \mathrm{E}-02$ & $1.34 \mathrm{E}-02$ \\
\hline 0.625 & $1.40 \mathrm{E}-02$ & $1.39 \mathrm{E}-02$ & $1.39 \mathrm{E}-02$ \\
\hline 0.65 & $1.45 \mathrm{E}-02$ & $1.45 \mathrm{E}-02$ & $1.45 \mathrm{E}-02$ \\
\hline 0.675 & $1.51 \mathrm{E}-02$ & $1.51 \mathrm{E}-02$ & $1.51 \mathrm{E}-02$ \\
\hline 0.7 & $1.58 \mathrm{E}-02$ & $1.58 \mathrm{E}-02$ & $1.58 \mathrm{E}-02$ \\
\hline 0.725 & $1.65 \mathrm{E}-02$ & $1.64 \mathrm{E}-02$ & $1.64 \mathrm{E}-02$ \\
\hline 0.75 & $1.74 \mathrm{E}-02$ & $1.74 \mathrm{E}-02$ & $1.74 \mathrm{E}-02$ \\
\hline 0.775 & $1.82 \mathrm{E}-02$ & $1.82 \mathrm{E}-02$ & $1.82 \mathrm{E}-02$ \\
\hline
\end{tabular}




\begin{tabular}{|c|c|c|c|}
\hline 0.8 & $1.92 \mathrm{E}-02$ & $1.92 \mathrm{E}-02$ & $1.92 \mathrm{E}-02$ \\
\hline 0.825 & $2.00 \mathrm{E}-02$ & $2.00 \mathrm{E}-02$ & $2.00 \mathrm{E}-02$ \\
\hline 0.85 & $2.11 \mathrm{E}-02$ & $2.11 \mathrm{E}-02$ & $2.11 \mathrm{E}-02$ \\
\hline 0.875 & $2.26 \mathrm{E}-02$ & $2.26 \mathrm{E}-02$ & $2.38 \mathrm{E}-02$ \\
\hline 0.9 & $2.38 \mathrm{E}-02$ & $2.38 \mathrm{E}-02$ & $2.58 \mathrm{E}-02$ \\
\hline 0.925 & $2.58 \mathrm{E}-02$ & $2.57 \mathrm{E}-02$ & $2.80 \mathrm{E}-02$ \\
\hline 0.95 & $2.80 \mathrm{E}-02$ & $2.80 \mathrm{E}-02$ & $3.17 \mathrm{E}-02$ \\
\hline 0.975 & $3.17 \mathrm{E}-02$ & $3.17 \mathrm{E}-02$ & $3.96 \mathrm{E}-02$ \\
\hline 0.99 & $3.96 \mathrm{E}-02$ & $3.96 \mathrm{E}-02$ & \\
\hline
\end{tabular}




\section{Appendix B}

\section{Statistics and Cumulative distribution function of Peak Dose from Drinking Water Pathway in mrem/yr at $1 \mathrm{pCi} / \mathrm{g}$ for Approach 2}

\begin{tabular}{|c|c|c|c|c|c|c|c|c|c|c|}
\hline Repetition & 1 & 2 & 3 & 4 & 5 & 6 & 7 & 8 & 9 & 10 \\
\hline Mean & $1.32 \mathrm{E}-02$ & $1.32 \mathrm{E}-02$ & $.32 \mathrm{E}-02$ & $1.32 \mathrm{E}-02$ & $1.32 \mathrm{E}-02$ & $1.31 \mathrm{E}-02$ & $1.31 \mathrm{E}-02$ & $1.31 \mathrm{E}-02$ & $1.31 \mathrm{E}-02$ & $1.31 \mathrm{E}-02$ \\
\hline Std. Dev. & $7.87 \mathrm{E}-03$ & $7.86 \mathrm{E}-03$ & $7.85 \mathrm{E}-03$ & 7.84E-03 & 7.84E-03 & 7.84E-03 & 7.84E-03 & $7.85 \mathrm{E}-03$ & 7.82E-03 & $7.84 \mathrm{E}-03$ \\
\hline Minimum & $1.59 \mathrm{E}-03$ & $1.59 \mathrm{E}-03$ & .59E-03 & $1.59 \mathrm{E}-03$ & $1.59 \mathrm{E}-03$ & $1.59 \mathrm{E}-03$ & $1.59 \mathrm{E}-03$ & $1.59 \mathrm{E}-03$ & $1.59 \mathrm{E}-03$ & $1.59 \mathrm{E}-03$ \\
\hline Maximum & $48 \mathrm{E}-02$ & $48 \mathrm{E}-02$ & $48 \mathrm{E}-02$ & $7.48 \mathrm{E}-02$ & $7.48 \mathrm{E}-02$ & $7.48 \mathrm{E}-02$ & $7.48 \mathrm{E}-02$ & $7.48 \mathrm{E}-02$ & 7.48E-02 & $7.48 \mathrm{E}-02$ \\
\hline \multicolumn{11}{|l|}{ Percentiles } \\
\hline 0.01 & $2.28 \mathrm{E}-03$ & $2.28 \mathrm{E}-03$ & $2.28 \mathrm{E}-03$ & $2.02 \mathrm{E}-0 \mathrm{~J}$ & $2.02 \mathrm{E}-0 \mathrm{~J}$ & $2.02 \mathrm{E}-0 \mathrm{~J}$ & 2.32E-03 & $2.28 \mathrm{E}-03$ & $2.28 \mathrm{E}-03$ & $2.28 \mathrm{E}-03$ \\
\hline 0.025 & $.97 \mathrm{E}-03$ & $.97 \mathrm{E}-03$ & 97E-03 & $.98 \mathrm{E}-03$ & $2.98 \mathrm{E}-03$ & $2.97 \mathrm{E}-03$ & $2.97 \mathrm{E}-03$ & $2.97 \mathrm{E}-03$ & $2.97 \mathrm{E}-03$ & $2.97 \mathrm{E}-03$ \\
\hline 0.05 & $.64 \mathrm{E}-03$ & $3.64 \mathrm{E}-03$ & 64E-03 & $3.68 \mathrm{E}-03$ & $3.68 \mathrm{E}-03$ & $3.66 \mathrm{E}-03$ & $3.66 \mathrm{E}-03$ & $3.65 \mathrm{E}-03$ & $3.65 \mathrm{E}-03$ & $3.65 \mathrm{E}-03$ \\
\hline 0.075 & $30 \mathrm{E}-03$ & $1 \mathrm{E}-03$ & $31 \mathrm{E}-03$ & $33 \mathrm{E}-03$ & $4.33 \mathrm{E}-03$ & $31 \mathrm{E}-03$ & $4.32 \mathrm{E}-03$ & $4.31 \mathrm{E}-03$ & $4.31 \mathrm{E}-03$ & $4.31 \mathrm{E}-03$ \\
\hline 0.1 & $7 \mathrm{E}-03$ & 78E-03 & 77E-03 & $.78 \mathrm{E}-03$ & $4.78 \mathrm{E}-03$ & $76 \mathrm{E}-03$ & $4.77 \mathrm{E}-03$ & $4.76 \mathrm{E}-03$ & $4.76 \mathrm{E}-03$ & $4.76 \mathrm{E}-03$ \\
\hline 0.125 & $5.26 \mathrm{E}-03$ & $5.26 \mathrm{E}-03$ & 26E-03 & $5.26 \mathrm{E}-03$ & $5.26 \mathrm{E}-03$ & $5.25 \mathrm{E}-03$ & $5.26 \mathrm{E}-03$ & $5.26 \mathrm{E}-03$ & $5.26 \mathrm{E}-03$ & $5.26 \mathrm{E}-03$ \\
\hline 0.15 & $5.68 \mathrm{E}-03$ & $5.68 \mathrm{E}-03$ & $5.68 \mathrm{E}-03$ & $5.68 \mathrm{E}-03$ & 5.69E-03 & $5.67 \mathrm{E}-03$ & $5.68 \mathrm{E}-03$ & $5.68 \mathrm{E}-03$ & $5.68 \mathrm{E}-03$ & $.68 \mathrm{E}-03$ \\
\hline 0.175 & $6.16 \mathrm{E}-03$ & $6.15 \mathrm{E}-03$ & $6.16 \mathrm{E}-03$ & $6.16 \mathrm{E}-03$ & $6.16 \mathrm{E}-03$ & $6.13 \mathrm{E}-03$ & $6.15 \mathrm{E}-03$ & $6.15 \mathrm{E}-03$ & $6.13 \mathrm{E}-03$ & $.13 \mathrm{E}-03$ \\
\hline 0.2 & $6.54 \mathrm{E}-03$ & $6.54 \mathrm{E}-03$ & 56E-03 & $6.54 \mathrm{E}-03$ & $6.56 \mathrm{E}-03$ & $.52 \mathrm{E}-03$ & $6.53 \mathrm{E}-03$ & $6.53 \mathrm{E}-03$ & $5.53 \mathrm{E}-03$ & $.53 \mathrm{E}-03$ \\
\hline 0.225 & $99 \mathrm{E}-03$ & $6.98 \mathrm{E}-03$ & $00 \mathrm{E}-03$ & 99E-03 & $6.99 \mathrm{E}-03$ & $.96 \mathrm{E}-03$ & $6.99 \mathrm{E}-03$ & 7.00E-03 & $6.98 \mathrm{E}-03$ & $.97 \mathrm{E}-03$ \\
\hline 0.25 & $3 \mathrm{E}-03$ & $2 \mathrm{E}-03$ & $43 \mathrm{E}-03$ & $42 \mathrm{E}-03$ & $.42 \mathrm{E}-03$ & $36 \mathrm{E}-03$ & $7.43 \mathrm{E}-03$ & 7.44E-03 & $7.42 \mathrm{E}-03$ & $42 \mathrm{E}-03$ \\
\hline 0.275 & $7 \mathrm{E}-03$ & $6 \mathrm{E}-03$ & E-03 & -03 & $86 \mathrm{E}-03$ & $85 \mathrm{E}-03$ & $7.86 \mathrm{E}-03$ & $7.86 \mathrm{E}-03$ & $.86 \mathrm{E}-03$ & $86 \mathrm{E}-03$ \\
\hline 0.3 & 3 & & 3 & 3 & 3 & 3 & 3 & 3 & 3 & 03 \\
\hline 0 & & & & & & & & & & 03 \\
\hline & $8.95 \mathrm{E}-03$ & & & $8.95 \mathrm{E}-03$ & $8.95 \mathrm{E}-03$ & & 3 & 3 & 3 & $\overline{03}$ \\
\hline 0.375 & 3 & 3 & 3 & 03 & 03 & 03 & 03 & 03 & 03 & $.31 \mathrm{E}-03$ \\
\hline 0.4 & $9.76 \mathrm{E}-03$ & $9.76 \mathrm{E}-03$ & $9.75 \mathrm{E}-03$ & $9.74 \mathrm{E}-03$ & $9.76 \mathrm{E}-03$ & $9.75 \mathrm{E}-03$ & $9.76 \mathrm{E}-03$ & $9.76 \mathrm{E}-03$ & $9.75 \mathrm{E}-03$ & $9.75 \mathrm{E}-03$ \\
\hline 0.425 & $1.01 \mathrm{E}-02$ & 1.01E-02 & $1.01 \mathrm{E}-02$ & 1.01E-02 & $1.01 \mathrm{E}-02$ & $1.01 \mathrm{E}-02$ & $1.01 \mathrm{E}-02$ & $1.01 \mathrm{E}-02$ & $1.01 \mathrm{E}-02$ & $1.01 \mathrm{E}-02$ \\
\hline 0.45 & $1.05 \mathrm{E}-02$ & 1.05E-02 & $1.05 \mathrm{E}-02$ & 1.05E-02 & $1.05 \mathrm{E}-02$ & $1.05 \mathrm{E}-02$ & $1.05 \mathrm{E}-02$ & $1.05 \mathrm{E}-02$ & $1.05 \mathrm{E}-02$ & $1.05 \mathrm{E}-02$ \\
\hline 0.475 & $1.10 \mathrm{E}-02$ & 1.10E-02 & $1.10 \mathrm{E}-02$ & 1.10E-02 & $1.10 \mathrm{E}-02$ & $1.10 \mathrm{E}-02$ & $1.10 \mathrm{E}-02$ & 1.10E-02 & $1.10 \mathrm{E}-02$ & $1.10 \mathrm{E}-02$ \\
\hline 0.5 & $1.15 \mathrm{E}-02$ & $\mathrm{E}-02$ & $1.15 \mathrm{E}-02$ & $1.14 \mathrm{E}-02$ & $1.14 \mathrm{E}-02$ & 14E-02 & 1.15 & $1.14 \mathrm{E}-02$ & $1.14 \mathrm{E}-02$ & $1.14 \mathrm{E}-02$ \\
\hline 0 . & 1. & 22 & 32 & 02 & 02 & $J 2$ & 22 & -02 & -02 & 02 \\
\hline 0 & $1.25 \mathrm{E}-02$ & $1.25 \mathrm{E}-02$ & 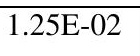 & 2 & $4=$ & 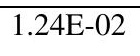 & $1.24 \mathrm{E}-02$ & $1.24 \mathrm{E}-02$ & $1.24 \mathrm{E}-02$ & 02 \\
\hline 0 & 2 & 2 & $1.29 \mathrm{E}-02$ & 2 & $1.29 \mathrm{E}-02$ & $1.29 \mathrm{E}-02$ & 2 & 2 & 2 & 02 \\
\hline 0.6 & 2 & 2 & 2 & 02 & 2 & 2 & 2 & 2 & 02 & 02 \\
\hline 0.625 & $1.40 \mathrm{E}-02$ & $1.39 \mathrm{E}-02$ & $1.39 \mathrm{E}-02$ & $1.39 \mathrm{E}-02$ & $1.39 \mathrm{E}-02$ & $1.38 \mathrm{E}-02$ & $1.38 \mathrm{E}-02$ & $1.38 \mathrm{E}-02$ & $1.38 \mathrm{E}-02$ & $1.38 \mathrm{E}-02$ \\
\hline 0.65 & $1.45 \mathrm{E}-02$ & $1.45 \mathrm{E}-02$ & $1.44 \mathrm{E}-02$ & 1.44E-02 & $1.44 \mathrm{E}-02$ & $1.44 \mathrm{E}-02$ & $1.44 \mathrm{E}-02$ & 1.44E-02 & $1.44 \mathrm{E}-02$ & $1.44 \mathrm{E}-02$ \\
\hline 0.675 & $1.51 \mathrm{E}-02$ & $1.51 \mathrm{E}-02$ & $1.51 \mathrm{E}-02$ & $1.51 \mathrm{E}-02$ & $1.51 \mathrm{E}-02$ & $1.51 \mathrm{E}-02$ & $1.51 \mathrm{E}-02$ & $1.51 \mathrm{E}-02$ & $1.51 \mathrm{E}-02$ & $1.51 \mathrm{E}-02$ \\
\hline 0.7 & $1.58 \mathrm{E}-02$ & $1.58 \mathrm{E}-02$ & $1.58 \mathrm{E}-02$ & $1.58 \mathrm{E}-02$ & $1.58 \mathrm{E}-02$ & $1.57 \mathrm{E}-02$ & $1.57 \mathrm{E}-02$ & $1.57 \mathrm{E}-02$ & $1.57 \mathrm{E}-02$ & $1.57 \mathrm{E}-02$ \\
\hline 0.725 & $1.65 \mathrm{E}-02$ & 1.64E-02 & $1.64 \mathrm{E}-02$ & 1.64E-02 & 1.64E-02 & $1.63 \mathrm{E}-02$ & $1.63 \mathrm{E}-02$ & $1.63 \mathrm{E}-02$ & $1.63 \mathrm{E}-02$ & $1.63 \mathrm{E}-02$ \\
\hline 0.75 & $1.74 \mathrm{E}-02$ & $1.74 \mathrm{E}-02$ & $1.73 \mathrm{E}-02$ & $1.73 \mathrm{E}-02$ & 1.73E-02 & $1.72 \mathrm{E}-02$ & $1.72 \mathrm{E}-02$ & $1.72 \mathrm{E}-02$ & $1.72 \mathrm{E}-02$ & $1.72 \mathrm{E}-02$ \\
\hline 0.775 & $1.82 \mathrm{E}-02$ & $1.82 \mathrm{E}-02$ & $1.82 \mathrm{E}-02$ & $1.82 \mathrm{E}-02$ & $1.82 \mathrm{E}-02$ & $1.81 \mathrm{E}-02$ & $1.81 \mathrm{E}-02$ & $1.81 \mathrm{E}-02$ & $1.81 \mathrm{E}-02$ & $1.81 \mathrm{E}-02$ \\
\hline
\end{tabular}




\begin{tabular}{|c|c|c|c|c|c|c|c|c|c|c|}
\hline 0.8 & $1.92 \mathrm{E}-02$ & $1.92 \mathrm{E}-02$ & $1.92 \mathrm{E}-02$ & $1.91 \mathrm{E}-02$ & $1.91 \mathrm{E}-02$ & $1.91 \mathrm{E}-02$ & $1.91 \mathrm{E}-02$ & $1.90 \mathrm{E}-02$ & $1.90 \mathrm{E}-02$ & $1.90 \mathrm{E}-02$ \\
\hline 0.825 & $2.00 \mathrm{E}-02$ & $2.00 \mathrm{E}-02$ & $2.00 \mathrm{E}-02$ & $2.00 \mathrm{E}-02$ & $1.99 \mathrm{E}-02$ & $1.99 \mathrm{E}-02$ & $1.99 \mathrm{E}-02$ & $1.99 \mathrm{E}-02$ & $1.98 \mathrm{E}-02$ & $1.99 \mathrm{E}-02$ \\
\hline 0.85 & $2.11 \mathrm{E}-02$ & $2.11 \mathrm{E}-02$ & $2.11 \mathrm{E}-02$ & $2.11 \mathrm{E}-02$ & $2.11 \mathrm{E}-02$ & $2.11 \mathrm{E}-02$ & $2.11 \mathrm{E}-02$ & $2.11 \mathrm{E}-02$ & $2.11 \mathrm{E}-02$ & $2.11 \mathrm{E}-02$ \\
\hline 0.875 & $2.26 \mathrm{E}-02$ & $2.26 \mathrm{E}-02$ & $2.25 \mathrm{E}-02$ & $2.25 \mathrm{E}-02$ & $2.25 \mathrm{E}-02$ & $2.25 \mathrm{E}-02$ & $2.25 \mathrm{E}-02$ & $2.25 \mathrm{E}-02$ & $2.25 \mathrm{E}-02$ & $2.25 \mathrm{E}-02$ \\
\hline 0.9 & $2.38 \mathrm{E}-02$ & $2.38 \mathrm{E}-02$ & $2.38 \mathrm{E}-02$ & $2.38 \mathrm{E}-02$ & $2.38 \mathrm{E}-02$ & $2.38 \mathrm{E}-02$ & $2.38 \mathrm{E}-02$ & $2.38 \mathrm{E}-02$ & $2.38 \mathrm{E}-02$ & $2.38 \mathrm{E}-02$ \\
\hline 0.925 & $2.58 \mathrm{E}-02$ & $2.57 \mathrm{E}-02$ & $2.57 \mathrm{E}-02$ & $2.57 \mathrm{E}-02$ & $2.57 \mathrm{E}-02$ & $2.57 \mathrm{E}-02$ & $2.57 \mathrm{E}-02$ & $2.57 \mathrm{E}-02$ & $2.57 \mathrm{E}-02$ & $2.57 \mathrm{E}-02$ \\
\hline 0.95 & $2.80 \mathrm{E}-02$ & $2.79 \mathrm{E}-02$ & $2.78 \mathrm{E}-02$ & $2.77 \mathrm{E}-02$ & $2.77 \mathrm{E}-02$ & $2.77 \mathrm{E}-02$ & $2.79 \mathrm{E}-02$ & $2.80 \mathrm{E}-02$ & $2.78 \mathrm{E}-02$ & $2.79 \mathrm{E}-02$ \\
\hline 0.975 & $3.17 \mathrm{E}-02$ & $3.17 \mathrm{E}-02$ & $3.17 \mathrm{E}-02$ & $3.17 \mathrm{E}-02$ & $3.17 \mathrm{E}-02$ & $3.17 \mathrm{E}-02$ & $3.17 \mathrm{E}-02$ & $3.18 \mathrm{E}-02$ & $3.17 \mathrm{E}-02$ & $3.18 \mathrm{E}-02$ \\
\hline 0.99 & $3.96 \mathrm{E}-02$ & $3.96 \mathrm{E}-02$ & $3.96 \mathrm{E}-02$ & $3.96 \mathrm{E}-02$ & $3.96 \mathrm{E}-02$ & $3.96 \mathrm{E}-02$ & $3.96 \mathrm{E}-02$ & $3.96 \mathrm{E}-02$ & $3.93 \mathrm{E}-02$ & $3.93 \mathrm{E}-02$ \\
\hline
\end{tabular}




\section{Appendix C}

\section{Statistics and Cumulative distribution function of Peak Dose from All Pathways in $\mathrm{mrem} / \mathrm{yr}$ at $1 \mathrm{pCi} / \mathrm{g}$ for 2000 observations and 3 repetitions}

\begin{tabular}{|c|c|c|c|}
\hline Mean & $1.93 \mathrm{E}-02$ & $1.93 \mathrm{E}-02$ & $1.93 \mathrm{E}-02$ \\
\hline Std. Dev. & $1.15 \mathrm{E}-02$ & $1.15 \mathrm{E}-02$ & $1.15 \mathrm{E}-02$ \\
\hline Minimum & $2.32 \mathrm{E}-03$ & $2.32 \mathrm{E}-03$ & $2.32 \mathrm{E}-03$ \\
\hline Maximum & $1.10 \mathrm{E}-01$ & $1.10 \mathrm{E}-01$ & $1.10 \mathrm{E}-01$ \\
\hline \multicolumn{4}{|l|}{ Percentile } \\
\hline 0.01 & $3.34 \mathrm{E}-03$ & $3.34 \mathrm{E}-03$ & $3.34 \mathrm{E}-03$ \\
\hline 0.025 & $4.35 \mathrm{E}-03$ & $4.35 \mathrm{E}-03$ & $4.35 \mathrm{E}-03$ \\
\hline 0.05 & 5.33E-03 & $5.33 \mathrm{E}-03$ & $5.33 \mathrm{E}-03$ \\
\hline 0.075 & $6.31 \mathrm{E}-03$ & $6.31 \mathrm{E}-03$ & $6.31 \mathrm{E}-03$ \\
\hline 0.1 & $6.99 \mathrm{E}-03$ & $6.99 \mathrm{E}-03$ & $6.99 \mathrm{E}-03$ \\
\hline 0.125 & 7.70E-03 & $7.70 \mathrm{E}-03$ & $7.70 \mathrm{E}-03$ \\
\hline 0.15 & $8.32 \mathrm{E}-03$ & $8.32 \mathrm{E}-03$ & $8.32 \mathrm{E}-03$ \\
\hline 0.175 & $9.03 \mathrm{E}-03$ & $9.03 \mathrm{E}-03$ & $9.03 \mathrm{E}-03$ \\
\hline 0.2 & $9.58 \mathrm{E}-03$ & $9.58 \mathrm{E}-03$ & $9.58 \mathrm{E}-03$ \\
\hline 0.225 & $1.02 \mathrm{E}-02$ & $1.02 \mathrm{E}-02$ & $1.02 \mathrm{E}-02$ \\
\hline 0.25 & $1.09 \mathrm{E}-02$ & $1.09 \mathrm{E}-02$ & $1.09 \mathrm{E}-02$ \\
\hline 0.275 & $1.15 \mathrm{E}-02$ & $1.15 \mathrm{E}-02$ & $1.15 \mathrm{E}-02$ \\
\hline 0.3 & $1.21 \mathrm{E}-02$ & $1.21 \mathrm{E}-02$ & $1.21 \mathrm{E}-02$ \\
\hline 0.325 & $1.26 \mathrm{E}-02$ & $1.26 \mathrm{E}-02$ & $1.26 \mathrm{E}-02$ \\
\hline 0.35 & $1.31 \mathrm{E}-02$ & $1.31 \mathrm{E}-02$ & $1.31 \mathrm{E}-02$ \\
\hline 0.375 & $1.37 \mathrm{E}-02$ & $1.37 \mathrm{E}-02$ & $1.37 \mathrm{E}-02$ \\
\hline 0.4 & $1.43 \mathrm{E}-02$ & $1.43 \mathrm{E}-02$ & $1.43 \mathrm{E}-02$ \\
\hline 0.425 & $1.49 \mathrm{E}-02$ & $1.48 \mathrm{E}-02$ & $1.49 \mathrm{E}-02$ \\
\hline 0.45 & $1.54 \mathrm{E}-02$ & $1.54 \mathrm{E}-02$ & $1.54 \mathrm{E}-02$ \\
\hline 0.475 & $1.61 \mathrm{E}-02$ & $1.61 \mathrm{E}-02$ & $1.61 \mathrm{E}-02$ \\
\hline 0.5 & $1.69 \mathrm{E}-02$ & $1.68 \mathrm{E}-02$ & $1.69 \mathrm{E}-02$ \\
\hline 0.525 & $1.76 \mathrm{E}-02$ & $1.75 \mathrm{E}-02$ & $1.75 \mathrm{E}-02$ \\
\hline 0.55 & $1.83 \mathrm{E}-02$ & $1.83 \mathrm{E}-02$ & $1.83 \mathrm{E}-02$ \\
\hline 0.575 & $1.90 \mathrm{E}-02$ & $1.89 \mathrm{E}-02$ & $1.90 \mathrm{E}-02$ \\
\hline 0.6 & $1.97 \mathrm{E}-02$ & $1.97 \mathrm{E}-02$ & $1.97 \mathrm{E}-02$ \\
\hline 0.625 & $2.05 \mathrm{E}-02$ & $2.04 \mathrm{E}-02$ & $2.04 \mathrm{E}-02$ \\
\hline 0.65 & $2.13 \mathrm{E}-02$ & $2.12 \mathrm{E}-02$ & $2.12 \mathrm{E}-02$ \\
\hline 0.675 & $2.21 \mathrm{E}-02$ & $2.21 \mathrm{E}-02$ & $2.21 \mathrm{E}-02$ \\
\hline 0.7 & $2.31 \mathrm{E}-02$ & $2.31 \mathrm{E}-02$ & $2.31 \mathrm{E}-02$ \\
\hline 0.725 & $2.41 \mathrm{E}-02$ & $2.41 \mathrm{E}-02$ & $2.41 \mathrm{E}-02$ \\
\hline 0.75 & $2.55 \mathrm{E}-02$ & $2.54 \mathrm{E}-02$ & $2.55 \mathrm{E}-02$ \\
\hline 0.775 & $2.67 \mathrm{E}-02$ & $2.67 \mathrm{E}-02$ & $2.67 \mathrm{E}-02$ \\
\hline 0.8 & $2.81 \mathrm{E}-02$ & $2.81 \mathrm{E}-02$ & $2.81 \mathrm{E}-02$ \\
\hline
\end{tabular}




\begin{tabular}{|l|l|l|l|}
\hline 0.825 & $2.93 \mathrm{E}-02$ & $2.93 \mathrm{E}-02$ & $2.93 \mathrm{E}-02$ \\
\hline 0.85 & $3.09 \mathrm{E}-02$ & $3.09 \mathrm{E}-02$ & $3.09 \mathrm{E}-02$ \\
\hline 0.875 & $3.31 \mathrm{E}-02$ & $3.31 \mathrm{E}-02$ & $3.31 \mathrm{E}-02$ \\
\hline 0.9 & $3.49 \mathrm{E}-02$ & $3.49 \mathrm{E}-02$ & $3.49 \mathrm{E}-02$ \\
\hline 0.925 & $3.78 \mathrm{E}-02$ & $3.77 \mathrm{E}-02$ & $3.78 \mathrm{E}-02$ \\
\hline 0.95 & $4.11 \mathrm{E}-02$ & $4.11 \mathrm{E}-02$ & $4.11 \mathrm{E}-02$ \\
\hline 0.975 & $4.65 \mathrm{E}-02$ & $4.65 \mathrm{E}-02$ & $4.65 \mathrm{E}-02$ \\
\hline 0.99 & $5.80 \mathrm{E}-02$ & $5.80 \mathrm{E}-02$ & $5.80 \mathrm{E}-02$ \\
\hline
\end{tabular}




\title{
Quality Control (QC) for Dose Modeling Evaluations and Technical Support Document for the Authorized Limits Request for the C-746-U Landfill at the Paducah Gaseous Diffusion Plant, Paducah, Kentucky \\ (Oak Ridge Institute for Science and Education, May 2011)
}

\author{
By \\ John A. Volpe, Ph.D. \\ Performance Results Corporation
}

Disclaimer-This document was not developed by ORISE; it is included as an appendix per the request of DOE - PPPO as additional documentation in support of the DOE-PPPO Authorized Limits Request for the C - 746 - U Landfill at the Paducah Gaseous Diffusion Plant. 
THIS PAGE INTENTIONALLY LEFT BLANK 
July 21,2011

Dr. Richard R. Bonczek

U.S. Department of Energy

Portsmouth/Paducah Project Office

1017 Majestic Drive

Lexington, KY 40513

\section{Subject: Quality Control (QC) for Dose Modeling Evaluations and Technical Support Document for the Authorized Limits Request for the C-746-U Landfill at the Paducah Gaseous Diffusion Plant, Paducah, Kentucky (Oak Ridge Institute for Science and Education, May 2011)}

Dear Dr. Bonczek:

RESRAD and RESRAD OFFSITE outputs are provided in Attachment 1 utilizing the input parameters in Attachment 2 provided and used by the Oak Ridge Institute for Science and Education (ORISE) for development of single radionuclide soil guidelines for the C-746-U Landfill at the Paducah Gaseous Diffusion Plant, Paducah, Kentucky (ORISE, May 2011). Quality Control was conducted for all scenarios assessed by ORISE.

The Quality Control RESRAD and RESRAD OFFSITE results were checked against Table 6.1 of the ORISE May 2011 document. The only observed difference was in the output for the onsite Resident Farmer. However, these difference are minor and do not impact the final Single Radionuclide Soil Guidelines.

If you have question regarding the QC, please contact me at 502-330-0222.

Sincerely,

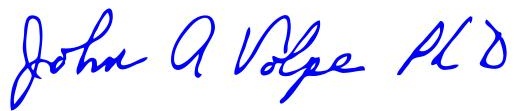

John A. Volpe, Ph.D.

Executive Management Consultant

Performance Results Corporation

Attachments

C: Tim Ecklelard, PRC 
ATTACHMENT 1 
RESRAD, Version $6.5 \quad T^{13 / 2}$ Limit $=180$ days

Summary : RESRAD Parameters for U-Landfill Trespasser

File : C: $\backslash$ RESRAD_FAMILY $\backslash$ RESRAD \USERFILES $\backslash Q C F O R S R S G \backslash T R E S P A S S E R \_S R S G-70$ YRS.RAD

Table of Contents

Part I: Mixture Sums and Single Radionuclide Guidelines

Dose Conversion Factor (and Related) Parameter Summary ... 2

Site-Specific Parameter Summary ................ 8

Summary of Pathway Selections .................... 18

Contaminated Zone and Total Dose Summary ............. 19

Total Dose Components

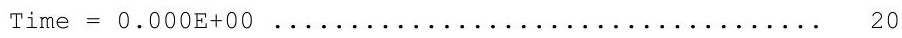

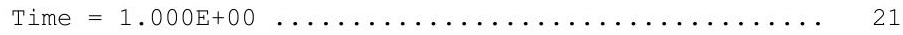

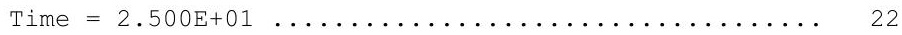

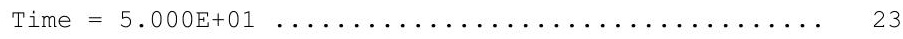

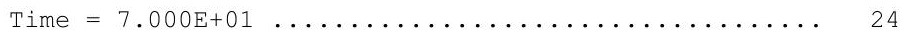

Dose/Source Ratios Summed Over All Pathways ........... 25

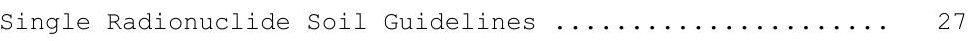

Dose Per Nuclide Summed Over All Pathways ............ 28

Soil Concentration Per Nuclide ................ 30 
Summary : RESRAD Parameters for U-Landfill Trespasser

File : C: \RESRAD_FAMILY \RESRAD \USERFILES \QCFORSRSG \TRESPASSER_SRSG-70YRS.RAD

Dose Conversion Factor (and Related) Parameter Summary

Dose Library: ICRP 60 \& ICRP 72 (Adult)

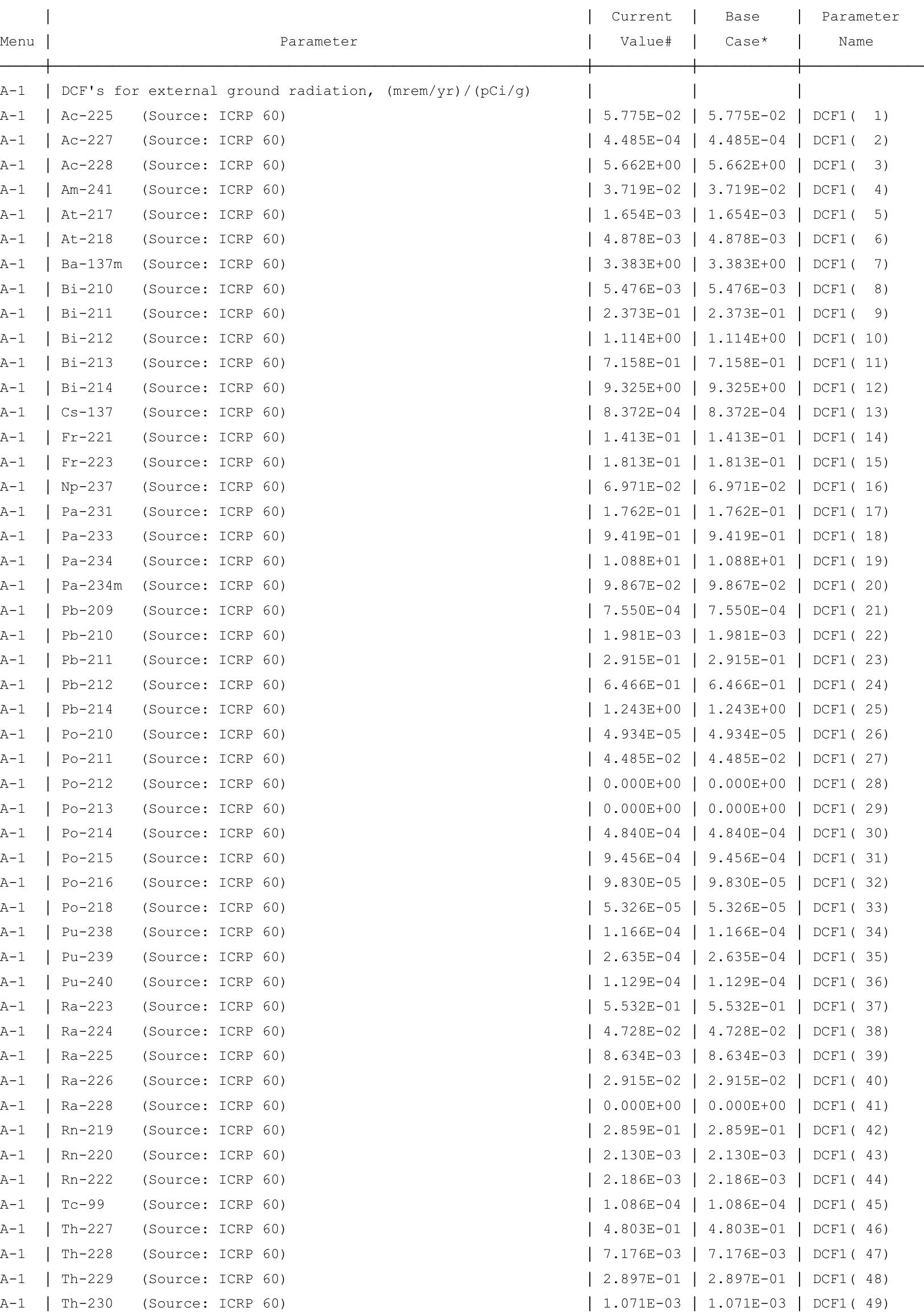


RESRAD, Version $6.5 \quad \mathrm{~T}^{1 / 2}$ Limit $=180$ days

Summary : RESRAD Parameters for U-Landfill Trespasser

File : C: \RESRAD_FAMILY \RESRAD \USERFILES \QCFORSRSG \TRESPASSER_SRSG-70YRS.RAD

Dose Conversion Factor (and Related) Parameter Summary (continued) Dose Library: ICRP 60 \& ICRP 72 (Adult)

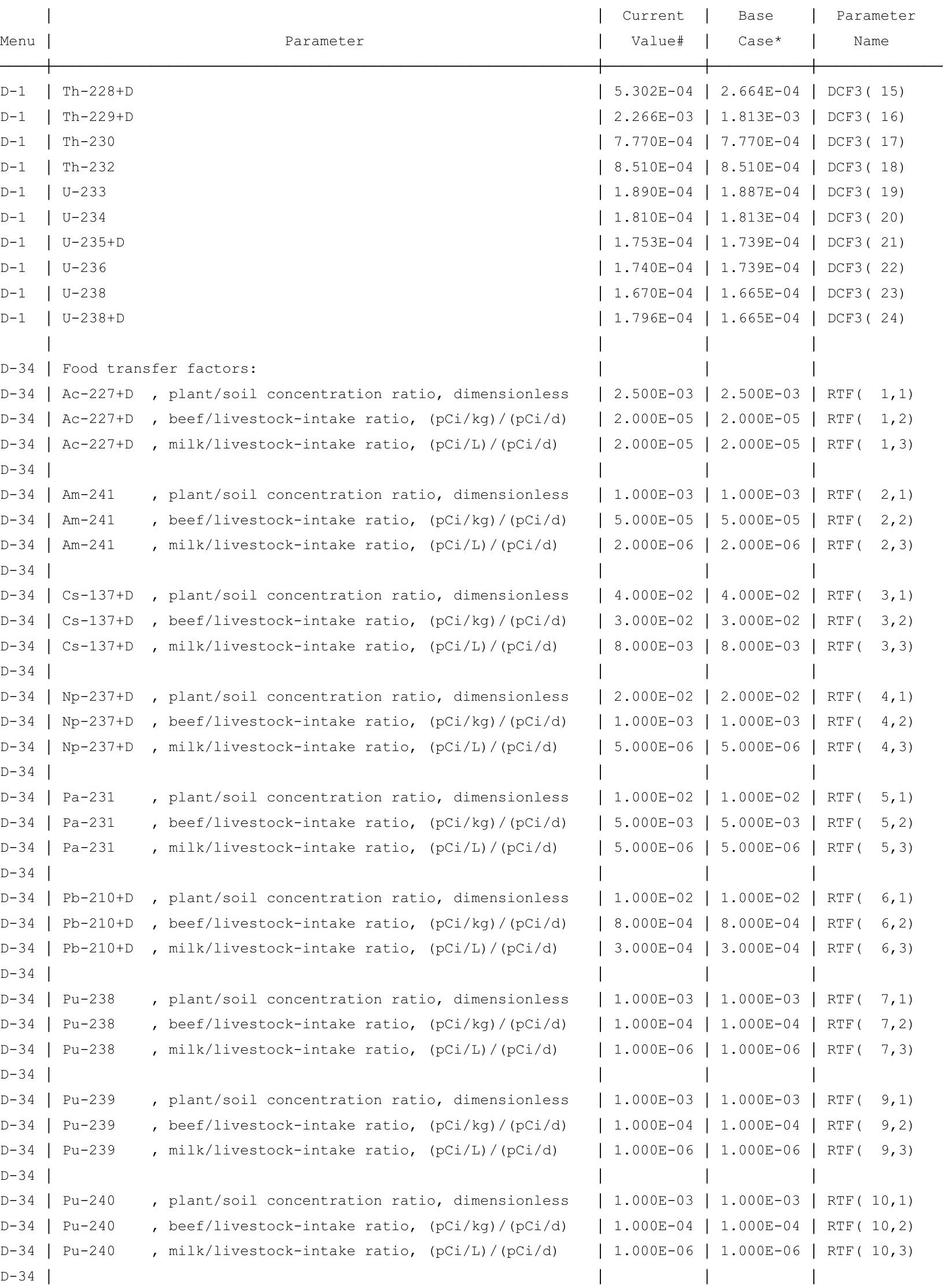


RESRAD, Version $6.5 \quad \mathrm{~T}^{1} 1 / 2$ Limit $=180$ days

Summary : RESRAD Parameters for U-Landfill Trespasser

File : C: \RESRAD_FAMILY \RESRAD \USERFILES $\backslash Q C F O R S R S G \backslash T R E S P A S S E R \_S R S G-7 O Y R S . R A D$

Site-Specific Parameter Summary (continued)

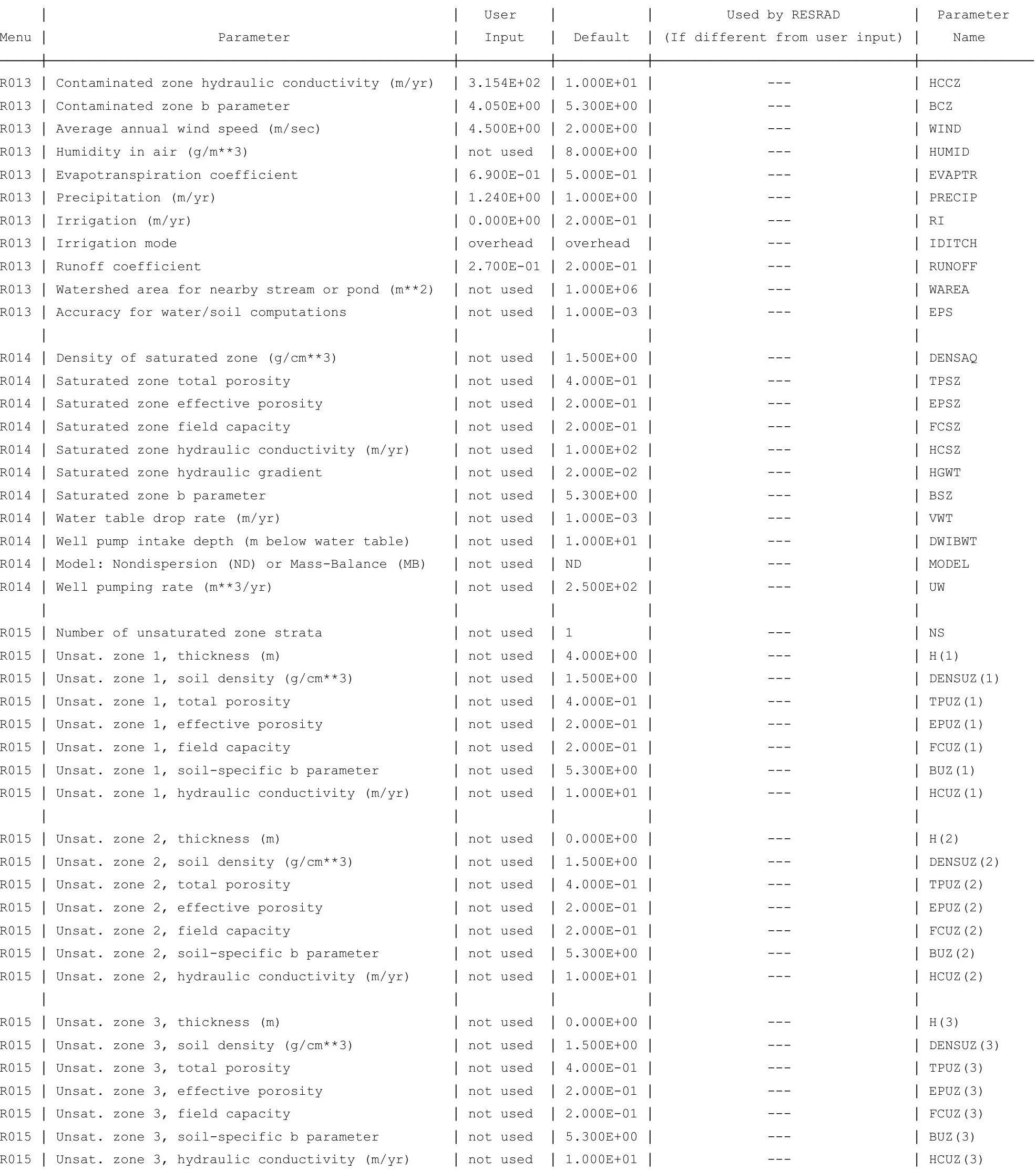


RESRAD, Version $6.5 \quad \mathrm{~T}^{1} \frac{1}{2}$ Limit $=180$ days

Summary : RESRAD Parameters for U-Landfill Trespasser

File : C: \RESRAD_FAMILY \RESRAD \USERFILES \QCFORSRSG TTRESPASSER_SRSG-7OYRS.RAD

Site-Specific Parameter Summary (continued)

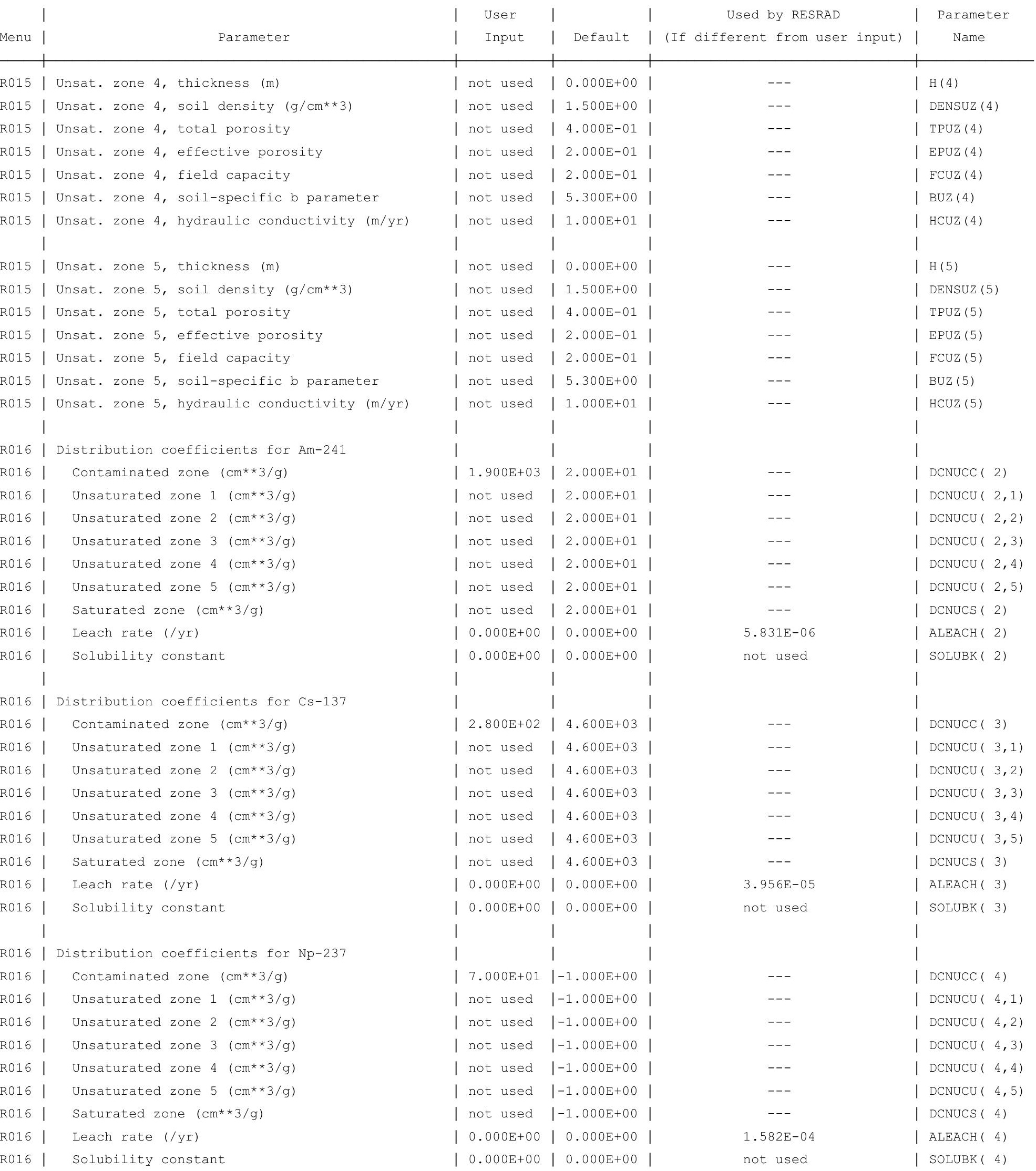


RESRAD, Version $6.5 \quad \mathrm{~T}^{1} 1 / 2$ Limit $=180$ days

Summary : RESRAD Parameters for U-Landfill Trespasser

File : C: \RESRAD_FAMILY \RESRAD UUSERFILES \QCFORSRSG TTRESPASSER_SRSG-7OYRS.RAD

Site-Specific Parameter Summary (continued)

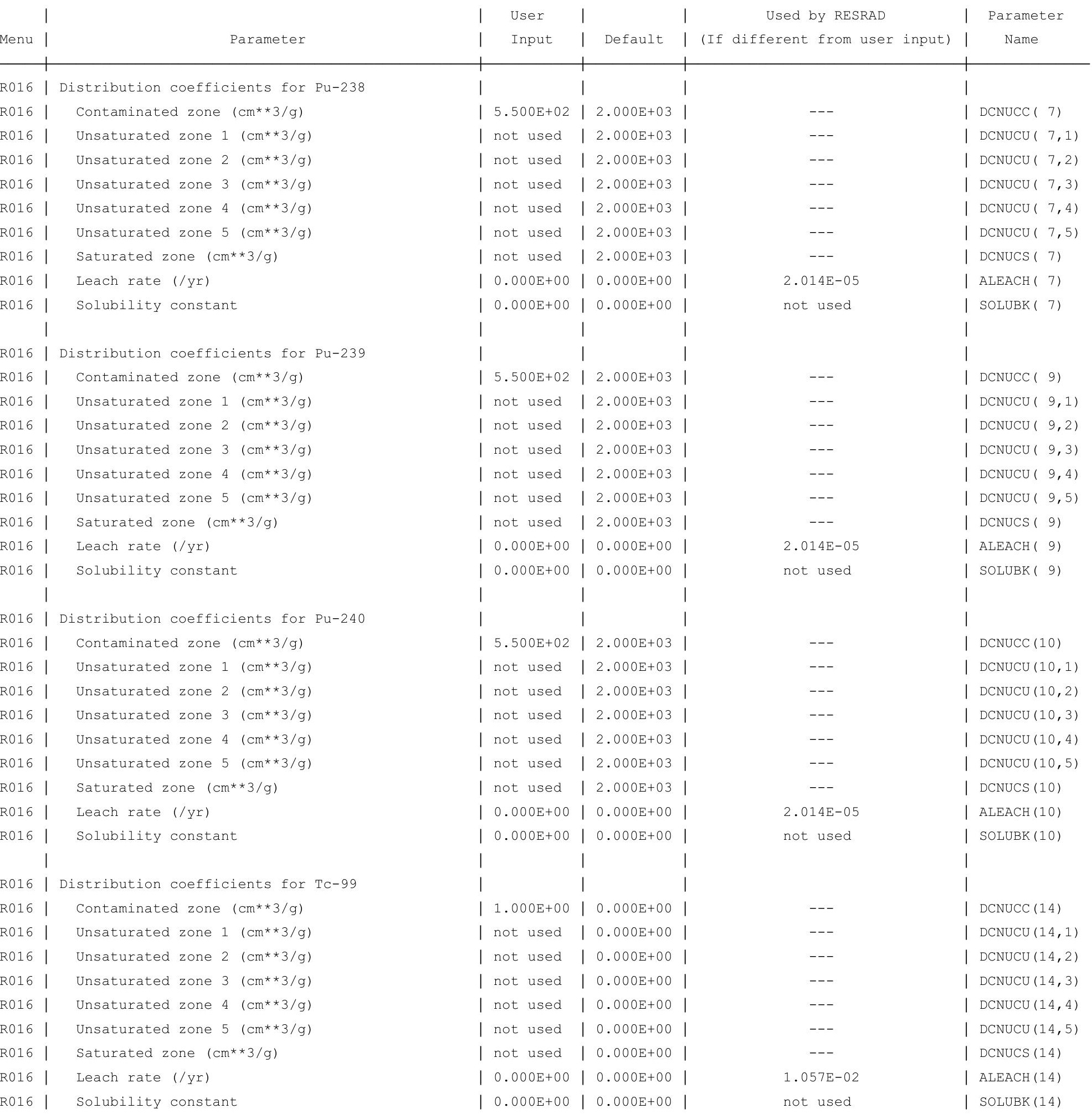


RESRAD, Version $6.5 \quad \mathrm{~T}^{1} 1 / 2$ Limit $=180$ days

Summary : RESRAD Parameters for U-Landfill Trespasser

File : C: \RESRAD_FAMILY \RESRAD \USERFILES \QCFORSRSG \TRESPASSER_SRSG-7OYRS.RAD

Site-Specific Parameter Summary (continued)

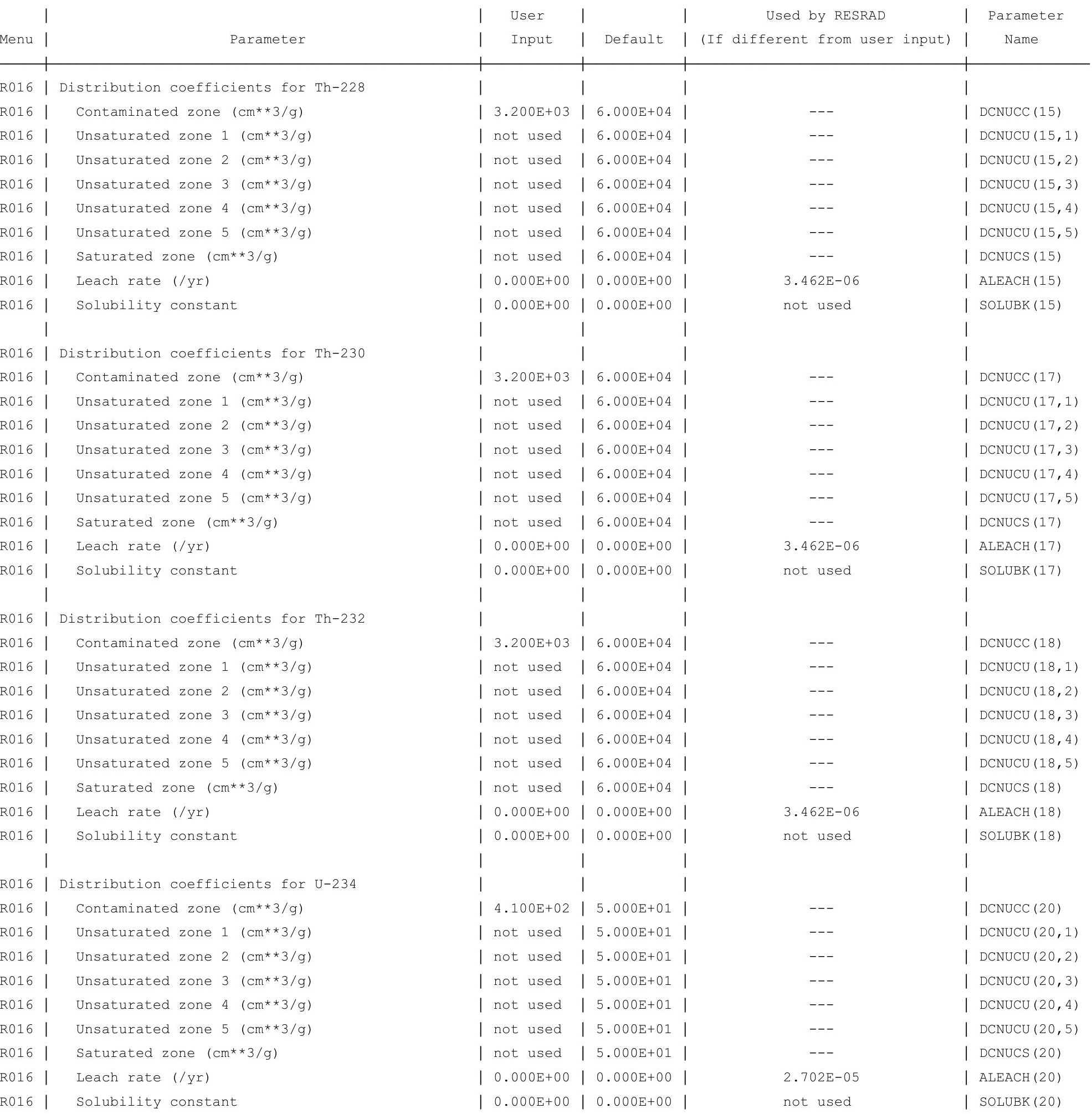


RESRAD, Version $6.5 \quad \mathrm{~T}^{1 / 2}$ Limit $=180$ days

Summary : RESRAD Parameters for U-Landfill Trespasser

File : C: \RESRAD_FAMILY \RESRAD \USERFILES \QCFORSRSG \TRESPASSER_SRSG-7OYRS.RAD

Site-Specific Parameter Summary (continued)

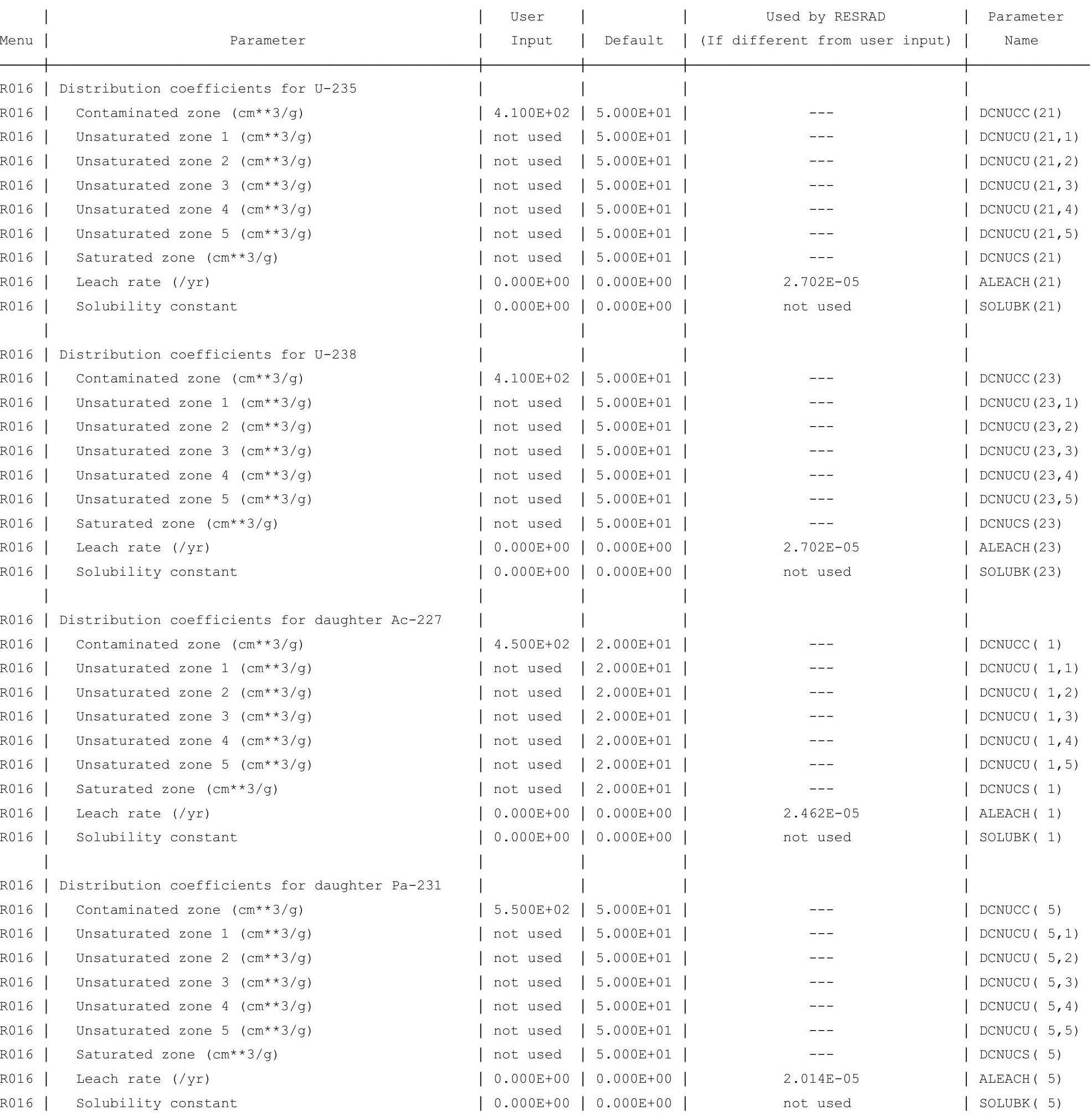


RESRAD, Version $6.5 \quad \mathrm{~T}^{1} 1 / 2$ Limit $=180$ days

Summary : RESRAD Parameters for U-Landfill Trespasser

File : C: \RESRAD_FAMILY \RESRAD \USERFILES \QCFORSRSG \TRESPASSER_SRSG-7OYRS.RAD

Site-Specific Parameter Summary (continued)

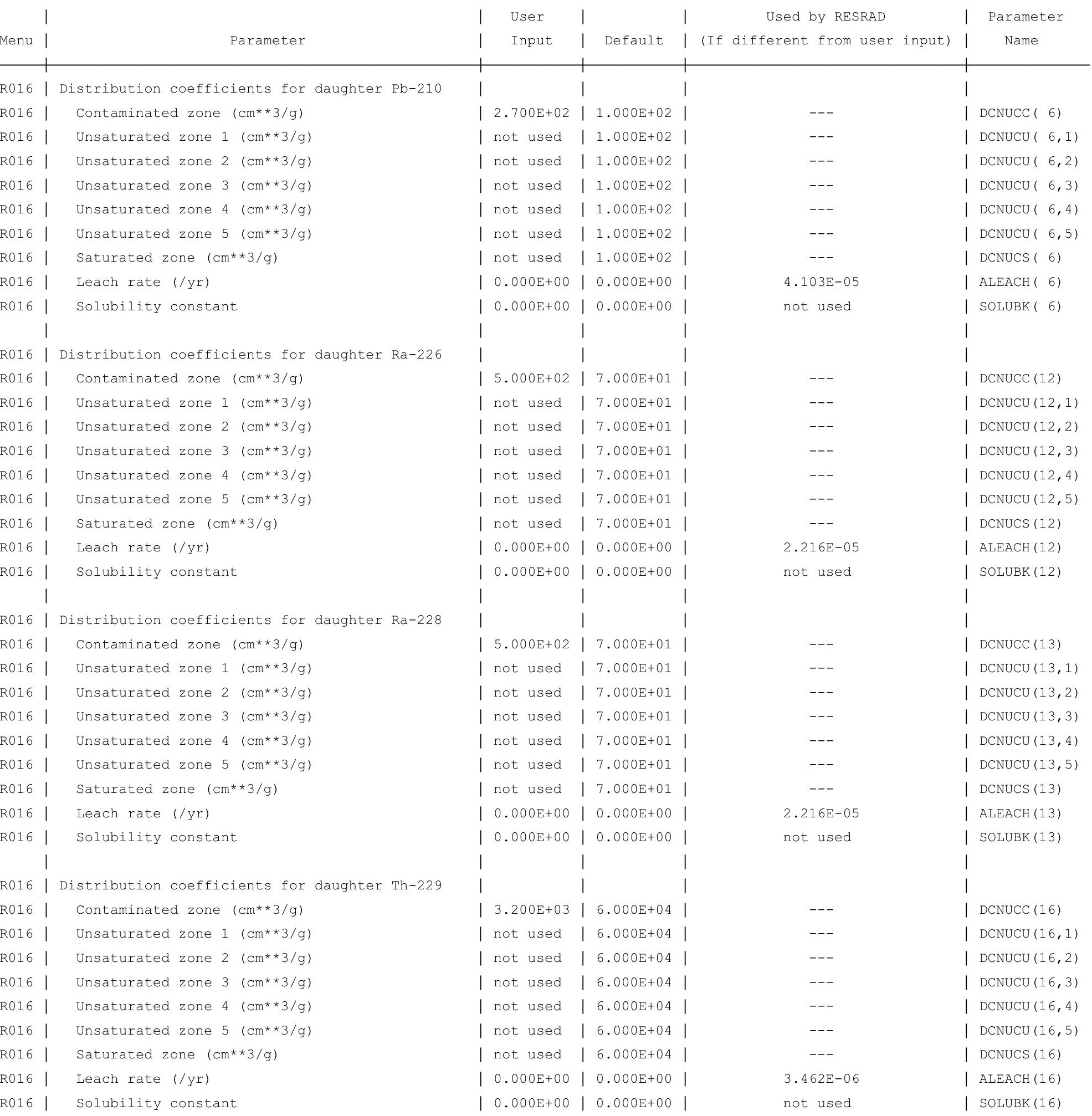


RESRAD, Version $6.5 \quad \mathrm{~T}^{1} \frac{1}{2}$ Limit $=180$ days

Summary : RESRAD Parameters for U-Landfill Trespasser

File : C: \RESRAD_FAMILY \RESRAD \USERFILES \QCFORSRSG $\backslash$ TRESPASSER_SRSG-7OYRS.RAD

Site-Specific Parameter Summary (continued)

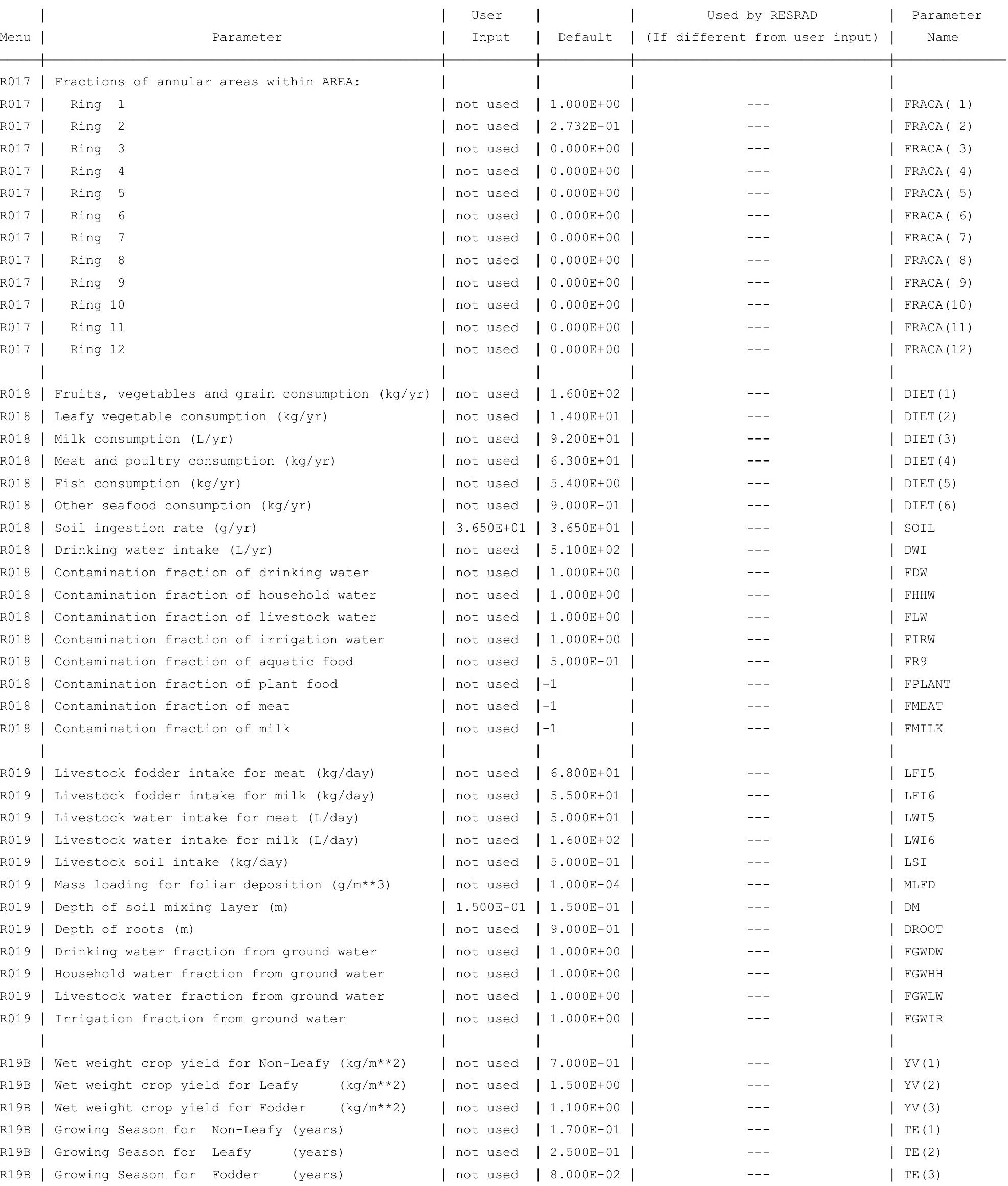


RESRAD, Version $6.5 \quad \mathrm{~T}^{1} 1 / 2$ Limit $=180$ days

Summary : RESRAD Parameters for U-Landfill Trespasser

File : C: $\backslash$ RESRAD_FAMILY $\backslash$ RESRAD $\backslash U S E R F I L E S \backslash Q C F O R S R S G \backslash T R E S P A S S E R \_S R S G-70$ YRS.RAD

Site-Specific Parameter Summary (continued)

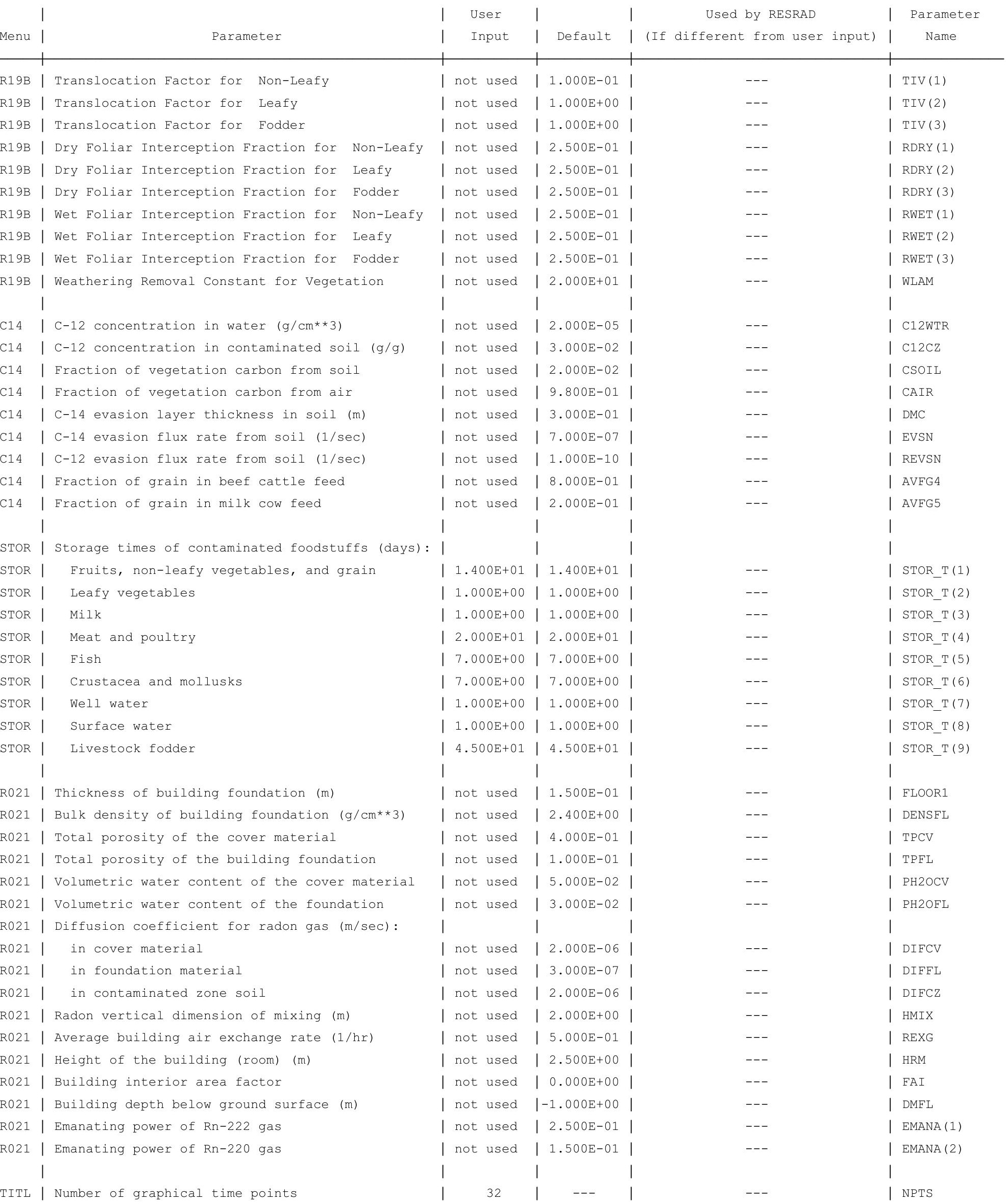

TITL | Number of graphical time points 
RESRAD, Version $6.5 \quad T^{13 / 2}$ Limit $=180$ days

Summary : RESRAD Parameters for U-Landfill Trespasser

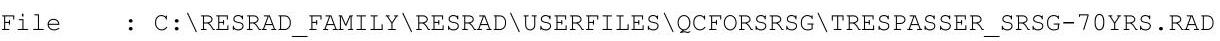

Contaminated Zone Dimensions

Area: 89436.00 square meters

Thickness:

Cover Depth:
Initial Soil Concentrations, pCi/g

$\begin{array}{ll}\mathrm{Am}-241 & 1.000 \mathrm{E}+00 \\ \mathrm{Cs}-137 & 1.000 \mathrm{E}+00 \\ \mathrm{~Np}-237 & 1.000 \mathrm{E}+00 \\ \mathrm{Pu}-238 & 1.000 \mathrm{E}+00 \\ \mathrm{Pu}-239 & 1.000 \mathrm{E}+00 \\ \mathrm{Pu}-240 & 1.000 \mathrm{E}+00 \\ \mathrm{TC}-99 & 1.000 \mathrm{E}+00 \\ \mathrm{Th}-228 & 1.000 \mathrm{E}+00 \\ \mathrm{Th}-230 & 1.000 \mathrm{E}+00 \\ \mathrm{Th}-232 & 1.000 \mathrm{E}+00 \\ \mathrm{U}-234 & 1.000 \mathrm{E}+00 \\ \mathrm{U}-235 & 1.000 \mathrm{E}+00 \\ \mathrm{U}-238 & 1.000 \mathrm{E}+00\end{array}$

Total Dose TDOSE(t), mrem/yr

Basic Radiation Dose Limit $=1.000 \mathrm{E}+02 \mathrm{mrem} / \mathrm{yr}$

Total Mixture Sum $M(t)$ = Fraction of Basic Dose Limit Received at Time (t)
$t$ (years): $0.000 \mathrm{E}+00 \quad 1.000 \mathrm{E}+00 \quad 2.500 \mathrm{E}+01 \quad 5.000 \mathrm{E}+01 \quad 7.000 \mathrm{E}+01$
TDOSE $(t): \begin{array}{lllll}1.188 \mathrm{E}-01 & 1.004 \mathrm{E}-01 & 1.928 \mathrm{E}-01 & 2.374 \mathrm{E}-01 & 2.715 \mathrm{E}-01\end{array}$
$M(t): \begin{array}{lllll}1.188 \mathrm{E}-03 & 1.004 \mathrm{E}-03 & 1.928 \mathrm{E}-03 & 2.374 \mathrm{E}-03 & 2.715 \mathrm{E}-03\end{array}$

Maximum TDOSE $(t): 2.715 \mathrm{E}-01 \mathrm{mrem} / \mathrm{yr}$ at $t=7.000 \mathrm{E}+01$ years 
RESRAD, Version 6.5

$\mathrm{T}^{1 / 2}$ Limit $=180$ days

ummary : RESRAD Parameters for U-Landfill Trespasser

File : C: \RESRAD_FAMILY \RESRAD \USERFILES \QCFORSRSG \TRESPASSER_SRSG-7OYRS.RAD

Total Dose Contributions TDOSE (i,p,t) for Individual Radionuclides (i) and Pathways (p) As mrem/yr and Fraction of Total Dose At $t=0.000 \mathrm{E}+00$ years

Water Independent Pathways (Inhalation excludes radon)

\begin{tabular}{|c|c|c|c|c|c|c|c|c|c|c|c|c|c|c|}
\hline \multirow{2}{*}{ Nuclide } & \multicolumn{2}{|c|}{ Ground } & \multicolumn{2}{|c|}{ Inhalation } & \multicolumn{2}{|c|}{ Radon } & \multicolumn{2}{|c|}{ Plant } & \multicolumn{2}{|c|}{ Meat } & \multicolumn{2}{|c|}{ Milk } & \multicolumn{2}{|c|}{ Soil } \\
\hline & mrem/yr & fract. & mrem/yr & fract. & mrem/yr & fract. & mrem/yr & fract. & mrem/yr & fract. & mrem/yr & fract. & mrem/yr & fract. \\
\hline-241 & $1.457 \mathrm{E}-06$ & 0.0000 & $0.000 \mathrm{E}+00$ & 0.0000 & $0.000 \mathrm{E}+00$ & 0.0000 & $0.000 \mathrm{E}+00$ & 0.0000 & $0.000 \mathrm{E}+00$ & 0.0000 & $0.000 \mathrm{E}+00$ & 0.0000 & $0.000 \mathrm{E}+00$ & 0.0000 \\
\hline-137 & $2.060 \mathrm{E}-02$ & 0.1734 & $0.000 \mathrm{E}+00$ & 0.0000 & $0.000 \mathrm{E}+00$ & 0.0000 & $0.000 \mathrm{E}+00$ & 0.0000 & $0.000 \mathrm{E}+00$ & 0.0000 & $0.000 \mathrm{E}+00$ & 0.0000 & $0.000 \mathrm{E}+00$ & 0.0000 \\
\hline-237 & $3.453 E-03$ & 0.0291 & $0.000 \mathrm{E}+00$ & 0.0000 & $0.000 \mathrm{E}+00$ & 0.0000 & $0.000 \mathrm{E}+00$ & 0.0000 & $0.000 \mathrm{E}+00$ & 0.0000 & $0.000 \mathrm{E}+00$ & 0.0000 & $0.000 \mathrm{E}+00$ & 0.0000 \\
\hline-238 & $2.641 E-08$ & 0.0000 & $0.000 \mathrm{E}+00$ & 0.0000 & $0.000 \mathrm{E}+00$ & 0.0000 & $0.000 \mathrm{E}+00$ & 0.0000 & $0.000 \mathrm{E}+00$ & 0.0000 & $0.000 \mathrm{E}+00$ & 0.0000 & $0.000 \mathrm{E}+00$ & 0.0000 \\
\hline-239 & $6.302 E-07$ & 0.0000 & $0.000 \mathrm{E}+00$ & 0.0000 & $0.000 \mathrm{E}+00$ & 0.0000 & $0.000 \mathrm{E}+00$ & 0.0000 & $0.000 \mathrm{E}+00$ & 0.0000 & $0.000 \mathrm{E}+00$ & 0.0000 & $0.000 \mathrm{E}+00$ & 0.0000 \\
\hline-240 & $2.567 \mathrm{E}-08$ & 0.0000 & $0.000 \mathrm{E}+00$ & 0.0000 & $0.000 \mathrm{E}+00$ & 0.0000 & $0.000 \mathrm{E}+00$ & 0.0000 & $0.000 \mathrm{E}+00$ & 0.0000 & $0.000 \mathrm{E}+00$ & 0.0000 & $0.000 \mathrm{E}+00$ & 0.0000 \\
\hline 99 & $4.063 E-08$ & 0.0000 & $0.000 \mathrm{E}+00$ & 0.0000 & $0.000 \mathrm{E}+00$ & 0.0000 & $0.000 \mathrm{E}+00$ & 0.0000 & $0.000 \mathrm{E}+00$ & 0.0000 & $0.000 \mathrm{E}+00$ & 0.0000 & $0.000 \mathrm{E}+00$ & 0.0000 \\
\hline-228 & $8.889 \mathrm{E}-02$ & 0.7483 & $0.000 \mathrm{E}+00$ & 0.0000 & $0.000 \mathrm{E}+00$ & 0.0000 & $0.000 \mathrm{E}+00$ & 0.0000 & $0.000 \mathrm{E}+00$ & 0.0000 & $0.000 \mathrm{E}+00$ & 0.0000 & $0.000 \mathrm{E}+00$ & 0.0000 \\
\hline 230 & $2.131 \mathrm{E}-05$ & 0.0002 & $0.000 \mathrm{E}+00$ & 0.0000 & $0.000 \mathrm{E}+00$ & 0.0000 & $0.000 \mathrm{E}+00$ & 0.0000 & $0.000 \mathrm{E}+00$ & 0.0000 & $0.000 \mathrm{E}+00$ & 0.0000 & $0.000 \mathrm{E}+00$ & 0.0000 \\
\hline-232 & $3.329 E-03$ & 0.0280 & $0.000 \mathrm{E}+00$ & 0.0000 & $0.000 \mathrm{E}+00$ & 0.0000 & $0.000 \mathrm{E}+00$ & 0.0000 & $0.000 \mathrm{E}+00$ & 0.0000 & $0.000 \mathrm{E}+00$ & 0.0000 & $0.000 \mathrm{E}+00$ & 0.0000 \\
\hline 34 & $1.754 \mathrm{E}-07$ & 0.0000 & $0.000 \mathrm{E}+00$ & 0.0000 & $0.000 \mathrm{E}+00$ & 0.0000 & $0.000 \mathrm{E}+00$ & 0.0000 & $0.000 \mathrm{E}+00$ & 0.0000 & $0.000 \mathrm{E}+00$ & 0.0000 & $0.000 \mathrm{E}+00$ & 0.0000 \\
\hline 35 & $1.627 \mathrm{E}-03$ & 0.0137 & $0.000 \mathrm{E}+00$ & 0.0000 & $0.000 \mathrm{E}+00$ & 0.0000 & $0.000 \mathrm{E}+00$ & 0.0000 & $0.000 \mathrm{E}+00$ & 0.0000 & $0.000 \mathrm{E}+00$ & 0.0000 & $0.000 \mathrm{E}+00$ & 0.0000 \\
\hline 38 & $8.774 \mathrm{E}-04$ & 0.0074 & $0.000 \mathrm{E}+00$ & 0.0000 & $0.000 \mathrm{E}+00$ & 0.0000 & $0.000 \mathrm{E}+00$ & 0.0000 & $0.000 \mathrm{E}+00$ & 0.0000 & $0.000 \mathrm{E}+00$ & 0.0000 & $0.000 \mathrm{E}+00$ & 0.0000 \\
\hline & $1.188 \mathrm{E}-01$ & 1.0000 & $0.000 \mathrm{E}+00$ & 0.0000 & $0.000 \mathrm{E}+00$ & 0.0000 & $0.000 \mathrm{E}+00$ & 0.0000 & $0.000 \mathrm{E}+00$ & 0.0000 & $0.000 \mathrm{E}+00$ & 0.0000 & $.000 \mathrm{E}+00$ & 0.0000 \\
\hline
\end{tabular}

Total Dose Contributions TDOSE(i,p,t) for Individual Radionuclides (i) and Pathways (p) As mrem/yr and Fraction of Total Dose At $t=0.000 \mathrm{E}+00$ years

Water Dependent Pathways

\begin{tabular}{|c|c|c|c|c|c|c|c|c|c|c|c|c|c|c|}
\hline & \multicolumn{2}{|c|}{ Water } & \multicolumn{2}{|c|}{ Fish } & \multicolumn{2}{|c|}{ Radon } & \multicolumn{2}{|c|}{ Plant } & \multicolumn{2}{|c|}{ Meat } & \multicolumn{2}{|c|}{ Milk } & \multicolumn{2}{|c|}{ All Pathways* } \\
\hline clide & mrem/yr & fract. & mrem/yr & fract. & mrem/yr & fract. & mrem/yr & fract. & mrem/yr & fract. & mrem/yr & fract. & mrem/yr & fract. \\
\hline-241 & $0.000 \mathrm{E}+00$ & 0.0000 & $0.000 \mathrm{E}+00$ & 0.0000 & $0.000 \mathrm{E}+00$ & 0.0000 & $0.000 \mathrm{E}+00$ & 0.0000 & $0.000 \mathrm{E}+00$ & 0.0000 & $0.000 \mathrm{E}+00$ & 0.0000 & $1.457 \mathrm{E}-06$ & 0.0000 \\
\hline-137 & $0.000 \mathrm{E}+00$ & 0.0000 & $0.000 \mathrm{E}+00$ & 0.0000 & $0.000 \mathrm{E}+00$ & 0.0000 & $0.000 \mathrm{E}+00$ & 0.0000 & $0.000 \mathrm{E}+00$ & 0.0000 & $0.000 \mathrm{E}+00$ & 0.0000 & $2.060 \mathrm{E}-02$ & 0.1734 \\
\hline-237 & $0.000 \mathrm{E}+00$ & 0.0000 & $0.000 \mathrm{E}+00$ & 0.0000 & $0.000 \mathrm{E}+00$ & 0.0000 & $0.000 \mathrm{E}+00$ & 0.0000 & $0.000 \mathrm{E}+00$ & 0.0000 & $0.000 \mathrm{E}+00$ & 0.0000 & $3.453 E-03$ & 0.0291 \\
\hline 238 & $0.000 \mathrm{E}+00$ & 0.0000 & $0.000 \mathrm{E}+00$ & 0.0000 & $0.000 \mathrm{E}+00$ & 0.0000 & $0.000 \mathrm{E}+00$ & 0.0000 & $0.000 \mathrm{E}+00$ & 0.0000 & $0.000 \mathrm{E}+00$ & 0.0000 & $2.641 \mathrm{E}-08$ & 0.0000 \\
\hline 239 & $0.000 \mathrm{E}+00$ & 0.0000 & $0.000 \mathrm{E}+00$ & 0.0000 & $0.000 \mathrm{E}+00$ & 0.0000 & $0.000 \mathrm{E}+00$ & 0.0000 & $0.000 \mathrm{E}+00$ & 0.0000 & $0.000 \mathrm{E}+00$ & 0.0000 & $6.302 \mathrm{E}-07$ & 0.0000 \\
\hline 240 & $0.000 \mathrm{E}+00$ & 0.0000 & $0.000 \mathrm{E}+00$ & 0.0000 & $0.000 \mathrm{E}+00$ & 0.0000 & $0.000 \mathrm{E}+00$ & 0.0000 & $0.000 \mathrm{E}+00$ & 0.0000 & $0.000 \mathrm{E}+00$ & 0.0000 & $2.567 \mathrm{E}-08$ & 0.0000 \\
\hline 99 & $0.000 \mathrm{E}+00$ & 0.0000 & $0.000 \mathrm{E}+00$ & 0.0000 & $0.000 \mathrm{E}+00$ & 0.0000 & $0.000 \mathrm{E}+00$ & 0.0000 & $0.000 \mathrm{E}+00$ & 0.0000 & $0.000 \mathrm{E}+00$ & 0.0000 & $4.063 E-08$ & 0.0000 \\
\hline 228 & $0.000 \mathrm{E}+00$ & 0.0000 & $0.000 \mathrm{E}+00$ & 0.0000 & $0.000 \mathrm{E}+00$ & 0.0000 & $0.000 \mathrm{E}+00$ & 0.0000 & $0.000 \mathrm{E}+00$ & 0.0000 & $0.000 \mathrm{E}+00$ & 0.0000 & $8.889 \mathrm{E}-02$ & 0.7483 \\
\hline 230 & $0.000 \mathrm{E}+00$ & 0.0000 & $0.000 \mathrm{E}+00$ & 0.0000 & $0.000 \mathrm{E}+00$ & 0.0000 & $0.000 \mathrm{E}+00$ & 0.0000 & $0.000 \mathrm{E}+00$ & 0.0000 & $0.000 \mathrm{E}+00$ & 0.0000 & $2.131 \mathrm{E}-05$ & 0.0002 \\
\hline 232 & $0.000 \mathrm{E}+00$ & 0.0000 & $0.000 \mathrm{E}+00$ & 0.0000 & $0.000 \mathrm{E}+00$ & 0.0000 & $0.000 \mathrm{E}+00$ & 0.0000 & $0.000 \mathrm{E}+00$ & 0.0000 & $0.000 \mathrm{E}+00$ & 0.0000 & $3.329 E-03$ & 0.0280 \\
\hline & $0.000 \mathrm{E}+00$ & 0.0000 & $0.000 \mathrm{E}+00$ & 0.0000 & $0.000 \mathrm{E}+00$ & 0.0000 & $0.000 \mathrm{E}+00$ & 0.0000 & $0.000 \mathrm{E}+00$ & 0.0000 & $0.000 \mathrm{E}+00$ & 0.0000 & $1.754 \mathrm{E}-07$ & 0.0000 \\
\hline 35 & $0.000 \mathrm{E}+00$ & 0.0000 & $0.000 \mathrm{E}+00$ & 0.0000 & $0.000 \mathrm{E}+00$ & 0.0000 & $0.000 \mathrm{E}+00$ & 0.0000 & $0.000 \mathrm{E}+00$ & 0.0000 & $0.000 \mathrm{E}+00$ & 0.0000 & $1.627 \mathrm{E}-03$ & 0.0137 \\
\hline 38 & $0.000 \mathrm{E}+00$ & 0.0000 & $0.000 \mathrm{E}+00$ & 0.0000 & $0.000 \mathrm{E}+00$ & 0.0000 & $0.000 \mathrm{E}+00$ & 0.0000 & $0.000 \mathrm{E}+00$ & 0.0000 & $0.000 \mathrm{E}+00$ & 0.0000 & $8.774 \mathrm{E}-04$ & 0.0074 \\
\hline & $0.000 \mathrm{E}+00$ & 0.0000 & $0.000 \mathrm{E}+00$ & 0.0000 & $0.000 \mathrm{E}+00$ & 0.0000 & $0.000 \mathrm{E}+00$ & 0.0000 & $0.000 \mathrm{E}+00$ & 0.0000 & $.000 E+00$ & 000 & -01 & 1.0000 \\
\hline
\end{tabular}

* Sum of all water independent and dependent pathways. 
RESRAD, Version 6.5

$\mathrm{T}^{1 / 2}$ Limit $=180$ days

ummary : RESRAD Parameters for U-Landfill Trespasser

File : C: \RESRAD_FAMILY \RESRAD \USERFILES \QCFORSRSG \TRESPASSER_SRSG-7OYRS.RAD

Total Dose Contributions TDOSE (i,p,t) for Individual Radionuclides (i) and Pathways (p) As mrem/yr and Fraction of Total Dose At $t=1.000 \mathrm{E}+00$ years

Water Independent Pathways (Inhalation excludes radon)

\begin{tabular}{|c|c|c|c|c|c|c|c|c|c|c|c|c|c|c|}
\hline \multirow{2}{*}{ Nuclide } & \multicolumn{2}{|c|}{ Ground } & \multicolumn{2}{|c|}{ Inhalation } & \multicolumn{2}{|c|}{ Radon } & \multicolumn{2}{|c|}{ Plant } & \multicolumn{2}{|c|}{ Meat } & \multicolumn{2}{|c|}{ Milk } & \multicolumn{2}{|c|}{ Soil } \\
\hline & mrem/yr & fract. & mrem/yr & fract. & mrem/yr & fract. & mrem/yr & fract. & mrem/yr & fract. & mrem/yr & fract. & mrem/yr & fract. \\
\hline-241 & $1.498 E-06$ & 0.0000 & $0.000 \mathrm{E}+00$ & 0.0000 & $0.000 \mathrm{E}+00$ & 0.0000 & $0.000 \mathrm{E}+00$ & 0.0000 & $0.000 \mathrm{E}+00$ & 0.0000 & $0.000 \mathrm{E}+00$ & 0.0000 & $0.000 \mathrm{E}+00$ & 0.0000 \\
\hline-137 & $2.029 \mathrm{E}-02$ & 0.2020 & $0.000 \mathrm{E}+00$ & 0.0000 & $0.000 \mathrm{E}+00$ & 0.0000 & $0.000 \mathrm{E}+00$ & 0.0000 & $0.000 \mathrm{E}+00$ & 0.0000 & $0.000 \mathrm{E}+00$ & 0.0000 & $0.000 \mathrm{E}+00$ & 0.0000 \\
\hline-237 & $3.490 \mathrm{E}-03$ & 0.0347 & $0.000 \mathrm{E}+00$ & 0.0000 & $0.000 \mathrm{E}+00$ & 0.0000 & $0.000 \mathrm{E}+00$ & 0.0000 & $0.000 \mathrm{E}+00$ & 0.0000 & $0.000 \mathrm{E}+00$ & 0.0000 & $0.000 \mathrm{E}+00$ & 0.0000 \\
\hline-238 & $2.667 \mathrm{E}-08$ & 0.0000 & $0.000 \mathrm{E}+00$ & 0.0000 & $0.000 \mathrm{E}+00$ & 0.0000 & $0.000 \mathrm{E}+00$ & 0.0000 & $0.000 \mathrm{E}+00$ & 0.0000 & $0.000 \mathrm{E}+00$ & 0.0000 & $0.000 \mathrm{E}+00$ & 0.0000 \\
\hline-239 & $6.378 E-07$ & 0.0000 & $0.000 \mathrm{E}+00$ & 0.0000 & $0.000 \mathrm{E}+00$ & 0.0000 & $0.000 \mathrm{E}+00$ & 0.0000 & $0.000 \mathrm{E}+00$ & 0.0000 & $0.000 \mathrm{E}+00$ & 0.0000 & $0.000 \mathrm{E}+00$ & 0.0000 \\
\hline-240 & $2.612 \mathrm{E}-08$ & 0.0000 & $0.000 \mathrm{E}+00$ & 0.0000 & $0.000 \mathrm{E}+00$ & 0.0000 & $0.000 \mathrm{E}+00$ & 0.0000 & $0.000 \mathrm{E}+00$ & 0.0000 & $0.000 \mathrm{E}+00$ & 0.0000 & $0.000 \mathrm{E}+00$ & 0.0000 \\
\hline 99 & $4.098 E-08$ & 0.0000 & $0.000 \mathrm{E}+00$ & 0.0000 & $0.000 \mathrm{E}+00$ & 0.0000 & $0.000 \mathrm{E}+00$ & 0.0000 & $0.000 \mathrm{E}+00$ & 0.0000 & $0.000 \mathrm{E}+00$ & 0.0000 & $0.000 \mathrm{E}+00$ & 0.0000 \\
\hline-228 & $6.226 \mathrm{E}-02$ & 0.6198 & $0.000 \mathrm{E}+00$ & 0.0000 & $0.000 \mathrm{E}+00$ & 0.0000 & $0.000 \mathrm{E}+00$ & 0.0000 & $0.000 \mathrm{E}+00$ & 0.0000 & $0.000 \mathrm{E}+00$ & 0.0000 & $0.000 \mathrm{E}+00$ & 0.0000 \\
\hline 230 & $6.276 \mathrm{E}-05$ & 0.0006 & $0.000 \mathrm{E}+00$ & 0.0000 & $0.000 \mathrm{E}+00$ & 0.0000 & $0.000 \mathrm{E}+00$ & 0.0000 & $0.000 \mathrm{E}+00$ & 0.0000 & $0.000 \mathrm{E}+00$ & 0.0000 & $0.000 \mathrm{E}+00$ & 0.0000 \\
\hline-232 & $1.181 E-02$ & 0.1176 & $0.000 \mathrm{E}+00$ & 0.0000 & $0.000 \mathrm{E}+00$ & 0.0000 & $0.000 \mathrm{E}+00$ & 0.0000 & $0.000 \mathrm{E}+00$ & 0.0000 & $0.000 \mathrm{E}+00$ & 0.0000 & $0.000 \mathrm{E}+00$ & 0.0000 \\
\hline 34 & $1.789 \mathrm{E}-07$ & 0.0000 & $0.000 \mathrm{E}+00$ & 0.0000 & $0.000 \mathrm{E}+00$ & 0.0000 & $0.000 \mathrm{E}+00$ & 0.0000 & $0.000 \mathrm{E}+00$ & 0.0000 & $0.000 \mathrm{E}+00$ & 0.0000 & $0.000 \mathrm{E}+00$ & 0.0000 \\
\hline 35 & $1.648 E-03$ & 0.0164 & $0.000 \mathrm{E}+00$ & 0.0000 & $0.000 \mathrm{E}+00$ & 0.0000 & $0.000 \mathrm{E}+00$ & 0.0000 & $0.000 \mathrm{E}+00$ & 0.0000 & $0.000 \mathrm{E}+00$ & 0.0000 & $0.000 \mathrm{E}+00$ & 0.0000 \\
\hline 38 & $8.846 E-04$ & 0.0088 & $0.000 \mathrm{E}+00$ & 0.0000 & $0.000 \mathrm{E}+00$ & 0.0000 & $0.000 \mathrm{E}+00$ & 0.0000 & $0.000 \mathrm{E}+00$ & 0.0000 & $0.000 \mathrm{E}+00$ & 0.0000 & $0.000 \mathrm{E}+00$ & 0.0000 \\
\hline & $1.004 \mathrm{E}-01$ & 1.0000 & $0.000 \mathrm{E}+00$ & 0.0000 & $0.000 \mathrm{E}+00$ & 0.0000 & $0.000 \mathrm{E}+00$ & 0.0000 & $0.000 \mathrm{E}+00$ & 0.0000 & $0.000 \mathrm{E}+00$ & 0.0000 & $.000 \mathrm{E}+00$ & 0.0000 \\
\hline
\end{tabular}

Total Dose Contributions TDOSE(i,p,t) for Individual Radionuclides (i) and Pathways (p) As mrem/yr and Fraction of Total Dose At $t=1.000 \mathrm{E}+00$ years

Water Dependent Pathways

\begin{tabular}{|c|c|c|c|c|c|c|c|c|c|c|c|c|c|c|}
\hline \multirow{2}{*}{$\begin{array}{l}\text { Radio- } \\
\text { Nuclide }\end{array}$} & \multicolumn{2}{|c|}{ Water } & \multicolumn{2}{|c|}{ Fish } & \multicolumn{2}{|c|}{ Radon } & \multicolumn{2}{|c|}{ Plant } & \multicolumn{2}{|c|}{ Meat } & \multicolumn{2}{|c|}{ Milk } & \multicolumn{2}{|c|}{ All Pathways* } \\
\hline & mrem/yr & fract. & mrem/yr & fract. & mrem/yr & fract. & mrem/yr & fract. & mrem/yr & fract. & mrem/yr & fract. & mrem/yr & fract. \\
\hline 241 & $0.000 \mathrm{E}+00$ & 0.0000 & $0.000 \mathrm{E}+00$ & 0.0000 & $0.000 \mathrm{E}+00$ & 0.0000 & $0.000 \mathrm{E}+00$ & 0.0000 & $0.000 \mathrm{E}+00$ & 0.0000 & $0.000 \mathrm{E}+00$ & 0.0000 & $1.498 \mathrm{E}-06$ & 0.0000 \\
\hline-137 & $0.000 \mathrm{E}+00$ & 0.0000 & $0.000 \mathrm{E}+00$ & 0.0000 & $0.000 \mathrm{E}+00$ & 0.0000 & $0.000 \mathrm{E}+00$ & 0.0000 & $0.000 \mathrm{E}+00$ & 0.0000 & $0.000 \mathrm{E}+00$ & 0.0000 & $2.029 \mathrm{E}-02$ & 0.2020 \\
\hline-237 & $0.000 \mathrm{E}+00$ & 0.0000 & $0.000 \mathrm{E}+00$ & 0.0000 & $0.000 \mathrm{E}+00$ & 0.0000 & $0.000 \mathrm{E}+00$ & 0.0000 & $0.000 \mathrm{E}+00$ & 0.0000 & $0.000 \mathrm{E}+00$ & 0.0000 & $3.490 \mathrm{E}-03$ & 0.0347 \\
\hline-238 & $0.000 \mathrm{E}+00$ & 0.0000 & $0.000 \mathrm{E}+00$ & 0.0000 & $0.000 \mathrm{E}+00$ & 0.0000 & $0.000 \mathrm{E}+00$ & 0.0000 & $0.000 \mathrm{E}+00$ & 0.0000 & $0.000 \mathrm{E}+00$ & 0.0000 & $2.667 \mathrm{E}-08$ & 0.0000 \\
\hline-239 & $0.000 \mathrm{E}+00$ & 0.0000 & $0.000 \mathrm{E}+00$ & 0.0000 & $0.000 \mathrm{E}+00$ & 0.0000 & $0.000 \mathrm{E}+00$ & 0.0000 & $0.000 \mathrm{E}+00$ & 0.0000 & $0.000 E+00$ & 0.0000 & $6.378 E-07$ & 0.0000 \\
\hline-240 & $0.000 \mathrm{E}+00$ & 0.0000 & $0.000 \mathrm{E}+00$ & 0.0000 & $0.000 \mathrm{E}+00$ & 0.0000 & $0.000 \mathrm{E}+00$ & 0.0000 & $0.000 \mathrm{E}+00$ & 0.0000 & $0.000 E+00$ & 0.0000 & $2.612 \mathrm{E}-08$ & 0.0000 \\
\hline 99 & $0.000 \mathrm{E}+00$ & 0.0000 & $0.000 \mathrm{E}+00$ & 0.0000 & $0.000 \mathrm{E}+00$ & 0.0000 & $0.000 \mathrm{E}+00$ & 0.0000 & $0.000 \mathrm{E}+00$ & 0.0000 & $0.000 \mathrm{E}+00$ & 0.0000 & $4.098 E-08$ & 0.0000 \\
\hline-228 & $0.000 \mathrm{E}+00$ & 0.0000 & $0.000 \mathrm{E}+00$ & 0.0000 & $0.000 \mathrm{E}+00$ & 0.0000 & $0.000 \mathrm{E}+00$ & 0.0000 & $0.000 \mathrm{E}+00$ & 0.0000 & $0.000 \mathrm{E}+00$ & 0.0000 & $6.226 \mathrm{E}-02$ & 0.6198 \\
\hline-230 & $0.000 \mathrm{E}+00$ & 0.0000 & $0.000 \mathrm{E}+00$ & 0.0000 & $0.000 \mathrm{E}+00$ & 0.0000 & $0.000 \mathrm{E}+00$ & 0.0000 & $0.000 \mathrm{E}+00$ & 0.0000 & $0.000 E+00$ & 0.0000 & $6.276 \mathrm{E}-05$ & 0.0006 \\
\hline 232 & $0.000 \mathrm{E}+00$ & 0.0000 & $0.000 \mathrm{E}+00$ & 0.0000 & $0.000 \mathrm{E}+00$ & 0.0000 & $0.000 \mathrm{E}+00$ & 0.0000 & $0.000 \mathrm{E}+00$ & 0.0000 & $0.000 \mathrm{E}+00$ & 0.0000 & $1.181 \mathrm{E}-02$ & 0.1176 \\
\hline 34 & $0.000 \mathrm{E}+00$ & 0.0000 & $0.000 \mathrm{E}+00$ & 0.0000 & $0.000 \mathrm{E}+00$ & 0.0000 & $0.000 \mathrm{E}+00$ & 0.0000 & $0.000 \mathrm{E}+00$ & 0.0000 & $0.000 \mathrm{E}+00$ & 0.0000 & $1.789 \mathrm{E}-07$ & 0.0000 \\
\hline 35 & $0.000 \mathrm{E}+00$ & 0.0000 & $0.000 \mathrm{E}+00$ & 0.0000 & $0.000 \mathrm{E}+00$ & 0.0000 & $0.000 \mathrm{E}+00$ & 0.0000 & $0.000 \mathrm{E}+00$ & 0.0000 & $0.000 \mathrm{E}+00$ & 0.0000 & $1.648 \mathrm{E}-03$ & 0.0164 \\
\hline 38 & $0.000 \mathrm{E}+00$ & 0.0000 & $0.000 \mathrm{E}+00$ & 0.0000 & $0.000 \mathrm{E}+00$ & 0.0000 & $0.000 \mathrm{E}+00$ & 0.0000 & $0.000 \mathrm{E}+00$ & 0.0000 & $0.000 \mathrm{E}+00$ & 0.0000 & $8.846 E-04$ & 0.0088 \\
\hline & $0.000 \mathrm{E}+00$ & 0.0000 & $0.000 \mathrm{E}+00$ & 0.0000 & $0.000 \mathrm{E}+00$ & 0.0000 & $0.000 \mathrm{E}+00$ & 0.0000 & $0.000 \mathrm{E}+00$ & 0.0000 & $0.000 \mathrm{E}+00$ & 0.0000 & $4 E-01$ & 1. \\
\hline
\end{tabular}

* Sum of all water independent and dependent pathways. 
RESRAD, Version 6.5

$\mathrm{T}^{1 / 2}$ Limit $=180$ days

ummary : RESRAD Parameters for U-Landfill Trespasser

File : C: \RESRAD_FAMILY \RESRAD \USERFILES \QCFORSRSG \TRESPASSER_SRSG-7OYRS.RAD

Total Dose Contributions TDOSE (i,p,t) for Individual Radionuclides (i) and Pathways (p) As mrem/yr and Fraction of Total Dose At $t=2.500 \mathrm{E}+01$ years

Water Independent Pathways (Inhalation excludes radon)

\begin{tabular}{|c|c|c|c|c|c|c|c|c|c|c|c|c|c|c|}
\hline \multirow{2}{*}{ Nuclide } & \multicolumn{2}{|c|}{ Ground } & \multicolumn{2}{|c|}{ Inhalation } & \multicolumn{2}{|c|}{ Radon } & \multicolumn{2}{|c|}{ Plant } & \multicolumn{2}{|c|}{ Meat } & \multicolumn{2}{|c|}{ Milk } & \multicolumn{2}{|c|}{ Soil } \\
\hline & mrem/yr & fract. & mrem/yr & fract. & mrem/yr & fract. & mrem/yr & fract. & mrem/yr & fract. & mrem/yr & fract. & mrem/yr & fract. \\
\hline-241 & $2.876 \mathrm{E}-06$ & 0.0000 & $3.639 \mathrm{E}-06$ & 0.0000 & $0.000 \mathrm{E}+00$ & 0.0000 & $0.000 \mathrm{E}+00$ & 0.0000 & $0.000 \mathrm{E}+00$ & 0.0000 & $0.000 \mathrm{E}+00$ & 0.0000 & $1.379 \mathrm{E}-04$ & 0.0007 \\
\hline-137 & $1.426 \mathrm{E}-02$ & 0.0740 & $8.522 \mathrm{E}-10$ & 0.0000 & $0.000 \mathrm{E}+00$ & 0.0000 & $0.000 \mathrm{E}+00$ & 0.0000 & $0.000 \mathrm{E}+00$ & 0.0000 & $0.000 \mathrm{E}+00$ & 0.0000 & $5.176 \mathrm{E}-06$ & 0.0000 \\
\hline-237 & $4.516 \mathrm{E}-03$ & 0.0234 & $1.968 \mathrm{E}-06$ & 0.0000 & $0.000 \mathrm{E}+00$ & 0.0000 & $0.000 \mathrm{E}+00$ & 0.0000 & $0.000 \mathrm{E}+00$ & 0.0000 & $0.000 \mathrm{E}+00$ & 0.0000 & $7.934 \mathrm{E}-05$ & 0.0004 \\
\hline-238 & $3.372 \mathrm{E}-08$ & 0.0000 & $3.552 E-06$ & 0.0000 & $0.000 \mathrm{E}+00$ & 0.0000 & $0.000 \mathrm{E}+00$ & 0.0000 & $0.000 \mathrm{E}+00$ & 0.0000 & $0.000 \mathrm{E}+00$ & 0.0000 & $1.350 \mathrm{E}-04$ & 0.0007 \\
\hline-239 & $8.493 E-07$ & 0.0000 & $4.736 \mathrm{E}-06$ & 0.0000 & $0.000 \mathrm{E}+00$ & 0.0000 & $0.000 \mathrm{E}+00$ & 0.0000 & $0.000 \mathrm{E}+00$ & 0.0000 & $0.000 \mathrm{E}+00$ & 0.0000 & $1.794 \mathrm{E}-04$ & 0.0009 \\
\hline-240 & $3.980 \mathrm{E}-08$ & 0.0000 & $4.726 \mathrm{E}-06$ & 0.0000 & $0.000 \mathrm{E}+00$ & 0.0000 & $0.000 \mathrm{E}+00$ & 0.0000 & $0.000 \mathrm{E}+00$ & 0.0000 & $0.000 \mathrm{E}+00$ & 0.0000 & $1.790 \mathrm{E}-04$ & 0.0009 \\
\hline 99 & $5.038 E-08$ & 0.0000 & 3. $922 \mathrm{E}-10$ & 0.0000 & $0.000 \mathrm{E}+00$ & 0.0000 & $0.000 \mathrm{E}+00$ & 0.0000 & $0.000 \mathrm{E}+00$ & 0.0000 & $0.000 \mathrm{E}+00$ & 0.0000 & $3.514 \mathrm{E}-07$ & 0.0000 \\
\hline-228 & $1.209 \mathrm{E}-05$ & 0.0001 & $1.682 \mathrm{E}-10$ & 0.0000 & $0.000 \mathrm{E}+00$ & 0.0000 & $0.000 \mathrm{E}+00$ & 0.0000 & $0.000 \mathrm{E}+00$ & 0.0000 & $0.000 \mathrm{E}+00$ & 0.0000 & $1.004 \mathrm{E}-08$ & 0.0000 \\
\hline 230 & 1. $243 E-03$ & 0.0064 & $3.956 \mathrm{E}-06$ & 0.0000 & $0.000 \mathrm{E}+00$ & 0.0000 & $0.000 \mathrm{E}+00$ & 0.0000 & $0.000 \mathrm{E}+00$ & 0.0000 & $0.000 \mathrm{E}+00$ & 0.0000 & $1.577 \mathrm{E}-04$ & 0.0008 \\
\hline-232 & $1.677 \mathrm{E}-01$ & 0.8700 & $6.554 \mathrm{E}-06$ & 0.0000 & $0.000 \mathrm{E}+00$ & 0.0000 & $0.000 \mathrm{E}+00$ & 0.0000 & $0.000 \mathrm{E}+00$ & 0.0000 & $0.000 \mathrm{E}+00$ & 0.0000 & $7.335 \mathrm{E}-04$ & 0.0038 \\
\hline 34 & $4.159 \mathrm{E}-07$ & 0.0000 & $3.723 E-07$ & 0.0000 & $0.000 \mathrm{E}+00$ & 0.0000 & $0.000 \mathrm{E}+00$ & 0.0000 & $0.000 \mathrm{E}+00$ & 0.0000 & $0.000 \mathrm{E}+00$ & 0.0000 & $3.516 \mathrm{E}-05$ & 0.0002 \\
\hline 35 & $2.222 \mathrm{E}-03$ & 0.0115 & $3.430 \mathrm{E}-07$ & 0.0000 & $0.000 \mathrm{E}+00$ & 0.0000 & $0.000 \mathrm{E}+00$ & 0.0000 & $0.000 \mathrm{E}+00$ & 0.0000 & $0.000 \mathrm{E}+00$ & 0.0000 & $3.443 E-05$ & 0.0002 \\
\hline 38 & $1.075 E-03$ & 0.0056 & $3.162 \mathrm{E}-07$ & 0.0000 & $0.000 \mathrm{E}+00$ & 0.0000 & $0.000 \mathrm{E}+00$ & 0.0000 & $0.000 \mathrm{E}+00$ & 0.0000 & $0.000 \mathrm{E}+00$ & 0.0000 & $3.485 E-05$ & 0.0002 \\
\hline & $1.911 \mathrm{E}-01$ & 0.9910 & $3.016 \mathrm{E}-05$ & 0.0002 & $0.000 \mathrm{E}+00$ & 0.0000 & $0.000 \mathrm{E}+00$ & 0.0000 & $0.000 \mathrm{E}+00$ & 0.0000 & $0.000 \mathrm{E}+00$ & 0.0000 & $1.712 \mathrm{E}-03$ & 0.0089 \\
\hline
\end{tabular}

Total Dose Contributions TDOSE(i,p,t) for Individual Radionuclides (i) and Pathways (p) As mrem/yr and Fraction of Total Dose At $t=2.500 \mathrm{E}+01$ years

Water Dependent Pathways

\begin{tabular}{|c|c|c|c|c|c|c|c|c|c|c|c|c|c|c|}
\hline \multirow{2}{*}{$\begin{array}{l}\text { Radio- } \\
\text { Nuclide }\end{array}$} & \multicolumn{2}{|c|}{ Water } & \multicolumn{2}{|c|}{ Fish } & \multicolumn{2}{|c|}{ Radon } & \multicolumn{2}{|c|}{ Plant } & \multicolumn{2}{|c|}{ Meat } & \multicolumn{2}{|c|}{ Milk } & \multicolumn{2}{|c|}{ All Pathways* } \\
\hline & mrem/yr & fract. & mrem/yr & fract. & mrem/yr & fract. & mrem/yr & fract. & mrem/yr & fract. & mrem/yr & fract. & mrem/yr & fract. \\
\hline 241 & $0.000 \mathrm{E}+00$ & 0.0000 & $0.000 \mathrm{E}+00$ & 0.0000 & $0.000 \mathrm{E}+00$ & 0.0000 & $0.000 \mathrm{E}+00$ & 0.0000 & $0.000 \mathrm{E}+00$ & 0.0000 & $0.000 \mathrm{E}+00$ & 0.0000 & $1.444 \mathrm{E}-04$ & 0.0007 \\
\hline-137 & $0.000 \mathrm{E}+00$ & 0.0000 & $0.000 \mathrm{E}+00$ & 0.0000 & $0.000 \mathrm{E}+00$ & 0.0000 & $0.000 \mathrm{E}+00$ & 0.0000 & $0.000 \mathrm{E}+00$ & 0.0000 & $0.000 \mathrm{E}+00$ & 0.0000 & $1.426 \mathrm{E}-02$ & 0.0740 \\
\hline-237 & $0.000 \mathrm{E}+00$ & 0.0000 & $0.000 \mathrm{E}+00$ & 0.0000 & $0.000 \mathrm{E}+00$ & 0.0000 & $0.000 \mathrm{E}+00$ & 0.0000 & $0.000 \mathrm{E}+00$ & 0.0000 & $0.000 \mathrm{E}+00$ & 0.0000 & $4.597 \mathrm{E}-03$ & 0.0238 \\
\hline-238 & $0.000 \mathrm{E}+00$ & 0.0000 & $0.000 \mathrm{E}+00$ & 0.0000 & $0.000 \mathrm{E}+00$ & 0.0000 & $0.000 \mathrm{E}+00$ & 0.0000 & $0.000 \mathrm{E}+00$ & 0.0000 & $0.000 \mathrm{E}+00$ & 0.0000 & $1.386 \mathrm{E}-04$ & 0.0007 \\
\hline-239 & $0.000 \mathrm{E}+00$ & 0.0000 & $0.000 \mathrm{E}+00$ & 0.0000 & $0.000 \mathrm{E}+00$ & 0.0000 & $0.000 \mathrm{E}+00$ & 0.0000 & $0.000 \mathrm{E}+00$ & 0.0000 & $0.000 E+00$ & 0.0000 & $1.850 \mathrm{E}-04$ & 0.0010 \\
\hline-240 & $0.000 \mathrm{E}+00$ & 0.0000 & $0.000 \mathrm{E}+00$ & 0.0000 & $0.000 \mathrm{E}+00$ & 0.0000 & $0.000 \mathrm{E}+00$ & 0.0000 & $0.000 \mathrm{E}+00$ & 0.0000 & $0.000 E+00$ & 0.0000 & $1.838 \mathrm{E}-04$ & 0.0010 \\
\hline 99 & $0.000 \mathrm{E}+00$ & 0.0000 & $0.000 \mathrm{E}+00$ & 0.0000 & $0.000 \mathrm{E}+00$ & 0.0000 & $0.000 \mathrm{E}+00$ & 0.0000 & $0.000 \mathrm{E}+00$ & 0.0000 & $0.000 \mathrm{E}+00$ & 0.0000 & $4.022 \mathrm{E}-07$ & 0.0000 \\
\hline-228 & $0.000 \mathrm{E}+00$ & 0.0000 & $0.000 \mathrm{E}+00$ & 0.0000 & $0.000 \mathrm{E}+00$ & 0.0000 & $0.000 \mathrm{E}+00$ & 0.0000 & $0.000 \mathrm{E}+00$ & 0.0000 & $0.000 \mathrm{E}+00$ & 0.0000 & $1.210 \mathrm{E}-05$ & 0.0001 \\
\hline-230 & $0.000 \mathrm{E}+00$ & 0.0000 & $0.000 \mathrm{E}+00$ & 0.0000 & $0.000 \mathrm{E}+00$ & 0.0000 & $0.000 \mathrm{E}+00$ & 0.0000 & $0.000 \mathrm{E}+00$ & 0.0000 & $0.000 E+00$ & 0.0000 & $1.405 \mathrm{E}-03$ & 0.0073 \\
\hline 232 & $0.000 \mathrm{E}+00$ & 0.0000 & $0.000 \mathrm{E}+00$ & 0.0000 & $0.000 \mathrm{E}+00$ & 0.0000 & $0.000 \mathrm{E}+00$ & 0.0000 & $0.000 \mathrm{E}+00$ & 0.0000 & $0.000 \mathrm{E}+00$ & 0.0000 & $1.685 \mathrm{E}-01$ & 0.8738 \\
\hline 34 & $0.000 \mathrm{E}+00$ & 0.0000 & $0.000 \mathrm{E}+00$ & 0.0000 & $0.000 \mathrm{E}+00$ & 0.0000 & $0.000 \mathrm{E}+00$ & 0.0000 & $0.000 \mathrm{E}+00$ & 0.0000 & $0.000 \mathrm{E}+00$ & 0.0000 & $3.594 \mathrm{E}-05$ & 0.0002 \\
\hline 35 & $0.000 \mathrm{E}+00$ & 0.0000 & $0.000 \mathrm{E}+00$ & 0.0000 & $0.000 \mathrm{E}+00$ & 0.0000 & $0.000 \mathrm{E}+00$ & 0.0000 & $0.000 \mathrm{E}+00$ & 0.0000 & $0.000 \mathrm{E}+00$ & 0.0000 & $2.256 \mathrm{E}-03$ & 0.0117 \\
\hline 38 & $0.000 \mathrm{E}+00$ & 0.0000 & $0.000 \mathrm{E}+00$ & 0.0000 & $0.000 \mathrm{E}+00$ & 0.0000 & $0.000 \mathrm{E}+00$ & 0.0000 & $0.000 \mathrm{E}+00$ & 0.0000 & $0.000 \mathrm{E}+00$ & 0.0000 & 1.110E-03 & 0.0058 \\
\hline & $0.000 \mathrm{E}+00$ & 0.0000 & $0.000 \mathrm{E}+00$ & 0.0000 & $0.000 \mathrm{E}+00$ & 0.0000 & $0.000 \mathrm{E}+00$ & 0.0000 & $0.000 \mathrm{E}+00$ & 0.0000 & $0.000 \mathrm{E}+00$ & 0.0000 & -01 & 1. \\
\hline
\end{tabular}

* Sum of all water independent and dependent pathways. 
RESRAD, Version 6.5

$\mathrm{T}^{1 / 2}$ Limit $=180$ days

ummary : RESRAD Parameters for U-Landfill Trespasser

File : C: \RESRAD_FAMILY \RESRAD \USERFILES \QCFORSRSG \TRESPASSER_SRSG-7OYRS.RAD

Total Dose Contributions TDOSE (i,p,t) for Individual Radionuclides (i) and Pathways (p) As mrem/yr and Fraction of Total Dose At $t=5.000 \mathrm{E}+01$ years

Water Independent Pathways (Inhalation excludes radon)

\begin{tabular}{|c|c|c|c|c|c|c|c|c|c|c|c|c|c|c|}
\hline \multirow{2}{*}{ Nuclide } & \multicolumn{2}{|c|}{ Ground } & \multicolumn{2}{|c|}{ Inhalation } & \multicolumn{2}{|c|}{ Radon } & \multicolumn{2}{|c|}{ Plant } & \multicolumn{2}{|c|}{ Meat } & \multicolumn{2}{|c|}{ Milk } & \multicolumn{2}{|c|}{ Soil } \\
\hline & mrem/yr & fract. & mrem/yr & fract. & mrem/yr & fract. & mrem/yr & fract. & mrem/yr & fract. & mrem/yr & fract. & mrem/yr & fract. \\
\hline-241 & $5.626 \mathrm{E}-06$ & 0.0000 & $7.437 \mathrm{E}-06$ & 0.0000 & $0.000 \mathrm{E}+00$ & 0.0000 & $0.000 \mathrm{E}+00$ & 0.0000 & $0.000 \mathrm{E}+00$ & 0.0000 & $0.000 \mathrm{E}+00$ & 0.0000 & $2.819 \mathrm{E}-04$ & 0.0012 \\
\hline-137 & $9.872 \mathrm{E}-03$ & 0.0416 & $1.017 \mathrm{E}-09$ & 0.0000 & $0.000 \mathrm{E}+00$ & 0.0000 & $0.000 \mathrm{E}+00$ & 0.0000 & $0.000 \mathrm{E}+00$ & 0.0000 & $0.000 \mathrm{E}+00$ & 0.0000 & $6.176 \mathrm{E}-06$ & 0.0000 \\
\hline-237 & $5.910 \mathrm{E}-03$ & 0.0249 & $4.171 \mathrm{E}-06$ & 0.0000 & $0.000 \mathrm{E}+00$ & 0.0000 & $0.000 \mathrm{E}+00$ & 0.0000 & $0.000 \mathrm{E}+00$ & 0.0000 & $0.000 \mathrm{E}+00$ & 0.0000 & $1.682 \mathrm{E}-04$ & 0.0007 \\
\hline-238 & $4.307 E-08$ & 0.0000 & $6.200 E-06$ & 0.0000 & $0.000 \mathrm{E}+00$ & 0.0000 & $0.000 \mathrm{E}+00$ & 0.0000 & $0.000 \mathrm{E}+00$ & 0.0000 & $0.000 \mathrm{E}+00$ & 0.0000 & $2.357 \mathrm{E}-04$ & 0.0010 \\
\hline-239 & $1.145 \mathrm{E}-06$ & 0.0000 & $1.006 \mathrm{E}-05$ & 0.0000 & $0.000 \mathrm{E}+00$ & 0.0000 & $0.000 \mathrm{E}+00$ & 0.0000 & $0.000 \mathrm{E}+00$ & 0.0000 & $0.000 \mathrm{E}+00$ & 0.0000 & $3.812 E-04$ & 0.0016 \\
\hline-240 & $6.171 \mathrm{E}-08$ & 0.0000 & $1.003 \mathrm{E}-05$ & 0.0000 & $0.000 \mathrm{E}+00$ & 0.0000 & $0.000 \mathrm{E}+00$ & 0.0000 & $0.000 \mathrm{E}+00$ & 0.0000 & $0.000 \mathrm{E}+00$ & 0.0000 & $3.798 \mathrm{E}-04$ & 0.0016 \\
\hline 99 & $6.246 E-08$ & 0.0000 & $6.406 \mathrm{E}-10$ & 0.0000 & $0.000 \mathrm{E}+00$ & 0.0000 & $0.000 \mathrm{E}+00$ & 0.0000 & $0.000 \mathrm{E}+00$ & 0.0000 & $0.000 \mathrm{E}+00$ & 0.0000 & $5.740 \mathrm{E}-07$ & 0.0000 \\
\hline-228 & $1.646 \mathrm{E}-09$ & 0.0000 & $4.170 \mathrm{E}-14$ & 0.0000 & $0.000 \mathrm{E}+00$ & 0.0000 & $0.000 \mathrm{E}+00$ & 0.0000 & $0.000 \mathrm{E}+00$ & 0.0000 & $0.000 \mathrm{E}+00$ & 0.0000 & 2. $491 E-12$ & 0.0000 \\
\hline 230 & $2.923 E-03$ & 0.0123 & $8.429 \mathrm{E}-06$ & 0.0000 & $0.000 \mathrm{E}+00$ & 0.0000 & $0.000 \mathrm{E}+00$ & 0.0000 & $0.000 \mathrm{E}+00$ & 0.0000 & $0.000 \mathrm{E}+00$ & 0.0000 & $3.612 \mathrm{E}-04$ & 0.0015 \\
\hline-232 & $2.106 \mathrm{E}-01$ & 0.8872 & $1.425 E-05$ & 0.0001 & $0.000 \mathrm{E}+00$ & 0.0000 & $0.000 \mathrm{E}+00$ & 0.0000 & $0.000 \mathrm{E}+00$ & 0.0000 & $0.000 \mathrm{E}+00$ & 0.0000 & $1.621 \mathrm{E}-03$ & 0.0068 \\
\hline 34 & $1.092 \mathrm{E}-06$ & 0.0000 & $7.934 \mathrm{E}-07$ & 0.0000 & $0.000 \mathrm{E}+00$ & 0.0000 & $0.000 \mathrm{E}+00$ & 0.0000 & $0.000 \mathrm{E}+00$ & 0.0000 & $0.000 \mathrm{E}+00$ & 0.0000 & $7.483 \mathrm{E}-05$ & 0.0003 \\
\hline 35 & $3.036 \mathrm{E}-03$ & 0.0128 & $7.531 \mathrm{E}-07$ & 0.0000 & $0.000 \mathrm{E}+00$ & 0.0000 & $0.000 \mathrm{E}+00$ & 0.0000 & $0.000 \mathrm{E}+00$ & 0.0000 & $0.000 \mathrm{E}+00$ & 0.0000 & $7.447 \mathrm{E}-05$ & 0.0003 \\
\hline 38 & $1.318 E-03$ & 0.0056 & $6.725 E-07$ & 0.0000 & $0.000 \mathrm{E}+00$ & 0.0000 & $0.000 \mathrm{E}+00$ & 0.0000 & $0.000 \mathrm{E}+00$ & 0.0000 & $0.000 \mathrm{E}+00$ & 0.0000 & $7.412 \mathrm{E}-05$ & 0.0003 \\
\hline & $2.337 \mathrm{E}-01$ & 0.9843 & $6.279 \mathrm{E}-05$ & 0.0003 & $0.000 \mathrm{E}+00$ & 0.0000 & $0.000 \mathrm{E}+00$ & 0.0000 & $0.000 \mathrm{E}+00$ & 0.0000 & $0.000 \mathrm{E}+00$ & 0.0000 & $3.659 \mathrm{E}-03$ & 0.0154 \\
\hline
\end{tabular}

Total Dose Contributions TDOSE(i,p,t) for Individual Radionuclides (i) and Pathways (p) As mrem/yr and Fraction of Total Dose At $t=5.000 \mathrm{E}+01$ years

Water Dependent Pathways

\begin{tabular}{|c|c|c|c|c|c|c|c|c|c|c|c|c|c|c|}
\hline \multirow{2}{*}{$\begin{array}{l}\text { Radio- } \\
\text { Nuclide }\end{array}$} & \multicolumn{2}{|c|}{ Water } & \multicolumn{2}{|c|}{ Fish } & \multicolumn{2}{|c|}{ Radon } & \multicolumn{2}{|c|}{ Plant } & \multicolumn{2}{|c|}{ Meat } & \multicolumn{2}{|c|}{ Milk } & \multicolumn{2}{|c|}{ All Pathways* } \\
\hline & mrem/yr & fract. & mrem/yr & fract. & mrem/yr & fract. & mrem/yr & fract. & mrem/yr & fract. & mrem/yr & fract. & mrem/yr & fract. \\
\hline 241 & $0.000 \mathrm{E}+00$ & 0.0000 & $0.000 \mathrm{E}+00$ & 0.0000 & $0.000 \mathrm{E}+00$ & 0.0000 & $0.000 \mathrm{E}+00$ & 0.0000 & $0.000 \mathrm{E}+00$ & 0.0000 & $0.000 \mathrm{E}+00$ & 0.0000 & $2.949 \mathrm{E}-04$ & 0.0012 \\
\hline-137 & $0.000 \mathrm{E}+00$ & 0.0000 & $0.000 \mathrm{E}+00$ & 0.0000 & $0.000 \mathrm{E}+00$ & 0.0000 & $0.000 \mathrm{E}+00$ & 0.0000 & $0.000 \mathrm{E}+00$ & 0.0000 & $0.000 \mathrm{E}+00$ & 0.0000 & $9.878 \mathrm{E}-03$ & 0.0416 \\
\hline-237 & $0.000 \mathrm{E}+00$ & 0.0000 & $0.000 \mathrm{E}+00$ & 0.0000 & $0.000 \mathrm{E}+00$ & 0.0000 & $0.000 \mathrm{E}+00$ & 0.0000 & $0.000 \mathrm{E}+00$ & 0.0000 & $0.000 \mathrm{E}+00$ & 0.0000 & $6.082 E-03$ & 0.0256 \\
\hline-238 & $0.000 \mathrm{E}+00$ & 0.0000 & $0.000 \mathrm{E}+00$ & 0.0000 & $0.000 \mathrm{E}+00$ & 0.0000 & $0.000 \mathrm{E}+00$ & 0.0000 & $0.000 \mathrm{E}+00$ & 0.0000 & $0.000 \mathrm{E}+00$ & 0.0000 & $2.420 \mathrm{E}-04$ & 0.0010 \\
\hline-239 & $0.000 \mathrm{E}+00$ & 0.0000 & $0.000 \mathrm{E}+00$ & 0.0000 & $0.000 \mathrm{E}+00$ & 0.0000 & $0.000 \mathrm{E}+00$ & 0.0000 & $0.000 \mathrm{E}+00$ & 0.0000 & $0.000 \mathrm{E}+00$ & 0.0000 & $3.925 \mathrm{E}-04$ & 0.0017 \\
\hline-240 & $0.000 \mathrm{E}+00$ & 0.0000 & $0.000 \mathrm{E}+00$ & 0.0000 & $0.000 \mathrm{E}+00$ & 0.0000 & $0.000 \mathrm{E}+00$ & 0.0000 & $0.000 \mathrm{E}+00$ & 0.0000 & $0.000 E+00$ & 0.0000 & $3.899 \mathrm{E}-04$ & 0.0016 \\
\hline 99 & $0.000 \mathrm{E}+00$ & 0.0000 & $0.000 \mathrm{E}+00$ & 0.0000 & $0.000 \mathrm{E}+00$ & 0.0000 & $0.000 \mathrm{E}+00$ & 0.0000 & $0.000 \mathrm{E}+00$ & 0.0000 & $0.000 \mathrm{E}+00$ & 0.0000 & $6.371 \mathrm{E}-07$ & 0.0000 \\
\hline-228 & $0.000 \mathrm{E}+00$ & 0.0000 & $0.000 \mathrm{E}+00$ & 0.0000 & $0.000 \mathrm{E}+00$ & 0.0000 & $0.000 \mathrm{E}+00$ & 0.0000 & $0.000 \mathrm{E}+00$ & 0.0000 & $0.000 \mathrm{E}+00$ & 0.0000 & $1.649 \mathrm{E}-09$ & 0.0000 \\
\hline-230 & $0.000 \mathrm{E}+00$ & 0.0000 & $0.000 \mathrm{E}+00$ & 0.0000 & $0.000 \mathrm{E}+00$ & 0.0000 & $0.000 \mathrm{E}+00$ & 0.0000 & $0.000 \mathrm{E}+00$ & 0.0000 & $0.000 E+00$ & 0.0000 & $3.293 E-03$ & 0.0139 \\
\hline 232 & $0.000 \mathrm{E}+00$ & 0.0000 & $0.000 \mathrm{E}+00$ & 0.0000 & $0.000 \mathrm{E}+00$ & 0.0000 & $0.000 \mathrm{E}+00$ & 0.0000 & $0.000 \mathrm{E}+00$ & 0.0000 & $0.000 \mathrm{E}+00$ & 0.0000 & $2.123 E-01$ & 0.8940 \\
\hline 34 & $0.000 \mathrm{E}+00$ & 0.0000 & $0.000 \mathrm{E}+00$ & 0.0000 & $0.000 \mathrm{E}+00$ & 0.0000 & $0.000 \mathrm{E}+00$ & 0.0000 & $0.000 \mathrm{E}+00$ & 0.0000 & $0.000 \mathrm{E}+00$ & 0.0000 & $7.671 \mathrm{E}-05$ & 0.0003 \\
\hline 35 & $0.000 \mathrm{E}+00$ & 0.0000 & $0.000 \mathrm{E}+00$ & 0.0000 & $0.000 \mathrm{E}+00$ & 0.0000 & $0.000 \mathrm{E}+00$ & 0.0000 & $0.000 \mathrm{E}+00$ & 0.0000 & $0.000 \mathrm{E}+00$ & 0.0000 & $3.111 \mathrm{E}-03$ & 0.0131 \\
\hline 38 & $0.000 \mathrm{E}+00$ & 0.0000 & $0.000 \mathrm{E}+00$ & 0.0000 & $0.000 \mathrm{E}+00$ & 0.0000 & $0.000 \mathrm{E}+00$ & 0.0000 & $0.000 \mathrm{E}+00$ & 0.0000 & $0.000 \mathrm{E}+00$ & 0.0000 & $1.393 E-03$ & 0.0059 \\
\hline & $0.000 \mathrm{E}+00$ & 0.0000 & $0.000 \mathrm{E}+00$ & 0.0000 & $0.000 \mathrm{E}+00$ & 0.0000 & $0.000 \mathrm{E}+00$ & 0.0000 & $0.000 \mathrm{E}+00$ & 0.0000 & $0.000 \mathrm{E}+00$ & 0.0000 & $4 E-01$ & 1. \\
\hline
\end{tabular}

* Sum of all water independent and dependent pathways. 
RESRAD, Version 6.5

$\mathrm{T}^{1 / 2}$ Limit $=180$ days

ummary : RESRAD Parameters for U-Landfill Trespasser

File : C: \RESRAD_FAMILY \RESRAD \USERFILES \QCFORSRSG \TRESPASSER_SRSG-7OYRS.RAD

Total Dose Contributions TDOSE (i,p,t) for Individual Radionuclides (i) and Pathways (p) As mrem/yr and Fraction of Total Dose At $t=7.000 \mathrm{E}+01$ years

Water Independent Pathways (Inhalation excludes radon)

\begin{tabular}{|c|c|c|c|c|c|c|c|c|c|c|c|c|c|c|}
\hline \multirow{2}{*}{ Nuclide } & \multicolumn{2}{|c|}{ Ground } & \multicolumn{2}{|c|}{ Inhalation } & \multicolumn{2}{|c|}{ Radon } & \multicolumn{2}{|c|}{ Plant } & \multicolumn{2}{|c|}{ Meat } & \multicolumn{2}{|c|}{ Milk } & \multicolumn{2}{|c|}{ Soil } \\
\hline & mrem/yr & fract. & mrem/yr & fract. & mrem/yr & fract. & mrem/yr & fract. & mrem/yr & fract. & mrem/yr & fract. & mrem/yr & fract. \\
\hline-241 & $9.593 E-06$ & 0.0000 & $1.026 \mathrm{E}-05$ & 0.0000 & $0.000 \mathrm{E}+00$ & 0.0000 & $0.000 \mathrm{E}+00$ & 0.0000 & $0.000 \mathrm{E}+00$ & 0.0000 & $0.000 \mathrm{E}+00$ & 0.0000 & $3.887 \mathrm{E}-04$ & 0.0014 \\
\hline-137 & $7.357 \mathrm{E}-03$ & 0.0271 & $9.114 \mathrm{E}-10$ & 0.0000 & $0.000 \mathrm{E}+00$ & 0.0000 & $0.000 \mathrm{E}+00$ & 0.0000 & $0.000 \mathrm{E}+00$ & 0.0000 & $0.000 \mathrm{E}+00$ & 0.0000 & $5.536 \mathrm{E}-06$ & 0.0000 \\
\hline-237 & $7.331 E-03$ & 0.0270 & $5.921 \mathrm{E}-06$ & 0.0000 & $0.000 \mathrm{E}+00$ & 0.0000 & $0.000 \mathrm{E}+00$ & 0.0000 & $0.000 \mathrm{E}+00$ & 0.0000 & $0.000 \mathrm{E}+00$ & 0.0000 & $2.387 \mathrm{E}-04$ & 0.0009 \\
\hline-238 & $5.243 E-08$ & 0.0000 & $7.535 E-06$ & 0.0000 & $0.000 \mathrm{E}+00$ & 0.0000 & $0.000 \mathrm{E}+00$ & 0.0000 & $0.000 \mathrm{E}+00$ & 0.0000 & $0.000 \mathrm{E}+00$ & 0.0000 & $2.865 E-04$ & 0.0011 \\
\hline-239 & $1.453 \mathrm{E}-06$ & 0.0000 & $1.432 \mathrm{E}-05$ & 0.0001 & $0.000 \mathrm{E}+00$ & 0.0000 & $0.000 \mathrm{E}+00$ & 0.0000 & $0.000 \mathrm{E}+00$ & 0.0000 & $0.000 \mathrm{E}+00$ & 0.0000 & $5.424 \mathrm{E}-04$ & 0.0020 \\
\hline-240 & $8.764 \mathrm{E}-08$ & 0.0000 & $1.424 \mathrm{E}-05$ & 0.0001 & $0.000 \mathrm{E}+00$ & 0.0000 & $0.000 \mathrm{E}+00$ & 0.0000 & $0.000 \mathrm{E}+00$ & 0.0000 & $0.000 \mathrm{E}+00$ & 0.0000 & $5.394 \mathrm{E}-04$ & 0.0020 \\
\hline 99 & $7.418 \mathrm{E}-08$ & 0.0000 & 7. $383 \mathrm{E}-10$ & 0.0000 & $0.000 \mathrm{E}+00$ & 0.0000 & $0.000 \mathrm{E}+00$ & 0.0000 & $0.000 \mathrm{E}+00$ & 0.0000 & $0.000 \mathrm{E}+00$ & 0.0000 & $6.615 \mathrm{E}-07$ & 0.0000 \\
\hline-228 & 1. $330 \mathrm{E}-12$ & 0.0000 & $4.234 \mathrm{E}-17$ & 0.0000 & $0.000 \mathrm{E}+00$ & 0.0000 & $0.000 \mathrm{E}+00$ & 0.0000 & $0.000 \mathrm{E}+00$ & 0.0000 & $0.000 \mathrm{E}+00$ & 0.0000 & $2.528 E-15$ & 0.0000 \\
\hline-230 & $4.685 E-03$ & 0.0173 & $1.202 \mathrm{E}-05$ & 0.0000 & $0.000 \mathrm{E}+00$ & 0.0000 & $0.000 \mathrm{E}+00$ & 0.0000 & $0.000 \mathrm{E}+00$ & 0.0000 & $0.000 \mathrm{E}+00$ & 0.0000 & $5.489 \mathrm{E}-04$ & 0.0020 \\
\hline-232 & $2.414 \mathrm{E}-01$ & 0.8891 & $2.030 E-05$ & 0.0001 & $0.000 \mathrm{E}+00$ & 0.0000 & $0.000 \mathrm{E}+00$ & 0.0000 & $0.000 \mathrm{E}+00$ & 0.0000 & $0.000 \mathrm{E}+00$ & 0.0000 & $2.313 \mathrm{E}-03$ & 0.0085 \\
\hline 234 & $2.099 \mathrm{E}-06$ & 0.0000 & $1.131 \mathrm{E}-06$ & 0.0000 & $0.000 \mathrm{E}+00$ & 0.0000 & $0.000 \mathrm{E}+00$ & 0.0000 & $0.000 \mathrm{E}+00$ & 0.0000 & $0.000 \mathrm{E}+00$ & 0.0000 & $1.066 \mathrm{E}-04$ & 0.0004 \\
\hline 35 & $3.899 \mathrm{E}-03$ & 0.0144 & $1.103 \mathrm{E}-06$ & 0.0000 & $0.000 \mathrm{E}+00$ & 0.0000 & $0.000 \mathrm{E}+00$ & 0.0000 & $0.000 \mathrm{E}+00$ & 0.0000 & $0.000 \mathrm{E}+00$ & 0.0000 & $1.076 \mathrm{E}-04$ & 0.0004 \\
\hline 38 & $1.554 \mathrm{E}-03$ & 0.0057 & $9.572 \mathrm{E}-07$ & 0.0000 & $0.000 \mathrm{E}+00$ & 0.0000 & $0.000 \mathrm{E}+00$ & 0.0000 & $0.000 \mathrm{E}+00$ & 0.0000 & $0.000 \mathrm{E}+00$ & 0.0000 & $1.055 \mathrm{E}-04$ & 0.0004 \\
\hline & $2.663 E-01$ & 0.9806 & $8.779 \mathrm{E}-05$ & 0.0003 & $0.000 \mathrm{E}+00$ & 0.0000 & $0.000 \mathrm{E}+00$ & 0.0000 & $0.000 \mathrm{E}+00$ & 0.0000 & $0.000 \mathrm{E}+00$ & 0.0000 & $5.183 E-03$ & 0.0191 \\
\hline
\end{tabular}

Total Dose Contributions TDOSE(i,p,t) for Individual Radionuclides (i) and Pathways (p) As mrem/yr and Fraction of Total Dose At $t=7.000 \mathrm{E}+01$ years

Water Dependent Pathways

\begin{tabular}{|c|c|c|c|c|c|c|c|c|c|c|c|c|c|c|}
\hline \multirow{2}{*}{$\begin{array}{l}\text { Radio- } \\
\text { Nuclide }\end{array}$} & \multicolumn{2}{|c|}{ Water } & \multicolumn{2}{|c|}{ Fish } & \multicolumn{2}{|c|}{ Radon } & \multicolumn{2}{|c|}{ Plant } & \multicolumn{2}{|c|}{ Meat } & \multicolumn{2}{|c|}{ Milk } & \multicolumn{2}{|c|}{ All Pathways* } \\
\hline & mrem/yr & fract. & mrem/yr & fract. & mrem/yr & fract. & mrem/yr & fract. & mrem/yr & fract. & mrem/yr & fract. & mrem/yr & fract. \\
\hline 241 & $0.000 \mathrm{E}+00$ & 0.0000 & $0.000 \mathrm{E}+00$ & 0.0000 & $0.000 \mathrm{E}+00$ & 0.0000 & $0.000 \mathrm{E}+00$ & 0.0000 & $0.000 \mathrm{E}+00$ & 0.0000 & $0.000 \mathrm{E}+00$ & 0.0000 & $4.085 E-04$ & 0.0015 \\
\hline-137 & $0.000 \mathrm{E}+00$ & 0.0000 & $0.000 \mathrm{E}+00$ & 0.0000 & $0.000 \mathrm{E}+00$ & 0.0000 & $0.000 \mathrm{E}+00$ & 0.0000 & $0.000 \mathrm{E}+00$ & 0.0000 & $0.000 \mathrm{E}+00$ & 0.0000 & 7. $362 \mathrm{E}-03$ & 0.0271 \\
\hline-237 & $0.000 \mathrm{E}+00$ & 0.0000 & $0.000 \mathrm{E}+00$ & 0.0000 & $0.000 \mathrm{E}+00$ & 0.0000 & $0.000 \mathrm{E}+00$ & 0.0000 & $0.000 \mathrm{E}+00$ & 0.0000 & $0.000 \mathrm{E}+00$ & 0.0000 & $7.575 E-03$ & 0.0279 \\
\hline-238 & $0.000 \mathrm{E}+00$ & 0.0000 & $0.000 \mathrm{E}+00$ & 0.0000 & $0.000 \mathrm{E}+00$ & 0.0000 & $0.000 \mathrm{E}+00$ & 0.0000 & $0.000 \mathrm{E}+00$ & 0.0000 & $0.000 \mathrm{E}+00$ & 0.0000 & $2.941 \mathrm{E}-04$ & 0.0011 \\
\hline-239 & $0.000 \mathrm{E}+00$ & 0.0000 & $0.000 \mathrm{E}+00$ & 0.0000 & $0.000 \mathrm{E}+00$ & 0.0000 & $0.000 \mathrm{E}+00$ & 0.0000 & $0.000 \mathrm{E}+00$ & 0.0000 & $0.000 E+00$ & 0.0000 & $5.581 \mathrm{E}-04$ & 0.0021 \\
\hline-240 & $0.000 \mathrm{E}+00$ & 0.0000 & $0.000 \mathrm{E}+00$ & 0.0000 & $0.000 \mathrm{E}+00$ & 0.0000 & $0.000 \mathrm{E}+00$ & 0.0000 & $0.000 \mathrm{E}+00$ & 0.0000 & $0.000 E+00$ & 0.0000 & $5.538 \mathrm{E}-04$ & 0.0020 \\
\hline 99 & $0.000 \mathrm{E}+00$ & 0.0000 & $0.000 \mathrm{E}+00$ & 0.0000 & $0.000 \mathrm{E}+00$ & 0.0000 & $0.000 \mathrm{E}+00$ & 0.0000 & $0.000 \mathrm{E}+00$ & 0.0000 & $0.000 \mathrm{E}+00$ & 0.0000 & 7. $364 \mathrm{E}-07$ & 0.0000 \\
\hline-228 & $0.000 \mathrm{E}+00$ & 0.0000 & $0.000 \mathrm{E}+00$ & 0.0000 & $0.000 \mathrm{E}+00$ & 0.0000 & $0.000 \mathrm{E}+00$ & 0.0000 & $0.000 \mathrm{E}+00$ & 0.0000 & $0.000 \mathrm{E}+00$ & 0.0000 & 1. $333 \mathrm{E}-12$ & 0.0000 \\
\hline-230 & $0.000 \mathrm{E}+00$ & 0.0000 & $0.000 \mathrm{E}+00$ & 0.0000 & $0.000 \mathrm{E}+00$ & 0.0000 & $0.000 \mathrm{E}+00$ & 0.0000 & $0.000 \mathrm{E}+00$ & 0.0000 & $0.000 E+00$ & 0.0000 & $5.246 \mathrm{E}-03$ & 0.0193 \\
\hline 232 & $0.000 \mathrm{E}+00$ & 0.0000 & $0.000 \mathrm{E}+00$ & 0.0000 & $0.000 \mathrm{E}+00$ & 0.0000 & $0.000 \mathrm{E}+00$ & 0.0000 & $0.000 \mathrm{E}+00$ & 0.0000 & $0.000 \mathrm{E}+00$ & 0.0000 & $2.438 E-01$ & 0.8977 \\
\hline 34 & $0.000 \mathrm{E}+00$ & 0.0000 & $0.000 \mathrm{E}+00$ & 0.0000 & $0.000 \mathrm{E}+00$ & 0.0000 & $0.000 \mathrm{E}+00$ & 0.0000 & $0.000 \mathrm{E}+00$ & 0.0000 & $0.000 \mathrm{E}+00$ & 0.0000 & $1.098 \mathrm{E}-04$ & 0.0004 \\
\hline 35 & $0.000 \mathrm{E}+00$ & 0.0000 & $0.000 \mathrm{E}+00$ & 0.0000 & $0.000 \mathrm{E}+00$ & 0.0000 & $0.000 \mathrm{E}+00$ & 0.0000 & $0.000 \mathrm{E}+00$ & 0.0000 & $0.000 \mathrm{E}+00$ & 0.0000 & $4.007 E-03$ & 0.0148 \\
\hline 38 & $0.000 \mathrm{E}+00$ & 0.0000 & $0.000 \mathrm{E}+00$ & 0.0000 & $0.000 \mathrm{E}+00$ & 0.0000 & $0.000 \mathrm{E}+00$ & 0.0000 & $0.000 \mathrm{E}+00$ & 0.0000 & $0.000 \mathrm{E}+00$ & 0.0000 & $1.660 \mathrm{E}-03$ & 0.0061 \\
\hline & $0.000 \mathrm{E}+00$ & 0.0000 & $0.000 \mathrm{E}+00$ & 0.0000 & $0.000 \mathrm{E}+00$ & 0.0000 & $0.000 \mathrm{E}+00$ & 0.0000 & $0.000 \mathrm{E}+00$ & 0.0000 & $0.000 \mathrm{E}+00$ & 0.0000 & -01 & 1. \\
\hline
\end{tabular}

* Sum of all water independent and dependent pathways. 
RESRAD, Version $6.5 \quad \mathrm{~T}^{1 / 2}$ Limit $=180$ days

Summary : RESRAD Parameters for U-Landfill Trespasser

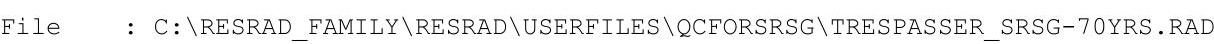

Dose/Source Ratios Summed Over All Pathways

Parent and Progeny Principal Radionuclide Contributions Indicated

Parent Product Thread DSR $(j, t)$ At Time in Years (mrem/yr)/(pCi/g)

(i) (j) Fraction 0.000E+00 1.000 E+00 2.500E+01 5.000 E+01 7.000 E+01

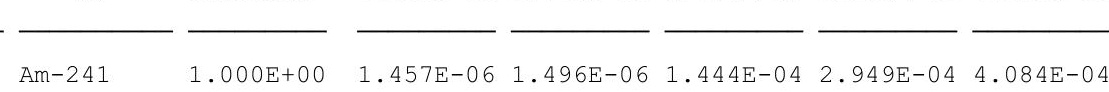

$\begin{array}{lllllll}\mathrm{Np}-237+\mathrm{D} & 1.000 \mathrm{E}+00 & 5.599 \mathrm{E}-10 & 1.695 \mathrm{E}-09 & 3.728 \mathrm{E}-08 & 9.593 \mathrm{E}-08 & 1.644 \mathrm{E}-07\end{array}$

$\begin{array}{lllllll}\mathrm{U}-233 & 1.000 \mathrm{E}+00 & 6.695 \mathrm{E}-19 & 4.735 \mathrm{E}-18 & 1.858 \mathrm{E}-14 & 1.476 \mathrm{E}-13 & 4.022 \mathrm{E}-13\end{array}$

$\begin{array}{lllllll}\text { Th-229+D } & 1.000 \mathrm{E}+00 & 3.971 \mathrm{E}-20 & 5.999 \mathrm{E}-19 & 3.419 \mathrm{E}-15 & 3.406 \mathrm{E}-14 & 1.120 \mathrm{E}-13\end{array}$

$\sum \operatorname{DSR}(j) \quad 1.457 \mathrm{E}-06 \quad 1.498 \mathrm{E}-06 \quad 1.444 \mathrm{E}-04 \quad 2.949 \mathrm{E}-04 \quad 4.085 \mathrm{E}-04$

Cs-137+D $\quad 1.000 \mathrm{E}+00 \quad 2.060 \mathrm{E}-02 \quad 2.029 \mathrm{E}-02 \quad 1.426 \mathrm{E}-02 \quad 9.878 \mathrm{E}-03 \quad 7.362 \mathrm{E}-03$

$\begin{array}{lllllll}\mathrm{Np}-237+\mathrm{D} & 1.000 \mathrm{E}+00 & 3.453 \mathrm{E}-03 & 3.490 \mathrm{E}-03 & 4.597 \mathrm{E}-03 & 6.082 \mathrm{E}-03 & 7.575 \mathrm{E}-03\end{array}$

$\begin{array}{lllllll}\mathrm{U}-233 & 1.000 \mathrm{E}+00 & 6.197 \mathrm{E}-12 & 1.880 \mathrm{E}-11 & 4.556 \mathrm{E}-09 & 1.851 \mathrm{E}-08 & 3.649 \mathrm{E}-08\end{array}$

$\begin{array}{llllllll}\text { Th-229+D } \quad 1.000 \mathrm{E}+00 & 4.903 \mathrm{E}-13 & 3.458 \mathrm{E}-12 & 1.253 \mathrm{E}-09 & 6.365 \mathrm{E}-09 & 1.511 \mathrm{E}-08\end{array}$

$\operatorname{LDSR}(j) \quad 3.453 \mathrm{E}-03 \quad 3.490 \mathrm{E}-03 \quad 4.597 \mathrm{E}-03 \quad 6.082 \mathrm{E}-03 \quad 7.575 \mathrm{E}-03$

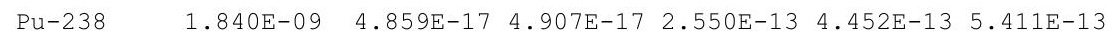

$\begin{array}{lllllll}\mathrm{Pu}-238 & 1.000 \mathrm{E}+00 & 2.641 \mathrm{E}-08 & 2.667 \mathrm{E}-08 & 1.386 \mathrm{E}-04 & 2.419 \mathrm{E}-04 & 2.941 \mathrm{E}-04\end{array}$

$\begin{array}{lllllll}\mathrm{U}-234 & 1.000 \mathrm{E}+00 & 2.486 \mathrm{E}-13 & 7.549 \mathrm{E}-13 & 2.342 \mathrm{E}-09 & 8.961 \mathrm{E}-09 & 1.656 \mathrm{E}-08\end{array}$

$\begin{array}{lllllll}\mathrm{Th}-230 & 1.000 \mathrm{E}+00 & 3.358 \mathrm{E}-18 & 2.380 \mathrm{E}-17 & 1.212 \mathrm{E}-12 & 9.470 \mathrm{E}-12 & 2.502 \mathrm{E}-11\end{array}$

$\begin{array}{llllllll}\mathrm{Ra}-226+\mathrm{D} & 1.000 \mathrm{E}+00 & 4.363 \mathrm{E}-17 & 6.572 \mathrm{E}-16 & 3.284 \mathrm{E}-12 & 2.901 \mathrm{E}-11 & 8.757 \mathrm{E}-11\end{array}$

$\mathrm{Pb}-210+\mathrm{D} \quad 1.000 \mathrm{E}+00 \quad 2.379 \mathrm{E}-23 \quad 7.401 \mathrm{E}-22 \quad 6.838 \mathrm{E}-15 \quad 1.868 \mathrm{E}-13 \quad 8.841 \mathrm{E}-13$

$\begin{array}{llllll}\operatorname{DSSR}(j) \quad 2.641 \mathrm{E}-08 & 2.667 \mathrm{E}-08 & 1.386 \mathrm{E}-04 & 2.420 \mathrm{E}-04 & 2.941 \mathrm{E}-04\end{array}$

$\begin{array}{lllllll}\text { Pu-239 } & 1.000 \mathrm{E}+00 & 6.302 \mathrm{E}-07 & 6.378 \mathrm{E}-07 & 1.850 \mathrm{E}-04 & 3.925 \mathrm{E}-04 & 5.581 \mathrm{E}-04\end{array}$

$\begin{array}{lllllll}\mathrm{U}-235+\mathrm{D} & 1.000 \mathrm{E}+00 & 8.030 \mathrm{E}-13 & 2.436 \mathrm{E}-12 & 5.659 \mathrm{E}-11 & 1.542 \mathrm{E}-10 & 2.766 \mathrm{E}-10\end{array}$

$\begin{array}{lllllll}\mathrm{Pa}-231 & 1.000 \mathrm{E}+00 & 2.330 \mathrm{E}-18 & 1.646 \mathrm{E}-17 & 9.404 \mathrm{E}-15 & 5.933 \mathrm{E}-14 & 1.535 \mathrm{E}-13\end{array}$

$\begin{array}{lllllll}A C-227+D & 1.000 E+00 & 2.010 E-19 & 3.022 \mathrm{E}-18 & 1.564 \mathrm{E}-14 & 1.404 \mathrm{E}-13 & 4.252 \mathrm{E}-13\end{array}$

$\begin{array}{lllllll}\operatorname{DDSR}(j) & 6.302 \mathrm{E}-07 & 6.378 \mathrm{E}-07 & 1.850 \mathrm{E}-04 & 3.925 \mathrm{E}-04 & 5.581 \mathrm{E}-04\end{array}$

$\begin{array}{llllll}\text { Pu-240 4.950E-08 } & 1.271 \mathrm{E}-15 & 1.293 \mathrm{E}-15 & 9.098 \mathrm{E}-12 & 1.930 \mathrm{E}-11 & 2.741 \mathrm{E}-11\end{array}$

$\begin{array}{lllllll}\mathrm{Pu}-240 & 1.000 \mathrm{E}+00 & 2.567 \mathrm{E}-08 & 2.612 \mathrm{E}-08 & 1.838 \mathrm{E}-04 & 3.899 \mathrm{E}-04 & 5.538 \mathrm{E}-04\end{array}$

$\begin{array}{lllllll}\mathrm{U}-236 & 1.000 \mathrm{E}+00 & 1.038 \mathrm{E}-15 & 3.165 \mathrm{E}-15 & 2.580 \mathrm{E}-11 & 1.084 \mathrm{E}-10 & 2.152 \mathrm{E}-10\end{array}$

$\begin{array}{lllllll}\mathrm{Th}-232 & 1.000 \mathrm{E}+00 & 4.987 \mathrm{E}-26 & 3.547 \mathrm{E}-25 & 8.061 \mathrm{E}-20 & 6.713 \mathrm{E}-19 & 1.861 \mathrm{E}-18\end{array}$

$\begin{array}{llllllll}\mathrm{Ra}-228+\mathrm{D} & 1.000 \mathrm{E}+00 & 3.271 \mathrm{E}-22 & 4.816 \mathrm{E}-21 & 1.454 \mathrm{E}-17 & 9.118 \mathrm{E}-17 & 2.265 \mathrm{E}-16\end{array}$

$\begin{array}{llllllll}\text { Th-228+D } & 1.000 \mathrm{E}+00 & 5.216 \mathrm{E}-23 & 1.501 \mathrm{E}-21 & 2.491 \mathrm{E}-17 & 1.723 \mathrm{E}-16 & 4.318 \mathrm{E}-16\end{array}$

$\begin{array}{llllll}\operatorname{DSRR}(j) \quad 2.567 \mathrm{E}-08 & 2.612 \mathrm{E}-08 & 1.838 \mathrm{E}-04 & 3.899 \mathrm{E}-04 & 5.538 \mathrm{E}-04\end{array}$

$\begin{array}{lllllll}\text { TC-99 } & 1.000 \mathrm{E}+00 & 4.063 \mathrm{E}-08 & 4.098 \mathrm{E}-08 & 4.022 \mathrm{E}-07 & 6.371 \mathrm{E}-07 & 7.364 \mathrm{E}-07\end{array}$

$\begin{array}{lllllll}\mathrm{Th}-228+\mathrm{D} & 1.000 \mathrm{E}+00 & 8.889 \mathrm{E}-02 & 6.226 \mathrm{E}-02 & 1.210 \mathrm{E}-05 & 1.649 \mathrm{E}-09 & 1.333 \mathrm{E}-12\end{array}$

$\begin{array}{lllllll}\text { Th-230 } & 1.000 \mathrm{E}+00 & 7.878 \mathrm{E}-07 & 8.012 \mathrm{E}-07 & 1.560 \mathrm{E}-04 & 3.311 \mathrm{E}-04 & 4.713 \mathrm{E}-04\end{array}$

$\begin{array}{lllllll}\mathrm{Ra}-226+\mathrm{D} & 1.000 \mathrm{E}+00 & 2.053 \mathrm{E}-05 & 6.196 \mathrm{E}-05 & 1.244 \mathrm{E}-03 & 2.931 \mathrm{E}-03 & 4.701 \mathrm{E}-03\end{array}$

$\begin{array}{llllllll}\mathrm{Pb}-210+\mathrm{D} & 1.000 \mathrm{E}+00 & 1.860 \mathrm{E}-11 & 1.304 \mathrm{E}-10 & 4.663 \mathrm{E}-06 & 3.121 \mathrm{E}-05 & 7.413 \mathrm{E}-05\end{array}$

EDSR $(j) \quad 2.131 \mathrm{E}-05 \quad 6.276 \mathrm{E}-05 \quad 1.405 \mathrm{E}-03 \quad 3.293 \mathrm{E}-03 \quad 5.246 \mathrm{E}-03$ 
RESRAD, Version $6.5 \quad T^{1 / 2}$ Limit $=180$ days

Summary : RESRAD Parameters for U-Landfill Trespasser

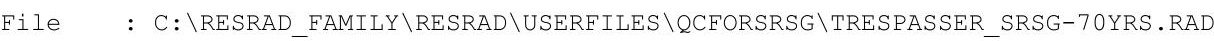

Individual Nuclide Dose Summed Over All Pathways

Parent Nuclide and Branch Fraction Indicated

Nuclide Parent THF(i) DOSE $(j, t), \mathrm{mrem} / \mathrm{yr}$

(j) (i) $\quad t=0.000 \mathrm{E}+001.000 \mathrm{E}+002.500 \mathrm{E}+015.000 \mathrm{E}+01 \quad 7.000 \mathrm{E}+01$

Am-241 Am-241 1.000E+00 $1.457 \mathrm{E}-06 \quad 1.496 \mathrm{E}-06 \quad 1.444 \mathrm{E}-04 \quad 2.949 \mathrm{E}-04 \quad 4.084 \mathrm{E}-04$

Np-237 Am-241 $1.000 \mathrm{E}+00 \quad 5.599 \mathrm{E}-10 \quad 1.695 \mathrm{E}-09 \quad 3.728 \mathrm{E}-08 \quad 9.593 \mathrm{E}-08 \quad 1.644 \mathrm{E}-07$

$\begin{array}{llllllllll}\mathrm{Np}-237 & \mathrm{~Np}-237 & 1.000 \mathrm{E}+00 & 3.453 \mathrm{E}-03 & 3.490 \mathrm{E}-03 & 4.597 \mathrm{E}-03 & 6.082 \mathrm{E}-03 & 7.575 \mathrm{E}-03\end{array}$

Np-237 $\sum \operatorname{DOSE}(j) \quad 3.453 \mathrm{E}-03 \quad 3.490 \mathrm{E}-03 \quad 4.597 \mathrm{E}-03 \quad 6.082 \mathrm{E}-03 \quad 7.576 \mathrm{E}-03$

U-233 Am-241 $1.000 \mathrm{E}+00 \quad 6.695 \mathrm{E}-19 \quad 4.735 \mathrm{E}-18 \quad 1.858 \mathrm{E}-14 \quad 1.476 \mathrm{E}-13 \quad 4.022 \mathrm{E}-13$

$\begin{array}{lllllllll}\mathrm{U}-233 & \mathrm{~Np}-237 & 1.000 \mathrm{E}+00 & 6.197 \mathrm{E}-12 & 1.880 \mathrm{E}-11 & 4.556 \mathrm{E}-09 & 1.851 \mathrm{E}-08 & 3.649 \mathrm{E}-08\end{array}$

U-233 $\quad$ DOSE $(j) \quad 6.197 \mathrm{E}-12 \quad 1.880 \mathrm{E}-11 \quad 4.556 \mathrm{E}-09 \quad 1.851 \mathrm{E}-08 \quad 3.649 \mathrm{E}-08$

Th-229 Am-241 $\quad 1.000 \mathrm{E}+00 \quad 3.971 \mathrm{E}-20 \quad 5.999 \mathrm{E}-19 \quad 3.419 \mathrm{E}-15 \quad 3.406 \mathrm{E}-14 \quad 1.120 \mathrm{E}-13$

Th-229 Np-237 $1.000 \mathrm{E}+00 \quad 4.903 \mathrm{E}-13 \quad 3.458 \mathrm{E}-12 \quad 1.253 \mathrm{E}-09 \quad 6.365 \mathrm{E}-09 \quad 1.511 \mathrm{E}-08$

Th-229 $\sum \operatorname{DOSE}(j) \quad 4.903 \mathrm{E}-13 \quad 3.458 \mathrm{E}-12 \quad 1.253 \mathrm{E}-09 \quad 6.365 \mathrm{E}-09 \quad 1.511 \mathrm{E}-08$

Cs-137 Cs-137 $1.000 \mathrm{E}+00$

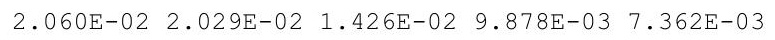

$\begin{array}{lllllll}\text { Pu-238 } & 1.840 \mathrm{E}-09 & 4.859 \mathrm{E}-17 & 4.907 \mathrm{E}-17 & 2.550 \mathrm{E}-13 & 4.452 \mathrm{E}-13 & 5.411 \mathrm{E}-13\end{array}$

$\begin{array}{lllllll}\mathrm{Pu}-238 & 1.000 \mathrm{E}+00 & 2.641 \mathrm{E}-08 & 2.667 \mathrm{E}-08 & 1.386 \mathrm{E}-04 & 2.419 \mathrm{E}-04 & 2.941 \mathrm{E}-04\end{array}$

$\begin{array}{llllll}\operatorname{DOSE}(j) & 2.641 \mathrm{E}-08 & 2.667 \mathrm{E}-08 & 1.386 \mathrm{E}-04 & 2.419 \mathrm{E}-04 & 2.941 \mathrm{E}-04\end{array}$

$\begin{array}{lllllll}\mathrm{Pu}-238 & 1.000 \mathrm{E}+00 & 2.486 \mathrm{E}-13 & 7.549 \mathrm{E}-13 & 2.342 \mathrm{E}-09 & 8.961 \mathrm{E}-09 & 1.656 \mathrm{E}-08\end{array}$

$\begin{array}{lllllll}\mathrm{U}-234 & 1.000 \mathrm{E}+00 & 1.753 \mathrm{E}-07 & 1.784 \mathrm{E}-07 & 3.576 \mathrm{E}-05 & 7.589 \mathrm{E}-05 & 1.080 \mathrm{E}-04\end{array}$

$\begin{array}{lllllll}\mathrm{U}-238 & 9.999 \mathrm{E}-01 & 2.492 \mathrm{E}-13 & 7.595 \mathrm{E}-13 & 2.586 \mathrm{E}-09 & 1.086 \mathrm{E}-08 & 2.159 \mathrm{E}-08\end{array}$

$\begin{array}{llllll}\operatorname{DOSE}(j) & 1.753 \mathrm{E}-07 & 1.784 \mathrm{E}-07 & 3.577 \mathrm{E}-05 & 7.591 \mathrm{E}-05 & 1.080 \mathrm{E}-04\end{array}$

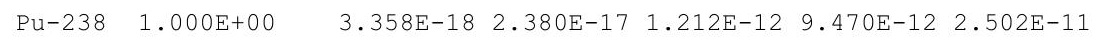

$\begin{array}{llllllll}T h-230 & 1.000 \mathrm{E}+00 \quad 7.878 \mathrm{E}-07 & 8.012 \mathrm{E}-07 & 1.560 \mathrm{E}-04 & 3.311 \mathrm{E}-04 & 4.713 \mathrm{E}-04\end{array}$

$\begin{array}{lllllll}\mathrm{U}-234 & 1.000 \mathrm{E}+00 & 3.556 \mathrm{E}-12 & 1.083 \mathrm{E}-11 & 3.580 \mathrm{E}-08 & 1.504 \mathrm{E}-07 & 2.989 \mathrm{E}-07\end{array}$

$\begin{array}{lllllll}\mathrm{U}-238 & 9.999 \mathrm{E}-01 & 3.365 \mathrm{E}-18 & 2.390 \mathrm{E}-17 & 1.294 \mathrm{E}-12 & 1.077 \mathrm{E}-11 & 2.987 \mathrm{E}-11\end{array}$

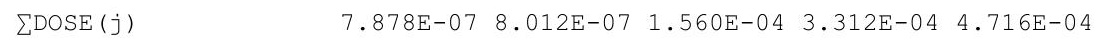

Ra-226 Pu-238 1.000E+00

$\begin{array}{lllll}4.363 \mathrm{E}-17 & 6.572 \mathrm{E}-16 & 3.284 \mathrm{E}-12 & 2.901 \mathrm{E}-11 & 8.757 \mathrm{E}-11\end{array}$

$\begin{array}{lllllll}\text { Th-230 } & 1.000 \mathrm{E}+00 & 2.053 \mathrm{E}-05 & 6.196 \mathrm{E}-05 & 1.244 \mathrm{E}-03 & 2.931 \mathrm{E}-03 & 4.701 \mathrm{E}-03\end{array}$

$\begin{array}{llllllll}\mathrm{U}-234 & 1.000 \mathrm{E}+00 & 6.163 \mathrm{E}-11 & 4.340 \mathrm{E}-10 & 1.430 \mathrm{E}-07 & 6.685 \mathrm{E}-07 & 1.499 \mathrm{E}-06\end{array}$

$\begin{array}{lllllll}\mathrm{U}-238 & 9.999 \mathrm{E}-01 & 4.369 \mathrm{E}-17 & 6.593 \mathrm{E}-16 & 3.451 \mathrm{E}-12 & 3.196 \mathrm{E}-11 & 1.001 \mathrm{E}-10\end{array}$

$\sum \operatorname{DOSE}(j)$

$2.053 \mathrm{E}-05 \quad 6.196 \mathrm{E}-05 \quad 1.244 \mathrm{E}-03 \quad 2.931 \mathrm{E}-03 \quad 4.702 \mathrm{E}-03$

$\begin{array}{lllllll}\mathrm{Pu}-238 & 1.000 \mathrm{E}+00 & 2.379 \mathrm{E}-23 & 7.401 \mathrm{E}-22 & 6.838 \mathrm{E}-15 & 1.868 \mathrm{E}-13 & 8.841 \mathrm{E}-13\end{array}$

$\begin{array}{lllllll}\mathrm{Th}-230 & 1.000 \mathrm{E}+00 & 1.860 \mathrm{E}-11 & 1.304 \mathrm{E}-10 & 4.663 \mathrm{E}-06 & 3.121 \mathrm{E}-05 & 7.413 \mathrm{E}-05\end{array}$

$\begin{array}{lllllll}\mathrm{U}-234 & 1.000 \mathrm{E}+00 & 4.195 \mathrm{E}-17 & 6.314 \mathrm{E}-16 & 3.796 \mathrm{E}-10 & 5.291 \mathrm{E}-09 & 1.815 \mathrm{E}-08\end{array}$

$\begin{array}{lllllll}\mathrm{U}-238 & 9.999 \mathrm{E}-01 & 2.382 \mathrm{E}-23 & 7.420 \mathrm{E}-22 & 7.122 \mathrm{E}-15 & 2.026 \mathrm{E}-13 & 9.906 \mathrm{E}-13\end{array}$

$\operatorname{LDOSE}(j)$

$\begin{array}{llll}1.860 \mathrm{E}-11 & 1.304 \mathrm{E}-10 \quad 4.664 \mathrm{E}-06 & 3.122 \mathrm{E}-05 & 7.415 \mathrm{E}-05\end{array}$

Pu-239 1.000E+00

$6.302 \mathrm{E}-07 \quad 6.378 \mathrm{E}-07 \quad 1.850 \mathrm{E}-04 \quad 3.925 \mathrm{E}-04 \quad 5.581 \mathrm{E}-04$

$\begin{array}{lllllll}\mathrm{Pu}-239 & 1.000 \mathrm{E}+00 & 8.030 \mathrm{E}-13 & 2.436 \mathrm{E}-12 & 5.659 \mathrm{E}-11 & 1.542 \mathrm{E}-10 & 2.766 \mathrm{E}-10\end{array}$

$\begin{array}{lllllll}\mathrm{U}-235 & 1.000 \mathrm{E}+00 & 1.627 \mathrm{E}-03 & 1.648 \mathrm{E}-03 & 2.254 \mathrm{E}-03 & 3.101 \mathrm{E}-03 & 3.987 \mathrm{E}-03\end{array}$

$\operatorname{LDOSE}(j)$

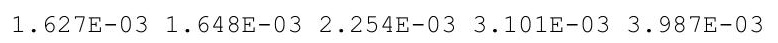


RESRAD, Version $6.5 \quad T^{13 / 2}$ Limit $=180$ days

Summary : RESRAD Parameters for U-Landfill Trespasser

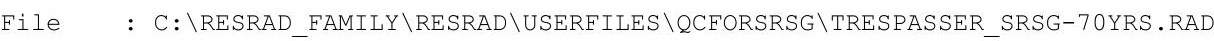

Individual Nuclide Dose Summed Over All Pathways

Parent Nuclide and Branch Fraction Indicated

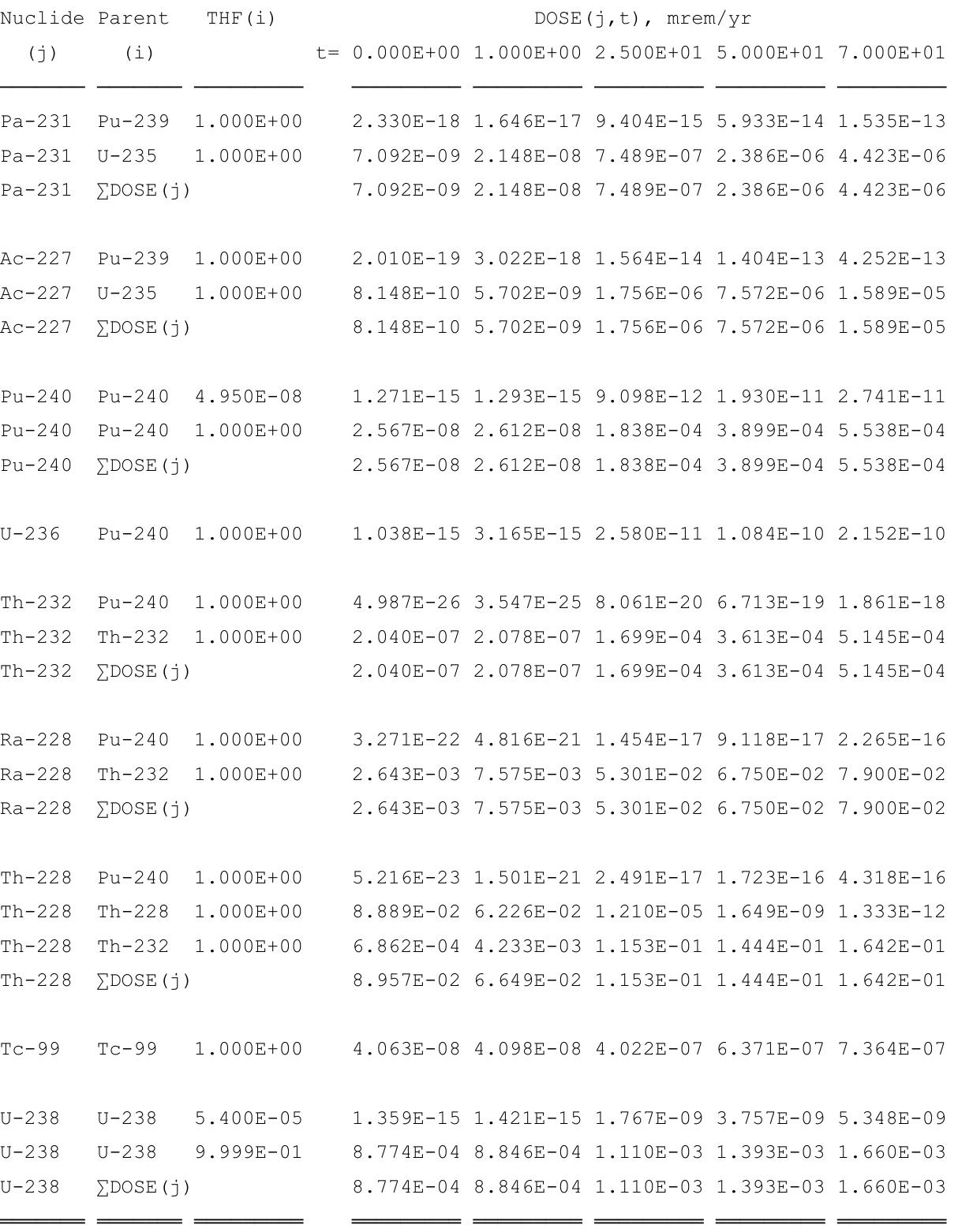

THF (i) is the thread fraction of the parent nuclide. 
RESRAD, Version $6.5 \quad \mathrm{~T}^{1 / 2}$ Limit $=180$ days

Summary : RESRAD Parameters for U-Landfill Trespasser

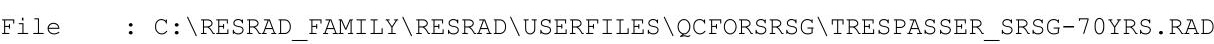

Individual Nuclide Soil Concentration

Parent Nuclide and Branch Fraction Indicated

Nuclide Parent THF(i) $\quad S(j, t), p c i / g$

\section{(j)}

(i)

Am-241 Am-241 $1.000 \mathrm{E}+00$

Np-237 Am-241 $1.000 \mathrm{E}+00$

$\mathrm{Np}-237 \quad \mathrm{~Np}-237 \quad 1.000 \mathrm{E}+00$

Np-237 $\sum S(j):$

U-233 Am-241 $1.000 \mathrm{E}+00$

U-233 Np-237 $1.000 \mathrm{E}+00$

U-233 $\sum S(j):$

Th-229

Th-229

Th-229

Cs -137

$\mathrm{Pu}-238$

$\mathrm{Pu}-238$

Pu-238

$\mathrm{U}-234$

$\mathrm{U}-234$

$\mathrm{U}-234$

$\mathrm{U}-234$

Th -230

Th-230

Th -230

Th-230

Th -230

$\mathrm{Ra}-226$

$\mathrm{Ra}-226$

$\mathrm{Ra}-226$

$\mathrm{Ra}-226$

$\operatorname{Ra}-226$

$\mathrm{Pb}-210$

$\mathrm{Pb}-210$

$\mathrm{Pb}-210$

$\mathrm{Pb}-210$

$\mathrm{Pb}-210$

$\mathrm{Pu}-239$

$\mathrm{U}-235$

$\mathrm{U}-235$

$\mathrm{U}-235$
$\mathrm{Am}-241 \quad 1.000 \mathrm{E}+00$

Np-237 1.000E+00

$\sum S(j):$

Cs-137 1.000E+00

Pu-238 1.840E-09

$\mathrm{Pu}-238 \quad 1.000 \mathrm{E}+00$

$\sum S(j):$

$\mathrm{U}-234 \quad 1.000 \mathrm{E}+00$

$\mathrm{U}-238 \quad 9.999 \mathrm{E}-01$

$\sum S(j):$

$\mathrm{Pu}-238 \quad 1.000 \mathrm{E}+00$

Th-230 1.000E+00

$\mathrm{U}-234 \quad 1.000 \mathrm{E}+00$

$\sum S(j):$

$\mathrm{Pu}-238 \quad 1.000 \mathrm{E}+00$

Th-230 1.000E+00

$\mathrm{U}-234 \quad 1.000 \mathrm{E}+00$

U-238 9.999E-01

$\sum S(j):$

$\mathrm{Pu}-238 \quad 1.000 \mathrm{E}+00$

$\mathrm{U}-234 \quad 1.000 \mathrm{E}+00$

$\mathrm{U}-238 \quad 9.999 \mathrm{E}-01$

$\sum S(j):$

$\mathrm{Pu}-239 \quad 1.000 \mathrm{E}+00$

Pu-239 $1.000 \mathrm{E}+00$

$\mathrm{U}-2351.000 \mathrm{E}+00$

$\sum S(j):$
$\mathrm{Pu}-238 \quad 1.000 \mathrm{E}+00$

$\mathrm{U}-238 \quad 9.999 \mathrm{E}-01$

Th-230 1.000E+00 $t=0.000 \mathrm{E}+00 \quad 1.000 \mathrm{E}+00 \quad 2.500 \mathrm{E}+01 \quad 5.000 \mathrm{E}+01 \quad 7.000 \mathrm{E}+01$

$\begin{array}{lllll}1.000 \mathrm{E}+00 & 9.984 \mathrm{E}-01 & 9.606 \mathrm{E}-01 & 9.227 \mathrm{E}-01 & 8.934 \mathrm{E}-01\end{array}$

$0.000 \mathrm{E}+00 \quad 3.236 \mathrm{E}-07 \quad 7.921 \mathrm{E}-06 \quad 1.550 \mathrm{E}-05 \quad 2.132 \mathrm{E}-05$

$1.000 \mathrm{E}+00 \quad 9.998 \mathrm{E}-01 \quad 9.960 \mathrm{E}-01 \quad 9.921 \mathrm{E}-01 \quad 9.890 \mathrm{E}-01$

$\begin{array}{llllll}1.000 \mathrm{E}+00 & 9.998 \mathrm{E}-01 & 9.961 \mathrm{E}-01 & 9.921 \mathrm{E}-01 & 9.890 \mathrm{E}-01\end{array}$

$0.000 \mathrm{E}+00 \quad 7.078 \mathrm{E}-13 \quad 4.361 \mathrm{E}-10 \quad 1.719 \mathrm{E}-09 \quad 3.329 \mathrm{E}-09$

$0.000 \mathrm{E}+00 \quad 4.373 \mathrm{E}-06 \quad 1.091 \mathrm{E}-04 \quad 2.176 \mathrm{E}-04 \quad 3.041 \mathrm{E}-04$

$0.000 \mathrm{E}+00 \quad 4.373 \mathrm{E}-06 \quad 1.091 \mathrm{E}-04 \quad 2.176 \mathrm{E}-04 \quad 3.041 \mathrm{E}-04$

$\begin{array}{lllll}0.000 \mathrm{E}+00 & 2.228 \mathrm{E}-17 & 3.442 \mathrm{E}-13 & 2.722 \mathrm{E}-12 & 7.399 \mathrm{E}-12\end{array}$

$0.000 \mathrm{E}+00 \quad 2.065 \mathrm{E}-10 \quad 1.287 \mathrm{E}-07 \quad 5.138 \mathrm{E}-07 \quad 1.005 \mathrm{E}-06$

$0.000 \mathrm{E}+00 \quad 2.065 \mathrm{E}-10 \quad 1.287 \mathrm{E}-07 \quad 5.138 \mathrm{E}-07 \quad 1.005 \mathrm{E}-06$

$\begin{array}{lllll}1.000 \mathrm{E}+00 & 9.771 \mathrm{E}-01 & 5.607 \mathrm{E}-01 & 3.144 \mathrm{E}-01 & 1.979 \mathrm{E}-01\end{array}$

1.840E-09 1.825E-09 1.509E-09 1.238E-09 1.057E-09

$\begin{array}{llllll}1.000 \mathrm{E}+00 & 9.921 \mathrm{E}-01 \quad 8.204 \mathrm{E}-01 \quad 6.730 \mathrm{E}-01 \quad 5.744 \mathrm{E}-01\end{array}$

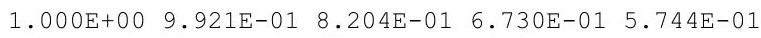

$\begin{array}{lllll}0.000 \mathrm{E}+00 & 2.824 \mathrm{E}-06 & 6.427 \mathrm{E}-05 & 1.170 \mathrm{E}-04 & 1.522 \mathrm{E}-04\end{array}$

$\begin{array}{lllll}1.000 \mathrm{E}+00 & 1.000 \mathrm{E}+00 & 9.993 \mathrm{E}-01 & 9.985 \mathrm{E}-01 & 9.979 \mathrm{E}-01\end{array}$

$0.000 \mathrm{E}+00 \quad 2.835 \mathrm{E}-06 \quad 7.082 \mathrm{E}-05 \quad 1.415 \mathrm{E}-04 \quad 1.980 \mathrm{E}-04$

$1.000 \mathrm{E}+00 \quad 1.000 \mathrm{E}+00 \quad 9.994 \mathrm{E}-01 \quad 9.988 \mathrm{E}-01 \quad 9.983 \mathrm{E}-01$

$0.000 \mathrm{E}+00 \quad 1.273 \mathrm{E}-11 \quad 7.471 \mathrm{E}-09 \quad 2.805 \mathrm{E}-08 \quad 5.235 \mathrm{E}-08$

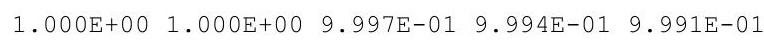
$\begin{array}{llllll}0.000 \mathrm{E}+00 & 9.002 \mathrm{E}-06 & 2.249 \mathrm{E}-04 & 4.496 \mathrm{E}-04 & 6.292 \mathrm{E}-04\end{array}$ $0.000 \mathrm{E}+00 \quad 1.276 \mathrm{E}-11 \quad 7.970 \mathrm{E}-09 \quad 3.186 \mathrm{E}-08 \quad 6.242 \mathrm{E}-08$ $\begin{array}{lllll}1.000 \mathrm{E}+00 & 1.000 \mathrm{E}+00 & 9.999 \mathrm{E}-01 & 9.998 \mathrm{E}-01 & 9.998 \mathrm{E}-01\end{array}$

$\begin{array}{lllll}0.000 \mathrm{E}+00 & 1.839 \mathrm{E}-15 & 2.733 \mathrm{E}-11 & 2.079 \mathrm{E}-10 & 5.484 \mathrm{E}-10\end{array}$ $\begin{array}{lllll}0.000 \mathrm{E}+00 & 4.331 \mathrm{E}-04 & 1.077 \mathrm{E}-02 & 2.141 \mathrm{E}-02 & 2.983 \mathrm{E}-02\end{array}$ $0.000 \mathrm{E}+00 \quad 1.950 \mathrm{E}-09 \quad 1.214 \mathrm{E}-06 \quad 4.835 \mathrm{E}-06 \quad 9.444 \mathrm{E}-06$ $\begin{array}{llllll}0.000 \mathrm{E}+00 & 1.842 \mathrm{E}-15 & 2.870 \mathrm{E}-11 & 2.288 \mathrm{E}-10 & 6.262 \mathrm{E}-10\end{array}$ $0.000 \mathrm{E}+00 \quad 4.331 \mathrm{E}-04 \quad 1.077 \mathrm{E}-02 \quad 2.141 \mathrm{E}-02 \quad 2.984 \mathrm{E}-02$

$0.000 \mathrm{E}+00 \quad 1.421 \mathrm{E}-17 \quad 4.623 \mathrm{E}-12 \quad 6.196 \mathrm{E}-11 \quad 2.084 \mathrm{E}-10$ $0.000 \mathrm{E}+00 \quad 6.662 \mathrm{E}-06 \quad 3.286 \mathrm{E}-03 \quad 1.057 \mathrm{E}-02 \quad 1.773 \mathrm{E}-02$ $\begin{array}{llllll}0.000 \mathrm{E}+00 & 2.004 \mathrm{E}-11 & 2.619 \mathrm{E}-07 & 1.772 \mathrm{E}-06 & 4.307 \mathrm{E}-06\end{array}$ $0.000 \mathrm{E}+00 \quad 1.423 \mathrm{E}-17 \quad 4.811 \mathrm{E}-12 \quad 6.715 \mathrm{E}-11 \quad 2.333 \mathrm{E}-10$

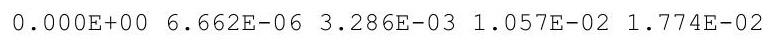

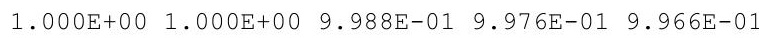
$\begin{array}{lllll}0.000 \mathrm{E}+00 & 9.848 \mathrm{E}-10 & 2.460 \mathrm{E}-08 & 4.915 \mathrm{E}-08 & 6.876 \mathrm{E}-08\end{array}$ $\begin{array}{lllll}1.000 \mathrm{E}+00 & 1.000 \mathrm{E}+00 & 9.993 \mathrm{E}-01 & 9.986 \mathrm{E}-01 & 9.981 \mathrm{E}-01\end{array}$ $\begin{array}{lllll}1.000 \mathrm{E}+00 & 1.000 \mathrm{E}+00 & 9.993 \mathrm{E}-01 & 9.986 \mathrm{E}-01 & 9.981 \mathrm{E}-01\end{array}$ 
RESRAD, Version $6.5 \quad T^{1 / 2}$ Limit $=180$ days

Summary : RESRAD Parameters for U-Landfill Trespasser

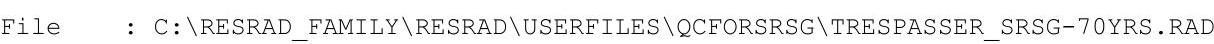

Individual Nuclide Soil Concentration

Parent Nuclide and Branch Fraction Indicated

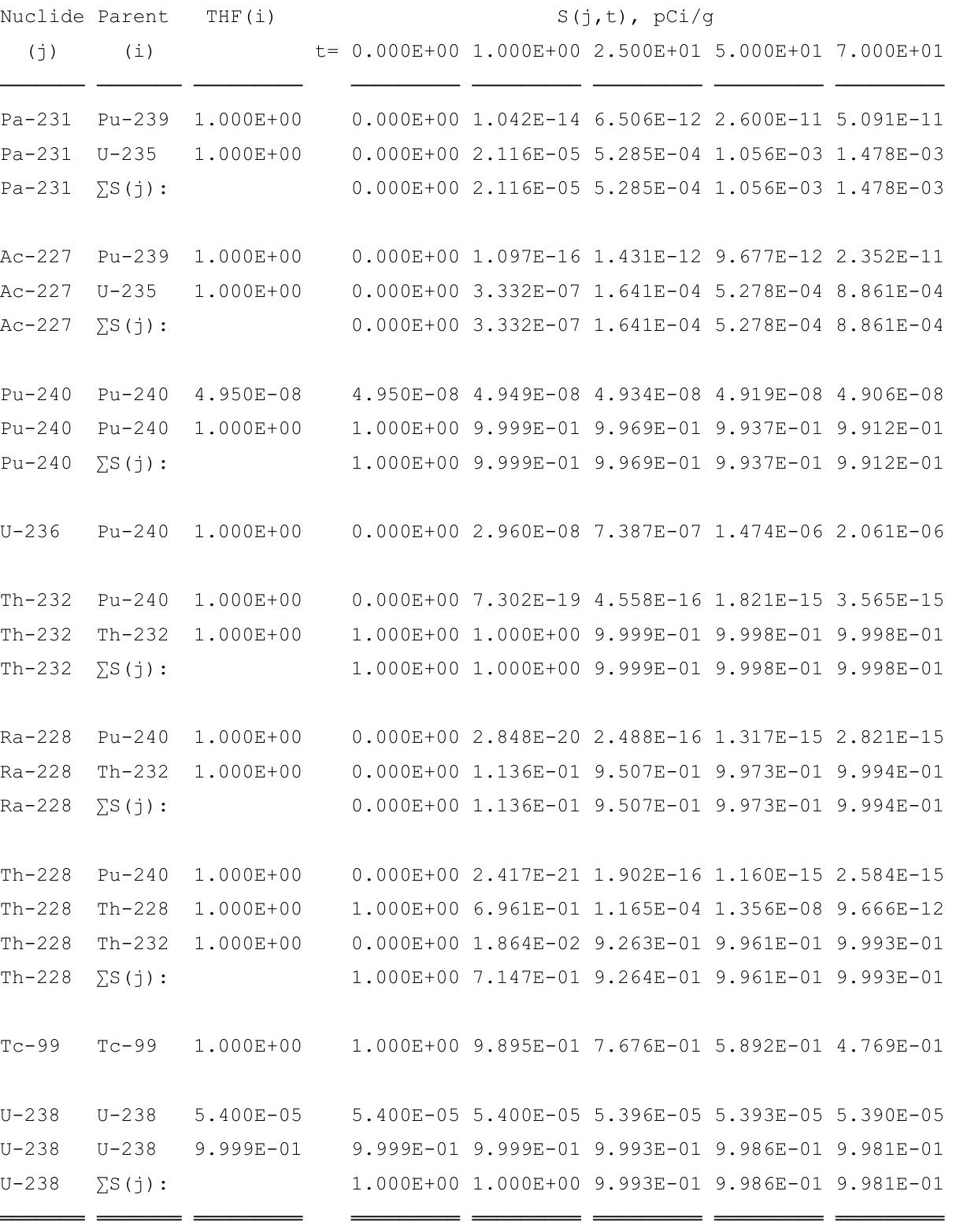

THF (i) is the thread fraction of the parent nuclide.

RESCALC.EXE execution time $=3.63$ seconds 
RESRAD, Version $6.5 \quad T^{1 / 2}$ Limit $=180$ days

07/21/2011 16:52 Page

Summary : RESRAD Parameters for U-Landfill Resident Gardener

File : C: \RESRAD_FAMILY \RESRAD \USERFILES \QCFORSRSG $\backslash R E S I D E N T G A R D E N E R-S R S G-M A Y 11 . R A D$

Table of Contents

Part I: Mixture Sums and Single Radionuclide Guidelines

Dose Conversion Factor (and Related) Parameter Summary ... 2

Site-Specific Parameter Summary ............... 8

Summary of Pathway Selections .................... 18

Contaminated Zone and Total Dose Summary ............. 19

Total Dose Components

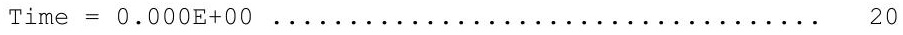

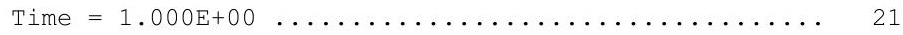

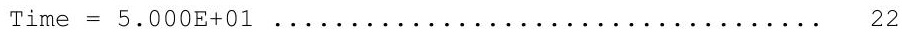

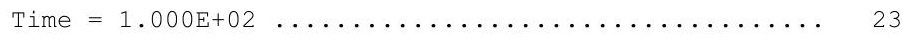

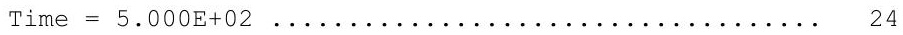

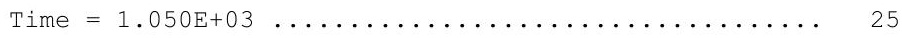

Dose/Source Ratios Summed Over All Pathways .......... 26

Single Radionuclide Soil Guidelines ............... 28

Dose Per Nuclide Summed Over All Pathways ............ 29

Soil Concentration Per Nuclide ................ 31 
RESRAD, Version $6.5 \quad T^{1 / 2}$ Limit $=180$ days

07/21/2011 16:52 Page

Summary : RESRAD Parameters for U-Landfill Resident Gardener

File : C: \RESRAD_FAMILY \RESRAD \USERFILES \QCFORSRSG \RESIDENTGARDENER-SRSG-MAY11.RAD

Dose Conversion Factor (and Related) Parameter Summary

Dose Library: ICRP 60 \& ICRP 72 (Adult)

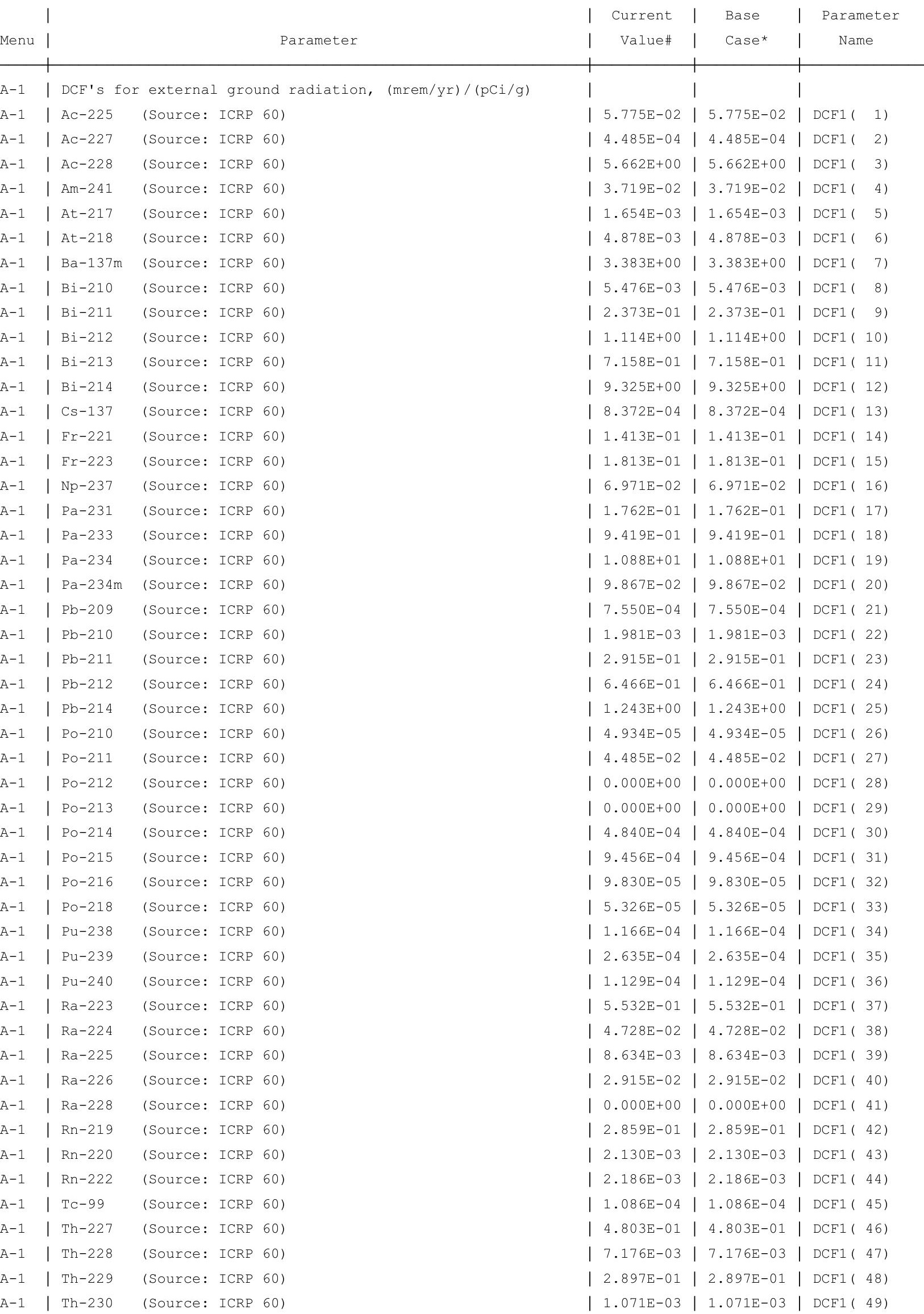


RESRAD, Version $6.5 \quad \mathrm{~T}^{1 / 2}$ Limit $=180$ days

$07 / 21 / 2011$

Summary : RESRAD Parameters for U-Landfill Resident Gardener

File : C: \RESRAD_FAMILY \RESRAD \USERFILES \QCFORSRSG $\backslash$ RESIDENTGARDENER-SRSG-MAY11.RAD

Dose Conversion Factor (and Related) Parameter Summary (continued)

Dose Library: ICRP 60 \& ICRP 72 (Adult)

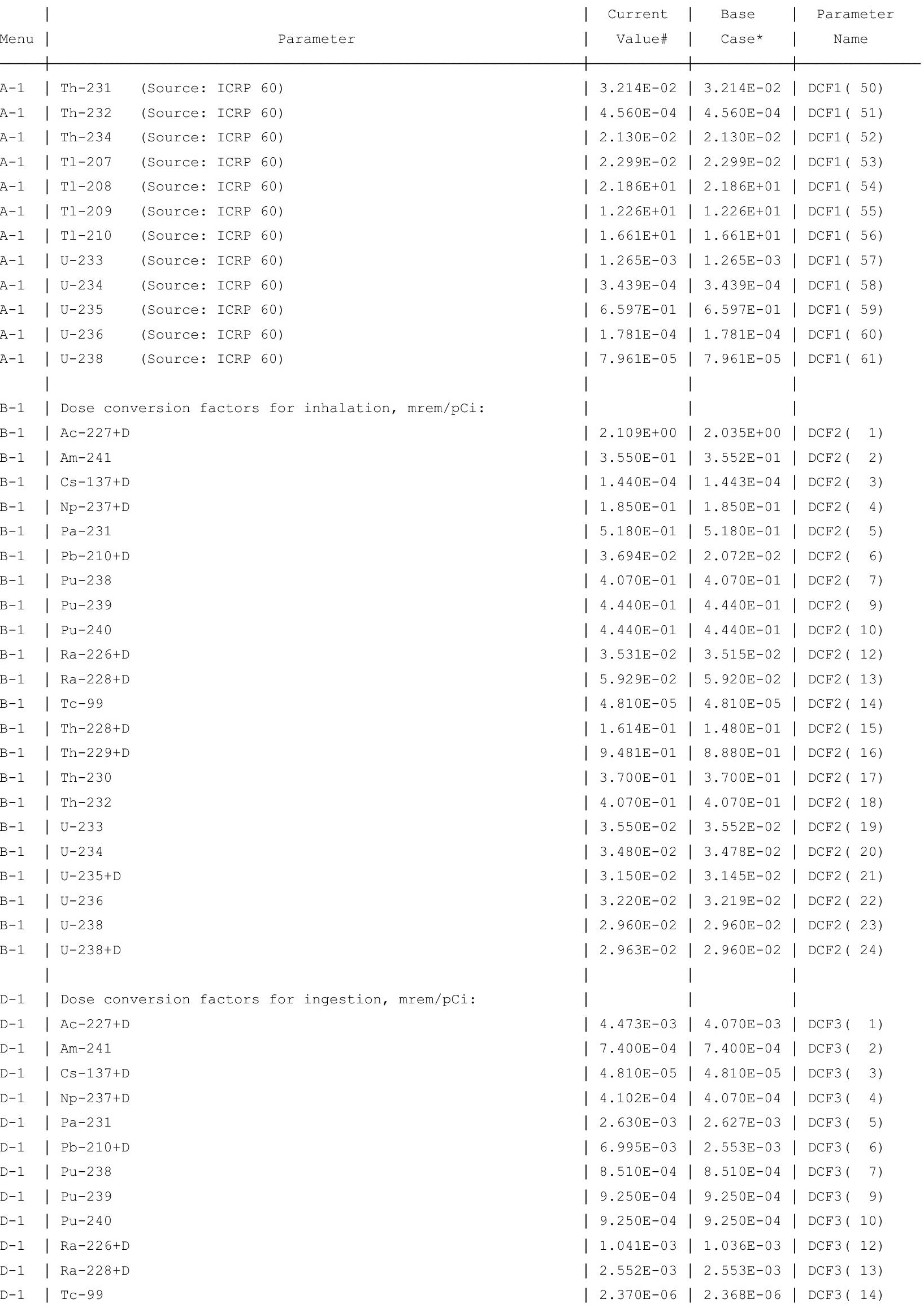


RESRAD, Version $6.5 \quad \mathrm{~T}^{1 / 2}$ Limit $=180$ days

ummary : RESRAD Parameters for U-Landfill Resident Gardener

File : C: \RESRAD_FAMILY \RESRAD \USERFILES \QCFORSRSG $\backslash$ RESIDENTGARDENER-SRSG-MAY11.RAD

Dose Conversion Factor (and Related) Parameter Summary (continued) Dose Library: ICRP 60 \& ICRP 72 (Adult)

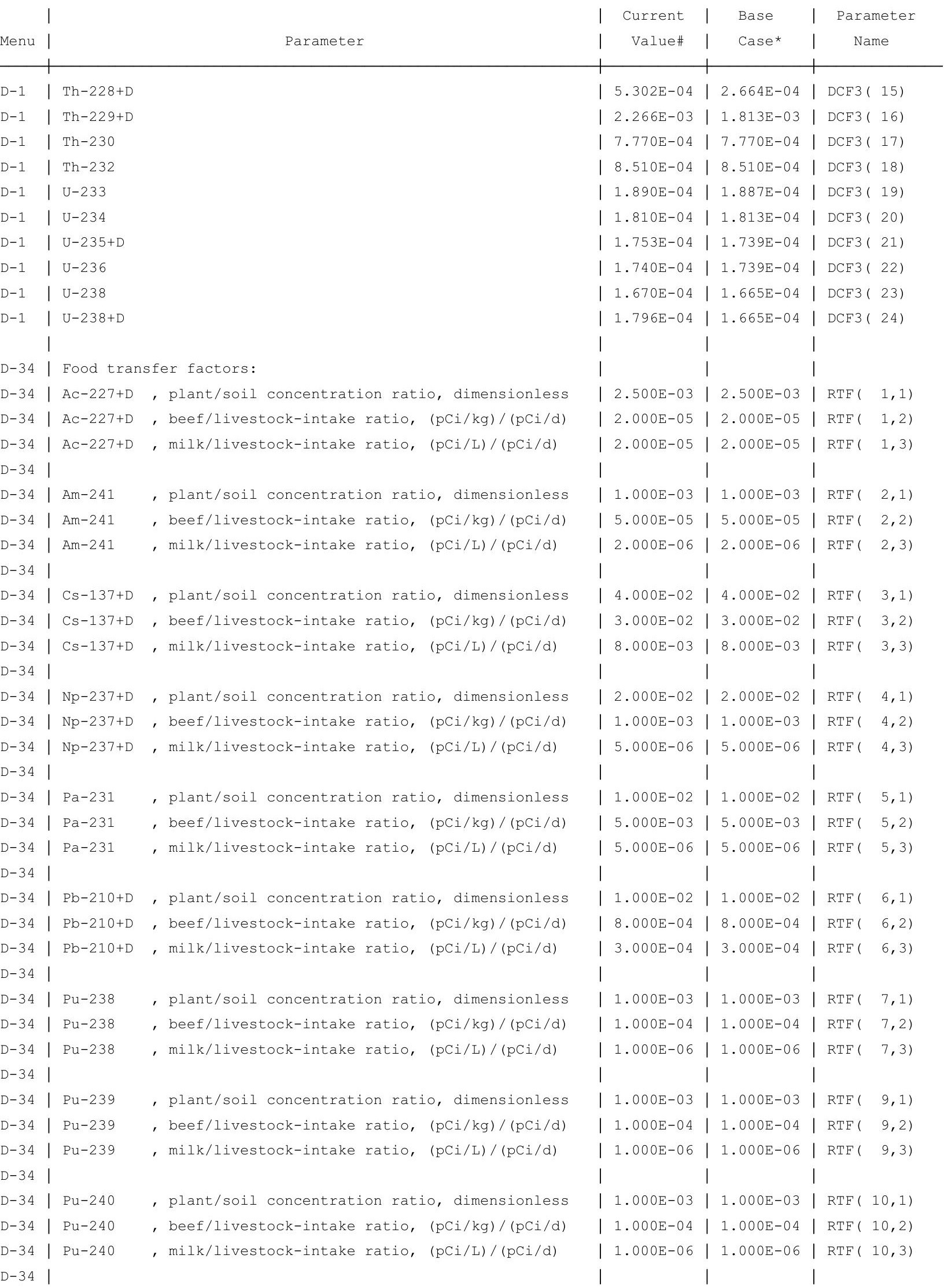


RESRAD, Version $6.5 \quad T^{1 / 2}$ Limit $=180$ days

Summary : RESRAD Parameters for U-Landfill Resident Gardener

File : C: \RESRAD FAMILY \RESRAD \USERFILES \QCFORSRSG $\backslash$ RESIDENTGARDENER-SRSG-MAY11.RAD

Site-Specific Parameter Summary (continued)

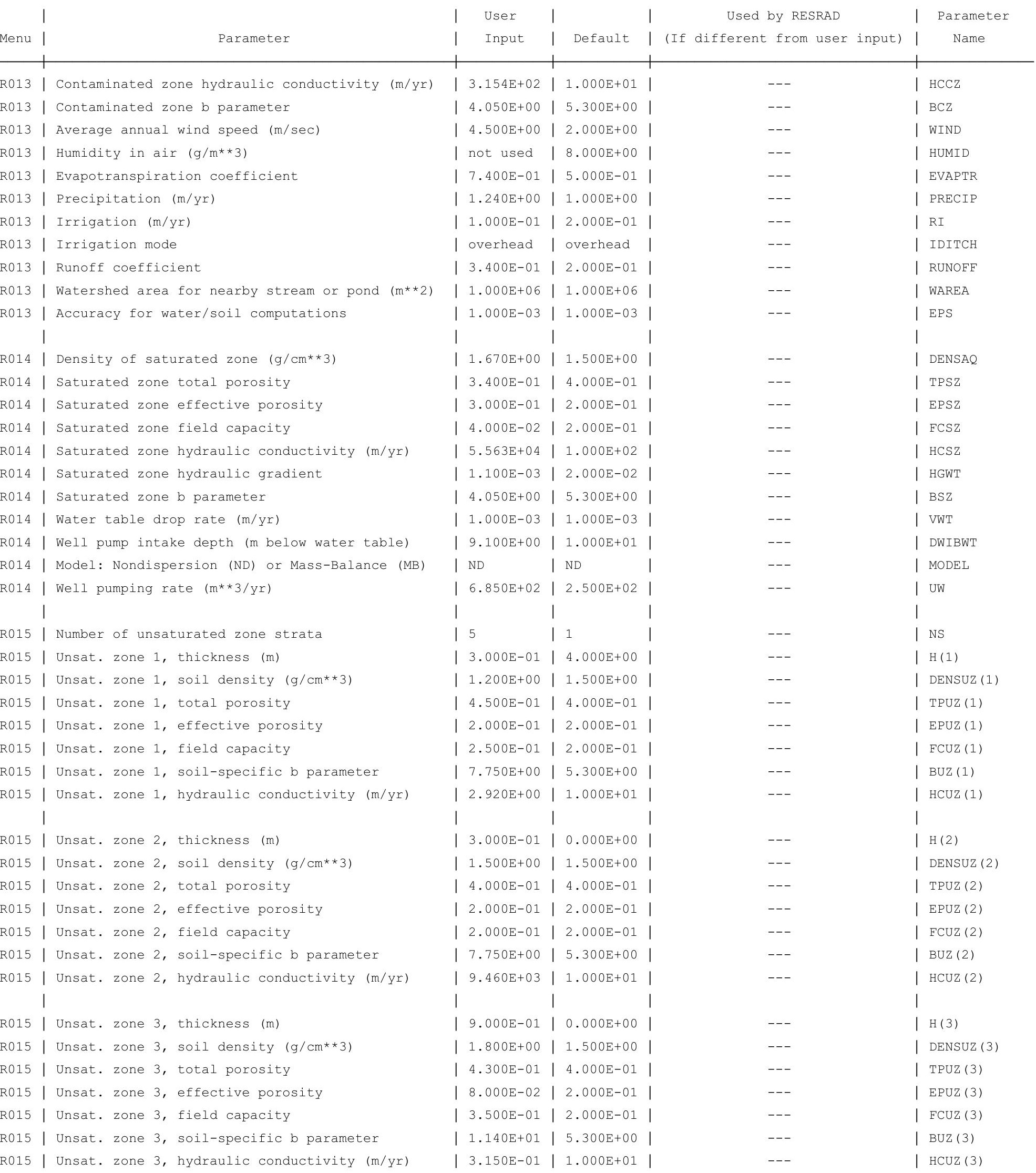


RESRAD, Version $6.5 \quad \mathrm{~T}^{1 / 2}$ Limit $=180$ days

Summary : RESRAD Parameters for U-Landfill Resident Gardener

File : C: \RESRAD FAMILY \RESRAD \USERFILES \QCFORSRSG $\backslash$ RESIDENTGARDENER-SRSG-MAY11.RAD

Site-Specific Parameter Summary (continued)

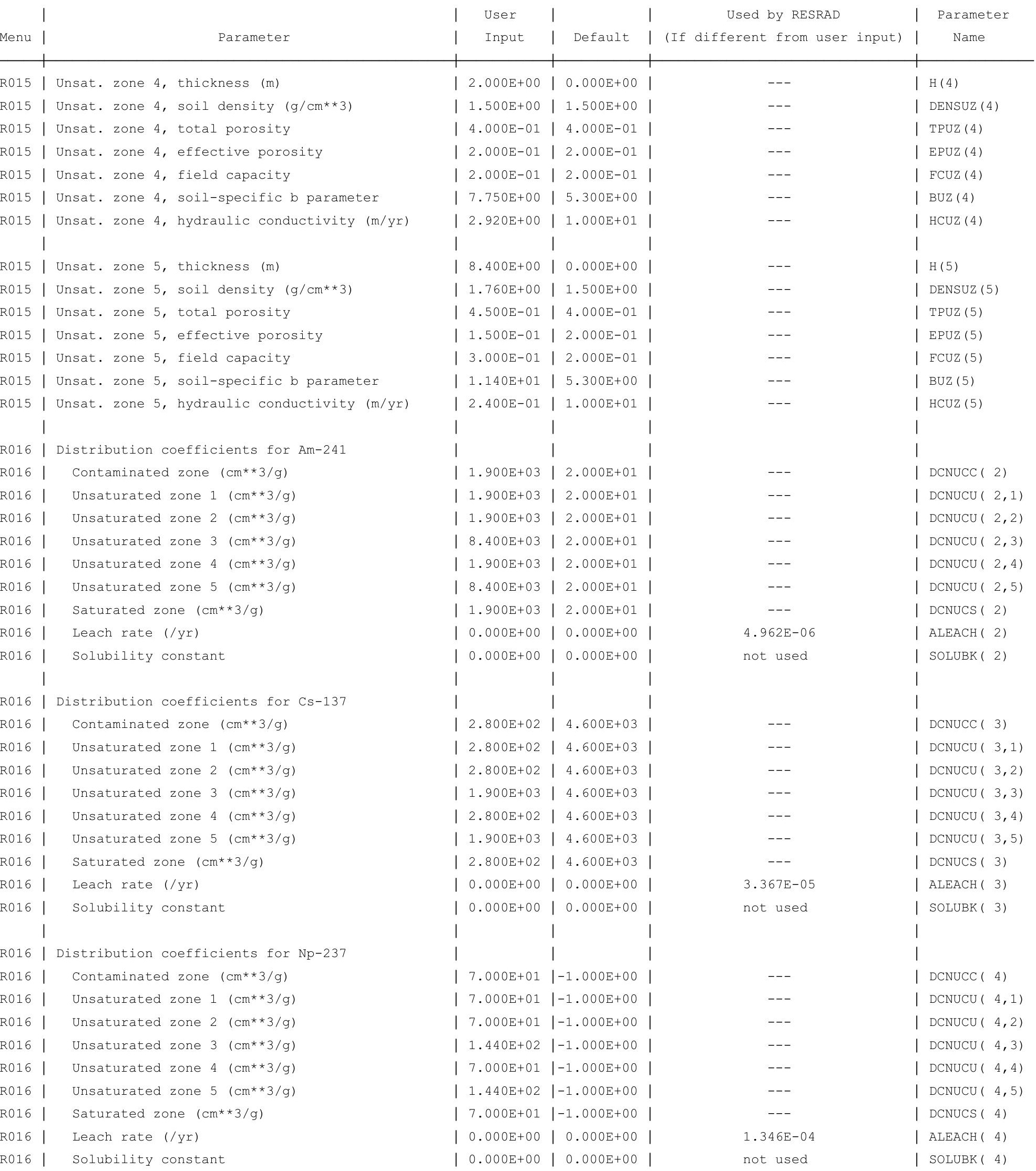


RESRAD, Version $6.5 \quad \mathrm{~T}^{1} \frac{1}{2}$ Limit $=180$ days

Summary : RESRAD Parameters for U-Landfill Resident Gardener

File : C: \RESRAD_FAMILY \RESRAD \USERFILES \QCFORSRSG \RESIDENTGARDENER-SRSG-MAY11.RAD

Site-Specific Parameter Summary (continued)

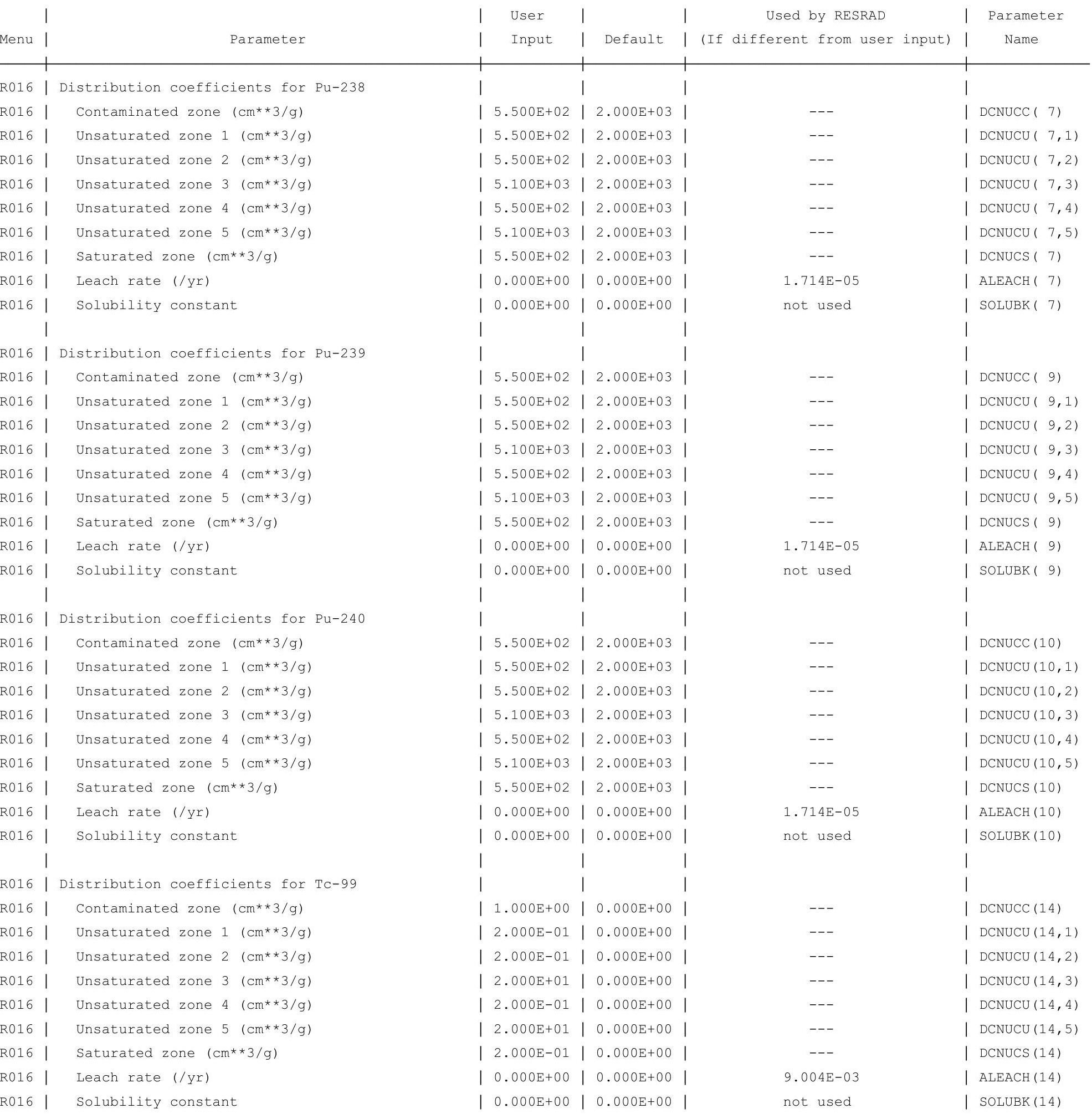


RESRAD, Version $6.5 \quad \mathrm{~T}^{1 / 2}$ Limit $=180$ days

Summary : RESRAD Parameters for U-Landfill Resident Gardener

File : C: \RESRAD FAMILY \RESRAD \USERFILES \QCFORSRSG \RESIDENTGARDENER-SRSG-MAY11.RAD

Site-Specific Parameter Summary (continued)

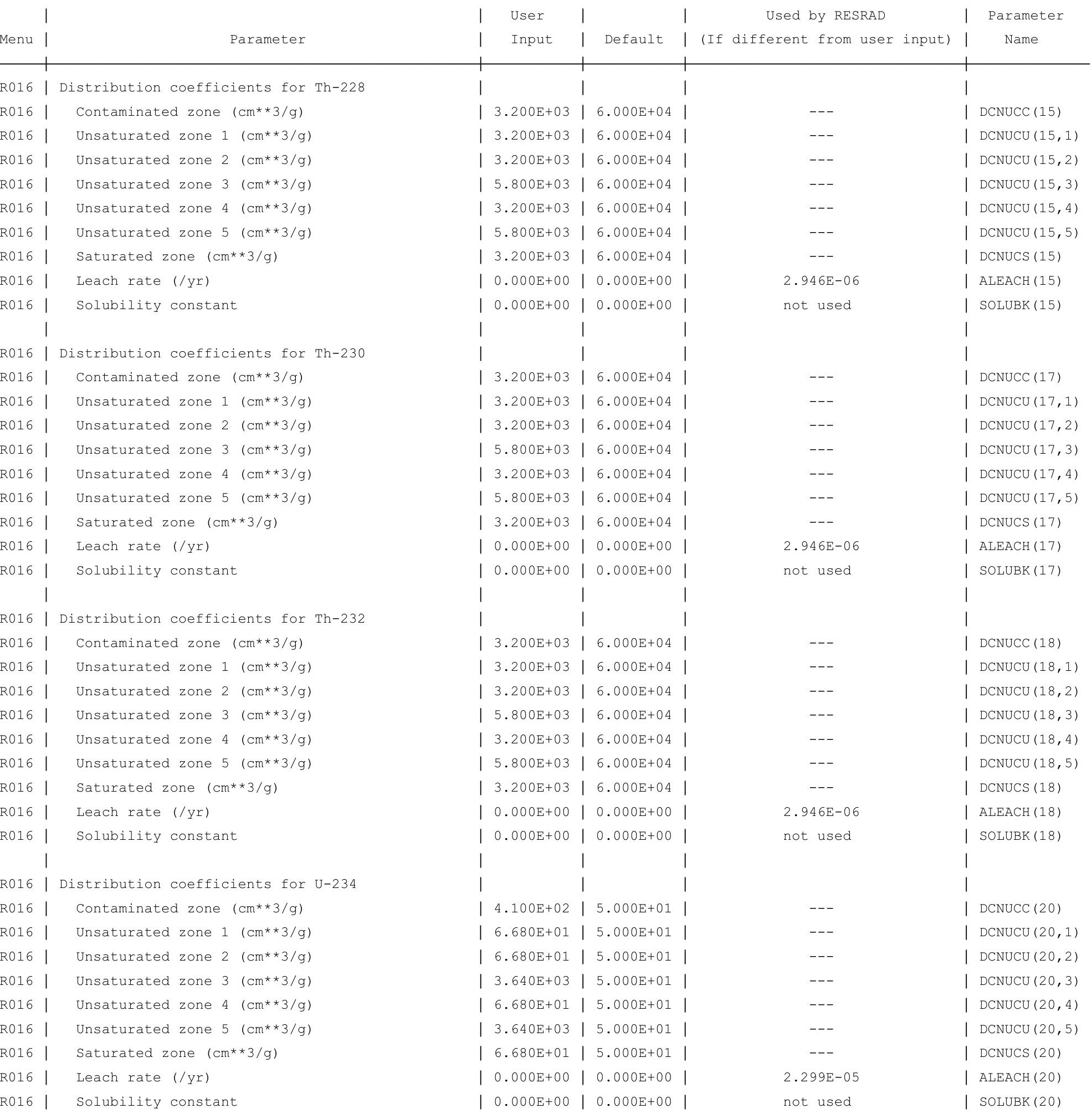


RESRAD, Version $6.5 \quad \mathrm{~T}^{1 / 2}$ Limit $=180$ days

Summary : RESRAD Parameters for U-Landfill Resident Gardener

File : C: \RESRAD FAMILY \RESRAD \USERFILES \QCFORSRSG \RESIDENTGARDENER-SRSG-MAY11.RAD

Site-Specific Parameter Summary (continued)

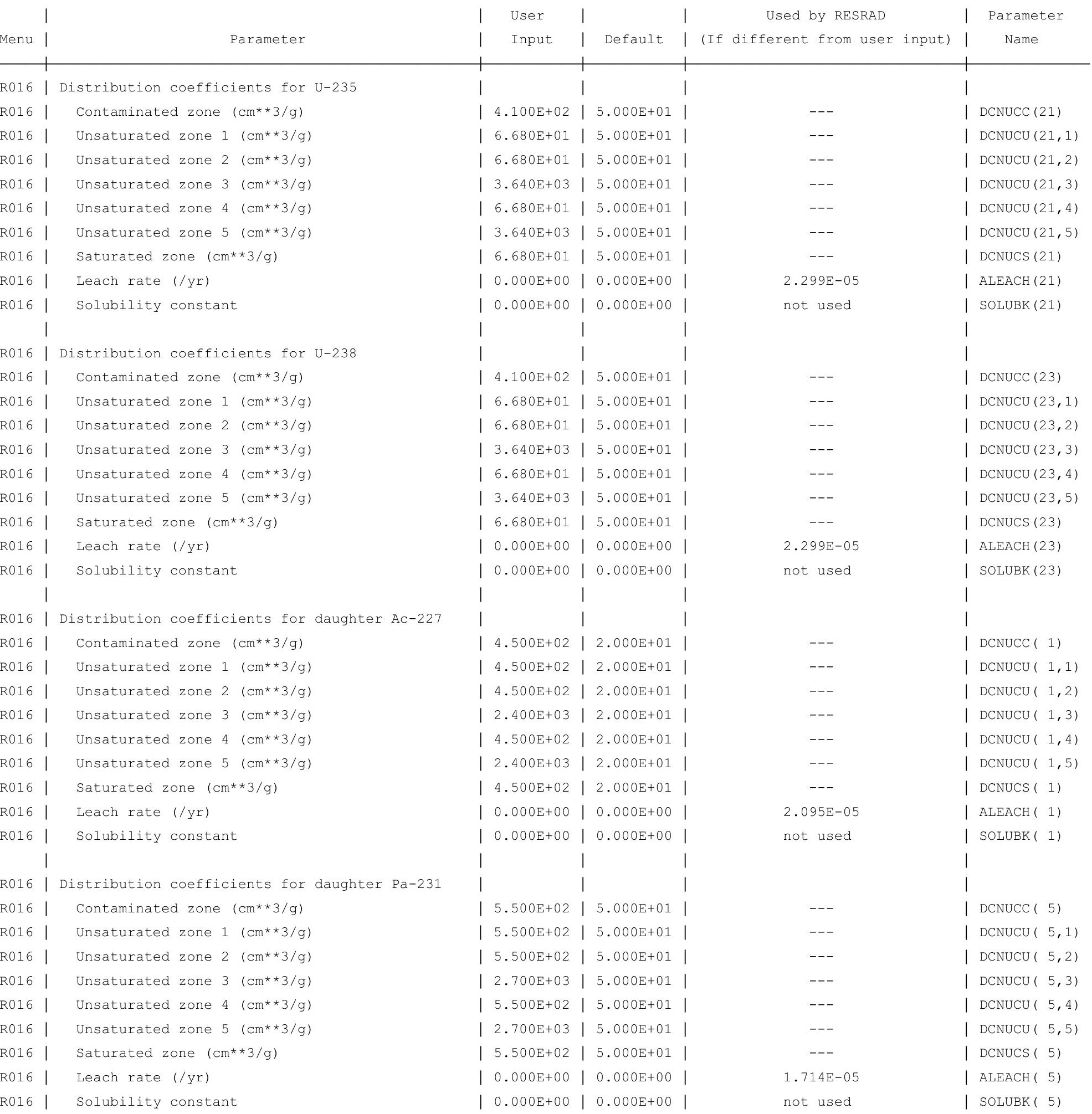


RESRAD, Version $6.5 \quad \mathrm{~T}^{1 / 2}$ Limit $=180$ days

$07 / 21 / 2011$

16:52 Page 1

Summary : RESRAD Parameters for U-Landfill Resident Gardener

File : C: \RESRAD FAMILY \RESRAD \USERFILES \QCFORSRSG $\backslash$ RESIDENTGARDENER-SRSG-MAY11.RAD

Site-Specific Parameter Summary (continued)

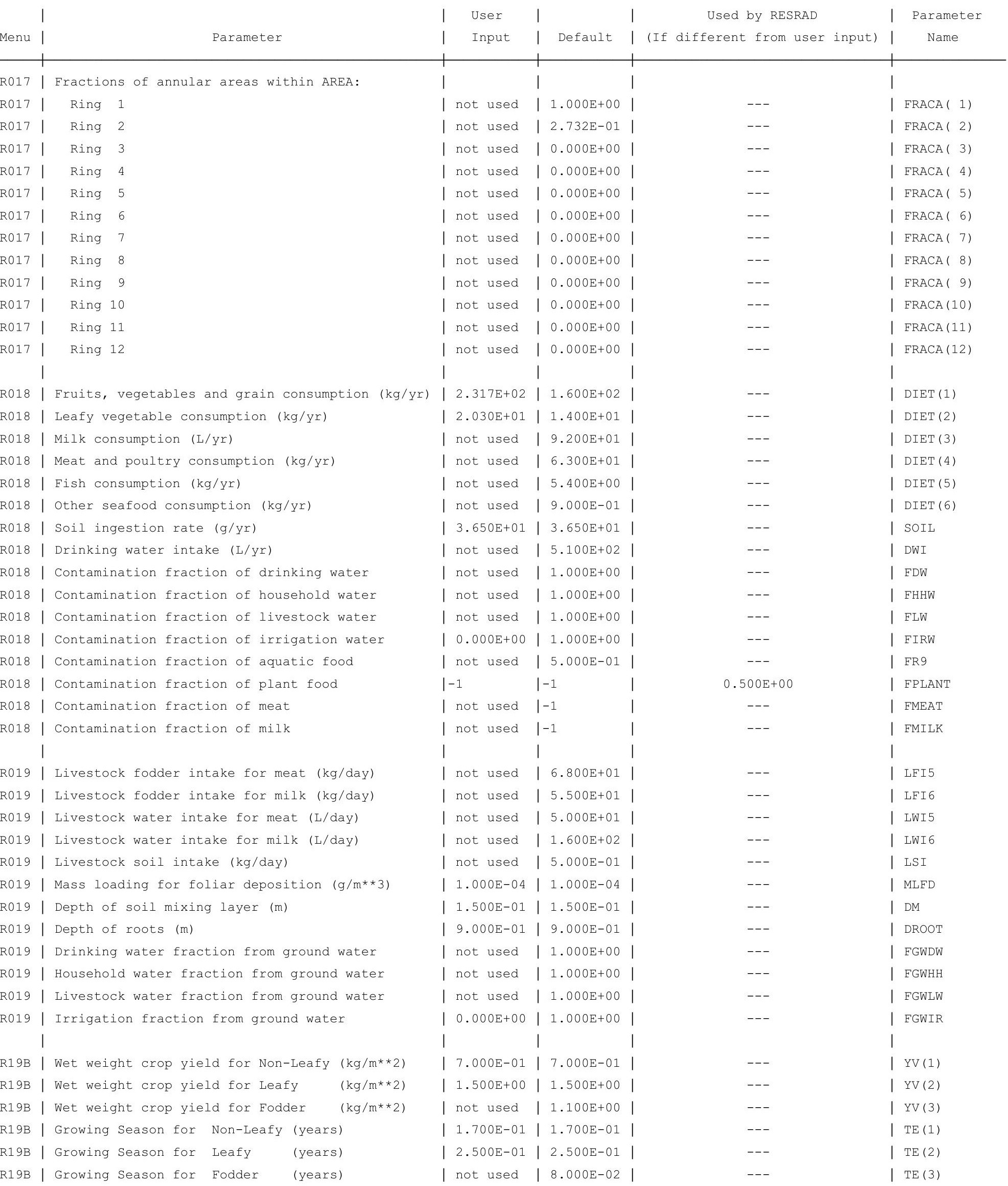


RESRAD, Version $6.5 \quad \mathrm{~T}^{1 / 2}$ Limit $=180$ days

Summary : RESRAD Parameters for U-Landfill Resident Gardener

File : C: \RESRAD FAMILY \RESRAD \USERFILES \QCFORSRSG $\backslash$ RESIDENTGARDENER-SRSG-MAY11.RAD

Site-Specific Parameter Summary (continued)

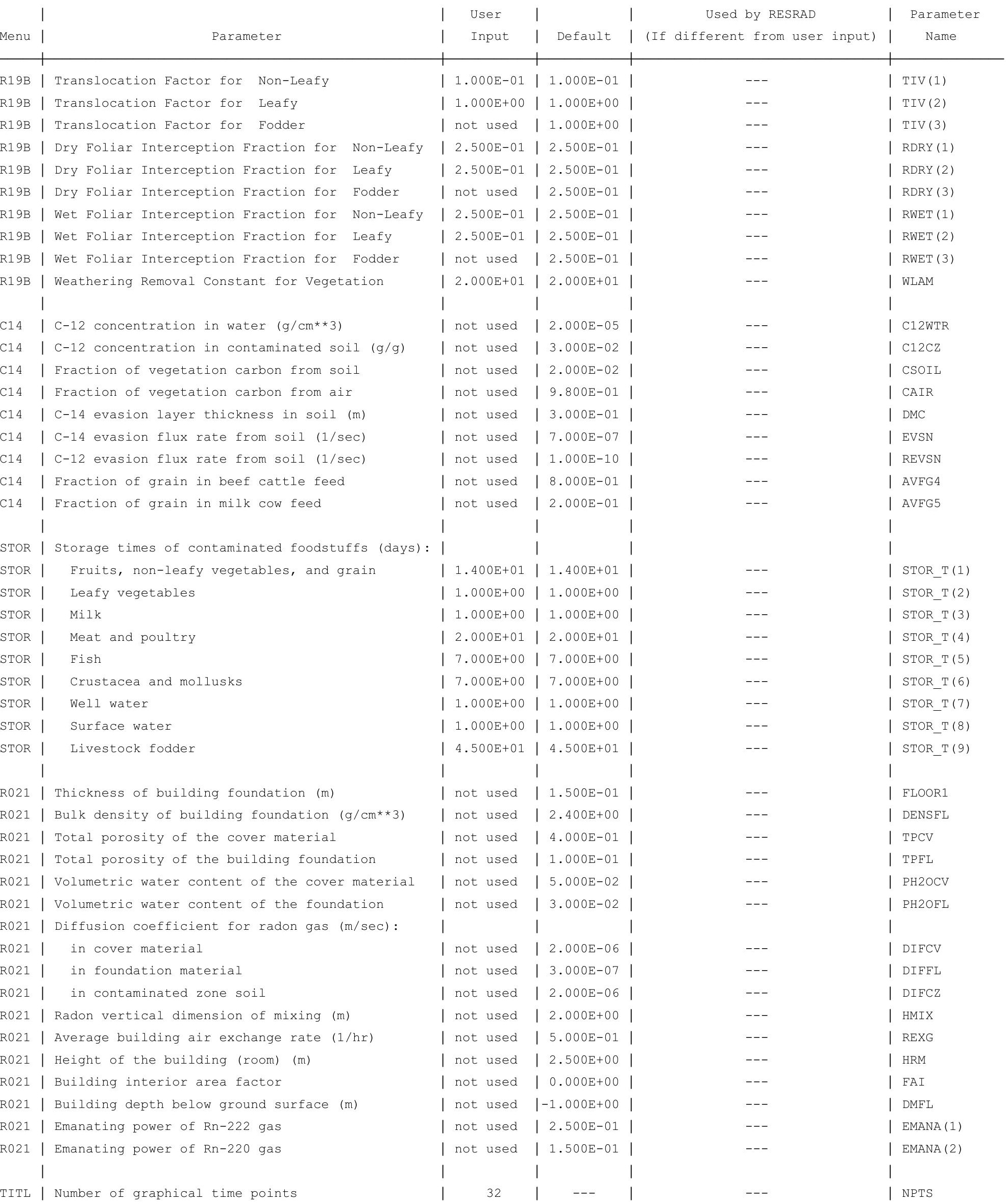

TITL | Number of graphical time points 
RESRAD, Version $6.5 \quad$ T1/2 Limit $=180$ days

Summary : RESRAD Parameters for U-Landfill Resident Gardener

File : C: $\backslash$ RESRAD_FAMILY $\backslash R E S R A D \backslash U S E R F I L E S \backslash Q C F O R S R S G \backslash R E S I D E N T G A R D E N E R-S R S G-M A Y 11 . R A D$

Contaminated Zone Dimensions

Area: $\quad 89436.00$ square meters

Thickness:

Cover Depth:

\begin{abstract}
13.40 meters
1.52 meters
\end{abstract}

Initial Soil Concentrations, pci/g

$\begin{array}{ll}\mathrm{Am}-241 & 1.000 \mathrm{E}+00 \\ \mathrm{Cs}-137 & 1.000 \mathrm{E}+00 \\ \mathrm{~Np}-237 & 1.000 \mathrm{E}+00 \\ \mathrm{Pu}-238 & 1.000 \mathrm{E}+00 \\ \mathrm{Pu}-239 & 1.000 \mathrm{E}+00 \\ \mathrm{Pu}-240 & 1.000 \mathrm{E}+00 \\ \mathrm{TC}-99 & 1.000 \mathrm{E}+00 \\ \mathrm{Th}-228 & 1.000 \mathrm{E}+00 \\ \mathrm{Th}-230 & 1.000 \mathrm{E}+00 \\ \mathrm{Th}-232 & 1.000 \mathrm{E}+00 \\ \mathrm{U}-234 & 1.000 \mathrm{E}+00 \\ \mathrm{U}-235 & 1.000 \mathrm{E}+00 \\ \mathrm{U}-238 & 1.000 \mathrm{E}+00\end{array}$

Total Dose TDOSE(t), mrem/yr

Basic Radiation Dose Limit $=1.000 \mathrm{E}+02 \mathrm{mrem} / \mathrm{yr}$

Total Mixture Sum $M(t)=$ Fraction of Basic Dose Limit Received at Time (t)

$\begin{array}{rllllll}t \text { (years) }: & 0.000 \mathrm{E}+00 & 1.000 \mathrm{E}+00 & 5.000 \mathrm{E}+01 & 1.000 \mathrm{E}+02 & 5.000 \mathrm{E}+02 & 1.050 \mathrm{E}+03 \\ \text { TDOSE }(t): & 1.396 \mathrm{E}-06 & 1.038 \mathrm{E}-06 & 2.247 \mathrm{E}-06 & 3.048 \mathrm{E}-06 & 3.446 \mathrm{E}-05 & 2.235 \mathrm{E}-01 \\ \mathrm{M}(\mathrm{t}): & 1.396 \mathrm{E}-08 & 1.038 \mathrm{E}-08 & 2.247 \mathrm{E}-08 & 3.048 \mathrm{E}-08 & 3.446 \mathrm{E}-07 & 2.235 \mathrm{E}-03\end{array}$

Maximum TDOSE $(t): 2.235 \mathrm{E}-01 \mathrm{mrem} / \mathrm{yr}$ at $t=1.050 \mathrm{E}+03$ years 
RESRAD, Version 6.5

$\mathrm{T}^{1 / 2}$ Limit $=180$ days

$07 / 21 / 2011$

16:52 Page 20

ummary : RESRAD Parameters for U-Landfill Resident Gardener

File : C: \RESRAD FAMILY \RESRAD \USERFILES \QCFORSRSG \RESIDENTGARDENER-SRSG-MAY11.RAD

Total Dose Contributions TDOSE (i,p,t) for Individual Radionuclides (i) and Pathways (p) As mrem/yr and Fraction of Total Dose At $t=0.000 \mathrm{E}+00$ years

Water Independent Pathways (Inhalation excludes radon)

\begin{tabular}{|c|c|c|c|c|c|c|c|c|c|c|c|c|c|c|}
\hline \multirow{2}{*}{ Nuclide } & \multicolumn{2}{|c|}{ Ground } & \multicolumn{2}{|c|}{ Inhalation } & \multicolumn{2}{|c|}{ Radon } & \multicolumn{2}{|c|}{ Plant } & \multicolumn{2}{|c|}{ Meat } & \multicolumn{2}{|c|}{ Milk } & \multicolumn{2}{|c|}{ Soil } \\
\hline & mrem/yr & fract. & mrem/yr & fract. & mrem/yr & fract. & mrem/yr & fract. & mrem/yr & fract. & mrem/yr & fract. & mrem/yr & fract. \\
\hline-241 & $1.546 \mathrm{E}-19$ & 0.0000 & $0.000 \mathrm{E}+00$ & 0.0000 & $0.000 \mathrm{E}+00$ & 0.0000 & $0.000 \mathrm{E}+00$ & 0.0000 & $0.000 \mathrm{E}+00$ & 0.0000 & $0.000 \mathrm{E}+00$ & 0.0000 & $0.000 \mathrm{E}+00$ & 0.0000 \\
\hline-137 & $1.262 E-09$ & 0.0009 & $0.000 \mathrm{E}+00$ & 0.0000 & $0.000 \mathrm{E}+00$ & 0.0000 & $0.000 \mathrm{E}+00$ & 0.0000 & $0.000 \mathrm{E}+00$ & 0.0000 & $0.000 \mathrm{E}+00$ & 0.0000 & $0.000 \mathrm{E}+00$ & 0.0000 \\
\hline-237 & $9.536 \mathrm{E}-13$ & 0.0000 & $0.000 \mathrm{E}+00$ & 0.0000 & $0.000 \mathrm{E}+00$ & 0.0000 & $0.000 \mathrm{E}+00$ & 0.0000 & $0.000 \mathrm{E}+00$ & 0.0000 & $0.000 \mathrm{E}+00$ & 0.0000 & $0.000 \mathrm{E}+00$ & 0.0000 \\
\hline-238 & $8.139 E-23$ & 0.0000 & $0.000 \mathrm{E}+00$ & 0.0000 & $0.000 \mathrm{E}+00$ & 0.0000 & $0.000 \mathrm{E}+00$ & 0.0000 & $0.000 \mathrm{E}+00$ & 0.0000 & $0.000 \mathrm{E}+00$ & 0.0000 & $0.000 \mathrm{E}+00$ & 0.0000 \\
\hline-239 & $1.202 \mathrm{E}-17$ & 0.0000 & $0.000 \mathrm{E}+00$ & 0.0000 & $0.000 \mathrm{E}+00$ & 0.0000 & $0.000 \mathrm{E}+00$ & 0.0000 & $0.000 \mathrm{E}+00$ & 0.0000 & $0.000 \mathrm{E}+00$ & 0.0000 & $0.000 \mathrm{E}+00$ & 0.0000 \\
\hline-240 & $1.143 \mathrm{E}-24$ & 0.0000 & $0.000 \mathrm{E}+00$ & 0.0000 & $0.000 \mathrm{E}+00$ & 0.0000 & $0.000 \mathrm{E}+00$ & 0.0000 & $0.000 \mathrm{E}+00$ & 0.0000 & $0.000 \mathrm{E}+00$ & 0.0000 & $0.000 \mathrm{E}+00$ & 0.0000 \\
\hline 99 & $5.758 E-26$ & 0.0000 & $0.000 \mathrm{E}+00$ & 0.0000 & $0.000 \mathrm{E}+00$ & 0.0000 & $0.000 \mathrm{E}+00$ & 0.0000 & $0.000 \mathrm{E}+00$ & 0.0000 & $0.000 \mathrm{E}+00$ & 0.0000 & $0.000 \mathrm{E}+00$ & 0.0000 \\
\hline-228 & $1.382 \mathrm{E}-06$ & 0.9905 & $0.000 \mathrm{E}+00$ & 0.0000 & $0.000 \mathrm{E}+00$ & 0.0000 & $0.000 \mathrm{E}+00$ & 0.0000 & $0.000 \mathrm{E}+00$ & 0.0000 & $0.000 \mathrm{E}+00$ & 0.0000 & $0.000 \mathrm{E}+00$ & 0.0000 \\
\hline 230 & $3.774 \mathrm{E}-11$ & 0.0000 & $0.000 \mathrm{E}+00$ & 0.0000 & $0.000 \mathrm{E}+00$ & 0.0000 & $0.000 \mathrm{E}+00$ & 0.0000 & $0.000 \mathrm{E}+00$ & 0.0000 & $0.000 \mathrm{E}+00$ & 0.0000 & $0.000 \mathrm{E}+00$ & 0.0000 \\
\hline-232 & $1.178 E-08$ & 0.0084 & $0.000 \mathrm{E}+00$ & 0.0000 & $0.000 \mathrm{E}+00$ & 0.0000 & $0.000 \mathrm{E}+00$ & 0.0000 & $0.000 \mathrm{E}+00$ & 0.0000 & $0.000 \mathrm{E}+00$ & 0.0000 & $0.000 \mathrm{E}+00$ & 0.0000 \\
\hline 234 & $1.133 E-16$ & 0.0000 & $0.000 \mathrm{E}+00$ & 0.0000 & $0.000 \mathrm{E}+00$ & 0.0000 & $0.000 \mathrm{E}+00$ & 0.0000 & $0.000 \mathrm{E}+00$ & 0.0000 & $0.000 \mathrm{E}+00$ & 0.0000 & $0.000 \mathrm{E}+00$ & 0.0000 \\
\hline 35 & 1. $245 \mathrm{E}-14$ & 0.0000 & $0.000 \mathrm{E}+00$ & 0.0000 & $0.000 \mathrm{E}+00$ & 0.0000 & $0.000 \mathrm{E}+00$ & 0.0000 & $0.000 \mathrm{E}+00$ & 0.0000 & $0.000 \mathrm{E}+00$ & 0.0000 & $0.000 \mathrm{E}+00$ & 0.0000 \\
\hline 38 & $1.420 \mathrm{E}-10$ & 0.0001 & $0.000 \mathrm{E}+00$ & 0.0000 & $0.000 \mathrm{E}+00$ & 0.0000 & $0.000 \mathrm{E}+00$ & 0.0000 & $0.000 \mathrm{E}+00$ & 0.0000 & $0.000 \mathrm{E}+00$ & 0.0000 & $0.000 \mathrm{E}+00$ & 0.0000 \\
\hline & $1.396 \mathrm{E}-06$ & 1.0000 & $0.000 \mathrm{E}+00$ & 0.0000 & $0.000 \mathrm{E}+00$ & 0.0000 & $0.000 \mathrm{E}+00$ & 0.0000 & $0.000 \mathrm{E}+00$ & 0.0000 & $0.000 \mathrm{E}+00$ & 0.0000 & $0.000 \mathrm{E}+00$ & 0.0000 \\
\hline
\end{tabular}

Total Dose Contributions TDOSE(i,p,t) for Individual Radionuclides (i) and Pathways (p) As mrem/yr and Fraction of Total Dose At $t=0.000 \mathrm{E}+00$ years

Water Dependent Pathways

\begin{tabular}{|c|c|c|c|c|c|c|c|c|c|c|c|c|c|c|}
\hline \multirow{2}{*}{ Nuclide } & \multicolumn{2}{|c|}{ Water } & \multicolumn{2}{|c|}{ Fish } & \multicolumn{2}{|c|}{ Radon } & \multicolumn{2}{|c|}{ Plant } & \multicolumn{2}{|c|}{ Meat } & \multicolumn{2}{|c|}{ Milk } & \multicolumn{2}{|c|}{ All Pathways* } \\
\hline & mrem/yr & fract. & mrem/yr & fract. & mrem/yr & fract. & mrem/yr & fract. & mrem/yr & fract. & mrem/yr & fract. & mrem/yr & fract. \\
\hline-241 & $0.000 \mathrm{E}+00$ & 0.0000 & $0.000 \mathrm{E}+00$ & 0.0000 & $0.000 \mathrm{E}+00$ & 0.0000 & $0.000 \mathrm{E}+00$ & 0.0000 & $0.000 \mathrm{E}+00$ & 0.0000 & $0.000 \mathrm{E}+00$ & 0.0000 & $1.546 \mathrm{E}-19$ & 0.0000 \\
\hline-137 & $0.000 \mathrm{E}+00$ & 0.0000 & $0.000 \mathrm{E}+00$ & 0.0000 & $0.000 \mathrm{E}+00$ & 0.0000 & $0.000 \mathrm{E}+00$ & 0.0000 & $0.000 \mathrm{E}+00$ & 0.0000 & $0.000 \mathrm{E}+00$ & 0.0000 & $1.262 \mathrm{E}-09$ & 0.0009 \\
\hline-237 & $0.000 \mathrm{E}+00$ & 0.0000 & $0.000 \mathrm{E}+00$ & 0.0000 & $0.000 \mathrm{E}+00$ & 0.0000 & $0.000 \mathrm{E}+00$ & 0.0000 & $0.000 \mathrm{E}+00$ & 0.0000 & $0.000 \mathrm{E}+00$ & 0.0000 & $9.536 \mathrm{E}-13$ & 0.0000 \\
\hline 238 & $0.000 \mathrm{E}+00$ & 0.0000 & $0.000 \mathrm{E}+00$ & 0.0000 & $0.000 \mathrm{E}+00$ & 0.0000 & $0.000 \mathrm{E}+00$ & 0.0000 & $0.000 \mathrm{E}+00$ & 0.0000 & $0.000 \mathrm{E}+00$ & 0.0000 & $8.139 \mathrm{E}-23$ & 0.0000 \\
\hline 239 & $0.000 \mathrm{E}+00$ & 0.0000 & $0.000 \mathrm{E}+00$ & 0.0000 & $0.000 \mathrm{E}+00$ & 0.0000 & $0.000 \mathrm{E}+00$ & 0.0000 & $0.000 \mathrm{E}+00$ & 0.0000 & $0.000 \mathrm{E}+00$ & 0.0000 & $1.202 \mathrm{E}-17$ & 0.0000 \\
\hline 240 & $0.000 \mathrm{E}+00$ & 0.0000 & $0.000 \mathrm{E}+00$ & 0.0000 & $0.000 \mathrm{E}+00$ & 0.0000 & $0.000 \mathrm{E}+00$ & 0.0000 & $0.000 \mathrm{E}+00$ & 0.0000 & $0.000 \mathrm{E}+00$ & 0.0000 & $1.143 \mathrm{E}-24$ & 0.0000 \\
\hline 99 & $0.000 \mathrm{E}+00$ & 0.0000 & $0.000 \mathrm{E}+00$ & 0.0000 & $0.000 \mathrm{E}+00$ & 0.0000 & $0.000 \mathrm{E}+00$ & 0.0000 & $0.000 \mathrm{E}+00$ & 0.0000 & $0.000 \mathrm{E}+00$ & 0.0000 & $5.758 \mathrm{E}-26$ & 0.0000 \\
\hline 228 & $0.000 \mathrm{E}+00$ & 0.0000 & $0.000 \mathrm{E}+00$ & 0.0000 & $0.000 \mathrm{E}+00$ & 0.0000 & $0.000 \mathrm{E}+00$ & 0.0000 & $0.000 \mathrm{E}+00$ & 0.0000 & $0.000 \mathrm{E}+00$ & 0.0000 & $1.382 \mathrm{E}-06$ & 0.9905 \\
\hline 230 & $0.000 \mathrm{E}+00$ & 0.0000 & $0.000 \mathrm{E}+00$ & 0.0000 & $0.000 \mathrm{E}+00$ & 0.0000 & $0.000 \mathrm{E}+00$ & 0.0000 & $0.000 \mathrm{E}+00$ & 0.0000 & $0.000 \mathrm{E}+00$ & 0.0000 & $3.774 \mathrm{E}-11$ & 0.0000 \\
\hline 232 & $0.000 \mathrm{E}+00$ & 0.0000 & $0.000 \mathrm{E}+00$ & 0.0000 & $0.000 \mathrm{E}+00$ & 0.0000 & $0.000 \mathrm{E}+00$ & 0.0000 & $0.000 \mathrm{E}+00$ & 0.0000 & $0.000 \mathrm{E}+00$ & 0.0000 & $1.178 \mathrm{E}-08$ & 0.0084 \\
\hline & $0.000 \mathrm{E}+00$ & 0.0000 & $0.000 \mathrm{E}+00$ & 0.0000 & $0.000 \mathrm{E}+00$ & 0.0000 & $0.000 \mathrm{E}+00$ & 0.0000 & $0.000 \mathrm{E}+00$ & 0.0000 & $0.000 \mathrm{E}+00$ & 0.0000 & $1.133 \mathrm{E}-16$ & 0.0000 \\
\hline 35 & $0.000 \mathrm{E}+00$ & 0.0000 & $0.000 \mathrm{E}+00$ & 0.0000 & $0.000 \mathrm{E}+00$ & 0.0000 & $0.000 \mathrm{E}+00$ & 0.0000 & $0.000 \mathrm{E}+00$ & 0.0000 & $0.000 \mathrm{E}+00$ & 0.0000 & $1.245 \mathrm{E}-14$ & 0.0000 \\
\hline 38 & $0.000 \mathrm{E}+00$ & 0.0000 & $0.000 \mathrm{E}+00$ & 0.0000 & $0.000 \mathrm{E}+00$ & 0.0000 & $0.000 \mathrm{E}+00$ & 0.0000 & $0.000 \mathrm{E}+00$ & 0.0000 & $0.000 \mathrm{E}+00$ & 0.0000 & 1. $420 \mathrm{E}-10$ & 0.0001 \\
\hline & $0.000 \mathrm{E}+00$ & 0.0000 & $0.000 \mathrm{E}+00$ & 0.0000 & $0.000 \mathrm{E}+00$ & 0.0000 & $0.000 \mathrm{E}+00$ & 0.0000 & $0.000 \mathrm{E}+00$ & 0.0000 & $0.000 \mathrm{E}+00$ & 000 & -06 & 1.0000 \\
\hline
\end{tabular}

* Sum of all water independent and dependent pathways. 
RESRAD, Version 6.5

$\mathrm{T}^{1 / 2}$ Limit $=180$ days

$07 / 21 / 2011$

16:52 Page

ummary : RESRAD Parameters for U-Landfill Resident Gardener

File : C: \RESRAD_FAMILY \RESRAD \USERFILES \QCFORSRSG \RESIDENTGARDENER-SRSG-MAY11.RAD

Total Dose Contributions TDOSE (i,p,t) for Individual Radionuclides (i) and Pathways (p) As mrem/yr and Fraction of Total Dose At $t=1.000 \mathrm{E}+00$ years

Water Independent Pathways (Inhalation excludes radon)

\begin{tabular}{|c|c|c|c|c|c|c|c|c|c|c|c|c|c|c|}
\hline \multirow{2}{*}{ Nuclide } & \multicolumn{2}{|c|}{ Ground } & \multicolumn{2}{|c|}{ Inhalation } & \multicolumn{2}{|c|}{ Radon } & \multicolumn{2}{|c|}{ Plant } & \multicolumn{2}{|c|}{ Meat } & \multicolumn{2}{|c|}{ Milk } & \multicolumn{2}{|c|}{ Soil } \\
\hline & mrem/yr & fract. & mrem/yr & fract. & mrem/yr & fract. & mrem/yr & fract. & mrem/yr & fract. & mrem/yr & fract. & mrem/yr & fract. \\
\hline-241 & $4.680 \mathrm{E}-19$ & 0.0000 & $0.000 \mathrm{E}+00$ & 0.0000 & $0.000 \mathrm{E}+00$ & 0.0000 & $0.000 \mathrm{E}+00$ & 0.0000 & $0.000 \mathrm{E}+00$ & 0.0000 & $0.000 \mathrm{E}+00$ & 0.0000 & $0.000 \mathrm{E}+00$ & 0.0000 \\
\hline-137 & $1.243 E-09$ & 0.0012 & $0.000 \mathrm{E}+00$ & 0.0000 & $0.000 \mathrm{E}+00$ & 0.0000 & $0.000 \mathrm{E}+00$ & 0.0000 & $0.000 \mathrm{E}+00$ & 0.0000 & $0.000 \mathrm{E}+00$ & 0.0000 & $0.000 \mathrm{E}+00$ & 0.0000 \\
\hline-237 & $9.638 E-13$ & 0.0000 & $0.000 \mathrm{E}+00$ & 0.0000 & $0.000 \mathrm{E}+00$ & 0.0000 & $0.000 \mathrm{E}+00$ & 0.0000 & $0.000 \mathrm{E}+00$ & 0.0000 & $0.000 \mathrm{E}+00$ & 0.0000 & $0.000 \mathrm{E}+00$ & 0.0000 \\
\hline-238 & 1. $209 \mathrm{E}-21$ & 0.0000 & $0.000 \mathrm{E}+00$ & 0.0000 & $0.000 \mathrm{E}+00$ & 0.0000 & $0.000 \mathrm{E}+00$ & 0.0000 & $0.000 \mathrm{E}+00$ & 0.0000 & $0.000 \mathrm{E}+00$ & 0.0000 & $0.000 \mathrm{E}+00$ & 0.0000 \\
\hline-239 & $1.217 \mathrm{E}-17$ & 0.0000 & $0.000 \mathrm{E}+00$ & 0.0000 & $0.000 \mathrm{E}+00$ & 0.0000 & $0.000 \mathrm{E}+00$ & 0.0000 & $0.000 \mathrm{E}+00$ & 0.0000 & $0.000 \mathrm{E}+00$ & 0.0000 & $0.000 \mathrm{E}+00$ & 0.0000 \\
\hline-240 & $1.188 \mathrm{E}-24$ & 0.0000 & $0.000 \mathrm{E}+00$ & 0.0000 & $0.000 \mathrm{E}+00$ & 0.0000 & $0.000 \mathrm{E}+00$ & 0.0000 & $0.000 \mathrm{E}+00$ & 0.0000 & $0.000 \mathrm{E}+00$ & 0.0000 & $0.000 \mathrm{E}+00$ & 0.0000 \\
\hline 99 & $5.817 \mathrm{E}-26$ & 0.0000 & $0.000 \mathrm{E}+00$ & 0.0000 & $0.000 \mathrm{E}+00$ & 0.0000 & $0.000 \mathrm{E}+00$ & 0.0000 & $0.000 \mathrm{E}+00$ & 0.0000 & $0.000 \mathrm{E}+00$ & 0.0000 & $0.000 \mathrm{E}+00$ & 0.0000 \\
\hline-228 & $9.680 \mathrm{E}-07$ & 0.9321 & $0.000 \mathrm{E}+00$ & 0.0000 & $0.000 \mathrm{E}+00$ & 0.0000 & $0.000 \mathrm{E}+00$ & 0.0000 & $0.000 \mathrm{E}+00$ & 0.0000 & $0.000 \mathrm{E}+00$ & 0.0000 & $0.000 \mathrm{E}+00$ & 0.0000 \\
\hline-230 & 1. $139 \mathrm{E}-10$ & 0.0001 & $0.000 \mathrm{E}+00$ & 0.0000 & $0.000 \mathrm{E}+00$ & 0.0000 & $0.000 \mathrm{E}+00$ & 0.0000 & $0.000 \mathrm{E}+00$ & 0.0000 & $0.000 \mathrm{E}+00$ & 0.0000 & $0.000 \mathrm{E}+00$ & 0.0000 \\
\hline-232 & $6.899 E-08$ & 0.0664 & $0.000 \mathrm{E}+00$ & 0.0000 & $0.000 \mathrm{E}+00$ & 0.0000 & $0.000 \mathrm{E}+00$ & 0.0000 & $0.000 \mathrm{E}+00$ & 0.0000 & $0.000 \mathrm{E}+00$ & 0.0000 & $0.000 \mathrm{E}+00$ & 0.0000 \\
\hline 234 & $7.978 E-16$ & 0.0000 & $0.000 \mathrm{E}+00$ & 0.0000 & $0.000 \mathrm{E}+00$ & 0.0000 & $0.000 \mathrm{E}+00$ & 0.0000 & $0.000 \mathrm{E}+00$ & 0.0000 & $0.000 \mathrm{E}+00$ & 0.0000 & $0.000 \mathrm{E}+00$ & 0.0000 \\
\hline 35 & $1.266 \mathrm{E}-14$ & 0.0000 & $0.000 \mathrm{E}+00$ & 0.0000 & $0.000 \mathrm{E}+00$ & 0.0000 & $0.000 \mathrm{E}+00$ & 0.0000 & $0.000 \mathrm{E}+00$ & 0.0000 & $0.000 \mathrm{E}+00$ & 0.0000 & $0.000 \mathrm{E}+00$ & 0.0000 \\
\hline 38 & $1.431 \mathrm{E}-10$ & 0.0001 & $0.000 \mathrm{E}+00$ & 0.0000 & $0.000 \mathrm{E}+00$ & 0.0000 & $0.000 \mathrm{E}+00$ & 0.0000 & $0.000 \mathrm{E}+00$ & 0.0000 & $0.000 \mathrm{E}+00$ & 0.0000 & $0.000 \mathrm{E}+00$ & 0.0000 \\
\hline & $1.038 E-06$ & 1.0000 & $0.000 \mathrm{E}+00$ & 0.0000 & $0.000 \mathrm{E}+00$ & 0.0000 & $0.000 \mathrm{E}+00$ & 0.0000 & $0.000 \mathrm{E}+00$ & 0.0000 & $0.000 \mathrm{E}+00$ & 0.0000 & $0.000 \mathrm{E}+00$ & 0.0000 \\
\hline
\end{tabular}

Total Dose Contributions TDOSE(i,p,t) for Individual Radionuclides (i) and Pathways (p) As mrem/yr and Fraction of Total Dose At $t=1.000 \mathrm{E}+00$ years

Water Dependent Pathways

\begin{tabular}{|c|c|c|c|c|c|c|c|c|c|c|c|c|c|c|}
\hline & \multicolumn{2}{|c|}{ Water } & \multicolumn{2}{|c|}{ Fish } & \multicolumn{2}{|c|}{ Radon } & \multicolumn{2}{|c|}{ Plant } & \multicolumn{2}{|c|}{ Meat } & \multicolumn{2}{|c|}{ Milk } & \multicolumn{2}{|c|}{ All Pathways* } \\
\hline clide & mrem/yr & fract. & mrem/yr & fract. & mrem/yr & fract. & mrem/yr & fract. & mrem/yr & fract. & mrem/yr & fract. & mrem/yr & fract. \\
\hline-241 & $0.000 \mathrm{E}+00$ & 0.0000 & $0.000 \mathrm{E}+00$ & 0.0000 & $0.000 \mathrm{E}+00$ & 0.0000 & $0.000 \mathrm{E}+00$ & 0.0000 & $0.000 \mathrm{E}+00$ & 0.0000 & $0.000 \mathrm{E}+00$ & 0.0000 & $4.680 \mathrm{E}-19$ & 0.0000 \\
\hline-137 & $0.000 \mathrm{E}+00$ & 0.0000 & $0.000 \mathrm{E}+00$ & 0.0000 & $0.000 \mathrm{E}+00$ & 0.0000 & $0.000 \mathrm{E}+00$ & 0.0000 & $0.000 \mathrm{E}+00$ & 0.0000 & $0.000 \mathrm{E}+00$ & 0.0000 & $1.243 E-09$ & 0.0012 \\
\hline-237 & $0.000 \mathrm{E}+00$ & 0.0000 & $0.000 \mathrm{E}+00$ & 0.0000 & $0.000 \mathrm{E}+00$ & 0.0000 & $0.000 \mathrm{E}+00$ & 0.0000 & $0.000 \mathrm{E}+00$ & 0.0000 & $0.000 \mathrm{E}+00$ & 0.0000 & $9.638 \mathrm{E}-13$ & 0.0000 \\
\hline 238 & $0.000 \mathrm{E}+00$ & 0.0000 & $0.000 \mathrm{E}+00$ & 0.0000 & $0.000 \mathrm{E}+00$ & 0.0000 & $0.000 \mathrm{E}+00$ & 0.0000 & $0.000 \mathrm{E}+00$ & 0.0000 & $0.000 \mathrm{E}+00$ & 0.0000 & $1.209 \mathrm{E}-21$ & 0.0000 \\
\hline 239 & $0.000 \mathrm{E}+00$ & 0.0000 & $0.000 \mathrm{E}+00$ & 0.0000 & $0.000 \mathrm{E}+00$ & 0.0000 & $0.000 \mathrm{E}+00$ & 0.0000 & $0.000 \mathrm{E}+00$ & 0.0000 & $0.000 \mathrm{E}+00$ & 0.0000 & $1.217 \mathrm{E}-17$ & 0.0000 \\
\hline 240 & $0.000 \mathrm{E}+00$ & 0.0000 & $0.000 \mathrm{E}+00$ & 0.0000 & $0.000 \mathrm{E}+00$ & 0.0000 & $0.000 \mathrm{E}+00$ & 0.0000 & $0.000 \mathrm{E}+00$ & 0.0000 & $0.000 \mathrm{E}+00$ & 0.0000 & $1.188 \mathrm{E}-24$ & 0.0000 \\
\hline 99 & $0.000 \mathrm{E}+00$ & 0.0000 & $0.000 \mathrm{E}+00$ & 0.0000 & $0.000 \mathrm{E}+00$ & 0.0000 & $0.000 \mathrm{E}+00$ & 0.0000 & $0.000 \mathrm{E}+00$ & 0.0000 & $0.000 \mathrm{E}+00$ & 0.0000 & $5.817 \mathrm{E}-26$ & 0.0000 \\
\hline 228 & $0.000 \mathrm{E}+00$ & 0.0000 & $0.000 \mathrm{E}+00$ & 0.0000 & $0.000 \mathrm{E}+00$ & 0.0000 & $0.000 \mathrm{E}+00$ & 0.0000 & $0.000 \mathrm{E}+00$ & 0.0000 & $0.000 \mathrm{E}+00$ & 0.0000 & $9.680 \mathrm{E}-07$ & 0.9321 \\
\hline 230 & $0.000 \mathrm{E}+00$ & 0.0000 & $0.000 \mathrm{E}+00$ & 0.0000 & $0.000 \mathrm{E}+00$ & 0.0000 & $0.000 \mathrm{E}+00$ & 0.0000 & $0.000 \mathrm{E}+00$ & 0.0000 & $0.000 \mathrm{E}+00$ & 0.0000 & $1.139 \mathrm{E}-10$ & 0.0001 \\
\hline 232 & $0.000 \mathrm{E}+00$ & 0.0000 & $0.000 \mathrm{E}+00$ & 0.0000 & $0.000 \mathrm{E}+00$ & 0.0000 & $0.000 \mathrm{E}+00$ & 0.0000 & $0.000 \mathrm{E}+00$ & 0.0000 & $0.000 \mathrm{E}+00$ & 0.0000 & $6.899 \mathrm{E}-08$ & 0.0664 \\
\hline & $0.000 \mathrm{E}+00$ & 0.0000 & $0.000 \mathrm{E}+00$ & 0.0000 & $0.000 \mathrm{E}+00$ & 0.0000 & $0.000 \mathrm{E}+00$ & 0.0000 & $0.000 \mathrm{E}+00$ & 0.0000 & $0.000 \mathrm{E}+00$ & 0.0000 & $7.978 \mathrm{E}-16$ & 0.0000 \\
\hline 35 & $0.000 \mathrm{E}+00$ & 0.0000 & $0.000 \mathrm{E}+00$ & 0.0000 & $0.000 \mathrm{E}+00$ & 0.0000 & $0.000 \mathrm{E}+00$ & 0.0000 & $0.000 \mathrm{E}+00$ & 0.0000 & $0.000 \mathrm{E}+00$ & 0.0000 & $1.266 \mathrm{E}-14$ & 0.0000 \\
\hline 38 & $0.000 \mathrm{E}+00$ & 0.0000 & $0.000 \mathrm{E}+00$ & 0.0000 & $0.000 \mathrm{E}+00$ & 0.0000 & $0.000 \mathrm{E}+00$ & 0.0000 & $0.000 \mathrm{E}+00$ & 0.0000 & $0.000 \mathrm{E}+00$ & 0.0000 & $1.431 \mathrm{E}-10$ & 0.0001 \\
\hline & $0.000 \mathrm{E}+00$ & 0.0000 & $0.000 \mathrm{E}+00$ & 0.0000 & $0.000 \mathrm{E}+00$ & 0.0000 & $0.000 \mathrm{E}+00$ & 0.0000 & $0.000 \mathrm{E}+00$ & 0.0000 & $0.000 E+00$ & 000 & -06 & 1.0000 \\
\hline
\end{tabular}

* Sum of all water independent and dependent pathways. 
RESRAD, Version 6.5

ummary : RESRAD Parameters for U-Landfill Resident Gardener

: C: \RESRAD_FAMILY \RESRAD \USERFILES $\backslash Q$ CFORSRSG \RESIDENTGARDENER-SRSG-MAY11.RAD

Total Dose Contributions TDOSE (i,p,t) for Individual Radionuclides (i) and Pathways (p) As mrem/yr and Fraction of Total Dose At $t=5.000 \mathrm{E}+01$ years

Water Independent Pathways (Inhalation excludes radon)

\begin{tabular}{|c|c|c|c|c|c|c|c|c|c|c|c|c|c|c|}
\hline \multirow{2}{*}{ Nuclide } & \multicolumn{2}{|c|}{ Ground } & \multicolumn{2}{|c|}{ Inhalation } & \multicolumn{2}{|c|}{ Radon } & \multicolumn{2}{|c|}{ Plant } & \multicolumn{2}{|c|}{ Meat } & \multicolumn{2}{|c|}{ Milk } & \multicolumn{2}{|c|}{ Soil } \\
\hline & mrem/yr & fract. & mrem/yr & fract. & mrem/yr & fract. & mrem/yr & fract. & mrem/yr & fract. & mrem/yr & fract. & mrem/yr & fract. \\
\hline-241 & $2.564 \mathrm{E}-17$ & 0.0000 & $0.000 \mathrm{E}+00$ & 0.0000 & $0.000 \mathrm{E}+00$ & 0.0000 & $0.000 \mathrm{E}+00$ & 0.0000 & $0.000 \mathrm{E}+00$ & 0.0000 & $0.000 \mathrm{E}+00$ & 0.0000 & $0.000 \mathrm{E}+00$ & 0.0000 \\
\hline-137 & $6.050 \mathrm{E}-10$ & 0.0003 & $0.000 \mathrm{E}+00$ & 0.0000 & $0.000 \mathrm{E}+00$ & 0.0000 & $0.000 \mathrm{E}+00$ & 0.0000 & $0.000 \mathrm{E}+00$ & 0.0000 & $0.000 \mathrm{E}+00$ & 0.0000 & $0.000 \mathrm{E}+00$ & 0.0000 \\
\hline-237 & $1.629 \mathrm{E}-12$ & 0.0000 & $0.000 \mathrm{E}+00$ & 0.0000 & $0.000 \mathrm{E}+00$ & 0.0000 & $0.000 \mathrm{E}+00$ & 0.0000 & $0.000 \mathrm{E}+00$ & 0.0000 & $0.000 \mathrm{E}+00$ & 0.0000 & $0.000 \mathrm{E}+00$ & 0.0000 \\
\hline-238 & $5.266 \mathrm{E}-17$ & 0.0000 & $0.000 \mathrm{E}+00$ & 0.0000 & $0.000 \mathrm{E}+00$ & 0.0000 & $0.000 \mathrm{E}+00$ & 0.0000 & $0.000 \mathrm{E}+00$ & 0.0000 & $0.000 \mathrm{E}+00$ & 0.0000 & $0.000 \mathrm{E}+00$ & 0.0000 \\
\hline-239 & $2.183 E-17$ & 0.0000 & $0.000 \mathrm{E}+00$ & 0.0000 & $0.000 \mathrm{E}+00$ & 0.0000 & $0.000 \mathrm{E}+00$ & 0.0000 & $0.000 \mathrm{E}+00$ & 0.0000 & $0.000 \mathrm{E}+00$ & 0.0000 & $0.000 \mathrm{E}+00$ & 0.0000 \\
\hline-240 & $2.681 \mathrm{E}-21$ & 0.0000 & $0.000 \mathrm{E}+00$ & 0.0000 & $0.000 \mathrm{E}+00$ & 0.0000 & $0.000 \mathrm{E}+00$ & 0.0000 & $0.000 \mathrm{E}+00$ & 0.0000 & $0.000 \mathrm{E}+00$ & 0.0000 & $0.000 \mathrm{E}+00$ & 0.0000 \\
\hline 99 & $9.575 E-26$ & 0.0000 & $0.000 \mathrm{E}+00$ & 0.0000 & $0.000 \mathrm{E}+00$ & 0.0000 & $0.000 \mathrm{E}+00$ & 0.0000 & $0.000 \mathrm{E}+00$ & 0.0000 & $0.000 \mathrm{E}+00$ & 0.0000 & $0.000 \mathrm{E}+00$ & 0.0000 \\
\hline-228 & $2.527 E-14$ & 0.0000 & $0.000 \mathrm{E}+00$ & 0.0000 & $0.000 \mathrm{E}+00$ & 0.0000 & $0.000 \mathrm{E}+00$ & 0.0000 & $0.000 \mathrm{E}+00$ & 0.0000 & $0.000 \mathrm{E}+00$ & 0.0000 & $0.000 \mathrm{E}+00$ & 0.0000 \\
\hline-230 & $5.320 \mathrm{E}-09$ & 0.0024 & $0.000 \mathrm{E}+00$ & 0.0000 & $0.000 \mathrm{E}+00$ & 0.0000 & $0.000 \mathrm{E}+00$ & 0.0000 & $0.000 \mathrm{E}+00$ & 0.0000 & $0.000 \mathrm{E}+00$ & 0.0000 & $0.000 \mathrm{E}+00$ & 0.0000 \\
\hline-232 & $2.241 E-06$ & 0.9973 & $0.000 \mathrm{E}+00$ & 0.0000 & $0.000 \mathrm{E}+00$ & 0.0000 & $0.000 \mathrm{E}+00$ & 0.0000 & $0.000 \mathrm{E}+00$ & 0.0000 & $0.000 \mathrm{E}+00$ & 0.0000 & $0.000 \mathrm{E}+00$ & 0.0000 \\
\hline 234 & 1. $213 \mathrm{E}-12$ & 0.0000 & $0.000 \mathrm{E}+00$ & 0.0000 & $0.000 \mathrm{E}+00$ & 0.0000 & $0.000 \mathrm{E}+00$ & 0.0000 & $0.000 \mathrm{E}+00$ & 0.0000 & $0.000 \mathrm{E}+00$ & 0.0000 & $0.000 \mathrm{E}+00$ & 0.0000 \\
\hline 35 & $9.238 \mathrm{E}-14$ & 0.0000 & $0.000 \mathrm{E}+00$ & 0.0000 & $0.000 \mathrm{E}+00$ & 0.0000 & $0.000 \mathrm{E}+00$ & 0.0000 & $0.000 \mathrm{E}+00$ & 0.0000 & $0.000 \mathrm{E}+00$ & 0.0000 & $0.000 \mathrm{E}+00$ & 0.0000 \\
\hline 38 & $2.116 \mathrm{E}-10$ & 0.0001 & $0.000 \mathrm{E}+00$ & 0.0000 & $0.000 \mathrm{E}+00$ & 0.0000 & $0.000 \mathrm{E}+00$ & 0.0000 & $0.000 \mathrm{E}+00$ & 0.0000 & $0.000 \mathrm{E}+00$ & 0.0000 & $0.000 \mathrm{E}+00$ & 0.0000 \\
\hline & $2.247 \mathrm{E}-06$ & 1.0000 & $0.000 \mathrm{E}+00$ & 0.0000 & $0.000 \mathrm{E}+00$ & 0.0000 & $0.000 \mathrm{E}+00$ & 0.0000 & $0.000 \mathrm{E}+00$ & 0.0000 & $0.000 \mathrm{E}+00$ & 0.0000 & $0.000 \mathrm{E}+00$ & 0.0000 \\
\hline
\end{tabular}

Total Dose Contributions TDOSE(i,p,t) for Individual Radionuclides (i) and Pathways (p) As mrem/yr and Fraction of Total Dose At $t=5.000 \mathrm{E}+01$ years

Water Dependent Pathways

\begin{tabular}{|c|c|c|c|c|c|c|c|c|c|c|c|c|c|c|}
\hline \multirow{2}{*}{$\begin{array}{l}\text { Radio- } \\
\text { Nuclide }\end{array}$} & \multicolumn{2}{|c|}{ Water } & \multicolumn{2}{|c|}{ Fish } & \multicolumn{2}{|c|}{ Radon } & \multicolumn{2}{|c|}{ Plant } & \multicolumn{2}{|c|}{ Meat } & \multicolumn{2}{|c|}{ Milk } & \multicolumn{2}{|c|}{ All Pathways* } \\
\hline & mrem/yr & fract. & mrem/yr & fract. & mrem/yr & fract. & mrem/yr & fract. & mrem/yr & fract. & mrem/yr & fract. & mrem/yr & fract. \\
\hline 241 & $0.000 \mathrm{E}+00$ & 0.0000 & $0.000 \mathrm{E}+00$ & 0.0000 & $0.000 \mathrm{E}+00$ & 0.0000 & $0.000 \mathrm{E}+00$ & 0.0000 & $0.000 \mathrm{E}+00$ & 0.0000 & $0.000 \mathrm{E}+00$ & 0.0000 & $2.564 \mathrm{E}-17$ & 0.0000 \\
\hline-137 & $0.000 \mathrm{E}+00$ & 0.0000 & $0.000 \mathrm{E}+00$ & 0.0000 & $0.000 \mathrm{E}+00$ & 0.0000 & $0.000 \mathrm{E}+00$ & 0.0000 & $0.000 \mathrm{E}+00$ & 0.0000 & $0.000 \mathrm{E}+00$ & 0.0000 & $6.050 \mathrm{E}-10$ & 0.0003 \\
\hline-237 & $0.000 \mathrm{E}+00$ & 0.0000 & $0.000 \mathrm{E}+00$ & 0.0000 & $0.000 \mathrm{E}+00$ & 0.0000 & $0.000 \mathrm{E}+00$ & 0.0000 & $0.000 \mathrm{E}+00$ & 0.0000 & $0.000 \mathrm{E}+00$ & 0.0000 & $1.629 \mathrm{E}-12$ & 0.0000 \\
\hline-238 & $0.000 \mathrm{E}+00$ & 0.0000 & $0.000 \mathrm{E}+00$ & 0.0000 & $0.000 \mathrm{E}+00$ & 0.0000 & $0.000 \mathrm{E}+00$ & 0.0000 & $0.000 \mathrm{E}+00$ & 0.0000 & $0.000 \mathrm{E}+00$ & 0.0000 & $5.266 \mathrm{E}-17$ & 0.0000 \\
\hline-239 & $0.000 \mathrm{E}+00$ & 0.0000 & $0.000 \mathrm{E}+00$ & 0.0000 & $0.000 \mathrm{E}+00$ & 0.0000 & $0.000 \mathrm{E}+00$ & 0.0000 & $0.000 \mathrm{E}+00$ & 0.0000 & $0.000 E+00$ & 0.0000 & $2.183 \mathrm{E}-17$ & 0.0000 \\
\hline-240 & $0.000 \mathrm{E}+00$ & 0.0000 & $0.000 \mathrm{E}+00$ & 0.0000 & $0.000 \mathrm{E}+00$ & 0.0000 & $0.000 \mathrm{E}+00$ & 0.0000 & $0.000 \mathrm{E}+00$ & 0.0000 & $0.000 E+00$ & 0.0000 & $2.681 \mathrm{E}-21$ & 0.0000 \\
\hline-99 & $0.000 \mathrm{E}+00$ & 0.0000 & $0.000 \mathrm{E}+00$ & 0.0000 & $0.000 \mathrm{E}+00$ & 0.0000 & $0.000 \mathrm{E}+00$ & 0.0000 & $0.000 \mathrm{E}+00$ & 0.0000 & $0.000 \mathrm{E}+00$ & 0.0000 & $9.575 \mathrm{E}-26$ & 0.0000 \\
\hline-228 & $0.000 \mathrm{E}+00$ & 0.0000 & $0.000 \mathrm{E}+00$ & 0.0000 & $0.000 \mathrm{E}+00$ & 0.0000 & $0.000 \mathrm{E}+00$ & 0.0000 & $0.000 \mathrm{E}+00$ & 0.0000 & $0.000 \mathrm{E}+00$ & 0.0000 & $2.527 \mathrm{E}-14$ & 0.0000 \\
\hline-230 & $0.000 \mathrm{E}+00$ & 0.0000 & $0.000 \mathrm{E}+00$ & 0.0000 & $0.000 \mathrm{E}+00$ & 0.0000 & $0.000 \mathrm{E}+00$ & 0.0000 & $0.000 \mathrm{E}+00$ & 0.0000 & $0.000 E+00$ & 0.0000 & $5.320 \mathrm{E}-09$ & 0.0024 \\
\hline 232 & $0.000 \mathrm{E}+00$ & 0.0000 & $0.000 \mathrm{E}+00$ & 0.0000 & $0.000 \mathrm{E}+00$ & 0.0000 & $0.000 \mathrm{E}+00$ & 0.0000 & $0.000 \mathrm{E}+00$ & 0.0000 & $0.000 \mathrm{E}+00$ & 0.0000 & $2.241 E-06$ & 0.9973 \\
\hline 34 & $0.000 \mathrm{E}+00$ & 0.0000 & $0.000 \mathrm{E}+00$ & 0.0000 & $0.000 \mathrm{E}+00$ & 0.0000 & $0.000 \mathrm{E}+00$ & 0.0000 & $0.000 \mathrm{E}+00$ & 0.0000 & $0.000 \mathrm{E}+00$ & 0.0000 & 1. $213 \mathrm{E}-12$ & 0.0000 \\
\hline 35 & $0.000 \mathrm{E}+00$ & 0.0000 & $0.000 \mathrm{E}+00$ & 0.0000 & $0.000 \mathrm{E}+00$ & 0.0000 & $0.000 \mathrm{E}+00$ & 0.0000 & $0.000 \mathrm{E}+00$ & 0.0000 & $0.000 \mathrm{E}+00$ & 0.0000 & $9.238 \mathrm{E}-14$ & 0.0000 \\
\hline 38 & $0.000 \mathrm{E}+00$ & 0.0000 & $0.000 \mathrm{E}+00$ & 0.0000 & $0.000 \mathrm{E}+00$ & 0.0000 & $0.000 \mathrm{E}+00$ & 0.0000 & $0.000 \mathrm{E}+00$ & 0.0000 & $0.000 \mathrm{E}+00$ & 0.0000 & $2.116 \mathrm{E}-10$ & 0.0001 \\
\hline & $0.000 \mathrm{E}+00$ & 0.0000 & $0.000 \mathrm{E}+00$ & 0.0000 & $0.000 \mathrm{E}+00$ & 0.0000 & $0.000 \mathrm{E}+00$ & 0.0000 & $0.000 \mathrm{E}+00$ & 0.0000 & $0.000 \mathrm{E}+00$ & 0.0000 & $7 E-06$ & 1. \\
\hline
\end{tabular}

* Sum of all water independent and dependent pathways. 
RESRAD, Version 6.5

$\mathrm{T}^{1 / 2}$ Limit $=180$ days

$07 / 21 / 2011$

16:52 Page

ummary : RESRAD Parameters for U-Landfill Resident Gardener

File : C: \RESRAD_FAMILY \RESRAD \USERFILES \QCFORSRSG \RESIDENTGARDENER-SRSG-MAY11.RAD

Total Dose Contributions TDOSE (i,p,t) for Individual Radionuclides (i) and Pathways (p) As mrem/yr and Fraction of Total Dose At $t=1.000 \mathrm{E}+02$ years

Water Independent Pathways (Inhalation excludes radon)

\begin{tabular}{|c|c|c|c|c|c|c|c|c|c|c|c|c|c|c|}
\hline \multirow[b]{2}{*}{ uclide } & \multicolumn{2}{|c|}{ Ground } & \multicolumn{2}{|c|}{ Inhalation } & \multicolumn{2}{|c|}{ Radon } & \multicolumn{2}{|c|}{ Plant } & \multicolumn{2}{|c|}{ Meat } & \multicolumn{2}{|c|}{ Milk } & \multicolumn{2}{|c|}{ Soil } \\
\hline & mrem/yr & fract. & mrem/yr & fract. & mrem/yr & fract. & mrem/yr & fract. & mrem/yr & fract. & mrem/yr & fract. & mrem/yr & fract. \\
\hline-241 & $8.401 \mathrm{E}-17$ & 0.0000 & $0.000 \mathrm{E}+00$ & 0.0000 & $0.000 \mathrm{E}+00$ & 0.0000 & $0.000 \mathrm{E}+00$ & 0.0000 & $0.000 \mathrm{E}+00$ & 0.0000 & $0.000 \mathrm{E}+00$ & 0.0000 & $0.000 \mathrm{E}+00$ & 0.0000 \\
\hline-137 & $2.901 E-10$ & 0.0001 & $0.000 \mathrm{E}+00$ & 0.0000 & $0.000 \mathrm{E}+00$ & 0.0000 & $0.000 \mathrm{E}+00$ & 0.0000 & $0.000 \mathrm{E}+00$ & 0.0000 & $0.000 \mathrm{E}+00$ & 0.0000 & $0.000 \mathrm{E}+00$ & 0.0000 \\
\hline-237 & $2.788 \mathrm{E}-12$ & 0.0000 & $0.000 \mathrm{E}+00$ & 0.0000 & $0.000 \mathrm{E}+00$ & 0.0000 & $0.000 \mathrm{E}+00$ & 0.0000 & $0.000 \mathrm{E}+00$ & 0.0000 & $0.000 \mathrm{E}+00$ & 0.0000 & $0.000 \mathrm{E}+00$ & 0.0000 \\
\hline 238 & $5.323 E-16$ & 0.0000 & $0.000 \mathrm{E}+00$ & 0.0000 & $0.000 \mathrm{E}+00$ & 0.0000 & $0.000 \mathrm{E}+00$ & 0.0000 & $0.000 \mathrm{E}+00$ & 0.0000 & $0.000 \mathrm{E}+00$ & 0.0000 & $0.000 \mathrm{E}+00$ & 0.0000 \\
\hline 239 & $3.966 \mathrm{E}-17$ & 0.0000 & $0.000 \mathrm{E}+00$ & 0.0000 & $0.000 \mathrm{E}+00$ & 0.0000 & $0.000 \mathrm{E}+00$ & 0.0000 & $0.000 \mathrm{E}+00$ & 0.0000 & $0.000 \mathrm{E}+00$ & 0.0000 & $0.000 \mathrm{E}+00$ & 0.0000 \\
\hline 240 & 1. $783 \mathrm{E}-20$ & 0.0000 & $0.000 \mathrm{E}+00$ & 0.0000 & $0.000 \mathrm{E}+00$ & 0.0000 & $0.000 \mathrm{E}+00$ & 0.0000 & $0.000 \mathrm{E}+00$ & 0.0000 & $0.000 \mathrm{E}+00$ & 0.0000 & $0.000 \mathrm{E}+00$ & 0.0000 \\
\hline 99 & $1.592 \mathrm{E}-25$ & 0.0000 & $0.000 \mathrm{E}+00$ & 0.0000 & $0.000 \mathrm{E}+00$ & 0.0000 & $0.000 \mathrm{E}+00$ & 0.0000 & $0.000 \mathrm{E}+00$ & 0.0000 & $0.000 \mathrm{E}+00$ & 0.0000 & $0.000 \mathrm{E}+00$ & 0.0000 \\
\hline 228 & $4.618 E-22$ & 0.0000 & $0.000 \mathrm{E}+00$ & 0.0000 & $0.000 \mathrm{E}+00$ & 0.0000 & $0.000 \mathrm{E}+00$ & 0.0000 & $0.000 \mathrm{E}+00$ & 0.0000 & $0.000 \mathrm{E}+00$ & 0.0000 & $0.000 \mathrm{E}+00$ & 0.0000 \\
\hline 230 & $1.479 \mathrm{E}-08$ & 0.0049 & $0.000 \mathrm{E}+00$ & 0.0000 & $0.000 \mathrm{E}+00$ & 0.0000 & $0.000 \mathrm{E}+00$ & 0.0000 & $0.000 \mathrm{E}+00$ & 0.0000 & $0.000 \mathrm{E}+00$ & 0.0000 & $0.000 \mathrm{E}+00$ & 0.0000 \\
\hline 232 & $3.033 E-06$ & 0.9949 & $0.000 \mathrm{E}+00$ & 0.0000 & $0.000 \mathrm{E}+00$ & 0.0000 & $0.000 \mathrm{E}+00$ & 0.0000 & $0.000 \mathrm{E}+00$ & 0.0000 & $0.000 \mathrm{E}+00$ & 0.0000 & $0.000 \mathrm{E}+00$ & 0.0000 \\
\hline 34 & $6.737 E-12$ & 0.0000 & $0.000 \mathrm{E}+00$ & 0.0000 & $0.000 \mathrm{E}+00$ & 0.0000 & $0.000 \mathrm{E}+00$ & 0.0000 & $0.000 \mathrm{E}+00$ & 0.0000 & $0.000 \mathrm{E}+00$ & 0.0000 & $0.000 \mathrm{E}+00$ & 0.0000 \\
\hline 35 & $3.388 E-13$ & 0.0000 & $0.000 \mathrm{E}+00$ & 0.0000 & $0.000 \mathrm{E}+00$ & 0.0000 & $0.000 \mathrm{E}+00$ & 0.0000 & $0.000 \mathrm{E}+00$ & 0.0000 & $0.000 \mathrm{E}+00$ & 0.0000 & $0.000 \mathrm{E}+00$ & 0.0000 \\
\hline 38 & $3.153 \mathrm{E}-10$ & 0.0001 & $0.000 \mathrm{E}+00$ & 0.0000 & $0.000 \mathrm{E}+00$ & 0.0000 & $0.000 \mathrm{E}+00$ & 0.0000 & $0.000 \mathrm{E}+00$ & 0.0000 & $0.000 \mathrm{E}+00$ & 0.0000 & $0.000 \mathrm{E}+00$ & 0.0000 \\
\hline & $3.048 E-06$ & 1.0000 & $0.000 \mathrm{E}+00$ & 0.0000 & $0.000 \mathrm{E}+00$ & 0.0000 & $0.000 \mathrm{E}+00$ & 0.0000 & $0.000 \mathrm{E}+00$ & 0.0000 & $0.000 \mathrm{E}+00$ & 0.0000 & $.000 \mathrm{E}+00$ & 0.0000 \\
\hline
\end{tabular}

Total Dose Contributions TDOSE(i,p,t) for Individual Radionuclides (i) and Pathways (p) As mrem/yr and Fraction of Total Dose At $t=1.000 \mathrm{E}+02$ years

Water Dependent Pathways

\begin{tabular}{|c|c|c|c|c|c|c|c|c|c|c|c|c|c|c|}
\hline \multirow{2}{*}{ Nuclide } & \multicolumn{2}{|c|}{ Water } & \multicolumn{2}{|c|}{ Fish } & \multicolumn{2}{|c|}{ Radon } & \multicolumn{2}{|c|}{ Plant } & \multicolumn{2}{|c|}{ Meat } & \multicolumn{2}{|c|}{ Milk } & \multicolumn{2}{|c|}{ All Pathways* } \\
\hline & mrem/yr & fract. & mrem/yr & fract. & mrem/yr & fract. & mrem/yr & fract. & mrem/yr & fract. & mrem/yr & fract. & mrem/yr & fract. \\
\hline-241 & $0.000 \mathrm{E}+00$ & 0.0000 & $0.000 \mathrm{E}+00$ & 0.0000 & $0.000 \mathrm{E}+00$ & 0.0000 & $0.000 \mathrm{E}+00$ & 0.0000 & $0.000 \mathrm{E}+00$ & 0.0000 & $0.000 \mathrm{E}+00$ & 0.0000 & $8.401 \mathrm{E}-17$ & 0.0000 \\
\hline-137 & $0.000 \mathrm{E}+00$ & 0.0000 & $0.000 \mathrm{E}+00$ & 0.0000 & $0.000 \mathrm{E}+00$ & 0.0000 & $0.000 \mathrm{E}+00$ & 0.0000 & $0.000 \mathrm{E}+00$ & 0.0000 & $0.000 \mathrm{E}+00$ & 0.0000 & $2.901 \mathrm{E}-10$ & 0.0001 \\
\hline-237 & $0.000 \mathrm{E}+00$ & 0.0000 & $0.000 \mathrm{E}+00$ & 0.0000 & $0.000 \mathrm{E}+00$ & 0.0000 & $0.000 \mathrm{E}+00$ & 0.0000 & $0.000 \mathrm{E}+00$ & 0.0000 & $0.000 \mathrm{E}+00$ & 0.0000 & $2.788 \mathrm{E}-12$ & 0.0000 \\
\hline 238 & $0.000 \mathrm{E}+00$ & 0.0000 & $0.000 \mathrm{E}+00$ & 0.0000 & $0.000 \mathrm{E}+00$ & 0.0000 & $0.000 \mathrm{E}+00$ & 0.0000 & $0.000 \mathrm{E}+00$ & 0.0000 & $0.000 \mathrm{E}+00$ & 0.0000 & $5.323 E-16$ & 0.0000 \\
\hline 239 & $0.000 \mathrm{E}+00$ & 0.0000 & $0.000 \mathrm{E}+00$ & 0.0000 & $0.000 \mathrm{E}+00$ & 0.0000 & $0.000 \mathrm{E}+00$ & 0.0000 & $0.000 \mathrm{E}+00$ & 0.0000 & $0.000 \mathrm{E}+00$ & 0.0000 & $3.966 \mathrm{E}-17$ & 0.0000 \\
\hline 240 & $0.000 \mathrm{E}+00$ & 0.0000 & $0.000 \mathrm{E}+00$ & 0.0000 & $0.000 \mathrm{E}+00$ & 0.0000 & $0.000 \mathrm{E}+00$ & 0.0000 & $0.000 \mathrm{E}+00$ & 0.0000 & $0.000 \mathrm{E}+00$ & 0.0000 & $1.783 \mathrm{E}-20$ & 0.0000 \\
\hline 99 & $0.000 \mathrm{E}+00$ & 0.0000 & $0.000 \mathrm{E}+00$ & 0.0000 & $0.000 \mathrm{E}+00$ & 0.0000 & $0.000 \mathrm{E}+00$ & 0.0000 & $0.000 \mathrm{E}+00$ & 0.0000 & $0.000 \mathrm{E}+00$ & 0.0000 & $1.592 \mathrm{E}-25$ & 0.0000 \\
\hline 228 & $0.000 \mathrm{E}+00$ & 0.0000 & $0.000 \mathrm{E}+00$ & 0.0000 & $0.000 \mathrm{E}+00$ & 0.0000 & $0.000 \mathrm{E}+00$ & 0.0000 & $0.000 \mathrm{E}+00$ & 0.0000 & $0.000 \mathrm{E}+00$ & 0.0000 & $4.618 E-22$ & 0.0000 \\
\hline 230 & $0.000 \mathrm{E}+00$ & 0.0000 & $0.000 \mathrm{E}+00$ & 0.0000 & $0.000 \mathrm{E}+00$ & 0.0000 & $0.000 \mathrm{E}+00$ & 0.0000 & $0.000 \mathrm{E}+00$ & 0.0000 & $0.000 \mathrm{E}+00$ & 0.0000 & $1.479 \mathrm{E}-08$ & 0.0049 \\
\hline 232 & $0.000 \mathrm{E}+00$ & 0.0000 & $0.000 \mathrm{E}+00$ & 0.0000 & $0.000 \mathrm{E}+00$ & 0.0000 & $0.000 \mathrm{E}+00$ & 0.0000 & $0.000 \mathrm{E}+00$ & 0.0000 & $0.000 \mathrm{E}+00$ & 0.0000 & $3.033 E-06$ & 0.9949 \\
\hline & $0.000 \mathrm{E}+00$ & 0.0000 & $0.000 \mathrm{E}+00$ & 0.0000 & $0.000 \mathrm{E}+00$ & 0.0000 & $0.000 \mathrm{E}+00$ & 0.0000 & $0.000 \mathrm{E}+00$ & 0.0000 & $0.000 \mathrm{E}+00$ & 0.0000 & $6.737 \mathrm{E}-12$ & 0.0000 \\
\hline 35 & $0.000 \mathrm{E}+00$ & 0.0000 & $0.000 \mathrm{E}+00$ & 0.0000 & $0.000 \mathrm{E}+00$ & 0.0000 & $0.000 \mathrm{E}+00$ & 0.0000 & $0.000 \mathrm{E}+00$ & 0.0000 & $0.000 \mathrm{E}+00$ & 0.0000 & $3.388 \mathrm{E}-13$ & 0.0000 \\
\hline 38 & $0.000 \mathrm{E}+00$ & 0.0000 & $0.000 \mathrm{E}+00$ & 0.0000 & $0.000 \mathrm{E}+00$ & 0.0000 & $0.000 \mathrm{E}+00$ & 0.0000 & $0.000 \mathrm{E}+00$ & 0.0000 & $0.000 \mathrm{E}+00$ & 0.0000 & $3.153 \mathrm{E}-10$ & 0.0001 \\
\hline & $0.000 \mathrm{E}+00$ & 0.0000 & $0.000 \mathrm{E}+00$ & 0.0000 & $0.000 \mathrm{E}+00$ & 0.0000 & $0.000 \mathrm{E}+00$ & 0.0000 & $0.000 \mathrm{E}+00$ & 0.0000 & $0.000 E+00$ & 000 & -06 & 1.0000 \\
\hline
\end{tabular}

* Sum of all water independent and dependent pathways. 
RESRAD, Version 6.5

$\mathrm{T}^{1 / 2}$ Limit $=180$ days

$07 / 21 / 2011$

16:52 Page 24

ummary : RESRAD Parameters for U-Landfill Resident Gardener

: C: $\backslash$ RESRAD FAMILY \RESRAD \USERFILES \QCFORSRSG $\backslash R E S I D E N T G A R D E N E R-S R S G-M A Y 11$.RAD

Total Dose Contributions TDOSE(i,p,t) for Individual Radionuclides (i) and Pathways (p) As mrem/yr and Fraction of Total Dose At $t=5.000 \mathrm{E}+02$ years

Water Independent Pathways (Inhalation excludes radon)

\begin{tabular}{|c|c|c|c|c|c|c|c|c|c|c|c|c|c|c|}
\hline \multirow{2}{*}{ Nuclide } & \multicolumn{2}{|c|}{ Ground } & \multicolumn{2}{|c|}{ Inhalation } & \multicolumn{2}{|c|}{ Radon } & \multicolumn{2}{|c|}{ Plant } & \multicolumn{2}{|c|}{ Meat } & \multicolumn{2}{|c|}{ Milk } & \multicolumn{2}{|c|}{ Soil } \\
\hline & mrem/yr & fract. & mrem/yr & fract. & mrem/yr & fract. & mrem/yr & fract. & mrem/yr & fract. & mrem/yr & fract. & mrem/yr & fract. \\
\hline-241 & $2.295 E-14$ & 0.0000 & $0.000 \mathrm{E}+00$ & 0.0000 & $0.000 \mathrm{E}+00$ & 0.0000 & $0.000 \mathrm{E}+00$ & 0.0000 & $0.000 \mathrm{E}+00$ & 0.0000 & $0.000 \mathrm{E}+00$ & 0.0000 & $0.000 \mathrm{E}+00$ & 0.0000 \\
\hline-137 & $8.104 \mathrm{E}-13$ & 0.0000 & $0.000 \mathrm{E}+00$ & 0.0000 & $0.000 \mathrm{E}+00$ & 0.0000 & $0.000 \mathrm{E}+00$ & 0.0000 & $0.000 \mathrm{E}+00$ & 0.0000 & $0.000 \mathrm{E}+00$ & 0.0000 & $0.000 \mathrm{E}+00$ & 0.0000 \\
\hline-237 & $2.044 \mathrm{E}-10$ & 0.0000 & $0.000 \mathrm{E}+00$ & 0.0000 & $0.000 \mathrm{E}+00$ & 0.0000 & $0.000 \mathrm{E}+00$ & 0.0000 & $0.000 \mathrm{E}+00$ & 0.0000 & $0.000 \mathrm{E}+00$ & 0.0000 & $0.000 \mathrm{E}+00$ & 0.0000 \\
\hline-238 & $5.607 \mathrm{E}-13$ & 0.0000 & $0.000 \mathrm{E}+00$ & 0.0000 & $0.000 \mathrm{E}+00$ & 0.0000 & $0.000 \mathrm{E}+00$ & 0.0000 & $0.000 \mathrm{E}+00$ & 0.0000 & $0.000 \mathrm{E}+00$ & 0.0000 & $0.000 \mathrm{E}+00$ & 0.0000 \\
\hline-239 & $4.708 E-15$ & 0.0000 & $0.000 \mathrm{E}+00$ & 0.0000 & $0.000 \mathrm{E}+00$ & 0.0000 & $0.000 \mathrm{E}+00$ & 0.0000 & $0.000 \mathrm{E}+00$ & 0.0000 & $0.000 \mathrm{E}+00$ & 0.0000 & $0.000 \mathrm{E}+00$ & 0.0000 \\
\hline-240 & $5.719 \mathrm{E}-18$ & 0.0000 & $0.000 \mathrm{E}+00$ & 0.0000 & $0.000 \mathrm{E}+00$ & 0.0000 & $0.000 \mathrm{E}+00$ & 0.0000 & $0.000 \mathrm{E}+00$ & 0.0000 & $0.000 \mathrm{E}+00$ & 0.0000 & $0.000 \mathrm{E}+00$ & 0.0000 \\
\hline 99 & $9.310 \mathrm{E}-24$ & 0.0000 & $0.000 \mathrm{E}+00$ & 0.0000 & $0.000 \mathrm{E}+00$ & 0.0000 & $0.000 \mathrm{E}+00$ & 0.0000 & $0.000 \mathrm{E}+00$ & 0.0000 & $0.000 \mathrm{E}+00$ & 0.0000 & $0.000 \mathrm{E}+00$ & 0.0000 \\
\hline-228 & $0.000 \mathrm{E}+00$ & 0.0000 & $0.000 \mathrm{E}+00$ & 0.0000 & $0.000 \mathrm{E}+00$ & 0.0000 & $0.000 \mathrm{E}+00$ & 0.0000 & $0.000 \mathrm{E}+00$ & 0.0000 & $0.000 \mathrm{E}+00$ & 0.0000 & $0.000 \mathrm{E}+00$ & 0.0000 \\
\hline-230 & $1.071 \mathrm{E}-06$ & 0.0311 & $0.000 \mathrm{E}+00$ & 0.0000 & $0.000 \mathrm{E}+00$ & 0.0000 & $0.000 \mathrm{E}+00$ & 0.0000 & $0.000 \mathrm{E}+00$ & 0.0000 & $0.000 \mathrm{E}+00$ & 0.0000 & $0.000 \mathrm{E}+00$ & 0.0000 \\
\hline-232 & $3.338 E-05$ & 0.9686 & $0.000 \mathrm{E}+00$ & 0.0000 & $0.000 \mathrm{E}+00$ & 0.0000 & $0.000 \mathrm{E}+00$ & 0.0000 & $0.000 \mathrm{E}+00$ & 0.0000 & $0.000 \mathrm{E}+00$ & 0.0000 & $0.000 \mathrm{E}+00$ & 0.0000 \\
\hline 234 & $2.496 \mathrm{E}-09$ & 0.0001 & $0.000 \mathrm{E}+00$ & 0.0000 & $0.000 \mathrm{E}+00$ & 0.0000 & $0.000 \mathrm{E}+00$ & 0.0000 & $0.000 \mathrm{E}+00$ & 0.0000 & $0.000 \mathrm{E}+00$ & 0.0000 & $0.000 \mathrm{E}+00$ & 0.0000 \\
\hline 35 & $7.033 E-11$ & 0.0000 & $0.000 \mathrm{E}+00$ & 0.0000 & $0.000 \mathrm{E}+00$ & 0.0000 & $0.000 \mathrm{E}+00$ & 0.0000 & $0.000 \mathrm{E}+00$ & 0.0000 & $0.000 \mathrm{E}+00$ & 0.0000 & $0.000 \mathrm{E}+00$ & 0.0000 \\
\hline 38 & $7.680 \mathrm{E}-09$ & 0.0002 & $0.000 \mathrm{E}+00$ & 0.0000 & $0.000 \mathrm{E}+00$ & 0.0000 & $0.000 \mathrm{E}+00$ & 0.0000 & $0.000 \mathrm{E}+00$ & 0.0000 & $0.000 \mathrm{E}+00$ & 0.0000 & $0.000 \mathrm{E}+00$ & 0.0000 \\
\hline & $3.446 E-05$ & 1.0000 & $0.000 \mathrm{E}+00$ & 0.0000 & $0.000 \mathrm{E}+00$ & 0.0000 & $0.000 \mathrm{E}+00$ & 0.0000 & $0.000 \mathrm{E}+00$ & 0.0000 & $0.000 \mathrm{E}+00$ & 0.0000 & $0.000 \mathrm{E}+00$ & 0.0000 \\
\hline
\end{tabular}

Total Dose Contributions TDOSE(i,p,t) for Individual Radionuclides (i) and Pathways (p) As mrem/yr and Fraction of Total Dose At $t=5.000 \mathrm{E}+02$ years

Water Dependent Pathways

\begin{tabular}{|c|c|c|c|c|c|c|c|c|c|c|c|c|c|c|}
\hline \multirow{2}{*}{$\begin{array}{l}\text { Radio- } \\
\text { Nuclide }\end{array}$} & \multicolumn{2}{|c|}{ Water } & \multicolumn{2}{|c|}{ Fish } & \multicolumn{2}{|c|}{ Radon } & \multicolumn{2}{|c|}{ Plant } & \multicolumn{2}{|c|}{ Meat } & \multicolumn{2}{|c|}{ Milk } & \multicolumn{2}{|c|}{ All Pathways* } \\
\hline & mrem/yr & fract. & mrem/yr & fract. & mrem/yr & fract. & mrem/yr & fract. & mrem/yr & fract. & mrem/yr & fract. & mrem/yr & fract. \\
\hline 241 & $0.000 \mathrm{E}+00$ & 0.0000 & $0.000 \mathrm{E}+00$ & 0.0000 & $0.000 \mathrm{E}+00$ & 0.0000 & $0.000 \mathrm{E}+00$ & 0.0000 & $0.000 \mathrm{E}+00$ & 0.0000 & $0.000 \mathrm{E}+00$ & 0.0000 & $2.295 E-14$ & 0.0000 \\
\hline-137 & $0.000 \mathrm{E}+00$ & 0.0000 & $0.000 \mathrm{E}+00$ & 0.0000 & $0.000 \mathrm{E}+00$ & 0.0000 & $0.000 \mathrm{E}+00$ & 0.0000 & $0.000 \mathrm{E}+00$ & 0.0000 & $0.000 \mathrm{E}+00$ & 0.0000 & $8.104 \mathrm{E}-13$ & 0.0000 \\
\hline-237 & $0.000 \mathrm{E}+00$ & 0.0000 & $0.000 \mathrm{E}+00$ & 0.0000 & $0.000 \mathrm{E}+00$ & 0.0000 & $0.000 \mathrm{E}+00$ & 0.0000 & $0.000 \mathrm{E}+00$ & 0.0000 & $0.000 \mathrm{E}+00$ & 0.0000 & $2.044 \mathrm{E}-10$ & 0.0000 \\
\hline-238 & $0.000 \mathrm{E}+00$ & 0.0000 & $0.000 \mathrm{E}+00$ & 0.0000 & $0.000 \mathrm{E}+00$ & 0.0000 & $0.000 \mathrm{E}+00$ & 0.0000 & $0.000 \mathrm{E}+00$ & 0.0000 & $0.000 \mathrm{E}+00$ & 0.0000 & $5.607 \mathrm{E}-13$ & 0.0000 \\
\hline-239 & $0.000 \mathrm{E}+00$ & 0.0000 & $0.000 \mathrm{E}+00$ & 0.0000 & $0.000 \mathrm{E}+00$ & 0.0000 & $0.000 \mathrm{E}+00$ & 0.0000 & $0.000 \mathrm{E}+00$ & 0.0000 & $0.000 E+00$ & 0.0000 & $4.708 E-15$ & 0.0000 \\
\hline-240 & $0.000 \mathrm{E}+00$ & 0.0000 & $0.000 \mathrm{E}+00$ & 0.0000 & $0.000 \mathrm{E}+00$ & 0.0000 & $0.000 \mathrm{E}+00$ & 0.0000 & $0.000 \mathrm{E}+00$ & 0.0000 & $0.000 E+00$ & 0.0000 & $5.719 \mathrm{E}-18$ & 0.0000 \\
\hline 99 & $0.000 \mathrm{E}+00$ & 0.0000 & $0.000 \mathrm{E}+00$ & 0.0000 & $0.000 \mathrm{E}+00$ & 0.0000 & $0.000 \mathrm{E}+00$ & 0.0000 & $0.000 \mathrm{E}+00$ & 0.0000 & $0.000 \mathrm{E}+00$ & 0.0000 & $9.310 \mathrm{E}-24$ & 0.0000 \\
\hline-228 & $0.000 \mathrm{E}+00$ & 0.0000 & $0.000 \mathrm{E}+00$ & 0.0000 & $0.000 \mathrm{E}+00$ & 0.0000 & $0.000 \mathrm{E}+00$ & 0.0000 & $0.000 \mathrm{E}+00$ & 0.0000 & $0.000 \mathrm{E}+00$ & 0.0000 & $0.000 \mathrm{E}+00$ & 0.0000 \\
\hline-230 & $0.000 \mathrm{E}+00$ & 0.0000 & $0.000 \mathrm{E}+00$ & 0.0000 & $0.000 \mathrm{E}+00$ & 0.0000 & $0.000 \mathrm{E}+00$ & 0.0000 & $0.000 \mathrm{E}+00$ & 0.0000 & $0.000 E+00$ & 0.0000 & $1.071 \mathrm{E}-06$ & 0.0311 \\
\hline 232 & $0.000 \mathrm{E}+00$ & 0.0000 & $0.000 \mathrm{E}+00$ & 0.0000 & $0.000 \mathrm{E}+00$ & 0.0000 & $0.000 \mathrm{E}+00$ & 0.0000 & $0.000 \mathrm{E}+00$ & 0.0000 & $0.000 \mathrm{E}+00$ & 0.0000 & $3.338 E-05$ & 0.9686 \\
\hline 34 & $0.000 \mathrm{E}+00$ & 0.0000 & $0.000 \mathrm{E}+00$ & 0.0000 & $0.000 \mathrm{E}+00$ & 0.0000 & $0.000 \mathrm{E}+00$ & 0.0000 & $0.000 \mathrm{E}+00$ & 0.0000 & $0.000 \mathrm{E}+00$ & 0.0000 & $2.496 \mathrm{E}-09$ & 0.0001 \\
\hline 35 & $0.000 \mathrm{E}+00$ & 0.0000 & $0.000 \mathrm{E}+00$ & 0.0000 & $0.000 \mathrm{E}+00$ & 0.0000 & $0.000 \mathrm{E}+00$ & 0.0000 & $0.000 \mathrm{E}+00$ & 0.0000 & $0.000 \mathrm{E}+00$ & 0.0000 & $7.033 E-11$ & 0.0000 \\
\hline 38 & $0.000 \mathrm{E}+00$ & 0.0000 & $0.000 \mathrm{E}+00$ & 0.0000 & $0.000 \mathrm{E}+00$ & 0.0000 & $0.000 \mathrm{E}+00$ & 0.0000 & $0.000 \mathrm{E}+00$ & 0.0000 & $0.000 \mathrm{E}+00$ & 0.0000 & $7.680 \mathrm{E}-09$ & 0.0002 \\
\hline & $0.000 \mathrm{E}+00$ & 0.0000 & $0.000 \mathrm{E}+00$ & 0.0000 & $0.000 \mathrm{E}+00$ & 0.0000 & $0.000 \mathrm{E}+00$ & 0.0000 & $0.000 \mathrm{E}+00$ & 0.0000 & $0.000 \mathrm{E}+00$ & 0.0000 & $16 E-05$ & 1.0000 \\
\hline
\end{tabular}

* Sum of all water independent and dependent pathways. 
RESRAD, Version 6.5

$\mathrm{T}^{1 / 2}$ Limit $=180$ days

$07 / 21 / 2011$

16:52 Page

25

ummary : RESRAD Parameters for U-Landfill Resident Gardener

: C: \RESRAD_FAMILY \RESRAD \USERFILES $\backslash Q$ CFORSRSG \RESIDENTGARDENER-SRSG-MAY11.RAD

Total Dose Contributions TDOSE (i,p,t) for Individual Radionuclides (i) and Pathways (p) As mrem/yr and Fraction of Total Dose At $t=1.050 \mathrm{E}+03$ years

Water Independent Pathways (Inhalation excludes radon)

\begin{tabular}{|c|c|c|c|c|c|c|c|c|c|c|c|c|c|c|}
\hline \multirow{2}{*}{ Nuclide } & \multicolumn{2}{|c|}{ Ground } & \multicolumn{2}{|c|}{ Inhalation } & \multicolumn{2}{|c|}{ Radon } & \multicolumn{2}{|c|}{ Plant } & \multicolumn{2}{|c|}{ Meat } & \multicolumn{2}{|c|}{ Milk } & \multicolumn{2}{|c|}{ Soil } \\
\hline & mrem/yr & fract. & mrem/yr & fract. & mrem/yr & fract. & mrem/yr & fract. & mrem/yr & fract. & mrem/yr & fract. & mrem/yr & fract. \\
\hline-241 & 1. $216 \mathrm{E}-11$ & 0.0000 & $0.000 \mathrm{E}+00$ & 0.0000 & $0.000 \mathrm{E}+00$ & 0.0000 & $1.983 \mathrm{E}-04$ & 0.0009 & $0.000 \mathrm{E}+00$ & 0.0000 & $0.000 \mathrm{E}+00$ & 0.0000 & $0.000 \mathrm{E}+00$ & 0.0000 \\
\hline-137 & $2.495 E-16$ & 0.0000 & $0.000 \mathrm{E}+00$ & 0.0000 & $0.000 \mathrm{E}+00$ & 0.0000 & 7. $688 \mathrm{E}-14$ & 0.0000 & $0.000 \mathrm{E}+00$ & 0.0000 & $0.000 \mathrm{E}+00$ & 0.0000 & $0.000 \mathrm{E}+00$ & 0.0000 \\
\hline-237 & $7.109 \mathrm{E}-08$ & 0.0000 & $0.000 \mathrm{E}+00$ & 0.0000 & $0.000 \mathrm{E}+00$ & 0.0000 & $1.025 \mathrm{E}-02$ & 0.0459 & $0.000 \mathrm{E}+00$ & 0.0000 & $0.000 \mathrm{E}+00$ & 0.0000 & $0.000 \mathrm{E}+00$ & 0.0000 \\
\hline-238 & $1.302 \mathrm{E}-10$ & 0.0000 & $0.000 \mathrm{E}+00$ & 0.0000 & $0.000 \mathrm{E}+00$ & 0.0000 & $6.108 \mathrm{E}-07$ & 0.0000 & $0.000 \mathrm{E}+00$ & 0.0000 & $0.000 \mathrm{E}+00$ & 0.0000 & $0.000 \mathrm{E}+00$ & 0.0000 \\
\hline-239 & 3. $338 E-12$ & 0.0000 & $0.000 \mathrm{E}+00$ & 0.0000 & $0.000 \mathrm{E}+00$ & 0.0000 & $1.268 \mathrm{E}-03$ & 0.0057 & $0.000 \mathrm{E}+00$ & 0.0000 & $0.000 \mathrm{E}+00$ & 0.0000 & $0.000 \mathrm{E}+00$ & 0.0000 \\
\hline-240 & $8.095 \mathrm{E}-16$ & 0.0000 & $0.000 \mathrm{E}+00$ & 0.0000 & $0.000 \mathrm{E}+00$ & 0.0000 & $1.170 \mathrm{E}-03$ & 0.0052 & $0.000 \mathrm{E}+00$ & 0.0000 & $0.000 \mathrm{E}+00$ & 0.0000 & $0.000 \mathrm{E}+00$ & 0.0000 \\
\hline 99 & $2.503 E-21$ & 0.0000 & $0.000 \mathrm{E}+00$ & 0.0000 & $0.000 \mathrm{E}+00$ & 0.0000 & $1.325 \mathrm{E}-06$ & 0.0000 & $0.000 \mathrm{E}+00$ & 0.0000 & $0.000 \mathrm{E}+00$ & 0.0000 & $0.000 \mathrm{E}+00$ & 0.0000 \\
\hline-228 & $0.000 \mathrm{E}+00$ & 0.0000 & $0.000 \mathrm{E}+00$ & 0.0000 & $0.000 \mathrm{E}+00$ & 0.0000 & $0.000 \mathrm{E}+00$ & 0.0000 & $0.000 \mathrm{E}+00$ & 0.0000 & $0.000 \mathrm{E}+00$ & 0.0000 & $0.000 \mathrm{E}+00$ & 0.0000 \\
\hline-230 & $8.967 \mathrm{E}-05$ & 0.0004 & $0.000 \mathrm{E}+00$ & 0.0000 & $0.000 \mathrm{E}+00$ & 0.0000 & $5.809 \mathrm{E}-02$ & 0.2600 & $0.000 \mathrm{E}+00$ & 0.0000 & $0.000 \mathrm{E}+00$ & 0.0000 & $0.000 \mathrm{E}+00$ & 0.0000 \\
\hline-232 & $9.244 \mathrm{E}-04$ & 0.0041 & $0.000 \mathrm{E}+00$ & 0.0000 & $0.000 \mathrm{E}+00$ & 0.0000 & $1.481 \mathrm{E}-01$ & 0.6629 & $0.000 \mathrm{E}+00$ & 0.0000 & $0.000 \mathrm{E}+00$ & 0.0000 & $0.000 \mathrm{E}+00$ & 0.0000 \\
\hline 234 & $4.542 \mathrm{E}-07$ & 0.0000 & $0.000 \mathrm{E}+00$ & 0.0000 & $0.000 \mathrm{E}+00$ & 0.0000 & $9.271 \mathrm{E}-04$ & 0.0041 & $0.000 \mathrm{E}+00$ & 0.0000 & $0.000 \mathrm{E}+00$ & 0.0000 & $0.000 \mathrm{E}+00$ & 0.0000 \\
\hline 35 & $2.349 \mathrm{E}-08$ & 0.0000 & $0.000 \mathrm{E}+00$ & 0.0000 & $0.000 \mathrm{E}+00$ & 0.0000 & $1.767 \mathrm{E}-03$ & 0.0079 & $0.000 \mathrm{E}+00$ & 0.0000 & $0.000 \mathrm{E}+00$ & 0.0000 & $0.000 \mathrm{E}+00$ & 0.0000 \\
\hline 38 & $6.200 \mathrm{E}-07$ & 0.0000 & $0.000 \mathrm{E}+00$ & 0.0000 & $0.000 \mathrm{E}+00$ & 0.0000 & $6.329 \mathrm{E}-04$ & 0.0028 & $0.000 \mathrm{E}+00$ & 0.0000 & $0.000 \mathrm{E}+00$ & 0.0000 & $0.000 \mathrm{E}+00$ & 0.0000 \\
\hline & $1.015 E-03$ & 0.0045 & $0.000 \mathrm{E}+00$ & 0.0000 & $0.000 \mathrm{E}+00$ & 0.0000 & $2.225 \mathrm{E}-01$ & 0.9955 & $0.000 \mathrm{E}+00$ & 0.0000 & $0.000 \mathrm{E}+00$ & 0.0000 & $0.000 \mathrm{E}+00$ & 0.0000 \\
\hline
\end{tabular}

Total Dose Contributions TDOSE(i,p,t) for Individual Radionuclides (i) and Pathways (p) As mrem/yr and Fraction of Total Dose At $t=1.050 \mathrm{E}+03$ years

Water Dependent Pathways

\begin{tabular}{|c|c|c|c|c|c|c|c|c|c|c|c|c|c|c|}
\hline \multirow{2}{*}{$\begin{array}{l}\text { Radio- } \\
\text { Nuclide }\end{array}$} & \multicolumn{2}{|c|}{ Water } & \multicolumn{2}{|c|}{ Fish } & \multicolumn{2}{|c|}{ Radon } & \multicolumn{2}{|c|}{ Plant } & \multicolumn{2}{|c|}{ Meat } & \multicolumn{2}{|c|}{ Milk } & \multicolumn{2}{|c|}{ All Pathways* } \\
\hline & mrem/yr & fract. & mrem/yr & fract. & mrem/yr & fract. & mrem/yr & fract. & mrem/yr & fract. & mrem/yr & fract. & mrem/yr & fract. \\
\hline 241 & $0.000 \mathrm{E}+00$ & 0.0000 & $0.000 \mathrm{E}+00$ & 0.0000 & $0.000 \mathrm{E}+00$ & 0.0000 & $0.000 \mathrm{E}+00$ & 0.0000 & $0.000 \mathrm{E}+00$ & 0.0000 & $0.000 \mathrm{E}+00$ & 0.0000 & $1.983 \mathrm{E}-04$ & 0.0009 \\
\hline-137 & $0.000 \mathrm{E}+00$ & 0.0000 & $0.000 \mathrm{E}+00$ & 0.0000 & $0.000 \mathrm{E}+00$ & 0.0000 & $0.000 \mathrm{E}+00$ & 0.0000 & $0.000 \mathrm{E}+00$ & 0.0000 & $0.000 \mathrm{E}+00$ & 0.0000 & $7.713 \mathrm{E}-14$ & 0.0000 \\
\hline-237 & $0.000 \mathrm{E}+00$ & 0.0000 & $0.000 \mathrm{E}+00$ & 0.0000 & $0.000 \mathrm{E}+00$ & 0.0000 & $0.000 \mathrm{E}+00$ & 0.0000 & $0.000 \mathrm{E}+00$ & 0.0000 & $0.000 \mathrm{E}+00$ & 0.0000 & $1.025 \mathrm{E}-02$ & 0.0459 \\
\hline-238 & $0.000 \mathrm{E}+00$ & 0.0000 & $0.000 \mathrm{E}+00$ & 0.0000 & $0.000 \mathrm{E}+00$ & 0.0000 & $0.000 \mathrm{E}+00$ & 0.0000 & $0.000 \mathrm{E}+00$ & 0.0000 & $0.000 \mathrm{E}+00$ & 0.0000 & $6.110 \mathrm{E}-07$ & 0.0000 \\
\hline-239 & $0.000 \mathrm{E}+00$ & 0.0000 & $0.000 \mathrm{E}+00$ & 0.0000 & $0.000 \mathrm{E}+00$ & 0.0000 & $0.000 \mathrm{E}+00$ & 0.0000 & $0.000 \mathrm{E}+00$ & 0.0000 & $0.000 E+00$ & 0.0000 & $1.268 \mathrm{E}-03$ & 0.0057 \\
\hline-240 & $0.000 \mathrm{E}+00$ & 0.0000 & $0.000 \mathrm{E}+00$ & 0.0000 & $0.000 \mathrm{E}+00$ & 0.0000 & $0.000 \mathrm{E}+00$ & 0.0000 & $0.000 \mathrm{E}+00$ & 0.0000 & $0.000 E+00$ & 0.0000 & $1.170 \mathrm{E}-03$ & 0.0052 \\
\hline 99 & $0.000 \mathrm{E}+00$ & 0.0000 & $0.000 \mathrm{E}+00$ & 0.0000 & $0.000 \mathrm{E}+00$ & 0.0000 & $0.000 \mathrm{E}+00$ & 0.0000 & $0.000 \mathrm{E}+00$ & 0.0000 & $0.000 \mathrm{E}+00$ & 0.0000 & 1. $325 \mathrm{E}-06$ & 0.0000 \\
\hline-228 & $0.000 \mathrm{E}+00$ & 0.0000 & $0.000 \mathrm{E}+00$ & 0.0000 & $0.000 \mathrm{E}+00$ & 0.0000 & $0.000 \mathrm{E}+00$ & 0.0000 & $0.000 \mathrm{E}+00$ & 0.0000 & $0.000 \mathrm{E}+00$ & 0.0000 & $0.000 \mathrm{E}+00$ & 0.0000 \\
\hline-230 & $0.000 \mathrm{E}+00$ & 0.0000 & $0.000 \mathrm{E}+00$ & 0.0000 & $0.000 \mathrm{E}+00$ & 0.0000 & $0.000 \mathrm{E}+00$ & 0.0000 & $0.000 \mathrm{E}+00$ & 0.0000 & $0.000 E+00$ & 0.0000 & $5.818 \mathrm{E}-02$ & 0.2604 \\
\hline 232 & $0.000 \mathrm{E}+00$ & 0.0000 & $0.000 \mathrm{E}+00$ & 0.0000 & $0.000 \mathrm{E}+00$ & 0.0000 & $0.000 \mathrm{E}+00$ & 0.0000 & $0.000 \mathrm{E}+00$ & 0.0000 & $0.000 \mathrm{E}+00$ & 0.0000 & $1.491 \mathrm{E}-01$ & 0.6671 \\
\hline 34 & $0.000 \mathrm{E}+00$ & 0.0000 & $0.000 \mathrm{E}+00$ & 0.0000 & $0.000 \mathrm{E}+00$ & 0.0000 & $0.000 \mathrm{E}+00$ & 0.0000 & $0.000 \mathrm{E}+00$ & 0.0000 & $0.000 \mathrm{E}+00$ & 0.0000 & $9.276 \mathrm{E}-04$ & 0.0042 \\
\hline 35 & $0.000 \mathrm{E}+00$ & 0.0000 & $0.000 \mathrm{E}+00$ & 0.0000 & $0.000 \mathrm{E}+00$ & 0.0000 & $0.000 \mathrm{E}+00$ & 0.0000 & $0.000 \mathrm{E}+00$ & 0.0000 & $0.000 \mathrm{E}+00$ & 0.0000 & $1.767 \mathrm{E}-03$ & 0.0079 \\
\hline 38 & $0.000 \mathrm{E}+00$ & 0.0000 & $0.000 \mathrm{E}+00$ & 0.0000 & $0.000 \mathrm{E}+00$ & 0.0000 & $0.000 \mathrm{E}+00$ & 0.0000 & $0.000 \mathrm{E}+00$ & 0.0000 & $0.000 \mathrm{E}+00$ & 0.0000 & $6.335 E-04$ & 0.0028 \\
\hline & $0.000 \mathrm{E}+00$ & 0.0000 & $0.000 \mathrm{E}+00$ & 0.0000 & $0.000 \mathrm{E}+00$ & 0.0000 & $0.000 \mathrm{E}+00$ & 0.0000 & $0.000 \mathrm{E}+00$ & 0.0000 & $0.000 \mathrm{E}+00$ & 0.0000 & $5 E-01$ & 1. \\
\hline
\end{tabular}

* Sum of all water independent and dependent pathways. 
RESRAD, Version $6.5 \quad T^{1 / 2}$ Limit $=180$ days

ummary : RESRAD Parameters for U-Landfill Resident Gardener

File : C: \RESRAD_FAMILY \RESRAD \USERFILES \QCFORSRSG \RESIDENTGARDENER-SRSG-MAY11.RAD

Dose/Source Ratios Summed Over All Pathways

Parent and Progeny Principal Radionuclide Contributions Indicated

Parent Product Thread DSR $(j, t)$ At Time in Years (mrem/yr)/(pCi/g)

(i)

(j)

$\begin{array}{ll}\mathrm{Am}-241 & 1.000 \mathrm{E}+00 \\ \mathrm{~Np}-237+\mathrm{D} & 1.000 \mathrm{E}+00 \\ \mathrm{U}-233 & 1.000 \mathrm{E}+00 \\ \mathrm{Th}-229+\mathrm{D} & 1.000 \mathrm{E}+00 \\ \operatorname{\sum DSR}(j) & \end{array}$

$\mathrm{Np}-237+\mathrm{D}$

$\mathrm{U}-233$

Th-229+D

$\sum \operatorname{DSR}(j)$

$\mathrm{Pu}-238$

$\mathrm{Pu}-238$

U-234

Th-230

Ra-226+D

$\mathrm{Pb}-210+\mathrm{D}$

$\sum \operatorname{DSR}(j)$

Pu-239

$\mathrm{U}-235+\mathrm{D}$

$\mathrm{Pa}-231$

Ac $-227+D$

$\sum \operatorname{DSR}(j)$

Pu-240

$\mathrm{Pu}-240$

U-236

Th-232

$\mathrm{Ra}-228+\mathrm{D}$

Th-228+D

$\sum \operatorname{DSR}(j)$

TC-99

Th $-228+\mathrm{D}$

1. $000 \mathrm{E}+00$

Th-230

1. $000 \mathrm{E}+0$

Ra-226+D

1. $000 \mathrm{E}+00$

$\mathrm{Pb}-210+\mathrm{D}$

$1.000 \mathrm{E}+00$

$\sum \operatorname{DSR}(j)$
$0.000 \mathrm{E}+00 \quad 1.000 \mathrm{E}+00 \quad 5.000 \mathrm{E}+01 \quad 1.000 \mathrm{E}+02 \quad 5.000 \mathrm{E}+02 \quad 1.050 \mathrm{E}+03$

$\begin{array}{llllll}1.936 \mathrm{E}-33 & 1.989 \mathrm{E}-33 & 7.353 \mathrm{E}-33 & 2.792 \mathrm{E}-32 & 1.208 \mathrm{E}-27 & 1.965 \mathrm{E}-04\end{array}$

$\begin{array}{lllllll}1.546 \mathrm{E}-19 & 4.680 \mathrm{E}-19 & 2.562 \mathrm{E}-17 & 8.382 \mathrm{E}-17 & 2.263 \mathrm{E}-14 & 1.773 \mathrm{E}-06\end{array}$

$3.506 \mathrm{E}-30 \quad 2.479 \mathrm{E}-29 \quad 4.863 \mathrm{E}-26 \quad 3.503 \mathrm{E}-25 \quad 1.053 \mathrm{E}-21 \quad 3.056 \mathrm{E}-10$

$2.399 \mathrm{E}-26 \quad 3.618 \mathrm{E}-25 \quad 1.710 \mathrm{E}-20 \quad 1.868 \mathrm{E}-19 \quad 3.195 \mathrm{E}-16 \quad 5.403 \mathrm{E}-11$

$\begin{array}{lllllll}1.546 \mathrm{E}-19 & 4.680 \mathrm{E}-19 & 2.564 \mathrm{E}-17 & 8.401 \mathrm{E}-17 & 2.295 \mathrm{E}-14 & 1.983 \mathrm{E}-04\end{array}$

$\begin{array}{lllllll}1.000 \mathrm{E}+00 & 1.262 \mathrm{E}-09 & 1.243 \mathrm{E}-09 & 6.050 \mathrm{E}-10 & 2.901 \mathrm{E}-10 & 8.104 \mathrm{E}-13 & 7.713 \mathrm{E}-14\end{array}$

$\begin{array}{lllllll}1.000 \mathrm{E}+00 & 9.536 \mathrm{E}-13 & 9.638 \mathrm{E}-13 & 1.625 \mathrm{E}-12 & 2.770 \mathrm{E}-12 & 1.974 \mathrm{E}-10 & 1.025 \mathrm{E}-02\end{array}$

$\begin{array}{llllllll}1.000 \mathrm{E}+00 & 3.245 \mathrm{E}-23 & 9.844 \mathrm{E}-23 & 6.100 \mathrm{E}-21 & 2.264 \mathrm{E}-20 & 1.650 \mathrm{E}-17 & 2.871 \mathrm{E}-06\end{array}$

$\begin{array}{lllllll}1.000 \mathrm{E}+00 & 2.962 \mathrm{E}-19 & 2.086 \mathrm{E}-18 & 3.196 \mathrm{E}-15 & 1.788 \mathrm{E}-14 & 7.080 \mathrm{E}-12 & 6.801 \mathrm{E}-07\end{array}$

$9.536 \mathrm{E}-13 \quad 9.638 \mathrm{E}-13 \quad 1.629 \mathrm{E}-12 \quad 2.788 \mathrm{E}-12 \quad 2.044 \mathrm{E}-10 \quad 1.025 \mathrm{E}-02$

$\begin{array}{lllllll}1.840 E-09 & 2.162 E-33 & 2.183 E-33 & 3.520 E-33 & 5.731 E-33 & 2.831 E-31 & 5.505 E-16\end{array}$

$\begin{array}{lllllllll}1.000 \mathrm{E}+00 & 1.175 \mathrm{E}-24 & 1.186 \mathrm{E}-24 & 1.913 \mathrm{E}-24 & 3.115 \mathrm{E}-24 & 1.539 \mathrm{E}-22 & 2.992 \mathrm{E}-07\end{array}$

$\begin{array}{lllllll}1.000 \mathrm{E}+00 & 9.778 \mathrm{E}-30 & 2.969 \mathrm{E}-29 & 1.973 \mathrm{E}-27 & 7.960 \mathrm{E}-27 & 1.690 \mathrm{E}-23 & 2.276 \mathrm{E}-07\end{array}$

$\begin{array}{lllllll}1.000 \mathrm{E}+00 & 1.028 \mathrm{E}-33 & 7.286 \mathrm{E}-33 & 1.599 \mathrm{E}-29 & 1.302 \mathrm{E}-28 & 1.306 \mathrm{E}-24 & 3.273 \mathrm{E}-09\end{array}$

$\begin{array}{lllllll}1.000 \mathrm{E}+00 \quad 8.021 \mathrm{E}-23 & 1.208 \mathrm{E}-21 & 5.266 \mathrm{E}-17 & 5.323 \mathrm{E}-16 & 5.607 \mathrm{E}-13 & 3.143 \mathrm{E}-08\end{array}$

$\begin{array}{lllllll}1.000 \mathrm{E}+00 & 2.326 \mathrm{E}-31 & 7.210 \mathrm{E}-30 & 7.772 \mathrm{E}-24 & 1.314 \mathrm{E}-22 & 3.671 \mathrm{E}-19 & 4.946 \mathrm{E}-08\end{array}$

$\begin{array}{llllll}8.139 \mathrm{E}-23 & 1.209 \mathrm{E}-21 & 5.266 \mathrm{E}-17 & 5.323 \mathrm{E}-16 & 5.607 \mathrm{E}-13 & 6.110 \mathrm{E}-07\end{array}$

$\begin{array}{lllllllll}1.000 \mathrm{E}+00 & 1.202 \mathrm{E}-17 & 1.217 \mathrm{E}-17 & 2.183 \mathrm{E}-17 & 3.965 \mathrm{E}-17 & 4.690 \mathrm{E}-15 & 1.268 \mathrm{E}-03\end{array}$

$\begin{array}{lllllll}1.000 \mathrm{E}+00 & 6.135 \mathrm{E}-24 & 1.861 \mathrm{E}-23 & 1.146 \mathrm{E}-21 & 4.227 \mathrm{E}-21 & 2.931 \mathrm{E}-18 & 6.291 \mathrm{E}-10\end{array}$

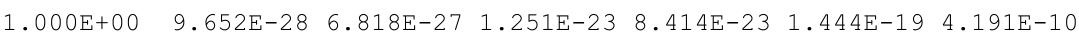

$\begin{array}{lllllllll}1.000 \mathrm{E}+00 & 2.288 \mathrm{E}-27 & 3.434 \mathrm{E}-26 & 1.276 \mathrm{E}-21 & 1.169 \mathrm{E}-20 & 1.476 \mathrm{E}-17 & 1.686 \mathrm{E}-10\end{array}$

$\begin{array}{llllll}1.202 \mathrm{E}-17 & 1.217 \mathrm{E}-17 & 2.183 \mathrm{E}-17 & 3.966 \mathrm{E}-17 & 4.708 \mathrm{E}-15 & 1.268 \mathrm{E}-03\end{array}$

$\begin{array}{lllllllll}4.950 E-08 & 5.653 E-32 & 5.753 E-32 & 1.359 E-31 & 3.267 E-31 & 3.647 E-28 & 5.789 E-11\end{array}$

$\begin{array}{llllllll}1.000 \mathrm{E}+00 & 1.142 \mathrm{E}-24 & 1.162 \mathrm{E}-24 & 2.746 \mathrm{E}-24 & 6.601 \mathrm{E}-24 & 7.367 \mathrm{E}-21 & 1.170 \mathrm{E}-03\end{array}$

$\begin{array}{lllllll}1.000 \mathrm{E}+00 & 2.162 \mathrm{E}-32 & 6.590 \mathrm{E}-32 & 5.335 \mathrm{E}-30 & 2.602 \mathrm{E}-29 & 1.686 \mathrm{E}-25 & 1.804 \mathrm{E}-08\end{array}$

$\begin{array}{lllllll}1.000 \mathrm{E}+00 \quad 2.845 \mathrm{E}-43 & 2.028 \mathrm{E}-42 & 5.480 \mathrm{E}-39 & 5.478 \mathrm{E}-38 & 2.238 \mathrm{E}-33 & 9.371 \mathrm{E}-16\end{array}$

$\begin{array}{llllllll}1.000 \mathrm{E}+00 & 1.371 \mathrm{E}-28 & 2.018 \mathrm{E}-27 & 3.762 \mathrm{E}-23 & 2.542 \mathrm{E}-22 & 1.470 \mathrm{E}-19 & 1.102 \mathrm{E}-13\end{array}$

$\begin{array}{llllllll}1.000 \mathrm{E}+00 & 8.111 \mathrm{E}-28 & 2.334 \mathrm{E}-26 & 2.641 \mathrm{E}-21 & 1.757 \mathrm{E}-20 & 5.564 \mathrm{E}-18 & 1.510 \mathrm{E}-15\end{array}$

$\begin{array}{llllll}1.143 \mathrm{E}-24 & 1.188 \mathrm{E}-24 & 2.681 \mathrm{E}-21 & 1.783 \mathrm{E}-20 & 5.719 \mathrm{E}-18 & 1.170 \mathrm{E}-03\end{array}$

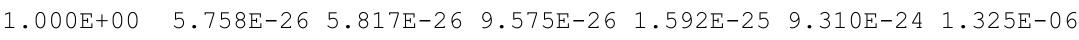

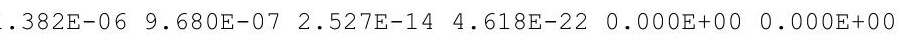

$2.412 \mathrm{E}-22 \quad 2.453 \mathrm{E}-22 \quad 5.590 \mathrm{E}-22 \quad 1.295 \mathrm{E}-21 \quad 1.078 \mathrm{E}-18 \quad 1.104 \mathrm{E}-03$ $\begin{array}{llllll}3.774 \mathrm{E}-11 & 1.139 \mathrm{E}-10 & 5.320 \mathrm{E}-09 & 1.479 \mathrm{E}-08 & 1.071 \mathrm{E}-06 & 2.165 \mathrm{E}-02\end{array}$ $\begin{array}{llllll}1.819 \mathrm{E}-19 & 1.271 \mathrm{E}-18 & 1.299 \mathrm{E}-15 & 5.314 \mathrm{E}-15 & 7.678 \mathrm{E}-13 & 3.543 \mathrm{E}-02\end{array}$ $3.774 \mathrm{E}-11 \quad 1.139 \mathrm{E}-10 \quad 5.320 \mathrm{E}-09 \quad 1.479 \mathrm{E}-08 \quad 1.071 \mathrm{E}-06 \quad 5.818 \mathrm{E}-02$ 
RESRAD, Version $6.5 \quad T^{1 / 2}$ Limit $=180$ days

Summary : RESRAD Parameters for U-Landfill Resident Gardener

File : C: $\backslash$ RESRAD FAMILY \RESRAD \USERFILES $\backslash Q C F O R S R S G \backslash R E S I D E N T G A R D E N E R-S R S G-M A Y 11$.RAD

Dose/Source Ratios Summed Over All Pathways

Parent and Progeny Principal Radionuclide Contributions Indicated

\begin{tabular}{|c|c|c|c|c|c|c|c|c|}
\hline $\begin{array}{l}\text { Parent } \\
\text { (i) }\end{array}$ & $\begin{array}{c}\text { Product } \\
\text { (j) }\end{array}$ & $\begin{array}{l}\text { Thread } \\
\text { Fraction }\end{array}$ & $\begin{array}{r}\text { DSR } \\
0.000 \mathrm{E}+00\end{array}$ & $\begin{array}{l}(j, t) \text { At } T \\
1.000 \mathrm{E}+00\end{array}$ & $\begin{array}{l}\text { ime in Year } \\
5.000 \mathrm{E}+01\end{array}$ & $\begin{array}{l}\text { Es (mrem/ } \\
1.000 \mathrm{E}+02\end{array}$ & $\begin{array}{l}/ \mathrm{yr}) /(\mathrm{pCi} / \mathrm{g} \\
5.000 \mathrm{E}+02\end{array}$ & $1.050 E+03$ \\
\hline-232 & $\mathrm{Th}-232$ & $1.000 \mathrm{E}+00$ & $1.166 \mathrm{E}-24$ & $1.188 \mathrm{E}-24$ & $2.949 \mathrm{E}-24$ & $7.462 \mathrm{E}-24$ & 1. $252 \mathrm{E}-20$ & $1.221 \mathrm{E}-03$ \\
\hline-232 & $\mathrm{Ra}-228+\mathrm{D}$ & $1.000 \mathrm{E}+00$ & $1.107 \mathrm{E}-09$ & $3.174 \mathrm{E}-09$ & $2.784 \mathrm{E}-08$ & $4.079 \mathrm{E}-08$ & $8.497 \mathrm{E}-07$ & $1.458 \mathrm{E}-01$ \\
\hline-232 & $\mathrm{Th}-228+\mathrm{D}$ & $1.000 \mathrm{E}+00$ & $1.067 \mathrm{E}-08$ & $6.581 \mathrm{E}-08$ & $2.213 E-06$ & $2.992 E-06$ & $3.253 E-05$ & $2.007 E-03$ \\
\hline-232 & $\sum \operatorname{DSR}(j)$ & & $1.178 \mathrm{E}-08$ & $6.899 \mathrm{E}-08$ & $2.241 \mathrm{E}-06$ & $3.033 E-06$ & $3.338 E-05$ & 1. $491 \mathrm{E}-01$ \\
\hline 234 & $U-234$ & $1.000 \mathrm{E}+00$ & $6.896 \mathrm{E}-24$ & $7.019 \mathrm{E}-24$ & $1.670 \mathrm{E}-23$ & $4.047 E-23$ & 4. $798 E-20$ & $6.337 \mathrm{E}-04$ \\
\hline 234 & Th -230 & $1.000 \mathrm{E}+00$ & $1.089 \mathrm{E}-27$ & $3.315 E-27$ & $2.540 \mathrm{E}-25$ & $1.171 \mathrm{E}-24$ & $4.838 E-21$ & $1.037 \mathrm{E}-05$ \\
\hline 234 & $\mathrm{Ra}-226+\mathrm{D}$ & $1.000 \mathrm{E}+00$ & $1.133 \mathrm{E}-16$ & $7.978 E-16$ & $1.213 \mathrm{E}-12$ & $6.737 E-12$ & $2.496 E-09$ & $1.097 \mathrm{E}-04$ \\
\hline 234 & $\mathrm{~Pb}-210+\mathrm{D}$ & $1.000 \mathrm{E}+00$ & $4.102 E-25$ & $6.153 E-24$ & $2.201 \mathrm{E}-19$ & $1.935 \mathrm{E}-18$ & $1.678 \mathrm{E}-15$ & $1.738 \mathrm{E}-04$ \\
\hline 234 & $\sum \operatorname{DSR}(j)$ & & $1.133 \mathrm{E}-16$ & $7.978 E-16$ & $1.213 \mathrm{E}-12$ & $6.737 E-12$ & $2.496 \mathrm{E}-09$ & $9.276 E-04$ \\
\hline $235+D$ & $\mathrm{U}-235+\mathrm{D}$ & $1.000 \mathrm{E}+00$ & 1. $243 \mathrm{E}-14$ & $1.259 \mathrm{E}-14$ & $2.306 \mathrm{E}-14$ & $4.276 \mathrm{E}-14$ & $5.981 \mathrm{E}-12$ & $6.155 \mathrm{E}-04$ \\
\hline$-235+D$ & $\mathrm{~Pa}-231$ & $1.000 \mathrm{E}+00$ & $2.937 \mathrm{E}-18$ & $8.896 \mathrm{E}-18$ & $5.031 \mathrm{E}-16$ & $1.701 \mathrm{E}-15$ & $5.876 \mathrm{E}-13$ & $8.145 \mathrm{E}-04$ \\
\hline$-235+D$ & $A C-227+D$ & $1.000 \mathrm{E}+00$ & $9.274 \mathrm{E}-18$ & $6.481 \mathrm{E}-17$ & $6.882 \mathrm{E}-14$ & $2.943 E-13$ & $6.376 \mathrm{E}-11$ & $3.373 E-04$ \\
\hline$-235+D$ & $\sum \operatorname{DSR}(j)$ & & $1.245 \mathrm{E}-14$ & $1.266 \mathrm{E}-14$ & $9.238 \mathrm{E}-14$ & $3.388 \mathrm{E}-13$ & $7.033 E-11$ & $1.767 \mathrm{E}-03$ \\
\hline-238 & $U-238$ & $5.400 E-05$ & $0.000 \mathrm{E}+00$ & $0.000 \mathrm{E}+00$ & $0.000 \mathrm{E}+00$ & $0.000 \mathrm{E}+00$ & $0.000 \mathrm{E}+00$ & $3.167 \mathrm{E}-08$ \\
\hline$-238+D$ & $\mathrm{U}-238+\mathrm{D}$ & $9.999 E-01$ & $1.420 \mathrm{E}-10$ & $1.431 \mathrm{E}-10$ & $2.116 \mathrm{E}-10$ & $3.153 \mathrm{E}-10$ & $7.678 \mathrm{E}-09$ & $6.313 \mathrm{E}-04$ \\
\hline $238+D$ & $\mathrm{U}-234$ & $9.999 \mathrm{E}-01$ & $9.803 E-30$ & $2.988 E-29$ & $2.392 E-27$ & $1.153 E-26$ & $6.812 \mathrm{E}-23$ & $1.890 \mathrm{E}-06$ \\
\hline$-238+D$ & $T h-230$ & $9.999 \mathrm{E}-01$ & $1.030 E-33$ & $7.316 E-33$ & $1.818 \mathrm{E}-29$ & $1.668 E-28$ & $3.430 E-24$ & $1.541 \mathrm{E}-08$ \\
\hline$-238+D$ & $\mathrm{Ra}-226+\mathrm{D}$ & $9.999 \mathrm{E}-01$ & $8.034 E-23$ & 1. $212 \mathrm{E}-21$ & $5.801 \mathrm{E}-17$ & $6.420 \mathrm{E}-16$ & $1.201 \mathrm{E}-12$ & $1.127 \mathrm{E}-07$ \\
\hline$-238+D$ & $\mathrm{~Pb}-210+\mathrm{D}$ & $9.999 \mathrm{E}-01$ & $2.329 E-31$ & $7.229 E-30$ & $8.430 \mathrm{E}-24$ & $1.546 \mathrm{E}-22$ & 7. $612 \mathrm{E}-19$ & $1.734 \mathrm{E}-07$ \\
\hline$-238+D$ & $\sum \operatorname{DSR}(j)$ & & $1.420 \mathrm{E}-10$ & $1.431 \mathrm{E}-10$ & $2.116 \mathrm{E}-10$ & $3.153 \mathrm{E}-10$ & $7.680 \mathrm{E}-09$ & $6.335 E-04$ \\
\hline
\end{tabular}

The DSR includes contributions from associated (half-life $\leq 180$ days) daughters. 
RESRAD, Version $6.5 \quad \mathrm{~T}^{1 / 2}$ Limit $=180$ days

$07 / 21 / 2011$

$16: 52$ Page

28

mmary : RESRAD Parameters for U-Landfill Resident Gardener

File : C: \RESRAD_FAMILY \RESRAD \USERFILES \QCFORSRSG $\backslash$ RESIDENTGARDENER-SRSG-MAY11.RAD

Single Radionuclide Soil Guidelines $G(i, t)$ in $\mathrm{pCi} / \mathrm{g}$

Basic Radiation Dose Limit $=1.000 \mathrm{E}+02 \mathrm{mrem} / \mathrm{yr}$

Nuclide

\begin{tabular}{|c|c|c|c|c|c|c|}
\hline (i) & $t=0.000 E+00$ & $1.000 \mathrm{E}+00$ & $5.000 \mathrm{E}+01$ & $1.000 \mathrm{E}+02$ & $5.000 \mathrm{E}+02$ & $1.050 \mathrm{E}+03$ \\
\hline $1-241$ & $\star 3.431 \mathrm{E}+12$ & $\star 3.431 \mathrm{E}+12$ & $\star 3.431 \mathrm{E}+12$ & $\star 3.431 \mathrm{E}+12$ & $\star 3.431 \mathrm{E}+12$ & $5.044 \mathrm{E}+05$ \\
\hline$s-137$ & $7.925 E+10$ & $8.043 E+10$ & $1.653 \mathrm{E}+11$ & $3.447 \mathrm{E}+11$ & $\star 8.704 \mathrm{E}+13$ & $\star 8.704 \mathrm{E}+13$ \\
\hline$p-237$ & $\star 7.047 \mathrm{E}+08$ & $\star 7.047 \mathrm{E}+08$ & $\star 7.047 \mathrm{E}+08$ & $\star 7.047 \mathrm{E}+08$ & $\star 7.047 \mathrm{E}+08$ & $9.756 \mathrm{E}+03$ \\
\hline$u-238$ & $\star 1.712 \mathrm{E}+13$ & $\star 1.712 \mathrm{E}+13$ & $\star 1.712 \mathrm{E}+13$ & $\star 1.712 \mathrm{E}+13$ & $\star 1.712 \mathrm{E}+13$ & $1.637 \mathrm{E}+08$ \\
\hline $\mathrm{Pu}-239$ & $\star 6.214 \mathrm{E}+10$ & $\star 6.214 \mathrm{E}+10$ & $* 6.214 \mathrm{E}+10$ & $\star 6.214 \mathrm{E}+10$ & $\star 6.214 \mathrm{E}+10$ & $7.884 \mathrm{E}+04$ \\
\hline $\mathrm{Pu}-240$ & $\star 2.278 E+11$ & $\star 2.278 \mathrm{E}+11$ & $\star 2.278 \mathrm{E}+11$ & $\star 2.278 \mathrm{E}+11$ & $\star 2.278 \mathrm{E}+11$ & $8.550 \mathrm{E}+04$ \\
\hline TC-99 & $* 1.697 \mathrm{E}+10$ & $* 1.697 \mathrm{E}+10$ & $\star 1.697 \mathrm{E}+10$ & $* 1.697 \mathrm{E}+10$ & $\star 1.697 \mathrm{E}+10$ & $7.545 \mathrm{E}+07$ \\
\hline Th-228 & $7.234 \mathrm{E}+07$ & $1.033 \mathrm{E}+08$ & $\star 8.195 \mathrm{E}+14$ & $\star 8.195 \mathrm{E}+14$ & $\star 8.195 \mathrm{E}+14$ & $\star 8.195 \mathrm{E}+14$ \\
\hline Th-230 & $\star 2.018 \mathrm{E}+10$ & $\star 2.018 \mathrm{E}+10$ & $1.880 \mathrm{E}+10$ & $6.761 \mathrm{E}+09$ & $9.336 \mathrm{E}+07$ & $1.719 \mathrm{E}+03$ \\
\hline Th-232 & $\star 1.097 \mathrm{E}+05$ & $* 1.097 \mathrm{E}+05$ & $* 1.097 \mathrm{E}+05$ & $\star 1.097 \mathrm{E}+05$ & $\star 1.097 \mathrm{E}+05$ & $6.708 \mathrm{E}+02$ \\
\hline $\mathrm{U}-234$ & $\star 6.247 \mathrm{E}+09$ & $\star 6.247 \mathrm{E}+09$ & $\star 6.247 \mathrm{E}+09$ & $* 6.247 \mathrm{E}+09$ & $\star 6.247 \mathrm{E}+09$ & $1.078 \mathrm{E}+05$ \\
\hline 35 & $\star 2.161 \mathrm{E}+06$ & $\star 2.161 \mathrm{E}+06$ & $\star 2.161 \mathrm{E}+06$ & $\star 2.161 \mathrm{E}+06$ & $\star 2.161 \mathrm{E}+06$ & $5.658 \mathrm{E}+04$ \\
\hline 238 & $\star 3.361 \mathrm{E}+05$ & $\star 3.361 \mathrm{E}+05$ & $\star 3.361 \mathrm{E}+05$ & $\star 3.361 \mathrm{E}+05$ & $\star 3.361 \mathrm{E}+05$ & $1.578 \mathrm{E}+05$ \\
\hline
\end{tabular}

*At specific activity limit

Summed Dose/Source Ratios DSR (i,t) in (mrem/yr)/(pCi/g)

and Single Radionuclide Soil Guidelines G(i,t) in pCi/g

at tmin = time of minimum single radionuclide soil guideline

and at $\operatorname{tmax}=$ time of maximum total dose $=1.050 \mathrm{E}+03$ years

\begin{tabular}{|c|c|c|c|c|c|c|}
\hline $\begin{array}{l}\text { uclide } \\
\text { (i) }\end{array}$ & $\begin{array}{l}\text { Initial } \\
(\mathrm{pCi} / \mathrm{g})\end{array}$ & $\begin{array}{c}\text { tmin } \\
\text { (years) }\end{array}$ & $\operatorname{DSR}(i, \operatorname{tmin})$ & $\begin{array}{c}G(i, \operatorname{tmin}) \\
(\mathrm{pCi} / \mathrm{g})\end{array}$ & $\operatorname{DSR}(i, \operatorname{tmax})$ & $\begin{array}{c}G(i, t \max ) \\
(p C i / g)\end{array}$ \\
\hline $1-241$ & $1.000 \mathrm{E}+00$ & $1.050 \mathrm{E}+03$ & 1. $983 E-04$ & $5.044 \mathrm{E}+05$ & 1. $983 \mathrm{E}-04$ & $5.044 \mathrm{E}+05$ \\
\hline-137 & $1.000 \mathrm{E}+00$ & $0.000 \mathrm{E}+00$ & $1.262 \mathrm{E}-09$ & $7.925 \mathrm{E}+10$ & 7. $713 \mathrm{E}-14$ & $\star 8.704 \mathrm{E}+13$ \\
\hline-237 & $1.000 \mathrm{E}+00$ & $1.050 \mathrm{E}+03$ & $1.025 \mathrm{E}-02$ & $9.756 \mathrm{E}+03$ & $1.025 \mathrm{E}-02$ & $9.756 \mathrm{E}+03$ \\
\hline-238 & $1.000 \mathrm{E}+00$ & $1.050 \mathrm{E}+03$ & $6.110 \mathrm{E}-07$ & $1.637 \mathrm{E}+08$ & $6.110 \mathrm{E}-07$ & $1.637 \mathrm{E}+08$ \\
\hline-239 & $1.000 \mathrm{E}+00$ & $1.050 \mathrm{E}+03$ & $1.268 E-03$ & $7.884 \mathrm{E}+04$ & $1.268 E-03$ & $7.884 \mathrm{E}+04$ \\
\hline-240 & $1.000 \mathrm{E}+00$ & $1.050 \mathrm{E}+03$ & $1.170 \mathrm{E}-03$ & $8.550 \mathrm{E}+04$ & $1.170 \mathrm{E}-03$ & $8.550 \mathrm{E}+04$ \\
\hline-99 & $1.000 \mathrm{E}+00$ & $1.050 E+03$ & $1.325 E-06$ & $7.545 \mathrm{E}+07$ & 1. $325 E-06$ & $7.545 E+07$ \\
\hline-228 & $1.000 \mathrm{E}+00$ & $0.000 \mathrm{E}+00$ & $1.382 \mathrm{E}-06$ & $7.234 \mathrm{E}+07$ & $0.000 \mathrm{E}+00$ & $\star 8.195 \mathrm{E}+14$ \\
\hline-230 & $1.000 \mathrm{E}+00$ & $1.050 \mathrm{E}+03$ & $5.818 \mathrm{E}-02$ & $1.719 \mathrm{E}+03$ & $5.818 \mathrm{E}-02$ & $1.719 \mathrm{E}+03$ \\
\hline 32 & $1.000 \mathrm{E}+00$ & $1.050 \mathrm{E}+03$ & $1.491 \mathrm{E}-01$ & $6.708 \mathrm{E}+02$ & $1.491 \mathrm{E}-01$ & $6.708 \mathrm{E}+02$ \\
\hline 4 & $1.000 \mathrm{E}+00$ & $1.050 E+03$ & $9.276 \mathrm{E}-04$ & $1.078 E+05$ & $9.276 \mathrm{E}-04$ & $1.078 E+05$ \\
\hline & $1.000 \mathrm{E}+00$ & $1.050 \mathrm{E}+03$ & $1.767 \mathrm{E}-03$ & $5.658 \mathrm{E}+04$ & $1.767 \mathrm{E}-03$ & $5.658 \mathrm{E}+04$ \\
\hline 38 & $1.000 \mathrm{E}+00$ & $1.050 \mathrm{E}+03$ & $6.335 \mathrm{E}-04$ & $1.578 \mathrm{E}+05$ & $6.335 \mathrm{E}-04$ & $1.578 \mathrm{E}+05$ \\
\hline
\end{tabular}

*At specific activity limit 
RESRAD, Version 6.5

mmary : RESRAD Parameters for U-Landfill Resident Gardener

File $\quad$ : $: \backslash$ RESRAD FAMILY $\backslash$ RESRAD \USERFILES $\backslash Q C F O R S R S G \backslash R E S I D E N T G A R D E N E R-S R S G-M A Y 11 . R A D$

Individual Nuclide Dose Summed Over All Pathways

Parent Nuclide and Branch Fraction Indicated

Nuclide Parent THF(i) DOSE $(j, t)$, mrem/yr

\begin{tabular}{|c|c|c|}
\hline$(j)$ & (i) & \\
\hline$n-241$ & $A m-241$ & $1.000 \mathrm{E}+00$ \\
\hline-237 & $A m-241$ & $1.000 \mathrm{E}+00$ \\
\hline $\mathrm{Np}-237$ & $\mathrm{~Np}-237$ & $1.000 \mathrm{E}+00$ \\
\hline $\mathrm{Np}-237$ & $\sum \operatorname{DOSE}(j$ & \\
\hline
\end{tabular}

$\mathrm{U}-233 \quad \mathrm{Am}-241 \quad 1.000 \mathrm{E}+00$

$\mathrm{U}-233 \quad \mathrm{~Np}-237 \quad 1.000 \mathrm{E}+00$

U-233 $\quad$ DDOSE $(j)$

Th-229 Am-241 $1.000 \mathrm{E}+00$

Th-229 Np-237 1.000E+00

Th-229 $\sum \operatorname{DOSE}(j)$

Cs-137 Cs-137 1.000E+00

$\mathrm{Pu}-238 \mathrm{Pu}-238 \quad 1.840 \mathrm{E}-09$

$\mathrm{Pu}-238$

Pu-238

$\mathrm{U}-234$

$\mathrm{U}-234$

$\mathrm{U}-234$

$\mathrm{U}-234$

Th-230

Th-230

Th -230

Th-230

Th-230

$\mathrm{Ra}-226$

$\mathrm{Ra}-226$

$\mathrm{Ra}-226$

$\mathrm{Ra}-226$

$\mathrm{Ra}-226$

$\mathrm{Pb}-210$

$\mathrm{Pb}-210$

$\mathrm{Pb}-210$

$\mathrm{Pb}-210$

$\mathrm{Pb}-210$

$\mathrm{Pu}-239$

$\mathrm{Pu}-239 \quad 1.000 \mathrm{E}+00$ $\mathrm{U}-2351.000 \mathrm{E}+00$ ¿DOSE (j) $\mathrm{t}=0.000 \mathrm{E}+00 \quad 1.000 \mathrm{E}+00 \quad 5.000 \mathrm{E}+01 \quad 1.000 \mathrm{E}+02 \quad 5.000 \mathrm{E}+02 \quad 1.050 \mathrm{E}+03$

$\begin{array}{llllll}0.000 \mathrm{E}+00 & 0.000 \mathrm{E}+00 & 0.000 \mathrm{E}+00 & 0.000 \mathrm{E}+00 & 1.208 \mathrm{E}-27 & 1.965 \mathrm{E}-04\end{array}$

$\begin{array}{llllll}1.546 \mathrm{E}-19 & 4.680 \mathrm{E}-19 & 2.562 \mathrm{E}-17 & 8.382 \mathrm{E}-17 & 2.263 \mathrm{E}-14 & 1.773 \mathrm{E}-06\end{array}$

$\begin{array}{llllll}9.536 \mathrm{E}-13 & 9.638 \mathrm{E}-13 & 1.625 \mathrm{E}-12 & 2.770 \mathrm{E}-12 & 1.974 \mathrm{E}-10 & 1.025 \mathrm{E}-02\end{array}$

$\begin{array}{llllll}9.536 \mathrm{E}-13 & 9.638 \mathrm{E}-13 & 1.625 \mathrm{E}-12 & 2.770 \mathrm{E}-12 & 1.974 \mathrm{E}-10 & 1.025 \mathrm{E}-02\end{array}$

$3.506 \mathrm{E}-30 \quad 2.479 \mathrm{E}-29 \quad 4.863 \mathrm{E}-26 \quad 3.503 \mathrm{E}-25 \quad 1.053 \mathrm{E}-21 \quad 3.056 \mathrm{E}-10$

$\begin{array}{llllll}3.245 \mathrm{E}-23 & 9.844 \mathrm{E}-23 & 6.100 \mathrm{E}-21 & 2.264 \mathrm{E}-20 & 1.650 \mathrm{E}-17 & 2.871 \mathrm{E}-06\end{array}$

$\begin{array}{llllll}3.245 \mathrm{E}-23 & 9.844 \mathrm{E}-23 & 6.100 \mathrm{E}-21 & 2.264 \mathrm{E}-20 & 1.650 \mathrm{E}-17 & 2.871 \mathrm{E}-06\end{array}$

$2.399 \mathrm{E}-26 \quad 3.618 \mathrm{E}-25 \quad 1.710 \mathrm{E}-20 \quad 1.868 \mathrm{E}-19 \quad 3.195 \mathrm{E}-16 \quad 5.403 \mathrm{E}-11$

$\begin{array}{llllll}2.962 \mathrm{E}-19 & 2.086 \mathrm{E}-18 & 3.196 \mathrm{E}-15 & 1.788 \mathrm{E}-14 & 7.080 \mathrm{E}-12 & 6.801 \mathrm{E}-07\end{array}$

$\begin{array}{llllll}2.962 \mathrm{E}-19 & 2.086 \mathrm{E}-18 & 3.196 \mathrm{E}-15 & 1.788 \mathrm{E}-14 & 7.080 \mathrm{E}-12 & 6.802 \mathrm{E}-07\end{array}$

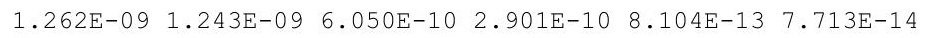

$\begin{array}{llllll}0.000 \mathrm{E}+00 & 0.000 \mathrm{E}+00 & 0.000 \mathrm{E}+00 & 0.000 \mathrm{E}+00 & 0.000 \mathrm{E}+00 & 5.505 \mathrm{E}-16\end{array}$

$\begin{array}{llllll}1.175 \mathrm{E}-24 & 1.186 \mathrm{E}-24 & 1.913 \mathrm{E}-24 & 3.115 \mathrm{E}-24 & 1.539 \mathrm{E}-22 & 2.992 \mathrm{E}-07\end{array}$

$\begin{array}{llllll}1.175 \mathrm{E}-24 & 1.186 \mathrm{E}-24 & 1.913 \mathrm{E}-24 & 3.115 \mathrm{E}-24 & 1.539 \mathrm{E}-22 & 2.992 \mathrm{E}-07\end{array}$

$\begin{array}{llllll}9.778 \mathrm{E}-30 & 2.969 \mathrm{E}-29 & 1.973 \mathrm{E}-27 & 7.960 \mathrm{E}-27 & 1.690 \mathrm{E}-23 & 2.276 \mathrm{E}-07\end{array}$

$\begin{array}{lllllll}6.896 \mathrm{E}-24 & 7.019 \mathrm{E}-24 & 1.670 \mathrm{E}-23 & 4.047 \mathrm{E}-23 & 4.798 \mathrm{E}-20 & 6.337 \mathrm{E}-04\end{array}$

$\begin{array}{llllll}9.803 \mathrm{E}-30 & 2.988 \mathrm{E}-29 & 2.392 \mathrm{E}-27 & 1.153 \mathrm{E}-26 & 6.812 \mathrm{E}-23 & 1.890 \mathrm{E}-06\end{array}$

$\begin{array}{llllll}6.896 \mathrm{E}-24 & 7.019 \mathrm{E}-24 & 1.671 \mathrm{E}-23 & 4.049 \mathrm{E}-23 & 4.806 \mathrm{E}-20 & 6.358 \mathrm{E}-04\end{array}$

$\begin{array}{llllll}0.000 \mathrm{E}+00 & 0.000 \mathrm{E}+00 & 1.599 \mathrm{E}-29 & 1.302 \mathrm{E}-28 & 1.306 \mathrm{E}-24 & 3.273 \mathrm{E}-09\end{array}$

$\begin{array}{llllll}2.412 \mathrm{E}-22 & 2.453 \mathrm{E}-22 & 5.590 \mathrm{E}-22 & 1.295 \mathrm{E}-21 & 1.078 \mathrm{E}-18 & 1.104 \mathrm{E}-03\end{array}$

$\begin{array}{llllll}1.089 \mathrm{E}-27 & 3.315 \mathrm{E}-27 & 2.540 \mathrm{E}-25 & 1.171 \mathrm{E}-24 & 4.838 \mathrm{E}-21 & 1.037 \mathrm{E}-05\end{array}$

$\begin{array}{llllll}0.000 \mathrm{E}+00 & 0.000 \mathrm{E}+00 & 1.818 \mathrm{E}-29 & 1.668 \mathrm{E}-28 & 3.430 \mathrm{E}-24 & 1.541 \mathrm{E}-08\end{array}$

$\begin{array}{llllll}2.412 \mathrm{E}-22 & 2.453 \mathrm{E}-22 & 5.592 \mathrm{E}-22 & 1.297 \mathrm{E}-21 & 1.082 \mathrm{E}-18 & 1.115 \mathrm{E}-03\end{array}$

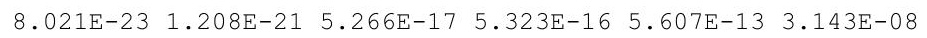
$\begin{array}{llllll}3.774 \mathrm{E}-11 & 1.139 \mathrm{E}-10 & 5.320 \mathrm{E}-09 & 1.479 \mathrm{E}-08 & 1.071 \mathrm{E}-06 & 2.165 \mathrm{E}-02\end{array}$ $\begin{array}{llllll}1.133 \mathrm{E}-16 & 7.978 \mathrm{E}-16 & 1.213 \mathrm{E}-12 & 6.737 \mathrm{E}-12 & 2.496 \mathrm{E}-09 & 1.097 \mathrm{E}-04\end{array}$ $\begin{array}{llllll}8.034 \mathrm{E}-23 & 1.212 \mathrm{E}-21 & 5.801 \mathrm{E}-17 & 6.420 \mathrm{E}-16 & 1.201 \mathrm{E}-12 & 1.127 \mathrm{E}-07\end{array}$ $\begin{array}{llllll}3.774 \mathrm{E}-11 & 1.139 \mathrm{E}-10 & 5.321 \mathrm{E}-09 & 1.480 \mathrm{E}-08 & 1.074 \mathrm{E}-06 & 2.176 \mathrm{E}-02\end{array}$

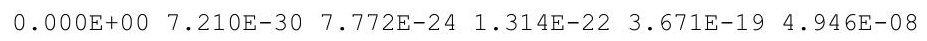
$\begin{array}{llllll}1.819 \mathrm{E}-19 & 1.271 \mathrm{E}-18 & 1.299 \mathrm{E}-15 & 5.314 \mathrm{E}-15 & 7.678 \mathrm{E}-13 & 3.543 \mathrm{E}-02\end{array}$ $\begin{array}{llllll}4.102 \mathrm{E}-25 & 6.153 \mathrm{E}-24 & 2.201 \mathrm{E}-19 & 1.935 \mathrm{E}-18 & 1.678 \mathrm{E}-15 & 1.738 \mathrm{E}-04\end{array}$ $0.000 \mathrm{E}+00 \quad 7.229 \mathrm{E}-30 \quad 8.430 \mathrm{E}-24 \quad 1.546 \mathrm{E}-22 \quad 7.612 \mathrm{E}-19 \quad 1.734 \mathrm{E}-07$ $\begin{array}{llllll}1.819 \mathrm{E}-19 & 1.271 \mathrm{E}-18 & 1.299 \mathrm{E}-15 & 5.316 \mathrm{E}-15 & 7.695 \mathrm{E}-13 & 3.560 \mathrm{E}-02\end{array}$

$\begin{array}{llllll}1.202 \mathrm{E}-17 & 1.217 \mathrm{E}-17 & 2.183 \mathrm{E}-17 & 3.965 \mathrm{E}-17 & 4.690 \mathrm{E}-15 & 1.268 \mathrm{E}-03\end{array}$

$\begin{array}{llllll}6.135 \mathrm{E}-24 & 1.861 \mathrm{E}-23 & 1.146 \mathrm{E}-21 & 4.227 \mathrm{E}-21 & 2.931 \mathrm{E}-18 & 6.291 \mathrm{E}-10\end{array}$ $\begin{array}{lllllll}1.243 \mathrm{E}-14 & 1.259 \mathrm{E}-14 & 2.306 \mathrm{E}-14 & 4.276 \mathrm{E}-14 & 5.981 \mathrm{E}-12 & 6.155 \mathrm{E}-04\end{array}$ $\begin{array}{llllll}1.243 \mathrm{E}-14 & 1.259 \mathrm{E}-14 & 2.306 \mathrm{E}-14 & 4.276 \mathrm{E}-14 & 5.981 \mathrm{E}-12 & 6.155 \mathrm{E}-04\end{array}$ 
RESRAD, Version $6.5 \quad T^{1 / 2}$ Limit $=180$ days

Summary : RESRAD Parameters for U-Landfill Resident Gardener

File : C: $\backslash$ RESRAD FAMILY \RESRAD \USERFILES $\backslash Q C F O R S R S G \backslash R E S I D E N T G A R D E N E R-S R S G-M A Y 11$.RAD

Individual Nuclide Dose Summed Over All Pathways

Parent Nuclide and Branch Fraction Indicated

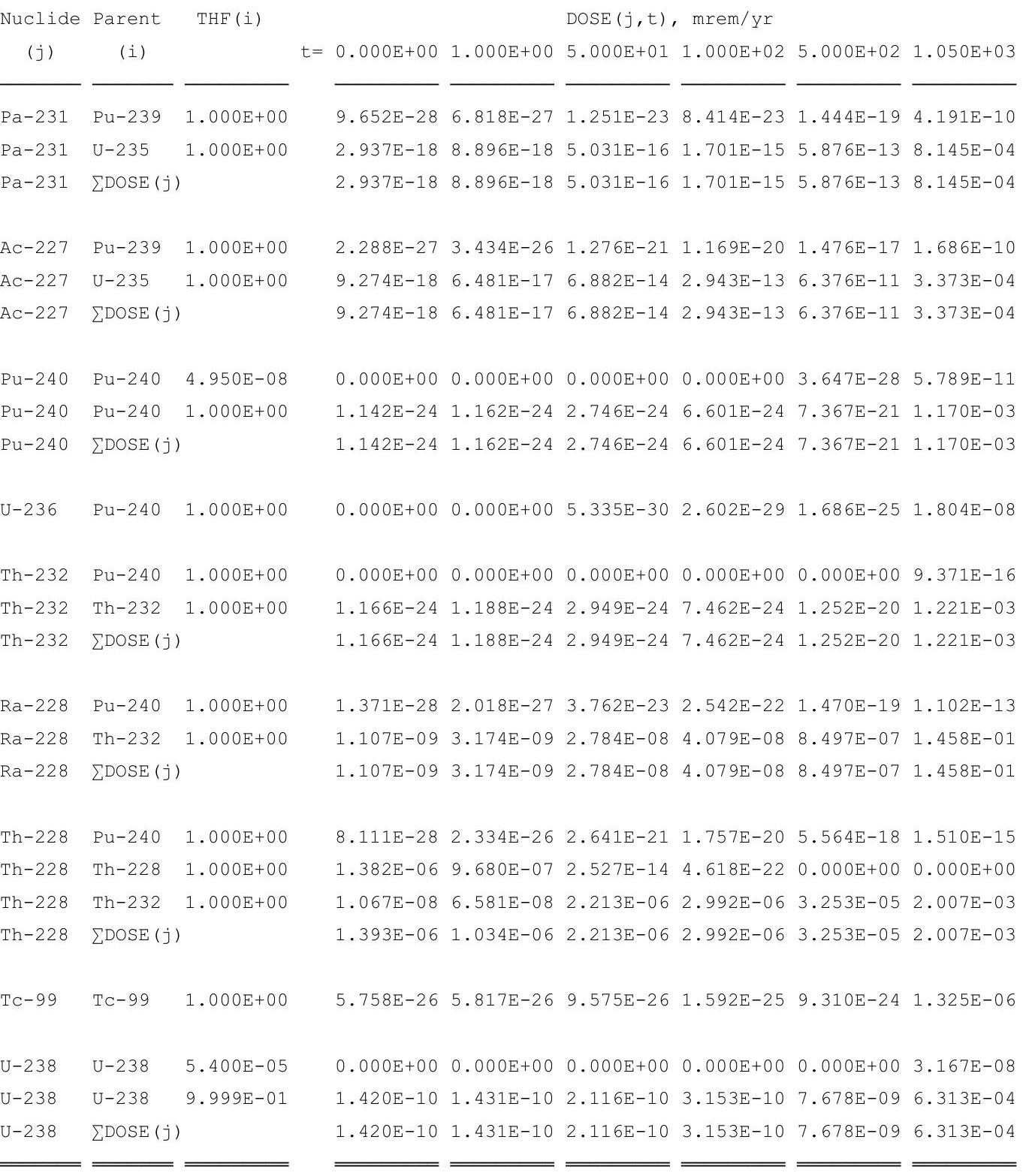

THF (i) is the thread fraction of the parent nuclide. 
RESRAD, Version 6.5

Summary : RESRAD Parameters for U-Landfill Resident Gardener

File : C: \RESRAD_FAMILY \RESRAD \USERFILES \QCFORSRSG \RESIDENTGARDENER-SRSG-MAY11.RAD

Individual Nuclide Soil Concentration

Parent Nuclide and Branch Fraction Indicated

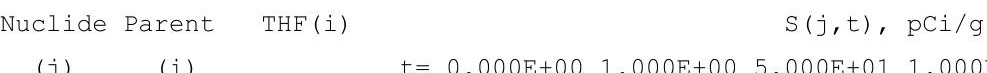

\section{(j)}

Am-241 Am-241 1.000E+00

Np-237 Am-241 1.000E+00

$\mathrm{Np}-237 \quad \mathrm{~Np}-237 \quad 1.000 \mathrm{E}+00$

Np-237 $\sum S(j):$

$\mathrm{U}-233 \quad \mathrm{Am}-241 \quad 1.000 \mathrm{E}+00$

$\mathrm{U}-233 \mathrm{~Np}-237 \quad 1.000 \mathrm{E}+00$

U-233 $\sum S(j):$

Th-229 Am-241 1.000E+00

$\mathrm{Th}-229 \mathrm{~Np}-237 \quad 1.000 \mathrm{E}+00$

Th-229 $\sum S(j):$

Cs-137 Cs-137 1.000E+00

$\mathrm{Pu}-238$

$\mathrm{Pu}-238$

$\mathrm{Pu}-238$

$\mathrm{U}-234$

$\mathrm{U}-234$

$\mathrm{U}-234$

$\mathrm{U}-234$

Th -230

$\mathrm{Th}-230$

$\mathrm{Th}-230$

Th-230

$\mathrm{Th}-230$

$\mathrm{Ra}-226$

$\mathrm{Ra}-226$

$\mathrm{Ra}-226$

$\mathrm{Ra}-226$

$\mathrm{Ra}-226$

$\mathrm{Pb}-210$

$\mathrm{Pb}-210$

$\mathrm{Pb}-210$

$\mathrm{Pb}-210$

$\mathrm{Pb}-210$

Pu-239

$\mathrm{U}-235$

$\mathrm{U}-235$

$\mathrm{U}-235$
Pu-238 1.840E-09

$\sum S(j):$

$\mathrm{Pu}-238 \quad 1.000 \mathrm{E}+00$

U-234 $1.000 \mathrm{E}+00$

U-238 9.999E-01

$\sum S(j):$

$\mathrm{Pu}-238 \quad 1.000 \mathrm{E}+00$

$\mathrm{U}-2389.999 \mathrm{E}-01$

$\sum S(j):$

$\mathrm{Pu}-238 \quad 1.000 \mathrm{E}+00$

$\mathrm{Th}-230 \quad 1.000 \mathrm{E}+00$

U-234 1.000E+00

U-238 9.999E-01

$\sum S(j):$

$\mathrm{Pu}-238 \quad 1.000 \mathrm{E}+00$

Th-230 1.000E+00

$\mathrm{U}-234 \quad 1.000 \mathrm{E}+00$

U-238 9.999E-01

$\sum S(j):$

Pu-239 1.000E+00

$\mathrm{Pu}-239 \quad 1.000 \mathrm{E}+00$

U-235 1.000E+00

$\sum S(j):$
$\mathrm{Pu}-238 \quad 1.000 \mathrm{E}+00$

Th-230 1.000E+00

$\mathrm{U}-2341.000 \mathrm{E}+00$
$=0.000 \mathrm{E}+00 \quad 1.000 \mathrm{E}+00 \quad 5.000 \mathrm{E}+01 \quad 1.000 \mathrm{E}+02 \quad 5.000 \mathrm{E}+02 \quad 1.050 \mathrm{E}+03$

$\begin{array}{lllllll}1.000 \mathrm{E}+00 & 9.984 \mathrm{E}-01 & 9.227 \mathrm{E}-01 & 8.514 \mathrm{E}-01 & 4.474 \mathrm{E}-01 & 1.847 \mathrm{E}-01\end{array}$

$0.000 \mathrm{E}+00 \quad 3.236 \mathrm{E}-07 \quad 1.551 \mathrm{E}-05 \quad 2.971 \mathrm{E}-05 \quad 1.071 \mathrm{E}-04 \quad 1.502 \mathrm{E}-04$

$\begin{array}{lllllll}1.000 \mathrm{E}+00 & 9.999 \mathrm{E}-01 & 9.933 \mathrm{E}-01 & 9.866 \mathrm{E}-01 & 9.348 \mathrm{E}-01 & 8.679 \mathrm{E}-01\end{array}$ $\begin{array}{llllll}1.000 \mathrm{E}+00 & 9.999 \mathrm{E}-01 & 9.933 \mathrm{E}-01 & 9.866 \mathrm{E}-01 & 9.349 \mathrm{E}-01 & 8.681 \mathrm{E}-01\end{array}$

$0.000 \mathrm{E}+00 \quad 7.078 \mathrm{E}-13 \quad 1.719 \mathrm{E}-09 \quad 6.681 \mathrm{E}-09 \quad 1.339 \mathrm{E}-07 \quad 4.489 \mathrm{E}-07$

$0.000 \mathrm{E}+00 \quad 4.373 \mathrm{E}-06 \quad 2.178 \mathrm{E}-04 \quad 4.338 \mathrm{E}-04 \quad 2.100 \mathrm{E}-03 \quad 4.219 \mathrm{E}-03$ $\begin{array}{llllll}0.000 \mathrm{E}+00 & 4.373 \mathrm{E}-06 & 2.178 \mathrm{E}-04 & 4.338 \mathrm{E}-04 & 2.100 \mathrm{E}-03 & 4.219 \mathrm{E}-03\end{array}$

$\begin{array}{lllllll}0.000 \mathrm{E}+00 & 2.228 \mathrm{E}-17 & 2.723 \mathrm{E}-12 & 2.129 \mathrm{E}-11 & 2.229 \mathrm{E}-09 & 1.651 \mathrm{E}-08\end{array}$ $0.000 \mathrm{E}+00 \quad 2.065 \mathrm{E}-10 \quad 5.140 \mathrm{E}-07 \quad 2.047 \mathrm{E}-06 \quad 4.944 \mathrm{E}-05 \quad 2.079 \mathrm{E}-04$ $0.000 \mathrm{E}+00 \quad 2.065 \mathrm{E}-10 \quad 5.140 \mathrm{E}-07 \quad 2.047 \mathrm{E}-06 \quad 4.944 \mathrm{E}-05 \quad 2.079 \mathrm{E}-04$

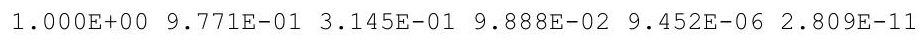

1.840E-09 1.825E-09 1.239E-09 8.336E-10 3.513E-11 4.514E-13 $\begin{array}{llllll}1.000 \mathrm{E}+00 & 9.921 \mathrm{E}-01 & 6.731 \mathrm{E}-01 & 4.531 \mathrm{E}-01 & 1.909 \mathrm{E}-02 & 2.453 \mathrm{E}-04\end{array}$ $1.000 \mathrm{E}+00 \quad 9.921 \mathrm{E}-01 \quad 6.731 \mathrm{E}-01 \quad 4.531 \mathrm{E}-01 \quad 1.909 \mathrm{E}-02 \quad 2.453 \mathrm{E}-04$

$0.000 \mathrm{E}+00 \quad 2.824 \mathrm{E}-06 \quad 1.170 \mathrm{E}-04 \quad 1.956 \mathrm{E}-04 \quad 3.478 \mathrm{E}-04 \quad 3.495 \mathrm{E}-04$ $\begin{array}{lllllll}1.000 \mathrm{E}+00 & 1.000 \mathrm{E}+00 & 9.987 \mathrm{E}-01 & 9.974 \mathrm{E}-01 & 9.872 \mathrm{E}-01 & 9.732 \mathrm{E}-01\end{array}$ $\begin{array}{llllll}0.000 \mathrm{E}+00 & 2.835 \mathrm{E}-06 & 1.416 \mathrm{E}-04 & 2.828 \mathrm{E}-04 & 1.400 \mathrm{E}-03 & 2.901 \mathrm{E}-03\end{array}$ $\begin{array}{lllllll}1.000 \mathrm{E}+00 & 1.000 \mathrm{E}+00 & 9.990 \mathrm{E}-01 & 9.979 \mathrm{E}-01 & 9.889 \mathrm{E}-01 & 9.765 \mathrm{E}-01\end{array}$

$0.000 \mathrm{E}+00 \quad 1.273 \mathrm{E}-11 \quad 2.806 \mathrm{E}-08 \quad 9.953 \mathrm{E}-08 \quad 1.203 \mathrm{E}-06 \quad 2.925 \mathrm{E}-06$ $\begin{array}{lllllll}1.000 \mathrm{E}+00 & 1.000 \mathrm{E}+00 & 9.994 \mathrm{E}-01 & 9.988 \mathrm{E}-01 & 9.940 \mathrm{E}-01 & 9.875 \mathrm{E}-01\end{array}$ $0.000 \mathrm{E}+00 \quad 9.002 \mathrm{E}-06 \quad 4.497 \mathrm{E}-04 \quad 8.985 \mathrm{E}-04 \quad 4.459 \mathrm{E}-03 \quad 9.266 \mathrm{E}-03$ $\begin{array}{lllllll}0.000 \mathrm{E}+00 & 1.276 \mathrm{E}-11 & 3.187 \mathrm{E}-08 & 1.273 \mathrm{E}-07 & 3.158 \mathrm{E}-06 & 1.377 \mathrm{E}-05\end{array}$

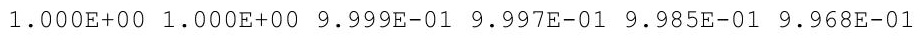

$\begin{array}{llllll}0.000 \mathrm{E}+00 & 1.839 \mathrm{E}-15 & 2.079 \mathrm{E}-10 & 1.510 \mathrm{E}-09 & 1.010 \mathrm{E}-07 & 5.219 \mathrm{E}-07\end{array}$ $0.000 \mathrm{E}+00 \quad 4.331 \mathrm{E}-04 \quad 2.141 \mathrm{E}-02 \quad 4.233 \mathrm{E}-02 \quad 1.933 \mathrm{E}-01 \quad 3.597 \mathrm{E}-01$ $0.000 \mathrm{E}+00 \quad 1.950 \mathrm{E}-09 \quad 4.835 \mathrm{E}-06 \quad 1.918 \mathrm{E}-05 \quad 4.498 \mathrm{E}-04 \quad 1.821 \mathrm{E}-03$ $\begin{array}{lllllll}0.000 \mathrm{E}+00 & 1.842 \mathrm{E}-15 & 2.288 \mathrm{E}-10 & 1.819 \mathrm{E}-09 & 2.162 \mathrm{E}-07 & 1.871 \mathrm{E}-06\end{array}$ $0.000 \mathrm{E}+00 \quad 4.331 \mathrm{E}-04 \quad 2.142 \mathrm{E}-02 \quad 4.235 \mathrm{E}-02 \quad 1.937 \mathrm{E}-01 \quad 3.615 \mathrm{E}-01$

$0.000 \mathrm{E}+00 \quad 1.421 \mathrm{E}-17 \quad 6.197 \mathrm{E}-11 \quad 7.204 \mathrm{E}-10 \quad 8.683 \mathrm{E}-08 \quad 4.891 \mathrm{E}-07$ $0.000 \mathrm{E}+00 \quad 6.662 \mathrm{E}-06 \quad 1.057 \mathrm{E}-02 \quad 2.944 \mathrm{E}-02 \quad 1.819 \mathrm{E}-01 \quad 3.507 \mathrm{E}-01$ $0.000 \mathrm{E}+00 \quad 2.004 \mathrm{E}-11 \quad 1.773 \mathrm{E}-06 \quad 1.066 \mathrm{E}-05 \quad 3.970 \mathrm{E}-04 \quad 1.719 \mathrm{E}-03$ $0.000 \mathrm{E}+00 \quad 1.423 \mathrm{E}-17 \quad 6.716 \mathrm{E}-11 \quad 8.469 \mathrm{E}-10 \quad 1.799 \mathrm{E}-07 \quad 1.714 \mathrm{E}-06$ $0.000 \mathrm{E}+00 \quad 6.662 \mathrm{E}-06 \quad 1.057 \mathrm{E}-02 \quad 2.945 \mathrm{E}-02 \quad 1.823 \mathrm{E}-01 \quad 3.524 \mathrm{E}-01$ $\begin{array}{llllll}1.000 \mathrm{E}+00 & 1.000 \mathrm{E}+00 & 9.977 \mathrm{E}-01 & 9.954 \mathrm{E}-01 & 9.773 \mathrm{E}-01 & 9.529 \mathrm{E}-01\end{array}$ $0.000 \mathrm{E}+00 \quad 9.848 \mathrm{E}-10 \quad 4.916 \mathrm{E}-08 \quad 9.815 \mathrm{E}-08 \quad 4.840 \mathrm{E}-07 \quad 9.974 \mathrm{E}-07$ $\begin{array}{llllllll}1.000 \mathrm{E}+00 & 1.000 \mathrm{E}+00 & 9.989 \mathrm{E}-01 & 9.977 \mathrm{E}-01 & 9.886 \mathrm{E}-01 & 9.761 \mathrm{E}-01\end{array}$ $\begin{array}{lllllll}1.000 \mathrm{E}+00 & 1.000 \mathrm{E}+00 & 9.989 \mathrm{E}-01 & 9.977 \mathrm{E}-01 & 9.886 \mathrm{E}-01 & 9.761 \mathrm{E}-01\end{array}$ 
RESRAD, Version $6.5 \quad T^{1 / 2}$ Limit $=180$ days

Summary : RESRAD Parameters for U-Landfill Resident Gardener

File : C: \RESRAD FAMILY \RESRAD \USERFILES \QCFORSRSG $\backslash$ RESIDENTGARDENER-SRSG-MAY11.RAD

Individual Nuclide Soil Concentration

Parent Nuclide and Branch Fraction Indicated

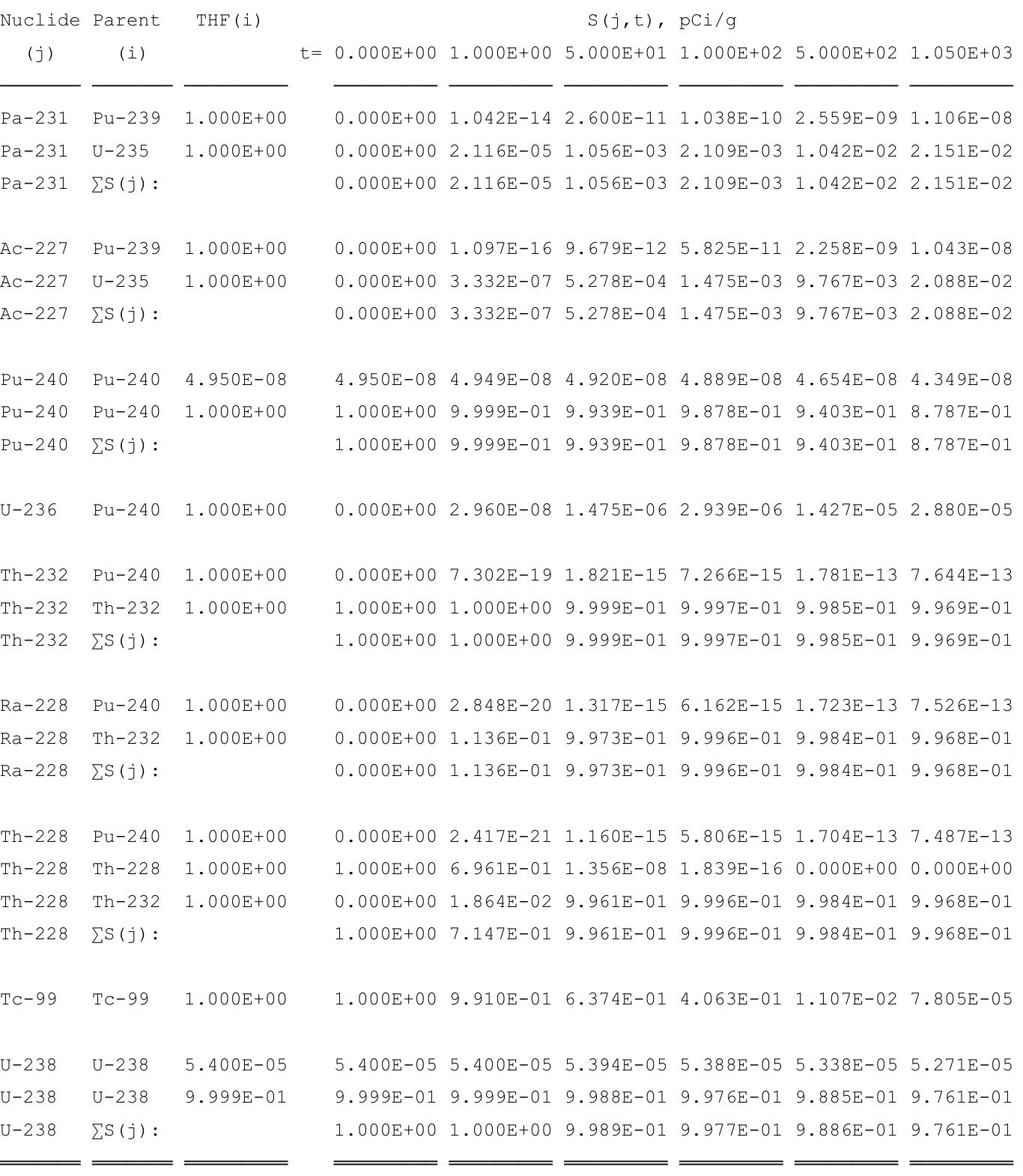

THF (i) is the thread fraction of the parent nuclide.

RESCALC.EXE execution time = 9.91 seconds 
RESRAD, Version $6.5 \quad \mathrm{~T}^{1 / 2}$ Limit $=180$ days

07/21/2011 16:37 Page

Summary : RESRAD Parameters for Resident Farmer U-Landfill

File : C: \RESRAD_FAMILY \RESRAD \USERFILES \QCFORSRSG \ONSITERF_SRSG-MAY1.RAD

Dose Conversion Factor (and Related) Parameter Summary

Dose Library: ICRP 60 \& ICRP 72 (Adult)

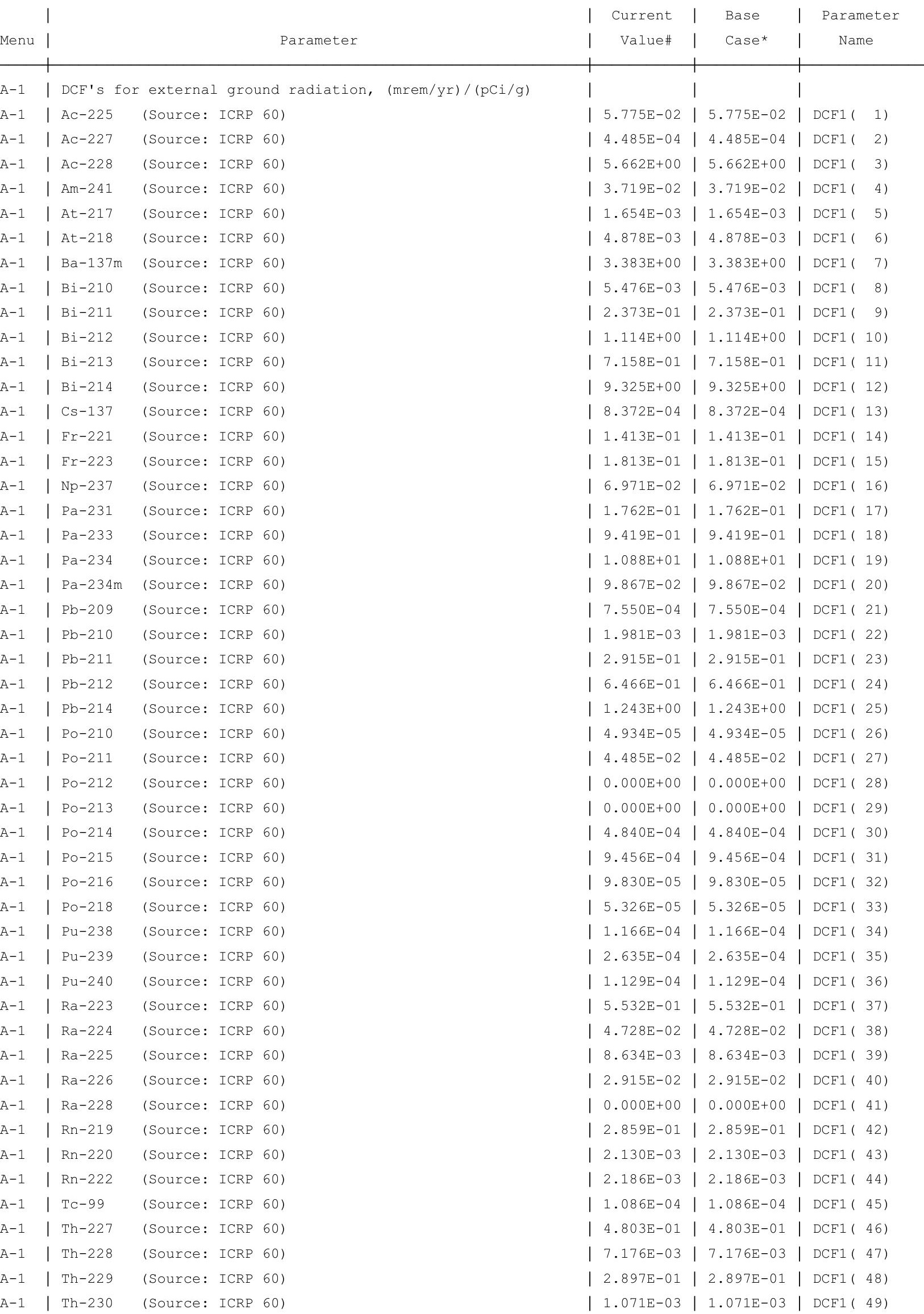


RESRAD, Version $6.5 \quad \mathrm{~T}^{1 / 2}$ Limit $=180$ days

Summary : RESRAD Parameters for Resident Farmer U-Landfill

File : C: $\backslash$ RESRAD FAMILY \RESRAD \USERFILES $\backslash Q C F O R S R S G$ ONSITERF SRSG-MAY1.RAD

Dose Conversion Factor (and Related) Parameter Summary (continued)

Dose Library: ICRP 60 \& ICRP 72 (Adult)

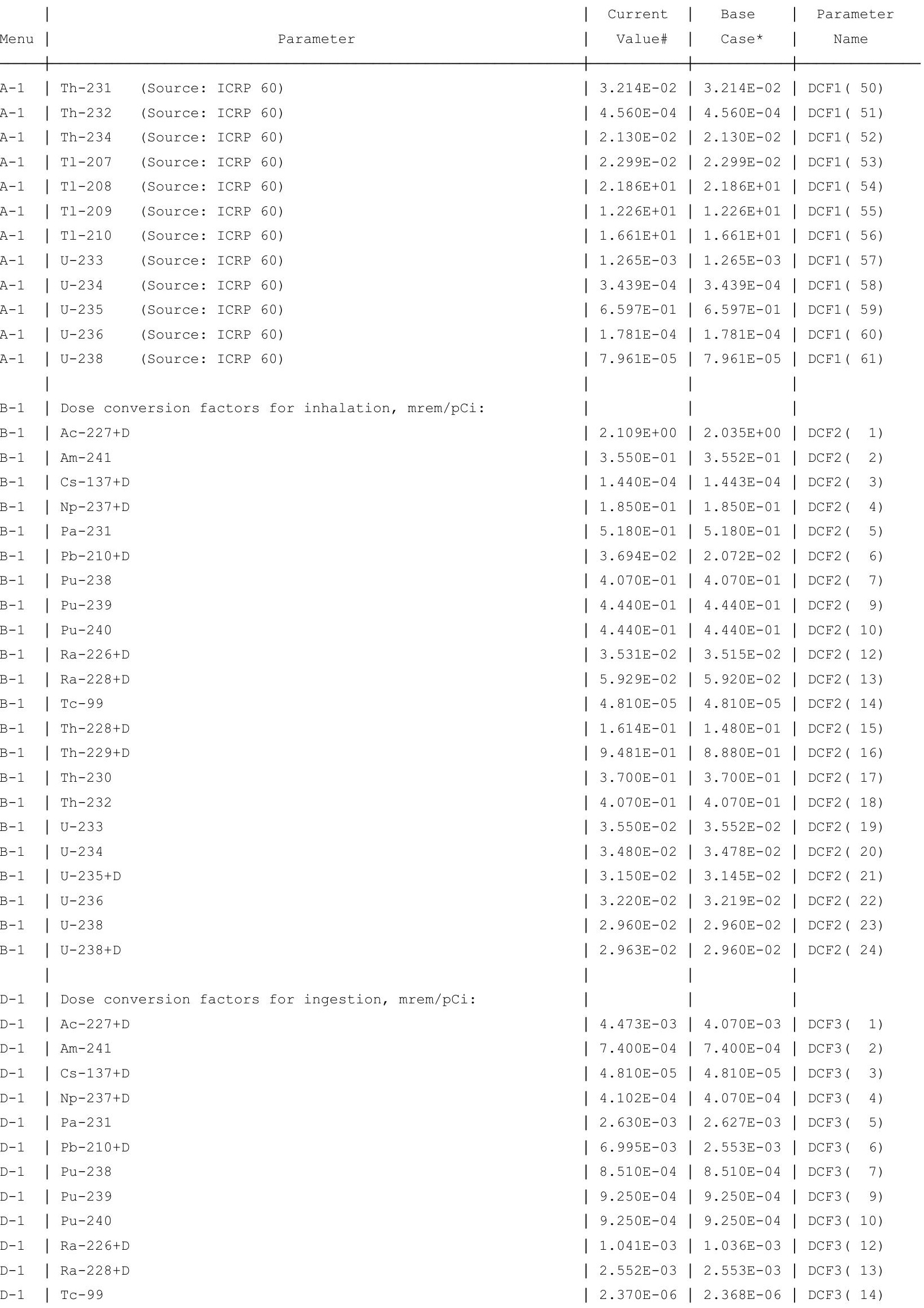


RESRAD, Version $6.5 \quad \mathrm{~T}^{1 / 2}$ Limit $=180$ days

Summary : RESRAD Parameters for Resident Farmer U-Landfill

File : C: $\backslash$ RESRAD_FAMILY $\backslash$ RESRAD $\backslash U S E R F I L E S \backslash Q C F O R S R S G$ ONSITERF_SRSG-MAY1.RAD

Dose Conversion Factor (and Related) Parameter Summary (continued) Dose Library: ICRP 60 \& ICRP 72 (Adult)

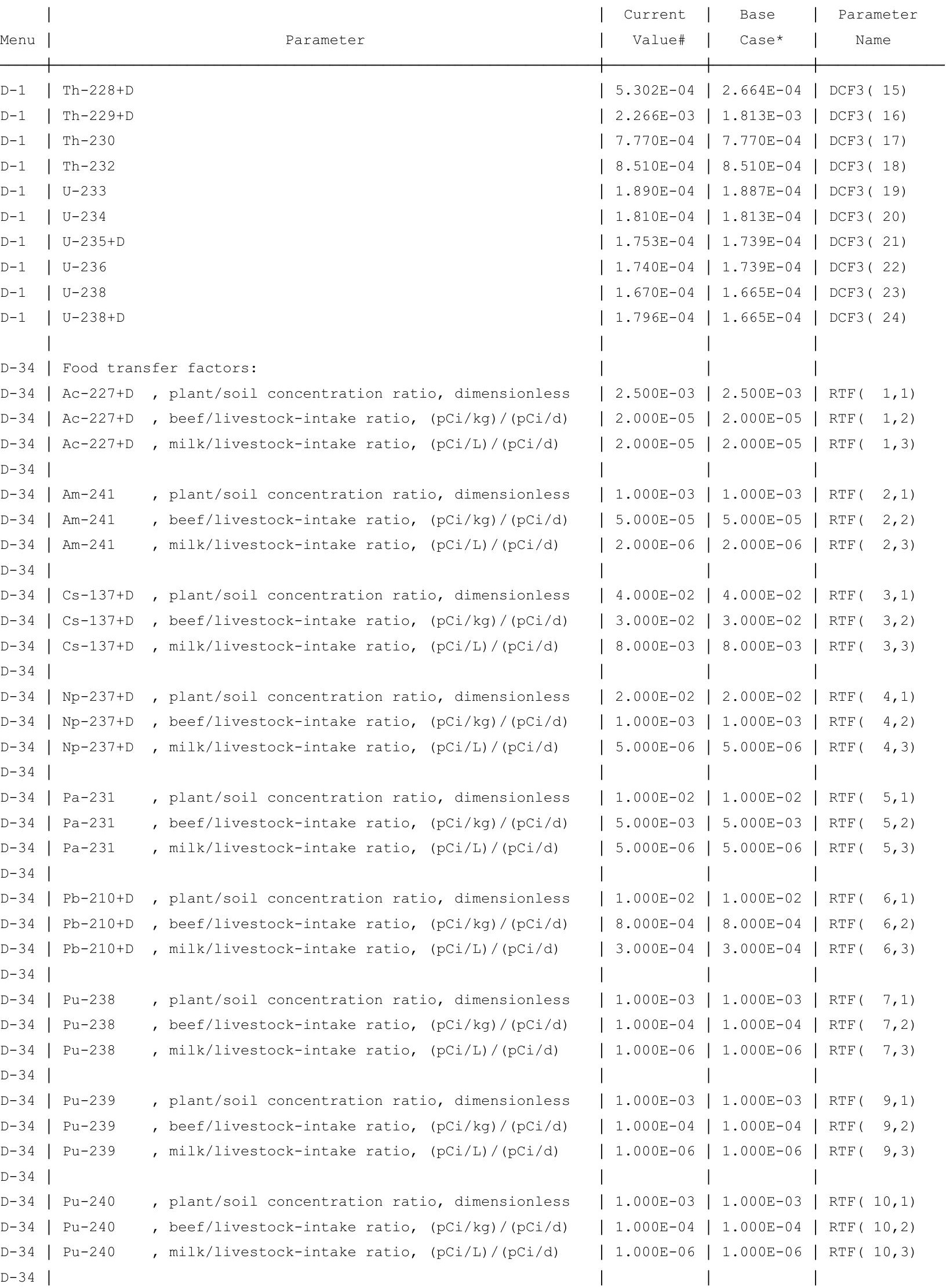


RESRAD, Version $6.5 \quad T^{11 / 2}$ Limit $=180$ days

Summary : RESRAD Parameters for Resident Farmer U-Landfill

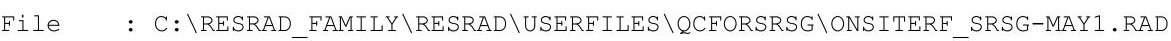

Dose Conversion Factor (and Related) Parameter Summary (continued)

Dose Library: ICRP 60 \& ICRP 72 (Adult)

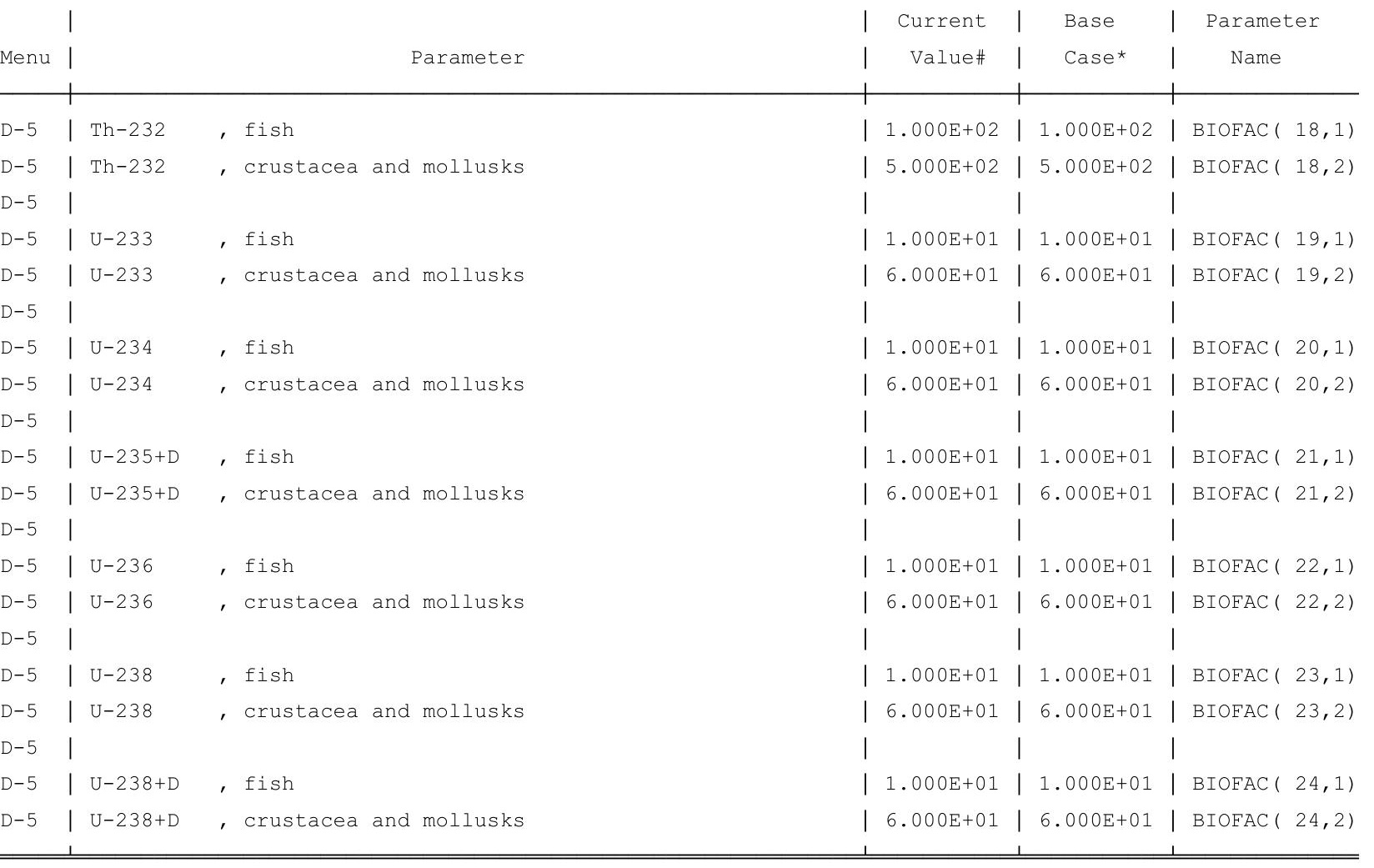

\#For DCFl(xxx) only, factors are for infinite depth \& area. See ETFG table in Ground Pathway of Detailed Report. *Base Case means Default.Lib w/o Associate Nuclide contributions. 
RESRAD, Version $6.5 \quad T^{1 / 2}$ Limit $=180$ days

Summary : RESRAD Parameters for Resident Farmer U-Landfill

File : C: \RESRAD_FAMILY \RESRAD \USERFILES \QCFORSRSG \ONSITERF_SRSG-MAY1.RAD

Site-Specific Parameter Summary (continued)

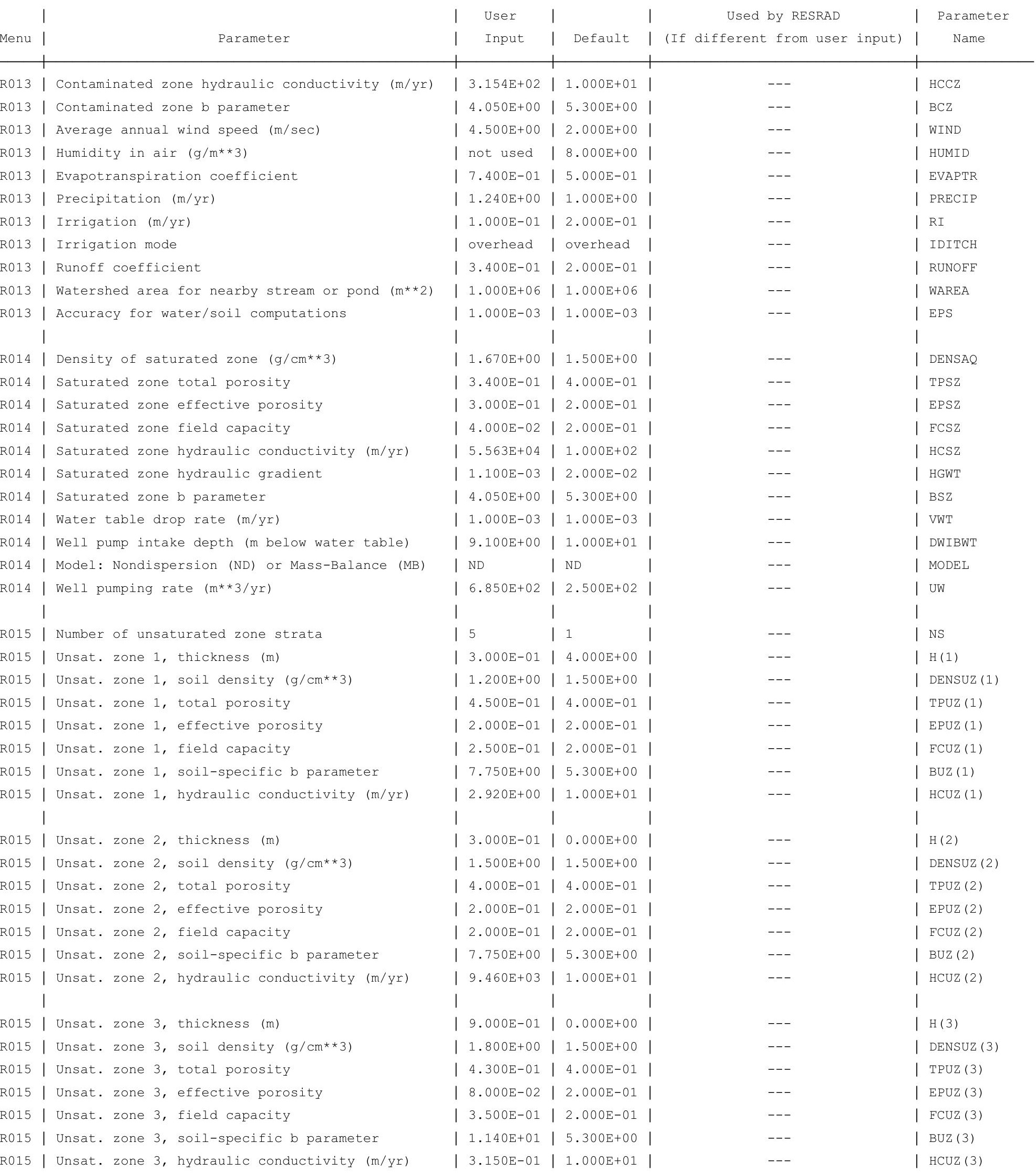


RESRAD, Version $6.5 \quad \mathrm{~T}^{1} \frac{1}{2}$ Limit $=180$ days

ummary : RESRAD Parameters for Resident Farmer U-Landfill

File : C: \RESRAD_FAMILY \RESRAD \USERFILES \QCFORSRSG $O$ ONSITERF_SRSG-MAY1.RAD

Site-Specific Parameter Summary (continued)

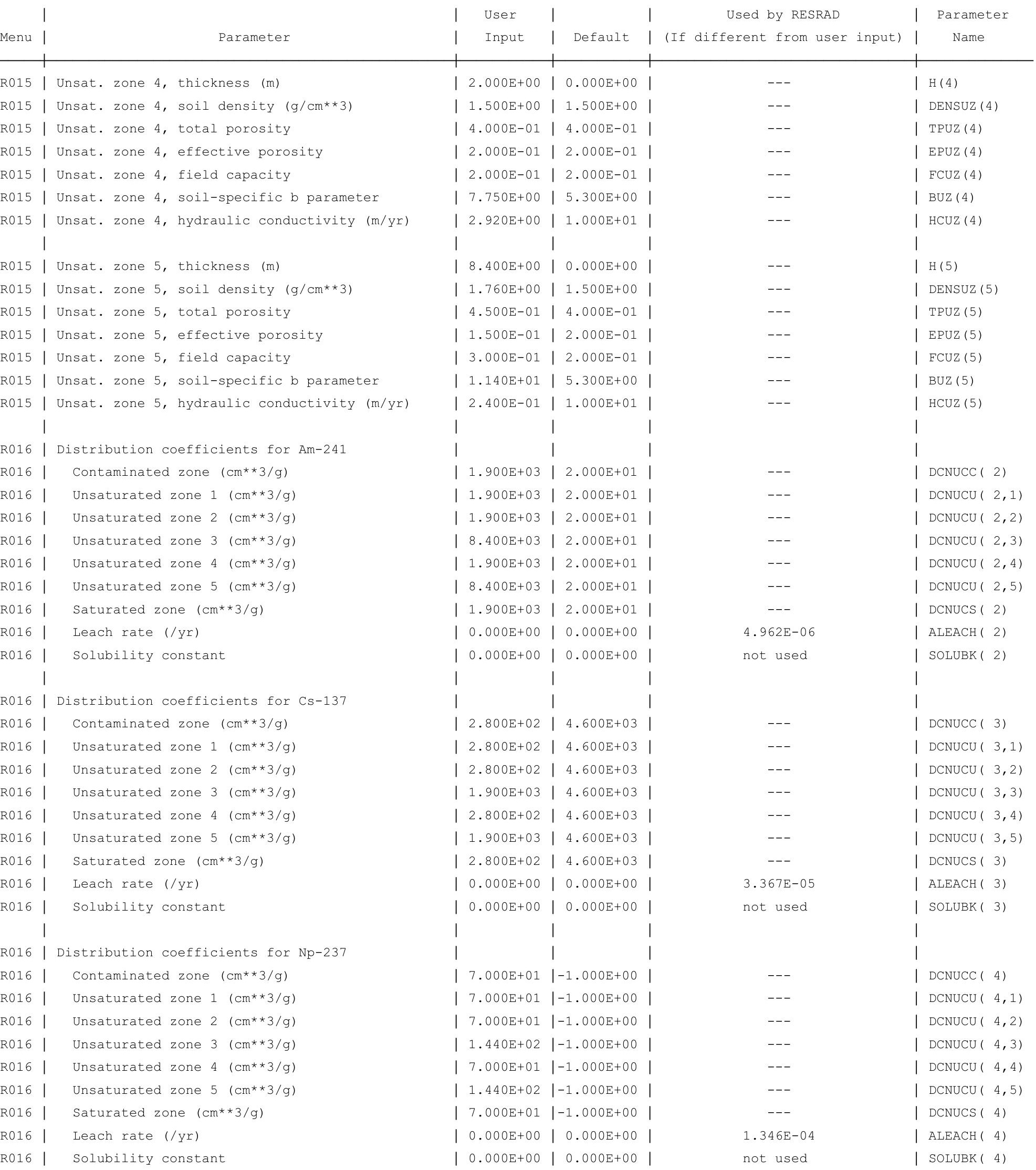


RESRAD, Version $6.5 \quad \mathrm{~T}^{1} \frac{1}{2}$ Limit $=180$ days

07/21/2011 16:37 Page

Summary : RESRAD Parameters for Resident Farmer U-Landfill

File : C: \RESRAD_FAMILY \RESRAD \USERFILES \QCFORSRSG $O$ ONSITERF_SRSG-MAY1.RAD

Site-Specific Parameter Summary (continued)

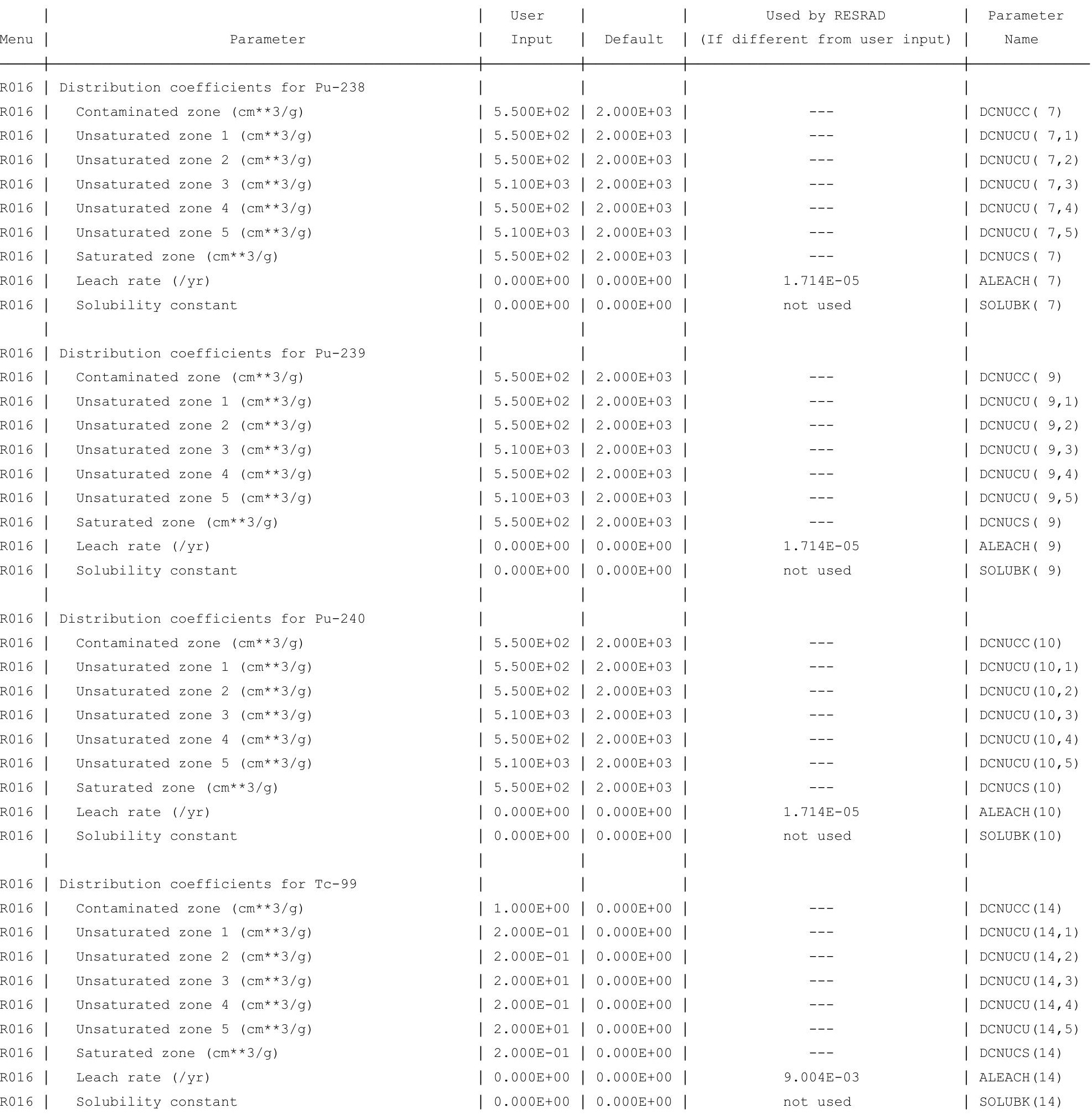


RESRAD, Version $6.5 \quad \mathrm{~T}^{1} \frac{1}{2}$ Limit $=180$ days

07/21/2011 16:37 Page

Summary : RESRAD Parameters for Resident Farmer U-Landfill

File : C: \RESRAD_FAMILY \RESRAD \USERFILES \QCFORSRSG $O$ ONSITERF_SRSG-MAY1.RAD

Site-Specific Parameter Summary (continued)

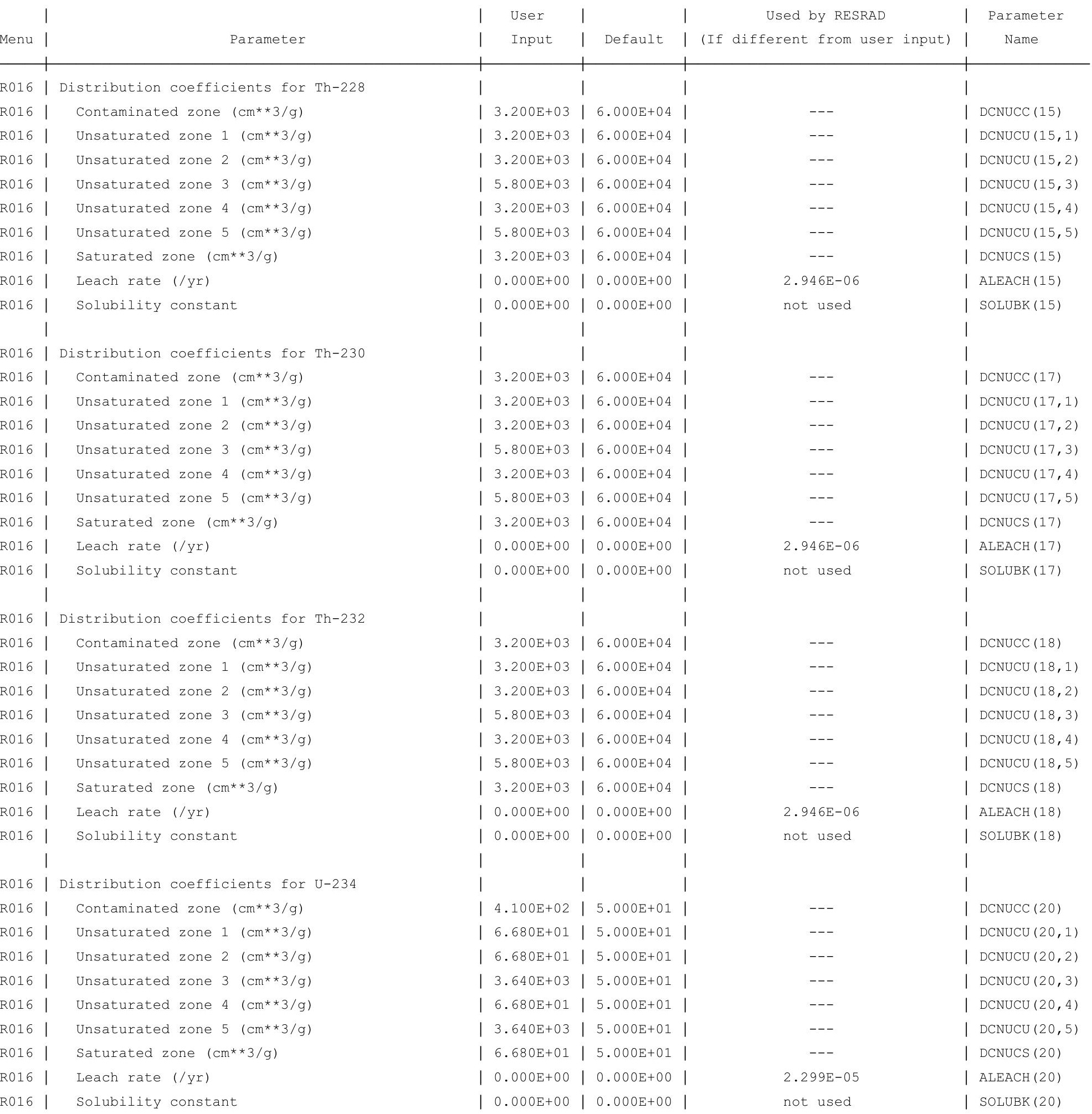


RESRAD, Version $6.5 \quad \mathrm{~T}^{1} \frac{1}{2}$ Limit $=180$ days

Summary : RESRAD Parameters for Resident Farmer U-Landfill

File : C: \RESRAD_FAMILY \RESRAD \USERFILES \QCFORSRSG $\backslash$ ONSITERF_SRSG-MAY1.RAD

Site-Specific Parameter Summary (continued)

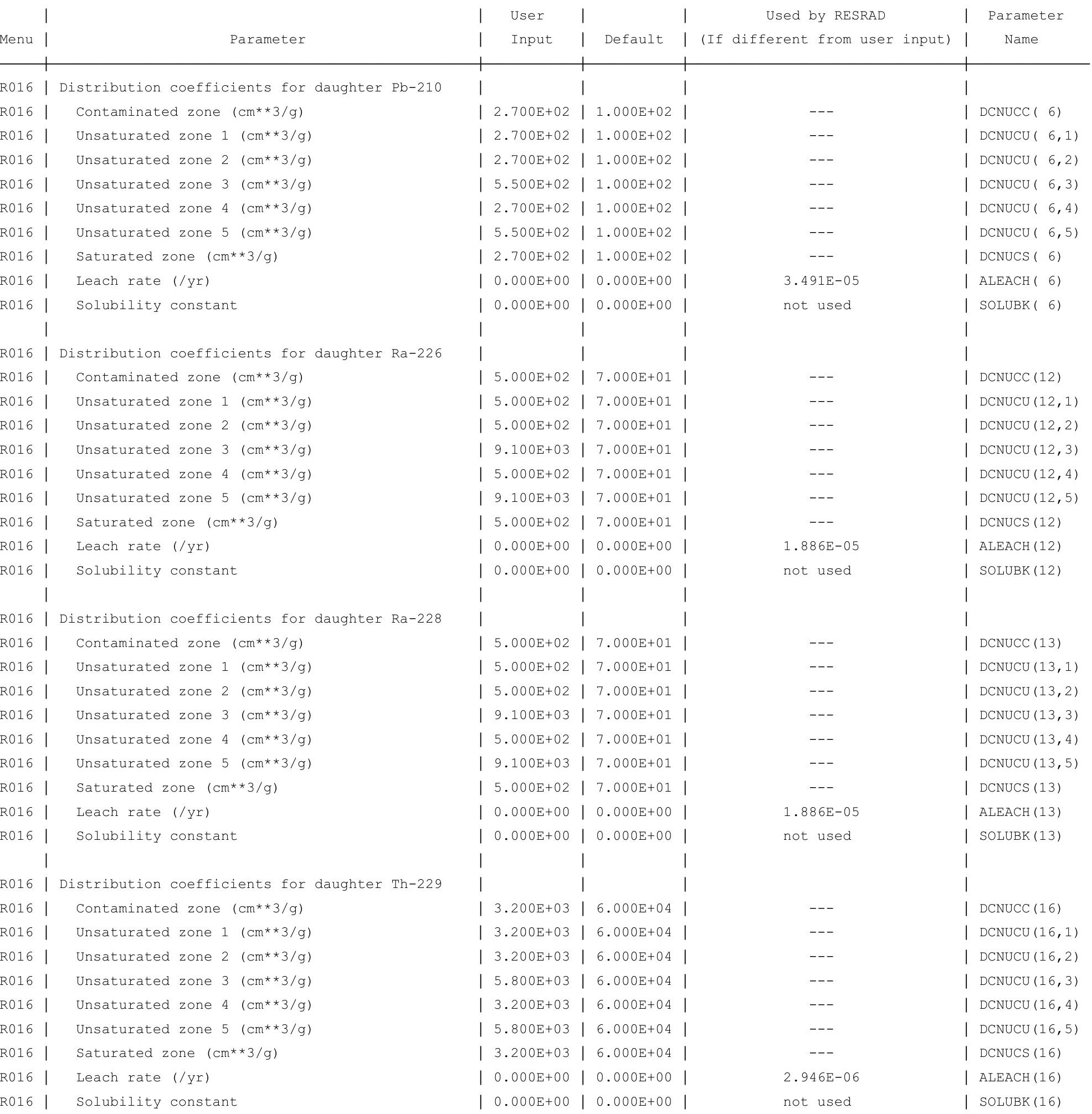


RESRAD, Version $6.5 \quad T^{1 / 2}$ Limit $=180$ days

Summary : RESRAD Parameters for Resident Farmer U-Landfill

File : C: $\backslash$ RESRAD_FAMILY $\backslash R E S R A D \backslash U S E R F I L E S \backslash Q C F O R S R S G$ ONSITERF_SRSG-MAYI.RAD

Site-Specific Parameter Summary (continued)

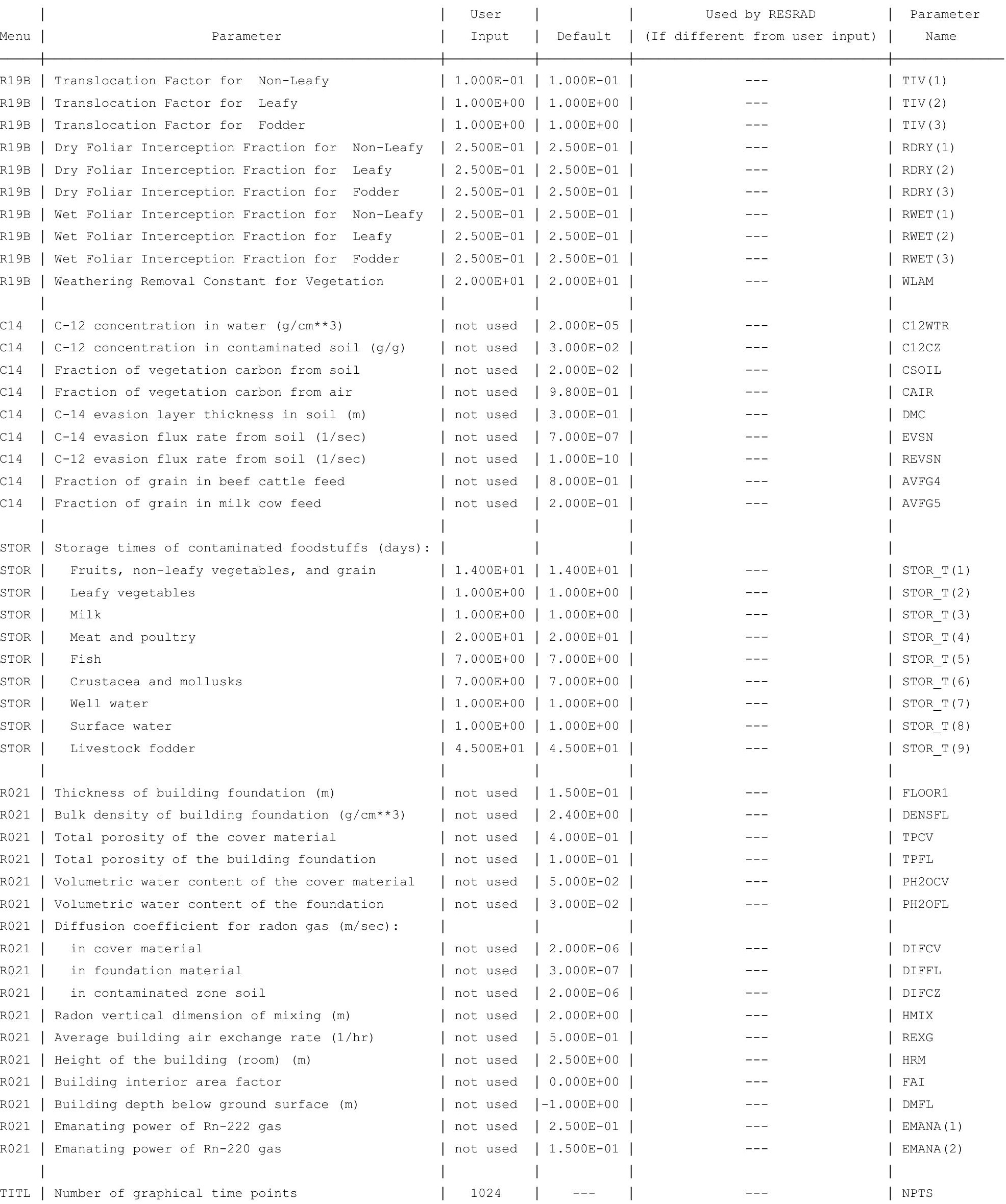


RESRAD, Version $6.5 \quad \mathrm{~T}^{1 / 2}$ Limit $=180$ days

Summary : RESRAD Parameters for Resident Farmer U-Landfill

File : C: \RESRAD_FAMILY \RESRAD \USERFILES \QCFORSRSG \ONSITERF_SRSG-MAY1.RAD

Contaminated Zone Dimensions

Area: 89436.00 square meters

Thickness:

Cover Depth:

\begin{abstract}
13.40 meters
1.52 meters
\end{abstract}

Initial Soil Concentrations, pCi/g

$\begin{array}{ll}\mathrm{Am}-241 & 1.000 \mathrm{E}+00 \\ \mathrm{Cs}-137 & 1.000 \mathrm{E}+00 \\ \mathrm{~Np}-237 & 1.000 \mathrm{E}+00 \\ \mathrm{Pu}-238 & 1.000 \mathrm{E}+00 \\ \mathrm{Pu}-239 & 1.000 \mathrm{E}+00 \\ \mathrm{Pu}-240 & 1.000 \mathrm{E}+00 \\ \mathrm{TC}-99 & 1.000 \mathrm{E}+00 \\ \mathrm{Th}-228 & 1.000 \mathrm{E}+00 \\ \mathrm{Th}-230 & 1.000 \mathrm{E}+00 \\ \mathrm{Th}-232 & 1.000 \mathrm{E}+00 \\ \mathrm{U}-234 & 1.000 \mathrm{E}+00 \\ \mathrm{U}-235 & 1.000 \mathrm{E}+00 \\ \mathrm{U}-238 & 1.000 \mathrm{E}+00\end{array}$

Total Dose TDOSE(t), mrem/yr

Basic Radiation Dose Limit $=1.000 \mathrm{E}+02 \mathrm{mrem} / \mathrm{yr}$

Total Mixture Sum $M(t)$ = Fraction of Basic Dose Limit Received at Time (t)

$\begin{array}{rllllll}t \text { (years) : } & 0.000 \mathrm{E}+00 & 1.000 \mathrm{E}+00 & 5.000 \mathrm{E}+01 & 1.000 \mathrm{E}+02 & 5.000 \mathrm{E}+02 & 1.050 \mathrm{E}+03 \\ \mathrm{TDOSE}(\mathrm{t}): & 1.396 \mathrm{E}-06 & 1.038 \mathrm{E}-06 & 2.247 \mathrm{E}-06 & 3.048 \mathrm{E}-06 & 2.071 \mathrm{E}-01 & 2.462 \mathrm{E}-01 \\ \mathrm{M}(\mathrm{t}): & 1.396 \mathrm{E}-08 & 1.038 \mathrm{E}-08 & 2.247 \mathrm{E}-08 & 3.048 \mathrm{E}-08 & 2.071 \mathrm{E}-03 & 2.462 \mathrm{E}-03\end{array}$

Maximum TDOSE(t): $4.080 \mathrm{E}-01 \mathrm{mrem} / \mathrm{yr}$ at $t=424.6 \pm 0.8$ years

Total Dose Contributions TDOSE(i,p,t) for Individual Radionuclides (i) and Pathways (p) As mrem/yr and Fraction of Total Dose At $t=4.246 \mathrm{E}+02$ years

Water Independent Pathways (Inhalation excludes radon)

\begin{tabular}{|c|c|c|c|c|c|c|c|c|c|c|c|c|c|c|}
\hline & \multicolumn{2}{|c|}{ Ground } & \multicolumn{2}{|c|}{ Inhalation } & \multicolumn{2}{|c|}{ Radon } & \multicolumn{2}{|c|}{ Plant } & \multicolumn{2}{|c|}{ Meat } & \multicolumn{2}{|c|}{ Milk } & \multicolumn{2}{|c|}{ Soil } \\
\hline clide & mrem/yr & fract. & mrem/yr & fract. & mrem/yr & fract. & mrem/yr & fract. & mrem/yr & fract. & mrem/yr & fract. & mrem/yr & fract. \\
\hline 241 & $9.151 E-15$ & 0.0000 & $0.000 \mathrm{E}+00$ & 0.0000 & $0.000 \mathrm{E}+00$ & 0.0000 & $0.000 \mathrm{E}+00$ & 0.0000 & $0.000 \mathrm{E}+00$ & 0.0000 & $0.000 \mathrm{E}+00$ & 0.0000 & $0.000 \mathrm{E}+00$ & 0.0000 \\
\hline-137 & $2.456 \mathrm{E}-12$ & 0.0000 & $0.000 \mathrm{E}+00$ & 0.0000 & $0.000 \mathrm{E}+00$ & 0.0000 & $0.000 \mathrm{E}+00$ & 0.0000 & $0.000 \mathrm{E}+00$ & 0.0000 & $0.000 \mathrm{E}+00$ & 0.0000 & $0.000 \mathrm{E}+00$ & 0.0000 \\
\hline-237 & $9.131 \mathrm{E}-11$ & 0.0000 & $0.000 \mathrm{E}+00$ & 0.0000 & $0.000 \mathrm{E}+00$ & 0.0000 & $0.000 \mathrm{E}+00$ & 0.0000 & $0.000 \mathrm{E}+00$ & 0.0000 & $0.000 \mathrm{E}+00$ & 0.0000 & $0.000 \mathrm{E}+00$ & 0.0000 \\
\hline-238 & $2.254 \mathrm{E}-13$ & 0.0000 & $0.000 \mathrm{E}+00$ & 0.0000 & $0.000 \mathrm{E}+00$ & 0.0000 & $0.000 \mathrm{E}+00$ & 0.0000 & $0.000 \mathrm{E}+00$ & 0.0000 & $0.000 \mathrm{E}+00$ & 0.0000 & $0.000 \mathrm{E}+00$ & 0.0000 \\
\hline-239 & $1.913 \mathrm{E}-15$ & 0.0000 & $0.000 \mathrm{E}+00$ & 0.0000 & $0.000 \mathrm{E}+00$ & 0.0000 & $0.000 \mathrm{E}+00$ & 0.0000 & $0.000 \mathrm{E}+00$ & 0.0000 & $0.000 \mathrm{E}+00$ & 0.0000 & $0.000 \mathrm{E}+00$ & 0.0000 \\
\hline-240 & $2.609 E-18$ & 0.0000 & $0.000 \mathrm{E}+00$ & 0.0000 & $0.000 \mathrm{E}+00$ & 0.0000 & $0.000 \mathrm{E}+00$ & 0.0000 & $0.000 \mathrm{E}+00$ & 0.0000 & $0.000 \mathrm{E}+00$ & 0.0000 & $0.000 \mathrm{E}+00$ & 0.0000 \\
\hline 99 & 4. $323 E-24$ & 0.0000 & $0.000 \mathrm{E}+00$ & 0.0000 & $0.000 \mathrm{E}+00$ & 0.0000 & $0.000 \mathrm{E}+00$ & 0.0000 & $0.000 \mathrm{E}+00$ & 0.0000 & $0.000 \mathrm{E}+00$ & 0.0000 & $0.000 \mathrm{E}+00$ & 0.0000 \\
\hline-228 & $0.000 \mathrm{E}+00$ & 0.0000 & $0.000 \mathrm{E}+00$ & 0.0000 & $0.000 \mathrm{E}+00$ & 0.0000 & $0.000 \mathrm{E}+00$ & 0.0000 & $0.000 \mathrm{E}+00$ & 0.0000 & $0.000 \mathrm{E}+00$ & 0.0000 & $0.000 \mathrm{E}+00$ & 0.0000 \\
\hline-230 & $5.490 \mathrm{E}-07$ & 0.0000 & $0.000 \mathrm{E}+00$ & 0.0000 & $0.000 \mathrm{E}+00$ & 0.0000 & $0.000 \mathrm{E}+00$ & 0.0000 & $0.000 \mathrm{E}+00$ & 0.0000 & $0.000 \mathrm{E}+00$ & 0.0000 & $0.000 \mathrm{E}+00$ & 0.0000 \\
\hline 232 & $2.122 \mathrm{E}-05$ & 0.0001 & $0.000 \mathrm{E}+00$ & 0.0000 & $0.000 \mathrm{E}+00$ & 0.0000 & $0.000 \mathrm{E}+00$ & 0.0000 & $0.000 \mathrm{E}+00$ & 0.0000 & $0.000 \mathrm{E}+00$ & 0.0000 & $0.000 \mathrm{E}+00$ & 0.0000 \\
\hline 34 & $1.081 E-09$ & 0.0000 & $0.000 \mathrm{E}+00$ & 0.0000 & $0.000 \mathrm{E}+00$ & 0.0000 & $0.000 \mathrm{E}+00$ & 0.0000 & $0.000 \mathrm{E}+00$ & 0.0000 & $0.000 \mathrm{E}+00$ & 0.0000 & $0.000 \mathrm{E}+00$ & 0.0000 \\
\hline 35 & $3.027 E-11$ & 0.0000 & $0.000 \mathrm{E}+00$ & 0.0000 & $0.000 \mathrm{E}+00$ & 0.0000 & $0.000 \mathrm{E}+00$ & 0.0000 & $0.000 \mathrm{E}+00$ & 0.0000 & $0.000 \mathrm{E}+00$ & 0.0000 & $0.000 \mathrm{E}+00$ & 0.0000 \\
\hline 38 & $4.206 \mathrm{E}-09$ & 0.0000 & $0.000 \mathrm{E}+00$ & 0.0000 & $0.000 \mathrm{E}+00$ & 0.0000 & $0.000 \mathrm{E}+00$ & 0.0000 & $0.000 \mathrm{E}+00$ & 0.0000 & $0.000 \mathrm{E}+00$ & 0.0000 & $0.000 \mathrm{E}+00$ & 0.0000 \\
\hline & $2.177 \mathrm{E}-05$ & 0.0001 & $.000 \mathrm{E}+00$ & 0.0000 & $0.000 \mathrm{E}+00$ & 0.0000 & $0.000 \mathrm{E}+00$ & 0.0000 & $0.000 \mathrm{E}+00$ & 0.0000 & $0.000 \mathrm{E}+00$ & 000 & $0 \mathrm{E}+00$ & 00 \\
\hline
\end{tabular}


RESRAD, Version $6.5 \quad \mathrm{~T}^{1} \frac{1}{2}$ Limit $=180$ days

ummary : RESRAD Parameters for Resident Farmer U-Landfill

File : C: \RESRAD_FAMILY \RESRAD \USERFILES \QCFORSRSG \ONSITERF_SRSG-MAY1.RAD

Total Dose Contributions TDOSE (i,p,t) for Individual Radionuclides (i) and Pathways (p) As mrem/yr and Fraction of Total Dose At $t=4.246 \mathrm{E}+02$ years

Water Dependent Pathways

\begin{tabular}{|c|c|c|c|c|c|c|c|c|c|c|c|c|c|c|}
\hline & \multicolumn{2}{|c|}{ Water } & \multicolumn{2}{|c|}{ Fish } & \multicolumn{2}{|c|}{ Radon } & \multicolumn{2}{|c|}{ Plant } & \multicolumn{2}{|c|}{ Meat } & \multicolumn{2}{|c|}{ Milk } & \multicolumn{2}{|c|}{ All Pathways* } \\
\hline clide & mrem/yr & fract. & mrem/yr & fract. & mrem/yr & fract. & mrem/yr & fract. & mrem/yr & fract. & mrem/yr & fract. & mrem/yr & fract. \\
\hline-241 & $0.000 \mathrm{E}+00$ & 0.0000 & $0.000 \mathrm{E}+00$ & 0.0000 & $0.000 \mathrm{E}+00$ & 0.0000 & $0.000 \mathrm{E}+00$ & 0.0000 & $0.000 \mathrm{E}+00$ & 0.0000 & $0.000 \mathrm{E}+00$ & 0.0000 & $9.151 \mathrm{E}-15$ & 0.0000 \\
\hline-137 & $0.000 \mathrm{E}+00$ & 0.0000 & $0.000 \mathrm{E}+00$ & 0.0000 & $0.000 \mathrm{E}+00$ & 0.0000 & $0.000 \mathrm{E}+00$ & 0.0000 & $0.000 \mathrm{E}+00$ & 0.0000 & $0.000 \mathrm{E}+00$ & 0.0000 & $2.456 \mathrm{E}-12$ & 0.0000 \\
\hline-237 & $0.000 \mathrm{E}+00$ & 0.0000 & $0.000 \mathrm{E}+00$ & 0.0000 & $0.000 \mathrm{E}+00$ & 0.0000 & $0.000 \mathrm{E}+00$ & 0.0000 & $0.000 \mathrm{E}+00$ & 0.0000 & $0.000 \mathrm{E}+00$ & 0.0000 & $9.131 \mathrm{E}-11$ & 0.0000 \\
\hline-238 & $0.000 \mathrm{E}+00$ & 0.0000 & $0.000 \mathrm{E}+00$ & 0.0000 & $0.000 \mathrm{E}+00$ & 0.0000 & $0.000 \mathrm{E}+00$ & 0.0000 & $0.000 \mathrm{E}+00$ & 0.0000 & $0.000 \mathrm{E}+00$ & 0.0000 & $2.254 \mathrm{E}-13$ & 0.0000 \\
\hline-239 & $0.000 \mathrm{E}+00$ & 0.0000 & $0.000 \mathrm{E}+00$ & 0.0000 & $0.000 \mathrm{E}+00$ & 0.0000 & $0.000 \mathrm{E}+00$ & 0.0000 & $0.000 \mathrm{E}+00$ & 0.0000 & $0.000 \mathrm{E}+00$ & 0.0000 & $1.913 \mathrm{E}-15$ & 0.0000 \\
\hline-240 & $0.000 \mathrm{E}+00$ & 0.0000 & $0.000 \mathrm{E}+00$ & 0.0000 & $0.000 \mathrm{E}+00$ & 0.0000 & $0.000 \mathrm{E}+00$ & 0.0000 & $0.000 \mathrm{E}+00$ & 0.0000 & $0.000 \mathrm{E}+00$ & 0.0000 & $2.609 \mathrm{E}-18$ & 0.0000 \\
\hline-99 & $3.377 \mathrm{E}-01$ & 0.8278 & $0.000 \mathrm{E}+00$ & 0.0000 & $0.000 \mathrm{E}+00$ & 0.0000 & $3.155 \mathrm{E}-02$ & 0.0773 & $5.641 \mathrm{E}-04$ & 0.0014 & $3.813 E-02$ & 0.0935 & $4.079 \mathrm{E}-01$ & 0.9999 \\
\hline-228 & $0.000 \mathrm{E}+00$ & 0.0000 & $0.000 \mathrm{E}+00$ & 0.0000 & $0.000 \mathrm{E}+00$ & 0.0000 & $0.000 \mathrm{E}+00$ & 0.0000 & $0.000 \mathrm{E}+00$ & 0.0000 & $0.000 \mathrm{E}+00$ & 0.0000 & $0.000 \mathrm{E}+00$ & 0.0000 \\
\hline-230 & $0.000 \mathrm{E}+00$ & 0.0000 & $0.000 \mathrm{E}+00$ & 0.0000 & $0.000 \mathrm{E}+00$ & 0.0000 & $0.000 \mathrm{E}+00$ & 0.0000 & $0.000 \mathrm{E}+00$ & 0.0000 & $0.000 \mathrm{E}+00$ & 0.0000 & $5.490 \mathrm{E}-07$ & 0.0000 \\
\hline-232 & $0.000 \mathrm{E}+00$ & 0.0000 & $0.000 \mathrm{E}+00$ & 0.0000 & $0.000 \mathrm{E}+00$ & 0.0000 & $0.000 \mathrm{E}+00$ & 0.0000 & $0.000 \mathrm{E}+00$ & 0.0000 & $0.000 \mathrm{E}+00$ & 0.0000 & $2.122 \mathrm{E}-05$ & 0.0001 \\
\hline 234 & $0.000 \mathrm{E}+00$ & 0.0000 & $0.000 \mathrm{E}+00$ & 0.0000 & $0.000 \mathrm{E}+00$ & 0.0000 & $0.000 \mathrm{E}+00$ & 0.0000 & $0.000 \mathrm{E}+00$ & 0.0000 & $0.000 \mathrm{E}+00$ & 0.0000 & $1.081 \mathrm{E}-09$ & 0.0000 \\
\hline 35 & $0.000 \mathrm{E}+00$ & 0.0000 & $0.000 \mathrm{E}+00$ & 0.0000 & $0.000 \mathrm{E}+00$ & 0.0000 & $0.000 \mathrm{E}+00$ & 0.0000 & $0.000 \mathrm{E}+00$ & 0.0000 & $0.000 \mathrm{E}+00$ & 0.0000 & $3.027 \mathrm{E}-11$ & 0.0000 \\
\hline 38 & $0.000 \mathrm{E}+00$ & 0.0000 & $0.000 \mathrm{E}+00$ & 0.0000 & $0.000 \mathrm{E}+00$ & 0.0000 & $0.000 \mathrm{E}+00$ & 0.0000 & $0.000 \mathrm{E}+00$ & 0.0000 & $0.000 \mathrm{E}+00$ & 0.0000 & $4.206 \mathrm{E}-09$ & 0.0000 \\
\hline & $3.377 E-01$ & 0.8278 & $0.000 \mathrm{E}+00$ & 0.0000 & $0.000 \mathrm{E}+00$ & 0.0000 & $3.155 \mathrm{E}-02$ & 0.0773 & $.641 \mathrm{E}-04$ & 0.0014 & $3.813 E-02$ & 0.0935 & $E-01$ & 1.0000 \\
\hline
\end{tabular}

*Sum of all water independent and dependent pathways. 
RESRAD, Version 6.5

ummary : RESRAD Parameters for Resident Farmer U-Landfill

File : C: \RESRAD_FAMILY \RESRAD \USERFILES \QCFORSRSG \ONSITERF_SRSG-MAY1.RAD

Total Dose Contributions TDOSE (i,p,t) for Individual Radionuclides (i) and Pathways (p) As mrem/yr and Fraction of Total Dose At $t=0.000 \mathrm{E}+00$ years

Water Independent Pathways (Inhalation excludes radon)

\begin{tabular}{|c|c|c|c|c|c|c|c|c|c|c|c|c|c|c|}
\hline \multirow{2}{*}{ Nuclide } & \multicolumn{2}{|c|}{ Ground } & \multicolumn{2}{|c|}{ Inhalation } & \multicolumn{2}{|c|}{ Radon } & \multicolumn{2}{|c|}{ Plant } & \multicolumn{2}{|c|}{ Meat } & \multicolumn{2}{|c|}{ Milk } & \multicolumn{2}{|c|}{ Soil } \\
\hline & mrem/yr & fract. & mrem/yr & fract. & mrem/yr & fract. & mrem/yr & fract. & mrem/yr & fract. & mrem/yr & fract. & mrem/yr & fract. \\
\hline-241 & $1.546 \mathrm{E}-19$ & 0.0000 & $0.000 \mathrm{E}+00$ & 0.0000 & $0.000 \mathrm{E}+00$ & 0.0000 & $0.000 \mathrm{E}+00$ & 0.0000 & $0.000 \mathrm{E}+00$ & 0.0000 & $0.000 \mathrm{E}+00$ & 0.0000 & $0.000 \mathrm{E}+00$ & 0.0000 \\
\hline-137 & $1.262 E-09$ & 0.0009 & $0.000 \mathrm{E}+00$ & 0.0000 & $0.000 \mathrm{E}+00$ & 0.0000 & $0.000 \mathrm{E}+00$ & 0.0000 & $0.000 \mathrm{E}+00$ & 0.0000 & $0.000 \mathrm{E}+00$ & 0.0000 & $0.000 \mathrm{E}+00$ & 0.0000 \\
\hline-237 & $9.536 \mathrm{E}-13$ & 0.0000 & $0.000 \mathrm{E}+00$ & 0.0000 & $0.000 \mathrm{E}+00$ & 0.0000 & $0.000 \mathrm{E}+00$ & 0.0000 & $0.000 \mathrm{E}+00$ & 0.0000 & $0.000 \mathrm{E}+00$ & 0.0000 & $0.000 \mathrm{E}+00$ & 0.0000 \\
\hline-238 & $8.139 E-23$ & 0.0000 & $0.000 \mathrm{E}+00$ & 0.0000 & $0.000 \mathrm{E}+00$ & 0.0000 & $0.000 \mathrm{E}+00$ & 0.0000 & $0.000 \mathrm{E}+00$ & 0.0000 & $0.000 \mathrm{E}+00$ & 0.0000 & $0.000 \mathrm{E}+00$ & 0.0000 \\
\hline-239 & $1.202 \mathrm{E}-17$ & 0.0000 & $0.000 \mathrm{E}+00$ & 0.0000 & $0.000 \mathrm{E}+00$ & 0.0000 & $0.000 \mathrm{E}+00$ & 0.0000 & $0.000 \mathrm{E}+00$ & 0.0000 & $0.000 \mathrm{E}+00$ & 0.0000 & $0.000 \mathrm{E}+00$ & 0.0000 \\
\hline-240 & $1.143 \mathrm{E}-24$ & 0.0000 & $0.000 \mathrm{E}+00$ & 0.0000 & $0.000 \mathrm{E}+00$ & 0.0000 & $0.000 \mathrm{E}+00$ & 0.0000 & $0.000 \mathrm{E}+00$ & 0.0000 & $0.000 \mathrm{E}+00$ & 0.0000 & $0.000 \mathrm{E}+00$ & 0.0000 \\
\hline 99 & $5.758 E-26$ & 0.0000 & $0.000 \mathrm{E}+00$ & 0.0000 & $0.000 \mathrm{E}+00$ & 0.0000 & $0.000 \mathrm{E}+00$ & 0.0000 & $0.000 \mathrm{E}+00$ & 0.0000 & $0.000 \mathrm{E}+00$ & 0.0000 & $0.000 \mathrm{E}+00$ & 0.0000 \\
\hline-228 & $1.382 \mathrm{E}-06$ & 0.9905 & $0.000 \mathrm{E}+00$ & 0.0000 & $0.000 \mathrm{E}+00$ & 0.0000 & $0.000 \mathrm{E}+00$ & 0.0000 & $0.000 \mathrm{E}+00$ & 0.0000 & $0.000 \mathrm{E}+00$ & 0.0000 & $0.000 \mathrm{E}+00$ & 0.0000 \\
\hline 230 & $3.774 \mathrm{E}-11$ & 0.0000 & $0.000 \mathrm{E}+00$ & 0.0000 & $0.000 \mathrm{E}+00$ & 0.0000 & $0.000 \mathrm{E}+00$ & 0.0000 & $0.000 \mathrm{E}+00$ & 0.0000 & $0.000 \mathrm{E}+00$ & 0.0000 & $0.000 \mathrm{E}+00$ & 0.0000 \\
\hline-232 & $1.178 E-08$ & 0.0084 & $0.000 \mathrm{E}+00$ & 0.0000 & $0.000 \mathrm{E}+00$ & 0.0000 & $0.000 \mathrm{E}+00$ & 0.0000 & $0.000 \mathrm{E}+00$ & 0.0000 & $0.000 \mathrm{E}+00$ & 0.0000 & $0.000 \mathrm{E}+00$ & 0.0000 \\
\hline 34 & $1.133 E-16$ & 0.0000 & $0.000 \mathrm{E}+00$ & 0.0000 & $0.000 \mathrm{E}+00$ & 0.0000 & $0.000 \mathrm{E}+00$ & 0.0000 & $0.000 \mathrm{E}+00$ & 0.0000 & $0.000 \mathrm{E}+00$ & 0.0000 & $0.000 \mathrm{E}+00$ & 0.0000 \\
\hline 35 & 1. $245 \mathrm{E}-14$ & 0.0000 & $0.000 \mathrm{E}+00$ & 0.0000 & $0.000 \mathrm{E}+00$ & 0.0000 & $0.000 \mathrm{E}+00$ & 0.0000 & $0.000 \mathrm{E}+00$ & 0.0000 & $0.000 \mathrm{E}+00$ & 0.0000 & $0.000 \mathrm{E}+00$ & 0.0000 \\
\hline 38 & $1.420 \mathrm{E}-10$ & 0.0001 & $0.000 \mathrm{E}+00$ & 0.0000 & $0.000 \mathrm{E}+00$ & 0.0000 & $0.000 \mathrm{E}+00$ & 0.0000 & $0.000 \mathrm{E}+00$ & 0.0000 & $0.000 \mathrm{E}+00$ & 0.0000 & $0.000 \mathrm{E}+00$ & 0.0000 \\
\hline & $1.396 \mathrm{E}-06$ & 1.0000 & $0.000 \mathrm{E}+00$ & 0.0000 & $0.000 \mathrm{E}+00$ & 0.0000 & $0.000 \mathrm{E}+00$ & 0.0000 & $0.000 \mathrm{E}+00$ & 0.0000 & $0.000 \mathrm{E}+00$ & 0.0000 & $.000 \mathrm{E}+00$ & 0.0000 \\
\hline
\end{tabular}

Total Dose Contributions TDOSE(i,p,t) for Individual Radionuclides (i) and Pathways (p) As mrem/yr and Fraction of Total Dose At $t=0.000 \mathrm{E}+00$ years

Water Dependent Pathways

\begin{tabular}{|c|c|c|c|c|c|c|c|c|c|c|c|c|c|c|}
\hline \multirow{2}{*}{$\begin{array}{l}\text { Radio- } \\
\text { Nuclide }\end{array}$} & \multicolumn{2}{|c|}{ Water } & \multicolumn{2}{|c|}{ Fish } & \multicolumn{2}{|c|}{ Radon } & \multicolumn{2}{|c|}{ Plant } & \multicolumn{2}{|c|}{ Meat } & \multicolumn{2}{|c|}{ Milk } & \multicolumn{2}{|c|}{ All Pathways* } \\
\hline & mrem/yr & fract. & mrem/yr & fract. & mrem/yr & fract. & mrem/yr & fract. & mrem/yr & fract. & mrem/yr & fract. & mrem/yr & fract. \\
\hline 241 & $0.000 \mathrm{E}+00$ & 0.0000 & $0.000 \mathrm{E}+00$ & 0.0000 & $0.000 \mathrm{E}+00$ & 0.0000 & $0.000 \mathrm{E}+00$ & 0.0000 & $0.000 \mathrm{E}+00$ & 0.0000 & $0.000 \mathrm{E}+00$ & 0.0000 & $1.546 \mathrm{E}-19$ & 0.0000 \\
\hline-137 & $0.000 \mathrm{E}+00$ & 0.0000 & $0.000 \mathrm{E}+00$ & 0.0000 & $0.000 \mathrm{E}+00$ & 0.0000 & $0.000 \mathrm{E}+00$ & 0.0000 & $0.000 \mathrm{E}+00$ & 0.0000 & $0.000 \mathrm{E}+00$ & 0.0000 & $1.262 \mathrm{E}-09$ & 0.0009 \\
\hline-237 & $0.000 \mathrm{E}+00$ & 0.0000 & $0.000 \mathrm{E}+00$ & 0.0000 & $0.000 \mathrm{E}+00$ & 0.0000 & $0.000 \mathrm{E}+00$ & 0.0000 & $0.000 \mathrm{E}+00$ & 0.0000 & $0.000 \mathrm{E}+00$ & 0.0000 & $9.536 \mathrm{E}-13$ & 0.0000 \\
\hline-238 & $0.000 \mathrm{E}+00$ & 0.0000 & $0.000 \mathrm{E}+00$ & 0.0000 & $0.000 \mathrm{E}+00$ & 0.0000 & $0.000 \mathrm{E}+00$ & 0.0000 & $0.000 \mathrm{E}+00$ & 0.0000 & $0.000 \mathrm{E}+00$ & 0.0000 & $8.139 \mathrm{E}-23$ & 0.0000 \\
\hline-239 & $0.000 \mathrm{E}+00$ & 0.0000 & $0.000 \mathrm{E}+00$ & 0.0000 & $0.000 \mathrm{E}+00$ & 0.0000 & $0.000 \mathrm{E}+00$ & 0.0000 & $0.000 \mathrm{E}+00$ & 0.0000 & $0.000 E+00$ & 0.0000 & $1.202 \mathrm{E}-17$ & 0.0000 \\
\hline-240 & $0.000 \mathrm{E}+00$ & 0.0000 & $0.000 \mathrm{E}+00$ & 0.0000 & $0.000 \mathrm{E}+00$ & 0.0000 & $0.000 \mathrm{E}+00$ & 0.0000 & $0.000 \mathrm{E}+00$ & 0.0000 & $0.000 E+00$ & 0.0000 & $1.143 \mathrm{E}-24$ & 0.0000 \\
\hline-99 & $0.000 \mathrm{E}+00$ & 0.0000 & $0.000 \mathrm{E}+00$ & 0.0000 & $0.000 \mathrm{E}+00$ & 0.0000 & $0.000 \mathrm{E}+00$ & 0.0000 & $0.000 \mathrm{E}+00$ & 0.0000 & $0.000 \mathrm{E}+00$ & 0.0000 & $5.758 \mathrm{E}-26$ & 0.0000 \\
\hline-228 & $0.000 \mathrm{E}+00$ & 0.0000 & $0.000 \mathrm{E}+00$ & 0.0000 & $0.000 \mathrm{E}+00$ & 0.0000 & $0.000 \mathrm{E}+00$ & 0.0000 & $0.000 \mathrm{E}+00$ & 0.0000 & $0.000 \mathrm{E}+00$ & 0.0000 & $1.382 \mathrm{E}-06$ & 0.9905 \\
\hline-230 & $0.000 \mathrm{E}+00$ & 0.0000 & $0.000 \mathrm{E}+00$ & 0.0000 & $0.000 \mathrm{E}+00$ & 0.0000 & $0.000 \mathrm{E}+00$ & 0.0000 & $0.000 \mathrm{E}+00$ & 0.0000 & $0.000 E+00$ & 0.0000 & $3.774 \mathrm{E}-11$ & 0.0000 \\
\hline 232 & $0.000 \mathrm{E}+00$ & 0.0000 & $0.000 \mathrm{E}+00$ & 0.0000 & $0.000 \mathrm{E}+00$ & 0.0000 & $0.000 \mathrm{E}+00$ & 0.0000 & $0.000 \mathrm{E}+00$ & 0.0000 & $0.000 \mathrm{E}+00$ & 0.0000 & $1.178 \mathrm{E}-08$ & 0.0084 \\
\hline 34 & $0.000 \mathrm{E}+00$ & 0.0000 & $0.000 \mathrm{E}+00$ & 0.0000 & $0.000 \mathrm{E}+00$ & 0.0000 & $0.000 \mathrm{E}+00$ & 0.0000 & $0.000 \mathrm{E}+00$ & 0.0000 & $0.000 \mathrm{E}+00$ & 0.0000 & $1.133 \mathrm{E}-16$ & 0.0000 \\
\hline 35 & $0.000 \mathrm{E}+00$ & 0.0000 & $0.000 \mathrm{E}+00$ & 0.0000 & $0.000 \mathrm{E}+00$ & 0.0000 & $0.000 \mathrm{E}+00$ & 0.0000 & $0.000 \mathrm{E}+00$ & 0.0000 & $0.000 \mathrm{E}+00$ & 0.0000 & $1.245 \mathrm{E}-14$ & 0.0000 \\
\hline 38 & $0.000 \mathrm{E}+00$ & 0.0000 & $0.000 \mathrm{E}+00$ & 0.0000 & $0.000 \mathrm{E}+00$ & 0.0000 & $0.000 \mathrm{E}+00$ & 0.0000 & $0.000 \mathrm{E}+00$ & 0.0000 & $0.000 \mathrm{E}+00$ & 0.0000 & 1. $420 \mathrm{E}-10$ & 0.0001 \\
\hline & $0.000 \mathrm{E}+00$ & 0.0000 & $0.000 \mathrm{E}+00$ & 0.0000 & $0.000 \mathrm{E}+00$ & 0.0000 & $0.000 \mathrm{E}+00$ & 0.0000 & $0.000 \mathrm{E}+00$ & 0.0000 & $0.000 \mathrm{E}+00$ & 0.0000 & $6 \mathrm{E}-06$ & 1. \\
\hline
\end{tabular}

* Sum of all water independent and dependent pathways. 
RESRAD, Version 6.5

ummary : RESRAD Parameters for Resident Farmer U-Landfill

File : C: \RESRAD_FAMILY \RESRAD \USERFILES \QCFORSRSG \ONSITERF_SRSG-MAY1.RAD

Total Dose Contributions TDOSE (i,p,t) for Individual Radionuclides (i) and Pathways (p) As mrem/yr and Fraction of Total Dose At $t=1.000 \mathrm{E}+00$ years

Water Independent Pathways (Inhalation excludes radon)

\begin{tabular}{|c|c|c|c|c|c|c|c|c|c|c|c|c|c|c|}
\hline \multirow{2}{*}{ Nuclide } & \multicolumn{2}{|c|}{ Ground } & \multicolumn{2}{|c|}{ Inhalation } & \multicolumn{2}{|c|}{ Radon } & \multicolumn{2}{|c|}{ Plant } & \multicolumn{2}{|c|}{ Meat } & \multicolumn{2}{|c|}{ Milk } & \multicolumn{2}{|c|}{ Soil } \\
\hline & mrem/yr & fract. & mrem/yr & fract. & mrem/yr & fract. & mrem/yr & fract. & mrem/yr & fract. & mrem/yr & fract. & mrem/yr & fract. \\
\hline-241 & $4.680 \mathrm{E}-19$ & 0.0000 & $0.000 \mathrm{E}+00$ & 0.0000 & $0.000 \mathrm{E}+00$ & 0.0000 & $0.000 \mathrm{E}+00$ & 0.0000 & $0.000 \mathrm{E}+00$ & 0.0000 & $0.000 \mathrm{E}+00$ & 0.0000 & $0.000 \mathrm{E}+00$ & 0.0000 \\
\hline-137 & $1.243 E-09$ & 0.0012 & $0.000 \mathrm{E}+00$ & 0.0000 & $0.000 \mathrm{E}+00$ & 0.0000 & $0.000 \mathrm{E}+00$ & 0.0000 & $0.000 \mathrm{E}+00$ & 0.0000 & $0.000 \mathrm{E}+00$ & 0.0000 & $0.000 \mathrm{E}+00$ & 0.0000 \\
\hline-237 & $9.638 E-13$ & 0.0000 & $0.000 \mathrm{E}+00$ & 0.0000 & $0.000 \mathrm{E}+00$ & 0.0000 & $0.000 \mathrm{E}+00$ & 0.0000 & $0.000 \mathrm{E}+00$ & 0.0000 & $0.000 \mathrm{E}+00$ & 0.0000 & $0.000 \mathrm{E}+00$ & 0.0000 \\
\hline-238 & 1. $209 \mathrm{E}-21$ & 0.0000 & $0.000 \mathrm{E}+00$ & 0.0000 & $0.000 \mathrm{E}+00$ & 0.0000 & $0.000 \mathrm{E}+00$ & 0.0000 & $0.000 \mathrm{E}+00$ & 0.0000 & $0.000 \mathrm{E}+00$ & 0.0000 & $0.000 \mathrm{E}+00$ & 0.0000 \\
\hline-239 & $1.217 \mathrm{E}-17$ & 0.0000 & $0.000 \mathrm{E}+00$ & 0.0000 & $0.000 \mathrm{E}+00$ & 0.0000 & $0.000 \mathrm{E}+00$ & 0.0000 & $0.000 \mathrm{E}+00$ & 0.0000 & $0.000 \mathrm{E}+00$ & 0.0000 & $0.000 \mathrm{E}+00$ & 0.0000 \\
\hline-240 & $1.188 \mathrm{E}-24$ & 0.0000 & $0.000 \mathrm{E}+00$ & 0.0000 & $0.000 \mathrm{E}+00$ & 0.0000 & $0.000 \mathrm{E}+00$ & 0.0000 & $0.000 \mathrm{E}+00$ & 0.0000 & $0.000 \mathrm{E}+00$ & 0.0000 & $0.000 \mathrm{E}+00$ & 0.0000 \\
\hline 99 & $5.817 \mathrm{E}-26$ & 0.0000 & $0.000 \mathrm{E}+00$ & 0.0000 & $0.000 \mathrm{E}+00$ & 0.0000 & $0.000 \mathrm{E}+00$ & 0.0000 & $0.000 \mathrm{E}+00$ & 0.0000 & $0.000 \mathrm{E}+00$ & 0.0000 & $0.000 \mathrm{E}+00$ & 0.0000 \\
\hline-228 & $9.680 \mathrm{E}-07$ & 0.9321 & $0.000 \mathrm{E}+00$ & 0.0000 & $0.000 \mathrm{E}+00$ & 0.0000 & $0.000 \mathrm{E}+00$ & 0.0000 & $0.000 \mathrm{E}+00$ & 0.0000 & $0.000 \mathrm{E}+00$ & 0.0000 & $0.000 \mathrm{E}+00$ & 0.0000 \\
\hline 230 & 1. $139 \mathrm{E}-10$ & 0.0001 & $0.000 \mathrm{E}+00$ & 0.0000 & $0.000 \mathrm{E}+00$ & 0.0000 & $0.000 \mathrm{E}+00$ & 0.0000 & $0.000 \mathrm{E}+00$ & 0.0000 & $0.000 \mathrm{E}+00$ & 0.0000 & $0.000 \mathrm{E}+00$ & 0.0000 \\
\hline-232 & $6.899 E-08$ & 0.0664 & $0.000 \mathrm{E}+00$ & 0.0000 & $0.000 \mathrm{E}+00$ & 0.0000 & $0.000 \mathrm{E}+00$ & 0.0000 & $0.000 \mathrm{E}+00$ & 0.0000 & $0.000 \mathrm{E}+00$ & 0.0000 & $0.000 \mathrm{E}+00$ & 0.0000 \\
\hline 234 & $7.978 \mathrm{E}-16$ & 0.0000 & $0.000 \mathrm{E}+00$ & 0.0000 & $0.000 \mathrm{E}+00$ & 0.0000 & $0.000 \mathrm{E}+00$ & 0.0000 & $0.000 \mathrm{E}+00$ & 0.0000 & $0.000 \mathrm{E}+00$ & 0.0000 & $0.000 \mathrm{E}+00$ & 0.0000 \\
\hline 35 & $1.266 \mathrm{E}-14$ & 0.0000 & $0.000 \mathrm{E}+00$ & 0.0000 & $0.000 \mathrm{E}+00$ & 0.0000 & $0.000 \mathrm{E}+00$ & 0.0000 & $0.000 \mathrm{E}+00$ & 0.0000 & $0.000 \mathrm{E}+00$ & 0.0000 & $0.000 \mathrm{E}+00$ & 0.0000 \\
\hline 38 & $1.431 \mathrm{E}-10$ & 0.0001 & $0.000 \mathrm{E}+00$ & 0.0000 & $0.000 \mathrm{E}+00$ & 0.0000 & $0.000 \mathrm{E}+00$ & 0.0000 & $0.000 \mathrm{E}+00$ & 0.0000 & $0.000 \mathrm{E}+00$ & 0.0000 & $0.000 \mathrm{E}+00$ & 0.0000 \\
\hline & $1.038 E-06$ & 1.0000 & $0.000 \mathrm{E}+00$ & 0.0000 & $0.000 \mathrm{E}+00$ & 0.0000 & $0.000 \mathrm{E}+00$ & 0.0000 & $0.000 \mathrm{E}+00$ & 0.0000 & $0.000 \mathrm{E}+00$ & 0.0000 & $.000 \mathrm{E}+00$ & 0.0000 \\
\hline
\end{tabular}

Total Dose Contributions TDOSE(i,p,t) for Individual Radionuclides (i) and Pathways (p) As mrem/yr and Fraction of Total Dose At $t=1.000 \mathrm{E}+00$ years

Water Dependent Pathways

\begin{tabular}{|c|c|c|c|c|c|c|c|c|c|c|c|c|c|c|}
\hline \multirow{2}{*}{$\begin{array}{l}\text { Radio- } \\
\text { Nuclide }\end{array}$} & \multicolumn{2}{|c|}{ Water } & \multicolumn{2}{|c|}{ Fish } & \multicolumn{2}{|c|}{ Radon } & \multicolumn{2}{|c|}{ Plant } & \multicolumn{2}{|c|}{ Meat } & \multicolumn{2}{|c|}{ Milk } & \multicolumn{2}{|c|}{ All Pathways* } \\
\hline & mrem/yr & fract. & mrem/yr & fract. & mrem/yr & fract. & mrem/yr & fract. & mrem/yr & fract. & mrem/yr & fract. & mrem/yr & fract. \\
\hline 241 & $0.000 \mathrm{E}+00$ & 0.0000 & $0.000 \mathrm{E}+00$ & 0.0000 & $0.000 \mathrm{E}+00$ & 0.0000 & $0.000 \mathrm{E}+00$ & 0.0000 & $0.000 \mathrm{E}+00$ & 0.0000 & $0.000 \mathrm{E}+00$ & 0.0000 & $4.680 \mathrm{E}-19$ & 0.0000 \\
\hline-137 & $0.000 \mathrm{E}+00$ & 0.0000 & $0.000 \mathrm{E}+00$ & 0.0000 & $0.000 \mathrm{E}+00$ & 0.0000 & $0.000 \mathrm{E}+00$ & 0.0000 & $0.000 \mathrm{E}+00$ & 0.0000 & $0.000 \mathrm{E}+00$ & 0.0000 & $1.243 \mathrm{E}-09$ & 0.0012 \\
\hline-237 & $0.000 \mathrm{E}+00$ & 0.0000 & $0.000 \mathrm{E}+00$ & 0.0000 & $0.000 \mathrm{E}+00$ & 0.0000 & $0.000 \mathrm{E}+00$ & 0.0000 & $0.000 \mathrm{E}+00$ & 0.0000 & $0.000 \mathrm{E}+00$ & 0.0000 & $9.638 E-13$ & 0.0000 \\
\hline-238 & $0.000 \mathrm{E}+00$ & 0.0000 & $0.000 \mathrm{E}+00$ & 0.0000 & $0.000 \mathrm{E}+00$ & 0.0000 & $0.000 \mathrm{E}+00$ & 0.0000 & $0.000 \mathrm{E}+00$ & 0.0000 & $0.000 \mathrm{E}+00$ & 0.0000 & $1.209 \mathrm{E}-21$ & 0.0000 \\
\hline-239 & $0.000 \mathrm{E}+00$ & 0.0000 & $0.000 \mathrm{E}+00$ & 0.0000 & $0.000 \mathrm{E}+00$ & 0.0000 & $0.000 \mathrm{E}+00$ & 0.0000 & $0.000 \mathrm{E}+00$ & 0.0000 & $0.000 E+00$ & 0.0000 & $1.217 \mathrm{E}-17$ & 0.0000 \\
\hline-240 & $0.000 \mathrm{E}+00$ & 0.0000 & $0.000 \mathrm{E}+00$ & 0.0000 & $0.000 \mathrm{E}+00$ & 0.0000 & $0.000 \mathrm{E}+00$ & 0.0000 & $0.000 \mathrm{E}+00$ & 0.0000 & $0.000 E+00$ & 0.0000 & $1.188 \mathrm{E}-24$ & 0.0000 \\
\hline 99 & $0.000 \mathrm{E}+00$ & 0.0000 & $0.000 \mathrm{E}+00$ & 0.0000 & $0.000 \mathrm{E}+00$ & 0.0000 & $0.000 \mathrm{E}+00$ & 0.0000 & $0.000 \mathrm{E}+00$ & 0.0000 & $0.000 \mathrm{E}+00$ & 0.0000 & $5.817 \mathrm{E}-26$ & 0.0000 \\
\hline-228 & $0.000 \mathrm{E}+00$ & 0.0000 & $0.000 \mathrm{E}+00$ & 0.0000 & $0.000 \mathrm{E}+00$ & 0.0000 & $0.000 \mathrm{E}+00$ & 0.0000 & $0.000 \mathrm{E}+00$ & 0.0000 & $0.000 \mathrm{E}+00$ & 0.0000 & $9.680 \mathrm{E}-07$ & 0.9321 \\
\hline-230 & $0.000 \mathrm{E}+00$ & 0.0000 & $0.000 \mathrm{E}+00$ & 0.0000 & $0.000 \mathrm{E}+00$ & 0.0000 & $0.000 \mathrm{E}+00$ & 0.0000 & $0.000 \mathrm{E}+00$ & 0.0000 & $0.000 E+00$ & 0.0000 & $1.139 \mathrm{E}-10$ & 0.0001 \\
\hline 232 & $0.000 \mathrm{E}+00$ & 0.0000 & $0.000 \mathrm{E}+00$ & 0.0000 & $0.000 \mathrm{E}+00$ & 0.0000 & $0.000 \mathrm{E}+00$ & 0.0000 & $0.000 \mathrm{E}+00$ & 0.0000 & $0.000 \mathrm{E}+00$ & 0.0000 & $6.899 \mathrm{E}-08$ & 0.0664 \\
\hline 34 & $0.000 \mathrm{E}+00$ & 0.0000 & $0.000 \mathrm{E}+00$ & 0.0000 & $0.000 \mathrm{E}+00$ & 0.0000 & $0.000 \mathrm{E}+00$ & 0.0000 & $0.000 \mathrm{E}+00$ & 0.0000 & $0.000 \mathrm{E}+00$ & 0.0000 & $7.978 \mathrm{E}-16$ & 0.0000 \\
\hline 35 & $0.000 \mathrm{E}+00$ & 0.0000 & $0.000 \mathrm{E}+00$ & 0.0000 & $0.000 \mathrm{E}+00$ & 0.0000 & $0.000 \mathrm{E}+00$ & 0.0000 & $0.000 \mathrm{E}+00$ & 0.0000 & $0.000 \mathrm{E}+00$ & 0.0000 & $1.266 \mathrm{E}-14$ & 0.0000 \\
\hline 38 & $0.000 \mathrm{E}+00$ & 0.0000 & $0.000 \mathrm{E}+00$ & 0.0000 & $0.000 \mathrm{E}+00$ & 0.0000 & $0.000 \mathrm{E}+00$ & 0.0000 & $0.000 \mathrm{E}+00$ & 0.0000 & $0.000 \mathrm{E}+00$ & 0.0000 & 1. $431 \mathrm{E}-10$ & 0.0001 \\
\hline & $0.000 \mathrm{E}+00$ & 0.0000 & $0.000 \mathrm{E}+00$ & 0.0000 & $0.000 \mathrm{E}+00$ & 0.0000 & $0.000 \mathrm{E}+00$ & 0.0000 & $0.000 \mathrm{E}+00$ & 0.0000 & $0.000 \mathrm{E}+00$ & 0.0000 & $E-06$ & 1. \\
\hline
\end{tabular}

* Sum of all water independent and dependent pathways. 
RESRAD, Version 6.5

ummary : RESRAD Parameters for Resident Farmer U-Landfill

File : C: \RESRAD_FAMILY \RESRAD \USERFILES \QCFORSRSG \ONSITERF_SRSG-MAY1.RAD

Total Dose Contributions TDOSE(i,p,t) for Individual Radionuclides (i) and Pathways (p) As mrem/yr and Fraction of Total Dose At $t=5.000 \mathrm{E}+01$ years

Water Independent Pathways (Inhalation excludes radon)

\begin{tabular}{|c|c|c|c|c|c|c|c|c|c|c|c|c|c|c|}
\hline \multirow{2}{*}{ Nuclide } & \multicolumn{2}{|c|}{ Ground } & \multicolumn{2}{|c|}{ Inhalation } & \multicolumn{2}{|c|}{ Radon } & \multicolumn{2}{|c|}{ Plant } & \multicolumn{2}{|c|}{ Meat } & \multicolumn{2}{|c|}{ Milk } & \multicolumn{2}{|c|}{ Soil } \\
\hline & mrem/yr & fract. & mrem/yr & fract. & mrem/yr & fract. & mrem/yr & fract. & mrem/yr & fract. & mrem/yr & fract. & mrem/yr & fract. \\
\hline-241 & $2.564 \mathrm{E}-17$ & 0.0000 & $0.000 \mathrm{E}+00$ & 0.0000 & $0.000 \mathrm{E}+00$ & 0.0000 & $0.000 \mathrm{E}+00$ & 0.0000 & $0.000 \mathrm{E}+00$ & 0.0000 & $0.000 \mathrm{E}+00$ & 0.0000 & $0.000 \mathrm{E}+00$ & 0.0000 \\
\hline-137 & $6.050 \mathrm{E}-10$ & 0.0003 & $0.000 \mathrm{E}+00$ & 0.0000 & $0.000 \mathrm{E}+00$ & 0.0000 & $0.000 \mathrm{E}+00$ & 0.0000 & $0.000 \mathrm{E}+00$ & 0.0000 & $0.000 \mathrm{E}+00$ & 0.0000 & $0.000 \mathrm{E}+00$ & 0.0000 \\
\hline-237 & $1.629 \mathrm{E}-12$ & 0.0000 & $0.000 \mathrm{E}+00$ & 0.0000 & $0.000 \mathrm{E}+00$ & 0.0000 & $0.000 \mathrm{E}+00$ & 0.0000 & $0.000 \mathrm{E}+00$ & 0.0000 & $0.000 \mathrm{E}+00$ & 0.0000 & $0.000 \mathrm{E}+00$ & 0.0000 \\
\hline-238 & $5.266 \mathrm{E}-17$ & 0.0000 & $0.000 \mathrm{E}+00$ & 0.0000 & $0.000 \mathrm{E}+00$ & 0.0000 & $0.000 \mathrm{E}+00$ & 0.0000 & $0.000 \mathrm{E}+00$ & 0.0000 & $0.000 \mathrm{E}+00$ & 0.0000 & $0.000 \mathrm{E}+00$ & 0.0000 \\
\hline-239 & $2.183 E-17$ & 0.0000 & $0.000 \mathrm{E}+00$ & 0.0000 & $0.000 \mathrm{E}+00$ & 0.0000 & $0.000 \mathrm{E}+00$ & 0.0000 & $0.000 \mathrm{E}+00$ & 0.0000 & $0.000 \mathrm{E}+00$ & 0.0000 & $0.000 \mathrm{E}+00$ & 0.0000 \\
\hline-240 & $2.681 \mathrm{E}-21$ & 0.0000 & $0.000 \mathrm{E}+00$ & 0.0000 & $0.000 \mathrm{E}+00$ & 0.0000 & $0.000 \mathrm{E}+00$ & 0.0000 & $0.000 \mathrm{E}+00$ & 0.0000 & $0.000 \mathrm{E}+00$ & 0.0000 & $0.000 \mathrm{E}+00$ & 0.0000 \\
\hline 99 & $9.575 E-26$ & 0.0000 & $0.000 \mathrm{E}+00$ & 0.0000 & $0.000 \mathrm{E}+00$ & 0.0000 & $0.000 \mathrm{E}+00$ & 0.0000 & $0.000 \mathrm{E}+00$ & 0.0000 & $0.000 \mathrm{E}+00$ & 0.0000 & $0.000 \mathrm{E}+00$ & 0.0000 \\
\hline-228 & $2.527 E-14$ & 0.0000 & $0.000 \mathrm{E}+00$ & 0.0000 & $0.000 \mathrm{E}+00$ & 0.0000 & $0.000 \mathrm{E}+00$ & 0.0000 & $0.000 \mathrm{E}+00$ & 0.0000 & $0.000 \mathrm{E}+00$ & 0.0000 & $0.000 \mathrm{E}+00$ & 0.0000 \\
\hline-230 & $5.320 \mathrm{E}-09$ & 0.0024 & $0.000 \mathrm{E}+00$ & 0.0000 & $0.000 \mathrm{E}+00$ & 0.0000 & $0.000 \mathrm{E}+00$ & 0.0000 & $0.000 \mathrm{E}+00$ & 0.0000 & $0.000 \mathrm{E}+00$ & 0.0000 & $0.000 \mathrm{E}+00$ & 0.0000 \\
\hline-232 & $2.241 E-06$ & 0.9973 & $0.000 \mathrm{E}+00$ & 0.0000 & $0.000 \mathrm{E}+00$ & 0.0000 & $0.000 \mathrm{E}+00$ & 0.0000 & $0.000 \mathrm{E}+00$ & 0.0000 & $0.000 \mathrm{E}+00$ & 0.0000 & $0.000 \mathrm{E}+00$ & 0.0000 \\
\hline 234 & 1. $213 \mathrm{E}-12$ & 0.0000 & $0.000 \mathrm{E}+00$ & 0.0000 & $0.000 \mathrm{E}+00$ & 0.0000 & $0.000 \mathrm{E}+00$ & 0.0000 & $0.000 \mathrm{E}+00$ & 0.0000 & $0.000 \mathrm{E}+00$ & 0.0000 & $0.000 \mathrm{E}+00$ & 0.0000 \\
\hline 35 & $9.238 \mathrm{E}-14$ & 0.0000 & $0.000 \mathrm{E}+00$ & 0.0000 & $0.000 \mathrm{E}+00$ & 0.0000 & $0.000 \mathrm{E}+00$ & 0.0000 & $0.000 \mathrm{E}+00$ & 0.0000 & $0.000 \mathrm{E}+00$ & 0.0000 & $0.000 \mathrm{E}+00$ & 0.0000 \\
\hline 38 & $2.116 \mathrm{E}-10$ & 0.0001 & $0.000 \mathrm{E}+00$ & 0.0000 & $0.000 \mathrm{E}+00$ & 0.0000 & $0.000 \mathrm{E}+00$ & 0.0000 & $0.000 \mathrm{E}+00$ & 0.0000 & $0.000 \mathrm{E}+00$ & 0.0000 & $0.000 \mathrm{E}+00$ & 0.0000 \\
\hline & $2.247 \mathrm{E}-06$ & 1.0000 & $0.000 \mathrm{E}+00$ & 0.0000 & $0.000 \mathrm{E}+00$ & 0.0000 & $0.000 \mathrm{E}+00$ & 0.0000 & $0.000 \mathrm{E}+00$ & 0.0000 & $0.000 \mathrm{E}+00$ & 0.0000 & $0.000 \mathrm{E}+00$ & 0.0000 \\
\hline
\end{tabular}

Total Dose Contributions TDOSE(i,p,t) for Individual Radionuclides (i) and Pathways (p) As mrem/yr and Fraction of Total Dose At $t=5.000 \mathrm{E}+01$ years

Water Dependent Pathways

\begin{tabular}{|c|c|c|c|c|c|c|c|c|c|c|c|c|c|c|}
\hline \multirow{2}{*}{$\begin{array}{l}\text { Radio- } \\
\text { Nuclide }\end{array}$} & \multicolumn{2}{|c|}{ Water } & \multicolumn{2}{|c|}{ Fish } & \multicolumn{2}{|c|}{ Radon } & \multicolumn{2}{|c|}{ Plant } & \multicolumn{2}{|c|}{ Meat } & \multicolumn{2}{|c|}{ Milk } & \multicolumn{2}{|c|}{ All Pathways* } \\
\hline & mrem/yr & fract. & mrem/yr & fract. & mrem/yr & fract. & mrem/yr & fract. & mrem/yr & fract. & mrem/yr & fract. & mrem/yr & fract. \\
\hline 241 & $0.000 \mathrm{E}+00$ & 0.0000 & $0.000 \mathrm{E}+00$ & 0.0000 & $0.000 \mathrm{E}+00$ & 0.0000 & $0.000 \mathrm{E}+00$ & 0.0000 & $0.000 \mathrm{E}+00$ & 0.0000 & $0.000 \mathrm{E}+00$ & 0.0000 & $2.564 \mathrm{E}-17$ & 0.0000 \\
\hline-137 & $0.000 \mathrm{E}+00$ & 0.0000 & $0.000 \mathrm{E}+00$ & 0.0000 & $0.000 \mathrm{E}+00$ & 0.0000 & $0.000 \mathrm{E}+00$ & 0.0000 & $0.000 \mathrm{E}+00$ & 0.0000 & $0.000 \mathrm{E}+00$ & 0.0000 & $6.050 \mathrm{E}-10$ & 0.0003 \\
\hline-237 & $0.000 \mathrm{E}+00$ & 0.0000 & $0.000 \mathrm{E}+00$ & 0.0000 & $0.000 \mathrm{E}+00$ & 0.0000 & $0.000 \mathrm{E}+00$ & 0.0000 & $0.000 \mathrm{E}+00$ & 0.0000 & $0.000 \mathrm{E}+00$ & 0.0000 & $1.629 \mathrm{E}-12$ & 0.0000 \\
\hline-238 & $0.000 \mathrm{E}+00$ & 0.0000 & $0.000 \mathrm{E}+00$ & 0.0000 & $0.000 \mathrm{E}+00$ & 0.0000 & $0.000 \mathrm{E}+00$ & 0.0000 & $0.000 \mathrm{E}+00$ & 0.0000 & $0.000 \mathrm{E}+00$ & 0.0000 & $5.266 \mathrm{E}-17$ & 0.0000 \\
\hline-239 & $0.000 \mathrm{E}+00$ & 0.0000 & $0.000 \mathrm{E}+00$ & 0.0000 & $0.000 \mathrm{E}+00$ & 0.0000 & $0.000 \mathrm{E}+00$ & 0.0000 & $0.000 \mathrm{E}+00$ & 0.0000 & $0.000 E+00$ & 0.0000 & $2.183 \mathrm{E}-17$ & 0.0000 \\
\hline-240 & $0.000 \mathrm{E}+00$ & 0.0000 & $0.000 \mathrm{E}+00$ & 0.0000 & $0.000 \mathrm{E}+00$ & 0.0000 & $0.000 \mathrm{E}+00$ & 0.0000 & $0.000 \mathrm{E}+00$ & 0.0000 & $0.000 E+00$ & 0.0000 & $2.681 \mathrm{E}-21$ & 0.0000 \\
\hline-99 & $0.000 \mathrm{E}+00$ & 0.0000 & $0.000 \mathrm{E}+00$ & 0.0000 & $0.000 \mathrm{E}+00$ & 0.0000 & $0.000 \mathrm{E}+00$ & 0.0000 & $0.000 \mathrm{E}+00$ & 0.0000 & $0.000 \mathrm{E}+00$ & 0.0000 & $9.575 \mathrm{E}-26$ & 0.0000 \\
\hline-228 & $0.000 \mathrm{E}+00$ & 0.0000 & $0.000 \mathrm{E}+00$ & 0.0000 & $0.000 \mathrm{E}+00$ & 0.0000 & $0.000 \mathrm{E}+00$ & 0.0000 & $0.000 \mathrm{E}+00$ & 0.0000 & $0.000 \mathrm{E}+00$ & 0.0000 & $2.527 \mathrm{E}-14$ & 0.0000 \\
\hline-230 & $0.000 \mathrm{E}+00$ & 0.0000 & $0.000 \mathrm{E}+00$ & 0.0000 & $0.000 \mathrm{E}+00$ & 0.0000 & $0.000 \mathrm{E}+00$ & 0.0000 & $0.000 \mathrm{E}+00$ & 0.0000 & $0.000 E+00$ & 0.0000 & $5.320 \mathrm{E}-09$ & 0.0024 \\
\hline 232 & $0.000 \mathrm{E}+00$ & 0.0000 & $0.000 \mathrm{E}+00$ & 0.0000 & $0.000 \mathrm{E}+00$ & 0.0000 & $0.000 \mathrm{E}+00$ & 0.0000 & $0.000 \mathrm{E}+00$ & 0.0000 & $0.000 \mathrm{E}+00$ & 0.0000 & $2.241 E-06$ & 0.9973 \\
\hline 34 & $0.000 \mathrm{E}+00$ & 0.0000 & $0.000 \mathrm{E}+00$ & 0.0000 & $0.000 \mathrm{E}+00$ & 0.0000 & $0.000 \mathrm{E}+00$ & 0.0000 & $0.000 \mathrm{E}+00$ & 0.0000 & $0.000 \mathrm{E}+00$ & 0.0000 & 1. $213 \mathrm{E}-12$ & 0.0000 \\
\hline 35 & $0.000 \mathrm{E}+00$ & 0.0000 & $0.000 \mathrm{E}+00$ & 0.0000 & $0.000 \mathrm{E}+00$ & 0.0000 & $0.000 \mathrm{E}+00$ & 0.0000 & $0.000 \mathrm{E}+00$ & 0.0000 & $0.000 \mathrm{E}+00$ & 0.0000 & $9.238 \mathrm{E}-14$ & 0.0000 \\
\hline 38 & $0.000 \mathrm{E}+00$ & 0.0000 & $0.000 \mathrm{E}+00$ & 0.0000 & $0.000 \mathrm{E}+00$ & 0.0000 & $0.000 \mathrm{E}+00$ & 0.0000 & $0.000 \mathrm{E}+00$ & 0.0000 & $0.000 \mathrm{E}+00$ & 0.0000 & $2.116 \mathrm{E}-10$ & 0.0001 \\
\hline & $0.000 \mathrm{E}+00$ & 0.0000 & $0.000 \mathrm{E}+00$ & 0.0000 & $0.000 \mathrm{E}+00$ & 0.0000 & $0.000 \mathrm{E}+00$ & 0.0000 & $0.000 \mathrm{E}+00$ & 0.0000 & $0.000 \mathrm{E}+00$ & 0.0000 & $7 E-06$ & 1. \\
\hline
\end{tabular}

* Sum of all water independent and dependent pathways. 
RESRAD, Version 6.5

ummary : RESRAD Parameters for Resident Farmer U-Landfill

File : C: \RESRAD_FAMILY \RESRAD \USERFILES \QCFORSRSG \ONSITERF_SRSG-MAY1.RAD

Total Dose Contributions TDOSE (i,p,t) for Individual Radionuclides (i) and Pathways (p) As mrem/yr and Fraction of Total Dose At $t=1.000 \mathrm{E}+02$ years

Water Independent Pathways (Inhalation excludes radon)

\begin{tabular}{|c|c|c|c|c|c|c|c|c|c|c|c|c|c|c|}
\hline & \multicolumn{2}{|c|}{ Ground } & \multicolumn{2}{|c|}{ Inhalation } & \multicolumn{2}{|c|}{ Radon } & \multicolumn{2}{|c|}{ Plant } & \multicolumn{2}{|c|}{ Meat } & \multicolumn{2}{|c|}{ Milk } & \multicolumn{2}{|c|}{ Soil } \\
\hline clide & mrem/yr & fract. & mrem/yr & fract. & mrem/yr & fract. & mrem/yr & fract. & mrem/yr & fract. & mrem/yr & fract. & mrem/yr & fract. \\
\hline 241 & $8.401 E-17$ & 0.0000 & $0.000 \mathrm{E}+00$ & 0.0000 & $0.000 \mathrm{E}+00$ & 0.0000 & $0.000 \mathrm{E}+00$ & 0.0000 & $0.000 \mathrm{E}+00$ & 0.0000 & $0.000 \mathrm{E}+00$ & 0.0000 & $0.000 \mathrm{E}+00$ & 0.0000 \\
\hline-137 & $2.901 E-10$ & 0.0001 & $0.000 \mathrm{E}+00$ & 0.0000 & $0.000 \mathrm{E}+00$ & 0.0000 & $0.000 \mathrm{E}+00$ & 0.0000 & $0.000 \mathrm{E}+00$ & 0.0000 & $0.000 \mathrm{E}+00$ & 0.0000 & $0.000 \mathrm{E}+00$ & 0.0000 \\
\hline-237 & $2.788 E-12$ & 0.0000 & $0.000 \mathrm{E}+00$ & 0.0000 & $0.000 \mathrm{E}+00$ & 0.0000 & $0.000 \mathrm{E}+00$ & 0.0000 & $0.000 \mathrm{E}+00$ & 0.0000 & $0.000 \mathrm{E}+00$ & 0.0000 & $0.000 \mathrm{E}+00$ & 0.0000 \\
\hline-238 & $5.323 E-16$ & 0.0000 & $0.000 \mathrm{E}+00$ & 0.0000 & $0.000 \mathrm{E}+00$ & 0.0000 & $0.000 \mathrm{E}+00$ & 0.0000 & $0.000 \mathrm{E}+00$ & 0.0000 & $0.000 \mathrm{E}+00$ & 0.0000 & $0.000 \mathrm{E}+00$ & 0.0000 \\
\hline-239 & $3.966 \mathrm{E}-17$ & 0.0000 & $0.000 \mathrm{E}+00$ & 0.0000 & $0.000 \mathrm{E}+00$ & 0.0000 & $0.000 \mathrm{E}+00$ & 0.0000 & $0.000 \mathrm{E}+00$ & 0.0000 & $0.000 \mathrm{E}+00$ & 0.0000 & $0.000 \mathrm{E}+00$ & 0.0000 \\
\hline-240 & $1.783 E-20$ & 0.0000 & $0.000 \mathrm{E}+00$ & 0.0000 & $0.000 \mathrm{E}+00$ & 0.0000 & $0.000 \mathrm{E}+00$ & 0.0000 & $0.000 \mathrm{E}+00$ & 0.0000 & $0.000 \mathrm{E}+00$ & 0.0000 & $0.000 \mathrm{E}+00$ & 0.0000 \\
\hline 99 & 1. $592 \mathrm{E}-25$ & 0.0000 & $0.000 \mathrm{E}+00$ & 0.0000 & $0.000 \mathrm{E}+00$ & 0.0000 & $0.000 \mathrm{E}+00$ & 0.0000 & $0.000 \mathrm{E}+00$ & 0.0000 & $0.000 \mathrm{E}+00$ & 0.0000 & $0.000 \mathrm{E}+00$ & 0.0000 \\
\hline-228 & $4.618 E-22$ & 0.0000 & $0.000 \mathrm{E}+00$ & 0.0000 & $0.000 \mathrm{E}+00$ & 0.0000 & $0.000 \mathrm{E}+00$ & 0.0000 & $0.000 \mathrm{E}+00$ & 0.0000 & $0.000 \mathrm{E}+00$ & 0.0000 & $0.000 \mathrm{E}+00$ & 0.0000 \\
\hline-230 & $1.479 \mathrm{E}-08$ & 0.0049 & $0.000 \mathrm{E}+00$ & 0.0000 & $0.000 \mathrm{E}+00$ & 0.0000 & $0.000 \mathrm{E}+00$ & 0.0000 & $0.000 \mathrm{E}+00$ & 0.0000 & $0.000 \mathrm{E}+00$ & 0.0000 & $0.000 \mathrm{E}+00$ & 0.0000 \\
\hline-232 & $3.033 E-06$ & 0.9949 & $0.000 \mathrm{E}+00$ & 0.0000 & $0.000 \mathrm{E}+00$ & 0.0000 & $0.000 \mathrm{E}+00$ & 0.0000 & $0.000 \mathrm{E}+00$ & 0.0000 & $0.000 \mathrm{E}+00$ & 0.0000 & $0.000 \mathrm{E}+00$ & 0.0000 \\
\hline 234 & $6.737 \mathrm{E}-12$ & 0.0000 & $0.000 \mathrm{E}+00$ & 0.0000 & $0.000 \mathrm{E}+00$ & 0.0000 & $0.000 \mathrm{E}+00$ & 0.0000 & $0.000 \mathrm{E}+00$ & 0.0000 & $0.000 \mathrm{E}+00$ & 0.0000 & $0.000 \mathrm{E}+00$ & 0.0000 \\
\hline 235 & $3.388 \mathrm{E}-13$ & 0.0000 & $0.000 \mathrm{E}+00$ & 0.0000 & $0.000 \mathrm{E}+00$ & 0.0000 & $0.000 \mathrm{E}+00$ & 0.0000 & $0.000 \mathrm{E}+00$ & 0.0000 & $0.000 \mathrm{E}+00$ & 0.0000 & $0.000 \mathrm{E}+00$ & 0.0000 \\
\hline 38 & $3.153 \mathrm{E}-10$ & 0.0001 & $0.000 \mathrm{E}+00$ & 0.0000 & $0.000 \mathrm{E}+00$ & 0.0000 & $0.000 \mathrm{E}+00$ & 0.0000 & $0.000 \mathrm{E}+00$ & 0.0000 & $0.000 \mathrm{E}+00$ & 0.0000 & $0.000 \mathrm{E}+00$ & 0.0000 \\
\hline & $3.048 E-06$ & 1.0000 & $0.000 \mathrm{E}+00$ & 0.0000 & $0.000 \mathrm{E}+00$ & 0.0000 & $0.000 \mathrm{E}+00$ & 0.0000 & $0.000 \mathrm{E}+00$ & 0.0000 & $0.000 \mathrm{E}+00$ & 0.0000 & $0.000 \mathrm{E}+00$ & 0.0000 \\
\hline
\end{tabular}

Total Dose Contributions TDOSE(i,p,t) for Individual Radionuclides (i) and Pathways (p) As mrem/yr and Fraction of Total Dose At $t=1.000 \mathrm{E}+02$ years

Water Dependent Pathways

\begin{tabular}{|c|c|c|c|c|c|c|c|c|c|c|c|c|c|c|}
\hline & \multicolumn{2}{|c|}{ Water } & \multicolumn{2}{|c|}{ Fish } & \multicolumn{2}{|c|}{ Radon } & \multicolumn{2}{|c|}{ Plant } & \multicolumn{2}{|c|}{ Meat } & \multicolumn{2}{|c|}{ Milk } & \multicolumn{2}{|c|}{ All Pathways* } \\
\hline ide & mrem/yr & fract. & mrem/yr & fract. & mrem/yr & fract. & mrem/yr & fract. & mrem/yr & fract. & mrem/yr & fract. & mrem/yr & fract. \\
\hline-241 & $0.000 \mathrm{E}+00$ & 0.0000 & $0.000 \mathrm{E}+00$ & 0.0000 & $0.000 \mathrm{E}+00$ & 0.0000 & $0.000 \mathrm{E}+00$ & 0.0000 & $0.000 \mathrm{E}+00$ & 0.0000 & $0.000 E+00$ & 0.0000 & $8.401 \mathrm{E}-17$ & 0.0000 \\
\hline-137 & $0.000 \mathrm{E}+00$ & 0.0000 & $0.000 \mathrm{E}+00$ & 0.0000 & $0.000 \mathrm{E}+00$ & 0.0000 & $0.000 \mathrm{E}+00$ & 0.0000 & $0.000 \mathrm{E}+00$ & 0.0000 & $0.000 \mathrm{E}+00$ & 0.0000 & $2.901 \mathrm{E}-10$ & 0.0001 \\
\hline 7 & $0.000 \mathrm{E}+00$ & 0.0000 & $0.000 \mathrm{E}+00$ & 0.0000 & $0.000 \mathrm{E}+00$ & 0.0000 & $0.000 \mathrm{E}+00$ & 0.0000 & $0.000 \mathrm{E}+00$ & 0.0000 & $0.000 \mathrm{E}+00$ & 0.0000 & $2.788 \mathrm{E}-12$ & 0.0000 \\
\hline 238 & $0.000 \mathrm{E}+00$ & 0.0000 & $0.000 \mathrm{E}+00$ & 0.0000 & $0.000 \mathrm{E}+00$ & 0.0000 & $0.000 \mathrm{E}+00$ & 0.0000 & $0.000 \mathrm{E}+00$ & 0.0000 & $0.000 \mathrm{E}+00$ & 0.0000 & $5.323 E-16$ & 0.0000 \\
\hline 239 & $0.000 \mathrm{E}+00$ & 0.0000 & $0.000 \mathrm{E}+00$ & 0.0000 & $0.000 \mathrm{E}+00$ & 0.0000 & $0.000 \mathrm{E}+00$ & 0.0000 & $0.000 \mathrm{E}+00$ & 0.0000 & $0.000 \mathrm{E}+00$ & 0.0000 & $3.966 \mathrm{E}-17$ & 0.0000 \\
\hline-240 & $0.000 \mathrm{E}+00$ & 0.0000 & $0.000 \mathrm{E}+00$ & 0.0000 & $0.000 \mathrm{E}+00$ & 0.0000 & $0.000 \mathrm{E}+00$ & 0.0000 & $0.000 \mathrm{E}+00$ & 0.0000 & $0.000 \mathrm{E}+00$ & 0.0000 & $1.783 \mathrm{E}-20$ & 0.0000 \\
\hline 99 & $0.000 \mathrm{E}+00$ & 0.0000 & $0.000 \mathrm{E}+00$ & 0.0000 & $0.000 \mathrm{E}+00$ & 0.0000 & $0.000 \mathrm{E}+00$ & 0.0000 & $0.000 \mathrm{E}+00$ & 0.0000 & $0.000 \mathrm{E}+00$ & 0.0000 & $1.592 \mathrm{E}-25$ & 0.0000 \\
\hline-228 & $0.000 \mathrm{E}+00$ & 0.0000 & $0.000 \mathrm{E}+00$ & 0.0000 & $0.000 \mathrm{E}+00$ & 0.0000 & $0.000 \mathrm{E}+00$ & 0.0000 & $0.000 \mathrm{E}+00$ & 0.0000 & $0.000 \mathrm{E}+00$ & 0.0000 & 4. $618 \mathrm{E}-22$ & 0.0000 \\
\hline 230 & $0.000 \mathrm{E}+00$ & 0.0000 & $0.000 \mathrm{E}+00$ & 0.0000 & $0.000 \mathrm{E}+00$ & 0.0000 & $0.000 \mathrm{E}+00$ & 0.0000 & $0.000 \mathrm{E}+00$ & 0.0000 & $0.000 \mathrm{E}+00$ & 0.0000 & $1.479 \mathrm{E}-08$ & 0.0049 \\
\hline 232 & $0.000 \mathrm{E}+00$ & 0.0000 & $0.000 \mathrm{E}+00$ & 0.0000 & $0.000 \mathrm{E}+00$ & 0.0000 & $0.000 \mathrm{E}+00$ & 0.0000 & $0.000 \mathrm{E}+00$ & 0.0000 & $0.000 \mathrm{E}+00$ & 0.0000 & $3.033 E-06$ & 0.9949 \\
\hline 34 & $0.000 \mathrm{E}+00$ & 0.0000 & $0.000 \mathrm{E}+00$ & 0.0000 & $0.000 \mathrm{E}+00$ & 0.0000 & $0.000 \mathrm{E}+00$ & 0.0000 & $0.000 \mathrm{E}+00$ & 0.0000 & $0.000 \mathrm{E}+00$ & 0.0000 & $6.737 \mathrm{E}-12$ & 0.0000 \\
\hline & $0.000 \mathrm{E}+00$ & 0.0000 & $0.000 \mathrm{E}+00$ & 0.0000 & $0.000 \mathrm{E}+00$ & 0.0000 & $0.000 \mathrm{E}+00$ & 0.0000 & $0.000 \mathrm{E}+00$ & 0.0000 & $0.000 \mathrm{E}+00$ & 0.0000 & $3.388 \mathrm{E}-13$ & 0.0000 \\
\hline & $0.000 \mathrm{E}+00$ & 0.0000 & $0.000 \mathrm{E}+00$ & 0.0000 & $0.000 \mathrm{E}+00$ & 0.0000 & $0.000 \mathrm{E}+00$ & 0.0000 & $0.000 \mathrm{E}+00$ & 0.0000 & $0.000 \mathrm{E}+00$ & 0.0000 & $3.153 \mathrm{E}-10$ & 0.0001 \\
\hline & 0 & 00 & $\Xi+00$ & 00 & $E+00$ & 00 & $00 E+00$ & 00 & $.000 \mathrm{E}+00$ & 00 & $.000 \mathrm{E}+00$ & 000 & 06 & 0 \\
\hline
\end{tabular}

* Sum of all water independent and dependent pathways. 
RESRAD, Version 6.5

mmary : RESRAD Parameters for Resident Farmer U-Landfill

: C: \RESRAD_FAMILY \RESRAD \USERFILES \QCFORSRSG OONSITERF_SRSG-MAY1.RAD

Total Dose Contributions TDOSE(i,p,t) for Individual Radionuclides (i) and Pathways (p) As mrem/yr and Fraction of Total Dose At $t=5.000 \mathrm{E}+02$ years

Water Independent Pathways (Inhalation excludes radon)

\begin{tabular}{|c|c|c|c|c|c|c|c|c|c|c|c|c|c|c|}
\hline \multirow{2}{*}{ Nuclide } & \multicolumn{2}{|c|}{ Ground } & \multicolumn{2}{|c|}{ Inhalation } & \multicolumn{2}{|c|}{ Radon } & \multicolumn{2}{|c|}{ Plant } & \multicolumn{2}{|c|}{ Meat } & \multicolumn{2}{|c|}{ Milk } & \multicolumn{2}{|c|}{ Soil } \\
\hline & mrem/yr & fract. & mrem/yr & fract. & mrem/yr & fract. & mrem/yr & fract. & mrem/yr & fract. & mrem/yr & fract. & mrem/yr & fract. \\
\hline-241 & $2.295 E-14$ & 0.0000 & $0.000 \mathrm{E}+00$ & 0.0000 & $0.000 \mathrm{E}+00$ & 0.0000 & $0.000 \mathrm{E}+00$ & 0.0000 & $0.000 \mathrm{E}+00$ & 0.0000 & $0.000 \mathrm{E}+00$ & 0.0000 & $0.000 \mathrm{E}+00$ & 0.0000 \\
\hline-137 & $8.104 \mathrm{E}-13$ & 0.0000 & $0.000 \mathrm{E}+00$ & 0.0000 & $0.000 \mathrm{E}+00$ & 0.0000 & $0.000 \mathrm{E}+00$ & 0.0000 & $0.000 \mathrm{E}+00$ & 0.0000 & $0.000 \mathrm{E}+00$ & 0.0000 & $0.000 \mathrm{E}+00$ & 0.0000 \\
\hline-237 & $2.044 \mathrm{E}-10$ & 0.0000 & $0.000 \mathrm{E}+00$ & 0.0000 & $0.000 \mathrm{E}+00$ & 0.0000 & $0.000 \mathrm{E}+00$ & 0.0000 & $0.000 \mathrm{E}+00$ & 0.0000 & $0.000 \mathrm{E}+00$ & 0.0000 & $0.000 \mathrm{E}+00$ & 0.0000 \\
\hline-238 & $5.607 \mathrm{E}-13$ & 0.0000 & $0.000 \mathrm{E}+00$ & 0.0000 & $0.000 \mathrm{E}+00$ & 0.0000 & $0.000 \mathrm{E}+00$ & 0.0000 & $0.000 \mathrm{E}+00$ & 0.0000 & $0.000 \mathrm{E}+00$ & 0.0000 & $0.000 \mathrm{E}+00$ & 0.0000 \\
\hline-239 & $4.708 E-15$ & 0.0000 & $0.000 \mathrm{E}+00$ & 0.0000 & $0.000 \mathrm{E}+00$ & 0.0000 & $0.000 \mathrm{E}+00$ & 0.0000 & $0.000 \mathrm{E}+00$ & 0.0000 & $0.000 \mathrm{E}+00$ & 0.0000 & $0.000 \mathrm{E}+00$ & 0.0000 \\
\hline-240 & $5.719 \mathrm{E}-18$ & 0.0000 & $0.000 \mathrm{E}+00$ & 0.0000 & $0.000 \mathrm{E}+00$ & 0.0000 & $0.000 \mathrm{E}+00$ & 0.0000 & $0.000 \mathrm{E}+00$ & 0.0000 & $0.000 \mathrm{E}+00$ & 0.0000 & $0.000 \mathrm{E}+00$ & 0.0000 \\
\hline 99 & $9.310 \mathrm{E}-24$ & 0.0000 & $0.000 \mathrm{E}+00$ & 0.0000 & $0.000 \mathrm{E}+00$ & 0.0000 & $0.000 \mathrm{E}+00$ & 0.0000 & $0.000 \mathrm{E}+00$ & 0.0000 & $0.000 \mathrm{E}+00$ & 0.0000 & $0.000 \mathrm{E}+00$ & 0.0000 \\
\hline-228 & $0.000 \mathrm{E}+00$ & 0.0000 & $0.000 \mathrm{E}+00$ & 0.0000 & $0.000 \mathrm{E}+00$ & 0.0000 & $0.000 \mathrm{E}+00$ & 0.0000 & $0.000 \mathrm{E}+00$ & 0.0000 & $0.000 \mathrm{E}+00$ & 0.0000 & $0.000 \mathrm{E}+00$ & 0.0000 \\
\hline 230 & $1.071 \mathrm{E}-06$ & 0.0000 & $0.000 \mathrm{E}+00$ & 0.0000 & $0.000 \mathrm{E}+00$ & 0.0000 & $0.000 \mathrm{E}+00$ & 0.0000 & $0.000 \mathrm{E}+00$ & 0.0000 & $0.000 \mathrm{E}+00$ & 0.0000 & $0.000 \mathrm{E}+00$ & 0.0000 \\
\hline-232 & $3.338 E-05$ & 0.0002 & $0.000 \mathrm{E}+00$ & 0.0000 & $0.000 \mathrm{E}+00$ & 0.0000 & $0.000 \mathrm{E}+00$ & 0.0000 & $0.000 \mathrm{E}+00$ & 0.0000 & $0.000 \mathrm{E}+00$ & 0.0000 & $0.000 \mathrm{E}+00$ & 0.0000 \\
\hline 234 & $2.496 \mathrm{E}-09$ & 0.0000 & $0.000 \mathrm{E}+00$ & 0.0000 & $0.000 \mathrm{E}+00$ & 0.0000 & $0.000 \mathrm{E}+00$ & 0.0000 & $0.000 \mathrm{E}+00$ & 0.0000 & $0.000 \mathrm{E}+00$ & 0.0000 & $0.000 \mathrm{E}+00$ & 0.0000 \\
\hline 35 & $7.033 E-11$ & 0.0000 & $0.000 \mathrm{E}+00$ & 0.0000 & $0.000 \mathrm{E}+00$ & 0.0000 & $0.000 \mathrm{E}+00$ & 0.0000 & $0.000 \mathrm{E}+00$ & 0.0000 & $0.000 \mathrm{E}+00$ & 0.0000 & $0.000 \mathrm{E}+00$ & 0.0000 \\
\hline 38 & $7.680 \mathrm{E}-09$ & 0.0000 & $0.000 \mathrm{E}+00$ & 0.0000 & $0.000 \mathrm{E}+00$ & 0.0000 & $0.000 \mathrm{E}+00$ & 0.0000 & $0.000 \mathrm{E}+00$ & 0.0000 & $0.000 \mathrm{E}+00$ & 0.0000 & $0.000 \mathrm{E}+00$ & 0.0000 \\
\hline & $3.446 E-05$ & 0.0002 & $0.000 \mathrm{E}+00$ & 0.0000 & $0.000 \mathrm{E}+00$ & 0.0000 & $0.000 \mathrm{E}+00$ & 0.0000 & $0.000 \mathrm{E}+00$ & 0.0000 & $0.000 \mathrm{E}+00$ & 0.0000 & $.000 \mathrm{E}+00$ & 0.0000 \\
\hline
\end{tabular}

Total Dose Contributions TDOSE(i,p,t) for Individual Radionuclides (i) and Pathways (p) As mrem/yr and Fraction of Total Dose At $t=5.000 \mathrm{E}+02$ years

Water Dependent Pathways

\begin{tabular}{|c|c|c|c|c|c|c|c|c|c|c|c|c|c|c|}
\hline \multirow{2}{*}{$\begin{array}{l}\text { Radio- } \\
\text { Nuclide }\end{array}$} & \multicolumn{2}{|c|}{ Water } & \multicolumn{2}{|c|}{ Fish } & \multicolumn{2}{|c|}{ Radon } & \multicolumn{2}{|c|}{ Plant } & \multicolumn{2}{|c|}{ Meat } & \multicolumn{2}{|c|}{ Milk } & \multicolumn{2}{|c|}{ All Pathways* } \\
\hline & mrem/yr & fract. & mrem/yr & fract. & mrem/yr & fract. & mrem/yr & fract. & mrem/yr & fract. & mrem/yr & fract. & mrem/yr & fract. \\
\hline 241 & $0.000 \mathrm{E}+00$ & 0.0000 & $0.000 \mathrm{E}+00$ & 0.0000 & $0.000 \mathrm{E}+00$ & 0.0000 & $0.000 \mathrm{E}+00$ & 0.0000 & $0.000 \mathrm{E}+00$ & 0.0000 & $0.000 \mathrm{E}+00$ & 0.0000 & $2.295 E-14$ & 0.0000 \\
\hline-137 & $0.000 \mathrm{E}+00$ & 0.0000 & $0.000 \mathrm{E}+00$ & 0.0000 & $0.000 \mathrm{E}+00$ & 0.0000 & $0.000 \mathrm{E}+00$ & 0.0000 & $0.000 \mathrm{E}+00$ & 0.0000 & $0.000 \mathrm{E}+00$ & 0.0000 & $8.104 \mathrm{E}-13$ & 0.0000 \\
\hline-237 & $0.000 \mathrm{E}+00$ & 0.0000 & $0.000 \mathrm{E}+00$ & 0.0000 & $0.000 \mathrm{E}+00$ & 0.0000 & $0.000 \mathrm{E}+00$ & 0.0000 & $0.000 \mathrm{E}+00$ & 0.0000 & $0.000 \mathrm{E}+00$ & 0.0000 & $2.044 \mathrm{E}-10$ & 0.0000 \\
\hline-238 & $0.000 \mathrm{E}+00$ & 0.0000 & $0.000 \mathrm{E}+00$ & 0.0000 & $0.000 \mathrm{E}+00$ & 0.0000 & $0.000 \mathrm{E}+00$ & 0.0000 & $0.000 \mathrm{E}+00$ & 0.0000 & $0.000 \mathrm{E}+00$ & 0.0000 & $5.607 \mathrm{E}-13$ & 0.0000 \\
\hline-239 & $0.000 \mathrm{E}+00$ & 0.0000 & $0.000 \mathrm{E}+00$ & 0.0000 & $0.000 \mathrm{E}+00$ & 0.0000 & $0.000 \mathrm{E}+00$ & 0.0000 & $0.000 \mathrm{E}+00$ & 0.0000 & $0.000 E+00$ & 0.0000 & $4.708 E-15$ & 0.0000 \\
\hline-240 & $0.000 \mathrm{E}+00$ & 0.0000 & $0.000 \mathrm{E}+00$ & 0.0000 & $0.000 \mathrm{E}+00$ & 0.0000 & $0.000 \mathrm{E}+00$ & 0.0000 & $0.000 \mathrm{E}+00$ & 0.0000 & $0.000 E+00$ & 0.0000 & $5.719 \mathrm{E}-18$ & 0.0000 \\
\hline 99 & $1.714 \mathrm{E}-01$ & 0.8276 & $0.000 \mathrm{E}+00$ & 0.0000 & $0.000 \mathrm{E}+00$ & 0.0000 & $1.602 \mathrm{E}-02$ & 0.0774 & $2.868 E-04$ & 0.0014 & $1.936 \mathrm{E}-02$ & 0.0935 & $2.070 \mathrm{E}-01$ & 0.9998 \\
\hline-228 & $0.000 \mathrm{E}+00$ & 0.0000 & $0.000 \mathrm{E}+00$ & 0.0000 & $0.000 \mathrm{E}+00$ & 0.0000 & $0.000 \mathrm{E}+00$ & 0.0000 & $0.000 \mathrm{E}+00$ & 0.0000 & $0.000 E+00$ & 0.0000 & $0.000 \mathrm{E}+00$ & 0.0000 \\
\hline-230 & $0.000 \mathrm{E}+00$ & 0.0000 & $0.000 \mathrm{E}+00$ & 0.0000 & $0.000 \mathrm{E}+00$ & 0.0000 & $0.000 \mathrm{E}+00$ & 0.0000 & $0.000 \mathrm{E}+00$ & 0.0000 & $0.000 E+00$ & 0.0000 & $1.071 \mathrm{E}-06$ & 0.0000 \\
\hline 232 & $0.000 \mathrm{E}+00$ & 0.0000 & $0.000 \mathrm{E}+00$ & 0.0000 & $0.000 \mathrm{E}+00$ & 0.0000 & $0.000 \mathrm{E}+00$ & 0.0000 & $0.000 \mathrm{E}+00$ & 0.0000 & $0.000 \mathrm{E}+00$ & 0.0000 & $3.338 \mathrm{E}-05$ & 0.0002 \\
\hline 34 & $0.000 \mathrm{E}+00$ & 0.0000 & $0.000 \mathrm{E}+00$ & 0.0000 & $0.000 \mathrm{E}+00$ & 0.0000 & $0.000 \mathrm{E}+00$ & 0.0000 & $0.000 \mathrm{E}+00$ & 0.0000 & $0.000 \mathrm{E}+00$ & 0.0000 & $2.496 \mathrm{E}-09$ & 0.0000 \\
\hline 35 & $0.000 \mathrm{E}+00$ & 0.0000 & $0.000 \mathrm{E}+00$ & 0.0000 & $0.000 \mathrm{E}+00$ & 0.0000 & $0.000 \mathrm{E}+00$ & 0.0000 & $0.000 \mathrm{E}+00$ & 0.0000 & $0.000 \mathrm{E}+00$ & 0.0000 & $7.033 E-11$ & 0.0000 \\
\hline 38 & $0.000 \mathrm{E}+00$ & 0.0000 & $0.000 \mathrm{E}+00$ & 0.0000 & $0.000 \mathrm{E}+00$ & 0.0000 & $0.000 \mathrm{E}+00$ & 0.0000 & $0.000 \mathrm{E}+00$ & 0.0000 & $0.000 \mathrm{E}+00$ & 0.0000 & $7.680 \mathrm{E}-09$ & 0.0000 \\
\hline & $1.714 \mathrm{E}-01$ & 0.8276 & $0.000 \mathrm{E}+00$ & 0.0000 & $0.000 \mathrm{E}+00$ & 0.0000 & $1.602 \mathrm{E}-02$ & 0.0774 & $2.868 E-04$ & 0.0014 & $1.936 \mathrm{E}-02$ & 0.0935 & -01 & \\
\hline
\end{tabular}

* Sum of all water independent and dependent pathways. 
RESRAD, Version 6.5

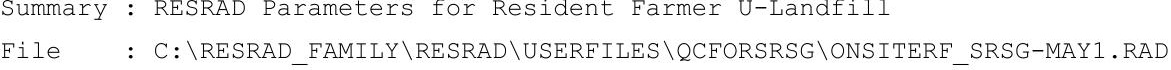

Total Dose Contributions TDOSE (i,p,t) for Individual Radionuclides (i) and Pathways (p) As mrem/yr and Fraction of Total Dose At $t=1.050 \mathrm{E}+03$ years

Water Independent Pathways (Inhalation excludes radon)

\begin{tabular}{|c|c|c|c|c|c|c|c|c|c|c|c|c|c|c|}
\hline \multirow{2}{*}{ Nuclide } & \multicolumn{2}{|c|}{ Ground } & \multicolumn{2}{|c|}{ Inhalation } & \multicolumn{2}{|c|}{ Radon } & \multicolumn{2}{|c|}{ Plant } & \multicolumn{2}{|c|}{ Meat } & \multicolumn{2}{|c|}{ Milk } & \multicolumn{2}{|c|}{ Soil } \\
\hline & mrem/yr & fract. & mrem/yr & fract. & mrem/yr & fract. & mrem/yr & fract. & mrem/yr & fract. & mrem/yr & fract. & mrem/yr & fract. \\
\hline-241 & 1. $216 \mathrm{E}-11$ & 0.0000 & $0.000 \mathrm{E}+00$ & 0.0000 & $0.000 \mathrm{E}+00$ & 0.0000 & $1.983 \mathrm{E}-04$ & 0.0008 & $3.514 \mathrm{E}-07$ & 0.0000 & $3.372 \mathrm{E}-08$ & 0.0000 & $0.000 \mathrm{E}+00$ & 0.0000 \\
\hline-137 & $2.495 E-16$ & 0.0000 & $0.000 \mathrm{E}+00$ & 0.0000 & $0.000 \mathrm{E}+00$ & 0.0000 & $7.688 \mathrm{E}-14$ & 0.0000 & $6.989 \mathrm{E}-14$ & 0.0000 & $5.159 \mathrm{E}-14$ & 0.0000 & $0.000 \mathrm{E}+00$ & 0.0000 \\
\hline-237 & $7.109 \mathrm{E}-08$ & 0.0000 & $0.000 \mathrm{E}+00$ & 0.0000 & $0.000 \mathrm{E}+00$ & 0.0000 & $1.025 \mathrm{E}-02$ & 0.0416 & $3.105 E-04$ & 0.0013 & $4.442 E-06$ & 0.0000 & $0.000 \mathrm{E}+00$ & 0.0000 \\
\hline-238 & 1. $302 \mathrm{E}-10$ & 0.0000 & $0.000 \mathrm{E}+00$ & 0.0000 & $0.000 \mathrm{E}+00$ & 0.0000 & $6.108 E-07$ & 0.0000 & $5.428 \mathrm{E}-09$ & 0.0000 & $1.536 \mathrm{E}-08$ & 0.0000 & $0.000 \mathrm{E}+00$ & 0.0000 \\
\hline-239 & $3.338 \mathrm{E}-12$ & 0.0000 & $0.000 \mathrm{E}+00$ & 0.0000 & $0.000 \mathrm{E}+00$ & 0.0000 & $1.268 \mathrm{E}-03$ & 0.0052 & $3.843 E-06$ & 0.0000 & $1.064 \mathrm{E}-07$ & 0.0000 & $0.000 \mathrm{E}+00$ & 0.0000 \\
\hline-240 & $8.095 \mathrm{E}-16$ & 0.0000 & $0.000 \mathrm{E}+00$ & 0.0000 & $0.000 \mathrm{E}+00$ & 0.0000 & $1.170 \mathrm{E}-03$ & 0.0047 & $3.544 \mathrm{E}-06$ & 0.0000 & $9.901 \mathrm{E}-08$ & 0.0000 & $0.000 \mathrm{E}+00$ & 0.0000 \\
\hline 99 & $2.503 E-21$ & 0.0000 & $0.000 \mathrm{E}+00$ & 0.0000 & $0.000 \mathrm{E}+00$ & 0.0000 & 1. $325 \mathrm{E}-06$ & 0.0000 & $4.021 E-09$ & 0.0000 & $1.113 \mathrm{E}-07$ & 0.0000 & $0.000 \mathrm{E}+00$ & 0.0000 \\
\hline-228 & $0.000 \mathrm{E}+00$ & 0.0000 & $0.000 \mathrm{E}+00$ & 0.0000 & $0.000 \mathrm{E}+00$ & 0.0000 & $0.000 \mathrm{E}+00$ & 0.0000 & $0.000 \mathrm{E}+00$ & 0.0000 & $0.000 \mathrm{E}+00$ & 0.0000 & $0.000 \mathrm{E}+00$ & 0.0000 \\
\hline-230 & $8.967 \mathrm{E}-05$ & 0.0004 & $0.000 \mathrm{E}+00$ & 0.0000 & $0.000 \mathrm{E}+00$ & 0.0000 & $5.809 \mathrm{E}-02$ & 0.2359 & $1.529 \mathrm{E}-03$ & 0.0062 & $2.709 \mathrm{E}-03$ & 0.0110 & $0.000 \mathrm{E}+00$ & 0.0000 \\
\hline-232 & $9.244 \mathrm{E}-04$ & 0.0038 & $0.000 \mathrm{E}+00$ & 0.0000 & $0.000 \mathrm{E}+00$ & 0.0000 & $1.481 \mathrm{E}-01$ & 0.6016 & $4.371 \mathrm{E}-03$ & 0.0178 & 1. $210 \mathrm{E}-02$ & 0.0492 & $0.000 \mathrm{E}+00$ & 0.0000 \\
\hline 234 & $4.542 \mathrm{E}-07$ & 0.0000 & $0.000 \mathrm{E}+00$ & 0.0000 & $0.000 \mathrm{E}+00$ & 0.0000 & $9.271 \mathrm{E}-04$ & 0.0038 & 1. $415 \mathrm{E}-05$ & 0.0001 & $4.547 E-05$ & 0.0002 & $0.000 \mathrm{E}+00$ & 0.0000 \\
\hline 235 & $2.349 \mathrm{E}-08$ & 0.0000 & $0.000 \mathrm{E}+00$ & 0.0000 & $0.000 \mathrm{E}+00$ & 0.0000 & $1.767 \mathrm{E}-03$ & 0.0072 & $1.303 E-04$ & 0.0005 & $3.189 \mathrm{E}-05$ & 0.0001 & $0.000 \mathrm{E}+00$ & 0.0000 \\
\hline 38 & $6.200 E-07$ & 0.0000 & $0.000 \mathrm{E}+00$ & 0.0000 & $0.000 \mathrm{E}+00$ & 0.0000 & $6.329 \mathrm{E}-04$ & 0.0026 & $6.525 \mathrm{E}-06$ & 0.0000 & $3.185 \mathrm{E}-05$ & 0.0001 & $0.000 \mathrm{E}+00$ & 0.0000 \\
\hline & $1.015 \mathrm{E}-03$ & 0.0041 & $0.000 \mathrm{E}+00$ & 0.0000 & $0.000 \mathrm{E}+00$ & 0.0000 & 2. $225 \mathrm{E}-01$ & 0.9034 & $6.369 \mathrm{E}-03$ & 0.0259 & $1.493 \mathrm{E}-02$ & 0.0606 & $0.000 \mathrm{E}+00$ & 0.0000 \\
\hline
\end{tabular}

Total Dose Contributions TDOSE(i,p,t) for Individual Radionuclides (i) and Pathways (p) As mrem/yr and Fraction of Total Dose At $t=1.050 \mathrm{E}+03$ years

Water Dependent Pathways

\begin{tabular}{|c|c|c|c|c|c|c|c|c|c|c|c|c|c|c|}
\hline \multirow{2}{*}{ Nuclide } & \multicolumn{2}{|c|}{ Water } & \multicolumn{2}{|c|}{ Fish } & \multicolumn{2}{|c|}{ Radon } & \multicolumn{2}{|c|}{ Plant } & \multicolumn{2}{|c|}{ Meat } & \multicolumn{2}{|c|}{ Milk } & \multicolumn{2}{|c|}{ All Pathways* } \\
\hline & mrem/yr & fract. & mrem/yr & fract. & mrem/yr & fract. & mrem/yr & fract. & mrem/yr & fract. & mrem/yr & fract. & mrem/yr & fract. \\
\hline-241 & $0.000 \mathrm{E}+00$ & 0.0000 & $0.000 \mathrm{E}+00$ & 0.0000 & $0.000 \mathrm{E}+00$ & 0.0000 & $0.000 \mathrm{E}+00$ & 0.0000 & $0.000 \mathrm{E}+00$ & 0.0000 & $0.000 \mathrm{E}+00$ & 0.0000 & $1.987 \mathrm{E}-04$ & 0.0008 \\
\hline-137 & $0.000 \mathrm{E}+00$ & 0.0000 & $0.000 \mathrm{E}+00$ & 0.0000 & $0.000 \mathrm{E}+00$ & 0.0000 & $0.000 \mathrm{E}+00$ & 0.0000 & $0.000 \mathrm{E}+00$ & 0.0000 & $0.000 \mathrm{E}+00$ & 0.0000 & $1.986 \mathrm{E}-13$ & 0.0000 \\
\hline-237 & $0.000 \mathrm{E}+00$ & 0.0000 & $0.000 \mathrm{E}+00$ & 0.0000 & $0.000 \mathrm{E}+00$ & 0.0000 & $0.000 \mathrm{E}+00$ & 0.0000 & $0.000 \mathrm{E}+00$ & 0.0000 & $0.000 \mathrm{E}+00$ & 0.0000 & $1.056 \mathrm{E}-02$ & 0.0429 \\
\hline 238 & $0.000 \mathrm{E}+00$ & 0.0000 & $0.000 \mathrm{E}+00$ & 0.0000 & $0.000 \mathrm{E}+00$ & 0.0000 & $0.000 \mathrm{E}+00$ & 0.0000 & $0.000 \mathrm{E}+00$ & 0.0000 & $0.000 \mathrm{E}+00$ & 0.0000 & $6.318 \mathrm{E}-07$ & 0.0000 \\
\hline 239 & $0.000 \mathrm{E}+00$ & 0.0000 & $0.000 \mathrm{E}+00$ & 0.0000 & $0.000 \mathrm{E}+00$ & 0.0000 & $0.000 \mathrm{E}+00$ & 0.0000 & $0.000 \mathrm{E}+00$ & 0.0000 & $0.000 \mathrm{E}+00$ & 0.0000 & $1.272 \mathrm{E}-03$ & 0.0052 \\
\hline 240 & $0.000 \mathrm{E}+00$ & 0.0000 & $0.000 \mathrm{E}+00$ & 0.0000 & $0.000 \mathrm{E}+00$ & 0.0000 & $0.000 \mathrm{E}+00$ & 0.0000 & $0.000 \mathrm{E}+00$ & 0.0000 & $0.000 \mathrm{E}+00$ & 0.0000 & $1.173 \mathrm{E}-03$ & 0.0048 \\
\hline 99 & $1.219 \mathrm{E}-03$ & 0.0049 & $0.000 \mathrm{E}+00$ & 0.0000 & $0.000 \mathrm{E}+00$ & 0.0000 & $1.139 \mathrm{E}-04$ & 0.0005 & $2.039 E-06$ & 0.0000 & $1.376 \mathrm{E}-04$ & 0.0006 & $1.474 \mathrm{E}-03$ & 0.0060 \\
\hline 228 & $0.000 \mathrm{E}+00$ & 0.0000 & $0.000 \mathrm{E}+00$ & 0.0000 & $0.000 \mathrm{E}+00$ & 0.0000 & $0.000 \mathrm{E}+00$ & 0.0000 & $0.000 \mathrm{E}+00$ & 0.0000 & $0.000 \mathrm{E}+00$ & 0.0000 & $0.000 \mathrm{E}+00$ & 0.0000 \\
\hline 230 & $0.000 \mathrm{E}+00$ & 0.0000 & $0.000 \mathrm{E}+00$ & 0.0000 & $0.000 \mathrm{E}+00$ & 0.0000 & $0.000 \mathrm{E}+00$ & 0.0000 & $0.000 \mathrm{E}+00$ & 0.0000 & $0.000 \mathrm{E}+00$ & 0.0000 & $6.242 \mathrm{E}-02$ & 0.2535 \\
\hline 232 & $0.000 \mathrm{E}+00$ & 0.0000 & $0.000 \mathrm{E}+00$ & 0.0000 & $0.000 \mathrm{E}+00$ & 0.0000 & $0.000 \mathrm{E}+00$ & 0.0000 & $0.000 \mathrm{E}+00$ & 0.0000 & $0.000 \mathrm{E}+00$ & 0.0000 & $1.655 \mathrm{E}-01$ & 0.6723 \\
\hline & $0.000 \mathrm{E}+00$ & 0.0000 & $0.000 \mathrm{E}+00$ & 0.0000 & $0.000 \mathrm{E}+00$ & 0.0000 & $0.000 \mathrm{E}+00$ & 0.0000 & $0.000 \mathrm{E}+00$ & 0.0000 & $0.000 \mathrm{E}+00$ & 0.0000 & $9.872 \mathrm{E}-04$ & 0.0040 \\
\hline 35 & $0.000 \mathrm{E}+00$ & 0.0000 & $0.000 \mathrm{E}+00$ & 0.0000 & $0.000 \mathrm{E}+00$ & 0.0000 & $0.000 \mathrm{E}+00$ & 0.0000 & $0.000 \mathrm{E}+00$ & 0.0000 & $0.000 \mathrm{E}+00$ & 0.0000 & $1.929 \mathrm{E}-03$ & 0.0078 \\
\hline 38 & $0.000 \mathrm{E}+00$ & 0.0000 & $0.000 \mathrm{E}+00$ & 0.0000 & $0.000 \mathrm{E}+00$ & 0.0000 & $0.000 \mathrm{E}+00$ & 0.0000 & $0.000 \mathrm{E}+00$ & 0.0000 & $0.000 \mathrm{E}+00$ & 0.0000 & $6.719 \mathrm{E}-04$ & 0.0027 \\
\hline & $1.219 \mathrm{~F}$ & 0.0049 & $0.000 \mathrm{E}+00$ & 0.0000 & $0.000 \mathrm{E}+00$ & 0.0000 & $1.139 \mathrm{E}-04$ & 0.0005 & $2.039 E-06$ & 0.0000 & $1.376 E-04$ & 006 & -01 & 1.0000 \\
\hline
\end{tabular}

* Sum of all water independent and dependent pathways. 
RESRAD, Version 6.5

Summary : RESRAD Parameters for Resident Farmer U-Landfill

File : C: \RESRAD FAMILY \RESRAD \USERFILES \QCFORSRSG ONSITERF SRSG-MAY1.RAD

Dose/Source Ratios Summed Over All Pathways

Parent and Progeny Principal Radionuclide Contributions Indicated

Parent Product Thread DSR $(j, t)$ At Time in Years (mrem/yr)/(pCi/g)

(i)

(j) Fraction

$\begin{array}{ll}\mathrm{Am}-241 & 1.000 \mathrm{E}+00 \\ \mathrm{~Np}-237+\mathrm{D} & 1.000 \mathrm{E}+00 \\ \mathrm{U}-233 & 1.000 \mathrm{E}+00 \\ \mathrm{Th}-229+\mathrm{D} & 1.000 \mathrm{E}+00 \\ \operatorname{CDSR}(j) & \end{array}$

$\sum \operatorname{DSR}(j)$

Cs $-137+D$

$\mathrm{Np}-237+\mathrm{D}$

$\mathrm{U}-233$

Th-229+D

$\sum \operatorname{DSR}(j)$

$\mathrm{Pu}-238$

\section{$\mathrm{Pu}-238$}

$\mathrm{U}-234$

$\mathrm{Th}-230$

$\mathrm{Ra}-226+\mathrm{D}$

$\mathrm{Pb}-210+\mathrm{D}$

$\sum \operatorname{DSR}(j)$

$\mathrm{Pu}-239$

$\mathrm{U}-235+\mathrm{D}$

$\mathrm{Pa}-231$

$\mathrm{AC}-227+\mathrm{D}$

$\sum \operatorname{DSR}(j)$

$\mathrm{Pu}-240$

\section{Pu-240}

U-236

Th-232

$\mathrm{Ra}-228+\mathrm{D}$

Th-228+D

$\sum \mathrm{DSR}(j)$

TC-99

Th-228+D

Th-230

Ra-226+D

$\mathrm{Pb}-210+\mathrm{D}$

$\sum \mathrm{DSR}(j)$
$0.000 \mathrm{E}+00 \quad 1.000 \mathrm{E}+00 \quad 5.000 \mathrm{E}+01 \quad 1.000 \mathrm{E}+02 \quad 5.000 \mathrm{E}+02 \quad 1.050 \mathrm{E}+03$

$\begin{array}{llllll}1.936 \mathrm{E}-33 & 1.989 \mathrm{E}-33 & 7.353 \mathrm{E}-33 & 2.792 \mathrm{E}-32 & 1.208 \mathrm{E}-27 & 1.968 \mathrm{E}-04\end{array}$

$\begin{array}{llllllll}1.546 \mathrm{E}-19 & 4.680 \mathrm{E}-19 & 2.562 \mathrm{E}-17 & 8.382 \mathrm{E}-17 & 2.263 \mathrm{E}-14 & 1.827 \mathrm{E}-06\end{array}$

$3.506 \mathrm{E}-30 \quad 2.479 \mathrm{E}-29 \quad 4.863 \mathrm{E}-26 \quad 3.503 \mathrm{E}-25 \quad 1.053 \mathrm{E}-21 \quad 3.241 \mathrm{E}-10$

$2.399 \mathrm{E}-26 \quad 3.618 \mathrm{E}-25 \quad 1.710 \mathrm{E}-20 \quad 1.868 \mathrm{E}-19 \quad 3.195 \mathrm{E}-16 \quad 5.422 \mathrm{E}-11$

$\begin{array}{lllllll}1.546 \mathrm{E}-19 & 4.680 \mathrm{E}-19 & 2.564 \mathrm{E}-17 & 8.401 \mathrm{E}-17 & 2.295 \mathrm{E}-14 & 1.987 \mathrm{E}-04\end{array}$

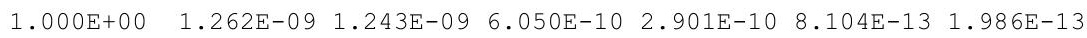

$\begin{array}{lllllllll}1.000 \mathrm{E}+00 & 9.536 \mathrm{E}-13 & 9.638 \mathrm{E}-13 & 1.625 \mathrm{E}-12 & 2.770 \mathrm{E}-12 & 1.974 \mathrm{E}-10 & 1.056 \mathrm{E}-02\end{array}$

$\begin{array}{llllllll}1.000 \mathrm{E}+00 & 3.245 \mathrm{E}-23 & 9.844 \mathrm{E}-23 & 6.100 \mathrm{E}-21 & 2.264 \mathrm{E}-20 & 1.650 \mathrm{E}-17 & 3.045 \mathrm{E}-06\end{array}$

$\begin{array}{lllllll}1.000 \mathrm{E}+00 & 2.962 \mathrm{E}-19 & 2.086 \mathrm{E}-18 & 3.196 \mathrm{E}-15 & 1.788 \mathrm{E}-14 & 7.080 \mathrm{E}-12 & 6.825 \mathrm{E}-07\end{array}$

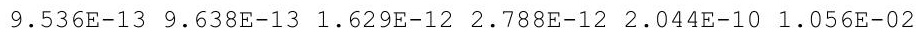

$\begin{array}{lllllll}1.840 E-09 & 2.162 E-33 & 2.183 E-33 & 3.520 E-33 & 5.731 E-33 & 2.831 E-31 & 5.523 E-16\end{array}$

$1.000 \mathrm{E}+00 \quad 1.175 \mathrm{E}-24 \quad 1.186 \mathrm{E}-24 \quad 1.913 \mathrm{E}-24 \quad 3.115 \mathrm{E}-24 \quad 1.539 \mathrm{E}-22 \quad 3.001 \mathrm{E}-07$ $\begin{array}{llllllll}1.000 \mathrm{E}+00 & 9.778 \mathrm{E}-30 & 2.969 \mathrm{E}-29 & 1.973 \mathrm{E}-27 & 7.960 \mathrm{E}-27 & 1.690 \mathrm{E}-23 & 2.414 \mathrm{E}-07\end{array}$ $\begin{array}{lllllll}1.000 \mathrm{E}+00 & 1.028 \mathrm{E}-33 & 7.286 \mathrm{E}-33 & 1.599 \mathrm{E}-29 & 1.302 \mathrm{E}-28 & 1.306 \mathrm{E}-24 & 3.284 \mathrm{E}-09\end{array}$ $\begin{array}{lllllll}1.000 \mathrm{E}+00 & 8.021 \mathrm{E}-23 & 1.208 \mathrm{E}-21 & 5.266 \mathrm{E}-17 & 5.323 \mathrm{E}-16 & 5.607 \mathrm{E}-13 & 3.500 \mathrm{E}-08\end{array}$ $\begin{array}{llllllll}1.000 \mathrm{E}+00 & 2.326 \mathrm{E}-31 & 7.210 \mathrm{E}-30 & 7.772 \mathrm{E}-24 & 1.314 \mathrm{E}-22 & 3.671 \mathrm{E}-19 & 5.193 \mathrm{E}-08\end{array}$ $\begin{array}{llllll}8.139 \mathrm{E}-23 & 1.209 \mathrm{E}-21 & 5.266 \mathrm{E}-17 & 5.323 \mathrm{E}-16 & 5.607 \mathrm{E}-13 & 6.318 \mathrm{E}-07\end{array}$

$\begin{array}{llllllll}1.000 \mathrm{E}+00 & 1.202 \mathrm{E}-17 & 1.217 \mathrm{E}-17 & 2.183 \mathrm{E}-17 & 3.965 \mathrm{E}-17 & 4.690 \mathrm{E}-15 & 1.272 \mathrm{E}-03\end{array}$ $\begin{array}{llllllll}1.000 \mathrm{E}+00 & 6.135 \mathrm{E}-24 & 1.861 \mathrm{E}-23 & 1.146 \mathrm{E}-21 & 4.227 \mathrm{E}-21 & 2.931 \mathrm{E}-18 & 6.673 \mathrm{E}-10\end{array}$ $\begin{array}{lllllll}1.000 \mathrm{E}+00 & 9.652 \mathrm{E}-28 & 6.818 \mathrm{E}-27 & 1.251 \mathrm{E}-23 & 8.414 \mathrm{E}-23 & 1.444 \mathrm{E}-19 & 4.828 \mathrm{E}-10\end{array}$ $\begin{array}{llllllll}1.000 \mathrm{E}+00 & 2.288 \mathrm{E}-27 & 3.434 \mathrm{E}-26 & 1.276 \mathrm{E}-21 & 1.169 \mathrm{E}-20 & 1.476 \mathrm{E}-17 & 1.691 \mathrm{E}-10\end{array}$ $\begin{array}{lllllll}1.202 \mathrm{E}-17 & 1.217 \mathrm{E}-17 & 2.183 \mathrm{E}-17 & 3.966 \mathrm{E}-17 & 4.708 \mathrm{E}-15 & 1.272 \mathrm{E}-03\end{array}$

$\begin{array}{lllllll}4.950 \mathrm{E}-08 & 5.653 \mathrm{E}-32 & 5.753 \mathrm{E}-32 & 1.359 \mathrm{E}-31 & 3.267 \mathrm{E}-31 & 3.647 \mathrm{E}-28 & 5.807 \mathrm{E}-11\end{array}$

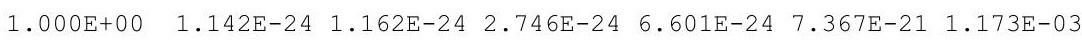
$\begin{array}{llllllll}1.000 \mathrm{E}+00 & 2.162 \mathrm{E}-32 & 6.590 \mathrm{E}-32 & 5.335 \mathrm{E}-30 & 2.602 \mathrm{E}-29 & 1.686 \mathrm{E}-25 & 1.913 \mathrm{E}-08\end{array}$ $\begin{array}{lllllll}1.000 \mathrm{E}+00 \quad 2.845 \mathrm{E}-43 & 2.028 \mathrm{E}-42 & 5.480 \mathrm{E}-39 & 5.478 \mathrm{E}-38 & 2.238 \mathrm{E}-33 & 9.403 \mathrm{E}-16\end{array}$ $\begin{array}{llllllll}1.000 \mathrm{E}+00 & 1.371 \mathrm{E}-28 & 2.018 \mathrm{E}-27 & 3.762 \mathrm{E}-23 & 2.542 \mathrm{E}-22 & 1.470 \mathrm{E}-19 & 1.226 \mathrm{E}-13\end{array}$ $\begin{array}{llllllll}1.000 \mathrm{E}+00 & 8.111 \mathrm{E}-28 & 2.334 \mathrm{E}-26 & 2.641 \mathrm{E}-21 & 1.757 \mathrm{E}-20 & 5.564 \mathrm{E}-18 & 1.531 \mathrm{E}-15\end{array}$ $\begin{array}{llllll}1.143 \mathrm{E}-24 & 1.188 \mathrm{E}-24 & 2.681 \mathrm{E}-21 & 1.783 \mathrm{E}-20 & 5.719 \mathrm{E}-18 & 1.173 \mathrm{E}-03\end{array}$

$\begin{array}{llllllll}1.000 \mathrm{E}+00 & 5.758 \mathrm{E}-26 & 5.817 \mathrm{E}-26 & 9.575 \mathrm{E}-26 & 1.592 \mathrm{E}-25 & 2.070 \mathrm{E}-01 & 1.474 \mathrm{E}-03\end{array}$ $\begin{array}{lllllll}1.000 \mathrm{E}+00 & 1.382 \mathrm{E}-06 & 9.680 \mathrm{E}-07 & 2.527 \mathrm{E}-14 & 4.618 \mathrm{E}-22 & 0.000 \mathrm{E}+00 \quad 0.000 \mathrm{E}+00\end{array}$ $\begin{array}{lllllll}1.000 \mathrm{E}+00 \quad 2.412 \mathrm{E}-22 & 2.453 \mathrm{E}-22 & 5.590 \mathrm{E}-22 & 1.295 \mathrm{E}-21 & 1.078 \mathrm{E}-18 & 1.108 \mathrm{E}-03\end{array}$ $\begin{array}{lllllll}1.000 \mathrm{E}+00 & 3.774 \mathrm{E}-11 & 1.139 \mathrm{E}-10 & 5.320 \mathrm{E}-09 & 1.479 \mathrm{E}-08 & 1.071 \mathrm{E}-06 & 2.411 \mathrm{E}-02\end{array}$ $\begin{array}{lllllll}1.000 \mathrm{E}+00 & 1.819 \mathrm{E}-19 & 1.271 \mathrm{E}-18 & 1.299 \mathrm{E}-15 & 5.314 \mathrm{E}-15 & 7.678 \mathrm{E}-13 & 3.720 \mathrm{E}-02\end{array}$ $\begin{array}{llllll}3.774 \mathrm{E}-11 & 1.139 \mathrm{E}-10 & 5.320 \mathrm{E}-09 & 1.479 \mathrm{E}-08 & 1.071 \mathrm{E}-06 & 6.242 \mathrm{E}-02\end{array}$ 
RESRAD, Version $6.5 \quad \mathrm{~T}^{1} \frac{1}{2}$ Limit $=180$ days

Summary : RESRAD Parameters for Resident Farmer U-Landfill

File : C: \RESRAD_FAMILY \RESRAD \USERFILES \QCFORSRSG $O$ ONSITERF_SRSG-MAY1.RAD

Dose/Source Ratios Summed Over All Pathways

Parent and Progeny Principal Radionuclide Contributions Indicated

\begin{tabular}{|c|c|c|c|c|c|c|c|c|}
\hline $\begin{array}{l}\text { Parent } \\
\text { (i) }\end{array}$ & $\begin{array}{l}\text { Product } \\
\text { (j) }\end{array}$ & $\begin{array}{l}\text { Thread } \\
\text { Fraction }\end{array}$ & $\begin{array}{r}\text { DSR } \\
0.000 \mathrm{E}+00\end{array}$ & $\begin{array}{l}(j, t) \text { At } T \\
1.000 E+00\end{array}$ & $\begin{array}{l}\text { Ime in Year } \\
5.000 \mathrm{E}+01\end{array}$ & $\begin{array}{l}\text { Es (mrem/ } \\
1.000 \mathrm{E}+02\end{array}$ & $\begin{array}{l}/ \mathrm{yr}) /(\mathrm{pCi} / \mathrm{g} \\
5.000 \mathrm{E}+02\end{array}$ & $1.050 \mathrm{E}+03$ \\
\hline 232 & $\mathrm{Th}-232$ & $1.000 \mathrm{E}+00$ & $1.166 \mathrm{E}-24$ & $1.188 \mathrm{E}-24$ & $2.949 E-24$ & $7.462 \mathrm{E}-24$ & 1. $252 \mathrm{E}-20$ & 1. $225 \mathrm{E}-03$ \\
\hline 232 & $\mathrm{Ra}-228+\mathrm{D}$ & $1.000 \mathrm{E}+00$ & $1.107 \mathrm{E}-09$ & $3.174 \mathrm{E}-09$ & $2.784 \mathrm{E}-08$ & $4.079 \mathrm{E}-08$ & $8.497 \mathrm{E}-07$ & $1.623 \mathrm{E}-01$ \\
\hline-232 & $\mathrm{Th}-228+\mathrm{D}$ & $1.000 \mathrm{E}+00$ & $1.067 \mathrm{E}-08$ & $6.581 \mathrm{E}-08$ & $2.213 E-06$ & $2.992 \mathrm{E}-06$ & $3.253 E-05$ & $2.034 \mathrm{E}-03$ \\
\hline-232 & $\sum \operatorname{DSR}(j)$ & & $1.178 \mathrm{E}-08$ & $6.899 \mathrm{E}-08$ & $2.241 \mathrm{E}-06$ & $3.033 E-06$ & $3.338 E-05$ & $1.655 \mathrm{E}-01$ \\
\hline-234 & $\mathrm{U}-234$ & $1.000 \mathrm{E}+00$ & $6.896 \mathrm{E}-24$ & $7.019 \mathrm{E}-24$ & $1.670 \mathrm{E}-23$ & $4.047 \mathrm{E}-23$ & $4.798 E-20$ & $6.722 \mathrm{E}-04$ \\
\hline-234 & $T h-230$ & $1.000 \mathrm{E}+00$ & $1.089 \mathrm{E}-27$ & $3.315 E-27$ & $2.540 \mathrm{E}-25$ & $1.171 \mathrm{E}-24$ & $4.838 E-21$ & $1.040 \mathrm{E}-05$ \\
\hline 234 & $\mathrm{Ra}-226+\mathrm{D}$ & $1.000 \mathrm{E}+00$ & $1.133 \mathrm{E}-16$ & $7.978 E-16$ & $1.213 E-12$ & $6.737 E-12$ & $2.496 E-09$ & 1. $221 \mathrm{E}-04$ \\
\hline 234 & $\mathrm{~Pb}-210+\mathrm{D}$ & $1.000 \mathrm{E}+00$ & $4.102 E-25$ & $6.153 E-24$ & $2.201 \mathrm{E}-19$ & 1. $935 \mathrm{E}-18$ & $1.678 \mathrm{E}-15$ & $1.825 \mathrm{E}-04$ \\
\hline 234 & $\sum \operatorname{DSR}(j)$ & & $1.133 \mathrm{E}-16$ & 7. $978 \mathrm{E}-16$ & $1.213 \mathrm{E}-12$ & $6.737 \mathrm{E}-12$ & $2.496 \mathrm{E}-09$ & $9.872 \mathrm{E}-04$ \\
\hline$-235+D$ & $\mathrm{U}-235+\mathrm{D}$ & $1.000 \mathrm{E}+00$ & 1. $243 \mathrm{E}-14$ & $1.259 \mathrm{E}-14$ & $2.306 \mathrm{E}-14$ & $4.276 \mathrm{E}-14$ & $5.981 \mathrm{E}-12$ & $6.528 E-04$ \\
\hline$-235+D$ & $\mathrm{~Pa}-231$ & $1.000 \mathrm{E}+00$ & $2.937 \mathrm{E}-18$ & $8.896 \mathrm{E}-18$ & $5.031 \mathrm{E}-16$ & $1.701 \mathrm{E}-15$ & $5.876 \mathrm{E}-13$ & $9.383 E-04$ \\
\hline$-235+D$ & $A C-227+D$ & $1.000 \mathrm{E}+00$ & $9.274 \mathrm{E}-18$ & $6.481 \mathrm{E}-17$ & $6.882 \mathrm{E}-14$ & $2.943 E-13$ & $6.376 \mathrm{E}-11$ & $3.384 \mathrm{E}-04$ \\
\hline$-235+D$ & $\sum \operatorname{DSR}(j)$ & & $1.245 \mathrm{E}-14$ & $1.266 \mathrm{E}-14$ & $9.238 \mathrm{E}-14$ & $3.388 \mathrm{E}-13$ & $7.033 E-11$ & $1.929 \mathrm{E}-03$ \\
\hline-238 & $U-238$ & $5.400 \mathrm{E}-05$ & $0.000 \mathrm{E}+00$ & $0.000 \mathrm{E}+00$ & $0.000 \mathrm{E}+00$ & $0.000 \mathrm{E}+00$ & $0.000 \mathrm{E}+00$ & $3.359 \mathrm{E}-08$ \\
\hline$-238+D$ & $\mathrm{U}-238+\mathrm{D}$ & $9.999 \mathrm{E}-01$ & $1.420 \mathrm{E}-10$ & $1.431 \mathrm{E}-10$ & $2.116 \mathrm{E}-10$ & $3.153 \mathrm{E}-10$ & $7.678 \mathrm{E}-09$ & $6.695 \mathrm{E}-04$ \\
\hline $238+D$ & $\mathrm{U}-234$ & $9.999 \mathrm{E}-01$ & $9.803 E-30$ & $2.988 E-29$ & $2.392 E-27$ & $1.153 E-26$ & $6.812 \mathrm{E}-23$ & $2.005 E-06$ \\
\hline$-238+D$ & $T h-230$ & $9.999 \mathrm{E}-01$ & $1.030 E-33$ & $7.316 E-33$ & $1.818 \mathrm{E}-29$ & $1.668 E-28$ & $3.430 E-24$ & $1.547 \mathrm{E}-08$ \\
\hline$-238+D$ & $\mathrm{Ra}-226+\mathrm{D}$ & $9.999 \mathrm{E}-01$ & $8.034 \mathrm{E}-23$ & 1. $212 \mathrm{E}-21$ & $5.801 \mathrm{E}-17$ & $6.420 \mathrm{E}-16$ & $1.201 \mathrm{E}-12$ & $1.255 \mathrm{E}-07$ \\
\hline$-238+D$ & $\mathrm{~Pb}-210+\mathrm{D}$ & $9.999 \mathrm{E}-01$ & $2.329 E-31$ & $7.229 E-30$ & $8.430 \mathrm{E}-24$ & $1.546 \mathrm{E}-22$ & $7.612 E-19$ & $1.821 \mathrm{E}-07$ \\
\hline$-238+D$ & $\sum \operatorname{DSR}(j)$ & & $1.420 \mathrm{E}-10$ & $1.431 \mathrm{E}-10$ & $2.116 \mathrm{E}-10$ & $3.153 \mathrm{E}-10$ & $7.680 \mathrm{E}-09$ & $6.719 \mathrm{E}-04$ \\
\hline
\end{tabular}

The DSR includes contributions from associated (half-life $\leq 180$ days) daughters. 
RESRAD, Version $6.5 \quad T^{1 / 2}$ Limit $=180$ days

mary : RESRAD Parameters for Resident Farmer U-Landfill

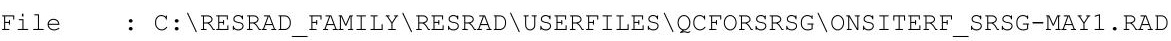

Single Radionuclide Soil Guidelines $G(i, t)$ in $\mathrm{pCi} / \mathrm{g}$

Basic Radiation Dose Limit $=1.000 \mathrm{E}+02 \mathrm{mrem} / \mathrm{yr}$

Nuclide

\begin{tabular}{|c|c|c|c|c|c|c|}
\hline (i) & $t=0.000 E+00$ & $1.000 \mathrm{E}+00$ & $5.000 \mathrm{E}+01$ & $1.000 \mathrm{E}+02$ & $5.000 \mathrm{E}+02$ & $1.050 \mathrm{E}+03$ \\
\hline-241 & $\star 3.431 \mathrm{E}+12$ & $\star 3.431 \mathrm{E}+12$ & $\star 3.431 \mathrm{E}+12$ & $\star 3.431 \mathrm{E}+12$ & $\star 3.431 \mathrm{E}+12$ & $5.034 \mathrm{E}+05$ \\
\hline-137 & 7. $925 \mathrm{E}+10$ & $8.043 E+10$ & $1.653 \mathrm{E}+11$ & $3.447 \mathrm{E}+11$ & $\star 8.704 \mathrm{E}+13$ & $\star 8.704 \mathrm{E}+13$ \\
\hline-237 & $* 7.047 \mathrm{E}+08$ & $* 7.047 \mathrm{E}+08$ & $\star 7.047 \mathrm{E}+08$ & $* 7.047 \mathrm{E}+08$ & $* 7.047 \mathrm{E}+08$ & $9.465 \mathrm{E}+03$ \\
\hline $1-238$ & $\star 1.712 \mathrm{E}+13$ & $\star 1.712 \mathrm{E}+13$ & $* 1.712 \mathrm{E}+13$ & $* 1.712 \mathrm{E}+13$ & $\star 1.712 \mathrm{E}+13$ & $1.583 E+08$ \\
\hline$u-239$ & $* 6.214 \mathrm{E}+10$ & $* 6.214 \mathrm{E}+10$ & $* 6.214 \mathrm{E}+10$ & $* 6.214 \mathrm{E}+10$ & $* 6.214 \mathrm{E}+10$ & $7.860 \mathrm{E}+04$ \\
\hline$u-240$ & $\star 2.278 \mathrm{E}+11$ & $\star 2.278 \mathrm{E}+11$ & $\star 2.278 \mathrm{E}+11$ & $\star 2.278 \mathrm{E}+11$ & $* 2.278 \mathrm{E}+11$ & $8.524 E+04$ \\
\hline$c-99$ & $\star 1.697 \mathrm{E}+10$ & $\star 1.697 \mathrm{E}+10$ & $\star 1.697 \mathrm{E}+10$ & $\star 1.697 \mathrm{E}+10$ & $4.830 \mathrm{E}+02$ & $6.786 \mathrm{E}+04$ \\
\hline$h-228$ & $7.234 \mathrm{E}+07$ & $1.033 \mathrm{E}+08$ & $\star 8.195 \mathrm{E}+14$ & $\star 8.195 \mathrm{E}+14$ & $\star 8.195 \mathrm{E}+14$ & $* 8.195 E+14$ \\
\hline Th-230 & $\star 2.018 \mathrm{E}+10$ & $* 2.018 \mathrm{E}+10$ & $1.880 \mathrm{E}+10$ & $6.761 \mathrm{E}+09$ & $9.336 \mathrm{E}+07$ & $1.602 \mathrm{E}+03$ \\
\hline Th-232 & $\star 1.097 \mathrm{E}+05$ & $\star 1.097 \mathrm{E}+05$ & $\star 1.097 \mathrm{E}+05$ & $\star 1.097 \mathrm{E}+05$ & $\star 1.097 \mathrm{E}+05$ & $6.041 E+02$ \\
\hline $\mathrm{J}-234$ & $\star 6.247 \mathrm{E}+09$ & $\star 6.247 \mathrm{E}+09$ & $\star 6.247 \mathrm{E}+09$ & $\star 6.247 \mathrm{E}+09$ & $* 6.247 \mathrm{E}+09$ & $1.013 \mathrm{E}+05$ \\
\hline $\mathrm{U}-235$ & $\star 2.161 \mathrm{E}+06$ & $\star 2.161 \mathrm{E}+06$ & $* 2.161 \mathrm{E}+06$ & $\star 2.161 \mathrm{E}+06$ & $\star 2.161 \mathrm{E}+06$ & $5.183 \mathrm{E}+04$ \\
\hline $\mathrm{J}-238$ & $\star 3.361 \mathrm{E}+05$ & $\star 3.361 \mathrm{E}+05$ & $* 3.361 \mathrm{E}+05$ & $* 3.361 \mathrm{E}+05$ & $\star 3.361 \mathrm{E}+05$ & $1.488 E+05$ \\
\hline
\end{tabular}

*At specific activity limit

Summed Dose/Source Ratios DSR (i,t) in (mrem/yr)/(pCi/g) and Single Radionuclide Soil Guidelines $\mathrm{G}(i, t)$ in $\mathrm{pCi} / \mathrm{g}$

at tmin $=$ time of minimum single radionuclide soil guideline and at $\operatorname{tmax}=$ time of maximum total dose $=424.6 \pm 0.8$ years

\begin{tabular}{|c|c|c|c|c|c|c|}
\hline $\begin{array}{l}\text { uclide } \\
\text { (i) }\end{array}$ & $\begin{array}{l}\text { Initial } \\
(\mathrm{pCi} / \mathrm{g})\end{array}$ & $\begin{array}{c}\text { tmin } \\
\text { (years) }\end{array}$ & $\operatorname{DSR}(i, \operatorname{tmin})$ & $\begin{array}{c}\mathrm{G}(\mathrm{i}, \mathrm{tmin}) \\
\quad(\mathrm{pCi} / \mathrm{g})\end{array}$ & $\operatorname{DSR}(i, \operatorname{tmax})$ & $\begin{array}{c}G(i, t \max ) \\
(\mathrm{pCi} / \mathrm{g})\end{array}$ \\
\hline-241 & $1.000 \mathrm{E}+00$ & $1.050 \mathrm{E}+03$ & $1.987 \mathrm{E}-04$ & $5.034 \mathrm{E}+05$ & $9.151 \mathrm{E}-15$ & $* 3.431 \mathrm{E}+12$ \\
\hline 137 & $1.000 \mathrm{E}+00$ & $0.000 \mathrm{E}+00$ & $1.262 \mathrm{E}-09$ & $7.925 E+10$ & $2.456 \mathrm{E}-12$ & $4.071 \mathrm{E}+13$ \\
\hline 237 & $1.000 \mathrm{E}+00$ & $1.050 \mathrm{E}+03$ & $1.056 \mathrm{E}-02$ & $9.465 \mathrm{E}+03$ & $9.131 \mathrm{E}-11$ & $\star 7.047 \mathrm{E}+08$ \\
\hline 238 & $1.000 \mathrm{E}+00$ & $1.050 \mathrm{E}+03$ & $6.318 \mathrm{E}-07$ & $1.583 \mathrm{E}+08$ & $2.254 \mathrm{E}-13$ & $\star 1.712 \mathrm{E}+13$ \\
\hline-239 & $1.000 \mathrm{E}+00$ & $1.050 \mathrm{E}+03$ & $1.272 \mathrm{E}-03$ & $7.860 \mathrm{E}+04$ & $1.913 \mathrm{E}-15$ & $\star 6.214 \mathrm{E}+10$ \\
\hline-240 & $1.000 \mathrm{E}+00$ & $1.050 \mathrm{E}+03$ & $1.173 \mathrm{E}-03$ & $8.524 \mathrm{E}+04$ & $2.609 \mathrm{E}-18$ & $\star 2.278 \mathrm{E}+11$ \\
\hline-99 & $1.000 \mathrm{E}+00$ & $424.6 \pm 0.8$ & $4.079 \mathrm{E}-01$ & $2.451 \mathrm{E}+02$ & $4.079 \mathrm{E}-01$ & $2.451 \mathrm{E}+02$ \\
\hline-228 & $1.000 \mathrm{E}+00$ & $0.000 \mathrm{E}+00$ & $1.382 \mathrm{E}-06$ & $7.234 \mathrm{E}+07$ & $0.000 \mathrm{E}+00$ & $\star 8.195 \mathrm{E}+14$ \\
\hline-230 & $1.000 \mathrm{E}+00$ & $1.050 \mathrm{E}+03$ & $6.242 \mathrm{E}-02$ & $1.602 \mathrm{E}+03$ & $5.490 \mathrm{E}-07$ & $1.822 \mathrm{E}+08$ \\
\hline-232 & $1.000 \mathrm{E}+00$ & $1.050 \mathrm{E}+03$ & $1.655 \mathrm{E}-01$ & $6.041 \mathrm{E}+02$ & $2.122 \mathrm{E}-05$ & $\star 1.097 \mathrm{E}+05$ \\
\hline 34 & $1.000 \mathrm{E}+00$ & $1.050 \mathrm{E}+03$ & $9.872 \mathrm{E}-04$ & $1.013 E+05$ & $1.081 \mathrm{E}-09$ & $* 6.247 \mathrm{E}+09$ \\
\hline & $1.000 \mathrm{E}+00$ & $1.050 \mathrm{E}+03$ & $1.929 \mathrm{E}-03$ & $5.183 E+04$ & $3.027 \mathrm{E}-11$ & $\star 2.161 \mathrm{E}+06$ \\
\hline 238 & $1.000 \mathrm{E}+00$ & $1.050 \mathrm{E}+03$ & $6.719 \mathrm{E}-04$ & $1.488 \mathrm{E}+05$ & $4.206 \mathrm{E}-09$ & $* 3.361 \mathrm{E}+05$ \\
\hline
\end{tabular}

*At specific activity limit 
RESRAD, Version 6.5

Summary : RESRAD Parameters for Resident Farmer U-Landfill

File : C: \RESRAD_FAMILY \RESRAD \USERFILES \QCFORSRSG $O$ ONSITERF_SRSG-MAY1.RAD

Individual Nuclide Dose Summed Over All Pathways

Parent Nuclide and Branch Fraction Indicated

Nuclide Parent THF(i) DOSE $(j, t)$, mrem/yr

\begin{tabular}{|c|c|c|}
\hline$(j)$ & (i) & \\
\hline-241 & $A m-241$ & $1.000 \mathrm{E}+00$ \\
\hline$p-237$ & $A m-241$ & $1.000 \mathrm{E}+00$ \\
\hline $\mathrm{Np}-237$ & $\mathrm{~Np}-237$ & $1.000 \mathrm{E}+00$ \\
\hline Np-237 & $\sum \operatorname{DOSE}(j$ & \\
\hline
\end{tabular}

$\mathrm{U}-233 \quad \mathrm{Am}-241 \quad 1.000 \mathrm{E}+00$

$\mathrm{U}-233 \quad \mathrm{~Np}-237 \quad 1.000 \mathrm{E}+00$

U-233 $\quad$ DOSE $(j)$

Th-229 Am-241 $1.000 \mathrm{~F}+00$

Th-229 Np-237 1.000E+00

Th-229 $\sum \operatorname{DOSE}(j)$

Cs-137 Cs-137 1.000E+00

Pu-238 $\mathrm{Pu}-238 \quad 1.840 \mathrm{E}-09$

$\mathrm{Pu}-238$

$\mathrm{Pu}-238$

$\mathrm{U}-234$

$\mathrm{U}-234$

$\mathrm{U}-234$

$\mathrm{U}-234$

Th-230

Th -230

Th -230

Th-230

Th-230

$\mathrm{Ra}-226$

$\mathrm{Ra}-226$

$\mathrm{Ra}-226$

$\mathrm{Ra}-226$

$\mathrm{Ra}-226$

$\mathrm{Pb}-210$

$\mathrm{Pb}-210$

$\mathrm{Pb}-210$

$\mathrm{Pb}-210$

$\mathrm{Pb}-210$

$\mathrm{Pu}-239$

$\mathrm{U}-235$

$\mathrm{U}-235$

$\mathrm{U}-235$
$\mathrm{Pu}-238 \quad 1.000 \mathrm{E}+00$

$\sum \operatorname{DOSE}(j)$

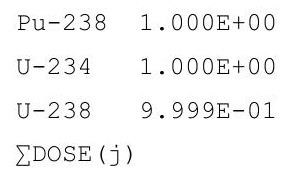

Pu-238 1.000E+00

Th-230 1.000E+00

$\mathrm{U}-234 \quad 1.000 \mathrm{E}+00$

$\sum \operatorname{DOSE}(j)$

Pu-238 1.000E+00

Th-230 1.000E+00

$\mathrm{U}-238 \quad 9.999 \mathrm{E}-01$

$\sum \operatorname{DOSE}(j)$

$\mathrm{Pu}-238 \quad 1.000 \mathrm{E}+00$

Th-230 1.000E+00

U-234 $1.000 \mathrm{E}+00$

U-238 9.999E-01

$\operatorname{DOSE}(j)$

Pu-239 1.000E+00

$\mathrm{Pu}-239 \quad 1.000 \mathrm{E}+00$

U-235 $1.000 \mathrm{E}+00$

$\sum \operatorname{DOSE}(j)$
U-238 $9.999 \mathrm{E}-01$

$\mathrm{U}-234 \quad 1.000 \mathrm{E}+00$ $t=0.000 \mathrm{E}+00 \quad 1.000 \mathrm{E}+00 \quad 5.000 \mathrm{E}+01 \quad 1.000 \mathrm{E}+02 \quad 5.000 \mathrm{E}+02 \quad 1.050 \mathrm{E}+03$

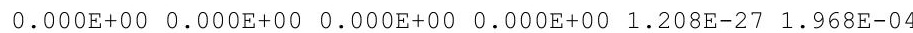

$\begin{array}{llllll}1.546 \mathrm{E}-19 & 4.680 \mathrm{E}-19 & 2.562 \mathrm{E}-17 & 8.382 \mathrm{E}-17 & 2.263 \mathrm{E}-14 & 1.827 \mathrm{E}-06\end{array}$

$\begin{array}{llllll}9.536 \mathrm{E}-13 & 9.638 \mathrm{E}-13 & 1.625 \mathrm{E}-12 & 2.770 \mathrm{E}-12 & 1.974 \mathrm{E}-10 & 1.056 \mathrm{E}-02\end{array}$

$\begin{array}{llllll}9.536 \mathrm{E}-13 & 9.638 \mathrm{E}-13 & 1.625 \mathrm{E}-12 & 2.770 \mathrm{E}-12 & 1.974 \mathrm{E}-10 & 1.056 \mathrm{E}-02\end{array}$

$3.506 \mathrm{E}-30 \quad 2.479 \mathrm{E}-29 \quad 4.863 \mathrm{E}-26 \quad 3.503 \mathrm{E}-25 \quad 1.053 \mathrm{E}-21 \quad 3.241 \mathrm{E}-10$

$\begin{array}{llllll}3.245 \mathrm{E}-23 & 9.844 \mathrm{E}-23 & 6.100 \mathrm{E}-21 & 2.264 \mathrm{E}-20 & 1.650 \mathrm{E}-17 & 3.045 \mathrm{E}-06\end{array}$

$\begin{array}{llllll}3.245 \mathrm{E}-23 & 9.844 \mathrm{E}-23 & 6.100 \mathrm{E}-21 & 2.264 \mathrm{E}-20 & 1.650 \mathrm{E}-17 & 3.045 \mathrm{E}-06\end{array}$

$2.399 \mathrm{E}-26 \quad 3.618 \mathrm{E}-25 \quad 1.710 \mathrm{E}-20 \quad 1.868 \mathrm{E}-19 \quad 3.195 \mathrm{E}-16 \quad 5.422 \mathrm{E}-11$

$2.962 \mathrm{E}-19 \quad 2.086 \mathrm{E}-18 \quad 3.196 \mathrm{E}-15 \quad 1.788 \mathrm{E}-14 \quad 7.080 \mathrm{E}-12 \quad 6.825 \mathrm{E}-07$

$\begin{array}{llllll}2.962 \mathrm{E}-19 & 2.086 \mathrm{E}-18 & 3.196 \mathrm{E}-15 & 1.788 \mathrm{E}-14 & 7.080 \mathrm{E}-12 & 6.825 \mathrm{E}-07\end{array}$

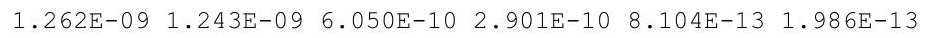

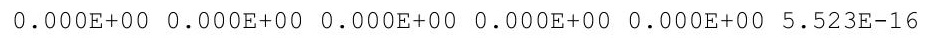

$\begin{array}{llllll}1.175 \mathrm{E}-24 & 1.186 \mathrm{E}-24 & 1.913 \mathrm{E}-24 & 3.115 \mathrm{E}-24 & 1.539 \mathrm{E}-22 & 3.001 \mathrm{E}-07\end{array}$

$\begin{array}{llllll}1.175 \mathrm{E}-24 & 1.186 \mathrm{E}-24 & 1.913 \mathrm{E}-24 & 3.115 \mathrm{E}-24 & 1.539 \mathrm{E}-22 & 3.001 \mathrm{E}-07\end{array}$

$9.778 \mathrm{E}-30 \quad 2.969 \mathrm{E}-29 \quad 1.973 \mathrm{E}-27 \quad 7.960 \mathrm{E}-27 \quad 1.690 \mathrm{E}-23 \quad 2.414 \mathrm{E}-07$

$\begin{array}{lllllll}6.896 \mathrm{E}-24 & 7.019 \mathrm{E}-24 & 1.670 \mathrm{E}-23 & 4.047 \mathrm{E}-23 & 4.798 \mathrm{E}-20 & 6.722 \mathrm{E}-04\end{array}$

$\begin{array}{llllll}9.803 E-30 & 2.988 \mathrm{E}-29 & 2.392 \mathrm{E}-27 & 1.153 \mathrm{E}-26 & 6.812 \mathrm{E}-23 & 2.005 \mathrm{E}-06\end{array}$

$\begin{array}{llllll}6.896 \mathrm{E}-24 & 7.019 \mathrm{E}-24 & 1.671 \mathrm{E}-23 & 4.049 \mathrm{E}-23 & 4.806 \mathrm{E}-20 & 6.744 \mathrm{E}-04\end{array}$

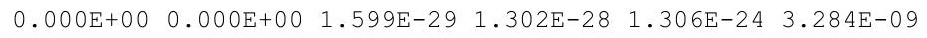

$\begin{array}{llllll}2.412 \mathrm{E}-22 & 2.453 \mathrm{E}-22 & 5.590 \mathrm{E}-22 & 1.295 \mathrm{E}-21 & 1.078 \mathrm{E}-18 & 1.108 \mathrm{E}-03\end{array}$

$\begin{array}{llllll}1.089 \mathrm{E}-27 & 3.315 \mathrm{E}-27 & 2.540 \mathrm{E}-25 & 1.171 \mathrm{E}-24 & 4.838 \mathrm{E}-21 & 1.040 \mathrm{E}-05\end{array}$

$\begin{array}{llllll}0.000 \mathrm{E}+00 & 0.000 \mathrm{E}+00 & 1.818 \mathrm{E}-29 & 1.668 \mathrm{E}-28 & 3.430 \mathrm{E}-24 & 1.547 \mathrm{E}-08\end{array}$

$\begin{array}{llllll}2.412 \mathrm{E}-22 & 2.453 \mathrm{E}-22 & 5.592 \mathrm{E}-22 & 1.297 \mathrm{E}-21 & 1.082 \mathrm{E}-18 & 1.118 \mathrm{E}-03\end{array}$

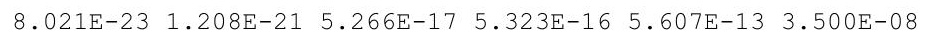
$\begin{array}{llllll}3.774 \mathrm{E}-11 & 1.139 \mathrm{E}-10 & 5.320 \mathrm{E}-09 & 1.479 \mathrm{E}-08 & 1.071 \mathrm{E}-06 & 2.411 \mathrm{E}-02\end{array}$ $\begin{array}{llllll}1.133 \mathrm{E}-16 & 7.978 \mathrm{E}-16 & 1.213 \mathrm{E}-12 & 6.737 \mathrm{E}-12 & 2.496 \mathrm{E}-09 & 1.221 \mathrm{E}-04\end{array}$ $\begin{array}{llllll}8.034 \mathrm{E}-23 & 1.212 \mathrm{E}-21 & 5.801 \mathrm{E}-17 & 6.420 \mathrm{E}-16 & 1.201 \mathrm{E}-12 & 1.255 \mathrm{E}-07\end{array}$ $\begin{array}{llllll}3.774 \mathrm{E}-11 & 1.139 \mathrm{E}-10 & 5.321 \mathrm{E}-09 & 1.480 \mathrm{E}-08 & 1.074 \mathrm{E}-06 & 2.423 \mathrm{E}-02\end{array}$

$0.000 \mathrm{E}+00 \quad 7.210 \mathrm{E}-30 \quad 7.772 \mathrm{E}-24 \quad 1.314 \mathrm{E}-22 \quad 3.671 \mathrm{E}-19 \quad 5.193 \mathrm{E}-08$ $\begin{array}{llllll}1.819 \mathrm{E}-19 & 1.271 \mathrm{E}-18 & 1.299 \mathrm{E}-15 & 5.314 \mathrm{E}-15 & 7.678 \mathrm{E}-13 & 3.720 \mathrm{E}-02\end{array}$ $\begin{array}{llllll}4.102 \mathrm{E}-25 & 6.153 \mathrm{E}-24 & 2.201 \mathrm{E}-19 & 1.935 \mathrm{E}-18 & 1.678 \mathrm{E}-15 & 1.825 \mathrm{E}-04\end{array}$ $0.000 \mathrm{E}+00 \quad 7.229 \mathrm{E}-30 \quad 8.430 \mathrm{E}-24 \quad 1.546 \mathrm{E}-22 \quad 7.612 \mathrm{E}-19 \quad 1.821 \mathrm{E}-07$ $\begin{array}{llllll}1.819 \mathrm{E}-19 & 1.271 \mathrm{E}-18 & 1.299 \mathrm{E}-15 & 5.316 \mathrm{E}-15 & 7.695 \mathrm{E}-13 & 3.738 \mathrm{E}-02\end{array}$

$\begin{array}{llllll}1.202 \mathrm{E}-17 & 1.217 \mathrm{E}-17 & 2.183 \mathrm{E}-17 & 3.965 \mathrm{E}-17 & 4.690 \mathrm{E}-15 & 1.272 \mathrm{E}-03\end{array}$

$\begin{array}{llllll}6.135 \mathrm{E}-24 & 1.861 \mathrm{E}-23 & 1.146 \mathrm{E}-21 & 4.227 \mathrm{E}-21 & 2.931 \mathrm{E}-18 & 6.673 \mathrm{E}-10\end{array}$ $\begin{array}{lllllll}1.243 \mathrm{E}-14 & 1.259 \mathrm{E}-14 & 2.306 \mathrm{E}-14 & 4.276 \mathrm{E}-14 & 5.981 \mathrm{E}-12 & 6.528 \mathrm{E}-04\end{array}$ $\begin{array}{llllll}1.243 \mathrm{E}-14 & 1.259 \mathrm{E}-14 & 2.306 \mathrm{E}-14 & 4.276 \mathrm{E}-14 & 5.981 \mathrm{E}-12 & 6.528 \mathrm{E}-04\end{array}$ 
RESRAD, Version $6.5 \quad \mathrm{~T}^{1 / 2}$ Limit $=180$ days

ummary : RESRAD Parameters for Resident Farmer U-Landfill

File : C: $\backslash$ RESRAD_FAMILY $\backslash R E S R A D \backslash U S E R F I L E S \backslash Q C F O R S R S G$ ONSITERF_SRSG-MAYI.RAD

Individual Nuclide Dose Summed Over All Pathways

Parent Nuclide and Branch Fraction Indicated

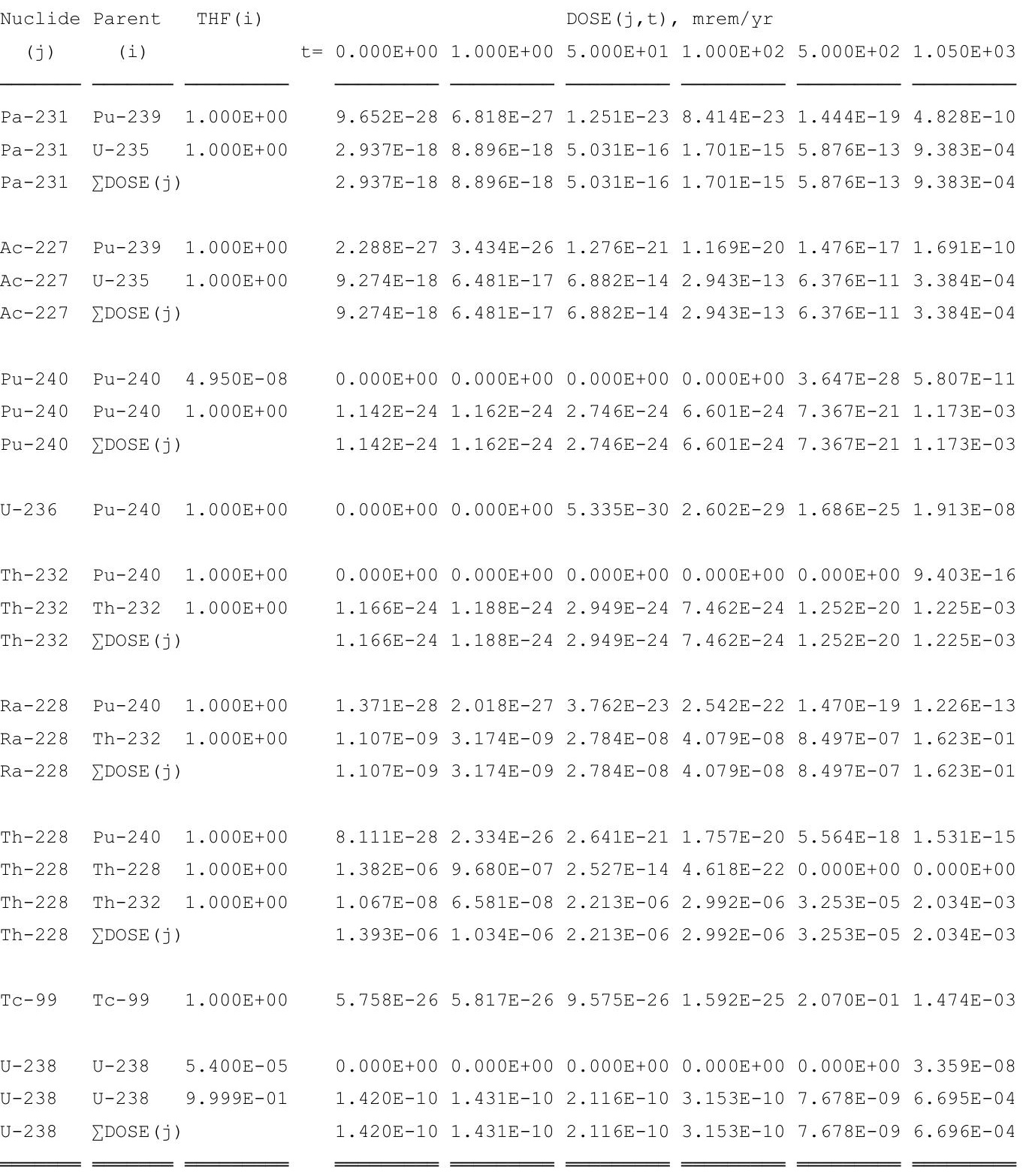

THF (i) is the thread fraction of the parent nuclide. 
RESRAD, Version 6.5

Summary : RESRAD Parameters for Resident Farmer U-Landfill

File : C: \RESRAD_FAMILY \RESRAD \USERFILES \QCFORSRSG \ONSITERF_SRSG-MAY1.RAD

Individual Nuclide Soil Concentration

Parent Nuclide and Branch Fraction Indicated

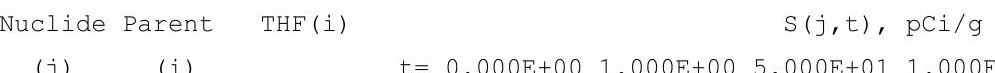

\section{(j)}

Am-241 Am-241 1.000E+00

Np-237 Am-241 1.000E+00

$\mathrm{Np}-237 \quad \mathrm{~Np}-237 \quad 1.000 \mathrm{E}+00$

Np-237 $\sum S(j):$

U-233 Am-241 1.000E+00

$\mathrm{U}-233 \mathrm{~Np}-237 \quad 1.000 \mathrm{E}+00$

U-233 $\sum S(j):$

Th-229 Am-241 1.000E+00

$\mathrm{Th}-229 \mathrm{~Np}-237 \quad 1.000 \mathrm{E}+00$

Th-229 $\sum S(j):$

Cs-137 Cs-137 1.000E+00

$\mathrm{Pu}-238$

$\mathrm{Pu}-238$

$\mathrm{Pu}-238$

$\mathrm{U}-234$

$\mathrm{U}-234$

$\mathrm{U}-234$

$\mathrm{U}-234$

Th -230

$\mathrm{Th}-230$

$\mathrm{Th}-230$

Th-230

Th-230

$\mathrm{Ra}-226$

$\mathrm{Ra}-226$

$\mathrm{Ra}-226$

$\mathrm{Ra}-226$

$\mathrm{Ra}-226$

$\mathrm{Pb}-210$

$\mathrm{Pb}-210$

$\mathrm{Pb}-210$

$\mathrm{Pb}-210$

$\mathrm{Pb}-210$

$\mathrm{Pu}-239$

$\mathrm{U}-235$

$\mathrm{U}-235$

$\mathrm{U}-235$
Pu-238 1.840E-09

$\mathrm{Pu}-238 \quad 1.000 \mathrm{E}+00$

$\sum S(j):$

$\mathrm{Pu}-238 \quad 1.000 \mathrm{E}+00$

$\mathrm{U}-234 \quad 1.000 \mathrm{E}+00$

U-238 9.999E-01

$\sum S(j):$

$\mathrm{Pu}-238 \quad 1.000 \mathrm{E}+00$

Th-230 1.000E+00

U-234 $1.000 \mathrm{E}+00$

$\mathrm{U}-2389.999 \mathrm{E}-01$

$\sum S(j):$

$\mathrm{Pu}-238 \quad 1.000 \mathrm{E}+00$

$\mathrm{Th}-230 \quad 1.000 \mathrm{E}+00$

$\mathrm{U}-234 \quad 1.000 \mathrm{E}+00$

U-238 9.999E-01

$\sum S(j):$

$\mathrm{Pu}-238 \quad 1.000 \mathrm{E}+00$

Th-230 1.000E+00

$\mathrm{U}-234 \quad 1.000 \mathrm{E}+00$

U-238 9.999E-01

$\sum S(j):$

$\mathrm{Pu}-239 \quad 1.000 \mathrm{E}+00$

$\mathrm{U}-2351.000 \mathrm{E}+00$

$\sum S(j):$
$\mathrm{Pu}-239 \quad 1.000 \mathrm{E}+00$
$=0.000 \mathrm{E}+001.000 \mathrm{E}+00 \quad 5.000 \mathrm{E}+01 \quad 1.000 \mathrm{E}+02 \quad 5.000 \mathrm{E}+02 \quad 1.050 \mathrm{E}+03$

$\begin{array}{lllllll}1.000 \mathrm{E}+00 & 9.984 \mathrm{E}-01 & 9.227 \mathrm{E}-01 & 8.514 \mathrm{E}-01 & 4.474 \mathrm{E}-01 & 1.847 \mathrm{E}-01\end{array}$

$0.000 \mathrm{E}+00 \quad 3.236 \mathrm{E}-07 \quad 1.551 \mathrm{E}-05 \quad 2.971 \mathrm{E}-05 \quad 1.071 \mathrm{E}-04 \quad 1.502 \mathrm{E}-04$

$\begin{array}{lllllll}1.000 \mathrm{E}+00 & 9.999 \mathrm{E}-01 & 9.933 \mathrm{E}-01 & 9.866 \mathrm{E}-01 & 9.348 \mathrm{E}-01 & 8.679 \mathrm{E}-01\end{array}$ $\begin{array}{llllll}1.000 \mathrm{E}+00 & 9.999 \mathrm{E}-01 & 9.933 \mathrm{E}-01 & 9.866 \mathrm{E}-01 & 9.349 \mathrm{E}-01 & 8.681 \mathrm{E}-01\end{array}$

$0.000 \mathrm{E}+00 \quad 7.078 \mathrm{E}-13 \quad 1.719 \mathrm{E}-09 \quad 6.681 \mathrm{E}-09 \quad 1.339 \mathrm{E}-07 \quad 4.489 \mathrm{E}-07$

$0.000 \mathrm{E}+00 \quad 4.373 \mathrm{E}-06 \quad 2.178 \mathrm{E}-04 \quad 4.338 \mathrm{E}-04 \quad 2.100 \mathrm{E}-03 \quad 4.219 \mathrm{E}-03$

$\begin{array}{llllll}0.000 \mathrm{E}+00 & 4.373 \mathrm{E}-06 & 2.178 \mathrm{E}-04 & 4.338 \mathrm{E}-04 & 2.100 \mathrm{E}-03 & 4.219 \mathrm{E}-03\end{array}$

$\begin{array}{lllllll}0.000 \mathrm{E}+00 & 2.228 \mathrm{E}-17 & 2.723 \mathrm{E}-12 & 2.129 \mathrm{E}-11 & 2.229 \mathrm{E}-09 & 1.651 \mathrm{E}-08\end{array}$

$0.000 \mathrm{E}+00 \quad 2.065 \mathrm{E}-10 \quad 5.140 \mathrm{E}-07 \quad 2.047 \mathrm{E}-06 \quad 4.944 \mathrm{E}-05 \quad 2.079 \mathrm{E}-04$ $0.000 \mathrm{E}+00 \quad 2.065 \mathrm{E}-10 \quad 5.140 \mathrm{E}-07 \quad 2.047 \mathrm{E}-06 \quad 4.944 \mathrm{E}-05 \quad 2.079 \mathrm{E}-04$

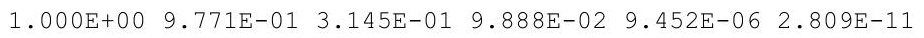

1.840E-09 1.825E-09 1.239E-09 8.336E-10 3.513E-11 4.514E-13

$\begin{array}{llllll}1.000 \mathrm{E}+00 & 9.921 \mathrm{E}-01 & 6.731 \mathrm{E}-01 & 4.531 \mathrm{E}-01 & 1.909 \mathrm{E}-02 & 2.453 \mathrm{E}-04\end{array}$

$1.000 \mathrm{E}+00 \quad 9.921 \mathrm{E}-01 \quad 6.731 \mathrm{E}-01 \quad 4.531 \mathrm{E}-01 \quad 1.909 \mathrm{E}-02 \quad 2.453 \mathrm{E}-04$

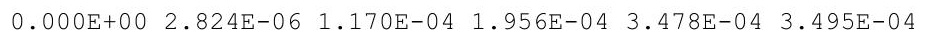

$\begin{array}{lllllll}1.000 \mathrm{E}+00 & 1.000 \mathrm{E}+00 & 9.987 \mathrm{E}-01 & 9.974 \mathrm{E}-01 & 9.872 \mathrm{E}-01 & 9.732 \mathrm{E}-01\end{array}$

$\begin{array}{llllll}0.000 \mathrm{E}+00 & 2.835 \mathrm{E}-06 & 1.416 \mathrm{E}-04 & 2.828 \mathrm{E}-04 & 1.400 \mathrm{E}-03 & 2.901 \mathrm{E}-03\end{array}$

$\begin{array}{lllllll}1.000 \mathrm{E}+00 & 1.000 \mathrm{E}+00 & 9.990 \mathrm{E}-01 & 9.979 \mathrm{E}-01 & 9.889 \mathrm{E}-01 & 9.765 \mathrm{E}-01\end{array}$

$0.000 \mathrm{E}+00 \quad 1.273 \mathrm{E}-11 \quad 2.806 \mathrm{E}-08 \quad 9.953 \mathrm{E}-08 \quad 1.203 \mathrm{E}-06 \quad 2.925 \mathrm{E}-06$ $\begin{array}{lllllll}1.000 \mathrm{E}+00 & 1.000 \mathrm{E}+00 & 9.994 \mathrm{E}-01 & 9.988 \mathrm{E}-01 & 9.940 \mathrm{E}-01 & 9.875 \mathrm{E}-01\end{array}$ $0.000 \mathrm{E}+00 \quad 9.002 \mathrm{E}-06 \quad 4.497 \mathrm{E}-04 \quad 8.985 \mathrm{E}-04 \quad 4.459 \mathrm{E}-03 \quad 9.266 \mathrm{E}-03$ $\begin{array}{lllllll}0.000 \mathrm{E}+00 & 1.276 \mathrm{E}-11 & 3.187 \mathrm{E}-08 & 1.273 \mathrm{E}-07 & 3.158 \mathrm{E}-06 & 1.377 \mathrm{E}-05\end{array}$ $\begin{array}{llllll}1.000 \mathrm{E}+00 & 1.000 \mathrm{E}+00 & 9.999 \mathrm{E}-01 & 9.997 \mathrm{E}-01 & 9.985 \mathrm{E}-01 & 9.968 \mathrm{E}-01\end{array}$

$\begin{array}{llllll}0.000 \mathrm{E}+00 & 1.839 \mathrm{E}-15 & 2.079 \mathrm{E}-10 & 1.510 \mathrm{E}-09 & 1.010 \mathrm{E}-07 & 5.219 \mathrm{E}-07\end{array}$ $0.000 \mathrm{E}+00 \quad 4.331 \mathrm{E}-04 \quad 2.141 \mathrm{E}-02 \quad 4.233 \mathrm{E}-02 \quad 1.933 \mathrm{E}-01 \quad 3.597 \mathrm{E}-01$ $0.000 \mathrm{E}+00 \quad 1.950 \mathrm{E}-09 \quad 4.835 \mathrm{E}-06 \quad 1.918 \mathrm{E}-05 \quad 4.498 \mathrm{E}-04 \quad 1.821 \mathrm{E}-03$ $\begin{array}{lllllll}0.000 \mathrm{E}+00 & 1.842 \mathrm{E}-15 & 2.288 \mathrm{E}-10 & 1.819 \mathrm{E}-09 & 2.162 \mathrm{E}-07 & 1.871 \mathrm{E}-06\end{array}$ $0.000 \mathrm{E}+00 \quad 4.331 \mathrm{E}-04 \quad 2.142 \mathrm{E}-02 \quad 4.235 \mathrm{E}-02 \quad 1.937 \mathrm{E}-01 \quad 3.615 \mathrm{E}-01$

$0.000 \mathrm{E}+00 \quad 1.421 \mathrm{E}-17 \quad 6.197 \mathrm{E}-11 \quad 7.204 \mathrm{E}-10 \quad 8.683 \mathrm{E}-08 \quad 4.891 \mathrm{E}-07$ $0.000 \mathrm{E}+00 \quad 6.662 \mathrm{E}-06 \quad 1.057 \mathrm{E}-02 \quad 2.944 \mathrm{E}-02 \quad 1.819 \mathrm{E}-01 \quad 3.507 \mathrm{E}-01$ $0.000 \mathrm{E}+00 \quad 2.004 \mathrm{E}-11 \quad 1.773 \mathrm{E}-06 \quad 1.066 \mathrm{E}-05 \quad 3.970 \mathrm{E}-04 \quad 1.719 \mathrm{E}-03$ $0.000 \mathrm{E}+00 \quad 1.423 \mathrm{E}-17 \quad 6.716 \mathrm{E}-11 \quad 8.469 \mathrm{E}-10 \quad 1.799 \mathrm{E}-07 \quad 1.714 \mathrm{E}-06$ $0.000 \mathrm{E}+00 \quad 6.662 \mathrm{E}-06 \quad 1.057 \mathrm{E}-02 \quad 2.945 \mathrm{E}-02 \quad 1.823 \mathrm{E}-01 \quad 3.524 \mathrm{E}-01$ $\begin{array}{llllll}1.000 \mathrm{E}+00 & 1.000 \mathrm{E}+00 & 9.977 \mathrm{E}-01 & 9.954 \mathrm{E}-01 & 9.773 \mathrm{E}-01 & 9.529 \mathrm{E}-01\end{array}$ $0.000 \mathrm{E}+00 \quad 9.848 \mathrm{E}-10 \quad 4.916 \mathrm{E}-08 \quad 9.815 \mathrm{E}-08 \quad 4.840 \mathrm{E}-07 \quad 9.974 \mathrm{E}-07$ $\begin{array}{llllllll}1.000 \mathrm{E}+00 & 1.000 \mathrm{E}+00 & 9.989 \mathrm{E}-01 & 9.977 \mathrm{E}-01 & 9.886 \mathrm{E}-01 & 9.761 \mathrm{E}-01\end{array}$ $\begin{array}{lllllll}1.000 \mathrm{E}+00 & 1.000 \mathrm{E}+00 & 9.989 \mathrm{E}-01 & 9.977 \mathrm{E}-01 & 9.886 \mathrm{E}-01 & 9.761 \mathrm{E}-01\end{array}$ 
RESRAD, Version 6.5

Summary : RESRAD Parameters for Resident Farmer U-Landfill

File : C: \RESRAD_FAMILY \RESRAD \USERFILES \QCFORSRSG $O$ ONSITERF_SRSG-MAY1.RAD

Individual Nuclide Soil Concentration

Parent Nuclide and Branch Fraction Indicated

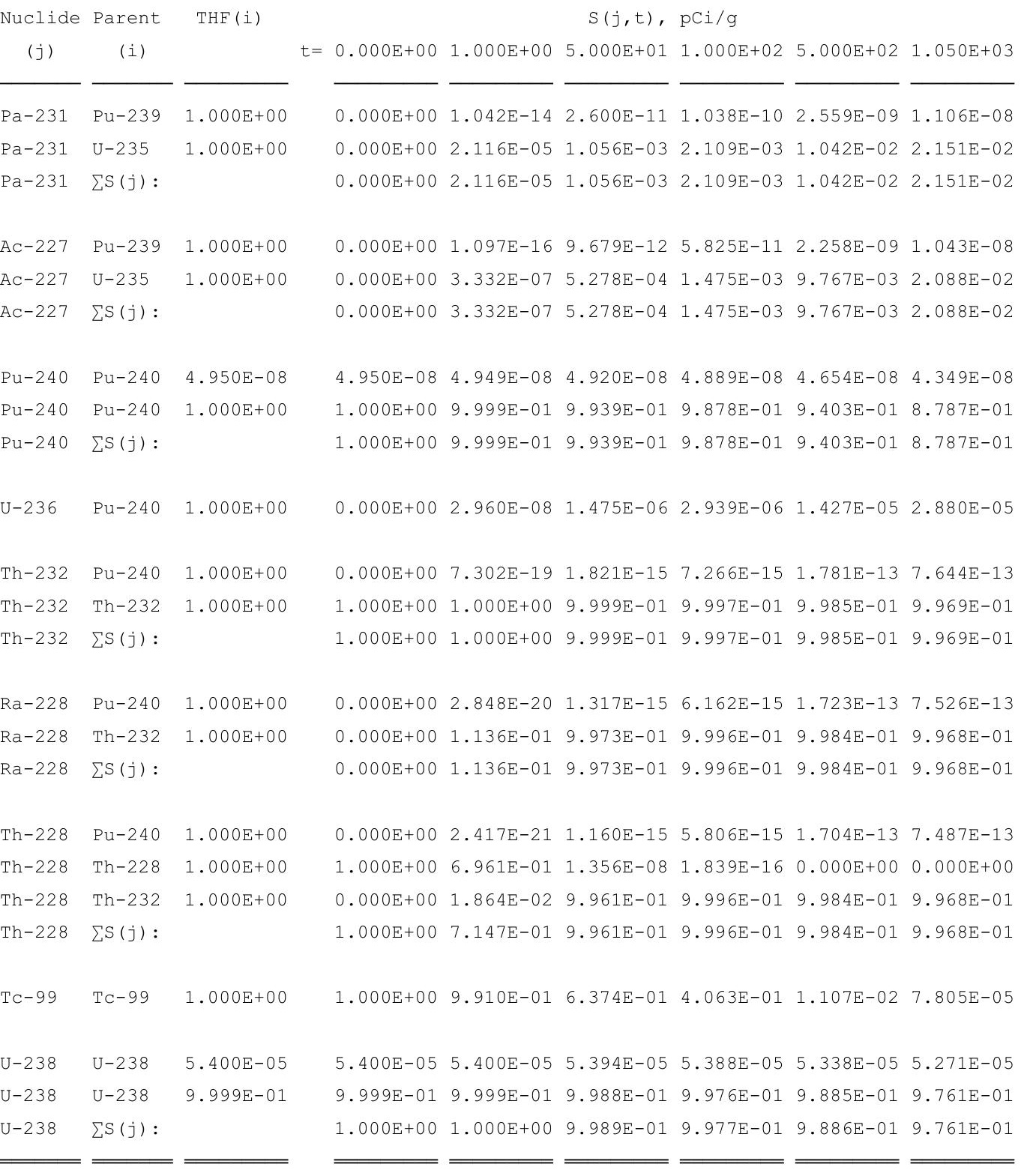

THF (i) is the thread fraction of the parent nuclide.

RESCALC.EXE execution time $=270.43$ seconds 
RESRAD-OFFSITE, Version $2.5 \quad \mathrm{~T}^{1 / 2}$ Limit $=180$ days

Parent Dose Report

Title : RESRAD-OFFSITE Parameters for Offsite Resident Farmer

File : OFFSITE-RF_SRSG-7-11.ROF

Table of Contents

Part I: Mixture Sums and Single Radionuclide Guidelines

Dose Conversion Factor (and Related) Parameter Summary ... 2

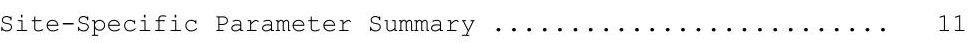

Summary of Pathway Selections $\ldots \ldots \ldots \ldots \ldots \ldots \ldots \ldots \ldots .48$

Contaminated zone and Total Dose Summary ............. 49

Total Dose Components

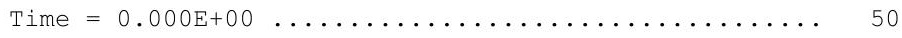

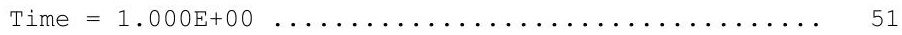

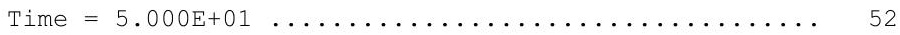

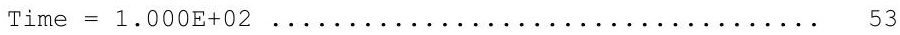

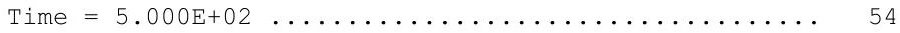

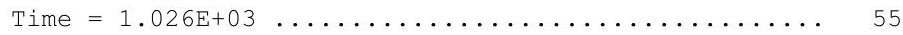

Dose/Source Ratios Summed Over All Pathways ............ 56

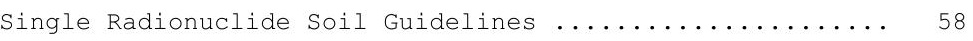

Dose Per Nuclide Summed Over All Pathways ............. 59

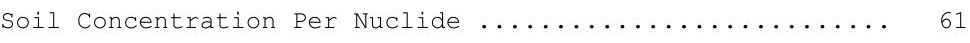

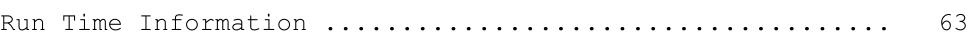


RESRAD-OFFSITE, Version 2.5

Parent Dose Report

Title : RESRAD-OFFSITE Parameters for Offsite Resident Farmer

File : OFFSITE-RF_SRSG-7-11.ROF

Dose Conversion Factor (and Related) Parameter Summary

Current Library: ICRP 60

Default Library: ICRP 60

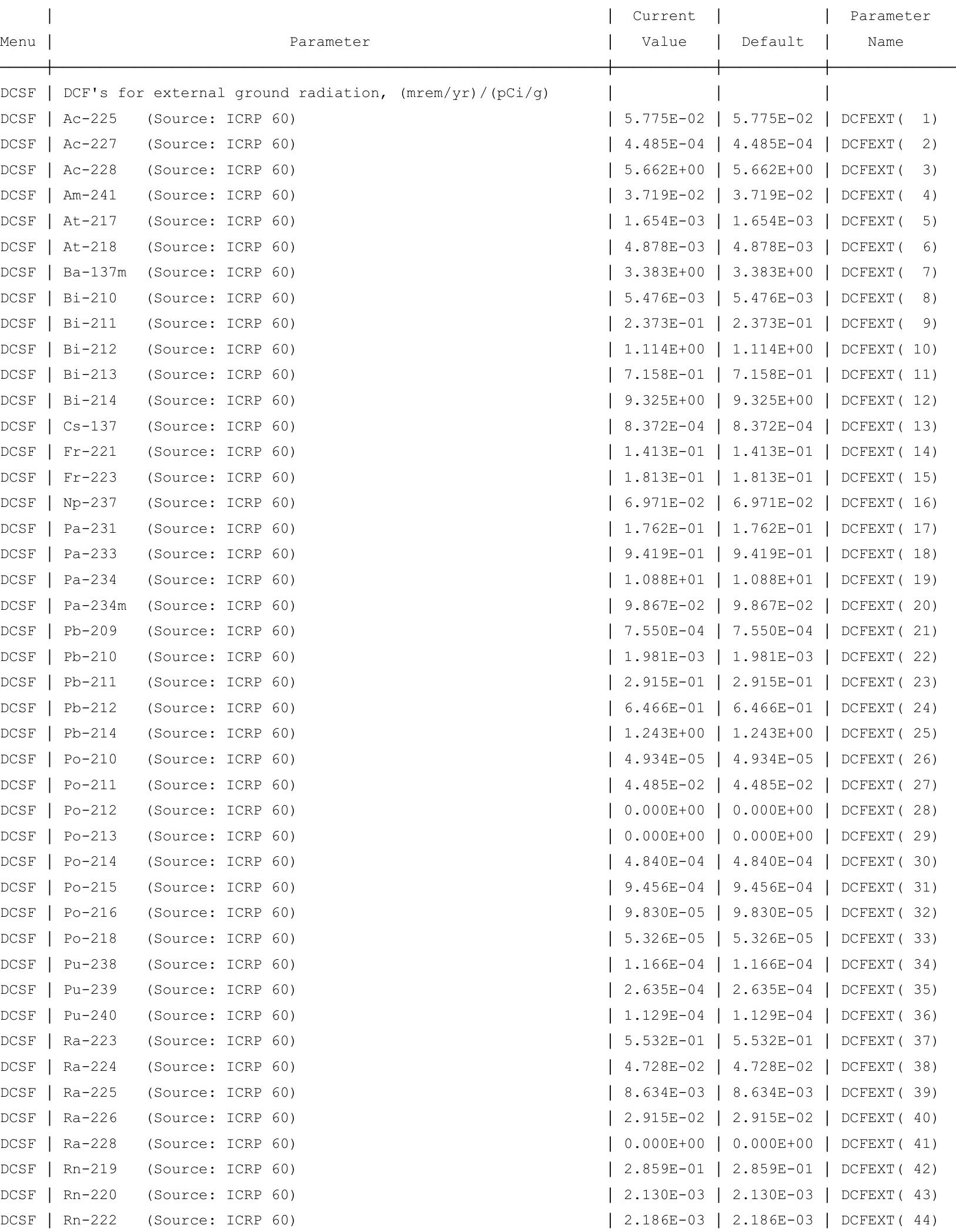


RESRAD-OFFSITE, Version $2.5 \quad \mathrm{~T}^{1 / 2}$ Limit $=180$ days

Parent Dose Report

Title : RESRAD-OFFSITE Parameters for offsite Resident Farmer

File : OFFSITE-RF_SRSG-7-11.ROF

Dose Conversion Factor (and Related) Parameter Summary (continued)

Current Library: ICRP 60

Default Library: ICRP 60

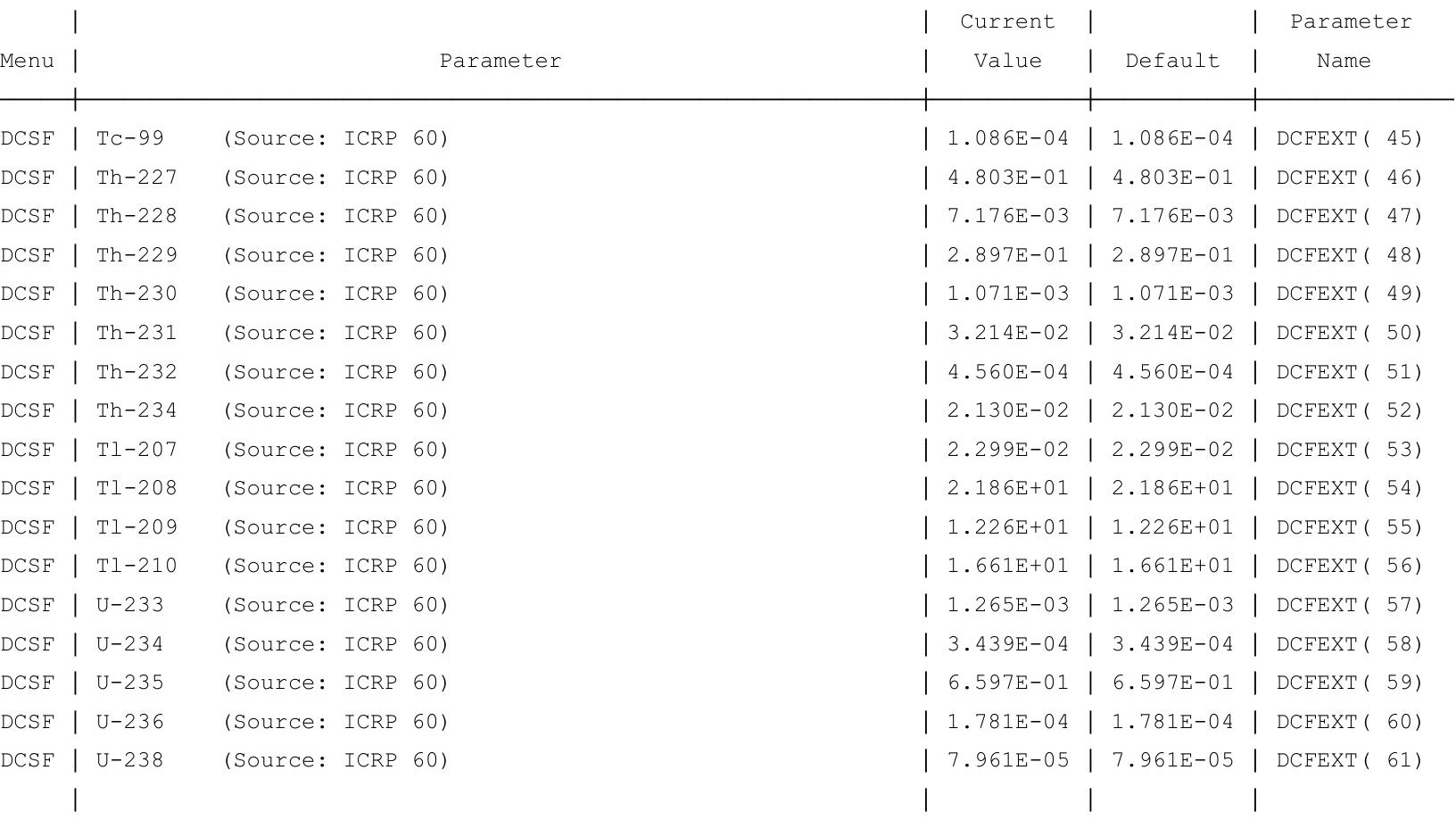

Current Library: ICRP 72 (Adult)

Default Library: ICRP 72 (Adult)

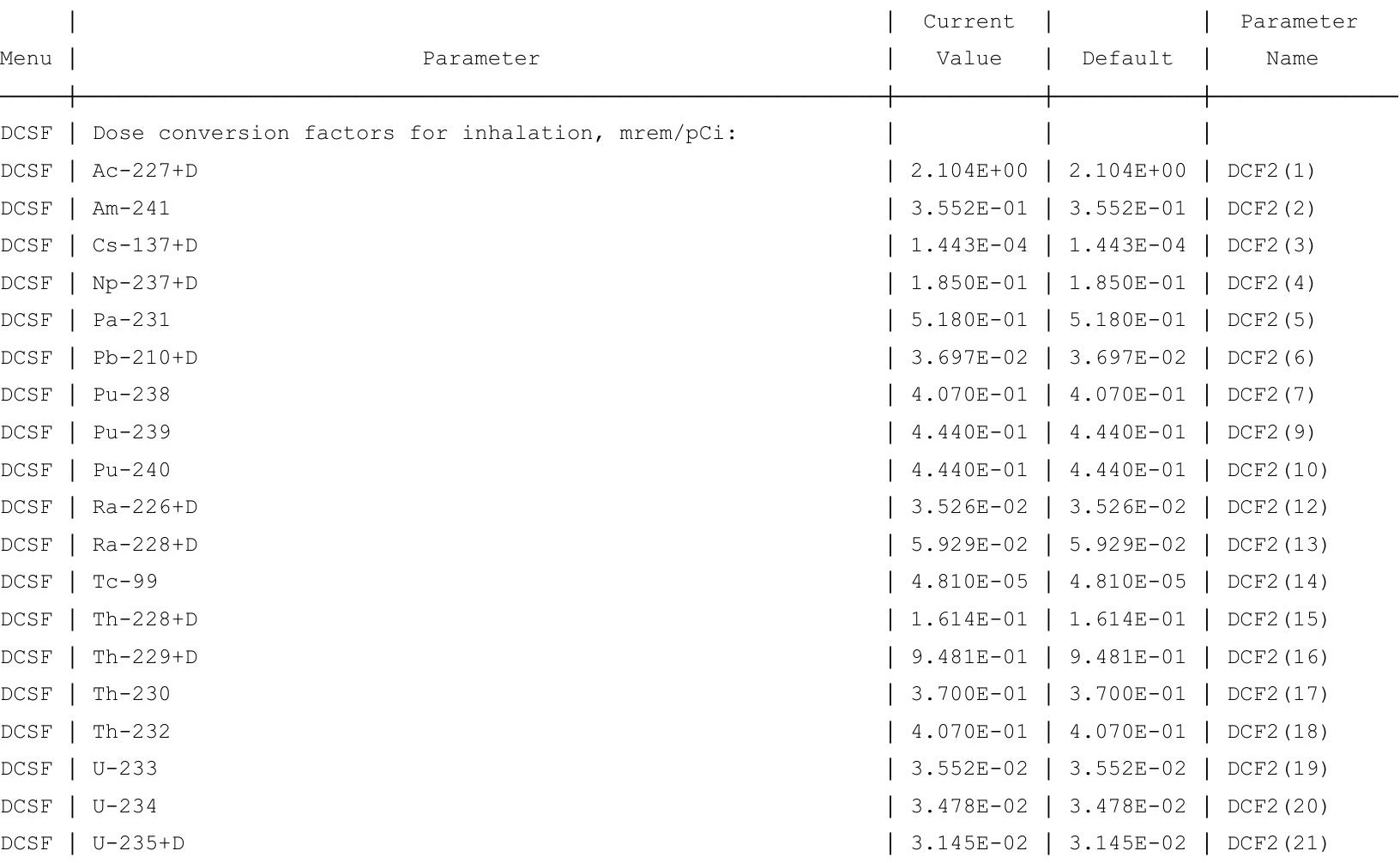


RESRAD-OFFSITE, Version $2.5 \quad \mathrm{~T}^{1 / 2}$ Limit $=180$ days

Parent Dose Report

Title : RESRAD-OFFSITE Parameters for Offsite Resident Farmer

File : OFFSITE-RF_SRSG-7-11.ROF

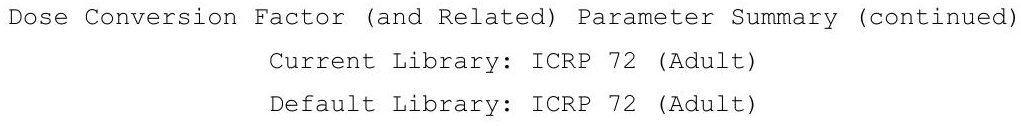

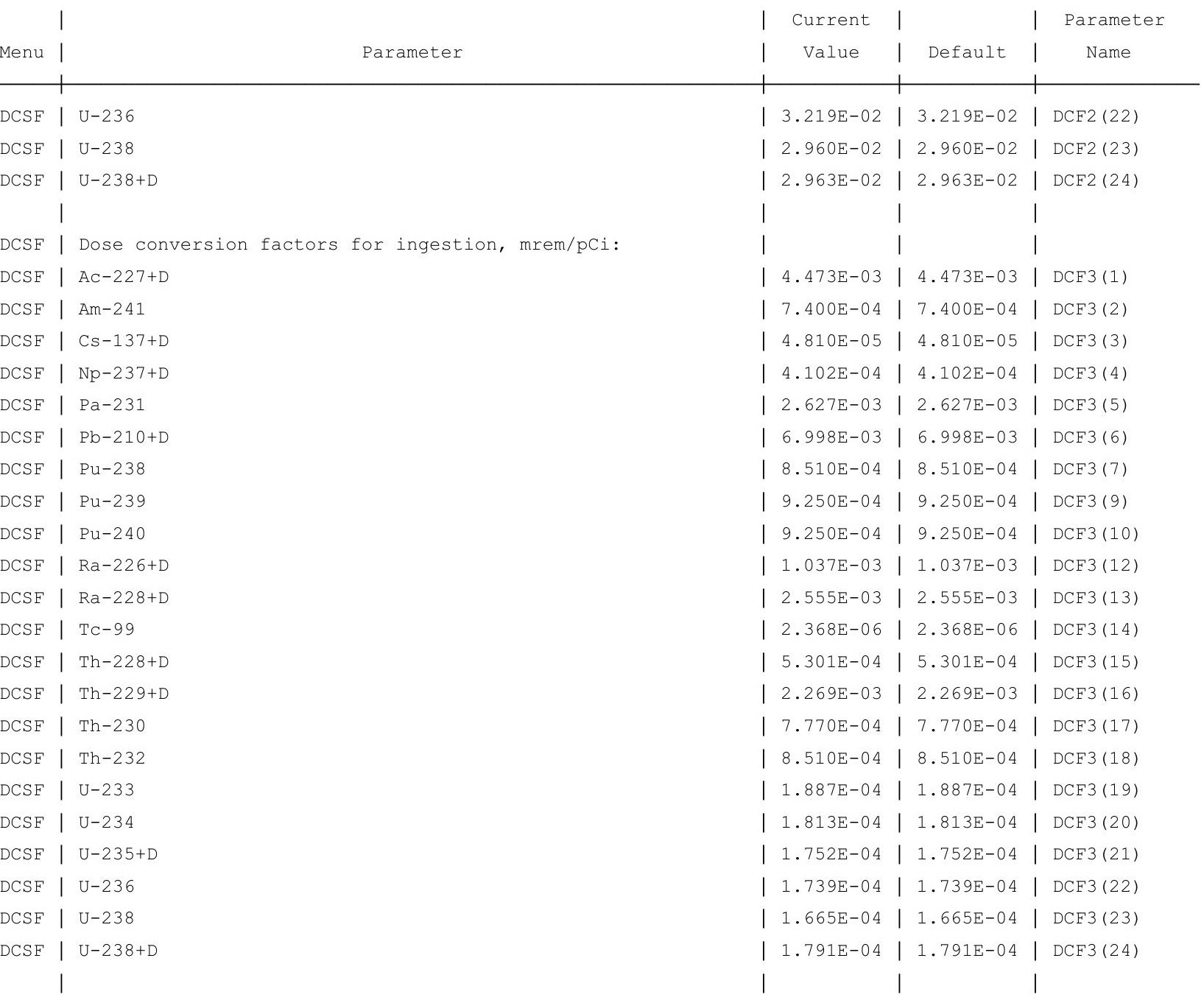


RESRAD-OFFSITE, Version 2.5

Parent Dose Report
itle : RESRAD-OFFSITE Parameters for offsite Resident Farmer

File : OFFSITE-RF_SRSG-7-11.ROF

Dose Conversion Factor (and Related) Parameter Summary (continued)

Current Library: RESRAD Default Transfer factors

Default Library: RESRAD Default Transfer factors

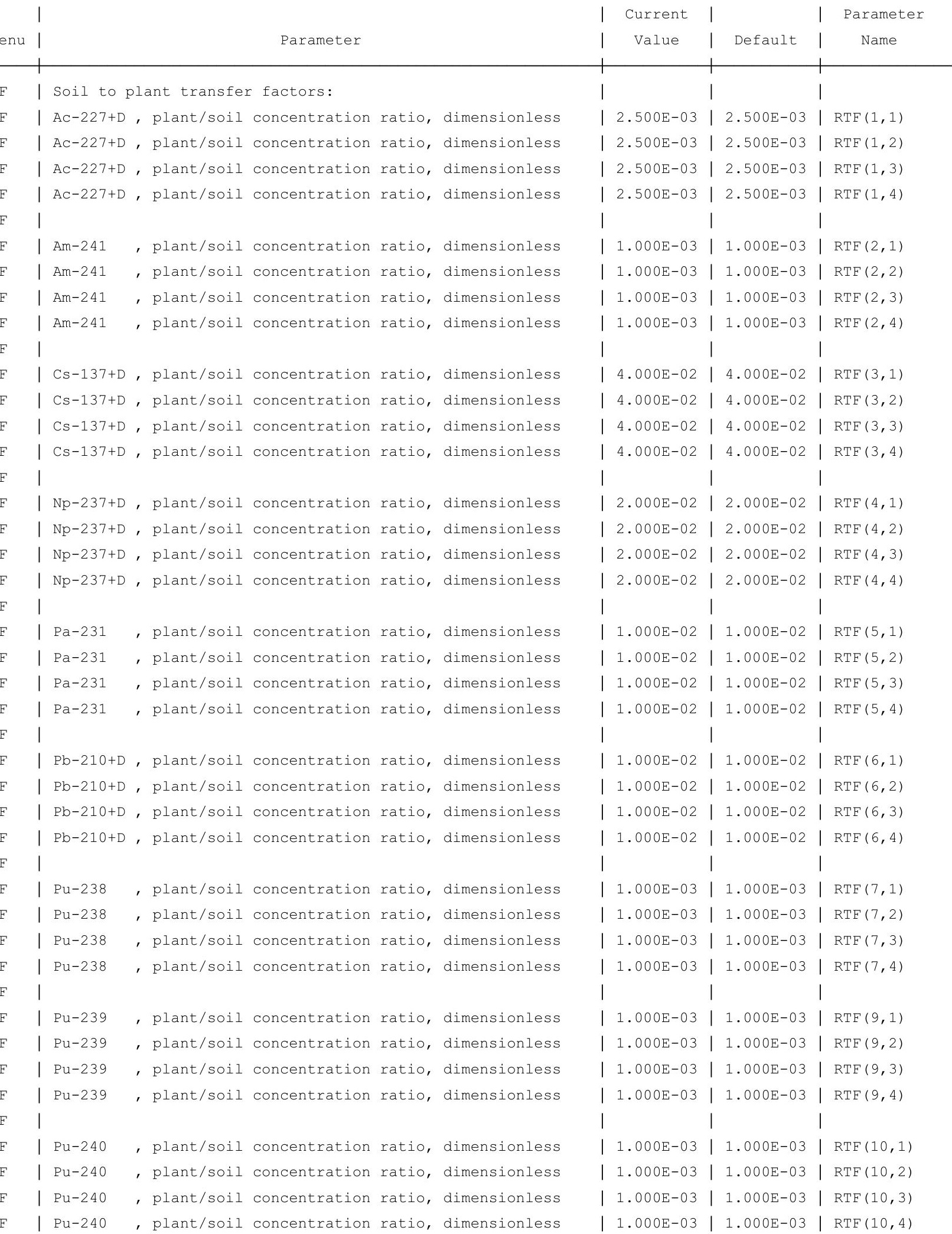


RESRAD-OFFSITE, Version 2.5

\section{rent Dose Report \\ Title : RESRAD-OFFSITE Parameters for Offsite Resident Farmer}

File : OFFSITE-RF_SRSG-7-11.ROF

Dose Conversion Factor (and Related) Parameter Summary (continued)

Current Library: RESRAD Default Transfer factors

Default Library: RESRAD Default Transfer factors

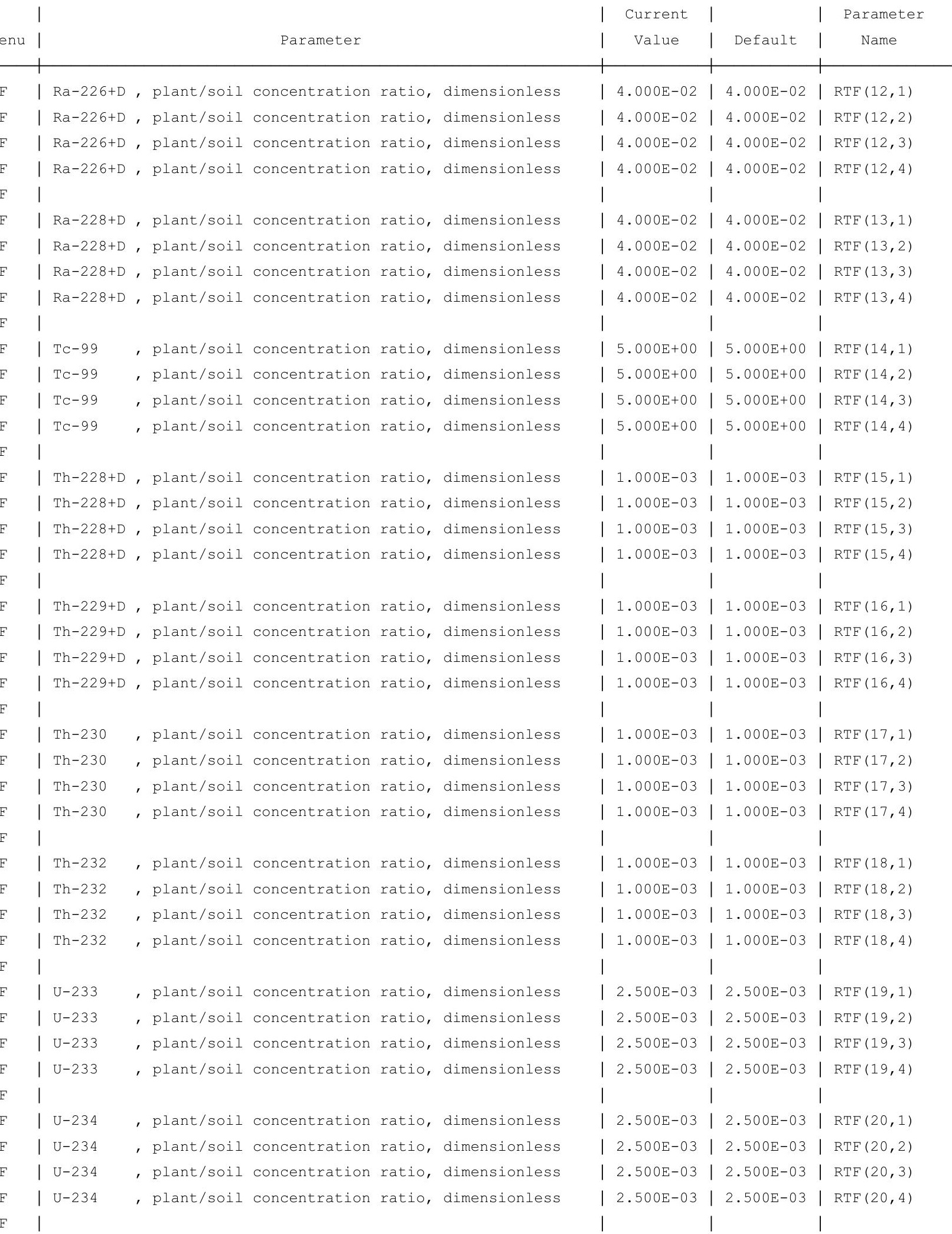


RESRAD-OFFSITE, Version 2.5

Parent Dose Report

Title : RESRAD-OFFSITE Parameters for offsite Resident Farmer

File : OFFSITE-RF_SRSG-7-11.ROF

Dose Conversion Factor (and Related) Parameter Summary (continued)

Current Library: RESRAD Default Transfer factors

Default Library: RESRAD Default Transfer factors

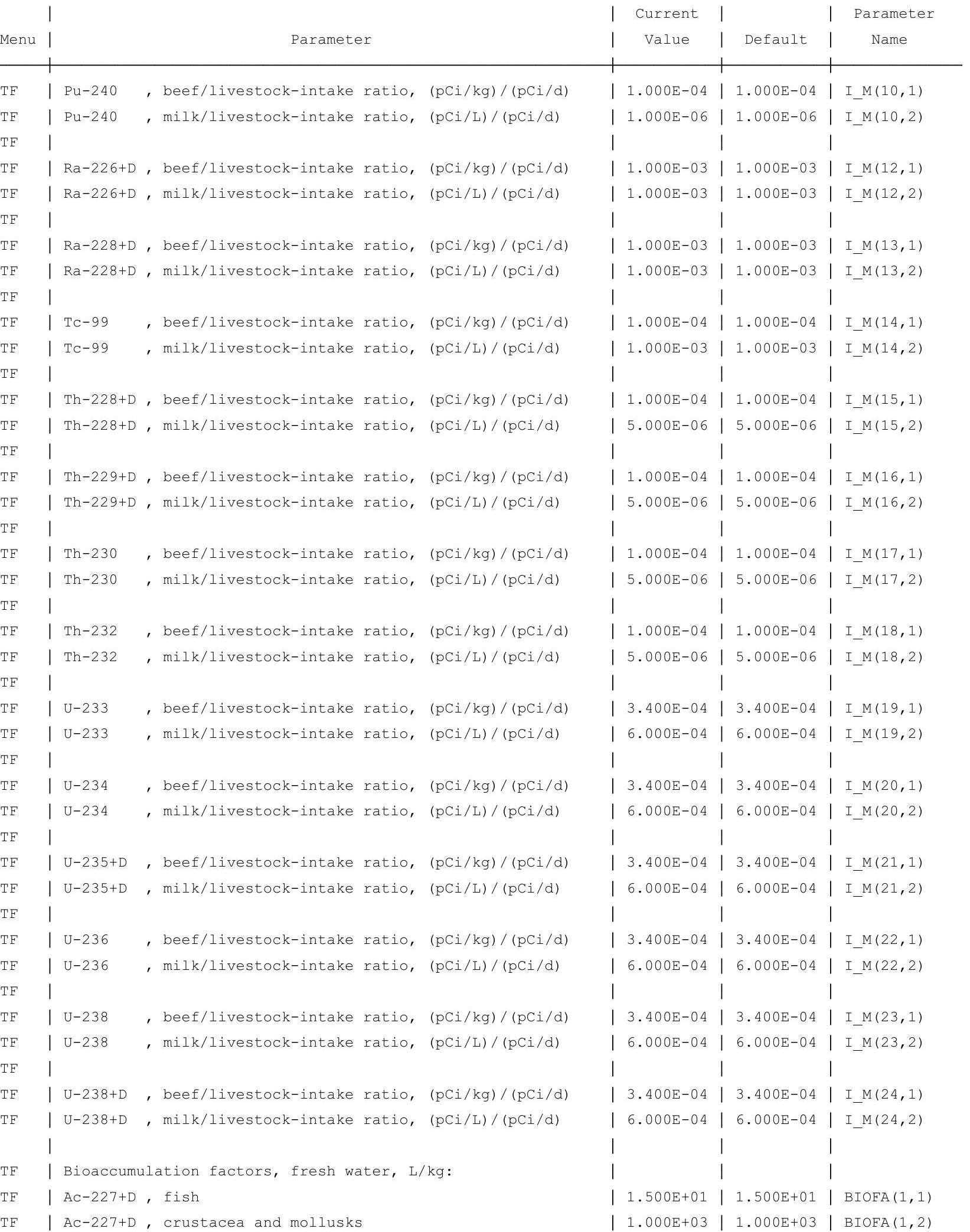


RESRAD-OFFSITE, Version 2.5

Parent Dose Report

Title : RESRAD-OFFSITE Parameters for Offsite Resident Farmer

File : OFFSITE-RF_SRSG-7-11.ROF

Dose Conversion Factor (and Related) Parameter Summary (continued)

Current Library: RESRAD Default Transfer factors

Default Library: RESRAD Default Transfer factors

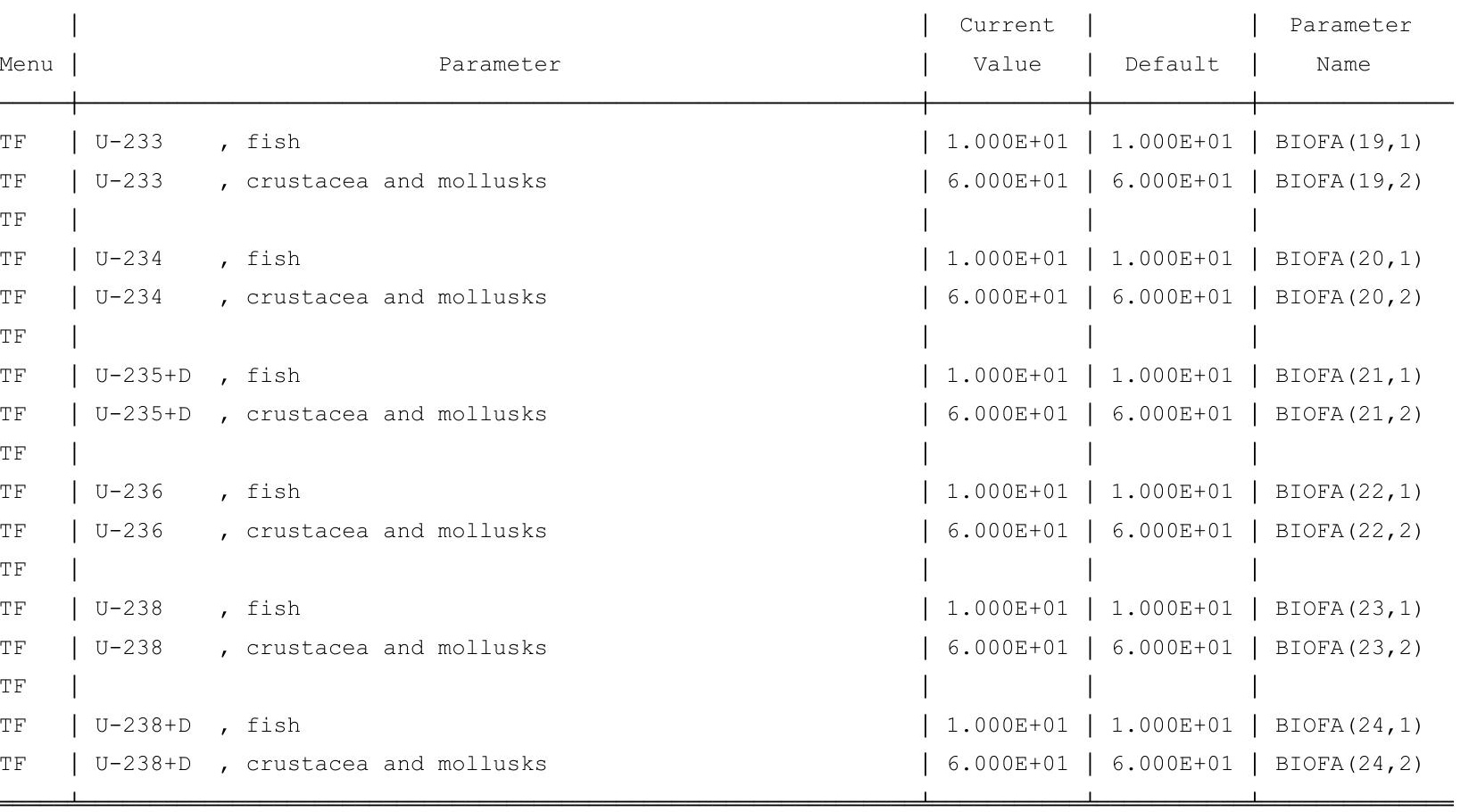


RESRAD-OFFSITE, Version 2.5

Parent Dose Report

Title : RESRAD-OFFSITE Parameters for Offsite Resident Farmer

File : OFFSITE-RF SRSG-7-11.ROF

Site-Specific Parameter Summary

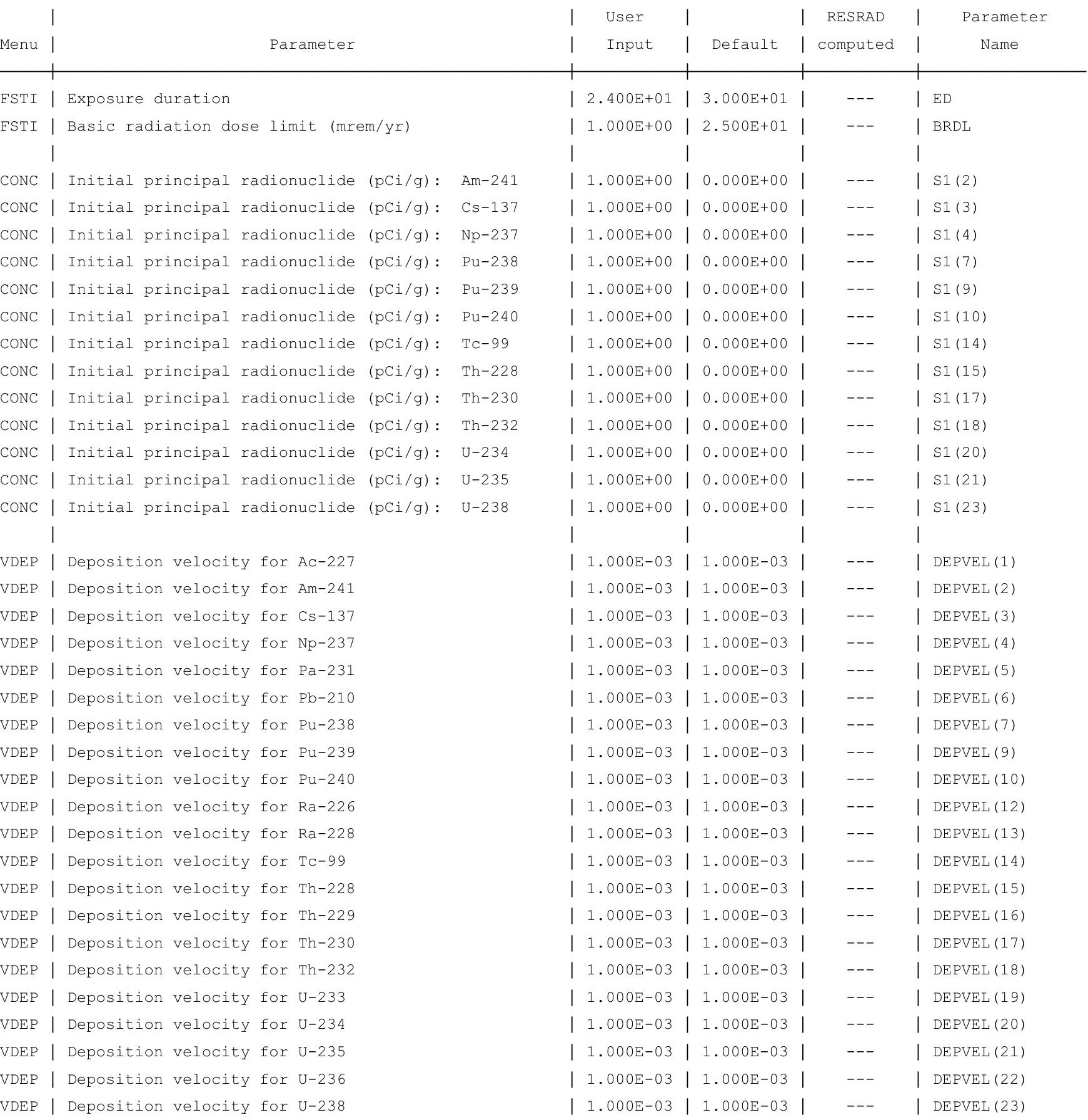


RESRAD-OFFSITE, Version $2.5 \quad \mathrm{~T}^{1 / 2}$ Limit $=180$ days

Parent Dose Report

Title : RESRAD-OFFSITE Parameters for Offsite Resident Farmer

File : OFFSITE-RF_SRSG-7-11.ROF

Site-Specific Parameter Summary (continued)

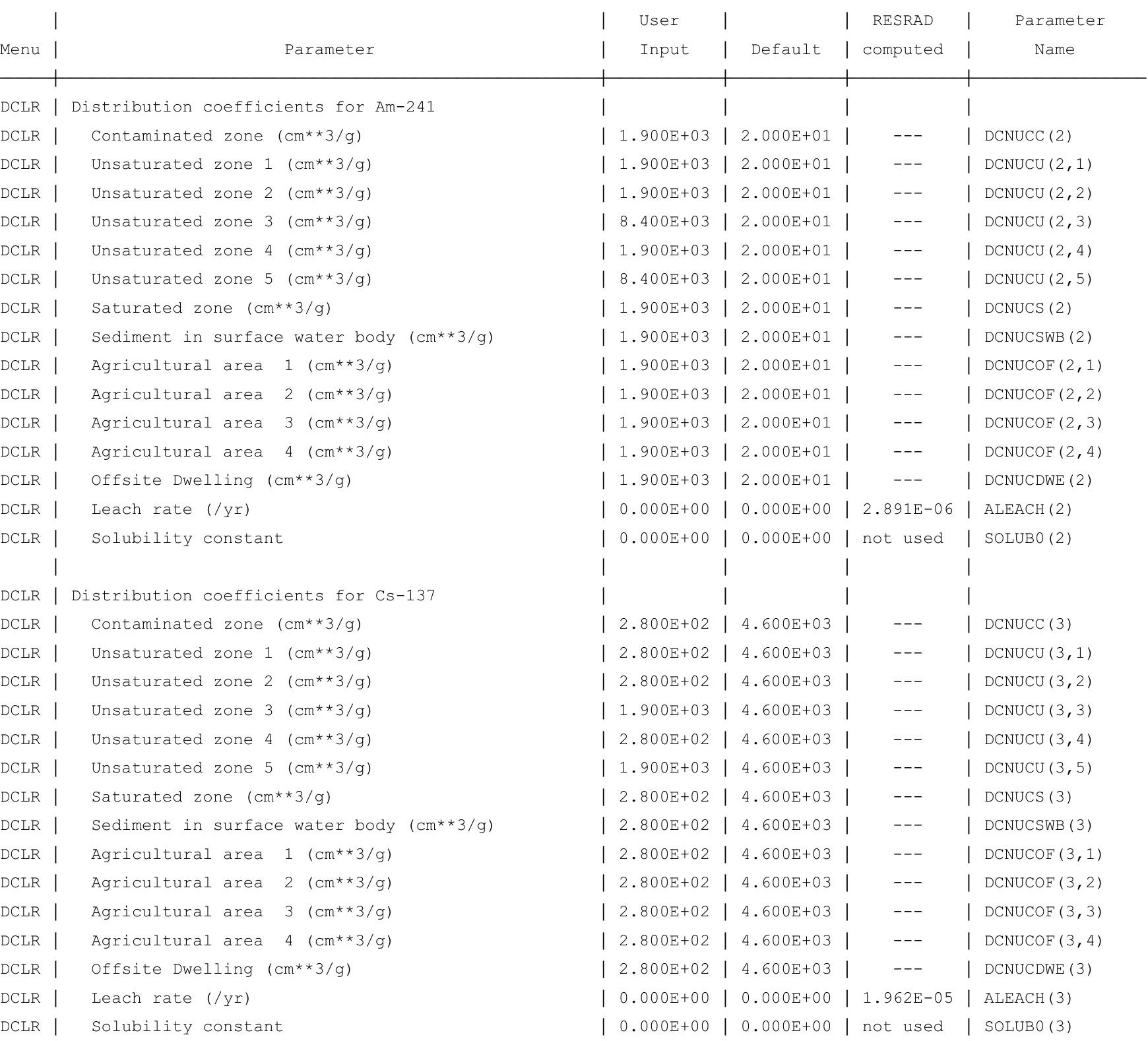


RESRAD-OFFSITE, Version $2.5 \quad \mathrm{~T}^{1 / 2}$ Limit $=180$ days

Parent Dose Report

Title : RESRAD-OFFSITE Parameters for Offsite Resident Farmer

File : OFFSITE-RF_SRSG-7-11.ROF

Site-Specific Parameter Summary (continued)

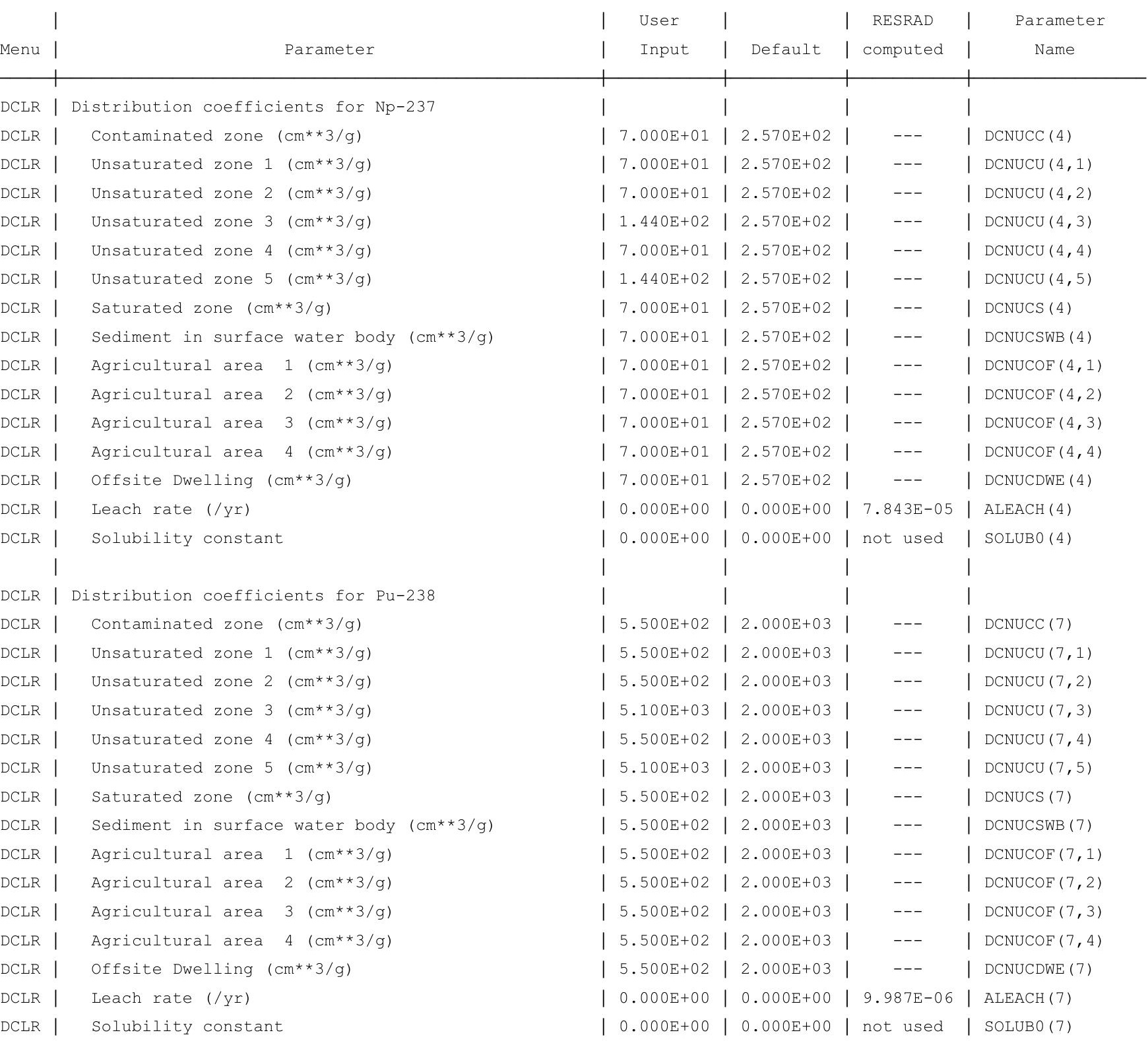


RESRAD-OFFSITE, Version $2.5 \quad \mathrm{~T}^{1 / 2}$ Limit $=180$ days

Parent Dose Report

Title : RESRAD-OFFSITE Parameters for Offsite Resident Farmer

File : OFFSITE-RF_SRSG-7-11.ROF

Site-Specific Parameter Summary (continued)

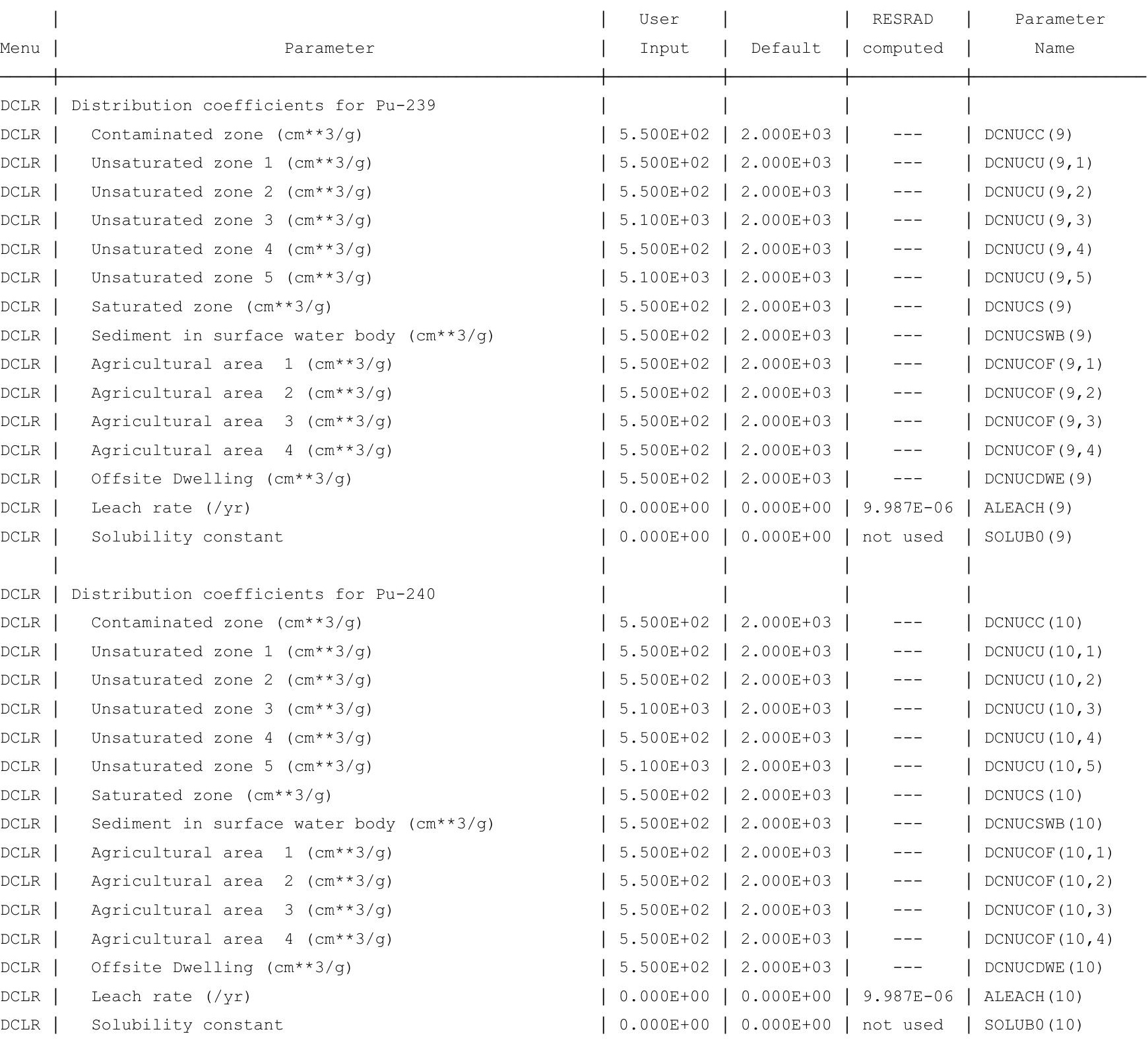


RESRAD-OFFSITE, Version $2.5 \quad \mathrm{~T}^{1 / 2}$ Limit $=180$ days

Parent Dose Report

Title : RESRAD-OFFSITE Parameters for Offsite Resident Farmer

File : OFFSITE-RF_SRSG-7-11.ROF

Site-Specific Parameter Summary (continued)

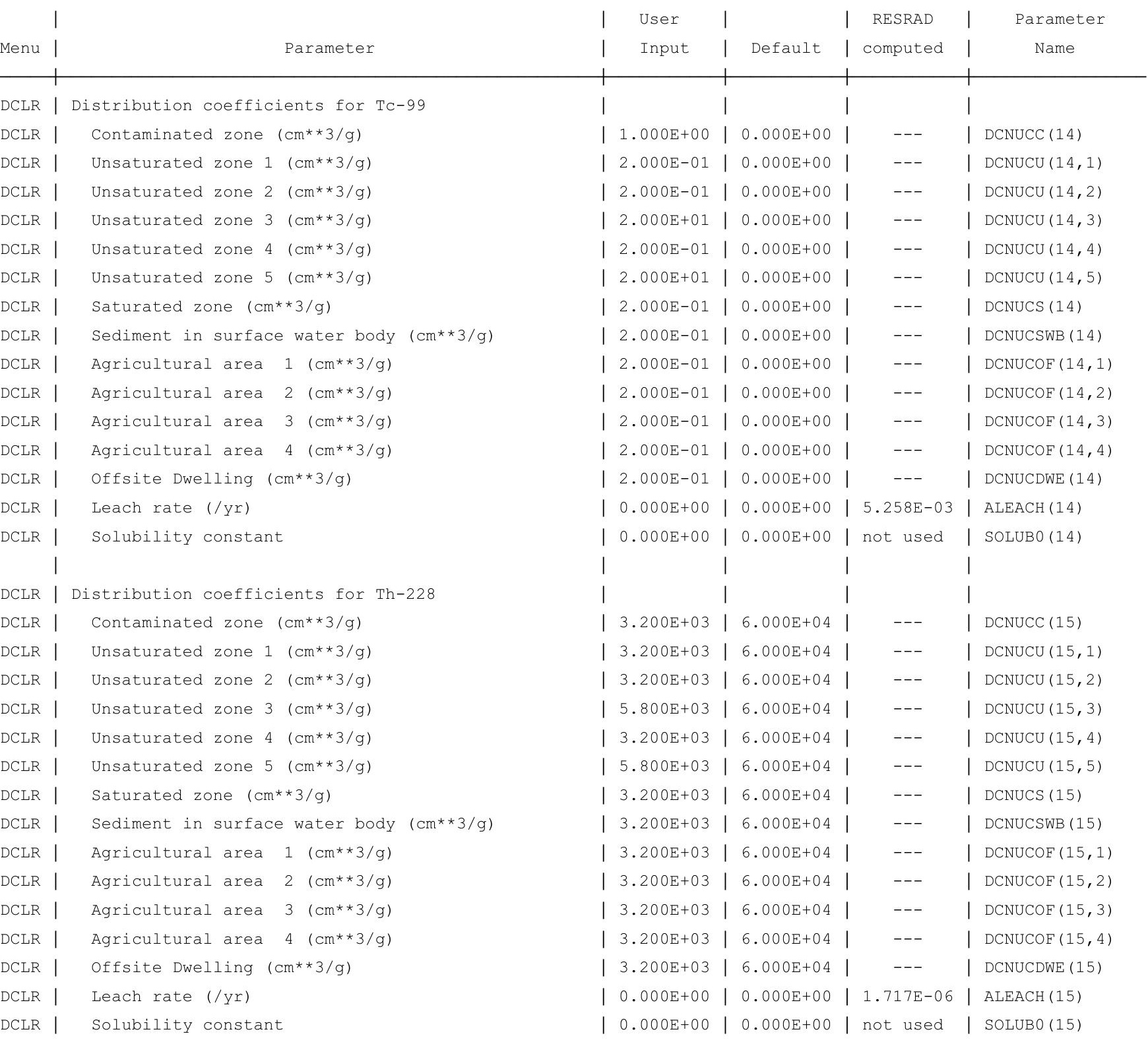


RESRAD-OFFSITE, Version $2.5 \quad \mathrm{~T}^{1 / 2}$ Limit $=180$ days

Parent Dose Report

Title : RESRAD-OFFSITE Parameters for Offsite Resident Farmer

File : OFFSITE-RF_SRSG-7-11.ROF

Site-Specific Parameter Summary (continued)

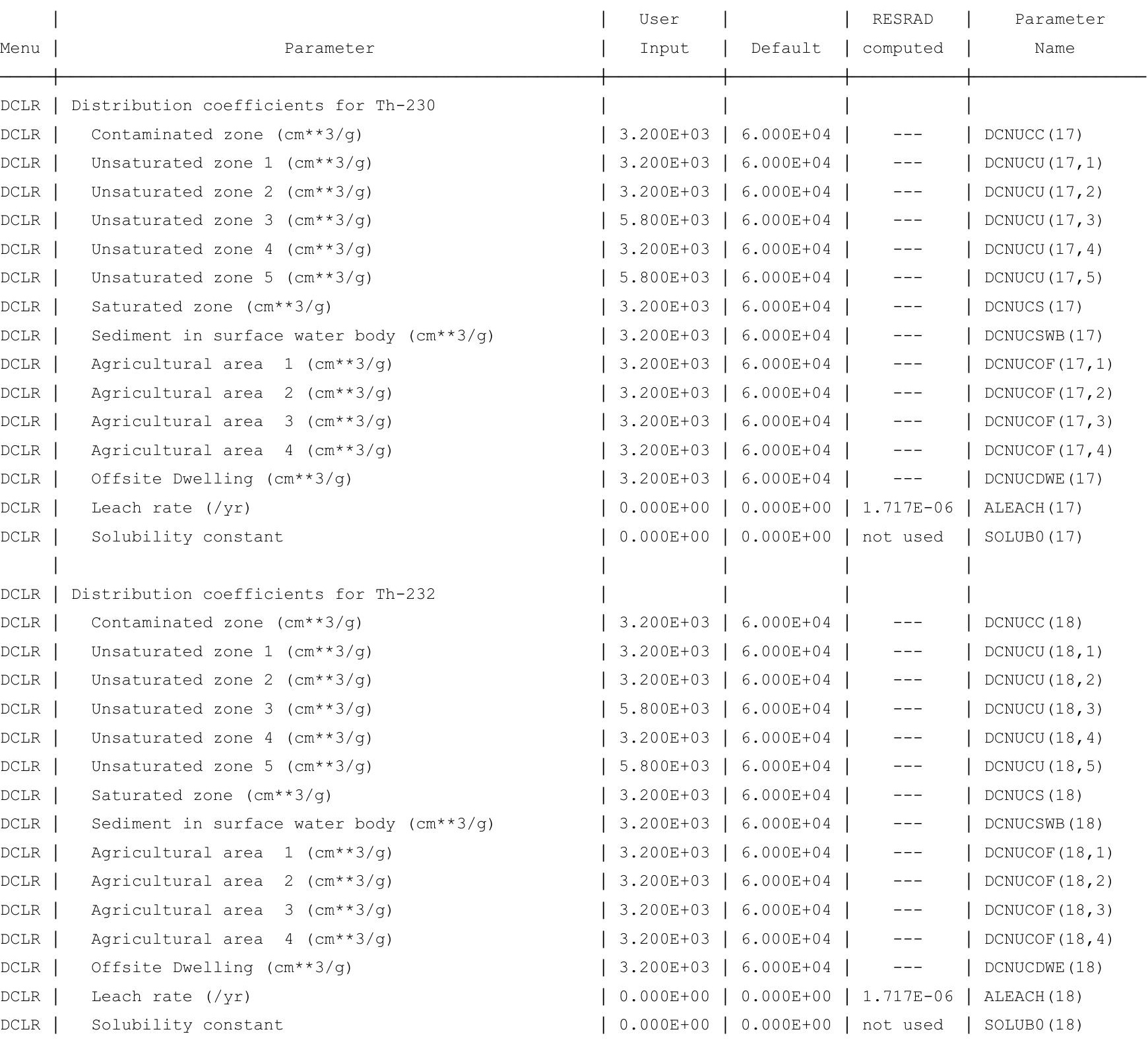


RESRAD-OFFSITE, Version $2.5 \quad \mathrm{~T}^{1 / 2}$ Limit $=180$ days

Parent Dose Report

Title : RESRAD-OFFSITE Parameters for Offsite Resident Farmer

File : OFFSITE-RF_SRSG-7-11.ROF

Site-Specific Parameter Summary (continued)

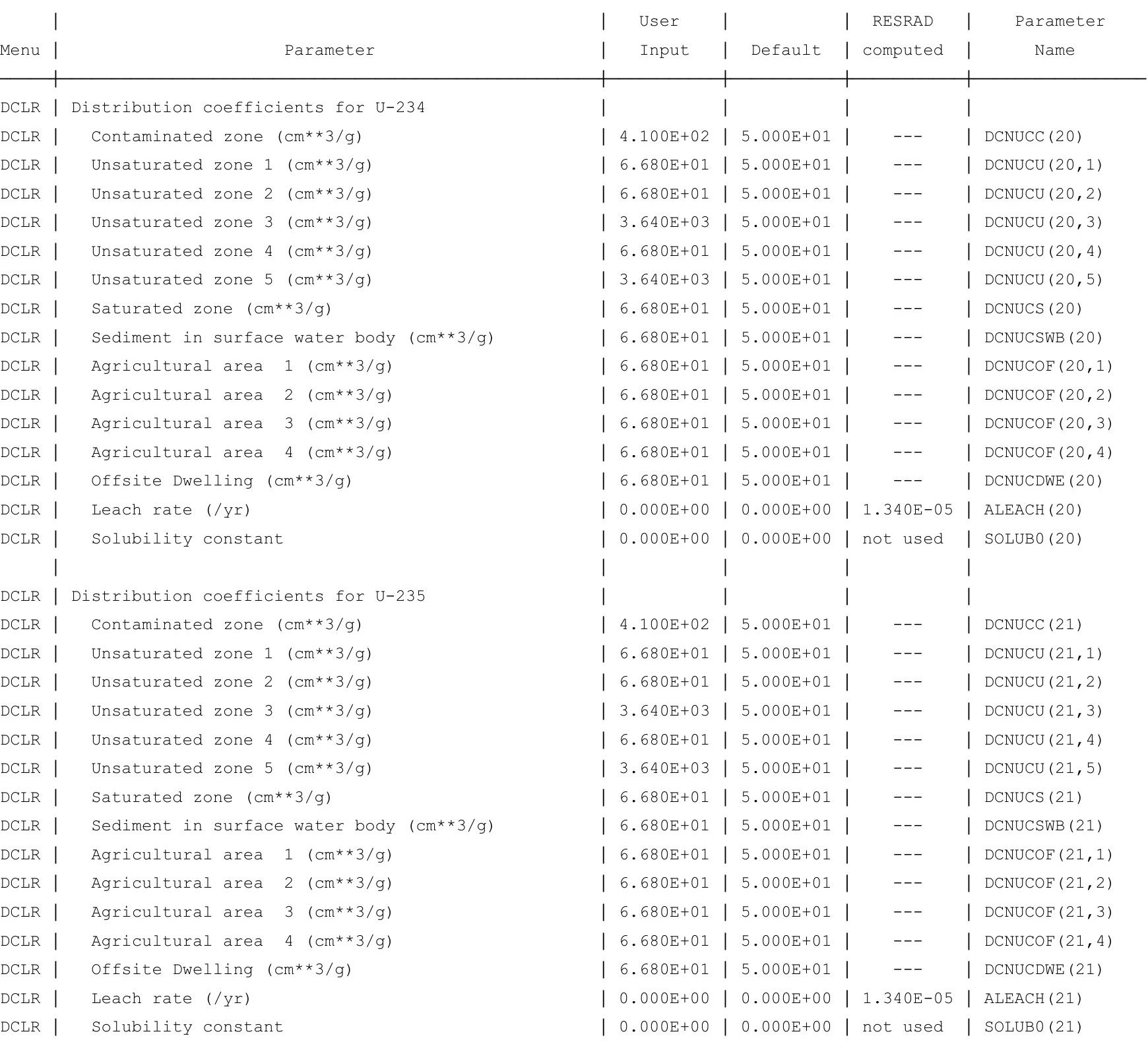


RESRAD-OFFSITE, Version $2.5 \quad \mathrm{~T}^{1 / 2}$ Limit $=180$ days

Parent Dose Report

Title : RESRAD-OFFSITE Parameters for Offsite Resident Farmer

File : OFFSITE-RF_SRSG-7-11.ROF

Site-Specific Parameter Summary (continued)

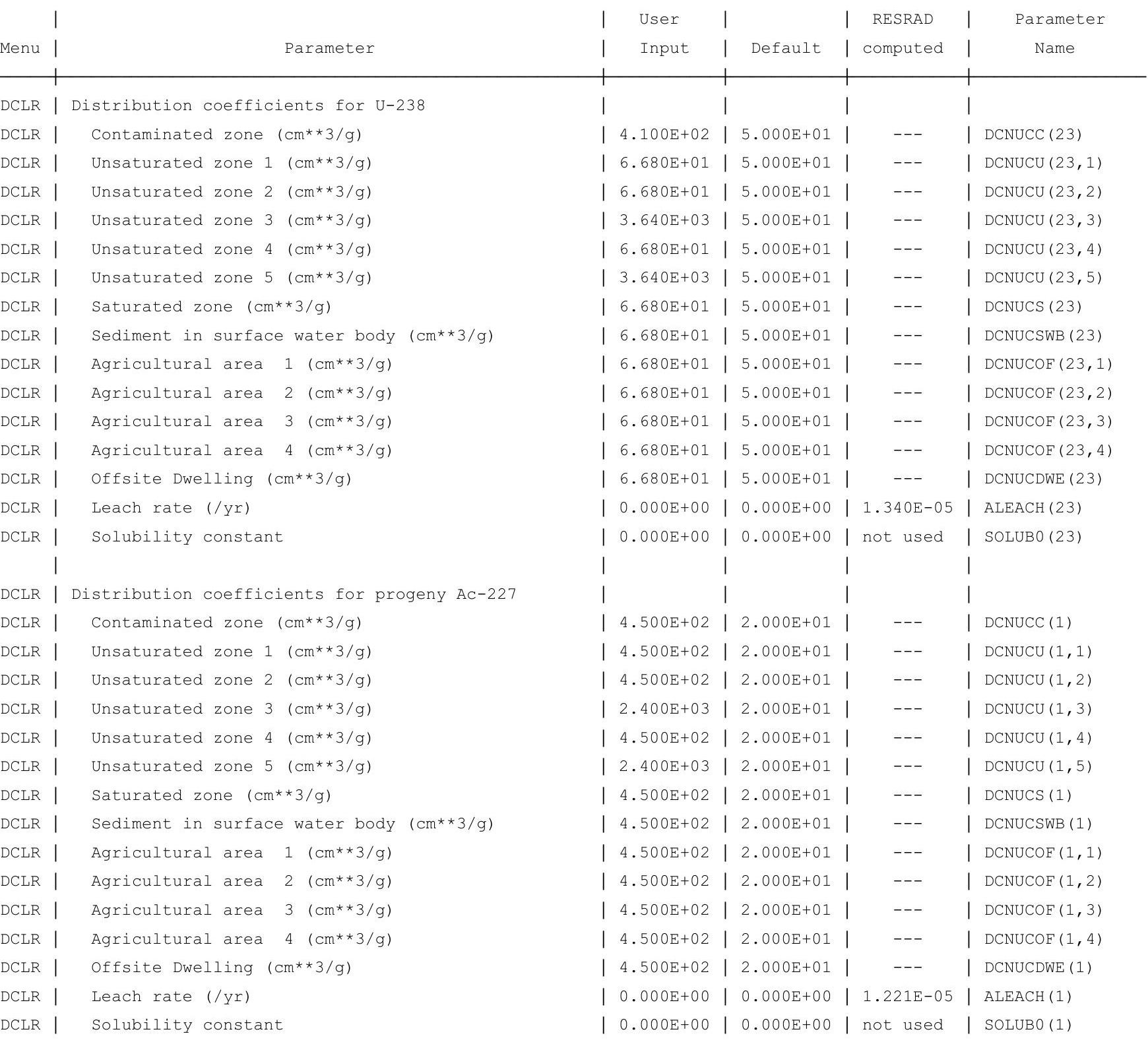


RESRAD-OFFSITE, Version $2.5 \quad \mathrm{~T}^{1 / 2}$ Limit $=180$ days

Parent Dose Report

Title : RESRAD-OFFSITE Parameters for Offsite Resident Farmer

File : OFFSITE-RF_SRSG-7-11.ROF

Site-Specific Parameter Summary (continued)

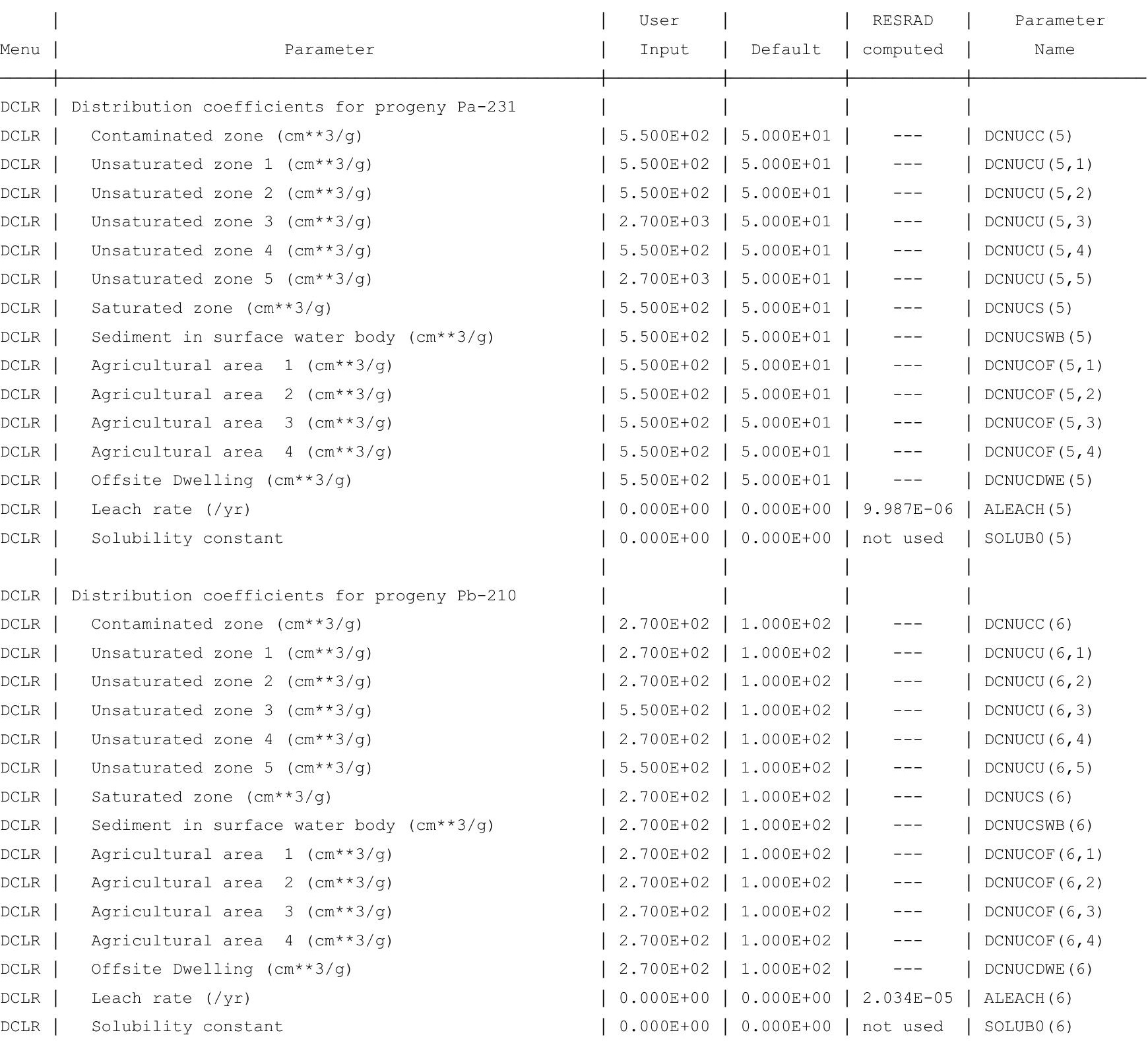


RESRAD-OFFSITE, Version $2.5 \quad \mathrm{~T}^{1 / 2}$ Limit $=180$ days

Parent Dose Report

Title : RESRAD-OFFSITE Parameters for offsite Resident Farmer

File : OFFSITE-RF_SRSG-7-11.ROF

Site-Specific Parameter Summary (continued)

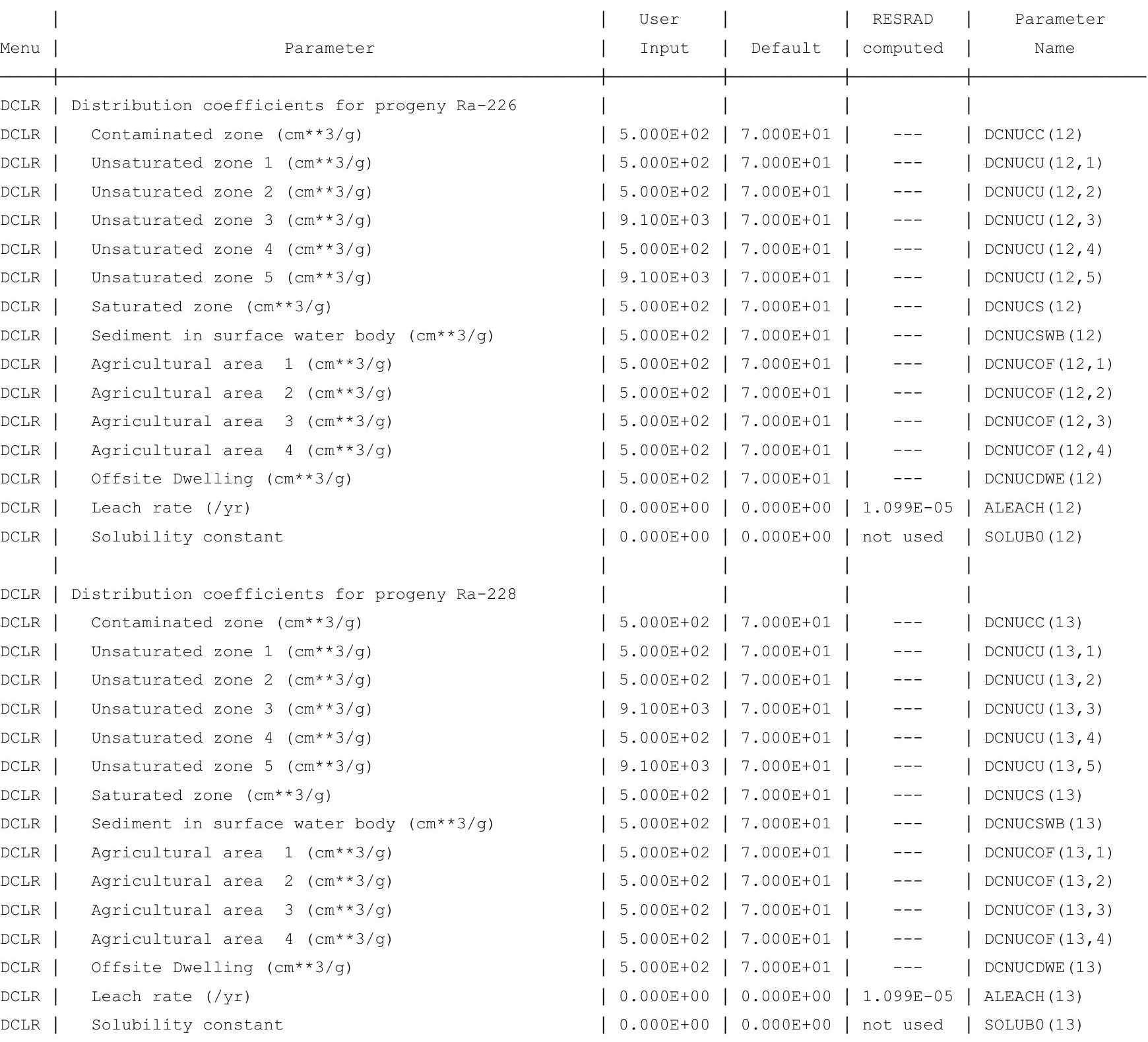


RESRAD-OFFSITE, Version $2.5 \quad \mathrm{~T}^{1 / 2}$ Limit $=180$ days

Parent Dose Report

Title : RESRAD-OFFSITE Parameters for Offsite Resident Farmer

File : OFFSITE-RF_SRSG-7-11.ROF

Site-Specific Parameter Summary (continued)

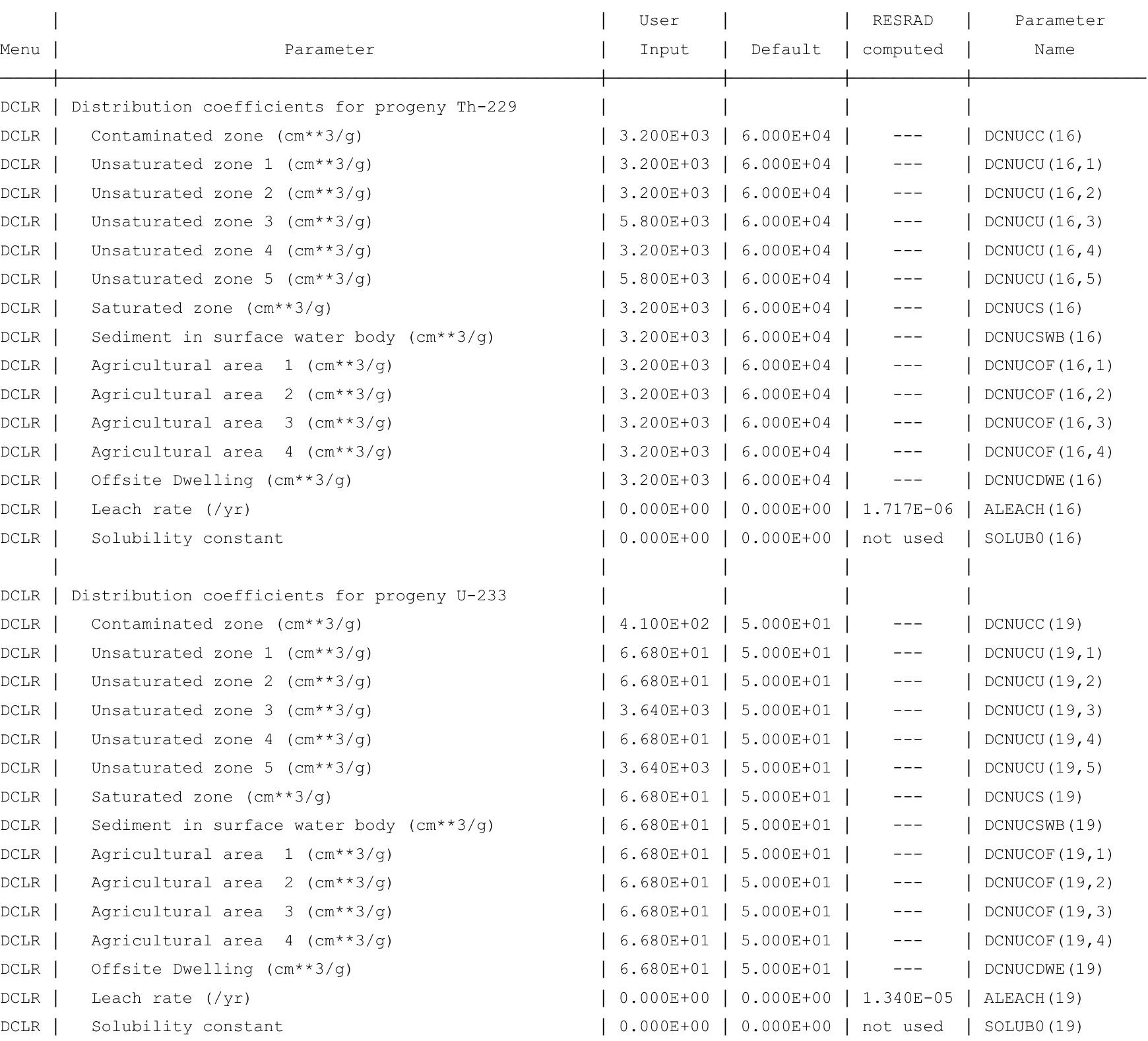


RESRAD-OFFSITE, Version $2.5 \quad T^{1 / 2}$ Limit $=180$ days

Parent Dose Report

File : OFFSITE-RF_SRSG-7-11.ROF

Site-Specific Parameter Summary (continued)

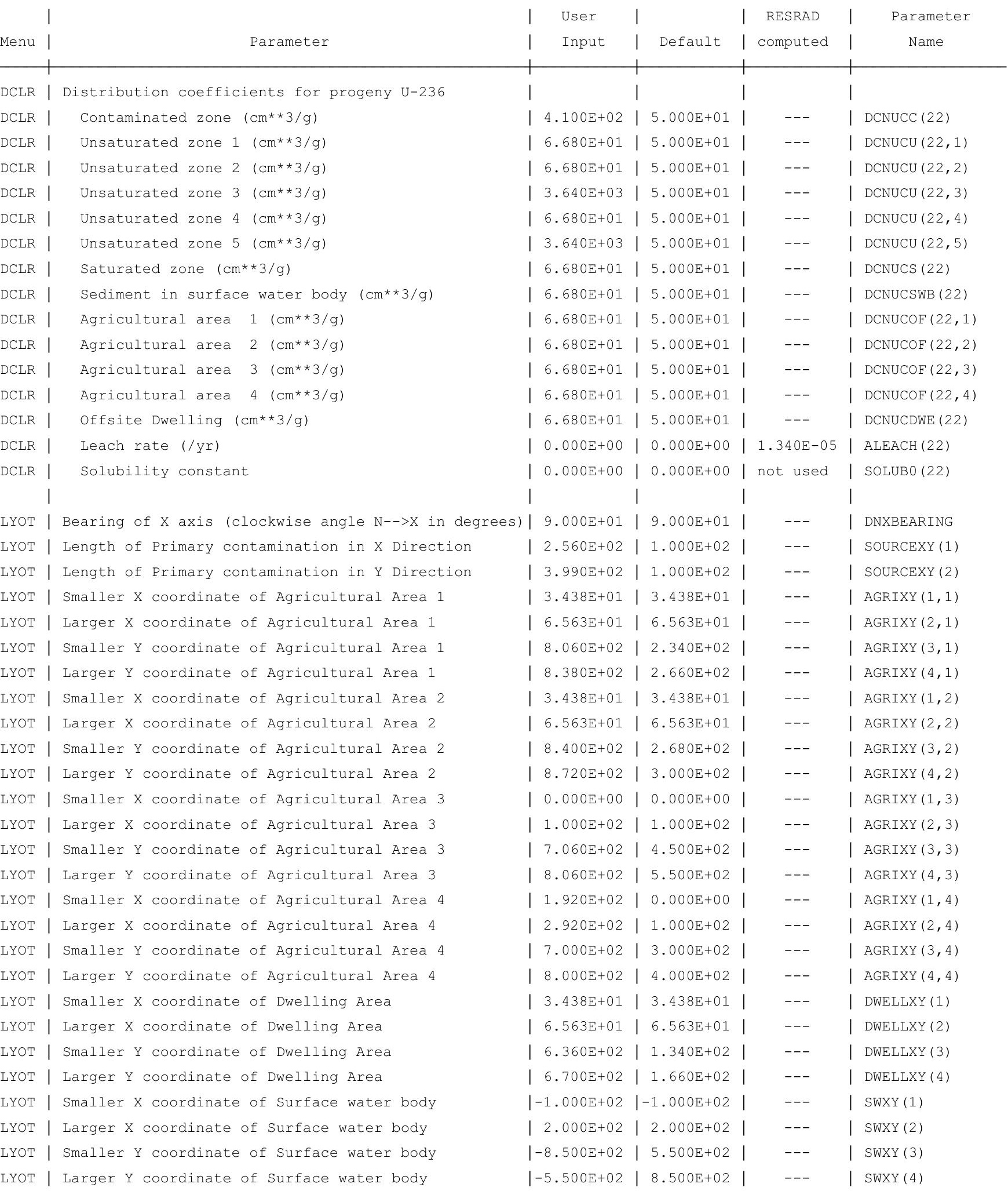


RESRAD-OFFSITE, Version 2.

Parent Dose Report

Title : RESRAD-OFFSITE Parameters for Offsite Resident Farmer

File : OFFSITE-RF SRSG-7-11.ROF

Site-Specific Parameter Summary (continued)

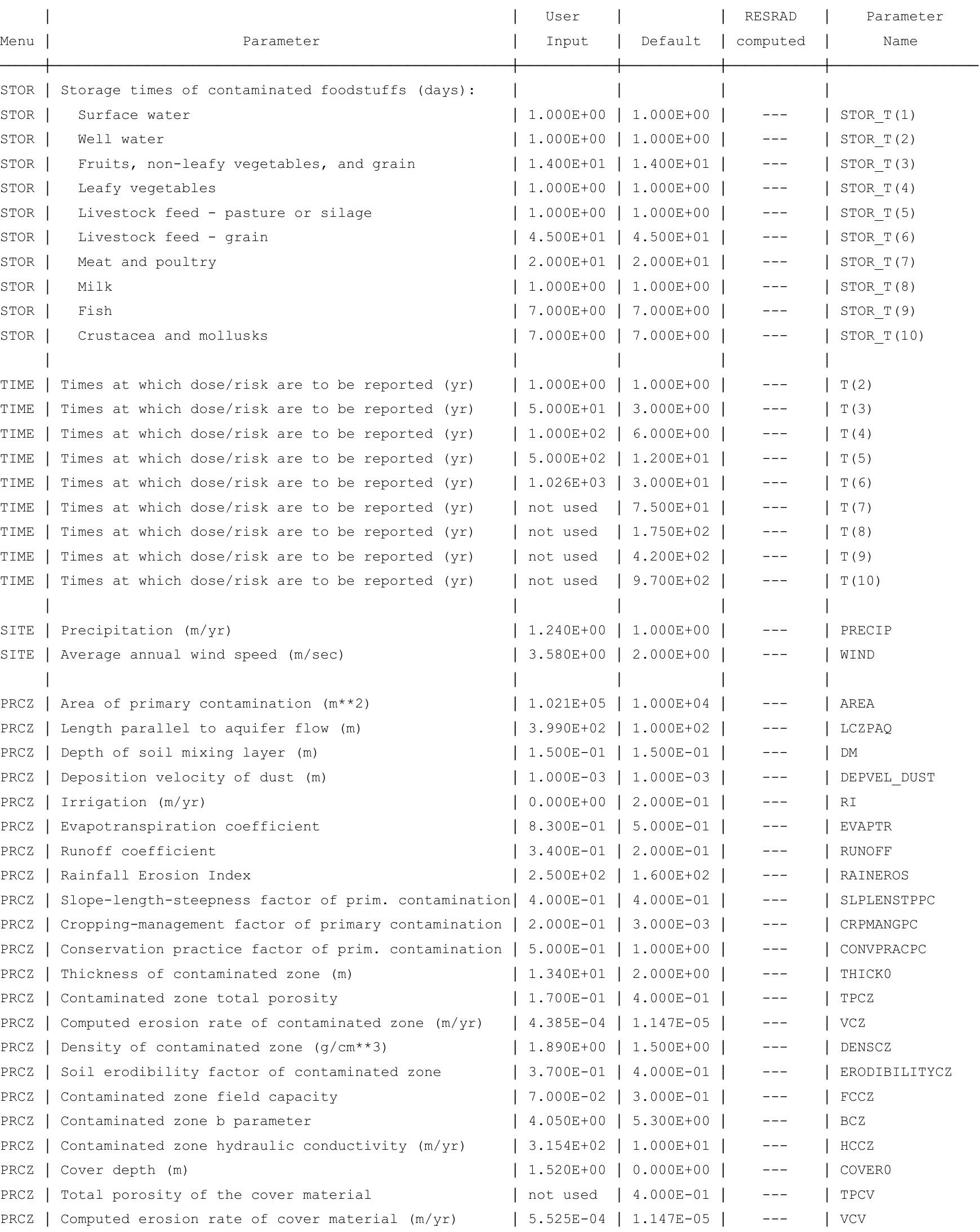


RESRAD-OFFSITE, Version 2.

Parent Dose Report

Title : RESRAD-OFFSITE Parameters for Offsite Resident Farmer

File : OFFSITE-RF SRSG-7-11.ROF

Site-Specific Parameter Summary (continued)

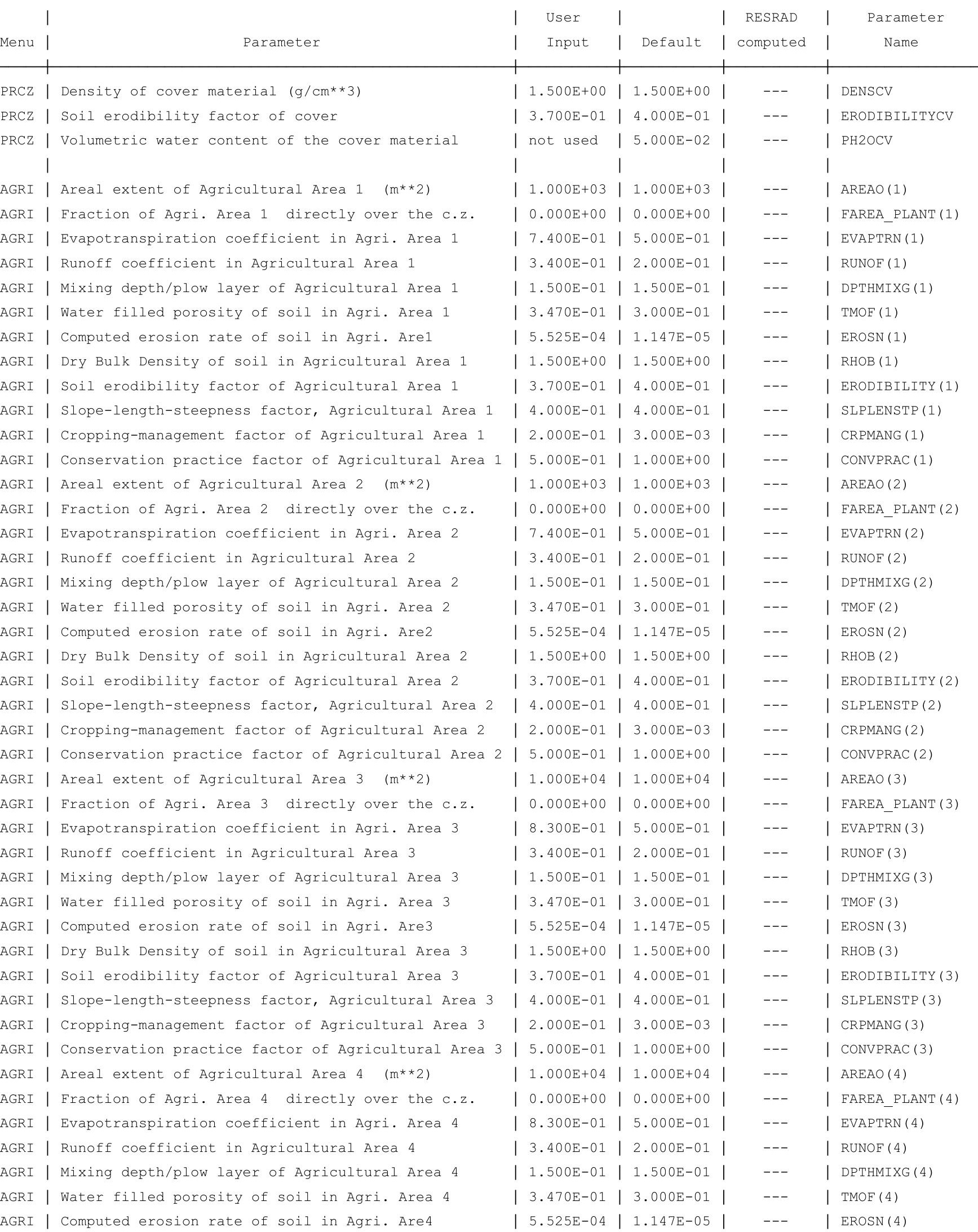


RESRAD-OFFSITE, Version $2.5 \quad \mathrm{~T}^{1} \frac{1}{2}$ Limit $=180$ days

Parent Dose Report
tele: RESRAD-OFFSITE Parameters for Offsite Resident Farmer

File : OFFSITE-RF_SRSG-7-11.ROF

Site-Specific Parameter Summary (continued)

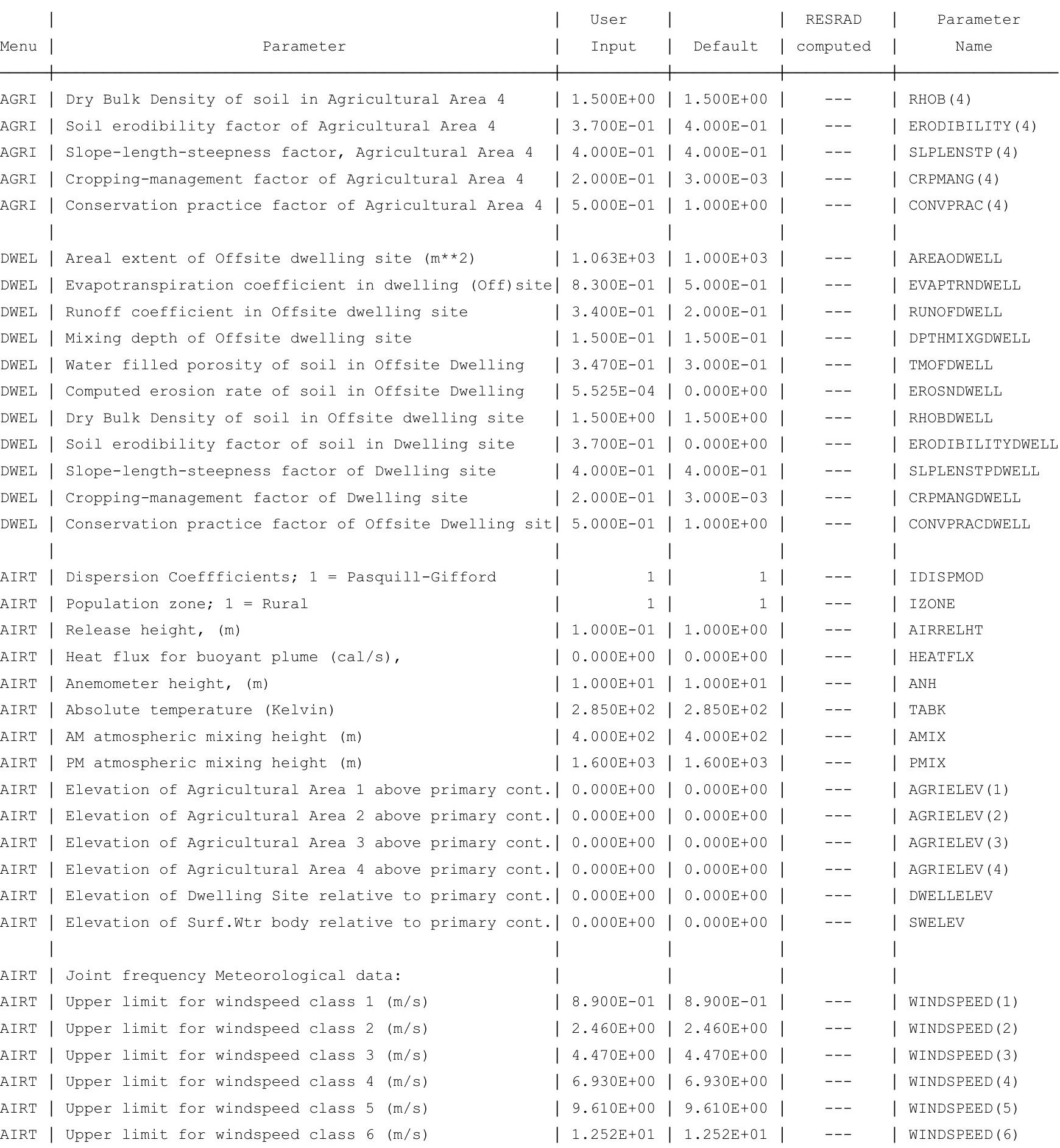


RESRAD-OFFSITE, Version 2.5

arent Dose Report

File : OFFSITE-RF_SRSG-7-11.ROF

Site-Specific Parameter Summary (continued)

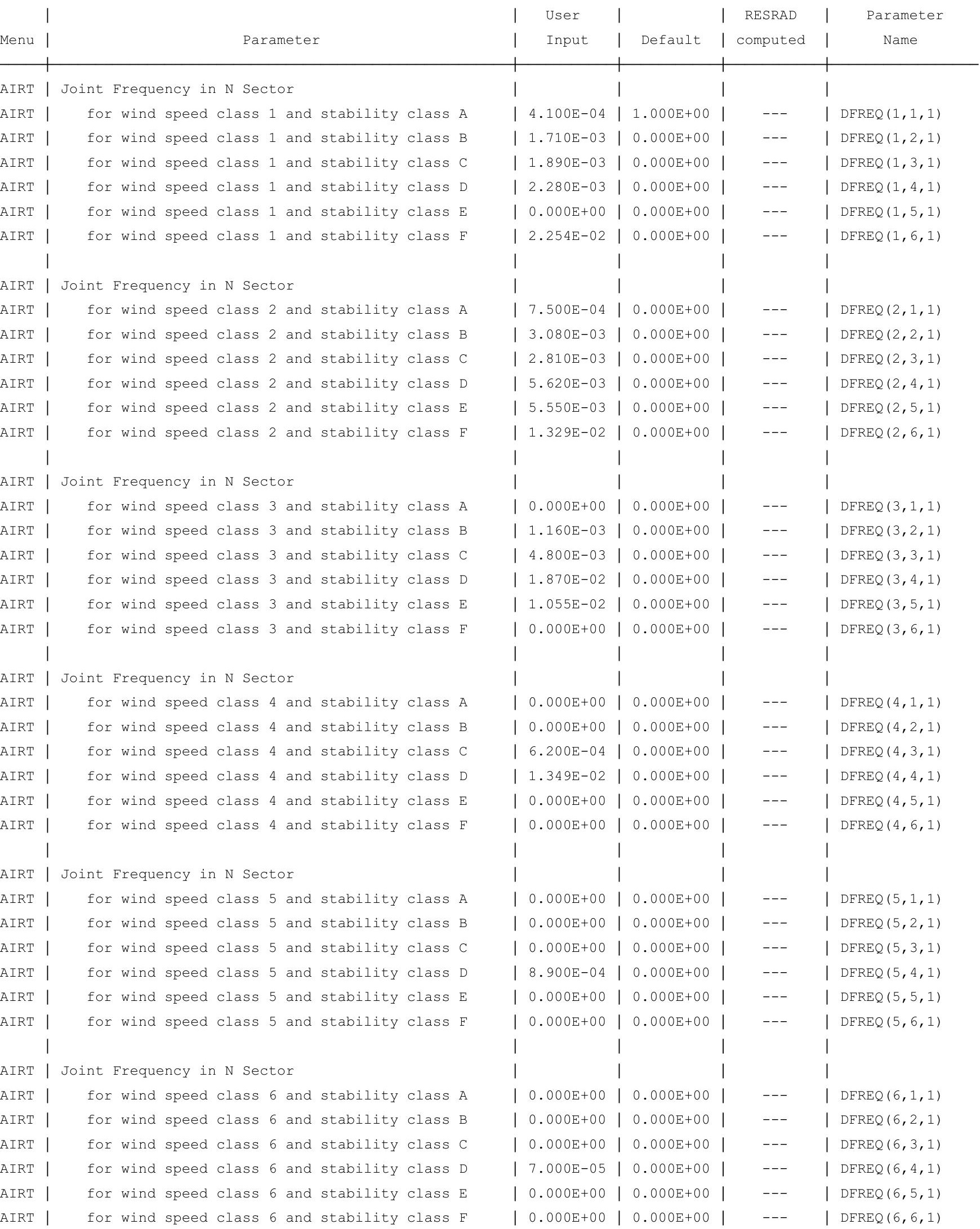


RESRAD-OFFSITE, Version 2.5

arent Dose Report

Title : RESRAD-OFFSITE Parameters for Offsite Resident Farmer

File : OFFSITE-RF SRSG-7-11.ROF

Site-Specific Parameter Summary (continued)

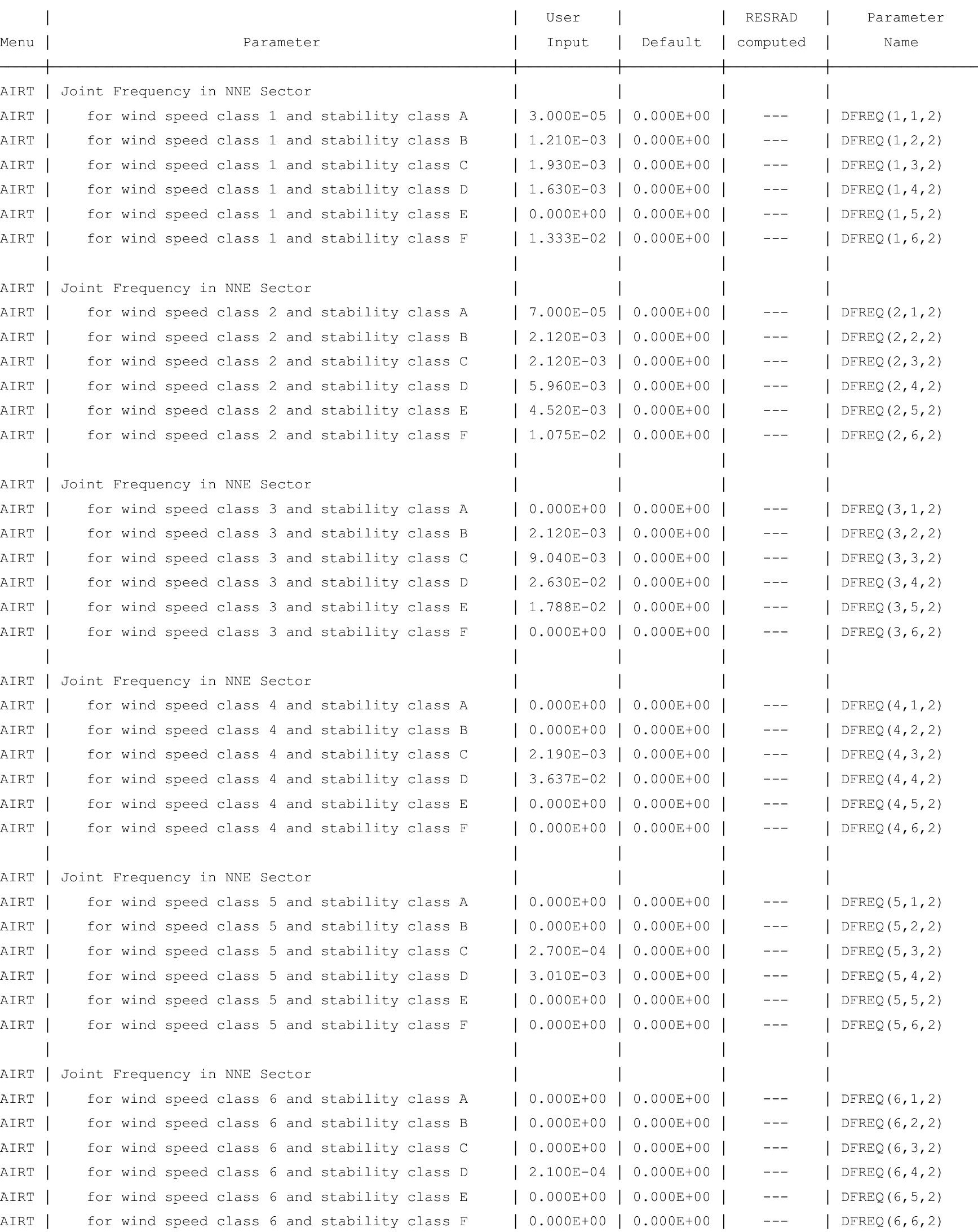


RESRAD-OFFSITE, Version $2.5 \quad \mathrm{~T}^{1 / 2}$ Limit $=180$ days

tle : RESRAD-OFFSITE Parameters for offsite Resident Farmer

File : OFFSITE-RF_SRSG-7-11.ROF

Site-Specific Parameter Summary (continued)

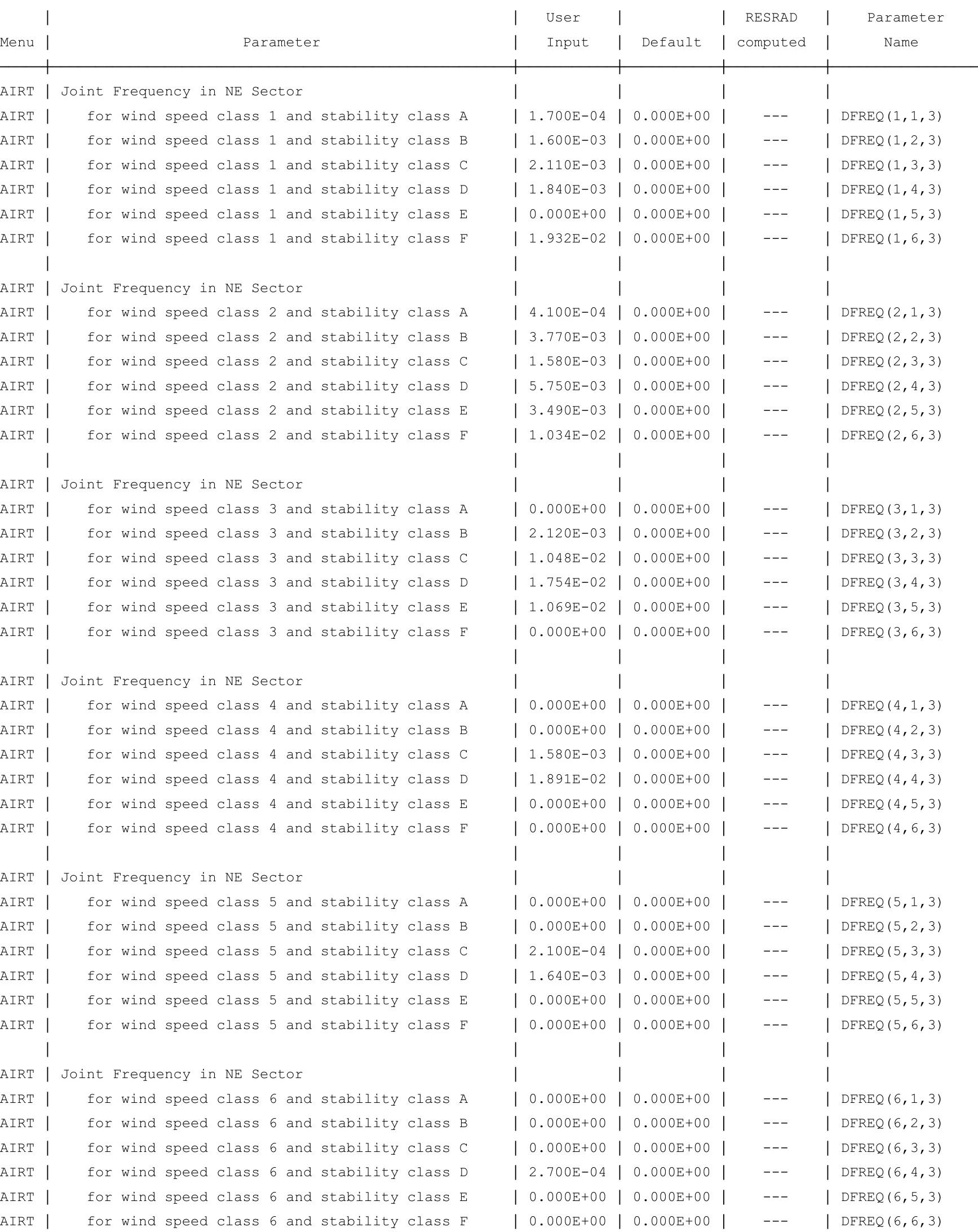


RESRAD-OFFSITE, Version $2.5 \quad \mathrm{~T}^{1 / 2}$ Limit $=180$ days

tle : RESRAD-OFFSITE Parameters for offsite Resident Farmer

File : OFFSITE-RF_SRSG-7-11.ROF

Site-Specific Parameter Summary (continued)

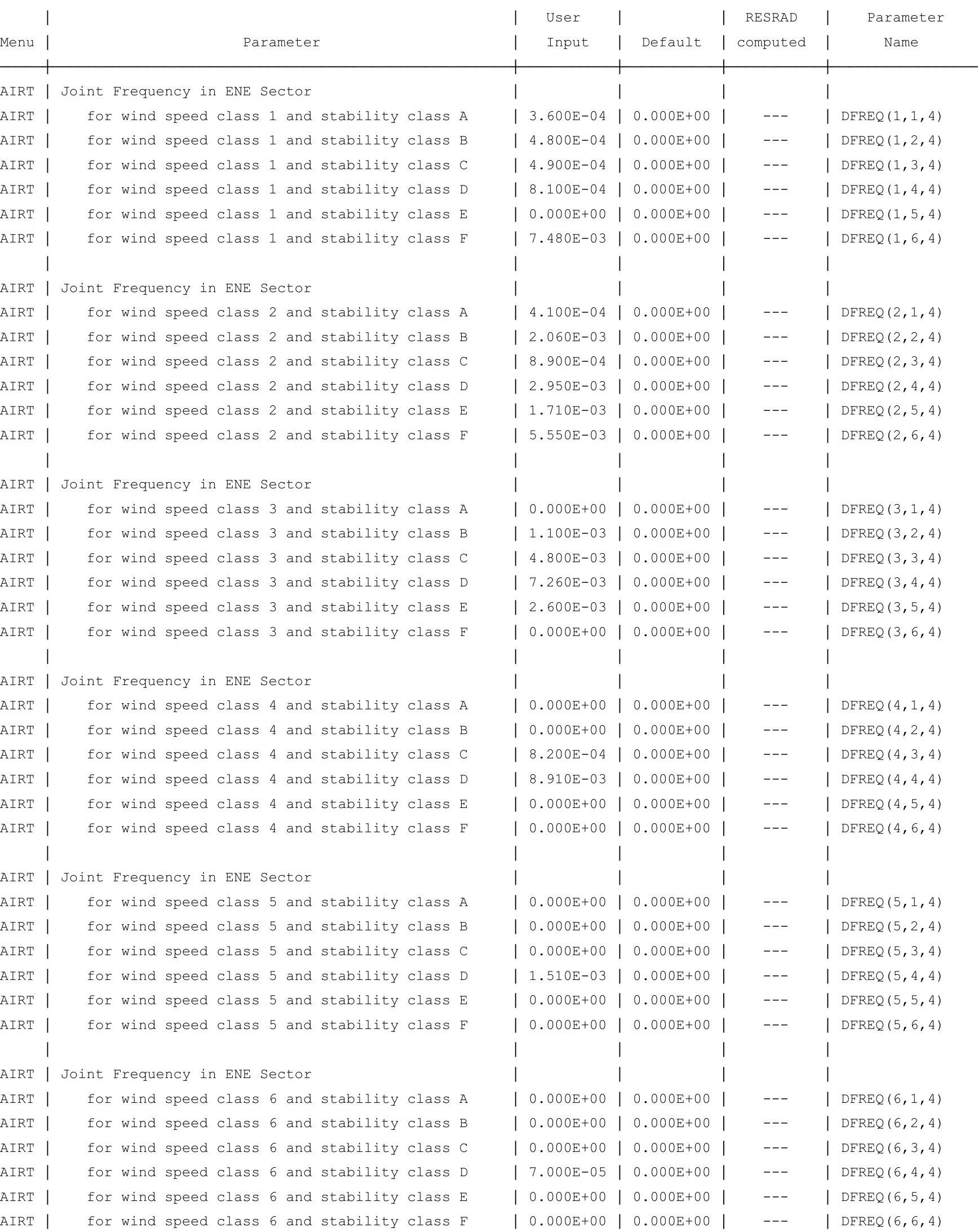


RESRAD-OFFSITE, Version 2.5

Parent Dose Report

Title : RESRAD-OFFSITE Parameters for Offsite Resident Farmer

File : OFFSITE-RF SRSG-7-11.ROF

Site-Specific Parameter Summary (continued)

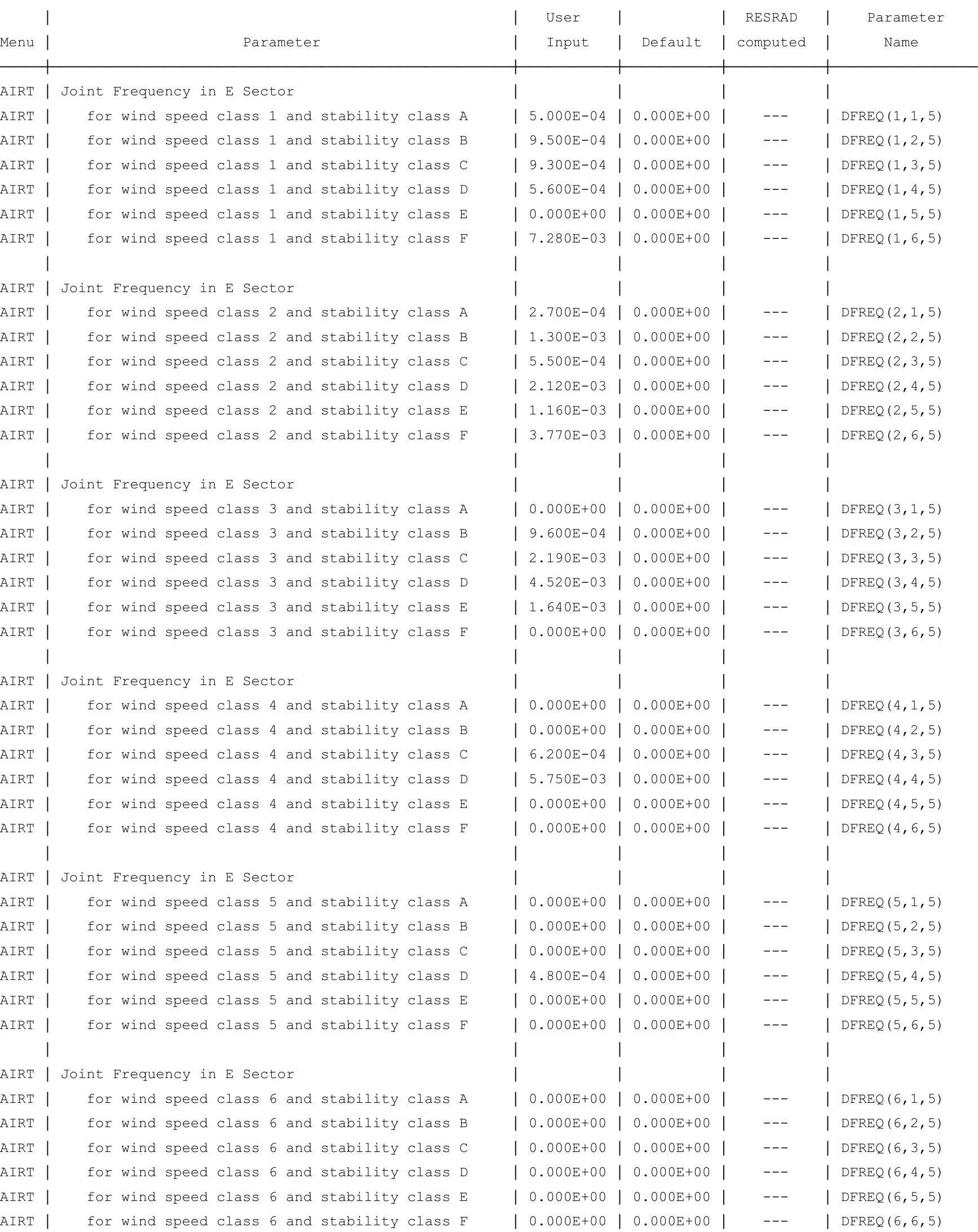


RESRAD-OFFSITE, Version 2.5

Parent Dose Report

Title : RESRAD-OFFSITE Parameters for Offsite Resident Farmer

File : OFFSITE-RF SRSG-7-11.ROF

Site-Specific Parameter Summary (continued)

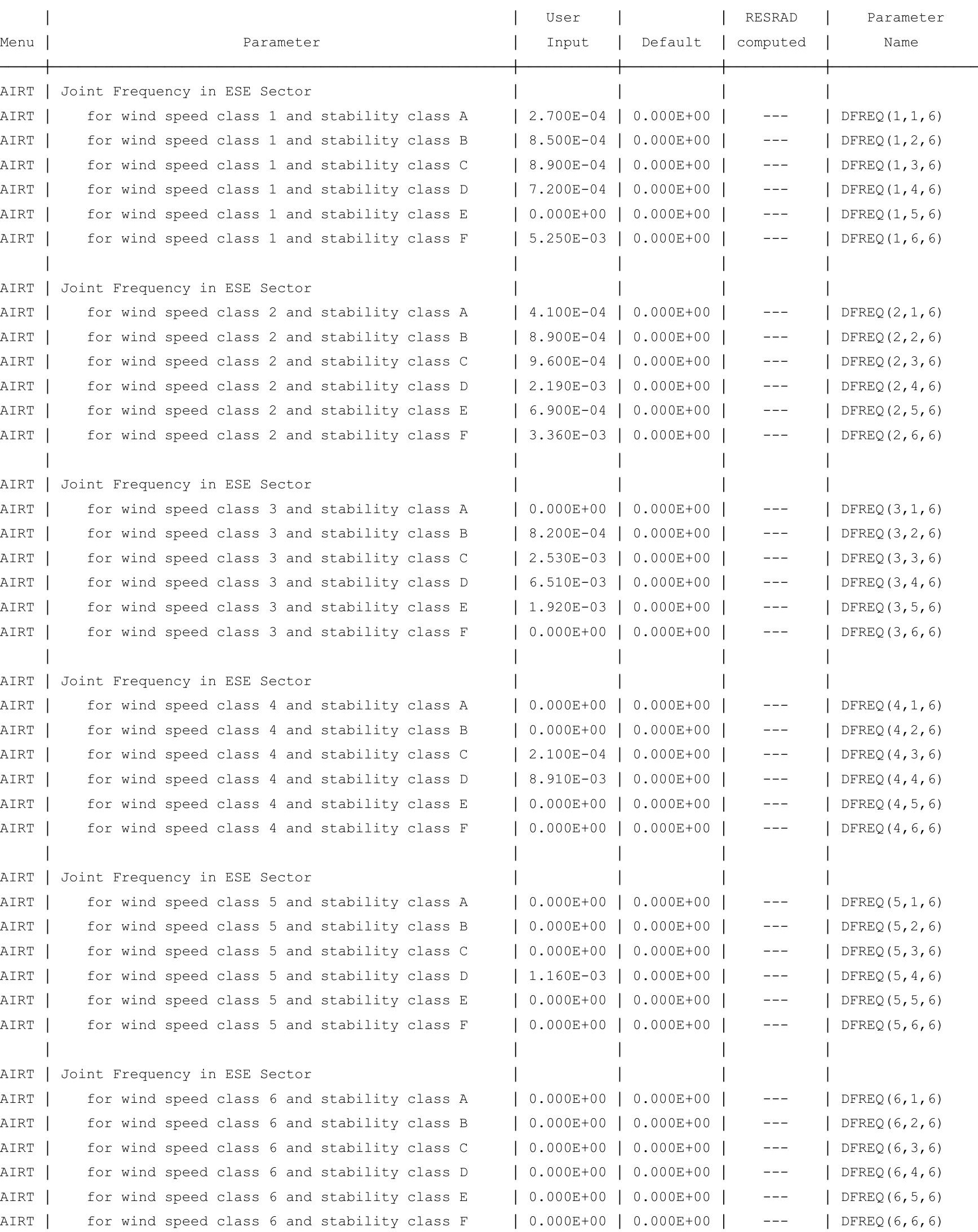


RESRAD-OFFSITE, Version $2.5 \quad T^{1 / 2}$ Limit $=180$ days

Parent Dose Report

Title : RESRAD-OFFSITE Parameters for Offsite Resident Farmer

File : OFFSITE-RF SRSG-7-11.ROF

Site-Specific Parameter Summary (continued)

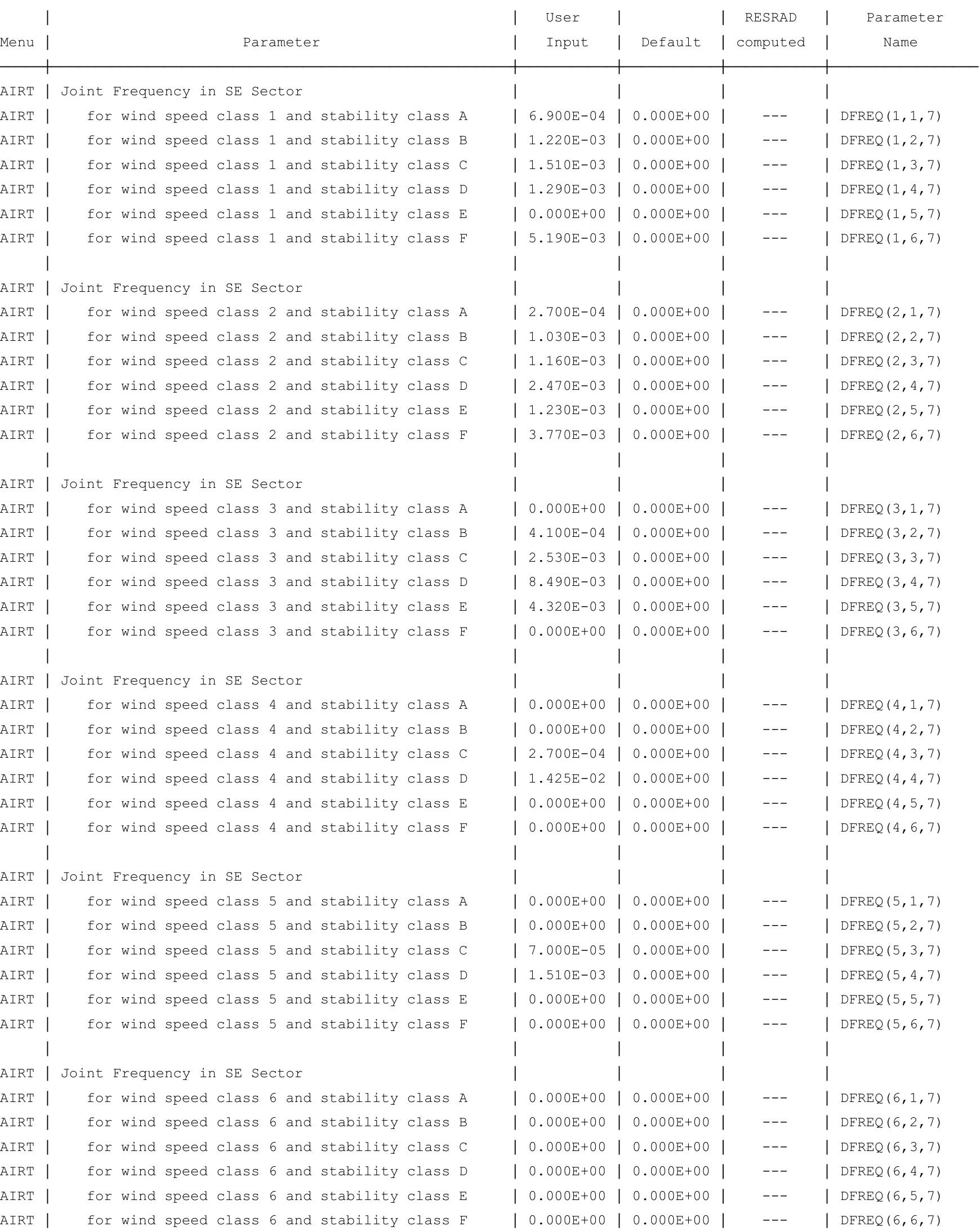


RESRAD-OFFSITE, Version 2.5

Parent Dose Report

Title : RESRAD-OFFSITE Parameters for Offsite Resident Farmer

File : OFFSITE-RF SRSG-7-11.ROF

Site-Specific Parameter Summary (continued)

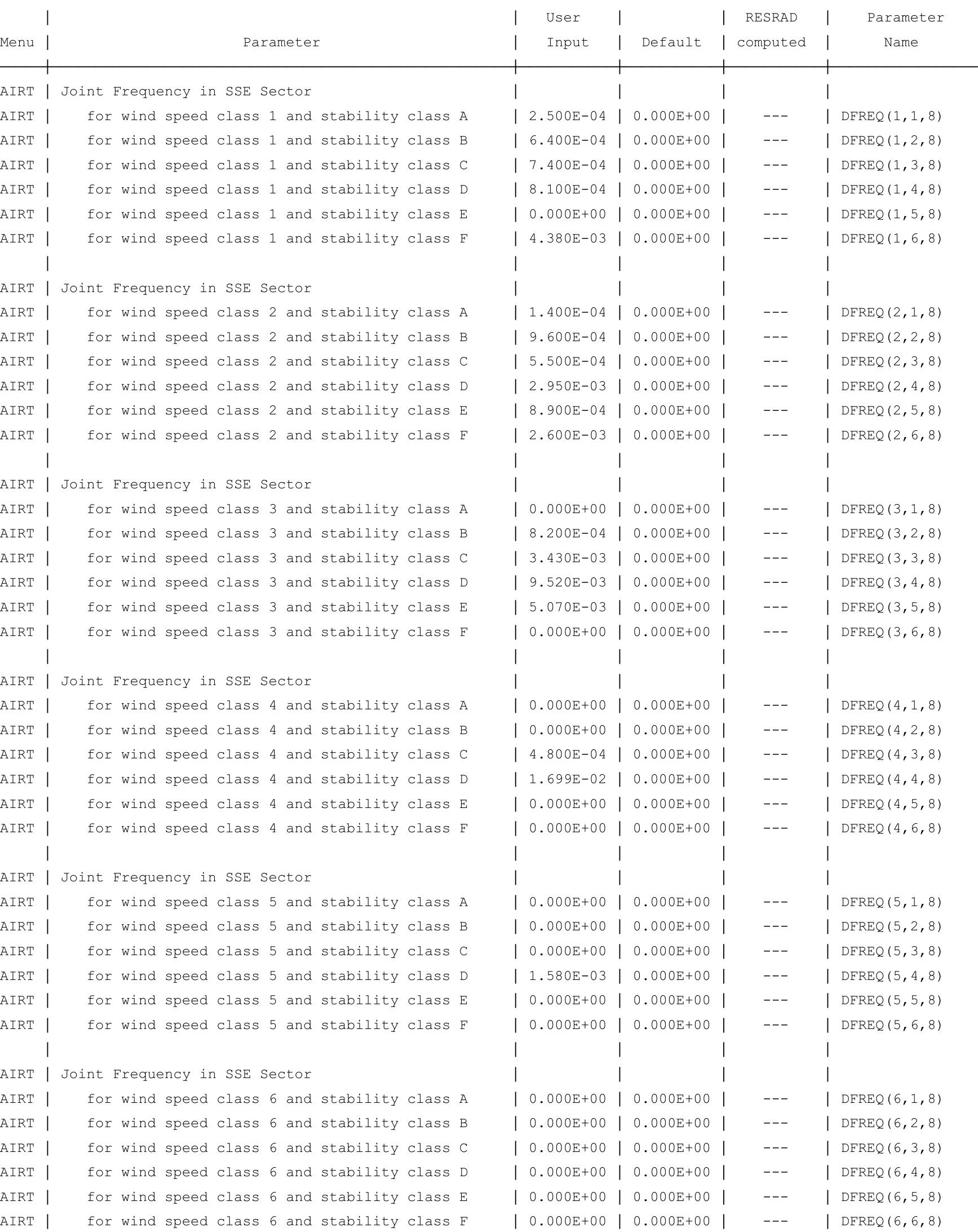


RESRAD-OFFSITE, Version 2.5

Parent Dose Report

Title : RESRAD-OFFSITE Parameters for Offsite Resident Farmer

File : OFFSITE-RF SRSG-7-11.ROF

Site-Specific Parameter Summary (continued)

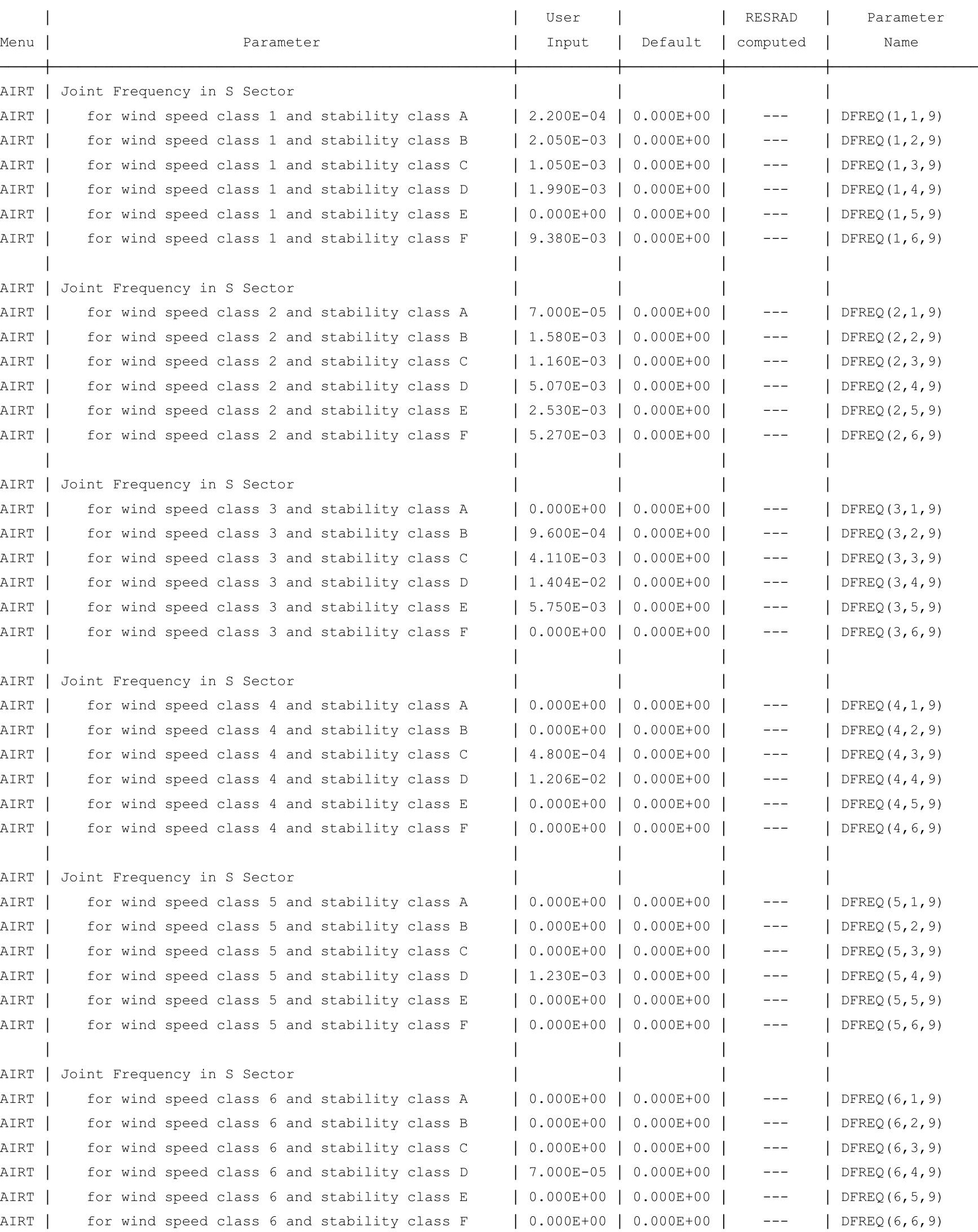


RESRAD-OFFSITE, Version 2.5

Parent Dose Report

Title : RESRAD-OFFSITE Parameters for Offsite Resident Farmer

File : OFFSITE-RF SRSG-7-11.ROF

Site-Specific Parameter Summary (continued)

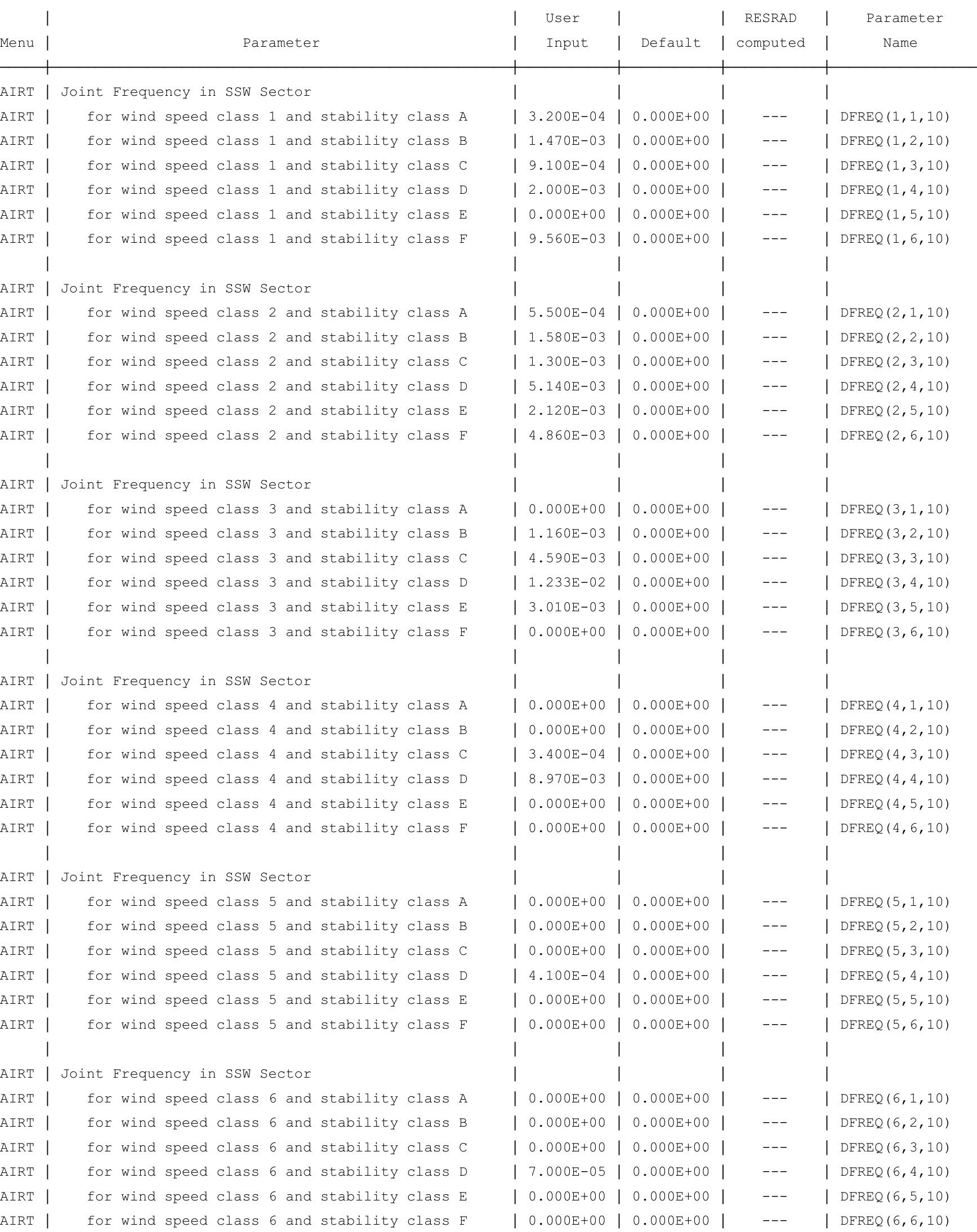


RESRAD-OFFSITE, Version $2.5 \quad T^{1 / 2}$ Limit $=180$ days

Parent Dose Report

Title : RESRAD-OFFSITE Parameters for Offsite Resident Farmer

File : OFFSITE-RF SRSG-7-11.ROF

Site-Specific Parameter Summary (continued)

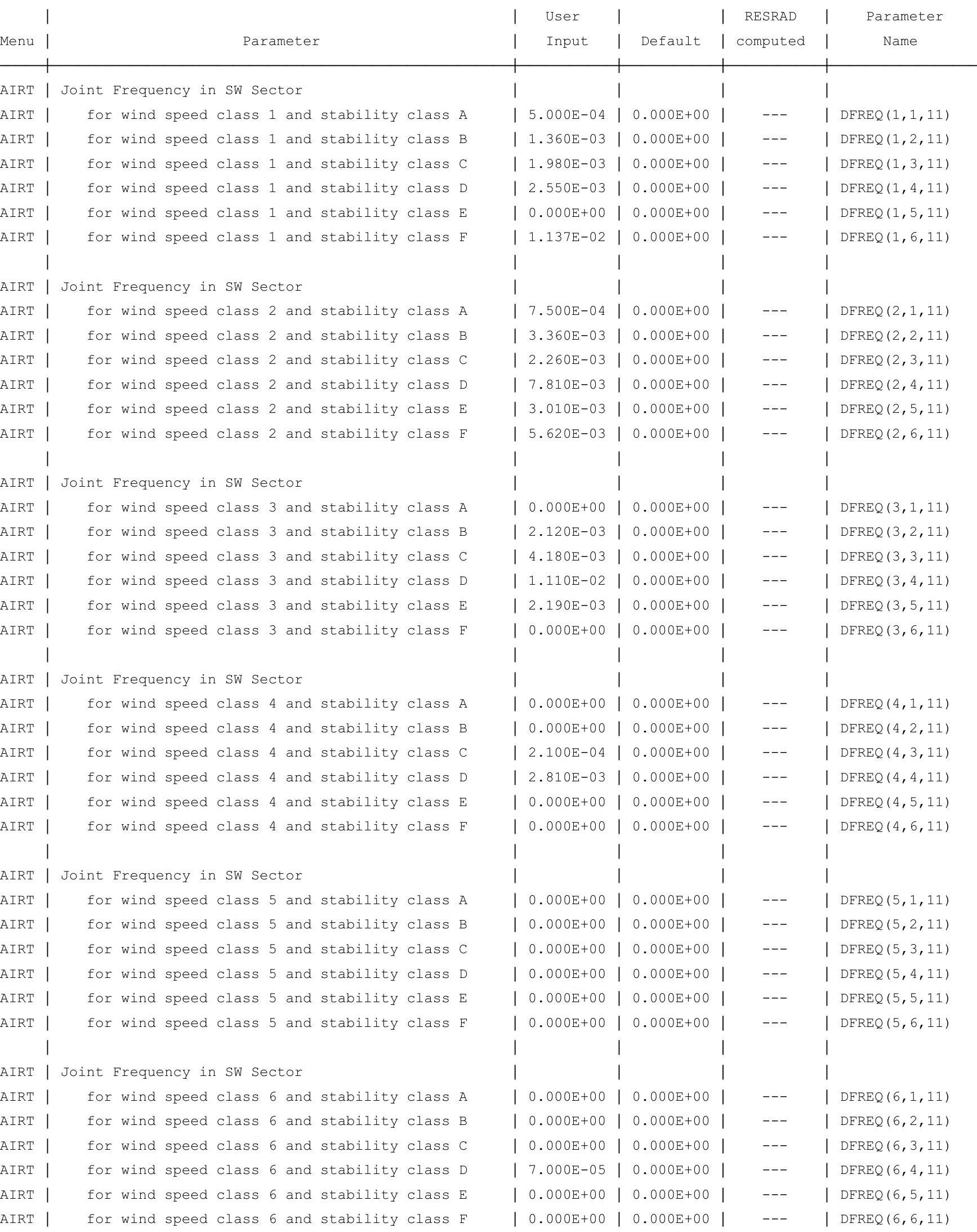


RESRAD-OFFSITE, Version $2.5 \quad \mathrm{~T}^{1 / 2}$ Limit $=180$ days

tle : RESRAD-OFFSITE Parameters for offsite Resident Farmer

File : OFFSITE-RF_SRSG-7-11.ROF

Site-Specific Parameter Summary (continued)

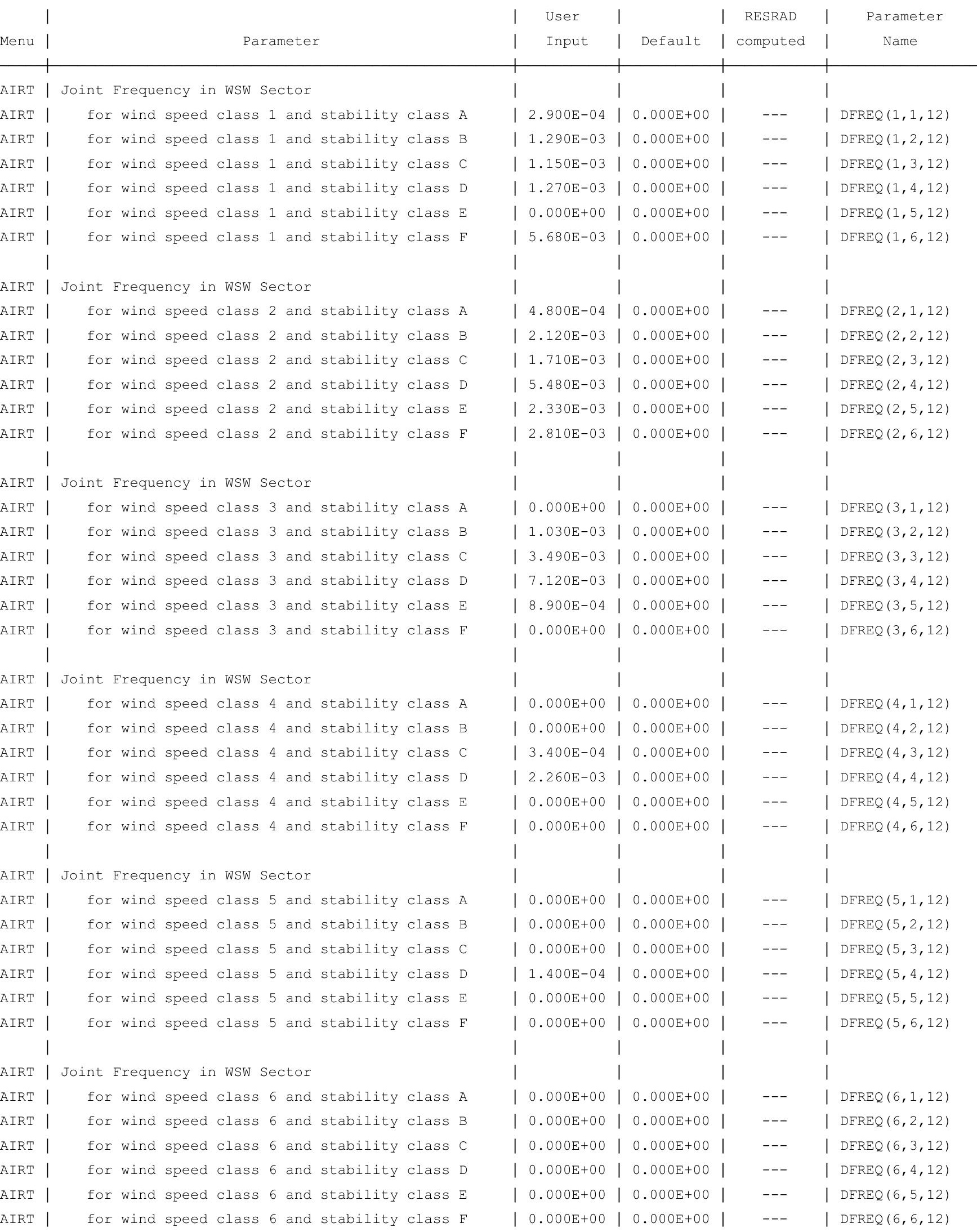


RESRAD-OFFSITE, Version 2.5

Parent Dose Report

Title : RESRAD-OFFSITE Parameters for Offsite Resident Farmer

File : OFFSITE-RF SRSG-7-11.ROF

Site-Specific Parameter Summary (continued)

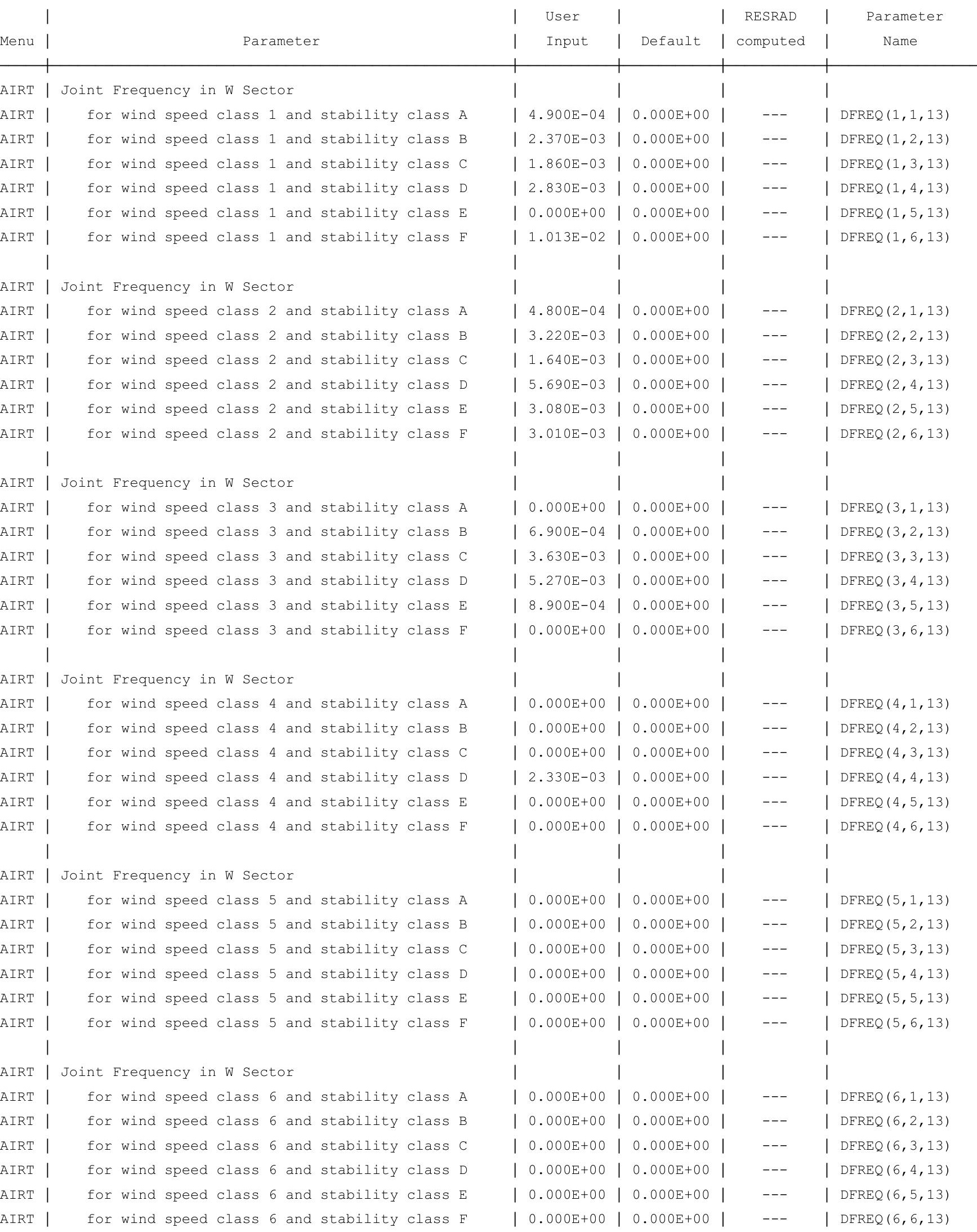


RESRAD-OFFSITE, Version $2.5 \quad \mathrm{~T}^{1 / 2}$ Limit $=180$ days

tle : RESRAD-OFFSITE Parameters for offsite Resident Farmer

File : OFFSITE-RF_SRSG-7-11.ROF

Site-Specific Parameter Summary (continued)

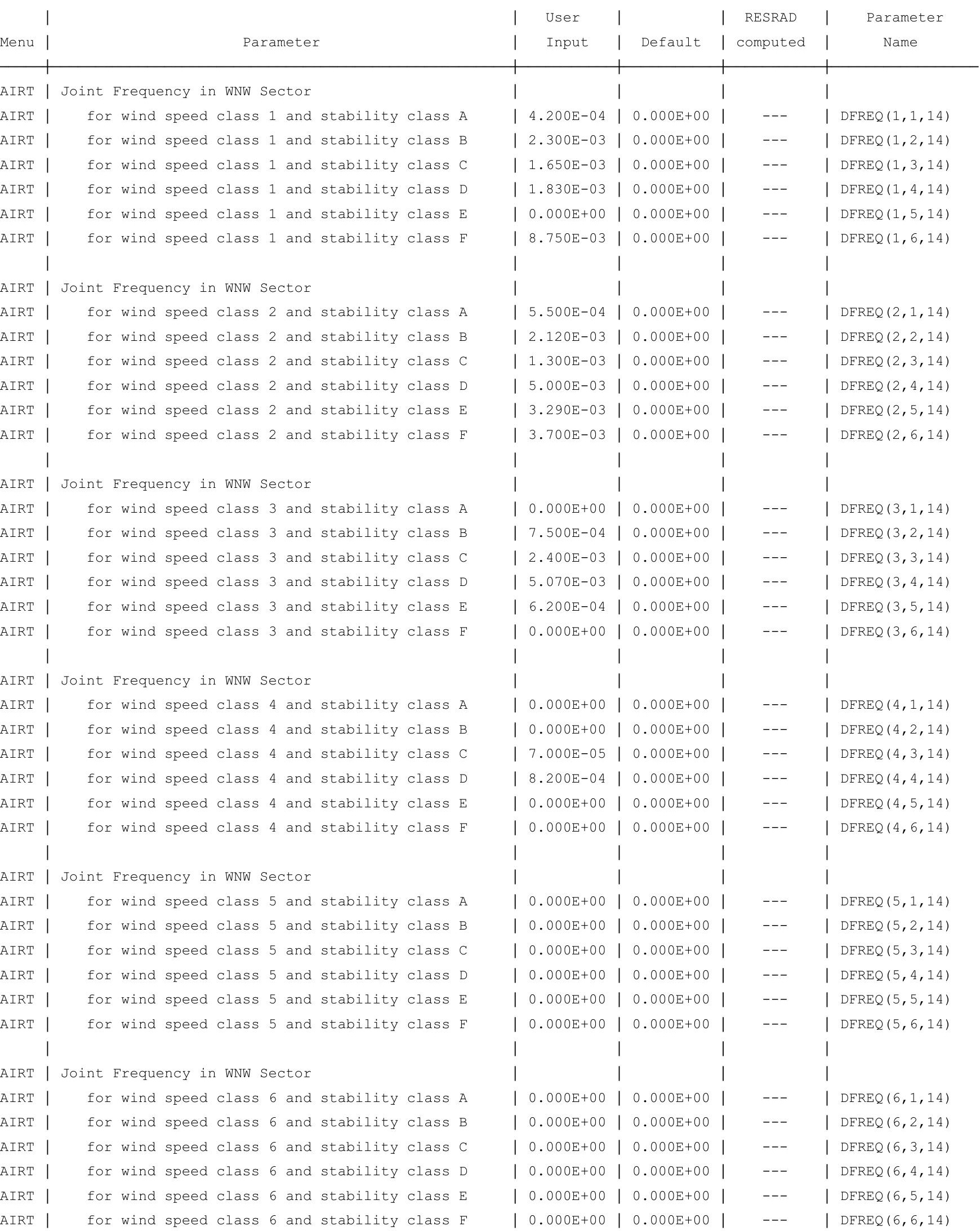


RESRAD-OFFSITE, Version 2.5

Parent Dose Report

Title : RESRAD-OFFSITE Parameters for Offsite Resident Farmer

File : OFFSITE-RF SRSG-7-11.ROF

Site-Specific Parameter Summary (continued)

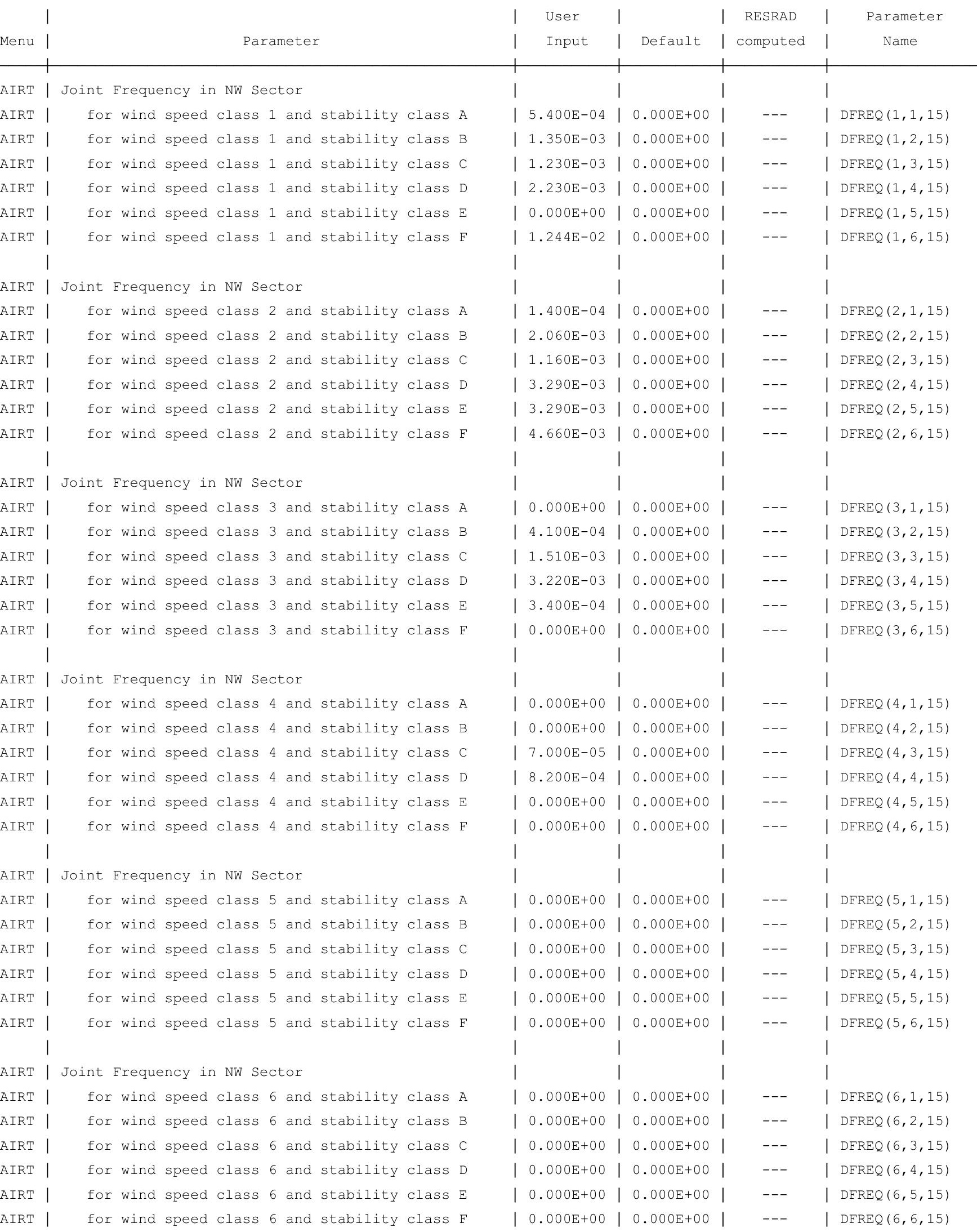


RESRAD-OFFSITE, Version 2.5

Parent Dose Report

Title : RESRAD-OFFSITE Parameters for Offsite Resident Farmer

File : OFFSITE-RF SRSG-7-11.ROF

Site-Specific Parameter Summary (continued)

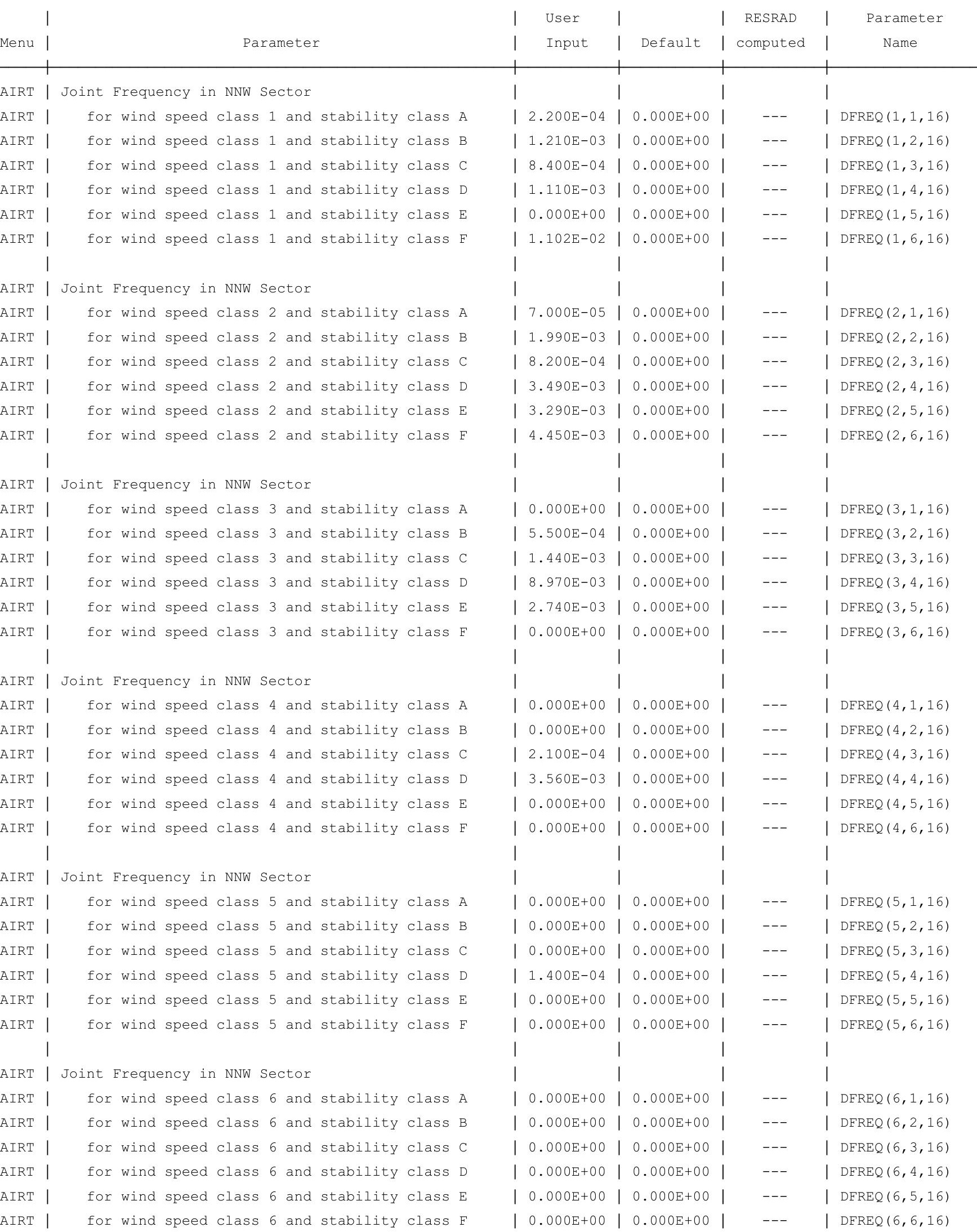


RESRAD-OFFSITE, Version $2.5 \quad \mathrm{~T}^{1 / 2}$ Limit $=180$ days

Parent Dose Report

Title : RESRAD-OFFSITE Parameters for Offsite Resident Farmer

File : OFFSITE-RF_SRSG-7-11.ROF

Site-Specific Parameter Summary (continued)

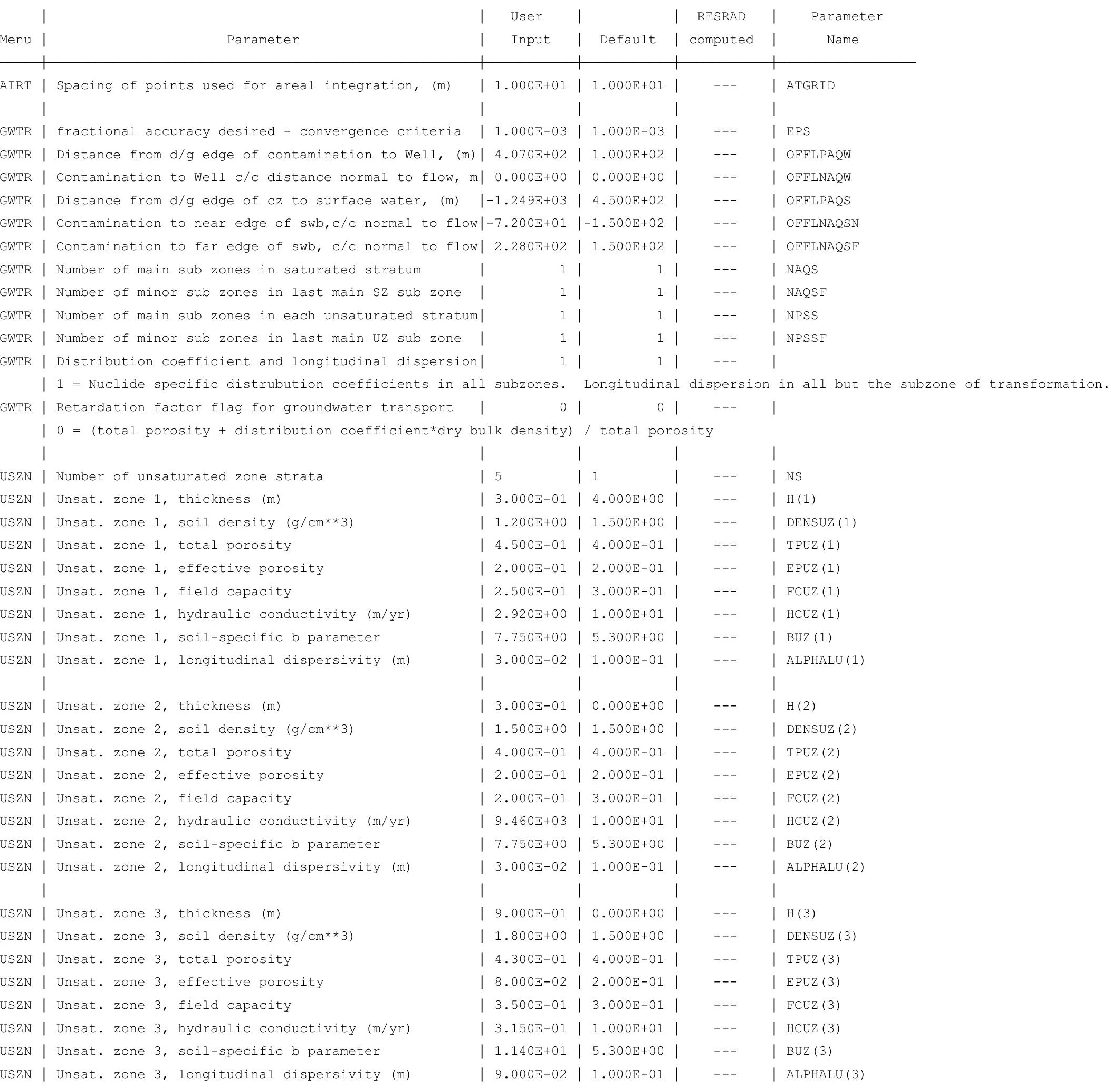


RESRAD-OFFSITE, Version 2.5

Parent Dose Report

Title : RESRAD-OFFSITE Parameters for Offsite Resident Farmer

File : OFFSITE-RF SRSG-7-11.ROF

Site-Specific Parameter Summary (continued)

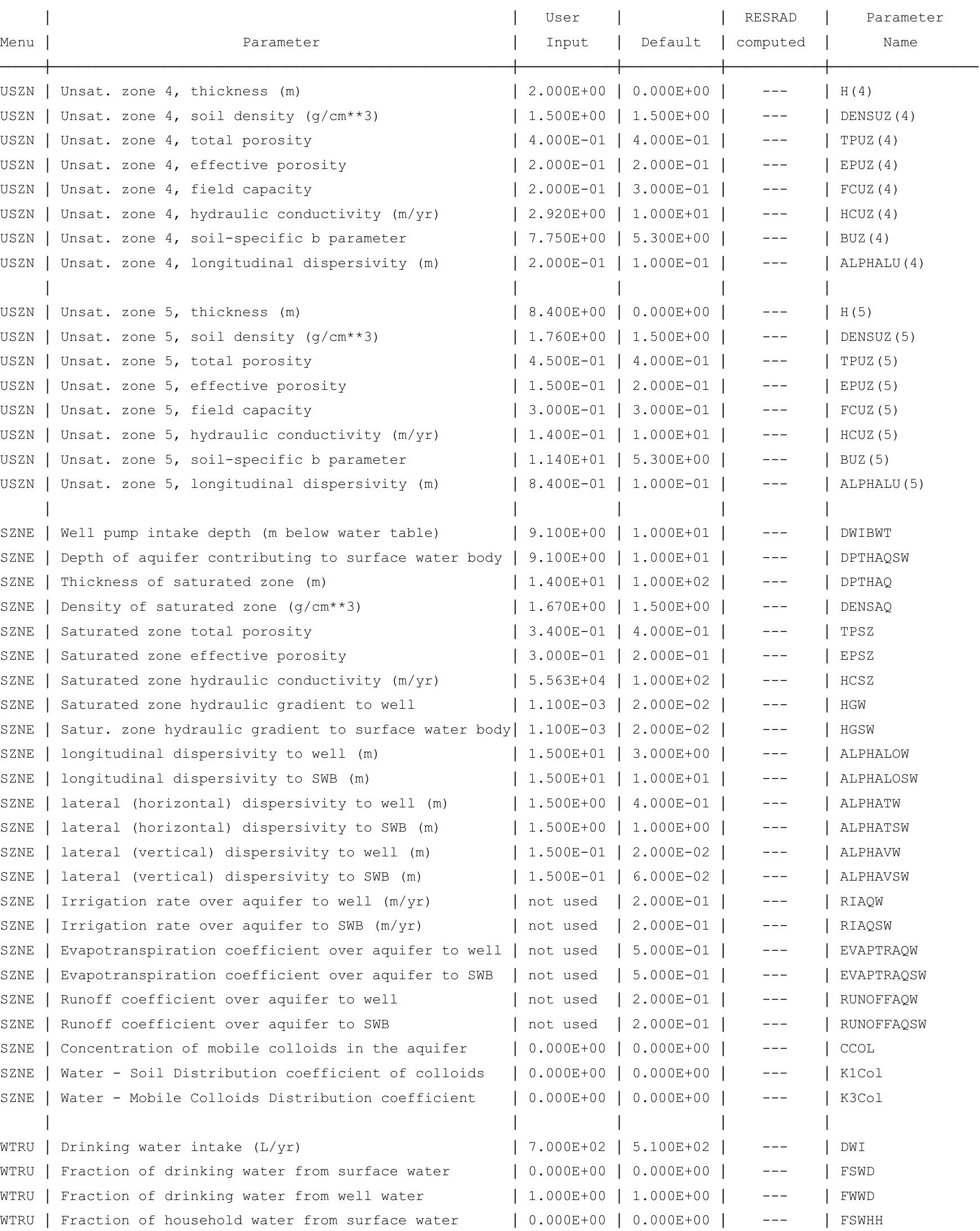


RESRAD-OFFSITE, Version 2.

Parent Dose Report

Title : RESRAD-OFFSITE Parameters for Offsite Resident Farmer

File : OFFSITE-RF SRSG-7-11.ROF

Site-Specific Parameter Summary (continued)

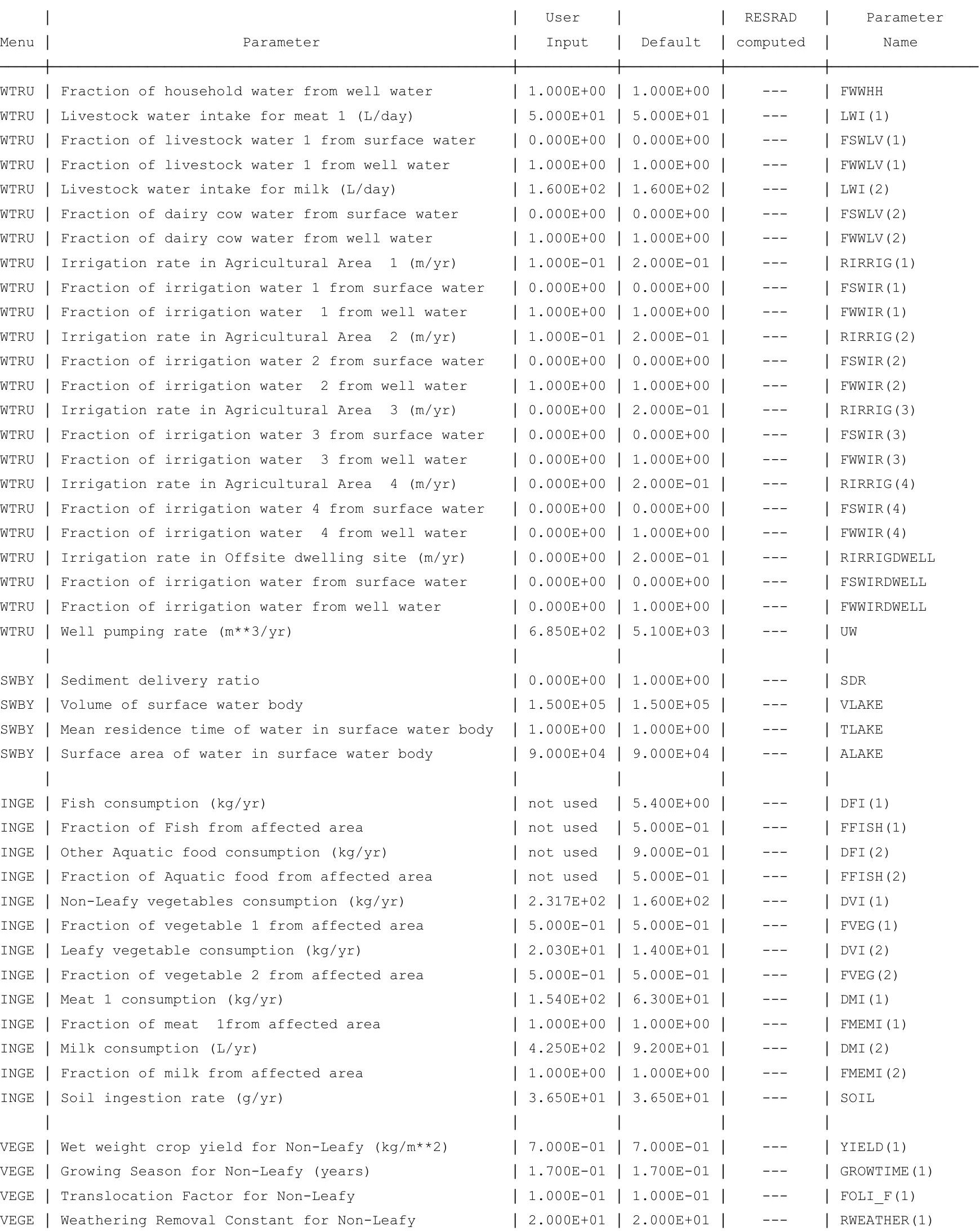


RESRAD-OFFSITE, Version $2.5 \quad \mathrm{~T}^{1 / 2}$ Limit $=180$ days

Parent Dose Report

Title : RESRAD-OFFSITE Parameters for Offsite Resident Farmer

File : OFFSITE-RF_SRSG-7-11.ROF

Site-Specific Parameter Summary (continued)

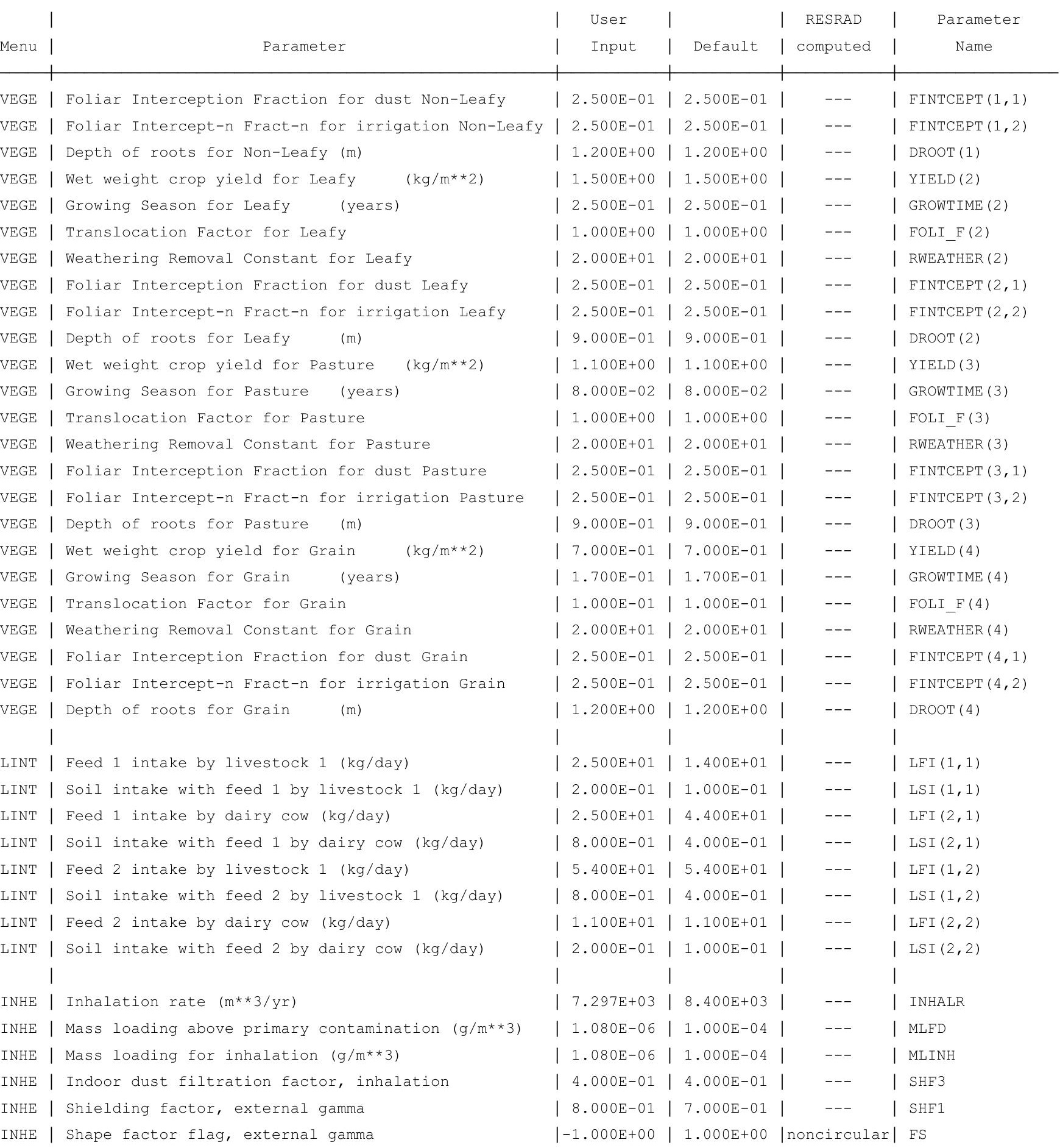

INHE Shape factor flag, external gamma 
RESRAD-OFFSITE, Version $2.5 \quad \mathrm{~T}^{1 / 2}$ Limit $=180$ days

Parent Dose Report

Title : RESRAD-OFFSITE Parameters for Offsite Resident Farmer

File : OFFSITE-RF SRSG-7-11.ROF

Site-Specific Parameter Summary (continued)

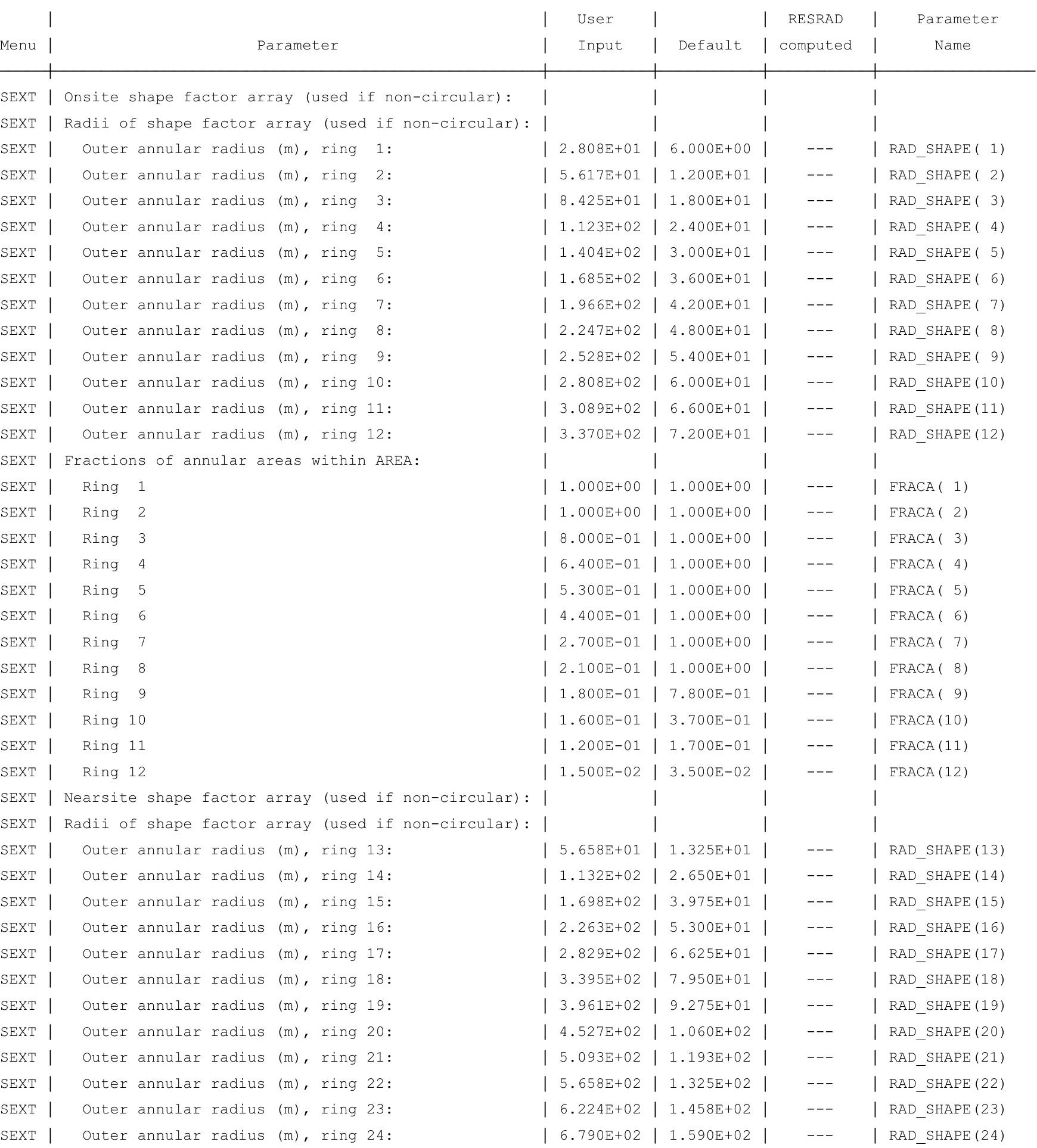


RESRAD-OFFSITE, Version $2.5 \quad \mathrm{~T}^{1 / 2}$ Limit $=180$ days

Title : RESRAD-OFFSITE Parameters for Offsite Resident Farmer

File : OFFSITE-RF_SRSG-7-11.ROF

Site-Specific Parameter Summary (continued)

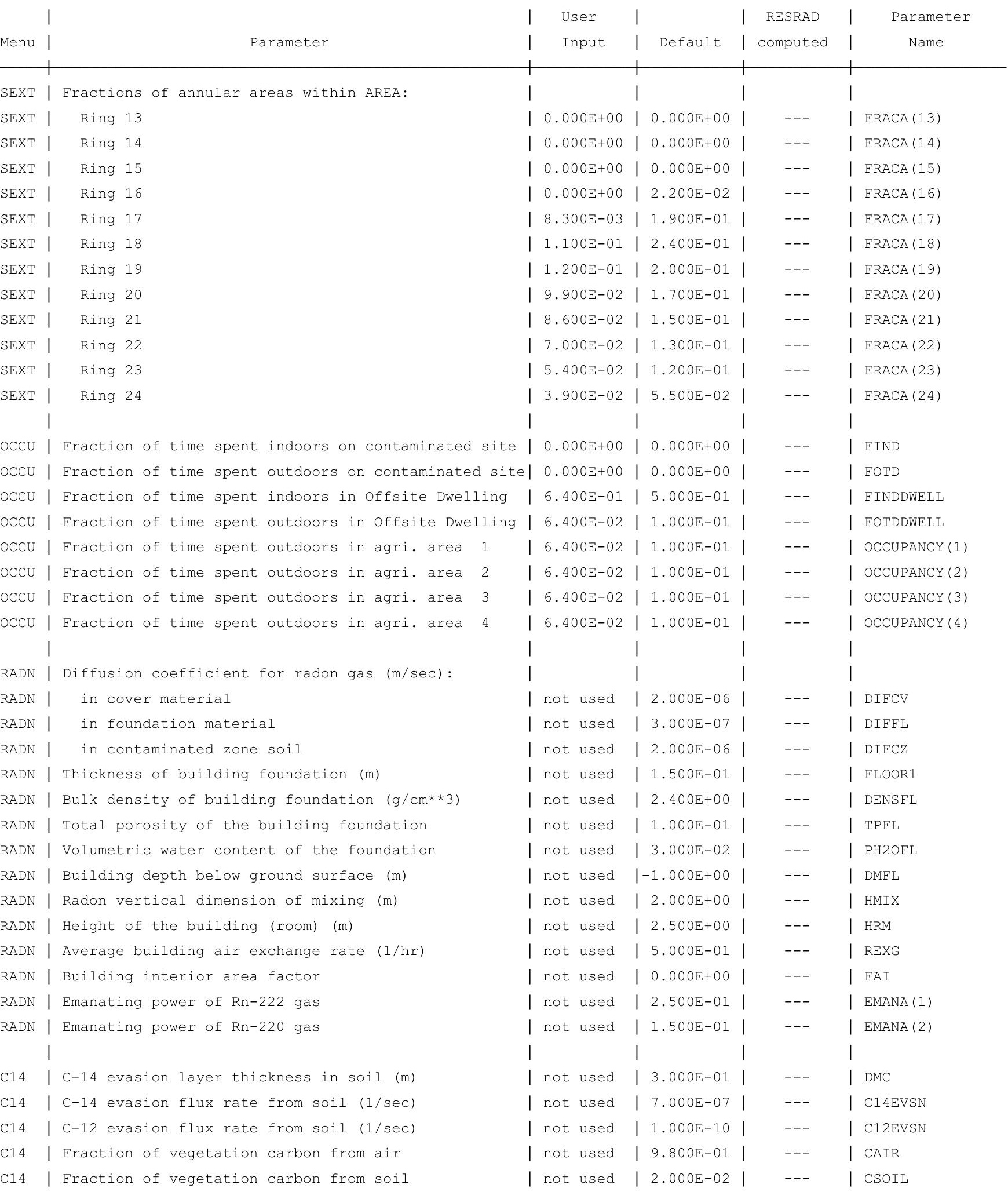


RESRAD-OFFSITE, Version 2.5

Parent Dose Report

Title : RESRAD-OFFSITE Parameters for Offsite Resident Farmer

File : OFFSITE-RF_SRSG-7-11.ROF

Site-Specific Parameter Summary (continued)

Parameter
Menu

Summary of Pathway Selections

\begin{tabular}{l|c} 
Pathway & User Selection \\
\hline 1 -- external gamma & active \\
2 -- inhalation (w/o radon) & active \\
3 -- plant ingestion & active \\
4 -- meat ingestion & active \\
5 -- milk ingestion & active \\
6 -- aquatic foods & suppressed \\
7 -- drinking water & active \\
8 -- soil ingestion & active \\
9 -- radon & suppressed \\
\hline \hline
\end{tabular}


RESRAD-OFFSITE, Version $2.5 \quad \mathrm{~T}^{1 / 2}$ Limit $=180$ days

Parent Dose Report

Title : RESRAD-OFFSITE Parameters for Offsite Resident Farmer

File : OFFSITE-RF_SRSG-7-11.ROF

Contaminated Zone Dimensions

Area: 102144.00 square meters

Thickness: $\quad 13.40$ meters

Cover Depth:
Initial Soil Concentrations, pCi/g

$\begin{array}{ll}\mathrm{Am}-241 & 1.000 \mathrm{E}+00 \\ \mathrm{Cs}-137 & 1.000 \mathrm{E}+00 \\ \mathrm{~Np}-237 & 1.000 \mathrm{E}+00 \\ \mathrm{Pu}-238 & 1.000 \mathrm{E}+00 \\ \mathrm{Pu}-239 & 1.000 \mathrm{E}+00 \\ \mathrm{Pu}-240 & 1.000 \mathrm{E}+00 \\ \mathrm{TC}-99 & 1.000 \mathrm{E}+00 \\ \mathrm{Th}-228 & 1.000 \mathrm{E}+00 \\ \mathrm{Th}-230 & 1.000 \mathrm{E}+00 \\ \mathrm{Th}-232 & 1.000 \mathrm{E}+00 \\ \mathrm{U}-234 & 1.000 \mathrm{E}+00 \\ \mathrm{U}-235 & 1.000 \mathrm{E}+00 \\ \mathrm{U}-238 & 1.000 \mathrm{E}+00\end{array}$

Total Dose TDOSE(t), mrem/yr

Basic Radiation Dose Limit $=1.000 \mathrm{E}+00 \mathrm{mrem} / \mathrm{yr}$

Total Mixture Sum $M(t)$ = Fraction of Basic Dose Limit Received at Time (t) 
RESRAD-OFFSITE, Version 2 .

Parent Dose Report

Title : RESRAD-OFFSITE Parameters for Offsite Resident Farmer

File : OFFSITE-RF_SRSG-7-11.ROF

Total Dose Contributions TDOSE (i,p,t) for Individual Radionuclides (i) and Pathways (p) in mrem/yr and as a Percentage of Total Dose at $t=0$ years

From releases to ground water and to surface water

\begin{tabular}{|c|c|c|c|c|c|c|c|c|c|c|c|c|c|c|c|c|}
\hline & \multicolumn{2}{|c|}{ Ground } & \multicolumn{2}{|l|}{ Fish } & \multicolumn{2}{|c|}{ Radon } & \multicolumn{2}{|c|}{ Plant } & \multicolumn{2}{|l|}{ Meat } & \multicolumn{2}{|l|}{ Milk } & \multicolumn{2}{|l|}{ Soil } & \multicolumn{2}{|c|}{ Water } \\
\hline clide & Dose & \% & Dose & $\%$ & Dose & \% & Dose & \% & Dose & \% & Dose & \% & Dose & \% & Dose & $\%$ \\
\hline-241 & $0.00 \mathrm{E}+00$ & 0 & $0.00 \mathrm{E}+00$ & 0 & $0.00 \mathrm{E}+00$ & 0 & $0.00 \mathrm{E}+00$ & 0 & $0.00 \mathrm{E}+00$ & 0 & $0.00 \mathrm{E}+00$ & 0 & $0.00 \mathrm{E}+00$ & 0 & $0.00 \mathrm{E}+00$ & 0 \\
\hline-137 & $0.00 \mathrm{E}+00$ & 0 & $0.00 \mathrm{E}+00$ & 0 & $0.00 \mathrm{E}+00$ & 0 & $0.00 \mathrm{E}+00$ & 0 & $0.00 \mathrm{E}+00$ & 0 & $0.00 \mathrm{E}+00$ & 0 & $0.00 \mathrm{E}+00$ & 0 & $0.00 \mathrm{E}+00$ & 0 \\
\hline-237 & $0.00 \mathrm{E}+00$ & 0 & $0.00 \mathrm{E}+00$ & 0 & $0.00 \mathrm{E}+00$ & 0 & $0.00 \mathrm{E}+00$ & 0 & $0.00 \mathrm{E}+00$ & 0 & $0.00 \mathrm{E}+00$ & 0 & $0.00 \mathrm{E}+00$ & 0 & $0.00 \mathrm{E}+00$ & 0 \\
\hline-238 & $0.00 \mathrm{E}+00$ & 0 & $0.00 \mathrm{E}+00$ & 0 & $0.00 \mathrm{E}+00$ & 0 & $0.00 \mathrm{E}+00$ & 0 & $0.00 \mathrm{E}+00$ & 0 & $0.00 \mathrm{E}+00$ & 0 & $0.00 \mathrm{E}+00$ & 0 & $0.00 \mathrm{E}+00$ & 0 \\
\hline-239 & $0.00 \mathrm{E}+00$ & 0 & $0.00 \mathrm{E}+00$ & 0 & $0.00 \mathrm{E}+00$ & 0 & $0.00 \mathrm{E}+00$ & 0 & $0.00 \mathrm{E}+00$ & 0 & $0.00 \mathrm{E}+00$ & 0 & $0.00 \mathrm{E}+00$ & 0 & $0.00 \mathrm{E}+00$ & 0 \\
\hline-240 & $0.00 \mathrm{E}+00$ & 0 & $0.00 \mathrm{E}+00$ & 0 & $0.00 \mathrm{E}+00$ & 0 & $0.00 \mathrm{E}+00$ & 0 & $0.00 \mathrm{E}+00$ & 0 & $0.00 \mathrm{E}+00$ & 0 & $0.00 \mathrm{E}+00$ & 0 & $0.00 \mathrm{E}+00$ & 0 \\
\hline-99 & $0.00 \mathrm{E}+00$ & 0 & $0.00 E+00$ & 0 & $0.00 E+00$ & 0 & $0.00 \mathrm{E}+00$ & 0 & $0.00 \mathrm{E}+00$ & 0 & $0.00 E+00$ & 0 & $0.00 \mathrm{E}+00$ & 0 & $0.00 \mathrm{E}+00$ & 0 \\
\hline-228 & $0.00 \mathrm{E}+00$ & 0 & $0.00 \mathrm{E}+00$ & 0 & $0.00 \mathrm{E}+00$ & 0 & $0.00 \mathrm{E}+00$ & 0 & $0.00 \mathrm{E}+00$ & 0 & $0.00 \mathrm{E}+00$ & 0 & $0.00 \mathrm{E}+00$ & 0 & $0.00 \mathrm{E}+00$ & 0 \\
\hline-230 & $0.00 \mathrm{E}+00$ & 0 & $0.00 \mathrm{E}+00$ & 0 & $0.00 \mathrm{E}+00$ & 0 & $0.00 \mathrm{E}+00$ & 0 & $0.00 \mathrm{E}+00$ & 0 & $0.00 \mathrm{E}+00$ & 0 & $0.00 \mathrm{E}+00$ & 0 & $0.00 \mathrm{E}+00$ & 0 \\
\hline-232 & $0.00 \mathrm{E}+00$ & 0 & $0.00 E+00$ & 0 & $0.00 \mathrm{E}+00$ & 0 & $0.00 \mathrm{E}+00$ & 0 & $0.00 \mathrm{E}+00$ & 0 & $0.00 \mathrm{E}+00$ & 0 & $0.00 \mathrm{E}+00$ & 0 & $0.00 \mathrm{E}+00$ & 0 \\
\hline 234 & $0.00 \mathrm{E}+00$ & 0 & $0.00 \mathrm{E}+00$ & 0 & $0.00 \mathrm{E}+00$ & 0 & $0.00 \mathrm{E}+00$ & 0 & $0.00 \mathrm{E}+00$ & 0 & $0.00 \mathrm{E}+00$ & 0 & $0.00 \mathrm{E}+00$ & 0 & $0.00 \mathrm{E}+00$ & 0 \\
\hline 235 & $0.00 \mathrm{E}+00$ & 0 & $0.00 \mathrm{E}+00$ & 0 & $0.00 \mathrm{E}+00$ & 0 & $0.00 \mathrm{E}+00$ & 0 & $0.00 \mathrm{E}+00$ & 0 & $0.00 \mathrm{E}+00$ & 0 & $0.00 \mathrm{E}+00$ & 0 & $0.00 \mathrm{E}+00$ & 0 \\
\hline 38 & $0.00 \mathrm{E}+00$ & 0 & $0.00 E+00$ & 0 & $0.00 \mathrm{E}+00$ & 0 & $0.00 \mathrm{E}+00$ & 0 & $0.00 \mathrm{E}+00$ & 0 & $0.00 \mathrm{E}+00$ & 0 & $0.00 \mathrm{E}+00$ & 0 & $0.00 \mathrm{E}+00$ & 0 \\
\hline & $0.00 \mathrm{E}+00$ & 0 & $0.00 \mathrm{E}+00$ & 0 & $0.00 \mathrm{E}+00$ & 0 & $0.00 \mathrm{E}+00$ & 0 & $0.00 \mathrm{E}+00$ & 0 & $0.00 \mathrm{E}+00$ & 0 & $0.00 \mathrm{E}+00$ & 0 & $.00 \mathrm{E}+00$ & 0 \\
\hline
\end{tabular}

Total Dose Contributions TDOSE (i,p,t) for Individual Radionuclides (i) and Pathways (p)

in mrem/yr and as a Percentage of Total Dose at $t=0$ years

Directly from primary contamination and from release to atmosphere (Inhalation excludes radon)

\begin{tabular}{|c|c|c|c|c|c|c|c|c|c|c|c|c|c|c|c|c|}
\hline & \multicolumn{2}{|c|}{ Ground } & \multicolumn{2}{|c|}{ Inhalation } & \multicolumn{2}{|c|}{ Radon } & \multicolumn{2}{|c|}{ Plant } & \multicolumn{2}{|l|}{ Meat } & \multicolumn{2}{|l|}{ Milk } & \multicolumn{2}{|l|}{ Soil } & \multicolumn{2}{|c|}{ All Pathways* } \\
\hline clide & Dose & $\%$ & Dose & $\%$ & Dose & $\%$ & Dose & 음 & Dose & $\%$ & Dose & 음 & Dose & $\%$ & Dose & $\%$ \\
\hline-241 & 7. $62 \mathrm{E}-28$ & 0 & $0.00 \mathrm{E}+00$ & 0 & $0.00 E+00$ & 0 & $0.00 \mathrm{E}+00$ & 0 & $0.00 \mathrm{E}+00$ & 0 & $0.00 \mathrm{E}+00$ & 0 & $0.00 \mathrm{E}+00$ & 0 & 7. $62 \mathrm{E}-28$ & 0 \\
\hline-137 & $6.22 E-18$ & 0 & $0.00 E+00$ & 0 & $0.00 E+00$ & 0 & $0.00 \mathrm{E}+00$ & 0 & $0.00 \mathrm{E}+00$ & 0 & $0.00 E+00$ & 0 & $0.00 \mathrm{E}+00$ & 0 & $6.22 \mathrm{E}-18$ & 0 \\
\hline-237 & $4.70 E-21$ & 0 & $0.00 E+00$ & 0 & $0.00 E+00$ & 0 & $0.00 \mathrm{E}+00$ & 0 & $0.00 \mathrm{E}+00$ & 0 & $0.00 E+00$ & 0 & $0.00 \mathrm{E}+00$ & 0 & $4.70 E-21$ & 0 \\
\hline-238 & 4. $03 E-31$ & 0 & $0.00 E+00$ & 0 & $0.00 \mathrm{E}+00$ & 0 & $0.00 \mathrm{E}+00$ & 0 & $0.00 \mathrm{E}+00$ & 0 & $0.00 \mathrm{E}+00$ & 0 & $0.00 \mathrm{E}+00$ & 0 & $4.03 E-31$ & 0 \\
\hline-239 & $5.93 E-26$ & 0 & $0.00 \mathrm{E}+00$ & 0 & $0.00 \mathrm{E}+00$ & 0 & $0.00 \mathrm{E}+00$ & 0 & $0.00 \mathrm{E}+00$ & 0 & $0.00 \mathrm{E}+00$ & 0 & $0.00 \mathrm{E}+00$ & 0 & $5.93 E-26$ & 0 \\
\hline-240 & $5.63 E-33$ & 0 & $0.00 E+00$ & 0 & $0.00 \mathrm{E}+00$ & 0 & $0.00 \mathrm{E}+00$ & 0 & $0.00 \mathrm{E}+00$ & 0 & $0.00 E+00$ & 0 & $0.00 \mathrm{E}+00$ & 0 & $5.63 E-33$ & 0 \\
\hline-99 & $2.84 E-34$ & 0 & $0.00 E+00$ & 0 & $0.00 \mathrm{E}+00$ & 0 & $0.00 \mathrm{E}+00$ & 0 & $0.00 \mathrm{E}+00$ & 0 & $0.00 E+00$ & 0 & $0.00 \mathrm{E}+00$ & 0 & $2.84 E-34$ & 0 \\
\hline-228 & $6.82 \mathrm{E}-15$ & 99 & $0.00 \mathrm{E}+00$ & 0 & $0.00 \mathrm{E}+00$ & 0 & $0.00 \mathrm{E}+00$ & 0 & $0.00 \mathrm{E}+00$ & 0 & $0.00 \mathrm{E}+00$ & 0 & $0.00 \mathrm{E}+00$ & 0 & $6.82 \mathrm{E}-15$ & 99 \\
\hline-230 & $1.86 \mathrm{E}-19$ & 0 & $0.00 E+00$ & 0 & $0.00 \mathrm{E}+00$ & 0 & $0.00 \mathrm{E}+00$ & 0 & $0.00 \mathrm{E}+00$ & 0 & $0.00 E+00$ & 0 & $0.00 \mathrm{E}+00$ & 0 & $1.86 \mathrm{E}-19$ & 0 \\
\hline-232 & $5.82 E-17$ & 1 & $0.00 E+00$ & 0 & $0.00 \mathrm{E}+00$ & 0 & $0.00 \mathrm{E}+00$ & 0 & $0.00 \mathrm{E}+00$ & 0 & $0.00 \mathrm{E}+00$ & 0 & $0.00 \mathrm{E}+00$ & 0 & $5.82 \mathrm{E}-17$ & 1 \\
\hline 34 & $5.60 \mathrm{E}-25$ & 0 & $0.00 \mathrm{E}+00$ & 0 & $0.00 \mathrm{E}+00$ & 0 & $0.00 \mathrm{E}+00$ & 0 & $0.00 \mathrm{E}+00$ & 0 & $0.00 \mathrm{E}+00$ & 0 & $0.00 \mathrm{E}+00$ & 0 & $5.60 \mathrm{E}-25$ & 0 \\
\hline 35 & $6.13 E-23$ & 0 & $0.00 E+00$ & 0 & $0.00 E+00$ & 0 & $0.00 \mathrm{E}+00$ & 0 & $0.00 \mathrm{E}+00$ & 0 & $0.00 E+00$ & 0 & $0.00 \mathrm{E}+00$ & 0 & $6.13 E-23$ & 0 \\
\hline 38 & 7. $00 \mathrm{E}-19$ & 0 & $0.00 E+00$ & 0 & $0.00 \mathrm{E}+00$ & 0 & $0.00 \mathrm{E}+00$ & 0 & $0.00 \mathrm{E}+00$ & 0 & $0.00 E+00$ & 0 & $0.00 \mathrm{E}+00$ & 0 & $7.00 \mathrm{E}-19$ & 0 \\
\hline & $6.88 E-15$ & 100 & $0.00 \mathrm{E}+00$ & 0 & $0.00 \mathrm{E}+00$ & 0 & $0.00 \mathrm{E}+00$ & 0 & $0.00 \mathrm{E}+00$ & 0 & $0.00 \mathrm{E}+00$ & 0 & $0.00 \mathrm{E}+00$ & 0 & $6.88 \mathrm{E}-15$ & 100 \\
\hline
\end{tabular}

* Sum of dose from all releases and from primary contamination. 
RESRAD-OFFSITE, Version 2 .

Parent Dose Report

Title : RESRAD-OFFSITE Parameters for Offsite Resident Farmer

File : OFFSITE-RF_SRSG-7-11.ROF

Total Dose Contributions TDOSE (i,p,t) for Individual Radionuclides (i) and Pathways (p) in mrem/yr and as a Percentage of Total Dose at $t=1$ years

From releases to ground water and to surface water

\begin{tabular}{|c|c|c|c|c|c|c|c|c|c|c|c|c|c|c|c|c|}
\hline & \multicolumn{2}{|c|}{ Ground } & \multicolumn{2}{|l|}{ Fish } & \multicolumn{2}{|c|}{ Radon } & \multicolumn{2}{|c|}{ Plant } & \multicolumn{2}{|l|}{ Meat } & \multicolumn{2}{|l|}{ Milk } & \multicolumn{2}{|l|}{ Soil } & \multicolumn{2}{|c|}{ Water } \\
\hline clide & Dose & \% & Dose & $\%$ & Dose & \% & Dose & \% & Dose & \% & Dose & \% & Dose & \% & Dose & $\%$ \\
\hline-241 & $0.00 \mathrm{E}+00$ & 0 & $0.00 \mathrm{E}+00$ & 0 & $0.00 \mathrm{E}+00$ & 0 & $0.00 \mathrm{E}+00$ & 0 & $0.00 \mathrm{E}+00$ & 0 & $0.00 \mathrm{E}+00$ & 0 & $0.00 \mathrm{E}+00$ & 0 & $0.00 \mathrm{E}+00$ & 0 \\
\hline-137 & $0.00 \mathrm{E}+00$ & 0 & $0.00 \mathrm{E}+00$ & 0 & $0.00 \mathrm{E}+00$ & 0 & $0.00 \mathrm{E}+00$ & 0 & $0.00 \mathrm{E}+00$ & 0 & $0.00 \mathrm{E}+00$ & 0 & $0.00 \mathrm{E}+00$ & 0 & $0.00 \mathrm{E}+00$ & 0 \\
\hline-237 & $0.00 \mathrm{E}+00$ & 0 & $0.00 \mathrm{E}+00$ & 0 & $0.00 \mathrm{E}+00$ & 0 & $0.00 \mathrm{E}+00$ & 0 & $0.00 \mathrm{E}+00$ & 0 & $0.00 \mathrm{E}+00$ & 0 & $0.00 \mathrm{E}+00$ & 0 & $0.00 \mathrm{E}+00$ & 0 \\
\hline-238 & $0.00 \mathrm{E}+00$ & 0 & $0.00 \mathrm{E}+00$ & 0 & $0.00 \mathrm{E}+00$ & 0 & $0.00 \mathrm{E}+00$ & 0 & $0.00 \mathrm{E}+00$ & 0 & $0.00 \mathrm{E}+00$ & 0 & $0.00 \mathrm{E}+00$ & 0 & $0.00 \mathrm{E}+00$ & 0 \\
\hline-239 & $0.00 \mathrm{E}+00$ & 0 & $0.00 \mathrm{E}+00$ & 0 & $0.00 \mathrm{E}+00$ & 0 & $0.00 \mathrm{E}+00$ & 0 & $0.00 \mathrm{E}+00$ & 0 & $0.00 \mathrm{E}+00$ & 0 & $0.00 \mathrm{E}+00$ & 0 & $0.00 \mathrm{E}+00$ & 0 \\
\hline-240 & $0.00 \mathrm{E}+00$ & 0 & $0.00 \mathrm{E}+00$ & 0 & $0.00 \mathrm{E}+00$ & 0 & $0.00 \mathrm{E}+00$ & 0 & $0.00 \mathrm{E}+00$ & 0 & $0.00 \mathrm{E}+00$ & 0 & $0.00 \mathrm{E}+00$ & 0 & $0.00 \mathrm{E}+00$ & 0 \\
\hline-99 & $0.00 \mathrm{E}+00$ & 0 & $0.00 E+00$ & 0 & $0.00 E+00$ & 0 & $0.00 \mathrm{E}+00$ & 0 & $0.00 \mathrm{E}+00$ & 0 & $0.00 E+00$ & 0 & $0.00 \mathrm{E}+00$ & 0 & $0.00 \mathrm{E}+00$ & 0 \\
\hline-228 & $0.00 \mathrm{E}+00$ & 0 & $0.00 \mathrm{E}+00$ & 0 & $0.00 \mathrm{E}+00$ & 0 & $0.00 \mathrm{E}+00$ & 0 & $0.00 \mathrm{E}+00$ & 0 & $0.00 \mathrm{E}+00$ & 0 & $0.00 \mathrm{E}+00$ & 0 & $0.00 \mathrm{E}+00$ & 0 \\
\hline-230 & $0.00 \mathrm{E}+00$ & 0 & $0.00 \mathrm{E}+00$ & 0 & $0.00 \mathrm{E}+00$ & 0 & $0.00 \mathrm{E}+00$ & 0 & $0.00 \mathrm{E}+00$ & 0 & $0.00 \mathrm{E}+00$ & 0 & $0.00 \mathrm{E}+00$ & 0 & $0.00 \mathrm{E}+00$ & 0 \\
\hline-232 & $0.00 \mathrm{E}+00$ & 0 & $0.00 E+00$ & 0 & $0.00 \mathrm{E}+00$ & 0 & $0.00 \mathrm{E}+00$ & 0 & $0.00 \mathrm{E}+00$ & 0 & $0.00 \mathrm{E}+00$ & 0 & $0.00 \mathrm{E}+00$ & 0 & $0.00 \mathrm{E}+00$ & 0 \\
\hline 234 & $0.00 \mathrm{E}+00$ & 0 & $0.00 \mathrm{E}+00$ & 0 & $0.00 \mathrm{E}+00$ & 0 & $0.00 \mathrm{E}+00$ & 0 & $0.00 \mathrm{E}+00$ & 0 & $0.00 \mathrm{E}+00$ & 0 & $0.00 \mathrm{E}+00$ & 0 & $0.00 \mathrm{E}+00$ & 0 \\
\hline 235 & $0.00 \mathrm{E}+00$ & 0 & $0.00 \mathrm{E}+00$ & 0 & $0.00 \mathrm{E}+00$ & 0 & $0.00 \mathrm{E}+00$ & 0 & $0.00 \mathrm{E}+00$ & 0 & $0.00 \mathrm{E}+00$ & 0 & $0.00 \mathrm{E}+00$ & 0 & $0.00 \mathrm{E}+00$ & 0 \\
\hline 38 & $0.00 \mathrm{E}+00$ & 0 & $0.00 E+00$ & 0 & $0.00 \mathrm{E}+00$ & 0 & $0.00 \mathrm{E}+00$ & 0 & $0.00 \mathrm{E}+00$ & 0 & $0.00 \mathrm{E}+00$ & 0 & $0.00 \mathrm{E}+00$ & 0 & $0.00 \mathrm{E}+00$ & 0 \\
\hline & $0.00 \mathrm{E}+00$ & 0 & $0.00 \mathrm{E}+00$ & 0 & $0.00 \mathrm{E}+00$ & 0 & $0.00 \mathrm{E}+00$ & 0 & $0.00 \mathrm{E}+00$ & 0 & $0.00 \mathrm{E}+00$ & 0 & $0.00 \mathrm{E}+00$ & 0 & $.00 \mathrm{E}+00$ & 0 \\
\hline
\end{tabular}

Total Dose Contributions TDOSE (i,p,t) for Individual Radionuclides (i) and Pathways (p)

in mrem/yr and as a Percentage of Total Dose at $t=1$ years

Directly from primary contamination and from release to atmosphere (Inhalation excludes radon)

\begin{tabular}{|c|c|c|c|c|c|c|c|c|c|c|c|c|c|c|c|c|}
\hline & \multicolumn{2}{|c|}{ Ground } & \multicolumn{2}{|c|}{ Inhalation } & \multicolumn{2}{|c|}{ Radon } & \multicolumn{2}{|c|}{ Plant } & \multicolumn{2}{|l|}{ Meat } & \multicolumn{2}{|l|}{ Milk } & \multicolumn{2}{|l|}{ Soil } & \multicolumn{2}{|c|}{ All Pathways* } \\
\hline clide & Dose & $\%$ & Dose & $\%$ & Dose & $\%$ & Dose & 음 & Dose & $\%$ & Dose & 음 & Dose & $\%$ & Dose & $\%$ \\
\hline-241 & $2.30 E-27$ & 0 & $0.00 \mathrm{E}+00$ & 0 & $0.00 E+00$ & 0 & $0.00 \mathrm{E}+00$ & 0 & $0.00 \mathrm{E}+00$ & 0 & $0.00 \mathrm{E}+00$ & 0 & $0.00 \mathrm{E}+00$ & 0 & 2. $30 \mathrm{E}-27$ & 0 \\
\hline-137 & $6.13 E-18$ & 0 & $0.00 E+00$ & 0 & $0.00 E+00$ & 0 & $0.00 \mathrm{E}+00$ & 0 & $0.00 \mathrm{E}+00$ & 0 & $0.00 E+00$ & 0 & $0.00 \mathrm{E}+00$ & 0 & $6.13 E-18$ & 0 \\
\hline-237 & $4.75 E-21$ & 0 & $0.00 \mathrm{E}+00$ & 0 & $0.00 E+00$ & 0 & $0.00 \mathrm{E}+00$ & 0 & $0.00 \mathrm{E}+00$ & 0 & $0.00 E+00$ & 0 & $0.00 \mathrm{E}+00$ & 0 & $4.75 E-21$ & 0 \\
\hline-238 & $5.97 E-30$ & 0 & $0.00 \mathrm{E}+00$ & 0 & $0.00 \mathrm{E}+00$ & 0 & $0.00 \mathrm{E}+00$ & 0 & $0.00 \mathrm{E}+00$ & 0 & $0.00 \mathrm{E}+00$ & 0 & $0.00 \mathrm{E}+00$ & 0 & $5.97 E-30$ & 0 \\
\hline-239 & $5.99 E-26$ & 0 & $0.00 \mathrm{E}+00$ & 0 & $0.00 \mathrm{E}+00$ & 0 & $0.00 \mathrm{E}+00$ & 0 & $0.00 \mathrm{E}+00$ & 0 & $0.00 \mathrm{E}+00$ & 0 & $0.00 \mathrm{E}+00$ & 0 & $5.99 \mathrm{E}-26$ & 0 \\
\hline-240 & $5.84 E-33$ & 0 & $0.00 \mathrm{E}+00$ & 0 & $0.00 \mathrm{E}+00$ & 0 & $0.00 \mathrm{E}+00$ & 0 & $0.00 \mathrm{E}+00$ & 0 & $0.00 E+00$ & 0 & $0.00 \mathrm{E}+00$ & 0 & $5.84 \mathrm{E}-33$ & 0 \\
\hline-99 & $2.88 E-34$ & 0 & $0.00 \mathrm{E}+00$ & 0 & $0.00 \mathrm{E}+00$ & 0 & $0.00 \mathrm{E}+00$ & 0 & $0.00 \mathrm{E}+00$ & 0 & $0.00 E+00$ & 0 & $0.00 \mathrm{E}+00$ & 0 & $2.88 E-34$ & 0 \\
\hline-228 & $4.77 \mathrm{E}-15$ & 93 & $0.00 \mathrm{E}+00$ & 0 & $0.00 \mathrm{E}+00$ & 0 & $0.00 \mathrm{E}+00$ & 0 & $0.00 \mathrm{E}+00$ & 0 & $0.00 \mathrm{E}+00$ & 0 & $0.00 \mathrm{E}+00$ & 0 & $4.77 \mathrm{E}-15$ & 93 \\
\hline-230 & $5.61 E-19$ & 0 & $0.00 E+00$ & 0 & $0.00 \mathrm{E}+00$ & 0 & $0.00 \mathrm{E}+00$ & 0 & $0.00 \mathrm{E}+00$ & 0 & $0.00 E+00$ & 0 & $0.00 \mathrm{E}+00$ & 0 & $5.61 \mathrm{E}-19$ & 0 \\
\hline-232 & $3.40 \mathrm{E}-16$ & 7 & $0.00 \mathrm{E}+00$ & 0 & $0.00 \mathrm{E}+00$ & 0 & $0.00 \mathrm{E}+00$ & 0 & $0.00 \mathrm{E}+00$ & 0 & $0.00 \mathrm{E}+00$ & 0 & $0.00 \mathrm{E}+00$ & 0 & $3.40 \mathrm{E}-16$ & 7 \\
\hline 34 & $3.93 E-24$ & 0 & $0.00 \mathrm{E}+00$ & 0 & $0.00 \mathrm{E}+00$ & 0 & $0.00 \mathrm{E}+00$ & 0 & $0.00 \mathrm{E}+00$ & 0 & $0.00 \mathrm{E}+00$ & 0 & $0.00 \mathrm{E}+00$ & 0 & $3.93 E-24$ & 0 \\
\hline 35 & $6.23 E-23$ & 0 & $0.00 \mathrm{E}+00$ & 0 & $0.00 \mathrm{E}+00$ & 0 & $0.00 \mathrm{E}+00$ & 0 & $0.00 \mathrm{E}+00$ & 0 & $0.00 \mathrm{E}+00$ & 0 & $0.00 \mathrm{E}+00$ & 0 & $6.23 E-23$ & 0 \\
\hline 38 & 7. $05 E-19$ & 0 & $0.00 \mathrm{E}+00$ & 0 & $0.00 \mathrm{E}+00$ & 0 & $0.00 \mathrm{E}+00$ & 0 & $0.00 \mathrm{E}+00$ & 0 & $0.00 E+00$ & 0 & $0.00 \mathrm{E}+00$ & 0 & $7.05 E-19$ & 0 \\
\hline & $5.12 \mathrm{E}-15$ & 100 & $0.00 \mathrm{E}+00$ & 0 & $0.00 \mathrm{E}+00$ & 0 & $0.00 \mathrm{E}+00$ & 0 & $0.00 \mathrm{E}+00$ & 0 & $0.00 \mathrm{E}+00$ & 0 & $0.00 \mathrm{E}+00$ & 0 & $5.12 \mathrm{E}-15$ & 100 \\
\hline
\end{tabular}

* Sum of dose from all releases and from primary contamination. 
RESRAD-OFFSITE, Version 2 .

Parent Dose Report

Title : RESRAD-OFFSITE Parameters for Offsite Resident Farmer

File : OFFSITE-RF_SRSG-7-11.ROF

Total Dose Contributions TDOSE (i,p,t) for Individual Radionuclides (i) and Pathways (p) in mrem/yr and as a Percentage of Total Dose at $t=50$ years

From releases to ground water and to surface water

\begin{tabular}{|c|c|c|c|c|c|c|c|c|c|c|c|c|c|c|c|c|}
\hline & \multicolumn{2}{|c|}{ Ground } & \multicolumn{2}{|l|}{ Fish } & \multicolumn{2}{|c|}{ Radon } & \multicolumn{2}{|c|}{ Plant } & \multicolumn{2}{|l|}{ Meat } & \multicolumn{2}{|l|}{ Milk } & \multicolumn{2}{|l|}{ Soil } & \multicolumn{2}{|c|}{ Water } \\
\hline ide & Dose & $\%$ & Dose & $\%$ & Dose & 응 & Dose & $\frac{\circ}{0}$ & Dose & \% & Dose & 응 & Dose & $\%$ & Dose & $\%$ \\
\hline-241 & $0.00 \mathrm{E}+00$ & 0 & $0.00 E+00$ & 0 & $0.00 \mathrm{E}+00$ & 0 & $0.00 \mathrm{E}+00$ & 0 & $0.00 \mathrm{E}+00$ & 0 & $0.00 \mathrm{E}+00$ & 0 & $0.00 \mathrm{E}+00$ & 0 & $0.00 \mathrm{E}+00$ & 0 \\
\hline-137 & $0.00 \mathrm{E}+00$ & 0 & $0.00 \mathrm{E}+00$ & 0 & $0.00 \mathrm{E}+00$ & 0 & $0.00 \mathrm{E}+00$ & 0 & $0.00 \mathrm{E}+00$ & 0 & $0.00 \mathrm{E}+00$ & 0 & $0.00 \mathrm{E}+00$ & 0 & $0.00 \mathrm{E}+00$ & 0 \\
\hline-237 & $0.00 \mathrm{E}+00$ & 0 & $0.00 \mathrm{E}+00$ & 0 & $0.00 \mathrm{E}+00$ & 0 & $0.00 \mathrm{E}+00$ & 0 & $0.00 \mathrm{E}+00$ & 0 & $0.00 \mathrm{E}+00$ & 0 & $0.00 \mathrm{E}+00$ & 0 & $0.00 \mathrm{E}+00$ & 0 \\
\hline-238 & $0.00 \mathrm{E}+00$ & 0 & $0.00 \mathrm{E}+00$ & 0 & $0.00 E+00$ & 0 & $0.00 \mathrm{E}+00$ & 0 & $0.00 \mathrm{E}+00$ & 0 & $0.00 E+00$ & 0 & $0.00 \mathrm{E}+00$ & 0 & $0.00 \mathrm{E}+00$ & 0 \\
\hline-239 & $0.00 \mathrm{E}+00$ & 0 & $0.00 \mathrm{E}+00$ & 0 & $0.00 \mathrm{E}+00$ & 0 & $0.00 \mathrm{E}+00$ & 0 & $0.00 \mathrm{E}+00$ & 0 & $0.00 \mathrm{E}+00$ & 0 & $0.00 \mathrm{E}+00$ & 0 & $0.00 \mathrm{E}+00$ & 0 \\
\hline-240 & $0.00 \mathrm{E}+00$ & 0 & $0.00 \mathrm{E}+00$ & 0 & $0.00 \mathrm{E}+00$ & 0 & $0.00 \mathrm{E}+00$ & 0 & $0.00 \mathrm{E}+00$ & 0 & $0.00 \mathrm{E}+00$ & 0 & $0.00 \mathrm{E}+00$ & 0 & $0.00 \mathrm{E}+00$ & 0 \\
\hline-99 & $0.00 \mathrm{E}+00$ & 0 & $0.00 \mathrm{E}+00$ & 0 & $0.00 \mathrm{E}+00$ & 0 & $0.00 \mathrm{E}+00$ & 0 & $0.00 \mathrm{E}+00$ & 0 & $0.00 E+00$ & 0 & $0.00 \mathrm{E}+00$ & 0 & $0.00 \mathrm{E}+00$ & 0 \\
\hline-228 & $0.00 \mathrm{E}+00$ & 0 & $0.00 \mathrm{E}+00$ & 0 & $0.00 \mathrm{E}+00$ & 0 & $0.00 \mathrm{E}+00$ & 0 & $0.00 \mathrm{E}+00$ & 0 & $0.00 \mathrm{E}+00$ & 0 & $0.00 \mathrm{E}+00$ & 0 & $0.00 \mathrm{E}+00$ & 0 \\
\hline-230 & $0.00 \mathrm{E}+00$ & 0 & $0.00 \mathrm{E}+00$ & 0 & $0.00 \mathrm{E}+00$ & 0 & $0.00 \mathrm{E}+00$ & 0 & $0.00 \mathrm{E}+00$ & 0 & $0.00 \mathrm{E}+00$ & 0 & $0.00 \mathrm{E}+00$ & 0 & $0.00 \mathrm{E}+00$ & 0 \\
\hline-232 & $0.00 \mathrm{E}+00$ & 0 & $0.00 \mathrm{E}+00$ & 0 & $0.00 \mathrm{E}+00$ & 0 & $0.00 \mathrm{E}+00$ & 0 & $0.00 \mathrm{E}+00$ & 0 & $0.00 \mathrm{E}+00$ & 0 & $0.00 \mathrm{E}+00$ & 0 & $0.00 \mathrm{E}+00$ & 0 \\
\hline 4 & $0.00 \mathrm{E}+00$ & 0 & $0.00 \mathrm{E}+00$ & 0 & $0.00 \mathrm{E}+00$ & 0 & $0.00 \mathrm{E}+00$ & 0 & $0.00 \mathrm{E}+00$ & 0 & $0.00 \mathrm{E}+00$ & 0 & $0.00 \mathrm{E}+00$ & 0 & $0.00 \mathrm{E}+00$ & 0 \\
\hline 35 & $0.00 \mathrm{E}+00$ & 0 & $0.00 \mathrm{E}+00$ & 0 & $0.00 \mathrm{E}+00$ & 0 & $0.00 \mathrm{E}+00$ & 0 & $0.00 \mathrm{E}+00$ & 0 & $0.00 \mathrm{E}+00$ & 0 & $0.00 \mathrm{E}+00$ & 0 & $0.00 \mathrm{E}+00$ & 0 \\
\hline 38 & $0.00 \mathrm{E}+00$ & 0 & $0.00 \mathrm{E}+00$ & 0 & $0.00 \mathrm{E}+00$ & 0 & $0.00 \mathrm{E}+00$ & 0 & $0.00 \mathrm{E}+00$ & 0 & $0.00 \mathrm{E}+00$ & 0 & $0.00 \mathrm{E}+00$ & 0 & $0.00 \mathrm{E}+00$ & 0 \\
\hline & $0.00 \mathrm{E}+00$ & 0 & $0.00 E+00$ & 0 & $0.00 \mathrm{E}+00$ & 0 & $0.00 \mathrm{E}+00$ & 0 & $0.00 \mathrm{E}+00$ & 0 & $0.00 \mathrm{E}+00$ & 0 & $0.00 \mathrm{E}+00$ & 0 & $0.00 \mathrm{E}+00$ & \\
\hline
\end{tabular}

Total Dose Contributions TDOSE(i,p,t) for Individual Radionuclides (i) and Pathways (p) in mrem/yr and as a Percentage of Total Dose at $t=50$ years

Directly from primary contamination and from release to atmosphere (Inhalation excludes radon)

\begin{tabular}{|c|c|c|c|c|c|c|c|c|c|c|c|c|c|c|c|c|}
\hline & \multicolumn{2}{|c|}{ Ground } & \multicolumn{2}{|c|}{ Inhalation } & \multicolumn{2}{|c|}{ Radon } & \multicolumn{2}{|c|}{ Plant } & \multicolumn{2}{|l|}{ Meat } & \multicolumn{2}{|l|}{ Milk } & \multicolumn{2}{|l|}{ Soil } & \multicolumn{2}{|c|}{ All Pathways* } \\
\hline clide & Dose & \% & Dose & $\%$ & Dose & $\%$ & Dose & \% & Dose & $\%$ & Dose & \% & Dose & \% & Dose & $\%$ \\
\hline-241 & $1.21 \mathrm{E}-25$ & 0 & $0.00 \mathrm{E}+00$ & 0 & $0.00 \mathrm{E}+00$ & 0 & $0.00 \mathrm{E}+00$ & 0 & $0.00 \mathrm{E}+00$ & 0 & $0.00 \mathrm{E}+00$ & 0 & $0.00 \mathrm{E}+00$ & 0 & 1. $21 \mathrm{E}-25$ & 0 \\
\hline-137 & $2.89 \mathrm{E}-18$ & 0 & $0.00 \mathrm{E}+00$ & 0 & $0.00 \mathrm{E}+00$ & 0 & $0.00 \mathrm{E}+00$ & 0 & $0.00 \mathrm{E}+00$ & 0 & $0.00 \mathrm{E}+00$ & 0 & $0.00 \mathrm{E}+00$ & 0 & $2.89 \mathrm{E}-18$ & 0 \\
\hline-237 & 7. $71 \mathrm{E}-21$ & 0 & $0.00 \mathrm{E}+00$ & 0 & $0.00 \mathrm{E}+00$ & 0 & $0.00 \mathrm{E}+00$ & 0 & $0.00 \mathrm{E}+00$ & 0 & $0.00 \mathrm{E}+00$ & 0 & $0.00 \mathrm{E}+00$ & 0 & $7.71 \mathrm{E}-21$ & 0 \\
\hline-238 & $2.53 E-25$ & 0 & $0.00 \mathrm{E}+00$ & 0 & $0.00 \mathrm{E}+00$ & 0 & $0.00 \mathrm{E}+00$ & 0 & $0.00 \mathrm{E}+00$ & 0 & $0.00 \mathrm{E}+00$ & 0 & $0.00 \mathrm{E}+00$ & 0 & $2.53 E-25$ & 0 \\
\hline-239 & $1.03 E-25$ & 0 & $0.00 \mathrm{E}+00$ & 0 & $0.00 \mathrm{E}+00$ & 0 & $0.00 \mathrm{E}+00$ & 0 & $0.00 \mathrm{E}+00$ & 0 & $0.00 \mathrm{E}+00$ & 0 & $0.00 \mathrm{E}+00$ & 0 & $1.03 E-25$ & 0 \\
\hline-240 & 1.29E-29 & 0 & $0.00 \mathrm{E}+00$ & 0 & $0.00 \mathrm{E}+00$ & 0 & $0.00 \mathrm{E}+00$ & 0 & $0.00 \mathrm{E}+00$ & 0 & $0.00 \mathrm{E}+00$ & 0 & $0.00 \mathrm{E}+00$ & 0 & 1. $29 \mathrm{E}-29$ & 0 \\
\hline-99 & $5.28 E-34$ & 0 & $0.00 \mathrm{E}+00$ & 0 & $0.00 \mathrm{E}+00$ & 0 & $0.00 \mathrm{E}+00$ & 0 & $0.00 \mathrm{E}+00$ & 0 & $0.00 \mathrm{E}+00$ & 0 & $0.00 \mathrm{E}+00$ & 0 & $5.28 \mathrm{E}-34$ & 0 \\
\hline-228 & $1.22 \mathrm{E}-22$ & 0 & $0.00 \mathrm{E}+00$ & 0 & $0.00 \mathrm{E}+00$ & 0 & $0.00 \mathrm{E}+00$ & 0 & $0.00 \mathrm{E}+00$ & 0 & $0.00 \mathrm{E}+00$ & 0 & $0.00 \mathrm{E}+00$ & 0 & 1. $22 \mathrm{E}-22$ & 0 \\
\hline-230 & $2.55 \mathrm{E}-17$ & 0 & $0.00 \mathrm{E}+00$ & 0 & $0.00 \mathrm{E}+00$ & 0 & $0.00 \mathrm{E}+00$ & 0 & $0.00 \mathrm{E}+00$ & 0 & $0.00 \mathrm{E}+00$ & 0 & $0.00 \mathrm{E}+00$ & 0 & $2.55 \mathrm{E}-17$ & 0 \\
\hline-232 & $1.08 \mathrm{E}-14$ & 100 & $0.00 \mathrm{E}+00$ & 0 & $0.00 \mathrm{E}+00$ & 0 & $0.00 \mathrm{E}+00$ & 0 & $0.00 \mathrm{E}+00$ & 0 & $0.00 \mathrm{E}+00$ & 0 & $0.00 \mathrm{E}+00$ & 0 & $1.08 \mathrm{E}-14$ & 100 \\
\hline 234 & $5.82 \mathrm{E}-21$ & 0 & $0.00 \mathrm{E}+00$ & 0 & $0.00 \mathrm{E}+00$ & 0 & $0.00 \mathrm{E}+00$ & 0 & $0.00 \mathrm{E}+00$ & 0 & $0.00 \mathrm{E}+00$ & 0 & $0.00 \mathrm{E}+00$ & 0 & $5.82 \mathrm{E}-21$ & 0 \\
\hline 235 & $4.39 E-22$ & 0 & $0.00 \mathrm{E}+00$ & 0 & $0.00 \mathrm{E}+00$ & 0 & $0.00 \mathrm{E}+00$ & 0 & $0.00 \mathrm{E}+00$ & 0 & $0.00 \mathrm{E}+00$ & 0 & $0.00 \mathrm{E}+00$ & 0 & $4.39 E-22$ & 0 \\
\hline 38 & $1.01 \mathrm{E}-18$ & 0 & $0.00 \mathrm{E}+00$ & 0 & $0.00 \mathrm{E}+00$ & 0 & $0.00 \mathrm{E}+00$ & 0 & $0.00 \mathrm{E}+00$ & 0 & $0.00 \mathrm{E}+00$ & 0 & $0.00 \mathrm{E}+00$ & 0 & $1.01 \mathrm{E}-18$ & 0 \\
\hline & $1.08 \mathrm{E}-14$ & 100 & $0.00 \mathrm{E}+00$ & 0 & $0.00 \mathrm{E}+00$ & 0 & $0.00 \mathrm{E}+00$ & 0 & $0.00 \mathrm{E}+00$ & 0 & $0.00 \mathrm{E}+00$ & 0 & $0.00 \mathrm{E}+00$ & 0 & 1. $08 \mathrm{E}-14$ & 100 \\
\hline
\end{tabular}


RESRAD-OFFSITE, Version 2 .

Parent Dose Report

Title : RESRAD-OFFSITE Parameters for Offsite Resident Farmer

File : OFFSITE-RF_SRSG-7-11.ROF

Total Dose Contributions TDOSE (i,p,t) for Individual Radionuclides (i) and Pathways (p) in mrem/yr and as a Percentage of Total Dose at $t=100$ years

From releases to ground water and to surface water

\begin{tabular}{|c|c|c|c|c|c|c|c|c|c|c|c|c|c|c|c|c|}
\hline & \multicolumn{2}{|c|}{ Ground } & \multicolumn{2}{|l|}{ Fish } & \multicolumn{2}{|c|}{ Radon } & \multicolumn{2}{|c|}{ Plant } & \multicolumn{2}{|l|}{ Meat } & \multicolumn{2}{|l|}{ Milk } & \multicolumn{2}{|l|}{ Soil } & \multicolumn{2}{|c|}{ Water } \\
\hline ide & Dose & $\%$ & Dose & $\%$ & Dose & 응 & Dose & $\frac{\circ}{0}$ & Dose & \% & Dose & 응 & Dose & $\%$ & Dose & $\%$ \\
\hline-241 & $0.00 \mathrm{E}+00$ & 0 & $0.00 E+00$ & 0 & $0.00 \mathrm{E}+00$ & 0 & $0.00 \mathrm{E}+00$ & 0 & $0.00 \mathrm{E}+00$ & 0 & $0.00 \mathrm{E}+00$ & 0 & $0.00 \mathrm{E}+00$ & 0 & $0.00 \mathrm{E}+00$ & 0 \\
\hline-137 & $0.00 \mathrm{E}+00$ & 0 & $0.00 \mathrm{E}+00$ & 0 & $0.00 \mathrm{E}+00$ & 0 & $0.00 \mathrm{E}+00$ & 0 & $0.00 \mathrm{E}+00$ & 0 & $0.00 \mathrm{E}+00$ & 0 & $0.00 \mathrm{E}+00$ & 0 & $0.00 \mathrm{E}+00$ & 0 \\
\hline-237 & $0.00 \mathrm{E}+00$ & 0 & $0.00 \mathrm{E}+00$ & 0 & $0.00 \mathrm{E}+00$ & 0 & $0.00 \mathrm{E}+00$ & 0 & $0.00 \mathrm{E}+00$ & 0 & $0.00 \mathrm{E}+00$ & 0 & $0.00 \mathrm{E}+00$ & 0 & $0.00 \mathrm{E}+00$ & 0 \\
\hline-238 & $0.00 \mathrm{E}+00$ & 0 & $0.00 \mathrm{E}+00$ & 0 & $0.00 E+00$ & 0 & $0.00 \mathrm{E}+00$ & 0 & $0.00 \mathrm{E}+00$ & 0 & $0.00 E+00$ & 0 & $0.00 \mathrm{E}+00$ & 0 & $0.00 \mathrm{E}+00$ & 0 \\
\hline-239 & $0.00 \mathrm{E}+00$ & 0 & $0.00 \mathrm{E}+00$ & 0 & $0.00 \mathrm{E}+00$ & 0 & $0.00 \mathrm{E}+00$ & 0 & $0.00 \mathrm{E}+00$ & 0 & $0.00 \mathrm{E}+00$ & 0 & $0.00 \mathrm{E}+00$ & 0 & $0.00 \mathrm{E}+00$ & 0 \\
\hline-240 & $0.00 \mathrm{E}+00$ & 0 & $0.00 \mathrm{E}+00$ & 0 & $0.00 \mathrm{E}+00$ & 0 & $0.00 \mathrm{E}+00$ & 0 & $0.00 \mathrm{E}+00$ & 0 & $0.00 \mathrm{E}+00$ & 0 & $0.00 \mathrm{E}+00$ & 0 & $0.00 \mathrm{E}+00$ & 0 \\
\hline-99 & $0.00 \mathrm{E}+00$ & 0 & $0.00 \mathrm{E}+00$ & 0 & $0.00 \mathrm{E}+00$ & 0 & $0.00 \mathrm{E}+00$ & 0 & $0.00 \mathrm{E}+00$ & 0 & $0.00 E+00$ & 0 & $0.00 \mathrm{E}+00$ & 0 & $0.00 \mathrm{E}+00$ & 0 \\
\hline-228 & $0.00 \mathrm{E}+00$ & 0 & $0.00 \mathrm{E}+00$ & 0 & $0.00 \mathrm{E}+00$ & 0 & $0.00 \mathrm{E}+00$ & 0 & $0.00 \mathrm{E}+00$ & 0 & $0.00 \mathrm{E}+00$ & 0 & $0.00 \mathrm{E}+00$ & 0 & $0.00 \mathrm{E}+00$ & 0 \\
\hline-230 & $0.00 \mathrm{E}+00$ & 0 & $0.00 \mathrm{E}+00$ & 0 & $0.00 \mathrm{E}+00$ & 0 & $0.00 \mathrm{E}+00$ & 0 & $0.00 \mathrm{E}+00$ & 0 & $0.00 \mathrm{E}+00$ & 0 & $0.00 \mathrm{E}+00$ & 0 & $0.00 \mathrm{E}+00$ & 0 \\
\hline-232 & $0.00 \mathrm{E}+00$ & 0 & $0.00 \mathrm{E}+00$ & 0 & $0.00 \mathrm{E}+00$ & 0 & $0.00 \mathrm{E}+00$ & 0 & $0.00 \mathrm{E}+00$ & 0 & $0.00 \mathrm{E}+00$ & 0 & $0.00 \mathrm{E}+00$ & 0 & $0.00 \mathrm{E}+00$ & 0 \\
\hline 4 & $0.00 \mathrm{E}+00$ & 0 & $0.00 \mathrm{E}+00$ & 0 & $0.00 \mathrm{E}+00$ & 0 & $0.00 \mathrm{E}+00$ & 0 & $0.00 \mathrm{E}+00$ & 0 & $0.00 \mathrm{E}+00$ & 0 & $0.00 \mathrm{E}+00$ & 0 & $0.00 \mathrm{E}+00$ & 0 \\
\hline 35 & $0.00 \mathrm{E}+00$ & 0 & $0.00 \mathrm{E}+00$ & 0 & $0.00 \mathrm{E}+00$ & 0 & $0.00 \mathrm{E}+00$ & 0 & $0.00 \mathrm{E}+00$ & 0 & $0.00 \mathrm{E}+00$ & 0 & $0.00 \mathrm{E}+00$ & 0 & $0.00 \mathrm{E}+00$ & 0 \\
\hline 38 & $0.00 \mathrm{E}+00$ & 0 & $0.00 \mathrm{E}+00$ & 0 & $0.00 \mathrm{E}+00$ & 0 & $0.00 \mathrm{E}+00$ & 0 & $0.00 \mathrm{E}+00$ & 0 & $0.00 \mathrm{E}+00$ & 0 & $0.00 \mathrm{E}+00$ & 0 & $0.00 \mathrm{E}+00$ & 0 \\
\hline & $0.00 \mathrm{E}+00$ & 0 & $0.00 E+00$ & 0 & $0.00 \mathrm{E}+00$ & 0 & $0.00 \mathrm{E}+00$ & 0 & $0.00 \mathrm{E}+00$ & 0 & $0.00 \mathrm{E}+00$ & 0 & $0.00 \mathrm{E}+00$ & 0 & $0.00 \mathrm{E}+00$ & \\
\hline
\end{tabular}

Total Dose Contributions TDOSE(i,p,t) for Individual Radionuclides (i) and Pathways (p) in mrem/yr and as a Percentage of Total Dose at $t=100$ years

Directly from primary contamination and from release to atmosphere (Inhalation excludes radon)

\begin{tabular}{|c|c|c|c|c|c|c|c|c|c|c|c|c|c|c|c|c|}
\hline & \multicolumn{2}{|c|}{ Ground } & \multicolumn{2}{|c|}{ Inhalation } & \multicolumn{2}{|c|}{ Radon } & \multicolumn{2}{|c|}{ Plant } & \multicolumn{2}{|l|}{ Meat } & \multicolumn{2}{|l|}{ Milk } & \multicolumn{2}{|l|}{ Soil } & \multicolumn{2}{|c|}{ All Pathways* } \\
\hline clide & Dose & $\%$ & Dose & $\%$ & Dose & $\%$ & Dose & \% & Dose & $\%$ & Dose & \% & Dose & \% & Dose & $\%$ \\
\hline-241 & $3.81 \mathrm{E}-25$ & 0 & $0.00 \mathrm{E}+00$ & 0 & $0.00 \mathrm{E}+00$ & 0 & $0.00 \mathrm{E}+00$ & 0 & $0.00 \mathrm{E}+00$ & 0 & $0.00 \mathrm{E}+00$ & 0 & $0.00 \mathrm{E}+00$ & 0 & $3.81 \mathrm{E}-25$ & 0 \\
\hline-137 & 1. $34 \mathrm{E}-18$ & 0 & $0.00 \mathrm{E}+00$ & 0 & $0.00 \mathrm{E}+00$ & 0 & $0.00 \mathrm{E}+00$ & 0 & $0.00 \mathrm{E}+00$ & 0 & $0.00 \mathrm{E}+00$ & 0 & $0.00 \mathrm{E}+00$ & 0 & 1. $34 \mathrm{E}-18$ & 0 \\
\hline-237 & 1. $27 \mathrm{E}-20$ & 0 & $0.00 \mathrm{E}+00$ & 0 & $0.00 \mathrm{E}+00$ & 0 & $0.00 \mathrm{E}+00$ & 0 & $0.00 \mathrm{E}+00$ & 0 & $0.00 \mathrm{E}+00$ & 0 & $0.00 \mathrm{E}+00$ & 0 & $1.27 \mathrm{E}-20$ & 0 \\
\hline-238 & $2.49 \mathrm{E}-24$ & 0 & $0.00 \mathrm{E}+00$ & 0 & $0.00 \mathrm{E}+00$ & 0 & $0.00 \mathrm{E}+00$ & 0 & $0.00 \mathrm{E}+00$ & 0 & $0.00 \mathrm{E}+00$ & 0 & $0.00 \mathrm{E}+00$ & 0 & $2.49 \mathrm{E}-24$ & 0 \\
\hline-239 & 1. $78 \mathrm{E}-25$ & 0 & $0.00 \mathrm{E}+00$ & 0 & $0.00 \mathrm{E}+00$ & 0 & $0.00 \mathrm{E}+00$ & 0 & $0.00 \mathrm{E}+00$ & 0 & $0.00 \mathrm{E}+00$ & 0 & $0.00 \mathrm{E}+00$ & 0 & $1.78 \mathrm{E}-25$ & 0 \\
\hline-240 & $8.39 E-29$ & 0 & $0.00 \mathrm{E}+00$ & 0 & $0.00 \mathrm{E}+00$ & 0 & $0.00 \mathrm{E}+00$ & 0 & $0.00 \mathrm{E}+00$ & 0 & $0.00 \mathrm{E}+00$ & 0 & $0.00 \mathrm{E}+00$ & 0 & $8.39 \mathrm{E}-29$ & 0 \\
\hline-99 & $9.82 E-34$ & 0 & $0.00 \mathrm{E}+00$ & 0 & $0.00 \mathrm{E}+00$ & 0 & $0.00 \mathrm{E}+00$ & 0 & $0.00 \mathrm{E}+00$ & 0 & $0.00 \mathrm{E}+00$ & 0 & $0.00 \mathrm{E}+00$ & 0 & $9.82 \mathrm{E}-34$ & 0 \\
\hline-228 & $2.17 E-30$ & 0 & $0.00 \mathrm{E}+00$ & 0 & $0.00 \mathrm{E}+00$ & 0 & $0.00 \mathrm{E}+00$ & 0 & $0.00 \mathrm{E}+00$ & 0 & $0.00 \mathrm{E}+00$ & 0 & $0.00 \mathrm{E}+00$ & 0 & $2.17 E-30$ & 0 \\
\hline-230 & $6.90 \mathrm{E}-17$ & 0 & $0.00 \mathrm{E}+00$ & 0 & $0.00 \mathrm{E}+00$ & 0 & $0.00 \mathrm{E}+00$ & 0 & $0.00 \mathrm{E}+00$ & 0 & $0.00 \mathrm{E}+00$ & 0 & $0.00 \mathrm{E}+00$ & 0 & $6.90 \mathrm{E}-17$ & 0 \\
\hline-232 & $1.43 E-14$ & 99 & $0.00 \mathrm{E}+00$ & 0 & $0.00 \mathrm{E}+00$ & 0 & $0.00 \mathrm{E}+00$ & 0 & $0.00 \mathrm{E}+00$ & 0 & $0.00 \mathrm{E}+00$ & 0 & $0.00 \mathrm{E}+00$ & 0 & $1.43 E-14$ & 99 \\
\hline 234 & $3.15 \mathrm{E}-20$ & 0 & $0.00 \mathrm{E}+00$ & 0 & $0.00 \mathrm{E}+00$ & 0 & $0.00 \mathrm{E}+00$ & 0 & $0.00 \mathrm{E}+00$ & 0 & $0.00 \mathrm{E}+00$ & 0 & $0.00 \mathrm{E}+00$ & 0 & $3.15 \mathrm{E}-20$ & 0 \\
\hline 235 & $1.55 \mathrm{E}-21$ & 0 & $0.00 \mathrm{E}+00$ & 0 & $0.00 \mathrm{E}+00$ & 0 & $0.00 \mathrm{E}+00$ & 0 & $0.00 \mathrm{E}+00$ & 0 & $0.00 \mathrm{E}+00$ & 0 & $0.00 \mathrm{E}+00$ & 0 & 1. $55 \mathrm{E}-21$ & 0 \\
\hline 38 & $1.46 \mathrm{E}-18$ & 0 & $0.00 \mathrm{E}+00$ & 0 & $0.00 \mathrm{E}+00$ & 0 & $0.00 \mathrm{E}+00$ & 0 & $0.00 \mathrm{E}+00$ & 0 & $0.00 \mathrm{E}+00$ & 0 & $0.00 \mathrm{E}+00$ & 0 & $1.46 \mathrm{E}-18$ & 0 \\
\hline al & 1. $43 \mathrm{E}-14$ & 100 & $0.00 \mathrm{E}+00$ & 0 & $0.00 \mathrm{E}+00$ & 0 & $0.00 \mathrm{E}+00$ & 0 & $0.00 \mathrm{E}+00$ & 0 & $0.00 \mathrm{E}+00$ & 0 & $0.00 \mathrm{E}+00$ & 0 & 1. $43 \mathrm{E}-14$ & 00 \\
\hline
\end{tabular}


RESRAD-OFFSITE, Version 2 .

Parent Dose Report

Title : RESRAD-OFFSITE Parameters for Offsite Resident Farmer

File : OFFSITE-RF_SRSG-7-11.ROF

Total Dose Contributions TDOSE (i,p,t) for Individual Radionuclides (i) and Pathways (p) in mrem/yr and as a Percentage of Total Dose at $t=500$ years

From releases to ground water and to surface water

\begin{tabular}{|c|c|c|c|c|c|c|c|c|c|c|c|c|c|c|c|c|}
\hline & \multicolumn{2}{|c|}{ Ground } & \multicolumn{2}{|l|}{ Fish } & \multicolumn{2}{|c|}{ Radon } & \multicolumn{2}{|c|}{ Plant } & \multicolumn{2}{|l|}{ Meat } & \multicolumn{2}{|l|}{ Milk } & \multicolumn{2}{|l|}{ Soil } & \multicolumn{2}{|c|}{ Water } \\
\hline clide & Dose & \% & Dose & $\%$ & Dose & $\%$ & Dose & \% & Dose & $\%$ & Dose & $\%$ & Dose & \% & Dose & $\%$ \\
\hline-241 & $0.00 \mathrm{E}+00$ & 0 & $0.00 \mathrm{E}+00$ & 0 & $0.00 \mathrm{E}+00$ & 0 & $0.00 \mathrm{E}+00$ & 0 & $0.00 E+00$ & 0 & $0.00 \mathrm{E}+00$ & 0 & $0.00 \mathrm{E}+00$ & 0 & $0.00 \mathrm{E}+00$ & 0 \\
\hline-137 & $0.00 \mathrm{E}+00$ & 0 & $0.00 \mathrm{E}+00$ & 0 & $0.00 \mathrm{E}+00$ & 0 & $0.00 \mathrm{E}+00$ & 0 & $0.00 \mathrm{E}+00$ & 0 & $0.00 \mathrm{E}+00$ & 0 & $0.00 \mathrm{E}+00$ & 0 & $0.00 \mathrm{E}+00$ & 0 \\
\hline-237 & $0.00 \mathrm{E}+00$ & 0 & $0.00 \mathrm{E}+00$ & 0 & $0.00 \mathrm{E}+00$ & 0 & $0.00 \mathrm{E}+00$ & 0 & $0.00 \mathrm{E}+00$ & 0 & $0.00 \mathrm{E}+00$ & 0 & $0.00 \mathrm{E}+00$ & 0 & $0.00 \mathrm{E}+00$ & 0 \\
\hline-238 & $0.00 \mathrm{E}+00$ & 0 & $0.00 \mathrm{E}+00$ & 0 & $0.00 \mathrm{E}+00$ & 0 & $0.00 \mathrm{E}+00$ & 0 & $0.00 E+00$ & 0 & $0.00 \mathrm{E}+00$ & 0 & $0.00 \mathrm{E}+00$ & 0 & $0.00 \mathrm{E}+00$ & 0 \\
\hline-239 & $0.00 \mathrm{E}+00$ & 0 & $0.00 \mathrm{E}+00$ & 0 & $0.00 \mathrm{E}+00$ & 0 & $0.00 \mathrm{E}+00$ & 0 & $0.00 \mathrm{E}+00$ & 0 & $0.00 \mathrm{E}+00$ & 0 & $0.00 \mathrm{E}+00$ & 0 & $0.00 \mathrm{E}+00$ & 0 \\
\hline-240 & $0.00 \mathrm{E}+00$ & 0 & $0.00 \mathrm{E}+00$ & 0 & $0.00 \mathrm{E}+00$ & 0 & $0.00 \mathrm{E}+00$ & 0 & $0.00 \mathrm{E}+00$ & 0 & $0.00 \mathrm{E}+00$ & 0 & $0.00 \mathrm{E}+00$ & 0 & $0.00 \mathrm{E}+00$ & 0 \\
\hline-99 & $1.74 \mathrm{E}-08$ & 0 & $0.00 \mathrm{E}+00$ & 0 & $0.00 \mathrm{E}+00$ & 0 & $4.77 E-03$ & 25 & $1.43 E-05$ & 0 & $1.26 E-03$ & 7 & $1.47 \mathrm{E}-08$ & 0 & $1.30 \mathrm{E}-02$ & 68 \\
\hline-228 & $0.00 \mathrm{E}+00$ & 0 & $0.00 \mathrm{E}+00$ & 0 & $0.00 \mathrm{E}+00$ & 0 & $0.00 \mathrm{E}+00$ & 0 & $0.00 \mathrm{E}+00$ & 0 & $0.00 \mathrm{E}+00$ & 0 & $0.00 \mathrm{E}+00$ & 0 & $0.00 \mathrm{E}+00$ & 0 \\
\hline-230 & $0.00 \mathrm{E}+00$ & 0 & $0.00 \mathrm{E}+00$ & 0 & $0.00 \mathrm{E}+00$ & 0 & $0.00 \mathrm{E}+00$ & 0 & $0.00 \mathrm{E}+00$ & 0 & $0.00 \mathrm{E}+00$ & 0 & $0.00 \mathrm{E}+00$ & 0 & $0.00 \mathrm{E}+00$ & 0 \\
\hline-232 & $0.00 \mathrm{E}+00$ & 0 & $0.00 \mathrm{E}+00$ & 0 & $0.00 \mathrm{E}+00$ & 0 & $0.00 \mathrm{E}+00$ & 0 & $0.00 \mathrm{E}+00$ & 0 & $0.00 \mathrm{E}+00$ & 0 & $0.00 \mathrm{E}+00$ & 0 & $0.00 \mathrm{E}+00$ & 0 \\
\hline 234 & $0.00 \mathrm{E}+00$ & 0 & $0.00 \mathrm{E}+00$ & 0 & $0.00 \mathrm{E}+00$ & 0 & $0.00 \mathrm{E}+00$ & 0 & $0.00 \mathrm{E}+00$ & 0 & $0.00 \mathrm{E}+00$ & 0 & $0.00 \mathrm{E}+00$ & 0 & $0.00 \mathrm{E}+00$ & 0 \\
\hline 235 & $0.00 \mathrm{E}+00$ & 0 & $0.00 \mathrm{E}+00$ & 0 & $0.00 \mathrm{E}+00$ & 0 & $0.00 \mathrm{E}+00$ & 0 & $0.00 \mathrm{E}+00$ & 0 & $0.00 \mathrm{E}+00$ & 0 & $0.00 \mathrm{E}+00$ & 0 & $0.00 \mathrm{E}+00$ & 0 \\
\hline 38 & $0.00 \mathrm{E}+00$ & 0 & $0.00 \mathrm{E}+00$ & 0 & $0.00 \mathrm{E}+00$ & 0 & $0.00 \mathrm{E}+00$ & 0 & $0.00 \mathrm{E}+00$ & 0 & $0.00 \mathrm{E}+00$ & 0 & $0.00 \mathrm{E}+00$ & 0 & $0.00 \mathrm{E}+00$ & 0 \\
\hline & $1.74 \mathrm{E}-08$ & 0 & $0.00 \mathrm{E}+00$ & 0 & $0.00 \mathrm{E}+00$ & 0 & $4.77 E-03$ & 25 & $1.43 E-05$ & 0 & $1.26 \mathrm{E}-03$ & 7 & $1.47 \mathrm{E}-08$ & 0 & 1. $30 \mathrm{E}-02$ & 68 \\
\hline
\end{tabular}

Total Dose Contributions TDOSE(i,p,t) for Individual Radionuclides (i) and Pathways (p) in mrem/yr and as a Percentage of Total Dose at $t=500$ years

Directly from primary contamination and from release to atmosphere (Inhalation excludes radon)

\begin{tabular}{|c|c|c|c|c|c|c|c|c|c|c|c|c|c|c|c|c|}
\hline & \multicolumn{2}{|c|}{ Ground } & \multicolumn{2}{|c|}{ Inhalation } & \multicolumn{2}{|c|}{ Radon } & \multicolumn{2}{|c|}{ Plant } & \multicolumn{2}{|l|}{ Meat } & \multicolumn{2}{|l|}{ Milk } & \multicolumn{2}{|l|}{ Soil } & \multicolumn{2}{|c|}{ All Pathways* } \\
\hline clide & Dose & $\%$ & Dose & $\%$ & Dose & $\%$ & Dose & \% & Dose & $\%$ & Dose & \% & Dose & \% & Dose & $\%$ \\
\hline-241 & $7.52 \mathrm{E}-23$ & 0 & $0.00 \mathrm{E}+00$ & 0 & $0.00 \mathrm{E}+00$ & 0 & $0.00 \mathrm{E}+00$ & 0 & $0.00 \mathrm{E}+00$ & 0 & $0.00 \mathrm{E}+00$ & 0 & $0.00 \mathrm{E}+00$ & 0 & $7.52 \mathrm{E}-23$ & 0 \\
\hline-137 & $2.88 \mathrm{E}-21$ & 0 & $0.00 \mathrm{E}+00$ & 0 & $0.00 \mathrm{E}+00$ & 0 & $0.00 \mathrm{E}+00$ & 0 & $0.00 \mathrm{E}+00$ & 0 & $0.00 \mathrm{E}+00$ & 0 & $0.00 \mathrm{E}+00$ & 0 & $2.88 \mathrm{E}-21$ & 0 \\
\hline-237 & $6.79 \mathrm{E}-19$ & 0 & $0.00 \mathrm{E}+00$ & 0 & $0.00 \mathrm{E}+00$ & 0 & $0.00 \mathrm{E}+00$ & 0 & $0.00 \mathrm{E}+00$ & 0 & $0.00 \mathrm{E}+00$ & 0 & $0.00 \mathrm{E}+00$ & 0 & $6.79 \mathrm{E}-19$ & 0 \\
\hline-238 & $2.11 \mathrm{E}-21$ & 0 & $0.00 \mathrm{E}+00$ & 0 & $0.00 \mathrm{E}+00$ & 0 & $0.00 \mathrm{E}+00$ & 0 & $0.00 \mathrm{E}+00$ & 0 & $0.00 \mathrm{E}+00$ & 0 & $0.00 \mathrm{E}+00$ & 0 & $2.11 \mathrm{E}-21$ & 0 \\
\hline-239 & 1. $45 \mathrm{E}-23$ & 0 & $0.00 \mathrm{E}+00$ & 0 & $0.00 \mathrm{E}+00$ & 0 & $0.00 \mathrm{E}+00$ & 0 & $0.00 \mathrm{E}+00$ & 0 & $0.00 \mathrm{E}+00$ & 0 & $0.00 \mathrm{E}+00$ & 0 & 1. $45 \mathrm{E}-23$ & 0 \\
\hline-240 & $2.23 E-26$ & 0 & $0.00 \mathrm{E}+00$ & 0 & $0.00 \mathrm{E}+00$ & 0 & $0.00 \mathrm{E}+00$ & 0 & $0.00 \mathrm{E}+00$ & 0 & $0.00 \mathrm{E}+00$ & 0 & $0.00 \mathrm{E}+00$ & 0 & $2.23 E-26$ & 0 \\
\hline-99 & 1. $40 \mathrm{E}-31$ & 0 & $0.00 \mathrm{E}+00$ & 0 & $0.00 \mathrm{E}+00$ & 0 & $0.00 \mathrm{E}+00$ & 0 & $0.00 \mathrm{E}+00$ & 0 & $0.00 \mathrm{E}+00$ & 0 & $0.00 \mathrm{E}+00$ & 0 & 1. $91 \mathrm{E}-02$ & 100 \\
\hline-228 & $0.00 \mathrm{E}+00$ & 0 & $0.00 \mathrm{E}+00$ & 0 & $0.00 \mathrm{E}+00$ & 0 & $0.00 \mathrm{E}+00$ & 0 & $0.00 \mathrm{E}+00$ & 0 & $0.00 \mathrm{E}+00$ & 0 & $0.00 \mathrm{E}+00$ & 0 & $0.00 \mathrm{E}+00$ & 0 \\
\hline-230 & $4.02 \mathrm{E}-15$ & 0 & $0.00 \mathrm{E}+00$ & 0 & $0.00 \mathrm{E}+00$ & 0 & $0.00 \mathrm{E}+00$ & 0 & $0.00 \mathrm{E}+00$ & 0 & $0.00 \mathrm{E}+00$ & 0 & $0.00 \mathrm{E}+00$ & 0 & $4.02 \mathrm{E}-15$ & 0 \\
\hline-232 & $1.30 \mathrm{E}-13$ & 0 & $0.00 \mathrm{E}+00$ & 0 & $0.00 E+00$ & 0 & $0.00 \mathrm{E}+00$ & 0 & $0.00 \mathrm{E}+00$ & 0 & $0.00 E+00$ & 0 & $0.00 \mathrm{E}+00$ & 0 & 1. $30 \mathrm{E}-13$ & 0 \\
\hline 234 & $9.38 \mathrm{E}-18$ & 0 & $0.00 \mathrm{E}+00$ & 0 & $0.00 \mathrm{E}+00$ & 0 & $0.00 \mathrm{E}+00$ & 0 & $0.00 \mathrm{E}+00$ & 0 & $0.00 \mathrm{E}+00$ & 0 & $0.00 \mathrm{E}+00$ & 0 & $9.38 \mathrm{E}-18$ & 0 \\
\hline 235 & $2.43 E-19$ & 0 & $0.00 \mathrm{E}+00$ & 0 & $0.00 \mathrm{E}+00$ & 0 & $0.00 \mathrm{E}+00$ & 0 & $0.00 \mathrm{E}+00$ & 0 & $0.00 \mathrm{E}+00$ & 0 & $0.00 \mathrm{E}+00$ & 0 & $2.43 E-19$ & 0 \\
\hline 38 & $2.77 \mathrm{E}-17$ & 0 & $0.00 \mathrm{E}+00$ & 0 & $0.00 \mathrm{E}+00$ & 0 & $0.00 \mathrm{E}+00$ & 0 & $0.00 \mathrm{E}+00$ & 0 & $0.00 \mathrm{E}+00$ & 0 & $0.00 \mathrm{E}+00$ & 0 & $2.77 \mathrm{E}-17$ & 0 \\
\hline & 1. $34 \mathrm{E}-13$ & 0 & $0.00 \mathrm{E}+00$ & 0 & $0.00 \mathrm{E}+00$ & 0 & $0.00 \mathrm{E}+00$ & 0 & $0.00 \mathrm{E}+00$ & 0 & $0.00 \mathrm{E}+00$ & 0 & $0.00 \mathrm{E}+00$ & 0 & 1. $91 \mathrm{E}-02$ & 100 \\
\hline
\end{tabular}


RESRAD-OFFSITE, Version 2 .

Parent Dose Report

Title : RESRAD-OFFSITE Parameters for Offsite Resident Farmer

File : OFFSITE-RF_SRSG-7-11.ROF

Total Dose Contributions TDOSE (i,p,t) for Individual Radionuclides (i) and Pathways (p) in mrem/yr and as a Percentage of Total Dose at $t=1026$ years

From releases to ground water and to surface water

\begin{tabular}{|c|c|c|c|c|c|c|c|c|c|c|c|c|c|c|c|c|}
\hline & \multicolumn{2}{|c|}{ Ground } & \multicolumn{2}{|l|}{ Fish } & \multicolumn{2}{|c|}{ Radon } & \multicolumn{2}{|c|}{ Plant } & \multicolumn{2}{|l|}{ Meat } & \multicolumn{2}{|l|}{$\operatorname{Milk}$} & \multicolumn{2}{|l|}{ Soil } & \multicolumn{2}{|c|}{ Water } \\
\hline clide & Dose & $\%$ & Dose & $\%$ & Dose & 응 & Dose & 웅 & Dose & $\%$ & Dose & 음 & Dose & $\frac{\circ}{0}$ & Dose & 응 \\
\hline $1-241$ & $0.00 \mathrm{E}+00$ & 0 & $0.00 \mathrm{E}+00$ & 0 & $0.00 \mathrm{E}+00$ & 0 & $0.00 \mathrm{E}+00$ & 0 & $0.00 \mathrm{E}+00$ & 0 & $0.00 \mathrm{E}+00$ & 0 & $0.00 \mathrm{E}+00$ & 0 & $0.00 \mathrm{E}+00$ & 0 \\
\hline-137 & $0.00 \mathrm{E}+00$ & 0 & $0.00 \mathrm{E}+00$ & 0 & $0.00 \mathrm{E}+00$ & 0 & $0.00 \mathrm{E}+00$ & 0 & $0.00 \mathrm{E}+00$ & 0 & $0.00 E+00$ & 0 & $0.00 \mathrm{E}+00$ & 0 & $0.00 \mathrm{E}+00$ & 0 \\
\hline-237 & $0.00 \mathrm{E}+00$ & 0 & $0.00 \mathrm{E}+00$ & 0 & $0.00 \mathrm{E}+00$ & 0 & $0.00 \mathrm{E}+00$ & 0 & $0.00 \mathrm{E}+00$ & 0 & $0.00 \mathrm{E}+00$ & 0 & $0.00 \mathrm{E}+00$ & 0 & $0.00 \mathrm{E}+00$ & 0 \\
\hline-238 & $0.00 \mathrm{E}+00$ & 0 & $0.00 \mathrm{E}+00$ & 0 & $0.00 \mathrm{E}+00$ & 0 & $0.00 \mathrm{E}+00$ & 0 & $0.00 \mathrm{E}+00$ & 0 & $0.00 \mathrm{E}+00$ & 0 & $0.00 \mathrm{E}+00$ & 0 & $0.00 \mathrm{E}+00$ & 0 \\
\hline-239 & $0.00 \mathrm{E}+00$ & 0 & $0.00 \mathrm{E}+00$ & 0 & $0.00 \mathrm{E}+00$ & 0 & $0.00 \mathrm{E}+00$ & 0 & $0.00 \mathrm{E}+00$ & 0 & $0.00 E+00$ & 0 & $0.00 \mathrm{E}+00$ & 0 & $0.00 \mathrm{E}+00$ & 0 \\
\hline-240 & $0.00 \mathrm{E}+00$ & 0 & $0.00 \mathrm{E}+00$ & 0 & $0.00 \mathrm{E}+00$ & 0 & $0.00 \mathrm{E}+00$ & 0 & $0.00 \mathrm{E}+00$ & 0 & $0.00 \mathrm{E}+00$ & 0 & $0.00 \mathrm{E}+00$ & 0 & $0.00 \mathrm{E}+00$ & 0 \\
\hline-99 & $2.53 E-08$ & 0 & $0.00 \mathrm{E}+00$ & 0 & $0.00 \mathrm{E}+00$ & 0 & $6.92 E-03$ & 25 & $2.07 E-05$ & 0 & $1.83 E-03$ & 7 & $2.13 E-08$ & 0 & $1.88 \mathrm{E}-02$ & 68 \\
\hline-228 & $0.00 \mathrm{E}+00$ & 0 & $0.00 \mathrm{E}+00$ & 0 & $0.00 \mathrm{E}+00$ & 0 & $0.00 \mathrm{E}+00$ & 0 & $0.00 \mathrm{E}+00$ & 0 & $0.00 \mathrm{E}+00$ & 0 & $0.00 \mathrm{E}+00$ & 0 & $0.00 \mathrm{E}+00$ & 0 \\
\hline-230 & $0.00 \mathrm{E}+00$ & 0 & $0.00 \mathrm{E}+00$ & 0 & $0.00 \mathrm{E}+00$ & 0 & $0.00 \mathrm{E}+00$ & 0 & $0.00 \mathrm{E}+00$ & 0 & $0.00 \mathrm{E}+00$ & 0 & $0.00 \mathrm{E}+00$ & 0 & $0.00 \mathrm{E}+00$ & 0 \\
\hline-232 & $0.00 \mathrm{E}+00$ & 0 & $0.00 \mathrm{E}+00$ & 0 & $0.00 \mathrm{E}+00$ & 0 & $0.00 \mathrm{E}+00$ & 0 & $0.00 \mathrm{E}+00$ & 0 & $0.00 \mathrm{E}+00$ & 0 & $0.00 \mathrm{E}+00$ & 0 & $0.00 \mathrm{E}+00$ & 0 \\
\hline 234 & $0.00 \mathrm{E}+00$ & 0 & $0.00 \mathrm{E}+00$ & 0 & $0.00 \mathrm{E}+00$ & 0 & $0.00 \mathrm{E}+00$ & 0 & $0.00 \mathrm{E}+00$ & 0 & $0.00 \mathrm{E}+00$ & 0 & $0.00 \mathrm{E}+00$ & 0 & $0.00 \mathrm{E}+00$ & 0 \\
\hline 235 & $0.00 \mathrm{E}+00$ & 0 & $0.00 \mathrm{E}+00$ & 0 & $0.00 \mathrm{E}+00$ & 0 & $0.00 \mathrm{E}+00$ & 0 & $0.00 \mathrm{E}+00$ & 0 & $0.00 \mathrm{E}+00$ & 0 & $0.00 \mathrm{E}+00$ & 0 & $0.00 \mathrm{E}+00$ & 0 \\
\hline 238 & $0.00 \mathrm{E}+00$ & 0 & $0.00 E+00$ & 0 & $0.00 \mathrm{E}+00$ & 0 & $0.00 \mathrm{E}+00$ & 0 & $0.00 \mathrm{E}+00$ & 0 & $0.00 \mathrm{E}+00$ & 0 & $0.00 \mathrm{E}+00$ & 0 & $0.00 \mathrm{E}+00$ & 0 \\
\hline & $2.53 E-08$ & 0 & $0.00 \mathrm{E}+00$ & 0 & $0.00 \mathrm{E}+00$ & 0 & $6.92 \mathrm{E}-03$ & 25 & $2.07 \mathrm{E}-05$ & 0 & $1.83 E-03$ & 7 & $2.13 E-08$ & 0 & 1. $88 \mathrm{E}-02$ & 68 \\
\hline
\end{tabular}

Total Dose Contributions TDOSE(i,p,t) for Individual Radionuclides (i) and Pathways (p) in mrem/yr and as a Percentage of Total Dose at $t=1026$ years

Directly from primary contamination and from release to atmosphere (Inhalation excludes radon)

\begin{tabular}{|c|c|c|c|c|c|c|c|c|c|c|c|c|c|c|c|c|}
\hline & \multicolumn{2}{|c|}{ Ground } & \multicolumn{2}{|c|}{ Inhalation } & \multicolumn{2}{|c|}{ Radon } & \multicolumn{2}{|c|}{ Plant } & \multicolumn{2}{|l|}{ Meat } & \multicolumn{2}{|l|}{ Milk } & \multicolumn{2}{|l|}{ Soil } & \multicolumn{2}{|c|}{ All Pathways* } \\
\hline clide & Dose & $\%$ & Dose & $\%$ & Dose & $\%$ & Dose & 음 & Dose & $\%$ & Dose & 음 & Dose & $\%$ & Dose & $\%$ \\
\hline-241 & $1.99 \mathrm{E}-20$ & 0 & $0.00 E+00$ & 0 & $0.00 E+00$ & 0 & $0.00 \mathrm{E}+00$ & 0 & $0.00 \mathrm{E}+00$ & 0 & $0.00 \mathrm{E}+00$ & 0 & $0.00 \mathrm{E}+00$ & 0 & $1.99 \mathrm{E}-20$ & 0 \\
\hline-137 & $8.95 E-25$ & 0 & $0.00 E+00$ & 0 & $0.00 E+00$ & 0 & $0.00 \mathrm{E}+00$ & 0 & $0.00 \mathrm{E}+00$ & 0 & $0.00 E+00$ & 0 & $0.00 \mathrm{E}+00$ & 0 & $8.95 E-25$ & 0 \\
\hline-237 & $1.20 \mathrm{E}-16$ & 0 & $0.00 E+00$ & 0 & $0.00 E+00$ & 0 & $0.00 \mathrm{E}+00$ & 0 & $0.00 \mathrm{E}+00$ & 0 & $0.00 E+00$ & 0 & $0.00 \mathrm{E}+00$ & 0 & 1. $20 \mathrm{E}-16$ & 0 \\
\hline-238 & $2.97 E-19$ & 0 & $0.00 E+00$ & 0 & $0.00 \mathrm{E}+00$ & 0 & $0.00 \mathrm{E}+00$ & 0 & $0.00 \mathrm{E}+00$ & 0 & $0.00 \mathrm{E}+00$ & 0 & $0.00 \mathrm{E}+00$ & 0 & $2.97 E-19$ & 0 \\
\hline-239 & 4. $71 E-21$ & 0 & $0.00 \mathrm{E}+00$ & 0 & $0.00 \mathrm{E}+00$ & 0 & $0.00 \mathrm{E}+00$ & 0 & $0.00 \mathrm{E}+00$ & 0 & $0.00 \mathrm{E}+00$ & 0 & $0.00 \mathrm{E}+00$ & 0 & 4. $71 \mathrm{E}-21$ & 0 \\
\hline-240 & $1.83 E-24$ & 0 & $0.00 E+00$ & 0 & $0.00 \mathrm{E}+00$ & 0 & $0.00 \mathrm{E}+00$ & 0 & $0.00 \mathrm{E}+00$ & 0 & $0.00 E+00$ & 0 & $0.00 \mathrm{E}+00$ & 0 & $1.83 E-24$ & 0 \\
\hline-99 & $9.53 E-29$ & 0 & $0.00 E+00$ & 0 & $0.00 \mathrm{E}+00$ & 0 & $0.00 \mathrm{E}+00$ & 0 & $0.00 \mathrm{E}+00$ & 0 & $0.00 E+00$ & 0 & $0.00 \mathrm{E}+00$ & 0 & $2.76 \mathrm{E}-02$ & 100 \\
\hline-228 & $0.00 \mathrm{E}+00$ & 0 & $0.00 \mathrm{E}+00$ & 0 & $0.00 \mathrm{E}+00$ & 0 & $0.00 \mathrm{E}+00$ & 0 & $0.00 \mathrm{E}+00$ & 0 & $0.00 \mathrm{E}+00$ & 0 & $0.00 \mathrm{E}+00$ & 0 & $0.00 \mathrm{E}+00$ & 0 \\
\hline-230 & $2.11 E-13$ & 0 & $0.00 E+00$ & 0 & $0.00 \mathrm{E}+00$ & 0 & $0.00 \mathrm{E}+00$ & 0 & $0.00 \mathrm{E}+00$ & 0 & $0.00 E+00$ & 0 & $0.00 \mathrm{E}+00$ & 0 & $2.11 \mathrm{E}-13$ & 0 \\
\hline-232 & $2.41 E-12$ & 0 & $0.00 E+00$ & 0 & $0.00 \mathrm{E}+00$ & 0 & $0.00 \mathrm{E}+00$ & 0 & $0.00 \mathrm{E}+00$ & 0 & $0.00 \mathrm{E}+00$ & 0 & $0.00 \mathrm{E}+00$ & 0 & $2.41 \mathrm{E}-12$ & 0 \\
\hline 34 & $1.04 \mathrm{E}-15$ & 0 & $0.00 \mathrm{E}+00$ & 0 & $0.00 \mathrm{E}+00$ & 0 & $0.00 \mathrm{E}+00$ & 0 & $0.00 \mathrm{E}+00$ & 0 & $0.00 \mathrm{E}+00$ & 0 & $0.00 \mathrm{E}+00$ & 0 & $1.04 \mathrm{E}-15$ & 0 \\
\hline 35 & $4.16 \mathrm{E}-17$ & 0 & $0.00 \mathrm{E}+00$ & 0 & $0.00 \mathrm{E}+00$ & 0 & $0.00 \mathrm{E}+00$ & 0 & $0.00 \mathrm{E}+00$ & 0 & $0.00 \mathrm{E}+00$ & 0 & $0.00 \mathrm{E}+00$ & 0 & $4.16 \mathrm{E}-17$ & 0 \\
\hline 38 & $1.33 E-15$ & 0 & $0.00 E+00$ & 0 & $0.00 \mathrm{E}+00$ & 0 & $0.00 \mathrm{E}+00$ & 0 & $0.00 \mathrm{E}+00$ & 0 & $0.00 E+00$ & 0 & $0.00 \mathrm{E}+00$ & 0 & 1. $33 E-15$ & 0 \\
\hline & $2.62 \mathrm{E}-12$ & 0 & $0.00 \mathrm{E}+00$ & 0 & $0.00 \mathrm{E}+00$ & 0 & $0.00 \mathrm{E}+00$ & 0 & $0.00 \mathrm{E}+00$ & 0 & $0.00 \mathrm{E}+00$ & 0 & $0.00 \mathrm{E}+00$ & 0 & $2.76 \mathrm{E}-02$ & 100 \\
\hline
\end{tabular}


RESRAD-OFFSITE, Version 2.

Parent Dose Report

Title : RESRAD-OFFSITE Parameters for Offsite Resident Farmer

File : OFFSITE-RF SRSG-7-11.ROF

Dose/Source Ratios Summed Over All Pathways

Parent and Progeny Principal Radionuclide Contributions Indicated

Parent Product Thread DSR $(j, t) \quad(m r e m / y r) /(p C i / g)$

(i)

(j)

$\begin{array}{ll}\mathrm{Am}-241 & 1.000 \mathrm{E}+00 \\ \mathrm{~Np}-237+\mathrm{D} & 1.000 \mathrm{E}+00 \\ \mathrm{U}-233 & 1.000 \mathrm{E}+00 \\ \mathrm{Th}-229+\mathrm{D} & 1.000 \mathrm{E}+00 \\ \operatorname{\sum DSR}(j) & \end{array}$

Cs $-137+$

(1)

$\mathrm{Np}-237+\mathrm{D}$

$\mathrm{U}-233$

1. $000 \mathrm{E}+00$

Th-229+D

$\sum \operatorname{DSR}(j)$

Pu-238

Pu-238

U-234

1. $000 \mathrm{E}+00$

Th-230

1. $000 \mathrm{E}+00$

Ra-226+D

1. $000 \mathrm{E}+00$

$\mathrm{Pb}-210+\mathrm{D}$

1. $000 \mathrm{E}+00$

$\sum \operatorname{DSR}(j)$

1. $000 \mathrm{E}+00$

$\mathrm{Pu}-239$

1. $000 \mathrm{E}+00$

$\mathrm{U}-235+\mathrm{D}$

1. $000 \mathrm{E}+00$

$\mathrm{Pa}-231$

1. $000 \mathrm{E}+00$

Ac-227+D

1. $000 \mathrm{E}+00$

$\sum \operatorname{DSR}(j)$

$\mathrm{Pu}-240$

4. $950 E-08$

$0.000 \mathrm{E}+00 \quad 1.000 \mathrm{E}+00 \quad 5.000 \mathrm{E}+01 \quad 1.000 \mathrm{E}+02 \quad 5.000 \mathrm{E}+02 \quad 1.026 \mathrm{E}+03$

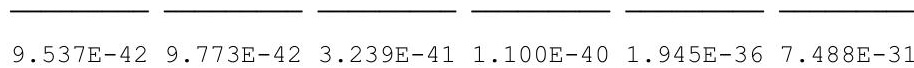

$\begin{array}{lllllll}7.621 \mathrm{E}-28 & 2.305 \mathrm{E}-27 & 1.212 \mathrm{E}-25 & 3.805 \mathrm{E}-25 & 7.396 \mathrm{E}-23 & 1.966 \mathrm{E}-20\end{array}$

$\begin{array}{llllll}1.731 E-38 & 1.222 E-37 & 2.283 E-34 & 1.567 E-33 & 3.197 E-30 & 4.568 E-27\end{array}$

$\begin{array}{llllll}1.187 \mathrm{E}-34 & 1.786 \mathrm{E}-33 & 8.205 \mathrm{E}-29 & 8.729 \mathrm{E}-28 & 1.204 \mathrm{E}-24 & 2.598 \mathrm{E}-22\end{array}$

$\begin{array}{llllll}7.621 \mathrm{E}-28 & 2.305 \mathrm{E}-27 & 1.213 \mathrm{E}-25 & 3.813 \mathrm{E}-25 & 7.516 \mathrm{E}-23 & 1.992 \mathrm{E}-20\end{array}$

$\begin{array}{llllll}.220 E-18 & 6.125 E-18 & 2.886 E-18 & 1.340 E-18 & 2.881 E-21 & 8.954 E-25\end{array}$

$\begin{array}{llllll}.700 \mathrm{E}-21 & 4.747 \mathrm{E}-21 & 7.698 \mathrm{E}-21 & 1.261 \mathrm{E}-20 & 6.527 \mathrm{E}-19 & 1.171 \mathrm{E}-16\end{array}$

$\begin{array}{llllll}.599 \mathrm{E}-31 & 4.847 \mathrm{E}-31 & 2.866 \mathrm{E}-29 & 1.014 \mathrm{E}-28 & 5.033 \mathrm{E}-26 & 4.386 \mathrm{E}-23\end{array}$

$\begin{array}{llllll}1.463 \mathrm{E}-27 & 1.028 \mathrm{E}-26 & 1.534 \mathrm{E}-23 & 8.359 \mathrm{E}-23 & 2.673 \mathrm{E}-20 & 3.336 \mathrm{E}-18\end{array}$

$\begin{array}{lllllll}4.700 \mathrm{E}-21 & 4.747 \mathrm{E}-21 & 7.713 \mathrm{E}-21 & 1.269 \mathrm{E}-20 & 6.794 \mathrm{E}-19 & 1.205 \mathrm{E}-16\end{array}$

$\mathrm{Pu}-240$

$\begin{array}{llllll}1.000 \mathrm{E}+00 \quad 5.628 \mathrm{E}-33 & 5.719 \mathrm{E}-33 & 1.262 \mathrm{E}-32 & 2.831 \mathrm{E}-32 & 1.811 \mathrm{E}-29 & 8.872 \mathrm{E}-26\end{array}$

$\mathrm{U}-236$

$1.000 \mathrm{E}+00$

$\begin{array}{lllllll}1.065 E-40 & 3.243 E-40 & 2.449 E-38 & 1.113 E-37 & 4.093 E-34 & 4.966 E-30\end{array}$

Th-232

$1.000 \mathrm{E}+00$

$\begin{array}{lllllll}0.000 \mathrm{E}+00 & 0.000 \mathrm{E}+00 & 0.000 \mathrm{E}+00 & 0.000 \mathrm{E}+00 & 5.308 \mathrm{E}-42 & 1.757 \mathrm{E}-37\end{array}$

$\mathrm{Ra}-228+\mathrm{D}$

$1.000 \mathrm{E}+00$

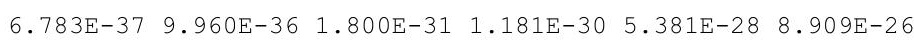

Th $-228+\mathrm{D}$

1. $000 \mathrm{E}+00$

$\sum \operatorname{DSR}(j)$

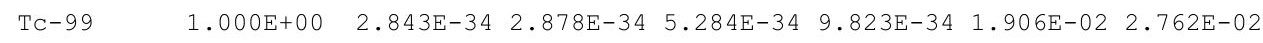

Th-228+D 1.000E+00 6.816E-15 $4.771 \mathrm{E}-15 \quad 1.217 \mathrm{E}-22 \quad 2.172 \mathrm{E}-30 \quad 0.000 \mathrm{E}+00 \quad 0.000 \mathrm{E}+00$ 
RESRAD-OFFSITE, Version 2.

Parent Dose Report

Title : RESRAD-OFFSITE Parameters for Offsite Resident Farmer

File : OFFSITE-RF_SRSG-7-11.ROF

Dose/Source Ratios Summed Over All Pathways

Parent and Progeny Principal Radionuclide Contributions Indicated

\begin{tabular}{|c|c|c|c|c|c|c|c|c|}
\hline Parent & Product & Thread & & $\operatorname{DSR}(j$, & t) $\quad($ mrem $/ y$ & r) / ( $\mathrm{pCi} / \mathrm{g})$ & & \\
\hline (i) & $(j)$ & Fraction & $0.000 \mathrm{E}+00$ & $1.000 \mathrm{E}+00$ & $5.000 \mathrm{E}+01$ & $1.000 \mathrm{E}+02$ & $5.000 \mathrm{E}+02$ & $1.026 \mathrm{E}+03$ \\
\hline-230 & $T h-230$ & $1.000 \mathrm{E}+00$ & $1.189 \mathrm{E}-30$ & $1.207 E-30$ & $2.577 E-30$ & $5.589 \mathrm{E}-30$ & $2.731 \mathrm{E}-27$ & $9.387 \mathrm{E}-24$ \\
\hline-230 & $\mathrm{Ra}-226+\mathrm{D}$ & $1.000 \mathrm{E}+00$ & $1.860 \mathrm{E}-19$ & $5.610 \mathrm{E}-19$ & $2.552 \mathrm{E}-17$ & $6.905 \mathrm{E}-17$ & $4.024 \mathrm{E}-15$ & $2.105 E-13$ \\
\hline-230 & $\mathrm{~Pb}-210+\mathrm{D}$ & $1.000 \mathrm{E}+00$ & $8.984 \mathrm{E}-28$ & $6.263 E-27$ & $6.208 E-24$ & $2.463 E-23$ & $2.775 E-21$ & $2.524 \mathrm{E}-19$ \\
\hline-230 & $\sum \operatorname{DSR}(j)$ & & $1.860 \mathrm{E}-19$ & $5.610 \mathrm{E}-19$ & $2.552 \mathrm{E}-17$ & $6.905 \mathrm{E}-17$ & $4.024 \mathrm{E}-15$ & $2.105 E-13$ \\
\hline-232 & Th-232 & $1.000 \mathrm{E}+00$ & $5.745 E-33$ & $5.844 \mathrm{E}-33$ & $1.351 \mathrm{E}-32$ & $3.175 \mathrm{E}-32$ & $2.963 E-29$ & $2.383 E-25$ \\
\hline-232 & $\mathrm{Ra}-228+\mathrm{D}$ & $1.000 \mathrm{E}+00$ & $5.458 \mathrm{E}-18$ & $1.564 \mathrm{E}-17$ & $1.332 \mathrm{E}-16$ & $1.894 \mathrm{E}-16$ & $3.104 \mathrm{E}-15$ & $1.228 \mathrm{E}-13$ \\
\hline-232 & $T h-228+D$ & $1.000 \mathrm{E}+00$ & $5.270 \mathrm{E}-17$ & $3.244 \mathrm{E}-16$ & $1.066 \mathrm{E}-14$ & $1.407 \mathrm{E}-14$ & $1.267 \mathrm{E}-13$ & $2.287 \mathrm{E}-12$ \\
\hline-232 & $\sum \operatorname{DSR}(j)$ & & $5.816 \mathrm{E}-17$ & $3.401 \mathrm{E}-16$ & $1.079 \mathrm{E}-14$ & $1.426 \mathrm{E}-14$ & $1.298 \mathrm{E}-13$ & $2.410 \mathrm{E}-12$ \\
\hline 234 & $\mathrm{U}-234$ & $1.000 \mathrm{E}+00$ & $3.398 E-32$ & $3.454 \mathrm{E}-32$ & $7.678 E-32$ & $1.735 \mathrm{E}-31$ & $1.179 \mathrm{E}-28$ & $6.245 E-25$ \\
\hline-234 & $T h-230$ & $1.000 \mathrm{E}+00$ & $5.364 \mathrm{E}-36$ & $1.631 \mathrm{E}-35$ & $1.172 \mathrm{E}-33$ & $5.055 \mathrm{E}-33$ & $1.229 \mathrm{E}-29$ & $8.650 \mathrm{E}-26$ \\
\hline 234 & $\mathrm{Ra}-226+\mathrm{D}$ & $1.000 \mathrm{E}+00$ & $5.596 \mathrm{E}-25$ & $3.933 E-24$ & $5.821 \mathrm{E}-21$ & $3.145 \mathrm{E}-20$ & $9.384 \mathrm{E}-18$ & $1.042 \mathrm{E}-15$ \\
\hline-234 & $\mathrm{~Pb}-210+\mathrm{D}$ & $1.000 \mathrm{E}+00$ & $2.030 \mathrm{E}-33$ & $3.037 \mathrm{E}-32$ & $1.052 \mathrm{E}-27$ & $8.967 \mathrm{E}-27$ & $6.069 \mathrm{E}-24$ & $1.209 \mathrm{E}-21$ \\
\hline 234 & $\sum \operatorname{DSR}(j)$ & & $5.596 \mathrm{E}-25$ & $3.933 E-24$ & $5.821 \mathrm{E}-21$ & $3.145 \mathrm{E}-20$ & $9.384 \mathrm{E}-18$ & $1.042 \mathrm{E}-15$ \\
\hline$-235+D$ & $\mathrm{U}-235+\mathrm{D}$ & $1.000 \mathrm{E}+00$ & $6.128 E-23$ & $6.198 \mathrm{E}-23$ & $1.083 E-22$ & 1. $913 \mathrm{E}-22$ & $1.816 \mathrm{E}-20$ & $7.232 \mathrm{E}-18$ \\
\hline$-235+D$ & $\mathrm{~Pa}-231$ & $1.000 \mathrm{E}+00$ & $1.448 \mathrm{E}-26$ & $4.381 \mathrm{E}-26$ & $2.379 E-24$ & $7.714 \mathrm{E}-24$ & $1.910 \mathrm{E}-21$ & $6.667 \mathrm{E}-19$ \\
\hline$-235+D$ & $A c-227+D$ & $1.000 \mathrm{E}+00$ & $4.580 \mathrm{E}-26$ & $3.195 \mathrm{E}-25$ & $3.279 \mathrm{E}-22$ & 1. $355 \mathrm{E}-21$ & $2.231 \mathrm{E}-19$ & $3.366 \mathrm{E}-17$ \\
\hline 235 & $\sum \operatorname{DSR}(j)$ & & $6.134 \mathrm{E}-23$ & $6.234 \mathrm{E}-23$ & $4.385 E-22$ & $1.554 \mathrm{E}-21$ & $2.432 \mathrm{E}-19$ & $4.156 \mathrm{E}-17$ \\
\hline-238 & $\mathrm{U}-238$ & $5.400 \mathrm{E}-05$ & $0.000 \mathrm{E}+00$ & $0.000 \mathrm{E}+00$ & $0.000 \mathrm{E}+00$ & $0.000 \mathrm{E}+00$ & $0.000 \mathrm{E}+00$ & $0.000 \mathrm{E}+00$ \\
\hline$-238+D$ & $\mathrm{U}-238+\mathrm{D}$ & $9.999 \mathrm{E}-01$ & $6.998 \mathrm{E}-19$ & $7.050 \mathrm{E}-19$ & $1.011 \mathrm{E}-18$ & 1. $460 \mathrm{E}-18$ & $2.771 \mathrm{E}-17$ & 1. $329 \mathrm{E}-15$ \\
\hline$-238+D$ & $\mathrm{U}-234$ & $9.999 \mathrm{E}-01$ & $4.830 \mathrm{E}-38$ & $1.470 \mathrm{E}-37$ & $1.099 \mathrm{E}-35$ & $4.943 E-35$ & $1.673 E-31$ & $1.820 \mathrm{E}-27$ \\
\hline$-238+D$ & Th-230 & $9.999 \mathrm{E}-01$ & $5.085 E-42$ & 3. $603 E-41$ & $8.386 \mathrm{E}-38$ & $7.201 \mathrm{E}-37$ & $8.719 \mathrm{E}-33$ & $1.259 \mathrm{E}-28$ \\
\hline$-238+D$ & $\mathrm{Ra}-226+\mathrm{D}$ & $9.999 \mathrm{E}-01$ & $3.792 \mathrm{E}-31$ & $5.970 \mathrm{E}-30$ & $2.783 \mathrm{E}-25$ & $2.998 \mathrm{E}-24$ & $4.516 \mathrm{E}-21$ & $1.047 \mathrm{E}-18$ \\
\hline $38+D$ & $\mathrm{~Pb}-210+\mathrm{D}$ & $9.999 \mathrm{E}-01$ & $1.122 \mathrm{E}-38$ & $4.009 \mathrm{E}-38$ & $4.030 \mathrm{E}-32$ & $7.166 \mathrm{E}-31$ & $2.754 \mathrm{E}-27$ & $1.178 \mathrm{E}-24$ \\
\hline-238 & $\sum \operatorname{DSR}(j)$ & & $6.998 \mathrm{E}-19$ & $7.050 \mathrm{E}-19$ & $1.011 \mathrm{E}-18$ & $1.460 \mathrm{E}-18$ & $2.772 \mathrm{E}-17$ & $1.331 \mathrm{E}-15$ \\
\hline
\end{tabular}

The DSR includes contributions from associated (half-life $\leq 180$ days) daughters. 
RESRAD-OFFSITE, Version 2.

Parent Dose Report

Title : RESRAD-OFFSITE Parameters for offsite Resident Farmer

File : OFFSITE-RF SRSG-7-11.ROF

Individual Nuclide Dose Summed Over All Pathways

Parent Nuclide and Thread Fraction Indicated

Nuclide Parent THF(i) DOSE $(j, t)$, mrem/yr

\begin{tabular}{|c|c|c|}
\hline (j) & (i) & \\
\hline$A m-241$ & $A m-241$ & $1.000 \mathrm{E}+00$ \\
\hline-237 & $\mathrm{Am}-241$ & $1.000 \mathrm{E}+00$ \\
\hline $\mathrm{Np}-237$ & $\mathrm{~Np}-237$ & $1.000 \mathrm{E}+00$ \\
\hline-237 & $\sum$ DOSE ( & ): \\
\hline
\end{tabular}

$\mathrm{U}-233 \quad \mathrm{Am}-241 \quad 1.000 \mathrm{E}+00$

$\mathrm{U}-233 \quad \mathrm{~Np}-237 \quad 1.000 \mathrm{E}+00$

U-233 $\operatorname{DOSE}(j):$

Th-229 Am-241 1.000E+00

Th-229 Np-237 $1.000 \mathrm{E}+00$

Th-229 $\operatorname{DDOSE}(j)$ :

Cs-137 Cs-137 1.000E+00

$\mathrm{Pu}-238$

$\mathrm{Pu}-238$

$\mathrm{Pu}-238$

$\mathrm{U}-234$

$\mathrm{U}-234$

$\mathrm{U}-234$

$\mathrm{U}-234$

Th -230

Th -230

Th-230

Th-230

Th-230

$\mathrm{Ra}-226$

$\mathrm{Ra}-226$

$\mathrm{Ra}-226$

$\mathrm{Ra}-226$

$\mathrm{Ra}-226$

$\mathrm{Pb}-210 \mathrm{Pu}-238 \quad 1.000 \mathrm{E}+00$

$\mathrm{Pb}-210 \mathrm{Th}-230 \quad 1.000 \mathrm{E}+00$

$\mathrm{Pb}-210 \quad \mathrm{U}-234 \quad 1.000 \mathrm{E}+00$

$\mathrm{Pb}-210 \mathrm{U}-238 \quad 9.999 \mathrm{E}-01$

$\mathrm{Pb}-210 \quad \sum \operatorname{DOSE}(j):$

Pu-239 Pu-239 1.000E+00 $\mathrm{t}=0.000 \mathrm{E}+00 \quad 1.000 \mathrm{E}+00 \quad 5.000 \mathrm{E}+01 \quad 1.000 \mathrm{E}+02 \quad 5.000 \mathrm{E}+02 \quad 1.026 \mathrm{E}+03$

$9.537 \mathrm{E}-42 \quad 9.773 \mathrm{E}-42 \quad 3.239 \mathrm{E}-41 \quad 1.100 \mathrm{E}-40 \quad 1.945 \mathrm{E}-36 \quad 7.488 \mathrm{E}-31$

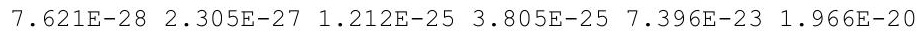

$\begin{array}{llllll}4.700 \mathrm{E}-21 & 4.747 \mathrm{E}-21 & 7.698 \mathrm{E}-21 & 1.261 \mathrm{E}-20 & 6.527 \mathrm{E}-19 & 1.171 \mathrm{E}-16\end{array}$

$\begin{array}{llllll}4.700 \mathrm{E}-21 & 4.747 \mathrm{E}-21 & 7.698 \mathrm{E}-21 & 1.261 \mathrm{E}-20 & 6.527 \mathrm{E}-19 & 1.171 \mathrm{E}-16\end{array}$

$\begin{array}{llllll}1.731 E-38 & 1.222 \mathrm{E}-37 & 2.283 \mathrm{E}-34 & 1.567 \mathrm{E}-33 & 3.197 \mathrm{E}-30 & 4.568 \mathrm{E}-27\end{array}$

$\begin{array}{llllll}1.599 \mathrm{E}-31 & 4.847 \mathrm{E}-31 & 2.866 \mathrm{E}-29 & 1.014 \mathrm{E}-28 & 5.033 \mathrm{E}-26 & 4.386 \mathrm{E}-23\end{array}$

$\begin{array}{llllll}1.599 \mathrm{E}-31 & 4.847 \mathrm{E}-31 & 2.866 \mathrm{E}-29 & 1.014 \mathrm{E}-28 & 5.033 \mathrm{E}-26 & 4.387 \mathrm{E}-23\end{array}$

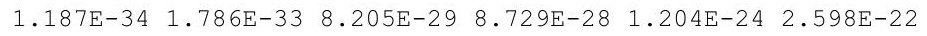

$\begin{array}{llllll}1.463 \mathrm{E}-27 & 1.028 \mathrm{E}-26 & 1.534 \mathrm{E}-23 & 8.359 \mathrm{E}-23 & 2.673 \mathrm{E}-20 & 3.336 \mathrm{E}-18\end{array}$

$\begin{array}{llllll}1.463 \mathrm{E}-27 & 1.028 \mathrm{E}-26 & 1.534 \mathrm{E}-23 & 8.359 \mathrm{E}-23 & 2.673 \mathrm{E}-20 & 3.337 \mathrm{E}-18\end{array}$

$\begin{array}{llllll}6.220 \mathrm{E}-18 & 6.125 \mathrm{E}-18 & 2.886 \mathrm{E}-18 & 1.340 \mathrm{E}-18 & 2.881 \mathrm{E}-21 & 8.954 \mathrm{E}-25\end{array}$

$\begin{array}{llllll}1.065 E-41 & 1.074 E-41 & 1.618 E-41 & 2.457 E-41 & 6.961 E-40 & 5.653 E-38\end{array}$

$\begin{array}{llllll}5.790 \mathrm{E}-33 & 5.838 \mathrm{E}-33 & 8.794 \mathrm{E}-33 & 1.336 \mathrm{E}-32 & 3.783 \mathrm{E}-31 & 3.072 \mathrm{E}-29\end{array}$

$\begin{array}{llllll}5.790 \mathrm{E}-33 & 5.838 \mathrm{E}-33 & 8.794 \mathrm{E}-33 & 1.336 \mathrm{E}-32 & 3.783 \mathrm{E}-31 & 3.072 \mathrm{E}-29\end{array}$

$\begin{array}{llllll}4.817 \mathrm{E}-38 & 1.461 \mathrm{E}-37 & 9.066 \mathrm{E}-36 & 3.412 \mathrm{E}-35 & 4.151 \mathrm{E}-32 & 2.242 \mathrm{E}-28\end{array}$

$\begin{array}{llllll}3.398 \mathrm{E}-32 & 3.454 \mathrm{E}-32 & 7.678 \mathrm{E}-32 & 1.735 \mathrm{E}-31 & 1.179 \mathrm{E}-28 & 6.245 \mathrm{E}-25\end{array}$

$\begin{array}{llllll}4.830 \mathrm{E}-38 & 1.470 \mathrm{E}-37 & 1.099 \mathrm{E}-35 & 4.943 \mathrm{E}-35 & 1.673 \mathrm{E}-31 & 1.820 \mathrm{E}-27\end{array}$

$\begin{array}{llllll}3.398 \mathrm{E}-32 & 3.454 \mathrm{E}-32 & 7.680 \mathrm{E}-32 & 1.736 \mathrm{E}-31 & 1.181 \mathrm{E}-28 & 6.266 \mathrm{E}-25\end{array}$

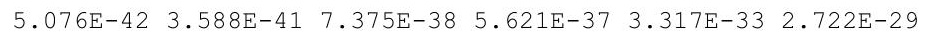

$\begin{array}{llllll}1.189 \mathrm{E}-30 & 1.207 \mathrm{E}-30 & 2.577 \mathrm{E}-30 & 5.589 \mathrm{E}-30 & 2.731 \mathrm{E}-27 & 9.387 \mathrm{E}-24\end{array}$

$\begin{array}{llllll}5.364 \mathrm{E}-36 & 1.631 \mathrm{E}-35 & 1.172 \mathrm{E}-33 & 5.055 \mathrm{E}-33 & 1.229 \mathrm{E}-29 & 8.650 \mathrm{E}-26\end{array}$

$\begin{array}{llllll}5.085 \mathrm{E}-42 & 3.603 \mathrm{E}-41 & 8.386 \mathrm{E}-38 & 7.201 \mathrm{E}-37 & 8.719 \mathrm{E}-33 & 1.259 \mathrm{E}-28\end{array}$

$\begin{array}{llllll}1.189 \mathrm{E}-30 & 1.207 \mathrm{E}-30 & 2.579 \mathrm{E}-30 & 5.594 \mathrm{E}-30 & 2.744 \mathrm{E}-27 & 9.474 \mathrm{E}-24\end{array}$

$\begin{array}{llllll}3.969 \mathrm{E}-31 & 5.963 \mathrm{E}-30 & 2.526 \mathrm{E}-25 & 2.485 \mathrm{E}-24 & 2.108 \mathrm{E}-21 & 2.972 \mathrm{E}-19\end{array}$

$\begin{array}{lllllll}1.860 \mathrm{E}-19 & 5.610 \mathrm{E}-19 & 2.552 \mathrm{E}-17 & 6.905 \mathrm{E}-17 & 4.024 \mathrm{E}-15 & 2.105 \mathrm{E}-13\end{array}$

$\begin{array}{llllll}5.596 \mathrm{E}-25 & 3.933 \mathrm{E}-24 & 5.821 \mathrm{E}-21 & 3.145 \mathrm{E}-20 & 9.384 \mathrm{E}-18 & 1.042 \mathrm{E}-15\end{array}$

$\begin{array}{llllll}3.792 \mathrm{E}-31 & 5.970 \mathrm{E}-30 & 2.783 \mathrm{E}-25 & 2.998 \mathrm{E}-24 & 4.516 \mathrm{E}-21 & 1.047 \mathrm{E}-18\end{array}$

$\begin{array}{llllll}1.860 \mathrm{E}-19 & 5.611 \mathrm{E}-19 & 2.552 \mathrm{E}-17 & 6.908 \mathrm{E}-17 & 4.033 \mathrm{E}-15 & 2.116 \mathrm{E}-13\end{array}$

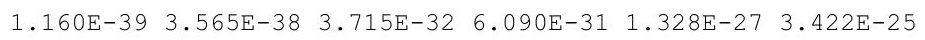

$\begin{array}{lllllll}8.984 \mathrm{E}-28 & 6.263 \mathrm{E}-27 & 6.208 \mathrm{E}-24 & 2.463 \mathrm{E}-23 & 2.775 \mathrm{E}-21 & 2.524 \mathrm{E}-19\end{array}$

$2.030 \mathrm{E}-33 \quad 3.037 \mathrm{E}-32 \quad 1.052 \mathrm{E}-27 \quad 8.967 \mathrm{E}-27 \quad 6.069 \mathrm{E}-24 \quad 1.209 \mathrm{E}-21$

$\begin{array}{lllllll}1.122 \mathrm{E}-38 & 4.009 \mathrm{E}-38 & 4.030 \mathrm{E}-32 & 7.166 \mathrm{E}-31 & 2.754 \mathrm{E}-27 & 1.178 \mathrm{E}-24\end{array}$

$\begin{array}{llllll}8.984 \mathrm{E}-28 & 6.263 \mathrm{E}-27 & 6.209 \mathrm{E}-24 & 2.464 \mathrm{E}-23 & 2.781 \mathrm{E}-21 & 2.536 \mathrm{E}-19\end{array}$

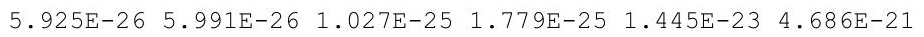


RESRAD-OFFSITE, Version 2.

Parent Dose Report

Title : RESRAD-OFFSITE Parameters for Offsite Resident Farmer

File : OFFSITE-RF_SRSG-7-11.ROF

Individual Nuclide Dose Summed Over All Pathways

Parent Nuclide and Thread Fraction Indicated

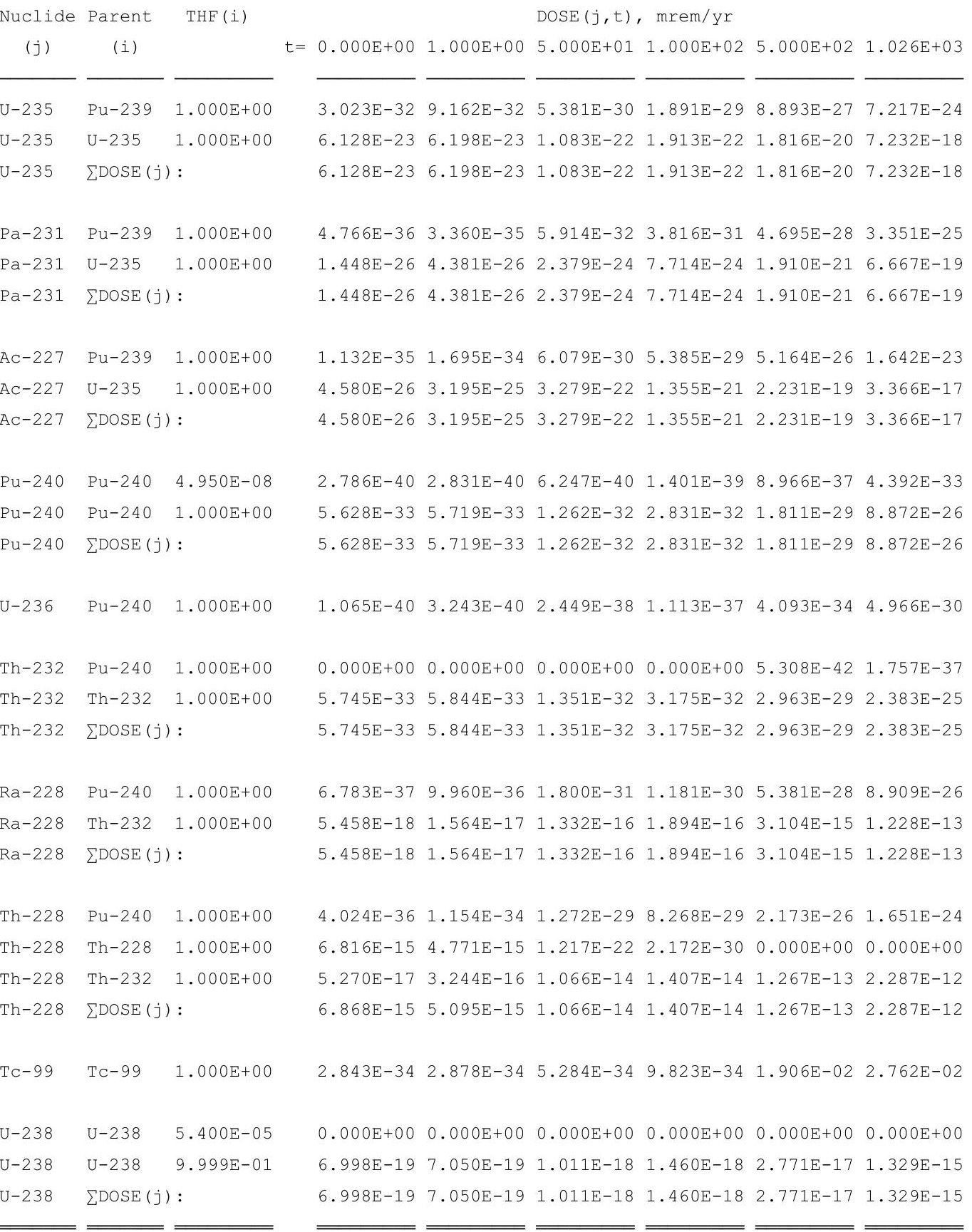

THF (i) is the thread fraction of the parent nuclide. 
RESRAD-OFFSITE, Version 2.

Parent Dose Report

Title : RESRAD-OFFSITE Parameters for offsite Resident Farmer

File : OFFSITE-RF SRSG-7-11.ROF

Individual Nuclide Soil Concentration

Parent Nuclide and Thread Fraction Indicated

\begin{tabular}{|c|c|c|c|c|c|c|c|c|}
\hline $\begin{array}{c}\text { uclide } \\
\text { (j) }\end{array}$ & $\begin{array}{c}\text { Parent } \\
\text { (i) }\end{array}$ & THF (i) & $t=0.000 \mathrm{E}+00$ & $1.000 \mathrm{E}+00$ & $\begin{array}{r}S(j, t) \\
5.000 \mathrm{E}+01\end{array}$ & $\begin{array}{l}\mathrm{pCi} / \mathrm{g} \\
1.000 \mathrm{E}+02\end{array}$ & $5.000 \mathrm{E}+02$ & $1.026 \mathrm{E}+03$ \\
\hline$n-241$ & $A m-241$ & $1.000 \mathrm{E}+00$ & $1.000 \mathrm{E}+00$ & $9.984 \mathrm{E}-01$ & $9.228 \mathrm{E}-01$ & $8.516 \mathrm{E}-01$ & $4.478 \mathrm{E}-01$ & $1.924 \mathrm{E}-01$ \\
\hline-237 & Am-241 & $1.000 \mathrm{E}+00$ & $0.000 \mathrm{E}+00$ & $3.236 \mathrm{E}-07$ & $1.553 \mathrm{E}-05$ & $2.980 E-05$ & $1.089 \mathrm{E}-04$ & $1.548 \mathrm{E}-04$ \\
\hline-237 & $N p-237$ & $1.000 \mathrm{E}+00$ & $1.000 \mathrm{E}+00$ & $9.999 \mathrm{E}-01$ & $9.961 \mathrm{E}-01$ & $9.922 \mathrm{E}-01$ & $9.614 \mathrm{E}-01$ & $9.224 \mathrm{E}-01$ \\
\hline-237 & $\sum S(j):$ & & $1.000 \mathrm{E}+00$ & $9.999 E-01$ & $9.961 E-01$ & $9.922 \mathrm{E}-01$ & $9.615 E-01$ & $9.225 \mathrm{E}-01$ \\
\hline-233 & $A m-241$ & $1.000 \mathrm{E}+00$ & $0.000 \mathrm{E}+00$ & $7.085 E-13$ & $1.721 \mathrm{E}-09$ & $6.696 \mathrm{E}-09$ & $1.355 \mathrm{E}-07$ & $4.447 \mathrm{E}-07$ \\
\hline-233 & $N p-237$ & $1.000 \mathrm{E}+00$ & $0.000 \mathrm{E}+00$ & $4.373 E-06$ & $2.181 \mathrm{E}-04$ & 4. $352 \mathrm{E}-04$ & $2.135 E-03$ & $4.271 \mathrm{E}-03$ \\
\hline-233 & $\sum S(j):$ & & $0.000 \mathrm{E}+00$ & $4.373 E-06$ & $2.181 E-04$ & $4.352 E-04$ & $2.135 E-03$ & $4.271 \mathrm{E}-03$ \\
\hline $1-229$ & $A m-241$ & $1.000 \mathrm{E}+00$ & $0.000 \mathrm{E}+00$ & $2.235 E-17$ & $2.725 E-12$ & $2.132 \mathrm{E}-11$ & $2.249 E-09$ & $1.584 \mathrm{E}-08$ \\
\hline-229 & $\mathrm{~Np}-237$ & $1.000 \mathrm{E}+00$ & $0.000 \mathrm{E}+00$ & $2.067 \mathrm{E}-10$ & $5.146 \mathrm{E}-07$ & $2.052 \mathrm{E}-06$ & $4.999 \mathrm{E}-05$ & $2.035 E-04$ \\
\hline $1-229$ & $\sum S(j):$ & & $0.000 \mathrm{E}+00$ & $2.067 E-10$ & $5.146 E-07$ & $2.052 E-06$ & $4.999 \mathrm{E}-05$ & $2.036 E-04$ \\
\hline$s-137$ & $\mathrm{Cs}-137$ & $1.000 \mathrm{E}+00$ & $1.000 \mathrm{E}+00$ & $9.771 \mathrm{E}-01$ & $3.147 \mathrm{E}-01$ & $9.902 \mathrm{E}-02$ & $9.519 \mathrm{E}-06$ & $4.966 \mathrm{E}-11$ \\
\hline$x-238$ & $\mathrm{Pu}-238$ & $1.840 \mathrm{E}-09$ & $1.840 E-09$ & $1.826 \mathrm{E}-09$ & $1.239 \mathrm{E}-09$ & $8.342 E-10$ & $3.525 E-11$ & $5.498 \mathrm{E}-13$ \\
\hline-238 & $\mathrm{Pu}-238$ & $1.000 \mathrm{E}+00$ & $1.000 \mathrm{E}+00$ & $9.921 \mathrm{E}-01$ & $6.733 E-01$ & $4.534 \mathrm{E}-01$ & 1. $916 \mathrm{E}-02$ & $2.988 E-04$ \\
\hline-238 & $\sum S(j):$ & & $1.000 \mathrm{E}+00$ & $9.921 \mathrm{E}-01$ & $6.733 E-01$ & $4.534 \mathrm{E}-01$ & $1.916 \mathrm{E}-02$ & $2.988 E-04$ \\
\hline 234 & $\mathrm{Pu}-238$ & $1.000 \mathrm{E}+00$ & $0.000 \mathrm{E}+00$ & $2.824 \mathrm{E}-06$ & $1.170 \mathrm{E}-04$ & $1.957 \mathrm{E}-04$ & $3.494 \mathrm{E}-04$ & $3.531 \mathrm{E}-04$ \\
\hline 234 & $\mathrm{U}-234$ & $1.000 \mathrm{E}+00$ & $1.000 \mathrm{E}+00$ & $1.000 \mathrm{E}+00$ & $9.992 \mathrm{E}-01$ & $9.984 \mathrm{E}-01$ & $9.919 \mathrm{E}-01$ & $9.835 E-01$ \\
\hline 234 & $\mathrm{U}-238$ & $9.999 \mathrm{E}-01$ & $0.000 \mathrm{E}+00$ & $2.835 E-06$ & $1.416 E-04$ & $2.831 E-04$ & $1.407 \mathrm{E}-03$ & $2.865 E-03$ \\
\hline 034 & $\sum S(j):$ & & $1.000 \mathrm{E}+00$ & $1.000 \mathrm{E}+00$ & $9.994 \mathrm{E}-01$ & $9.989 \mathrm{E}-01$ & $9.937 \mathrm{E}-01$ & $9.867 \mathrm{E}-01$ \\
\hline
\end{tabular}

$\mathrm{Th}-230 \mathrm{Pu}-238 \quad 1.000 \mathrm{E}+00$

Th-230 Th-230 1.000E+00

$0.000 \mathrm{E}+00 \quad 1.274 \mathrm{E}-11 \quad 2.807 \mathrm{E}-08 \quad 9.959 \mathrm{E}-08 \quad 1.206 \mathrm{E}-06 \quad 2.867 \mathrm{E}-06$ $\begin{array}{lllllll}1.000 \mathrm{E}+00 & 1.000 \mathrm{E}+00 & 9.995 \mathrm{E}-01 & 9.989 \mathrm{E}-01 & 9.947 \mathrm{E}-01 & 9.891 \mathrm{E}-01\end{array}$ $0.000 \mathrm{E}+00 \quad 9.002 \mathrm{E}-06 \quad 4.498 \mathrm{E}-04 \quad 8.990 \mathrm{E}-04 \quad 4.471 \mathrm{E}-03 \quad 9.109 \mathrm{E}-03$ $0.000 \mathrm{E}+00 \quad 1.277 \mathrm{E}-11 \quad 3.188 \mathrm{E}-08 \quad 1.274 \mathrm{E}-07 \quad 3.168 \mathrm{E}-06 \quad 1.325 \mathrm{E}-05$ $\begin{array}{lllllll}1.000 \mathrm{E}+00 & 1.000 \mathrm{E}+00 & 9.999 \mathrm{E}-01 & 9.998 \mathrm{E}-01 & 9.991 \mathrm{E}-01 & 9.982 \mathrm{E}-01\end{array}$

$0.000 \mathrm{E}+00 \quad 1.844 \mathrm{E}-15 \quad 2.080 \mathrm{E}-10 \quad 1.511 \mathrm{E}-09 \quad 1.013 \mathrm{E}-07 \quad 5.006 \mathrm{E}-07$ $0.000 \mathrm{E}+00 \quad 4.331 \mathrm{E}-04 \quad 2.142 \mathrm{E}-02 \quad 4.235 \mathrm{E}-02 \quad 1.937 \mathrm{E}-01 \quad 3.549 \mathrm{E}-01$ $0.000 \mathrm{E}+00 \quad 1.951 \mathrm{E}-09 \quad 4.837 \mathrm{E}-06 \quad 1.920 \mathrm{E}-05 \quad 4.512 \mathrm{E}-04 \quad 1.756 \mathrm{E}-03$ $0.000 \mathrm{E}+00 \quad 1.891 \mathrm{E}-15 \quad 2.289 \mathrm{E}-10 \quad 1.820 \mathrm{E}-09 \quad 2.170 \mathrm{E}-07 \quad 1.764 \mathrm{E}-06$ $0.000 \mathrm{E}+00 \quad 4.331 \mathrm{E}-04 \quad 2.142 \mathrm{E}-02 \quad 4.237 \mathrm{E}-02 \quad 1.942 \mathrm{E}-01 \quad 3.566 \mathrm{E}-01$

$0.000 \mathrm{E}+00 \quad 1.431 \mathrm{E}-17 \quad 6.200 \mathrm{E}-11 \quad 7.209 \mathrm{E}-10 \quad 8.712 \mathrm{E}-08 \quad 4.685 \mathrm{E}-07$ $0.000 \mathrm{E}+00 \quad 6.669 \mathrm{E}-06 \quad 1.058 \mathrm{E}-02 \quad 2.946 \mathrm{E}-02 \quad 1.823 \mathrm{E}-01 \quad 3.458 \mathrm{E}-01$ $0.000 \mathrm{E}+00 \quad 2.010 \mathrm{E}-11 \quad 1.773 \mathrm{E}-06 \quad 1.066 \mathrm{E}-05 \quad 3.984 \mathrm{E}-04 \quad 1.656 \mathrm{E}-03$ $0.000 \mathrm{E}+00 \quad 5.806 \mathrm{E}-17 \quad 6.719 \mathrm{E}-11 \quad 8.476 \mathrm{E}-10 \quad 1.806 \mathrm{E}-07 \quad 1.612 \mathrm{E}-06$ $0.000 \mathrm{E}+00 \quad 6.669 \mathrm{E}-06 \quad 1.058 \mathrm{E}-02 \quad 2.947 \mathrm{E}-02 \quad 1.827 \mathrm{E}-01 \quad 3.475 \mathrm{E}-01$ Pu-239 Pu-239 1.000E+00 $1.000 E+00 \quad 1.000 E+00 \quad 9.981 E-01 \quad 9.961 E-01 \quad 9.808 E-019.610 E-01$ 
RESRAD-OFFSITE, Version 2.

Parent Dose Report

Title : RESRAD-OFFSITE Parameters for Offsite Resident Farmer

File : OFFSITE-RF_SRSG-7-11.ROF

Individual Nuclide Soil Concentration

Parent Nuclide and Thread Fraction Indicated

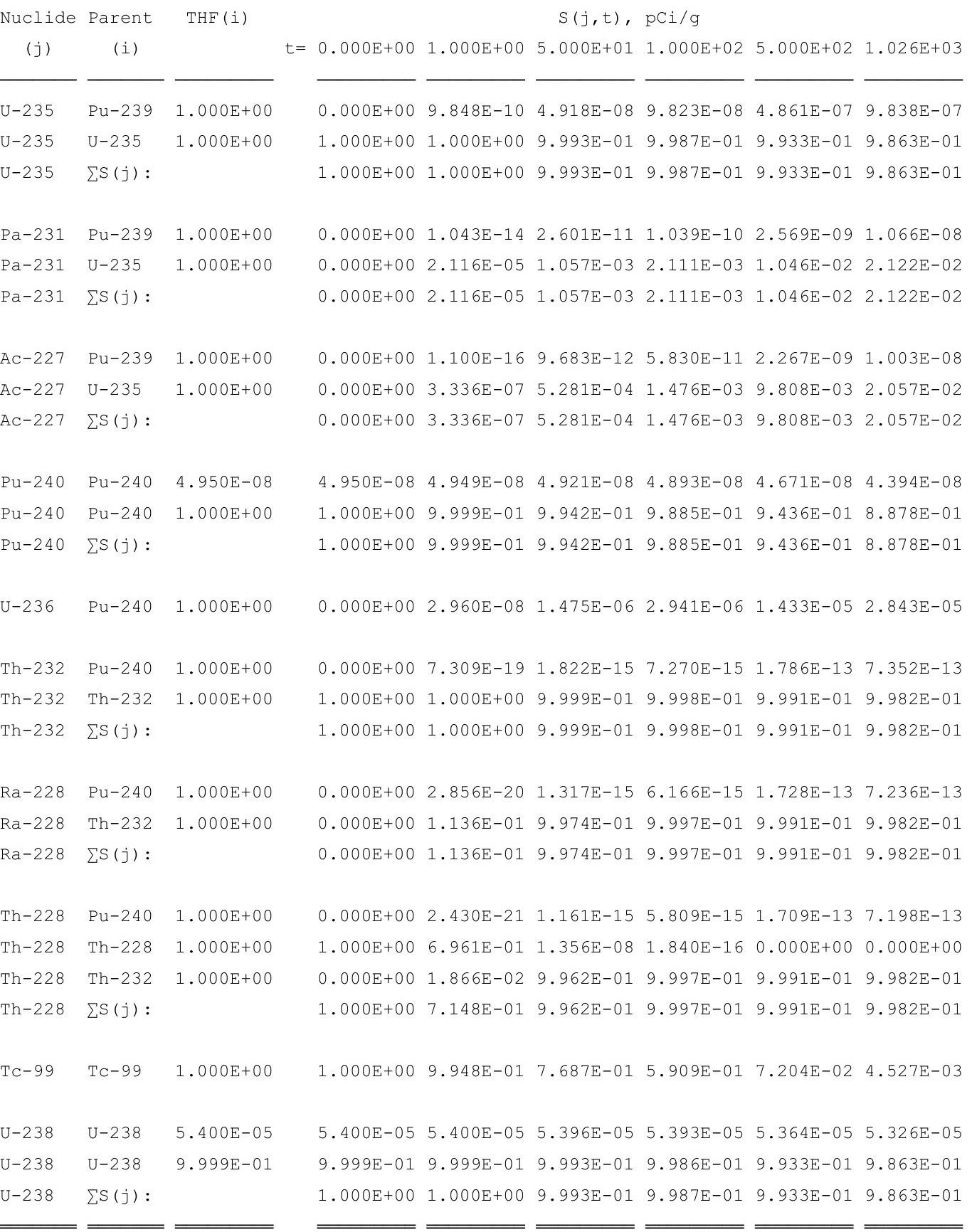

THF (i) is the thread fraction of the parent nuclide. 
RESRAD-OFFSITE, Version $2.5 \quad \mathrm{~T}^{1 / 2}$ Limit $=180$ days

Parent Dose Report

Title : RESRAD-OFFSITE Parameters for Offsite Resident Farmer

File : OFFSITE-RF_SRSG-7-11.ROF

Run Time Information

ResOCalc.EXE execution began at 17:22 on 07/21/2011

ResOCalc.EXE execution ended at 17:37 on 07/21/2011

ResOCalc.EXE execution time 15 minutes 3 seconds 
RESRAD, Version $6.5 \quad \mathrm{~T}^{1} \frac{1}{2}$ Limit $=180$ days

07/21/2011 17:07 Page

Summary : RESRAD Parameters for U-Landfill Recreational User

File : C: $\backslash$ RESRAD FAMILY \RESRAD \USERFILES $\backslash Q C F O R S R S G \backslash R U$ SRSG-MAY11.RAD

Table of Contents

Part I: Mixture Sums and Single Radionuclide Guidelines

Dose Conversion Factor (and Related) Parameter Summary ... 2

Site-Specific Parameter Summary ................ 8

Summary of Pathway Selections .................. 18

Contaminated Zone and Total Dose Summary ............. 19

Total Dose Components

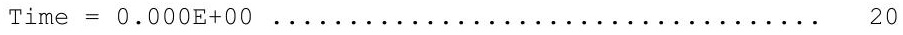

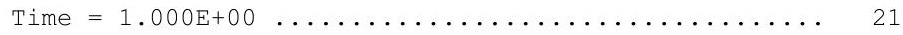

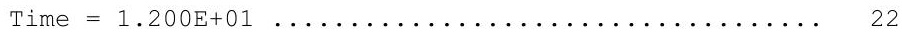

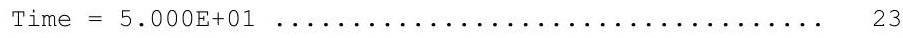

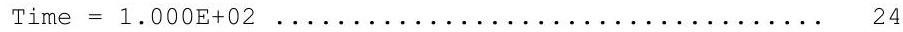

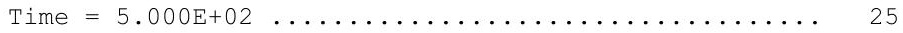

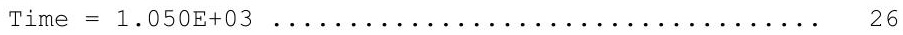

Dose/Source Ratios Summed Over All Pathways .......... 27

Single Radionuclide Soil Guidelines ................ 29

Dose Per Nuclide Summed Over All Pathways ........... 30

Soil Concentration Per Nuclide ............... 32 
Summary : RESRAD Parameters for U-Landfill Recreational User

File : C: $\backslash$ RESRAD_FAMILY $\backslash$ RESRAD $\backslash U S E R F I L E S \backslash Q C F O R S R S G \backslash R U \_S R S G-M A Y 11 . R A D$

Dose Conversion Factor (and Related) Parameter Summary

Dose Library: RU for U-Landfill Plus ICRP 60 \& ICRP 72 (Age 15)

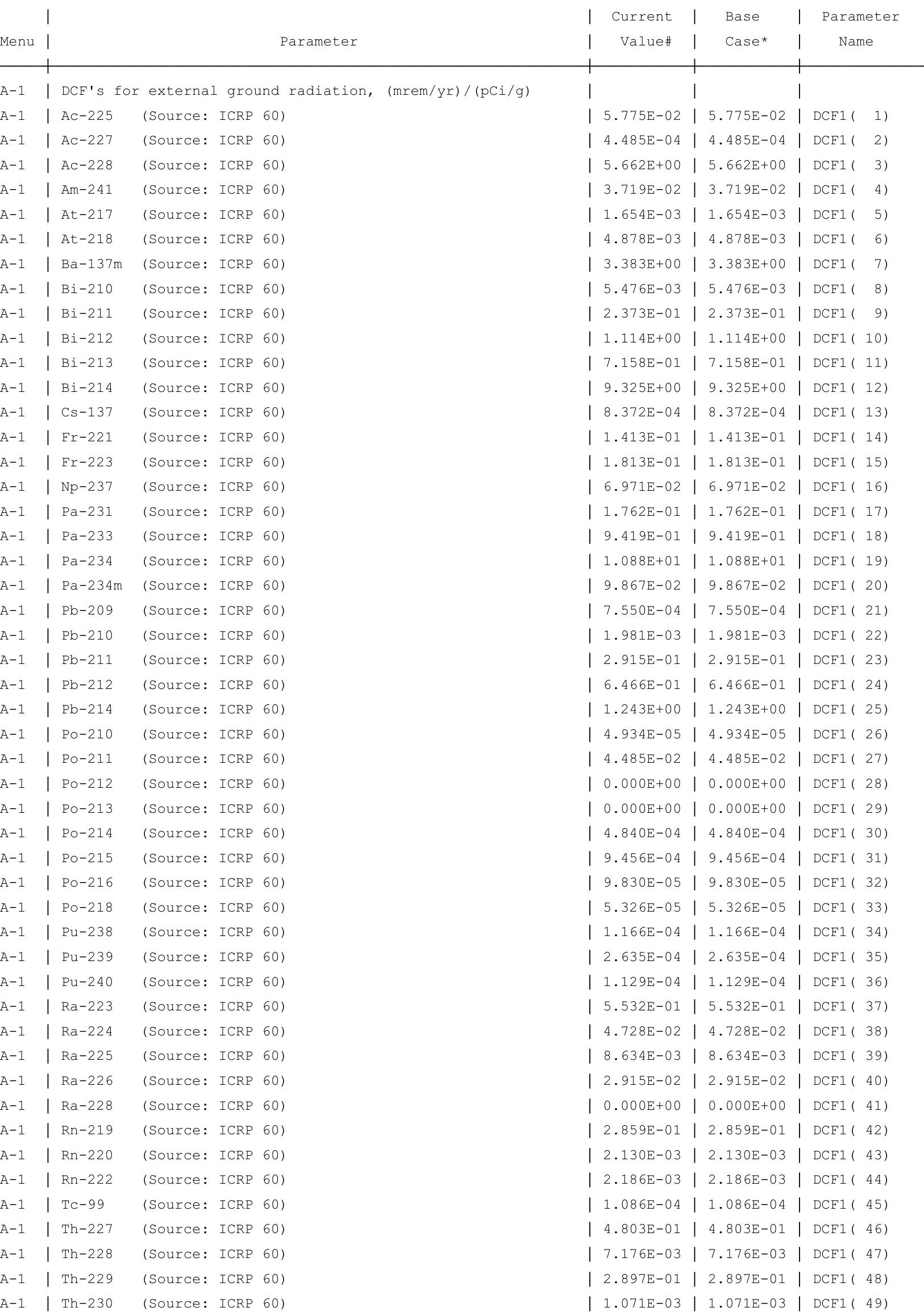


Summary : RESRAD Parameters for U-Landfill Recreational User

File : C: $\backslash$ RESRAD FAMILY \RESRAD \USERFILES $\backslash Q C F O R S R S G \backslash R U$ SRSG-MAY11.RAD

Dose Conversion Factor (and Related) Parameter Summary (continued)

Dose Library: RU for U-Landfill Plus ICRP 60 \& ICRP 72 (Age 15)

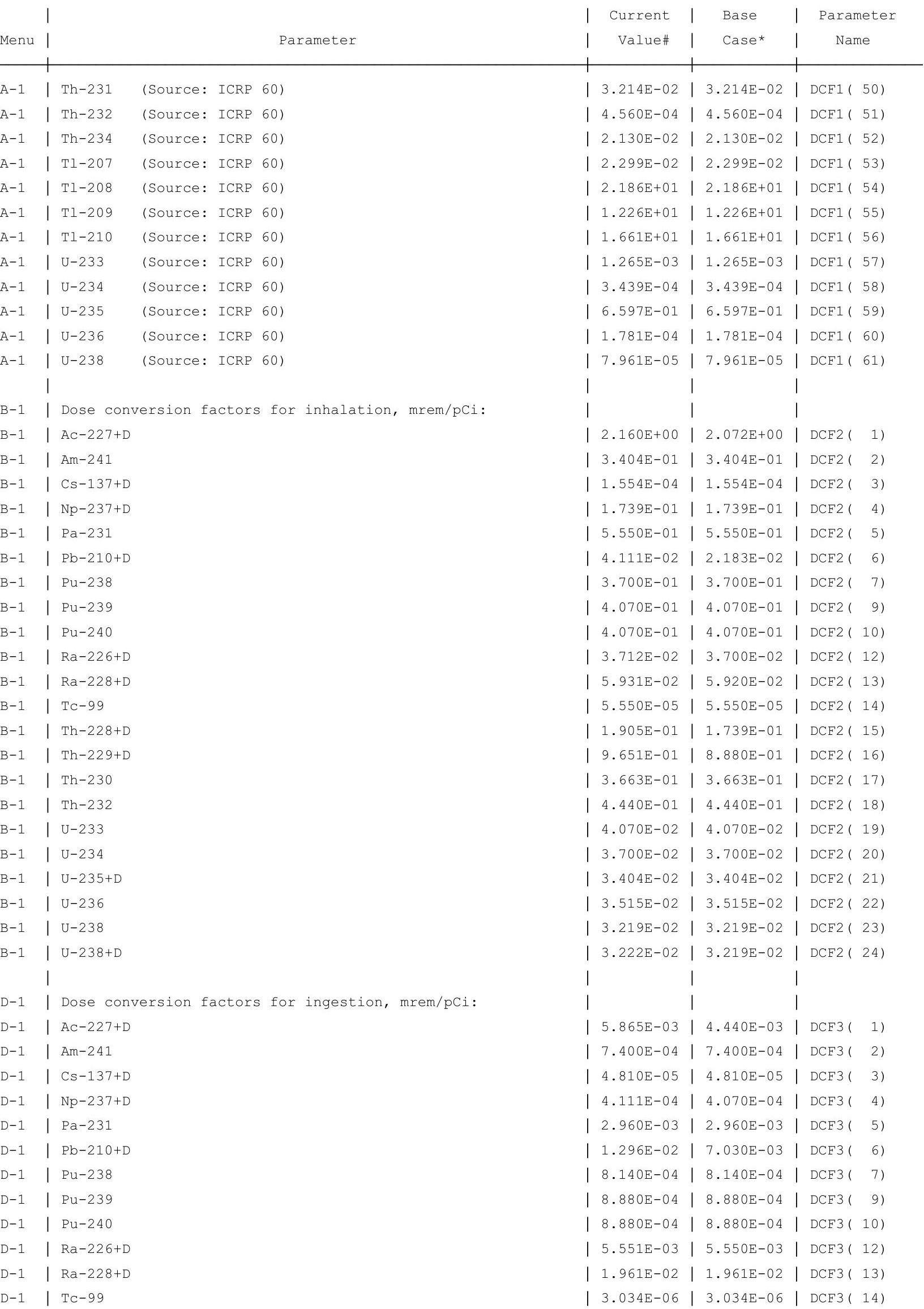


RESRAD, Version $6.5 \quad \mathrm{~T}^{1 / 2}$ Limit $=180$ days

ummary : RESRAD Parameters for U-Landfill Recreational User

File : C: $\backslash$ RESRAD_FAMILY $\backslash R E S R A D \backslash U S E R F I L E S \backslash Q C F O R S R S G \backslash R U \_S R S G-M A Y 11 . R A D$

Dose Conversion Factor (and Related) Parameter Summary (continued)

Dose Library: RU for U-Landfill Plus ICRP 60 \& ICRP 72 (Age 15)

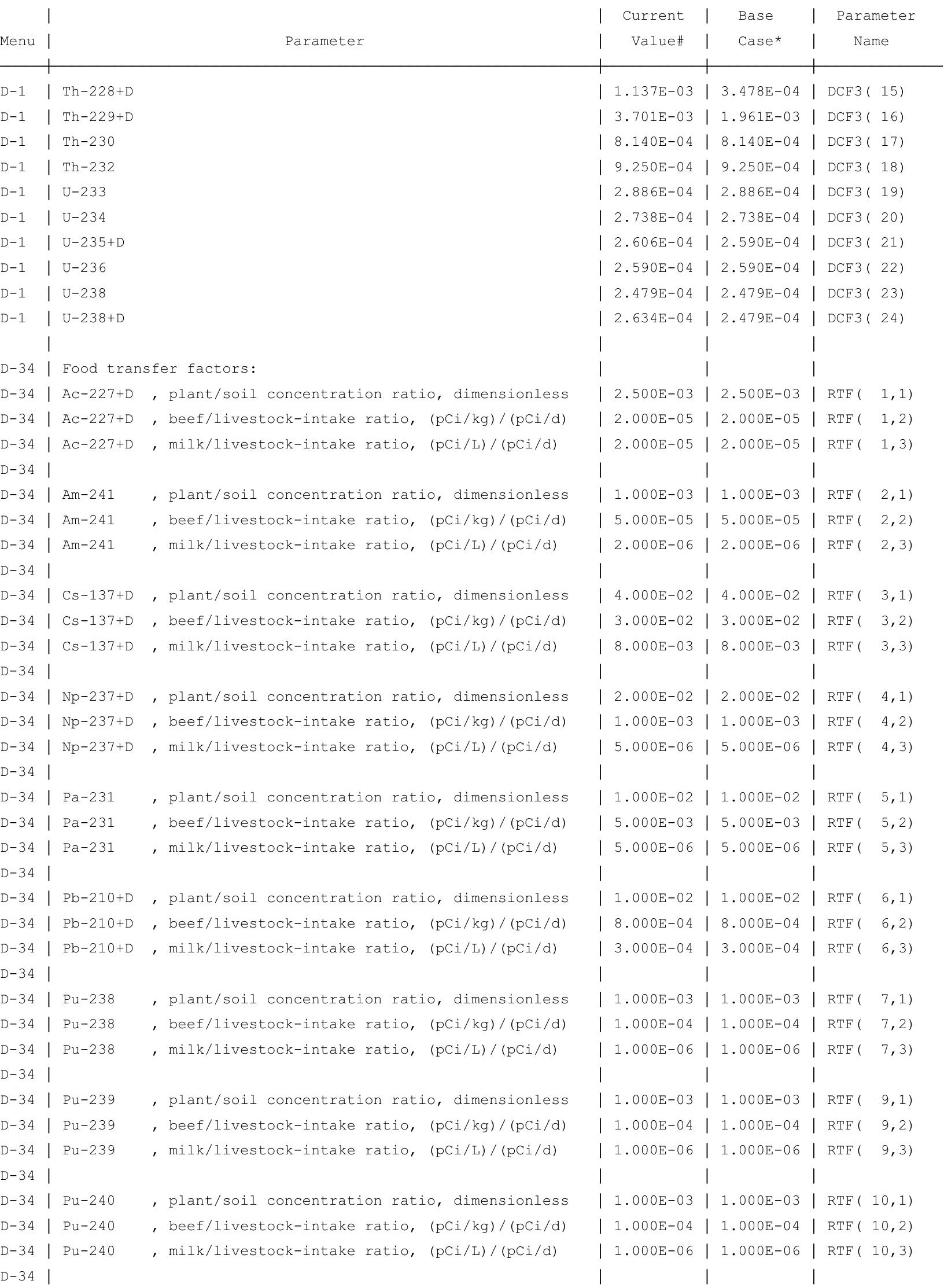


RESRAD, Version $6.5 \quad \mathrm{~T}^{1 / 2}$ Limit $=180$ days

Summary : RESRAD Parameters for U-Landfill Recreational User

File : C: $\backslash$ RESRAD_FAMILY $\backslash R E S R A D \backslash U S E R F I L E S \backslash Q C F O R S R S G \backslash R U \_S R S G-M A Y 11 . R A D$

Dose Conversion Factor (and Related) Parameter Summary (continued)

Dose Library: RU for U-Landfill Plus ICRP 60 \& ICRP 72 (Age 15)

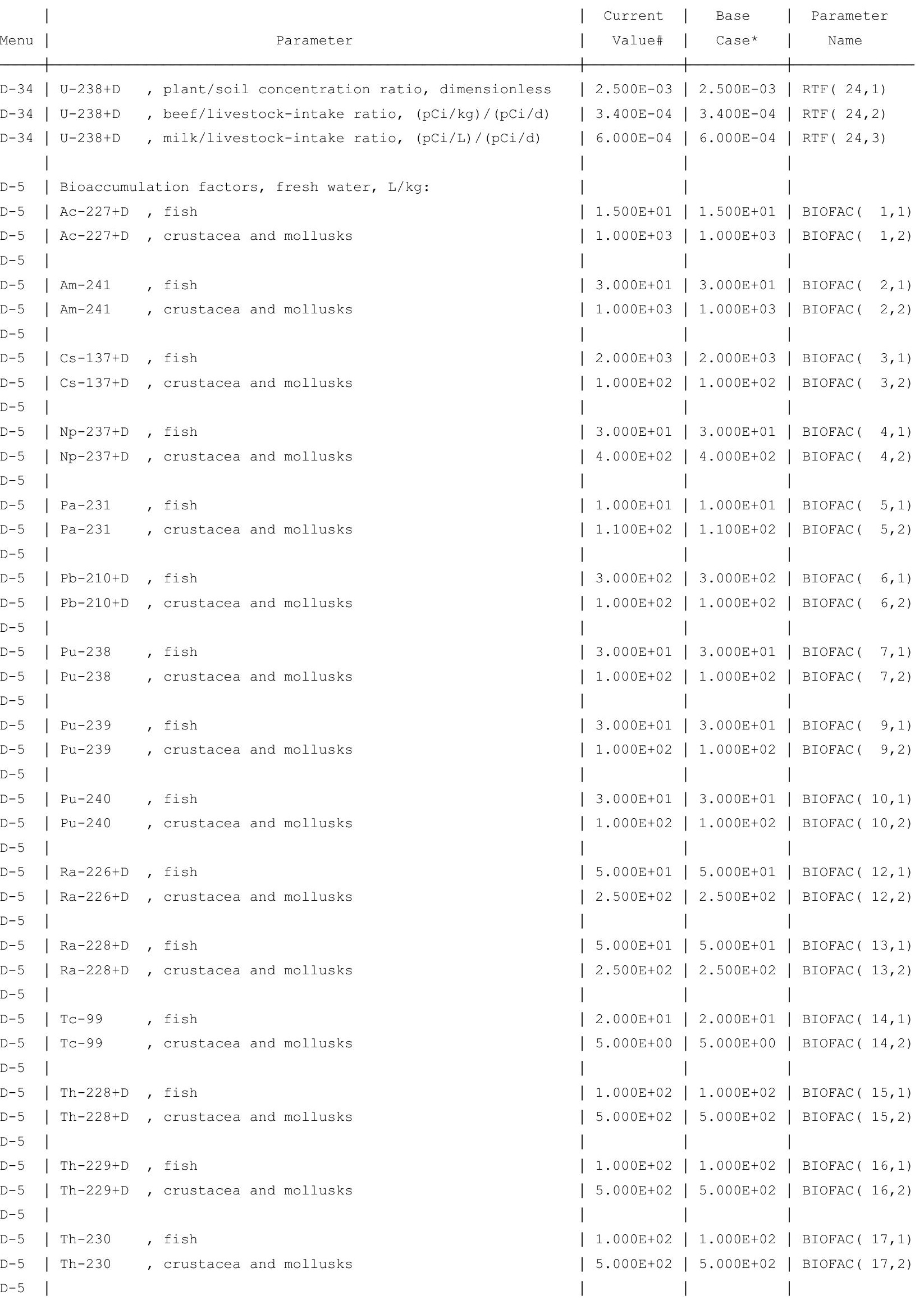


RESRAD, Version $6.5 \quad T^{13 / 2}$ Limit $=180$ days

Summary : RESRAD Parameters for U-Landfill Recreational User

File : C: $\backslash$ RESRAD_FAMILY $\backslash$ RESRAD $\backslash U S E R F I L E S \backslash Q C F O R S R S G \backslash R U \_S R S G-M A Y 11 . R A D$

Dose Conversion Factor (and Related) Parameter Summary (continued)

Dose Library: RU for U-Landfill Plus ICRP 60 \& ICRP 72 (Age 15)

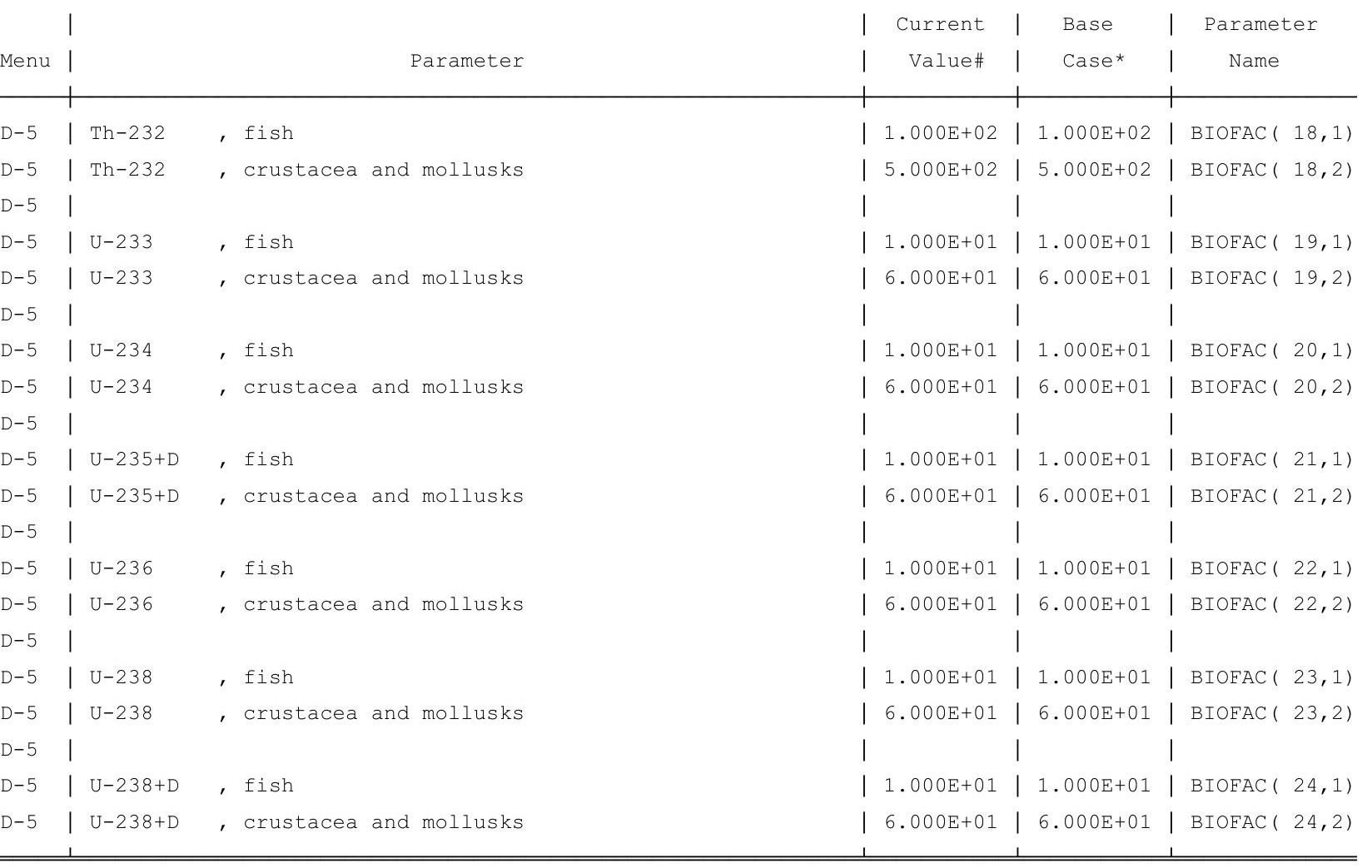

\#For DCFl(xxx) only, factors are for infinite depth \& area. See ETFG table in Ground Pathway of Detailed Report. *Base Case means Default.Lib w/o Associate Nuclide contributions. 
RESRAD, Version $6.5 \quad \mathrm{~T}^{1 / 2}$ Limit $=180$ days

Summary : RESRAD Parameters for U-Landfill Recreational User

File : C: \RESRAD FAMILY \RESRAD \USERFILES $\backslash Q C F O R S R S G \backslash R U$ SRSG-MAY11.RAD

Site-Specific Parameter Summary (continued)

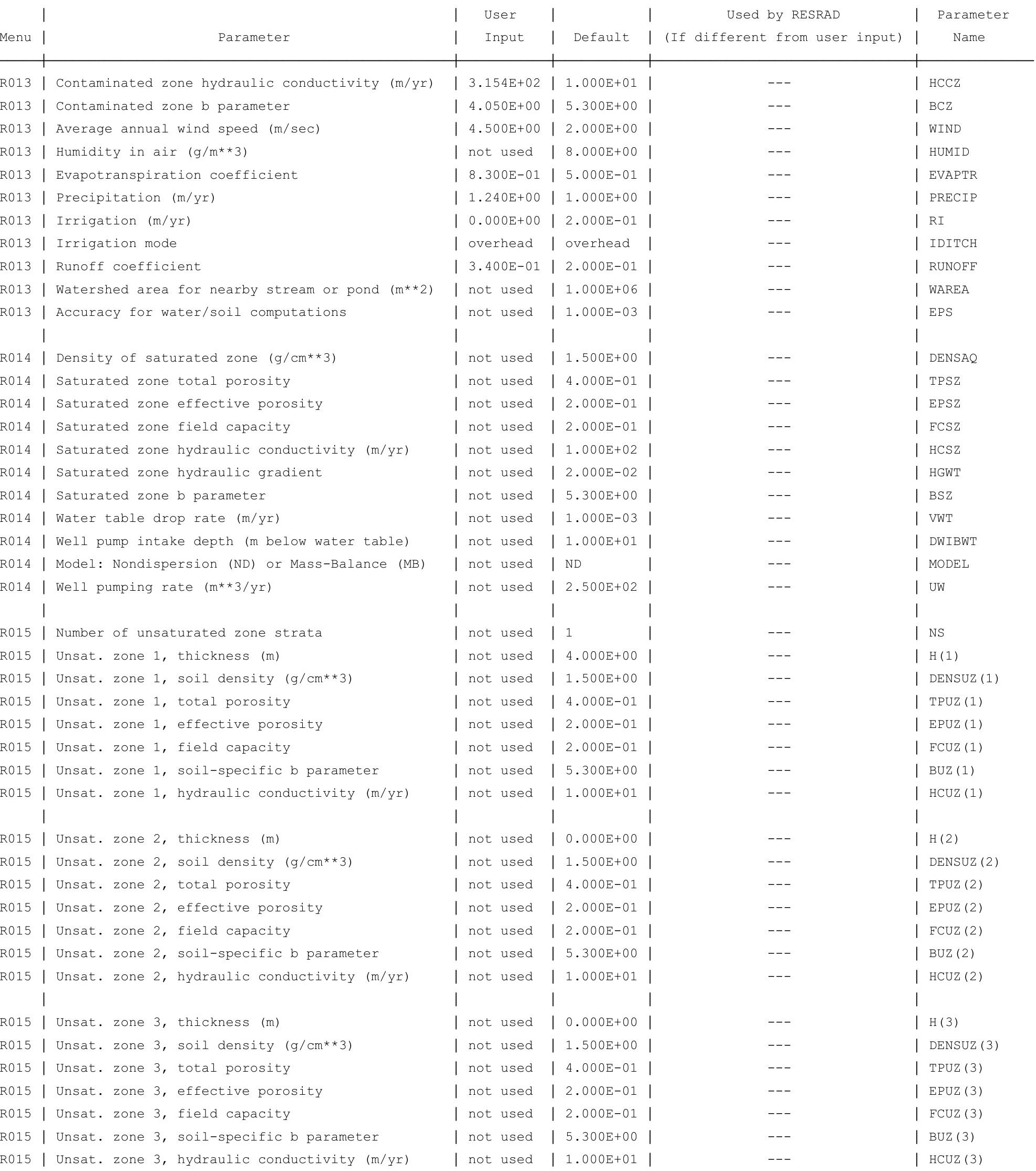


RESRAD, Version $6.5 \quad \mathrm{~T}^{1 / 2}$ Limit $=180$ days

$07 / 21 / 2011$

17:07 Page

Summary : RESRAD Parameters for U-Landfill Recreational User

File : C: \RESRAD FAMILY \RESRAD \USERFILES $\backslash Q C F O R S R S G \backslash R U$ SRSG-MAY11.RAD

Site-Specific Parameter Summary (continued)

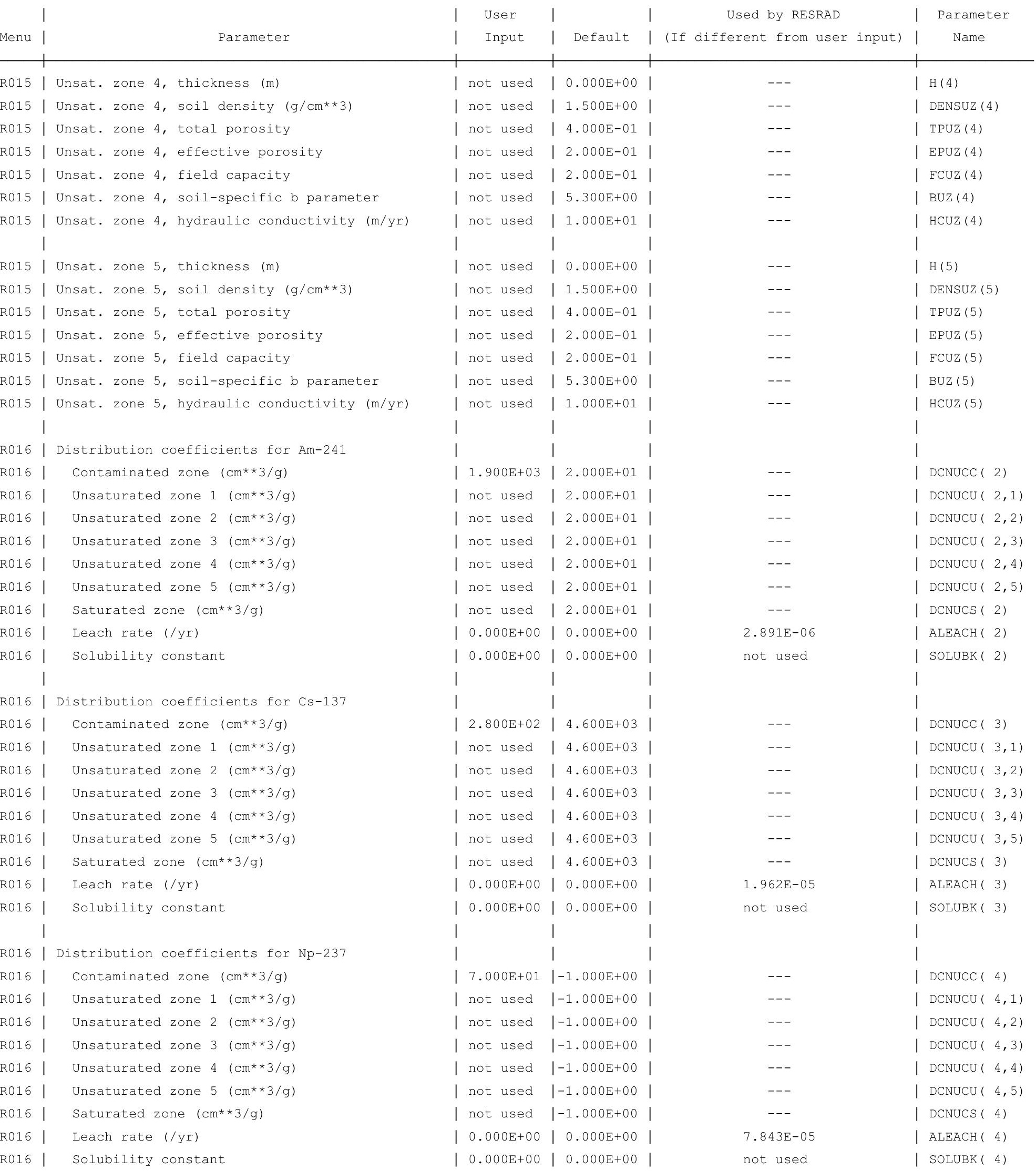


RESRAD, Version $6.5 \quad \mathrm{~T}^{1 / 2}$ Limit $=180$ days

Summary : RESRAD Parameters for U-Landfill Recreational User

File : C: $\backslash$ RESRAD_FAMILY \RESRAD \USERFILES $\backslash Q C F O R S R S G \backslash R U$ SRSG-MAY11.RAD

Site-Specific Parameter Summary (continued)

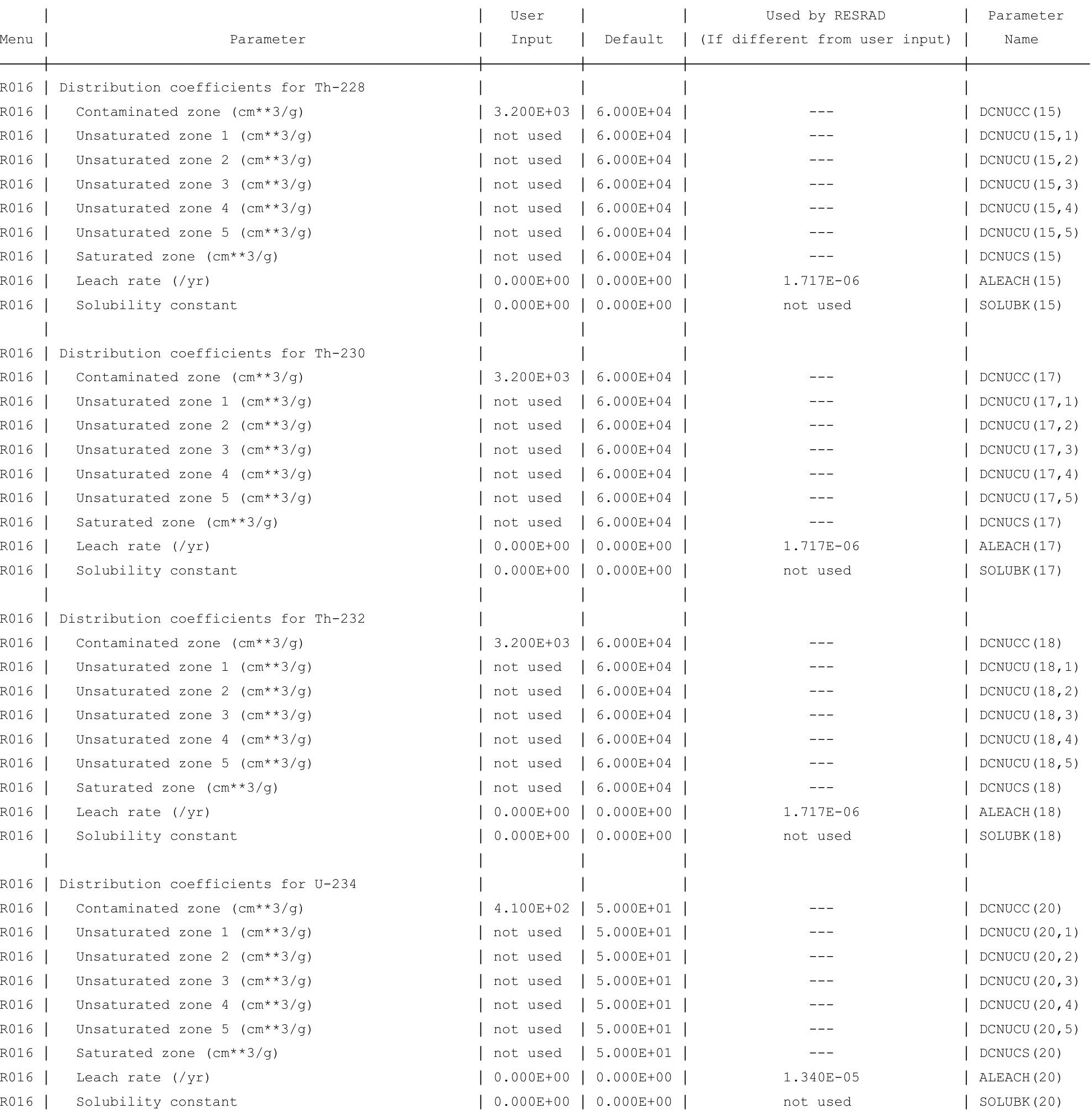


RESRAD, Version $6.5 \quad \mathrm{~T}^{1 / 2}$ Limit $=180$ days

Summary : RESRAD Parameters for U-Landfill Recreational User

File : C: $\backslash$ RESRAD_FAMILY \RESRAD \USERFILES $\backslash Q C F O R S R S G \backslash R U$ SRSG-MAY11.RAD

Site-Specific Parameter Summary (continued)

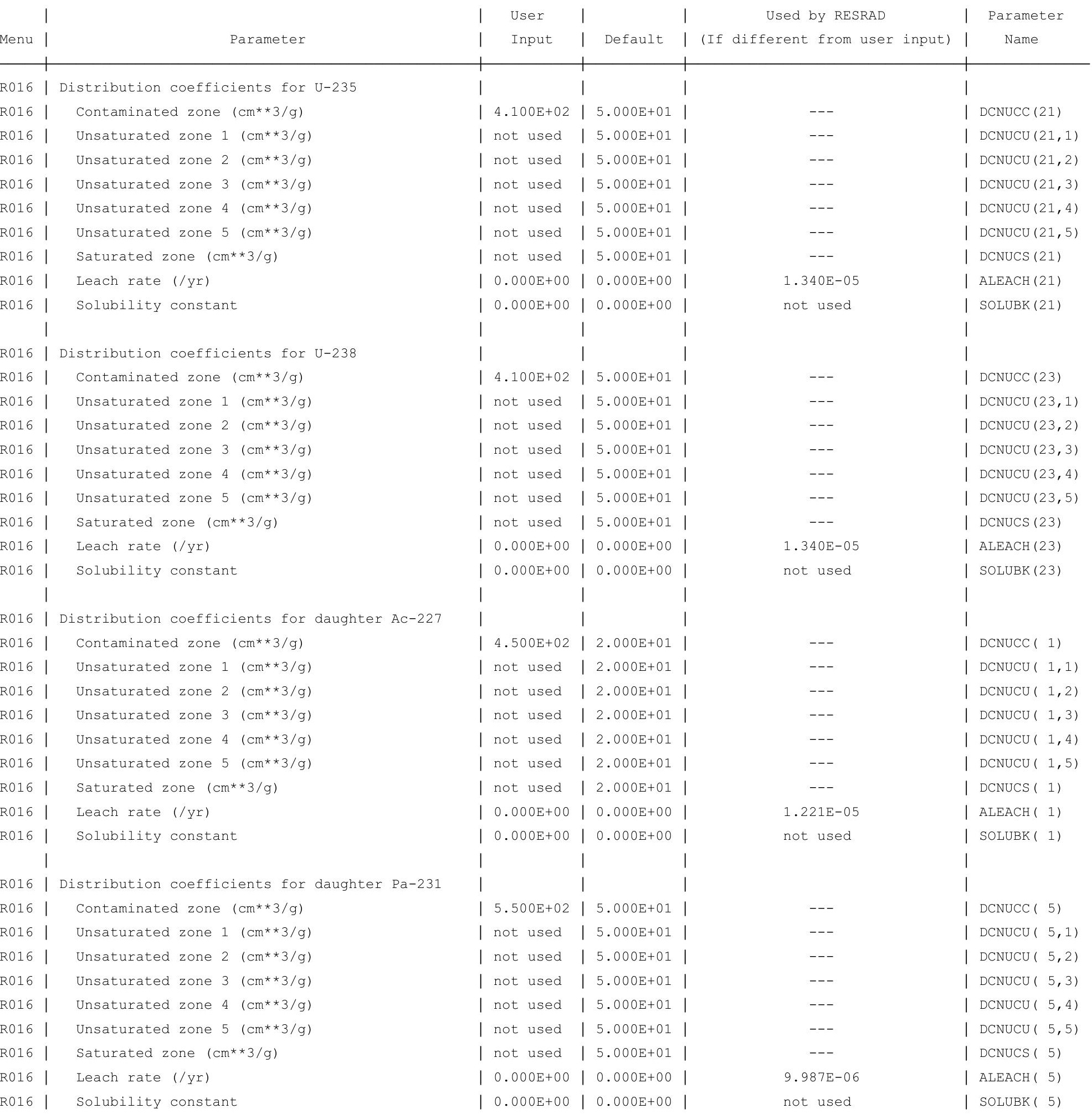


RESRAD, Version $6.5 \quad \mathrm{~T}^{1 / 2}$ Limit $=180$ days

$07 / 21 / 2011$

17:07 Page

14

Summary : RESRAD Parameters for U-Landfill Recreational User

File : C: $\backslash$ RESRAD_FAMILY $\backslash R E S R A D \backslash U S E R F I L E S \backslash Q C F O R S R S G \backslash R U \_S R S G-M A Y 11 . R A D$

Site-Specific Parameter Summary (continued)

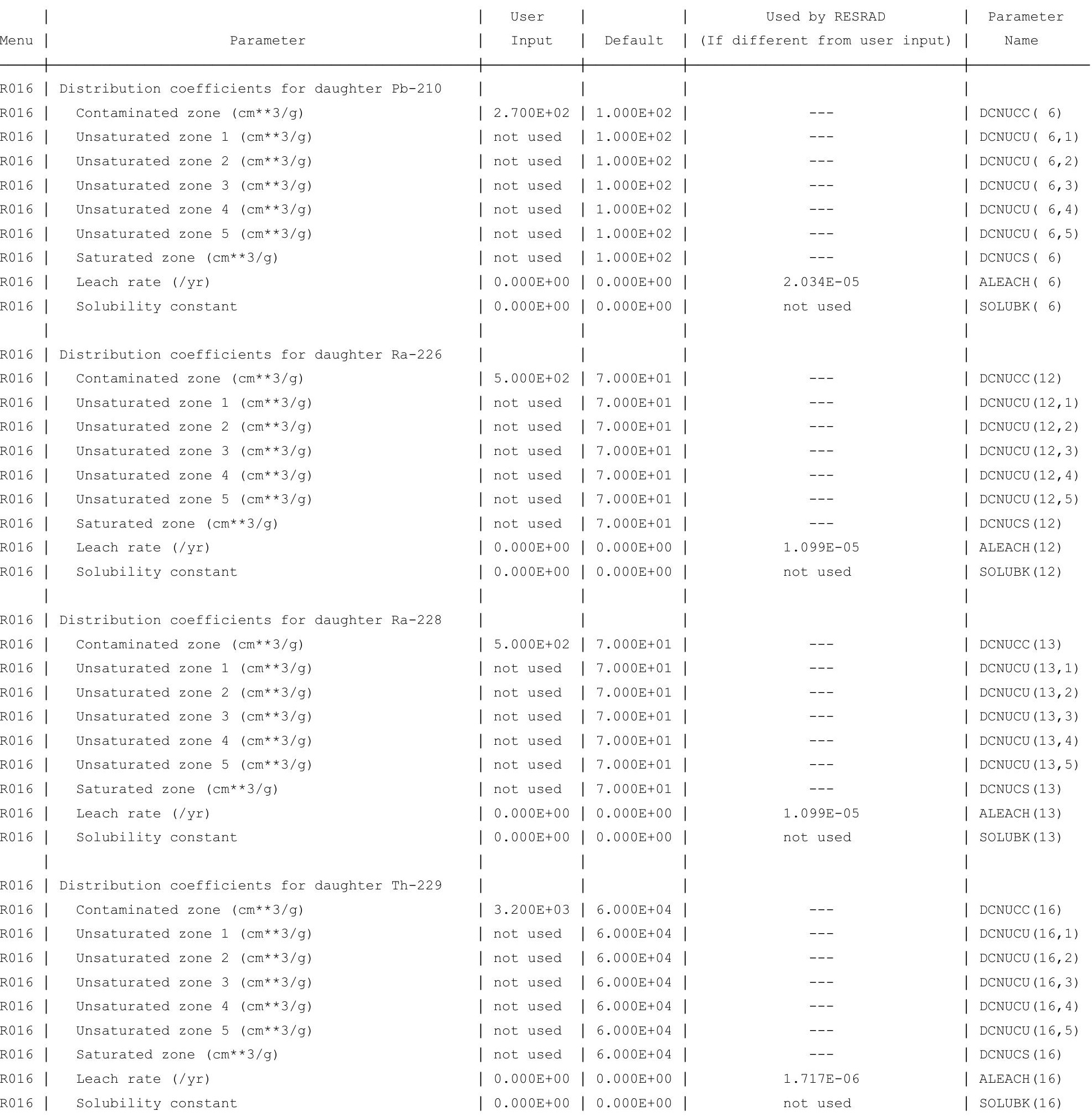


RESRAD, Version $6.5 \quad \mathrm{~T}^{1 / 2}$ Limit $=180$ days

Summary : RESRAD Parameters for U-Landfill Recreational User

File $\quad C: \backslash$ RESRAD FAMILY \RESRAD \USERFILES $\backslash Q C F O R S R S G \backslash R U$ SRSG-MAY11.RAD

Site-Specific Parameter Summary (continued)

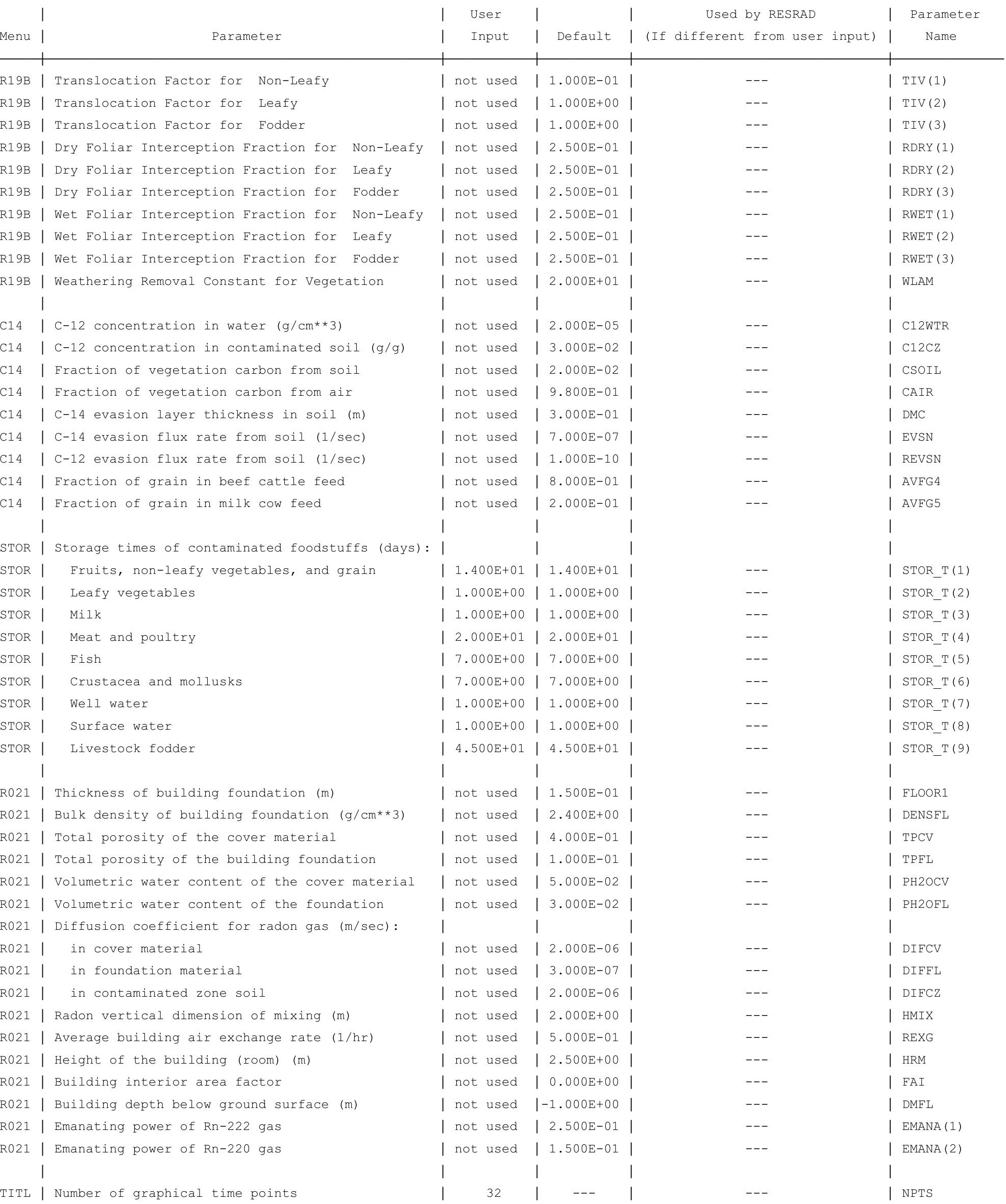

TITL | Number of graphical time points 
RESRAD, Version $6.5 \quad T^{11 / 2}$ Limit $=180$ days

Summary : RESRAD Parameters for U-Landfill Recreational User

File : C: $\backslash$ RESRAD_FAMILY $\backslash$ RESRAD $\backslash U S E R F I L E S \backslash Q C F O R S R S G \backslash R U \_S R S G-M A Y 11 . R A D$

Contaminated Zone Dimensions

Area: $\quad 89436.00$ square meters

Thickness:

Cover Depth:

\begin{abstract}
13.40 meters
1.52 meters
\end{abstract}

Initial Soil Concentrations, pci/g

$\begin{array}{ll}\mathrm{Am}-241 & 1.000 \mathrm{E}+00 \\ \mathrm{Cs}-137 & 1.000 \mathrm{E}+00 \\ \mathrm{~Np}-237 & 1.000 \mathrm{E}+00 \\ \mathrm{Pu}-238 & 1.000 \mathrm{E}+00 \\ \mathrm{Pu}-239 & 1.000 \mathrm{E}+00 \\ \mathrm{Pu}-240 & 1.000 \mathrm{E}+00 \\ \mathrm{TC}-99 & 1.000 \mathrm{E}+00 \\ \mathrm{Th}-228 & 1.000 \mathrm{E}+00 \\ \mathrm{Th}-230 & 1.000 \mathrm{E}+00 \\ \mathrm{Th}-232 & 1.000 \mathrm{E}+00 \\ \mathrm{U}-234 & 1.000 \mathrm{E}+00 \\ \mathrm{U}-235 & 1.000 \mathrm{E}+00 \\ \mathrm{U}-238 & 1.000 \mathrm{E}+00\end{array}$

Total Dose TDOSE(t), mrem/yr

Basic Radiation Dose Limit $=1.000 \mathrm{E}+00 \mathrm{mrem} / \mathrm{yr}$

Total Mixture Sum $M(t)$ = Fraction of Basic Dose Limit Received at Time (t)

$\begin{array}{rlllllll}t \text { (years) }: & 0.000 \mathrm{E}+00 & 1.000 \mathrm{E}+00 & 1.200 \mathrm{E}+01 & 5.000 \mathrm{E}+01 & 1.000 \mathrm{E}+02 & 5.000 \mathrm{E}+02 & 1.050 \mathrm{E}+03 \\ \mathrm{TDOSE}(\mathrm{t}): & 1.342 \mathrm{E}-07 & 9.986 \mathrm{E}-08 & 1.182 \mathrm{E}-07 & 2.161 \mathrm{E}-07 & 2.931 \mathrm{E}-07 & 3.316 \mathrm{E}-06 & 9.778 \mathrm{E}-05 \\ \mathrm{M}(\mathrm{t}): & 1.342 \mathrm{E}-07 & 9.986 \mathrm{E}-08 & 1.182 \mathrm{E}-07 & 2.161 \mathrm{E}-07 & 2.931 \mathrm{E}-07 & 3.316 \mathrm{E}-06 & 9.778 \mathrm{E}-05\end{array}$

Maximum TDOSE $(t): 9.778 \mathrm{E}-05 \mathrm{mrem} / \mathrm{yr}$ at $t=1.050 \mathrm{E}+03$ years 
RESRAD, Version 6.5

$\mathrm{T}^{1 / 2}$ Limit $=180$ days

$07 / 21 / 2011$

17:07 Page 20

Summary : RESRAD Parameters for U-Landfill Recreational User
File : C: $\backslash$ RESRAD_FAMILY \RESRAD \USERFILES $\backslash Q C F O R S R S G \backslash R U$ SRSG-MAY11.RAD

Total Dose Contributions TDOSE(i,p,t) for Individual Radionuclides (i) and Pathways (p) As mrem/yr and Fraction of Total Dose At $t=0.000 \mathrm{E}+00$ years

Water Independent Pathways (Inhalation excludes radon)

\begin{tabular}{|c|c|c|c|c|c|c|c|c|c|c|c|c|c|c|}
\hline \multirow{2}{*}{ Nuclide } & \multicolumn{2}{|c|}{ Ground } & \multicolumn{2}{|c|}{ Inhalation } & \multicolumn{2}{|c|}{ Radon } & \multicolumn{2}{|c|}{ Plant } & \multicolumn{2}{|c|}{ Meat } & \multicolumn{2}{|c|}{ Milk } & \multicolumn{2}{|c|}{ Soil } \\
\hline & mrem/yr & fract. & mrem/yr & fract. & mrem/yr & fract. & mrem/yr & fract. & mrem/yr & fract. & mrem/yr & fract. & mrem/yr & fract. \\
\hline-241 & $1.487 \mathrm{E}-20$ & 0.0000 & $0.000 \mathrm{E}+00$ & 0.0000 & $0.000 \mathrm{E}+00$ & 0.0000 & $0.000 \mathrm{E}+00$ & 0.0000 & $0.000 \mathrm{E}+00$ & 0.0000 & $0.000 \mathrm{E}+00$ & 0.0000 & $0.000 \mathrm{E}+00$ & 0.0000 \\
\hline-137 & 1. $213 \mathrm{E}-10$ & 0.0009 & $0.000 \mathrm{E}+00$ & 0.0000 & $0.000 \mathrm{E}+00$ & 0.0000 & $0.000 \mathrm{E}+00$ & 0.0000 & $0.000 \mathrm{E}+00$ & 0.0000 & $0.000 \mathrm{E}+00$ & 0.0000 & $0.000 \mathrm{E}+00$ & 0.0000 \\
\hline-237 & $9.169 \mathrm{E}-14$ & 0.0000 & $0.000 \mathrm{E}+00$ & 0.0000 & $0.000 \mathrm{E}+00$ & 0.0000 & $0.000 \mathrm{E}+00$ & 0.0000 & $0.000 \mathrm{E}+00$ & 0.0000 & $0.000 \mathrm{E}+00$ & 0.0000 & $0.000 \mathrm{E}+00$ & 0.0000 \\
\hline-238 & $7.826 E-24$ & 0.0000 & $0.000 \mathrm{E}+00$ & 0.0000 & $0.000 \mathrm{E}+00$ & 0.0000 & $0.000 \mathrm{E}+00$ & 0.0000 & $0.000 \mathrm{E}+00$ & 0.0000 & $0.000 \mathrm{E}+00$ & 0.0000 & $0.000 \mathrm{E}+00$ & 0.0000 \\
\hline-239 & $1.156 \mathrm{E}-18$ & 0.0000 & $0.000 \mathrm{E}+00$ & 0.0000 & $0.000 \mathrm{E}+00$ & 0.0000 & $0.000 \mathrm{E}+00$ & 0.0000 & $0.000 \mathrm{E}+00$ & 0.0000 & $0.000 \mathrm{E}+00$ & 0.0000 & $0.000 \mathrm{E}+00$ & 0.0000 \\
\hline-240 & $1.099 \mathrm{E}-25$ & 0.0000 & $0.000 \mathrm{E}+00$ & 0.0000 & $0.000 \mathrm{E}+00$ & 0.0000 & $0.000 \mathrm{E}+00$ & 0.0000 & $0.000 \mathrm{E}+00$ & 0.0000 & $0.000 \mathrm{E}+00$ & 0.0000 & $0.000 \mathrm{E}+00$ & 0.0000 \\
\hline 99 & $5.547 \mathrm{E}-27$ & 0.0000 & $0.000 \mathrm{E}+00$ & 0.0000 & $0.000 \mathrm{E}+00$ & 0.0000 & $0.000 \mathrm{E}+00$ & 0.0000 & $0.000 \mathrm{E}+00$ & 0.0000 & $0.000 \mathrm{E}+00$ & 0.0000 & $0.000 \mathrm{E}+00$ & 0.0000 \\
\hline-228 & $1.329 \mathrm{E}-07$ & 0.9905 & $0.000 \mathrm{E}+00$ & 0.0000 & $0.000 \mathrm{E}+00$ & 0.0000 & $0.000 \mathrm{E}+00$ & 0.0000 & $0.000 \mathrm{E}+00$ & 0.0000 & $0.000 \mathrm{E}+00$ & 0.0000 & $0.000 \mathrm{E}+00$ & 0.0000 \\
\hline 230 & $3.629 \mathrm{E}-12$ & 0.0000 & $0.000 \mathrm{E}+00$ & 0.0000 & $0.000 \mathrm{E}+00$ & 0.0000 & $0.000 \mathrm{E}+00$ & 0.0000 & $0.000 \mathrm{E}+00$ & 0.0000 & $0.000 \mathrm{E}+00$ & 0.0000 & $0.000 \mathrm{E}+00$ & 0.0000 \\
\hline-232 & $1.133 E-09$ & 0.0084 & $0.000 \mathrm{E}+00$ & 0.0000 & $0.000 \mathrm{E}+00$ & 0.0000 & $0.000 \mathrm{E}+00$ & 0.0000 & $0.000 \mathrm{E}+00$ & 0.0000 & $0.000 \mathrm{E}+00$ & 0.0000 & $0.000 \mathrm{E}+00$ & 0.0000 \\
\hline 34 & $1.090 \mathrm{E}-17$ & 0.0000 & $0.000 \mathrm{E}+00$ & 0.0000 & $0.000 \mathrm{E}+00$ & 0.0000 & $0.000 \mathrm{E}+00$ & 0.0000 & $0.000 \mathrm{E}+00$ & 0.0000 & $0.000 \mathrm{E}+00$ & 0.0000 & $0.000 \mathrm{E}+00$ & 0.0000 \\
\hline 35 & $1.197 \mathrm{E}-15$ & 0.0000 & $0.000 \mathrm{E}+00$ & 0.0000 & $0.000 \mathrm{E}+00$ & 0.0000 & $0.000 \mathrm{E}+00$ & 0.0000 & $0.000 \mathrm{E}+00$ & 0.0000 & $0.000 \mathrm{E}+00$ & 0.0000 & $0.000 \mathrm{E}+00$ & 0.0000 \\
\hline 38 & $1.365 E-11$ & 0.0001 & $0.000 \mathrm{E}+00$ & 0.0000 & $0.000 \mathrm{E}+00$ & 0.0000 & $0.000 \mathrm{E}+00$ & 0.0000 & $0.000 \mathrm{E}+00$ & 0.0000 & $0.000 \mathrm{E}+00$ & 0.0000 & $0.000 \mathrm{E}+00$ & 0.0000 \\
\hline & 1. $342 \mathrm{E}-07$ & 1.0000 & $0.000 \mathrm{E}+00$ & 0.0000 & $0.000 \mathrm{E}+00$ & 0.0000 & $0.000 \mathrm{E}+00$ & 0.0000 & $0.000 \mathrm{E}+00$ & 0.0000 & $0.000 \mathrm{E}+00$ & 0.0000 & $.000 \mathrm{E}+00$ & 0.0000 \\
\hline
\end{tabular}

Total Dose Contributions TDOSE(i,p,t) for Individual Radionuclides (i) and Pathways (p) As mrem/yr and Fraction of Total Dose At $t=0.000 \mathrm{E}+00$ years

Water Dependent Pathways

\begin{tabular}{|c|c|c|c|c|c|c|c|c|c|c|c|c|c|c|}
\hline \multirow{2}{*}{ Nuclide } & \multicolumn{2}{|c|}{ Water } & \multicolumn{2}{|c|}{ Fish } & \multicolumn{2}{|c|}{ Radon } & \multicolumn{2}{|c|}{ Plant } & \multicolumn{2}{|c|}{ Meat } & \multicolumn{2}{|c|}{ Milk } & \multicolumn{2}{|c|}{ All Pathways* } \\
\hline & mrem/yr & fract. & mrem/yr & fract. & mrem/yr & fract. & mrem/yr & fract. & mrem/yr & fract. & mrem/yr & fract. & mrem/yr & fract. \\
\hline-241 & $0.000 \mathrm{E}+00$ & 0.0000 & $0.000 \mathrm{E}+00$ & 0.0000 & $0.000 \mathrm{E}+00$ & 0.0000 & $0.000 \mathrm{E}+00$ & 0.0000 & $0.000 \mathrm{E}+00$ & 0.0000 & $0.000 \mathrm{E}+00$ & 0.0000 & $1.487 \mathrm{E}-20$ & 0.0000 \\
\hline-137 & $0.000 \mathrm{E}+00$ & 0.0000 & $0.000 \mathrm{E}+00$ & 0.0000 & $0.000 \mathrm{E}+00$ & 0.0000 & $0.000 \mathrm{E}+00$ & 0.0000 & $0.000 \mathrm{E}+00$ & 0.0000 & $0.000 \mathrm{E}+00$ & 0.0000 & 1. $213 \mathrm{E}-10$ & 0.0009 \\
\hline-237 & $0.000 \mathrm{E}+00$ & 0.0000 & $0.000 \mathrm{E}+00$ & 0.0000 & $0.000 \mathrm{E}+00$ & 0.0000 & $0.000 \mathrm{E}+00$ & 0.0000 & $0.000 \mathrm{E}+00$ & 0.0000 & $0.000 \mathrm{E}+00$ & 0.0000 & $9.169 \mathrm{E}-14$ & 0.0000 \\
\hline-238 & $0.000 \mathrm{E}+00$ & 0.0000 & $0.000 \mathrm{E}+00$ & 0.0000 & $0.000 \mathrm{E}+00$ & 0.0000 & $0.000 \mathrm{E}+00$ & 0.0000 & $0.000 \mathrm{E}+00$ & 0.0000 & $0.000 \mathrm{E}+00$ & 0.0000 & $7.826 \mathrm{E}-24$ & 0.0000 \\
\hline 239 & $0.000 \mathrm{E}+00$ & 0.0000 & $0.000 \mathrm{E}+00$ & 0.0000 & $0.000 \mathrm{E}+00$ & 0.0000 & $0.000 \mathrm{E}+00$ & 0.0000 & $0.000 \mathrm{E}+00$ & 0.0000 & $0.000 \mathrm{E}+00$ & 0.0000 & $1.156 \mathrm{E}-18$ & 0.0000 \\
\hline-240 & $0.000 \mathrm{E}+00$ & 0.0000 & $0.000 \mathrm{E}+00$ & 0.0000 & $0.000 \mathrm{E}+00$ & 0.0000 & $0.000 \mathrm{E}+00$ & 0.0000 & $0.000 \mathrm{E}+00$ & 0.0000 & $0.000 \mathrm{E}+00$ & 0.0000 & $1.099 \mathrm{E}-25$ & 0.0000 \\
\hline 99 & $0.000 \mathrm{E}+00$ & 0.0000 & $0.000 \mathrm{E}+00$ & 0.0000 & $0.000 \mathrm{E}+00$ & 0.0000 & $0.000 \mathrm{E}+00$ & 0.0000 & $0.000 \mathrm{E}+00$ & 0.0000 & $0.000 \mathrm{E}+00$ & 0.0000 & $5.547 \mathrm{E}-27$ & 0.0000 \\
\hline-228 & $0.000 \mathrm{E}+00$ & 0.0000 & $0.000 \mathrm{E}+00$ & 0.0000 & $0.000 \mathrm{E}+00$ & 0.0000 & $0.000 \mathrm{E}+00$ & 0.0000 & $0.000 \mathrm{E}+00$ & 0.0000 & $0.000 \mathrm{E}+00$ & 0.0000 & $1.329 \mathrm{E}-07$ & 0.9905 \\
\hline-230 & $0.000 \mathrm{E}+00$ & 0.0000 & $0.000 \mathrm{E}+00$ & 0.0000 & $0.000 \mathrm{E}+00$ & 0.0000 & $0.000 \mathrm{E}+00$ & 0.0000 & $0.000 \mathrm{E}+00$ & 0.0000 & $0.000 \mathrm{E}+00$ & 0.0000 & $3.629 \mathrm{E}-12$ & 0.0000 \\
\hline-232 & $0.000 \mathrm{E}+00$ & 0.0000 & $0.000 \mathrm{E}+00$ & 0.0000 & $0.000 \mathrm{E}+00$ & 0.0000 & $0.000 \mathrm{E}+00$ & 0.0000 & $0.000 \mathrm{E}+00$ & 0.0000 & $0.000 \mathrm{E}+00$ & 0.0000 & $1.133 \mathrm{E}-09$ & 0.0084 \\
\hline 234 & $0.000 \mathrm{E}+00$ & 0.0000 & $0.000 \mathrm{E}+00$ & 0.0000 & $0.000 \mathrm{E}+00$ & 0.0000 & $0.000 \mathrm{E}+00$ & 0.0000 & $0.000 \mathrm{E}+00$ & 0.0000 & $0.000 \mathrm{E}+00$ & 0.0000 & $1.090 \mathrm{E}-17$ & 0.0000 \\
\hline 35 & $0.000 \mathrm{E}+00$ & 0.0000 & $0.000 \mathrm{E}+00$ & 0.0000 & $0.000 \mathrm{E}+00$ & 0.0000 & $0.000 \mathrm{E}+00$ & 0.0000 & $0.000 \mathrm{E}+00$ & 0.0000 & $0.000 \mathrm{E}+00$ & 0.0000 & $1.197 \mathrm{E}-15$ & 0.0000 \\
\hline 38 & $0.000 \mathrm{E}+00$ & 0.0000 & $0.000 \mathrm{E}+00$ & 0.0000 & $0.000 \mathrm{E}+00$ & 0.0000 & $0.000 \mathrm{E}+00$ & 0.0000 & $0.000 \mathrm{E}+00$ & 0.0000 & $0.000 \mathrm{E}+00$ & 0.0000 & 1. $365 \mathrm{E}-11$ & 0.0001 \\
\hline & $0.000 \mathrm{E}+00$ & 0.0000 & $0.000 \mathrm{E}+00$ & 0.0000 & $0.000 \mathrm{E}+00$ & 0.0000 & $0.000 \mathrm{E}+00$ & 0.0000 & $0.000 \mathrm{E}+00$ & 0.0000 & $0.000 \mathrm{E}+00$ & 0.0000 & 1. $342 E-07$ & 1.0000 \\
\hline
\end{tabular}

* Sum of all water independent and dependent pathways. 
RESRAD, Version 6.5

$\mathrm{T}^{1 / 2}$ Limit $=180$ days

$07 / 21 / 2011$

17:07 Page

ummary : RESRAD Parameters for U-Landfill Recreational User

File : C: $\backslash$ RESRAD_FAMILY \RESRAD \USERFILES $\backslash Q C F O R S R S G \backslash R U \_S R S G-M A Y 11 . R A D$

Total Dose Contributions TDOSE (i,p,t) for Individual Radionuclides (i) and Pathways (p) As mrem/yr and Fraction of Total Dose At $t=1.000 \mathrm{E}+00$ years

Water Independent Pathways (Inhalation excludes radon)

\begin{tabular}{|c|c|c|c|c|c|c|c|c|c|c|c|c|c|c|}
\hline \multirow{2}{*}{ Nuclide } & \multicolumn{2}{|c|}{ Ground } & \multicolumn{2}{|c|}{ Inhalation } & \multicolumn{2}{|c|}{ Radon } & \multicolumn{2}{|c|}{ Plant } & \multicolumn{2}{|c|}{ Meat } & \multicolumn{2}{|c|}{ Milk } & \multicolumn{2}{|c|}{ Soil } \\
\hline & mrem/yr & fract. & mrem/yr & fract. & mrem/yr & fract. & mrem/yr & fract. & mrem/yr & fract. & mrem/yr & fract. & mrem/yr & fract. \\
\hline-241 & $4.500 \mathrm{E}-20$ & 0.0000 & $0.000 \mathrm{E}+00$ & 0.0000 & $0.000 \mathrm{E}+00$ & 0.0000 & $0.000 \mathrm{E}+00$ & 0.0000 & $0.000 \mathrm{E}+00$ & 0.0000 & $0.000 \mathrm{E}+00$ & 0.0000 & $0.000 \mathrm{E}+00$ & 0.0000 \\
\hline-137 & $1.196 \mathrm{E}-10$ & 0.0012 & $0.000 \mathrm{E}+00$ & 0.0000 & $0.000 \mathrm{E}+00$ & 0.0000 & $0.000 \mathrm{E}+00$ & 0.0000 & $0.000 \mathrm{E}+00$ & 0.0000 & $0.000 \mathrm{E}+00$ & 0.0000 & $0.000 \mathrm{E}+00$ & 0.0000 \\
\hline-237 & $9.268 \mathrm{E}-14$ & 0.0000 & $0.000 \mathrm{E}+00$ & 0.0000 & $0.000 \mathrm{E}+00$ & 0.0000 & $0.000 \mathrm{E}+00$ & 0.0000 & $0.000 \mathrm{E}+00$ & 0.0000 & $0.000 \mathrm{E}+00$ & 0.0000 & $0.000 \mathrm{E}+00$ & 0.0000 \\
\hline-238 & $1.163 \mathrm{E}-22$ & 0.0000 & $0.000 \mathrm{E}+00$ & 0.0000 & $0.000 \mathrm{E}+00$ & 0.0000 & $0.000 \mathrm{E}+00$ & 0.0000 & $0.000 \mathrm{E}+00$ & 0.0000 & $0.000 \mathrm{E}+00$ & 0.0000 & $0.000 \mathrm{E}+00$ & 0.0000 \\
\hline-239 & $1.170 \mathrm{E}-18$ & 0.0000 & $0.000 \mathrm{E}+00$ & 0.0000 & $0.000 \mathrm{E}+00$ & 0.0000 & $0.000 \mathrm{E}+00$ & 0.0000 & $0.000 \mathrm{E}+00$ & 0.0000 & $0.000 \mathrm{E}+00$ & 0.0000 & $0.000 \mathrm{E}+00$ & 0.0000 \\
\hline-240 & $1.142 \mathrm{E}-25$ & 0.0000 & $0.000 \mathrm{E}+00$ & 0.0000 & $0.000 \mathrm{E}+00$ & 0.0000 & $0.000 \mathrm{E}+00$ & 0.0000 & $0.000 \mathrm{E}+00$ & 0.0000 & $0.000 \mathrm{E}+00$ & 0.0000 & $0.000 \mathrm{E}+00$ & 0.0000 \\
\hline 99 & $5.625 E-27$ & 0.0000 & $0.000 \mathrm{E}+00$ & 0.0000 & $0.000 \mathrm{E}+00$ & 0.0000 & $0.000 \mathrm{E}+00$ & 0.0000 & $0.000 \mathrm{E}+00$ & 0.0000 & $0.000 \mathrm{E}+00$ & 0.0000 & $0.000 \mathrm{E}+00$ & 0.0000 \\
\hline-228 & $9.308 \mathrm{E}-08$ & 0.9321 & $0.000 \mathrm{E}+00$ & 0.0000 & $0.000 \mathrm{E}+00$ & 0.0000 & $0.000 \mathrm{E}+00$ & 0.0000 & $0.000 \mathrm{E}+00$ & 0.0000 & $0.000 \mathrm{E}+00$ & 0.0000 & $0.000 \mathrm{E}+00$ & 0.0000 \\
\hline 230 & $1.095 \mathrm{E}-11$ & 0.0001 & $0.000 \mathrm{E}+00$ & 0.0000 & $0.000 \mathrm{E}+00$ & 0.0000 & $0.000 \mathrm{E}+00$ & 0.0000 & $0.000 \mathrm{E}+00$ & 0.0000 & $0.000 \mathrm{E}+00$ & 0.0000 & $0.000 \mathrm{E}+00$ & 0.0000 \\
\hline-232 & $6.633 E-09$ & 0.0664 & $0.000 \mathrm{E}+00$ & 0.0000 & $0.000 \mathrm{E}+00$ & 0.0000 & $0.000 \mathrm{E}+00$ & 0.0000 & $0.000 \mathrm{E}+00$ & 0.0000 & $0.000 \mathrm{E}+00$ & 0.0000 & $0.000 \mathrm{E}+00$ & 0.0000 \\
\hline 234 & $7.671 \mathrm{E}-17$ & 0.0000 & $0.000 \mathrm{E}+00$ & 0.0000 & $0.000 \mathrm{E}+00$ & 0.0000 & $0.000 \mathrm{E}+00$ & 0.0000 & $0.000 \mathrm{E}+00$ & 0.0000 & $0.000 \mathrm{E}+00$ & 0.0000 & $0.000 \mathrm{E}+00$ & 0.0000 \\
\hline 35 & $1.217 \mathrm{E}-15$ & 0.0000 & $0.000 \mathrm{E}+00$ & 0.0000 & $0.000 \mathrm{E}+00$ & 0.0000 & $0.000 \mathrm{E}+00$ & 0.0000 & $0.000 \mathrm{E}+00$ & 0.0000 & $0.000 \mathrm{E}+00$ & 0.0000 & $0.000 \mathrm{E}+00$ & 0.0000 \\
\hline 38 & $1.376 \mathrm{E}-11$ & 0.0001 & $0.000 \mathrm{E}+00$ & 0.0000 & $0.000 \mathrm{E}+00$ & 0.0000 & $0.000 \mathrm{E}+00$ & 0.0000 & $0.000 \mathrm{E}+00$ & 0.0000 & $0.000 \mathrm{E}+00$ & 0.0000 & $0.000 \mathrm{E}+00$ & 0.0000 \\
\hline & $9.986 E-08$ & 1.0000 & $0.000 \mathrm{E}+00$ & 0.0000 & $0.000 \mathrm{E}+00$ & 0.0000 & $0.000 \mathrm{E}+00$ & 0.0000 & $0.000 \mathrm{E}+00$ & 0.0000 & $0.000 \mathrm{E}+00$ & 0.0000 & $0.000 \mathrm{E}+00$ & 0.0000 \\
\hline
\end{tabular}

Total Dose Contributions TDOSE(i,p,t) for Individual Radionuclides (i) and Pathways (p) As mrem/yr and Fraction of Total Dose At $t=1.000 \mathrm{E}+00$ years

Water Dependent Pathways

\begin{tabular}{|c|c|c|c|c|c|c|c|c|c|c|c|c|c|c|}
\hline & \multicolumn{2}{|c|}{ Water } & \multicolumn{2}{|c|}{ Fish } & \multicolumn{2}{|c|}{ Radon } & \multicolumn{2}{|c|}{ Plant } & \multicolumn{2}{|c|}{ Meat } & \multicolumn{2}{|c|}{ Milk } & \multicolumn{2}{|c|}{ All Pathways* } \\
\hline clide & mrem/yr & fract. & mrem/yr & fract. & mrem/yr & fract. & mrem/yr & fract. & mrem/yr & fract. & mrem/yr & fract. & mrem/yr & fract. \\
\hline-241 & $0.000 \mathrm{E}+00$ & 0.0000 & $0.000 \mathrm{E}+00$ & 0.0000 & $0.000 \mathrm{E}+00$ & 0.0000 & $0.000 \mathrm{E}+00$ & 0.0000 & $0.000 \mathrm{E}+00$ & 0.0000 & $0.000 \mathrm{E}+00$ & 0.0000 & $4.500 \mathrm{E}-20$ & 0.0000 \\
\hline-137 & $0.000 \mathrm{E}+00$ & 0.0000 & $0.000 \mathrm{E}+00$ & 0.0000 & $0.000 \mathrm{E}+00$ & 0.0000 & $0.000 \mathrm{E}+00$ & 0.0000 & $0.000 \mathrm{E}+00$ & 0.0000 & $0.000 \mathrm{E}+00$ & 0.0000 & $1.196 \mathrm{E}-10$ & 0.0012 \\
\hline-237 & $0.000 \mathrm{E}+00$ & 0.0000 & $0.000 \mathrm{E}+00$ & 0.0000 & $0.000 \mathrm{E}+00$ & 0.0000 & $0.000 \mathrm{E}+00$ & 0.0000 & $0.000 \mathrm{E}+00$ & 0.0000 & $0.000 \mathrm{E}+00$ & 0.0000 & $9.268 \mathrm{E}-14$ & 0.0000 \\
\hline 238 & $0.000 \mathrm{E}+00$ & 0.0000 & $0.000 \mathrm{E}+00$ & 0.0000 & $0.000 \mathrm{E}+00$ & 0.0000 & $0.000 \mathrm{E}+00$ & 0.0000 & $0.000 \mathrm{E}+00$ & 0.0000 & $0.000 \mathrm{E}+00$ & 0.0000 & $1.163 \mathrm{E}-22$ & 0.0000 \\
\hline 239 & $0.000 \mathrm{E}+00$ & 0.0000 & $0.000 \mathrm{E}+00$ & 0.0000 & $0.000 \mathrm{E}+00$ & 0.0000 & $0.000 \mathrm{E}+00$ & 0.0000 & $0.000 \mathrm{E}+00$ & 0.0000 & $0.000 \mathrm{E}+00$ & 0.0000 & $1.170 \mathrm{E}-18$ & 0.0000 \\
\hline 240 & $0.000 \mathrm{E}+00$ & 0.0000 & $0.000 \mathrm{E}+00$ & 0.0000 & $0.000 \mathrm{E}+00$ & 0.0000 & $0.000 \mathrm{E}+00$ & 0.0000 & $0.000 \mathrm{E}+00$ & 0.0000 & $0.000 \mathrm{E}+00$ & 0.0000 & $1.142 \mathrm{E}-25$ & 0.0000 \\
\hline 99 & $0.000 \mathrm{E}+00$ & 0.0000 & $0.000 \mathrm{E}+00$ & 0.0000 & $0.000 \mathrm{E}+00$ & 0.0000 & $0.000 \mathrm{E}+00$ & 0.0000 & $0.000 \mathrm{E}+00$ & 0.0000 & $0.000 \mathrm{E}+00$ & 0.0000 & $5.625 \mathrm{E}-27$ & 0.0000 \\
\hline 228 & $0.000 \mathrm{E}+00$ & 0.0000 & $0.000 \mathrm{E}+00$ & 0.0000 & $0.000 \mathrm{E}+00$ & 0.0000 & $0.000 \mathrm{E}+00$ & 0.0000 & $0.000 \mathrm{E}+00$ & 0.0000 & $0.000 \mathrm{E}+00$ & 0.0000 & $9.308 \mathrm{E}-08$ & 0.9321 \\
\hline 230 & $0.000 \mathrm{E}+00$ & 0.0000 & $0.000 \mathrm{E}+00$ & 0.0000 & $0.000 \mathrm{E}+00$ & 0.0000 & $0.000 \mathrm{E}+00$ & 0.0000 & $0.000 \mathrm{E}+00$ & 0.0000 & $0.000 \mathrm{E}+00$ & 0.0000 & $1.095 \mathrm{E}-11$ & 0.0001 \\
\hline 232 & $0.000 \mathrm{E}+00$ & 0.0000 & $0.000 \mathrm{E}+00$ & 0.0000 & $0.000 \mathrm{E}+00$ & 0.0000 & $0.000 \mathrm{E}+00$ & 0.0000 & $0.000 \mathrm{E}+00$ & 0.0000 & $0.000 \mathrm{E}+00$ & 0.0000 & $6.633 E-09$ & 0.0664 \\
\hline & $0.000 \mathrm{E}+00$ & 0.0000 & $0.000 \mathrm{E}+00$ & 0.0000 & $0.000 \mathrm{E}+00$ & 0.0000 & $0.000 \mathrm{E}+00$ & 0.0000 & $0.000 \mathrm{E}+00$ & 0.0000 & $0.000 \mathrm{E}+00$ & 0.0000 & $7.671 \mathrm{E}-17$ & 0.0000 \\
\hline 35 & $0.000 \mathrm{E}+00$ & 0.0000 & $0.000 \mathrm{E}+00$ & 0.0000 & $0.000 \mathrm{E}+00$ & 0.0000 & $0.000 \mathrm{E}+00$ & 0.0000 & $0.000 \mathrm{E}+00$ & 0.0000 & $0.000 \mathrm{E}+00$ & 0.0000 & $1.217 \mathrm{E}-15$ & 0.0000 \\
\hline 38 & $0.000 \mathrm{E}+00$ & 0.0000 & $0.000 \mathrm{E}+00$ & 0.0000 & $0.000 \mathrm{E}+00$ & 0.0000 & $0.000 \mathrm{E}+00$ & 0.0000 & $0.000 \mathrm{E}+00$ & 0.0000 & $0.000 \mathrm{E}+00$ & 0.0000 & $1.376 \mathrm{E}-11$ & 0.0001 \\
\hline & $0.000 \mathrm{E}+00$ & 0.0000 & $0.000 \mathrm{E}+00$ & 0.0000 & $0.000 \mathrm{E}+00$ & 0.0000 & $0.000 \mathrm{E}+00$ & 0.0000 & $0.000 \mathrm{E}+00$ & 0.0000 & $0.000 E+00$ & 000 & -08 & 1.0000 \\
\hline
\end{tabular}

* Sum of all water independent and dependent pathways. 
RESRAD, Version 6.5

$\mathrm{T}^{1 / 2}$ Limit $=180$ days

$07 / 21 / 2011$

$17: 07$

ummary : RESRAD Parameters for U-Landfill Recreational User

File : C: $\backslash$ RESRAD_FAMILY \RESRAD \USERFILES $\backslash Q C F O R S R S G \backslash R U \_S R S G-M A Y 11 . R A D$

Total Dose Contributions TDOSE (i,p,t) for Individual Radionuclides (i) and Pathways (p) As mrem/yr and Fraction of Total Dose At $t=1.200 \mathrm{E}+01$ years

Water Independent Pathways (Inhalation excludes radon)

\begin{tabular}{|c|c|c|c|c|c|c|c|c|c|c|c|c|c|c|}
\hline \multirow{2}{*}{ Nuclide } & \multicolumn{2}{|c|}{ Ground } & \multicolumn{2}{|c|}{ Inhalation } & \multicolumn{2}{|c|}{ Radon } & \multicolumn{2}{|c|}{ Plant } & \multicolumn{2}{|c|}{ Meat } & \multicolumn{2}{|c|}{ Milk } & \multicolumn{2}{|c|}{ Soil } \\
\hline & mrem/yr & fract. & mrem/yr & fract. & mrem/yr & fract. & mrem/yr & fract. & mrem/yr & fract. & mrem/yr & fract. & mrem/yr & fract. \\
\hline-241 & $4.182 \mathrm{E}-19$ & 0.0000 & $0.000 \mathrm{E}+00$ & 0.0000 & $0.000 \mathrm{E}+00$ & 0.0000 & $0.000 \mathrm{E}+00$ & 0.0000 & $0.000 \mathrm{E}+00$ & 0.0000 & $0.000 \mathrm{E}+00$ & 0.0000 & $0.000 \mathrm{E}+00$ & 0.0000 \\
\hline-137 & $1.017 \mathrm{E}-10$ & 0.0009 & $0.000 \mathrm{E}+00$ & 0.0000 & $0.000 \mathrm{E}+00$ & 0.0000 & $0.000 \mathrm{E}+00$ & 0.0000 & $0.000 \mathrm{E}+00$ & 0.0000 & $0.000 \mathrm{E}+00$ & 0.0000 & $0.000 \mathrm{E}+00$ & 0.0000 \\
\hline-237 & $1.043 E-13$ & 0.0000 & $0.000 \mathrm{E}+00$ & 0.0000 & $0.000 \mathrm{E}+00$ & 0.0000 & $0.000 \mathrm{E}+00$ & 0.0000 & $0.000 \mathrm{E}+00$ & 0.0000 & $0.000 \mathrm{E}+00$ & 0.0000 & $0.000 \mathrm{E}+00$ & 0.0000 \\
\hline-238 & $6.388 E-20$ & 0.0000 & $0.000 \mathrm{E}+00$ & 0.0000 & $0.000 \mathrm{E}+00$ & 0.0000 & $0.000 \mathrm{E}+00$ & 0.0000 & $0.000 \mathrm{E}+00$ & 0.0000 & $0.000 \mathrm{E}+00$ & 0.0000 & $0.000 \mathrm{E}+00$ & 0.0000 \\
\hline-239 & 1. $334 \mathrm{E}-18$ & 0.0000 & $0.000 \mathrm{E}+00$ & 0.0000 & $0.000 \mathrm{E}+00$ & 0.0000 & $0.000 \mathrm{E}+00$ & 0.0000 & $0.000 \mathrm{E}+00$ & 0.0000 & $0.000 \mathrm{E}+00$ & 0.0000 & $0.000 \mathrm{E}+00$ & 0.0000 \\
\hline-240 & $4.313 E-24$ & 0.0000 & $0.000 \mathrm{E}+00$ & 0.0000 & $0.000 \mathrm{E}+00$ & 0.0000 & $0.000 \mathrm{E}+00$ & 0.0000 & $0.000 \mathrm{E}+00$ & 0.0000 & $0.000 \mathrm{E}+00$ & 0.0000 & $0.000 \mathrm{E}+00$ & 0.0000 \\
\hline 99 & $6.555 E-27$ & 0.0000 & $0.000 \mathrm{E}+00$ & 0.0000 & $0.000 \mathrm{E}+00$ & 0.0000 & $0.000 \mathrm{E}+00$ & 0.0000 & $0.000 \mathrm{E}+00$ & 0.0000 & $0.000 \mathrm{E}+00$ & 0.0000 & $0.000 \mathrm{E}+00$ & 0.0000 \\
\hline-228 & $1.847 \mathrm{E}-09$ & 0.0156 & $0.000 \mathrm{E}+00$ & 0.0000 & $0.000 \mathrm{E}+00$ & 0.0000 & $0.000 \mathrm{E}+00$ & 0.0000 & $0.000 \mathrm{E}+00$ & 0.0000 & $0.000 \mathrm{E}+00$ & 0.0000 & $0.000 \mathrm{E}+00$ & 0.0000 \\
\hline 230 & $9.820 \mathrm{E}-11$ & 0.0008 & $0.000 \mathrm{E}+00$ & 0.0000 & $0.000 \mathrm{E}+00$ & 0.0000 & $0.000 \mathrm{E}+00$ & 0.0000 & $0.000 \mathrm{E}+00$ & 0.0000 & $0.000 \mathrm{E}+00$ & 0.0000 & $0.000 \mathrm{E}+00$ & 0.0000 \\
\hline-232 & $1.162 \mathrm{E}-07$ & 0.9826 & $0.000 \mathrm{E}+00$ & 0.0000 & $0.000 \mathrm{E}+00$ & 0.0000 & $0.000 \mathrm{E}+00$ & 0.0000 & $0.000 \mathrm{E}+00$ & 0.0000 & $0.000 \mathrm{E}+00$ & 0.0000 & $0.000 \mathrm{E}+00$ & 0.0000 \\
\hline 234 & $5.533 E-15$ & 0.0000 & $0.000 \mathrm{E}+00$ & 0.0000 & $0.000 \mathrm{E}+00$ & 0.0000 & $0.000 \mathrm{E}+00$ & 0.0000 & $0.000 \mathrm{E}+00$ & 0.0000 & $0.000 \mathrm{E}+00$ & 0.0000 & $0.000 \mathrm{E}+00$ & 0.0000 \\
\hline 35 & $1.805 \mathrm{E}-15$ & 0.0000 & $0.000 \mathrm{E}+00$ & 0.0000 & $0.000 \mathrm{E}+00$ & 0.0000 & $0.000 \mathrm{E}+00$ & 0.0000 & $0.000 \mathrm{E}+00$ & 0.0000 & $0.000 \mathrm{E}+00$ & 0.0000 & $0.000 \mathrm{E}+00$ & 0.0000 \\
\hline 38 & $1.502 \mathrm{E}-11$ & 0.0001 & $0.000 \mathrm{E}+00$ & 0.0000 & $0.000 \mathrm{E}+00$ & 0.0000 & $0.000 \mathrm{E}+00$ & 0.0000 & $0.000 \mathrm{E}+00$ & 0.0000 & $0.000 \mathrm{E}+00$ & 0.0000 & $0.000 \mathrm{E}+00$ & 0.0000 \\
\hline & $1.182 \mathrm{E}-07$ & 1.0000 & $0.000 \mathrm{E}+00$ & 0.0000 & $0.000 \mathrm{E}+00$ & 0.0000 & $0.000 \mathrm{E}+00$ & 0.0000 & $0.000 \mathrm{E}+00$ & 0.0000 & $0.000 \mathrm{E}+00$ & 0.0000 & $0.000 \mathrm{E}+00$ & 0.0000 \\
\hline
\end{tabular}

Total Dose Contributions TDOSE(i,p,t) for Individual Radionuclides (i) and Pathways (p) As mrem/yr and Fraction of Total Dose At $t=1.200 \mathrm{E}+01$ years

Water Dependent Pathways

\begin{tabular}{|c|c|c|c|c|c|c|c|c|c|c|c|c|c|c|}
\hline \multirow{2}{*}{$\begin{array}{l}\text { Radio- } \\
\text { Nuclide }\end{array}$} & \multicolumn{2}{|c|}{ Water } & \multicolumn{2}{|c|}{ Fish } & \multicolumn{2}{|c|}{ Radon } & \multicolumn{2}{|c|}{ Plant } & \multicolumn{2}{|c|}{ Meat } & \multicolumn{2}{|c|}{ Milk } & \multicolumn{2}{|c|}{ All Pathways* } \\
\hline & mrem/yr & fract. & mrem/yr & fract. & mrem/yr & fract. & mrem/yr & fract. & mrem/yr & fract. & mrem/yr & fract. & mrem/yr & fract. \\
\hline 241 & $0.000 \mathrm{E}+00$ & 0.0000 & $0.000 \mathrm{E}+00$ & 0.0000 & $0.000 \mathrm{E}+00$ & 0.0000 & $0.000 \mathrm{E}+00$ & 0.0000 & $0.000 \mathrm{E}+00$ & 0.0000 & $0.000 \mathrm{E}+00$ & 0.0000 & $4.182 \mathrm{E}-19$ & 0.0000 \\
\hline-137 & $0.000 \mathrm{E}+00$ & 0.0000 & $0.000 \mathrm{E}+00$ & 0.0000 & $0.000 \mathrm{E}+00$ & 0.0000 & $0.000 \mathrm{E}+00$ & 0.0000 & $0.000 \mathrm{E}+00$ & 0.0000 & $0.000 \mathrm{E}+00$ & 0.0000 & $1.017 \mathrm{E}-10$ & 0.0009 \\
\hline-237 & $0.000 \mathrm{E}+00$ & 0.0000 & $0.000 \mathrm{E}+00$ & 0.0000 & $0.000 \mathrm{E}+00$ & 0.0000 & $0.000 \mathrm{E}+00$ & 0.0000 & $0.000 \mathrm{E}+00$ & 0.0000 & $0.000 \mathrm{E}+00$ & 0.0000 & $1.043 E-13$ & 0.0000 \\
\hline-238 & $0.000 \mathrm{E}+00$ & 0.0000 & $0.000 \mathrm{E}+00$ & 0.0000 & $0.000 \mathrm{E}+00$ & 0.0000 & $0.000 \mathrm{E}+00$ & 0.0000 & $0.000 \mathrm{E}+00$ & 0.0000 & $0.000 \mathrm{E}+00$ & 0.0000 & $6.388 \mathrm{E}-20$ & 0.0000 \\
\hline-239 & $0.000 \mathrm{E}+00$ & 0.0000 & $0.000 \mathrm{E}+00$ & 0.0000 & $0.000 \mathrm{E}+00$ & 0.0000 & $0.000 \mathrm{E}+00$ & 0.0000 & $0.000 \mathrm{E}+00$ & 0.0000 & $0.000 E+00$ & 0.0000 & $1.334 \mathrm{E}-18$ & 0.0000 \\
\hline-240 & $0.000 \mathrm{E}+00$ & 0.0000 & $0.000 \mathrm{E}+00$ & 0.0000 & $0.000 \mathrm{E}+00$ & 0.0000 & $0.000 \mathrm{E}+00$ & 0.0000 & $0.000 \mathrm{E}+00$ & 0.0000 & $0.000 E+00$ & 0.0000 & $4.313 E-24$ & 0.0000 \\
\hline-99 & $0.000 \mathrm{E}+00$ & 0.0000 & $0.000 \mathrm{E}+00$ & 0.0000 & $0.000 \mathrm{E}+00$ & 0.0000 & $0.000 \mathrm{E}+00$ & 0.0000 & $0.000 \mathrm{E}+00$ & 0.0000 & $0.000 \mathrm{E}+00$ & 0.0000 & $6.555 \mathrm{E}-27$ & 0.0000 \\
\hline-228 & $0.000 \mathrm{E}+00$ & 0.0000 & $0.000 \mathrm{E}+00$ & 0.0000 & $0.000 \mathrm{E}+00$ & 0.0000 & $0.000 \mathrm{E}+00$ & 0.0000 & $0.000 \mathrm{E}+00$ & 0.0000 & $0.000 \mathrm{E}+00$ & 0.0000 & $1.847 \mathrm{E}-09$ & 0.0156 \\
\hline-230 & $0.000 \mathrm{E}+00$ & 0.0000 & $0.000 \mathrm{E}+00$ & 0.0000 & $0.000 \mathrm{E}+00$ & 0.0000 & $0.000 \mathrm{E}+00$ & 0.0000 & $0.000 \mathrm{E}+00$ & 0.0000 & $0.000 E+00$ & 0.0000 & $9.820 \mathrm{E}-11$ & 0.0008 \\
\hline 232 & $0.000 \mathrm{E}+00$ & 0.0000 & $0.000 \mathrm{E}+00$ & 0.0000 & $0.000 \mathrm{E}+00$ & 0.0000 & $0.000 \mathrm{E}+00$ & 0.0000 & $0.000 \mathrm{E}+00$ & 0.0000 & $0.000 \mathrm{E}+00$ & 0.0000 & $1.162 \mathrm{E}-07$ & 0.9826 \\
\hline 34 & $0.000 \mathrm{E}+00$ & 0.0000 & $0.000 \mathrm{E}+00$ & 0.0000 & $0.000 \mathrm{E}+00$ & 0.0000 & $0.000 \mathrm{E}+00$ & 0.0000 & $0.000 \mathrm{E}+00$ & 0.0000 & $0.000 \mathrm{E}+00$ & 0.0000 & $5.533 \mathrm{E}-15$ & 0.0000 \\
\hline 35 & $0.000 \mathrm{E}+00$ & 0.0000 & $0.000 \mathrm{E}+00$ & 0.0000 & $0.000 \mathrm{E}+00$ & 0.0000 & $0.000 \mathrm{E}+00$ & 0.0000 & $0.000 \mathrm{E}+00$ & 0.0000 & $0.000 \mathrm{E}+00$ & 0.0000 & $1.805 \mathrm{E}-15$ & 0.0000 \\
\hline 38 & $0.000 \mathrm{E}+00$ & 0.0000 & $0.000 \mathrm{E}+00$ & 0.0000 & $0.000 \mathrm{E}+00$ & 0.0000 & $0.000 \mathrm{E}+00$ & 0.0000 & $0.000 \mathrm{E}+00$ & 0.0000 & $0.000 \mathrm{E}+00$ & 0.0000 & $1.502 \mathrm{E}-11$ & 0.0001 \\
\hline & $0.000 \mathrm{E}+00$ & 0.0000 & $0.000 \mathrm{E}+00$ & 0.0000 & $0.000 \mathrm{E}+00$ & 0.0000 & $0.000 \mathrm{E}+00$ & 0.0000 & $0.000 \mathrm{E}+00$ & 0.0000 & $0.000 \mathrm{E}+00$ & 0.0000 & $1.182 \mathrm{E}-07$ & 1.0000 \\
\hline
\end{tabular}

* Sum of all water independent and dependent pathways. 
RESRAD, Version 6.5

$\mathrm{T}^{1 / 2}$ Limit $=180$ days

$07 / 21 / 2011$

17:07 Page

23

Summary : RESRAD Parameters for U-Landfill Recreational User
File : C: $\backslash$ RESRAD_FAMILY \RESRAD \USERFILES $\backslash Q C F O R S R S G \backslash R U$ SRSG-MAY11.RAD

Total Dose Contributions TDOSE(i,p,t) for Individual Radionuclides (i) and Pathways (p) As mrem/yr and Fraction of Total Dose At $t=5.000 \mathrm{E}+01$ years

Water Independent Pathways (Inhalation excludes radon)

\begin{tabular}{|c|c|c|c|c|c|c|c|c|c|c|c|c|c|c|}
\hline \multirow{2}{*}{ Nuclide } & \multicolumn{2}{|c|}{ Ground } & \multicolumn{2}{|c|}{ Inhalation } & \multicolumn{2}{|c|}{ Radon } & \multicolumn{2}{|c|}{ Plant } & \multicolumn{2}{|c|}{ Meat } & \multicolumn{2}{|c|}{ Milk } & \multicolumn{2}{|c|}{ Soil } \\
\hline & mrem/yr & fract. & mrem/yr & fract. & mrem/yr & fract. & mrem/yr & fract. & mrem/yr & fract. & mrem/yr & fract. & mrem/yr & fract. \\
\hline-241 & $2.469 \mathrm{E}-18$ & 0.0000 & $0.000 \mathrm{E}+00$ & 0.0000 & $0.000 \mathrm{E}+00$ & 0.0000 & $0.000 \mathrm{E}+00$ & 0.0000 & $0.000 \mathrm{E}+00$ & 0.0000 & $0.000 \mathrm{E}+00$ & 0.0000 & $0.000 \mathrm{E}+00$ & 0.0000 \\
\hline-137 & $5.821 E-11$ & 0.0003 & $0.000 \mathrm{E}+00$ & 0.0000 & $0.000 \mathrm{E}+00$ & 0.0000 & $0.000 \mathrm{E}+00$ & 0.0000 & $0.000 \mathrm{E}+00$ & 0.0000 & $0.000 \mathrm{E}+00$ & 0.0000 & $0.000 \mathrm{E}+00$ & 0.0000 \\
\hline-237 & $1.570 \mathrm{E}-13$ & 0.0000 & $0.000 \mathrm{E}+00$ & 0.0000 & $0.000 \mathrm{E}+00$ & 0.0000 & $0.000 \mathrm{E}+00$ & 0.0000 & $0.000 \mathrm{E}+00$ & 0.0000 & $0.000 \mathrm{E}+00$ & 0.0000 & $0.000 \mathrm{E}+00$ & 0.0000 \\
\hline-238 & $5.065 E-18$ & 0.0000 & $0.000 \mathrm{E}+00$ & 0.0000 & $0.000 \mathrm{E}+00$ & 0.0000 & $0.000 \mathrm{E}+00$ & 0.0000 & $0.000 \mathrm{E}+00$ & 0.0000 & $0.000 \mathrm{E}+00$ & 0.0000 & $0.000 \mathrm{E}+00$ & 0.0000 \\
\hline-239 & $2.100 \mathrm{E}-18$ & 0.0000 & $0.000 \mathrm{E}+00$ & 0.0000 & $0.000 \mathrm{E}+00$ & 0.0000 & $0.000 \mathrm{E}+00$ & 0.0000 & $0.000 \mathrm{E}+00$ & 0.0000 & $0.000 \mathrm{E}+00$ & 0.0000 & $0.000 \mathrm{E}+00$ & 0.0000 \\
\hline-240 & $2.579 \mathrm{E}-22$ & 0.0000 & $0.000 \mathrm{E}+00$ & 0.0000 & $0.000 \mathrm{E}+00$ & 0.0000 & $0.000 \mathrm{E}+00$ & 0.0000 & $0.000 \mathrm{E}+00$ & 0.0000 & $0.000 \mathrm{E}+00$ & 0.0000 & $0.000 \mathrm{E}+00$ & 0.0000 \\
\hline 99 & $1.112 \mathrm{E}-26$ & 0.0000 & $0.000 \mathrm{E}+00$ & 0.0000 & $0.000 \mathrm{E}+00$ & 0.0000 & $0.000 \mathrm{E}+00$ & 0.0000 & $0.000 \mathrm{E}+00$ & 0.0000 & $0.000 \mathrm{E}+00$ & 0.0000 & $0.000 \mathrm{E}+00$ & 0.0000 \\
\hline-228 & $2.430 \mathrm{E}-15$ & 0.0000 & $0.000 \mathrm{E}+00$ & 0.0000 & $0.000 \mathrm{E}+00$ & 0.0000 & $0.000 \mathrm{E}+00$ & 0.0000 & $0.000 \mathrm{E}+00$ & 0.0000 & $0.000 \mathrm{E}+00$ & 0.0000 & $0.000 \mathrm{E}+00$ & 0.0000 \\
\hline 230 & $5.116 \mathrm{E}-10$ & 0.0024 & $0.000 \mathrm{E}+00$ & 0.0000 & $0.000 \mathrm{E}+00$ & 0.0000 & $0.000 \mathrm{E}+00$ & 0.0000 & $0.000 \mathrm{E}+00$ & 0.0000 & $0.000 \mathrm{E}+00$ & 0.0000 & $0.000 \mathrm{E}+00$ & 0.0000 \\
\hline-232 & $2.155 E-07$ & 0.9973 & $0.000 \mathrm{E}+00$ & 0.0000 & $0.000 \mathrm{E}+00$ & 0.0000 & $0.000 \mathrm{E}+00$ & 0.0000 & $0.000 \mathrm{E}+00$ & 0.0000 & $0.000 \mathrm{E}+00$ & 0.0000 & $0.000 \mathrm{E}+00$ & 0.0000 \\
\hline 34 & $1.167 \mathrm{E}-13$ & 0.0000 & $0.000 \mathrm{E}+00$ & 0.0000 & $0.000 \mathrm{E}+00$ & 0.0000 & $0.000 \mathrm{E}+00$ & 0.0000 & $0.000 \mathrm{E}+00$ & 0.0000 & $0.000 \mathrm{E}+00$ & 0.0000 & $0.000 \mathrm{E}+00$ & 0.0000 \\
\hline 35 & $8.886 \mathrm{E}-15$ & 0.0000 & $0.000 \mathrm{E}+00$ & 0.0000 & $0.000 \mathrm{E}+00$ & 0.0000 & $0.000 \mathrm{E}+00$ & 0.0000 & $0.000 \mathrm{E}+00$ & 0.0000 & $0.000 \mathrm{E}+00$ & 0.0000 & $0.000 \mathrm{E}+00$ & 0.0000 \\
\hline 38 & $2.035 E-11$ & 0.0001 & $0.000 \mathrm{E}+00$ & 0.0000 & $0.000 \mathrm{E}+00$ & 0.0000 & $0.000 \mathrm{E}+00$ & 0.0000 & $0.000 \mathrm{E}+00$ & 0.0000 & $0.000 \mathrm{E}+00$ & 0.0000 & $0.000 \mathrm{E}+00$ & 0.0000 \\
\hline & $2.161 \mathrm{E}-07$ & 1.0000 & $0.000 \mathrm{E}+00$ & 0.0000 & $0.000 \mathrm{E}+00$ & 0.0000 & $0.000 \mathrm{E}+00$ & 0.0000 & $0.000 \mathrm{E}+00$ & 0.0000 & $0.000 \mathrm{E}+00$ & 0.0000 & $.000 \mathrm{E}+00$ & 0.0000 \\
\hline
\end{tabular}

Total Dose Contributions TDOSE(i,p,t) for Individual Radionuclides (i) and Pathways (p) As mrem/yr and Fraction of Total Dose At $t=5.000 \mathrm{E}+01$ years

Water Dependent Pathways

\begin{tabular}{|c|c|c|c|c|c|c|c|c|c|c|c|c|c|c|}
\hline \multirow{2}{*}{ Nuclide } & \multicolumn{2}{|c|}{ Water } & \multicolumn{2}{|c|}{ Fish } & \multicolumn{2}{|c|}{ Radon } & \multicolumn{2}{|c|}{ Plant } & \multicolumn{2}{|c|}{ Meat } & \multicolumn{2}{|c|}{ Milk } & \multicolumn{2}{|c|}{ All Pathways* } \\
\hline & mrem/yr & fract. & mrem/yr & fract. & mrem/yr & fract. & mrem/yr & fract. & mrem/yr & fract. & mrem/yr & fract. & mrem/yr & fract. \\
\hline-241 & $0.000 \mathrm{E}+00$ & 0.0000 & $0.000 \mathrm{E}+00$ & 0.0000 & $0.000 \mathrm{E}+00$ & 0.0000 & $0.000 \mathrm{E}+00$ & 0.0000 & $0.000 \mathrm{E}+00$ & 0.0000 & $0.000 E+00$ & 0.0000 & $2.469 \mathrm{E}-18$ & 0.0000 \\
\hline-137 & $0.000 \mathrm{E}+00$ & 0.0000 & $0.000 \mathrm{E}+00$ & 0.0000 & $0.000 \mathrm{E}+00$ & 0.0000 & $0.000 \mathrm{E}+00$ & 0.0000 & $0.000 \mathrm{E}+00$ & 0.0000 & $0.000 \mathrm{E}+00$ & 0.0000 & $5.821 \mathrm{E}-11$ & 0.0003 \\
\hline-237 & $0.000 \mathrm{E}+00$ & 0.0000 & $0.000 \mathrm{E}+00$ & 0.0000 & $0.000 \mathrm{E}+00$ & 0.0000 & $0.000 \mathrm{E}+00$ & 0.0000 & $0.000 \mathrm{E}+00$ & 0.0000 & $0.000 \mathrm{E}+00$ & 0.0000 & $1.570 \mathrm{E}-13$ & 0.0000 \\
\hline-238 & $0.000 \mathrm{E}+00$ & 0.0000 & $0.000 \mathrm{E}+00$ & 0.0000 & $0.000 \mathrm{E}+00$ & 0.0000 & $0.000 \mathrm{E}+00$ & 0.0000 & $0.000 \mathrm{E}+00$ & 0.0000 & $0.000 \mathrm{E}+00$ & 0.0000 & $5.065 \mathrm{E}-18$ & 0.0000 \\
\hline-239 & $0.000 \mathrm{E}+00$ & 0.0000 & $0.000 \mathrm{E}+00$ & 0.0000 & $0.000 \mathrm{E}+00$ & 0.0000 & $0.000 \mathrm{E}+00$ & 0.0000 & $0.000 \mathrm{E}+00$ & 0.0000 & $0.000 \mathrm{E}+00$ & 0.0000 & $2.100 \mathrm{E}-18$ & 0.0000 \\
\hline-240 & $0.000 \mathrm{E}+00$ & 0.0000 & $0.000 \mathrm{E}+00$ & 0.0000 & $0.000 \mathrm{E}+00$ & 0.0000 & $0.000 \mathrm{E}+00$ & 0.0000 & $0.000 \mathrm{E}+00$ & 0.0000 & $0.000 \mathrm{E}+00$ & 0.0000 & $2.579 E-22$ & 0.0000 \\
\hline-99 & $0.000 \mathrm{E}+00$ & 0.0000 & $0.000 \mathrm{E}+00$ & 0.0000 & $0.000 \mathrm{E}+00$ & 0.0000 & $0.000 \mathrm{E}+00$ & 0.0000 & $0.000 \mathrm{E}+00$ & 0.0000 & $0.000 \mathrm{E}+00$ & 0.0000 & $1.112 \mathrm{E}-26$ & 0.0000 \\
\hline-228 & $0.000 \mathrm{E}+00$ & 0.0000 & $0.000 \mathrm{E}+00$ & 0.0000 & $0.000 \mathrm{E}+00$ & 0.0000 & $0.000 \mathrm{E}+00$ & 0.0000 & $0.000 \mathrm{E}+00$ & 0.0000 & $0.000 \mathrm{E}+00$ & 0.0000 & $2.430 \mathrm{E}-15$ & 0.0000 \\
\hline 230 & $0.000 \mathrm{E}+00$ & 0.0000 & $0.000 \mathrm{E}+00$ & 0.0000 & $0.000 \mathrm{E}+00$ & 0.0000 & $0.000 \mathrm{E}+00$ & 0.0000 & $0.000 \mathrm{E}+00$ & 0.0000 & $0.000 \mathrm{E}+00$ & 0.0000 & $5.116 \mathrm{E}-10$ & 0.0024 \\
\hline 232 & $0.000 \mathrm{E}+00$ & 0.0000 & $0.000 \mathrm{E}+00$ & 0.0000 & $0.000 \mathrm{E}+00$ & 0.0000 & $0.000 \mathrm{E}+00$ & 0.0000 & $0.000 \mathrm{E}+00$ & 0.0000 & $0.000 \mathrm{E}+00$ & 0.0000 & $2.155 \mathrm{E}-07$ & 0.9973 \\
\hline 34 & $0.000 \mathrm{E}+00$ & 0.0000 & $0.000 \mathrm{E}+00$ & 0.0000 & $0.000 \mathrm{E}+00$ & 0.0000 & $0.000 \mathrm{E}+00$ & 0.0000 & $0.000 \mathrm{E}+00$ & 0.0000 & $0.000 \mathrm{E}+00$ & 0.0000 & $1.167 \mathrm{E}-13$ & 0.0000 \\
\hline 35 & $0.000 \mathrm{E}+00$ & 0.0000 & $0.000 \mathrm{E}+00$ & 0.0000 & $0.000 \mathrm{E}+00$ & 0.0000 & $0.000 \mathrm{E}+00$ & 0.0000 & $0.000 \mathrm{E}+00$ & 0.0000 & $0.000 \mathrm{E}+00$ & 0.0000 & $8.886 \mathrm{E}-15$ & 0.0000 \\
\hline 38 & $0.000 \mathrm{E}+00$ & 0.0000 & $0.000 \mathrm{E}+00$ & 0.0000 & $0.000 \mathrm{E}+00$ & 0.0000 & $0.000 \mathrm{E}+00$ & 0.0000 & $0.000 \mathrm{E}+00$ & 0.0000 & $0.000 \mathrm{E}+00$ & 0.0000 & $2.035 \mathrm{E}-11$ & 0.0001 \\
\hline & $0.000 \mathrm{E}+00$ & 0.0000 & $0.000 \mathrm{E}+00$ & 0.0000 & $0.000 \mathrm{E}+00$ & 0.0000 & $0.000 \mathrm{E}+00$ & 0.0000 & $0.000 \mathrm{E}+00$ & 0.0000 & $0.000 \mathrm{E}+00$ & 0.0000 & $1 E-07$ & 1.0000 \\
\hline
\end{tabular}

* Sum of all water independent and dependent pathways. 
RESRAD, Version 6.5

$\mathrm{T}^{1 / 2}$ Limit $=180$ days

$07 / 21 / 2011$

17:07 Page

24

Summary : RESRAD Parameters for U-Landfill Recreational User
File : C: $\backslash$ RESRAD_FAMILY \RESRAD $\backslash U S E R F I L E S \backslash Q C F O R S R S G \backslash R U$ SRSG-MAY11.RAD

Total Dose Contributions TDOSE(i,p,t) for Individual Radionuclides (i) and Pathways (p) As mrem/yr and Fraction of Total Dose At $t=1.000 \mathrm{E}+02$ years

Water Independent Pathways (Inhalation excludes radon)

\begin{tabular}{|c|c|c|c|c|c|c|c|c|c|c|c|c|c|c|}
\hline \multirow{2}{*}{ Nuclide } & \multicolumn{2}{|c|}{ Ground } & \multicolumn{2}{|c|}{ Inhalation } & \multicolumn{2}{|c|}{ Radon } & \multicolumn{2}{|c|}{ Plant } & \multicolumn{2}{|c|}{ Meat } & \multicolumn{2}{|c|}{ Milk } & \multicolumn{2}{|c|}{ Soil } \\
\hline & mrem/yr & fract. & mrem/yr & fract. & mrem/yr & fract. & mrem/yr & fract. & mrem/yr & fract. & mrem/yr & fract. & mrem/yr & fract. \\
\hline-241 & $8.102 \mathrm{E}-18$ & 0.0000 & $0.000 \mathrm{E}+00$ & 0.0000 & $0.000 \mathrm{E}+00$ & 0.0000 & $0.000 \mathrm{E}+00$ & 0.0000 & $0.000 \mathrm{E}+00$ & 0.0000 & $0.000 \mathrm{E}+00$ & 0.0000 & $0.000 \mathrm{E}+00$ & 0.0000 \\
\hline-137 & $2.793 E-11$ & 0.0001 & $0.000 \mathrm{E}+00$ & 0.0000 & $0.000 \mathrm{E}+00$ & 0.0000 & $0.000 \mathrm{E}+00$ & 0.0000 & $0.000 \mathrm{E}+00$ & 0.0000 & $0.000 \mathrm{E}+00$ & 0.0000 & $0.000 \mathrm{E}+00$ & 0.0000 \\
\hline-237 & $2.696 \mathrm{E}-13$ & 0.0000 & $0.000 \mathrm{E}+00$ & 0.0000 & $0.000 \mathrm{E}+00$ & 0.0000 & $0.000 \mathrm{E}+00$ & 0.0000 & $0.000 \mathrm{E}+00$ & 0.0000 & $0.000 \mathrm{E}+00$ & 0.0000 & $0.000 \mathrm{E}+00$ & 0.0000 \\
\hline-238 & $5.122 \mathrm{E}-17$ & 0.0000 & $0.000 \mathrm{E}+00$ & 0.0000 & $0.000 \mathrm{E}+00$ & 0.0000 & $0.000 \mathrm{E}+00$ & 0.0000 & $0.000 \mathrm{E}+00$ & 0.0000 & $0.000 \mathrm{E}+00$ & 0.0000 & $0.000 \mathrm{E}+00$ & 0.0000 \\
\hline-239 & $3.817 \mathrm{E}-18$ & 0.0000 & $0.000 \mathrm{E}+00$ & 0.0000 & $0.000 \mathrm{E}+00$ & 0.0000 & $0.000 \mathrm{E}+00$ & 0.0000 & $0.000 \mathrm{E}+00$ & 0.0000 & $0.000 \mathrm{E}+00$ & 0.0000 & $0.000 \mathrm{E}+00$ & 0.0000 \\
\hline-240 & $1.716 \mathrm{E}-21$ & 0.0000 & $0.000 \mathrm{E}+00$ & 0.0000 & $0.000 \mathrm{E}+00$ & 0.0000 & $0.000 \mathrm{E}+00$ & 0.0000 & $0.000 \mathrm{E}+00$ & 0.0000 & $0.000 \mathrm{E}+00$ & 0.0000 & $0.000 \mathrm{E}+00$ & 0.0000 \\
\hline 99 & $2.231 E-26$ & 0.0000 & $0.000 \mathrm{E}+00$ & 0.0000 & $0.000 \mathrm{E}+00$ & 0.0000 & $0.000 \mathrm{E}+00$ & 0.0000 & $0.000 \mathrm{E}+00$ & 0.0000 & $0.000 \mathrm{E}+00$ & 0.0000 & $0.000 \mathrm{E}+00$ & 0.0000 \\
\hline-228 & $4.441 E-23$ & 0.0000 & $0.000 \mathrm{E}+00$ & 0.0000 & $0.000 \mathrm{E}+00$ & 0.0000 & $0.000 \mathrm{E}+00$ & 0.0000 & $0.000 \mathrm{E}+00$ & 0.0000 & $0.000 \mathrm{E}+00$ & 0.0000 & $0.000 \mathrm{E}+00$ & 0.0000 \\
\hline-230 & 1. $423 E-09$ & 0.0049 & $0.000 \mathrm{E}+00$ & 0.0000 & $0.000 \mathrm{E}+00$ & 0.0000 & $0.000 \mathrm{E}+00$ & 0.0000 & $0.000 \mathrm{E}+00$ & 0.0000 & $0.000 \mathrm{E}+00$ & 0.0000 & $0.000 \mathrm{E}+00$ & 0.0000 \\
\hline-232 & $2.917 \mathrm{E}-07$ & 0.9949 & $0.000 \mathrm{E}+00$ & 0.0000 & $0.000 \mathrm{E}+00$ & 0.0000 & $0.000 \mathrm{E}+00$ & 0.0000 & $0.000 \mathrm{E}+00$ & 0.0000 & $0.000 \mathrm{E}+00$ & 0.0000 & $0.000 \mathrm{E}+00$ & 0.0000 \\
\hline 34 & $6.482 \mathrm{E}-13$ & 0.0000 & $0.000 \mathrm{E}+00$ & 0.0000 & $0.000 \mathrm{E}+00$ & 0.0000 & $0.000 \mathrm{E}+00$ & 0.0000 & $0.000 \mathrm{E}+00$ & 0.0000 & $0.000 \mathrm{E}+00$ & 0.0000 & $0.000 \mathrm{E}+00$ & 0.0000 \\
\hline 35 & $3.260 \mathrm{E}-14$ & 0.0000 & $0.000 \mathrm{E}+00$ & 0.0000 & $0.000 \mathrm{E}+00$ & 0.0000 & $0.000 \mathrm{E}+00$ & 0.0000 & $0.000 \mathrm{E}+00$ & 0.0000 & $0.000 \mathrm{E}+00$ & 0.0000 & $0.000 \mathrm{E}+00$ & 0.0000 \\
\hline 38 & $3.035 E-11$ & 0.0001 & $0.000 \mathrm{E}+00$ & 0.0000 & $0.000 \mathrm{E}+00$ & 0.0000 & $0.000 \mathrm{E}+00$ & 0.0000 & $0.000 \mathrm{E}+00$ & 0.0000 & $0.000 \mathrm{E}+00$ & 0.0000 & $0.000 \mathrm{E}+00$ & 0.0000 \\
\hline & $2.931 E-07$ & 1.0000 & $0.000 \mathrm{E}+00$ & 0.0000 & $0.000 \mathrm{E}+00$ & 0.0000 & $0.000 \mathrm{E}+00$ & 0.0000 & $0.000 \mathrm{E}+00$ & 0.0000 & $0.000 \mathrm{E}+00$ & 0.0000 & $0.000 \mathrm{E}+00$ & 0.0000 \\
\hline
\end{tabular}

Total Dose Contributions TDOSE(i,p,t) for Individual Radionuclides (i) and Pathways (p) As mrem/yr and Fraction of Total Dose At $t=1.000 \mathrm{E}+02$ years

Water Dependent Pathways

\begin{tabular}{|c|c|c|c|c|c|c|c|c|c|c|c|c|c|c|}
\hline \multirow{2}{*}{ Nuclide } & \multicolumn{2}{|c|}{ Water } & \multicolumn{2}{|c|}{ Fish } & \multicolumn{2}{|c|}{ Radon } & \multicolumn{2}{|c|}{ Plant } & \multicolumn{2}{|c|}{ Meat } & \multicolumn{2}{|c|}{ Milk } & \multicolumn{2}{|c|}{ All Pathways* } \\
\hline & mrem/yr & fract. & mrem/yr & fract. & mrem/yr & fract. & mrem/yr & fract. & mrem/yr & fract. & mrem/yr & fract. & mrem/yr & fract. \\
\hline-241 & $0.000 \mathrm{E}+00$ & 0.0000 & $0.000 \mathrm{E}+00$ & 0.0000 & $0.000 \mathrm{E}+00$ & 0.0000 & $0.000 \mathrm{E}+00$ & 0.0000 & $0.000 \mathrm{E}+00$ & 0.0000 & $0.000 \mathrm{E}+00$ & 0.0000 & $8.102 \mathrm{E}-18$ & 0.0000 \\
\hline-137 & $0.000 \mathrm{E}+00$ & 0.0000 & $0.000 \mathrm{E}+00$ & 0.0000 & $0.000 \mathrm{E}+00$ & 0.0000 & $0.000 \mathrm{E}+00$ & 0.0000 & $0.000 \mathrm{E}+00$ & 0.0000 & $0.000 \mathrm{E}+00$ & 0.0000 & $2.793 E-11$ & 0.0001 \\
\hline-237 & $0.000 \mathrm{E}+00$ & 0.0000 & $0.000 \mathrm{E}+00$ & 0.0000 & $0.000 \mathrm{E}+00$ & 0.0000 & $0.000 \mathrm{E}+00$ & 0.0000 & $0.000 \mathrm{E}+00$ & 0.0000 & $0.000 \mathrm{E}+00$ & 0.0000 & $2.696 \mathrm{E}-13$ & 0.0000 \\
\hline-238 & $0.000 \mathrm{E}+00$ & 0.0000 & $0.000 \mathrm{E}+00$ & 0.0000 & $0.000 \mathrm{E}+00$ & 0.0000 & $0.000 \mathrm{E}+00$ & 0.0000 & $0.000 \mathrm{E}+00$ & 0.0000 & $0.000 \mathrm{E}+00$ & 0.0000 & $5.122 \mathrm{E}-17$ & 0.0000 \\
\hline 239 & $0.000 \mathrm{E}+00$ & 0.0000 & $0.000 \mathrm{E}+00$ & 0.0000 & $0.000 \mathrm{E}+00$ & 0.0000 & $0.000 \mathrm{E}+00$ & 0.0000 & $0.000 \mathrm{E}+00$ & 0.0000 & $0.000 \mathrm{E}+00$ & 0.0000 & $3.817 \mathrm{E}-18$ & 0.0000 \\
\hline-240 & $0.000 \mathrm{E}+00$ & 0.0000 & $0.000 \mathrm{E}+00$ & 0.0000 & $0.000 \mathrm{E}+00$ & 0.0000 & $0.000 \mathrm{E}+00$ & 0.0000 & $0.000 \mathrm{E}+00$ & 0.0000 & $0.000 \mathrm{E}+00$ & 0.0000 & $1.716 \mathrm{E}-21$ & 0.0000 \\
\hline 99 & $0.000 \mathrm{E}+00$ & 0.0000 & $0.000 \mathrm{E}+00$ & 0.0000 & $0.000 \mathrm{E}+00$ & 0.0000 & $0.000 \mathrm{E}+00$ & 0.0000 & $0.000 \mathrm{E}+00$ & 0.0000 & $0.000 \mathrm{E}+00$ & 0.0000 & $2.231 \mathrm{E}-26$ & 0.0000 \\
\hline-228 & $0.000 \mathrm{E}+00$ & 0.0000 & $0.000 \mathrm{E}+00$ & 0.0000 & $0.000 \mathrm{E}+00$ & 0.0000 & $0.000 \mathrm{E}+00$ & 0.0000 & $0.000 \mathrm{E}+00$ & 0.0000 & $0.000 \mathrm{E}+00$ & 0.0000 & $4.441 \mathrm{E}-23$ & 0.0000 \\
\hline-230 & $0.000 \mathrm{E}+00$ & 0.0000 & $0.000 \mathrm{E}+00$ & 0.0000 & $0.000 \mathrm{E}+00$ & 0.0000 & $0.000 \mathrm{E}+00$ & 0.0000 & $0.000 \mathrm{E}+00$ & 0.0000 & $0.000 \mathrm{E}+00$ & 0.0000 & $1.423 E-09$ & 0.0049 \\
\hline-232 & $0.000 \mathrm{E}+00$ & 0.0000 & $0.000 \mathrm{E}+00$ & 0.0000 & $0.000 \mathrm{E}+00$ & 0.0000 & $0.000 \mathrm{E}+00$ & 0.0000 & $0.000 \mathrm{E}+00$ & 0.0000 & $0.000 \mathrm{E}+00$ & 0.0000 & $2.917 \mathrm{E}-07$ & 0.9949 \\
\hline 234 & $0.000 \mathrm{E}+00$ & 0.0000 & $0.000 \mathrm{E}+00$ & 0.0000 & $0.000 \mathrm{E}+00$ & 0.0000 & $0.000 \mathrm{E}+00$ & 0.0000 & $0.000 \mathrm{E}+00$ & 0.0000 & $0.000 \mathrm{E}+00$ & 0.0000 & $6.482 \mathrm{E}-13$ & 0.0000 \\
\hline 35 & $0.000 \mathrm{E}+00$ & 0.0000 & $0.000 \mathrm{E}+00$ & 0.0000 & $0.000 \mathrm{E}+00$ & 0.0000 & $0.000 \mathrm{E}+00$ & 0.0000 & $0.000 \mathrm{E}+00$ & 0.0000 & $0.000 \mathrm{E}+00$ & 0.0000 & $3.260 \mathrm{E}-14$ & 0.0000 \\
\hline 38 & $0.000 \mathrm{E}+00$ & 0.0000 & $0.000 \mathrm{E}+00$ & 0.0000 & $0.000 \mathrm{E}+00$ & 0.0000 & $0.000 \mathrm{E}+00$ & 0.0000 & $0.000 \mathrm{E}+00$ & 0.0000 & $0.000 \mathrm{E}+00$ & 0.0000 & $3.035 \mathrm{E}-11$ & 0.0001 \\
\hline & $0.000 \mathrm{E}+00$ & 0.0000 & $0.000 \mathrm{E}+00$ & 0.0000 & $0.000 \mathrm{E}+00$ & 0.0000 & $0.000 \mathrm{E}+00$ & 0.0000 & $0.000 \mathrm{E}+00$ & 0.0000 & $0.000 \mathrm{E}+00$ & 0.0000 & $.931 E-07$ & 1.0000 \\
\hline
\end{tabular}

* Sum of all water independent and dependent pathways. 
RESRAD, Version 6.5

$\mathrm{T}^{1 / 2}$ Limit $=180$ days

$07 / 21 / 2011$

17:07 Page

25

Summary : RESRAD Parameters for U-Landfill Recreational User
File : C: $\backslash$ RESRAD_FAMILY \RESRAD \USERFILES $\backslash Q C F O R S R S G \backslash R U$ SRSG-MAY11.RAD

Total Dose Contributions TDOSE(i,p,t) for Individual Radionuclides (i) and Pathways (p) As mrem/yr and Fraction of Total Dose At $t=5.000 \mathrm{E}+02$ years

Water Independent Pathways (Inhalation excludes radon)

\begin{tabular}{|c|c|c|c|c|c|c|c|c|c|c|c|c|c|c|}
\hline \multirow{2}{*}{ Nuclide } & \multicolumn{2}{|c|}{ Ground } & \multicolumn{2}{|c|}{ Inhalation } & \multicolumn{2}{|c|}{ Radon } & \multicolumn{2}{|c|}{ Plant } & \multicolumn{2}{|c|}{ Meat } & \multicolumn{2}{|c|}{ Milk } & \multicolumn{2}{|c|}{ Soil } \\
\hline & mrem/yr & fract. & mrem/yr & fract. & mrem/yr & fract. & mrem/yr & fract. & mrem/yr & fract. & mrem/yr & fract. & mrem/yr & fract. \\
\hline-241 & $2.243 E-15$ & 0.0000 & $0.000 \mathrm{E}+00$ & 0.0000 & $0.000 \mathrm{E}+00$ & 0.0000 & $0.000 \mathrm{E}+00$ & 0.0000 & $0.000 \mathrm{E}+00$ & 0.0000 & $0.000 \mathrm{E}+00$ & 0.0000 & $0.000 \mathrm{E}+00$ & 0.0000 \\
\hline-137 & $7.847 \mathrm{E}-14$ & 0.0000 & $0.000 \mathrm{E}+00$ & 0.0000 & $0.000 \mathrm{E}+00$ & 0.0000 & $0.000 \mathrm{E}+00$ & 0.0000 & $0.000 \mathrm{E}+00$ & 0.0000 & $0.000 \mathrm{E}+00$ & 0.0000 & $0.000 \mathrm{E}+00$ & 0.0000 \\
\hline-237 & $2.021 E-11$ & 0.0000 & $0.000 \mathrm{E}+00$ & 0.0000 & $0.000 \mathrm{E}+00$ & 0.0000 & $0.000 \mathrm{E}+00$ & 0.0000 & $0.000 \mathrm{E}+00$ & 0.0000 & $0.000 \mathrm{E}+00$ & 0.0000 & $0.000 \mathrm{E}+00$ & 0.0000 \\
\hline-238 & $5.408 E-14$ & 0.0000 & $0.000 \mathrm{E}+00$ & 0.0000 & $0.000 \mathrm{E}+00$ & 0.0000 & $0.000 \mathrm{E}+00$ & 0.0000 & $0.000 \mathrm{E}+00$ & 0.0000 & $0.000 \mathrm{E}+00$ & 0.0000 & $0.000 \mathrm{E}+00$ & 0.0000 \\
\hline-239 & $4.543 E-16$ & 0.0000 & $0.000 \mathrm{E}+00$ & 0.0000 & $0.000 \mathrm{E}+00$ & 0.0000 & $0.000 \mathrm{E}+00$ & 0.0000 & $0.000 \mathrm{E}+00$ & 0.0000 & $0.000 \mathrm{E}+00$ & 0.0000 & $0.000 \mathrm{E}+00$ & 0.0000 \\
\hline-240 & $5.515 \mathrm{E}-19$ & 0.0000 & $0.000 \mathrm{E}+00$ & 0.0000 & $0.000 \mathrm{E}+00$ & 0.0000 & $0.000 \mathrm{E}+00$ & 0.0000 & $0.000 \mathrm{E}+00$ & 0.0000 & $0.000 \mathrm{E}+00$ & 0.0000 & $0.000 \mathrm{E}+00$ & 0.0000 \\
\hline 99 & $5.839 E-24$ & 0.0000 & $0.000 \mathrm{E}+00$ & 0.0000 & $0.000 \mathrm{E}+00$ & 0.0000 & $0.000 \mathrm{E}+00$ & 0.0000 & $0.000 \mathrm{E}+00$ & 0.0000 & $0.000 \mathrm{E}+00$ & 0.0000 & $0.000 \mathrm{E}+00$ & 0.0000 \\
\hline-228 & $0.000 \mathrm{E}+00$ & 0.0000 & $0.000 \mathrm{E}+00$ & 0.0000 & $0.000 \mathrm{E}+00$ & 0.0000 & $0.000 \mathrm{E}+00$ & 0.0000 & $0.000 \mathrm{E}+00$ & 0.0000 & $0.000 \mathrm{E}+00$ & 0.0000 & $0.000 \mathrm{E}+00$ & 0.0000 \\
\hline-230 & $1.032 \mathrm{E}-07$ & 0.0311 & $0.000 \mathrm{E}+00$ & 0.0000 & $0.000 \mathrm{E}+00$ & 0.0000 & $0.000 \mathrm{E}+00$ & 0.0000 & $0.000 \mathrm{E}+00$ & 0.0000 & $0.000 \mathrm{E}+00$ & 0.0000 & $0.000 \mathrm{E}+00$ & 0.0000 \\
\hline-232 & $3.212 \mathrm{E}-06$ & 0.9686 & $0.000 \mathrm{E}+00$ & 0.0000 & $0.000 \mathrm{E}+00$ & 0.0000 & $0.000 \mathrm{E}+00$ & 0.0000 & $0.000 \mathrm{E}+00$ & 0.0000 & $0.000 \mathrm{E}+00$ & 0.0000 & $0.000 \mathrm{E}+00$ & 0.0000 \\
\hline 234 & $2.407 \mathrm{E}-10$ & 0.0001 & $0.000 \mathrm{E}+00$ & 0.0000 & $0.000 \mathrm{E}+00$ & 0.0000 & $0.000 \mathrm{E}+00$ & 0.0000 & $0.000 \mathrm{E}+00$ & 0.0000 & $0.000 \mathrm{E}+00$ & 0.0000 & $0.000 \mathrm{E}+00$ & 0.0000 \\
\hline 35 & $6.791 \mathrm{E}-12$ & 0.0000 & $0.000 \mathrm{E}+00$ & 0.0000 & $0.000 \mathrm{E}+00$ & 0.0000 & $0.000 \mathrm{E}+00$ & 0.0000 & $0.000 \mathrm{E}+00$ & 0.0000 & $0.000 \mathrm{E}+00$ & 0.0000 & $0.000 \mathrm{E}+00$ & 0.0000 \\
\hline 38 & $7.420 \mathrm{E}-10$ & 0.0002 & $0.000 \mathrm{E}+00$ & 0.0000 & $0.000 \mathrm{E}+00$ & 0.0000 & $0.000 \mathrm{E}+00$ & 0.0000 & $0.000 \mathrm{E}+00$ & 0.0000 & $0.000 \mathrm{E}+00$ & 0.0000 & $0.000 \mathrm{E}+00$ & 0.0000 \\
\hline & $3.316 E-06$ & 1.0000 & $0.000 \mathrm{E}+00$ & 0.0000 & $0.000 \mathrm{E}+00$ & 0.0000 & $0.000 \mathrm{E}+00$ & 0.0000 & $0.000 \mathrm{E}+00$ & 0.0000 & $0.000 \mathrm{E}+00$ & 0.0000 & $0.000 \mathrm{E}+00$ & 0.0000 \\
\hline
\end{tabular}

Total Dose Contributions TDOSE(i,p,t) for Individual Radionuclides (i) and Pathways (p) As mrem/yr and Fraction of Total Dose At $t=5.000 \mathrm{E}+02$ years

Water Dependent Pathways

\begin{tabular}{|c|c|c|c|c|c|c|c|c|c|c|c|c|c|c|}
\hline \multirow{2}{*}{ Nuclide } & \multicolumn{2}{|c|}{ Water } & \multicolumn{2}{|c|}{ Fish } & \multicolumn{2}{|c|}{ Radon } & \multicolumn{2}{|c|}{ Plant } & \multicolumn{2}{|c|}{ Meat } & \multicolumn{2}{|c|}{ Milk } & \multicolumn{2}{|c|}{ All Pathways* } \\
\hline & mrem/yr & fract. & mrem/yr & fract. & mrem/yr & fract. & mrem/yr & fract. & mrem/yr & fract. & mrem/yr & fract. & mrem/yr & fract. \\
\hline-241 & $0.000 \mathrm{E}+00$ & 0.0000 & $0.000 \mathrm{E}+00$ & 0.0000 & $0.000 \mathrm{E}+00$ & 0.0000 & $0.000 \mathrm{E}+00$ & 0.0000 & $0.000 \mathrm{E}+00$ & 0.0000 & $0.000 \mathrm{E}+00$ & 0.0000 & $2.243 E-15$ & 0.0000 \\
\hline-137 & $0.000 \mathrm{E}+00$ & 0.0000 & $0.000 \mathrm{E}+00$ & 0.0000 & $0.000 \mathrm{E}+00$ & 0.0000 & $0.000 \mathrm{E}+00$ & 0.0000 & $0.000 \mathrm{E}+00$ & 0.0000 & $0.000 \mathrm{E}+00$ & 0.0000 & $7.847 \mathrm{E}-14$ & 0.0000 \\
\hline-237 & $0.000 \mathrm{E}+00$ & 0.0000 & $0.000 \mathrm{E}+00$ & 0.0000 & $0.000 \mathrm{E}+00$ & 0.0000 & $0.000 \mathrm{E}+00$ & 0.0000 & $0.000 \mathrm{E}+00$ & 0.0000 & $0.000 \mathrm{E}+00$ & 0.0000 & $2.021 \mathrm{E}-11$ & 0.0000 \\
\hline-238 & $0.000 \mathrm{E}+00$ & 0.0000 & $0.000 \mathrm{E}+00$ & 0.0000 & $0.000 \mathrm{E}+00$ & 0.0000 & $0.000 \mathrm{E}+00$ & 0.0000 & $0.000 \mathrm{E}+00$ & 0.0000 & $0.000 \mathrm{E}+00$ & 0.0000 & $5.408 \mathrm{E}-14$ & 0.0000 \\
\hline 239 & $0.000 \mathrm{E}+00$ & 0.0000 & $0.000 \mathrm{E}+00$ & 0.0000 & $0.000 \mathrm{E}+00$ & 0.0000 & $0.000 \mathrm{E}+00$ & 0.0000 & $0.000 \mathrm{E}+00$ & 0.0000 & $0.000 \mathrm{E}+00$ & 0.0000 & $4.543 E-16$ & 0.0000 \\
\hline-240 & $0.000 \mathrm{E}+00$ & 0.0000 & $0.000 \mathrm{E}+00$ & 0.0000 & $0.000 \mathrm{E}+00$ & 0.0000 & $0.000 \mathrm{E}+00$ & 0.0000 & $0.000 \mathrm{E}+00$ & 0.0000 & $0.000 \mathrm{E}+00$ & 0.0000 & $5.515 \mathrm{E}-19$ & 0.0000 \\
\hline 99 & $0.000 \mathrm{E}+00$ & 0.0000 & $0.000 \mathrm{E}+00$ & 0.0000 & $0.000 \mathrm{E}+00$ & 0.0000 & $0.000 \mathrm{E}+00$ & 0.0000 & $0.000 \mathrm{E}+00$ & 0.0000 & $0.000 \mathrm{E}+00$ & 0.0000 & $5.839 E-24$ & 0.0000 \\
\hline-228 & $0.000 \mathrm{E}+00$ & 0.0000 & $0.000 \mathrm{E}+00$ & 0.0000 & $0.000 \mathrm{E}+00$ & 0.0000 & $0.000 \mathrm{E}+00$ & 0.0000 & $0.000 \mathrm{E}+00$ & 0.0000 & $0.000 \mathrm{E}+00$ & 0.0000 & $0.000 \mathrm{E}+00$ & 0.0000 \\
\hline-230 & $0.000 \mathrm{E}+00$ & 0.0000 & $0.000 \mathrm{E}+00$ & 0.0000 & $0.000 \mathrm{E}+00$ & 0.0000 & $0.000 \mathrm{E}+00$ & 0.0000 & $0.000 \mathrm{E}+00$ & 0.0000 & $0.000 \mathrm{E}+00$ & 0.0000 & $1.032 \mathrm{E}-07$ & 0.0311 \\
\hline-232 & $0.000 \mathrm{E}+00$ & 0.0000 & $0.000 \mathrm{E}+00$ & 0.0000 & $0.000 \mathrm{E}+00$ & 0.0000 & $0.000 \mathrm{E}+00$ & 0.0000 & $0.000 \mathrm{E}+00$ & 0.0000 & $0.000 \mathrm{E}+00$ & 0.0000 & $3.212 \mathrm{E}-06$ & 0.9686 \\
\hline 234 & $0.000 \mathrm{E}+00$ & 0.0000 & $0.000 \mathrm{E}+00$ & 0.0000 & $0.000 \mathrm{E}+00$ & 0.0000 & $0.000 \mathrm{E}+00$ & 0.0000 & $0.000 \mathrm{E}+00$ & 0.0000 & $0.000 \mathrm{E}+00$ & 0.0000 & $2.407 \mathrm{E}-10$ & 0.0001 \\
\hline 35 & $0.000 \mathrm{E}+00$ & 0.0000 & $0.000 \mathrm{E}+00$ & 0.0000 & $0.000 \mathrm{E}+00$ & 0.0000 & $0.000 \mathrm{E}+00$ & 0.0000 & $0.000 \mathrm{E}+00$ & 0.0000 & $0.000 \mathrm{E}+00$ & 0.0000 & $6.791 \mathrm{E}-12$ & 0.0000 \\
\hline 38 & $0.000 \mathrm{E}+00$ & 0.0000 & $0.000 \mathrm{E}+00$ & 0.0000 & $0.000 \mathrm{E}+00$ & 0.0000 & $0.000 \mathrm{E}+00$ & 0.0000 & $0.000 \mathrm{E}+00$ & 0.0000 & $0.000 \mathrm{E}+00$ & 0.0000 & 7. $420 \mathrm{E}-10$ & 0.0002 \\
\hline & $0.000 \mathrm{E}+00$ & 0.0000 & $0.000 \mathrm{E}+00$ & 0.0000 & $0.000 \mathrm{E}+00$ & 0.0000 & $0.000 \mathrm{E}+00$ & 0.0000 & $0.000 \mathrm{E}+00$ & 0.0000 & $0.000 \mathrm{E}+00$ & 0.0000 & $16 E-06$ & 1.0000 \\
\hline
\end{tabular}

* Sum of all water independent and dependent pathways. 
RESRAD, Version 6.5

$\mathrm{T}^{1 / 2}$ Limit $=180$ days

$07 / 21 / 2011$

17:07 Page

Summary : RESRAD Parameters for U-Landfill Recreational User
File : C: $\backslash$ RESRAD_FAMILY $\backslash R E S R A D \backslash U S E R F I L E S \backslash Q C F O R S R S G \backslash R U$ SRSG-MAY11.RAD

Total Dose Contributions TDOSE(i,p,t) for Individual Radionuclides (i) and Pathways (p) As mrem/yr and Fraction of Total Dose At $t=1.050 \mathrm{E}+03$ years

Water Independent Pathways (Inhalation excludes radon)

\begin{tabular}{|c|c|c|c|c|c|c|c|c|c|c|c|c|c|c|}
\hline \multirow{2}{*}{ Nuclide } & \multicolumn{2}{|c|}{ Ground } & \multicolumn{2}{|c|}{ Inhalation } & \multicolumn{2}{|c|}{ Radon } & \multicolumn{2}{|c|}{ Plant } & \multicolumn{2}{|c|}{ Meat } & \multicolumn{2}{|c|}{ Milk } & \multicolumn{2}{|c|}{ Soil } \\
\hline & mrem/yr & fract. & mrem/yr & fract. & mrem/yr & fract. & mrem/yr & fract. & mrem/yr & fract. & mrem/yr & fract. & mrem/yr & fract. \\
\hline-241 & 1. $214 \mathrm{E}-12$ & 0.0000 & $0.000 \mathrm{E}+00$ & 0.0000 & $0.000 \mathrm{E}+00$ & 0.0000 & $0.000 \mathrm{E}+00$ & 0.0000 & $0.000 \mathrm{E}+00$ & 0.0000 & $0.000 \mathrm{E}+00$ & 0.0000 & $0.000 \mathrm{E}+00$ & 0.0000 \\
\hline-137 & $2.435 E-17$ & 0.0000 & $0.000 \mathrm{E}+00$ & 0.0000 & $0.000 \mathrm{E}+00$ & 0.0000 & $0.000 \mathrm{E}+00$ & 0.0000 & $0.000 \mathrm{E}+00$ & 0.0000 & $0.000 \mathrm{E}+00$ & 0.0000 & $0.000 \mathrm{E}+00$ & 0.0000 \\
\hline-237 & $7.245 E-09$ & 0.0001 & $0.000 \mathrm{E}+00$ & 0.0000 & $0.000 \mathrm{E}+00$ & 0.0000 & $0.000 \mathrm{E}+00$ & 0.0000 & $0.000 \mathrm{E}+00$ & 0.0000 & $0.000 \mathrm{E}+00$ & 0.0000 & $0.000 \mathrm{E}+00$ & 0.0000 \\
\hline-238 & 1. $260 \mathrm{E}-11$ & 0.0000 & $0.000 \mathrm{E}+00$ & 0.0000 & $0.000 \mathrm{E}+00$ & 0.0000 & $0.000 \mathrm{E}+00$ & 0.0000 & $0.000 \mathrm{E}+00$ & 0.0000 & $0.000 \mathrm{E}+00$ & 0.0000 & $0.000 \mathrm{E}+00$ & 0.0000 \\
\hline-239 & $3.234 \mathrm{E}-13$ & 0.0000 & $0.000 \mathrm{E}+00$ & 0.0000 & $0.000 \mathrm{E}+00$ & 0.0000 & $0.000 \mathrm{E}+00$ & 0.0000 & $0.000 \mathrm{E}+00$ & 0.0000 & $0.000 \mathrm{E}+00$ & 0.0000 & $0.000 \mathrm{E}+00$ & 0.0000 \\
\hline-240 & $7.834 \mathrm{E}-17$ & 0.0000 & $0.000 \mathrm{E}+00$ & 0.0000 & $0.000 \mathrm{E}+00$ & 0.0000 & $0.000 \mathrm{E}+00$ & 0.0000 & $0.000 \mathrm{E}+00$ & 0.0000 & $0.000 \mathrm{E}+00$ & 0.0000 & $0.000 \mathrm{E}+00$ & 0.0000 \\
\hline 99 & $1.233 E-20$ & 0.0000 & $0.000 \mathrm{E}+00$ & 0.0000 & $0.000 \mathrm{E}+00$ & 0.0000 & $0.000 \mathrm{E}+00$ & 0.0000 & $0.000 \mathrm{E}+00$ & 0.0000 & $0.000 \mathrm{E}+00$ & 0.0000 & $0.000 \mathrm{E}+00$ & 0.0000 \\
\hline-228 & $0.000 \mathrm{E}+00$ & 0.0000 & $0.000 \mathrm{E}+00$ & 0.0000 & $0.000 \mathrm{E}+00$ & 0.0000 & $0.000 \mathrm{E}+00$ & 0.0000 & $0.000 \mathrm{E}+00$ & 0.0000 & $0.000 \mathrm{E}+00$ & 0.0000 & $0.000 \mathrm{E}+00$ & 0.0000 \\
\hline 230 & $8.661 \mathrm{E}-06$ & 0.0886 & $0.000 \mathrm{E}+00$ & 0.0000 & $0.000 \mathrm{E}+00$ & 0.0000 & $0.000 \mathrm{E}+00$ & 0.0000 & $0.000 \mathrm{E}+00$ & 0.0000 & $0.000 \mathrm{E}+00$ & 0.0000 & $0.000 \mathrm{E}+00$ & 0.0000 \\
\hline-232 & $8.900 E-05$ & 0.9103 & $0.000 \mathrm{E}+00$ & 0.0000 & $0.000 \mathrm{E}+00$ & 0.0000 & $0.000 \mathrm{E}+00$ & 0.0000 & $0.000 \mathrm{E}+00$ & 0.0000 & $0.000 \mathrm{E}+00$ & 0.0000 & $0.000 \mathrm{E}+00$ & 0.0000 \\
\hline 34 & $4.396 E-08$ & 0.0004 & $0.000 \mathrm{E}+00$ & 0.0000 & $0.000 \mathrm{E}+00$ & 0.0000 & $0.000 \mathrm{E}+00$ & 0.0000 & $0.000 \mathrm{E}+00$ & 0.0000 & $0.000 \mathrm{E}+00$ & 0.0000 & $0.000 \mathrm{E}+00$ & 0.0000 \\
\hline 35 & $2.279 E-09$ & 0.0000 & $0.000 \mathrm{E}+00$ & 0.0000 & $0.000 \mathrm{E}+00$ & 0.0000 & $0.000 \mathrm{E}+00$ & 0.0000 & $0.000 \mathrm{E}+00$ & 0.0000 & $0.000 \mathrm{E}+00$ & 0.0000 & $0.000 \mathrm{E}+00$ & 0.0000 \\
\hline 38 & $6.021 E-08$ & 0.0006 & $0.000 \mathrm{E}+00$ & 0.0000 & $0.000 \mathrm{E}+00$ & 0.0000 & $0.000 \mathrm{E}+00$ & 0.0000 & $0.000 \mathrm{E}+00$ & 0.0000 & $0.000 \mathrm{E}+00$ & 0.0000 & $0.000 \mathrm{E}+00$ & 0.0000 \\
\hline & $9.778 E-05$ & 1.0000 & $0.000 \mathrm{E}+00$ & 0.0000 & $0.000 \mathrm{E}+00$ & 0.0000 & $0.000 \mathrm{E}+00$ & 0.0000 & $0.000 \mathrm{E}+00$ & 0.0000 & $0.000 \mathrm{E}+00$ & 0.0000 & $.000 \mathrm{E}+00$ & 0.0000 \\
\hline
\end{tabular}

Total Dose Contributions TDOSE(i,p,t) for Individual Radionuclides (i) and Pathways (p) As mrem/yr and Fraction of Total Dose At $t=1.050 \mathrm{E}+03$ years

Water Dependent Pathways

\begin{tabular}{|c|c|c|c|c|c|c|c|c|c|c|c|c|c|c|}
\hline \multirow{2}{*}{ Nuclide } & \multicolumn{2}{|c|}{ Water } & \multicolumn{2}{|c|}{ Fish } & \multicolumn{2}{|c|}{ Radon } & \multicolumn{2}{|c|}{ Plant } & \multicolumn{2}{|c|}{ Meat } & \multicolumn{2}{|c|}{ Milk } & \multicolumn{2}{|c|}{ All Pathways* } \\
\hline & mrem/yr & fract. & mrem/yr & fract. & mrem/yr & fract. & mrem/yr & fract. & mrem/yr & fract. & mrem/yr & fract. & mrem/yr & fract. \\
\hline-241 & $0.000 \mathrm{E}+00$ & 0.0000 & $0.000 \mathrm{E}+00$ & 0.0000 & $0.000 \mathrm{E}+00$ & 0.0000 & $0.000 \mathrm{E}+00$ & 0.0000 & $0.000 \mathrm{E}+00$ & 0.0000 & $0.000 \mathrm{E}+00$ & 0.0000 & 1. $214 \mathrm{E}-12$ & 0.0000 \\
\hline-137 & $0.000 \mathrm{E}+00$ & 0.0000 & $0.000 \mathrm{E}+00$ & 0.0000 & $0.000 \mathrm{E}+00$ & 0.0000 & $0.000 \mathrm{E}+00$ & 0.0000 & $0.000 \mathrm{E}+00$ & 0.0000 & $0.000 \mathrm{E}+00$ & 0.0000 & $2.435 \mathrm{E}-17$ & 0.0000 \\
\hline-237 & $0.000 \mathrm{E}+00$ & 0.0000 & $0.000 \mathrm{E}+00$ & 0.0000 & $0.000 \mathrm{E}+00$ & 0.0000 & $0.000 \mathrm{E}+00$ & 0.0000 & $0.000 \mathrm{E}+00$ & 0.0000 & $0.000 \mathrm{E}+00$ & 0.0000 & $7.245 E-09$ & 0.0001 \\
\hline-238 & $0.000 \mathrm{E}+00$ & 0.0000 & $0.000 \mathrm{E}+00$ & 0.0000 & $0.000 \mathrm{E}+00$ & 0.0000 & $0.000 \mathrm{E}+00$ & 0.0000 & $0.000 \mathrm{E}+00$ & 0.0000 & $0.000 \mathrm{E}+00$ & 0.0000 & $1.260 \mathrm{E}-11$ & 0.0000 \\
\hline-239 & $0.000 \mathrm{E}+00$ & 0.0000 & $0.000 \mathrm{E}+00$ & 0.0000 & $0.000 \mathrm{E}+00$ & 0.0000 & $0.000 \mathrm{E}+00$ & 0.0000 & $0.000 \mathrm{E}+00$ & 0.0000 & $0.000 \mathrm{E}+00$ & 0.0000 & $3.234 \mathrm{E}-13$ & 0.0000 \\
\hline-240 & $0.000 \mathrm{E}+00$ & 0.0000 & $0.000 \mathrm{E}+00$ & 0.0000 & $0.000 \mathrm{E}+00$ & 0.0000 & $0.000 \mathrm{E}+00$ & 0.0000 & $0.000 \mathrm{E}+00$ & 0.0000 & $0.000 \mathrm{E}+00$ & 0.0000 & $7.834 \mathrm{E}-17$ & 0.0000 \\
\hline-99 & $0.000 \mathrm{E}+00$ & 0.0000 & $0.000 \mathrm{E}+00$ & 0.0000 & $0.000 \mathrm{E}+00$ & 0.0000 & $0.000 \mathrm{E}+00$ & 0.0000 & $0.000 \mathrm{E}+00$ & 0.0000 & $0.000 \mathrm{E}+00$ & 0.0000 & $1.233 E-20$ & 0.0000 \\
\hline-228 & $0.000 \mathrm{E}+00$ & 0.0000 & $0.000 \mathrm{E}+00$ & 0.0000 & $0.000 \mathrm{E}+00$ & 0.0000 & $0.000 \mathrm{E}+00$ & 0.0000 & $0.000 \mathrm{E}+00$ & 0.0000 & $0.000 \mathrm{E}+00$ & 0.0000 & $0.000 \mathrm{E}+00$ & 0.0000 \\
\hline-230 & $0.000 \mathrm{E}+00$ & 0.0000 & $0.000 \mathrm{E}+00$ & 0.0000 & $0.000 \mathrm{E}+00$ & 0.0000 & $0.000 \mathrm{E}+00$ & 0.0000 & $0.000 \mathrm{E}+00$ & 0.0000 & $0.000 \mathrm{E}+00$ & 0.0000 & $8.661 \mathrm{E}-06$ & 0.0886 \\
\hline 232 & $0.000 \mathrm{E}+00$ & 0.0000 & $0.000 \mathrm{E}+00$ & 0.0000 & $0.000 \mathrm{E}+00$ & 0.0000 & $0.000 \mathrm{E}+00$ & 0.0000 & $0.000 \mathrm{E}+00$ & 0.0000 & $0.000 \mathrm{E}+00$ & 0.0000 & $8.900 \mathrm{E}-05$ & 0.9103 \\
\hline 34 & $0.000 \mathrm{E}+00$ & 0.0000 & $0.000 \mathrm{E}+00$ & 0.0000 & $0.000 \mathrm{E}+00$ & 0.0000 & $0.000 \mathrm{E}+00$ & 0.0000 & $0.000 \mathrm{E}+00$ & 0.0000 & $0.000 \mathrm{E}+00$ & 0.0000 & $4.396 \mathrm{E}-08$ & 0.0004 \\
\hline 35 & $0.000 \mathrm{E}+00$ & 0.0000 & $0.000 \mathrm{E}+00$ & 0.0000 & $0.000 \mathrm{E}+00$ & 0.0000 & $0.000 \mathrm{E}+00$ & 0.0000 & $0.000 \mathrm{E}+00$ & 0.0000 & $0.000 \mathrm{E}+00$ & 0.0000 & $2.279 \mathrm{E}-09$ & 0.0000 \\
\hline 38 & $0.000 \mathrm{E}+00$ & 0.0000 & $0.000 \mathrm{E}+00$ & 0.0000 & $0.000 \mathrm{E}+00$ & 0.0000 & $0.000 \mathrm{E}+00$ & 0.0000 & $0.000 \mathrm{E}+00$ & 0.0000 & $0.000 \mathrm{E}+00$ & 0.0000 & $6.021 \mathrm{E}-08$ & 0.0006 \\
\hline & $0.000 \mathrm{E}+00$ & 0.0000 & $0.000 \mathrm{E}+00$ & 0.0000 & $0.000 \mathrm{E}+00$ & 0.0000 & $0.000 \mathrm{E}+00$ & 0.0000 & $0.000 \mathrm{E}+00$ & 0.0000 & $0.000 \mathrm{E}+00$ & 0.0000 & $8 E-05$ & 1.0000 \\
\hline
\end{tabular}

* Sum of all water independent and dependent pathways. 
RESRAD, Version 6.5

$\mathrm{T}^{1 / 2}$ Limit $=180$ days

$07 / 21 / 2011$

ummary : RESRAD Parameters for U-Landfill Recreational User

File $\quad C: \backslash$ RESRAD FAMILY \RESRAD \USERFILES $\backslash Q C F O R S R S G \backslash R U$ SRSG-MAY11.RAD

Dose/Source Ratios Summed Over All Pathways

Parent and Progeny Principal Radionuclide Contributions Indicated

Parent Product Thread DSR $(j, t)$ At Time in Years (mrem/yr)/(pCi/g)

(i)

(j)

\begin{tabular}{ll}
\hline Am-241 & $1.000 \mathrm{E}+00$ \\
$\mathrm{~Np}-237+\mathrm{D}$ & $1.000 \mathrm{E}+00$ \\
$\mathrm{U}-233$ & $1.000 \mathrm{E}+00$ \\
$\mathrm{Th}-229+\mathrm{D}$ & $1.000 \mathrm{E}+00$ \\
$\operatorname{\sum DSR}(j)$ &
\end{tabular}

Cs $-137+D$

Np $-237+D$

$\mathrm{U}-233$

Th-229+D

$\sum \operatorname{DSR}(j)$

$\mathrm{Pu}-238$

$\mathrm{Pu}-238$

U-234

Th-230

Ra-226+D

$\mathrm{Pb}-210+\mathrm{D}$

$\operatorname{\sum DSR}(j)$

$\mathrm{Pu}-239$

U-235+D

$\mathrm{Pa}-231$

AC-227+D

$\sum \operatorname{DSR}(j)$

$\mathrm{Pu}-240$

Pu-240

$\mathrm{U}-236$

Th-232

$\mathrm{Ra}-228+\mathrm{D}$

Th $-228+D$

$\operatorname{\sum DSR}(j)$

TC-99

Th-228+D

Th-230

Ra-226+D

$\mathrm{Pb}-210+\mathrm{D}$

$\operatorname{\sum DSR}(j)$

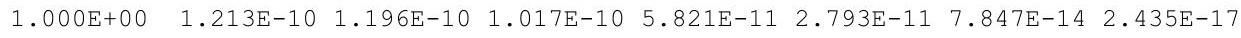

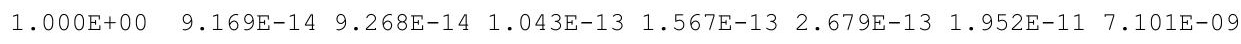

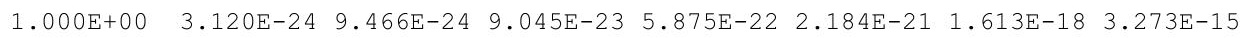

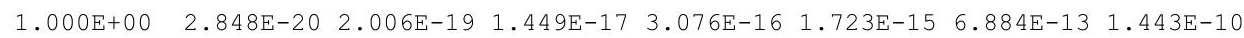
$\begin{array}{lllllll}9.169 \mathrm{E}-14 & 9.268 \mathrm{E}-14 & 1.043 \mathrm{E}-13 & 1.570 \mathrm{E}-13 & 2.696 \mathrm{E}-13 & 2.021 \mathrm{E}-11 & 7.245 \mathrm{E}-09\end{array}$

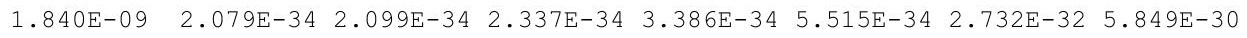

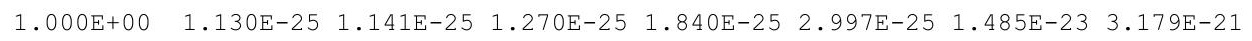
$\begin{array}{llllllll}1.000 \mathrm{E}+00 & 9.402 \mathrm{E}-31 & 2.855 \mathrm{E}-30 & 2.767 \mathrm{E}-29 & 1.897 \mathrm{E}-28 & 7.660 \mathrm{E}-28 & 1.633 \mathrm{E}-24 & 2.820 \mathrm{E}-20\end{array}$

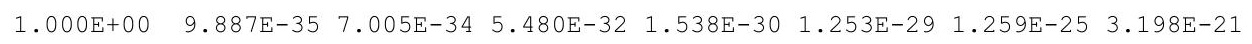
$\begin{array}{llllllll}1.000 \mathrm{E}+00 & 7.713 \mathrm{E}-24 & 1.162 \mathrm{E}-22 & 6.388 \mathrm{E}-20 & 5.065 \mathrm{E}-18 & 5.122 \mathrm{E}-17 & 5.408 \mathrm{E}-14 & 1.260 \mathrm{E}-11\end{array}$ $\begin{array}{llllllll}1.000 \mathrm{E}+00 & 2.237 \mathrm{E}-32 & 6.933 \mathrm{E}-31 & 2.743 \mathrm{E}-27 & 7.476 \mathrm{E}-25 & 1.264 \mathrm{E}-23 & 3.542 \mathrm{E}-20 & 1.664 \mathrm{E}-17\end{array}$ $\begin{array}{lllllll}7.826 \mathrm{E}-24 & 1.163 \mathrm{E}-22 & 6.388 \mathrm{E}-20 & 5.065 \mathrm{E}-18 & 5.122 \mathrm{E}-17 & 5.408 \mathrm{E}-14 & 1.260 \mathrm{E}-11\end{array}$

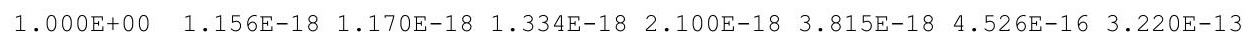
$\begin{array}{llllllll}1.000 \mathrm{E}+00 & 5.899 \mathrm{E}-25 & 1.789 \mathrm{E}-24 & 1.707 \mathrm{E}-23 & 1.102 \mathrm{E}-22 & 4.068 \mathrm{E}-22 & 2.830 \mathrm{E}-19 & 5.291 \mathrm{E}-16\end{array}$ $\begin{array}{llllllll}1.000 \mathrm{E}+00 & 9.281 \mathrm{E}-29 & 6.556 \mathrm{E}-28 & 4.931 \mathrm{E}-26 & 1.203 \mathrm{E}-24 & 8.097 \mathrm{E}-24 & 1.394 \mathrm{E}-20 & 2.092 \mathrm{E}-17\end{array}$ $\begin{array}{llllllll}1.000 \mathrm{E}+00 & 2.200 \mathrm{E}-28 & 3.302 \mathrm{E}-27 & 1.741 \mathrm{E}-24 & 1.227 \mathrm{E}-22 & 1.125 \mathrm{E}-21 & 1.425 \mathrm{E}-18 & 8.591 \mathrm{E}-16\end{array}$ $\begin{array}{lllllll}1.156 \mathrm{E}-18 & 1.170 \mathrm{E}-18 & 1.334 \mathrm{E}-18 & 2.100 \mathrm{E}-18 & 3.817 \mathrm{E}-18 & 4.543 \mathrm{E}-16 & 3.234 \mathrm{E}-13\end{array}$

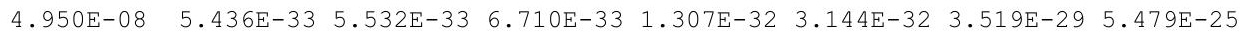

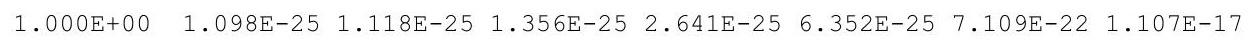
$\begin{array}{llllllll}1.000 \mathrm{E}+00 & 2.079 \mathrm{E}-33 & 6.337 \mathrm{E}-33 & 6.427 \mathrm{E}-32 & 5.132 \mathrm{E}-31 & 2.504 \mathrm{E}-30 & 1.628 \mathrm{E}-26 & 6.574 \mathrm{E}-22\end{array}$ $\begin{array}{llllllll}1.000 \mathrm{E}+00 & 2.803 \mathrm{E}-44 & 1.948 \mathrm{E}-43 & 1.599 \mathrm{E}-41 & 5.271 \mathrm{E}-40 & 5.270 \mathrm{E}-39 & 2.159 \mathrm{E}-34 & 2.528 \mathrm{E}-29\end{array}$ $\begin{array}{llllllll}1.000 \mathrm{E}+00 & 1.318 \mathrm{E}-29 & 1.940 \mathrm{E}-28 & 8.230 \mathrm{E}-26 & 3.618 \mathrm{E}-24 & 2.445 \mathrm{E}-23 & 1.417 \mathrm{E}-20 & 4.042 \mathrm{E}-18\end{array}$ $\begin{array}{lllllllll}1.000 \mathrm{E}+00 & 7.799 \mathrm{E}-29 & 2.244 \mathrm{E}-27 & 4.095 \mathrm{E}-24 & 2.540 \mathrm{E}-22 & 1.691 \mathrm{E}-21 & 5.366 \mathrm{E}-19 & 6.323 \mathrm{E}-17\end{array}$

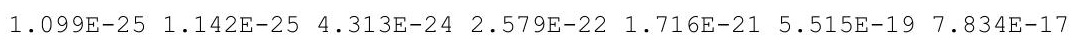

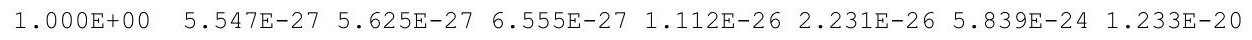

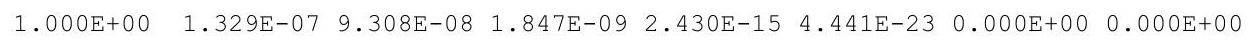

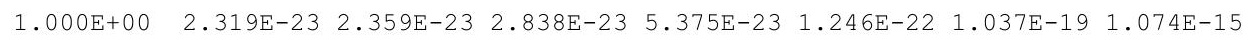
$\begin{array}{llllllll}1.000 \mathrm{E}+00 & 3.629 \mathrm{E}-12 & 1.095 \mathrm{E}-11 & 9.820 \mathrm{E}-11 & 5.116 \mathrm{E}-10 & 1.423 \mathrm{E}-09 & 1.032 \mathrm{E}-07 & 8.661 \mathrm{E}-06\end{array}$ $\begin{array}{llllllll}1.000 \mathrm{E}+00 & 1.749 \mathrm{E}-20 & 1.222 \mathrm{E}-19 & 7.985 \mathrm{E}-18 & 1.249 \mathrm{E}-16 & 5.113 \mathrm{E}-16 & 7.402 \mathrm{E}-14 & 1.190 \mathrm{E}-11\end{array}$

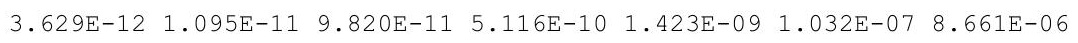


RESRAD, Version 6.5

$\mathrm{T}^{1 / 2}$ Limit $=180$ days

07/21/2011 17:07 Page

Summary : RESRAD Parameters for U-Landfill Recreational User

File : C: $\backslash$ RESRAD FAMILY \RESRAD \USERFILES $\backslash Q C F O R S R S G \backslash R U$ SRSG-MAY11.RAD

Dose/Source Ratios Summed Over All Pathways

Parent and Progeny Principal Radionuclide Contributions Indicated

\begin{tabular}{|c|c|c|c|c|c|c|c|c|c|}
\hline Parent & Product & Thread & & $\operatorname{DSR}(j, t)$ & At Time in & Years & (mrem/yr) / & $(\mathrm{pCi} / \mathrm{g})$ & \\
\hline (i) & (j) & Fraction & $0.000 \mathrm{E}+00$ & $1.000 \mathrm{E}+00$ & $1.200 \mathrm{E}+01$ & $5.000 \mathrm{E}+01$ & $1.000 \mathrm{E}+02$ & $5.000 \mathrm{E}+02$ & $1.050 \mathrm{E}+03$ \\
\hline-232 & $\mathrm{Th}-232$ & $1.000 \mathrm{E}+00$ & $1.121 \mathrm{E}-25$ & $1.142 \mathrm{E}-25$ & $1.401 \mathrm{E}-25$ & $2.836 \mathrm{E}-25$ & $7.176 \mathrm{E}-25$ & 1. $205 \mathrm{E}-21$ & $3.277 \mathrm{E}-17$ \\
\hline $1-232$ & $\mathrm{Ra}-228+\mathrm{D}$ & $1.000 \mathrm{E}+00$ & 1. $065 \mathrm{E}-10$ & $3.052 \mathrm{E}-10$ & $1.565 \mathrm{E}-09$ & $2.678 \mathrm{E}-09$ & $3.923 E-09$ & $8.176 \mathrm{E}-08$ & $5.322 \mathrm{E}-06$ \\
\hline$h-232$ & $\mathrm{Th}-228+\mathrm{D}$ & $1.000 \mathrm{E}+00$ & $1.026 \mathrm{E}-09$ & $6.328 E-09$ & $1.146 \mathrm{E}-07$ & $2.128 E-07$ & $2.877 E-07$ & $3.130 \mathrm{E}-06$ & $8.368 E-05$ \\
\hline$h-232$ & $\sum \operatorname{DSR}(j)$ & & $1.133 E-09$ & $6.633 E-09$ & $1.162 \mathrm{E}-07$ & $2.155 \mathrm{E}-07$ & $2.917 \mathrm{E}-07$ & $3.212 \mathrm{E}-06$ & $8.900 \mathrm{E}-05$ \\
\hline-234 & $\mathrm{U}-234$ & $1.000 \mathrm{E}+00$ & $6.631 E-25$ & $6.749 \mathrm{E}-25$ & $8.200 \mathrm{E}-25$ & $1.607 \mathrm{E}-24$ & $3.895 E-24$ & $4.636 \mathrm{E}-21$ & $7.854 \mathrm{E}-17$ \\
\hline-234 & Th-230 & $1.000 \mathrm{E}+00$ & $1.047 \mathrm{E}-28$ & $3.188 \mathrm{E}-28$ & $3.193 E-27$ & $2.443 E-26$ & $1.127 \mathrm{E}-25$ & $4.665 \mathrm{E}-22$ & $1.013 \mathrm{E}-17$ \\
\hline-234 & $\mathrm{Ra}-226+\mathrm{D}$ & $1.000 \mathrm{E}+00$ & $1.090 \mathrm{E}-17$ & $7.671 \mathrm{E}-17$ & $5.533 \mathrm{E}-15$ & $1.167 \mathrm{E}-13$ & $6.482 \mathrm{E}-13$ & $2.407 \mathrm{E}-10$ & $4.396 \mathrm{E}-08$ \\
\hline-234 & $\mathrm{~Pb}-210+\mathrm{D}$ & $1.000 \mathrm{E}+00$ & $3.944 E-26$ & $5.916 \mathrm{E}-25$ & $3.094 \mathrm{E}-22$ & $2.118 \mathrm{E}-20$ & $1.862 \mathrm{E}-19$ & 1. $619 \mathrm{E}-16$ & $5.847 \mathrm{E}-14$ \\
\hline-234 & $\sum \operatorname{DSR}(j)$ & & $1.090 \mathrm{E}-17$ & $7.671 \mathrm{E}-17$ & $5.533 E-15$ & $1.167 \mathrm{E}-13$ & $6.482 \mathrm{E}-13$ & $2.407 \mathrm{E}-10$ & $4.396 \mathrm{E}-08$ \\
\hline$-235+D$ & $\mathrm{U}-235+\mathrm{D}$ & $1.000 \mathrm{E}+00$ & $1.195 \mathrm{E}-15$ & 1. $210 \mathrm{E}-15$ & 1. $387 \mathrm{E}-15$ & $2.218 E-15$ & $4.115 \mathrm{E}-15$ & $5.779 \mathrm{E}-13$ & $5.183 \mathrm{E}-10$ \\
\hline$-235+D$ & $\mathrm{~Pa}-231$ & $1.000 \mathrm{E}+00$ & $2.825 E-19$ & $8.554 \mathrm{E}-19$ & $8.006 \mathrm{E}-18$ & 4. $840 \mathrm{E}-17$ & $1.637 \mathrm{E}-16$ & $5.673 \mathrm{E}-14$ & $4.068 \mathrm{E}-11$ \\
\hline$-235+D$ & $A C-227+D$ & $1.000 \mathrm{E}+00$ & 8.917E-19 & $6.232 \mathrm{E}-18$ & $4.105 \mathrm{E}-16$ & $6.620 \mathrm{E}-15$ & $2.832 E-14$ & $6.156 \mathrm{E}-12$ & $1.720 \mathrm{E}-09$ \\
\hline$-235+D$ & $\sum \operatorname{DSR}(j)$ & & $1.197 \mathrm{E}-15$ & $1.217 \mathrm{E}-15$ & $1.805 \mathrm{E}-15$ & $8.886 \mathrm{E}-15$ & $3.260 \mathrm{E}-14$ & $6.791 \mathrm{E}-12$ & $2.279 \mathrm{E}-09$ \\
\hline-238 & $\mathrm{U}-238$ & $5.400 \mathrm{E}-05$ & $0.000 \mathrm{E}+00$ & $0.000 \mathrm{E}+00$ & $0.000 \mathrm{E}+00$ & $0.000 \mathrm{E}+00$ & $0.000 \mathrm{E}+00$ & $0.000 \mathrm{E}+00$ & $1.636 E-39$ \\
\hline$-238+D$ & $\mathrm{U}-238+\mathrm{D}$ & $9.999 \mathrm{E}-01$ & 1. $365 \mathrm{E}-11$ & 1. $376 \mathrm{E}-11$ & 1. $502 \mathrm{E}-11$ & $2.035 \mathrm{E}-11$ & $3.035 E-11$ & 7. $419 \mathrm{E}-10$ & $6.017 E-08$ \\
\hline$J-238+D$ & $\mathrm{U}-234$ & $9.999 E-01$ & $9.426 \mathrm{E}-31$ & $2.873 E-30$ & $2.906 \mathrm{E}-29$ & $2.301 E-28$ & $1.110 \mathrm{E}-27$ & $6.582 \mathrm{E}-24$ & $2.342 E-19$ \\
\hline$J-238+D$ & $\mathrm{Th}-230$ & $9.999 E-01$ & $9.906 \mathrm{E}-35$ & $7.035 \mathrm{E}-34$ & $5.662 \mathrm{E}-32$ & $1.749 \mathrm{E}-30$ & 1. $605 \mathrm{E}-29$ & $3.309 \mathrm{E}-25$ & $1.508 \mathrm{E}-20$ \\
\hline$J-238+D$ & $\mathrm{Ra}-226+\mathrm{D}$ & $9.999 \mathrm{E}-01$ & $7.725 E-24$ & $1.165 E-22$ & $6.546 \mathrm{E}-20$ & $5.580 \mathrm{E}-18$ & $6.178 \mathrm{E}-17$ & $1.159 \mathrm{E}-13$ & $4.523 E-11$ \\
\hline$J-238+D$ & $\mathrm{~Pb}-210+\mathrm{D}$ & $9.999 E-01$ & $2.239 E-32$ & $6.951 E-31$ & $2.798 E-27$ & $8.109 E-25$ & 1. $488 \mathrm{E}-23$ & $7.347 \mathrm{E}-20$ & $5.837 \mathrm{E}-17$ \\
\hline$-238+D$ & $\sum \operatorname{DSR}(j)$ & & $1.365 \mathrm{E}-11$ & 1. $376 \mathrm{E}-11$ & $1.502 \mathrm{E}-11$ & $2.035 \mathrm{E}-11$ & $3.035 \mathrm{E}-11$ & $7.420 \mathrm{E}-10$ & $6.021 \mathrm{E}-08$ \\
\hline
\end{tabular}

The DSR includes contributions from associated (half-life $\leq 180$ days) daughters. 
RESRAD, Version $6.5 \quad T^{1 / 2}$ Limit $=180$ days

ummary : RESRAD Parameters for U-Landfill Recreational User

File $\quad$ : C: $\backslash$ RESRAD FAMILY $\backslash R E S R A D \backslash U S E R F I L E S \backslash Q C F O R S R S G \backslash R U$ SRSG-MAY11.RAD

Single Radionuclide Soil Guidelines G(i,t) in pCi/g

Basic Radiation Dose Limit $=1.000 \mathrm{E}+00 \mathrm{mrem} / \mathrm{yr}$

Nuclide

\begin{tabular}{|c|c|c|c|c|c|c|c|}
\hline (i) & $t=0.000 \mathrm{E}+00$ & $1.000 \mathrm{E}+00$ & $1.200 \mathrm{E}+01$ & $5.000 \mathrm{E}+01$ & $1.000 \mathrm{E}+02$ & $5.000 \mathrm{E}+02$ & $1.050 \mathrm{E}+03$ \\
\hline-241 & $\star 3.431 \mathrm{E}+12$ & $\star 3.431 \mathrm{E}+12$ & $\star 3.431 \mathrm{E}+12$ & $\star 3.431 \mathrm{E}+12$ & $* 3.431 \mathrm{E}+12$ & $* 3.431 \mathrm{E}+12$ & $8.235 E+11$ \\
\hline-137 & $8.242 E+09$ & $8.364 \mathrm{E}+09$ & $9.831 E+09$ & $1.718 \mathrm{E}+10$ & $3.580 \mathrm{E}+10$ & $1.274 \mathrm{E}+13$ & $\star 8.704 \mathrm{E}+13$ \\
\hline-237 & $\star 7.047 \mathrm{E}+08$ & $\star 7.047 \mathrm{E}+08$ & $\star 7.047 \mathrm{E}+08$ & $\star 7.047 \mathrm{E}+08$ & $\star 7.047 \mathrm{E}+08$ & $\star 7.047 \mathrm{E}+08$ & $1.380 \mathrm{E}+08$ \\
\hline-238 & $\star 1.712 \mathrm{E}+13$ & $\star 1.712 \mathrm{E}+13$ & $\star 1.712 \mathrm{E}+13$ & $\star 1.712 \mathrm{E}+13$ & $\star 1.712 \mathrm{E}+13$ & $\star 1.712 \mathrm{E}+13$ & $7.937 \mathrm{E}+10$ \\
\hline-239 & $\star 6.214 \mathrm{E}+10$ & $* 6.214 \mathrm{E}+10$ & $* 6.214 \mathrm{E}+10$ & $* 6.214 \mathrm{E}+10$ & $\star 6.214 \mathrm{E}+10$ & $* 6.214 \mathrm{E}+10$ & $* 6.214 \mathrm{E}+1 \mathrm{C}$ \\
\hline-240 & $\star 2.278 \mathrm{E}+11$ & $\star 2.278 \mathrm{E}+11$ & $\star 2.278 \mathrm{E}+11$ & $\star 2.278 \mathrm{E}+11$ & $\star 2.278 \mathrm{E}+11$ & $\star 2.278 \mathrm{E}+11$ & $\star 2.278 \mathrm{E}+1$ \\
\hline-99 & $\star 1.697 \mathrm{E}+10$ & $\star 1.697 \mathrm{E}+10$ & $\star 1.697 \mathrm{E}+10$ & $* 1.697 \mathrm{E}+10$ & $\star 1.697 \mathrm{E}+10$ & $\star 1.697 \mathrm{E}+10$ & $* 1.697 \mathrm{E}+10$ \\
\hline-228 & $7.523 \mathrm{E}+06$ & $1.074 \mathrm{E}+07$ & $5.414 \mathrm{E}+08$ & $4.116 \mathrm{E}+14$ & $\star 8.195 \mathrm{E}+14$ & $\star 8.195 \mathrm{E}+14$ & $\star 8.195 \mathrm{E}+14$ \\
\hline-230 & $\star 2.018 \mathrm{E}+10$ & $\star 2.018 \mathrm{E}+10$ & $1.018 \mathrm{E}+10$ & $1.955 \mathrm{E}+09$ & $7.028 \mathrm{E}+08$ & $9.688 \mathrm{E}+06$ & $1.155 \mathrm{E}+0$ \\
\hline$h-232$ & $* 1.097 \mathrm{E}+05$ & $\star 1.097 \mathrm{E}+05$ & $\star 1.097 \mathrm{E}+05$ & $\star 1.097 \mathrm{E}+05$ & $* 1.097 \mathrm{E}+05$ & $* 1.097 \mathrm{E}+05$ & $1.124 \mathrm{E}+04$ \\
\hline 234 & $* 6.247 \mathrm{E}+09$ & $\star 6.247 \mathrm{E}+09$ & $\star 6.247 \mathrm{E}+09$ & $\star 6.247 \mathrm{E}+09$ & $* 6.247 \mathrm{E}+09$ & $4.154 \mathrm{E}+09$ & $2.275 \mathrm{E}+07$ \\
\hline 35 & $\star 2.161 \mathrm{E}+06$ & $\star 2.161 \mathrm{E}+06$ & $\star 2.161 \mathrm{E}+06$ & $\star 2.161 \mathrm{E}+06$ & $\star 2.161 \mathrm{E}+06$ & $\star 2.161 \mathrm{E}+06$ & $\star 2.161 \mathrm{E}+06$ \\
\hline 38 & $\star 3.361 \mathrm{E}+05$ & $\star 3.361 \mathrm{E}+05$ & $\star 3.361 \mathrm{E}+05$ & $\star 3.361 \mathrm{E}+05$ & $\star 3.361 \mathrm{E}+05$ & $\star 3.361 \mathrm{E}+05$ & $\star 3.361 \mathrm{E}+05$ \\
\hline
\end{tabular}

${ }^{*}$ At specific activity limit

Summed Dose/Source Ratios DSR(i,t) in (mrem/yr)/(pCi/g)

and Single Radionuclide Soil Guidelines $\mathrm{G}(i, t)$ in $\mathrm{pCi} / \mathrm{g}$

at tmin = time of minimum single radionuclide soil guideline

and at $\operatorname{tmax}=$ time of maximum total dose $=1.050 \mathrm{E}+03$ years

\begin{tabular}{|c|c|c|c|c|c|c|}
\hline $\begin{array}{l}\text { uclide } \\
\text { (i) }\end{array}$ & $\begin{array}{l}\text { Initial } \\
(\mathrm{pCi} / \mathrm{g})\end{array}$ & $\begin{array}{c}\text { tmin } \\
\text { (years) }\end{array}$ & $\operatorname{DSR}(i, \operatorname{tmin})$ & $\begin{array}{c}G(i, \operatorname{tmin}) \\
(\mathrm{pCi} / \mathrm{g})\end{array}$ & $\operatorname{DSR}(i, \operatorname{tmax})$ & $\begin{array}{c}G(i, t \operatorname{tmax}) \\
(\mathrm{pCi} / \mathrm{g})\end{array}$ \\
\hline-241 & $1.000 \mathrm{E}+00$ & $1.050 \mathrm{E}+03$ & $1.214 \mathrm{E}-12$ & $8.235 E+11$ & $1.214 \mathrm{E}-12$ & $8.235 E+11$ \\
\hline-137 & $1.000 \mathrm{E}+00$ & $0.000 \mathrm{E}+00$ & $1.213 \mathrm{E}-10$ & $8.242 E+09$ & $2.435 \mathrm{E}-17$ & $\star 8.704 \mathrm{E}+13$ \\
\hline-237 & $1.000 \mathrm{E}+00$ & $1.050 \mathrm{E}+03$ & $7.245 \mathrm{E}-09$ & $1.380 \mathrm{E}+08$ & $7.245 \mathrm{E}-09$ & $1.380 \mathrm{E}+08$ \\
\hline 238 & $1.000 \mathrm{E}+00$ & $1.050 \mathrm{E}+03$ & $1.260 \mathrm{E}-11$ & $7.937 \mathrm{E}+10$ & $1.260 \mathrm{E}-11$ & $7.937 \mathrm{E}+10$ \\
\hline $\mathrm{Pu}-239$ & $1.000 \mathrm{E}+00$ & $1.050 \mathrm{E}+03$ & $3.234 \mathrm{E}-13$ & $* 6.214 \mathrm{E}+10$ & $3.234 \mathrm{E}-13$ & $* 6.214 \mathrm{E}+10$ \\
\hline$u-240$ & $1.000 \mathrm{E}+00$ & $1.050 \mathrm{E}+03$ & $7.834 \mathrm{E}-17$ & $\star 2.278 \mathrm{E}+11$ & $7.834 \mathrm{E}-17$ & $\star 2.278 \mathrm{E}+11$ \\
\hline$c-99$ & $1.000 \mathrm{E}+00$ & $1.050 \mathrm{E}+03$ & $1.233 \mathrm{E}-20$ & $\star 1.697 \mathrm{E}+10$ & $1.233 \mathrm{E}-20$ & $\star 1.697 \mathrm{E}+10$ \\
\hline-228 & $1.000 \mathrm{E}+00$ & $0.000 \mathrm{E}+00$ & $1.329 \mathrm{E}-07$ & $7.523 \mathrm{E}+06$ & $0.000 \mathrm{E}+00$ & $\star 8.195 \mathrm{E}+14$ \\
\hline 230 & $1.000 \mathrm{E}+00$ & $1.050 \mathrm{E}+03$ & $8.661 \mathrm{E}-06$ & $1.155 \mathrm{E}+05$ & $8.661 \mathrm{E}-06$ & $1.155 \mathrm{E}+05$ \\
\hline-232 & $1.000 \mathrm{E}+00$ & $1.050 \mathrm{E}+03$ & $8.900 \mathrm{E}-05$ & $1.124 \mathrm{E}+04$ & $8.900 \mathrm{E}-05$ & $1.124 \mathrm{E}+04$ \\
\hline 34 & $1.000 \mathrm{E}+00$ & $1.050 \mathrm{E}+03$ & $4.396 \mathrm{E}-08$ & $2.275 \mathrm{E}+07$ & $4.396 \mathrm{E}-08$ & $2.275 \mathrm{E}+07$ \\
\hline 35 & $1.000 \mathrm{E}+00$ & $1.050 E+03$ & $2.279 \mathrm{E}-09$ & $\star 2.161 \mathrm{E}+06$ & $2.279 \mathrm{E}-09$ & $\star 2.161 \mathrm{E}+06$ \\
\hline 238 & $1.000 \mathrm{E}+00$ & $1.050 \mathrm{E}+03$ & $6.021 \mathrm{E}-08$ & $\star 3.361 E+05$ & $6.021 \mathrm{E}-08$ & $\star 3.361 \mathrm{E}+05$ \\
\hline
\end{tabular}

*At specific activity limit 
RESRAD, Version 6.5

$\mathrm{T}^{1 / 2}$ Limit $=180$ days

$07 / 21 / 2011$

17:07 Page

30

mmary : RESRAD Parameters for U-Landfill Recreational User

File : C: $\backslash$ RESRAD FAMILY \RESRAD \USERFILES $\backslash Q C F O R S R S G \backslash R U$ SRSG-MAY11.RAD

Individual Nuclide Dose Summed Over All Pathways

Parent Nuclide and Branch Fraction Indicated

Nuclide Parent THF(i) DOSE $(j, t), \mathrm{mrem} / \mathrm{yr}$

\begin{tabular}{|c|c|c|}
\hline$(j)$ & (i) & \\
\hline-241 & $A m-241$ & $1.000 \mathrm{E}+00$ \\
\hline$p-237$ & $A m-241$ & $1.000 \mathrm{E}+00$ \\
\hline $\mathrm{Np}-237$ & $\mathrm{~Np}-237$ & $1.000 \mathrm{E}+00$ \\
\hline Np-237 & $\sum \operatorname{DOSE}(j$ & \\
\hline
\end{tabular}

$\mathrm{U}-233 \quad \mathrm{Am}-241 \quad 1.000 \mathrm{E}+00$

$\mathrm{U}-233 \quad \mathrm{~Np}-237 \quad 1.000 \mathrm{E}+00$

U-233 $\quad$ DOSE $(j)$

Th-229 Am-241 $1.000 \mathrm{E}+00$

Th-229 Np-237 1.000E+00

Th-229 $\sum \operatorname{DOSE}(j)$

Cs $-137 \quad$ Cs $-137 \quad 1.000 E+00$

$\mathrm{Pu}-238$

$\mathrm{Pu}-238$

$\mathrm{Pu}-238$

$\mathrm{U}-234$

$\mathrm{U}-234$

$\mathrm{U}-234$

$\mathrm{U}-234$

Th-230

Th-230

Th -230

Th-230

Th -230

$\mathrm{Ra}-226$

$\mathrm{Ra}-226$

$\mathrm{Ra}-226$

$\mathrm{Ra}-226$

$\mathrm{Ra}-226$

$\mathrm{Pb}-210$

$\mathrm{Pb}-210$

$\mathrm{Pb}-210$

$\mathrm{Pb}-210$

$\mathrm{Pb}-210$

$\mathrm{Pu}-239$

Pu-239 1.000E+00 $\mathrm{U}-2351.000 \mathrm{E}+00$ $\sum \operatorname{DOSE}(j)$ $t=0.000 \mathrm{E}+00 \quad 1.000 \mathrm{E}+00 \quad 1.200 \mathrm{E}+01 \quad 5.000 \mathrm{E}+01 \quad 1.000 \mathrm{E}+02 \quad 5.000 \mathrm{E}+02 \quad 1.050 \mathrm{E}+03$

$\begin{array}{lllllll}1.487 \mathrm{E}-20 & 4.500 \mathrm{E}-20 & 4.182 \mathrm{E}-19 & 2.467 \mathrm{E}-18 & 8.084 \mathrm{E}-18 & 2.212 \mathrm{E}-15 & 1.203 \mathrm{E}-12\end{array}$ $9.169 \mathrm{E}-14 \quad 9.268 \mathrm{E}-14 \quad 1.043 \mathrm{E}-13 \quad 1.567 \mathrm{E}-13 \quad 2.679 \mathrm{E}-13 \quad 1.952 \mathrm{E}-11 \quad 7.101 \mathrm{E}-09$ $9.169 \mathrm{E}-14 \quad 9.268 \mathrm{E}-14 \quad 1.043 \mathrm{E}-13 \quad 1.567 \mathrm{E}-13 \quad 2.679 \mathrm{E}-13 \quad 1.952 \mathrm{E}-11 \quad 7.102 \mathrm{E}-09$

$0.000 \mathrm{E}+00 \quad 2.384 \mathrm{E}-30 \quad 1.820 \mathrm{E}-28 \quad 4.682 \mathrm{E}-27 \quad 3.376 \mathrm{E}-26 \quad 1.025 \mathrm{E}-22 \quad 3.455 \mathrm{E}-19$ $3.120 \mathrm{E}-24 \quad 9.466 \mathrm{E}-24 \quad 9.045 \mathrm{E}-23 \quad 5.875 \mathrm{E}-22 \quad 2.184 \mathrm{E}-21 \quad 1.613 \mathrm{E}-18 \quad 3.273 \mathrm{E}-15$ $3.120 \mathrm{E}-24 \quad 9.466 \mathrm{E}-24 \quad 9.045 \mathrm{E}-23 \quad 5.875 \mathrm{E}-22 \quad 2.184 \mathrm{E}-21 \quad 1.613 \mathrm{E}-18 \quad 3.273 \mathrm{E}-15$

$2.306 \mathrm{E}-27 \quad 3.479 \mathrm{E}-26 \quad 1.949 \mathrm{E}-23 \quad 1.645 \mathrm{E}-21 \quad 1.799 \mathrm{E}-20 \quad 3.100 \mathrm{E}-17 \quad 1.142 \mathrm{E}-14$ $2.848 \mathrm{E}-20 \quad 2.006 \mathrm{E}-19 \quad 1.449 \mathrm{E}-17 \quad 3.076 \mathrm{E}-16 \quad 1.723 \mathrm{E}-15 \quad 6.884 \mathrm{E}-13 \quad 1.443 \mathrm{E}-10$ $2.848 \mathrm{E}-20 \quad 2.006 \mathrm{E}-19 \quad 1.449 \mathrm{E}-17 \quad 3.076 \mathrm{E}-16 \quad 1.723 \mathrm{E}-15 \quad 6.884 \mathrm{E}-13 \quad 1.443 \mathrm{E}-10$ $\begin{array}{llllllll}1.213 \mathrm{E}-10 & 1.196 \mathrm{E}-10 & 1.017 \mathrm{E}-10 & 5.821 \mathrm{E}-11 & 2.793 \mathrm{E}-11 & 7.847 \mathrm{E}-14 & 2.435 \mathrm{E}-17\end{array}$ $\begin{array}{llllll}0.000 \mathrm{E}+00 & 0.000 \mathrm{E}+00 & 0.000 \mathrm{E}+00 & 0.000 \mathrm{E}+00 & 0.000 \mathrm{E}+00 & 0.000 \mathrm{E}+00 \quad 5.849 \mathrm{E}-30\end{array}$

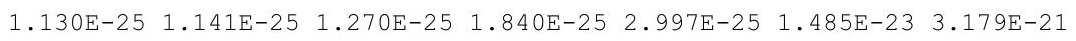

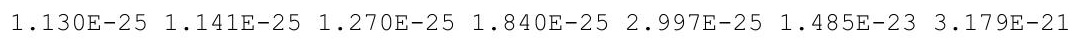

$\begin{array}{lllllll}0.000 \mathrm{E}+00 & 2.855 \mathrm{E}-30 & 2.767 \mathrm{E}-29 & 1.897 \mathrm{E}-28 & 7.660 \mathrm{E}-28 & 1.633 \mathrm{E}-24 & 2.820 \mathrm{E}-20\end{array}$ $\begin{array}{llllllll}6.631 \mathrm{E}-25 & 6.749 \mathrm{E}-25 & 8.200 \mathrm{E}-25 & 1.607 \mathrm{E}-24 & 3.895 \mathrm{E}-24 & 4.636 \mathrm{E}-21 & 7.854 \mathrm{E}-17\end{array}$ $\begin{array}{lllllll}0.000 \mathrm{E}+00 & 2.873 \mathrm{E}-30 & 2.906 \mathrm{E}-29 & 2.301 \mathrm{E}-28 & 1.110 \mathrm{E}-27 & 6.582 \mathrm{E}-24 & 2.342 \mathrm{E}-19\end{array}$ $\begin{array}{llllllll}6.631 \mathrm{E}-25 & 6.749 \mathrm{E}-25 & 8.201 \mathrm{E}-25 & 1.607 \mathrm{E}-24 & 3.897 \mathrm{E}-24 & 4.644 \mathrm{E}-21 & 7.880 \mathrm{E}-17\end{array}$

$\begin{array}{llllllll}0.000 \mathrm{E}+00 & 0.000 \mathrm{E}+00 & 0.000 \mathrm{E}+00 & 1.538 \mathrm{E}-30 & 1.253 \mathrm{E}-29 & 1.259 \mathrm{E}-25 & 3.198 \mathrm{E}-21\end{array}$ $\begin{array}{llllllll}2.319 \mathrm{E}-23 & 2.359 \mathrm{E}-23 & 2.838 \mathrm{E}-23 & 5.375 \mathrm{E}-23 & 1.246 \mathrm{E}-22 & 1.037 \mathrm{E}-19 & 1.074 \mathrm{E}-15\end{array}$ $\begin{array}{lllllll}1.047 \mathrm{E}-28 & 3.188 \mathrm{E}-28 & 3.193 \mathrm{E}-27 & 2.443 \mathrm{E}-26 & 1.127 \mathrm{E}-25 & 4.665 \mathrm{E}-22 & 1.013 \mathrm{E}-17\end{array}$ $0.000 \mathrm{E}+00 \quad 0.000 \mathrm{E}+00 \quad 0.000 \mathrm{E}+00 \quad 1.749 \mathrm{E}-30 \quad 1.605 \mathrm{E}-29 \quad 3.309 \mathrm{E}-25 \quad 1.508 \mathrm{E}-20$ $2.319 \mathrm{E}-23 \quad 2.359 \mathrm{E}-23 \quad 2.838 \mathrm{E}-23 \quad 5.378 \mathrm{E}-23 \quad 1.247 \mathrm{E}-22 \quad 1.041 \mathrm{E}-19 \quad 1.084 \mathrm{E}-15$

$\begin{array}{lllllll}7.713 \mathrm{E}-24 & 1.162 \mathrm{E}-22 & 6.388 \mathrm{E}-20 & 5.065 \mathrm{E}-18 & 5.122 \mathrm{E}-17 & 5.408 \mathrm{E}-14 & 1.260 \mathrm{E}-11\end{array}$ $\begin{array}{lllllll}3.629 \mathrm{E}-12 & 1.095 \mathrm{E}-11 & 9.820 \mathrm{E}-11 & 5.116 \mathrm{E}-10 & 1.423 \mathrm{E}-09 & 1.032 \mathrm{E}-07 & 8.661 \mathrm{E}-06\end{array}$ $\begin{array}{lllllll}1.090 \mathrm{E}-17 & 7.671 \mathrm{E}-17 & 5.533 \mathrm{E}-15 & 1.167 \mathrm{E}-13 & 6.482 \mathrm{E}-13 & 2.407 \mathrm{E}-10 & 4.396 \mathrm{E}-08\end{array}$ $\begin{array}{lllllll}7.725 \mathrm{E}-24 & 1.165 \mathrm{E}-22 & 6.546 \mathrm{E}-20 & 5.580 \mathrm{E}-18 & 6.178 \mathrm{E}-17 & 1.159 \mathrm{E}-13 & 4.523 \mathrm{E}-11\end{array}$ 3.629E-12 1.095E-11 9.821E-11 5.117E-10 1.423E-09 1.035E-07 8.705E-06

$0.000 \mathrm{E}+00 \quad 0.000 \mathrm{E}+00 \quad 2.743 \mathrm{E}-27 \quad 7.476 \mathrm{E}-25 \quad 1.264 \mathrm{E}-23 \quad 3.542 \mathrm{E}-20 \quad 1.664 \mathrm{E}-17$ $\begin{array}{lllllll}1.749 \mathrm{E}-20 & 1.222 \mathrm{E}-19 & 7.985 \mathrm{E}-18 & 1.249 \mathrm{E}-16 & 5.113 \mathrm{E}-16 & 7.402 \mathrm{E}-14 & 1.190 \mathrm{E}-11\end{array}$ $3.944 \mathrm{E}-26 \quad 5.916 \mathrm{E}-25 \quad 3.094 \mathrm{E}-22 \quad 2.118 \mathrm{E}-20 \quad 1.862 \mathrm{E}-19 \quad 1.619 \mathrm{E}-16 \quad 5.847 \mathrm{E}-14$ $0.000 \mathrm{E}+00 \quad 0.000 \mathrm{E}+00 \quad 2.798 \mathrm{E}-27 \quad 8.109 \mathrm{E}-25 \quad 1.488 \mathrm{E}-23 \quad 7.347 \mathrm{E}-20 \quad 5.837 \mathrm{E}-17$ $\begin{array}{lllllll}1.749 \mathrm{E}-20 & 1.222 \mathrm{E}-19 & 7.985 \mathrm{E}-18 & 1.250 \mathrm{E}-16 & 5.115 \mathrm{E}-16 & 7.418 \mathrm{E}-14 & 1.196 \mathrm{E}-11\end{array}$ $\begin{array}{lllllll}1.156 \mathrm{E}-18 & 1.170 \mathrm{E}-18 & 1.334 \mathrm{E}-18 & 2.100 \mathrm{E}-18 & 3.815 \mathrm{E}-18 & 4.526 \mathrm{E}-16 & 3.220 \mathrm{E}-13\end{array}$

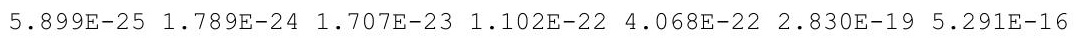

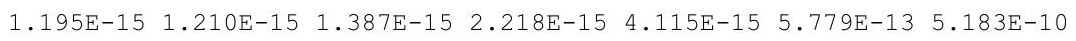
1.195E-15 1.210E-15 1.387E-15 2.218E-15 4.115E-15 5.779E-13 5.183E-10 
RESRAD, Version 6.5

Summary : RESRAD Parameters for U-Landfill Recreational User

File : C: $\backslash$ RESRAD FAMILY \RESRAD \USERFILES $\backslash Q C F O R S R S G \backslash R U$ SRSG-MAY11.RAD

Individual Nuclide Dose Summed Over All Pathways

Parent Nuclide and Branch Fraction Indicated

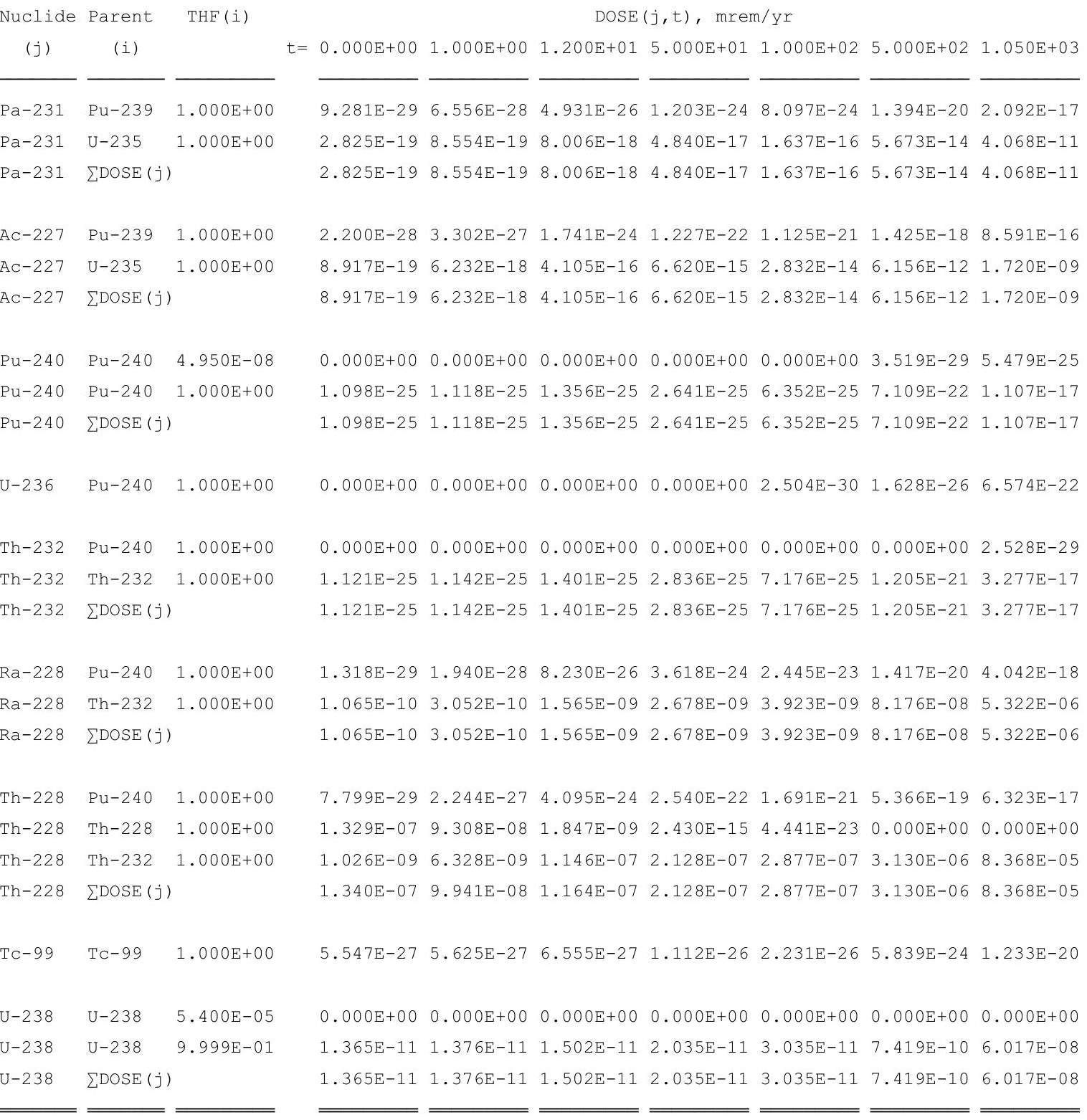

THF (i) is the thread fraction of the parent nuclide. 
RESRAD, Version 6.5

Summary : RESRAD Parameters for U-Landfill Recreational User

File : C: $\backslash$ RESRAD FAMILY \RESRAD \USERFILES $\backslash Q C F O R S R S G \backslash R U$ SRSG-MAY11.RAD

Individual Nuclide Soil Concentration

Parent Nuclide and Branch Fraction Indicated

Nuclide Parent THF(
(j)

(i)

$\mathrm{Am}-241$

$\mathrm{Am}-241 \quad 1.000 \mathrm{E}+00$

Np-237

Np-237

Np-237

$\mathrm{Am}-241 \quad 1.000 \mathrm{E}+00$

Np-237 1.000E+00

$\sum S(j):$

$\mathrm{U}-233$

$\mathrm{U}-233$

$\mathrm{U}-233$

Th-229

Th-229

Th-229

Cs -137

$\mathrm{Pu}-238$

$\mathrm{Pu}-238$

$\mathrm{Pu}-238$

$\mathrm{U}-234$

$\mathrm{U}-234$

$\mathrm{U}-234$

$\mathrm{U}-234$

Th-230

Th -230

Th -230

Th-230

$\mathrm{Th}-230$

$\mathrm{Ra}-226$

$\mathrm{Ra}-226$

$\mathrm{Ra}-226$

$\mathrm{Ra}-226$

$\mathrm{Ra}-226$

$\mathrm{Pb}-210$

$\mathrm{Pb}-210$

$\mathrm{Pb}-210$

$\mathrm{Pb}-210$

$\mathrm{Pb}-210$

$\mathrm{Pu}-239$

$\mathrm{Am}-241 \quad 1.000 \mathrm{E}+00$ $\mathrm{Np}-237 \quad 1.000 \mathrm{E}+00$ $\sum S(j):$

Am-241 $1.000 \mathrm{E}+00$ Np-237 1.000E+00 $\sum S(j):$

Cs-137 1.000E+00

Pu-238 1.840E-09

$\mathrm{Pu}-238 \quad 1.000 \mathrm{E}+00$

$\sum S(j):$

$\mathrm{Pu}-238 \quad 1.000 \mathrm{E}+00$

$\mathrm{U}-234 \quad 1.000 \mathrm{E}+00$

U-238 $9.999 \mathrm{E}-01$

$\sum S(j):$

Pu-238 1.000E+00

Th-230 1.000E+00

$\mathrm{U}-234 \quad 1.000 \mathrm{E}+00$

$\mathrm{U}-238 \quad 9.999 \mathrm{E}-01$

$\sum S(j):$

Pu-238 $1.000 \mathrm{E}+00$

Th-230 $1.000 \mathrm{E}+00$

$\mathrm{U}-234 \quad 1.000 \mathrm{E}+00$

$\mathrm{U}-238 \quad 9.999 \mathrm{E}-01$

$\sum S(j):$

$\mathrm{Pu}-238 \quad 1.000 \mathrm{E}+00$

Th-230 1.000E+00

$\mathrm{U}-2341.000 \mathrm{E}+00$

$\mathrm{U}-238 \quad 9.999 \mathrm{E}-01$

$\sum S(j):$

Pu-239 1.000E+00

$\mathrm{Pu}-239 \quad 1.000 \mathrm{E}+00$

$\mathrm{U}-2351.000 \mathrm{E}+00$

$\sum S(j):$
$\mathrm{S}(j, \mathrm{t}), \mathrm{pCi} / \mathrm{g}$

$\mathrm{t}=0.000 \mathrm{E}+00 \quad 1.000 \mathrm{E}+00 \quad 1.200 \mathrm{E}+01 \quad 5.000 \mathrm{E}+01 \quad 1.000 \mathrm{E}+02 \quad 5.000 \mathrm{E}+02 \quad 1.050 \mathrm{E}+03$

$\begin{array}{lllllllllllll}1.000 \mathrm{E}+00 & 9.984 \mathrm{E}-01 & 9.809 \mathrm{E}-01 & 9.228 \mathrm{E}-01 & 8.516 \mathrm{E}-01 & 4.478 \mathrm{E}-01 & 1.851 \mathrm{E}-01\end{array}$

$0.000 \mathrm{E}+00 \quad 3.236 \mathrm{E}-07 \quad 3.848 \mathrm{E}-06 \quad 1.553 \mathrm{E}-05 \quad 2.980 \mathrm{E}-05 \quad 1.089 \mathrm{E}-04 \quad 1.559 \mathrm{E}-04$

$\begin{array}{lllllll}1.000 \mathrm{E}+00 & 9.999 \mathrm{E}-01 & 9.991 \mathrm{E}-01 & 9.961 \mathrm{E}-01 & 9.922 \mathrm{E}-01 & 9.614 \mathrm{E}-01 & 9.206 \mathrm{E}-01\end{array}$

$\begin{array}{llllllll}1.000 \mathrm{E}+00 & 9.999 \mathrm{E}-01 & 9.991 \mathrm{E}-01 & 9.961 \mathrm{E}-01 & 9.922 \mathrm{E}-01 & 9.615 \mathrm{E}-01 & 9.208 \mathrm{E}-01\end{array}$

$0.000 \mathrm{E}+00 \quad 7.078 \mathrm{E}-13 \quad 1.013 \mathrm{E}-10 \quad 1.721 \mathrm{E}-09 \quad 6.696 \mathrm{E}-09 \quad 1.355 \mathrm{E}-07 \quad 4.608 \mathrm{E}-07$

$0.000 \mathrm{E}+00 \quad 4.373 \mathrm{E}-06 \quad 5.245 \mathrm{E}-05 \quad 2.181 \mathrm{E}-04 \quad 4.352 \mathrm{E}-04 \quad 2.135 \mathrm{E}-03 \quad 4.366 \mathrm{E}-03$

$\begin{array}{lllllll}0.000 \mathrm{E}+00 & 4.373 \mathrm{E}-06 & 5.245 \mathrm{E}-05 & 2.181 \mathrm{E}-04 & 4.352 \mathrm{E}-04 & 2.135 \mathrm{E}-03 & 4.366 \mathrm{E}-03\end{array}$

$\begin{array}{lllllll}0.000 \mathrm{E}+00 & 2.228 \mathrm{E}-17 & 3.832 \mathrm{E}-14 & 2.725 \mathrm{E}-12 & 2.132 \mathrm{E}-11 & 2.249 \mathrm{E}-09 & 1.683 \mathrm{E}-08\end{array}$

$\begin{array}{lllllll}0.000 \mathrm{E}+00 & 2.065 \mathrm{E}-10 & 2.971 \mathrm{E}-08 & 5.146 \mathrm{E}-07 & 2.052 \mathrm{E}-06 & 4.999 \mathrm{E}-05 & 2.128 \mathrm{E}-04\end{array}$

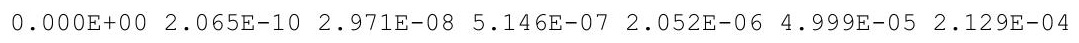

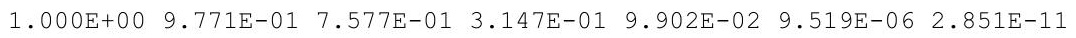

$\begin{array}{lllllll}1.840 \mathrm{E}-09 & 1.826 \mathrm{E}-09 & 1.673 \mathrm{E}-09 & 1.239 \mathrm{E}-09 & 8.342 \mathrm{E}-10 & 3.525 \mathrm{E}-11 & 4.548 \mathrm{E}-13\end{array}$

$\begin{array}{lllllllll}1.000 \mathrm{E}+00 & 9.921 \mathrm{E}-01 & 9.094 \mathrm{E}-01 & 6.733 \mathrm{E}-01 & 4.534 \mathrm{E}-01 & 1.916 \mathrm{E}-02 & 2.472 \mathrm{E}-04\end{array}$

$\begin{array}{lllllllll}1.000 \mathrm{E}+00 & 9.921 \mathrm{E}-01 & 9.094 \mathrm{E}-01 & 6.733 \mathrm{E}-01 & 4.534 \mathrm{E}-01 & 1.916 \mathrm{E}-02 & 2.472 \mathrm{E}-04\end{array}$

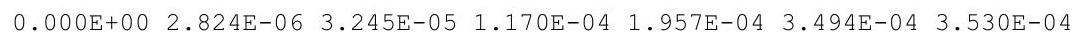

$\begin{array}{llllllll}1.000 \mathrm{E}+00 & 1.000 \mathrm{E}+00 & 9.998 \mathrm{E}-01 & 9.992 \mathrm{E}-01 & 9.984 \mathrm{E}-01 & 9.919 \mathrm{E}-01 & 9.831 \mathrm{E}-01\end{array}$

$\begin{array}{lllllll}0.000 \mathrm{E}+00 & 2.835 \mathrm{E}-06 & 3.401 \mathrm{E}-05 & 1.416 \mathrm{E}-04 & 2.831 \mathrm{E}-04 & 1.407 \mathrm{E}-03 & 2.931 \mathrm{E}-03\end{array}$

$\begin{array}{llllllll}1.000 \mathrm{E}+00 & 1.000 \mathrm{E}+00 & 9.999 \mathrm{E}-01 & 9.994 \mathrm{E}-01 & 9.989 \mathrm{E}-01 & 9.937 \mathrm{E}-01 & 9.864 \mathrm{E}-01\end{array}$

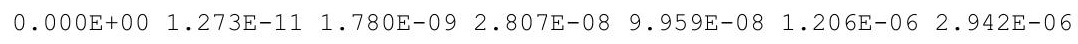
$\begin{array}{llllllll}1.000 \mathrm{E}+00 & 1.000 \mathrm{E}+00 & 9.999 \mathrm{E}-01 & 9.995 \mathrm{E}-01 & 9.989 \mathrm{E}-01 & 9.947 \mathrm{E}-01 & 9.888 \mathrm{E}-01\end{array}$ $\begin{array}{lllllll}0.000 \mathrm{E}+00 & 9.002 \mathrm{E}-06 & 1.080 \mathrm{E}-04 & 4.498 \mathrm{E}-04 & 8.990 \mathrm{E}-04 & 4.471 \mathrm{E}-03 & 9.319 \mathrm{E}-03\end{array}$ $\begin{array}{lllllll}0.000 \mathrm{E}+00 & 1.276 \mathrm{E}-11 & 1.837 \mathrm{E}-09 & 3.188 \mathrm{E}-08 & 1.274 \mathrm{E}-07 & 3.168 \mathrm{E}-06 & 1.387 \mathrm{E}-05\end{array}$ $\begin{array}{llllllll}1.000 \mathrm{E}+00 & 1.000 \mathrm{E}+00 & 1.000 \mathrm{E}+00 & 9.999 \mathrm{E}-01 & 9.998 \mathrm{E}-01 & 9.991 \mathrm{E}-01 & 9.981 \mathrm{E}-01\end{array}$

$0.000 \mathrm{E}+00 \quad 1.839 \mathrm{E}-15 \quad 3.105 \mathrm{E}-12 \quad 2.080 \mathrm{E}-10 \quad 1.511 \mathrm{E}-09 \quad 1.013 \mathrm{E}-07 \quad 5.253 \mathrm{E}-07$ $\begin{array}{lllllll}0.000 \mathrm{E}+00 & 4.331 \mathrm{E}-04 & 5.184 \mathrm{E}-03 & 2.142 \mathrm{E}-02 & 4.235 \mathrm{E}-02 & 1.937 \mathrm{E}-01 & 3.613 \mathrm{E}-01\end{array}$ $\begin{array}{lllllll}0.000 \mathrm{E}+00 & 1.950 \mathrm{E}-09 & 2.803 \mathrm{E}-07 & 4.837 \mathrm{E}-06 & 1.920 \mathrm{E}-05 & 4.512 \mathrm{E}-04 & 1.833 \mathrm{E}-03\end{array}$ $\begin{array}{lllllll}0.000 \mathrm{E}+00 & 1.842 \mathrm{E}-15 & 3.179 \mathrm{E}-12 & 2.289 \mathrm{E}-10 & 1.820 \mathrm{E}-09 & 2.170 \mathrm{E}-07 & 1.885 \mathrm{E}-06\end{array}$ $\begin{array}{lllllll}0.000 \mathrm{E}+00 & 4.331 \mathrm{E}-04 & 5.185 \mathrm{E}-03 & 2.142 \mathrm{E}-02 & 4.237 \mathrm{E}-02 & 1.942 \mathrm{E}-01 & 3.632 \mathrm{E}-01\end{array}$

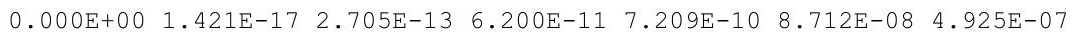
$\begin{array}{lllllll}0.000 \mathrm{E}+00 & 6.663 \mathrm{E}-06 & 8.578 \mathrm{E}-04 & 1.058 \mathrm{E}-02 & 2.946 \mathrm{E}-02 & 1.823 \mathrm{E}-01 & 3.524 \mathrm{E}-01\end{array}$ $\begin{array}{lllllll}0.000 \mathrm{E}+00 & 2.004 \mathrm{E}-11 & 3.184 \mathrm{E}-08 & 1.773 \mathrm{E}-06 & 1.066 \mathrm{E}-05 & 3.984 \mathrm{E}-04 & 1.731 \mathrm{E}-03\end{array}$ $\begin{array}{lllllll}0.000 \mathrm{E}+00 & 1.423 \mathrm{E}-17 & 2.757 \mathrm{E}-13 & 6.719 \mathrm{E}-11 & 8.476 \mathrm{E}-10 & 1.806 \mathrm{E}-07 & 1.727 \mathrm{E}-06\end{array}$ $\begin{array}{lllllllll}0.000 \mathrm{E}+00 & 6.663 \mathrm{E}-06 & 8.578 \mathrm{E}-04 & 1.058 \mathrm{E}-02 & 2.947 \mathrm{E}-02 & 1.827 \mathrm{E}-01 & 3.541 \mathrm{E}-01\end{array}$

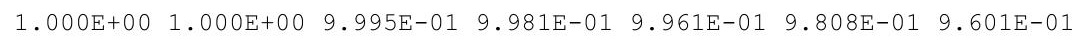
$0.000 \mathrm{E}+00 \quad 9.848 \mathrm{E}-10 \quad 1.181 \mathrm{E}-08 \quad 4.918 \mathrm{E}-08 \quad 9.823 \mathrm{E}-08 \quad 4.861 \mathrm{E}-07 \quad 1.006 \mathrm{E}-06$ $\begin{array}{lllllllll}1.000 \mathrm{E}+00 & 1.000 \mathrm{E}+00 & 9.998 \mathrm{E}-01 & 9.993 \mathrm{E}-01 & 9.987 \mathrm{E}-01 & 9.933 \mathrm{E}-01 & 9.860 \mathrm{E}-01\end{array}$ $\begin{array}{lllllll}1.000 \mathrm{E}+00 & 1.000 \mathrm{E}+00 & 9.998 \mathrm{E}-01 & 9.993 \mathrm{E}-01 & 9.987 \mathrm{E}-01 & 9.933 \mathrm{E}-01 & 9.860 \mathrm{E}-01\end{array}$ 
RESRAD, Version 6.5

Summary : RESRAD Parameters for U-Landfill Recreational User

File : C: $\backslash$ RESRAD FAMILY \RESRAD \USERFILES $\backslash Q C F O R S R S G \backslash R U$ SRSG-MAY11.RAD

Individual Nuclide Soil Concentration

Parent Nuclide and Branch Fraction Indicated

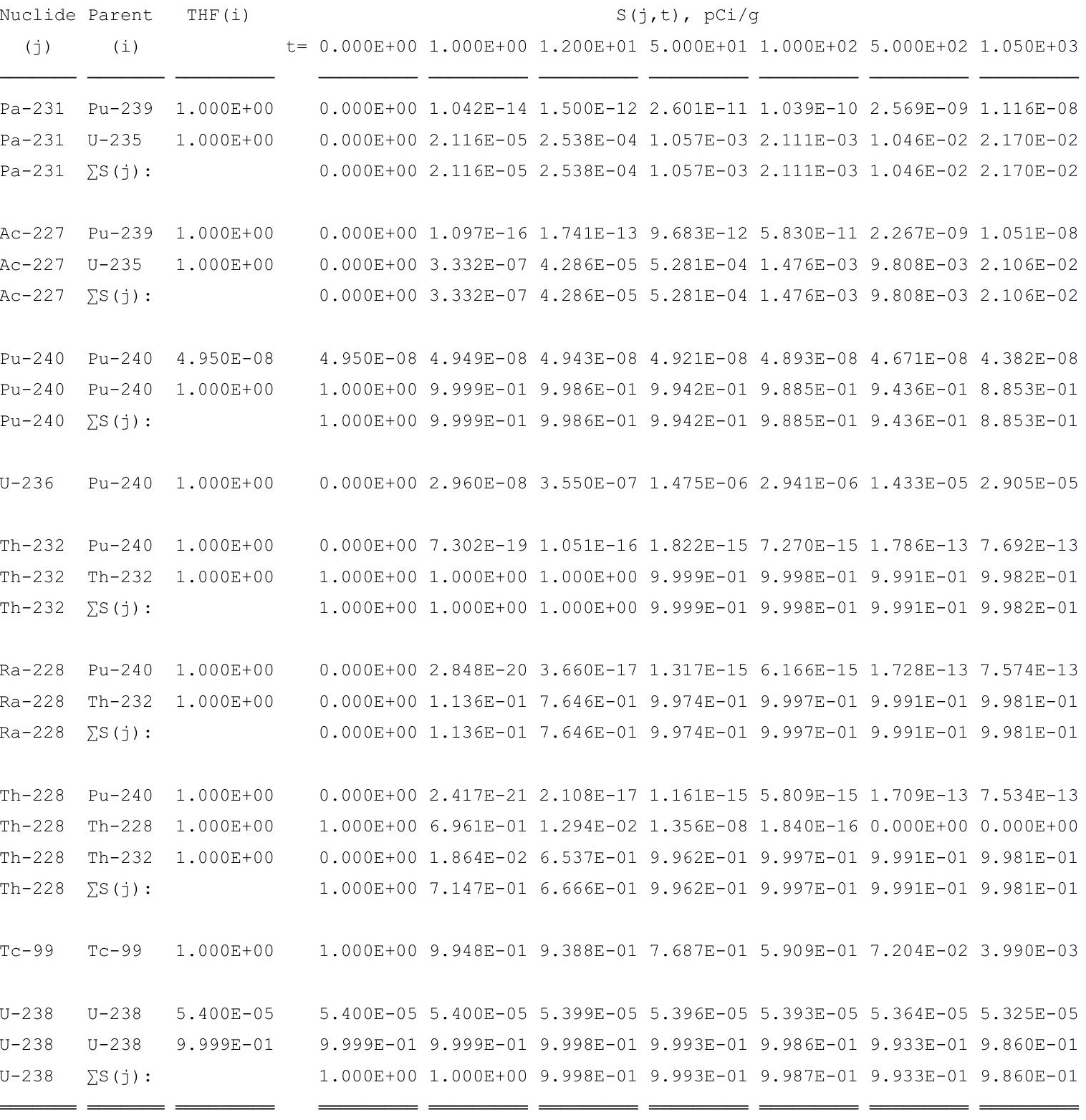

THF (i) is the thread fraction of the parent nuclide.

RESCALC.EXE execution time $=8.09$ seconds 
RESRAD, Version $6.5 \quad$ T1/2 Limit $=180$ days

07/21/2011 $17: 10 \quad$ Page

Summary : RESRAD Parameters for U-Landfill Outdoor Worker

File : C: \RESRAD FAMILY \RESRAD \USERFILES \QCFORSRSG \OUTDOORWORKER-SRSG-MAY11.RAD

Table of Contents

Part I: Mixture Sums and Single Radionuclide Guidelines

Dose Conversion Factor (and Related) Parameter Summary ... 2

Site-Specific Parameter Summary ............... 8

Summary of Pathway Selections .................... 18

Contaminated Zone and Total Dose Summary ............. 19

Total Dose Components

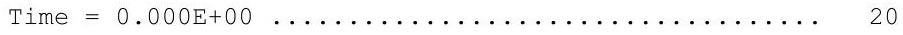

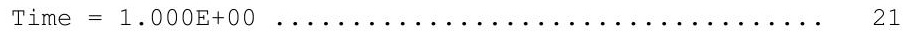

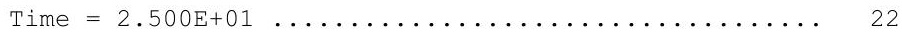

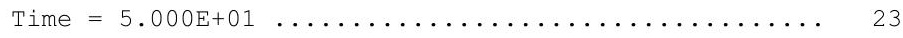

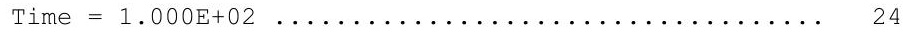

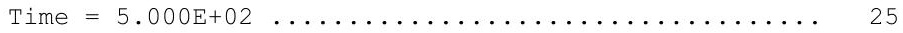

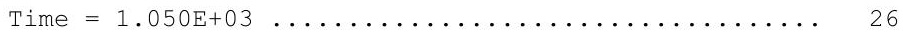

Dose/Source Ratios Summed Over All Pathways .......... 27

Single Radionuclide Soil Guidelines ................ 29

Dose Per Nuclide Summed Over All Pathways ........... 30

Soil Concentration Per Nuclide ............... 32 
RESRAD, Version $6.5 \quad T^{1 / 2}$ Limit $=180$ days

07/21/2011 17:10 Page

Summary : RESRAD Parameters for U-Landfill Outdoor Worker

File : C: \RESRAD_FAMILY \RESRAD \USERFILES \QCFORSRSG \OUTDOORWORKER-SRSG-MAY11.RAD

Dose Conversion Factor (and Related) Parameter Summary

Dose Library: ICRP 60 \& ICRP 72 (Adult)

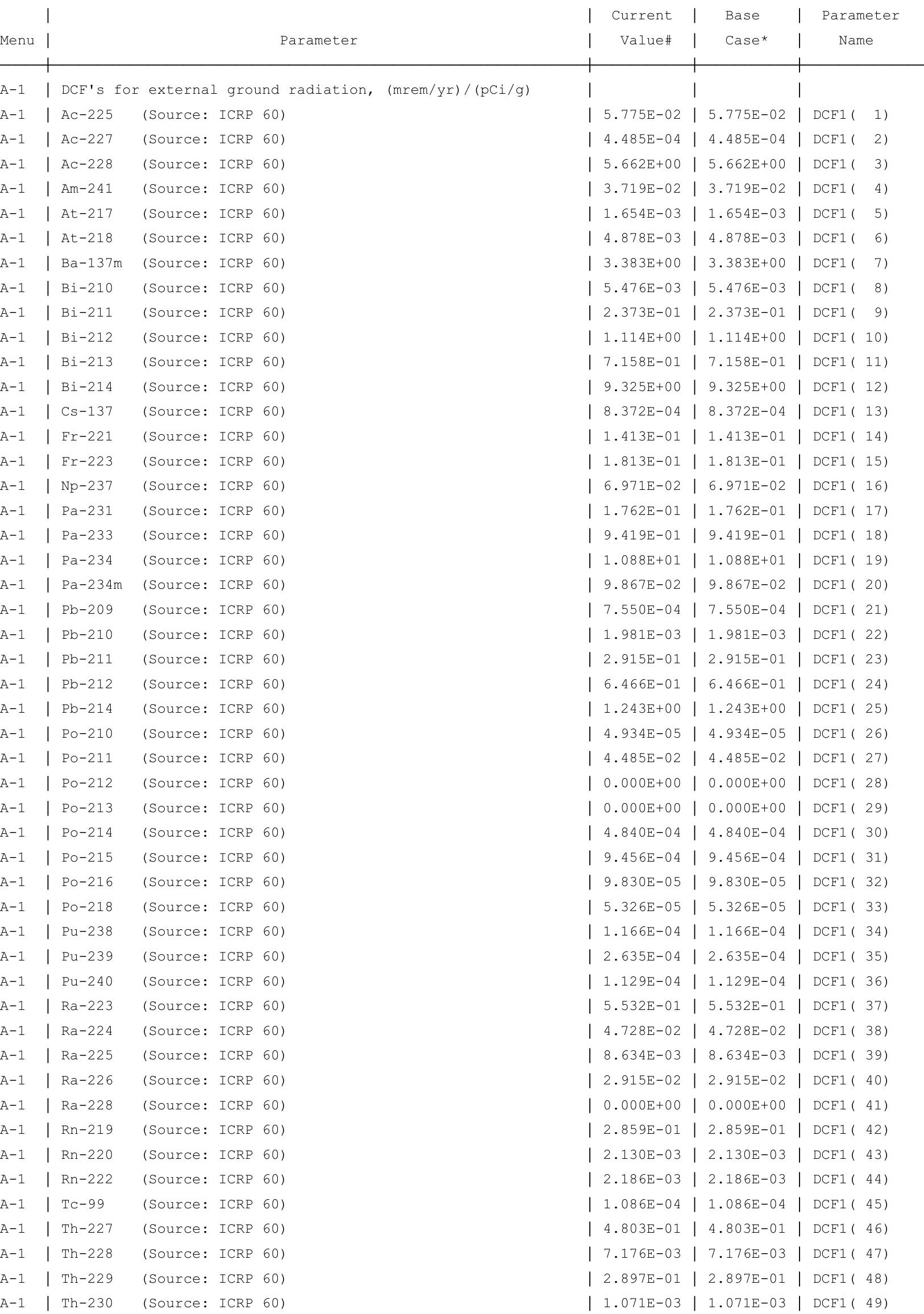


RESRAD, Version $6.5 \quad \mathrm{~T}^{1 / 2}$ Limit $=180$ days

Summary : RESRAD Parameters for U-Landfill Outdoor Worker

File $\quad$ : C: $\backslash$ RESRAD FAMILY \RESRAD \USERFILES $\backslash Q C F O R S R S G \backslash O U T D O O R W O R K E R-S R S G-M A Y 11 . R A D$

Dose Conversion Factor (and Related) Parameter Summary (continued)

Dose Library: ICRP 60 \& ICRP 72 (Adult)

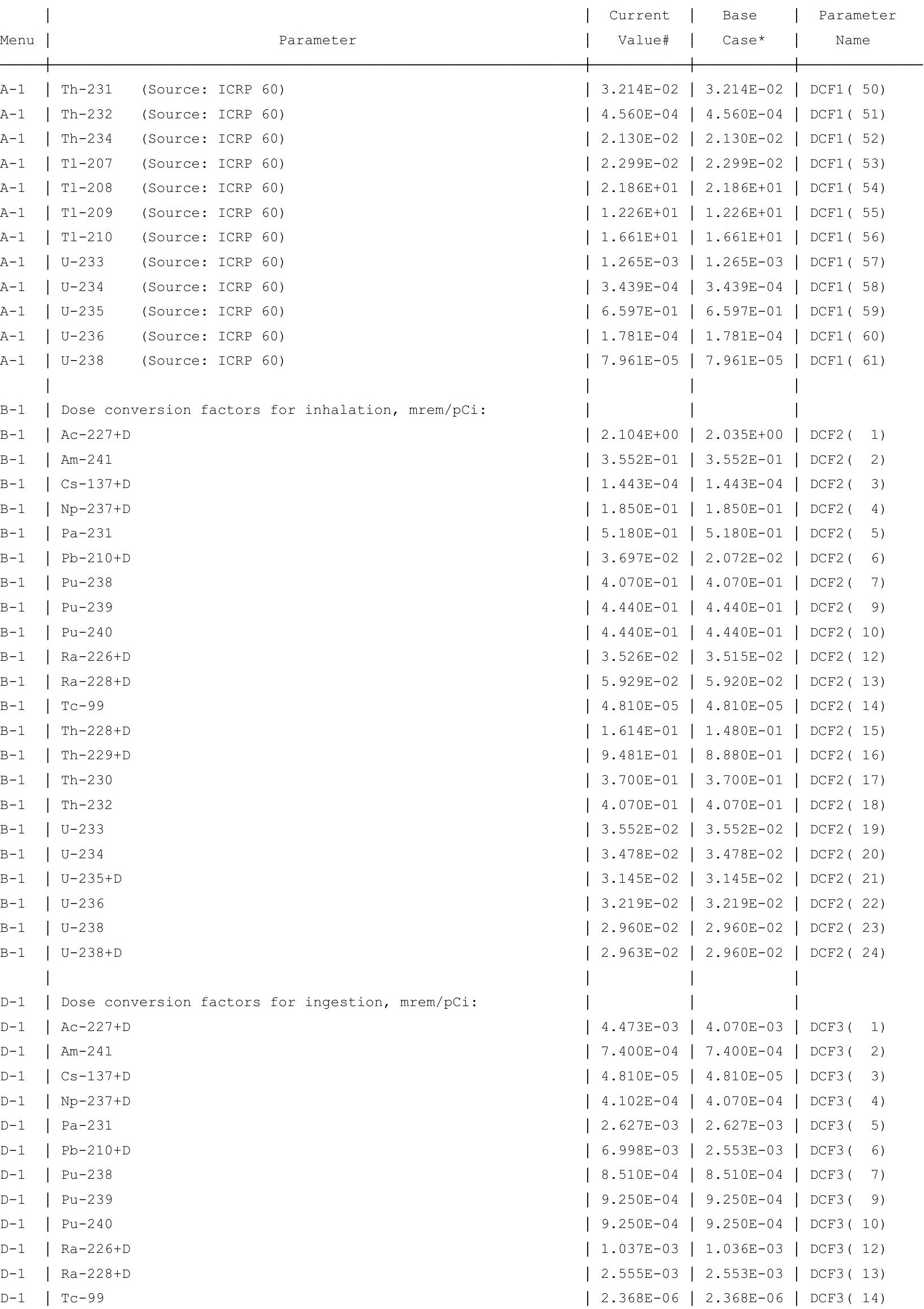


RESRAD, Version $6.5 \quad \mathrm{~T}^{\mathbb{1} 1 / 2}$ Limit $=180$ days

ummary : RESRAD Parameters for U-Landfill Outdoor Worker

File : C: \RESRAD_FAMILY \RESRAD \USERFILES \QCFORSRSG \OUTDOORWORKER-SRSG-MAY11.RAD

Dose Conversion Factor (and Related) Parameter Summary (continued) Dose Library: ICRP 60 \& ICRP 72 (Adult)

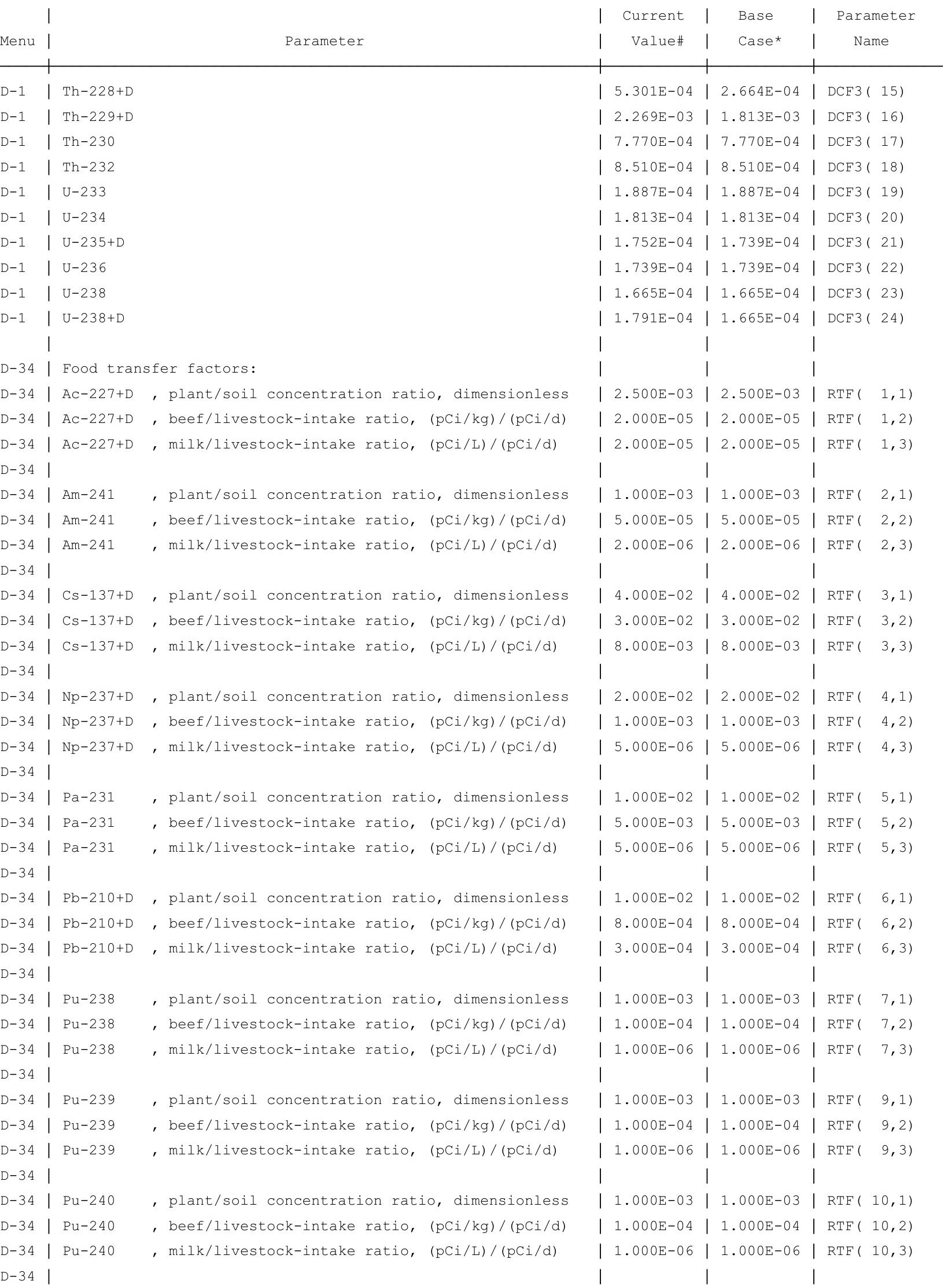


RESRAD, Version $6.5 \quad T^{1 / 2}$ Limit $=180$ days

Summary : RESRAD Parameters for U-Landfill Outdoor Worker

File : C: \RESRAD_FAMILY \RESRAD \USERFILES \QCFORSRSG \OUTDOORWORKER-SRSG-MAY11.RAD

Site-Specific Parameter Summary (continued)

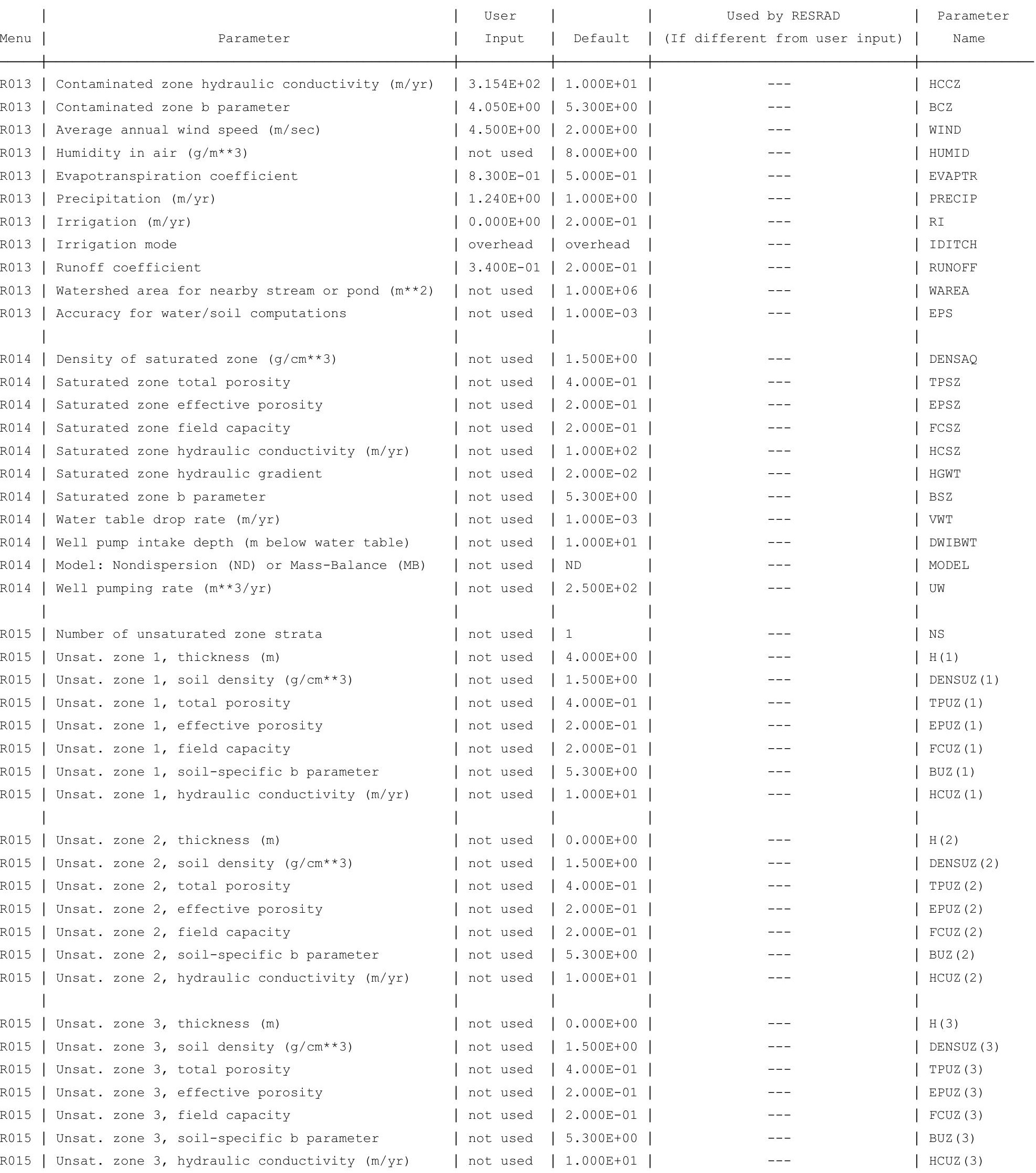


RESRAD, Version $6.5 \quad T^{1 / 2}$ Limit $=180$ days

$07 / 21 / 2011$

17:10 Page

10

Summary : RESRAD Parameters for U-Landfill Outdoor Worker

File : C: $\backslash$ RESRAD_FAMILY \RESRAD \USERFILES $\backslash Q C F O R S R S G O U T D O O R W O R K E R-S R S G-M A Y 11 . R A D$

Site-Specific Parameter Summary (continued)

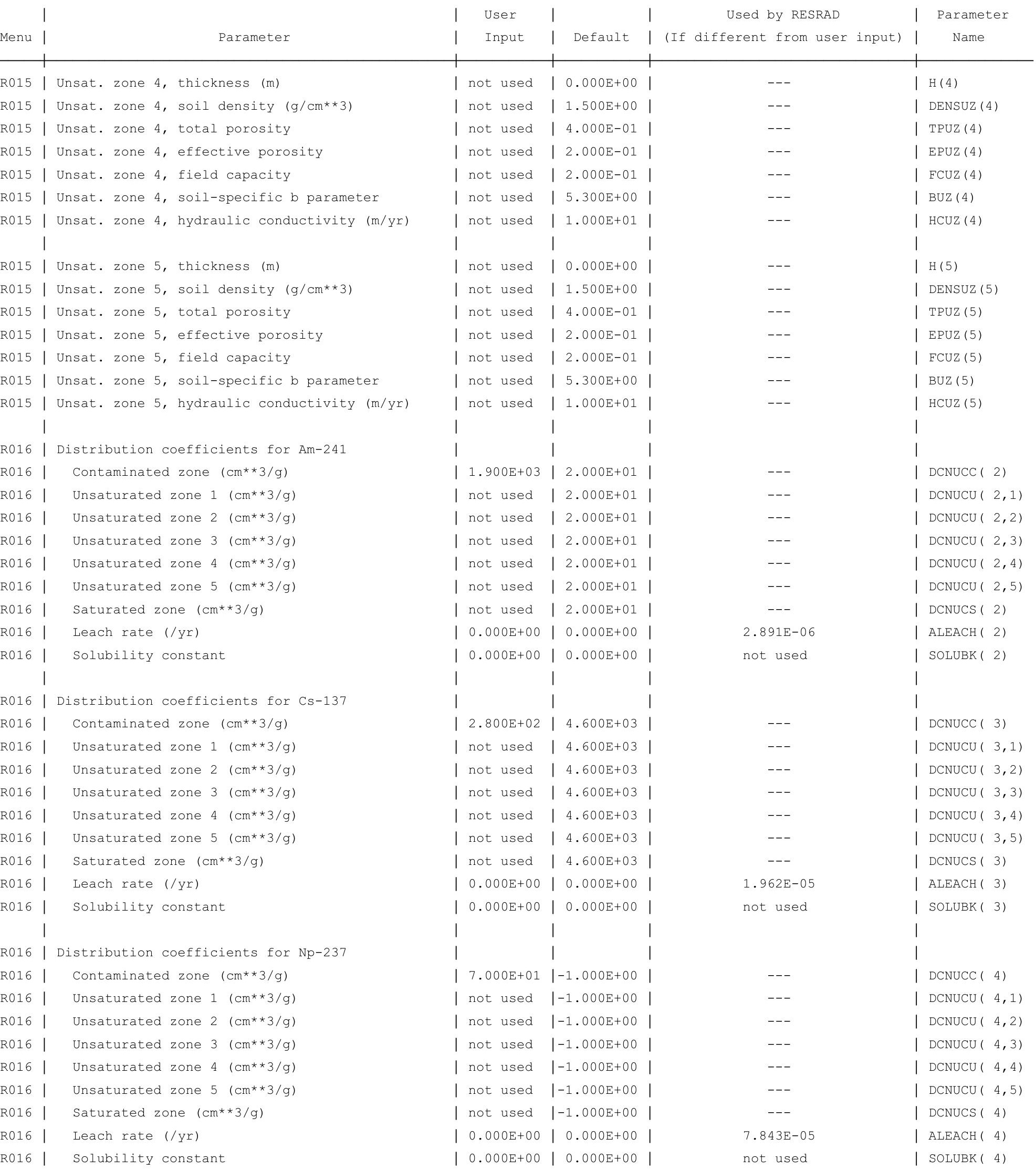


RESRAD, Version $6.5 \quad \mathrm{~T}^{1} \frac{1}{2}$ Limit $=180$ days

07/21/2011 17:10 Page

Summary : RESRAD Parameters for U-Landfill Outdoor Worker

File : C: \RESRAD_FAMILY \RESRAD \USERFILES \QCFORSRSG $O$ OUTDOORWORKER-SRSG-MAY11.RAD

Site-Specific Parameter Summary (continued)

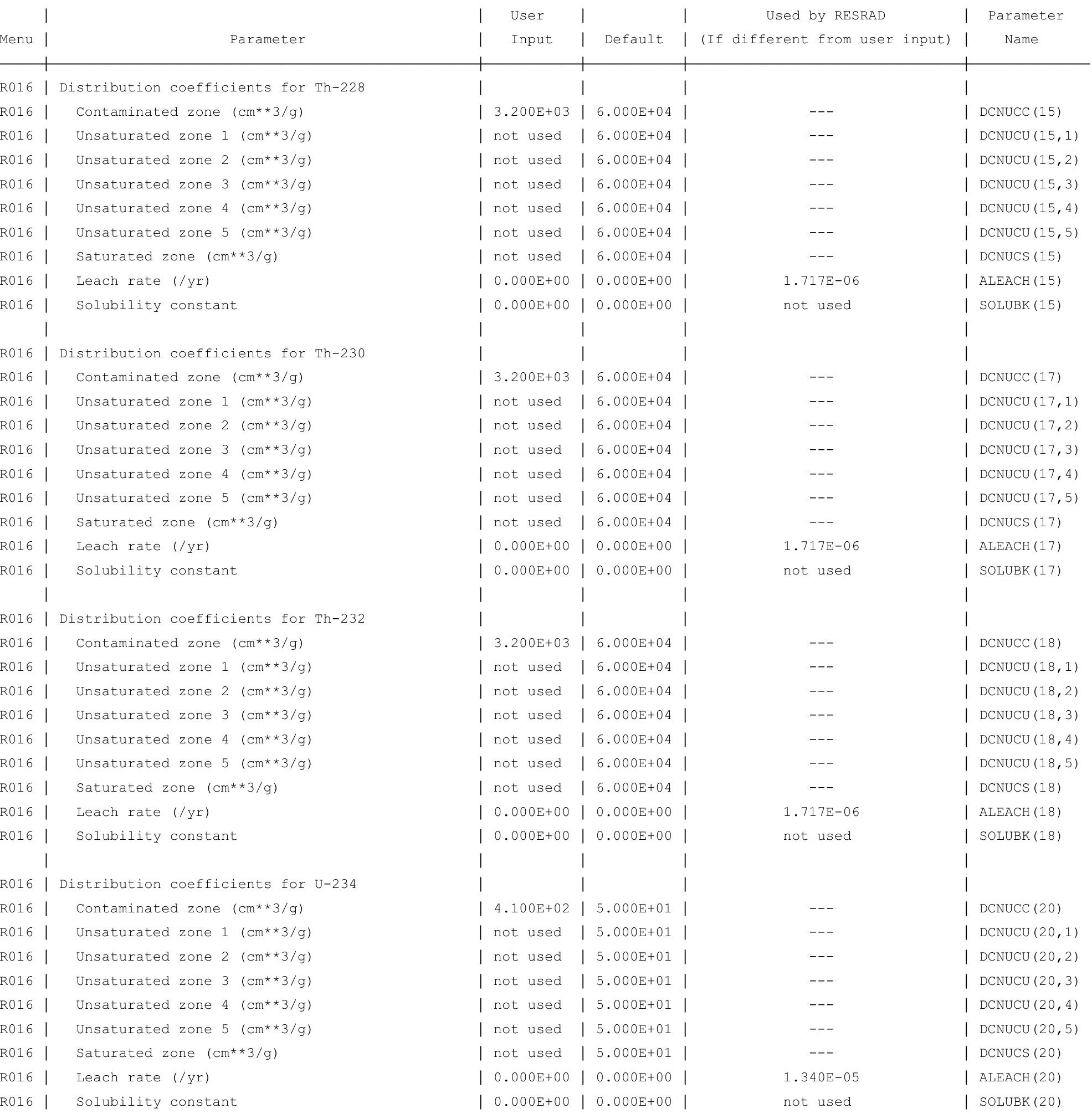


RESRAD, Version $6.5 \quad \mathrm{~T}^{1} \frac{1}{2}$ Limit $=180$ days

07/21/2011 17:10 Page

Summary : RESRAD Parameters for U-Landfill Outdoor Worker

File : C: \RESRAD_FAMILY \RESRAD \USERFILES \QCFORSRSG $O$ OUTDOORWORKER-SRSG-MAY11.RAD

Site-Specific Parameter Summary (continued)

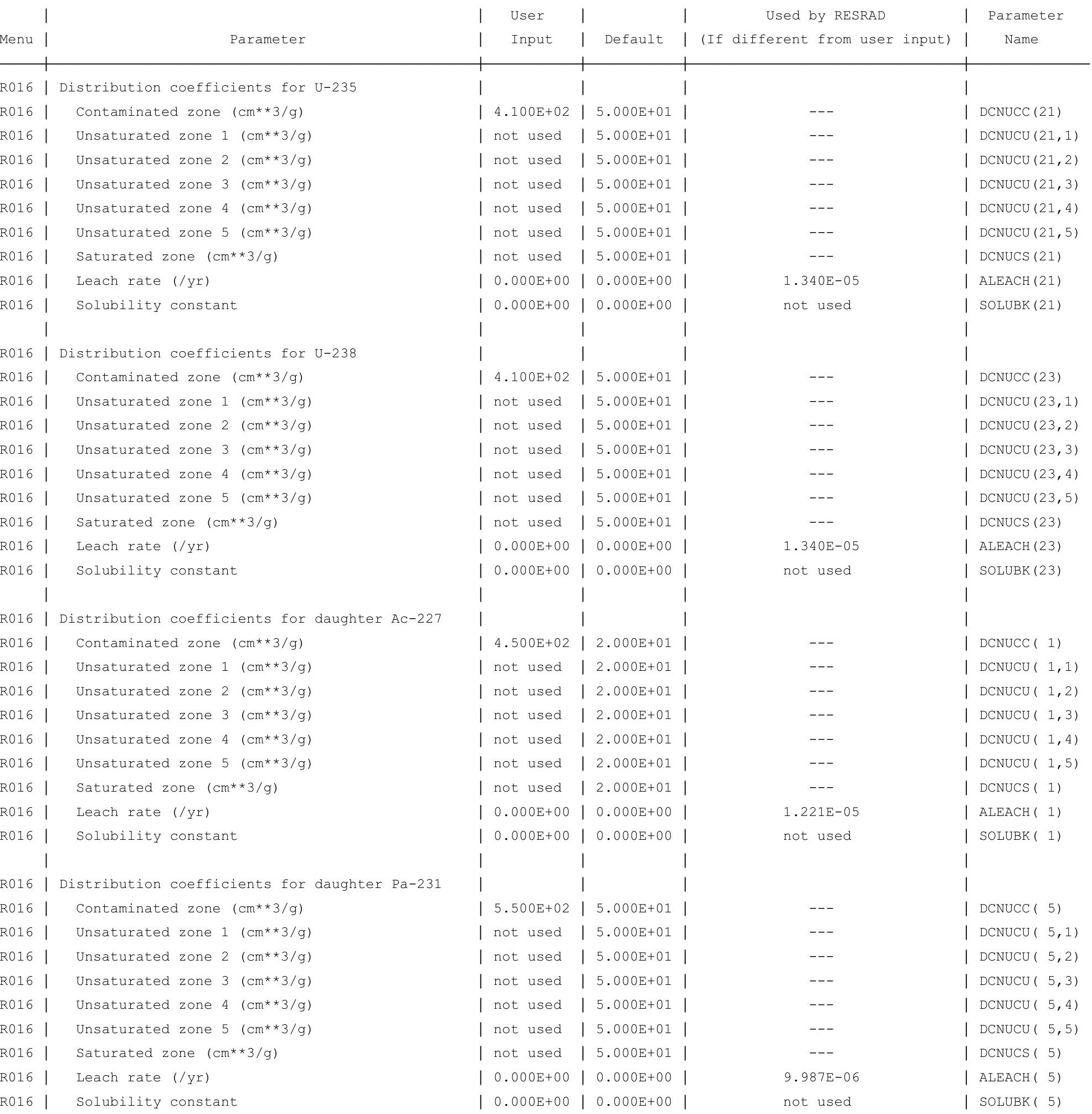


RESRAD, Version $6.5 \quad \mathrm{~T}^{1} \frac{1}{2}$ Limit $=180$ days

07/21/2011 17:10 Page 14

Summary : RESRAD Parameters for U-Landfill Outdoor Worker

File : C: \RESRAD_FAMILY \RESRAD \USERFILES \QCFORSRSG $O$ OUTDOORWORKER-SRSG-MAY11.RAD

Site-Specific Parameter Summary (continued)

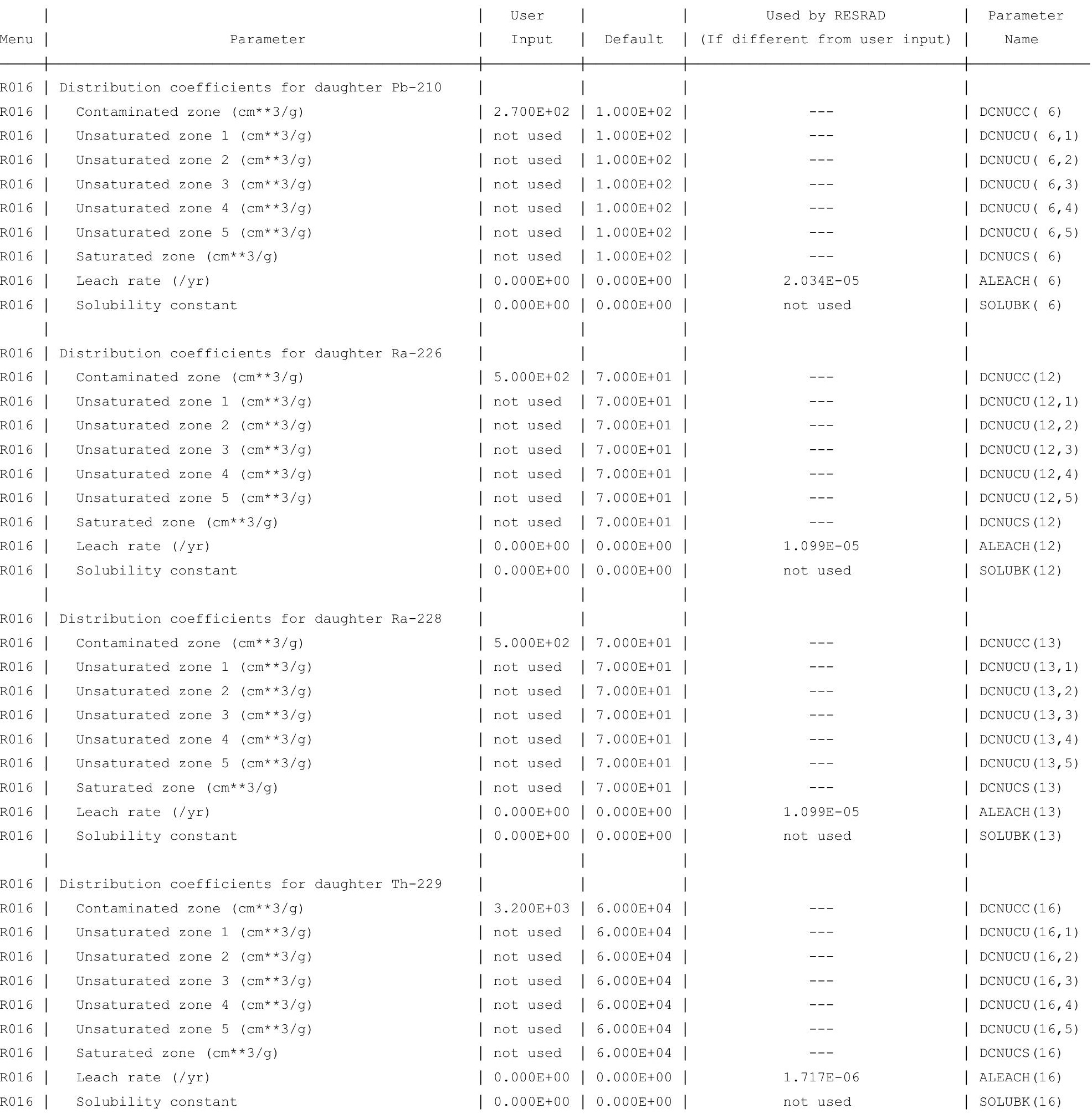


RESRAD, Version $6.5 \quad T^{1 / 2}$ Limit $=180$ days

$07 / 21 / 2011$

17:10 Page

16

Summary : RESRAD Parameters for U-Landfill Outdoor Worker

File : C: $\backslash$ RESRAD_FAMILY \RESRAD \USERFILES $\backslash Q C F O R S R S G O U T D O O R W O R K E R-S R S G-M A Y 11 . R A D$

Site-Specific Parameter Summary (continued)

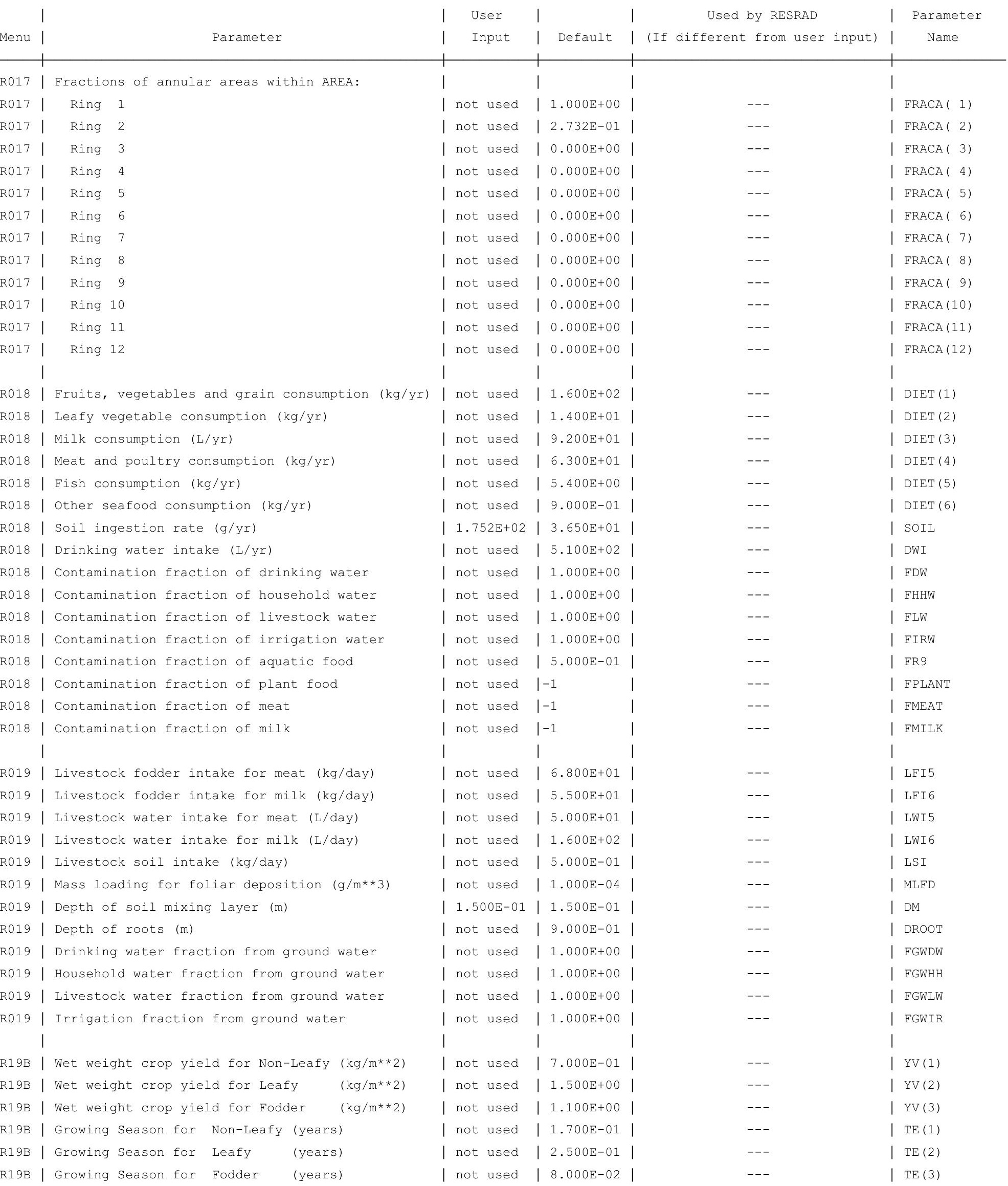


RESRAD, Version $6.5 \quad T^{1 / 2}$ Limit $=180$ days

Summary : RESRAD Parameters for U-Landfill Outdoor Worker

File : C: $\backslash$ RESRAD_FAMILY \RESRAD \USERFILES $\backslash Q C F O R S R S G O U T D O O R W O R K E R-S R S G-M A Y 11 . R A D$

Site-Specific Parameter Summary (continued)

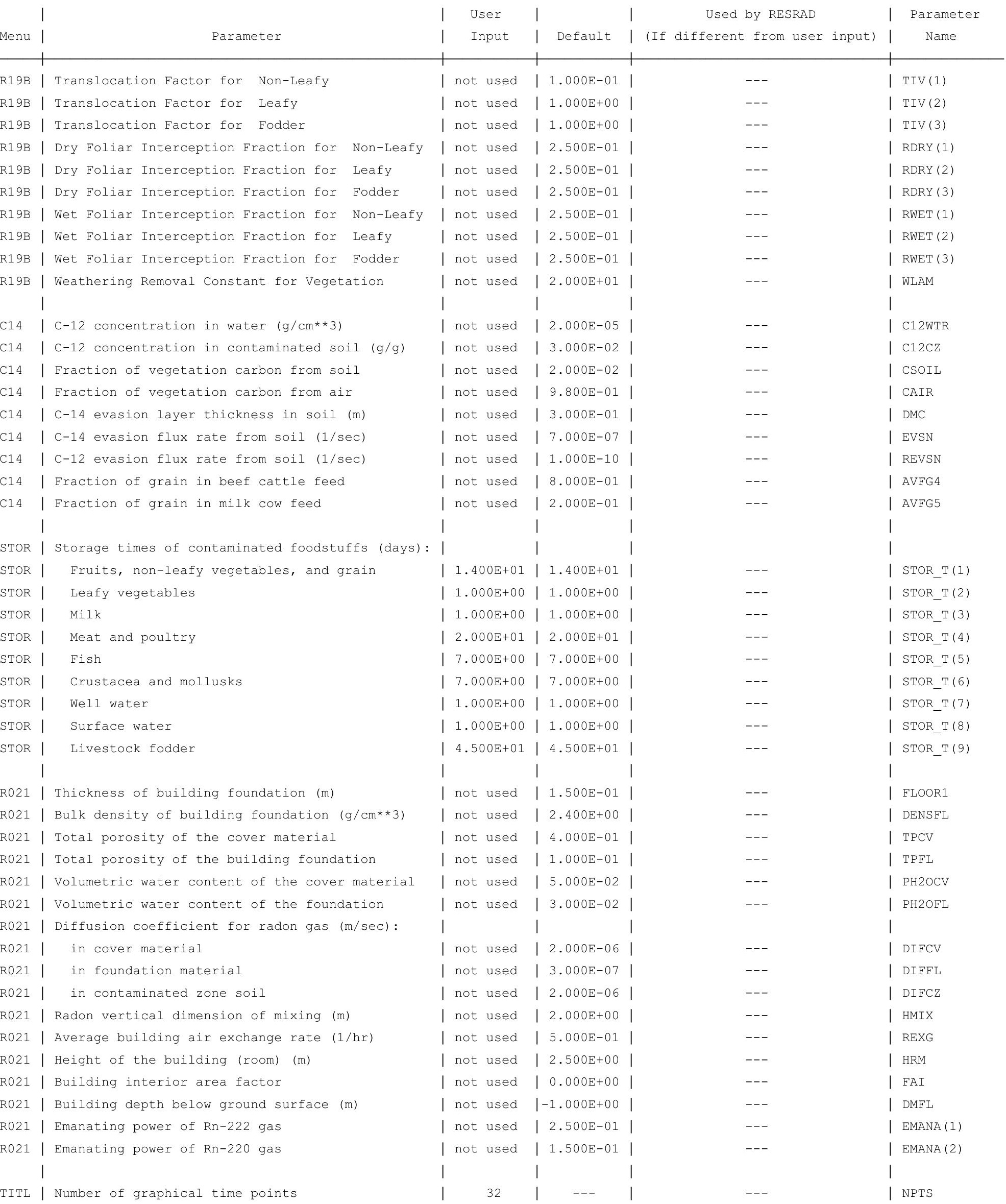


RESRAD, Version $6.5 \quad$ T1/2 Limit $=180$ days

07/21/2011 17:10 Page

Summary : RESRAD Parameters for U-Landfill Outdoor Worker

File : C: $\backslash$ RESRAD_FAMILY $\backslash R E S R A D \backslash U S E R F I L E S \backslash Q C F O R S R S G \backslash O U T D O O R W O R K E R-S R S G-M A Y 11 . R A D$

Contaminated Zone Dimensions

Area: $\quad 89436.00$ square meters

Cover Depth:

\begin{abstract}
13.40 meters
1.52 meters
\end{abstract}

Initial Soil Concentrations, pCi/g

$\begin{array}{ll}\mathrm{Am}-241 & 1.000 \mathrm{E}+00 \\ \mathrm{Cs}-137 & 1.000 \mathrm{E}+00 \\ \mathrm{~Np}-237 & 1.000 \mathrm{E}+00 \\ \mathrm{Pu}-238 & 1.000 \mathrm{E}+00 \\ \mathrm{Pu}-239 & 1.000 \mathrm{E}+00 \\ \mathrm{Pu}-240 & 1.000 \mathrm{E}+00 \\ \mathrm{TC}-99 & 1.000 \mathrm{E}+00 \\ \mathrm{Th}-228 & 1.000 \mathrm{E}+00 \\ \mathrm{Th}-230 & 1.000 \mathrm{E}+00 \\ \mathrm{Th}-232 & 1.000 \mathrm{E}+00 \\ \mathrm{U}-234 & 1.000 \mathrm{E}+00 \\ \mathrm{U}-235 & 1.000 \mathrm{E}+00 \\ \mathrm{U}-238 & 1.000 \mathrm{E}+00\end{array}$

Total Dose TDOSE(t), mrem/yr

Basic Radiation Dose Limit $=1.000 \mathrm{E}+00 \mathrm{mrem} / \mathrm{yr}$

Total Mixture Sum $M(t)$ = Eraction of Basic Dose Limit Received at Time (t)
$t$ (years)
$0.000 \mathrm{E}+00 \quad 1.000 \mathrm{E}+00 \quad 2.500 \mathrm{E}+01$
$5.000 \mathrm{E}+01$
$1.000 \mathrm{E}+02 \quad 5.000 \mathrm{E}+02 \quad 1.050 \mathrm{E}+03$
TDOSE $(t): \quad 2.852 \mathrm{E}-07 \quad 2.122 \mathrm{E}-07 \quad 3.690 \mathrm{E}-07$
4. 592E-07
$6.229 \mathrm{E}-07$
$7.047 \mathrm{E}-06 \quad 2.078 \mathrm{E}-04$
$\mathrm{M}(\mathrm{t})$
$2.852 \mathrm{E}-07$
$2.122 \mathrm{E}-07 \quad 3.690 \mathrm{E}-07$
4. $592 \mathrm{E}-07$
$6.229 \mathrm{E}-07$
7. $047 \mathrm{E}-06$
$2.078 \mathrm{E}-04$

Maximum TDOSE $(t): 2.078 \mathrm{E}-04 \mathrm{mrem} / \mathrm{yr}$ at $t=1.050 \mathrm{E}+03$ years 
RESRAD, Version 6.5

$07 / 21 / 2011$

20

Summary : RESRAD Parameters for U-Landfill Outdoor Worker
File : C: $\backslash$ RESRAD_FAMILY $\backslash$ RESRAD $\backslash U S E R F I L E S \backslash Q C F O R S R S G \backslash O U T D O O R W O R K E R-S R S G-M A Y 11 . R A D$

Total Dose Contributions TDOSE (i,p,t) for Individual Radionuclides (i) and Pathways (p) As mrem/yr and Fraction of Total Dose At $t=0.000 \mathrm{E}+00$ years

Water Independent Pathways (Inhalation excludes radon)

\begin{tabular}{|c|c|c|c|c|c|c|c|c|c|c|c|c|c|c|}
\hline \multirow{2}{*}{$\begin{array}{l}\text { Radio- } \\
\text { Nuclide }\end{array}$} & \multicolumn{2}{|c|}{ Ground } & \multicolumn{2}{|c|}{ Inhalation } & \multicolumn{2}{|c|}{ Radon } & \multicolumn{2}{|c|}{ Plant } & \multicolumn{2}{|c|}{ Meat } & \multicolumn{2}{|c|}{ Milk } & \multicolumn{2}{|c|}{ Soil } \\
\hline & mrem/yr & fract. & mrem/yr & fract. & mrem/yr & fract. & mrem/yr & fract. & mrem/yr & fract. & mrem/yr & fract. & mrem/yr & fract. \\
\hline $1-241$ & $3.160 \mathrm{E}-20$ & 0.0000 & $0.000 \mathrm{E}+00$ & 0.0000 & $0.000 \mathrm{E}+00$ & 0.0000 & $0.000 \mathrm{E}+00$ & 0.0000 & $0.000 \mathrm{E}+00$ & 0.0000 & $0.000 \mathrm{E}+00$ & 0.0000 & $0.000 \mathrm{E}+00$ & 0.0000 \\
\hline-137 & $2.578 \mathrm{E}-10$ & 0.0009 & $0.000 \mathrm{E}+00$ & 0.0000 & $0.000 \mathrm{E}+00$ & 0.0000 & $0.000 \mathrm{E}+00$ & 0.0000 & $0.000 \mathrm{E}+00$ & 0.0000 & $0.000 \mathrm{E}+00$ & 0.0000 & $0.000 \mathrm{E}+00$ & 0.0000 \\
\hline-237 & $1.948 \mathrm{E}-13$ & 0.0000 & $0.000 \mathrm{E}+00$ & 0.0000 & $0.000 \mathrm{E}+00$ & 0.0000 & $0.000 \mathrm{E}+00$ & 0.0000 & $0.000 \mathrm{E}+00$ & 0.0000 & $0.000 \mathrm{E}+00$ & 0.0000 & $0.000 \mathrm{E}+00$ & 0.0000 \\
\hline-238 & $1.663 \mathrm{E}-23$ & 0.0000 & $0.000 \mathrm{E}+00$ & 0.0000 & $0.000 \mathrm{E}+00$ & 0.0000 & $0.000 \mathrm{E}+00$ & 0.0000 & $0.000 \mathrm{E}+00$ & 0.0000 & $0.000 \mathrm{E}+00$ & 0.0000 & $0.000 \mathrm{E}+00$ & 0.0000 \\
\hline-239 & $2.456 \mathrm{E}-18$ & 0.0000 & $0.000 \mathrm{E}+00$ & 0.0000 & $0.000 \mathrm{E}+00$ & 0.0000 & $0.000 \mathrm{E}+00$ & 0.0000 & $0.000 \mathrm{E}+00$ & 0.0000 & $0.000 \mathrm{E}+00$ & 0.0000 & $0.000 \mathrm{E}+00$ & 0.0000 \\
\hline-240 & $2.335 E-25$ & 0.0000 & $0.000 \mathrm{E}+00$ & 0.0000 & $0.000 \mathrm{E}+00$ & 0.0000 & $0.000 \mathrm{E}+00$ & 0.0000 & $0.000 \mathrm{E}+00$ & 0.0000 & $0.000 \mathrm{E}+00$ & 0.0000 & $0.000 \mathrm{E}+00$ & 0.0000 \\
\hline-99 & $1.179 \mathrm{E}-26$ & 0.0000 & $0.000 \mathrm{E}+00$ & 0.0000 & $0.000 \mathrm{E}+00$ & 0.0000 & $0.000 \mathrm{E}+00$ & 0.0000 & $0.000 \mathrm{E}+00$ & 0.0000 & $0.000 \mathrm{E}+00$ & 0.0000 & $0.000 \mathrm{E}+00$ & 0.0000 \\
\hline-228 & $2.825 \mathrm{E}-07$ & 0.9905 & $0.000 \mathrm{E}+00$ & 0.0000 & $0.000 \mathrm{E}+00$ & 0.0000 & $0.000 \mathrm{E}+00$ & 0.0000 & $0.000 \mathrm{E}+00$ & 0.0000 & $0.000 \mathrm{E}+00$ & 0.0000 & $0.000 \mathrm{E}+00$ & 0.0000 \\
\hline-230 & 7. $712 \mathrm{E}-12$ & 0.0000 & $0.000 \mathrm{E}+00$ & 0.0000 & $0.000 \mathrm{E}+00$ & 0.0000 & $0.000 \mathrm{E}+00$ & 0.0000 & $0.000 \mathrm{E}+00$ & 0.0000 & $0.000 \mathrm{E}+00$ & 0.0000 & $0.000 \mathrm{E}+00$ & 0.0000 \\
\hline-232 & $2.407 E-09$ & 0.0084 & $0.000 \mathrm{E}+00$ & 0.0000 & $0.000 \mathrm{E}+00$ & 0.0000 & $0.000 \mathrm{E}+00$ & 0.0000 & $0.000 \mathrm{E}+00$ & 0.0000 & $0.000 \mathrm{E}+00$ & 0.0000 & $0.000 \mathrm{E}+00$ & 0.0000 \\
\hline 34 & $2.315 E-17$ & 0.0000 & $0.000 \mathrm{E}+00$ & 0.0000 & $0.000 \mathrm{E}+00$ & 0.0000 & $0.000 \mathrm{E}+00$ & 0.0000 & $0.000 \mathrm{E}+00$ & 0.0000 & $0.000 \mathrm{E}+00$ & 0.0000 & $0.000 \mathrm{E}+00$ & 0.0000 \\
\hline & $2.543 E-15$ & 0.0000 & $0.000 \mathrm{E}+00$ & 0.0000 & $0.000 \mathrm{E}+00$ & 0.0000 & $0.000 \mathrm{E}+00$ & 0.0000 & $0.000 \mathrm{E}+00$ & 0.0000 & $0.000 \mathrm{E}+00$ & 0.0000 & $0.000 \mathrm{E}+00$ & 0.0000 \\
\hline 38 & $2.901 \mathrm{E}-11$ & 0.0001 & $0.000 \mathrm{E}+00$ & 0.0000 & $0.000 \mathrm{E}+00$ & 0.0000 & $0.000 \mathrm{E}+00$ & 0.0000 & $0.000 \mathrm{E}+00$ & 0.0000 & $0.000 \mathrm{E}+00$ & 0.0000 & $0.000 \mathrm{E}+00$ & 0.0000 \\
\hline & $2.852 E-07$ & 1.0000 & $0.000 \mathrm{E}+00$ & 0.0000 & $0.000 \mathrm{E}+00$ & 0.0000 & $0.000 \mathrm{E}+00$ & 0.0000 & $0.000 \mathrm{E}+00$ & 000 & $0.000 \mathrm{E}+00$ & 000 & \pm+00 & 000 \\
\hline
\end{tabular}

Total Dose Contributions TDOSE(i,p,t) for Individual Radionuclides (i) and Pathways (p) As mrem/yr and Fraction of Total Dose At $t=0.000 \mathrm{E}+00$ years

Water Dependent Pathways

\begin{tabular}{|c|c|c|c|c|c|c|c|c|c|c|c|c|c|c|}
\hline & \multicolumn{2}{|c|}{ Water } & \multicolumn{2}{|c|}{ Fish } & \multicolumn{2}{|c|}{ Radon } & \multicolumn{2}{|c|}{ Plant } & \multicolumn{2}{|c|}{ Meat } & \multicolumn{2}{|c|}{ Milk } & \multicolumn{2}{|c|}{ All Pathways* } \\
\hline clide & mrem/yr & fract. & mrem/yr & fract. & mrem/yr & fract. & mrem/yr & fract. & mrem/yr & fract. & mrem/yr & fract. & mrem/yr & fract. \\
\hline-241 & $0.000 \mathrm{E}+00$ & 0.0000 & $0.000 \mathrm{E}+00$ & 0.0000 & $0.000 \mathrm{E}+00$ & 0.0000 & $0.000 \mathrm{E}+00$ & 0.0000 & $0.000 \mathrm{E}+00$ & 0.0000 & $0.000 \mathrm{E}+00$ & 0.0000 & $3.160 \mathrm{E}-20$ & 0.0000 \\
\hline-137 & $0.000 \mathrm{E}+00$ & 0.0000 & $0.000 \mathrm{E}+00$ & 0.0000 & $0.000 \mathrm{E}+00$ & 0.0000 & $0.000 \mathrm{E}+00$ & 0.0000 & $0.000 \mathrm{E}+00$ & 0.0000 & $0.000 \mathrm{E}+00$ & 0.0000 & $2.578 \mathrm{E}-10$ & 0.0009 \\
\hline-237 & $0.000 \mathrm{E}+00$ & 0.0000 & $0.000 \mathrm{E}+00$ & 0.0000 & $0.000 \mathrm{E}+00$ & 0.0000 & $0.000 \mathrm{E}+00$ & 0.0000 & $0.000 \mathrm{E}+00$ & 0.0000 & $0.000 \mathrm{E}+00$ & 0.0000 & $1.948 \mathrm{E}-13$ & 0.0000 \\
\hline 238 & $0.000 \mathrm{E}+00$ & 0.0000 & $0.000 \mathrm{E}+00$ & 0.0000 & $0.000 \mathrm{E}+00$ & 0.0000 & $0.000 \mathrm{E}+00$ & 0.0000 & $0.000 \mathrm{E}+00$ & 0.0000 & $0.000 \mathrm{E}+00$ & 0.0000 & $1.663 E-23$ & 0.0000 \\
\hline 239 & $0.000 \mathrm{E}+00$ & 0.0000 & $0.000 \mathrm{E}+00$ & 0.0000 & $0.000 \mathrm{E}+00$ & 0.0000 & $0.000 \mathrm{E}+00$ & 0.0000 & $0.000 \mathrm{E}+00$ & 0.0000 & $0.000 \mathrm{E}+00$ & 0.0000 & $2.456 \mathrm{E}-18$ & 0.0000 \\
\hline 240 & $0.000 \mathrm{E}+00$ & 0.0000 & $0.000 \mathrm{E}+00$ & 0.0000 & $0.000 \mathrm{E}+00$ & 0.0000 & $0.000 \mathrm{E}+00$ & 0.0000 & $0.000 \mathrm{E}+00$ & 0.0000 & $0.000 \mathrm{E}+00$ & 0.0000 & $2.335 E-25$ & 0.0000 \\
\hline 99 & $0.000 \mathrm{E}+00$ & 0.0000 & $0.000 \mathrm{E}+00$ & 0.0000 & $0.000 \mathrm{E}+00$ & 0.0000 & $0.000 \mathrm{E}+00$ & 0.0000 & $0.000 \mathrm{E}+00$ & 0.0000 & $0.000 \mathrm{E}+00$ & 0.0000 & $1.179 \mathrm{E}-26$ & 0.0000 \\
\hline 228 & $0.000 \mathrm{E}+00$ & 0.0000 & $0.000 \mathrm{E}+00$ & 0.0000 & $0.000 \mathrm{E}+00$ & 0.0000 & $0.000 \mathrm{E}+00$ & 0.0000 & $0.000 \mathrm{E}+00$ & 0.0000 & $0.000 \mathrm{E}+00$ & 0.0000 & $2.825 E-07$ & 0.9905 \\
\hline 230 & $0.000 \mathrm{E}+00$ & 0.0000 & $0.000 \mathrm{E}+00$ & 0.0000 & $0.000 \mathrm{E}+00$ & 0.0000 & $0.000 \mathrm{E}+00$ & 0.0000 & $0.000 \mathrm{E}+00$ & 0.0000 & $0.000 \mathrm{E}+00$ & 0.0000 & 7. $712 \mathrm{E}-12$ & 0.0000 \\
\hline 232 & $0.000 \mathrm{E}+00$ & 0.0000 & $0.000 \mathrm{E}+00$ & 0.0000 & $0.000 \mathrm{E}+00$ & 0.0000 & $0.000 \mathrm{E}+00$ & 0.0000 & $0.000 \mathrm{E}+00$ & 0.0000 & $0.000 \mathrm{E}+00$ & 0.0000 & $2.407 \mathrm{E}-09$ & 0.0084 \\
\hline & $0.000 \mathrm{E}+00$ & 0.0000 & $0.000 \mathrm{E}+00$ & 0.0000 & $0.000 \mathrm{E}+00$ & 0.0000 & $0.000 \mathrm{E}+00$ & 0.0000 & $0.000 \mathrm{E}+00$ & 0.0000 & $0.000 \mathrm{E}+00$ & 0.0000 & $2.315 \mathrm{E}-17$ & 0.0000 \\
\hline 35 & $0.000 \mathrm{E}+00$ & 0.0000 & $0.000 \mathrm{E}+00$ & 0.0000 & $0.000 \mathrm{E}+00$ & 0.0000 & $0.000 \mathrm{E}+00$ & 0.0000 & $0.000 \mathrm{E}+00$ & 0.0000 & $0.000 \mathrm{E}+00$ & 0.0000 & $2.543 E-15$ & 0.0000 \\
\hline 38 & $0.000 \mathrm{E}+00$ & 0.0000 & $0.000 \mathrm{E}+00$ & 0.0000 & $0.000 \mathrm{E}+00$ & 0.0000 & $0.000 \mathrm{E}+00$ & 0.0000 & $0.000 \mathrm{E}+00$ & 0.0000 & $0.000 \mathrm{E}+00$ & 0.0000 & $2.901 \mathrm{E}-11$ & 0.0001 \\
\hline & $0.000 \mathrm{E}+00$ & 0.0000 & $0.000 \mathrm{E}+00$ & 0.0000 & $0.000 \mathrm{E}+00$ & 0.0000 & $0.000 \mathrm{E}+00$ & 0.0000 & $0.000 \mathrm{E}+00$ & 0.0000 & $0.000 E+00$ & 000 & -07 & 1.0000 \\
\hline
\end{tabular}

* Sum of all water independent and dependent pathways. 
RESRAD, Version 6.5

$07 / 21 / 2011$

21

Summary : RESRAD Parameters for U-Landfill Outdoor Worker
File : C: $\backslash$ RESRAD_FAMILY $\backslash$ RESRAD $\backslash U S E R F I L E S \backslash Q C F O R S R S G \backslash O U T D O O R W O R K E R-S R S G-M A Y 11 . R A D$

Total Dose Contributions TDOSE (i,p,t) for Individual Radionuclides (i) and Pathways (p) As mrem/yr and Fraction of Total Dose At $t=1.000 \mathrm{E}+00$ years

Water Independent Pathways (Inhalation excludes radon)

\begin{tabular}{|c|c|c|}
\hline clide & mrem/yr & fract. \\
\hline $1-241$ & $9.563 \mathrm{E}-20$ & 0.0000 \\
\hline-137 & $2.541 E-10$ & 0.0012 \\
\hline-237 & $1.969 \mathrm{E}-13$ & 0.0000 \\
\hline-238 & $2.471 E-22$ & 0.0000 \\
\hline-239 & $2.486 \mathrm{E}-18$ & 0.0000 \\
\hline-240 & $2.427 \mathrm{E}-25$ & 0.0000 \\
\hline-99 & $1.195 \mathrm{E}-26$ & 0.0000 \\
\hline-228 & $1.978 \mathrm{E}-07$ & 0.9321 \\
\hline-230 & $2.327 \mathrm{E}-11$ & 0.0001 \\
\hline 232 & $1.410 \mathrm{E}-08$ & 0.0664 \\
\hline 234 & $1.630 \mathrm{E}-16$ & 0.0000 \\
\hline 235 & $2.587 \mathrm{E}-15$ & 0.0000 \\
\hline 238 & $2.924 \mathrm{E}-11$ & 0.0001 \\
\hline & $2 \cdot 12$ & 1.0000 \\
\hline
\end{tabular}

Radio-

Total

$2.122 \mathrm{E}-07 \quad 1.0000$

\begin{tabular}{|c|c|c|c|}
\hline \multicolumn{2}{|c|}{ Inhalation } & \multicolumn{2}{|c|}{ Radon } \\
\hline rem/yr & fract. & mrem/yr & fract. \\
\hline $000 \mathrm{E}+00$ & 0.0000 & $0.000 \mathrm{E}+00$ & 0.0000 \\
\hline $000 \mathrm{E}+00$ & 0.0000 & $0.000 \mathrm{E}+00$ & 0.0000 \\
\hline $000 \mathrm{E}+00$ & 0.0000 & $0.000 \mathrm{E}+00$ & 0.0000 \\
\hline $000 \mathrm{E}+00$ & 0.0000 & $0.000 \mathrm{E}+00$ & 0.0000 \\
\hline $000 \mathrm{E}+00$ & 0.0000 & $0.000 \mathrm{E}+00$ & 0.0000 \\
\hline $.000 \mathrm{E}+00$ & 0.0000 & $0.000 \mathrm{E}+00$ & 0.0000 \\
\hline $000 \mathrm{E}+00$ & 0.0000 & $0.000 \mathrm{E}+00$ & 0.0000 \\
\hline $000 \mathrm{E}+00$ & 0.0000 & $0.000 \mathrm{E}+00$ & 0.0000 \\
\hline $000 \mathrm{E}+00$ & 0.0000 & $0.000 \mathrm{E}+00$ & 0.0000 \\
\hline $000 \mathrm{E}+00$ & 0.0000 & $0.000 \mathrm{E}+00$ & 0.0000 \\
\hline $000 \mathrm{E}+00$ & 0.0000 & $0.000 \mathrm{E}+00$ & 0.0000 \\
\hline $.000 \mathrm{E}+00$ & 0.0000 & $0.000 \mathrm{E}+00$ & 0.0000 \\
\hline $.000 \mathrm{E}+00$ & 0.0000 & $0.000 \mathrm{E}+00$ & 0.0000 \\
\hline & & 0.0 & 0. \\
\hline
\end{tabular}

\begin{tabular}{ll} 
Meat \\
\hline mrem/yr fract. \\
\cline { 1 - 2 } & \\
$0.000 \mathrm{E}+00$ & 0.0000 \\
$0.000 \mathrm{E}+00$ & 0.0000 \\
$0.000 \mathrm{E}+00$ & 0.0000 \\
$0.000 \mathrm{E}+00$ & 0.0000 \\
$0.000 \mathrm{E}+00$ & 0.0000 \\
$0.000 \mathrm{E}+00$ & 0.0000 \\
$0.000 \mathrm{E}+00$ & 0.0000 \\
$0.000 \mathrm{E}+00$ & 0.0000 \\
$0.000 \mathrm{E}+00$ & 0.0000 \\
$0.000 \mathrm{E}+00$ & 0.0000 \\
$0.000 \mathrm{E}+00$ & 0.0000 \\
$0.000 \mathrm{E}+00$ & 0.0000 \\
$0.000 \mathrm{E}+00$ & 0.0000 \\
\hline \hline $0.000 \mathrm{E}+00$ & 0.0000
\end{tabular}

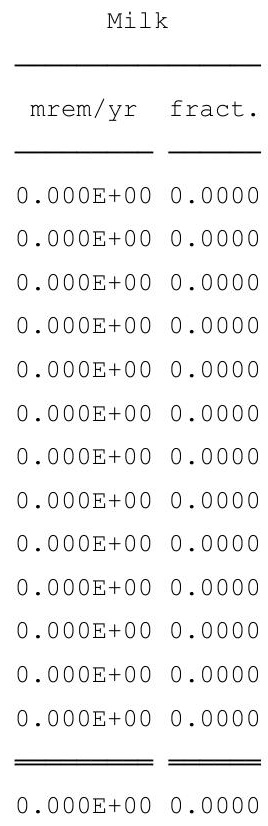

Total Dose Contributions TDOSE(i,p,t) for Individual Radionuclides (i) and Pathways (p) As mrem/yr and Fraction of Total Dose At $t=1.000 \mathrm{E}+00$ years

Water Dependent Pathways

\begin{tabular}{|c|c|c|c|c|c|c|}
\hline & \multicolumn{2}{|c|}{ Water } & \multicolumn{2}{|c|}{ Fish } & \multicolumn{2}{|c|}{ Radon } \\
\hline clide & mrem/yr & fract. & mrem/yr & fract. & mrem/yr & fract. \\
\hline 41 & $0.000 \mathrm{E}+00$ & 0.0000 & $0.000 \mathrm{E}+00$ & 0.0000 & $0.000 \mathrm{E}+00$ & 0.0000 \\
\hline-137 & $0.000 \mathrm{E}+00$ & 0.0000 & $0.000 \mathrm{E}+00$ & 0.0000 & $0.000 \mathrm{E}+00$ & 0.0000 \\
\hline-237 & $0.000 \mathrm{E}+00$ & 0.0000 & $0.000 \mathrm{E}+00$ & 0.0000 & $0.000 \mathrm{E}+00$ & 0.0000 \\
\hline-238 & $0.000 \mathrm{E}+00$ & 0.0000 & $0.000 \mathrm{E}+00$ & 0.0000 & $0.000 \mathrm{E}+00$ & 0.0000 \\
\hline-239 & $0.000 \mathrm{E}+00$ & 0.0000 & $0.000 \mathrm{E}+00$ & 0.0000 & $0.000 \mathrm{E}+00$ & 0.0000 \\
\hline-240 & $0.000 \mathrm{E}+00$ & 0.0000 & $0.000 \mathrm{E}+00$ & 0.0000 & $0.000 \mathrm{E}+00$ & 0.0000 \\
\hline-99 & $0.000 \mathrm{E}+00$ & 0.0000 & $0.000 \mathrm{E}+00$ & 0.0000 & $0.000 \mathrm{E}+00$ & 0.0000 \\
\hline-228 & $0.000 \mathrm{E}+00$ & 0.0000 & $0.000 \mathrm{E}+00$ & 0.0000 & $0.000 \mathrm{E}+00$ & 0.0000 \\
\hline-230 & $0.000 \mathrm{E}+00$ & 0.0000 & $0.000 \mathrm{E}+00$ & 0.0000 & $0.000 \mathrm{E}+00$ & 0.0000 \\
\hline-232 & $0.000 \mathrm{E}+00$ & 0.0000 & $0.000 \mathrm{E}+00$ & 0.0000 & $0.000 \mathrm{E}+00$ & 0.0000 \\
\hline 234 & $0.000 \mathrm{E}+00$ & 0.0000 & $0.000 \mathrm{E}+00$ & 0.0000 & $0.000 \mathrm{E}+00$ & 0.0000 \\
\hline 235 & $0.000 \mathrm{E}+00$ & 0.0000 & $0.000 \mathrm{E}+00$ & 0.0000 & $0.000 \mathrm{E}+00$ & 0.0000 \\
\hline 38 & $0.000 \mathrm{E}+00$ & 0.0000 & $0.000 \mathrm{E}+00$ & 0.0000 & $0.000 \mathrm{E}+00$ & 0.0000 \\
\hline & $0.000 \mathrm{E}+00$ & 0.0000 & $0.000 \mathrm{E}+00$ & 0.0000 & $0.000 \mathrm{E}+00$ & 0.0000 \\
\hline
\end{tabular}

\begin{tabular}{|c|c|c|c|}
\hline \multicolumn{2}{|c|}{ Plant } & \multicolumn{2}{|c|}{ Meat } \\
\hline mrem/yr & fract. & mrem/yr & fract. \\
\hline $0.000 \mathrm{E}+00$ & 0.0000 & $0.000 \mathrm{E}+00$ & 0.0000 \\
\hline $0.000 \mathrm{E}+00$ & 0.0000 & $0.000 \mathrm{E}+00$ & 0.0000 \\
\hline $0.000 \mathrm{E}+00$ & 0.0000 & $0.000 \mathrm{E}+00$ & 0.0000 \\
\hline $0.000 \mathrm{E}+00$ & 0.0000 & $0.000 \mathrm{E}+00$ & 0.0000 \\
\hline $0.000 \mathrm{E}+00$ & 0.0000 & $0.000 \mathrm{E}+00$ & 0.0000 \\
\hline $0.000 \mathrm{E}+00$ & 0.0000 & $0.000 \mathrm{E}+00$ & 0.0000 \\
\hline $0.000 \mathrm{E}+00$ & 0.0000 & $0.000 \mathrm{E}+00$ & 0.0000 \\
\hline $0.000 \mathrm{E}+00$ & 0.0000 & $0.000 \mathrm{E}+00$ & 0.0000 \\
\hline $0.000 \mathrm{E}+00$ & 0.0000 & $0.000 \mathrm{E}+00$ & 0.0000 \\
\hline $0.000 \mathrm{E}+00$ & 0.0000 & $0.000 \mathrm{E}+00$ & 0.0000 \\
\hline $0.000 \mathrm{E}+00$ & 0.0000 & $0.000 \mathrm{E}+00$ & 0.0000 \\
\hline $0.000 \mathrm{E}+00$ & 0.0000 & $0.000 \mathrm{E}+00$ & 0.0000 \\
\hline $0.000 \mathrm{E}+00$ & 0.0000 & $0.000 \mathrm{E}+00$ & 0.0000 \\
\hline
\end{tabular}

$0.000 \mathrm{E}+00 \quad 0.0000 \quad 0.000 \mathrm{E}+00 \quad 0.0000$

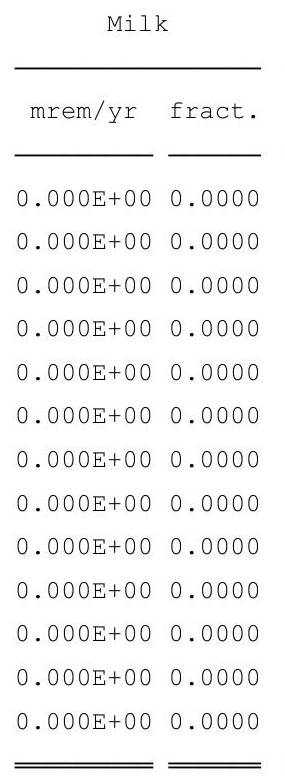

$0.000 \mathrm{E}+00 \quad 0.0000$
Soil mrem/yr fract. $0.000 \mathrm{E}+00 \quad 0.0000$ $0.000 \mathrm{E}+00 \quad 0.0000$ $0.000 \mathrm{E}+00 \quad 0.0000$ $0.000 \mathrm{E}+00 \quad 0.0000$ $0.000 \mathrm{E}+00 \quad 0.0000$ $0.000 \mathrm{E}+00 \quad 0.0000$ $0.000 \mathrm{E}+00 \quad 0.0000$ $0.000 \mathrm{E}+00 \quad 0.0000$ $0.000 \mathrm{E}+00 \quad 0.0000$ $0.000 \mathrm{E}+00 \quad 0.0000$ $0.000 \mathrm{E}+00 \quad 0.0000$ $0.000 \mathrm{E}+00 \quad 0.0000$ $0.000 \mathrm{E}+00 \quad 0.0000$ $0.000 \mathrm{E}+00 \quad 0.0000$

*Sum of all water independent and dependent pathways.

All Pathways* mrem/yr fract. $9.563 \mathrm{E}-20 \quad 0.0000$ $2.541 \mathrm{E}-10 \quad 0.0012$ $1.969 \mathrm{E}-13 \quad 0.0000$ $2.471 \mathrm{E}-22 \quad 0.0000$ $2.486 \mathrm{E}-18 \quad 0.0000$ $2.427 \mathrm{E}-25 \quad 0.0000$ $1.195 \mathrm{E}-26 \quad 0.0000$ $\begin{array}{lll}1.978 \mathrm{E}-07 & 0.9321\end{array}$ $2.327 \mathrm{E}-11 \quad 0.0001$ $1.410 \mathrm{E}-08 \quad 0.0664$ $1.630 \mathrm{E}-16 \quad 0.0000$ $2.587 \mathrm{E}-15 \quad 0.0000$ $2.924 \mathrm{E}-11 \quad 0.0001$

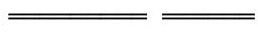
$2.122 \mathrm{E}-07 \quad 1.0000$ 
RESRAD, Version 6.5

$07 / 21 / 2011$

22

Summary : RESRAD Parameters for U-Landfill Outdoor Worker
File : C: $\backslash$ RESRAD_FAMILY $\backslash$ RESRAD $\backslash U S E R F I L E S \backslash Q C F O R S R S G \backslash O U T D O O R W O R K E R-S R S G-M A Y 11 . R A D$

Total Dose Contributions TDOSE (i,p,t) for Individual Radionuclides (i) and Pathways (p) As mrem/yr and Fraction of Total Dose At $t=2.500 \mathrm{E}+01$ years

Water Independent Pathways (Inhalation excludes radon)

\begin{tabular}{|c|c|c|c|c|c|c|c|c|c|c|c|c|c|c|}
\hline \multirow{2}{*}{ Nuclide } & \multicolumn{2}{|c|}{ Ground } & \multicolumn{2}{|c|}{ Inhalation } & \multicolumn{2}{|c|}{ Radon } & \multicolumn{2}{|c|}{ Plant } & \multicolumn{2}{|c|}{ Meat } & \multicolumn{2}{|c|}{ Milk } & \multicolumn{2}{|c|}{ Soil } \\
\hline & mrem/yr & fract. & mrem/yr & fract. & mrem/yr & fract. & mrem/yr & fract. & mrem/yr & fract. & mrem/yr & fract. & mrem/yr & fract. \\
\hline-241 & $2.064 \mathrm{E}-18$ & 0.0000 & $0.000 \mathrm{E}+00$ & 0.0000 & $0.000 \mathrm{E}+00$ & 0.0000 & $0.000 \mathrm{E}+00$ & 0.0000 & $0.000 \mathrm{E}+00$ & 0.0000 & $0.000 \mathrm{E}+00$ & 0.0000 & $0.000 \mathrm{E}+00$ & 0.0000 \\
\hline-137 & 1. $786 \mathrm{E}-10$ & 0.0005 & $0.000 \mathrm{E}+00$ & 0.0000 & $0.000 \mathrm{E}+00$ & 0.0000 & $0.000 \mathrm{E}+00$ & 0.0000 & $0.000 \mathrm{E}+00$ & 0.0000 & $0.000 \mathrm{E}+00$ & 0.0000 & $0.000 \mathrm{E}+00$ & 0.0000 \\
\hline-237 & $2.549 \mathrm{E}-13$ & 0.0000 & $0.000 \mathrm{E}+00$ & 0.0000 & $0.000 \mathrm{E}+00$ & 0.0000 & $0.000 \mathrm{E}+00$ & 0.0000 & $0.000 \mathrm{E}+00$ & 0.0000 & $0.000 \mathrm{E}+00$ & 0.0000 & $0.000 \mathrm{E}+00$ & 0.0000 \\
\hline-238 & 1. $226 \mathrm{E}-18$ & 0.0000 & $0.000 \mathrm{E}+00$ & 0.0000 & $0.000 \mathrm{E}+00$ & 0.0000 & $0.000 \mathrm{E}+00$ & 0.0000 & $0.000 \mathrm{E}+00$ & 0.0000 & $0.000 \mathrm{E}+00$ & 0.0000 & $0.000 \mathrm{E}+00$ & 0.0000 \\
\hline-239 & 3. $311 \mathrm{E}-18$ & 0.0000 & $0.000 \mathrm{E}+00$ & 0.0000 & $0.000 \mathrm{E}+00$ & 0.0000 & $0.000 \mathrm{E}+00$ & 0.0000 & $0.000 \mathrm{E}+00$ & 0.0000 & $0.000 \mathrm{E}+00$ & 0.0000 & $0.000 \mathrm{E}+00$ & 0.0000 \\
\hline-240 & $8.021 \mathrm{E}-23$ & 0.0000 & $0.000 \mathrm{E}+00$ & 0.0000 & $0.000 \mathrm{E}+00$ & 0.0000 & $0.000 \mathrm{E}+00$ & 0.0000 & $0.000 \mathrm{E}+00$ & 0.0000 & $0.000 \mathrm{E}+00$ & 0.0000 & $0.000 \mathrm{E}+00$ & 0.0000 \\
\hline 99 & $1.669 \mathrm{E}-26$ & 0.0000 & $0.000 \mathrm{E}+00$ & 0.0000 & $0.000 \mathrm{E}+00$ & 0.0000 & $0.000 \mathrm{E}+00$ & 0.0000 & $0.000 \mathrm{E}+00$ & 0.0000 & $0.000 \mathrm{E}+00$ & 0.0000 & $0.000 \mathrm{E}+00$ & 0.0000 \\
\hline-228 & 3. $819 \mathrm{E}-11$ & 0.0001 & $0.000 \mathrm{E}+00$ & 0.0000 & $0.000 \mathrm{E}+00$ & 0.0000 & $0.000 \mathrm{E}+00$ & 0.0000 & $0.000 \mathrm{E}+00$ & 0.0000 & $0.000 \mathrm{E}+00$ & 0.0000 & $0.000 \mathrm{E}+00$ & 0.0000 \\
\hline-230 & $4.644 \mathrm{E}-10$ & 0.0013 & $0.000 \mathrm{E}+00$ & 0.0000 & $0.000 \mathrm{E}+00$ & 0.0000 & $0.000 \mathrm{E}+00$ & 0.0000 & $0.000 \mathrm{E}+00$ & 0.0000 & $0.000 \mathrm{E}+00$ & 0.0000 & $0.000 \mathrm{E}+00$ & 0.0000 \\
\hline-232 & $3.683 E-07$ & 0.9981 & $0.000 \mathrm{E}+00$ & 0.0000 & $0.000 \mathrm{E}+00$ & 0.0000 & $0.000 \mathrm{E}+00$ & 0.0000 & $0.000 \mathrm{E}+00$ & 0.0000 & $0.000 \mathrm{E}+00$ & 0.0000 & $0.000 \mathrm{E}+00$ & 0.0000 \\
\hline 234 & $5.341 \mathrm{E}-14$ & 0.0000 & $0.000 \mathrm{E}+00$ & 0.0000 & $0.000 \mathrm{E}+00$ & 0.0000 & $0.000 \mathrm{E}+00$ & 0.0000 & $0.000 \mathrm{E}+00$ & 0.0000 & $0.000 \mathrm{E}+00$ & 0.0000 & $0.000 \mathrm{E}+00$ & 0.0000 \\
\hline 35 & $7.086 \mathrm{E}-15$ & 0.0000 & $0.000 \mathrm{E}+00$ & 0.0000 & $0.000 \mathrm{E}+00$ & 0.0000 & $0.000 \mathrm{E}+00$ & 0.0000 & $0.000 \mathrm{E}+00$ & 0.0000 & $0.000 \mathrm{E}+00$ & 0.0000 & $0.000 \mathrm{E}+00$ & 0.0000 \\
\hline 38 & $3.542 \mathrm{E}-11$ & 0.0001 & $0.000 \mathrm{E}+00$ & 0.0000 & $0.000 \mathrm{E}+00$ & 0.0000 & $0.000 \mathrm{E}+00$ & 0.0000 & $0.000 \mathrm{E}+00$ & 0.0000 & $0.000 \mathrm{E}+00$ & 0.0000 & $0.000 \mathrm{E}+00$ & 0.0000 \\
\hline & $3.690 \mathrm{E}-07$ & 1.0000 & $0.000 \mathrm{E}+00$ & 0.0000 & $0.000 \mathrm{E}+00$ & 0.0000 & $0.000 \mathrm{E}+00$ & 0.0000 & $0.000 \mathrm{E}+00$ & 0.0000 & $0.000 \mathrm{E}+00$ & 0.0000 & $0.000 \mathrm{E}+00$ & 0.0000 \\
\hline
\end{tabular}

Total Dose Contributions TDOSE(i,p,t) for Individual Radionuclides (i) and Pathways (p) As mrem/yr and Fraction of Total Dose At $t=2.500 \mathrm{E}+01$ years

Water Dependent Pathways

\begin{tabular}{|c|c|c|c|c|c|c|c|c|c|c|c|c|c|c|}
\hline \multirow{2}{*}{$\begin{array}{l}\text { Radio- } \\
\text { Nuclide }\end{array}$} & \multicolumn{2}{|c|}{ Water } & \multicolumn{2}{|c|}{ Fish } & \multicolumn{2}{|c|}{ Radon } & \multicolumn{2}{|c|}{ Plant } & \multicolumn{2}{|c|}{ Meat } & \multicolumn{2}{|c|}{ Milk } & \multicolumn{2}{|c|}{ All Pathways* } \\
\hline & mrem/yr & fract. & mrem/yr & fract. & mrem/yr & fract. & mrem/yr & fract. & mrem/yr & fract. & mrem/yr & fract. & mrem/yr & fract. \\
\hline 241 & $0.000 \mathrm{E}+00$ & 0.0000 & $0.000 \mathrm{E}+00$ & 0.0000 & $0.000 \mathrm{E}+00$ & 0.0000 & $0.000 \mathrm{E}+00$ & 0.0000 & $0.000 \mathrm{E}+00$ & 0.0000 & $0.000 \mathrm{E}+00$ & 0.0000 & $2.064 \mathrm{E}-18$ & 0.0000 \\
\hline-137 & $0.000 \mathrm{E}+00$ & 0.0000 & $0.000 \mathrm{E}+00$ & 0.0000 & $0.000 \mathrm{E}+00$ & 0.0000 & $0.000 \mathrm{E}+00$ & 0.0000 & $0.000 \mathrm{E}+00$ & 0.0000 & $0.000 \mathrm{E}+00$ & 0.0000 & $1.786 \mathrm{E}-10$ & 0.0005 \\
\hline-237 & $0.000 \mathrm{E}+00$ & 0.0000 & $0.000 \mathrm{E}+00$ & 0.0000 & $0.000 \mathrm{E}+00$ & 0.0000 & $0.000 \mathrm{E}+00$ & 0.0000 & $0.000 \mathrm{E}+00$ & 0.0000 & $0.000 \mathrm{E}+00$ & 0.0000 & $2.549 \mathrm{E}-13$ & 0.0000 \\
\hline-238 & $0.000 \mathrm{E}+00$ & 0.0000 & $0.000 \mathrm{E}+00$ & 0.0000 & $0.000 \mathrm{E}+00$ & 0.0000 & $0.000 \mathrm{E}+00$ & 0.0000 & $0.000 \mathrm{E}+00$ & 0.0000 & $0.000 \mathrm{E}+00$ & 0.0000 & $1.226 \mathrm{E}-18$ & 0.0000 \\
\hline-239 & $0.000 \mathrm{E}+00$ & 0.0000 & $0.000 \mathrm{E}+00$ & 0.0000 & $0.000 \mathrm{E}+00$ & 0.0000 & $0.000 \mathrm{E}+00$ & 0.0000 & $0.000 \mathrm{E}+00$ & 0.0000 & $0.000 E+00$ & 0.0000 & $3.311 \mathrm{E}-18$ & 0.0000 \\
\hline-240 & $0.000 \mathrm{E}+00$ & 0.0000 & $0.000 \mathrm{E}+00$ & 0.0000 & $0.000 \mathrm{E}+00$ & 0.0000 & $0.000 \mathrm{E}+00$ & 0.0000 & $0.000 \mathrm{E}+00$ & 0.0000 & $0.000 E+00$ & 0.0000 & $8.021 E-23$ & 0.0000 \\
\hline-99 & $0.000 \mathrm{E}+00$ & 0.0000 & $0.000 \mathrm{E}+00$ & 0.0000 & $0.000 \mathrm{E}+00$ & 0.0000 & $0.000 \mathrm{E}+00$ & 0.0000 & $0.000 \mathrm{E}+00$ & 0.0000 & $0.000 \mathrm{E}+00$ & 0.0000 & $1.669 \mathrm{E}-26$ & 0.0000 \\
\hline-228 & $0.000 \mathrm{E}+00$ & 0.0000 & $0.000 \mathrm{E}+00$ & 0.0000 & $0.000 \mathrm{E}+00$ & 0.0000 & $0.000 \mathrm{E}+00$ & 0.0000 & $0.000 \mathrm{E}+00$ & 0.0000 & $0.000 \mathrm{E}+00$ & 0.0000 & $3.819 \mathrm{E}-11$ & 0.0001 \\
\hline-230 & $0.000 \mathrm{E}+00$ & 0.0000 & $0.000 \mathrm{E}+00$ & 0.0000 & $0.000 \mathrm{E}+00$ & 0.0000 & $0.000 \mathrm{E}+00$ & 0.0000 & $0.000 \mathrm{E}+00$ & 0.0000 & $0.000 E+00$ & 0.0000 & $4.644 \mathrm{E}-10$ & 0.0013 \\
\hline 232 & $0.000 \mathrm{E}+00$ & 0.0000 & $0.000 \mathrm{E}+00$ & 0.0000 & $0.000 \mathrm{E}+00$ & 0.0000 & $0.000 \mathrm{E}+00$ & 0.0000 & $0.000 \mathrm{E}+00$ & 0.0000 & $0.000 \mathrm{E}+00$ & 0.0000 & $3.683 E-07$ & 0.9981 \\
\hline 34 & $0.000 \mathrm{E}+00$ & 0.0000 & $0.000 \mathrm{E}+00$ & 0.0000 & $0.000 \mathrm{E}+00$ & 0.0000 & $0.000 \mathrm{E}+00$ & 0.0000 & $0.000 \mathrm{E}+00$ & 0.0000 & $0.000 \mathrm{E}+00$ & 0.0000 & $5.341 \mathrm{E}-14$ & 0.0000 \\
\hline 35 & $0.000 \mathrm{E}+00$ & 0.0000 & $0.000 \mathrm{E}+00$ & 0.0000 & $0.000 \mathrm{E}+00$ & 0.0000 & $0.000 \mathrm{E}+00$ & 0.0000 & $0.000 \mathrm{E}+00$ & 0.0000 & $0.000 \mathrm{E}+00$ & 0.0000 & $7.086 \mathrm{E}-15$ & 0.0000 \\
\hline 38 & $0.000 \mathrm{E}+00$ & 0.0000 & $0.000 \mathrm{E}+00$ & 0.0000 & $0.000 \mathrm{E}+00$ & 0.0000 & $0.000 \mathrm{E}+00$ & 0.0000 & $0.000 \mathrm{E}+00$ & 0.0000 & $0.000 \mathrm{E}+00$ & 0.0000 & $3.542 \mathrm{E}-11$ & 0.0001 \\
\hline & $0.000 \mathrm{E}+00$ & 0.0000 & $0.000 \mathrm{E}+00$ & 0.0000 & $0.000 \mathrm{E}+00$ & 0.0000 & $0.000 \mathrm{E}+00$ & 0.0000 & $0.000 \mathrm{E}+00$ & 0.0000 & $0.000 \mathrm{E}+00$ & 0.0000 & $0 E-07$ & 1.0000 \\
\hline
\end{tabular}

* Sum of all water independent and dependent pathways. 
RESRAD, Version 6.5

$07 / 21 / 2011$

23

Summary : RESRAD Parameters for U-Landfill Outdoor Worker
File : C: $\backslash$ RESRAD_FAMILY $\backslash$ RESRAD $\backslash U S E R F I L E S \backslash Q C F O R S R S G \backslash O U T D O O R W O R K E R-S R S G-M A Y 11 . R A D$

Total Dose Contributions TDOSE (i,p,t) for Individual Radionuclides (i) and Pathways (p) As mrem/yr and Fraction of Total Dose At $t=5.000 \mathrm{E}+01$ years

Water Independent Pathways (Inhalation excludes radon)

\begin{tabular}{|c|c|c|c|c|c|c|c|c|c|c|c|c|c|c|}
\hline \multirow{2}{*}{ Nuclide } & \multicolumn{2}{|c|}{ Ground } & \multicolumn{2}{|c|}{ Inhalation } & \multicolumn{2}{|c|}{ Radon } & \multicolumn{2}{|c|}{ Plant } & \multicolumn{2}{|c|}{ Meat } & \multicolumn{2}{|c|}{ Milk } & \multicolumn{2}{|c|}{ Soil } \\
\hline & mrem/yr & fract. & mrem/yr & fract. & mrem/yr & fract. & mrem/yr & fract. & mrem/yr & fract. & mrem/yr & fract. & mrem/yr & fract. \\
\hline-241 & $5.246 \mathrm{E}-18$ & 0.0000 & $0.000 \mathrm{E}+00$ & 0.0000 & $0.000 \mathrm{E}+00$ & 0.0000 & $0.000 \mathrm{E}+00$ & 0.0000 & $0.000 \mathrm{E}+00$ & 0.0000 & $0.000 \mathrm{E}+00$ & 0.0000 & $0.000 \mathrm{E}+00$ & 0.0000 \\
\hline-137 & 1. $237 \mathrm{E}-10$ & 0.0003 & $0.000 \mathrm{E}+00$ & 0.0000 & $0.000 \mathrm{E}+00$ & 0.0000 & $0.000 \mathrm{E}+00$ & 0.0000 & $0.000 \mathrm{E}+00$ & 0.0000 & $0.000 \mathrm{E}+00$ & 0.0000 & $0.000 \mathrm{E}+00$ & 0.0000 \\
\hline-237 & $3.337 E-13$ & 0.0000 & $0.000 \mathrm{E}+00$ & 0.0000 & $0.000 \mathrm{E}+00$ & 0.0000 & $0.000 \mathrm{E}+00$ & 0.0000 & $0.000 \mathrm{E}+00$ & 0.0000 & $0.000 \mathrm{E}+00$ & 0.0000 & $0.000 \mathrm{E}+00$ & 0.0000 \\
\hline-238 & $1.076 \mathrm{E}-17$ & 0.0000 & $0.000 \mathrm{E}+00$ & 0.0000 & $0.000 \mathrm{E}+00$ & 0.0000 & $0.000 \mathrm{E}+00$ & 0.0000 & $0.000 \mathrm{E}+00$ & 0.0000 & $0.000 \mathrm{E}+00$ & 0.0000 & $0.000 \mathrm{E}+00$ & 0.0000 \\
\hline-239 & $4.463 E-18$ & 0.0000 & $0.000 \mathrm{E}+00$ & 0.0000 & $0.000 \mathrm{E}+00$ & 0.0000 & $0.000 \mathrm{E}+00$ & 0.0000 & $0.000 \mathrm{E}+00$ & 0.0000 & $0.000 \mathrm{E}+00$ & 0.0000 & $0.000 \mathrm{E}+00$ & 0.0000 \\
\hline-240 & $5.480 \mathrm{E}-22$ & 0.0000 & $0.000 \mathrm{E}+00$ & 0.0000 & $0.000 \mathrm{E}+00$ & 0.0000 & $0.000 \mathrm{E}+00$ & 0.0000 & $0.000 \mathrm{E}+00$ & 0.0000 & $0.000 \mathrm{E}+00$ & 0.0000 & $0.000 \mathrm{E}+00$ & 0.0000 \\
\hline 99 & $2.364 \mathrm{E}-26$ & 0.0000 & $0.000 \mathrm{E}+00$ & 0.0000 & $0.000 \mathrm{E}+00$ & 0.0000 & $0.000 \mathrm{E}+00$ & 0.0000 & $0.000 \mathrm{E}+00$ & 0.0000 & $0.000 \mathrm{E}+00$ & 0.0000 & $0.000 \mathrm{E}+00$ & 0.0000 \\
\hline-228 & $5.163 \mathrm{E}-15$ & 0.0000 & $0.000 \mathrm{E}+00$ & 0.0000 & $0.000 \mathrm{E}+00$ & 0.0000 & $0.000 \mathrm{E}+00$ & 0.0000 & $0.000 \mathrm{E}+00$ & 0.0000 & $0.000 \mathrm{E}+00$ & 0.0000 & $0.000 \mathrm{E}+00$ & 0.0000 \\
\hline-230 & $1.087 \mathrm{E}-09$ & 0.0024 & $0.000 \mathrm{E}+00$ & 0.0000 & $0.000 \mathrm{E}+00$ & 0.0000 & $0.000 \mathrm{E}+00$ & 0.0000 & $0.000 \mathrm{E}+00$ & 0.0000 & $0.000 \mathrm{E}+00$ & 0.0000 & $0.000 \mathrm{E}+00$ & 0.0000 \\
\hline-232 & $4.579 E-07$ & 0.9973 & $0.000 \mathrm{E}+00$ & 0.0000 & $0.000 \mathrm{E}+00$ & 0.0000 & $0.000 \mathrm{E}+00$ & 0.0000 & $0.000 \mathrm{E}+00$ & 0.0000 & $0.000 \mathrm{E}+00$ & 0.0000 & $0.000 \mathrm{E}+00$ & 0.0000 \\
\hline 234 & $2.480 \mathrm{E}-13$ & 0.0000 & $0.000 \mathrm{E}+00$ & 0.0000 & $0.000 \mathrm{E}+00$ & 0.0000 & $0.000 \mathrm{E}+00$ & 0.0000 & $0.000 \mathrm{E}+00$ & 0.0000 & $0.000 \mathrm{E}+00$ & 0.0000 & $0.000 \mathrm{E}+00$ & 0.0000 \\
\hline 235 & $1.888 \mathrm{E}-14$ & 0.0000 & $0.000 \mathrm{E}+00$ & 0.0000 & $0.000 \mathrm{E}+00$ & 0.0000 & $0.000 \mathrm{E}+00$ & 0.0000 & $0.000 \mathrm{E}+00$ & 0.0000 & $0.000 \mathrm{E}+00$ & 0.0000 & $0.000 \mathrm{E}+00$ & 0.0000 \\
\hline 38 & 4. $325 E-11$ & 0.0001 & $0.000 \mathrm{E}+00$ & 0.0000 & $0.000 \mathrm{E}+00$ & 0.0000 & $0.000 \mathrm{E}+00$ & 0.0000 & $0.000 \mathrm{E}+00$ & 0.0000 & $0.000 \mathrm{E}+00$ & 0.0000 & $0.000 \mathrm{E}+00$ & 0.0000 \\
\hline & $4.592 \mathrm{E}-07$ & 1.0000 & $0.000 \mathrm{E}+00$ & 0.0000 & $0.000 \mathrm{E}+00$ & 0.0000 & $0.000 \mathrm{E}+00$ & 0.0000 & $0.000 \mathrm{E}+00$ & 0.0000 & $0.000 \mathrm{E}+00$ & 0.0000 & $0.000 \mathrm{E}+00$ & 0.0000 \\
\hline
\end{tabular}

Total Dose Contributions TDOSE(i,p,t) for Individual Radionuclides (i) and Pathways (p) As mrem/yr and Fraction of Total Dose At $t=5.000 \mathrm{E}+01$ years

Water Dependent Pathways

\begin{tabular}{|c|c|c|c|c|c|c|c|c|c|c|c|c|c|c|}
\hline & \multicolumn{2}{|c|}{ Water } & \multicolumn{2}{|c|}{ Fish } & \multicolumn{2}{|c|}{ Radon } & \multicolumn{2}{|c|}{ Plant } & \multicolumn{2}{|c|}{ Meat } & \multicolumn{2}{|c|}{ Milk } & \multicolumn{2}{|c|}{ All Pathways* } \\
\hline clide & mrem/yr & fract. & mrem/yr & fract. & mrem/yr & fract. & mrem/yr & fract. & mrem/yr & fract. & mrem/yr & fract. & mrem/yr & fract. \\
\hline-241 & $0.000 \mathrm{E}+00$ & 0.0000 & $0.000 \mathrm{E}+00$ & 0.0000 & $0.000 \mathrm{E}+00$ & 0.0000 & $0.000 \mathrm{E}+00$ & 0.0000 & $0.000 \mathrm{E}+00$ & 0.0000 & $0.000 \mathrm{E}+00$ & 0.0000 & $5.246 \mathrm{E}-18$ & 0.0000 \\
\hline-137 & $0.000 \mathrm{E}+00$ & 0.0000 & $0.000 \mathrm{E}+00$ & 0.0000 & $0.000 \mathrm{E}+00$ & 0.0000 & $0.000 \mathrm{E}+00$ & 0.0000 & $0.000 \mathrm{E}+00$ & 0.0000 & $0.000 \mathrm{E}+00$ & 0.0000 & $1.237 \mathrm{E}-10$ & 0.0003 \\
\hline-237 & $0.000 \mathrm{E}+00$ & 0.0000 & $0.000 \mathrm{E}+00$ & 0.0000 & $0.000 \mathrm{E}+00$ & 0.0000 & $0.000 \mathrm{E}+00$ & 0.0000 & $0.000 \mathrm{E}+00$ & 0.0000 & $0.000 \mathrm{E}+00$ & 0.0000 & $3.337 \mathrm{E}-13$ & 0.0000 \\
\hline 238 & $0.000 \mathrm{E}+00$ & 0.0000 & $0.000 \mathrm{E}+00$ & 0.0000 & $0.000 \mathrm{E}+00$ & 0.0000 & $0.000 \mathrm{E}+00$ & 0.0000 & $0.000 \mathrm{E}+00$ & 0.0000 & $0.000 \mathrm{E}+00$ & 0.0000 & $1.076 \mathrm{E}-17$ & 0.0000 \\
\hline 239 & $0.000 \mathrm{E}+00$ & 0.0000 & $0.000 \mathrm{E}+00$ & 0.0000 & $0.000 \mathrm{E}+00$ & 0.0000 & $0.000 \mathrm{E}+00$ & 0.0000 & $0.000 \mathrm{E}+00$ & 0.0000 & $0.000 \mathrm{E}+00$ & 0.0000 & $4.463 \mathrm{E}-18$ & 0.0000 \\
\hline 240 & $0.000 \mathrm{E}+00$ & 0.0000 & $0.000 \mathrm{E}+00$ & 0.0000 & $0.000 \mathrm{E}+00$ & 0.0000 & $0.000 \mathrm{E}+00$ & 0.0000 & $0.000 \mathrm{E}+00$ & 0.0000 & $0.000 \mathrm{E}+00$ & 0.0000 & $5.480 \mathrm{E}-22$ & 0.0000 \\
\hline 99 & $0.000 \mathrm{E}+00$ & 0.0000 & $0.000 \mathrm{E}+00$ & 0.0000 & $0.000 \mathrm{E}+00$ & 0.0000 & $0.000 \mathrm{E}+00$ & 0.0000 & $0.000 \mathrm{E}+00$ & 0.0000 & $0.000 \mathrm{E}+00$ & 0.0000 & $2.364 \mathrm{E}-26$ & 0.0000 \\
\hline 228 & $0.000 \mathrm{E}+00$ & 0.0000 & $0.000 \mathrm{E}+00$ & 0.0000 & $0.000 \mathrm{E}+00$ & 0.0000 & $0.000 \mathrm{E}+00$ & 0.0000 & $0.000 \mathrm{E}+00$ & 0.0000 & $0.000 \mathrm{E}+00$ & 0.0000 & $5.163 \mathrm{E}-15$ & 0.0000 \\
\hline 230 & $0.000 \mathrm{E}+00$ & 0.0000 & $0.000 \mathrm{E}+00$ & 0.0000 & $0.000 \mathrm{E}+00$ & 0.0000 & $0.000 \mathrm{E}+00$ & 0.0000 & $0.000 \mathrm{E}+00$ & 0.0000 & $0.000 \mathrm{E}+00$ & 0.0000 & $1.087 \mathrm{E}-09$ & 0.0024 \\
\hline 232 & $0.000 \mathrm{E}+00$ & 0.0000 & $0.000 \mathrm{E}+00$ & 0.0000 & $0.000 \mathrm{E}+00$ & 0.0000 & $0.000 \mathrm{E}+00$ & 0.0000 & $0.000 \mathrm{E}+00$ & 0.0000 & $0.000 \mathrm{E}+00$ & 0.0000 & $4.579 E-07$ & 0.9973 \\
\hline & $0.000 \mathrm{E}+00$ & 0.0000 & $0.000 \mathrm{E}+00$ & 0.0000 & $0.000 \mathrm{E}+00$ & 0.0000 & $0.000 \mathrm{E}+00$ & 0.0000 & $0.000 \mathrm{E}+00$ & 0.0000 & $0.000 \mathrm{E}+00$ & 0.0000 & $2.480 \mathrm{E}-13$ & 0.0000 \\
\hline 35 & $0.000 \mathrm{E}+00$ & 0.0000 & $0.000 \mathrm{E}+00$ & 0.0000 & $0.000 \mathrm{E}+00$ & 0.0000 & $0.000 \mathrm{E}+00$ & 0.0000 & $0.000 \mathrm{E}+00$ & 0.0000 & $0.000 \mathrm{E}+00$ & 0.0000 & $1.888 \mathrm{E}-14$ & 0.0000 \\
\hline 38 & $0.000 \mathrm{E}+00$ & 0.0000 & $0.000 \mathrm{E}+00$ & 0.0000 & $0.000 \mathrm{E}+00$ & 0.0000 & $0.000 \mathrm{E}+00$ & 0.0000 & $0.000 \mathrm{E}+00$ & 0.0000 & $0.000 \mathrm{E}+00$ & 0.0000 & 4. $325 \mathrm{E}-11$ & 0.0001 \\
\hline & $0.000 \mathrm{E}+00$ & 0.0000 & $0.000 \mathrm{E}+00$ & 0.0000 & $0.000 \mathrm{E}+00$ & 0.0000 & $0.000 \mathrm{E}+00$ & 0.0000 & $0.000 \mathrm{E}+00$ & 0.0000 & $0.000 \mathrm{E}+00$ & 000 & -07 & 1.0000 \\
\hline
\end{tabular}

* Sum of all water independent and dependent pathways. 
RESRAD, Version 6.5

$07 / 21 / 2011$

24

Summary : RESRAD Parameters for U-Landfill Outdoor Worker
File : C: $\backslash$ RESRAD_FAMILY $\backslash$ RESRAD $\backslash U S E R F I L E S \backslash Q C F O R S R S G \backslash O U T D O O R W O R K E R-S R S G-M A Y 11 . R A D$

Total Dose Contributions TDOSE (i,p,t) for Individual Radionuclides (i) and Pathways (p) As mrem/yr and Fraction of Total Dose At $t=1.000 \mathrm{E}+02$ years

Water Independent Pathways (Inhalation excludes radon)

\begin{tabular}{|c|c|c|c|c|c|c|c|c|c|c|c|c|c|c|}
\hline \multirow{2}{*}{ Nuclide } & \multicolumn{2}{|c|}{ Ground } & \multicolumn{2}{|c|}{ Inhalation } & \multicolumn{2}{|c|}{ Radon } & \multicolumn{2}{|c|}{ Plant } & \multicolumn{2}{|c|}{ Meat } & \multicolumn{2}{|c|}{ Milk } & \multicolumn{2}{|c|}{ Soil } \\
\hline & mrem/yr & fract. & mrem/yr & fract. & mrem/yr & fract. & mrem/yr & fract. & mrem/yr & fract. & mrem/yr & fract. & mrem/yr & fract. \\
\hline-241 & $1.722 \mathrm{E}-17$ & 0.0000 & $0.000 \mathrm{E}+00$ & 0.0000 & $0.000 \mathrm{E}+00$ & 0.0000 & $0.000 \mathrm{E}+00$ & 0.0000 & $0.000 \mathrm{E}+00$ & 0.0000 & $0.000 \mathrm{E}+00$ & 0.0000 & $0.000 \mathrm{E}+00$ & 0.0000 \\
\hline-137 & $5.936 \mathrm{E}-11$ & 0.0001 & $0.000 \mathrm{E}+00$ & 0.0000 & $0.000 \mathrm{E}+00$ & 0.0000 & $0.000 \mathrm{E}+00$ & 0.0000 & $0.000 \mathrm{E}+00$ & 0.0000 & $0.000 \mathrm{E}+00$ & 0.0000 & $0.000 \mathrm{E}+00$ & 0.0000 \\
\hline-237 & $5.729 \mathrm{E}-13$ & 0.0000 & $0.000 \mathrm{E}+00$ & 0.0000 & $0.000 \mathrm{E}+00$ & 0.0000 & $0.000 \mathrm{E}+00$ & 0.0000 & $0.000 \mathrm{E}+00$ & 0.0000 & $0.000 \mathrm{E}+00$ & 0.0000 & $0.000 \mathrm{E}+00$ & 0.0000 \\
\hline-238 & $1.088 E-16$ & 0.0000 & $0.000 \mathrm{E}+00$ & 0.0000 & $0.000 \mathrm{E}+00$ & 0.0000 & $0.000 \mathrm{E}+00$ & 0.0000 & $0.000 \mathrm{E}+00$ & 0.0000 & $0.000 \mathrm{E}+00$ & 0.0000 & $0.000 \mathrm{E}+00$ & 0.0000 \\
\hline-239 & $8.110 \mathrm{E}-18$ & 0.0000 & $0.000 \mathrm{E}+00$ & 0.0000 & $0.000 \mathrm{E}+00$ & 0.0000 & $0.000 \mathrm{E}+00$ & 0.0000 & $0.000 \mathrm{E}+00$ & 0.0000 & $0.000 \mathrm{E}+00$ & 0.0000 & $0.000 \mathrm{E}+00$ & 0.0000 \\
\hline-240 & $3.646 \mathrm{E}-21$ & 0.0000 & $0.000 \mathrm{E}+00$ & 0.0000 & $0.000 \mathrm{E}+00$ & 0.0000 & $0.000 \mathrm{E}+00$ & 0.0000 & $0.000 \mathrm{E}+00$ & 0.0000 & $0.000 \mathrm{E}+00$ & 0.0000 & $0.000 \mathrm{E}+00$ & 0.0000 \\
\hline 99 & $4.741 E-26$ & 0.0000 & $0.000 \mathrm{E}+00$ & 0.0000 & $0.000 \mathrm{E}+00$ & 0.0000 & $0.000 \mathrm{E}+00$ & 0.0000 & $0.000 \mathrm{E}+00$ & 0.0000 & $0.000 \mathrm{E}+00$ & 0.0000 & $0.000 \mathrm{E}+00$ & 0.0000 \\
\hline-228 & $9.437 \mathrm{E}-23$ & 0.0000 & $0.000 \mathrm{E}+00$ & 0.0000 & $0.000 \mathrm{E}+00$ & 0.0000 & $0.000 \mathrm{E}+00$ & 0.0000 & $0.000 \mathrm{E}+00$ & 0.0000 & $0.000 \mathrm{E}+00$ & 0.0000 & $0.000 \mathrm{E}+00$ & 0.0000 \\
\hline 230 & $3.024 \mathrm{E}-09$ & 0.0049 & $0.000 \mathrm{E}+00$ & 0.0000 & $0.000 \mathrm{E}+00$ & 0.0000 & $0.000 \mathrm{E}+00$ & 0.0000 & $0.000 \mathrm{E}+00$ & 0.0000 & $0.000 \mathrm{E}+00$ & 0.0000 & $0.000 \mathrm{E}+00$ & 0.0000 \\
\hline-232 & $6.198 E-07$ & 0.9949 & $0.000 \mathrm{E}+00$ & 0.0000 & $0.000 \mathrm{E}+00$ & 0.0000 & $0.000 \mathrm{E}+00$ & 0.0000 & $0.000 \mathrm{E}+00$ & 0.0000 & $0.000 \mathrm{E}+00$ & 0.0000 & $0.000 \mathrm{E}+00$ & 0.0000 \\
\hline 34 & $1.377 \mathrm{E}-12$ & 0.0000 & $0.000 \mathrm{E}+00$ & 0.0000 & $0.000 \mathrm{E}+00$ & 0.0000 & $0.000 \mathrm{E}+00$ & 0.0000 & $0.000 \mathrm{E}+00$ & 0.0000 & $0.000 \mathrm{E}+00$ & 0.0000 & $0.000 \mathrm{E}+00$ & 0.0000 \\
\hline 35 & $6.928 E-14$ & 0.0000 & $0.000 \mathrm{E}+00$ & 0.0000 & $0.000 \mathrm{E}+00$ & 0.0000 & $0.000 \mathrm{E}+00$ & 0.0000 & $0.000 \mathrm{E}+00$ & 0.0000 & $0.000 \mathrm{E}+00$ & 0.0000 & $0.000 \mathrm{E}+00$ & 0.0000 \\
\hline 38 & $6.449 \mathrm{E}-11$ & 0.0001 & $0.000 \mathrm{E}+00$ & 0.0000 & $0.000 \mathrm{E}+00$ & 0.0000 & $0.000 \mathrm{E}+00$ & 0.0000 & $0.000 \mathrm{E}+00$ & 0.0000 & $0.000 \mathrm{E}+00$ & 0.0000 & $0.000 \mathrm{E}+00$ & 0.0000 \\
\hline & $6.229 \mathrm{E}-07$ & 1.0000 & $0.000 \mathrm{E}+00$ & 0.0000 & $0.000 \mathrm{E}+00$ & 0.0000 & $0.000 \mathrm{E}+00$ & 0.0000 & $0.000 \mathrm{E}+00$ & 0.0000 & $0.000 \mathrm{E}+00$ & 0.0000 & $.000 \mathrm{E}+00$ & 0.0000 \\
\hline
\end{tabular}

Total Dose Contributions TDOSE(i,p,t) for Individual Radionuclides (i) and Pathways (p) As mrem/yr and Fraction of Total Dose At $t=1.000 \mathrm{E}+02$ years

Water Dependent Pathways

\begin{tabular}{|c|c|c|c|c|c|c|c|c|c|c|c|c|c|c|}
\hline \multirow{2}{*}{$\begin{array}{l}\text { Radio- } \\
\text { Nuclide }\end{array}$} & \multicolumn{2}{|c|}{ Water } & \multicolumn{2}{|c|}{ Fish } & \multicolumn{2}{|c|}{ Radon } & \multicolumn{2}{|c|}{ Plant } & \multicolumn{2}{|c|}{ Meat } & \multicolumn{2}{|c|}{ Milk } & \multicolumn{2}{|c|}{ All Pathways* } \\
\hline & mrem/yr & fract. & mrem/yr & fract. & mrem/yr & fract. & mrem/yr & fract. & mrem/yr & fract. & mrem/yr & fract. & mrem/yr & fract. \\
\hline 241 & $0.000 \mathrm{E}+00$ & 0.0000 & $0.000 \mathrm{E}+00$ & 0.0000 & $0.000 \mathrm{E}+00$ & 0.0000 & $0.000 \mathrm{E}+00$ & 0.0000 & $0.000 \mathrm{E}+00$ & 0.0000 & $0.000 \mathrm{E}+00$ & 0.0000 & $1.722 \mathrm{E}-17$ & 0.0000 \\
\hline-137 & $0.000 \mathrm{E}+00$ & 0.0000 & $0.000 \mathrm{E}+00$ & 0.0000 & $0.000 \mathrm{E}+00$ & 0.0000 & $0.000 \mathrm{E}+00$ & 0.0000 & $0.000 \mathrm{E}+00$ & 0.0000 & $0.000 \mathrm{E}+00$ & 0.0000 & $5.936 \mathrm{E}-11$ & 0.0001 \\
\hline-237 & $0.000 \mathrm{E}+00$ & 0.0000 & $0.000 \mathrm{E}+00$ & 0.0000 & $0.000 \mathrm{E}+00$ & 0.0000 & $0.000 \mathrm{E}+00$ & 0.0000 & $0.000 \mathrm{E}+00$ & 0.0000 & $0.000 \mathrm{E}+00$ & 0.0000 & $5.729 \mathrm{E}-13$ & 0.0000 \\
\hline-238 & $0.000 \mathrm{E}+00$ & 0.0000 & $0.000 \mathrm{E}+00$ & 0.0000 & $0.000 \mathrm{E}+00$ & 0.0000 & $0.000 \mathrm{E}+00$ & 0.0000 & $0.000 \mathrm{E}+00$ & 0.0000 & $0.000 \mathrm{E}+00$ & 0.0000 & $1.088 \mathrm{E}-16$ & 0.0000 \\
\hline-239 & $0.000 \mathrm{E}+00$ & 0.0000 & $0.000 \mathrm{E}+00$ & 0.0000 & $0.000 \mathrm{E}+00$ & 0.0000 & $0.000 \mathrm{E}+00$ & 0.0000 & $0.000 \mathrm{E}+00$ & 0.0000 & $0.000 E+00$ & 0.0000 & $8.110 \mathrm{E}-18$ & 0.0000 \\
\hline-240 & $0.000 \mathrm{E}+00$ & 0.0000 & $0.000 \mathrm{E}+00$ & 0.0000 & $0.000 \mathrm{E}+00$ & 0.0000 & $0.000 \mathrm{E}+00$ & 0.0000 & $0.000 \mathrm{E}+00$ & 0.0000 & $0.000 E+00$ & 0.0000 & $3.646 \mathrm{E}-21$ & 0.0000 \\
\hline-99 & $0.000 \mathrm{E}+00$ & 0.0000 & $0.000 \mathrm{E}+00$ & 0.0000 & $0.000 \mathrm{E}+00$ & 0.0000 & $0.000 \mathrm{E}+00$ & 0.0000 & $0.000 \mathrm{E}+00$ & 0.0000 & $0.000 \mathrm{E}+00$ & 0.0000 & $4.741 E-26$ & 0.0000 \\
\hline-228 & $0.000 \mathrm{E}+00$ & 0.0000 & $0.000 \mathrm{E}+00$ & 0.0000 & $0.000 \mathrm{E}+00$ & 0.0000 & $0.000 \mathrm{E}+00$ & 0.0000 & $0.000 \mathrm{E}+00$ & 0.0000 & $0.000 \mathrm{E}+00$ & 0.0000 & $9.437 \mathrm{E}-23$ & 0.0000 \\
\hline-230 & $0.000 \mathrm{E}+00$ & 0.0000 & $0.000 \mathrm{E}+00$ & 0.0000 & $0.000 \mathrm{E}+00$ & 0.0000 & $0.000 \mathrm{E}+00$ & 0.0000 & $0.000 \mathrm{E}+00$ & 0.0000 & $0.000 E+00$ & 0.0000 & $3.024 \mathrm{E}-09$ & 0.0049 \\
\hline-232 & $0.000 \mathrm{E}+00$ & 0.0000 & $0.000 \mathrm{E}+00$ & 0.0000 & $0.000 \mathrm{E}+00$ & 0.0000 & $0.000 \mathrm{E}+00$ & 0.0000 & $0.000 \mathrm{E}+00$ & 0.0000 & $0.000 \mathrm{E}+00$ & 0.0000 & $6.198 \mathrm{E}-07$ & 0.9949 \\
\hline 234 & $0.000 \mathrm{E}+00$ & 0.0000 & $0.000 \mathrm{E}+00$ & 0.0000 & $0.000 \mathrm{E}+00$ & 0.0000 & $0.000 \mathrm{E}+00$ & 0.0000 & $0.000 \mathrm{E}+00$ & 0.0000 & $0.000 \mathrm{E}+00$ & 0.0000 & $1.377 \mathrm{E}-12$ & 0.0000 \\
\hline 35 & $0.000 \mathrm{E}+00$ & 0.0000 & $0.000 \mathrm{E}+00$ & 0.0000 & $0.000 \mathrm{E}+00$ & 0.0000 & $0.000 \mathrm{E}+00$ & 0.0000 & $0.000 \mathrm{E}+00$ & 0.0000 & $0.000 \mathrm{E}+00$ & 0.0000 & $6.928 E-14$ & 0.0000 \\
\hline 38 & $0.000 \mathrm{E}+00$ & 0.0000 & $0.000 \mathrm{E}+00$ & 0.0000 & $0.000 \mathrm{E}+00$ & 0.0000 & $0.000 \mathrm{E}+00$ & 0.0000 & $0.000 \mathrm{E}+00$ & 0.0000 & $0.000 \mathrm{E}+00$ & 0.0000 & $6.449 \mathrm{E}-11$ & 0.0001 \\
\hline & $0.000 \mathrm{E}+00$ & 0.0000 & $0.000 \mathrm{E}+00$ & 0.0000 & $0.000 \mathrm{E}+00$ & 0.0000 & $0.000 \mathrm{E}+00$ & 0.0000 & $0.000 \mathrm{E}+00$ & 0.0000 & $0.000 \mathrm{E}+00$ & 0.0000 & $229 E-07$ & 1.0000 \\
\hline
\end{tabular}

* Sum of all water independent and dependent pathways. 
RESRAD, Version 6.5

$07 / 21 / 2011$

25

Summary : RESRAD Parameters for U-Landfill Outdoor Worker
File : C: $\backslash$ RESRAD_FAMILY $\backslash$ RESRAD $\backslash U S E R F I L E S \backslash Q C F O R S R S G \backslash O U T D O O R W O R K E R-S R S G-M A Y 11 . R A D$

Total Dose Contributions TDOSE (i,p,t) for Individual Radionuclides (i) and Pathways (p) As mrem/yr and Fraction of Total Dose At $t=5.000 \mathrm{E}+02$ years

Water Independent Pathways (Inhalation excludes radon)

\begin{tabular}{|c|c|c|c|c|c|c|c|c|c|c|c|c|c|c|}
\hline \multirow{2}{*}{$\begin{array}{l}\text { Radio- } \\
\text { Nuclide }\end{array}$} & \multicolumn{2}{|c|}{ Ground } & \multicolumn{2}{|c|}{ Inhalation } & \multicolumn{2}{|c|}{ Radon } & \multicolumn{2}{|c|}{ Plant } & \multicolumn{2}{|c|}{ Meat } & \multicolumn{2}{|c|}{ Milk } & \multicolumn{2}{|c|}{ Soil } \\
\hline & mrem/yr & fract. & mrem/yr & fract. & mrem/yr & fract. & mrem/yr & fract. & mrem/yr & fract. & mrem/yr & fract. & mrem/yr & fract. \\
\hline $1-241$ & $4.766 \mathrm{E}-15$ & 0.0000 & $0.000 \mathrm{E}+00$ & 0.0000 & $0.000 \mathrm{E}+00$ & 0.0000 & $0.000 \mathrm{E}+00$ & 0.0000 & $0.000 \mathrm{E}+00$ & 0.0000 & $0.000 \mathrm{E}+00$ & 0.0000 & $0.000 \mathrm{E}+00$ & 0.0000 \\
\hline-137 & $1.667 \mathrm{E}-13$ & 0.0000 & $0.000 \mathrm{E}+00$ & 0.0000 & $0.000 \mathrm{E}+00$ & 0.0000 & $0.000 \mathrm{E}+00$ & 0.0000 & $0.000 \mathrm{E}+00$ & 0.0000 & $0.000 \mathrm{E}+00$ & 0.0000 & $0.000 \mathrm{E}+00$ & 0.0000 \\
\hline-237 & 4. $294 \mathrm{E}-11$ & 0.0000 & $0.000 \mathrm{E}+00$ & 0.0000 & $0.000 \mathrm{E}+00$ & 0.0000 & $0.000 \mathrm{E}+00$ & 0.0000 & $0.000 \mathrm{E}+00$ & 0.0000 & $0.000 \mathrm{E}+00$ & 0.0000 & $0.000 \mathrm{E}+00$ & 0.0000 \\
\hline-238 & $1.149 \mathrm{E}-13$ & 0.0000 & $0.000 \mathrm{E}+00$ & 0.0000 & $0.000 \mathrm{E}+00$ & 0.0000 & $0.000 \mathrm{E}+00$ & 0.0000 & $0.000 \mathrm{E}+00$ & 0.0000 & $0.000 \mathrm{E}+00$ & 0.0000 & $0.000 \mathrm{E}+00$ & 0.0000 \\
\hline-239 & $9.655 \mathrm{E}-16$ & 0.0000 & $0.000 \mathrm{E}+00$ & 0.0000 & $0.000 \mathrm{E}+00$ & 0.0000 & $0.000 \mathrm{E}+00$ & 0.0000 & $0.000 \mathrm{E}+00$ & 0.0000 & $0.000 \mathrm{E}+00$ & 0.0000 & $0.000 \mathrm{E}+00$ & 0.0000 \\
\hline-240 & $1.172 \mathrm{E}-18$ & 0.0000 & $0.000 \mathrm{E}+00$ & 0.0000 & $0.000 \mathrm{E}+00$ & 0.0000 & $0.000 \mathrm{E}+00$ & 0.0000 & $0.000 \mathrm{E}+00$ & 0.0000 & $0.000 \mathrm{E}+00$ & 0.0000 & $0.000 \mathrm{E}+00$ & 0.0000 \\
\hline-99 & $1.241 \mathrm{E}-23$ & 0.0000 & $0.000 \mathrm{E}+00$ & 0.0000 & $0.000 \mathrm{E}+00$ & 0.0000 & $0.000 \mathrm{E}+00$ & 0.0000 & $0.000 \mathrm{E}+00$ & 0.0000 & $0.000 \mathrm{E}+00$ & 0.0000 & $0.000 \mathrm{E}+00$ & 0.0000 \\
\hline-228 & $0.000 \mathrm{E}+00$ & 0.0000 & $0.000 \mathrm{E}+00$ & 0.0000 & $0.000 \mathrm{E}+00$ & 0.0000 & $0.000 \mathrm{E}+00$ & 0.0000 & $0.000 \mathrm{E}+00$ & 0.0000 & $0.000 \mathrm{E}+00$ & 0.0000 & $0.000 \mathrm{E}+00$ & 0.0000 \\
\hline-230 & $2.193 \mathrm{E}-07$ & 0.0311 & $0.000 \mathrm{E}+00$ & 0.0000 & $0.000 \mathrm{E}+00$ & 0.0000 & $0.000 \mathrm{E}+00$ & 0.0000 & $0.000 \mathrm{E}+00$ & 0.0000 & $0.000 \mathrm{E}+00$ & 0.0000 & $0.000 \mathrm{E}+00$ & 0.0000 \\
\hline-232 & $6.825 E-06$ & 0.9686 & $0.000 \mathrm{E}+00$ & 0.0000 & $0.000 \mathrm{E}+00$ & 0.0000 & $0.000 \mathrm{E}+00$ & 0.0000 & $0.000 \mathrm{E}+00$ & 0.0000 & $0.000 \mathrm{E}+00$ & 0.0000 & $0.000 \mathrm{E}+00$ & 0.0000 \\
\hline 34 & $5.115 \mathrm{E}-10$ & 0.0001 & $0.000 \mathrm{E}+00$ & 0.0000 & $0.000 \mathrm{E}+00$ & 0.0000 & $0.000 \mathrm{E}+00$ & 0.0000 & $0.000 \mathrm{E}+00$ & 0.0000 & $0.000 \mathrm{E}+00$ & 0.0000 & $0.000 \mathrm{E}+00$ & 0.0000 \\
\hline 35 & $1.443 \mathrm{E}-11$ & 0.0000 & $0.000 \mathrm{E}+00$ & 0.0000 & $0.000 \mathrm{E}+00$ & 0.0000 & $0.000 \mathrm{E}+00$ & 0.0000 & $0.000 \mathrm{E}+00$ & 0.0000 & $0.000 \mathrm{E}+00$ & 0.0000 & $0.000 \mathrm{E}+00$ & 0.0000 \\
\hline 38 & $1.577 \mathrm{E}-09$ & 0.0002 & $0.000 \mathrm{E}+00$ & 0.0000 & $0.000 \mathrm{E}+00$ & 0.0000 & $0.000 \mathrm{E}+00$ & 0.0000 & $0.000 \mathrm{E}+00$ & 0.0000 & $0.000 \mathrm{E}+00$ & 0.0000 & $0.000 \mathrm{E}+00$ & 0.0000 \\
\hline & $7.047 \mathrm{E}-06$ & 1.0000 & $0.000 \mathrm{E}+00$ & 0.0000 & $0.000 \mathrm{E}+00$ & 0.0000 & $0.000 \mathrm{E}+00$ & 0.0000 & $0.000 \mathrm{E}+00$ & 000 & $0.000 \mathrm{E}+00$ & 000 & \pm+00 & 000 \\
\hline
\end{tabular}

Total Dose Contributions TDOSE(i,p,t) for Individual Radionuclides (i) and Pathways (p) As mrem/yr and Fraction of Total Dose At $t=5.000 \mathrm{E}+02$ years

Water Dependent Pathways

\begin{tabular}{|c|c|c|c|c|c|c|c|c|c|c|c|c|c|c|}
\hline \multirow{2}{*}{$\begin{array}{l}\text { Radio- } \\
\text { Nuclide }\end{array}$} & \multicolumn{2}{|c|}{ Water } & \multicolumn{2}{|c|}{ Fish } & \multicolumn{2}{|c|}{ Radon } & \multicolumn{2}{|c|}{ Plant } & \multicolumn{2}{|c|}{ Meat } & \multicolumn{2}{|c|}{ Milk } & \multicolumn{2}{|c|}{ All Pathways* } \\
\hline & mrem/yr & fract. & mrem/yr & fract. & mrem/yr & fract. & mrem/yr & fract. & mrem/yr & fract. & mrem/yr & fract. & mrem/yr & fract. \\
\hline 241 & $0.000 \mathrm{E}+00$ & 0.0000 & $0.000 \mathrm{E}+00$ & 0.0000 & $0.000 \mathrm{E}+00$ & 0.0000 & $0.000 \mathrm{E}+00$ & 0.0000 & $0.000 \mathrm{E}+00$ & 0.0000 & $0.000 \mathrm{E}+00$ & 0.0000 & $4.766 \mathrm{E}-15$ & 0.0000 \\
\hline-137 & $0.000 \mathrm{E}+00$ & 0.0000 & $0.000 \mathrm{E}+00$ & 0.0000 & $0.000 \mathrm{E}+00$ & 0.0000 & $0.000 \mathrm{E}+00$ & 0.0000 & $0.000 \mathrm{E}+00$ & 0.0000 & $0.000 \mathrm{E}+00$ & 0.0000 & $1.667 \mathrm{E}-13$ & 0.0000 \\
\hline-237 & $0.000 \mathrm{E}+00$ & 0.0000 & $0.000 \mathrm{E}+00$ & 0.0000 & $0.000 \mathrm{E}+00$ & 0.0000 & $0.000 \mathrm{E}+00$ & 0.0000 & $0.000 \mathrm{E}+00$ & 0.0000 & $0.000 \mathrm{E}+00$ & 0.0000 & $4.294 \mathrm{E}-11$ & 0.0000 \\
\hline-238 & $0.000 \mathrm{E}+00$ & 0.0000 & $0.000 \mathrm{E}+00$ & 0.0000 & $0.000 \mathrm{E}+00$ & 0.0000 & $0.000 \mathrm{E}+00$ & 0.0000 & $0.000 \mathrm{E}+00$ & 0.0000 & $0.000 \mathrm{E}+00$ & 0.0000 & $1.149 \mathrm{E}-13$ & 0.0000 \\
\hline-239 & $0.000 \mathrm{E}+00$ & 0.0000 & $0.000 \mathrm{E}+00$ & 0.0000 & $0.000 \mathrm{E}+00$ & 0.0000 & $0.000 \mathrm{E}+00$ & 0.0000 & $0.000 \mathrm{E}+00$ & 0.0000 & $0.000 E+00$ & 0.0000 & $9.655 \mathrm{E}-16$ & 0.0000 \\
\hline-240 & $0.000 \mathrm{E}+00$ & 0.0000 & $0.000 \mathrm{E}+00$ & 0.0000 & $0.000 \mathrm{E}+00$ & 0.0000 & $0.000 \mathrm{E}+00$ & 0.0000 & $0.000 \mathrm{E}+00$ & 0.0000 & $0.000 E+00$ & 0.0000 & $1.172 \mathrm{E}-18$ & 0.0000 \\
\hline-99 & $0.000 \mathrm{E}+00$ & 0.0000 & $0.000 \mathrm{E}+00$ & 0.0000 & $0.000 \mathrm{E}+00$ & 0.0000 & $0.000 \mathrm{E}+00$ & 0.0000 & $0.000 \mathrm{E}+00$ & 0.0000 & $0.000 \mathrm{E}+00$ & 0.0000 & $1.241 \mathrm{E}-23$ & 0.0000 \\
\hline-228 & $0.000 \mathrm{E}+00$ & 0.0000 & $0.000 \mathrm{E}+00$ & 0.0000 & $0.000 \mathrm{E}+00$ & 0.0000 & $0.000 \mathrm{E}+00$ & 0.0000 & $0.000 \mathrm{E}+00$ & 0.0000 & $0.000 \mathrm{E}+00$ & 0.0000 & $0.000 \mathrm{E}+00$ & 0.0000 \\
\hline-230 & $0.000 \mathrm{E}+00$ & 0.0000 & $0.000 \mathrm{E}+00$ & 0.0000 & $0.000 \mathrm{E}+00$ & 0.0000 & $0.000 \mathrm{E}+00$ & 0.0000 & $0.000 \mathrm{E}+00$ & 0.0000 & $0.000 E+00$ & 0.0000 & $2.193 \mathrm{E}-07$ & 0.0311 \\
\hline-232 & $0.000 \mathrm{E}+00$ & 0.0000 & $0.000 \mathrm{E}+00$ & 0.0000 & $0.000 \mathrm{E}+00$ & 0.0000 & $0.000 \mathrm{E}+00$ & 0.0000 & $0.000 \mathrm{E}+00$ & 0.0000 & $0.000 \mathrm{E}+00$ & 0.0000 & $6.825 E-06$ & 0.9686 \\
\hline 34 & $0.000 \mathrm{E}+00$ & 0.0000 & $0.000 \mathrm{E}+00$ & 0.0000 & $0.000 \mathrm{E}+00$ & 0.0000 & $0.000 \mathrm{E}+00$ & 0.0000 & $0.000 \mathrm{E}+00$ & 0.0000 & $0.000 \mathrm{E}+00$ & 0.0000 & $5.115 \mathrm{E}-10$ & 0.0001 \\
\hline 35 & $0.000 \mathrm{E}+00$ & 0.0000 & $0.000 \mathrm{E}+00$ & 0.0000 & $0.000 \mathrm{E}+00$ & 0.0000 & $0.000 \mathrm{E}+00$ & 0.0000 & $0.000 \mathrm{E}+00$ & 0.0000 & $0.000 \mathrm{E}+00$ & 0.0000 & $1.443 \mathrm{E}-11$ & 0.0000 \\
\hline 38 & $0.000 \mathrm{E}+00$ & 0.0000 & $0.000 \mathrm{E}+00$ & 0.0000 & $0.000 \mathrm{E}+00$ & 0.0000 & $0.000 \mathrm{E}+00$ & 0.0000 & $0.000 \mathrm{E}+00$ & 0.0000 & $0.000 \mathrm{E}+00$ & 0.0000 & $1.577 \mathrm{E}-09$ & 0.0002 \\
\hline & $0.000 \mathrm{E}+00$ & 0.0000 & $0.000 \mathrm{E}+00$ & 0.0000 & $0.000 \mathrm{E}+00$ & 0.0000 & $0.000 \mathrm{E}+00$ & 0.0000 & $0.000 \mathrm{E}+00$ & 0.0000 & $0.000 \mathrm{E}+00$ & 0.0000 & $7 E-06$ & 1. \\
\hline
\end{tabular}

* Sum of all water independent and dependent pathways. 
RESRAD, Version 6.5

$07 / 21 / 2011$

Summary : RESRAD Parameters for U-Landfill Outdoor Worker
File : C: $\backslash$ RESRAD_FAMILY \RESRAD \USERFILES \QCFORSRSG $O$ OUTDOORWORKER-SRSG-MAY11.RAD

Total Dose Contributions TDOSE (i,p,t) for Individual Radionuclides (i) and Pathways (p) As mrem/yr and Fraction of Total Dose At $t=1.050 \mathrm{E}+03$ years

Water Independent Pathways (Inhalation excludes radon)

\begin{tabular}{|c|c|c|c|c|c|c|c|c|c|c|c|c|c|c|}
\hline \multirow{2}{*}{ Nuclide } & \multicolumn{2}{|c|}{ Ground } & \multicolumn{2}{|c|}{ Inhalation } & \multicolumn{2}{|c|}{ Radon } & \multicolumn{2}{|c|}{ Plant } & \multicolumn{2}{|c|}{ Meat } & \multicolumn{2}{|c|}{ Milk } & \multicolumn{2}{|c|}{ Soil } \\
\hline & mrem/yr & fract. & mrem/yr & fract. & mrem/yr & fract. & mrem/yr & fract. & mrem/yr & fract. & mrem/yr & fract. & mrem/yr & fract. \\
\hline-241 & $2.581 \mathrm{E}-12$ & 0.0000 & $0.000 \mathrm{E}+00$ & 0.0000 & $0.000 \mathrm{E}+00$ & 0.0000 & $0.000 \mathrm{E}+00$ & 0.0000 & $0.000 \mathrm{E}+00$ & 0.0000 & $0.000 \mathrm{E}+00$ & 0.0000 & $0.000 \mathrm{E}+00$ & 0.0000 \\
\hline-137 & $5.175 E-17$ & 0.0000 & $0.000 \mathrm{E}+00$ & 0.0000 & $0.000 \mathrm{E}+00$ & 0.0000 & $0.000 \mathrm{E}+00$ & 0.0000 & $0.000 \mathrm{E}+00$ & 0.0000 & $0.000 \mathrm{E}+00$ & 0.0000 & $0.000 \mathrm{E}+00$ & 0.0000 \\
\hline-237 & $1.540 \mathrm{E}-08$ & 0.0001 & $0.000 \mathrm{E}+00$ & 0.0000 & $0.000 \mathrm{E}+00$ & 0.0000 & $0.000 \mathrm{E}+00$ & 0.0000 & $0.000 \mathrm{E}+00$ & 0.0000 & $0.000 \mathrm{E}+00$ & 0.0000 & $0.000 \mathrm{E}+00$ & 0.0000 \\
\hline-238 & $2.677 \mathrm{E}-11$ & 0.0000 & $0.000 \mathrm{E}+00$ & 0.0000 & $0.000 \mathrm{E}+00$ & 0.0000 & $0.000 \mathrm{E}+00$ & 0.0000 & $0.000 \mathrm{E}+00$ & 0.0000 & $0.000 \mathrm{E}+00$ & 0.0000 & $0.000 \mathrm{E}+00$ & 0.0000 \\
\hline-239 & $6.871 E-13$ & 0.0000 & $0.000 \mathrm{E}+00$ & 0.0000 & $0.000 \mathrm{E}+00$ & 0.0000 & $0.000 \mathrm{E}+00$ & 0.0000 & $0.000 \mathrm{E}+00$ & 0.0000 & $0.000 \mathrm{E}+00$ & 0.0000 & $0.000 \mathrm{E}+00$ & 0.0000 \\
\hline-240 & $1.665 \mathrm{E}-16$ & 0.0000 & $0.000 \mathrm{E}+00$ & 0.0000 & $0.000 \mathrm{E}+00$ & 0.0000 & $0.000 \mathrm{E}+00$ & 0.0000 & $0.000 \mathrm{E}+00$ & 0.0000 & $0.000 \mathrm{E}+00$ & 0.0000 & $0.000 \mathrm{E}+00$ & 0.0000 \\
\hline 99 & $2.619 E-20$ & 0.0000 & $0.000 \mathrm{E}+00$ & 0.0000 & $0.000 \mathrm{E}+00$ & 0.0000 & $0.000 \mathrm{E}+00$ & 0.0000 & $0.000 \mathrm{E}+00$ & 0.0000 & $0.000 \mathrm{E}+00$ & 0.0000 & $0.000 \mathrm{E}+00$ & 0.0000 \\
\hline-228 & $0.000 \mathrm{E}+00$ & 0.0000 & $0.000 \mathrm{E}+00$ & 0.0000 & $0.000 \mathrm{E}+00$ & 0.0000 & $0.000 \mathrm{E}+00$ & 0.0000 & $0.000 \mathrm{E}+00$ & 0.0000 & $0.000 \mathrm{E}+00$ & 0.0000 & $0.000 \mathrm{E}+00$ & 0.0000 \\
\hline-230 & $1.840 \mathrm{E}-05$ & 0.0886 & $0.000 \mathrm{E}+00$ & 0.0000 & $0.000 \mathrm{E}+00$ & 0.0000 & $0.000 \mathrm{E}+00$ & 0.0000 & $0.000 \mathrm{E}+00$ & 0.0000 & $0.000 \mathrm{E}+00$ & 0.0000 & $0.000 \mathrm{E}+00$ & 0.0000 \\
\hline-232 & $1.891 E-04$ & 0.9103 & $0.000 \mathrm{E}+00$ & 0.0000 & $0.000 \mathrm{E}+00$ & 0.0000 & $0.000 \mathrm{E}+00$ & 0.0000 & $0.000 \mathrm{E}+00$ & 0.0000 & $0.000 \mathrm{E}+00$ & 0.0000 & $0.000 \mathrm{E}+00$ & 0.0000 \\
\hline 234 & $9.341 \mathrm{E}-08$ & 0.0004 & $0.000 \mathrm{E}+00$ & 0.0000 & $0.000 \mathrm{E}+00$ & 0.0000 & $0.000 \mathrm{E}+00$ & 0.0000 & $0.000 \mathrm{E}+00$ & 0.0000 & $0.000 \mathrm{E}+00$ & 0.0000 & $0.000 \mathrm{E}+00$ & 0.0000 \\
\hline 35 & $4.843 E-09$ & 0.0000 & $0.000 \mathrm{E}+00$ & 0.0000 & $0.000 \mathrm{E}+00$ & 0.0000 & $0.000 \mathrm{E}+00$ & 0.0000 & $0.000 \mathrm{E}+00$ & 0.0000 & $0.000 \mathrm{E}+00$ & 0.0000 & $0.000 \mathrm{E}+00$ & 0.0000 \\
\hline 38 & $1.280 \mathrm{E}-07$ & 0.0006 & $0.000 \mathrm{E}+00$ & 0.0000 & $0.000 \mathrm{E}+00$ & 0.0000 & $0.000 \mathrm{E}+00$ & 0.0000 & $0.000 \mathrm{E}+00$ & 0.0000 & $0.000 \mathrm{E}+00$ & 0.0000 & $0.000 \mathrm{E}+00$ & 0.0000 \\
\hline & $2.078 E-04$ & 1.0000 & $0.000 \mathrm{E}+00$ & 0.0000 & $0.000 \mathrm{E}+00$ & 0.0000 & $0.000 \mathrm{E}+00$ & 0.0000 & $0.000 \mathrm{E}+00$ & 0.0000 & $0.000 \mathrm{E}+00$ & 0.0000 & $.000 \mathrm{E}+00$ & 0.0000 \\
\hline
\end{tabular}

Total Dose Contributions TDOSE(i,p,t) for Individual Radionuclides (i) and Pathways (p) As mrem/yr and Fraction of Total Dose At $t=1.050 \mathrm{E}+03$ years

Water Dependent Pathways

\begin{tabular}{|c|c|c|c|c|c|c|c|c|c|c|c|c|c|c|}
\hline \multirow{2}{*}{$\begin{array}{l}\text { Radio- } \\
\text { Nuclide }\end{array}$} & \multicolumn{2}{|c|}{ Water } & \multicolumn{2}{|c|}{ Fish } & \multicolumn{2}{|c|}{ Radon } & \multicolumn{2}{|c|}{ Plant } & \multicolumn{2}{|c|}{ Meat } & \multicolumn{2}{|c|}{ Milk } & \multicolumn{2}{|c|}{ All Pathways* } \\
\hline & mrem/yr & fract. & mrem/yr & fract. & mrem/yr & fract. & mrem/yr & fract. & mrem/yr & fract. & mrem/yr & fract. & mrem/yr & fract. \\
\hline 241 & $0.000 \mathrm{E}+00$ & 0.0000 & $0.000 \mathrm{E}+00$ & 0.0000 & $0.000 \mathrm{E}+00$ & 0.0000 & $0.000 \mathrm{E}+00$ & 0.0000 & $0.000 \mathrm{E}+00$ & 0.0000 & $0.000 \mathrm{E}+00$ & 0.0000 & $2.581 \mathrm{E}-12$ & 0.0000 \\
\hline-137 & $0.000 \mathrm{E}+00$ & 0.0000 & $0.000 \mathrm{E}+00$ & 0.0000 & $0.000 \mathrm{E}+00$ & 0.0000 & $0.000 \mathrm{E}+00$ & 0.0000 & $0.000 \mathrm{E}+00$ & 0.0000 & $0.000 \mathrm{E}+00$ & 0.0000 & $5.175 \mathrm{E}-17$ & 0.0000 \\
\hline-237 & $0.000 \mathrm{E}+00$ & 0.0000 & $0.000 \mathrm{E}+00$ & 0.0000 & $0.000 \mathrm{E}+00$ & 0.0000 & $0.000 \mathrm{E}+00$ & 0.0000 & $0.000 \mathrm{E}+00$ & 0.0000 & $0.000 \mathrm{E}+00$ & 0.0000 & $1.540 \mathrm{E}-08$ & 0.0001 \\
\hline-238 & $0.000 \mathrm{E}+00$ & 0.0000 & $0.000 \mathrm{E}+00$ & 0.0000 & $0.000 \mathrm{E}+00$ & 0.0000 & $0.000 \mathrm{E}+00$ & 0.0000 & $0.000 \mathrm{E}+00$ & 0.0000 & $0.000 \mathrm{E}+00$ & 0.0000 & $2.677 \mathrm{E}-11$ & 0.0000 \\
\hline-239 & $0.000 \mathrm{E}+00$ & 0.0000 & $0.000 \mathrm{E}+00$ & 0.0000 & $0.000 \mathrm{E}+00$ & 0.0000 & $0.000 \mathrm{E}+00$ & 0.0000 & $0.000 \mathrm{E}+00$ & 0.0000 & $0.000 E+00$ & 0.0000 & $6.871 \mathrm{E}-13$ & 0.0000 \\
\hline-240 & $0.000 \mathrm{E}+00$ & 0.0000 & $0.000 \mathrm{E}+00$ & 0.0000 & $0.000 \mathrm{E}+00$ & 0.0000 & $0.000 \mathrm{E}+00$ & 0.0000 & $0.000 \mathrm{E}+00$ & 0.0000 & $0.000 E+00$ & 0.0000 & $1.665 \mathrm{E}-16$ & 0.0000 \\
\hline 99 & $0.000 \mathrm{E}+00$ & 0.0000 & $0.000 \mathrm{E}+00$ & 0.0000 & $0.000 \mathrm{E}+00$ & 0.0000 & $0.000 \mathrm{E}+00$ & 0.0000 & $0.000 \mathrm{E}+00$ & 0.0000 & $0.000 \mathrm{E}+00$ & 0.0000 & $2.619 \mathrm{E}-20$ & 0.0000 \\
\hline-228 & $0.000 \mathrm{E}+00$ & 0.0000 & $0.000 \mathrm{E}+00$ & 0.0000 & $0.000 \mathrm{E}+00$ & 0.0000 & $0.000 \mathrm{E}+00$ & 0.0000 & $0.000 \mathrm{E}+00$ & 0.0000 & $0.000 \mathrm{E}+00$ & 0.0000 & $0.000 \mathrm{E}+00$ & 0.0000 \\
\hline-230 & $0.000 \mathrm{E}+00$ & 0.0000 & $0.000 \mathrm{E}+00$ & 0.0000 & $0.000 \mathrm{E}+00$ & 0.0000 & $0.000 \mathrm{E}+00$ & 0.0000 & $0.000 \mathrm{E}+00$ & 0.0000 & $0.000 E+00$ & 0.0000 & $1.840 \mathrm{E}-05$ & 0.0886 \\
\hline 232 & $0.000 \mathrm{E}+00$ & 0.0000 & $0.000 \mathrm{E}+00$ & 0.0000 & $0.000 \mathrm{E}+00$ & 0.0000 & $0.000 \mathrm{E}+00$ & 0.0000 & $0.000 \mathrm{E}+00$ & 0.0000 & $0.000 \mathrm{E}+00$ & 0.0000 & $1.891 \mathrm{E}-04$ & 0.9103 \\
\hline 34 & $0.000 \mathrm{E}+00$ & 0.0000 & $0.000 \mathrm{E}+00$ & 0.0000 & $0.000 \mathrm{E}+00$ & 0.0000 & $0.000 \mathrm{E}+00$ & 0.0000 & $0.000 \mathrm{E}+00$ & 0.0000 & $0.000 \mathrm{E}+00$ & 0.0000 & $9.341 \mathrm{E}-08$ & 0.0004 \\
\hline 35 & $0.000 \mathrm{E}+00$ & 0.0000 & $0.000 \mathrm{E}+00$ & 0.0000 & $0.000 \mathrm{E}+00$ & 0.0000 & $0.000 \mathrm{E}+00$ & 0.0000 & $0.000 \mathrm{E}+00$ & 0.0000 & $0.000 \mathrm{E}+00$ & 0.0000 & $4.843 E-09$ & 0.0000 \\
\hline 38 & $0.000 \mathrm{E}+00$ & 0.0000 & $0.000 \mathrm{E}+00$ & 0.0000 & $0.000 \mathrm{E}+00$ & 0.0000 & $0.000 \mathrm{E}+00$ & 0.0000 & $0.000 \mathrm{E}+00$ & 0.0000 & $0.000 \mathrm{E}+00$ & 0.0000 & $1.280 \mathrm{E}-07$ & 0.0006 \\
\hline & $0.000 \mathrm{E}+00$ & 0.0000 & $0.000 \mathrm{E}+00$ & 0.0000 & $0.000 \mathrm{E}+00$ & 0.0000 & $0.000 \mathrm{E}+00$ & 0.0000 & $0.000 \mathrm{E}+00$ & 0.0000 & $0.000 \mathrm{E}+00$ & 0.0000 & $3 E-04$ & 1. \\
\hline
\end{tabular}

* Sum of all water independent and dependent pathways. 
RESRAD, Version 6.5

$\mathrm{T}^{1 / 2}$ Limit $=180$ days

07/21/2011

Summary : RESRAD Parameters for U-Landfill Outdoor Worker

File : C: \RESRAD FAMILY \RESRAD \USERFILES \QCFORSRSG OOUTDOORWORKER-SRSG-MAY11.RAD

Dose/Source Ratios Summed Over All Pathways

Parent and Progeny Principal Radionuclide Contributions Indicated

Parent Product Thread DSR $(j, t)$ At Time in Years (mrem/yr)/(pCi/g)

(i)

(j)

\begin{tabular}{ll}
\hline Am-241 & $1.000 \mathrm{E}+00$ \\
$\mathrm{~Np}-237+\mathrm{D}$ & $1.000 \mathrm{E}+00$ \\
$\mathrm{U}-233$ & $1.000 \mathrm{E}+00$ \\
$\mathrm{Th}-229+\mathrm{D}$ & $1.000 \mathrm{E}+00$ \\
$\operatorname{\sum DSR}(j)$ &
\end{tabular}

Cs $-137+D$

Np-237+D

U-233

Th-229+D

$\sum \operatorname{DSR}(j)$

$\mathrm{Pu}-238$

$\mathrm{Pu}-238$

U-234

Th-230

Ra-226+D

$\mathrm{Pb}-210+\mathrm{D}$

$\operatorname{\sum DSR}(j)$

$\mathrm{Pu}-239$

U-235+D

$\mathrm{Pa}-231$

Ac-227+D

$\sum \operatorname{DSR}(j)$

$\mathrm{Pu}-240$

Pu-240

U-236

Th-232

Ra-228+D

Th-228+D

$\sum \operatorname{DSR}(j)$

TC-99

Th-228+D

Th-230

Ra-226+D

$\mathrm{Pb}-210+\mathrm{D}$

$\sum \operatorname{DSR}(j)$

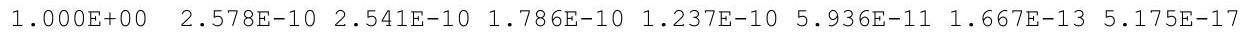

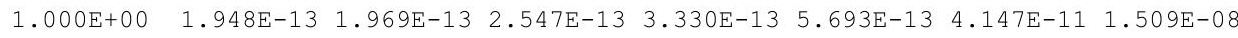
$\begin{array}{llllllll}1.000 \mathrm{E}+00 & 6.631 \mathrm{E}-24 & 2.011 \mathrm{E}-23 & 4.612 \mathrm{E}-22 & 1.248 \mathrm{E}-21 & 4.641 \mathrm{E}-21 & 3.427 \mathrm{E}-18 & 6.954 \mathrm{E}-15\end{array}$ $\begin{array}{llllllll}1.000 \mathrm{E}+00 & 6.053 \mathrm{E}-20 & 4.262 \mathrm{E}-19 & 1.402 \mathrm{E}-16 & 6.537 \mathrm{E}-16 & 3.662 \mathrm{E}-15 & 1.463 \mathrm{E}-12 & 3.066 \mathrm{E}-10\end{array}$ $\begin{array}{lllllll}1.948 \mathrm{E}-13 & 1.969 \mathrm{E}-13 & 2.549 \mathrm{E}-13 & 3.337 \mathrm{E}-13 & 5.729 \mathrm{E}-13 & 4.294 \mathrm{E}-11 & 1.540 \mathrm{E}-08\end{array}$

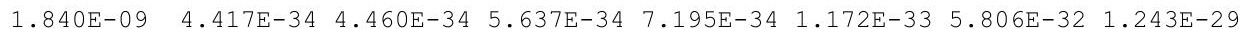

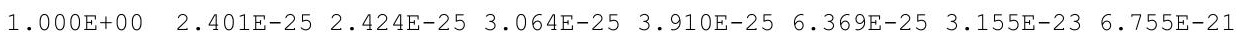
$\begin{array}{lllllllll}1.000 \mathrm{E}+00 & 1.998 \mathrm{E}-30 & 6.068 \mathrm{E}-30 & 1.436 \mathrm{E}-28 & 4.032 \mathrm{E}-28 & 1.628 \mathrm{E}-27 & 3.470 \mathrm{E}-24 & 5.993 \mathrm{E}-20\end{array}$ $\begin{array}{lllllllll}1.000 \mathrm{E}+00 & 2.101 \mathrm{E}-34 & 1.489 \mathrm{E}-33 & 5.829 \mathrm{E}-31 & 3.268 \mathrm{E}-30 & 2.663 \mathrm{E}-29 & 2.676 \mathrm{E}-25 & 6.795 \mathrm{E}-21\end{array}$ $\begin{array}{llllllll}1.000 \mathrm{E}+00 & 1.639 \mathrm{E}-23 & 2.469 \mathrm{E}-22 & 1.226 \mathrm{E}-18 & 1.076 \mathrm{E}-17 & 1.088 \mathrm{E}-16 & 1.149 \mathrm{E}-13 & 2.677 \mathrm{E}-11\end{array}$ $\begin{array}{llllllll}1.000 \mathrm{E}+00 & 4.753 \mathrm{E}-32 & 1.473 \mathrm{E}-30 & 1.013 \mathrm{E}-25 & 1.589 \mathrm{E}-24 & 2.687 \mathrm{E}-23 & 7.527 \mathrm{E}-20 & 3.536 \mathrm{E}-17\end{array}$ $\begin{array}{lllllll}1.663 \mathrm{E}-23 & 2.471 \mathrm{E}-22 & 1.226 \mathrm{E}-18 & 1.076 \mathrm{E}-17 & 1.088 \mathrm{E}-16 & 1.149 \mathrm{E}-13 & 2.677 \mathrm{E}-11\end{array}$

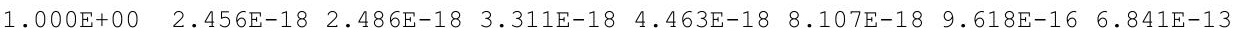
$\begin{array}{llllllll}1.000 \mathrm{E}+00 & 1.254 \mathrm{E}-24 & 3.802 \mathrm{E}-24 & 8.688 \mathrm{E}-23 & 2.343 \mathrm{E}-22 & 8.645 \mathrm{E}-22 & 6.015 \mathrm{E}-19 & 1.124 \mathrm{E}-15\end{array}$ $\begin{array}{llllllll}1.000 \mathrm{E}+00 & 1.972 \mathrm{E}-28 & 1.393 \mathrm{E}-27 & 5.002 \mathrm{E}-25 & 2.557 \mathrm{E}-24 & 1.721 \mathrm{E}-23 & 2.963 \mathrm{E}-20 & 4.446 \mathrm{E}-17\end{array}$ $\begin{array}{llllllll}1.000 \mathrm{E}+00 & 4.675 \mathrm{E}-28 & 7.017 \mathrm{E}-27 & 3.194 \mathrm{E}-23 & 2.608 \mathrm{E}-22 & 2.391 \mathrm{E}-21 & 3.028 \mathrm{E}-18 & 1.826 \mathrm{E}-15\end{array}$ $2.456 \mathrm{E}-18 \quad 2.486 \mathrm{E}-18 \quad 3.311 \mathrm{E}-18 \quad 4.463 \mathrm{E}-18 \quad 8.110 \mathrm{E}-18 \quad 9.655 \mathrm{E}-16 \quad 6.871 \mathrm{E}-13$

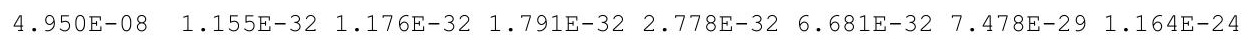

$\begin{array}{llllllll}1.000 \mathrm{E}+00 & 2.334 \mathrm{E}-25 & 2.375 \mathrm{E}-25 & 3.619 \mathrm{E}-25 & 5.612 \mathrm{E}-25 & 1.350 \mathrm{E}-24 & 1.511 \mathrm{E}-21 & 2.352 \mathrm{E}-17\end{array}$ $\begin{array}{llllllll}1.000 \mathrm{E}+00 & 4.417 \mathrm{E}-33 & 1.347 \mathrm{E}-32 & 3.517 \mathrm{E}-31 & 1.091 \mathrm{E}-30 & 5.321 \mathrm{E}-30 & 3.459 \mathrm{E}-26 & 1.397 \mathrm{E}-21\end{array}$ $\begin{array}{llllllll}1.000 \mathrm{E}+00 & 5.745 \mathrm{E}-44 & 4.148 \mathrm{E}-43 & 1.798 \mathrm{E}-40 & 1.120 \mathrm{E}-39 & 1.120 \mathrm{E}-38 & 4.587 \mathrm{E}-34 & 5.372 \mathrm{E}-29\end{array}$ $\begin{array}{llllllll}1.000 \mathrm{E}+00 & 2.801 \mathrm{E}-29 & 4.123 \mathrm{E}-28 & 1.234 \mathrm{E}-24 & 7.689 \mathrm{E}-24 & 5.197 \mathrm{E}-23 & 3.012 \mathrm{E}-20 & 8.590 \mathrm{E}-18\end{array}$ $\begin{array}{llllllll}1.000 \mathrm{E}+00 & 1.657 \mathrm{E}-28 & 4.769 \mathrm{E}-27 & 7.862 \mathrm{E}-23 & 5.398 \mathrm{E}-22 & 3.593 \mathrm{E}-21 & 1.140 \mathrm{E}-18 & 1.344 \mathrm{E}-16\end{array}$

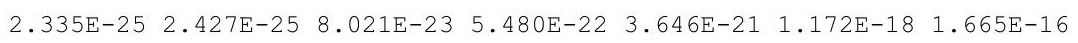

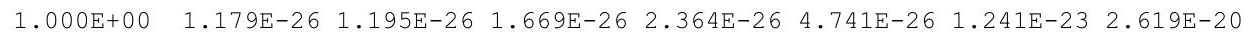

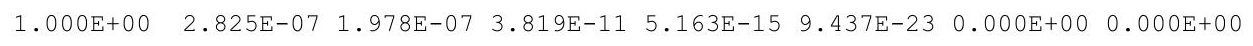

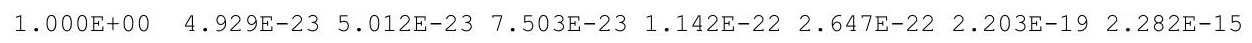
$\begin{array}{llllllll}1.000 \mathrm{E}+00 & 7.712 \mathrm{E}-12 & 2.327 \mathrm{E}-11 & 4.644 \mathrm{E}-10 & 1.087 \mathrm{E}-09 & 3.024 \mathrm{E}-09 & 2.193 \mathrm{E}-07 & 1.840 \mathrm{E}-05\end{array}$ $\begin{array}{llllllll}1.000 \mathrm{E}+00 & 3.717 \mathrm{E}-20 & 2.596 \mathrm{E}-19 & 6.907 \mathrm{E}-17 & 2.655 \mathrm{E}-16 & 1.087 \mathrm{E}-15 & 1.573 \mathrm{E}-13 & 2.528 \mathrm{E}-11\end{array}$ $\begin{array}{lllllll}7.712 \mathrm{E}-12 & 2.327 \mathrm{E}-11 & 4.644 \mathrm{E}-10 & 1.087 \mathrm{E}-09 & 3.024 \mathrm{E}-09 & 2.193 \mathrm{E}-07 & 1.840 \mathrm{E}-05\end{array}$ 
RESRAD, Version $6.5 \quad \mathrm{~T}^{1 / 2}$ Limit $=180$ days

ummary : RESRAD Parameters for U-Landfill Outdoor Worker

File $\quad$ : $C: \backslash$ RESRAD FAMILY \RESRAD \USERFILES $\backslash Q C F O R S R S G \backslash O U T D O O R W O R K E R-S R S G-M A Y 11 . R A D$

Dose/Source Ratios Summed Over All Pathways

Parent and Progeny Principal Radionuclide Contributions Indicated

\begin{tabular}{|c|c|c|c|c|c|c|c|c|c|}
\hline Parent & Product & Thread & & $\operatorname{DSR}(j, t)$ & At Time in & n Years & (mrem/yr) / & $(\mathrm{pCi} / \mathrm{g})$ & \\
\hline (i) & $(j)$ & Fraction & $0.000 \mathrm{E}+00$ & $1.000 \mathrm{E}+00$ & $2.500 \mathrm{E}+01$ & $5.000 \mathrm{E}+01$ & $1.000 \mathrm{E}+02$ & $5.000 \mathrm{E}+02$ & $1.050 \mathrm{E}+03$ \\
\hline-232 & $\mathrm{Th}-232$ & $1.000 \mathrm{E}+00$ & $2.382 \mathrm{E}-25$ & $2.427 E-25$ & $3.789 \mathrm{E}-25$ & $6.027 E-25$ & $1.525 \mathrm{E}-24$ & $2.561 \mathrm{E}-21$ & $6.965 \mathrm{E}-17$ \\
\hline $1-232$ & $\mathrm{Ra}-228+\mathrm{D}$ & $1.000 \mathrm{E}+00$ & $2.263 E-10$ & $6.486 \mathrm{E}-10$ & 4. 499E-09 & $5.690 \mathrm{E}-09$ & $8.336 \mathrm{E}-09$ & $1.737 \mathrm{E}-07$ & $1.131 \mathrm{E}-05$ \\
\hline$h-232$ & $\mathrm{Th}-228+\mathrm{D}$ & $1.000 \mathrm{E}+00$ & $2.181 E-09$ & $1.345 \mathrm{E}-08$ & $3.638 \mathrm{E}-07$ & $4.522 \mathrm{E}-07$ & $6.114 \mathrm{E}-07$ & $6.652 \mathrm{E}-06$ & $1.778 \mathrm{E}-04$ \\
\hline-232 & $\sum \operatorname{DSR}(j)$ & & $2.407 E-09$ & $1.410 \mathrm{E}-08$ & $3.683 \mathrm{E}-07$ & $4.579 \mathrm{E}-07$ & $6.198 \mathrm{E}-07$ & $6.825 \mathrm{E}-06$ & $1.891 \mathrm{E}-04$ \\
\hline-234 & $\mathrm{U}-234$ & $1.000 \mathrm{E}+00$ & $1.409 \mathrm{E}-24$ & $1.434 \mathrm{E}-24$ & $2.194 \mathrm{E}-24$ & $3.415 \mathrm{E}-24$ & $8.276 \mathrm{E}-24$ & $9.851 \mathrm{E}-21$ & $1.669 \mathrm{E}-16$ \\
\hline-234 & Th-230 & $1.000 \mathrm{E}+00$ & $2.225 E-28$ & $6.774 \mathrm{E}-28$ & 1. $722 \mathrm{E}-26$ & $5.192 \mathrm{E}-26$ & $2.394 \mathrm{E}-25$ & $9.912 \mathrm{E}-22$ & $2.152 \mathrm{E}-17$ \\
\hline-234 & $\mathrm{Ra}-226+\mathrm{D}$ & $1.000 \mathrm{E}+00$ & $2.315 E-17$ & $1.630 \mathrm{E}-16$ & $5.341 \mathrm{E}-14$ & $2.480 \mathrm{E}-13$ & $1.377 \mathrm{E}-12$ & $5.115 \mathrm{E}-10$ & $9.341 \mathrm{E}-08$ \\
\hline-234 & $\mathrm{~Pb}-210+\mathrm{D}$ & $1.000 \mathrm{E}+00$ & $8.381 E-26$ & $1.257 \mathrm{E}-24$ & $5.622 \mathrm{E}-21$ & $4.500 \mathrm{E}-20$ & $3.956 \mathrm{E}-19$ & $3.440 \mathrm{E}-16$ & 1. $243 \mathrm{E}-13$ \\
\hline-234 & $\sum \operatorname{DSR}(j)$ & & $2.315 \mathrm{E}-17$ & $1.630 \mathrm{E}-16$ & $5.341 \mathrm{E}-14$ & $2.480 \mathrm{E}-13$ & 1. $377 \mathrm{E}-12$ & $5.115 \mathrm{E}-10$ & $9.341 \mathrm{E}-08$ \\
\hline$-235+D$ & $\mathrm{U}-235+\mathrm{D}$ & $1.000 \mathrm{E}+00$ & $2.540 \mathrm{E}-15$ & $2.572 \mathrm{E}-15$ & $3.460 \mathrm{E}-15$ & 4. $713 \mathrm{E}-15$ & $8.745 E-15$ & 1. $228 \mathrm{E}-12$ & 1.101E-09 \\
\hline$-235+D$ & $\mathrm{~Pa}-231$ & $1.000 \mathrm{E}+00$ & $6.002 \mathrm{E}-19$ & $1.818 \mathrm{E}-18$ & $3.984 \mathrm{E}-17$ & $1.028 \mathrm{E}-16$ & $3.478 \mathrm{E}-16$ & 1. $206 \mathrm{E}-13$ & $8.644 \mathrm{E}-11$ \\
\hline$-235+D$ & $A C-227+D$ & $1.000 \mathrm{E}+00$ & $1.895 \mathrm{E}-18$ & $1.324 \mathrm{E}-17$ & $3.586 \mathrm{E}-15$ & $1.407 \mathrm{E}-14$ & $6.019 \mathrm{E}-14$ & 1. $308 \mathrm{E}-11$ & $3.655 E-09$ \\
\hline$-235+D$ & $\sum \operatorname{DSR}(j)$ & & $2.543 E-15$ & $2.587 \mathrm{E}-15$ & $7.086 \mathrm{E}-15$ & $1.888 \mathrm{E}-14$ & $6.928 E-14$ & 1. $443 \mathrm{E}-11$ & $4.843 E-09$ \\
\hline-238 & $\mathrm{U}-238$ & $5.400 \mathrm{E}-05$ & $0.000 \mathrm{E}+00$ & $0.000 \mathrm{E}+00$ & $0.000 \mathrm{E}+00$ & $0.000 \mathrm{E}+00$ & $0.000 \mathrm{E}+00$ & $0.000 \mathrm{E}+00$ & $3.476 E-39$ \\
\hline$-238+D$ & $\mathrm{U}-238+\mathrm{D}$ & $9.999 \mathrm{E}-01$ & $2.901 \mathrm{E}-11$ & $2.924 \mathrm{E}-11$ & $3.542 \mathrm{E}-11$ & $4.325 E-11$ & $6.449 \mathrm{E}-11$ & $1.576 \mathrm{E}-09$ & $1.279 \mathrm{E}-07$ \\
\hline$-238+D$ & $\mathrm{U}-234$ & $9.999 \mathrm{E}-01$ & $2.003 E-30$ & $6.105 E-30$ & $1.586 \mathrm{E}-28$ & $4.889 \mathrm{E}-28$ & $2.358 \mathrm{E}-27$ & 1. $399 \mathrm{E}-23$ & $4.978 E-19$ \\
\hline$J-238+D$ & $T h-230$ & $9.999 \mathrm{E}-01$ & $2.105 E-34$ & $1.495 \mathrm{E}-33$ & $6.226 \mathrm{E}-31$ & $3.717 \mathrm{E}-30$ & $3.411 \mathrm{E}-29$ & $7.032 E-25$ & $3.204 \mathrm{E}-20$ \\
\hline$J-238+D$ & $\mathrm{Ra}-226+\mathrm{D}$ & $9.999 \mathrm{E}-01$ & $1.642 \mathrm{E}-23$ & $2.477 E-22$ & 1. $288 \mathrm{E}-18$ & $1.186 \mathrm{E}-17$ & $1.313 E-16$ & $2.462 \mathrm{E}-13$ & $9.612 \mathrm{E}-11$ \\
\hline$J-238+D$ & $\mathrm{~Pb}-210+\mathrm{D}$ & $9.999 \mathrm{E}-01$ & $4.759 E-32$ & $1.477 \mathrm{E}-30$ & $1.055 \mathrm{E}-25$ & $1.723 \mathrm{E}-24$ & $3.161 \mathrm{E}-23$ & $1.561 \mathrm{E}-19$ & 1. $240 \mathrm{E}-16$ \\
\hline$-238+D$ & $\sum \operatorname{DSR}(j)$ & & $2.901 \mathrm{E}-11$ & $2.924 \mathrm{E}-11$ & $3.542 \mathrm{E}-11$ & 4. $325 \mathrm{E}-11$ & $6.449 \mathrm{E}-11$ & $1.577 \mathrm{E}-09$ & $1.280 \mathrm{E}-07$ \\
\hline
\end{tabular}

The DSR includes contributions from associated (half-life $\leq 180$ days) daughters. 
RESRAD, Version $6.5 \quad T^{1 / 2}$ Limit $=180$ days

ummary : RESRAD Parameters for U-Landfill Outdoor Worker

File $\quad$ : C: $\backslash$ RESRAD FAMILY \RESRAD \USERFILES $\backslash Q C F O R S R S G \backslash O U T D O O R W O R K E R-S R S G-M A Y 11 . R A D$

Single Radionuclide Soil Guidelines G(i,t) in pCi/g

Basic Radiation Dose Limit $=1.000 \mathrm{E}+00 \mathrm{mrem} / \mathrm{yr}$

Nuclide

\begin{tabular}{|c|c|c|c|c|c|c|c|}
\hline (i) & $t=0.000 \mathrm{E}+00$ & $1.000 \mathrm{E}+00$ & $2.500 \mathrm{E}+01$ & $5.000 \mathrm{E}+01$ & $1.000 \mathrm{E}+02$ & $5.000 \mathrm{E}+02$ & $1.050 \mathrm{E}+03$ \\
\hline-241 & $\star 3.431 \mathrm{E}+12$ & $\star 3.431 \mathrm{E}+12$ & $\star 3.431 \mathrm{E}+12$ & $\star 3.431 \mathrm{E}+12$ & $* 3.431 \mathrm{E}+12$ & $* 3.431 \mathrm{E}+12$ & $3.875 E+11$ \\
\hline-137 & $3.879 E+09$ & $3.936 \mathrm{E}+09$ & $5.600 \mathrm{E}+09$ & $8.084 E+09$ & $1.685 E+10$ & $5.997 \mathrm{E}+12$ & $\star 8.704 \mathrm{E}+13$ \\
\hline-237 & $\star 7.047 \mathrm{E}+08$ & $\star 7.047 \mathrm{E}+08$ & $\star 7.047 \mathrm{E}+08$ & $\star 7.047 \mathrm{E}+08$ & $\star 7.047 \mathrm{E}+08$ & $\star 7.047 \mathrm{E}+08$ & $6.495 \mathrm{E}+07$ \\
\hline-238 & $\star 1.712 \mathrm{E}+13$ & $\star 1.712 \mathrm{E}+13$ & $\star 1.712 \mathrm{E}+13$ & $\star 1.712 \mathrm{E}+13$ & $* 1.712 \mathrm{E}+13$ & $8.701 \mathrm{E}+12$ & $3.735 \mathrm{E}+1 \mathrm{C}$ \\
\hline-239 & $\star 6.214 \mathrm{E}+10$ & $* 6.214 \mathrm{E}+10$ & $* 6.214 \mathrm{E}+10$ & $* 6.214 \mathrm{E}+10$ & $\star 6.214 \mathrm{E}+10$ & $* 6.214 \mathrm{E}+10$ & $* 6.214 \mathrm{E}+1 \mathrm{C}$ \\
\hline-240 & $\star 2.278 \mathrm{E}+11$ & $\star 2.278 \mathrm{E}+11$ & $\star 2.278 \mathrm{E}+11$ & $\star 2.278 \mathrm{E}+11$ & $\star 2.278 \mathrm{E}+11$ & $\star 2.278 \mathrm{E}+11$ & $\star 2.278 \mathrm{E}+1$ \\
\hline$=-99$ & $\star 1.697 \mathrm{E}+10$ & $\star 1.697 \mathrm{E}+10$ & $\star 1.697 \mathrm{E}+10$ & $* 1.697 \mathrm{E}+10$ & $\star 1.697 \mathrm{E}+10$ & $\star 1.697 \mathrm{E}+10$ & $* 1.697 \mathrm{E}+10$ \\
\hline-228 & $3.540 \mathrm{E}+06$ & $5.056 \mathrm{E}+06$ & $2.619 \mathrm{E}+10$ & $1.937 \mathrm{E}+14$ & $\star 8.195 \mathrm{E}+14$ & $\star 8.195 \mathrm{E}+14$ & $\star 8.195 \mathrm{E}+14$ \\
\hline-230 & $\star 2.018 \mathrm{E}+10$ & $\star 2.018 \mathrm{E}+10$ & $2.153 \mathrm{E}+09$ & $9.198 \mathrm{E}+08$ & $3.307 \mathrm{E}+08$ & $4.559 \mathrm{E}+06$ & $5.434 \mathrm{E}+0$ \\
\hline$h-232$ & $* 1.097 \mathrm{E}+05$ & $\star 1.097 \mathrm{E}+05$ & $\star 1.097 \mathrm{E}+05$ & $\star 1.097 \mathrm{E}+05$ & $* 1.097 \mathrm{E}+05$ & $* 1.097 \mathrm{E}+05$ & $5.287 \mathrm{E}+03$ \\
\hline 234 & $* 6.247 \mathrm{E}+09$ & $\star 6.247 \mathrm{E}+09$ & $\star 6.247 \mathrm{E}+09$ & $\star 6.247 \mathrm{E}+09$ & $* 6.247 \mathrm{E}+09$ & $1.955 \mathrm{E}+09$ & $1.071 \mathrm{E}+07$ \\
\hline 35 & $\star 2.161 \mathrm{E}+06$ & $\star 2.161 \mathrm{E}+06$ & $\star 2.161 \mathrm{E}+06$ & $\star 2.161 \mathrm{E}+06$ & $\star 2.161 \mathrm{E}+06$ & $\star 2.161 \mathrm{E}+06$ & $\star 2.161 \mathrm{E}+06$ \\
\hline 38 & $\star 3.361 \mathrm{E}+05$ & $\star 3.361 \mathrm{E}+05$ & $\star 3.361 \mathrm{E}+05$ & $\star 3.361 \mathrm{E}+05$ & $\star 3.361 \mathrm{E}+05$ & $\star 3.361 \mathrm{E}+05$ & $\star 3.361 \mathrm{E}+05$ \\
\hline
\end{tabular}

*At specific activity limit

Summed Dose/Source Ratios DSR(i,t) in (mrem/yr)/(pCi/g)

and Single Radionuclide Soil Guidelines $\mathrm{G}(i, t)$ in $\mathrm{pCi} / \mathrm{g}$

at tmin = time of minimum single radionuclide soil guideline

and at $\operatorname{tmax}=$ time of maximum total dose $=1.050 \mathrm{E}+03$ years

\begin{tabular}{|c|c|c|c|c|c|c|}
\hline $\begin{array}{l}\text { uclide } \\
\text { (i) }\end{array}$ & $\begin{array}{l}\text { Initial } \\
(\mathrm{pCi} / \mathrm{g})\end{array}$ & $\begin{array}{c}\text { tmin } \\
\text { (years) }\end{array}$ & $\operatorname{DSR}(i, \operatorname{tmin})$ & $\begin{array}{c}\mathrm{G}(\mathrm{i}, \mathrm{tmin}) \\
\quad(\mathrm{pCi} / \mathrm{g})\end{array}$ & $\operatorname{DSR}(i, \operatorname{tmax})$ & $\begin{array}{l}G(i, t \max ) \\
(\mathrm{pCi} / \mathrm{g})\end{array}$ \\
\hline 241 & $1.000 \mathrm{E}+00$ & $1.050 \mathrm{E}+03$ & $2.581 \mathrm{E}-12$ & $3.875 E+11$ & $2.581 \mathrm{E}-12$ & $3.875 E+11$ \\
\hline-137 & $1.000 \mathrm{E}+00$ & $0.000 \mathrm{E}+00$ & $2.578 \mathrm{E}-10$ & $3.879 E+09$ & $5.175 \mathrm{E}-17$ & $\star 8.704 \mathrm{E}+13$ \\
\hline 237 & $1.000 \mathrm{E}+00$ & $1.050 \mathrm{E}+03$ & $1.540 \mathrm{E}-08$ & $6.495 \mathrm{E}+07$ & $1.540 \mathrm{E}-08$ & $6.495 \mathrm{E}+07$ \\
\hline-238 & $1.000 \mathrm{E}+00$ & $1.050 \mathrm{E}+03$ & $2.677 \mathrm{E}-11$ & $3.735 \mathrm{E}+10$ & $2.677 \mathrm{E}-11$ & $3.735 \mathrm{E}+10$ \\
\hline-239 & $1.000 \mathrm{E}+00$ & $1.050 \mathrm{E}+03$ & $6.871 \mathrm{E}-13$ & $* 6.214 \mathrm{E}+10$ & $6.871 E-13$ & $\star 6.214 \mathrm{E}+10$ \\
\hline$u-240$ & $1.000 \mathrm{E}+00$ & $1.050 \mathrm{E}+03$ & $1.665 \mathrm{E}-16$ & $\star 2.278 \mathrm{E}+11$ & $1.665 \mathrm{E}-16$ & $\star 2.278 \mathrm{E}+11$ \\
\hline$c-99$ & $1.000 \mathrm{E}+00$ & $1.050 \mathrm{E}+03$ & $2.619 \mathrm{E}-20$ & $\star 1.697 \mathrm{E}+10$ & $2.619 \mathrm{E}-20$ & $* 1.697 \mathrm{E}+10$ \\
\hline Th -228 & $1.000 \mathrm{E}+00$ & $0.000 \mathrm{E}+00$ & $2.825 \mathrm{E}-07$ & $3.540 \mathrm{E}+06$ & $0.000 \mathrm{E}+00$ & $\star 8.195 \mathrm{E}+14$ \\
\hline Th-230 & $1.000 \mathrm{E}+00$ & $1.050 \mathrm{E}+03$ & $1.840 \mathrm{E}-05$ & $5.434 \mathrm{E}+04$ & $1.840 \mathrm{E}-05$ & $5.434 \mathrm{E}+04$ \\
\hline-232 & $1.000 \mathrm{E}+00$ & $1.050 \mathrm{E}+03$ & $1.891 \mathrm{E}-04$ & $5.287 E+03$ & $1.891 \mathrm{E}-04$ & $5.287 \mathrm{E}+03$ \\
\hline 34 & $1.000 \mathrm{E}+00$ & $1.050 \mathrm{E}+03$ & $9.341 \mathrm{E}-08$ & $1.071 \mathrm{E}+07$ & $9.341 \mathrm{E}-08$ & $1.071 \mathrm{E}+07$ \\
\hline 35 & $1.000 \mathrm{E}+00$ & $1.050 \mathrm{E}+03$ & $4.843 \mathrm{E}-09$ & $\star 2.161 \mathrm{E}+06$ & $4.843 \mathrm{E}-09$ & $\star 2.161 \mathrm{E}+06$ \\
\hline 238 & $1.000 \mathrm{E}+00$ & $1.050 \mathrm{E}+03$ & $1.280 \mathrm{E}-07$ & $\star 3.361 \mathrm{E}+05$ & $1.280 \mathrm{E}-07$ & $\star 3.361 \mathrm{E}+05$ \\
\hline
\end{tabular}

*At specific activity limit 
RESRAD, Version 6.5

$07 / 21 / 2011$

17:10 Page

mmary : RESRAD Parameters for U-Landfill Outdoor Worker

File : C: \RESRAD_FAMILY \RESRAD \USERFILES \QCFORSRSG \OUTDOORWORKER-SRSG-MAY11.RAD

Individual Nuclide Dose Summed Over All Pathways

Parent Nuclide and Branch Fraction Indicated

Nuclide Parent THF(i) DOSE $(j, t), \mathrm{mrem} / \mathrm{yr}$

\begin{tabular}{|c|c|c|}
\hline$(j)$ & (i) & \\
\hline$m-241$ & $A m-241$ & $1.000 \mathrm{E}+00$ \\
\hline$p-237$ & Am-241 & $1.000 \mathrm{E}+00$ \\
\hline-237 & $N p-237$ & $1.000 \mathrm{E}+00$ \\
\hline 237 & $\sum \mathrm{DOSE}$ & \\
\hline
\end{tabular}

$\mathrm{U}-233 \mathrm{Am}-241 \quad 1.000 \mathrm{E}+00$

$\mathrm{U}-233 \mathrm{~Np}-237 \quad 1.000 \mathrm{E}+00$

U-233 $\quad$ DDOSE $(j)$

Th-229 Am-241 1.000E+00

$\mathrm{Th}-229 \quad \mathrm{~Np}-237 \quad 1.000 \mathrm{E}+00$

Th-229 ¿DOSE $(j)$

Cs-137 Cs $-137 \quad 1.000 \mathrm{E}+00$

$\mathrm{Pu}-238$

$\mathrm{Pu}-238$

$\mathrm{Pu}-238$

$\mathrm{U}-234$

$\mathrm{U}-234$

$\mathrm{U}-234$

$\mathrm{U}-234$

Th -230

$\mathrm{Th}-230$

$\mathrm{Th}-230$

$\mathrm{Th}-230$

$\mathrm{Th}-230$

$\mathrm{Ra}-226$

$\mathrm{Ra}-226$

$\mathrm{Ra}-226$

$\mathrm{Ra}-226$

$\mathrm{Ra}-226$

$\mathrm{Pb}-210$

$\mathrm{Pb}-210$

$\mathrm{Pb}-210$

$\mathrm{Pb}-210$

$\mathrm{Pb}-210$

$P u-239$

Pu-238 1.840E-09 $\mathrm{Pu}-238 \quad 1.000 \mathrm{E}+00$ $\sum \operatorname{DOSE}(j)$

$\mathrm{Pu}-238 \quad 1.000 \mathrm{E}+00$ $\mathrm{U}-234 \quad 1.000 \mathrm{E}+00$ U-238 9.999E-01 $\sum \operatorname{DOSE}(j)$

$\mathrm{Pu}-238 \quad 1.000 \mathrm{E}+00$ Th-230 1.000E+00 $\mathrm{U}-234 \quad 1.000 \mathrm{E}+00$ U-238 9.999E-01 $\sum \operatorname{DOSE}(j)$

$\mathrm{Pu}-238 \quad 1.000 \mathrm{E}+00$ $\mathrm{Th}-230 \quad 1.000 \mathrm{E}+00$ $\mathrm{U}-234 \quad 1.000 \mathrm{E}+00$ U-238 9.999E-01 $\sum \operatorname{DOSE}(j)$

$\mathrm{Pu}-238 \quad 1.000 \mathrm{E}+00$ Th-230 1.000E+00 $\mathrm{U}-234 \quad 1.000 \mathrm{E}+00$ U-238 9.999E-01 $\sum \operatorname{DOSE}(j)$

$\mathrm{Pu}-239 \quad 1.000 \mathrm{E}+00$

$\mathrm{Pu}-239$ 1.000E+00 U-235 $1.000 \mathrm{E}+00$ $\sum \operatorname{DOSE}(j)$ $t=0.000 \mathrm{E}+001.000 \mathrm{E}+00 \quad 2.500 \mathrm{E}+01 \quad 5.000 \mathrm{E}+01 \quad 1.000 \mathrm{E}+02 \quad 5.000 \mathrm{E}+02 \quad 1.050 \mathrm{E}+03$

$\begin{array}{lllllll}3.160 \mathrm{E}-20 & 9.563 \mathrm{E}-20 & 2.064 \mathrm{E}-18 & 5.243 \mathrm{E}-18 & 1.718 \mathrm{E}-17 & 4.700 \mathrm{E}-15 & 2.556 \mathrm{E}-12\end{array}$ $\begin{array}{lllllll}1.948 \mathrm{E}-13 & 1.969 \mathrm{E}-13 & 2.547 \mathrm{E}-13 & 3.330 \mathrm{E}-13 & 5.693 \mathrm{E}-13 & 4.147 \mathrm{E}-11 & 1.509 \mathrm{E}-08\end{array}$ $\begin{array}{lllllll}1.948 \mathrm{E}-13 & 1.969 \mathrm{E}-13 & 2.547 \mathrm{E}-13 & 3.330 \mathrm{E}-13 & 5.693 \mathrm{E}-13 & 4.148 \mathrm{E}-11 & 1.509 \mathrm{E}-08\end{array}$

$0.000 \mathrm{E}+00 \quad 5.066 \mathrm{E}-30 \quad 1.880 \mathrm{E}-27 \quad 9.948 \mathrm{E}-27 \quad 7.175 \mathrm{E}-26 \quad 2.177 \mathrm{E}-22 \quad 7.342 \mathrm{E}-19$ $6.631 \mathrm{E}-24 \quad 2.011 \mathrm{E}-23 \quad 4.612 \mathrm{E}-22 \quad 1.248 \mathrm{E}-21 \quad 4.641 \mathrm{E}-21 \quad 3.427 \mathrm{E}-18 \quad 6.954 \mathrm{E}-15$ $6.631 \mathrm{E}-24 \quad 2.011 \mathrm{E}-23 \quad 4.613 \mathrm{E}-22 \quad 1.248 \mathrm{E}-21 \quad 4.641 \mathrm{E}-21 \quad 3.428 \mathrm{E}-18 \quad 6.955 \mathrm{E}-15$

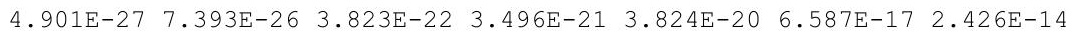
$6.053 \mathrm{E}-20 \quad 4.262 \mathrm{E}-19 \quad 1.402 \mathrm{E}-16 \quad 6.537 \mathrm{E}-16 \quad 3.662 \mathrm{E}-15 \quad 1.463 \mathrm{E}-12 \quad 3.066 \mathrm{E}-10$ $6.053 E-20 \quad 4.262 E-19 \quad 1.402 E-16 \quad 6.537 E-16 \quad 3.662 E-15 \quad 1.463 E-12 \quad 3.067 E-10$ $2.578 \mathrm{E}-10 \quad 2.541 \mathrm{E}-10 \quad 1.786 \mathrm{E}-10 \quad 1.237 \mathrm{E}-10 \quad 5.936 \mathrm{E}-11 \quad 1.667 \mathrm{E}-13 \quad 5.175 \mathrm{E}-17$ $\begin{array}{lllllll}0.000 \mathrm{E}+00 & 0.000 \mathrm{E}+00 & 0.000 \mathrm{E}+00 & 0.000 \mathrm{E}+00 & 0.000 \mathrm{E}+00 & 0.000 \mathrm{E}+00 & 1.243 \mathrm{E}-29\end{array}$ $2.401 \mathrm{E}-25 \quad 2.424 \mathrm{E}-25 \quad 3.064 \mathrm{E}-25 \quad 3.910 \mathrm{E}-25 \quad 6.369 \mathrm{E}-25 \quad 3.155 \mathrm{E}-23 \quad 6.755 \mathrm{E}-21$ $2.401 \mathrm{E}-25 \quad 2.424 \mathrm{E}-25 \quad 3.064 \mathrm{E}-25 \quad 3.910 \mathrm{E}-25 \quad 6.369 \mathrm{E}-25 \quad 3.155 \mathrm{E}-23 \quad 6.755 \mathrm{E}-21$

$1.998 \mathrm{E}-30 \quad 6.068 \mathrm{E}-30 \quad 1.436 \mathrm{E}-28 \quad 4.032 \mathrm{E}-28 \quad 1.628 \mathrm{E}-27 \quad 3.470 \mathrm{E}-24 \quad 5.993 \mathrm{E}-20$ $\begin{array}{llllllll}1.409 \mathrm{E}-24 & 1.434 \mathrm{E}-24 & 2.194 \mathrm{E}-24 & 3.415 \mathrm{E}-24 & 8.276 \mathrm{E}-24 & 9.851 \mathrm{E}-21 & 1.669 \mathrm{E}-16\end{array}$ $2.003 \mathrm{E}-30 \quad 6.105 \mathrm{E}-30 \quad 1.586 \mathrm{E}-28 \quad 4.889 \mathrm{E}-28 \quad 2.358 \mathrm{E}-27 \quad 1.399 \mathrm{E}-23 \quad 4.978 \mathrm{E}-19$ $\begin{array}{llllllll}1.409 \mathrm{E}-24 & 1.434 \mathrm{E}-24 & 2.194 \mathrm{E}-24 & 3.416 \mathrm{E}-24 & 8.280 \mathrm{E}-24 & 9.868 \mathrm{E}-21 & 1.675 \mathrm{E}-16\end{array}$

$0.000 \mathrm{E}+00 \quad 0.000 \mathrm{E}+00 \quad 0.000 \mathrm{E}+00 \quad 3.268 \mathrm{E}-30 \quad 2.663 \mathrm{E}-29 \quad 2.676 \mathrm{E}-25 \quad 6.795 \mathrm{E}-21$ $\begin{array}{lllllll}4.929 \mathrm{E}-23 & 5.012 \mathrm{E}-23 & 7.503 \mathrm{E}-23 & 1.142 \mathrm{E}-22 & 2.647 \mathrm{E}-22 & 2.203 \mathrm{E}-19 & 2.282 \mathrm{E}-15\end{array}$ $\begin{array}{lllllll}2.225 \mathrm{E}-28 & 6.774 \mathrm{E}-28 & 1.722 \mathrm{E}-26 & 5.192 \mathrm{E}-26 & 2.394 \mathrm{E}-25 & 9.912 \mathrm{E}-22 & 2.152 \mathrm{E}-17\end{array}$

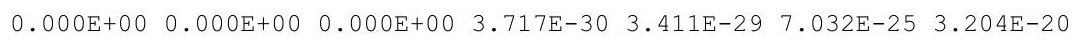
$\begin{array}{lllllll}4.929 E-23 & 5.012 E-23 & 7.505 E-23 & 1.143 E-22 & 2.650 E-22 & 2.213 E-19 & 2.304 E-15\end{array}$

$\begin{array}{lllllll}1.639 \mathrm{E}-23 & 2.469 \mathrm{E}-22 & 1.226 \mathrm{E}-18 & 1.076 \mathrm{E}-17 & 1.088 \mathrm{E}-16 & 1.149 \mathrm{E}-13 & 2.677 \mathrm{E}-11\end{array}$ $\begin{array}{llllllll}7.712 \mathrm{E}-12 & 2.327 \mathrm{E}-11 & 4.644 \mathrm{E}-10 & 1.087 \mathrm{E}-09 & 3.024 \mathrm{E}-09 & 2.193 \mathrm{E}-07 & 1.840 \mathrm{E}-05\end{array}$ $2.315 \mathrm{E}-17 \quad 1.630 \mathrm{E}-16 \quad 5.341 \mathrm{E}-14 \quad 2.480 \mathrm{E}-13 \quad 1.377 \mathrm{E}-12 \quad 5.115 \mathrm{E}-10 \quad 9.341 \mathrm{E}-08$ $\begin{array}{llllllll}1.642 \mathrm{E}-23 & 2.477 \mathrm{E}-22 & 1.288 \mathrm{E}-18 & 1.186 \mathrm{E}-17 & 1.313 \mathrm{E}-16 & 2.462 \mathrm{E}-13 & 9.612 \mathrm{E}-11\end{array}$ $\begin{array}{lllllll}7.712 \mathrm{E}-12 & 2.327 \mathrm{E}-11 & 4.645 \mathrm{E}-10 & 1.087 \mathrm{E}-09 & 3.025 \mathrm{E}-09 & 2.199 \mathrm{E}-07 & 1.850 \mathrm{E}-05\end{array}$

$\begin{array}{lllllll}0.000 \mathrm{E}+00 & 1.473 \mathrm{E}-30 & 1.013 \mathrm{E}-25 & 1.589 \mathrm{E}-24 & 2.687 \mathrm{E}-23 & 7.527 \mathrm{E}-20 & 3.536 \mathrm{E}-17\end{array}$ $\begin{array}{llllllll}3.717 \mathrm{E}-20 & 2.596 \mathrm{E}-19 & 6.907 \mathrm{E}-17 & 2.655 \mathrm{E}-16 & 1.087 \mathrm{E}-15 & 1.573 \mathrm{E}-13 & 2.528 \mathrm{E}-11\end{array}$ $\begin{array}{lllllll}8.381 \mathrm{E}-26 & 1.257 \mathrm{E}-24 & 5.622 \mathrm{E}-21 & 4.500 \mathrm{E}-20 & 3.956 \mathrm{E}-19 & 3.440 \mathrm{E}-16 & 1.243 \mathrm{E}-13\end{array}$ $0.000 \mathrm{E}+00 \quad 1.477 \mathrm{E}-30 \quad 1.055 \mathrm{E}-25 \quad 1.723 \mathrm{E}-24 \quad 3.161 \mathrm{E}-23 \quad 1.561 \mathrm{E}-19 \quad 1.240 \mathrm{E}-16$ $\begin{array}{lllllll}3.717 \mathrm{E}-20 & 2.596 \mathrm{E}-19 & 6.907 \mathrm{E}-17 & 2.655 \mathrm{E}-16 & 1.087 \mathrm{E}-15 & 1.576 \mathrm{E}-13 & 2.541 \mathrm{E}-11\end{array}$ $2.456 \mathrm{E}-18 \quad 2.486 \mathrm{E}-18 \quad 3.311 \mathrm{E}-18 \quad 4.463 \mathrm{E}-18 \quad 8.107 \mathrm{E}-18 \quad 9.618 \mathrm{E}-16 \quad 6.841 \mathrm{E}-13$ $\begin{array}{lllllll}1.254 E-24 & 3.802 E-24 & 8.688 E-23 & 2.343 E-22 & 8.645 E-22 & 6.015 E-19 & 1.124 E-15\end{array}$ $2.540 \mathrm{E}-15 \quad 2.572 \mathrm{E}-15 \quad 3.460 \mathrm{E}-15 \quad 4.713 \mathrm{E}-15 \quad 8.745 \mathrm{E}-15 \quad 1.228 \mathrm{E}-12 \quad 1.101 \mathrm{E}-09$ $2.540 \mathrm{E}-15 \quad 2.572 \mathrm{E}-15 \quad 3.460 \mathrm{E}-15 \quad 4.713 \mathrm{E}-15 \quad 8.745 \mathrm{E}-15 \quad 1.228 \mathrm{E}-12 \quad 1.101 \mathrm{E}-09$ 
RESRAD, Version 6.5

Summary : RESRAD Parameters for U-Landfill Outdoor Worker

File : C: \RESRAD_FAMILY \RESRAD \USERFILES \QCFORSRSG $O$ OUTDOORWORKER-SRSG-MAY11.RAD

Individual Nuclide Dose Summed Over All Pathways

Parent Nuclide and Branch Fraction Indicated

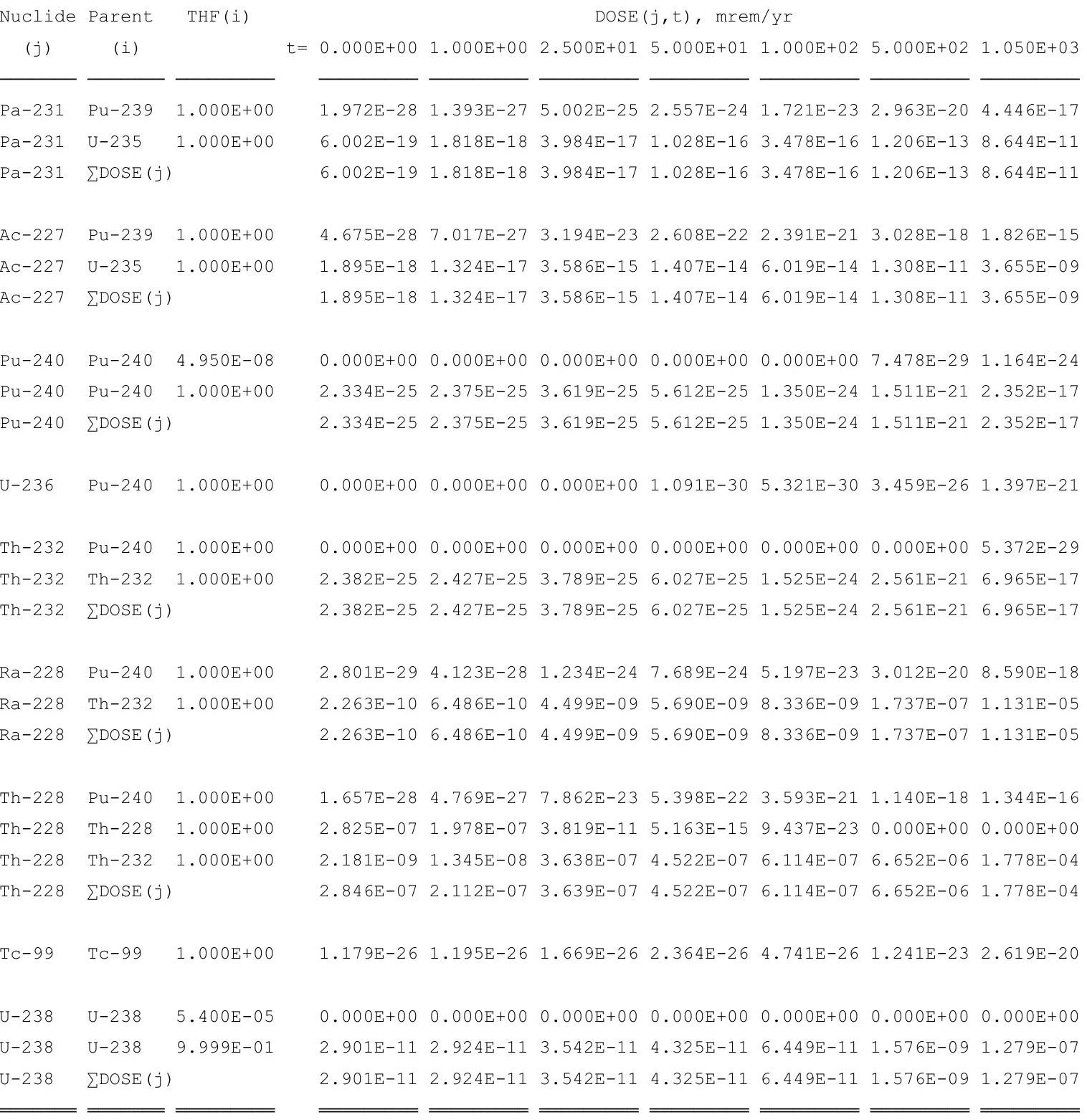

THF (i) is the thread fraction of the parent nuclide. 
RESRAD, Version 6.5

ummary : RESRAD Parameters for U-Landfill Outdoor Worker

File $\quad$ : $C: \backslash$ RESRAD FAMILY \RESRAD \USERFILES $\backslash Q C F O R S R S G \backslash O U T D O O R W O R K E R-S R S G-M A Y 11 . R A D$

Individual Nuclide Soil Concentration

Parent Nuclide and Branch Fraction Indicated

Nuclide Parent THF(

(j)

(i)

Am-241 Am-241 1.000E+00

Np-237 Am-241 $1.000 \mathrm{E}+00$

Np-237 Np-237 1.000E+00

Np-237 $\sum S(j):$

$\mathrm{U}-233 \quad \mathrm{Am}-241 \quad 1.000 \mathrm{E}+00$

$\mathrm{U}-233 \quad \mathrm{~Np}-237 \quad 1.000 \mathrm{E}+00$

U-233 $\sum S(j):$

Th-229

Th-229

Th-229

Cs-137

$\mathrm{Pu}-238$

$\mathrm{Pu}-238$

$\mathrm{Pu}-238$

$\mathrm{U}-234$

$\mathrm{U}-234$

$\mathrm{U}-234$

$\mathrm{U}-234$

Th-230

Th -230

Th -230

Th-230

$\mathrm{Th}-230$

$\mathrm{Ra}-226$

$\mathrm{Ra}-226$

$\mathrm{Ra}-226$

$\mathrm{Ra}-226$

$\mathrm{Ra}-226$

$\mathrm{Pb}-210$

$\mathrm{Pb}-210$

$\mathrm{Pb}-210$

$\mathrm{Pb}-210$

$\mathrm{Pb}-210$

$\mathrm{Pu}-239$

$\mathrm{Am}-241 \quad 1.000 \mathrm{E}+00$

Np-237 1.000E+00

$\sum S(j):$

Cs-137 1.000E+00

Pu-238 1.840E-09

$\mathrm{Pu}-238 \quad 1.000 \mathrm{E}+00$

$\sum S(j):$

$\mathrm{Pu}-238 \quad 1.000 \mathrm{E}+00$

$\mathrm{U}-234 \quad 1.000 \mathrm{E}+00$

U-238 $9.999 \mathrm{E}-01$

$\sum S(j):$

Pu-238 1.000E+00

Th-230 1.000E+00

$\mathrm{U}-234 \quad 1.000 \mathrm{E}+00$

$\mathrm{U}-238 \quad 9.999 \mathrm{E}-01$

$\sum S(j):$

Pu-238 $1.000 \mathrm{E}+00$

Th-230 1.000E+00

$\mathrm{U}-234 \quad 1.000 \mathrm{E}+00$

$\mathrm{U}-238 \quad 9.999 \mathrm{E}-01$

$\sum S(j):$

Pu-238 1.000E+00

Th-230 1.000E+00

$\mathrm{U}-2341.000 \mathrm{E}+00$

$\mathrm{U}-238 \quad 9.999 \mathrm{E}-01$

$\sum S(j):$

Pu-239 1.000E+00

$\mathrm{Pu}-239 \quad 1.000 \mathrm{E}+00$

$\mathrm{U}-2351.000 \mathrm{E}+00$

$\sum S(j):$
$\mathrm{S}(j, t), \mathrm{pCi} / \mathrm{g}$

$\mathrm{t}=0.000 \mathrm{E}+00 \quad 1.000 \mathrm{E}+00 \quad 2.500 \mathrm{E}+01 \quad 5.000 \mathrm{E}+01 \quad 1.000 \mathrm{E}+02 \quad 5.000 \mathrm{E}+02 \quad 1.050 \mathrm{E}+03$

$\begin{array}{lllllllllllll}1.000 \mathrm{E}+00 & 9.984 \mathrm{E}-01 & 9.606 \mathrm{E}-01 & 9.228 \mathrm{E}-01 & 8.516 \mathrm{E}-01 & 4.478 \mathrm{E}-01 & 1.851 \mathrm{E}-01\end{array}$

$0.000 \mathrm{E}+00 \quad 3.236 \mathrm{E}-07 \quad 7.929 \mathrm{E}-06 \quad 1.553 \mathrm{E}-05 \quad 2.980 \mathrm{E}-05 \quad 1.089 \mathrm{E}-04 \quad 1.559 \mathrm{E}-04$

$\begin{array}{lllllll}1.000 \mathrm{E}+00 & 9.999 \mathrm{E}-01 & 9.980 \mathrm{E}-01 & 9.961 \mathrm{E}-01 & 9.922 \mathrm{E}-01 & 9.614 \mathrm{E}-01 & 9.206 \mathrm{E}-01\end{array}$

$\begin{array}{lllllll}1.000 \mathrm{E}+00 & 9.999 \mathrm{E}-01 & 9.980 \mathrm{E}-01 & 9.961 \mathrm{E}-01 & 9.922 \mathrm{E}-01 & 9.615 \mathrm{E}-01 & 9.208 \mathrm{E}-01\end{array}$

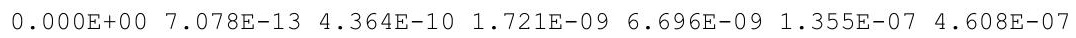

$0.000 \mathrm{E}+00 \quad 4.373 \mathrm{E}-06 \quad 1.092 \mathrm{E}-04 \quad 2.181 \mathrm{E}-04 \quad 4.352 \mathrm{E}-04 \quad 2.135 \mathrm{E}-03 \quad 4.366 \mathrm{E}-03$

$\begin{array}{lllllll}0.000 \mathrm{E}+00 & 4.373 \mathrm{E}-06 & 1.092 \mathrm{E}-04 & 2.181 \mathrm{E}-04 & 4.352 \mathrm{E}-04 & 2.135 \mathrm{E}-03 & 4.366 \mathrm{E}-03\end{array}$

$\begin{array}{lllllll}0.000 \mathrm{E}+00 & 2.228 \mathrm{E}-17 & 3.445 \mathrm{E}-13 & 2.725 \mathrm{E}-12 & 2.132 \mathrm{E}-11 & 2.249 \mathrm{E}-09 & 1.683 \mathrm{E}-08\end{array}$

$0.000 \mathrm{E}+00 \quad 2.065 \mathrm{E}-10 \quad 1.288 \mathrm{E}-07 \quad 5.146 \mathrm{E}-07 \quad 2.052 \mathrm{E}-06 \quad 4.999 \mathrm{E}-05 \quad 2.128 \mathrm{E}-04$

$\begin{array}{lllllll}0.000 \mathrm{E}+00 & 2.065 \mathrm{E}-10 & 1.288 \mathrm{E}-07 & 5.146 \mathrm{E}-07 & 2.052 \mathrm{E}-06 & 4.999 \mathrm{E}-05 & 2.129 \mathrm{E}-04\end{array}$

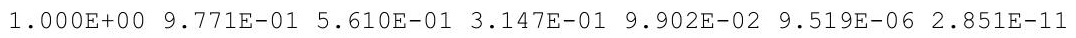

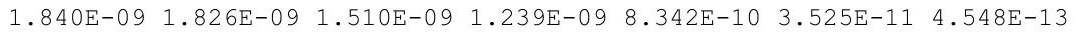

$\begin{array}{lllllllll}1.000 \mathrm{E}+00 & 9.921 \mathrm{E}-01 & 8.206 \mathrm{E}-01 & 6.733 \mathrm{E}-01 & 4.534 \mathrm{E}-01 & 1.916 \mathrm{E}-02 & 2.472 \mathrm{E}-04\end{array}$

$\begin{array}{llllllll}1.000 \mathrm{E}+00 & 9.921 \mathrm{E}-01 & 8.206 \mathrm{E}-01 & 6.733 \mathrm{E}-01 & 4.534 \mathrm{E}-01 & 1.916 \mathrm{E}-02 & 2.472 \mathrm{E}-04\end{array}$

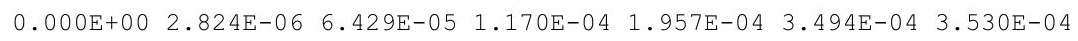

$\begin{array}{llllllll}1.000 \mathrm{E}+00 & 1.000 \mathrm{E}+00 & 9.996 \mathrm{E}-01 & 9.992 \mathrm{E}-01 & 9.984 \mathrm{E}-01 & 9.919 \mathrm{E}-01 & 9.831 \mathrm{E}-01\end{array}$

$\begin{array}{lllllll}0.000 \mathrm{E}+00 & 2.835 \mathrm{E}-06 & 7.084 \mathrm{E}-05 & 1.416 \mathrm{E}-04 & 2.831 \mathrm{E}-04 & 1.407 \mathrm{E}-03 & 2.931 \mathrm{E}-03\end{array}$

$\begin{array}{lllllll}1.000 \mathrm{E}+00 & 1.000 \mathrm{E}+00 & 9.997 \mathrm{E}-01 & 9.994 \mathrm{E}-01 & 9.989 \mathrm{E}-01 & 9.937 \mathrm{E}-01 & 9.864 \mathrm{E}-01\end{array}$

$\begin{array}{lllllll}0.000 \mathrm{E}+00 & 1.273 \mathrm{E}-11 & 7.473 \mathrm{E}-09 & 2.807 \mathrm{E}-08 & 9.959 \mathrm{E}-08 & 1.206 \mathrm{E}-06 & 2.942 \mathrm{E}-06\end{array}$ $\begin{array}{llllllll}1.000 \mathrm{E}+00 & 1.000 \mathrm{E}+00 & 9.997 \mathrm{E}-01 & 9.995 \mathrm{E}-01 & 9.989 \mathrm{E}-01 & 9.947 \mathrm{E}-01 & 9.888 \mathrm{E}-01\end{array}$ $\begin{array}{lllllll}0.000 \mathrm{E}+00 & 9.002 \mathrm{E}-06 & 2.250 \mathrm{E}-04 & 4.498 \mathrm{E}-04 & 8.990 \mathrm{E}-04 & 4.471 \mathrm{E}-03 & 9.319 \mathrm{E}-03\end{array}$ $\begin{array}{llllllll}0.000 \mathrm{E}+00 & 1.276 \mathrm{E}-11 & 7.972 \mathrm{E}-09 & 3.188 \mathrm{E}-08 & 1.274 \mathrm{E}-07 & 3.168 \mathrm{E}-06 & 1.387 \mathrm{E}-05\end{array}$ $\begin{array}{lllllll}1.000 \mathrm{E}+00 & 1.000 \mathrm{E}+00 & 1.000 \mathrm{E}+00 & 9.999 \mathrm{E}-01 & 9.998 \mathrm{E}-01 & 9.991 \mathrm{E}-01 & 9.981 \mathrm{E}-01\end{array}$

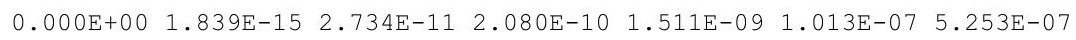
$\begin{array}{lllllll}0.000 \mathrm{E}+00 & 4.331 \mathrm{E}-04 & 1.077 \mathrm{E}-02 & 2.142 \mathrm{E}-02 & 4.235 \mathrm{E}-02 & 1.937 \mathrm{E}-01 & 3.613 \mathrm{E}-01\end{array}$ $0.000 \mathrm{E}+00 \quad 1.950 \mathrm{E}-09 \quad 1.214 \mathrm{E}-06 \quad 4.837 \mathrm{E}-06 \quad 1.920 \mathrm{E}-05 \quad 4.512 \mathrm{E}-04 \quad 1.833 \mathrm{E}-03$ $\begin{array}{lllllll}0.000 \mathrm{E}+00 & 1.842 \mathrm{E}-15 & 2.870 \mathrm{E}-11 & 2.289 \mathrm{E}-10 & 1.820 \mathrm{E}-09 & 2.170 \mathrm{E}-07 & 1.885 \mathrm{E}-06\end{array}$ $\begin{array}{lllllll}0.000 \mathrm{E}+00 & 4.331 \mathrm{E}-04 & 1.077 \mathrm{E}-02 & 2.142 \mathrm{E}-02 & 4.237 \mathrm{E}-02 & 1.942 \mathrm{E}-01 & 3.632 \mathrm{E}-01\end{array}$

$\begin{array}{lllllll}0.000 \mathrm{E}+00 & 1.421 \mathrm{E}-17 & 4.624 \mathrm{E}-12 & 6.200 \mathrm{E}-11 & 7.209 \mathrm{E}-10 & 8.712 \mathrm{E}-08 & 4.925 \mathrm{E}-07\end{array}$ $\begin{array}{lllllll}0.000 \mathrm{E}+00 & 6.663 \mathrm{E}-06 & 3.287 \mathrm{E}-03 & 1.058 \mathrm{E}-02 & 2.946 \mathrm{E}-02 & 1.823 \mathrm{E}-01 & 3.524 \mathrm{E}-01\end{array}$ $\begin{array}{llllllll}0.000 \mathrm{E}+00 & 2.004 \mathrm{E}-11 & 2.619 \mathrm{E}-07 & 1.773 \mathrm{E}-06 & 1.066 \mathrm{E}-05 & 3.984 \mathrm{E}-04 & 1.731 \mathrm{E}-03\end{array}$ $\begin{array}{llllllll}0.000 \mathrm{E}+00 & 1.423 \mathrm{E}-17 & 4.812 \mathrm{E}-12 & 6.719 \mathrm{E}-11 & 8.476 \mathrm{E}-10 & 1.806 \mathrm{E}-07 & 1.727 \mathrm{E}-06\end{array}$

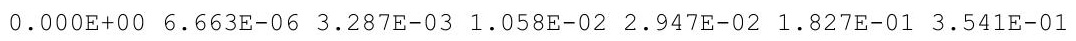

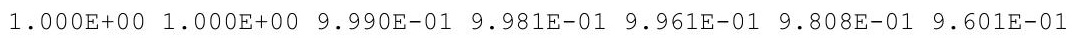
$0.000 \mathrm{E}+00 \quad 9.848 \mathrm{E}-10 \quad 2.461 \mathrm{E}-08 \quad 4.918 \mathrm{E}-08 \quad 9.823 \mathrm{E}-08 \quad 4.861 \mathrm{E}-07 \quad 1.006 \mathrm{E}-06$ $\begin{array}{llllllll}1.000 \mathrm{E}+00 & 1.000 \mathrm{E}+00 & 9.997 \mathrm{E}-01 & 9.993 \mathrm{E}-01 & 9.987 \mathrm{E}-01 & 9.933 \mathrm{E}-01 & 9.860 \mathrm{E}-01\end{array}$ $\begin{array}{lllllll}1.000 \mathrm{E}+00 & 1.000 \mathrm{E}+00 & 9.997 \mathrm{E}-01 & 9.993 \mathrm{E}-01 & 9.987 \mathrm{E}-01 & 9.933 \mathrm{E}-01 & 9.860 \mathrm{E}-01\end{array}$ 
RESRAD, Version $6.5 \quad \mathrm{~T}^{1} \frac{1}{2}$ Limit $=180$ days

Summary : RESRAD Parameters for U-Landfill Worker

File : C: $\backslash$ RESRAD_FAMILY \RESRAD \USERFILES $\backslash Q C F O R S R S G \backslash L A N F F I L L W O R K E R \_S R S G-M A Y 11 . R A D$

Table of Contents

Part I: Mixture Sums and Single Radionuclide Guidelines

Dose Conversion Factor (and Related) Parameter Summary ... 2

Site-Specific Parameter Summary ................ 8

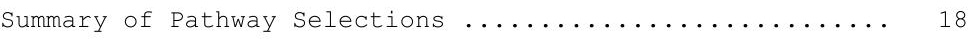

Contaminated Zone and Total Dose Summary ............. 19

Total Dose Components

Time $=0.000 \mathrm{E}+00 \ldots \ldots \ldots \ldots \ldots \ldots \ldots \ldots \ldots \ldots \ldots \ldots \ldots \ldots \ldots \ldots \ldots \ldots$

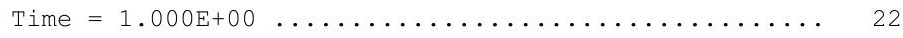

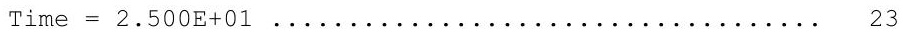

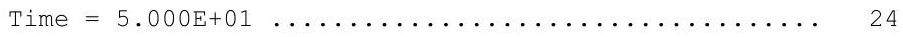

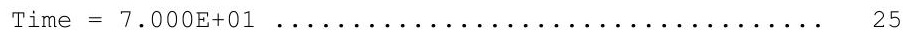

Dose/Source Ratios Summed Over All Pathways ........... 26

Single Radionuclide Soil Guidelines ............... 28

Dose Per Nuclide Summed Over All Pathways ............ 29

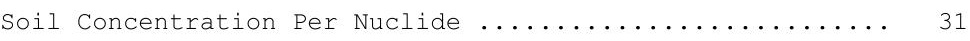


Summary : RESRAD Parameters for U-Landfill Worker

File : C: $\backslash$ RESRAD_FAMILY \RESRAD \USERFILES $\backslash Q C F O R S R S G \backslash L A N F F I L L W O R K E R \_S R S G-M A Y 11 . R A D$

Dose Conversion Factor (and Related) Parameter Summary

Dose Library: ICRP 60 \& ICRP 72 (Adult)

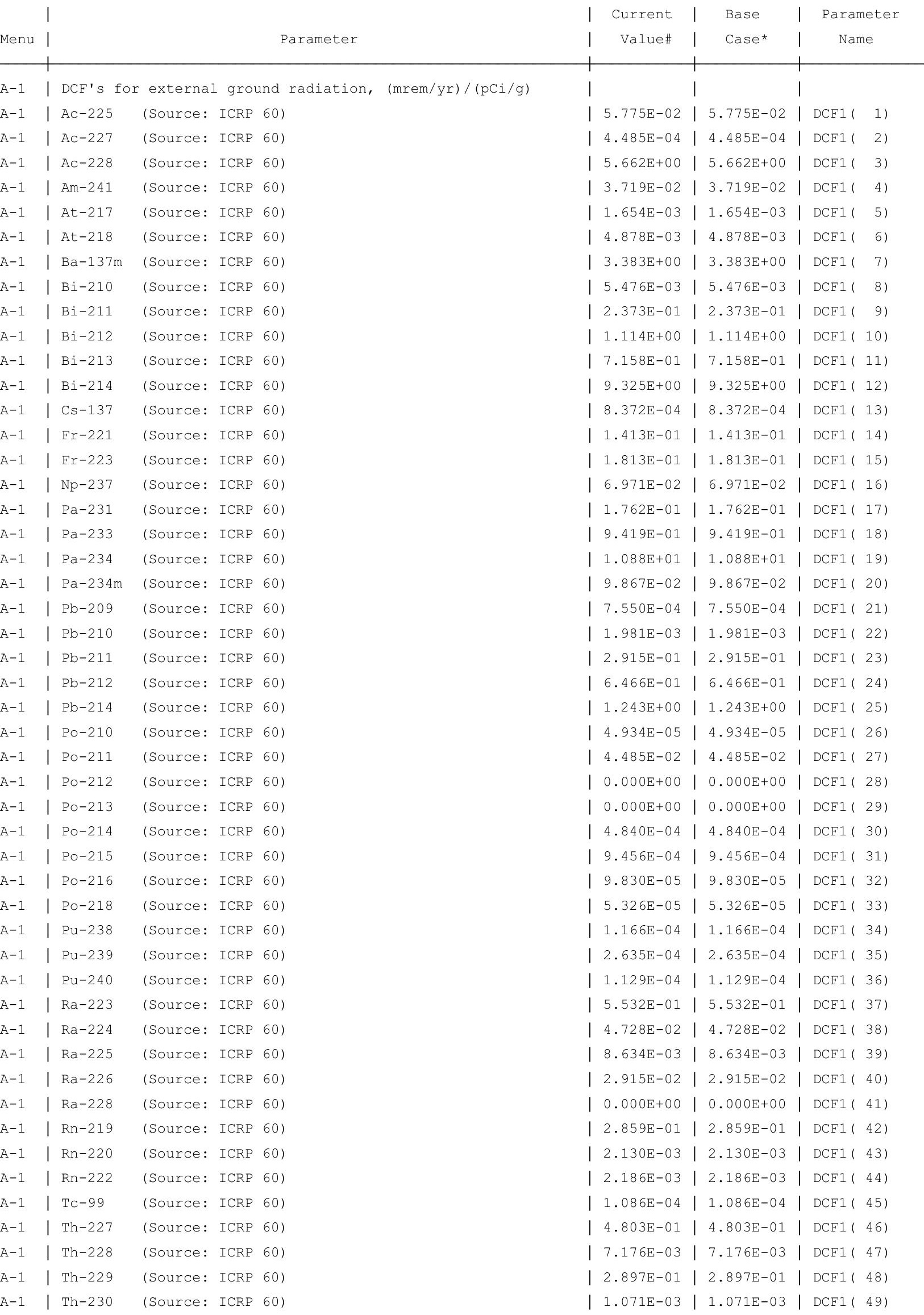


RESRAD, Version $6.5 \quad \mathrm{~T}^{1 / 2}$ Limit $=180$ days

Summary : RESRAD Parameters for U-Landfill Worker

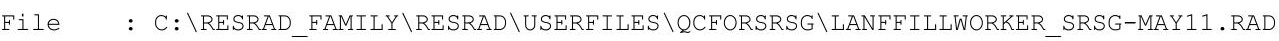

Dose Conversion Factor (and Related) Parameter Summary (continued)

Dose Library: ICRP 60 \& ICRP 72 (Adult)

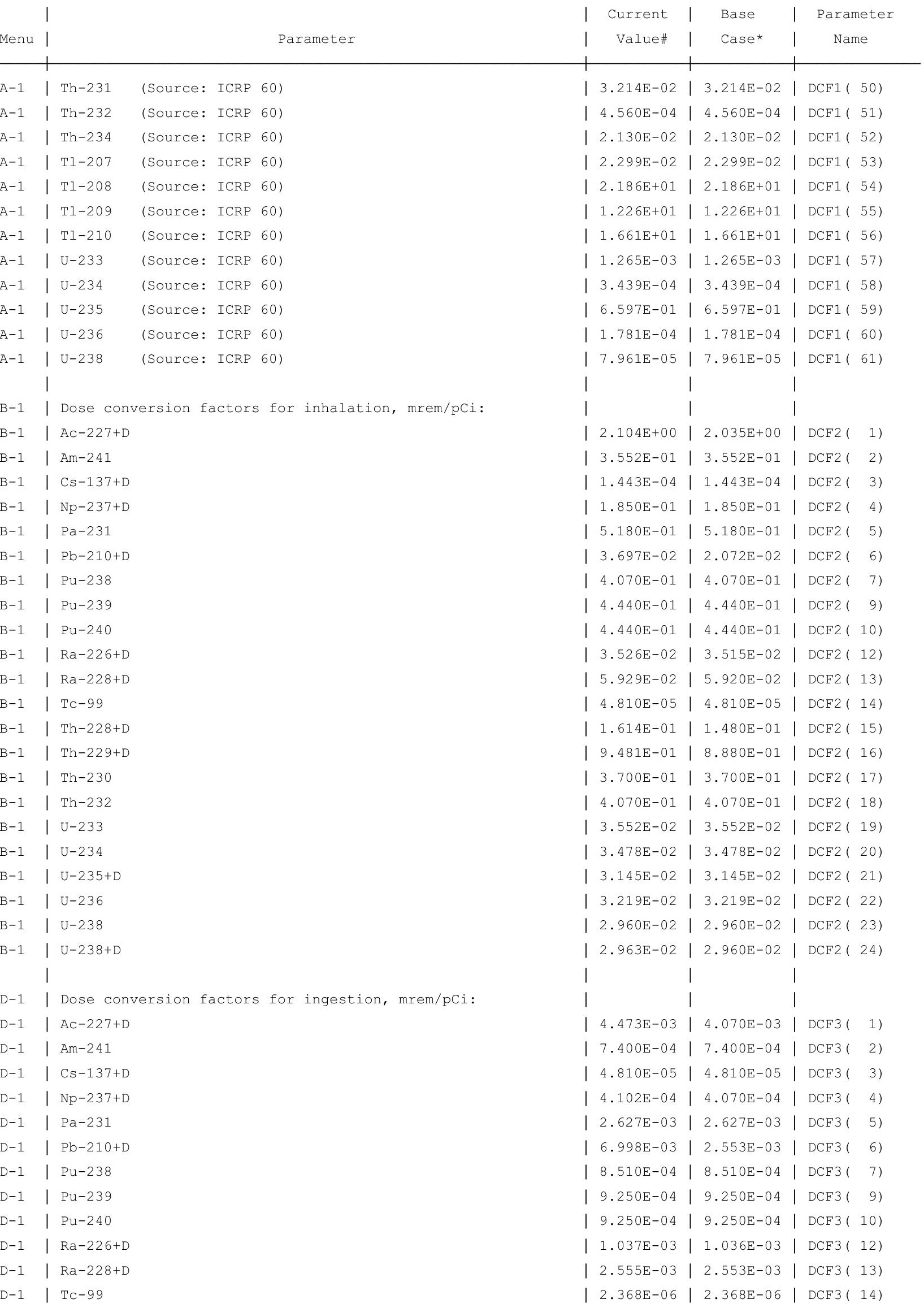


RESRAD, Version $6.5 \quad T^{1 / 2}$ Limit $=180$ days

ummary : RESRAD Parameters for U-Landfill Worker

File : C: $\backslash$ RESRAD_FAMILY \RESRAD \USERFILES $\backslash Q C F O R S R S G \backslash L A N F F I L L W O R K E R \_S R S G-M A Y 11 . R A D$

Dose Conversion Factor (and Related) Parameter Summary (continued)

Dose Library: ICRP 60 \& ICRP 72 (Adult)

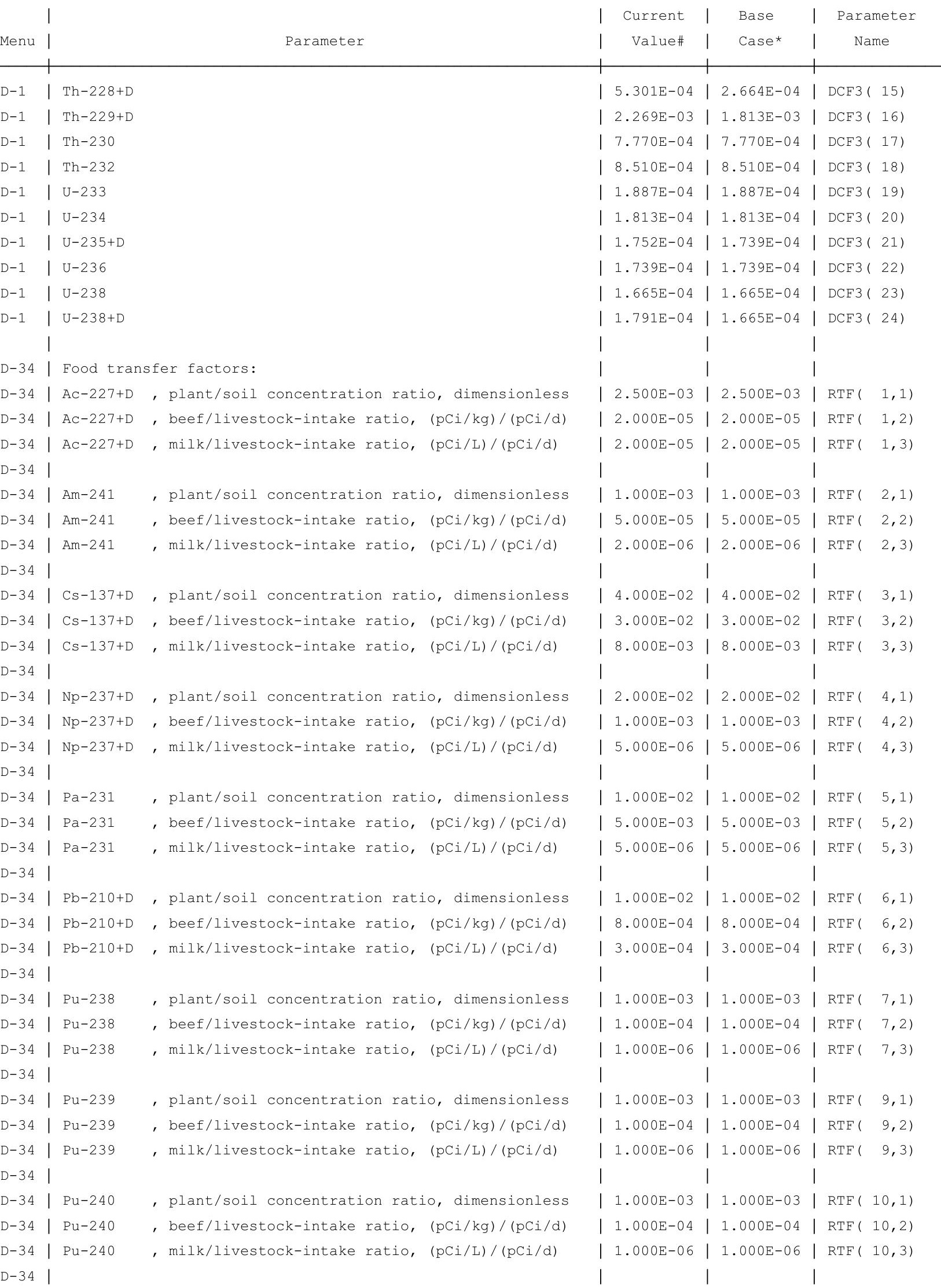


RESRAD, Version $6.5 \quad \mathrm{~T}^{1 / 2}$ Limit $=180$ days

07/21/2011 17:18 Page

Summary : RESRAD Parameters for U-Landfill Worker

File : C: $\backslash$ RESRAD_FAMILY \RESRAD \USERFILES $\backslash Q C F O R S R S G \backslash L A N F F I L L W O R K E R \_S R S G-M A Y 11 . R A D$

Site-Specific Parameter Summary (continued)

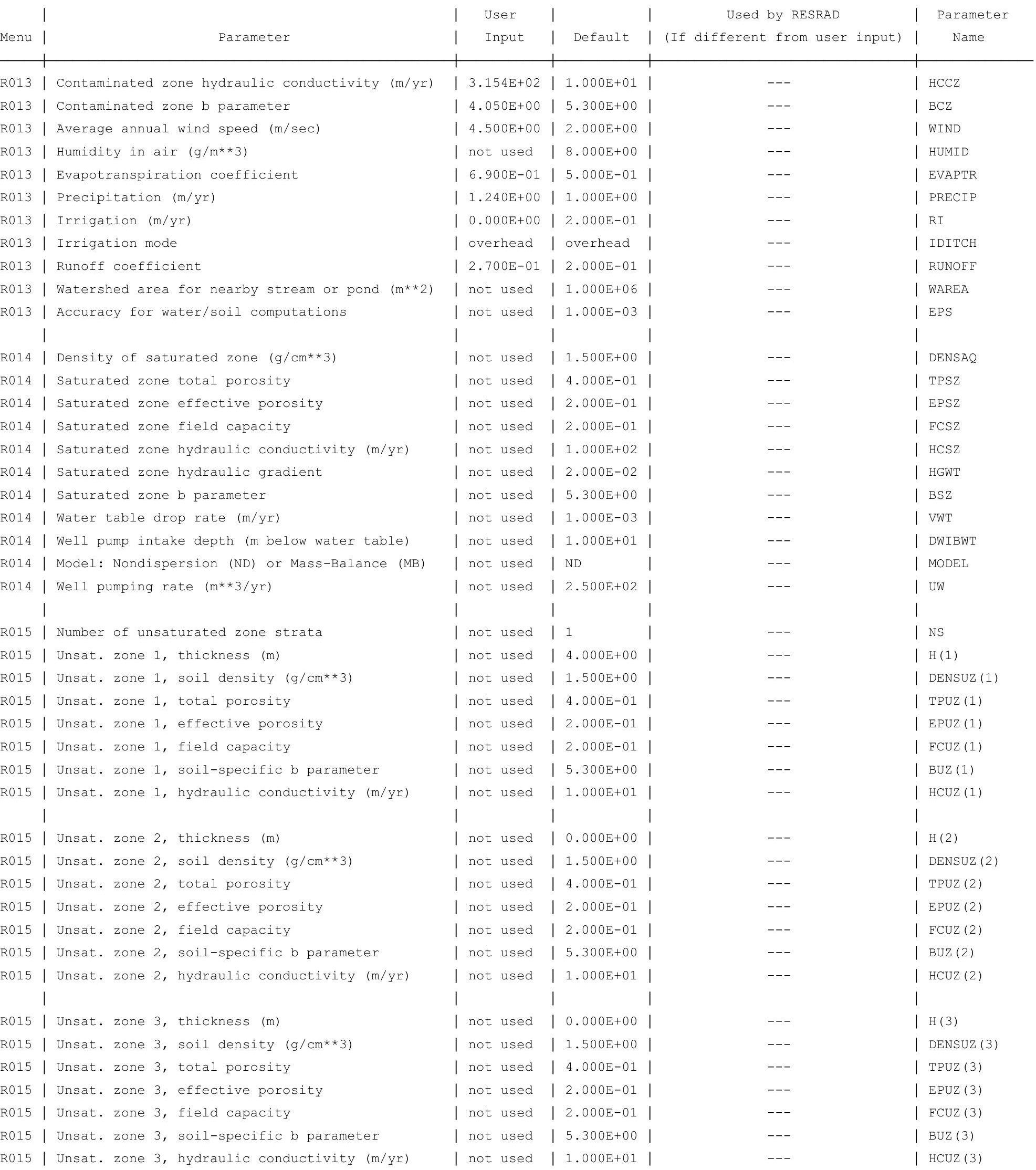


RESRAD, Version $6.5 \quad \mathrm{~T}^{1 / 2}$ Limit $=180$ days

Summary : RESRAD Parameters for U-Landfill Worker

File : C: $\backslash$ RESRAD_FAMILY \RESRAD \USERFILES $\backslash Q C F O R S R S G \backslash L A N F F I L L W O R K E R \_S R S G-M A Y 11 . R A D$

Site-Specific Parameter Summary (continued)

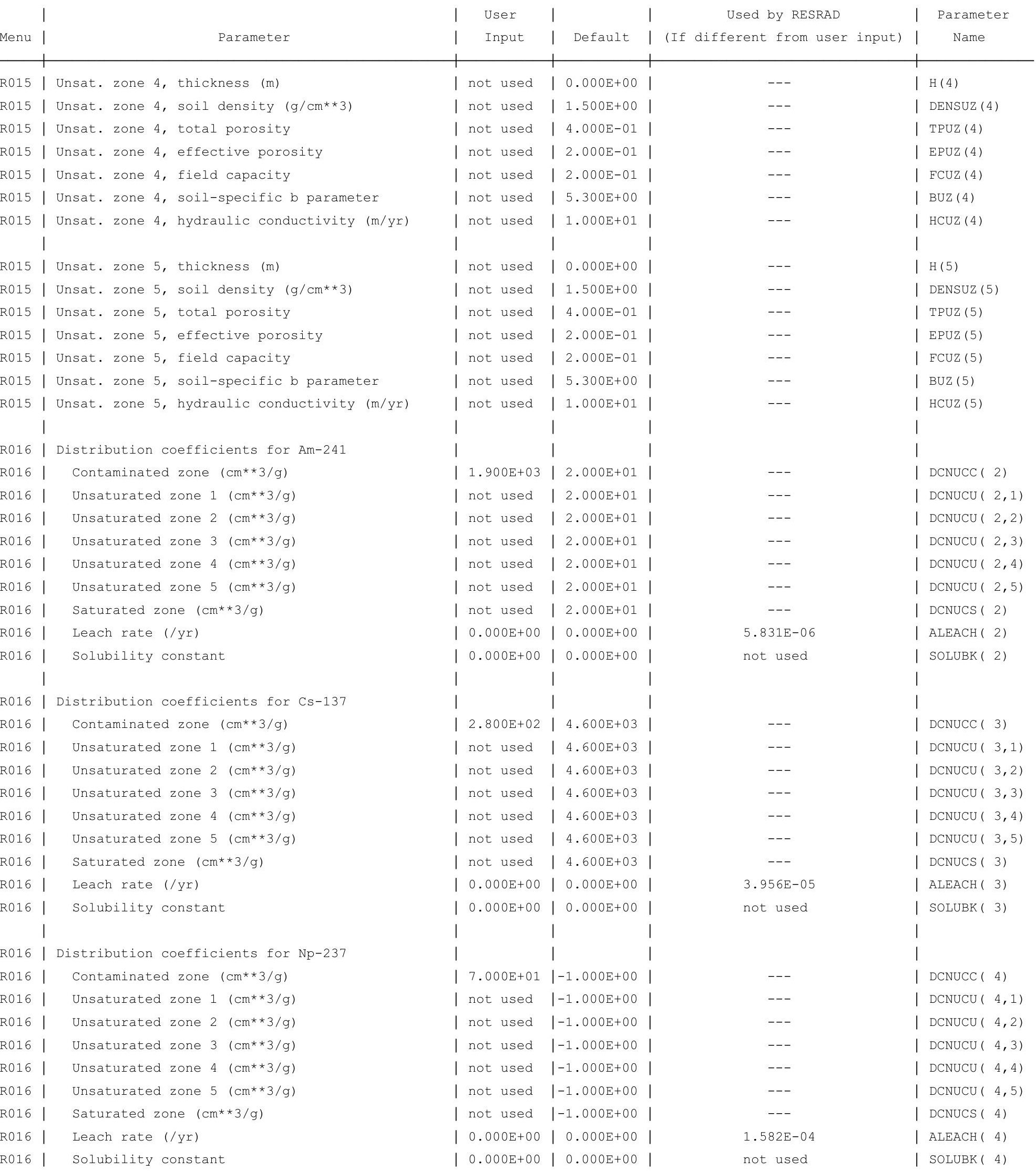


RESRAD, Version $6.5 \quad \mathrm{~T}^{1 / 2}$ Limit $=180$ days

Summary : RESRAD Parameters for U-Landfill Worker

File : C: $\backslash$ RESRAD_FAMILY \RESRAD \USERFILES $\backslash Q C F O R S R S G \backslash L A N F F I L L W O R K E R \_S R S G-M A Y 11 . R A D$

Site-Specific Parameter Summary (continued)

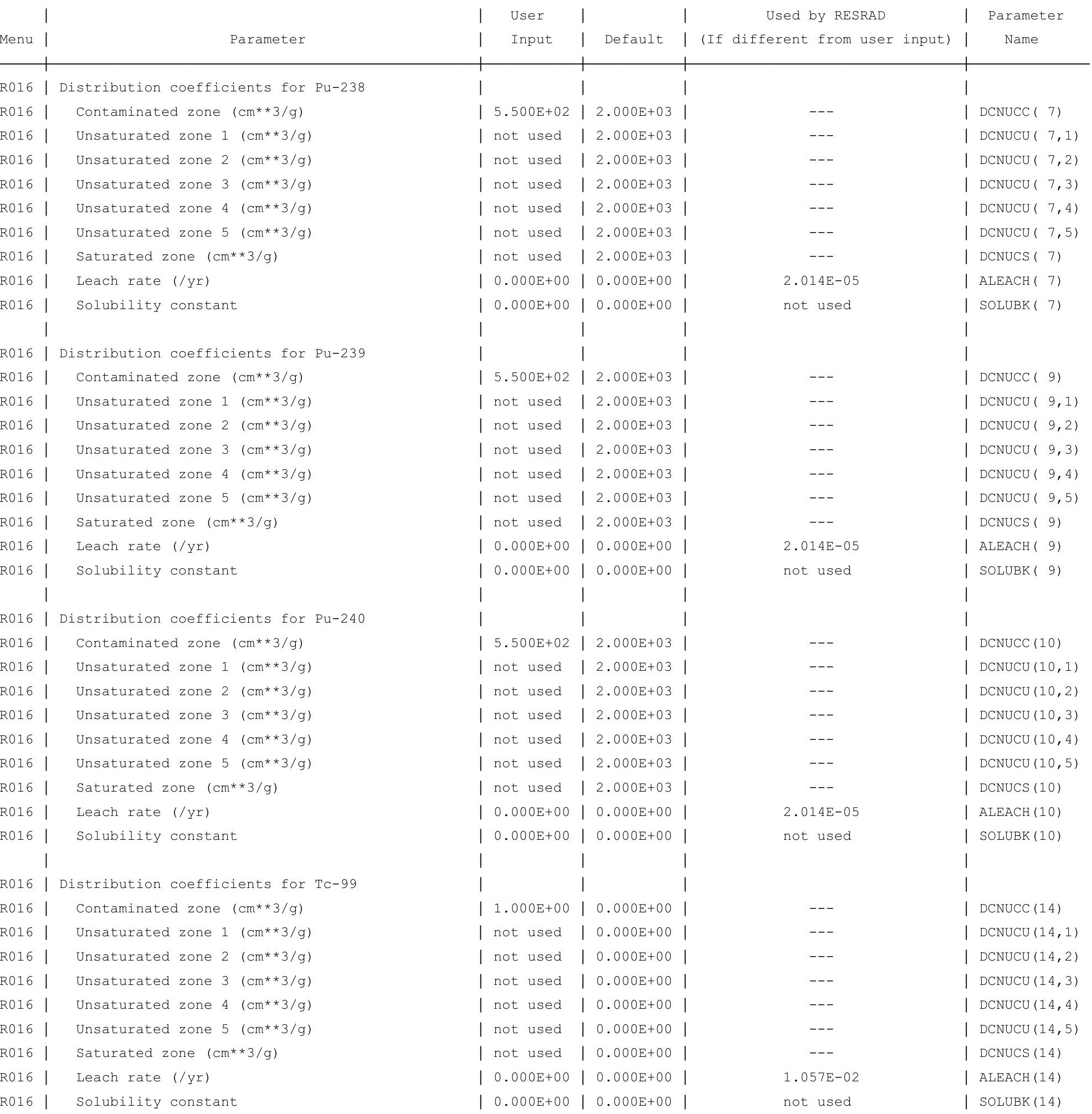


RESRAD, Version $6.5 \quad \mathrm{~T}^{1 / 2}$ Limit $=180$ days

07/21/2011 17:18 Page 12

Summary : RESRAD Parameters for U-Landfill Worker

File : C: $\backslash$ RESRAD_FAMILY \RESRAD \USERFILES $\backslash Q C F O R S R S G \backslash L A N F F I L L W O R K E R \_S R S G-M A Y 11 . R A D$

Site-Specific Parameter Summary (continued)

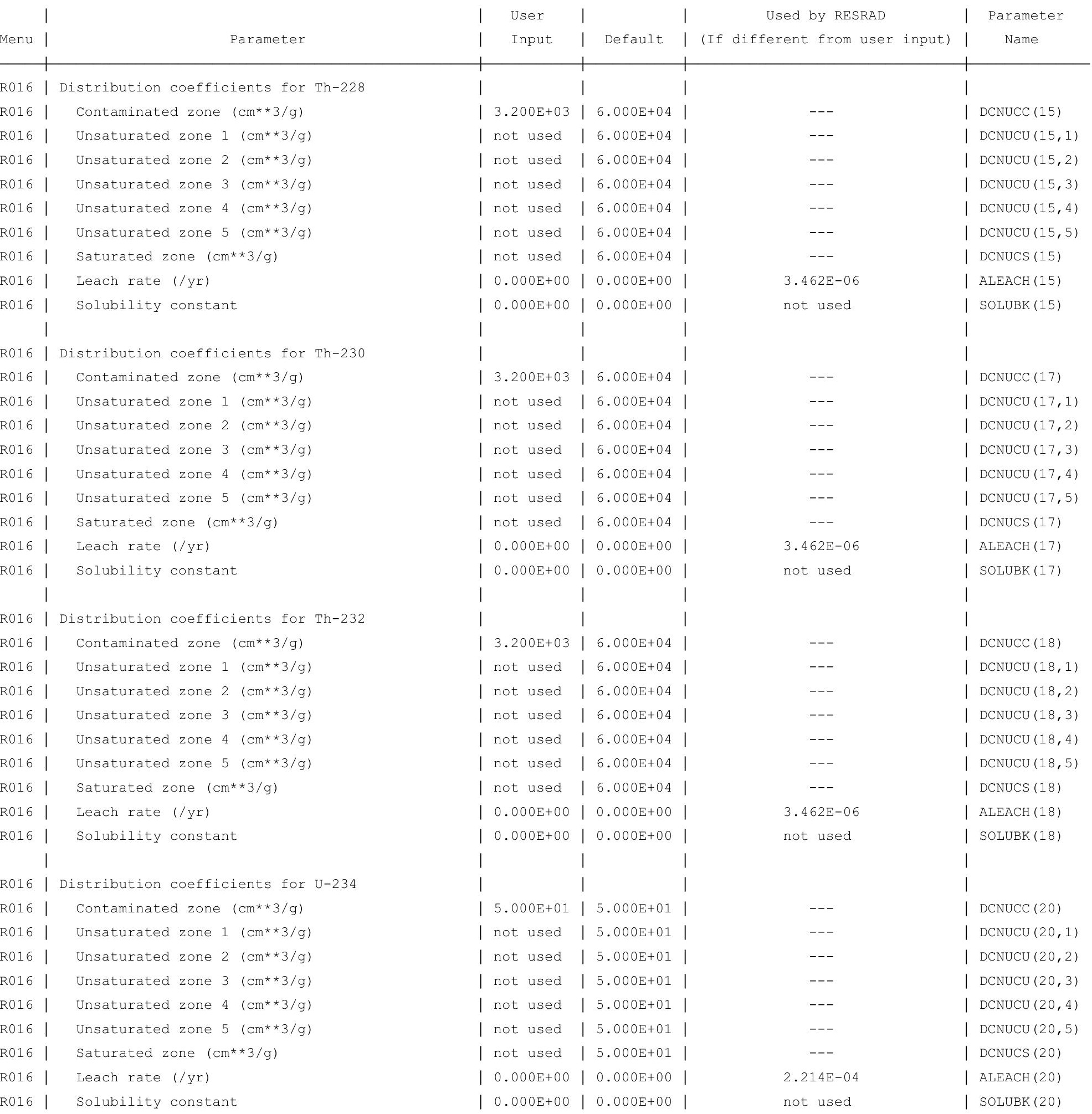


RESRAD, Version $6.5 \quad \mathrm{~T}^{1 / 2}$ Limit $=180$ days

07/21/2011 17:18 Page 13

Summary : RESRAD Parameters for U-Landfill Worker

File : C: $\backslash$ RESRAD_FAMILY \RESRAD \USERFILES $\backslash Q C F O R S R S G \backslash L A N F F I L L W O R K E R \_S R S G-M A Y 11 . R A D$

Site-Specific Parameter Summary (continued)

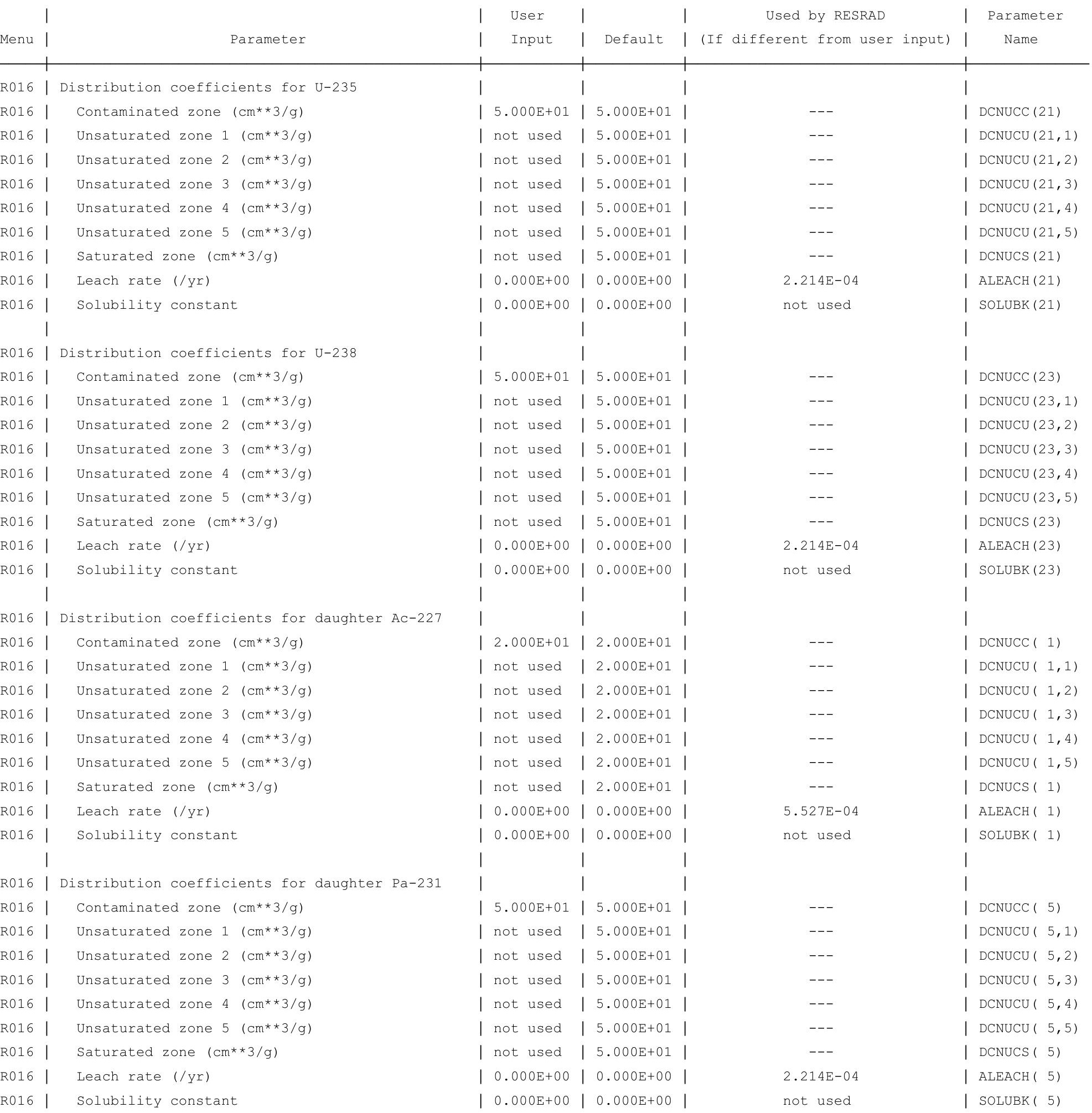


RESRAD, Version $6.5 \quad \mathrm{~T}^{1 / 2}$ Limit $=180$ days

Summary : RESRAD Parameters for U-Landfill Worker

File : C: $\backslash$ RESRAD_FAMILY \RESRAD \USERFILES $\backslash Q C F O R S R S G \backslash L A N F F I L L W O R K E R \_S R S G-M A Y 11 . R A D$

Site-Specific Parameter Summary (continued)

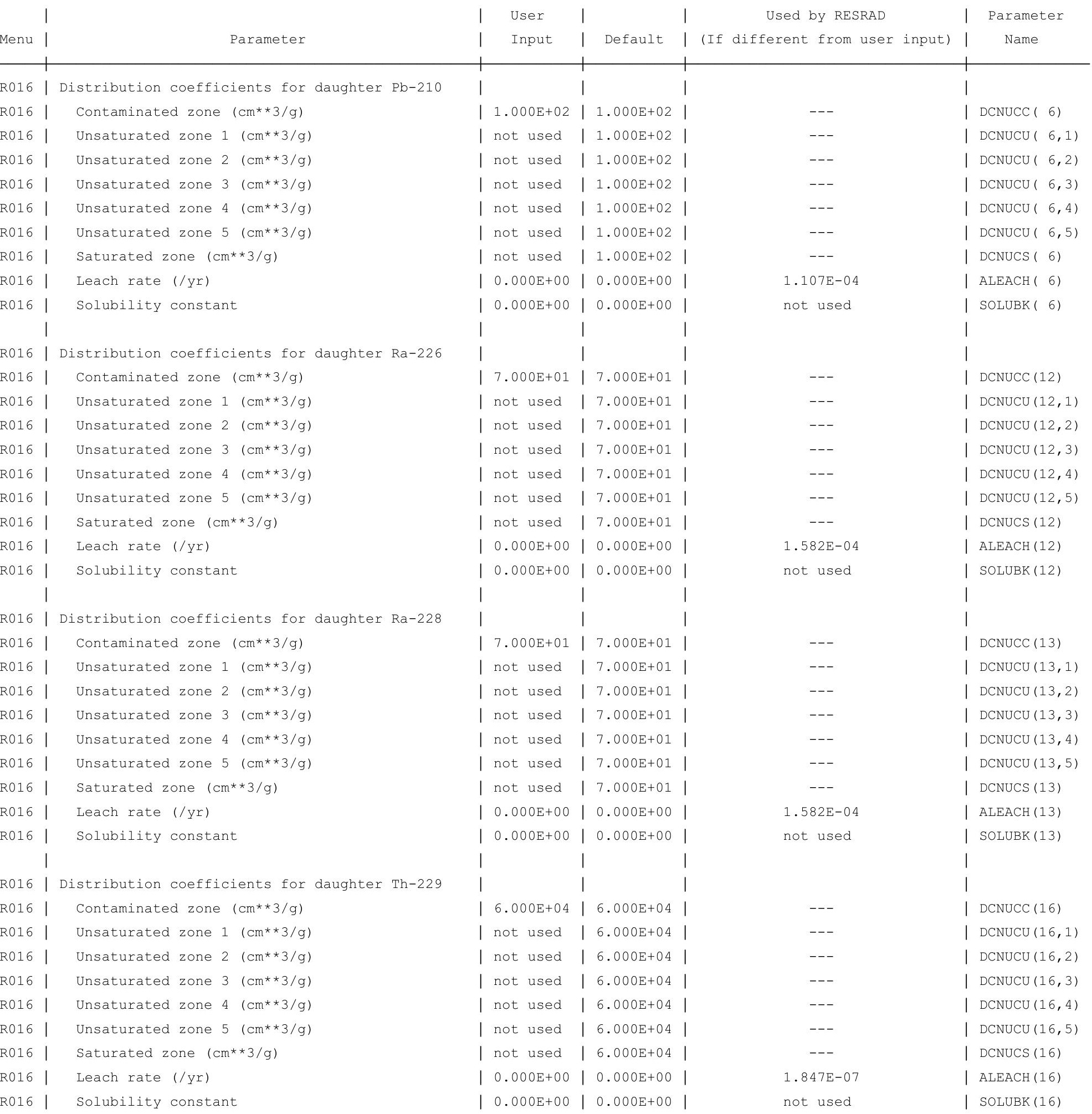


RESRAD, Version $6.5 \quad \mathrm{~T}^{1 / 2}$ Limit $=180$ days

Summary : RESRAD Parameters for U-Landfill Worker

File : C: $\backslash$ RESRAD_FAMILY \RESRAD \USERFILES $\backslash Q C F O R S R S G \backslash L A N F F I L L W O R K E R \_S R S G-M A Y 11 . R A D$

Site-Specific Parameter Summary (continued)

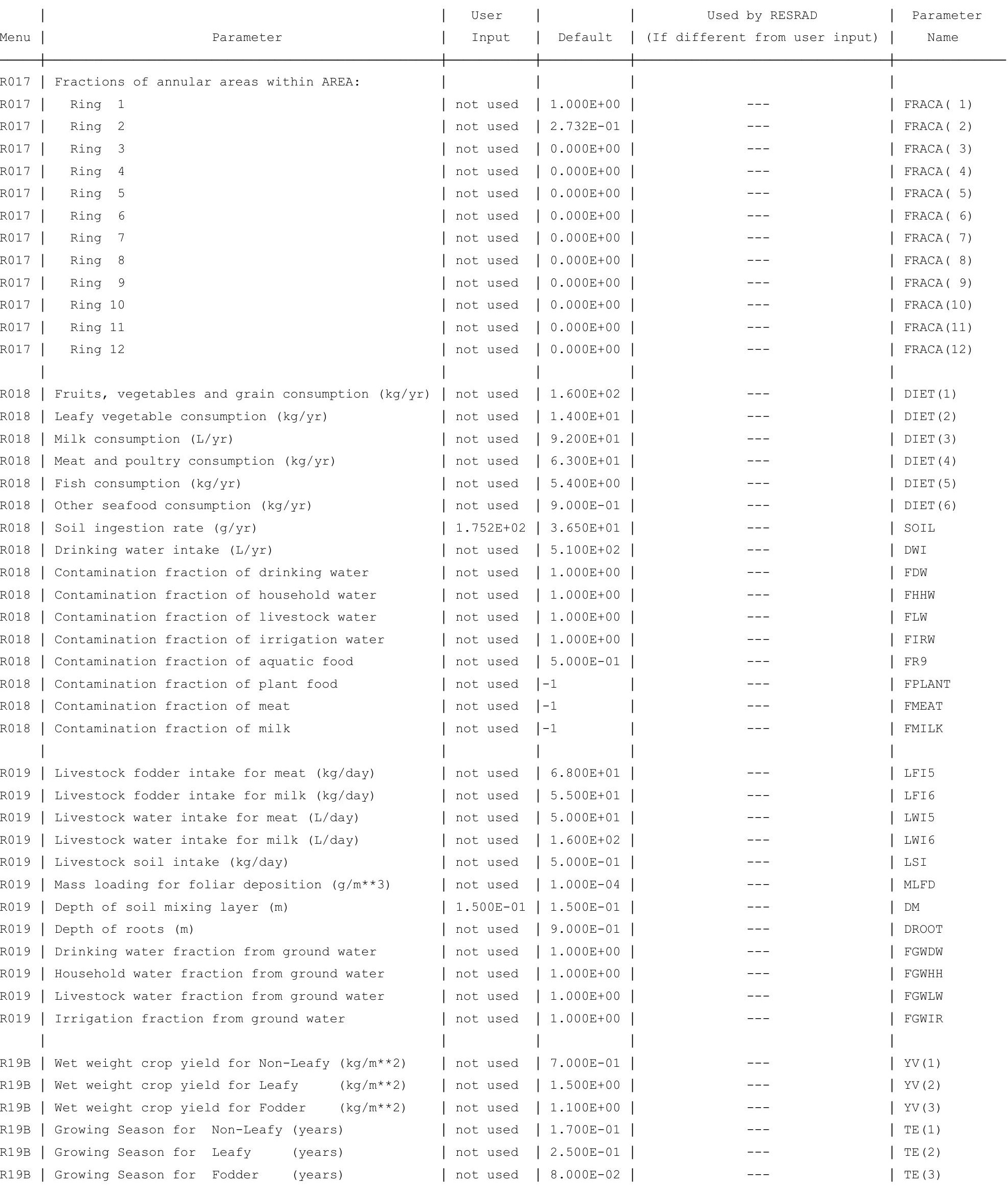


RESRAD, Version $6.5 \quad \mathrm{~T}^{1 / 2}$ Limit $=180$ days

Summary : RESRAD Parameters for U-Landfill Worker

File : C: $\backslash$ RESRAD_FAMILY \RESRAD \USERFILES $\backslash Q C F O R S R S G \backslash L A N F F I L L W O R K E R \_S R S G-M A Y 11 . R A D$

Site-Specific Parameter Summary (continued)

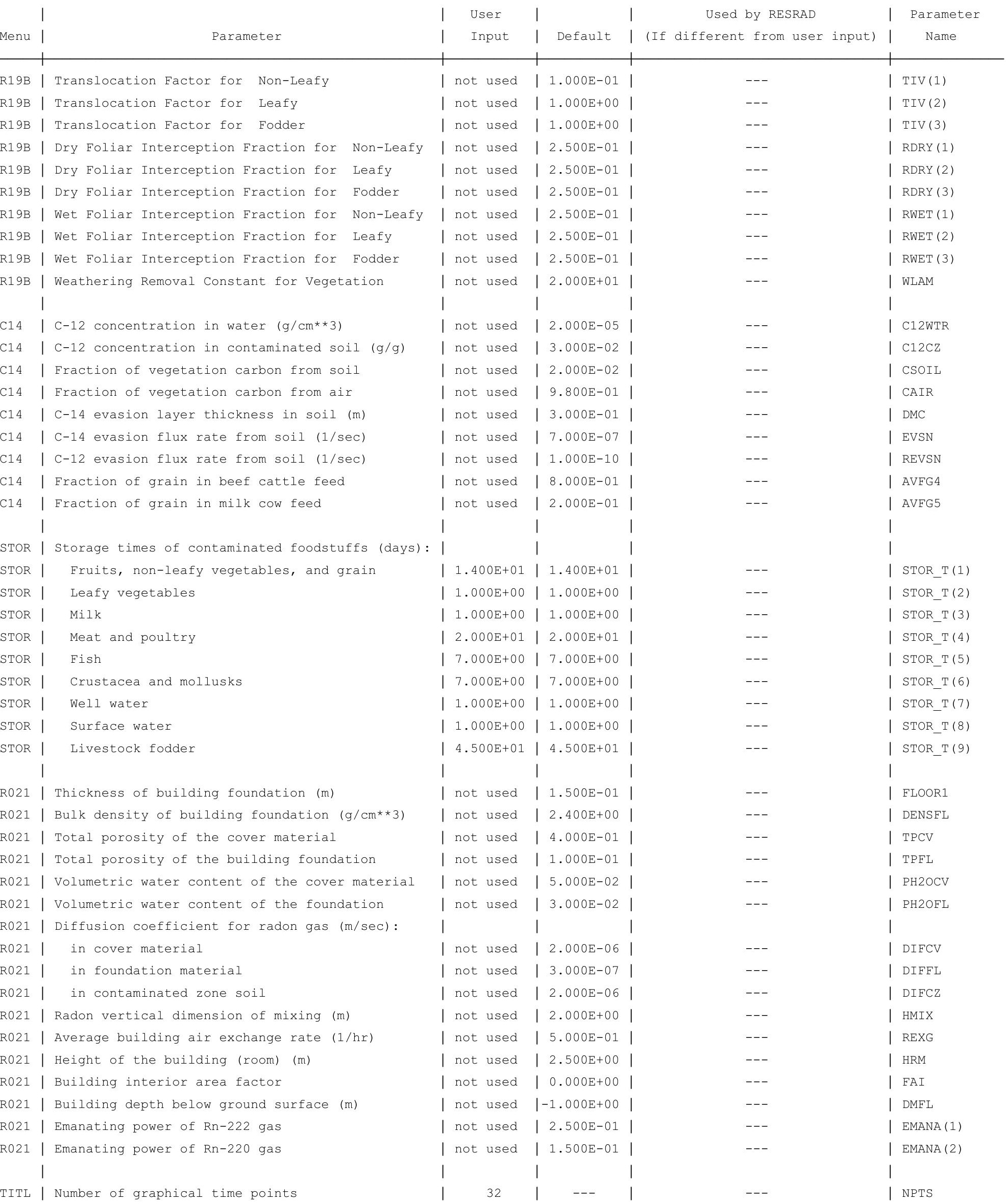

TITL | Number of graphical time points 
RESRAD, Version $6.5 \quad T^{1 / 2}$ Limit $=180$ days

Summary : RESRAD Parameters for U-Landfill Worker

File : C: $\backslash$ RESRAD_FAMILY \RESRAD \USERFILES $\backslash Q C F O R S R S G \backslash L A N F F I L L W O R K E R \_S R S G-M A Y 11 . R A D$

Contaminated Zone Dimensions

Area: 89436.00 square meters

Thickness:

Cover Depth:

\begin{abstract}
13.40 meters
0.00 meters
\end{abstract}

Initial Soil Concentrations, pci/g

$\begin{array}{ll}\mathrm{Am}-241 & 1.000 \mathrm{E}+00 \\ \mathrm{Cs}-137 & 1.000 \mathrm{E}+00 \\ \mathrm{~Np}-237 & 1.000 \mathrm{E}+00 \\ \mathrm{Pu}-238 & 1.000 \mathrm{E}+00 \\ \mathrm{Pu}-239 & 1.000 \mathrm{E}+00 \\ \mathrm{Pu}-240 & 1.000 \mathrm{E}+00 \\ \mathrm{Tc}-99 & 1.000 \mathrm{E}+00 \\ \mathrm{Th}-228 & 1.000 \mathrm{E}+00 \\ \mathrm{Th}-230 & 1.000 \mathrm{E}+00 \\ \mathrm{Th}-232 & 1.000 \mathrm{E}+00 \\ \mathrm{U}-234 & 1.000 \mathrm{E}+00 \\ \mathrm{U}-235 & 1.000 \mathrm{E}+00 \\ \mathrm{U}-238 & 1.000 \mathrm{E}+00\end{array}$

Total Dose TDOSE(t), mrem/yr

Basic Radiation Dose Limit $=1.000 \mathrm{E}+02 \mathrm{mrem} / \mathrm{yr}$

Total Mixture Sum $M(t)$ = Fraction of Basic Dose Limit Received at Time (t)

$\begin{array}{rlllll}t \text { (years) }: & 0.000 \mathrm{E}+00 & 1.000 \mathrm{E}+00 & 2.500 \mathrm{E}+01 & 5.000 \mathrm{E}+01 & 7.000 \mathrm{E}+01 \\ \text { TDOSE }(t): & 2.455 \mathrm{E}+00 & 2.192 \mathrm{E}+00 & 3.283 \mathrm{E}+00 & 3.318 \mathrm{E}+00 & 3.275 \mathrm{E}+00 \\ \mathrm{M}(\mathrm{t}): & 2.455 \mathrm{E}-02 & 2.192 \mathrm{E}-02 & 3.283 \mathrm{E}-02 & 3.318 \mathrm{E}-02 & 3.275 \mathrm{E}-02\end{array}$

Maximum TDOSE (t): $3.339 \mathrm{E}+00 \mathrm{mrem} / \mathrm{yr}$ at $t=36.73 \pm 0.07$ years

Total Dose Contributions TDOSE (i,p,t) for Individual Radionuclides (i) and Pathways (p) As mrem/yr and Fraction of Total Dose At $t=3.673 \mathrm{E}+01$ years

Water Independent Pathways (Inhalation excludes radon)

\begin{tabular}{|c|c|c|c|c|c|c|c|c|c|c|c|c|c|c|}
\hline & \multicolumn{2}{|c|}{ Ground } & \multicolumn{2}{|c|}{ Inhalation } & \multicolumn{2}{|c|}{ Radon } & \multicolumn{2}{|c|}{ Plant } & \multicolumn{2}{|c|}{ Meat } & \multicolumn{2}{|c|}{ Milk } & \multicolumn{2}{|c|}{ Soil } \\
\hline clide & mrem/yr & fract. & mrem/yr & fract. & mrem/yr & fract. & mrem/yr & fract. & mrem/yr & fract. & mrem/yr & fract. & mrem/yr & fract. \\
\hline-241 & $5.937 \mathrm{E}-03$ & 0.0018 & $1.702 \mathrm{E}-04$ & 0.0001 & $0.000 \mathrm{E}+00$ & 0.0000 & $0.000 \mathrm{E}+00$ & 0.0000 & $0.000 \mathrm{E}+00$ & 0.0000 & $0.000 \mathrm{E}+00$ & 0.0000 & $2.076 \mathrm{E}-02$ & 0.0062 \\
\hline-137 & $2.243 E-01$ & 0.0672 & $3.101 \mathrm{E}-08$ & 0.0000 & $0.000 \mathrm{E}+00$ & 0.0000 & $0.000 \mathrm{E}+00$ & 0.0000 & $0.000 \mathrm{E}+00$ & 0.0000 & $0.000 \mathrm{E}+00$ & 0.0000 & $6.052 E-04$ & 0.0002 \\
\hline-237 & $1.683 E-01$ & 0.0504 & $9.357 \mathrm{E}-05$ & 0.0000 & $0.000 \mathrm{E}+00$ & 0.0000 & $0.000 \mathrm{E}+00$ & 0.0000 & $0.000 \mathrm{E}+00$ & 0.0000 & $0.000 \mathrm{E}+00$ & 0.0000 & $1.215 \mathrm{E}-02$ & 0.0036 \\
\hline-238 & $1.475 E-05$ & 0.0000 & $1.542 \mathrm{E}-04$ & 0.0000 & $0.000 \mathrm{E}+00$ & 0.0000 & $0.000 \mathrm{E}+00$ & 0.0000 & $0.000 \mathrm{E}+00$ & 0.0000 & $0.000 \mathrm{E}+00$ & 0.0000 & $1.887 \mathrm{E}-02$ & 0.0057 \\
\hline-239 & $4.414 \mathrm{E}-05$ & 0.0000 & $2.255 \mathrm{E}-04$ & 0.0001 & $0.000 \mathrm{E}+00$ & 0.0000 & $0.000 \mathrm{E}+00$ & 0.0000 & $0.000 \mathrm{E}+00$ & 0.0000 & $0.000 \mathrm{E}+00$ & 0.0000 & $2.750 \mathrm{E}-02$ & 0.0082 \\
\hline-240 & $1.905 E-05$ & 0.0000 & $2.248 \mathrm{E}-04$ & 0.0001 & $0.000 \mathrm{E}+00$ & 0.0000 & $0.000 \mathrm{E}+00$ & 0.0000 & $0.000 \mathrm{E}+00$ & 0.0000 & $0.000 \mathrm{E}+00$ & 0.0000 & $2.742 \mathrm{E}-02$ & 0.0082 \\
\hline-99 & $1.234 \mathrm{E}-05$ & 0.0000 & $1.650 \mathrm{E}-08$ & 0.0000 & $0.000 \mathrm{E}+00$ & 0.0000 & $0.000 \mathrm{E}+00$ & 0.0000 & $0.000 \mathrm{E}+00$ & 0.0000 & $0.000 \mathrm{E}+00$ & 0.0000 & $4.757 \mathrm{E}-05$ & 0.0000 \\
\hline-228 & $2.236 \mathrm{E}-06$ & 0.0000 & $1.143 \mathrm{E}-10$ & 0.0000 & $0.000 \mathrm{E}+00$ & 0.0000 & $0.000 \mathrm{E}+00$ & 0.0000 & $0.000 \mathrm{E}+00$ & 0.0000 & $0.000 \mathrm{E}+00$ & 0.0000 & $2.198 \mathrm{E}-08$ & 0.0000 \\
\hline-230 & $2.825 E-02$ & 0.0085 & $1.885 \mathrm{E}-04$ & 0.0001 & $0.000 \mathrm{E}+00$ & 0.0000 & $0.000 \mathrm{E}+00$ & 0.0000 & $0.000 \mathrm{E}+00$ & 0.0000 & $0.000 \mathrm{E}+00$ & 0.0000 & $2.498 E-02$ & 0.0075 \\
\hline-232 & $2.505 E+00$ & 0.7503 & $3.174 \mathrm{E}-04$ & 0.0001 & $0.000 \mathrm{E}+00$ & 0.0000 & $0.000 \mathrm{E}+00$ & 0.0000 & $0.000 \mathrm{E}+00$ & 0.0000 & $0.000 \mathrm{E}+00$ & 0.0000 & $1.160 \mathrm{E}-01$ & 0.0347 \\
\hline 234 & $6.235 \mathrm{E}-05$ & 0.0000 & $1.761 \mathrm{E}-05$ & 0.0000 & $0.000 \mathrm{E}+00$ & 0.0000 & $0.000 \mathrm{E}+00$ & 0.0000 & $0.000 \mathrm{E}+00$ & 0.0000 & $0.000 \mathrm{E}+00$ & 0.0000 & $5.363 E-03$ & 0.0016 \\
\hline 35 & $1.153 \mathrm{E}-01$ & 0.0345 & $1.642 \mathrm{E}-05$ & 0.0000 & $0.000 \mathrm{E}+00$ & 0.0000 & $0.000 \mathrm{E}+00$ & 0.0000 & $0.000 \mathrm{E}+00$ & 0.0000 & $0.000 \mathrm{E}+00$ & 0.0000 & $5.278 E-03$ & 0.0016 \\
\hline 38 & $2.571 \mathrm{E}-02$ & 0.0077 & $1.495 \mathrm{E}-05$ & 0.0000 & $0.000 \mathrm{E}+00$ & 0.0000 & $0.000 \mathrm{E}+00$ & 0.0000 & $0.000 \mathrm{E}+00$ & 0.0000 & $0.000 \mathrm{E}+00$ & 0.0000 & $5.291 \mathrm{E}-03$ & 0.0016 \\
\hline & $3.073 E+00$ & 0.9204 & $1.423 \mathrm{E}-03$ & 0.0004 & $0.000 \mathrm{E}+00$ & 0.0000 & $0.000 \mathrm{E}+00$ & 0.0000 & $0.000 \mathrm{E}+00$ & 0.0000 & $0.000 \mathrm{E}+00$ & 0.0000 & $.642 \mathrm{E}-01$ & \\
\hline
\end{tabular}


RESRAD, Version $6.5 \quad \mathrm{~T}^{1 / 2}$ Limit $=180$ days

Summary : RESRAD Parameters for U-Landfill Worker

File : C: $\backslash$ RESRAD_FAMILY $\backslash R E S R A D \backslash U S E R F I L E S \backslash Q C F O R S R S G \backslash L A N F F I L L W O R K E R \_S R S G-M A Y 11 . R A D$

Total Dose Contributions TDOSE (i,p,t) for Individual Radionuclides (i) and Pathways (p) As mrem/yr and Fraction of Total Dose At $t=3.673 \mathrm{E}+01$ years

Water Dependent Pathways

\begin{tabular}{|c|c|c|c|c|c|c|c|c|c|c|c|c|c|c|}
\hline & \multicolumn{2}{|c|}{ Water } & \multicolumn{2}{|c|}{ Fish } & \multicolumn{2}{|c|}{ Radon } & \multicolumn{2}{|c|}{ Plant } & \multicolumn{2}{|c|}{ Meat } & \multicolumn{2}{|c|}{ Milk } & \multicolumn{2}{|c|}{ All Pathways* } \\
\hline clide & mrem/yr & fract. & mrem/yr & fract. & mrem/yr & fract. & mrem/yr & fract. & mrem/yr & fract. & mrem/yr & fract. & mrem/yr & fract. \\
\hline-241 & $0.000 \mathrm{E}+00$ & 0.0000 & $0.000 \mathrm{E}+00$ & 0.0000 & $0.000 \mathrm{E}+00$ & 0.0000 & $0.000 \mathrm{E}+00$ & 0.0000 & $0.000 \mathrm{E}+00$ & 0.0000 & $0.000 \mathrm{E}+00$ & 0.0000 & $2.687 \mathrm{E}-02$ & 0.0080 \\
\hline-137 & $0.000 \mathrm{E}+00$ & 0.0000 & $0.000 \mathrm{E}+00$ & 0.0000 & $0.000 \mathrm{E}+00$ & 0.0000 & $0.000 \mathrm{E}+00$ & 0.0000 & $0.000 \mathrm{E}+00$ & 0.0000 & $0.000 \mathrm{E}+00$ & 0.0000 & $2.249 \mathrm{E}-01$ & 0.0674 \\
\hline-237 & $0.000 \mathrm{E}+00$ & 0.0000 & $0.000 \mathrm{E}+00$ & 0.0000 & $0.000 \mathrm{E}+00$ & 0.0000 & $0.000 \mathrm{E}+00$ & 0.0000 & $0.000 \mathrm{E}+00$ & 0.0000 & $0.000 \mathrm{E}+00$ & 0.0000 & $1.805 \mathrm{E}-01$ & 0.0541 \\
\hline-238 & $0.000 \mathrm{E}+00$ & 0.0000 & $0.000 \mathrm{E}+00$ & 0.0000 & $0.000 \mathrm{E}+00$ & 0.0000 & $0.000 \mathrm{E}+00$ & 0.0000 & $0.000 \mathrm{E}+00$ & 0.0000 & $0.000 \mathrm{E}+00$ & 0.0000 & $1.904 \mathrm{E}-02$ & 0.0057 \\
\hline 239 & $0.000 \mathrm{E}+00$ & 0.0000 & $0.000 \mathrm{E}+00$ & 0.0000 & $0.000 \mathrm{E}+00$ & 0.0000 & $0.000 \mathrm{E}+00$ & 0.0000 & $0.000 \mathrm{E}+00$ & 0.0000 & $0.000 \mathrm{E}+00$ & 0.0000 & $2.777 \mathrm{E}-02$ & 0.0083 \\
\hline-240 & $0.000 \mathrm{E}+00$ & 0.0000 & $0.000 \mathrm{E}+00$ & 0.0000 & $0.000 \mathrm{E}+00$ & 0.0000 & $0.000 \mathrm{E}+00$ & 0.0000 & $0.000 \mathrm{E}+00$ & 0.0000 & $0.000 \mathrm{E}+00$ & 0.0000 & $2.766 \mathrm{E}-02$ & 0.0083 \\
\hline-99 & $0.000 \mathrm{E}+00$ & 0.0000 & $0.000 \mathrm{E}+00$ & 0.0000 & $0.000 \mathrm{E}+00$ & 0.0000 & $0.000 \mathrm{E}+00$ & 0.0000 & $0.000 \mathrm{E}+00$ & 0.0000 & $0.000 \mathrm{E}+00$ & 0.0000 & $5.993 E-05$ & 0.0000 \\
\hline-228 & $0.000 \mathrm{E}+00$ & 0.0000 & $0.000 \mathrm{E}+00$ & 0.0000 & $0.000 \mathrm{E}+00$ & 0.0000 & $0.000 \mathrm{E}+00$ & 0.0000 & $0.000 \mathrm{E}+00$ & 0.0000 & $0.000 \mathrm{E}+00$ & 0.0000 & $2.258 E-06$ & 0.0000 \\
\hline-230 & $0.000 \mathrm{E}+00$ & 0.0000 & $0.000 \mathrm{E}+00$ & 0.0000 & $0.000 \mathrm{E}+00$ & 0.0000 & $0.000 \mathrm{E}+00$ & 0.0000 & $0.000 \mathrm{E}+00$ & 0.0000 & $0.000 \mathrm{E}+00$ & 0.0000 & $5.342 \mathrm{E}-02$ & 0.0160 \\
\hline-232 & $0.000 \mathrm{E}+00$ & 0.0000 & $0.000 \mathrm{E}+00$ & 0.0000 & $0.000 \mathrm{E}+00$ & 0.0000 & $0.000 \mathrm{E}+00$ & 0.0000 & $0.000 \mathrm{E}+00$ & 0.0000 & $0.000 \mathrm{E}+00$ & 0.0000 & $2.622 \mathrm{E}+00$ & 0.7852 \\
\hline 34 & $0.000 \mathrm{E}+00$ & 0.0000 & $0.000 \mathrm{E}+00$ & 0.0000 & $0.000 \mathrm{E}+00$ & 0.0000 & $0.000 \mathrm{E}+00$ & 0.0000 & $0.000 \mathrm{E}+00$ & 0.0000 & $0.000 \mathrm{E}+00$ & 0.0000 & $5.443 E-03$ & 0.0016 \\
\hline 35 & $0.000 \mathrm{E}+00$ & 0.0000 & $0.000 \mathrm{E}+00$ & 0.0000 & $0.000 \mathrm{E}+00$ & 0.0000 & $0.000 \mathrm{E}+00$ & 0.0000 & $0.000 \mathrm{E}+00$ & 0.0000 & $0.000 \mathrm{E}+00$ & 0.0000 & $1.206 \mathrm{E}-01$ & 0.0361 \\
\hline 00 & $0.000 \mathrm{E}+00$ & 0.0000 & $0.000 \mathrm{E}+00$ & 0.0000 & $0.000 \mathrm{E}+00$ & 0.0000 & $0.000 \mathrm{E}+00$ & 0.0000 & $0.000 \mathrm{E}+00$ & 0.0000 & $0.000 \mathrm{E}+00$ & 0.0000 & $3.102 \mathrm{E}-02$ & 0.0093 \\
\hline & $0.000 \mathrm{E}+00$ & 0.0000 & $0.000 \mathrm{E}+00$ & 0.0000 & $0.000 \mathrm{E}+00$ & 0.0000 & $0.000 \mathrm{E}+00$ & 0.0000 & $0.000 \mathrm{E}+00$ & 0.0000 & $0.000 \mathrm{E}+00$ & 0.0000 & $\Xi+00$ & 1.0 \\
\hline
\end{tabular}

* Sum of all water independent and dependent pathways. 
RESRAD, Version 6.5

$\mathrm{T}^{1 / 2}$ Limit $=180$ days

07/21/2011 $17: 18 \quad$ Page 21

mmary : RESRAD Parameters for U-Landfill Worker

: C: \RESRAD_FAMILY \RESRAD \USERFILES \QCFORSRSG \LANFFILLWORKER_SRSG-MAY11.RAD

Total Dose Contributions TDOSE (i,p,t) for Individual Radionuclides (i) and Pathways (p) As mrem/yr and Fraction of Total Dose At $t=0.000 \mathrm{E}+00$ years

Water Independent Pathways (Inhalation excludes radon)

\begin{tabular}{|c|c|c|c|c|c|c|c|c|c|c|c|c|c|c|}
\hline \multirow{2}{*}{ Nuclide } & \multicolumn{2}{|c|}{ Ground } & \multicolumn{2}{|c|}{ Inhalation } & \multicolumn{2}{|c|}{ Radon } & \multicolumn{2}{|c|}{ Plant } & \multicolumn{2}{|c|}{ Meat } & \multicolumn{2}{|c|}{ Milk } & \multicolumn{2}{|c|}{ Soil } \\
\hline & mrem/yr & fract. & mrem/yr & fract. & mrem/yr & fract. & mrem/yr & fract. & mrem/yr & fract. & mrem/yr & fract. & mrem/yr & fract. \\
\hline-241 & $6.297 E-03$ & 0.0026 & $1.806 \mathrm{E}-04$ & 0.0001 & $0.000 \mathrm{E}+00$ & 0.0000 & $0.000 \mathrm{E}+00$ & 0.0000 & $0.000 \mathrm{E}+00$ & 0.0000 & $0.000 \mathrm{E}+00$ & 0.0000 & $2.202 \mathrm{E}-02$ & 0.0090 \\
\hline-137 & $5.248 E-01$ & 0.2138 & $7.257 \mathrm{E}-08$ & 0.0000 & $0.000 \mathrm{E}+00$ & 0.0000 & $0.000 \mathrm{E}+00$ & 0.0000 & $0.000 \mathrm{E}+00$ & 0.0000 & $0.000 \mathrm{E}+00$ & 0.0000 & $1.416 \mathrm{E}-03$ & 0.0006 \\
\hline-237 & $1.693 \mathrm{E}-01$ & 0.0690 & $9.411 \mathrm{E}-05$ & 0.0000 & $0.000 \mathrm{E}+00$ & 0.0000 & $0.000 \mathrm{E}+00$ & 0.0000 & $0.000 \mathrm{E}+00$ & 0.0000 & $0.000 \mathrm{E}+00$ & 0.0000 & 1. $222 \mathrm{E}-02$ & 0.0050 \\
\hline-238 & $1.972 \mathrm{E}-05$ & 0.0000 & $2.062 E-04$ & 0.0001 & $0.000 \mathrm{E}+00$ & 0.0000 & $0.000 \mathrm{E}+00$ & 0.0000 & $0.000 \mathrm{E}+00$ & 0.0000 & $0.000 \mathrm{E}+00$ & 0.0000 & $2.525 \mathrm{E}-02$ & 0.0103 \\
\hline-239 & $4.422 E-05$ & 0.0000 & $2.259 \mathrm{E}-04$ & 0.0001 & $0.000 \mathrm{E}+00$ & 0.0000 & $0.000 \mathrm{E}+00$ & 0.0000 & $0.000 \mathrm{E}+00$ & 0.0000 & $0.000 \mathrm{E}+00$ & 0.0000 & $2.755 \mathrm{E}-02$ & 0.0112 \\
\hline-240 & $1.913 \mathrm{E}-05$ & 0.0000 & $2.259 \mathrm{E}-04$ & 0.0001 & $0.000 \mathrm{E}+00$ & 0.0000 & $0.000 \mathrm{E}+00$ & 0.0000 & $0.000 \mathrm{E}+00$ & 0.0000 & $0.000 \mathrm{E}+00$ & 0.0000 & $2.755 \mathrm{E}-02$ & 0.0112 \\
\hline 99 & $1.820 \mathrm{E}-05$ & 0.0000 & $2.434 \mathrm{E}-08$ & 0.0000 & $0.000 \mathrm{E}+00$ & 0.0000 & $0.000 \mathrm{E}+00$ & 0.0000 & $0.000 \mathrm{E}+00$ & 0.0000 & $0.000 \mathrm{E}+00$ & 0.0000 & $7.016 \mathrm{E}-05$ & 0.0000 \\
\hline-228 & $1.347 \mathrm{E}+00$ & 0.5487 & $6.888 \mathrm{E}-05$ & 0.0000 & $0.000 \mathrm{E}+00$ & 0.0000 & $0.000 \mathrm{E}+00$ & 0.0000 & $0.000 \mathrm{E}+00$ & 0.0000 & $0.000 \mathrm{E}+00$ & 0.0000 & 1. $324 \mathrm{E}-02$ & 0.0054 \\
\hline-230 & $5.615 E-04$ & 0.0002 & $1.882 \mathrm{E}-04$ & 0.0001 & $0.000 \mathrm{E}+00$ & 0.0000 & $0.000 \mathrm{E}+00$ & 0.0000 & $0.000 \mathrm{E}+00$ & 0.0000 & $0.000 \mathrm{E}+00$ & 0.0000 & $2.315 \mathrm{E}-02$ & 0.0094 \\
\hline-232 & $6.493 E-02$ & 0.0264 & $2.093 E-04$ & 0.0001 & $0.000 \mathrm{E}+00$ & 0.0000 & $0.000 \mathrm{E}+00$ & 0.0000 & $0.000 \mathrm{E}+00$ & 0.0000 & $0.000 \mathrm{E}+00$ & 0.0000 & $2.986 \mathrm{E}-02$ & 0.0122 \\
\hline 234 & $5.806 \mathrm{E}-05$ & 0.0000 & $1.769 \mathrm{E}-05$ & 0.0000 & $0.000 \mathrm{E}+00$ & 0.0000 & $0.000 \mathrm{E}+00$ & 0.0000 & $0.000 \mathrm{E}+00$ & 0.0000 & $0.000 \mathrm{E}+00$ & 0.0000 & $5.399 \mathrm{E}-03$ & 0.0022 \\
\hline 35 & $1.161 \mathrm{E}-01$ & 0.0473 & 1. $600 \mathrm{E}-05$ & 0.0000 & $0.000 \mathrm{E}+00$ & 0.0000 & $0.000 \mathrm{E}+00$ & 0.0000 & $0.000 \mathrm{E}+00$ & 0.0000 & $0.000 \mathrm{E}+00$ & 0.0000 & $5.217 \mathrm{E}-03$ & 0.0021 \\
\hline 38 & $2.592 \mathrm{E}-02$ & 0.0106 & $1.507 \mathrm{E}-05$ & 0.0000 & $0.000 \mathrm{E}+00$ & 0.0000 & $0.000 \mathrm{E}+00$ & 0.0000 & $0.000 \mathrm{E}+00$ & 0.0000 & $0.000 \mathrm{E}+00$ & 0.0000 & $5.333 E-03$ & 0.0022 \\
\hline & $2.255 E+00$ & 0.9186 & $1.448 \mathrm{E}-03$ & 0.0006 & $0.000 \mathrm{E}+00$ & 0.0000 & $0.000 \mathrm{E}+00$ & 0.0000 & $0.000 \mathrm{E}+00$ & 0.0000 & $0.000 \mathrm{E}+00$ & 0.0000 & 1. $983 \mathrm{E}-01$ & 0.0808 \\
\hline
\end{tabular}

Total Dose Contributions TDOSE(i,p,t) for Individual Radionuclides (i) and Pathways (p) As mrem/yr and Fraction of Total Dose At $t=0.000 \mathrm{E}+00$ years

Water Dependent Pathways

\begin{tabular}{|c|c|c|c|c|c|c|c|c|c|c|c|c|c|c|}
\hline \multirow{2}{*}{$\begin{array}{l}\text { Radio- } \\
\text { Nuclide }\end{array}$} & \multicolumn{2}{|c|}{ Water } & \multicolumn{2}{|c|}{ Fish } & \multicolumn{2}{|c|}{ Radon } & \multicolumn{2}{|c|}{ Plant } & \multicolumn{2}{|c|}{ Meat } & \multicolumn{2}{|c|}{ Milk } & \multicolumn{2}{|c|}{ All Pathways* } \\
\hline & mrem/yr & fract. & mrem/yr & fract. & mrem/yr & fract. & mrem/yr & fract. & mrem/yr & fract. & mrem/yr & fract. & mrem/yr & fract. \\
\hline 241 & $0.000 \mathrm{E}+00$ & 0.0000 & $0.000 \mathrm{E}+00$ & 0.0000 & $0.000 \mathrm{E}+00$ & 0.0000 & $0.000 \mathrm{E}+00$ & 0.0000 & $0.000 \mathrm{E}+00$ & 0.0000 & $0.000 \mathrm{E}+00$ & 0.0000 & $2.850 \mathrm{E}-02$ & 0.0116 \\
\hline-137 & $0.000 \mathrm{E}+00$ & 0.0000 & $0.000 \mathrm{E}+00$ & 0.0000 & $0.000 \mathrm{E}+00$ & 0.0000 & $0.000 \mathrm{E}+00$ & 0.0000 & $0.000 \mathrm{E}+00$ & 0.0000 & $0.000 \mathrm{E}+00$ & 0.0000 & $5.262 \mathrm{E}-01$ & 0.2144 \\
\hline-237 & $0.000 \mathrm{E}+00$ & 0.0000 & $0.000 \mathrm{E}+00$ & 0.0000 & $0.000 \mathrm{E}+00$ & 0.0000 & $0.000 \mathrm{E}+00$ & 0.0000 & $0.000 \mathrm{E}+00$ & 0.0000 & $0.000 \mathrm{E}+00$ & 0.0000 & $1.816 \mathrm{E}-01$ & 0.0740 \\
\hline-238 & $0.000 \mathrm{E}+00$ & 0.0000 & $0.000 \mathrm{E}+00$ & 0.0000 & $0.000 \mathrm{E}+00$ & 0.0000 & $0.000 \mathrm{E}+00$ & 0.0000 & $0.000 \mathrm{E}+00$ & 0.0000 & $0.000 \mathrm{E}+00$ & 0.0000 & $2.547 \mathrm{E}-02$ & 0.0104 \\
\hline-239 & $0.000 \mathrm{E}+00$ & 0.0000 & $0.000 \mathrm{E}+00$ & 0.0000 & $0.000 \mathrm{E}+00$ & 0.0000 & $0.000 \mathrm{E}+00$ & 0.0000 & $0.000 \mathrm{E}+00$ & 0.0000 & $0.000 \mathrm{E}+00$ & 0.0000 & $2.782 \mathrm{E}-02$ & 0.0113 \\
\hline-240 & $0.000 \mathrm{E}+00$ & 0.0000 & $0.000 \mathrm{E}+00$ & 0.0000 & $0.000 \mathrm{E}+00$ & 0.0000 & $0.000 \mathrm{E}+00$ & 0.0000 & $0.000 \mathrm{E}+00$ & 0.0000 & $0.000 E+00$ & 0.0000 & $2.779 \mathrm{E}-02$ & 0.0113 \\
\hline 99 & $0.000 \mathrm{E}+00$ & 0.0000 & $0.000 \mathrm{E}+00$ & 0.0000 & $0.000 \mathrm{E}+00$ & 0.0000 & $0.000 \mathrm{E}+00$ & 0.0000 & $0.000 \mathrm{E}+00$ & 0.0000 & $0.000 \mathrm{E}+00$ & 0.0000 & $8.838 E-05$ & 0.0000 \\
\hline-228 & $0.000 \mathrm{E}+00$ & 0.0000 & $0.000 \mathrm{E}+00$ & 0.0000 & $0.000 \mathrm{E}+00$ & 0.0000 & $0.000 \mathrm{E}+00$ & 0.0000 & $0.000 \mathrm{E}+00$ & 0.0000 & $0.000 \mathrm{E}+00$ & 0.0000 & $1.360 \mathrm{E}+00$ & 0.5542 \\
\hline-230 & $0.000 \mathrm{E}+00$ & 0.0000 & $0.000 \mathrm{E}+00$ & 0.0000 & $0.000 \mathrm{E}+00$ & 0.0000 & $0.000 \mathrm{E}+00$ & 0.0000 & $0.000 \mathrm{E}+00$ & 0.0000 & $0.000 E+00$ & 0.0000 & $2.390 \mathrm{E}-02$ & 0.0097 \\
\hline 232 & $0.000 \mathrm{E}+00$ & 0.0000 & $0.000 \mathrm{E}+00$ & 0.0000 & $0.000 \mathrm{E}+00$ & 0.0000 & $0.000 \mathrm{E}+00$ & 0.0000 & $0.000 \mathrm{E}+00$ & 0.0000 & $0.000 \mathrm{E}+00$ & 0.0000 & $9.499 \mathrm{E}-02$ & 0.0387 \\
\hline 34 & $0.000 \mathrm{E}+00$ & 0.0000 & $0.000 \mathrm{E}+00$ & 0.0000 & $0.000 \mathrm{E}+00$ & 0.0000 & $0.000 \mathrm{E}+00$ & 0.0000 & $0.000 \mathrm{E}+00$ & 0.0000 & $0.000 \mathrm{E}+00$ & 0.0000 & $5.475 E-03$ & 0.0022 \\
\hline 35 & $0.000 \mathrm{E}+00$ & 0.0000 & $0.000 \mathrm{E}+00$ & 0.0000 & $0.000 \mathrm{E}+00$ & 0.0000 & $0.000 \mathrm{E}+00$ & 0.0000 & $0.000 \mathrm{E}+00$ & 0.0000 & $0.000 \mathrm{E}+00$ & 0.0000 & $1.213 \mathrm{E}-01$ & 0.0494 \\
\hline 38 & $0.000 \mathrm{E}+00$ & 0.0000 & $0.000 \mathrm{E}+00$ & 0.0000 & $0.000 \mathrm{E}+00$ & 0.0000 & $0.000 \mathrm{E}+00$ & 0.0000 & $0.000 \mathrm{E}+00$ & 0.0000 & $0.000 \mathrm{E}+00$ & 0.0000 & $3.127 \mathrm{E}-02$ & 0.0127 \\
\hline & $0.000 \mathrm{E}+00$ & 0.0000 & $0.000 \mathrm{E}+00$ & 0.0000 & $0.000 \mathrm{E}+00$ & 0.0000 & $0.000 \mathrm{E}+00$ & 0.0000 & $0.000 \mathrm{E}+00$ & 0.0000 & $0.000 \mathrm{E}+00$ & 0.0000 & $.455 E+00$ & 1. \\
\hline
\end{tabular}

* Sum of all water independent and dependent pathways. 
RESRAD, Version 6.5

$\mathrm{T}^{1 / 2}$ Limit = 180 days

07/21/2011 17:18 Page 22

umary : RESRAD Parameters for U-Landfill Worker

: C: \RESRAD_FAMILY \RESRAD \USERFILES \QCFORSRSG \LANFFILLWORKER_SRSG-MAY11.RAD

Total Dose Contributions TDOSE(i,p,t) for Individual Radionuclides (i) and Pathways (p) As mrem/yr and Fraction of Total Dose At $t=1.000 \mathrm{E}+00$ years

Water Independent Pathways (Inhalation excludes radon)

\begin{tabular}{|c|c|c|c|c|c|c|c|c|c|c|c|c|c|c|}
\hline \multirow{2}{*}{ Nuclide } & \multicolumn{2}{|c|}{ Ground } & \multicolumn{2}{|c|}{ Inhalation } & \multicolumn{2}{|c|}{ Radon } & \multicolumn{2}{|c|}{ Plant } & \multicolumn{2}{|c|}{ Meat } & \multicolumn{2}{|c|}{ Milk } & \multicolumn{2}{|c|}{ Soil } \\
\hline & mrem/yr & fract. & mrem/yr & fract. & mrem/yr & fract. & mrem/yr & fract. & mrem/yr & fract. & mrem/yr & fract. & mrem/yr & fract. \\
\hline-241 & $6.287 E-03$ & 0.0029 & $1.803 \mathrm{E}-04$ & 0.0001 & $0.000 \mathrm{E}+00$ & 0.0000 & $0.000 \mathrm{E}+00$ & 0.0000 & $0.000 \mathrm{E}+00$ & 0.0000 & $0.000 \mathrm{E}+00$ & 0.0000 & $2.199 \mathrm{E}-02$ & 0.0100 \\
\hline-137 & $5.128 E-01$ & 0.2339 & $7.091 \mathrm{E}-08$ & 0.0000 & $0.000 \mathrm{E}+00$ & 0.0000 & $0.000 \mathrm{E}+00$ & 0.0000 & $0.000 \mathrm{E}+00$ & 0.0000 & $0.000 \mathrm{E}+00$ & 0.0000 & $1.384 \mathrm{E}-03$ & 0.0006 \\
\hline-237 & $1.693 \mathrm{E}-01$ & 0.0772 & $9.410 \mathrm{E}-05$ & 0.0000 & $0.000 \mathrm{E}+00$ & 0.0000 & $0.000 \mathrm{E}+00$ & 0.0000 & $0.000 \mathrm{E}+00$ & 0.0000 & $0.000 \mathrm{E}+00$ & 0.0000 & 1. $222 \mathrm{E}-02$ & 0.0056 \\
\hline-238 & $1.956 \mathrm{E}-05$ & 0.0000 & $2.046 E-04$ & 0.0001 & $0.000 \mathrm{E}+00$ & 0.0000 & $0.000 \mathrm{E}+00$ & 0.0000 & $0.000 \mathrm{E}+00$ & 0.0000 & $0.000 \mathrm{E}+00$ & 0.0000 & $2.505 E-02$ & 0.0114 \\
\hline-239 & $4.422 E-05$ & 0.0000 & $2.259 \mathrm{E}-04$ & 0.0001 & $0.000 \mathrm{E}+00$ & 0.0000 & $0.000 \mathrm{E}+00$ & 0.0000 & $0.000 \mathrm{E}+00$ & 0.0000 & $0.000 \mathrm{E}+00$ & 0.0000 & $2.755 E-02$ & 0.0126 \\
\hline-240 & $1.913 \mathrm{E}-05$ & 0.0000 & $2.258 \mathrm{E}-04$ & 0.0001 & $0.000 \mathrm{E}+00$ & 0.0000 & $0.000 \mathrm{E}+00$ & 0.0000 & $0.000 \mathrm{E}+00$ & 0.0000 & $0.000 \mathrm{E}+00$ & 0.0000 & $2.754 \mathrm{E}-02$ & 0.0126 \\
\hline 99 & $1.801 E-05$ & 0.0000 & $2.408 E-08$ & 0.0000 & $0.000 \mathrm{E}+00$ & 0.0000 & $0.000 \mathrm{E}+00$ & 0.0000 & $0.000 \mathrm{E}+00$ & 0.0000 & $0.000 \mathrm{E}+00$ & 0.0000 & $6.942 \mathrm{E}-05$ & 0.0000 \\
\hline-228 & $9.377 \mathrm{E}-01$ & 0.4277 & $4.794 \mathrm{E}-05$ & 0.0000 & $0.000 \mathrm{E}+00$ & 0.0000 & $0.000 \mathrm{E}+00$ & 0.0000 & $0.000 \mathrm{E}+00$ & 0.0000 & $0.000 \mathrm{E}+00$ & 0.0000 & $9.218 E-03$ & 0.0042 \\
\hline 230 & 1. $323 E-03$ & 0.0006 & $1.882 \mathrm{E}-04$ & 0.0001 & $0.000 \mathrm{E}+00$ & 0.0000 & $0.000 \mathrm{E}+00$ & 0.0000 & $0.000 \mathrm{E}+00$ & 0.0000 & $0.000 \mathrm{E}+00$ & 0.0000 & $2.317 \mathrm{E}-02$ & 0.0106 \\
\hline-232 & $2.188 E-01$ & 0.0998 & $2.153 E-04$ & 0.0001 & $0.000 \mathrm{E}+00$ & 0.0000 & $0.000 \mathrm{E}+00$ & 0.0000 & $0.000 \mathrm{E}+00$ & 0.0000 & $0.000 \mathrm{E}+00$ & 0.0000 & $3.852 \mathrm{E}-02$ & 0.0176 \\
\hline 234 & $5.806 E-05$ & 0.0000 & $1.769 \mathrm{E}-05$ & 0.0000 & $0.000 \mathrm{E}+00$ & 0.0000 & $0.000 \mathrm{E}+00$ & 0.0000 & $0.000 \mathrm{E}+00$ & 0.0000 & $0.000 \mathrm{E}+00$ & 0.0000 & $5.398 E-03$ & 0.0025 \\
\hline 35 & $1.161 \mathrm{E}-01$ & 0.0529 & 1. $600 \mathrm{E}-05$ & 0.0000 & $0.000 \mathrm{E}+00$ & 0.0000 & $0.000 \mathrm{E}+00$ & 0.0000 & $0.000 \mathrm{E}+00$ & 0.0000 & $0.000 \mathrm{E}+00$ & 0.0000 & $5.218 \mathrm{E}-03$ & 0.0024 \\
\hline 38 & $2.592 \mathrm{E}-02$ & 0.0118 & $1.507 \mathrm{E}-05$ & 0.0000 & $0.000 \mathrm{E}+00$ & 0.0000 & $0.000 \mathrm{E}+00$ & 0.0000 & $0.000 \mathrm{E}+00$ & 0.0000 & $0.000 \mathrm{E}+00$ & 0.0000 & $5.332 \mathrm{E}-03$ & 0.0024 \\
\hline & $1.988 \mathrm{E}+00$ & 0.9069 & $1.431 \mathrm{E}-03$ & 0.0007 & $0.000 \mathrm{E}+00$ & 0.0000 & $0.000 \mathrm{E}+00$ & 0.0000 & $0.000 \mathrm{E}+00$ & 0.0000 & $0.000 \mathrm{E}+00$ & 0.0000 & $.026 \mathrm{E}-01$ & 0.0924 \\
\hline
\end{tabular}

Total Dose Contributions TDOSE(i,p,t) for Individual Radionuclides (i) and Pathways (p) As mrem/yr and Fraction of Total Dose At $t=1.000 \mathrm{E}+00$ years

Water Dependent Pathways

\begin{tabular}{|c|c|c|c|c|c|c|c|c|c|c|c|c|c|c|}
\hline & \multicolumn{2}{|c|}{ Water } & \multicolumn{2}{|c|}{ Fish } & \multicolumn{2}{|c|}{ Radon } & \multicolumn{2}{|c|}{ Plant } & \multicolumn{2}{|c|}{ Meat } & \multicolumn{2}{|c|}{ Milk } & \multicolumn{2}{|c|}{ All Pathways* } \\
\hline clide & mrem/yr & fract. & mrem/yr & fract. & mrem/yr & fract. & mrem/yr & fract. & mrem/yr & fract. & mrem/yr & fract. & mrem/yr & fract. \\
\hline-241 & $0.000 \mathrm{E}+00$ & 0.0000 & $0.000 \mathrm{E}+00$ & 0.0000 & $0.000 \mathrm{E}+00$ & 0.0000 & $0.000 \mathrm{E}+00$ & 0.0000 & $0.000 \mathrm{E}+00$ & 0.0000 & $0.000 \mathrm{E}+00$ & 0.0000 & $2.845 E-02$ & 0.0130 \\
\hline-137 & $0.000 \mathrm{E}+00$ & 0.0000 & $0.000 \mathrm{E}+00$ & 0.0000 & $0.000 \mathrm{E}+00$ & 0.0000 & $0.000 \mathrm{E}+00$ & 0.0000 & $0.000 \mathrm{E}+00$ & 0.0000 & $0.000 \mathrm{E}+00$ & 0.0000 & $5.142 \mathrm{E}-01$ & 0.2345 \\
\hline-237 & $0.000 \mathrm{E}+00$ & 0.0000 & $0.000 \mathrm{E}+00$ & 0.0000 & $0.000 \mathrm{E}+00$ & 0.0000 & $0.000 \mathrm{E}+00$ & 0.0000 & $0.000 \mathrm{E}+00$ & 0.0000 & $0.000 \mathrm{E}+00$ & 0.0000 & $1.816 \mathrm{E}-01$ & 0.0828 \\
\hline 238 & $0.000 \mathrm{E}+00$ & 0.0000 & $0.000 \mathrm{E}+00$ & 0.0000 & $0.000 \mathrm{E}+00$ & 0.0000 & $0.000 \mathrm{E}+00$ & 0.0000 & $0.000 \mathrm{E}+00$ & 0.0000 & $0.000 \mathrm{E}+00$ & 0.0000 & $2.527 \mathrm{E}-02$ & 0.0115 \\
\hline 239 & $0.000 \mathrm{E}+00$ & 0.0000 & $0.000 \mathrm{E}+00$ & 0.0000 & $0.000 \mathrm{E}+00$ & 0.0000 & $0.000 \mathrm{E}+00$ & 0.0000 & $0.000 \mathrm{E}+00$ & 0.0000 & $0.000 \mathrm{E}+00$ & 0.0000 & $2.782 \mathrm{E}-02$ & 0.0127 \\
\hline 240 & $0.000 \mathrm{E}+00$ & 0.0000 & $0.000 \mathrm{E}+00$ & 0.0000 & $0.000 \mathrm{E}+00$ & 0.0000 & $0.000 \mathrm{E}+00$ & 0.0000 & $0.000 \mathrm{E}+00$ & 0.0000 & $0.000 \mathrm{E}+00$ & 0.0000 & $2.779 \mathrm{E}-02$ & 0.0127 \\
\hline 99 & $0.000 \mathrm{E}+00$ & 0.0000 & $0.000 \mathrm{E}+00$ & 0.0000 & $0.000 \mathrm{E}+00$ & 0.0000 & $0.000 \mathrm{E}+00$ & 0.0000 & $0.000 \mathrm{E}+00$ & 0.0000 & $0.000 \mathrm{E}+00$ & 0.0000 & $8.745 E-05$ & 0.0000 \\
\hline 228 & $0.000 \mathrm{E}+00$ & 0.0000 & $0.000 \mathrm{E}+00$ & 0.0000 & $0.000 \mathrm{E}+00$ & 0.0000 & $0.000 \mathrm{E}+00$ & 0.0000 & $0.000 \mathrm{E}+00$ & 0.0000 & $0.000 \mathrm{E}+00$ & 0.0000 & $9.469 \mathrm{E}-01$ & 0.4319 \\
\hline 230 & $0.000 \mathrm{E}+00$ & 0.0000 & $0.000 \mathrm{E}+00$ & 0.0000 & $0.000 \mathrm{E}+00$ & 0.0000 & $0.000 \mathrm{E}+00$ & 0.0000 & $0.000 \mathrm{E}+00$ & 0.0000 & $0.000 \mathrm{E}+00$ & 0.0000 & $2.468 E-02$ & 0.0113 \\
\hline 232 & $0.000 \mathrm{E}+00$ & 0.0000 & $0.000 \mathrm{E}+00$ & 0.0000 & $0.000 \mathrm{E}+00$ & 0.0000 & $0.000 \mathrm{E}+00$ & 0.0000 & $0.000 \mathrm{E}+00$ & 0.0000 & $0.000 \mathrm{E}+00$ & 0.0000 & $2.576 \mathrm{E}-01$ & 0.1175 \\
\hline & $0.000 \mathrm{E}+00$ & 0.0000 & $0.000 \mathrm{E}+00$ & 0.0000 & $0.000 \mathrm{E}+00$ & 0.0000 & $0.000 \mathrm{E}+00$ & 0.0000 & $0.000 \mathrm{E}+00$ & 0.0000 & $0.000 \mathrm{E}+00$ & 0.0000 & $5.474 \mathrm{E}-03$ & 0.0025 \\
\hline 35 & $0.000 \mathrm{E}+00$ & 0.0000 & $0.000 \mathrm{E}+00$ & 0.0000 & $0.000 \mathrm{E}+00$ & 0.0000 & $0.000 \mathrm{E}+00$ & 0.0000 & $0.000 \mathrm{E}+00$ & 0.0000 & $0.000 \mathrm{E}+00$ & 0.0000 & $1.213 \mathrm{E}-01$ & 0.0553 \\
\hline 38 & $0.000 \mathrm{E}+00$ & 0.0000 & $0.000 \mathrm{E}+00$ & 0.0000 & $0.000 \mathrm{E}+00$ & 0.0000 & $0.000 \mathrm{E}+00$ & 0.0000 & $0.000 \mathrm{E}+00$ & 0.0000 & $0.000 \mathrm{E}+00$ & 0.0000 & $3.127 \mathrm{E}-02$ & 0.0143 \\
\hline & $0.000 \mathrm{E}+00$ & 0.0000 & $0.000 \mathrm{E}+00$ & 0.0000 & $0.000 \mathrm{E}+00$ & 0.0000 & $0.000 \mathrm{E}+00$ & 0.0000 & $0.000 \mathrm{E}+00$ & 0.0000 & $0.000 E+00$ & 000 & +00 & 1.0000 \\
\hline
\end{tabular}

* Sum of all water independent and dependent pathways. 
RESRAD, Version 6.5

$\mathrm{T}^{1 / 2}$ Limit $=180$ days

mmary : RESRAD Parameters for U-Landfill Worker

File : C: \RESRAD FAMILY \RESRAD \USERFILES $\backslash Q C F O R S R S G \backslash L A N F F I L L W O R K E R \quad S R S G-M A Y 11 . R A D$

Total Dose Contributions TDOSE (i,p,t) for Individual Radionuclides (i) and Pathways (p) As mrem/yr and Fraction of Total Dose At $t=2.500 \mathrm{E}+01$ years

Water Independent Pathways (Inhalation excludes radon)

\begin{tabular}{|c|c|c|c|c|c|c|c|c|c|c|c|c|c|c|}
\hline \multirow{2}{*}{ Nuclide } & \multicolumn{2}{|c|}{ Ground } & \multicolumn{2}{|c|}{ Inhalation } & \multicolumn{2}{|c|}{ Radon } & \multicolumn{2}{|c|}{ Plant } & \multicolumn{2}{|c|}{ Meat } & \multicolumn{2}{|c|}{ Milk } & \multicolumn{2}{|c|}{ Soil } \\
\hline & mrem/yr & fract. & mrem/yr & fract. & mrem/yr & fract. & mrem/yr & fract. & mrem/yr & fract. & mrem/yr & fract. & mrem/yr & fract. \\
\hline-241 & $6.050 E-03$ & 0.0018 & $1.734 \mathrm{E}-04$ & 0.0001 & $0.000 \mathrm{E}+00$ & 0.0000 & $0.000 \mathrm{E}+00$ & 0.0000 & $0.000 \mathrm{E}+00$ & 0.0000 & $0.000 \mathrm{E}+00$ & 0.0000 & $2.115 \mathrm{E}-02$ & 0.0064 \\
\hline-137 & $2.943 E-01$ & 0.0896 & $4.069 \mathrm{E}-08$ & 0.0000 & $0.000 \mathrm{E}+00$ & 0.0000 & $0.000 \mathrm{E}+00$ & 0.0000 & $0.000 \mathrm{E}+00$ & 0.0000 & $0.000 \mathrm{E}+00$ & 0.0000 & $7.940 \mathrm{E}-04$ & 0.0002 \\
\hline-237 & $1.686 \mathrm{E}-01$ & 0.0514 & $9.374 \mathrm{E}-05$ & 0.0000 & $0.000 \mathrm{E}+00$ & 0.0000 & $0.000 \mathrm{E}+00$ & 0.0000 & $0.000 \mathrm{E}+00$ & 0.0000 & $0.000 \mathrm{E}+00$ & 0.0000 & $1.217 \mathrm{E}-02$ & 0.0037 \\
\hline-238 & $1.618 E-05$ & 0.0000 & $1.692 \mathrm{E}-04$ & 0.0001 & $0.000 \mathrm{E}+00$ & 0.0000 & $0.000 \mathrm{E}+00$ & 0.0000 & $0.000 \mathrm{E}+00$ & 0.0000 & $0.000 \mathrm{E}+00$ & 0.0000 & $2.071 E-02$ & 0.0063 \\
\hline-239 & $4.417 E-05$ & 0.0000 & $2.256 \mathrm{E}-04$ & 0.0001 & $0.000 \mathrm{E}+00$ & 0.0000 & $0.000 \mathrm{E}+00$ & 0.0000 & $0.000 \mathrm{E}+00$ & 0.0000 & $0.000 \mathrm{E}+00$ & 0.0000 & $2.752 E-02$ & 0.0084 \\
\hline-240 & $1.907 \mathrm{E}-05$ & 0.0000 & $2.251 \mathrm{E}-04$ & 0.0001 & $0.000 \mathrm{E}+00$ & 0.0000 & $0.000 \mathrm{E}+00$ & 0.0000 & $0.000 \mathrm{E}+00$ & 0.0000 & $0.000 \mathrm{E}+00$ & 0.0000 & $2.746 \mathrm{E}-02$ & 0.0084 \\
\hline 99 & $1.397 \mathrm{E}-05$ & 0.0000 & $1.868 \mathrm{E}-08$ & 0.0000 & $0.000 \mathrm{E}+00$ & 0.0000 & $0.000 \mathrm{E}+00$ & 0.0000 & $0.000 \mathrm{E}+00$ & 0.0000 & $0.000 \mathrm{E}+00$ & 0.0000 & $5.385 E-05$ & 0.0000 \\
\hline-228 & $1.569 \mathrm{E}-04$ & 0.0000 & $8.021 \mathrm{E}-09$ & 0.0000 & $0.000 \mathrm{E}+00$ & 0.0000 & $0.000 \mathrm{E}+00$ & 0.0000 & $0.000 \mathrm{E}+00$ & 0.0000 & $0.000 \mathrm{E}+00$ & 0.0000 & $1.542 \mathrm{E}-06$ & 0.0000 \\
\hline-230 & $1.947 \mathrm{E}-02$ & 0.0059 & $1.884 \mathrm{E}-04$ & 0.0001 & $0.000 \mathrm{E}+00$ & 0.0000 & $0.000 \mathrm{E}+00$ & 0.0000 & $0.000 \mathrm{E}+00$ & 0.0000 & $0.000 \mathrm{E}+00$ & 0.0000 & $2.418 \mathrm{E}-02$ & 0.0074 \\
\hline-232 & $2.389 \mathrm{E}+00$ & 0.7277 & $3.121 \mathrm{E}-04$ & 0.0001 & $0.000 \mathrm{E}+00$ & 0.0000 & $0.000 \mathrm{E}+00$ & 0.0000 & $0.000 \mathrm{E}+00$ & 0.0000 & $0.000 \mathrm{E}+00$ & 0.0000 & $1.125 \mathrm{E}-01$ & 0.0343 \\
\hline 34 & $5.999 E-05$ & 0.0000 & $1.764 \mathrm{E}-05$ & 0.0000 & $0.000 \mathrm{E}+00$ & 0.0000 & $0.000 \mathrm{E}+00$ & 0.0000 & $0.000 \mathrm{E}+00$ & 0.0000 & $0.000 \mathrm{E}+00$ & 0.0000 & $5.374 \mathrm{E}-03$ & 0.0016 \\
\hline 35 & $1.155 \mathrm{E}-01$ & 0.0352 & 1. $623 \mathrm{E}-05$ & 0.0000 & $0.000 \mathrm{E}+00$ & 0.0000 & $0.000 \mathrm{E}+00$ & 0.0000 & $0.000 \mathrm{E}+00$ & 0.0000 & $0.000 \mathrm{E}+00$ & 0.0000 & $5.252 \mathrm{E}-03$ & 0.0016 \\
\hline 38 & $2.578 E-02$ & 0.0079 & $1.499 \mathrm{E}-05$ & 0.0000 & $0.000 \mathrm{E}+00$ & 0.0000 & $0.000 \mathrm{E}+00$ & 0.0000 & $0.000 \mathrm{E}+00$ & 0.0000 & $0.000 \mathrm{E}+00$ & 0.0000 & $5.304 \mathrm{E}-03$ & 0.0016 \\
\hline & $3.019 \mathrm{E}+00$ & 0.9196 & $1.437 \mathrm{E}-03$ & 0.0004 & $0.000 \mathrm{E}+00$ & 0.0000 & $0.000 \mathrm{E}+00$ & 0.0000 & $0.000 \mathrm{E}+00$ & 0.0000 & $0.000 \mathrm{E}+00$ & 0.0000 & $.625 E-01$ & 0.0800 \\
\hline
\end{tabular}

Total Dose Contributions TDOSE(i,p,t) for Individual Radionuclides (i) and Pathways (p) As mrem/yr and Fraction of Total Dose At $t=2.500 \mathrm{E}+01$ years

Water Dependent Pathways

\begin{tabular}{|c|c|c|c|c|c|c|c|c|c|c|c|c|c|c|}
\hline \multirow{2}{*}{$\begin{array}{l}\text { Radio- } \\
\text { Nuclide }\end{array}$} & \multicolumn{2}{|c|}{ Water } & \multicolumn{2}{|c|}{ Fish } & \multicolumn{2}{|c|}{ Radon } & \multicolumn{2}{|c|}{ Plant } & \multicolumn{2}{|c|}{ Meat } & \multicolumn{2}{|c|}{ Milk } & \multicolumn{2}{|c|}{ All Pathways* } \\
\hline & mrem/yr & fract. & mrem/yr & fract. & mrem/yr & fract. & mrem/yr & fract. & mrem/yr & fract. & mrem/yr & fract. & mrem/yr & fract. \\
\hline 241 & $0.000 \mathrm{E}+00$ & 0.0000 & $0.000 \mathrm{E}+00$ & 0.0000 & $0.000 \mathrm{E}+00$ & 0.0000 & $0.000 \mathrm{E}+00$ & 0.0000 & $0.000 \mathrm{E}+00$ & 0.0000 & $0.000 \mathrm{E}+00$ & 0.0000 & $2.738 \mathrm{E}-02$ & 0.0083 \\
\hline-137 & $0.000 \mathrm{E}+00$ & 0.0000 & $0.000 \mathrm{E}+00$ & 0.0000 & $0.000 \mathrm{E}+00$ & 0.0000 & $0.000 \mathrm{E}+00$ & 0.0000 & $0.000 \mathrm{E}+00$ & 0.0000 & $0.000 \mathrm{E}+00$ & 0.0000 & $2.950 \mathrm{E}-01$ & 0.0899 \\
\hline-237 & $0.000 \mathrm{E}+00$ & 0.0000 & $0.000 \mathrm{E}+00$ & 0.0000 & $0.000 \mathrm{E}+00$ & 0.0000 & $0.000 \mathrm{E}+00$ & 0.0000 & $0.000 \mathrm{E}+00$ & 0.0000 & $0.000 \mathrm{E}+00$ & 0.0000 & $1.809 \mathrm{E}-01$ & 0.0551 \\
\hline-238 & $0.000 \mathrm{E}+00$ & 0.0000 & $0.000 \mathrm{E}+00$ & 0.0000 & $0.000 \mathrm{E}+00$ & 0.0000 & $0.000 \mathrm{E}+00$ & 0.0000 & $0.000 \mathrm{E}+00$ & 0.0000 & $0.000 \mathrm{E}+00$ & 0.0000 & $2.090 \mathrm{E}-02$ & 0.0064 \\
\hline-239 & $0.000 \mathrm{E}+00$ & 0.0000 & $0.000 \mathrm{E}+00$ & 0.0000 & $0.000 \mathrm{E}+00$ & 0.0000 & $0.000 \mathrm{E}+00$ & 0.0000 & $0.000 \mathrm{E}+00$ & 0.0000 & $0.000 E+00$ & 0.0000 & $2.779 E-02$ & 0.0085 \\
\hline-240 & $0.000 \mathrm{E}+00$ & 0.0000 & $0.000 \mathrm{E}+00$ & 0.0000 & $0.000 \mathrm{E}+00$ & 0.0000 & $0.000 \mathrm{E}+00$ & 0.0000 & $0.000 \mathrm{E}+00$ & 0.0000 & $0.000 E+00$ & 0.0000 & $2.771 \mathrm{E}-02$ & 0.0084 \\
\hline-99 & $0.000 \mathrm{E}+00$ & 0.0000 & $0.000 \mathrm{E}+00$ & 0.0000 & $0.000 \mathrm{E}+00$ & 0.0000 & $0.000 \mathrm{E}+00$ & 0.0000 & $0.000 \mathrm{E}+00$ & 0.0000 & $0.000 \mathrm{E}+00$ & 0.0000 & $6.784 \mathrm{E}-05$ & 0.0000 \\
\hline-228 & $0.000 \mathrm{E}+00$ & 0.0000 & $0.000 \mathrm{E}+00$ & 0.0000 & $0.000 \mathrm{E}+00$ & 0.0000 & $0.000 \mathrm{E}+00$ & 0.0000 & $0.000 \mathrm{E}+00$ & 0.0000 & $0.000 \mathrm{E}+00$ & 0.0000 & $1.584 \mathrm{E}-04$ & 0.0000 \\
\hline-230 & $0.000 \mathrm{E}+00$ & 0.0000 & $0.000 \mathrm{E}+00$ & 0.0000 & $0.000 \mathrm{E}+00$ & 0.0000 & $0.000 \mathrm{E}+00$ & 0.0000 & $0.000 \mathrm{E}+00$ & 0.0000 & $0.000 E+00$ & 0.0000 & $4.384 \mathrm{E}-02$ & 0.0134 \\
\hline 232 & $0.000 \mathrm{E}+00$ & 0.0000 & $0.000 \mathrm{E}+00$ & 0.0000 & $0.000 \mathrm{E}+00$ & 0.0000 & $0.000 \mathrm{E}+00$ & 0.0000 & $0.000 \mathrm{E}+00$ & 0.0000 & $0.000 \mathrm{E}+00$ & 0.0000 & $2.502 \mathrm{E}+00$ & 0.7621 \\
\hline 34 & $0.000 \mathrm{E}+00$ & 0.0000 & $0.000 \mathrm{E}+00$ & 0.0000 & $0.000 \mathrm{E}+00$ & 0.0000 & $0.000 \mathrm{E}+00$ & 0.0000 & $0.000 \mathrm{E}+00$ & 0.0000 & $0.000 \mathrm{E}+00$ & 0.0000 & $5.452 \mathrm{E}-03$ & 0.0017 \\
\hline 35 & $0.000 \mathrm{E}+00$ & 0.0000 & $0.000 \mathrm{E}+00$ & 0.0000 & $0.000 \mathrm{E}+00$ & 0.0000 & $0.000 \mathrm{E}+00$ & 0.0000 & $0.000 \mathrm{E}+00$ & 0.0000 & $0.000 \mathrm{E}+00$ & 0.0000 & $1.208 \mathrm{E}-01$ & 0.0368 \\
\hline 38 & $0.000 \mathrm{E}+00$ & 0.0000 & $0.000 \mathrm{E}+00$ & 0.0000 & $0.000 \mathrm{E}+00$ & 0.0000 & $0.000 \mathrm{E}+00$ & 0.0000 & $0.000 \mathrm{E}+00$ & 0.0000 & $0.000 \mathrm{E}+00$ & 0.0000 & $3.110 \mathrm{E}-02$ & 0.0095 \\
\hline & $0.000 \mathrm{E}+00$ & 0.0000 & $0.000 \mathrm{E}+00$ & 0.0000 & $0.000 \mathrm{E}+00$ & 0.0000 & $0.000 \mathrm{E}+00$ & 0.0000 & $0.000 \mathrm{E}+00$ & 0.0000 & $0.000 \mathrm{E}+00$ & 0.0000 & $3.283 E+00$ & 1.0000 \\
\hline
\end{tabular}

* Sum of all water independent and dependent pathways. 
RESRAD, Version 6.5

$\mathrm{T}^{1 / 2}$ Limit = 180 days

07/21/2011 17:18 Page 24

mmary : RESRAD Parameters for U-Landfill Worker

: C: \RESRAD_FAMILY \RESRAD \USERFILES \QCFORSRSG \LANFFILLWORKER_SRSG-MAY11.RAD

Total Dose Contributions TDOSE (i,p,t) for Individual Radionuclides (i) and Pathways (p) As mrem/yr and Fraction of Total Dose At $t=5.000 \mathrm{E}+01$ years

Water Independent Pathways (Inhalation excludes radon)

\begin{tabular}{|c|c|c|c|c|c|c|c|c|c|c|c|c|c|c|}
\hline \multirow{2}{*}{ Nuclide } & \multicolumn{2}{|c|}{ Ground } & \multicolumn{2}{|c|}{ Inhalation } & \multicolumn{2}{|c|}{ Radon } & \multicolumn{2}{|c|}{ Plant } & \multicolumn{2}{|c|}{ Meat } & \multicolumn{2}{|c|}{ Milk } & \multicolumn{2}{|c|}{ Soil } \\
\hline & mrem/yr & fract. & mrem/yr & fract. & mrem/yr & fract. & mrem/yr & fract. & mrem/yr & fract. & mrem/yr & fract. & mrem/yr & fract. \\
\hline-241 & $5.812 \mathrm{E}-03$ & 0.0018 & $1.666 \mathrm{E}-04$ & 0.0001 & $0.000 \mathrm{E}+00$ & 0.0000 & $0.000 \mathrm{E}+00$ & 0.0000 & $0.000 \mathrm{E}+00$ & 0.0000 & $0.000 \mathrm{E}+00$ & 0.0000 & $2.032 \mathrm{E}-02$ & 0.0061 \\
\hline-137 & $1.650 \mathrm{E}-01$ & 0.0497 & $2.281 \mathrm{E}-08$ & 0.0000 & $0.000 \mathrm{E}+00$ & 0.0000 & $0.000 \mathrm{E}+00$ & 0.0000 & $0.000 \mathrm{E}+00$ & 0.0000 & $0.000 \mathrm{E}+00$ & 0.0000 & $4.452 \mathrm{E}-04$ & 0.0001 \\
\hline-237 & $1.680 \mathrm{E}-01$ & 0.0506 & $9.338 \mathrm{E}-05$ & 0.0000 & $0.000 \mathrm{E}+00$ & 0.0000 & $0.000 \mathrm{E}+00$ & 0.0000 & $0.000 \mathrm{E}+00$ & 0.0000 & $0.000 \mathrm{E}+00$ & 0.0000 & $1.212 \mathrm{E}-02$ & 0.0037 \\
\hline-238 & $1.328 E-05$ & 0.0000 & $1.388 E-04$ & 0.0000 & $0.000 \mathrm{E}+00$ & 0.0000 & $0.000 \mathrm{E}+00$ & 0.0000 & $0.000 \mathrm{E}+00$ & 0.0000 & $0.000 \mathrm{E}+00$ & 0.0000 & $1.699 \mathrm{E}-02$ & 0.0051 \\
\hline-239 & $4.412 E-05$ & 0.0000 & $2.253 \mathrm{E}-04$ & 0.0001 & $0.000 \mathrm{E}+00$ & 0.0000 & $0.000 \mathrm{E}+00$ & 0.0000 & $0.000 \mathrm{E}+00$ & 0.0000 & $0.000 \mathrm{E}+00$ & 0.0000 & $2.748 E-02$ & 0.0083 \\
\hline-240 & $1.901 \mathrm{E}-05$ & 0.0000 & $2.244 \mathrm{E}-04$ & 0.0001 & $0.000 \mathrm{E}+00$ & 0.0000 & $0.000 \mathrm{E}+00$ & 0.0000 & $0.000 \mathrm{E}+00$ & 0.0000 & $0.000 \mathrm{E}+00$ & 0.0000 & $2.738 \mathrm{E}-02$ & 0.0083 \\
\hline 99 & $1.072 \mathrm{E}-05$ & 0.0000 & $1.434 \mathrm{E}-08$ & 0.0000 & $0.000 \mathrm{E}+00$ & 0.0000 & $0.000 \mathrm{E}+00$ & 0.0000 & $0.000 \mathrm{E}+00$ & 0.0000 & $0.000 \mathrm{E}+00$ & 0.0000 & $4.134 \mathrm{E}-05$ & 0.0000 \\
\hline-228 & $1.827 \mathrm{E}-08$ & 0.0000 & $9.341 \mathrm{E}-13$ & 0.0000 & $0.000 \mathrm{E}+00$ & 0.0000 & $0.000 \mathrm{E}+00$ & 0.0000 & $0.000 \mathrm{E}+00$ & 0.0000 & $0.000 \mathrm{E}+00$ & 0.0000 & $1.796 \mathrm{E}-10$ & 0.0000 \\
\hline-230 & $3.811 \mathrm{E}-02$ & 0.0115 & $1.887 \mathrm{E}-04$ & 0.0001 & $0.000 \mathrm{E}+00$ & 0.0000 & $0.000 \mathrm{E}+00$ & 0.0000 & $0.000 \mathrm{E}+00$ & 0.0000 & $0.000 \mathrm{E}+00$ & 0.0000 & $2.602 \mathrm{E}-02$ & 0.0078 \\
\hline-232 & $2.535 E+00$ & 0.7641 & $3.188 E-04$ & 0.0001 & $0.000 \mathrm{E}+00$ & 0.0000 & $0.000 \mathrm{E}+00$ & 0.0000 & $0.000 \mathrm{E}+00$ & 0.0000 & $0.000 \mathrm{E}+00$ & 0.0000 & $1.169 \mathrm{E}-01$ & 0.0352 \\
\hline 234 & $6.612 \mathrm{E}-05$ & 0.0000 & $1.758 \mathrm{E}-05$ & 0.0000 & $0.000 \mathrm{E}+00$ & 0.0000 & $0.000 \mathrm{E}+00$ & 0.0000 & $0.000 \mathrm{E}+00$ & 0.0000 & $0.000 \mathrm{E}+00$ & 0.0000 & $5.350 \mathrm{E}-03$ & 0.0016 \\
\hline 35 & $1.150 \mathrm{E}-01$ & 0.0347 & $1.667 \mathrm{E}-05$ & 0.0000 & $0.000 \mathrm{E}+00$ & 0.0000 & $0.000 \mathrm{E}+00$ & 0.0000 & $0.000 \mathrm{E}+00$ & 0.0000 & $0.000 \mathrm{E}+00$ & 0.0000 & $5.312 \mathrm{E}-03$ & 0.0016 \\
\hline 38 & $2.564 \mathrm{E}-02$ & 0.0077 & $1.491 \mathrm{E}-05$ & 0.0000 & $0.000 \mathrm{E}+00$ & 0.0000 & $0.000 \mathrm{E}+00$ & 0.0000 & $0.000 \mathrm{E}+00$ & 0.0000 & $0.000 \mathrm{E}+00$ & 0.0000 & $5.275 E-03$ & 0.0016 \\
\hline & $3.053 E+00$ & 0.9201 & $1.405 \mathrm{E}-03$ & 0.0004 & $0.000 \mathrm{E}+00$ & 0.0000 & $0.000 \mathrm{E}+00$ & 0.0000 & $0.000 \mathrm{E}+00$ & 0.0000 & $0.000 \mathrm{E}+00$ & 0.0000 & $.636 \mathrm{E}-01$ & 0.0195 \\
\hline
\end{tabular}

Total Dose Contributions TDOSE(i,p,t) for Individual Radionuclides (i) and Pathways (p) As mrem/yr and Fraction of Total Dose At $t=5.000 \mathrm{E}+01$ years

Water Dependent Pathways

\begin{tabular}{|c|c|c|c|c|c|c|c|c|c|c|c|c|c|c|}
\hline & \multicolumn{2}{|c|}{ Water } & \multicolumn{2}{|c|}{ Fish } & \multicolumn{2}{|c|}{ Radon } & \multicolumn{2}{|c|}{ Plant } & \multicolumn{2}{|c|}{ Meat } & \multicolumn{2}{|c|}{ Milk } & \multicolumn{2}{|c|}{ All Pathways* } \\
\hline clide & mrem/yr & fract. & mrem/yr & fract. & mrem/yr & fract. & mrem/yr & fract. & mrem/yr & fract. & mrem/yr & fract. & mrem/yr & fract. \\
\hline-241 & $0.000 \mathrm{E}+00$ & 0.0000 & $0.000 \mathrm{E}+00$ & 0.0000 & $0.000 \mathrm{E}+00$ & 0.0000 & $0.000 \mathrm{E}+00$ & 0.0000 & $0.000 \mathrm{E}+00$ & 0.0000 & $0.000 \mathrm{E}+00$ & 0.0000 & $2.630 \mathrm{E}-02$ & 0.0079 \\
\hline-137 & $0.000 \mathrm{E}+00$ & 0.0000 & $0.000 \mathrm{E}+00$ & 0.0000 & $0.000 \mathrm{E}+00$ & 0.0000 & $0.000 \mathrm{E}+00$ & 0.0000 & $0.000 \mathrm{E}+00$ & 0.0000 & $0.000 \mathrm{E}+00$ & 0.0000 & $1.654 \mathrm{E}-01$ & 0.0499 \\
\hline-237 & $0.000 \mathrm{E}+00$ & 0.0000 & $0.000 \mathrm{E}+00$ & 0.0000 & $0.000 \mathrm{E}+00$ & 0.0000 & $0.000 \mathrm{E}+00$ & 0.0000 & $0.000 \mathrm{E}+00$ & 0.0000 & $0.000 \mathrm{E}+00$ & 0.0000 & $1.802 \mathrm{E}-01$ & 0.0543 \\
\hline 238 & $0.000 \mathrm{E}+00$ & 0.0000 & $0.000 \mathrm{E}+00$ & 0.0000 & $0.000 \mathrm{E}+00$ & 0.0000 & $0.000 \mathrm{E}+00$ & 0.0000 & $0.000 \mathrm{E}+00$ & 0.0000 & $0.000 \mathrm{E}+00$ & 0.0000 & $1.714 \mathrm{E}-02$ & 0.0052 \\
\hline 239 & $0.000 \mathrm{E}+00$ & 0.0000 & $0.000 \mathrm{E}+00$ & 0.0000 & $0.000 \mathrm{E}+00$ & 0.0000 & $0.000 \mathrm{E}+00$ & 0.0000 & $0.000 \mathrm{E}+00$ & 0.0000 & $0.000 \mathrm{E}+00$ & 0.0000 & $2.775 \mathrm{E}-02$ & 0.0084 \\
\hline 240 & $0.000 \mathrm{E}+00$ & 0.0000 & $0.000 \mathrm{E}+00$ & 0.0000 & $0.000 \mathrm{E}+00$ & 0.0000 & $0.000 \mathrm{E}+00$ & 0.0000 & $0.000 \mathrm{E}+00$ & 0.0000 & $0.000 \mathrm{E}+00$ & 0.0000 & $2.762 \mathrm{E}-02$ & 0.0083 \\
\hline 99 & $0.000 \mathrm{E}+00$ & 0.0000 & $0.000 \mathrm{E}+00$ & 0.0000 & $0.000 \mathrm{E}+00$ & 0.0000 & $0.000 \mathrm{E}+00$ & 0.0000 & $0.000 \mathrm{E}+00$ & 0.0000 & $0.000 \mathrm{E}+00$ & 0.0000 & $5.208 E-05$ & 0.0000 \\
\hline 228 & $0.000 \mathrm{E}+00$ & 0.0000 & $0.000 \mathrm{E}+00$ & 0.0000 & $0.000 \mathrm{E}+00$ & 0.0000 & $0.000 \mathrm{E}+00$ & 0.0000 & $0.000 \mathrm{E}+00$ & 0.0000 & $0.000 \mathrm{E}+00$ & 0.0000 & $1.845 \mathrm{E}-08$ & 0.0000 \\
\hline 230 & $0.000 \mathrm{E}+00$ & 0.0000 & $0.000 \mathrm{E}+00$ & 0.0000 & $0.000 \mathrm{E}+00$ & 0.0000 & $0.000 \mathrm{E}+00$ & 0.0000 & $0.000 \mathrm{E}+00$ & 0.0000 & $0.000 \mathrm{E}+00$ & 0.0000 & $6.432 \mathrm{E}-02$ & 0.0194 \\
\hline 232 & $0.000 \mathrm{E}+00$ & 0.0000 & $0.000 \mathrm{E}+00$ & 0.0000 & $0.000 \mathrm{E}+00$ & 0.0000 & $0.000 \mathrm{E}+00$ & 0.0000 & $0.000 \mathrm{E}+00$ & 0.0000 & $0.000 \mathrm{E}+00$ & 0.0000 & $2.652 \mathrm{E}+00$ & 0.7994 \\
\hline & $0.000 \mathrm{E}+00$ & 0.0000 & $0.000 \mathrm{E}+00$ & 0.0000 & $0.000 \mathrm{E}+00$ & 0.0000 & $0.000 \mathrm{E}+00$ & 0.0000 & $0.000 \mathrm{E}+00$ & 0.0000 & $0.000 \mathrm{E}+00$ & 0.0000 & $5.434 \mathrm{E}-03$ & 0.0016 \\
\hline 35 & $0.000 \mathrm{E}+00$ & 0.0000 & $0.000 \mathrm{E}+00$ & 0.0000 & $0.000 \mathrm{E}+00$ & 0.0000 & $0.000 \mathrm{E}+00$ & 0.0000 & $0.000 \mathrm{E}+00$ & 0.0000 & $0.000 \mathrm{E}+00$ & 0.0000 & $1.203 E-01$ & 0.0363 \\
\hline 38 & $0.000 \mathrm{E}+00$ & 0.0000 & $0.000 \mathrm{E}+00$ & 0.0000 & $0.000 \mathrm{E}+00$ & 0.0000 & $0.000 \mathrm{E}+00$ & 0.0000 & $0.000 \mathrm{E}+00$ & 0.0000 & $0.000 \mathrm{E}+00$ & 0.0000 & $3.093 E-02$ & 0.0093 \\
\hline & $0.000 \mathrm{E}+00$ & 0.0000 & $0.000 \mathrm{E}+00$ & 0.0000 & $0.000 \mathrm{E}+00$ & 0.0000 & $0.000 \mathrm{E}+00$ & 0.0000 & $0.000 \mathrm{E}+00$ & 0.0000 & $0.000 E+00$ & 000 & +00 & 1.0000 \\
\hline
\end{tabular}

* Sum of all water independent and dependent pathways. 
RESRAD, Version 6.5

$\mathrm{T}^{1 / 2}$ Limit = 180 days

07/21/2011 $17: 18$ Page 25

ummary : RESRAD Parameters for U-Landfill Worker

: C: \RESRAD_FAMILY \RESRAD \USERFILES \QCFORSRSG \LANFFILLWORKER_SRSG-MAY11.RAD

Total Dose Contributions TDOSE (i,p,t) for Individual Radionuclides (i) and Pathways (p) As mrem/yr and Fraction of Total Dose At $t=7.000 \mathrm{E}+01$ years

Water Independent Pathways (Inhalation excludes radon)

\begin{tabular}{|c|c|c|c|c|c|c|c|c|c|c|c|c|c|c|}
\hline \multirow{2}{*}{ Nuclide } & \multicolumn{2}{|c|}{ Ground } & \multicolumn{2}{|c|}{ Inhalation } & \multicolumn{2}{|c|}{ Radon } & \multicolumn{2}{|c|}{ Plant } & \multicolumn{2}{|c|}{ Meat } & \multicolumn{2}{|c|}{ Milk } & \multicolumn{2}{|c|}{ Soil } \\
\hline & mrem/yr & fract. & mrem/yr & fract. & mrem/yr & fract. & mrem/yr & fract. & mrem/yr & fract. & mrem/yr & fract. & mrem/yr & fract. \\
\hline-241 & $5.629 \mathrm{E}-03$ & 0.0017 & 1. $613 \mathrm{E}-04$ & 0.0000 & $0.000 \mathrm{E}+00$ & 0.0000 & $0.000 \mathrm{E}+00$ & 0.0000 & $0.000 \mathrm{E}+00$ & 0.0000 & $0.000 \mathrm{E}+00$ & 0.0000 & $1.968 \mathrm{E}-02$ & 0.0060 \\
\hline-137 & $1.038 E-01$ & 0.0317 & $1.436 \mathrm{E}-08$ & 0.0000 & $0.000 \mathrm{E}+00$ & 0.0000 & $0.000 \mathrm{E}+00$ & 0.0000 & $0.000 \mathrm{E}+00$ & 0.0000 & $0.000 \mathrm{E}+00$ & 0.0000 & $2.802 \mathrm{E}-04$ & 0.0001 \\
\hline-237 & $1.674 \mathrm{E}-01$ & 0.0511 & $9.308 \mathrm{E}-05$ & 0.0000 & $0.000 \mathrm{E}+00$ & 0.0000 & $0.000 \mathrm{E}+00$ & 0.0000 & $0.000 \mathrm{E}+00$ & 0.0000 & $0.000 \mathrm{E}+00$ & 0.0000 & $1.208 \mathrm{E}-02$ & 0.0037 \\
\hline-238 & $1.134 \mathrm{E}-05$ & 0.0000 & $1.185 E-04$ & 0.0000 & $0.000 \mathrm{E}+00$ & 0.0000 & $0.000 \mathrm{E}+00$ & 0.0000 & $0.000 \mathrm{E}+00$ & 0.0000 & $0.000 \mathrm{E}+00$ & 0.0000 & $1.450 \mathrm{E}-02$ & 0.0044 \\
\hline-239 & $4.408 E-05$ & 0.0000 & $2.251 \mathrm{E}-04$ & 0.0001 & $0.000 \mathrm{E}+00$ & 0.0000 & $0.000 \mathrm{E}+00$ & 0.0000 & $0.000 \mathrm{E}+00$ & 0.0000 & $0.000 \mathrm{E}+00$ & 0.0000 & $2.746 \mathrm{E}-02$ & 0.0084 \\
\hline-240 & $1.897 \mathrm{E}-05$ & 0.0000 & $2.239 \mathrm{E}-04$ & 0.0001 & $0.000 \mathrm{E}+00$ & 0.0000 & $0.000 \mathrm{E}+00$ & 0.0000 & $0.000 \mathrm{E}+00$ & 0.0000 & $0.000 \mathrm{E}+00$ & 0.0000 & $2.731 E-02$ & 0.0083 \\
\hline 99 & $8.680 E-06$ & 0.0000 & $1.161 \mathrm{E}-08$ & 0.0000 & $0.000 \mathrm{E}+00$ & 0.0000 & $0.000 \mathrm{E}+00$ & 0.0000 & $0.000 \mathrm{E}+00$ & 0.0000 & $0.000 \mathrm{E}+00$ & 0.0000 & $3.346 \mathrm{E}-05$ & 0.0000 \\
\hline-228 & 1. $302 \mathrm{E}-11$ & 0.0000 & $6.658 \mathrm{E}-16$ & 0.0000 & $0.000 \mathrm{E}+00$ & 0.0000 & $0.000 \mathrm{E}+00$ & 0.0000 & $0.000 \mathrm{E}+00$ & 0.0000 & $0.000 \mathrm{E}+00$ & 0.0000 & $1.280 \mathrm{E}-13$ & 0.0000 \\
\hline-230 & $5.281 \mathrm{E}-02$ & 0.0161 & $1.889 \mathrm{E}-04$ & 0.0001 & $0.000 \mathrm{E}+00$ & 0.0000 & $0.000 \mathrm{E}+00$ & 0.0000 & $0.000 \mathrm{E}+00$ & 0.0000 & $0.000 \mathrm{E}+00$ & 0.0000 & $2.776 \mathrm{E}-02$ & 0.0085 \\
\hline-232 & $2.542 \mathrm{E}+00$ & 0.7760 & $3.191 \mathrm{E}-04$ & 0.0001 & $0.000 \mathrm{E}+00$ & 0.0000 & $0.000 \mathrm{E}+00$ & 0.0000 & $0.000 \mathrm{E}+00$ & 0.0000 & $0.000 \mathrm{E}+00$ & 0.0000 & $1.171 \mathrm{E}-01$ & 0.0357 \\
\hline 234 & $7.400 \mathrm{E}-05$ & 0.0000 & $1.753 \mathrm{E}-05$ & 0.0000 & $0.000 \mathrm{E}+00$ & 0.0000 & $0.000 \mathrm{E}+00$ & 0.0000 & $0.000 \mathrm{E}+00$ & 0.0000 & $0.000 \mathrm{E}+00$ & 0.0000 & $5.331 \mathrm{E}-03$ & 0.0016 \\
\hline 35 & $1.146 \mathrm{E}-01$ & 0.0350 & $1.708 \mathrm{E}-05$ & 0.0000 & $0.000 \mathrm{E}+00$ & 0.0000 & $0.000 \mathrm{E}+00$ & 0.0000 & $0.000 \mathrm{E}+00$ & 0.0000 & $0.000 \mathrm{E}+00$ & 0.0000 & $5.368 \mathrm{E}-03$ & 0.0016 \\
\hline 38 & $2.553 E-02$ & 0.0078 & $1.484 \mathrm{E}-05$ & 0.0000 & $0.000 \mathrm{E}+00$ & 0.0000 & $0.000 \mathrm{E}+00$ & 0.0000 & $0.000 \mathrm{E}+00$ & 0.0000 & $0.000 \mathrm{E}+00$ & 0.0000 & $5.252 \mathrm{E}-03$ & 0.0016 \\
\hline & $3.012 \mathrm{E}+00$ & 0.9196 & $1.379 \mathrm{E}-03$ & 0.0004 & $0.000 \mathrm{E}+00$ & 0.0000 & $0.000 \mathrm{E}+00$ & 0.0000 & $0.000 \mathrm{E}+00$ & 0.0000 & $0.000 \mathrm{E}+00$ & 0.0000 & $.621 \mathrm{E}-01$ & 0.0800 \\
\hline
\end{tabular}

Total Dose Contributions TDOSE(i,p,t) for Individual Radionuclides (i) and Pathways (p) As mrem/yr and Fraction of Total Dose At $t=7.000 \mathrm{E}+01$ years

Water Dependent Pathways

\begin{tabular}{|c|c|c|c|c|c|c|c|c|c|c|c|c|c|c|}
\hline \multirow{2}{*}{$\begin{array}{l}\text { Radio- } \\
\text { Nuclide }\end{array}$} & \multicolumn{2}{|c|}{ Water } & \multicolumn{2}{|c|}{ Fish } & \multicolumn{2}{|c|}{ Radon } & \multicolumn{2}{|c|}{ Plant } & \multicolumn{2}{|c|}{ Meat } & \multicolumn{2}{|c|}{ Milk } & \multicolumn{2}{|c|}{ All Pathways* } \\
\hline & mrem/yr & fract. & mrem/yr & fract. & mrem/yr & fract. & mrem/yr & fract. & mrem/yr & fract. & mrem/yr & fract. & mrem/yr & fract. \\
\hline 241 & $0.000 \mathrm{E}+00$ & 0.0000 & $0.000 \mathrm{E}+00$ & 0.0000 & $0.000 \mathrm{E}+00$ & 0.0000 & $0.000 \mathrm{E}+00$ & 0.0000 & $0.000 \mathrm{E}+00$ & 0.0000 & $0.000 \mathrm{E}+00$ & 0.0000 & $2.547 \mathrm{E}-02$ & 0.0078 \\
\hline-137 & $0.000 \mathrm{E}+00$ & 0.0000 & $0.000 \mathrm{E}+00$ & 0.0000 & $0.000 \mathrm{E}+00$ & 0.0000 & $0.000 \mathrm{E}+00$ & 0.0000 & $0.000 \mathrm{E}+00$ & 0.0000 & $0.000 \mathrm{E}+00$ & 0.0000 & $1.041 \mathrm{E}-01$ & 0.0318 \\
\hline-237 & $0.000 \mathrm{E}+00$ & 0.0000 & $0.000 \mathrm{E}+00$ & 0.0000 & $0.000 \mathrm{E}+00$ & 0.0000 & $0.000 \mathrm{E}+00$ & 0.0000 & $0.000 \mathrm{E}+00$ & 0.0000 & $0.000 \mathrm{E}+00$ & 0.0000 & $1.796 \mathrm{E}-01$ & 0.0548 \\
\hline-238 & $0.000 \mathrm{E}+00$ & 0.0000 & $0.000 \mathrm{E}+00$ & 0.0000 & $0.000 \mathrm{E}+00$ & 0.0000 & $0.000 \mathrm{E}+00$ & 0.0000 & $0.000 \mathrm{E}+00$ & 0.0000 & $0.000 \mathrm{E}+00$ & 0.0000 & $1.463 \mathrm{E}-02$ & 0.0045 \\
\hline-239 & $0.000 \mathrm{E}+00$ & 0.0000 & $0.000 \mathrm{E}+00$ & 0.0000 & $0.000 \mathrm{E}+00$ & 0.0000 & $0.000 \mathrm{E}+00$ & 0.0000 & $0.000 \mathrm{E}+00$ & 0.0000 & $0.000 E+00$ & 0.0000 & $2.772 \mathrm{E}-02$ & 0.0085 \\
\hline-240 & $0.000 \mathrm{E}+00$ & 0.0000 & $0.000 \mathrm{E}+00$ & 0.0000 & $0.000 \mathrm{E}+00$ & 0.0000 & $0.000 \mathrm{E}+00$ & 0.0000 & $0.000 \mathrm{E}+00$ & 0.0000 & $0.000 E+00$ & 0.0000 & $2.755 \mathrm{E}-02$ & 0.0084 \\
\hline 99 & $0.000 \mathrm{E}+00$ & 0.0000 & $0.000 \mathrm{E}+00$ & 0.0000 & $0.000 \mathrm{E}+00$ & 0.0000 & $0.000 \mathrm{E}+00$ & 0.0000 & $0.000 \mathrm{E}+00$ & 0.0000 & $0.000 \mathrm{E}+00$ & 0.0000 & $4.215 \mathrm{E}-05$ & 0.0000 \\
\hline-228 & $0.000 \mathrm{E}+00$ & 0.0000 & $0.000 \mathrm{E}+00$ & 0.0000 & $0.000 \mathrm{E}+00$ & 0.0000 & $0.000 \mathrm{E}+00$ & 0.0000 & $0.000 \mathrm{E}+00$ & 0.0000 & $0.000 \mathrm{E}+00$ & 0.0000 & 1. $315 \mathrm{E}-11$ & 0.0000 \\
\hline-230 & $0.000 \mathrm{E}+00$ & 0.0000 & $0.000 \mathrm{E}+00$ & 0.0000 & $0.000 \mathrm{E}+00$ & 0.0000 & $0.000 \mathrm{E}+00$ & 0.0000 & $0.000 \mathrm{E}+00$ & 0.0000 & $0.000 E+00$ & 0.0000 & $8.077 \mathrm{E}-02$ & 0.0247 \\
\hline 232 & $0.000 \mathrm{E}+00$ & 0.0000 & $0.000 \mathrm{E}+00$ & 0.0000 & $0.000 \mathrm{E}+00$ & 0.0000 & $0.000 \mathrm{E}+00$ & 0.0000 & $0.000 \mathrm{E}+00$ & 0.0000 & $0.000 \mathrm{E}+00$ & 0.0000 & $2.659 \mathrm{E}+00$ & 0.8119 \\
\hline 34 & $0.000 \mathrm{E}+00$ & 0.0000 & $0.000 \mathrm{E}+00$ & 0.0000 & $0.000 \mathrm{E}+00$ & 0.0000 & $0.000 \mathrm{E}+00$ & 0.0000 & $0.000 \mathrm{E}+00$ & 0.0000 & $0.000 \mathrm{E}+00$ & 0.0000 & $5.422 \mathrm{E}-03$ & 0.0017 \\
\hline 35 & $0.000 \mathrm{E}+00$ & 0.0000 & $0.000 \mathrm{E}+00$ & 0.0000 & $0.000 \mathrm{E}+00$ & 0.0000 & $0.000 \mathrm{E}+00$ & 0.0000 & $0.000 \mathrm{E}+00$ & 0.0000 & $0.000 \mathrm{E}+00$ & 0.0000 & $1.200 \mathrm{E}-01$ & 0.0366 \\
\hline 38 & $0.000 \mathrm{E}+00$ & 0.0000 & $0.000 \mathrm{E}+00$ & 0.0000 & $0.000 \mathrm{E}+00$ & 0.0000 & $0.000 \mathrm{E}+00$ & 0.0000 & $0.000 \mathrm{E}+00$ & 0.0000 & $0.000 \mathrm{E}+00$ & 0.0000 & $3.079 \mathrm{E}-02$ & 0.0094 \\
\hline & $0.000 \mathrm{E}+00$ & 0.0000 & $0.000 \mathrm{E}+00$ & 0.0000 & $0.000 \mathrm{E}+00$ & 0.0000 & $0.000 \mathrm{E}+00$ & 0.0000 & $0.000 \mathrm{E}+00$ & 0.0000 & $0.000 \mathrm{E}+00$ & 0.0000 & $75 E+00$ & 1.0000 \\
\hline
\end{tabular}

* Sum of all water independent and dependent pathways. 
RESRAD, Version $6.5 \quad \mathrm{~T}^{1 / 2}$ Limit $=180$ days

Summary : RESRAD Parameters for U-Landfill Worker

File : C: $\backslash$ RESRAD_FAMILY $\backslash$ RESRAD \USERFILES $\backslash Q C F O R S R S G \backslash L A N F F I L L W O R K E R \_S R S G-M A Y 11 . R A D$

Dose/Source Ratios Summed Over All Pathways

Parent and Progeny Principal Radionuclide Contributions Indicated

Parent Product Thread DSR $(j, t)$ At Time in Years (mrem/yr)/(pCi/g)

(i) (j) Fraction $0.000 \mathrm{E}+001.000 \mathrm{E}+00 \quad 2.500 \mathrm{E}+01 \quad 5.000 \mathrm{E}+01 \quad 7.000 \mathrm{E}+01$

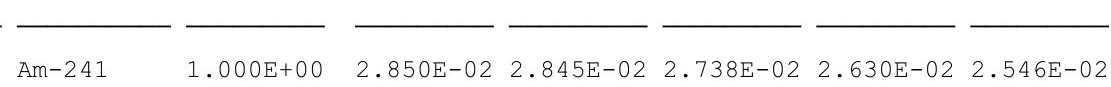

$\begin{array}{lllllll}\mathrm{Np}-237+\mathrm{D} & 1.000 \mathrm{E}+00 & 2.940 \mathrm{E}-08 & 8.812 \mathrm{E}-08 & 1.467 \mathrm{E}-06 & 2.842 \mathrm{E}-06 & 3.898 \mathrm{E}-06\end{array}$

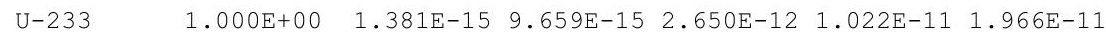

$\begin{array}{lllllll}\text { Th-229+D } & 1.000 \mathrm{E}+00 & 1.757 \mathrm{E}-18 & 2.634 \mathrm{E}-17 & 1.151 \mathrm{E}-13 & 8.819 \mathrm{E}-13 & 2.375 \mathrm{E}-12\end{array}$

$\begin{array}{llllll}\operatorname{DDSR}(j) & 2.850 \mathrm{E}-02 & 2.845 \mathrm{E}-02 & 2.738 \mathrm{E}-02 & 2.630 \mathrm{E}-02 & 2.547 \mathrm{E}-02\end{array}$

Cs-137+D $\quad 1.000 \mathrm{E}+00 \quad 5.262 \mathrm{E}-01 \quad 5.142 \mathrm{E}-01 \quad 2.950 \mathrm{E}-01 \quad 1.654 \mathrm{E}-01 \quad 1.041 \mathrm{E}-01$

$\mathrm{Np}-237+\mathrm{D} \quad 1.000 \mathrm{E}+00 \quad 1.816 \mathrm{E}-01 \quad 1.816 \mathrm{E}-01 \quad 1.809 \mathrm{E}-01 \quad 1.802 \mathrm{E}-01 \quad 1.796 \mathrm{E}-01$

$\begin{array}{lllllll}\mathrm{U}-233 & 1.000 \mathrm{E}+00 & 1.279 \mathrm{E}-08 & 3.837 \mathrm{E}-08 & 6.493 \mathrm{E}-07 & 1.280 \mathrm{E}-06 & 1.780 \mathrm{E}-06\end{array}$

$\begin{array}{llllllll}\mathrm{Th}-229+\mathrm{D} & 1.000 \mathrm{E}+00 & 2.170 \mathrm{E}-11 & 1.519 \mathrm{E}-10 & 4.217 \mathrm{E}-08 & 1.647 \mathrm{E}-07 & 3.200 \mathrm{E}-07\end{array}$

$\operatorname{LDSR}(j) \quad 1.816 \mathrm{E}-01 \quad 1.816 \mathrm{E}-01 \quad 1.809 \mathrm{E}-01 \quad 1.802 \mathrm{E}-01 \quad 1.796 \mathrm{E}-01$

$\begin{array}{lllllll}\mathrm{Pu}-238 & 1.840 \mathrm{E}-09 & 4.687 \mathrm{E}-11 & 4.650 \mathrm{E}-11 & 3.845 \mathrm{E}-11 & 3.154 \mathrm{E}-11 & 2.692 \mathrm{E}-11\end{array}$

$\begin{array}{llllllll}\mathrm{Pu}-238 & 1.000 \mathrm{E}+00 & 2.547 \mathrm{E}-02 & 2.527 \mathrm{E}-02 & 2.090 \mathrm{E}-02 & 1.714 \mathrm{E}-02 & 1.463 \mathrm{E}-02\end{array}$

$\begin{array}{lllllll}\mathrm{U}-234 & 1.000 \mathrm{E}+00 & 7.741 \mathrm{E}-09 & 2.314 \mathrm{E}-08 & 3.574 \mathrm{E}-07 & 6.422 \mathrm{E}-07 & 8.314 \mathrm{E}-07\end{array}$

$\begin{array}{llllllll}\text { Th-230 } 1.000 \mathrm{E}+00 & 9.980 \mathrm{E}-14 & 6.969 \mathrm{E}-13 & 1.822 \mathrm{E}-10 & 6.698 \mathrm{E}-10 & 1.241 \mathrm{E}-09\end{array}$

Ra-226+D $\quad 1.000 \mathrm{E}+00 \quad 8.233 \mathrm{E}-16 \quad 1.233 \mathrm{E}-14 \quad 5.179 \mathrm{E}-11 \quad 3.815 \mathrm{E}-10 \quad 9.962 \mathrm{E}-10$

$\begin{array}{llllllll}\mathrm{Pb}-210+\mathrm{D} & 1.000 \mathrm{E}+00 & 5.966 \mathrm{E}-19 & 1.837 \mathrm{E}-17 & 1.044 \mathrm{E}-12 & 1.342 \mathrm{E}-11 & 4.456 \mathrm{E}-11\end{array}$

$\operatorname{LDSR}(j) \quad 2.547 \mathrm{E}-02 \quad 2.527 \mathrm{E}-02 \quad 2.090 \mathrm{E}-02 \quad 1.714 \mathrm{E}-02 \quad 1.463 \mathrm{E}-02$

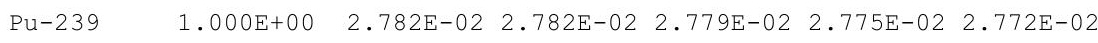

$\begin{array}{lllllll}\mathrm{U}-235+\mathrm{D} & 1.000 \mathrm{E}+00 & 5.975 \mathrm{E}-11 & 1.792 \mathrm{E}-10 & 3.037 \mathrm{E}-09 & 5.994 \mathrm{E}-09 & 8.345 \mathrm{E}-09\end{array}$

$\begin{array}{lllllll}\mathrm{Pa}-231 & 1.000 \mathrm{E}+00 & 3.749 \mathrm{E}-16 & 2.624 \mathrm{E}-15 & 7.283 \mathrm{E}-13 & 2.844 \mathrm{E}-12 & 5.524 \mathrm{E}-12\end{array}$

$\begin{array}{lllllll}\mathrm{AC}-227+\mathrm{D} & 1.000 \mathrm{E}+00 & 1.227 \mathrm{E}-17 & 1.828 \mathrm{E}-16 & 6.725 \mathrm{E}-13 & 4.394 \mathrm{E}-12 & 1.055 \mathrm{E}-11\end{array}$

$\begin{array}{llllll}\operatorname{LDSR}(j) & 2.782 \mathrm{E}-02 & 2.782 \mathrm{E}-02 & 2.779 \mathrm{E}-02 & 2.775 \mathrm{E}-02 & 2.772 \mathrm{E}-02\end{array}$

$\begin{array}{lllllll}\mathrm{Pu}-240 & 4.950 \mathrm{E}-08 & 1.376 \mathrm{E}-09 & 1.376 \mathrm{E}-09 & 1.371 \mathrm{E}-09 & 1.367 \mathrm{E}-09 & 1.364 \mathrm{E}-09\end{array}$

$\begin{array}{lllllll}\mathrm{Pu}-240 & 1.000 \mathrm{E}+00 & 2.779 \mathrm{E}-02 & 2.779 \mathrm{E}-02 & 2.771 \mathrm{E}-02 & 2.762 \mathrm{E}-02 & 2.755 \mathrm{E}-02\end{array}$

$\begin{array}{lllllll}\mathrm{U}-236 & 1.000 \mathrm{E}+00 & 7.734 \mathrm{E}-11 & 2.320 \mathrm{E}-10 & 3.927 \mathrm{E}-09 & 7.744 \mathrm{E}-09 & 1.077 \mathrm{E}-08\end{array}$

$\begin{array}{lllllll}\mathrm{Th}-232 & 1.000 \mathrm{E}+00 & 6.238 \mathrm{E}-21 & 4.366 \mathrm{E}-20 & 1.214 \mathrm{E}-17 & 4.745 \mathrm{E}-17 & 9.226 \mathrm{E}-17\end{array}$

$\begin{array}{lllllll}\mathrm{Ra}-228+\mathrm{D} & 1.000 \mathrm{E}+00 & 7.279 \mathrm{E}-21 & 1.065 \mathrm{E}-19 & 2.653 \mathrm{E}-16 & 1.365 \mathrm{E}-15 & 2.898 \mathrm{E}-15\end{array}$

$\begin{array}{lllllll}\text { Th-228+D } & 1.000 \mathrm{E}+00 & 7.964 \mathrm{E}-22 & 2.280 \mathrm{E}-20 & 3.254 \mathrm{E}-16 & 1.921 \mathrm{E}-15 & 4.240 \mathrm{E}-15\end{array}$

$\operatorname{EDSR}(j) \quad 2.779 \mathrm{E}-02 \quad 2.779 \mathrm{E}-02 \quad 2.771 \mathrm{E}-02 \quad 2.762 \mathrm{E}-02 \quad 2.755 \mathrm{E}-02$

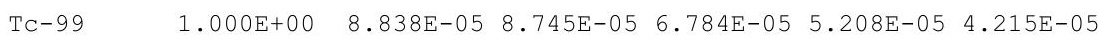

Th-228+D $\quad 1.000 \mathrm{E}+00 \quad 1.360 \mathrm{E}+00 \quad 9.469 \mathrm{E}-01 \quad 1.584 \mathrm{E}-04 \quad 1.845 \mathrm{E}-08 \quad 1.315 \mathrm{E}-11$

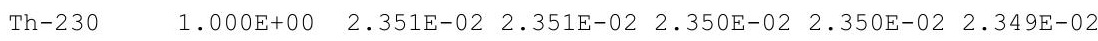

$\begin{array}{llllllll}\mathrm{Ra}-226+\mathrm{D} & 1.000 \mathrm{E}+00 & 3.877 \mathrm{E}-04 & 1.163 \mathrm{E}-03 & 1.963 \mathrm{E}-02 & 3.858 \mathrm{E}-02 & 5.354 \mathrm{E}-02\end{array}$

$\begin{array}{llllllll}\mathrm{Pb}-210+\mathrm{D} & 1.000 \mathrm{E}+00 & 4.669 \mathrm{E}-07 & 3.239 \mathrm{E}-06 & 7.124 \mathrm{E}-04 & 2.244 \mathrm{E}-03 & 3.740 \mathrm{E}-03\end{array}$

$\operatorname{LDSR}(j) \quad 2.390 \mathrm{E}-02 \quad 2.468 \mathrm{E}-02 \quad 4.384 \mathrm{E}-02 \quad 6.432 \mathrm{E}-02 \quad 8.077 \mathrm{E}-02$ 
RESRAD, Version $6.5 \quad T^{13 / 2}$ Limit $=180$ days

07/21/2011 $17: 18 \quad$ Page 27

ummary : RESRAD Parameters for U-Landfill Worker

File : C: $\backslash$ RESRAD_FAMILY $\backslash R E S R A D \backslash U S E R F I L E S \backslash Q C F O R S R S G \backslash L A N F F I L L W O R K E R \_S R S G-M A Y 11 . R A D$

Dose/Source Ratios Summed Over All Pathways

Parent and Progeny Principal Radionuclide Contributions Indicated

\begin{tabular}{|c|c|c|c|c|c|c|c|}
\hline Parent & Product & Thread & $\operatorname{DSR}(j, t)$ & At Time in & n Years & (mrem/yr) / & $(\mathrm{pCi} / \mathrm{g})$ \\
\hline (i) & (j) & Fraction & $0.000 \mathrm{E}+00$ & $1.000 \mathrm{E}+00$ & $2.500 \mathrm{E}+01$ & $5.000 \mathrm{E}+01$ & $7.000 \mathrm{E}+01$ \\
\hline-232 & Th-232 & $1.000 \mathrm{E}+00$ & $2.563 E-02$ & $2.563 \mathrm{E}-02$ & $2.563 \mathrm{E}-02$ & $2.563 \mathrm{E}-02$ & $2.562 \mathrm{E}-02$ \\
\hline-232 & $\mathrm{Ra}-228+\mathrm{D}$ & $1.000 \mathrm{E}+00$ & $5.888 E-02$ & $1.676 \mathrm{E}-01$ & $9.683 \mathrm{E}-01$ & $1.013 \mathrm{E}+00$ & $1.015 \mathrm{E}+00$ \\
\hline-232 & $\mathrm{Th}-228+\mathrm{D}$ & $1.000 \mathrm{E}+00$ & $1.048 \mathrm{E}-02$ & $6.433 \mathrm{E}-02$ & $1.508 \mathrm{E}+00$ & $1.614 \mathrm{E}+00$ & 1. $619 \mathrm{E}+00$ \\
\hline-232 & $\sum \operatorname{DSR}(j)$ & & $9.499 \mathrm{E}-02$ & $2.576 \mathrm{E}-01$ & $2.502 \mathrm{E}+00$ & $2.652 \mathrm{E}+00$ & $2.659 \mathrm{E}+00$ \\
\hline-234 & $U-234$ & $1.000 \mathrm{E}+00$ & $5.475 E-03$ & $5.474 \mathrm{E}-03$ & $5.444 \mathrm{E}-03$ & $5.414 \mathrm{E}-03$ & $5.390 E-03$ \\
\hline 234 & Th-230 & $1.000 \mathrm{E}+00$ & $1.058 \mathrm{E}-07$ & $3.174 \mathrm{E}-07$ & $5.381 \mathrm{E}-06$ & $1.062 E-05$ & $1.480 \mathrm{E}-05$ \\
\hline-234 & $\mathrm{Ra}-226+\mathrm{D}$ & $1.000 \mathrm{E}+00$ & $1.163 \mathrm{E}-09$ & $8.142 \mathrm{E}-09$ & $2.255 \mathrm{E}-06$ & $8.781 \mathrm{E}-06$ & $1.702 \mathrm{E}-05$ \\
\hline-234 & $\mathrm{~Pb}-210+\mathrm{D}$ & $1.000 \mathrm{E}+00$ & 1. 052E-12 & $1.568 \mathrm{E}-11$ & $5.794 \mathrm{E}-08$ & $3.798 \mathrm{E}-07$ & $9.134 \mathrm{E}-07$ \\
\hline 234 & $\sum \operatorname{DSR}(j)$ & & $5.475 E-03$ & $5.474 \mathrm{E}-03$ & $5.452 \mathrm{E}-03$ & $5.434 \mathrm{E}-03$ & $5.422 E-03$ \\
\hline$-235+D$ & $\mathrm{U}-235+\mathrm{D}$ & $1.000 \mathrm{E}+00$ & $1.213 \mathrm{E}-01$ & 1. $213 \mathrm{E}-01$ & $1.207 \mathrm{E}-01$ & $1.200 \mathrm{E}-01$ & $1.195 \mathrm{E}-01$ \\
\hline$-235+D$ & $\mathrm{~Pa}-231$ & $1.000 \mathrm{E}+00$ & $1.142 \mathrm{E}-06$ & $3.425 E-06$ & $5.790 \mathrm{E}-05$ & $1.140 \mathrm{E}-04$ & $1.584 \mathrm{E}-04$ \\
\hline$-235+D$ & $A C-227+D$ & $1.000 \mathrm{E}+00$ & $4.975 E-08$ & $3.450 \mathrm{E}-07$ & $7.536 \mathrm{E}-05$ & $2.362 E-04$ & $3.925 E-04$ \\
\hline$-235+D$ & $\sum \operatorname{DSR}(j)$ & & $1.213 \mathrm{E}-01$ & $1.213 \mathrm{E}-01$ & $1.208 \mathrm{E}-01$ & $1.203 \mathrm{E}-01$ & $1.200 \mathrm{E}-01$ \\
\hline-238 & $\mathrm{U}-238$ & $5.400 E-05$ & $2.693 E-07$ & $2.692 \mathrm{E}-07$ & $2.678 E-07$ & $2.663 E-07$ & $2.652 E-07$ \\
\hline$-238+D$ & $\mathrm{U}-238+\mathrm{D}$ & $9.999 \mathrm{E}-01$ & $3.127 \mathrm{E}-02$ & $3.127 \mathrm{E}-02$ & $3.110 \mathrm{E}-02$ & $3.093 E-02$ & $3.079 \mathrm{E}-02$ \\
\hline$-238+D$ & $\mathrm{U}-234$ & $9.999 \mathrm{E}-01$ & $7.760 \mathrm{E}-09$ & $2.328 E-08$ & $3.936 \mathrm{E}-07$ & $7.751 \mathrm{E}-07$ & $1.077 \mathrm{E}-06$ \\
\hline$-238+D$ & $\mathrm{Th}-230$ & $9.999 \mathrm{E}-01$ & $9.998 E-14$ & $6.998 E-13$ & $1.943 \mathrm{E}-10$ & $7.592 \mathrm{E}-10$ & $1.475 \mathrm{E}-09$ \\
\hline$-238+D$ & $\mathrm{Ra}-226+\mathrm{D}$ & $9.999 \mathrm{E}-01$ & $8.246 \mathrm{E}-16$ & $1.237 \mathrm{E}-14$ & $5.436 \mathrm{E}-11$ & $4.193 \mathrm{E}-10$ & $1.135 \mathrm{E}-09$ \\
\hline$-238+D$ & $\mathrm{~Pb}-210+\mathrm{D}$ & $9.999 \mathrm{E}-01$ & $5.974 \mathrm{E}-19$ & $1.842 \mathrm{E}-17$ & $1.086 \mathrm{E}-12$ & $1.453 \mathrm{E}-11$ & $4.979 E-11$ \\
\hline$-238+D$ & $\sum \operatorname{DSR}(j)$ & & $3.127 \mathrm{E}-02$ & $3.127 \mathrm{E}-02$ & $3.110 \mathrm{E}-02$ & $3.093 E-02$ & $3.079 E-02$ \\
\hline
\end{tabular}

The DSR includes contributions from associated (half-life $\leq 180$ days) daughters. 
RESRAD, Version $6.5 \quad \mathrm{~T}^{1 / 2}$ Limit $=180$ days

Summary : RESRAD Parameters for U-Landfill Worker

File : C: $\backslash$ RESRAD_FAMILY $\backslash R E S R A D \backslash U S E R F I L E S \backslash Q C F O R S R S G \backslash L A N F F I L L W O R K E R \_S R S G-M A Y 11 . R A D$

Single Radionuclide Soil Guidelines $G(i, t)$ in $\mathrm{pCi} / \mathrm{g}$

Basic Radiation Dose Limit $=1.000 \mathrm{E}+02 \mathrm{mrem} / \mathrm{yr}$

Nuclide

\begin{tabular}{ccccccc} 
(i) & $\mathrm{t}=$ & $0.000 \mathrm{E}+00$ & $1.000 \mathrm{E}+00$ & $2.500 \mathrm{E}+01$ & $5.000 \mathrm{E}+01$ & $7.000 \mathrm{E}+01$ \\
\cline { 1 - 1 } $\mathrm{Am}-241$ & & $3.509 \mathrm{E}+03$ & $3.514 \mathrm{E}+03$ & $3.653 \mathrm{E}+03$ & $3.802 \mathrm{E}+03$ & $3.927 \mathrm{E}+03$ \\
$\mathrm{Cs}-137$ & & $1.900 \mathrm{E}+02$ & $1.945 \mathrm{E}+02$ & $3.389 \mathrm{E}+02$ & $6.045 \mathrm{E}+02$ & $9.603 \mathrm{E}+02$ \\
$\mathrm{~Np}-237$ & & $5.507 \mathrm{E}+02$ & $5.507 \mathrm{E}+02$ & $5.528 \mathrm{E}+02$ & $5.550 \mathrm{E}+02$ & $5.568 \mathrm{E}+02$ \\
$\mathrm{Pu}-238$ & & $3.926 \mathrm{E}+03$ & $3.957 \mathrm{E}+03$ & $4.785 \mathrm{E}+03$ & $5.833 \mathrm{E}+03$ & $6.834 \mathrm{E}+03$ \\
$\mathrm{Pu}-239$ & & $3.595 \mathrm{E}+03$ & $3.595 \mathrm{E}+03$ & $3.599 \mathrm{E}+03$ & $3.603 \mathrm{E}+03$ & $3.607 \mathrm{E}+03$ \\
$\mathrm{Pu}-240$ & & $3.598 \mathrm{E}+03$ & $3.598 \mathrm{E}+03$ & $3.609 \mathrm{E}+03$ & $3.621 \mathrm{E}+03$ & $3.630 \mathrm{E}+03$ \\
$\mathrm{TC}-99$ & & $1.131 \mathrm{E}+06$ & $1.143 \mathrm{E}+06$ & $1.474 \mathrm{E}+06$ & $1.920 \mathrm{E}+06$ & $2.373 \mathrm{E}+06$ \\
$\mathrm{Th}-228$ & $7.351 \mathrm{E}+01$ & $1.056 \mathrm{E}+02$ & $6.312 \mathrm{E}+05$ & $5.420 \mathrm{E}+09$ & $7.605 \mathrm{E}+12$ \\
$\mathrm{Th}-230$ & $4.184 \mathrm{E}+03$ & $4.052 \mathrm{E}+03$ & $2.281 \mathrm{E}+03$ & $1.555 \mathrm{E}+03$ & $1.238 \mathrm{E}+03$ \\
$\mathrm{Th}-232$ & $1.053 \mathrm{E}+03$ & $3.883 \mathrm{E}+02$ & $3.997 \mathrm{E}+01$ & $3.770 \mathrm{E}+01$ & $3.761 \mathrm{E}+01$ \\
$\mathrm{U}-234$ & $1.826 \mathrm{E}+04$ & $1.827 \mathrm{E}+04$ & $1.834 \mathrm{E}+04$ & $1.840 \mathrm{E}+04$ & $1.844 \mathrm{E}+04$ \\
$\mathrm{U}-235$ & $8.242 \mathrm{E}+02$ & $8.244 \mathrm{E}+02$ & $8.279 \mathrm{E}+02$ & $8.309 \mathrm{E}+02$ & $8.332 \mathrm{E}+02$ \\
$\mathrm{U}-238$ & $3.198 \mathrm{E}+03$ & $3.198 \mathrm{E}+03$ & $3.215 \mathrm{E}+03$ & $3.233 \mathrm{E}+03$ & $3.248 \mathrm{E}+03$ \\
\hline \hline
\end{tabular}

Summed Dose/Source Ratios DSR(i,t) in (mrem/yr)/(pCi/g) and Single Radionuclide Soil Guidelines $G(i, t)$ in pCi/g at tmin = time of minimum single radionuclide soil guideline and at tmax $=$ time of maximum total dose $=36.73 \pm 0.07$ years

\begin{tabular}{|c|c|c|c|c|c|c|}
\hline $\begin{array}{l}\text { uclide } \\
\text { (i) }\end{array}$ & $\begin{array}{l}\text { Initial } \\
(\mathrm{pCi} / \mathrm{g})\end{array}$ & $\begin{array}{c}\text { tmin } \\
\text { (years) }\end{array}$ & $\operatorname{DSR}(i, \operatorname{tmin})$ & $\begin{array}{c}\mathrm{G}(\mathrm{i}, \mathrm{tmin}) \\
(\mathrm{pCi} / \mathrm{g})\end{array}$ & $\operatorname{DSR}(i, t \max )$ & $\begin{array}{c}G(i, t \max ) \\
(\mathrm{pC} i / g)\end{array}$ \\
\hline $1-241$ & $1.000 \mathrm{E}+00$ & $0.000 \mathrm{E}+00$ & $2.850 \mathrm{E}-02$ & $3.509 \mathrm{E}+03$ & $2.687 \mathrm{E}-02$ & $3.722 \mathrm{E}+03$ \\
\hline-137 & $1.000 \mathrm{E}+00$ & $0.000 \mathrm{E}+00$ & $5.262 \mathrm{E}-01$ & $1.900 \mathrm{E}+02$ & $2.249 \mathrm{E}-01$ & $4.447 \mathrm{E}+02$ \\
\hline-237 & $1.000 \mathrm{E}+00$ & $0.000 \mathrm{E}+00$ & $1.816 \mathrm{E}-01$ & $5.507 \mathrm{E}+02$ & $1.805 \mathrm{E}-01$ & $5.539 \mathrm{E}+02$ \\
\hline-238 & $1.000 \mathrm{E}+00$ & $0.000 \mathrm{E}+00$ & $2.547 \mathrm{E}-02$ & $3.926 \mathrm{E}+03$ & $1.904 \mathrm{E}-02$ & $5.251 \mathrm{E}+03$ \\
\hline-239 & $1.000 \mathrm{E}+00$ & $0.000 \mathrm{E}+00$ & $2.782 \mathrm{E}-02$ & $3.595 \mathrm{E}+03$ & $2.777 \mathrm{E}-02$ & $3.601 \mathrm{E}+03$ \\
\hline-240 & $1.000 \mathrm{E}+00$ & $0.000 \mathrm{E}+00$ & $2.779 \mathrm{E}-02$ & $3.598 \mathrm{E}+03$ & $2.766 \mathrm{E}-02$ & $3.615 \mathrm{E}+03$ \\
\hline$=-99$ & $1.000 \mathrm{E}+00$ & $0.000 \mathrm{E}+00$ & $8.838 \mathrm{E}-05$ & $1.131 \mathrm{E}+06$ & $5.993 E-05$ & $1.669 \mathrm{E}+06$ \\
\hline-228 & $1.000 \mathrm{E}+00$ & $0.000 \mathrm{E}+00$ & $1.360 \mathrm{E}+00$ & $7.351 \mathrm{E}+01$ & $2.258 \mathrm{E}-06$ & $4.429 \mathrm{E}+07$ \\
\hline-230 & $1.000 \mathrm{E}+00$ & $7.000 \mathrm{E}+01$ & $8.077 \mathrm{E}-02$ & $1.238 \mathrm{E}+03$ & $5.342 \mathrm{E}-02$ & $1.872 \mathrm{E}+03$ \\
\hline-232 & $1.000 \mathrm{E}+00$ & $7.000 \mathrm{E}+01$ & $2.659 \mathrm{E}+00$ & $3.761 \mathrm{E}+01$ & $2.622 \mathrm{E}+00$ & $3.814 \mathrm{E}+01$ \\
\hline 234 & $1.000 \mathrm{E}+00$ & $0.000 \mathrm{E}+00$ & $5.475 E-03$ & $1.826 \mathrm{E}+04$ & $5.443 E-03$ & $1.837 \mathrm{E}+04$ \\
\hline 235 & $1.000 \mathrm{E}+00$ & $0.000 \mathrm{E}+00$ & $1.213 E-01$ & $8.242 E+02$ & $1.206 \mathrm{E}-01$ & $8.294 \mathrm{E}+02$ \\
\hline 238 & $1.000 \mathrm{E}+00$ & $0.000 \mathrm{E}+00$ & $3.127 \mathrm{E}-02$ & $3.198 \mathrm{E}+03$ & $3.102 \mathrm{E}-02$ & $3.224 \mathrm{E}+03$ \\
\hline
\end{tabular}


RESRAD, Version $6.5 \quad \mathrm{~T}^{1} \frac{1}{2}$ Limit $=180$ days

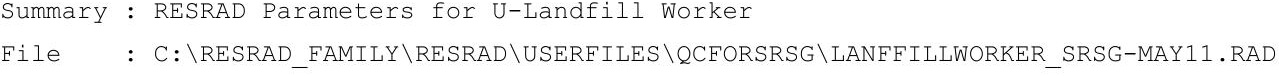

Individual Nuclide Dose Summed Over All Pathways

Parent Nuclide and Branch Fraction Indicated

Nuclide Parent THF(i) DOSE $(j, t)$, mrem/yr

\begin{tabular}{|c|c|c|c|c|c|c|c|c|}
\hline$(j)$ & (i) & & $t=$ & $0.000 \mathrm{E}+00$ & $1.000 \mathrm{E}+00$ & $2.500 \mathrm{E}+01$ & $5.000 \mathrm{E}+01$ & $7.000 \mathrm{E}+01$ \\
\hline 4 & $\mathrm{Am}-241$ & $1.000 \mathrm{E}+00$ & & $2.850 \mathrm{E}-02$ & $2.845 \mathrm{E}-02$ & $2.738 \mathrm{E}-0$ & -02 & $-c$ \\
\hline
\end{tabular}

$\mathrm{Np}-237 \quad \mathrm{Am}-241 \quad 1.000 \mathrm{E}+00$

$2.940 \mathrm{E}-08 \quad 8.812 \mathrm{E}-08 \quad 1.467 \mathrm{E}-06 \quad 2.842 \mathrm{E}-06 \quad 3.898 \mathrm{E}-06$

$\mathrm{Np}-237 \quad \mathrm{~Np}-237 \quad 1.000 \mathrm{E}+00$

Np-237 $\sum$ DOSE $(j)$

$\mathrm{U}-233 \quad \mathrm{Am}-241 \quad 1.000 \mathrm{E}+00$

$\mathrm{U}-233 \quad \mathrm{~Np}-237 \quad 1.000 \mathrm{E}+00$

U-233 $\sum$ DOSE $(j)$

Th-229 Am-241 1.000E+00

$\mathrm{Th}-229 \quad \mathrm{~Np}-237 \quad 1.000 \mathrm{E}+00$

Th-229 $\sum \mathrm{DOSE}(j)$

Cs-137 Cs $-137 \quad 1.000 E+00$

$1.816 \mathrm{E}-01 \quad 1.816 \mathrm{E}-01 \quad 1.809 \mathrm{E}-01 \quad 1.802 \mathrm{E}-01 \quad 1.796 \mathrm{E}-01$

$\begin{array}{llllll}1.816 \mathrm{E}-01 & 1.816 \mathrm{E}-01 & 1.809 \mathrm{E}-01 & 1.802 \mathrm{E}-01 & 1.796 \mathrm{E}-01\end{array}$

$\begin{array}{lllll}1.381 \mathrm{E}-15 & 9.659 \mathrm{E}-15 & 2.650 \mathrm{E}-12 & 1.022 \mathrm{E}-11 & 1.966 \mathrm{E}-11\end{array}$

$\begin{array}{lllll}1.279 \mathrm{E}-08 & 3.837 \mathrm{E}-08 & 6.493 \mathrm{E}-07 & 1.280 \mathrm{E}-06 & 1.780 \mathrm{E}-06\end{array}$

$\begin{array}{lllll}1.279 \mathrm{E}-08 & 3.837 \mathrm{E}-08 & 6.493 \mathrm{E}-07 & 1.280 \mathrm{E}-06 & 1.780 \mathrm{E}-06\end{array}$

$\begin{array}{llllll}1.757 \mathrm{E}-18 & 2.634 \mathrm{E}-17 & 1.151 \mathrm{E}-13 & 8.819 \mathrm{E}-13 & 2.375 \mathrm{E}-12\end{array}$

$\begin{array}{llllll}2.170 \mathrm{E}-11 & 1.519 \mathrm{E}-10 & 4.217 \mathrm{E}-08 & 1.647 \mathrm{E}-07 & 3.200 \mathrm{E}-07\end{array}$

$2.170 \mathrm{E}-11 \quad 1.519 \mathrm{E}-10 \quad 4.217 \mathrm{E}-08 \quad 1.647 \mathrm{E}-07 \quad 3.200 \mathrm{E}-07$

$\begin{array}{llllll}5.262 \mathrm{E}-01 & 5.142 \mathrm{E}-01 & 2.950 \mathrm{E}-01 & 1.654 \mathrm{E}-01 & 1.041 \mathrm{E}-01\end{array}$

$\mathrm{Pu}-238 \quad 1.840 \mathrm{E}-09$

$\begin{array}{lllll}4.687 E-11 & 4.650 E-11 & 3.845 E-11 & 3.154 E-11 & 2.692 E-11\end{array}$

$\begin{array}{lllllllll}\mathrm{Pu}-238 & 1.000 \mathrm{E}+00 \quad 2.547 \mathrm{E}-02 & 2.527 \mathrm{E}-02 & 2.090 \mathrm{E}-02 & 1.714 \mathrm{E}-02 & 1.463 \mathrm{E}-02\end{array}$

$\sum \operatorname{DOSE}(j)$

$2.547 \mathrm{E}-02 \quad 2.527 \mathrm{E}-02 \quad 2.090 \mathrm{E}-02 \quad 1.714 \mathrm{E}-02 \quad 1.463 \mathrm{E}-02$

$\mathrm{Pu}-238 \quad 1.000 \mathrm{E}+00$

$\begin{array}{llllll}7.741 E-09 & 2.314 E-08 & 3.574 E-07 & 6.422 E-07 & 8.314 E-07\end{array}$

$\mathrm{U}-234 \quad 1.000 \mathrm{E}+00$

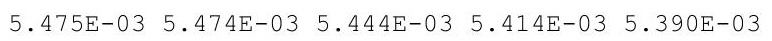

$\mathrm{U}-238 \quad 9.999 \mathrm{E}-01$

$\begin{array}{llllll}7.760 \mathrm{E}-09 & 2.328 \mathrm{E}-08 & 3.936 \mathrm{E}-07 & 7.751 \mathrm{E}-07 & 1.077 \mathrm{E}-06\end{array}$

$\sum \operatorname{DOSE}(j)$

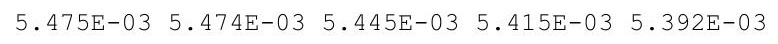

$\mathrm{Pu}-238 \quad 1.000 \mathrm{E}+00$

$9.980 \mathrm{E}-14 \quad 6.969 \mathrm{E}-13 \quad 1.822 \mathrm{E}-10 \quad 6.698 \mathrm{E}-10 \quad 1.241 \mathrm{E}-09$

Th-230 1.000E+00

$\begin{array}{llllll}2.351 \mathrm{E}-02 & 2.351 \mathrm{E}-02 & 2.350 \mathrm{E}-02 & 2.350 \mathrm{E}-02 & 2.349 \mathrm{E}-02\end{array}$

$\begin{array}{llllll}1.058 \mathrm{E}-07 & 3.174 \mathrm{E}-07 & 5.381 \mathrm{E}-06 & 1.062 \mathrm{E}-05 & 1.480 \mathrm{E}-05\end{array}$

$\mathrm{U}-234 \quad 1.000 \mathrm{E}+00$

$\begin{array}{llllll}9.998 \mathrm{E}-14 & 6.998 \mathrm{E}-13 & 1.943 \mathrm{E}-10 & 7.592 \mathrm{E}-10 & 1.475 \mathrm{E}-09\end{array}$

$\mathrm{U}-238 \quad 9.999 \mathrm{E}-01$

$\begin{array}{llllll}2.351 E-02 & 2.351 E-02 & 2.351 E-02 & 2.351 E-02 & 2.350 E-02\end{array}$

$\mathrm{Pu}-238 \quad 1.000 \mathrm{E}+00$

$\begin{array}{llllll}8.233 E-16 & 1.233 E-14 & 5.179 E-11 & 3.815 E-10 & 9.962 E-10\end{array}$

$\mathrm{Th}-230 \quad 1.000 \mathrm{E}+00$

$3.877 \mathrm{E}-04 \quad 1.163 \mathrm{E}-03 \quad 1.963 \mathrm{E}-02 \quad 3.858 \mathrm{E}-02 \quad 5.354 \mathrm{E}-02$

$\begin{array}{llllll}1.163 \mathrm{E}-09 & 8.142 \mathrm{E}-09 & 2.255 \mathrm{E}-06 & 8.781 \mathrm{E}-06 & 1.702 \mathrm{E}-05\end{array}$

$\mathrm{U}-234 \quad 1.000 \mathrm{E}+00$

$8.246 \mathrm{E}-16 \quad 1.237 \mathrm{E}-14 \quad 5.436 \mathrm{E}-11 \quad 4.193 \mathrm{E}-10 \quad 1.135 \mathrm{E}-09$

$\mathrm{U}-238 \quad 9.999 \mathrm{E}-01$

$3.878 E-04 \quad 1.163 E-03 \quad 1.963 E-02 \quad 3.859 E-02 \quad 5.355 E-02$

$\mathrm{Pu}-238 \quad 1.000 \mathrm{E}+00$

$\begin{array}{llllll}5.966 \mathrm{E}-19 & 1.837 \mathrm{E}-17 & 1.044 \mathrm{E}-12 & 1.342 \mathrm{E}-11 & 4.456 \mathrm{E}-11\end{array}$

$\begin{array}{lllll}4.669 \mathrm{E}-07 & 3.239 \mathrm{E}-06 & 7.124 \mathrm{E}-04 & 2.244 \mathrm{E}-03 & 3.740 \mathrm{E}-03\end{array}$

$\begin{array}{lllll}1.052 \mathrm{E}-12 & 1.568 \mathrm{E}-11 & 5.794 \mathrm{E}-08 & 3.798 \mathrm{E}-07 & 9.134 \mathrm{E}-07\end{array}$

$\begin{array}{llllll}5.974 \mathrm{E}-19 & 1.842 \mathrm{E}-17 & 1.086 \mathrm{E}-12 & 1.453 \mathrm{E}-11 & 4.979 \mathrm{E}-11\end{array}$

$\begin{array}{llllll}4.669 \mathrm{E}-07 & 3.239 \mathrm{E}-06 & 7.125 \mathrm{E}-04 & 2.245 \mathrm{E}-03 & 3.741 \mathrm{E}-03\end{array}$

$\begin{array}{lllll}2.782 E-02 & 2.782 E-02 & 2.779 E-02 & 2.775 E-02 & 2.772 E-02\end{array}$

$\begin{array}{llllll}\mathrm{Pu}-239 & 1.000 \mathrm{E}+00 \quad 5.975 \mathrm{E}-11 & 1.792 \mathrm{E}-10 & 3.037 \mathrm{E}-09 & 5.994 \mathrm{E}-09 & 8.345 \mathrm{E}-09\end{array}$

$\begin{array}{lllllllll}\mathrm{U}-235 & 1.000 \mathrm{E}+00 \quad 1.213 \mathrm{E}-01 & 1.213 \mathrm{E}-01 & 1.207 \mathrm{E}-01 & 1.200 \mathrm{E}-01 & 1.195 \mathrm{E}-01\end{array}$

$\sum \operatorname{DOSE}(j)$

$1.213 \mathrm{E}-01 \quad 1.213 \mathrm{E}-01 \quad 1.207 \mathrm{E}-01 \quad 1.200 \mathrm{E}-01 \quad 1.195 \mathrm{E}-01$ 
RESRAD, Version $6.5 \quad \mathrm{~T}^{1 / 2}$ Limit $=180$ days

Summary : RESRAD Parameters for U-Landfill Worker

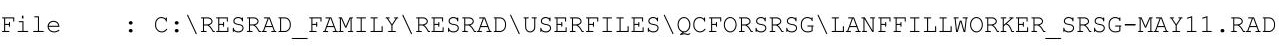

Individual Nuclide Dose Summed Over All Pathways

Parent Nuclide and Branch Fraction Indicated

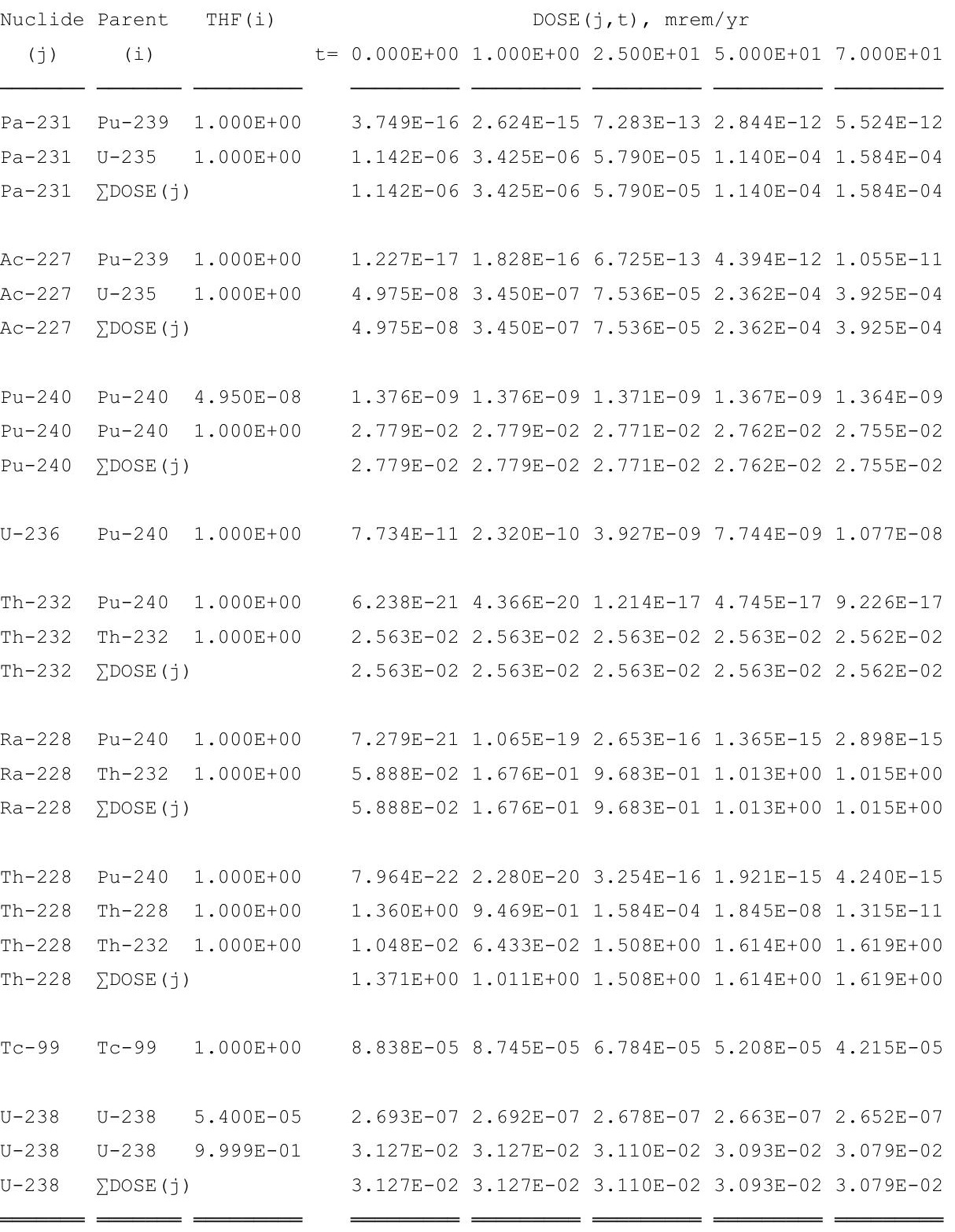

THF (i) is the thread fraction of the parent nuclide. 
RESRAD, Version $6.5 \quad \mathrm{~T}^{1 / 2}$ Limit $=180$ days

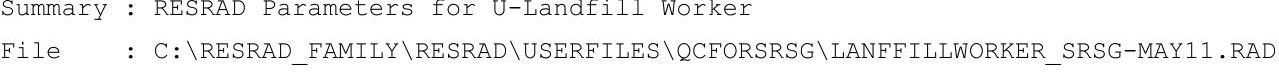

Individual Nuclide Soil Concentration

Parent Nuclide and Branch Fraction Indicated

Nuclide Parent THF(i) $\quad S(j, t), \mathrm{pCi} / \mathrm{g}$

\begin{tabular}{|c|c|c|c|c|c|c|c|}
\hline (j) & (i) & & $t=0.000 \mathrm{E}+00$ & $1.000 \mathrm{E}+00$ & $2.500 \mathrm{E}+01$ & $5.000 \mathrm{E}+01$ & $7.000 \mathrm{E}+01$ \\
\hline-241 & $A m-241$ & $1.000 \mathrm{E}+00$ & $1.000 \mathrm{E}+00$ & $9.984 \mathrm{E}-01$ & $9.606 \mathrm{E}-01$ & $9.227 \mathrm{E}-01$ & $8.934 \mathrm{E}-01$ \\
\hline-237 & $A m-241$ & $1.000 \mathrm{E}+00$ & $0.000 \mathrm{E}+00$ & $3.236 \mathrm{E}-07$ & $7.921 E-06$ & $1.550 \mathrm{E}-05$ & $2.132 \mathrm{E}-05$ \\
\hline-237 & $\mathrm{~Np}-237$ & $1.000 \mathrm{E}+00$ & $1.000 \mathrm{E}+00$ & $9.998 \mathrm{E}-01$ & $9.960 \mathrm{E}-01$ & $9.921 \mathrm{E}-01$ & $9.890 \mathrm{E}-01$ \\
\hline-237 & $\sum S(j):$ & & $1.000 \mathrm{E}+00$ & $9.998 \mathrm{E}-01$ & $9.961 \mathrm{E}-01$ & $9.921 \mathrm{E}-01$ & $9.890 \mathrm{E}-01$ \\
\hline 233 & $A m-241$ & $1.000 \mathrm{E}+00$ & $0.000 \mathrm{E}+00$ & $7.078 \mathrm{E}-13$ & $4.354 \mathrm{E}-10$ & $1.713 \mathrm{E}-09$ & $3.314 \mathrm{E}-09$ \\
\hline 233 & $\mathrm{~Np}-237$ & $1.000 \mathrm{E}+00$ & $0.000 \mathrm{E}+00$ & $4.372 \mathrm{E}-06$ & $1.088 \mathrm{E}-04$ & $2.166 \mathrm{E}-04$ & $3.020 \mathrm{E}-04$ \\
\hline 233 & $\sum S(j):$ & & $0.000 \mathrm{E}+00$ & $4.372 \mathrm{E}-06$ & $1.088 \mathrm{E}-04$ & $2.166 \mathrm{E}-04$ & $3.020 \mathrm{E}-04$ \\
\hline-229 & $A m-241$ & $1.000 \mathrm{E}+00$ & $0.000 \mathrm{E}+00$ & $2.228 \mathrm{E}-17$ & $3.438 \mathrm{E}-13$ & $2.715 \mathrm{E}-12$ & $7.374 \mathrm{E}-12$ \\
\hline-229 & $\mathrm{~Np}-237$ & $1.000 \mathrm{E}+00$ & $0.000 \mathrm{E}+00$ & $2.065 E-10$ & $1.285 \mathrm{E}-07$ & $5.121 \mathrm{E}-07$ & $1.001 \mathrm{E}-06$ \\
\hline-229 & $\sum S(j):$ & & $0.000 \mathrm{E}+00$ & $2.065 \mathrm{E}-10$ & $1.285 \mathrm{E}-07$ & $5.121 \mathrm{E}-07$ & $1.001 \mathrm{E}-06$ \\
\hline$s-137$ & $\mathrm{Cs}-137$ & $1.000 \mathrm{E}+00$ & $1.000 \mathrm{E}+00$ & $9.771 \mathrm{E}-01$ & $5.607 \mathrm{E}-01$ & $3.144 \mathrm{E}-01$ & $1.979 \mathrm{E}-01$ \\
\hline 8 & $\mathrm{Pu}-238$ & $1.840 \mathrm{E}-09$ & $1.840 \mathrm{E}-09$ & $1.825 \mathrm{E}-09$ & $1.509 \mathrm{E}-09$ & $1.238 \mathrm{E}-09$ & $1.057 \mathrm{E}-09$ \\
\hline $\mathrm{Pu}-238$ & $\mathrm{Pu}-238$ & $1.000 \mathrm{E}+00$ & $1.000 \mathrm{E}+00$ & $9.921 \mathrm{E}-01$ & $8.204 \mathrm{E}-01$ & $6.730 \mathrm{E}-01$ & $5.744 \mathrm{E}-01$ \\
\hline-238 & $\sum S(j):$ & & $1.000 \mathrm{E}+00$ & $9.921 \mathrm{E}-01$ & $8.204 \mathrm{E}-01$ & $6.730 \mathrm{E}-01$ & $5.744 \mathrm{E}-01$ \\
\hline 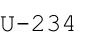 & $\mathrm{Pu}-238$ & $1.000 \mathrm{E}+00$ & $0.000 \mathrm{E}+00$ & $2.823 E-06$ & $6.411 E-05$ & $1.163 \mathrm{E}-04$ & $1.510 \mathrm{E}-04$ \\
\hline$J-234$ & $\mathrm{U}-234$ & $1.000 \mathrm{E}+00$ & $1.000 \mathrm{E}+00$ & $9.998 \mathrm{E}-01$ & $9.944 \mathrm{E}-01$ & $9.889 \mathrm{E}-01$ & $9.844 \mathrm{E}-01$ \\
\hline 234 & $\mathrm{U}-238$ & $9.999 \mathrm{E}-01$ & $0.000 \mathrm{E}+00$ & $2.834 \mathrm{E}-06$ & $7.048 \mathrm{E}-05$ & $1.402 \mathrm{E}-04$ & $1.954 \mathrm{E}-04$ \\
\hline 234 & $\sum S(j):$ & & $1.000 \mathrm{E}+00$ & $9.998 \mathrm{E}-01$ & $9.945 E-01$ & $9.891 \mathrm{E}-01$ & $9.848 \mathrm{E}-01$ \\
\hline
\end{tabular}

Th-230 Pu-238 $1.000 \mathrm{E}+00 \quad 0.000 \mathrm{E}+00 \quad 1.273 \mathrm{E}-11 \quad 7.459 \mathrm{E}-09 \quad 2.796 \mathrm{E}-08 \quad 5.211 \mathrm{E}-08$

Th-230 Th-230 $1.000 \mathrm{E}+00 \quad 1.000 \mathrm{E}+00 \quad 1.000 \mathrm{E}+00 \quad 9.997 \mathrm{E}-01 \quad 9.994 \mathrm{E}-01 \quad 9.991 \mathrm{E}-01$

Th-230 U-234 $1.000 \mathrm{E}+00 \quad 0.000 \mathrm{E}+00 \quad 9.001 \mathrm{E}-06 \quad 2.244 \mathrm{E}-04 \quad 4.474 \mathrm{E}-04 \quad 6.249 \mathrm{E}-04$

Th-230 U-238 $9.999 \mathrm{E}-01 \quad 0.000 \mathrm{E}+00 \quad 1.276 \mathrm{E}-11 \quad 7.944 \mathrm{E}-09 \quad 3.166 \mathrm{E}-08 \quad 6.186 \mathrm{E}-08$

Th-230 $\sum \mathrm{S}(j): \quad 1.000 \mathrm{E}+00 \quad 1.000 \mathrm{E}+00 \quad 9.999 \mathrm{E}-01 \quad 9.998 \mathrm{E}-01 \quad 9.998 \mathrm{E}-01$

$\begin{array}{llllllll}\mathrm{Ra}-226 & \mathrm{Pu}-238 & 1.000 \mathrm{E}+00 & 0.000 \mathrm{E}+00 & 1.839 \mathrm{E}-15 & 2.728 \mathrm{E}-11 & 2.070 \mathrm{E}-10 & 5.451 \mathrm{E}-10\end{array}$

Ra-226 Th-230 $1.000 \mathrm{E}+00 \quad 0.000 \mathrm{E}+00 \quad 4.331 \mathrm{E}-04 \quad 1.075 \mathrm{E}-02 \quad 2.134 \mathrm{E}-02 \quad 2.969 \mathrm{E}-02$

$\mathrm{Ra}-226 \mathrm{U}-234 \quad 1.000 \mathrm{E}+00 \quad 0.000 \mathrm{E}+00 \quad 1.949 \mathrm{E}-09 \quad 1.210 \mathrm{E}-06 \quad 4.808 \mathrm{E}-06 \quad 9.372 \mathrm{E}-06$

Ra-226 U-238 9.999E-01 $0.000 \mathrm{E}+00 \quad 1.842 \mathrm{E}-15 \quad 2.860 \mathrm{E}-11 \quad 2.273 \mathrm{E}-10 \quad 6.205 \mathrm{E}-10$

$\operatorname{Ra}-226 \sum \mathrm{S}(\mathrm{j}): \quad 0.000 \mathrm{E}+00 \quad 4.331 \mathrm{E}-04 \quad 1.075 \mathrm{E}-02 \quad 2.134 \mathrm{E}-02 \quad 2.970 \mathrm{E}-02$

$\mathrm{Pb}-210 \quad \mathrm{Pu}-238 \quad 1.000 \mathrm{E}+00 \quad 0.000 \mathrm{E}+00 \quad 1.420 \mathrm{E}-17 \quad 4.614 \mathrm{E}-12 \quad 6.171 \mathrm{E}-11 \quad 2.072 \mathrm{E}-10$

$\mathrm{Pb}-210 \mathrm{Th}-230 \quad 1.000 \mathrm{E}+00 \quad 0.000 \mathrm{E}+00 \quad 6.662 \mathrm{E}-06 \quad 3.280 \mathrm{E}-03 \quad 1.054 \mathrm{E}-02 \quad 1.765 \mathrm{E}-02$

$\mathrm{Pb}-210 \quad \mathrm{U}-234 \quad 1.000 \mathrm{E}+00 \quad 0.000 \mathrm{E}+00 \quad 2.004 \mathrm{E}-11 \quad 2.612 \mathrm{E}-07 \quad 1.763 \mathrm{E}-06 \quad 4.276 \mathrm{E}-06$

$\mathrm{Pb}-210 \quad \mathrm{U}-238 \quad 9.999 \mathrm{E}-01 \quad 0.000 \mathrm{E}+00 \quad 1.423 \mathrm{E}-17 \quad 4.797 \mathrm{E}-12 \quad 6.674 \mathrm{E}-11 \quad 2.313 \mathrm{E}-10$

$\mathrm{Pb}-210 \sum \mathrm{S}(\mathrm{j}): \quad 0.000 \mathrm{E}+00 \quad 6.662 \mathrm{E}-06 \quad 3.281 \mathrm{E}-03 \quad 1.054 \mathrm{E}-02 \quad 1.765 \mathrm{E}-02$

Pu-239 Pu-239 $1.000 \mathrm{E}+00 \quad 1.000 \mathrm{E}+00 \quad 1.000 \mathrm{E}+00 \quad 9.988 \mathrm{E}-01 \quad 9.976 \mathrm{E}-01 \quad 9.966 \mathrm{E}-01$

$\begin{array}{llllllll}\mathrm{U}-235 & \mathrm{Pu}-239 & 1.000 \mathrm{E}+00 & 0.000 \mathrm{E}+00 & 9.847 \mathrm{E}-10 & 2.454 \mathrm{E}-08 & 4.891 \mathrm{E}-08 & 6.829 \mathrm{E}-08\end{array}$

$\mathrm{U}-235 \quad \mathrm{U}-235 \quad 1.000 \mathrm{E}+00 \quad 1.000 \mathrm{E}+00 \quad 9.998 \mathrm{E}-01 \quad 9.945 \mathrm{E}-01 \quad 9.890 \mathrm{E}-01 \quad 9.846 \mathrm{E}-01$

$\mathrm{U}-235 \sum \mathrm{S}(\mathrm{j}): \quad 1.000 \mathrm{E}+00 \quad 9.998 \mathrm{E}-01 \quad 9.945 \mathrm{E}-01 \quad 9.890 \mathrm{E}-01 \quad 9.846 \mathrm{E}-01$ 
RESRAD, Version $6.5 \quad T^{13 / 2}$ Limit $=180$ days

07/21/2011 $17: 18 \quad$ Page 32

Summary : RESRAD Parameters for U-Landfill Worker

File : C: $\backslash$ RESRAD FAMILY $\backslash$ RESRAD \USERFILES $\backslash Q C F O R S R S G \backslash L A N F F I L L W O R K E R$ SRSG-MAY11.RAD

Individual Nuclide Soil Concentration

Parent Nuclide and Branch Fraction Indicated

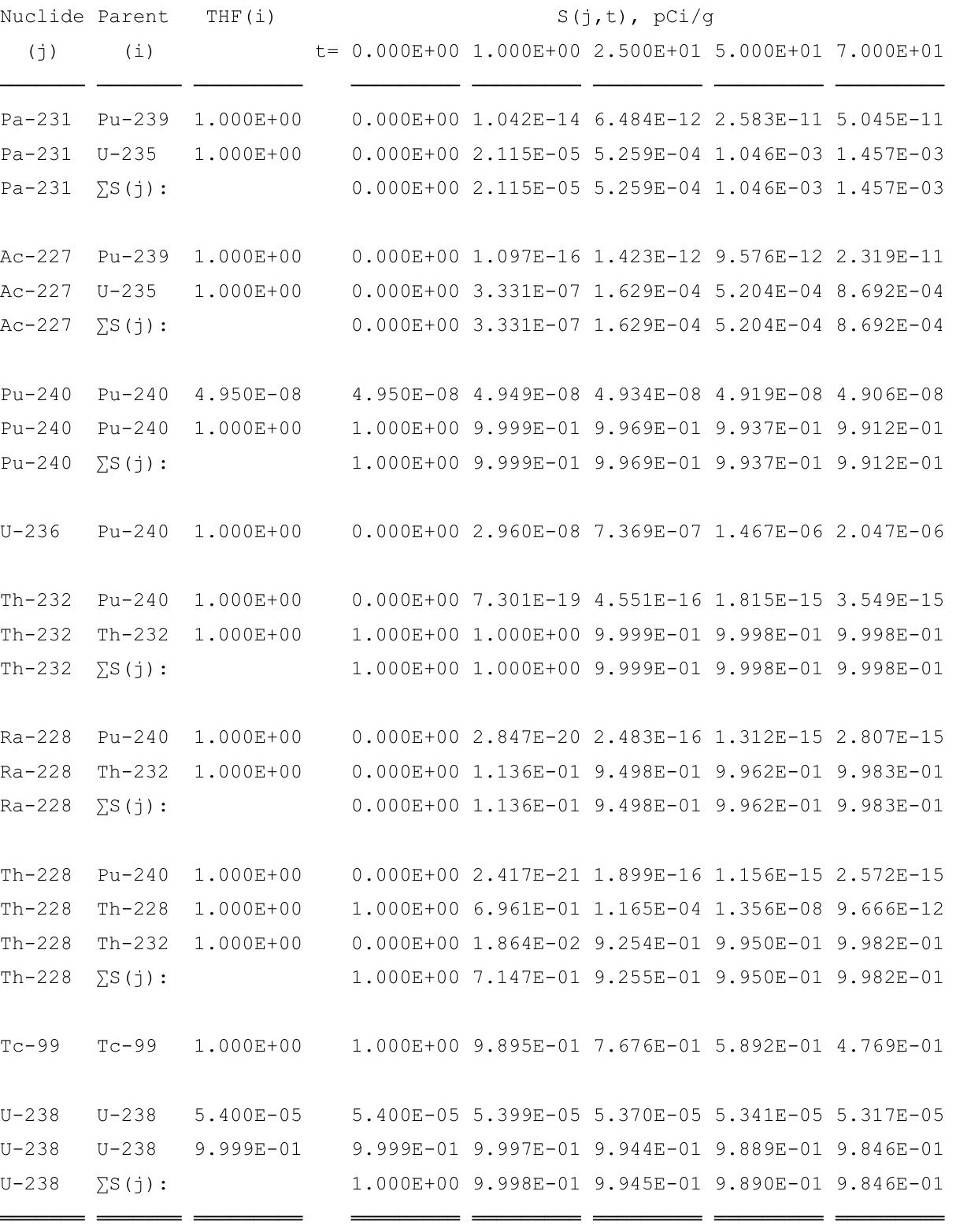

THF(i) is the thread fraction of the parent nuclide.

RESCALC.EXE execution time $=3.22$ seconds 
ATTACHMENT 2 
RESRAD Table of Input Parameters for the C-746-U Landfill Onsite Receptor Scenarios

\begin{tabular}{|c|c|c|c|c|c|c|c|c|c|}
\hline $\begin{array}{c}\text { Input Screen Title } \\
\text { and Parameter } \\
\text { Name }\end{array}$ & Unit & $\begin{array}{c}\text { Code } \\
\text { Default } \\
\text { Value }\end{array}$ & $\begin{array}{c}\text { Code- } \\
\text { Accepted } \\
\text { Values }^{a}\end{array}$ & Receptor $^{b}$ & $\begin{array}{c}\text { Deterministic } \\
\text { Value }\end{array}$ & Type $^{c}$ & Priority $^{d}$ & Justification & References \\
\hline \multicolumn{10}{|l|}{ Source } \\
\hline $\begin{array}{c}\text { Radionuclide } \\
\text { concentration }\end{array}$ & $\mathrm{pCi} / \mathrm{g}$ & $\begin{array}{l}100 \text { (Nuclide } \\
\text { specific) }\end{array}$ & Site specific & All & $\begin{array}{c}\text { Unit } \\
\text { concentration for: } \\
\text { Am-241 } \\
\text { Cs-137 } \\
\text { Np-237 } \\
\text { Pu-238 } \\
\text { Pu-239 } \\
\text { Pu-240 } \\
\text { Tc-99 } \\
\text { Th-228 } \\
\text { Th-230 } \\
\text { Th-232 } \\
\text { U-234 } \\
\text { U-235 } \\
\text { U-238 }\end{array}$ & $P$ & 2 & $\begin{array}{l}\text { The radionuclide concentration used is } 1 \mathrm{pCi} / \mathrm{g} \\
\text { for each parent radionuclide listed. Site- } \\
\text { specific values for the 6-year waste inventory } \\
\text { (May } 2003 \text { - May 2009) were not used as } \\
\text { input values. The list of radionuclides used } \\
\text { was provided to ORISE by DOE. Radioactive } \\
\text { secular equilibrium was not assumed in the } \\
\text { analysis for the uranium, actinium, and } \\
\text { thorium decay series due to the nature of the } \\
\text { PGDP's uranium enrichment mission. }\end{array}$ & $\begin{array}{l}\text { DOE 2003a } \\
\text { DOE SOW for } \\
\text { C-746-U landfill } \\
\text { and DOE } \\
\text { Project } \\
\text { Communication } \\
\text { (May 2010) }\end{array}$ \\
\hline
\end{tabular}

Transport Factors

\begin{tabular}{|c|c|c|c|c|c|c|c|c|c|}
\hline $\begin{array}{c}\text { Distribution } \\
\text { coefficients: } \\
\text { contaminated zone }\end{array}$ & $\mathrm{cm}^{3} / \mathrm{g}$ & $\begin{array}{l}\text { Nuclide } \\
\text { Specific } \\
\text { (Default } \\
\text { values } \\
\text { available) }\end{array}$ & $\begin{array}{l}\text { Nuclide } \\
\text { Specific }\end{array}$ & All & $\begin{array}{l}\text { Nuclide Specific } \\
\text { (See Attachment I) }\end{array}$ & $P$ & 1 & $\begin{array}{l}\text { Tables with site-specific distribution } \\
\text { coefficients for the parent and progeny } \\
\text { radionuclides are available in } \\
\text { Attachment I immediately following this table } \\
\text { of parameters. }\end{array}$ & $\begin{array}{c}\text { DOE 2003b } \\
\text { Table Att. 1, } \\
\text { page C3-314, } \\
\text { Table C.3.1., } \\
\text { page C3-301 } \\
\\
\text { DOE Project } \\
\text { Communication } \\
\text { (March 2010) }\end{array}$ \\
\hline $\begin{array}{c}\text { Distribution } \\
\text { coefficients: } \\
\text { unsaturated zones }\end{array}$ & $\mathrm{cm}^{3} / \mathrm{g}$ & $\begin{array}{l}\text { Nuclide } \\
\text { Specific } \\
\text { (Default } \\
\text { values } \\
\text { available) }\end{array}$ & $\begin{array}{l}\text { Nuclide } \\
\text { Specific }\end{array}$ & All & $\begin{array}{l}\text { Nuclide Specific } \\
\text { (See Attachment I) }\end{array}$ & $P$ & 1 & $\begin{array}{l}\text { Tables with site-specific distribution } \\
\text { coefficients for the parent and progeny } \\
\text { radionuclides are available in } \\
\text { Attachment I immediately following this table } \\
\text { of parameters. }\end{array}$ & $\begin{array}{c}\text { DOE 2003b } \\
\text { Table Att. 1, } \\
\text { page C3-314, } \\
\text { Table C.3.1., } \\
\text { page C3-301 } \\
\\
\text { DOE Project } \\
\text { Communication } \\
\text { (March 2010) }\end{array}$ \\
\hline $\begin{array}{c}\text { Distribution } \\
\text { coefficients: saturated } \\
\text { zones }\end{array}$ & $\mathrm{cm}^{3} / \mathrm{g}$ & $\begin{array}{l}\text { Nuclide } \\
\text { Specific } \\
\text { (Default } \\
\text { values }\end{array}$ & $\begin{array}{l}\text { Nuclide } \\
\text { Specific }\end{array}$ & All & $\begin{array}{l}\text { Nuclide Specific } \\
\text { (See Attachment I) }\end{array}$ & $P$ & 1 & $\begin{array}{l}\text { Tables with site-specific distribution } \\
\text { coefficients for the parent and daughter } \\
\text { radionuclides are available in } \\
\text { Attachment I immediately following this table }\end{array}$ & $\begin{array}{l}\text { DOE 2003b } \\
\text { Table Att. 1, } \\
\text { page C3-314, } \\
\text { Table C.3.1., }\end{array}$ \\
\hline
\end{tabular}


RESRAD Table of Input Parameters for the C-746-U Landfill Onsite Receptor Scenarios

\begin{tabular}{|c|c|c|c|c|c|c|c|c|c|}
\hline $\begin{array}{c}\text { Input Screen Title } \\
\text { and Parameter } \\
\text { Name }\end{array}$ & Unit & $\begin{array}{c}\text { Code } \\
\text { Default } \\
\text { Value }\end{array}$ & $\begin{array}{c}\text { Code- } \\
\text { Accepted } \\
\text { Values }^{a}\end{array}$ & Receptor ${ }^{b}$ & $\begin{array}{l}\text { Deterministic } \\
\text { Value }\end{array}$ & Type $^{c}$ & Priority $^{d}$ & Justification & References \\
\hline & & available) & & & & & & of parameters. & $\begin{array}{c}\text { page C3-301, } \\
\text { Table 4.7, } \\
\text { page 4-21 } \\
\text { DOE Project } \\
\text { Communication } \\
\text { (March 2010) }\end{array}$ \\
\hline $\begin{array}{c}\text { Number of } \\
\text { unsaturated zones }\end{array}$ & $-{ }^{e}$ & 1 & $\begin{array}{l}0-5 \\
\text { (integer } \\
\text { value) }\end{array}$ & All & 5 & P & 3 & $\begin{array}{l}\text { There are five unsaturated zones (UZ) } \\
\text { considered for receptors evaluated during the } \\
\text { Operational Period and the Post-Institutional } \\
\text { Control Period. These correspond to the } \\
\text { layers under waste. The maximum number of } \\
\text { layers accepted by the code is five. } \\
\text { Only the Landfill Worker and the Trespasser } \\
\text { are evaluated during the Operational Period, } \\
\text { the other receptors are evaluated during the } \\
\text { Post-Institutional Control Period. } \\
\text { It is important to note that even though the } \\
\text { UZ values input into the code correspond to } \\
\text { each receptor in accordance to its period of } \\
\text { evaluation, the UZ parameters will not be } \\
\text { applicable for the Trespasser, Outdoor } \\
\text { Worker, Recreational User or the Landfill } \\
\text { Worker. This is because the pathways } \\
\text { considering the UZ are suppressed as per the } \\
\text { conceptual site model. } \\
\text { Below are the five zones considered: } \\
\text { UZ 1= Protective layer (native soil) } \\
\text { UZ } 2=\text { Gravel layer } \\
\text { UZ } 3=\text { Clay barrier } \\
\text { UZ } 4=\text { Alluvium soils (native/subgrade) } \\
\text { UZ } 5=\text { Clay confining unit (native) }\end{array}$ & $\begin{array}{c}\text { DOE } 2003 \mathrm{~b} \\
\text { Fig. 4.3, } \\
\text { page 4-16, } \\
\text { Table 4.4, } \\
\text { page 4-9, } \\
\text { Fig. 4.5, } \\
\text { page 4-18, } \\
\text { Table Att.2, } \\
\text { page C3-315, }\end{array}$ \\
\hline $\begin{array}{l}\text { Time since placement } \\
\text { of material }\end{array}$ & $\mathrm{yr}$ & 0 & $0-100$ & All & 27 & P & 3 & $\begin{array}{l}\text { It is assumed that waste material was initially } \\
\text { placed in the landfill on May } 2003 \text { and that } \\
\text { the landfill will close in } 2030 .\end{array}$ & $\begin{array}{c}\text { DOE Project } \\
\text { Communication } \\
\text { with DOE-PPPO } \\
\text { (May 2010) } \\
\end{array}$ \\
\hline $\begin{array}{l}\text { Groundwater } \\
\text { concentration }\end{array}$ & $\mathrm{pCi} / \mathrm{L}$ & $\begin{array}{l}0^{\mathrm{f}} \text { (Nuclide } \\
\text { specific) }\end{array}$ & $0-1 E+34$ & All & 0 & P & 3 & $\begin{array}{l}\text { The default value is assigned; however, it is } \\
\text { not used by the code. This parameter is one of } \\
\text { the options in RESRAD to derive distribution }\end{array}$ & Yu et al. 2001 \\
\hline
\end{tabular}


RESRAD Table of Input Parameters for the C-746-U Landfill Onsite Receptor Scenarios

\begin{tabular}{|c|c|c|c|c|c|c|c|c|c|}
\hline $\begin{array}{c}\text { Input Screen Title } \\
\text { and Parameter } \\
\text { Name }\end{array}$ & Unit & $\begin{array}{c}\text { Code } \\
\text { Default } \\
\text { Value }\end{array}$ & $\begin{array}{c}\text { Code- } \\
\text { Accepted } \\
\text { Values }^{a}\end{array}$ & Receptor ${ }^{b}$ & $\begin{array}{c}\text { Deterministic } \\
\text { Value }\end{array}$ & Type $^{c}$ & Priority $^{d}$ & Justification & References \\
\hline & & & & & & & & $\begin{array}{l}\text { coefficients (Kds) when site-specific data is } \\
\text { not available. In this case site-specific Kds are } \\
\text { available and are used by the code; therefore, } \\
\text { there was no need to use this option to derive } \\
\text { them. }\end{array}$ & \\
\hline Leach rate ${ }^{g}$ & $1 / \mathrm{yr}$ & $\begin{array}{l}0 \text { (Nuclide } \\
\text { specific) }\end{array}$ & $0-1 E+34$ & All & 0 & $\mathrm{P}$ & 3 & $\begin{array}{l}\text { The default value is assigned; however, it is } \\
\text { not used by the code. This parameter is one of } \\
\text { the options in RESRAD to derive distribution } \\
\text { coefficients (Kds) when site-specific data is } \\
\text { not available. In this case site-specific Kds are } \\
\text { available and are used by the code; therefore, } \\
\text { there was no need to use this option to derive } \\
\text { them. }\end{array}$ & Yu et al. 2001 \\
\hline Solubility limit & $\mathrm{mol} / \mathrm{L}$ & $\begin{array}{l}0 \text { (Nuclide } \\
\text { specific) }\end{array}$ & $0-1 E+34$ & All & 0 & $\mathrm{P}$ & 3 & $\begin{array}{l}\text { The default value is assigned; however, it is } \\
\text { not used by the code. This parameter is one of } \\
\text { the options in RESRAD to derive distribution } \\
\text { coefficients (Kds) when site-specific data is } \\
\text { not available. In this case site-specific Kds are } \\
\text { available and are used by the code; therefore, } \\
\text { there was no need to use this option to derive } \\
\text { them. }\end{array}$ & Yu et al. 2001 \\
\hline Use plant/soil ratio & check box & Yes/No & $N A^{h}$ & All & $\begin{array}{l}\text { Box checked for } \\
\text { all except Np-237 }\end{array}$ & NA & 3 & $\begin{array}{l}\text { The default value is "checked", but the code } \\
\text { will not allow input of site specific distribution } \\
\text { coefficients for Np- } 237 \text { unless the box is } \\
\text { unchecked. Confirmed that this approach was } \\
\text { appropriate with Dr. Charley Yu, ANL. }\end{array}$ & $\begin{array}{c}\text { Project } \\
\text { Communication } \\
\text { with } \\
\text { Dr. Charley Yu } \\
\text { (April 2010) }\end{array}$ \\
\hline
\end{tabular}

Calculation Parameters

\begin{tabular}{|c|c|c|c|c|c|c|c|c|c|}
\hline \multirow{2}{*}{$\begin{array}{l}\text { Basic radiation dose } \\
\text { limit }\end{array}$} & \multirow{2}{*}{$\mathrm{mrem} / \mathrm{yr}$} & \multirow{2}{*}{25} & \multirow{2}{*}{$\begin{array}{l}1 \mathrm{E}-2- \\
1 \mathrm{E}+4\end{array}$} & $\begin{array}{c}\text { RF } \\
\text { RG } \\
\mathrm{T} \\
\mathrm{L}\end{array}$ & 100 & \multirow{2}{*}{ NA } & \multirow{2}{*}{3} & \multirow{2}{*}{$\begin{array}{l}\text { Three target dose constraints of } 1,15,25 \\
\mathrm{mrem} / \mathrm{yr} \text { and a primary dose limit of } 100 \\
\mathrm{mrem} / \mathrm{yr} \text { are considered in this project. } \\
\text { However, a target dose constraint of } 1 \\
\mathrm{mrem} / \mathrm{yr} \text { and a primary dose limit of } 100 \\
\mathrm{mrem} / \mathrm{yr} \text { are used for the RESRAD runs. } \\
\\
\text { Note that changing the basic radiation dose } \\
\text { limit in the code will not change the Dose to } \\
\text { Source Ratio (DSR) which is used in the } \\
\text { calculation for single radionuclide soil } \\
\text { guidelines. }\end{array}$} & \multirow[t]{2}{*}{$\begin{array}{l}\text { DOE SOW to } \\
\text { ORISE for } \\
\text { C-746-U } \\
\text { landfill, } \\
\text { Section 2, } \\
\text { Item 3 }\end{array}$} \\
\hline & & & & $\begin{array}{l}\text { W } \\
\mathrm{RU}\end{array}$ & 1 & & & & \\
\hline
\end{tabular}


RESRAD Table of Input Parameters for the C-746-U Landfill Onsite Receptor Scenarios

\begin{tabular}{|c|c|c|c|c|c|c|c|c|c|}
\hline $\begin{array}{c}\text { Input Screen Title } \\
\text { and Parameter } \\
\text { Name }\end{array}$ & Unit & $\begin{array}{c}\text { Code } \\
\text { Default } \\
\text { Value }\end{array}$ & $\begin{array}{l}\text { Code- } \\
\text { Accepted } \\
\text { Values }^{a}\end{array}$ & Receptor ${ }^{b}$ & $\begin{array}{c}\text { Deterministic } \\
\text { Value }\end{array}$ & Type $e^{c}$ & Priority $^{d}$ & Justification & References \\
\hline & & & & $\begin{array}{l}\text { RF } \\
\text { RG } \\
W \\
\text { RU } \\
\end{array}$ & $\begin{array}{c}1,50,100,500 \\
1050\end{array}$ & & & $\begin{array}{l}\text { A time horizon of } 1,050 \text { years is used in order } \\
\text { to calculate single radionuclide soil guidelines. } \\
\text { This is assumed to allow for in- growth and } \\
\text { decay since PGDP has been in operation for } \\
\text { about } 50 \text { years (since about } 1960 \text { to2010). }\end{array}$ & $\begin{array}{l}\mathrm{DOE} / \mathrm{CH} / 8901 \\
\text { and } \\
\text { DOE Order } \\
5400.5\end{array}$ \\
\hline Times for calculations & $\mathrm{yr}$ & $\begin{array}{c}1,3,10,30 \\
100,300 \\
1000\end{array}$ & $0-1 \mathrm{E}+5$ & $\begin{array}{l}\mathrm{T} \\
\mathrm{L}\end{array}$ & $1,50,70$ & P & 3 & $\begin{array}{l}\text { A time horizon of } 70 \text { years is used for the } \\
\text { Landfill Worker and the Trespasser since } \\
\text { these receptors are modeled during the } \\
\text { Operational Period of the Landfill. The } \\
\text { Operational Period of the Landfill is } \\
\text { considered to be } 20 \text { years per DOE } 2003 \mathrm{~b} \text { and } \\
50 \text { years are included to allow for in- growth } \\
\text { and decay due to PGDP being in operation for } \\
\text { about } 50 \text { years. }\end{array}$ & $\begin{array}{l}\text { Communication } \\
\text { (May 2010 and } \\
\text { July 2010) } \\
\text { DOE 2003b }\end{array}$ \\
\hline
\end{tabular}

Contaminated Zone Parameters

\begin{tabular}{|c|c|c|c|c|c|c|c|c|c|}
\hline $\begin{array}{l}\text { Area of contaminated } \\
\text { zone }\end{array}$ & $\mathrm{m}^{2}$ & 10,000 & $\begin{array}{l}1 \mathrm{E}-4- \\
1 \mathrm{E}+15\end{array}$ & All & 89,436 & $P$ & 2 & $\begin{array}{l}\text { The contaminated zone is composed of four } \\
\text { different waste forms. The waste forms types } \\
\text { are soil, concrete, metal, and organic (lumber } \\
\text { and debris). The total waste disposal area of } \\
\text { the landfill is used as the area of the } \\
\text { contaminated zone. When filled the landfill } \\
\text { disposal area will encompass } 22.1 \text { acres } \\
\text { (approximately } 89,436 \text { square meters). } \\
\text { However, the total permitted landfill site will } \\
\text { encompass } 59.7 \text { acres. }\end{array}$ & $\begin{array}{l}\text { DOE SOW for } \\
\text { C-746-U landfill } \\
\\
\text { DOE 2003b } \\
\text { Section 3.2, } \\
\text { page 3-11, } \\
\text { Table 4.5, } \\
\text { page 4-13 }\end{array}$ \\
\hline $\begin{array}{l}\text { Thickness of } \\
\text { contaminated zone }\end{array}$ & $\mathrm{m}$ & 2 & $\begin{array}{l}1 \mathrm{E}-5- \\
1 \mathrm{E}+3\end{array}$ & All & 13.4 & $P$ & 2 & $\begin{array}{l}\text { This value is the average thickness for the } \\
\text { waste forms when the landfill is full. }\end{array}$ & $\begin{array}{c}\text { DOE 2003b } \\
\text { Table 4.5, } \\
\text { page 4-13, } \\
\text { Table Att.3, } \\
\text { page C3-315 }\end{array}$ \\
\hline $\begin{array}{l}\text { Length parallel to } \\
\text { aquifer flow }\end{array}$ & $\mathrm{m}$ & 100 & $\begin{array}{l}1 \mathrm{E}-4- \\
1 \mathrm{E}+6\end{array}$ & All & 399 & $P$ & 2 & $\begin{array}{l}\text { This value of } 399 \mathrm{~m} \text { is the conservative longest } \\
\text { dimension between the upgradient edge of } \\
\text { the contaminated zone and the downgradient } \\
\text { edge, parallel to the aquifer. }\end{array}$ & $\begin{array}{l}\text { Lee et al. } 1995 \\
\text { Fig 2-4, page } 17\end{array}$ \\
\hline
\end{tabular}

Cover and Contaminated Zone Hydrological Data 
RESRAD Table of Input Parameters for the C-746-U Landfill Onsite Receptor Scenarios

\begin{tabular}{|c|c|c|c|c|c|c|c|c|c|}
\hline $\begin{array}{l}\text { Input Screen Title } \\
\text { and Parameter } \\
\text { Name }\end{array}$ & Unit & $\begin{array}{l}\text { Code } \\
\text { Default } \\
\text { Value }\end{array}$ & $\begin{array}{l}\text { Code- } \\
\text { Accepted } \\
\text { Values }^{a}\end{array}$ & Receptor ${ }^{b}$ & $\begin{array}{l}\text { Deterministic } \\
\text { Value }\end{array}$ & Type ${ }^{c}$ & Priority $^{d}$ & Justification & References \\
\hline Cover depth & $\mathrm{m}$ & 0 & $0-100$ & $\begin{array}{l}\text { RF } \\
\text { RG } \\
\text { W } \\
\text { RU }\end{array}$ & 0.152 & $P$ & 2 & $\begin{array}{l}\text { For receptors exposed during the Post- } \\
\text { Institutional Control Period this value is the } \\
\text { depth of the final cover planned for the } \\
\text { landfill. The landfill cover will have six layers } \\
\text { with a total thickness of } 5 \mathrm{ft} \text { ( } 1.52 \text { meters). This } \\
\text { applies to all receptors except for the } \\
\text { Trespasser and Landfill Worker. The } \\
\text { Trespasser and the Landfill Worker are } \\
\text { exposed during the Operational Period. } \\
\text { During this period the cover has a layer of } \\
\text { vegetative soil and its depth is expected to be } \\
6 \text { in ( } 0.152 \text { meters) A cover is assumed for the } \\
\text { Trespasser; however, no cover is assumed for } \\
\text { the Landfill Worker. }\end{array}$ & $\begin{array}{c}\text { DOE } 2003 b \\
\text { Section } 3.2, \\
\text { page } 3-11, \\
\text { page } 3-13, \\
\text { Fig. } 4.3, \\
\text { page } 4-16, \\
\text { Fig. } 4.5, \\
\text { page } 4-18\end{array}$ \\
\hline $\begin{array}{l}\text { Density of cover } \\
\text { material }\end{array}$ & $\mathrm{g} / \mathrm{cm} 3$ & 1.5 & $1 E-3-22.5$ & All & 1.5 & $P$ & 1 & $\begin{array}{l}\text { For receptors exposed during the Post- } \\
\text { Institutional Control Period the value for the } \\
\text { density of the cover was obtained from the } \\
\text { previous RESRAD study for the landfill } \\
\text { described in DOE } 2003 \mathrm{~b} \text {. This applies to all } \\
\text { receptors except for the Trespasser and the } \\
\text { Landfill Worker. This value was also confirmed } \\
\text { with DOE to be a site specific value for the } \\
\text { final cover. The Trespasser is exposed during } \\
\text { the operational period and the density of the } \\
\text { cover is also } 1.5 \mathrm{~g} / \mathrm{cm}^{3} \text { as provided by geologist } \\
\text { and engineer. This parameter is not applicable } \\
\text { to the Landfill Worker since no cover is } \\
\text { assumed for this receptor. }\end{array}$ & $\begin{array}{c}\text { DOE 2003b } \\
\text { Table Att.5, } \\
\text { page C3-316 } \\
\text { DOE Project } \\
\text { Communication } \\
\text { with geologist } \\
\text { and engineer } \\
\text { (April 2010) }\end{array}$ \\
\hline Cover erosion rate & $\mathrm{m} / \mathrm{yr}$ & 0.001 & $0-5$ & All & 0.0006 & $P, B$ & 2 & $\begin{array}{l}\text { This value was obtained from the previous } \\
\text { RESRAD study for the landfill described in DOE } \\
\text { 2003b. }\end{array}$ & $\begin{array}{l}\text { DOE 2003b } \\
\text { Table Att.5, } \\
\text { page C3-316 }\end{array}$ \\
\hline $\begin{array}{c}\text { Density of } \\
\text { contaminated zone }\end{array}$ & $\mathrm{g} / \mathrm{cm} 3$ & 1.5 & $1 E-3-22.5$ & All & 1.89 & $\mathrm{P}$ & 1 & $\begin{array}{l}\text { The densities of the waste forms were used to } \\
\text { calculate the weighted average density for the } \\
\text { contaminated zone which is approximately } \\
1.89 \mathrm{~g} / \mathrm{cm}^{3} \text {. }\end{array}$ & $\begin{array}{l}\text { DOE } 2003 b \\
\text { Table } 4.5 \\
\text { page } 4-13\end{array}$ \\
\hline $\begin{array}{l}\text { Contaminated zone } \\
\text { total porosity }\end{array}$ & - & 0.4 & $1 E-5-1$ & All & 0.17 & $P$ & 2 & $\begin{array}{l}\text { The site-specific value available is } 0.168 \\
\mathrm{vol} / \mathrm{vol} \text {. }\end{array}$ & $\begin{array}{l}\text { DOE 2003b } \\
\text { Table 4.4, } \\
\text { page 4-9 }\end{array}$ \\
\hline $\begin{array}{l}\text { Contaminated zone } \\
\text { field capacity }\end{array}$ & - & 0.2 & $1 E-34-1$ & All & 0.07 & $P$ & 3 & $\begin{array}{l}\text { The site-specific value available is } 0.073 \\
\mathrm{vol} / \mathrm{vol} \text {. }\end{array}$ & $\begin{array}{l}\text { DOE 2003b } \\
\text { Table 4.4, } \\
\text { page 4-9 }\end{array}$ \\
\hline Contaminated zone & $\mathrm{m} / \mathrm{yr}$ & 0.001 & $0-5$ & All & 0.0006 & $P, B$ & 2 & This value was obtained from the previous & DOE 2003b \\
\hline
\end{tabular}


RESRAD Table of Input Parameters for the C-746-U Landfill Onsite Receptor Scenarios

\begin{tabular}{|c|c|c|c|c|c|c|c|c|c|}
\hline $\begin{array}{l}\text { Input Screen Title } \\
\text { and Parameter } \\
\text { Name }\end{array}$ & Unit & $\begin{array}{l}\text { Code } \\
\text { Default } \\
\text { Value }\end{array}$ & $\begin{array}{l}\text { Code- } \\
\text { Accepted } \\
\text { Values }^{a}\end{array}$ & Receptor $^{b}$ & $\begin{array}{l}\text { Deterministic } \\
\text { Value }\end{array}$ & Type $^{c}$ & Priority $^{d}$ & Justification & References \\
\hline erosion rate & & & & & & & & $\begin{array}{l}\text { RESRAD study for the landfill described in DOE } \\
\text { 2003b. }\end{array}$ & $\begin{array}{l}\text { Table Att.3, } \\
\text { page C3-315 }\end{array}$ \\
\hline $\begin{array}{l}\text { Contaminated zone } \\
\text { hydraulic conductivity }\end{array}$ & $\mathrm{m} / \mathrm{yr}$ & 10 & $\begin{array}{l}1 \mathrm{E}-3- \\
1 \mathrm{E}+10\end{array}$ & All & 315.4 & $P$ & 2 & $\begin{array}{l}\text { The hydraulic conductivity for waste forms 1-4 } \\
\text { is } 1.0 \mathrm{E}-3 \mathrm{~cm} / \mathrm{s} \text { (approximately } 315.4 \mathrm{~m} / \mathrm{yr} \text { ). }\end{array}$ & $\begin{array}{l}\text { DOE 2003b } \\
\text { Fig. } 4.5, \\
\text { page } 4-18\end{array}$ \\
\hline $\begin{array}{l}\text { Contaminated zone b } \\
\text { parameter }\end{array}$ & - & 5.3 & $0-15$ & All & 4.05 & $\mathrm{P}$ & 2 & $\begin{array}{l}\text { DOE geologist determined that the most } \\
\text { appropriate value for the contaminated zone } \\
\text { b parameter available in Yu et al. } 1993 \text { is the } \\
\text { one for sand. It is known that the } \\
\text { contaminated zone (waste) will have high } \\
\text { porosity and high permeability. When } \\
\text { selecting a deterministic value for this input } \\
\text { parameter, the closest material and } \\
\text { corresponding Soil b Parameter, as developed } \\
\text { by Clapp and Hornberger (Yu et al. 1993), for } \\
\text { concrete, steel and soil waste is sand. Clapp \& } \\
\text { Hornberger do not offer a corresponding Soil } \\
\text { b Parameter for landfill waste. }\end{array}$ & $\begin{array}{c}\text { Yu et al. } 1993 \\
\text { page } 83 \\
\text { DOE Project } \\
\text { Communication } \\
\text { with geologist } \\
\text { (July 2010) }\end{array}$ \\
\hline \multirow{4}{*}{$\begin{array}{l}\text { Evapotranspiration } \\
\text { coefficient }\end{array}$} & \multirow{4}{*}{-} & \multirow{4}{*}{0.5} & \multirow{4}{*}{$0-0.999$} & $\begin{array}{l}\mathrm{RF} \\
\mathrm{RG}\end{array}$ & 0.74 & \multirow{4}{*}{$P$} & \multirow{4}{*}{2} & $\begin{array}{l}\text { The value for the Resident Farmer, Resident } \\
\text { Gardener, Worker and Recreational User were } \\
\text { calculated using the HELP Output data for the } \\
\text { Post-Institutional Control Period. }\end{array}$ & \multirow{4}{*}{$\begin{array}{c}\text { DOE 2003b } \\
\text { pages, C3-93, } \\
\text { C3-243 } \\
\text { Yu et al. } 1993 \\
\text { page } 78\end{array}$} \\
\hline & & & & $\begin{array}{l}\text { W } \\
\text { RU }\end{array}$ & 0.83 & & & $\begin{array}{l}\text { The value for the Trespasser and the Landfill } \\
\text { Worker was calculated using the HELP Output } \\
\text { data for the Operational Period. }\end{array}$ & \\
\hline & & & & & & & & $\begin{array}{l}\text { The equation used to calculate these values is } \\
\text { available in Yu et al. } 1993 \text {. } \\
\text { The calculations are available in Attachment II } \\
\text { following this table. }\end{array}$ & \\
\hline & & & & $\begin{array}{l}\mathrm{T} \\
\mathrm{L}\end{array}$ & 0.69 & & & $\begin{array}{l}\text { The code initially did not run when using an } \\
\text { irrigation rate of } 0.1 \mathrm{~m} / \mathrm{yr} \text { and an } \\
\text { evapotranspiration coefficient of } 0.74 \text { for the } \\
\text { Resident Farmer. It generated an output file } \\
\text { with instructions to make appropriate } \\
\text { changes in order for it run. Adjustments had } \\
\text { to be made to the code's graphic points and } \\
\text { the number of dose points. The RESRAD } \\
\text { output file with the instructions is available in } \\
\text { Attachment III following this table. }\end{array}$ & \\
\hline
\end{tabular}


RESRAD Table of Input Parameters for the C-746-U Landfill Onsite Receptor Scenarios

\begin{tabular}{|c|c|c|c|c|c|c|c|c|c|}
\hline $\begin{array}{c}\text { Input Screen Title } \\
\text { and Parameter } \\
\text { Name }\end{array}$ & Unit & $\begin{array}{c}\text { Code } \\
\text { Default } \\
\text { Value }\end{array}$ & $\begin{array}{c}\text { Code- } \\
\text { Accepted } \\
\text { Values }^{a}\end{array}$ & Receptor $^{b}$ & $\begin{array}{l}\text { Deterministic } \\
\text { Value }\end{array}$ & Type ${ }^{c}$ & Priority $^{d}$ & Justification & References \\
\hline Wind speed & $\mathrm{m} / \mathrm{s}$ & 2 & $1 E-4-20$ & All & 4.5 & $P$ & 2 & $\begin{array}{l}\text { The average prevailing wind at the PGDP is } \\
\text { from the south to southwest at approximately } \\
10 \mathrm{mph} \text { ( } 4.5 \text { meters/seconds). }\end{array}$ & $\begin{array}{l}\text { PRS } 2008 \\
\text { page 1-4 }\end{array}$ \\
\hline Precipitation rate & $\mathrm{m} / \mathrm{yr}$ & 1 & $0-10$ & All & 1.24 & $P$ & 2 & $\begin{array}{l}\text { The yearly precipitation averages about } 49 \\
\text { inches ( } 1.24 \text { meters). }\end{array}$ & $\begin{array}{l}\text { PRS } 2008 \\
\text { page 1-4 }\end{array}$ \\
\hline Irrigation rate & $\mathrm{m} / \mathrm{yr}$ & 0.2 & $0-10$ & $\begin{array}{l}\text { W } \\
\text { RU } \\
T \\
\text { L }\end{array}$ & 0.1 & B & 3 & $\begin{array}{l}\text { Irrigation in the Paducah, Kentucky area is } \\
\text { considered to be unlikely. In the event } \\
\text { irrigation is necessary, the water will primarily } \\
\text { come from uncontaminated surface water } \\
\text { and not from groundwater (well). Information } \\
\text { from the USGS shows that surface water is the } \\
\text { main source of water used in Kentucky for } \\
\text { irrigation (Kenny et al. 2009). The Paducah } \\
\text { area (i.e., where PGDP is located) receives } \\
\text { about an average of } 49 \text { inches (1.24 m) of } \\
\text { precipitation per year (PRS 2008). According } \\
\text { to ATSDR 2002, the farms in McCracken } \\
\text { County, KY (i.e., where Paducah is located) } \\
\text { rely on rainfall to water their crops. For } \\
\text { conservatism in the modeling, and as } \\
\text { recommended by DOE-PPPO, it was assumed } \\
\text { that the Resident Farmer uses contaminated } \\
\text { well water for irrigation of agricultural areas } \\
\text { (i.e., fruit, grain, non-leafy and leafy } \\
\text { vegetables). However, due to limitations in } \\
\text { the RESRAD (onsite) code, the Resident } \\
\text { Farmer (onsite) scenario includes irrigation of } \\
\text { fodder besides the agricultural areas. } \\
\text { Alternatively, the Resident Gardener uses } \\
\text { water for irrigation of plants (i.e., fruit, grain, } \\
\text { non-leafy and leafy vegetables) from an } \\
\text { uncontaminated source (e.g., municipal water } \\
\text { source). Even though this receptor is modeled } \\
\text { with RESRAD (onsite), irrigation of fodder will } \\
\text { not be included for this receptor because the } \\
\text { meat and milk ingestion pathways are } \\
\text { excluded in this receptor scenario. An } \\
\text { irrigation rate of } 0.1 \mathrm{~m} / \mathrm{yr} \text { is used for the } \\
\text { Resident Farmer (onsite), and the Resident } \\
\text { Gardener. } \\
\text { An irrigation rate of } 0 \text { m/yr or no irrigation is }\end{array}$ & $\begin{array}{c}\text { DOE Project } \\
\text { Communication } \\
\text { with DOE-PPPO } \\
\text { (April 2011) } \\
\text { Kenny et al. } \\
2009 \\
\text { ATSDR } 2002 \\
\text { page } 8\end{array}$ \\
\hline
\end{tabular}


RESRAD Table of Input Parameters for the C-746-U Landfill Onsite Receptor Scenarios

\begin{tabular}{|c|c|c|c|c|c|c|c|c|c|}
\hline $\begin{array}{c}\text { Input Screen Title } \\
\text { and Parameter } \\
\text { Name }\end{array}$ & Unit & $\begin{array}{c}\text { Code } \\
\text { Default } \\
\text { Value }\end{array}$ & $\begin{array}{l}\text { Code- } \\
\text { Accepted }^{a} \\
\text { Values }^{a}\end{array}$ & Receptor ${ }^{b}$ & $\begin{array}{c}\text { Deterministic } \\
\text { Value }\end{array}$ & Type $^{c}$ & Priority $^{d}$ & Justification & References \\
\hline & & & & & & & & $\begin{array}{l}\text { assumed for the Landfill Worker, Trespasser, } \\
\text { Recreational User, and Outdoor Worker. } \\
\text { The code initially did not run when using an } \\
\text { irrigation rate of } 0.1 \mathrm{~m} / \mathrm{yr} \text { and an } \\
\text { evapotranspiration coefficient of } 0.74 \text { for the } \\
\text { Resident Farmer. It generated an output file } \\
\text { with instructions to make appropriate } \\
\text { changes in order for it run. Adjustments had } \\
\text { to be made to the code's graphic points and } \\
\text { the number of dose points. The RESRAD } \\
\text { output file with the instructions is available in } \\
\text { Attachment III following this table. }\end{array}$ & \\
\hline Irrigation mode & - & Overhead & $\begin{array}{l}\text { Overhead/ } \\
\text { ditch }\end{array}$ & All & Overhead & B & 3 & $\begin{array}{l}\text { The default input is used. } \\
\text { Irrigation is not applicable for the Workers, } \\
\text { Recreational User, or the Trespasser. In order } \\
\text { to suppress this parameter for these } \\
\text { receptors only the following pathways are } \\
\text { used: external gamma, inhalation, and soil } \\
\text { ingestion. }\end{array}$ & Yu et al. 2001 \\
\hline Runoff coefficient & - & 0.2 & $0-1$ & $\begin{array}{l}\text { RF } \\
\text { RG } \\
\text { W } \\
\text { RU }\end{array}$ & 0.34 & & 2 & $\begin{array}{l}\text { The values for the Resident Farmer, Resident } \\
\text { Gardener, Outdoor Worker and Recreational } \\
\text { User were calculated using the HELP Output } \\
\text { data for the Post-Institutional Control Period. } \\
\text { The value for the Trespasser and Landfill } \\
\text { Worker was calculated using the HELP Output } \\
\text { data for the Operational Period. } \\
\text { The equation used to calculate these values is } \\
\text { available in Yu et al. 1993. } \\
\text { The calculations are available in Attachment II } \\
\text { following this table. }\end{array}$ & $\begin{array}{c}\text { DOE } 2003 \mathrm{~b} \\
\text { pages C3-93, } \\
\text { C3-243 } \\
\text { Yu et al. } 1993 \\
\text { page } 73\end{array}$ \\
\hline $\begin{array}{l}\text { Watershed area for } \\
\text { nearby stream or pond }\end{array}$ & $\mathrm{m}^{2}$ & $1,000,000$ & $\begin{array}{l}1 E-4- \\
1 E+34\end{array}$ & All & $1,000,000$ & & 3 & $\begin{array}{l}\text { This parameter refers to the site-specific area } \\
\text { that drains into the nearby pond. } \\
\text { A default value is assumed. } \\
\text { No site-specific value available. }\end{array}$ & Yu et al. 2001 \\
\hline $\begin{array}{l}\text { Accuracy for water } \\
\text { soil computation }\end{array}$ & - & 0.001 & $0-0.1$ & All & 0.001 & NA & 3 & $\begin{array}{l}\text { This parameter refers to the fractional } \\
\text { accuracy desired (convergence criterion) in } \\
\text { the Romberg integration used to obtain } \\
\text { water/soil concentration ratios. }\end{array}$ & Yu et al. 2001 \\
\hline
\end{tabular}


RESRAD Table of Input Parameters for the C-746-U Landfill Onsite Receptor Scenarios

\begin{tabular}{|c|c|c|c|c|c|c|c|c|}
\hline $\begin{array}{c}\text { Input Screen Title } \\
\text { and Parameter } \\
\text { Name }\end{array}$ & Unit & $\begin{array}{c}\text { Code } \\
\text { Default } \\
\text { Value }\end{array}$ & $\begin{array}{c}\text { Code- } \\
\text { Accepted } \\
\text { Values }^{a}\end{array}$ & Receptor $^{b}$ & $\begin{array}{c}\text { Deterministic } \\
\text { Value }\end{array}$ & Type $^{c}$ & Priority & Justification \\
\hline & & & & & & & $\begin{array}{c}\text { A default value is assumed. No site-specific } \\
\text { value available. }\end{array}$ & \\
\hline
\end{tabular}

Saturated Zone Hydrological Data

\begin{tabular}{|c|c|c|c|c|c|c|c|c|c|}
\hline $\begin{array}{l}\text { Density of saturated } \\
\text { zone }\end{array}$ & $\mathrm{g} / \mathrm{cm}^{3}$ & 1.5 & $1 E-3-22.5$ & All & 1.67 & $P$ & 1 & $\begin{array}{l}\text { This value was obtained from the previous } \\
\text { RESRAD study for the landfill described in DOE } \\
\text { 2003b. }\end{array}$ & $\begin{array}{c}\text { DOE 2003b } \\
\text { Table 4.7, page } \\
\text { 4-21, Table } \\
\text { Att.4., page C3- } \\
315 \\
\end{array}$ \\
\hline $\begin{array}{l}\text { Saturated zone total } \\
\text { porosity }\end{array}$ & - & 0.4 & $1 \mathrm{E}-5-1$ & All & 0.34 & $P$ & 1 & $\begin{array}{l}\text { This value was obtained from the previous } \\
\text { RESRAD study for the landfill described in DOE } \\
\text { 2003b. }\end{array}$ & $\begin{array}{l}\text { DOE 2003b } \\
\text { Table Att.4., } \\
\text { page C3-315 }\end{array}$ \\
\hline $\begin{array}{l}\text { Saturated zone } \\
\text { effective porosity }\end{array}$ & - & 0.2 & $1 \mathrm{E}-34-1$ & All & 0.3 & $\mathrm{P}$ & 1 & $\begin{array}{l}\text { This value was obtained from the previous } \\
\text { RESRAD study for the landfill described in DOE } \\
\text { 2003b. }\end{array}$ & $\begin{array}{c}\text { DOE 2003b } \\
\text { Table 4.7, page } \\
\text { 4-21, Table } \\
\text { Att.4., page C3- } \\
315 \\
\end{array}$ \\
\hline $\begin{array}{l}\text { Saturated zone field } \\
\text { capacity }\end{array}$ & - & 0.2 & $1 E-34-1$ & All & 0.04 & $P$ & 3 & $\begin{array}{l}\text { This value was obtained from the previous } \\
\text { RESRAD study for the landfill described in DOE } \\
\text { 2003b. }\end{array}$ & $\begin{array}{l}\text { DOE 2003b } \\
\text { Table Att.4., } \\
\text { page C3-315 }\end{array}$ \\
\hline $\begin{array}{c}\text { Saturated zone } \\
\text { hydraulic conductivity }\end{array}$ & $\mathrm{m} / \mathrm{yr}$ & 100 & $\begin{array}{l}1 E-3- \\
1 E+10\end{array}$ & All & 55630 & $P$ & 1 & $\begin{array}{l}\text { This value was obtained from the previous } \\
\text { RESRAD study for the landfill described in DOE } \\
\text { 2003b. This value was verified by DOE } \\
\text { geologist. }\end{array}$ & $\begin{array}{c}\text { DOE 2003b } \\
\text { Table Att.4., } \\
\text { page C3-315 } \\
\\
\text { DOE Project } \\
\text { Communication } \\
\text { with geologist } \\
\text { and engineer } \\
\text { (April 2010) }\end{array}$ \\
\hline $\begin{array}{l}\text { Saturated zone } \\
\text { hydraulic gradient }\end{array}$ & - & 0.02 & $1 \mathrm{E}-10-10$ & All & 0.0011 & $\mathrm{P}$ & 2 & $\begin{array}{l}\text { This value was obtained from the previous } \\
\text { RESRAD study for the landfill described in DOE } \\
\text { 2003b. }\end{array}$ & $\begin{array}{l}\text { DOE 2003b } \\
\text { Table Att.4., } \\
\text { page C3-315 }\end{array}$ \\
\hline $\begin{array}{l}\text { Saturated zone } b \\
\text { parameter }\end{array}$ & - & 5.3 & $1 E-34-15$ & All & 4.05 & $P$ & 2 & $\begin{array}{l}\text { DOE geologist determined that saturated zone } \\
\text { consists of a mixture of gravel and sand and } \\
\text { recommended a value from Yu et al. } 1993 \\
\text { based on sand. }\end{array}$ & $\begin{array}{l}\text { Yu et al. } 1993 \\
\text { DOE Project } \\
\text { Communication } \\
\text { with geologist } \\
\text { (April 2010) }\end{array}$ \\
\hline Water table drop rate & $\mathrm{m} / \mathrm{yr}$ & 0.001 & $0-5$ & All & 0.001 & $P$ & 3 & $\begin{array}{l}\text { The default value is used. } \\
\text { No site-specific value was available. }\end{array}$ & Yu et al. 2001 \\
\hline Well pump intake & $\mathrm{m}$ & 10 & $1 \mathrm{E}-5-$ & All & 9.1 & $P$ & 2 & The value of $9.1 \mathrm{~m}$ is used for the Resident & DOE Project \\
\hline
\end{tabular}


RESRAD Table of Input Parameters for the C-746-U Landfill Onsite Receptor Scenarios

\begin{tabular}{|c|c|c|c|c|c|c|c|c|c|}
\hline $\begin{array}{c}\text { Input Screen Title } \\
\text { and Parameter } \\
\text { Name }\end{array}$ & Unit & $\begin{array}{c}\text { Code } \\
\text { Default } \\
\text { Value }\end{array}$ & $\begin{array}{c}\text { Code- } \\
\text { Accepted } \\
\text { Values }^{a}\end{array}$ & Receptor $^{b}$ & $\begin{array}{c}\text { Deterministic } \\
\text { Value }\end{array}$ & $T_{y p e^{c}}$ & Priority $^{d}$ & Justification & References \\
\hline $\begin{array}{c}\text { depth (below water } \\
\text { table) }\end{array}$ & & & 1,000 & & & & & $\begin{array}{l}\text { Farmer since this value was recommended by } \\
\text { LATA (Los Alamos Technical Associates) } \\
\text { Kentucky. In addition, the value for the well } \\
\text { pump intake depth in RESRAD was modified in } \\
\text { order to achieve consistency with the depth } \\
\text { of aquifer contributing to well in RESRAD- } \\
\text { OFFSITE as suggested by Argonne National } \\
\text { Laboratory (ANL) expert. } \\
\text { This parameter is suppressed for the Resident } \\
\text { Gardener, Workers, Recreational User and the } \\
\text { Trespasser by choosing the applicable } \\
\text { pathways. }\end{array}$ & $\begin{array}{c}\text { Communication } \\
\text { with DOE } \\
\text { consultant } \\
\text { (November } \\
\text { 2010) }\end{array}$ \\
\hline $\begin{array}{l}\text { Model: nondispersion } \\
\text { (ND) or mass-balance } \\
\text { (MB) }\end{array}$ & - & ND & $\mathrm{ND} / \mathrm{MB}$ & All & ND & $P$ & 3 & $\begin{array}{l}\text { A default model was assumed for the } \\
\text { Resident Farmer, since this is the only } \\
\text { receptor that will have a well and site specific } \\
\text { information is not available. } \\
\text { The meat, milk, plant and drinking water } \\
\text { ingestion pathways are suppressed for the } \\
\text { Workers, Recreational User, and Trespasser } \\
\text { since these pathways are not considered in } \\
\text { the conceptual site model for these receptors. } \\
\text { The meat, milk, and drinking water ingestion } \\
\text { pathways are suppressed for Resident } \\
\text { Gardener. T he plant ingestion pathway is } \\
\text { active for this receptor; however, the water is } \\
\text { obtained from uncontaminated sources. }\end{array}$ & Yu et al. 2001 \\
\hline Well pumping rate & $\mathrm{m}^{3} / \mathrm{yr}$ & 250 & $0-1 E+10$ & All & 685 & $B, P$ & 2 & $\begin{array}{l}\text { This value is modified to achieve consistency } \\
\text { with the calculated well pumping rate in } \\
\text { RESRAD-OFFSITE. This applies to the Resident } \\
\text { Farmer and Resident Gardener. The value } \\
\text { calculated by RESRAD-OFFSITE for the well } \\
\text { pumping rate corresponds to } 685 \mathrm{~m}^{3} / \mathrm{yr} \text {. This } \\
\text { approach was suggested by ANL. } \\
\text { The meat, milk, plant and drinking water } \\
\text { ingestion pathways are suppressed for the } \\
\text { Workers, Recreational User, and Trespasser } \\
\text { since these pathways are not considered in } \\
\text { the conceptual site model for these receptors. }\end{array}$ & $\begin{array}{l}\text { DOE Project } \\
\text { Communication } \\
\text { with DOE } \\
\text { consultant } \\
\text { (November } \\
\text { 2010) }\end{array}$ \\
\hline
\end{tabular}


RESRAD Table of Input Parameters for the C-746-U Landfill Onsite Receptor Scenarios

\begin{tabular}{|c|c|c|c|c|c|c|c|c|c|}
\hline $\begin{array}{c}\text { Input Screen Title } \\
\text { and Parameter } \\
\text { Name }\end{array}$ & Unit & $\begin{array}{c}\text { Code } \\
\text { Default } \\
\text { Value }\end{array}$ & $\begin{array}{c}\text { Code- } \\
\text { Accepted } \\
\text { Values }^{a}\end{array}$ & Receptor ${ }^{b}$ & $\begin{array}{c}\text { Deterministic } \\
\text { Value }\end{array}$ & Type $^{c}$ & Priority $^{d}$ & Justification & References \\
\hline & & & & & & & & $\begin{array}{l}\text { The meat, milk, and drinking water ingestion } \\
\text { pathways are suppressed for Resident } \\
\text { Gardener. The plant ingestion pathway is } \\
\text { active for this receptor; however, the water is } \\
\text { obtained from uncontaminated sources. }\end{array}$ & \\
\hline
\end{tabular}

Uncontaminated Unsaturated Zone Parameters

\begin{tabular}{|c|c|c|c|c|c|c|c|c|c|}
\hline $\begin{array}{l}\text { Unsaturated zone } \\
\text { thickness }\end{array}$ & $\mathrm{m}$ & 4 & $0-10,000$ & All & $\begin{array}{l}\text { Zone } 1=0.3 \\
\text { Zone } 2=0.3 \\
\text { Zone } 3=0.9 \\
\text { Zone } 4=2.0 \\
\text { Zone } 5=8.4\end{array}$ & $P$ & 1 & $\begin{array}{l}\text { These values were obtained from the previous } \\
\text { RESRAD study for the landfill described in DOE } \\
\text { 2003b. }\end{array}$ & $\begin{array}{l}\text { DOE 2003b } \\
\text { Table Att.2, } \\
\text { page C3-315 }\end{array}$ \\
\hline $\begin{array}{l}\text { Unsaturated zone } \\
\text { density }\end{array}$ & $\mathrm{g} / \mathrm{cm}^{3}$ & 1.5 & $1 \mathrm{E}-3-22.5$ & All & $\begin{array}{c}\text { Zone } 1=1.2 \\
\text { Zone } 2=1.5 \\
\text { Zone } 3=1.8 \\
\text { Zone } 4=1.5 \\
\text { Zone } 5=1.76 \\
\end{array}$ & $P$ & 2 & $\begin{array}{l}\text { These values were obtained from the previous } \\
\text { RESRAD study for the landfill described in DOE } \\
\text { 2003b. }\end{array}$ & $\begin{array}{l}\text { DOE 2003b } \\
\text { Table Att.2, } \\
\text { page C3-315 }\end{array}$ \\
\hline $\begin{array}{l}\text { Unsaturated zone } \\
\text { total porosity }\end{array}$ & - & 0.4 & $1 E-5-1$ & All & $\begin{array}{c}\text { Zone } 1=0.45 \\
\text { Zone } 2=0.4 \\
\text { Zone } 3=0.43 \\
\text { Zone } 4=0.4 \\
\text { Zone } 5=0.45\end{array}$ & $P$ & 2 & $\begin{array}{l}\text { These values were obtained from the previous } \\
\text { RESRAD study for the landfill described in DOE } \\
\text { 2003b. } \\
\text { The values for UZ1 and UZ2 were transposed } \\
\text { as recommended by DOE. }\end{array}$ & $\begin{array}{c}\text { DOE 2003b } \\
\text { Table Att.2, } \\
\text { page C3-315 } \\
\text { DOE Project } \\
\text { Communication } \\
\text { with DOE-PPPO } \\
\text { (October 2010) }\end{array}$ \\
\hline $\begin{array}{l}\text { Unsaturated zone } \\
\text { effective porosity }\end{array}$ & - & 0.2 & $1 E-34-1$ & All & $\begin{array}{c}\text { Zone } 1=0.2 \\
\text { Zone } 2=0.2 \\
\text { Zone } 3=0.08 \\
\text { Zone } 4=0.2 \\
\text { Zone } 5=0.15\end{array}$ & $P$ & 2 & $\begin{array}{l}\text { These values were calculated using equation } \\
4.4 \text { from Yu et al. } 1993 \text { as this approach was } \\
\text { accepted by ANL rather than using the values } \\
\text { available in DOE 2003b. This approach was } \\
\text { taken to ensure that the effective porosity } \\
\text { was less than the total porosity. }\end{array}$ & $\begin{array}{l}\text { Yu et al. } 1993 \\
\text { Project } \\
\text { Communication } \\
\text { with DOE } \\
\text { consultant } \\
\text { (October 2010) } \\
\end{array}$ \\
\hline $\begin{array}{l}\text { Unsaturated zone } \\
\text { field capacity }\end{array}$ & - & 0.2 & $1 E-34-1$ & All & $\begin{aligned} & \text { Zone } 1=0.25 \\
& \text { Zone } 2=0.2 \\
& \text { Zone } 3=0.35 \\
& \text { Zone } 4=0.2 \\
& \text { Zone } 5=0.3\end{aligned}$ & $P$ & 3 & $\begin{array}{l}\text { These values were obtained from the previous } \\
\text { RESRAD study for the landfill described in DOE } \\
\text { 2003b. } \\
\text { The values for UZ1 and UZ2 were transposed } \\
\text { as recommended by DOE. }\end{array}$ & $\begin{array}{c}\text { DOE 2003b } \\
\text { Table Att.2, } \\
\text { page C3-315 } \\
\text { Project } \\
\text { Communication } \\
\text { with DOE-PPPO } \\
\text { (October 2010) }\end{array}$ \\
\hline $\begin{array}{l}\text { Unsaturated zone, } \\
\text { soil-specific b } \\
\text { parameter }\end{array}$ & - & 5.3 & $0-15$ & All & $\begin{array}{l}\text { Zone } 1=7.75 \\
\text { Zone } 2=7.75 \\
\text { Zone } 3=11.4\end{array}$ & $P$ & 2 & $\begin{array}{l}\text { DOE evaluated the unsaturated zone and } \\
\text { determined that the value for Silty Clay Loam } \\
\text { from Yu et al. } 1993 \text { was most appropriate for }\end{array}$ & $\begin{array}{l}\text { Yu et al. } 1993 \\
\text { DOE Project }\end{array}$ \\
\hline
\end{tabular}


RESRAD Table of Input Parameters for the C-746-U Landfill Onsite Receptor Scenarios

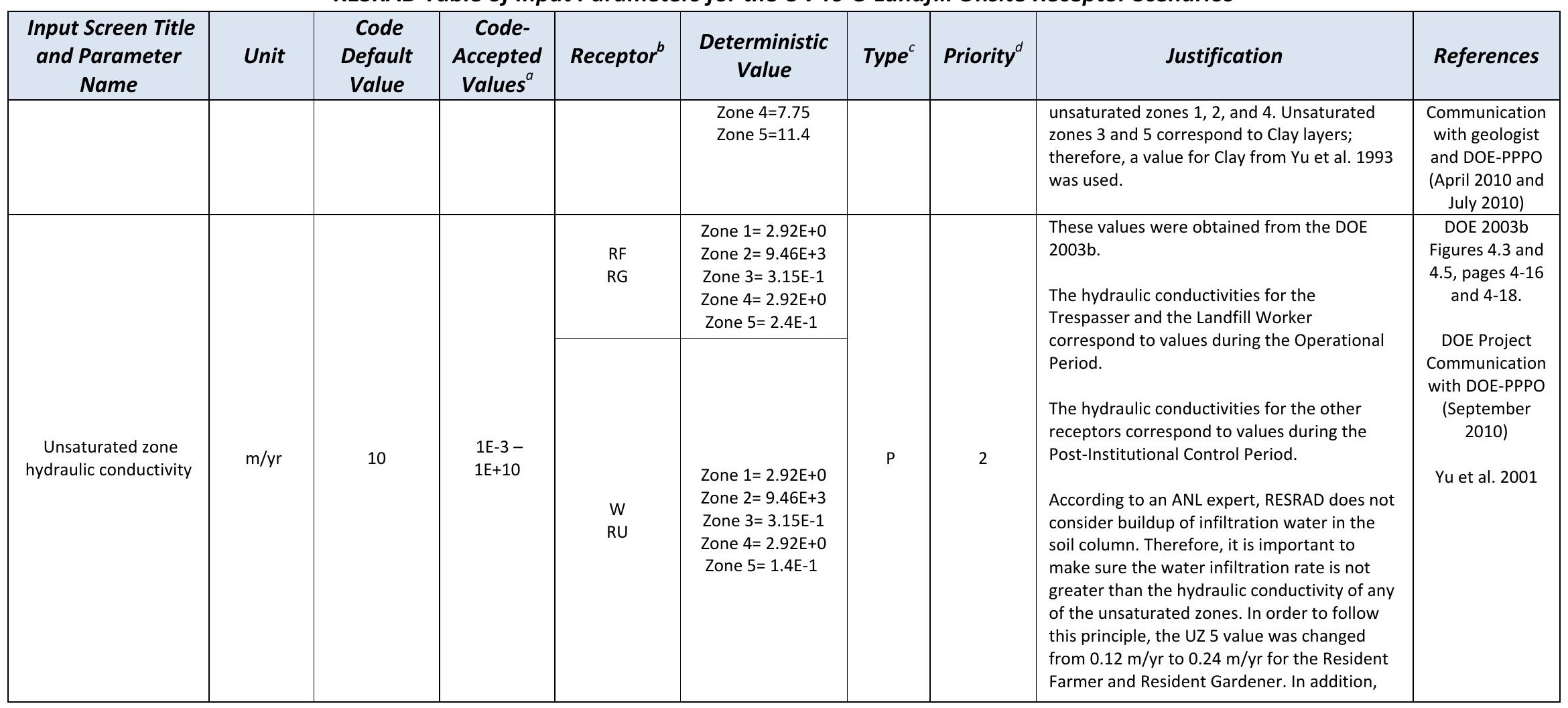


RESRAD Table of Input Parameters for the C-746-U Landfill Onsite Receptor Scenarios

\begin{tabular}{|c|c|c|c|c|c|c|c|c|c|}
\hline $\begin{array}{c}\text { Input Screen Title } \\
\text { and Parameter } \\
\text { Name }\end{array}$ & Unit & $\begin{array}{c}\text { Code } \\
\text { Default } \\
\text { Value }\end{array}$ & $\begin{array}{c}\text { Code- } \\
\text { Accepted } \\
\text { Values }^{a}\end{array}$ & Receptor ${ }^{b}$ & $\begin{array}{c}\text { Deterministic } \\
\text { Value }\end{array}$ & Type $^{c}$ & Priority $^{d}$ & Justification & References \\
\hline & & & & $\begin{array}{l}\mathrm{T} \\
\mathrm{L}\end{array}$ & 更 & & & $\begin{array}{l}\text { the UZ } 5 \text { value was changed from } 0.12 \mathrm{~m} / \mathrm{yr} \text { to } \\
0.14 \mathrm{~m} / \mathrm{yr} \text { for the Outdoor Worker and } \\
\text { Recreational User. For the Trespasser and } \\
\text { Landfill Worker the UZ } 3 \text { value was changed } \\
\text { besides the value of UZ } 5 \text { value since the } \\
\text { infiltration rate calculated was greater than } \\
\text { the value of the hydraulic conductivities for } \\
\text { these zones. The value for UZ } 3 \text { was changed } \\
\text { from } 0.0315 \mathrm{~m} / \mathrm{yr} \text { to } 0.281 \mathrm{~m} / \mathrm{yr} \text { and the value } \\
\text { for UZ } 5 \text { was changed from } 0.12 \mathrm{~m} / \mathrm{yr} \text { to } 0.281 \\
\mathrm{~m} / \mathrm{yr} \text {. } \\
\text { Although all the receptors have corresponding } \\
\text { hydraulic conductivities (that are greater than } \\
\text { the infiltration rate), these are only used by } \\
\text { the code in the Resident Farmer and Gardener } \\
\text { scenarios. In these scenarios, the code uses } \\
\text { the hydraulic conductivities (besides other } \\
\text { parameters related to the unsaturated zones), } \\
\text { when at least one of the following ingestion } \\
\text { pathways is active; drinking water, plant, milk, } \\
\text { and/or meat. In the case of the Resident } \\
\text { Farmer, all of these pathways are active and } \\
\text { in the case of the Resident Gardener the plant } \\
\text { ingestion pathway is active. For the Workers, } \\
\text { Recreational User and the Trespasser, these } \\
\text { ingestion pathways mentioned are } \\
\text { suppressed; therefore, the unsaturated zones } \\
\text { parameters are not used by the code. } \\
\text { The infiltration rate calculations are in } \\
\text { Attachment II following this table. }\end{array}$ & \\
\hline
\end{tabular}

Occupancy, Inhalation, and External Gamma Parameters

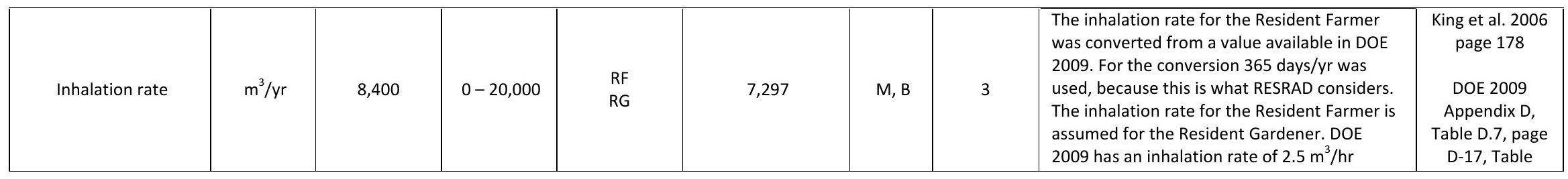


RESRAD Table of Input Parameters for the C-746-U Landfill Onsite Receptor Scenarios

\begin{tabular}{|c|c|c|c|c|c|c|c|c|c|}
\hline $\begin{array}{c}\text { Input Screen Title } \\
\text { and Parameter } \\
\text { Name }\end{array}$ & Unit & $\begin{array}{c}\text { Code } \\
\text { Default } \\
\text { Value }\end{array}$ & $\begin{array}{c}\text { Code- } \\
\text { Accepted } \\
\text { Values }^{a}\end{array}$ & Receptor ${ }^{b}$ & $\begin{array}{c}\text { Deterministic } \\
\text { Value }\end{array}$ & Type $^{c}$ & Priority $^{d}$ & Justification & References \\
\hline & & & & $\begin{array}{l}\text { W } \\
\text { RU } \\
\text { T } \\
\text { L }\end{array}$ & 20,000 & & & $\begin{array}{l}\left.\text { (21,900 } \mathrm{m}^{3} / \mathrm{yr}\right) \text { for the Workers, Recreational } \\
\text { User, and the Trespasser. The maximum value } \\
\text { allowed by RESRAD is } 20,000 \mathrm{~m}^{3} / \mathrm{yr} \text {, thus this } \\
\text { value is used. } \\
\text { See Attachment II following this table of } \\
\text { parameters. }\end{array}$ & $\begin{array}{c}\text { D.38, pages D- } \\
\text { 48, Table D.17, } \\
\text { page D-27 }\end{array}$ \\
\hline $\begin{array}{l}\text { Mass loading for } \\
\text { inhalation }\end{array}$ & $\mathrm{g} / \mathrm{m}^{3}$ & $1.00 \mathrm{E}-04$ & $0-2$ & $\begin{array}{l}\text { RF } \\
\text { RG } \\
\text { RU } \\
T\end{array}$ & 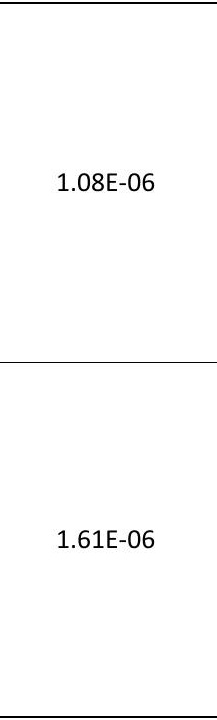 & $P, B$ & 2 & $\begin{array}{l}\text { The following equation was used to calculate } \\
\text { the Mass Loading for Inhalation or Air-to-Soil } \\
\text { concentration ratio (ASR): } \\
\text { ASR = 1/ PEF; PEF is the particulate emission } \\
\text { factor. } \\
\text { The PEF values used to calculate the mass } \\
\text { loading for inhalation are available in DOE } \\
\text { 2009. The PEF values were converted into } \\
\text { RESRAD compatible units. } \\
\text { The mass loading for inhalation for the } \\
\text { Resident Farmer is assumed for the Resident } \\
\text { Gardener. } \\
\text { The mass loading for inhalation for the } \\
\text { Recreational User is assumed for the } \\
\text { Trespasser. } \\
\text { See Attachment II following this table of } \\
\text { parameters }\end{array}$ & $\begin{array}{l}\text { King et al. } 2006 \\
\text { page } 178 \\
\text { DOE } 2009 \\
\text { Appendix D, } \\
\text { Table D.7, page } \\
\text { D-17, Table } \\
\text { D.38, pages D- } \\
\text { 48, Table D.17, } \\
\text { page D-27 }\end{array}$ \\
\hline Exposure duration & $\mathrm{yr}$ & 30 & $1-1,000$ & $\begin{array}{l}\mathrm{RF} \\
\mathrm{RG}\end{array}$ & 24 & B & 3 & $\begin{array}{l}\text { The exposure duration is the span of time, in } \\
\text { years, during which an individual is expected } \\
\text { to spend time on the site. This value is used in } \\
\text { calculating lifetime cancer risk from exposure } \\
\text { to radionuclide contamination. It is also used } \\
\text { to calculate time-integrated dose if the } \\
\text { exposure duration is less than a year. }\end{array}$ & $\begin{array}{c}\text { DOE } 2009 \\
\text { Appendix D, } \\
\text { Table D.8, page } \\
\text { D-18, Table } \\
\text { D.18, page D- } \\
\text { 28, Table D.40, } \\
\text { page D-50 }\end{array}$ \\
\hline
\end{tabular}


RESRAD Table of Input Parameters for the C-746-U Landfill Onsite Receptor Scenarios

\begin{tabular}{|c|c|c|c|c|c|c|c|c|c|}
\hline $\begin{array}{c}\text { Input Screen Title } \\
\text { and Parameter } \\
\text { Name }\end{array}$ & Unit & $\begin{array}{c}\text { Code } \\
\text { Default } \\
\text { Value }\end{array}$ & $\begin{array}{l}\text { Code- } \\
\text { Accepted } \\
\text { Values }^{a}\end{array}$ & Receptor $^{b}$ & $\begin{array}{l}\text { Deterministic } \\
\text { Value }\end{array}$ & Type $^{c}$ & Priority $^{d}$ & Justification & References \\
\hline & & & & $\begin{array}{l}\text { W } \\
\text { L }\end{array}$ & 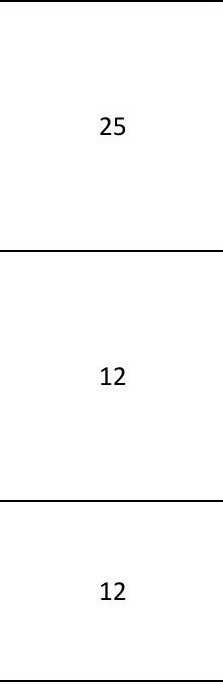 & & & $\begin{array}{l}\text { These values were obtained from DOE } 2009 . \\
\text { The exposure duration is available in the } \\
\text { tables of Appendix D. } \\
\text { For the Resident Farmer and the Resident } \\
\text { Gardener the adult value for "Rural Resident" } \\
\text { is used. } \\
\text { For the Workers the value for "Industrial } \\
\text { Worker or Excavation Worker" is used since } \\
\text { these values are equivalent. } \\
\text { For the Recreational User the value for the } \\
\text { "Recreational User (Teen)" is used. } \\
\text { For the Trespasser the value for the } \\
\text { "Recreational User (adult)" is used. } \\
\text { See Attachment II following this table of } \\
\text { parameters. }\end{array}$ & \\
\hline $\begin{array}{l}\text { Indoor dust filtration } \\
\text { factor }\end{array}$ & - & 0.4 & $0-1$ & All & 0.4 & $P, B$ & 2 & $\begin{array}{l}\text { The default value is used. Indoor time fraction } \\
\text { is the driver for application of this parameter. } \\
\text { In instances where there is no indoor } \\
\text { occupancy, this parameter will not be applied. }\end{array}$ & Yu et al. 2001 \\
\hline $\begin{array}{l}\text { External gamma } \\
\text { shielding factor }\end{array}$ & - & 0.7 & $0-1$ & $\begin{array}{l}\text { RF } \\
\text { RG } \\
W \\
L\end{array}$ & 0.8 & $\mathrm{P}$ & 2 & $\begin{array}{l}\text { The external gamma shielding factors are } \\
\text { available for the Resident Farmer, Workers, } \\
\text { and Recreational User in DOE } 2009 \text {. The value } \\
\text { is } 0.2 \text { for all these receptors except for the } \\
\text { Recreational User which is } 0 \text {. The RESRAD } \\
\text { input values correspond to } 0.8 \text { and } 1 \text {. The } \\
\text { shielding factor of } 0.8 \text { implies that the indoor } \\
\text { levels of external radiation are } 20 \% \text { lower } \\
\text { than the outdoor levels. A shielding factor of } 1 \\
\text { implies that there is no shielding. } \\
\text { The Resident Gardener is assumed to have the } \\
\text { same shielding factor as the Resident Farmer. } \\
\text { The Trespasser is assumed to have the same } \\
\text { shielding factor as the Recreational User. } \\
\text { See Attachment II following this table of }\end{array}$ & $\begin{array}{c}\text { DOE } 2009 \\
\text { Appendix D, } \\
\text { Table D.8, page } \\
\text { D-18, Table } \\
\text { D.18, page D- } \\
\text { 28, and Table } \\
\text { D.40, page D-50 }\end{array}$ \\
\hline
\end{tabular}


RESRAD Table of Input Parameters for the C-746-U Landfill Onsite Receptor Scenarios

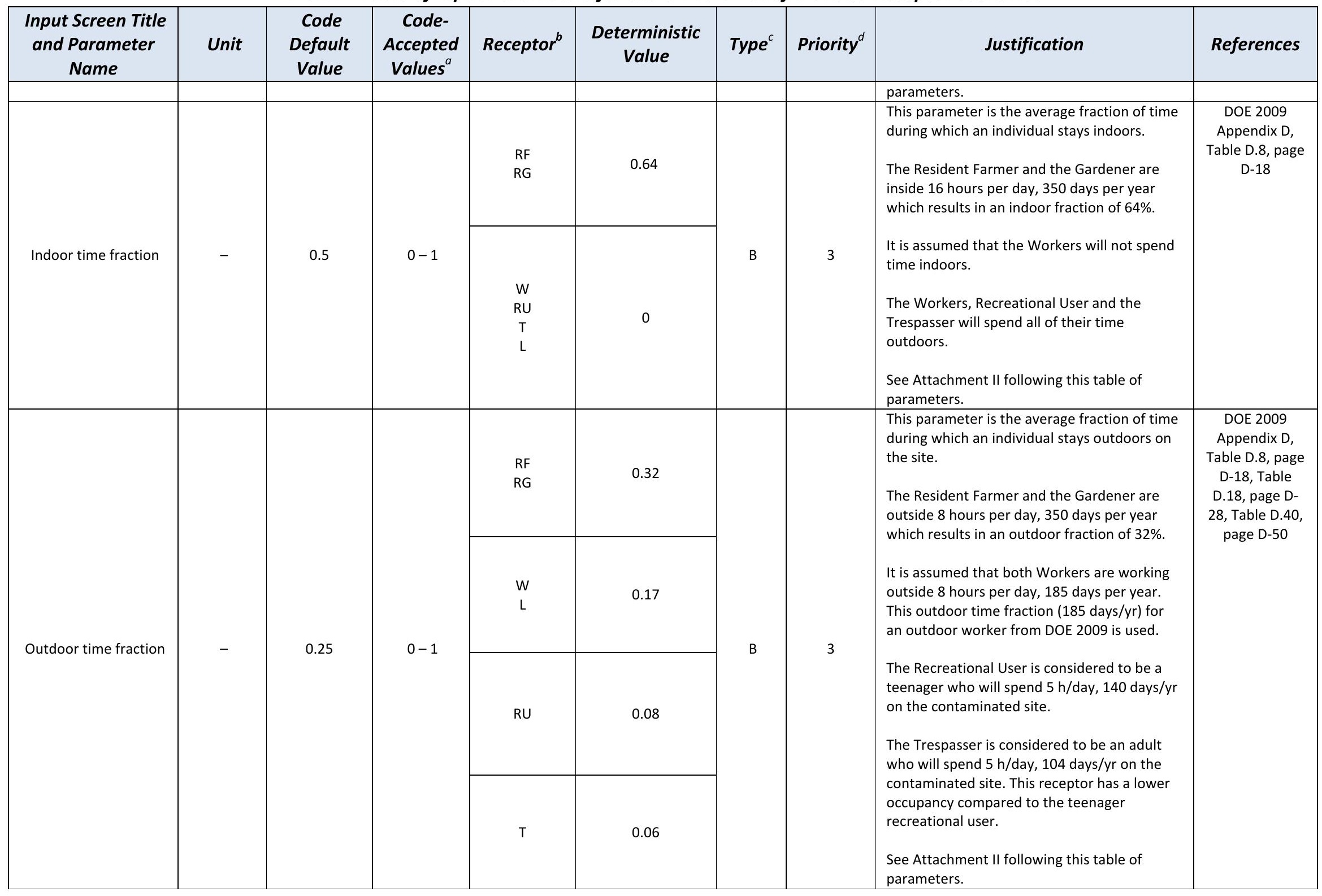


RESRAD Table of Input Parameters for the C-746-U Landfill Onsite Receptor Scenarios

\begin{tabular}{|c|c|c|c|c|c|c|c|c|c|}
\hline $\begin{array}{c}\text { Input Screen Title } \\
\text { and Parameter } \\
\text { Name }\end{array}$ & Unit & $\begin{array}{c}\text { Code } \\
\text { Default } \\
\text { Value }\end{array}$ & $\begin{array}{c}\text { Code- } \\
\text { Accepted } \\
\text { Values }^{a}\end{array}$ & Receptor ${ }^{b}$ & $\begin{array}{c}\text { Deterministic } \\
\text { Value }\end{array}$ & Type ${ }^{c}$ & Priority $^{d}$ & Justification & References \\
\hline $\begin{array}{l}\text { Shape of the } \\
\text { contaminated zone } \\
\text { (shape factor flag) }\end{array}$ & - & Circular & $\begin{array}{l}\text { Circular/ } \\
\text { non- } \\
\text { circular }\end{array}$ & All & Circular & $P$ & 3 & $\begin{array}{l}\text { It is assumed that the receptor is located in } \\
\text { the middle of the contaminated zone. } \\
\text { Therefore, the circular shape was assumed } \\
\text { instead of the noncircular shape. By default, } \\
\text { the receptor is assumed to be placed in the } \\
\text { middle of a circularly shaped contaminated } \\
\text { zone. }\end{array}$ & Yu et al. 2001 \\
\hline
\end{tabular}

Ingestion Pathway, Dietary Data

\begin{tabular}{|c|c|c|c|c|c|c|c|c|c|}
\hline $\begin{array}{l}\text { Fruit, vegetable, and } \\
\text { grain consumption }\end{array}$ & $\mathrm{kg} / \mathrm{yr}$ & 160 & $0-1,000$ & All & 231.7 & $\mathrm{M}, \mathrm{B}$ & 2 & $\begin{array}{l}\text { The value was converted from Table D.9 in } \\
\text { DOE 2009, which is for home grown } \\
\text { vegetables. It does not specify fruit, and grain, } \\
\text { thus for RESRAD a ratio was obtained to } \\
\text { assign a value for fruit, vegetable and grain } \\
\text { consumption and a value for leafy vegetable } \\
\text { consumption. } \\
\text { The calculation is included in Attachment II. } \\
\text { This parameter applies to the Resident Farmer } \\
\text { and Resident Gardener since the ingestion } \\
\text { pathway for plants/ home-grown produce is } \\
\text { applicable for these receptors. } \\
\text { The plant ingestion pathway is suppressed for } \\
\text { the Workers, Recreational User, and } \\
\text { Trespasser since this pathway is not } \\
\text { considered in the conceptual site model for } \\
\text { these receptors. } \\
\text { See Attachment II following this table of } \\
\text { parameters. }\end{array}$ & $\begin{array}{c}\text { DOE } 2009 \\
\text { Appendix D, } \\
\text { Table D.9, page } \\
\text { D-19 }\end{array}$ \\
\hline $\begin{array}{l}\text { Leafy vegetable } \\
\text { consumption }\end{array}$ & $\mathrm{kg} / \mathrm{yr}$ & 14 & $0-100$ & All & 20.3 & $M, B$ & 3 & $\begin{array}{l}\text { The value was converted from Table D.9 in } \\
\text { DOE 2009, which is for home grown } \\
\text { vegetables. It does not specify fruit, and grain, } \\
\text { thus for RESRAD a ratio was obtained to } \\
\text { assign a value for fruit, vegetable and grain } \\
\text { consumption and a value for leafy vegetable } \\
\text { consumption. } \\
\text { The calculation is included in Attachment II. } \\
\text { This parameter applies to the Resident Farmer } \\
\text { and Resident Gardener since the ingestion }\end{array}$ & $\begin{array}{c}\text { DOE } 2009 \\
\text { Appendix D, } \\
\text { Table D.9, page } \\
\text { D-19 }\end{array}$ \\
\hline
\end{tabular}


RESRAD Table of Input Parameters for the C-746-U Landfill Onsite Receptor Scenarios

\begin{tabular}{|c|c|c|c|c|c|c|c|c|c|}
\hline $\begin{array}{c}\text { Input Screen Title } \\
\text { and Parameter } \\
\text { Name }\end{array}$ & Unit & $\begin{array}{c}\text { Code } \\
\text { Default } \\
\text { Value }\end{array}$ & $\begin{array}{c}\text { Code- } \\
\text { Accepted } \\
\text { Values }^{a}\end{array}$ & Receptor ${ }^{b}$ & $\begin{array}{c}\text { Deterministic } \\
\text { Value }\end{array}$ & Type ${ }^{c}$ & Priority $^{d}$ & Justification & References \\
\hline & & & & & & & & $\begin{array}{l}\text { pathway for plants/ home-grown produce is } \\
\text { applicable for these receptors. } \\
\text { The plant ingestion pathway is suppressed for } \\
\text { the Workers, Recreational User, and } \\
\text { Trespasser since this pathway is not } \\
\text { considered in the conceptual site model for } \\
\text { these receptors. } \\
\text { See Attachment II following this table of } \\
\text { parameters. }\end{array}$ & \\
\hline Milk consumption & $L / y r$ & 92 & $0-1,000$ & All & 425 & $M, B$ & 2 & $\begin{array}{l}\text { This value was converted from Table D.11 in } \\
\text { DOE } 2009 . \\
\text { The density of whole milk, } 1030 \mathrm{~kg} / \mathrm{cubic} \\
\text { meter, was used to convert the value into } \\
\text { L/yr. } \\
\text { This parameter is applicable for the Resident } \\
\text { Farmer. } \\
\text { This parameter is not applicable for the } \\
\text { Resident Gardener, Workers, Recreational } \\
\text { User, or the Trespasser; therefore, the milk } \\
\text { ingestion pathway is suppressed. } \\
\text { See Attachment II following this table of } \\
\text { parameters. }\end{array}$ & $\begin{array}{l}\text { DOE } 2009 \\
\text { Appendix D, } \\
\text { Table D.11, } \\
\text { page D-21 }\end{array}$ \\
\hline $\begin{array}{l}\text { Meat and poultry } \\
\text { consumption }\end{array}$ & $\mathrm{kg} / \mathrm{yr}$ & 63 & $0-300$ & All & 154 & $\mathrm{M}, \mathrm{B}$ & 3 & $\begin{array}{l}\text { This value was converted from Table D.10, } \\
\text { D.12, and D.13 in DOE } 2009 \text {. The value is the } \\
\text { sum of the values obtained for beef, pork and } \\
\text { poultry, since they are in separate tables. The } \\
\text { value for eggs is available, but eggs are not } \\
\text { considered poultry. } \\
\text { This parameter is applicable for the Resident } \\
\text { Farmer. } \\
\text { This parameter is not applicable for the } \\
\text { Resident Gardener, Workers, Recreational } \\
\text { User or the Trespasser; therefore, the meat } \\
\text { ingestion pathway is suppressed. } \\
\text { See Attachment II following this table of }\end{array}$ & $\begin{array}{c}\text { DOE } 2009 \\
\text { Appendix D, } \\
\text { Table D.10, } \\
\text { D.12, and D.13, } \\
\text { pages D-20, D- } \\
22 \text { and D-23 }\end{array}$ \\
\hline
\end{tabular}


RESRAD Table of Input Parameters for the C-746-U Landfill Onsite Receptor Scenarios

\begin{tabular}{|c|c|c|c|c|c|c|c|c|c|}
\hline $\begin{array}{l}\text { Input Screen Title } \\
\text { and Parameter } \\
\text { Name }\end{array}$ & Unit & $\begin{array}{l}\text { Code } \\
\text { Default } \\
\text { Value }\end{array}$ & $\begin{array}{l}\text { Code- } \\
\text { Accepted } \\
\text { Values }^{a}\end{array}$ & Receptor ${ }^{b}$ & $\begin{array}{c}\text { Deterministic } \\
\text { Value }\end{array}$ & Type $^{c}$ & Priority $^{d}$ & Justification & References \\
\hline & & & & & & & & parameters. & \\
\hline Fish consumption & $\mathrm{kg} / \mathrm{yr}$ & 5.4 & $0-1,000$ & All & 5.4 & $M, B$ & 3 & $\begin{array}{l}\text { The aquatic foods ingestion pathway is } \\
\text { suppressed in RESRAD for all receptors } \\
\text { because it is not considered part of the } \\
\text { conceptual site model. }\end{array}$ & Yu et al. 2001 \\
\hline $\begin{array}{l}\text { Other seafood } \\
\text { consumption }\end{array}$ & $\mathrm{kg} / \mathrm{yr}$ & 0.9 & $0-100$ & All & 0.9 & $M, B$ & 3 & $\begin{array}{l}\text { The aquatic foods ingestion pathway is } \\
\text { suppressed in RESRAD for all receptors } \\
\text { because it is not considered part of the } \\
\text { conceptual site model. }\end{array}$ & Yu et al. 2001 \\
\hline \multirow[b]{2}{*}{ Soil ingestion rate } & \multirow[b]{2}{*}{$\mathrm{g} / \mathrm{yr}$} & \multirow[b]{2}{*}{36.5} & \multirow[b]{2}{*}{$0-10,000$} & $\begin{array}{l}\text { RF } \\
\text { RG } \\
\text { RU } \\
\text { T }\end{array}$ & 36.5 & \multirow[b]{2}{*}{$\mathrm{M}, \mathrm{B}$} & \multirow[b]{2}{*}{2} & \multirow{2}{*}{$\begin{array}{l}\text { This value was converted from Table D.5 in } \\
\text { DOE } 2009 . \\
\text { Reference DOE } 2009 \text { assumes a lower } \\
\text { ingestion rate for workers who spend part of } \\
\text { the day outdoors. It is assumed the Workers } \\
\text { are working outside and perform duties that } \\
\text { result in a higher soil ingestion rate. } \\
\text { For the Recreational User the value available } \\
\text { in Table D.15 in DOE } 2009 \text { is for ingestion of } \\
\text { sediment. This value was assumed for the soil } \\
\text { ingestion rate. } \\
\text { See Attachment II following this table of } \\
\text { parameters. }\end{array}$} & \multirow[t]{2}{*}{$\begin{array}{c}\text { DOE } 2009 \\
\text { Appendix D, } \\
\text { Table D.5, page } \\
\text { D-15, Table } \\
\text { D.15, page D- } \\
\text { 25, Table D.37, } \\
\text { page D-47 }\end{array}$} \\
\hline & & & & $\begin{array}{l}\text { W } \\
\mathrm{L}\end{array}$ & 175.2 & & & & \\
\hline Drinking water intake & $\mathrm{L} / \mathrm{yr}$ & 510 & $0-10,000$ & All & 700 & $M, B$ & 2 & $\begin{array}{l}\text { This value was converted from Table D. } 1 \text { in } \\
\text { DOE } 2009 \\
\text { This parameter is applicable for the Resident } \\
\text { Farmer. } \\
\text { This parameter is not applicable for the } \\
\text { Resident Gardener, Workers, Recreational } \\
\text { User or the Trespasser; therefore, the drinking } \\
\text { water ingestion pathway is suppressed. } \\
\text { See Attachment II following this table of } \\
\text { parameters. }\end{array}$ & $\begin{array}{c}\text { DOE } 2009 \\
\text { Appendix D, } \\
\text { Table D.1, page } \\
\text { D-11 }\end{array}$ \\
\hline $\begin{array}{c}\text { Drinking water } \\
\text { contaminated fraction }\end{array}$ & - & 1 & $0-1$ & All & 1 & $B, P$ & 3 & $\begin{array}{l}\text { This parameter allows specification of the } \\
\text { fraction of contaminated intake for the } \\
\text { drinking water pathway. The remaining } \\
\text { balance (if value }<1 \text { ) of the drinking water is }\end{array}$ & Yu et al. 2001 \\
\hline
\end{tabular}


RESRAD Table of Input Parameters for the C-746-U Landfill Onsite Receptor Scenarios

\begin{tabular}{|c|c|c|c|c|c|c|c|c|c|}
\hline $\begin{array}{c}\text { Input Screen Title } \\
\text { and Parameter } \\
\text { Name }\end{array}$ & Unit & $\begin{array}{c}\text { Code } \\
\text { Default } \\
\text { Value }\end{array}$ & $\begin{array}{c}\text { Code- } \\
\text { Accepted } \\
\text { Values }^{a}\end{array}$ & Receptor $^{b}$ & $\begin{array}{c}\text { Deterministic } \\
\text { Value }\end{array}$ & Type $^{c}$ & Priority $^{d}$ & Justification & References \\
\hline & & & & & & & & $\begin{array}{l}\text { from off-site sources, which are assumed to } \\
\text { be uncontaminated. } \\
\text { A default value of } 1 \text { was assumed for the } \\
\text { Resident Farmer. } \\
\text { This parameter is not applicable for the } \\
\text { Resident Gardener, Workers, Recreational } \\
\text { User or the Trespasser; therefore, the drinking } \\
\text { water ingestion pathway is suppressed. }\end{array}$ & \\
\hline $\begin{array}{l}\text { Household water } \\
\text { contaminated fraction }\end{array}$ & - & 1 & $0-1$ & All & 1 & $B, P$ & 3 & $\begin{array}{l}\text { A default value of } 1 \text { is assumed. This default } \\
\text { value of } 1 \text { indicates that all household water is } \\
\text { from an on-site source. However, this } \\
\text { parameter is not used by the code since it is } \\
\text { related to the radon pathway and this } \\
\text { pathway is deactivated. }\end{array}$ & Yu et al. 2001 \\
\hline $\begin{array}{l}\text { Livestock water } \\
\text { contaminated fraction }\end{array}$ & - & 1 & $0-1$ & All & 1 & $B, P$ & 3 & $\begin{array}{l}\text { A default value of } 1 \text { is assumed for the } \\
\text { Resident Farmer. This default value of } 1 \\
\text { indicates that all livestock water is from an } \\
\text { on-site source. } \\
\text { This parameter is related to the milk and meat } \\
\text { ingestion pathways and these pathways are } \\
\text { not applicable for the Resident Gardener, } \\
\text { Workers, Recreational User, or the } \\
\text { Trespasser. Therefore, the meat and milk } \\
\text { ingestion pathways are deactivated for these } \\
\text { receptors. }\end{array}$ & Yu et al. 2001 \\
\hline \multirow{2}{*}{$\begin{array}{c}\text { Irrigation water } \\
\text { contaminated fraction }\end{array}$} & \multirow{2}{*}{-} & \multirow{2}{*}{1} & \multirow{2}{*}{$0-1$} & $\begin{array}{l}\text { RF } \\
\text { W } \\
\text { RU } \\
\text { T } \\
\text { L }\end{array}$ & 1 & \multirow{2}{*}{$B, P$} & \multirow{2}{*}{3} & $\begin{array}{l}\text { The default value of } 1 \text { is assumed for the } \\
\text { Resident Farmer. This default value of } 1 \\
\text { indicates that all irrigation water is from an } \\
\text { on-site source. } \\
\text { A value of " } 0 \text { " is used for the Resident }\end{array}$ & \multirow[t]{2}{*}{$\begin{array}{l}\text { DOE Project } \\
\text { Communicatior } \\
\text { with DOE-PPPO } \\
\text { (September } \\
\text { 2010) }\end{array}$} \\
\hline & & & & RG & 0 & & & $\begin{array}{l}\text { Gardener since this receptor will use an oft- } \\
\text { site water source. } \\
\text { This parameter is related to the plant, meat, } \\
\text { and milk ingestion pathways and these are } \\
\text { not applicable for the Workers, Recreational } \\
\text { User, and the Trespasser. Therefore, the }\end{array}$ & \\
\hline
\end{tabular}


RESRAD Table of Input Parameters for the C-746-U Landfill Onsite Receptor Scenarios

\begin{tabular}{|c|c|c|c|c|c|c|c|c|c|}
\hline $\begin{array}{c}\text { Input Screen Title } \\
\text { and Parameter } \\
\text { Name }\end{array}$ & Unit & $\begin{array}{c}\text { Code } \\
\text { Default } \\
\text { Value }\end{array}$ & $\begin{array}{c}\text { Code- } \\
\text { Accepted } \\
\text { Values }^{a}\end{array}$ & Receptor $^{b}$ & $\begin{array}{c}\text { Deterministic } \\
\text { Value }\end{array}$ & Type & Priority $^{d}$ & Justification & References \\
\hline & & & & & & & & $\begin{array}{l}\text { plant, meat and milk ingestion pathways are } \\
\text { suppressed for these receptors. }\end{array}$ & \\
\hline $\begin{array}{c}\text { Aquatic food } \\
\text { contaminated fraction }\end{array}$ & - & 0.5 & $0-1$ & All & 0.5 & $\mathrm{~B}, \mathrm{P}$ & 2 & $\begin{array}{l}\text { A default value of } 0.5 \text { indicates that } 50 \% \text { of } \\
\text { aquatic food is being obtained from on-site } \\
\text { sources. } \\
\text { The aquatic food pathway is not considered in } \\
\text { the conceptual site model and it is } \\
\text { deactivated for all receptors. Therefore, this } \\
\text { parameter is not used by the code. }\end{array}$ & Yu et al. 2001 \\
\hline $\begin{array}{c}\text { Plant food } \\
\text { contaminated fraction }\end{array}$ & - & -1 & 0 to 1 or -1 & All & -1 & $\mathrm{~B}, \mathrm{P}$ & 3 & $\begin{array}{l}\text { The default value of }-1 \text { specifies that the } \\
\text { contaminated fraction of plant food is } \\
\text { calculated from the appropriate area factor in } \\
\text { the code (see page A-8 of Yu et al. 2001). } \\
\text { The plant ingestion pathway is suppressed for } \\
\text { the Workers, Recreational User, and } \\
\text { Trespasser since this pathway is not } \\
\text { considered in the conceptual site model for } \\
\text { these receptors. }\end{array}$ & Yu et al. 2001 \\
\hline $\begin{array}{l}\text { Meat contaminated } \\
\text { fraction }\end{array}$ & - & -1 & 0 to 1 or -1 & All & -1 & $\mathrm{~B}, \mathrm{P}$ & 3 & $\begin{array}{l}\text { A default value of - } 1 \text { was assumed for the } \\
\text { Resident Farmer. The default value of }-1 \\
\text { specifies that the contaminated fraction of } \\
\text { meat is calculated from the appropriate area } \\
\text { factor in the code. } \\
\text { The meat ingestion pathway is suppressed for } \\
\text { the Resident Gardener, Workers, Recreational } \\
\text { User, and Trespasser since this pathway is not } \\
\text { considered in the conceptual site model for } \\
\text { these receptors. }\end{array}$ & Yu et al. 2001 \\
\hline $\begin{array}{l}\text { Milk contaminated } \\
\text { fraction }\end{array}$ & - & -1 & 0 to 1 or -1 & All & -1 & $\mathrm{~B}, \mathrm{P}$ & 3 & $\begin{array}{l}\text { The default value of }-1 \text { specifies that the } \\
\text { contaminated fraction of milk is calculated } \\
\text { from the appropriate area factor in the code. } \\
\text { The milk ingestion pathway is suppressed for } \\
\text { the Resident Gardener, Workers, Recreational } \\
\text { User, and Trespasser since this pathway is not }\end{array}$ & Yu et al. 2001 \\
\hline
\end{tabular}


RESRAD Table of Input Parameters for the C-746-U Landfill Onsite Receptor Scenarios

\begin{tabular}{|c|c|c|c|c|c|c|c|c|}
\hline $\begin{array}{c}\text { Input Screen Title } \\
\text { and Parameter } \\
\text { Name }\end{array}$ & Unit & $\begin{array}{c}\text { Code } \\
\text { Default } \\
\text { Value }\end{array}$ & $\begin{array}{c}\text { Code- } \\
\text { Accepted } \\
\text { Values }^{a}\end{array}$ & Receptor $^{b}$ & $\begin{array}{c}\text { Deterministic } \\
\text { Value }\end{array}$ & Type $^{c}$ & Priority & Justification \\
\hline & & & & & & & $\begin{array}{c}\text { considered in the conceptual site model for } \\
\text { these receptors. }\end{array}$ \\
\hline
\end{tabular}

Ingestion Pathway, Nondietary Data

\begin{tabular}{|c|c|c|c|c|c|c|c|c|c|}
\hline $\begin{array}{l}\text { Livestock fodder } \\
\text { intake for meat }\end{array}$ & $\mathrm{kg} / \mathrm{d}$ & 68 & $0-300$ & All & 25 & $\mathrm{M}$ & 3 & $\begin{array}{l}\text { This parameter is for the daily intake of } \\
\text { fodder by livestock kept for meat } \\
\text { consumption. The code uses the area factor to } \\
\text { calculate the contaminated intake. } \\
\text { The meat ingestion pathway is suppressed for } \\
\text { the Resident Gardener, Workers, Recreational } \\
\text { User, and Trespasser since this pathway is not } \\
\text { considered in the conceptual site model for } \\
\text { these receptors. }\end{array}$ & $\begin{array}{c}\text { DOE } 2009 \\
\text { Appendix D, } \\
\text { Table D.46, } \\
\text { page D-56 }\end{array}$ \\
\hline $\begin{array}{l}\text { Livestock fodder } \\
\text { intake for milk }\end{array}$ & $\mathrm{kg} / \mathrm{d}$ & 55 & $0-300$ & All & 25 & $M$ & 3 & $\begin{array}{l}\text { This parameter is for the daily intake of } \\
\text { fodder by livestock kept for milk consumption. } \\
\text { The code uses the area factor to calculate the } \\
\text { contaminated intake. } \\
\text { The milk ingestion pathway is suppressed for } \\
\text { the Resident Gardener, Workers, Recreational } \\
\text { User, and Trespasser since this pathway is not } \\
\text { considered in the conceptual site model for } \\
\text { these receptors. }\end{array}$ & $\begin{array}{c}\text { DOE } 2009 \\
\text { Appendix D, } \\
\text { Table D.47, } \\
\text { page D-57 }\end{array}$ \\
\hline $\begin{array}{l}\text { Livestock water intake } \\
\text { for meat }\end{array}$ & $\mathrm{L} / \mathrm{d}$ & 50 & $0-500$ & All & 50 & $\mathrm{M}$ & 3 & $\begin{array}{l}\text { This parameter is for the daily intake of water } \\
\text { by livestock kept for meat consumption. } \\
\text { The code uses the area factor to calculate the } \\
\text { contaminated intake. } \\
\text { The meat ingestion pathway is suppressed for } \\
\text { the Resident Gardener, Workers, Recreational } \\
\text { User, and Trespasser since this pathway is not } \\
\text { considered in the conceptual site model for } \\
\text { these receptors. }\end{array}$ & $\begin{array}{c}\text { DOE } 2009 \\
\text { Appendix D, } \\
\text { Table D.46, } \\
\text { page D-56 }\end{array}$ \\
\hline $\begin{array}{l}\text { Livestock water intake } \\
\text { for milk }\end{array}$ & $\mathrm{L} / \mathrm{d}$ & 160 & $0-500$ & All & 160 & $M$ & 3 & $\begin{array}{l}\text { The default value is used for the Resident } \\
\text { Farmer. } \\
\text { The milk ingestion pathway is suppressed for } \\
\text { the Resident Gardener, Workers, Recreational } \\
\text { User, and Trespasser since this pathway is not } \\
\text { considered in the conceptual site model for }\end{array}$ & Yu et al. 2001 \\
\hline
\end{tabular}


RESRAD Table of Input Parameters for the C-746-U Landfill Onsite Receptor Scenarios

\begin{tabular}{|c|c|c|c|c|c|c|c|c|c|}
\hline $\begin{array}{c}\text { Input Screen Title } \\
\text { and Parameter } \\
\text { Name }\end{array}$ & Unit & $\begin{array}{c}\text { Code } \\
\text { Default } \\
\text { Value }\end{array}$ & $\begin{array}{c}\text { Code- } \\
\text { Accepted } \\
\text { Values }^{a}\end{array}$ & Receptor ${ }^{b}$ & $\begin{array}{c}\text { Deterministic } \\
\text { Value }\end{array}$ & Type $^{c}$ & Priority $^{d}$ & Justification & References \\
\hline & & & & & & & & these receptors. & \\
\hline Livestock intake of soil & $\mathrm{kg} / \mathrm{d}$ & 0.5 & $0-10$ & All & 1 & $M$ & 3 & $\begin{array}{l}\text { This parameter reflects the daily intake of soil } \\
\text { by livestock kept for meat or milk } \\
\text { consumption. } \\
\text { DOE } 2009 \text { has separate tables for livestock soil } \\
\text { ingestion. A value of } 1 \mathrm{~kg} / \mathrm{d} \text { is listed for beef } \\
\text { and dairy in each table, thus for the Resident } \\
\text { Farmer, this value will be used. } \\
\text { The meat and milk ingestion pathways are } \\
\text { suppressed for the Resident Gardener, } \\
\text { Workers, Recreational User, and Trespasser } \\
\text { since these pathways are not considered in } \\
\text { the conceptual site model for these receptors. }\end{array}$ & $\begin{array}{c}\text { DOE } 2009 \\
\text { Appendix D, } \\
\text { Table D.46 and } \\
\text { D.47, page D-56 } \\
\text { and D-57 }\end{array}$ \\
\hline $\begin{array}{l}\text { Mass loading for foliar } \\
\text { deposition }\end{array}$ & $\mathrm{g} / \mathrm{m}^{3}$ & $1.00 \mathrm{E}-04$ & $0-1$ & All & $1.00 \mathrm{E}-04$ & $P$ & 3 & $\begin{array}{l}\text { The average mass loading of airborne } \\
\text { contaminated soil particles in a garden during } \\
\text { the growing season. } \\
\text { A default value was assumed for the Resident } \\
\text { Farmer and the Resident Gardener, since } \\
\text { plant ingestion is a pathway for these } \\
\text { receptors and site specific information is not } \\
\text { available. } \\
\text { The plant ingestion pathway is suppressed for } \\
\text { the Workers, Recreational User, and } \\
\text { Trespasser since this pathway is not } \\
\text { considered in the conceptual site model for } \\
\text { these receptors. }\end{array}$ & Yu et al. 2001 \\
\hline $\begin{array}{c}\text { Depth of soil mixing } \\
\text { layer }\end{array}$ & $\mathrm{m}$ & 0.15 & $0-1$ & All & 0.15 & $P$ & 2 & $\begin{array}{l}\text { Used in calculating the depth factor for dust } \\
\text { inhalation and soil ingestion pathways and for } \\
\text { foliar deposition for the plant, meat, and milk } \\
\text { ingestion pathways. The depth factor is the } \\
\text { fraction of the resuspendable soil particles at } \\
\text { the ground surface that are contaminated. It } \\
\text { is calculated by assuming that mixing of soil } \\
\text { will occur in the soil mixing layer. } \\
\text { A default value was assumed and is applied to } \\
\text { all receptors since the inhalation and soil } \\
\text { ingestion pathways apply to all receptors and }\end{array}$ & Yu et al. 2001 \\
\hline
\end{tabular}


RESRAD Table of Input Parameters for the C-746-U Landfill Onsite Receptor Scenarios

\begin{tabular}{|c|c|c|c|c|c|c|c|c|c|}
\hline $\begin{array}{c}\text { Input Screen Title } \\
\text { and Parameter } \\
\text { Name }\end{array}$ & Unit & $\begin{array}{c}\text { Code } \\
\text { Default } \\
\text { Value }\end{array}$ & $\begin{array}{c}\text { Code- } \\
\text { Accepted } \\
\text { Values }^{a}\end{array}$ & Receptor $^{b}$ & $\begin{array}{l}\text { Deterministic } \\
\text { Value }\end{array}$ & Type $^{c}$ & Priority $^{d}$ & Justification & References \\
\hline & & & & & & & & $\begin{array}{l}\text { site specific information is not available. } \\
\text { The meat, milk, and plant ingestion pathways } \\
\text { are suppressed for the Workers, Recreational } \\
\text { User, and Trespasser since these pathways } \\
\text { are not considered in the conceptual site } \\
\text { model for these receptors. } \\
\text { The meat and milk ingestion pathways are } \\
\text { suppressed for the Resident Gardener since } \\
\text { these pathways are not considered in the } \\
\text { conceptual site model for this receptor. }\end{array}$ & \\
\hline Depth of roots & $\mathrm{m}$ & 0.9 & $0-100$ & All & 0.9 & $P$ & 1 & $\begin{array}{l}\text { The maximum root depth below the ground } \\
\text { surface. } \\
\text { A default value was assumed for the Resident } \\
\text { Farmer, since meat, milk, and plant ingestion } \\
\text { are pathways for this receptor and site } \\
\text { specific information is not available. } \\
\text { The meat, milk, and plant ingestion pathways } \\
\text { are suppressed for the Workers, Recreational } \\
\text { User, and Trespasser since these pathways } \\
\text { are not considered in the conceptual site } \\
\text { model for these receptors. } \\
\text { The meat and milk ingestion pathways are } \\
\text { suppressed for the Resident Gardener since } \\
\text { these pathways are not considered in the } \\
\text { conceptual site model for this receptor. }\end{array}$ & Yu et al. 2001 \\
\hline $\begin{array}{l}\text { Groundwater } \\
\text { fractional usage for } \\
\text { drinking water }\end{array}$ & - & 1 & $0-1$ & All & 1 & $B, P$ & 3 & $\begin{array}{l}\text { The four groundwater fractional usage } \\
\text { parameters (drinking water, household water, } \\
\text { livestock water, and irrigation water) are } \\
\text { included primarily for all groundwater (well or } \\
\text { spring) and surface water (pond or river) } \\
\text { scenarios. Hence, the fractions will usually be } \\
\text { set at } 1 \text { or } 0 \text {. A value of } 1 \text { specifies } 100 \% \\
\text { groundwater usage and } 0 \text { specifies } 100 \% \\
\text { surface water usage. } \\
\text { A default value was assumed for the Resident } \\
\text { Farmer, since drinking water ingestion is a }\end{array}$ & Yu et al. 2001 \\
\hline
\end{tabular}


RESRAD Table of Input Parameters for the C-746-U Landfill Onsite Receptor Scenarios

\begin{tabular}{|c|c|c|c|c|c|c|c|c|c|}
\hline $\begin{array}{c}\text { Input Screen Title } \\
\text { and Parameter } \\
\text { Name }\end{array}$ & Unit & $\begin{array}{c}\text { Code } \\
\text { Default } \\
\text { Value }\end{array}$ & $\begin{array}{c}\text { Code- } \\
\text { Accepted } \\
\text { Values }^{a}\end{array}$ & Receptor $^{b}$ & $\begin{array}{l}\text { Deterministic } \\
\text { Value }\end{array}$ & Type $^{c}$ & Priority $^{d}$ & Justification & References \\
\hline & & & & & & & & $\begin{array}{l}\text { pathway for this receptor and site specific } \\
\text { information is not available. } \\
\text { The drinking water ingestion pathway is } \\
\text { suppressed for the Resident Gardener, } \\
\text { Workers, Recreational User, and Trespasser } \\
\text { since this pathway is not considered in the } \\
\text { conceptual site model for these receptors. }\end{array}$ & \\
\hline $\begin{array}{l}\text { Groundwater } \\
\text { fractional usage for } \\
\text { household water }\end{array}$ & - & 1 & $0-1$ & All & 1 & $B, P$ & 3 & $\begin{array}{l}\text { The four groundwater fractional usage } \\
\text { parameters (drinking water, household water, } \\
\text { livestock water, and irrigation water) are } \\
\text { included primarily for all groundwater (well or } \\
\text { spring) and surface water (pond or river) } \\
\text { scenarios. Hence, the fractions will usually be } \\
\text { set at } 1 \text { or } 0 \text {. A value of } 1 \text { specifies } 100 \% \\
\text { groundwater usage and } 0 \text { specifies } 100 \% \\
\text { surface water usage. } \\
\text { A default value was assumed for the Resident } \\
\text { Farmer, since it is reflected in the pathways } \\
\text { for this receptor and site specific information } \\
\text { is not available. } \\
\text { The meat, milk, and plant ingestion pathways } \\
\text { are suppressed for the Workers, Recreational } \\
\text { User, and Trespasser since these pathways } \\
\text { are not considered in the conceptual site } \\
\text { model for these receptors. } \\
\text { The meat and milk ingestion pathways are } \\
\text { suppressed for the Resident Gardener since } \\
\text { these pathways are not considered in the } \\
\text { conceptual site model for this receptor. }\end{array}$ & Yu et al. 2001 \\
\hline $\begin{array}{l}\text { Groundwater } \\
\text { fractional usage for } \\
\text { livestock water }\end{array}$ & - & 1 & $0-1$ & All & 1 & $B, P$ & 3 & $\begin{array}{l}\text { The four groundwater fractional usage } \\
\text { parameters (drinking water, household water, } \\
\text { livestock water, and irrigation water) are } \\
\text { included primarily for all groundwater (well or } \\
\text { spring) and surface water (pond or river) } \\
\text { scenarios. Hence, the fractions will usually be } \\
\text { set at } 1 \text { or } 0 \text {. A value of } 1 \text { specifies } 100 \% \\
\text { groundwater usage and } 0 \text { specifies } 100 \% \\
\text { surface water usage. }\end{array}$ & Yu et al. 2001 \\
\hline
\end{tabular}


RESRAD Table of Input Parameters for the C-746-U Landfill Onsite Receptor Scenarios

\begin{tabular}{|c|c|c|c|c|c|c|c|c|c|}
\hline $\begin{array}{c}\text { Input Screen Title } \\
\text { and Parameter } \\
\text { Name }\end{array}$ & Unit & $\begin{array}{c}\text { Code } \\
\text { Default } \\
\text { Value }\end{array}$ & $\begin{array}{c}\text { Code- } \\
\text { Accepted } \\
\text { Values }^{a}\end{array}$ & Receptor $^{b}$ & $\begin{array}{l}\text { Deterministic } \\
\text { Value }\end{array}$ & Type $^{c}$ & Priority $^{d}$ & Justification & References \\
\hline & & & & & & & & $\begin{array}{l}\text { A default value was assumed for the Resident } \\
\text { Farmer since it is reflected in the pathways for } \\
\text { this receptor and site specific information is } \\
\text { not available. } \\
\text { The meat and milk ingestion pathways are } \\
\text { suppressed for the Resident Gardener, } \\
\text { Workers, Recreational User, and Trespasser } \\
\text { since these pathways are not considered in } \\
\text { the conceptual site model. }\end{array}$ & \\
\hline $\begin{array}{l}\text { Groundwater } \\
\text { fractional usage for } \\
\text { irrigation water }\end{array}$ & - & 1 & $0-1$ & $\begin{array}{l}\text { RF } \\
\text { W } \\
\text { RU } \\
\text { T } \\
\text { L }\end{array}$ & 1 & $B, P$ & 3 & $\begin{array}{l}\text { The four groundwater fractional usage } \\
\text { parameters (drinking water, household water, } \\
\text { livestock water, and irrigation water) are } \\
\text { included primarily for all groundwater (well or } \\
\text { spring) and surface water (pond or river) } \\
\text { scenarios. Hence, the fractions will usually be } \\
\text { set at } 1 \text { or } 0 \text {. A value of } 1 \text { specifies } 100 \% \\
\text { groundwater usage and } 0 \text { specifies } 100 \% \\
\text { surface water usage. } \\
\text { A value of } 1 \text { is used for the Resident Farmer } \\
\text { and because the conceptual site model } \\
\text { assumed this individual will obtain irrigation } \\
\text { water from groundwater. } \\
\text { A value of } 0 \text { is used the Resident Gardener } \\
\text { because the conceptual site model assumes } \\
\text { this individual will obtain uncontaminated } \\
\text { irrigation water from offsite (e.g., a municipal } \\
\text { water source). } \\
\text { The plant ingestion pathway is suppressed for } \\
\text { the Workers, Recreational User, and } \\
\text { Trespasser since this pathway is not } \\
\text { considered in the conceptual site model for } \\
\text { these receptors. }\end{array}$ & $\begin{array}{l}\text { Yu et al. } 2001 \\
\text { DOE Project } \\
\text { Communication } \\
\text { with DOE-PPPO } \\
\text { (September } \\
\text { 2010) }\end{array}$ \\
\hline
\end{tabular}

Plant Factors 
RESRAD Table of Input Parameters for the C-746-U Landfill Onsite Receptor Scenarios

\begin{tabular}{|c|c|c|c|c|c|c|c|c|c|}
\hline $\begin{array}{c}\text { Input Screen Title } \\
\text { and Parameter } \\
\text { Name }\end{array}$ & Unit & $\begin{array}{c}\text { Code } \\
\text { Default } \\
\text { Value }\end{array}$ & $\begin{array}{l}\text { Code- } \\
\text { Accepted } \\
\text { Values }^{a}\end{array}$ & Receptor ${ }^{b}$ & $\begin{array}{c}\text { Deterministic } \\
\text { Value }\end{array}$ & Type $^{c}$ & Priority $^{d}$ & Justification & References \\
\hline $\begin{array}{l}\text { Wet-weight crop } \\
\text { yields for non-leafy } \\
\text { vegetables }\end{array}$ & $\mathrm{kg} / \mathrm{m}^{2}$ & 0.7 & $0.01-3$ & All & 0.7 & $P$ & 2 & $\begin{array}{l}\text { The weight of the edible portion of plant food } \\
\text { produced per unit land area for different food } \\
\text { classes. The code has wet weight crop yield } \\
\text { for non-leafy, leafy, and fodder. Non-leafy and } \\
\text { leafy vegetables are for human consumption; } \\
\text { fodder is for animal consumption. } \\
\text { A default value was assumed for the Resident } \\
\text { Farmer and Resident Gardener since it is } \\
\text { reflected in the pathway for these receptors } \\
\text { and site specific information is not available. } \\
\text { The plant ingestion pathway is suppressed for } \\
\text { the Workers, Recreational User, and } \\
\text { Trespasser since this pathway is not } \\
\text { considered in the conceptual site model for } \\
\text { these receptors. }\end{array}$ & Yu et al. 2001 \\
\hline $\begin{array}{l}\text { Wet-weight crop } \\
\text { yields for leafy } \\
\text { vegetables }\end{array}$ & $\mathrm{kg} / \mathrm{m}^{2}$ & 1.5 & $0.01-3$ & All & 1.5 & $P$ & 3 & $\begin{array}{l}\text { A default value was assumed for the Resident } \\
\text { Farmer and Resident Gardener since the } \\
\text { ingestion pathway for home-grown produce is } \\
\text { applicable for these receptors and site specific } \\
\text { information is not available. } \\
\text { The plant ingestion pathway is suppressed for } \\
\text { the Workers, Recreational User, and } \\
\text { Trespasser since this pathway is not } \\
\text { considered in the conceptual site model for } \\
\text { these receptors. }\end{array}$ & Yu et al. 2001 \\
\hline $\begin{array}{l}\text { Wet-weight crop } \\
\text { yields for fodder }\end{array}$ & $\mathrm{kg} / \mathrm{m}^{2}$ & 1.1 & $0.01-3$ & All & 1.1 & $P$ & 3 & $\begin{array}{l}\text { A default value was assumed for the Resident } \\
\text { Farmer since meat and milk ingestion is } \\
\text { applicable and a site specific value is not } \\
\text { available. } \\
\text { The meat and milk ingestion pathways are } \\
\text { suppressed for the Resident Gardener, } \\
\text { Workers, Recreational User, and Trespasser } \\
\text { since these pathways are not considered in } \\
\text { the conceptual site model for these receptors. }\end{array}$ & Yu et al. 2001 \\
\hline $\begin{array}{l}\text { Length of growing } \\
\text { season for non-leafy } \\
\text { vegetables }\end{array}$ & $\mathrm{yr}$ & 0.17 & $0.01-1$ & All & 0.17 & $P$ & 3 & $\begin{array}{l}\text { The exposure time to contamination for the } \\
\text { plant food during the growing season. The } \\
\text { contamination can reach the edible portion of } \\
\text { the plant food through foliar deposition, root }\end{array}$ & Yu et al. 2001 \\
\hline
\end{tabular}


RESRAD Table of Input Parameters for the C-746-U Landfill Onsite Receptor Scenarios

\begin{tabular}{|c|c|c|c|c|c|c|c|c|c|}
\hline $\begin{array}{c}\text { Input Screen Title } \\
\text { and Parameter } \\
\text { Name }\end{array}$ & Unit & $\begin{array}{c}\text { Code } \\
\text { Default } \\
\text { Value }\end{array}$ & $\begin{array}{c}\text { Code- } \\
\text { Accepted } \\
\text { Values }^{a}\end{array}$ & Receptor $^{b}$ & $\begin{array}{l}\text { Deterministic } \\
\text { Value }\end{array}$ & Type $^{c}$ & Priority $^{d}$ & Justification & References \\
\hline & & & & & & & & $\begin{array}{l}\text { uptake, and water irrigation. } \\
\text { The code has length of growing season for } \\
\text { non-leafy vegetables, leafy vegetables, and } \\
\text { fodder. } \\
\text { A default value was assumed for the Resident } \\
\text { Farmer and Resident Gardener since plant } \\
\text { ingestion is applicable and a site specific value } \\
\text { is not available. } \\
\text { The plant ingestion pathway is suppressed for } \\
\text { the Workers, Recreational User, and } \\
\text { Trespasser since this pathway is not } \\
\text { considered in the conceptual site model for } \\
\text { these receptors. }\end{array}$ & \\
\hline $\begin{array}{l}\text { Length of growing } \\
\text { season for leafy } \\
\text { vegetables }\end{array}$ & $\mathrm{yr}$ & 0.25 & $0.01-1$ & All & 0.25 & $\mathrm{P}$ & 3 & $\begin{array}{l}\text { The exposure time to contamination for the } \\
\text { plant food during the growing season. The } \\
\text { contamination can reach the edible portion of } \\
\text { the plant food through foliar deposition, root } \\
\text { uptake, and water irrigation. } \\
\text { The code has length of growing season for } \\
\text { non-leafy vegetables, leafy vegetables, and } \\
\text { fodder. } \\
\text { A default value was assumed for the Resident } \\
\text { Farmer and Resident Gardener since plant } \\
\text { ingestion is applicable and a site specific value } \\
\text { is not available. } \\
\text { The plant ingestion pathway is suppressed for } \\
\text { the Workers, Recreational User, and } \\
\text { Trespasser since this pathway is not } \\
\text { considered in the conceptual site model for } \\
\text { these receptors. }\end{array}$ & Yu et al. 2001 \\
\hline $\begin{array}{l}\text { Length of growing } \\
\text { season for fodder }\end{array}$ & $\mathrm{yr}$ & 0.08 & $0.01-1$ & All & 0.08 & $P$ & 3 & $\begin{array}{l}\text { The exposure time to contamination for the } \\
\text { plant food during the growing season. The } \\
\text { contamination can reach the edible portion of } \\
\text { the plant food through foliar deposition, root } \\
\text { uptake, and water irrigation. }\end{array}$ & Yu et al. 2001 \\
\hline
\end{tabular}


RESRAD Table of Input Parameters for the C-746-U Landfill Onsite Receptor Scenarios

\begin{tabular}{|c|c|c|c|c|c|c|c|c|c|}
\hline $\begin{array}{c}\text { Input Screen Title } \\
\text { and Parameter } \\
\text { Name }\end{array}$ & Unit & $\begin{array}{c}\text { Code } \\
\text { Default } \\
\text { Value }\end{array}$ & $\begin{array}{c}\text { Code- } \\
\text { Accepted } \\
\text { Values }^{a}\end{array}$ & Receptor $^{b}$ & $\begin{array}{l}\text { Deterministic } \\
\text { Value }\end{array}$ & Type $^{c}$ & Priority $^{d}$ & Justification & References \\
\hline & & & & & & & & $\begin{array}{l}\text { The code has length of growing season for } \\
\text { non-leafy vegetables, leafy vegetables, and } \\
\text { fodder. } \\
\text { A default value was assumed for the Resident } \\
\text { Farmer because meat and milk ingestion are } \\
\text { applicable and a site specific value is not } \\
\text { available. } \\
\text { The meat and milk ingestion pathways are } \\
\text { suppressed for the Resident Gardener, } \\
\text { Workers, Recreational User, and Trespasser } \\
\text { since these pathways are not considered in } \\
\text { the conceptual site model for these receptors. }\end{array}$ & \\
\hline $\begin{array}{l}\text { Translocation factor } \\
\text { for non-leafy } \\
\text { vegetables }\end{array}$ & - & 0.1 & $0-1$ & All & 0.1 & $P$ & 3 & $\begin{array}{l}\text { The fraction of the contamination that is } \\
\text { retained on the foliage that is transferred to } \\
\text { the edible portion of the plant. } \\
\text { The code has three food categories, non-leafy } \\
\text { (includes non-leafy vegetables, fruit, and } \\
\text { grain) and leafy vegetables for human and } \\
\text { fodder for animal consumption. } \\
\text { A default value was assumed for the Resident } \\
\text { Farmer and Resident Gardener since plant } \\
\text { ingestion is applicable and a site specific value } \\
\text { is not available. } \\
\text { The plant ingestion pathway is suppressed for } \\
\text { the Workers, Recreational User, and } \\
\text { Trespasser since this pathway is not } \\
\text { considered in the conceptual site model for } \\
\text { these receptors. }\end{array}$ & Yu et al. 2001 \\
\hline $\begin{array}{l}\text { Translocation factor } \\
\text { for leafy vegetables }\end{array}$ & - & 1 & $0-1$ & All & 1 & $P$ & 3 & $\begin{array}{l}\text { The fraction of the contamination that is } \\
\text { retained on the foliage that is transferred to } \\
\text { the edible portion of the plant. } \\
\text { The code has three food categories, non-leafy } \\
\text { (includes non-leafy vegetables, fruit, and } \\
\text { grain) and leafy vegetables for human and } \\
\text { fodder for animal consumption. }\end{array}$ & Yu et al. 2001 \\
\hline
\end{tabular}


RESRAD Table of Input Parameters for the C-746-U Landfill Onsite Receptor Scenarios

\begin{tabular}{|c|c|c|c|c|c|c|c|c|c|}
\hline $\begin{array}{c}\text { Input Screen Title } \\
\text { and Parameter } \\
\text { Name }\end{array}$ & Unit & $\begin{array}{c}\text { Code } \\
\text { Default } \\
\text { Value }\end{array}$ & $\begin{array}{c}\text { Code- } \\
\text { Accepted } \\
\text { Values }^{a}\end{array}$ & Receptor ${ }^{b}$ & $\begin{array}{c}\text { Deterministic } \\
\text { Value }\end{array}$ & Type $^{c}$ & Priority $^{d}$ & Justification & References \\
\hline & & & & & & & & $\begin{array}{l}\text { A default value was assumed for the Resident } \\
\text { Farmer and Resident Gardener since plant } \\
\text { ingestion is applicable and a site specific value } \\
\text { is not available. } \\
\text { The plant ingestion pathway is suppressed for } \\
\text { the Workers, Recreational User, and } \\
\text { Trespasser since this pathway is not } \\
\text { considered in the conceptual site model for } \\
\text { these receptors. }\end{array}$ & \\
\hline $\begin{array}{l}\text { Translocation factor } \\
\text { for fodder }\end{array}$ & - & 1 & $0-1$ & All & 1 & $P$ & 3 & $\begin{array}{l}\text { The fraction of the contamination that is } \\
\text { retained on the foliage that is transferred to } \\
\text { the edible portion of the plant. The code has } \\
\text { three food categories, non-leafy (includes } \\
\text { non-leafy vegetables, fruit, and grain) and } \\
\text { leafy vegetables for human and fodder for } \\
\text { animal consumption (in all three values). } \\
\text { A default value was assumed for the Resident } \\
\text { Farmer because meat and milk ingestion are } \\
\text { applicable and a site specific value is not } \\
\text { available. } \\
\text { The meat and milk ingestion pathways are } \\
\text { suppressed for the Resident Gardener, } \\
\text { Workers, Recreational User, and Trespasser } \\
\text { since these pathways are not considered in } \\
\text { the conceptual site model for these receptors. }\end{array}$ & Yu et al. 2001 \\
\hline $\begin{array}{l}\text { Weathering removal } \\
\text { constant }\end{array}$ & $1 / \mathrm{yr}$ & 20 & $1-40$ & All & 20 & $\mathrm{P}$ & 2 & $\begin{array}{l}\text { The weathering process would remove } \\
\text { contaminants from foliage of the plant food. } \\
\text { The process is characterized by a removal } \\
\text { constant and reduces the amount of } \\
\text { contaminants on foliage exponentially during } \\
\text { the exposure period. } \\
\text { A default value was assumed for the Resident } \\
\text { Farmer and Resident Gardener since plant } \\
\text { ingestion is applicable and a site specific value } \\
\text { is not available. } \\
\text { The plant ingestion pathway is suppressed for } \\
\text { the Workers, Recreational User, and }\end{array}$ & Yu et al. 2001 \\
\hline
\end{tabular}


RESRAD Table of Input Parameters for the C-746-U Landfill Onsite Receptor Scenarios

\begin{tabular}{|c|c|c|c|c|c|c|c|c|c|}
\hline $\begin{array}{c}\text { Input Screen Title } \\
\text { and Parameter } \\
\text { Name }\end{array}$ & Unit & $\begin{array}{c}\text { Code } \\
\text { Default } \\
\text { Value }\end{array}$ & $\begin{array}{c}\text { Code- } \\
\text { Accepted } \\
\text { Values }^{a}\end{array}$ & Receptor $^{b}$ & $\begin{array}{l}\text { Deterministic } \\
\text { Value }\end{array}$ & Type $^{c}$ & Priority $^{d}$ & Justification & References \\
\hline & & & & & & & & $\begin{array}{l}\text { Trespasser since this pathway is not } \\
\text { considered in the conceptual site model for } \\
\text { these receptors. }\end{array}$ & \\
\hline $\begin{array}{l}\text { Wet foliar } \\
\text { interception fraction } \\
\text { for non-leafy } \\
\text { vegetables }\end{array}$ & - & 0.25 & $0-1$ & All & 0.25 & $P$ & 3 & $\begin{array}{l}\text { The fraction of deposited radionuclides that is } \\
\text { retained on the foliage of the plant food. Both } \\
\text { dry deposition (from airborne particulates) } \\
\text { and the wet deposition processes (from } \\
\text { irrigation) are considered. } \\
\text { The code has wet as well as dry foliar } \\
\text { interception fraction for non-leafy, leafy (for } \\
\text { human consumption), and fodder (for animal } \\
\text { consumption). } \\
\text { A default value was assumed for the Resident } \\
\text { Farmer and Resident Gardener since plant } \\
\text { ingestion is applicable and a site specific value } \\
\text { is not available. } \\
\text { The plant ingestion pathway is suppressed for } \\
\text { the Workers, Recreational User, and } \\
\text { Trespasser since this pathway is not } \\
\text { considered in the conceptual site model for } \\
\text { these receptors. }\end{array}$ & Yu et al. 2001 \\
\hline $\begin{array}{l}\text { Wet foliar } \\
\text { interception fraction } \\
\text { for leafy vegetables }\end{array}$ & - & 0.25 & $0-1$ & All & 0.25 & $P$ & 2 & $\begin{array}{l}\text { The fraction of deposited radionuclides that is } \\
\text { retained on the foliage of the plant food. Both } \\
\text { dry deposition (from airborne particulates) } \\
\text { and the wet deposition processes (from } \\
\text { irrigation) are considered. } \\
\text { The code has wet as well as dry foliar } \\
\text { interception fraction for non-leafy, leafy (for } \\
\text { human consumption), and fodder (for animal } \\
\text { consumption). } \\
\text { A default value was assumed for the Resident } \\
\text { Farmer and Resident Gardener since plant } \\
\text { ingestion is applicable and a site specific value } \\
\text { is not available. } \\
\text { The plant ingestion pathway is suppressed for } \\
\text { the Workers, Recreational User, and }\end{array}$ & Yu et al. 2001 \\
\hline
\end{tabular}


RESRAD Table of Input Parameters for the C-746-U Landfill Onsite Receptor Scenarios

\begin{tabular}{|c|c|c|c|c|c|c|c|c|c|}
\hline $\begin{array}{c}\text { Input Screen Title } \\
\text { and Parameter } \\
\text { Name }\end{array}$ & Unit & $\begin{array}{c}\text { Code } \\
\text { Default } \\
\text { Value }\end{array}$ & $\begin{array}{c}\text { Code- } \\
\text { Accepted } \\
\text { Values }^{a}\end{array}$ & Receptor $^{b}$ & $\begin{array}{l}\text { Deterministic } \\
\text { Value }\end{array}$ & Type $^{c}$ & Priority $^{d}$ & Justification & References \\
\hline & & & & & & & & $\begin{array}{l}\text { Trespasser since this pathway is not } \\
\text { considered in the conceptual site model for } \\
\text { these receptors. }\end{array}$ & \\
\hline $\begin{array}{l}\text { Wet foliar } \\
\text { interception fraction } \\
\text { for fodder }\end{array}$ & - & 0.25 & $0-1$ & All & 0.25 & $\mathrm{P}$ & 3 & $\begin{array}{l}\text { The fraction of deposited radionuclides that is } \\
\text { retained on the foliage of the plant food. Both } \\
\text { dry deposition (from airborne particulates) } \\
\text { and the wet deposition processes (from } \\
\text { irrigation) are considered. } \\
\text { The code has wet as well as dry foliar } \\
\text { interception fraction for non-leafy, leafy (for } \\
\text { human consumption), and fodder (for animal } \\
\text { consumption). } \\
\text { A default value was assumed for the Resident } \\
\text { Farmer because meat and milk ingestion are } \\
\text { applicable and a site specific value is not } \\
\text { available. } \\
\text { The meat and milk ingestion pathways are } \\
\text { suppressed for the Resident Gardener, } \\
\text { Workers, Recreational User, and Trespasser } \\
\text { since these pathways are not considered in } \\
\text { the conceptual site model for these receptors. }\end{array}$ & Yu et al. 2001 \\
\hline $\begin{array}{l}\text { Dry foliar interception } \\
\text { fraction for non-leafy } \\
\text { vegetables }\end{array}$ & - & 0.25 & $0-1$ & All & 0.25 & $P$ & 3 & $\begin{array}{l}\text { The fraction of deposited radionuclides that is } \\
\text { retained on the foliage of the plant food. Both } \\
\text { the dry deposition (from airborne } \\
\text { particulates) and the wet deposition } \\
\text { processes (from irrigation) are considered. } \\
\text { The code has wet as well as dry foliar } \\
\text { interception fraction for non-leafy, leafy (for } \\
\text { human consumption), and fodder (for animal } \\
\text { consumption). } \\
\text { A default value was assumed for the Resident } \\
\text { Farmer and Resident Gardener since plant } \\
\text { ingestion is applicable and a site specific value } \\
\text { is not available. } \\
\text { The plant ingestion pathway is suppressed for } \\
\text { the Workers, Recreational User, and }\end{array}$ & Yu et al. 2001 \\
\hline
\end{tabular}


RESRAD Table of Input Parameters for the C-746-U Landfill Onsite Receptor Scenarios

\begin{tabular}{|c|c|c|c|c|c|c|c|c|c|}
\hline $\begin{array}{c}\text { Input Screen Title } \\
\text { and Parameter } \\
\text { Name }\end{array}$ & Unit & $\begin{array}{c}\text { Code } \\
\text { Default } \\
\text { Value }\end{array}$ & $\begin{array}{c}\text { Code- } \\
\text { Accepted } \\
\text { Values }^{a}\end{array}$ & Receptor $^{b}$ & $\begin{array}{l}\text { Deterministic } \\
\text { Value }\end{array}$ & Type $^{c}$ & Priority $^{d}$ & Justification & References \\
\hline & & & & & & & & $\begin{array}{l}\text { Trespasser since this pathway is not } \\
\text { considered in the conceptual site model for } \\
\text { these receptors. }\end{array}$ & \\
\hline $\begin{array}{l}\text { Dry foliar interception } \\
\text { fraction for leafy } \\
\text { vegetables }\end{array}$ & - & 0.25 & $0-1$ & All & 0.25 & $\mathrm{P}$ & 3 & $\begin{array}{l}\text { The fraction of deposited radionuclides that is } \\
\text { retained on the foliage of the plant food. Both } \\
\text { the dry deposition (from airborne } \\
\text { particulates) and the wet deposition } \\
\text { processes (from irrigation) are considered. } \\
\text { The code has wet as well as dry foliar } \\
\text { interception fraction for non-leafy, leafy (for } \\
\text { human consumption), and fodder (for animal } \\
\text { consumption). } \\
\text { A default value was assumed for the Resident } \\
\text { Farmer and Resident Gardener since plant } \\
\text { ingestion is applicable and a site specific value } \\
\text { is not available. } \\
\text { The plant ingestion pathway is suppressed for } \\
\text { the Workers, Recreational User, and } \\
\text { Trespasser since this pathway is not } \\
\text { considered in the conceptual site model for } \\
\text { these receptors. }\end{array}$ & Yu et al. 2001 \\
\hline $\begin{array}{l}\text { Dry foliar interception } \\
\text { fraction for fodder }\end{array}$ & - & 0.25 & $0-1$ & All & 0.25 & $P$ & 3 & $\begin{array}{l}\text { The fraction of deposited radionuclides that is } \\
\text { retained on the foliage of the plant food. Both } \\
\text { the dry deposition (from airborne } \\
\text { particulates) and the wet deposition } \\
\text { processes (from irrigation) are considered. } \\
\text { The code has wet as well as dry foliar } \\
\text { interception fraction for non-leafy, leafy (for } \\
\text { human consumption), and fodder (for animal } \\
\text { consumption). } \\
\text { A default value was assumed for the Resident } \\
\text { Farmer because meat and milk ingestion are } \\
\text { applicable and a site specific value is not } \\
\text { available. } \\
\text { The meat and milk ingestion pathways are } \\
\text { suppressed for the Resident Gardener, }\end{array}$ & Yu et al. 2001 \\
\hline
\end{tabular}


RESRAD Table of Input Parameters for the C-746-U Landfill Onsite Receptor Scenarios

\begin{tabular}{|c|c|c|c|c|c|c|c|c|c|}
\hline $\begin{array}{c}\text { Input Screen Title } \\
\text { and Parameter } \\
\text { Name }\end{array}$ & Unit & $\begin{array}{c}\text { Code } \\
\text { Default } \\
\text { Value }\end{array}$ & $\begin{array}{c}\text { Code- } \\
\text { Accepted } \\
\text { Values }^{a}\end{array}$ & Receptor ${ }^{b}$ & $\begin{array}{l}\text { Deterministic } \\
\text { Value }\end{array}$ & Type $e^{c}$ & Priority $^{d}$ & Justification & References \\
\hline & & & & & & & & $\begin{array}{l}\text { Workers, Recreational User, and Trespasser } \\
\text { since these pathways are not considered in } \\
\text { the conceptual site model for these receptors. }\end{array}$ & \\
\hline
\end{tabular}

Storage Times before Use Data

\begin{tabular}{|c|c|c|c|c|c|c|c|c|c|}
\hline $\begin{array}{l}\text { Storage times for } \\
\text { fruits, non-leafy } \\
\text { vegetables, and grain }\end{array}$ & $d$ & 14 & $0-1 E+34$ & All & 14 & B & 3 & $\begin{array}{l}\text { The storage times are used to calculate } \\
\text { radioactive ingrowth and decay adjustment } \\
\text { factors for food and feed due to storage. } \\
\text { The code has values for fruits, non-leafy } \\
\text { vegetables, and grain (one category), leafy } \\
\text { vegetables, milk, well and surface water, } \\
\text { livestock fodder, meat, fish and crustacea; } \\
\text { and mollusks. } \\
\text { A default value was assumed for the Resident } \\
\text { Farmer and Resident Gardener since plant } \\
\text { ingestion is applicable and a site specific value } \\
\text { is not available. } \\
\text { The plant ingestion pathway is suppressed for } \\
\text { the Workers, Recreational User, and } \\
\text { Trespasser since this pathway is not } \\
\text { considered in the conceptual site model for } \\
\text { these receptors. }\end{array}$ & Yu et al. 2001 \\
\hline $\begin{array}{l}\text { Storage times for leafy } \\
\text { vegetables }\end{array}$ & $d$ & 1 & $0-1 E+34$ & All & 1 & B & 3 & $\begin{array}{l}\text { The storage times are used to calculate } \\
\text { radioactive ingrowth and decay adjustment } \\
\text { factors for food and feed due to storage. } \\
\text { The code has values for fruits, non-leafy } \\
\text { vegetables, and grain (one category), leafy } \\
\text { vegetables, milk, well and surface water, } \\
\text { livestock fodder, meat, fish and crustacea; } \\
\text { and mollusks. } \\
\text { A default value was assumed for the Resident } \\
\text { Farmer and Resident Gardener since plant } \\
\text { ingestion is applicable and a site specific value } \\
\text { is not available. } \\
\text { The plant ingestion pathway is suppressed for } \\
\text { the Workers, Recreational User, and }\end{array}$ & Yu et al. 2001 \\
\hline
\end{tabular}


RESRAD Table of Input Parameters for the C-746-U Landfill Onsite Receptor Scenarios

\begin{tabular}{|c|c|c|c|c|c|c|c|c|c|}
\hline $\begin{array}{c}\text { Input Screen Title } \\
\text { and Parameter } \\
\text { Name }\end{array}$ & Unit & $\begin{array}{c}\text { Code } \\
\text { Default } \\
\text { Value }\end{array}$ & $\begin{array}{l}\text { Code- } \\
\text { Accepted } \\
\text { Values }^{a}\end{array}$ & Receptor ${ }^{b}$ & $\begin{array}{l}\text { Deterministic } \\
\text { Value }\end{array}$ & Type $^{c}$ & Priority $^{d}$ & Justification & References \\
\hline & & & & & & & & $\begin{array}{l}\text { Trespasser since this pathway is not } \\
\text { considered in the conceptual site model for } \\
\text { these receptors. }\end{array}$ & \\
\hline Storage times for milk & d & 1 & $0-1 E+34$ & All & 1 & B & 3 & $\begin{array}{l}\text { The storage times are used to calculate } \\
\text { radioactive ingrowth and decay adjustment } \\
\text { factors for food and feed due to storage. } \\
\text { The code has values for fruits, non-leafy } \\
\text { vegetables, and grain (one category), leafy } \\
\text { vegetables, milk, well and surface water, } \\
\text { livestock fodder, meat, fish and crustacea; } \\
\text { and mollusks. } \\
\text { A default value was assumed for the Resident } \\
\text { Farmer since milk ingestion is applicable and a } \\
\text { site specific value is not available. } \\
\text { The milk ingestion pathway is suppressed for } \\
\text { the Residential Gardener, Workers, } \\
\text { Recreational User, and Trespasser since this } \\
\text { pathway is not considered in the conceptual } \\
\text { site model for these receptors. }\end{array}$ & Yu et al. 2001 \\
\hline $\begin{array}{l}\text { Storage times for } \\
\text { meat }\end{array}$ & d & 20 & $0-1 E+34$ & All & 20 & B & 3 & $\begin{array}{l}\text { The storage times are used to calculate } \\
\text { radioactive ingrowth and decay adjustment } \\
\text { factors for food and feed due to storage. } \\
\text { The code has values for fruits, non-leafy } \\
\text { vegetables, and grain (one category), leafy } \\
\text { vegetables, milk, well and surface water, } \\
\text { livestock fodder, meat, fish and crustacea; } \\
\text { and mollusks. } \\
\text { A default value was assumed for the Resident } \\
\text { Farmer since meat ingestion is applicable and } \\
\text { a site specific value is not available. } \\
\text { The meat ingestion pathway is suppressed for } \\
\text { the Resident Gardner, Workers, Recreational } \\
\text { User, and Trespasser since this pathway is not } \\
\text { considered in the conceptual site model for } \\
\text { these receptors. }\end{array}$ & Yu et al. 2001 \\
\hline Storage times for fish & d & 7 & $0-1 E+34$ & All & 7 & B & 3 & The storage times are used to calculate & Yu et al. 2001 \\
\hline
\end{tabular}


RESRAD Table of Input Parameters for the C-746-U Landfill Onsite Receptor Scenarios

\begin{tabular}{|c|c|c|c|c|c|c|c|c|c|}
\hline $\begin{array}{c}\text { Input Screen Title } \\
\text { and Parameter } \\
\text { Name }\end{array}$ & Unit & $\begin{array}{c}\text { Code } \\
\text { Default } \\
\text { Value }\end{array}$ & $\begin{array}{c}\text { Code- } \\
\text { Accepted } \\
\text { Values }^{a}\end{array}$ & Receptor ${ }^{b}$ & $\begin{array}{c}\text { Deterministic } \\
\text { Value }\end{array}$ & Type $^{c}$ & Priority $^{d}$ & Justification & References \\
\hline & & & & & & & & $\begin{array}{l}\text { radioactive ingrowth and decay adjustment } \\
\text { factors for food and feed due to storage. } \\
\text { The code has values for fruits, non-leafy } \\
\text { vegetables, and grain (one category), leafy } \\
\text { vegetables, milk, well and surface water, } \\
\text { livestock fodder, meat, fish and crustacea; } \\
\text { and mollusks. } \\
\text { A default value was assumed; however, the } \\
\text { aquatic foods ingestion pathway is suppressed } \\
\text { for all receptors since this pathway is not } \\
\text { considered in the conceptual site model. }\end{array}$ & \\
\hline $\begin{array}{l}\text { Storage times for } \\
\text { crustacea and mollusks }\end{array}$ & $d$ & 7 & $0-1 E+34$ & All & 7 & B & 3 & $\begin{array}{l}\text { The storage times are used to calculate } \\
\text { radioactive ingrowth and decay adjustment } \\
\text { factors for food and feed due to storage. } \\
\text { The code has values for fruits, non-leafy } \\
\text { vegetables, and grain (one category), leafy } \\
\text { vegetables, milk, well and surface water, } \\
\text { livestock fodder, meat, fish and crustacea; } \\
\text { and mollusks. } \\
\text { A default value was assumed; however, the } \\
\text { aquatic foods ingestion pathway is suppressed } \\
\text { for all receptors since this pathway is not } \\
\text { considered in the conceptual site model. }\end{array}$ & Yu et al. 2001 \\
\hline $\begin{array}{l}\text { Storage times for well } \\
\text { water }\end{array}$ & $d$ & 1 & $0-1 E+34$ & All & 1 & B & 3 & $\begin{array}{l}\text { The storage times are used to calculate } \\
\text { radioactive ingrowth and decay adjustment } \\
\text { factors for food and feed due to storage. } \\
\text { The code has values for fruits, non-leafy } \\
\text { vegetables, and grain (one category), leafy } \\
\text { vegetables, milk, well and surface water, } \\
\text { livestock fodder, meat, fish and crustacea; } \\
\text { and mollusks. } \\
\text { A default value was assumed for the Resident } \\
\text { Farmer since this receptor would be } \\
\text { potentially affected by contaminated well } \\
\text { water and a site specific value is not available. }\end{array}$ & Yu et al. 2001 \\
\hline
\end{tabular}


RESRAD Table of Input Parameters for the C-746-U Landfill Onsite Receptor Scenarios

\begin{tabular}{|c|c|c|c|c|c|c|c|c|c|}
\hline $\begin{array}{c}\text { Input Screen Title } \\
\text { and Parameter } \\
\text { Name }\end{array}$ & Unit & $\begin{array}{c}\text { Code } \\
\text { Default } \\
\text { Value }\end{array}$ & $\begin{array}{c}\text { Code- } \\
\text { Accepted } \\
\text { Values }^{a}\end{array}$ & Receptor $^{b}$ & $\begin{array}{c}\text { Deterministic } \\
\text { Value }\end{array}$ & Type $^{c}$ & Priority $^{d}$ & Justification & References \\
\hline & & & & & & & & $\begin{array}{l}\text { The meat, milk, plant, and drinking water } \\
\text { ingestion pathways are suppressed for the } \\
\text { Workers, Recreational User, and Trespasser } \\
\text { since these pathways are not considered in } \\
\text { the conceptual site model for these receptors. } \\
\text { The meat, milk, and drinking water ingestion } \\
\text { pathways are suppressed for the Resident } \\
\text { Gardener since these pathways are not } \\
\text { considered in the conceptual site model for } \\
\text { this receptor. }\end{array}$ & \\
\hline $\begin{array}{l}\text { Storage times for } \\
\text { surface water }\end{array}$ & $d$ & 1 & $0-1 E+34$ & All & 1 & B & 3 & $\begin{array}{l}\text { The storage times are used to calculate } \\
\text { radioactive ingrowth and decay adjustment } \\
\text { factors for food and feed due to storage. } \\
\text { The code has values for fruits, non-leafy } \\
\text { vegetables, and grain (one category), leafy } \\
\text { vegetables, milk, well and surface water, } \\
\text { livestock fodder, meat, fish and crustacea; } \\
\text { and mollusks. } \\
\text { A default value was assumed for the Resident } \\
\text { Farmer since this receptor would be } \\
\text { potentially affected by contaminated surface } \\
\text { water and a site specific value is not available. } \\
\text { The meat, milk, plant, and drinking water } \\
\text { ingestion pathways are suppressed for the } \\
\text { Workers, Recreational User, and Trespasser } \\
\text { since these pathways are not considered in } \\
\text { the conceptual site model for these receptors. } \\
\text { The meat, milk, and drinking water ingestion } \\
\text { pathways are suppressed for the Resident } \\
\text { Gardener since these pathways are not } \\
\text { considered in the conceptual site model for } \\
\text { this receptor. }\end{array}$ & Yu et al. 2001 \\
\hline $\begin{array}{l}\text { Storage times for } \\
\text { livestock fodder }\end{array}$ & $d$ & 45 & $0-1 E+34$ & All & 45 & B & 3 & $\begin{array}{l}\text { For livestock fodder the storage time is an } \\
\text { annual average. The default value is obtained } \\
\text { by assuming } 6 \text { months of outside gazing and } 6 \\
\text { months of silage fodder with an average silo } \\
\text { time of } 3 \text { months. }\end{array}$ & Yu et al. 2001 \\
\hline
\end{tabular}


RESRAD Table of Input Parameters for the C-746-U Landfill Onsite Receptor Scenarios

\begin{tabular}{|c|c|c|c|c|c|c|c|c|c|}
\hline $\begin{array}{c}\text { Input Screen Title } \\
\text { and Parameter } \\
\text { Name }\end{array}$ & Unit & $\begin{array}{c}\text { Code } \\
\text { Default } \\
\text { Value }\end{array}$ & $\begin{array}{c}\text { Code- } \\
\text { Accepted } \\
\text { Values }^{a}\end{array}$ & Receptor ${ }^{b}$ & $\begin{array}{c}\text { Deterministic } \\
\text { Value }\end{array}$ & Type $^{c}$ & Priority $^{d}$ & Justification & References \\
\hline & & & & & & & & $\begin{array}{l}\text { A default value was assumed for the Resident } \\
\text { Farmer because meat and milk ingestion are } \\
\text { applicable and a site specific value is not } \\
\text { available. } \\
\text { The meat and milk ingestion pathways are } \\
\text { suppressed for the Resident Gardener, } \\
\text { Workers, Recreational User, and Trespasser } \\
\text { since these pathways are not considered in } \\
\text { the conceptual site model for these receptors. }\end{array}$ & \\
\hline \multirow{2}{*}{$\begin{array}{l}\text { Inhalation dose } \\
\text { conversion factors }\end{array}$} & \multirow{2}{*}{$\mathrm{mrem} / \mathrm{pCi}$} & \multirow{2}{*}{$\begin{array}{c}\text { Nuclide } \\
\text { Specific } \\
\text { (Default } \\
\text { values } \\
\text { available) }\end{array}$} & \multirow{2}{*}{$\begin{array}{l}\text { Nuclide } \\
\text { Specific }\end{array}$} & $\begin{array}{c}\text { RF } \\
\text { RG } \\
W \\
T \\
L\end{array}$ & $\begin{array}{l}\text { Nuclide Specific } \\
\text { (ICRP } 72 \text { (Adult)) }\end{array}$ & \multirow[t]{2}{*}{ M } & \multirow[t]{2}{*}{3} & \multirow{2}{*}{$\begin{array}{l}\text { The ICRP } 72 \text { Adult and Age } 15 \text { (internal dose } \\
\text { conversion factors) libraries are selected in } \\
\text { conjunction with the ICRP } 60 \text { (external dose } \\
\text { conversion factors) library to obtain results in } \\
\text { Total Effective Dose (TED). } \\
\text { The Recreational User is the only receptor } \\
\text { who is a teenager; therefore, the applicable } \\
\text { library is ICRP } 72 \text { (Age 15). }\end{array}$} & \multirow[t]{2}{*}{ Yu et al. 2001} \\
\hline & & & & RU & $\begin{array}{l}\text { Nuclide Specific } \\
\text { (ICRP } 72 \text { (Age 15)) }\end{array}$ & & & & \\
\hline \multirow[t]{2}{*}{$\begin{array}{l}\text { Ingestion dose } \\
\text { conversion factors }\end{array}$} & \multirow{2}{*}{$\mathrm{mrem} / \mathrm{pCi}$} & \multirow{2}{*}{$\begin{array}{l}\text { Nuclide } \\
\text { Specific } \\
\text { (Default } \\
\text { values } \\
\text { available) }\end{array}$} & \multirow[t]{2}{*}{$\begin{array}{l}\text { Nuclide } \\
\text { Specific }\end{array}$} & $\begin{array}{l}\text { RF } \\
\text { RG } \\
W \\
T \\
L \\
\end{array}$ & $\begin{array}{l}\text { Nuclide Specific } \\
\text { (ICRP } 72 \text { (Adult)) }\end{array}$ & \multirow[t]{2}{*}{ M } & \multirow[t]{2}{*}{3} & \multirow{2}{*}{$\begin{array}{l}\text { The ICRP } 72 \text { Adult and Age } 15 \text { (internal dose } \\
\text { conversion factors) libraries are selected in } \\
\text { conjunction with the ICRP } 60 \text { (external dose } \\
\text { conversion factors) library to obtain results in } \\
\text { Total Effective Dose (TED). } \\
\text { The Recreational User is the only receptor } \\
\text { who is a teenager; therefore, the applicable } \\
\text { library is ICRP } 72 \text { (Age 15). }\end{array}$} & \multirow[t]{2}{*}{ Yu et al. 2001} \\
\hline & & & & RU & $\begin{array}{c}\text { Nuclide Specific } \\
\text { (ICRP } 72 \text { (Age 15)) }\end{array}$ & & & & \\
\hline Slope factor- external & $\begin{array}{l}\text { (risk/yr)/ } \\
(\mathrm{pCi} / \mathrm{g})\end{array}$ & $\begin{array}{c}\text { Nuclide } \\
\text { Specific } \\
\text { (Default } \\
\text { values } \\
\text { available) }\end{array}$ & $\begin{array}{l}\text { Nuclide } \\
\text { Specific }\end{array}$ & All & $\begin{array}{l}\text { Nuclide Specific } \\
\text { (Default values) }\end{array}$ & M & 3 & Default value is used. & Yu et al. 2001 \\
\hline $\begin{array}{l}\text { Slope factor - } \\
\text { inhalation }\end{array}$ & risk/pCi & $\begin{array}{c}\text { Nuclide } \\
\text { Specific } \\
\text { (Default } \\
\text { values } \\
\text { available) }\end{array}$ & $\begin{array}{l}\text { Nuclide } \\
\text { Specific }\end{array}$ & All & $\begin{array}{l}\text { Nuclide Specific } \\
\text { (Default values) }\end{array}$ & M & 3 & Default value is used. & Yu et al. 2001 \\
\hline
\end{tabular}


RESRAD Table of Input Parameters for the C-746-U Landfill Onsite Receptor Scenarios

\begin{tabular}{|c|c|c|c|c|c|c|c|c|c|}
\hline $\begin{array}{c}\text { Input Screen Title } \\
\text { and Parameter } \\
\text { Name }\end{array}$ & Unit & $\begin{array}{c}\text { Code } \\
\text { Default } \\
\text { Value }\end{array}$ & $\begin{array}{c}\text { Code- } \\
\text { Accepted } \\
\text { Values }^{a}\end{array}$ & Receptor ${ }^{b}$ & $\begin{array}{c}\text { Deterministic } \\
\text { Value }\end{array}$ & Type ${ }^{c}$ & Priority $^{d}$ & Justification & References \\
\hline $\begin{array}{l}\text { Slope factor - } \\
\text { ingestion }\end{array}$ & risk/pCi & $\begin{array}{c}\text { Nuclide } \\
\text { Specific } \\
\text { (Default } \\
\text { values } \\
\text { available) } \\
\end{array}$ & $\begin{array}{l}\text { Nuclide } \\
\text { Specific }\end{array}$ & All & $\begin{array}{l}\text { Nuclide Specific } \\
\text { (Default values) }\end{array}$ & M & 3 & Default value is used. & Yu et al. 2001 \\
\hline Plant transfer factor & - & $\begin{array}{c}\text { Element } \\
\text { Specific } \\
\text { (Default } \\
\text { values } \\
\text { available) }\end{array}$ & $\begin{array}{l}\text { Element } \\
\text { Specific }\end{array}$ & All & $\begin{array}{l}\text { Nuclide Specific } \\
\text { (Default values) }\end{array}$ & $P$ & 1 & Default value is used. & Yu et al. 2001 \\
\hline Meat transfer factor & $\begin{array}{l}(\mathrm{pCi} / \mathrm{kg}) / \\
(\mathrm{pCi} / \mathrm{d})\end{array}$ & $\begin{array}{l}\text { Element } \\
\text { Specific } \\
\text { (Default } \\
\text { values } \\
\text { available) }\end{array}$ & $\begin{array}{l}\text { Element } \\
\text { Specific }\end{array}$ & All & $\begin{array}{l}\text { Nuclide Specific } \\
\text { (Default values) }\end{array}$ & $P$ & 2 & Default value is used. & Yu et al. 2001 \\
\hline Milk transfer factor & $\begin{array}{l}(\mathrm{pCi} / \mathrm{L}) / \\
(\mathrm{pCi} / \mathrm{d})\end{array}$ & $\begin{array}{c}\text { Element } \\
\text { Specific } \\
\text { (Default } \\
\text { values } \\
\text { available) } \\
\end{array}$ & $\begin{array}{l}\text { Element } \\
\text { Specific }\end{array}$ & All & $\begin{array}{l}\text { Nuclide Specific } \\
\text { (Default values) }\end{array}$ & $P$ & 2 & Default value is used. & Yu et al. 2001 \\
\hline $\begin{array}{l}\text { Bioaccumulation } \\
\text { factor for fish }\end{array}$ & $\begin{array}{l}(\mathrm{pCi} / \mathrm{kg}) / \\
(\mathrm{pCi} / \mathrm{L})\end{array}$ & $\begin{array}{c}\text { Element } \\
\text { Specific } \\
\text { (Default } \\
\text { values } \\
\text { available) }\end{array}$ & $\begin{array}{l}\text { Element } \\
\text { Specific }\end{array}$ & All & $\begin{array}{l}\text { Nuclide Specific } \\
\text { (Default values) }\end{array}$ & $P$ & 2 & Default value is used. & Yu et al. 2001 \\
\hline $\begin{array}{l}\text { Bioaccumulation } \\
\text { factor for crustacea } \\
\text { and mollusks }\end{array}$ & $\begin{array}{l}(\mathrm{pCi} / \mathrm{kg}) / \\
(\mathrm{pCi} / \mathrm{L})\end{array}$ & $\begin{array}{c}\text { Element } \\
\text { Specific } \\
\text { (Default } \\
\text { values } \\
\text { available) }\end{array}$ & $\begin{array}{l}\text { Element } \\
\text { Specific }\end{array}$ & All & $\begin{array}{l}\text { Nuclide Specific } \\
\text { (Default values }\end{array}$ & $P$ & 3 & Default value is used. & Yu et al. 2001 \\
\hline
\end{tabular}


a RESRAD does not provide code-accepted values for element- or nuclide-specific parameters

b The receptors considered for the selection of parameters are the Resident Farmer (RF), Resident Gardener (RG), Outdoor Worker (W), Recreational User (RU) Trespasser $(T)$ and the Landfill Worker $(L)$

c $\mathrm{P}=$ physical, $\mathrm{B}=$ behavioral, $\mathrm{M}=$ metabolic; when more than one type is listed, the first is primary and the next is secondary. The RESRAD parameters that are not classified, because of their function in the code are considered as "NA= not applicable" in this table.

d According to NUREG/CR-6697, it is necessary to establish priorities about which parameters to collect data for and use for distribution analysis. The parameters were ranked into three levels of priority: 1 (high priority), 2 (medium priority), and 3 (low priority).

e " $\_$" indicates that the parameter is dimensionless.

$f$ Groundwater concentration can be input only if time since placement of material is $>0$.

$\mathrm{g}$ This parameter should be used only if radionuclide leach rates are known.

h $\quad \mathrm{NA}=$ not applicable.

The Radon and Carbon-14 parameters are not included as part of this table because these radionuclides are not included in the contaminants of concern for this project. RESRAD allows the user to edit radon parameters only when a radon parent for either Rn-222 (U-238, U-234, Th-230, or Ra-226) or Rn-220 (Th-232, Ra-228, or Th-228) is present as a contaminant. Similarly, a user will have access to carbon-14 (C-14) parameters only if C-14 is a contaminant.

Notes:

The template for the table of parameters was created based on information available in NUREG/CR-6697 ANL/EAD/TM-98 "Development of Probabilistic RESRAD 6.0 and RESRAD-Build 3.0 Computer Codes" and the RESRAD 6.0 Manual. 
Attachment I

Distribution Coefficients 


\section{Distribution Coefficients $\left(\mathrm{Kds}, \mathrm{cm}^{3} / \mathrm{g}\right)^{\mathrm{a}, \mathrm{b}}$ for parent radionuclides in the contaminated zone, the unsaturated zones, and the saturated zone}

\begin{tabular}{|c|c|c|c|c|c|c|c|c|c|c|c|c|}
\hline Radionuclide & Am-241 & Cs-137 & Np-237 & Pu-238 & Pu-239/240 & Tc-99 & Th-228 & Th-230 & Th-232 & U-234 & U-235 & U-238 \\
\hline Contaminated Zone $^{c}$ & 1900 & 280 & 70 & 550 & 550 & 1 & 3200 & 3200 & 3200 & 410 & 410 & 410 \\
\hline $\begin{array}{c}\text { Unsaturated Zone } 1 \\
\text { (Protective layer } \\
\text { (native soil)) }\end{array}$ & 1900 & 280 & 70 & 550 & 550 & 0.2 & 3200 & 3200 & 3200 & 66.8 & 66.8 & 66.8 \\
\hline $\begin{array}{c}\text { Unsaturated Zone } 2 \\
\text { (Gravel layer) }\end{array}$ & 1900 & 280 & 70 & 550 & 550 & 0.2 & 3200 & 3200 & 3200 & 66.8 & 66.8 & 66.8 \\
\hline $\begin{array}{l}\text { Unsaturated Zone } 3 \\
\text { (Clay barrier) }\end{array}$ & 8400 & 1900 & 144 & 5100 & 5100 & 20 & 5800 & 5800 & 5800 & 3640 & 3640 & 3640 \\
\hline $\begin{array}{l}\text { Unsaturated Zone } 4 \\
\text { (Alluvium soils } \\
\text { (native/subgrade)) }\end{array}$ & 1900 & 280 & 70 & 550 & 550 & 0.2 & 3200 & 3200 & 3200 & 66.8 & 66.8 & 66.8 \\
\hline $\begin{array}{c}\text { Unsaturated Zone } 5 \\
\text { (Clay confining unit } \\
\text { (native)) }\end{array}$ & 8400 & 1900 & 144 & 5100 & 5100 & 20 & 5800 & 5800 & 5800 & 3640 & 3640 & 3640 \\
\hline Saturated Zone(RGA) & 1900 & 280 & 70 & 550 & 550 & 0.2 & 3200 & 3200 & 3200 & 66.8 & 66.8 & 66.8 \\
\hline
\end{tabular}

\footnotetext{
a Distribution coefficients for Am-241, Np-237, Th-230, Th-232, U-234 and U-238 were obtained from DOE 2003b, page C3-313 and Table Att. 1. Distribution coefficient of radionuclides and their daughter products in different zones, page C3-314. It was assumed that the Kd for U-235 was similar to the Kd for U-234 and U-238 since the Kds are chemical specific.

${ }^{b}$ Distribution coefficients for Cs-137, Th-228, Pu-238, Pu-239, and Pu-240 were obtained through "Project Communication" with the Waste Disposal Options Project Team from Paducah, KY. The distribution coefficients for Tc-99 are available in Table C.3.1. Chemical and physical properties of different classes of chemicals identified as COPCs for the C-746-U Landfill of DOE 2003b, page C3301. Table 4.5 DUST model input parameters, page 4-12, has Kds for Tc-99 and Uranium.

${ }^{c}$ The contaminated zone includes four Waste Forms such as: Soil (Waste Form 1), Concrete (Waste Form 2), Metal (Waste Form 3), and Organic (Waste Form 4). This information was obtained from figure Fig. 4.5. Schematic diagram of DUST model layers and materials for the Post-Institutional Control Period under the gradual failure and immediate failure scenarios of DOE 2003b, page 4-18.
} 


\section{Distribution Coefficients $\left(\mathrm{Kds}, \mathrm{cm}^{3} / \mathrm{g}\right)^{\mathrm{d}}$ for progeny radionuclides in the contaminated zone, the unsaturated zones and the saturated zone}

\begin{tabular}{|c|c|c|c|c|c|c|c|c|}
\hline Radionuclide & Ac-227 & Pa-231 & Pb-210 & Ra-226 & Ra-228 & Th-229 & U-233 & U-236 \\
\hline Contaminated Zone & 450 & 550 & 270 & 500 & 500 & 3200 & 410 & 410 \\
\hline $\begin{array}{c}\text { Unsaturated Zone 1 } \\
\text { (Protective layer } \\
\text { (native soil)) }\end{array}$ & 450 & 550 & 270 & 500 & 500 & 3200 & 66.8 & 66.8 \\
\hline $\begin{array}{c}\text { Unsaturated Zone 2 } \\
\text { (Gravel layer) }\end{array}$ & 450 & 550 & 270 & 500 & 500 & 3200 & 66.8 & 66.8 \\
\hline $\begin{array}{c}\text { Unsaturated Zone 3 } \\
\text { (Clay barrier) }\end{array}$ & 2400 & 2700 & 550 & 9100 & 9100 & 5800 & 3640 & 3640 \\
\hline $\begin{array}{c}\text { Unsaturated Zone 4 } \\
\text { (Alluvium soils } \\
\text { (native/subgrade)) }\end{array}$ & 450 & 550 & 270 & 500 & 500 & 3200 & 66.8 & 66.8 \\
\hline $\begin{array}{c}\text { Unsaturated Zone 5 } \\
\text { (Clay confining unit } \\
\text { (native)) }\end{array}$ & 2400 & 2700 & 550 & 9100 & 9100 & 5800 & 3640 & 3640 \\
\hline Saturated Zone(RGA) & 450 & 550 & 270 & 500 & 500 & 3200 & 66.8 & 66.8 \\
\hline
\end{tabular}

\footnotetext{
d Distribution coefficients for Ac-227, Pa-231, Pb-210, Ra-226, Ra-228, Th-229, and U-236 were obtained through "Project Communication" with the Waste Disposal Options Project Team from Paducah, KY. It was assumed that the Kds for U-233 was similar to the Kds for the other uranium isotopes (i.e. U-234, U-235, U-236 and U-238), since the Kds are chemical specific.

e The contaminated zone includes four Waste Forms such as: Soil (Waste Form 1), Concrete (Waste Form 2), Metal (Waste Form 3), and Organic (Waste Form 4). This information was obtained from figure Fig. 4.5. Schematic diagram of DUST model layers and materials for the Post Institutional Control Period under the gradual failure and immediate failure scenarios of DOE $2003 \mathrm{~b}$, page $4-18$.
} 
Attachment II

Calculations and Applicable Parameters from DOE 2009, Appendix D, Converted into RESRAD Compatible Units 


\section{Section A. Runoff Coefficient and Evapotranspiration Coefficient Calculations}

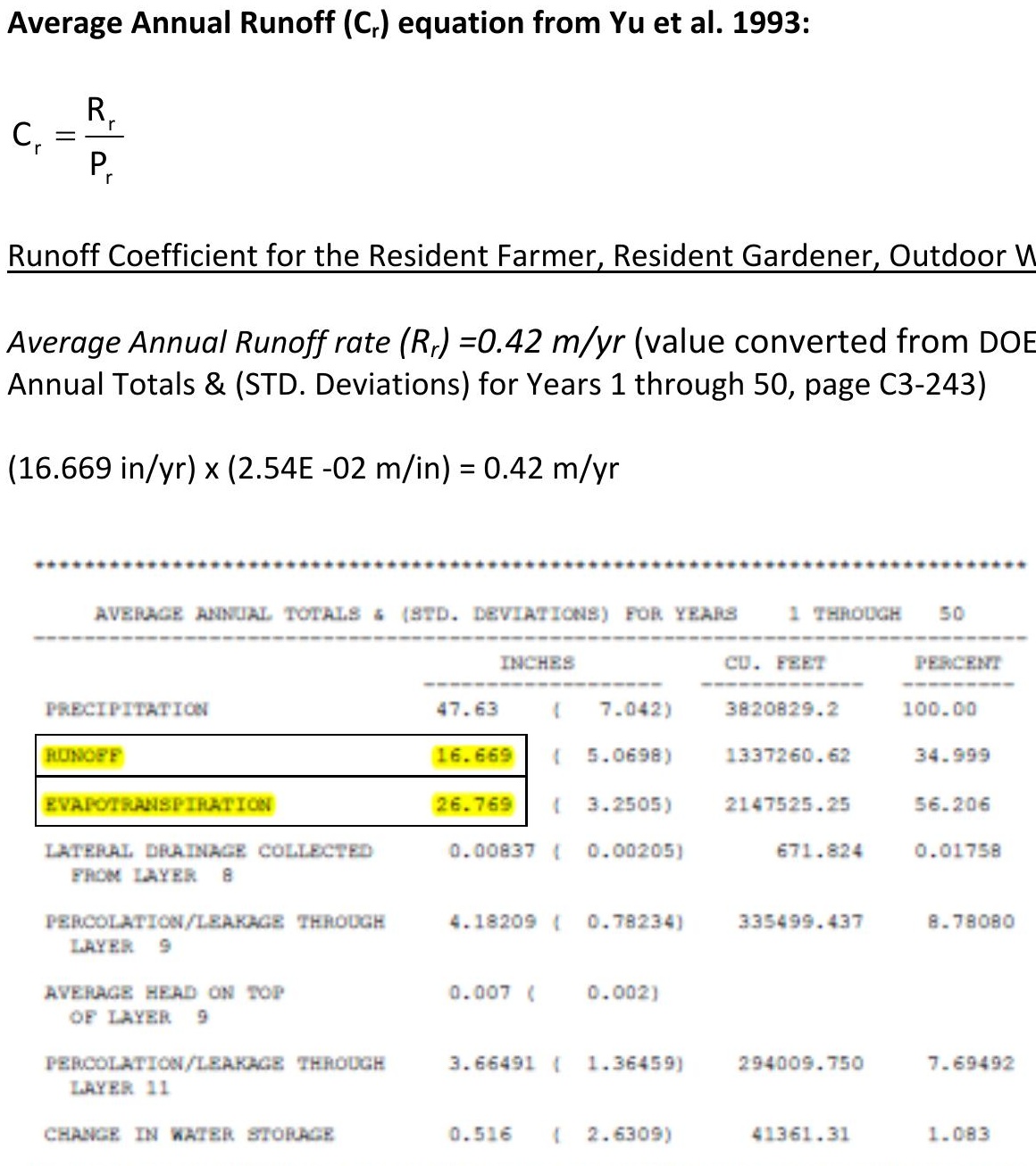

Values from the HELP Output List 3 that were used to determine input parameters are highlighted. 


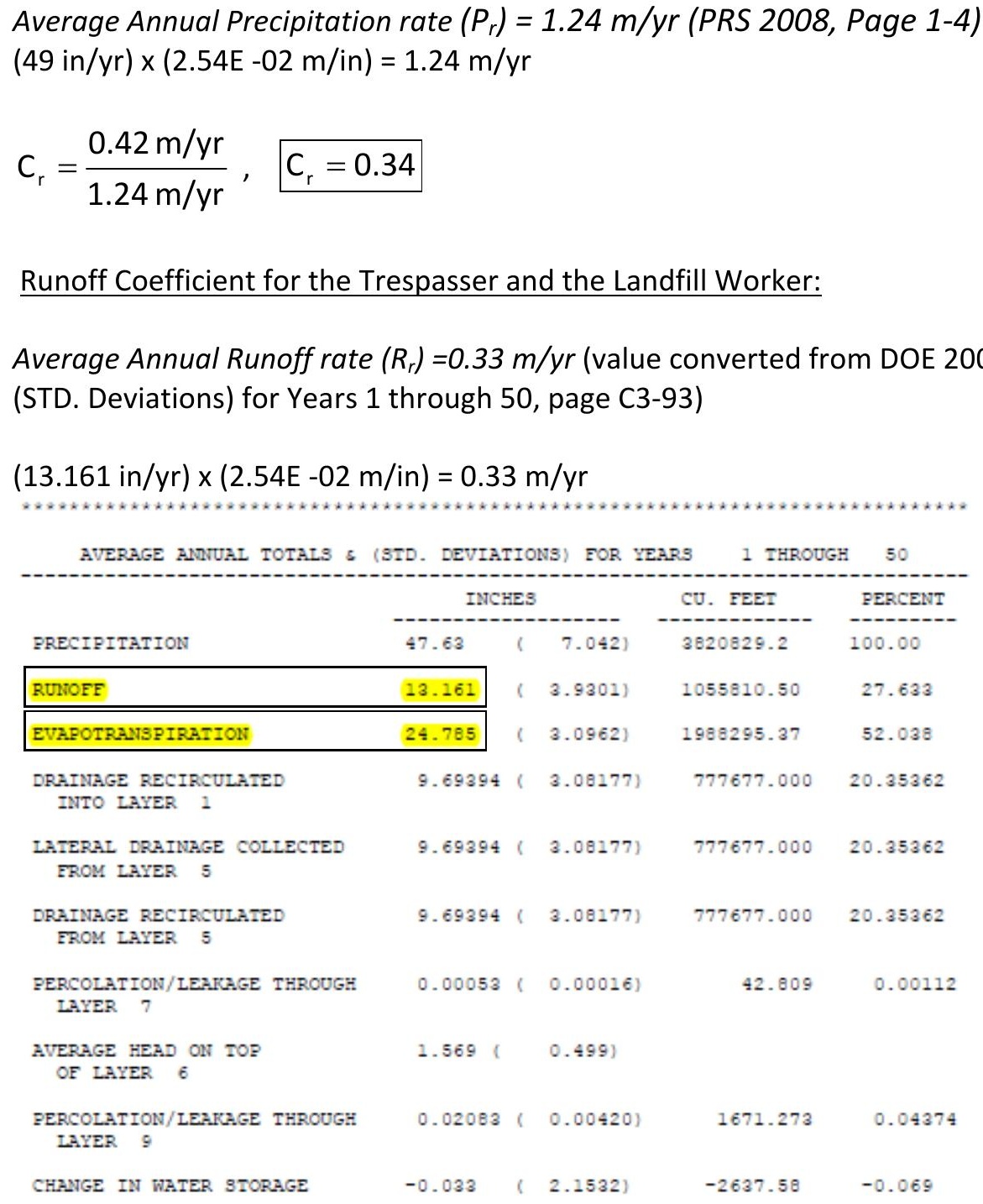

Cathe

Values from the HELP Output List 1 that were used to determine input parameters are highlighted. 


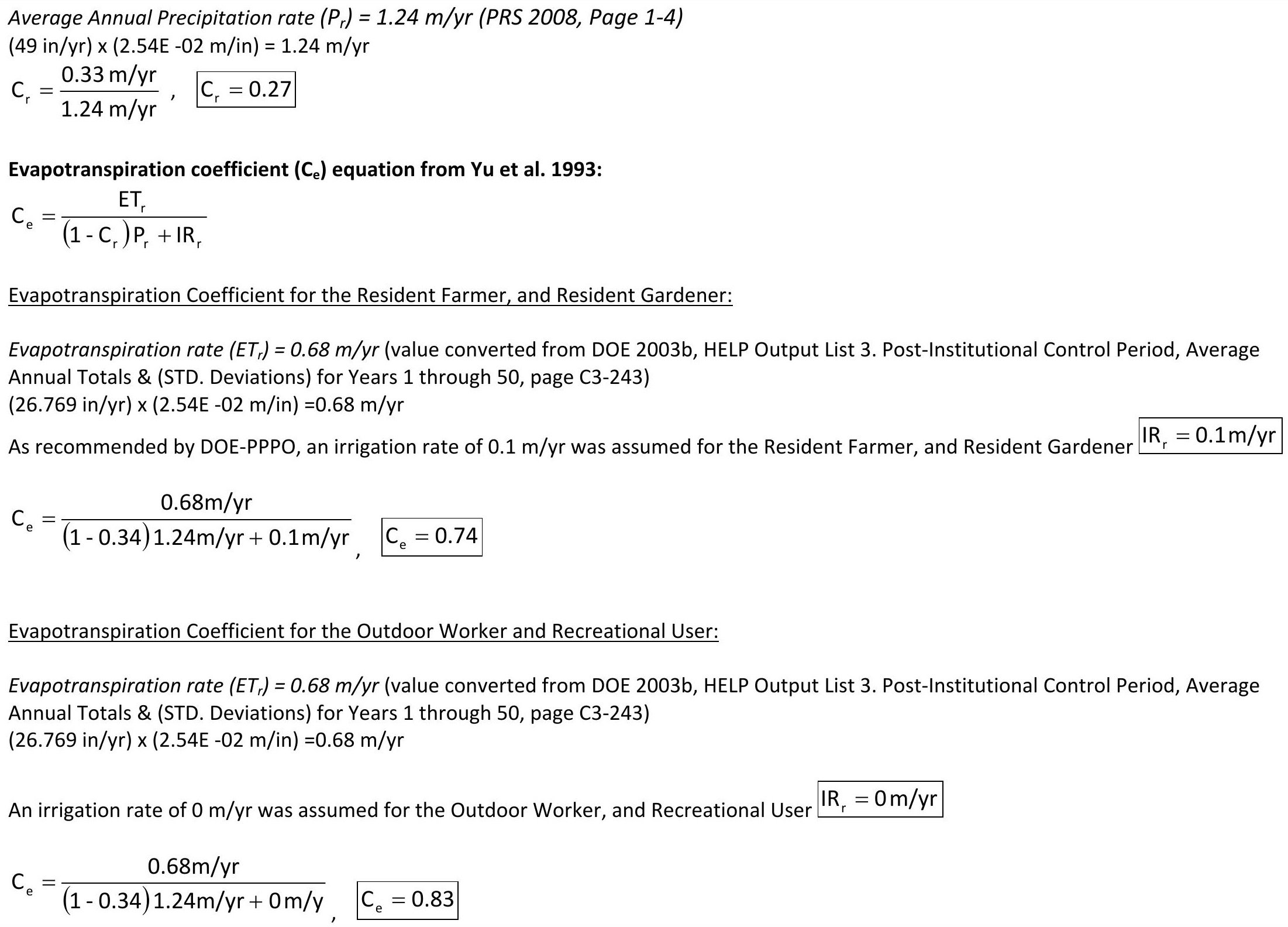




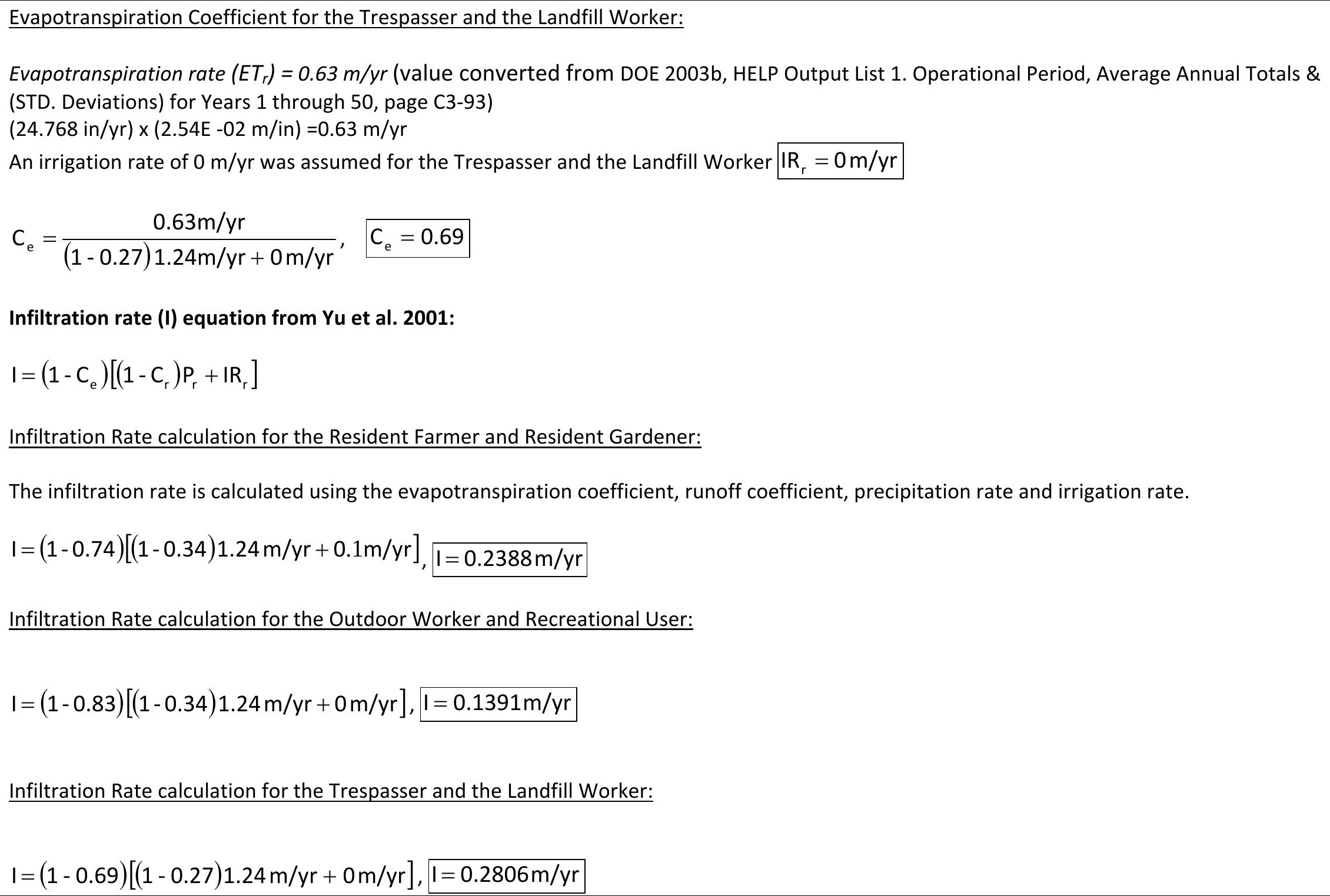




\section{Section B. Parameters Applicable to the Resident Farmer and the Resident Gardener (In Some Cases)}

\section{Drinking Water Intake}

\begin{tabular}{|c|c|c|c|c|c|c|c|c|}
\hline \multicolumn{5}{|c|}{$\begin{array}{l}\text { Parameters from the Risk Methods Document (DOE 2009), Appendix D } \\
\text { Table D.l. Reasonable maximum exposure assumptions and human intake factors for ingestion of water by a } \\
\text { rural resident }^{\mathrm{a}}\end{array}$} & \multicolumn{4}{|c|}{$\begin{array}{l}\text { Conversion of Parameter Units into RESRAD } \\
\text { Compatible Units }\end{array}$} \\
\hline \multicolumn{5}{|c|}{ Equations: } & $\begin{array}{l}\text { Ingestion } \\
\text { Rate = IR } \\
\text { (L/day) }\end{array}$ & $\begin{array}{l}\text { Exposure } \\
\text { frequency } \\
=\mathrm{EF} \text { in } \\
\text { (days/yr) }\end{array}$ & $\begin{array}{c}\text { RESRAD- } \\
\text { Drinking } \\
\text { water } \\
\text { intake (L/yr) } \\
\text { obtained by } \\
\text { multiplying } \\
\text { IR X EF }\end{array}$ & Receptor \\
\hline & $\begin{array}{l}\text { Parameter } \\
\text { Chemical concentration in water }=\mathrm{C}_{\pi} \\
\text { Radiological activity }=\mathrm{A}_{\pi} \\
\text { Ingestion Rate }=\mathrm{IR} \\
\text { Exposure frequency }=\mathrm{EF} \\
\text { Exposure duration }=\mathrm{ED}\end{array}$ & $\begin{array}{c}\text { Units } \\
\mathrm{mg} / \mathrm{L} \\
\mathrm{pCiL} \\
\mathrm{L} / \mathrm{d} \\
\\
\mathrm{d} / \text { year } \\
\text { years }\end{array}$ & $\begin{array}{c}\text { Value used } \\
\text { Chemical-specific } \\
\text { Chemical-specific } \\
2 \text { (acult) } \\
1.5 \text { (child) } \\
350 \\
24 \text { (adult) } \\
6 \text { (child) }\end{array}$ & $\begin{array}{c}\text { References }^{b} \\
-- \\
- \\
-114]\end{array}$ & 2 & 350 & 700 & $\begin{array}{l}\text { Adult Rural } \\
\text { Resident } \\
\text { which } \\
\text { corresponds } \\
\text { to the } \\
\text { "Resident } \\
\text { Farmer" }\end{array}$ \\
\hline & $\begin{array}{l}\text { Body weight }=\text { BW } \\
\text { Averaging time = AT }\end{array}$ & $\begin{array}{c}\mathrm{kg} \\
\mathrm{yr} \times \text { day } / \mathrm{yr} .\end{array}$ & $\begin{array}{c}70 \text { (adult) } \\
15 \text { (child) } \\
70 \times 365 \text { (carcinogen) } \\
\mathrm{ED} \times 365 \text { (noncarcinoge }\end{array}$ & $\begin{array}{l}\text { [14] } \\
{[14]}\end{array}$ & & & & \\
\hline a & $\begin{array}{l}\text { Equation from [1]. } \\
\text { References follow Table D. } 50 .\end{array}$ & & & & & & & \\
\hline
\end{tabular}




\section{Soil Ingestion Rate}

Parameters from the Risk Methods Document (DOE 2009), Appendix D

Table D.5. Reasonable maximum exposure assumptions and human intake factors for incidental ingestion soil by a rural resident ${ }^{2}$

\section{Equations:}

Chemical Intake $\left[\mathrm{mg} /(\mathrm{kg} \times\right.$ day $]=\frac{C_{s} \times C F \times E F \times F I \times E D \times I R}{B W \times A T}$

Radionuclide Intake $(\mathrm{pCi})=A_{s} \times C F_{\text {rad }} \times E F \times F I \times E D \times I R$

\begin{tabular}{|c|c|c|c|}
\hline Parameter & Units & Value used & References $^{b}$ \\
\hline Chemical concentration in soil $=\mathrm{C}_{3}$ & $\mathrm{mg} / \mathrm{kg}$ & Chemical-specific & - \\
\hline Radiological activity $=A_{s}$ & $\mathrm{pCi} / \mathrm{g}$ & Chemical-specific & $\ldots$ \\
\hline Conversion factor $=\mathbf{C F}$ & $\mathrm{kg} / \mathrm{mg}$ & $10^{-5}$ & $\ldots$ \\
\hline Conversion factor $=\mathbf{C F}_{\text {rad }}$ & $\mathrm{g} / \mathrm{mg}$ & $10^{-3}$ & $\ldots$ \\
\hline Exposure frequency $=\mathbf{E F}$ & days $/ y r$ & 350 & [14] \\
\hline Fraction ingested $=\mathbf{F I}$ & unitless & 1 & [14] \\
\hline \multirow[t]{2}{*}{ Exposure curation $=\mathrm{ED}$} & years & 24 (adult) & [14] \\
\hline & & 6 (child) & \\
\hline \multirow[t]{2}{*}{ Ingestion rate of soil = IR } & $\mathrm{mg} / \mathrm{d}$ & 100 (adult) & [14] \\
\hline & & 200 (child) & \\
\hline \multirow[t]{2}{*}{ Body weight $=$ BW } & $\mathrm{kg}$ & 70 (adult) & [14] \\
\hline & & 15 (child) & \\
\hline \multirow[t]{2}{*}{ Averaging time $=\mathrm{AT}$} & $\mathrm{yr} \times \mathrm{day} / \mathrm{yr}$ & $70 \times 365$ (carcinogen) & [14] \\
\hline & & $\mathrm{ED} \times 365$ (noncarcinogen) & \\
\hline
\end{tabular}

Equation from [1]
Conversion of Parameter Units into RESRAD Compatible Units

\begin{tabular}{|c|c|c|c|c|}
\hline $\begin{array}{c}\text { Conversion } \\
\text { factor }= \\
\mathrm{Cf}_{\mathrm{rad}} \\
(\mathrm{g} / \mathrm{mg})\end{array}$ & $\begin{array}{l}\text { Ingestion } \\
\text { rate of } \\
\text { soil = IR } \\
\text { (mg/day) }\end{array}$ & $\begin{array}{c}\text { Exposure } \\
\text { frequency = } \\
\text { EF (days/yr) }\end{array}$ & $\begin{array}{c}\text { RESRAD - } \\
\text { Soil } \\
\text { ingestion } \\
\text { (g/yr) } \\
\text { obtained by } \\
\text { multiplying } \\
\text { Cf }_{\text {rad }} \text { X IR X } \\
\text { EF }\end{array}$ & Receptor \\
\hline $1.00 \mathrm{E}-03$ & 100 & 365 & 36.5 & $\begin{array}{l}\text { Adult Rural } \\
\text { Resident } \\
\text { which } \\
\text { corresponds } \\
\text { to the } \\
\text { "Resident } \\
\text { Farmer" }\end{array}$ \\
\hline \multicolumn{5}{|c|}{$\begin{array}{l}\text { Note: The exposure frequency of } 365 \text { days/yr is used in the conversion, } \\
\text { instead of } 350 \text { days/yr since RESRAD uses time fractions to correct for } \\
\text { occupancy. }\end{array}$} \\
\hline
\end{tabular}


Inhalation Rate and Mass Loading for Inhalation

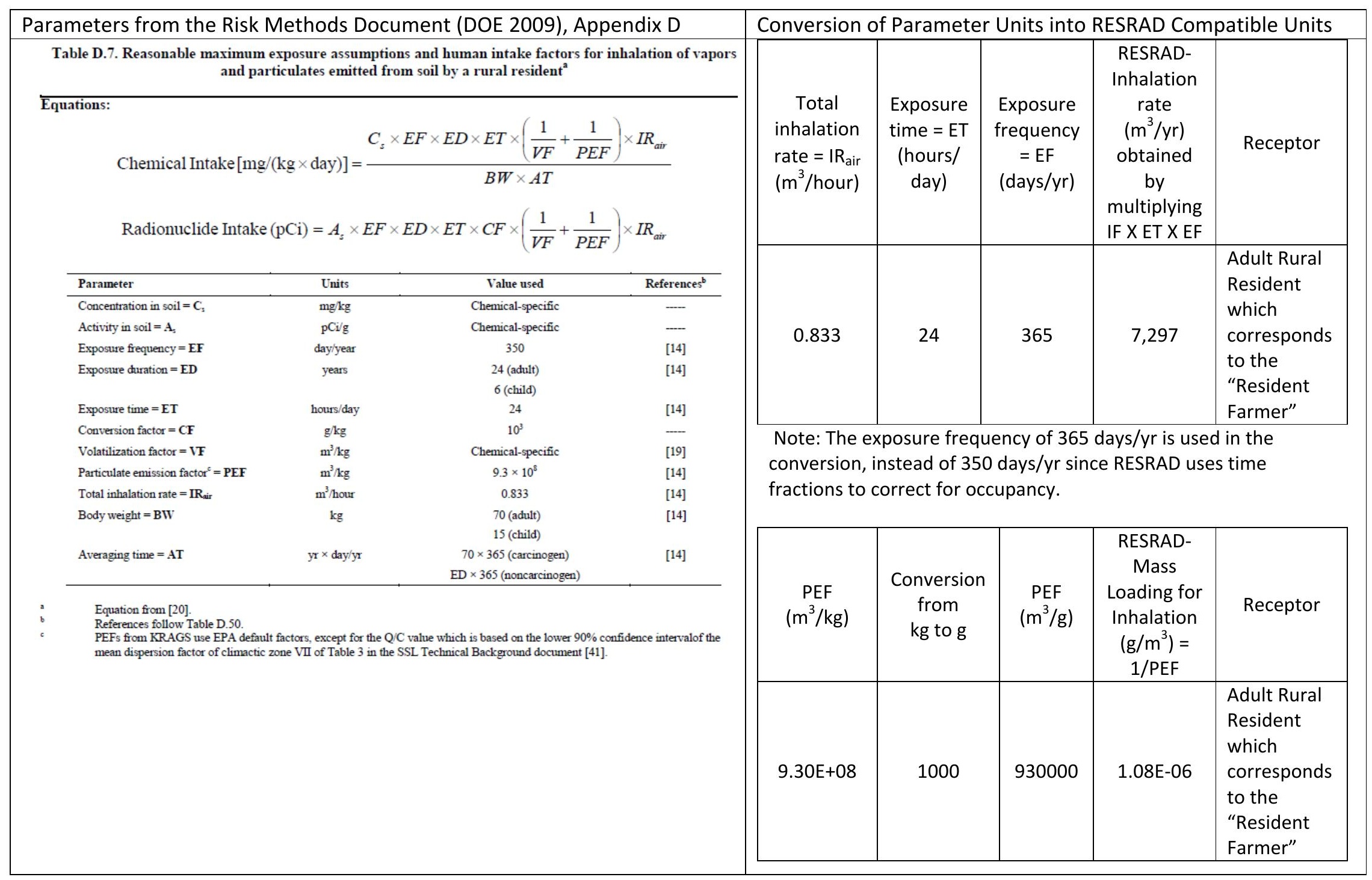


External Gamma Shielding Factor and Exposure Duration

\begin{tabular}{|c|c|c|c|c|c|c|c|}
\hline \multirow{2}{*}{\multicolumn{4}{|c|}{$\begin{array}{l}\text { Parameters from the Risk Methods Document (DOE 2009), Appendix D } \\
\text { Table D.8. Reasonable maximum exposure assumptions and human intake factors for external exposure to } \\
\text { ionizing radiation from soil by a rural resident }{ }^{\mathrm{a}}\end{array}$}} & \multicolumn{4}{|c|}{$\begin{array}{l}\text { Conversion of Parameter Units into RESRAD } \\
\text { Compatible Units }\end{array}$} \\
\hline & & & & \multirow{4}{*}{$\begin{array}{c}\text { Exposure } \\
\text { duration = ED } \\
\text { (years) -no } \\
\text { conversion } \\
\text { required since } \\
\text { it is in RESRAD } \\
\text { units }\end{array}$} & \multirow{4}{*}{$\begin{array}{l}\text { Gamma } \\
\text { shielding } \\
\text { factor }= \\
\text { Se } \\
\text { (unitless) }\end{array}$} & \multirow{4}{*}{ Receptor } & \multirow{4}{*}{$\begin{array}{l}\text { RESRAD } \\
\text { external } \\
\text { gamma } \\
\text { shielding } \\
\text { factor }\end{array}$} \\
\hline \multicolumn{4}{|c|}{ Absorbed Dose $[(\mathrm{pCi} \times$ year $) / \mathrm{g}]=A_{s} \times E D \times E F \times\left(1-S_{e}\right) \times T_{\epsilon}$} & & & & \\
\hline Parameter & Units & Value used & References $^{\mathrm{b}}$ & & & & \\
\hline Activity in soil $=A_{8}$ & $\mathrm{pCi} / \mathrm{g}$ & Chemical-specific & - & & & & \\
\hline Exposure duration = ED & year & $\begin{array}{l}24 \text { (adult) } \\
6 \text { (child) }\end{array}$ & [14] & \multirow{5}{*}{24} & \multirow{5}{*}{0.2} & \multirow{5}{*}{$\begin{array}{l}\text { Adult Rural } \\
\text { Resident } \\
\text { which } \\
\text { corresponds } \\
\text { to the } \\
\text { "Resident } \\
\text { Farmer" }\end{array}$} & \multirow{5}{*}{$1-0.2=0.8$} \\
\hline Exposure frequency $=\mathbf{E F}$ & day/day & $350 / 365$ & [14] & & & & \\
\hline Gamma shielding factor $=\mathrm{S}_{\mathrm{e}}$ & unitless & 0.2 & {$[20]$} & & & & \\
\hline Gamma exposure time factor $=T_{\text {e }}$ & $\mathrm{hr} / \mathrm{hr}$ & $24 / 24$ & [20] & & & & \\
\hline $\begin{array}{l}\text { a Equation from [20]. } \\
\text { b References follow Table D. } 50 .\end{array}$ & & & & & & & \\
\hline
\end{tabular}

Indoor and Outdoor occupancy fractions

\begin{tabular}{|c|c|c|}
\hline \multicolumn{3}{|c|}{ Resident Farmer Occupancy fractions } \\
\hline & Days & Fractions for RESRAD \\
\hline $1 / 3$ of the time outdoors & 117 & 0.32 \\
\hline $2 / 3$ of the time indoors & 233 & 0.64 \\
\hline Total Days Onsite & 350 & \\
\hline Total Fraction & & 0.96 \\
\hline
\end{tabular}

Note: The Resident Farmer spends 350 days on site. 
Fruit, non-leafy vegetable, and grain consumption and Leafy vegetables consumption

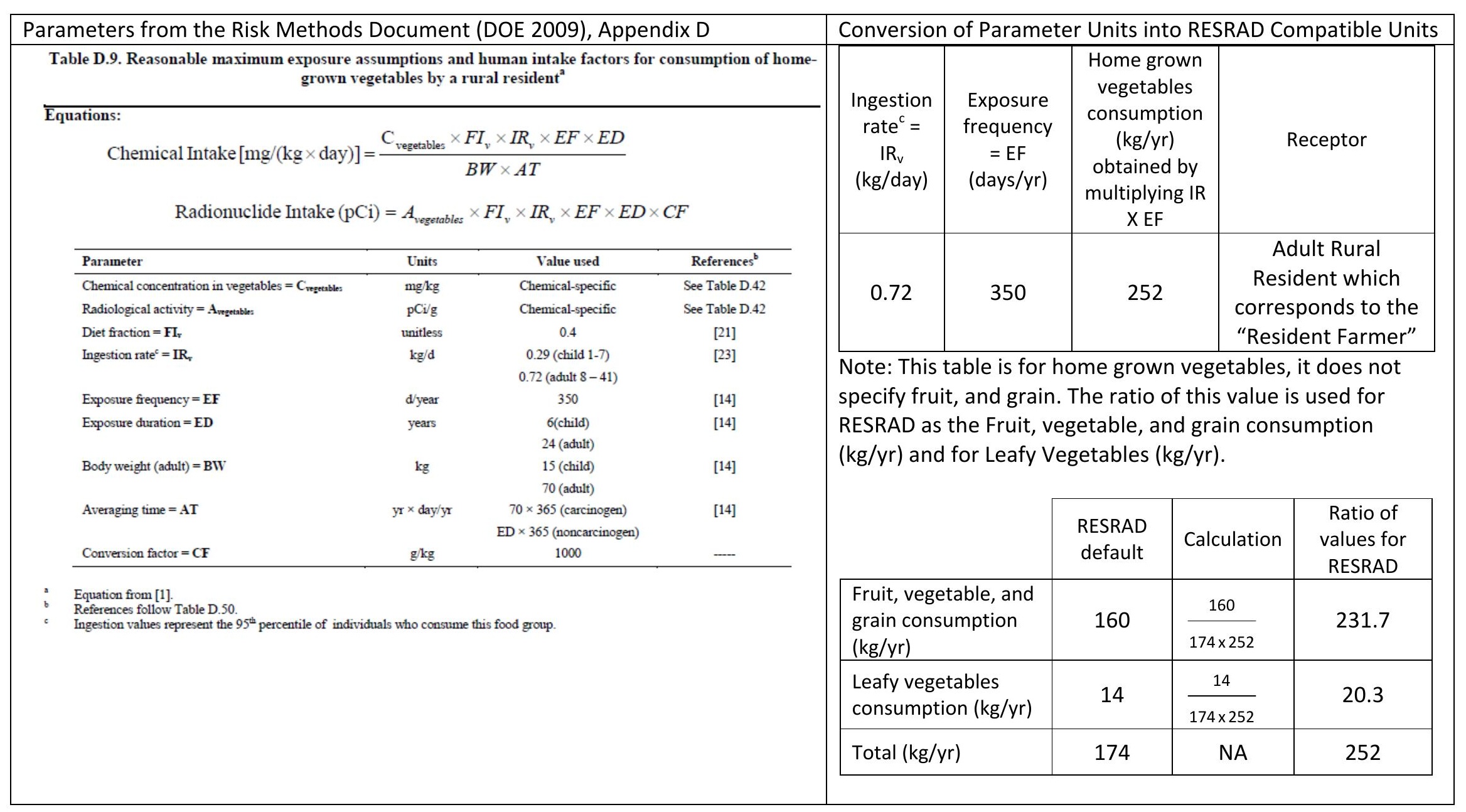




\section{Milk Consumption}

\begin{tabular}{|c|c|c|c|}
\hline \multirow{2}{*}{\multicolumn{4}{|c|}{$\begin{array}{l}\text { Parameters from the Risk Methods Document (DOE 2009), Appendix D } \\
\text { Table D.11. Reasonable maximum exposure assumptions and human intake factors for consumption of mi } \\
\text { by a rural resident }^{a}\end{array}$}} \\
\hline & & & \\
\hline \multicolumn{4}{|l|}{ Equations: } \\
\hline \multicolumn{4}{|c|}{ Chemical Intake $[\mathrm{mg} /(\mathrm{kg} \times$ day $)]=\frac{C_{\text {milk }} \times F I_{m} \times I R_{m} \times E F \times E D}{B W \times A T}$} \\
\hline \multicolumn{4}{|c|}{ Radionuclide Intake $(\mathrm{pCi})=A_{m i l k} \times F I_{m} \times I R_{m} \times E F \times E D$} \\
\hline Parameter & Units & Value used & References $^{b}$ \\
\hline Chemical concentration in milk $=\mathrm{C}_{\text {mill }}$ & $\mathrm{mg} / \mathrm{kg}$ & Chemical-specific & See Table D.47 \\
\hline Radiological activity in milk $=A_{\text {mill }}$ & $\mathrm{pCi} / \mathrm{kg}$ & Chemical-specific & See Table D.47 \\
\hline \multirow[t]{2}{*}{ Milk ingestion rate ${ }^{c}=\mathrm{IR}_{\mathrm{m}}$} & $\mathrm{kg} / \mathrm{day}$ & 0.9 (child $1-7$ ) & [23] \\
\hline & & 1.25 (adult $8-41$ ) & \\
\hline Diet fraction $=\mathbf{F I}_{\mathbf{m}}$ & unitless & 1 & [21] \\
\hline Exposure frequency $=\mathbf{E F}$ & $d$ /year & 350 & [14] \\
\hline \multirow[t]{2}{*}{ Exposure duration $=\mathrm{ED}$} & years & 6 (child) & [14] \\
\hline & & 24 (adult) & \\
\hline \multirow[t]{2}{*}{ Body weight $($ adult) $=\mathrm{BW}$} & $\mathrm{kg}$ & 15 (child) & [14] \\
\hline & & 70 (adult) & \\
\hline \multirow[t]{2}{*}{ Averaging time $=\mathrm{AT}$} & $\mathrm{yr} \times$ day $/ \mathrm{yr}$ & $70 \times 365$ (carcinogen) & [14] \\
\hline & & $\mathrm{ED} \times 365$ (noncarcinogen) & \\
\hline
\end{tabular}

\begin{tabular}{|c|c|c|c|c|}
\hline \multicolumn{5}{|c|}{ Conversion of Parameter Units into RESRAD Compatible Units } \\
\hline $\begin{array}{c}\text { Milk } \\
\text { ingestion } \\
\text { rate }^{c}=I_{\mathrm{b}} \\
(\mathrm{kg} / \text { day) }\end{array}$ & $\begin{array}{l}\text { Exposure } \\
\text { frequency } \\
=\mathrm{EF} \\
\text { (days/yr) }\end{array}$ & $\begin{array}{c}\text { Milk } \\
\text { consumption } \\
\text { (kg/yr) } \\
\text { obtained by } \\
\text { multiplying IR } \\
\text { X EF }\end{array}$ & $\begin{array}{l}\text { RESRAD-Milk } \\
\text { consumption } \\
\text { (L/yr) obtained } \\
\text { by diving the } \\
\text { milk } \\
\text { consumption } \\
\text { (kg/yr) by the } \\
\text { density of milk } \\
\text { and then } \\
\text { multiplying by } \\
1000\end{array}$ & Receptor \\
\hline 1.25 & 350 & 437.5 & 425 & $\begin{array}{l}\text { Adult Rural } \\
\text { Resident } \\
\text { which } \\
\text { corresponds } \\
\text { to the } \\
\text { "Resident } \\
\text { Farmer" }\end{array}$ \\
\hline
\end{tabular}

Equation from [1].

References follow Table D. 50 .
Ingestion values represent the $95^{\text {t }}$ percentile of individuals who consume this food group

Density of milk, cow, whole $=1030 \mathrm{~kg} / \mathrm{m}^{3}$

1 cubic meter $=1000$ liters

This density was obtained from an online

source: http://physics.info/density/ 
Meat and Poultry Consumption

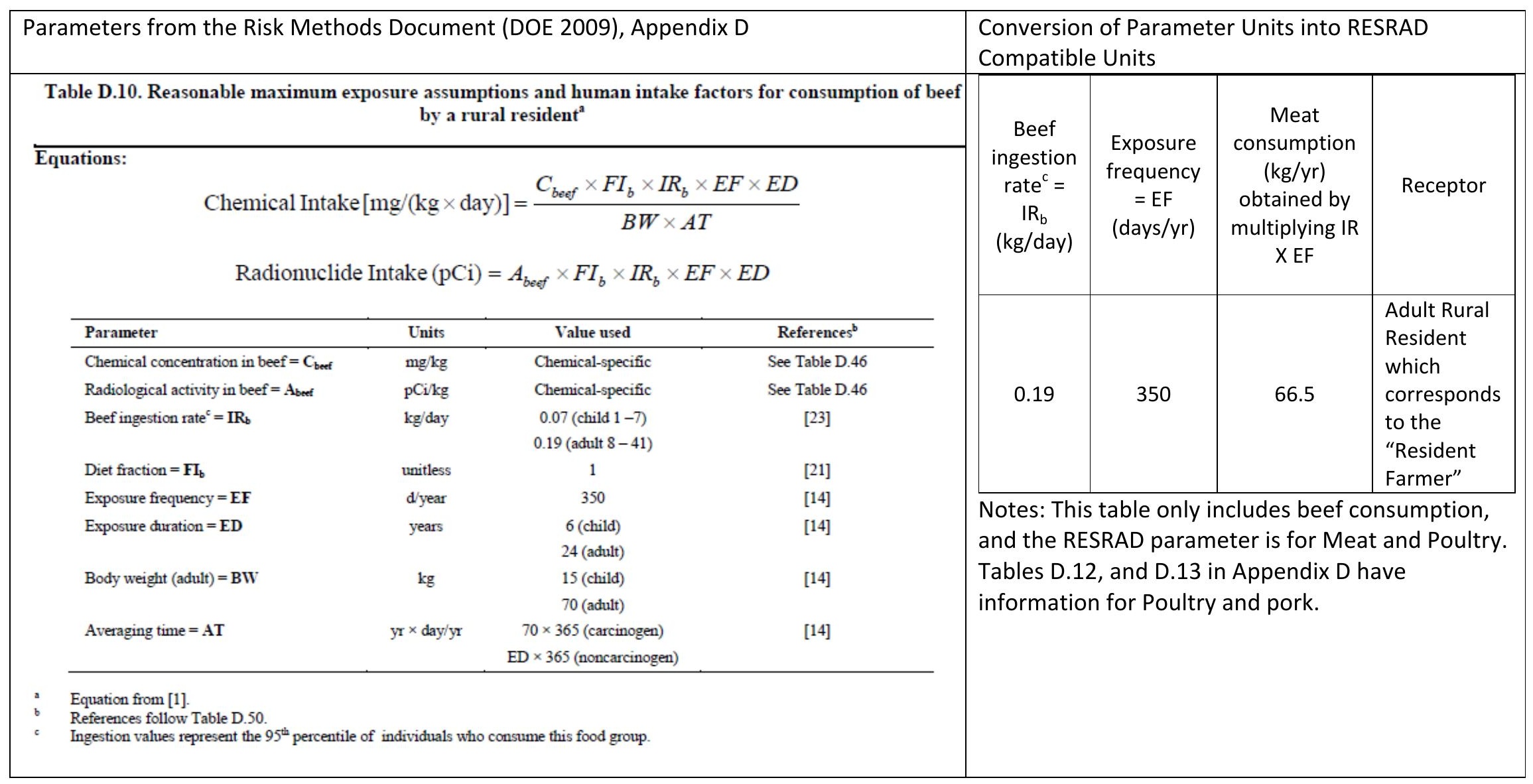


Meat and Poultry Consumption (cont.)

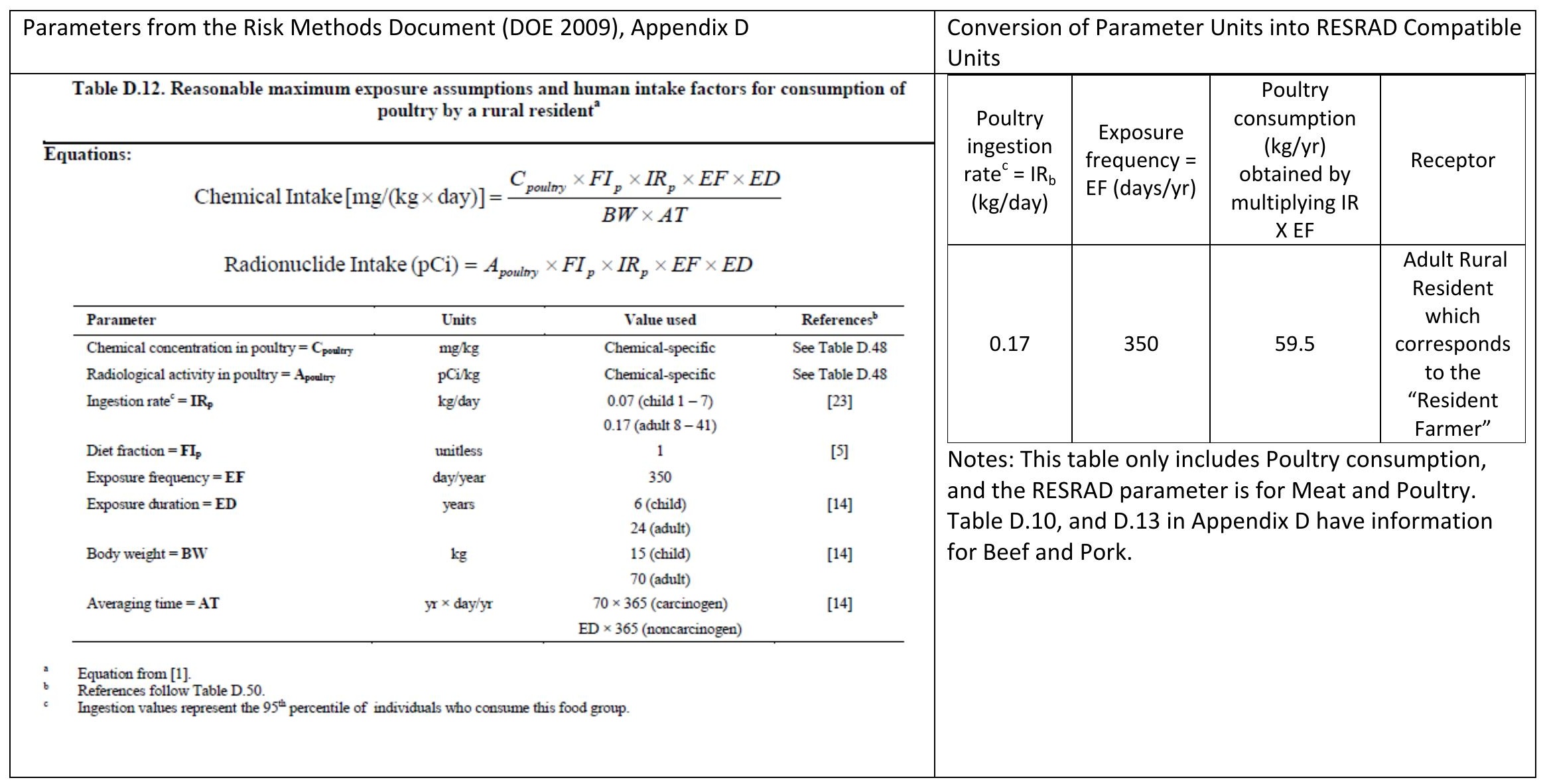


Meat and Poultry Consumption (cont.)

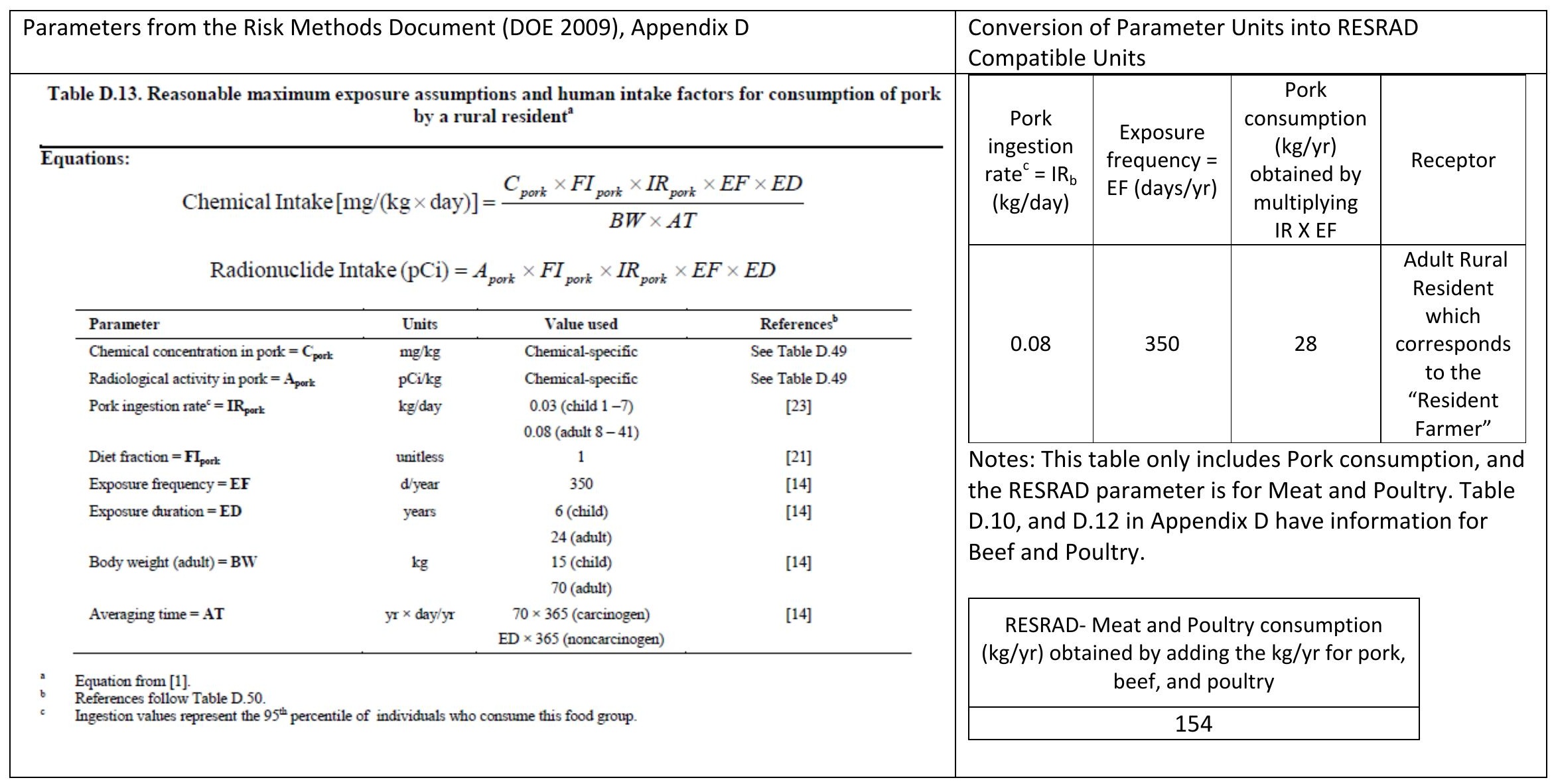




\section{Section C. Parameters Applicable to the Outdoor Worker and the Landfill Worker}

\section{Soil Ingestion Rate}

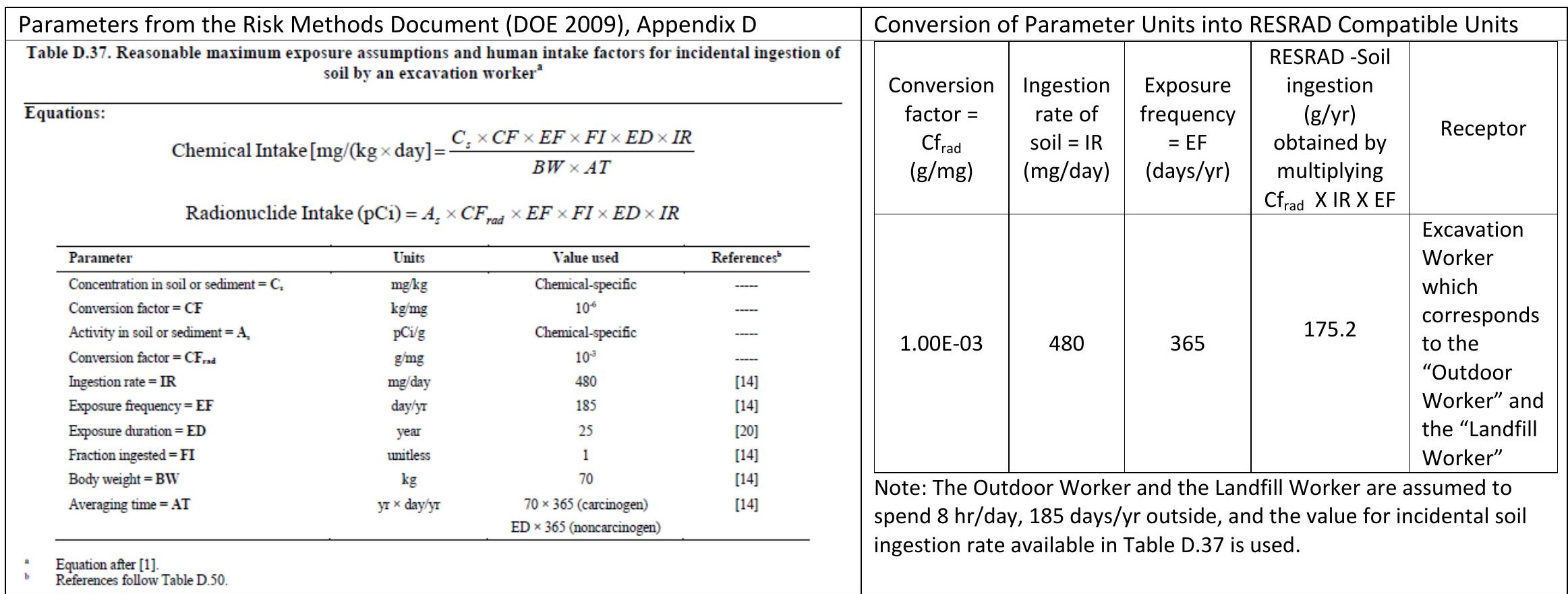


Inhalation Rate and Mass Loading for Inhalation

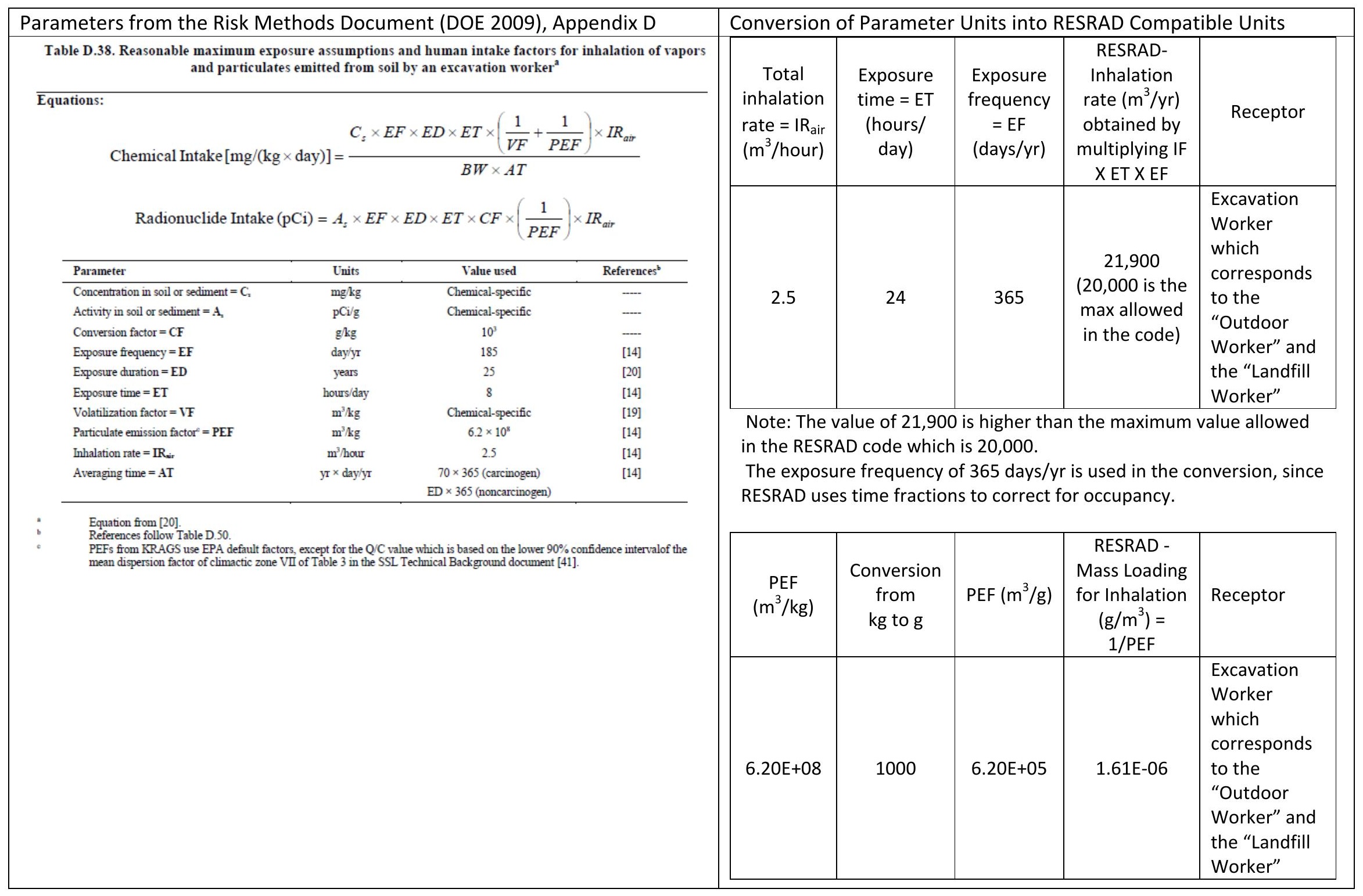


External Gamma Shielding Factor and Exposure Duration

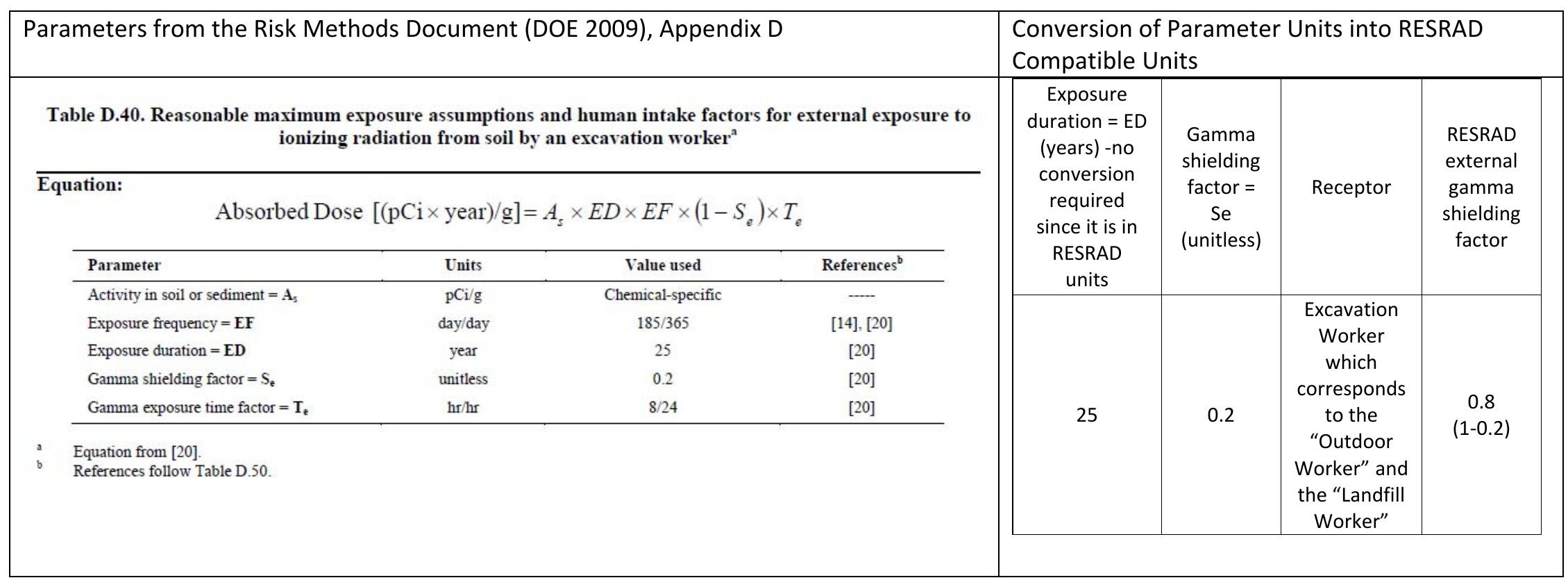




\section{Outdoor Time Fraction}

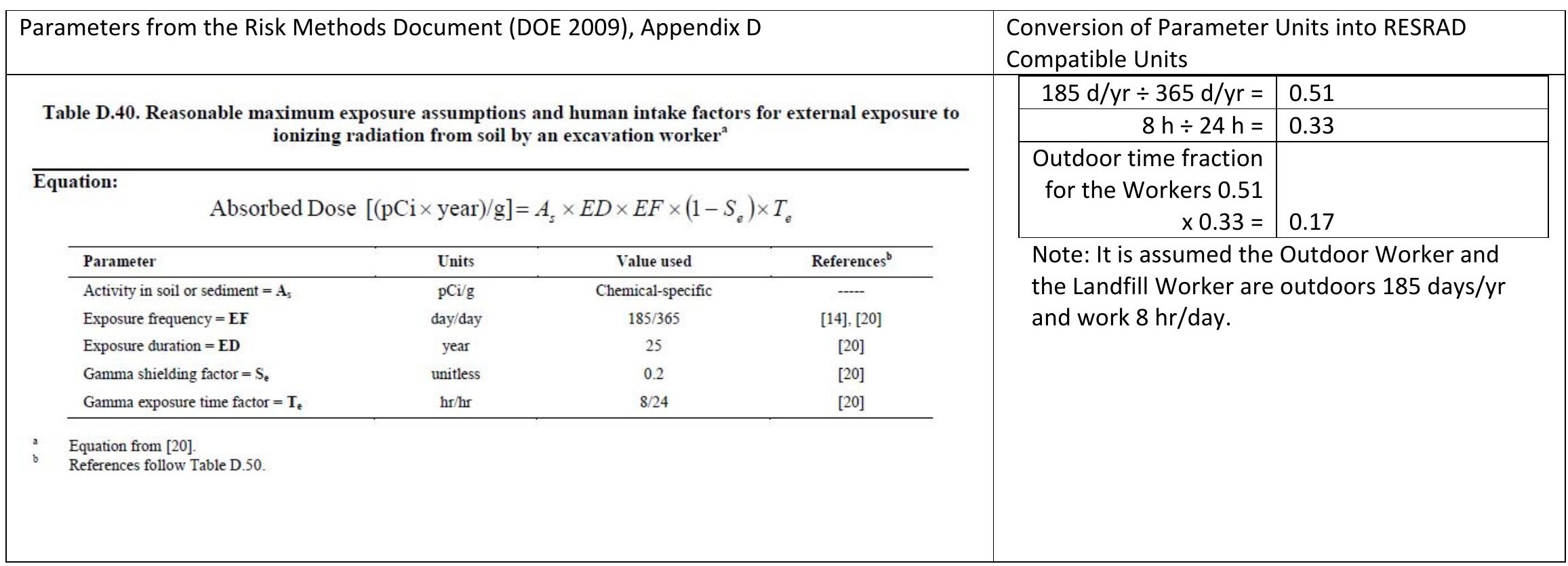




\section{Section D. Parameters Applicable to the Recreational User and Trespasser (In Some Cases)}

\section{Soil Ingestion Rate}

\begin{tabular}{|c|c|c|c|c|c|c|c|c|}
\hline \multirow{2}{*}{\multicolumn{4}{|c|}{$\begin{array}{l}\text { Parameters from the Risk Methods Document (DOE 2009), Appendix D } \\
\begin{array}{c}\text { Table D.15. Reasonable maximum exposure assumptions and human intake factors for incidental ingestion of } \\
\text { sediment by a recreational user }\end{array} \\
\end{array}$}} & \multicolumn{5}{|c|}{ Conversion of Parameter Units into RESRAD Compatible Units } \\
\hline & & & & \multirow[b]{2}{*}{$\begin{array}{l}\text { Conversion } \\
\text { factor }= \\
\mathrm{Cf}_{\text {rad }} \\
(\mathrm{g} / \mathrm{mg})\end{array}$} & \multirow[b]{2}{*}{$\begin{array}{l}\text { Ingestion } \\
\text { rate of } \\
\text { soil = IR } \\
\text { (mg/day) }\end{array}$} & \multirow[b]{2}{*}{$\begin{array}{l}\text { Exposure } \\
\text { frequency } \\
\quad=\mathrm{EF} \\
\text { (days/yr) }\end{array}$} & \multirow{2}{*}{$\begin{array}{c}\text { RESRAD -Soil } \\
\text { ingestion } \\
\text { (g/yr) } \\
\text { obtained by } \\
\text { multiplying } \\
\text { Cf }_{\text {rad }} \text { X IR X } \\
\text { EF }\end{array}$} & \multirow[b]{2}{*}{ Receptor } \\
\hline $\begin{array}{l}\text { Equations: } \\
\text { Chemical Intake }[1 \\
\text { Radionuclide Int } \\
\end{array}$ & $\begin{array}{l}\text { lay }]=\frac{C_{s e}}{=A_{s e d}} \times C\end{array}$ & $\begin{aligned} & F \times E D \times E T \times C F \\
& B W \times A T \\
& E D \times E T \times C F_{2}\end{aligned}$ & $\frac{\times F I}{F I}$ & & & & & \\
\hline Parameter & Units & Value used & References $^{b}$ & \multirow{7}{*}{ 1.00E-03 } & \multirow{7}{*}{100} & \multirow{7}{*}{365} & \multirow{7}{*}{36.5} & \multirow{7}{*}{$\begin{array}{l}\text { Recreational } \\
\text { User which } \\
\text { corresponds } \\
\text { to the } \\
\text { "Recreational } \\
\text { User" }\end{array}$} \\
\hline Concentration in sediment $=C_{x d}$ & $\mathrm{mg} / \mathrm{kg}$ & Chemical-specific & -- & & & & & \\
\hline Conversion factor $=\mathbf{C F}$ & $\mathrm{kg} / \mathrm{mg}$ & $10^{-5}$ & - & & & & & \\
\hline Activity in soil $=A_{\text {sed }}$ & $\mathrm{pCi} i \mathrm{~g}$ & Chemical-specific & - & & & & & \\
\hline Conversion factor $=\mathrm{CF}_{\mathrm{rad}}$ & $g / \mathrm{mg}$ & $10^{-3}$ & - & & & & & \\
\hline Exposure frequency $=\mathbf{E F}$ & day/yr & 104 (adult) & [14] & & & & & \\
\hline \multirow{3}{*}{ Exposure duration $=\mathrm{ED}$} & \multirow{3}{*}{ year } & 140 (child and teen) & \multirow{3}{*}{ [14] } & & & & & \\
\hline & & 12 (teen) & & \multirow{4}{*}{\multicolumn{5}{|c|}{$\begin{array}{l}\text { Notes: The exposure frequency of } 365 \text { days/yr is used in the } \\
\text { conversion, instead of } 140 \text { days/yr (teen) or } 104 \text { days/yr (adult) since } \\
\text { RESRAD uses time fractions to correct for occupancy. }\end{array}$}} \\
\hline & & 6 (child) & & & & & & \\
\hline Exposure time $=\mathbf{E T}$ & hr/day & 5 & [14] & & & & & \\
\hline Conversion factor $=\mathbf{C F}_{2}$ & day/hr & $1 / 24$ & - & & & & & \\
\hline \multirow[t]{3}{*}{ Ingestion rate $=$ IR } & $\mathrm{mg} / \mathrm{day}$ & 100 (adult) & [14] & & & & & \\
\hline & & 100 (teen) & & & & & & \\
\hline & & 200 (child) & & & & & & \\
\hline Fraction ingested $=\mathbf{F I}$ & unitless & 1 & [14] & & & & & \\
\hline \multirow[t]{3}{*}{ Body weight $=\mathrm{BW}$} & $\mathrm{kg}$ & 70 (adult) & [14] & & & & & \\
\hline & & 43 (teen) & & & & & & \\
\hline & & 15 (child) & & & & & & \\
\hline \multirow[t]{2}{*}{ Averaging time $=\mathrm{AT}$} & $\mathrm{yr} \times$ day $/ \mathrm{yr}$ & $70 \times 365$ (carcinogen) & [14] & & & & & \\
\hline & & ED $\times 365$ (noncarcinogen) & & & & & & \\
\hline $\begin{array}{l}\text { Equation after [1]. } \\
\text { References follow Table D. } 50 \text {. }\end{array}$ & & & & & & & & \\
\hline
\end{tabular}


Inhalation Rate and Mass Loading for Inhalation

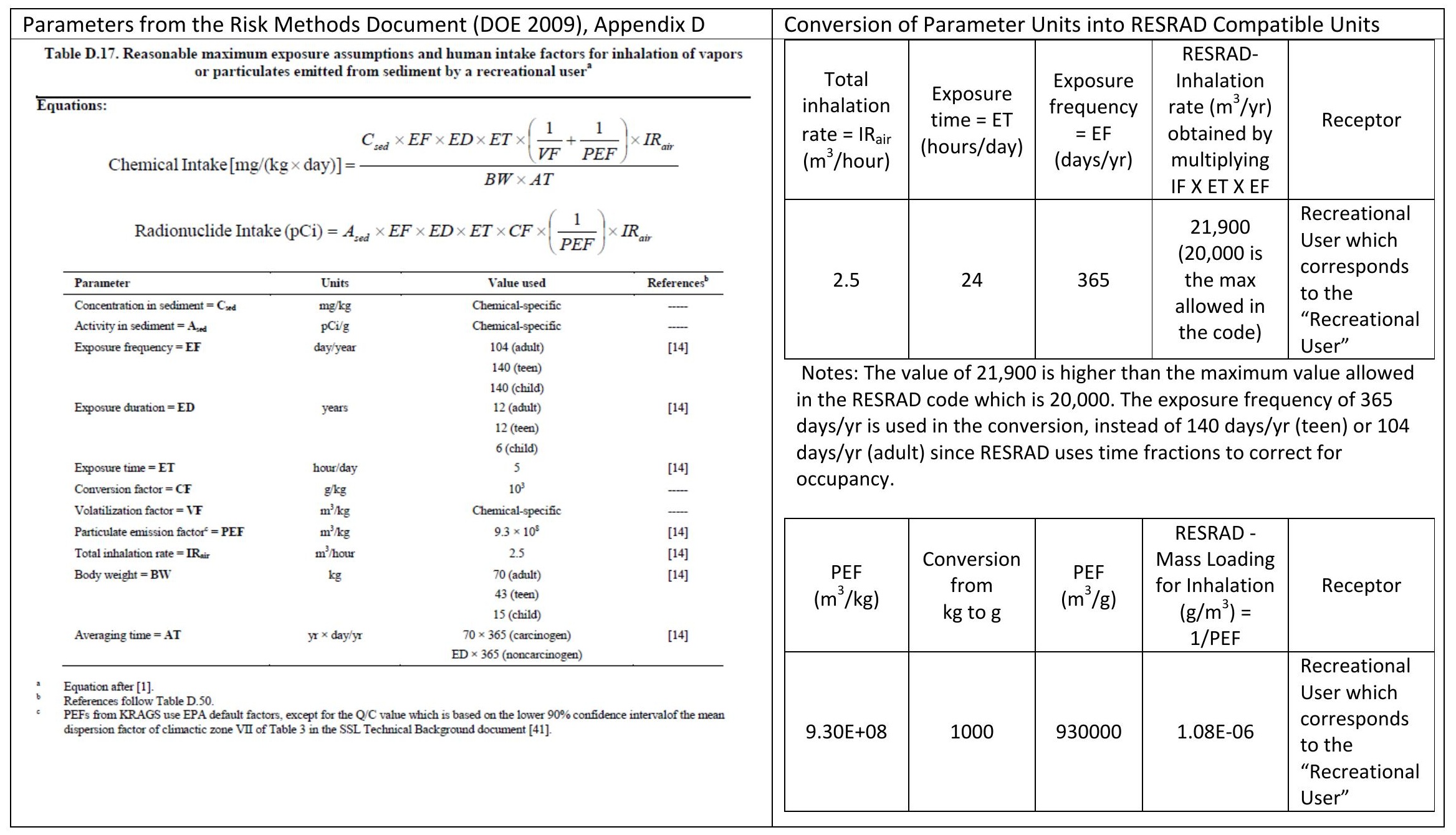


External Gamma Shielding Factor and Exposure Duration

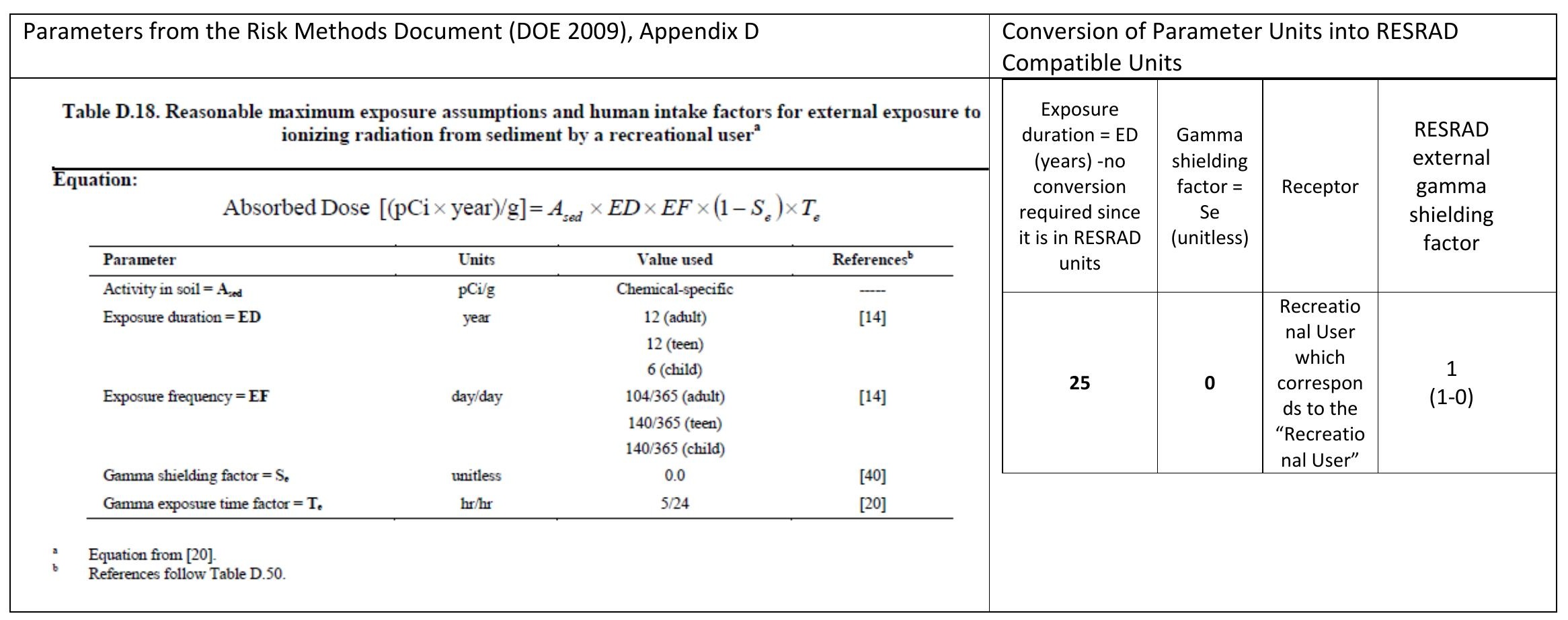

Outdoor Time Fraction (Recreational User-Teenager)

\begin{tabular}{|r|l|}
\hline $140 \mathrm{~d} / \mathrm{yr} \div 365 \mathrm{~d} / \mathrm{yr}=$ & 0.38 \\
\hline $5 \mathrm{~h} \div 24 \mathrm{~h}=$ & 0.21 \\
\hline Outdoor time fraction for & \\
the RU-teenager & \\
$0.38 \times 0.21=$ & 0.08 \\
\hline
\end{tabular}

Note: The Recreational User is considered to be a teenager who will spend $5 \mathrm{~h} /$ day, 140 days/yr on the contaminated site. 
Outdoor Time Fraction (Trespasser-Adult)

\begin{tabular}{|c|c|}
\hline $104 d / y r \div 365 d / y r=$ & 0.28 \\
\hline $5 \mathrm{~h} \div 24 \mathrm{~h}=$ & 0.21 \\
\hline $\begin{array}{r}\text { Outdoor time fraction for } \\
\text { the Trespasser-Adult } \\
0.28 \times 0.21=\end{array}$ & 0.06 \\
\hline $\begin{array}{l}\text { Note: The Trespasser is consid } \\
\text { spend } 5 \text { h/day, } 104 \text { days/yr on } \\
\text { receptor has a lower occupanc } \\
\text { User. }\end{array}$ & $\begin{array}{l}\text { ered to be an adult who will } \\
\text { the contaminated site. This } \\
y \text { than the teen Recreational }\end{array}$ \\
\hline
\end{tabular}




\section{Section E. Parameters applicable to beef and dairy from the Risk Methods Document (DOE 2009), Appendix D}

Table D.46. Reasonable maximum exposure assumptions for concentration or activity of COPCs in beef ${ }^{a}$

\begin{tabular}{|c|c|c|c|}
\hline \multicolumn{4}{|l|}{$\begin{array}{l}\text { Equations: } \\
\qquad C_{\text {beef }}=F_{b e}\end{array}$} \\
\hline Parameter & Units & Value used & References $^{b}$ \\
\hline Chemical concentration in beef $=\mathrm{C}_{\text {beef }}$ & $\mathrm{mg} / \mathrm{kg}$ or $\mathrm{pCi} / \mathrm{g}$ & Chemical-specific & Calculated \\
\hline Forage-beef transfer factor $=\mathbf{F}_{\text {beef }}$ & day $/ \mathrm{kg}$ & Chemical-specific & --- \\
\hline Chemical concentration in pasture $=\mathrm{C}_{\text {forage }}$ & $\mathrm{mg} / \mathrm{kg}$ or $\mathrm{pCi} / \mathrm{g}$ & Chemical-specific & Calculated \\
\hline Area of contact $^{c}=\mathbf{A C}$ & unitless & $\mathrm{AS} / \mathrm{AD}$ & $-\ldots$ \\
\hline Area of $\mathrm{SWMU}=\mathrm{AS}$ & acres & SWMU-specific & - \\
\hline Area of beef range $=\mathbf{A D}$ & acres & 2 & [29] \\
\hline Fraction of beef's food from site when on site $=f_{s}$ & unitless & 1.0 & [5] \\
\hline Quantity of pasture ingested daily by beef $=Q_{f}$ & $\mathrm{~kg} /$ day & 25 & [25] \\
\hline Chemical concentration in soil or sediment $=\mathrm{C}_{\mathrm{s}}$ & $\mathrm{mg} / \mathrm{kg}$ or $\mathrm{pCi} / \mathrm{g}$ & Chemical-specific & 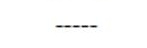 \\
\hline Quantity of soil ingested daily by beef $=Q_{s}$ & $\mathrm{~kg} /$ day & 1 & [26] \\
\hline Contaminant concentration in water $=\mathrm{C}_{\mathrm{w}}$ & $\mathrm{mg} / \mathrm{L}$ or $\mathrm{pCi} / \mathrm{L}$ & Chemical-specific & - \\
\hline Conversion factor for radionuclides $=\mathrm{CF}_{\mathrm{rad}}$ & $\mathrm{kg} / \mathrm{g}$ & $10^{-3}$ & $\ldots$ \\
\hline Quantity of water ingested daily by beef $=Q_{w}$ & L/day & 50 & [25] \\
\hline Soil to plant uptake (dry) $=\mathbf{R}_{\text {upp }}$ & unitless & $\begin{array}{l}\text { Chemical-specific } \\
\text { or } 38 \times \mathrm{K}_{\text {ow }}^{-0.58}\end{array}$ & [8] \\
\hline Soil resuspension multiplier $=\mathbf{R}_{e s}$ & unitless & 0.25 & [3] \\
\hline
\end{tabular}

Equations after [1], [2], [3], [4].

AC cerences follow Table D.s.

$\mathrm{AC}$ cannot be greater than 1.
All ingested water is considered to be from SWMU or SWMU area.

Values that were used to determine input parameters are highlighted. 
Table D.47. Reasonable maximum exposure assumptions for concentration or activity of COPCs in milk

\begin{tabular}{|c|c|c|c|}
\hline \multicolumn{4}{|l|}{ Equations: } \\
\hline Parameter & Units & Value used & References $^{b}$ \\
\hline Chemical concentration in milk $=\mathrm{C}_{\text {milk }}$ & $\mathrm{mg} / \mathrm{kg}$ or $\mathrm{pCi} / \mathrm{g}$ & Chemical-specific & Calculated \\
\hline Forage-milk transfer factor $=\mathbf{F}_{\text {milk }}$ & day $/ \mathrm{kg}$ & Chemical-specific & $\ldots$ \\
\hline Chemical concentration in pasture $=\mathrm{C}_{\text {forage }}$ & $\mathrm{mg} / \mathrm{kg}$ or $\mathrm{pCi} / \mathrm{g}$ & Chemical-specific & Calculated \\
\hline Area of contact $^{c}=\mathrm{AC}$ & unitless & $\mathrm{AS} / \mathrm{AD}$ & $\ldots$ \\
\hline Area of SWMU $=$ AS & acres & SWMU-specific & $\ldots$ \\
\hline Area of dairy range $=\mathrm{AD}$ & acres & 2 & [29] \\
\hline Fraction of dairy's food from site when on site $=\mathbf{f}_{s}$ & unitless & 1.0 & [5] \\
\hline Quantity of pasture ingested daily by dairy $=Q_{f}$ & $\mathrm{~kg} /$ day & 25 & [25] \\
\hline Chemical concentration in soil or sediment $=\mathrm{C}_{5}$ & $\mathrm{mg} / \mathrm{kg}$ or $\mathrm{pCi} / \mathrm{g}$ & Chemical-specific & $\ldots$ \\
\hline Quantity of soil ingested daily by dairy $=Q_{s}$ & $\mathrm{~kg} /$ day & 1 & [26] \\
\hline Contaminant concentration in water $=\mathrm{C}_{\mathrm{w}}$ & $\mathrm{mg} / \mathrm{L}$ or $\mathrm{pCi} / \mathrm{L}$ & Chemical-specific & $\ldots$ \\
\hline Conversion factor for radionuclides $=\mathbf{C F}_{\text {rad }}$ & $\mathrm{kg} / \mathrm{g}$ & $10^{-3}$ & $\ldots$ \\
\hline Quantity of water ingested daily by dairy $=Q_{w}$ & L/day & 60 & [25] \\
\hline Soil to plant uptake (dry) $=R_{\mathrm{upp}}$ & unitless & $\begin{array}{l}\text { Chemical-specific } \\
\text { or } 38 \times \mathrm{K}_{\mathrm{ow}}^{-0.58}\end{array}$ & [8] \\
\hline Soil resuspension multiplier $=R_{e s}$ & unitless & 0.25 & [3] \\
\hline
\end{tabular}

Equations after [1], [2], [3], [4].

All references follow Table D.50.

AC cannot be greater than 1 .
All ingested water is considered to be from SWMU or SWMU area.

Values that were used to determine input parameters are highlighted. 


\section{Attachment III \\ RESRAD Error/OUTPUT File for the Resident Farmer}


The code displayed an error message for the Resident Farmer when running it with an irrigation rate of $0.1 \mathrm{~m} / \mathrm{yr}$ and an evapotranspiration coefficient of 0.74 . The message is below:
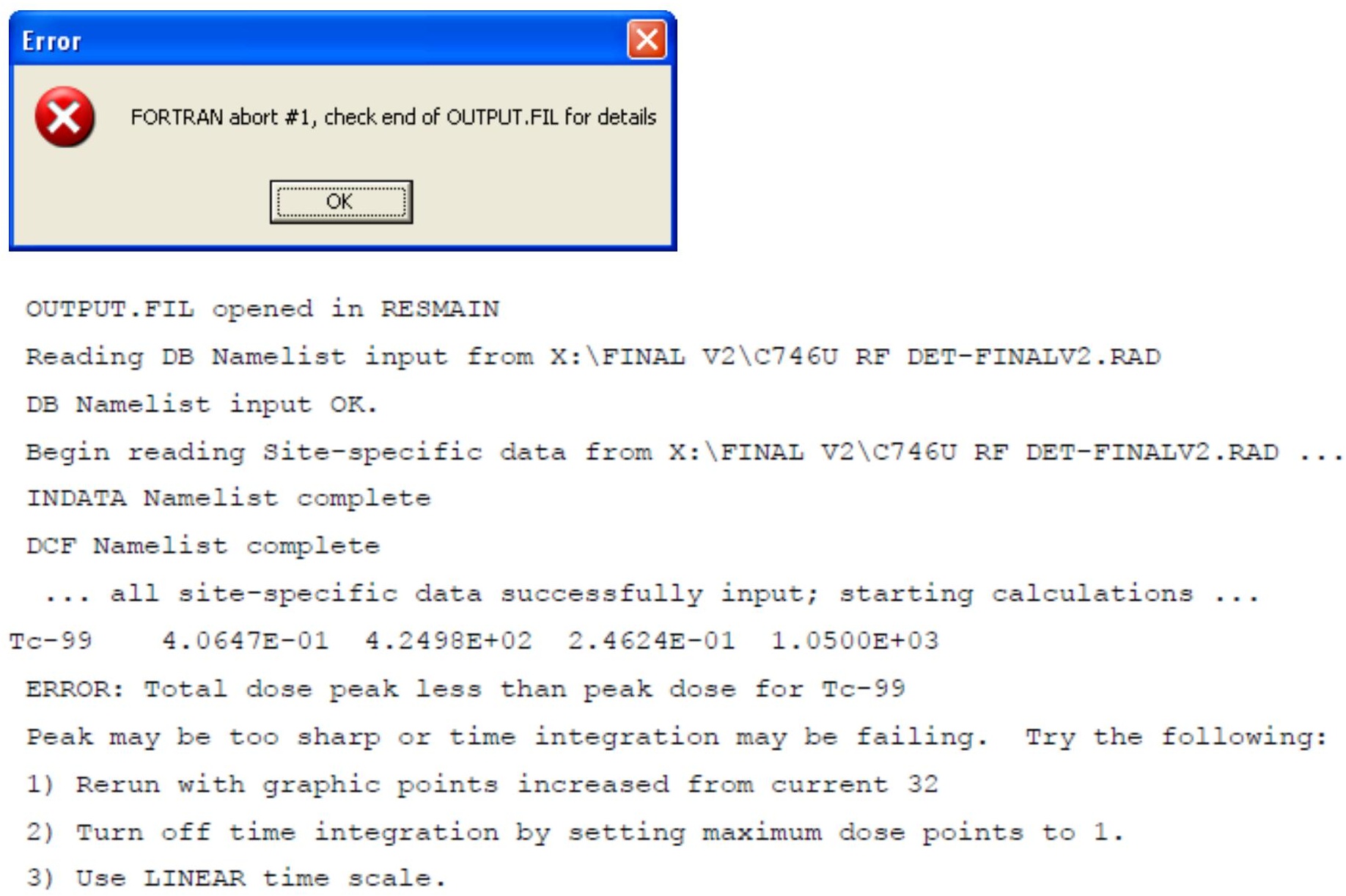

The code ran successfully after increasing the graphic points from 32 (default) to 64 and setting the maximum dose points from 17 (default) to 1 as indicated in the output file above. 


\section{References}

ATSDR 2002, Public Health Assessment for the Paducah Gaseous Diffusion Plant (USDOE) Paducah, McCracken County, Kentucky (May 2002).

DOE 2003a. Authorized Limits Request for Solid Waste Disposal at Landfill C-746-U at the Paducah Gaseous Diffusion Plant, (November 2002; revised January 2003).

DOE 2003b. Risk and Performance Evaluation of the C-746-U Landfill at the Paducah Gaseous Diffusion Plant, Paducah, Kentucky, DOE/OR/072041\&D2R1 (2003).

DOE 2009. Methods for Conducting Risk Assessments and Risk Evaluations at the Paducah Gaseous Diffusion Plant Paducah, Kentucky Volume 1. Human Health, DOE/LX/07-0107\&D1/V1 (2009).

DOE Statement of Work (SOW) for C-746-U Landfill provided to ORISE on December 2009.

DOE C-746-U landfill inventory spreadsheet for total waste disposed from May 2003 through May 2009.

DOE Project Communication with the Waste Disposal Operations Project Team from Paducah, KY, March 2010 (Email correspondence 03/29/2010 from Rich Bonczek).

DOE Project Communication with the Geologist from Paducah, KY, April 2010 (Email correspondence 04/05/2010 from Raulie Casteel).

DOE Project Communication with Geologist and Engineer from Paducah, KY, April 2010 (Email correspondence 04/07/2010 from Raulie Casteel).

DOE Project Communication with the Facility Representative DOE-PPPO from Paducah, KY, May 2010 (Email correspondence 05/05/2010 from Don Dihel).

DOE Project Communication May, 2010 (Discussion between ORISE and Rich Bonczek during a meeting held at ORISE on 05/17/2010).

DOE Project Communication June, 2010 (Email correspondence 06/02/2010 from ORISE to DOE).

DOE Project Communication July, 2010 (Discussion between ORISE and DOE-PPPO during a meeting held at ORISE on 07/12/2010).

DOE Project Communication September, 2010 (Discussion between ORISE and DOE-PPPO during a conference call held on 09/29/2010). 
DOE Project Communication October, 2010 (Discussion between ORISE and DOE-PPPO during a conference call held on 10/7/2010). DOE Project Communication November, 2010 (Email correspondence 11/03/2010 from ORISE to DOE consultant).

DOE Project Communication April, 2011 (ORISE and DOE-PPPO biweekly conference call on 04/13/2011 and email correspondence 04/14/2011 from ORISE to DOE-PPPO).

DOE Order 458.1, Radiation Protection of the Public and the Environment (DOE 2011).

DOE Order 5400.5, Radiation Protection of the Public and the Environment (DOE 1993).

Kenny, J. F. et al. 2009. Estimated Use of Water in the United States in 2005, Circular 1344, U.S. Department of Interior, U.S. Geological Survey (2009).

King, David A. and Karen Keil, 2006. Comparison of Standard Radiological Risk Models and Using RESRAD to Derive Generic Risk-Based Area Factors for Final Status Surveys, Risk Analysis, Vol. 26, No. 1.

Lee, D. W., J. C. Wang, and D. C. Kocher, 1995. Operating Limit Study for the Proposed Solid Waste Landfill at Paducah Gaseous Diffusion Plant, ORNL/TM-13008.

PRS 2008. 2006 Paducah Site Annual Site Environmental Report for Calendar Year 2006, PRS-ENM-0034 Volume I, Paducah Remediation Services (September 2008).

Yu, C., C. Loureiro, J. J. Cheng, L.G. Jones, Y.Y. Wang, Y.P. Chia, and E. Faillace, 1993. Data Collection Handbook to Support Modeling Impacts of Radioactive Material in Soil.

Yu C., D. LePoire, E. Gnanapragasam, J. Arnish, S. Kamboj, B.M. Biwer, J.-J. Cheng, A. Zielen, and S.Y. Chen, 2000. Development of Probabilistic RESRAD 6.0 and RESRAD-Build 3.0 Computer Codes, NUREG/CR-6697 ANL/EAD/TM-98.

Yu, C., A.J. Zielen, J.J. Cheng, D.J. LePoire, E. Gnanapragasam, S. Kamboj, J. Arnish, A. Wallo, III, W.A. Williams, and H. Peterson, 2001. User's Manual for RESRAD Version 6, ANL/EAD-4, Argonne National Laboratory. 
RESRAD-OFFSITE Table of Input Parameters for the C-746-U Landfill Offsite Resident Farmer Scenario

\begin{tabular}{|c|c|c|c|c|c|c|c|}
\hline $\begin{array}{c}\text { Input Screen Title } \\
\text { and Parameter } \\
\text { Name }\end{array}$ & Units & $\begin{array}{l}\text { Default } \\
\text { Value }^{\text {a }}\end{array}$ & $\begin{array}{l}\text { Code-Accepted } \\
\text { Values }^{b} \\
\text { Physical or } \\
\text { Numerical }^{\mathrm{C}} \text { (N) } \\
\text { Range }\end{array}$ & $\begin{array}{c}\text { Deterministic } \\
\text { Value }\end{array}$ & Type $^{d} \quad$ Priority & Justification & References \\
\hline
\end{tabular}

\section{Preliminary Inputs}

\begin{tabular}{|c|c|c|c|c|c|c|c|c|c|}
\hline $\begin{array}{l}\text { Radiological units } \\
\text { for activity }\end{array}$ & $\begin{array}{c}\mathrm{Ci}, \mathrm{Bq} \\
\mathrm{dps}, \mathrm{dpm}\end{array}$ & $\mathrm{pCi}$ & $\begin{array}{l}\text { Ci, Bq, dps, } \\
\text { dpm }\end{array}$ & & $\mathrm{pCi}$ & $N A^{f}$ & & Default units are used. & Yu et al. 2007 \\
\hline $\begin{array}{l}\text { Radiological units } \\
\text { for dose }\end{array}$ & $\begin{array}{l}\text { rem and } \\
\text { Sv }\end{array}$ & mrem & rem, Sv & & mrem & NA & & Default units are used. & Yu et al. 2007 \\
\hline $\begin{array}{l}\text { Basic radiation dose } \\
\text { limit }\end{array}$ & $\mathrm{mrem} / \mathrm{yr}$ & 25 & $\begin{array}{l}1 E-34- \\
1 E+34\end{array}$ & $\mathrm{~N}$ & 1 & NA & 3 & $\begin{array}{l}\text { The target dose constraints of } 1,15,25 \text { and } 100 \\
\text { mrem/yr are considered in this project. However, the } \\
\text { basic radiation dose constraint used for the RESRAD } \\
\text { run is } 1 \mathrm{mrem} / \mathrm{yr} \text {. If the basic radiation dose limit is } \\
\text { changed it will not change the Dose to Source Ratio } \\
\text { (DSR) which is used in the calculation for single } \\
\text { radionuclide soil guidelines. }\end{array}$ & $\begin{array}{l}\text { DOE SOW for C- } \\
746-U \text { landfill, } \\
\text { Section 2, item } 3\end{array}$ \\
\hline Exposure duration & $\mathrm{yr}$ & 30 & $1-1,000$ & & 24 & B & 3 & $\begin{array}{l}\text { The exposure duration is the span of time, in years, } \\
\text { during which an individual is expected to spend time } \\
\text { on the site. This value is used in calculating lifetime } \\
\text { cancer risk from exposure to radionuclide } \\
\text { contamination. It is also used to calculate time- } \\
\text { integrated dose if exposure duration is less than a } \\
\text { year. This value is obtained from DOE 2009. The } \\
\text { exposure duration is available in the tables of } \\
\text { Appendix D. For the Resident Farmer, the value for } \\
\text { "Rural Resident" is used. }\end{array}$ & $\begin{array}{c}\text { DOE } 2009 \\
\text { Appendix D,Table } \\
\text { D.8, page D-18 }\end{array}$ \\
\hline $\begin{array}{l}\text { Number of } \\
\text { unsaturated zone }\end{array}$ & $-{ }_{-} \mathbf{g}$ & 1 & $0-5$ & $\mathrm{~N}$ & 5 & P & 3 & $\begin{array}{l}\text { There are five unsaturated zones (UZ) considered. } \\
\text { These correspond to the layers under waste during } \\
\text { the Post-Institutional Control Period. Below are the } \\
\text { five zones: } \\
\text { UZ 1 = Protective layer (native soil) } \\
\text { UZ } 2 \text { = Gravel layer } \\
\text { UZ } 3 \text { = Clay barrier } \\
\text { UZ } 4=\text { Alluvium soils (native/subgrade) } \\
\text { UZ } 5 \text { = Clay confining unit (native) }\end{array}$ & $\begin{array}{c}\text { DOE 2003b } \\
\text { Table 4.4, page 4- } \\
\text { 9, Fig. 4.5, page 4- } \\
\text { 18, Table Att.2, } \\
\text { page C3-315 }\end{array}$ \\
\hline \multicolumn{10}{|l|}{ Site Layout } \\
\hline Bearing of $X$ axis & degrees & 90 & $0-360$ & $\mathrm{P}$ & 90 & $P$ & & Default value is used. & Yu et al. 2007 \\
\hline $\begin{array}{l}\mathrm{X} \text { dimension of } \\
\text { Primary }\end{array}$ & $\mathrm{m}$ & 100 & $\begin{array}{l}-80,000- \\
+80,000\end{array}$ & & 256 & P & 2 & $\begin{array}{l}\text { The primary contamination is modeled as a rectangle } \\
\text { for atmospheric release and transport calculations. }\end{array}$ & Lee et al. 1995 \\
\hline
\end{tabular}


RESRAD-OFFSITE Table of Input Parameters for the C-746-U Landfill Offsite Resident Farmer Scenario

\begin{tabular}{|c|c|c|c|c|c|c|c|c|}
\hline $\begin{array}{c}\text { Input Screen Title } \\
\text { and Parameter } \\
\text { Name }\end{array}$ & Units & $\begin{array}{l}\text { Default } \\
\text { Value }^{\mathrm{a}}\end{array}$ & $\begin{array}{l}\text { Code-Accepted } \\
\text { Values }^{b} \\
\text { Physical or } \\
\text { Numerical }{ }^{\mathrm{C}} \text { (N) } \\
\text { Range } \\
\end{array}$ & $\begin{array}{l}\text { Deterministic } \\
\text { Value }\end{array}$ & Type $^{d}$ & Priority & Justification & References \\
\hline contamination & & & & & & & $\begin{array}{l}\text { The lengths of the sides of the rectangle are used to } \\
\text { define the rectangular region for the atmospheric } \\
\text { transport calculations. The area is no longer an input, } \\
\text { but is obtained as the product of these two } \\
\text { perpendicular dimensions. The landfill does not have } \\
\text { a rectangular shape ;therefore, the two sides }(x, y) \text { of } \\
\text { the pentagon with maximum length were selected. }\end{array}$ & Yu et al. 2007 \\
\hline $\begin{array}{l}\text { Y dimension of } \\
\text { Primary } \\
\text { contamination }\end{array}$ & $\mathrm{m}$ & 100 & $\begin{array}{l}-80,000- \\
+80,000\end{array}$ & 399 & $P$ & 2 & $\begin{array}{l}\text { The primary contamination is modeled as a rectangle } \\
\text { for atmospheric release and transport calculations. } \\
\text { The lengths of the sides of the rectangle are used to } \\
\text { define the rectangular region for the atmospheric } \\
\text { transport calculations. The area is no longer an input, } \\
\text { but is obtained as the product of these two } \\
\text { perpendicular dimensions. The landfill does not have } \\
\text { a rectangular shape; therefore, the two sides }(x, y) \text { of } \\
\text { the pentagon with maximum length were selected. }\end{array}$ & $\begin{array}{l}\text { Lee et al. } 1995 \\
\text { Yu et al. } 2007\end{array}$ \\
\hline $\begin{array}{l}\text { Smaller } x \\
\text { coordinate of the } \\
\text { fruit, grain, } \\
\text { nonleafy vegetables } \\
\text { plot } \\
\end{array}$ & $\mathrm{m}$ & 34.375 & $\begin{array}{l}-80,000- \\
+80,000\end{array}$ & 34.375 & $P$ & 3 & \multirow[t]{4}{*}{$\begin{array}{l}\text { A plot, with an area }=1,000 \text { square meters (RESRAD } \\
\text { OFFSITE default), is located north of the } \\
\text { contaminated zone near the well (which is located } \\
407 \text { meters north/downgradient of the contaminated } \\
\text { zone). }\end{array}$} & \multirow[t]{4}{*}{ Yu et al. 2007} \\
\hline $\begin{array}{l}\text { Larger } x \text { coordinate } \\
\text { of the fruit, grain, } \\
\text { nonleafy vegetables } \\
\text { plot }\end{array}$ & $\mathrm{m}$ & 65.625 & $\begin{array}{l}-80,000- \\
+80,000\end{array}$ & 65.625 & $P$ & 3 & & \\
\hline $\begin{array}{l}\text { Smaller y } \\
\text { coordinate of the } \\
\text { fruit, grain, } \\
\text { nonleafy vegetables } \\
\text { plot }\end{array}$ & $\mathrm{m}$ & 234 & $\begin{array}{l}-80,000- \\
+80,000\end{array}$ & 806 & P & 3 & & \\
\hline $\begin{array}{l}\text { Larger y coordinate } \\
\text { of the fruit, grain, } \\
\text { nonleafy vegetables } \\
\text { plot }\end{array}$ & $\mathrm{m}$ & 266 & $\begin{array}{l}-80,000- \\
+80,000\end{array}$ & 838 & $P$ & 3 & & \\
\hline $\begin{array}{c}\text { Smaller } x \\
\text { coordinate of the } \\
\text { leafy vegetables } \\
\text { plot }\end{array}$ & $\mathrm{m}$ & 34.375 & $\begin{array}{l}-80,000- \\
+80,000\end{array}$ & 34.375 & $P$ & 3 & $\begin{array}{l}\text { A plot, with an area }=1,000 \text { square meters (RESRAD } \\
\text { OFFSITE default), is located north of the } \\
\text { contaminated zone near the well (which is located } \\
407 \text { meters north/downgradient of the contaminated } \\
\text { zone). }\end{array}$ & Yu et al. 2007 \\
\hline
\end{tabular}


RESRAD-OFFSITE Table of Input Parameters for the C-746-U Landfill Offsite Resident Farmer Scenario

\begin{tabular}{|c|c|c|c|c|c|c|c|c|}
\hline $\begin{array}{c}\text { Input Screen Title } \\
\text { and Parameter } \\
\text { Name }\end{array}$ & Units & $\begin{array}{l}\text { Default } \\
\text { Value }^{\mathrm{a}}\end{array}$ & $\begin{array}{r}\text { Code-Acce } \\
\text { Values } \\
\text { Physical } \\
\text { Numerical } \\
\text { Range }\end{array}$ & $\begin{array}{l}\text { Deterministic } \\
\text { Value }\end{array}$ & Type $^{d}$ & Priority $^{e}$ & Justification & References \\
\hline $\begin{array}{c}\text { Larger } x \text { coordinate } \\
\text { of the leafy } \\
\text { vegetables plot }\end{array}$ & $\mathrm{m}$ & 65.625 & $\begin{array}{l}-80,000- \\
+80,000\end{array}$ & 65.625 & $P$ & 3 & & \\
\hline $\begin{array}{c}\text { Smaller y } \\
\text { coordinate of the } \\
\text { leafy vegetables } \\
\text { plot }\end{array}$ & $\mathrm{m}$ & 268 & $\begin{array}{l}-80,000- \\
+80,000\end{array}$ & 840 & $P$ & 3 & & \\
\hline $\begin{array}{l}\text { Larger y coordinate } \\
\text { of the leafy } \\
\text { vegetables plot }\end{array}$ & $\mathrm{m}$ & 300 & $\begin{array}{l}-80,000- \\
+80,000\end{array}$ & 872 & $P$ & 3 & & \\
\hline $\begin{array}{l}\text { Smaller } x \\
\text { coordinate of the } \\
\text { pasture, silage } \\
\text { growing area }\end{array}$ & $\mathrm{m}$ & 0 & $\begin{array}{l}-80,000- \\
+80,000\end{array}$ & 0 & $P$ & 3 & \multirow{4}{*}{$\begin{array}{l}\text { A plot, with an area }=10,000 \text { square meters (RESRAD } \\
\text { OFFSITE default), is located north of the } \\
\text { contaminated zone near the well (which is located } \\
407 \text { meters north/downgradient of the contaminated } \\
\text { zone). }\end{array}$} & \multirow[t]{4}{*}{ Yu et al. 2007} \\
\hline $\begin{array}{l}\text { Larger } x \text { coordinate } \\
\text { of the pasture, } \\
\text { silage growing area }\end{array}$ & $\mathrm{m}$ & 100 & $\begin{array}{l}-80,000- \\
+80,000\end{array}$ & 100 & $P$ & 3 & & \\
\hline $\begin{array}{l}\text { Smaller y } \\
\text { coordinate of the } \\
\text { pasture, silage } \\
\text { growing area }\end{array}$ & $\mathrm{m}$ & 450 & $\begin{array}{l}-80,000- \\
+80,000\end{array}$ & 706 & $P$ & 3 & & \\
\hline $\begin{array}{l}\text { Larger y coordinate } \\
\text { of the pasture, } \\
\text { silage growing area }\end{array}$ & $\mathrm{m}$ & 550 & $\begin{array}{l}-80,000- \\
+80,000\end{array}$ & 806 & $P$ & 3 & & \\
\hline $\begin{array}{l}\text { Smaller } x \\
\text { coordinate of the } \\
\text { grain fields }\end{array}$ & $\mathrm{m}$ & 0 & $\begin{array}{l}-80,000- \\
+80,000\end{array}$ & 192 & $\mathrm{P}$ & 3 & \multirow{4}{*}{$\begin{array}{l}\text { A plot, with an area }=10,000 \text { square meters (RESRAD } \\
\text { OFFSITE default), is located north of the } \\
\text { contaminated zone near the well (which is located } \\
407 \text { meters north/downgradient of the contaminated } \\
\text { zone). }\end{array}$} & \multirow[t]{4}{*}{ Yu et al. 2007} \\
\hline $\begin{array}{l}\text { Larger } x \text { coordinate } \\
\text { of the grain fields }\end{array}$ & $\mathrm{m}$ & 100 & $\begin{array}{l}-80,000- \\
+80,000\end{array}$ & 292 & $P$ & 3 & & \\
\hline $\begin{array}{l}\text { Smaller y } \\
\text { coordinate of the } \\
\text { grain fields }\end{array}$ & $\mathrm{m}$ & 300 & $\begin{array}{l}-80,000- \\
+80,000\end{array}$ & 700 & $P$ & 3 & & \\
\hline $\begin{array}{l}\text { Larger y coordinate } \\
\text { of the grain fields }\end{array}$ & $\mathrm{m}$ & 400 & $\begin{array}{l}-80,000- \\
+80,000\end{array}$ & 800 & $P$ & 3 & & \\
\hline $\begin{array}{c}\text { Smaller } x \\
\text { coordinate of the } \\
\text { dwelling site }\end{array}$ & $\mathrm{m}$ & 34.375 & $\begin{array}{l}-80,000- \\
+80,000\end{array}$ & 34.375 & $\mathrm{P}$ & 3 & \multirow{2}{*}{$\begin{array}{l}\text { A plot, with an area }=1,000 \text { square meters (RESRAD } \\
\text { OFFSITE default), is located north of the } \\
\text { contaminated zone near the well (which is located } \\
407 \text { meters north/downgradient of the contaminated } \\
\text { zone). }\end{array}$} & \multirow[t]{2}{*}{ Yu et al. 200} \\
\hline $\begin{array}{l}\text { Larger } x \text { coordinate } \\
\text { of the dwelling site }\end{array}$ & $\mathrm{m}$ & 65.625 & $\begin{array}{l}-80,000- \\
+80,000\end{array}$ & 65.625 & $\mathrm{P}$ & 3 & & \\
\hline
\end{tabular}


RESRAD-OFFSITE Table of Input Parameters for the C-746-U Landfill Offsite Resident Farmer Scenario

\begin{tabular}{|c|c|c|c|c|c|c|c|c|}
\hline $\begin{array}{l}\text { Input Screen Title } \\
\text { and Parameter } \\
\text { Name }\end{array}$ & Units & $\begin{array}{l}\text { Default } \\
\text { Value }^{\mathrm{a}}\end{array}$ & $\begin{array}{c}\text { Code-Accepted } \\
\text { Values }^{b} \\
\text { Physical or } \\
\text { Numerical }^{\mathrm{C}}(\mathrm{N}) \\
\text { Range }^{\text {Rang }}\end{array}$ & $\begin{array}{l}\text { Deterministic } \\
\text { Value }\end{array}$ & Type $^{d}$ & Priority & Justification & References \\
\hline $\begin{array}{c}\text { Smaller y } \\
\text { coordinate of the } \\
\text { dwelling site }\end{array}$ & $\mathrm{m}$ & 134 & $\begin{array}{l}-80,000- \\
+80,000\end{array}$ & 636 & $P$ & 3 & & \\
\hline $\begin{array}{l}\text { Larger y coordinate } \\
\text { of the dwelling site }\end{array}$ & $\mathrm{m}$ & 166 & $\begin{array}{l}-80,000- \\
+80,000\end{array}$ & 670 & $P$ & 3 & & \\
\hline $\begin{array}{c}\text { Smaller } x \\
\text { coordinate of the } \\
\text { surface-water body }\end{array}$ & $\mathrm{m}$ & -100 & $\begin{array}{l}-80,000- \\
+80,000\end{array}$ & -100 & $P$ & 3 & \multirow{4}{*}{$\begin{array}{l}\text { A plot, with an area }=90,000 \text { square meters (RESRAD } \\
\text { OFFSITE default), is located south of the } \\
\text { contaminated zone/upgradient. The surface water } \\
\text { body is not included in the CSM. }\end{array}$} & \multirow[t]{4}{*}{ Yu et al. 2007} \\
\hline $\begin{array}{l}\text { Larger } x \text { coordinate } \\
\text { of the surface- } \\
\text { water body }\end{array}$ & $\mathrm{m}$ & 200 & $\begin{array}{l}-80,000- \\
+80,000\end{array}$ & 200 & $P$ & 3 & & \\
\hline $\begin{array}{c}\text { Smaller y } \\
\text { coordinate of the } \\
\text { surface-water body }\end{array}$ & $\mathrm{m}$ & 550 & $\begin{array}{l}-80,000- \\
+80,000\end{array}$ & -850 & P & 3 & & \\
\hline $\begin{array}{l}\text { Larger y coordinate } \\
\text { of the surface- } \\
\text { water body }\end{array}$ & $\mathrm{m}$ & 850 & $\begin{array}{l}-80,000- \\
+80,000\end{array}$ & -550 & $P$ & 3 & & \\
\hline
\end{tabular}

Source

\begin{tabular}{|c|c|c|c|c|c|c|c|c|c|}
\hline $\begin{array}{c}\text { Nuclide } \\
\text { concentration }\end{array}$ & $\mathrm{pCi} / \mathrm{g}$ & 100 & $0-1 \mathrm{E}+34$ & $\mathrm{~N}$ & $\begin{array}{c}\text { Unit } \\
\text { concentration } \\
\text { for: } \\
\text { Am-241 } \\
\text { Cs-137 } \\
\text { Np-237 } \\
\text { Pu-238 } \\
\text { Pu-239 } \\
\text { Pu-240 } \\
\text { Tc-99 } \\
\text { Th-228 } \\
\text { Th-230 } \\
\text { Th-232 } \\
\text { U-234 } \\
\text { U-235 } \\
\text { U-238 } \\
\end{array}$ & $P$ & 2 & $\begin{array}{l}\text { The radionuclide concentration used is } 1 \mathrm{pCi} / \mathrm{g} \text { for } \\
\text { each parent radionuclide listed. Site-specific values } \\
\text { for the 6-year waste inventory (May 2003- May 2009) } \\
\text { were not used as input values. The list of } \\
\text { radionuclides used was provided to ORISE by DOE. } \\
\text { Radioactive secular equilibrium was not assumed in } \\
\text { the analysis for the uranium, actinium, and thorium } \\
\text { decay series due to the nature of the PGDP's uranium } \\
\text { enrichment mission. }\end{array}$ & $\begin{array}{c}\text { DOE 2003a } \\
\text { DOE SOW for C- } \\
746-U \text { landfill and } \\
\text { DOE Project } \\
\text { Communication } \\
\text { (May2010) }\end{array}$ \\
\hline \multicolumn{10}{|c|}{ Source Release and Deposition Velocity } \\
\hline $\begin{array}{c}\text { Release to } \\
\text { groundwater, leach }\end{array}$ & $1 / \mathrm{yr}$ & 0 & $0-1 E+34$ & $\mathrm{~N}$ & 0 & $P$ & 3 & $\begin{array}{l}\text { The fraction of the available radionuclide leached out } \\
\text { from the contaminated zone per unit of time. If a }\end{array}$ & Yu et al. 2007 \\
\hline
\end{tabular}


RESRAD-OFFSITE Table of Input Parameters for the C-746-U Landfill Offsite Resident Farmer Scenario

\begin{tabular}{|c|c|c|c|c|c|c|c|c|c|}
\hline \multirow{2}{*}{$\begin{array}{c}\text { Input Screen Title } \\
\text { and Parameter } \\
\text { Name } \\
\text { rate }\end{array}$} & \multirow[t]{2}{*}{ Units } & \multirow[t]{2}{*}{$\begin{array}{l}\text { Default } \\
\text { Value }^{a}\end{array}$} & \multicolumn{2}{|c|}{$\begin{array}{l}\text { Code-Accepted } \\
\text { Values }^{b} \\
\text { Physical or } \\
\text { Numerical }^{c} \text { (N) } \\
\text { Range }\end{array}$} & \multirow[t]{2}{*}{$\begin{array}{l}\text { Deterministic } \\
\text { Value }\end{array}$} & \multirow[t]{2}{*}{ Type } & Priority ${ }^{e}$ & Justification & \multirow[t]{2}{*}{ References } \\
\hline & & & & & & & & $\begin{array}{l}\text { zero is entered, the code will estimate a release rate } \\
\text { on the basis of the equilibrium desorption } \\
\text { concentration. The default value is used. }\end{array}$ & \\
\hline Deposition velocity & $\mathrm{m} / \mathrm{s}$ & $\begin{array}{c}0.001 \\
0.01(\mathrm{Cl}, \mathrm{l}) \\
0(\mathrm{Xe})\end{array}$ & $0-1 E+34$ & $\mathrm{~N}$ & 0.001 & $P$ & 2 & $\begin{array}{l}\text { For nuclides that are transported by contaminated } \\
\text { dust, it is the settling velocity of dust. If the nuclide is } \\
\text { being transported in the form of a gas (water vapor, } \\
\text { carbon dioxide, radon, etc.), a value of zero may be } \\
\text { entered. The default value is used. }\end{array}$ & Yu et al. 2007 \\
\hline
\end{tabular}

Distribution Coefficients

\begin{tabular}{|c|c|c|c|c|c|c|c|c|c|}
\hline Contaminated zone & $\mathrm{cm}^{3} / \mathrm{g}$ & $\begin{array}{l}\text { Nuclide- } \\
\text { dependent } \\
\text { (Default values } \\
\text { available) }\end{array}$ & $0-1 E+34$ & $\mathrm{~N}$ & $\begin{array}{l}\text { Nuclide- } \\
\text { dependent (see } \\
\text { Attachment I) }\end{array}$ & $P$ & 1 & $\begin{array}{l}\text { Tables with site-specific distribution coefficients for } \\
\text { the parent and daughter radionuclides are available } \\
\text { immediately following this table of parameters. }\end{array}$ & $\begin{array}{c}\text { DOE 2003b } \\
\text { Table Att. 1, page } \\
\text { C3-314, Table } \\
\text { C.3.1., page C3- } \\
301 \\
\\
\text { DOE Project } \\
\text { Communication } \\
\text { (March 2010) } \\
\text { Yu et al. } 2001 \\
\end{array}$ \\
\hline Unsaturated zone & $\mathrm{cm}^{3} / \mathrm{g}$ & $\begin{array}{l}\text { Nuclide- } \\
\text { dependent } \\
\text { (Default values } \\
\text { available) }\end{array}$ & $0-1 E+34$ & $\mathrm{~N}$ & $\begin{array}{l}\text { Nuclide- } \\
\text { dependent (see } \\
\text { Attachment I) }\end{array}$ & $P$ & 1 & $\begin{array}{l}\text { Tables with site-specific distribution coefficients for } \\
\text { the parent and daughter radionuclides are available } \\
\text { immediately following this table of parameters. }\end{array}$ & $\begin{array}{c}\text { DOE 2003b } \\
\text { Table Att. 1, page } \\
\text { C3-314, Table } \\
\text { C.3.1., page C3- } \\
301 \\
\\
\text { DOE Project } \\
\text { Communication } \\
\text { (March 2010) } \\
\text { Yu et al. } 2001\end{array}$ \\
\hline Saturated zone & $\mathrm{cm}^{3} / \mathrm{g}$ & $\begin{array}{l}\text { Nuclide- } \\
\text { dependent } \\
\text { (Default values } \\
\text { available) }\end{array}$ & $0-1 E+34$ & $\mathrm{~N}$ & $\begin{array}{l}\text { Nuclide- } \\
\text { dependent (see } \\
\text { Attachment I) }\end{array}$ & $P$ & 1 & $\begin{array}{l}\text { Tables with site-specific distribution coefficients for } \\
\text { the parent and daughter radionuclides are available } \\
\text { immediately following this table of parameters. }\end{array}$ & $\begin{array}{c}\text { DOE 2003b } \\
\text { Table Att. 1, page } \\
\text { C3-314, Table } \\
\text { C.3.1., page C3- } \\
\text { 301, } \\
\text { Table 4.7., page 4- } \\
21\end{array}$ \\
\hline
\end{tabular}


RESRAD-OFFSITE Table of Input Parameters for the C-746-U Landfill Offsite Resident Farmer Scenario

\begin{tabular}{|c|c|c|c|c|c|c|c|c|c|}
\hline \multirow[t]{2}{*}{$\begin{array}{l}\text { Input Screen Title } \\
\text { and Parameter } \\
\text { Name }\end{array}$} & \multirow[t]{2}{*}{ Units } & \multirow[t]{2}{*}{$\begin{array}{l}\text { Default } \\
\text { Value }^{a}\end{array}$} & \multicolumn{2}{|c|}{$\begin{array}{l}\text { Code-Accepted } \\
\text { Values }^{b} \\
\text { Physical or } \\
\text { Numerical }{ }^{\mathrm{C}} \text { (N) } \\
\text { Range }\end{array}$} & \multirow[t]{2}{*}{$\begin{array}{l}\text { Deterministic } \\
\text { Value }\end{array}$} & \multirow[t]{2}{*}{ Type $^{d}$} & \multirow[t]{2}{*}{ Priority ${ }^{e}$} & \multirow[t]{2}{*}{ Justification } & \multirow{2}{*}{$\begin{array}{c}\text { References } \\
\text { DOE Project } \\
\text { Communication } \\
\text { (March 2010) }\end{array}$} \\
\hline & & & & & & & & & \\
\hline $\begin{array}{l}\text { Sediment in surface } \\
\text { water body }\end{array}$ & $\mathrm{cm}^{3} / \mathrm{g}$ & $\begin{array}{l}\text { Nuclide- } \\
\text { dependent } \\
\text { (Default values } \\
\text { available) }\end{array}$ & $0-1 E+34$ & $\mathrm{~N}$ & $\begin{array}{l}\text { Nuclide- } \\
\text { dependent (see } \\
\text { Attachment I) }\end{array}$ & $P$ & 1 & $\begin{array}{l}\text { Tables with site-specific distribution coefficients for } \\
\text { the parent and daughter radionuclides are available } \\
\text { immediately following this table of parameters. }\end{array}$ & $\begin{array}{l}\text { DOE Project } \\
\text { Communication } \\
\text { (March 2010) }\end{array}$ \\
\hline $\begin{array}{l}\text { Fruit, grain, } \\
\text { nonleafy fields }\end{array}$ & $\mathrm{cm}^{3} / \mathrm{g}$ & $\begin{array}{c}\text { Nuclide- } \\
\text { dependent } \\
\text { (Default values } \\
\text { available) }\end{array}$ & $0-1 E+34$ & $\mathrm{~N}$ & $\begin{array}{l}\text { Nuclide- } \\
\text { dependent (see } \\
\text { Attachment I) }\end{array}$ & $P$ & 1 & $\begin{array}{l}\text { Tables with site-specific distribution coefficients for } \\
\text { the parent and daughter radionuclides are available } \\
\text { immediately following this table of parameters. }\end{array}$ & $\begin{array}{l}\text { DOE Project } \\
\text { Communication } \\
\text { (March 2010) }\end{array}$ \\
\hline $\begin{array}{l}\text { Leafy vegetable } \\
\text { fields }\end{array}$ & $\mathrm{cm}^{3} / \mathrm{g}$ & $\begin{array}{c}\text { Nuclide- } \\
\text { dependent } \\
\text { (Default values } \\
\text { available) }\end{array}$ & $0-1 E+34$ & $\mathrm{~N}$ & $\begin{array}{l}\text { Nuclide- } \\
\text { dependent (see } \\
\text { Attachment I) }\end{array}$ & $P$ & 1 & $\begin{array}{l}\text { Tables with site-specific distribution coefficients for } \\
\text { the parent and daughter radionuclides are available } \\
\text { immediately following this table of parameters. }\end{array}$ & $\begin{array}{c}\text { DOE Project } \\
\text { Communication } \\
\text { (March 2010) }\end{array}$ \\
\hline $\begin{array}{l}\text { Pasture, silage } \\
\text { growing areas }\end{array}$ & $\mathrm{cm}^{3} / \mathrm{g}$ & $\begin{array}{l}\text { Nuclide- } \\
\text { dependent } \\
\text { (Default values } \\
\text { available) }\end{array}$ & $0-1 E+34$ & $\mathrm{~N}$ & $\begin{array}{l}\text { Nuclide- } \\
\text { dependent (see } \\
\text { Attachment I) }\end{array}$ & $P$ & 1 & $\begin{array}{l}\text { Tables with site-specific distribution coefficients for } \\
\text { the parent and daughter radionuclides are available } \\
\text { immediately following this table of parameters. }\end{array}$ & $\begin{array}{l}\text { DOE Project } \\
\text { Communication } \\
\text { (March 2010) }\end{array}$ \\
\hline $\begin{array}{l}\text { Livestock feed grain } \\
\text { fields }\end{array}$ & $\mathrm{cm}^{3} / \mathrm{g}$ & $\begin{array}{c}\text { Nuclide- } \\
\text { dependent } \\
\text { (Default values } \\
\text { available) }\end{array}$ & $0-1 E+34$ & $\mathrm{~N}$ & $\begin{array}{l}\text { Nuclide- } \\
\text { dependent (see } \\
\text { Attachment I) }\end{array}$ & $P$ & 1 & $\begin{array}{l}\text { Tables with site-specific distribution coefficients for } \\
\text { the parent and daughter radionuclides are available } \\
\text { immediately following this table of parameters. }\end{array}$ & $\begin{array}{l}\text { DOE Project } \\
\text { Communication } \\
\text { (March 2010) }\end{array}$ \\
\hline Offsite dwelling site & $\mathrm{cm}^{3} / \mathrm{g}$ & $\begin{array}{c}\text { Nuclide- } \\
\text { dependent } \\
\text { (Default values } \\
\text { available) }\end{array}$ & $0-1 E+34$ & $\mathrm{~N}$ & $\begin{array}{l}\text { Nuclide- } \\
\text { dependent (see } \\
\text { Attachment I) }\end{array}$ & $P$ & 1 & $\begin{array}{l}\text { Tables with site-specific distribution coefficients for } \\
\text { the parent and daughter radionuclides are available } \\
\text { immediately following this table of parameters. }\end{array}$ & $\begin{array}{l}\text { DOE Project } \\
\text { Communication } \\
\text { (March 2010) }\end{array}$ \\
\hline
\end{tabular}

Dose Conversion and Slope Factors

\begin{tabular}{|c|c|c|c|c|c|c|c|c|}
\hline $\begin{array}{l}\text { External dose } \\
\text { conversion factors }\end{array}$ & $\begin{array}{c}\text { (mrem/yr) } \\
\text { per } \\
\text { (pCi/g) }\end{array}$ & $\begin{array}{l}\text { Nuclide- } \\
\text { specific } \\
\text { (default values } \\
\text { available) }\end{array}$ & $\begin{array}{c}\text { Nuclide- } \\
\text { specific } \\
\text { (default } \\
\text { values } \\
\text { available) }\end{array}$ & $\begin{array}{c}\text { Nuclide-specific } \\
\text { (ICRP } 60 \text { values } \\
\text { available) }\end{array}$ & $M$ & 3 & $\begin{array}{l}\text { The ICRP } 60 \text { (external dose conversion factors) library } \\
\text { is selected in conjunction with the ICRP } 72 \text { Adult } \\
\text { (internal dose conversion factors) library to obtain } \\
\text { results in Total Effective Dose (TED). }\end{array}$ & Yu et al. 2007 \\
\hline $\begin{array}{l}\text { Inhalation dose } \\
\text { conversion factors }\end{array}$ & $\mathrm{mrem} / \mathrm{pCi}$ & $\begin{array}{l}\text { Nuclide- } \\
\text { specific } \\
\text { (default values } \\
\text { available) }\end{array}$ & $\begin{array}{c}\text { Nuclide- } \\
\text { specific } \\
\text { (default } \\
\text { values } \\
\text { available) }\end{array}$ & $\begin{array}{c}\text { Nuclide-specific } \\
\text { (ICRP } 72 \text { values } \\
\text { available) }\end{array}$ & $M$ & 3 & $\begin{array}{l}\text { The ICRP } 72 \text { Adult (internal dose conversion factors) } \\
\text { library is selected in conjunction with the ICRP } 60 \\
\text { (external dose conversion factors) library to obtain } \\
\text { results in Total Effective Dose (TED). }\end{array}$ & Yu et al. 2007 \\
\hline
\end{tabular}


RESRAD-OFFSITE Table of Input Parameters for the C-746-U Landfill Offsite Resident Farmer Scenario

\begin{tabular}{|c|c|c|c|c|c|c|c|c|}
\hline $\begin{array}{c}\text { Input Screen Title } \\
\text { and Parameter } \\
\text { Name }\end{array}$ & Units & $\begin{array}{l}\text { Default } \\
\text { Value }^{\mathrm{a}}\end{array}$ & $\begin{array}{r}\text { Code-Acce } \\
\text { Values } \\
\text { Physical } \\
\text { Numerical } \\
\text { Range } \\
\end{array}$ & $\begin{array}{l}\text { Deterministic } \\
\text { Value }\end{array}$ & Type $^{d}$ & Priority $^{\mathrm{e}}$ & Justification & References \\
\hline $\begin{array}{l}\text { Ingestion dose } \\
\text { conversion factors }\end{array}$ & $\mathrm{mrem} / \mathrm{pCi}$ & $\begin{array}{l}\text { Nuclide- } \\
\text { specific } \\
\text { (default values } \\
\text { available) }\end{array}$ & $\begin{array}{c}\text { Nuclide- } \\
\text { specific } \\
\text { (default } \\
\text { values } \\
\text { available) } \\
\end{array}$ & $\begin{array}{c}\text { Nuclide-specific } \\
\text { (ICRP } 72 \text { values } \\
\text { available) }\end{array}$ & $M$ & 3 & $\begin{array}{l}\text { The ICRP } 72 \text { Adult (internal dose conversion factors) } \\
\text { library is selected in conjunction with the ICRP } 60 \\
\text { (external dose conversion factors) library to obtain } \\
\text { results in Total Effective Dose (TED). }\end{array}$ & Yu et al. 2007 \\
\hline $\begin{array}{l}\text { Slope factor -- } \\
\text { external }\end{array}$ & $\begin{array}{l}\text { (risk/yr) } \\
\text { per } \\
(\mathrm{pCi} / \mathrm{g})\end{array}$ & $\begin{array}{l}\text { Nuclide- } \\
\text { specific } \\
\text { (default values } \\
\text { available) }\end{array}$ & $\begin{array}{c}\text { Nuclide- } \\
\text { specific } \\
\text { (default } \\
\text { values } \\
\text { available) } \\
\end{array}$ & $\begin{array}{l}\text { Nuclide-specific } \\
\text { (default values } \\
\text { available) }\end{array}$ & $M$ & 3 & Default values are used. & Yu et al. 2007 \\
\hline $\begin{array}{l}\text { Slope factor -- } \\
\text { inhalation }\end{array}$ & risk/pCi & $\begin{array}{l}\text { Nuclide- } \\
\text { specific } \\
\text { (default values } \\
\text { available) }\end{array}$ & $\begin{array}{c}\text { Nuclide- } \\
\text { specific } \\
\text { (default } \\
\text { values } \\
\text { available) } \\
\end{array}$ & $\begin{array}{l}\text { Nuclide-specific } \\
\text { (default values } \\
\text { available) }\end{array}$ & M & 3 & Default values are used. & Yu et al. 2007 \\
\hline $\begin{array}{l}\text { Slope factor -- food } \\
\text { ingestion }\end{array}$ & risk/pCi & $\begin{array}{l}\text { Nuclide- } \\
\text { specific } \\
\text { (default values } \\
\text { available) }\end{array}$ & $\begin{array}{c}\text { Nuclide- } \\
\text { specific } \\
\text { (default } \\
\text { values } \\
\text { available) } \\
\end{array}$ & $\begin{array}{l}\text { Nuclide-specific } \\
\text { (default values } \\
\text { available) }\end{array}$ & $M$ & 3 & Default values are used. & Yu et al. 2007 \\
\hline $\begin{array}{l}\text { Slope factor -- } \\
\text { water ingestion }\end{array}$ & risk/pCi & $\begin{array}{l}\text { Nuclide- } \\
\text { specific } \\
\text { (default values } \\
\text { available) }\end{array}$ & $\begin{array}{c}\text { Nuclide- } \\
\text { specific } \\
\text { (default } \\
\text { values } \\
\text { available) } \\
\end{array}$ & $\begin{array}{l}\text { Nuclide-specific } \\
\text { (default values } \\
\text { available) }\end{array}$ & M & 3 & Default values are used. & Yu et al. 2007 \\
\hline $\begin{array}{l}\text { Slope factor -- soil } \\
\text { ingestion }\end{array}$ & risk/pCi & $\begin{array}{l}\text { Nuclide- } \\
\text { specific } \\
\text { (default values } \\
\text { available) }\end{array}$ & $\begin{array}{l}\text { Nuclide- } \\
\text { specific } \\
\text { (default } \\
\text { values } \\
\text { available) }\end{array}$ & $\begin{array}{l}\text { Nuclide-specific } \\
\text { (default values } \\
\text { available) }\end{array}$ & M & 3 & Default values are used. & Yu et al. 2007 \\
\hline
\end{tabular}

Transfer Factors

\begin{tabular}{|c|c|c|c|c|c|c|c|c|}
\hline $\begin{array}{c}\text { Fruit, grain, } \\
\text { nonleafy vegetables } \\
\text { transfer factor }\end{array}$ & $\begin{array}{c}(\mathrm{pCi} / \mathrm{kg}) / \\
(\mathrm{pCi} / \mathrm{kg})\end{array}$ & $\begin{array}{c}\text { Element- } \\
\text { dependent } \\
\text { (Default values } \\
\text { available) }\end{array}$ & $0-1 \mathrm{E}+34$ & $\mathrm{~N}$ & $\begin{array}{c}\text { Element- } \\
\text { dependent } \\
\text { (default values } \\
\text { available) }\end{array}$ & $\mathrm{P}$ & 1 & Yu et al. 2007 \\
\hline $\begin{array}{c}\text { Leafy vegetables } \\
\text { transfer factor }\end{array}$ & $\begin{array}{c}\text { (pCi/kg)/ } / \mathrm{kgalues} \text { are used. } \\
(\mathrm{pCi} / \mathrm{kg})\end{array}$ & $\begin{array}{c}\text { Element- } \\
\text { dependent } \\
\text { (Default values } \\
\text { available })\end{array}$ & $0-1 \mathrm{E}+34$ & $\mathrm{~N}$ & $\begin{array}{c}\text { Element- } \\
\text { dependent } \\
\text { (default values } \\
\text { available) }\end{array}$ & $\mathrm{P}$ & 1 & Default values are used. \\
\hline
\end{tabular}


RESRAD-OFFSITE Table of Input Parameters for the C-746-U Landfill Offsite Resident Farmer Scenario

\begin{tabular}{|c|c|c|c|c|c|c|c|c|c|}
\hline $\begin{array}{c}\text { Input Screen Title } \\
\text { and Parameter } \\
\text { Name }\end{array}$ & Units & $\begin{array}{l}\text { Default } \\
\text { Value }^{a}\end{array}$ & $\begin{array}{r}\text { Code-Accep } \\
\text { Values } \\
\text { Physical } \\
\text { Numerical } \\
\text { Range } \\
\end{array}$ & & $\begin{array}{l}\text { Deterministic } \\
\text { Value }\end{array}$ & Type $^{d}$ & Priority $^{\mathrm{e}}$ & Justification & References \\
\hline $\begin{array}{l}\text { Pasture and silage } \\
\text { transfer factor }\end{array}$ & $\begin{array}{l}(\mathrm{pCi} / \mathrm{kg}) / \\
(\mathrm{pCi} / \mathrm{kg})\end{array}$ & $\begin{array}{c}\text { Element- } \\
\text { dependent } \\
\text { (Default values } \\
\text { available) }\end{array}$ & $0-1 E+34$ & $\mathrm{~N}$ & $\begin{array}{c}\text { Element- } \\
\text { dependent } \\
\text { (default values } \\
\text { available) } \\
\end{array}$ & $P$ & 1 & Default values are used. & Yu et al. 2007 \\
\hline $\begin{array}{l}\text { Livestock feed grain } \\
\text { transfer factor }\end{array}$ & $\begin{array}{l}(\mathrm{pCi} / \mathrm{kg}) / \\
(\mathrm{pCi} / \mathrm{kg})\end{array}$ & $\begin{array}{c}\text { Element- } \\
\text { dependent } \\
\text { (Default values } \\
\text { available) } \\
\end{array}$ & $0-1 E+34$ & $\mathrm{~N}$ & $\begin{array}{c}\text { Element- } \\
\text { dependent } \\
\text { (default values } \\
\text { available) } \\
\end{array}$ & $P$ & 1 & Default values are used. & Yu et al. 2007 \\
\hline $\begin{array}{l}\text { Meat transfer } \\
\text { factor }\end{array}$ & $\begin{array}{l}(\mathrm{pCi} / \mathrm{kg}) / \\
(\mathrm{pCi} / \mathrm{d})\end{array}$ & $\begin{array}{c}\text { Element- } \\
\text { dependent } \\
\text { (Default values } \\
\text { available) } \\
\end{array}$ & $0-1 E+34$ & $\mathrm{~N}$ & $\begin{array}{c}\text { Element- } \\
\text { dependent } \\
\text { (default values } \\
\text { available) } \\
\end{array}$ & $P$ & 2 & Default values are used. & Yu et al. 2007 \\
\hline Milk transfer factor & $\begin{array}{l}(\mathrm{pCi} / \mathrm{L}) / \\
(\mathrm{pCi} / \mathrm{d})\end{array}$ & $\begin{array}{c}\text { Element- } \\
\text { dependent } \\
\text { (Default values } \\
\text { available) }\end{array}$ & $0-1 E+34$ & $\mathrm{~N}$ & $\begin{array}{c}\text { Element- } \\
\text { dependent } \\
\text { (default values } \\
\text { available) } \\
\end{array}$ & $P$ & 2 & Default values are used. & Yu et al. 2007 \\
\hline $\begin{array}{l}\text { Bioaccumulation } \\
\text { factor for fish }\end{array}$ & $\begin{array}{l}(\mathrm{pCi} / \mathrm{kg}) / \\
(\mathrm{pCi} / \mathrm{L})\end{array}$ & $\begin{array}{c}\text { Element- } \\
\text { dependent } \\
\text { (Default values } \\
\text { available) } \\
\end{array}$ & $0-1 E+34$ & $\mathrm{~N}$ & $\begin{array}{c}\text { Element- } \\
\text { dependent } \\
\text { (default values } \\
\text { available) } \\
\end{array}$ & $P$ & 2 & Default values are used. & Yu et al. 2007 \\
\hline $\begin{array}{l}\text { Bioaccumulation } \\
\text { factor for crustacea } \\
\text { and mollusks }\end{array}$ & $\begin{array}{l}(\mathrm{pCi} / \mathrm{kg}) / \\
(\mathrm{pCi} / \mathrm{L})\end{array}$ & $\begin{array}{c}\text { Element- } \\
\text { dependent } \\
\text { (Default values } \\
\text { available) } \\
\end{array}$ & $0-1 E+34$ & $\mathrm{~N}$ & $\begin{array}{c}\text { Element- } \\
\text { dependent } \\
\text { (default values } \\
\text { available) } \\
\end{array}$ & $P$ & 3 & Default values are used. & Yu et al. 2007 \\
\hline
\end{tabular}

Reporting Times

\begin{tabular}{|c|c|c|c|c|c|c|c|c|}
\hline $\begin{array}{l}\text { Times at which } \\
\text { output is reported }\end{array}$ & $\mathrm{yr}$ & $\begin{array}{c}1,3,6,12,30 \\
75,175,420 \\
970\end{array}$ & $0-1 E+5$ & $\begin{array}{c}1,50,100,500 \\
1026\end{array}$ & $P$ & 3 & $\begin{array}{l}\text { A time horizon of } 1,050 \text { years is used to calculate soil } \\
\text { guidelines. This is assumed to allow for in- growth } \\
\text { and decay since the plant has been in operation for } \\
\text { about } 50 \text { years (since about } 1960 \text { to 2010). } \\
\text { The time horizon is the sum of the maximum user- } \\
\text { specified reporting time and the exposure duration. } \\
\text { For instance, in this case for a time horizon of } 1050 \\
\text { yrs, the maximum reporting time is } 1026 \text { yrs for an } \\
\text { exposure duration of } 24 \text { yrs. }\end{array}$ & $\begin{array}{l}\mathrm{DOE} / \mathrm{CH} / 8901 \text { and } \\
\mathrm{DOE} \text { Order } 5400.5 \\
\\
\text { DOE Project } \\
\text { Communication } \\
\text { (May 2010) }\end{array}$ \\
\hline
\end{tabular}

Storage Times

Storage time for d 1 $0-1 \mathrm{E}+34$ \begin{tabular}{l|l}
$\mathrm{N}$ & 1
\end{tabular} \begin{tabular}{l|l}
1 & $\mathrm{~B}$ \\
\hline
\end{tabular} 3 Default value is used. 
RESRAD-OFFSITE Table of Input Parameters for the C-746-U Landfill Offsite Resident Farmer Scenario

\begin{tabular}{|c|c|c|c|c|c|c|c|c|c|}
\hline $\begin{array}{c}\text { Input Screen Title } \\
\text { and Parameter } \\
\text { Name }\end{array}$ & Units & $\begin{array}{l}\text { Default } \\
\text { Value }^{\text {a }}\end{array}$ & $\begin{array}{r}\text { Code-Acce } \\
\text { Values } \\
\text { Physical } \\
\text { Numerica } \\
\text { Range }\end{array}$ & & $\begin{array}{l}\text { Deterministic } \\
\text { Value }\end{array}$ & Type $^{d}$ & Priority $^{e}$ & Justification & References \\
\hline surface water & & & & & & & & & \\
\hline $\begin{array}{l}\text { Storage time for } \\
\text { well water }\end{array}$ & $d$ & 1 & $0-1 E+34$ & $\mathrm{~N}$ & 1 & B & 3 & Default value is used. & Yu et al. 2007 \\
\hline $\begin{array}{c}\text { Storage time for } \\
\text { fruits, grain, and } \\
\text { nonleafy vegetables }\end{array}$ & $d$ & 14 & $0-1 E+34$ & $\mathrm{~N}$ & 14 & B & 3 & Default value is used. & Yu et al. 2007 \\
\hline $\begin{array}{l}\text { Storage time for } \\
\text { leafy vegetables }\end{array}$ & $d$ & 1 & $0-1 E+34$ & $\mathrm{~N}$ & 1 & B & 3 & Default value is used. & Yu et al. 2007 \\
\hline $\begin{array}{l}\text { Storage time for } \\
\text { pasture and silage }\end{array}$ & $d$ & 1 & $0-1 E+34$ & $\mathrm{~N}$ & 1 & B & 3 & Default value is used. & Yu et al. 2007 \\
\hline $\begin{array}{l}\text { Storage time for } \\
\text { livestock feed grain }\end{array}$ & $d$ & 45 & $0-1 E+34$ & $\mathrm{~N}$ & 45 & B & 3 & Default value is used. & Yu et al. 2007 \\
\hline $\begin{array}{c}\text { Storage time for } \\
\text { meat }\end{array}$ & $d$ & 20 & $0-1 E+34$ & $\mathrm{~N}$ & 20 & B & 3 & Default value is used. & Yu et al. 2007 \\
\hline $\begin{array}{l}\text { Storage time for } \\
\text { milk }\end{array}$ & $d$ & 1 & $0-1 E+34$ & $\mathrm{~N}$ & 1 & B & 3 & Default value is used. & Yu et al. 2007 \\
\hline $\begin{array}{l}\text { Storage time for } \\
\text { fish }\end{array}$ & $d$ & 7 & $0-1 E+34$ & $\mathrm{~N}$ & 7 & B & 3 & Default value is used. & Yu et al. 2007 \\
\hline $\begin{array}{c}\text { Storage time for } \\
\text { crustacea and } \\
\text { mollusks }\end{array}$ & $d$ & 7 & $0-1 E+34$ & $\mathrm{~N}$ & 7 & B & 3 & Default value is used. & Yu et al. 2007 \\
\hline \multicolumn{10}{|l|}{$\begin{array}{l}\text { Physical and } \\
\text { Hydrological }\end{array}$} \\
\hline Precipitation & $\mathrm{m} / \mathrm{yr}$ & 1 & $0-10$ & & 1.24 & $\mathrm{P}$ & 2 & $\begin{array}{l}\text { The yearly precipitation averages about } 49 \text { inches } \\
\text { (approximately } 1.24 \text { meters). }\end{array}$ & $\begin{array}{l}\text { PRS 2008a } \\
\text { page 1-4 } \\
\text { DOE 2003b } \\
\text { page 2-5 }\end{array}$ \\
\hline Wind speed & $\mathrm{m} / \mathrm{s}$ & 2 & $1 E-4-20$ & & $\begin{array}{l}\text { Actual values } \\
\text { will be from } \\
\text { Paducah read } \\
\text { meteorological } \\
\text { star file }\end{array}$ & $\mathrm{P}$ & 2 & $\begin{array}{l}\text { The STAR file selected from the RESRAD-OFFSITE } \\
\text { code is called KY_Paducah.str. } \\
\text { The wind speed is divided into six intervals in order to } \\
\text { specify the joint frequency distribution of wind speed } \\
\text { and atmospheric stability in each direction of a wind } \\
\text { rose. This is the average wind speed for the wind } \\
\text { speed interval. }\end{array}$ & Yu et al. 2007 \\
\hline \multicolumn{10}{|l|}{$\begin{array}{l}\text { Primary } \\
\text { Contamination }\end{array}$} \\
\hline Area of primary & $\mathrm{m}^{2}$ & 10,000 & Calculated & & Calculated & $\mathrm{P}$ & 2 & The contaminated zone is composed of four different & DOE SOW for $\mathrm{C}$ \\
\hline
\end{tabular}


RESRAD-OFFSITE Table of Input Parameters for the C-746-U Landfill Offsite Resident Farmer Scenario

\begin{tabular}{|c|c|c|c|c|c|c|c|c|}
\hline $\begin{array}{l}\text { Input Screen Title } \\
\text { and Parameter } \\
\text { Name }\end{array}$ & Units & $\begin{array}{l}\text { Default } \\
\text { Value }^{\mathrm{a}}\end{array}$ & $\begin{array}{c}\text { Code-Accepted } \\
\text { Values }^{b} \\
\text { Physical or } \\
\text { Numerical }^{\mathrm{C}}(\mathrm{N}) \\
\text { Range }^{\text {Rang }}\end{array}$ & $\begin{array}{l}\text { Deterministic } \\
\text { Value }\end{array}$ & Type $^{d}$ & Priority ${ }^{e}$ & Justification & References \\
\hline contamination & & & & & & & $\begin{array}{l}\text { waste forms. The waste forms types are soil, } \\
\text { concrete, metal, and organic (lumber and debris). The } \\
\text { total waste disposal area of the landfill is calculated } \\
\text { by the code, it is not an input. The calculated area of } \\
\text { the contaminated zone is approximately } 91,000 \\
\text { square meters (not exactly } 89,436 \text { square meters } \\
\text { which is the total disposal area when the landfill is } \\
\text { filled). The code calculated this area based on input } \\
\text { values from dimensions of the waste disposal area } \\
\text { available in Lee et al. } 1995 \text {. }\end{array}$ & $\begin{array}{l}\text { 746-U landfill } \\
\text { DOE 2003b } \\
\text { Section } 3.2 \text {, } \\
\text { page } 3-11 \text {, } \\
\text { Table 4.5, } \\
\text { page } 4-13 \\
\text { Lee et al. } 1995 \\
\text { Fig } 2-4 \text {, } \\
\text { page } 17\end{array}$ \\
\hline $\begin{array}{l}\text { Length of } \\
\text { contamination } \\
\text { parallel to aquifer } \\
\text { flow }\end{array}$ & $\mathrm{m}$ & 100 & $1 E-4-1 E+6$ & 399 & $P$ & 2 & $\begin{array}{l}\text { This value of } 399 \mathrm{~m} \text { is the conservative longest } \\
\text { dimension between the upgradient edge of the } \\
\text { contaminated zone and the downgradient edge, } \\
\text { parallel to the aquifer. }\end{array}$ & $\begin{array}{l}\text { Lee et al. } 1995 \\
\text { Fig 2-4, } \\
\text { page } 17\end{array}$ \\
\hline $\begin{array}{l}\text { Depth of soil mixing } \\
\text { layer }(\mathrm{m})\end{array}$ & $\mathrm{m}$ & 0.15 & $0-1$ & 0.15 & $P, B$ & 2 & Default value is used. & Yu et al. 2007 \\
\hline $\begin{array}{l}\text { Deposition velocity } \\
\text { of dust ( } \mathrm{m} / \mathrm{s})\end{array}$ & $\mathrm{m} / \mathrm{s}$ & 0.001 & $0-0.01$ & 0.001 & $\mathrm{P}$ & & $\begin{array}{l}\text { This is the average velocity with which dust settles } \\
\text { onto the contaminated zone. It is used to calculate } \\
\text { the release to the atmosphere. The default value is } \\
\text { used per communication with DOE geologist. }\end{array}$ & $\begin{array}{l}\text { Yu et al. } 2007 \\
\text { DOE Project } \\
\text { Communication } \\
\text { with geologist } \\
\text { (April 2010) }\end{array}$ \\
\hline $\begin{array}{l}\text { Irrigation applied } \\
\text { per year }(\mathrm{m} / \mathrm{yr})\end{array}$ & $\mathrm{m} / \mathrm{yr}$ & 0.2 & $0-10$ & 0 & B & 3 & $\begin{array}{l}\text { The irrigation rate for the contaminated zone is set to } \\
\text { "0" since the Resident Farmer is located offsite. }\end{array}$ & Yu et al. 2007 \\
\hline $\begin{array}{l}\text { Evapotranspiration } \\
\text { coefficient }\end{array}$ & -- & 0.5 & $0-0.999$ & 0.83 & $P$ & 2 & $\begin{array}{l}\text { This value was calculated from the HELP Output data } \\
\text { for the Post-Institutional Control Period. The } \\
\text { equation used to calculate the value is available in Yu } \\
\text { et al. } 1993 . \\
\text { The calculations are available in Attachment II } \\
\text { following this table. }\end{array}$ & $\begin{array}{c}\text { DOE 2003b } \\
\text { page C3-243 } \\
\text { Yu et al.1993 } \\
\text { page } 78\end{array}$ \\
\hline Runoff coefficient & -- & 0.2 & $0-1$ & 0.34 & $\mathrm{P}$ & 2 & $\begin{array}{l}\text { This value was calculated from the HELP Output data } \\
\text { for the Post-Institutional Control Period. The } \\
\text { equation used to calculate the value is available in Yu } \\
\text { et al. } 1993 . \\
\text { The calculations are available in Attachment II } \\
\text { following this table. }\end{array}$ & $\begin{array}{l}\text { DOE 2003b } \\
\text { Page C3-243 } \\
\text { Yu et al. } 1993 \\
\text { page } 73\end{array}$ \\
\hline Rainfall and runoff & -- & 160 & $0-1,000$ & 250 & $P$ & 2 & This value was obtained from Wischmeier et al. 1978 & Wischmeier et al. \\
\hline
\end{tabular}


RESRAD-OFFSITE Table of Input Parameters for the C-746-U Landfill Offsite Resident Farmer Scenario

\begin{tabular}{|c|c|c|c|c|c|c|c|c|}
\hline $\begin{array}{c}\text { Input Screen Title } \\
\text { and Parameter } \\
\text { Name }\end{array}$ & Units & $\begin{array}{l}\text { Default } \\
\text { Value }^{\mathrm{a}}\end{array}$ & $\begin{array}{c}\text { Code-Accepted } \\
\text { Values }^{b} \\
\text { Physical or } \\
\text { Numerical' (N) } \\
\text { Range }\end{array}$ & $\begin{array}{l}\text { Deterministic } \\
\text { Value }\end{array}$ & Type $^{d}$ & Priority ${ }^{e}$ & Justification & References \\
\hline & & & & & & & and agreed upon by DOE geologist. & $\begin{array}{c}1978 \\
\text { Figure 1, page } 5 \\
\text { (Predicting } \\
\text { Rainfall Erosion } \\
\text { Losses) } \\
\\
\text { DOE Project } \\
\text { Communication } \\
\text { with geologist } \\
\text { (April 2010) }\end{array}$ \\
\hline $\begin{array}{l}\text { Slope-length- } \\
\text { steepness factor }\end{array}$ & -- & 0.4 & $0-10$ & 0.4 & $P$ & 2 & $\begin{array}{l}\text { DOE geologist recommended a value of } 0.4 \text { based on } \\
\text { site topography. }\end{array}$ & $\begin{array}{c}\text { Yu et al. } 2007 \\
\text { DOE Project } \\
\text { Communication } \\
\text { with geologist } \\
\text { (April 2010) }\end{array}$ \\
\hline $\begin{array}{l}\text { Cover and } \\
\text { management factor }\end{array}$ & -- & 0.003 & $0-1$ & 0.2 & $B, P$ & 2 & $\begin{array}{l}\text { DOE geologist recommended value based on no } \\
\text { appreciable canopy and } 20 \% \text { ground cover. }\end{array}$ & $\begin{array}{l}\text { Yu et al. } 2007 \\
\text { DOE Project } \\
\text { Communication } \\
\text { with geologist } \\
\text { (April 2010) }\end{array}$ \\
\hline $\begin{array}{l}\text { Support practice } \\
\text { factor }\end{array}$ & -- & 1 & $0-1$ & 0.5 & $B, P$ & 2 & DOE geologist recommended value. & $\begin{array}{l}\text { Yu et al. } 2007 \\
\text { DOE Project } \\
\text { Communication } \\
\text { with geologist } \\
\text { (July 2010) }\end{array}$ \\
\hline
\end{tabular}

Contaminated Zone

\begin{tabular}{|c|c|c|c|c|c|c|c|c|}
\hline $\begin{array}{c}\text { Thickness of } \\
\text { contaminated zone }\end{array}$ & $\mathrm{m}$ & 2 & $\begin{array}{c}1 \mathrm{E}-5- \\
1,000\end{array}$ & 13.4 & $\mathrm{P}$ & 2 & $\begin{array}{c}\text { This value is the average thickness for the waste } \\
\text { forms when the landfill is full. }\end{array}$ & $\begin{array}{c}\text { Table 4.5, } \\
\text { page 4-13, } \\
\text { Table Att.3, } \\
\text { page C3-315 }\end{array}$ \\
\hline $\begin{array}{c}\text { Total porosity of } \\
\text { contaminated zone }\end{array}$ & -- & 0.4 & $1 \mathrm{E}-5-1$ & & 0.17 & $\mathrm{P}$ & 2 & $\begin{array}{c}\text { The site-specific value available is 0.168 vol/vol. } \\
\text { Table } 4.4, \\
\text { page 4-9 }\end{array}$ \\
\hline $\begin{array}{c}\text { Dry bulk density of } \\
\text { contaminated zone }\end{array}$ & $\mathrm{g} / \mathrm{cm}^{3}$ & 1.5 & $1 \mathrm{E}-3-22.5$ & & 1.89 & $\mathrm{P}$ & 1 & $\begin{array}{c}\text { The densities of the waste forms were used to } \\
\text { calculate the weighted average density for the }\end{array}$ \\
\hline
\end{tabular}


RESRAD-OFFSITE Table of Input Parameters for the C-746-U Landfill Offsite Resident Farmer Scenario

\begin{tabular}{|c|c|c|c|c|c|c|c|c|}
\hline $\begin{array}{c}\text { Input Screen Title } \\
\text { and Parameter } \\
\text { Name }\end{array}$ & Units & $\begin{array}{l}\text { Default } \\
\text { Value }^{\mathrm{a}}\end{array}$ & 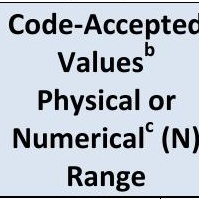 & $\begin{array}{l}\text { Deterministic } \\
\text { Value }\end{array}$ & Type $^{d}$ & Priority ${ }^{\mathrm{e}}$ & Justification & References \\
\hline & & & & & & & $\begin{array}{l}\text { contaminated zone which is approximately } \\
1.89 \mathrm{~g} / \mathrm{cm}^{3} \text {. }\end{array}$ & page $4-13$ \\
\hline $\begin{array}{l}\text { Soil erodibility } \\
\text { factor of } \\
\text { contaminated zone }\end{array}$ & tons/acre & 0.4 & $0-0.5$ & 0.37 & P & 2 & $\begin{array}{l}\text { DOE geologist recommended value based on silty clay } \\
\text { loam and } 0.5 \% \text { organic matter. }\end{array}$ & $\begin{array}{c}\text { Yu et al. } 2007 \\
\text { Table } 2.4-2, \\
\text { page B-31 } \\
\\
\text { DOE Project } \\
\text { Communication } \\
\text { with geologist } \\
\text { (May 2010) }\end{array}$ \\
\hline $\begin{array}{l}\text { Field capacity of } \\
\text { contaminated zone }\end{array}$ & -- & 0.3 & $1 E-5-1$ & 0.07 & P & 3 & The site-specific value available is $0.073 \mathrm{vol} / \mathrm{vol}$. & $\begin{array}{l}\text { DOE 2003b } \\
\text { Table 4.4, } \\
\text { page 4-9 }\end{array}$ \\
\hline $\begin{array}{l}\text { Soil b parameter of } \\
\text { contaminated zone }\end{array}$ & -- & 5.3 & $0-15$ & 4.05 & $\mathrm{P}$ & 2 & $\begin{array}{l}\text { DOE geologist determined that the most appropriate } \\
\text { value for the contaminated zone b available in Yu et } \\
\text { al. } 1993 \text { is the one for sand. It is known that the } \\
\text { contaminated zone (waste) will have high porosity } \\
\text { and high permeability. When selecting a } \\
\text { deterministic value for this input parameter, the } \\
\text { closest material and corresponding Soil b Parameter, } \\
\text { as developed by Clapp \& and Hornberger (Yu et al. } \\
\text { 1993), for concrete, steel and soil waste is sand. } \\
\text { Clapp \& Hornberger do not offer a corresponding Soil } \\
\text { b Parameter for landfill waste material. This value } \\
\text { according to the geologist should be low. }\end{array}$ & $\begin{array}{l}\text { Yu et al. } 1993 \\
\text { page } 83 \\
\\
\text { DOE project } \\
\text { Communication } \\
\text { with geologist } \\
\text { (July 2010) }\end{array}$ \\
\hline $\begin{array}{c}\text { Hydraulic } \\
\text { conductivity of } \\
\text { contaminated zone }\end{array}$ & $\mathrm{m} / \mathrm{yr}$ & 10 & $\begin{array}{l}1 E-3- \\
1 E+10\end{array}$ & 315.4 & P & 2 & $\begin{array}{l}\text { The hydraulic conductivity for waste forms } 1-4 \text { is } \\
1.0 \mathrm{E}^{-3} \mathrm{~cm} / \mathrm{s}(315.4 \mathrm{~m} / \mathrm{yr}) \text {. }\end{array}$ & $\begin{array}{l}\text { DOE 2003b } \\
\text { Fig. } 4.5 \text {, page } 4-18\end{array}$ \\
\hline
\end{tabular}

Clean Cover

\begin{tabular}{|c|c|c|c|c|c|c|c|c|}
\hline $\begin{array}{l}\text { Thickness of clean } \\
\text { cover }\end{array}$ & $\mathrm{m}$ & 0 & $0-100$ & 1.52 & $P$ & 2 & $\begin{array}{l}\text { For receptors exposed during the post-institutional } \\
\text { control period this value is the depth of the final } \\
\text { cover planned for the landfill. The landfill cover will } \\
\text { have six layers with a total thickness of } 5 \mathrm{ft} \text { ( } 1.52 \\
\text { meters). }\end{array}$ & $\begin{array}{c}\text { DOE 2003b } \\
\text { Section 3.2, page } \\
\text { 3-11, Fig. 4.3, } \\
\text { page 4-16 } \\
\\
\text { DOE Project } \\
\text { Communication } \\
\text { with geologist and } \\
\text { engineer } \\
\text { (April 2010) }\end{array}$ \\
\hline
\end{tabular}


RESRAD-OFFSITE Table of Input Parameters for the C-746-U Landfill Offsite Resident Farmer Scenario

\begin{tabular}{|c|c|c|c|c|c|c|c|c|}
\hline $\begin{array}{c}\text { Input Screen Title } \\
\text { and Parameter } \\
\text { Name }\end{array}$ & Units & $\begin{array}{l}\text { Default } \\
\text { Value }^{a}\end{array}$ & $\begin{array}{r}\text { Code-Accep }^{\text {Values }^{b}} \\
\text { Physical } \\
\text { Numerical } \\
\text { Range } \\
\end{array}$ & $\begin{array}{l}\text { Deterministic } \\
\text { Value }\end{array}$ & Type $^{d}$ & Priority & Justification & References \\
\hline $\begin{array}{l}\text { Total porosity of } \\
\text { clean cover }\end{array}$ & -- & 0.4 & $1 E-5-1$ & 0.3 & P & 2 & $\begin{array}{l}\text { DOE geologist recommended a value for vegetative } \\
\text { soil cover (root zone, layer } 1 \text { ) available in DOE 2003b. }\end{array}$ & $\begin{array}{l}\text { DOE Project } \\
\text { Communication } \\
\text { with geologist } \\
\text { (May 2010) and } \\
\text { DOE 2003b } \\
\text { Table 4.4 } \\
\end{array}$ \\
\hline $\begin{array}{l}\text { Dry bulk density of } \\
\text { clean cover }\end{array}$ & $\mathrm{g} / \mathrm{cm}^{3}$ & 1.5 & $1 E-3-22.5$ & 1.5 & $P$ & 2 & $\begin{array}{l}\text { The value for the density of the cover was obtained } \\
\text { from the previous RESRAD study for the landfill } \\
\text { described in DOE 2003b. This value was also } \\
\text { confirmed with DOE to be a site specific value for the } \\
\text { final cover. }\end{array}$ & $\begin{array}{c}\text { DOE 2003b } \\
\text { Table Att.5, page } \\
\text { C3-316 } \\
\text { DOE Project } \\
\text { Communication } \\
\text { with geologist and } \\
\text { engineer } \\
\text { (April 2010) } \\
\end{array}$ \\
\hline $\begin{array}{l}\text { Soil erodibility } \\
\text { factor of clean } \\
\text { cover }\end{array}$ & tons/acre & 0.4 & $0-0.5$ & 0.37 & $\mathrm{P}$ & 2 & $\begin{array}{l}\text { DOE geologist recommended value based on silty clay } \\
\text { loam and } 0.5 \% \text { organic matter. }\end{array}$ & $\begin{array}{c}\text { Yu et al. } 2007 \\
\text { Table 2.4-2, page } \\
\text { B-31 } \\
\\
\text { DOE Project } \\
\text { Communication } \\
\text { with geologist } \\
\text { (May 2010) } \\
\end{array}$ \\
\hline $\begin{array}{l}\text { Volumetric water } \\
\text { content of clean } \\
\text { cover }\end{array}$ & -- & 0.05 & $0-1$ & 0.347 & $\mathrm{P}$ & 2 & $\begin{array}{l}\text { DOE geologist recommended value based on silty clay } \\
\text { loam and normal distribution. However, this } \\
\text { parameter is only used by the code when the radon } \\
\text { pathway is active and radon is included in the } \\
\text { conceptual site model. }\end{array}$ & $\begin{array}{l}\text { Yu et al. } 2007 \\
\text { DOE Project } \\
\text { Communication } \\
\text { with geologist } \\
\text { (April 2010) }\end{array}$ \\
\hline
\end{tabular}

Agriculture Area Parameters

Fruit, Grain, and Non-leafy Vegetables Field

\begin{tabular}{|c|c|c|c|c|c|c|c|c|}
\hline $\begin{array}{l}\text { Area for fruit, grain, } \\
\text { and non-leafy } \\
\text { vegetables field }\end{array}$ & $\mathrm{m}^{2}$ & 1,000 & Calculated & $\begin{array}{l}\text { Calculated by } \\
\text { the code }\end{array}$ & B & 3 & $\begin{array}{l}\text { The fruit, grain and non-leafy vegetable growing area, } \\
\text { the leafy vegetable growing area, the pasture and } \\
\text { silage growing area, the livestock feed grain growing } \\
\text { area, and the dwelling site are all approximated by } \\
\text { rectangular shapes in the atmospheric transport } \\
\text { model. The sides of these rectangles must be parallel }\end{array}$ & Yu et al. 2007 \\
\hline
\end{tabular}


RESRAD-OFFSITE Table of Input Parameters for the C-746-U Landfill Offsite Resident Farmer Scenario

\begin{tabular}{|c|c|c|c|c|c|c|c|c|}
\hline $\begin{array}{c}\text { Input Screen Title } \\
\text { and Parameter } \\
\text { Name }\end{array}$ & Units & $\begin{array}{l}\text { Default } \\
\text { Value }^{\mathrm{a}}\end{array}$ & $\begin{array}{c}\text { Code-Accepted } \\
\text { Values }^{b} \\
\text { Physical or } \\
\text { Numerical }^{c} \text { (N) } \\
\text { Range }^{\text {Rumed }}\end{array}$ & $\begin{array}{l}\text { Deterministic } \\
\text { Value }\end{array}$ & Type $^{d}$ & Priority ${ }^{e}$ & Justification & References \\
\hline & & & & & & & to the sides of the primary contamination. & \\
\hline $\begin{array}{l}\text { Fraction of area } \\
\text { directly over } \\
\text { primary } \\
\text { contamination for } \\
\text { fruit, grain, and } \\
\text { nonleafy vegetables } \\
\text { field }\end{array}$ & -- & 0 & $0-1$ & 0 & $B, P$ & 3 & $\begin{array}{l}\text { Default value is used since the receptor is outside of } \\
\text { the contaminated zone. }\end{array}$ & Yu et al. 2007 \\
\hline $\begin{array}{l}\text { Irrigation applied } \\
\text { per year for fruit, } \\
\text { grain, and nonleafy } \\
\text { vegetables field }\end{array}$ & $\mathrm{m} / \mathrm{yr}$ & 0.2 & $0-10$ & 0.1 & B & 3 & $\begin{array}{l}\text { Irrigation in the Paducah, Kentucky area is considered } \\
\text { to be unlikely. In the event irrigation is necessary, the } \\
\text { water will primarily come from uncontaminated } \\
\text { surface water and not from groundwater (well). } \\
\text { Information from the USGS shows that surface water } \\
\text { is the main source of water used in Kentucky for } \\
\text { irrigation (Kenny et al. 2009). The Paducah area (i.e., } \\
\text { where PGDP is located) receives about an average of } \\
49 \text { inches (1.24 m) of precipitation per year (PRS } \\
2008 \text { a). According to ATSDR 2002, the farms in } \\
\text { McCracken County, KY (i.e., where Paducah is } \\
\text { located) rely on rainfall to water their crops. For } \\
\text { conservatism in the modeling, and as recommended } \\
\text { by DOE-PPPO, it was assumed that the Offsite } \\
\text { Resident Farmer uses contaminated well water for } \\
\text { irrigation of agricultural areas (i.e., fruit, grain, non- } \\
\text { leafy and leafy vegetables). An irrigation rate of } 0.1 \\
\text { m/yr is used for the Offsite Resident Farmer's } \\
\text { agricultural areas (i.e., fruit, grain, non-leafy and leafy } \\
\text { vegetables). } \\
\text { The fruits, grains, non-leafy vegetables, and leafy } \\
\text { vegetables are for human consumption. }\end{array}$ & $\begin{array}{c}\text { DOE Project } \\
\text { Communication } \\
\text { with DOE-PPPO } \\
\text { (April 2011) } \\
\text { PRS 2008a } \\
\text { page 1-4 } \\
\text { ATSDR } 2002 \\
\begin{array}{c}\text { Yu et al. } 1993 \\
\text { page } 75\end{array} \\
\text { Yu et al. } 2007 \\
\text { Kenny et al. } 2009\end{array}$ \\
\hline $\begin{array}{l}\text { Evapotranspiration } \\
\text { coefficient for fruit, } \\
\text { grain, and nonleafy } \\
\text { vegetables field }\end{array}$ & -- & 0.5 & $0-0.999$ & 0.74 & $P$ & 2 & $\begin{array}{l}\text { This value was calculated from the HELP Output data } \\
\text { for the Post-Institutional Control Period. The } \\
\text { equation used to calculate the value is available in Yu } \\
\text { et al. } 1993 . \\
\text { The calculations are available in Attachment II } \\
\text { following this table. }\end{array}$ & $\begin{array}{l}\text { DOE } 2003 \mathrm{~b} \\
\text { page C3-243 } \\
\text { Yu et al. } 1993 \\
\text { page } 78\end{array}$ \\
\hline $\begin{array}{l}\text { Runoff coefficient } \\
\text { for fruit, grain, and }\end{array}$ & -- & 0.2 & $0-1$ & 0.34 & P & 2 & $\begin{array}{l}\text { This value was calculated from the HELP Output data } \\
\text { for the Post-Institutional Control Period. The }\end{array}$ & $\begin{array}{l}\text { DOE 2003b } \\
\text { page C3-243 }\end{array}$ \\
\hline
\end{tabular}


RESRAD-OFFSITE Table of Input Parameters for the C-746-U Landfill Offsite Resident Farmer Scenario

\begin{tabular}{|c|c|c|c|c|c|c|c|c|}
\hline $\begin{array}{c}\text { Input Screen Title } \\
\text { and Parameter } \\
\text { Name }\end{array}$ & Units & $\begin{array}{l}\text { Default } \\
\text { Value }^{\mathrm{a}}\end{array}$ & $\begin{array}{l}\text { Code-Accepted } \\
\text { Values }^{b} \\
\text { Physical or } \\
\text { Numerical }{ }^{\mathrm{C}} \text { (N) } \\
\text { Range }\end{array}$ & $\begin{array}{l}\text { Deterministic } \\
\text { Value }\end{array}$ & Type $^{d}$ & Priority $^{e}$ & Justification & References \\
\hline $\begin{array}{l}\text { nonleafy vegetables } \\
\text { field }\end{array}$ & & & & & & & $\begin{array}{l}\text { calculated value is } 0.34 \text {. The equation used to } \\
\text { calculate the value is available in Yu et al. } 1993 . \\
\text { The calculations are available in Attachment II } \\
\text { following this table. }\end{array}$ & $\begin{array}{l}\text { Yu et al. } 1993 \\
\text { page } 73\end{array}$ \\
\hline $\begin{array}{l}\text { Depth of soil mixing } \\
\text { layer or plow layer } \\
\text { for fruit, grain, and } \\
\text { nonleafy vegetables } \\
\text { field } \\
\end{array}$ & $\mathrm{m}$ & 0.15 & $0-1$ & 0.15 & $P, B$ & 2 & Default value is used. & Yu et al. 2007 \\
\hline $\begin{array}{l}\text { Volumetric water } \\
\text { content for fruit, } \\
\text { grain, and nonleafy } \\
\text { vegetables field }\end{array}$ & -- & 0.3 & $1 E-5-1$ & 0.347 & $P$ & 2 & $\begin{array}{l}\text { DOE geologist recommended value based on silty clay } \\
\text { loam and normal distribution. }\end{array}$ & $\begin{array}{l}\text { Yu et al. } 2007 \\
\text { DOE project } \\
\text { communication } \\
\text { with geologist } \\
\text { (April 2010) }\end{array}$ \\
\hline $\begin{array}{l}\text { Dry bulk density of } \\
\text { soil for fruit, grain, } \\
\text { and nonleafy } \\
\text { vegetables field }\end{array}$ & $\mathrm{g} / \mathrm{cm}^{3}$ & 1.5 & $1 E-3-22.5$ & 1.5 & $P$ & 2 & Default value is used. & Yu et al. 2007 \\
\hline $\begin{array}{l}\text { Soil erodibility } \\
\text { factor for fruit, } \\
\text { grain, and nonleafy } \\
\text { vegetables field }\end{array}$ & tons/acre & 0.4 & $0-0.5$ & 0.37 & P & 2 & $\begin{array}{l}\text { DOE geologist recommended value based on silty clay } \\
\text { loam and } 0.5 \% \text { organic matter. }\end{array}$ & $\begin{array}{c}\text { Yu et al. } 2007 \\
\text { Table 2.4-2, page } \\
\text { B-31 } \\
\text { DOE Project } \\
\text { Communication } \\
\text { with geologist } \\
\text { (May 2010) }\end{array}$ \\
\hline $\begin{array}{l}\text { Slope-length- } \\
\text { steepness factor for } \\
\text { fruit, grain, and } \\
\text { nonleafy vegetables } \\
\text { field }\end{array}$ & -- & 0.4 & $0-10$ & 0.4 & $P$ & 2 & $\begin{array}{l}\text { DOE geologist recommended to use } 0.4 \text { based on site } \\
\text { topography. }\end{array}$ & $\begin{array}{l}\text { Yu et al. } 2007 \\
\text { DOE Project } \\
\text { Communication } \\
\text { with geologist } \\
\text { (April 2010) } \\
\end{array}$ \\
\hline $\begin{array}{l}\text { Cover and } \\
\text { management factor } \\
\text { for fruit, grain, and } \\
\text { nonleafy vegetables } \\
\text { field }\end{array}$ & -- & 0.003 & $0-1$ & 0.2 & $B, P$ & 2 & $\begin{array}{l}\text { DOE geologist recommended value based on no } \\
\text { appreciable canopy and } 20 \% \text { ground cover. }\end{array}$ & $\begin{array}{l}\text { Yu et al. } 2007 \\
\text { DOE Project } \\
\text { Communication } \\
\text { with geologist } \\
\text { (April 2010) }\end{array}$ \\
\hline
\end{tabular}


RESRAD-OFFSITE Table of Input Parameters for the C-746-U Landfill Offsite Resident Farmer Scenario

\begin{tabular}{|c|c|c|c|c|c|c|c|c|}
\hline $\begin{array}{c}\text { Input Screen Title } \\
\text { and Parameter } \\
\text { Name }\end{array}$ & Units & $\begin{array}{l}\text { Default } \\
\text { Value }^{\mathrm{a}}\end{array}$ & $\begin{array}{l}\text { Code-Accepted } \\
\text { Values }^{b} \\
\text { Physical or } \\
\text { Numerical }^{\mathrm{C}} \text { (N) } \\
\text { Range }^{\text {Rang }}\end{array}$ & $\begin{array}{l}\text { Deterministic } \\
\text { Value }\end{array}$ & Type $^{d}$ & Priority ${ }^{e}$ & Justification & References \\
\hline $\begin{array}{l}\text { Support practice } \\
\text { factor for fruit, } \\
\text { grain, and nonleafy } \\
\text { vegetables field }\end{array}$ & -- & 1 & $0-1$ & 0.5 & $B, P$ & 2 & DOE geologist recommended value. & $\begin{array}{l}\text { Yu et al. } 2007 \\
\text { DOE Project } \\
\text { Communication } \\
\text { with geologist } \\
\text { (July 2010) }\end{array}$ \\
\hline
\end{tabular}

Leafy Vegetable Field

\begin{tabular}{|c|c|c|c|c|c|c|c|c|}
\hline $\begin{array}{l}\text { Area for leafy } \\
\text { vegetable field }\end{array}$ & $\mathrm{m}^{2}$ & 1,000 & Calculated & $\begin{array}{l}\text { Calculated by } \\
\text { the code }\end{array}$ & B & 3 & $\begin{array}{l}\text { The fruit, grain and non-leafy vegetable growing area, } \\
\text { the leafy vegetable growing area, the pasture and } \\
\text { silage growing area, the livestock feed grain growing } \\
\text { area, and the dwelling site are all approximated by } \\
\text { rectangular shapes in the atmospheric transport } \\
\text { model. The sides of these rectangles must be parallel } \\
\text { to the sides of the primary contamination. }\end{array}$ & Yu et al. 2007 \\
\hline $\begin{array}{l}\text { Fraction of area } \\
\text { directly over } \\
\text { primary } \\
\text { contamination for } \\
\text { leafy vegetable field }\end{array}$ & -- & 0 & $0-1$ & 0 & $B, P$ & 3 & $\begin{array}{l}\text { Default value is used since the receptor is located } \\
\text { outside the contaminated zone. }\end{array}$ & Yu et al. 2007 \\
\hline $\begin{array}{l}\text { Irrigation applied } \\
\text { per year for leafy } \\
\text { vegetable field }\end{array}$ & $\mathrm{m} / \mathrm{yr}$ & 0.2 & $0-10$ & 0.1 & B & 3 & $\begin{array}{l}\text { Irrigation in the Paducah, Kentucky area is considered } \\
\text { to be unlikely. In the event irrigation is necessary, the } \\
\text { water will primarily come from uncontaminated } \\
\text { surface water and not from groundwater (well). } \\
\text { Information from the USGS shows that surface water } \\
\text { is the main source of water used in Kentucky for } \\
\text { irrigation (Kenny et al. 2009). The Paducah area (i.e., } \\
\text { where PGDP is located) receives about an average of } \\
49 \text { inches ( } 1.24 \mathrm{~m} \text { ) of precipitation per year (PRS } \\
2008 \text { ). According to ATSDR 2002, the farms in } \\
\text { McCracken County, KY (i.e., where Paducah is } \\
\text { located) rely on rainfall to water their crops. For } \\
\text { conservatism in the modeling, and as recommended } \\
\text { by DOE-PPPO, it was assumed that the Offsite } \\
\text { Resident Farmer uses contaminated well water for } \\
\text { irrigation of agricultural areas (i.e., fruit, grain, non- } \\
\text { leafy and leafy vegetables). An irrigation rate of } 0.1 \\
\mathrm{~m} / \mathrm{yr} \text { is used for the Offsite Resident Farmer's } \\
\text { agricultural areas (i.e., fruit, grain, non-leafy and leafy } \\
\text { vegetables). }\end{array}$ & $\begin{array}{c}\text { DOE Project } \\
\text { Communication } \\
\text { with DOE-PPPO } \\
\text { (April 2011) } \\
\text { PRS 2008a } \\
\text { page 1-4 } \\
\text { ATSDR } 2002 \\
\text { page } 8 \\
\text { Yu et al. } 1993 \\
\text { page } 75 \\
\text { Yu et al. } 2007 \\
\text { Kenny et al. } 2009\end{array}$ \\
\hline
\end{tabular}


RESRAD-OFFSITE Table of Input Parameters for the C-746-U Landfill Offsite Resident Farmer Scenario

\begin{tabular}{|c|c|c|c|c|c|c|c|c|}
\hline $\begin{array}{c}\text { Input Screen Title } \\
\text { and Parameter } \\
\text { Name }\end{array}$ & Units & $\begin{array}{l}\text { Default } \\
\text { Value }^{a}\end{array}$ & $\begin{array}{c}\text { Code-Accepte } \\
\text { Values }^{\mathrm{b}} \\
\text { Physical or }^{\text {Phy }} \\
\text { Numerical }^{\mathrm{C}} \text { (N } \\
\text { Range }\end{array}$ & $\begin{array}{l}\text { Deterministic } \\
\text { Value }\end{array}$ & Type $^{d}$ & Priority $^{\mathrm{e}}$ & Justification & References \\
\hline & & & & & & & $\begin{array}{l}\text { The fruits, grains, non-leafy vegetables, and leafy } \\
\text { vegetables are for human consumption. }\end{array}$ & \\
\hline $\begin{array}{l}\text { Evapotranspiration } \\
\text { coefficient for leafy } \\
\text { vegetable field }\end{array}$ & -- & 0.5 & $0-0.999$ & 0.74 & $P$ & 2 & $\begin{array}{l}\text { This value was calculated using the HELP Output data } \\
\text { for the Post-Institutional Control Period. The } \\
\text { equation used to calculate the value is available in Yu } \\
\text { et al. } 1993 . \\
\text { The calculations are available in Attachment II } \\
\text { following this table. }\end{array}$ & $\begin{array}{c}\text { DOE } 2003 \mathrm{~b} \\
\text { page C3-243 } \\
\text { Yu et al. } 1993 \\
\text { page } 78\end{array}$ \\
\hline $\begin{array}{l}\text { Runoff coefficient } \\
\text { for leafy vegetable } \\
\text { field }\end{array}$ & -- & 0.2 & $0-1$ & 0.34 & $P$ & 2 & $\begin{array}{l}\text { This value was calculated from the HELP Output data } \\
\text { for the Post-Institutional Control Period. The } \\
\text { calculated value is } 0.34 \text {. The equation used to } \\
\text { calculate the value is available in Yu et al. } 1993 \text {. } \\
\text { The calculations are available in Attachment II } \\
\text { following this table. }\end{array}$ & $\begin{array}{l}\text { DOE 2003b } \\
\text { page C3-243 } \\
\text { Yu et al. } 1993 \\
\text { page } 73\end{array}$ \\
\hline $\begin{array}{l}\text { Depth of soil mixing } \\
\text { layer or plow layer } \\
\text { for leafy vegetable } \\
\text { field }\end{array}$ & $\mathrm{m}$ & 0.15 & $0-1$ & 0.15 & $P, B$ & 2 & Default value is used. & Yu et al. 2007 \\
\hline $\begin{array}{l}\text { Volumetric water } \\
\text { content for leafy } \\
\text { vegetable field }\end{array}$ & -- & 0.3 & $1 E-5-1$ & 0.347 & $P$ & 2 & $\begin{array}{l}\text { DOE geologist recommended value based on silty clay } \\
\text { loam and normal distribution. }\end{array}$ & $\begin{array}{l}\text { Yu et al. } 2007 \\
\\
\text { DOE Project } \\
\text { Communication } \\
\text { with geologist } \\
\text { (April 2010) }\end{array}$ \\
\hline $\begin{array}{l}\text { Dry bulk density of } \\
\text { soil for leafy } \\
\text { vegetable field }\end{array}$ & $\mathrm{g} / \mathrm{cm}^{3}$ & 1.5 & $1 E-3-22.5$ & 1.5 & $P$ & 2 & Default value is used. & Yu et al. 2007 \\
\hline $\begin{array}{l}\text { Soil erodibility } \\
\text { factor for leafy } \\
\text { vegetable field }\end{array}$ & tons/acre & 0.4 & $0-0.5$ & 0.37 & $P$ & 2 & $\begin{array}{l}\text { DOE geologist recommended value based on silty clay } \\
\text { loam and } 0.5 \% \text { organic matter. }\end{array}$ & $\begin{array}{l}\text { Yu et al. } 2007 \\
\text { Table 2.4-2, page } \\
\text { B-31 } \\
\text { DOE Project } \\
\text { Communication } \\
\text { with geologist } \\
\text { (May 2010) }\end{array}$ \\
\hline $\begin{array}{l}\text { Slope-length- } \\
\text { steepness factor for }\end{array}$ & -- & 0.4 & $0-10$ & 0.4 & P & 2 & $\begin{array}{l}\text { DOE geologist recommended a value of } 0.4 \text { based on } \\
\text { site topography. }\end{array}$ & Yu et al. 2007 \\
\hline
\end{tabular}


RESRAD-OFFSITE Table of Input Parameters for the C-746-U Landfill Offsite Resident Farmer Scenario

\begin{tabular}{|c|c|c|c|c|c|c|c|c|}
\hline $\begin{array}{c}\text { Input Screen Title } \\
\text { and Parameter } \\
\text { Name }\end{array}$ & Units & $\begin{array}{l}\text { Default } \\
\text { Value }^{a}\end{array}$ & $\begin{array}{l}\text { Code-Accepted } \\
\text { Values }^{b} \\
\text { Physical or } \\
\text { Numerical }^{c}(\mathrm{~N}) \\
\text { Range }\end{array}$ & $\begin{array}{l}\text { Deterministic } \\
\text { Value }\end{array}$ & Type $^{d}$ & Priority $^{\mathrm{e}}$ & Justification & References \\
\hline leafy vegetable field & & & & & & & & $\begin{array}{c}\text { DOE Project } \\
\text { Communication } \\
\text { with geologist } \\
\text { (April 2010) }\end{array}$ \\
\hline $\begin{array}{c}\text { Cover and } \\
\text { management factor } \\
\text { for leafy vegetable } \\
\text { field }\end{array}$ & -- & 0.003 & $0-1$ & 0.2 & $B, P$ & 2 & $\begin{array}{l}\text { DOE geologist recommended value based on no } \\
\text { appreciable canopy and } 20 \% \text { ground cover. }\end{array}$ & $\begin{array}{l}\text { Yu et al. } 2007 \\
\text { DOE Project } \\
\text { Communication } \\
\text { with geologist } \\
\text { (April 2010) }\end{array}$ \\
\hline $\begin{array}{l}\text { Support practice } \\
\text { factor for leafy } \\
\text { vegetable field }\end{array}$ & -- & 1 & $0-1$ & 0.5 & $B, P$ & 2 & DOE geologist recommended value. & $\begin{array}{l}\text { Yu et al. } 2007 \\
\text { DOE Project } \\
\text { Communication } \\
\text { with geologist } \\
\text { (July 2010) }\end{array}$ \\
\hline
\end{tabular}

Livestock Feed Growing Area Parameters

Pasture and Silage Field

\begin{tabular}{|c|c|c|c|c|c|c|c|c|}
\hline $\begin{array}{l}\text { Area for pasture } \\
\text { and silage field }\end{array}$ & $\mathrm{m}^{2}$ & 10,000 & Calculated & $\begin{array}{l}\text { Calculated by } \\
\text { the code }\end{array}$ & B & 3 & $\begin{array}{l}\text { The fruit, grain and non-leafy vegetable growing area, } \\
\text { the leafy vegetable growing area, the pasture and } \\
\text { silage growing area, the livestock feed grain growing } \\
\text { area, and the dwelling site are all approximated by } \\
\text { rectangular shapes in the atmospheric transport } \\
\text { model. The sides of these rectangles must be parallel } \\
\text { to the sides of the primary contamination. }\end{array}$ & Yu et al. 2007 \\
\hline $\begin{array}{l}\text { Fraction of area } \\
\text { directly over } \\
\text { primary } \\
\text { contamination for } \\
\text { pasture and silage } \\
\text { field }\end{array}$ & -- & 0 & $0-1$ & 0 & $B, P$ & 3 & $\begin{array}{l}\text { Default is used since the receptor is located outside } \\
\text { the contaminated zone. }\end{array}$ & Yu et al. 2007 \\
\hline $\begin{array}{l}\text { Irrigation applied } \\
\text { per year for pasture } \\
\text { and silage field }\end{array}$ & $\mathrm{m} / \mathrm{yr}$ & 0.2 & $0-10$ & 0 & B & 3 & $\begin{array}{l}\text { The irrigation rate was set to } 0 \mathrm{~m} / \mathrm{yr} \text { as requested by } \\
\text { DOE-PPPO, since no irrigation is being considered for } \\
\text { the pasture and silage field. Irrigation in the Paducah, } \\
\text { Kentucky area is considered to be unlikely. In the } \\
\text { event irrigation is necessary, the water will primarily } \\
\text { come from uncontaminated surface water and not }\end{array}$ & $\begin{array}{c}\text { DOE Project } \\
\text { Communication } \\
\text { with DOE-PPPO } \\
\text { (September 2010) } \\
\text { DOE Project }\end{array}$ \\
\hline
\end{tabular}


RESRAD-OFFSITE Table of Input Parameters for the C-746-U Landfill Offsite Resident Farmer Scenario

\begin{tabular}{|c|c|c|c|c|c|c|c|c|}
\hline $\begin{array}{c}\text { Input Screen Title } \\
\text { and Parameter } \\
\text { Name }\end{array}$ & Units & $\begin{array}{l}\text { Default } \\
\text { Value }^{\mathrm{a}}\end{array}$ & $\begin{array}{l}\text { Code-Acceptec } \\
\text { Values }^{b} \\
\text { Physical or } \\
\text { Numerical }{ }^{c}(\mathrm{~N}) \\
\text { Range }\end{array}$ & $\begin{array}{l}\text { Deterministic } \\
\text { Value }\end{array}$ & Type $^{d}$ & Priority $^{e}$ & Justification & References \\
\hline & & & & & & & $\begin{array}{l}\text { from groundwater (well). Information from the USGS } \\
\text { shows that surface water is the main source of water } \\
\text { used in Kentucky for irrigation (Kenny et al. 2009). } \\
\text { The pasture and silage and livestock feed grain are } \\
\text { for livestock consumption. }\end{array}$ & $\begin{array}{c}\text { Communication } \\
\text { with DOE-PPPO } \\
\text { (April 2011) } \\
\text { Kenny et al. } 2009\end{array}$ \\
\hline $\begin{array}{l}\text { Evapotranspiration } \\
\text { coefficient for } \\
\text { pasture and silage } \\
\text { field }\end{array}$ & -- & 0.5 & $0-0.999$ & 0.83 & $P$ & 2 & $\begin{array}{l}\text { This value was calculated using the HELP Output data } \\
\text { for the Post-Institutional Control Period. The } \\
\text { equation used to calculate the value is available in Yu } \\
\text { et al. } 1993 . \\
\text { The calculations are available in Attachment II } \\
\text { following this table. }\end{array}$ & $\begin{array}{l}\text { DOE } 2003 \mathrm{~b} \\
\text { page C3-243 } \\
\text { Yu et al. } 1993 \\
\text { page } 78\end{array}$ \\
\hline $\begin{array}{l}\text { Runoff coefficient } \\
\text { for pasture and } \\
\text { silage field }\end{array}$ & -- & 0.2 & $0-1$ & 0.34 & $P$ & 2 & $\begin{array}{l}\text { This value was calculated from the HELP Output data } \\
\text { for the Post-Institutional Control Period. The } \\
\text { calculated value is } 0.34 \text {. The equation used to } \\
\text { calculate the value is available in Yu et al. } 1993 \text {. } \\
\text { The calculations are available in Attachment II } \\
\text { following this table. }\end{array}$ & $\begin{array}{l}\text { DOE } 2003 b \\
\text { page C3-243 } \\
\text { Yu et al. } 1993 \\
\text { page } 73\end{array}$ \\
\hline $\begin{array}{l}\text { Depth of soil mixing } \\
\text { layer or plow layer } \\
\text { for pasture and } \\
\text { silage field } \\
\end{array}$ & $\mathrm{m}$ & 0.15 & $0-1$ & 0.15 & $P, B$ & 2 & Default value is used. & Yu et al. 2007 \\
\hline $\begin{array}{l}\text { Volumetric water } \\
\text { content for pasture } \\
\text { and silage field }\end{array}$ & -- & 0.3 & $1 E-5-1$ & 0.347 & $\mathrm{P}$ & 2 & $\begin{array}{l}\text { DOE geologist recommended value based on silty clay } \\
\text { loam and normal distribution. }\end{array}$ & $\begin{array}{l}\text { Yu et al. } 2007 \\
\text { DOE project } \\
\text { Communication } \\
\text { with geologist } \\
\text { (April 2010) }\end{array}$ \\
\hline $\begin{array}{l}\text { Dry bulk density of } \\
\text { soil for pasture and } \\
\text { silage field }\end{array}$ & $\mathrm{g} / \mathrm{cm}^{3}$ & 1.5 & $1 E-3-22.5$ & 1.5 & $\mathrm{P}$ & 2 & Default value is used. & Yu et al. 2007 \\
\hline $\begin{array}{l}\text { Soil erodibility } \\
\text { factor for pasture } \\
\text { and silage field }\end{array}$ & tons/acre & 0.4 & $0-0.5$ & 0.37 & $P$ & 2 & $\begin{array}{l}\text { DOE geologist recommended value based on silty clay } \\
\text { loam and } 0.5 \% \text { organic matter. }\end{array}$ & $\begin{array}{l}\text { Yu et al. } 2007 \\
\text { Table 2.4-2, page } \\
\text { B-31 } \\
\text { DOE Project } \\
\text { Communication } \\
\text { with geologist }\end{array}$ \\
\hline
\end{tabular}


RESRAD-OFFSITE Table of Input Parameters for the C-746-U Landfill Offsite Resident Farmer Scenario

\begin{tabular}{|c|c|c|c|c|c|c|c|c|}
\hline $\begin{array}{c}\text { Input Screen Title } \\
\text { and Parameter } \\
\text { Name }\end{array}$ & Units & $\begin{array}{l}\text { Default } \\
\text { Value }^{a}\end{array}$ & $\begin{array}{c}\text { Code-Accepted } \\
\text { Values }^{b} \\
\text { Physical or } \\
\text { Numerical }^{\mathrm{C}} \text { (N) } \\
\text { Range }^{\text {Rang }}\end{array}$ & $\begin{array}{l}\text { Deterministic } \\
\text { Value }\end{array}$ & Type $^{d}$ & Priority $^{\mathrm{e}}$ & Justification & References \\
\hline & & & & & & & & (May 2010) \\
\hline $\begin{array}{c}\text { Slope-length- } \\
\text { steepness factor for } \\
\text { pasture and silage } \\
\text { field }\end{array}$ & -- & 0.4 & $0-10$ & 0.4 & P & 2 & $\begin{array}{l}\text { DOE geologist recommended to use } 0.4 \text { based on site } \\
\text { topography. }\end{array}$ & $\begin{array}{l}\text { Yu et al. } 2007 \\
\text { DOE Project } \\
\text { Communication } \\
\text { with geologist } \\
\text { (April 2010) }\end{array}$ \\
\hline $\begin{array}{l}\text { Cover and } \\
\text { management factor } \\
\text { for pasture and } \\
\text { silage field }\end{array}$ & -- & 0.003 & $0-1$ & 0.2 & $B, P$ & 2 & $\begin{array}{l}\text { DOE geologist recommended value based on no } \\
\text { appreciable canopy and } 20 \% \text { ground cover. }\end{array}$ & $\begin{array}{l}\text { Yu et al. } 2007 \\
\text { DOE Project } \\
\text { Communication } \\
\text { with geologist } \\
\text { (April 2010) }\end{array}$ \\
\hline $\begin{array}{l}\text { Support practice } \\
\text { factor for pasture } \\
\text { and silage field }\end{array}$ & -- & 1 & $0-1$ & 0.5 & $B, P$ & 2 & DOE geologist recommended value. & $\begin{array}{l}\text { Yu et al. } 2007 \\
\\
\text { DOE Project } \\
\text { Communication } \\
\text { with geologist } \\
\text { (July 2010) }\end{array}$ \\
\hline
\end{tabular}

Grain Field

\begin{tabular}{|c|c|c|c|c|c|c|c|c|}
\hline Area for grain field & $\mathrm{m}^{2}$ & 10,000 & Calculated & $\begin{array}{l}\text { Calculated by } \\
\text { the code }\end{array}$ & B & & $\begin{array}{l}\text { The fruit, grain and non-leafy vegetable growing area, } \\
\text { the leafy vegetable growing area, the pasture and } \\
\text { silage growing area, the livestock feed grain growing } \\
\text { area, and the dwelling site are all approximated by } \\
\text { rectangular shapes in the atmospheric transport } \\
\text { model. The sides of these rectangles must be parallel } \\
\text { to the sides of the primary contamination. }\end{array}$ & Yu et al. 2007 \\
\hline $\begin{array}{l}\text { Fraction of area } \\
\text { directly over } \\
\text { primary } \\
\text { contamination for } \\
\text { grain field } \\
\end{array}$ & -- & 0 & $0-1$ & 0 & $B, P$ & & $\begin{array}{l}\text { Default value is used since the receptor is outside the } \\
\text { contaminated zone. }\end{array}$ & Yu et al. 2007 \\
\hline $\begin{array}{l}\text { Irrigation applied } \\
\text { per year for grain } \\
\text { field }\end{array}$ & $\mathrm{m} / \mathrm{yr}$ & 0.2 & $0-10$ & 0 & B & 3 & $\begin{array}{l}\text { The irrigation rate was set to } 0 \mathrm{~m} / \mathrm{yr} \text { as requested by } \\
\text { DOE-PPPO, since no irrigation is being considered for } \\
\text { the grain field. Irrigation in the Paducah, Kentucky } \\
\text { area is considered to be unlikely. In the event } \\
\text { irrigation is necessary, the water will primarily come } \\
\text { from uncontaminated surface water and not from } \\
\text { groundwater (well). Information from the USGS }\end{array}$ & $\begin{array}{c}\text { DOE Project } \\
\text { Communication } \\
\text { with DOE-PPPO } \\
\text { (September 2010) } \\
\\
\text { DOE Project } \\
\text { Communication }\end{array}$ \\
\hline
\end{tabular}


RESRAD-OFFSITE Table of Input Parameters for the C-746-U Landfill Offsite Resident Farmer Scenario

\begin{tabular}{|c|c|c|c|c|c|c|c|c|}
\hline $\begin{array}{c}\text { Input Screen Title } \\
\text { and Parameter } \\
\text { Name }\end{array}$ & Units & $\begin{array}{l}\text { Default } \\
\text { Value }^{\mathrm{a}}\end{array}$ & $\begin{array}{l}\text { Code-Accepted } \\
\text { Values }^{b} \\
\text { Physical or } \\
\text { Numerical }{ }^{\mathrm{C}} \text { (N) } \\
\text { Range }\end{array}$ & $\begin{array}{l}\text { Deterministic } \\
\text { Value }\end{array}$ & Type $^{d}$ & Priority ${ }^{e}$ & Justification & References \\
\hline & & & & & & & $\begin{array}{l}\text { shows that surface water is the main source of water } \\
\text { used in Kentucky for irrigation (Kenny et al. 2009). } \\
\text { The pasture and silage and livestock feed grain are } \\
\text { for livestock consumption. }\end{array}$ & $\begin{array}{l}\text { with DOE-PPPO } \\
\text { (April 2011) } \\
\text { Kenny et al. } 2009 \\
\text { Yu et al. } 2007\end{array}$ \\
\hline $\begin{array}{l}\text { Evapotranspiration } \\
\text { coefficient for grain } \\
\text { field }\end{array}$ & -- & 0.5 & $0-0.999$ & 0.83 & $\mathrm{P}$ & 2 & $\begin{array}{l}\text { This value was calculated using the HELP Output data } \\
\text { for the Post-Institutional Control Period. The } \\
\text { equation used to calculate the value is available in Yu } \\
\text { et al. } 1993 . \\
\text { The calculations are available in Attachment II } \\
\text { following this table. }\end{array}$ & $\begin{array}{l}\text { DOE } 2003 \mathrm{~b} \\
\text { page C3-243 } \\
\text { Yu et al. } 1993 \\
\text { page } 78\end{array}$ \\
\hline $\begin{array}{l}\text { Runoff coefficient } \\
\text { for grain field }\end{array}$ & -- & 0.2 & $0-1$ & 0.34 & $P$ & 2 & $\begin{array}{l}\text { This value was calculated from the HELP Output data } \\
\text { for the Post-Institutional Control Period. The } \\
\text { calculated value is } 0.34 \text {. The equation used to } \\
\text { calculate the value is available in Yu et al. } 1993 \text {. } \\
\text { The calculations are available in Attachment II } \\
\text { following this table. }\end{array}$ & $\begin{array}{l}\text { DOE } 2003 b \\
\text { page C3-243 } \\
\text { Yu et al. } 1993 \\
\text { page } 73\end{array}$ \\
\hline $\begin{array}{l}\text { Depth of soil mixing } \\
\text { layer or plow layer } \\
\text { for grain field }\end{array}$ & $\mathrm{m}$ & 0.15 & $0-1$ & 0.15 & $P, B$ & 2 & Default value is used. & Yu et al. 2007 \\
\hline $\begin{array}{l}\text { Volumetric water } \\
\text { content for grain } \\
\text { field }\end{array}$ & -- & 0.3 & $1 E-5-1$ & 0.347 & $P$ & 2 & $\begin{array}{l}\text { DOE geologist recommended value based on silty clay } \\
\text { loam and normal distribution. }\end{array}$ & $\begin{array}{l}\text { Yu et al. } 2007 \\
\text { DOE Project } \\
\text { Communication } \\
\text { with geologist } \\
\text { (April 2010) }\end{array}$ \\
\hline $\begin{array}{l}\text { Dry bulk density of } \\
\text { soil for grain field }\end{array}$ & $\mathrm{g} / \mathrm{cm}^{3}$ & 1.5 & $1 E-3-22.5$ & 1.5 & $\mathrm{P}$ & 2 & Default value is used. & Yu et al. 2007 \\
\hline $\begin{array}{l}\text { Soil erodibility } \\
\text { factor for grain field }\end{array}$ & tons/acre & 0.4 & $0-0.5$ & 0.37 & $P$ & 2 & $\begin{array}{l}\text { DOE geologist recommended value based on silty clay } \\
\text { loam and } 0.5 \% \text { organic matter. }\end{array}$ & $\begin{array}{l}\text { Yu et al. } 2007 \\
\text { Table 2.4-2, page } \\
\text { B-31 } \\
\text { DOE Project } \\
\text { Communication } \\
\text { with geologist } \\
\text { (May 2010) }\end{array}$ \\
\hline Slope-length- & -- & 0.4 & $0-10$ & 0.4 & $P$ & 2 & DOE geologist recommended a value of 0.4 based on & Yu et al. 2007 \\
\hline
\end{tabular}


RESRAD-OFFSITE Table of Input Parameters for the C-746-U Landfill Offsite Resident Farmer Scenario

\begin{tabular}{|c|c|c|c|c|c|c|c|c|}
\hline $\begin{array}{c}\text { Input Screen Title } \\
\text { and Parameter } \\
\text { Name }\end{array}$ & Units & $\begin{array}{l}\text { Default } \\
\text { Value }^{\mathrm{a}}\end{array}$ & 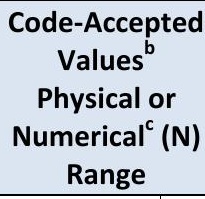 & $\begin{array}{l}\text { Deterministic } \\
\text { Value }\end{array}$ & Type $^{d}$ & Priority & Justification & References \\
\hline $\begin{array}{l}\text { steepness factor for } \\
\text { grain field }\end{array}$ & & & & & & & site topography. & $\begin{array}{c}\text { DOE Project } \\
\text { Communication } \\
\text { with geologist } \\
\text { (April 2010) } \\
\end{array}$ \\
\hline $\begin{array}{l}\text { Cover and } \\
\text { management factor } \\
\text { for grain field }\end{array}$ & -- & 0.003 & $0-1$ & 0.2 & $B, P$ & 2 & $\begin{array}{l}\text { DOE geologist recommended value based on no } \\
\text { appreciable canopy and } 20 \% \text { ground cover. }\end{array}$ & $\begin{array}{l}\text { Yu et al. } 2007 \\
\\
\text { DOE Project } \\
\text { Communication } \\
\text { with geologist } \\
\text { (April 2010) }\end{array}$ \\
\hline $\begin{array}{l}\text { Support practice } \\
\text { factor for grain field }\end{array}$ & -- & 1 & $0-1$ & 0.5 & $B, P$ & 2 & DOE geologist recommended value. & $\begin{array}{l}\text { Yu et al. } 2007 \\
\text { DOE Project } \\
\text { Communication } \\
\text { with geologist } \\
\text { (July 2010) }\end{array}$ \\
\hline
\end{tabular}

Offsite Dwelling Area Parameters

\begin{tabular}{|c|c|c|c|c|c|c|c|c|}
\hline $\begin{array}{l}\text { Area of offsite } \\
\text { dwelling site }\end{array}$ & $\mathrm{m}^{2}$ & 1,000 & Calculated & $\begin{array}{l}\text { Calculated by } \\
\text { the code }\end{array}$ & B & 3 & $\begin{array}{l}\text { The fruit, grain and non-leafy vegetable growing area, } \\
\text { the leafy vegetable growing area, the pasture and } \\
\text { silage growing area, the livestock feed grain growing } \\
\text { area, and the dwelling site are all approximated by } \\
\text { rectangular shapes in the atmospheric transport } \\
\text { model. The sides of these rectangles must be parallel } \\
\text { to the sides of the primary contamination. }\end{array}$ & Yu et al. 2007 \\
\hline $\begin{array}{l}\text { Irrigation applied } \\
\text { per year to home } \\
\text { garden or lawn }\end{array}$ & $\mathrm{m} / \mathrm{yr}$ & 0.2 & $0-10$ & 0 & B & 3 & $\begin{array}{l}\text { The irrigation rate was set to } 0 \mathrm{~m} / \mathrm{yr} \text { as requested by } \\
\text { DOE-PPPO, since no irrigation is being considered for } \\
\text { the dwelling site. Irrigation in the Paducah, Kentucky } \\
\text { area is considered to be unlikely. In the event } \\
\text { irrigation is necessary, the water will primarily come } \\
\text { from uncontaminated surface water and not from } \\
\text { groundwater (well). Information from the USGS } \\
\text { shows that surface water is the main source of water } \\
\text { used in Kentucky for irrigation (Kenny et al. 2009). }\end{array}$ & $\begin{array}{c}\text { DOE Project } \\
\text { Communication } \\
\text { with DOE-PPPO } \\
\text { (September 2010) } \\
\text { Kenny et al. } 2009\end{array}$ \\
\hline $\begin{array}{l}\text { Evapotranspiration } \\
\text { coefficient for } \\
\text { dwelling site }\end{array}$ & -- & 0.5 & $0-0.999$ & 0.83 & $P$ & 2 & $\begin{array}{l}\text { This value was calculated using the HELP Output data } \\
\text { for the Post-Institutional Control Period. The } \\
\text { equation used to calculate the value is available in Yu } \\
\text { et al. } 1993 \text {. }\end{array}$ & $\begin{array}{l}\text { DOE } 2003 \mathrm{~b} \\
\text { page C3-243 } \\
\text { Yu et al. } 1993\end{array}$ \\
\hline
\end{tabular}


RESRAD-OFFSITE Table of Input Parameters for the C-746-U Landfill Offsite Resident Farmer Scenario

\begin{tabular}{|c|c|c|c|c|c|c|c|c|}
\hline $\begin{array}{c}\text { Input Screen Title } \\
\text { and Parameter } \\
\text { Name }\end{array}$ & Units & $\begin{array}{l}\text { Default } \\
\text { Value }^{\mathrm{a}}\end{array}$ & $\begin{array}{c}\text { Code-Accepted } \\
\text { Values }^{b} \\
\text { Physical or } \\
\text { Numerical }^{c} \text { (N) } \\
\text { Range }^{\text {Rumed }}\end{array}$ & $\begin{array}{l}\text { Deterministic } \\
\text { Value }\end{array}$ & Type $^{d}$ & Priority ${ }^{e}$ & Justification & References \\
\hline & & & & & & & $\begin{array}{l}\text { The calculations are available in Attachment II } \\
\text { following this table. }\end{array}$ & page 78 \\
\hline $\begin{array}{l}\text { Runoff coefficient } \\
\text { for dwelling site }\end{array}$ & -- & 0.2 & $0-1$ & 0.34 & P & 2 & $\begin{array}{l}\text { This value was calculated from the HELP Output data } \\
\text { for the Post-Institutional Control Period. The } \\
\text { calculated value is 0.34. The equation used to } \\
\text { calculate the value is available in Yu et al. } 1993 \text {. } \\
\text { The calculations are available in Attachment II } \\
\text { following this table. }\end{array}$ & $\begin{array}{l}\text { DOE } 2003 \mathrm{~b} \\
\text { page C3-243 } \\
\text { Yu et al. } 1993 \\
\text { page } 73\end{array}$ \\
\hline $\begin{array}{l}\text { Depth of soil mixing } \\
\text { layer for dwelling } \\
\text { site }\end{array}$ & $\mathrm{m}$ & 0.15 & $0-1$ & 0.15 & $P, B$ & 2 & Default value is used. & Yu et al. 2007 \\
\hline $\begin{array}{l}\text { Volumetric water } \\
\text { content for dwelling } \\
\text { site }\end{array}$ & -- & 0.3 & $1 E-5-1$ & 0.347 & $P$ & 2 & $\begin{array}{l}\text { DOE geologist recommended value based on silty clay } \\
\text { loam and normal distribution. }\end{array}$ & $\begin{array}{l}\text { Yu et al. } 2007 \\
\\
\text { DOE Project } \\
\text { Communication } \\
\text { with geologist } \\
\text { (April 2010) }\end{array}$ \\
\hline $\begin{array}{l}\text { Dry bulk density of } \\
\text { soil for dwelling site }\end{array}$ & $\mathrm{g} / \mathrm{cm}^{3}$ & 1.5 & $1 \mathrm{E}-3-22.5$ & 1.5 & P & 2 & Default value is used. & Yu et al. 2007 \\
\hline $\begin{array}{c}\text { Soil erodibility } \\
\text { factor for dwelling } \\
\text { site }\end{array}$ & tons/acre & 0 & $0-0.5$ & 0.37 & P & 2 & $\begin{array}{l}\text { DOE geologist recommended value based on silty clay } \\
\text { loam and } 0.5 \% \text { organic matter. }\end{array}$ & $\begin{array}{l}\text { Yu et al. } 2007 \\
\text { Table 2.4-2, page } \\
\text { B-31 } \\
\text { DOE Project } \\
\text { Communication } \\
\text { with geologist } \\
\text { (May 2010) }\end{array}$ \\
\hline $\begin{array}{l}\text { Slope-length- } \\
\text { steepness factor for } \\
\text { dwelling site }\end{array}$ & -- & 0.4 & $0-10$ & 0.4 & $P$ & 2 & $\begin{array}{l}\text { DOE geologist recommended a value of } 0.4 \text { based on } \\
\text { site topography. }\end{array}$ & $\begin{array}{l}\text { Yu et al. } 2007 \\
\text { DOE Project } \\
\text { Communication } \\
\text { with geologist } \\
\text { (April 2010) }\end{array}$ \\
\hline $\begin{array}{c}\text { Cover and } \\
\text { management factor } \\
\text { for dwelling site }\end{array}$ & -- & 0.003 & $0-1$ & 0.2 & $B, P$ & 2 & $\begin{array}{l}\text { DOE geologist recommended value based on no } \\
\text { appreciable canopy and } 20 \% \text { ground cover. }\end{array}$ & $\begin{array}{l}\text { Yu et al. } 2007 \\
\text { DOE Project } \\
\text { Communication } \\
\text { with geologist }\end{array}$ \\
\hline
\end{tabular}


RESRAD-OFFSITE Table of Input Parameters for the C-746-U Landfill Offsite Resident Farmer Scenario

\begin{tabular}{|c|c|c|c|c|c|c|c|c|}
\hline $\begin{array}{c}\text { Input Screen Title } \\
\text { and Parameter } \\
\text { Name }\end{array}$ & Units & $\begin{array}{l}\text { Default } \\
\text { Value }^{\mathrm{a}}\end{array}$ & $\begin{array}{c}\text { Code-Accepted } \\
\text { Values }^{b} \\
\text { Physical or }^{\text {Pacal }} \\
\text { Numerical }^{\mathrm{C}} \text { (N) } \\
\text { Range }\end{array}$ & $\begin{array}{l}\text { Deterministic } \\
\text { Value }\end{array}$ & Type $^{d}$ & Priority ${ }^{e}$ & Justification & References \\
\hline & & & & & & & & (April 2010) \\
\hline $\begin{array}{l}\text { Support practice } \\
\text { factor for dwelling } \\
\text { site }\end{array}$ & -- & 1 & $0-1$ & 0.5 & $B, P$ & 2 & DOE geologist recommended value. & $\begin{array}{l}\text { Yu et al. } 2007 \\
\text { DOE Project } \\
\text { Communication } \\
\text { with geologist } \\
\text { (July 2010) }\end{array}$ \\
\hline
\end{tabular}

Atmospheric Transport

\begin{tabular}{|c|c|c|c|c|c|c|c|c|}
\hline Release height & $\mathrm{m}$ & 1 & $0-100$ & 0.1 & $\mathrm{P}$ & 2 & $\begin{array}{l}\text { The code does not allow a value of less than } 0.1 \text { thus } \\
\text { this value is selected because the release height is } \\
\text { assumed to be at ground level. }\end{array}$ & Yu et al. 2007 \\
\hline Release heat flux & $\mathrm{cal} / \mathrm{s}$ & 0 & $0-1 E+10$ & 0 & & 2 & Default value is used. & Yu et al. 2007 \\
\hline Anemometer height & $\mathrm{m}$ & 10 & $0-100$ & 10 & $\mathrm{P}$ & 2 & Default value is used. & Yu et al. 2007 \\
\hline $\begin{array}{l}\text { Ambient } \\
\text { temperature }\end{array}$ & $\mathrm{K}$ & 285 & $250-320$ & 285 & $\mathrm{P}$ & 2 & Default value is used. & Yu et al. 2007 \\
\hline $\begin{array}{l}\text { AM atmospheric } \\
\text { mixing height }\end{array}$ & $\mathrm{m}$ & 400 & $0-3,000$ & 400 & $\mathrm{P}$ & 2 & Default value is used. & Yu et al. 2007 \\
\hline $\begin{array}{l}\text { PM atmospheric } \\
\text { mixing height }\end{array}$ & $\mathrm{m}$ & 1,600 & $0-3,000$ & 1600 & $P$ & 2 & Default value is used. & Yu et al. 2007 \\
\hline $\begin{array}{l}\text { Dispersion model } \\
\text { coefficients }\end{array}$ & -- & Pasquill-Gifford & $\begin{array}{c}\text { Briggs } \\
\text { rural/urban, } \\
\text { Pasquill- } \\
\text { Gifford } \\
\end{array}$ & Pasquill-Gifford & $\mathrm{P}$ & 2 & $\begin{array}{l}\text { Pasquill-Gifford should be used for releases at or near } \\
\text { ground level. }\end{array}$ & Yu et al. 2007 \\
\hline Windspeed Terrain & -- & Rural & $\begin{array}{l}\text { Rural, } \\
\text { urban }\end{array}$ & Rural & $\mathrm{P}$ & 2 & Rural is appropriate for the terrain. & Yu et al. 2007 \\
\hline $\begin{array}{l}\text { Fruit, grain, } \\
\text { nonleafy vegetable } \\
\text { plot }\end{array}$ & $\mathrm{m}$ & 0 & $0-100$ & 0 & $\mathrm{P}$ & 2 & Default value is used. & Yu et al. 2007 \\
\hline Leafy vegetable plot & $\mathrm{m}$ & 0 & $0-100$ & 0 & $\mathrm{P}$ & 2 & Default value is used. & Yu et al. 2007 \\
\hline $\begin{array}{l}\text { Pasture, silage } \\
\text { growing area }\end{array}$ & $\mathrm{m}$ & 0 & $0-100$ & 0 & $\mathrm{P}$ & 2 & Default value is used. & Yu et al. 2007 \\
\hline Grain fields & $\mathrm{m}$ & 0 & $0-100$ & 0 & $\mathrm{P}$ & 2 & Default value is used. & Yu et al. 2007 \\
\hline Dwelling site & $\mathrm{m}$ & 0 & $0-100$ & 0 & $\mathrm{P}$ & 2 & Default value is used. & Yu et al. 2007 \\
\hline Surface water body & $\mathrm{m}$ & 0 & $0-100$ & 0 & $\mathrm{P}$ & 2 & Default value is used. & Yu et al. 2007 \\
\hline $\begin{array}{l}\text { Grid spacing for } \\
\text { areal integration }\end{array}$ & $\mathrm{m}$ & 10 & $0-500$ & 10 & $\mathrm{P}$ & 2 & Default value is used. & Yu et al. 2007 \\
\hline $\begin{array}{l}\text { Joint frequency of } \\
\text { wind speed and }\end{array}$ & -- & $1(\mathrm{~S}$ to $\mathrm{N})$ & $0-1$ & $\begin{array}{l}\text { Actual values } \\
\text { will be from }\end{array}$ & $\mathrm{P}$ & 3 & $\begin{array}{l}\text { When a star file is read in the information for all } 16 \\
\text { sectors is read in. This parameter indicates the joint }\end{array}$ & Yu et al. 2007 \\
\hline
\end{tabular}


RESRAD-OFFSITE Table of Input Parameters for the C-746-U Landfill Offsite Resident Farmer Scenario

\begin{tabular}{|c|c|c|c|c|c|c|c|c|}
\hline $\begin{array}{c}\text { Input Screen Title } \\
\text { and Parameter } \\
\text { Name }\end{array}$ & Units & $\begin{array}{l}\text { Default } \\
\text { Value }^{a}\end{array}$ & $\begin{array}{l}\text { Code-Accepted } \\
\text { Values }^{\mathrm{b}} \\
\text { Physical or } \\
\text { Numerical }^{\mathrm{C}} \text { (N) } \\
\text { Range }\end{array}$ & $\begin{array}{l}\text { Deterministic } \\
\text { Value }\end{array}$ & Type $^{d}$ & Priority ${ }^{\mathrm{e}}$ & Justification & References \\
\hline $\begin{array}{l}\text { stability class for a } \\
16 \text { sector windrose }\end{array}$ & & & & $\begin{array}{l}\text { Paducah, KY } \\
\quad \text { read } \\
\text { metereological } \\
\text { STAR file }\end{array}$ & & & $\begin{array}{l}\text { frequency that is displayed on the input screen; } \\
\text { however all } 16 \text { sectors are used in the model. The } \\
\text { STAR file selected is called KY_Paducah.str. }\end{array}$ & \\
\hline Wind speed & $\mathrm{m} / \mathrm{s}$ & $\begin{array}{c}0.89,2.46 \\
4.47,6.93,9.61 \\
12.52\end{array}$ & $0.001-20$ & $\begin{array}{r}0.89,2.46,4.47 \\
6.93,9.61,12.52\end{array}$ & $P$ & 2 & $\begin{array}{l}\text { Default values are used. The wind speed is divided } \\
\text { into six intervals in order to specify the joint } \\
\text { frequency distribution of wind speed and } \\
\text { atmospheric stability in each direction of a wind rose. } \\
\text { This is the average wind speed for the wind speed } \\
\text { interval. }\end{array}$ & Yu et al. 2007 \\
\hline
\end{tabular}

Unsaturated Zone Parameters

\begin{tabular}{|c|c|c|c|c|c|c|c|c|}
\hline \multirow{5}{*}{$\begin{array}{l}\text { Unsaturated zone } \\
\text { thickness }\end{array}$} & \multirow{5}{*}{$\mathrm{m}$} & \multirow{5}{*}{4} & \multirow{5}{*}{$\begin{array}{r}0.01- \\
10,000\end{array}$} & Zone $1=0.3$ & \multirow{5}{*}{$\mathrm{P}$} & \multirow{5}{*}{1} & \multirow{5}{*}{$\begin{array}{l}\text { This value was obtained from the previous RESRAD } \\
\text { study for the landfill described in DOE 2003b. }\end{array}$} & \multirow{5}{*}{$\begin{array}{c}\text { DOE 2003b } \\
\text { Table Att.2, page } \\
\text { C3-315 }\end{array}$} \\
\hline & & & & Zone $2=0.3$ & & & & \\
\hline & & & & Zone $3=0.9$ & & & & \\
\hline & & & & Zone $4=2.0$ & & & & \\
\hline & & & & Zone $5=8.4$ & & & & \\
\hline \multirow{5}{*}{$\begin{array}{l}\text { Unsaturated zone } \\
\text { dry bulk density }\end{array}$} & \multirow{5}{*}{$\mathrm{g} / \mathrm{cm}^{3}$} & \multirow{5}{*}{1.5} & \multirow{5}{*}{$1 \mathrm{E}-3-22.5$} & Zone $1=1.2$ & \multirow{5}{*}{$P$} & \multirow{5}{*}{2} & \multirow{5}{*}{$\begin{array}{l}\text { This value was obtained from the previous RESRAD } \\
\text { study for the landfill described in DOE 2003b. }\end{array}$} & \multirow{5}{*}{$\begin{array}{c}\text { DOE 2003b } \\
\text { Table Att.2, page } \\
\text { C3-315 }\end{array}$} \\
\hline & & & & Zone $2=1.5$ & & & & \\
\hline & & & & Zone $3=1.8$ & & & & \\
\hline & & & & Zone $4=1.5$ & & & & \\
\hline & & & & Zone $5=1.76$ & & & & \\
\hline \multirow{5}{*}{$\begin{array}{l}\text { Unsaturated zone } \\
\text { total porosity }\end{array}$} & \multirow{5}{*}{--} & \multirow{5}{*}{0.4} & \multirow{5}{*}{$1 \mathrm{E}-5-1$} & Zone $1=0.45$ & \multirow{5}{*}{$\mathrm{P}$} & \multirow{5}{*}{2} & \multirow{5}{*}{$\begin{array}{l}\text { This value was obtained from the previous RESRAD } \\
\text { study for the landfill described in DOE 2003b. } \\
\text { The values for UZ1 and UZ2 were transposed as } \\
\text { recommended by DOE. }\end{array}$} & \multirow{5}{*}{$\begin{array}{c}\text { DOE 2003b } \\
\text { Table Att.2, page } \\
\text { C3-315 } \\
\text { DOE Project } \\
\text { Communication } \\
\text { with DOE-PPPO } \\
\text { (October 2010) }\end{array}$} \\
\hline & & & & Zone $2=0.4$ & & & & \\
\hline & & & & Zone $3=0.43$ & & & & \\
\hline & & & & Zone $4=0.4$ & & & & \\
\hline & & & & Zone $5=0.45$ & & & & \\
\hline \multirow{5}{*}{$\begin{array}{l}\text { Unsaturated zone } \\
\text { effective porosity }\end{array}$} & \multirow{5}{*}{--} & \multirow{5}{*}{0.2} & \multirow{5}{*}{$1 \mathrm{E}-5-1$} & Zone $1=0.2$ & \multirow{5}{*}{$\mathrm{P}$} & \multirow{5}{*}{2} & \multirow{5}{*}{$\begin{array}{l}\text { These values were calculated using equation } 4.4 \text { from } \\
\text { Yu et al. } 1993 \text { as this approach was accepted by ANL } \\
\text { rather than using the values available in DOE 2003b. } \\
\text { This approach was taken to ensure that the effective } \\
\text { porosity was less than the total porosity. }\end{array}$} & \multirow{5}{*}{$\begin{array}{c}\text { Yu et al. } 1993 \\
\text { Project } \\
\text { Communication } \\
\text { with DOE } \\
\text { consultant } \\
\text { (October 2010) }\end{array}$} \\
\hline & & & & Zone $2=0.2$ & & & & \\
\hline & & & & Zone $3=0.08$ & & & & \\
\hline & & & & Zone $4=0.2$ & & & & \\
\hline & & & & Zone $5=0.15$ & & & & \\
\hline Unsaturated zone & - & 0.3 & $1 \mathrm{E}-5-1$ & Zone $1=0.25$ & $P$ & 3 & These values were obtained from the previous & DOE 2003b \\
\hline
\end{tabular}


RESRAD-OFFSITE Table of Input Parameters for the C-746-U Landfill Offsite Resident Farmer Scenario

\begin{tabular}{|c|c|c|c|c|c|c|c|c|}
\hline $\begin{array}{l}\text { Input Screen Title } \\
\text { and Parameter } \\
\text { Name }\end{array}$ & Units & $\begin{array}{l}\text { Default } \\
\text { Value }^{a}\end{array}$ & $\begin{array}{r}\text { Code-Accep } \\
\text { Values }^{b} \\
\text { Physical c } \\
\text { Numerical }^{c} \\
\text { Range }\end{array}$ & $\begin{array}{c}\text { Deterministic } \\
\text { Value }\end{array}$ & Type $^{d}$ & Priority ${ }^{\mathrm{e}}$ & Justification & References \\
\hline \multirow[t]{4}{*}{ field capacity } & & & & Zone $2=0.2$ & & & \multirow{4}{*}{$\begin{array}{l}\text { RESRAD study for the landfill described in DOE 2003b. } \\
\text { The values for UZ1 and UZ2 were transposed as } \\
\text { recommended by DOE. }\end{array}$} & \multirow{2}{*}{$\begin{array}{l}\text { Table Att.2, page } \\
\text { C3-315 }\end{array}$} \\
\hline & & & & Zone $3=0.35$ & & & & \\
\hline & & & & Zone $4=0.2$ & & & & DOE Project \\
\hline & & & & Zone $5=0.3$ & & & & $\begin{array}{c}\text { with DOE-PPPO } \\
\text { (July 2010) }\end{array}$ \\
\hline \multirow{5}{*}{$\begin{array}{l}\text { Unsaturated zone } \\
\text { hydraulic } \\
\text { conductivity }\end{array}$} & \multirow{5}{*}{$\mathrm{m} / \mathrm{yr}$} & \multirow{5}{*}{10} & \multirow{5}{*}{$1 E-3-1 E+6$} & Zone $1=2.92 \mathrm{E} 0$ & \multirow{5}{*}{$\mathrm{P}$} & \multirow{5}{*}{2} & \multirow{5}{*}{$\begin{array}{l}\text { This value was obtained from the previous RESRAD } \\
\text { study for the landfill described in DOE } 2003 \mathrm{~b} \text {. The } \\
\text { value for unsaturated zone } 5 \text { was changed from } 0.12 \\
\mathrm{~m} / \mathrm{yr} \text { to } 0.14 \mathrm{~m} / \mathrm{yr} \text { to allow the code to run as agreed } \\
\text { with DOE. }\end{array}$} & DOE 2003b \\
\hline & & & & Zone $2=9.46 \mathrm{E}+3$ & & & & Table Att.2, page \\
\hline & & & & Zone $3=3.15 \mathrm{E}-1$ & & & & C3-315 \\
\hline & & & & Zone $4=2.92 \mathrm{E} 0$ & & & & \\
\hline & & & & Zone $5=1.4 \mathrm{E}-1$ & & & & $\begin{array}{c}\text { Communication } \\
\text { (June 2010) }\end{array}$ \\
\hline \multirow{5}{*}{$\begin{array}{l}\text { Unsaturated zone } \\
\text { soil b parameter }\end{array}$} & \multirow{5}{*}{--} & \multirow{5}{*}{5.3} & \multirow{5}{*}{$0-15$} & Zone $1=7.75$ & \multirow{5}{*}{$P$} & \multirow{5}{*}{2} & \multirow{5}{*}{$\begin{array}{l}\text { DOE geologist evaluated the unsaturated zone and } \\
\text { determined that the value for Silty Clay Loam from Yu } \\
\text { et al. } 1993 \text { was most appropriate. }\end{array}$} & Yu et al. 1993 \\
\hline & & & & Zone $2=7.75$ & & & & \\
\hline & & & & Zone $3=11.4$ & & & & $\begin{array}{l}\text { DOE Project } \\
\text { Communication }\end{array}$ \\
\hline & & & & Zone $4=7.75$ & & & & with geologist \\
\hline & & & & Zone $5=11.4$ & & & & (April 2010) \\
\hline \multirow{5}{*}{$\begin{array}{l}\text { Unsaturated zone } \\
\text { longitudinal } \\
\text { dispersivity }\end{array}$} & \multirow{5}{*}{$\mathrm{m}$} & \multirow{5}{*}{0.1} & \multirow{5}{*}{$0-100$} & Zone $1=0.03$ & \multirow{5}{*}{$P$} & \multirow{5}{*}{2} & \multirow{5}{*}{$\begin{array}{l}\text { According to ANL expert, in general, the value of this } \\
\text { parameter is dependent on the thickness of the } \\
\text { unsaturated zone, and ranges from one hundredth of } \\
\text { the thickness to the order of the thickness. A value of } \\
1 / 10 \text { of the thickness might be more appropriate for } \\
\text { this parameter. } \\
\text { A value of } 1 / 10 \text { of the thickness was used for each } \\
\text { unsaturated zone as suggested. }\end{array}$} & Yu et al. 2007 \\
\hline & & & & Zone $2=0.03$ & & & & ROE Proiect \\
\hline & & & & Zone $3=0.09$ & & & & Communication \\
\hline & & & & Zone $4=0.2$ & & & & $\begin{array}{l}\text { with DOE } \\
\text { consultant }\end{array}$ \\
\hline & & & & Zone $5=0.84$ & & & & (November 2010) \\
\hline
\end{tabular}

Saturated Zone Hydrological Data

\begin{tabular}{|c|c|c|c|c|c|c|c|c|}
\hline $\begin{array}{c}\text { Thickness of } \\
\text { saturated zone }\end{array}$ & $\mathrm{m}$ & 100 & $0-1,000$ & & 14 & $\mathrm{P}$ & 2 & DOE geologist recommended value. \\
\hline $\begin{array}{c}\text { Dry bulk density of } \\
\text { saturated zone }\end{array}$ & $\mathrm{g} / \mathrm{cm}^{3}$ & 1.5 & $1 \mathrm{E}-3-22.5$ & & 1.67 & $\mathrm{P}$ & 1 & $\begin{array}{c}\text { This value was obtained from the previous RESRAD } \\
\text { study for the landfill described in DOE 2003b. } \\
\text { (April 2010) }\end{array}$ \\
\hline
\end{tabular}


RESRAD-OFFSITE Table of Input Parameters for the C-746-U Landfill Offsite Resident Farmer Scenario

\begin{tabular}{|c|c|c|c|c|c|c|c|c|}
\hline $\begin{array}{l}\text { Input Screen Title } \\
\text { and Parameter } \\
\text { Name }\end{array}$ & Units & $\begin{array}{l}\text { Default } \\
\text { Value }^{\mathrm{a}}\end{array}$ & $\begin{array}{c}\text { Code-Acceptec } \\
\text { Values }^{b} \\
\text { Physical or } \\
\text { Numerical' (N) } \\
\text { Range }\end{array}$ & $\begin{array}{l}\text { Deterministic } \\
\text { Value }\end{array}$ & Type $^{d}$ & Priority & Justification & References \\
\hline & & & & & & & & page C3-315 \\
\hline $\begin{array}{l}\text { Saturated zone } \\
\text { total porosity }\end{array}$ & -- & 0.4 & $1 E-5-1$ & 0.34 & $\mathrm{P}$ & 1 & $\begin{array}{l}\text { This value was obtained from the previous RESRAD } \\
\text { study for the landfill described in DOE 2003b. }\end{array}$ & $\begin{array}{c}\text { DOE 2003b } \\
\text { Table Att.4., page } \\
\text { C3-315 }\end{array}$ \\
\hline $\begin{array}{l}\text { Saturated zone } \\
\text { effective porosity }\end{array}$ & -- & 0.2 & $1 E-5-1$ & 0.3 & $\mathrm{P}$ & 1 & $\begin{array}{l}\text { This value was obtained from the previous RESRAD } \\
\text { study for the landfill described in DOE 2003b. }\end{array}$ & $\begin{array}{l}\text { DOE 2003b } \\
\text { Table 4.7, page 4- } \\
\text { 21, Table Att.4., } \\
\text { page C3-315 }\end{array}$ \\
\hline $\begin{array}{l}\text { Saturated zone } \\
\text { hydraulic } \\
\text { conductivity }\end{array}$ & $\mathrm{m} / \mathrm{yr}$ & 100 & $\begin{array}{l}1 E-3- \\
1 E+10\end{array}$ & 55630 & $P$ & 1 & $\begin{array}{l}\text { This value was obtained from the previous RESRAD } \\
\text { study for the landfill described in DOE 2003b. This } \\
\text { value was verified by DOE geologist. }\end{array}$ & $\begin{array}{l}\text { DOE 2003b } \\
\text { Table Att.4., page } \\
\text { C3-315 } \\
\text { DOE Project } \\
\text { Communication } \\
\text { with geologist and } \\
\text { engineer (April } \\
\text { 2010) }\end{array}$ \\
\hline $\begin{array}{c}\text { Saturated zone } \\
\text { hydraulic gradient } \\
\text { to well }\end{array}$ & -- & 0.02 & $1 \mathrm{E}-10-10$ & 0.0011 & $P$ & 2 & $\begin{array}{l}\text { This value was obtained from the previous RESRAD } \\
\text { study for the landfill described in DOE 2003b. }\end{array}$ & $\begin{array}{c}\text { DOE 2003b } \\
\text { Table Att.4., page } \\
\text { C3-315 }\end{array}$ \\
\hline $\begin{array}{c}\text { Saturated } \\
\text { zone longitudinal } \\
\text { dispersivity to well }\end{array}$ & $\mathrm{m}$ & 3 & $0-1,000$ & 15 & $\mathrm{P}$ & 2 & $\begin{array}{l}\text { This value was obtained from DOE 2003b and agreed } \\
\text { upon by DOE geologist. } \\
\text { In addition, this value was provided by site modeling } \\
\text { experts in Paducah (i.e., the values for saturated zone } \\
\text { longitudinal, horizontal lateral and vertical lateral } \\
\text { dispersivity were provided by Chad Drummond, and } \\
\text { are used by Los Alamos Technical Associates (LATA) } \\
\text { KY for their modeling). }\end{array}$ & $\begin{array}{c}\text { DOE 2003b } \\
\text { Table 4.7, page 4- } \\
21 \\
\text { DOE Project } \\
\text { Communication } \\
\text { with geologist } \\
\text { (April 2010) } \\
\text { PRS 2008b } \\
\text { Table 3.5, page 3- } \\
36 \\
\text { DOE Project } \\
\text { Communication } \\
\text { with DOE } \\
\text { consultant } \\
\text { (November 2010) } \\
\text { DOE Project } \\
\end{array}$ \\
\hline
\end{tabular}


RESRAD-OFFSITE Table of Input Parameters for the C-746-U Landfill Offsite Resident Farmer Scenario

\begin{tabular}{|c|c|c|c|c|c|c|c|c|}
\hline $\begin{array}{c}\text { Input Screen Title } \\
\text { and Parameter } \\
\text { Name }\end{array}$ & Units & $\begin{array}{l}\text { Default } \\
\text { Value }^{\mathrm{a}}\end{array}$ & $\begin{array}{l}\text { Code-Acceptec } \\
\text { Values }^{b} \\
\text { Physical or } \\
\text { Numerical }{ }^{\mathrm{c}}(\mathrm{N}) \\
\text { Range }\end{array}$ & $\begin{array}{l}\text { Deterministic } \\
\text { Value }\end{array}$ & Type $^{d}$ & Priority & Justification & References \\
\hline & & & & & & & & $\begin{array}{c}\text { Communication } \\
\text { with DOE-PPPO } \\
\text { (April 2011) }\end{array}$ \\
\hline $\begin{array}{l}\text { Saturated zone } \\
\text { horizontal lateral } \\
\text { dispersivity to well }\end{array}$ & $\mathrm{m}$ & 0.4 & $0-1,000$ & 1.5 & $P$ & 2 & $\begin{array}{l}\text { This value was provided by site modeling experts in } \\
\text { Paducah (i.e., the values for saturated zone } \\
\text { longitudinal, horizontal lateral and vertical lateral } \\
\text { dispersivity were provided by Chad Drummond, and } \\
\text { are used by Los Alamos Technical Associates (LATA) } \\
\text { KY for their modeling). }\end{array}$ & $\begin{array}{l}\text { DOE Project } \\
\text { Communication } \\
\text { with DOE-PPPO } \\
\text { (April 2011) }\end{array}$ \\
\hline $\begin{array}{c}\text { Saturated zone } \\
\text { vertical lateral } \\
\text { dispersivity to well }\end{array}$ & $\mathrm{m}$ & 0.02 & $0-1,000$ & 0.15 & $\mathrm{P}$ & 2 & $\begin{array}{l}\text { This value was provided by site modeling experts in } \\
\text { Paducah (i.e., the values for saturated zone } \\
\text { longitudinal, horizontal lateral and vertical lateral } \\
\text { dispersivity were provided by Chad Drummond, and } \\
\text { are used by Los Alamos Technical Associates (LATA) } \\
\text { KY for their modeling). }\end{array}$ & $\begin{array}{c}\text { DOE Project } \\
\text { Communication } \\
\text { with DOE-PPPO } \\
\text { (April 2011) }\end{array}$ \\
\hline $\begin{array}{l}\text { Depth of aquifer } \\
\text { contributing to well }\end{array}$ & $\mathrm{m}$ & 10 & $\begin{array}{l}1 \mathrm{E}-4- \\
1,000\end{array}$ & 9.1 & $\mathrm{P}$ & 2 & $\begin{array}{l}\text { The value of } 9.1 \mathrm{~m} \text { is used for the Resident Farmer } \\
\text { since this value was recommended by LATA (Los } \\
\text { Alamos Technical Associates) Kentucky. In addition, } \\
\text { the value for the well pump intake depth in RESRAD } \\
\text { was modified in order to achieve consistency with the } \\
\text { depth of aquifer contributing to well in RESRAD- } \\
\text { OFFSITE as suggested by Argonne National } \\
\text { Laboratory (ANL) expert. }\end{array}$ & $\begin{array}{l}\text { DOE Project } \\
\text { Communication } \\
\text { with DOE } \\
\text { consultant } \\
\text { (November 2010) }\end{array}$ \\
\hline $\begin{array}{c}\text { Saturated zone } \\
\text { hydraulic gradient } \\
\text { to surface water } \\
\text { body }\end{array}$ & -- & 0.02 & $1 \mathrm{E}-10-10$ & 0.0011 & $\mathrm{P}$ & 3 & $\begin{array}{l}\text { Assumed to be the same as hydraulic gradient to the } \\
\text { well. }\end{array}$ & $\begin{array}{c}\text { DOE 2003b } \\
\text { Table Att.4., page } \\
\text { C3-315 }\end{array}$ \\
\hline $\begin{array}{l}\text { Saturated zone } \\
\text { longitudinal } \\
\text { dispersivity to } \\
\text { surface water body }\end{array}$ & $\mathrm{m}$ & 10 & $0-1,000$ & 15 & $P$ & 3 & $\begin{array}{l}\text { This value was obtained from DOE 2003b and agreed } \\
\text { upon by DOE geologist. } \\
\text { In addition, this value was recommended by Chad } \\
\text { Drummond (Los Alamos Technical Associates (LATA) } \\
\text { KY) in April } 2011 .\end{array}$ & $\begin{array}{c}\text { DOE 2003b } \\
\text { Table 4.7, page 4- } \\
21 \\
\text { DOE Project } \\
\text { Communication } \\
\text { with geologist } \\
\text { (April 2010) } \\
\text { DOE Project } \\
\text { Communication } \\
\text { with DOE-PPPO } \\
\text { (April 2011) }\end{array}$ \\
\hline
\end{tabular}


RESRAD-OFFSITE Table of Input Parameters for the C-746-U Landfill Offsite Resident Farmer Scenario

\begin{tabular}{|c|c|c|c|c|c|c|c|c|}
\hline $\begin{array}{c}\text { Input Screen Title } \\
\text { and Parameter } \\
\text { Name }\end{array}$ & Units & $\begin{array}{l}\text { Default } \\
\text { Value }^{\mathrm{a}}\end{array}$ & $\begin{array}{c}\text { Code-Accepted } \\
\text { Values }^{b} \\
\text { Physical or } \\
\text { Numerical }^{c} \text { (N) } \\
\text { Range }^{\text {Rang }}\end{array}$ & $\begin{array}{l}\text { Deterministic } \\
\text { Value }\end{array}$ & Type $^{d}$ & Priority $^{\mathrm{e}}$ & Justification & References \\
\hline $\begin{array}{l}\text { Saturated zone } \\
\text { horizontal lateral } \\
\text { dispersivity to } \\
\text { surface water body }\end{array}$ & $\mathrm{m}$ & 1 & $0-1,000$ & 1.5 & $\mathrm{P}$ & 3 & $\begin{array}{l}\text { This value was recommended by Chad Drummond } \\
\text { (Los Alamos Technical Associates (LATA) KY) in April } \\
2011 .\end{array}$ & $\begin{array}{l}\text { DOE Project } \\
\text { Communication } \\
\text { with DOE-PPPO } \\
\text { (April 2011) }\end{array}$ \\
\hline $\begin{array}{l}\text { Saturated zone } \\
\text { vertical lateral } \\
\text { dispersivity to } \\
\text { surface water body }\end{array}$ & $\mathrm{m}$ & 0.06 & $0-1,000$ & 0.15 & $P$ & 3 & $\begin{array}{l}\text { This value was recommended by Chad Drummond } \\
\text { (Los Alamos Technical Associates (LATA) KY) in April } \\
2011 .\end{array}$ & $\begin{array}{c}\text { DOE Project } \\
\text { Communication } \\
\text { with DOE-PPPO } \\
\text { (April 2011) } \\
\end{array}$ \\
\hline $\begin{array}{l}\text { Depth of aquifer } \\
\text { contributing to } \\
\text { surface water body }\end{array}$ & $\mathrm{m}$ & 10 & $0-1,000$ & 9.1 & $\mathrm{P}$ & 3 & $\begin{array}{l}\text { The value of } 9.1 \mathrm{~m} \text { was recommended by LATA (Los } \\
\text { Alamos Technical Associates) Kentucky for the depth } \\
\text { of aquifer contributing to well. However, this value is } \\
\text { assumed for the depth of aquifer contributing to } \\
\text { surface water body. This modification will not impact } \\
\text { the results since the surface water body is not } \\
\text { considered in the CSM. }\end{array}$ & $\begin{array}{c}\text { DOE Project } \\
\text { Communication } \\
\text { with DOE } \\
\text { consultant } \\
\text { (November 2010) }\end{array}$ \\
\hline
\end{tabular}

Surface Water Body Parameters

\begin{tabular}{|c|c|c|c|c|c|c|c|c|c|}
\hline $\begin{array}{l}\text { Sediment delivery } \\
\text { ratio }\end{array}$ & -- & 1 & $0-1$ & & 0 & $P$ & 3 & $\begin{array}{l}\text { DOE geologist recommended a value of } 0 \text { since this is } \\
\text { the fraction of the contaminated soil that is eroded } \\
\text { from the area of primary contamination that reaches } \\
\text { the surface water body. }\end{array}$ & $\begin{array}{l}\text { Yu et al. } 2007 \\
\text { DOE Project } \\
\text { Communication } \\
\text { with geologist } \\
\text { (April 2010) }\end{array}$ \\
\hline $\begin{array}{l}\text { Volume of surface } \\
\text { water body }\end{array}$ & $\mathrm{m}^{3}$ & 150,000 & $1-1 E+34$ & $\mathrm{~N}$ & 150000 & $P$ & 3 & Default value is used. & Yu et al. 2007 \\
\hline $\begin{array}{c}\text { Mean residence } \\
\text { time of water in } \\
\text { surface water body }\end{array}$ & $\mathrm{yr}$ & 1 & $\begin{array}{l}1 E-4- \\
1 E+34\end{array}$ & $\mathrm{~N}$ & 1 & $\mathrm{P}$ & 3 & Default value is used. & Yu et al. 2007 \\
\hline
\end{tabular}

Groundwater Transport Parameters

Distance from Downgradient Edge of Contamination to:

\begin{tabular}{|c|c|c|c|c|c|c|c|c|}
\hline $\begin{array}{c}\text { Well in the } \\
\text { direction parallel to } \\
\text { aquifer flow }\end{array}$ & $\mathrm{m}$ & 100 & $\begin{array}{c}-16,000- \\
+16,000\end{array}$ & 407 & $\mathrm{P}, \mathrm{B}$ & 2 & $\begin{array}{l}\text { This is the distance, in meters, between two lines that } \\
\text { are perpendicular to the direction of aquifer flow, } \\
\text { one at the down gradient edge of the primary }\end{array}$ & $\begin{array}{c}\text { Yu et at. 2007 } \\
\text { DOE 2003b }\end{array}$ \\
\hline
\end{tabular}


RESRAD-OFFSITE Table of Input Parameters for the C-746-U Landfill Offsite Resident Farmer Scenario

\begin{tabular}{|c|c|c|c|c|c|c|c|c|}
\hline $\begin{array}{c}\text { Input Screen Title } \\
\text { and Parameter } \\
\text { Name }\end{array}$ & Units & $\begin{array}{l}\text { Default } \\
\text { Value }^{\mathrm{a}}\end{array}$ & $\begin{array}{l}\text { Code-Acceptec } \\
\text { Values }^{b} \\
\text { Physical or } \\
\text { Numerical }{ }^{c}(\mathrm{~N}) \\
\text { Range }\end{array}$ & $\begin{array}{l}\text { Deterministic } \\
\text { Value }\end{array}$ & Type $^{d}$ & Priority $^{e}$ & Justification & References \\
\hline & & & & & & & $\begin{array}{l}\text { contamination and the other at the well. This value is } \\
\text { set at "0" for onsite receptors to put the well at } \\
\text { downgradient edge of the primary contaminated } \\
\text { zone. For the offsite receptor, the well is located at } \\
407 \mathrm{~m} \text { from the downgradient edge of the } \\
\text { contaminated zone. This point corresponds to an } \\
\text { exposure point previously evaluated by DOE at the } \\
\text { property boundary. }\end{array}$ & page 4-1 \\
\hline $\begin{array}{l}\text { Surface water body } \\
\text { in the direction } \\
\text { parallel to aquifer } \\
\text { flow }\end{array}$ & $\mathrm{m}$ & 600 & $\begin{array}{l}-16,000- \\
+16,000\end{array}$ & -1249 & $P$ & 3 & $\begin{array}{l}\text { Setting this to a negative value will cause the code to } \\
\text { skip the groundwater transport calculations to the } \\
\text { surface water body. } \\
\text { Surface water is not considered in the CSM. }\end{array}$ & Yu et at. 2007 \\
\hline $\begin{array}{l}\text { Well in the } \\
\text { direction } \\
\text { perpendicular to } \\
\text { aquifer flow }\end{array}$ & $\mathrm{m}$ & 0 & $\begin{array}{l}-16,000- \\
+16,000\end{array}$ & 0 & $P, B$ & 2 & $\begin{array}{l}\text { The well is located } 407 \text { meters downgradient to the } \\
\text { primary contaminated zone. }\end{array}$ & Yu et at. 2007 \\
\hline $\begin{array}{l}\text { Near edge of } \\
\text { surface water body } \\
\text { in the direction } \\
\text { perpendicular to } \\
\text { aquifer flow }\end{array}$ & $\mathrm{m}$ & -150 & $\begin{array}{l}-16,000- \\
+16,000\end{array}$ & -72 & $P$ & 3 & $\begin{array}{l}\text { The surface water body is located upgradient to the } \\
\text { primary contaminated zone since it is not considered } \\
\text { in the CSM. }\end{array}$ & Yu et at. 2007 \\
\hline $\begin{array}{l}\text { Far edge of surface } \\
\text { water body in the } \\
\text { direction } \\
\text { perpendicular to } \\
\text { aquifer flow } \\
\end{array}$ & $\mathrm{m}$ & 150 & $\begin{array}{l}-16,000- \\
+16,000\end{array}$ & 228 & $P$ & 3 & $\begin{array}{l}\text { The surface water body is located upgradient to the } \\
\text { primary contaminated zone since it is not considered } \\
\text { in the CSM. }\end{array}$ & Yu et at. 2007 \\
\hline $\begin{array}{l}\text { Convergence } \\
\text { criterion (fractional } \\
\text { accuracy desired) }\end{array}$ & -- & 0.001 & $0-0.1$ & 0.001 & $P$ & 3 & $\begin{array}{l}\text { Default value is used. The surface water body is } \\
\text { located upgradient to the primary contaminated zone } \\
\text { since it is not considered in the CSM. }\end{array}$ & Yu et at. 2007 \\
\hline $\begin{array}{l}\text { Main subzones in } \\
\text { saturated zone }\end{array}$ & -- & 1 & $1-1024$ & 1 & NA & 3 & Default value is used. & Yu et al. 2007 \\
\hline $\begin{array}{l}\text { Main subzones in } \\
\text { each partially } \\
\text { saturated zone }\end{array}$ & -- & 1 & $1-1024$ & 1 & NA & 3 & Default value is used. & Yu et al. 2007 \\
\hline
\end{tabular}


RESRAD-OFFSITE Table of Input Parameters for the C-746-U Landfill Offsite Resident Farmer Scenario

\begin{tabular}{|c|c|c|c|c|c|c|c|c|}
\hline $\begin{array}{l}\text { Input Screen Title } \\
\text { and Parameter } \\
\text { Name }\end{array}$ & Units & $\begin{array}{l}\text { Default } \\
\text { Value }^{a}\end{array}$ & $\begin{array}{c}\text { Code-Accepted } \\
\text { Values }^{b} \\
\text { Physical or } \\
\text { Numerical } \\
\text { Range } \\
\text { Ra) } \\
\end{array}$ & $\begin{array}{c}\text { Deterministic } \\
\text { Value }\end{array}$ & Type $^{d}$ & Priority & Justification & References \\
\hline $\begin{array}{l}\text { Nuclide-specific } \\
\text { retardation in all } \\
\text { subzones, } \\
\text { longitudinal } \\
\text { dispersion in all but } \\
\text { the subzone of } \\
\text { transformation? }\end{array}$ & -- & Yes & Yes/No & Yes & NA & 3 & Default value is used. & Yu et at. 2007 \\
\hline $\begin{array}{l}\text { Longitudinal } \\
\text { dispersion in all } \\
\text { subzones, nuclide- } \\
\text { specific retardation } \\
\text { in all but the } \\
\text { subzone of } \\
\text { transformation, } \\
\text { parent retardation } \\
\text { in zone of } \\
\text { transformation? }\end{array}$ & -- & No & Yes/No & No & NA & 3 & Default value is used. & Yu et at. 2007 \\
\hline $\begin{array}{c}\text { Longitudinal } \\
\text { dispersion in all } \\
\text { subzones, nuclide- } \\
\text { specific retardation } \\
\text { in all but the } \\
\text { subzone of } \\
\text { transformation, } \\
\text { progeny retardation } \\
\text { in zone of } \\
\text { transformation? } \\
\end{array}$ & -- & No & Yes/No & No & NA & 3 & Default value is used. & Yu et at. 2007 \\
\hline $\begin{array}{l}\text { Quantity of water } \\
\text { consumed by an } \\
\text { individual }\end{array}$ & $\mathrm{L} / \mathrm{yr}$ & 510 & $0-1,000$ & 700 & $\mathrm{M}, \mathrm{B}$ & 2 & $\begin{array}{l}\text { This value was converted from Table D.1 in DOE } \\
2009 . \\
\text { See Attachment II following this table of parameters. }\end{array}$ & $\begin{array}{c}\text { DOE } 2009 \\
\text { Appendix D, } \\
\text { Table D.1, page D- } \\
11 \\
\end{array}$ \\
\hline $\begin{array}{l}\text { Fraction of water } \\
\text { from surface body } \\
\text { for human } \\
\text { consumption }\end{array}$ & -- & 0 & $0-1$ & 0 & B, P & 3 & $\begin{array}{l}\text { This parameter is the fraction of water that is } \\
\text { obtained from the contaminated surface water body } \\
\text { for the specific use. If water is obtained from other } \\
\text { sources (contaminated well, uncontaminated outside } \\
\text { source), the fraction will be less than one. } \\
\text { It is assumed that all drinking water will come from } \\
\text { the well; therefore, the fraction of water from } \\
\text { contaminated surface water body is } 0 \text {. }\end{array}$ & Yu et al. 2007 \\
\hline
\end{tabular}


RESRAD-OFFSITE Table of Input Parameters for the C-746-U Landfill Offsite Resident Farmer Scenario

\begin{tabular}{|c|c|c|c|c|c|c|c|c|}
\hline $\begin{array}{c}\text { Input Screen Title } \\
\text { and Parameter } \\
\text { Name }\end{array}$ & Units & $\begin{array}{l}\text { Default } \\
\text { Value }^{a}\end{array}$ & $\begin{array}{l}\text { Code-Acceptec } \\
\text { Values }^{b} \\
\text { Physical or } \\
\text { Numerical }{ }^{c} \text { (N) } \\
\text { Range }\end{array}$ & $\begin{array}{l}\text { Deterministic } \\
\text { Value }\end{array}$ & Type $^{d}$ & Priority $^{\mathbf{e}}$ & Justification & References \\
\hline $\begin{array}{l}\text { Fraction of water } \\
\text { from well for } \\
\text { human } \\
\text { consumption }\end{array}$ & -- & 1 & $0-1$ & 1 & $B, P$ & 2 & $\begin{array}{l}\text { This parameter is the fraction of water that is } \\
\text { obtained from the contaminated well for the specific } \\
\text { use. If water is obtained from other sources } \\
\text { (contaminated surface water body, uncontaminated } \\
\text { outside source), the fraction will be less than one. } \\
\text { It is assumed that all drinking water will come from } \\
\text { the well; therefore, the fraction of water from the } \\
\text { contaminated well is } 1 .\end{array}$ & Yu et al. 2007 \\
\hline $\begin{array}{l}\text { Number of } \\
\text { household } \\
\text { individuals } \\
\text { consuming and } \\
\text { using water } \\
\end{array}$ & -- & 4 & $0-1,000$ & 4 & B & 3 & $\begin{array}{l}\text { Default value is used. The number of individuals } \\
\text { consuming and using water from the well is used to } \\
\text { estimate the minimum amount of water that is being } \\
\text { extracted from the well. This is not used in the } \\
\text { computational code. }\end{array}$ & Yu et al. 2007 \\
\hline $\begin{array}{l}\text { Quantity of water } \\
\text { for use indoors of } \\
\text { dwelling per } \\
\text { individual }\end{array}$ & $L / d$ & 225 & $0-1,000$ & 225 & $M, B$ & 3 & $\begin{array}{l}\text { Default value is used. This is the total amount of } \\
\text { water used in the house. It includes water used for } \\
\text { cleaning, washing, showering/bathing, etc. } \\
\text { It is also used by the interface to estimate the volume } \\
\text { of water that needs to be extracted from the well to } \\
\text { satisfy the specified needs. }\end{array}$ & Yu et al. 2007 \\
\hline $\begin{array}{l}\text { Fraction of water } \\
\text { from surface body } \\
\text { for use indoors of } \\
\text { dwelling }\end{array}$ & -- & 0 & $0-1$ & 0 & $B, P$ & 3 & $\begin{array}{l}\text { This parameter is the fraction of water that is } \\
\text { obtained from the contaminated surface water body } \\
\text { for the specific use. If water is obtained from other } \\
\text { sources (contaminated well, uncontaminated outside } \\
\text { source), the fraction will be less than one. } \\
\text { It is assumed that all water will come from a } \\
\text { contaminated well. }\end{array}$ & Yu et al. 2007 \\
\hline $\begin{array}{l}\text { Fraction of water } \\
\text { from well for use } \\
\text { indoors of dwelling }\end{array}$ & -- & 1 & $0-1$ & 1 & $B, P$ & 2 & $\begin{array}{l}\text { This parameter is the fraction of water that is } \\
\text { obtained from the contaminated well for the specific } \\
\text { use. If water is obtained from other sources } \\
\text { (contaminated surface water body, uncontaminated } \\
\text { outside source), the fraction will be less than one. } \\
\text { It is assumed that all water will come from a } \\
\text { contaminated well. }\end{array}$ & Yu et al. 2007 \\
\hline \multicolumn{9}{|l|}{ Beef Cattle } \\
\hline $\begin{array}{l}\text { Quantity of water } \\
\text { for beef cattle }\end{array}$ & $L / d$ & 50 & $0-500$ & 50 & $M, B$ & 2 & $\begin{array}{l}\text { The value used corresponds to the quantity of water } \\
\text { ingested daily by beef, available in DOE } 2009 \text {. }\end{array}$ & $\begin{array}{c}\text { DOE } 2009 \\
\text { Appendix D, Table }\end{array}$ \\
\hline
\end{tabular}


RESRAD-OFFSITE Table of Input Parameters for the C-746-U Landfill Offsite Resident Farmer Scenario

\begin{tabular}{|c|c|c|c|c|c|c|c|c|}
\hline $\begin{array}{c}\text { Input Screen Title } \\
\text { and Parameter } \\
\text { Name }\end{array}$ & Units & $\begin{array}{l}\text { Default } \\
\text { Value }^{\mathrm{a}}\end{array}$ & 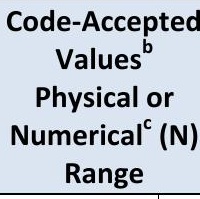 & $\begin{array}{c}\text { Deterministic } \\
\text { Value }\end{array}$ & Type $^{d}$ & Priority & Justification & References \\
\hline & & & & & & & See Attachment II following this table of parameters. & D.46, Page D-56. \\
\hline $\begin{array}{l}\text { Fraction of water } \\
\text { from surface body } \\
\text { for beef cattle }\end{array}$ & -- & 0 & $0-1$ & 0 & $B, P$ & 3 & $\begin{array}{l}\text { This parameter is the fraction of water that is } \\
\text { obtained from the contaminated surface water body } \\
\text { for the specific use. If water is obtained from other } \\
\text { sources (contaminated well, uncontaminated outside } \\
\text { source), the fraction will be less than one. } \\
\text { It is assumed that all water will come from a } \\
\text { contaminated well. }\end{array}$ & Yu et al. 2007 \\
\hline $\begin{array}{l}\text { Fraction of water } \\
\text { from well for beef } \\
\text { cattle }\end{array}$ & -- & 1 & $0-1$ & 1 & $B, P$ & 2 & $\begin{array}{l}\text { This parameter is the fraction of water that is } \\
\text { obtained from the contaminated well for the specific } \\
\text { use. If water is obtained from other sources } \\
\text { (contaminated surface water body, uncontaminated } \\
\text { outside source), the fraction will be less than one. } \\
\text { It is assumed that all water will come from a } \\
\text { contaminated well. }\end{array}$ & Yu et al. 2007 \\
\hline $\begin{array}{l}\text { Number of cattle } \\
\text { for beef cattle }\end{array}$ & -- & 2 & $0-10$ & 2 & B & 3 & Default value is used. & Yu et al. 2007 \\
\hline
\end{tabular}

\section{Dairy Cows}

\begin{tabular}{|c|c|c|c|c|c|c|c|c|}
\hline $\begin{array}{l}\text { Quantity of water } \\
\text { for dairy cows }\end{array}$ & $L / d$ & 160 & $0-1,000$ & 160 & $M, B$ & 2 & The default value is used. & Yu et al. 2007 \\
\hline $\begin{array}{l}\text { Fraction of water } \\
\text { from surface body } \\
\text { for dairy cows }\end{array}$ & -- & 0 & $0-1$ & 0 & $B, P$ & 3 & $\begin{array}{l}\text { This parameter is the fraction of water that is } \\
\text { obtained from the contaminated surface water body } \\
\text { for the specific use. If water is obtained from other } \\
\text { sources (contaminated well, uncontaminated outside } \\
\text { source), the fraction will be less than one. } \\
\text { It is assumed that all water will come from a } \\
\text { contaminated well. }\end{array}$ & Yu et al. 2007 \\
\hline $\begin{array}{l}\text { Fraction of water } \\
\text { from well for dairy } \\
\text { cows }\end{array}$ & -- & 1 & $0-1$ & 1 & $B, P$ & 2 & $\begin{array}{l}\text { This parameter is the fraction of water that is } \\
\text { obtained from the contaminated well for the specific } \\
\text { use. If water is obtained from other sources } \\
\text { (contaminated surface water body, uncontaminated } \\
\text { outside source), the fraction will be less than one. } \\
\text { It is assumed that all water will come from a } \\
\text { contaminated well. }\end{array}$ & Yu et al. 2007 \\
\hline
\end{tabular}


RESRAD-OFFSITE Table of Input Parameters for the C-746-U Landfill Offsite Resident Farmer Scenario

\begin{tabular}{|c|c|c|c|c|c|c|c|c|}
\hline $\begin{array}{c}\text { Input Screen Title } \\
\text { and Parameter } \\
\text { Name }\end{array}$ & Units & $\begin{array}{l}\text { Default } \\
\text { Value }^{a}\end{array}$ & $\begin{array}{l}\text { Code-Accepted } \\
\text { Values }^{b} \\
\text { Physical or }^{\mathrm{C}} \\
\text { Numerical } \\
\text { Range }\end{array}$ & $\begin{array}{l}\text { Deterministic } \\
\text { Value }\end{array}$ & Type $^{d}$ & Priority $^{\mathrm{e}}$ & Justification & References \\
\hline $\begin{array}{c}\text { Number of cows for } \\
\text { dairy cows }\end{array}$ & -- & 2 & $0-10$ & 2 & B & 3 & Default value is used. & Yu et al. 2007 \\
\hline $\begin{array}{l}\text { Fraction of water } \\
\text { from surface body } \\
\text { for fruit, grain, and } \\
\text { nonleafy vegetables }\end{array}$ & -- & 0 & $0-1$ & 0 & $B, P$ & 3 & $\begin{array}{l}\text { This parameter is the fraction of water that is } \\
\text { obtained from the contaminated surface water body } \\
\text { for the specific use. If water is obtained from other } \\
\text { sources (contaminated well, uncontaminated outside } \\
\text { source), the fraction will be less than one. } \\
\text { It is assumed that all water will come from a } \\
\text { contaminated well. }\end{array}$ & $\begin{array}{c}\text { DOE Project } \\
\text { Communication } \\
\text { with DOE-PPPO } \\
\text { (April 2011) } \\
\text { Yu et al. } 2007\end{array}$ \\
\hline $\begin{array}{l}\text { Fraction of water } \\
\text { from well for fruit, } \\
\text { grain, and nonleafy } \\
\text { vegetables }\end{array}$ & -- & 1 & $0-1$ & 1 & $B, P$ & 2 & $\begin{array}{l}\text { This parameter is the fraction of water that is } \\
\text { obtained from the contaminated well for the specific } \\
\text { use. If water is obtained from other sources } \\
\text { (contaminated surface water body, uncontaminated } \\
\text { outside source), the fraction will be less than one. } \\
\text { It is assumed that all water will come from a } \\
\text { contaminated well. }\end{array}$ & $\begin{array}{c}\text { DOE Project } \\
\text { Communication } \\
\text { with DOE-PPPO } \\
\text { (April 2011) } \\
\text { Yu et al. } 2007\end{array}$ \\
\hline
\end{tabular}

Leafy Vegetables

\begin{tabular}{|c|c|c|c|c|c|c|c|c|}
\hline $\begin{array}{l}\text { Fraction of water } \\
\text { from surface body } \\
\text { for leafy vegetables }\end{array}$ & -- & 0 & $0-1$ & 0 & $\mathrm{~B}, \mathrm{P}$ & 3 & $\begin{array}{l}\text { This parameter is the fraction of water that is } \\
\text { obtained from the contaminated surface water body } \\
\text { for the specific use. If water is obtained from other } \\
\text { sources (contaminated well, uncontaminated outside } \\
\text { source), the fraction will be less than one. } \\
\text { It is assumed that all water will come from a } \\
\text { contaminated well. }\end{array}$ & $\begin{array}{c}\text { DOE Project } \\
\text { Communication } \\
\text { with DOE-PPPO } \\
\text { (April 2011) } \\
\text { Yu et al. } 2007\end{array}$ \\
\hline $\begin{array}{l}\text { Fraction of water } \\
\text { from well for leafy } \\
\text { vegetables }\end{array}$ & -- & 1 & $0-1$ & 1 & $\mathrm{~B}, \mathrm{P}$ & 2 & $\begin{array}{l}\text { This parameter is the fraction of water that is } \\
\text { obtained from the contaminated well for the specific } \\
\text { use. If water is obtained from other sources } \\
\text { (contaminated surface water body, uncontaminated } \\
\text { outside source), the fraction will be less than one. } \\
\text { It is assumed that all water will come from a } \\
\text { contaminated well. }\end{array}$ & $\begin{array}{c}\text { DOE Project } \\
\text { Communication } \\
\text { with DOE-PPPO } \\
\text { (April 2011) } \\
\text { Yu et al. } 2007\end{array}$ \\
\hline
\end{tabular}

Pasture and Silage

Fraction of water


RESRAD-OFFSITE Table of Input Parameters for the C-746-U Landfill Offsite Resident Farmer Scenario

\begin{tabular}{|c|c|c|c|c|c|c|c|c|}
\hline $\begin{array}{c}\text { Input Screen Title } \\
\text { and Parameter } \\
\text { Name }\end{array}$ & Units & $\begin{array}{l}\text { Default } \\
\text { Value }^{a}\end{array}$ & $\begin{array}{l}\text { Code-Accepted } \\
\text { Values }^{b} \\
\text { Physical or } \\
\text { Numerical }^{\mathrm{C}}(\mathrm{N}) \\
\text { Range }^{2}\end{array}$ & $\begin{array}{l}\text { Deterministic } \\
\text { Value }\end{array}$ & Type $^{d}$ & Priority ${ }^{e}$ & Justification & References \\
\hline $\begin{array}{c}\text { from surface body } \\
\text { for pasture and } \\
\text { silage }\end{array}$ & & & & & & & $\begin{array}{l}\text { contaminated surface water body for the specific use. } \\
\text { If water is obtained from other sources } \\
\text { (contaminated well, uncontaminated outside source), } \\
\text { the fraction will be less than one. } \\
\text { It is assumed that all water will come from an } \\
\text { uncontaminated outside source. }\end{array}$ & $\begin{array}{l}\text { Communication } \\
\text { with DOE-PPPO } \\
\text { (October 2010) } \\
\text { Yu et al. } 2007\end{array}$ \\
\hline $\begin{array}{l}\text { Fraction of water } \\
\text { from well for } \\
\text { pasture and silage }\end{array}$ & -- & 1 & $0-1$ & 0 & $B, P$ & 2 & $\begin{array}{l}\text { This parameter is the fraction of water that is } \\
\text { obtained from the contaminated well for the specific } \\
\text { use. If water is obtained from other sources } \\
\text { (contaminated surface water body, uncontaminated } \\
\text { outside source), the fraction will be less than one. } \\
\text { It is assumed that all water will come from an } \\
\text { uncontaminated outside source. }\end{array}$ & $\begin{array}{c}\text { DOE Project } \\
\text { Communication } \\
\text { with DOE-PPPO } \\
\text { (October 2010) } \\
\text { Yu et al. } 2007\end{array}$ \\
\hline
\end{tabular}

Livestock Feed Grain

\begin{tabular}{|c|c|c|c|c|c|c|c|c|}
\hline $\begin{array}{c}\text { Fraction of water } \\
\text { from surface body } \\
\text { for livestock feed } \\
\text { grain }\end{array}$ & -- & 0 & $0-1$ & 0 & $\mathrm{~B}, \mathrm{P}$ & 3 & $\begin{array}{l}\text { This is the fraction of water that is obtained from the } \\
\text { contaminated surface water body for the specific use. } \\
\text { If water is obtained from other sources } \\
\text { (contaminated well, uncontaminated outside source), } \\
\text { the fraction will be less than one. } \\
\text { It is assumed that all water will come from an } \\
\text { uncontaminated outside source. }\end{array}$ & $\begin{array}{c}\text { DOE Project } \\
\text { Communication } \\
\text { with DOE-PPPO } \\
\text { (October 2010) } \\
\text { Yu et al. } 2007\end{array}$ \\
\hline $\begin{array}{l}\text { Fraction of water } \\
\text { from well for } \\
\text { livestock feed grain }\end{array}$ & -- & 1 & $0-1$ & 0 & $B, P$ & 2 & $\begin{array}{l}\text { This parameter is the fraction of water that is } \\
\text { obtained from the contaminated well for the specific } \\
\text { use. If water is obtained from other sources } \\
\text { (contaminated surface water body, uncontaminated } \\
\text { outside source), the fraction will be less than one. } \\
\text { It is assumed that all water will come from an } \\
\text { uncontaminated outside source. }\end{array}$ & $\begin{array}{c}\text { DOE Project } \\
\text { Communication } \\
\text { with DOE-PPPO } \\
\text { (October 2010) } \\
\text { Yu et al. } 2007\end{array}$ \\
\hline
\end{tabular}

Offsite Dwelling Site

\begin{tabular}{|c|c|c|c|c|c|c|c|c|}
\hline $\begin{array}{c}\text { Fraction of water } \\
\text { from surface body } \\
\text { for offsite dwelling } \\
\text { site }\end{array}$ & -- & 0 & $0-1$ & & 0 & B, P & 3 & $\begin{array}{l}\text { This is the fraction of water that is obtained from the } \\
\text { contaminated surface water body for the specific use. } \\
\text { If water is obtained from other sources } \\
\text { (contaminated well, uncontaminated outside source), }\end{array}$ \\
$\begin{array}{c}\text { Communication } \\
\text { with DOE-PPPO } \\
\text { (October 2010) }\end{array}$ \\
\hline
\end{tabular}


RESRAD-OFFSITE Table of Input Parameters for the C-746-U Landfill Offsite Resident Farmer Scenario

\begin{tabular}{|c|c|c|c|c|c|c|c|c|}
\hline $\begin{array}{l}\text { Input Screen Title } \\
\text { and Parameter } \\
\text { Name }\end{array}$ & Units & $\begin{array}{l}\text { Default } \\
\text { Value }^{\mathrm{a}}\end{array}$ & $\begin{array}{r}\text { Code-Acce } \\
\text { Values } \\
\text { Physical } \\
\text { Numerical } \\
\text { Range }\end{array}$ & $\begin{array}{l}\text { Deterministic } \\
\text { Value }\end{array}$ & Type $^{d}$ & Priority ${ }^{e}$ & Justification & References \\
\hline & & & & & & & $\begin{array}{l}\text { the fraction will be less than one. } \\
\text { It is assumed that all water will come from an } \\
\text { uncontaminated outside source. }\end{array}$ & Yu et al. 2007 \\
\hline $\begin{array}{l}\text { Fraction of water } \\
\text { from well for offsite } \\
\text { dwelling site }\end{array}$ & -- & 1 & $0-1$ & 0 & $B, P$ & 2 & $\begin{array}{l}\text { This parameter is the fraction of water that is } \\
\text { obtained from the contaminated well for the specific } \\
\text { use. If water is obtained from other sources } \\
\text { (contaminated surface water body, uncontaminated } \\
\text { outside source), the fraction will be less than one. } \\
\text { It is assumed that all water will come from an } \\
\text { uncontaminated outside source. }\end{array}$ & $\begin{array}{c}\text { DOE Project } \\
\text { Communication } \\
\text { with DOE-PPPO } \\
\text { (October 2010) } \\
\text { Yu et al. } 2007\end{array}$ \\
\hline Well pumping rate & $\mathrm{m}^{3} / \mathrm{yr}$ & 5,100 & $0-100,000$ & $\begin{array}{l}\text { Calculated by } \\
\text { the code }\end{array}$ & $B, P$ & 2 & Default is used. & Yu et al. 2007 \\
\hline $\begin{array}{l}\text { Well pumping rate } \\
\text { needed to specified } \\
\text { water use for } \\
\text { livestock feed grain }\end{array}$ & $\mathrm{m}^{3} / \mathrm{yr}$ & $5,084.17$ & Calculated & $\begin{array}{l}\text { Calculated by } \\
\text { the code }\end{array}$ & $B, P$ & 3 & Default value is used. & Yu et al. 2007 \\
\hline
\end{tabular}

\section{Ingestion Rates}

Consumption Rate

\begin{tabular}{|c|c|c|c|c|c|c|c|c|}
\hline $\begin{array}{l}\text { Drinking water } \\
\text { intake }\end{array}$ & $\mathrm{L} / \mathrm{yr}$ & 510 & $0-1,000$ & 700 & $M, B$ & 2 & $\begin{array}{l}\text { This value was converted from Table D.1 in DOE } \\
2009 . \\
\text { See Attachment II following this table of parameters. }\end{array}$ & $\begin{array}{c}\text { DOE } 2009 \\
\text { Appendix D, } \\
\text { Table D.1, page D- } \\
11\end{array}$ \\
\hline Fish consumption & $\mathrm{kg} / \mathrm{yr}$ & 5.4 & $0-1,000$ & 5.4 & $\mathrm{M}, \mathrm{B}$ & 3 & $\begin{array}{l}\text { The aquatic foods ingestion pathway is suppressed in } \\
\text { RESRAD OFFSITE for all receptors because it is not } \\
\text { considered part of the conceptual site model. }\end{array}$ & Yu et el. 2007 \\
\hline $\begin{array}{l}\text { Other aquatic food } \\
\text { consumption }\end{array}$ & $\mathrm{kg} / \mathrm{yr}$ & 0.9 & $0-100$ & 0.9 & $\mathrm{M}, \mathrm{B}$ & 3 & $\begin{array}{l}\text { The aquatic foods ingestion pathway is suppressed in } \\
\text { RESRAD OFFSITE for all receptors because it is not } \\
\text { considered part of the conceptual site model. }\end{array}$ & Yu et el. 2007 \\
\hline $\begin{array}{l}\text { Fruit, grain, } \\
\text { nonleafy vegetables } \\
\text { consumption }\end{array}$ & $\mathrm{kg} / \mathrm{yr}$ & 160 & $0-1,000$ & 231.7 & $\mathrm{M}, \mathrm{B}$ & 2 & $\begin{array}{l}\text { The value was converted from Table D.9 in DOE 2009, } \\
\text { which is for home grown vegetables. It does not } \\
\text { specify fruit, and grain, thus for RESRAD a ratio was } \\
\text { obtained to assign a value for fruit, vegetable and } \\
\text { grain consumption and a value for leafy vegetable } \\
\text { consumption. }\end{array}$ & $\begin{array}{c}\text { DOE } 2009 \\
\text { Appendix D, } \\
\text { Table D.9, page D- } \\
19\end{array}$ \\
\hline
\end{tabular}


RESRAD-OFFSITE Table of Input Parameters for the C-746-U Landfill Offsite Resident Farmer Scenario

\begin{tabular}{|c|c|c|c|c|c|c|c|c|}
\hline $\begin{array}{l}\text { Input Screen Title } \\
\text { and Parameter } \\
\text { Name }\end{array}$ & Units & $\begin{array}{l}\text { Default } \\
\text { Value }^{a}\end{array}$ & $\begin{array}{r}\text { Code-Accep } \\
\text { Values }^{b} \\
\text { Physical } \\
\text { Numerical } \\
\text { Range }\end{array}$ & $\begin{array}{l}\text { Deterministic } \\
\text { Value }\end{array}$ & Type $^{d}$ & Priority ${ }^{e}$ & Justification & References \\
\hline & & & & & & & The calculation is included in Attachment II. & \\
\hline $\begin{array}{l}\text { Leafy vegetables } \\
\text { consumption }\end{array}$ & $\mathrm{kg} / \mathrm{yr}$ & 14 & $0-100$ & 20.3 & $M, B$ & 3 & $\begin{array}{l}\text { The value was converted from Table D.9 in DOE 2009, } \\
\text { which is for home grown vegetables. It does not } \\
\text { specify fruit, and grain, thus for RESRAD a ratio was } \\
\text { obtained to assign a value for fruit, vegetable and } \\
\text { grain consumption and a value for leafy vegetable } \\
\text { consumption. } \\
\text { The calculation is included in Attachment II. }\end{array}$ & $\begin{array}{c}\text { DOE } 2009 \\
\text { Appendix D, Table } \\
\text { D.9, page D-19 }\end{array}$ \\
\hline Meat consumption & $\mathrm{kg} / \mathrm{yr}$ & 63 & $0-300$ & 154 & $\mathrm{M}, \mathrm{B}$ & 3 & $\begin{array}{l}\text { This value was converted from Table D.10, D.12, and } \\
\text { D.13 in DOE } 2009 \text {. The value is the sum of the values } \\
\text { obtained for beef, pork and poultry, since they are in } \\
\text { separate tables. The value for eggs is available, but } \\
\text { eggs are not considered poultry. } \\
\text { See Attachment II following this table of parameters. }\end{array}$ & $\begin{array}{l}\text { DOE } 2009 \\
\text { Appendix D, Table } \\
\text { D.10, D.12, and } \\
\text { D.13, pages D-20, } \\
\text { D-22 and D-23 }\end{array}$ \\
\hline Milk consumption & $\mathrm{L} / \mathrm{yr}$ & 92 & $0-1,000$ & 425 & $\mathrm{M}, \mathrm{B}$ & 2 & $\begin{array}{l}\text { This value was converted from Table D.11 in DOE } \\
\text { 2009. The density of whole milk, } 1030 \mathrm{~kg} / \mathrm{cubic} \\
\text { meter, was used to convert the value into L/yr. } \\
\text { See Attachment II following this table of parameters. }\end{array}$ & $\begin{array}{c}\text { DOE } 2009 \\
\text { Appendix D, } \\
\text { Table D.11, page } \\
\text { D-21 }\end{array}$ \\
\hline $\begin{array}{l}\text { Soil (incidental) } \\
\text { ingestion rate }\end{array}$ & $g / y r$ & 36.5 & $0-10,000$ & 36.5 & $M, B$ & 2 & $\begin{array}{l}\text { This value was converted from Table D.5 in DOE } \\
2009 . \\
\text { See Attachment II following this table of parameters. }\end{array}$ & $\begin{array}{c}\text { DOE } 2009 \\
\text { Appendix D,Table } \\
\text { D.5, page D-15 }\end{array}$ \\
\hline $\begin{array}{l}\text { Drinking water } \\
\text { intake from } \\
\text { affected area }\end{array}$ & -- & 1 & $0-1$ & 1 & $B, P$ & 3 & $\begin{array}{l}\text { This is the fraction of drinking water consumed by an } \\
\text { individual that is obtained from the contaminated } \\
\text { source. }\end{array}$ & Yu et al. 2007 \\
\hline $\begin{array}{l}\text { Fish consumption } \\
\text { from affected area }\end{array}$ & -- & 0.5 & $0-1$ & 0.5 & $B, P$ & 2 & $\begin{array}{l}\text { This is the fraction of fish consumed by an individual } \\
\text { that is obtained from the contaminated surface water } \\
\text { body. } \\
\text { This parameter is suppressed by turning off the } \\
\text { aquatic food pathway because it is not considered in } \\
\text { the conceptual site model. }\end{array}$ & Yu et al. 2007 \\
\hline $\begin{array}{l}\text { Other aquatic food } \\
\text { consumption from } \\
\text { affected area }\end{array}$ & -- & 0.5 & $0-1$ & 0.5 & $B, P$ & 2 & $\begin{array}{l}\text { This is the fraction of the other aquatic food } \\
\text { consumed by an individual that is obtained from the } \\
\text { contaminated surface water body. The aquatic foods } \\
\text { ingestion pathway is suppressed in RESRAD for all } \\
\text { receptors because it is not considered part of the }\end{array}$ & Yu et al. 2007 \\
\hline
\end{tabular}


RESRAD-OFFSITE Table of Input Parameters for the C-746-U Landfill Offsite Resident Farmer Scenario

\begin{tabular}{|c|c|c|c|c|c|c|c|c|}
\hline $\begin{array}{c}\text { Input Screen Title } \\
\text { and Parameter } \\
\text { Name }\end{array}$ & Units & $\begin{array}{l}\text { Default } \\
\text { Value }^{a}\end{array}$ & $\begin{array}{c}\text { Code-Accepted } \\
\text { Values }^{\mathrm{b}} \\
\text { Physical or } \\
\text { Numerical }^{\mathrm{c}} \text { (N) } \\
\text { Range }^{\text {Rang }} \\
\end{array}$ & $\begin{array}{l}\text { Deterministic } \\
\text { Value }\end{array}$ & Type $^{d}$ & Priority $^{\mathrm{e}}$ & Justification & References \\
\hline & & & & & & & conceptual site model. & \\
\hline $\begin{array}{c}\text { Fruit, grain, } \\
\text { nonleafy vegetables } \\
\text { consumption from } \\
\text { affected area }\end{array}$ & -- & 0.5 & $0-1$ & 0.5 & $B, P$ & 3 & $\begin{array}{l}\text { This is the fraction of fruit, nonleafy vegetables, or } \\
\text { grain consumed by an individual that is obtained } \\
\text { from contaminated agricultural areas. }\end{array}$ & Yu et al. 2007 \\
\hline $\begin{array}{l}\text { Leafy vegetables } \\
\text { consumption from } \\
\text { affected area }\end{array}$ & -- & 0.5 & $0-1$ & 0.5 & $B, P$ & 3 & $\begin{array}{l}\text { This is the fraction of leafy vegetables consumed by } \\
\text { an individual that is obtained from contaminated } \\
\text { agricultural areas. }\end{array}$ & Yu et al. 2007 \\
\hline $\begin{array}{l}\text { Meat consumption } \\
\text { from affected area }\end{array}$ & -- & 1 & $0-1$ & 1 & $B, P$ & 3 & $\begin{array}{l}\text { This is the fraction of meat consumed by an } \\
\text { individual that is produced using contaminated feed } \\
\text { and water. }\end{array}$ & Yu et al. 2007 \\
\hline $\begin{array}{l}\text { Milk consumption } \\
\text { from affected area }\end{array}$ & -- & 1 & $0-1$ & 1 & $\mathrm{~B}, \mathrm{P}$ & 3 & $\begin{array}{l}\text { This is the fraction of milk consumed by an individual } \\
\text { that is produced using contaminated feed and water. }\end{array}$ & Yu et al. 2007 \\
\hline
\end{tabular}

\section{Livestock Intakes}

\begin{tabular}{|c|c|c|c|c|c|c|c|c|}
\hline \multicolumn{9}{|l|}{ Beef Cattle } \\
\hline $\begin{array}{l}\text { Water intake for } \\
\text { beef cattle }\end{array}$ & $L / d$ & 50 & $0-500$ & 50 & $M$ & 3 & $\begin{array}{l}\text { The value used corresponds to the quantity of water } \\
\text { ingested daily by beef, available in DOE } 2009 . \\
\text { See Attachment II following this table of parameters. }\end{array}$ & $\begin{array}{c}\text { DOE } 2009 \\
\text { Appendix D, Table } \\
\text { D.46, Page D-56. }\end{array}$ \\
\hline $\begin{array}{l}\text { Pasture and silage } \\
\text { intake for beef } \\
\text { cattle }\end{array}$ & $\mathrm{kg} / \mathrm{d}$ & 14 & $0-300$ & 25 & $M$ & 3 & $\begin{array}{l}\text { The value used corresponds to the quantity of } \\
\text { pasture ingested daily by beef, available in DOE } 2009 . \\
\text { See Attachment II following this table of parameters. }\end{array}$ & $\begin{array}{c}\text { DOE } 2009 \\
\text { Appendix D, Table } \\
\text { D.46, Page D-56. }\end{array}$ \\
\hline $\begin{array}{l}\text { Grain intake for } \\
\text { beef cattle }\end{array}$ & $\mathrm{kg} / \mathrm{d}$ & 54 & $0-300$ & 54 & $M$ & 3 & $\begin{array}{l}\text { Default value is used because there is no site specific } \\
\text { value. }\end{array}$ & Yu et al. 2007 \\
\hline $\begin{array}{l}\text { Soil from pasture } \\
\text { and silage intake for } \\
\text { beef cattle }\end{array}$ & $\mathrm{kg} / \mathrm{d}$ & 0.1 & $0-10$ & 0.2 & M & 3 & $\begin{array}{l}\text { DOE } 2009 \text { specifies a value of } 1 \mathrm{~kg} / \mathrm{d} \text { for soil ingested } \\
\text { daily by beef. The default values were used to } \\
\text { develop a ratio, by which this value was calculated. } \\
\text { See Attachment II following this table of parameters. }\end{array}$ & $\begin{array}{c}\text { DOE 2009, } \\
\text { Appendix D, Table } \\
\text { D.46, page D-56 }\end{array}$ \\
\hline $\begin{array}{l}\text { Soil from grain } \\
\text { intake for beef } \\
\quad \text { cattle }\end{array}$ & $\mathrm{kg} / \mathrm{d}$ & 0.4 & $0-10$ & 0.8 & $M$ & 3 & $\begin{array}{l}\text { DOE } 2009 \text { specifies a value of } 1 \mathrm{~kg} / \mathrm{d} \text { for soil ingested } \\
\text { daily by beef. The default values were used to } \\
\text { develop a ratio, by which this value was calculated. } \\
\text { See Attachment II following this table of parameters. }\end{array}$ & $\begin{array}{c}\text { DOE 2009, } \\
\text { Appendix D, Table } \\
\text { D.46, page D-56 }\end{array}$ \\
\hline
\end{tabular}

Dairy Cows 
RESRAD-OFFSITE Table of Input Parameters for the C-746-U Landfill Offsite Resident Farmer Scenario

\begin{tabular}{|c|c|c|c|c|c|c|c|c|}
\hline $\begin{array}{c}\text { Input Screen Title } \\
\text { and Parameter } \\
\text { Name }\end{array}$ & Units & $\begin{array}{l}\text { Default } \\
\text { Value }^{a}\end{array}$ & $\begin{array}{l}\text { Code-Accepted } \\
\text { Values }^{b} \\
\text { Physical or } \\
\text { Numerical }{ }^{\mathrm{C}} \text { (N) } \\
\text { Range }\end{array}$ & $\begin{array}{l}\text { Deterministic } \\
\text { Value }\end{array}$ & Type $^{d}$ & Priority & Justification & References \\
\hline $\begin{array}{l}\text { Water intake for } \\
\text { dairy cows }\end{array}$ & $L / d$ & 160 & $0-500$ & 160 & M & 3 & The default value is used. & Yu et al. 2007 \\
\hline $\begin{array}{l}\text { Pasture and silage } \\
\text { intake for dairy } \\
\text { cows }\end{array}$ & $\mathrm{kg} / \mathrm{d}$ & 44 & $0-300$ & 25 & M & 3 & $\begin{array}{l}\text { The value used corresponds to the quantity of } \\
\text { pasture ingested daily by dairy, available in DOE } \\
2009 \text {. } \\
\text { See Attachment II following this table of parameters. }\end{array}$ & $\begin{array}{c}\text { DOE } 2009 \\
\text { Appendix D, Table } \\
\text { D.47, Page D-57 }\end{array}$ \\
\hline $\begin{array}{l}\text { Grain intake for } \\
\text { dairy cows }\end{array}$ & $\mathrm{kg} / \mathrm{d}$ & 11 & $0-300$ & 11 & M & 3 & $\begin{array}{l}\text { Default value is used because there is no site specific } \\
\text { value. }\end{array}$ & Yu et al. 2007 \\
\hline $\begin{array}{l}\text { Soil from pasture } \\
\text { and silage intake for } \\
\text { dairy cows }\end{array}$ & $\mathrm{kg} / \mathrm{d}$ & 0.4 & $0-10$ & 0.8 & M & 3 & $\begin{array}{l}\text { DOE } 2009 \text { specifies a value of } 1 \mathrm{~kg} / \mathrm{d} \text { for soil ingested } \\
\text { daily by dairy. The default values were used to } \\
\text { develop a ratio, by which this value was calculated. } \\
\text { See Attachment II following this table of parameters. }\end{array}$ & $\begin{array}{c}\text { DOE 2009, } \\
\text { Appendix D, Table } \\
\text { D.47, page D-57 }\end{array}$ \\
\hline $\begin{array}{l}\text { Soil from grain } \\
\text { intake for dairy } \\
\text { cows }\end{array}$ & $\mathrm{kg} / \mathrm{d}$ & 0.1 & $0-10$ & 0.2 & M & 3 & $\begin{array}{l}\text { DOE } 2009 \text { specifies a value of } 1 \mathrm{~kg} / \mathrm{d} \text { for soil ingested } \\
\text { daily by dairy. The default values were used to } \\
\text { develop a ratio, by which this value was calculated. } \\
\text { See Attachment II following this table of parameters. }\end{array}$ & $\begin{array}{c}\text { DOE 2009, } \\
\text { Appendix D, Table } \\
\text { D.47, page D-57 }\end{array}$ \\
\hline
\end{tabular}

Livestock Feed Factors

Pasture and Silage
\begin{tabular}{|c|c|c|c|c|c|c|c|c|}
\hline $\begin{array}{c}\text { Wet weight crop } \\
\text { yield of pasture and } \\
\text { silage }\end{array}$ & $\mathrm{kg} / \mathrm{m}^{2}$ & 1.1 & $0.01-3$ & & 1.1 & $\mathrm{P}$ & 3 & Default value is used. \\
\hline $\begin{array}{c}\text { Duration of growing } \\
\text { season of pasture } \\
\text { and silage }\end{array}$ & $\mathrm{yr}$ & 0.08 & $0.01-1$ & & 0.08 & $\mathrm{P}$ & 3 & Default value is used. \\
\hline $\begin{array}{c}\text { Foliage to food } \\
\text { transfer coefficient } \\
\text { of pasture and } \\
\text { silage }\end{array}$ & -- & 1 & $0-1$ & 1 & & $\mathrm{P}$ & 3 & Ye07 et al. 2007 \\
\hline $\begin{array}{c}\text { Weathering } \\
\text { removal constant of } \\
\text { pasture and silage }\end{array}$ & $1 / \mathrm{yr}$ & 20 & $1-40$ & & 20 & $\mathrm{P}$ & 2 & Default value is used. \\
\hline $\begin{array}{c}\text { Foliar interception } \\
\text { factor for irrigation } \\
\text { of pasture and }\end{array}$ & -- & 0.25 & $0-1$ & & 0.25 & $\mathrm{P}$ & 3 & Default value is used. \\
\hline
\end{tabular}


RESRAD-OFFSITE Table of Input Parameters for the C-746-U Landfill Offsite Resident Farmer Scenario

\begin{tabular}{|c|c|c|c|c|c|c|c|c|}
\hline $\begin{array}{c}\text { Input Screen Title } \\
\text { and Parameter } \\
\text { Name }\end{array}$ & Units & $\begin{array}{l}\text { Default } \\
\text { Value }^{\mathrm{a}}\end{array}$ & $\begin{array}{c}\text { Code-Accepted } \\
\text { Values }^{\text {b }} \\
\text { Physical or } \\
\text { Numerical }^{\mathrm{C}} \text { (N) } \\
\text { Range }^{\text {Rang }}\end{array}$ & $\begin{array}{l}\text { Deterministic } \\
\text { Value }\end{array}$ & Type $^{d}$ & Priority $^{e}$ & Justification & References \\
\hline \multicolumn{9}{|l|}{ silage } \\
\hline $\begin{array}{l}\text { Foliar interception } \\
\text { factor for dust of } \\
\text { pasture and silage }\end{array}$ & -- & 0.25 & $0-1$ & 0.25 & $P$ & 3 & Default value is used. & Yu et al. 2007 \\
\hline $\begin{array}{c}\text { Root depth of } \\
\text { pasture and silage }\end{array}$ & $\mathrm{m}$ & 0.9 & $0-3$ & 0.9 & P & 1 & Default value is used. & Yu et al. 2007 \\
\hline
\end{tabular}

\section{Grain}

\begin{tabular}{|c|c|c|c|c|c|c|c|l|}
\hline $\begin{array}{c}\text { Wet weight crop } \\
\text { yield of grain }\end{array}$ & $\mathrm{kg} / \mathrm{m}^{2}$ & 0.7 & $0.01-3$ & 0.7 & $\mathrm{P}$ & 3 & Yefault value is used. \\
\hline $\begin{array}{c}\text { Duration of growing } \\
\text { season of grain }\end{array}$ & $\mathrm{yr}$ & 0.17 & $0.01-1$ & 0.17 & $\mathrm{P}$ & 3 & Default value is used. \\
\hline $\begin{array}{c}\text { Foliage to food } \\
\text { transfer coefficient } \\
\text { of grain }\end{array}$ & -- & 0.1 & $0-1$ & 0.1 & $\mathrm{P}$ & 3 & Default value is used. \\
\hline $\begin{array}{c}\text { Weathering } \\
\text { removal constant of } \\
\text { grain }\end{array}$ & $1 / \mathrm{yr}$ & 20 & $1-40$ & 20 & $\mathrm{P}$ & 2 & Yu et al. 2007 \\
\hline $\begin{array}{c}\text { Foliar interception } \\
\text { factor for irrigation } \\
\text { of grain }\end{array}$ & -- & 0.25 & $0-1$ & & 0.25 & $\mathrm{P}$ & 3 & Default value is used. \\
\hline $\begin{array}{c}\text { Foliar interception } \\
\text { factor for dust of } \\
\text { grain }\end{array}$ & -- & 0.25 & $0-1$ & & 0.25 & $\mathrm{P}$ & 3 & Yu et al. 2007 \\
\hline Root depth of grain & $\mathrm{m}$ & 1.2 & $0-10$ & & 1.2 & $\mathrm{P}$ & 1 & Default value is used. \\
\hline
\end{tabular}

\section{Plant Factors}

\begin{tabular}{|c|c|c|c|c|c|c|c|c|}
\hline $\begin{array}{l}\text { Wet weight crop } \\
\text { yield of fruit, grain, } \\
\text { and nonleafy } \\
\text { vegetables }\end{array}$ & $\mathrm{kg} / \mathrm{m}^{2}$ & 0.7 & $0.01-3$ & 0.7 & $P$ & 3 & $\begin{array}{l}\text { The weight of the edible portion of plant food } \\
\text { produced per unit land area for different food } \\
\text { classes. The code has wet weight crop yield for non- } \\
\text { leafy, leafy, and fodder. Non-leafy and leafy } \\
\text { vegetables are for human consumption; fodder is for } \\
\text { animal consumption. } \\
\text { Default value is used. }\end{array}$ & Yu et al. 2007 \\
\hline $\begin{array}{l}\text { Duration of growing } \\
\text { season of fruit, } \\
\text { grain, and nonleafy } \\
\text { vegetables }\end{array}$ & $\mathrm{yr}$ & 0.17 & $0.01-1$ & 0.17 & $P$ & 3 & $\begin{array}{l}\text { This is the period of time over which the crop is } \\
\text { grown. It is assumed that the plant is exposed to } \\
\text { contamination by foliar interception during this } \\
\text { period and that all the irrigation is applied during this }\end{array}$ & Yu et al. 2007 \\
\hline
\end{tabular}


RESRAD-OFFSITE Table of Input Parameters for the C-746-U Landfill Offsite Resident Farmer Scenario

\begin{tabular}{|c|c|c|c|c|c|c|c|c|}
\hline $\begin{array}{c}\text { Input Screen Title } \\
\text { and Parameter } \\
\text { Name }\end{array}$ & Units & $\begin{array}{l}\text { Default } \\
\text { Value }^{a}\end{array}$ & $\begin{array}{l}\text { Code-Accepted } \\
\text { Values }^{b} \\
\text { Physical or }^{c} \\
\text { Numerical }{ }^{\mathrm{C}} \text { (N) } \\
\text { Range }^{\text {Nang }}\end{array}$ & $\begin{array}{l}\text { Deterministic } \\
\text { Value }\end{array}$ & Type $^{d}$ & Priority ${ }^{\mathrm{e}}$ & Justification & References \\
\hline & & & & & & & $\begin{array}{l}\text { period. } \\
\text { Default value is used. }\end{array}$ & \\
\hline $\begin{array}{l}\text { Foliage to food } \\
\text { transfer coefficient } \\
\text { of fruit, grain, and } \\
\text { nonleafy vegetables }\end{array}$ & -- & 0.1 & $0-1$ & 0.1 & $P$ & 3 & Default value is used. & Yu et al. 2007 \\
\hline $\begin{array}{l}\text { Weathering } \\
\text { removal constant of } \\
\text { fruit, grain, and } \\
\text { nonleafy vegetables }\end{array}$ & $1 / \mathrm{yr}$ & 20 & $1-40$ & 20 & $P$ & 2 & Default value is used. & Yu et al. 2007 \\
\hline $\begin{array}{l}\text { Foliar interception } \\
\text { factor for irrigation } \\
\text { of fruit, grain, and } \\
\text { nonleafy vegetables }\end{array}$ & -- & 0.25 & $0-1$ & 0.25 & $P$ & 2 & Default value is used. & Yu et al. 2007 \\
\hline $\begin{array}{l}\text { Foliar interception } \\
\text { factor for dust of } \\
\text { fruit, grain, and } \\
\text { nonleafy vegetables }\end{array}$ & -- & 0.25 & $0-1$ & 0.25 & $P$ & 3 & Default value is used. & Yu et al. 2007 \\
\hline $\begin{array}{l}\text { Root depth of fruit, } \\
\text { grain, and nonleafy } \\
\text { vegetables }\end{array}$ & $\mathrm{m}$ & 1.2 & $0-10$ & 1.2 & $P$ & 1 & Default value is used. & Yu et al. 2007 \\
\hline
\end{tabular}

\section{Leafy Vegetables}

\begin{tabular}{|c|c|c|c|c|c|c|c|c|}
\hline $\begin{array}{c}\text { Wet weight crop } \\
\text { yield of leafy } \\
\text { vegetables }\end{array}$ & $\mathrm{kg} / \mathrm{m}^{2}$ & 1.5 & $0.01-3$ & 1.5 & $\mathrm{P}$ & 3 & Yefault value is used. \\
\hline $\begin{array}{c}\text { Duration of growing } \\
\text { season of leafy } \\
\text { vegetables }\end{array}$ & $\mathrm{yr}$ & 0.25 & $0.01-1$ & 0.25 & $\mathrm{P}$ & 3 & Default value is used. \\
\hline $\begin{array}{c}\text { Foliage to food } \\
\text { transfer coefficient } \\
\text { of leafy vegetables }\end{array}$ & -- & 1 & $0-1$ & 1 & $\mathrm{P}$ & 3 & Default value is used. \\
\hline $\begin{array}{c}\text { Weathering } \\
\text { removal constant of } \\
\text { leafy vegetables }\end{array}$ & $1 / \mathrm{yr}$ & 20 & $1-40$ & 2007 & Yu et al. 2007 \\
\hline $\begin{array}{c}\text { Foliar interception } \\
\text { factor for irrigation } \\
\text { of leafy vegetables }\end{array}$ & -- & 0.25 & $0-1$ & & 0.25 & $\mathrm{P}$ & 2 & Default value is used. \\
\hline
\end{tabular}


RESRAD-OFFSITE Table of Input Parameters for the C-746-U Landfill Offsite Resident Farmer Scenario

\begin{tabular}{|c|c|c|c|c|c|c|c|c|}
\hline $\begin{array}{c}\text { Input Screen Title } \\
\text { and Parameter } \\
\text { Name }\end{array}$ & Units & $\begin{array}{l}\text { Default } \\
\text { Value }^{a}\end{array}$ & $\begin{array}{l}\text { Code-Accepted } \\
\text { Values }^{b} \\
\text { Physical or } \\
\text { Numerical }{ }^{\mathrm{C}} \text { (N) } \\
\text { Range }\end{array}$ & $\begin{array}{l}\text { Deterministic } \\
\text { Value }\end{array}$ & Type $^{d}$ & Priority $^{e}$ & Justification & References \\
\hline $\begin{array}{l}\text { Foliar interception } \\
\text { factor for dust of } \\
\text { leafy vegetables }\end{array}$ & -- & 0.25 & $0-1$ & 0.25 & $P$ & 3 & Default value is used. & Yu et al. 2007 \\
\hline $\begin{array}{l}\text { Root depth of leafy } \\
\text { vegetables }\end{array}$ & $\mathrm{m}$ & 0.9 & $0-3$ & 0.9 & $\mathrm{P}$ & 1 & Default value is used. & Yu et al. 2007 \\
\hline
\end{tabular}

Inhalation and External Gamma Data

\begin{tabular}{|c|c|c|c|c|c|c|c|c|}
\hline Inhalation rate & $\mathrm{m}^{3} / \mathrm{yr}$ & 8,400 & $0-20,000$ & 7,297 & $M, B$ & 3 & $\begin{array}{l}\text { The inhalation rate for the Resident Farmer was } \\
\text { converted from a value available in DOE 2009. For } \\
\text { the conversion } 365 \text { days/yr were used, because this is } \\
\text { what RESRAD considers. }\end{array}$ & $\begin{array}{c}\text { DOE } 2009 \\
\text { Appendix D, Table } \\
\text { D.7, page D-17 } \\
\\
\text { King et al. } 2006 \\
\text { Page } 178\end{array}$ \\
\hline $\begin{array}{l}\text { Mass loading for } \\
\text { inhalation }\end{array}$ & $\mathrm{g} / \mathrm{m}^{3}$ & 0.0001 & $0-2$ & $1.08 \mathrm{E}-06$ & $P, B$ & 2 & $\begin{array}{l}\text { The following equation was used to calculate the } \\
\text { Mass Loading for Inhalation or Air-to-Soil } \\
\text { Concentration Ratio (ASR): ASR = 1/ PEF. } \\
\text { The PEF values used to calculate the mass loading for } \\
\text { inhalation are available in DOE 2009. The PEF value } \\
\text { was converted into RESRAD compatible units. } \\
\text { See Attachment II following this table of parameters. }\end{array}$ & $\begin{array}{l}\text { King et al. } 2006 \\
\text { page } 178 \\
\\
\text { DOE } 2009 \\
\text { Appendix D, Table } \\
\text { D.7 (Resident } \\
\text { Farmer = Rural } \\
\text { Resident), page D- } \\
17 \\
\end{array}$ \\
\hline $\begin{array}{l}\text { Mean onsite mass } \\
\text { loading }\end{array}$ & $\mathrm{g} / \mathrm{m}^{3}$ & 0.0001 & $0-2$ & $1.08 \mathrm{E}-06$ & $P, B$ & 2 & $\begin{array}{l}\text { This is the average mass loading of airborne } \\
\text { contaminated soil particles, above the primary } \\
\text { contamination. It is used to estimate the contaminant } \\
\text { release rate to the atmosphere. }\end{array}$ & Yu et al. 2007 \\
\hline $\begin{array}{l}\text { Indoor dust } \\
\text { filtration factor } \\
\text { (indoor to outdoor } \\
\text { dust concentration) }\end{array}$ & -- & 0.4 & $0-1$ & 0.4 & $P, B$ & 2 & $\begin{array}{l}\text { The default value is used. Indoor time fraction is the } \\
\text { driver for application of this parameter. In instances } \\
\text { where there is no indoor occupancy, this parameter } \\
\text { will not be applied. }\end{array}$ & Yu et al. 2007 \\
\hline $\begin{array}{l}\text { External gamma } \\
\text { shielding } \\
\text { (penetration) factor }\end{array}$ & -- & 0.7 & $0-1$ & 0.8 & $P$ & 2 & $\begin{array}{l}\text { The external gamma shielding factor is available for } \\
\text { the Resident Farmer in DOE } 2009 \text {. } \\
\text { The value used in the code is actually the fraction of } \\
\text { outdoor gamma radiation that penetrates the } \\
\text { building. } \\
\text { See Attachment II following this table of parameters. }\end{array}$ & $\begin{array}{c}\text { DOE } 2009 \\
\text { Appendix D, Table } \\
\text { D.8, page D-18 } \\
\text { Yu et al. } 2007\end{array}$ \\
\hline
\end{tabular}


RESRAD-OFFSITE Table of Input Parameters for the C-746-U Landfill Offsite Resident Farmer Scenario

\begin{tabular}{|c|c|c|c|c|c|c|c|c|}
\hline $\begin{array}{c}\text { Input Screen Title } \\
\text { and Parameter } \\
\text { Name }\end{array}$ & Units & $\begin{array}{l}\text { Default } \\
\text { Value }^{\mathrm{a}}\end{array}$ & $\begin{array}{l}\text { Code-Accepted } \\
\text { Values }^{b} \\
\text { Physical or } \\
\text { Numerical' }{ }^{\mathrm{C}} \text { (N) } \\
\text { Range }^{\text {Rang }}\end{array}$ & $\begin{array}{l}\text { Deterministic } \\
\text { Value }\end{array}$ & Type $^{d}$ & Priority $^{e}$ & Justification & References \\
\hline
\end{tabular}

External Radiation Shape and Area Factors

\begin{tabular}{|c|c|c|c|c|c|c|c|c|}
\hline Dwelling location & & Offsite & $\begin{array}{l}\text { Onsite or } \\
\text { offsite }\end{array}$ & Offsite & $P$ & 3 & $\begin{array}{l}\text { The receptor is located outside the contaminated } \\
\text { zone. }\end{array}$ & Yu et al. 2007 \\
\hline Scale & $\mathrm{m}$ & 200 & $>0-32,000$ & 1000 & $\mathrm{P}$ & 3 & $\begin{array}{l}\text { This scale is chosen to fully encompass the primary } \\
\text { contamination. }\end{array}$ & Yu et al. 2007 \\
\hline $\begin{array}{l}\text { Dwelling location } \\
\text { coordinate in } X- \\
\text { direction } \\
\end{array}$ & $\mathrm{m}$ & 100 & $\begin{array}{l}-16,000- \\
+16,000\end{array}$ & 190.375 & $P$ & 3 & $\begin{array}{l}\text { The dwelling is located near the well, north of the } \\
\text { contaminated zone. }\end{array}$ & \\
\hline $\begin{array}{l}\text { Dwelling location } \\
\text { coordinate in } y^{-} \\
\text {direction }\end{array}$ & $\mathrm{m}$ & 0 & $\begin{array}{l}-16,000- \\
+16,000\end{array}$ & 670 & $P$ & 3 & $\begin{array}{l}\text { The dwelling is located near the well, } 300 \text { meters } \\
\text { north of the north edge of the contaminated zone. }\end{array}$ & \\
\hline \multirow{12}{*}{ Radius } & \multirow{12}{*}{$\mathrm{m}$} & 13.25 & \multirow{12}{*}{ Calculated } & Calculated & \multirow{12}{*}{$\mathrm{P}$} & \multirow{12}{*}{3} & \multirow[t]{12}{*}{ Calculated by the code. } & \multirow[t]{12}{*}{ Yu et al. 2007} \\
\hline & & 26.5 & & Calculated & & & & \\
\hline & & 39.75 & & Calculated & & & & \\
\hline & & 53 & & Calculated & & & & \\
\hline & & 66.25 & & Calculated & & & & \\
\hline & & 79.5 & & Calculated & & & & \\
\hline & & 92.75 & & Calculated & & & & \\
\hline & & 106 & & Calculated & & & & \\
\hline & & 119.25 & & Calculated & & & & \\
\hline & & 132.5 & & Calculated & & & & \\
\hline & & 145.75 & & Calculated & & & & \\
\hline & & 159 & & Calculated & & & & \\
\hline \multirow{12}{*}{ Fraction } & \multirow{12}{*}{--} & 0 & \multirow{12}{*}{ Calculated } & Calculated & \multirow{12}{*}{$\mathrm{P}$} & \multirow{12}{*}{3} & \multirow[t]{12}{*}{ Calculated by the code. } & \multirow[t]{12}{*}{ Yu et al. 2007} \\
\hline & & 0 & & Calculated & & & & \\
\hline & & 0 & & Calculated & & & & \\
\hline & & 0.024 & & Calculated & & & & \\
\hline & & 0.19 & & Calculated & & & & \\
\hline & & 0.24 & & Calculated & & & & \\
\hline & & 0.2 & & Calculated & & & & \\
\hline & & 0.17 & & Calculated & & & & \\
\hline & & 0.15 & & Calculated & & & & \\
\hline & & 0.13 & & Calculated & & & & \\
\hline & & 0.12 & & Calculated & & & & \\
\hline & & 0.052 & & Calculated & & & & \\
\hline
\end{tabular}


RESRAD-OFFSITE Table of Input Parameters for the C-746-U Landfill Offsite Resident Farmer Scenario

\begin{tabular}{|c|c|c|c|c|c|c|c|c|}
\hline $\begin{array}{c}\text { Input Screen Title } \\
\text { and Parameter } \\
\text { Name }\end{array}$ & Units & $\begin{array}{l}\text { Default } \\
\text { Value }^{\mathrm{a}}\end{array}$ & $\begin{array}{r}\text { Code-Acce } \\
\text { Values } \\
\text { Physical } \\
\text { Numerical } \\
\text { Range }\end{array}$ & $\begin{array}{l}\text { Deterministic } \\
\text { Value }\end{array}$ & Type $^{d}$ & Priority & Justification & References \\
\hline $\begin{array}{l}\text { Shape of the } \\
\text { primary } \\
\text { contamination }\end{array}$ & -- & Polygonal & $\begin{array}{l}\text { Circular or } \\
\text { polygonal }\end{array}$ & Polygonal & $P$ & 3 & $\begin{array}{l}\text { The coordinates of the waste area were used to } \\
\text { create the shape of the contaminated area. }\end{array}$ & $\begin{array}{l}\text { Yu et al. } 2007 \\
\text { Lee et al. } 1995\end{array}$ \\
\hline $\begin{array}{l}\mathrm{X} \text { coordinate of the } \\
\text { vertices of polygon } \\
\text { of the primary } \\
\text { contamination }\end{array}$ & $\mathrm{m}$ & none & $\begin{array}{l}-16,000- \\
+16,000\end{array}$ & $\begin{array}{r}X 1=98, \\
X 2=256, \\
X 3=256, \\
X 4=0, \\
X 5=0, \\
X 6=98\end{array}$ & $P$ & 3 & $\begin{array}{l}\text { The coordinates of the waste area were used to } \\
\text { create the shape of the contaminated area. }\end{array}$ & Lee et al. 1995 \\
\hline $\begin{array}{l}Y \text { coordinate of the } \\
\text { vertices of polygon } \\
\text { of the primary } \\
\text { contamination }\end{array}$ & $\mathrm{m}$ & none & $\begin{array}{l}-16,000- \\
+16,000\end{array}$ & $\begin{array}{c}Y 1=0, \\
Y 2=0, \\
Y 3=399, \\
Y 4=399, \\
Y 5=210, \\
Y 6=0\end{array}$ & $P$ & 3 & $\begin{array}{l}\text { The coordinates of the waste area were used to } \\
\text { create the shape of the contaminated area. }\end{array}$ & Lee et al. 1995 \\
\hline
\end{tabular}

Occupancy Factors

\begin{tabular}{|c|c|c|c|c|c|c|c|c|}
\hline $\begin{array}{l}\text { Indoor time fraction } \\
\text { on primary } \\
\text { contamination }\end{array}$ & -- & 0 & $0-1$ & 0 & B & 3 & $\begin{array}{l}\text { This parameter is the average fraction of time during } \\
\text { which an individual stays indoors. } \\
\text { The default value is used. The Resident Farmer does } \\
\text { not spend any time onsite. }\end{array}$ & Yu et al. 2007 \\
\hline $\begin{array}{l}\text { Outdoor time } \\
\text { fraction on primary } \\
\text { contamination }\end{array}$ & -- & 0 & $0-1$ & 0 & B & 3 & $\begin{array}{l}\text { This parameter is the average fraction of time during } \\
\text { which an individual stays outdoors on the site. } \\
\text { The default value is used. The Resident Farmer does } \\
\text { not spend any time onsite. }\end{array}$ & Yu et al. 2007 \\
\hline $\begin{array}{l}\text { Indoor time fraction } \\
\text { on offsite dwelling } \\
\text { site }\end{array}$ & -- & 0.5 & $0-1$ & 0.64 & B & 3 & $\begin{array}{l}\text { This parameter is the average fraction of time during } \\
\text { which an individual stays indoors. } \\
\text { The Resident Farmer is inside } 16 \text { hours per day, } 350 \\
\text { days per year which results in an indoor fraction of } \\
64 \% \text {. }\end{array}$ & $\begin{array}{c}\text { DOE } 2009 \\
\text { Appendix D, } \\
\text { Table D.8, page D- } \\
18\end{array}$ \\
\hline $\begin{array}{l}\text { Outdoor time } \\
\text { fraction on offsite } \\
\text { dwelling site }\end{array}$ & -- & 0.1 & $0-1$ & 0.064 & B & 3 & $\begin{array}{l}\text { This parameter is the average fraction of time during } \\
\text { which an individual stays outdoors on the site. } \\
\text { The Resident Farmer is outside } 8 \text { hours per day, } 350 \\
\text { days per year which results in an outdoor fraction of } \\
32 \% \text {. }\end{array}$ & $\begin{array}{c}\text { DOE } 2009 \\
\text { Appendix D, Table } \\
\text { D.8, page D-18 }\end{array}$ \\
\hline
\end{tabular}


RESRAD-OFFSITE Table of Input Parameters for the C-746-U Landfill Offsite Resident Farmer Scenario

\begin{tabular}{|c|c|c|c|c|c|c|c|c|}
\hline $\begin{array}{c}\text { Input Screen Title } \\
\text { and Parameter } \\
\text { Name }\end{array}$ & Units & $\begin{array}{l}\text { Default } \\
\text { Value }^{a}\end{array}$ & $\begin{array}{c}\text { Code-Accepted } \\
\text { Values }^{b} \\
\text { Physical or } \\
\text { Numerical }{ }^{\mathrm{C}} \text { (N) } \\
\text { Range }\end{array}$ & $\begin{array}{l}\text { Deterministic } \\
\text { Value }\end{array}$ & Type $^{d}$ & Priority $^{e}$ & Justification & References \\
\hline & & & & & & & $\begin{array}{l}\text { The outdoor fraction of } 0.32 \text { is divided by the number } \\
\text { of outdoor locations (5) to determine the time } \\
\text { fraction. }\end{array}$ & \\
\hline $\begin{array}{c}\text { Time fraction in } \\
\text { fruit, grain, and } \\
\text { nonleafy vegetable } \\
\text { fields }\end{array}$ & -- & 0.1 & $0-1$ & 0.064 & B & 3 & $\begin{array}{l}\text { This parameter is the average fraction of time during } \\
\text { which an individual stays outdoors on the site. } \\
\text { The Resident Farmer is outside } 8 \text { hours per day, } 350 \\
\text { days per year which results in an outdoor fraction of } \\
32 \% \text {. } \\
\text { The outdoor fraction of } 0.32 \text { is divided by the number } \\
\text { of outdoor locations (5) to determine the time } \\
\text { fraction. }\end{array}$ & $\begin{array}{c}\text { DOE } 2009 \\
\text { Appendix D, Table } \\
\text { D.8, page D-18 }\end{array}$ \\
\hline $\begin{array}{l}\text { Time fraction in } \\
\text { leafy vegetable } \\
\text { fields }\end{array}$ & -- & 0.1 & $0-1$ & 0.064 & B & 3 & $\begin{array}{l}\text { This parameter is the average fraction of time during } \\
\text { which an individual stays outdoors on the site. } \\
\text { The Resident Farmer is outside } 8 \text { hours per day, } 350 \\
\text { days per year which results in an outdoor fraction of } \\
32 \% \text {. } \\
\text { The outdoor fraction of } 0.32 \text { is divided by the number } \\
\text { of outdoor locations (5) to determine the time } \\
\text { fraction. }\end{array}$ & $\begin{array}{c}\text { DOE } 2009 \\
\text { Appendix D, Table } \\
\text { D.8, page D-18 }\end{array}$ \\
\hline $\begin{array}{l}\text { Time fraction in } \\
\text { pasture and silage } \\
\text { fields }\end{array}$ & -- & 0.1 & $0-1$ & 0.064 & B & 3 & $\begin{array}{l}\text { This parameter is the average fraction of time during } \\
\text { which an individual stays outdoors on the site. } \\
\text { The Resident Farmer is outside } 8 \text { hours per day, } 350 \\
\text { days per year which results in an outdoor fraction of } \\
32 \% \text {. } \\
\text { The outdoor fraction of } 0.32 \text { is divided by the number } \\
\text { of outdoor locations (5) to determine the time } \\
\text { fraction. }\end{array}$ & $\begin{array}{c}\text { DOE } 2009 \\
\text { Appendix D, Table } \\
\text { D.8, page D-18 }\end{array}$ \\
\hline
\end{tabular}


RESRAD-OFFSITE Table of Input Parameters for the C-746-U Landfill Offsite Resident Farmer Scenario

\begin{tabular}{|c|c|c|c|c|c|c|c|c|}
\hline $\begin{array}{c}\text { Input Screen Title } \\
\text { and Parameter } \\
\text { Name }\end{array}$ & Units & $\begin{array}{l}\text { Default } \\
\text { Value }^{a}\end{array}$ & $\begin{array}{c}\text { Code-Accepted } \\
\text { Values }^{b} \\
\text { Physical or } \\
\text { Numerical }^{\mathrm{C}} \text { (N) } \\
\text { Range }^{\text {Rang }}\end{array}$ & $\begin{array}{l}\text { Deterministic } \\
\text { Value }\end{array}$ & Type $^{d}$ & Priority $^{\mathrm{e}}$ & Justification & References \\
\hline $\begin{array}{l}\text { Time fraction in } \\
\text { livestock grain fields }\end{array}$ & -- & 0.1 & $0-1$ & 0.064 & B & 3 & $\begin{array}{l}\text { This parameter is the average fraction of time during } \\
\text { which an individual stays outdoors on the site. } \\
\text { The Resident Farmer is outside } 8 \text { hours per day, } 350 \\
\text { days per year which results in an outdoor fraction of } \\
32 \% \text {. } \\
\text { The outdoor fraction of } 0.32 \text { is divided by the number } \\
\text { of outdoor locations (5) to determine the time } \\
\text { fraction. }\end{array}$ & $\begin{array}{c}\text { DOE } 2009 \\
\text { Appendix D, Table } \\
\text { D.8, page D-18 }\end{array}$ \\
\hline
\end{tabular}

a The default values listed in this table are the default values in the RESRAD-OFFSITE code Version 2.

b RESRAD-OFFSITE does not provide code-accepted values for element- or nuclide-specific parameters.

c Numerical range is the range defined in a program file to prevent code crashes.

d $P=$ physical, $B=$ behavioral, $M=$ metabolic; when more than one type is listed, the first is primary and the next is secondary.

e According to NUREG/CR-6697, it is necessary to establish priorities about which parameters to collect data for and use for distribution analysis. The parameters were ranked into three levels of priority: 1 (high priority), 2 (medium priority), and 3 (low priority).

f $\quad \mathrm{NA}=$ not applicable.

g Two hyphens indicate that the parameter is dimensionless.

Notes: According to the RESRAD-OFFSITE manual, the Radon parameters can be changed only if a radon precursor is selected in the radionuclide list and the radon pathway is turned on. Similarly, a user will have access to carbon-14 (C-14) or tritium (H-3) parameters only if C-14 or $\mathrm{H}-3$ radionuclides are selected as a contaminant.

The information in this table was obtained from the User's Manual for RESRAD-OFFSITE Version 2 
Attachment I

Distribution Coefficients 
Distribution Coefficients $\left(\mathrm{Kds}, \mathrm{cm}^{3} / \mathrm{g}\right)^{\mathrm{a}, \mathrm{b}}$ for parent radionuclides in the contaminated zone, the unsaturated zone, and the saturated zone

\begin{tabular}{|c|c|c|c|c|c|c|c|c|c|c|c|c|}
\hline Radionuclide & Am-241 & Cs-137 & Np-237 & Pu-238 & Pu-239/240 & Tc-99 & Th-228 & Th-230 & Th-232 & U-234 & U-235 & U-238 \\
\hline Contaminated Zone ${ }^{c}$ & 1900 & 280 & 70 & 550 & 550 & 1 & 3200 & 3200 & 3200 & 410 & 410 & 410 \\
\hline $\begin{array}{l}\text { Unsaturated Zone } 1 \\
\text { (Protective layer } \\
\text { (native soil)) }\end{array}$ & 1900 & 280 & 70 & 550 & 550 & 0.2 & 3200 & 3200 & 3200 & 66.8 & 66.8 & 66.8 \\
\hline $\begin{array}{l}\text { Unsaturated Zone } 2 \\
\text { (Gravel layer (no } \\
\text { collection)) }\end{array}$ & 1900 & 280 & 70 & 550 & 550 & 0.2 & 3200 & 3200 & 3200 & 66.8 & 66.8 & 66.8 \\
\hline $\begin{array}{c}\text { Unsaturated Zone } 3 \\
\text { (Clay barrier) }\end{array}$ & 8400 & 1900 & 144 & 5100 & 5100 & 20 & 5800 & 5800 & 5800 & 3640 & 3640 & 3640 \\
\hline $\begin{array}{l}\text { Unsaturated Zone } 4 \\
\text { (Alluvium soils } \\
\text { (native/subgrade)) }\end{array}$ & 1900 & 280 & 70 & 550 & 550 & 0.2 & 3200 & 3200 & 3200 & 66.8 & 66.8 & 66.8 \\
\hline $\begin{array}{c}\text { Unsaturated Zone } 5 \\
\text { (Clay confining unit } \\
\text { (native)) }\end{array}$ & 8400 & 1900 & 144 & 5100 & 5100 & 20 & 5800 & 5800 & 5800 & 3640 & 3640 & 3640 \\
\hline Saturated Zone(RGA) & 1900 & 280 & 70 & 550 & 550 & 0.2 & 3200 & 3200 & 3200 & 66.8 & 66.8 & 66.8 \\
\hline
\end{tabular}

\footnotetext{
a Distribution coefficients for Am-241, Np-237, Th-230, Th-232, U-234 and U-238 were obtained from DOE 2003b, page C3-313 and Table Att. 1. Distribution coefficient of radionuclides and their daughter products in different zones, page C3-314. It was assumed that the Kd for U-235 was similar to the Kd for U-234 and U-238 since the Kds are chemical specific.

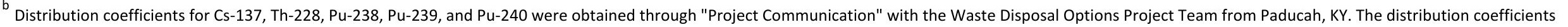
for Tc-99 are available in Table C.3.1. Chemical and physical properties of different classes of chemicals identified as COPCs for the C-746-U Landfill of DOE 2003b, page C3-301. Table 4.5 DUST model input parameters, page 4-12, has Kds for Tc-99 and Uranium.

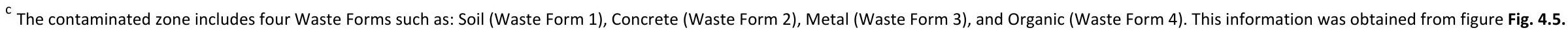
Schematic diagram of DUST model layers and materials for the Post-Institutional Control Period under the gradual failure and immediate failure scenarios of DOE 2003b, page 4-18.
} 
Distribution Coefficients $\left(\mathrm{Kds}, \mathrm{cm}^{3} / \mathrm{g}\right)^{\mathrm{d}}$ for progeny radionuclides in the contaminated zone, the unsaturated zones, and the saturated zone

\begin{tabular}{|c|c|c|c|c|c|c|c|c|}
\hline Radionuclide & Ac-227 & Pa-231 & Pb-210 & Ra-226 & Ra-228 & Th-229 & U-233 & U-236 \\
\hline $\begin{array}{c}\text { Contaminated Zone } \\
\text { e }\end{array}$ & 450 & 550 & 270 & 500 & 500 & 3200 & 410 & 410 \\
\hline $\begin{array}{c}\text { Unsaturated Zone 1 } \\
\text { (Protective layer } \\
\text { (native soi)) }\end{array}$ & 450 & 550 & 270 & 500 & 500 & 3200 & 66.8 & 66.8 \\
\hline $\begin{array}{c}\text { Unsaturated Zone 2 } \\
\text { (Gravel layer (no } \\
\text { collection)) }\end{array}$ & 450 & 550 & 270 & 500 & 500 & 3200 & 66.8 & 66.8 \\
\hline $\begin{array}{c}\text { Unsaturated Zone 3 } \\
\text { (Clay barrier) }\end{array}$ & 2400 & 2700 & 550 & 9100 & 9100 & 5800 & 3640 & 3640 \\
\hline $\begin{array}{c}\text { Unsaturated Zone 4 } \\
\text { (Alluvium soils } \\
\text { (native/subgrade)) }\end{array}$ & 450 & 550 & 270 & 500 & 500 & 3200 & 66.8 & 66.8 \\
\hline $\begin{array}{c}\text { Unsaturated Zone 5 } \\
\text { (Clay confining unit } \\
\text { (native)) }\end{array}$ & 2400 & 2700 & 550 & 9100 & 9100 & 5800 & 3640 & 3640 \\
\hline \begin{tabular}{c} 
Saturated Zone (RGA) \\
\hline
\end{tabular} & 450 & 550 & 270 & 500 & 500 & 3200 & 66.8 & 66.8 \\
\hline
\end{tabular}

\footnotetext{
d Distribution coefficients for Ac-227, Pa-231, Pb-210, Ra-226, Ra-228, Th-229, and U-236 were obtained through "Project Communication" with the Waste Disposal Options Project Team from Paducah, KY. It was assumed that the Kds for U-233 was similar to the Kds for the other uranium isotopes (i.e. U-234, U-235, U-236 and U-238), since the Kds are chemical specific.

e The contaminated zone includes four Waste Forms such as: Soil (Waste Form 1), Concrete (Waste Form 2), Metal (Waste Form 3), and Organic (Waste Form 4). This information was obtained from figure Fig. 4.5. Schematic diagram of DUST model layers and materials for the Post Institutional Control Period under the gradual failure and immediate failure scenarios of DOE $2003 \mathrm{~b}$, page 4-18.
} 
Distribution Coefficients ( $\mathrm{Kds}, \mathrm{cm}^{3} / \mathrm{g}$ ) for parent radionuclides in the sediment in surface water body; fruit, grain, nonleafy fields; leafy vegetable fields; pasture, silage growing areas; livestock feed grain fields; and dwelling site ${ }^{f}$

\begin{tabular}{|c|c|c|c|c|c|c|c|c|c|c|c|c|}
\hline Radionuclide & Am-241 & Cs-137 & Np-237 & Pu-238 & $\mathrm{Pu}-239 / 240$ & Tc-99 & Th-228 & Th-230 & Th-232 & U-234 & U-235 & U-238 \\
\hline $\begin{array}{c}\text { Sediment in } \\
\text { Surface Water } \\
\text { Body }\end{array}$ & 1900 & 280 & 70 & 550 & 550 & 0.2 & 3200 & 3200 & 3200 & 66.8 & 66.8 & 66.8 \\
\hline $\begin{array}{l}\text { Fruit, Grain, } \\
\text { Nonleafy Fields }\end{array}$ & 1900 & 280 & 70 & 550 & 550 & 0.2 & 3200 & 3200 & 3200 & 66.8 & 66.8 & 66.8 \\
\hline $\begin{array}{l}\text { Leafy Vegetable } \\
\text { Fields }\end{array}$ & 1900 & 280 & 70 & 550 & 550 & 0.2 & 3200 & 3200 & 3200 & 66.8 & 66.8 & 66.8 \\
\hline $\begin{array}{l}\text { Pasture, Silage } \\
\text { Growing Areas }\end{array}$ & 1900 & 280 & 70 & 550 & 550 & 0.2 & 3200 & 3200 & 3200 & 66.8 & 66.8 & 66.8 \\
\hline $\begin{array}{l}\text { Livestock Feed } \\
\text { Grain Fields }\end{array}$ & 1900 & 280 & 70 & 550 & 550 & 0.2 & 3200 & 3200 & 3200 & 66.8 & 66.8 & 66.8 \\
\hline Dwelling Site & 1900 & 280 & 70 & 550 & 550 & 0.2 & 3200 & 3200 & 3200 & 66.8 & 66.8 & 66.8 \\
\hline
\end{tabular}

\footnotetext{
${ }^{\mathrm{f}}$ The Kds for native soil (Unsaturated Zone 2) were assumed for these areas.
} 
Distribution Coefficients ( $\mathrm{Kds}, \mathrm{cm}^{3} / \mathrm{g}$ ) for progeny in the sediment in surface water body; fruit, grain, nonleafy fields; leafy vegetable fields; pasture, silage growing areas; livestock feed grain fields; and dwelling site

\begin{tabular}{|c|c|c|c|c|c|c|c|c|}
\hline Radionuclide & Ac-227 & $\mathrm{Pa}-231$ & $\mathrm{~Pb}-210$ & Ra-226 & Ra-228 & Th-229 & U-233 & U-236 \\
\hline Sediment in Surface Water Body & 450 & 550 & 270 & 500 & 500 & 3200 & 66.8 & 66.8 \\
\hline Fruit, Grain, Nonleafy Fields & 450 & 550 & 270 & 500 & 500 & 3200 & 66.8 & 66.8 \\
\hline Pasture, Silage Growing Areas & 450 & 550 & 270 & 500 & 500 & 3200 & 66.8 & 66.8 \\
\hline Livestock Feed Grain Fields & 450 & 550 & 270 & 500 & 500 & 3200 & 66.8 & 66.8 \\
\hline Dwelling Site & 450 & 550 & 270 & 500 & 500 & 3200 & 66.8 & 66.8 \\
\hline
\end{tabular}


Attachment II

Calculations and Applicable Parameters from DOE 2009, Appendix D, Converted into RESRAD Compatible Units 


\section{Section A. Runoff Coefficient and Evapotranspiration Coefficient Calculations}

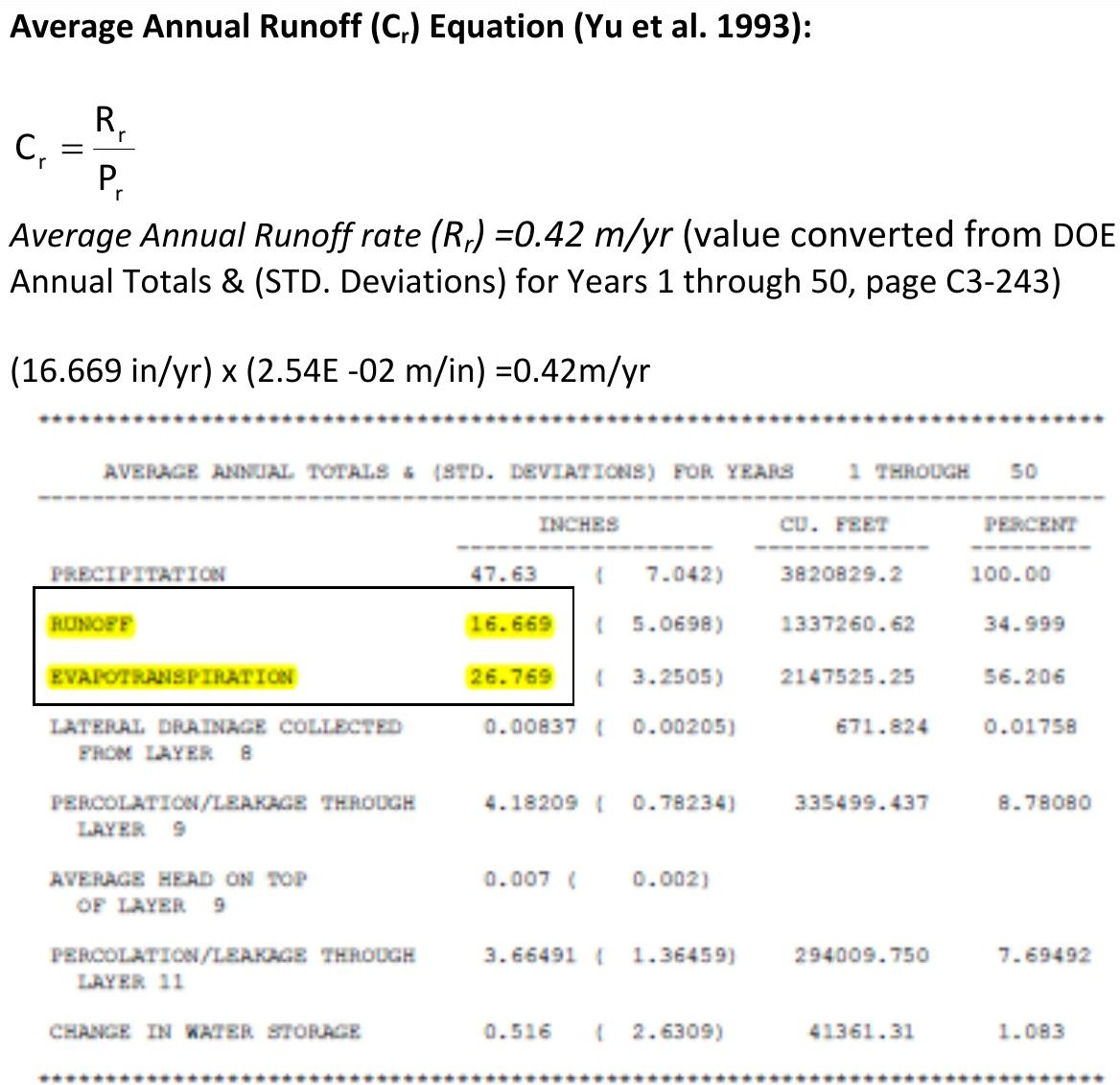

Values from the HELP Output List 3 that were used to determine input parameters are highlighted.

Average Annual Precipitation rate $\left(P_{r}\right)=1.24 \mathrm{~m} / \mathrm{yr}$ (PRS 2008a, Page 1-4)

(49 in/yr) x (2.54E $-02 \mathrm{~m} / \mathrm{in})=1.24 \mathrm{~m} / \mathrm{yr}$

$C_{r}=\frac{0.42 \mathrm{~m} / \mathrm{yr}}{1.24 \mathrm{~m} / \mathrm{yr}}, C_{r}=0.34$ 


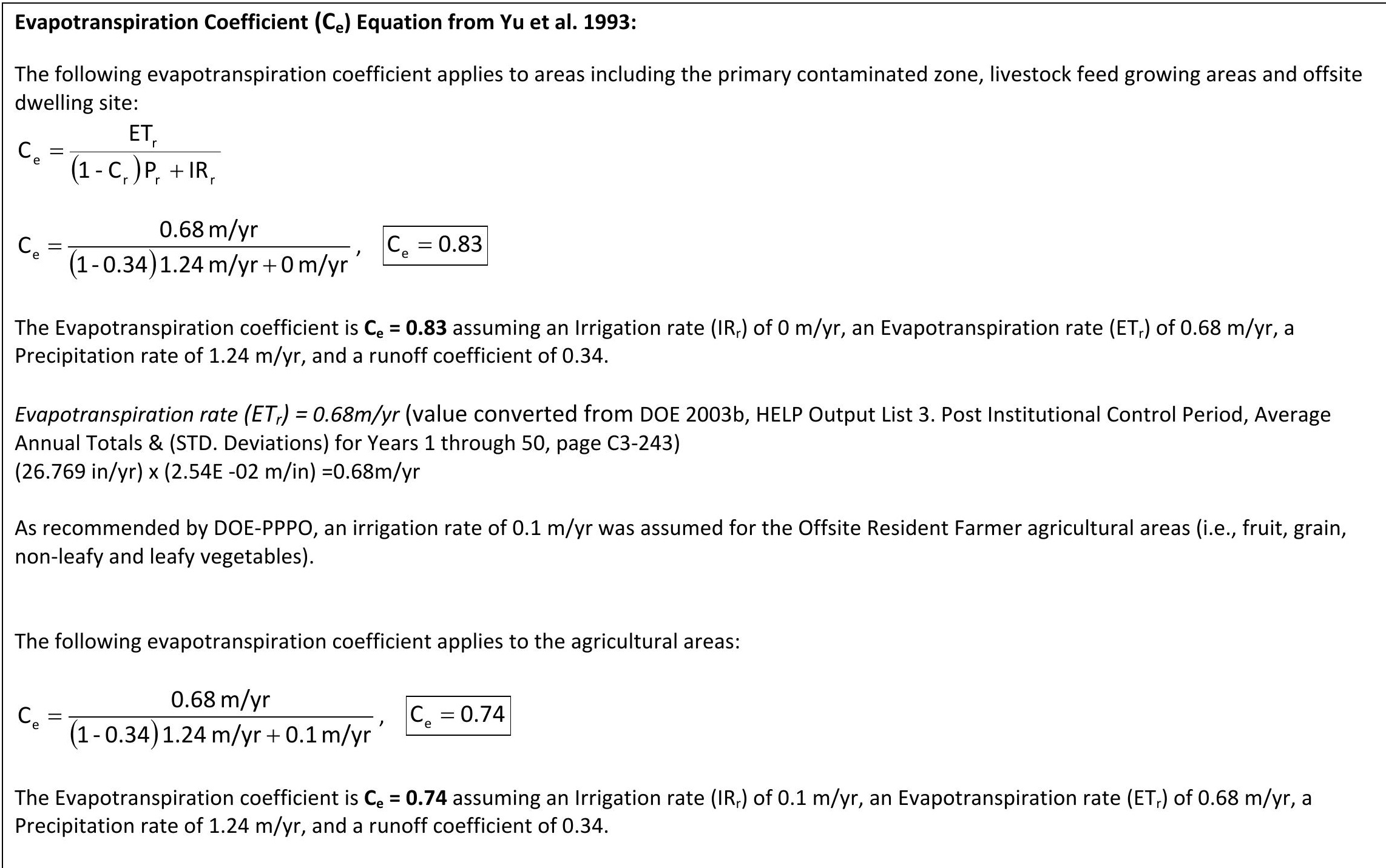




\section{Section B. Parameters Applicable to the Resident Farmer from DOE 2009, Appendix D Converted into RESRAD Compatible Units}

\section{Drinking Water Intake}

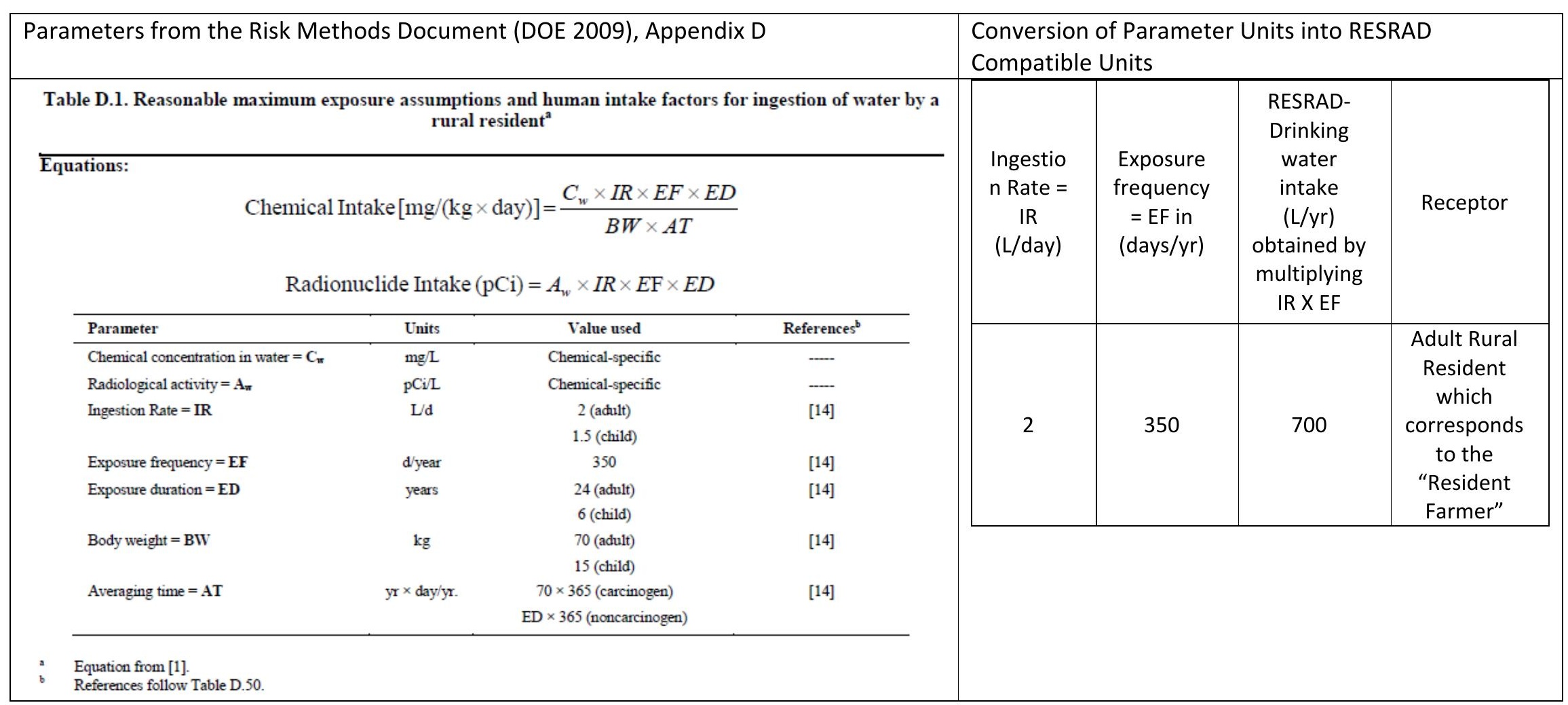




\section{Soil Ingestion Rate}

Parameters from the Risk Methods Document (DOE 2009), Appendix D

Table D.5. Reasonable maximum exposure assumptions and human intake factors for incidental ingestion soil by a rural resident ${ }^{a}$

$$
\text { Equations: }
$$$$
\text { Chemical Intake }\left[\mathrm{mg} /(\mathrm{kg} \times \text { day }]=\frac{C_{s} \times C F \times E F \times F I \times E D \times I R}{B W \times A T}\right.
$$

Radionuclide Intake $(\mathrm{pCi})=A_{s} \times C F_{\text {rad }} \times E F \times F I \times E D \times I R$

\begin{tabular}{|c|c|c|c|}
\hline Parameter & Units & Value used & References $^{\mathrm{b}}$ \\
\hline Chemical concentration in soil $=\mathrm{C}_{\mathrm{F}}$ & $\mathrm{mg} / \mathrm{kg}$ & Chemical-specific & $\ldots$ \\
\hline Radiological activity $=\mathbf{A}_{\mathbf{s}}$ & pCi/g & Chemical-specific & $\ldots$ \\
\hline Conversion factor $=\mathbf{C F}$ & $\mathrm{kg} / \mathrm{mg}$ & $10^{-6}$ & - \\
\hline Conversion factor $=\mathbf{C F}_{\mathrm{rad}}$ & $\mathrm{g} / \mathrm{mg}$ & $10^{-3}$ & $\ldots$ \\
\hline Exposure frequency $=\mathbf{E F}$ & days/yr & 350 & [14] \\
\hline Fraction ingested = FI & unitless & 1 & [14] \\
\hline \multirow[t]{2}{*}{ Exposure curation = ED } & years & 24 (adult) & [14] \\
\hline & & 6 (child) & \\
\hline \multirow[t]{2}{*}{ Ingestion rate of soil = IR } & $\mathrm{mg} / \mathrm{d}$ & 100 (adult) & [14] \\
\hline & & 200 (child) & \\
\hline \multirow[t]{2}{*}{ Body weight $=$ BW } & $\mathrm{kg}$ & 70 (adult) & [14] \\
\hline & & 15 (child) & \\
\hline \multirow{2}{*}{ Averaging time $=\mathrm{AT}$} & $\mathrm{yr} \times \mathrm{day} / \mathrm{yr}$ & $70 \times 365$ (carcinogen) & [14] \\
\hline & & $\mathrm{ED} \times 365$ (noncarcinogen) & \\
\hline
\end{tabular}

Equation from [1]
Conversion of Parameter Units into RESRAD Compatible Units

\begin{tabular}{|c|c|c|c|l|}
\hline $\begin{array}{c}\text { Conversion } \\
\text { factor }= \\
\mathrm{Cf}_{\text {rad }} \\
(\mathrm{g} / \mathrm{mg})\end{array}$ & $\begin{array}{c}\text { Ingestion } \\
\text { rate of } \\
\text { soil = IR } \\
\text { (mg/day) }\end{array}$ & $\begin{array}{c}\text { Exposure } \\
\text { frequenc } \\
\mathrm{y}=\mathrm{EF} \\
\text { (days/yr) }\end{array}$ & $\begin{array}{c}\text { RESRAD -Soil } \\
\text { ingestion } \\
\text { (g/yr) } \\
\text { obtained by } \\
\text { multiplying } \\
\mathrm{Cf}_{\text {rad }} \text { X IR X EF }\end{array}$ & Receptor \\
\hline $1.00 \mathrm{E}-03$ & 100 & 365 & 36.5 & $\begin{array}{l}\text { Adult Rural } \\
\text { Resident } \\
\text { which } \\
\text { corresponds } \\
\text { to the } \\
\text { "Resident } \\
\text { Farmer" }\end{array}$ \\
\hline
\end{tabular}

Note: The exposure frequency of $365 \mathrm{~d} / \mathrm{yr}$ is used in the conversion, instead of $350 \mathrm{~d} / \mathrm{yr}$ since RESRAD uses time fractions to correct for occupancy. 
Inhalation Rate and Mass Loading for Inhalation

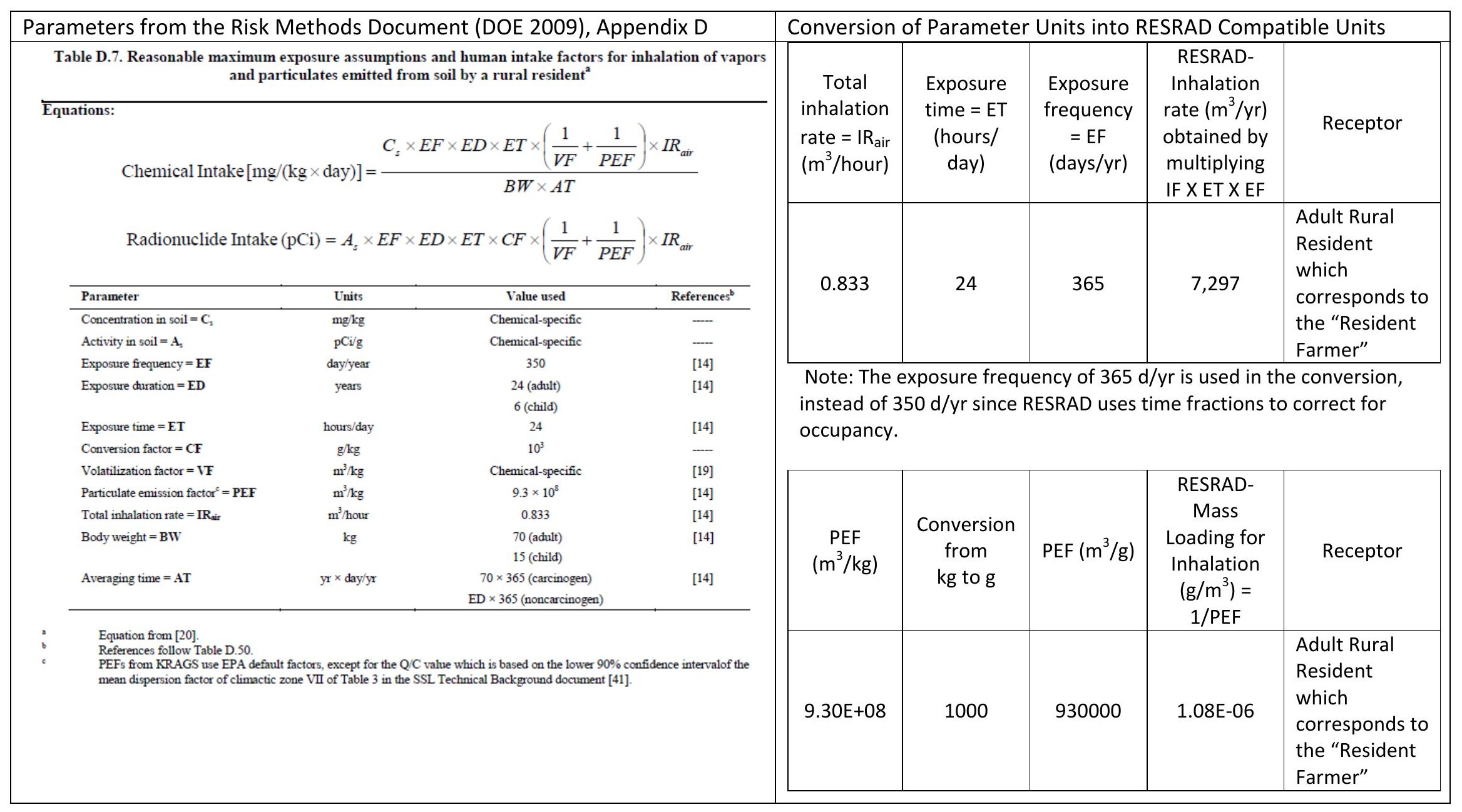


External Gamma Shielding Factor and Exposure Duration

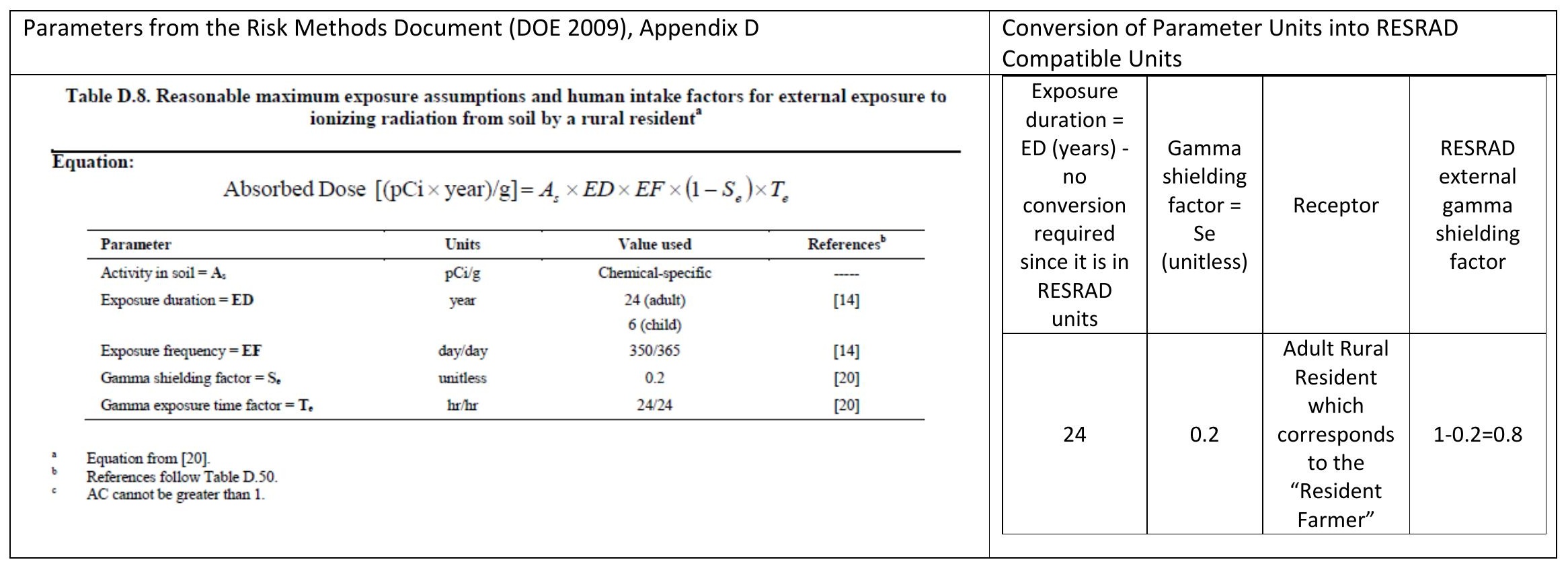

\section{Indoor and Outdoor Occupancy Fractions}

\begin{tabular}{|c|c|c|}
\hline \multicolumn{3}{|c|}{ Resident Farmer Occupancy fractions } \\
\hline & Days & Fractions for RESRAD \\
\hline $1 / 3$ of the time outdoors & 117 & 0.32 \\
\hline $2 / 3$ of the time indoors & 233 & 0.64 \\
\hline Total Days Onsite & 350 & \\
\hline Total Fraction & & 0.96 \\
\hline
\end{tabular}

Note: The Resident Farmer spends 350 days on site.

The fraction of time spent outdoors was divided by 5 , in order to equally distribute the time spent outdoors and in the different farm areas. This fraction was 0.064 . 
Fruit, Non-Leafy Vegetable, and Grain Consumption and Leafy Vegetables Consumption

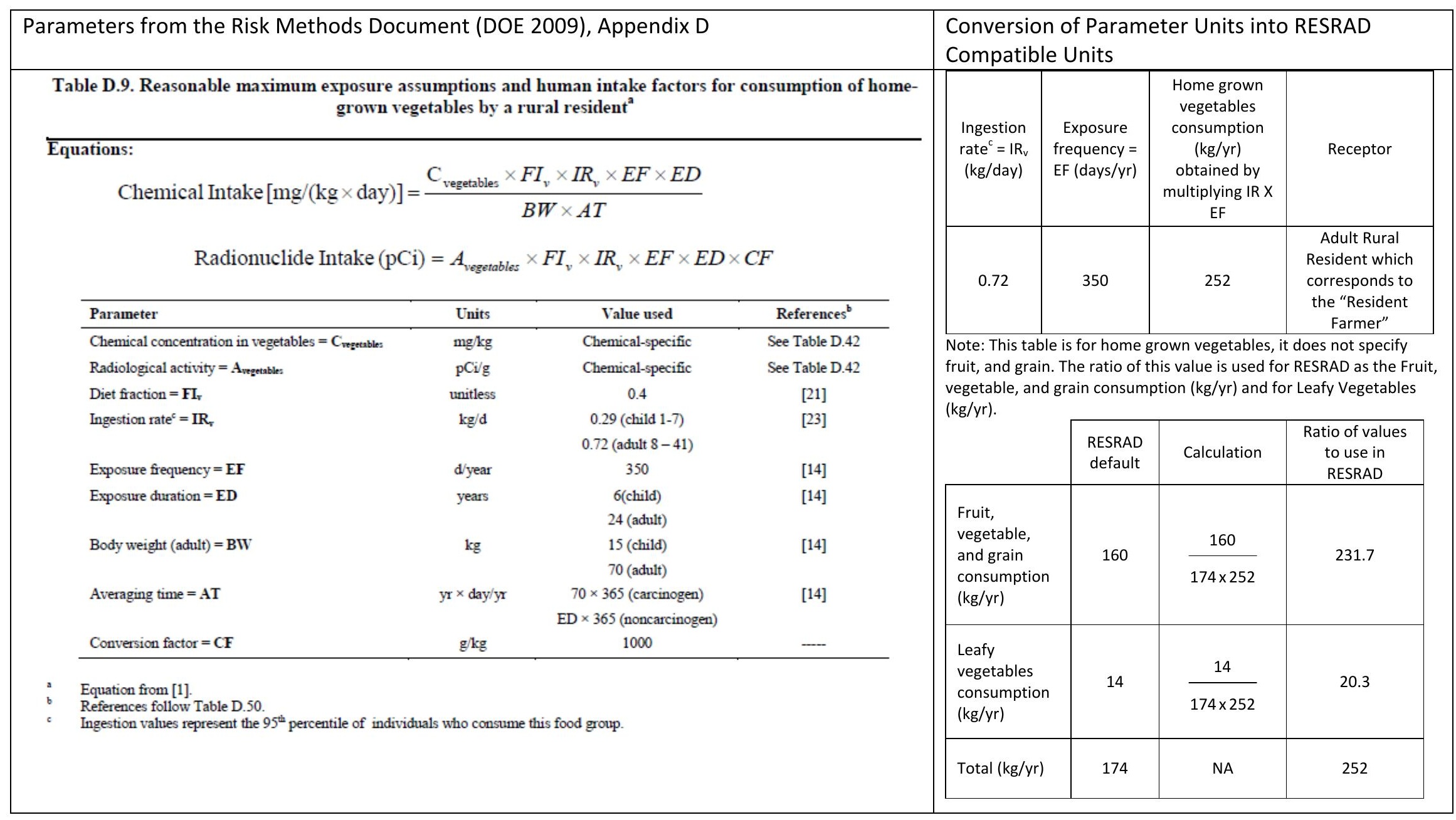




\section{Milk Consumption}

\section{Parameters from the Risk Methods Document (DOE 2009), Appendix D}

Table D.11. Reasonable maximum exposure assumptions and human intake factors for consumption of mil by a rural resident ${ }^{\mathrm{a}}$

$$
\text { Equations: }
$$

Chemical Intake $[\mathrm{mg} /(\mathrm{kg} \times$ day $)]=\frac{C_{\text {milk }} \times F I_{m} \times I R_{m} \times E F \times E D}{B W \times A T}$

Radionuclide Intake $(\mathrm{pCi})=A_{m i k} \times F I_{m} \times I R_{m} \times E F \times E D$

\begin{tabular}{|c|c|c|c|}
\hline Parameter & Units & Value used & References $^{b}$ \\
\hline Chemical concentration in milk $=\mathrm{C}_{\text {mill }}$ & $\mathrm{mg} / \mathrm{kg}$ & Chemical-specific & See Table D.47 \\
\hline Radiological activity in milk $=\mathbf{A}_{\operatorname{mill}}$ & $\mathrm{pCi} / \mathrm{kg}$ & Chemical-specific & See Table D.47 \\
\hline Milk ingestion rate ${ }^{c}=\mathrm{IR}_{\mathrm{m}}$ & $\mathrm{kg} /$ day & $\begin{array}{c}0.9 \text { (child } 1-7 \text { ) } \\
1.25 \text { (adult } 8-41 \text { ) }\end{array}$ & [23] \\
\hline Diet fraction $=\mathbf{F I}_{\mathbf{m}}$ & unitless & 1 & [21] \\
\hline Exposure frequency $=\mathbf{E F}$ & $d /$ year & 350 & [14] \\
\hline Exposure duration $=\mathrm{ED}$ & years & $\begin{array}{l}6 \text { (child) } \\
24 \text { (adult) }\end{array}$ & [14] \\
\hline Body weight (adult) $=\mathrm{BW}$ & $\mathrm{kg}$ & $\begin{array}{l}15 \text { (child) } \\
70 \text { (adult) }\end{array}$ & [14] \\
\hline Averaging time $=\mathrm{AT}$ & $\mathrm{yr} \times$ day $/ \mathrm{yr}$ & $\begin{array}{c}70 \times 365 \text { (carcinogen) } \\
\text { ED } \times 365 \text { (noncarcinogen) }\end{array}$ & [14] \\
\hline
\end{tabular}

\section{Equation from [1]}

References follow Table D. 50 .
ingestion values represent the $95^{\text {t }}$ percentile of individuals who consume this food group.

\begin{tabular}{|c|c|c|c|c|}
\hline \multicolumn{5}{|c|}{ Conversion of Parameter Units into RESRAD Compatible Units } \\
\hline $\begin{array}{c}\text { Milk } \\
\text { ingestion } \\
\text { rate }^{\mathrm{c}}= \\
\mathrm{IR}_{\mathrm{b}} \\
\text { (kg/day) }\end{array}$ & $\begin{array}{l}\text { Exposure } \\
\text { frequency } \\
=\mathrm{EF} \\
\text { (days/yr) }\end{array}$ & $\begin{array}{l}\text { Milk } \\
\text { consumption } \\
(\mathrm{kg} / \mathrm{yr}) \\
\text { obtained by } \\
\text { multiplying IR } \\
\text { X EF }\end{array}$ & $\begin{array}{l}\text { RESRAD-Milk } \\
\text { consumption } \\
\text { (L/yr) } \\
\text { obtained by } \\
\text { diving the } \\
\text { milk } \\
\text { consumption } \\
\text { (kg/yr) by the } \\
\text { density of } \\
\text { milk and then } \\
\text { multiplying by } \\
1000\end{array}$ & Receptor \\
\hline 1.25 & 350 & 437.5 & 425 & $\begin{array}{l}\text { Adult Rural } \\
\text { Resident } \\
\text { which } \\
\text { corresponds } \\
\text { to the } \\
\text { "Resident } \\
\text { Farmer" }\end{array}$ \\
\hline
\end{tabular}

Density of milk, cow, whole $=1030 \mathrm{~kg} / \mathrm{m}^{3}$

1 cubic meter $=1000$ liters

This density was obtained from an online source: http://physics.info/density/ 
Meat and Poultry Consumption

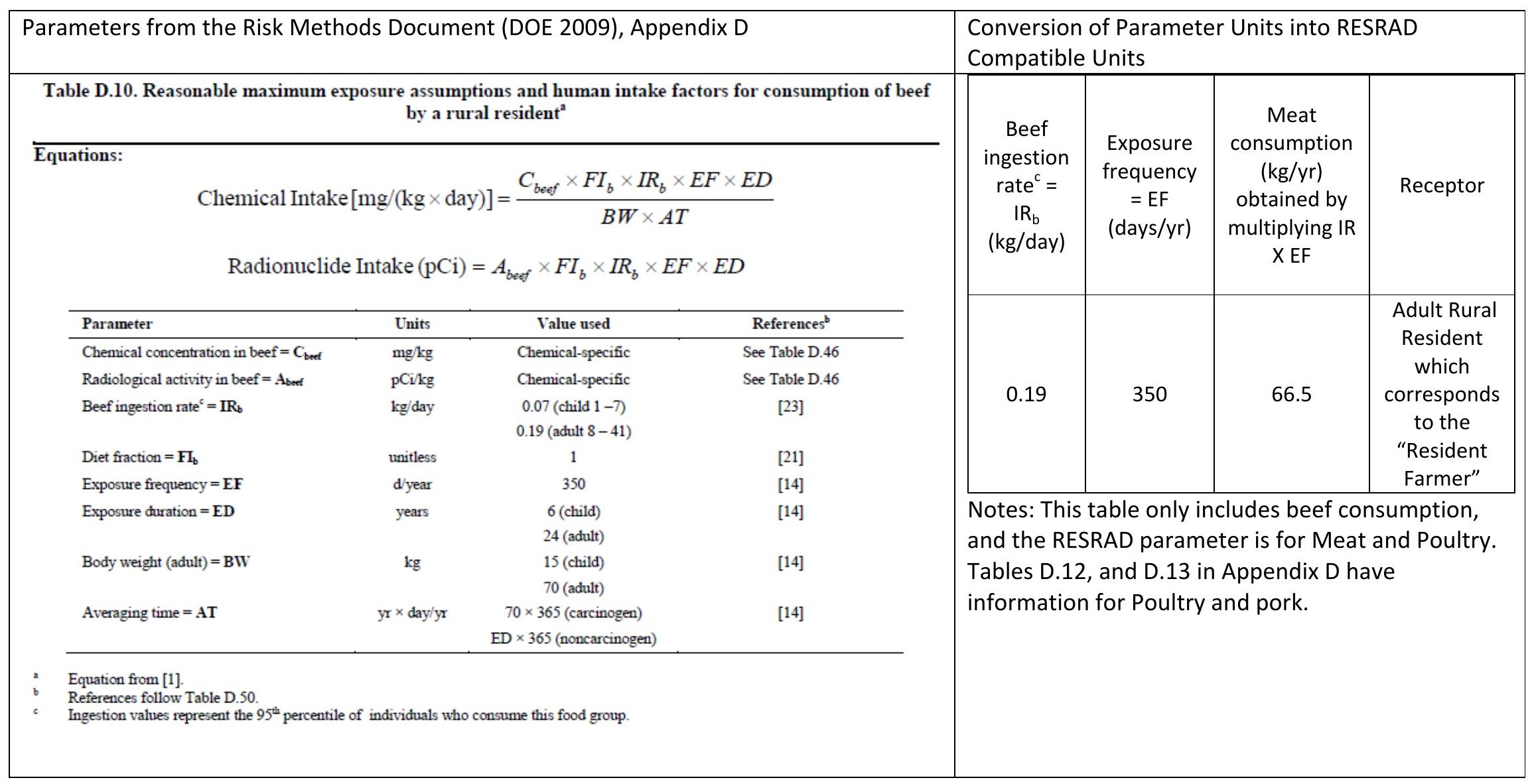


Meat and Poultry Consumption (cont.)

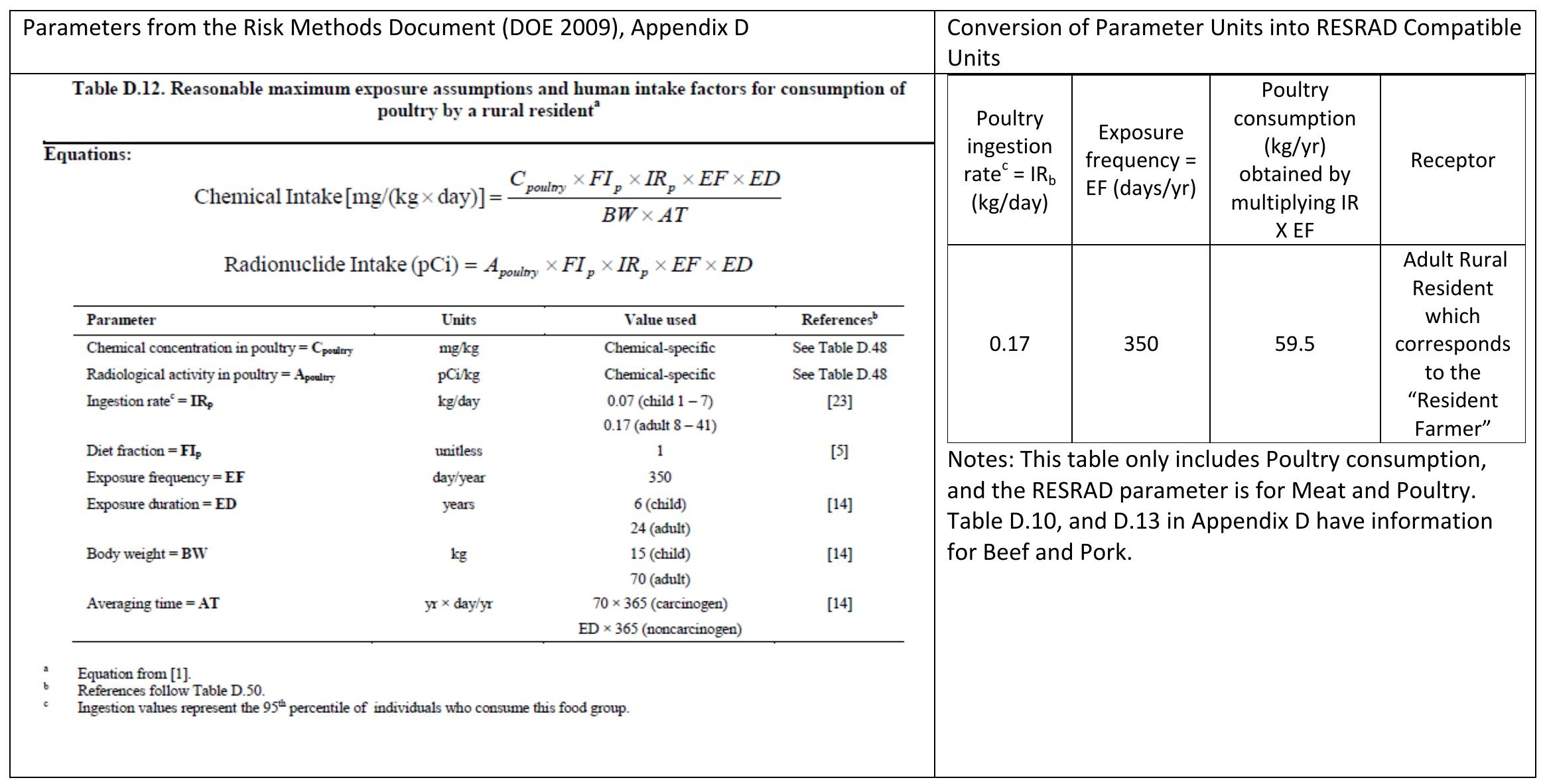


Meat and Poultry Consumption (cont.)

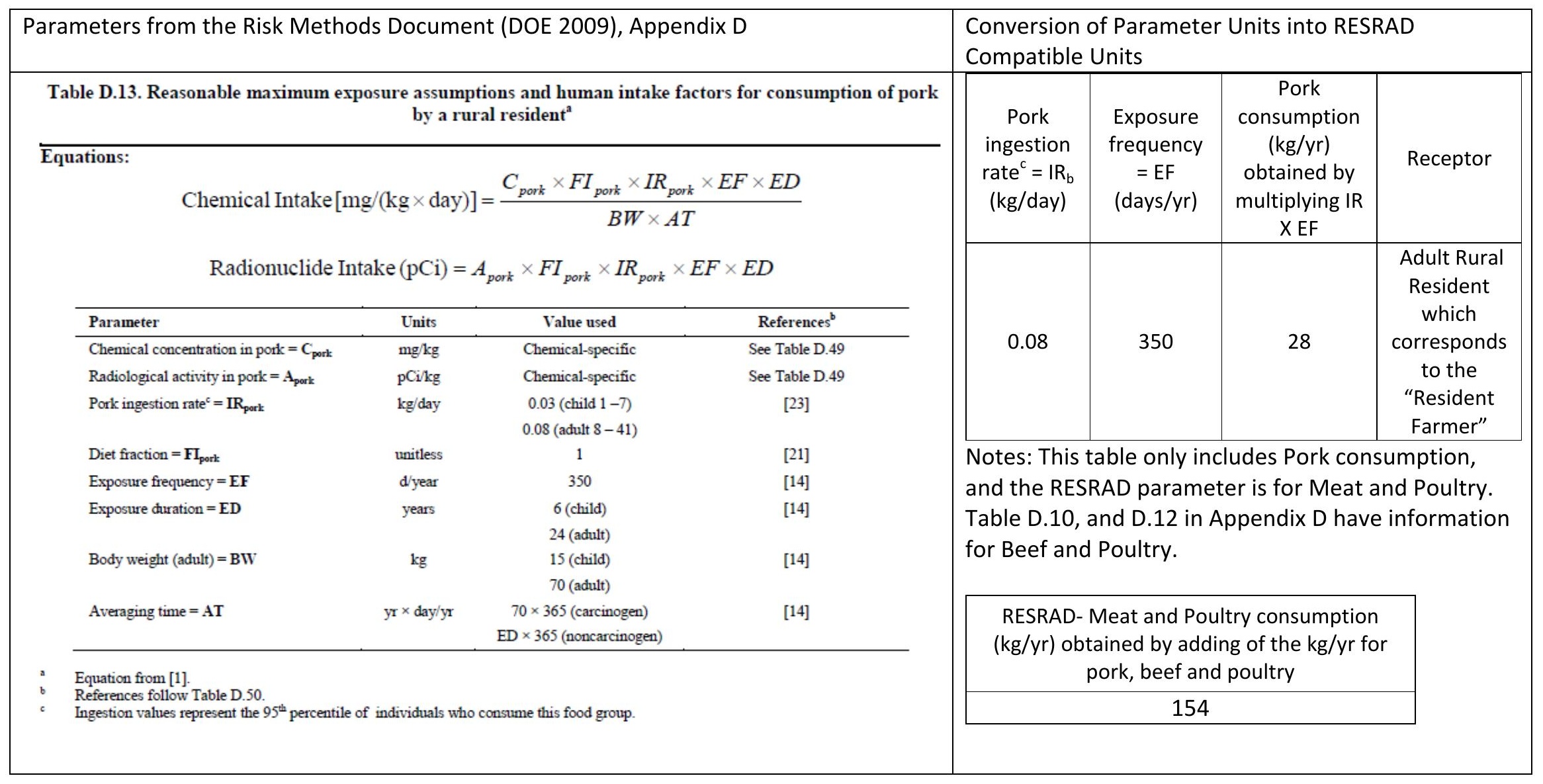




\section{Section C. Parameters Applicable to Beef and Dairy from DOE 2009, Appendix D}

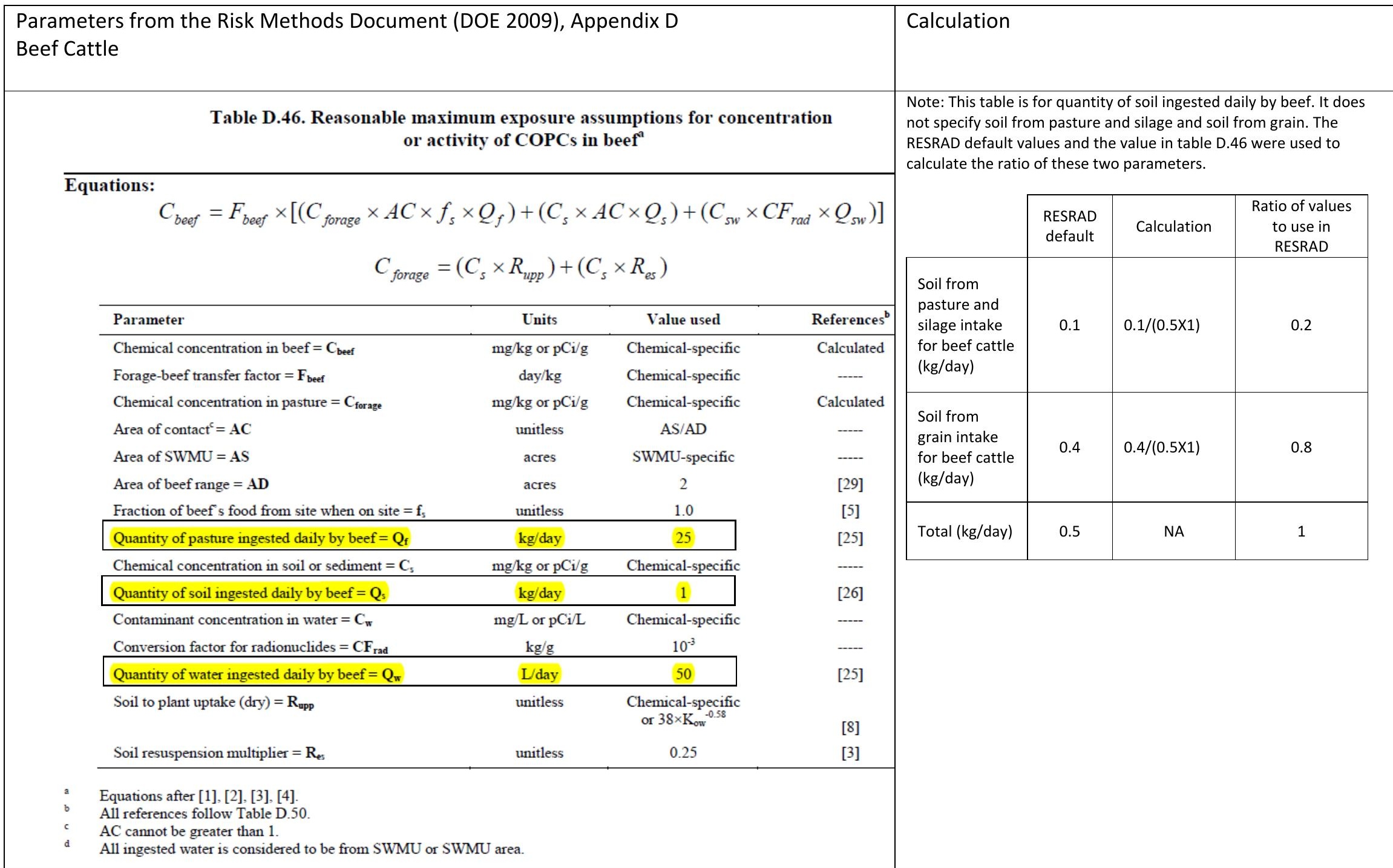

Values that were used to determine input parameters are highlighted. 


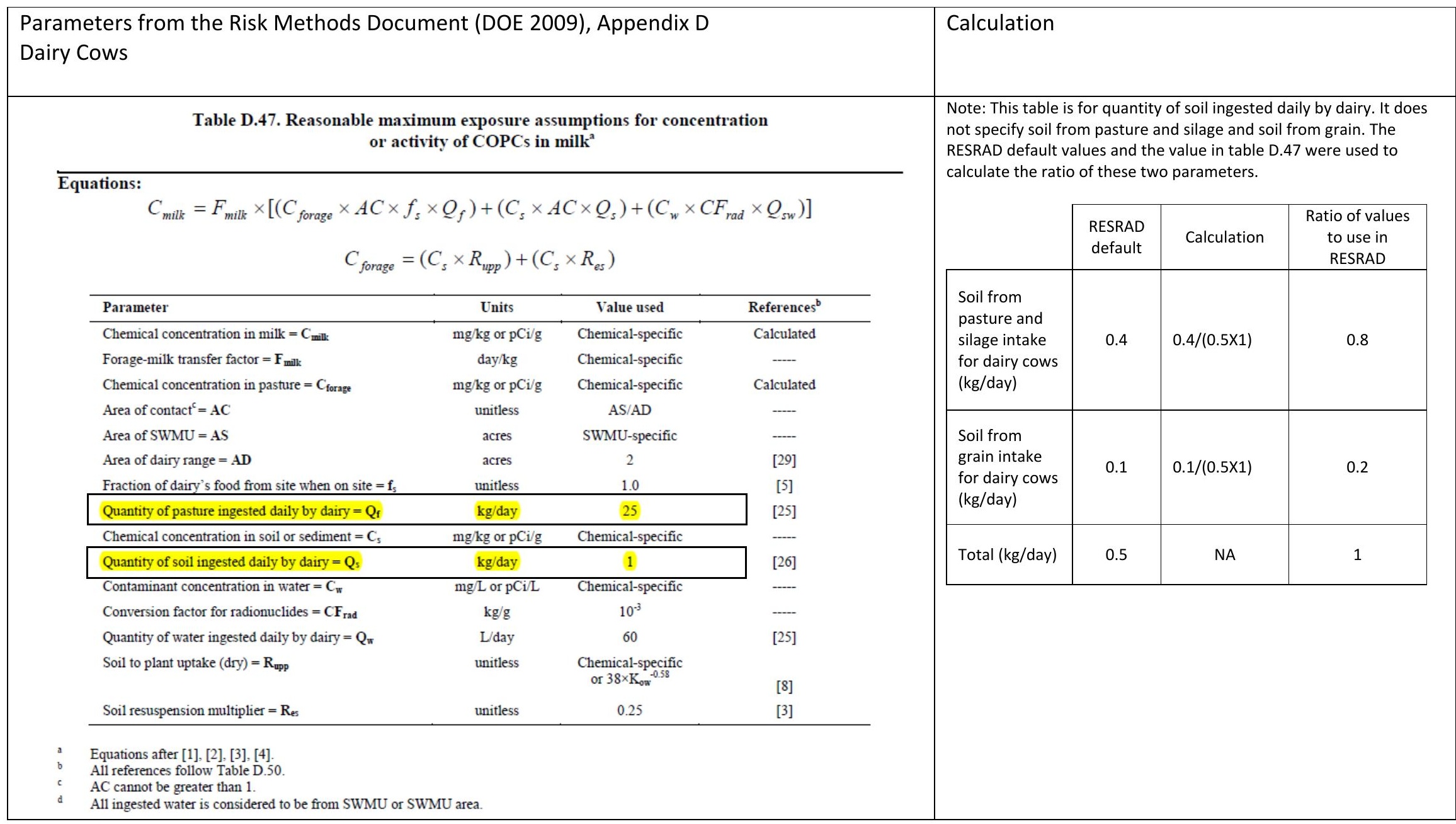

Values that were used to determine input parameters are highlighted. 


\section{References}

ATSDR 2002, Public Health Assessment for the Paducah Gaseous Diffusion Plant (USDOE) Paducah, McCracken County, Kentucky (May 2002).

DOE 2003a. Authorized Limits Request for Solid Waste Disposal at Landfill C-746-U at the Paducah Gaseous Diffusion Plant, (November 2002; revised January 2003).

DOE 2003b. Risk and Performance Evaluation of the C-746-U Landfill at the Paducah Gaseous Diffusion Plant, Paducah, Kentucky, DOE/OR/072041\&D2R1 (2003).

DOE 2009. Methods for Conducting Risk Assessments and Risk Evaluations at the Paducah Gaseous Diffusion Plant Paducah, Kentucky Volume 1. Human Health, DOE/LX/07-0107\&D1/V1 (2009).

DOE Statement of Work (SOW) for C-746-U Landfill provided to ORISE on December 2009.

DOE C-746-U landfill inventory spreadsheet for total waste disposed from May 2003 through May 2009.

DOE Project Communication with the Waste Disposal Options Project Team from Paducah, KY, March 2010 (Latest email correspondence 03/29/2010 from Rich Bonczek).

DOE Project Communication with the Geologist from Paducah, KY, April 2010 (Latest email correspondence 04/05/2010 from Raulie Casteel).

DOE Project Communication with Geologist and Engineer from Paducah, KY, April 2010 (Latest email correspondence 04/07/2010 from Raulie Casteel).

DOE Project Communication with the Geologist from Paducah, KY, April 2010 (Latest email correspondence 04/28/2010 from Raulie Casteel). DOE Project Communication May, 2010 (Discussion between ORISE and Rich Bonczek during a meeting held at ORISE on 05/17/2010).

DOE Project Communication June, 2010 (Email correspondence 06/02/2010 from ORISE to DOE).

DOE Project Communication July, 2010 (Discussion between ORISE and DOE-PPPO during a meeting held at ORISE on 07/12/2010).

DOE Project Communication September, 2010 (Discussion between ORISE and DOE-PPPO during a conference call held on 09/29/2010). 
DOE Project Communication October, 2010 (Discussion between ORISE and DOE-PPPO during a conference call held on 10/7/2010).

DOE Project Communication November, 2010 (Email correspondence 11/03/2010 from ORISE to DOE consultant).

DOE Project Communication April, 2011 (ORISE and DOE-PPPO biweekly conference call on 04/13/2011 and email correspondence 04/14/2011 from ORISE to DOE-PPPO).

DOE Project Communication April, 2011 (ORISE and DOE-PPPO email correspondence 04/8/2011 from Chad Drummond to DOE-PPPO from DOEPPPO to ORISE).

DOE Order 458.1, Radiation Protection of the Public and the Environment (DOE 2011).

DOE Order 5400.5, Radiation Protection of the Public and the Environment (DOE 1993).

Kenny, J. F. et al. 2009. Estimated Use of Water in the United States in 2005, Circular 1344, U.S. Department of Interior, U.S. Geological Survey (2009).

King, David A. and Karen Keil, 2006. Comparison of Standard Radiological Risk Models and Using RESRAD to Derive Generic Risk-Based Area Factors for Final Status Surveys, Risk Analysis, Vol. 26, No. 1.

Lee, D. W., J. C. Wang, and D. C. Kocher, 1995. Operating Limit Study for the Proposed Solid Waste Landfill at Paducah Gaseous Diffusion Plant, ORNL/TM-13008.

PRS 2008a. 2006 Paducah Site Annual Site Environmental Report for Calendar Year 2006, PRS-ENM-0034 Volume I, Paducah Remediation Services (September 2008).

PRS 2008b. 2008 Update of the Paducah Gaseous Diffusion Plant Site Wide Groundwater Flow Model, PRS-ENR-0028.

Wischmeier, W.H., and D.D. Smith 1978. Predicting Rainfall Erosion Losses: A Guide to Conservation Planning, AH537/12/78.

Yu, C., C. Loureiro, J. J. Cheng, L.G. Jones, Y.Y. Wang, Y.P. Chia, and E. Faillace, 1993. Data Collection Handbook to Support Modeling Impacts of Radioactive Material in Soil.

Yu C., D. LePoire, E. Gnanapragasam, J. Arnish, S. Kamboj, B.M. Biwer, J.-J. Cheng, A. Zielen, and S.Y. Chen, 2000. Development of Probabilistic RESRAD 6.0 and RESRAD-Build 3.0 Computer Codes, NUREG/CR-6697 ANL/EAD/TM-98. 
Yu, C., A.J. Zielen, J.J. Cheng, D.J. LePoire, E. Gnanapragasam, S. Kamboj, J. Arnish, A. Wallo, III, W.A. Williams, and H. Peterson, 2007. User's Manual for RESRAD OFFSITE Version 2, ANL/EVS/TM/07-1, DOE /HS-0005, NUREG/CR-6937, Argonne National Laboratory. 


\title{
Quality Control (QC) for the Peak Dose Assessment for Proposed DOE-PPPO Authorized Limits (Oak Ridge Institute for Science and Education, July 2011)
}

\author{
By \\ John A. Volpe, Ph.D. \\ Performance Results Corporation
}


THIS PAGE INTENTIONALLY LEFT BLANK 
July 21, 2011

Dr. Richard R. Bonczek

U.S. Department of Energy

Portsmouth/Paducah Project Office

1017 Majestic Drive

Lexington, KY 40513

\section{Subject: Quality Control (QC) of Forward Runs for Dose Modeling Evaluations and Technical Support Document for the Authorized Limits Request for the C-746-U Landfill at the Paducah Gaseous Diffusion Plant, Paducah, Kentucky (Oak Ridge Institute for Science and Education, May 2011)}

Dear Dr. Bonczek:

RESRAD and RESRAD OFFSITE outputs are provided in Attachment 1 utilizing input parameters in Attachment 2 provided and used by the Oak Ridge Institute for Science and Education (ORISE) for development of single radionuclide soil guidelines for the C-746-U Landfill at the Paducah Gaseous Diffusion Plant, Paducah, Kentucky. Quality Control was conducted for all scenarios assessed by ORISE. The activity for each radionuclide provided by DOE in Attachment 3 was used for the forward run scenarios.

The radiation dose is provided in Attachment 1 for the forward run scenarios. The radiation dose was determined using the input parameters provided by ORISE in Attachment 2 and the activity for each radionuclide provided by DOE in Attachment 3, Attachment 4 provides a comparison of the forward run QC RESRAD and RESRAD OFFSITE outputs and the ORISE forward run RESRAD and RESRAD OFFSITE outputs.

As shown in Attachment 4, small differences were observed in the output for the forward run scenarios.

If you have question regarding the QC, please contact me at 502-330-0222.

Sincerely,

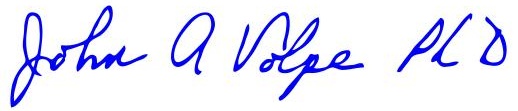

John A. Volpe, Ph.D.

Executive Management Consultant

Performance Results Corporation

Attachments

C: Tim Ecklelard, PRC 
ATTACHMENT 1 


\section{LANDFILL WORKER}

RESRAD U-Landfill Landfill Worker Forward Run 70 Years

Contaminated Zone Dimensions Initial Soil Concentrations, pCi/g

\begin{tabular}{ccll}
\hline \multicolumn{2}{c}{ Area: 89436.00 square meters } & Am-241 & $3.500 \mathrm{E}+01$ \\
Thickness: & 13.40 meters & Cs-137 & $1.900 \mathrm{E}+01$ \\
Cover Depth: & 0.00 meters & Np-237 & $5.500 \mathrm{E}+00$ \\
& & Pu-238 & $3.900 \mathrm{E}+01$ \\
& & Pu-239 & $3.600 \mathrm{E}+01$ \\
& Pu-240 & $3.600 \mathrm{E}+01$ \\
& Tc-99 & $5.200 \mathrm{E}+01$ \\
& Th-228 & $4.000 \mathrm{E}+00$ \\
& Th-230 & $1.000 \mathrm{E}+02$ \\
& Th-232 & $4.000 \mathrm{E}+00$ \\
& U-234 & $1.600 \mathrm{E}+02$ \\
& $\mathrm{U}-235$ & $6.500 \mathrm{E}+00$ \\
& $\mathrm{U}-238$ & $1.600 \mathrm{E}+02$
\end{tabular}

Total Dose TDOSE(t), mrem/yr

Basic Radiation Dose Limit $=1.000 \mathrm{E}+02 \mathrm{mrem} / \mathrm{yr}$

Total Mixture Sum M(t) = Fraction of Basic Dose Limit Received at Time (t)

\begin{tabular}{llllll}
$\mathrm{t}$ (years): & $0.000 \mathrm{E}+00$ & $1.000 \mathrm{E}+00$ & $2.500 \mathrm{E}+01$ & $5.000 \mathrm{E}+01$ & $7.000 \mathrm{E}+01$ \\
\hline TDOSE $(\mathrm{t}):$ & $2.988 \mathrm{E}+01$ & $2.871 \mathrm{E}+01$ & $3.140 \mathrm{E}+01$ & $3.136 \mathrm{E}+01$ & $3.171 \mathrm{E}+01$ \\
$\mathrm{M}(\mathrm{t}):$ & $2.988 \mathrm{E}-01$ & $2.871 \mathrm{E}-01$ & $3.140 \mathrm{E}-01$ & $3.136 \mathrm{E}-01$ & $3.171 \mathrm{E}-01$
\end{tabular}

Maximum TDOSE(t): $3.171 \mathrm{E}+01 \mathrm{mrem} / \mathrm{yr}$ at $\mathrm{t}=7.000 \mathrm{E}+01$ years 


\section{LANDFILL WORKER}

RESRAD U-Landfill Landfill Worker Forward Run 70 Years at Proposed Authorized Limits

Contaminated Zone Dimensions Initial Soil Concentrations, pCi/g

\begin{tabular}{ccll}
\hline Area: 89436.00 square meters & Am-241 & $7.000 \mathrm{E}+01$ \\
Thickness: & 13.40 meters & $\mathrm{Cs}-137$ & $3.800 \mathrm{E}+01$ \\
Cover Depth: & 0.00 meters & $\mathrm{Np}-237$ & $1.100 \mathrm{E}+01$ \\
& & $\mathrm{Pu}-238$ & $7.800 \mathrm{E}+01$ \\
& & $\mathrm{Pu}-239$ & $7.200 \mathrm{E}+01$ \\
& $\mathrm{Pu}-240$ & $7.200 \mathrm{E}+01$ \\
& Tc-99 & $1.040 \mathrm{E}+02$ \\
& Th-228 & $8.000 \mathrm{E}+00$ \\
& Th-230 & $2.000 \mathrm{E}+02$ \\
& Th-232 & $8.000 \mathrm{E}+00$ \\
& $\mathrm{U}-234$ & $3.200 \mathrm{E}+02$ \\
& $\mathrm{U}-235$ & $1.300 \mathrm{E}+01$ \\
& $\mathrm{U}-238$ & $3.200 \mathrm{E}+02$
\end{tabular}

Total Dose TDOSE(t), mrem/yr

Basic Radiation Dose Limit $=1.000 \mathrm{E}+02 \mathrm{mrem} / \mathrm{yr}$

Total Mixture Sum M(t) = Fraction of Basic Dose Limit Received at Time (t)

\begin{tabular}{llllll}
$\mathrm{t}$ (years): & $0.000 \mathrm{E}+00$ & $1.000 \mathrm{E}+00$ & $2.500 \mathrm{E}+01$ & $5.000 \mathrm{E}+01$ & $7.000 \mathrm{E}+01$ \\
\hline TDOSE $(\mathrm{t}):$ & $5.975 \mathrm{E}+01$ & $5.742 \mathrm{E}+01$ & $6.280 \mathrm{E}+01$ & $6.272 \mathrm{E}+01$ & $6.342 \mathrm{E}+01$ \\
$\mathrm{M}(\mathrm{t}):$ & $5.975 \mathrm{E}-01$ & $5.742 \mathrm{E}-01$ & $6.280 \mathrm{E}-01$ & $6.272 \mathrm{E}-01$ & $6.342 \mathrm{E}-01$
\end{tabular}

Maximum TDOSE(t): $6.342 \mathrm{E}+01 \mathrm{mrem} / \mathrm{yr}$ at $\mathrm{t}=7.000 \mathrm{E}+01$ years 


\section{TRESPASSER}

\section{RESRAD U-Landfill Trespasser Forward Run 70 Years}

Contaminated Zone Dimensions Initial Soil Concentrations, pCi/g

Area: 89436.00 square meters $\quad$ Am-241 $3.500 \mathrm{E}+01$

Thickness: 13.40 meters $\quad$ Cs-137 1.900E+01

Cover Depth: 0.15 meters $\quad$ Np-237 5.500E+00

Pu-238 3.900E +01

Pu-239 3.600E +01

Pu-240 3.600E+01

Tc-99 5.200E +01

Th-228 4.000E +00

Th-230 1.000E +02

Th-232 4.000E +00

$\mathrm{U}-234 \quad 1.600 \mathrm{E}+02$

$\mathrm{U}-235 \quad 6.500 \mathrm{E}+00$

$\mathrm{U}-238 \quad 1.600 \mathrm{E}+02$

Total Dose TDOSE(t), mrem/yr

Basic Radiation Dose Limit $=1.000 \mathrm{E}+02 \mathrm{mrem} / \mathrm{yr}$

Total Mixture Sum M(t) = Fraction of Basic Dose Limit Received at Time (t)

\begin{tabular}{llllll}
\hline $\mathrm{t}$ (years): & $0.000 \mathrm{E}+00$ & $1.000 \mathrm{E}+00$ & $2.500 \mathrm{E}+01$ & $5.000 \mathrm{E}+01$ & $7.000 \mathrm{E}+01$ \\
\hline TDOSE $(\mathrm{t}):$ & $9.324 \mathrm{E}-01$ & $8.597 \mathrm{E}-01$ & $1.333 \mathrm{E}+00$ & $1.703 \mathrm{E}+00$ & $2.056 \mathrm{E}+00$ \\
$\mathrm{M}(\mathrm{t}):$ & $9.324 \mathrm{E}-03$ & $8.597 \mathrm{E}-03$ & $1.333 \mathrm{E}-02$ & $1.703 \mathrm{E}-02$ & $2.056 \mathrm{E}-02$
\end{tabular}

Maximum TDOSE(t): $2.056 \mathrm{E}+00 \mathrm{mrem} / \mathrm{yr}$ at $\mathrm{t}=7.000 \mathrm{E}+01$ years 


\section{TRESPASSER}

RESRAD U-Landfill Trespasser Forward Run 70 Years at Proposed Authorized Limits

Contaminated Zone Dimensions Initial Soil Concentrations, pCi/g

Area: 89436.00 square meters $\quad$ Am-241 $\quad 7.000 \mathrm{E}+01$

Thickness: 13.40 meters $\quad$ Cs-137 3.800E+01

Cover Depth: $\quad 0.15$ meters $\quad$ Np-237 $1.100 \mathrm{E}+01$

Pu-238 7.800E+01

Pu-239 7.200E +01

Pu-240 7.200E+01

Tc-99 1.040E +02

Th-228 8.000E +00

Th-230 2.000E +02

Th-232 8.000E +00

U-234 3.200E+02

U-235 $1.300 \mathrm{E}+01$

U-238 3.200E+02

Total Dose TDOSE(t), mrem/yr

Basic Radiation Dose Limit $=1.000 \mathrm{E}+02 \mathrm{mrem} / \mathrm{yr}$

Total Mixture Sum M(t) = Fraction of Basic Dose Limit Received at Time $(\mathrm{t})$

\begin{tabular}{lccccc}
\hline $\mathrm{t}$ (years): & $0.000 \mathrm{E}+00$ & $1.000 \mathrm{E}+00$ & $2.500 \mathrm{E}+01$ & $5.000 \mathrm{E}+01$ & $7.000 \mathrm{E}+01$ \\
\hline $\mathrm{TDOSE}(\mathrm{t}):$ & $1.865 \mathrm{E}+00$ & $1.719 \mathrm{E}+00$ & $2.665 \mathrm{E}+00$ & $3.406 \mathrm{E}+00$ & $4.112 \mathrm{E}+00$ \\
$\mathrm{M}(\mathrm{t}):$ & $1.865 \mathrm{E}-02$ & $1.719 \mathrm{E}-02$ & $2.665 \mathrm{E}-02$ & $3.406 \mathrm{E}-02$ & $4.112 \mathrm{E}-02$
\end{tabular}

Maximum TDOSE(t): 4.112E+00 mrem/yr at $\mathrm{t}=7.000 \mathrm{E}+01$ years 


\section{RESIDENT GARDENER}

\section{RESRAD Parameters for U-Landfill Resident Gardener Forward Run 1050 Years}

Contaminated Zone Dimensions Initial Soil Concentrations, pCi/g

\begin{tabular}{|c|c|c|c|}
\hline & Am-241 & $3.500 \mathrm{E}+01$ \\
\hline Area: 89436.00 square meters & 13.40 meters & Cs-137 & $1.900 \mathrm{E}+01$ \\
\hline \multirow[t]{11}{*}{ Cover Depth: } & 1.52 meters & Np-237 & $5.500 \mathrm{E}+00$ \\
\hline & & Pu-238 & $3.900 \mathrm{E}+01$ \\
\hline & & $\mathrm{Pu}-239$ & $3.600 \mathrm{E}+01$ \\
\hline & & $\mathrm{Pu}-240$ & $3.600 \mathrm{E}+01$ \\
\hline & & Тc-99 & $5.200 \mathrm{E}+01$ \\
\hline & & Th-228 & $4.000 \mathrm{E}+00$ \\
\hline & & Th-230 & $1.000 \mathrm{E}+02$ \\
\hline & & Th-232 & $4.000 \mathrm{E}+00$ \\
\hline & & $\mathrm{U}-234$ & $1.600 \mathrm{E}+02$ \\
\hline & & U-235 & $6.500 \mathrm{E}+00$ \\
\hline & & U-238 & $1.600 \mathrm{E}+02$ \\
\hline
\end{tabular}

Total Dose TDOSE(t), mrem/yr

Basic Radiation Dose Limit $=1.000 \mathrm{E}+02 \mathrm{mrem} / \mathrm{yr}$

Total Mixture Sum M(t) = Fraction of Basic Dose Limit Received at Time (t)

\begin{tabular}{lllllll}
\hline $\mathrm{t}$ (years): & $0.000 \mathrm{E}+00$ & $1.000 \mathrm{E}+00$ & $5.000 \mathrm{E}+01$ & $1.000 \mathrm{E}+02$ & $5.000 \mathrm{E}+02$ & $1.050 \mathrm{E}+03$ \\
\hline TDOSE(t): & $5.627 \mathrm{E}-06$ & $4.206 \mathrm{E}-06$ & $9.541 \mathrm{E}-06$ & $1.367 \mathrm{E}-05$ & $2.423 \mathrm{E}-04$ & $6.827 \mathrm{E}+00$ \\
$\mathrm{M}(\mathrm{t}):$ & $5.627 \mathrm{E}-08$ & $4.206 \mathrm{E}-08$ & $9.541 \mathrm{E}-08$ & $1.367 \mathrm{E}-07$ & $2.423 \mathrm{E}-06$ & $6.827 \mathrm{E}-02$
\end{tabular}

Maximum TDOSE(t): $6.827 \mathrm{E}+00 \mathrm{mrem} / \mathrm{yr}$ at $\mathrm{t}=1.050 \mathrm{E}+03$ years

RESRAD Parameters for U-Landfill Resident Gardener Forward Run 10,000 Years

\begin{tabular}{llllllll}
\hline tyears): & $0.000 \mathrm{E}+00$ & $1.000 \mathrm{E}+00$ & $5.000 \mathrm{E}+01$ & $1.000 \mathrm{E}+02$ & $5.000 \mathrm{E}+02$ & $1.050 \mathrm{E}+03$ & $1.000 \mathrm{E}+04$ \\
TDOSE $(\mathrm{t}):$ & $5.627 \mathrm{E}-06$ & $4.206 \mathrm{E}-06$ & $9.541 \mathrm{E}-06$ & $1.367 \mathrm{E}-05$ & $2.423 \mathrm{E}-04$ & $6.827 \mathrm{E}+00$ & $2.359 \mathrm{E}+03$ \\
$\mathrm{M}(\mathrm{t}):$ & $5.627 \mathrm{E}-08$ & $4.206 \mathrm{E}-08$ & $9.541 \mathrm{E}-08$ & $1.367 \mathrm{E}-07$ & $2.423 \mathrm{E}-06$ & $6.827 \mathrm{E}-02$ & $2.359 \mathrm{E}+01$
\end{tabular}

Maximum TDOSE(t): $2.359 \mathrm{E}+03 \mathrm{mrem} / \mathrm{yr}$ at $\mathrm{t}=1.000 \mathrm{E}+04$ years

RESRAD Parameters for U-Landfill Resident Gardener Forward Run 100,000 Years

$\begin{array}{lllllllll}\mathrm{t} \text { (years): } & 0.000 \mathrm{E}+00 & 1.000 \mathrm{E}+00 & 5.000 \mathrm{E}+01 & 1.000 \mathrm{E}+02 & 5.000 \mathrm{E}+02 & 1.050 \mathrm{E}+03 & 1.000 \mathrm{E}+04 & 1.000 \mathrm{E}+05 \\ \text { TDOSE(t): } & 5.627 \mathrm{E}-06 & 4.206 \mathrm{E}-06 & 9.541 \mathrm{E}-06 & 1.367 \mathrm{E}-05 & 2.423 \mathrm{E}-04 & 6.827 \mathrm{E}+00 & 2.359 \mathrm{E}+03 & 0.000 \mathrm{E}+00 \\ \mathrm{M}(\mathrm{t}): & 5.627 \mathrm{E}-08 & 4.206 \mathrm{E}-08 & 9.541 \mathrm{E}-08 & 1.367 \mathrm{E}-07 & 2.423 \mathrm{E}-06 & 6.827 \mathrm{E}-02 & 2.359 \mathrm{E}+01 & 0.000 \mathrm{E}+00\end{array}$

Maximum TDOSE(t): $2.370 \mathrm{E}+03 \mathrm{mrem} / \mathrm{yr}$ at $\mathrm{t}=12931$ years 


\section{RESIDENT GARDENER}

\section{RESRAD Parameters for U-Landfill Resident Gardener Forward Run at Proposed Authorized}

Limits

Contaminated Zone Dimensions Initial Soil Concentrations, pCi/g

\begin{tabular}{ccll}
\hline \multicolumn{1}{c}{ Area: 89436.00 square meters } & Am-241 & $7.000 \mathrm{E}+01$ \\
Thickness: & 13.40 meters & Cs-137 & $3.800 \mathrm{E}+01$ \\
Cover Depth: & 1.52 meters & Np-237 & $1.100 \mathrm{E}+01$ \\
& & Pu-238 & $7.800 \mathrm{E}+01$ \\
& & Pu-239 & $7.200 \mathrm{E}+01$ \\
& Pu-240 & $7.200 \mathrm{E}+01$ \\
& Tc-99 & $1.040 \mathrm{E}+02$ \\
& Th-228 & $8.000 \mathrm{E}+00$ \\
& Th-230 & $2.000 \mathrm{E}+02$ \\
& Th-232 & $8.000 \mathrm{E}+00$ \\
& U-234 & $3.200 \mathrm{E}+02$ \\
& $\mathrm{U}-235$ & $1.300 \mathrm{E}+01$ \\
& $\mathrm{U}-238$ & $3.200 \mathrm{E}+02$
\end{tabular}

Total Dose TDOSE(t), mrem/yr

Basic Radiation Dose Limit $=1.000 \mathrm{E}+02 \mathrm{mrem} / \mathrm{yr}$

Total Mixture Sum M(t) = Fraction of Basic Dose Limit Received at Time (t)

\begin{tabular}{lllllll}
\hline $\mathrm{t}$ (years): & $0.000 \mathrm{E}+00$ & $1.000 \mathrm{E}+00$ & $5.000 \mathrm{E}+01$ & $1.000 \mathrm{E}+02$ & $5.000 \mathrm{E}+02$ & $1.050 \mathrm{E}+03$ \\
TDOSE $(\mathrm{t}):$ & $1.125 \mathrm{E}-05$ & $8.412 \mathrm{E}-06$ & $1.908 \mathrm{E}-05$ & $2.733 \mathrm{E}-05$ & $4.845 \mathrm{E}-04$ & $1.365 \mathrm{E}+01$ \\
$\mathrm{M}(\mathrm{t}):$ & $1.125 \mathrm{E}-07$ & $8.412 \mathrm{E}-08$ & $1.908 \mathrm{E}-07$ & $2.733 \mathrm{E}-07$ & $4.845 \mathrm{E}-06$ & $1.365 \mathrm{E}-01$
\end{tabular}

Maximum TDOSE(t): $1.365 \mathrm{E}+01 \mathrm{mrem} / \mathrm{yr}$ at $\mathrm{t}=1.050 \mathrm{E}+03$ years 


\title{
RECREATIONAL USER
}

\section{RESRAD U-Landfill Recreational User Resident Forward Run 1050 Years}

\author{
Contaminated Zone Dimensions Initial Soil Concentrations, pCi/g
}

\begin{tabular}{ccll}
\hline \multicolumn{2}{c}{ Area: 89436.00 square meters } & Am-241 & $3.500 \mathrm{E}+01$ \\
Thickness: & 13.40 meters & Cs-137 & $1.900 \mathrm{E}+01$ \\
Cover Depth: & 1.52 meters & Np-237 & $5.500 \mathrm{E}+00$ \\
& & Pu-238 & $3.900 \mathrm{E}+01$ \\
& Pu-239 & $3.600 \mathrm{E}+01$ \\
& Pu-240 & $3.600 \mathrm{E}+01$ \\
& Tc-99 & $5.200 \mathrm{E}+01$ \\
& Th-228 & $4.000 \mathrm{E}+00$ \\
& Th-230 & $1.000 \mathrm{E}+02$ \\
& Th-232 & $4.000 \mathrm{E}+00$ \\
& U-234 & $1.600 \mathrm{E}+02$ \\
& U-235 & $6.500 \mathrm{E}+00$ \\
& U-238 & $1.600 \mathrm{E}+02$
\end{tabular}

Total Dose TDOSE(t), mrem/yr

Basic Radiation Dose Limit $=1.000 \mathrm{E}+00 \mathrm{mrem} / \mathrm{yr}$

Total Mixture Sum M(t) = Fraction of Basic Dose Limit Received at Time (t)

\begin{tabular}{llllllll}
\hline $\mathrm{t}$ (years): & $0.000 \mathrm{E}+00$ & $1.000 \mathrm{E}+00$ & $1.200 \mathrm{E}+01$ & $5.000 \mathrm{E}+01$ & $1.000 \mathrm{E}+02$ & $5.000 \mathrm{E}+02$ & $1.050 \mathrm{E}+03$ \\
\hline TDOSE(t): & $5.411 \mathrm{E}-07$ & $4.044 \mathrm{E}-07$ & $4.862 \mathrm{E}-07$ & $9.175 \mathrm{E}-07$ & $1.314 \mathrm{E}-06$ & $2.333 \mathrm{E}-05$ & $1.239 \mathrm{E}-03$ \\
$\mathrm{M}(\mathrm{t}):$ & $5.411 \mathrm{E}-07$ & $4.044 \mathrm{E}-07$ & $4.862 \mathrm{E}-07$ & $9.175 \mathrm{E}-07$ & $1.314 \mathrm{E}-06$ & $2.333 \mathrm{E}-05$ & $1.239 \mathrm{E}-03$
\end{tabular}

Maximum TDOSE(t): $1.239 \mathrm{E}-03 \mathrm{mrem} / \mathrm{yr}$ at $\mathrm{t}=1.050 \mathrm{E}+03$ years

RESRAD U-Landfill Recreational User Resident Forward Run 10,000 Years

\begin{tabular}{lllllllll}
$\mathrm{t}$ (years): & $0.000 \mathrm{E}+00$ & $1.000 \mathrm{E}+00$ & $1.200 \mathrm{E}+01$ & $5.000 \mathrm{E}+01$ & $1.000 \mathrm{E}+02$ & $5.000 \mathrm{E}+02$ & $1.050 \mathrm{E}+03$ & $1.000 \mathrm{E}+04$ \\
\hline TDOSE(t): & $5.411 \mathrm{E}-07$ & $4.044 \mathrm{E}-07$ & $4.862 \mathrm{E}-07$ & $9.175 \mathrm{E}-07$ & $1.314 \mathrm{E}-06$ & $2.333 \mathrm{E}-05$ & $1.239 \mathrm{E}-03$ & $9.490 \mathrm{E}+01$ \\
$\mathrm{M}(\mathrm{t}):$ & $5.411 \mathrm{E}-07$ & $4.044 \mathrm{E}-07$ & $4.862 \mathrm{E}-07$ & $9.175 \mathrm{E}-07$ & $1.314 \mathrm{E}-06$ & $2.333 \mathrm{E}-05$ & $1.239 \mathrm{E}-03$ & $9.490 \mathrm{E}+01$
\end{tabular}

Maximum TDOSE(t): $9.490 \mathrm{E}+01 \mathrm{mrem} / \mathrm{yr}$ at $\mathrm{t}=1.000 \mathrm{E}+04$ years

\section{RESRAD U-Landfill Recreational User Resident Forward Run 10,000}

$\begin{array}{llllllllll}\mathrm{t} \text { (years): } & 0.000 \mathrm{E}+00 & 1.000 \mathrm{E}+00 & 1.200 \mathrm{E}+01 & 5.000 \mathrm{E}+01 & 1.000 \mathrm{E}+02 & 5.000 \mathrm{E}+02 & 1.050 \mathrm{E}+03 & 1.000 \mathrm{E}+04 & 1.000 \mathrm{E}+05\end{array}$

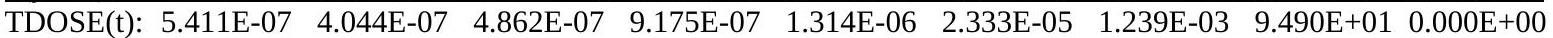
$\mathrm{M}(\mathrm{t}): \quad 5.411 \mathrm{E}-07 \quad 4.044 \mathrm{E}-07 \quad 4.862 \mathrm{E}-07 \quad 9.175 \mathrm{E}-07 \quad 1.314 \mathrm{E}-06 \quad 2.333 \mathrm{E}-05 \quad 1.239 \mathrm{E}-03 \quad 9.490 \mathrm{E}+01 \quad 0.000 \mathrm{E}+00$

Maximum TDOSE(t): 9.649E+01 mrem/yr at $\mathrm{t}=19703$ years 


\section{RECREATIONAL USER}

RESRAD U-Landfill Recreational User Resident Forward Run 1050 Years at Proposed Authorized Limits

Contaminated Zone Dimensions $\quad$ Initial Soil Concentrations, pCi/g

\begin{tabular}{cccc}
\hline Area: 89436.00 square meters & Am-241 & $7.000 \mathrm{E}+01$ \\
Thickness: & 13.40 meters & $\mathrm{Cs}-137$ & $3.800 \mathrm{E}+01$ \\
Cover Depth: & 1.52 meters & $\mathrm{Np}-237$ & $1.100 \mathrm{E}+01$ \\
& & $\mathrm{Pu}-238$ & $7.800 \mathrm{E}+01$ \\
& & $\mathrm{Pu}-239$ & $7.200 \mathrm{E}+01$ \\
& $\mathrm{Pu}-240$ & $7.200 \mathrm{E}+01$ \\
& Tc-99 & $1.040 \mathrm{E}+02$ \\
& Th-228 & $8.000 \mathrm{E}+00$ \\
& Th-230 & $2.000 \mathrm{E}+02$ \\
& Th-232 & $8.000 \mathrm{E}+00$ \\
& $\mathrm{U}-234$ & $3.200 \mathrm{E}+02$ \\
& $\mathrm{U}-235$ & $1.300 \mathrm{E}+01$ \\
& $\mathrm{U}-238$ & $3.200 \mathrm{E}+02$
\end{tabular}

Total Dose TDOSE(t), mrem/yr

Basic Radiation Dose Limit $=1.000 \mathrm{E}+00 \mathrm{mrem} / \mathrm{yr}$

Total Mixture Sum M(t) = Fraction of Basic Dose Limit Received at Time (t)

\begin{tabular}{clllllll}
\hline $\mathrm{t}($ years): & $0.000 \mathrm{E}+00$ & $1.000 \mathrm{E}+00$ & $1.200 \mathrm{E}+01$ & $5.000 \mathrm{E}+01$ & $1.000 \mathrm{E}+02$ & $5.000 \mathrm{E}+02$ & $1.050 \mathrm{E}+03$ \\
TDOSE(t): & $1.082 \mathrm{E}-06$ & $8.088 \mathrm{E}-07$ & $9.723 \mathrm{E}-07$ & $1.835 \mathrm{E}-06$ & $2.629 \mathrm{E}-06$ & $4.666 \mathrm{E}-05$ & $2.478 \mathrm{E}-03$ \\
$\mathrm{M}(\mathrm{t}):$ & $1.082 \mathrm{E}-06$ & $8.088 \mathrm{E}-07$ & $9.723 \mathrm{E}-07$ & $1.835 \mathrm{E}-06$ & $2.629 \mathrm{E}-06$ & $4.666 \mathrm{E}-05$ & $2.478 \mathrm{E}-03$
\end{tabular}

Maximum TDOSE(t): $2.478 E-03 \mathrm{mrem} / \mathrm{yr}$ at $\mathrm{t}=1.050 \mathrm{E}+03$ years 


\section{OUTDOOR WORKER}

\section{RESRAD U-Landfill Outdoor Worker Resident Forward Run 1050 Years}

Contaminated Zone Dimensions Initial Soil Concentrations, pCi/g

\begin{tabular}{ccll}
\hline Area: 89436.00 square meters & Am-241 & $3.500 \mathrm{E}+01$ \\
Thickness: & 13.40 meters & $\mathrm{Cs}-137$ & $1.900 \mathrm{E}+01$ \\
Cover Depth: & 1.52 meters & $\mathrm{Np}-237$ & $5.500 \mathrm{E}+00$ \\
& & $\mathrm{Pu}-238$ & $3.900 \mathrm{E}+01$ \\
& & $\mathrm{Pu}-239$ & $3.600 \mathrm{E}+01$ \\
& $\mathrm{Pu}-240$ & $3.600 \mathrm{E}+01$ \\
& Tc-99 & $5.200 \mathrm{E}+01$ \\
& Th-228 & $4.000 \mathrm{E}+00$ \\
& Th-230 & $1.000 \mathrm{E}+02$ \\
& Th-232 & $4.000 \mathrm{E}+00$ \\
& $\mathrm{U}-234$ & $1.600 \mathrm{E}+02$ \\
& $\mathrm{U}-235$ & $6.500 \mathrm{E}+00$ \\
& $\mathrm{U}-238$ & $1.600 \mathrm{E}+02$
\end{tabular}

Total Dose TDOSE(t), mrem/yr

Basic Radiation Dose Limit $=1.000 \mathrm{E}+00 \mathrm{mrem} / \mathrm{yr}$

Total Mixture Sum M(t) = Fraction of Basic Dose Limit Received at Time (t)

\begin{tabular}{lccccccc}
\hline $\mathrm{t}($ years): & $0.000 \mathrm{E}+00$ & $1.000 \mathrm{E}+00$ & $2.500 \mathrm{E}+01$ & $5.000 \mathrm{E}+01$ & $1.000 \mathrm{E}+02$ & $5.000 \mathrm{E}+02$ & $1.050 \mathrm{E}+03$ \\
TDOSE(t): & $1.150 \mathrm{E}-06$ & $8.594 \mathrm{E}-07$ & $1.529 \mathrm{E}-06$ & $1.950 \mathrm{E}-06$ & $2.793 \mathrm{E}-06$ & $4.957 \mathrm{E}-05$ & $2.632 \mathrm{E}-03$ \\
$\mathrm{M}(\mathrm{t}):$ & $1.150 \mathrm{E}-06$ & $8.594 \mathrm{E}-07$ & $1.529 \mathrm{E}-06$ & $1.950 \mathrm{E}-06$ & $2.793 \mathrm{E}-06$ & $4.957 \mathrm{E}-05$ & $2.632 \mathrm{E}-03$
\end{tabular}

Maximum TDOSE(t): 2.632E-03 mrem/yr at $t=1.050 \mathrm{E}+03$ years

\section{RESRAD U-Landfill Outdoor Worker Resident Forward Run 10,000 Years}

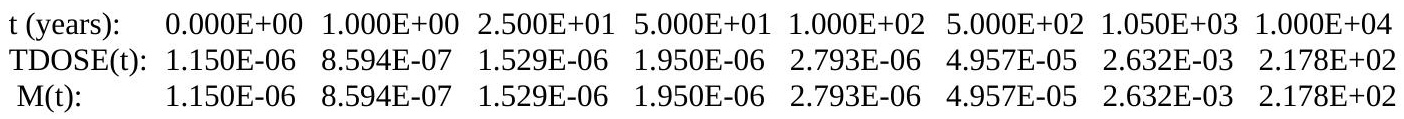

$\mathrm{t}$ (years): $\quad 0.000 \mathrm{E}+00 \quad 1.000 \mathrm{E}+00 \quad 2.500 \mathrm{E}+01 \quad 5.000 \mathrm{E}+01 \quad 1.000 \mathrm{E}+02 \quad 5.000 \mathrm{E}+02 \quad 1.050 \mathrm{E}+03 \quad 1.000 \mathrm{E}+04$ TDOSE(t): $1.150 \mathrm{E}-06 \quad 8.594 \mathrm{E}-07 \quad 1.529 \mathrm{E}-06 \quad 1.950 \mathrm{E}-06 \quad 2.793 \mathrm{E}-06 \quad 4.957 \mathrm{E}-05 \quad 2.632 \mathrm{E}-03 \quad 2.178 \mathrm{E}+02$ $\mathrm{M}(\mathrm{t}): \quad 1.150 \mathrm{E}-06 \quad 8.594 \mathrm{E}-07 \quad 1.529 \mathrm{E}-06 \quad 1.950 \mathrm{E}-06 \quad 2.793 \mathrm{E}-06 \quad 4.957 \mathrm{E}-05 \quad 2.632 \mathrm{E}-03 \quad 2.178 \mathrm{E}+02$

Maximum TDOSE(t): $2.178 \mathrm{E}+02 \mathrm{mrem} / \mathrm{yr}$ at $\mathrm{t}=10,000$ years

\section{RESRAD U-Landfill Outdoor Worker Resident Forward Run 100,000 Years}

$$
\begin{array}{clllllllll}
\mathrm{t} \text { (years): } & 0.000 \mathrm{E}+00 & 1.000 \mathrm{E}+00 & 2.500 \mathrm{E}+01 & 5.000 \mathrm{E}+01 & 1.000 \mathrm{E}+02 & 5.000 \mathrm{E}+02 & 1.050 \mathrm{E}+03 & 1.000 \mathrm{E}+04 & 1.000 \mathrm{E}+05 \\
\text { TDOSE(t): } & 1.150 \mathrm{E}-06 & 8.594 \mathrm{E}-07 & 1.529 \mathrm{E}-06 & 1.950 \mathrm{E}-06 & 2.793 \mathrm{E}-06 & 4.957 \mathrm{E}-05 & 2.632 \mathrm{E}-03 & 2.178 \mathrm{E}+02 & 0.000 \mathrm{E}+00 \\
\mathrm{M}(\mathrm{t}): & 1.150 \mathrm{E}-06 & 8.594 \mathrm{E}-07 & 1.529 \mathrm{E}-06 & 1.950 \mathrm{E}-06 & 2.793 \mathrm{E}-06 & 4.957 \mathrm{E}-05 & 2.632 \mathrm{E}-03 & 2.178 \mathrm{E}+02 & 0.000 \mathrm{E}+00
\end{array}
$$

Maximum TDOSE(t): $2.211 E+02 \mathrm{mrem} / \mathrm{yr}$ at $\mathrm{t}=19,046$ years 


\section{OUTDOOR WORKER}

RESRAD U-Landfill Outdoor Worker Resident Forward Run 1050 Years at Proposed Authorized Limits

Contaminated Zone Dimensions Initial Soil Concentrations, pCi/g

\begin{tabular}{ccll}
\hline Area: 89436.00 square meters & Am-241 & $7.000 \mathrm{E}+01$ \\
Thickness: & 13.40 meters & $\mathrm{Cs}-137$ & $3.800 \mathrm{E}+01$ \\
Cover Depth: & 1.52 meters & $\mathrm{Np}-237$ & $1.100 \mathrm{E}+01$ \\
& & $\mathrm{Pu}-238$ & $7.800 \mathrm{E}+01$ \\
& & $\mathrm{Pu}-239$ & $7.200 \mathrm{E}+01$ \\
& $\mathrm{Pu}-240$ & $7.200 \mathrm{E}+01$ \\
& Tc-99 & $1.040 \mathrm{E}+02$ \\
& Th-228 & $8.000 \mathrm{E}+00$ \\
& Th-230 & $2.000 \mathrm{E}+02$ \\
& Th-232 & $8.000 \mathrm{E}+00$ \\
& $\mathrm{U}-234$ & $3.200 \mathrm{E}+02$ \\
& $\mathrm{U}-235$ & $1.300 \mathrm{E}+01$ \\
& $\mathrm{U}-238$ & $3.200 \mathrm{E}+02$
\end{tabular}

Total Dose TDOSE(t), mrem/yr

Basic Radiation Dose Limit $=1.000 \mathrm{E}+00 \mathrm{mrem} / \mathrm{yr}$

Total Mixture Sum M(t) = Fraction of Basic Dose Limit Received at Time (t)

\begin{tabular}{llllllll}
\hline $\mathrm{t}($ years): & $0.000 \mathrm{E}+00$ & $1.000 \mathrm{E}+00$ & $2.500 \mathrm{E}+01$ & $5.000 \mathrm{E}+01$ & $1.000 \mathrm{E}+02$ & $5.000 \mathrm{E}+02$ & $1.050 \mathrm{E}+03$ \\
TDOSE(t): & $2.300 \mathrm{E}-06$ & $1.719 \mathrm{E}-06$ & $3.058 \mathrm{E}-06$ & $3.899 \mathrm{E}-06$ & $5.586 \mathrm{E}-06$ & $9.914 \mathrm{E}-05$ & $5.265 \mathrm{E}-03$ \\
$\mathrm{M}(\mathrm{t}):$ & $2.300 \mathrm{E}-06$ & $1.719 \mathrm{E}-06$ & $3.058 \mathrm{E}-06$ & $3.899 \mathrm{E}-06$ & $5.586 \mathrm{E}-06$ & $9.914 \mathrm{E}-05$ & $5.265 \mathrm{E}-03$
\end{tabular}

Maximum TDOSE(t): $5.265 \mathrm{E}-03 \mathrm{mrem} / \mathrm{yr}$ at $\mathrm{t}=1.050 \mathrm{E}+03$ years 


\section{RESIDENT FARMER ONSITE}

\section{RESRAD Parameters for Resident Farmer U-Landfill Forward Run 1,050 Years}

Contaminated Zone Dimensions Initial Soil Concentrations, pCi/g

\begin{tabular}{cccc}
\hline Area: 89436.00 square meters & Am-241 & $3.500 \mathrm{E}+01$ \\
Thickness: & 13.40 meters & Cs-137 & $1.900 \mathrm{E}+01$ \\
Cover Depth: & 1.52 meters & Np-237 & $5.500 \mathrm{E}+00$ \\
& & Pu-238 & $3.900 \mathrm{E}+01$ \\
& & Pu-239 & $3.600 \mathrm{E}+01$ \\
& Pu-240 & $3.600 \mathrm{E}+01$ \\
& Tc-99 & $5.200 \mathrm{E}+01$ \\
& Th-228 & $4.000 \mathrm{E}+00$ \\
& Th-230 & $1.000 \mathrm{E}+02$ \\
& Th-232 & $4.000 \mathrm{E}+00$ \\
& U-234 & $1.600 \mathrm{E}+02$ \\
& $\mathrm{U}-235$ & $6.500 \mathrm{E}+00$ \\
& $\mathrm{U}-238$ & $1.600 \mathrm{E}+02$
\end{tabular}

Total Dose TDOSE(t), mrem/yr

Basic Radiation Dose Limit $=1.000 \mathrm{E}+02 \mathrm{mrem} / \mathrm{yr}$

Total Mixture Sum M(t) = Fraction of Basic Dose Limit Received at Time (t)

\begin{tabular}{lllllll}
\hline $\mathrm{t}$ (years): & $0.000 \mathrm{E}+00$ & $1.000 \mathrm{E}+00$ & $5.000 \mathrm{E}+01$ & $1.000 \mathrm{E}+02$ & $5.000 \mathrm{E}+02$ & $1.050 \mathrm{E}+03$ \\
$\mathrm{TDOSE}(\mathrm{t}):$ & $5.627 \mathrm{E}-06$ & $4.206 \mathrm{E}-06$ & $9.541 \mathrm{E}-06$ & $1.367 \mathrm{E}-05$ & $1.076 \mathrm{E}+01$ & $7.405 \mathrm{E}+00$ \\
$\mathrm{M}(\mathrm{t}):$ & $5.627 \mathrm{E}-08$ & $4.206 \mathrm{E}-08$ & $9.541 \mathrm{E}-08$ & $1.367 \mathrm{E}-07$ & $1.076 \mathrm{E}-01$ & $7.405 \mathrm{E}-02$
\end{tabular}

Maximum TDOSE(t): $2.119 \mathrm{E}+01 \mathrm{mrem} / \mathrm{yr}$ at $\mathrm{t}=424.6 \pm 0.8$ years

RESRAD Parameters for Resident Farmer U-Landfill Forward Run 10,000 Years

$\mathrm{t}$ (years): $0.000 \mathrm{E}+00 \quad 1.000 \mathrm{E}+00 \quad 5.000 \mathrm{E}+01 \quad 1.000 \mathrm{E}+02 \quad 5.000 \mathrm{E}+02 \quad 1.050 \mathrm{E}+03 \quad 1.000 \mathrm{E}+04$

TDOSE(t): 5.627E-06 4.206E-06 9.541E-06 1.367E-05 1.077E+01 $7.412 \mathrm{E}+00 \quad 2.719 \mathrm{E}+03$

$\mathrm{M}(\mathrm{t}):$ 5.627E-08 4.206E-08 9.541E-08 1.367E-07 1.077E-01 7.412E-02 2.719E+01

RESRAD Parameters for Resident Farmer U-Landfill Forward Run 100,000 Years

Maximum TDOSE(t): $2.719 \mathrm{E}+03 \mathrm{mrem} / \mathrm{yr}$ at $\mathrm{t}=100,000$ Years

$\begin{array}{lllllllll}\mathrm{t} \text { (years): } & 0.000 \mathrm{E}+00 & 1.000 \mathrm{E}+00 & 5.000 \mathrm{E}+01 & 1.000 \mathrm{E}+02 & 5.000 \mathrm{E}+02 & 1.050 \mathrm{E}+03 & 1.000 \mathrm{E}+04 & 1.000 \mathrm{E}+05 \\ \text { TDOSE(t): } & 5.627 \mathrm{E}-06 & 4.206 \mathrm{E}-06 & 9.541 \mathrm{E}-06 & 1.367 \mathrm{E}-05 & 1.077 \mathrm{E}+01 & 7.412 \mathrm{E}+00 & 2.719 \mathrm{E}+03 & 3.773 \mathrm{E}-02 \\ \mathrm{M}(\mathrm{t}): & 5.627 \mathrm{E}-08 & .206 \mathrm{E}-08 & 9.541 \mathrm{E}-08 & 1.367 \mathrm{E}-07 & 1.077 \mathrm{E}-01 & 7.412 \mathrm{E}-02 & 2.719 \mathrm{E}+01 & 3.773 \mathrm{E}-04\end{array}$

Maximum TDOSE(t): $2.731 \mathrm{E}+03 \mathrm{mrem} / \mathrm{yr}$ at $\mathrm{t}=12780$ years 


\section{RESIDENT FARMER ONSITE}

RESRAD Parameters for Resident Farmer U-Landfill Forward Run 1,050 Years at Proposed Authorized Limits

\begin{tabular}{ccll}
\multicolumn{2}{c}{ Contaminated Zone Dimensions } & \multicolumn{2}{c}{ Initial Soil Concentrations, pCi/g } \\
\hline \multicolumn{2}{c}{ Area: 89436.00 square meters } & Am-241 & $7.000 \mathrm{E}+01$ \\
Thickness: & 13.40 meters & Cs-137 & $3.800 \mathrm{E}+01$ \\
Cover Depth: & 1.52 meters & Np-237 & $1.100 \mathrm{E}+01$ \\
& & Pu-238 & $7.800 \mathrm{E}+01$ \\
& & Pu-239 & $7.200 \mathrm{E}+01$ \\
& Pu-240 & $7.200 \mathrm{E}+01$ \\
& Tc-99 & $1.040 \mathrm{E}+02$ \\
& Th-228 & $8.000 \mathrm{E}+00$ \\
& Th-230 & $2.000 \mathrm{E}+02$ \\
& Th-232 & $8.000 \mathrm{E}+00$ \\
& U-234 & $3.200 \mathrm{E}+02$ \\
& U-235 & $1.300 \mathrm{E}+01$ \\
& U-238 & $3.200 \mathrm{E}+02$
\end{tabular}

Total Dose TDOSE(t), mrem/yr

Basic Radiation Dose Limit $=1.000 \mathrm{E}+02 \mathrm{mrem} / \mathrm{yr}$

Total Mixture Sum M(t) = Fraction of Basic Dose Limit Received at Time ( $\mathrm{t})$

t (years): $0.000 \mathrm{E}+00 \quad 1.000 \mathrm{E}+00 \quad 5.000 \mathrm{E}+01 \quad 1.000 \mathrm{E}+02 \quad 5.000 \mathrm{E}+02 \quad 1.050 \mathrm{E}+03$

TDOSE(t): 1.125E-05 8.412E-06 1.908E-05 2.733E-05 2.151E+01 $1.481 \mathrm{E}+01$

$\mathrm{M}(\mathrm{t}): 1.125 \mathrm{E}-07$ 8.412E-08 1.908E-07 2.733E-07 2.151E-01 1.481E-01

Maximum TDOSE(t): $4.239 \mathrm{E}+01 \mathrm{mrem} / \mathrm{yr}$ at $\mathrm{t}=424.6 \pm 0.8$ years 


\title{
RESIDE FARMER OFFSITE
}

\section{RESRAD-OFFSITE Parameters for Offsite Resident Farmer Forward Run 1,050 Years}

\author{
Contaminated Zone Dimensions Initial Soil Concentrations, pCi/g
}

\begin{tabular}{ccll}
\hline \multicolumn{2}{c}{ Area: 102144.00 square meters } & Am-241 & $3.500 \mathrm{E}+01$ \\
Thickness: & 13.40 meters & Cs-137 & $1.900 \mathrm{E}+01$ \\
Cover Depth: & 1.52 meters & Np-237 & $5.500 \mathrm{E}+00$ \\
& & Pu-238 & $3.900 \mathrm{E}+01$ \\
& & Pu-239 & $3.600 \mathrm{E}+01$ \\
& Pu-240 & $3.600 \mathrm{E}+01$ \\
& Tc-99 & $5.200 \mathrm{E}+01$ \\
& Th-228 & $4.000 \mathrm{E}+00$ \\
& Th-230 & $1.000 \mathrm{E}+02$ \\
& Th-232 & $4.000 \mathrm{E}+00$ \\
& $\mathrm{U}-234$ & $1.600 \mathrm{E}+02$ \\
& $\mathrm{U}-235$ & $6.500 \mathrm{E}+00$ \\
& $\mathrm{U}-238$ & $1.600 \mathrm{E}+02$
\end{tabular}

Total Dose TDOSE(t), mrem/yr

Basic Radiation Dose Limit $=1.000 \mathrm{E}+00 \mathrm{mrem} / \mathrm{yr}$

Total Mixture Sum M(t) = Fraction of Basic Dose Limit Received at Time (t)

\begin{tabular}{lllllll}
\hline $\mathrm{t}$ (years): & $0.000 \mathrm{E}+00$ & $1.000 \mathrm{E}+00$ & $5.000 \mathrm{E}+01$ & $1.000 \mathrm{E}+02$ & $5.000 \mathrm{E}+02$ & $1.026 \mathrm{E}+03$ \\
$\mathrm{TDOSE}(\mathrm{t}):$ & $2.774 \mathrm{E}-14$ & $2.073 \mathrm{E}-14$ & $4.593 \mathrm{E}-14$ & $6.422 \mathrm{E}-14$ & $9.910 \mathrm{E}-01$ & $1.436 \mathrm{E}+00$ \\
$\mathrm{M}(\mathrm{t}):$ & $2.774 \mathrm{E}-14$ & $.073 \mathrm{E}-14$ & $4.593 \mathrm{E}-14$ & $6.422 \mathrm{E}-14$ & $9.910 \mathrm{E}-01$ & $1.436 \mathrm{E}+00$
\end{tabular}

\section{Maximum TDOSE(t): $1.869 E+00 \mathrm{mrem} / \mathrm{yr}$ at $\mathrm{t}=772$ years}

Basic Radiation Dose Limit $=1.000 \mathrm{E}+00 \mathrm{mrem} / \mathrm{yr}$

Total Mixture Sum M(t) = Fraction of Basic Dose Limit Received at Time $(\mathrm{t})$

RESRAD-OFFSITE Parameters for Offsite Resident Farmer Forward Run 1,050

$\begin{array}{llllllll}\mathrm{t} \text { (years): } & 0.000 \mathrm{E}+00 & 1.000 \mathrm{E}+00 & 5.000 \mathrm{E}+01 & 1.000 \mathrm{E}+02 & 5.000 \mathrm{E}+02 & 1.026 \mathrm{E}+03 & 1.000 \mathrm{E}+04 \\ \text { TDOSE(t): } & 2.789 \mathrm{E}-14 & 2.096 \mathrm{E}-14 & 4.593 \mathrm{E}-14 & 6.422 \mathrm{E}-14 & 9.915 \mathrm{E}-01 & 1.436 \mathrm{E}+00 & 2.180 \mathrm{E}+00 \\ \mathrm{M}(\mathrm{t}): & 2.789 \mathrm{E}-14 & 2.096 \mathrm{E}-14 & 4.593 \mathrm{E}-14 & 6.422 \mathrm{E}-14 & 9.915 \mathrm{E}-01 & 1.436 \mathrm{E}+00 & 2.180 \mathrm{E}+00\end{array}$

Maximum TDOSE(t): $2.180 \mathrm{E}+00 \mathrm{mrem} / \mathrm{yr}$ at $\mathrm{t}=10024$ years

$\begin{array}{cllllllll}\mathrm{t} \text { (years): } & 0.000 \mathrm{E}+00 & 1.000 \mathrm{E}+00 & 5.000 \mathrm{E}+01 & 1.000 \mathrm{E}+02 & 5.000 \mathrm{E}+02 & 1.026 \mathrm{E}+03 & 1.000 \mathrm{E}+04 & 1.000 \mathrm{E}+05 \\ \text { TDOSE(t): } & 3.125 \mathrm{E}-14 & 2.881 \mathrm{E}-14 & 4.593 \mathrm{E}-14 & 6.423 \mathrm{E}-14 & 9.278 \mathrm{E}-13 & 3.108 \mathrm{E}-11 & 2.179 \mathrm{E}+00 & 1.987 \mathrm{E}+00 \\ \mathrm{M}(\mathrm{t}): & 3.125 \mathrm{E}-14 & 2.881 \mathrm{E}-14 & 4.593 \mathrm{E}-14 & 6.423 \mathrm{E}-14 & 9.278 \mathrm{E}-13 & 3.108 \mathrm{E}-11 & 2.179 \mathrm{E}+00 & 1.987 \mathrm{E}+00\end{array}$

Maximum TDOSE(t): $2.179 \mathrm{E}+00 \mathrm{mrem} / \mathrm{yr}$ at $\mathrm{t}=10061$ years 


\section{RESRAD-OFFSITE Parameters for Offsite Resident Farmer Forward Run 1,050 Years at Proposed Authorized Limits}

Contaminated Zone Dimensions Initial Soil Concentrations, pCi/g

\begin{tabular}{cccc}
\hline \multicolumn{2}{c}{ Area: 102144.00 square meters } & Am-241 & $7.000 \mathrm{E}+01$ \\
Thickness: & 13.40 meters & Cs-137 & $3.800 \mathrm{E}+01$ \\
Cover Depth: & 1.52 meters & Np-237 & $1.100 \mathrm{E}+01$ \\
& & Pu-238 & $7.800 \mathrm{E}+01$ \\
& & Pu-239 & $7.200 \mathrm{E}+01$ \\
& Pu-240 & $7.200 \mathrm{E}+01$ \\
& Tc-99 & $1.040 \mathrm{E}+02$ \\
& Th-228 & $8.000 \mathrm{E}+00$ \\
& Th-230 & $2.000 \mathrm{E}+02$ \\
& Th-232 & $8.000 \mathrm{E}+00$ \\
& U-234 & $3.200 \mathrm{E}+02$ \\
& $\mathrm{U}-235$ & $1.300 \mathrm{E}+01$ \\
& $\mathrm{U}-238$ & $3.200 \mathrm{E}+02$
\end{tabular}

Total Dose TDOSE(t), mrem/yr

Basic Radiation Dose Limit $=1.000 \mathrm{E}+00 \mathrm{mrem} / \mathrm{yr}$

Total Mixture Sum M(t) = Fraction of Basic Dose Limit Received at Time (t)

\begin{tabular}{lcccccc}
\hline $\mathrm{t}$ (years): & $0.000 \mathrm{E}+00$ & $1.000 \mathrm{E}+00$ & $5.000 \mathrm{E}+01$ & $1.000 \mathrm{E}+02$ & $5.000 \mathrm{E}+02$ & $1.026 \mathrm{E}+03$ \\
$\mathrm{TDOSE}(\mathrm{t}):$ & $5.549 \mathrm{E}-14$ & $4.146 \mathrm{E}-14$ & $9.186 \mathrm{E}-14$ & $1.284 \mathrm{E}-13$ & $1.982 \mathrm{E}+00$ & $2.872 \mathrm{E}+00$ \\
$\mathrm{M}(\mathrm{t}):$ & $5.549 \mathrm{E}-14$ & $4.146 \mathrm{E}-14$ & $9.186 \mathrm{E}-14$ & $1.284 \mathrm{E}-13$ & $1.982 \mathrm{E}+00$ & $2.872 \mathrm{E}+00$
\end{tabular}

Maximum TDOSE(t): $3.737 \mathrm{E}+00 \mathrm{mrem} / \mathrm{yr}$ at $\mathrm{t}=772$ years 
RESRAD, Version $6.5 \quad T^{1 / 2}$ Limit $=180$ days

07/20/2011 15:43 Page

Summary : RESRAD Parameters for U-Landfill Worker Forward Run

File : C: \RESRAD_FAMILY \RESRAD \USERFILES $\backslash Q C J U L Y 2011 \backslash$ LANFFILLWORKER_FORWARDRUN-70YRS.RAD

Table of Contents

Part I: Mixture Sums and Single Radionuclide Guidelines

Dose Conversion Factor (and Related) Parameter Summary ... 2

Site-Specific Parameter Summary ............... 8

Summary of Pathway Selections .................... 18

Contaminated Zone and Total Dose Summary ............. 19

Total Dose Components

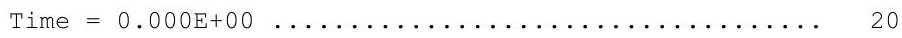

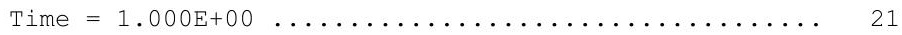

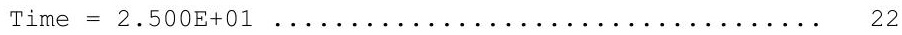

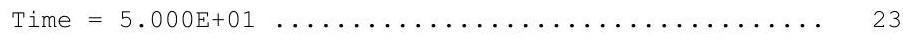

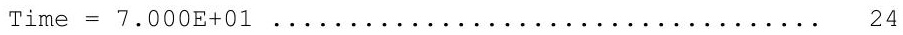

Dose/Source Ratios Summed Over All Pathways ........... 25

Single Radionuclide Soil Guidelines ............... 27

Dose Per Nuclide Summed Over All Pathways ............ 28

Soil Concentration Per Nuclide ..................... 30 
RESRAD, Version $6.5 \quad \mathrm{~T}^{1 / 2}$ Limit $=180$ days

07/20/2011 15:43 Page

Summary : RESRAD Parameters for U-Landfill Worker Forward Run

File : C: $\backslash$ RESRAD_FAMILY $\backslash$ RESRAD \USERFILES $\backslash Q C J U L Y 2011 \backslash$ LANFFILLWORKER_FORWARDRUN-70YRS.RAD

Dose Conversion Factor (and Related) Parameter Summary

Dose Library: ICRP 60 \& ICRP 72 (Adult)

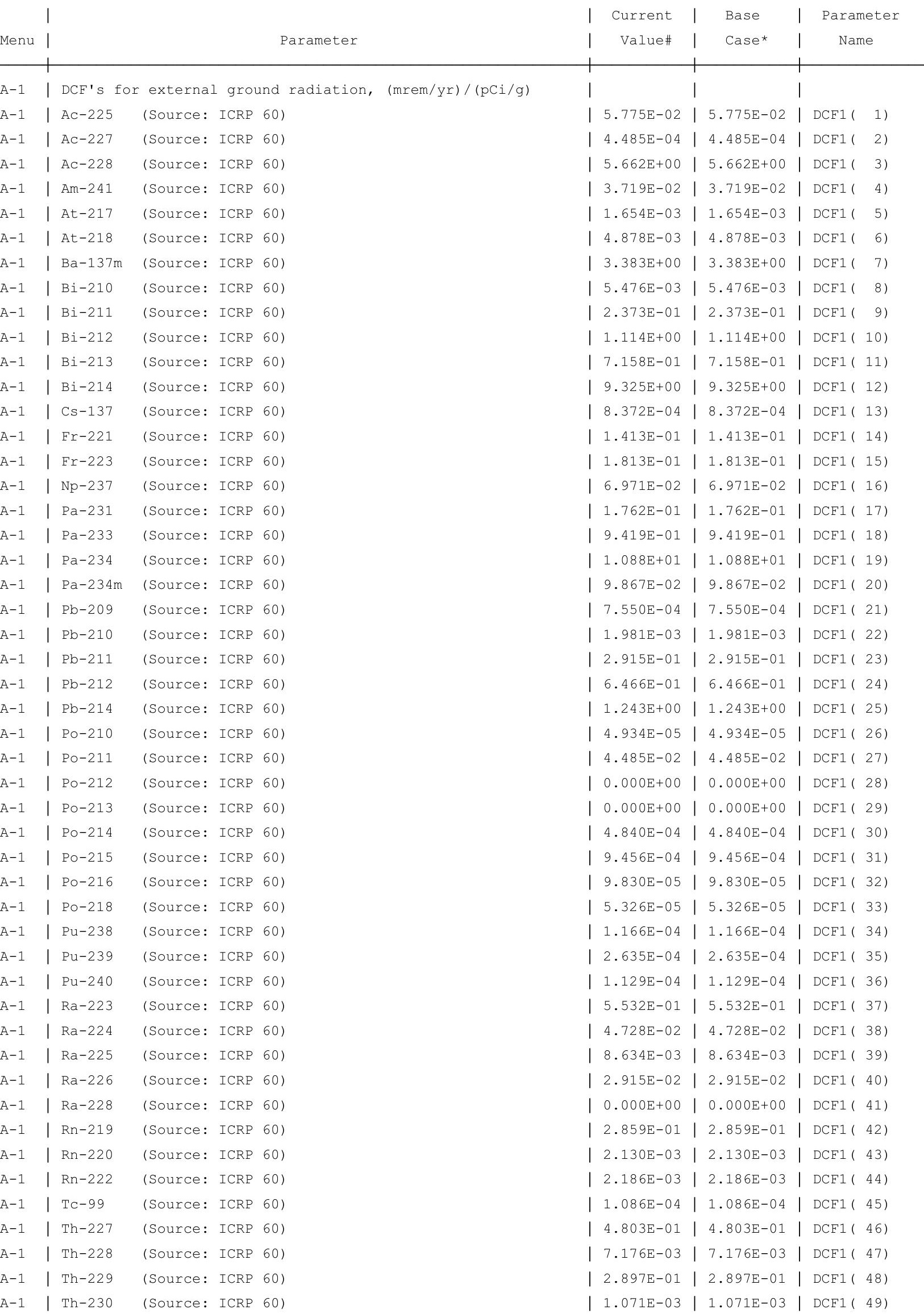


RESRAD, Version $6.5 \quad \mathrm{~T}^{1 / 2}$ Limit $=180$ days

07/20/2011 15:43 Page

Summary : RESRAD Parameters for U-Landfill Worker Forward Run

File : C: \RESRAD_FAMILY \RESRAD \USERFILES $\backslash Q C J U L Y 2011 \backslash$ LANFFILLWORKER_FORWARDRUN-70YRS.RAD

Dose Conversion Factor (and Related) Parameter Summary (continued)

Dose Library: ICRP 60 \& ICRP 72 (Adult)

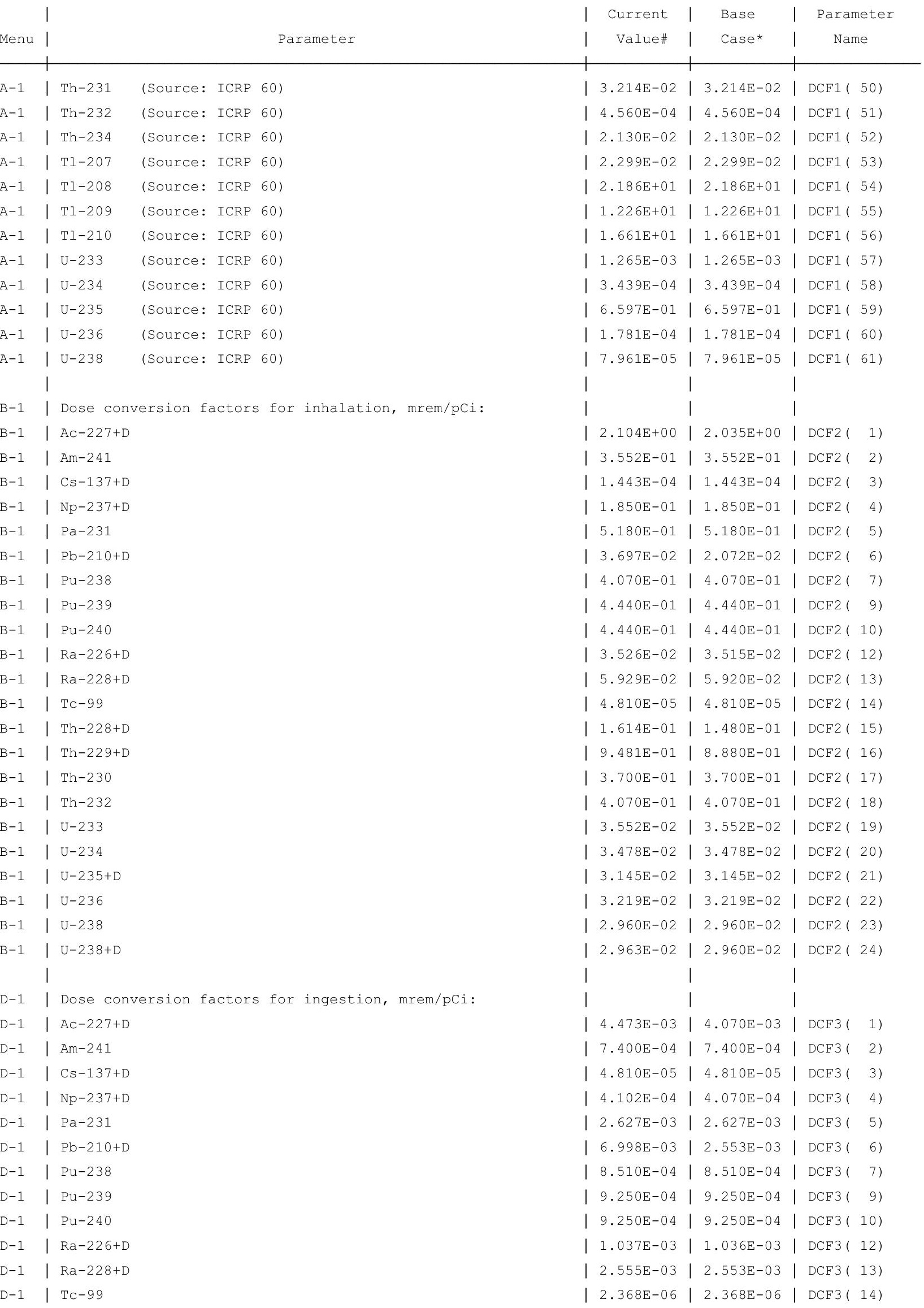


RESRAD, Version $6.5 \quad T^{1 / 2}$ Limit $=180$ days

ummary : RESRAD Parameters for U-Landfill Worker Forward Run

File : C: \RESRAD_FAMILY \RESRAD \USERFILES $\backslash Q C J U L Y 2011 \backslash$ LANFFILLWORKER_FORWARDRUN-70YRS.RAD

Dose Conversion Factor (and Related) Parameter Summary (continued) Dose Library: ICRP 60 \& ICRP 72 (Adult)

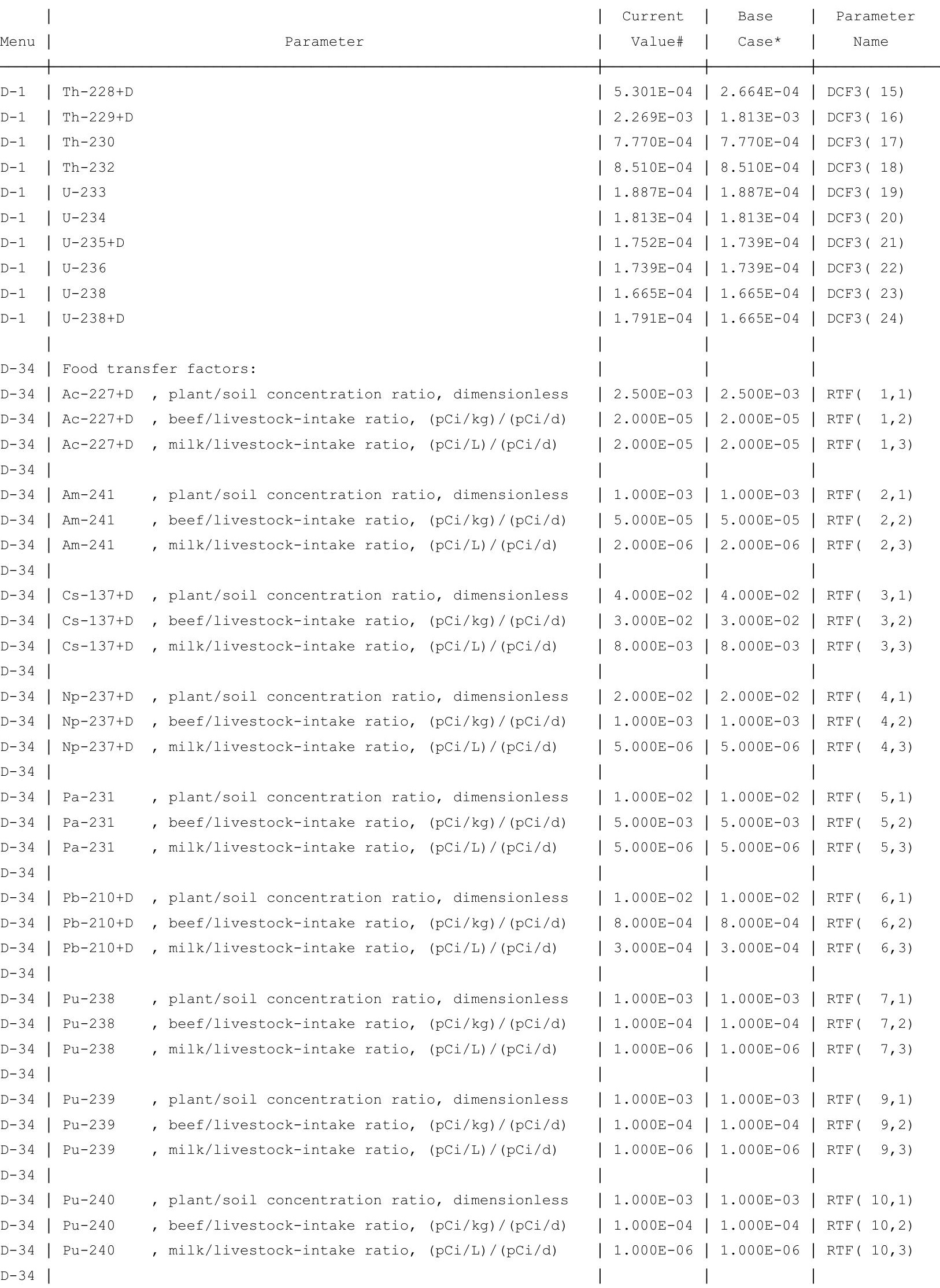


RESRAD, Version $6.5 \quad T^{1 / 2}$ Limit $=180$ days

$07 / 20 / 2011$

$15: 43$ Page

10

ummary : RESRAD Parameters for U-Landfill Worker Forward Run

File : C: \RESRAD_FAMILY \RESRAD \USERFILES $\backslash Q C J U L Y 2011 \backslash$ LANFFILLWORKER_FORWARDRUN-70YRS.RAD

Site-Specific Parameter Summary (continued)

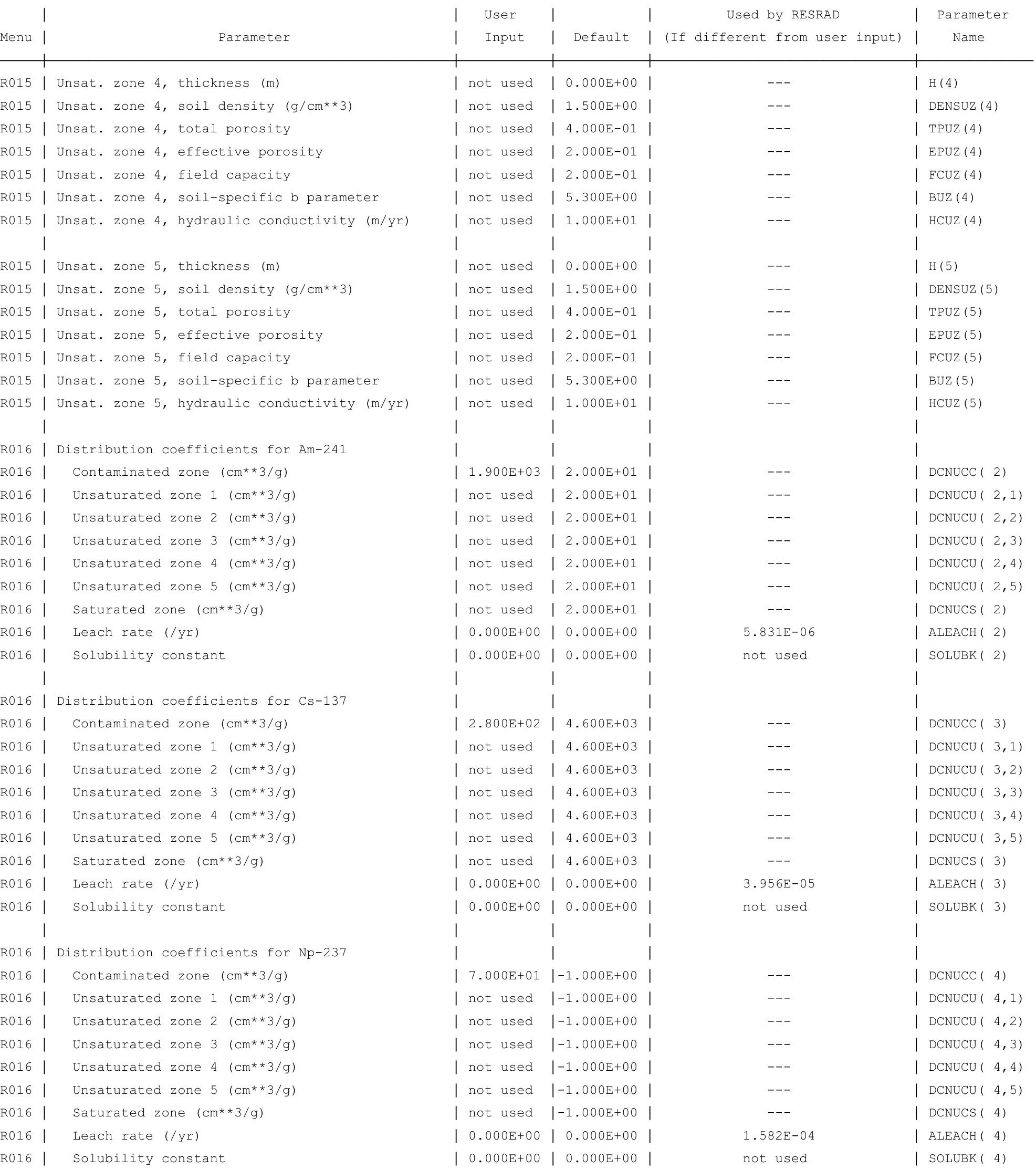


RESRAD, Version $6.5 \quad \mathrm{~T}^{1} 1 / 2$ Limit $=180$ days

$07 / 20 / 2011$

15:43 Page

Summary : RESRAD Parameters for U-Landfill Worker Forward Run

File : C: \RESRAD_FAMILY\RESRAD \USERFILES $\backslash Q C J U L Y 2011 \backslash$ LANFFILLWORKER_FORWARDRUN-70YRS.RAD

Site-Specific Parameter Summary (continued)

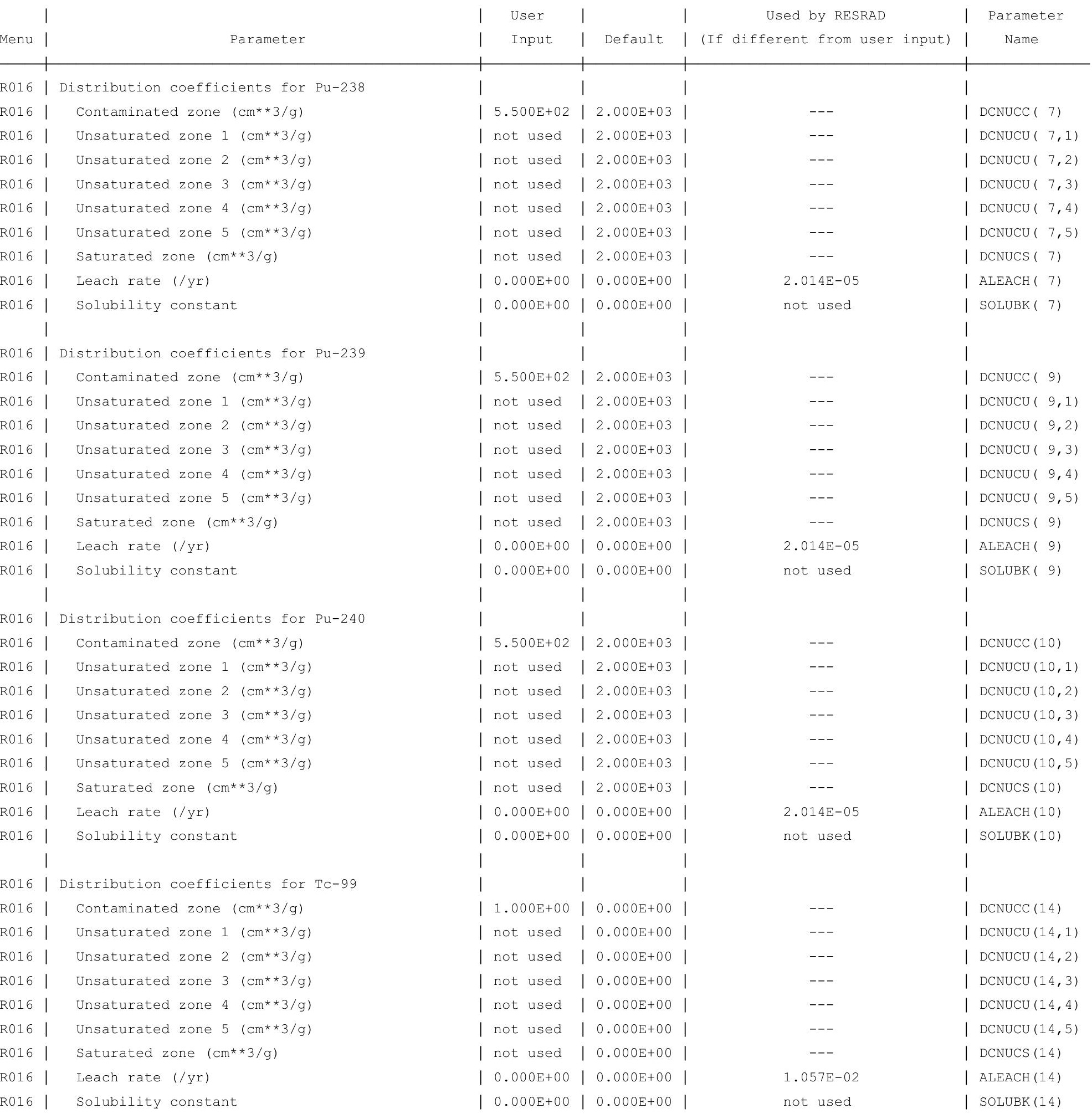


RESRAD, Version $6.5 \quad \mathrm{~T}^{1} 1 / 2$ Limit $=180$ days

$07 / 20 / 2011$

15:43 Page

Summary : RESRAD Parameters for U-Landfill Worker Forward Run

File : C: \RESRAD FAMILY \RESRAD \USERFILES \QCJULY2011 \LANFFILLWORKER FORWARDRUN-70YRS.RAD

Site-Specific Parameter Summary (continued)

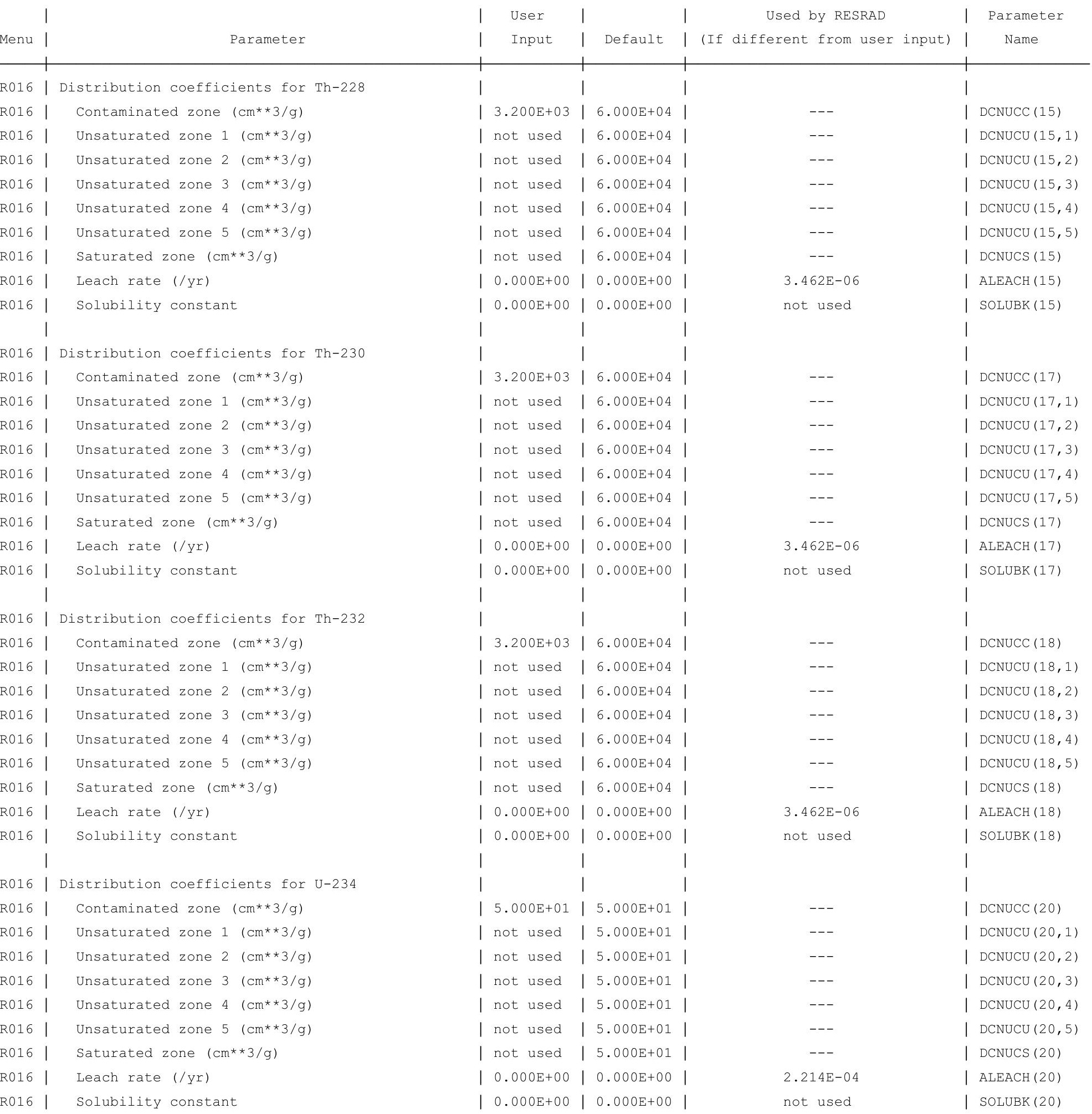


RESRAD, Version $6.5 \quad \mathrm{~T}^{1} \frac{1}{2}$ Limit $=180$ days

$07 / 20 / 2011$

15:43 Page

Summary : RESRAD Parameters for U-Landfill Worker Forward Run

File : C: \RESRAD_FAMILY\RESRAD \USERFILES $\backslash Q C J U L Y 2011 \backslash$ LANFFILLWORKER_FORWARDRUN-70YRS.RAD

Site-Specific Parameter Summary (continued)

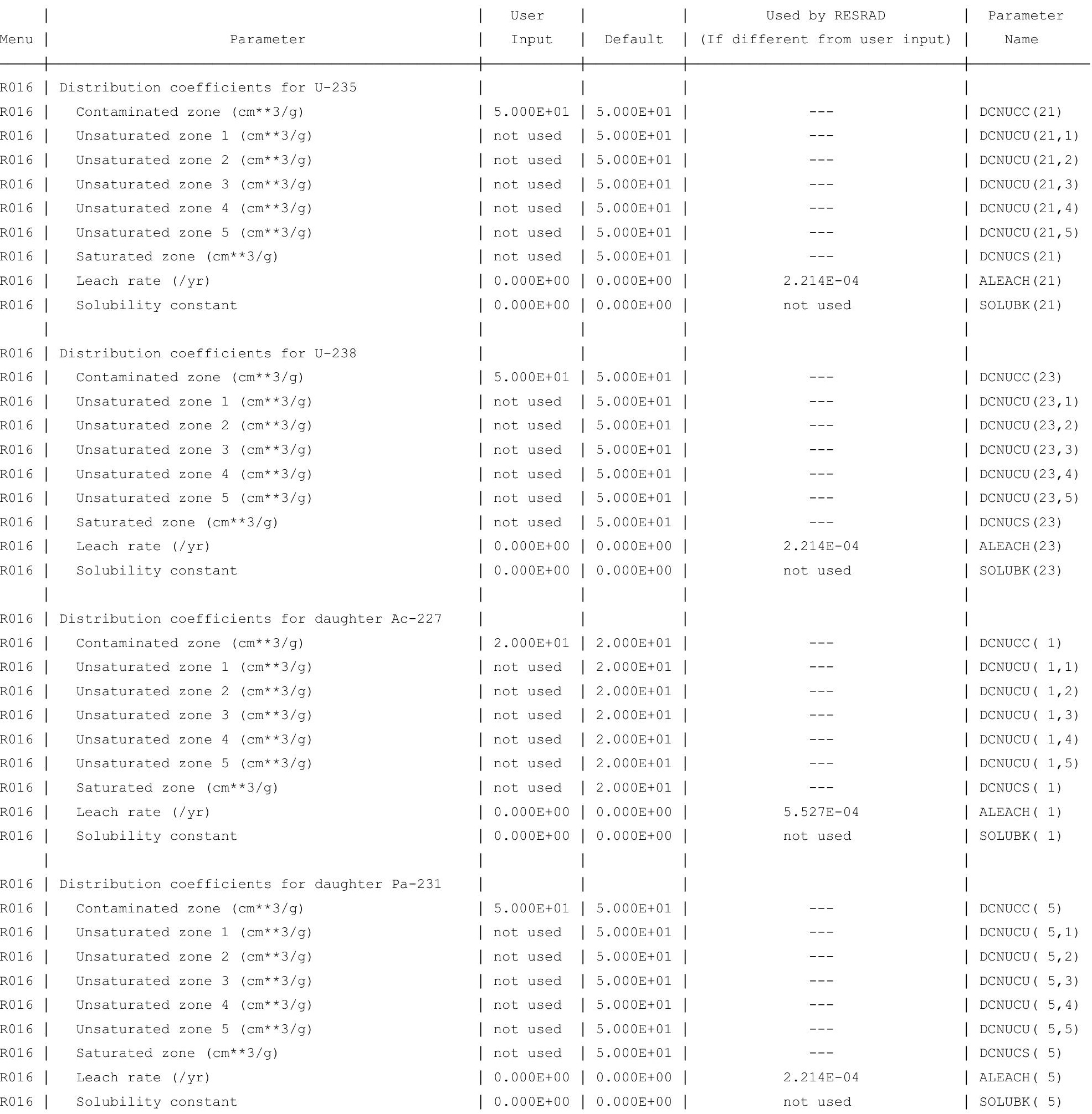


RESRAD, Version $6.5 \quad \mathrm{~T}^{1} 1 / 2$ Limit $=180$ days

$07 / 20 / 2011$

$15: 43$ Page

14

Summary : RESRAD Parameters for U-Landfill Worker Forward Run

File : C: \RESRAD_FAMILY \RESRAD \USERFILES $\backslash Q C J U L Y 2011 \backslash$ LANFFILLWORKER_FORWARDRUN-70YRS.RAD

Site-Specific Parameter Summary (continued)

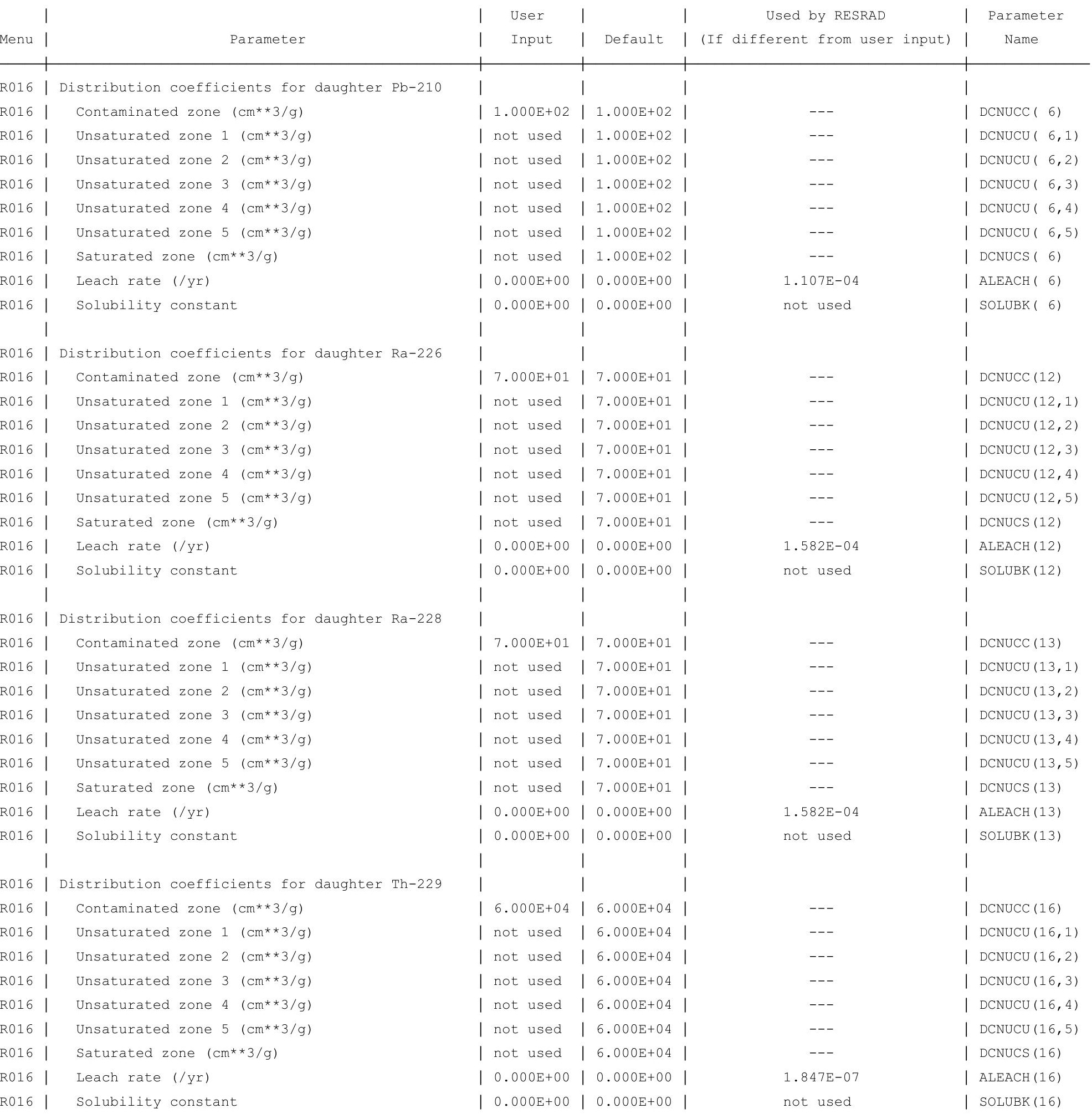


RESRAD, Version $6.5 \quad T^{1 / 2}$ Limit $=180$ days

$07 / 20 / 2011$

15:43 Page

17

ummary : RESRAD Parameters for U-Landfill Worker Forward Run

File : C: $\backslash$ RESRAD_FAMILY $\backslash$ RESRAD \USERFILES $\backslash Q C J U L Y 2011 \backslash$ LANFFILLWORKER_FORWARDRUN-70YRS.RAD

Site-Specific Parameter Summary (continued)

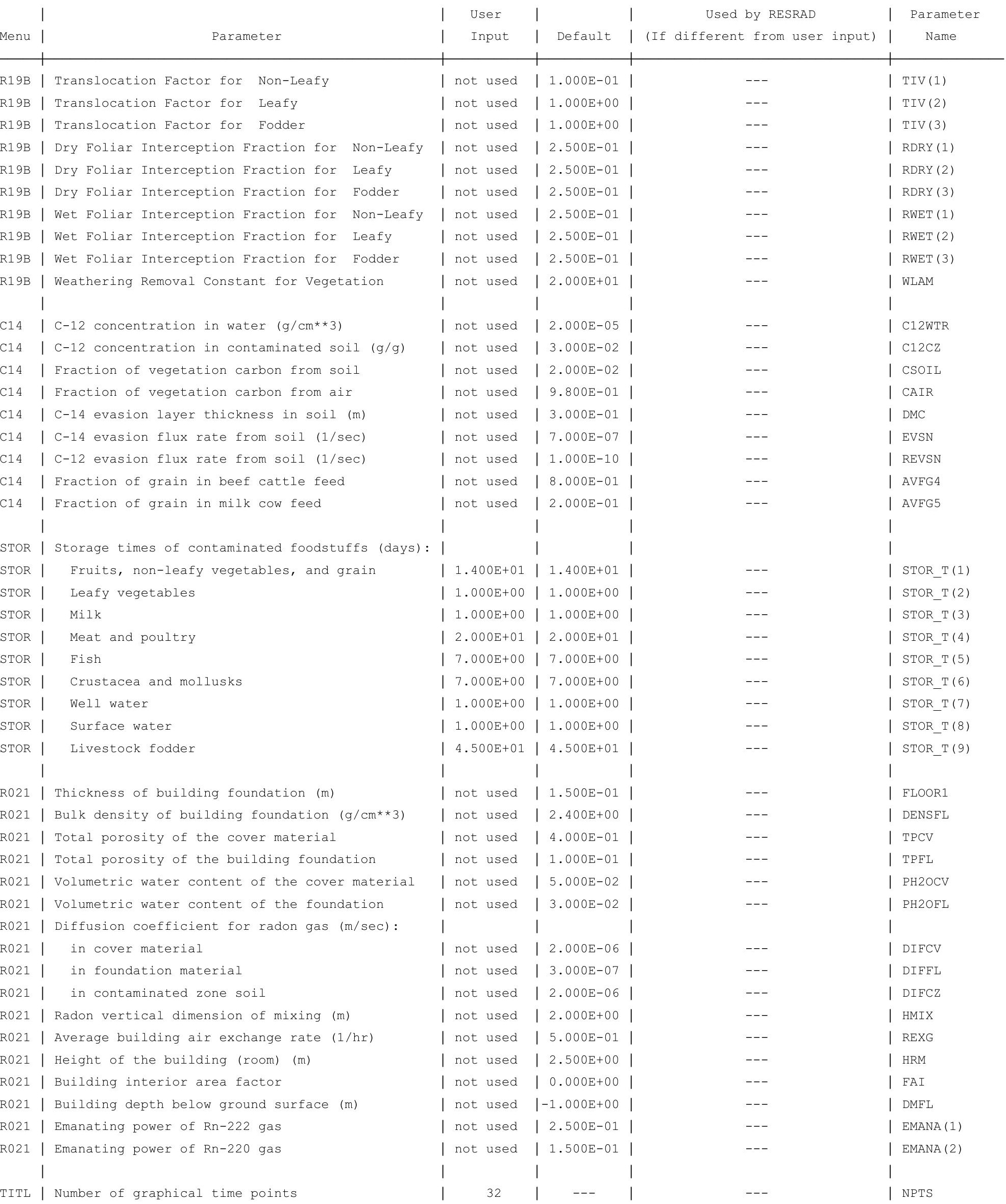

TITL | Number of graphical time points 
RESRAD, Version $6.5 \quad \mathrm{~T}^{1 / 2}$ Limit $=180$ days

07/20/2011 15:43 Page 1

Summary : RESRAD Parameters for U-Landfill Worker Forward Run

File : C: \RESRAD_FAMILY \RESRAD \USERFILES $\backslash Q C J U L Y 2011 \backslash$ LANFFILLWORKER_FORWARDRUN-70YRS.RAD

Contaminated Zone Dimensions

Area: 89436.00 square meters

Thickness:

Cover Depth:

\begin{abstract}
13.40 meters
0.00 meters
\end{abstract}

Initial Soil Concentrations, pci/g

$\begin{array}{ll}\mathrm{Am}-241 & 3.500 \mathrm{E}+01 \\ \mathrm{Cs}-137 & 1.900 \mathrm{E}+01 \\ \mathrm{~Np}-237 & 5.500 \mathrm{E}+00 \\ \mathrm{Pu}-238 & 3.900 \mathrm{E}+01 \\ \mathrm{Pu}-239 & 3.600 \mathrm{E}+01 \\ \mathrm{Pu}-240 & 3.600 \mathrm{E}+01 \\ \mathrm{TC}-99 & 5.200 \mathrm{E}+01 \\ \mathrm{Th}-228 & 4.000 \mathrm{E}+00 \\ \mathrm{Th}-230 & 1.000 \mathrm{E}+02 \\ \mathrm{Th}-232 & 4.000 \mathrm{E}+00 \\ \mathrm{U}-234 & 1.600 \mathrm{E}+02 \\ \mathrm{U}-235 & 6.500 \mathrm{E}+00 \\ \mathrm{U}-238 & 1.600 \mathrm{E}+02\end{array}$

Total Dose TDOSE(t), mrem/yr

Basic Radiation Dose Limit $=1.000 \mathrm{E}+02 \mathrm{mrem} / \mathrm{yr}$

Total Mixture Sum $M(t)$ = Fraction of Basic Dose Limit Received at Time (t)
$t$ (years): $\begin{array}{llllll}0.000 \mathrm{E}+00 & 1.000 \mathrm{E}+00 & 2.500 \mathrm{E}+01 & 5.000 \mathrm{E}+01 & 7.000 \mathrm{E}+01\end{array}$
TDOSE $(t): \begin{array}{lllll}2.987 \mathrm{E}+01 & 2.871 \mathrm{E}+01 & 3.140 \mathrm{E}+01 & 3.136 \mathrm{E}+01 & 3.171 \mathrm{E}+01\end{array}$
$M(t): \quad \begin{array}{lllll}2.987 \mathrm{E}-01 & 2.871 \mathrm{E}-01 & 3.140 \mathrm{E}-01 & 3.136 \mathrm{E}-01 & 3.171 \mathrm{E}-01\end{array}$

Maximum TDOSE $(t): \quad 3.171 \mathrm{E}+01 \mathrm{mrem} / \mathrm{yr}$ at $t=7.000 \mathrm{E}+01$ years 
RESRAD, Version 6.5

Mmary : RESRAD Parameters for U-Landfill Worker Forward Run

: C: $\backslash$ RESRAD FAMILY \RESRAD \USERFILES $\backslash Q C J U L Y 2011 \backslash$ LANFFILLWORKER FORWARDRUN-70YRS.RAD

Total Dose Contributions TDOSE(i,p,t) for Individual Radionuclides (i) and Pathways (p) As mrem/yr and Fraction of Total Dose At $t=0.000 \mathrm{E}+00$ years

Water Independent Pathways (Inhalation excludes radon)

\begin{tabular}{|c|c|c|c|c|c|c|c|c|c|c|c|c|c|c|}
\hline \multirow{2}{*}{ Nuclide } & \multicolumn{2}{|c|}{ Ground } & \multicolumn{2}{|c|}{ Inhalation } & \multicolumn{2}{|c|}{ Radon } & \multicolumn{2}{|c|}{ Plant } & \multicolumn{2}{|c|}{ Meat } & \multicolumn{2}{|c|}{ Milk } & \multicolumn{2}{|c|}{ Soil } \\
\hline & mrem/yr & fract. & mrem/yr & fract. & mrem/yr & fract. & mrem/yr & fract. & mrem/yr & fract. & mrem/yr & fract. & mrem/yr & fract. \\
\hline-241 & $2.204 \mathrm{E}-01$ & 0.0074 & $6.319 \mathrm{E}-03$ & 0.0002 & $0.000 \mathrm{E}+00$ & 0.0000 & $0.000 \mathrm{E}+00$ & 0.0000 & $0.000 \mathrm{E}+00$ & 0.0000 & $0.000 \mathrm{E}+00$ & 0.0000 & $7.708 \mathrm{E}-01$ & 0.0258 \\
\hline-137 & $9.972 \mathrm{E}+00$ & 0.3338 & $1.379 \mathrm{E}-06$ & 0.0000 & $0.000 \mathrm{E}+00$ & 0.0000 & $0.000 \mathrm{E}+00$ & 0.0000 & $0.000 \mathrm{E}+00$ & 0.0000 & $0.000 \mathrm{E}+00$ & 0.0000 & $2.691 \mathrm{E}-02$ & 0.0009 \\
\hline-237 & $9.311 \mathrm{E}-01$ & 0.0312 & $5.176 \mathrm{E}-04$ & 0.0000 & $0.000 \mathrm{E}+00$ & 0.0000 & $0.000 \mathrm{E}+00$ & 0.0000 & $0.000 \mathrm{E}+00$ & 0.0000 & $0.000 \mathrm{E}+00$ & 0.0000 & $6.719 \mathrm{E}-02$ & 0.0022 \\
\hline-238 & $7.691 \mathrm{E}-04$ & 0.0000 & $8.043 E-03$ & 0.0003 & $0.000 \mathrm{E}+00$ & 0.0000 & $0.000 \mathrm{E}+00$ & 0.0000 & $0.000 \mathrm{E}+00$ & 0.0000 & $0.000 \mathrm{E}+00$ & 0.0000 & $9.846 \mathrm{E}-01$ & 0.0330 \\
\hline-239 & $1.592 \mathrm{E}-03$ & 0.0001 & $8.131 \mathrm{E}-03$ & 0.0003 & $0.000 \mathrm{E}+00$ & 0.0000 & $0.000 \mathrm{E}+00$ & 0.0000 & $0.000 \mathrm{E}+00$ & 0.0000 & $0.000 \mathrm{E}+00$ & 0.0000 & $9.918 \mathrm{E}-01$ & 0.0332 \\
\hline-240 & $6.888 \mathrm{E}-04$ & 0.0000 & $8.131 \mathrm{E}-03$ & 0.0003 & $0.000 \mathrm{E}+00$ & 0.0000 & $0.000 \mathrm{E}+00$ & 0.0000 & $0.000 \mathrm{E}+00$ & 0.0000 & $0.000 \mathrm{E}+00$ & 0.0000 & $9.917 \mathrm{E}-01$ & 0.0332 \\
\hline 99 & $9.464 \mathrm{E}-04$ & 0.0000 & $1.266 \mathrm{E}-06$ & 0.0000 & $0.000 \mathrm{E}+00$ & 0.0000 & $0.000 \mathrm{E}+00$ & 0.0000 & $0.000 \mathrm{E}+00$ & 0.0000 & $0.000 \mathrm{E}+00$ & 0.0000 & $3.648 E-03$ & 0.0001 \\
\hline-228 & $5.388 \mathrm{E}+00$ & 0.1804 & $2.755 \mathrm{E}-04$ & 0.0000 & $0.000 \mathrm{E}+00$ & 0.0000 & $0.000 \mathrm{E}+00$ & 0.0000 & $0.000 \mathrm{E}+00$ & 0.0000 & $0.000 \mathrm{E}+00$ & 0.0000 & $5.297 \mathrm{E}-02$ & 0.0018 \\
\hline-230 & $5.615 E-02$ & 0.0019 & $1.882 \mathrm{E}-02$ & 0.0006 & $0.000 \mathrm{E}+00$ & 0.0000 & $0.000 \mathrm{E}+00$ & 0.0000 & $0.000 \mathrm{E}+00$ & 0.0000 & $0.000 \mathrm{E}+00$ & 0.0000 & $2.315 \mathrm{E}+00$ & 0.0775 \\
\hline-232 & $2.597 \mathrm{E}-01$ & 0.0087 & $8.373 E-04$ & 0.0000 & $0.000 \mathrm{E}+00$ & 0.0000 & $0.000 \mathrm{E}+00$ & 0.0000 & $0.000 \mathrm{E}+00$ & 0.0000 & $0.000 \mathrm{E}+00$ & 0.0000 & $1.194 \mathrm{E}-01$ & 0.0040 \\
\hline 234 & $9.290 \mathrm{E}-03$ & 0.0003 & $2.831 \mathrm{E}-03$ & 0.0001 & $0.000 \mathrm{E}+00$ & 0.0000 & $0.000 \mathrm{E}+00$ & 0.0000 & $0.000 \mathrm{E}+00$ & 0.0000 & $0.000 \mathrm{E}+00$ & 0.0000 & $8.639 \mathrm{E}-01$ & 0.0289 \\
\hline 35 & $7.546 \mathrm{E}-01$ & 0.0253 & $1.040 \mathrm{E}-04$ & 0.0000 & $0.000 \mathrm{E}+00$ & 0.0000 & $0.000 \mathrm{E}+00$ & 0.0000 & $0.000 \mathrm{E}+00$ & 0.0000 & $0.000 \mathrm{E}+00$ & 0.0000 & $3.391 \mathrm{E}-02$ & 0.0011 \\
\hline 38 & $4.148 \mathrm{E}+00$ & 0.1388 & $2.411 \mathrm{E}-03$ & 0.0001 & $0.000 \mathrm{E}+00$ & 0.0000 & $0.000 \mathrm{E}+00$ & 0.0000 & $0.000 \mathrm{E}+00$ & 0.0000 & $0.000 \mathrm{E}+00$ & 0.0000 & $8.533 E-01$ & 0.0286 \\
\hline & $2.174 \mathrm{E}+01$ & 0.7278 & $5.643 E-02$ & 0.0019 & $0.000 \mathrm{E}+00$ & 0.0000 & $0.000 \mathrm{E}+00$ & 0.0000 & $0.000 \mathrm{E}+00$ & 0.0000 & $0.000 \mathrm{E}+00$ & 0.0000 & $8.075 E+00$ & 0.2703 \\
\hline
\end{tabular}

Total Dose Contributions TDOSE(i,p,t) for Individual Radionuclides (i) and Pathways (p) As mrem/yr and Fraction of Total Dose At $t=0.000 \mathrm{E}+00$ years

Water Dependent Pathways

\begin{tabular}{|c|c|c|c|c|c|c|c|c|c|c|c|c|c|c|}
\hline \multirow{2}{*}{$\begin{array}{l}\text { Radio- } \\
\text { Nuclide }\end{array}$} & \multicolumn{2}{|c|}{ Water } & \multicolumn{2}{|c|}{ Fish } & \multicolumn{2}{|c|}{ Radon } & \multicolumn{2}{|c|}{ Plant } & \multicolumn{2}{|c|}{ Meat } & \multicolumn{2}{|c|}{ Milk } & \multicolumn{2}{|c|}{ All Pathways* } \\
\hline & mrem/yr & fract. & mrem/yr & fract. & mrem/yr & fract. & mrem/yr & fract. & mrem/yr & fract. & mrem/yr & fract. & mrem/yr & fract. \\
\hline 241 & $0.000 \mathrm{E}+00$ & 0.0000 & $0.000 \mathrm{E}+00$ & 0.0000 & $0.000 \mathrm{E}+00$ & 0.0000 & $0.000 \mathrm{E}+00$ & 0.0000 & $0.000 \mathrm{E}+00$ & 0.0000 & $0.000 \mathrm{E}+00$ & 0.0000 & $9.975 \mathrm{E}-01$ & 0.0334 \\
\hline-137 & $0.000 \mathrm{E}+00$ & 0.0000 & $0.000 \mathrm{E}+00$ & 0.0000 & $0.000 \mathrm{E}+00$ & 0.0000 & $0.000 \mathrm{E}+00$ & 0.0000 & $0.000 \mathrm{E}+00$ & 0.0000 & $0.000 \mathrm{E}+00$ & 0.0000 & $9.998 \mathrm{E}+00$ & 0.3347 \\
\hline-237 & $0.000 \mathrm{E}+00$ & 0.0000 & $0.000 \mathrm{E}+00$ & 0.0000 & $0.000 \mathrm{E}+00$ & 0.0000 & $0.000 \mathrm{E}+00$ & 0.0000 & $0.000 \mathrm{E}+00$ & 0.0000 & $0.000 \mathrm{E}+00$ & 0.0000 & $9.988 E-01$ & 0.0334 \\
\hline-238 & $0.000 \mathrm{E}+00$ & 0.0000 & $0.000 \mathrm{E}+00$ & 0.0000 & $0.000 \mathrm{E}+00$ & 0.0000 & $0.000 \mathrm{E}+00$ & 0.0000 & $0.000 \mathrm{E}+00$ & 0.0000 & $0.000 \mathrm{E}+00$ & 0.0000 & $9.934 \mathrm{E}-01$ & 0.0333 \\
\hline-239 & $0.000 \mathrm{E}+00$ & 0.0000 & $0.000 \mathrm{E}+00$ & 0.0000 & $0.000 \mathrm{E}+00$ & 0.0000 & $0.000 \mathrm{E}+00$ & 0.0000 & $0.000 \mathrm{E}+00$ & 0.0000 & $0.000 E+00$ & 0.0000 & $1.002 \mathrm{E}+00$ & 0.0335 \\
\hline-240 & $0.000 \mathrm{E}+00$ & 0.0000 & $0.000 \mathrm{E}+00$ & 0.0000 & $0.000 \mathrm{E}+00$ & 0.0000 & $0.000 \mathrm{E}+00$ & 0.0000 & $0.000 \mathrm{E}+00$ & 0.0000 & $0.000 E+00$ & 0.0000 & $1.001 \mathrm{E}+00$ & 0.0335 \\
\hline 99 & $0.000 \mathrm{E}+00$ & 0.0000 & $0.000 \mathrm{E}+00$ & 0.0000 & $0.000 \mathrm{E}+00$ & 0.0000 & $0.000 \mathrm{E}+00$ & 0.0000 & $0.000 \mathrm{E}+00$ & 0.0000 & $0.000 \mathrm{E}+00$ & 0.0000 & $4.596 \mathrm{E}-03$ & 0.0002 \\
\hline-228 & $0.000 \mathrm{E}+00$ & 0.0000 & $0.000 \mathrm{E}+00$ & 0.0000 & $0.000 \mathrm{E}+00$ & 0.0000 & $0.000 \mathrm{E}+00$ & 0.0000 & $0.000 \mathrm{E}+00$ & 0.0000 & $0.000 \mathrm{E}+00$ & 0.0000 & $5.442 \mathrm{E}+00$ & 0.1821 \\
\hline-230 & $0.000 \mathrm{E}+00$ & 0.0000 & $0.000 \mathrm{E}+00$ & 0.0000 & $0.000 \mathrm{E}+00$ & 0.0000 & $0.000 \mathrm{E}+00$ & 0.0000 & $0.000 \mathrm{E}+00$ & 0.0000 & $0.000 E+00$ & 0.0000 & $2.390 \mathrm{E}+00$ & 0.0800 \\
\hline 232 & $0.000 \mathrm{E}+00$ & 0.0000 & $0.000 \mathrm{E}+00$ & 0.0000 & $0.000 \mathrm{E}+00$ & 0.0000 & $0.000 \mathrm{E}+00$ & 0.0000 & $0.000 \mathrm{E}+00$ & 0.0000 & $0.000 \mathrm{E}+00$ & 0.0000 & $3.800 \mathrm{E}-01$ & 0.0127 \\
\hline 34 & $0.000 \mathrm{E}+00$ & 0.0000 & $0.000 \mathrm{E}+00$ & 0.0000 & $0.000 \mathrm{E}+00$ & 0.0000 & $0.000 \mathrm{E}+00$ & 0.0000 & $0.000 \mathrm{E}+00$ & 0.0000 & $0.000 \mathrm{E}+00$ & 0.0000 & $8.760 \mathrm{E}-01$ & 0.0293 \\
\hline 35 & $0.000 \mathrm{E}+00$ & 0.0000 & $0.000 \mathrm{E}+00$ & 0.0000 & $0.000 \mathrm{E}+00$ & 0.0000 & $0.000 \mathrm{E}+00$ & 0.0000 & $0.000 \mathrm{E}+00$ & 0.0000 & $0.000 \mathrm{E}+00$ & 0.0000 & $7.887 \mathrm{E}-01$ & 0.0264 \\
\hline 38 & $0.000 \mathrm{E}+00$ & 0.0000 & $0.000 \mathrm{E}+00$ & 0.0000 & $0.000 \mathrm{E}+00$ & 0.0000 & $0.000 \mathrm{E}+00$ & 0.0000 & $0.000 \mathrm{E}+00$ & 0.0000 & $0.000 \mathrm{E}+00$ & 0.0000 & $5.004 \mathrm{E}+00$ & 0.1675 \\
\hline & $0.000 \mathrm{E}+00$ & 0.0000 & $0.000 \mathrm{E}+00$ & 0.0000 & $0.000 \mathrm{E}+00$ & 0.0000 & $0.000 \mathrm{E}+00$ & 0.0000 & $0.000 \mathrm{E}+00$ & 0.0000 & $0.000 \mathrm{E}+00$ & 0.0000 & $7 E+01$ & 1. \\
\hline
\end{tabular}

* Sum of all water independent and dependent pathways. 
RESRAD, Version 6.5

ummary : RESRAD Parameters for U-Landfill Worker Forward Run

: C: \RESRAD FAMILY \RESRAD \USERFILES \QCJULY2011 \LANFFILLWORKER FORWARDRUN-70YRS.RAD

Total Dose Contributions TDOSE(i,p,t) for Individual Radionuclides (i) and Pathways (p) As mrem/yr and Fraction of Total Dose At $t=1.000 \mathrm{E}+00$ years

Water Independent Pathways (Inhalation excludes radon)

\begin{tabular}{|c|c|c|c|c|c|c|c|c|c|c|c|c|c|c|}
\hline \multirow{2}{*}{ Nuclide } & \multicolumn{2}{|c|}{ Ground } & \multicolumn{2}{|c|}{ Inhalation } & \multicolumn{2}{|c|}{ Radon } & \multicolumn{2}{|c|}{ Plant } & \multicolumn{2}{|c|}{ Meat } & \multicolumn{2}{|c|}{ Milk } & \multicolumn{2}{|c|}{ Soil } \\
\hline & mrem/yr & fract. & mrem/yr & fract. & mrem/yr & fract. & mrem/yr & fract. & mrem/yr & fract. & mrem/yr & fract. & mrem/yr & fract. \\
\hline-241 & $2.200 E-01$ & 0.0077 & $6.309 \mathrm{E}-03$ & 0.0002 & $0.000 \mathrm{E}+00$ & 0.0000 & $0.000 \mathrm{E}+00$ & 0.0000 & $0.000 \mathrm{E}+00$ & 0.0000 & $0.000 \mathrm{E}+00$ & 0.0000 & 7. $695 \mathrm{E}-01$ & 0.0268 \\
\hline-137 & $9.743 E+00$ & 0.3394 & $1.347 \mathrm{E}-06$ & 0.0000 & $0.000 \mathrm{E}+00$ & 0.0000 & $0.000 \mathrm{E}+00$ & 0.0000 & $0.000 \mathrm{E}+00$ & 0.0000 & $0.000 \mathrm{E}+00$ & 0.0000 & $2.629 \mathrm{E}-02$ & 0.0009 \\
\hline-237 & $9.309 \mathrm{E}-01$ & 0.0324 & $5.175 \mathrm{E}-04$ & 0.0000 & $0.000 \mathrm{E}+00$ & 0.0000 & $0.000 \mathrm{E}+00$ & 0.0000 & $0.000 \mathrm{E}+00$ & 0.0000 & $0.000 \mathrm{E}+00$ & 0.0000 & $6.718 \mathrm{E}-02$ & 0.0023 \\
\hline-238 & $7.630 \mathrm{E}-04$ & 0.0000 & 7. $980 \mathrm{E}-03$ & 0.0003 & $0.000 \mathrm{E}+00$ & 0.0000 & $0.000 \mathrm{E}+00$ & 0.0000 & $0.000 \mathrm{E}+00$ & 0.0000 & $0.000 \mathrm{E}+00$ & 0.0000 & $9.768 \mathrm{E}-01$ & 0.0340 \\
\hline-239 & $1.592 \mathrm{E}-03$ & 0.0001 & $8.131 \mathrm{E}-03$ & 0.0003 & $0.000 \mathrm{E}+00$ & 0.0000 & $0.000 \mathrm{E}+00$ & 0.0000 & $0.000 \mathrm{E}+00$ & 0.0000 & $0.000 \mathrm{E}+00$ & 0.0000 & $9.917 \mathrm{E}-01$ & 0.0345 \\
\hline-240 & $6.888 \mathrm{E}-04$ & 0.0000 & $8.130 \mathrm{E}-03$ & 0.0003 & $0.000 \mathrm{E}+00$ & 0.0000 & $0.000 \mathrm{E}+00$ & 0.0000 & $0.000 \mathrm{E}+00$ & 0.0000 & $0.000 \mathrm{E}+00$ & 0.0000 & $9.916 \mathrm{E}-01$ & 0.0345 \\
\hline 99 & $9.365 E-04$ & 0.0000 & $1.252 \mathrm{E}-06$ & 0.0000 & $0.000 \mathrm{E}+00$ & 0.0000 & $0.000 \mathrm{E}+00$ & 0.0000 & $0.000 \mathrm{E}+00$ & 0.0000 & $0.000 \mathrm{E}+00$ & 0.0000 & $3.610 \mathrm{E}-03$ & 0.0001 \\
\hline-228 & $3.751 \mathrm{E}+00$ & 0.1306 & $1.918 \mathrm{E}-04$ & 0.0000 & $0.000 \mathrm{E}+00$ & 0.0000 & $0.000 \mathrm{E}+00$ & 0.0000 & $0.000 \mathrm{E}+00$ & 0.0000 & $0.000 \mathrm{E}+00$ & 0.0000 & $3.687 \mathrm{E}-02$ & 0.0013 \\
\hline-230 & 1. $323 \mathrm{E}-01$ & 0.0046 & $1.882 \mathrm{E}-02$ & 0.0007 & $0.000 \mathrm{E}+00$ & 0.0000 & $0.000 \mathrm{E}+00$ & 0.0000 & $0.000 \mathrm{E}+00$ & 0.0000 & $0.000 \mathrm{E}+00$ & 0.0000 & $2.317 \mathrm{E}+00$ & 0.0807 \\
\hline-232 & $8.753 E-01$ & 0.0305 & $8.611 \mathrm{E}-04$ & 0.0000 & $0.000 \mathrm{E}+00$ & 0.0000 & $0.000 \mathrm{E}+00$ & 0.0000 & $0.000 \mathrm{E}+00$ & 0.0000 & $0.000 \mathrm{E}+00$ & 0.0000 & $1.541 \mathrm{E}-01$ & 0.0054 \\
\hline 34 & $9.289 \mathrm{E}-03$ & 0.0003 & $2.830 E-03$ & 0.0001 & $0.000 \mathrm{E}+00$ & 0.0000 & $0.000 \mathrm{E}+00$ & 0.0000 & $0.000 \mathrm{E}+00$ & 0.0000 & $0.000 \mathrm{E}+00$ & 0.0000 & $8.637 \mathrm{E}-01$ & 0.0301 \\
\hline 35 & 7. $545 \mathrm{E}-01$ & 0.0263 & $1.040 \mathrm{E}-04$ & 0.0000 & $0.000 \mathrm{E}+00$ & 0.0000 & $0.000 \mathrm{E}+00$ & 0.0000 & $0.000 \mathrm{E}+00$ & 0.0000 & $0.000 \mathrm{E}+00$ & 0.0000 & $3.392 \mathrm{E}-02$ & 0.0012 \\
\hline 38 & $4.147 \mathrm{E}+00$ & 0.1444 & $2.411 \mathrm{E}-03$ & 0.0001 & $0.000 \mathrm{E}+00$ & 0.0000 & $0.000 \mathrm{E}+00$ & 0.0000 & $0.000 \mathrm{E}+00$ & 0.0000 & $0.000 \mathrm{E}+00$ & 0.0000 & $8.531 \mathrm{E}-01$ & 0.0297 \\
\hline & $2.057 E+01$ & 0.7164 & $5.629 \mathrm{E}-02$ & 0.0020 & $0.000 \mathrm{E}+00$ & 0.0000 & $0.000 \mathrm{E}+00$ & 0.0000 & $0.000 \mathrm{E}+00$ & 0.0000 & $0.000 \mathrm{E}+00$ & 0.0000 & $8.085 E+00$ & 0.2816 \\
\hline
\end{tabular}

Total Dose Contributions TDOSE(i,p,t) for Individual Radionuclides (i) and Pathways (p) As mrem/yr and Fraction of Total Dose At $t=1.000 \mathrm{E}+00$ years

Water Dependent Pathways

\begin{tabular}{|c|c|c|c|c|c|c|c|c|c|c|c|c|c|c|}
\hline \multirow{2}{*}{$\begin{array}{l}\text { Radio- } \\
\text { Nuclide }\end{array}$} & \multicolumn{2}{|c|}{ Water } & \multicolumn{2}{|c|}{ Fish } & \multicolumn{2}{|c|}{ Radon } & \multicolumn{2}{|c|}{ Plant } & \multicolumn{2}{|c|}{ Meat } & \multicolumn{2}{|c|}{ Milk } & \multicolumn{2}{|c|}{ All Pathways* } \\
\hline & mrem/yr & fract. & mrem/yr & fract. & mrem/yr & fract. & mrem/yr & fract. & mrem/yr & fract. & mrem/yr & fract. & mrem/yr & fract. \\
\hline 241 & $0.000 \mathrm{E}+00$ & 0.0000 & $0.000 \mathrm{E}+00$ & 0.0000 & $0.000 \mathrm{E}+00$ & 0.0000 & $0.000 \mathrm{E}+00$ & 0.0000 & $0.000 \mathrm{E}+00$ & 0.0000 & $0.000 \mathrm{E}+00$ & 0.0000 & $9.959 \mathrm{E}-01$ & 0.0347 \\
\hline-137 & $0.000 \mathrm{E}+00$ & 0.0000 & $0.000 \mathrm{E}+00$ & 0.0000 & $0.000 \mathrm{E}+00$ & 0.0000 & $0.000 \mathrm{E}+00$ & 0.0000 & $0.000 \mathrm{E}+00$ & 0.0000 & $0.000 \mathrm{E}+00$ & 0.0000 & $9.770 \mathrm{E}+00$ & 0.3403 \\
\hline-237 & $0.000 \mathrm{E}+00$ & 0.0000 & $0.000 \mathrm{E}+00$ & 0.0000 & $0.000 \mathrm{E}+00$ & 0.0000 & $0.000 \mathrm{E}+00$ & 0.0000 & $0.000 \mathrm{E}+00$ & 0.0000 & $0.000 \mathrm{E}+00$ & 0.0000 & $9.986 \mathrm{E}-01$ & 0.0348 \\
\hline-238 & $0.000 \mathrm{E}+00$ & 0.0000 & $0.000 \mathrm{E}+00$ & 0.0000 & $0.000 \mathrm{E}+00$ & 0.0000 & $0.000 \mathrm{E}+00$ & 0.0000 & $0.000 \mathrm{E}+00$ & 0.0000 & $0.000 \mathrm{E}+00$ & 0.0000 & $9.856 \mathrm{E}-01$ & 0.0343 \\
\hline-239 & $0.000 \mathrm{E}+00$ & 0.0000 & $0.000 \mathrm{E}+00$ & 0.0000 & $0.000 \mathrm{E}+00$ & 0.0000 & $0.000 \mathrm{E}+00$ & 0.0000 & $0.000 \mathrm{E}+00$ & 0.0000 & $0.000 \mathrm{E}+00$ & 0.0000 & $1.001 \mathrm{E}+00$ & 0.0349 \\
\hline-240 & $0.000 \mathrm{E}+00$ & 0.0000 & $0.000 \mathrm{E}+00$ & 0.0000 & $0.000 \mathrm{E}+00$ & 0.0000 & $0.000 \mathrm{E}+00$ & 0.0000 & $0.000 \mathrm{E}+00$ & 0.0000 & $0.000 E+00$ & 0.0000 & $1.000 \mathrm{E}+00$ & 0.0348 \\
\hline 99 & $0.000 \mathrm{E}+00$ & 0.0000 & $0.000 \mathrm{E}+00$ & 0.0000 & $0.000 \mathrm{E}+00$ & 0.0000 & $0.000 \mathrm{E}+00$ & 0.0000 & $0.000 \mathrm{E}+00$ & 0.0000 & $0.000 \mathrm{E}+00$ & 0.0000 & $4.547 \mathrm{E}-03$ & 0.0002 \\
\hline-228 & $0.000 \mathrm{E}+00$ & 0.0000 & $0.000 \mathrm{E}+00$ & 0.0000 & $0.000 \mathrm{E}+00$ & 0.0000 & $0.000 \mathrm{E}+00$ & 0.0000 & $0.000 \mathrm{E}+00$ & 0.0000 & $0.000 \mathrm{E}+00$ & 0.0000 & $3.788 \mathrm{E}+00$ & 0.1319 \\
\hline-230 & $0.000 \mathrm{E}+00$ & 0.0000 & $0.000 \mathrm{E}+00$ & 0.0000 & $0.000 \mathrm{E}+00$ & 0.0000 & $0.000 \mathrm{E}+00$ & 0.0000 & $0.000 \mathrm{E}+00$ & 0.0000 & $0.000 E+00$ & 0.0000 & $2.468 \mathrm{E}+00$ & 0.0860 \\
\hline 232 & $0.000 \mathrm{E}+00$ & 0.0000 & $0.000 \mathrm{E}+00$ & 0.0000 & $0.000 \mathrm{E}+00$ & 0.0000 & $0.000 \mathrm{E}+00$ & 0.0000 & $0.000 \mathrm{E}+00$ & 0.0000 & $0.000 \mathrm{E}+00$ & 0.0000 & $1.030 \mathrm{E}+00$ & 0.0359 \\
\hline 34 & $0.000 \mathrm{E}+00$ & 0.0000 & $0.000 \mathrm{E}+00$ & 0.0000 & $0.000 \mathrm{E}+00$ & 0.0000 & $0.000 \mathrm{E}+00$ & 0.0000 & $0.000 \mathrm{E}+00$ & 0.0000 & $0.000 \mathrm{E}+00$ & 0.0000 & $8.759 \mathrm{E}-01$ & 0.0305 \\
\hline 35 & $0.000 \mathrm{E}+00$ & 0.0000 & $0.000 \mathrm{E}+00$ & 0.0000 & $0.000 \mathrm{E}+00$ & 0.0000 & $0.000 \mathrm{E}+00$ & 0.0000 & $0.000 \mathrm{E}+00$ & 0.0000 & $0.000 \mathrm{E}+00$ & 0.0000 & $7.885 E-01$ & 0.0275 \\
\hline 38 & $0.000 \mathrm{E}+00$ & 0.0000 & $0.000 \mathrm{E}+00$ & 0.0000 & $0.000 \mathrm{E}+00$ & 0.0000 & $0.000 \mathrm{E}+00$ & 0.0000 & $0.000 \mathrm{E}+00$ & 0.0000 & $0.000 \mathrm{E}+00$ & 0.0000 & $5.002 \mathrm{E}+00$ & 0.1742 \\
\hline & $0.000 \mathrm{E}+00$ & 0.0000 & $0.000 \mathrm{E}+00$ & 0.0000 & $0.000 \mathrm{E}+00$ & 0.0000 & $0.000 \mathrm{E}+00$ & 0.0000 & $0.000 \mathrm{E}+00$ & 0.0000 & $0.000 \mathrm{E}+00$ & 0.0000 & $71 E+01$ & 1. \\
\hline
\end{tabular}

* Sum of all water independent and dependent pathways. 
RESRAD, Version 6.5

mmary : RESRAD Parameters for U-Landfill Worker Forward Run

: C: \RESRAD_FAMILY \RESRAD \USERFILES \QCJULY2011 \LANFFILLWORKER_FORWARDRUN-70YRS.RAD

Total Dose Contributions TDOSE (i,p,t) for Individual Radionuclides (i) and Pathways (p) As mrem/yr and Fraction of Total Dose At $t=2.500 \mathrm{E}+01$ years

Water Independent Pathways (Inhalation excludes radon)

\begin{tabular}{|c|c|c|c|c|c|c|c|c|c|c|c|c|c|c|}
\hline \multirow{2}{*}{ Nuclide } & \multicolumn{2}{|c|}{ Ground } & \multicolumn{2}{|c|}{ Inhalation } & \multicolumn{2}{|c|}{ Radon } & \multicolumn{2}{|c|}{ Plant } & \multicolumn{2}{|c|}{ Meat } & \multicolumn{2}{|c|}{ Milk } & \multicolumn{2}{|c|}{ Soil } \\
\hline & mrem/yr & fract. & mrem/yr & fract. & mrem/yr & fract. & mrem/yr & fract. & mrem/yr & fract. & mrem/yr & fract. & mrem/yr & fract. \\
\hline-241 & $2.117 \mathrm{E}-01$ & 0.0067 & $6.070 \mathrm{E}-03$ & 0.0002 & $0.000 \mathrm{E}+00$ & 0.0000 & $0.000 \mathrm{E}+00$ & 0.0000 & $0.000 \mathrm{E}+00$ & 0.0000 & $0.000 \mathrm{E}+00$ & 0.0000 & $7.404 \mathrm{E}-01$ & 0.0236 \\
\hline-137 & $5.591 E+00$ & 0.1781 & $7.730 \mathrm{E}-07$ & 0.0000 & $0.000 \mathrm{E}+00$ & 0.0000 & $0.000 \mathrm{E}+00$ & 0.0000 & $0.000 \mathrm{E}+00$ & 0.0000 & $0.000 \mathrm{E}+00$ & 0.0000 & $1.509 \mathrm{E}-02$ & 0.0005 \\
\hline-237 & $9.274 \mathrm{E}-01$ & 0.0295 & $5.156 \mathrm{E}-04$ & 0.0000 & $0.000 \mathrm{E}+00$ & 0.0000 & $0.000 \mathrm{E}+00$ & 0.0000 & $0.000 \mathrm{E}+00$ & 0.0000 & $0.000 \mathrm{E}+00$ & 0.0000 & $6.693 \mathrm{E}-02$ & 0.0021 \\
\hline-238 & $6.311 E-04$ & 0.0000 & $6.598 E-03$ & 0.0002 & $0.000 \mathrm{E}+00$ & 0.0000 & $0.000 \mathrm{E}+00$ & 0.0000 & $0.000 \mathrm{E}+00$ & 0.0000 & $0.000 \mathrm{E}+00$ & 0.0000 & $8.077 \mathrm{E}-01$ & 0.0257 \\
\hline-239 & $1.590 \mathrm{E}-03$ & 0.0001 & $8.121 \mathrm{E}-03$ & 0.0003 & $0.000 \mathrm{E}+00$ & 0.0000 & $0.000 \mathrm{E}+00$ & 0.0000 & $0.000 \mathrm{E}+00$ & 0.0000 & $0.000 \mathrm{E}+00$ & 0.0000 & $9.906 \mathrm{E}-01$ & 0.0315 \\
\hline-240 & $6.867 \mathrm{E}-04$ & 0.0000 & $8.105 \mathrm{E}-03$ & 0.0003 & $0.000 \mathrm{E}+00$ & 0.0000 & $0.000 \mathrm{E}+00$ & 0.0000 & $0.000 \mathrm{E}+00$ & 0.0000 & $0.000 \mathrm{E}+00$ & 0.0000 & $9.886 \mathrm{E}-01$ & 0.0315 \\
\hline 99 & $7.265 E-04$ & 0.0000 & $9.716 \mathrm{E}-07$ & 0.0000 & $0.000 \mathrm{E}+00$ & 0.0000 & $0.000 \mathrm{E}+00$ & 0.0000 & $0.000 \mathrm{E}+00$ & 0.0000 & $0.000 \mathrm{E}+00$ & 0.0000 & $2.800 \mathrm{E}-03$ & 0.0001 \\
\hline-228 & $6.275 E-04$ & 0.0000 & $3.208 \mathrm{E}-08$ & 0.0000 & $0.000 \mathrm{E}+00$ & 0.0000 & $0.000 \mathrm{E}+00$ & 0.0000 & $0.000 \mathrm{E}+00$ & 0.0000 & $0.000 \mathrm{E}+00$ & 0.0000 & $6.169 \mathrm{E}-06$ & 0.0000 \\
\hline-230 & $1.947 \mathrm{E}+00$ & 0.0620 & $1.884 \mathrm{E}-02$ & 0.0006 & $0.000 \mathrm{E}+00$ & 0.0000 & $0.000 \mathrm{E}+00$ & 0.0000 & $0.000 \mathrm{E}+00$ & 0.0000 & $0.000 \mathrm{E}+00$ & 0.0000 & $2.418 \mathrm{E}+00$ & 0.0770 \\
\hline-232 & $9.555 \mathrm{E}+00$ & 0.3043 & $1.248 E-03$ & 0.0000 & $0.000 \mathrm{E}+00$ & 0.0000 & $0.000 \mathrm{E}+00$ & 0.0000 & $0.000 \mathrm{E}+00$ & 0.0000 & $0.000 \mathrm{E}+00$ & 0.0000 & $4.500 \mathrm{E}-01$ & 0.0143 \\
\hline 234 & $9.599 \mathrm{E}-03$ & 0.0003 & $2.822 \mathrm{E}-03$ & 0.0001 & $0.000 \mathrm{E}+00$ & 0.0000 & $0.000 \mathrm{E}+00$ & 0.0000 & $0.000 \mathrm{E}+00$ & 0.0000 & $0.000 \mathrm{E}+00$ & 0.0000 & $8.599 \mathrm{E}-01$ & 0.0274 \\
\hline 35 & $7.509 \mathrm{E}-01$ & 0.0239 & $1.055 \mathrm{E}-04$ & 0.0000 & $0.000 \mathrm{E}+00$ & 0.0000 & $0.000 \mathrm{E}+00$ & 0.0000 & $0.000 \mathrm{E}+00$ & 0.0000 & $0.000 \mathrm{E}+00$ & 0.0000 & $3.414 \mathrm{E}-02$ & 0.0011 \\
\hline 38 & $4.125 E+00$ & 0.1314 & $2.398 E-03$ & 0.0001 & $0.000 \mathrm{E}+00$ & 0.0000 & $0.000 \mathrm{E}+00$ & 0.0000 & $0.000 \mathrm{E}+00$ & 0.0000 & $0.000 \mathrm{E}+00$ & 0.0000 & $8.487 \mathrm{E}-01$ & 0.0270 \\
\hline & $2.312 \mathrm{E}+01$ & 0.7364 & $5.483 E-02$ & 0.0017 & $0.000 \mathrm{E}+00$ & 0.0000 & $0.000 \mathrm{E}+00$ & 0.0000 & $0.000 \mathrm{E}+00$ & 0.0000 & $0.000 \mathrm{E}+00$ & 0.0000 & $8.223 E+00$ & 0.2619 \\
\hline
\end{tabular}

Total Dose Contributions TDOSE(i,p,t) for Individual Radionuclides (i) and Pathways (p) As mrem/yr and Fraction of Total Dose At $t=2.500 \mathrm{E}+01$ years

Water Dependent Pathways

\begin{tabular}{|c|c|c|c|c|c|c|c|c|c|c|c|c|c|c|}
\hline \multirow{2}{*}{ Nuclide } & \multicolumn{2}{|c|}{ Water } & \multicolumn{2}{|c|}{ Fish } & \multicolumn{2}{|c|}{ Radon } & \multicolumn{2}{|c|}{ Plant } & \multicolumn{2}{|c|}{ Meat } & \multicolumn{2}{|c|}{ Milk } & \multicolumn{2}{|c|}{ All Pathways* } \\
\hline & mrem/yr & fract. & mrem/yr & fract. & mrem/yr & fract. & mrem/yr & fract. & mrem/yr & fract. & mrem/yr & fract. & mrem/yr & fract. \\
\hline-241 & $0.000 \mathrm{E}+00$ & 0.0000 & $0.000 \mathrm{E}+00$ & 0.0000 & $0.000 \mathrm{E}+00$ & 0.0000 & $0.000 \mathrm{E}+00$ & 0.0000 & $0.000 \mathrm{E}+00$ & 0.0000 & $0.000 \mathrm{E}+00$ & 0.0000 & $9.582 \mathrm{E}-01$ & 0.0305 \\
\hline-137 & $0.000 \mathrm{E}+00$ & 0.0000 & $0.000 \mathrm{E}+00$ & 0.0000 & $0.000 \mathrm{E}+00$ & 0.0000 & $0.000 \mathrm{E}+00$ & 0.0000 & $0.000 \mathrm{E}+00$ & 0.0000 & $0.000 \mathrm{E}+00$ & 0.0000 & $5.606 \mathrm{E}+00$ & 0.1785 \\
\hline-237 & $0.000 \mathrm{E}+00$ & 0.0000 & $0.000 \mathrm{E}+00$ & 0.0000 & $0.000 \mathrm{E}+00$ & 0.0000 & $0.000 \mathrm{E}+00$ & 0.0000 & $0.000 \mathrm{E}+00$ & 0.0000 & $0.000 \mathrm{E}+00$ & 0.0000 & $9.949 \mathrm{E}-01$ & 0.0317 \\
\hline-238 & $0.000 \mathrm{E}+00$ & 0.0000 & $0.000 \mathrm{E}+00$ & 0.0000 & $0.000 \mathrm{E}+00$ & 0.0000 & $0.000 \mathrm{E}+00$ & 0.0000 & $0.000 \mathrm{E}+00$ & 0.0000 & $0.000 \mathrm{E}+00$ & 0.0000 & $8.150 \mathrm{E}-01$ & 0.0260 \\
\hline 239 & $0.000 \mathrm{E}+00$ & 0.0000 & $0.000 \mathrm{E}+00$ & 0.0000 & $0.000 \mathrm{E}+00$ & 0.0000 & $0.000 \mathrm{E}+00$ & 0.0000 & $0.000 \mathrm{E}+00$ & 0.0000 & $0.000 \mathrm{E}+00$ & 0.0000 & $1.000 \mathrm{E}+00$ & 0.0319 \\
\hline-240 & $0.000 \mathrm{E}+00$ & 0.0000 & $0.000 \mathrm{E}+00$ & 0.0000 & $0.000 \mathrm{E}+00$ & 0.0000 & $0.000 \mathrm{E}+00$ & 0.0000 & $0.000 \mathrm{E}+00$ & 0.0000 & $0.000 \mathrm{E}+00$ & 0.0000 & $9.974 \mathrm{E}-01$ & 0.0318 \\
\hline 99 & $0.000 \mathrm{E}+00$ & 0.0000 & $0.000 \mathrm{E}+00$ & 0.0000 & $0.000 \mathrm{E}+00$ & 0.0000 & $0.000 \mathrm{E}+00$ & 0.0000 & $0.000 \mathrm{E}+00$ & 0.0000 & $0.000 \mathrm{E}+00$ & 0.0000 & $3.528 \mathrm{E}-03$ & 0.0001 \\
\hline-228 & $0.000 \mathrm{E}+00$ & 0.0000 & $0.000 \mathrm{E}+00$ & 0.0000 & $0.000 \mathrm{E}+00$ & 0.0000 & $0.000 \mathrm{E}+00$ & 0.0000 & $0.000 \mathrm{E}+00$ & 0.0000 & $0.000 \mathrm{E}+00$ & 0.0000 & $6.337 \mathrm{E}-04$ & 0.0000 \\
\hline-230 & $0.000 \mathrm{E}+00$ & 0.0000 & $0.000 \mathrm{E}+00$ & 0.0000 & $0.000 \mathrm{E}+00$ & 0.0000 & $0.000 \mathrm{E}+00$ & 0.0000 & $0.000 \mathrm{E}+00$ & 0.0000 & $0.000 \mathrm{E}+00$ & 0.0000 & $4.384 \mathrm{E}+00$ & 0.1396 \\
\hline-232 & $0.000 \mathrm{E}+00$ & 0.0000 & $0.000 \mathrm{E}+00$ & 0.0000 & $0.000 \mathrm{E}+00$ & 0.0000 & $0.000 \mathrm{E}+00$ & 0.0000 & $0.000 \mathrm{E}+00$ & 0.0000 & $0.000 \mathrm{E}+00$ & 0.0000 & $1.001 \mathrm{E}+01$ & 0.3187 \\
\hline 234 & $0.000 \mathrm{E}+00$ & 0.0000 & $0.000 \mathrm{E}+00$ & 0.0000 & $0.000 \mathrm{E}+00$ & 0.0000 & $0.000 \mathrm{E}+00$ & 0.0000 & $0.000 \mathrm{E}+00$ & 0.0000 & $0.000 \mathrm{E}+00$ & 0.0000 & $8.723 E-01$ & 0.0278 \\
\hline 35 & $0.000 \mathrm{E}+00$ & 0.0000 & $0.000 \mathrm{E}+00$ & 0.0000 & $0.000 \mathrm{E}+00$ & 0.0000 & $0.000 \mathrm{E}+00$ & 0.0000 & $0.000 \mathrm{E}+00$ & 0.0000 & $0.000 \mathrm{E}+00$ & 0.0000 & $7.852 \mathrm{E}-01$ & 0.0250 \\
\hline 38 & $0.000 \mathrm{E}+00$ & 0.0000 & $0.000 \mathrm{E}+00$ & 0.0000 & $0.000 \mathrm{E}+00$ & 0.0000 & $0.000 \mathrm{E}+00$ & 0.0000 & $0.000 \mathrm{E}+00$ & 0.0000 & $0.000 \mathrm{E}+00$ & 0.0000 & $4.976 \mathrm{E}+00$ & 0.1585 \\
\hline & $0.000 \mathrm{E}+00$ & 0.0000 & $0.000 \mathrm{E}+00$ & 0.0000 & $0.000 \mathrm{E}+00$ & 0.0000 & $0.000 \mathrm{E}+00$ & 0.0000 & $0.000 \mathrm{E}+00$ & 0.0000 & $0.000 \mathrm{E}+00$ & 0.0000 & $3.140 \mathrm{E}+01$ & 1.0000 \\
\hline
\end{tabular}

* Sum of all water independent and dependent pathways. 
RESRAD, Version 6.5

Mmary : RESRAD Parameters for U-Landfill Worker Forward Run

: C: \RESRAD FAMILY \RESRAD \USERFILES \QCJULY2011 \LANFFILLWORKER FORWARDRUN-70YRS.RAD

Total Dose Contributions TDOSE(i,p,t) for Individual Radionuclides (i) and Pathways (p) As mrem/yr and Fraction of Total Dose At $t=5.000 \mathrm{E}+01$ years

Water Independent Pathways (Inhalation excludes radon)

\begin{tabular}{|c|c|c|c|c|c|c|c|c|c|c|c|c|c|c|}
\hline \multirow{2}{*}{ Nuclide } & \multicolumn{2}{|c|}{ Ground } & \multicolumn{2}{|c|}{ Inhalation } & \multicolumn{2}{|c|}{ Radon } & \multicolumn{2}{|c|}{ Plant } & \multicolumn{2}{|c|}{ Meat } & \multicolumn{2}{|c|}{ Milk } & \multicolumn{2}{|c|}{ Soil } \\
\hline & mrem/yr & fract. & mrem/yr & fract. & mrem/yr & fract. & mrem/yr & fract. & mrem/yr & fract. & mrem/yr & fract. & mrem/yr & fract. \\
\hline-241 & $2.034 \mathrm{E}-01$ & 0.0065 & $5.831 \mathrm{E}-03$ & 0.0002 & $0.000 \mathrm{E}+00$ & 0.0000 & $0.000 \mathrm{E}+00$ & 0.0000 & $0.000 \mathrm{E}+00$ & 0.0000 & $0.000 \mathrm{E}+00$ & 0.0000 & $7.112 \mathrm{E}-01$ & 0.0227 \\
\hline-137 & $3.135 E+00$ & 0.1000 & $4.334 \mathrm{E}-07$ & 0.0000 & $0.000 \mathrm{E}+00$ & 0.0000 & $0.000 \mathrm{E}+00$ & 0.0000 & $0.000 \mathrm{E}+00$ & 0.0000 & $0.000 \mathrm{E}+00$ & 0.0000 & $8.458 E-03$ & 0.0003 \\
\hline-237 & $9.237 \mathrm{E}-01$ & 0.0295 & $5.136 \mathrm{E}-04$ & 0.0000 & $0.000 \mathrm{E}+00$ & 0.0000 & $0.000 \mathrm{E}+00$ & 0.0000 & $0.000 \mathrm{E}+00$ & 0.0000 & $0.000 \mathrm{E}+00$ & 0.0000 & $6.667 \mathrm{E}-02$ & 0.0021 \\
\hline-238 & $5.179 \mathrm{E}-04$ & 0.0000 & $5.413 E-03$ & 0.0002 & $0.000 \mathrm{E}+00$ & 0.0000 & $0.000 \mathrm{E}+00$ & 0.0000 & $0.000 \mathrm{E}+00$ & 0.0000 & $0.000 \mathrm{E}+00$ & 0.0000 & $6.627 \mathrm{E}-01$ & 0.0211 \\
\hline-239 & $1.588 \mathrm{E}-03$ & 0.0001 & $8.111 \mathrm{E}-03$ & 0.0003 & $0.000 \mathrm{E}+00$ & 0.0000 & $0.000 \mathrm{E}+00$ & 0.0000 & $0.000 \mathrm{E}+00$ & 0.0000 & $0.000 \mathrm{E}+00$ & 0.0000 & $9.894 \mathrm{E}-01$ & 0.0315 \\
\hline-240 & $6.845 \mathrm{E}-04$ & 0.0000 & $8.080 \mathrm{E}-03$ & 0.0003 & $0.000 \mathrm{E}+00$ & 0.0000 & $0.000 \mathrm{E}+00$ & 0.0000 & $0.000 \mathrm{E}+00$ & 0.0000 & $0.000 \mathrm{E}+00$ & 0.0000 & $9.855 \mathrm{E}-01$ & 0.0314 \\
\hline 99 & $5.577 \mathrm{E}-04$ & 0.0000 & $7.458 \mathrm{E}-07$ & 0.0000 & $0.000 \mathrm{E}+00$ & 0.0000 & $0.000 \mathrm{E}+00$ & 0.0000 & $0.000 \mathrm{E}+00$ & 0.0000 & $0.000 \mathrm{E}+00$ & 0.0000 & $2.150 \mathrm{E}-03$ & 0.0001 \\
\hline-228 & $7.308 \mathrm{E}-08$ & 0.0000 & $3.736 \mathrm{E}-12$ & 0.0000 & $0.000 \mathrm{E}+00$ & 0.0000 & $0.000 \mathrm{E}+00$ & 0.0000 & $0.000 \mathrm{E}+00$ & 0.0000 & $0.000 \mathrm{E}+00$ & 0.0000 & 7. $184 \mathrm{E}-10$ & 0.0000 \\
\hline-230 & $3.811 \mathrm{E}+00$ & 0.1215 & $1.887 \mathrm{E}-02$ & 0.0006 & $0.000 \mathrm{E}+00$ & 0.0000 & $0.000 \mathrm{E}+00$ & 0.0000 & $0.000 \mathrm{E}+00$ & 0.0000 & $0.000 \mathrm{E}+00$ & 0.0000 & $2.602 \mathrm{E}+00$ & 0.0830 \\
\hline-232 & $1.014 \mathrm{E}+01$ & 0.3233 & $1.275 E-03$ & 0.0000 & $0.000 \mathrm{E}+00$ & 0.0000 & $0.000 \mathrm{E}+00$ & 0.0000 & $0.000 \mathrm{E}+00$ & 0.0000 & $0.000 \mathrm{E}+00$ & 0.0000 & $4.674 \mathrm{E}-01$ & 0.0149 \\
\hline 234 & $1.058 \mathrm{E}-02$ & 0.0003 & $2.813 \mathrm{E}-03$ & 0.0001 & $0.000 \mathrm{E}+00$ & 0.0000 & $0.000 \mathrm{E}+00$ & 0.0000 & $0.000 \mathrm{E}+00$ & 0.0000 & $0.000 \mathrm{E}+00$ & 0.0000 & $8.560 \mathrm{E}-01$ & 0.0273 \\
\hline 35 & $7.476 \mathrm{E}-01$ & 0.0238 & $1.083 \mathrm{E}-04$ & 0.0000 & $0.000 \mathrm{E}+00$ & 0.0000 & $0.000 \mathrm{E}+00$ & 0.0000 & $0.000 \mathrm{E}+00$ & 0.0000 & $0.000 \mathrm{E}+00$ & 0.0000 & $3.453 \mathrm{E}-02$ & 0.0011 \\
\hline 38 & $4.102 \mathrm{E}+00$ & 0.1308 & $2.385 E-03$ & 0.0001 & $0.000 \mathrm{E}+00$ & 0.0000 & $0.000 \mathrm{E}+00$ & 0.0000 & $0.000 \mathrm{E}+00$ & 0.0000 & $0.000 \mathrm{E}+00$ & 0.0000 & $8.441 \mathrm{E}-01$ & 0.0269 \\
\hline & $2.308 E+01$ & 0.7359 & $5.340 \mathrm{E}-02$ & 0.0017 & $0.000 \mathrm{E}+00$ & 0.0000 & $0.000 \mathrm{E}+00$ & 0.0000 & $0.000 \mathrm{E}+00$ & 0.0000 & $0.000 \mathrm{E}+00$ & 0.0000 & $8.230 \mathrm{E}+00$ & 0.2624 \\
\hline
\end{tabular}

Total Dose Contributions TDOSE(i,p,t) for Individual Radionuclides (i) and Pathways (p) As mrem/yr and Fraction of Total Dose At $t=5.000 \mathrm{E}+01$ years

Water Dependent Pathways

\begin{tabular}{|c|c|c|c|c|c|c|c|c|c|c|c|c|c|c|}
\hline \multirow{2}{*}{$\begin{array}{l}\text { Radio- } \\
\text { Nuclide }\end{array}$} & \multicolumn{2}{|c|}{ Water } & \multicolumn{2}{|c|}{ Fish } & \multicolumn{2}{|c|}{ Radon } & \multicolumn{2}{|c|}{ Plant } & \multicolumn{2}{|c|}{ Meat } & \multicolumn{2}{|c|}{ Milk } & \multicolumn{2}{|c|}{ All Pathways* } \\
\hline & mrem/yr & fract. & mrem/yr & fract. & mrem/yr & fract. & mrem/yr & fract. & mrem/yr & fract. & mrem/yr & fract. & mrem/yr & fract. \\
\hline 241 & $0.000 \mathrm{E}+00$ & 0.0000 & $0.000 \mathrm{E}+00$ & 0.0000 & $0.000 \mathrm{E}+00$ & 0.0000 & $0.000 \mathrm{E}+00$ & 0.0000 & $0.000 \mathrm{E}+00$ & 0.0000 & $0.000 \mathrm{E}+00$ & 0.0000 & $9.205 \mathrm{E}-01$ & 0.0294 \\
\hline-137 & $0.000 \mathrm{E}+00$ & 0.0000 & $0.000 \mathrm{E}+00$ & 0.0000 & $0.000 \mathrm{E}+00$ & 0.0000 & $0.000 \mathrm{E}+00$ & 0.0000 & $0.000 \mathrm{E}+00$ & 0.0000 & $0.000 \mathrm{E}+00$ & 0.0000 & $3.143 \mathrm{E}+00$ & 0.1002 \\
\hline-237 & $0.000 \mathrm{E}+00$ & 0.0000 & $0.000 \mathrm{E}+00$ & 0.0000 & $0.000 \mathrm{E}+00$ & 0.0000 & $0.000 \mathrm{E}+00$ & 0.0000 & $0.000 \mathrm{E}+00$ & 0.0000 & $0.000 \mathrm{E}+00$ & 0.0000 & $9.909 \mathrm{E}-01$ & 0.0316 \\
\hline-238 & $0.000 \mathrm{E}+00$ & 0.0000 & $0.000 \mathrm{E}+00$ & 0.0000 & $0.000 \mathrm{E}+00$ & 0.0000 & $0.000 \mathrm{E}+00$ & 0.0000 & $0.000 \mathrm{E}+00$ & 0.0000 & $0.000 \mathrm{E}+00$ & 0.0000 & $6.686 \mathrm{E}-01$ & 0.0213 \\
\hline-239 & $0.000 \mathrm{E}+00$ & 0.0000 & $0.000 \mathrm{E}+00$ & 0.0000 & $0.000 \mathrm{E}+00$ & 0.0000 & $0.000 \mathrm{E}+00$ & 0.0000 & $0.000 \mathrm{E}+00$ & 0.0000 & $0.000 E+00$ & 0.0000 & $9.991 \mathrm{E}-01$ & 0.0319 \\
\hline-240 & $0.000 \mathrm{E}+00$ & 0.0000 & $0.000 \mathrm{E}+00$ & 0.0000 & $0.000 \mathrm{E}+00$ & 0.0000 & $0.000 \mathrm{E}+00$ & 0.0000 & $0.000 \mathrm{E}+00$ & 0.0000 & $0.000 E+00$ & 0.0000 & $9.943 \mathrm{E}-01$ & 0.0317 \\
\hline-99 & $0.000 \mathrm{E}+00$ & 0.0000 & $0.000 \mathrm{E}+00$ & 0.0000 & $0.000 \mathrm{E}+00$ & 0.0000 & $0.000 \mathrm{E}+00$ & 0.0000 & $0.000 \mathrm{E}+00$ & 0.0000 & $0.000 \mathrm{E}+00$ & 0.0000 & $2.708 E-03$ & 0.0001 \\
\hline-228 & $0.000 \mathrm{E}+00$ & 0.0000 & $0.000 \mathrm{E}+00$ & 0.0000 & $0.000 \mathrm{E}+00$ & 0.0000 & $0.000 \mathrm{E}+00$ & 0.0000 & $0.000 \mathrm{E}+00$ & 0.0000 & $0.000 \mathrm{E}+00$ & 0.0000 & $7.380 \mathrm{E}-08$ & 0.0000 \\
\hline-230 & $0.000 \mathrm{E}+00$ & 0.0000 & $0.000 \mathrm{E}+00$ & 0.0000 & $0.000 \mathrm{E}+00$ & 0.0000 & $0.000 \mathrm{E}+00$ & 0.0000 & $0.000 \mathrm{E}+00$ & 0.0000 & $0.000 E+00$ & 0.0000 & $6.432 \mathrm{E}+00$ & 0.2051 \\
\hline 232 & $0.000 \mathrm{E}+00$ & 0.0000 & $0.000 \mathrm{E}+00$ & 0.0000 & $0.000 \mathrm{E}+00$ & 0.0000 & $0.000 \mathrm{E}+00$ & 0.0000 & $0.000 \mathrm{E}+00$ & 0.0000 & $0.000 \mathrm{E}+00$ & 0.0000 & $1.061 \mathrm{E}+01$ & 0.3383 \\
\hline 34 & $0.000 \mathrm{E}+00$ & 0.0000 & $0.000 \mathrm{E}+00$ & 0.0000 & $0.000 \mathrm{E}+00$ & 0.0000 & $0.000 \mathrm{E}+00$ & 0.0000 & $0.000 \mathrm{E}+00$ & 0.0000 & $0.000 \mathrm{E}+00$ & 0.0000 & $8.694 \mathrm{E}-01$ & 0.0277 \\
\hline 35 & $0.000 \mathrm{E}+00$ & 0.0000 & $0.000 \mathrm{E}+00$ & 0.0000 & $0.000 \mathrm{E}+00$ & 0.0000 & $0.000 \mathrm{E}+00$ & 0.0000 & $0.000 \mathrm{E}+00$ & 0.0000 & $0.000 \mathrm{E}+00$ & 0.0000 & $7.822 \mathrm{E}-01$ & 0.0249 \\
\hline 38 & $0.000 \mathrm{E}+00$ & 0.0000 & $0.000 \mathrm{E}+00$ & 0.0000 & $0.000 \mathrm{E}+00$ & 0.0000 & $0.000 \mathrm{E}+00$ & 0.0000 & $0.000 \mathrm{E}+00$ & 0.0000 & $0.000 \mathrm{E}+00$ & 0.0000 & $4.949 \mathrm{E}+00$ & 0.1578 \\
\hline & $0.000 \mathrm{E}+00$ & 0.0000 & $0.000 \mathrm{E}+00$ & 0.0000 & $0.000 \mathrm{E}+00$ & 0.0000 & $0.000 \mathrm{E}+00$ & 0.0000 & $0.000 \mathrm{E}+00$ & 0.0000 & $0.000 \mathrm{E}+00$ & 0.0000 & $3.136 \mathrm{E}+01$ & 1. \\
\hline
\end{tabular}

* Sum of all water independent and dependent pathways. 
RESRAD, Version 6.5

Mmary : RESRAD Parameters for U-Landfill Worker Forward Run

: C: \RESRAD FAMILY \RESRAD \USERFILES \QCJULY2011 \LANFFILLWORKER FORWARDRUN-70YRS.RAD

Total Dose Contributions TDOSE(i,p,t) for Individual Radionuclides (i) and Pathways (p) As mrem/yr and Fraction of Total Dose At $t=7.000 \mathrm{E}+01$ years

Water Independent Pathways (Inhalation excludes radon)

\begin{tabular}{|c|c|c|c|c|c|c|c|c|c|c|c|c|c|c|}
\hline \multirow[b]{2}{*}{ Nuclide } & \multicolumn{2}{|c|}{ Ground } & \multicolumn{2}{|c|}{ Inhalation } & \multicolumn{2}{|c|}{ Radon } & \multicolumn{2}{|c|}{ Plant } & \multicolumn{2}{|c|}{ Meat } & \multicolumn{2}{|c|}{ Milk } & \multicolumn{2}{|c|}{ Soil } \\
\hline & mrem/yr & fract. & mrem/yr & fract. & mrem/yr & fract. & mrem/yr & fract. & mrem/yr & fract. & mrem/yr & fract. & mrem/yr & fract. \\
\hline-241 & $1.970 \mathrm{E}-01$ & 0.0062 & $5.646 E-03$ & 0.0002 & $0.000 \mathrm{E}+00$ & 0.0000 & $0.000 \mathrm{E}+00$ & 0.0000 & $0.000 \mathrm{E}+00$ & 0.0000 & $0.000 \mathrm{E}+00$ & 0.0000 & $6.887 E-01$ & 0.0217 \\
\hline-137 & $1.973 \mathrm{E}+00$ & 0.0622 & $2.728 \mathrm{E}-07$ & 0.0000 & $0.000 \mathrm{E}+00$ & 0.0000 & $0.000 \mathrm{E}+00$ & 0.0000 & $0.000 \mathrm{E}+00$ & 0.0000 & $0.000 \mathrm{E}+00$ & 0.0000 & $5.324 \mathrm{E}-03$ & 0.0002 \\
\hline-237 & $9.208 E-01$ & 0.0290 & $5.119 \mathrm{E}-04$ & 0.0000 & $0.000 \mathrm{E}+00$ & 0.0000 & $0.000 \mathrm{E}+00$ & 0.0000 & $0.000 \mathrm{E}+00$ & 0.0000 & $0.000 \mathrm{E}+00$ & 0.0000 & $6.646 \mathrm{E}-02$ & 0.0021 \\
\hline-238 & $4.422 E-04$ & 0.0000 & $4.620 E-03$ & 0.0001 & $0.000 \mathrm{E}+00$ & 0.0000 & $0.000 \mathrm{E}+00$ & 0.0000 & $0.000 \mathrm{E}+00$ & 0.0000 & $0.000 \mathrm{E}+00$ & 0.0000 & $5.656 \mathrm{E}-01$ & 0.0178 \\
\hline-239 & $1.587 \mathrm{E}-03$ & 0.0001 & $8.103 E-03$ & 0.0003 & $0.000 \mathrm{E}+00$ & 0.0000 & $0.000 \mathrm{E}+00$ & 0.0000 & $0.000 \mathrm{E}+00$ & 0.0000 & $0.000 \mathrm{E}+00$ & 0.0000 & $9.884 \mathrm{E}-01$ & 0.0312 \\
\hline-240 & $6.828 \mathrm{E}-04$ & 0.0000 & $8.059 \mathrm{E}-03$ & 0.0003 & $0.000 \mathrm{E}+00$ & 0.0000 & $0.000 \mathrm{E}+00$ & 0.0000 & $0.000 \mathrm{E}+00$ & 0.0000 & $0.000 \mathrm{E}+00$ & 0.0000 & $9.830 \mathrm{E}-01$ & 0.0310 \\
\hline 99 & $4.513 E-04$ & 0.0000 & $6.036 E-07$ & 0.0000 & $0.000 \mathrm{E}+00$ & 0.0000 & $0.000 \mathrm{E}+00$ & 0.0000 & $0.000 \mathrm{E}+00$ & 0.0000 & $0.000 \mathrm{E}+00$ & 0.0000 & $1.740 \mathrm{E}-03$ & 0.0001 \\
\hline 228 & $5.209 \mathrm{E}-11$ & 0.0000 & $2.663 E-15$ & 0.0000 & $0.000 \mathrm{E}+00$ & 0.0000 & $0.000 \mathrm{E}+00$ & 0.0000 & $0.000 \mathrm{E}+00$ & 0.0000 & $0.000 \mathrm{E}+00$ & 0.0000 & $5.121 \mathrm{E}-13$ & 0.0000 \\
\hline 230 & $5.281 \mathrm{E}+00$ & 0.1666 & $1.889 \mathrm{E}-02$ & 0.0006 & $0.000 \mathrm{E}+00$ & 0.0000 & $0.000 \mathrm{E}+00$ & 0.0000 & $0.000 \mathrm{E}+00$ & 0.0000 & $0.000 \mathrm{E}+00$ & 0.0000 & $2.776 \mathrm{E}+00$ & 0.0876 \\
\hline-232 & $1.017 \mathrm{E}+01$ & 0.3206 & $1.276 \mathrm{E}-03$ & 0.0000 & $0.000 \mathrm{E}+00$ & 0.0000 & $0.000 \mathrm{E}+00$ & 0.0000 & $0.000 \mathrm{E}+00$ & 0.0000 & $0.000 \mathrm{E}+00$ & 0.0000 & $4.682 \mathrm{E}-01$ & 0.0148 \\
\hline 34 & $1.184 \mathrm{E}-02$ & 0.0004 & $2.806 E-03$ & 0.0001 & $0.000 \mathrm{E}+00$ & 0.0000 & $0.000 \mathrm{E}+00$ & 0.0000 & $0.000 \mathrm{E}+00$ & 0.0000 & $0.000 \mathrm{E}+00$ & 0.0000 & $8.529 \mathrm{E}-01$ & 0.0269 \\
\hline 35 & $7.451 \mathrm{E}-01$ & 0.0235 & $1.110 \mathrm{E}-04$ & 0.0000 & $0.000 \mathrm{E}+00$ & 0.0000 & $0.000 \mathrm{E}+00$ & 0.0000 & $0.000 \mathrm{E}+00$ & 0.0000 & $0.000 \mathrm{E}+00$ & 0.0000 & $3.489 \mathrm{E}-02$ & 0.0011 \\
\hline 38 & $4.084 \mathrm{E}+00$ & 0.1288 & $2.375 \mathrm{E}-03$ & 0.0001 & $0.000 \mathrm{E}+00$ & 0.0000 & $0.000 \mathrm{E}+00$ & 0.0000 & $0.000 \mathrm{E}+00$ & 0.0000 & $0.000 \mathrm{E}+00$ & 0.0000 & $8.404 \mathrm{E}-01$ & 0.0265 \\
\hline & 2 & 75 & $.240 E-02$ & 0.0017 & $0.000 \mathrm{E}+00$ & 0. & $0.000 \mathrm{E}+00$ & 000 & $E+00$ & 0 & +00 & 0 & +00 & 0 \\
\hline
\end{tabular}

Total Dose Contributions TDOSE(i,p,t) for Individual Radionuclides (i) and Pathways (p) As mrem/yr and Fraction of Total Dose At $t=7.000 \mathrm{E}+01$ years

Water Dependent Pathways

\begin{tabular}{|c|c|c|c|c|c|c|c|c|c|c|c|c|c|c|}
\hline \multirow{2}{*}{$\begin{array}{l}\text { Radio- } \\
\text { Nuclide }\end{array}$} & \multicolumn{2}{|c|}{ Water } & \multicolumn{2}{|c|}{ Fish } & \multicolumn{2}{|c|}{ Radon } & \multicolumn{2}{|c|}{ Plant } & \multicolumn{2}{|c|}{ Meat } & \multicolumn{2}{|c|}{ Milk } & \multicolumn{2}{|c|}{ All Pathways* } \\
\hline & mrem/yr & fract. & mrem/yr & fract. & mrem/yr & fract. & mrem/yr & fract. & mrem/yr & fract. & mrem/yr & fract. & mrem/yr & fract. \\
\hline 241 & $0.000 \mathrm{E}+00$ & 0.0000 & $0.000 \mathrm{E}+00$ & 0.0000 & $0.000 \mathrm{E}+00$ & 0.0000 & $0.000 \mathrm{E}+00$ & 0.0000 & $0.000 \mathrm{E}+00$ & 0.0000 & $0.000 \mathrm{E}+00$ & 0.0000 & $8.913 \mathrm{E}-01$ & 0.0281 \\
\hline-137 & $0.000 \mathrm{E}+00$ & 0.0000 & $0.000 \mathrm{E}+00$ & 0.0000 & $0.000 \mathrm{E}+00$ & 0.0000 & $0.000 \mathrm{E}+00$ & 0.0000 & $0.000 \mathrm{E}+00$ & 0.0000 & $0.000 \mathrm{E}+00$ & 0.0000 & $1.978 \mathrm{E}+00$ & 0.0624 \\
\hline-237 & $0.000 \mathrm{E}+00$ & 0.0000 & $0.000 \mathrm{E}+00$ & 0.0000 & $0.000 \mathrm{E}+00$ & 0.0000 & $0.000 \mathrm{E}+00$ & 0.0000 & $0.000 \mathrm{E}+00$ & 0.0000 & $0.000 \mathrm{E}+00$ & 0.0000 & $9.878 E-01$ & 0.0312 \\
\hline-238 & $0.000 \mathrm{E}+00$ & 0.0000 & $0.000 \mathrm{E}+00$ & 0.0000 & $0.000 \mathrm{E}+00$ & 0.0000 & $0.000 \mathrm{E}+00$ & 0.0000 & $0.000 \mathrm{E}+00$ & 0.0000 & $0.000 \mathrm{E}+00$ & 0.0000 & $5.707 \mathrm{E}-01$ & 0.0180 \\
\hline-239 & $0.000 \mathrm{E}+00$ & 0.0000 & $0.000 \mathrm{E}+00$ & 0.0000 & $0.000 \mathrm{E}+00$ & 0.0000 & $0.000 \mathrm{E}+00$ & 0.0000 & $0.000 \mathrm{E}+00$ & 0.0000 & $0.000 E+00$ & 0.0000 & $9.981 \mathrm{E}-01$ & 0.0315 \\
\hline-240 & $0.000 \mathrm{E}+00$ & 0.0000 & $0.000 \mathrm{E}+00$ & 0.0000 & $0.000 \mathrm{E}+00$ & 0.0000 & $0.000 \mathrm{E}+00$ & 0.0000 & $0.000 \mathrm{E}+00$ & 0.0000 & $0.000 E+00$ & 0.0000 & $9.918 \mathrm{E}-01$ & 0.0313 \\
\hline-99 & $0.000 \mathrm{E}+00$ & 0.0000 & $0.000 \mathrm{E}+00$ & 0.0000 & $0.000 \mathrm{E}+00$ & 0.0000 & $0.000 \mathrm{E}+00$ & 0.0000 & $0.000 \mathrm{E}+00$ & 0.0000 & $0.000 \mathrm{E}+00$ & 0.0000 & $2.192 \mathrm{E}-03$ & 0.0001 \\
\hline-228 & $0.000 \mathrm{E}+00$ & 0.0000 & $0.000 \mathrm{E}+00$ & 0.0000 & $0.000 \mathrm{E}+00$ & 0.0000 & $0.000 \mathrm{E}+00$ & 0.0000 & $0.000 \mathrm{E}+00$ & 0.0000 & $0.000 \mathrm{E}+00$ & 0.0000 & $5.260 \mathrm{E}-11$ & 0.0000 \\
\hline-230 & $0.000 \mathrm{E}+00$ & 0.0000 & $0.000 \mathrm{E}+00$ & 0.0000 & $0.000 \mathrm{E}+00$ & 0.0000 & $0.000 \mathrm{E}+00$ & 0.0000 & $0.000 \mathrm{E}+00$ & 0.0000 & $0.000 E+00$ & 0.0000 & $8.077 \mathrm{E}+00$ & 0.2547 \\
\hline 232 & $0.000 \mathrm{E}+00$ & 0.0000 & $0.000 \mathrm{E}+00$ & 0.0000 & $0.000 \mathrm{E}+00$ & 0.0000 & $0.000 \mathrm{E}+00$ & 0.0000 & $0.000 \mathrm{E}+00$ & 0.0000 & $0.000 \mathrm{E}+00$ & 0.0000 & $1.064 \mathrm{E}+01$ & 0.3355 \\
\hline 34 & $0.000 \mathrm{E}+00$ & 0.0000 & $0.000 \mathrm{E}+00$ & 0.0000 & $0.000 \mathrm{E}+00$ & 0.0000 & $0.000 \mathrm{E}+00$ & 0.0000 & $0.000 \mathrm{E}+00$ & 0.0000 & $0.000 \mathrm{E}+00$ & 0.0000 & $8.676 \mathrm{E}-01$ & 0.0274 \\
\hline 35 & $0.000 \mathrm{E}+00$ & 0.0000 & $0.000 \mathrm{E}+00$ & 0.0000 & $0.000 \mathrm{E}+00$ & 0.0000 & $0.000 \mathrm{E}+00$ & 0.0000 & $0.000 \mathrm{E}+00$ & 0.0000 & $0.000 \mathrm{E}+00$ & 0.0000 & $7.801 \mathrm{E}-01$ & 0.0246 \\
\hline 38 & $0.000 \mathrm{E}+00$ & 0.0000 & $0.000 \mathrm{E}+00$ & 0.0000 & $0.000 \mathrm{E}+00$ & 0.0000 & $0.000 \mathrm{E}+00$ & 0.0000 & $0.000 \mathrm{E}+00$ & 0.0000 & $0.000 \mathrm{E}+00$ & 0.0000 & $4.927 \mathrm{E}+00$ & 0.1554 \\
\hline & $0.000 \mathrm{E}+00$ & 0.0000 & $0.000 \mathrm{E}+00$ & 0.0000 & $0.000 \mathrm{E}+00$ & 0.0000 & $0.000 \mathrm{E}+00$ & 0.0000 & $0.000 \mathrm{E}+00$ & 0.0000 & $0.000 \mathrm{E}+00$ & 0.0000 & $3.171 \mathrm{E}+01$ & 1. \\
\hline
\end{tabular}

* Sum of all water independent and dependent pathways. 
RESRAD, Version $6.5 \quad \mathrm{~T}^{1 / 2}$ Limit $=180$ days

umary : RESRAD Parameters for U-Landfill Worker Forward Run

File : C: $\backslash$ RESRAD FAMILY \RESRAD \USERFILES \QCJULY2011 \LANFFILLWORKER FORWARDRUN-70YRS.RAD

Dose/Source Ratios Summed Over All Pathways

Parent and Progeny Principal Radionuclide Contributions Indicated

Parent Product Thread DSR $(j, t)$ At Time in Years (mrem/yr)/(pCi/g)

Fraction $0.000 \mathrm{E}+001.000 \mathrm{E}+00 \quad 2.500 \mathrm{E}+01 \quad 5.000 \mathrm{E}+01 \quad 7.000 \mathrm{E}+01$

\begin{tabular}{|c|c|c|c|c|c|c|}
\hline Am-241 & $1.000 \mathrm{E}+00$ & $2.850 \mathrm{E}-02$ & $2.845 \mathrm{E}-02$ & $2.738 \mathrm{E}-02$ & $2.630 \mathrm{E}-02$ & $2.546 \mathrm{E}-02$ \\
\hline $\mathrm{Np}-237+\mathrm{D}$ & $1.000 \mathrm{E}+00$ & $2.940 E-08$ & $8.812 \mathrm{E}-08$ & $1.467 \mathrm{E}-06$ & $2.842 \mathrm{E}-06$ & $3.898 \mathrm{E}-06$ \\
\hline $\mathrm{U}-233$ & $1.000 \mathrm{E}+00$ & $1.381 \mathrm{E}-15$ & $9.659 \mathrm{E}-15$ & $2.650 \mathrm{E}-12$ & $1.022 \mathrm{E}-11$ & 1. $966 \mathrm{E}-11$ \\
\hline$T h-229+D$ & $1.000 \mathrm{E}+00$ & $1.757 \mathrm{E}-18$ & $2.634 \mathrm{E}-17$ & $1.151 \mathrm{E}-13$ & $8.819 \mathrm{E}-13$ & $2.375 E-12$ \\
\hline$\sum \operatorname{DSR}(j)$ & & $2.850 \mathrm{E}-02$ & $2.845 \mathrm{E}-02$ & $2.738 \mathrm{E}-02$ & $2.630 \mathrm{E}-02$ & $2.547 \mathrm{E}-02$ \\
\hline
\end{tabular}

$\mathrm{Cs}-137+\mathrm{D} \quad 1.000 \mathrm{E}+00 \quad 5.262 \mathrm{E}-01 \quad 5.142 \mathrm{E}-01 \quad 2.950 \mathrm{E}-01 \quad 1.654 \mathrm{E}-01 \quad 1.041 \mathrm{E}-01$

$\mathrm{Np}-237+\mathrm{D} \quad 1.000 \mathrm{E}+00 \quad 1.816 \mathrm{E}-01 \quad 1.816 \mathrm{E}-01 \quad 1.809 \mathrm{E}-01 \quad 1.802 \mathrm{E}-01 \quad 1.796 \mathrm{E}-01$

$\begin{array}{llllllll}\mathrm{U}-233 & 1.000 \mathrm{E}+00 & 1.279 \mathrm{E}-08 & 3.837 \mathrm{E}-08 & 6.493 \mathrm{E}-07 & 1.280 \mathrm{E}-06 & 1.780 \mathrm{E}-06\end{array}$

$\begin{array}{llllllll}\mathrm{Th}-229+\mathrm{D} & 1.000 \mathrm{E}+00 & 2.170 \mathrm{E}-11 & 1.519 \mathrm{E}-10 & 4.217 \mathrm{E}-08 & 1.647 \mathrm{E}-07 & 3.200 \mathrm{E}-07\end{array}$

$\operatorname{\sum DSR}(j) \quad 1.816 \mathrm{E}-01 \quad 1.816 \mathrm{E}-011.809 \mathrm{E}-01 \quad 1.802 \mathrm{E}-011.796 \mathrm{E}-01$

Pu-238 1.840E-09 4.687E-11 4.650E-11 3.845E-11 3.154E-11 2.692E-11

$\begin{array}{lllllll}\mathrm{Pu}-238 & 1.000 \mathrm{E}+00 & 2.547 \mathrm{E}-02 & 2.527 \mathrm{E}-02 & 2.090 \mathrm{E}-02 & 1.714 \mathrm{E}-02 & 1.463 \mathrm{E}-02\end{array}$

$\begin{array}{lllllll}\mathrm{U}-234 & 1.000 \mathrm{E}+00 & 7.741 \mathrm{E}-09 & 2.314 \mathrm{E}-08 & 3.574 \mathrm{E}-07 & 6.422 \mathrm{E}-07 & 8.314 \mathrm{E}-07\end{array}$

$\begin{array}{llllllll}\mathrm{Th}-230 & 1.000 \mathrm{E}+00 & 9.980 \mathrm{E}-14 & 6.969 \mathrm{E}-13 & 1.822 \mathrm{E}-10 & 6.698 \mathrm{E}-10 & 1.241 \mathrm{E}-09\end{array}$

$\mathrm{Ra}-226+\mathrm{D} \quad 1.000 \mathrm{E}+00 \quad 8.233 \mathrm{E}-16 \quad 1.233 \mathrm{E}-14 \quad 5.179 \mathrm{E}-11 \quad 3.815 \mathrm{E}-10 \quad 9.962 \mathrm{E}-10$

$\mathrm{Pb}-210+\mathrm{D} \quad 1.000 \mathrm{E}+00 \quad 5.966 \mathrm{E}-19 \quad 1.837 \mathrm{E}-17 \quad 1.044 \mathrm{E}-12 \quad 1.342 \mathrm{E}-11 \quad 4.456 \mathrm{E}-11$

$\operatorname{EDSR}(j) \quad 2.547 \mathrm{E}-02 \quad 2.527 \mathrm{E}-02 \quad 2.090 \mathrm{E}-02 \quad 1.714 \mathrm{E}-02 \quad 1.463 \mathrm{E}-02$

$\begin{array}{lllllllll}\mathrm{Pu}-239 & 1.000 \mathrm{E}+00 & 2.782 \mathrm{E}-02 & 2.782 \mathrm{E}-02 & 2.779 \mathrm{E}-02 & 2.775 \mathrm{E}-02 & 2.772 \mathrm{E}-02\end{array}$

$\mathrm{U}-235+\mathrm{D} \quad 1.000 \mathrm{E}+00 \quad 5.975 \mathrm{E}-11 \quad 1.792 \mathrm{E}-10 \quad 3.037 \mathrm{E}-09 \quad 5.994 \mathrm{E}-09 \quad 8.345 \mathrm{E}-09$

$\begin{array}{lllllll}\mathrm{Pa}-231 & 1.000 \mathrm{E}+00 & 3.749 \mathrm{E}-16 & 2.624 \mathrm{E}-15 & 7.283 \mathrm{E}-13 & 2.844 \mathrm{E}-12 & 5.524 \mathrm{E}-12\end{array}$

$\mathrm{AC}-227+\mathrm{D} \quad 1.000 \mathrm{E}+00 \quad 1.227 \mathrm{E}-17 \quad 1.828 \mathrm{E}-16 \quad 6.725 \mathrm{E}-13 \quad 4.394 \mathrm{E}-12 \quad 1.055 \mathrm{E}-11$

$\operatorname{LDSR}(j) \quad 2.782 \mathrm{E}-02 \quad 2.782 \mathrm{E}-02 \quad 2.779 \mathrm{E}-02 \quad 2.775 \mathrm{E}-02 \quad 2.772 \mathrm{E}-02$

Pu-240 4.950E-08 1.376E-09 $1.376 \mathrm{E}-09 \quad 1.371 \mathrm{E}-09 \quad 1.367 \mathrm{E}-09 \quad 1.364 \mathrm{E}-09$

$\begin{array}{llllllll}\mathrm{Pu}-240 \quad 1.000 \mathrm{E}+00 & 2.779 \mathrm{E}-02 & 2.779 \mathrm{E}-02 & 2.771 \mathrm{E}-02 & 2.762 \mathrm{E}-02 & 2.755 \mathrm{E}-02\end{array}$

$\begin{array}{llllllll}\mathrm{U}-236 & 1.000 \mathrm{E}+00 & 7.734 \mathrm{E}-11 & 2.320 \mathrm{E}-10 & 3.927 \mathrm{E}-09 & 7.744 \mathrm{E}-09 & 1.077 \mathrm{E}-08\end{array}$

$\begin{array}{lllllll}\mathrm{Th}-232 & 1.000 \mathrm{E}+00 & 6.238 \mathrm{E}-21 & 4.366 \mathrm{E}-20 & 1.214 \mathrm{E}-17 & 4.745 \mathrm{E}-17 & 9.226 \mathrm{E}-17\end{array}$

$\mathrm{Ra}-228+\mathrm{D} \quad 1.000 \mathrm{E}+00 \quad 7.279 \mathrm{E}-21 \quad 1.065 \mathrm{E}-19 \quad 2.653 \mathrm{E}-16 \quad 1.365 \mathrm{E}-15 \quad 2.898 \mathrm{E}-15$

$\begin{array}{lllllll}\mathrm{Th}-228+\mathrm{D} & 1.000 \mathrm{E}+00 & 7.964 \mathrm{E}-22 & 2.280 \mathrm{E}-20 & 3.254 \mathrm{E}-16 & 1.921 \mathrm{E}-15 & 4.240 \mathrm{E}-15\end{array}$

$\operatorname{LDSR}(j) \quad 2.779 \mathrm{E}-02 \quad 2.779 \mathrm{E}-02 \quad 2.771 \mathrm{E}-02 \quad 2.762 \mathrm{E}-02 \quad 2.755 \mathrm{E}-02$

TC-99 1.000E+00 8.838E-05 8.745E-05 6.784E-05 5.208E-05 4.215E-05

Th-228+D 1.000E+00 1.360E+00 9.469E-01 $1.584 \mathrm{E}-04 \quad 1.845 \mathrm{E}-08 \quad 1.315 \mathrm{E}-11$

$\begin{array}{llllllll}\mathrm{Th}-230 & 1.000 \mathrm{E}+00 & 2.351 \mathrm{E}-02 & 2.351 \mathrm{E}-02 & 2.350 \mathrm{E}-02 & 2.350 \mathrm{E}-02 & 2.349 \mathrm{E}-02\end{array}$

$\mathrm{Ra}-226+\mathrm{D} \quad 1.000 \mathrm{E}+00 \quad 3.877 \mathrm{E}-04 \quad 1.163 \mathrm{E}-03 \quad 1.963 \mathrm{E}-02 \quad 3.858 \mathrm{E}-02 \quad 5.354 \mathrm{E}-02$

$\mathrm{Pb}-210+\mathrm{D} \quad 1.000 \mathrm{E}+00 \quad 4.669 \mathrm{E}-07 \quad 3.239 \mathrm{E}-06 \quad 7.124 \mathrm{E}-04 \quad 2.244 \mathrm{E}-03 \quad 3.740 \mathrm{E}-03$

$\operatorname{\sum DSR}(j) \quad 2.390 \mathrm{E}-02 \quad 2.468 \mathrm{E}-02 \quad 4.384 \mathrm{E}-02 \quad 6.432 \mathrm{E}-02 \quad 8.077 \mathrm{E}-02$ 
RESRAD, Version $6.5 \quad \mathrm{~T}^{1 / 2}$ Limit $=180$ days

07/20/2011 15:43 Page

Summary : RESRAD Parameters for U-Landfill Worker Forward Run

File : C: $\backslash$ RESRAD_FAMILY $\backslash$ RESRAD \USERFILES $\backslash Q C J U L Y 2011 \backslash$ LANFFILLWORKER_FORWARDRUN-70YRS.RAD

Dose/Source Ratios Summed Over All Pathways

Parent and Progeny Principal Radionuclide Contributions Indicated

\begin{tabular}{|c|c|c|c|c|c|c|c|}
\hline Parent & Product & Thread & $\operatorname{DSR}(j, t)$ & At Time ir & $n$ Years & (mrem/yr) / & $(\mathrm{pCi} / \mathrm{g})$ \\
\hline (i) & (j) & Fraction & $0.000 \mathrm{E}+00$ & $1.000 \mathrm{E}+00$ & $2.500 \mathrm{E}+01$ & $5.000 \mathrm{E}+01$ & $7.000 \mathrm{E}+01$ \\
\hline$h-232$ & Th-232 & $1.000 \mathrm{E}+00$ & $2.563 E-02$ & $2.563 \mathrm{E}-02$ & $2.563 E-02$ & $2.563 E-02$ & $2.562 \mathrm{E}-02$ \\
\hline$h-232$ & $\mathrm{Ra}-228+\mathrm{D}$ & $1.000 \mathrm{E}+00$ & $5.888 E-02$ & $1.676 \mathrm{E}-01$ & $9.683 E-01$ & $1.013 \mathrm{E}+00$ & $1.015 \mathrm{E}+00$ \\
\hline Th-232 & $\mathrm{Th}-228+\mathrm{D}$ & $1.000 \mathrm{E}+00$ & $1.048 \mathrm{E}-02$ & $6.433 E-02$ & $1.508 \mathrm{E}+00$ & $1.614 \mathrm{E}+00$ & $1.619 \mathrm{E}+00$ \\
\hline$h-232$ & $\sum \operatorname{DSR}(j)$ & & $9.499 \mathrm{E}-02$ & $2.576 \mathrm{E}-01$ & $2.502 \mathrm{E}+00$ & $2.652 \mathrm{E}+00$ & $2.659 \mathrm{E}+00$ \\
\hline-234 & $\mathrm{U}-234$ & $1.000 \mathrm{E}+00$ & $5.475 E-03$ & $5.474 \mathrm{E}-03$ & $5.444 \mathrm{E}-03$ & $5.414 \mathrm{E}-03$ & $5.390 \mathrm{E}-03$ \\
\hline-234 & $T h-230$ & $1.000 \mathrm{E}+00$ & $1.058 \mathrm{E}-07$ & $3.174 \mathrm{E}-07$ & $5.381 E-06$ & $1.062 \mathrm{E}-05$ & $1.480 \mathrm{E}-05$ \\
\hline-234 & $\mathrm{Ra}-226+\mathrm{D}$ & $1.000 \mathrm{E}+00$ & $1.163 \mathrm{E}-09$ & $8.142 \mathrm{E}-09$ & $2.255 \mathrm{E}-06$ & $8.781 \mathrm{E}-06$ & $1.702 \mathrm{E}-05$ \\
\hline-234 & $\mathrm{~Pb}-210+\mathrm{D}$ & $1.000 \mathrm{E}+00$ & $1.052 \mathrm{E}-12$ & $1.568 \mathrm{E}-11$ & $5.794 \mathrm{E}-08$ & $3.798 \mathrm{E}-07$ & $9.134 \mathrm{E}-07$ \\
\hline-234 & $\sum \operatorname{DSR}(j)$ & & $5.475 E-03$ & $5.474 \mathrm{E}-03$ & $5.452 E-03$ & $5.434 \mathrm{E}-03$ & $5.422 E-03$ \\
\hline$J-235+D$ & $\mathrm{U}-235+\mathrm{D}$ & $1.000 \mathrm{E}+00$ & $1.213 \mathrm{E}-01$ & $1.213 \mathrm{E}-01$ & $1.207 \mathrm{E}-01$ & $1.200 \mathrm{E}-01$ & $1.195 \mathrm{E}-01$ \\
\hline$J-235+D$ & $\mathrm{~Pa}-231$ & $1.000 \mathrm{E}+00$ & $1.142 \mathrm{E}-06$ & $3.425 \mathrm{E}-06$ & $5.790 \mathrm{E}-05$ & $1.140 \mathrm{E}-04$ & $1.584 \mathrm{E}-04$ \\
\hline$J-235+D$ & $A C-227+D$ & $1.000 \mathrm{E}+00$ & $4.975 \mathrm{E}-08$ & $3.450 \mathrm{E}-07$ & $7.536 \mathrm{E}-05$ & $2.362 \mathrm{E}-04$ & $3.925 \mathrm{E}-04$ \\
\hline$J-235+D$ & $\sum \operatorname{DSR}(j)$ & & $1.213 E-01$ & $1.213 \mathrm{E}-01$ & $1.208 \mathrm{E}-01$ & $1.203 \mathrm{E}-01$ & $1.200 \mathrm{E}-01$ \\
\hline $\mathrm{J}-238$ & $\mathrm{U}-238$ & $5.400 \mathrm{E}-05$ & $2.693 E-07$ & $2.692 \mathrm{E}-07$ & $2.678 \mathrm{E}-07$ & $2.663 \mathrm{E}-07$ & $2.652 \mathrm{E}-07$ \\
\hline$J-238+D$ & $\mathrm{U}-238+\mathrm{D}$ & $9.999 \mathrm{E}-01$ & $3.127 \mathrm{E}-02$ & $3.127 \mathrm{E}-02$ & $3.110 \mathrm{E}-02$ & $3.093 E-02$ & $3.079 E-02$ \\
\hline$J-238+D$ & $\mathrm{U}-234$ & $9.999 \mathrm{E}-01$ & $7.760 \mathrm{E}-09$ & $2.328 \mathrm{E}-08$ & $3.936 \mathrm{E}-07$ & $7.751 \mathrm{E}-07$ & $1.077 \mathrm{E}-06$ \\
\hline$J-238+D$ & $T h-230$ & $9.999 \mathrm{E}-01$ & $9.998 E-14$ & $6.998 E-13$ & $1.943 E-10$ & $7.592 \mathrm{E}-10$ & $1.475 \mathrm{E}-09$ \\
\hline$J-238+D$ & $\mathrm{Ra}-226+\mathrm{D}$ & $9.999 \mathrm{E}-01$ & $8.246 E-16$ & $1.237 \mathrm{E}-14$ & $5.436 \mathrm{E}-11$ & $4.193 \mathrm{E}-10$ & $1.135 \mathrm{E}-09$ \\
\hline$J-238+D$ & $\mathrm{~Pb}-210+\mathrm{D}$ & $9.999 \mathrm{E}-01$ & $5.974 \mathrm{E}-19$ & $1.842 \mathrm{E}-17$ & $1.086 \mathrm{E}-12$ & $1.453 \mathrm{E}-11$ & $4.979 \mathrm{E}-11$ \\
\hline$J-238+D$ & $\sum \operatorname{DSR}(j)$ & & $3.127 \mathrm{E}-02$ & $3.127 \mathrm{E}-02$ & $3.110 \mathrm{E}-02$ & $3.093 E-02$ & $3.079 E-02$ \\
\hline
\end{tabular}

The DSR includes contributions from associated (half-life $\leq 180$ days) daughters. 
RESRAD, Version $6.5 \quad \mathrm{~T}^{1 / 2}$ Limit $=180$ days

07/20/2011 15:43 Page

Summary : RESRAD Parameters for U-Landfill Worker Forward Run

File : C: \RESRAD_FAMILY \RESRAD \USERFILES $\backslash Q C J U L Y 2011 \backslash$ LANFFILLWORKER_FORWARDRUN-70YRS.RAD

Single Radionuclide Soil Guidelines $G(i, t)$ in $\mathrm{pCi} / \mathrm{g}$

Basic Radiation Dose Limit $=1.000 \mathrm{E}+02 \mathrm{mrem} / \mathrm{yr}$

Nuclide

\begin{tabular}{ccccccc} 
(i) & $\mathrm{t}=$ & $0.000 \mathrm{E}+00$ & $1.000 \mathrm{E}+00$ & $2.500 \mathrm{E}+01$ & $5.000 \mathrm{E}+01$ & $7.000 \mathrm{E}+01$ \\
\cline { 1 - 1 } $\mathrm{Am}-241$ & & $3.509 \mathrm{E}+03$ & $3.514 \mathrm{E}+03$ & $3.653 \mathrm{E}+03$ & $3.802 \mathrm{E}+03$ & $3.927 \mathrm{E}+03$ \\
$\mathrm{Cs}-137$ & & $1.900 \mathrm{E}+02$ & $1.945 \mathrm{E}+02$ & $3.389 \mathrm{E}+02$ & $6.045 \mathrm{E}+02$ & $9.603 \mathrm{E}+02$ \\
$\mathrm{~Np}-237$ & & $5.507 \mathrm{E}+02$ & $5.507 \mathrm{E}+02$ & $5.528 \mathrm{E}+02$ & $5.550 \mathrm{E}+02$ & $5.568 \mathrm{E}+02$ \\
$\mathrm{Pu}-238$ & & $3.926 \mathrm{E}+03$ & $3.957 \mathrm{E}+03$ & $4.785 \mathrm{E}+03$ & $5.833 \mathrm{E}+03$ & $6.834 \mathrm{E}+03$ \\
$\mathrm{Pu}-239$ & & $3.595 \mathrm{E}+03$ & $3.595 \mathrm{E}+03$ & $3.599 \mathrm{E}+03$ & $3.603 \mathrm{E}+03$ & $3.607 \mathrm{E}+03$ \\
$\mathrm{Pu}-240$ & & $3.598 \mathrm{E}+03$ & $3.598 \mathrm{E}+03$ & $3.609 \mathrm{E}+03$ & $3.621 \mathrm{E}+03$ & $3.630 \mathrm{E}+03$ \\
$\mathrm{TC}-99$ & & $1.131 \mathrm{E}+06$ & $1.143 \mathrm{E}+06$ & $1.474 \mathrm{E}+06$ & $1.920 \mathrm{E}+06$ & $2.373 \mathrm{E}+06$ \\
$\mathrm{Th}-228$ & $7.351 \mathrm{E}+01$ & $1.056 \mathrm{E}+02$ & $6.312 \mathrm{E}+05$ & $5.420 \mathrm{E}+09$ & $7.605 \mathrm{E}+12$ \\
$\mathrm{Th}-230$ & $4.184 \mathrm{E}+03$ & $4.052 \mathrm{E}+03$ & $2.281 \mathrm{E}+03$ & $1.555 \mathrm{E}+03$ & $1.238 \mathrm{E}+03$ \\
$\mathrm{Th}-232$ & $1.053 \mathrm{E}+03$ & $3.883 \mathrm{E}+02$ & $3.997 \mathrm{E}+01$ & $3.770 \mathrm{E}+01$ & $3.761 \mathrm{E}+01$ \\
$\mathrm{U}-234$ & $1.826 \mathrm{E}+04$ & $1.827 \mathrm{E}+04$ & $1.834 \mathrm{E}+04$ & $1.840 \mathrm{E}+04$ & $1.844 \mathrm{E}+04$ \\
$\mathrm{U}-235$ & $8.242 \mathrm{E}+02$ & $8.244 \mathrm{E}+02$ & $8.279 \mathrm{E}+02$ & $8.309 \mathrm{E}+02$ & $8.332 \mathrm{E}+02$ \\
$\mathrm{U}-238$ & $3.198 \mathrm{E}+03$ & $3.198 \mathrm{E}+03$ & $3.215 \mathrm{E}+03$ & $3.233 \mathrm{E}+03$ & $3.248 \mathrm{E}+03$ \\
\hline \hline
\end{tabular}

Summed Dose/Source Ratios DSR (i,t) in (mrem/yr)/(pCi/g) and Single Radionuclide Soil Guidelines G(i,t) in pCi/g at tmin = time of minimum single radionuclide soil guideline and at $\operatorname{tmax}=$ time of maximum total dose $=7.000 \mathrm{E}+01$ years

\begin{tabular}{|c|c|c|c|c|c|c|}
\hline $\begin{array}{l}\text { uclide } \\
\text { (i) }\end{array}$ & $\begin{array}{l}\text { Initial } \\
(\mathrm{pCi} / \mathrm{g})\end{array}$ & $\begin{array}{c}\text { tmin } \\
\text { (years) }\end{array}$ & $\operatorname{DSR}(i, \operatorname{tmin})$ & $\begin{array}{c}\mathrm{G}(\mathrm{i}, \mathrm{tmin}) \\
(\mathrm{pCi} / \mathrm{g})\end{array}$ & $\operatorname{DSR}(i, t \max )$ & $\begin{array}{c}G(i, t \max ) \\
(\mathrm{pCi} / \mathrm{g})\end{array}$ \\
\hline$m-241$ & $3.500 \mathrm{E}+01$ & $0.000 \mathrm{E}+00$ & $2.850 \mathrm{E}-02$ & $3.509 \mathrm{E}+03$ & $2.547 \mathrm{E}-02$ & $3.927 \mathrm{E}+03$ \\
\hline-137 & $1.900 \mathrm{E}+01$ & $0.000 \mathrm{E}+00$ & $5.262 \mathrm{E}-01$ & $1.900 \mathrm{E}+02$ & $1.041 \mathrm{E}-01$ & $9.603 E+02$ \\
\hline-237 & $5.500 \mathrm{E}+00$ & $0.000 \mathrm{E}+00$ & $1.816 \mathrm{E}-01$ & $5.507 \mathrm{E}+02$ & $1.796 E-01$ & $5.568 \mathrm{E}+02$ \\
\hline$u-238$ & $3.900 E+01$ & $0.000 \mathrm{E}+00$ & $2.547 E-02$ & $3.926 \mathrm{E}+03$ & $1.463 E-02$ & $6.834 \mathrm{E}+03$ \\
\hline-239 & $3.600 \mathrm{E}+01$ & $0.000 \mathrm{E}+00$ & $2.782 \mathrm{E}-02$ & $3.595 \mathrm{E}+03$ & $2.772 \mathrm{E}-02$ & $3.607 \mathrm{E}+03$ \\
\hline$x-240$ & $3.600 \mathrm{E}+01$ & $0.000 \mathrm{E}+00$ & $2.779 E-02$ & $3.598 E+03$ & $2.755 E-02$ & $3.630 \mathrm{E}+03$ \\
\hline-99 & $5.200 \mathrm{E}+01$ & $0.000 \mathrm{E}+00$ & $8.838 \mathrm{E}-05$ & $1.131 \mathrm{E}+06$ & $4.215 E-05$ & $2.373 E+06$ \\
\hline-228 & $4.000 \mathrm{E}+00$ & $0.000 \mathrm{E}+00$ & $1.360 \mathrm{E}+00$ & 7. $351 \mathrm{E}+01$ & 1. $315 E-11$ & 7. $605 \mathrm{E}+12$ \\
\hline-230 & $1.000 \mathrm{E}+02$ & $7.000 \mathrm{E}+01$ & $8.077 \mathrm{E}-02$ & $1.238 \mathrm{E}+03$ & $8.077 E-02$ & $1.238 \mathrm{E}+03$ \\
\hline$h-232$ & $4.000 E+00$ & $7.000 \mathrm{E}+01$ & $2.659 \mathrm{E}+00$ & $3.761 E+01$ & $2.659 \mathrm{E}+00$ & $3.761 E+01$ \\
\hline-234 & $1.600 \mathrm{E}+02$ & $0.000 \mathrm{E}+00$ & $5.475 E-03$ & $1.826 \mathrm{E}+04$ & $5.422 E-03$ & $1.844 \mathrm{E}+04$ \\
\hline 235 & $6.500 \mathrm{E}+00$ & $0.000 \mathrm{E}+00$ & $1.213 \mathrm{E}-01$ & $8.242 \mathrm{E}+02$ & $1.200 E-01$ & $8.332 E+02$ \\
\hline 238 & $1.600 \mathrm{E}+02$ & $0.000 \mathrm{E}+00$ & $3.127 \mathrm{E}-02$ & $3.198 \mathrm{E}+03$ & $3.079 \mathrm{E}-02$ & $3.248 E+03$ \\
\hline
\end{tabular}


RESRAD, Version 6.5

Summary : RESRAD Parameters for U-Landfill Worker Forward Run

File : C: \RESRAD FAMILY \RESRAD \USERFILES \QCJULY2011 \LANFFILLWORKER FORWARDRUN-70YRS.RAD

Individual Nuclide Dose Summed Over All Pathways

Parent Nuclide and Branch Fraction Indicated

Nuclide Parent THF(i) DOSE $(j, t), \operatorname{mrem} / \mathrm{yr}$

(j) (i)

Am-241 Am-241 1.000E+00

$\mathrm{Np}-237 \quad \mathrm{Am}-241 \quad 1.000 \mathrm{E}+00$

$\mathrm{Np}-237 \quad \mathrm{~Np}-237 \quad 1.000 \mathrm{E}+00$

Np-237 $\sum$ DOSE $(j)$

U-233 Am-241 1.000E+00

$\mathrm{U}-233 \mathrm{~Np}-237 \quad 1.000 \mathrm{E}+00$

U-233 $\quad$ DDOSE $(j)$

Th-229

$\mathrm{Th}-229$

$\mathrm{Th}-229$

$\mathrm{Cs}-137$

$\mathrm{Pu}-238$

$\mathrm{Pu}-238$

$\mathrm{Pu}-238$

$\mathrm{U}-234$

$\mathrm{U}-234$

$\mathrm{U}-234$

$\mathrm{U}-234$

Th -230

$\mathrm{Th}-230$

$\mathrm{Th}-230$

$\mathrm{Th}-230$

Th-230

$\mathrm{Ra}-226$

$\mathrm{Ra}-226$

$\mathrm{Ra}-226$

$\mathrm{Ra}-226$

$\mathrm{Ra}-226$

$\mathrm{Pb}-210$

$\mathrm{Pb}-210$

$\mathrm{Pb}-210$

$\mathrm{Pb}-210$

$\mathrm{Pb}-210$

$\mathrm{Pu}-239$

$\mathrm{U}-235$

$\mathrm{U}-235$

$\mathrm{U}-235$
Am-241 1.000E+00

$\mathrm{Np}-237 \quad 1.000 \mathrm{E}+00$

$\sum \operatorname{DOSE}(j)$

$\mathrm{Pu}-238$ 1.840E-09

$\sum \operatorname{DOSE}(j)$

$\mathrm{Pu}-238 \quad 1.000 \mathrm{E}+00$

$\mathrm{U}-234 \quad 1.000 \mathrm{E}+00$

U-238 9.999E-01

$\mathrm{Pu}-238 \quad 1.000 \mathrm{E}+00$

Th-230 1.000E+00

U-234 $1.000 \mathrm{E}+00$

$\sum \operatorname{DOSE}(j)$

$\mathrm{Pu}-238 \quad 1.000 \mathrm{E}+00$

Th-230 1.000E+00

$\mathrm{U}-2341.000 \mathrm{E}+00$

U-238 9.999E-01

$\sum \operatorname{DOSE}(j)$

$\mathrm{Pu}-238 \quad 1.000 \mathrm{E}+00$

Th-230 1.000E+00

$\mathrm{U}-234 \quad 1.000 \mathrm{E}+00$

$\sum \operatorname{DOSE}(j)$

$\mathrm{Pu}-239 \quad 1.000 \mathrm{E}+00$

$\mathrm{Pu}-239 \quad 1.000 \mathrm{E}+00$

$\mathrm{U}-2351.000 \mathrm{E}+00$

$\sum \operatorname{DOSE}(j)$
$\mathrm{Cs}-137 \quad 1.000 \mathrm{E}+00$

$\mathrm{Pu}-238 \quad 1.000 \mathrm{E}+00$

$\sum \operatorname{DOSE}(j)$

$\mathrm{U}-238 \quad 9.999 \mathrm{E}-01$

$\mathrm{U}-2389.999 \mathrm{E}-01$
$=0.000 \mathrm{E}+00 \quad 1.000 \mathrm{E}+00 \quad 2.500 \mathrm{E}+01 \quad 5.000 \mathrm{E}+01 \quad 7.000 \mathrm{E}+01$

$\begin{array}{llllll}9.975 \mathrm{E}-01 & 9.959 \mathrm{E}-01 & 9.581 \mathrm{E}-01 & 9.204 \mathrm{E}-01 & 8.912 \mathrm{E}-01\end{array}$

1.029E-06 3.084E-06 5.133E-05 9.946E-05 1.364E-04

9.988E-01 9.986E-01 9.949E-01 9.909E-01 9.878E-01

9.988E-01 9.987E-01 9.949E-01 9.910E-01 9.879E-01

$\begin{array}{llllll}4.832 E-14 & 3.380 E-13 & 9.274 E-11 & 3.577 E-10 & 6.881 E-10\end{array}$

$7.035 \mathrm{E}-08 \quad 2.110 \mathrm{E}-07 \quad 3.571 \mathrm{E}-06 \quad 7.038 \mathrm{E}-06 \quad 9.788 \mathrm{E}-06$

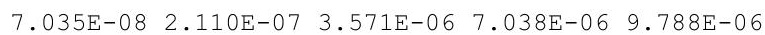

6.148E-17 9.218E-16 4.027E-12 3.087E-11 8.311E-11

$\begin{array}{llllll}1.193 \mathrm{E}-10 & 8.353 \mathrm{E}-10 & 2.319 \mathrm{E}-07 & 9.059 \mathrm{E}-07 & 1.760 \mathrm{E}-06\end{array}$

$\begin{array}{lllll}1.193 \mathrm{E}-10 & 8.353 \mathrm{E}-10 & 2.319 \mathrm{E}-07 & 9.059 \mathrm{E}-07 & 1.760 \mathrm{E}-06\end{array}$

$9.998 \mathrm{E}+00 \quad 9.770 \mathrm{E}+00 \quad 5.606 \mathrm{E}+00 \quad 3.143 \mathrm{E}+00 \quad 1.978 \mathrm{E}+00$

1.828E-09 1.813E-09 1.500E-09 1.230E-09 1.050E-09

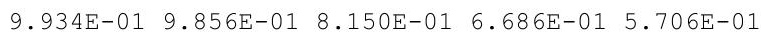

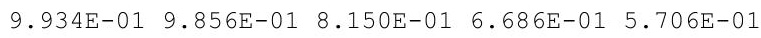

3.019E-07 9.024E-07 1.394E-05 2.505E-05 3.242E-05

8.760E-01 8.758E-01 8.711E-01 8.662E-01 8.624E-01

$\begin{array}{llllll}1.242 \mathrm{E}-06 & 3.724 \mathrm{E}-06 & 6.297 \mathrm{E}-05 & 1.240 \mathrm{E}-04 & 1.724 \mathrm{E}-04\end{array}$

$8.760 \mathrm{E}-01 \quad 8.758 \mathrm{E}-01 \quad 8.712 \mathrm{E}-01 \quad 8.664 \mathrm{E}-01 \quad 8.626 \mathrm{E}-01$

$\begin{array}{lllll}3.892 \mathrm{E}-12 & 2.718 \mathrm{E}-11 & 7.107 \mathrm{E}-09 & 2.612 \mathrm{E}-08 & 4.840 \mathrm{E}-08\end{array}$

$\begin{array}{llllll}2.351 \mathrm{E}+00 & 2.351 \mathrm{E}+00 & 2.350 \mathrm{E}+00 & 2.350 \mathrm{E}+00 & 2.349 \mathrm{E}+00\end{array}$

$\begin{array}{lllll}1.693 \mathrm{E}-05 & 5.078 \mathrm{E}-05 & 8.609 \mathrm{E}-04 & 1.700 \mathrm{E}-03 & 2.368 \mathrm{E}-03\end{array}$

$\begin{array}{llllll}1.600 \mathrm{E}-11 & 1.120 \mathrm{E}-10 & 3.109 \mathrm{E}-08 & 1.215 \mathrm{E}-07 & 2.360 \mathrm{E}-07\end{array}$

$\begin{array}{llllll}2.351 E+00 & 2.351 E+00 & 2.351 E+00 & 2.351 E+00 & 2.351 E+00\end{array}$

$\begin{array}{llllll}3.211 E-14 & 4.808 E-13 & 2.020 E-09 & 1.488 E-08 & 3.885 E-08\end{array}$

$3.877 \mathrm{E}-02 \quad 1.163 \mathrm{E}-01 \quad 1.963 \mathrm{E}+00 \quad 3.858 \mathrm{E}+00 \quad 5.354 \mathrm{E}+00$

$\begin{array}{llllll}1.862 \mathrm{E}-07 & 1.303 \mathrm{E}-06 & 3.607 \mathrm{E}-04 & 1.405 \mathrm{E}-03 & 2.723 \mathrm{E}-03\end{array}$

$\begin{array}{lllll}1.319 \mathrm{E}-13 & 1.979 \mathrm{E}-12 & 8.697 \mathrm{E}-09 & 6.709 \mathrm{E}-08 & 1.816 \mathrm{E}-07\end{array}$

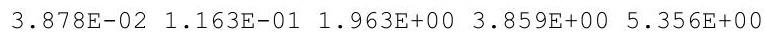

$2.327 \mathrm{E}-17 \quad 7.164 \mathrm{E}-16 \quad 4.072 \mathrm{E}-11 \quad 5.235 \mathrm{E}-10 \quad 1.738 \mathrm{E}-09$ $\begin{array}{lllll}4.669 \mathrm{E}-05 & 3.239 \mathrm{E}-04 & 7.124 \mathrm{E}-02 & 2.244 \mathrm{E}-01 & 3.740 \mathrm{E}-01\end{array}$ $\begin{array}{lllll}1.684 \mathrm{E}-10 & 2.509 \mathrm{E}-09 & 9.270 \mathrm{E}-06 & 6.076 \mathrm{E}-05 & 1.461 \mathrm{E}-04\end{array}$ $\begin{array}{llllll}9.558 \mathrm{E}-17 & 2.946 \mathrm{E}-15 & 1.738 \mathrm{E}-10 & 2.324 \mathrm{E}-09 & 7.967 \mathrm{E}-09\end{array}$ $\begin{array}{lllll}4.669 \mathrm{E}-05 & 3.239 \mathrm{E}-04 & 7.125 \mathrm{E}-02 & 2.245 \mathrm{E}-01 & 3.742 \mathrm{E}-01\end{array}$

$1.002 \mathrm{E}+00 \quad 1.001 \mathrm{E}+00 \quad 1.000 \mathrm{E}+00 \quad 9.991 \mathrm{E}-01 \quad 9.981 \mathrm{E}-01$

$2.151 E-09 \quad 6.452 E-09 \quad 1.093 E-07 \quad 2.158 E-07 \quad 3.004 E-07$

$\begin{array}{lllllll}7.886 \mathrm{E}-01 & 7.885 \mathrm{E}-01 & 7.843 \mathrm{E}-01 & 7.800 \mathrm{E}-01 & 7.765 \mathrm{E}-01\end{array}$

$7.886 \mathrm{E}-01 \quad 7.885 \mathrm{E}-01 \quad 7.843 \mathrm{E}-01 \quad 7.800 \mathrm{E}-01 \quad 7.765 \mathrm{E}-01$ 
RESRAD, Version $6.5 \quad \mathrm{~T}^{1 / 2}$ Limit $=180$ days

07/20/2011 15:43 Page

Summary : RESRAD Parameters for U-Landfill Worker Forward Run

File : C: \RESRAD_FAMILY \RESRAD \USERFILES $\backslash Q C J U L Y 2011 \backslash$ LANFFILLWORKER_FORWARDRUN-70YRS.RAD

Individual Nuclide Dose Summed Over All Pathways

Parent Nuclide and Branch Fraction Indicated

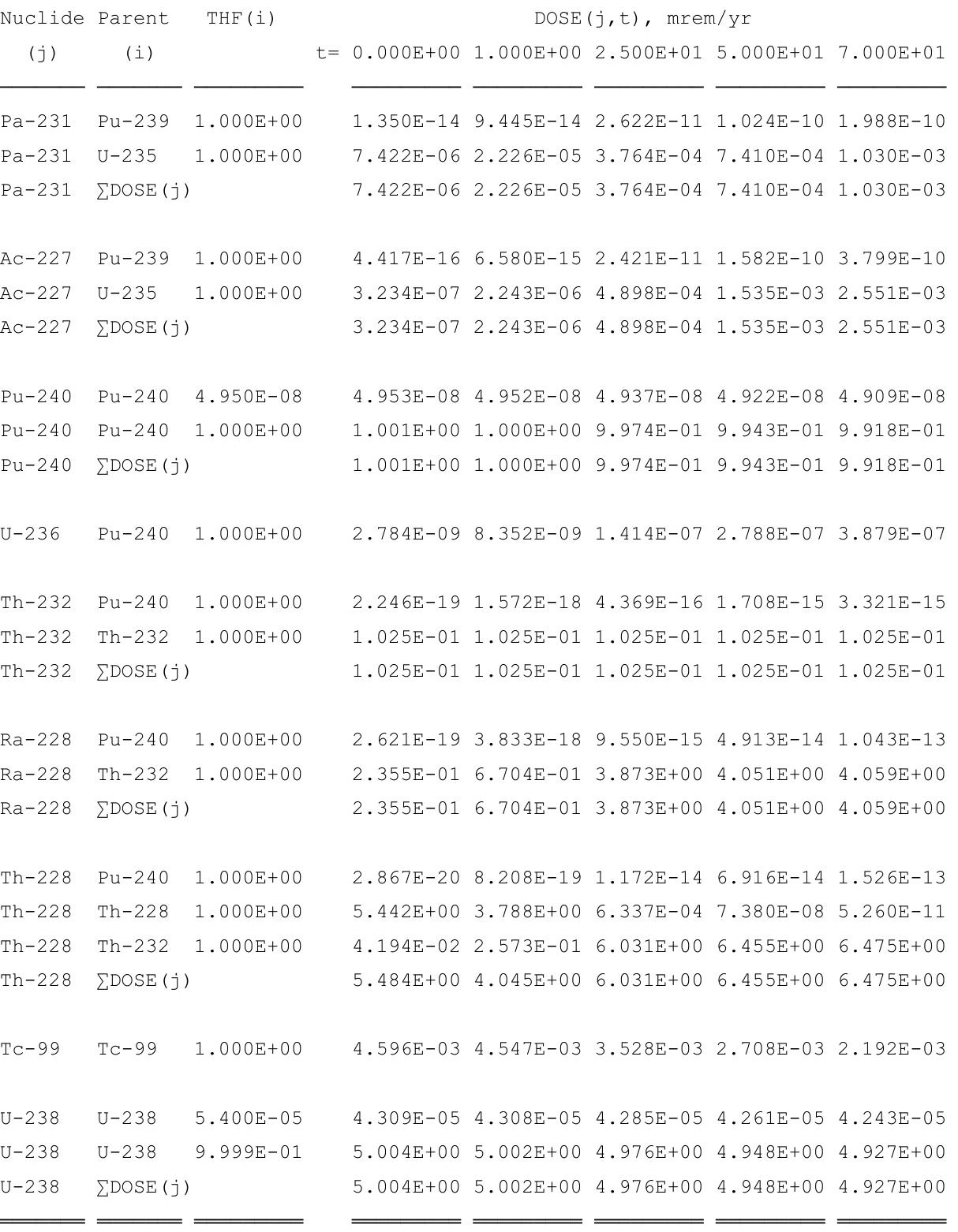

THF (i) is the thread fraction of the parent nuclide. 
RESRAD, Version 6.5

Summary : RESRAD Parameters for U-Landfill Worker Forward Run

File : C: \RESRAD_FAMILY \RESRAD \USERFILES $\backslash Q C J U L Y 2011 \backslash$ LANFFILLWORKER_FORWARDRUN-70YRS.RAD

Individual Nuclide Soil Concentration

Parent Nuclide and Branch Fraction Indicated

Nuclide Parent THF(i) $\quad S(j, t), \mathrm{pCi} / \mathrm{g}$

\begin{tabular}{|c|c|c|c|c|c|c|c|c|}
\hline$(j)$ & (i) & & $t=$ & $0.000 \mathrm{E}+00$ & $1.000 \mathrm{E}+00$ & $2.500 E+01$ & $5.000 \mathrm{E}+01$ & $7.000 \mathrm{E}+01$ \\
\hline$n-241$ & Am-241 & $1.000 \mathrm{E}+00$ & & $3.500 \mathrm{E}+01$ & $3.494 \mathrm{E}+01$ & $3.362 E+01$ & $3.229 E+01$ & $3.127 \mathrm{E}+01$ \\
\hline$p-237$ & Am-241 & $1.000 \mathrm{E}+00$ & & $0.000 \mathrm{E}+00$ & $1.133 \mathrm{E}-05$ & $2.772 \mathrm{E}-04$ & $5.424 \mathrm{E}-04$ & 7. $463 E-04$ \\
\hline-237 & $\mathrm{~Np}-237$ & $1.000 \mathrm{E}+00$ & & $5.500 \mathrm{E}+00$ & $5.499 \mathrm{E}+00$ & $5.478 \mathrm{E}+00$ & $5.457 \mathrm{E}+00$ & $5.439 \mathrm{E}+00$ \\
\hline$p-237$ & $\sum S(j):$ & & & $5.500 \mathrm{E}+00$ & $5.499 \mathrm{E}+00$ & $5.479 \mathrm{E}+00$ & $5.457 \mathrm{E}+00$ & $5.440 \mathrm{E}+00$ \\
\hline-233 & $A m-241$ & $1.000 \mathrm{E}+00$ & & $0.000 \mathrm{E}+00$ & $2.477 \mathrm{E}-11$ & $1.524 \mathrm{E}-08$ & $5.995 \mathrm{E}-08$ & $1.160 \mathrm{E}-07$ \\
\hline-233 & $N p-237$ & $1.000 \mathrm{E}+00$ & & $0.000 \mathrm{E}+00$ & $2.405 \mathrm{E}-05$ & $5.984 \mathrm{E}-04$ & $1.191 \mathrm{E}-03$ & $1.661 \mathrm{E}-03$ \\
\hline-233 & $\sum S(j):$ & & & $0.000 \mathrm{E}+00$ & $2.405 E-05$ & $5.984 E-04$ & $1.191 E-03$ & $1.661 \mathrm{E}-03$ \\
\hline$h-229$ & $A m-241$ & $1.000 \mathrm{E}+00$ & & $0.000 \mathrm{E}+00$ & $7.799 \mathrm{E}-16$ & $1.203 E-11$ & $9.503 E-11$ & $2.581 \mathrm{E}-10$ \\
\hline$h-229$ & $\mathrm{~Np}-237$ & $1.000 \mathrm{E}+00$ & & $0.000 \mathrm{E}+00$ & $1.136 \mathrm{E}-09$ & $7.070 \mathrm{E}-07$ & $2.817 E-06$ & $5.503 E-06$ \\
\hline Ch-229 & $\sum S(j):$ & & & $0.000 \mathrm{E}+00$ & $1.136 E-09$ & $7.070 E-07$ & $2.817 E-06$ & $5.503 E-06$ \\
\hline $\mathrm{Cs}-137$ & $\mathrm{Cs}-137$ & $1.000 \mathrm{E}+00$ & & $1.900 \mathrm{E}+01$ & $1.857 \mathrm{E}+01$ & $1.065 E+01$ & $5.973 E+00$ & $3.760 \mathrm{E}+00$ \\
\hline$u-238$ & $\mathrm{Pu}-238$ & $1.840 \mathrm{E}-09$ & & $7.176 \mathrm{E}-08$ & $7.119 \mathrm{E}-08$ & $5.887 E-08$ & $4.829 E-08$ & $4.122 E-08$ \\
\hline$u-238$ & $\mathrm{Pu}-238$ & $1.000 \mathrm{E}+00$ & & $3.900 \mathrm{E}+01$ & $3.869 \mathrm{E}+01$ & $3.199 \mathrm{E}+01$ & $2.625 E+01$ & $2.240 \mathrm{E}+01$ \\
\hline$u-238$ & $\sum S(j):$ & & & $3.900 \mathrm{E}+01$ & $3.869 \mathrm{E}+01$ & $3.199 \mathrm{E}+01$ & $2.625 E+01$ & $2.240 \mathrm{E}+01$ \\
\hline-234 & $\mathrm{Pu}-238$ & $1.000 \mathrm{E}+00$ & & $0.000 \mathrm{E}+00$ & $1.101 \mathrm{E}-04$ & $2.500 \mathrm{E}-03$ & $4.538 E-03$ & $5.890 \mathrm{E}-03$ \\
\hline-234 & $\mathrm{U}-234$ & $1.000 \mathrm{E}+00$ & & $1.600 \mathrm{E}+02$ & $1.600 \mathrm{E}+02$ & $1.591 \mathrm{E}+02$ & $1.582 \mathrm{E}+02$ & $1.575 \mathrm{E}+02$ \\
\hline 234 & $\mathrm{U}-238$ & $9.999 \mathrm{E}-01$ & & $0.000 \mathrm{E}+00$ & $4.535 E-04$ & $1.128 \mathrm{E}-02$ & $2.243 E-02$ & $3.126 \mathrm{E}-02$ \\
\hline-234 & $\sum S(j):$ & & & $1.600 \mathrm{E}+02$ & $1.600 \mathrm{E}+02$ & $1.591 \mathrm{E}+02$ & $1.582 \mathrm{E}+02$ & $1.575 \mathrm{E}+02$ \\
\hline
\end{tabular}

$\mathrm{Th}-230 \mathrm{Pu}-238 \quad 1.000 \mathrm{E}+00$

Th-230 Th-230 1.000E+00

$\mathrm{Th}-230 \mathrm{U}-234 \quad 1.000 \mathrm{E}+00$

$\mathrm{Th}-230 \quad \mathrm{U}-238 \quad 9.999 \mathrm{E}-01$

Th-230 $\sum S(j):$

$\mathrm{Ra}-226 \mathrm{Pu}-238 \quad 1.000 \mathrm{E}+00$

$0.000 \mathrm{E}+00 \quad 4.963 \mathrm{E}-10 \quad 2.909 \mathrm{E}-07 \quad 1.090 \mathrm{E}-06 \quad 2.032 \mathrm{E}-06$ $\begin{array}{llllll}1.000 \mathrm{E}+02 & 1.000 \mathrm{E}+02 & 9.997 \mathrm{E}+01 & 9.994 \mathrm{E}+01 & 9.991 \mathrm{E}+01\end{array}$ $0.000 \mathrm{E}+00 \quad 1.440 \mathrm{E}-03 \quad 3.590 \mathrm{E}-02 \quad 7.159 \mathrm{E}-02 \quad 9.999 \mathrm{E}-02$ $0.000 \mathrm{E}+00 \quad 2.041 \mathrm{E}-09 \quad 1.271 \mathrm{E}-06 \quad 5.065 \mathrm{E}-06 \quad 9.897 \mathrm{E}-06$ $1.000 \mathrm{E}+02 \quad 1.000 \mathrm{E}+02 \quad 1.000 \mathrm{E}+02 \quad 1.000 \mathrm{E}+02 \quad 1.000 \mathrm{E}+02$

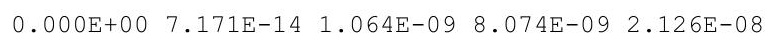
$\begin{array}{lllll}0.000 \mathrm{E}+00 & 4.331 \mathrm{E}-02 & 1.075 \mathrm{E}+00 & 2.134 \mathrm{E}+00 & 2.969 \mathrm{E}+00\end{array}$ $0.000 \mathrm{E}+00 \quad 3.119 \mathrm{E}-07 \quad 1.936 \mathrm{E}-04 \quad 7.693 \mathrm{E}-04 \quad 1.500 \mathrm{E}-03$ $\begin{array}{lllll}0.000 E+00 & 2.947 E-13 & 4.576 E-09 & 3.637 E-08 & 9.928 E-08\end{array}$ $0.000 \mathrm{E}+00 \quad 4.331 \mathrm{E}-02 \quad 1.075 \mathrm{E}+00 \quad 2.134 \mathrm{E}+00 \quad 2.971 \mathrm{E}+00$

$0.000 \mathrm{E}+00 \quad 5.540 \mathrm{E}-16 \quad 1.799 \mathrm{E}-10 \quad 2.407 \mathrm{E}-09 \quad 8.081 \mathrm{E}-09$ $\begin{array}{llllll}0.000 \mathrm{E}+00 & 6.662 \mathrm{E}-04 & 3.280 \mathrm{E}-01 & 1.054 \mathrm{E}+00 & 1.765 \mathrm{E}+00\end{array}$ $0.000 \mathrm{E}+00 \quad 3.207 \mathrm{E}-09 \quad 4.179 \mathrm{E}-05 \quad 2.821 \mathrm{E}-04 \quad 6.842 \mathrm{E}-04$ $0.000 \mathrm{E}+00 \quad 2.276 \mathrm{E}-15 \quad 7.675 \mathrm{E}-10 \quad 1.068 \mathrm{E}-08 \quad 3.701 \mathrm{E}-08$ $0.000 \mathrm{E}+00 \quad 6.662 \mathrm{E}-04 \quad 3.281 \mathrm{E}-01 \quad 1.054 \mathrm{E}+00 \quad 1.766 \mathrm{E}+00$ $\begin{array}{lllll}3.600 E+01 & 3.600 E+01 & 3.596 E+01 & 3.591 E+01 & 3.588 E+01\end{array}$ $0.000 \mathrm{E}+00 \quad 3.545 \mathrm{E}-08 \quad 8.834 \mathrm{E}-07 \quad 1.761 \mathrm{E}-06 \quad 2.458 \mathrm{E}-06$ $\begin{array}{llll}6.500 \mathrm{E}+00 & 6.499 \mathrm{E}+00 \quad 6.464 \mathrm{E}+00 \quad 6.428 \mathrm{E}+00 \quad 6.400 \mathrm{E}+00\end{array}$

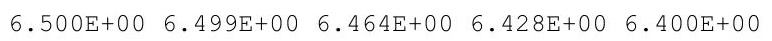


RESRAD, Version $6.5 \quad T^{1 / 2}$ Limit $=180$ days

07/20/2011 15:43 Page

Summary : RESRAD Parameters for U-Landfill Worker Forward Run

File : C: \RESRAD_FAMILY \RESRAD \USERFILES $\backslash Q C J U L Y 2011 \backslash$ LANFFILLWORKER_FORWARDRUN-70YRS.RAD

Individual Nuclide Soil Concentration

Parent Nuclide and Branch Fraction Indicated

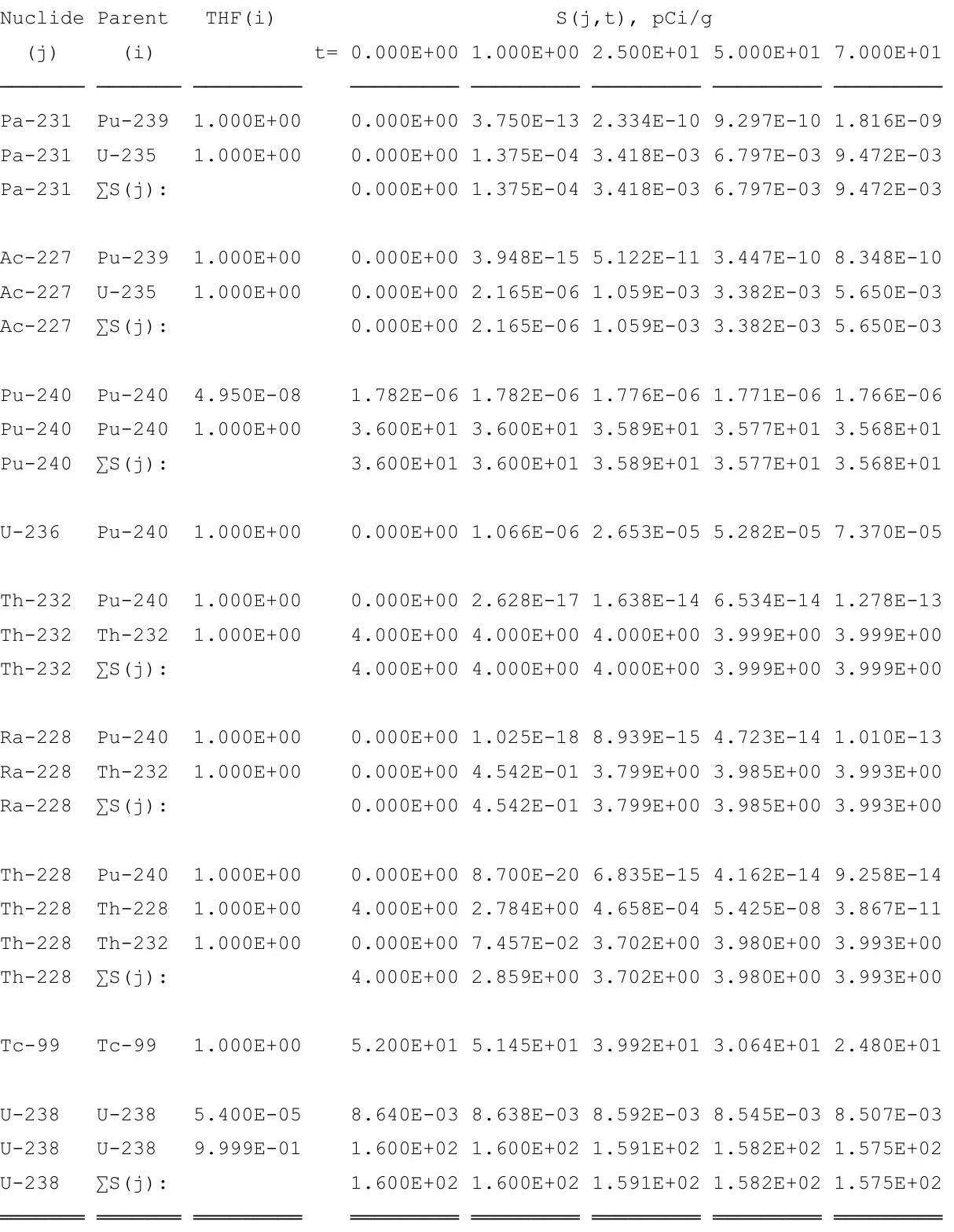

THF (i) is the thread fraction of the parent nuclide.

RESCALC.EXE execution time $=2.87$ seconds 
Summary : RESRAD Parameters for U-Landfill Worker Forward Run Proposed AIs

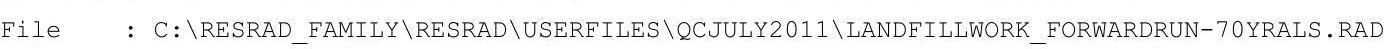

Dose Conversion Factor (and Related) Parameter Summary

Dose Library: ICRP 60 \& ICRP 72 (Adult)

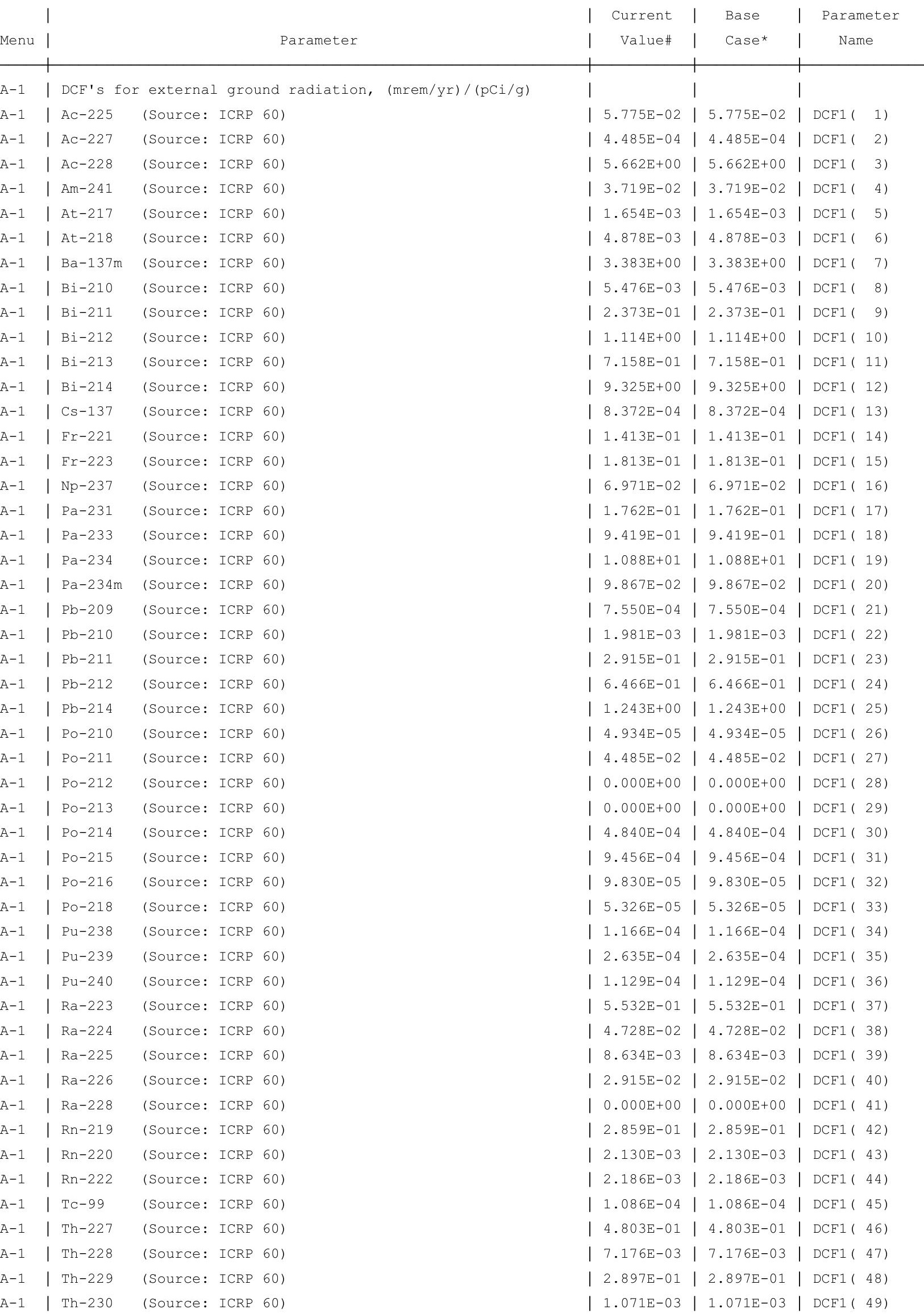


Summary : RESRAD Parameters for U-Landfill Worker Forward Run Proposed AIs

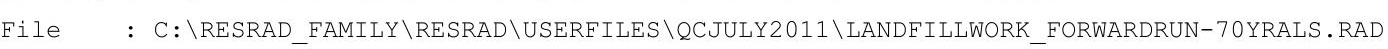

Dose Conversion Factor (and Related) Parameter Summary (continued)

Dose Library: ICRP 60 \& ICRP 72 (Adult)

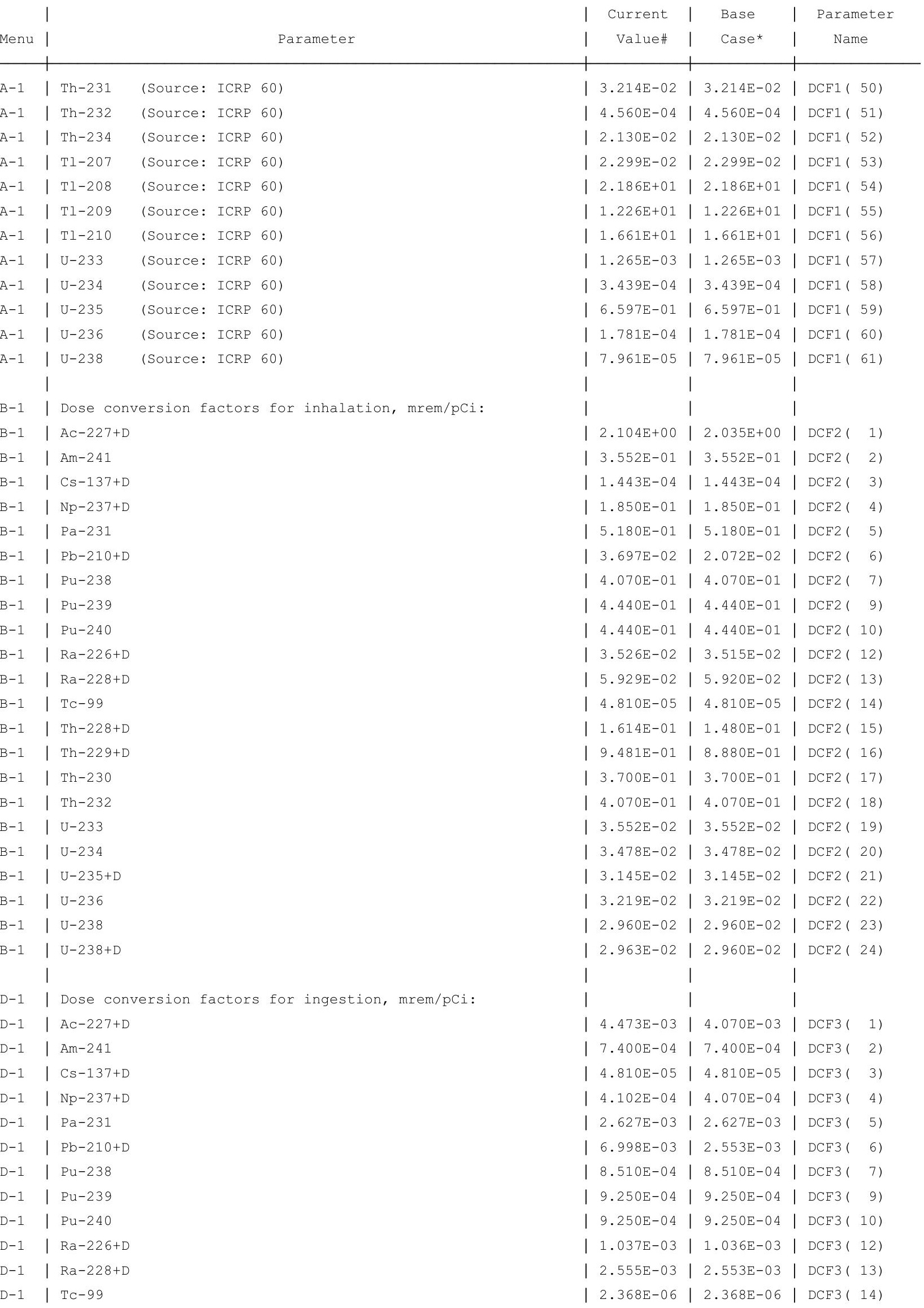


RESRAD, Version $6.5 \quad T^{1 / 2}$ Limit $=180$ days $\quad$ 07/20/2011 15:45 Page

Summary : RESRAD Parameters for U-Landfill Worker Forward Run Proposed ALs

File : C: \RESRAD_FAMILY \RESRAD \USERFILES $\backslash Q C J U L Y 2011 \backslash$ LANDFILLWORK_FORWARDRUN-70YRALS.RAD

Dose Conversion Factor (and Related) Parameter Summary (continued)

Dose Library: ICRP 60 \& ICRP 72 (Adult)

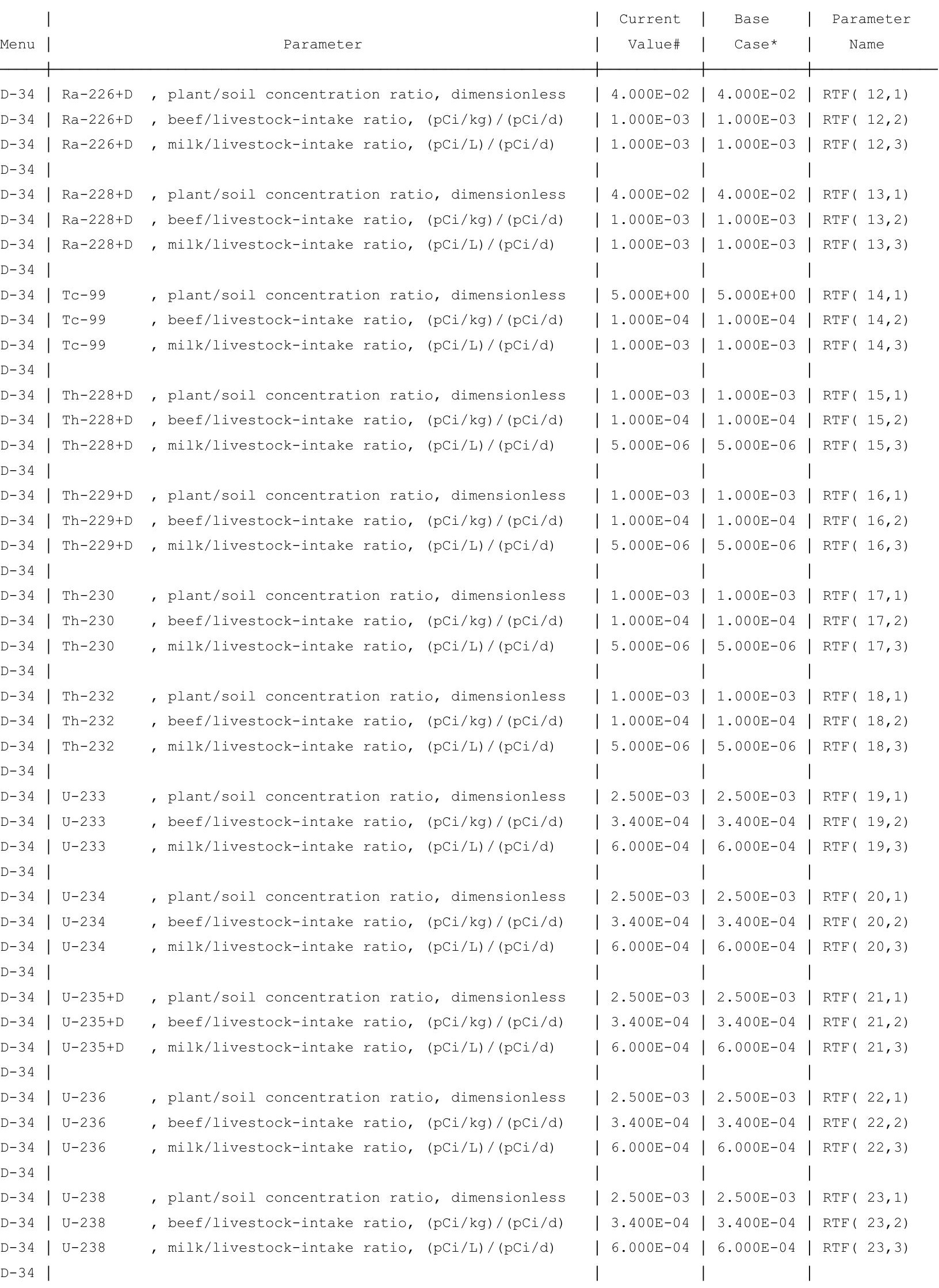


RESRAD, Version $6.5 \quad$ T1/2 Limit $=180$ days $\quad$ 07/20/2011 15:45 Page

Summary : RESRAD Parameters for U-Landfill Worker Forward Run Proposed ALs

File : C: $\backslash$ RESRAD_FAMILY \RESRAD \USERFILES $\backslash Q C J U L Y 2011 \backslash$ LANDFILLWORK_FORWARDRUN-70YRALS.RAD

Dose Conversion Factor (and Related) Parameter Summary (continued)

Dose Library: ICRP 60 \& ICRP 72 (Adult)

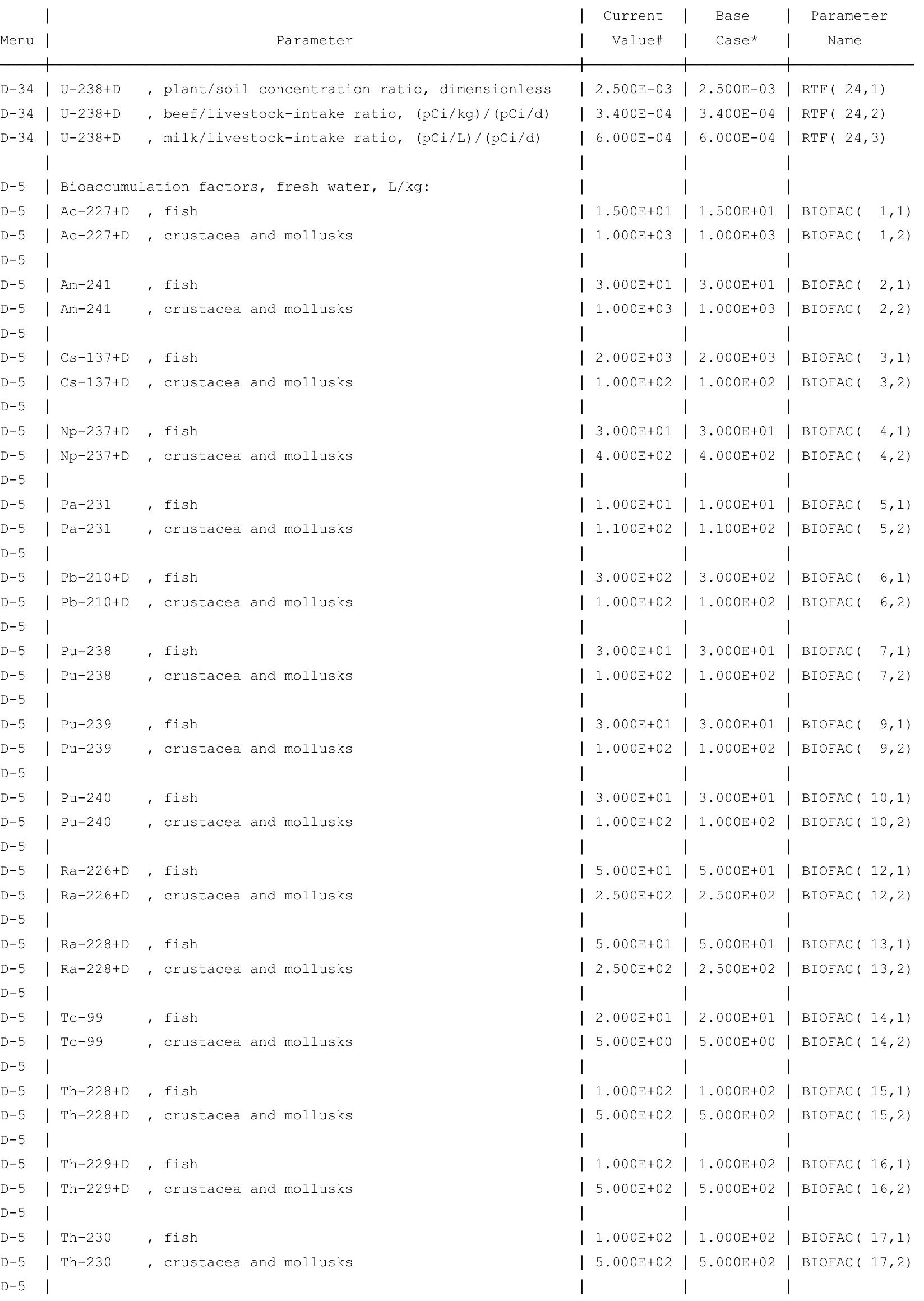




\section{RESRAD, Version $6.5 \quad T^{1 / 2}$ Limit $=180$ days $\quad 07 / 20 / 2011 \quad 15: 45$ Page}

Summary : RESRAD Parameters for U-Landfill Worker Forward Run Proposed ALs

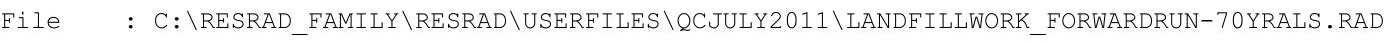

Dose Conversion Factor (and Related) Parameter Summary (continued)

Dose Library: ICRP 60 \& ICRP 72 (Adult)

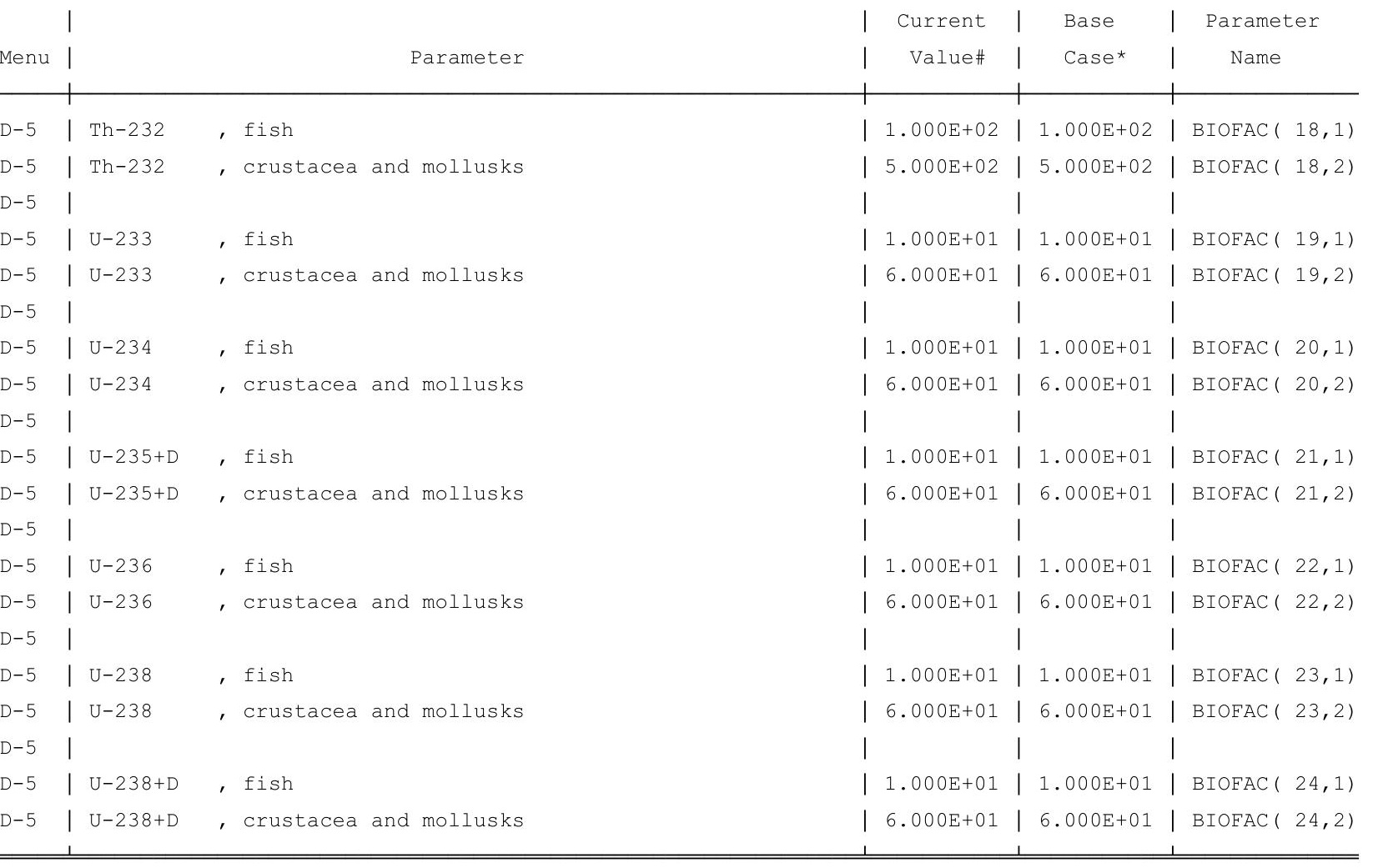

\#For DCFl(xxx) only, factors are for infinite depth \& area. See ETFG table in Ground Pathway of Detailed Report. *Base Case means Default.Lib w/o Associate Nuclide contributions. 
RESRAD, Version $6.5 \quad$ T1/2 Limit $=180$ days $\quad$ 07/20/2011 15:45 Page

Summary : RESRAD Parameters for U-Landfill Worker Forward Run Proposed ALs

File : C: $\backslash$ RESRAD_FAMILY \RESRAD \USERFILES $\backslash Q C J U L Y 2011 \backslash$ LANDFILLWORK_FORWARDRUN-70YRALS.RAD

Site-Specific Parameter Summary (continued)

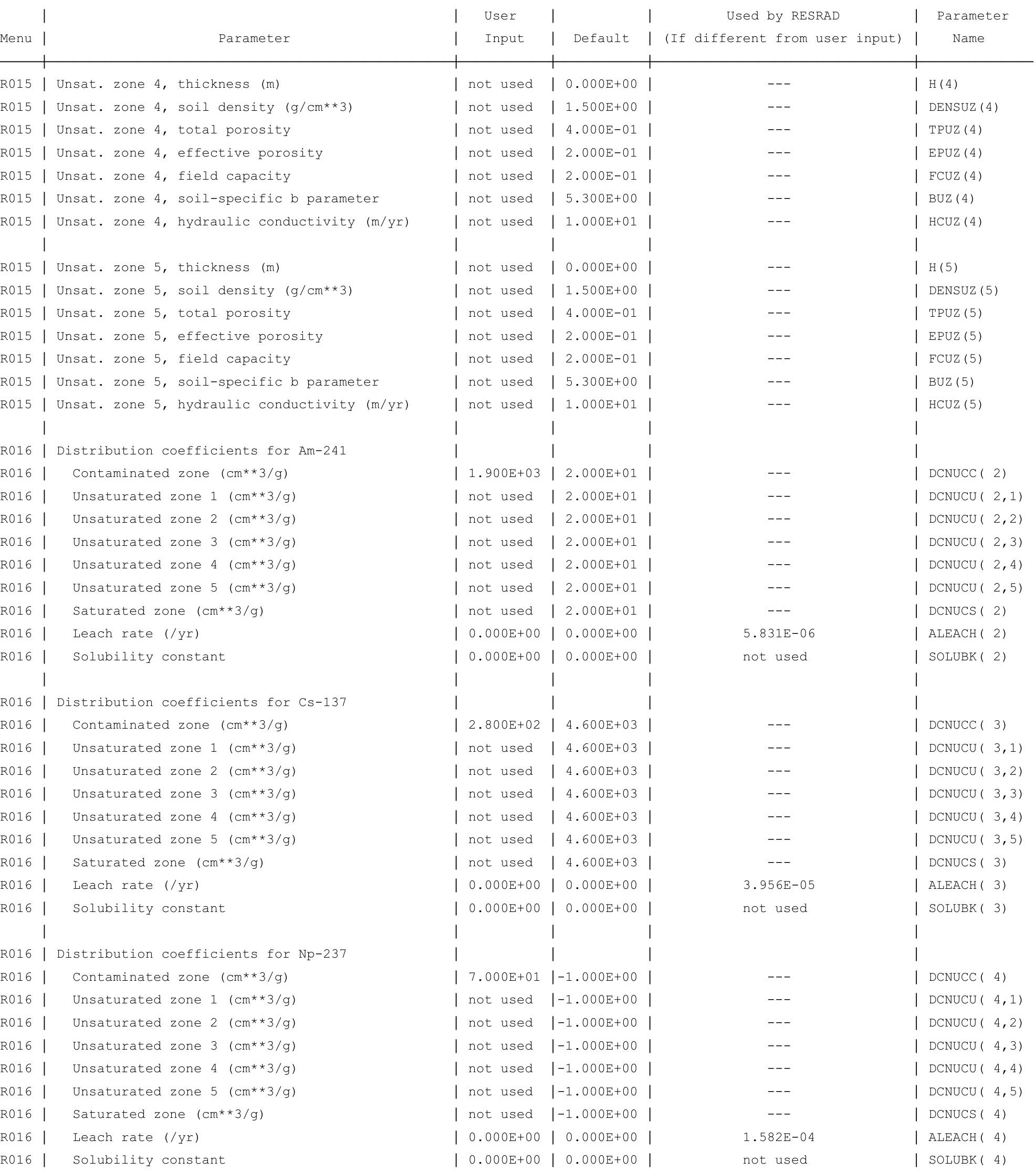

R016 Solubility constant

\begin{tabular}{|l|l|}
$\mid 0.000 \mathrm{E}+00$ & $0.000 \mathrm{E}+00$ \\
$\mid 0.000 \mathrm{E}+00$ & $0.000 \mathrm{E}+00$
\end{tabular} \mid

| SOLUBK ( 4) 
RESRAD, Version $6.5 \quad$ T1/2 Limit $=180$ days $\quad$ 07/20/2011 15:45 Page

Summary : RESRAD Parameters for U-Landfill Worker Forward Run Proposed ALs

File : C: $\backslash$ RESRAD_FAMILY \RESRAD \USERFILES $\backslash Q C J U L Y 2011 \backslash$ LANDFILLWORK_FORWARDRUN-70YRALS.RAD

Site-Specific Parameter Summary (continued)

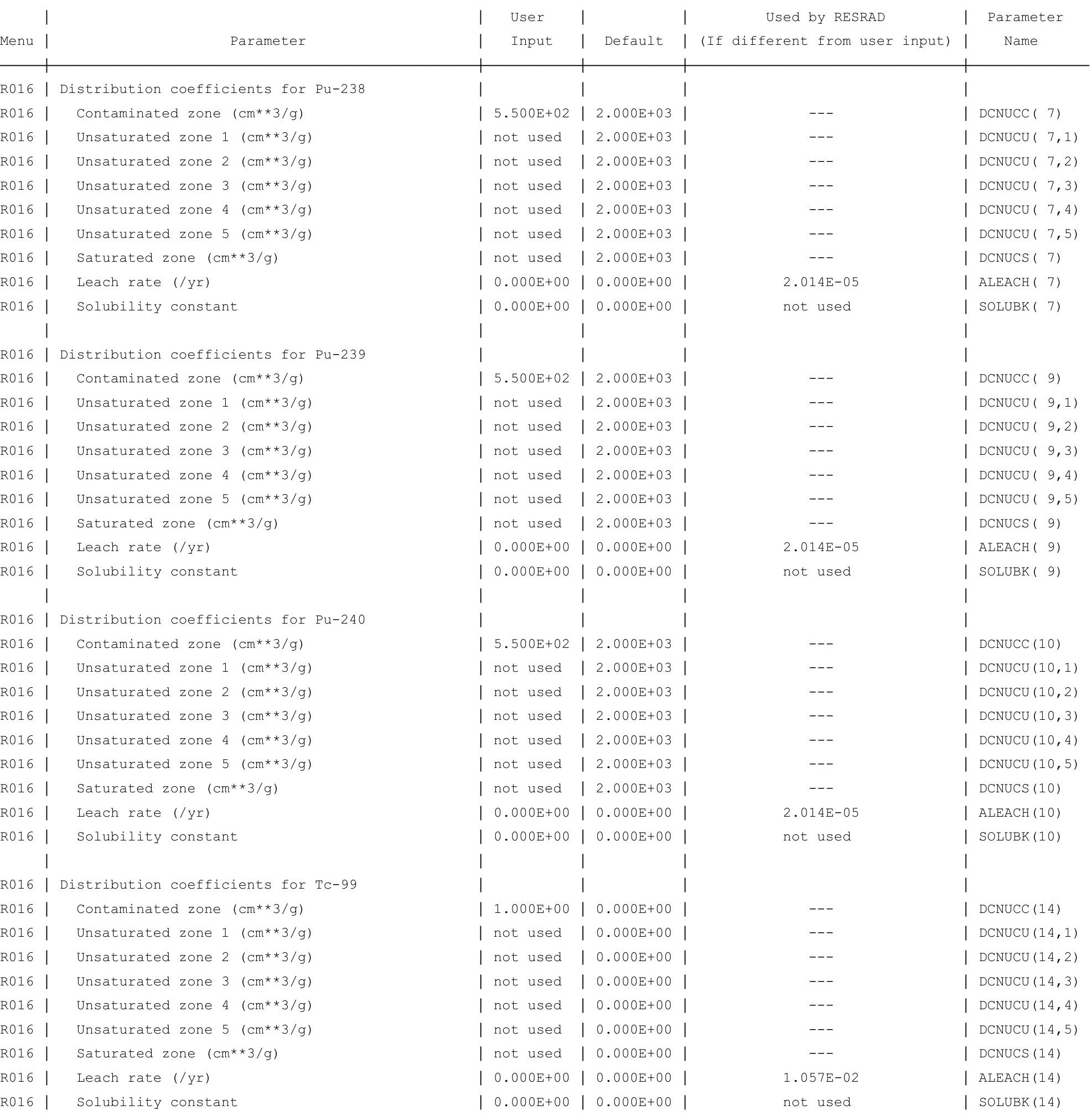


RESRAD, Version $6.5 \quad$ T1/2 Limit $=180$ days $\quad$ 07/20/2011 15:45 Page

Summary : RESRAD Parameters for U-Landfill Worker Forward Run Proposed ALs

File : C: $\backslash$ RESRAD_FAMILY \RESRAD \USERFILES $\backslash Q C J U L Y 2011 \backslash$ LANDFILLWORK_FORWARDRUN-70YRALS.RAD

Site-Specific Parameter Summary (continued)

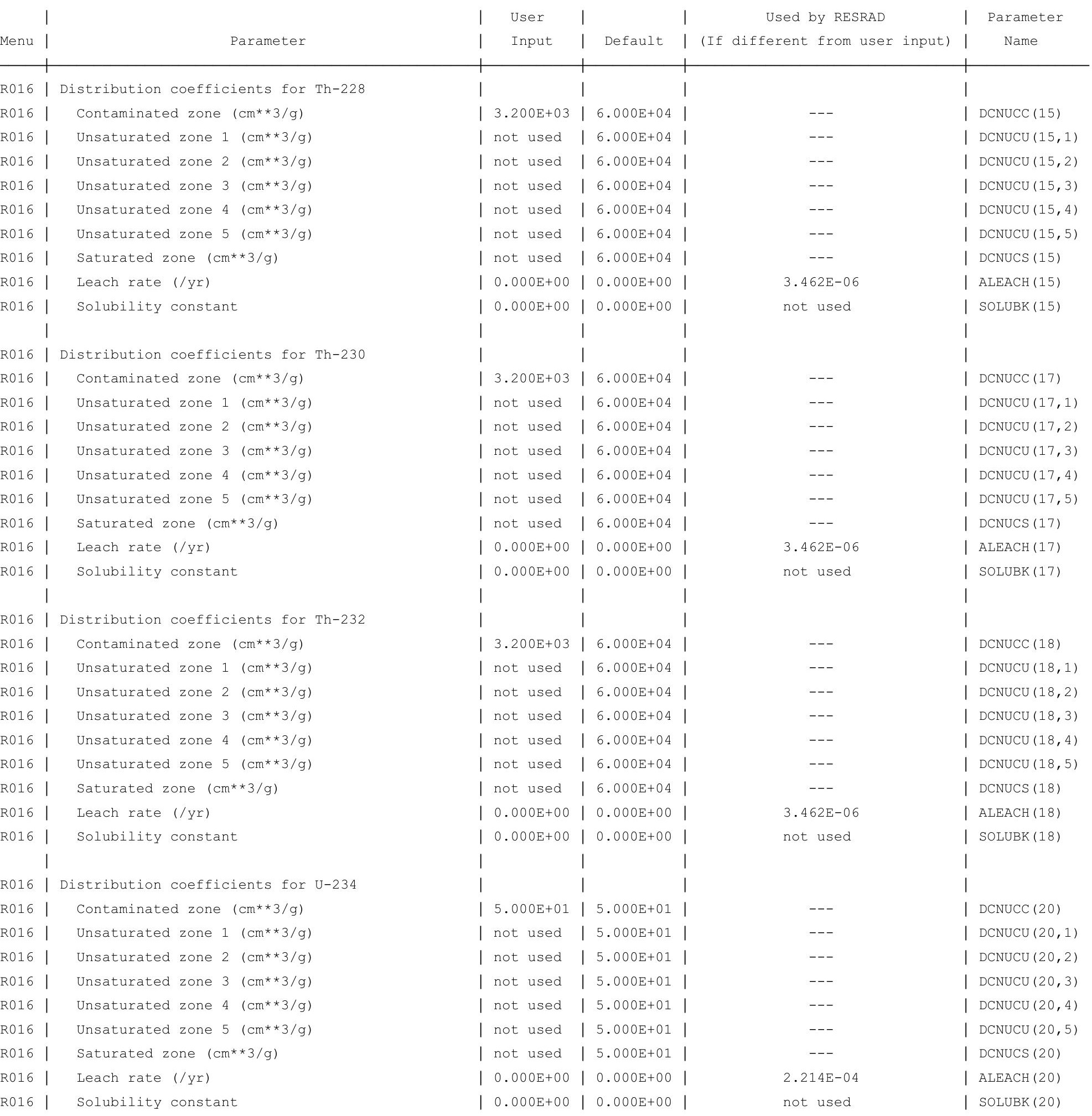


RESRAD, Version $6.5 \quad$ T1/2 Limit $=180$ days $\quad$ 07/20/2011 15:45 Page

Summary : RESRAD Parameters for U-Landfill Worker Forward Run Proposed ALs

File : C: $\backslash$ RESRAD_FAMILY \RESRAD \USERFILES $\backslash Q C J U L Y 2011 \backslash$ LANDFILLWORK_FORWARDRUN-70YRALS.RAD

Site-Specific Parameter Summary (continued)

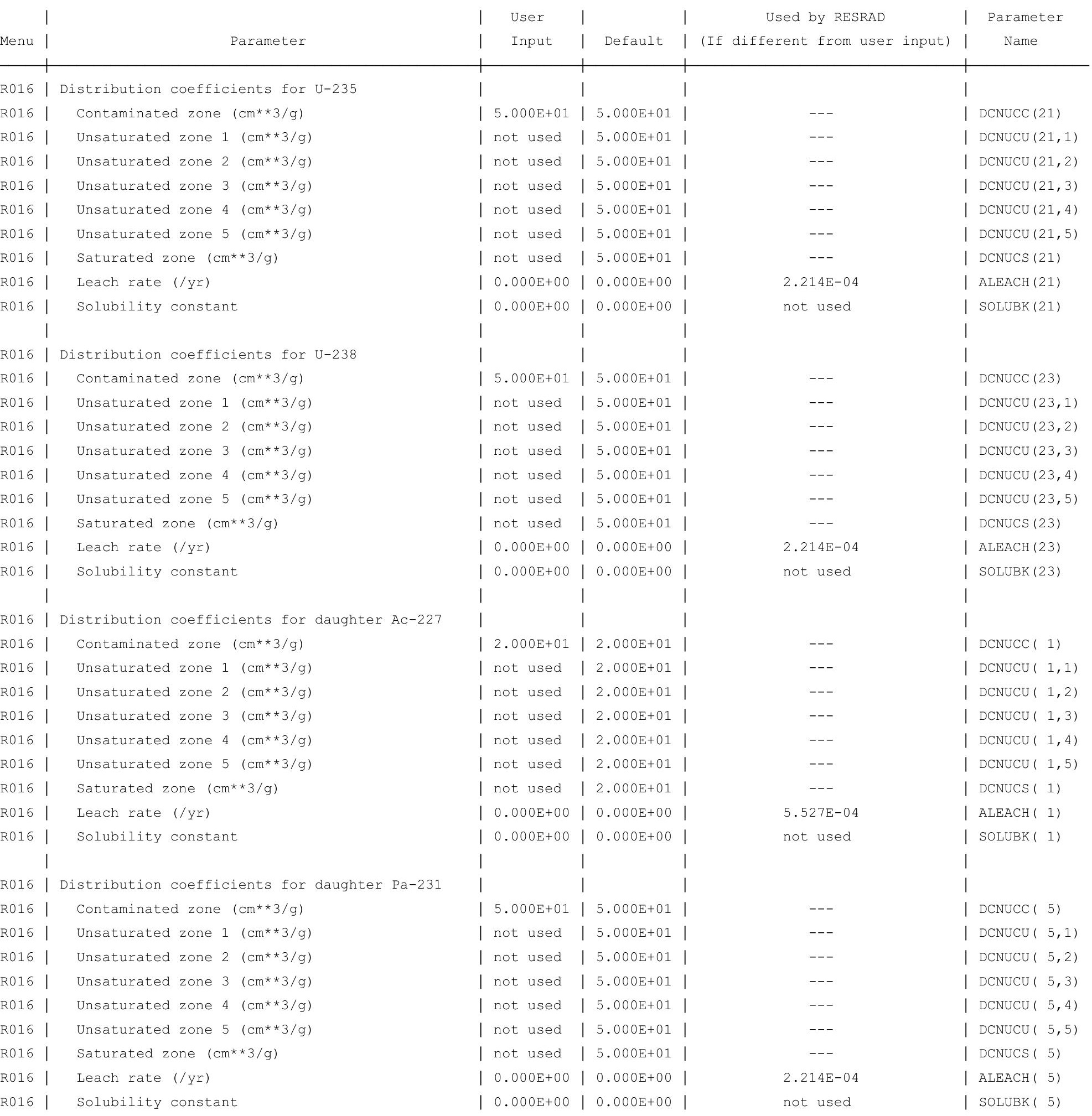

R016 | Solubility constant

| $0.000 \mathrm{E}+00 \mid 0.000 \mathrm{E}+00$

\begin{tabular}{l|l}
$0.000 \mathrm{E}+00$ & $0.000 \mathrm{E}+00$
\end{tabular} not used

I SOLUBK( 5) 
RESRAD, Version $6.5 \quad$ T1/2 Limit $=180$ days $\quad$ 07/20/2011 15:45 Page

Summary : RESRAD Parameters for U-Landfill Worker Forward Run Proposed ALs

File : C: $\backslash$ RESRAD_FAMILY \RESRAD \USERFILES $\backslash Q C J U L Y 2011 \backslash$ LANDFILLWORK_FORWARDRUN-70YRALS.RAD

Site-Specific Parameter Summary (continued)

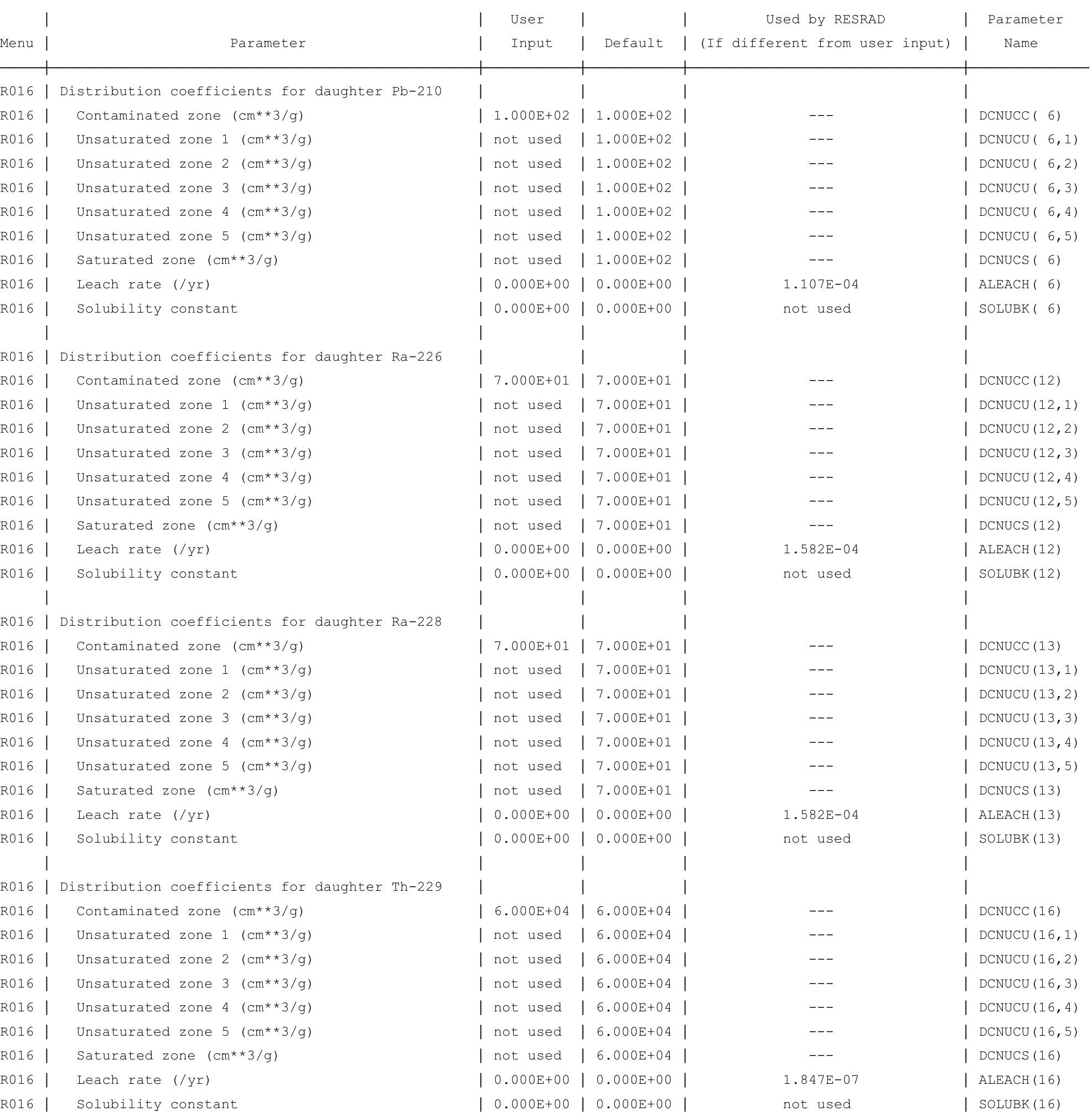

R016 | Solubility constant

\begin{tabular}{|l|l|}
$\mid 0.000 \mathrm{E}+00$ & $0.000 \mathrm{E}+00$ \\
$\mid 0.000 \mathrm{E}+00$ & $0.000 \mathrm{E}+00$
\end{tabular} \mid

| SOLUBK (16) 
RESRAD, Version $6.5 \quad$ T1/2 Limit $=180$ days

07/20/2011 $15: 45$ Page

Summary : RESRAD Parameters for U-Landfill Worker Forward Run Proposed ALs

File : C: \RESRAD_FAMILY \RESRAD \USERFILES $\backslash Q C J U L Y 2011 \backslash$ LANDFILLWORK_FORWARDRUN-70YRALS.RAD

Contaminated Zone Dimensions

Area: 89436.00 square meters

Thickness:

Cover Depth:

\begin{abstract}
13.40 meters
0.00 meters
\end{abstract}

Initial Soil Concentrations, pCi/g

$\begin{array}{ll}\mathrm{Am}-241 & 7.000 \mathrm{E}+01 \\ \mathrm{Cs}-137 & 3.800 \mathrm{E}+01 \\ \mathrm{~Np}-237 & 1.100 \mathrm{E}+01 \\ \mathrm{Pu}-238 & 7.800 \mathrm{E}+01 \\ \mathrm{Pu}-239 & 7.200 \mathrm{E}+01 \\ \mathrm{Pu}-240 & 7.200 \mathrm{E}+01 \\ \mathrm{TC}-99 & 1.040 \mathrm{E}+02 \\ \mathrm{Th}-228 & 8.000 \mathrm{E}+00 \\ \mathrm{Th}-230 & 2.000 \mathrm{E}+02 \\ \mathrm{Th}-232 & 8.000 \mathrm{E}+00 \\ \mathrm{U}-234 & 3.200 \mathrm{E}+02 \\ \mathrm{U}-235 & 1.300 \mathrm{E}+01 \\ \mathrm{U}-238 & 3.200 \mathrm{E}+02\end{array}$

Total Dose TDOSE(t), mrem/yr

Basic Radiation Dose Limit $=1.000 \mathrm{E}+02 \mathrm{mrem} / \mathrm{yr}$

Total Mixture Sum $M(t)$ = Fraction of Basic Dose Limit Received at Time (t)
$t$ (years):
$0.000 \mathrm{E}+00 \quad 1.000 \mathrm{E}+00$
2. $500 \mathrm{E}+01$
$5.000 \mathrm{E}+01 \quad 7.000 \mathrm{E}+01$
TDOSE $(t): \quad 5.975 \mathrm{E}+01 \quad 5.742 \mathrm{E}+01$
6. $280 \mathrm{E}+01$
$6.272 \mathrm{E}+01$
$6.342 \mathrm{E}+01$
$\mathrm{M}(\mathrm{t})$
$5.975 \mathrm{E}-01$
$5.742 \mathrm{E}-01$
6. $280 \mathrm{E}-01$
$6.272 \mathrm{E}-01$
$6.342 \mathrm{E}-01$

Maximum TDOSE $(\mathrm{t}): 6.342 \mathrm{E}+01 \mathrm{mrem} / \mathrm{yr}$ at $t=7.000 \mathrm{E}+01$ years 


\section{RESRAD, Version $6.5 \quad$ T1/2 Limit $=180$ days $\quad$ 07/20/2011 $15: 45$ Page}

Summary : RESRAD Parameters for U-Landfill Worker Forward Run Proposed ALs

File : C: \RESRAD_FAMILY \RESRAD \USERFILES $\backslash Q C J U L Y 2011 \backslash$ LANDFILLWORK_FORWARDRUN-70YRALS.RAD

Total Dose Contributions TDOSE(i,p,t) for Individual Radionuclides (i) and Pathways (p) As mrem/yr and Fraction of Total Dose At $t=0.000 \mathrm{E}+00$ years

Water Independent Pathways (Inhalation excludes radon)

\begin{tabular}{|c|c|c|c|c|c|c|c|c|c|c|c|c|c|c|}
\hline & \multicolumn{2}{|c|}{ Ground } & \multicolumn{2}{|c|}{ Inhalation } & \multicolumn{2}{|c|}{ Radon } & \multicolumn{2}{|c|}{ Plant } & \multicolumn{2}{|c|}{ Meat } & \multicolumn{2}{|c|}{ Milk } & \multicolumn{2}{|c|}{ Soil } \\
\hline Iide & mrem/yr & fract. & mrem/yr & fract. & mrem/yr & fract. & mrem/yr & fract. & mrem/yr & fract. & mrem/yr & fract. & mrem/yr & fract. \\
\hline-241 & $4.408 E-01$ & 0.0074 & $1.264 \mathrm{E}-02$ & 0.0002 & $0.000 \mathrm{E}+00$ & 0.0000 & $0.000 \mathrm{E}+00$ & 0.0000 & $0.000 \mathrm{E}+00$ & 0.0000 & $0.000 \mathrm{E}+00$ & 0.0000 & $1.542 \mathrm{E}+00$ & 0.0258 \\
\hline-137 & $1.994 \mathrm{E}+01$ & 0.3338 & $2.758 \mathrm{E}-06$ & 0.0000 & $0.000 \mathrm{E}+00$ & 0.0000 & $0.000 \mathrm{E}+00$ & 0.0000 & $0.000 \mathrm{E}+00$ & 0.0000 & $0.000 \mathrm{E}+00$ & 0.0000 & $5.381 E-02$ & 0.0009 \\
\hline-237 & $1.862 \mathrm{E}+00$ & 0.0312 & $1.035 \mathrm{E}-03$ & 0.0000 & $0.000 \mathrm{E}+00$ & 0.0000 & $0.000 \mathrm{E}+00$ & 0.0000 & $0.000 \mathrm{E}+00$ & 0.0000 & $0.000 \mathrm{E}+00$ & 0.0000 & $1.344 \mathrm{E}-01$ & 0.0022 \\
\hline 238 & $1.538 E-03$ & 0.0000 & $1.609 \mathrm{E}-02$ & 0.0003 & $0.000 \mathrm{E}+00$ & 0.0000 & $0.000 \mathrm{E}+00$ & 0.0000 & $0.000 \mathrm{E}+00$ & 0.0000 & $0.000 \mathrm{E}+00$ & 0.0000 & $1.969 \mathrm{E}+00$ & 0.0330 \\
\hline 239 & $3.184 \mathrm{E}-03$ & 0.0001 & $1.626 \mathrm{E}-02$ & 0.0003 & $0.000 \mathrm{E}+00$ & 0.0000 & $0.000 \mathrm{E}+00$ & 0.0000 & $0.000 \mathrm{E}+00$ & 0.0000 & $0.000 \mathrm{E}+00$ & 0.0000 & $1.984 \mathrm{E}+00$ & 0.0332 \\
\hline 240 & $1.378 E-03$ & 0.0000 & $1.626 \mathrm{E}-02$ & 0.0003 & $0.000 \mathrm{E}+00$ & 0.0000 & $0.000 \mathrm{E}+00$ & 0.0000 & $0.000 \mathrm{E}+00$ & 0.0000 & $0.000 \mathrm{E}+00$ & 0.0000 & $1.983 \mathrm{E}+00$ & 0.0332 \\
\hline 99 & $1.893 E-03$ & 0.0000 & $2.531 E-06$ & 0.0000 & $0.000 \mathrm{E}+00$ & 0.0000 & $0.000 \mathrm{E}+00$ & 0.0000 & $0.000 \mathrm{E}+00$ & 0.0000 & $0.000 \mathrm{E}+00$ & 0.0000 & $7.296 \mathrm{E}-03$ & 0.0001 \\
\hline 228 & $1.078 \mathrm{E}+01$ & 0.1804 & $5.510 \mathrm{E}-04$ & 0.0000 & $0.000 \mathrm{E}+00$ & 0.0000 & $0.000 \mathrm{E}+00$ & 0.0000 & $0.000 \mathrm{E}+00$ & 0.0000 & $0.000 \mathrm{E}+00$ & 0.0000 & $1.059 \mathrm{E}-01$ & 0.0018 \\
\hline 230 & $1.123 \mathrm{E}-01$ & 0.0019 & $3.765 \mathrm{E}-02$ & 0.0006 & $0.000 \mathrm{E}+00$ & 0.0000 & $0.000 \mathrm{E}+00$ & 0.0000 & $0.000 \mathrm{E}+00$ & 0.0000 & $0.000 \mathrm{E}+00$ & 0.0000 & $4.630 \mathrm{E}+00$ & 0.0775 \\
\hline 232 & $5.194 \mathrm{E}-01$ & 0.0087 & $1.675 \mathrm{E}-03$ & 0.0000 & $0.000 \mathrm{E}+00$ & 0.0000 & $0.000 \mathrm{E}+00$ & 0.0000 & $0.000 \mathrm{E}+00$ & 0.0000 & $0.000 \mathrm{E}+00$ & 0.0000 & $2.388 \mathrm{E}-01$ & 0.0040 \\
\hline 34 & $1.858 \mathrm{E}-02$ & 0.0003 & $5.662 \mathrm{E}-03$ & 0.0001 & $0.000 \mathrm{E}+00$ & 0.0000 & $0.000 \mathrm{E}+00$ & 0.0000 & $0.000 \mathrm{E}+00$ & 0.0000 & $0.000 \mathrm{E}+00$ & 0.0000 & $1.728 \mathrm{E}+00$ & 0.0289 \\
\hline 35 & $1.509 \mathrm{E}+00$ & 0.0253 & $2.080 \mathrm{E}-04$ & 0.0000 & $0.000 \mathrm{E}+00$ & 0.0000 & $0.000 \mathrm{E}+00$ & 0.0000 & $0.000 \mathrm{E}+00$ & 0.0000 & $0.000 \mathrm{E}+00$ & 0.0000 & $6.782 \mathrm{E}-02$ & 0.0011 \\
\hline 38 & $8.296 \mathrm{E}+00$ & 0.1388 & $4.823 E-03$ & 0.0001 & $0.000 \mathrm{E}+00$ & 0.0000 & $0.000 \mathrm{E}+00$ & 0.0000 & $0.000 \mathrm{E}+00$ & 0.0000 & $0.000 \mathrm{E}+00$ & 0.0000 & $1.707 \mathrm{E}+00$ & 0.0286 \\
\hline & $4.349 E+01$ & 0.7278 & $1.129 \mathrm{E}-01$ & 0.0019 & $0.000 \mathrm{E}+00$ & 0.0000 & $0.000 \mathrm{E}+00$ & 0.0000 & $0.000 \mathrm{E}+00$ & 0.0000 & $0.000 \mathrm{E}+00$ & 0.0000 & +01 & 0.2703 \\
\hline
\end{tabular}

Total Dose Contributions TDOSE(i,p,t) for Individual Radionuclides (i) and Pathways (p) As mrem/yr and Fraction of Total Dose At $t=0.000 \mathrm{E}+00$ years

Water Dependent Pathways

\begin{tabular}{|c|c|c|c|c|c|c|c|c|c|c|c|c|c|c|}
\hline \multirow{2}{*}{ Nuclide } & \multicolumn{2}{|c|}{ Water } & \multicolumn{2}{|c|}{ Fish } & \multicolumn{2}{|c|}{ Radon } & \multicolumn{2}{|c|}{ Plant } & \multicolumn{2}{|c|}{ Meat } & \multicolumn{2}{|c|}{ Milk } & \multicolumn{2}{|c|}{ All Pathways* } \\
\hline & mrem/yr & fract. & mrem/yr & fract. & mrem/yr & fract. & mrem/yr & fract. & mrem/yr & fract. & mrem/yr & fract. & mrem/yr & fract. \\
\hline-241 & $0.000 \mathrm{E}+00$ & 0.0000 & $0.000 \mathrm{E}+00$ & 0.0000 & $0.000 \mathrm{E}+00$ & 0.0000 & $0.000 \mathrm{E}+00$ & 0.0000 & $0.000 \mathrm{E}+00$ & 0.0000 & $0.000 \mathrm{E}+00$ & 0.0000 & $1.995 \mathrm{E}+00$ & 0.0334 \\
\hline-137 & $0.000 \mathrm{E}+00$ & 0.0000 & $0.000 \mathrm{E}+00$ & 0.0000 & $0.000 \mathrm{E}+00$ & 0.0000 & $0.000 \mathrm{E}+00$ & 0.0000 & $0.000 \mathrm{E}+00$ & 0.0000 & $0.000 \mathrm{E}+00$ & 0.0000 & $2.000 \mathrm{E}+01$ & 0.3347 \\
\hline-237 & $0.000 \mathrm{E}+00$ & 0.0000 & $0.000 \mathrm{E}+00$ & 0.0000 & $0.000 \mathrm{E}+00$ & 0.0000 & $0.000 \mathrm{E}+00$ & 0.0000 & $0.000 \mathrm{E}+00$ & 0.0000 & $0.000 \mathrm{E}+00$ & 0.0000 & $1.998 \mathrm{E}+00$ & 0.0334 \\
\hline-238 & $0.000 \mathrm{E}+00$ & 0.0000 & $0.000 \mathrm{E}+00$ & 0.0000 & $0.000 \mathrm{E}+00$ & 0.0000 & $0.000 \mathrm{E}+00$ & 0.0000 & $0.000 \mathrm{E}+00$ & 0.0000 & $0.000 \mathrm{E}+00$ & 0.0000 & $1.987 \mathrm{E}+00$ & 0.0333 \\
\hline 239 & $0.000 \mathrm{E}+00$ & 0.0000 & $0.000 \mathrm{E}+00$ & 0.0000 & $0.000 \mathrm{E}+00$ & 0.0000 & $0.000 \mathrm{E}+00$ & 0.0000 & $0.000 \mathrm{E}+00$ & 0.0000 & $0.000 \mathrm{E}+00$ & 0.0000 & $2.003 E+00$ & 0.0335 \\
\hline-240 & $0.000 \mathrm{E}+00$ & 0.0000 & $0.000 \mathrm{E}+00$ & 0.0000 & $0.000 \mathrm{E}+00$ & 0.0000 & $0.000 \mathrm{E}+00$ & 0.0000 & $0.000 \mathrm{E}+00$ & 0.0000 & $0.000 \mathrm{E}+00$ & 0.0000 & $2.001 E+00$ & 0.0335 \\
\hline 99 & $0.000 \mathrm{E}+00$ & 0.0000 & $0.000 \mathrm{E}+00$ & 0.0000 & $0.000 \mathrm{E}+00$ & 0.0000 & $0.000 \mathrm{E}+00$ & 0.0000 & $0.000 \mathrm{E}+00$ & 0.0000 & $0.000 \mathrm{E}+00$ & 0.0000 & $9.192 \mathrm{E}-03$ & 0.0002 \\
\hline-228 & $0.000 \mathrm{E}+00$ & 0.0000 & $0.000 \mathrm{E}+00$ & 0.0000 & $0.000 \mathrm{E}+00$ & 0.0000 & $0.000 \mathrm{E}+00$ & 0.0000 & $0.000 \mathrm{E}+00$ & 0.0000 & $0.000 \mathrm{E}+00$ & 0.0000 & $1.088 \mathrm{E}+01$ & 0.1821 \\
\hline-230 & $0.000 \mathrm{E}+00$ & 0.0000 & $0.000 \mathrm{E}+00$ & 0.0000 & $0.000 \mathrm{E}+00$ & 0.0000 & $0.000 \mathrm{E}+00$ & 0.0000 & $0.000 \mathrm{E}+00$ & 0.0000 & $0.000 \mathrm{E}+00$ & 0.0000 & $4.780 \mathrm{E}+00$ & 0.0800 \\
\hline-232 & $0.000 \mathrm{E}+00$ & 0.0000 & $0.000 \mathrm{E}+00$ & 0.0000 & $0.000 \mathrm{E}+00$ & 0.0000 & $0.000 \mathrm{E}+00$ & 0.0000 & $0.000 \mathrm{E}+00$ & 0.0000 & $0.000 \mathrm{E}+00$ & 0.0000 & 7. 599E-01 & 0.0127 \\
\hline 234 & $0.000 \mathrm{E}+00$ & 0.0000 & $0.000 \mathrm{E}+00$ & 0.0000 & $0.000 \mathrm{E}+00$ & 0.0000 & $0.000 \mathrm{E}+00$ & 0.0000 & $0.000 \mathrm{E}+00$ & 0.0000 & $0.000 \mathrm{E}+00$ & 0.0000 & $1.752 \mathrm{E}+00$ & 0.0293 \\
\hline 35 & $0.000 \mathrm{E}+00$ & 0.0000 & $0.000 \mathrm{E}+00$ & 0.0000 & $0.000 \mathrm{E}+00$ & 0.0000 & $0.000 \mathrm{E}+00$ & 0.0000 & $0.000 \mathrm{E}+00$ & 0.0000 & $0.000 \mathrm{E}+00$ & 0.0000 & $1.577 \mathrm{E}+00$ & 0.0264 \\
\hline 38 & $0.000 \mathrm{E}+00$ & 0.0000 & $0.000 \mathrm{E}+00$ & 0.0000 & $0.000 \mathrm{E}+00$ & 0.0000 & $0.000 \mathrm{E}+00$ & 0.0000 & $0.000 \mathrm{E}+00$ & 0.0000 & $0.000 \mathrm{E}+00$ & 0.0000 & $1.001 \mathrm{E}+01$ & 0.1675 \\
\hline & $0.000 \mathrm{E}+00$ & 0.0000 & $0.000 \mathrm{E}+00$ & 0.0000 & $0.000 \mathrm{E}+00$ & 0.0000 & $0.000 \mathrm{E}+00$ & 0.0000 & $0.000 \mathrm{E}+00$ & 0.0000 & $0.000 \mathrm{E}+00$ & 0.0000 & $75 E+01$ & 1.0000 \\
\hline
\end{tabular}

* Sum of all water independent and dependent pathways. 


\section{RESRAD, Version $6.5 \quad$ T1/2 Limit $=180$ days $\quad$ 07/20/2011 $15: 45$ Page}

Summary : RESRAD Parameters for U-Landfill Worker Forward Run Proposed ALs

File : C: \RESRAD_FAMILY \RESRAD \USERFILES $\backslash Q C J U L Y 2011 \backslash$ LANDFILLWORK_FORWARDRUN-70YRALS.RAD

Total Dose Contributions TDOSE(i,p,t) for Individual Radionuclides (i) and Pathways (p) As mrem/yr and Fraction of Total Dose At $t=1.000 \mathrm{E}+00$ years

Water Independent Pathways (Inhalation excludes radon)

\begin{tabular}{|c|c|c|c|c|c|c|c|c|c|c|c|c|c|c|}
\hline & \multicolumn{2}{|c|}{ Ground } & \multicolumn{2}{|c|}{ Inhalation } & \multicolumn{2}{|c|}{ Radon } & \multicolumn{2}{|c|}{ Plant } & \multicolumn{2}{|c|}{ Meat } & \multicolumn{2}{|c|}{ Milk } & \multicolumn{2}{|c|}{ Soil } \\
\hline Iide & mrem/yr & fract. & mrem/yr & fract. & mrem/yr & fract. & mrem/yr & fract. & mrem/yr & fract. & mrem/yr & fract. & mrem/yr & fract. \\
\hline-241 & $4.401 \mathrm{E}-01$ & 0.0077 & $1.262 \mathrm{E}-02$ & 0.0002 & $0.000 \mathrm{E}+00$ & 0.0000 & $0.000 \mathrm{E}+00$ & 0.0000 & $0.000 \mathrm{E}+00$ & 0.0000 & $0.000 \mathrm{E}+00$ & 0.0000 & $1.539 \mathrm{E}+00$ & 0.0268 \\
\hline-137 & $1.949 \mathrm{E}+01$ & 0.3394 & $2.694 \mathrm{E}-06$ & 0.0000 & $0.000 \mathrm{E}+00$ & 0.0000 & $0.000 \mathrm{E}+00$ & 0.0000 & $0.000 \mathrm{E}+00$ & 0.0000 & $0.000 \mathrm{E}+00$ & 0.0000 & $5.258 \mathrm{E}-02$ & 0.0009 \\
\hline-237 & $1.862 \mathrm{E}+00$ & 0.0324 & $1.035 \mathrm{E}-03$ & 0.0000 & $0.000 \mathrm{E}+00$ & 0.0000 & $0.000 \mathrm{E}+00$ & 0.0000 & $0.000 \mathrm{E}+00$ & 0.0000 & $0.000 \mathrm{E}+00$ & 0.0000 & $1.344 \mathrm{E}-01$ & 0.0023 \\
\hline 238 & $1.526 E-03$ & 0.0000 & $1.596 \mathrm{E}-02$ & 0.0003 & $0.000 \mathrm{E}+00$ & 0.0000 & $0.000 \mathrm{E}+00$ & 0.0000 & $0.000 \mathrm{E}+00$ & 0.0000 & $0.000 \mathrm{E}+00$ & 0.0000 & $1.954 \mathrm{E}+00$ & 0.0340 \\
\hline 239 & $3.184 \mathrm{E}-03$ & 0.0001 & $1.626 \mathrm{E}-02$ & 0.0003 & $0.000 \mathrm{E}+00$ & 0.0000 & $0.000 \mathrm{E}+00$ & 0.0000 & $0.000 \mathrm{E}+00$ & 0.0000 & $0.000 \mathrm{E}+00$ & 0.0000 & $1.983 \mathrm{E}+00$ & 0.0345 \\
\hline 240 & $1.378 E-03$ & 0.0000 & $1.626 \mathrm{E}-02$ & 0.0003 & $0.000 \mathrm{E}+00$ & 0.0000 & $0.000 \mathrm{E}+00$ & 0.0000 & $0.000 \mathrm{E}+00$ & 0.0000 & $0.000 \mathrm{E}+00$ & 0.0000 & $1.983 \mathrm{E}+00$ & 0.0345 \\
\hline 99 & $1.873 E-03$ & 0.0000 & $2.505 E-06$ & 0.0000 & $0.000 \mathrm{E}+00$ & 0.0000 & $0.000 \mathrm{E}+00$ & 0.0000 & $0.000 \mathrm{E}+00$ & 0.0000 & $0.000 \mathrm{E}+00$ & 0.0000 & $7.220 \mathrm{E}-03$ & 0.0001 \\
\hline-228 & $7.501 \mathrm{E}+00$ & 0.1306 & $3.835 \mathrm{E}-04$ & 0.0000 & $0.000 \mathrm{E}+00$ & 0.0000 & $0.000 \mathrm{E}+00$ & 0.0000 & $0.000 \mathrm{E}+00$ & 0.0000 & $0.000 \mathrm{E}+00$ & 0.0000 & 7. $375 E-02$ & 0.0013 \\
\hline 230 & $2.647 \mathrm{E}-01$ & 0.0046 & $3.765 \mathrm{E}-02$ & 0.0007 & $0.000 \mathrm{E}+00$ & 0.0000 & $0.000 \mathrm{E}+00$ & 0.0000 & $0.000 \mathrm{E}+00$ & 0.0000 & $0.000 \mathrm{E}+00$ & 0.0000 & $4.633 \mathrm{E}+00$ & 0.0807 \\
\hline 232 & $1.751 \mathrm{E}+00$ & 0.0305 & $1.722 \mathrm{E}-03$ & 0.0000 & $0.000 \mathrm{E}+00$ & 0.0000 & $0.000 \mathrm{E}+00$ & 0.0000 & $0.000 \mathrm{E}+00$ & 0.0000 & $0.000 \mathrm{E}+00$ & 0.0000 & $3.081 \mathrm{E}-01$ & 0.0054 \\
\hline 34 & $1.858 \mathrm{E}-02$ & 0.0003 & $5.661 \mathrm{E}-03$ & 0.0001 & $0.000 \mathrm{E}+00$ & 0.0000 & $0.000 \mathrm{E}+00$ & 0.0000 & $0.000 \mathrm{E}+00$ & 0.0000 & $0.000 \mathrm{E}+00$ & 0.0000 & $1.727 \mathrm{E}+00$ & 0.0301 \\
\hline 35 & $1.509 \mathrm{E}+00$ & 0.0263 & $2.081 E-04$ & 0.0000 & $0.000 \mathrm{E}+00$ & 0.0000 & $0.000 \mathrm{E}+00$ & 0.0000 & $0.000 \mathrm{E}+00$ & 0.0000 & $0.000 \mathrm{E}+00$ & 0.0000 & $6.783 \mathrm{E}-02$ & 0.0012 \\
\hline 38 & $8.294 \mathrm{E}+00$ & 0.1444 & $4.822 E-03$ & 0.0001 & $0.000 \mathrm{E}+00$ & 0.0000 & $0.000 \mathrm{E}+00$ & 0.0000 & $0.000 \mathrm{E}+00$ & 0.0000 & $0.000 \mathrm{E}+00$ & 0.0000 & $1.706 \mathrm{E}+00$ & 0.0297 \\
\hline & $4.113 E+01$ & 0.7164 & $1.126 \mathrm{E}-01$ & 0.0020 & $0.000 \mathrm{E}+00$ & 0.0000 & $0.000 \mathrm{E}+00$ & 0.0000 & $0.000 \mathrm{E}+00$ & 0.0000 & $0.000 \mathrm{E}+00$ & 0.0000 & +01 & 0.2816 \\
\hline
\end{tabular}

Total Dose Contributions TDOSE(i,p,t) for Individual Radionuclides (i) and Pathways (p) As mrem/yr and Fraction of Total Dose At $t=1.000 \mathrm{E}+00$ years

Water Dependent Pathways

\begin{tabular}{|c|c|c|c|c|c|c|c|c|c|c|c|c|c|c|}
\hline \multirow{2}{*}{ Nuclide } & \multicolumn{2}{|c|}{ Water } & \multicolumn{2}{|c|}{ Fish } & \multicolumn{2}{|c|}{ Radon } & \multicolumn{2}{|c|}{ Plant } & \multicolumn{2}{|c|}{ Meat } & \multicolumn{2}{|c|}{ Milk } & \multicolumn{2}{|c|}{ All Pathways* } \\
\hline & mrem/yr & fract. & mrem/yr & fract. & mrem/yr & fract. & mrem/yr & fract. & mrem/yr & fract. & mrem/yr & fract. & mrem/yr & fract. \\
\hline-241 & $0.000 \mathrm{E}+00$ & 0.0000 & $0.000 \mathrm{E}+00$ & 0.0000 & $0.000 \mathrm{E}+00$ & 0.0000 & $0.000 \mathrm{E}+00$ & 0.0000 & $0.000 \mathrm{E}+00$ & 0.0000 & $0.000 \mathrm{E}+00$ & 0.0000 & $1.992 \mathrm{E}+00$ & 0.0347 \\
\hline-137 & $0.000 \mathrm{E}+00$ & 0.0000 & $0.000 \mathrm{E}+00$ & 0.0000 & $0.000 \mathrm{E}+00$ & 0.0000 & $0.000 \mathrm{E}+00$ & 0.0000 & $0.000 \mathrm{E}+00$ & 0.0000 & $0.000 \mathrm{E}+00$ & 0.0000 & $1.954 \mathrm{E}+01$ & 0.3403 \\
\hline 237 & $0.000 \mathrm{E}+00$ & 0.0000 & $0.000 \mathrm{E}+00$ & 0.0000 & $0.000 \mathrm{E}+00$ & 0.0000 & $0.000 \mathrm{E}+00$ & 0.0000 & $0.000 \mathrm{E}+00$ & 0.0000 & $0.000 \mathrm{E}+00$ & 0.0000 & $1.997 \mathrm{E}+00$ & 0.0348 \\
\hline-238 & $0.000 \mathrm{E}+00$ & 0.0000 & $0.000 \mathrm{E}+00$ & 0.0000 & $0.000 \mathrm{E}+00$ & 0.0000 & $0.000 \mathrm{E}+00$ & 0.0000 & $0.000 \mathrm{E}+00$ & 0.0000 & $0.000 \mathrm{E}+00$ & 0.0000 & $1.971 \mathrm{E}+00$ & 0.0343 \\
\hline-239 & $0.000 \mathrm{E}+00$ & 0.0000 & $0.000 \mathrm{E}+00$ & 0.0000 & $0.000 \mathrm{E}+00$ & 0.0000 & $0.000 \mathrm{E}+00$ & 0.0000 & $0.000 \mathrm{E}+00$ & 0.0000 & $0.000 \mathrm{E}+00$ & 0.0000 & $2.003 E+00$ & 0.0349 \\
\hline-240 & $0.000 \mathrm{E}+00$ & 0.0000 & $0.000 \mathrm{E}+00$ & 0.0000 & $0.000 \mathrm{E}+00$ & 0.0000 & $0.000 \mathrm{E}+00$ & 0.0000 & $0.000 \mathrm{E}+00$ & 0.0000 & $0.000 \mathrm{E}+00$ & 0.0000 & $2.001 \mathrm{E}+00$ & 0.0348 \\
\hline 99 & $0.000 \mathrm{E}+00$ & 0.0000 & $0.000 \mathrm{E}+00$ & 0.0000 & $0.000 \mathrm{E}+00$ & 0.0000 & $0.000 \mathrm{E}+00$ & 0.0000 & $0.000 \mathrm{E}+00$ & 0.0000 & $0.000 \mathrm{E}+00$ & 0.0000 & $9.095 \mathrm{E}-03$ & 0.0002 \\
\hline-228 & $0.000 \mathrm{E}+00$ & 0.0000 & $0.000 \mathrm{E}+00$ & 0.0000 & $0.000 \mathrm{E}+00$ & 0.0000 & $0.000 \mathrm{E}+00$ & 0.0000 & $0.000 \mathrm{E}+00$ & 0.0000 & $0.000 \mathrm{E}+00$ & 0.0000 & $7.575 \mathrm{E}+00$ & 0.1319 \\
\hline-230 & $0.000 \mathrm{E}+00$ & 0.0000 & $0.000 \mathrm{E}+00$ & 0.0000 & $0.000 \mathrm{E}+00$ & 0.0000 & $0.000 \mathrm{E}+00$ & 0.0000 & $0.000 \mathrm{E}+00$ & 0.0000 & $0.000 \mathrm{E}+00$ & 0.0000 & $4.935 E+00$ & 0.0860 \\
\hline-232 & $0.000 \mathrm{E}+00$ & 0.0000 & $0.000 \mathrm{E}+00$ & 0.0000 & $0.000 \mathrm{E}+00$ & 0.0000 & $0.000 \mathrm{E}+00$ & 0.0000 & $0.000 \mathrm{E}+00$ & 0.0000 & $0.000 \mathrm{E}+00$ & 0.0000 & $2.061 \mathrm{E}+00$ & 0.0359 \\
\hline 234 & $0.000 \mathrm{E}+00$ & 0.0000 & $0.000 \mathrm{E}+00$ & 0.0000 & $0.000 \mathrm{E}+00$ & 0.0000 & $0.000 \mathrm{E}+00$ & 0.0000 & $0.000 \mathrm{E}+00$ & 0.0000 & $0.000 \mathrm{E}+00$ & 0.0000 & $1.752 \mathrm{E}+00$ & 0.0305 \\
\hline 35 & $0.000 \mathrm{E}+00$ & 0.0000 & $0.000 \mathrm{E}+00$ & 0.0000 & $0.000 \mathrm{E}+00$ & 0.0000 & $0.000 \mathrm{E}+00$ & 0.0000 & $0.000 \mathrm{E}+00$ & 0.0000 & $0.000 \mathrm{E}+00$ & 0.0000 & $1.577 \mathrm{E}+00$ & 0.0275 \\
\hline 38 & $0.000 \mathrm{E}+00$ & 0.0000 & $0.000 \mathrm{E}+00$ & 0.0000 & $0.000 \mathrm{E}+00$ & 0.0000 & $0.000 \mathrm{E}+00$ & 0.0000 & $0.000 \mathrm{E}+00$ & 0.0000 & $0.000 \mathrm{E}+00$ & 0.0000 & $1.000 \mathrm{E}+01$ & 0.1742 \\
\hline & $0.000 \mathrm{E}+00$ & 0.0000 & $0.000 \mathrm{E}+00$ & 0.0000 & $0.000 \mathrm{E}+00$ & 0.0000 & $0.000 \mathrm{E}+00$ & 0.0000 & $0.000 \mathrm{E}+00$ & 0.0000 & $0.000 \mathrm{E}+00$ & 0.0000 & +01 & 000 \\
\hline
\end{tabular}

* Sum of all water independent and dependent pathways. 


\section{RESRAD, Version $6.5 \quad$ T1/2 Limit $=180$ days $\quad$ 07/20/2011 $15: 45$ Page}

Summary : RESRAD Parameters for U-Landfill Worker Forward Run Proposed ALs

File : C: \RESRAD_FAMILY \RESRAD \USERFILES $\backslash Q C J U L Y 2011 \backslash$ LANDFILLWORK_FORWARDRUN-70YRALS.RAD

Total Dose Contributions TDOSE(i,p,t) for Individual Radionuclides (i) and Pathways (p) As mrem/yr and Fraction of Total Dose At $t=2.500 \mathrm{E}+01$ years

Water Independent Pathways (Inhalation excludes radon)

\begin{tabular}{|c|c|c|c|c|c|c|c|c|c|c|c|c|c|c|}
\hline & \multicolumn{2}{|c|}{ Ground } & \multicolumn{2}{|c|}{ Inhalation } & \multicolumn{2}{|c|}{ Radon } & \multicolumn{2}{|c|}{ Plant } & \multicolumn{2}{|c|}{ Meat } & \multicolumn{2}{|c|}{ Milk } & \multicolumn{2}{|c|}{ Soil } \\
\hline Iide & mrem/yr & fract. & mrem/yr & fract. & mrem/yr & fract. & mrem/yr & fract. & mrem/yr & fract. & mrem/yr & fract. & mrem/yr & fract. \\
\hline-241 & $4.235 E-01$ & 0.0067 & $1.214 \mathrm{E}-02$ & 0.0002 & $0.000 \mathrm{E}+00$ & 0.0000 & $0.000 \mathrm{E}+00$ & 0.0000 & $0.000 \mathrm{E}+00$ & 0.0000 & $0.000 \mathrm{E}+00$ & 0.0000 & $1.481 \mathrm{E}+00$ & 0.0236 \\
\hline-137 & $1.118 \mathrm{E}+01$ & 0.1781 & $1.546 \mathrm{E}-06$ & 0.0000 & $0.000 \mathrm{E}+00$ & 0.0000 & $0.000 \mathrm{E}+00$ & 0.0000 & $0.000 \mathrm{E}+00$ & 0.0000 & $0.000 \mathrm{E}+00$ & 0.0000 & $3.017 \mathrm{E}-02$ & 0.0005 \\
\hline-237 & $1.855 \mathrm{E}+00$ & 0.0295 & $1.031 \mathrm{E}-03$ & 0.0000 & $0.000 \mathrm{E}+00$ & 0.0000 & $0.000 \mathrm{E}+00$ & 0.0000 & $0.000 \mathrm{E}+00$ & 0.0000 & $0.000 \mathrm{E}+00$ & 0.0000 & $1.339 \mathrm{E}-01$ & 0.0021 \\
\hline 238 & 1. $262 \mathrm{E}-03$ & 0.0000 & $1.320 \mathrm{E}-02$ & 0.0002 & $0.000 \mathrm{E}+00$ & 0.0000 & $0.000 \mathrm{E}+00$ & 0.0000 & $0.000 \mathrm{E}+00$ & 0.0000 & $0.000 \mathrm{E}+00$ & 0.0000 & $1.615 \mathrm{E}+00$ & 0.0257 \\
\hline 239 & $3.180 \mathrm{E}-03$ & 0.0001 & $1.624 \mathrm{E}-02$ & 0.0003 & $0.000 \mathrm{E}+00$ & 0.0000 & $0.000 \mathrm{E}+00$ & 0.0000 & $0.000 \mathrm{E}+00$ & 0.0000 & $0.000 \mathrm{E}+00$ & 0.0000 & $1.981 \mathrm{E}+00$ & 0.0315 \\
\hline 240 & $1.373 E-03$ & 0.0000 & $1.621 \mathrm{E}-02$ & 0.0003 & $0.000 \mathrm{E}+00$ & 0.0000 & $0.000 \mathrm{E}+00$ & 0.0000 & $0.000 \mathrm{E}+00$ & 0.0000 & $0.000 \mathrm{E}+00$ & 0.0000 & $1.977 \mathrm{E}+00$ & 0.0315 \\
\hline 99 & $1.453 E-03$ & 0.0000 & 1. $943 E-06$ & 0.0000 & $0.000 \mathrm{E}+00$ & 0.0000 & $0.000 \mathrm{E}+00$ & 0.0000 & $0.000 \mathrm{E}+00$ & 0.0000 & $0.000 \mathrm{E}+00$ & 0.0000 & $5.601 \mathrm{E}-03$ & 0.0001 \\
\hline-228 & $1.255 \mathrm{E}-03$ & 0.0000 & $6.417 \mathrm{E}-08$ & 0.0000 & $0.000 \mathrm{E}+00$ & 0.0000 & $0.000 \mathrm{E}+00$ & 0.0000 & $0.000 \mathrm{E}+00$ & 0.0000 & $0.000 \mathrm{E}+00$ & 0.0000 & $1.234 \mathrm{E}-05$ & 0.0000 \\
\hline 230 & $3.895 E+00$ & 0.0620 & $3.769 \mathrm{E}-02$ & 0.0006 & $0.000 \mathrm{E}+00$ & 0.0000 & $0.000 \mathrm{E}+00$ & 0.0000 & $0.000 \mathrm{E}+00$ & 0.0000 & $0.000 \mathrm{E}+00$ & 0.0000 & $4.836 \mathrm{E}+00$ & 0.0770 \\
\hline 232 & $1.911 \mathrm{E}+01$ & 0.3043 & $2.497 \mathrm{E}-03$ & 0.0000 & $0.000 \mathrm{E}+00$ & 0.0000 & $0.000 \mathrm{E}+00$ & 0.0000 & $0.000 \mathrm{E}+00$ & 0.0000 & $0.000 \mathrm{E}+00$ & 0.0000 & $9.000 \mathrm{E}-01$ & 0.0143 \\
\hline 34 & $1.920 \mathrm{E}-02$ & 0.0003 & $5.643 \mathrm{E}-03$ & 0.0001 & $0.000 \mathrm{E}+00$ & 0.0000 & $0.000 \mathrm{E}+00$ & 0.0000 & $0.000 \mathrm{E}+00$ & 0.0000 & $0.000 \mathrm{E}+00$ & 0.0000 & $1.720 \mathrm{E}+00$ & 0.0274 \\
\hline 35 & $1.502 \mathrm{E}+00$ & 0.0239 & $2.110 \mathrm{E}-04$ & 0.0000 & $0.000 \mathrm{E}+00$ & 0.0000 & $0.000 \mathrm{E}+00$ & 0.0000 & $0.000 \mathrm{E}+00$ & 0.0000 & $0.000 \mathrm{E}+00$ & 0.0000 & $6.828 \mathrm{E}-02$ & 0.0011 \\
\hline 38 & $8.250 \mathrm{E}+00$ & 0.1314 & $4.797 E-03$ & 0.0001 & $0.000 \mathrm{E}+00$ & 0.0000 & $0.000 \mathrm{E}+00$ & 0.0000 & $0.000 \mathrm{E}+00$ & 0.0000 & $0.000 \mathrm{E}+00$ & 0.0000 & $1.697 \mathrm{E}+00$ & 0.0270 \\
\hline & $4.624 \mathrm{E}+01$ & 0.7364 & $1.097 \mathrm{E}-01$ & 0.0017 & $0.000 \mathrm{E}+00$ & 0.0000 & $0.000 \mathrm{E}+00$ & 0.0000 & $0.000 \mathrm{E}+00$ & 0.0000 & $0.000 \mathrm{E}+00$ & 0.0000 & +01 & 619 \\
\hline
\end{tabular}

Total Dose Contributions TDOSE(i,p,t) for Individual Radionuclides (i) and Pathways (p) As mrem/yr and Fraction of Total Dose At $t=2.500 \mathrm{E}+01$ years

Water Dependent Pathways

\begin{tabular}{|c|c|c|c|c|c|c|c|c|c|c|c|c|c|c|}
\hline \multirow{2}{*}{ Nuclide } & \multicolumn{2}{|c|}{ Water } & \multicolumn{2}{|c|}{ Fish } & \multicolumn{2}{|c|}{ Radon } & \multicolumn{2}{|c|}{ Plant } & \multicolumn{2}{|c|}{ Meat } & \multicolumn{2}{|c|}{ Milk } & \multicolumn{2}{|c|}{ All Pathways* } \\
\hline & mrem/yr & fract. & mrem/yr & fract. & mrem/yr & fract. & mrem/yr & fract. & mrem/yr & fract. & mrem/yr & fract. & mrem/yr & fract. \\
\hline-241 & $0.000 \mathrm{E}+00$ & 0.0000 & $0.000 \mathrm{E}+00$ & 0.0000 & $0.000 \mathrm{E}+00$ & 0.0000 & $0.000 \mathrm{E}+00$ & 0.0000 & $0.000 \mathrm{E}+00$ & 0.0000 & $0.000 \mathrm{E}+00$ & 0.0000 & $1.916 \mathrm{E}+00$ & 0.0305 \\
\hline-137 & $0.000 \mathrm{E}+00$ & 0.0000 & $0.000 \mathrm{E}+00$ & 0.0000 & $0.000 \mathrm{E}+00$ & 0.0000 & $0.000 \mathrm{E}+00$ & 0.0000 & $0.000 \mathrm{E}+00$ & 0.0000 & $0.000 \mathrm{E}+00$ & 0.0000 & $1.121 \mathrm{E}+01$ & 0.1785 \\
\hline-237 & $0.000 \mathrm{E}+00$ & 0.0000 & $0.000 \mathrm{E}+00$ & 0.0000 & $0.000 \mathrm{E}+00$ & 0.0000 & $0.000 \mathrm{E}+00$ & 0.0000 & $0.000 \mathrm{E}+00$ & 0.0000 & $0.000 \mathrm{E}+00$ & 0.0000 & $1.990 \mathrm{E}+00$ & 0.0317 \\
\hline-238 & $0.000 \mathrm{E}+00$ & 0.0000 & $0.000 \mathrm{E}+00$ & 0.0000 & $0.000 \mathrm{E}+00$ & 0.0000 & $0.000 \mathrm{E}+00$ & 0.0000 & $0.000 \mathrm{E}+00$ & 0.0000 & $0.000 \mathrm{E}+00$ & 0.0000 & $1.630 \mathrm{E}+00$ & 0.0260 \\
\hline 239 & $0.000 \mathrm{E}+00$ & 0.0000 & $0.000 \mathrm{E}+00$ & 0.0000 & $0.000 \mathrm{E}+00$ & 0.0000 & $0.000 \mathrm{E}+00$ & 0.0000 & $0.000 \mathrm{E}+00$ & 0.0000 & $0.000 \mathrm{E}+00$ & 0.0000 & $2.001 \mathrm{E}+00$ & 0.0319 \\
\hline-240 & $0.000 \mathrm{E}+00$ & 0.0000 & $0.000 \mathrm{E}+00$ & 0.0000 & $0.000 \mathrm{E}+00$ & 0.0000 & $0.000 \mathrm{E}+00$ & 0.0000 & $0.000 \mathrm{E}+00$ & 0.0000 & $0.000 \mathrm{E}+00$ & 0.0000 & $1.995 \mathrm{E}+00$ & 0.0318 \\
\hline 99 & $0.000 \mathrm{E}+00$ & 0.0000 & $0.000 \mathrm{E}+00$ & 0.0000 & $0.000 \mathrm{E}+00$ & 0.0000 & $0.000 \mathrm{E}+00$ & 0.0000 & $0.000 \mathrm{E}+00$ & 0.0000 & $0.000 \mathrm{E}+00$ & 0.0000 & $7.056 \mathrm{E}-03$ & 0.0001 \\
\hline-228 & $0.000 \mathrm{E}+00$ & 0.0000 & $0.000 \mathrm{E}+00$ & 0.0000 & $0.000 \mathrm{E}+00$ & 0.0000 & $0.000 \mathrm{E}+00$ & 0.0000 & $0.000 \mathrm{E}+00$ & 0.0000 & $0.000 \mathrm{E}+00$ & 0.0000 & $1.267 \mathrm{E}-03$ & 0.0000 \\
\hline-230 & $0.000 \mathrm{E}+00$ & 0.0000 & $0.000 \mathrm{E}+00$ & 0.0000 & $0.000 \mathrm{E}+00$ & 0.0000 & $0.000 \mathrm{E}+00$ & 0.0000 & $0.000 \mathrm{E}+00$ & 0.0000 & $0.000 \mathrm{E}+00$ & 0.0000 & $8.769 \mathrm{E}+00$ & 0.1396 \\
\hline-232 & $0.000 \mathrm{E}+00$ & 0.0000 & $0.000 \mathrm{E}+00$ & 0.0000 & $0.000 \mathrm{E}+00$ & 0.0000 & $0.000 \mathrm{E}+00$ & 0.0000 & $0.000 \mathrm{E}+00$ & 0.0000 & $0.000 \mathrm{E}+00$ & 0.0000 & $2.001 E+01$ & 0.3187 \\
\hline 234 & $0.000 \mathrm{E}+00$ & 0.0000 & $0.000 \mathrm{E}+00$ & 0.0000 & $0.000 \mathrm{E}+00$ & 0.0000 & $0.000 \mathrm{E}+00$ & 0.0000 & $0.000 \mathrm{E}+00$ & 0.0000 & $0.000 \mathrm{E}+00$ & 0.0000 & $1.745 \mathrm{E}+00$ & 0.0278 \\
\hline 35 & $0.000 \mathrm{E}+00$ & 0.0000 & $0.000 \mathrm{E}+00$ & 0.0000 & $0.000 \mathrm{E}+00$ & 0.0000 & $0.000 \mathrm{E}+00$ & 0.0000 & $0.000 \mathrm{E}+00$ & 0.0000 & $0.000 \mathrm{E}+00$ & 0.0000 & $1.570 \mathrm{E}+00$ & 0.0250 \\
\hline 38 & $0.000 \mathrm{E}+00$ & 0.0000 & $0.000 \mathrm{E}+00$ & 0.0000 & $0.000 \mathrm{E}+00$ & 0.0000 & $0.000 \mathrm{E}+00$ & 0.0000 & $0.000 \mathrm{E}+00$ & 0.0000 & $0.000 \mathrm{E}+00$ & 0.0000 & $9.952 \mathrm{E}+00$ & 0.1585 \\
\hline & $0.000 \mathrm{E}+00$ & 0.0000 & $0.000 \mathrm{E}+00$ & 0.0000 & $0.000 \mathrm{E}+00$ & 0.0000 & $0.000 \mathrm{E}+00$ & 0.0000 & $0.000 \mathrm{E}+00$ & 0.0000 & $0.000 \mathrm{E}+00$ & 0.0000 & $30 E+01$ & 1.0000 \\
\hline
\end{tabular}

* Sum of all water independent and dependent pathways. 


\section{RESRAD, Version $6.5 \quad$ T1/2 Limit $=180$ days $\quad$ 07/20/2011 $15: 45$ Page}

Summary : RESRAD Parameters for U-Landfill Worker Forward Run Proposed ALs

File : C: \RESRAD_FAMILY \RESRAD \USERFILES $\backslash Q C J U L Y 2011 \backslash$ LANDFILLWORK_FORWARDRUN-70YRALS.RAD

Total Dose Contributions TDOSE(i,p,t) for Individual Radionuclides (i) and Pathways (p) As mrem/yr and Fraction of Total Dose At $t=5.000 \mathrm{E}+01$ years

Water Independent Pathways (Inhalation excludes radon)

\begin{tabular}{|c|c|c|c|c|c|c|c|c|c|c|c|c|c|c|}
\hline & \multicolumn{2}{|c|}{ Ground } & \multicolumn{2}{|c|}{ Inhalation } & \multicolumn{2}{|c|}{ Radon } & \multicolumn{2}{|c|}{ Plant } & \multicolumn{2}{|c|}{ Meat } & \multicolumn{2}{|c|}{ Milk } & \multicolumn{2}{|c|}{ Soil } \\
\hline Iide & mrem/yr & fract. & mrem/yr & fract. & mrem/yr & fract. & mrem/yr & fract. & mrem/yr & fract. & mrem/yr & fract. & mrem/yr & fract. \\
\hline-241 & $4.069 \mathrm{E}-01$ & 0.0065 & $1.166 \mathrm{E}-02$ & 0.0002 & $0.000 \mathrm{E}+00$ & 0.0000 & $0.000 \mathrm{E}+00$ & 0.0000 & $0.000 \mathrm{E}+00$ & 0.0000 & $0.000 \mathrm{E}+00$ & 0.0000 & $1.422 \mathrm{E}+00$ & 0.0227 \\
\hline-137 & $6.269 \mathrm{E}+00$ & 0.1000 & $8.668 \mathrm{E}-07$ & 0.0000 & $0.000 \mathrm{E}+00$ & 0.0000 & $0.000 \mathrm{E}+00$ & 0.0000 & $0.000 \mathrm{E}+00$ & 0.0000 & $0.000 \mathrm{E}+00$ & 0.0000 & $1.692 \mathrm{E}-02$ & 0.0003 \\
\hline-237 & $1.847 \mathrm{E}+00$ & 0.0295 & $1.027 \mathrm{E}-03$ & 0.0000 & $0.000 \mathrm{E}+00$ & 0.0000 & $0.000 \mathrm{E}+00$ & 0.0000 & $0.000 \mathrm{E}+00$ & 0.0000 & $0.000 \mathrm{E}+00$ & 0.0000 & $1.333 \mathrm{E}-01$ & 0.0021 \\
\hline 238 & $1.036 \mathrm{E}-03$ & 0.0000 & $1.083 \mathrm{E}-02$ & 0.0002 & $0.000 \mathrm{E}+00$ & 0.0000 & $0.000 \mathrm{E}+00$ & 0.0000 & $0.000 \mathrm{E}+00$ & 0.0000 & $0.000 \mathrm{E}+00$ & 0.0000 & 1. $325 \mathrm{E}+00$ & 0.0211 \\
\hline 239 & $3.176 \mathrm{E}-03$ & 0.0001 & $1.622 \mathrm{E}-02$ & 0.0003 & $0.000 \mathrm{E}+00$ & 0.0000 & $0.000 \mathrm{E}+00$ & 0.0000 & $0.000 \mathrm{E}+00$ & 0.0000 & $0.000 \mathrm{E}+00$ & 0.0000 & $1.979 \mathrm{E}+00$ & 0.0315 \\
\hline 240 & $1.369 \mathrm{E}-03$ & 0.0000 & $1.616 \mathrm{E}-02$ & 0.0003 & $0.000 \mathrm{E}+00$ & 0.0000 & $0.000 \mathrm{E}+00$ & 0.0000 & $0.000 \mathrm{E}+00$ & 0.0000 & $0.000 \mathrm{E}+00$ & 0.0000 & $1.971 \mathrm{E}+00$ & 0.0314 \\
\hline 99 & $1.115 \mathrm{E}-03$ & 0.0000 & $1.492 \mathrm{E}-06$ & 0.0000 & $0.000 \mathrm{E}+00$ & 0.0000 & $0.000 \mathrm{E}+00$ & 0.0000 & $0.000 \mathrm{E}+00$ & 0.0000 & $0.000 \mathrm{E}+00$ & 0.0000 & $4.299 \mathrm{E}-03$ & 0.0001 \\
\hline 228 & $1.462 E-07$ & 0.0000 & $7.473 E-12$ & 0.0000 & $0.000 \mathrm{E}+00$ & 0.0000 & $0.000 \mathrm{E}+00$ & 0.0000 & $0.000 \mathrm{E}+00$ & 0.0000 & $0.000 \mathrm{E}+00$ & 0.0000 & $1.437 \mathrm{E}-09$ & 0.0000 \\
\hline 230 & $7.621 \mathrm{E}+00$ & 0.1215 & $3.774 \mathrm{E}-02$ & 0.0006 & $0.000 \mathrm{E}+00$ & 0.0000 & $0.000 \mathrm{E}+00$ & 0.0000 & $0.000 \mathrm{E}+00$ & 0.0000 & $0.000 \mathrm{E}+00$ & 0.0000 & $5.205 E+00$ & 0.0830 \\
\hline 232 & $2.028 E+01$ & 0.3233 & $2.550 \mathrm{E}-03$ & 0.0000 & $0.000 \mathrm{E}+00$ & 0.0000 & $0.000 \mathrm{E}+00$ & 0.0000 & $0.000 \mathrm{E}+00$ & 0.0000 & $0.000 \mathrm{E}+00$ & 0.0000 & $9.349 \mathrm{E}-01$ & 0.0149 \\
\hline & $2.116 \mathrm{E}-02$ & 0.0003 & $5.625 E-03$ & 0.0001 & $0.000 \mathrm{E}+00$ & 0.0000 & $0.000 \mathrm{E}+00$ & 0.0000 & $0.000 \mathrm{E}+00$ & 0.0000 & $0.000 \mathrm{E}+00$ & 0.0000 & $1.712 \mathrm{E}+00$ & 0.0273 \\
\hline 235 & $1.495 \mathrm{E}+00$ & 0.0238 & $2.167 \mathrm{E}-04$ & 0.0000 & $0.000 \mathrm{E}+00$ & 0.0000 & $0.000 \mathrm{E}+00$ & 0.0000 & $0.000 \mathrm{E}+00$ & 0.0000 & $0.000 \mathrm{E}+00$ & 0.0000 & $6.906 \mathrm{E}-02$ & 0.0011 \\
\hline 38 & $8.204 \mathrm{E}+00$ & 0.1308 & $4.770 \mathrm{E}-03$ & 0.0001 & $0.000 \mathrm{E}+00$ & 0.0000 & $0.000 \mathrm{E}+00$ & 0.0000 & $0.000 \mathrm{E}+00$ & 0.0000 & $0.000 \mathrm{E}+00$ & 0.0000 & $1.688 \mathrm{E}+00$ & 0.0269 \\
\hline & $4.615 E+01$ & 0.7359 & $1.068 \mathrm{E}-01$ & 0.0017 & $0.000 \mathrm{E}+00$ & 0.0000 & $0.000 \mathrm{E}+00$ & 0.0000 & $0.000 \mathrm{E}+00$ & 0.0000 & $0.000 \mathrm{E}+00$ & 0.0000 & +01 & 0.2624 \\
\hline
\end{tabular}

Total Dose Contributions TDOSE(i,p,t) for Individual Radionuclides (i) and Pathways (p) As mrem/yr and Fraction of Total Dose At $t=5.000 \mathrm{E}+01$ years

Water Dependent Pathways

\begin{tabular}{|c|c|c|c|c|c|c|c|c|c|c|c|c|c|c|}
\hline \multirow{2}{*}{$\begin{array}{l}\text { Radio- } \\
\text { Nuclide }\end{array}$} & \multicolumn{2}{|c|}{ Water } & \multicolumn{2}{|c|}{ Fish } & \multicolumn{2}{|c|}{ Radon } & \multicolumn{2}{|c|}{ Plant } & \multicolumn{2}{|c|}{ Meat } & \multicolumn{2}{|c|}{ Milk } & \multicolumn{2}{|c|}{ All Pathways* } \\
\hline & mrem/yr & fract. & mrem/yr & fract. & mrem/yr & fract. & mrem/yr & fract. & mrem/yr & fract. & mrem/yr & fract. & mrem/yr & fract. \\
\hline 241 & $0.000 \mathrm{E}+00$ & 0.0000 & $0.000 \mathrm{E}+00$ & 0.0000 & $0.000 \mathrm{E}+00$ & 0.0000 & $0.000 \mathrm{E}+00$ & 0.0000 & $0.000 \mathrm{E}+00$ & 0.0000 & $0.000 \mathrm{E}+00$ & 0.0000 & $1.841 \mathrm{E}+00$ & 0.0294 \\
\hline-137 & $0.000 \mathrm{E}+00$ & 0.0000 & $0.000 \mathrm{E}+00$ & 0.0000 & $0.000 \mathrm{E}+00$ & 0.0000 & $0.000 \mathrm{E}+00$ & 0.0000 & $0.000 \mathrm{E}+00$ & 0.0000 & $0.000 \mathrm{E}+00$ & 0.0000 & $6.286 \mathrm{E}+00$ & 0.1002 \\
\hline-237 & $0.000 \mathrm{E}+00$ & 0.0000 & $0.000 \mathrm{E}+00$ & 0.0000 & $0.000 \mathrm{E}+00$ & 0.0000 & $0.000 \mathrm{E}+00$ & 0.0000 & $0.000 \mathrm{E}+00$ & 0.0000 & $0.000 \mathrm{E}+00$ & 0.0000 & $1.982 \mathrm{E}+00$ & 0.0316 \\
\hline-238 & $0.000 \mathrm{E}+00$ & 0.0000 & $0.000 \mathrm{E}+00$ & 0.0000 & $0.000 \mathrm{E}+00$ & 0.0000 & $0.000 \mathrm{E}+00$ & 0.0000 & $0.000 \mathrm{E}+00$ & 0.0000 & $0.000 \mathrm{E}+00$ & 0.0000 & $1.337 \mathrm{E}+00$ & 0.0213 \\
\hline-239 & $0.000 \mathrm{E}+00$ & 0.0000 & $0.000 \mathrm{E}+00$ & 0.0000 & $0.000 \mathrm{E}+00$ & 0.0000 & $0.000 \mathrm{E}+00$ & 0.0000 & $0.000 \mathrm{E}+00$ & 0.0000 & $0.000 E+00$ & 0.0000 & $1.998 \mathrm{E}+00$ & 0.0319 \\
\hline-240 & $0.000 \mathrm{E}+00$ & 0.0000 & $0.000 \mathrm{E}+00$ & 0.0000 & $0.000 \mathrm{E}+00$ & 0.0000 & $0.000 \mathrm{E}+00$ & 0.0000 & $0.000 \mathrm{E}+00$ & 0.0000 & $0.000 E+00$ & 0.0000 & $1.989 \mathrm{E}+00$ & 0.0317 \\
\hline-99 & $0.000 \mathrm{E}+00$ & 0.0000 & $0.000 \mathrm{E}+00$ & 0.0000 & $0.000 \mathrm{E}+00$ & 0.0000 & $0.000 \mathrm{E}+00$ & 0.0000 & $0.000 \mathrm{E}+00$ & 0.0000 & $0.000 \mathrm{E}+00$ & 0.0000 & $5.416 \mathrm{E}-03$ & 0.0001 \\
\hline-228 & $0.000 \mathrm{E}+00$ & 0.0000 & $0.000 \mathrm{E}+00$ & 0.0000 & $0.000 \mathrm{E}+00$ & 0.0000 & $0.000 \mathrm{E}+00$ & 0.0000 & $0.000 \mathrm{E}+00$ & 0.0000 & $0.000 \mathrm{E}+00$ & 0.0000 & $1.476 \mathrm{E}-07$ & 0.0000 \\
\hline-230 & $0.000 \mathrm{E}+00$ & 0.0000 & $0.000 \mathrm{E}+00$ & 0.0000 & $0.000 \mathrm{E}+00$ & 0.0000 & $0.000 \mathrm{E}+00$ & 0.0000 & $0.000 \mathrm{E}+00$ & 0.0000 & $0.000 E+00$ & 0.0000 & $1.286 \mathrm{E}+01$ & 0.2051 \\
\hline 232 & $0.000 \mathrm{E}+00$ & 0.0000 & $0.000 \mathrm{E}+00$ & 0.0000 & $0.000 \mathrm{E}+00$ & 0.0000 & $0.000 \mathrm{E}+00$ & 0.0000 & $0.000 \mathrm{E}+00$ & 0.0000 & $0.000 \mathrm{E}+00$ & 0.0000 & $2.122 \mathrm{E}+01$ & 0.3383 \\
\hline 34 & $0.000 \mathrm{E}+00$ & 0.0000 & $0.000 \mathrm{E}+00$ & 0.0000 & $0.000 \mathrm{E}+00$ & 0.0000 & $0.000 \mathrm{E}+00$ & 0.0000 & $0.000 \mathrm{E}+00$ & 0.0000 & $0.000 \mathrm{E}+00$ & 0.0000 & $1.739 \mathrm{E}+00$ & 0.0277 \\
\hline 35 & $0.000 \mathrm{E}+00$ & 0.0000 & $0.000 \mathrm{E}+00$ & 0.0000 & $0.000 \mathrm{E}+00$ & 0.0000 & $0.000 \mathrm{E}+00$ & 0.0000 & $0.000 \mathrm{E}+00$ & 0.0000 & $0.000 \mathrm{E}+00$ & 0.0000 & $1.564 \mathrm{E}+00$ & 0.0249 \\
\hline 38 & $0.000 \mathrm{E}+00$ & 0.0000 & $0.000 \mathrm{E}+00$ & 0.0000 & $0.000 \mathrm{E}+00$ & 0.0000 & $0.000 \mathrm{E}+00$ & 0.0000 & $0.000 \mathrm{E}+00$ & 0.0000 & $0.000 \mathrm{E}+00$ & 0.0000 & $9.897 \mathrm{E}+00$ & 0.1578 \\
\hline & $0.000 \mathrm{E}+00$ & 0.0000 & $0.000 \mathrm{E}+00$ & 0.0000 & $0.000 \mathrm{E}+00$ & 0.0000 & $0.000 \mathrm{E}+00$ & 0.0000 & $0.000 \mathrm{E}+00$ & 0.0000 & $0.000 \mathrm{E}+00$ & 0.0000 & $2 E+01$ & 1. \\
\hline
\end{tabular}

* Sum of all water independent and dependent pathways. 


\section{RESRAD, Version $6.5 \quad$ T1/2 Limit $=180$ days $\quad$ 07/20/2011 $15: 45$ Page}

Summary : RESRAD Parameters for U-Landfill Worker Forward Run Proposed ALs

File : C: \RESRAD_FAMILY \RESRAD \USERFILES $\backslash Q C J U L Y 2011 \backslash$ LANDFILLWORK_FORWARDRUN-70YRALS.RAD

Total Dose Contributions TDOSE(i,p,t) for Individual Radionuclides (i) and Pathways (p) As mrem/yr and Fraction of Total Dose At $t=7.000 \mathrm{E}+01$ years

Water Independent Pathways (Inhalation excludes radon)

\begin{tabular}{|c|c|c|c|c|c|c|c|c|c|c|c|c|c|c|}
\hline \multirow{2}{*}{ Nuclide } & \multicolumn{2}{|c|}{ Ground } & \multicolumn{2}{|c|}{ Inhalation } & \multicolumn{2}{|c|}{ Radon } & \multicolumn{2}{|c|}{ Plant } & \multicolumn{2}{|c|}{ Meat } & \multicolumn{2}{|c|}{ Milk } & \multicolumn{2}{|c|}{ Soil } \\
\hline & mrem/yr & fract. & mrem/yr & fract. & mrem/yr & fract. & mrem/yr & fract. & mrem/yr & fract. & mrem/yr & fract. & mrem/yr & fract. \\
\hline-241 & $3.941 E-01$ & 0.0062 & $1.129 \mathrm{E}-02$ & 0.0002 & $0.000 \mathrm{E}+00$ & 0.0000 & $0.000 \mathrm{E}+00$ & 0.0000 & $0.000 \mathrm{E}+00$ & 0.0000 & $0.000 \mathrm{E}+00$ & 0.0000 & $1.377 \mathrm{E}+00$ & 0.0217 \\
\hline-137 & $3.946 \mathrm{E}+00$ & 0.0622 & $5.456 \mathrm{E}-07$ & 0.0000 & $0.000 \mathrm{E}+00$ & 0.0000 & $0.000 \mathrm{E}+00$ & 0.0000 & $0.000 \mathrm{E}+00$ & 0.0000 & $0.000 \mathrm{E}+00$ & 0.0000 & $1.065 \mathrm{E}-02$ & 0.0002 \\
\hline-237 & $1.842 \mathrm{E}+00$ & 0.0290 & $1.024 \mathrm{E}-03$ & 0.0000 & $0.000 \mathrm{E}+00$ & 0.0000 & $0.000 \mathrm{E}+00$ & 0.0000 & $0.000 \mathrm{E}+00$ & 0.0000 & $0.000 \mathrm{E}+00$ & 0.0000 & $1.329 \mathrm{E}-01$ & 0.0021 \\
\hline-238 & $8.843 E-04$ & 0.0000 & $9.240 \mathrm{E}-03$ & 0.0001 & $0.000 \mathrm{E}+00$ & 0.0000 & $0.000 \mathrm{E}+00$ & 0.0000 & $0.000 \mathrm{E}+00$ & 0.0000 & $0.000 \mathrm{E}+00$ & 0.0000 & $1.131 \mathrm{E}+00$ & 0.0178 \\
\hline-239 & $3.174 \mathrm{E}-03$ & 0.0001 & $1.621 \mathrm{E}-02$ & 0.0003 & $0.000 \mathrm{E}+00$ & 0.0000 & $0.000 \mathrm{E}+00$ & 0.0000 & $0.000 \mathrm{E}+00$ & 0.0000 & $0.000 \mathrm{E}+00$ & 0.0000 & $1.977 \mathrm{E}+00$ & 0.0312 \\
\hline-240 & $1.366 \mathrm{E}-03$ & 0.0000 & $1.612 \mathrm{E}-02$ & 0.0003 & $0.000 \mathrm{E}+00$ & 0.0000 & $0.000 \mathrm{E}+00$ & 0.0000 & $0.000 \mathrm{E}+00$ & 0.0000 & $0.000 \mathrm{E}+00$ & 0.0000 & $1.966 \mathrm{E}+00$ & 0.0310 \\
\hline 99 & $9.027 \mathrm{E}-04$ & 0.0000 & $1.207 \mathrm{E}-06$ & 0.0000 & $0.000 \mathrm{E}+00$ & 0.0000 & $0.000 \mathrm{E}+00$ & 0.0000 & $0.000 \mathrm{E}+00$ & 0.0000 & $0.000 \mathrm{E}+00$ & 0.0000 & $3.480 \mathrm{E}-03$ & 0.0001 \\
\hline-228 & $1.042 \mathrm{E}-10$ & 0.0000 & $5.326 \mathrm{E}-15$ & 0.0000 & $0.000 \mathrm{E}+00$ & 0.0000 & $0.000 \mathrm{E}+00$ & 0.0000 & $0.000 \mathrm{E}+00$ & 0.0000 & $0.000 \mathrm{E}+00$ & 0.0000 & $1.024 \mathrm{E}-12$ & 0.0000 \\
\hline-230 & $1.056 \mathrm{E}+01$ & 0.1666 & $3.779 \mathrm{E}-02$ & 0.0006 & $0.000 \mathrm{E}+00$ & 0.0000 & $0.000 \mathrm{E}+00$ & 0.0000 & $0.000 \mathrm{E}+00$ & 0.0000 & $0.000 \mathrm{E}+00$ & 0.0000 & $5.553 \mathrm{E}+00$ & 0.0876 \\
\hline-232 & $2.033 E+01$ & 0.3206 & $2.553 E-03$ & 0.0000 & $0.000 \mathrm{E}+00$ & 0.0000 & $0.000 \mathrm{E}+00$ & 0.0000 & $0.000 \mathrm{E}+00$ & 0.0000 & $0.000 \mathrm{E}+00$ & 0.0000 & $9.364 \mathrm{E}-01$ & 0.0148 \\
\hline 234 & $2.368 E-02$ & 0.0004 & $5.611 \mathrm{E}-03$ & 0.0001 & $0.000 \mathrm{E}+00$ & 0.0000 & $0.000 \mathrm{E}+00$ & 0.0000 & $0.000 \mathrm{E}+00$ & 0.0000 & $0.000 \mathrm{E}+00$ & 0.0000 & $1.706 \mathrm{E}+00$ & 0.0269 \\
\hline 35 & $1.490 \mathrm{E}+00$ & 0.0235 & $2.220 \mathrm{E}-04$ & 0.0000 & $0.000 \mathrm{E}+00$ & 0.0000 & $0.000 \mathrm{E}+00$ & 0.0000 & $0.000 \mathrm{E}+00$ & 0.0000 & $0.000 \mathrm{E}+00$ & 0.0000 & $6.978 \mathrm{E}-02$ & 0.0011 \\
\hline 38 & $8.168 \mathrm{E}+00$ & 0.1288 & $4.750 \mathrm{E}-03$ & 0.0001 & $0.000 \mathrm{E}+00$ & 0.0000 & $0.000 \mathrm{E}+00$ & 0.0000 & $0.000 \mathrm{E}+00$ & 0.0000 & $0.000 \mathrm{E}+00$ & 0.0000 & $1.681 \mathrm{E}+00$ & 0.0265 \\
\hline & $4.677 E+01$ & 0.7375 & $1.048 E-01$ & 0.0017 & $0.000 \mathrm{E}+00$ & 0.0000 & $0.000 \mathrm{E}+00$ & 0.0000 & $0.000 \mathrm{E}+00$ & 0.0000 & $0.000 \mathrm{E}+00$ & 0.0000 & 1. $654 \mathrm{E}+01$ & 0.2609 \\
\hline
\end{tabular}

Total Dose Contributions TDOSE(i,p,t) for Individual Radionuclides (i) and Pathways (p) As mrem/yr and Fraction of Total Dose At $t=7.000 \mathrm{E}+01$ years

Water Dependent Pathways

\begin{tabular}{|c|c|c|c|c|c|c|c|c|c|c|c|c|c|c|}
\hline \multirow{2}{*}{ Nuclide } & \multicolumn{2}{|c|}{ Water } & \multicolumn{2}{|c|}{ Fish } & \multicolumn{2}{|c|}{ Radon } & \multicolumn{2}{|c|}{ Plant } & \multicolumn{2}{|c|}{ Meat } & \multicolumn{2}{|c|}{ Milk } & \multicolumn{2}{|c|}{ All Pathways* } \\
\hline & mrem/yr & fract. & mrem/yr & fract. & mrem/yr & fract. & mrem/yr & fract. & mrem/yr & fract. & mrem/yr & fract. & mrem/yr & fract. \\
\hline-241 & $0.000 \mathrm{E}+00$ & 0.0000 & $0.000 \mathrm{E}+00$ & 0.0000 & $0.000 \mathrm{E}+00$ & 0.0000 & $0.000 \mathrm{E}+00$ & 0.0000 & $0.000 \mathrm{E}+00$ & 0.0000 & $0.000 \mathrm{E}+00$ & 0.0000 & $1.783 \mathrm{E}+00$ & 0.0281 \\
\hline-137 & $0.000 \mathrm{E}+00$ & 0.0000 & $0.000 \mathrm{E}+00$ & 0.0000 & $0.000 \mathrm{E}+00$ & 0.0000 & $0.000 \mathrm{E}+00$ & 0.0000 & $0.000 \mathrm{E}+00$ & 0.0000 & $0.000 \mathrm{E}+00$ & 0.0000 & $3.957 \mathrm{E}+00$ & 0.0624 \\
\hline-237 & $0.000 \mathrm{E}+00$ & 0.0000 & $0.000 \mathrm{E}+00$ & 0.0000 & $0.000 \mathrm{E}+00$ & 0.0000 & $0.000 \mathrm{E}+00$ & 0.0000 & $0.000 \mathrm{E}+00$ & 0.0000 & $0.000 \mathrm{E}+00$ & 0.0000 & $1.976 \mathrm{E}+00$ & 0.0312 \\
\hline-238 & $0.000 \mathrm{E}+00$ & 0.0000 & $0.000 \mathrm{E}+00$ & 0.0000 & $0.000 \mathrm{E}+00$ & 0.0000 & $0.000 \mathrm{E}+00$ & 0.0000 & $0.000 \mathrm{E}+00$ & 0.0000 & $0.000 \mathrm{E}+00$ & 0.0000 & $1.141 \mathrm{E}+00$ & 0.0180 \\
\hline 239 & $0.000 \mathrm{E}+00$ & 0.0000 & $0.000 \mathrm{E}+00$ & 0.0000 & $0.000 \mathrm{E}+00$ & 0.0000 & $0.000 \mathrm{E}+00$ & 0.0000 & $0.000 \mathrm{E}+00$ & 0.0000 & $0.000 \mathrm{E}+00$ & 0.0000 & $1.996 \mathrm{E}+00$ & 0.0315 \\
\hline-240 & $0.000 \mathrm{E}+00$ & 0.0000 & $0.000 \mathrm{E}+00$ & 0.0000 & $0.000 \mathrm{E}+00$ & 0.0000 & $0.000 \mathrm{E}+00$ & 0.0000 & $0.000 \mathrm{E}+00$ & 0.0000 & $0.000 \mathrm{E}+00$ & 0.0000 & $1.984 \mathrm{E}+00$ & 0.0313 \\
\hline 99 & $0.000 \mathrm{E}+00$ & 0.0000 & $0.000 \mathrm{E}+00$ & 0.0000 & $0.000 \mathrm{E}+00$ & 0.0000 & $0.000 \mathrm{E}+00$ & 0.0000 & $0.000 \mathrm{E}+00$ & 0.0000 & $0.000 \mathrm{E}+00$ & 0.0000 & $4.383 E-03$ & 0.0001 \\
\hline-228 & $0.000 \mathrm{E}+00$ & 0.0000 & $0.000 \mathrm{E}+00$ & 0.0000 & $0.000 \mathrm{E}+00$ & 0.0000 & $0.000 \mathrm{E}+00$ & 0.0000 & $0.000 \mathrm{E}+00$ & 0.0000 & $0.000 \mathrm{E}+00$ & 0.0000 & $1.052 \mathrm{E}-10$ & 0.0000 \\
\hline-230 & $0.000 \mathrm{E}+00$ & 0.0000 & $0.000 \mathrm{E}+00$ & 0.0000 & $0.000 \mathrm{E}+00$ & 0.0000 & $0.000 \mathrm{E}+00$ & 0.0000 & $0.000 \mathrm{E}+00$ & 0.0000 & $0.000 \mathrm{E}+00$ & 0.0000 & $1.615 \mathrm{E}+01$ & 0.2547 \\
\hline-232 & $0.000 \mathrm{E}+00$ & 0.0000 & $0.000 \mathrm{E}+00$ & 0.0000 & $0.000 \mathrm{E}+00$ & 0.0000 & $0.000 \mathrm{E}+00$ & 0.0000 & $0.000 \mathrm{E}+00$ & 0.0000 & $0.000 \mathrm{E}+00$ & 0.0000 & $2.127 \mathrm{E}+01$ & 0.3355 \\
\hline 234 & $0.000 \mathrm{E}+00$ & 0.0000 & $0.000 \mathrm{E}+00$ & 0.0000 & $0.000 \mathrm{E}+00$ & 0.0000 & $0.000 \mathrm{E}+00$ & 0.0000 & $0.000 \mathrm{E}+00$ & 0.0000 & $0.000 \mathrm{E}+00$ & 0.0000 & $1.735 \mathrm{E}+00$ & 0.0274 \\
\hline 35 & $0.000 \mathrm{E}+00$ & 0.0000 & $0.000 \mathrm{E}+00$ & 0.0000 & $0.000 \mathrm{E}+00$ & 0.0000 & $0.000 \mathrm{E}+00$ & 0.0000 & $0.000 \mathrm{E}+00$ & 0.0000 & $0.000 \mathrm{E}+00$ & 0.0000 & $1.560 \mathrm{E}+00$ & 0.0246 \\
\hline 38 & $0.000 \mathrm{E}+00$ & 0.0000 & $0.000 \mathrm{E}+00$ & 0.0000 & $0.000 \mathrm{E}+00$ & 0.0000 & $0.000 \mathrm{E}+00$ & 0.0000 & $0.000 \mathrm{E}+00$ & 0.0000 & $0.000 \mathrm{E}+00$ & 0.0000 & $9.854 \mathrm{E}+00$ & 0.1554 \\
\hline & $0.000 \mathrm{E}+00$ & 0.0000 & $0.000 \mathrm{E}+00$ & 0.0000 & $0.000 \mathrm{E}+00$ & 0.0000 & $0.000 \mathrm{E}+00$ & 0.0000 & $0.000 \mathrm{E}+00$ & 0.0000 & $0.000 \mathrm{E}+00$ & 0.0000 & $.342 E+01$ & 1.0000 \\
\hline
\end{tabular}

* Sum of all water independent and dependent pathways. 
RESRAD, Version $6.5 \quad$ T1/2 Limit $=180$ days $\quad$ 07/20/2011 15:45 Page

Summary : RESRAD Parameters for U-Landfill Worker Forward Run Proposed ALs

File : C: \RESRAD_FAMILY \RESRAD \USERFILES $\backslash Q C J U L Y 2011 \backslash$ LANDFILLWORK_FORWARDRUN-70YRALS.RAD

Dose/Source Ratios Summed Over All Pathways

Parent and Progeny Principal Radionuclide Contributions Indicated

Parent Product Thread DSR $(j, t)$ At Time in Years (mrem/yr)/ $(\mathrm{pCi} / \mathrm{g})$

(i) (j) Fraction $0.000 \mathrm{E}+001.000 \mathrm{E}+002.500 \mathrm{E}+015.000 \mathrm{E}+017.000 \mathrm{E}+01$

\section{$m-241$}

Am-241

Am-241

Am-241

Am-241

$C s-137+D$

$\mathrm{Np}-237+\mathrm{D}$

$\mathrm{Np}-237+\mathrm{D}$

$\mathrm{Np}-237+\mathrm{D}$

$\mathrm{Np}-237+\mathrm{D}$

$\mathrm{Pu}-238$

Pu-238

1. 840E-09

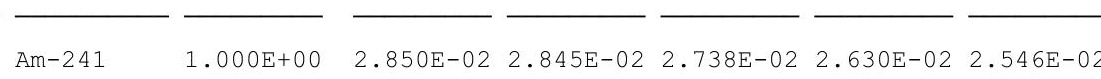

$\begin{array}{llllllll}\mathrm{Np}-237+\mathrm{D} & 1.000 \mathrm{E}+00 & 2.940 \mathrm{E}-08 & 8.812 \mathrm{E}-08 & 1.467 \mathrm{E}-06 & 2.842 \mathrm{E}-06 & 3.898 \mathrm{E}-06\end{array}$

$\begin{array}{llllllll}\mathrm{U}-233 & 1.000 \mathrm{E}+00 & 1.381 \mathrm{E}-15 & 9.659 \mathrm{E}-15 & 2.650 \mathrm{E}-12 & 1.022 \mathrm{E}-11 & 1.966 \mathrm{E}-11\end{array}$

$\begin{array}{llllllll}\mathrm{Th}-229+\mathrm{D} & 1.000 \mathrm{E}+00 & 1.757 \mathrm{E}-18 & 2.634 \mathrm{E}-17 & 1.151 \mathrm{E}-13 & 8.819 \mathrm{E}-13 & 2.375 \mathrm{E}-12\end{array}$

$\operatorname{LSR}(j)$

$\begin{array}{lllll}2.850 \mathrm{E}-02 & 2.845 \mathrm{E}-02 & 2.738 \mathrm{E}-02 & 2.630 \mathrm{E}-02 & 2.547 \mathrm{E}-02\end{array}$

$\mathrm{Cs}-137+\mathrm{D} \quad 1.000 \mathrm{E}+00 \quad 5.262 \mathrm{E}-01 \quad 5.142 \mathrm{E}-01 \quad 2.950 \mathrm{E}-01 \quad 1.654 \mathrm{E}-01 \quad 1.041 \mathrm{E}-01$

$\mathrm{Np}-237+\mathrm{D} \quad 1.000 \mathrm{E}+00 \quad 1.816 \mathrm{E}-01 \quad 1.816 \mathrm{E}-01 \quad 1.809 \mathrm{E}-01 \quad 1.802 \mathrm{E}-01 \quad 1.796 \mathrm{E}-01$

U-233 1.000E+00 1.279E-08 $3.837 \mathrm{E}-08 \quad 6.493 \mathrm{E}-07 \quad 1.280 \mathrm{E}-06 \quad 1.780 \mathrm{E}-06$

Th-229+D 1.000E+00 2.170E-11 $1.519 \mathrm{E}-10 \quad 4.217 \mathrm{E}-08 \quad 1.647 \mathrm{E}-07 \quad 3.200 \mathrm{E}-07$

$\operatorname{SDSR}(j) \quad 1.816 \mathrm{E}-01 \quad 1.816 \mathrm{E}-01 \quad 1.809 \mathrm{E}-01 \quad 1.802 \mathrm{E}-011.796 \mathrm{E}-01$

$\mathrm{Pu}-238$

$\begin{array}{lllllll}\mathrm{Pu}-238 & 1.000 \mathrm{E}+00 & 2.547 \mathrm{E}-02 & 2.527 \mathrm{E}-02 & 2.090 \mathrm{E}-02 & 1.714 \mathrm{E}-02 & 1.463 \mathrm{E}-02\end{array}$

$\begin{array}{llllllll}\mathrm{U}-234 & 1.000 \mathrm{E}+00 & 7.741 \mathrm{E}-09 & 2.314 \mathrm{E}-08 & 3.574 \mathrm{E}-07 & 6.422 \mathrm{E}-07 & 8.314 \mathrm{E}-07\end{array}$

$\begin{array}{llllllll}\mathrm{Th}-230 & 1.000 \mathrm{E}+00 & 9.980 \mathrm{E}-14 & 6.969 \mathrm{E}-13 & 1.822 \mathrm{E}-10 & 6.698 \mathrm{E}-10 & 1.241 \mathrm{E}-09\end{array}$

$\mathrm{Ra}-226+\mathrm{D} \quad 1.000 \mathrm{E}+00 \quad 8.233 \mathrm{E}-16 \quad 1.233 \mathrm{E}-14 \quad 5.179 \mathrm{E}-11 \quad 3.815 \mathrm{E}-10 \quad 9.962 \mathrm{E}-10$

$\mathrm{Pb}-210+\mathrm{D} \quad 1.000 \mathrm{E}+00 \quad 5.966 \mathrm{E}-19 \quad 1.837 \mathrm{E}-17 \quad 1.044 \mathrm{E}-12 \quad 1.342 \mathrm{E}-11 \quad 4.456 \mathrm{E}-11$

$\operatorname{LDSR}(j) \quad 2.547 \mathrm{E}-02 \quad 2.527 \mathrm{E}-02 \quad 2.090 \mathrm{E}-02 \quad 1.714 \mathrm{E}-02 \quad 1.463 \mathrm{E}-02$

$\begin{array}{llllllll}\mathrm{Pu}-239 & 1.000 \mathrm{E}+00 & 2.782 \mathrm{E}-02 & 2.782 \mathrm{E}-02 & 2.779 \mathrm{E}-02 & 2.775 \mathrm{E}-02 & 2.772 \mathrm{E}-02\end{array}$

$\mathrm{U}-235+\mathrm{D} \quad 1.000 \mathrm{E}+00 \quad 5.975 \mathrm{E}-11 \quad 1.792 \mathrm{E}-10 \quad 3.037 \mathrm{E}-09 \quad 5.994 \mathrm{E}-09 \quad 8.345 \mathrm{E}-09$

$\begin{array}{lllllll}\mathrm{Pa}-231 & 1.000 \mathrm{E}+00 & 3.749 \mathrm{E}-16 & 2.624 \mathrm{E}-15 & 7.283 \mathrm{E}-13 & 2.844 \mathrm{E}-12 & 5.524 \mathrm{E}-12\end{array}$

$\mathrm{AC}-227+\mathrm{D} \quad 1.000 \mathrm{E}+00 \quad 1.227 \mathrm{E}-17 \quad 1.828 \mathrm{E}-16 \quad 6.725 \mathrm{E}-13 \quad 4.394 \mathrm{E}-12 \quad 1.055 \mathrm{E}-11$

$\operatorname{LDSR}(j) \quad 2.782 \mathrm{E}-02 \quad 2.782 \mathrm{E}-02 \quad 2.779 \mathrm{E}-02 \quad 2.775 \mathrm{E}-02 \quad 2.772 \mathrm{E}-02$

$\begin{array}{lllllll}\mathrm{Pu}-240 \quad 4.950 \mathrm{E}-08 & 1.376 \mathrm{E}-09 & 1.376 \mathrm{E}-09 & 1.371 \mathrm{E}-09 & 1.367 \mathrm{E}-09 & 1.364 \mathrm{E}-09\end{array}$

$\begin{array}{llllllll}\mathrm{Pu}-240 \quad 1.000 \mathrm{E}+00 & 2.779 \mathrm{E}-02 & 2.779 \mathrm{E}-02 & 2.771 E-02 & 2.762 \mathrm{E}-02 & 2.755 \mathrm{E}-02\end{array}$

$\begin{array}{llllllll}\mathrm{U}-236 & 1.000 \mathrm{E}+00 & 7.734 \mathrm{E}-11 & 2.320 \mathrm{E}-10 & 3.927 \mathrm{E}-09 & 7.744 \mathrm{E}-09 & 1.077 \mathrm{E}-08\end{array}$

$\begin{array}{lllllll}\mathrm{Th}-232 & 1.000 \mathrm{E}+00 & 6.238 \mathrm{E}-21 & 4.366 \mathrm{E}-20 & 1.214 \mathrm{E}-17 & 4.745 \mathrm{E}-17 & 9.226 \mathrm{E}-17\end{array}$

$\mathrm{Ra}-228+\mathrm{D} \quad 1.000 \mathrm{E}+00 \quad 7.279 \mathrm{E}-21 \quad 1.065 \mathrm{E}-19 \quad 2.653 \mathrm{E}-16 \quad 1.365 \mathrm{E}-15 \quad 2.898 \mathrm{E}-15$

$\begin{array}{lllllll}\mathrm{Th}-228+\mathrm{D} & 1.000 \mathrm{E}+00 & 7.964 \mathrm{E}-22 & 2.280 \mathrm{E}-20 & 3.254 \mathrm{E}-16 & 1.921 \mathrm{E}-15 & 4.240 \mathrm{E}-15\end{array}$

$\operatorname{LDSR}(j) \quad 2.779 \mathrm{E}-02 \quad 2.779 \mathrm{E}-02 \quad 2.771 \mathrm{E}-02 \quad 2.762 \mathrm{E}-02 \quad 2.755 \mathrm{E}-02$

TC-99 1.000E+00 8.838E-05 8.745E-05 6.784E-05 5.208E-05 4.215E-05

$\begin{array}{lllllll}\mathrm{Th}-228+\mathrm{D} & 1.000 \mathrm{E}+00 & 1.360 \mathrm{E}+00 & 9.469 \mathrm{E}-01 & 1.584 \mathrm{E}-04 & 1.845 \mathrm{E}-08 & 1.315 \mathrm{E}-11\end{array}$

$\begin{array}{lllllll}\mathrm{Th}-230 & 1.000 \mathrm{E}+00 & 2.351 \mathrm{E}-02 & 2.351 \mathrm{E}-02 & 2.350 \mathrm{E}-02 & 2.350 \mathrm{E}-02 & 2.349 \mathrm{E}-02\end{array}$

$\mathrm{Ra}-226+\mathrm{D} \quad 1.000 \mathrm{E}+00 \quad 3.877 \mathrm{E}-04 \quad 1.163 \mathrm{E}-03 \quad 1.963 \mathrm{E}-02 \quad 3.858 \mathrm{E}-02 \quad 5.354 \mathrm{E}-02$

$\mathrm{Pb}-210+\mathrm{D} \quad 1.000 \mathrm{E}+00 \quad 4.669 \mathrm{E}-07 \quad 3.239 \mathrm{E}-06 \quad 7.124 \mathrm{E}-04 \quad 2.244 \mathrm{E}-03 \quad 3.740 \mathrm{E}-03$

$\operatorname{\sum DSR}(j) \quad 2.390 \mathrm{E}-02 \quad 2.468 \mathrm{E}-02 \quad 4.384 \mathrm{E}-02 \quad 6.432 \mathrm{E}-02 \quad 8.077 \mathrm{E}-02$ 
RESRAD, Version $6.5 \quad \mathrm{~T}^{1 / 2}$ Limit $=180$ days

Summary : RESRAD Parameters for U-Landfill Worker Forward Run Proposed ALs

File : C: \RESRAD_FAMILY \RESRAD \USERFILES $\backslash Q C J U L Y 2011 \backslash$ LANDFILLWORK_FORWARDRUN-70YRALS.RAD

Dose/Source Ratios Summed Over All Pathways

Parent and Progeny Principal Radionuclide Contributions Indicated

\begin{tabular}{|c|c|c|c|c|c|c|c|}
\hline Parent & Product & Thread & $\operatorname{DSR}(j, t)$ & At Time in & n Years & (mrem/yr) / & $(\mathrm{pCi} / \mathrm{g})$ \\
\hline (i) & (j) & Fraction & $0.000 \mathrm{E}+00$ & $1.000 \mathrm{E}+00$ & $2.500 \mathrm{E}+01$ & $5.000 \mathrm{E}+01$ & $7.000 \mathrm{E}+01$ \\
\hline-232 & Th-232 & $1.000 \mathrm{E}+00$ & $2.563 E-02$ & $2.563 \mathrm{E}-02$ & $2.563 \mathrm{E}-02$ & $2.563 \mathrm{E}-02$ & $2.562 \mathrm{E}-02$ \\
\hline-232 & $\mathrm{Ra}-228+\mathrm{D}$ & $1.000 \mathrm{E}+00$ & $5.888 E-02$ & $1.676 \mathrm{E}-01$ & $9.683 \mathrm{E}-01$ & $1.013 \mathrm{E}+00$ & $1.015 \mathrm{E}+00$ \\
\hline-232 & $\mathrm{Th}-228+\mathrm{D}$ & $1.000 \mathrm{E}+00$ & $1.048 \mathrm{E}-02$ & $6.433 \mathrm{E}-02$ & $1.508 \mathrm{E}+00$ & $1.614 \mathrm{E}+00$ & 1. $619 \mathrm{E}+00$ \\
\hline-232 & $\sum \operatorname{DSR}(j)$ & & $9.499 \mathrm{E}-02$ & $2.576 \mathrm{E}-01$ & $2.502 \mathrm{E}+00$ & $2.652 \mathrm{E}+00$ & $2.659 \mathrm{E}+00$ \\
\hline-234 & $U-234$ & $1.000 \mathrm{E}+00$ & $5.475 E-03$ & $5.474 \mathrm{E}-03$ & $5.444 \mathrm{E}-03$ & $5.414 \mathrm{E}-03$ & $5.390 E-03$ \\
\hline 234 & Th-230 & $1.000 \mathrm{E}+00$ & $1.058 \mathrm{E}-07$ & $3.174 \mathrm{E}-07$ & $5.381 \mathrm{E}-06$ & $1.062 E-05$ & $1.480 \mathrm{E}-05$ \\
\hline-234 & $\mathrm{Ra}-226+\mathrm{D}$ & $1.000 \mathrm{E}+00$ & $1.163 \mathrm{E}-09$ & $8.142 \mathrm{E}-09$ & $2.255 \mathrm{E}-06$ & $8.781 \mathrm{E}-06$ & $1.702 \mathrm{E}-05$ \\
\hline-234 & $\mathrm{~Pb}-210+\mathrm{D}$ & $1.000 \mathrm{E}+00$ & 1. 052E-12 & $1.568 \mathrm{E}-11$ & $5.794 \mathrm{E}-08$ & $3.798 \mathrm{E}-07$ & $9.134 \mathrm{E}-07$ \\
\hline 234 & $\sum \operatorname{DSR}(j)$ & & $5.475 E-03$ & $5.474 \mathrm{E}-03$ & $5.452 \mathrm{E}-03$ & $5.434 \mathrm{E}-03$ & $5.422 E-03$ \\
\hline$-235+D$ & $\mathrm{U}-235+\mathrm{D}$ & $1.000 \mathrm{E}+00$ & $1.213 \mathrm{E}-01$ & 1. $213 \mathrm{E}-01$ & $1.207 \mathrm{E}-01$ & $1.200 \mathrm{E}-01$ & $1.195 \mathrm{E}-01$ \\
\hline$-235+D$ & $\mathrm{~Pa}-231$ & $1.000 \mathrm{E}+00$ & $1.142 \mathrm{E}-06$ & $3.425 E-06$ & $5.790 \mathrm{E}-05$ & $1.140 \mathrm{E}-04$ & $1.584 \mathrm{E}-04$ \\
\hline$-235+D$ & $A C-227+D$ & $1.000 \mathrm{E}+00$ & $4.975 E-08$ & $3.450 \mathrm{E}-07$ & $7.536 \mathrm{E}-05$ & $2.362 E-04$ & $3.925 E-04$ \\
\hline$-235+D$ & $\sum \operatorname{DSR}(j)$ & & $1.213 \mathrm{E}-01$ & $1.213 \mathrm{E}-01$ & $1.208 \mathrm{E}-01$ & $1.203 \mathrm{E}-01$ & $1.200 \mathrm{E}-01$ \\
\hline-238 & $\mathrm{U}-238$ & $5.400 E-05$ & $2.693 E-07$ & $2.692 \mathrm{E}-07$ & $2.678 E-07$ & $2.663 E-07$ & $2.652 E-07$ \\
\hline$-238+D$ & $\mathrm{U}-238+\mathrm{D}$ & $9.999 \mathrm{E}-01$ & $3.127 \mathrm{E}-02$ & $3.127 \mathrm{E}-02$ & $3.110 \mathrm{E}-02$ & $3.093 E-02$ & $3.079 \mathrm{E}-02$ \\
\hline$-238+D$ & $\mathrm{U}-234$ & $9.999 \mathrm{E}-01$ & $7.760 \mathrm{E}-09$ & $2.328 E-08$ & $3.936 \mathrm{E}-07$ & $7.751 \mathrm{E}-07$ & $1.077 \mathrm{E}-06$ \\
\hline$-238+D$ & $\mathrm{Th}-230$ & $9.999 \mathrm{E}-01$ & $9.998 E-14$ & $6.998 E-13$ & $1.943 \mathrm{E}-10$ & $7.592 \mathrm{E}-10$ & $1.475 \mathrm{E}-09$ \\
\hline$-238+D$ & $\mathrm{Ra}-226+\mathrm{D}$ & $9.999 \mathrm{E}-01$ & $8.246 \mathrm{E}-16$ & $1.237 \mathrm{E}-14$ & $5.436 \mathrm{E}-11$ & $4.193 \mathrm{E}-10$ & $1.135 \mathrm{E}-09$ \\
\hline$-238+D$ & $\mathrm{~Pb}-210+\mathrm{D}$ & $9.999 \mathrm{E}-01$ & $5.974 \mathrm{E}-19$ & $1.842 \mathrm{E}-17$ & $1.086 \mathrm{E}-12$ & $1.453 \mathrm{E}-11$ & $4.979 E-11$ \\
\hline$-238+D$ & $\sum \operatorname{DSR}(j)$ & & $3.127 \mathrm{E}-02$ & $3.127 \mathrm{E}-02$ & $3.110 \mathrm{E}-02$ & $3.093 E-02$ & $3.079 E-02$ \\
\hline
\end{tabular}

The DSR includes contributions from associated (half-life $\leq 180$ days) daughters. 
RESRAD, Version $6.5 \quad$ T1/2 Limit $=180$ days $\quad$ 07/20/2011 15:45 Page

Summary : RESRAD Parameters for U-Landfill Worker Forward Run Proposed ALs

File : C: \RESRAD_FAMILY \RESRAD \USERFILES $\backslash Q C J U L Y 2011 \backslash$ LANDFILLWORK_FORWARDRUN-70YRALS.RAD

Single Radionuclide Soil Guidelines $G(i, t)$ in pCi/g

Basic Radiation Dose Limit $=1.000 \mathrm{E}+02 \mathrm{mrem} / \mathrm{yr}$

Nuclide

\begin{tabular}{|c|c|c|c|c|c|c|}
\hline (i) & $t=$ & $0.000 \mathrm{E}+00$ & $1.000 \mathrm{E}+00$ & $2.500 \mathrm{E}+01$ & $5.000 \mathrm{E}+01$ & $7.000 \mathrm{E}+01$ \\
\hline Am-241 & & $3.509 \mathrm{E}+03$ & $3.514 \mathrm{E}+03$ & $3.653 \mathrm{E}+03$ & $3.802 \mathrm{E}+03$ & $3.927 \mathrm{E}+03$ \\
\hline s -137 & & $1.900 \mathrm{E}+02$ & $1.945 \mathrm{E}+02$ & $3.389 \mathrm{E}+02$ & $6.045 E+02$ & $9.603 \mathrm{E}+02$ \\
\hline$N p-237$ & & $5.507 \mathrm{E}+02$ & $5.507 \mathrm{E}+02$ & $5.528 \mathrm{E}+02$ & $5.550 \mathrm{E}+02$ & $5.568 \mathrm{E}+02$ \\
\hline $\mathrm{Pu}-238$ & & $3.926 E+03$ & $3.957 E+03$ & $4.785 E+03$ & $5.833 E+03$ & $6.834 \mathrm{E}+03$ \\
\hline Pu-239 & & $3.595 \mathrm{E}+03$ & $3.595 E+03$ & $3.599 \mathrm{E}+03$ & $3.603 E+03$ & $3.607 \mathrm{E}+03$ \\
\hline$P u-240$ & & $3.598 \mathrm{E}+03$ & $3.598 E+03$ & $3.609 \mathrm{E}+03$ & $3.621 \mathrm{E}+03$ & $3.630 \mathrm{E}+03$ \\
\hline $\mathrm{TC}-99$ & & $1.131 \mathrm{E}+06$ & $1.143 \mathrm{E}+06$ & $1.474 \mathrm{E}+06$ & $1.920 \mathrm{E}+06$ & $2.373 E+06$ \\
\hline Th -228 & & 7. $351 \mathrm{E}+01$ & $1.056 \mathrm{E}+02$ & $6.312 \mathrm{E}+05$ & $5.420 \mathrm{E}+09$ & 7. $605 \mathrm{E}+12$ \\
\hline$T h-230$ & & $4.184 \mathrm{E}+03$ & $4.052 E+03$ & $2.281 \mathrm{E}+03$ & $1.555 \mathrm{E}+03$ & $1.238 \mathrm{E}+03$ \\
\hline$T h-232$ & & $1.053 \mathrm{E}+03$ & $3.883 E+02$ & $3.997 \mathrm{E}+01$ & $3.770 \mathrm{E}+01$ & $3.761 \mathrm{E}+01$ \\
\hline$U-234$ & & $1.826 \mathrm{E}+04$ & $1.827 \mathrm{E}+04$ & $1.834 \mathrm{E}+04$ & $1.840 \mathrm{E}+04$ & $1.844 \mathrm{E}+04$ \\
\hline$U-235$ & & $8.242 E+02$ & $8.244 E+02$ & $8.279 \mathrm{E}+02$ & $8.309 E+02$ & $8.332 E+02$ \\
\hline$U-238$ & & $3.198 \mathrm{E}+03$ & $3.198 \mathrm{E}+03$ & $3.215 \mathrm{E}+03$ & $3.233 E+03$ & $3.248 E+03$ \\
\hline
\end{tabular}

Summed Dose/Source Ratios DSR(i,t) in (mrem/yr)/(pCi/g) and Single Radionuclide Soil Guidelines G(i,t) in pCi/g at tmin = time of minimum single radionuclide soil guideline and at $\operatorname{tmax}=$ time of maximum total dose $=7.000 \mathrm{E}+01$ years

\begin{tabular}{|c|c|c|c|c|c|c|}
\hline $\begin{array}{l}\text { Juclide } \\
\text { (i) }\end{array}$ & $\begin{array}{l}\text { Initial } \\
(\mathrm{pCi} / \mathrm{g})\end{array}$ & $\begin{array}{c}\text { tmin } \\
\text { (years) }\end{array}$ & $\operatorname{DSR}(i, \operatorname{tmin})$ & $\begin{array}{c}\text { G }(i, \text { tmin }) \\
(\mathrm{pCi} / \mathrm{g})\end{array}$ & $\operatorname{DSR}(i, \operatorname{tmax})$ & $\begin{array}{c}\text { G }(i, \text { tmax }) \\
(\mathrm{pCi} / \mathrm{g})\end{array}$ \\
\hline$m-241$ & $7.000 \mathrm{E}+01$ & $0.000 \mathrm{E}+00$ & $2.850 \mathrm{E}-02$ & $3.509 \mathrm{E}+03$ & $2.547 \mathrm{E}-02$ & $3.927 E+03$ \\
\hline$s-137$ & $3.800 \mathrm{E}+01$ & $0.000 \mathrm{E}+00$ & $5.262 \mathrm{E}-01$ & $1.900 \mathrm{E}+02$ & $1.041 \mathrm{E}-01$ & $9.603 \mathrm{E}+02$ \\
\hline$p-237$ & $1.100 \mathrm{E}+01$ & $0.000 \mathrm{E}+00$ & $1.816 \mathrm{E}-01$ & $5.507 \mathrm{E}+02$ & $1.796 \mathrm{E}-01$ & $5.568 \mathrm{E}+02$ \\
\hline $1-238$ & $7.800 \mathrm{E}+01$ & $0.000 \mathrm{E}+00$ & $2.547 E-02$ & $3.926 E+03$ & $1.463 E-02$ & $6.834 \mathrm{E}+03$ \\
\hline-239 & $7.200 \mathrm{E}+01$ & $0.000 \mathrm{E}+00$ & $2.782 \mathrm{E}-02$ & $3.595 E+03$ & $2.772 \mathrm{E}-02$ & $3.607 \mathrm{E}+03$ \\
\hline$x-240$ & $7.200 \mathrm{E}+01$ & $0.000 \mathrm{E}+00$ & $2.779 \mathrm{E}-02$ & $3.598 \mathrm{E}+03$ & $2.755 \mathrm{E}-02$ & $3.630 \mathrm{E}+03$ \\
\hline$c-99$ & $1.040 \mathrm{E}+02$ & $0.000 \mathrm{E}+00$ & $8.838 \mathrm{E}-05$ & $1.131 \mathrm{E}+06$ & $4.215 E-05$ & $2.373 E+06$ \\
\hline-228 & $8.000 \mathrm{E}+00$ & $0.000 \mathrm{E}+00$ & $1.360 \mathrm{E}+00$ & $7.351 \mathrm{E}+01$ & 1. $315 \mathrm{E}-11$ & $7.605 \mathrm{E}+12$ \\
\hline-230 & $2.000 \mathrm{E}+02$ & $7.000 \mathrm{E}+01$ & $8.077 \mathrm{E}-02$ & 1. $238 \mathrm{E}+03$ & $8.077 \mathrm{E}-02$ & $1.238 \mathrm{E}+03$ \\
\hline $1-232$ & $8.000 \mathrm{E}+00$ & $7.000 \mathrm{E}+01$ & $2.659 \mathrm{E}+00$ & $3.761 \mathrm{E}+01$ & $2.659 \mathrm{E}+00$ & $3.761 \mathrm{E}+01$ \\
\hline 234 & $3.200 \mathrm{E}+02$ & $0.000 \mathrm{E}+00$ & $5.475 E-03$ & $1.826 \mathrm{E}+04$ & $5.422 \mathrm{E}-03$ & $1.844 \mathrm{E}+04$ \\
\hline 235 & $1.300 \mathrm{E}+01$ & $0.000 \mathrm{E}+00$ & $1.213 E-01$ & $8.242 E+02$ & $1.200 \mathrm{E}-01$ & $8.332 E+02$ \\
\hline 238 & $3.200 \mathrm{E}+02$ & $0.000 \mathrm{E}+00$ & $3.127 E-02$ & $3.198 E+03$ & $3.079 \mathrm{E}-02$ & $3.248 E+03$ \\
\hline
\end{tabular}


RESRAD, Version $6.5 \quad$ T1/2 Limit $=180$ days $\quad$ 07/20/2011 15:45 Page

Summary : RESRAD Parameters for U-Landfill Worker Forward Run Proposed ALs

File : C: \RESRAD_FAMILY \RESRAD \USERFILES $\backslash Q C J U L Y 2011 \backslash$ LANDFILLWORK_FORWARDRUN-70YRALS.RAD

Individual Nuclide Dose Summed Over All Pathways

Parent Nuclide and Branch Fraction Indicated

Nuclide Parent THF(i) DOSE $(j, t), \operatorname{mrem} / \mathrm{yr}$
(i)

(j)

$t=0.000 \mathrm{E}+00 \quad 1.000 \mathrm{E}+00 \quad 2.500 \mathrm{E}+01 \quad 5.000 \mathrm{E}+01 \quad 7.000 \mathrm{E}+01$

Am-241 Am-241 1.000E+00

$1.995 \mathrm{E}+00 \quad 1.992 \mathrm{E}+00 \quad 1.916 \mathrm{E}+00 \quad 1.841 \mathrm{E}+00 \quad 1.782 \mathrm{E}+00$

$\mathrm{Np}-237 \quad \mathrm{Am}-241 \quad 1.000 \mathrm{E}+00$

$2.058 \mathrm{E}-06 \quad 6.168 \mathrm{E}-06 \quad 1.027 \mathrm{E}-04 \quad 1.989 \mathrm{E}-04 \quad 2.729 \mathrm{E}-04$

$\mathrm{Np}-237 \quad \mathrm{~Np}-237 \quad 1.000 \mathrm{E}+00$

$1.998 \mathrm{E}+00 \quad 1.997 \mathrm{E}+00 \quad 1.990 \mathrm{E}+00 \quad 1.982 \mathrm{E}+00 \quad 1.976 \mathrm{E}+00$

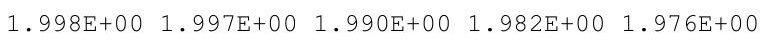

Am-241 1.000E+00

$9.664 \mathrm{E}-14 \quad 6.761 \mathrm{E}-13 \quad 1.855 \mathrm{E}-10 \quad 7.154 \mathrm{E}-10 \quad 1.376 \mathrm{E}-09$

$\mathrm{Np}-237 \quad 1.000 \mathrm{E}+00$

$1.407 \mathrm{E}-07 \quad 4.221 \mathrm{E}-07 \quad 7.142 \mathrm{E}-06 \quad 1.408 \mathrm{E}-05 \quad 1.958 \mathrm{E}-05$

$\sum \operatorname{DOSE}(j)$

$1.407 \mathrm{E}-07 \quad 4.221 \mathrm{E}-07 \quad 7.142 \mathrm{E}-06 \quad 1.408 \mathrm{E}-05 \quad 1.958 \mathrm{E}-05$

Am-241 1.000E+00 1.230E-16 $1.844 \mathrm{E}-15 \quad 8.054 \mathrm{E}-12 \quad 6.173 \mathrm{E}-11 \quad 1.662 \mathrm{E}-10$

Np-237 1.000E+00 2.387E-10 1.671E-09 4.638E-07 1.812E-06 3.520E-06

$\operatorname{LDOSE}(j) \quad 2.387 \mathrm{E}-10 \quad 1.671 \mathrm{E}-09 \quad 4.638 \mathrm{E}-07 \quad 1.812 \mathrm{E}-06 \quad 3.520 \mathrm{E}-06$

$\mathrm{Cs}-137 \quad 1.000 \mathrm{E}+00$

$2.000 \mathrm{E}+01 \quad 1.954 \mathrm{E}+01 \quad 1.121 \mathrm{E}+01 \quad 6.286 \mathrm{E}+00 \quad 3.957 \mathrm{E}+00$

$\mathrm{Pu}-238 \quad 1.840 \mathrm{E}-09$

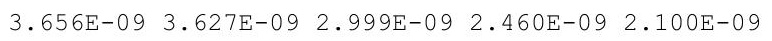

$\begin{array}{llllllll}\mathrm{Pu}-238 & 1.000 \mathrm{E}+00 & 1.987 \mathrm{E}+00 & 1.971 \mathrm{E}+00 & 1.630 \mathrm{E}+00 & 1.337 \mathrm{E}+00 & 1.141 \mathrm{E}+00\end{array}$

$\begin{array}{lllllll}\operatorname{DDOSE}(j) & 1.987 \mathrm{E}+00 & 1.971 \mathrm{E}+00 & 1.630 \mathrm{E}+00 & 1.337 \mathrm{E}+00 & 1.141 \mathrm{E}+00\end{array}$

$\mathrm{Pu}-238 \quad 1.000 \mathrm{E}+00 \quad 6.038 \mathrm{E}-07 \quad 1.805 \mathrm{E}-06 \quad 2.787 \mathrm{E}-05 \quad 5.009 \mathrm{E}-05 \quad 6.485 \mathrm{E}-05$

$\begin{array}{llllllll}\mathrm{U}-234 & 1.000 \mathrm{E}+00 & 1.752 \mathrm{E}+00 & 1.752 \mathrm{E}+00 & 1.742 \mathrm{E}+00 & 1.732 \mathrm{E}+00 & 1.725 \mathrm{E}+00\end{array}$

$\begin{array}{llllllll}\mathrm{U}-238 & 9.999 \mathrm{E}-01 \quad 2.483 \mathrm{E}-06 & 7.448 \mathrm{E}-06 & 1.259 \mathrm{E}-04 & 2.480 \mathrm{E}-04 & 3.447 \mathrm{E}-04\end{array}$

$\sum \operatorname{DOSE}(j)$

$\begin{array}{llllll}1.752 \mathrm{E}+00 & 1.752 \mathrm{E}+00 & 1.742 \mathrm{E}+00 & 1.733 \mathrm{E}+00 & 1.725 \mathrm{E}+00\end{array}$

$\mathrm{Pu}-238 \quad 1.000 \mathrm{E}+00$

$\begin{array}{lllll}7.784 \mathrm{E}-12 & 5.436 \mathrm{E}-11 & 1.421 \mathrm{E}-08 & 5.224 \mathrm{E}-08 & 9.681 \mathrm{E}-08\end{array}$

$\begin{array}{llllllll}\mathrm{Th}-230 & 1.000 \mathrm{E}+00 \quad 4.702 \mathrm{E}+00 & 4.702 \mathrm{E}+00 & 4.701 \mathrm{E}+00 & 4.699 \mathrm{E}+00 & 4.698 \mathrm{E}+00\end{array}$

$\begin{array}{lllllll}\mathrm{U}-234 & 1.000 \mathrm{E}+00 & 3.386 \mathrm{E}-05 & 1.016 \mathrm{E}-04 & 1.722 \mathrm{E}-03 & 3.400 \mathrm{E}-03 & 4.735 \mathrm{E}-03\end{array}$

$\begin{array}{llllllll}\mathrm{U}-238 & 9.999 \mathrm{E}-01 & 3.199 \mathrm{E}-11 & 2.239 \mathrm{E}-10 & 6.219 \mathrm{E}-08 & 2.429 \mathrm{E}-07 & 4.720 \mathrm{E}-07\end{array}$

$\sum \operatorname{DOSE}(j)$

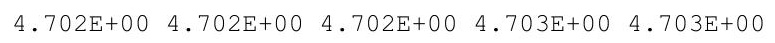

$\begin{array}{lllllll}\mathrm{Pu}-238 & 1.000 \mathrm{E}+00 & 6.422 \mathrm{E}-14 & 9.615 \mathrm{E}-13 & 4.040 \mathrm{E}-09 & 2.976 \mathrm{E}-08 & 7.770 \mathrm{E}-08 \\ \mathrm{Th}-230 & 1.000 \mathrm{E}+00 & 7.755 \mathrm{E}-02 & 2.326 \mathrm{E}-01 & 3.926 \mathrm{E}+00 & 7.716 \mathrm{E}+00 & 1.071 \mathrm{E}+01 \\ \mathrm{U}-234 & 1.000 \mathrm{E}+00 & 3.723 \mathrm{E}-07 & 2.606 \mathrm{E}-06 & 7.214 \mathrm{E}-04 & 2.810 \mathrm{E}-03 & 5.446 \mathrm{E}-03 \\ \mathrm{U}-238 & 9.999 \mathrm{E}-01 & 2.639 \mathrm{E}-13 & 3.957 \mathrm{E}-12 & 1.739 \mathrm{E}-08 & 1.342 \mathrm{E}-07 & 3.632 \mathrm{E}-07 \\ \text { LDOSE }(j) & 7.755 \mathrm{E}-02 & 2.326 \mathrm{E}-01 & 3.926 \mathrm{E}+00 & 7.719 \mathrm{E}+00 & 1.071 \mathrm{E}+01\end{array}$

$\begin{array}{llllllll}\mathrm{Pu}-238 \quad 1.000 \mathrm{E}+00 \quad 4.654 \mathrm{E}-17 & 1.433 \mathrm{E}-15 & 8.144 \mathrm{E}-11 & 1.047 \mathrm{E}-09 & 3.476 \mathrm{E}-09\end{array}$

$\begin{array}{lllllllll}\mathrm{Th}-230 & 1.000 \mathrm{E}+00 & 9.338 \mathrm{E}-05 & 6.478 \mathrm{E}-04 & 1.425 \mathrm{E}-01 & 4.489 \mathrm{E}-01 & 7.480 \mathrm{E}-01\end{array}$

$\begin{array}{llllllll}\mathrm{U}-234 & 1.000 \mathrm{E}+00 & 3.368 \mathrm{E}-10 & 5.017 \mathrm{E}-09 & 1.854 \mathrm{E}-05 & 1.215 \mathrm{E}-04 & 2.923 \mathrm{E}-04\end{array}$

$\begin{array}{llllllll}\mathrm{U}-238 & 9.999 \mathrm{E}-01 \quad 1.912 \mathrm{E}-16 & 5.893 \mathrm{E}-15 & 3.476 \mathrm{E}-10 & 4.649 \mathrm{E}-09 & 1.593 \mathrm{E}-08\end{array}$

$\sum \operatorname{DOSE}(j)$

$\begin{array}{llllll}9.338 E-05 & 6.478 E-04 & 1.425 E-01 & 4.490 E-01 & 7.483 E-01\end{array}$

$2.003 E+00 \quad 2.003 E+00 \quad 2.001 E+00 \quad 1.998 E+00 \quad 1.996 E+00$

$\begin{array}{llllllll}\mathrm{Pu}-239 & 1.000 \mathrm{E}+00 \quad 4.302 \mathrm{E}-09 & 1.290 \mathrm{E}-08 & 2.187 \mathrm{E}-07 & 4.316 \mathrm{E}-07 & 6.009 \mathrm{E}-07\end{array}$

$\begin{array}{lllllllll}\mathrm{U}-235 & 1.000 \mathrm{E}+00 & 1.577 \mathrm{E}+00 & 1.577 \mathrm{E}+00 & 1.569 \mathrm{E}+00 & 1.560 \mathrm{E}+00 & 1.553 \mathrm{E}+00\end{array}$

$\sum \operatorname{DOSE}(j)$

$\begin{array}{lllll}1.577 \mathrm{E}+00 & 1.577 \mathrm{E}+00 & 1.569 \mathrm{E}+00 & 1.560 \mathrm{E}+00 & 1.553 \mathrm{E}+00\end{array}$ 


\section{RESRAD, Version $6.5 \quad$ T1/2 Limit $=180$ days $\quad$ 07/20/2011 $15: 45$ Page}

Summary : RESRAD Parameters for U-Landfill Worker Forward Run Proposed ALs

File : C: \RESRAD_FAMILY \RESRAD \USERFILES $\backslash Q C J U L Y 2011 \backslash$ LANDFILLWORK_FORWARDRUN-70YRALS.RAD

Individual Nuclide Dose Summed Over All Pathways

Parent Nuclide and Branch Fraction Indicated

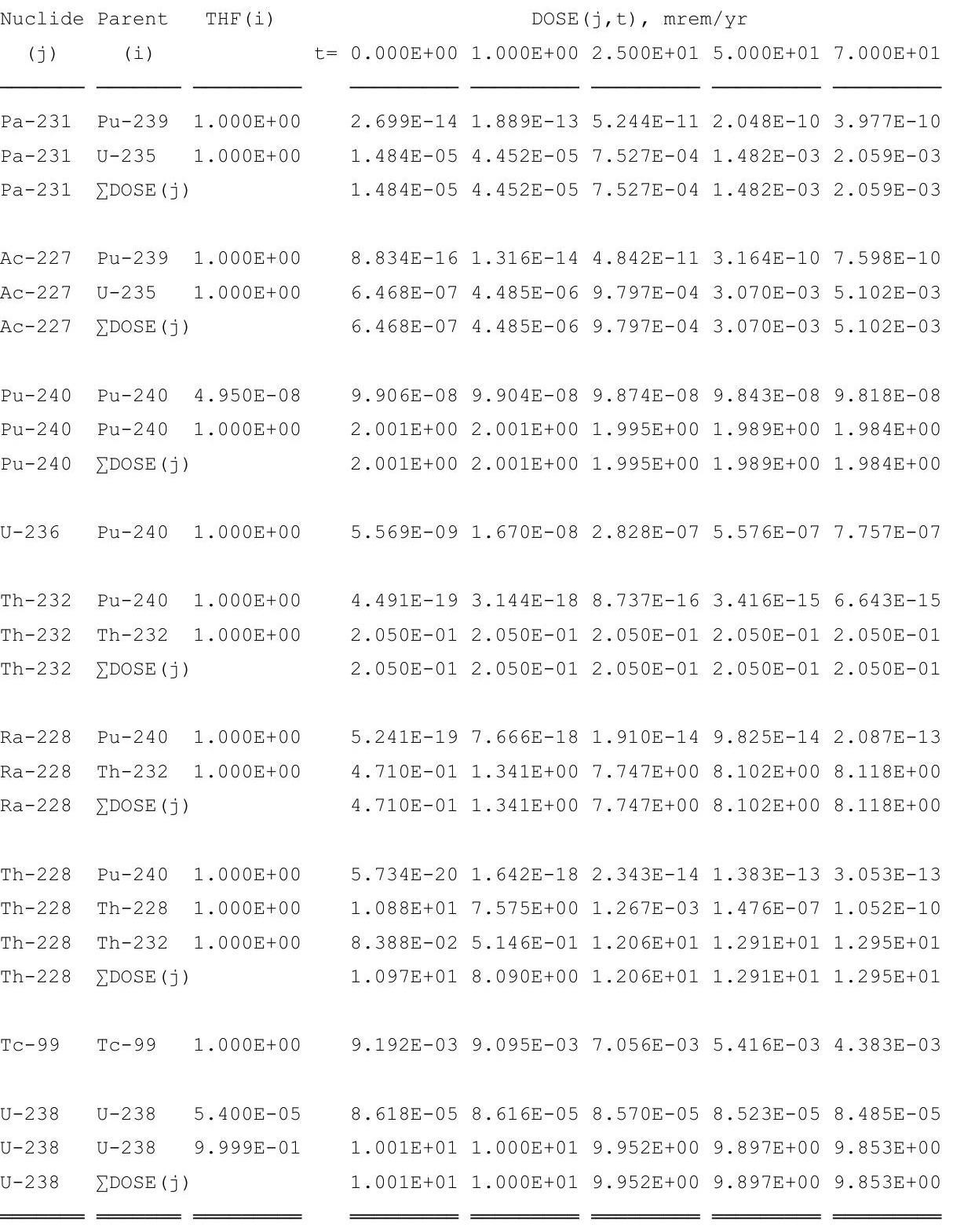

THF (i) is the thread fraction of the parent nuclide. 
RESRAD, Version $6.5 \quad$ T1/2 Limit $=180$ days $\quad$ 07/20/2011 15:45 Page

Summary : RESRAD Parameters for U-Landfill Worker Forward Run Proposed ALs

File : C: \RESRAD_FAMILY \RESRAD \USERFILES $\backslash Q C J U L Y 2011 \backslash$ LANDFILLWORK_FORWARDRUN-70YRALS.RAD

Individual Nuclide Soil Concentration

Parent Nuclide and Branch Fraction Indicated

Nuclide Parent THF(i) $\quad S(j, t), \mathrm{pCi} / \mathrm{g}$

(j) (i) $\quad t=0.000 \mathrm{E}+00 \quad 1.000 \mathrm{E}+00 \quad 2.500 \mathrm{E}+01 \quad 5.000 \mathrm{E}+01 \quad 7.000 \mathrm{E}+01$

$\overline{A m-241 \quad \overline{A m-241}} \overline{1.000 \mathrm{E}+00}$

-

$\begin{array}{lllll}7.000 \mathrm{E}+01 & 6.989 \mathrm{E}+01 & 6.724 \mathrm{E}+01 & 6.459 \mathrm{E}+01 & 6.254 \mathrm{E}+01\end{array}$

$\mathrm{Np}-237 \quad \mathrm{Am}-241 \quad 1.000 \mathrm{E}+00$

$0.000 \mathrm{E}+00 \quad 2.265 \mathrm{E}-05 \quad 5.545 \mathrm{E}-04 \quad 1.085 \mathrm{E}-03 \quad 1.493 \mathrm{E}-03$

$1.100 \mathrm{E}+01 \quad 1.100 \mathrm{E}+01 \quad 1.096 \mathrm{E}+01 \quad 1.091 \mathrm{E}+01 \quad 1.088 \mathrm{E}+01$

$\begin{array}{lllll}1.100 \mathrm{E}+01 & 1.100 \mathrm{E}+01 & 1.096 \mathrm{E}+01 & 1.091 \mathrm{E}+01 & 1.088 \mathrm{E}+01\end{array}$

Np-237 $\sum S(j):$

$\mathrm{U}-233 \quad \mathrm{Am}-241 \quad 1.000 \mathrm{E}+00$

$\begin{array}{lllll}0.000 E+00 \quad 4.954 E-11 ~ & 3.048 E-08 & 1.199 E-07 & 2.319 E-07\end{array}$

$\begin{array}{llllllll}\mathrm{Np}-237 & 1.000 \mathrm{E}+00 \quad 0.000 \mathrm{E}+00 & 4.810 \mathrm{E}-05 & 1.197 \mathrm{E}-03 & 2.382 \mathrm{E}-03 & 3.322 \mathrm{E}-03\end{array}$

$\sum S(j): \quad 0.000 E+00 \quad 4.810 E-05 \quad 1.197 E-03 \quad 2.382 E-03 \quad 3.323 E-03$

Th-229 Am-241 1.000E+00

$0.000 \mathrm{E}+00 \quad 1.560 \mathrm{E}-15 \quad 2.407 \mathrm{E}-11 \quad 1.901 \mathrm{E}-10 \quad 5.162 \mathrm{E}-10$

$\begin{array}{llllllll}\mathrm{Np}-237 \quad 1.000 \mathrm{E}+00 \quad 0.000 \mathrm{E}+00 & 2.271 \mathrm{E}-09 & 1.414 \mathrm{E}-06 & 5.633 \mathrm{E}-06 & 1.101 \mathrm{E}-05\end{array}$

$0.000 \mathrm{E}+00 \quad 2.271 \mathrm{E}-09 \quad 1.414 \mathrm{E}-06 \quad 5.633 \mathrm{E}-06 \quad 1.101 \mathrm{E}-05$

$\mathrm{Cs}-137 \quad 1.000 \mathrm{E}+00$

$\begin{array}{llllll}3.800 E+01 & 3.713 E+01 & 2.131 E+01 & 1.195 E+01 & 7.519 E+00\end{array}$

$\mathrm{Pu}-238 \quad 1.840 \mathrm{E}-09$

$\begin{array}{lllll}1.435 \mathrm{E}-07 & 1.424 \mathrm{E}-07 & 1.177 \mathrm{E}-07 & 9.659 \mathrm{E}-08 & 8.244 \mathrm{E}-08\end{array}$

$\begin{array}{llllllllll}\mathrm{Pu}-238 & 1.000 \mathrm{E}+00 \quad 7.800 \mathrm{E}+01 & 7.738 \mathrm{E}+01 & 6.399 \mathrm{E}+01 & 5.249 \mathrm{E}+01 & 4.480 \mathrm{E}+01\end{array}$

$\sum S(j): \quad 7.800 E+01 \quad 7.738 E+01 \quad 6.399 E+01 \quad 5.249 E+01 \quad 4.480 E+01$

$\begin{array}{llllllll}\mathrm{Pu}-238 & 1.000 \mathrm{E}+00 \quad 0.000 \mathrm{E}+00 & 2.202 \mathrm{E}-04 & 5.001 \mathrm{E}-03 & 9.075 \mathrm{E}-03 & 1.178 \mathrm{E}-02\end{array}$

$\begin{array}{lllllll}\mathrm{U}-234 & 1.000 \mathrm{E}+00 & 3.200 \mathrm{E}+02 & 3.199 \mathrm{E}+02 & 3.182 \mathrm{E}+02 & 3.164 \mathrm{E}+02 & 3.150 \mathrm{E}+02\end{array}$

$\begin{array}{lllllllll}\mathrm{U}-238 & 9.999 \mathrm{E}-01 & 0.000 \mathrm{E}+00 & 9.069 \mathrm{E}-04 & 2.255 \mathrm{E}-02 & 4.485 \mathrm{E}-02 & 6.252 \mathrm{E}-02\end{array}$

$\sum S(j): \quad 3.200 E+02 \quad 3.199 \mathrm{E}+02 \quad 3.182 \mathrm{E}+02 \quad 3.165 \mathrm{E}+02 \quad 3.151 \mathrm{E}+02$

$\mathrm{Pu}-238 \quad 1.000 \mathrm{E}+00 \quad 0.000 \mathrm{E}+00 \quad 9.926 \mathrm{E}-10 \quad 5.818 \mathrm{E}-07 \quad 2.181 \mathrm{E}-06 \quad 4.064 \mathrm{E}-06$

$\begin{array}{lllllll}\mathrm{Th}-230 & 1.000 \mathrm{E}+00 \quad 2.000 \mathrm{E}+02 & 2.000 \mathrm{E}+02 & 1.999 \mathrm{E}+02 & 1.999 \mathrm{E}+02 & 1.998 \mathrm{E}+02\end{array}$

$\begin{array}{llllllll}\mathrm{U}-234 & 1.000 \mathrm{E}+00 \quad 0.000 \mathrm{E}+00 & 2.880 \mathrm{E}-03 & 7.180 \mathrm{E}-02 & 1.432 \mathrm{E}-01 & 2.000 \mathrm{E}-01\end{array}$

$\begin{array}{llllllll}\mathrm{U}-238 & 9.999 \mathrm{E}-01 \quad 0.000 \mathrm{E}+00 & 4.082 \mathrm{E}-09 & 2.542 \mathrm{E}-06 & 1.013 \mathrm{E}-05 & 1.979 \mathrm{E}-05\end{array}$

$\sum S(j): \quad 2.000 E+02 \quad 2.000 E+02 \quad 2.000 E+02 \quad 2.000 E+02 \quad 2.000 E+02$

$\mathrm{Ra}-226 \mathrm{Pu}-238 \quad 1.000 \mathrm{E}+00$

$0.000 \mathrm{E}+00 \quad 1.434 \mathrm{E}-13 \quad 2.128 \mathrm{E}-09 \quad 1.615 \mathrm{E}-08 \quad 4.252 \mathrm{E}-08$

$\begin{array}{llllllll}\mathrm{Th}-230 & 1.000 \mathrm{E}+00 \quad 0.000 \mathrm{E}+00 & 8.662 \mathrm{E}-02 & 2.150 \mathrm{E}+00 & 4.267 \mathrm{E}+00 & 5.939 \mathrm{E}+00\end{array}$

$\begin{array}{llllllll}\mathrm{U}-234 & 1.000 \mathrm{E}+00 & 0.000 \mathrm{E}+00 & 6.238 \mathrm{E}-07 & 3.873 \mathrm{E}-04 & 1.539 \mathrm{E}-03 & 2.999 \mathrm{E}-03\end{array}$

$\begin{array}{llllllll}\mathrm{U}-238 & 9.999 \mathrm{E}-01 \quad 0.000 \mathrm{E}+00 & 5.895 \mathrm{E}-13 & 9.152 \mathrm{E}-09 & 7.274 \mathrm{E}-08 & 1.986 \mathrm{E}-07\end{array}$

$0.000 \mathrm{E}+00 \quad 8.662 \mathrm{E}-02 \quad 2.150 \mathrm{E}+00 \quad 4.269 \mathrm{E}+00 \quad 5.942 \mathrm{E}+00$

$\mathrm{Pu}-238 \quad 1.000 \mathrm{E}+00 \quad 0.000 \mathrm{E}+00 \quad 1.108 \mathrm{E}-15 \quad 3.599 \mathrm{E}-10 \quad 4.813 \mathrm{E}-09 \quad 1.616 \mathrm{E}-08$

$\begin{array}{llllllll}\mathrm{Th}-230 & 1.000 \mathrm{E}+00 & 0.000 \mathrm{E}+00 & 1.332 \mathrm{E}-03 & 6.561 \mathrm{E}-01 & 2.107 \mathrm{E}+00 & 3.530 \mathrm{E}+00\end{array}$

$\begin{array}{lllllll}\mathrm{U}-234 & 1.000 \mathrm{E}+00 \quad 0.000 \mathrm{E}+00 & 6.413 \mathrm{E}-09 & 8.358 \mathrm{E}-05 & 5.642 \mathrm{E}-04 & 1.368 \mathrm{E}-03\end{array}$

$\begin{array}{lllllll}\mathrm{U}-238 & 9.999 \mathrm{E}-01 \quad 0.000 \mathrm{E}+00 & 4.552 \mathrm{E}-15 & 1.535 \mathrm{E}-09 & 2.136 \mathrm{E}-08 & 7.403 \mathrm{E}-08\end{array}$

$\sum S(j): \quad 0.000 E+00 \quad 1.332 E-03 \quad 6.562 E-01 \quad 2.108 E+00 \quad 3.531 E+00$

$\mathrm{Pu}-239 \mathrm{Pu}-239 \quad 1.000 \mathrm{E}+00 \quad 7.200 \mathrm{E}+01 \quad 7.200 \mathrm{E}+01 \quad 7.191 \mathrm{E}+01 \quad 7.182 \mathrm{E}+01 \quad 7.175 \mathrm{E}+01$

$\mathrm{U}-235 \mathrm{Pu}-239 \quad 1.000 \mathrm{E}+00 \quad 0.000 \mathrm{E}+00 \quad 7.090 \mathrm{E}-08 \quad 1.767 \mathrm{E}-06 \quad 3.522 \mathrm{E}-06 \quad 4.917 \mathrm{E}-06$

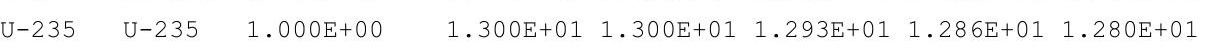

$\sum \mathrm{S}(j): \quad \begin{array}{llllll}1.300 \mathrm{E}+01 & 1.300 \mathrm{E}+01 & 1.293 \mathrm{E}+01 & 1.286 \mathrm{E}+01 & 1.280 \mathrm{E}+01\end{array}$ 
RESRAD, Version $6.5 \quad$ T1/2 Limit $=180$ days $\quad$ 07/20/2011 15:45 Page

Summary : RESRAD Parameters for U-Landfill Worker Forward Run Proposed ALs

File : C: \RESRAD_FAMILY \RESRAD \USERFILES $\backslash Q C J U L Y 2011 \backslash$ LANDFILLWORK_FORWARDRUN-70YRALS.RAD

Individual Nuclide Soil Concentration

Parent Nuclide and Branch Fraction Indicated

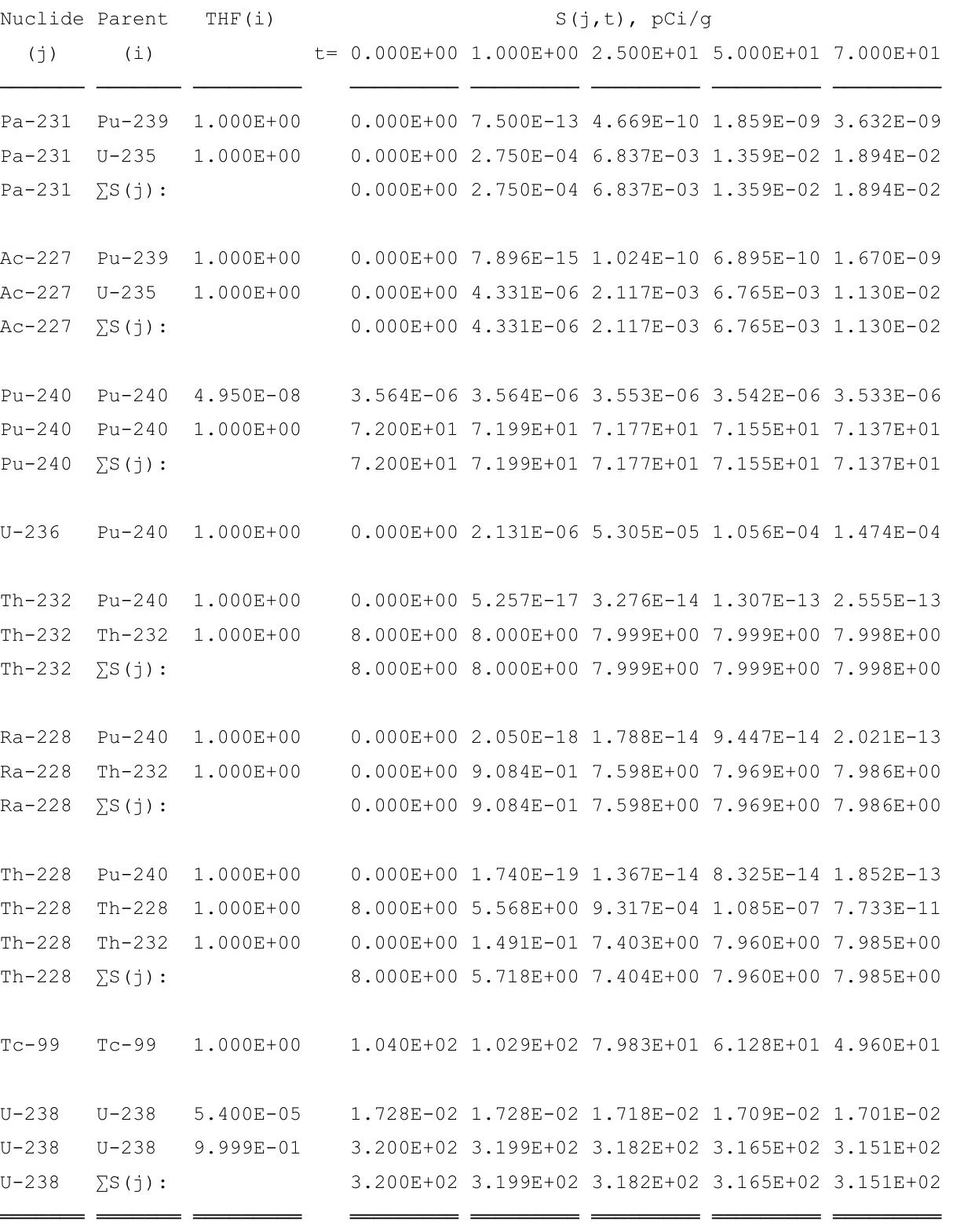

THF (i) is the thread fraction of the parent nuclide.

RESCALC.EXE execution time $=\quad 3.17$ seconds 
RESRAD, Version $6.5 \quad T^{1 / 2}$ Limit $=180$ days

07/20/2011 15:34 Page

Summary : RESRAD Parameters for U-Landfill Trespasser Forward Run

File : C: \RESRAD FAMILY \RESRAD \USERFILES \QCJULY2011 TTRESPASSER FORWARDRUN-70YRS.RAD

Table of Contents

Part I: Mixture Sums and Single Radionuclide Guidelines

Dose Conversion Factor (and Related) Parameter Summary ... 2

Site-Specific Parameter Summary ............... 8

Summary of Pathway Selections .................... 18

Contaminated Zone and Total Dose Summary ............. 19

Total Dose Components

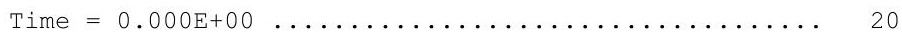

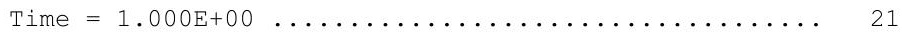

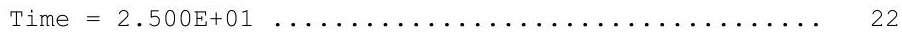

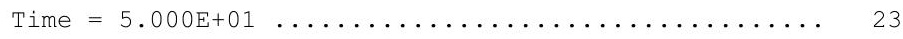

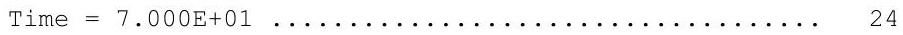

Dose/Source Ratios Summed Over All Pathways ........... 25

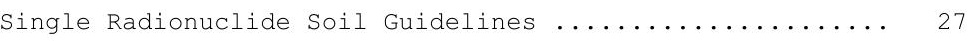

Dose Per Nuclide Summed Over All Pathways ............ 28

Soil Concentration Per Nuclide ................ 30 
Summary : RESRAD Parameters for U-Landfill Trespasser Forward Run

File : C: $\backslash$ RESRAD_FAMILY \RESRAD \USERFILES $\backslash Q C J U L Y 2011 \backslash$ TRESPASSER_FORWARDRUN-70YRS.RAD

Dose Conversion Factor (and Related) Parameter Summary

Dose Library: ICRP 60 \& ICRP 72 (Adult)

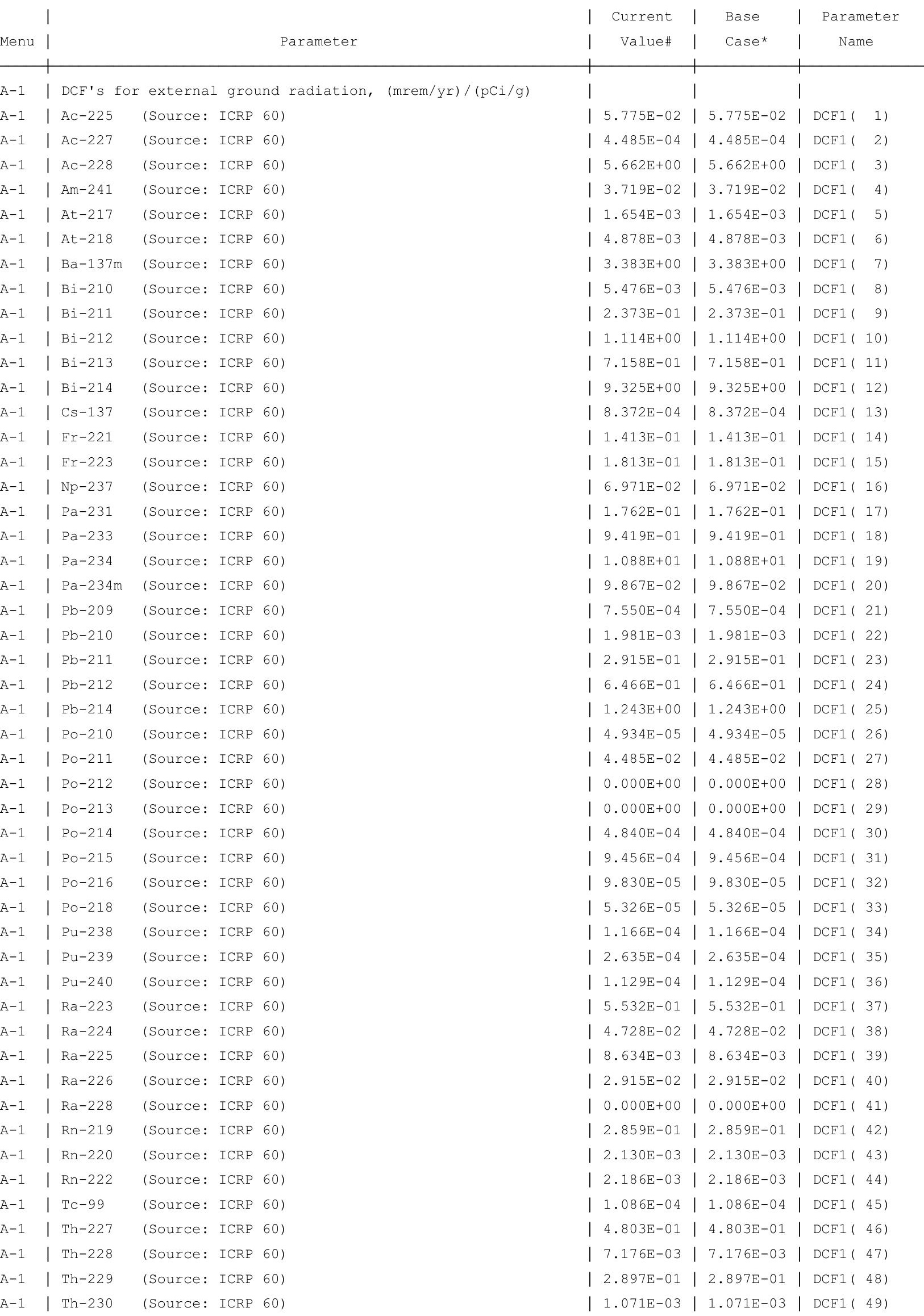


Summary : RESRAD Parameters for U-Landfill Trespasser Forward Run

File : C: \RESRAD_FAMILY \RESRAD \USERFILES $\backslash$ QCJULY2011 TTRESPASSER_FORWARDRUN-70YRS.RAD

Dose Conversion Factor (and Related) Parameter Summary (continued)

Dose Library: ICRP 60 \& ICRP 72 (Adult)

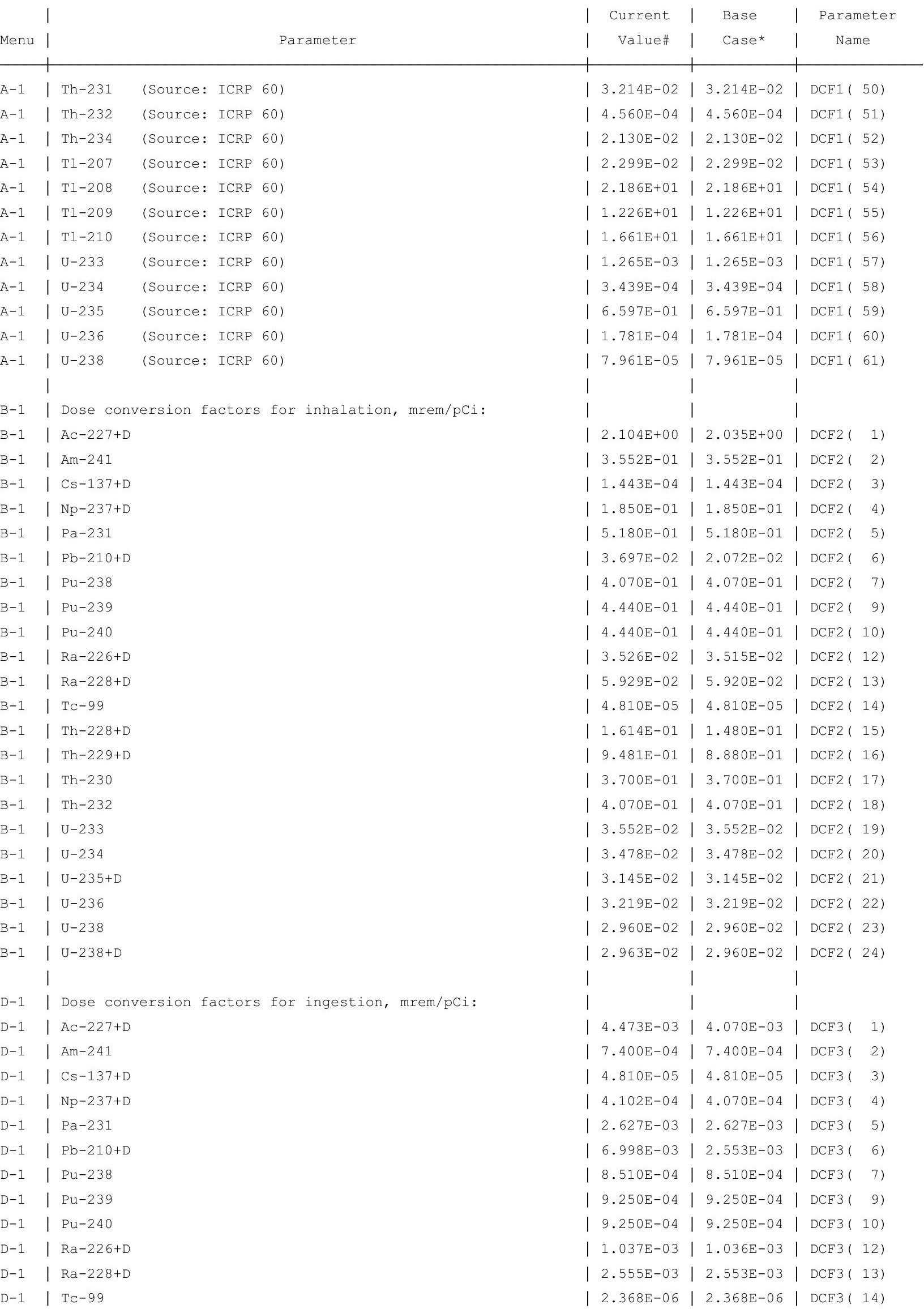


RESRAD, Version $6.5 \quad \mathrm{~T}^{1 / 2}$ Limit $=180$ days

Summary : RESRAD Parameters for U-Landfill Trespasser Forward Run

File : C: \RESRAD_FAMILY \RESRAD \USERFILES $\backslash Q C J U L Y 2011 \backslash$ TRESPASSER_FORWARDRUN-70YRS.RAD

Dose Conversion Factor (and Related) Parameter Summary (continued)

Dose Library: ICRP 60 \& ICRP 72 (Adult)

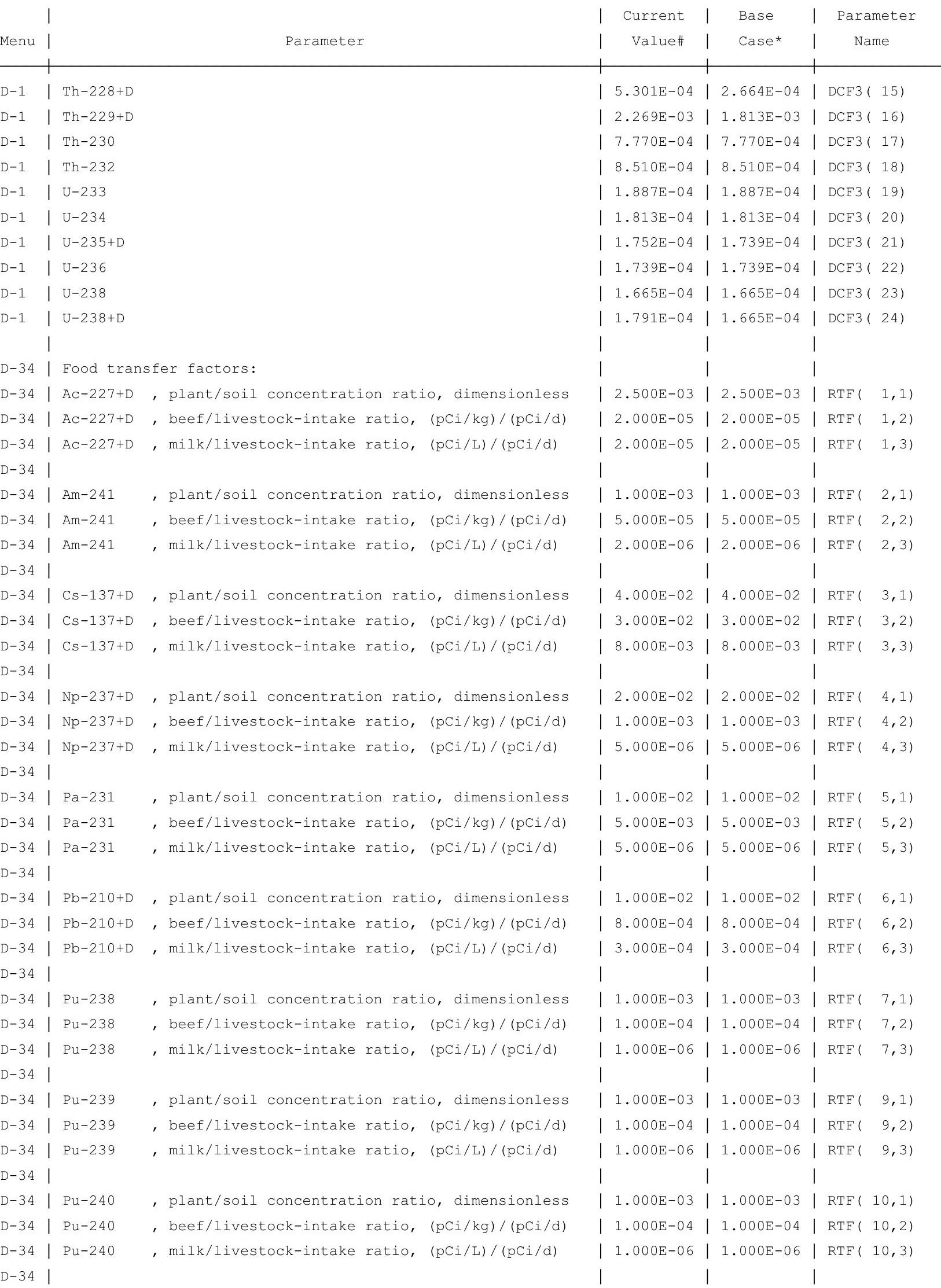


RESRAD, Version $6.5 \quad \mathrm{~T}^{1 / 2}$ Limit $=180$ days

Summary : RESRAD Parameters for U-Landfill Trespasser Forward Run

File : C: \RESRAD_FAMILY \RESRAD \USERFILES $\backslash Q C J U L Y 2011 \backslash$ TRESPASSER_FORWARDRUN-70YRS.RAD

Dose Conversion Factor (and Related) Parameter Summary (continued)

Dose Library: ICRP 60 \& ICRP 72 (Adult)

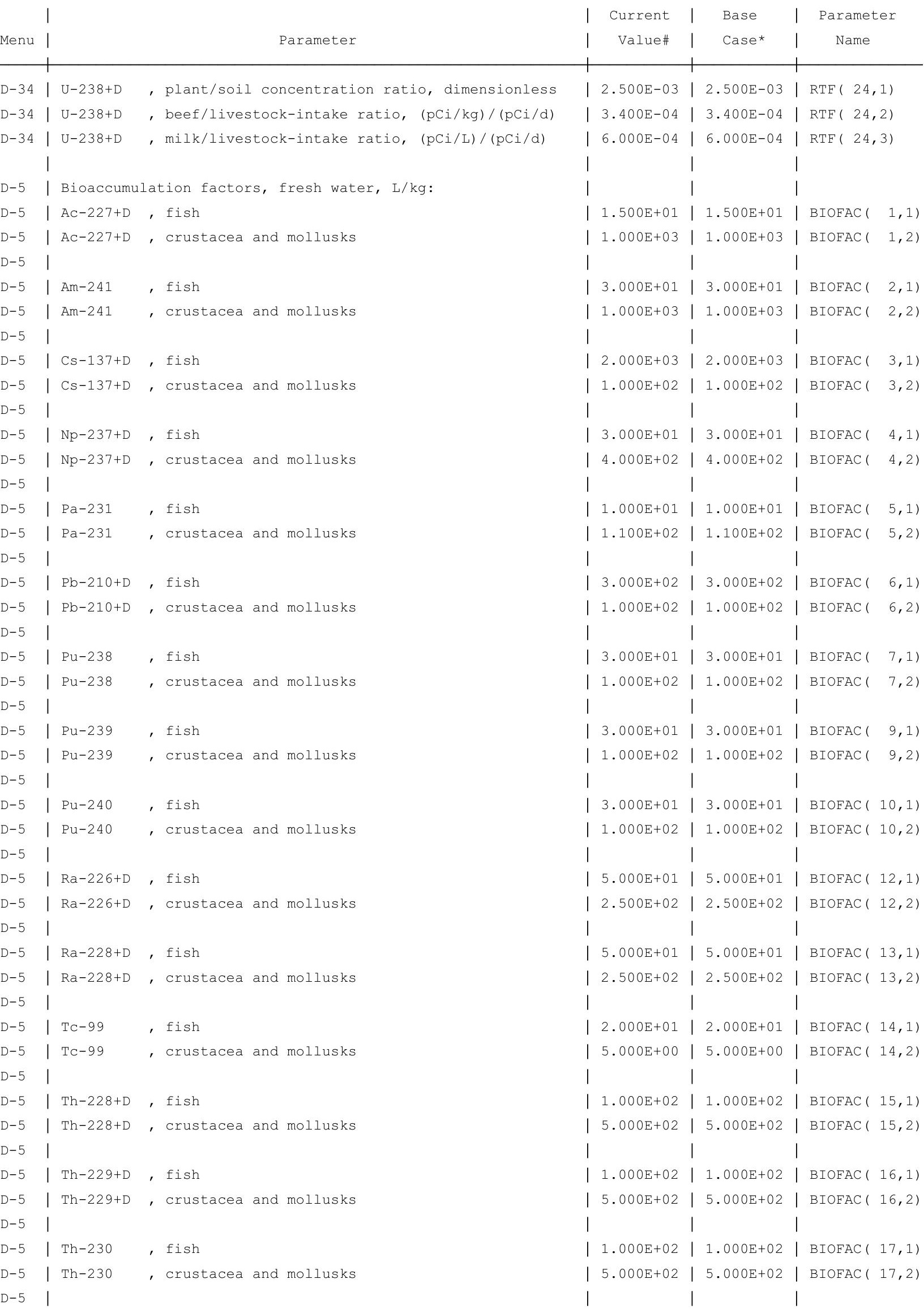


RESRAD, Version $6.5 \quad \mathrm{~T}^{1 / 2}$ Limit $=180$ days

Summary : RESRAD Parameters for U-Landfill Trespasser Forward Run

File : C: \RESRAD_FAMILY \RESRAD \USERFILES \QCJULY2011 TTRESPASSER_FORWARDRUN-70YRS.RAD

Site-Specific Parameter Summary (continued)

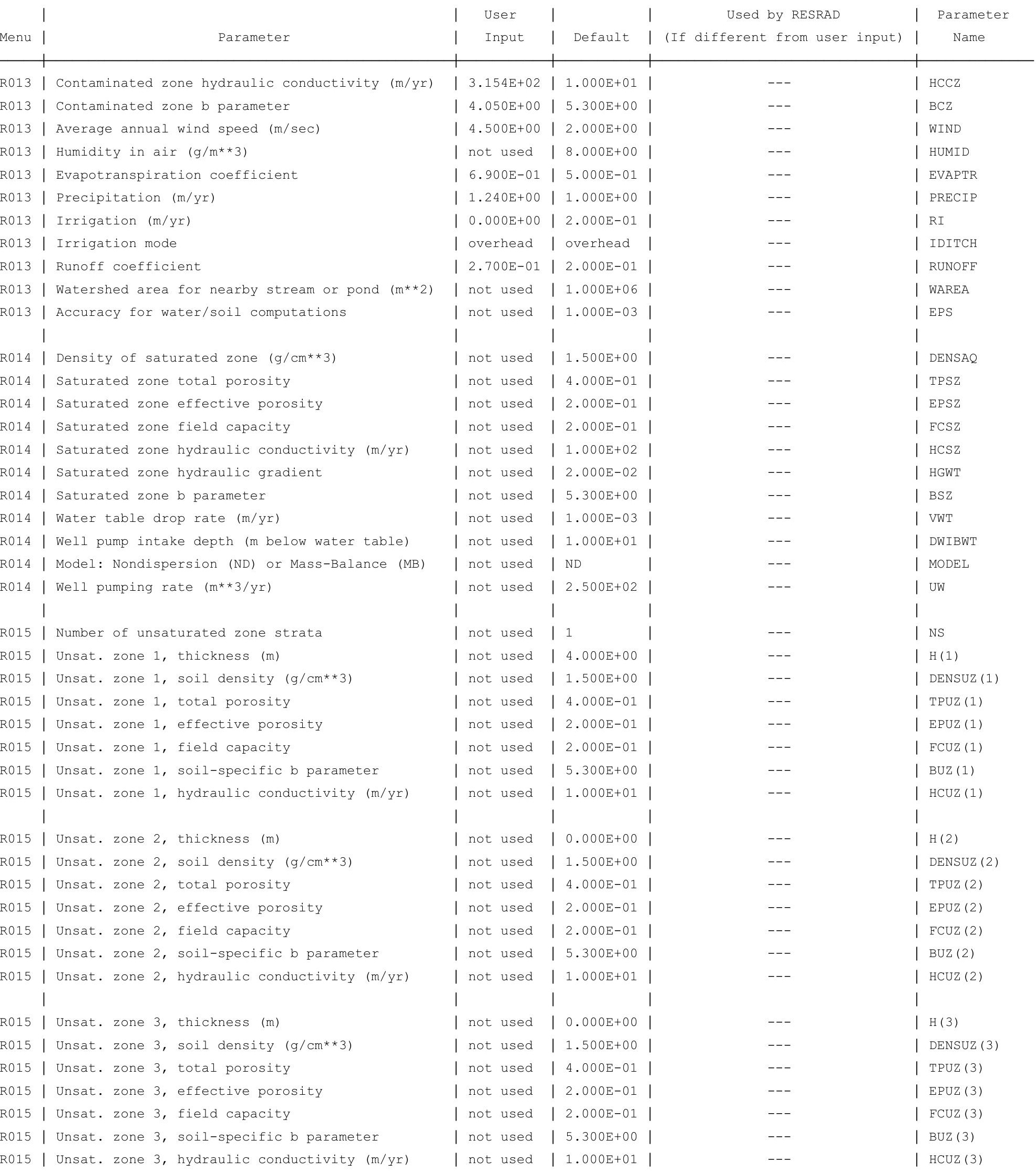


RESRAD, Version $6.5 \quad \mathrm{~T}^{1 / 2}$ Limit $=180$ days

Summary : RESRAD Parameters for U-Landfill Trespasser Forward Run

File : C: \RESRAD_FAMILY \RESRAD \USERFILES \QCJULY2011 TTRESPASSER_FORWARDRUN-70YRS.RAD

Site-Specific Parameter Summary (continued)

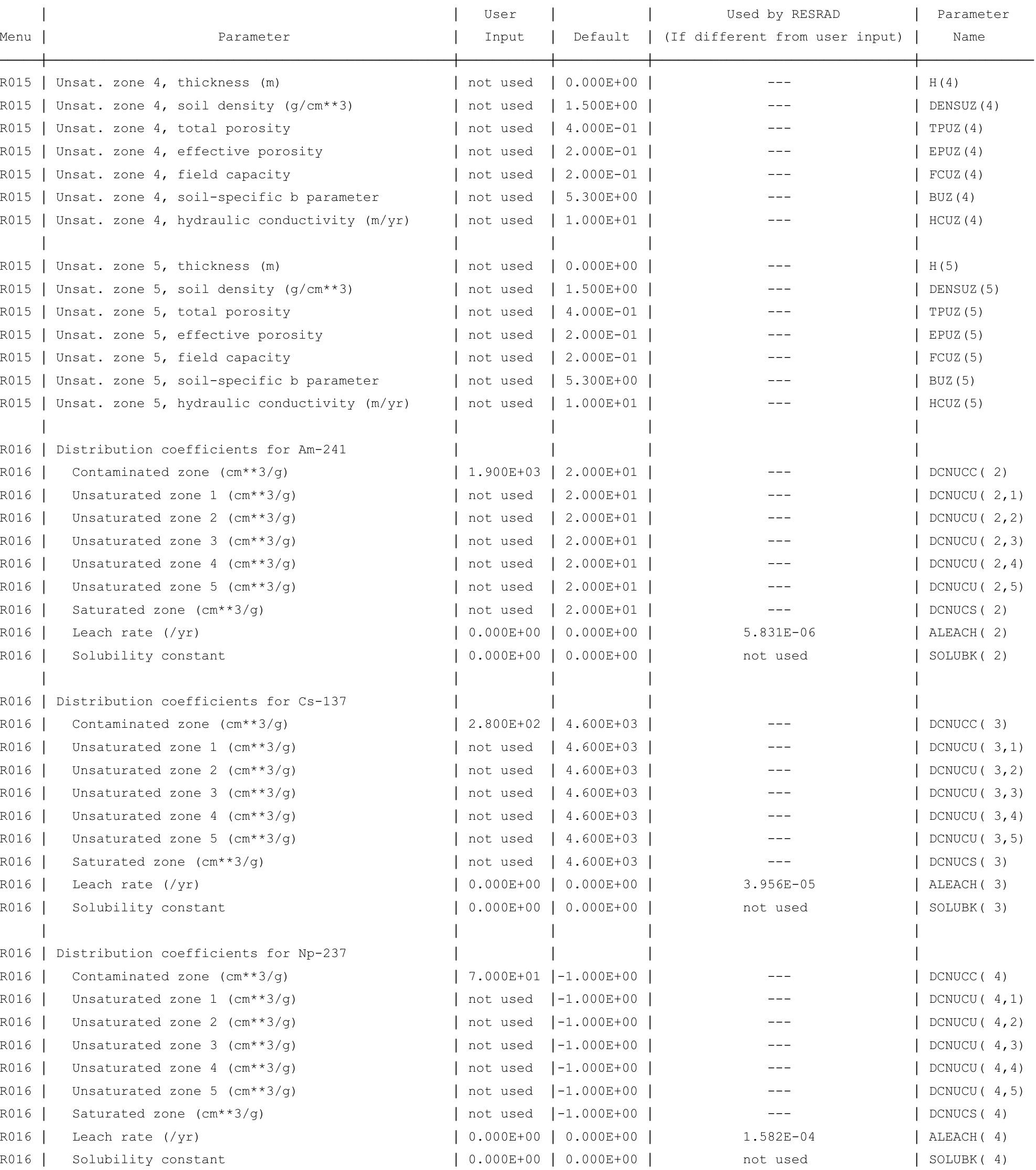


RESRAD, Version $6.5 \quad \mathrm{~T}^{1 / 2}$ Limit $=180$ days

Summary : RESRAD Parameters for U-Landfill Trespasser Forward Run

File : C: \RESRAD_FAMILY \RESRAD \USERFILES \QCJULY2011 TTRESPASSER_FORWARDRUN-70YRS.RAD

Site-Specific Parameter Summary (continued)

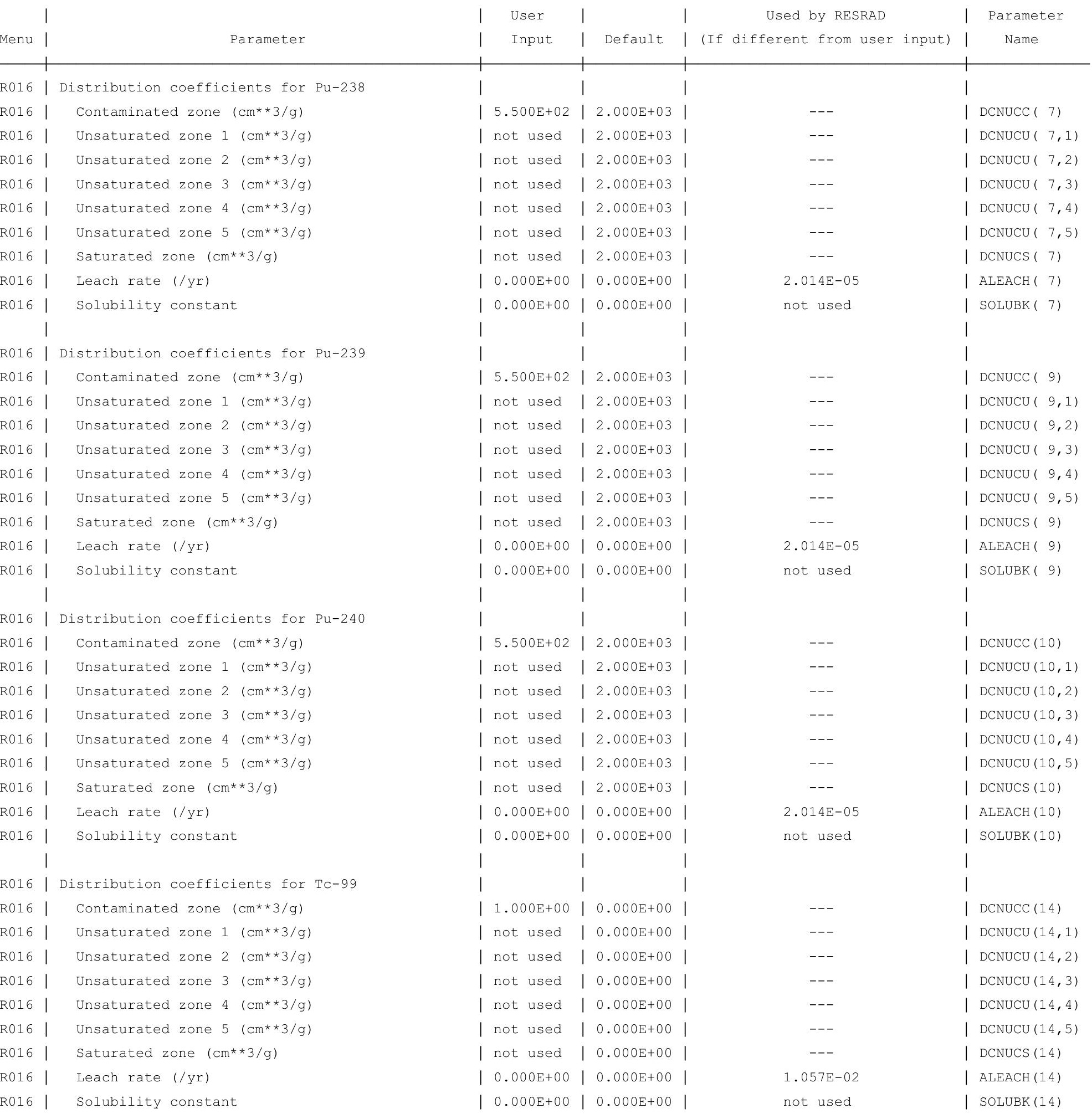


RESRAD, Version $6.5 \quad \mathrm{~T}^{1 / 2}$ Limit $=180$ days

Summary : RESRAD Parameters for U-Landfill Trespasser Forward Run

File : C: \RESRAD_FAMILY \RESRAD \USERFILES \QCJULY2011 TTRESPASSER_FORWARDRUN-70YRS.RAD

Site-Specific Parameter Summary (continued)

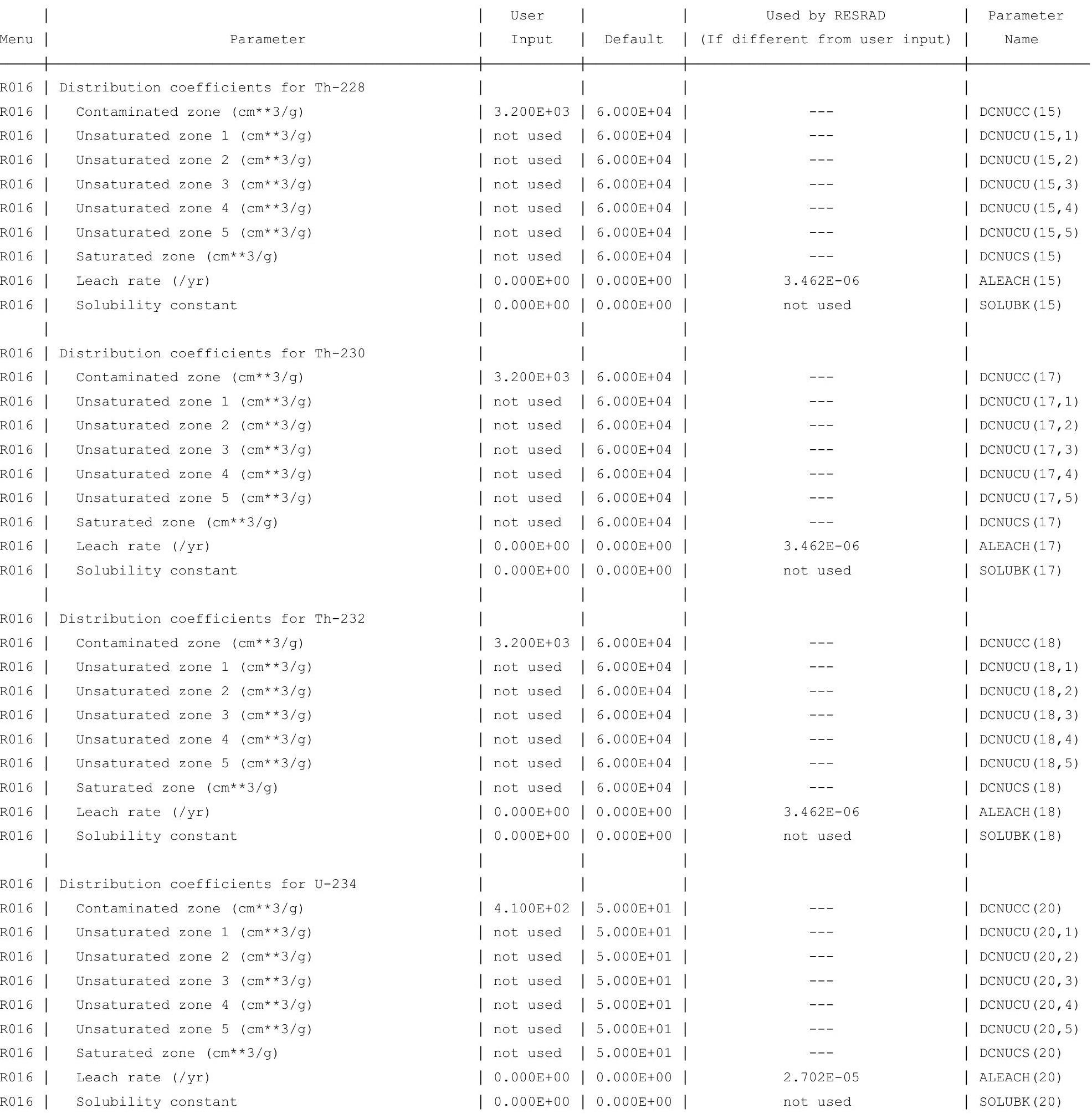


RESRAD, Version $6.5 \quad \mathrm{~T}^{1 / 2}$ Limit $=180$ days

Summary : RESRAD Parameters for U-Landfill Trespasser Forward Run

File : C: \RESRAD_FAMILY \RESRAD \USERFILES \QCJULY2011 TTRESPASSER_FORWARDRUN-70YRS.RAD

Site-Specific Parameter Summary (continued)

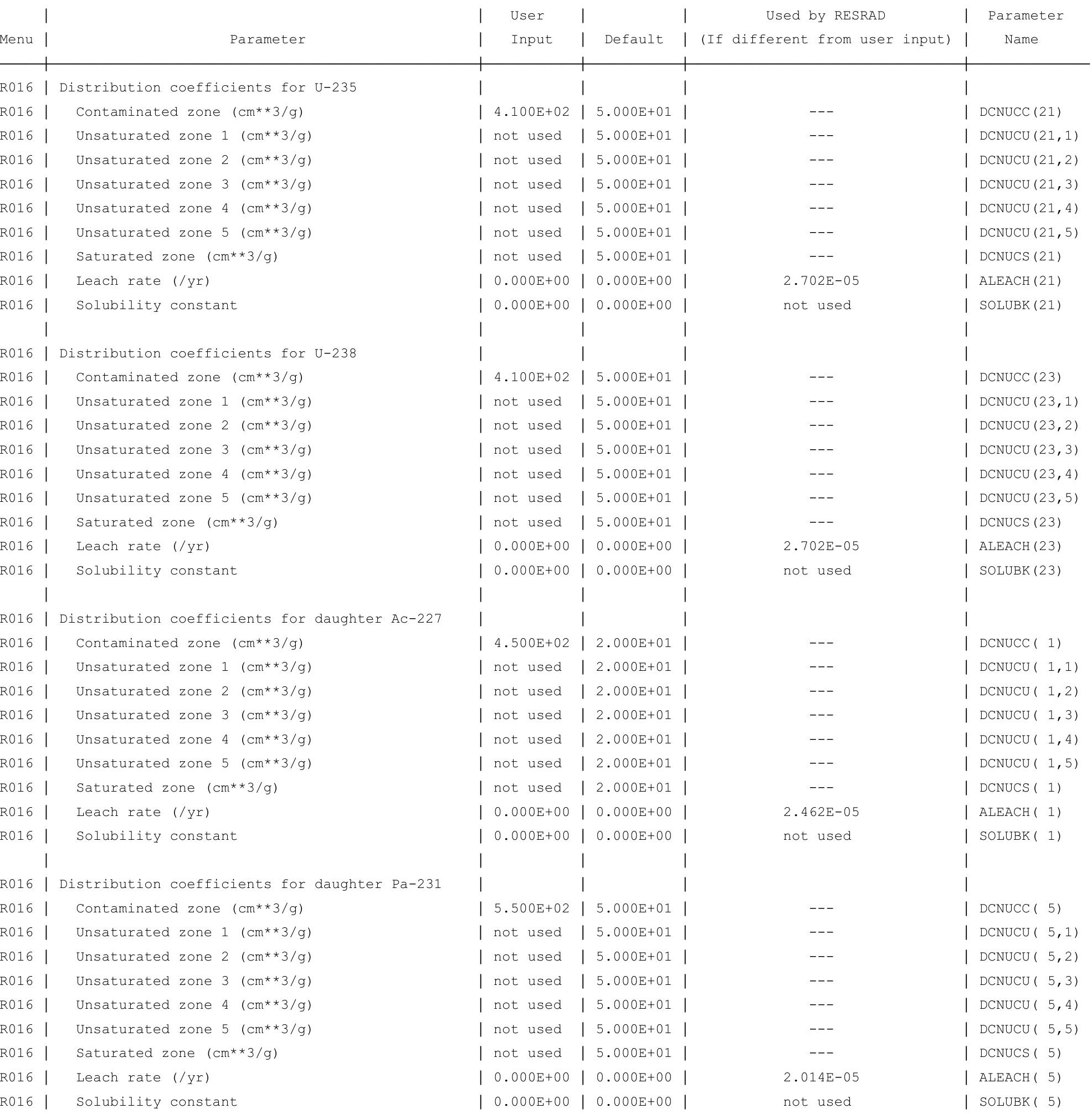


RESRAD, Version $6.5 \quad \mathrm{~T}^{1 / 2}$ Limit $=180$ days

Summary : RESRAD Parameters for U-Landfill Trespasser Forward Run

File : C: \RESRAD_FAMILY \RESRAD \USERFILES \QCJULY2011 TTRESPASSER_FORWARDRUN-70YRS.RAD

Site-Specific Parameter Summary (continued)

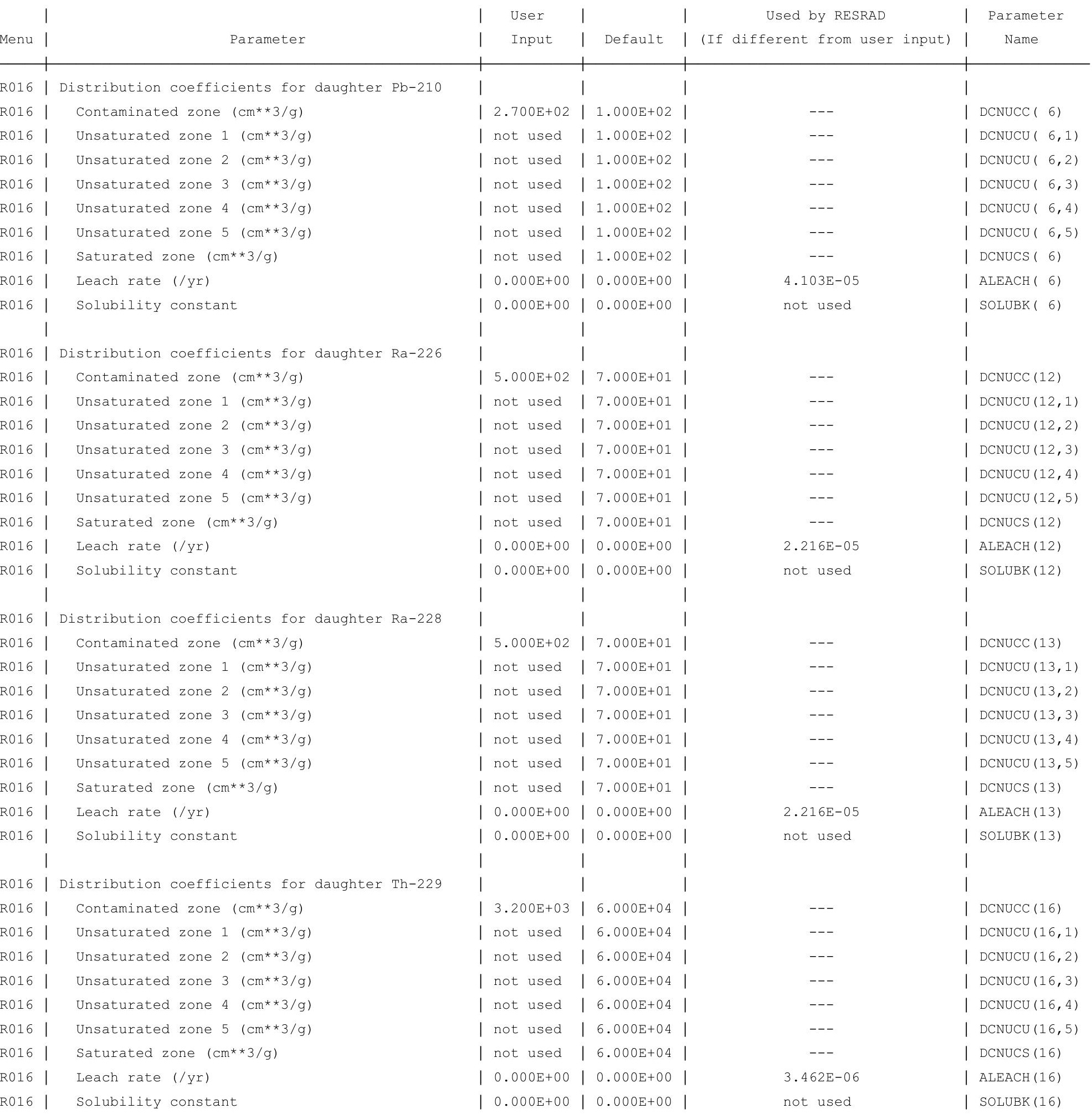


RESRAD, Version $6.5 \quad T^{1 / 2}$ Limit $=180$ days

Summary : RESRAD Parameters for U-Landfill Trespasser Forward Run

File : C: \RESRAD_FAMILY \RESRAD \USERFILES \QCJULY2011 TTRESPASSER_FORWARDRUN-70YRS.RAD

Site-Specific Parameter Summary (continued)

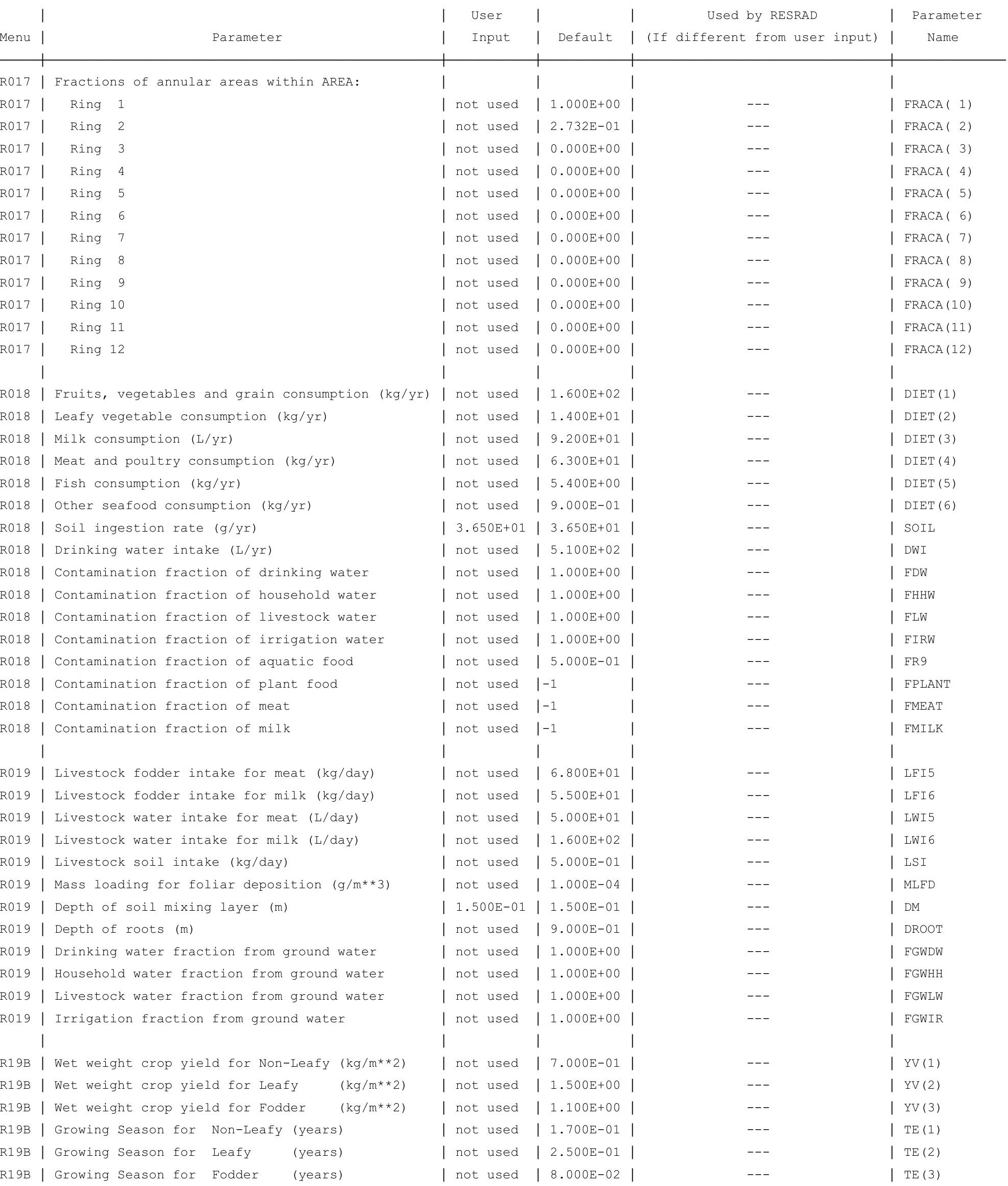


RESRAD, Version $6.5 \quad T^{1 / 2}$ Limit $=180$ days

Summary : RESRAD Parameters for U-Landfill Trespasser Forward Run

File : C: \RESRAD_FAMILY \RESRAD \USERFILES \QCJULY2011 TTRESPASSER_FORWARDRUN-70YRS.RAD

Site-Specific Parameter Summary (continued)

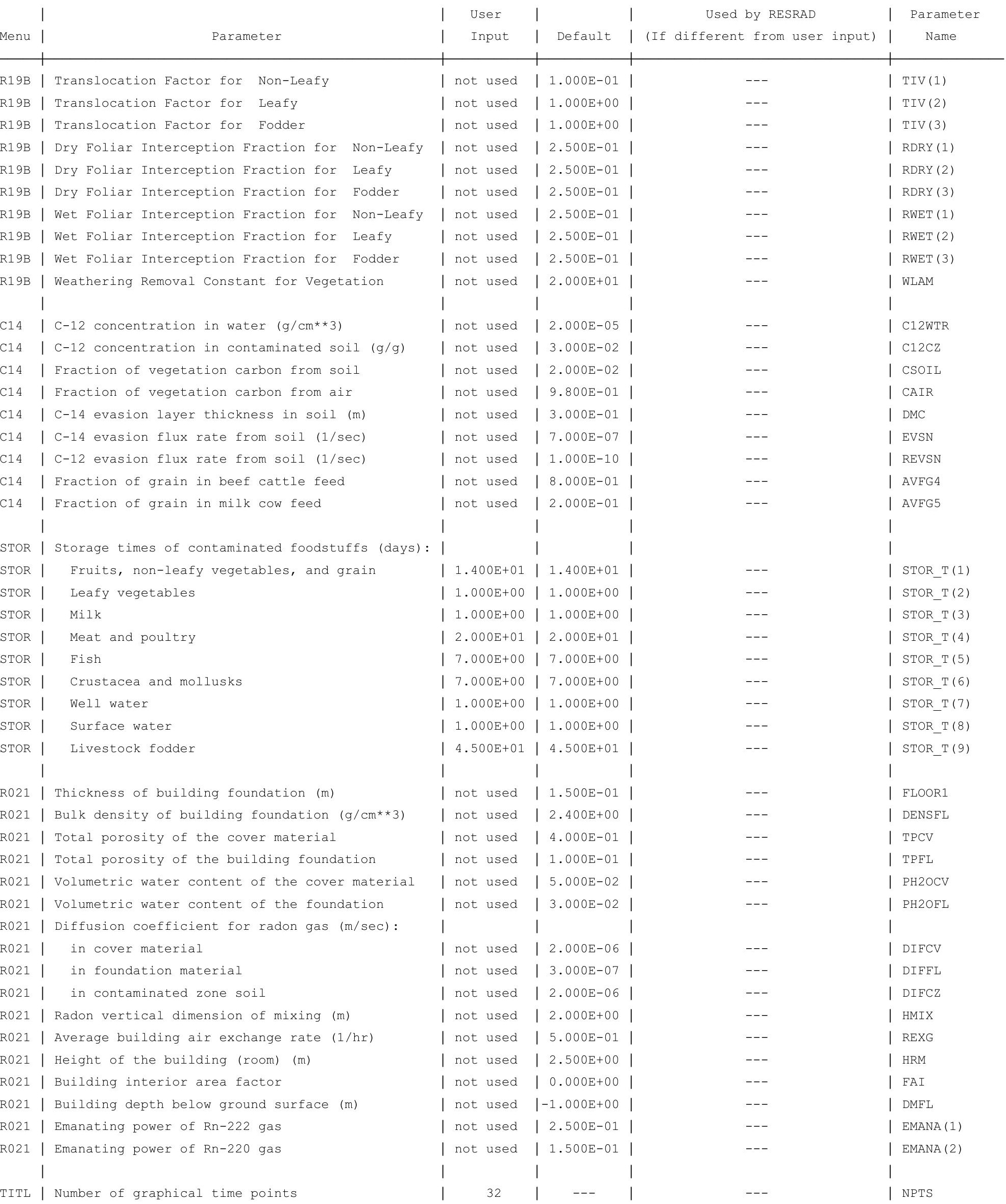

TITL | Number of graphical time points 
RESRAD, Version 6.5

Summary : RESRAD Parameters for U-Landfill Trespasser Forward Run

File : C: $\backslash$ RESRAD_FAMILY \RESRAD \USERFILES \QCJULY2011 TTRESPASSER_FORWARDRUN-70YRS.RAD

Contaminated Zone Dimensions

Area: $\quad 89436.00$ square meters

Thickness:

Cover Depth:

\begin{abstract}
13.40 meters
\end{abstract}
0.15 meters
Initial Soil Concentrations, pCi/g

$\begin{array}{ll}\mathrm{Am}-241 & 3.500 \mathrm{E}+01 \\ \mathrm{Cs}-137 & 1.900 \mathrm{E}+01 \\ \mathrm{~Np}-237 & 5.500 \mathrm{E}+00 \\ \mathrm{Pu}-238 & 3.900 \mathrm{E}+01 \\ \mathrm{Pu}-239 & 3.600 \mathrm{E}+01 \\ \mathrm{Pu}-240 & 3.600 \mathrm{E}+01 \\ \mathrm{TC}-99 & 5.200 \mathrm{E}+01 \\ \mathrm{Th}-228 & 4.000 \mathrm{E}+00 \\ \mathrm{Th}-230 & 1.000 \mathrm{E}+02 \\ \mathrm{Th}-232 & 4.000 \mathrm{E}+00 \\ \mathrm{U}-234 & 1.600 \mathrm{E}+02 \\ \mathrm{U}-235 & 6.500 \mathrm{E}+00 \\ \mathrm{U}-238 & 1.600 \mathrm{E}+02\end{array}$

Total Dose TDOSE(t), mrem/yr

Basic Radiation Dose Limit $=1.000 \mathrm{E}+02 \mathrm{mrem} / \mathrm{yr}$

Total Mixture Sum $M(t)$ = Fraction of Basic Dose Limit Received at Time (t)
$t$ (years): $\begin{array}{llllll}0.000 \mathrm{E}+00 & 1.000 \mathrm{E}+00 & 2.500 \mathrm{E}+01 & 5.000 \mathrm{E}+01 & 7.000 \mathrm{E}+01\end{array}$
TDOSE $(t): \begin{array}{lllll}9.324 \mathrm{E}-01 & 8.597 \mathrm{E}-01 & 1.333 \mathrm{E}+00 & 1.703 \mathrm{E}+00 & 2.056 \mathrm{E}+00\end{array}$
$M(t): \quad 9.324 \mathrm{E}-03 \quad 8.597 \mathrm{E}-03 \quad 1.333 \mathrm{E}-02 \quad 1.703 \mathrm{E}-02 \quad 2.056 \mathrm{E}-02$

Maximum TDOSE $(t): 2.056 \mathrm{E}+00 \mathrm{mrem} / \mathrm{yr}$ at $t=7.000 \mathrm{E}+01$ years 
RESRAD, Version 6.5

$07 / 20 / 2011 \quad 15: 34$

20

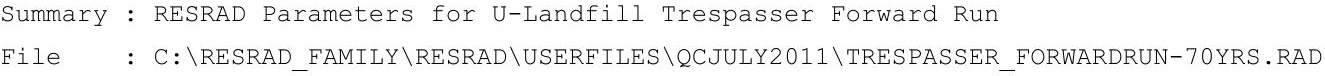

Total Dose Contributions TDOSE (i,p,t) for Individual Radionuclides (i) and Pathways (p) As mrem/yr and Fraction of Total Dose At $t=0.000 \mathrm{E}+00$ years

Water Independent Pathways (Inhalation excludes radon)

\begin{tabular}{|c|c|c|c|c|c|c|c|c|c|c|c|c|c|c|}
\hline \multirow{2}{*}{ Nuclide } & \multicolumn{2}{|c|}{ Ground } & \multicolumn{2}{|c|}{ Inhalation } & \multicolumn{2}{|c|}{ Radon } & \multicolumn{2}{|c|}{ Plant } & \multicolumn{2}{|c|}{ Meat } & \multicolumn{2}{|c|}{ Milk } & \multicolumn{2}{|c|}{ Soil } \\
\hline & mrem/yr & fract. & mrem/yr & fract. & mrem/yr & fract. & mrem/yr & fract. & mrem/yr & fract. & mrem/yr & fract. & mrem/yr & fract. \\
\hline-241 & $5.101 \mathrm{E}-05$ & 0.0001 & $0.000 \mathrm{E}+00$ & 0.0000 & $0.000 \mathrm{E}+00$ & 0.0000 & $0.000 \mathrm{E}+00$ & 0.0000 & $0.000 \mathrm{E}+00$ & 0.0000 & $0.000 \mathrm{E}+00$ & 0.0000 & $0.000 \mathrm{E}+00$ & 0.0000 \\
\hline-137 & $3.913 E-01$ & 0.4197 & $0.000 \mathrm{E}+00$ & 0.0000 & $0.000 \mathrm{E}+00$ & 0.0000 & $0.000 \mathrm{E}+00$ & 0.0000 & $0.000 \mathrm{E}+00$ & 0.0000 & $0.000 \mathrm{E}+00$ & 0.0000 & $0.000 \mathrm{E}+00$ & 0.0000 \\
\hline-237 & $1.899 \mathrm{E}-02$ & 0.0204 & $0.000 \mathrm{E}+00$ & 0.0000 & $0.000 \mathrm{E}+00$ & 0.0000 & $0.000 \mathrm{E}+00$ & 0.0000 & $0.000 \mathrm{E}+00$ & 0.0000 & $0.000 \mathrm{E}+00$ & 0.0000 & $0.000 \mathrm{E}+00$ & 0.0000 \\
\hline-238 & $1.030 \mathrm{E}-06$ & 0.0000 & $0.000 \mathrm{E}+00$ & 0.0000 & $0.000 \mathrm{E}+00$ & 0.0000 & $0.000 \mathrm{E}+00$ & 0.0000 & $0.000 \mathrm{E}+00$ & 0.0000 & $0.000 \mathrm{E}+00$ & 0.0000 & $0.000 \mathrm{E}+00$ & 0.0000 \\
\hline-239 & $2.269 \mathrm{E}-05$ & 0.0000 & $0.000 \mathrm{E}+00$ & 0.0000 & $0.000 \mathrm{E}+00$ & 0.0000 & $0.000 \mathrm{E}+00$ & 0.0000 & $0.000 \mathrm{E}+00$ & 0.0000 & $0.000 \mathrm{E}+00$ & 0.0000 & $0.000 \mathrm{E}+00$ & 0.0000 \\
\hline-240 & $9.241 \mathrm{E}-07$ & 0.0000 & $0.000 \mathrm{E}+00$ & 0.0000 & $0.000 \mathrm{E}+00$ & 0.0000 & $0.000 \mathrm{E}+00$ & 0.0000 & $0.000 \mathrm{E}+00$ & 0.0000 & $0.000 \mathrm{E}+00$ & 0.0000 & $0.000 \mathrm{E}+00$ & 0.0000 \\
\hline 99 & $2.113 E-06$ & 0.0000 & $0.000 \mathrm{E}+00$ & 0.0000 & $0.000 \mathrm{E}+00$ & 0.0000 & $0.000 \mathrm{E}+00$ & 0.0000 & $0.000 \mathrm{E}+00$ & 0.0000 & $0.000 \mathrm{E}+00$ & 0.0000 & $0.000 \mathrm{E}+00$ & 0.0000 \\
\hline-228 & $3.555 \mathrm{E}-01$ & 0.3813 & $0.000 \mathrm{E}+00$ & 0.0000 & $0.000 \mathrm{E}+00$ & 0.0000 & $0.000 \mathrm{E}+00$ & 0.0000 & $0.000 \mathrm{E}+00$ & 0.0000 & $0.000 \mathrm{E}+00$ & 0.0000 & $0.000 \mathrm{E}+00$ & 0.0000 \\
\hline-230 & $2.131 \mathrm{E}-03$ & 0.0023 & $0.000 \mathrm{E}+00$ & 0.0000 & $0.000 \mathrm{E}+00$ & 0.0000 & $0.000 \mathrm{E}+00$ & 0.0000 & $0.000 \mathrm{E}+00$ & 0.0000 & $0.000 \mathrm{E}+00$ & 0.0000 & $0.000 \mathrm{E}+00$ & 0.0000 \\
\hline-232 & $1.332 \mathrm{E}-02$ & 0.0143 & $0.000 \mathrm{E}+00$ & 0.0000 & $0.000 \mathrm{E}+00$ & 0.0000 & $0.000 \mathrm{E}+00$ & 0.0000 & $0.000 \mathrm{E}+00$ & 0.0000 & $0.000 \mathrm{E}+00$ & 0.0000 & $0.000 \mathrm{E}+00$ & 0.0000 \\
\hline 234 & $2.806 \mathrm{E}-05$ & 0.0000 & $0.000 \mathrm{E}+00$ & 0.0000 & $0.000 \mathrm{E}+00$ & 0.0000 & $0.000 \mathrm{E}+00$ & 0.0000 & $0.000 \mathrm{E}+00$ & 0.0000 & $0.000 \mathrm{E}+00$ & 0.0000 & $0.000 \mathrm{E}+00$ & 0.0000 \\
\hline 35 & $1.058 \mathrm{E}-02$ & 0.0113 & $0.000 \mathrm{E}+00$ & 0.0000 & $0.000 \mathrm{E}+00$ & 0.0000 & $0.000 \mathrm{E}+00$ & 0.0000 & $0.000 \mathrm{E}+00$ & 0.0000 & $0.000 \mathrm{E}+00$ & 0.0000 & $0.000 \mathrm{E}+00$ & 0.0000 \\
\hline 38 & $1.404 \mathrm{E}-01$ & 0.1506 & $0.000 \mathrm{E}+00$ & 0.0000 & $0.000 \mathrm{E}+00$ & 0.0000 & $0.000 \mathrm{E}+00$ & 0.0000 & $0.000 \mathrm{E}+00$ & 0.0000 & $0.000 \mathrm{E}+00$ & 0.0000 & $0.000 \mathrm{E}+00$ & 0.0000 \\
\hline & $9.324 \mathrm{E}-01$ & 1.0000 & $0.000 \mathrm{E}+00$ & 0.0000 & $0.000 \mathrm{E}+00$ & 0.0000 & $0.000 \mathrm{E}+00$ & 0.0000 & $0.000 \mathrm{E}+00$ & 0.0000 & $0.000 \mathrm{E}+00$ & 0.0000 & $0.000 \mathrm{E}+00$ & 0.0000 \\
\hline
\end{tabular}

Total Dose Contributions TDOSE(i,p,t) for Individual Radionuclides (i) and Pathways (p) As mrem/yr and Fraction of Total Dose At $t=0.000 \mathrm{E}+00$ years

Water Dependent Pathways

\begin{tabular}{|c|c|c|c|c|c|c|c|c|c|c|c|c|c|c|}
\hline \multirow{2}{*}{ Nuclide } & \multicolumn{2}{|c|}{ Water } & \multicolumn{2}{|c|}{ Fish } & \multicolumn{2}{|c|}{ Radon } & \multicolumn{2}{|c|}{ Plant } & \multicolumn{2}{|c|}{ Meat } & \multicolumn{2}{|c|}{ Milk } & \multicolumn{2}{|c|}{ All Pathways* } \\
\hline & mrem/yr & fract. & mrem/yr & fract. & mrem/yr & fract. & mrem/yr & fract. & mrem/yr & fract. & mrem/yr & fract. & mrem/yr & fract. \\
\hline-241 & $0.000 \mathrm{E}+00$ & 0.0000 & $0.000 \mathrm{E}+00$ & 0.0000 & $0.000 \mathrm{E}+00$ & 0.0000 & $0.000 \mathrm{E}+00$ & 0.0000 & $0.000 \mathrm{E}+00$ & 0.0000 & $0.000 \mathrm{E}+00$ & 0.0000 & $5.101 \mathrm{E}-05$ & 0.0001 \\
\hline-137 & $0.000 \mathrm{E}+00$ & 0.0000 & $0.000 \mathrm{E}+00$ & 0.0000 & $0.000 \mathrm{E}+00$ & 0.0000 & $0.000 \mathrm{E}+00$ & 0.0000 & $0.000 \mathrm{E}+00$ & 0.0000 & $0.000 \mathrm{E}+00$ & 0.0000 & $3.913 \mathrm{E}-01$ & 0.4197 \\
\hline-237 & $0.000 \mathrm{E}+00$ & 0.0000 & $0.000 \mathrm{E}+00$ & 0.0000 & $0.000 \mathrm{E}+00$ & 0.0000 & $0.000 \mathrm{E}+00$ & 0.0000 & $0.000 \mathrm{E}+00$ & 0.0000 & $0.000 \mathrm{E}+00$ & 0.0000 & $1.899 \mathrm{E}-02$ & 0.0204 \\
\hline-238 & $0.000 \mathrm{E}+00$ & 0.0000 & $0.000 \mathrm{E}+00$ & 0.0000 & $0.000 \mathrm{E}+00$ & 0.0000 & $0.000 \mathrm{E}+00$ & 0.0000 & $0.000 \mathrm{E}+00$ & 0.0000 & $0.000 \mathrm{E}+00$ & 0.0000 & $1.030 \mathrm{E}-06$ & 0.0000 \\
\hline 239 & $0.000 \mathrm{E}+00$ & 0.0000 & $0.000 \mathrm{E}+00$ & 0.0000 & $0.000 \mathrm{E}+00$ & 0.0000 & $0.000 \mathrm{E}+00$ & 0.0000 & $0.000 \mathrm{E}+00$ & 0.0000 & $0.000 \mathrm{E}+00$ & 0.0000 & $2.269 \mathrm{E}-05$ & 0.0000 \\
\hline-240 & $0.000 \mathrm{E}+00$ & 0.0000 & $0.000 \mathrm{E}+00$ & 0.0000 & $0.000 \mathrm{E}+00$ & 0.0000 & $0.000 \mathrm{E}+00$ & 0.0000 & $0.000 \mathrm{E}+00$ & 0.0000 & $0.000 \mathrm{E}+00$ & 0.0000 & $9.241 \mathrm{E}-07$ & 0.0000 \\
\hline 99 & $0.000 \mathrm{E}+00$ & 0.0000 & $0.000 \mathrm{E}+00$ & 0.0000 & $0.000 \mathrm{E}+00$ & 0.0000 & $0.000 \mathrm{E}+00$ & 0.0000 & $0.000 \mathrm{E}+00$ & 0.0000 & $0.000 \mathrm{E}+00$ & 0.0000 & $2.113 \mathrm{E}-06$ & 0.0000 \\
\hline-228 & $0.000 \mathrm{E}+00$ & 0.0000 & $0.000 \mathrm{E}+00$ & 0.0000 & $0.000 \mathrm{E}+00$ & 0.0000 & $0.000 \mathrm{E}+00$ & 0.0000 & $0.000 \mathrm{E}+00$ & 0.0000 & $0.000 \mathrm{E}+00$ & 0.0000 & $3.555 \mathrm{E}-01$ & 0.3813 \\
\hline-230 & $0.000 \mathrm{E}+00$ & 0.0000 & $0.000 \mathrm{E}+00$ & 0.0000 & $0.000 \mathrm{E}+00$ & 0.0000 & $0.000 \mathrm{E}+00$ & 0.0000 & $0.000 \mathrm{E}+00$ & 0.0000 & $0.000 \mathrm{E}+00$ & 0.0000 & $2.131 \mathrm{E}-03$ & 0.0023 \\
\hline-232 & $0.000 \mathrm{E}+00$ & 0.0000 & $0.000 \mathrm{E}+00$ & 0.0000 & $0.000 \mathrm{E}+00$ & 0.0000 & $0.000 \mathrm{E}+00$ & 0.0000 & $0.000 \mathrm{E}+00$ & 0.0000 & $0.000 \mathrm{E}+00$ & 0.0000 & $1.332 \mathrm{E}-02$ & 0.0143 \\
\hline 234 & $0.000 \mathrm{E}+00$ & 0.0000 & $0.000 \mathrm{E}+00$ & 0.0000 & $0.000 \mathrm{E}+00$ & 0.0000 & $0.000 \mathrm{E}+00$ & 0.0000 & $0.000 \mathrm{E}+00$ & 0.0000 & $0.000 \mathrm{E}+00$ & 0.0000 & $2.806 \mathrm{E}-05$ & 0.0000 \\
\hline 35 & $0.000 \mathrm{E}+00$ & 0.0000 & $0.000 \mathrm{E}+00$ & 0.0000 & $0.000 \mathrm{E}+00$ & 0.0000 & $0.000 \mathrm{E}+00$ & 0.0000 & $0.000 \mathrm{E}+00$ & 0.0000 & $0.000 \mathrm{E}+00$ & 0.0000 & $1.058 \mathrm{E}-02$ & 0.0113 \\
\hline 38 & $0.000 \mathrm{E}+00$ & 0.0000 & $0.000 \mathrm{E}+00$ & 0.0000 & $0.000 \mathrm{E}+00$ & 0.0000 & $0.000 \mathrm{E}+00$ & 0.0000 & $0.000 \mathrm{E}+00$ & 0.0000 & $0.000 \mathrm{E}+00$ & 0.0000 & $1.404 \mathrm{E}-01$ & 0.1506 \\
\hline & $0.000 \mathrm{E}+00$ & 0.0000 & $0.000 \mathrm{E}+00$ & 0.0000 & $0.000 \mathrm{E}+00$ & 0.0000 & $0.000 \mathrm{E}+00$ & 0.0000 & $0.000 \mathrm{E}+00$ & 0.0000 & $0.000 \mathrm{E}+00$ & 0.0000 & $24 \mathrm{E}-01$ & 1.0000 \\
\hline
\end{tabular}

* Sum of all water independent and dependent pathways. 
RESRAD, Version 6.5

$07 / 20 / 2011 \quad 15: 34$

ummary : RESRAD Parameters for U-Landfill Trespasser Forward Run

File : C: $\backslash$ RESRAD_FAMILY \RESRAD \USERFILES $\backslash Q C J U L Y 2011 \backslash$ TRESPASSER_FORWARDRUN-70YRS.RAD

Total Dose Contributions TDOSE (i,p,t) for Individual Radionuclides (i) and Pathways (p) As mrem/yr and Fraction of Total Dose At $t=1.000 \mathrm{E}+00$ years

Water Independent Pathways (Inhalation excludes radon)

\begin{tabular}{|c|c|c|c|c|c|c|c|c|c|c|c|c|c|c|}
\hline \multirow{2}{*}{ Nuclide } & \multicolumn{2}{|c|}{ Ground } & \multicolumn{2}{|c|}{ Inhalation } & \multicolumn{2}{|c|}{ Radon } & \multicolumn{2}{|c|}{ Plant } & \multicolumn{2}{|c|}{ Meat } & \multicolumn{2}{|c|}{ Milk } & \multicolumn{2}{|c|}{ Soil } \\
\hline & mrem/yr & fract. & mrem/yr & fract. & mrem/yr & fract. & mrem/yr & fract. & mrem/yr & fract. & mrem/yr & fract. & mrem/yr & fract. \\
\hline-241 & $5.243 E-05$ & 0.0001 & $0.000 \mathrm{E}+00$ & 0.0000 & $0.000 \mathrm{E}+00$ & 0.0000 & $0.000 \mathrm{E}+00$ & 0.0000 & $0.000 \mathrm{E}+00$ & 0.0000 & $0.000 \mathrm{E}+00$ & 0.0000 & $0.000 \mathrm{E}+00$ & 0.0000 \\
\hline-137 & $3.856 \mathrm{E}-01$ & 0.4485 & $0.000 \mathrm{E}+00$ & 0.0000 & $0.000 \mathrm{E}+00$ & 0.0000 & $0.000 \mathrm{E}+00$ & 0.0000 & $0.000 \mathrm{E}+00$ & 0.0000 & $0.000 \mathrm{E}+00$ & 0.0000 & $0.000 \mathrm{E}+00$ & 0.0000 \\
\hline-237 & $1.919 \mathrm{E}-02$ & 0.0223 & $0.000 \mathrm{E}+00$ & 0.0000 & $0.000 \mathrm{E}+00$ & 0.0000 & $0.000 \mathrm{E}+00$ & 0.0000 & $0.000 \mathrm{E}+00$ & 0.0000 & $0.000 \mathrm{E}+00$ & 0.0000 & $0.000 \mathrm{E}+00$ & 0.0000 \\
\hline-238 & $1.040 \mathrm{E}-06$ & 0.0000 & $0.000 \mathrm{E}+00$ & 0.0000 & $0.000 \mathrm{E}+00$ & 0.0000 & $0.000 \mathrm{E}+00$ & 0.0000 & $0.000 \mathrm{E}+00$ & 0.0000 & $0.000 \mathrm{E}+00$ & 0.0000 & $0.000 \mathrm{E}+00$ & 0.0000 \\
\hline-239 & $2.296 \mathrm{E}-05$ & 0.0000 & $0.000 \mathrm{E}+00$ & 0.0000 & $0.000 \mathrm{E}+00$ & 0.0000 & $0.000 \mathrm{E}+00$ & 0.0000 & $0.000 \mathrm{E}+00$ & 0.0000 & $0.000 \mathrm{E}+00$ & 0.0000 & $0.000 \mathrm{E}+00$ & 0.0000 \\
\hline-240 & $9.405 \mathrm{E}-07$ & 0.0000 & $0.000 \mathrm{E}+00$ & 0.0000 & $0.000 \mathrm{E}+00$ & 0.0000 & $0.000 \mathrm{E}+00$ & 0.0000 & $0.000 \mathrm{E}+00$ & 0.0000 & $0.000 \mathrm{E}+00$ & 0.0000 & $0.000 \mathrm{E}+00$ & 0.0000 \\
\hline 99 & $2.131 E-06$ & 0.0000 & $0.000 \mathrm{E}+00$ & 0.0000 & $0.000 \mathrm{E}+00$ & 0.0000 & $0.000 \mathrm{E}+00$ & 0.0000 & $0.000 \mathrm{E}+00$ & 0.0000 & $0.000 \mathrm{E}+00$ & 0.0000 & $0.000 \mathrm{E}+00$ & 0.0000 \\
\hline-228 & $2.490 \mathrm{E}-01$ & 0.2897 & $0.000 \mathrm{E}+00$ & 0.0000 & $0.000 \mathrm{E}+00$ & 0.0000 & $0.000 \mathrm{E}+00$ & 0.0000 & $0.000 \mathrm{E}+00$ & 0.0000 & $0.000 \mathrm{E}+00$ & 0.0000 & $0.000 \mathrm{E}+00$ & 0.0000 \\
\hline-230 & $6.276 \mathrm{E}-03$ & 0.0073 & $0.000 \mathrm{E}+00$ & 0.0000 & $0.000 \mathrm{E}+00$ & 0.0000 & $0.000 \mathrm{E}+00$ & 0.0000 & $0.000 \mathrm{E}+00$ & 0.0000 & $0.000 \mathrm{E}+00$ & 0.0000 & $0.000 \mathrm{E}+00$ & 0.0000 \\
\hline-232 & $4.723 E-02$ & 0.0549 & $0.000 \mathrm{E}+00$ & 0.0000 & $0.000 \mathrm{E}+00$ & 0.0000 & $0.000 \mathrm{E}+00$ & 0.0000 & $0.000 \mathrm{E}+00$ & 0.0000 & $0.000 \mathrm{E}+00$ & 0.0000 & $0.000 \mathrm{E}+00$ & 0.0000 \\
\hline 234 & $2.862 E-05$ & 0.0000 & $0.000 \mathrm{E}+00$ & 0.0000 & $0.000 \mathrm{E}+00$ & 0.0000 & $0.000 \mathrm{E}+00$ & 0.0000 & $0.000 \mathrm{E}+00$ & 0.0000 & $0.000 \mathrm{E}+00$ & 0.0000 & $0.000 \mathrm{E}+00$ & 0.0000 \\
\hline 35 & $1.071 \mathrm{E}-02$ & 0.0125 & $0.000 \mathrm{E}+00$ & 0.0000 & $0.000 \mathrm{E}+00$ & 0.0000 & $0.000 \mathrm{E}+00$ & 0.0000 & $0.000 \mathrm{E}+00$ & 0.0000 & $0.000 \mathrm{E}+00$ & 0.0000 & $0.000 \mathrm{E}+00$ & 0.0000 \\
\hline 38 & $1.415 E-01$ & 0.1646 & $0.000 \mathrm{E}+00$ & 0.0000 & $0.000 \mathrm{E}+00$ & 0.0000 & $0.000 \mathrm{E}+00$ & 0.0000 & $0.000 \mathrm{E}+00$ & 0.0000 & $0.000 \mathrm{E}+00$ & 0.0000 & $0.000 \mathrm{E}+00$ & 0.0000 \\
\hline & $8.597 \mathrm{E}-01$ & 1.0000 & $0.000 \mathrm{E}+00$ & 0.0000 & $0.000 \mathrm{E}+00$ & 0.0000 & $0.000 \mathrm{E}+00$ & 0.0000 & $0.000 \mathrm{E}+00$ & 0.0000 & $0.000 \mathrm{E}+00$ & 0.0000 & $0.000 \mathrm{E}+00$ & 0.0000 \\
\hline
\end{tabular}

Total Dose Contributions TDOSE(i,p,t) for Individual Radionuclides (i) and Pathways (p) As mrem/yr and Fraction of Total Dose At $t=1.000 \mathrm{E}+00$ years

Water Dependent Pathways

\begin{tabular}{|c|c|c|c|c|c|c|c|c|c|c|c|c|c|c|}
\hline \multirow{2}{*}{$\begin{array}{l}\text { Radio- } \\
\text { Nuclide }\end{array}$} & \multicolumn{2}{|c|}{ Water } & \multicolumn{2}{|c|}{ Fish } & \multicolumn{2}{|c|}{ Radon } & \multicolumn{2}{|c|}{ Plant } & \multicolumn{2}{|c|}{ Meat } & \multicolumn{2}{|c|}{ Milk } & \multicolumn{2}{|c|}{ All Pathways* } \\
\hline & mrem/yr & fract. & mrem/yr & fract. & mrem/yr & fract. & mrem/yr & fract. & mrem/yr & fract. & mrem/yr & fract. & mrem/yr & fract. \\
\hline 241 & $0.000 \mathrm{E}+00$ & 0.0000 & $0.000 \mathrm{E}+00$ & 0.0000 & $0.000 \mathrm{E}+00$ & 0.0000 & $0.000 \mathrm{E}+00$ & 0.0000 & $0.000 \mathrm{E}+00$ & 0.0000 & $0.000 \mathrm{E}+00$ & 0.0000 & $5.243 E-05$ & 0.0001 \\
\hline-137 & $0.000 \mathrm{E}+00$ & 0.0000 & $0.000 \mathrm{E}+00$ & 0.0000 & $0.000 \mathrm{E}+00$ & 0.0000 & $0.000 \mathrm{E}+00$ & 0.0000 & $0.000 \mathrm{E}+00$ & 0.0000 & $0.000 \mathrm{E}+00$ & 0.0000 & $3.856 \mathrm{E}-01$ & 0.4485 \\
\hline-237 & $0.000 \mathrm{E}+00$ & 0.0000 & $0.000 \mathrm{E}+00$ & 0.0000 & $0.000 \mathrm{E}+00$ & 0.0000 & $0.000 \mathrm{E}+00$ & 0.0000 & $0.000 \mathrm{E}+00$ & 0.0000 & $0.000 \mathrm{E}+00$ & 0.0000 & $1.919 \mathrm{E}-02$ & 0.0223 \\
\hline-238 & $0.000 \mathrm{E}+00$ & 0.0000 & $0.000 \mathrm{E}+00$ & 0.0000 & $0.000 \mathrm{E}+00$ & 0.0000 & $0.000 \mathrm{E}+00$ & 0.0000 & $0.000 \mathrm{E}+00$ & 0.0000 & $0.000 \mathrm{E}+00$ & 0.0000 & $1.040 \mathrm{E}-06$ & 0.0000 \\
\hline-239 & $0.000 \mathrm{E}+00$ & 0.0000 & $0.000 \mathrm{E}+00$ & 0.0000 & $0.000 \mathrm{E}+00$ & 0.0000 & $0.000 \mathrm{E}+00$ & 0.0000 & $0.000 \mathrm{E}+00$ & 0.0000 & $0.000 E+00$ & 0.0000 & $2.296 \mathrm{E}-05$ & 0.0000 \\
\hline-240 & $0.000 \mathrm{E}+00$ & 0.0000 & $0.000 \mathrm{E}+00$ & 0.0000 & $0.000 \mathrm{E}+00$ & 0.0000 & $0.000 \mathrm{E}+00$ & 0.0000 & $0.000 \mathrm{E}+00$ & 0.0000 & $0.000 E+00$ & 0.0000 & $9.405 \mathrm{E}-07$ & 0.0000 \\
\hline-99 & $0.000 \mathrm{E}+00$ & 0.0000 & $0.000 \mathrm{E}+00$ & 0.0000 & $0.000 \mathrm{E}+00$ & 0.0000 & $0.000 \mathrm{E}+00$ & 0.0000 & $0.000 \mathrm{E}+00$ & 0.0000 & $0.000 \mathrm{E}+00$ & 0.0000 & $2.131 \mathrm{E}-06$ & 0.0000 \\
\hline-228 & $0.000 \mathrm{E}+00$ & 0.0000 & $0.000 \mathrm{E}+00$ & 0.0000 & $0.000 \mathrm{E}+00$ & 0.0000 & $0.000 \mathrm{E}+00$ & 0.0000 & $0.000 \mathrm{E}+00$ & 0.0000 & $0.000 \mathrm{E}+00$ & 0.0000 & $2.490 \mathrm{E}-01$ & 0.2897 \\
\hline-230 & $0.000 \mathrm{E}+00$ & 0.0000 & $0.000 \mathrm{E}+00$ & 0.0000 & $0.000 \mathrm{E}+00$ & 0.0000 & $0.000 \mathrm{E}+00$ & 0.0000 & $0.000 \mathrm{E}+00$ & 0.0000 & $0.000 E+00$ & 0.0000 & $6.276 \mathrm{E}-03$ & 0.0073 \\
\hline-232 & $0.000 \mathrm{E}+00$ & 0.0000 & $0.000 \mathrm{E}+00$ & 0.0000 & $0.000 \mathrm{E}+00$ & 0.0000 & $0.000 \mathrm{E}+00$ & 0.0000 & $0.000 \mathrm{E}+00$ & 0.0000 & $0.000 \mathrm{E}+00$ & 0.0000 & $4.723 E-02$ & 0.0549 \\
\hline 34 & $0.000 \mathrm{E}+00$ & 0.0000 & $0.000 \mathrm{E}+00$ & 0.0000 & $0.000 \mathrm{E}+00$ & 0.0000 & $0.000 \mathrm{E}+00$ & 0.0000 & $0.000 \mathrm{E}+00$ & 0.0000 & $0.000 \mathrm{E}+00$ & 0.0000 & $2.862 E-05$ & 0.0000 \\
\hline 35 & $0.000 \mathrm{E}+00$ & 0.0000 & $0.000 \mathrm{E}+00$ & 0.0000 & $0.000 \mathrm{E}+00$ & 0.0000 & $0.000 \mathrm{E}+00$ & 0.0000 & $0.000 \mathrm{E}+00$ & 0.0000 & $0.000 \mathrm{E}+00$ & 0.0000 & $1.071 \mathrm{E}-02$ & 0.0125 \\
\hline 38 & $0.000 \mathrm{E}+00$ & 0.0000 & $0.000 \mathrm{E}+00$ & 0.0000 & $0.000 \mathrm{E}+00$ & 0.0000 & $0.000 \mathrm{E}+00$ & 0.0000 & $0.000 \mathrm{E}+00$ & 0.0000 & $0.000 \mathrm{E}+00$ & 0.0000 & 1. $415 \mathrm{E}-01$ & 0.1646 \\
\hline & $0.000 \mathrm{E}+00$ & 0.0000 & $0.000 \mathrm{E}+00$ & 0.0000 & $0.000 \mathrm{E}+00$ & 0.0000 & $0.000 \mathrm{E}+00$ & 0.0000 & $0.000 \mathrm{E}+00$ & 0.0000 & $0.000 \mathrm{E}+00$ & 0.0000 & $7 E-01$ & 1. \\
\hline
\end{tabular}

* Sum of all water independent and dependent pathways. 
RESRAD, Version 6.5

$07 / 20 / 2011 \quad 15: 34$

ummary : RESRAD Parameters for U-Landfill Trespasser Forward Run

File : C: $\backslash$ RESRAD_FAMILY \RESRAD \USERFILES $\backslash Q C J U L Y 2011 \backslash$ TRESPASSER_FORWARDRUN-70YRS.RAD

Total Dose Contributions TDOSE (i,p,t) for Individual Radionuclides (i) and Pathways (p) As mrem/yr and Fraction of Total Dose At $t=2.500 \mathrm{E}+01$ years

Water Independent Pathways (Inhalation excludes radon)

\begin{tabular}{|c|c|c|c|c|c|c|c|c|c|c|c|c|c|c|}
\hline \multirow{2}{*}{ Nuclide } & \multicolumn{2}{|c|}{ Ground } & \multicolumn{2}{|c|}{ Inhalation } & \multicolumn{2}{|c|}{ Radon } & \multicolumn{2}{|c|}{ Plant } & \multicolumn{2}{|c|}{ Meat } & \multicolumn{2}{|c|}{ Milk } & \multicolumn{2}{|c|}{ Soil } \\
\hline & mrem/yr & fract. & mrem/yr & fract. & mrem/yr & fract. & mrem/yr & fract. & mrem/yr & fract. & mrem/yr & fract. & mrem/yr & fract. \\
\hline-241 & $1.006 \mathrm{E}-04$ & 0.0001 & $1.274 \mathrm{E}-04$ & 0.0001 & $0.000 \mathrm{E}+00$ & 0.0000 & $0.000 \mathrm{E}+00$ & 0.0000 & $0.000 \mathrm{E}+00$ & 0.0000 & $0.000 \mathrm{E}+00$ & 0.0000 & $4.827 \mathrm{E}-03$ & 0.0036 \\
\hline-137 & $2.709 E-01$ & 0.2033 & $1.623 \mathrm{E}-08$ & 0.0000 & $0.000 \mathrm{E}+00$ & 0.0000 & $0.000 \mathrm{E}+00$ & 0.0000 & $0.000 \mathrm{E}+00$ & 0.0000 & $0.000 \mathrm{E}+00$ & 0.0000 & $9.835 E-05$ & 0.0001 \\
\hline-237 & $2.484 \mathrm{E}-02$ & 0.0186 & $1.082 \mathrm{E}-05$ & 0.0000 & $0.000 \mathrm{E}+00$ & 0.0000 & $0.000 \mathrm{E}+00$ & 0.0000 & $0.000 \mathrm{E}+00$ & 0.0000 & $0.000 \mathrm{E}+00$ & 0.0000 & $4.364 \mathrm{E}-04$ & 0.0003 \\
\hline-238 & $1.315 E-06$ & 0.0000 & $1.385 E-04$ & 0.0001 & $0.000 \mathrm{E}+00$ & 0.0000 & $0.000 \mathrm{E}+00$ & 0.0000 & $0.000 \mathrm{E}+00$ & 0.0000 & $0.000 \mathrm{E}+00$ & 0.0000 & $5.266 \mathrm{E}-03$ & 0.0040 \\
\hline-239 & $3.058 \mathrm{E}-05$ & 0.0000 & $1.705 \mathrm{E}-04$ & 0.0001 & $0.000 \mathrm{E}+00$ & 0.0000 & $0.000 \mathrm{E}+00$ & 0.0000 & $0.000 \mathrm{E}+00$ & 0.0000 & $0.000 \mathrm{E}+00$ & 0.0000 & $6.458 E-03$ & 0.0048 \\
\hline-240 & $1.433 \mathrm{E}-06$ & 0.0000 & $1.702 \mathrm{E}-04$ & 0.0001 & $0.000 \mathrm{E}+00$ & 0.0000 & $0.000 \mathrm{E}+00$ & 0.0000 & $0.000 \mathrm{E}+00$ & 0.0000 & $0.000 \mathrm{E}+00$ & 0.0000 & $6.445 \mathrm{E}-03$ & 0.0048 \\
\hline 99 & $2.620 E-06$ & 0.0000 & $2.040 E-08$ & 0.0000 & $0.000 \mathrm{E}+00$ & 0.0000 & $0.000 \mathrm{E}+00$ & 0.0000 & $0.000 \mathrm{E}+00$ & 0.0000 & $0.000 \mathrm{E}+00$ & 0.0000 & $1.826 \mathrm{E}-05$ & 0.0000 \\
\hline-228 & $4.837 E-05$ & 0.0000 & $6.726 \mathrm{E}-10$ & 0.0000 & $0.000 \mathrm{E}+00$ & 0.0000 & $0.000 \mathrm{E}+00$ & 0.0000 & $0.000 \mathrm{E}+00$ & 0.0000 & $0.000 \mathrm{E}+00$ & 0.0000 & $4.017 E-08$ & 0.0000 \\
\hline 230 & 1. $243 E-01$ & 0.0933 & $3.956 \mathrm{E}-04$ & 0.0003 & $0.000 \mathrm{E}+00$ & 0.0000 & $0.000 \mathrm{E}+00$ & 0.0000 & $0.000 \mathrm{E}+00$ & 0.0000 & $0.000 \mathrm{E}+00$ & 0.0000 & $1.577 \mathrm{E}-02$ & 0.0118 \\
\hline-232 & $6.710 E-01$ & 0.5035 & $2.622 E-05$ & 0.0000 & $0.000 \mathrm{E}+00$ & 0.0000 & $0.000 \mathrm{E}+00$ & 0.0000 & $0.000 \mathrm{E}+00$ & 0.0000 & $0.000 \mathrm{E}+00$ & 0.0000 & $2.936 \mathrm{E}-03$ & 0.0022 \\
\hline 34 & $6.654 \mathrm{E}-05$ & 0.0000 & $5.953 E-05$ & 0.0000 & $0.000 \mathrm{E}+00$ & 0.0000 & $0.000 \mathrm{E}+00$ & 0.0000 & $0.000 \mathrm{E}+00$ & 0.0000 & $0.000 \mathrm{E}+00$ & 0.0000 & $5.634 \mathrm{E}-03$ & 0.0042 \\
\hline 35 & $1.444 \mathrm{E}-02$ & 0.0108 & $2.226 \mathrm{E}-06$ & 0.0000 & $0.000 \mathrm{E}+00$ & 0.0000 & $0.000 \mathrm{E}+00$ & 0.0000 & $0.000 \mathrm{E}+00$ & 0.0000 & $0.000 \mathrm{E}+00$ & 0.0000 & $2.237 \mathrm{E}-04$ & 0.0002 \\
\hline 38 & $1.720 \mathrm{E}-01$ & 0.1291 & $5.060 \mathrm{E}-05$ & 0.0000 & $0.000 \mathrm{E}+00$ & 0.0000 & $0.000 \mathrm{E}+00$ & 0.0000 & $0.000 \mathrm{E}+00$ & 0.0000 & $0.000 \mathrm{E}+00$ & 0.0000 & $5.561 \mathrm{E}-03$ & 0.0042 \\
\hline & $1.278 \mathrm{E}+00$ & 0.9589 & $1.152 \mathrm{E}-03$ & 0.0009 & $0.000 \mathrm{E}+00$ & 0.0000 & $0.000 \mathrm{E}+00$ & 0.0000 & $0.000 \mathrm{E}+00$ & 0.0000 & $0.000 \mathrm{E}+00$ & 0.0000 & $5.367 E-02$ & 0.0403 \\
\hline
\end{tabular}

Total Dose Contributions TDOSE(i,p,t) for Individual Radionuclides (i) and Pathways (p) As mrem/yr and Fraction of Total Dose At $t=2.500 \mathrm{E}+01$ years

Water Dependent Pathways

\begin{tabular}{|c|c|c|c|c|c|c|c|c|c|c|c|c|c|c|}
\hline \multirow{2}{*}{$\begin{array}{l}\text { Radio- } \\
\text { Nuclide }\end{array}$} & \multicolumn{2}{|c|}{ Water } & \multicolumn{2}{|c|}{ Fish } & \multicolumn{2}{|c|}{ Radon } & \multicolumn{2}{|c|}{ Plant } & \multicolumn{2}{|c|}{ Meat } & \multicolumn{2}{|c|}{ Milk } & \multicolumn{2}{|c|}{ All Pathways* } \\
\hline & mrem/yr & fract. & mrem/yr & fract. & mrem/yr & fract. & mrem/yr & fract. & mrem/yr & fract. & mrem/yr & fract. & mrem/yr & fract. \\
\hline 241 & $0.000 \mathrm{E}+00$ & 0.0000 & $0.000 \mathrm{E}+00$ & 0.0000 & $0.000 \mathrm{E}+00$ & 0.0000 & $0.000 \mathrm{E}+00$ & 0.0000 & $0.000 \mathrm{E}+00$ & 0.0000 & $0.000 \mathrm{E}+00$ & 0.0000 & $5.055 \mathrm{E}-03$ & 0.0038 \\
\hline-137 & $0.000 \mathrm{E}+00$ & 0.0000 & $0.000 \mathrm{E}+00$ & 0.0000 & $0.000 \mathrm{E}+00$ & 0.0000 & $0.000 \mathrm{E}+00$ & 0.0000 & $0.000 \mathrm{E}+00$ & 0.0000 & $0.000 \mathrm{E}+00$ & 0.0000 & $2.710 \mathrm{E}-01$ & 0.2034 \\
\hline-237 & $0.000 \mathrm{E}+00$ & 0.0000 & $0.000 \mathrm{E}+00$ & 0.0000 & $0.000 \mathrm{E}+00$ & 0.0000 & $0.000 \mathrm{E}+00$ & 0.0000 & $0.000 \mathrm{E}+00$ & 0.0000 & $0.000 \mathrm{E}+00$ & 0.0000 & $2.529 \mathrm{E}-02$ & 0.0190 \\
\hline-238 & $0.000 \mathrm{E}+00$ & 0.0000 & $0.000 \mathrm{E}+00$ & 0.0000 & $0.000 \mathrm{E}+00$ & 0.0000 & $0.000 \mathrm{E}+00$ & 0.0000 & $0.000 \mathrm{E}+00$ & 0.0000 & $0.000 \mathrm{E}+00$ & 0.0000 & $5.406 \mathrm{E}-03$ & 0.0041 \\
\hline-239 & $0.000 \mathrm{E}+00$ & 0.0000 & $0.000 \mathrm{E}+00$ & 0.0000 & $0.000 \mathrm{E}+00$ & 0.0000 & $0.000 \mathrm{E}+00$ & 0.0000 & $0.000 \mathrm{E}+00$ & 0.0000 & $0.000 E+00$ & 0.0000 & $6.659 \mathrm{E}-03$ & 0.0050 \\
\hline-240 & $0.000 \mathrm{E}+00$ & 0.0000 & $0.000 \mathrm{E}+00$ & 0.0000 & $0.000 \mathrm{E}+00$ & 0.0000 & $0.000 \mathrm{E}+00$ & 0.0000 & $0.000 \mathrm{E}+00$ & 0.0000 & $0.000 E+00$ & 0.0000 & $6.617 \mathrm{E}-03$ & 0.0050 \\
\hline-99 & $0.000 \mathrm{E}+00$ & 0.0000 & $0.000 \mathrm{E}+00$ & 0.0000 & $0.000 \mathrm{E}+00$ & 0.0000 & $0.000 \mathrm{E}+00$ & 0.0000 & $0.000 \mathrm{E}+00$ & 0.0000 & $0.000 \mathrm{E}+00$ & 0.0000 & $2.090 \mathrm{E}-05$ & 0.0000 \\
\hline-228 & $0.000 \mathrm{E}+00$ & 0.0000 & $0.000 \mathrm{E}+00$ & 0.0000 & $0.000 \mathrm{E}+00$ & 0.0000 & $0.000 \mathrm{E}+00$ & 0.0000 & $0.000 \mathrm{E}+00$ & 0.0000 & $0.000 \mathrm{E}+00$ & 0.0000 & $4.841 \mathrm{E}-05$ & 0.0000 \\
\hline-230 & $0.000 \mathrm{E}+00$ & 0.0000 & $0.000 \mathrm{E}+00$ & 0.0000 & $0.000 \mathrm{E}+00$ & 0.0000 & $0.000 \mathrm{E}+00$ & 0.0000 & $0.000 \mathrm{E}+00$ & 0.0000 & $0.000 E+00$ & 0.0000 & $1.405 \mathrm{E}-01$ & 0.1054 \\
\hline 232 & $0.000 \mathrm{E}+00$ & 0.0000 & $0.000 \mathrm{E}+00$ & 0.0000 & $0.000 \mathrm{E}+00$ & 0.0000 & $0.000 \mathrm{E}+00$ & 0.0000 & $0.000 \mathrm{E}+00$ & 0.0000 & $0.000 \mathrm{E}+00$ & 0.0000 & $6.739 \mathrm{E}-01$ & 0.5058 \\
\hline 34 & $0.000 \mathrm{E}+00$ & 0.0000 & $0.000 \mathrm{E}+00$ & 0.0000 & $0.000 \mathrm{E}+00$ & 0.0000 & $0.000 \mathrm{E}+00$ & 0.0000 & $0.000 \mathrm{E}+00$ & 0.0000 & $0.000 \mathrm{E}+00$ & 0.0000 & $5.760 \mathrm{E}-03$ & 0.0043 \\
\hline 35 & $0.000 \mathrm{E}+00$ & 0.0000 & $0.000 \mathrm{E}+00$ & 0.0000 & $0.000 \mathrm{E}+00$ & 0.0000 & $0.000 \mathrm{E}+00$ & 0.0000 & $0.000 \mathrm{E}+00$ & 0.0000 & $0.000 \mathrm{E}+00$ & 0.0000 & $1.467 \mathrm{E}-02$ & 0.0110 \\
\hline 38 & $0.000 \mathrm{E}+00$ & 0.0000 & $0.000 \mathrm{E}+00$ & 0.0000 & $0.000 \mathrm{E}+00$ & 0.0000 & $0.000 \mathrm{E}+00$ & 0.0000 & $0.000 \mathrm{E}+00$ & 0.0000 & $0.000 \mathrm{E}+00$ & 0.0000 & $1.776 \mathrm{E}-01$ & 0.1333 \\
\hline & $0.000 \mathrm{E}+00$ & 0.0000 & $0.000 \mathrm{E}+00$ & 0.0000 & $0.000 \mathrm{E}+00$ & 0.0000 & $0.000 \mathrm{E}+00$ & 0.0000 & $0.000 \mathrm{E}+00$ & 0.0000 & $0.000 \mathrm{E}+00$ & 0.0000 & $1.333 \mathrm{E}+00$ & 1. \\
\hline
\end{tabular}

* Sum of all water independent and dependent pathways. 
RESRAD, Version 6.5

$07 / 20 / 2011 \quad 15: 34$

23

File : C: $\backslash$ RESRAD_FAMILY \RESRAD \USERFILES \QCJULY2011 \TRESPASSER_FORWARDRUN-70YRS.RAD
File

Total Dose Contributions TDOSE (i,p,t) for Individual Radionuclides (i) and Pathways (p) As mrem/yr and Fraction of Total Dose At $t=5.000 \mathrm{E}+01$ years

Water Independent Pathways (Inhalation excludes radon)

\begin{tabular}{|c|c|c|c|c|c|c|c|c|c|c|c|c|c|c|}
\hline \multirow{2}{*}{ Nuclide } & \multicolumn{2}{|c|}{ Ground } & \multicolumn{2}{|c|}{ Inhalation } & \multicolumn{2}{|c|}{ Radon } & \multicolumn{2}{|c|}{ Plant } & \multicolumn{2}{|c|}{ Meat } & \multicolumn{2}{|c|}{ Milk } & \multicolumn{2}{|c|}{ Soil } \\
\hline & mrem/yr & fract. & mrem/yr & fract. & mrem/yr & fract. & mrem/yr & fract. & mrem/yr & fract. & mrem/yr & fract. & mrem/yr & fract. \\
\hline-241 & $1.969 \mathrm{E}-04$ & 0.0001 & $2.604 \mathrm{E}-04$ & 0.0002 & $0.000 \mathrm{E}+00$ & 0.0000 & $0.000 \mathrm{E}+00$ & 0.0000 & $0.000 \mathrm{E}+00$ & 0.0000 & $0.000 \mathrm{E}+00$ & 0.0000 & $9.866 \mathrm{E}-03$ & 0.0058 \\
\hline-137 & $1.876 \mathrm{E}-01$ & 0.1102 & $1.936 \mathrm{E}-08$ & 0.0000 & $0.000 \mathrm{E}+00$ & 0.0000 & $0.000 \mathrm{E}+00$ & 0.0000 & $0.000 \mathrm{E}+00$ & 0.0000 & $0.000 \mathrm{E}+00$ & 0.0000 & $1.173 \mathrm{E}-04$ & 0.0001 \\
\hline-237 & $3.250 \mathrm{E}-02$ & 0.0191 & $2.294 \mathrm{E}-05$ & 0.0000 & $0.000 \mathrm{E}+00$ & 0.0000 & $0.000 \mathrm{E}+00$ & 0.0000 & $0.000 \mathrm{E}+00$ & 0.0000 & $0.000 \mathrm{E}+00$ & 0.0000 & $9.249 \mathrm{E}-04$ & 0.0005 \\
\hline-238 & 1. $680 \mathrm{E}-06$ & 0.0000 & $2.418 \mathrm{E}-04$ & 0.0001 & $0.000 \mathrm{E}+00$ & 0.0000 & $0.000 \mathrm{E}+00$ & 0.0000 & $0.000 \mathrm{E}+00$ & 0.0000 & $0.000 \mathrm{E}+00$ & 0.0000 & $9.193 \mathrm{E}-03$ & 0.0054 \\
\hline-239 & $4.120 \mathrm{E}-05$ & 0.0000 & 3. $623 \mathrm{E}-04$ & 0.0002 & $0.000 \mathrm{E}+00$ & 0.0000 & $0.000 \mathrm{E}+00$ & 0.0000 & $0.000 \mathrm{E}+00$ & 0.0000 & $0.000 \mathrm{E}+00$ & 0.0000 & $1.372 \mathrm{E}-02$ & 0.0081 \\
\hline-240 & $2.221 \mathrm{E}-06$ & 0.0000 & $3.609 \mathrm{E}-04$ & 0.0002 & $0.000 \mathrm{E}+00$ & 0.0000 & $0.000 \mathrm{E}+00$ & 0.0000 & $0.000 \mathrm{E}+00$ & 0.0000 & $0.000 \mathrm{E}+00$ & 0.0000 & $1.367 \mathrm{E}-02$ & 0.0080 \\
\hline 99 & $3.248 E-06$ & 0.0000 & $3.331 \mathrm{E}-08$ & 0.0000 & $0.000 \mathrm{E}+00$ & 0.0000 & $0.000 \mathrm{E}+00$ & 0.0000 & $0.000 \mathrm{E}+00$ & 0.0000 & $0.000 \mathrm{E}+00$ & 0.0000 & $2.982 \mathrm{E}-05$ & 0.0000 \\
\hline-228 & $6.585 \mathrm{E}-09$ & 0.0000 & $1.668 \mathrm{E}-13$ & 0.0000 & $0.000 \mathrm{E}+00$ & 0.0000 & $0.000 \mathrm{E}+00$ & 0.0000 & $0.000 \mathrm{E}+00$ & 0.0000 & $0.000 \mathrm{E}+00$ & 0.0000 & $9.960 \mathrm{E}-12$ & 0.0000 \\
\hline-230 & $2.923 E-01$ & 0.1717 & $8.429 E-04$ & 0.0005 & $0.000 \mathrm{E}+00$ & 0.0000 & $0.000 \mathrm{E}+00$ & 0.0000 & $0.000 \mathrm{E}+00$ & 0.0000 & $0.000 \mathrm{E}+00$ & 0.0000 & $3.612 \mathrm{E}-02$ & 0.0212 \\
\hline-232 & $8.425 E-01$ & 0.4948 & $5.698 \mathrm{E}-05$ & 0.0000 & $0.000 \mathrm{E}+00$ & 0.0000 & $0.000 \mathrm{E}+00$ & 0.0000 & $0.000 \mathrm{E}+00$ & 0.0000 & $0.000 \mathrm{E}+00$ & 0.0000 & $6.490 \mathrm{E}-03$ & 0.0038 \\
\hline 34 & $1.747 \mathrm{E}-04$ & 0.0001 & $1.269 \mathrm{E}-04$ & 0.0001 & $0.000 \mathrm{E}+00$ & 0.0000 & $0.000 \mathrm{E}+00$ & 0.0000 & $0.000 \mathrm{E}+00$ & 0.0000 & $0.000 \mathrm{E}+00$ & 0.0000 & $1.199 \mathrm{E}-02$ & 0.0070 \\
\hline 35 & $1.973 \mathrm{E}-02$ & 0.0116 & $4.887 \mathrm{E}-06$ & 0.0000 & $0.000 \mathrm{E}+00$ & 0.0000 & $0.000 \mathrm{E}+00$ & 0.0000 & $0.000 \mathrm{E}+00$ & 0.0000 & $0.000 \mathrm{E}+00$ & 0.0000 & $4.837 \mathrm{E}-04$ & 0.0003 \\
\hline 38 & $2.109 \mathrm{E}-01$ & 0.1239 & $1.076 \mathrm{E}-04$ & 0.0001 & $0.000 \mathrm{E}+00$ & 0.0000 & $0.000 \mathrm{E}+00$ & 0.0000 & $0.000 \mathrm{E}+00$ & 0.0000 & $0.000 \mathrm{E}+00$ & 0.0000 & $1.182 \mathrm{E}-02$ & 0.0069 \\
\hline & $1.586 \mathrm{E}+00$ & 0.9314 & $2.388 \mathrm{E}-03$ & 0.0014 & $0.000 \mathrm{E}+00$ & 0.0000 & $0.000 \mathrm{E}+00$ & 0.0000 & $0.000 \mathrm{E}+00$ & 0.0000 & $0.000 \mathrm{E}+00$ & 0.0000 & $1.144 \mathrm{E}-01$ & 0.0672 \\
\hline
\end{tabular}

Total Dose Contributions TDOSE(i,p,t) for Individual Radionuclides (i) and Pathways (p) As mrem/yr and Fraction of Total Dose At $t=5.000 \mathrm{E}+01$ years

Water Dependent Pathways

\begin{tabular}{|c|c|c|c|c|c|c|c|c|c|c|c|c|c|c|}
\hline \multirow{2}{*}{ Nuclide } & \multicolumn{2}{|c|}{ Water } & \multicolumn{2}{|c|}{ Fish } & \multicolumn{2}{|c|}{ Radon } & \multicolumn{2}{|c|}{ Plant } & \multicolumn{2}{|c|}{ Meat } & \multicolumn{2}{|c|}{ Milk } & \multicolumn{2}{|c|}{ All Pathways* } \\
\hline & mrem/yr & fract. & mrem/yr & fract. & mrem/yr & fract. & mrem/yr & fract. & mrem/yr & fract. & mrem/yr & fract. & mrem/yr & fract. \\
\hline-241 & $0.000 \mathrm{E}+00$ & 0.0000 & $0.000 \mathrm{E}+00$ & 0.0000 & $0.000 \mathrm{E}+00$ & 0.0000 & $0.000 \mathrm{E}+00$ & 0.0000 & $0.000 \mathrm{E}+00$ & 0.0000 & $0.000 \mathrm{E}+00$ & 0.0000 & $1.032 \mathrm{E}-02$ & 0.0061 \\
\hline-137 & $0.000 \mathrm{E}+00$ & 0.0000 & $0.000 \mathrm{E}+00$ & 0.0000 & $0.000 \mathrm{E}+00$ & 0.0000 & $0.000 \mathrm{E}+00$ & 0.0000 & $0.000 \mathrm{E}+00$ & 0.0000 & $0.000 \mathrm{E}+00$ & 0.0000 & $1.877 \mathrm{E}-01$ & 0.1102 \\
\hline-237 & $0.000 \mathrm{E}+00$ & 0.0000 & $0.000 \mathrm{E}+00$ & 0.0000 & $0.000 \mathrm{E}+00$ & 0.0000 & $0.000 \mathrm{E}+00$ & 0.0000 & $0.000 \mathrm{E}+00$ & 0.0000 & $0.000 \mathrm{E}+00$ & 0.0000 & $3.345 E-02$ & 0.0196 \\
\hline-238 & $0.000 \mathrm{E}+00$ & 0.0000 & $0.000 \mathrm{E}+00$ & 0.0000 & $0.000 \mathrm{E}+00$ & 0.0000 & $0.000 \mathrm{E}+00$ & 0.0000 & $0.000 \mathrm{E}+00$ & 0.0000 & $0.000 \mathrm{E}+00$ & 0.0000 & $9.436 \mathrm{E}-03$ & 0.0055 \\
\hline-239 & $0.000 \mathrm{E}+00$ & 0.0000 & $0.000 \mathrm{E}+00$ & 0.0000 & $0.000 \mathrm{E}+00$ & 0.0000 & $0.000 \mathrm{E}+00$ & 0.0000 & $0.000 \mathrm{E}+00$ & 0.0000 & $0.000 \mathrm{E}+00$ & 0.0000 & $1.413 \mathrm{E}-02$ & 0.0083 \\
\hline-240 & $0.000 \mathrm{E}+00$ & 0.0000 & $0.000 \mathrm{E}+00$ & 0.0000 & $0.000 \mathrm{E}+00$ & 0.0000 & $0.000 \mathrm{E}+00$ & 0.0000 & $0.000 \mathrm{E}+00$ & 0.0000 & $0.000 \mathrm{E}+00$ & 0.0000 & $1.403 E-02$ & 0.0082 \\
\hline-99 & $0.000 \mathrm{E}+00$ & 0.0000 & $0.000 \mathrm{E}+00$ & 0.0000 & $0.000 \mathrm{E}+00$ & 0.0000 & $0.000 \mathrm{E}+00$ & 0.0000 & $0.000 \mathrm{E}+00$ & 0.0000 & $0.000 \mathrm{E}+00$ & 0.0000 & $3.310 \mathrm{E}-05$ & 0.0000 \\
\hline-228 & $0.000 \mathrm{E}+00$ & 0.0000 & $0.000 \mathrm{E}+00$ & 0.0000 & $0.000 \mathrm{E}+00$ & 0.0000 & $0.000 \mathrm{E}+00$ & 0.0000 & $0.000 \mathrm{E}+00$ & 0.0000 & $0.000 \mathrm{E}+00$ & 0.0000 & $6.595 E-09$ & 0.0000 \\
\hline 230 & $0.000 \mathrm{E}+00$ & 0.0000 & $0.000 \mathrm{E}+00$ & 0.0000 & $0.000 \mathrm{E}+00$ & 0.0000 & $0.000 \mathrm{E}+00$ & 0.0000 & $0.000 \mathrm{E}+00$ & 0.0000 & $0.000 \mathrm{E}+00$ & 0.0000 & $3.293 E-01$ & 0.1934 \\
\hline 232 & $0.000 \mathrm{E}+00$ & 0.0000 & $0.000 \mathrm{E}+00$ & 0.0000 & $0.000 \mathrm{E}+00$ & 0.0000 & $0.000 \mathrm{E}+00$ & 0.0000 & $0.000 \mathrm{E}+00$ & 0.0000 & $0.000 \mathrm{E}+00$ & 0.0000 & $8.490 \mathrm{E}-01$ & 0.4986 \\
\hline 34 & $0.000 \mathrm{E}+00$ & 0.0000 & $0.000 \mathrm{E}+00$ & 0.0000 & $0.000 \mathrm{E}+00$ & 0.0000 & $0.000 \mathrm{E}+00$ & 0.0000 & $0.000 \mathrm{E}+00$ & 0.0000 & $0.000 \mathrm{E}+00$ & 0.0000 & $1.229 \mathrm{E}-02$ & 0.0072 \\
\hline 35 & $0.000 \mathrm{E}+00$ & 0.0000 & $0.000 \mathrm{E}+00$ & 0.0000 & $0.000 \mathrm{E}+00$ & 0.0000 & $0.000 \mathrm{E}+00$ & 0.0000 & $0.000 \mathrm{E}+00$ & 0.0000 & $0.000 \mathrm{E}+00$ & 0.0000 & $2.022 \mathrm{E}-02$ & 0.0119 \\
\hline & $0.000 \mathrm{E}+00$ & 0.0000 & $0.000 \mathrm{E}+00$ & 0.0000 & $0.000 \mathrm{E}+00$ & 0.0000 & $0.000 \mathrm{E}+00$ & 0.0000 & $0.000 \mathrm{E}+00$ & 0.0000 & $0.000 \mathrm{E}+00$ & 0.0000 & $2.229 \mathrm{E}-01$ & 0.1309 \\
\hline & $0.000 \mathrm{E}+00$ & 0.0000 & $0.000 \mathrm{E}+00$ & 0.0000 & $0.000 \mathrm{E}+00$ & 0.0000 & $0.000 \mathrm{E}+00$ & 0.0000 & $0.000 \mathrm{E}+00$ & 0.0000 & $0.000 \mathrm{E}+00$ & 0.0000 & $3 E+00$ & 1.0000 \\
\hline
\end{tabular}

* Sum of all water independent and dependent pathways. 
RESRAD, Version 6.5

$07 / 20 / 2011 \quad 15: 34$

24

File : C: $\backslash$ RESRAD_FAMILY \RESRAD \USERFILES $\backslash$ QCJULY2011 \TRESPASSER_FORWARDRUN-70YRS.RAD
File RAD Parameters for U-Landfill Trespasser Forward Run

Total Dose Contributions TDOSE (i,p,t) for Individual Radionuclides (i) and Pathways (p) As mrem/yr and Fraction of Total Dose At $t=7.000 \mathrm{E}+01$ years

Water Independent Pathways (Inhalation excludes radon)

\begin{tabular}{|c|c|c|c|c|c|c|c|c|c|c|c|c|c|c|}
\hline \multirow{2}{*}{ Nuclide } & \multicolumn{2}{|c|}{ Ground } & \multicolumn{2}{|c|}{ Inhalation } & \multicolumn{2}{|c|}{ Radon } & \multicolumn{2}{|c|}{ Plant } & \multicolumn{2}{|c|}{ Meat } & \multicolumn{2}{|c|}{ Milk } & \multicolumn{2}{|c|}{ Soil } \\
\hline & mrem/yr & fract. & mrem/yr & fract. & mrem/yr & fract. & mrem/yr & fract. & mrem/yr & fract. & mrem/yr & fract. & mrem/yr & fract. \\
\hline-241 & $3.358 E-04$ & 0.0002 & $3.591 \mathrm{E}-04$ & 0.0002 & $0.000 \mathrm{E}+00$ & 0.0000 & $0.000 \mathrm{E}+00$ & 0.0000 & $0.000 \mathrm{E}+00$ & 0.0000 & $0.000 \mathrm{E}+00$ & 0.0000 & $1.360 \mathrm{E}-02$ & 0.0066 \\
\hline-137 & 1. $398 E-01$ & 0.0680 & $1.735 \mathrm{E}-08$ & 0.0000 & $0.000 \mathrm{E}+00$ & 0.0000 & $0.000 \mathrm{E}+00$ & 0.0000 & $0.000 \mathrm{E}+00$ & 0.0000 & $0.000 \mathrm{E}+00$ & 0.0000 & $1.052 \mathrm{E}-04$ & 0.0001 \\
\hline-237 & $4.032 E-02$ & 0.0196 & $3.256 \mathrm{E}-05$ & 0.0000 & $0.000 \mathrm{E}+00$ & 0.0000 & $0.000 \mathrm{E}+00$ & 0.0000 & $0.000 \mathrm{E}+00$ & 0.0000 & $0.000 \mathrm{E}+00$ & 0.0000 & $1.313 E-03$ & 0.0006 \\
\hline-238 & $2.045 E-06$ & 0.0000 & $2.939 \mathrm{E}-04$ & 0.0001 & $0.000 \mathrm{E}+00$ & 0.0000 & $0.000 \mathrm{E}+00$ & 0.0000 & $0.000 \mathrm{E}+00$ & 0.0000 & $0.000 \mathrm{E}+00$ & 0.0000 & $1.117 \mathrm{E}-02$ & 0.0054 \\
\hline-239 & $5.231 E-05$ & 0.0000 & $5.154 \mathrm{E}-04$ & 0.0003 & $0.000 \mathrm{E}+00$ & 0.0000 & $0.000 \mathrm{E}+00$ & 0.0000 & $0.000 \mathrm{E}+00$ & 0.0000 & $0.000 \mathrm{E}+00$ & 0.0000 & $1.953 \mathrm{E}-02$ & 0.0095 \\
\hline-240 & $3.155 \mathrm{E}-06$ & 0.0000 & $5.126 \mathrm{E}-04$ & 0.0002 & $0.000 \mathrm{E}+00$ & 0.0000 & $0.000 \mathrm{E}+00$ & 0.0000 & $0.000 \mathrm{E}+00$ & 0.0000 & $0.000 \mathrm{E}+00$ & 0.0000 & $1.942 \mathrm{E}-02$ & 0.0094 \\
\hline 99 & $3.858 \mathrm{E}-06$ & 0.0000 & $3.839 \mathrm{E}-08$ & 0.0000 & $0.000 \mathrm{E}+00$ & 0.0000 & $0.000 \mathrm{E}+00$ & 0.0000 & $0.000 \mathrm{E}+00$ & 0.0000 & $0.000 \mathrm{E}+00$ & 0.0000 & $3.437 \mathrm{E}-05$ & 0.0000 \\
\hline-228 & $5.320 \mathrm{E}-12$ & 0.0000 & $1.693 \mathrm{E}-16$ & 0.0000 & $0.000 \mathrm{E}+00$ & 0.0000 & $0.000 \mathrm{E}+00$ & 0.0000 & $0.000 \mathrm{E}+00$ & 0.0000 & $0.000 \mathrm{E}+00$ & 0.0000 & $1.011 \mathrm{E}-14$ & 0.0000 \\
\hline-230 & $4.685 E-01$ & 0.2279 & $1.202 E-03$ & 0.0006 & $0.000 \mathrm{E}+00$ & 0.0000 & $0.000 \mathrm{E}+00$ & 0.0000 & $0.000 \mathrm{E}+00$ & 0.0000 & $0.000 \mathrm{E}+00$ & 0.0000 & $5.489 \mathrm{E}-02$ & 0.0267 \\
\hline-232 & $9.657 \mathrm{E}-01$ & 0.4696 & $8.121 \mathrm{E}-05$ & 0.0000 & $0.000 \mathrm{E}+00$ & 0.0000 & $0.000 \mathrm{E}+00$ & 0.0000 & $0.000 \mathrm{E}+00$ & 0.0000 & $0.000 \mathrm{E}+00$ & 0.0000 & $9.258 \mathrm{E}-03$ & 0.0045 \\
\hline 34 & $3.359 \mathrm{E}-04$ & 0.0002 & $1.809 \mathrm{E}-04$ & 0.0001 & $0.000 \mathrm{E}+00$ & 0.0000 & $0.000 \mathrm{E}+00$ & 0.0000 & $0.000 \mathrm{E}+00$ & 0.0000 & $0.000 \mathrm{E}+00$ & 0.0000 & $1.708 \mathrm{E}-02$ & 0.0083 \\
\hline 35 & $2.534 \mathrm{E}-02$ & 0.0123 & $7.161 \mathrm{E}-06$ & 0.0000 & $0.000 \mathrm{E}+00$ & 0.0000 & $0.000 \mathrm{E}+00$ & 0.0000 & $0.000 \mathrm{E}+00$ & 0.0000 & $0.000 \mathrm{E}+00$ & 0.0000 & $6.989 \mathrm{E}-04$ & 0.0003 \\
\hline 38 & $2.486 \mathrm{E}-01$ & 0.1209 & $1.531 \mathrm{E}-04$ & 0.0001 & $0.000 \mathrm{E}+00$ & 0.0000 & $0.000 \mathrm{E}+00$ & 0.0000 & $0.000 \mathrm{E}+00$ & 0.0000 & $0.000 \mathrm{E}+00$ & 0.0000 & $1.683 \mathrm{E}-02$ & 0.0082 \\
\hline & $1.889 \mathrm{E}+00$ & 0.9187 & $3.338 \mathrm{E}-03$ & 0.0016 & $0.000 \mathrm{E}+00$ & 0.0000 & $0.000 \mathrm{E}+00$ & 0.0000 & $0.000 \mathrm{E}+00$ & 0.0000 & $0.000 \mathrm{E}+00$ & 0.0000 & 1. $639 \mathrm{E}-01$ & 0.0797 \\
\hline
\end{tabular}

Total Dose Contributions TDOSE(i,p,t) for Individual Radionuclides (i) and Pathways (p) As mrem/yr and Fraction of Total Dose At $t=7.000 \mathrm{E}+01$ years

Water Dependent Pathways

\begin{tabular}{|c|c|c|c|c|c|c|c|c|c|c|c|c|c|c|}
\hline \multirow{2}{*}{ Nuclide } & \multicolumn{2}{|c|}{ Water } & \multicolumn{2}{|c|}{ Fish } & \multicolumn{2}{|c|}{ Radon } & \multicolumn{2}{|c|}{ Plant } & \multicolumn{2}{|c|}{ Meat } & \multicolumn{2}{|c|}{ Milk } & \multicolumn{2}{|c|}{ All Pathways* } \\
\hline & mrem/yr & fract. & mrem/yr & fract. & mrem/yr & fract. & mrem/yr & fract. & mrem/yr & fract. & mrem/yr & fract. & mrem/yr & fract. \\
\hline-241 & $0.000 \mathrm{E}+00$ & 0.0000 & $0.000 \mathrm{E}+00$ & 0.0000 & $0.000 \mathrm{E}+00$ & 0.0000 & $0.000 \mathrm{E}+00$ & 0.0000 & $0.000 \mathrm{E}+00$ & 0.0000 & $0.000 \mathrm{E}+00$ & 0.0000 & $1.430 \mathrm{E}-02$ & 0.0070 \\
\hline-137 & $0.000 \mathrm{E}+00$ & 0.0000 & $0.000 \mathrm{E}+00$ & 0.0000 & $0.000 \mathrm{E}+00$ & 0.0000 & $0.000 \mathrm{E}+00$ & 0.0000 & $0.000 \mathrm{E}+00$ & 0.0000 & $0.000 \mathrm{E}+00$ & 0.0000 & $1.399 \mathrm{E}-01$ & 0.0680 \\
\hline-237 & $0.000 \mathrm{E}+00$ & 0.0000 & $0.000 \mathrm{E}+00$ & 0.0000 & $0.000 \mathrm{E}+00$ & 0.0000 & $0.000 \mathrm{E}+00$ & 0.0000 & $0.000 \mathrm{E}+00$ & 0.0000 & $0.000 \mathrm{E}+00$ & 0.0000 & $4.166 \mathrm{E}-02$ & 0.0203 \\
\hline-238 & $0.000 \mathrm{E}+00$ & 0.0000 & $0.000 \mathrm{E}+00$ & 0.0000 & $0.000 \mathrm{E}+00$ & 0.0000 & $0.000 \mathrm{E}+00$ & 0.0000 & $0.000 \mathrm{E}+00$ & 0.0000 & $0.000 \mathrm{E}+00$ & 0.0000 & $1.147 \mathrm{E}-02$ & 0.0056 \\
\hline 239 & $0.000 \mathrm{E}+00$ & 0.0000 & $0.000 \mathrm{E}+00$ & 0.0000 & $0.000 \mathrm{E}+00$ & 0.0000 & $0.000 \mathrm{E}+00$ & 0.0000 & $0.000 \mathrm{E}+00$ & 0.0000 & $0.000 \mathrm{E}+00$ & 0.0000 & $2.009 \mathrm{E}-02$ & 0.0098 \\
\hline-240 & $0.000 \mathrm{E}+00$ & 0.0000 & $0.000 \mathrm{E}+00$ & 0.0000 & $0.000 \mathrm{E}+00$ & 0.0000 & $0.000 \mathrm{E}+00$ & 0.0000 & $0.000 \mathrm{E}+00$ & 0.0000 & $0.000 \mathrm{E}+00$ & 0.0000 & $1.994 \mathrm{E}-02$ & 0.0097 \\
\hline 99 & $0.000 \mathrm{E}+00$ & 0.0000 & $0.000 \mathrm{E}+00$ & 0.0000 & $0.000 \mathrm{E}+00$ & 0.0000 & $0.000 \mathrm{E}+00$ & 0.0000 & $0.000 \mathrm{E}+00$ & 0.0000 & $0.000 \mathrm{E}+00$ & 0.0000 & $3.826 \mathrm{E}-05$ & 0.0000 \\
\hline-228 & $0.000 \mathrm{E}+00$ & 0.0000 & $0.000 \mathrm{E}+00$ & 0.0000 & $0.000 \mathrm{E}+00$ & 0.0000 & $0.000 \mathrm{E}+00$ & 0.0000 & $0.000 \mathrm{E}+00$ & 0.0000 & $0.000 \mathrm{E}+00$ & 0.0000 & $5.330 \mathrm{E}-12$ & 0.0000 \\
\hline-230 & $0.000 \mathrm{E}+00$ & 0.0000 & $0.000 \mathrm{E}+00$ & 0.0000 & $0.000 \mathrm{E}+00$ & 0.0000 & $0.000 \mathrm{E}+00$ & 0.0000 & $0.000 \mathrm{E}+00$ & 0.0000 & $0.000 \mathrm{E}+00$ & 0.0000 & $5.246 \mathrm{E}-01$ & 0.2551 \\
\hline-232 & $0.000 \mathrm{E}+00$ & 0.0000 & $0.000 \mathrm{E}+00$ & 0.0000 & $0.000 \mathrm{E}+00$ & 0.0000 & $0.000 \mathrm{E}+00$ & 0.0000 & $0.000 \mathrm{E}+00$ & 0.0000 & $0.000 \mathrm{E}+00$ & 0.0000 & $9.750 \mathrm{E}-01$ & 0.4742 \\
\hline 234 & $0.000 \mathrm{E}+00$ & 0.0000 & $0.000 \mathrm{E}+00$ & 0.0000 & $0.000 \mathrm{E}+00$ & 0.0000 & $0.000 \mathrm{E}+00$ & 0.0000 & $0.000 \mathrm{E}+00$ & 0.0000 & $0.000 \mathrm{E}+00$ & 0.0000 & $1.760 \mathrm{E}-02$ & 0.0086 \\
\hline 35 & $0.000 \mathrm{E}+00$ & 0.0000 & $0.000 \mathrm{E}+00$ & 0.0000 & $0.000 \mathrm{E}+00$ & 0.0000 & $0.000 \mathrm{E}+00$ & 0.0000 & $0.000 \mathrm{E}+00$ & 0.0000 & $0.000 \mathrm{E}+00$ & 0.0000 & $2.605 E-02$ & 0.0127 \\
\hline 38 & $0.000 \mathrm{E}+00$ & 0.0000 & $0.000 \mathrm{E}+00$ & 0.0000 & $0.000 \mathrm{E}+00$ & 0.0000 & $0.000 \mathrm{E}+00$ & 0.0000 & $0.000 \mathrm{E}+00$ & 0.0000 & $0.000 \mathrm{E}+00$ & 0.0000 & $2.655 \mathrm{E}-01$ & 0.1291 \\
\hline & $0.000 \mathrm{E}+00$ & 0.0000 & $0.000 \mathrm{E}+00$ & 0.0000 & $0.000 \mathrm{E}+00$ & 0.0000 & $0.000 \mathrm{E}+00$ & 0.0000 & $0.000 \mathrm{E}+00$ & 0.0000 & $0.000 \mathrm{E}+00$ & 0.0000 & $2.056 \mathrm{E}+00$ & 1.0000 \\
\hline
\end{tabular}

* Sum of all water independent and dependent pathways. 
RESRAD, Version $6.5 \quad \mathrm{~T}^{1 / 2}$ Limit $=180$ days

Summary : RESRAD Parameters for U-Landfill Trespasser Forward Run

File : C: \RESRAD_FAMILY \RESRAD \USERFILES $\backslash Q C J U L Y 2011 \backslash$ TRESPASSER_FORWARDRUN-70YRS.RAD

Dose/Source Ratios Summed Over All Pathways

Parent and Progeny Principal Radionuclide Contributions Indicated

Parent Product Thread DSR $(j, t)$ At Time in Years (mrem/yr)/(pCi/g)

(i) (j) Fraction $0.000 \mathrm{E}+001.000 \mathrm{E}+002.500 \mathrm{E}+015.000 \mathrm{E}+017.000 \mathrm{E}+01$

\section{$-241$}

Am-241

Am-241

Am-241

Am-241

$C s-137+D$

$\mathrm{Np}-237+\mathrm{D}$

$\mathrm{Np}-237+\mathrm{D}$

$\mathrm{Np}-237+\mathrm{D}$

$\mathrm{Np}-237+\mathrm{D}$

$\mathrm{Pu}-238$

$\mathrm{Pu}-238$

$1.840 \mathrm{E}-09$

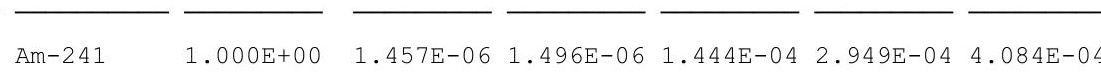

$\begin{array}{llllllll}\mathrm{Np}-237+\mathrm{D} & 1.000 \mathrm{E}+00 & 5.599 \mathrm{E}-10 & 1.695 \mathrm{E}-09 & 3.728 \mathrm{E}-08 & 9.593 \mathrm{E}-08 & 1.644 \mathrm{E}-07\end{array}$

$\begin{array}{lllllll}\mathrm{U}-233 & 1.000 \mathrm{E}+00 & 6.695 \mathrm{E}-19 & 4.735 \mathrm{E}-18 & 1.855 \mathrm{E}-14 & 1.474 \mathrm{E}-13 & 4.016 \mathrm{E}-13\end{array}$

$\begin{array}{lllllll}\mathrm{Th}-229+\mathrm{D} \quad 1.000 \mathrm{E}+00 & 3.971 \mathrm{E}-20 & 5.999 \mathrm{E}-19 & 3.419 \mathrm{E}-15 & 3.406 \mathrm{E}-14 & 1.120 \mathrm{E}-13\end{array}$

$\sum \operatorname{DSR}(j)$

$\begin{array}{llll}1.457 \mathrm{E}-06 & 1.498 \mathrm{E}-06 & 1.444 \mathrm{E}-04 & 2.950 \mathrm{E}-04 \quad 4.086 \mathrm{E}-04\end{array}$

$\mathrm{Cs}-137+\mathrm{D} \quad 1.000 \mathrm{E}+00 \quad 2.060 \mathrm{E}-02 \quad 2.029 \mathrm{E}-02 \quad 1.426 \mathrm{E}-02 \quad 9.878 \mathrm{E}-03 \quad 7.362 \mathrm{E}-03$

$\mathrm{Np}-237+\mathrm{D} \quad 1.000 \mathrm{E}+00 \quad 3.453 \mathrm{E}-03 \quad 3.490 \mathrm{E}-03 \quad 4.597 \mathrm{E}-03 \quad 6.082 \mathrm{E}-03 \quad 7.575 \mathrm{E}-03$

$\begin{array}{llllllll}\mathrm{U}-233 & 1.000 \mathrm{E}+00 & 6.197 \mathrm{E}-12 & 1.880 \mathrm{E}-11 & 4.550 \mathrm{E}-09 & 1.848 \mathrm{E}-08 & 3.644 \mathrm{E}-08\end{array}$

$\begin{array}{lllllllll}\mathrm{Th}-229+\mathrm{D} & 1.000 \mathrm{E}+00 & 4.903 \mathrm{E}-13 & 3.458 \mathrm{E}-12 & 1.253 \mathrm{E}-09 & 6.366 \mathrm{E}-09 & 1.511 \mathrm{E}-08\end{array}$

$\operatorname{EDSR}(j) \quad 3.453 \mathrm{E}-03 \quad 3.490 \mathrm{E}-03 \quad 4.597 \mathrm{E}-03 \quad 6.082 \mathrm{E}-03 \quad 7.575 \mathrm{E}-03$

$\mathrm{Pu}-238$

$\begin{array}{llllllll}\mathrm{Pu}-238 & 1.000 \mathrm{E}+00 & 2.641 \mathrm{E}-08 & 2.667 \mathrm{E}-08 & 1.386 \mathrm{E}-04 & 2.419 \mathrm{E}-04 & 2.941 \mathrm{E}-04\end{array}$

$\begin{array}{llllllll}\mathrm{U}-234 & 1.000 \mathrm{E}+00 & 2.486 \mathrm{E}-13 & 7.549 \mathrm{E}-13 & 2.346 \mathrm{E}-09 & 8.976 \mathrm{E}-09 & 1.658 \mathrm{E}-08\end{array}$

$\begin{array}{llllllll}\mathrm{Th}-230 & 1.000 \mathrm{E}+00 & 3.358 \mathrm{E}-18 & 2.380 \mathrm{E}-17 & 1.212 \mathrm{E}-12 & 9.470 \mathrm{E}-12 & 2.502 \mathrm{E}-11\end{array}$

$\begin{array}{llllllll}\mathrm{Ra}-226+\mathrm{D} & 1.000 \mathrm{E}+00 \quad 4.363 \mathrm{E}-17 & 6.572 \mathrm{E}-16 & 3.284 \mathrm{E}-12 & 2.901 \mathrm{E}-11 & 8.757 \mathrm{E}-11\end{array}$

$\mathrm{Pb}-210+\mathrm{D} \quad 1.000 \mathrm{E}+00 \quad 2.379 \mathrm{E}-23 \quad 7.401 \mathrm{E}-22 \quad 6.841 \mathrm{E}-15 \quad 1.869 \mathrm{E}-13 \quad 8.845 \mathrm{E}-13$

$\begin{array}{llllll}\operatorname{LDSR}(j) \quad 2.641 \mathrm{E}-08 & 2.667 \mathrm{E}-08 & 1.386 \mathrm{E}-04 & 2.420 \mathrm{E}-04 & 2.941 \mathrm{E}-04\end{array}$

$\begin{array}{llllllll}\mathrm{Pu}-239 & 1.000 \mathrm{E}+00 & 6.302 \mathrm{E}-07 & 6.378 \mathrm{E}-07 & 1.850 \mathrm{E}-04 & 3.925 \mathrm{E}-04 & 5.581 \mathrm{E}-04\end{array}$

$\begin{array}{llllllll}\mathrm{U}-235+\mathrm{D} & 1.000 \mathrm{E}+00 & 8.030 \mathrm{E}-13 & 2.436 \mathrm{E}-12 & 5.659 \mathrm{E}-11 & 1.542 \mathrm{E}-10 & 2.766 \mathrm{E}-10\end{array}$

$\begin{array}{lllllll}\mathrm{Pa}-231 & 1.000 \mathrm{E}+00 & 2.330 \mathrm{E}-18 & 1.646 \mathrm{E}-17 & 9.400 \mathrm{E}-15 & 5.929 \mathrm{E}-14 & 1.534 \mathrm{E}-13\end{array}$

$\mathrm{AC}-227+\mathrm{D} \quad 1.000 \mathrm{E}+00 \quad 2.010 \mathrm{E}-19 \quad 3.022 \mathrm{E}-18 \quad 1.564 \mathrm{E}-14 \quad 1.404 \mathrm{E}-13 \quad 4.252 \mathrm{E}-13$

$\operatorname{\sum DSR}(j) \quad 6.302 \mathrm{E}-07 \quad 6.378 \mathrm{E}-07 \quad 1.850 \mathrm{E}-04 \quad 3.925 \mathrm{E}-04 \quad 5.581 \mathrm{E}-04$

$\begin{array}{lllllll}\mathrm{Pu}-240 \quad 4.950 \mathrm{E}-08 & 1.271 \mathrm{E}-15 & 1.293 \mathrm{E}-15 & 9.098 \mathrm{E}-12 & 1.930 \mathrm{E}-11 & 2.741 \mathrm{E}-11\end{array}$

$\begin{array}{llllllll}\mathrm{Pu}-240 \quad 1.000 \mathrm{E}+00 & 2.567 \mathrm{E}-08 & 2.612 \mathrm{E}-08 & 1.838 \mathrm{E}-04 & 3.899 \mathrm{E}-04 & 5.538 \mathrm{E}-04\end{array}$

$\begin{array}{lllllll}\mathrm{U}-236 & 1.000 \mathrm{E}+00 & 1.038 \mathrm{E}-15 & 3.165 \mathrm{E}-15 & 2.579 \mathrm{E}-11 & 1.083 \mathrm{E}-10 & 2.151 \mathrm{E}-10\end{array}$

$\begin{array}{lllllll}\mathrm{Th}-232 & 1.000 \mathrm{E}+00 & 4.987 \mathrm{E}-26 & 3.547 \mathrm{E}-25 & 8.061 \mathrm{E}-20 & 6.713 \mathrm{E}-19 & 1.861 \mathrm{E}-18\end{array}$

$\mathrm{Ra}-228+\mathrm{D} \quad 1.000 \mathrm{E}+00 \quad 3.271 \mathrm{E}-22 \quad 4.816 \mathrm{E}-21 \quad 1.454 \mathrm{E}-17 \quad 9.119 \mathrm{E}-17 \quad 2.265 \mathrm{E}-16$

$\begin{array}{llllllll}\mathrm{Th}-228+\mathrm{D} & 1.000 \mathrm{E}+00 & 5.216 \mathrm{E}-23 & 1.501 \mathrm{E}-21 & 2.491 \mathrm{E}-17 & 1.723 \mathrm{E}-16 & 4.318 \mathrm{E}-16\end{array}$

$\operatorname{LDSR}(j) \quad 2.567 \mathrm{E}-08 \quad 2.612 \mathrm{E}-08 \quad 1.838 \mathrm{E}-04 \quad 3.899 \mathrm{E}-04 \quad 5.538 \mathrm{E}-04$

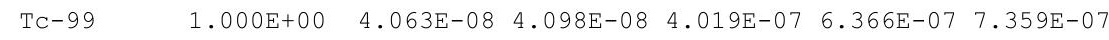

Th-228+D 1.000E+00 8.889E-02 $6.226 \mathrm{E}-02 \quad 1.210 \mathrm{E}-05 \quad 1.649 \mathrm{E}-09 \quad 1.333 \mathrm{E}-12$

Th-230 1.000E+00 7.878E-07 8.012E-07 $1.560 \mathrm{E}-04 \quad 3.311 \mathrm{E}-04 \quad 4.713 \mathrm{E}-04$

$\mathrm{Ra}-226+\mathrm{D} \quad 1.000 \mathrm{E}+00 \quad 2.053 \mathrm{E}-05 \quad 6.196 \mathrm{E}-05 \quad 1.244 \mathrm{E}-03 \quad 2.931 \mathrm{E}-03 \quad 4.701 \mathrm{E}-03$

$\mathrm{Pb}-210+\mathrm{D} \quad 1.000 \mathrm{E}+00 \quad 1.860 \mathrm{E}-11 \quad 1.304 \mathrm{E}-10 \quad 4.665 \mathrm{E}-06 \quad 3.123 \mathrm{E}-05 \quad 7.416 \mathrm{E}-05$

$\operatorname{LDSR}(j) \quad 2.131 \mathrm{E}-05 \quad 6.276 \mathrm{E}-05 \quad 1.405 \mathrm{E}-03 \quad 3.293 \mathrm{E}-03 \quad 5.246 \mathrm{E}-03$ 
RESRAD, Version $6.5 \quad \mathrm{~T}^{1 / 2}$ Limit $=180$ days

Summary : RESRAD Parameters for U-Landfill Trespasser Forward Run

File : C: \RESRAD_FAMILY \RESRAD \USERFILES $\backslash$ QCJULY2011 TTRESPASSER_FORWARDRUN-70YRS.RAD

Dose/Source Ratios Summed Over All Pathways

Parent and Progeny Principal Radionuclide Contributions Indicated

\begin{tabular}{|c|c|c|c|c|c|c|c|}
\hline Parent & Product & Thread & $\operatorname{DSR}(j, t)$ & At Time in & n Years & (mrem/yr) / & $(\mathrm{pCi} / \mathrm{g})$ \\
\hline (i) & (j) & Fraction & $0.000 \mathrm{E}+00$ & $1.000 \mathrm{E}+00$ & $2.500 \mathrm{E}+01$ & $5.000 \mathrm{E}+01$ & $7.000 \mathrm{E}+01$ \\
\hline-232 & Th-232 & $1.000 \mathrm{E}+00$ & $2.040 \mathrm{E}-07$ & $2.078 \mathrm{E}-07$ & $1.699 \mathrm{E}-04$ & $3.613 E-04$ & $5.145 E-04$ \\
\hline-232 & $\mathrm{Ra}-228+\mathrm{D}$ & $1.000 \mathrm{E}+00$ & $2.643 E-03$ & $7.575 E-03$ & $5.301 \mathrm{E}-02$ & $6.750 \mathrm{E}-02$ & $7.900 \mathrm{E}-02$ \\
\hline-232 & $\mathrm{Th}-228+\mathrm{D}$ & $1.000 \mathrm{E}+00$ & $6.862 \mathrm{E}-04$ & $4.233 E-03$ & $1.153 \mathrm{E}-01$ & $1.444 \mathrm{E}-01$ & 1. $642 \mathrm{E}-01$ \\
\hline-232 & $\sum \operatorname{DSR}(j)$ & & $3.329 \mathrm{E}-03$ & $1.181 \mathrm{E}-02$ & $1.685 \mathrm{E}-01$ & $2.123 \mathrm{E}-01$ & $2.438 E-01$ \\
\hline-234 & $\mathrm{U}-234$ & $1.000 \mathrm{E}+00$ & $1.753 \mathrm{E}-07$ & $1.784 \mathrm{E}-07$ & $3.582 \mathrm{E}-05$ & $7.601 \mathrm{E}-05$ & $1.082 \mathrm{E}-04$ \\
\hline 234 & Th-230 & $1.000 \mathrm{E}+00$ & $3.556 \mathrm{E}-12$ & $1.083 \mathrm{E}-11$ & $3.580 \mathrm{E}-08$ & $1.504 \mathrm{E}-07$ & $2.989 E-07$ \\
\hline-234 & $\mathrm{Ra}-226+\mathrm{D}$ & $1.000 \mathrm{E}+00$ & $6.163 \mathrm{E}-11$ & $4.340 \mathrm{E}-10$ & $1.430 \mathrm{E}-07$ & $6.684 \mathrm{E}-07$ & $1.499 \mathrm{E}-06$ \\
\hline-234 & $\mathrm{~Pb}-210+\mathrm{D}$ & $1.000 \mathrm{E}+00$ & $4.195 \mathrm{E}-17$ & $6.314 \mathrm{E}-16$ & $3.798 \mathrm{E}-10$ & $5.293 E-09$ & 1. $815 E-08$ \\
\hline 234 & $\sum \operatorname{DSR}(j)$ & & $1.754 \mathrm{E}-07$ & $1.789 \mathrm{E}-07$ & $3.600 \mathrm{E}-05$ & $7.683 E-05$ & $1.100 \mathrm{E}-04$ \\
\hline$-235+D$ & $\mathrm{U}-235+\mathrm{D}$ & $1.000 \mathrm{E}+00$ & $1.627 \mathrm{E}-03$ & $1.648 \mathrm{E}-03$ & $2.254 \mathrm{E}-03$ & $3.101 \mathrm{E}-03$ & $3.987 \mathrm{E}-03$ \\
\hline$-235+D$ & $\mathrm{~Pa}-231$ & $1.000 \mathrm{E}+00$ & $7.092 E-09$ & $2.148 E-08$ & $7.485 \mathrm{E}-07$ & $2.385 E-06$ & $4.421 E-06$ \\
\hline$-235+D$ & $A C-227+D$ & $1.000 \mathrm{E}+00$ & $8.148 \mathrm{E}-10$ & $5.702 \mathrm{E}-09$ & $1.756 \mathrm{E}-06$ & $7.572 \mathrm{E}-06$ & $1.589 \mathrm{E}-05$ \\
\hline$-235+D$ & $\sum \operatorname{DSR}(j)$ & & $1.627 \mathrm{E}-03$ & $1.648 \mathrm{E}-03$ & $2.256 \mathrm{E}-03$ & $3.111 \mathrm{E}-03$ & $4.007 \mathrm{E}-03$ \\
\hline-238 & $\mathrm{U}-238$ & $5.400 E-05$ & $1.359 \mathrm{E}-15$ & $1.421 \mathrm{E}-15$ & $1.762 \mathrm{E}-09$ & $3.746 \mathrm{E}-09$ & $5.332 E-09$ \\
\hline$-238+D$ & $\mathrm{U}-238+\mathrm{D}$ & $9.999 \mathrm{E}-01$ & $8.774 \mathrm{E}-04$ & $8.846 \mathrm{E}-04$ & $1.110 \mathrm{E}-03$ & $1.393 E-03$ & $1.660 \mathrm{E}-03$ \\
\hline$-238+D$ & $\mathrm{U}-234$ & $9.999 \mathrm{E}-01$ & $2.492 E-13$ & $7.595 \mathrm{E}-13$ & $2.590 \mathrm{E}-09$ & $1.088 \mathrm{E}-08$ & $2.162 \mathrm{E}-08$ \\
\hline$-238+D$ & $\mathrm{Th}-230$ & $9.999 \mathrm{E}-01$ & $3.365 E-18$ & $2.390 \mathrm{E}-17$ & $1.294 \mathrm{E}-12$ & $1.077 \mathrm{E}-11$ & $2.987 \mathrm{E}-11$ \\
\hline$-238+D$ & $\mathrm{Ra}-226+\mathrm{D}$ & $9.999 \mathrm{E}-01$ & $4.369 \mathrm{E}-17$ & $6.593 \mathrm{E}-16$ & $3.451 \mathrm{E}-12$ & $3.196 \mathrm{E}-11$ & $1.001 \mathrm{E}-10$ \\
\hline$-238+D$ & $\mathrm{~Pb}-210+\mathrm{D}$ & $9.999 \mathrm{E}-01$ & $2.382 E-23$ & $7.420 \mathrm{E}-22$ & $7.125 \mathrm{E}-15$ & $2.027 E-13$ & $9.911 \mathrm{E}-13$ \\
\hline$-238+D$ & $\sum \operatorname{DSR}(j)$ & & $8.774 \mathrm{E}-04$ & $8.846 \mathrm{E}-04$ & $1.110 \mathrm{E}-03$ & $1.393 E-03$ & $1.660 \mathrm{E}-03$ \\
\hline
\end{tabular}

The DSR includes contributions from associated (half-life $\leq 180$ days) daughters. 
RESRAD, Version $6.5 \quad \mathrm{~T}^{1 / 2}$ Limit $=180$ days

Summary : RESRAD Parameters for U-Landfill Trespasser Forward Run

File : C: \RESRAD_FAMILY \RESRAD \USERFILES $\backslash$ QCJULY2011 TTRESPASSER_FORWARDRUN-70YRS.RAD

Single Radionuclide Soil Guidelines $G(i, t)$ in $\mathrm{pCi} / \mathrm{g}$

Basic Radiation Dose Limit $=1.000 \mathrm{E}+02 \mathrm{mrem} / \mathrm{yr}$

Nuclide

\begin{tabular}{|c|c|c|c|c|c|}
\hline (i) & $\mathrm{t}=0.000 \mathrm{E}+00$ & $1.000 \mathrm{E}+00$ & $2.500 \mathrm{E}+01$ & $5.000 \mathrm{E}+01$ & $7.000 \mathrm{E}+01$ \\
\hline$m-241$ & $6.861 \mathrm{E}+07$ & $6.676 \mathrm{E}+07$ & $6.924 \mathrm{E}+05$ & $3.390 \mathrm{E}+05$ & $2.448 \mathrm{E}+05$ \\
\hline$s-137$ & $4.856 \mathrm{E}+03$ & $4.927 \mathrm{E}+03$ & $7.011 \mathrm{E}+03$ & $1.012 \mathrm{E}+04$ & $1.358 \mathrm{E}+04$ \\
\hline-237 & $2.896 \mathrm{E}+04$ & $2.866 \mathrm{E}+04$ & $2.175 E+04$ & $1.644 \mathrm{E}+04$ & $1.320 \mathrm{E}+04$ \\
\hline$u-238$ & $3.787 E+09$ & $3.750 E+09$ & $7.214 \mathrm{E}+05$ & $4.133 E+05$ & $3.400 E+05$ \\
\hline $\mathrm{Pu}-239$ & $1.587 \mathrm{E}+08$ & $1.568 \mathrm{E}+08$ & $5.406 \mathrm{E}+05$ & $2.548 \mathrm{E}+05$ & $1.792 \mathrm{E}+05$ \\
\hline $\mathrm{Pu}-240$ & $3.896 \mathrm{E}+09$ & $3.828 \mathrm{E}+09$ & $5.441 \mathrm{E}+05$ & $2.565 \mathrm{E}+05$ & $1.806 \mathrm{E}+05$ \\
\hline TC-99 & $2.461 \mathrm{E}+09$ & $2.440 \mathrm{E}+09$ & $2.488 E+08$ & $1.571 \mathrm{E}+08$ & $1.359 \mathrm{E}+08$ \\
\hline Th-228 & $1.125 \mathrm{E}+03$ & $1.606 \mathrm{E}+03$ & $8.262 E+06$ & $6.065 E+10$ & $7.505 \mathrm{E}+13$ \\
\hline$T h-230$ & $4.692 \mathrm{E}+06$ & $1.593 E+06$ & $7.119 \mathrm{E}+04$ & $3.037 E+04$ & $1.906 \mathrm{E}+04$ \\
\hline Th-232 & $3.004 \mathrm{E}+04$ & $8.469 \mathrm{E}+03$ & $5.935 E+02$ & $4.711 \mathrm{E}+02$ & $4.102 \mathrm{E}+02$ \\
\hline 34 & $5.702 \mathrm{E}+08$ & $5.590 \mathrm{E}+08$ & $2.778 \mathrm{E}+06$ & $1.301 \mathrm{E}+06$ & $9.092 \mathrm{E}+05$ \\
\hline 35 & $6.145 \mathrm{E}+04$ & $6.069 \mathrm{E}+04$ & $4.432 E+04$ & $3.214 \mathrm{E}+04$ & $2.495 \mathrm{E}+04$ \\
\hline 238 & $1.140 \mathrm{E}+05$ & $1.131 \mathrm{E}+05$ & $9.009 \mathrm{E}+04$ & $7.180 \mathrm{E}+04$ & $6.025 E+04$ \\
\hline
\end{tabular}

Summed Dose/Source Ratios DSR (i,t) in (mrem/yr)/(pCi/g) and Single Radionuclide Soil Guidelines G(i,t) in pCi/g at tmin = time of minimum single radionuclide soil guideline and at $\operatorname{tmax}=$ time of maximum total dose $=7.000 \mathrm{E}+01$ years

\begin{tabular}{|c|c|c|c|c|c|c|}
\hline $\begin{array}{l}\text { Juclide } \\
\text { (i) }\end{array}$ & $\begin{array}{l}\text { Initial } \\
(\mathrm{pCi} / \mathrm{g})\end{array}$ & $\begin{array}{c}\text { tmin } \\
\text { (years) }\end{array}$ & $\operatorname{DSR}(i, \operatorname{tmin})$ & $\begin{array}{c}G(i, \operatorname{tmin}) \\
(\mathrm{pCi} / \mathrm{g})\end{array}$ & $\operatorname{DSR}(i, \operatorname{tmax})$ & $\begin{array}{c}G(i, t \max ) \\
(\mathrm{pCi} / \mathrm{g})\end{array}$ \\
\hline$n-241$ & $3.500 \mathrm{E}+01$ & $7.000 \mathrm{E}+01$ & $4.086 \mathrm{E}-04$ & $2.448 E+05$ & $4.086 \mathrm{E}-04$ & $2.448 E+05$ \\
\hline-137 & $1.900 \mathrm{E}+01$ & $0.000 \mathrm{E}+00$ & $2.060 E-02$ & $4.856 \mathrm{E}+03$ & $7.362 E-03$ & $1.358 \mathrm{E}+04$ \\
\hline-237 & $5.500 \mathrm{E}+00$ & $7.000 \mathrm{E}+01$ & $7.575 E-03$ & $1.320 \mathrm{E}+04$ & $7.575 E-03$ & $1.320 \mathrm{E}+04$ \\
\hline$u-238$ & $3.900 \mathrm{E}+01$ & $7.000 \mathrm{E}+01$ & $2.941 E-04$ & $3.400 \mathrm{E}+05$ & $2.941 \mathrm{E}-04$ & $3.400 \mathrm{E}+05$ \\
\hline-239 & $3.600 \mathrm{E}+01$ & $7.000 \mathrm{E}+01$ & $5.581 E-04$ & $1.792 E+05$ & $5.581 E-04$ & $1.792 \mathrm{E}+05$ \\
\hline-240 & $3.600 \mathrm{E}+01$ & $7.000 \mathrm{E}+01$ & $5.538 \mathrm{E}-04$ & $1.806 \mathrm{E}+05$ & $5.538 E-04$ & $1.806 \mathrm{E}+05$ \\
\hline-99 & $5.200 \mathrm{E}+01$ & $7.000 \mathrm{E}+01$ & $7.359 \mathrm{E}-07$ & $1.359 \mathrm{E}+08$ & $7.359 \mathrm{E}-07$ & 1. $359 \mathrm{E}+08$ \\
\hline-228 & $4.000 \mathrm{E}+00$ & $0.000 \mathrm{E}+00$ & $8.889 E-02$ & $1.125 E+03$ & 1. $333 E-12$ & 7. $505 E+13$ \\
\hline-230 & $1.000 \mathrm{E}+02$ & $7.000 \mathrm{E}+01$ & $5.246 \mathrm{E}-03$ & $1.906 \mathrm{E}+04$ & $5.246 \mathrm{E}-03$ & $1.906 \mathrm{E}+04$ \\
\hline ch-232 & $4.000 E+00$ & $7.000 \mathrm{E}+01$ & $2.438 E-01$ & $4.102 E+02$ & $2.438 E-01$ & $4.102 E+02$ \\
\hline-234 & $1.600 \mathrm{E}+02$ & $7.000 \mathrm{E}+01$ & $1.100 \mathrm{E}-04$ & $9.092 E+05$ & $1.100 \mathrm{E}-04$ & $9.092 \mathrm{E}+05$ \\
\hline 235 & $6.500 \mathrm{E}+00$ & $7.000 \mathrm{E}+01$ & $4.007 E-03$ & $2.495 E+04$ & $4.007 E-03$ & $2.495 E+04$ \\
\hline 238 & $1.600 \mathrm{E}+02$ & $7.000 \mathrm{E}+01$ & $1.660 \mathrm{E}-03$ & $6.025 E+04$ & $1.660 \mathrm{E}-03$ & $6.025 E+04$ \\
\hline
\end{tabular}


RESRAD, Version 6.5

Summary : RESRAD Parameters for U-Landfill Trespasser Forward Run

File : C: \RESRAD_FAMILY \RESRAD \USERFILES $\backslash Q C J U L Y 2011 \backslash$ TRESPASSER_FORWARDRUN-70YRS.RAD

Individual Nuclide Dose Summed Over All Pathways

Parent Nuclide and Branch Fraction Indicated

Nuclide Parent THF(i) DOSE $(j, t), \operatorname{mrem} / \mathrm{yr}$

\begin{tabular}{|c|c|c|c|c|c|c|c|c|}
\hline$(j)$ & (i) & & $t=$ & $0.000 \mathrm{E}+00$ & $1.000 \mathrm{E}+00$ & $2.500 \mathrm{E}+01$ & $5.000 \mathrm{E}+01$ & $7.000 \mathrm{E}+01$ \\
\hline$m-241$ & Am-241 & $1.000 \mathrm{E}+00$ & & $5.099 \mathrm{E}-05$ & $5.237 \mathrm{E}-05$ & $5.054 \mathrm{E}-03$ & $1.032 \mathrm{E}-02$ & 1. $429 \mathrm{E}-02$ \\
\hline-237 & $A m-241$ & $1.000 \mathrm{E}+00$ & & $1.960 \mathrm{E}-08$ & $5.931 \mathrm{E}-08$ & $1.305 E-06$ & $3.357 \mathrm{E}-06$ & $5.755 \mathrm{E}-06$ \\
\hline-237 & $\mathrm{~Np}-237$ & $1.000 \mathrm{E}+00$ & & $1.899 \mathrm{E}-02$ & 1.919E-02 & $2.529 \mathrm{E}-02$ & $3.345 E-02$ & $4.166 \mathrm{E}-02$ \\
\hline-237 & $\sum \operatorname{DOSE}(j)$ & & & $1.899 \mathrm{E}-02$ & 1.919E-02 & $2.529 E-02$ & $3.345 E-02$ & $4.167 \mathrm{E}-02$ \\
\hline-233 & Am-241 & $1.000 \mathrm{E}+00$ & & $2.343 E-17$ & $1.657 \mathrm{E}-16$ & $6.494 \mathrm{E}-13$ & $5.157 \mathrm{E}-12$ & 1. $406 \mathrm{E}-11$ \\
\hline-233 & $N p-237$ & $1.000 \mathrm{E}+00$ & & $3.408 \mathrm{E}-11$ & $1.034 \mathrm{E}-10$ & $2.502 \mathrm{E}-08$ & $1.016 \mathrm{E}-07$ & $2.004 \mathrm{E}-07$ \\
\hline-233 & $\sum \operatorname{DOSE}(j)$ & & & $3.408 \mathrm{E}-11$ & $1.034 \mathrm{E}-10$ & $2.502 \mathrm{E}-08$ & $1.016 \mathrm{E}-07$ & $2.004 \mathrm{E}-07$ \\
\hline-229 & $A m-241$ & $1.000 \mathrm{E}+00$ & & $1.390 \mathrm{E}-18$ & $2.100 \mathrm{E}-17$ & $1.197 \mathrm{E}-13$ & $1.192 \mathrm{E}-12$ & $3.921 \mathrm{E}-12$ \\
\hline $1-229$ & $N p-237$ & $1.000 \mathrm{E}+00$ & & $2.697 \mathrm{E}-12$ & 1. $902 \mathrm{E}-11$ & $6.894 \mathrm{E}-09$ & $3.501 E-08$ & $8.311 \mathrm{E}-08$ \\
\hline-229 & $\sum \operatorname{DOSE}(j)$ & & & $2.697 \mathrm{E}-12$ & $1.902 \mathrm{E}-11$ & $6.894 E-09$ & $3.501 E-08$ & $8.311 E-08$ \\
\hline-137 & $\mathrm{Cs}-137$ & $1.000 \mathrm{E}+00$ & & 3. $913 \mathrm{E}-01$ & $3.856 \mathrm{E}-01$ & $2.710 \mathrm{E}-01$ & $1.877 \mathrm{E}-01$ & 1. $399 \mathrm{E}-01$ \\
\hline$u-238$ & $\mathrm{Pu}-238$ & $1.840 \mathrm{E}-09$ & & $1.895 \mathrm{E}-15$ & $1.914 \mathrm{E}-15$ & $9.947 \mathrm{E}-12$ & 1. $736 \mathrm{E}-11$ & $2.110 \mathrm{E}-11$ \\
\hline-238 & $\mathrm{Pu}-238$ & $1.000 \mathrm{E}+00$ & & $1.030 \mathrm{E}-06$ & $1.040 \mathrm{E}-06$ & $5.406 \mathrm{E}-03$ & $9.436 \mathrm{E}-03$ & $1.147 \mathrm{E}-02$ \\
\hline$u-238$ & $\sum \operatorname{DOSE}(j)$ & & & $1.030 \mathrm{E}-06$ & $1.040 \mathrm{E}-06$ & $5.406 \mathrm{E}-03$ & $9.436 \mathrm{E}-03$ & $1.147 \mathrm{E}-02$ \\
\hline-234 & $\mathrm{Pu}-238$ & $1.000 \mathrm{E}+00$ & & $9.694 \mathrm{E}-12$ & $2.944 \mathrm{E}-11$ & $9.149 \mathrm{E}-08$ & $3.501 E-07$ & $6.467 \mathrm{E}-07$ \\
\hline 234 & $U-234$ & $1.000 \mathrm{E}+00$ & & $2.805 E-05$ & $2.855 E-05$ & $5.732 \mathrm{E}-03$ & $1.216 E-02$ & $1.731 \mathrm{E}-02$ \\
\hline 4 & $\mathrm{U}-238$ & $9.999 \mathrm{E}-01$ & & $3.987 \mathrm{E}-11$ & 1. $215 \mathrm{E}-10$ & $4.144 \mathrm{E}-07$ & $1.741 E-06$ & $3.460 \mathrm{E}-06$ \\
\hline 234 & $\sum \operatorname{DOSE}(j)$ & & & $2.805 E-05$ & $2.855 E-05$ & $5.732 E-03$ & $1.216 \mathrm{E}-02$ & $1.731 E-02$ \\
\hline
\end{tabular}

Th-230 Pu-238 $1.000 \mathrm{E}+00$

$\begin{array}{lllll}1.310 \mathrm{E}-16 & 9.280 \mathrm{E}-16 \quad 4.726 \mathrm{E}-11 & 3.693 \mathrm{E}-10 & 9.758 \mathrm{E}-10\end{array}$

$\begin{array}{llllllll}\mathrm{Th}-230 & 1.000 \mathrm{E}+00 \quad 7.878 \mathrm{E}-05 & 8.012 \mathrm{E}-05 & 1.560 \mathrm{E}-02 & 3.311 \mathrm{E}-02 & 4.713 \mathrm{E}-02\end{array}$

$\begin{array}{llllllll}\mathrm{U}-234 & 1.000 \mathrm{E}+00 \quad 5.689 \mathrm{E}-10 & 1.733 \mathrm{E}-09 & 5.728 \mathrm{E}-06 & 2.407 \mathrm{E}-05 & 4.783 \mathrm{E}-05\end{array}$

$\begin{array}{llllllll}\mathrm{U}-238 & 9.999 \mathrm{E}-01 \quad 5.384 \mathrm{E}-16 & 3.823 \mathrm{E}-15 & 2.071 \mathrm{E}-10 & 1.723 \mathrm{E}-09 & 4.779 \mathrm{E}-09\end{array}$

$\sum \operatorname{DOSE}(j)$

$7.878 \mathrm{E}-05 \quad 8.012 \mathrm{E}-05 \quad 1.560 \mathrm{E}-02 \quad 3.313 \mathrm{E}-02 \quad 4.718 \mathrm{E}-02$

\begin{abstract}
$\mathrm{Pu}-238 \quad 1.000 \mathrm{E}+00$
$\begin{array}{llllll}1.701 E-15 & 2.563 E-14 & 1.281 E-10 & 1.131 E-09 & 3.415 E-09\end{array}$

$\mathrm{Th}-230 \quad 1.000 \mathrm{E}+00$

$2.053 \mathrm{E}-03 \quad 6.196 \mathrm{E}-03 \quad 1.244 \mathrm{E}-01 \quad 2.931 \mathrm{E}-01 \quad 4.701 \mathrm{E}-01$

$\begin{array}{llllllll}\mathrm{U}-234 & 1.000 \mathrm{E}+00 & 9.861 \mathrm{E}-09 & 6.944 \mathrm{E}-08 & 2.289 \mathrm{E}-05 & 1.070 \mathrm{E}-04 & 2.398 \mathrm{E}-04\end{array}$

$\begin{array}{lllllll}\mathrm{U}-238 & 9.999 \mathrm{E}-01 \quad 6.991 \mathrm{E}-15 & 1.055 \mathrm{E}-13 & 5.521 \mathrm{E}-10 & 5.113 \mathrm{E}-09 & 1.601 \mathrm{E}-08\end{array}$

$\sum \operatorname{DOSE}(j)$

$2.053 \mathrm{E}-03 \quad 6.196 \mathrm{E}-03 \quad 1.244 \mathrm{E}-01 \quad 2.932 \mathrm{E}-01 \quad 4.703 \mathrm{E}-01$
\end{abstract}

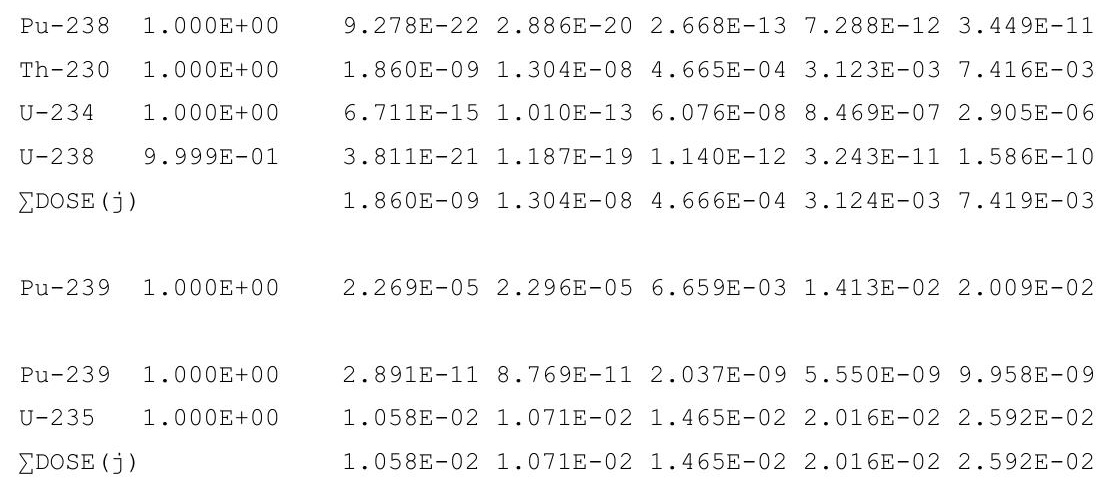


RESRAD, Version $6.5 \quad \mathrm{~T}^{1 / 2}$ Limit $=180$ days

Summary : RESRAD Parameters for U-Landfill Trespasser Forward Run

File : C: \RESRAD_FAMILY \RESRAD \USERFILES $\backslash Q C J U L Y 2011 \backslash$ TRESPASSER_FORWARDRUN-70YRS.RAD

Individual Nuclide Dose Summed Over All Pathways

Parent Nuclide and Branch Fraction Indicated

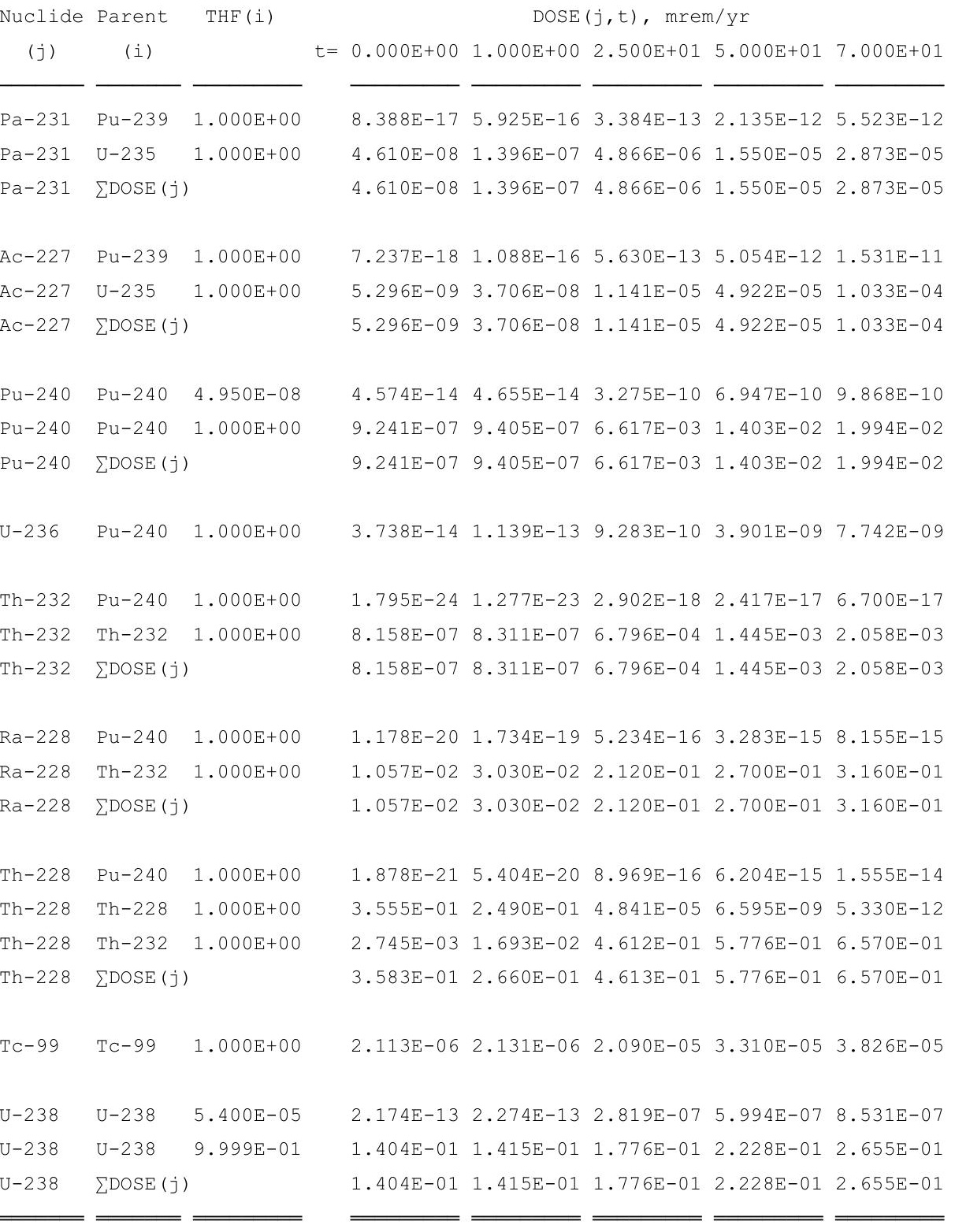

THF (i) is the thread fraction of the parent nuclide. 
RESRAD, Version $6.5 \quad \mathrm{~T}^{1 / 2}$ Limit $=180$ days

Summary : RESRAD Parameters for U-Landfill Trespasser Forward Run

File : C: \RESRAD_FAMILY \RESRAD \USERFILES $\backslash Q C J U L Y 2011 \backslash$ TRESPASSER_FORWARDRUN-70YRS.RAD

Individual Nuclide Soil Concentration

Parent Nuclide and Branch Fraction Indicated

Nuclide Parent THF(i) $\quad S(j, t), p C i / g$

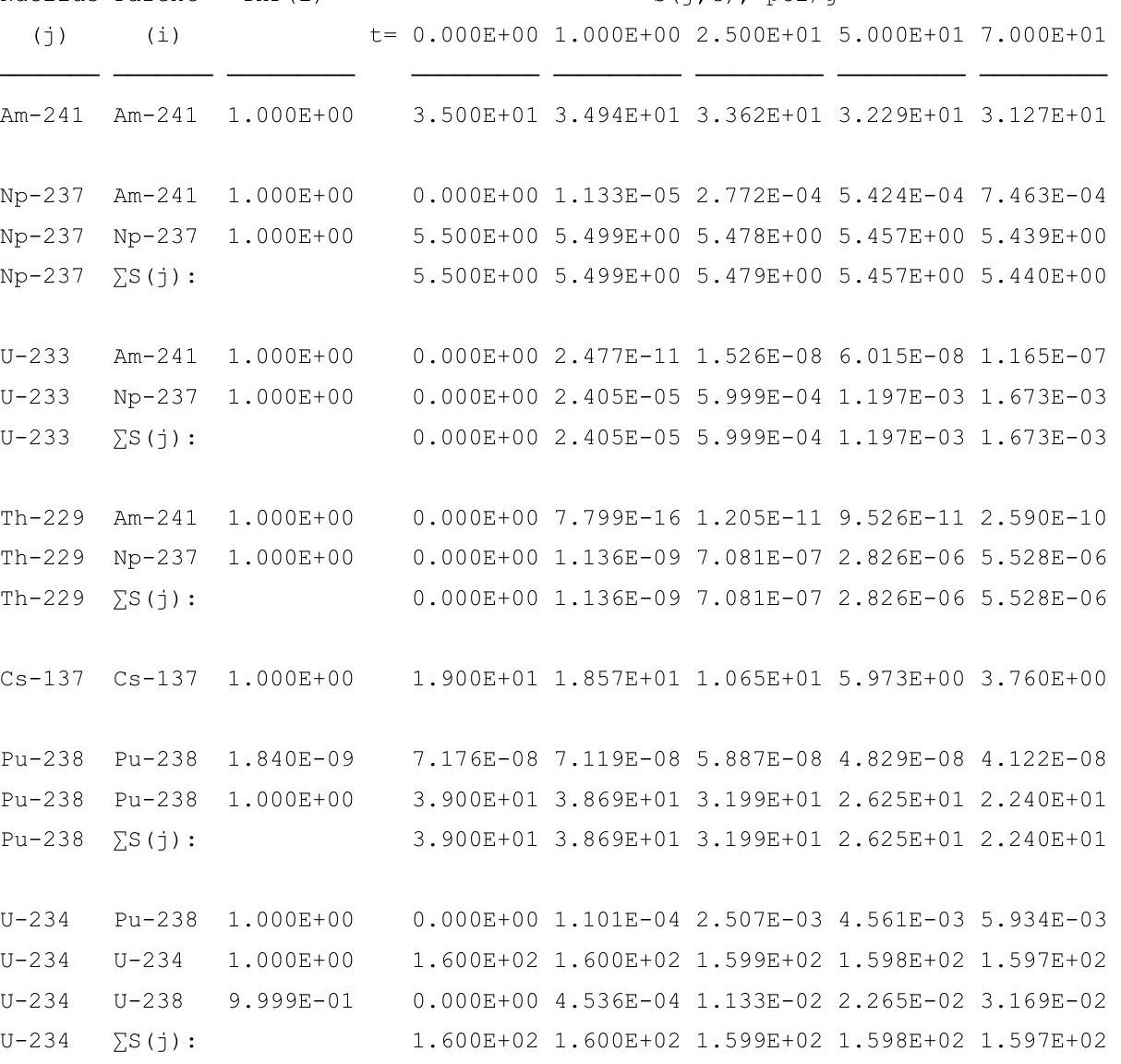

$\mathrm{Th}-230 \mathrm{Pu}-238 \quad 1.000 \mathrm{E}+00$

Th-230 Th-230 1.000E+00

$\mathrm{Th}-230 \mathrm{U}-234 \quad 1.000 \mathrm{E}+00$

$\mathrm{Th}-230 \quad \mathrm{U}-238 \quad 9.999 \mathrm{E}-01$

Th-230 $\sum S(j):$

$\mathrm{Ra}-226 \mathrm{Pu}-238 \quad 1.000 \mathrm{E}+00$

$0.000 \mathrm{E}+00 \quad 4.963 \mathrm{E}-10 \quad 2.914 \mathrm{E}-07 \quad 1.094 \mathrm{E}-06 \quad 2.042 \mathrm{E}-06$ $\begin{array}{llllll}1.000 \mathrm{E}+02 & 1.000 \mathrm{E}+02 & 9.997 \mathrm{E}+01 & 9.994 \mathrm{E}+01 & 9.991 \mathrm{E}+01\end{array}$ $0.000 \mathrm{E}+00 \quad 1.440 \mathrm{E}-03 \quad 3.599 \mathrm{E}-02 \quad 7.194 \mathrm{E}-02 \quad 1.007 \mathrm{E}-01$ $0.000 \mathrm{E}+00 \quad 2.041 \mathrm{E}-09 \quad 1.275 \mathrm{E}-06 \quad 5.098 \mathrm{E}-06 \quad 9.987 \mathrm{E}-06$ $1.000 \mathrm{E}+02 \quad 1.000 \mathrm{E}+02 \quad 1.000 \mathrm{E}+02 \quad 1.000 \mathrm{E}+02 \quad 1.000 \mathrm{E}+02$

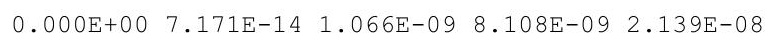
$\begin{array}{llllll}0.000 \mathrm{E}+00 & 4.331 \mathrm{E}-02 & 1.077 \mathrm{E}+00 & 2.141 \mathrm{E}+00 & 2.983 \mathrm{E}+00\end{array}$ $0.000 \mathrm{E}+00 \quad 3.119 \mathrm{E}-07 \quad 1.942 \mathrm{E}-04 \quad 7.735 \mathrm{E}-04 \quad 1.511 \mathrm{E}-03$ $\begin{array}{lllll}0.000 E+00 & 2.948 E-13 & 4.591 E-09 & 3.661 E-08 & 1.002 E-07\end{array}$ $0.000 \mathrm{E}+00 \quad 4.331 \mathrm{E}-02 \quad 1.077 \mathrm{E}+00 \quad 2.142 \mathrm{E}+00 \quad 2.985 \mathrm{E}+00$

$0.000 \mathrm{E}+00 \quad 5.540 \mathrm{E}-16 \quad 1.803 \mathrm{E}-10 \quad 2.417 \mathrm{E}-09 \quad 8.127 \mathrm{E}-09$ $\begin{array}{llllll}0.000 \mathrm{E}+00 & 6.662 \mathrm{E}-04 & 3.286 \mathrm{E}-01 & 1.057 \mathrm{E}+00 & 1.773 \mathrm{E}+00\end{array}$ $0.000 \mathrm{E}+00 \quad 3.207 \mathrm{E}-09 \quad 4.190 \mathrm{E}-05 \quad 2.836 \mathrm{E}-04 \quad 6.891 \mathrm{E}-04$ $0.000 \mathrm{E}+00 \quad 2.276 \mathrm{E}-15 \quad 7.698 \mathrm{E}-10 \quad 1.074 \mathrm{E}-08 \quad 3.733 \mathrm{E}-08$ $0.000 \mathrm{E}+00 \quad 6.662 \mathrm{E}-04 \quad 3.287 \mathrm{E}-01 \quad 1.057 \mathrm{E}+00 \quad 1.774 \mathrm{E}+00$ $\begin{array}{llll}3.600 \mathrm{E}+01 & 3.600 \mathrm{E}+01 & 3.596 \mathrm{E}+01 & 3.591 \mathrm{E}+01 \quad 3.588 \mathrm{E}+01\end{array}$ $\begin{array}{lllllll}\mathrm{Pu}-239 & 1.000 \mathrm{E}+00 & 0.000 \mathrm{E}+00 & 3.545 \mathrm{E}-08 & 8.855 \mathrm{E}-07 & 1.769 \mathrm{E}-06 & 2.475 \mathrm{E}-06\end{array}$ $\begin{array}{lllllll}\mathrm{U}-235 & 1.000 \mathrm{E}+00 & 6.500 \mathrm{E}+00 & 6.500 \mathrm{E}+00 & 6.496 \mathrm{E}+00 & 6.491 \mathrm{E}+00 & 6.488 \mathrm{E}+00\end{array}$ $\sum S(j)$ : 
RESRAD, Version $6.5 \quad \mathrm{~T}^{1 / 2}$ Limit $=180$ days

Summary : RESRAD Parameters for U-Landfill Trespasser Forward Run

File : C: \RESRAD_FAMILY \RESRAD \USERFILES $\backslash$ QCJULY2011 TTRESPASSER_FORWARDRUN-70YRS.RAD

Individual Nuclide Soil Concentration

Parent Nuclide and Branch Fraction Indicated

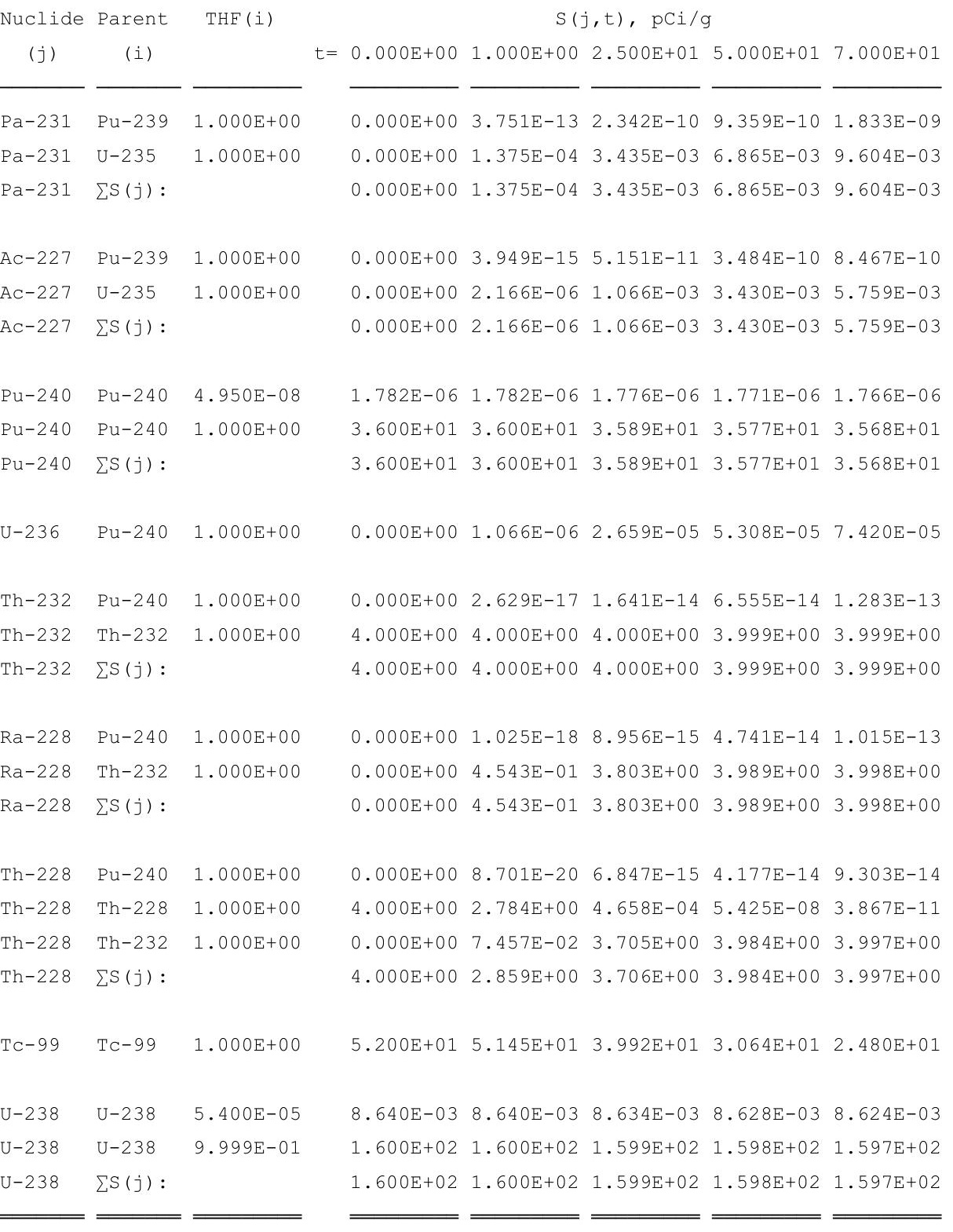

THF (i) is the thread fraction of the parent nuclide.

RESCALC.EXE execution time $=2.86$ seconds 
RESRAD, Version $6.5 \quad \mathrm{~T}^{1} \frac{1}{2}$ Limit $=180$ days

07/20/2011 08:14 Page

Summary : RESRAD Parameters for U-Landfill Trespasser Forward Run at Proposed ALs

File : C: \RESRAD_FAMILY \RESRAD \USERFILES \ULANDFILL-TRESPASSER_FORWARDRUN-70YRSALS.RAD

Table of Contents

Part I: Mixture Sums and Single Radionuclide Guidelines

Dose Conversion Factor (and Related) Parameter Summary ... 2

Site-Specific Parameter Summary ............... 8

Summary of Pathway Selections .................... 18

Contaminated Zone and Total Dose Summary ............. 19

Total Dose Components

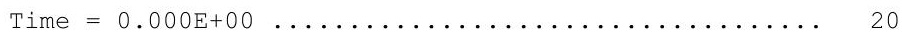

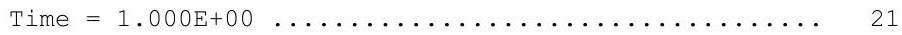

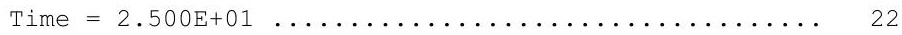

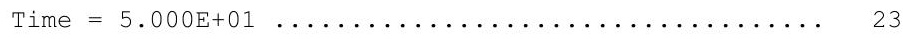

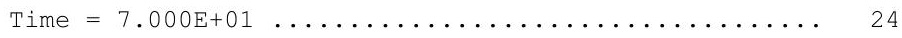

Dose/Source Ratios Summed Over All Pathways ........... 25

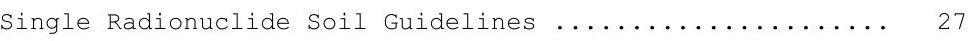

Dose Per Nuclide Summed Over All Pathways ............ 28

Soil Concentration Per Nuclide ................ 30 
Summary : RESRAD Parameters for U-Landfill Trespasser Forward Run at Proposed ALs

File : C: \RESRAD_FAMILY \RESRAD \USERFILES \ULANDFILL-TRESPASSER_FORWARDRUN-70YRSALS.RAD

Dose Conversion Factor (and Related) Parameter Summary

Dose Library: ICRP 60 \& ICRP 72 (Adult)

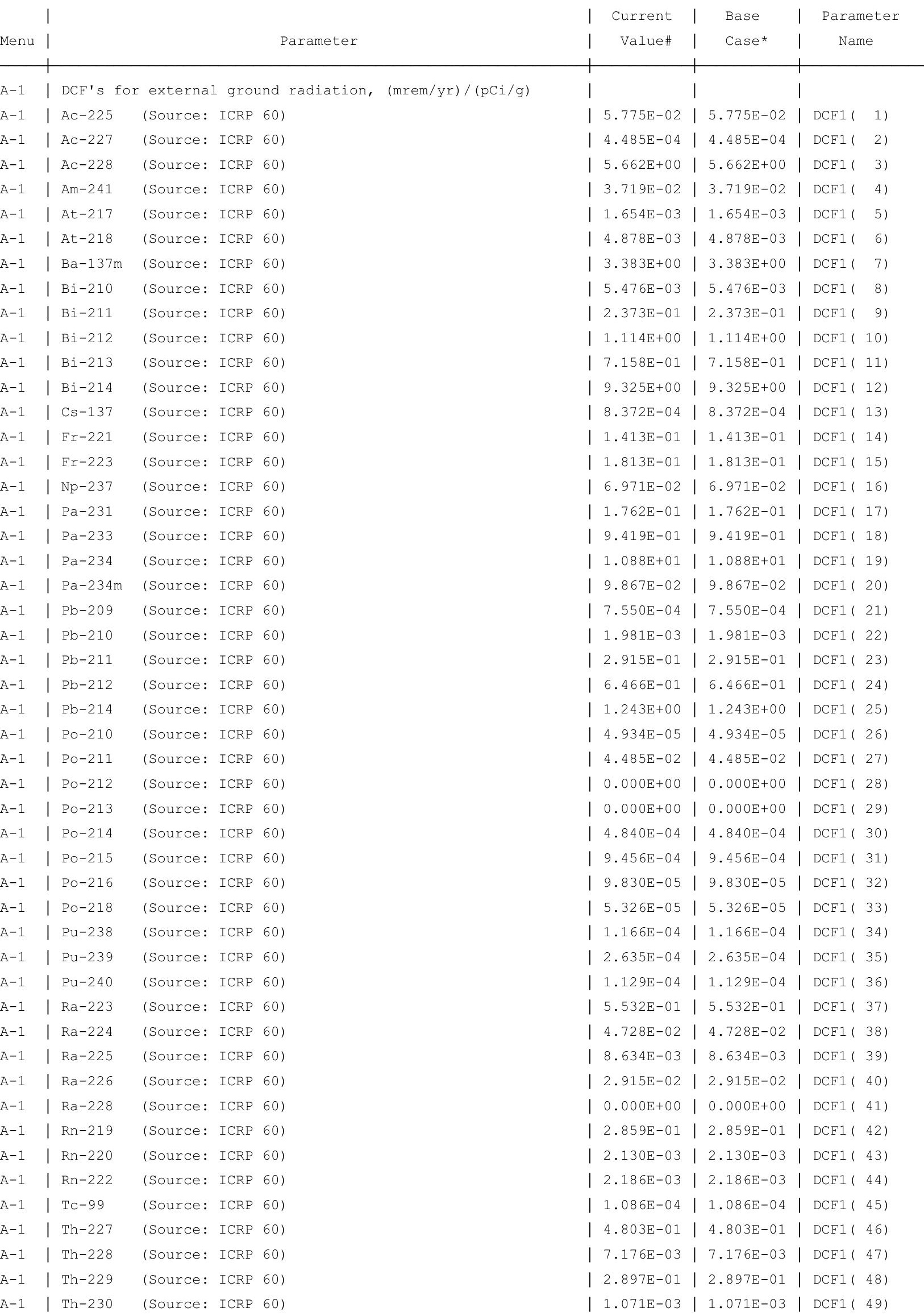


Summary : RESRAD Parameters for U-Landfill Trespasser Forward Run at Proposed ALs

File : C: \RESRAD_FAMILY \RESRAD \USERFILES \ULANDFILL-TRESPASSER_FORWARDRUN-70YRSALS.RAD

Dose Conversion Factor (and Related) Parameter Summary (continued)

Dose Library: ICRP 60 \& ICRP 72 (Adult)

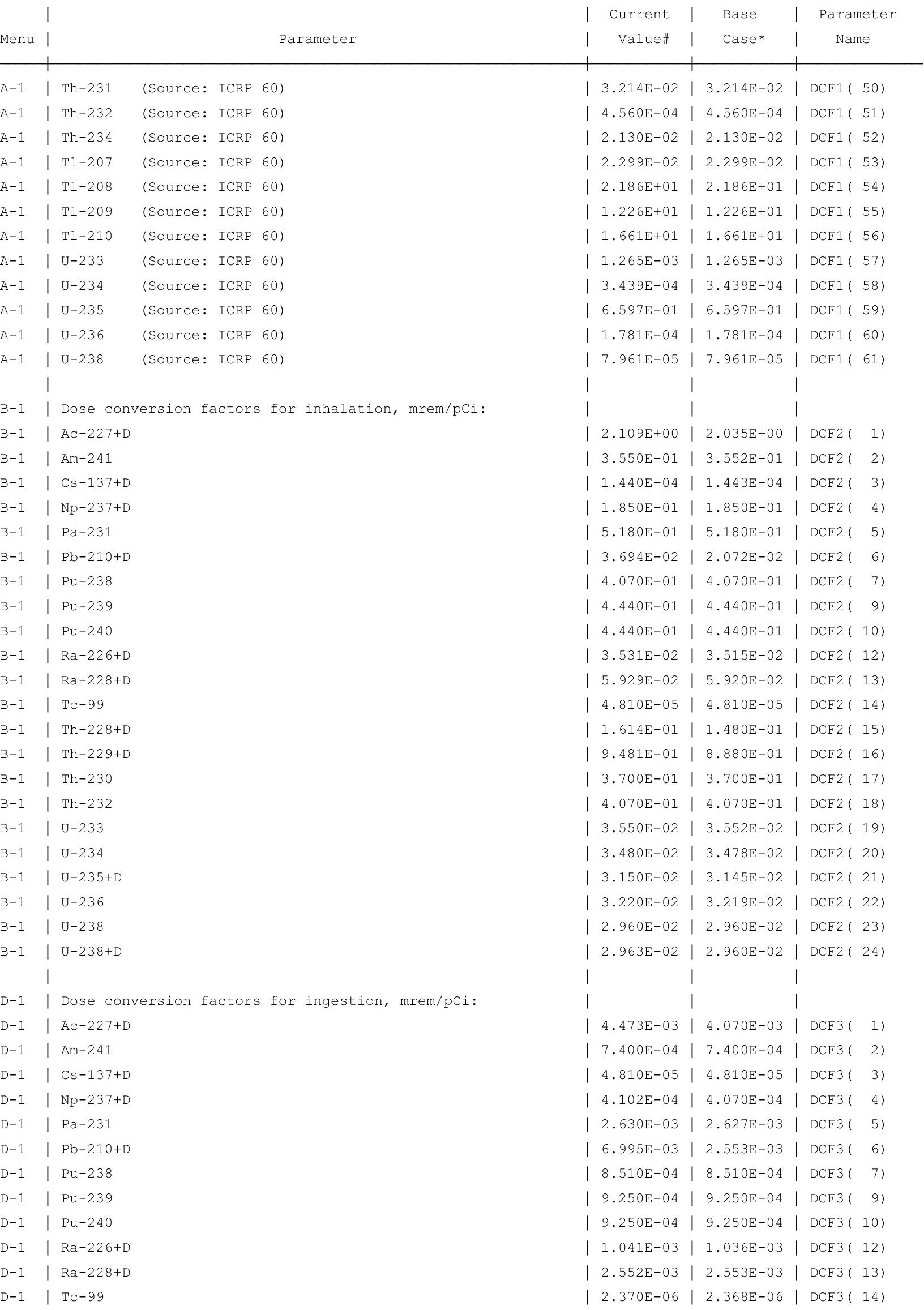


RESRAD, Version $6.5 \quad T^{1 / 2}$ Limit $=180$ days

Summary : RESRAD Parameters for U-Landfill Trespasser Forward Run at Proposed ALs

File : C: \RESRAD FAMILY \RESRAD \USERFILES \ULANDFILL-TRESPASSER FORWARDRUN-70YRSALS.RAD

Dose Conversion Factor (and Related) Parameter Summary (continued) Dose Library: ICRP 60 \& ICRP 72 (Adult)

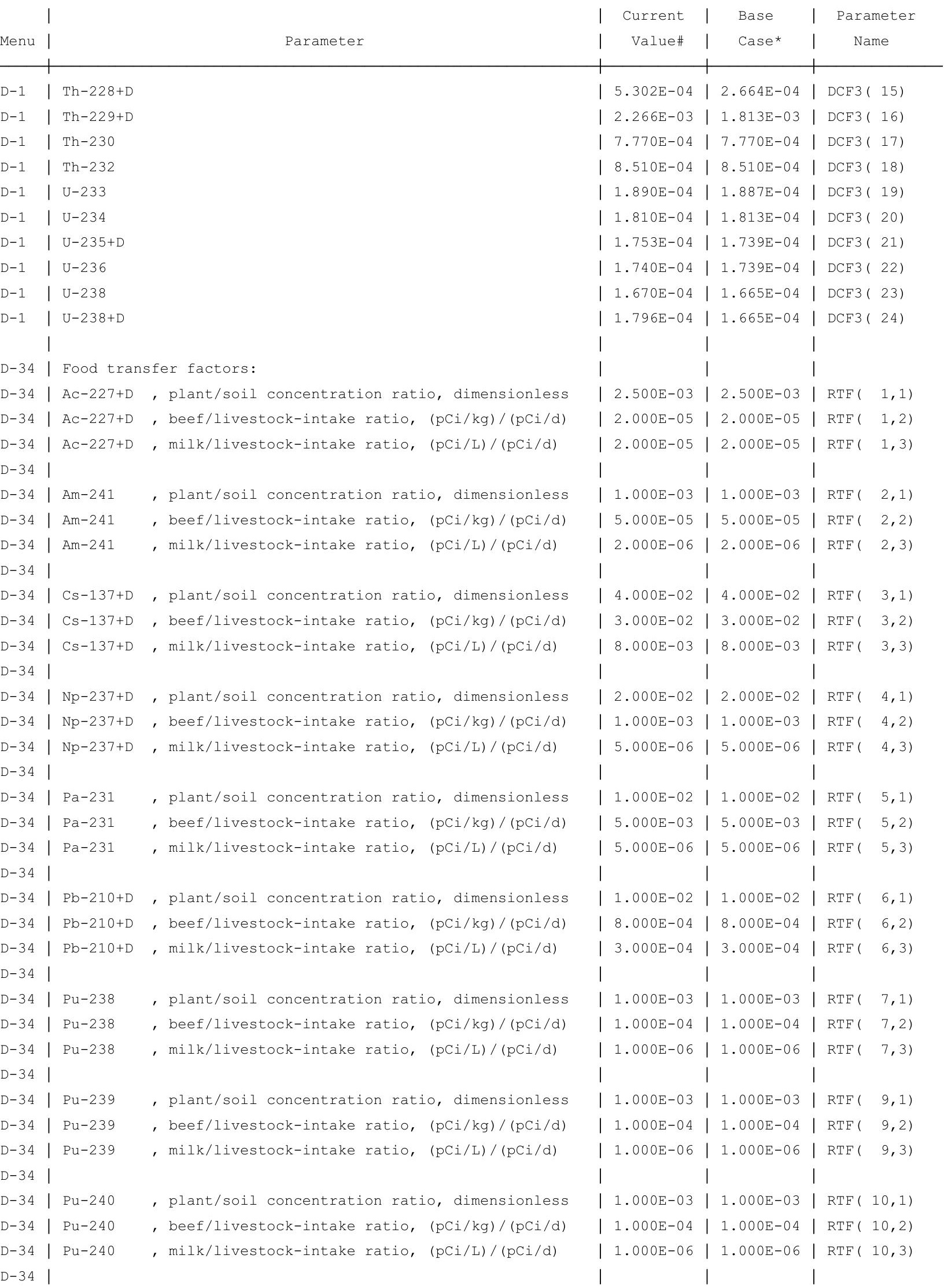


RESRAD, Version $6.5 \quad T^{13 / 2}$ Limit $=180$ days $\quad 07 / 20 / 2011 \quad 08: 14 \quad$ Page 10

Summary : RESRAD Parameters for U-Landfill Trespasser Forward Run at Proposed ALs

File : C: \RESRAD_FAMILY \RESRAD \USERFILES \ULANDFILL-TRESPASSER_FORWARDRUN-70YRSALS.RAD

Site-Specific Parameter Summary (continued)

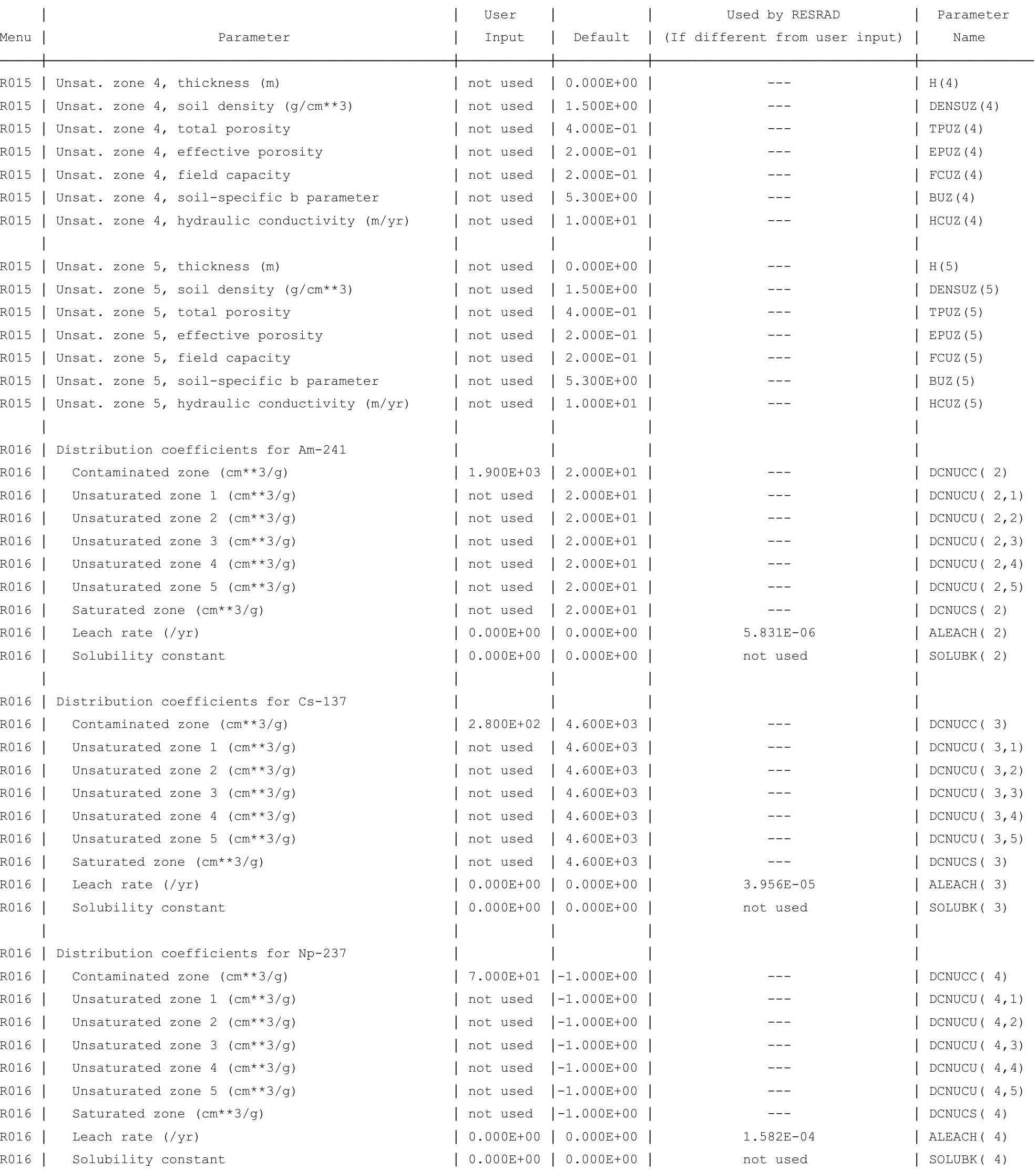


RESRAD, Version $6.5 \quad \mathrm{~T}^{1 / 2}$ Limit $=180$ days

Summary : RESRAD Parameters for U-Landfill Trespasser Forward Run at Proposed ALs

File : C: \RESRAD_FAMILY \RESRAD \USERFILES \ULANDFILL-TRESPASSER_FORWARDRUN-70YRSALS.RAD

Site-Specific Parameter Summary (continued)

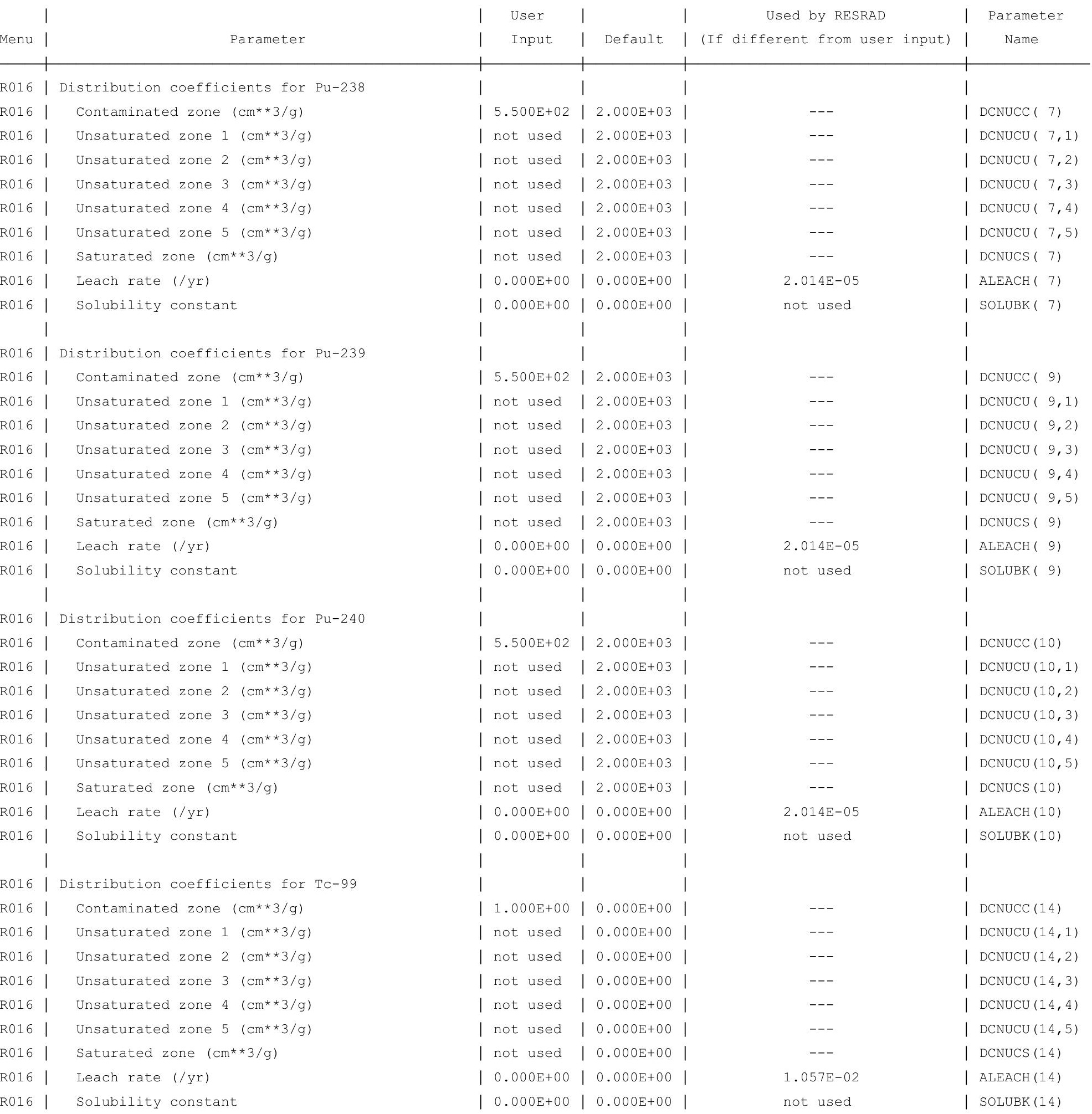


RESRAD, Version $6.5 \quad T^{13 / 2}$ Limit $=180$ days $\quad 07 / 20 / 2011 \quad 08: 14 \quad$ Page 12

Summary : RESRAD Parameters for U-Landfill Trespasser Forward Run at Proposed ALs

File : C: $\backslash$ RESRAD_FAMILY \RESRAD $\backslash$ USERFILES \ULANDFILL-TRESPASSER_FORWARDRUN-7OYRSALS.RAD

Site-Specific Parameter Summary (continued)

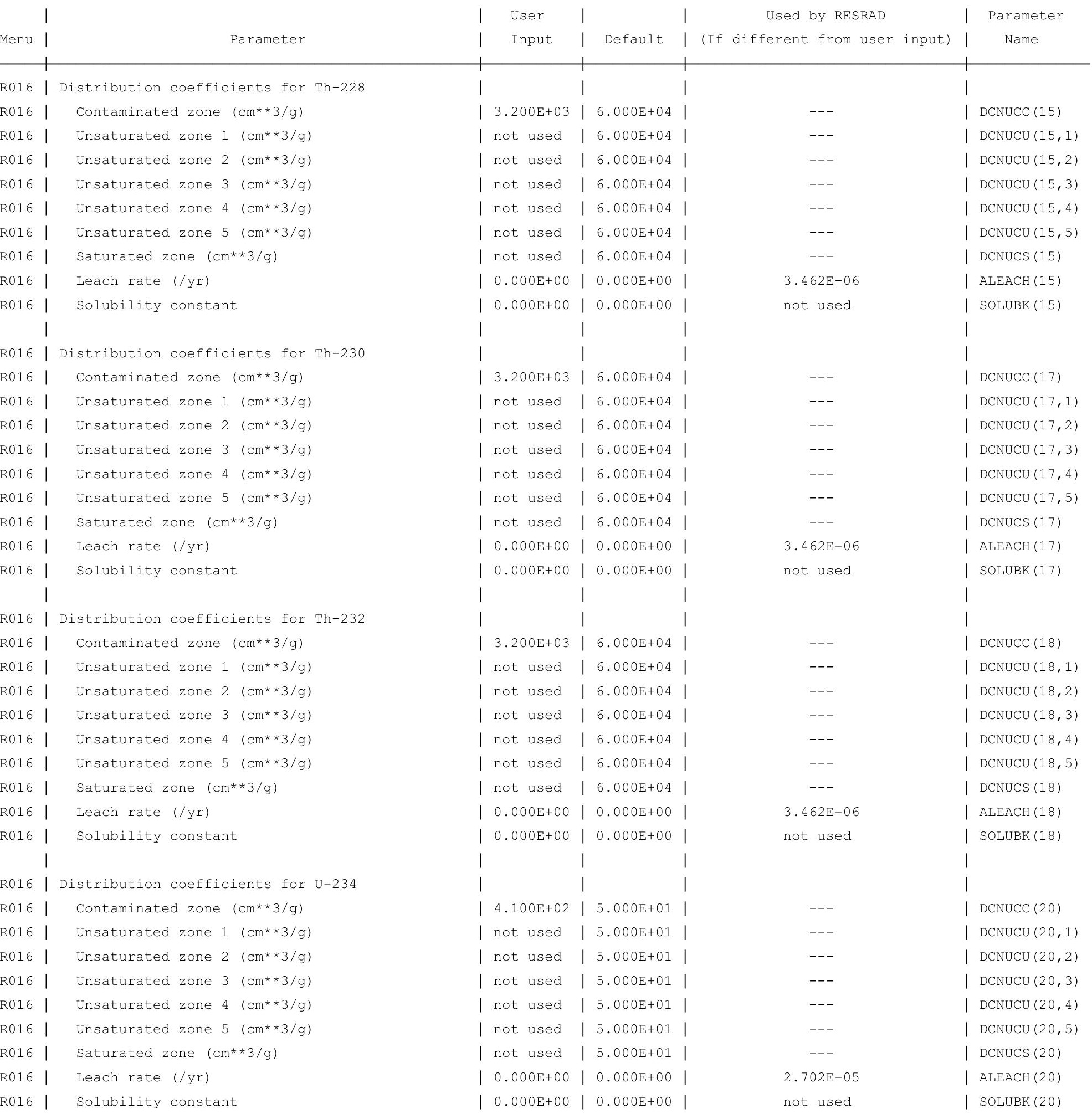


RESRAD, Version $6.5 \quad T^{13 / 2}$ Limit $=180$ days $\quad 07 / 20 / 2011 \quad 08: 14 \quad$ Page 13

Summary : RESRAD Parameters for U-Landfill Trespasser Forward Run at Proposed ALs

File : C: $\backslash$ RESRAD_FAMILY \RESRAD $\backslash$ USERFILES \ULANDFILL-TRESPASSER_FORWARDRUN-7OYRSALS.RAD

Site-Specific Parameter Summary (continued)

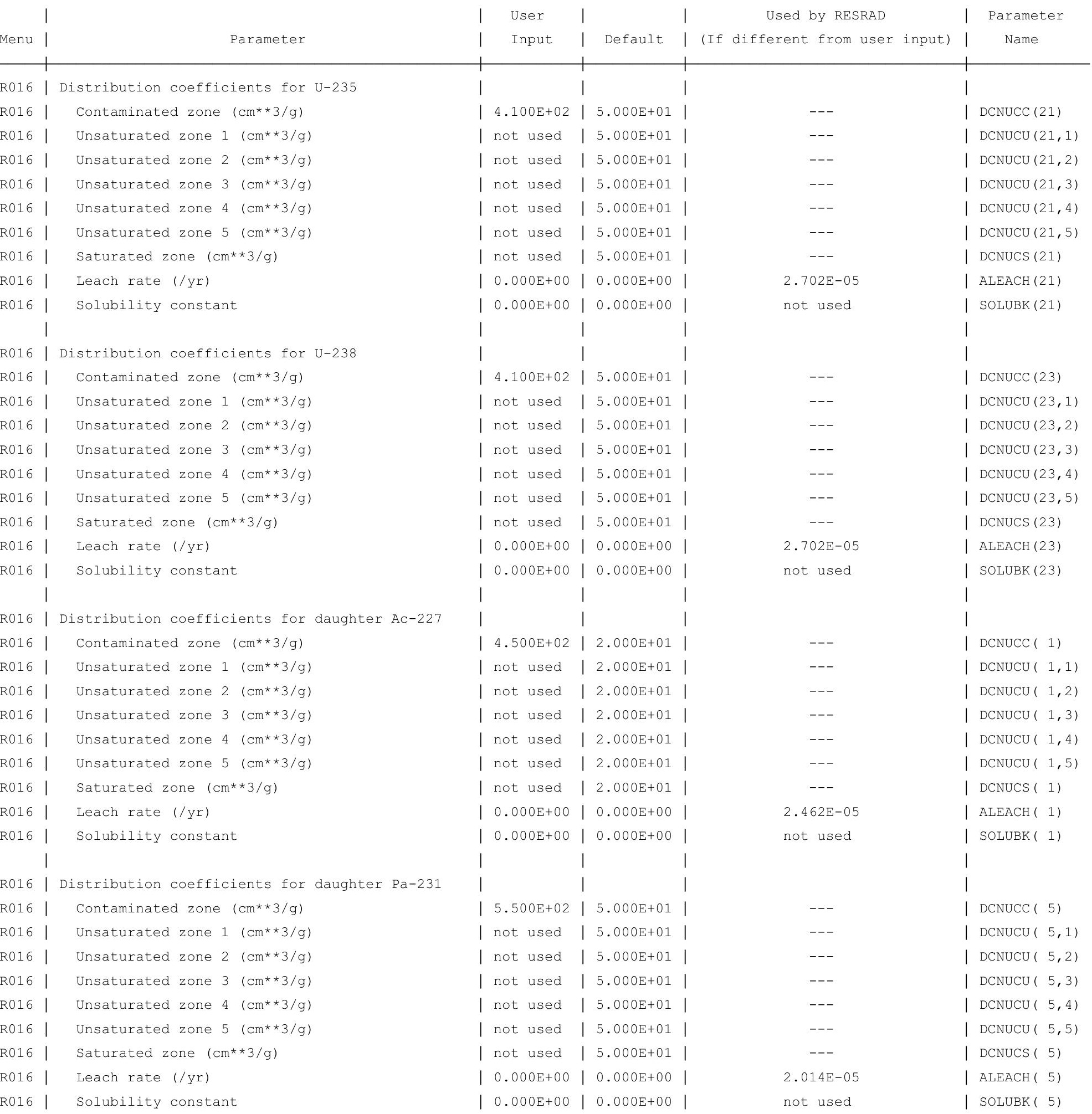


RESRAD, Version $6.5 \quad T^{13 / 2}$ Limit $=180$ days $\quad 07 / 20 / 2011 \quad 08: 14 \quad$ Page 14

Summary : RESRAD Parameters for U-Landfill Trespasser Forward Run at Proposed ALs

File : C: $\backslash$ RESRAD_FAMILY \RESRAD $\backslash$ USERFILES \ULANDFILL-TRESPASSER_FORWARDRUN-7OYRSALS.RAD

Site-Specific Parameter Summary (continued)

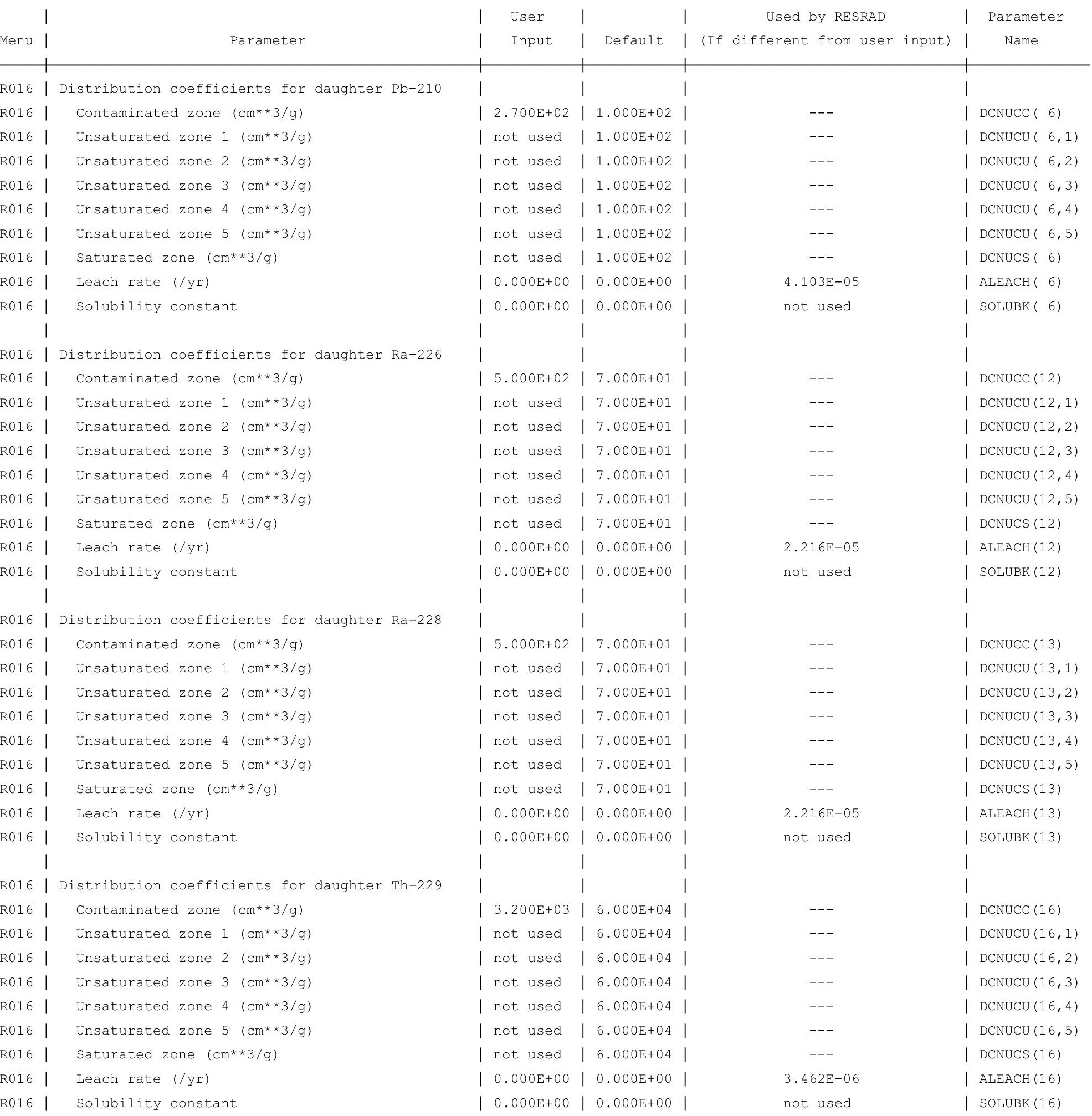


RESRAD, Version $6.5 \quad \mathrm{~T}^{1 / 2}$ Limit $=180$ days

Summary : RESRAD Parameters for U-Landfill Trespasser Forward Run at Proposed ALs

File : C: \RESRAD_FAMILY \RESRAD \USERFILES \ULANDFILL-TRESPASSER_FORWARDRUN-70YRSALS.RAD

Site-Specific Parameter Summary (continued)

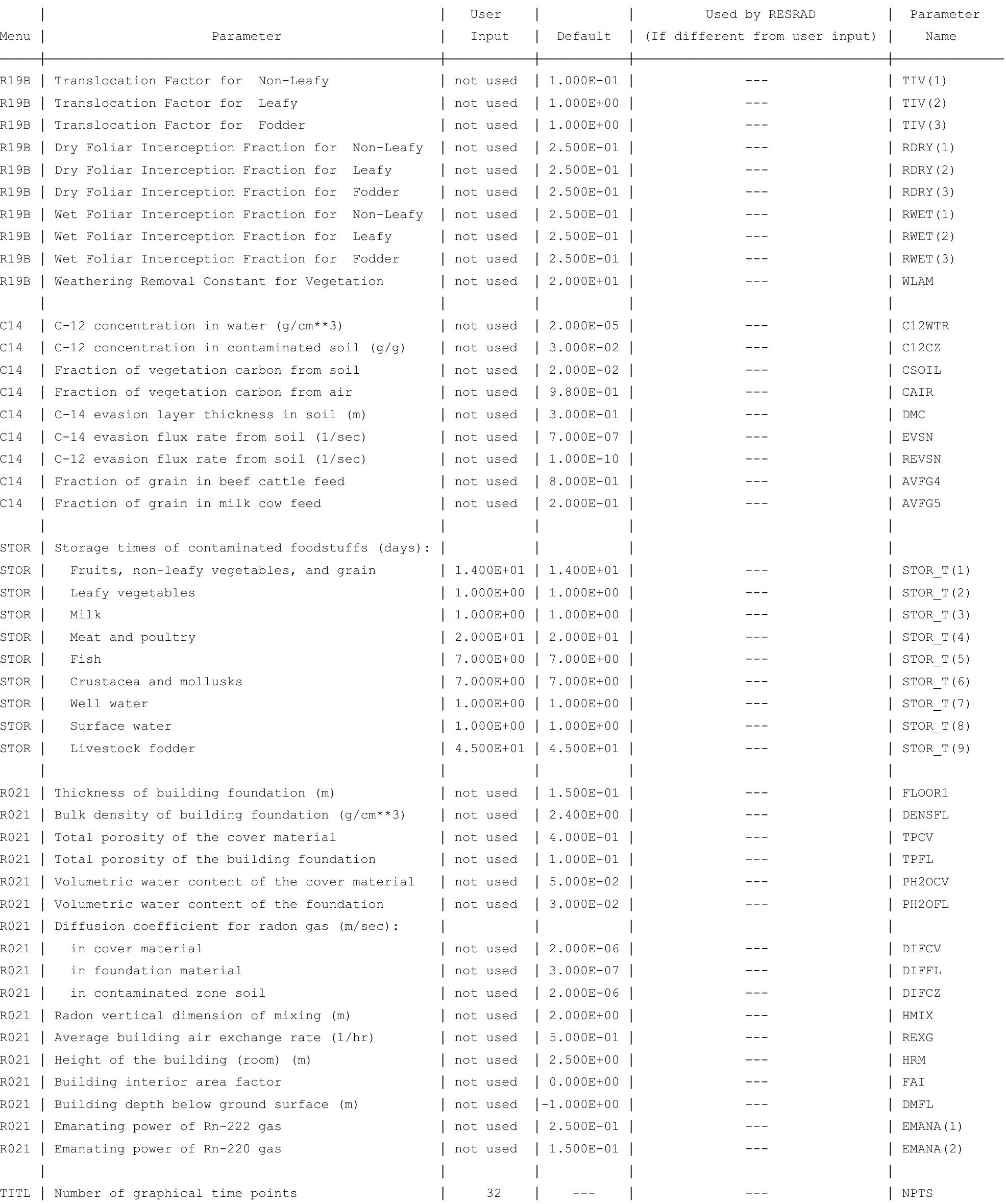

TITL | Number of graphical time points 
RESRAD, Version $6.5 \quad$ T1/2 Limit $=180$ days $\quad$ 07/20/2011 08:14 Page 19

Summary : RESRAD Parameters for U-Landfill Trespasser Forward Run at Proposed ALs

File : C: \RESRAD_FAMILY \RESRAD \USERFILES \ULANDFILL-TRESPASSER_FORWARDRUN-7OYRSALS.RAD

Contaminated Zone Dimensions

Area: 89436.00 square meters

Thickness:

Cover Depth:

\begin{abstract}
13.40 meters
\end{abstract}
0.15 meters
Initial Soil Concentrations, pCi/g

$\begin{array}{ll}\mathrm{Am}-241 & 7.000 \mathrm{E}+01 \\ \mathrm{Cs}-137 & 3.800 \mathrm{E}+01 \\ \mathrm{~Np}-237 & 1.100 \mathrm{E}+01 \\ \mathrm{Pu}-238 & 7.800 \mathrm{E}+01 \\ \mathrm{Pu}-239 & 7.200 \mathrm{E}+01 \\ \mathrm{Pu}-240 & 7.200 \mathrm{E}+01 \\ \mathrm{TC}-99 & 1.040 \mathrm{E}+02 \\ \mathrm{Th}-228 & 8.000 \mathrm{E}+00 \\ \mathrm{Th}-230 & 2.000 \mathrm{E}+02 \\ \mathrm{Th}-232 & 8.000 \mathrm{E}+00 \\ \mathrm{U}-234 & 3.200 \mathrm{E}+02 \\ \mathrm{U}-235 & 1.300 \mathrm{E}+01 \\ \mathrm{U}-238 & 3.200 \mathrm{E}+02\end{array}$

Total Dose TDOSE(t), mrem/yr

Basic Radiation Dose Limit $=1.000 \mathrm{E}+02 \mathrm{mrem} / \mathrm{yr}$

Total Mixture Sum $M(t)$ = Fraction of Basic Dose Limit Received at Time (t)
$t$ (years): $\begin{array}{llllll}0.000 \mathrm{E}+00 & 1.000 \mathrm{E}+00 & 2.500 \mathrm{E}+01 & 5.000 \mathrm{E}+01 & 7.000 \mathrm{E}+01\end{array}$
TDOSE (t): $\begin{array}{lllll}1.865 \mathrm{E}+00 & 1.719 \mathrm{E}+00 & 2.665 \mathrm{E}+00 & 3.406 \mathrm{E}+00 & 4.112 \mathrm{E}+00\end{array}$
$\mathrm{M}(\mathrm{t}): \begin{array}{lllll}1.865 \mathrm{E}-02 & 1.719 \mathrm{E}-02 & 2.665 \mathrm{E}-02 & 3.406 \mathrm{E}-02 & 4.112 \mathrm{E}-02\end{array}$

Maximum TDOSE (t): $4.112 \mathrm{E}+00 \mathrm{mrem} / \mathrm{yr}$ at $t=7.000 \mathrm{E}+01$ years 
RESRAD, Version $6.5 \quad$ T1/2 Limit $=180$ days $\quad 07 / 20 / 2011 \quad 08: 14 \quad$ Page 20

Summary : RESRAD Parameters for U-Landfill Trespasser Forward Run at Proposed ALs

File : C: \RESRAD_FAMILY \RESRAD \USERFILES \ULANDFILL-TRESPASSER_FORWARDRUN-70YRSALS.RAD

Total Dose Contributions TDOSE (i,p,t) for Individual Radionuclides (i) and Pathways (p) As mrem/yr and Fraction of Total Dose At $t=0.000 \mathrm{E}+00$ years

Water Independent Pathways (Inhalation excludes radon)

\begin{tabular}{|c|c|c|c|c|c|c|c|c|c|c|c|c|c|c|}
\hline \multirow{2}{*}{ Nuclide } & \multicolumn{2}{|c|}{ Ground } & \multicolumn{2}{|c|}{ Inhalation } & \multicolumn{2}{|c|}{ Radon } & \multicolumn{2}{|c|}{ Plant } & \multicolumn{2}{|c|}{ Meat } & \multicolumn{2}{|c|}{ Milk } & \multicolumn{2}{|c|}{ Soil } \\
\hline & mrem/yr & fract. & mrem/yr & fract. & mrem/yr & fract. & mrem/yr & fract. & mrem/yr & fract. & mrem/yr & fract. & mrem/yr & fract. \\
\hline-241 & $1.020 \mathrm{E}-04$ & 0.0001 & $0.000 \mathrm{E}+00$ & 0.0000 & $0.000 \mathrm{E}+00$ & 0.0000 & $0.000 \mathrm{E}+00$ & 0.0000 & $0.000 \mathrm{E}+00$ & 0.0000 & $0.000 \mathrm{E}+00$ & 0.0000 & $0.000 \mathrm{E}+00$ & 0.0000 \\
\hline-137 & $7.826 \mathrm{E}-01$ & 0.4197 & $0.000 \mathrm{E}+00$ & 0.0000 & $0.000 \mathrm{E}+00$ & 0.0000 & $0.000 \mathrm{E}+00$ & 0.0000 & $0.000 \mathrm{E}+00$ & 0.0000 & $0.000 \mathrm{E}+00$ & 0.0000 & $0.000 \mathrm{E}+00$ & 0.0000 \\
\hline-237 & $3.798 E-02$ & 0.0204 & $0.000 \mathrm{E}+00$ & 0.0000 & $0.000 \mathrm{E}+00$ & 0.0000 & $0.000 \mathrm{E}+00$ & 0.0000 & $0.000 \mathrm{E}+00$ & 0.0000 & $0.000 \mathrm{E}+00$ & 0.0000 & $0.000 \mathrm{E}+00$ & 0.0000 \\
\hline-238 & $2.060 E-06$ & 0.0000 & $0.000 \mathrm{E}+00$ & 0.0000 & $0.000 \mathrm{E}+00$ & 0.0000 & $0.000 \mathrm{E}+00$ & 0.0000 & $0.000 \mathrm{E}+00$ & 0.0000 & $0.000 \mathrm{E}+00$ & 0.0000 & $0.000 \mathrm{E}+00$ & 0.0000 \\
\hline-239 & $4.538 E-05$ & 0.0000 & $0.000 \mathrm{E}+00$ & 0.0000 & $0.000 \mathrm{E}+00$ & 0.0000 & $0.000 \mathrm{E}+00$ & 0.0000 & $0.000 \mathrm{E}+00$ & 0.0000 & $0.000 \mathrm{E}+00$ & 0.0000 & $0.000 \mathrm{E}+00$ & 0.0000 \\
\hline-240 & $1.848 \mathrm{E}-06$ & 0.0000 & $0.000 \mathrm{E}+00$ & 0.0000 & $0.000 \mathrm{E}+00$ & 0.0000 & $0.000 \mathrm{E}+00$ & 0.0000 & $0.000 \mathrm{E}+00$ & 0.0000 & $0.000 \mathrm{E}+00$ & 0.0000 & $0.000 \mathrm{E}+00$ & 0.0000 \\
\hline 99 & $4.225 E-06$ & 0.0000 & $0.000 \mathrm{E}+00$ & 0.0000 & $0.000 \mathrm{E}+00$ & 0.0000 & $0.000 \mathrm{E}+00$ & 0.0000 & $0.000 \mathrm{E}+00$ & 0.0000 & $0.000 \mathrm{E}+00$ & 0.0000 & $0.000 \mathrm{E}+00$ & 0.0000 \\
\hline-228 & 7. $111 \mathrm{E}-01$ & 0.3813 & $0.000 \mathrm{E}+00$ & 0.0000 & $0.000 \mathrm{E}+00$ & 0.0000 & $0.000 \mathrm{E}+00$ & 0.0000 & $0.000 \mathrm{E}+00$ & 0.0000 & $0.000 \mathrm{E}+00$ & 0.0000 & $0.000 \mathrm{E}+00$ & 0.0000 \\
\hline-230 & $4.263 E-03$ & 0.0023 & $0.000 \mathrm{E}+00$ & 0.0000 & $0.000 \mathrm{E}+00$ & 0.0000 & $0.000 \mathrm{E}+00$ & 0.0000 & $0.000 \mathrm{E}+00$ & 0.0000 & $0.000 \mathrm{E}+00$ & 0.0000 & $0.000 \mathrm{E}+00$ & 0.0000 \\
\hline-232 & $2.663 E-02$ & 0.0143 & $0.000 \mathrm{E}+00$ & 0.0000 & $0.000 \mathrm{E}+00$ & 0.0000 & $0.000 \mathrm{E}+00$ & 0.0000 & $0.000 \mathrm{E}+00$ & 0.0000 & $0.000 \mathrm{E}+00$ & 0.0000 & $0.000 \mathrm{E}+00$ & 0.0000 \\
\hline 234 & $5.612 \mathrm{E}-05$ & 0.0000 & $0.000 \mathrm{E}+00$ & 0.0000 & $0.000 \mathrm{E}+00$ & 0.0000 & $0.000 \mathrm{E}+00$ & 0.0000 & $0.000 \mathrm{E}+00$ & 0.0000 & $0.000 \mathrm{E}+00$ & 0.0000 & $0.000 \mathrm{E}+00$ & 0.0000 \\
\hline 35 & $2.116 \mathrm{E}-02$ & 0.0113 & $0.000 \mathrm{E}+00$ & 0.0000 & $0.000 \mathrm{E}+00$ & 0.0000 & $0.000 \mathrm{E}+00$ & 0.0000 & $0.000 \mathrm{E}+00$ & 0.0000 & $0.000 \mathrm{E}+00$ & 0.0000 & $0.000 \mathrm{E}+00$ & 0.0000 \\
\hline 38 & $2.808 E-01$ & 0.1506 & $0.000 \mathrm{E}+00$ & 0.0000 & $0.000 \mathrm{E}+00$ & 0.0000 & $0.000 \mathrm{E}+00$ & 0.0000 & $0.000 \mathrm{E}+00$ & 0.0000 & $0.000 \mathrm{E}+00$ & 0.0000 & $0.000 \mathrm{E}+00$ & 0.0000 \\
\hline & $1.865 E+00$ & 1.0000 & $0.000 \mathrm{E}+00$ & 0.0000 & $0.000 \mathrm{E}+00$ & 0.0000 & $0.000 \mathrm{E}+00$ & 0.0000 & $0.000 \mathrm{E}+00$ & 0.0000 & $0.000 \mathrm{E}+00$ & 0.0000 & $0.000 \mathrm{E}+00$ & 0.0000 \\
\hline
\end{tabular}

Total Dose Contributions TDOSE(i,p,t) for Individual Radionuclides (i) and Pathways (p) As mrem/yr and Fraction of Total Dose At $t=0.000 \mathrm{E}+00$ years

Water Dependent Pathways

\begin{tabular}{|c|c|c|c|c|c|c|c|c|c|c|c|c|c|c|}
\hline \multirow{2}{*}{ Nuclide } & \multicolumn{2}{|c|}{ Water } & \multicolumn{2}{|c|}{ Fish } & \multicolumn{2}{|c|}{ Radon } & \multicolumn{2}{|c|}{ Plant } & \multicolumn{2}{|c|}{ Meat } & \multicolumn{2}{|c|}{ Milk } & \multicolumn{2}{|c|}{ All Pathways* } \\
\hline & mrem/yr & fract. & mrem/yr & fract. & mrem/yr & fract. & mrem/yr & fract. & mrem/yr & fract. & mrem/yr & fract. & mrem/yr & fract. \\
\hline-241 & $0.000 \mathrm{E}+00$ & 0.0000 & $0.000 \mathrm{E}+00$ & 0.0000 & $0.000 \mathrm{E}+00$ & 0.0000 & $0.000 \mathrm{E}+00$ & 0.0000 & $0.000 \mathrm{E}+00$ & 0.0000 & $0.000 \mathrm{E}+00$ & 0.0000 & $1.020 \mathrm{E}-04$ & 0.0001 \\
\hline-137 & $0.000 \mathrm{E}+00$ & 0.0000 & $0.000 \mathrm{E}+00$ & 0.0000 & $0.000 \mathrm{E}+00$ & 0.0000 & $0.000 \mathrm{E}+00$ & 0.0000 & $0.000 \mathrm{E}+00$ & 0.0000 & $0.000 \mathrm{E}+00$ & 0.0000 & $7.826 \mathrm{E}-01$ & 0.4197 \\
\hline-237 & $0.000 \mathrm{E}+00$ & 0.0000 & $0.000 \mathrm{E}+00$ & 0.0000 & $0.000 \mathrm{E}+00$ & 0.0000 & $0.000 \mathrm{E}+00$ & 0.0000 & $0.000 \mathrm{E}+00$ & 0.0000 & $0.000 \mathrm{E}+00$ & 0.0000 & $3.798 E-02$ & 0.0204 \\
\hline-238 & $0.000 \mathrm{E}+00$ & 0.0000 & $0.000 \mathrm{E}+00$ & 0.0000 & $0.000 \mathrm{E}+00$ & 0.0000 & $0.000 \mathrm{E}+00$ & 0.0000 & $0.000 \mathrm{E}+00$ & 0.0000 & $0.000 \mathrm{E}+00$ & 0.0000 & $2.060 \mathrm{E}-06$ & 0.0000 \\
\hline-239 & $0.000 \mathrm{E}+00$ & 0.0000 & $0.000 \mathrm{E}+00$ & 0.0000 & $0.000 \mathrm{E}+00$ & 0.0000 & $0.000 \mathrm{E}+00$ & 0.0000 & $0.000 \mathrm{E}+00$ & 0.0000 & $0.000 \mathrm{E}+00$ & 0.0000 & $4.538 \mathrm{E}-05$ & 0.0000 \\
\hline-240 & $0.000 \mathrm{E}+00$ & 0.0000 & $0.000 \mathrm{E}+00$ & 0.0000 & $0.000 \mathrm{E}+00$ & 0.0000 & $0.000 \mathrm{E}+00$ & 0.0000 & $0.000 \mathrm{E}+00$ & 0.0000 & $0.000 \mathrm{E}+00$ & 0.0000 & $1.848 E-06$ & 0.0000 \\
\hline-99 & $0.000 \mathrm{E}+00$ & 0.0000 & $0.000 \mathrm{E}+00$ & 0.0000 & $0.000 \mathrm{E}+00$ & 0.0000 & $0.000 \mathrm{E}+00$ & 0.0000 & $0.000 \mathrm{E}+00$ & 0.0000 & $0.000 \mathrm{E}+00$ & 0.0000 & $4.225 E-06$ & 0.0000 \\
\hline-228 & $0.000 \mathrm{E}+00$ & 0.0000 & $0.000 \mathrm{E}+00$ & 0.0000 & $0.000 \mathrm{E}+00$ & 0.0000 & $0.000 \mathrm{E}+00$ & 0.0000 & $0.000 \mathrm{E}+00$ & 0.0000 & $0.000 \mathrm{E}+00$ & 0.0000 & $7.111 \mathrm{E}-01$ & 0.3813 \\
\hline 230 & $0.000 \mathrm{E}+00$ & 0.0000 & $0.000 \mathrm{E}+00$ & 0.0000 & $0.000 \mathrm{E}+00$ & 0.0000 & $0.000 \mathrm{E}+00$ & 0.0000 & $0.000 \mathrm{E}+00$ & 0.0000 & $0.000 \mathrm{E}+00$ & 0.0000 & $4.263 E-03$ & 0.0023 \\
\hline 232 & $0.000 \mathrm{E}+00$ & 0.0000 & $0.000 \mathrm{E}+00$ & 0.0000 & $0.000 \mathrm{E}+00$ & 0.0000 & $0.000 \mathrm{E}+00$ & 0.0000 & $0.000 \mathrm{E}+00$ & 0.0000 & $0.000 \mathrm{E}+00$ & 0.0000 & $2.663 E-02$ & 0.0143 \\
\hline 34 & $0.000 \mathrm{E}+00$ & 0.0000 & $0.000 \mathrm{E}+00$ & 0.0000 & $0.000 \mathrm{E}+00$ & 0.0000 & $0.000 \mathrm{E}+00$ & 0.0000 & $0.000 \mathrm{E}+00$ & 0.0000 & $0.000 \mathrm{E}+00$ & 0.0000 & $5.612 \mathrm{E}-05$ & 0.0000 \\
\hline 35 & $0.000 \mathrm{E}+00$ & 0.0000 & $0.000 \mathrm{E}+00$ & 0.0000 & $0.000 \mathrm{E}+00$ & 0.0000 & $0.000 \mathrm{E}+00$ & 0.0000 & $0.000 \mathrm{E}+00$ & 0.0000 & $0.000 \mathrm{E}+00$ & 0.0000 & $2.116 \mathrm{E}-02$ & 0.0113 \\
\hline 38 & $0.000 \mathrm{E}+00$ & 0.0000 & $0.000 \mathrm{E}+00$ & 0.0000 & $0.000 \mathrm{E}+00$ & 0.0000 & $0.000 \mathrm{E}+00$ & 0.0000 & $0.000 \mathrm{E}+00$ & 0.0000 & $0.000 \mathrm{E}+00$ & 0.0000 & $2.808 \mathrm{E}-01$ & 0.1506 \\
\hline & $0.000 \mathrm{E}+00$ & 0.0000 & $0.000 \mathrm{E}+00$ & 0.0000 & $0.000 \mathrm{E}+00$ & 0.0000 & $0.000 \mathrm{E}+00$ & 0.0000 & $0.000 \mathrm{E}+00$ & 0.0000 & $0.000 \mathrm{E}+00$ & 0.0000 & $5 E+00$ & 1.0000 \\
\hline
\end{tabular}

* Sum of all water independent and dependent pathways. 
RESRAD, Version $6.5 \quad$ T1/2 Limit $=180$ days $\quad$ 07/20/2011 08:14 Page 21

Summary : RESRAD Parameters for U-Landfill Trespasser Forward Run at Proposed ALs

File : C: \RESRAD_FAMILY \RESRAD \USERFILES \ULANDFILL-TRESPASSER_FORWARDRUN-70YRSALS.RAD

Total Dose Contributions TDOSE (i,p,t) for Individual Radionuclides (i) and Pathways (p) As mrem/yr and Fraction of Total Dose At $t=1.000 \mathrm{E}+00$ years

Water Independent Pathways (Inhalation excludes radon)

\begin{tabular}{|c|c|c|c|c|c|c|c|c|c|c|c|c|c|c|}
\hline \multirow{2}{*}{ Nuclide } & \multicolumn{2}{|c|}{ Ground } & \multicolumn{2}{|c|}{ Inhalation } & \multicolumn{2}{|c|}{ Radon } & \multicolumn{2}{|c|}{ Plant } & \multicolumn{2}{|c|}{ Meat } & \multicolumn{2}{|c|}{ Milk } & \multicolumn{2}{|c|}{ Soil } \\
\hline & mrem/yr & fract. & mrem/yr & fract. & mrem/yr & fract. & mrem/yr & fract. & mrem/yr & fract. & mrem/yr & fract. & mrem/yr & fract. \\
\hline-241 & $1.049 \mathrm{E}-04$ & 0.0001 & $0.000 \mathrm{E}+00$ & 0.0000 & $0.000 \mathrm{E}+00$ & 0.0000 & $0.000 \mathrm{E}+00$ & 0.0000 & $0.000 \mathrm{E}+00$ & 0.0000 & $0.000 \mathrm{E}+00$ & 0.0000 & $0.000 \mathrm{E}+00$ & 0.0000 \\
\hline-137 & 7. $712 \mathrm{E}-01$ & 0.4485 & $0.000 \mathrm{E}+00$ & 0.0000 & $0.000 \mathrm{E}+00$ & 0.0000 & $0.000 \mathrm{E}+00$ & 0.0000 & $0.000 \mathrm{E}+00$ & 0.0000 & $0.000 \mathrm{E}+00$ & 0.0000 & $0.000 \mathrm{E}+00$ & 0.0000 \\
\hline-237 & $3.839 \mathrm{E}-02$ & 0.0223 & $0.000 \mathrm{E}+00$ & 0.0000 & $0.000 \mathrm{E}+00$ & 0.0000 & $0.000 \mathrm{E}+00$ & 0.0000 & $0.000 \mathrm{E}+00$ & 0.0000 & $0.000 \mathrm{E}+00$ & 0.0000 & $0.000 \mathrm{E}+00$ & 0.0000 \\
\hline-238 & $2.080 E-06$ & 0.0000 & $0.000 \mathrm{E}+00$ & 0.0000 & $0.000 \mathrm{E}+00$ & 0.0000 & $0.000 \mathrm{E}+00$ & 0.0000 & $0.000 \mathrm{E}+00$ & 0.0000 & $0.000 \mathrm{E}+00$ & 0.0000 & $0.000 \mathrm{E}+00$ & 0.0000 \\
\hline-239 & $4.592 E-05$ & 0.0000 & $0.000 \mathrm{E}+00$ & 0.0000 & $0.000 \mathrm{E}+00$ & 0.0000 & $0.000 \mathrm{E}+00$ & 0.0000 & $0.000 \mathrm{E}+00$ & 0.0000 & $0.000 \mathrm{E}+00$ & 0.0000 & $0.000 \mathrm{E}+00$ & 0.0000 \\
\hline-240 & $1.881 \mathrm{E}-06$ & 0.0000 & $0.000 \mathrm{E}+00$ & 0.0000 & $0.000 \mathrm{E}+00$ & 0.0000 & $0.000 \mathrm{E}+00$ & 0.0000 & $0.000 \mathrm{E}+00$ & 0.0000 & $0.000 \mathrm{E}+00$ & 0.0000 & $0.000 \mathrm{E}+00$ & 0.0000 \\
\hline 99 & $4.262 \mathrm{E}-06$ & 0.0000 & $0.000 \mathrm{E}+00$ & 0.0000 & $0.000 \mathrm{E}+00$ & 0.0000 & $0.000 \mathrm{E}+00$ & 0.0000 & $0.000 \mathrm{E}+00$ & 0.0000 & $0.000 \mathrm{E}+00$ & 0.0000 & $0.000 \mathrm{E}+00$ & 0.0000 \\
\hline-228 & 4. $980 \mathrm{E}-01$ & 0.2897 & $0.000 \mathrm{E}+00$ & 0.0000 & $0.000 \mathrm{E}+00$ & 0.0000 & $0.000 \mathrm{E}+00$ & 0.0000 & $0.000 \mathrm{E}+00$ & 0.0000 & $0.000 \mathrm{E}+00$ & 0.0000 & $0.000 \mathrm{E}+00$ & 0.0000 \\
\hline-230 & 1. $255 \mathrm{E}-02$ & 0.0073 & $0.000 \mathrm{E}+00$ & 0.0000 & $0.000 \mathrm{E}+00$ & 0.0000 & $0.000 \mathrm{E}+00$ & 0.0000 & $0.000 \mathrm{E}+00$ & 0.0000 & $0.000 \mathrm{E}+00$ & 0.0000 & $0.000 \mathrm{E}+00$ & 0.0000 \\
\hline-232 & $9.446 E-02$ & 0.0549 & $0.000 \mathrm{E}+00$ & 0.0000 & $0.000 \mathrm{E}+00$ & 0.0000 & $0.000 \mathrm{E}+00$ & 0.0000 & $0.000 \mathrm{E}+00$ & 0.0000 & $0.000 \mathrm{E}+00$ & 0.0000 & $0.000 \mathrm{E}+00$ & 0.0000 \\
\hline 234 & $5.724 \mathrm{E}-05$ & 0.0000 & $0.000 \mathrm{E}+00$ & 0.0000 & $0.000 \mathrm{E}+00$ & 0.0000 & $0.000 \mathrm{E}+00$ & 0.0000 & $0.000 \mathrm{E}+00$ & 0.0000 & $0.000 \mathrm{E}+00$ & 0.0000 & $0.000 \mathrm{E}+00$ & 0.0000 \\
\hline 35 & $2.142 \mathrm{E}-02$ & 0.0125 & $0.000 \mathrm{E}+00$ & 0.0000 & $0.000 \mathrm{E}+00$ & 0.0000 & $0.000 \mathrm{E}+00$ & 0.0000 & $0.000 \mathrm{E}+00$ & 0.0000 & $0.000 \mathrm{E}+00$ & 0.0000 & $0.000 \mathrm{E}+00$ & 0.0000 \\
\hline 38 & $2.831 E-01$ & 0.1646 & $0.000 \mathrm{E}+00$ & 0.0000 & $0.000 \mathrm{E}+00$ & 0.0000 & $0.000 \mathrm{E}+00$ & 0.0000 & $0.000 \mathrm{E}+00$ & 0.0000 & $0.000 \mathrm{E}+00$ & 0.0000 & $0.000 \mathrm{E}+00$ & 0.0000 \\
\hline & $1.719 \mathrm{E}+00$ & 1.0000 & $0.000 \mathrm{E}+00$ & 0.0000 & $0.000 \mathrm{E}+00$ & 0.0000 & $0.000 \mathrm{E}+00$ & 0.0000 & $0.000 \mathrm{E}+00$ & 0.0000 & $0.000 \mathrm{E}+00$ & 0.0000 & $.000 \mathrm{E}+00$ & 0.0000 \\
\hline
\end{tabular}

Total Dose Contributions TDOSE(i,p,t) for Individual Radionuclides (i) and Pathways (p) As mrem/yr and Fraction of Total Dose At $t=1.000 \mathrm{E}+00$ years

Water Dependent Pathways

\begin{tabular}{|c|c|c|c|c|c|c|c|c|c|c|c|c|c|c|}
\hline \multirow{2}{*}{ Nuclide } & \multicolumn{2}{|c|}{ Water } & \multicolumn{2}{|c|}{ Fish } & \multicolumn{2}{|c|}{ Radon } & \multicolumn{2}{|c|}{ Plant } & \multicolumn{2}{|c|}{ Meat } & \multicolumn{2}{|c|}{ Milk } & \multicolumn{2}{|c|}{ All Pathways* } \\
\hline & mrem/yr & fract. & mrem/yr & fract. & mrem/yr & fract. & mrem/yr & fract. & mrem/yr & fract. & mrem/yr & fract. & mrem/yr & fract. \\
\hline-241 & $0.000 \mathrm{E}+00$ & 0.0000 & $0.000 \mathrm{E}+00$ & 0.0000 & $0.000 \mathrm{E}+00$ & 0.0000 & $0.000 \mathrm{E}+00$ & 0.0000 & $0.000 \mathrm{E}+00$ & 0.0000 & $0.000 \mathrm{E}+00$ & 0.0000 & $1.049 \mathrm{E}-04$ & 0.0001 \\
\hline-137 & $0.000 \mathrm{E}+00$ & 0.0000 & $0.000 \mathrm{E}+00$ & 0.0000 & $0.000 \mathrm{E}+00$ & 0.0000 & $0.000 \mathrm{E}+00$ & 0.0000 & $0.000 \mathrm{E}+00$ & 0.0000 & $0.000 \mathrm{E}+00$ & 0.0000 & 7. $712 \mathrm{E}-01$ & 0.4485 \\
\hline-237 & $0.000 \mathrm{E}+00$ & 0.0000 & $0.000 \mathrm{E}+00$ & 0.0000 & $0.000 \mathrm{E}+00$ & 0.0000 & $0.000 \mathrm{E}+00$ & 0.0000 & $0.000 \mathrm{E}+00$ & 0.0000 & $0.000 \mathrm{E}+00$ & 0.0000 & $3.839 \mathrm{E}-02$ & 0.0223 \\
\hline 238 & $0.000 \mathrm{E}+00$ & 0.0000 & $0.000 \mathrm{E}+00$ & 0.0000 & $0.000 \mathrm{E}+00$ & 0.0000 & $0.000 \mathrm{E}+00$ & 0.0000 & $0.000 \mathrm{E}+00$ & 0.0000 & $0.000 \mathrm{E}+00$ & 0.0000 & $2.080 \mathrm{E}-06$ & 0.0000 \\
\hline 239 & $0.000 \mathrm{E}+00$ & 0.0000 & $0.000 \mathrm{E}+00$ & 0.0000 & $0.000 \mathrm{E}+00$ & 0.0000 & $0.000 \mathrm{E}+00$ & 0.0000 & $0.000 \mathrm{E}+00$ & 0.0000 & $0.000 \mathrm{E}+00$ & 0.0000 & $4.592 \mathrm{E}-05$ & 0.0000 \\
\hline 240 & $0.000 \mathrm{E}+00$ & 0.0000 & $0.000 \mathrm{E}+00$ & 0.0000 & $0.000 \mathrm{E}+00$ & 0.0000 & $0.000 \mathrm{E}+00$ & 0.0000 & $0.000 \mathrm{E}+00$ & 0.0000 & $0.000 \mathrm{E}+00$ & 0.0000 & $1.881 \mathrm{E}-06$ & 0.0000 \\
\hline 99 & $0.000 \mathrm{E}+00$ & 0.0000 & $0.000 \mathrm{E}+00$ & 0.0000 & $0.000 \mathrm{E}+00$ & 0.0000 & $0.000 \mathrm{E}+00$ & 0.0000 & $0.000 \mathrm{E}+00$ & 0.0000 & $0.000 \mathrm{E}+00$ & 0.0000 & $4.262 \mathrm{E}-06$ & 0.0000 \\
\hline 228 & $0.000 \mathrm{E}+00$ & 0.0000 & $0.000 \mathrm{E}+00$ & 0.0000 & $0.000 \mathrm{E}+00$ & 0.0000 & $0.000 \mathrm{E}+00$ & 0.0000 & $0.000 \mathrm{E}+00$ & 0.0000 & $0.000 \mathrm{E}+00$ & 0.0000 & $4.980 \mathrm{E}-01$ & 0.2897 \\
\hline 230 & $0.000 \mathrm{E}+00$ & 0.0000 & $0.000 \mathrm{E}+00$ & 0.0000 & $0.000 \mathrm{E}+00$ & 0.0000 & $0.000 \mathrm{E}+00$ & 0.0000 & $0.000 \mathrm{E}+00$ & 0.0000 & $0.000 \mathrm{E}+00$ & 0.0000 & $1.255 \mathrm{E}-02$ & 0.0073 \\
\hline 232 & $0.000 \mathrm{E}+00$ & 0.0000 & $0.000 \mathrm{E}+00$ & 0.0000 & $0.000 \mathrm{E}+00$ & 0.0000 & $0.000 \mathrm{E}+00$ & 0.0000 & $0.000 \mathrm{E}+00$ & 0.0000 & $0.000 \mathrm{E}+00$ & 0.0000 & $9.446 \mathrm{E}-02$ & 0.0549 \\
\hline & $0.000 \mathrm{E}+00$ & 0.0000 & $0.000 \mathrm{E}+00$ & 0.0000 & $0.000 \mathrm{E}+00$ & 0.0000 & $0.000 \mathrm{E}+00$ & 0.0000 & $0.000 \mathrm{E}+00$ & 0.0000 & $0.000 \mathrm{E}+00$ & 0.0000 & $5.724 \mathrm{E}-05$ & 0.0000 \\
\hline 35 & $0.000 \mathrm{E}+00$ & 0.0000 & $0.000 \mathrm{E}+00$ & 0.0000 & $0.000 \mathrm{E}+00$ & 0.0000 & $0.000 \mathrm{E}+00$ & 0.0000 & $0.000 \mathrm{E}+00$ & 0.0000 & $0.000 \mathrm{E}+00$ & 0.0000 & $2.142 \mathrm{E}-02$ & 0.0125 \\
\hline 38 & $0.000 \mathrm{E}+00$ & 0.0000 & $0.000 \mathrm{E}+00$ & 0.0000 & $0.000 \mathrm{E}+00$ & 0.0000 & $0.000 \mathrm{E}+00$ & 0.0000 & $0.000 \mathrm{E}+00$ & 0.0000 & $0.000 \mathrm{E}+00$ & 0.0000 & $2.831 \mathrm{E}-01$ & 0.1646 \\
\hline & $0.000 \mathrm{E}+00$ & 0.0000 & $0.000 \mathrm{E}+00$ & 0.0000 & $0.000 \mathrm{E}+00$ & 0.0000 & $0.000 \mathrm{E}+00$ & 0.0000 & $0.000 \mathrm{E}+00$ & 0.0000 & $0.000 E+00$ & 000 & +00 & 1.0000 \\
\hline
\end{tabular}

* Sum of all water independent and dependent pathways. 
RESRAD, Version $6.5 \quad$ T1/2 Limit $=180$ days $\quad$ 07/20/2011 08:14 Page 22

Summary : RESRAD Parameters for U-Landfill Trespasser Forward Run at Proposed ALs

File : C: \RESRAD_FAMILY \RESRAD \USERFILES \ULANDFILL-TRESPASSER_FORWARDRUN-70YRSALS.RAD

Total Dose Contributions TDOSE (i,p,t) for Individual Radionuclides (i) and Pathways (p) As mrem/yr and Fraction of Total Dose At $t=2.500 \mathrm{E}+01$ years

Water Independent Pathways (Inhalation excludes radon)

\begin{tabular}{|c|c|c|c|c|c|c|c|c|c|c|c|c|c|c|}
\hline \multirow{2}{*}{ Nuclide } & \multicolumn{2}{|c|}{ Ground } & \multicolumn{2}{|c|}{ Inhalation } & \multicolumn{2}{|c|}{ Radon } & \multicolumn{2}{|c|}{ Plant } & \multicolumn{2}{|c|}{ Meat } & \multicolumn{2}{|c|}{ Milk } & \multicolumn{2}{|c|}{ Soil } \\
\hline & mrem/yr & fract. & mrem/yr & fract. & mrem/yr & fract. & mrem/yr & fract. & mrem/yr & fract. & mrem/yr & fract. & mrem/yr & fract. \\
\hline-241 & $2.013 E-04$ & 0.0001 & $2.547 \mathrm{E}-04$ & 0.0001 & $0.000 \mathrm{E}+00$ & 0.0000 & $0.000 \mathrm{E}+00$ & 0.0000 & $0.000 \mathrm{E}+00$ & 0.0000 & $0.000 \mathrm{E}+00$ & 0.0000 & $9.654 \mathrm{E}-03$ & 0.0036 \\
\hline-137 & $5.418 E-01$ & 0.2033 & $3.239 \mathrm{E}-08$ & 0.0000 & $0.000 \mathrm{E}+00$ & 0.0000 & $0.000 \mathrm{E}+00$ & 0.0000 & $0.000 \mathrm{E}+00$ & 0.0000 & $0.000 \mathrm{E}+00$ & 0.0000 & $1.967 \mathrm{E}-04$ & 0.0001 \\
\hline-237 & $4.968 E-02$ & 0.0186 & $2.165 E-05$ & 0.0000 & $0.000 \mathrm{E}+00$ & 0.0000 & $0.000 \mathrm{E}+00$ & 0.0000 & $0.000 \mathrm{E}+00$ & 0.0000 & $0.000 \mathrm{E}+00$ & 0.0000 & $8.727 \mathrm{E}-04$ & 0.0003 \\
\hline-238 & $2.630 E-06$ & 0.0000 & $2.770 E-04$ & 0.0001 & $0.000 \mathrm{E}+00$ & 0.0000 & $0.000 \mathrm{E}+00$ & 0.0000 & $0.000 \mathrm{E}+00$ & 0.0000 & $0.000 \mathrm{E}+00$ & 0.0000 & $1.053 \mathrm{E}-02$ & 0.0040 \\
\hline-239 & $6.115 \mathrm{E}-05$ & 0.0000 & $3.410 \mathrm{E}-04$ & 0.0001 & $0.000 \mathrm{E}+00$ & 0.0000 & $0.000 \mathrm{E}+00$ & 0.0000 & $0.000 \mathrm{E}+00$ & 0.0000 & $0.000 \mathrm{E}+00$ & 0.0000 & $1.292 \mathrm{E}-02$ & 0.0048 \\
\hline-240 & $2.866 \mathrm{E}-06$ & 0.0000 & $3.403 E-04$ & 0.0001 & $0.000 \mathrm{E}+00$ & 0.0000 & $0.000 \mathrm{E}+00$ & 0.0000 & $0.000 \mathrm{E}+00$ & 0.0000 & $0.000 \mathrm{E}+00$ & 0.0000 & $1.289 \mathrm{E}-02$ & 0.0048 \\
\hline 99 & $5.239 E-06$ & 0.0000 & $4.079 E-08$ & 0.0000 & $0.000 \mathrm{E}+00$ & 0.0000 & $0.000 \mathrm{E}+00$ & 0.0000 & $0.000 \mathrm{E}+00$ & 0.0000 & $0.000 \mathrm{E}+00$ & 0.0000 & $3.654 \mathrm{E}-05$ & 0.0000 \\
\hline-228 & $9.674 \mathrm{E}-05$ & 0.0000 & $1.345 \mathrm{E}-09$ & 0.0000 & $0.000 \mathrm{E}+00$ & 0.0000 & $0.000 \mathrm{E}+00$ & 0.0000 & $0.000 \mathrm{E}+00$ & 0.0000 & $0.000 \mathrm{E}+00$ & 0.0000 & $8.035 E-08$ & 0.0000 \\
\hline-230 & $2.486 \mathrm{E}-01$ & 0.0933 & $7.911 \mathrm{E}-04$ & 0.0003 & $0.000 \mathrm{E}+00$ & 0.0000 & $0.000 \mathrm{E}+00$ & 0.0000 & $0.000 \mathrm{E}+00$ & 0.0000 & $0.000 \mathrm{E}+00$ & 0.0000 & $3.153 \mathrm{E}-02$ & 0.0118 \\
\hline-232 & $1.342 \mathrm{E}+00$ & 0.5035 & $5.243 E-05$ & 0.0000 & $0.000 \mathrm{E}+00$ & 0.0000 & $0.000 \mathrm{E}+00$ & 0.0000 & $0.000 \mathrm{E}+00$ & 0.0000 & $0.000 \mathrm{E}+00$ & 0.0000 & $5.868 \mathrm{E}-03$ & 0.0022 \\
\hline 234 & $1.331 E-04$ & 0.0000 & $1.191 \mathrm{E}-04$ & 0.0000 & $0.000 \mathrm{E}+00$ & 0.0000 & $0.000 \mathrm{E}+00$ & 0.0000 & $0.000 \mathrm{E}+00$ & 0.0000 & $0.000 \mathrm{E}+00$ & 0.0000 & $1.125 \mathrm{E}-02$ & 0.0042 \\
\hline 35 & $2.888 E-02$ & 0.0108 & 4. $459 \mathrm{E}-06$ & 0.0000 & $0.000 \mathrm{E}+00$ & 0.0000 & $0.000 \mathrm{E}+00$ & 0.0000 & $0.000 \mathrm{E}+00$ & 0.0000 & $0.000 \mathrm{E}+00$ & 0.0000 & $4.476 \mathrm{E}-04$ & 0.0002 \\
\hline 38 & $3.440 \mathrm{E}-01$ & 0.1291 & $1.012 \mathrm{E}-04$ & 0.0000 & $0.000 \mathrm{E}+00$ & 0.0000 & $0.000 \mathrm{E}+00$ & 0.0000 & $0.000 \mathrm{E}+00$ & 0.0000 & $0.000 \mathrm{E}+00$ & 0.0000 & $1.115 \mathrm{E}-02$ & 0.0042 \\
\hline & $2.555 E+00$ & 0.9589 & $2.303 E-03$ & 0.0009 & $0.000 \mathrm{E}+00$ & 0.0000 & $0.000 \mathrm{E}+00$ & 0.0000 & $0.000 \mathrm{E}+00$ & 0.0000 & $0.000 \mathrm{E}+00$ & 0.0000 & $1.074 \mathrm{E}-01$ & 0.0403 \\
\hline
\end{tabular}

Total Dose Contributions TDOSE(i,p,t) for Individual Radionuclides (i) and Pathways (p) As mrem/yr and Fraction of Total Dose At $t=2.500 \mathrm{E}+01$ years

Water Dependent Pathways

\begin{tabular}{|c|c|c|c|c|c|c|c|c|c|c|c|c|c|c|}
\hline \multirow{2}{*}{ Nuclide } & \multicolumn{2}{|c|}{ Water } & \multicolumn{2}{|c|}{ Fish } & \multicolumn{2}{|c|}{ Radon } & \multicolumn{2}{|c|}{ Plant } & \multicolumn{2}{|c|}{ Meat } & \multicolumn{2}{|c|}{ Milk } & \multicolumn{2}{|c|}{ All Pathways* } \\
\hline & mrem/yr & fract. & mrem/yr & fract. & mrem/yr & fract. & mrem/yr & fract. & mrem/yr & fract. & mrem/yr & fract. & mrem/yr & fract. \\
\hline-241 & $0.000 \mathrm{E}+00$ & 0.0000 & $0.000 \mathrm{E}+00$ & 0.0000 & $0.000 \mathrm{E}+00$ & 0.0000 & $0.000 \mathrm{E}+00$ & 0.0000 & $0.000 \mathrm{E}+00$ & 0.0000 & $0.000 \mathrm{E}+00$ & 0.0000 & $1.011 \mathrm{E}-02$ & 0.0038 \\
\hline-137 & $0.000 \mathrm{E}+00$ & 0.0000 & $0.000 \mathrm{E}+00$ & 0.0000 & $0.000 \mathrm{E}+00$ & 0.0000 & $0.000 \mathrm{E}+00$ & 0.0000 & $0.000 \mathrm{E}+00$ & 0.0000 & $0.000 \mathrm{E}+00$ & 0.0000 & $5.420 \mathrm{E}-01$ & 0.2034 \\
\hline-237 & $0.000 \mathrm{E}+00$ & 0.0000 & $0.000 \mathrm{E}+00$ & 0.0000 & $0.000 \mathrm{E}+00$ & 0.0000 & $0.000 \mathrm{E}+00$ & 0.0000 & $0.000 \mathrm{E}+00$ & 0.0000 & $0.000 \mathrm{E}+00$ & 0.0000 & $5.057 \mathrm{E}-02$ & 0.0190 \\
\hline-238 & $0.000 \mathrm{E}+00$ & 0.0000 & $0.000 \mathrm{E}+00$ & 0.0000 & $0.000 \mathrm{E}+00$ & 0.0000 & $0.000 \mathrm{E}+00$ & 0.0000 & $0.000 \mathrm{E}+00$ & 0.0000 & $0.000 \mathrm{E}+00$ & 0.0000 & $1.081 \mathrm{E}-02$ & 0.0041 \\
\hline 239 & $0.000 \mathrm{E}+00$ & 0.0000 & $0.000 \mathrm{E}+00$ & 0.0000 & $0.000 \mathrm{E}+00$ & 0.0000 & $0.000 \mathrm{E}+00$ & 0.0000 & $0.000 \mathrm{E}+00$ & 0.0000 & $0.000 \mathrm{E}+00$ & 0.0000 & $1.332 \mathrm{E}-02$ & 0.0050 \\
\hline-240 & $0.000 \mathrm{E}+00$ & 0.0000 & $0.000 \mathrm{E}+00$ & 0.0000 & $0.000 \mathrm{E}+00$ & 0.0000 & $0.000 \mathrm{E}+00$ & 0.0000 & $0.000 \mathrm{E}+00$ & 0.0000 & $0.000 \mathrm{E}+00$ & 0.0000 & $1.323 E-02$ & 0.0050 \\
\hline 99 & $0.000 \mathrm{E}+00$ & 0.0000 & $0.000 \mathrm{E}+00$ & 0.0000 & $0.000 \mathrm{E}+00$ & 0.0000 & $0.000 \mathrm{E}+00$ & 0.0000 & $0.000 \mathrm{E}+00$ & 0.0000 & $0.000 \mathrm{E}+00$ & 0.0000 & $4.182 \mathrm{E}-05$ & 0.0000 \\
\hline-228 & $0.000 \mathrm{E}+00$ & 0.0000 & $0.000 \mathrm{E}+00$ & 0.0000 & $0.000 \mathrm{E}+00$ & 0.0000 & $0.000 \mathrm{E}+00$ & 0.0000 & $0.000 \mathrm{E}+00$ & 0.0000 & $0.000 \mathrm{E}+00$ & 0.0000 & $9.683 E-05$ & 0.0000 \\
\hline-230 & $0.000 \mathrm{E}+00$ & 0.0000 & $0.000 \mathrm{E}+00$ & 0.0000 & $0.000 \mathrm{E}+00$ & 0.0000 & $0.000 \mathrm{E}+00$ & 0.0000 & $0.000 \mathrm{E}+00$ & 0.0000 & $0.000 \mathrm{E}+00$ & 0.0000 & $2.809 E-01$ & 0.1054 \\
\hline-232 & $0.000 \mathrm{E}+00$ & 0.0000 & $0.000 \mathrm{E}+00$ & 0.0000 & $0.000 \mathrm{E}+00$ & 0.0000 & $0.000 \mathrm{E}+00$ & 0.0000 & $0.000 \mathrm{E}+00$ & 0.0000 & $0.000 \mathrm{E}+00$ & 0.0000 & $1.348 \mathrm{E}+00$ & 0.5058 \\
\hline 234 & $0.000 \mathrm{E}+00$ & 0.0000 & $0.000 \mathrm{E}+00$ & 0.0000 & $0.000 \mathrm{E}+00$ & 0.0000 & $0.000 \mathrm{E}+00$ & 0.0000 & $0.000 \mathrm{E}+00$ & 0.0000 & $0.000 \mathrm{E}+00$ & 0.0000 & $1.150 \mathrm{E}-02$ & 0.0043 \\
\hline 35 & $0.000 \mathrm{E}+00$ & 0.0000 & $0.000 \mathrm{E}+00$ & 0.0000 & $0.000 \mathrm{E}+00$ & 0.0000 & $0.000 \mathrm{E}+00$ & 0.0000 & $0.000 \mathrm{E}+00$ & 0.0000 & $0.000 \mathrm{E}+00$ & 0.0000 & $2.933 E-02$ & 0.0110 \\
\hline 38 & $0.000 \mathrm{E}+00$ & 0.0000 & $0.000 \mathrm{E}+00$ & 0.0000 & $0.000 \mathrm{E}+00$ & 0.0000 & $0.000 \mathrm{E}+00$ & 0.0000 & $0.000 \mathrm{E}+00$ & 0.0000 & $0.000 \mathrm{E}+00$ & 0.0000 & $3.552 \mathrm{E}-01$ & 0.1333 \\
\hline & $0.000 \mathrm{E}+00$ & 0.0000 & $0.000 \mathrm{E}+00$ & 0.0000 & $0.000 \mathrm{E}+00$ & 0.0000 & $0.000 \mathrm{E}+00$ & 0.0000 & $0.000 \mathrm{E}+00$ & 0.0000 & $0.000 \mathrm{E}+00$ & 0.0000 & $.665 E+00$ & 1.0000 \\
\hline
\end{tabular}

* Sum of all water independent and dependent pathways. 
RESRAD, Version $6.5 \quad$ T1/2 Limit $=180$ days $\quad$ 07/20/2011 08:14 Page 23

Summary : RESRAD Parameters for U-Landfill Trespasser Forward Run at Proposed ALs

File : C: \RESRAD_FAMILY \RESRAD \USERFILES \ULANDFILL-TRESPASSER_FORWARDRUN-70YRSALS.RAD

Total Dose Contributions TDOSE (i,p,t) for Individual Radionuclides (i) and Pathways (p) As mrem/yr and Fraction of Total Dose At $t=5.000 \mathrm{E}+01$ years

Water Independent Pathways (Inhalation excludes radon)

\begin{tabular}{|c|c|c|c|c|c|c|c|c|c|c|c|c|c|c|}
\hline \multirow{2}{*}{ Nuclide } & \multicolumn{2}{|c|}{ Ground } & \multicolumn{2}{|c|}{ Inhalation } & \multicolumn{2}{|c|}{ Radon } & \multicolumn{2}{|c|}{ Plant } & \multicolumn{2}{|c|}{ Meat } & \multicolumn{2}{|c|}{ Milk } & \multicolumn{2}{|c|}{ Soil } \\
\hline & mrem/yr & fract. & mrem/yr & fract. & mrem/yr & fract. & mrem/yr & fract. & mrem/yr & fract. & mrem/yr & fract. & mrem/yr & fract. \\
\hline-241 & $3.938 E-04$ & 0.0001 & $5.206 \mathrm{E}-04$ & 0.0002 & $0.000 \mathrm{E}+00$ & 0.0000 & $0.000 \mathrm{E}+00$ & 0.0000 & $0.000 \mathrm{E}+00$ & 0.0000 & $0.000 \mathrm{E}+00$ & 0.0000 & $1.973 \mathrm{E}-02$ & 0.0058 \\
\hline-137 & $3.751 E-01$ & 0.1102 & $3.864 \mathrm{E}-08$ & 0.0000 & $0.000 \mathrm{E}+00$ & 0.0000 & $0.000 \mathrm{E}+00$ & 0.0000 & $0.000 \mathrm{E}+00$ & 0.0000 & $0.000 \mathrm{E}+00$ & 0.0000 & $2.347 \mathrm{E}-04$ & 0.0001 \\
\hline-237 & $6.501 E-02$ & 0.0191 & $4.588 E-05$ & 0.0000 & $0.000 \mathrm{E}+00$ & 0.0000 & $0.000 \mathrm{E}+00$ & 0.0000 & $0.000 \mathrm{E}+00$ & 0.0000 & $0.000 \mathrm{E}+00$ & 0.0000 & $1.850 \mathrm{E}-03$ & 0.0005 \\
\hline-238 & $3.360 E-06$ & 0.0000 & $4.836 E-04$ & 0.0001 & $0.000 \mathrm{E}+00$ & 0.0000 & $0.000 \mathrm{E}+00$ & 0.0000 & $0.000 \mathrm{E}+00$ & 0.0000 & $0.000 \mathrm{E}+00$ & 0.0000 & $1.839 \mathrm{E}-02$ & 0.0054 \\
\hline-239 & $8.241 E-05$ & 0.0000 & $7.246 \mathrm{E}-04$ & 0.0002 & $0.000 \mathrm{E}+00$ & 0.0000 & $0.000 \mathrm{E}+00$ & 0.0000 & $0.000 \mathrm{E}+00$ & 0.0000 & $0.000 \mathrm{E}+00$ & 0.0000 & $2.745 E-02$ & 0.0081 \\
\hline-240 & $4.443 E-06$ & 0.0000 & $7.218 \mathrm{E}-04$ & 0.0002 & $0.000 \mathrm{E}+00$ & 0.0000 & $0.000 \mathrm{E}+00$ & 0.0000 & $0.000 \mathrm{E}+00$ & 0.0000 & $0.000 \mathrm{E}+00$ & 0.0000 & $2.734 \mathrm{E}-02$ & 0.0080 \\
\hline 99 & $6.496 \mathrm{E}-06$ & 0.0000 & $6.663 E-08$ & 0.0000 & $0.000 \mathrm{E}+00$ & 0.0000 & $0.000 \mathrm{E}+00$ & 0.0000 & $0.000 \mathrm{E}+00$ & 0.0000 & $0.000 \mathrm{E}+00$ & 0.0000 & $5.969 \mathrm{E}-05$ & 0.0000 \\
\hline-228 & $1.317 \mathrm{E}-08$ & 0.0000 & $3.336 \mathrm{E}-13$ & 0.0000 & $0.000 \mathrm{E}+00$ & 0.0000 & $0.000 \mathrm{E}+00$ & 0.0000 & $0.000 \mathrm{E}+00$ & 0.0000 & $0.000 \mathrm{E}+00$ & 0.0000 & 1.992E-11 & 0.0000 \\
\hline-230 & $5.847 \mathrm{E}-01$ & 0.1717 & $1.686 \mathrm{E}-03$ & 0.0005 & $0.000 \mathrm{E}+00$ & 0.0000 & $0.000 \mathrm{E}+00$ & 0.0000 & $0.000 \mathrm{E}+00$ & 0.0000 & $0.000 \mathrm{E}+00$ & 0.0000 & $7.224 \mathrm{E}-02$ & 0.0212 \\
\hline-232 & $1.685 \mathrm{E}+00$ & 0.4948 & $1.140 \mathrm{E}-04$ & 0.0000 & $0.000 \mathrm{E}+00$ & 0.0000 & $0.000 \mathrm{E}+00$ & 0.0000 & $0.000 \mathrm{E}+00$ & 0.0000 & $0.000 \mathrm{E}+00$ & 0.0000 & $1.297 \mathrm{E}-02$ & 0.0038 \\
\hline 234 & $3.494 \mathrm{E}-04$ & 0.0001 & $2.539 \mathrm{E}-04$ & 0.0001 & $0.000 \mathrm{E}+00$ & 0.0000 & $0.000 \mathrm{E}+00$ & 0.0000 & $0.000 \mathrm{E}+00$ & 0.0000 & $0.000 \mathrm{E}+00$ & 0.0000 & $2.394 \mathrm{E}-02$ & 0.0070 \\
\hline 35 & $3.947 \mathrm{E}-02$ & 0.0116 & $9.790 \mathrm{E}-06$ & 0.0000 & $0.000 \mathrm{E}+00$ & 0.0000 & $0.000 \mathrm{E}+00$ & 0.0000 & $0.000 \mathrm{E}+00$ & 0.0000 & $0.000 \mathrm{E}+00$ & 0.0000 & $9.680 \mathrm{E}-04$ & 0.0003 \\
\hline 38 & $4.218 E-01$ & 0.1239 & $2.152 E-04$ & 0.0001 & $0.000 \mathrm{E}+00$ & 0.0000 & $0.000 \mathrm{E}+00$ & 0.0000 & $0.000 \mathrm{E}+00$ & 0.0000 & $0.000 \mathrm{E}+00$ & 0.0000 & $2.372 \mathrm{E}-02$ & 0.0070 \\
\hline & $3.172 \mathrm{E}+00$ & 0.9314 & $4.775 E-03$ & 0.0014 & $0.000 \mathrm{E}+00$ & 0.0000 & $0.000 \mathrm{E}+00$ & 0.0000 & $0.000 \mathrm{E}+00$ & 0.0000 & $0.000 \mathrm{E}+00$ & 0.0000 & $.289 E-01$ & 0.0672 \\
\hline
\end{tabular}

Total Dose Contributions TDOSE(i,p,t) for Individual Radionuclides (i) and Pathways (p) As mrem/yr and Fraction of Total Dose At $t=5.000 \mathrm{E}+01$ years

Water Dependent Pathways

\begin{tabular}{|c|c|c|c|c|c|c|c|c|c|c|c|c|c|c|}
\hline \multirow{2}{*}{$\begin{array}{l}\text { Radio- } \\
\text { Nuclide }\end{array}$} & \multicolumn{2}{|c|}{ Water } & \multicolumn{2}{|c|}{ Fish } & \multicolumn{2}{|c|}{ Radon } & \multicolumn{2}{|c|}{ Plant } & \multicolumn{2}{|c|}{ Meat } & \multicolumn{2}{|c|}{ Milk } & \multicolumn{2}{|c|}{ All Pathways* } \\
\hline & mrem/yr & fract. & mrem/yr & fract. & mrem/yr & fract. & mrem/yr & fract. & mrem/yr & fract. & mrem/yr & fract. & mrem/yr & fract. \\
\hline 241 & $0.000 \mathrm{E}+00$ & 0.0000 & $0.000 \mathrm{E}+00$ & 0.0000 & $0.000 \mathrm{E}+00$ & 0.0000 & $0.000 \mathrm{E}+00$ & 0.0000 & $0.000 \mathrm{E}+00$ & 0.0000 & $0.000 \mathrm{E}+00$ & 0.0000 & $2.065 E-02$ & 0.0061 \\
\hline-137 & $0.000 \mathrm{E}+00$ & 0.0000 & $0.000 \mathrm{E}+00$ & 0.0000 & $0.000 \mathrm{E}+00$ & 0.0000 & $0.000 \mathrm{E}+00$ & 0.0000 & $0.000 \mathrm{E}+00$ & 0.0000 & $0.000 \mathrm{E}+00$ & 0.0000 & $3.754 \mathrm{E}-01$ & 0.1102 \\
\hline-237 & $0.000 \mathrm{E}+00$ & 0.0000 & $0.000 \mathrm{E}+00$ & 0.0000 & $0.000 \mathrm{E}+00$ & 0.0000 & $0.000 \mathrm{E}+00$ & 0.0000 & $0.000 \mathrm{E}+00$ & 0.0000 & $0.000 \mathrm{E}+00$ & 0.0000 & $6.690 \mathrm{E}-02$ & 0.0196 \\
\hline-238 & $0.000 \mathrm{E}+00$ & 0.0000 & $0.000 \mathrm{E}+00$ & 0.0000 & $0.000 \mathrm{E}+00$ & 0.0000 & $0.000 \mathrm{E}+00$ & 0.0000 & $0.000 \mathrm{E}+00$ & 0.0000 & $0.000 \mathrm{E}+00$ & 0.0000 & $1.887 \mathrm{E}-02$ & 0.0055 \\
\hline-239 & $0.000 \mathrm{E}+00$ & 0.0000 & $0.000 \mathrm{E}+00$ & 0.0000 & $0.000 \mathrm{E}+00$ & 0.0000 & $0.000 \mathrm{E}+00$ & 0.0000 & $0.000 \mathrm{E}+00$ & 0.0000 & $0.000 E+00$ & 0.0000 & $2.826 \mathrm{E}-02$ & 0.0083 \\
\hline-240 & $0.000 \mathrm{E}+00$ & 0.0000 & $0.000 \mathrm{E}+00$ & 0.0000 & $0.000 \mathrm{E}+00$ & 0.0000 & $0.000 \mathrm{E}+00$ & 0.0000 & $0.000 \mathrm{E}+00$ & 0.0000 & $0.000 E+00$ & 0.0000 & $2.807 \mathrm{E}-02$ & 0.0082 \\
\hline-99 & $0.000 \mathrm{E}+00$ & 0.0000 & $0.000 \mathrm{E}+00$ & 0.0000 & $0.000 \mathrm{E}+00$ & 0.0000 & $0.000 \mathrm{E}+00$ & 0.0000 & $0.000 \mathrm{E}+00$ & 0.0000 & $0.000 \mathrm{E}+00$ & 0.0000 & $6.625 \mathrm{E}-05$ & 0.0000 \\
\hline-228 & $0.000 \mathrm{E}+00$ & 0.0000 & $0.000 \mathrm{E}+00$ & 0.0000 & $0.000 \mathrm{E}+00$ & 0.0000 & $0.000 \mathrm{E}+00$ & 0.0000 & $0.000 \mathrm{E}+00$ & 0.0000 & $0.000 \mathrm{E}+00$ & 0.0000 & $1.319 \mathrm{E}-08$ & 0.0000 \\
\hline-230 & $0.000 \mathrm{E}+00$ & 0.0000 & $0.000 \mathrm{E}+00$ & 0.0000 & $0.000 \mathrm{E}+00$ & 0.0000 & $0.000 \mathrm{E}+00$ & 0.0000 & $0.000 \mathrm{E}+00$ & 0.0000 & $0.000 E+00$ & 0.0000 & $6.586 \mathrm{E}-01$ & 0.1934 \\
\hline 232 & $0.000 \mathrm{E}+00$ & 0.0000 & $0.000 \mathrm{E}+00$ & 0.0000 & $0.000 \mathrm{E}+00$ & 0.0000 & $0.000 \mathrm{E}+00$ & 0.0000 & $0.000 \mathrm{E}+00$ & 0.0000 & $0.000 \mathrm{E}+00$ & 0.0000 & $1.698 \mathrm{E}+00$ & 0.4986 \\
\hline 34 & $0.000 \mathrm{E}+00$ & 0.0000 & $0.000 \mathrm{E}+00$ & 0.0000 & $0.000 \mathrm{E}+00$ & 0.0000 & $0.000 \mathrm{E}+00$ & 0.0000 & $0.000 \mathrm{E}+00$ & 0.0000 & $0.000 \mathrm{E}+00$ & 0.0000 & $2.455 E-02$ & 0.0072 \\
\hline 35 & $0.000 \mathrm{E}+00$ & 0.0000 & $0.000 \mathrm{E}+00$ & 0.0000 & $0.000 \mathrm{E}+00$ & 0.0000 & $0.000 \mathrm{E}+00$ & 0.0000 & $0.000 \mathrm{E}+00$ & 0.0000 & $0.000 \mathrm{E}+00$ & 0.0000 & $4.044 \mathrm{E}-02$ & 0.0119 \\
\hline 38 & $0.000 \mathrm{E}+00$ & 0.0000 & $0.000 \mathrm{E}+00$ & 0.0000 & $0.000 \mathrm{E}+00$ & 0.0000 & $0.000 \mathrm{E}+00$ & 0.0000 & $0.000 \mathrm{E}+00$ & 0.0000 & $0.000 \mathrm{E}+00$ & 0.0000 & $4.458 \mathrm{E}-01$ & 0.1309 \\
\hline & $0.000 \mathrm{E}+00$ & 0.0000 & $0.000 \mathrm{E}+00$ & 0.0000 & $0.000 \mathrm{E}+00$ & 0.0000 & $0.000 \mathrm{E}+00$ & 0.0000 & $0.000 \mathrm{E}+00$ & 0.0000 & $0.000 \mathrm{E}+00$ & 0.0000 & $3.406 \mathrm{E}+00$ & 1. \\
\hline
\end{tabular}

* Sum of all water independent and dependent pathways. 
RESRAD, Version $6.5 \quad$ T1/2 Limit $=180$ days $\quad$ 07/20/2011 08:14 Page 24

Summary : RESRAD Parameters for U-Landfill Trespasser Forward Run at Proposed ALs

File : C: \RESRAD_FAMILY \RESRAD \USERFILES \ULANDFILL-TRESPASSER_FORWARDRUN-70YRSALS.RAD

Total Dose Contributions TDOSE (i,p,t) for Individual Radionuclides (i) and Pathways (p) As mrem/yr and Fraction of Total Dose At $t=7.000 \mathrm{E}+01$ years

Water Independent Pathways (Inhalation excludes radon)

\begin{tabular}{|c|c|c|c|c|c|c|c|c|c|c|c|c|c|c|}
\hline \multirow{2}{*}{ Nuclide } & \multicolumn{2}{|c|}{ Ground } & \multicolumn{2}{|c|}{ Inhalation } & \multicolumn{2}{|c|}{ Radon } & \multicolumn{2}{|c|}{ Plant } & \multicolumn{2}{|c|}{ Meat } & \multicolumn{2}{|c|}{ Milk } & \multicolumn{2}{|c|}{ Soil } \\
\hline & mrem/yr & fract. & mrem/yr & fract. & mrem/yr & fract. & mrem/yr & fract. & mrem/yr & fract. & mrem/yr & fract. & mrem/yr & fract. \\
\hline-241 & $6.715 E-04$ & 0.0002 & $7.179 \mathrm{E}-04$ & 0.0002 & $0.000 \mathrm{E}+00$ & 0.0000 & $0.000 \mathrm{E}+00$ & 0.0000 & $0.000 \mathrm{E}+00$ & 0.0000 & $0.000 \mathrm{E}+00$ & 0.0000 & $2.721 \mathrm{E}-02$ & 0.0066 \\
\hline-137 & $2.795 E-01$ & 0.0680 & $3.463 \mathrm{E}-08$ & 0.0000 & $0.000 \mathrm{E}+00$ & 0.0000 & $0.000 \mathrm{E}+00$ & 0.0000 & $0.000 \mathrm{E}+00$ & 0.0000 & $0.000 \mathrm{E}+00$ & 0.0000 & $2.104 \mathrm{E}-04$ & 0.0001 \\
\hline-237 & $8.064 \mathrm{E}-02$ & 0.0196 & $6.513 E-05$ & 0.0000 & $0.000 \mathrm{E}+00$ & 0.0000 & $0.000 \mathrm{E}+00$ & 0.0000 & $0.000 \mathrm{E}+00$ & 0.0000 & $0.000 \mathrm{E}+00$ & 0.0000 & $2.626 \mathrm{E}-03$ & 0.0006 \\
\hline-238 & $4.089 E-06$ & 0.0000 & $5.878 E-04$ & 0.0001 & $0.000 \mathrm{E}+00$ & 0.0000 & $0.000 \mathrm{E}+00$ & 0.0000 & $0.000 \mathrm{E}+00$ & 0.0000 & $0.000 \mathrm{E}+00$ & 0.0000 & $2.235 \mathrm{E}-02$ & 0.0054 \\
\hline-239 & $1.046 \mathrm{E}-04$ & 0.0000 & $1.031 \mathrm{E}-03$ & 0.0003 & $0.000 \mathrm{E}+00$ & 0.0000 & $0.000 \mathrm{E}+00$ & 0.0000 & $0.000 \mathrm{E}+00$ & 0.0000 & $0.000 \mathrm{E}+00$ & 0.0000 & $3.905 E-02$ & 0.0095 \\
\hline-240 & $6.310 \mathrm{E}-06$ & 0.0000 & $1.025 \mathrm{E}-03$ & 0.0002 & $0.000 \mathrm{E}+00$ & 0.0000 & $0.000 \mathrm{E}+00$ & 0.0000 & $0.000 \mathrm{E}+00$ & 0.0000 & $0.000 \mathrm{E}+00$ & 0.0000 & $3.884 \mathrm{E}-02$ & 0.0094 \\
\hline 99 & $7.715 E-06$ & 0.0000 & $7.679 E-08$ & 0.0000 & $0.000 \mathrm{E}+00$ & 0.0000 & $0.000 \mathrm{E}+00$ & 0.0000 & $0.000 \mathrm{E}+00$ & 0.0000 & $0.000 \mathrm{E}+00$ & 0.0000 & $6.880 \mathrm{E}-05$ & 0.0000 \\
\hline-228 & $1.064 \mathrm{E}-11$ & 0.0000 & $3.387 \mathrm{E}-16$ & 0.0000 & $0.000 \mathrm{E}+00$ & 0.0000 & $0.000 \mathrm{E}+00$ & 0.0000 & $0.000 \mathrm{E}+00$ & 0.0000 & $0.000 \mathrm{E}+00$ & 0.0000 & $2.023 E-14$ & 0.0000 \\
\hline-230 & $9.370 \mathrm{E}-01$ & 0.2278 & $2.404 \mathrm{E}-03$ & 0.0006 & $0.000 \mathrm{E}+00$ & 0.0000 & $0.000 \mathrm{E}+00$ & 0.0000 & $0.000 \mathrm{E}+00$ & 0.0000 & $0.000 \mathrm{E}+00$ & 0.0000 & $1.098 \mathrm{E}-01$ & 0.0267 \\
\hline-232 & $1.931 E+00$ & 0.4696 & $1.624 \mathrm{E}-04$ & 0.0000 & $0.000 \mathrm{E}+00$ & 0.0000 & $0.000 \mathrm{E}+00$ & 0.0000 & $0.000 \mathrm{E}+00$ & 0.0000 & $0.000 \mathrm{E}+00$ & 0.0000 & $1.850 \mathrm{E}-02$ & 0.0045 \\
\hline 234 & $6.718 \mathrm{E}-04$ & 0.0002 & $3.620 \mathrm{E}-04$ & 0.0001 & $0.000 \mathrm{E}+00$ & 0.0000 & $0.000 \mathrm{E}+00$ & 0.0000 & $0.000 \mathrm{E}+00$ & 0.0000 & $0.000 \mathrm{E}+00$ & 0.0000 & $3.411 \mathrm{E}-02$ & 0.0083 \\
\hline 35 & $5.068 \mathrm{E}-02$ & 0.0123 & $1.435 \mathrm{E}-05$ & 0.0000 & $0.000 \mathrm{E}+00$ & 0.0000 & $0.000 \mathrm{E}+00$ & 0.0000 & $0.000 \mathrm{E}+00$ & 0.0000 & $0.000 \mathrm{E}+00$ & 0.0000 & $1.399 \mathrm{E}-03$ & 0.0003 \\
\hline 38 & $4.971 E-01$ & 0.1209 & $3.063 E-04$ & 0.0001 & $0.000 \mathrm{E}+00$ & 0.0000 & $0.000 \mathrm{E}+00$ & 0.0000 & $0.000 \mathrm{E}+00$ & 0.0000 & $0.000 \mathrm{E}+00$ & 0.0000 & $3.376 \mathrm{E}-02$ & 0.0082 \\
\hline & $3.778 E+00$ & 0.9186 & $6.676 \mathrm{E}-03$ & 0.0016 & $0.000 \mathrm{E}+00$ & 0.0000 & $0.000 \mathrm{E}+00$ & 0.0000 & $0.000 \mathrm{E}+00$ & 0.0000 & $0.000 \mathrm{E}+00$ & 0.0000 & 3.279E-01 & 0.0797 \\
\hline
\end{tabular}

Total Dose Contributions TDOSE(i,p,t) for Individual Radionuclides (i) and Pathways (p) As mrem/yr and Fraction of Total Dose At $t=7.000 \mathrm{E}+01$ years

Water Dependent Pathways

\begin{tabular}{|c|c|c|c|c|c|c|c|c|c|c|c|c|c|c|}
\hline \multirow{2}{*}{ Nuclide } & \multicolumn{2}{|c|}{ Water } & \multicolumn{2}{|c|}{ Fish } & \multicolumn{2}{|c|}{ Radon } & \multicolumn{2}{|c|}{ Plant } & \multicolumn{2}{|c|}{ Meat } & \multicolumn{2}{|c|}{ Milk } & \multicolumn{2}{|c|}{ All Pathways* } \\
\hline & mrem/yr & fract. & mrem/yr & fract. & mrem/yr & fract. & mrem/yr & fract. & mrem/yr & fract. & mrem/yr & fract. & mrem/yr & fract. \\
\hline-241 & $0.000 \mathrm{E}+00$ & 0.0000 & $0.000 \mathrm{E}+00$ & 0.0000 & $0.000 \mathrm{E}+00$ & 0.0000 & $0.000 \mathrm{E}+00$ & 0.0000 & $0.000 \mathrm{E}+00$ & 0.0000 & $0.000 E+00$ & 0.0000 & $2.860 \mathrm{E}-02$ & 0.0070 \\
\hline-137 & $0.000 \mathrm{E}+00$ & 0.0000 & $0.000 \mathrm{E}+00$ & 0.0000 & $0.000 \mathrm{E}+00$ & 0.0000 & $0.000 \mathrm{E}+00$ & 0.0000 & $0.000 \mathrm{E}+00$ & 0.0000 & $0.000 \mathrm{E}+00$ & 0.0000 & $2.798 \mathrm{E}-01$ & 0.0680 \\
\hline-237 & $0.000 \mathrm{E}+00$ & 0.0000 & $0.000 \mathrm{E}+00$ & 0.0000 & $0.000 \mathrm{E}+00$ & 0.0000 & $0.000 \mathrm{E}+00$ & 0.0000 & $0.000 \mathrm{E}+00$ & 0.0000 & $0.000 \mathrm{E}+00$ & 0.0000 & $8.333 E-02$ & 0.0203 \\
\hline-238 & $0.000 \mathrm{E}+00$ & 0.0000 & $0.000 \mathrm{E}+00$ & 0.0000 & $0.000 \mathrm{E}+00$ & 0.0000 & $0.000 \mathrm{E}+00$ & 0.0000 & $0.000 \mathrm{E}+00$ & 0.0000 & $0.000 \mathrm{E}+00$ & 0.0000 & $2.294 \mathrm{E}-02$ & 0.0056 \\
\hline-239 & $0.000 \mathrm{E}+00$ & 0.0000 & $0.000 \mathrm{E}+00$ & 0.0000 & $0.000 \mathrm{E}+00$ & 0.0000 & $0.000 \mathrm{E}+00$ & 0.0000 & $0.000 \mathrm{E}+00$ & 0.0000 & $0.000 \mathrm{E}+00$ & 0.0000 & $4.019 \mathrm{E}-02$ & 0.0098 \\
\hline-240 & $0.000 \mathrm{E}+00$ & 0.0000 & $0.000 \mathrm{E}+00$ & 0.0000 & $0.000 \mathrm{E}+00$ & 0.0000 & $0.000 \mathrm{E}+00$ & 0.0000 & $0.000 \mathrm{E}+00$ & 0.0000 & $0.000 \mathrm{E}+00$ & 0.0000 & $3.987 \mathrm{E}-02$ & 0.0097 \\
\hline-99 & $0.000 \mathrm{E}+00$ & 0.0000 & $0.000 \mathrm{E}+00$ & 0.0000 & $0.000 \mathrm{E}+00$ & 0.0000 & $0.000 \mathrm{E}+00$ & 0.0000 & $0.000 \mathrm{E}+00$ & 0.0000 & $0.000 \mathrm{E}+00$ & 0.0000 & $7.659 \mathrm{E}-05$ & 0.0000 \\
\hline-228 & $0.000 \mathrm{E}+00$ & 0.0000 & $0.000 \mathrm{E}+00$ & 0.0000 & $0.000 \mathrm{E}+00$ & 0.0000 & $0.000 \mathrm{E}+00$ & 0.0000 & $0.000 \mathrm{E}+00$ & 0.0000 & $0.000 \mathrm{E}+00$ & 0.0000 & $1.066 \mathrm{E}-11$ & 0.0000 \\
\hline-230 & $0.000 \mathrm{E}+00$ & 0.0000 & $0.000 \mathrm{E}+00$ & 0.0000 & $0.000 \mathrm{E}+00$ & 0.0000 & $0.000 \mathrm{E}+00$ & 0.0000 & $0.000 \mathrm{E}+00$ & 0.0000 & $0.000 \mathrm{E}+00$ & 0.0000 & $1.049 \mathrm{E}+00$ & 0.2551 \\
\hline 232 & $0.000 \mathrm{E}+00$ & 0.0000 & $0.000 \mathrm{E}+00$ & 0.0000 & $0.000 \mathrm{E}+00$ & 0.0000 & $0.000 \mathrm{E}+00$ & 0.0000 & $0.000 \mathrm{E}+00$ & 0.0000 & $0.000 \mathrm{E}+00$ & 0.0000 & $1.950 \mathrm{E}+00$ & 0.4742 \\
\hline 34 & $0.000 \mathrm{E}+00$ & 0.0000 & $0.000 \mathrm{E}+00$ & 0.0000 & $0.000 \mathrm{E}+00$ & 0.0000 & $0.000 \mathrm{E}+00$ & 0.0000 & $0.000 \mathrm{E}+00$ & 0.0000 & $0.000 \mathrm{E}+00$ & 0.0000 & $3.514 \mathrm{E}-02$ & 0.0085 \\
\hline 35 & $0.000 \mathrm{E}+00$ & 0.0000 & $0.000 \mathrm{E}+00$ & 0.0000 & $0.000 \mathrm{E}+00$ & 0.0000 & $0.000 \mathrm{E}+00$ & 0.0000 & $0.000 \mathrm{E}+00$ & 0.0000 & $0.000 \mathrm{E}+00$ & 0.0000 & $5.210 \mathrm{E}-02$ & 0.0127 \\
\hline 38 & $0.000 \mathrm{E}+00$ & 0.0000 & $0.000 \mathrm{E}+00$ & 0.0000 & $0.000 \mathrm{E}+00$ & 0.0000 & $0.000 \mathrm{E}+00$ & 0.0000 & $0.000 \mathrm{E}+00$ & 0.0000 & $0.000 \mathrm{E}+00$ & 0.0000 & $5.312 \mathrm{E}-01$ & 0.1292 \\
\hline & $0.000 \mathrm{E}+00$ & 0.0000 & $0.000 \mathrm{E}+00$ & 0.0000 & $0.000 \mathrm{E}+00$ & 0.0000 & $0.000 \mathrm{E}+00$ & 0.0000 & $0.000 \mathrm{E}+00$ & 0.0000 & $0.000 \mathrm{E}+00$ & 0.0000 & $2 E+00$ & 1.0000 \\
\hline
\end{tabular}

* Sum of all water independent and dependent pathways. 
RESRAD, Version $6.5 \quad \mathrm{~T}^{1 / 2}$ Limit $=180$ days

Summary : RESRAD Parameters for U-Landfill Trespasser Forward Run at Proposed ALs

File : C: \RESRAD FAMILY \RESRAD \USERFILES \ULANDFILL-TRESPASSER FORWARDRUN-7OYRSALS.RAD

Dose/Source Ratios Summed Over All Pathways

Parent and Progeny Principal Radionuclide Contributions Indicated

Parent Product Thread DSR $(j, t)$ At Time in Years (mrem/yr)/(pCi/g)

(i) (j) Fraction $0.000 \mathrm{E}+001.000 \mathrm{E}+002.500 \mathrm{E}+015.000 \mathrm{E}+017.000 \mathrm{E}+01$

$\begin{array}{lllllll}\mathrm{Am}-241 & 1.000 \mathrm{E}+00 & & & \\ 1.457 \mathrm{E}-06 & 1.496 \mathrm{E}-06 & 1.444 \mathrm{E}-04 & 2.949 \mathrm{E}-04 & 4.084 \mathrm{E}-04\end{array}$

$\begin{array}{llllllll}\mathrm{Np}-237+\mathrm{D} & 1.000 \mathrm{E}+00 & 5.599 \mathrm{E}-10 & 1.695 \mathrm{E}-09 & 3.728 \mathrm{E}-08 & 9.593 \mathrm{E}-08 & 1.644 \mathrm{E}-07\end{array}$

$\begin{array}{lllllll}\mathrm{U}-233 & 1.000 \mathrm{E}+00 & 6.695 \mathrm{E}-19 & 4.735 \mathrm{E}-18 & 1.858 \mathrm{E}-14 & 1.476 \mathrm{E}-13 & 4.022 \mathrm{E}-13\end{array}$

$\begin{array}{llllllll}\mathrm{Th}-229+\mathrm{D} & 1.000 \mathrm{E}+00 & 3.971 \mathrm{E}-20 & 5.999 \mathrm{E}-19 & 3.419 \mathrm{E}-15 & 3.406 \mathrm{E}-14 & 1.120 \mathrm{E}-13\end{array}$

$\sum \operatorname{DSR}(j)$

$\begin{array}{lllll}1.457 E-06 & 1.498 \mathrm{E}-06 & 1.444 \mathrm{E}-04 & 2.949 \mathrm{E}-04 \quad 4.085 \mathrm{E}-04\end{array}$

$\begin{array}{lllllll}\mathrm{CS}-137+\mathrm{D} & 1.000 \mathrm{E}+00 \quad 2.060 \mathrm{E}-02 & 2.029 \mathrm{E}-02 & 1.426 \mathrm{E}-02 & 9.878 \mathrm{E}-03 & 7.362 \mathrm{E}-03\end{array}$

$\mathrm{Np}-237+\mathrm{D} \quad 1.000 \mathrm{E}+00 \quad 3.453 \mathrm{E}-03 \quad 3.490 \mathrm{E}-03 \quad 4.597 \mathrm{E}-03 \quad 6.082 \mathrm{E}-03 \quad 7.575 \mathrm{E}-03$

$\begin{array}{llllllll}\mathrm{U}-233 & 1.000 \mathrm{E}+00 & 6.197 \mathrm{E}-12 & 1.880 \mathrm{E}-11 & 4.556 \mathrm{E}-09 & 1.851 \mathrm{E}-08 & 3.649 \mathrm{E}-08\end{array}$

$\begin{array}{lllllllll}\mathrm{Th}-229+\mathrm{D} & 1.000 \mathrm{E}+00 & 4.903 \mathrm{E}-13 & 3.458 \mathrm{E}-12 & 1.253 \mathrm{E}-09 & 6.365 \mathrm{E}-09 & 1.511 \mathrm{E}-08\end{array}$

$\operatorname{\sum DSR}(j) \quad 3.453 \mathrm{E}-03 \quad 3.490 \mathrm{E}-03 \quad 4.597 \mathrm{E}-03 \quad 6.082 \mathrm{E}-03 \quad 7.575 \mathrm{E}-03$

Pu-238 1.840E-09 4.859E-17 4.907E-17 2.550E-13 4.452E-13 5.411E-13

$\begin{array}{llllllll}\mathrm{Pu}-238 & 1.000 \mathrm{E}+00 & 2.641 \mathrm{E}-08 & 2.667 \mathrm{E}-08 & 1.386 \mathrm{E}-04 & 2.419 \mathrm{E}-04 & 2.941 \mathrm{E}-04\end{array}$

$\begin{array}{lllllll}\mathrm{U}-234 & 1.000 \mathrm{E}+00 & 2.486 \mathrm{E}-13 & 7.549 \mathrm{E}-13 & 2.342 \mathrm{E}-09 & 8.961 \mathrm{E}-09 & 1.656 \mathrm{E}-08\end{array}$

$\begin{array}{llllllll}\mathrm{Th}-230 & 1.000 \mathrm{E}+00 & 3.358 \mathrm{E}-18 & 2.380 \mathrm{E}-17 & 1.212 \mathrm{E}-12 & 9.470 \mathrm{E}-12 & 2.502 \mathrm{E}-11\end{array}$

$\mathrm{Ra}-226+\mathrm{D} \quad 1.000 \mathrm{E}+00 \quad 4.363 \mathrm{E}-17 \quad 6.572 \mathrm{E}-16 \quad 3.284 \mathrm{E}-12 \quad 2.901 \mathrm{E}-11 \quad 8.757 \mathrm{E}-11$

$\mathrm{Pb}-210+\mathrm{D} \quad 1.000 \mathrm{E}+00 \quad 2.379 \mathrm{E}-23 \quad 7.401 \mathrm{E}-22 \quad 6.838 \mathrm{E}-15 \quad 1.868 \mathrm{E}-13 \quad 8.841 \mathrm{E}-13$

$\operatorname{EDSR}(j) \quad 2.641 \mathrm{E}-08 \quad 2.667 \mathrm{E}-08 \quad 1.386 \mathrm{E}-04 \quad 2.420 \mathrm{E}-04 \quad 2.941 \mathrm{E}-04$

$\begin{array}{llllllll}\mathrm{Pu}-239 & 1.000 \mathrm{E}+00 & 6.302 \mathrm{E}-07 & 6.378 \mathrm{E}-07 & 1.850 \mathrm{E}-04 & 3.925 \mathrm{E}-04 & 5.581 \mathrm{E}-04\end{array}$

$\mathrm{U}-235+\mathrm{D} \quad 1.000 \mathrm{E}+00 \quad 8.030 \mathrm{E}-13 \quad 2.436 \mathrm{E}-12 \quad 5.659 \mathrm{E}-11 \quad 1.542 \mathrm{E}-10 \quad 2.766 \mathrm{E}-10$

$\begin{array}{llllllll}\mathrm{Pa}-231 & 1.000 \mathrm{E}+00 & 2.330 \mathrm{E}-18 & 1.646 \mathrm{E}-17 & 9.404 \mathrm{E}-15 & 5.933 \mathrm{E}-14 & 1.535 \mathrm{E}-13\end{array}$

$\mathrm{AC}-227+\mathrm{D} \quad 1.000 \mathrm{E}+00 \quad 2.010 \mathrm{E}-19 \quad 3.022 \mathrm{E}-18 \quad 1.564 \mathrm{E}-14 \quad 1.404 \mathrm{E}-13 \quad 4.252 \mathrm{E}-13$

$\begin{array}{lllllll}\operatorname{DDSR}(j) & 6.302 \mathrm{E}-07 & 6.378 \mathrm{E}-07 & 1.850 \mathrm{E}-04 & 3.925 \mathrm{E}-04 & 5.581 \mathrm{E}-04\end{array}$

Pu-240 4.950E-08 $1.271 \mathrm{E}-15 \quad 1.293 \mathrm{E}-15 \quad 9.098 \mathrm{E}-12 \quad 1.930 \mathrm{E}-11 \quad 2.741 \mathrm{E}-11$

$\begin{array}{lllllll}\mathrm{Pu}-240 \quad 1.000 \mathrm{E}+00 & 2.567 \mathrm{E}-08 & 2.612 \mathrm{E}-08 & 1.838 \mathrm{E}-04 & 3.899 \mathrm{E}-04 & 5.538 \mathrm{E}-04\end{array}$

$\begin{array}{lllllll}\mathrm{U}-236 & 1.000 \mathrm{E}+00 & 1.038 \mathrm{E}-15 & 3.165 \mathrm{E}-15 & 2.580 \mathrm{E}-11 & 1.084 \mathrm{E}-10 & 2.152 \mathrm{E}-10\end{array}$

$\begin{array}{lllllll}\mathrm{Th}-232 & 1.000 \mathrm{E}+00 & 4.987 \mathrm{E}-26 & 3.547 \mathrm{E}-25 & 8.061 \mathrm{E}-20 & 6.713 \mathrm{E}-19 & 1.861 \mathrm{E}-18\end{array}$

$\mathrm{Ra}-228+\mathrm{D} \quad 1.000 \mathrm{E}+00 \quad 3.271 \mathrm{E}-22 \quad 4.816 \mathrm{E}-21 \quad 1.454 \mathrm{E}-17 \quad 9.118 \mathrm{E}-17 \quad 2.265 \mathrm{E}-16$

$\begin{array}{llllllll}\mathrm{Th}-228+\mathrm{D} & 1.000 \mathrm{E}+00 & 5.216 \mathrm{E}-23 & 1.501 \mathrm{E}-21 & 2.491 \mathrm{E}-17 & 1.723 \mathrm{E}-16 & 4.318 \mathrm{E}-16\end{array}$

$\operatorname{LDSR}(j) \quad 2.567 \mathrm{E}-08 \quad 2.612 \mathrm{E}-08 \quad 1.838 \mathrm{E}-04 \quad 3.899 \mathrm{E}-04 \quad 5.538 \mathrm{E}-04$

TC-99 1.000E+00 4.063E-08 4.098E-08 4.022E-07 6.371E-07 $7.364 \mathrm{E}-07$

Th-228+D 1.000E+00 8.889E-02 $6.226 \mathrm{E}-02 \quad 1.210 \mathrm{E}-05 \quad 1.649 \mathrm{E}-09 \quad 1.333 \mathrm{E}-12$

Th-230 1.000E+00 7.878E-07 8.012E-07 $1.560 \mathrm{E}-04 \quad 3.311 \mathrm{E}-04 \quad 4.713 \mathrm{E}-04$

$\mathrm{Ra}-226+\mathrm{D} \quad 1.000 \mathrm{E}+00 \quad 2.053 \mathrm{E}-05 \quad 6.196 \mathrm{E}-05 \quad 1.244 \mathrm{E}-03 \quad 2.931 \mathrm{E}-03 \quad 4.701 \mathrm{E}-03$

$\mathrm{Pb}-210+\mathrm{D} \quad 1.000 \mathrm{E}+00 \quad 1.860 \mathrm{E}-11 \quad 1.304 \mathrm{E}-10 \quad 4.663 \mathrm{E}-06 \quad 3.121 \mathrm{E}-05 \quad 7.413 \mathrm{E}-05$

$\operatorname{\sum DSR}(j) \quad 2.131 E-05 \quad 6.276 E-05 \quad 1.405 E-03 \quad 3.293 E-03 \quad 5.246 E-03$ 
RESRAD, Version $6.5 \quad \mathrm{~T}^{1 / 2}$ Limit $=180$ days

Summary : RESRAD Parameters for U-Landfill Trespasser Forward Run at Proposed ALs

File : C: \RESRAD_FAMILY \RESRAD \USERFILES \ULANDFILL-TRESPASSER_FORWARDRUN-7OYRSALS.RAD

Dose/Source Ratios Summed Over All Pathways

Parent and Progeny Principal Radionuclide Contributions Indicated

\begin{tabular}{|c|c|c|c|c|c|c|c|}
\hline Parent & Product & Thread & $\operatorname{DSR}(j, t)$ & At Time ir & Years & $($ mrem/yr) / & $(\mathrm{pCi} / \mathrm{g})$ \\
\hline (i) & $(j)$ & Fraction & $0.000 \mathrm{E}+00$ & $1.000 \mathrm{E}+00$ & $2.500 \mathrm{E}+01$ & $5.000 \mathrm{E}+01$ & $7.000 \mathrm{E}+01$ \\
\hline$h-232$ & $\mathrm{Th}-232$ & $1.000 \mathrm{E}+00$ & $2.040 \mathrm{E}-07$ & $2.078 \mathrm{E}-07$ & $1.699 \mathrm{E}-04$ & $3.613 E-04$ & $5.145 \mathrm{E}-04$ \\
\hline$h-232$ & $\mathrm{Ra}-228+\mathrm{D}$ & $1.000 \mathrm{E}+00$ & $2.643 E-03$ & $7.575 E-03$ & $5.301 \mathrm{E}-02$ & $6.750 \mathrm{E}-02$ & $7.900 \mathrm{E}-02$ \\
\hline Th-232 & $\mathrm{Th}-228+\mathrm{D}$ & $1.000 \mathrm{E}+00$ & $6.862 \mathrm{E}-04$ & $4.233 E-03$ & $1.153 E-01$ & $1.444 \mathrm{E}-01$ & 1. $642 \mathrm{E}-01$ \\
\hline$h-232$ & $\sum \operatorname{DSR}(j)$ & & 3. $329 \mathrm{E}-03$ & $1.181 \mathrm{E}-02$ & $1.685 \mathrm{E}-01$ & $2.123 \mathrm{E}-01$ & $2.438 \mathrm{E}-01$ \\
\hline-234 & $\mathrm{U}-234$ & $1.000 \mathrm{E}+00$ & $1.753 \mathrm{E}-07$ & $1.784 \mathrm{E}-07$ & $3.576 \mathrm{E}-05$ & $7.589 \mathrm{E}-05$ & $1.080 \mathrm{E}-04$ \\
\hline-234 & Th-230 & $1.000 \mathrm{E}+00$ & $3.556 \mathrm{E}-12$ & $1.083 \mathrm{E}-11$ & $3.580 \mathrm{E}-08$ & $1.504 \mathrm{E}-07$ & $2.989 \mathrm{E}-07$ \\
\hline-234 & $\mathrm{Ra}-226+\mathrm{D}$ & $1.000 \mathrm{E}+00$ & $6.163 \mathrm{E}-11$ & 4. $340 \mathrm{E}-10$ & $1.430 \mathrm{E}-07$ & $6.685 \mathrm{E}-07$ & $1.499 \mathrm{E}-06$ \\
\hline-234 & $\mathrm{~Pb}-210+\mathrm{D}$ & $1.000 \mathrm{E}+00$ & $4.195 \mathrm{E}-17$ & $6.314 \mathrm{E}-16$ & $3.796 \mathrm{E}-10$ & $5.291 \mathrm{E}-09$ & $1.815 \mathrm{E}-08$ \\
\hline-234 & $\sum \operatorname{DSR}(j)$ & & $1.754 \mathrm{E}-07$ & $1.789 \mathrm{E}-07$ & $3.594 \mathrm{E}-05$ & $7.671 \mathrm{E}-05$ & 1.098E-04 \\
\hline$J-235+D$ & $\mathrm{U}-235+\mathrm{D}$ & $1.000 \mathrm{E}+00$ & $1.627 \mathrm{E}-03$ & $1.648 \mathrm{E}-03$ & $2.254 \mathrm{E}-03$ & $3.101 \mathrm{E}-03$ & $3.987 \mathrm{E}-03$ \\
\hline$J-235+D$ & $\mathrm{~Pa}-231$ & $1.000 \mathrm{E}+00$ & $7.092 E-09$ & $2.148 \mathrm{E}-08$ & $7.489 \mathrm{E}-07$ & $2.386 \mathrm{E}-06$ & $4.423 E-06$ \\
\hline$J-235+D$ & $A C-227+D$ & $1.000 \mathrm{E}+00$ & $8.148 \mathrm{E}-10$ & $5.702 \mathrm{E}-09$ & $1.756 \mathrm{E}-06$ & $7.572 \mathrm{E}-06$ & $1.589 \mathrm{E}-05$ \\
\hline$J-235+D$ & $\sum \operatorname{DSR}(j)$ & & $1.627 \mathrm{E}-03$ & $1.648 \mathrm{E}-03$ & $2.256 \mathrm{E}-03$ & $3.111 \mathrm{E}-03$ & $4.007 \mathrm{E}-03$ \\
\hline$J-238$ & $U-238$ & $5.400 \mathrm{E}-05$ & $1.359 \mathrm{E}-15$ & $1.421 E-15$ & $1.767 \mathrm{E}-09$ & $3.757 \mathrm{E}-09$ & $5.348 E-09$ \\
\hline$J-238+D$ & $\mathrm{U}-238+\mathrm{D}$ & $9.999 \mathrm{E}-01$ & $8.774 \mathrm{E}-04$ & $8.846 \mathrm{E}-04$ & $1.110 \mathrm{E}-03$ & $1.393 \mathrm{E}-03$ & $1.660 \mathrm{E}-03$ \\
\hline$J-238+D$ & $\mathrm{U}-234$ & $9.999 \mathrm{E}-01$ & 2. $492 \mathrm{E}-13$ & $7.595 \mathrm{E}-13$ & $2.586 \mathrm{E}-09$ & $1.086 \mathrm{E}-08$ & $2.159 \mathrm{E}-08$ \\
\hline$J-238+D$ & $\mathrm{Th}-230$ & $9.999 \mathrm{E}-01$ & 3. $365 \mathrm{E}-18$ & $2.390 \mathrm{E}-17$ & $1.294 \mathrm{E}-12$ & $1.077 \mathrm{E}-11$ & $2.987 \mathrm{E}-11$ \\
\hline$J-238+D$ & $\mathrm{Ra}-226+\mathrm{D}$ & $9.999 \mathrm{E}-01$ & 4. $369 \mathrm{E}-17$ & $6.593 E-16$ & 3. $451 \mathrm{E}-12$ & $3.196 \mathrm{E}-11$ & $1.001 \mathrm{E}-10$ \\
\hline$J-238+D$ & $\mathrm{~Pb}-210+\mathrm{D}$ & $9.999 \mathrm{E}-01$ & $2.382 E-23$ & $7.420 \mathrm{E}-22$ & 7. $122 \mathrm{E}-15$ & $2.026 \mathrm{E}-13$ & $9.906 \mathrm{E}-13$ \\
\hline$J-238+D$ & $\sum \operatorname{DSR}(j)$ & & $8.774 \mathrm{E}-04$ & $8.846 \mathrm{E}-04$ & $1.110 \mathrm{E}-03$ & 1.393E-03 & $1.660 \mathrm{E}-03$ \\
\hline
\end{tabular}

The DSR includes contributions from associated (half-life $\leq 180$ days) daughters. 
RESRAD, Version $6.5 \quad \mathrm{~T}^{1 / 2}$ Limit $=180$ days

Summary : RESRAD Parameters for U-Landfill Trespasser Forward Run at Proposed ALs

File : C:\RESRAD_FAMILY \RESRAD UUSERFILES \ULANDFILL-TRESPASSER_FORWARDRUN-70YRSALS.RAD

Single Radionuclide Soil Guidelines G(i,t) in pCi/g

Basic Radiation Dose Limit $=1.000 \mathrm{E}+02 \mathrm{mrem} / \mathrm{yr}$

Nuclide

\begin{tabular}{|c|c|c|c|c|c|}
\hline (i) & $t=0.000 \mathrm{E}+00$ & $1.000 \mathrm{E}+00$ & $2.500 E+01$ & $5.000 \mathrm{E}+01$ & $7.000 \mathrm{E}+01$ \\
\hline$m-241$ & $6.861 \mathrm{E}+07$ & $6.676 \mathrm{E}+07$ & $6.924 \mathrm{E}+05$ & $3.390 \mathrm{E}+05$ & $2.448 \mathrm{E}+05$ \\
\hline$s-137$ & $4.856 \mathrm{E}+03$ & $4.927 \mathrm{E}+03$ & $7.011 \mathrm{E}+03$ & $1.012 \mathrm{E}+04$ & $1.358 \mathrm{E}+04$ \\
\hline-237 & $2.896 \mathrm{E}+04$ & $2.866 \mathrm{E}+04$ & $2.175 E+04$ & $1.644 \mathrm{E}+04$ & $1.320 \mathrm{E}+04$ \\
\hline$u-238$ & $3.787 E+09$ & $3.750 E+09$ & $7.214 \mathrm{E}+05$ & $4.133 E+05$ & $3.400 E+05$ \\
\hline $\mathrm{Pu}-239$ & $1.587 \mathrm{E}+08$ & $1.568 \mathrm{E}+08$ & $5.406 \mathrm{E}+05$ & $2.548 \mathrm{E}+05$ & $1.792 \mathrm{E}+05$ \\
\hline $\mathrm{Pu}-240$ & $3.896 \mathrm{E}+09$ & $3.828 \mathrm{E}+09$ & $5.441 \mathrm{E}+05$ & $2.565 \mathrm{E}+05$ & $1.806 \mathrm{E}+05$ \\
\hline TC-99 & $2.461 \mathrm{E}+09$ & $2.440 \mathrm{E}+09$ & $2.487 E+08$ & $1.570 \mathrm{E}+08$ & $1.358 \mathrm{E}+08$ \\
\hline Th-228 & $1.125 \mathrm{E}+03$ & $1.606 \mathrm{E}+03$ & $8.262 E+06$ & $6.065 E+10$ & $7.505 E+13$ \\
\hline$T h-230$ & $4.692 \mathrm{E}+06$ & $1.593 E+06$ & $7.119 \mathrm{E}+04$ & $3.037 E+04$ & $1.906 \mathrm{E}+04$ \\
\hline Th-232 & $3.004 \mathrm{E}+04$ & $8.469 \mathrm{E}+03$ & $5.935 E+02$ & $4.711 \mathrm{E}+02$ & $4.102 \mathrm{E}+02$ \\
\hline 34 & $5.702 \mathrm{E}+08$ & $5.590 \mathrm{E}+08$ & $2.782 \mathrm{E}+06$ & $1.304 \mathrm{E}+06$ & $9.106 \mathrm{E}+05$ \\
\hline 35 & $6.145 \mathrm{E}+04$ & $6.069 \mathrm{E}+04$ & $4.432 E+04$ & $3.214 \mathrm{E}+04$ & $2.495 \mathrm{E}+04$ \\
\hline 238 & $1.140 \mathrm{E}+05$ & $1.131 \mathrm{E}+05$ & $9.008 \mathrm{E}+04$ & $7.179 \mathrm{E}+04$ & $6.024 \mathrm{E}+04$ \\
\hline
\end{tabular}

Summed Dose/Source Ratios DSR(i,t) in (mrem/yr)/(pCi/g) and Single Radionuclide Soil Guidelines $G(i, t)$ in pCi/g at tmin = time of minimum single radionuclide soil guideline and at $\operatorname{tmax}=$ time of maximum total dose $=7.000 \mathrm{E}+01$ years

\begin{tabular}{|c|c|c|c|c|c|c|}
\hline $\begin{array}{l}\text { uclide } \\
\text { (i) }\end{array}$ & $\begin{array}{l}\text { Initial } \\
(\mathrm{pCi} / \mathrm{g})\end{array}$ & $\begin{array}{c}\text { tmin } \\
\text { (years) }\end{array}$ & $\operatorname{DSR}(i, \operatorname{tmin})$ & $\begin{array}{c}\mathrm{G}(\mathrm{i}, \mathrm{tmin}) \\
(\mathrm{pCi} / \mathrm{g})\end{array}$ & $\operatorname{DSR}(i, t \max )$ & $\begin{array}{c}G(i, t \max ) \\
(\mathrm{pC} i / g)\end{array}$ \\
\hline $1-241$ & $7.000 \mathrm{E}+01$ & $7.000 \mathrm{E}+01$ & $4.085 \mathrm{E}-04$ & $2.448 E+05$ & $4.085 \mathrm{E}-04$ & $2.448 \mathrm{E}+05$ \\
\hline-137 & $3.800 \mathrm{E}+01$ & $0.000 \mathrm{E}+00$ & $2.060 \mathrm{E}-02$ & $4.856 \mathrm{E}+03$ & 7. $362 \mathrm{E}-03$ & $1.358 \mathrm{E}+04$ \\
\hline-237 & $1.100 \mathrm{E}+01$ & $7.000 \mathrm{E}+01$ & $7.575 \mathrm{E}-03$ & $1.320 \mathrm{E}+04$ & $7.575 \mathrm{E}-03$ & $1.320 \mathrm{E}+04$ \\
\hline-238 & $7.800 \mathrm{E}+01$ & $7.000 \mathrm{E}+01$ & $2.941 \mathrm{E}-04$ & $3.400 \mathrm{E}+05$ & $2.941 \mathrm{E}-04$ & $3.400 \mathrm{E}+05$ \\
\hline-239 & $7.200 \mathrm{E}+01$ & $7.000 \mathrm{E}+01$ & $5.581 \mathrm{E}-04$ & $1.792 E+05$ & $5.581 \mathrm{E}-04$ & $1.792 \mathrm{E}+05$ \\
\hline-240 & $7.200 \mathrm{E}+01$ & $7.000 \mathrm{E}+01$ & $5.538 \mathrm{E}-04$ & $1.806 \mathrm{E}+05$ & $5.538 \mathrm{E}-04$ & $1.806 \mathrm{E}+05$ \\
\hline$=-99$ & $1.040 \mathrm{E}+02$ & $7.000 \mathrm{E}+01$ & $7.364 \mathrm{E}-07$ & $1.358 \mathrm{E}+08$ & $7.364 \mathrm{E}-07$ & $1.358 \mathrm{E}+08$ \\
\hline-228 & $8.000 \mathrm{E}+00$ & $0.000 \mathrm{E}+00$ & $8.889 \mathrm{E}-02$ & $1.125 \mathrm{E}+03$ & 1. $333 \mathrm{E}-12$ & $7.505 \mathrm{E}+13$ \\
\hline-230 & $2.000 \mathrm{E}+02$ & $7.000 \mathrm{E}+01$ & $5.246 \mathrm{E}-03$ & $1.906 \mathrm{E}+04$ & $5.246 \mathrm{E}-03$ & $1.906 \mathrm{E}+04$ \\
\hline-232 & $8.000 \mathrm{E}+00$ & $7.000 \mathrm{E}+01$ & $2.438 \mathrm{E}-01$ & $4.102 \mathrm{E}+02$ & $2.438 \mathrm{E}-01$ & $4.102 \mathrm{E}+02$ \\
\hline 234 & $3.200 \mathrm{E}+02$ & $7.000 \mathrm{E}+01$ & $1.098 E-04$ & $9.106 \mathrm{E}+05$ & $1.098 \mathrm{E}-04$ & $9.106 \mathrm{E}+05$ \\
\hline 235 & $1.300 \mathrm{E}+01$ & $7.000 \mathrm{E}+01$ & $4.007 E-03$ & $2.495 E+04$ & $4.007 E-03$ & $2.495 E+04$ \\
\hline 238 & $3.200 \mathrm{E}+02$ & $7.000 \mathrm{E}+01$ & $1.660 \mathrm{E}-03$ & $6.024 \mathrm{E}+04$ & $1.660 \mathrm{E}-03$ & $6.024 \mathrm{E}+04$ \\
\hline
\end{tabular}


RESRAD, Version 6.5

Summary : RESRAD Parameters for U-Landfill Trespasser Forward Run at Proposed ALs

File : C: \RESRAD FAMILY \RESRAD \USERFILES \ULANDFILL-TRESPASSER FORWARDRUN-70YRSALS.RAD

Individual Nuclide Dose Summed Over All Pathways

Parent Nuclide and Branch Fraction Indicated

Nuclide Parent THF(i) DOSE $(j, t), \operatorname{mrem} / \mathrm{yr}$

\begin{tabular}{|c|c|c|c|c|c|c|c|}
\hline (j) & (i) & $t=$ & $0.000 \mathrm{E}+00$ & $1.000 \mathrm{E}+00$ & $2.500 \mathrm{E}+01$ & $5.000 \mathrm{E}+01$ & $7.000 \mathrm{E}+01$ \\
\hline
\end{tabular}

Am-241 Am-241 1.000E+00 1.020E-04 1.047E-04 1.011E-02 2.064E-02 2.859E-02

Np-237 Am-241 1.000E+00

$\mathrm{Np}-237 \quad \mathrm{~Np}-237 \quad 1.000 \mathrm{E}+00$

Np-237 $\sum$ DOSE $(j)$

$\mathrm{U}-233 \mathrm{Am}-241 \quad 1.000 \mathrm{E}+00$

$\mathrm{U}-233 \mathrm{~Np}-237 \quad 1.000 \mathrm{E}+00$

U-233 $\quad$ DDOSE $(j)$

Th-229 Am-241 1.000F+00

$\mathrm{Th}-229 \quad \mathrm{~Np}-237 \quad 1.000 \mathrm{E}+00$

Th-229 $\sum \mathrm{DOSE}(j)$

$\mathrm{Cs}-137 \mathrm{Cs}-137 \quad 1.000 \mathrm{E}+00$

$\mathrm{Pu}-238$

$\mathrm{Pu}-238$

$\mathrm{Pu}-238$

$\mathrm{U}-234$

$\mathrm{U}-234$

$\mathrm{U}-234$

$\mathrm{U}-234$

Th -230

$\mathrm{Th}-230$

$\mathrm{Th}-230$

$\mathrm{Th}-230$

$\mathrm{Th}-230$

$\mathrm{Ra}-226$

$\mathrm{Ra}-226$

$\mathrm{Ra}-226$

$\mathrm{Ra}-226$

$\mathrm{Ra}-226$

$\mathrm{Pb}-210$

$\mathrm{Pb}-210$

$\mathrm{Pb}-210$

$\mathrm{Pb}-210$

$\mathrm{Pb}-210$

$\mathrm{Pu}-239$

$\mathrm{U}-235$

$\mathrm{U}-235$

$\mathrm{U}-235$

Pu-238 1.840E-09

$\mathrm{Pu}-238 \quad 1.000 \mathrm{E}+00$

$\sum \operatorname{DOSE}(j)$

$\mathrm{Pu}-238 \quad 1.000 \mathrm{E}+00$

$\mathrm{U}-234 \quad 1.000 \mathrm{E}+00$

U-238 9.999E-01

$\sum \operatorname{DOSE}(j)$

$\mathrm{Pu}-238 \quad 1.000 \mathrm{E}+00$

$\mathrm{Th}-230 \quad 1.000 \mathrm{E}+00$

U-234 $1.000 \mathrm{E}+00$

U-238 9.999E-01

$\sum \operatorname{DOSE}(j)$

$\mathrm{Pu}-238 \quad 1.000 \mathrm{E}+00$

Th-230 1.000E+00

$\mathrm{U}-234 \quad 1.000 \mathrm{E}+00$

U-238 9.999E-01

$\sum \operatorname{DOSE}(j)$

$\mathrm{Pu}-238 \quad 1.000 \mathrm{E}+00$

Th-230 1.000E+00

$\mathrm{U}-234 \quad 1.000 \mathrm{E}+00$

U-238 9.999E-01

$\sum \operatorname{DOSE}(j)$

$\mathrm{Pu}-239 \quad 1.000 \mathrm{E}+00$

$\mathrm{Pu}-239 \quad 1.000 \mathrm{E}+00$

$\mathrm{U}-2351.000 \mathrm{E}+00$

$\sum \operatorname{DOSE}(j)$ $\begin{array}{llllll}3.919 \mathrm{E}-08 & 1.186 \mathrm{E}-07 & 2.610 \mathrm{E}-06 & 6.715 \mathrm{E}-06 & 1.151 \mathrm{E}-05\end{array}$

$3.798 \mathrm{E}-02 \quad 3.839 \mathrm{E}-02 \quad 5.057 \mathrm{E}-02 \quad 6.690 \mathrm{E}-02 \quad 8.333 \mathrm{E}-02$

3.798E-02 3.839E-02 5.057E-02 6.691E-02 8.334E-02

4. $687 \mathrm{E}-17$ 3.314E-16 1.301E-12 1.033E-11 2.816E-11

$6.817 \mathrm{E}-112.068 \mathrm{E}-10 \quad 5.012 \mathrm{E}-08 \quad 2.036 \mathrm{E}-07 \quad 4.014 \mathrm{E}-07$

$6.817 \mathrm{E}-112.068 \mathrm{E}-10 \quad 5.012 \mathrm{E}-08 \quad 2.036 \mathrm{E}-07 \quad 4.015 \mathrm{E}-07$

$\begin{array}{lllll}2.780 \mathrm{E}-18 & 4.200 \mathrm{E}-17 & 2.393 \mathrm{E}-13 & 2.384 \mathrm{E}-12 & 7.840 \mathrm{E}-12\end{array}$

$5.393 \mathrm{E}-12 \quad 3.804 \mathrm{E}-11 \quad 1.379 \mathrm{E}-08 \quad 7.002 \mathrm{E}-08 \quad 1.662 \mathrm{E}-07$

$5.393 \mathrm{E}-12 \quad 3.804 \mathrm{E}-11 \quad 1.379 \mathrm{E}-08 \quad 7.002 \mathrm{E}-08 \quad 1.662 \mathrm{E}-07$

$\begin{array}{llllll}7.826 \mathrm{E}-01 & 7.712 \mathrm{E}-01 & 5.420 \mathrm{E}-01 & 3.754 \mathrm{E}-01 & 2.798 \mathrm{E}-01\end{array}$

3.790E-15 3.827E-15 $1.989 \mathrm{E}-11 \quad 3.472 \mathrm{E}-11 \quad 4.220 \mathrm{E}-11$

$2.060 \mathrm{E}-06 \quad 2.080 \mathrm{E}-06 \quad 1.081 \mathrm{E}-02 \quad 1.887 \mathrm{E}-02 \quad 2.294 \mathrm{E}-02$

2.060E-06 2.080E-06 1.081E-02 1.887E-02 2.294E-02

$\begin{array}{llllll}1.939 \mathrm{E}-11 & 5.888 \mathrm{E}-11 & 1.827 \mathrm{E}-07 & 6.990 \mathrm{E}-07 & 1.291 \mathrm{E}-06\end{array}$

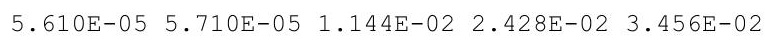

$\begin{array}{lllll}7.975 \mathrm{E}-11 & 2.430 \mathrm{E}-10 & 8.274 \mathrm{E}-07 & 3.477 \mathrm{E}-06 & 6.908 \mathrm{E}-06\end{array}$

5.610E-05 5.710E-05 1.145E-02 2.429E-02 3.457E-02

2.620E-16 1.856E-15 9.451E-11 $7.386 \mathrm{E}-10 \quad 1.952 \mathrm{E}-09$

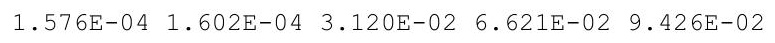

$1.138 \mathrm{E}-09 \quad 3.465 \mathrm{E}-09 \quad 1.146 \mathrm{E}-05 \quad 4.814 \mathrm{E}-05 \quad 9.565 \mathrm{E}-05$

$\begin{array}{lllll}1.077 \mathrm{E}-15 & 7.647 \mathrm{E}-15 & 4.142 \mathrm{E}-10 & 3.446 \mathrm{E}-09 & 9.557 \mathrm{E}-09\end{array}$

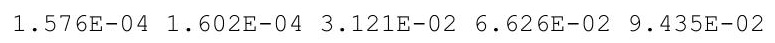

$\begin{array}{lllll}3.403 E-15 & 5.126 \mathrm{E}-14 & 2.562 \mathrm{E}-10 & 2.263 \mathrm{E}-09 & 6.831 \mathrm{E}-09\end{array}$ $4.105 \mathrm{E}-03 \quad 1.239 \mathrm{E}-02 \quad 2.488 \mathrm{E}-01 \quad 5.861 \mathrm{E}-01 \quad 9.401 \mathrm{E}-01$ $\begin{array}{llllll}1.972 \mathrm{E}-08 & 1.389 \mathrm{E}-07 & 4.578 \mathrm{E}-05 & 2.139 \mathrm{E}-04 & 4.796 \mathrm{E}-04\end{array}$ $\begin{array}{lllll}1.398 \mathrm{E}-14 & 2.110 \mathrm{E}-13 & 1.104 \mathrm{E}-09 & 1.023 \mathrm{E}-08 & 3.203 \mathrm{E}-08\end{array}$ $\begin{array}{llllll}4.105 \mathrm{E}-03 & 1.239 \mathrm{E}-02 & 2.488 \mathrm{E}-01 & 5.864 \mathrm{E}-01 & 9.406 \mathrm{E}-01\end{array}$

$1.856 \mathrm{E}-21 \quad 5.773 \mathrm{E}-20 \quad 5.334 \mathrm{E}-13 \quad 1.457 \mathrm{E}-11 \quad 6.896 \mathrm{E}-11$ $\begin{array}{lllll}3.720 \mathrm{E}-09 & 2.607 \mathrm{E}-08 & 9.327 \mathrm{E}-04 & 6.243 \mathrm{E}-03 & 1.483 \mathrm{E}-02\end{array}$ $1.342 \mathrm{E}-14 \quad 2.021 \mathrm{E}-13 \quad 1.215 \mathrm{E}-07 \quad 1.693 \mathrm{E}-06 \quad 5.807 \mathrm{E}-06$ $\begin{array}{lllll}7.622 \mathrm{E}-21 & 2.374 \mathrm{E}-19 & 2.279 \mathrm{E}-12 & 6.483 \mathrm{E}-11 & 3.170 \mathrm{E}-10\end{array}$ $\begin{array}{lllll}3.720 E-09 & 2.607 E-08 & 9.328 E-04 & 6.245 E-03 & 1.483 E-02\end{array}$

4.538E-05 4.592E-05 1.332E-02 2.826E-02 4.019E-02

$5.782 \mathrm{E}-11 \quad 1.754 \mathrm{E}-10 \quad 4.075 \mathrm{E}-09 \quad 1.110 \mathrm{E}-08 \quad 1.992 \mathrm{E}-08$ 2.116E-02 2.142E-02 2.930E-02 4.032E-02 5.183E-02 $2.116 \mathrm{E}-02 \quad 2.142 \mathrm{E}-02 \quad 2.930 \mathrm{E}-02 \quad 4.032 \mathrm{E}-02 \quad 5.183 \mathrm{E}-02$ 
RESRAD, Version $6.5 \quad T \frac{T}{1 / 2}$ Limit $=180$ days $\quad 07 / 20 / 2011 \quad 08: 14$ Page 29

Summary : RESRAD Parameters for U-Landfill Trespasser Forward Run at Proposed ALs

File : C: $\backslash$ RESRAD_FAMILY \RESRAD UUSERFILES \ULANDFILL-TRESPASSER_FORWARDRUN-70YRSALS.RAD

Individual Nuclide Dose Summed Over All Pathways

Parent Nuclide and Branch Fraction Indicated

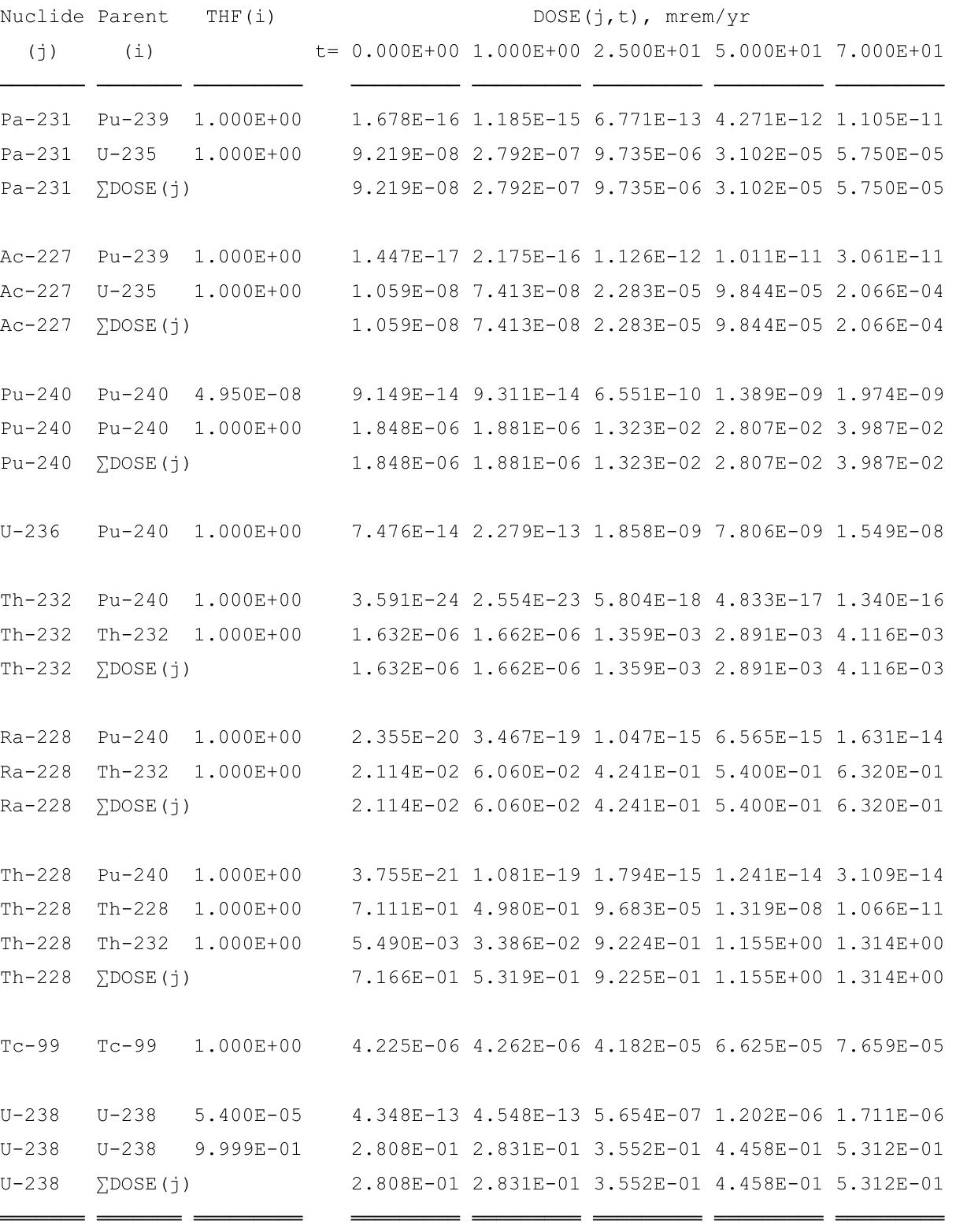

THF (i) is the thread fraction of the parent nuclide. 
RESRAD, Version $6.5 \quad \mathrm{~T}^{1 / 2}$ Limit $=180$ days

Summary : RESRAD Parameters for U-Landfill Trespasser Forward Run at Proposed ALs File : C: \RESRAD_FAMILY \RESRAD \USERFILES \ULANDFILL-TRESPASSER_FORWARDRUN-70YRSALS.RAD

Individual Nuclide Soil Concentration

Parent Nuclide and Branch Fraction Indicated

Nuclide Parent THF(i) $\quad S(j, t), p C i / g$

\begin{tabular}{|c|c|c|c|c|c|c|c|c|}
\hline (j) & (i) & & $t=$ & $0.000 \mathrm{E}+00$ & $1.000 \mathrm{E}+00$ & $2.500 \mathrm{E}+01$ & $5.000 \mathrm{E}+01$ & $7.000 \mathrm{E}+01$ \\
\hline$n-241$ & Am-241 & $1.000 \mathrm{E}+00$ & & $7.000 \mathrm{E}+01$ & $6.989 \mathrm{E}+01$ & $6.724 \mathrm{E}+01$ & $6.459 E+01$ & $6.254 \mathrm{E}+01$ \\
\hline-237 & $A m-241$ & $1.000 \mathrm{E}+00$ & & $0.000 \mathrm{E}+00$ & $2.265 E-05$ & $5.545 E-04$ & $1.085 E-03$ & 1. $493 \mathrm{E}-03$ \\
\hline-237 & $\mathrm{~Np}-237$ & $1.000 \mathrm{E}+00$ & & $1.100 \mathrm{E}+01$ & $1.100 \mathrm{E}+01$ & $1.096 \mathrm{E}+01$ & $1.091 E+01$ & $1.088 \mathrm{E}+01$ \\
\hline-237 & $\sum S(j):$ & & & $1.100 \mathrm{E}+01$ & $1.100 \mathrm{E}+01$ & $1.096 \mathrm{E}+01$ & $1.091 \mathrm{E}+01$ & $1.088 \mathrm{E}+01$ \\
\hline 233 & $A m-241$ & $1.000 \mathrm{E}+00$ & & $0.000 \mathrm{E}+00$ & 4. $955 \mathrm{E}-11$ & $3.053 E-08$ & $1.203 E-07$ & $2.330 \mathrm{E}-07$ \\
\hline 233 & $\mathrm{~Np}-237$ & $1.000 \mathrm{E}+00$ & & $0.000 \mathrm{E}+00$ & $4.810 \mathrm{E}-05$ & 1.200E-03 & $2.394 \mathrm{E}-03$ & $3.345 E-03$ \\
\hline 233 & $\sum S(j):$ & & & $0.000 \mathrm{E}+00$ & $4.810 \mathrm{E}-05$ & $1.200 \mathrm{E}-03$ & $2.394 E-03$ & $3.345 E-03$ \\
\hline
\end{tabular}

Th-229 Am-241 1.000E+00 0.000E+00 1.560E-15 2.410E-11 $1.905 \mathrm{E}-10 \quad 5.179 \mathrm{E}-10$

Th-229 Np-237 1.000E+00

Th-229 $\sum S(j):$

$0.000 \mathrm{E}+00 \quad 2.271 \mathrm{E}-09 \quad 1.416 \mathrm{E}-06 \quad 5.651 \mathrm{E}-06 \quad 1.106 \mathrm{E}-05$

$0.000 \mathrm{E}+00 \quad 2.271 \mathrm{E}-09 \quad 1.416 \mathrm{E}-06 \quad 5.651 \mathrm{E}-06 \quad 1.106 \mathrm{E}-05$

Cs-137 Cs $-137 \quad 1.000 E+00$

$\begin{array}{llllll}3.800 E+01 & 3.713 E+01 & 2.131 E+01 & 1.195 E+01 & 7.519 E+00\end{array}$

$\mathrm{Pu}-238$ 1.840E-09

$\begin{array}{lllll}1.435 \mathrm{E}-07 & 1.424 \mathrm{E}-07 & 1.177 \mathrm{E}-07 & 9.659 \mathrm{E}-08 & 8.244 \mathrm{E}-08\end{array}$

$\begin{array}{lllllllllll}\mathrm{Pu}-238 & 1.000 \mathrm{E}+00 & 7.800 \mathrm{E}+01 & 7.738 \mathrm{E}+01 & 6.399 \mathrm{E}+01 & 5.249 \mathrm{E}+01 & 4.480 \mathrm{E}+01\end{array}$

$\sum S(j): \quad 7.800 E+01 \quad 7.738 E+01 \quad 6.399 E+01 \quad 5.249 \mathrm{E}+01 \quad 4.480 \mathrm{E}+01$

$\begin{array}{lllllllll}\mathrm{Pu}-238 & 1.000 \mathrm{E}+00 \quad 0.000 \mathrm{E}+00 & 2.203 \mathrm{E}-04 & 5.013 \mathrm{E}-03 & 9.122 \mathrm{E}-03 & 1.187 \mathrm{E}-02\end{array}$

$\begin{array}{lllllll}\mathrm{U}-234 & 1.000 \mathrm{E}+00 & 3.200 \mathrm{E}+02 & 3.200 \mathrm{E}+02 & 3.198 \mathrm{E}+02 & 3.195 \mathrm{E}+02 & 3.193 \mathrm{E}+02\end{array}$

$\begin{array}{lllllllll}\mathrm{U}-238 & 9.999 \mathrm{E}-01 & 0.000 \mathrm{E}+00 & 9.071 \mathrm{E}-04 & 2.266 \mathrm{E}-02 & 4.529 \mathrm{E}-02 & 6.337 \mathrm{E}-02\end{array}$

$\sum \mathrm{S}(j): \quad 3.200 \mathrm{E}+02 \quad 3.200 \mathrm{E}+02 \quad 3.198 \mathrm{E}+02 \quad 3.196 \mathrm{E}+02 \quad 3.194 \mathrm{E}+02$

$\begin{array}{lllllll}\mathrm{Pu}-238 & 1.000 \mathrm{E}+00 \quad 0.000 \mathrm{E}+00 & 9.926 \mathrm{E}-10 & 5.827 \mathrm{E}-07 & 2.188 \mathrm{E}-06 \quad 4.084 \mathrm{E}-06\end{array}$

$\begin{array}{llllllll}\mathrm{Th}-230 & 1.000 \mathrm{E}+00 \quad 2.000 \mathrm{E}+02 & 2.000 \mathrm{E}+02 & 1.999 \mathrm{E}+02 & 1.999 \mathrm{E}+02 & 1.998 \mathrm{E}+02\end{array}$

$\begin{array}{lllllllll}\mathrm{U}-234 & 1.000 \mathrm{E}+00 \quad 0.000 \mathrm{E}+00 & 2.881 \mathrm{E}-03 & 7.198 \mathrm{E}-02 & 1.439 \mathrm{E}-01 & 2.013 \mathrm{E}-01\end{array}$

$\begin{array}{lllllllll}\mathrm{U}-238 & 9.999 \mathrm{E}-01 \quad 0.000 \mathrm{E}+00 & 4.083 \mathrm{E}-09 & 2.550 \mathrm{E}-06 & 1.020 \mathrm{E}-05 & 1.997 \mathrm{E}-05\end{array}$

$\sum \mathrm{S}(j): \quad 2.000 \mathrm{E}+02 \quad 2.000 \mathrm{E}+02 \quad 2.000 \mathrm{E}+02 \quad 2.000 \mathrm{E}+02 \quad 2.000 \mathrm{E}+02$

Ra-226 Pu-238 1.000E+00

$0.000 \mathrm{E}+00 \quad 1.434 \mathrm{E}-13 \quad 2.132 \mathrm{E}-09 \quad 1.622 \mathrm{E}-08 \quad 4.277 \mathrm{E}-08$

$\begin{array}{lllllllll}\mathrm{Th}-230 & 1.000 \mathrm{E}+00 \quad 0.000 \mathrm{E}+00 & 8.662 \mathrm{E}-02 & 2.153 \mathrm{E}+00 & 4.282 \mathrm{E}+00 & 5.967 \mathrm{E}+00\end{array}$

$\begin{array}{llllllll}\mathrm{U}-234 & 1.000 \mathrm{E}+00 & 0.000 \mathrm{E}+00 & 6.239 \mathrm{E}-07 & 3.884 \mathrm{E}-04 & 1.547 \mathrm{E}-03 & 3.022 \mathrm{E}-03\end{array}$

$\mathrm{Ra}-226 \quad \mathrm{U}-238 \quad 9.999 \mathrm{E}-01$

$0.000 \mathrm{E}+00 \quad 5.895 \mathrm{E}-13 \quad 9.182 \mathrm{E}-09 \quad 7.322 \mathrm{E}-08 \quad 2.004 \mathrm{E}-07$

$0.000 \mathrm{E}+00 \quad 8.662 \mathrm{E}-02 \quad 2.154 \mathrm{E}+00 \quad 4.283 \mathrm{E}+00 \quad 5.970 \mathrm{E}+00$

$\mathrm{Pb}-210 \quad \mathrm{Pu}-238 \quad 1.000 \mathrm{E}+00$

$\mathrm{Pb}-210 \mathrm{Th}-230 \quad 1.000 \mathrm{E}+00$

$0.000 \mathrm{E}+00 \quad 1.108 \mathrm{E}-15 \quad 3.606 \mathrm{E}-10 \quad 4.833 \mathrm{E}-09 \quad 1.625 \mathrm{E}-08$

$\begin{array}{llllll}0.000 \mathrm{E}+00 & 1.332 \mathrm{E}-03 & 6.572 \mathrm{E}-01 & 2.114 \mathrm{E}+00 & 3.547 \mathrm{E}+00\end{array}$

$0.000 \mathrm{E}+00 \quad 6.414 \mathrm{E}-09 \quad 8.380 \mathrm{E}-05 \quad 5.671 \mathrm{E}-04 \quad 1.378 \mathrm{E}-03$

$\mathrm{Pb}-210 \quad \mathrm{U}-238 \quad 9.999 \mathrm{E}-01$

$\begin{array}{llllll}0.000 \mathrm{E}+00 & 1.332 \mathrm{E}-03 & 6.573 \mathrm{E}-01 & 2.115 \mathrm{E}+00 & 3.548 \mathrm{E}+00\end{array}$

$\mathrm{Pu}-239 \mathrm{Pu}-239 \quad 1.000 \mathrm{E}+00$

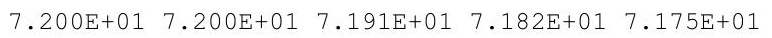

$\begin{array}{lllllll}\mathrm{Pu}-239 & 1.000 \mathrm{E}+00 \quad 0.000 \mathrm{E}+00 & 7.091 \mathrm{E}-08 & 1.771 \mathrm{E}-06 & 3.539 \mathrm{E}-06 & 4.951 \mathrm{E}-06\end{array}$

$\begin{array}{lllllll}\mathrm{U}-235 & 1.000 \mathrm{E}+00 & 1.300 \mathrm{E}+01 & 1.300 \mathrm{E}+01 & 1.299 \mathrm{E}+01 & 1.298 \mathrm{E}+01 & 1.298 \mathrm{E}+01\end{array}$

$\sum S(j):$

$\begin{array}{lllll}1.300 \mathrm{E}+01 & 1.300 \mathrm{E}+01 & 1.299 \mathrm{E}+01 & 1.298 \mathrm{E}+01 & 1.298 \mathrm{E}+01\end{array}$ 
RESRAD, Version $6.5 \quad \mathrm{~T}^{1 / 2}$ Limit $=180$ days

Summary : RESRAD Parameters for U-Landfill Trespasser Forward Run at Proposed ALs

File : C: \RESRAD_FAMILY \RESRAD \USERFILES \ULANDFILL-TRESPASSER_FORWARDRUN-70YRSALS.RAD

Individual Nuclide Soil Concentration

Parent Nuclide and Branch Fraction Indicated

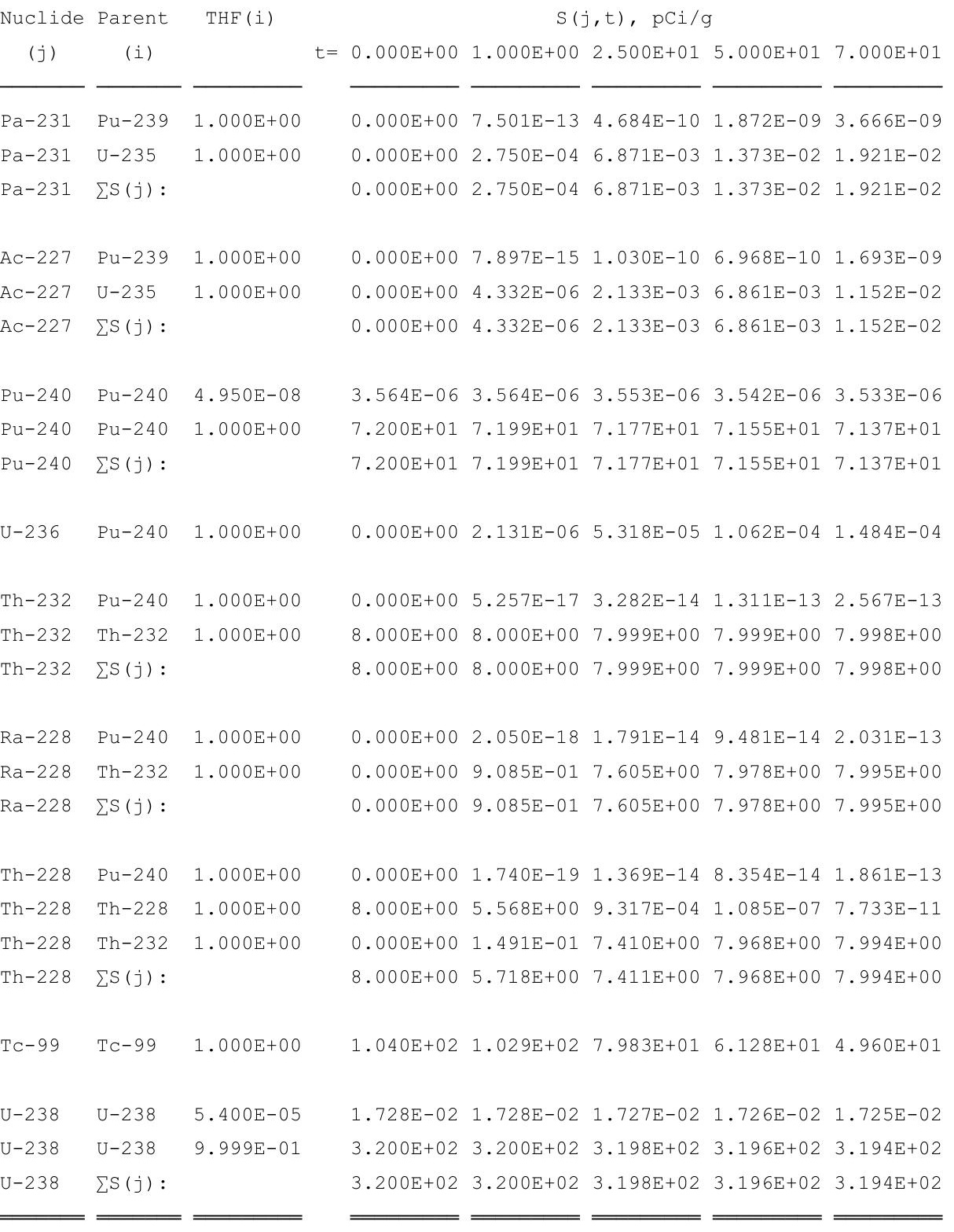

THF (i) is the thread fraction of the parent nuclide.

RESCALC.EXE execution time $=2.81$ seconds 
RESRAD, Version $6.5 \quad$ T1/2 Limit $=180$ days

07/20/2011 $15: 14 \quad$ Page

Summary : RESRAD Parameters for U-Landfill Outdoor Worker Forward Run

File : C: \RESRAD_FAMILY \RESRAD \USERFILES \QCJULY2011 \ULANDFILL-ODW_FORWARD_1050YRS.RAD

Table of Contents

Part I: Mixture Sums and Single Radionuclide Guidelines

Dose Conversion Factor (and Related) Parameter Summary ... 2

Site-Specific Parameter Summary ............... 8

Summary of Pathway Selections .................... 18

Contaminated Zone and Total Dose Summary ............. 19

Total Dose Components

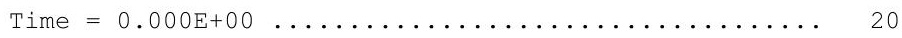

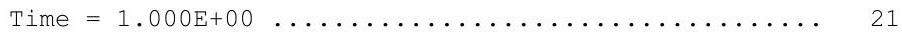

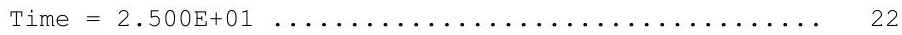

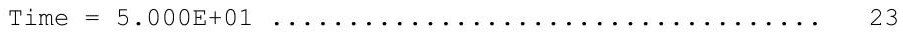

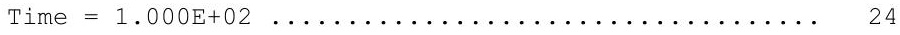

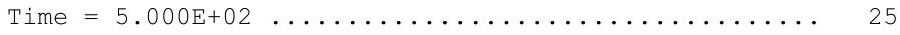

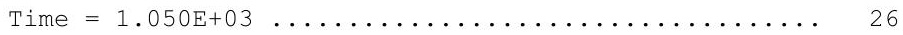

Dose/Source Ratios Summed Over All Pathways .......... 27

Single Radionuclide Soil Guidelines ................ 29

Dose Per Nuclide Summed Over All Pathways ............ 30

Soil Concentration Per Nuclide ............... 32 
Summary : RESRAD Parameters for U-Landfill Outdoor Worker Forward Run

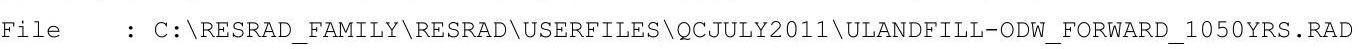

Dose Conversion Factor (and Related) Parameter Summary

Dose Library: ICRP 60 \& ICRP 72 (Adult)

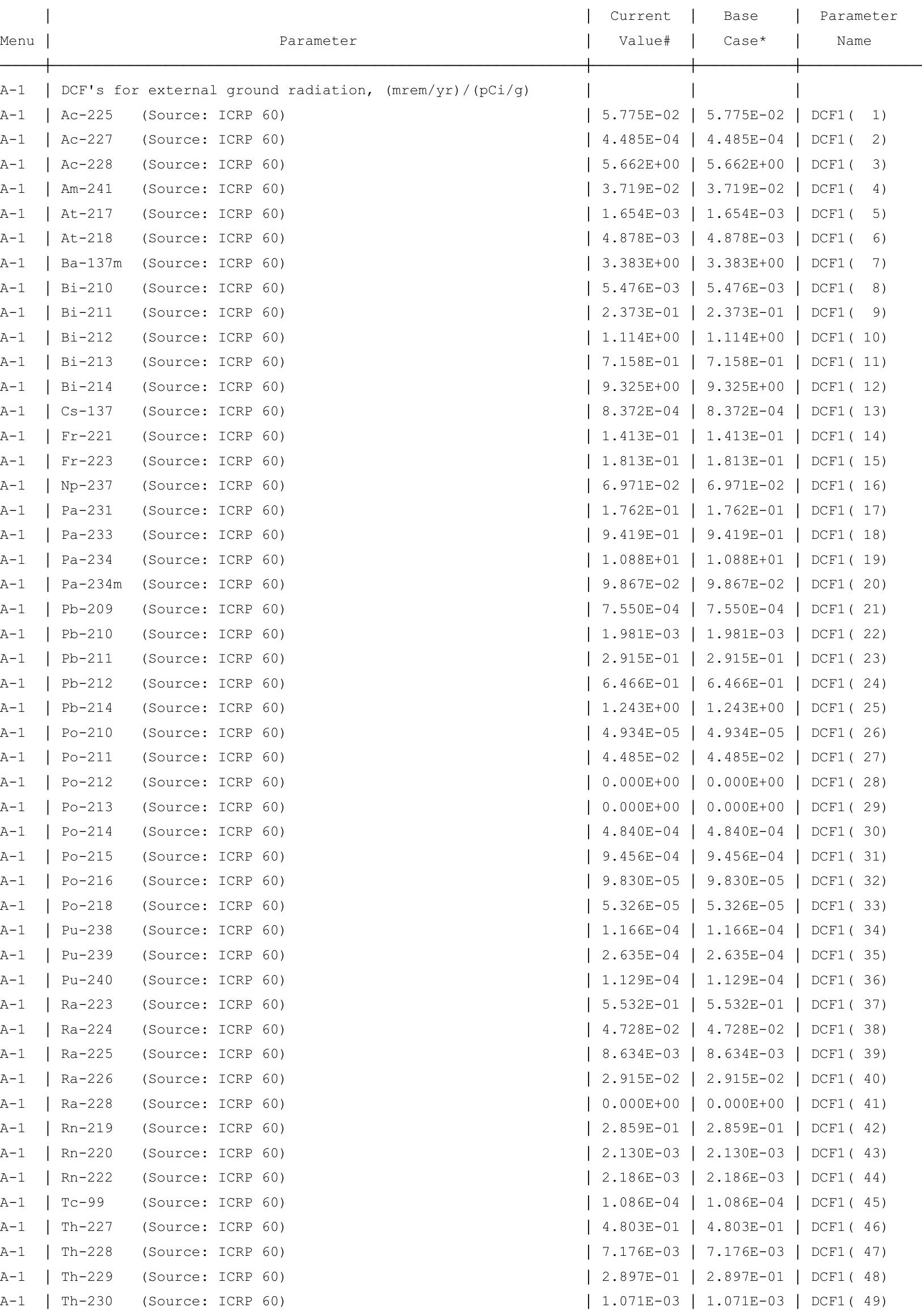


RESRAD, Version $6.5 \quad T^{1 / 2}$ Limit $=180$ days

07/20/2011 15:14 Page

Summary : RESRAD Parameters for U-Landfill Outdoor Worker Forward Run

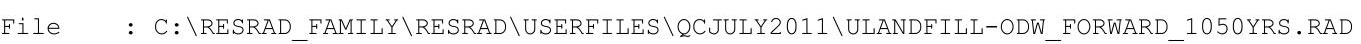

Dose Conversion Factor (and Related) Parameter Summary (continued)

Dose Library: ICRP 60 \& ICRP 72 (Adult)

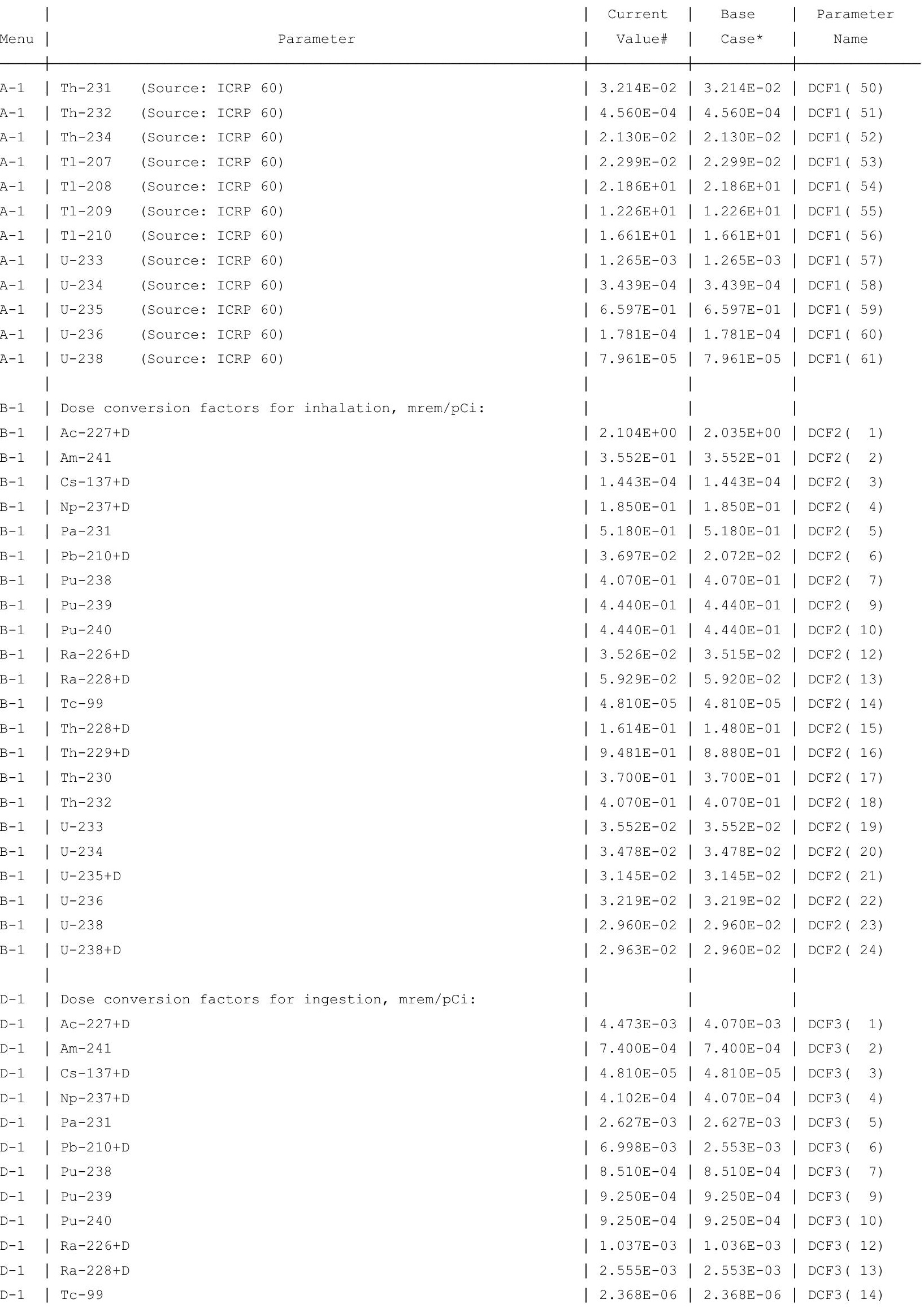


RESRAD, Version $6.5 \quad T^{1 / 2}$ Limit $=180$ days

ummary : RESRAD Parameters for U-Landfill Outdoor Worker Forward Run

File : C: \RESRAD_FAMILY \RESRAD \USERFILES \QCJULY2011 \ULANDFILL-ODW_FORWARD_1050YRS.RAD

Dose Conversion Factor (and Related) Parameter Summary (continued)

Dose Library: ICRP 60 \& ICRP 72 (Adult)

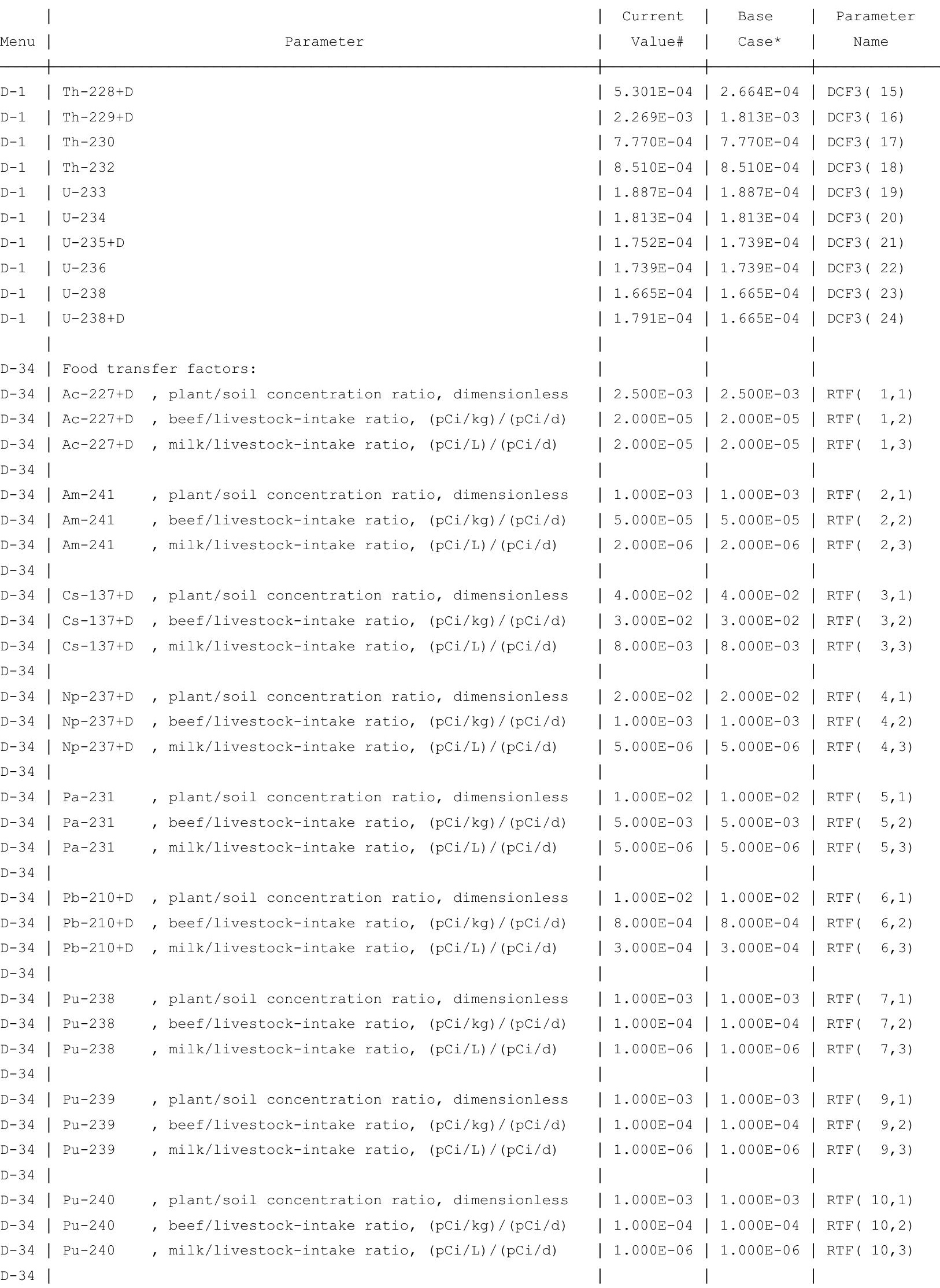


RESRAD, Version $6.5 \quad T^{1 / 2}$ Limit $=180$ days

07/20/2011 15:14 Page

Summary : RESRAD Parameters for U-Landfill Outdoor Worker Forward Run

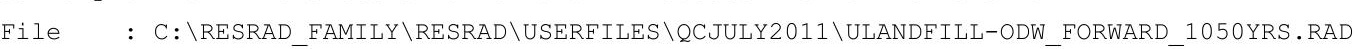

Site-Specific Parameter Summary (continued)

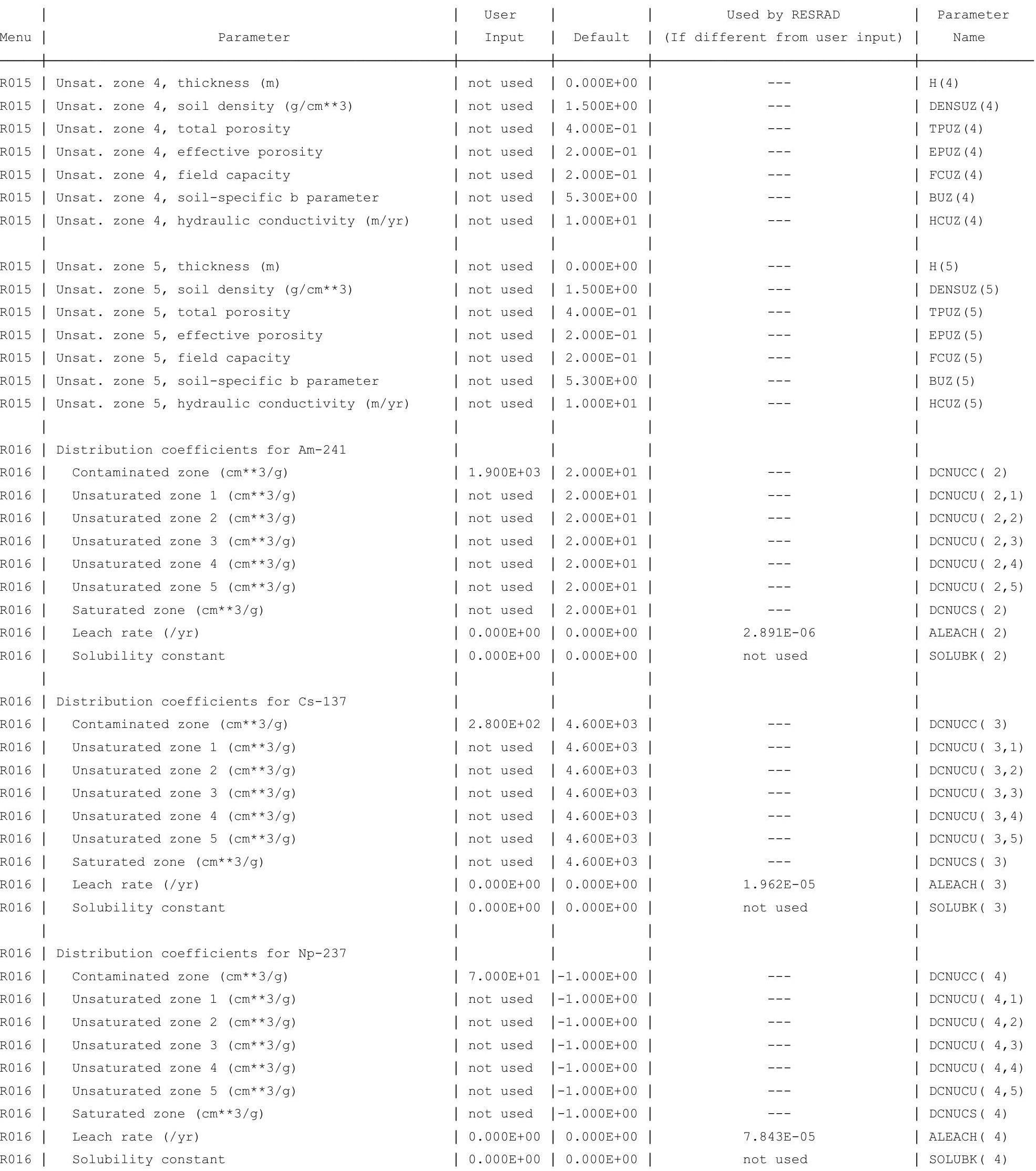


RESRAD, Version $6.5 \quad \mathrm{~T}^{1} \frac{1}{2}$ Limit $=180$ days

07/20/2011 15:14 Page

Summary : RESRAD Parameters for U-Landfill Outdoor Worker Forward Run

File : C: \RESRAD FAMILY \RESRAD \USERFILES \QCJULY2011 \ULANDFILL-ODW FORWARD 1050YRS.RAD

Site-Specific Parameter Summary (continued)

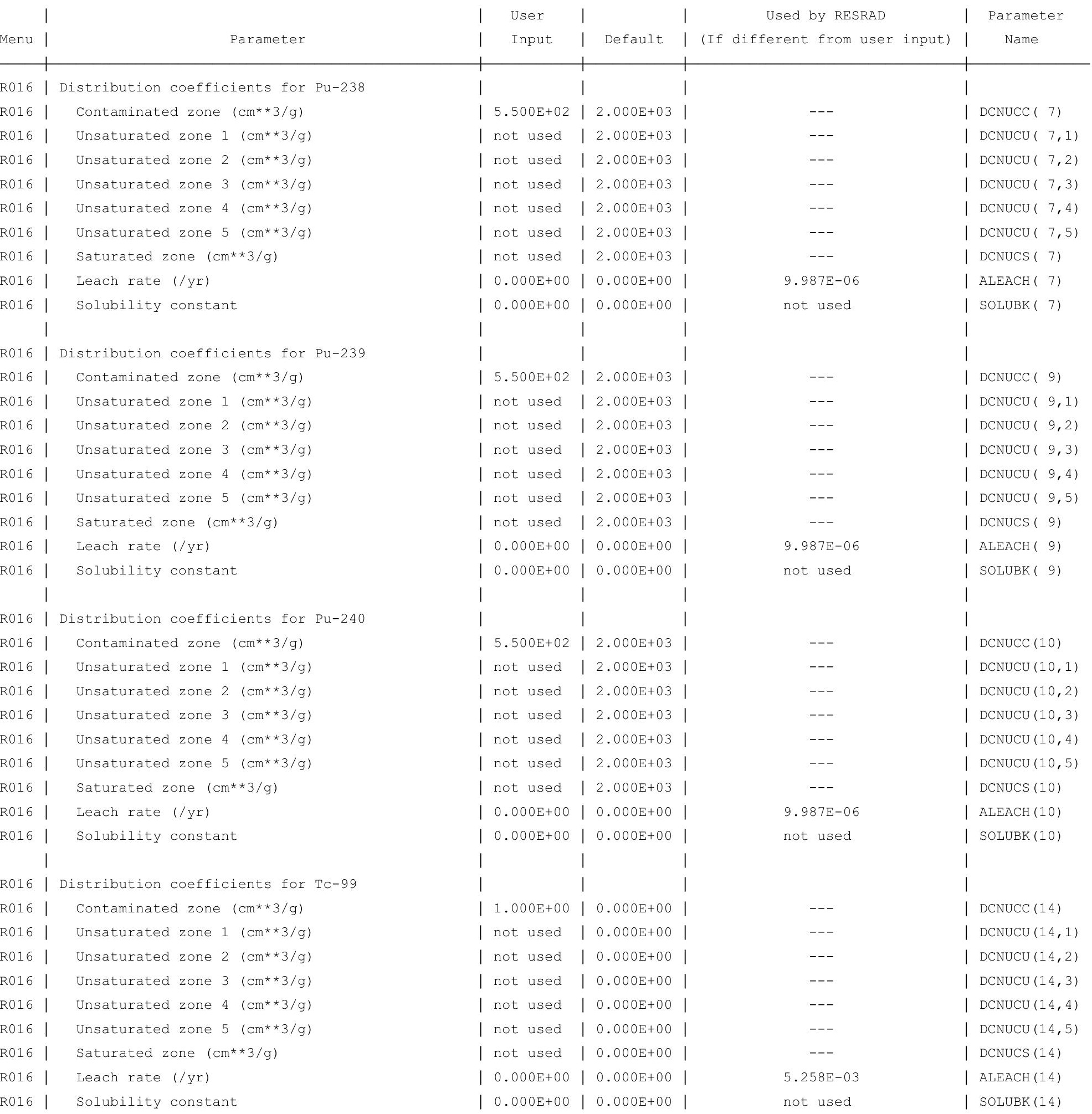


RESRAD, Version $6.5 \quad \mathrm{~T}^{1} \frac{1}{2}$ Limit $=180$ days

07/20/2011 15:14 Page

Summary : RESRAD Parameters for U-Landfill Outdoor Worker Forward Run

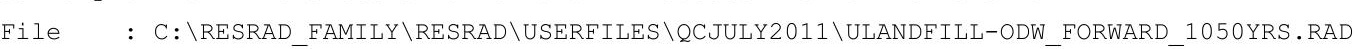

Site-Specific Parameter Summary (continued)

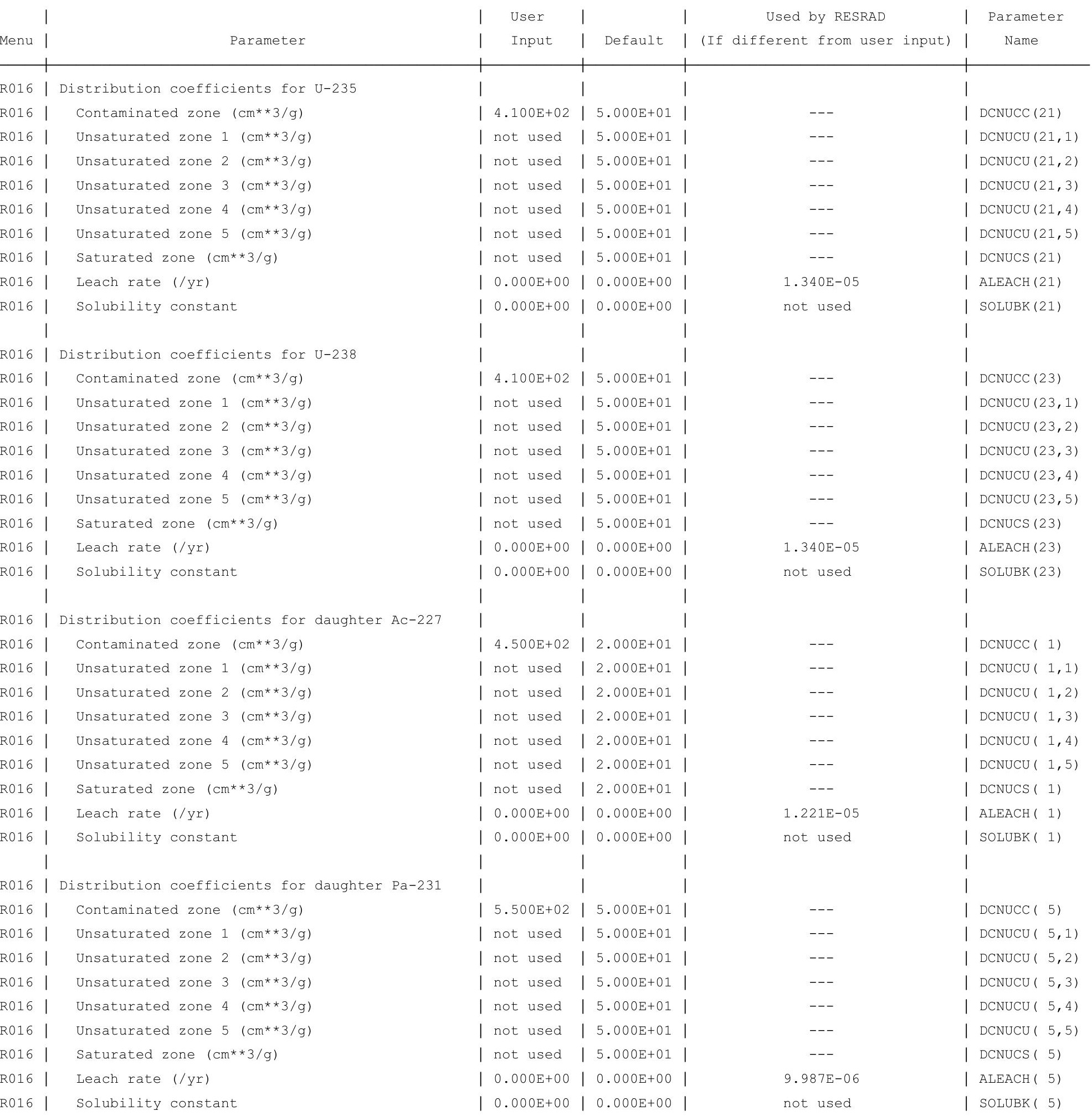


RESRAD, Version $6.5 \quad \mathrm{~T}^{1} \frac{1}{2}$ Limit $=180$ days

07/20/2011 15:14 Page 14 r

Summary : RESRAD Parameters for U-Landfill Outdoor Worker Forward Run

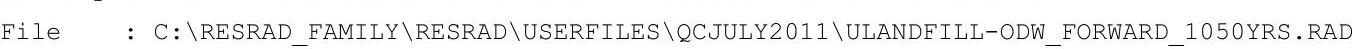

Site-Specific Parameter Summary (continued)

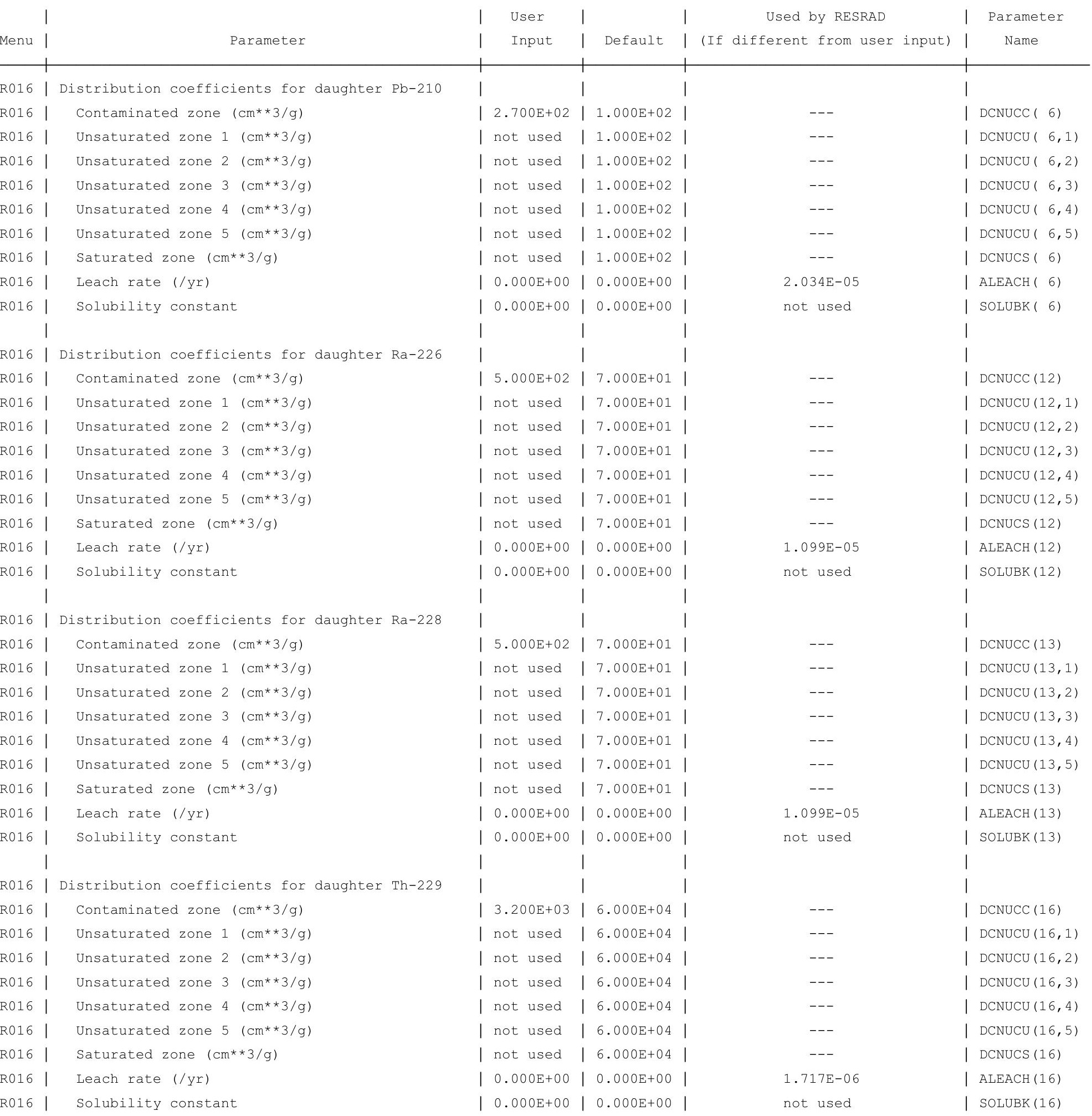


RESRAD, Version $6.5 \quad T^{1 / 2}$ Limit $=180$ days

$07 / 20 / 2011$

$15: 14$

Summary : RESRAD Parameters for U-Landfill Outdoor Worker Forward Run
File : C: \RESRAD_FAMILY \RESRAD \USERFILES $\backslash$ QCJULY2011 \ULANDFILL-ODW_FORWARD_1050YRS.RAD

Site-Specific Parameter Summary (continued)

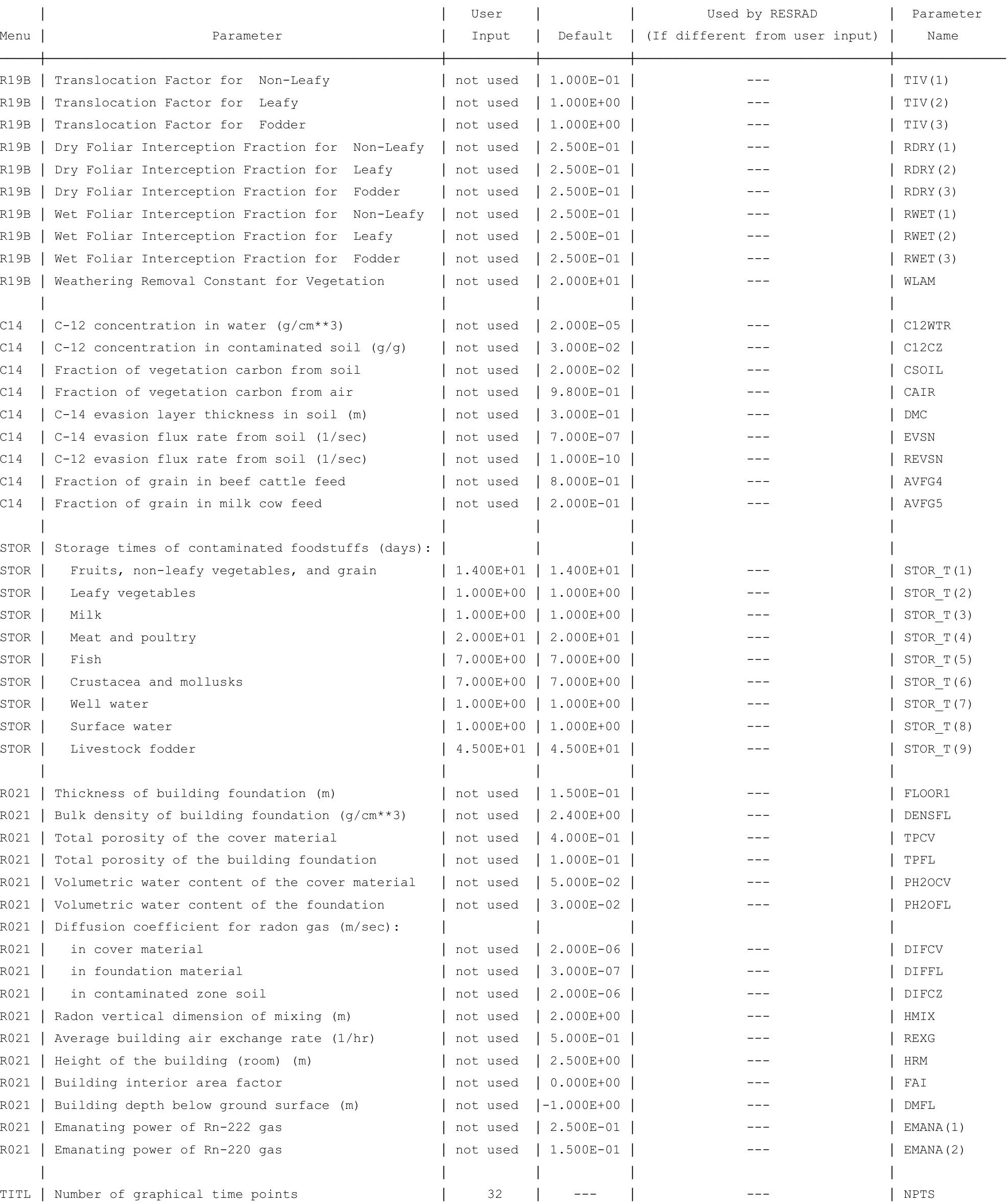


RESRAD, Version $6.5 \quad T^{13 / 2}$ Limit $=180$ days

Summary : RESRAD Parameters for U-Landfill Outdoor Worker Forward Run

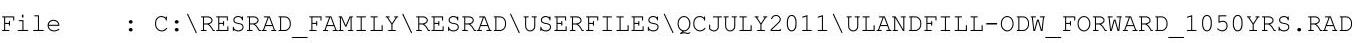

Contaminated Zone Dimensions

Area: $\quad 89436.00$ square meters

Thickness:

Cover Depth:

\begin{abstract}
13.40 meters
1.52 meters
\end{abstract}

Initial Soil Concentrations, pci/g

$\begin{array}{ll}\text { Am-241 } & 3.500 \mathrm{E}+01 \\ \mathrm{Cs}-137 & 1.900 \mathrm{E}+01 \\ \mathrm{~Np}-237 & 5.500 \mathrm{E}+00 \\ \mathrm{Pu}-238 & 3.900 \mathrm{E}+01 \\ \mathrm{Pu}-239 & 3.600 \mathrm{E}+01 \\ \mathrm{Pu}-240 & 3.600 \mathrm{E}+01 \\ \mathrm{Tc}-99 & 5.200 \mathrm{E}+01 \\ \mathrm{Th}-228 & 4.000 \mathrm{E}+00 \\ \text { Th-230 } & 1.000 \mathrm{E}+02 \\ \text { Th-232 } & 4.000 \mathrm{E}+00 \\ \mathrm{U}-234 & 1.600 \mathrm{E}+02 \\ \mathrm{U}-235 & 6.500 \mathrm{E}+00 \\ \mathrm{U}-238 & 1.600 \mathrm{E}+02\end{array}$

Total Dose TDOSE(t), mrem/yr

Basic Radiation Dose Limit $=1.000 \mathrm{E}+00 \mathrm{mrem} / \mathrm{yr}$

Total Mixture Sum $M(t)$ = Fraction of Basic Dose Limit Received at Time (t)

$\begin{array}{rlllllll}t \text { (years) }: & 0.000 \mathrm{E}+00 & 1.000 \mathrm{E}+00 & 2.500 \mathrm{E}+01 & 5.000 \mathrm{E}+01 & 1.000 \mathrm{E}+02 & 5.000 \mathrm{E}+02 & 1.050 \mathrm{E}+03 \\ \text { TDOSE }(\mathrm{t}): & 1.150 \mathrm{E}-06 & 8.594 \mathrm{E}-07 & 1.529 \mathrm{E}-06 & 1.950 \mathrm{E}-06 & 2.793 \mathrm{E}-06 & 4.957 \mathrm{E}-05 & 2.632 \mathrm{E}-03 \\ \mathrm{M}(\mathrm{t}): & 1.150 \mathrm{E}-06 & 8.594 \mathrm{E}-07 & 1.529 \mathrm{E}-06 & 1.950 \mathrm{E}-06 & 2.793 \mathrm{E}-06 & 4.957 \mathrm{E}-05 & 2.632 \mathrm{E}-03\end{array}$

Maximum TDOSE $(t): 2.632 \mathrm{E}-03 \mathrm{mrem} / \mathrm{yr}$ at $t=1.050 \mathrm{E}+03$ years 
RESRAD, Version 6.5

mmary : RESRAD Parameters for U-Landfill Outdoor Worker Forward Run

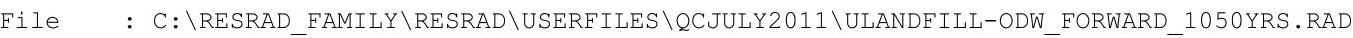

Total Dose Contributions TDOSE (i,p,t) for Individual Radionuclides (i) and Pathways (p) As mrem/yr and Fraction of Total Dose At $t=0.000 \mathrm{E}+00$ years

Water Independent Pathways (Inhalation excludes radon)

\begin{tabular}{|c|c|c|c|c|c|c|c|c|c|c|c|c|c|c|}
\hline \multirow{2}{*}{ Nuclide } & \multicolumn{2}{|c|}{ Ground } & \multicolumn{2}{|c|}{ Inhalation } & \multicolumn{2}{|c|}{ Radon } & \multicolumn{2}{|c|}{ Plant } & \multicolumn{2}{|c|}{ Meat } & \multicolumn{2}{|c|}{ Milk } & \multicolumn{2}{|c|}{ Soil } \\
\hline & mrem/yr & fract. & mrem/yr & fract. & mrem/yr & fract. & mrem/yr & fract. & mrem/yr & fract. & mrem/yr & fract. & mrem/yr & fract. \\
\hline-241 & $1.106 \mathrm{E}-18$ & 0.0000 & $0.000 \mathrm{E}+00$ & 0.0000 & $0.000 \mathrm{E}+00$ & 0.0000 & $0.000 \mathrm{E}+00$ & 0.0000 & $0.000 \mathrm{E}+00$ & 0.0000 & $0.000 \mathrm{E}+00$ & 0.0000 & $0.000 \mathrm{E}+00$ & 0.0000 \\
\hline-137 & $4.898 E-09$ & 0.0043 & $0.000 \mathrm{E}+00$ & 0.0000 & $0.000 \mathrm{E}+00$ & 0.0000 & $0.000 \mathrm{E}+00$ & 0.0000 & $0.000 \mathrm{E}+00$ & 0.0000 & $0.000 \mathrm{E}+00$ & 0.0000 & $0.000 \mathrm{E}+00$ & 0.0000 \\
\hline-237 & $1.072 \mathrm{E}-12$ & 0.0000 & $0.000 \mathrm{E}+00$ & 0.0000 & $0.000 \mathrm{E}+00$ & 0.0000 & $0.000 \mathrm{E}+00$ & 0.0000 & $0.000 \mathrm{E}+00$ & 0.0000 & $0.000 \mathrm{E}+00$ & 0.0000 & $0.000 \mathrm{E}+00$ & 0.0000 \\
\hline-238 & $6.486 E-22$ & 0.0000 & $0.000 \mathrm{E}+00$ & 0.0000 & $0.000 \mathrm{E}+00$ & 0.0000 & $0.000 \mathrm{E}+00$ & 0.0000 & $0.000 \mathrm{E}+00$ & 0.0000 & $0.000 \mathrm{E}+00$ & 0.0000 & $0.000 \mathrm{E}+00$ & 0.0000 \\
\hline-239 & $8.843 E-17$ & 0.0000 & $0.000 \mathrm{E}+00$ & 0.0000 & $0.000 \mathrm{E}+00$ & 0.0000 & $0.000 \mathrm{E}+00$ & 0.0000 & $0.000 \mathrm{E}+00$ & 0.0000 & $0.000 \mathrm{E}+00$ & 0.0000 & $0.000 \mathrm{E}+00$ & 0.0000 \\
\hline-240 & $8.408 E-24$ & 0.0000 & $0.000 \mathrm{E}+00$ & 0.0000 & $0.000 \mathrm{E}+00$ & 0.0000 & $0.000 \mathrm{E}+00$ & 0.0000 & $0.000 \mathrm{E}+00$ & 0.0000 & $0.000 \mathrm{E}+00$ & 0.0000 & $0.000 \mathrm{E}+00$ & 0.0000 \\
\hline 99 & $6.129 \mathrm{E}-25$ & 0.0000 & $0.000 \mathrm{E}+00$ & 0.0000 & $0.000 \mathrm{E}+00$ & 0.0000 & $0.000 \mathrm{E}+00$ & 0.0000 & $0.000 \mathrm{E}+00$ & 0.0000 & $0.000 \mathrm{E}+00$ & 0.0000 & $0.000 \mathrm{E}+00$ & 0.0000 \\
\hline-228 & $1.130 \mathrm{E}-06$ & 0.9827 & $0.000 \mathrm{E}+00$ & 0.0000 & $0.000 \mathrm{E}+00$ & 0.0000 & $0.000 \mathrm{E}+00$ & 0.0000 & $0.000 \mathrm{E}+00$ & 0.0000 & $0.000 \mathrm{E}+00$ & 0.0000 & $0.000 \mathrm{E}+00$ & 0.0000 \\
\hline 230 & 7. $712 \mathrm{E}-10$ & 0.0007 & $0.000 \mathrm{E}+00$ & 0.0000 & $0.000 \mathrm{E}+00$ & 0.0000 & $0.000 \mathrm{E}+00$ & 0.0000 & $0.000 \mathrm{E}+00$ & 0.0000 & $0.000 \mathrm{E}+00$ & 0.0000 & $0.000 \mathrm{E}+00$ & 0.0000 \\
\hline-232 & $9.628 E-09$ & 0.0084 & $0.000 \mathrm{E}+00$ & 0.0000 & $0.000 \mathrm{E}+00$ & 0.0000 & $0.000 \mathrm{E}+00$ & 0.0000 & $0.000 \mathrm{E}+00$ & 0.0000 & $0.000 \mathrm{E}+00$ & 0.0000 & $0.000 \mathrm{E}+00$ & 0.0000 \\
\hline 234 & $3.705 E-15$ & 0.0000 & $0.000 \mathrm{E}+00$ & 0.0000 & $0.000 \mathrm{E}+00$ & 0.0000 & $0.000 \mathrm{E}+00$ & 0.0000 & $0.000 \mathrm{E}+00$ & 0.0000 & $0.000 \mathrm{E}+00$ & 0.0000 & $0.000 \mathrm{E}+00$ & 0.0000 \\
\hline 35 & $1.653 \mathrm{E}-14$ & 0.0000 & $0.000 \mathrm{E}+00$ & 0.0000 & $0.000 \mathrm{E}+00$ & 0.0000 & $0.000 \mathrm{E}+00$ & 0.0000 & $0.000 \mathrm{E}+00$ & 0.0000 & $0.000 \mathrm{E}+00$ & 0.0000 & $0.000 \mathrm{E}+00$ & 0.0000 \\
\hline 38 & $4.641 E-09$ & 0.0040 & $0.000 \mathrm{E}+00$ & 0.0000 & $0.000 \mathrm{E}+00$ & 0.0000 & $0.000 \mathrm{E}+00$ & 0.0000 & $0.000 \mathrm{E}+00$ & 0.0000 & $0.000 \mathrm{E}+00$ & 0.0000 & $0.000 \mathrm{E}+00$ & 0.0000 \\
\hline & $1.150 \mathrm{E}-06$ & 1.0000 & $0.000 \mathrm{E}+00$ & 0.0000 & $0.000 \mathrm{E}+00$ & 0.0000 & $0.000 \mathrm{E}+00$ & 0.0000 & $0.000 \mathrm{E}+00$ & 0.0000 & $0.000 \mathrm{E}+00$ & 0.0000 & $0.000 \mathrm{E}+00$ & 0.0000 \\
\hline
\end{tabular}

Total Dose Contributions TDOSE(i,p,t) for Individual Radionuclides (i) and Pathways (p) As mrem/yr and Fraction of Total Dose At $t=0.000 \mathrm{E}+00$ years

Water Dependent Pathways

\begin{tabular}{|c|c|c|c|c|c|c|c|c|c|c|c|c|c|c|}
\hline \multirow{2}{*}{$\begin{array}{l}\text { Radio- } \\
\text { Nuclide }\end{array}$} & \multicolumn{2}{|c|}{ Water } & \multicolumn{2}{|c|}{ Fish } & \multicolumn{2}{|c|}{ Radon } & \multicolumn{2}{|c|}{ Plant } & \multicolumn{2}{|c|}{ Meat } & \multicolumn{2}{|c|}{ Milk } & \multicolumn{2}{|c|}{ All Pathways* } \\
\hline & mrem/yr & fract. & mrem/yr & fract. & mrem/yr & fract. & mrem/yr & fract. & mrem/yr & fract. & mrem/yr & fract. & mrem/yr & fract. \\
\hline 241 & $0.000 \mathrm{E}+00$ & 0.0000 & $0.000 \mathrm{E}+00$ & 0.0000 & $0.000 \mathrm{E}+00$ & 0.0000 & $0.000 \mathrm{E}+00$ & 0.0000 & $0.000 \mathrm{E}+00$ & 0.0000 & $0.000 \mathrm{E}+00$ & 0.0000 & $1.106 \mathrm{E}-18$ & 0.0000 \\
\hline-137 & $0.000 \mathrm{E}+00$ & 0.0000 & $0.000 \mathrm{E}+00$ & 0.0000 & $0.000 \mathrm{E}+00$ & 0.0000 & $0.000 \mathrm{E}+00$ & 0.0000 & $0.000 \mathrm{E}+00$ & 0.0000 & $0.000 \mathrm{E}+00$ & 0.0000 & $4.898 \mathrm{E}-09$ & 0.0043 \\
\hline-237 & $0.000 \mathrm{E}+00$ & 0.0000 & $0.000 \mathrm{E}+00$ & 0.0000 & $0.000 \mathrm{E}+00$ & 0.0000 & $0.000 \mathrm{E}+00$ & 0.0000 & $0.000 \mathrm{E}+00$ & 0.0000 & $0.000 \mathrm{E}+00$ & 0.0000 & $1.072 \mathrm{E}-12$ & 0.0000 \\
\hline-238 & $0.000 \mathrm{E}+00$ & 0.0000 & $0.000 \mathrm{E}+00$ & 0.0000 & $0.000 \mathrm{E}+00$ & 0.0000 & $0.000 \mathrm{E}+00$ & 0.0000 & $0.000 \mathrm{E}+00$ & 0.0000 & $0.000 \mathrm{E}+00$ & 0.0000 & $6.486 \mathrm{E}-22$ & 0.0000 \\
\hline-239 & $0.000 \mathrm{E}+00$ & 0.0000 & $0.000 \mathrm{E}+00$ & 0.0000 & $0.000 \mathrm{E}+00$ & 0.0000 & $0.000 \mathrm{E}+00$ & 0.0000 & $0.000 \mathrm{E}+00$ & 0.0000 & $0.000 E+00$ & 0.0000 & $8.843 E-17$ & 0.0000 \\
\hline-240 & $0.000 \mathrm{E}+00$ & 0.0000 & $0.000 \mathrm{E}+00$ & 0.0000 & $0.000 \mathrm{E}+00$ & 0.0000 & $0.000 \mathrm{E}+00$ & 0.0000 & $0.000 \mathrm{E}+00$ & 0.0000 & $0.000 E+00$ & 0.0000 & $8.408 E-24$ & 0.0000 \\
\hline-99 & $0.000 \mathrm{E}+00$ & 0.0000 & $0.000 \mathrm{E}+00$ & 0.0000 & $0.000 \mathrm{E}+00$ & 0.0000 & $0.000 \mathrm{E}+00$ & 0.0000 & $0.000 \mathrm{E}+00$ & 0.0000 & $0.000 \mathrm{E}+00$ & 0.0000 & $6.129 \mathrm{E}-25$ & 0.0000 \\
\hline-228 & $0.000 \mathrm{E}+00$ & 0.0000 & $0.000 \mathrm{E}+00$ & 0.0000 & $0.000 \mathrm{E}+00$ & 0.0000 & $0.000 \mathrm{E}+00$ & 0.0000 & $0.000 \mathrm{E}+00$ & 0.0000 & $0.000 \mathrm{E}+00$ & 0.0000 & $1.130 \mathrm{E}-06$ & 0.9827 \\
\hline-230 & $0.000 \mathrm{E}+00$ & 0.0000 & $0.000 \mathrm{E}+00$ & 0.0000 & $0.000 \mathrm{E}+00$ & 0.0000 & $0.000 \mathrm{E}+00$ & 0.0000 & $0.000 \mathrm{E}+00$ & 0.0000 & $0.000 E+00$ & 0.0000 & $7.712 \mathrm{E}-10$ & 0.0007 \\
\hline 232 & $0.000 \mathrm{E}+00$ & 0.0000 & $0.000 \mathrm{E}+00$ & 0.0000 & $0.000 \mathrm{E}+00$ & 0.0000 & $0.000 \mathrm{E}+00$ & 0.0000 & $0.000 \mathrm{E}+00$ & 0.0000 & $0.000 \mathrm{E}+00$ & 0.0000 & $9.628 \mathrm{E}-09$ & 0.0084 \\
\hline 34 & $0.000 \mathrm{E}+00$ & 0.0000 & $0.000 \mathrm{E}+00$ & 0.0000 & $0.000 \mathrm{E}+00$ & 0.0000 & $0.000 \mathrm{E}+00$ & 0.0000 & $0.000 \mathrm{E}+00$ & 0.0000 & $0.000 \mathrm{E}+00$ & 0.0000 & $3.705 E-15$ & 0.0000 \\
\hline 35 & $0.000 \mathrm{E}+00$ & 0.0000 & $0.000 \mathrm{E}+00$ & 0.0000 & $0.000 \mathrm{E}+00$ & 0.0000 & $0.000 \mathrm{E}+00$ & 0.0000 & $0.000 \mathrm{E}+00$ & 0.0000 & $0.000 \mathrm{E}+00$ & 0.0000 & $1.653 \mathrm{E}-14$ & 0.0000 \\
\hline 38 & $0.000 \mathrm{E}+00$ & 0.0000 & $0.000 \mathrm{E}+00$ & 0.0000 & $0.000 \mathrm{E}+00$ & 0.0000 & $0.000 \mathrm{E}+00$ & 0.0000 & $0.000 \mathrm{E}+00$ & 0.0000 & $0.000 \mathrm{E}+00$ & 0.0000 & $4.641 \mathrm{E}-09$ & 0.0040 \\
\hline & $0.000 \mathrm{E}+00$ & 0.0000 & $0.000 \mathrm{E}+00$ & 0.0000 & $0.000 \mathrm{E}+00$ & 0.0000 & $0.000 \mathrm{E}+00$ & 0.0000 & $0.000 \mathrm{E}+00$ & 0.0000 & $0.000 \mathrm{E}+00$ & 0.0000 & $50 \mathrm{E}-06$ & 1. \\
\hline
\end{tabular}

* Sum of all water independent and dependent pathways. 
RESRAD, Version 6.5

ummary : RESRAD Parameters for U-Landfill Outdoor Worker Forward Run

File : C: \RESRAD_FAMILY \RESRAD \USERFILES \QCJULY2011 \ULANDFILL-ODW_FORWARD_1050YRS.RAD

Total Dose Contributions TDOSE (i,p,t) for Individual Radionuclides (i) and Pathways (p) As mrem/yr and Fraction of Total Dose At $t=1.000 \mathrm{E}+00$ years

Water Independent Pathways (Inhalation excludes radon)

\begin{tabular}{|c|c|c|c|c|c|c|c|c|c|c|c|c|c|c|}
\hline \multirow{2}{*}{ Nuclide } & \multicolumn{2}{|c|}{ Ground } & \multicolumn{2}{|c|}{ Inhalation } & \multicolumn{2}{|c|}{ Radon } & \multicolumn{2}{|c|}{ Plant } & \multicolumn{2}{|c|}{ Meat } & \multicolumn{2}{|c|}{ Milk } & \multicolumn{2}{|c|}{ Soil } \\
\hline & mrem/yr & fract. & mrem/yr & fract. & mrem/yr & fract. & mrem/yr & fract. & mrem/yr & fract. & mrem/yr & fract. & mrem/yr & fract. \\
\hline-241 & $3.347 \mathrm{E}-18$ & 0.0000 & $0.000 \mathrm{E}+00$ & 0.0000 & $0.000 \mathrm{E}+00$ & 0.0000 & $0.000 \mathrm{E}+00$ & 0.0000 & $0.000 \mathrm{E}+00$ & 0.0000 & $0.000 \mathrm{E}+00$ & 0.0000 & $0.000 \mathrm{E}+00$ & 0.0000 \\
\hline-137 & $4.827 E-09$ & 0.0056 & $0.000 \mathrm{E}+00$ & 0.0000 & $0.000 \mathrm{E}+00$ & 0.0000 & $0.000 \mathrm{E}+00$ & 0.0000 & $0.000 \mathrm{E}+00$ & 0.0000 & $0.000 \mathrm{E}+00$ & 0.0000 & $0.000 \mathrm{E}+00$ & 0.0000 \\
\hline-237 & $1.083 \mathrm{E}-12$ & 0.0000 & $0.000 \mathrm{E}+00$ & 0.0000 & $0.000 \mathrm{E}+00$ & 0.0000 & $0.000 \mathrm{E}+00$ & 0.0000 & $0.000 \mathrm{E}+00$ & 0.0000 & $0.000 \mathrm{E}+00$ & 0.0000 & $0.000 \mathrm{E}+00$ & 0.0000 \\
\hline-238 & $9.637 \mathrm{E}-21$ & 0.0000 & $0.000 \mathrm{E}+00$ & 0.0000 & $0.000 \mathrm{E}+00$ & 0.0000 & $0.000 \mathrm{E}+00$ & 0.0000 & $0.000 \mathrm{E}+00$ & 0.0000 & $0.000 \mathrm{E}+00$ & 0.0000 & $0.000 \mathrm{E}+00$ & 0.0000 \\
\hline-239 & $8.949 \mathrm{E}-17$ & 0.0000 & $0.000 \mathrm{E}+00$ & 0.0000 & $0.000 \mathrm{E}+00$ & 0.0000 & $0.000 \mathrm{E}+00$ & 0.0000 & $0.000 \mathrm{E}+00$ & 0.0000 & $0.000 \mathrm{E}+00$ & 0.0000 & $0.000 \mathrm{E}+00$ & 0.0000 \\
\hline-240 & $8.736 \mathrm{E}-24$ & 0.0000 & $0.000 \mathrm{E}+00$ & 0.0000 & $0.000 \mathrm{E}+00$ & 0.0000 & $0.000 \mathrm{E}+00$ & 0.0000 & $0.000 \mathrm{E}+00$ & 0.0000 & $0.000 \mathrm{E}+00$ & 0.0000 & $0.000 \mathrm{E}+00$ & 0.0000 \\
\hline 99 & $6.215 E-25$ & 0.0000 & $0.000 \mathrm{E}+00$ & 0.0000 & $0.000 \mathrm{E}+00$ & 0.0000 & $0.000 \mathrm{E}+00$ & 0.0000 & $0.000 \mathrm{E}+00$ & 0.0000 & $0.000 \mathrm{E}+00$ & 0.0000 & $0.000 \mathrm{E}+00$ & 0.0000 \\
\hline-228 & 7. $912 \mathrm{E}-07$ & 0.9206 & $0.000 \mathrm{E}+00$ & 0.0000 & $0.000 \mathrm{E}+00$ & 0.0000 & $0.000 \mathrm{E}+00$ & 0.0000 & $0.000 \mathrm{E}+00$ & 0.0000 & $0.000 \mathrm{E}+00$ & 0.0000 & $0.000 \mathrm{E}+00$ & 0.0000 \\
\hline-230 & $2.327 E-09$ & 0.0027 & $0.000 \mathrm{E}+00$ & 0.0000 & $0.000 \mathrm{E}+00$ & 0.0000 & $0.000 \mathrm{E}+00$ & 0.0000 & $0.000 \mathrm{E}+00$ & 0.0000 & $0.000 \mathrm{E}+00$ & 0.0000 & $0.000 \mathrm{E}+00$ & 0.0000 \\
\hline-232 & $5.638 E-08$ & 0.0656 & $0.000 \mathrm{E}+00$ & 0.0000 & $0.000 \mathrm{E}+00$ & 0.0000 & $0.000 \mathrm{E}+00$ & 0.0000 & $0.000 \mathrm{E}+00$ & 0.0000 & $0.000 \mathrm{E}+00$ & 0.0000 & $0.000 \mathrm{E}+00$ & 0.0000 \\
\hline 34 & $2.608 E-14$ & 0.0000 & $0.000 \mathrm{E}+00$ & 0.0000 & $0.000 \mathrm{E}+00$ & 0.0000 & $0.000 \mathrm{E}+00$ & 0.0000 & $0.000 \mathrm{E}+00$ & 0.0000 & $0.000 \mathrm{E}+00$ & 0.0000 & $0.000 \mathrm{E}+00$ & 0.0000 \\
\hline 35 & 1. $682 \mathrm{E}-14$ & 0.0000 & $0.000 \mathrm{E}+00$ & 0.0000 & $0.000 \mathrm{E}+00$ & 0.0000 & $0.000 \mathrm{E}+00$ & 0.0000 & $0.000 \mathrm{E}+00$ & 0.0000 & $0.000 \mathrm{E}+00$ & 0.0000 & $0.000 \mathrm{E}+00$ & 0.0000 \\
\hline 38 & $4.678 E-09$ & 0.0054 & $0.000 \mathrm{E}+00$ & 0.0000 & $0.000 \mathrm{E}+00$ & 0.0000 & $0.000 \mathrm{E}+00$ & 0.0000 & $0.000 \mathrm{E}+00$ & 0.0000 & $0.000 \mathrm{E}+00$ & 0.0000 & $0.000 \mathrm{E}+00$ & 0.0000 \\
\hline & $8.594 \mathrm{E}-07$ & 1.0000 & $0.000 \mathrm{E}+00$ & 0.0000 & $0.000 \mathrm{E}+00$ & 0.0000 & $0.000 \mathrm{E}+00$ & 0.0000 & $0.000 \mathrm{E}+00$ & 0.0000 & $0.000 \mathrm{E}+00$ & 0.0000 & $0.000 \mathrm{E}+00$ & 0.0000 \\
\hline
\end{tabular}

Total Dose Contributions TDOSE(i,p,t) for Individual Radionuclides (i) and Pathways (p) As mrem/yr and Fraction of Total Dose At $t=1.000 \mathrm{E}+00$ years

Water Dependent Pathways

\begin{tabular}{|c|c|c|c|c|c|c|c|c|c|c|c|c|c|c|}
\hline \multirow{2}{*}{ Nuclide } & \multicolumn{2}{|c|}{ Water } & \multicolumn{2}{|c|}{ Fish } & \multicolumn{2}{|c|}{ Radon } & \multicolumn{2}{|c|}{ Plant } & \multicolumn{2}{|c|}{ Meat } & \multicolumn{2}{|c|}{ Milk } & \multicolumn{2}{|c|}{ All Pathways* } \\
\hline & mrem/yr & fract. & mrem/yr & fract. & mrem/yr & fract. & mrem/yr & fract. & mrem/yr & fract. & mrem/yr & fract. & mrem/yr & fract. \\
\hline-241 & $0.000 \mathrm{E}+00$ & 0.0000 & $0.000 \mathrm{E}+00$ & 0.0000 & $0.000 \mathrm{E}+00$ & 0.0000 & $0.000 \mathrm{E}+00$ & 0.0000 & $0.000 \mathrm{E}+00$ & 0.0000 & $0.000 \mathrm{E}+00$ & 0.0000 & $3.347 \mathrm{E}-18$ & 0.0000 \\
\hline-137 & $0.000 \mathrm{E}+00$ & 0.0000 & $0.000 \mathrm{E}+00$ & 0.0000 & $0.000 \mathrm{E}+00$ & 0.0000 & $0.000 \mathrm{E}+00$ & 0.0000 & $0.000 \mathrm{E}+00$ & 0.0000 & $0.000 \mathrm{E}+00$ & 0.0000 & $4.827 E-09$ & 0.0056 \\
\hline-237 & $0.000 \mathrm{E}+00$ & 0.0000 & $0.000 \mathrm{E}+00$ & 0.0000 & $0.000 \mathrm{E}+00$ & 0.0000 & $0.000 \mathrm{E}+00$ & 0.0000 & $0.000 \mathrm{E}+00$ & 0.0000 & $0.000 \mathrm{E}+00$ & 0.0000 & $1.083 \mathrm{E}-12$ & 0.0000 \\
\hline 238 & $0.000 \mathrm{E}+00$ & 0.0000 & $0.000 \mathrm{E}+00$ & 0.0000 & $0.000 \mathrm{E}+00$ & 0.0000 & $0.000 \mathrm{E}+00$ & 0.0000 & $0.000 \mathrm{E}+00$ & 0.0000 & $0.000 \mathrm{E}+00$ & 0.0000 & $9.637 \mathrm{E}-21$ & 0.0000 \\
\hline 239 & $0.000 \mathrm{E}+00$ & 0.0000 & $0.000 \mathrm{E}+00$ & 0.0000 & $0.000 \mathrm{E}+00$ & 0.0000 & $0.000 \mathrm{E}+00$ & 0.0000 & $0.000 \mathrm{E}+00$ & 0.0000 & $0.000 \mathrm{E}+00$ & 0.0000 & $8.949 \mathrm{E}-17$ & 0.0000 \\
\hline 240 & $0.000 \mathrm{E}+00$ & 0.0000 & $0.000 \mathrm{E}+00$ & 0.0000 & $0.000 \mathrm{E}+00$ & 0.0000 & $0.000 \mathrm{E}+00$ & 0.0000 & $0.000 \mathrm{E}+00$ & 0.0000 & $0.000 \mathrm{E}+00$ & 0.0000 & $8.736 \mathrm{E}-24$ & 0.0000 \\
\hline 99 & $0.000 \mathrm{E}+00$ & 0.0000 & $0.000 \mathrm{E}+00$ & 0.0000 & $0.000 \mathrm{E}+00$ & 0.0000 & $0.000 \mathrm{E}+00$ & 0.0000 & $0.000 \mathrm{E}+00$ & 0.0000 & $0.000 \mathrm{E}+00$ & 0.0000 & $6.215 \mathrm{E}-25$ & 0.0000 \\
\hline 228 & $0.000 \mathrm{E}+00$ & 0.0000 & $0.000 \mathrm{E}+00$ & 0.0000 & $0.000 \mathrm{E}+00$ & 0.0000 & $0.000 \mathrm{E}+00$ & 0.0000 & $0.000 \mathrm{E}+00$ & 0.0000 & $0.000 \mathrm{E}+00$ & 0.0000 & $7.912 \mathrm{E}-07$ & 0.9206 \\
\hline 230 & $0.000 \mathrm{E}+00$ & 0.0000 & $0.000 \mathrm{E}+00$ & 0.0000 & $0.000 \mathrm{E}+00$ & 0.0000 & $0.000 \mathrm{E}+00$ & 0.0000 & $0.000 \mathrm{E}+00$ & 0.0000 & $0.000 \mathrm{E}+00$ & 0.0000 & $2.327 \mathrm{E}-09$ & 0.0027 \\
\hline 232 & $0.000 \mathrm{E}+00$ & 0.0000 & $0.000 \mathrm{E}+00$ & 0.0000 & $0.000 \mathrm{E}+00$ & 0.0000 & $0.000 \mathrm{E}+00$ & 0.0000 & $0.000 \mathrm{E}+00$ & 0.0000 & $0.000 \mathrm{E}+00$ & 0.0000 & $5.638 \mathrm{E}-08$ & 0.0656 \\
\hline & $0.000 \mathrm{E}+00$ & 0.0000 & $0.000 \mathrm{E}+00$ & 0.0000 & $0.000 \mathrm{E}+00$ & 0.0000 & $0.000 \mathrm{E}+00$ & 0.0000 & $0.000 \mathrm{E}+00$ & 0.0000 & $0.000 \mathrm{E}+00$ & 0.0000 & $2.608 \mathrm{E}-14$ & 0.0000 \\
\hline 35 & $0.000 \mathrm{E}+00$ & 0.0000 & $0.000 \mathrm{E}+00$ & 0.0000 & $0.000 \mathrm{E}+00$ & 0.0000 & $0.000 \mathrm{E}+00$ & 0.0000 & $0.000 \mathrm{E}+00$ & 0.0000 & $0.000 \mathrm{E}+00$ & 0.0000 & $1.682 \mathrm{E}-14$ & 0.0000 \\
\hline 38 & $0.000 \mathrm{E}+00$ & 0.0000 & $0.000 \mathrm{E}+00$ & 0.0000 & $0.000 \mathrm{E}+00$ & 0.0000 & $0.000 \mathrm{E}+00$ & 0.0000 & $0.000 \mathrm{E}+00$ & 0.0000 & $0.000 \mathrm{E}+00$ & 0.0000 & $4.678 \mathrm{E}-09$ & 0.0054 \\
\hline & $0.000 \mathrm{E}+00$ & 0.0000 & $0.000 \mathrm{E}+00$ & 0.0000 & $0.000 \mathrm{E}+00$ & 0.0000 & $0.000 \mathrm{E}+00$ & 0.0000 & $0.000 \mathrm{E}+00$ & 0.0000 & $0.000 E+00$ & 000 & -07 & 1.0000 \\
\hline
\end{tabular}

* Sum of all water independent and dependent pathways. 
RESRAD, Version 6.5

mmary : RESRAD Parameters for U-Landfill Outdoor Worker Forward Run

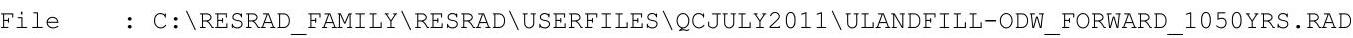

Total Dose Contributions TDOSE (i,p,t) for Individual Radionuclides (i) and Pathways (p) As mrem/yr and Fraction of Total Dose At $t=2.500 \mathrm{E}+01$ years

Water Independent Pathways (Inhalation excludes radon)

\begin{tabular}{|c|c|c|c|c|c|c|c|c|c|c|c|c|c|c|}
\hline \multirow{2}{*}{ Nuclide } & \multicolumn{2}{|c|}{ Ground } & \multicolumn{2}{|c|}{ Inhalation } & \multicolumn{2}{|c|}{ Radon } & \multicolumn{2}{|c|}{ Plant } & \multicolumn{2}{|c|}{ Meat } & \multicolumn{2}{|c|}{ Milk } & \multicolumn{2}{|c|}{ Soil } \\
\hline & mrem/yr & fract. & mrem/yr & fract. & mrem/yr & fract. & mrem/yr & fract. & mrem/yr & fract. & mrem/yr & fract. & mrem/yr & fract. \\
\hline-241 & $7.224 \mathrm{E}-17$ & 0.0000 & $0.000 \mathrm{E}+00$ & 0.0000 & $0.000 \mathrm{E}+00$ & 0.0000 & $0.000 \mathrm{E}+00$ & 0.0000 & $0.000 \mathrm{E}+00$ & 0.0000 & $0.000 \mathrm{E}+00$ & 0.0000 & $0.000 \mathrm{E}+00$ & 0.0000 \\
\hline-137 & $3.393 E-09$ & 0.0022 & $0.000 \mathrm{E}+00$ & 0.0000 & $0.000 \mathrm{E}+00$ & 0.0000 & $0.000 \mathrm{E}+00$ & 0.0000 & $0.000 \mathrm{E}+00$ & 0.0000 & $0.000 \mathrm{E}+00$ & 0.0000 & $0.000 \mathrm{E}+00$ & 0.0000 \\
\hline-237 & $1.402 \mathrm{E}-12$ & 0.0000 & $0.000 \mathrm{E}+00$ & 0.0000 & $0.000 \mathrm{E}+00$ & 0.0000 & $0.000 \mathrm{E}+00$ & 0.0000 & $0.000 \mathrm{E}+00$ & 0.0000 & $0.000 \mathrm{E}+00$ & 0.0000 & $0.000 \mathrm{E}+00$ & 0.0000 \\
\hline-238 & $4.782 \mathrm{E}-17$ & 0.0000 & $0.000 \mathrm{E}+00$ & 0.0000 & $0.000 \mathrm{E}+00$ & 0.0000 & $0.000 \mathrm{E}+00$ & 0.0000 & $0.000 \mathrm{E}+00$ & 0.0000 & $0.000 \mathrm{E}+00$ & 0.0000 & $0.000 \mathrm{E}+00$ & 0.0000 \\
\hline-239 & $1.192 \mathrm{E}-16$ & 0.0000 & $0.000 \mathrm{E}+00$ & 0.0000 & $0.000 \mathrm{E}+00$ & 0.0000 & $0.000 \mathrm{E}+00$ & 0.0000 & $0.000 \mathrm{E}+00$ & 0.0000 & $0.000 \mathrm{E}+00$ & 0.0000 & $0.000 \mathrm{E}+00$ & 0.0000 \\
\hline-240 & $2.888 \mathrm{E}-21$ & 0.0000 & $0.000 \mathrm{E}+00$ & 0.0000 & $0.000 \mathrm{E}+00$ & 0.0000 & $0.000 \mathrm{E}+00$ & 0.0000 & $0.000 \mathrm{E}+00$ & 0.0000 & $0.000 \mathrm{E}+00$ & 0.0000 & $0.000 \mathrm{E}+00$ & 0.0000 \\
\hline 99 & $8.680 \mathrm{E}-25$ & 0.0000 & $0.000 \mathrm{E}+00$ & 0.0000 & $0.000 \mathrm{E}+00$ & 0.0000 & $0.000 \mathrm{E}+00$ & 0.0000 & $0.000 \mathrm{E}+00$ & 0.0000 & $0.000 \mathrm{E}+00$ & 0.0000 & $0.000 \mathrm{E}+00$ & 0.0000 \\
\hline-228 & 1. $528 \mathrm{E}-10$ & 0.0001 & $0.000 \mathrm{E}+00$ & 0.0000 & $0.000 \mathrm{E}+00$ & 0.0000 & $0.000 \mathrm{E}+00$ & 0.0000 & $0.000 \mathrm{E}+00$ & 0.0000 & $0.000 \mathrm{E}+00$ & 0.0000 & $0.000 \mathrm{E}+00$ & 0.0000 \\
\hline-230 & $4.644 \mathrm{E}-08$ & 0.0304 & $0.000 \mathrm{E}+00$ & 0.0000 & $0.000 \mathrm{E}+00$ & 0.0000 & $0.000 \mathrm{E}+00$ & 0.0000 & $0.000 \mathrm{E}+00$ & 0.0000 & $0.000 \mathrm{E}+00$ & 0.0000 & $0.000 \mathrm{E}+00$ & 0.0000 \\
\hline-232 & $1.473 E-06$ & 0.9636 & $0.000 \mathrm{E}+00$ & 0.0000 & $0.000 \mathrm{E}+00$ & 0.0000 & $0.000 \mathrm{E}+00$ & 0.0000 & $0.000 \mathrm{E}+00$ & 0.0000 & $0.000 \mathrm{E}+00$ & 0.0000 & $0.000 \mathrm{E}+00$ & 0.0000 \\
\hline 234 & $8.545 E-12$ & 0.0000 & $0.000 \mathrm{E}+00$ & 0.0000 & $0.000 \mathrm{E}+00$ & 0.0000 & $0.000 \mathrm{E}+00$ & 0.0000 & $0.000 \mathrm{E}+00$ & 0.0000 & $0.000 \mathrm{E}+00$ & 0.0000 & $0.000 \mathrm{E}+00$ & 0.0000 \\
\hline 35 & $4.606 \mathrm{E}-14$ & 0.0000 & $0.000 \mathrm{E}+00$ & 0.0000 & $0.000 \mathrm{E}+00$ & 0.0000 & $0.000 \mathrm{E}+00$ & 0.0000 & $0.000 \mathrm{E}+00$ & 0.0000 & $0.000 \mathrm{E}+00$ & 0.0000 & $0.000 \mathrm{E}+00$ & 0.0000 \\
\hline 38 & $5.667 \mathrm{E}-09$ & 0.0037 & $0.000 \mathrm{E}+00$ & 0.0000 & $0.000 \mathrm{E}+00$ & 0.0000 & $0.000 \mathrm{E}+00$ & 0.0000 & $0.000 \mathrm{E}+00$ & 0.0000 & $0.000 \mathrm{E}+00$ & 0.0000 & $0.000 \mathrm{E}+00$ & 0.0000 \\
\hline & $1.529 \mathrm{E}-06$ & 1.0000 & $0.000 \mathrm{E}+00$ & 0.0000 & $0.000 \mathrm{E}+00$ & 0.0000 & $0.000 \mathrm{E}+00$ & 0.0000 & $0.000 \mathrm{E}+00$ & 0.0000 & $0.000 \mathrm{E}+00$ & 0.0000 & $0.000 \mathrm{E}+00$ & 0.0000 \\
\hline
\end{tabular}

Total Dose Contributions TDOSE(i,p,t) for Individual Radionuclides (i) and Pathways (p) As mrem/yr and Fraction of Total Dose At $t=2.500 \mathrm{E}+01$ years

Water Dependent Pathways

\begin{tabular}{|c|c|c|c|c|c|c|c|c|c|c|c|c|c|c|}
\hline \multirow{2}{*}{$\begin{array}{l}\text { Radio- } \\
\text { Nuclide }\end{array}$} & \multicolumn{2}{|c|}{ Water } & \multicolumn{2}{|c|}{ Fish } & \multicolumn{2}{|c|}{ Radon } & \multicolumn{2}{|c|}{ Plant } & \multicolumn{2}{|c|}{ Meat } & \multicolumn{2}{|c|}{ Milk } & \multicolumn{2}{|c|}{ All Pathways* } \\
\hline & mrem/yr & fract. & mrem/yr & fract. & mrem/yr & fract. & mrem/yr & fract. & mrem/yr & fract. & mrem/yr & fract. & mrem/yr & fract. \\
\hline 241 & $0.000 \mathrm{E}+00$ & 0.0000 & $0.000 \mathrm{E}+00$ & 0.0000 & $0.000 \mathrm{E}+00$ & 0.0000 & $0.000 \mathrm{E}+00$ & 0.0000 & $0.000 \mathrm{E}+00$ & 0.0000 & $0.000 \mathrm{E}+00$ & 0.0000 & $7.224 \mathrm{E}-17$ & 0.0000 \\
\hline-137 & $0.000 \mathrm{E}+00$ & 0.0000 & $0.000 \mathrm{E}+00$ & 0.0000 & $0.000 \mathrm{E}+00$ & 0.0000 & $0.000 \mathrm{E}+00$ & 0.0000 & $0.000 \mathrm{E}+00$ & 0.0000 & $0.000 \mathrm{E}+00$ & 0.0000 & $3.393 \mathrm{E}-09$ & 0.0022 \\
\hline-237 & $0.000 \mathrm{E}+00$ & 0.0000 & $0.000 \mathrm{E}+00$ & 0.0000 & $0.000 \mathrm{E}+00$ & 0.0000 & $0.000 \mathrm{E}+00$ & 0.0000 & $0.000 \mathrm{E}+00$ & 0.0000 & $0.000 \mathrm{E}+00$ & 0.0000 & $1.402 \mathrm{E}-12$ & 0.0000 \\
\hline-238 & $0.000 \mathrm{E}+00$ & 0.0000 & $0.000 \mathrm{E}+00$ & 0.0000 & $0.000 \mathrm{E}+00$ & 0.0000 & $0.000 \mathrm{E}+00$ & 0.0000 & $0.000 \mathrm{E}+00$ & 0.0000 & $0.000 \mathrm{E}+00$ & 0.0000 & $4.782 \mathrm{E}-17$ & 0.0000 \\
\hline-239 & $0.000 \mathrm{E}+00$ & 0.0000 & $0.000 \mathrm{E}+00$ & 0.0000 & $0.000 \mathrm{E}+00$ & 0.0000 & $0.000 \mathrm{E}+00$ & 0.0000 & $0.000 \mathrm{E}+00$ & 0.0000 & $0.000 E+00$ & 0.0000 & $1.192 \mathrm{E}-16$ & 0.0000 \\
\hline-240 & $0.000 \mathrm{E}+00$ & 0.0000 & $0.000 \mathrm{E}+00$ & 0.0000 & $0.000 \mathrm{E}+00$ & 0.0000 & $0.000 \mathrm{E}+00$ & 0.0000 & $0.000 \mathrm{E}+00$ & 0.0000 & $0.000 E+00$ & 0.0000 & $2.888 E-21$ & 0.0000 \\
\hline-99 & $0.000 \mathrm{E}+00$ & 0.0000 & $0.000 \mathrm{E}+00$ & 0.0000 & $0.000 \mathrm{E}+00$ & 0.0000 & $0.000 \mathrm{E}+00$ & 0.0000 & $0.000 \mathrm{E}+00$ & 0.0000 & $0.000 \mathrm{E}+00$ & 0.0000 & $8.680 \mathrm{E}-25$ & 0.0000 \\
\hline-228 & $0.000 \mathrm{E}+00$ & 0.0000 & $0.000 \mathrm{E}+00$ & 0.0000 & $0.000 \mathrm{E}+00$ & 0.0000 & $0.000 \mathrm{E}+00$ & 0.0000 & $0.000 \mathrm{E}+00$ & 0.0000 & $0.000 \mathrm{E}+00$ & 0.0000 & $1.528 \mathrm{E}-10$ & 0.0001 \\
\hline-230 & $0.000 \mathrm{E}+00$ & 0.0000 & $0.000 \mathrm{E}+00$ & 0.0000 & $0.000 \mathrm{E}+00$ & 0.0000 & $0.000 \mathrm{E}+00$ & 0.0000 & $0.000 \mathrm{E}+00$ & 0.0000 & $0.000 E+00$ & 0.0000 & $4.644 \mathrm{E}-08$ & 0.0304 \\
\hline 232 & $0.000 \mathrm{E}+00$ & 0.0000 & $0.000 \mathrm{E}+00$ & 0.0000 & $0.000 \mathrm{E}+00$ & 0.0000 & $0.000 \mathrm{E}+00$ & 0.0000 & $0.000 \mathrm{E}+00$ & 0.0000 & $0.000 \mathrm{E}+00$ & 0.0000 & $1.473 E-06$ & 0.9636 \\
\hline 34 & $0.000 \mathrm{E}+00$ & 0.0000 & $0.000 \mathrm{E}+00$ & 0.0000 & $0.000 \mathrm{E}+00$ & 0.0000 & $0.000 \mathrm{E}+00$ & 0.0000 & $0.000 \mathrm{E}+00$ & 0.0000 & $0.000 \mathrm{E}+00$ & 0.0000 & $8.545 \mathrm{E}-12$ & 0.0000 \\
\hline 35 & $0.000 \mathrm{E}+00$ & 0.0000 & $0.000 \mathrm{E}+00$ & 0.0000 & $0.000 \mathrm{E}+00$ & 0.0000 & $0.000 \mathrm{E}+00$ & 0.0000 & $0.000 \mathrm{E}+00$ & 0.0000 & $0.000 \mathrm{E}+00$ & 0.0000 & $4.606 \mathrm{E}-14$ & 0.0000 \\
\hline 38 & $0.000 \mathrm{E}+00$ & 0.0000 & $0.000 \mathrm{E}+00$ & 0.0000 & $0.000 \mathrm{E}+00$ & 0.0000 & $0.000 \mathrm{E}+00$ & 0.0000 & $0.000 \mathrm{E}+00$ & 0.0000 & $0.000 \mathrm{E}+00$ & 0.0000 & $5.667 \mathrm{E}-09$ & 0.0037 \\
\hline & $0.000 \mathrm{E}+00$ & 0.0000 & $0.000 \mathrm{E}+00$ & 0.0000 & $0.000 \mathrm{E}+00$ & 0.0000 & $0.000 \mathrm{E}+00$ & 0.0000 & $0.000 \mathrm{E}+00$ & 0.0000 & $0.000 \mathrm{E}+00$ & 0.0000 & $9 \mathrm{E}-06$ & 1. \\
\hline
\end{tabular}

* Sum of all water independent and dependent pathways. 
RESRAD, Version 6.5

mmary : RESRAD Parameters for U-Landfill Outdoor Worker Forward Run

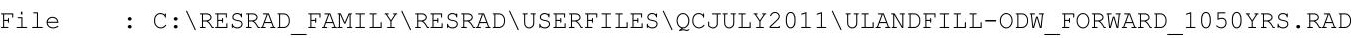

Total Dose Contributions TDOSE (i,p,t) for Individual Radionuclides (i) and Pathways (p) As mrem/yr and Fraction of Total Dose At $t=5.000 \mathrm{E}+01$ years

Water Independent Pathways (Inhalation excludes radon)

\begin{tabular}{|c|c|c|c|c|c|c|c|c|c|c|c|c|c|c|}
\hline \multirow{2}{*}{ Nuclide } & \multicolumn{2}{|c|}{ Ground } & \multicolumn{2}{|c|}{ Inhalation } & \multicolumn{2}{|c|}{ Radon } & \multicolumn{2}{|c|}{ Plant } & \multicolumn{2}{|c|}{ Meat } & \multicolumn{2}{|c|}{ Milk } & \multicolumn{2}{|c|}{ Soil } \\
\hline & mrem/yr & fract. & mrem/yr & fract. & mrem/yr & fract. & mrem/yr & fract. & mrem/yr & fract. & mrem/yr & fract. & mrem/yr & fract. \\
\hline-241 & $1.836 \mathrm{E}-16$ & 0.0000 & $0.000 \mathrm{E}+00$ & 0.0000 & $0.000 \mathrm{E}+00$ & 0.0000 & $0.000 \mathrm{E}+00$ & 0.0000 & $0.000 \mathrm{E}+00$ & 0.0000 & $0.000 \mathrm{E}+00$ & 0.0000 & $0.000 \mathrm{E}+00$ & 0.0000 \\
\hline-137 & $2.350 E-09$ & 0.0012 & $0.000 \mathrm{E}+00$ & 0.0000 & $0.000 \mathrm{E}+00$ & 0.0000 & $0.000 \mathrm{E}+00$ & 0.0000 & $0.000 \mathrm{E}+00$ & 0.0000 & $0.000 \mathrm{E}+00$ & 0.0000 & $0.000 \mathrm{E}+00$ & 0.0000 \\
\hline-237 & $1.835 \mathrm{E}-12$ & 0.0000 & $0.000 \mathrm{E}+00$ & 0.0000 & $0.000 \mathrm{E}+00$ & 0.0000 & $0.000 \mathrm{E}+00$ & 0.0000 & $0.000 \mathrm{E}+00$ & 0.0000 & $0.000 \mathrm{E}+00$ & 0.0000 & $0.000 \mathrm{E}+00$ & 0.0000 \\
\hline-238 & $4.197 \mathrm{E}-16$ & 0.0000 & $0.000 \mathrm{E}+00$ & 0.0000 & $0.000 \mathrm{E}+00$ & 0.0000 & $0.000 \mathrm{E}+00$ & 0.0000 & $0.000 \mathrm{E}+00$ & 0.0000 & $0.000 \mathrm{E}+00$ & 0.0000 & $0.000 \mathrm{E}+00$ & 0.0000 \\
\hline-239 & $1.607 \mathrm{E}-16$ & 0.0000 & $0.000 \mathrm{E}+00$ & 0.0000 & $0.000 \mathrm{E}+00$ & 0.0000 & $0.000 \mathrm{E}+00$ & 0.0000 & $0.000 \mathrm{E}+00$ & 0.0000 & $0.000 \mathrm{E}+00$ & 0.0000 & $0.000 \mathrm{E}+00$ & 0.0000 \\
\hline-240 & $1.973 \mathrm{E}-20$ & 0.0000 & $0.000 \mathrm{E}+00$ & 0.0000 & $0.000 \mathrm{E}+00$ & 0.0000 & $0.000 \mathrm{E}+00$ & 0.0000 & $0.000 \mathrm{E}+00$ & 0.0000 & $0.000 \mathrm{E}+00$ & 0.0000 & $0.000 \mathrm{E}+00$ & 0.0000 \\
\hline 99 & $1.229 \mathrm{E}-24$ & 0.0000 & $0.000 \mathrm{E}+00$ & 0.0000 & $0.000 \mathrm{E}+00$ & 0.0000 & $0.000 \mathrm{E}+00$ & 0.0000 & $0.000 \mathrm{E}+00$ & 0.0000 & $0.000 \mathrm{E}+00$ & 0.0000 & $0.000 \mathrm{E}+00$ & 0.0000 \\
\hline-228 & $2.065 E-14$ & 0.0000 & $0.000 \mathrm{E}+00$ & 0.0000 & $0.000 \mathrm{E}+00$ & 0.0000 & $0.000 \mathrm{E}+00$ & 0.0000 & $0.000 \mathrm{E}+00$ & 0.0000 & $0.000 \mathrm{E}+00$ & 0.0000 & $0.000 \mathrm{E}+00$ & 0.0000 \\
\hline-230 & $1.087 \mathrm{E}-07$ & 0.0558 & $0.000 \mathrm{E}+00$ & 0.0000 & $0.000 \mathrm{E}+00$ & 0.0000 & $0.000 \mathrm{E}+00$ & 0.0000 & $0.000 \mathrm{E}+00$ & 0.0000 & $0.000 \mathrm{E}+00$ & 0.0000 & $0.000 \mathrm{E}+00$ & 0.0000 \\
\hline-232 & $1.832 \mathrm{E}-06$ & 0.9395 & $0.000 \mathrm{E}+00$ & 0.0000 & $0.000 \mathrm{E}+00$ & 0.0000 & $0.000 \mathrm{E}+00$ & 0.0000 & $0.000 \mathrm{E}+00$ & 0.0000 & $0.000 \mathrm{E}+00$ & 0.0000 & $0.000 \mathrm{E}+00$ & 0.0000 \\
\hline 234 & $3.968 E-11$ & 0.0000 & $0.000 \mathrm{E}+00$ & 0.0000 & $0.000 \mathrm{E}+00$ & 0.0000 & $0.000 \mathrm{E}+00$ & 0.0000 & $0.000 \mathrm{E}+00$ & 0.0000 & $0.000 \mathrm{E}+00$ & 0.0000 & $0.000 \mathrm{E}+00$ & 0.0000 \\
\hline 35 & 1. $227 \mathrm{E}-13$ & 0.0000 & $0.000 \mathrm{E}+00$ & 0.0000 & $0.000 \mathrm{E}+00$ & 0.0000 & $0.000 \mathrm{E}+00$ & 0.0000 & $0.000 \mathrm{E}+00$ & 0.0000 & $0.000 \mathrm{E}+00$ & 0.0000 & $0.000 \mathrm{E}+00$ & 0.0000 \\
\hline 38 & $6.920 E-09$ & 0.0035 & $0.000 \mathrm{E}+00$ & 0.0000 & $0.000 \mathrm{E}+00$ & 0.0000 & $0.000 \mathrm{E}+00$ & 0.0000 & $0.000 \mathrm{E}+00$ & 0.0000 & $0.000 \mathrm{E}+00$ & 0.0000 & $0.000 \mathrm{E}+00$ & 0.0000 \\
\hline & $1.950 \mathrm{E}-06$ & 1.0000 & $0.000 \mathrm{E}+00$ & 0.0000 & $0.000 \mathrm{E}+00$ & 0.0000 & $0.000 \mathrm{E}+00$ & 0.0000 & $0.000 \mathrm{E}+00$ & 0.0000 & $0.000 \mathrm{E}+00$ & 0.0000 & $0.000 \mathrm{E}+00$ & 0.0000 \\
\hline
\end{tabular}

Total Dose Contributions TDOSE(i,p,t) for Individual Radionuclides (i) and Pathways (p) As mrem/yr and Fraction of Total Dose At $t=5.000 \mathrm{E}+01$ years

Water Dependent Pathways

\begin{tabular}{|c|c|c|c|c|c|c|c|c|c|c|c|c|c|c|}
\hline & \multicolumn{2}{|c|}{ Water } & \multicolumn{2}{|c|}{ Fish } & \multicolumn{2}{|c|}{ Radon } & \multicolumn{2}{|c|}{ Plant } & \multicolumn{2}{|c|}{ Meat } & \multicolumn{2}{|c|}{ Milk } & \multicolumn{2}{|c|}{ All Pathways* } \\
\hline clide & mrem/yr & fract. & mrem/yr & fract. & mrem/yr & fract. & mrem/yr & fract. & mrem/yr & fract. & mrem/yr & fract. & mrem/yr & fract. \\
\hline-241 & $0.000 \mathrm{E}+00$ & 0.0000 & $0.000 \mathrm{E}+00$ & 0.0000 & $0.000 \mathrm{E}+00$ & 0.0000 & $0.000 \mathrm{E}+00$ & 0.0000 & $0.000 \mathrm{E}+00$ & 0.0000 & $0.000 \mathrm{E}+00$ & 0.0000 & $1.836 \mathrm{E}-16$ & 0.0000 \\
\hline-137 & $0.000 \mathrm{E}+00$ & 0.0000 & $0.000 \mathrm{E}+00$ & 0.0000 & $0.000 \mathrm{E}+00$ & 0.0000 & $0.000 \mathrm{E}+00$ & 0.0000 & $0.000 \mathrm{E}+00$ & 0.0000 & $0.000 \mathrm{E}+00$ & 0.0000 & $2.350 \mathrm{E}-09$ & 0.0012 \\
\hline-237 & $0.000 \mathrm{E}+00$ & 0.0000 & $0.000 \mathrm{E}+00$ & 0.0000 & $0.000 \mathrm{E}+00$ & 0.0000 & $0.000 \mathrm{E}+00$ & 0.0000 & $0.000 \mathrm{E}+00$ & 0.0000 & $0.000 \mathrm{E}+00$ & 0.0000 & $1.835 \mathrm{E}-12$ & 0.0000 \\
\hline 238 & $0.000 \mathrm{E}+00$ & 0.0000 & $0.000 \mathrm{E}+00$ & 0.0000 & $0.000 \mathrm{E}+00$ & 0.0000 & $0.000 \mathrm{E}+00$ & 0.0000 & $0.000 \mathrm{E}+00$ & 0.0000 & $0.000 \mathrm{E}+00$ & 0.0000 & $4.197 \mathrm{E}-16$ & 0.0000 \\
\hline 239 & $0.000 \mathrm{E}+00$ & 0.0000 & $0.000 \mathrm{E}+00$ & 0.0000 & $0.000 \mathrm{E}+00$ & 0.0000 & $0.000 \mathrm{E}+00$ & 0.0000 & $0.000 \mathrm{E}+00$ & 0.0000 & $0.000 \mathrm{E}+00$ & 0.0000 & $1.607 \mathrm{E}-16$ & 0.0000 \\
\hline 240 & $0.000 \mathrm{E}+00$ & 0.0000 & $0.000 \mathrm{E}+00$ & 0.0000 & $0.000 \mathrm{E}+00$ & 0.0000 & $0.000 \mathrm{E}+00$ & 0.0000 & $0.000 \mathrm{E}+00$ & 0.0000 & $0.000 \mathrm{E}+00$ & 0.0000 & $1.973 \mathrm{E}-20$ & 0.0000 \\
\hline 99 & $0.000 \mathrm{E}+00$ & 0.0000 & $0.000 \mathrm{E}+00$ & 0.0000 & $0.000 \mathrm{E}+00$ & 0.0000 & $0.000 \mathrm{E}+00$ & 0.0000 & $0.000 \mathrm{E}+00$ & 0.0000 & $0.000 \mathrm{E}+00$ & 0.0000 & $1.229 \mathrm{E}-24$ & 0.0000 \\
\hline 228 & $0.000 \mathrm{E}+00$ & 0.0000 & $0.000 \mathrm{E}+00$ & 0.0000 & $0.000 \mathrm{E}+00$ & 0.0000 & $0.000 \mathrm{E}+00$ & 0.0000 & $0.000 \mathrm{E}+00$ & 0.0000 & $0.000 \mathrm{E}+00$ & 0.0000 & $2.065 E-14$ & 0.0000 \\
\hline 230 & $0.000 \mathrm{E}+00$ & 0.0000 & $0.000 \mathrm{E}+00$ & 0.0000 & $0.000 \mathrm{E}+00$ & 0.0000 & $0.000 \mathrm{E}+00$ & 0.0000 & $0.000 \mathrm{E}+00$ & 0.0000 & $0.000 \mathrm{E}+00$ & 0.0000 & $1.087 \mathrm{E}-07$ & 0.0558 \\
\hline 232 & $0.000 \mathrm{E}+00$ & 0.0000 & $0.000 \mathrm{E}+00$ & 0.0000 & $0.000 \mathrm{E}+00$ & 0.0000 & $0.000 \mathrm{E}+00$ & 0.0000 & $0.000 \mathrm{E}+00$ & 0.0000 & $0.000 \mathrm{E}+00$ & 0.0000 & $1.832 \mathrm{E}-06$ & 0.9395 \\
\hline & $0.000 \mathrm{E}+00$ & 0.0000 & $0.000 \mathrm{E}+00$ & 0.0000 & $0.000 \mathrm{E}+00$ & 0.0000 & $0.000 \mathrm{E}+00$ & 0.0000 & $0.000 \mathrm{E}+00$ & 0.0000 & $0.000 \mathrm{E}+00$ & 0.0000 & $3.968 \mathrm{E}-11$ & 0.0000 \\
\hline 35 & $0.000 \mathrm{E}+00$ & 0.0000 & $0.000 \mathrm{E}+00$ & 0.0000 & $0.000 \mathrm{E}+00$ & 0.0000 & $0.000 \mathrm{E}+00$ & 0.0000 & $0.000 \mathrm{E}+00$ & 0.0000 & $0.000 \mathrm{E}+00$ & 0.0000 & $1.227 \mathrm{E}-13$ & 0.0000 \\
\hline 38 & $0.000 \mathrm{E}+00$ & 0.0000 & $0.000 \mathrm{E}+00$ & 0.0000 & $0.000 \mathrm{E}+00$ & 0.0000 & $0.000 \mathrm{E}+00$ & 0.0000 & $0.000 \mathrm{E}+00$ & 0.0000 & $0.000 \mathrm{E}+00$ & 0.0000 & $6.920 \mathrm{E}-09$ & 0.0035 \\
\hline & $0.000 \mathrm{E}+00$ & 0.0000 & $0.000 \mathrm{E}+00$ & 0.0000 & $0.000 \mathrm{E}+00$ & 0.0000 & $0.000 \mathrm{E}+00$ & 0.0000 & $0.000 \mathrm{E}+00$ & 0.0000 & $0.000 \mathrm{E}+00$ & 000 & -06 & 1.0000 \\
\hline
\end{tabular}

* Sum of all water independent and dependent pathways. 
RESRAD, Version 6.5

mmary : RESRAD Parameters for U-Landfill Outdoor Worker Forward Run

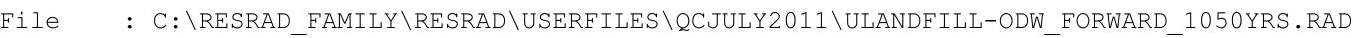

Total Dose Contributions TDOSE (i,p,t) for Individual Radionuclides (i) and Pathways (p) As mrem/yr and Fraction of Total Dose At $t=1.000 \mathrm{E}+02$ years

Water Independent Pathways (Inhalation excludes radon)

\begin{tabular}{|c|c|c|c|c|c|c|c|c|c|c|c|c|c|c|}
\hline \multirow{2}{*}{ Nuclide } & \multicolumn{2}{|c|}{ Ground } & \multicolumn{2}{|c|}{ Inhalation } & \multicolumn{2}{|c|}{ Radon } & \multicolumn{2}{|c|}{ Plant } & \multicolumn{2}{|c|}{ Meat } & \multicolumn{2}{|c|}{ Milk } & \multicolumn{2}{|c|}{ Soil } \\
\hline & mrem/yr & fract. & mrem/yr & fract. & mrem/yr & fract. & mrem/yr & fract. & mrem/yr & fract. & mrem/yr & fract. & mrem/yr & fract. \\
\hline-241 & $6.026 \mathrm{E}-16$ & 0.0000 & $0.000 \mathrm{E}+00$ & 0.0000 & $0.000 \mathrm{E}+00$ & 0.0000 & $0.000 \mathrm{E}+00$ & 0.0000 & $0.000 \mathrm{E}+00$ & 0.0000 & $0.000 \mathrm{E}+00$ & 0.0000 & $0.000 \mathrm{E}+00$ & 0.0000 \\
\hline-137 & $1.128 E-09$ & 0.0004 & $0.000 \mathrm{E}+00$ & 0.0000 & $0.000 \mathrm{E}+00$ & 0.0000 & $0.000 \mathrm{E}+00$ & 0.0000 & $0.000 \mathrm{E}+00$ & 0.0000 & $0.000 \mathrm{E}+00$ & 0.0000 & $0.000 \mathrm{E}+00$ & 0.0000 \\
\hline-237 & $3.151 \mathrm{E}-12$ & 0.0000 & $0.000 \mathrm{E}+00$ & 0.0000 & $0.000 \mathrm{E}+00$ & 0.0000 & $0.000 \mathrm{E}+00$ & 0.0000 & $0.000 \mathrm{E}+00$ & 0.0000 & $0.000 \mathrm{E}+00$ & 0.0000 & $0.000 \mathrm{E}+00$ & 0.0000 \\
\hline-238 & $4.245 E-15$ & 0.0000 & $0.000 \mathrm{E}+00$ & 0.0000 & $0.000 \mathrm{E}+00$ & 0.0000 & $0.000 \mathrm{E}+00$ & 0.0000 & $0.000 \mathrm{E}+00$ & 0.0000 & $0.000 \mathrm{E}+00$ & 0.0000 & $0.000 \mathrm{E}+00$ & 0.0000 \\
\hline-239 & $2.920 E-16$ & 0.0000 & $0.000 \mathrm{E}+00$ & 0.0000 & $0.000 \mathrm{E}+00$ & 0.0000 & $0.000 \mathrm{E}+00$ & 0.0000 & $0.000 \mathrm{E}+00$ & 0.0000 & $0.000 \mathrm{E}+00$ & 0.0000 & $0.000 \mathrm{E}+00$ & 0.0000 \\
\hline-240 & 1. $313 \mathrm{E}-19$ & 0.0000 & $0.000 \mathrm{E}+00$ & 0.0000 & $0.000 \mathrm{E}+00$ & 0.0000 & $0.000 \mathrm{E}+00$ & 0.0000 & $0.000 \mathrm{E}+00$ & 0.0000 & $0.000 \mathrm{E}+00$ & 0.0000 & $0.000 \mathrm{E}+00$ & 0.0000 \\
\hline 99 & $2.465 E-24$ & 0.0000 & $0.000 \mathrm{E}+00$ & 0.0000 & $0.000 \mathrm{E}+00$ & 0.0000 & $0.000 \mathrm{E}+00$ & 0.0000 & $0.000 \mathrm{E}+00$ & 0.0000 & $0.000 \mathrm{E}+00$ & 0.0000 & $0.000 \mathrm{E}+00$ & 0.0000 \\
\hline-228 & $3.775 E-22$ & 0.0000 & $0.000 \mathrm{E}+00$ & 0.0000 & $0.000 \mathrm{E}+00$ & 0.0000 & $0.000 \mathrm{E}+00$ & 0.0000 & $0.000 \mathrm{E}+00$ & 0.0000 & $0.000 \mathrm{E}+00$ & 0.0000 & $0.000 \mathrm{E}+00$ & 0.0000 \\
\hline-230 & $3.024 \mathrm{E}-07$ & 0.1082 & $0.000 \mathrm{E}+00$ & 0.0000 & $0.000 \mathrm{E}+00$ & 0.0000 & $0.000 \mathrm{E}+00$ & 0.0000 & $0.000 \mathrm{E}+00$ & 0.0000 & $0.000 \mathrm{E}+00$ & 0.0000 & $0.000 \mathrm{E}+00$ & 0.0000 \\
\hline-232 & $2.479 E-06$ & 0.8876 & $0.000 \mathrm{E}+00$ & 0.0000 & $0.000 \mathrm{E}+00$ & 0.0000 & $0.000 \mathrm{E}+00$ & 0.0000 & $0.000 \mathrm{E}+00$ & 0.0000 & $0.000 \mathrm{E}+00$ & 0.0000 & $0.000 \mathrm{E}+00$ & 0.0000 \\
\hline 234 & $2.204 \mathrm{E}-10$ & 0.0001 & $0.000 \mathrm{E}+00$ & 0.0000 & $0.000 \mathrm{E}+00$ & 0.0000 & $0.000 \mathrm{E}+00$ & 0.0000 & $0.000 \mathrm{E}+00$ & 0.0000 & $0.000 \mathrm{E}+00$ & 0.0000 & $0.000 \mathrm{E}+00$ & 0.0000 \\
\hline 35 & $4.503 E-13$ & 0.0000 & $0.000 \mathrm{E}+00$ & 0.0000 & $0.000 \mathrm{E}+00$ & 0.0000 & $0.000 \mathrm{E}+00$ & 0.0000 & $0.000 \mathrm{E}+00$ & 0.0000 & $0.000 \mathrm{E}+00$ & 0.0000 & $0.000 \mathrm{E}+00$ & 0.0000 \\
\hline 38 & $1.032 \mathrm{E}-08$ & 0.0037 & $0.000 \mathrm{E}+00$ & 0.0000 & $0.000 \mathrm{E}+00$ & 0.0000 & $0.000 \mathrm{E}+00$ & 0.0000 & $0.000 \mathrm{E}+00$ & 0.0000 & $0.000 \mathrm{E}+00$ & 0.0000 & $0.000 \mathrm{E}+00$ & 0.0000 \\
\hline & $2.793 E-06$ & 1.0000 & $0.000 \mathrm{E}+00$ & 0.0000 & $0.000 \mathrm{E}+00$ & 0.0000 & $0.000 \mathrm{E}+00$ & 0.0000 & $0.000 \mathrm{E}+00$ & 0.0000 & $0.000 \mathrm{E}+00$ & 0.0000 & $0.000 \mathrm{E}+00$ & 0.0000 \\
\hline
\end{tabular}

Total Dose Contributions TDOSE(i,p,t) for Individual Radionuclides (i) and Pathways (p) As mrem/yr and Fraction of Total Dose At $t=1.000 \mathrm{E}+02$ years

Water Dependent Pathways

\begin{tabular}{|c|c|c|c|c|c|c|c|c|c|c|c|c|c|c|}
\hline \multirow{2}{*}{$\begin{array}{l}\text { Radio- } \\
\text { Nuclide }\end{array}$} & \multicolumn{2}{|c|}{ Water } & \multicolumn{2}{|c|}{ Fish } & \multicolumn{2}{|c|}{ Radon } & \multicolumn{2}{|c|}{ Plant } & \multicolumn{2}{|c|}{ Meat } & \multicolumn{2}{|c|}{ Milk } & \multicolumn{2}{|c|}{ All Pathways* } \\
\hline & mrem/yr & fract. & mrem/yr & fract. & mrem/yr & fract. & mrem/yr & fract. & mrem/yr & fract. & mrem/yr & fract. & mrem/yr & fract. \\
\hline 241 & $0.000 \mathrm{E}+00$ & 0.0000 & $0.000 \mathrm{E}+00$ & 0.0000 & $0.000 \mathrm{E}+00$ & 0.0000 & $0.000 \mathrm{E}+00$ & 0.0000 & $0.000 \mathrm{E}+00$ & 0.0000 & $0.000 \mathrm{E}+00$ & 0.0000 & $6.026 \mathrm{E}-16$ & 0.0000 \\
\hline-137 & $0.000 \mathrm{E}+00$ & 0.0000 & $0.000 \mathrm{E}+00$ & 0.0000 & $0.000 \mathrm{E}+00$ & 0.0000 & $0.000 \mathrm{E}+00$ & 0.0000 & $0.000 \mathrm{E}+00$ & 0.0000 & $0.000 \mathrm{E}+00$ & 0.0000 & $1.128 \mathrm{E}-09$ & 0.0004 \\
\hline-237 & $0.000 \mathrm{E}+00$ & 0.0000 & $0.000 \mathrm{E}+00$ & 0.0000 & $0.000 \mathrm{E}+00$ & 0.0000 & $0.000 \mathrm{E}+00$ & 0.0000 & $0.000 \mathrm{E}+00$ & 0.0000 & $0.000 \mathrm{E}+00$ & 0.0000 & $3.151 \mathrm{E}-12$ & 0.0000 \\
\hline-238 & $0.000 \mathrm{E}+00$ & 0.0000 & $0.000 \mathrm{E}+00$ & 0.0000 & $0.000 \mathrm{E}+00$ & 0.0000 & $0.000 \mathrm{E}+00$ & 0.0000 & $0.000 \mathrm{E}+00$ & 0.0000 & $0.000 \mathrm{E}+00$ & 0.0000 & $4.245 \mathrm{E}-15$ & 0.0000 \\
\hline-239 & $0.000 \mathrm{E}+00$ & 0.0000 & $0.000 \mathrm{E}+00$ & 0.0000 & $0.000 \mathrm{E}+00$ & 0.0000 & $0.000 \mathrm{E}+00$ & 0.0000 & $0.000 \mathrm{E}+00$ & 0.0000 & $0.000 E+00$ & 0.0000 & $2.920 \mathrm{E}-16$ & 0.0000 \\
\hline-240 & $0.000 \mathrm{E}+00$ & 0.0000 & $0.000 \mathrm{E}+00$ & 0.0000 & $0.000 \mathrm{E}+00$ & 0.0000 & $0.000 \mathrm{E}+00$ & 0.0000 & $0.000 \mathrm{E}+00$ & 0.0000 & $0.000 E+00$ & 0.0000 & $1.313 \mathrm{E}-19$ & 0.0000 \\
\hline 99 & $0.000 \mathrm{E}+00$ & 0.0000 & $0.000 \mathrm{E}+00$ & 0.0000 & $0.000 \mathrm{E}+00$ & 0.0000 & $0.000 \mathrm{E}+00$ & 0.0000 & $0.000 \mathrm{E}+00$ & 0.0000 & $0.000 \mathrm{E}+00$ & 0.0000 & $2.465 E-24$ & 0.0000 \\
\hline-228 & $0.000 \mathrm{E}+00$ & 0.0000 & $0.000 \mathrm{E}+00$ & 0.0000 & $0.000 \mathrm{E}+00$ & 0.0000 & $0.000 \mathrm{E}+00$ & 0.0000 & $0.000 \mathrm{E}+00$ & 0.0000 & $0.000 \mathrm{E}+00$ & 0.0000 & $3.775 E-22$ & 0.0000 \\
\hline-230 & $0.000 \mathrm{E}+00$ & 0.0000 & $0.000 \mathrm{E}+00$ & 0.0000 & $0.000 \mathrm{E}+00$ & 0.0000 & $0.000 \mathrm{E}+00$ & 0.0000 & $0.000 \mathrm{E}+00$ & 0.0000 & $0.000 E+00$ & 0.0000 & $3.024 \mathrm{E}-07$ & 0.1082 \\
\hline 232 & $0.000 \mathrm{E}+00$ & 0.0000 & $0.000 \mathrm{E}+00$ & 0.0000 & $0.000 \mathrm{E}+00$ & 0.0000 & $0.000 \mathrm{E}+00$ & 0.0000 & $0.000 \mathrm{E}+00$ & 0.0000 & $0.000 \mathrm{E}+00$ & 0.0000 & $2.479 E-06$ & 0.8876 \\
\hline 34 & $0.000 \mathrm{E}+00$ & 0.0000 & $0.000 \mathrm{E}+00$ & 0.0000 & $0.000 \mathrm{E}+00$ & 0.0000 & $0.000 \mathrm{E}+00$ & 0.0000 & $0.000 \mathrm{E}+00$ & 0.0000 & $0.000 \mathrm{E}+00$ & 0.0000 & $2.204 \mathrm{E}-10$ & 0.0001 \\
\hline 35 & $0.000 \mathrm{E}+00$ & 0.0000 & $0.000 \mathrm{E}+00$ & 0.0000 & $0.000 \mathrm{E}+00$ & 0.0000 & $0.000 \mathrm{E}+00$ & 0.0000 & $0.000 \mathrm{E}+00$ & 0.0000 & $0.000 \mathrm{E}+00$ & 0.0000 & $4.503 E-13$ & 0.0000 \\
\hline 38 & $0.000 \mathrm{E}+00$ & 0.0000 & $0.000 \mathrm{E}+00$ & 0.0000 & $0.000 \mathrm{E}+00$ & 0.0000 & $0.000 \mathrm{E}+00$ & 0.0000 & $0.000 \mathrm{E}+00$ & 0.0000 & $0.000 \mathrm{E}+00$ & 0.0000 & $1.032 \mathrm{E}-08$ & 0.0037 \\
\hline & $0.000 \mathrm{E}+00$ & 0.0000 & $0.000 \mathrm{E}+00$ & 0.0000 & $0.000 \mathrm{E}+00$ & 0.0000 & $0.000 \mathrm{E}+00$ & 0.0000 & $0.000 \mathrm{E}+00$ & 0.0000 & $0.000 \mathrm{E}+00$ & 0.0000 & $3 E-06$ & 1. \\
\hline
\end{tabular}

* Sum of all water independent and dependent pathways. 
RESRAD, Version 6.5

mmary : RESRAD Parameters for U-Landfill Outdoor Worker Forward Run

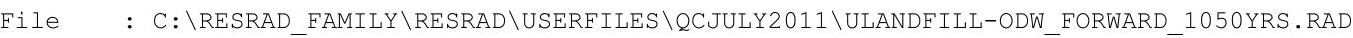

Total Dose Contributions TDOSE (i,p,t) for Individual Radionuclides (i) and Pathways (p) As mrem/yr and Fraction of Total Dose At $t=5.000 \mathrm{E}+02$ years

Water Independent Pathways (Inhalation excludes radon)

\begin{tabular}{|c|c|c|c|c|c|c|c|c|c|c|c|c|c|c|}
\hline \multirow[b]{2}{*}{ Nuclide } & \multicolumn{2}{|c|}{ Ground } & \multicolumn{2}{|c|}{ Inhalation } & \multicolumn{2}{|c|}{ Radon } & \multicolumn{2}{|c|}{ Plant } & \multicolumn{2}{|c|}{ Meat } & \multicolumn{2}{|c|}{ Milk } & \multicolumn{2}{|c|}{ Soil } \\
\hline & mrem/yr & fract. & mrem/yr & fract. & mrem/yr & fract. & mrem/yr & fract. & mrem/yr & fract. & mrem/yr & fract. & mrem/yr & fract. \\
\hline-241 & 1. $668 \mathrm{E}-13$ & 0.0000 & $0.000 \mathrm{E}+00$ & 0.0000 & $0.000 \mathrm{E}+00$ & 0.0000 & $0.000 \mathrm{E}+00$ & 0.0000 & $0.000 \mathrm{E}+00$ & 0.0000 & $0.000 \mathrm{E}+00$ & 0.0000 & $0.000 \mathrm{E}+00$ & 0.0000 \\
\hline-137 & $3.168 \mathrm{E}-12$ & 0.0000 & $0.000 \mathrm{E}+00$ & 0.0000 & $0.000 \mathrm{E}+00$ & 0.0000 & $0.000 \mathrm{E}+00$ & 0.0000 & $0.000 \mathrm{E}+00$ & 0.0000 & $0.000 \mathrm{E}+00$ & 0.0000 & $0.000 \mathrm{E}+00$ & 0.0000 \\
\hline-237 & $2.362 E-10$ & 0.0000 & $0.000 \mathrm{E}+00$ & 0.0000 & $0.000 \mathrm{E}+00$ & 0.0000 & $0.000 \mathrm{E}+00$ & 0.0000 & $0.000 \mathrm{E}+00$ & 0.0000 & $0.000 \mathrm{E}+00$ & 0.0000 & $0.000 \mathrm{E}+00$ & 0.0000 \\
\hline-238 & $4.482 E-12$ & 0.0000 & $0.000 \mathrm{E}+00$ & 0.0000 & $0.000 \mathrm{E}+00$ & 0.0000 & $0.000 \mathrm{E}+00$ & 0.0000 & $0.000 \mathrm{E}+00$ & 0.0000 & $0.000 \mathrm{E}+00$ & 0.0000 & $0.000 \mathrm{E}+00$ & 0.0000 \\
\hline-239 & $3.476 \mathrm{E}-14$ & 0.0000 & $0.000 \mathrm{E}+00$ & 0.0000 & $0.000 \mathrm{E}+00$ & 0.0000 & $0.000 \mathrm{E}+00$ & 0.0000 & $0.000 \mathrm{E}+00$ & 0.0000 & $0.000 \mathrm{E}+00$ & 0.0000 & $0.000 \mathrm{E}+00$ & 0.0000 \\
\hline-240 & $4.219 \mathrm{E}-17$ & 0.0000 & $0.000 \mathrm{E}+00$ & 0.0000 & $0.000 \mathrm{E}+00$ & 0.0000 & $0.000 \mathrm{E}+00$ & 0.0000 & $0.000 \mathrm{E}+00$ & 0.0000 & $0.000 \mathrm{E}+00$ & 0.0000 & $0.000 \mathrm{E}+00$ & 0.0000 \\
\hline 99 & $6.452 E-22$ & 0.0000 & $0.000 \mathrm{E}+00$ & 0.0000 & $0.000 \mathrm{E}+00$ & 0.0000 & $0.000 \mathrm{E}+00$ & 0.0000 & $0.000 \mathrm{E}+00$ & 0.0000 & $0.000 \mathrm{E}+00$ & 0.0000 & $0.000 \mathrm{E}+00$ & 0.0000 \\
\hline-228 & $0.000 \mathrm{E}+00$ & 0.0000 & $0.000 \mathrm{E}+00$ & 0.0000 & $0.000 \mathrm{E}+00$ & 0.0000 & $0.000 \mathrm{E}+00$ & 0.0000 & $0.000 \mathrm{E}+00$ & 0.0000 & $0.000 \mathrm{E}+00$ & 0.0000 & $0.000 \mathrm{E}+00$ & 0.0000 \\
\hline 230 & $2.193 E-05$ & 0.4425 & $0.000 \mathrm{E}+00$ & 0.0000 & $0.000 \mathrm{E}+00$ & 0.0000 & $0.000 \mathrm{E}+00$ & 0.0000 & $0.000 \mathrm{E}+00$ & 0.0000 & $0.000 \mathrm{E}+00$ & 0.0000 & $0.000 \mathrm{E}+00$ & 0.0000 \\
\hline-232 & $2.730 E-05$ & 0.5508 & $0.000 \mathrm{E}+00$ & 0.0000 & $0.000 \mathrm{E}+00$ & 0.0000 & $0.000 \mathrm{E}+00$ & 0.0000 & $0.000 \mathrm{E}+00$ & 0.0000 & $0.000 \mathrm{E}+00$ & 0.0000 & $0.000 \mathrm{E}+00$ & 0.0000 \\
\hline 34 & $8.184 \mathrm{E}-08$ & 0.0017 & $0.000 \mathrm{E}+00$ & 0.0000 & $0.000 \mathrm{E}+00$ & 0.0000 & $0.000 \mathrm{E}+00$ & 0.0000 & $0.000 \mathrm{E}+00$ & 0.0000 & $0.000 \mathrm{E}+00$ & 0.0000 & $0.000 \mathrm{E}+00$ & 0.0000 \\
\hline 35 & $9.380 \mathrm{E}-11$ & 0.0000 & $0.000 \mathrm{E}+00$ & 0.0000 & $0.000 \mathrm{E}+00$ & 0.0000 & $0.000 \mathrm{E}+00$ & 0.0000 & $0.000 \mathrm{E}+00$ & 0.0000 & $0.000 \mathrm{E}+00$ & 0.0000 & $0.000 \mathrm{E}+00$ & 0.0000 \\
\hline 38 & $2.523 E-07$ & 0.0051 & $0.000 \mathrm{E}+00$ & 0.0000 & $0.000 \mathrm{E}+00$ & 0.0000 & $0.000 \mathrm{E}+00$ & 0.0000 & $0.000 \mathrm{E}+00$ & 0.0000 & $0.000 \mathrm{E}+00$ & 0.0000 & $0.000 \mathrm{E}+00$ & 0.0000 \\
\hline & 4. & 0 & $0.000 \mathrm{E}+00$ & 0.0 & $0.000 \mathrm{E}+00$ & 0 . & $0.000 \mathrm{E}+00$ & 00 & +00 & 0 & +00 & & +00 & \\
\hline
\end{tabular}

Total Dose Contributions TDOSE(i,p,t) for Individual Radionuclides (i) and Pathways (p) As mrem/yr and Fraction of Total Dose At $t=5.000 \mathrm{E}+02$ years

Water Dependent Pathways

\begin{tabular}{|c|c|c|c|c|c|c|c|c|c|c|c|c|c|c|}
\hline & \multicolumn{2}{|c|}{ Water } & \multicolumn{2}{|c|}{ Fish } & \multicolumn{2}{|c|}{ Radon } & \multicolumn{2}{|c|}{ Plant } & \multicolumn{2}{|c|}{ Meat } & \multicolumn{2}{|c|}{ Milk } & \multicolumn{2}{|c|}{ All Pathways* } \\
\hline clide & mrem/yr & fract. & mrem/yr & fract. & mrem/yr & fract. & mrem/yr & fract. & mrem/yr & fract. & mrem/yr & fract. & mrem/yr & fract. \\
\hline-241 & $0.000 \mathrm{E}+00$ & 0.0000 & $0.000 \mathrm{E}+00$ & 0.0000 & $0.000 \mathrm{E}+00$ & 0.0000 & $0.000 \mathrm{E}+00$ & 0.0000 & $0.000 \mathrm{E}+00$ & 0.0000 & $0.000 \mathrm{E}+00$ & 0.0000 & $1.668 \mathrm{E}-13$ & 0.0000 \\
\hline-137 & $0.000 \mathrm{E}+00$ & 0.0000 & $0.000 \mathrm{E}+00$ & 0.0000 & $0.000 \mathrm{E}+00$ & 0.0000 & $0.000 \mathrm{E}+00$ & 0.0000 & $0.000 \mathrm{E}+00$ & 0.0000 & $0.000 \mathrm{E}+00$ & 0.0000 & $3.168 \mathrm{E}-12$ & 0.0000 \\
\hline-237 & $0.000 \mathrm{E}+00$ & 0.0000 & $0.000 \mathrm{E}+00$ & 0.0000 & $0.000 \mathrm{E}+00$ & 0.0000 & $0.000 \mathrm{E}+00$ & 0.0000 & $0.000 \mathrm{E}+00$ & 0.0000 & $0.000 \mathrm{E}+00$ & 0.0000 & $2.362 \mathrm{E}-10$ & 0.0000 \\
\hline 238 & $0.000 \mathrm{E}+00$ & 0.0000 & $0.000 \mathrm{E}+00$ & 0.0000 & $0.000 \mathrm{E}+00$ & 0.0000 & $0.000 \mathrm{E}+00$ & 0.0000 & $0.000 \mathrm{E}+00$ & 0.0000 & $0.000 \mathrm{E}+00$ & 0.0000 & $4.482 \mathrm{E}-12$ & 0.0000 \\
\hline 239 & $0.000 \mathrm{E}+00$ & 0.0000 & $0.000 \mathrm{E}+00$ & 0.0000 & $0.000 \mathrm{E}+00$ & 0.0000 & $0.000 \mathrm{E}+00$ & 0.0000 & $0.000 \mathrm{E}+00$ & 0.0000 & $0.000 \mathrm{E}+00$ & 0.0000 & $3.476 \mathrm{E}-14$ & 0.0000 \\
\hline 240 & $0.000 \mathrm{E}+00$ & 0.0000 & $0.000 \mathrm{E}+00$ & 0.0000 & $0.000 \mathrm{E}+00$ & 0.0000 & $0.000 \mathrm{E}+00$ & 0.0000 & $0.000 \mathrm{E}+00$ & 0.0000 & $0.000 \mathrm{E}+00$ & 0.0000 & $4.219 \mathrm{E}-17$ & 0.0000 \\
\hline 99 & $0.000 \mathrm{E}+00$ & 0.0000 & $0.000 \mathrm{E}+00$ & 0.0000 & $0.000 \mathrm{E}+00$ & 0.0000 & $0.000 \mathrm{E}+00$ & 0.0000 & $0.000 \mathrm{E}+00$ & 0.0000 & $0.000 \mathrm{E}+00$ & 0.0000 & $6.452 \mathrm{E}-22$ & 0.0000 \\
\hline 228 & $0.000 \mathrm{E}+00$ & 0.0000 & $0.000 \mathrm{E}+00$ & 0.0000 & $0.000 \mathrm{E}+00$ & 0.0000 & $0.000 \mathrm{E}+00$ & 0.0000 & $0.000 \mathrm{E}+00$ & 0.0000 & $0.000 \mathrm{E}+00$ & 0.0000 & $0.000 \mathrm{E}+00$ & 0.0000 \\
\hline 230 & $0.000 \mathrm{E}+00$ & 0.0000 & $0.000 \mathrm{E}+00$ & 0.0000 & $0.000 \mathrm{E}+00$ & 0.0000 & $0.000 \mathrm{E}+00$ & 0.0000 & $0.000 \mathrm{E}+00$ & 0.0000 & $0.000 \mathrm{E}+00$ & 0.0000 & $2.193 E-05$ & 0.4425 \\
\hline 232 & $0.000 \mathrm{E}+00$ & 0.0000 & $0.000 \mathrm{E}+00$ & 0.0000 & $0.000 \mathrm{E}+00$ & 0.0000 & $0.000 \mathrm{E}+00$ & 0.0000 & $0.000 \mathrm{E}+00$ & 0.0000 & $0.000 \mathrm{E}+00$ & 0.0000 & $2.730 \mathrm{E}-05$ & 0.5508 \\
\hline & $0.000 \mathrm{E}+00$ & 0.0000 & $0.000 \mathrm{E}+00$ & 0.0000 & $0.000 \mathrm{E}+00$ & 0.0000 & $0.000 \mathrm{E}+00$ & 0.0000 & $0.000 \mathrm{E}+00$ & 0.0000 & $0.000 \mathrm{E}+00$ & 0.0000 & $8.184 \mathrm{E}-08$ & 0.0017 \\
\hline 35 & $0.000 \mathrm{E}+00$ & 0.0000 & $0.000 \mathrm{E}+00$ & 0.0000 & $0.000 \mathrm{E}+00$ & 0.0000 & $0.000 \mathrm{E}+00$ & 0.0000 & $0.000 \mathrm{E}+00$ & 0.0000 & $0.000 \mathrm{E}+00$ & 0.0000 & $9.380 \mathrm{E}-11$ & 0.0000 \\
\hline 38 & $0.000 \mathrm{E}+00$ & 0.0000 & $0.000 \mathrm{E}+00$ & 0.0000 & $0.000 \mathrm{E}+00$ & 0.0000 & $0.000 \mathrm{E}+00$ & 0.0000 & $0.000 \mathrm{E}+00$ & 0.0000 & $0.000 \mathrm{E}+00$ & 0.0000 & $2.523 E-07$ & 0.0051 \\
\hline & $0.000 \mathrm{E}+00$ & 0.0000 & $0.000 \mathrm{E}+00$ & 0.0000 & $0.000 \mathrm{E}+00$ & 0.0000 & $0.000 \mathrm{E}+00$ & 0.0000 & $0.000 \mathrm{E}+00$ & 0.0000 & $0.000 \mathrm{E}+00$ & 000 & -05 & 1.0000 \\
\hline
\end{tabular}

* Sum of all water independent and dependent pathways. 
RESRAD, Version 6.5

Summary : RESRAD Parameters for U-Landfill Outdoor Worker Forward Run
File : C: $\backslash$ RESRAD_FAMILY \RESRAD \USERFILES $\backslash$ QCJULY2011 \ULANDFILL-ODW_FORWARD_1050YRS.RAD

Total Dose Contributions TDOSE (i,p,t) for Individual Radionuclides (i) and Pathways (p) As mrem/yr and Fraction of Total Dose At $t=1.050 \mathrm{E}+03$ years

Water Independent Pathways (Inhalation excludes radon)

\begin{tabular}{|c|c|c|c|c|c|c|c|c|c|c|c|c|c|c|}
\hline \multirow{2}{*}{ Nuclide } & \multicolumn{2}{|c|}{ Ground } & \multicolumn{2}{|c|}{ Inhalation } & \multicolumn{2}{|c|}{ Radon } & \multicolumn{2}{|c|}{ Plant } & \multicolumn{2}{|c|}{ Meat } & \multicolumn{2}{|c|}{ Milk } & \multicolumn{2}{|c|}{ Soil } \\
\hline & mrem/yr & fract. & mrem/yr & fract. & mrem/yr & fract. & mrem/yr & fract. & mrem/yr & fract. & mrem/yr & fract. & mrem/yr & fract. \\
\hline-241 & $9.032 \mathrm{E}-11$ & 0.0000 & $0.000 \mathrm{E}+00$ & 0.0000 & $0.000 \mathrm{E}+00$ & 0.0000 & $0.000 \mathrm{E}+00$ & 0.0000 & $0.000 \mathrm{E}+00$ & 0.0000 & $0.000 \mathrm{E}+00$ & 0.0000 & $0.000 \mathrm{E}+00$ & 0.0000 \\
\hline-137 & $9.832 \mathrm{E}-16$ & 0.0000 & $0.000 \mathrm{E}+00$ & 0.0000 & $0.000 \mathrm{E}+00$ & 0.0000 & $0.000 \mathrm{E}+00$ & 0.0000 & $0.000 \mathrm{E}+00$ & 0.0000 & $0.000 \mathrm{E}+00$ & 0.0000 & $0.000 \mathrm{E}+00$ & 0.0000 \\
\hline-237 & $8.468 E-08$ & 0.0000 & $0.000 \mathrm{E}+00$ & 0.0000 & $0.000 \mathrm{E}+00$ & 0.0000 & $0.000 \mathrm{E}+00$ & 0.0000 & $0.000 \mathrm{E}+00$ & 0.0000 & $0.000 \mathrm{E}+00$ & 0.0000 & $0.000 \mathrm{E}+00$ & 0.0000 \\
\hline-238 & $1.044 \mathrm{E}-09$ & 0.0000 & $0.000 \mathrm{E}+00$ & 0.0000 & $0.000 \mathrm{E}+00$ & 0.0000 & $0.000 \mathrm{E}+00$ & 0.0000 & $0.000 \mathrm{E}+00$ & 0.0000 & $0.000 \mathrm{E}+00$ & 0.0000 & $0.000 \mathrm{E}+00$ & 0.0000 \\
\hline-239 & $2.474 \mathrm{E}-11$ & 0.0000 & $0.000 \mathrm{E}+00$ & 0.0000 & $0.000 \mathrm{E}+00$ & 0.0000 & $0.000 \mathrm{E}+00$ & 0.0000 & $0.000 \mathrm{E}+00$ & 0.0000 & $0.000 \mathrm{E}+00$ & 0.0000 & $0.000 \mathrm{E}+00$ & 0.0000 \\
\hline-240 & $5.993 \mathrm{E}-15$ & 0.0000 & $0.000 \mathrm{E}+00$ & 0.0000 & $0.000 \mathrm{E}+00$ & 0.0000 & $0.000 \mathrm{E}+00$ & 0.0000 & $0.000 \mathrm{E}+00$ & 0.0000 & $0.000 \mathrm{E}+00$ & 0.0000 & $0.000 \mathrm{E}+00$ & 0.0000 \\
\hline 99 & 1. $362 \mathrm{E}-18$ & 0.0000 & $0.000 \mathrm{E}+00$ & 0.0000 & $0.000 \mathrm{E}+00$ & 0.0000 & $0.000 \mathrm{E}+00$ & 0.0000 & $0.000 \mathrm{E}+00$ & 0.0000 & $0.000 \mathrm{E}+00$ & 0.0000 & $0.000 \mathrm{E}+00$ & 0.0000 \\
\hline-228 & $0.000 \mathrm{E}+00$ & 0.0000 & $0.000 \mathrm{E}+00$ & 0.0000 & $0.000 \mathrm{E}+00$ & 0.0000 & $0.000 \mathrm{E}+00$ & 0.0000 & $0.000 \mathrm{E}+00$ & 0.0000 & $0.000 \mathrm{E}+00$ & 0.0000 & $0.000 \mathrm{E}+00$ & 0.0000 \\
\hline-230 & $1.840 \mathrm{E}-03$ & 0.6991 & $0.000 \mathrm{E}+00$ & 0.0000 & $0.000 \mathrm{E}+00$ & 0.0000 & $0.000 \mathrm{E}+00$ & 0.0000 & $0.000 \mathrm{E}+00$ & 0.0000 & $0.000 \mathrm{E}+00$ & 0.0000 & $0.000 \mathrm{E}+00$ & 0.0000 \\
\hline-232 & $7.565 E-04$ & 0.2874 & $0.000 \mathrm{E}+00$ & 0.0000 & $0.000 \mathrm{E}+00$ & 0.0000 & $0.000 \mathrm{E}+00$ & 0.0000 & $0.000 \mathrm{E}+00$ & 0.0000 & $0.000 \mathrm{E}+00$ & 0.0000 & $0.000 \mathrm{E}+00$ & 0.0000 \\
\hline 234 & 1. $495 \mathrm{E}-05$ & 0.0057 & $0.000 \mathrm{E}+00$ & 0.0000 & $0.000 \mathrm{E}+00$ & 0.0000 & $0.000 \mathrm{E}+00$ & 0.0000 & $0.000 \mathrm{E}+00$ & 0.0000 & $0.000 \mathrm{E}+00$ & 0.0000 & $0.000 \mathrm{E}+00$ & 0.0000 \\
\hline 35 & $3.148 \mathrm{E}-08$ & 0.0000 & $0.000 \mathrm{E}+00$ & 0.0000 & $0.000 \mathrm{E}+00$ & 0.0000 & $0.000 \mathrm{E}+00$ & 0.0000 & $0.000 \mathrm{E}+00$ & 0.0000 & $0.000 \mathrm{E}+00$ & 0.0000 & $0.000 \mathrm{E}+00$ & 0.0000 \\
\hline 38 & $2.047 E-05$ & 0.0078 & $0.000 \mathrm{E}+00$ & 0.0000 & $0.000 \mathrm{E}+00$ & 0.0000 & $0.000 \mathrm{E}+00$ & 0.0000 & $0.000 \mathrm{E}+00$ & 0.0000 & $0.000 \mathrm{E}+00$ & 0.0000 & $0.000 \mathrm{E}+00$ & 0.0000 \\
\hline & $2.632 \mathrm{E}-03$ & 1.0000 & $0.000 \mathrm{E}+00$ & 0.0000 & $0.000 \mathrm{E}+00$ & 0.0000 & $0.000 \mathrm{E}+00$ & 0.0000 & $0.000 \mathrm{E}+00$ & 0.0000 & $0.000 \mathrm{E}+00$ & 0.0000 & $0.000 \mathrm{E}+00$ & 0.0000 \\
\hline
\end{tabular}

Total Dose Contributions TDOSE(i,p,t) for Individual Radionuclides (i) and Pathways (p) As mrem/yr and Fraction of Total Dose At $t=1.050 \mathrm{E}+03$ years

Water Dependent Pathways

\begin{tabular}{|c|c|c|c|c|c|c|c|c|c|c|c|c|c|c|}
\hline \multirow{2}{*}{$\begin{array}{l}\text { Radio- } \\
\text { Nuclide }\end{array}$} & \multicolumn{2}{|c|}{ Water } & \multicolumn{2}{|c|}{ Fish } & \multicolumn{2}{|c|}{ Radon } & \multicolumn{2}{|c|}{ Plant } & \multicolumn{2}{|c|}{ Meat } & \multicolumn{2}{|c|}{ Milk } & \multicolumn{2}{|c|}{ All Pathways* } \\
\hline & mrem/yr & fract. & mrem/yr & fract. & mrem/yr & fract. & mrem/yr & fract. & mrem/yr & fract. & mrem/yr & fract. & mrem/yr & fract. \\
\hline 241 & $0.000 \mathrm{E}+00$ & 0.0000 & $0.000 \mathrm{E}+00$ & 0.0000 & $0.000 \mathrm{E}+00$ & 0.0000 & $0.000 \mathrm{E}+00$ & 0.0000 & $0.000 \mathrm{E}+00$ & 0.0000 & $0.000 \mathrm{E}+00$ & 0.0000 & $9.032 \mathrm{E}-11$ & 0.0000 \\
\hline-137 & $0.000 \mathrm{E}+00$ & 0.0000 & $0.000 \mathrm{E}+00$ & 0.0000 & $0.000 \mathrm{E}+00$ & 0.0000 & $0.000 \mathrm{E}+00$ & 0.0000 & $0.000 \mathrm{E}+00$ & 0.0000 & $0.000 \mathrm{E}+00$ & 0.0000 & $9.832 \mathrm{E}-16$ & 0.0000 \\
\hline-237 & $0.000 \mathrm{E}+00$ & 0.0000 & $0.000 \mathrm{E}+00$ & 0.0000 & $0.000 \mathrm{E}+00$ & 0.0000 & $0.000 \mathrm{E}+00$ & 0.0000 & $0.000 \mathrm{E}+00$ & 0.0000 & $0.000 \mathrm{E}+00$ & 0.0000 & $8.468 E-08$ & 0.0000 \\
\hline-238 & $0.000 \mathrm{E}+00$ & 0.0000 & $0.000 \mathrm{E}+00$ & 0.0000 & $0.000 \mathrm{E}+00$ & 0.0000 & $0.000 \mathrm{E}+00$ & 0.0000 & $0.000 \mathrm{E}+00$ & 0.0000 & $0.000 \mathrm{E}+00$ & 0.0000 & $1.044 \mathrm{E}-09$ & 0.0000 \\
\hline-239 & $0.000 \mathrm{E}+00$ & 0.0000 & $0.000 \mathrm{E}+00$ & 0.0000 & $0.000 \mathrm{E}+00$ & 0.0000 & $0.000 \mathrm{E}+00$ & 0.0000 & $0.000 \mathrm{E}+00$ & 0.0000 & $0.000 E+00$ & 0.0000 & $2.474 \mathrm{E}-11$ & 0.0000 \\
\hline-240 & $0.000 \mathrm{E}+00$ & 0.0000 & $0.000 \mathrm{E}+00$ & 0.0000 & $0.000 \mathrm{E}+00$ & 0.0000 & $0.000 \mathrm{E}+00$ & 0.0000 & $0.000 \mathrm{E}+00$ & 0.0000 & $0.000 E+00$ & 0.0000 & $5.993 E-15$ & 0.0000 \\
\hline 99 & $0.000 \mathrm{E}+00$ & 0.0000 & $0.000 \mathrm{E}+00$ & 0.0000 & $0.000 \mathrm{E}+00$ & 0.0000 & $0.000 \mathrm{E}+00$ & 0.0000 & $0.000 \mathrm{E}+00$ & 0.0000 & $0.000 \mathrm{E}+00$ & 0.0000 & 1. $362 \mathrm{E}-18$ & 0.0000 \\
\hline-228 & $0.000 \mathrm{E}+00$ & 0.0000 & $0.000 \mathrm{E}+00$ & 0.0000 & $0.000 \mathrm{E}+00$ & 0.0000 & $0.000 \mathrm{E}+00$ & 0.0000 & $0.000 \mathrm{E}+00$ & 0.0000 & $0.000 \mathrm{E}+00$ & 0.0000 & $0.000 \mathrm{E}+00$ & 0.0000 \\
\hline-230 & $0.000 \mathrm{E}+00$ & 0.0000 & $0.000 \mathrm{E}+00$ & 0.0000 & $0.000 \mathrm{E}+00$ & 0.0000 & $0.000 \mathrm{E}+00$ & 0.0000 & $0.000 \mathrm{E}+00$ & 0.0000 & $0.000 E+00$ & 0.0000 & $1.840 \mathrm{E}-03$ & 0.6991 \\
\hline 232 & $0.000 \mathrm{E}+00$ & 0.0000 & $0.000 \mathrm{E}+00$ & 0.0000 & $0.000 \mathrm{E}+00$ & 0.0000 & $0.000 \mathrm{E}+00$ & 0.0000 & $0.000 \mathrm{E}+00$ & 0.0000 & $0.000 \mathrm{E}+00$ & 0.0000 & $7.565 \mathrm{E}-04$ & 0.2874 \\
\hline 34 & $0.000 \mathrm{E}+00$ & 0.0000 & $0.000 \mathrm{E}+00$ & 0.0000 & $0.000 \mathrm{E}+00$ & 0.0000 & $0.000 \mathrm{E}+00$ & 0.0000 & $0.000 \mathrm{E}+00$ & 0.0000 & $0.000 \mathrm{E}+00$ & 0.0000 & $1.495 \mathrm{E}-05$ & 0.0057 \\
\hline 35 & $0.000 \mathrm{E}+00$ & 0.0000 & $0.000 \mathrm{E}+00$ & 0.0000 & $0.000 \mathrm{E}+00$ & 0.0000 & $0.000 \mathrm{E}+00$ & 0.0000 & $0.000 \mathrm{E}+00$ & 0.0000 & $0.000 \mathrm{E}+00$ & 0.0000 & $3.148 \mathrm{E}-08$ & 0.0000 \\
\hline 38 & $0.000 \mathrm{E}+00$ & 0.0000 & $0.000 \mathrm{E}+00$ & 0.0000 & $0.000 \mathrm{E}+00$ & 0.0000 & $0.000 \mathrm{E}+00$ & 0.0000 & $0.000 \mathrm{E}+00$ & 0.0000 & $0.000 \mathrm{E}+00$ & 0.0000 & $2.047 \mathrm{E}-05$ & 0.0078 \\
\hline & $0.000 \mathrm{E}+00$ & 0.0000 & $0.000 \mathrm{E}+00$ & 0.0000 & $0.000 \mathrm{E}+00$ & 0.0000 & $0.000 \mathrm{E}+00$ & 0.0000 & $0.000 \mathrm{E}+00$ & 0.0000 & $0.000 \mathrm{E}+00$ & 0.0000 & $2 E-03$ & 1. \\
\hline
\end{tabular}

* Sum of all water independent and dependent pathways. 
RESRAD, Version 6.5

$07 / 20 / 2011$

Summary : RESRAD Parameters for U-Landfill Outdoor Worker Forward Run

File : C: \RESRAD FAMILY \RESRAD \USERFILES \QCJULY2011 \ULANDFILL-ODW FORWARD 1050YRS.RAD

Dose/Source Ratios Summed Over All Pathways

Parent and Progeny Principal Radionuclide Contributions Indicated

Parent Product Thread DSR $(j, t)$ At Time in Years (mrem/yr)/(pCi/g)

(i)

(j)

$\begin{array}{ll}\mathrm{Am}-241 & 1.000 \mathrm{E}+00 \\ \mathrm{~Np}-237+\mathrm{D} & 1.000 \mathrm{E}+00 \\ \mathrm{U}-233 & 1.000 \mathrm{E}+00 \\ \mathrm{Th}-229+\mathrm{D} & 1.000 \mathrm{E}+00 \\ \operatorname{\sum DSR}(j) & \end{array}$

Cs $-137+D$

$\mathrm{Np}-237+\mathrm{D}$

U-233

Th-229+D

$\sum \operatorname{DSR}(j)$

$\mathrm{Pu}-238$

$\mathrm{Pu}-238$

U-234

Th-230

Ra-226+D

$\mathrm{Pb}-210+\mathrm{D}$

$\sum \operatorname{DSR}(j)$

Pu-239

U-235+D

$\mathrm{Pa}-231$

Ac-227+D

$\sum \operatorname{DSR}(j)$

$\mathrm{Pu}-240$

$\mathrm{Pu}-240$

U-236

Th-232

$\mathrm{Ra}-228+\mathrm{D}$

Th-228+D

$\sum \operatorname{DSR}(j)$

TC-99

Th-228+D

Th-230

Ra-226+D

$\mathrm{Pb}-210+\mathrm{D}$

$\sum \operatorname{DSR}(j)$ $\begin{array}{lllllllll}1.000 \mathrm{E}+00 & 2.578 \mathrm{E}-10 & 2.541 \mathrm{E}-10 & 1.786 \mathrm{E}-10 & 1.237 \mathrm{E}-10 & 5.936 \mathrm{E}-11 & 1.667 \mathrm{E}-13 & 5.175 \mathrm{E}-17\end{array}$

$1.000 \mathrm{E}+00 \quad 1.948 \mathrm{E}-13 \quad 1.969 \mathrm{E}-13 \quad 2.547 \mathrm{E}-13 \quad 3.330 \mathrm{E}-13 \quad 5.693 \mathrm{E}-13 \quad 4.147 \mathrm{E}-11 \quad 1.509 \mathrm{E}-08$ $\begin{array}{lllllllll}1.000 \mathrm{E}+00 & 6.631 \mathrm{E}-24 & 2.011 \mathrm{E}-23 & 4.612 \mathrm{E}-22 & 1.248 \mathrm{E}-21 & 4.641 \mathrm{E}-21 & 3.427 \mathrm{E}-18 & 6.954 \mathrm{E}-15\end{array}$ $1.000 \mathrm{E}+00 \quad 6.053 \mathrm{E}-20 \quad 4.262 \mathrm{E}-19 \quad 1.402 \mathrm{E}-16 \quad 6.537 \mathrm{E}-16 \quad 3.662 \mathrm{E}-15 \quad 1.463 \mathrm{E}-12 \quad 3.066 \mathrm{E}-10$ $\begin{array}{lllllll}1.948 \mathrm{E}-13 & 1.969 \mathrm{E}-13 & 2.549 \mathrm{E}-13 & 3.337 \mathrm{E}-13 & 5.729 \mathrm{E}-13 & 4.294 \mathrm{E}-11 & 1.540 \mathrm{E}-08\end{array}$

$1.840 \mathrm{E}-09 \quad 4.417 \mathrm{E}-34 \quad 4.460 \mathrm{E}-34 \quad 5.637 \mathrm{E}-34 \quad 7.195 \mathrm{E}-34 \quad 1.172 \mathrm{E}-33 \quad 5.806 \mathrm{E}-32 \quad 1.243 \mathrm{E}-29$

$1.000 \mathrm{E}+00 \quad 2.401 \mathrm{E}-25 \quad 2.424 \mathrm{E}-25 \quad 3.064 \mathrm{E}-25 \quad 3.910 \mathrm{E}-25 \quad 6.369 \mathrm{E}-25 \quad 3.155 \mathrm{E}-23 \quad 6.755 \mathrm{E}-21$ $\begin{array}{llllllll}1.000 \mathrm{E}+00 & 1.998 \mathrm{E}-30 & 6.068 \mathrm{E}-30 & 1.436 \mathrm{E}-28 & 4.032 \mathrm{E}-28 & 1.628 \mathrm{E}-27 & 3.470 \mathrm{E}-24 & 5.993 \mathrm{E}-20\end{array}$ $\begin{array}{llllllll}1.000 \mathrm{E}+00 & 2.101 \mathrm{E}-34 & 1.489 \mathrm{E}-33 & 5.829 \mathrm{E}-31 & 3.268 \mathrm{E}-30 & 2.663 \mathrm{E}-29 & 2.676 \mathrm{E}-25 & 6.795 \mathrm{E}-21\end{array}$ $\begin{array}{llllllllll}1.000 \mathrm{E}+00 & 1.639 \mathrm{E}-23 & 2.469 \mathrm{E}-22 & 1.226 \mathrm{E}-18 & 1.076 \mathrm{E}-17 & 1.088 \mathrm{E}-16 & 1.149 \mathrm{E}-13 & 2.677 \mathrm{E}-11\end{array}$ $\begin{array}{lllllllll}1.000 \mathrm{E}+00 \quad 4.753 \mathrm{E}-32 & 1.473 \mathrm{E}-30 & 1.013 \mathrm{E}-25 & 1.589 \mathrm{E}-24 & 2.687 \mathrm{E}-23 & 7.527 \mathrm{E}-20 & 3.536 \mathrm{E}-17\end{array}$ $\begin{array}{lllllll}1.663 \mathrm{E}-23 & 2.471 \mathrm{E}-22 & 1.226 \mathrm{E}-18 & 1.076 \mathrm{E}-17 & 1.088 \mathrm{E}-16 & 1.149 \mathrm{E}-13 & 2.677 \mathrm{E}-11\end{array}$

$1.000 \mathrm{E}+00 \quad 2.456 \mathrm{E}-18 \quad 2.486 \mathrm{E}-18 \quad 3.311 \mathrm{E}-18 \quad 4.463 \mathrm{E}-18 \quad 8.107 \mathrm{E}-18 \quad 9.618 \mathrm{E}-16 \quad 6.841 \mathrm{E}-13$ $\begin{array}{llllllll}1.000 \mathrm{E}+00 & 1.254 \mathrm{E}-24 & 3.802 \mathrm{E}-24 & 8.688 \mathrm{E}-23 & 2.343 \mathrm{E}-22 & 8.645 \mathrm{E}-22 & 6.015 \mathrm{E}-19 & 1.124 \mathrm{E}-15\end{array}$ $\begin{array}{lllllllll}1.000 \mathrm{E}+00 & 1.972 \mathrm{E}-28 & 1.393 \mathrm{E}-27 & 5.002 \mathrm{E}-25 & 2.557 \mathrm{E}-24 & 1.721 \mathrm{E}-23 & 2.963 \mathrm{E}-20 & 4.446 \mathrm{E}-17\end{array}$ $\begin{array}{lllllllll}1.000 \mathrm{E}+00 & 4.675 \mathrm{E}-28 & 7.017 \mathrm{E}-27 & 3.194 \mathrm{E}-23 & 2.608 \mathrm{E}-22 & 2.391 \mathrm{E}-21 & 3.028 \mathrm{E}-18 & 1.826 \mathrm{E}-15\end{array}$ $2.456 \mathrm{E}-18 \quad 2.486 \mathrm{E}-18 \quad 3.311 \mathrm{E}-18 \quad 4.463 \mathrm{E}-18 \quad 8.110 \mathrm{E}-18 \quad 9.655 \mathrm{E}-16 \quad 6.871 \mathrm{E}-13$

4.950E-08 1.155E-32 $1.176 \mathrm{E}-32 \quad 1.791 \mathrm{E}-32 \quad 2.778 \mathrm{E}-32 \quad 6.681 \mathrm{E}-32 \quad 7.478 \mathrm{E}-29 \quad 1.164 \mathrm{E}-24$

$\begin{array}{llllllll}1.000 \mathrm{E}+00 & 2.334 \mathrm{E}-25 & 2.375 \mathrm{E}-25 & 3.619 \mathrm{E}-25 & 5.612 \mathrm{E}-25 & 1.350 \mathrm{E}-24 & 1.511 \mathrm{E}-21 & 2.352 \mathrm{E}-17\end{array}$ $\begin{array}{llllllll}1.000 \mathrm{E}+00 \quad 4.417 \mathrm{E}-33 & 1.347 \mathrm{E}-32 & 3.517 \mathrm{E}-31 & 1.091 \mathrm{E}-30 & 5.321 \mathrm{E}-30 & 3.459 \mathrm{E}-26 & 1.397 \mathrm{E}-21\end{array}$ $\begin{array}{lllllllll}1.000 \mathrm{E}+00 \quad 5.745 \mathrm{E}-44 & 4.148 \mathrm{E}-43 & 1.798 \mathrm{E}-40 & 1.120 \mathrm{E}-39 & 1.120 \mathrm{E}-38 & 4.587 \mathrm{E}-34 & 5.372 \mathrm{E}-29\end{array}$ $\begin{array}{llllllll}1.000 \mathrm{E}+00 & 2.801 \mathrm{E}-29 & 4.123 \mathrm{E}-28 & 1.234 \mathrm{E}-24 & 7.689 \mathrm{E}-24 & 5.197 \mathrm{E}-23 & 3.012 \mathrm{E}-20 & 8.590 \mathrm{E}-18\end{array}$ $1.000 \mathrm{E}+00 \quad 1.657 \mathrm{E}-28 \quad 4.769 \mathrm{E}-27 \quad 7.862 \mathrm{E}-23 \quad 5.398 \mathrm{E}-22 \quad 3.593 \mathrm{E}-21 \quad 1.140 \mathrm{E}-18 \quad 1.344 \mathrm{E}-16$ $2.335 \mathrm{E}-25 \quad 2.427 \mathrm{E}-25 \quad 8.021 \mathrm{E}-23 \quad 5.480 \mathrm{E}-22 \quad 3.646 \mathrm{E}-21 \quad 1.172 \mathrm{E}-18 \quad 1.665 \mathrm{E}-16$

$\begin{array}{llllllll}1.000 \mathrm{E}+00 & 1.179 \mathrm{E}-26 & 1.195 \mathrm{E}-26 & 1.669 \mathrm{E}-26 & 2.364 \mathrm{E}-26 & 4.741 \mathrm{E}-26 & 1.241 \mathrm{E}-23 & 2.619 \mathrm{E}-20\end{array}$ $\begin{array}{llllllll}1.000 \mathrm{E}+00 & 2.825 \mathrm{E}-07 & 1.978 \mathrm{E}-07 & 3.819 \mathrm{E}-11 & 5.163 \mathrm{E}-15 & 9.437 \mathrm{E}-23 & 0.000 \mathrm{E}+00 & 0.000 \mathrm{E}+00\end{array}$

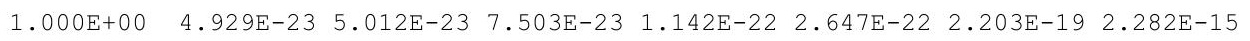
$\begin{array}{lllllllll}1.000 \mathrm{E}+00 \quad 7.712 \mathrm{E}-12 & 2.327 \mathrm{E}-11 & 4.644 \mathrm{E}-10 & 1.087 \mathrm{E}-09 & 3.024 \mathrm{E}-09 & 2.193 \mathrm{E}-07 & 1.840 \mathrm{E}-05\end{array}$ $\begin{array}{lllllllll}1.000 \mathrm{E}+00 & 3.717 \mathrm{E}-20 & 2.596 \mathrm{E}-19 & 6.907 \mathrm{E}-17 & 2.655 \mathrm{E}-16 & 1.087 \mathrm{E}-15 & 1.573 \mathrm{E}-13 & 2.528 \mathrm{E}-11\end{array}$ $\begin{array}{llllllll}7.712 \mathrm{E}-12 & 2.327 \mathrm{E}-11 & 4.644 \mathrm{E}-10 & 1.087 \mathrm{E}-09 & 3.024 \mathrm{E}-09 & 2.193 \mathrm{E}-07 & 1.840 \mathrm{E}-05\end{array}$ 
RESRAD, Version 6.5

Summary : RESRAD Parameters for U-Landfill Outdoor Worker Forward Run

File : C: \RESRAD FAMILY \RESRAD \USERFILES \QCJULY2011 \ULANDFILL-ODW FORWARD 1050YRS.RAD

Dose/Source Ratios Summed Over All Pathways

Parent and Progeny Principal Radionuclide Contributions Indicated

\begin{tabular}{|c|c|c|c|c|c|c|c|c|c|}
\hline Parent & Product & Thread & & $\operatorname{DSR}(j, t)$ & At Time in & Years & (mrem/yr) / & $(\mathrm{pCi} / \mathrm{g})$ & \\
\hline (i) & (j) & Fraction & $0.000 \mathrm{E}+00$ & $1.000 \mathrm{E}+00$ & $2.500 \mathrm{E}+01$ & $5.000 \mathrm{E}+01$ & $1.000 \mathrm{E}+02$ & $5.000 \mathrm{E}+02$ & $1.050 \mathrm{E}+03$ \\
\hline-232 & $\mathrm{Th}-232$ & $1.000 \mathrm{E}+00$ & $2.382 \mathrm{E}-25$ & $2.427 E-25$ & $3.789 \mathrm{E}-25$ & $6.027 \mathrm{E}-25$ & $1.525 \mathrm{E}-24$ & $2.561 \mathrm{E}-21$ & $6.965 \mathrm{E}-17$ \\
\hline $1-232$ & $\mathrm{Ra}-228+\mathrm{D}$ & $1.000 \mathrm{E}+00$ & $2.263 E-10$ & $6.486 \mathrm{E}-10$ & $4.499 \mathrm{E}-09$ & $5.690 \mathrm{E}-09$ & $8.336 \mathrm{E}-09$ & $1.737 \mathrm{E}-07$ & $1.131 \mathrm{E}-05$ \\
\hline$h-232$ & $\mathrm{Th}-228+\mathrm{D}$ & $1.000 \mathrm{E}+00$ & $2.181 E-09$ & $1.345 \mathrm{E}-08$ & $3.638 E-07$ & $4.522 \mathrm{E}-07$ & $6.114 \mathrm{E}-07$ & $6.652 \mathrm{E}-06$ & $1.778 \mathrm{E}-04$ \\
\hline$h-232$ & $\sum \operatorname{DSR}(j)$ & & $2.407 E-09$ & $1.410 \mathrm{E}-08$ & $3.683 \mathrm{E}-07$ & $4.579 \mathrm{E}-07$ & $6.198 \mathrm{E}-07$ & $6.825 \mathrm{E}-06$ & $1.891 \mathrm{E}-04$ \\
\hline-234 & $\mathrm{U}-234$ & $1.000 \mathrm{E}+00$ & $1.409 \mathrm{E}-24$ & $1.434 \mathrm{E}-24$ & $2.194 \mathrm{E}-24$ & $3.415 E-24$ & $8.276 \mathrm{E}-24$ & $9.851 \mathrm{E}-21$ & $1.669 \mathrm{E}-16$ \\
\hline-234 & Th-230 & $1.000 \mathrm{E}+00$ & $2.225 E-28$ & $6.774 \mathrm{E}-28$ & $1.722 \mathrm{E}-26$ & $5.192 \mathrm{E}-26$ & $2.394 \mathrm{E}-25$ & $9.912 \mathrm{E}-22$ & $2.152 \mathrm{E}-17$ \\
\hline-234 & $\mathrm{Ra}-226+\mathrm{D}$ & $1.000 \mathrm{E}+00$ & $2.315 E-17$ & $1.630 \mathrm{E}-16$ & $5.341 \mathrm{E}-14$ & $2.480 \mathrm{E}-13$ & 1. $377 \mathrm{E}-12$ & $5.115 \mathrm{E}-10$ & $9.341 \mathrm{E}-08$ \\
\hline-234 & $\mathrm{~Pb}-210+\mathrm{D}$ & $1.000 \mathrm{E}+00$ & $8.381 E-26$ & $1.257 \mathrm{E}-24$ & $5.622 \mathrm{E}-21$ & $4.500 \mathrm{E}-20$ & $3.956 \mathrm{E}-19$ & $3.440 \mathrm{E}-16$ & 1. $243 \mathrm{E}-13$ \\
\hline-234 & $\sum \operatorname{DSR}(j)$ & & $2.315 \mathrm{E}-17$ & $1.630 \mathrm{E}-16$ & $5.341 \mathrm{E}-14$ & $2.480 \mathrm{E}-13$ & 1. $377 \mathrm{E}-12$ & $5.115 \mathrm{E}-10$ & $9.341 \mathrm{E}-08$ \\
\hline$-235+D$ & $\mathrm{U}-235+\mathrm{D}$ & $1.000 \mathrm{E}+00$ & $2.540 \mathrm{E}-15$ & $2.572 \mathrm{E}-15$ & $3.460 \mathrm{E}-15$ & $4.713 E-15$ & $8.745 E-15$ & 1. $228 \mathrm{E}-12$ & $1.101 \mathrm{E}-09$ \\
\hline$-235+D$ & $\mathrm{~Pa}-231$ & $1.000 \mathrm{E}+00$ & $6.002 \mathrm{E}-19$ & $1.818 \mathrm{E}-18$ & $3.984 \mathrm{E}-17$ & $1.028 \mathrm{E}-16$ & $3.478 \mathrm{E}-16$ & 1. $206 \mathrm{E}-13$ & $8.644 \mathrm{E}-11$ \\
\hline$-235+D$ & $A C-227+D$ & $1.000 \mathrm{E}+00$ & $1.895 \mathrm{E}-18$ & 1. $324 \mathrm{E}-17$ & $3.586 \mathrm{E}-15$ & $1.407 \mathrm{E}-14$ & $6.019 \mathrm{E}-14$ & 1. $308 \mathrm{E}-11$ & $3.655 \mathrm{E}-09$ \\
\hline$-235+D$ & $\sum \operatorname{DSR}(j)$ & & $2.543 E-15$ & $2.587 \mathrm{E}-15$ & $7.086 \mathrm{E}-15$ & $1.888 \mathrm{E}-14$ & $6.928 \mathrm{E}-14$ & $1.443 \mathrm{E}-11$ & $4.843 E-09$ \\
\hline-238 & $\mathrm{U}-238$ & $5.400 \mathrm{E}-05$ & $0.000 \mathrm{E}+00$ & $0.000 \mathrm{E}+00$ & $0.000 \mathrm{E}+00$ & $0.000 \mathrm{E}+00$ & $0.000 \mathrm{E}+00$ & $0.000 \mathrm{E}+00$ & $3.476 \mathrm{E}-39$ \\
\hline$-238+D$ & $\mathrm{U}-238+\mathrm{D}$ & $9.999 \mathrm{E}-01$ & $2.901 \mathrm{E}-11$ & $2.924 \mathrm{E}-11$ & $3.542 \mathrm{E}-11$ & 4. $325 \mathrm{E}-11$ & $6.449 \mathrm{E}-11$ & $1.576 \mathrm{E}-09$ & $1.279 \mathrm{E}-07$ \\
\hline$-238+D$ & $\mathrm{U}-234$ & $9.999 E-01$ & $2.003 E-30$ & $6.105 E-30$ & $1.586 \mathrm{E}-28$ & $4.889 E-28$ & $2.358 E-27$ & $1.399 \mathrm{E}-23$ & 4. $978 \mathrm{E}-19$ \\
\hline$J-238+D$ & $\mathrm{Th}-230$ & $9.999 E-01$ & $2.105 E-34$ & $1.495 \mathrm{E}-33$ & $6.226 \mathrm{E}-31$ & $3.717 \mathrm{E}-30$ & $3.411 \mathrm{E}-29$ & $7.032 \mathrm{E}-25$ & $3.204 \mathrm{E}-20$ \\
\hline$J-238+D$ & $\mathrm{Ra}-226+\mathrm{D}$ & $9.999 \mathrm{E}-01$ & $1.642 \mathrm{E}-23$ & $2.477 \mathrm{E}-22$ & $1.288 \mathrm{E}-18$ & $1.186 \mathrm{E}-17$ & $1.313 E-16$ & $2.462 \mathrm{E}-13$ & $9.612 \mathrm{E}-11$ \\
\hline$J-238+D$ & $\mathrm{~Pb}-210+\mathrm{D}$ & $9.999 E-01$ & $4.759 E-32$ & $1.477 \mathrm{E}-30$ & $1.055 \mathrm{E}-25$ & $1.723 E-24$ & $3.161 \mathrm{E}-23$ & $1.561 \mathrm{E}-19$ & 1. $240 \mathrm{E}-16$ \\
\hline$-238+D$ & $\sum \operatorname{DSR}(j)$ & & $2.901 \mathrm{E}-11$ & $2.924 \mathrm{E}-11$ & $3.542 \mathrm{E}-11$ & $4.325 \mathrm{E}-11$ & $6.449 \mathrm{E}-11$ & $1.577 \mathrm{E}-09$ & $1.280 \mathrm{E}-07$ \\
\hline
\end{tabular}

The DSR includes contributions from associated (half-life $\leq 180$ days) daughters. 
RESRAD, Version $6.5 \quad \mathrm{~T}^{1 / 2}$ Limit $=180$ days

Mmary : RESRAD Parameters for U-Landfill Outdoor Worker Forward Run

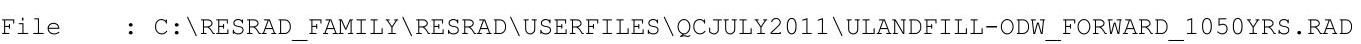

Single Radionuclide Soil Guidelines $G(i, t)$ in pCi/g

Basic Radiation Dose Limit $=1.000 \mathrm{E}+00 \mathrm{mrem} / \mathrm{yr}$

Nuclide

\begin{tabular}{|c|c|c|c|c|c|c|c|}
\hline (i) & $t=0.000 \mathrm{E}+00$ & $1.000 \mathrm{E}+00$ & $2.500 \mathrm{E}+01$ & $5.000 \mathrm{E}+01$ & $1.000 \mathrm{E}+02$ & $5.000 \mathrm{E}+02$ & $1.050 \mathrm{E}+03$ \\
\hline-241 & $\star 3.431 \mathrm{E}+12$ & $\star 3.431 \mathrm{E}+12$ & $\star 3.431 \mathrm{E}+12$ & $\star 3.431 \mathrm{E}+12$ & $* 3.431 \mathrm{E}+12$ & $* 3.431 \mathrm{E}+12$ & $3.875 E+11$ \\
\hline-137 & $3.879 E+09$ & $3.936 \mathrm{E}+09$ & $5.600 \mathrm{E}+09$ & $8.084 E+09$ & $1.685 E+10$ & $5.997 \mathrm{E}+12$ & $\star 8.704 \mathrm{E}+13$ \\
\hline-237 & $\star 7.047 \mathrm{E}+08$ & $\star 7.047 \mathrm{E}+08$ & $\star 7.047 \mathrm{E}+08$ & $\star 7.047 \mathrm{E}+08$ & $\star 7.047 \mathrm{E}+08$ & $\star 7.047 \mathrm{E}+08$ & $6.495 \mathrm{E}+07$ \\
\hline-238 & $\star 1.712 \mathrm{E}+13$ & $\star 1.712 \mathrm{E}+13$ & $\star 1.712 \mathrm{E}+13$ & $\star 1.712 \mathrm{E}+13$ & $* 1.712 \mathrm{E}+13$ & $8.701 \mathrm{E}+12$ & $3.735 \mathrm{E}+1 \mathrm{C}$ \\
\hline-239 & $\star 6.214 \mathrm{E}+10$ & $* 6.214 \mathrm{E}+10$ & $* 6.214 \mathrm{E}+10$ & $* 6.214 \mathrm{E}+10$ & $\star 6.214 \mathrm{E}+10$ & $* 6.214 \mathrm{E}+10$ & $* 6.214 \mathrm{E}+1 \mathrm{C}$ \\
\hline-240 & $\star 2.278 \mathrm{E}+11$ & $\star 2.278 \mathrm{E}+11$ & $\star 2.278 \mathrm{E}+11$ & $\star 2.278 \mathrm{E}+11$ & $\star 2.278 \mathrm{E}+11$ & $\star 2.278 \mathrm{E}+11$ & $\star 2.278 \mathrm{E}+1$ \\
\hline$=-99$ & $\star 1.697 \mathrm{E}+10$ & $\star 1.697 \mathrm{E}+10$ & $\star 1.697 \mathrm{E}+10$ & $* 1.697 \mathrm{E}+10$ & $\star 1.697 \mathrm{E}+10$ & $\star 1.697 \mathrm{E}+10$ & $* 1.697 \mathrm{E}+10$ \\
\hline-228 & $3.540 \mathrm{E}+06$ & $5.056 \mathrm{E}+06$ & $2.619 \mathrm{E}+10$ & $1.937 \mathrm{E}+14$ & $\star 8.195 \mathrm{E}+14$ & $\star 8.195 \mathrm{E}+14$ & $\star 8.195 \mathrm{E}+14$ \\
\hline-230 & $\star 2.018 \mathrm{E}+10$ & $\star 2.018 \mathrm{E}+10$ & $2.153 \mathrm{E}+09$ & $9.198 \mathrm{E}+08$ & $3.307 \mathrm{E}+08$ & $4.559 \mathrm{E}+06$ & $5.434 \mathrm{E}+0$ \\
\hline$h-232$ & $* 1.097 \mathrm{E}+05$ & $\star 1.097 \mathrm{E}+05$ & $\star 1.097 \mathrm{E}+05$ & $\star 1.097 \mathrm{E}+05$ & $* 1.097 \mathrm{E}+05$ & $* 1.097 \mathrm{E}+05$ & $5.287 \mathrm{E}+03$ \\
\hline 234 & $* 6.247 \mathrm{E}+09$ & $\star 6.247 \mathrm{E}+09$ & $\star 6.247 \mathrm{E}+09$ & $\star 6.247 \mathrm{E}+09$ & $* 6.247 \mathrm{E}+09$ & $1.955 \mathrm{E}+09$ & $1.071 \mathrm{E}+07$ \\
\hline 35 & $\star 2.161 \mathrm{E}+06$ & $\star 2.161 \mathrm{E}+06$ & $\star 2.161 \mathrm{E}+06$ & $\star 2.161 \mathrm{E}+06$ & $\star 2.161 \mathrm{E}+06$ & $\star 2.161 \mathrm{E}+06$ & $\star 2.161 \mathrm{E}+06$ \\
\hline 38 & $\star 3.361 \mathrm{E}+05$ & $\star 3.361 \mathrm{E}+05$ & $\star 3.361 \mathrm{E}+05$ & $\star 3.361 \mathrm{E}+05$ & $\star 3.361 \mathrm{E}+05$ & $\star 3.361 \mathrm{E}+05$ & $\star 3.361 \mathrm{E}+05$ \\
\hline
\end{tabular}

*At specific activity limit

Summed Dose/Source Ratios DSR(i,t) in (mrem/yr)/(pCi/g)

and Single Radionuclide Soil Guidelines $\mathrm{G}(i, \mathrm{t})$ in $\mathrm{pCi} / \mathrm{g}$

at tmin = time of minimum single radionuclide soil guideline

and at tmax $=$ time of maximum total dose $=1.050 \mathrm{E}+03$ years

\begin{tabular}{|c|c|c|c|c|c|c|}
\hline $\begin{array}{l}\text { liclide } \\
\text { (i) }\end{array}$ & $\begin{array}{l}\text { Initial } \\
(\mathrm{pCi} / \mathrm{g})\end{array}$ & $\begin{array}{c}\text { tmin } \\
\text { (years) }\end{array}$ & $\operatorname{DSR}(i, \operatorname{tmin})$ & $\begin{array}{c}G(i, \operatorname{tmin}) \\
(\mathrm{pCi} / \mathrm{g})\end{array}$ & $\operatorname{DSR}(i, \operatorname{tmax})$ & $\begin{array}{c}G(i, t \max ) \\
(\mathrm{pCi} / \mathrm{g})\end{array}$ \\
\hline-241 & $3.500 \mathrm{E}+01$ & $1.050 \mathrm{E}+03$ & $2.581 \mathrm{E}-12$ & $3.875 E+11$ & $2.581 \mathrm{E}-12$ & $3.875 E+11$ \\
\hline 137 & $1.900 \mathrm{E}+01$ & $0.000 \mathrm{E}+00$ & $2.578 \mathrm{E}-10$ & $3.879 E+09$ & $5.175 \mathrm{E}-17$ & $\star 8.704 \mathrm{E}+13$ \\
\hline 237 & $5.500 \mathrm{E}+00$ & $1.050 \mathrm{E}+03$ & $1.540 \mathrm{E}-08$ & $6.495 E+07$ & $1.540 \mathrm{E}-08$ & $6.495 \mathrm{E}+07$ \\
\hline-238 & $3.900 \mathrm{E}+01$ & $1.050 \mathrm{E}+03$ & $2.677 \mathrm{E}-11$ & $3.735 E+10$ & $2.677 \mathrm{E}-11$ & $3.735 \mathrm{E}+10$ \\
\hline-239 & $3.600 \mathrm{E}+01$ & $1.050 \mathrm{E}+03$ & $6.871 \mathrm{E}-13$ & $\star 6.214 \mathrm{E}+10$ & $6.871 E-13$ & $\star 6.214 \mathrm{E}+10$ \\
\hline-240 & $3.600 \mathrm{E}+01$ & $1.050 \mathrm{E}+03$ & $1.665 \mathrm{E}-16$ & $\star 2.278 \mathrm{E}+11$ & $1.665 \mathrm{E}-16$ & $\star 2.278 \mathrm{E}+11$ \\
\hline-99 & $5.200 \mathrm{E}+01$ & $1.050 \mathrm{E}+03$ & $2.619 \mathrm{E}-20$ & $\star 1.697 \mathrm{E}+10$ & $2.619 \mathrm{E}-20$ & $* 1.697 \mathrm{E}+10$ \\
\hline-228 & $4.000 \mathrm{E}+00$ & $0.000 \mathrm{E}+00$ & $2.825 \mathrm{E}-07$ & $3.540 \mathrm{E}+06$ & $0.000 \mathrm{E}+00$ & $\star 8.195 \mathrm{E}+14$ \\
\hline-230 & $1.000 \mathrm{E}+02$ & $1.050 \mathrm{E}+03$ & $1.840 \mathrm{E}-05$ & $5.434 \mathrm{E}+04$ & $1.840 \mathrm{E}-05$ & $5.434 \mathrm{E}+04$ \\
\hline-232 & $4.000 \mathrm{E}+00$ & $1.050 \mathrm{E}+03$ & $1.891 \mathrm{E}-04$ & $5.287 E+03$ & $1.891 \mathrm{E}-04$ & $5.287 \mathrm{E}+03$ \\
\hline 34 & $1.600 \mathrm{E}+02$ & $1.050 \mathrm{E}+03$ & $9.341 \mathrm{E}-08$ & $1.071 \mathrm{E}+07$ & $9.341 \mathrm{E}-08$ & $1.071 \mathrm{E}+07$ \\
\hline 35 & $6.500 \mathrm{E}+00$ & $1.050 \mathrm{E}+03$ & $4.843 \mathrm{E}-09$ & $\star 2.161 \mathrm{E}+06$ & $4.843 \mathrm{E}-09$ & $\star 2.161 \mathrm{E}+06$ \\
\hline 238 & $1.600 \mathrm{E}+02$ & $1.050 \mathrm{E}+03$ & $1.280 \mathrm{E}-07$ & $\star 3.361 E+05$ & $1.280 \mathrm{E}-07$ & $* 3.361 \mathrm{E}+05$ \\
\hline
\end{tabular}

*At specific activity limit 
RESRAD, Version 6.5

Summary : RESRAD Parameters for U-Landfill Outdoor Worker Forward Run

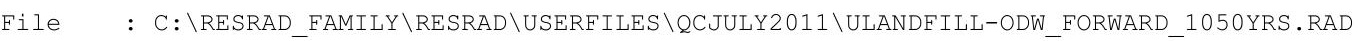

Individual Nuclide Dose Summed Over All Pathways

Parent Nuclide and Branch Fraction Indicated

Nuclide Parent THF(i) DOSE $(j, t), \mathrm{mrem} / \mathrm{yr}$

\begin{tabular}{|c|c|c|}
\hline$(j)$ & (i) & \\
\hline$m-241$ & $A m-241$ & $1.000 \mathrm{E}+00$ \\
\hline$p-237$ & Am-241 & $1.000 \mathrm{E}+00$ \\
\hline-237 & $N p-237$ & $1.000 \mathrm{E}+00$ \\
\hline 237 & $\sum \mathrm{DOSE}$ & \\
\hline
\end{tabular}

$\mathrm{U}-233 \mathrm{Am}-241 \quad 1.000 \mathrm{E}+00$

$\mathrm{U}-233 \mathrm{~Np}-237 \quad 1.000 \mathrm{E}+00$

U-233 $\quad$ DDOSE $(j)$

Th-229 Am-241 1.000E+00

$\mathrm{Th}-229 \quad \mathrm{~Np}-237 \quad 1.000 \mathrm{E}+00$

Th-229 $\sum$ DOSE $(j)$

Cs-137 Cs $-137 \quad 1.000 \mathrm{E}+00$

$\mathrm{Pu}-238$

$\mathrm{Pu}-238$

$\mathrm{Pu}-238$

$\mathrm{U}-234$

$\mathrm{U}-234$

$\mathrm{U}-234$

$\mathrm{U}-234$

$\mathrm{Th}-230$

$\mathrm{Th}-230$

$\mathrm{Th}-230$

$\mathrm{Th}-230$

$\mathrm{Th}-230$

$\mathrm{Ra}-226$

$\mathrm{Ra}-226$

$\mathrm{Ra}-226$

$\mathrm{Ra}-226$

$\mathrm{Ra}-226$

$\mathrm{Pb}-210$

$\mathrm{Pb}-210$

$\mathrm{Pb}-210$

$\mathrm{Pb}-210$

$\mathrm{Pb}-210$

$P u-239$

Pu-238 1.840E-09 $\mathrm{Pu}-238 \quad 1.000 \mathrm{E}+00$ $\sum \operatorname{DOSE}(j)$

$\mathrm{Pu}-238 \quad 1.000 \mathrm{E}+00$ $\mathrm{U}-234 \quad 1.000 \mathrm{E}+00$ U-238 9.999E-01 $\sum \operatorname{DOSE}(j)$

$\mathrm{Pu}-238 \quad 1.000 \mathrm{E}+00$ Th-230 1.000E+00 $\mathrm{U}-234 \quad 1.000 \mathrm{E}+00$ U-238 9.999E-01 $\sum \operatorname{DOSE}(j)$

$\mathrm{Pu}-238 \quad 1.000 \mathrm{E}+00$ $\mathrm{Th}-230 \quad 1.000 \mathrm{E}+00$ $\mathrm{U}-234 \quad 1.000 \mathrm{E}+00$ U-238 9.999E-01 $\sum \operatorname{DOSE}(j)$

$\mathrm{Pu}-238 \quad 1.000 \mathrm{E}+00$ Th-230 1.000E+00 $\mathrm{U}-234 \quad 1.000 \mathrm{E}+00$ U-238 9.999E-01 $\sum \operatorname{DOSE}(j)$

$\mathrm{Pu}-239 \quad 1.000 \mathrm{E}+00$

$\mathrm{Pu}-239$ 1.000E+00 U-235 $1.000 \mathrm{E}+00$ $\sum \operatorname{DOSE}(j)$ $t=0.000 \mathrm{E}+00 \quad 1.000 \mathrm{E}+00 \quad 2.500 \mathrm{E}+01 \quad 5.000 \mathrm{E}+01 \quad 1.000 \mathrm{E}+02 \quad 5.000 \mathrm{E}+02 \quad 1.050 \mathrm{E}+03$

$1.106 \mathrm{E}-18 \quad 3.347 \mathrm{E}-18 \quad 7.223 \mathrm{E}-17 \quad 1.835 \mathrm{E}-16 \quad 6.012 \mathrm{E}-16 \quad 1.645 \mathrm{E}-13 \quad 8.947 \mathrm{E}-11$

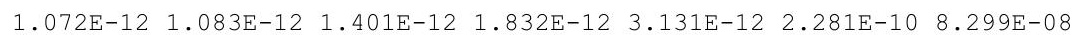
$1.072 \mathrm{E}-12 \quad 1.083 \mathrm{E}-12 \quad 1.401 \mathrm{E}-12 \quad 1.832 \mathrm{E}-12 \quad 3.132 \mathrm{E}-12 \quad 2.283 \mathrm{E}-10 \quad 8.308 \mathrm{E}-08$

$0.000 \mathrm{E}+00 \quad 1.773 \mathrm{E}-28 \quad 6.581 \mathrm{E}-26 \quad 3.482 \mathrm{E}-25 \quad 2.511 \mathrm{E}-24 \quad 7.620 \mathrm{E}-21 \quad 2.570 \mathrm{E}-17$ $\begin{array}{llllllll}3.647 \mathrm{E}-23 & 1.106 \mathrm{E}-22 & 2.537 \mathrm{E}-21 & 6.866 \mathrm{E}-21 & 2.553 \mathrm{E}-20 & 1.885 \mathrm{E}-17 & 3.825 \mathrm{E}-14\end{array}$ $\begin{array}{llllllll}3.647 \mathrm{E}-23 & 1.106 \mathrm{E}-22 & 2.537 \mathrm{E}-21 & 6.867 \mathrm{E}-21 & 2.553 \mathrm{E}-20 & 1.886 \mathrm{E}-17 & 3.827 \mathrm{E}-14\end{array}$

$\begin{array}{lllllll}1.715 \mathrm{E}-25 & 2.588 \mathrm{E}-24 & 1.338 \mathrm{E}-20 & 1.224 \mathrm{E}-19 & 1.338 \mathrm{E}-18 & 2.306 \mathrm{E}-15 & 8.490 \mathrm{E}-13\end{array}$ $3.329 \mathrm{E}-192.344 \mathrm{E}-18 \quad 7.710 \mathrm{E}-16 \quad 3.596 \mathrm{E}-15 \quad 2.014 \mathrm{E}-14 \quad 8.046 \mathrm{E}-12 \quad 1.686 \mathrm{E}-09$ $\begin{array}{lllllll}3.329 \mathrm{E}-19 & 2.344 \mathrm{E}-18 & 7.710 \mathrm{E}-16 & 3.596 \mathrm{E}-15 & 2.014 \mathrm{E}-14 & 8.048 \mathrm{E}-12 & 1.687 \mathrm{E}-09\end{array}$

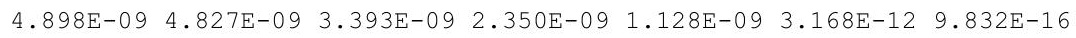
$\begin{array}{llllllll}0.000 \mathrm{E}+00 & 0.000 \mathrm{E}+00 & 0.000 \mathrm{E}+00 & 0.000 \mathrm{E}+00 & 0.000 \mathrm{E}+00 & 0.000 \mathrm{E}+00 & 4.847 \mathrm{E}-28\end{array}$ $\begin{array}{lllllll}9.362 \mathrm{E}-24 & 9.454 \mathrm{E}-24 & 1.195 \mathrm{E}-23 & 1.525 \mathrm{E}-23 & 2.484 \mathrm{E}-23 & 1.231 \mathrm{E}-21 & 2.634 \mathrm{E}-19\end{array}$

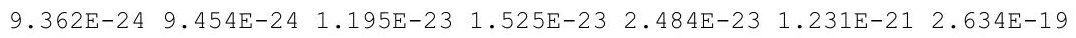

$\begin{array}{lllllll}7.792 \mathrm{E}-29 & 2.366 \mathrm{E}-28 & 5.602 \mathrm{E}-27 & 1.573 \mathrm{E}-26 & 6.349 \mathrm{E}-26 & 1.353 \mathrm{E}-22 & 2.337 \mathrm{E}-18\end{array}$ $\begin{array}{llllllll}2.254 \mathrm{E}-22 & 2.295 \mathrm{E}-22 & 3.510 \mathrm{E}-22 & 5.464 \mathrm{E}-22 & 1.324 \mathrm{E}-21 & 1.576 \mathrm{E}-18 & 2.670 \mathrm{E}-14\end{array}$ $\begin{array}{lllllll}3.205 \mathrm{E}-28 & 9.767 \mathrm{E}-28 & 2.537 \mathrm{E}-26 & 7.823 \mathrm{E}-26 & 3.773 \mathrm{E}-25 & 2.238 \mathrm{E}-21 & 7.964 \mathrm{E}-17\end{array}$ $\begin{array}{lllllll}2.254 \mathrm{E}-22 & 2.295 \mathrm{E}-22 & 3.510 \mathrm{E}-22 & 5.465 \mathrm{E}-22 & 1.325 \mathrm{E}-21 & 1.578 \mathrm{E}-18 & 2.679 \mathrm{E}-14\end{array}$

$0.000 \mathrm{E}+00 \quad 0.000 \mathrm{E}+00 \quad 0.000 \mathrm{E}+00 \quad 1.275 \mathrm{E}-28 \quad 1.038 \mathrm{E}-27 \quad 1.043 \mathrm{E}-23 \quad 2.650 \mathrm{E}-19$ $\begin{array}{llllllll}4.929 \mathrm{E}-21 & 5.012 \mathrm{E}-21 & 7.503 \mathrm{E}-21 & 1.142 \mathrm{E}-20 & 2.647 \mathrm{E}-20 & 2.203 \mathrm{E}-17 & 2.282 \mathrm{E}-13\end{array}$

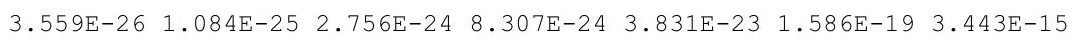
$0.000 \mathrm{E}+00 \quad 0.000 \mathrm{E}+00 \quad 0.000 \mathrm{E}+00 \quad 5.947 \mathrm{E}-28 \quad 5.457 \mathrm{E}-27 \quad 1.125 \mathrm{E}-22 \quad 5.127 \mathrm{E}-18$ $\begin{array}{llllllllll}4.929 \mathrm{E}-21 & 5.012 \mathrm{E}-21 & 7.506 \mathrm{E}-21 & 1.143 \mathrm{E}-20 & 2.651 \mathrm{E}-20 & 2.219 \mathrm{E}-17 & 2.317 \mathrm{E}-13\end{array}$ $\begin{array}{lllllll}6.392 E-22 & 9.628 E-21 & 4.782 E-17 & 4.197 E-16 & 4.245 E-15 & 4.482 E-12 & 1.044 E-09\end{array}$ $\begin{array}{lllllll}7.712 \mathrm{E}-10 & 2.327 \mathrm{E}-09 & 4.644 \mathrm{E}-08 & 1.087 \mathrm{E}-07 & 3.024 \mathrm{E}-07 & 2.193 \mathrm{E}-05 & 1.840 \mathrm{E}-03\end{array}$ $\begin{array}{lllllll}3.705 \mathrm{E}-15 & 2.608 \mathrm{E}-14 & 8.545 \mathrm{E}-12 & 3.968 \mathrm{E}-11 & 2.204 \mathrm{E}-10 & 8.184 \mathrm{E}-08 & 1.495 \mathrm{E}-05\end{array}$ $2.626 \mathrm{E}-21 \quad 3.963 \mathrm{E}-20 \quad 2.061 \mathrm{E}-16 \quad 1.897 \mathrm{E}-15 \quad 2.100 \mathrm{E}-14 \quad 3.939 \mathrm{E}-11 \quad 1.538 \mathrm{E}-08$ $\begin{array}{lllllll}7.712 \mathrm{E}-10 & 2.327 \mathrm{E}-09 & 4.645 \mathrm{E}-08 & 1.088 \mathrm{E}-07 & 3.026 \mathrm{E}-07 & 2.202 \mathrm{E}-05 & 1.855 \mathrm{E}-03\end{array}$

$\begin{array}{llllllll}0.000 \mathrm{E}+00 & 5.746 \mathrm{E}-29 & 3.949 \mathrm{E}-24 & 6.196 \mathrm{E}-23 & 1.048 \mathrm{E}-21 & 2.936 \mathrm{E}-18 & 1.379 \mathrm{E}-15\end{array}$ $\begin{array}{lllllllll}3.717 \mathrm{E}-18 & 2.596 \mathrm{E}-17 & 6.907 \mathrm{E}-15 & 2.655 \mathrm{E}-14 & 1.087 \mathrm{E}-13 & 1.573 \mathrm{E}-11 & 2.528 \mathrm{E}-09\end{array}$ $\begin{array}{lllllll}1.341 \mathrm{E}-23 & 2.012 \mathrm{E}-22 & 8.994 \mathrm{E}-19 & 7.200 \mathrm{E}-18 & 6.329 \mathrm{E}-17 & 5.505 \mathrm{E}-14 & 1.988 \mathrm{E}-11\end{array}$ $\begin{array}{lllllllll}0.000 \mathrm{E}+00 & 2.363 \mathrm{E}-28 & 1.687 \mathrm{E}-23 & 2.757 \mathrm{E}-22 & 5.058 \mathrm{E}-21 & 2.498 \mathrm{E}-17 & 1.985 \mathrm{E}-14\end{array}$ $\begin{array}{llllllll}3.717 \mathrm{E}-18 & 2.596 \mathrm{E}-17 & 6.907 \mathrm{E}-15 & 2.655 \mathrm{E}-14 & 1.087 \mathrm{E}-13 & 1.578 \mathrm{E}-11 & 2.548 \mathrm{E}-09\end{array}$ $\begin{array}{lllllll}8.843 E-17 & 8.949 E-17 & 1.192 \mathrm{E}-16 & 1.607 \mathrm{E}-16 & 2.919 \mathrm{E}-16 & 3.463 \mathrm{E}-14 & 2.463 \mathrm{E}-11\end{array}$ $\begin{array}{lllllll}4.513 E-23 & 1.369 \mathrm{E}-22 & 3.128 \mathrm{E}-21 & 8.434 \mathrm{E}-21 & 3.112 \mathrm{E}-20 & 2.165 \mathrm{E}-17 & 4.048 \mathrm{E}-14\end{array}$ $\begin{array}{llllllll}1.651 \mathrm{E}-14 & 1.672 \mathrm{E}-14 & 2.249 \mathrm{E}-14 & 3.064 \mathrm{E}-14 & 5.684 \mathrm{E}-14 & 7.982 \mathrm{E}-12 & 7.159 \mathrm{E}-09\end{array}$ $\begin{array}{llllllll}1.651 \mathrm{E}-14 & 1.672 \mathrm{E}-14 & 2.249 \mathrm{E}-14 & 3.064 \mathrm{E}-14 & 5.684 \mathrm{E}-14 & 7.982 \mathrm{E}-12 & 7.159 \mathrm{E}-09\end{array}$ 
RESRAD, Version 6.5

Summary : RESRAD Parameters for U-Landfill Outdoor Worker Forward Run

File : C: $\backslash$ RESRAD_FAMILY \RESRAD \USERFILES \QCJULY2011 \ULANDFILL-ODW_FORWARD_1050YRS.RAD

Individual Nuclide Dose Summed Over All Pathways

Parent Nuclide and Branch Fraction Indicated

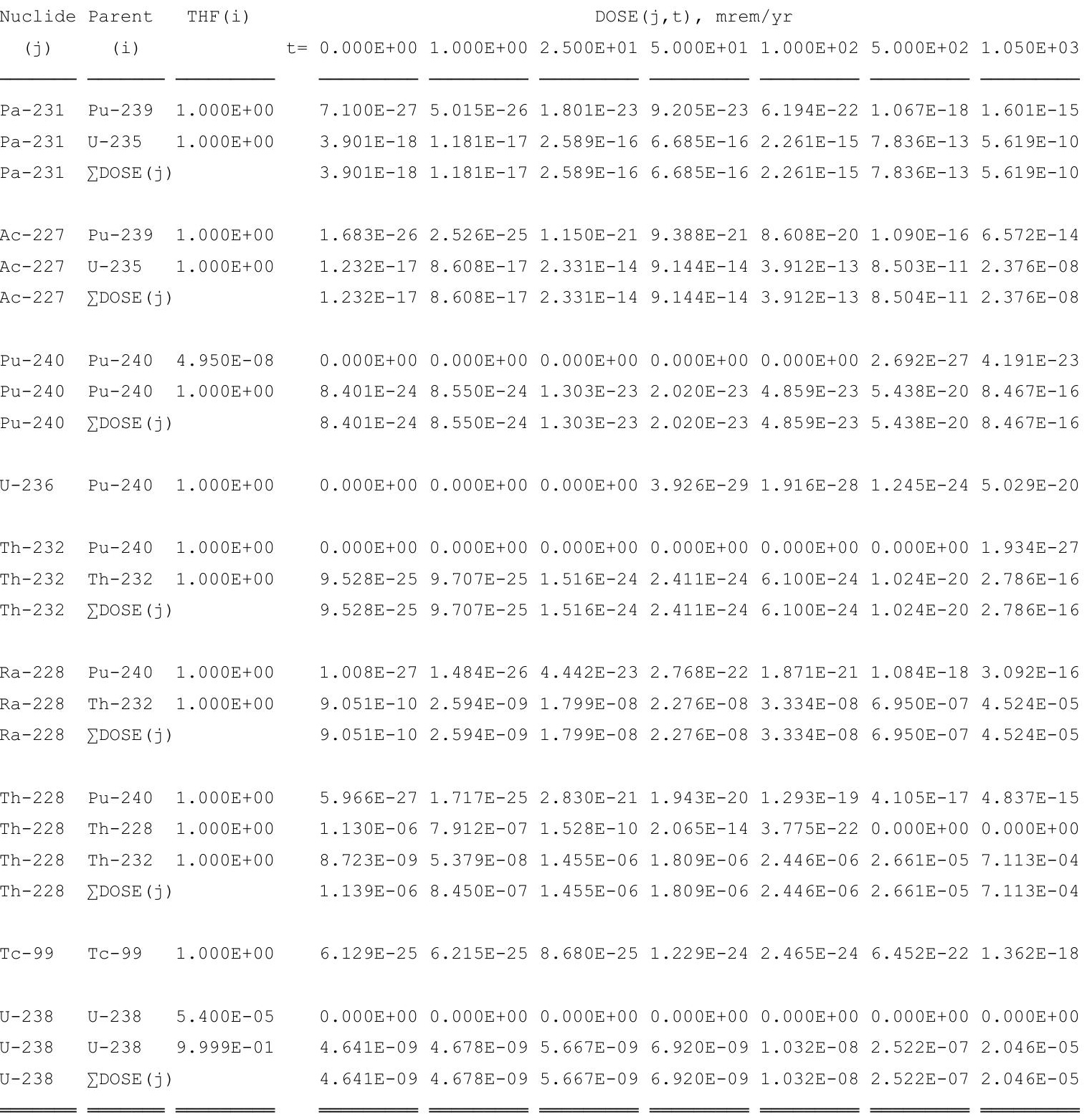

THF (i) is the thread fraction of the parent nuclide. 
RESRAD, Version 6.5

Summary : RESRAD Parameters for U-Landfill Outdoor Worker Forward Run

File : C: \RESRAD_FAMILY \RESRAD \USERFILES \QCJULY2011 \ULANDFILL-ODW_FORWARD 1050YRS.RAD

Individual Nuclide Soil Concentration

Parent Nuclide and Branch Fraction Indicated

Nuclide Parent THF(

(j)

Am-241

(i)

$\overline{A m-241} \overline{1.000 \mathrm{E}+00}$

Np-237 Am-241 $1.000 \mathrm{E}+00$

$\mathrm{Np}-237 \quad \mathrm{~Np}-237 \quad 1.000 \mathrm{E}+00$

Np-237 $\sum S(j):$

$\mathrm{U}-233 \quad \mathrm{Am}-241 \quad 1.000 \mathrm{E}+00$

$\mathrm{U}-233 \quad \mathrm{~Np}-237 \quad 1.000 \mathrm{E}+00$

U-233 $\sum S(j):$

Th -229

Th-229

Th-229

Cs -137

$\mathrm{Pu}-238$

$\mathrm{Pu}-238$

$\mathrm{Pu}-238$

$\mathrm{U}-234$

$\mathrm{U}-234$

$\mathrm{U}-234$

$\mathrm{U}-234$

Th-230

Th-230

Th -230

Th-230

Th-230

$\mathrm{Ra}-226$

$\mathrm{Ra}-226$

$\mathrm{Ra}-226$

$\mathrm{Ra}-226$

$\mathrm{Ra}-226$

$\mathrm{Pb}-210$

$\mathrm{Pb}-210$

$\mathrm{Pb}-210$

$\mathrm{Pb}-210$

$\mathrm{Pb}-210$

$\mathrm{Pu}-239$

$\mathrm{Am}-241 \quad 1.000 \mathrm{E}+00$

Np-237 1.000E+00

$\sum S(j):$

Cs $-137 \quad 1.000 E+00$

Pu-238 1.840E-09

Pu-238 1.000E+00

$\sum S(j):$

$\mathrm{Pu}-238 \quad 1.000 \mathrm{E}+00$

$\mathrm{U}-234 \quad 1.000 \mathrm{E}+00$

$\mathrm{U}-238 \quad 9.999 \mathrm{E}-01$

$\sum S(j):$

$\mathrm{Pu}-238 \quad 1.000 \mathrm{E}+00$

Th-230 1.000E+00

U-234 $1.000 \mathrm{E}+00$

U-238 $9.999 \mathrm{E}-01$

$\sum S(j):$

Pu-238 1.000E+00

Th-230 1.000E+00

$\mathrm{U}-234 \quad 1.000 \mathrm{E}+00$

U-238 9.999E-01

$\sum S(j):$

$\mathrm{Pu}-238 \quad 1.000 \mathrm{E}+00$

Th-230 1.000E+00

$\mathrm{U}-2341.000 \mathrm{E}+00$

$\mathrm{U}-238 \quad 9.999 \mathrm{E}-01$

$\sum S(j):$

Pu-239 $1.000 \mathrm{E}+00$

$\mathrm{Pu}-239 \quad 1.000 \mathrm{E}+00$

$\mathrm{U}-2351.000 \mathrm{E}+00$

$\sum S(j):$
$\mathrm{S}(j, \mathrm{t}), \mathrm{pCi} / \mathrm{g}$

$\mathrm{t}=0.000 \mathrm{E}+00 \quad 1.000 \mathrm{E}+00 \quad 2.500 \mathrm{E}+01 \quad 5.000 \mathrm{E}+01 \quad 1.000 \mathrm{E}+02 \quad 5.000 \mathrm{E}+02 \quad 1.050 \mathrm{E}+03$

$\begin{array}{lllllllllllll}3.500 \mathrm{E}+01 & 3.494 \mathrm{E}+01 & 3.362 \mathrm{E}+01 & 3.230 \mathrm{E}+01 & 2.981 \mathrm{E}+01 & 1.567 \mathrm{E}+01 & 6.478 \mathrm{E}+00\end{array}$

$0.000 \mathrm{E}+00 \quad 1.133 \mathrm{E}-05 \quad 2.775 \mathrm{E}-04 \quad 5.436 \mathrm{E}-04 \quad 1.043 \mathrm{E}-03 \quad 3.810 \mathrm{E}-03 \quad 5.458 \mathrm{E}-03$

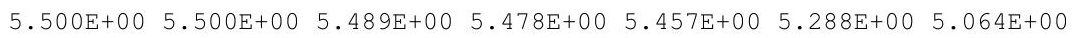

$\begin{array}{lllllll}5.500 \mathrm{E}+00 & 5.500 \mathrm{E}+00 & 5.489 \mathrm{E}+00 & 5.479 \mathrm{E}+00 & 5.458 \mathrm{E}+00 & 5.291 \mathrm{E}+00 & 5.069 \mathrm{E}+00\end{array}$

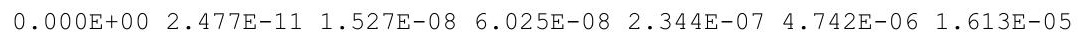

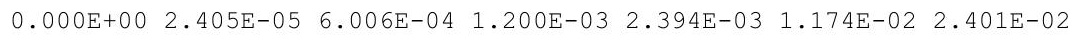

$\begin{array}{lllllll}0.000 \mathrm{E}+00 & 2.405 \mathrm{E}-05 & 6.006 \mathrm{E}-04 & 1.200 \mathrm{E}-03 & 2.394 \mathrm{E}-03 & 1.174 \mathrm{E}-02 & 2.403 \mathrm{E}-02\end{array}$

$0.000 \mathrm{E}+00 \quad 7.799 \mathrm{E}-16 \quad 1.206 \mathrm{E}-11 \quad 9.538 \mathrm{E}-11 \quad 7.463 \mathrm{E}-10 \quad 7.873 \mathrm{E}-08 \quad 5.891 \mathrm{E}-07$

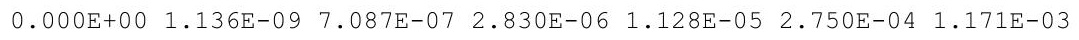

$\begin{array}{lllllll}0.000 \mathrm{E}+00 & 1.136 \mathrm{E}-09 & 7.087 \mathrm{E}-07 & 2.830 \mathrm{E}-06 & 1.128 \mathrm{E}-05 & 2.750 \mathrm{E}-04 & 1.171 \mathrm{E}-03\end{array}$

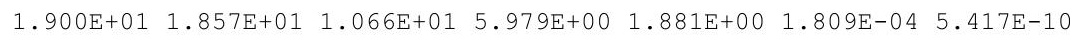

$\begin{array}{lllllll}7.176 \mathrm{E}-08 & 7.119 \mathrm{E}-08 & 5.888 \mathrm{E}-08 & 4.832 \mathrm{E}-08 & 3.254 \mathrm{E}-08 & 1.375 \mathrm{E}-09 & 1.774 \mathrm{E}-11\end{array}$

$\begin{array}{lllllllllll}3.900 \mathrm{E}+01 & 3.869 \mathrm{E}+01 & 3.200 \mathrm{E}+01 & 2.626 \mathrm{E}+01 & 1.768 \mathrm{E}+01 & 7.472 \mathrm{E}-01 & 9.639 \mathrm{E}-03\end{array}$

$\begin{array}{llllllllllll}3.900 \mathrm{E}+01 & 3.869 \mathrm{E}+01 & 3.200 \mathrm{E}+01 & 2.626 \mathrm{E}+01 & 1.768 \mathrm{E}+01 & 7.472 \mathrm{E}-01 & 9.639 \mathrm{E}-03\end{array}$

$0.000 \mathrm{E}+00 \quad 1.101 \mathrm{E}-04 \quad 2.507 \mathrm{E}-03 \quad 4.564 \mathrm{E}-03 \quad 7.633 \mathrm{E}-03 \quad 1.362 \mathrm{E}-02 \quad 1.377 \mathrm{E}-02$

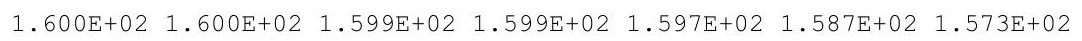

$\begin{array}{lllllllll}0.000 \mathrm{E}+00 & 4.536 \mathrm{E}-04 & 1.134 \mathrm{E}-02 & 2.266 \mathrm{E}-02 & 4.529 \mathrm{E}-02 & 2.251 \mathrm{E}-01 & 4.689 \mathrm{E}-01\end{array}$

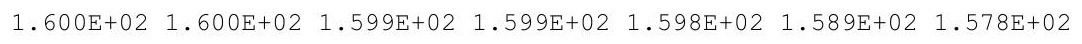

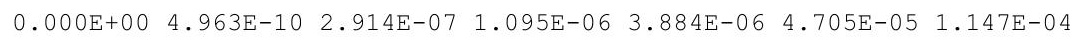
$\begin{array}{lllllllll}1.000 \mathrm{E}+02 & 1.000 \mathrm{E}+02 & 9.997 \mathrm{E}+01 & 9.995 \mathrm{E}+01 & 9.989 \mathrm{E}+01 & 9.947 \mathrm{E}+01 & 9.888 \mathrm{E}+01\end{array}$ $\begin{array}{llllllll}0.000 \mathrm{E}+00 & 1.440 \mathrm{E}-03 & 3.600 \mathrm{E}-02 & 7.197 \mathrm{E}-02 & 1.438 \mathrm{E}-01 & 7.153 \mathrm{E}-01 & 1.491 \mathrm{E}+00\end{array}$

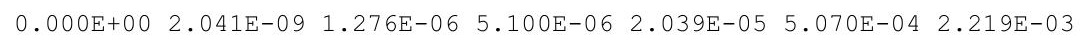

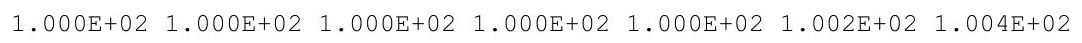

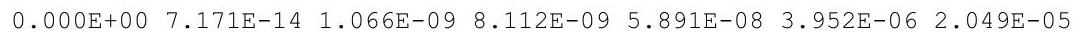
$\begin{array}{lllllll}0.000 \mathrm{E}+00 & 4.331 \mathrm{E}-02 & 1.077 \mathrm{E}+00 & 2.142 \mathrm{E}+00 & 4.235 \mathrm{E}+00 & 1.937 \mathrm{E}+01 & 3.613 \mathrm{E}+01\end{array}$ $\begin{array}{llllllll}0.000 \mathrm{E}+00 & 3.119 \mathrm{E}-07 & 1.942 \mathrm{E}-04 & 7.739 \mathrm{E}-04 & 3.071 \mathrm{E}-03 & 7.220 \mathrm{E}-02 & 2.933 \mathrm{E}-01\end{array}$ $\begin{array}{lllllll}0.000 \mathrm{E}+00 & 2.948 \mathrm{E}-13 & 4.592 \mathrm{E}-0 & 3.663 \mathrm{E}-08 & 2.913 \mathrm{E}-07 & 3.471 \mathrm{E}-05 & 3.016 \mathrm{E}-04\end{array}$ $\begin{array}{lllllll}0.000 \mathrm{E}+00 & 4.331 \mathrm{E}-02 & 1.077 \mathrm{E}+00 & 2.142 \mathrm{E}+00 & 4.238 \mathrm{E}+00 & 1.944 \mathrm{E}+01 & 3.643 \mathrm{E}+01\end{array}$

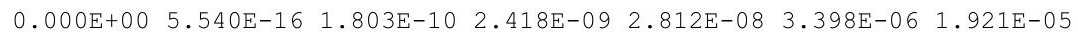
$\begin{array}{llllllll}0.000 \mathrm{E}+00 & 6.663 \mathrm{E}-04 & 3.287 \mathrm{E}-01 & 1.058 \mathrm{E}+00 & 2.946 \mathrm{E}+00 & 1.823 \mathrm{E}+01 & 3.524 \mathrm{E}+01\end{array}$ $\begin{array}{lllllll}0.000 \mathrm{E}+00 & 3.207 \mathrm{E}-09 & 4.191 \mathrm{E}-05 & 2.837 \mathrm{E}-04 & 1.706 \mathrm{E}-03 & 6.374 \mathrm{E}-02 & 2.769 \mathrm{E}-01\end{array}$ $\begin{array}{lllllll}0.000 \mathrm{E}+00 & 2.276 \mathrm{E}-15 & 7.700 \mathrm{E}-10 & 1.075 \mathrm{E}-08 & 1.356 \mathrm{E}-07 & 2.889 \mathrm{E}-05 & 2.763 \mathrm{E}-04\end{array}$ $\begin{array}{lllllll}0.000 \mathrm{E}+00 & 6.663 \mathrm{E}-04 & 3.287 \mathrm{E}-01 & 1.058 \mathrm{E}+00 & 2.947 \mathrm{E}+00 & 1.830 \mathrm{E}+01 & 3.551 \mathrm{E}+01\end{array}$ $\begin{array}{llllllll}3.600 \mathrm{E}+01 & 3.600 \mathrm{E}+01 & 3.597 \mathrm{E}+01 & 3.593 \mathrm{E}+01 & 3.586 \mathrm{E}+01 & 3.531 \mathrm{E}+01 & 3.456 \mathrm{E}+01\end{array}$

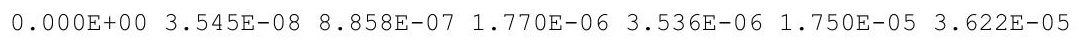

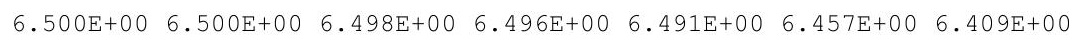

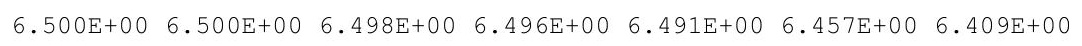


RESRAD, Version 6.5

Summary : RESRAD Parameters for U-Landfill Outdoor Worker Forward Run

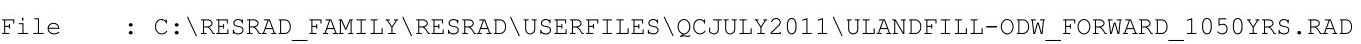

Individual Nuclide Soil Concentration

Parent Nuclide and Branch Fraction Indicated

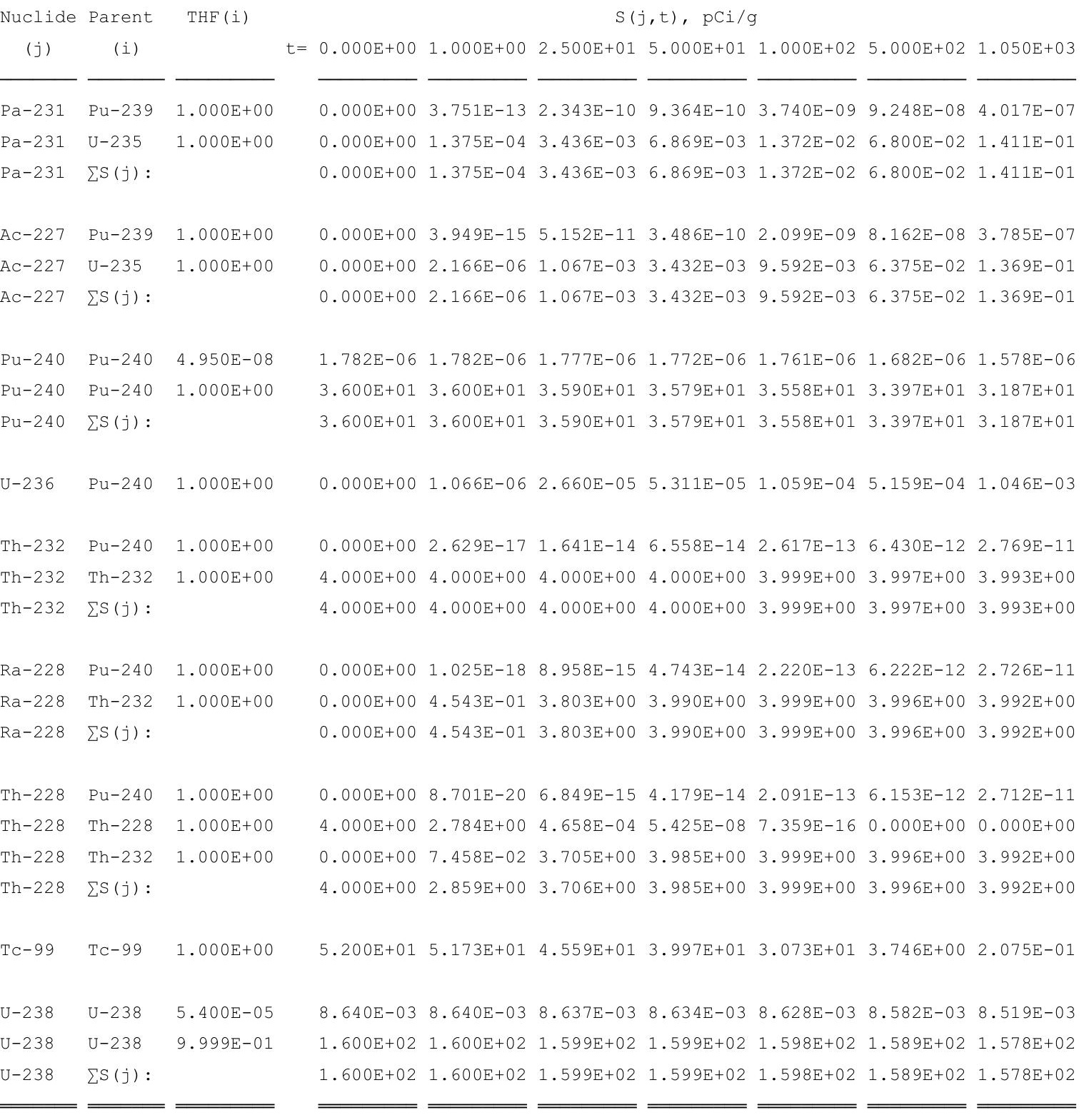

THF (i) is the thread fraction of the parent nuclide.

RESCALC.EXE execution time $=9.25$ seconds 
RESRAD, Version $6.5 \quad T^{13 / 2}$ Limit $=180$ days

07/20/2011 $15: 20$ Page

Summary : RESRAD Parameters for U-Landfill Outdoor Worker Forward Run at Proposed ALs

File : C:\RESRAD_FAMILY \RESRAD UUSERFILES \QCJULY2011 \ODW_FORWARD_1050YRSALS.RAD

Table of Contents

Part I: Mixture Sums and Single Radionuclide Guidelines

Dose Conversion Factor (and Related) Parameter Summary ... 2

Site-Specific Parameter Summary ................. 8

Summary of Pathway Selections .................... 18

Contaminated Zone and Total Dose Summary ............. 19

Total Dose Components

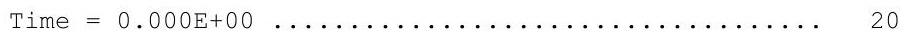

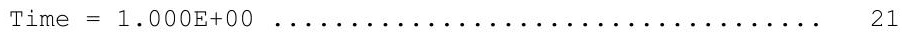

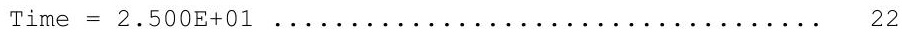

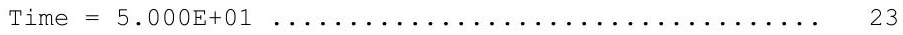

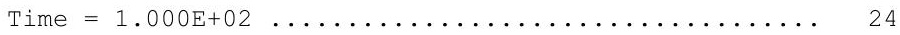

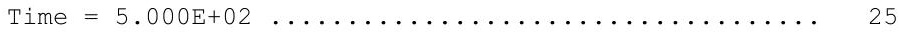

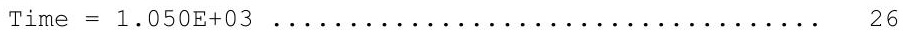

Dose/Source Ratios Summed Over All Pathways .......... 27

Single Radionuclide Soil Guidelines ................ 29

Dose Per Nuclide Summed Over All Pathways ............ 30

Soil Concentration Per Nuclide ............... 32 
Summary : RESRAD Parameters for U-Landfill Outdoor Worker Forward Run at Proposed ALS

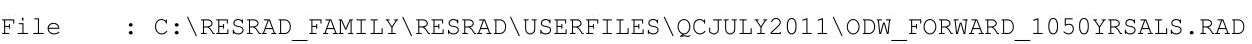

Dose Conversion Factor (and Related) Parameter Summary

Dose Library: ICRP 60 \& ICRP 72 (Adult)

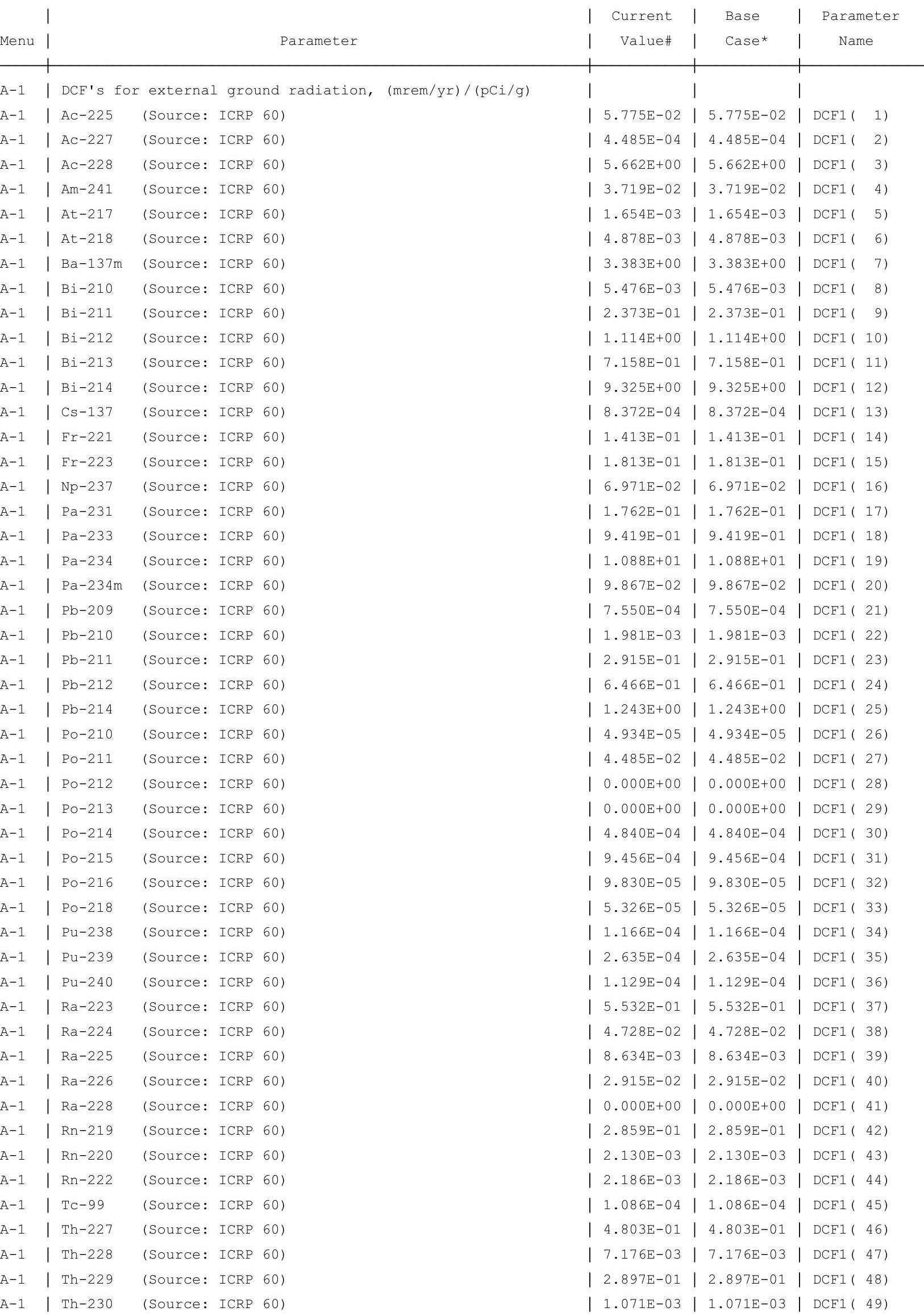


Summary : RESRAD Parameters for U-Landfill Outdoor Worker Forward Run at Proposed ALs File : C: \RESRAD_FAMILY \RESRAD \USERFILES $\backslash Q C J U L Y 2011 \backslash O D W$ FORWARD_1050YRSALS.RAD

Dose Conversion Factor (and Related) Parameter Summary (continued) Dose Library: ICRP 60 \& ICRP 72 (Adult)

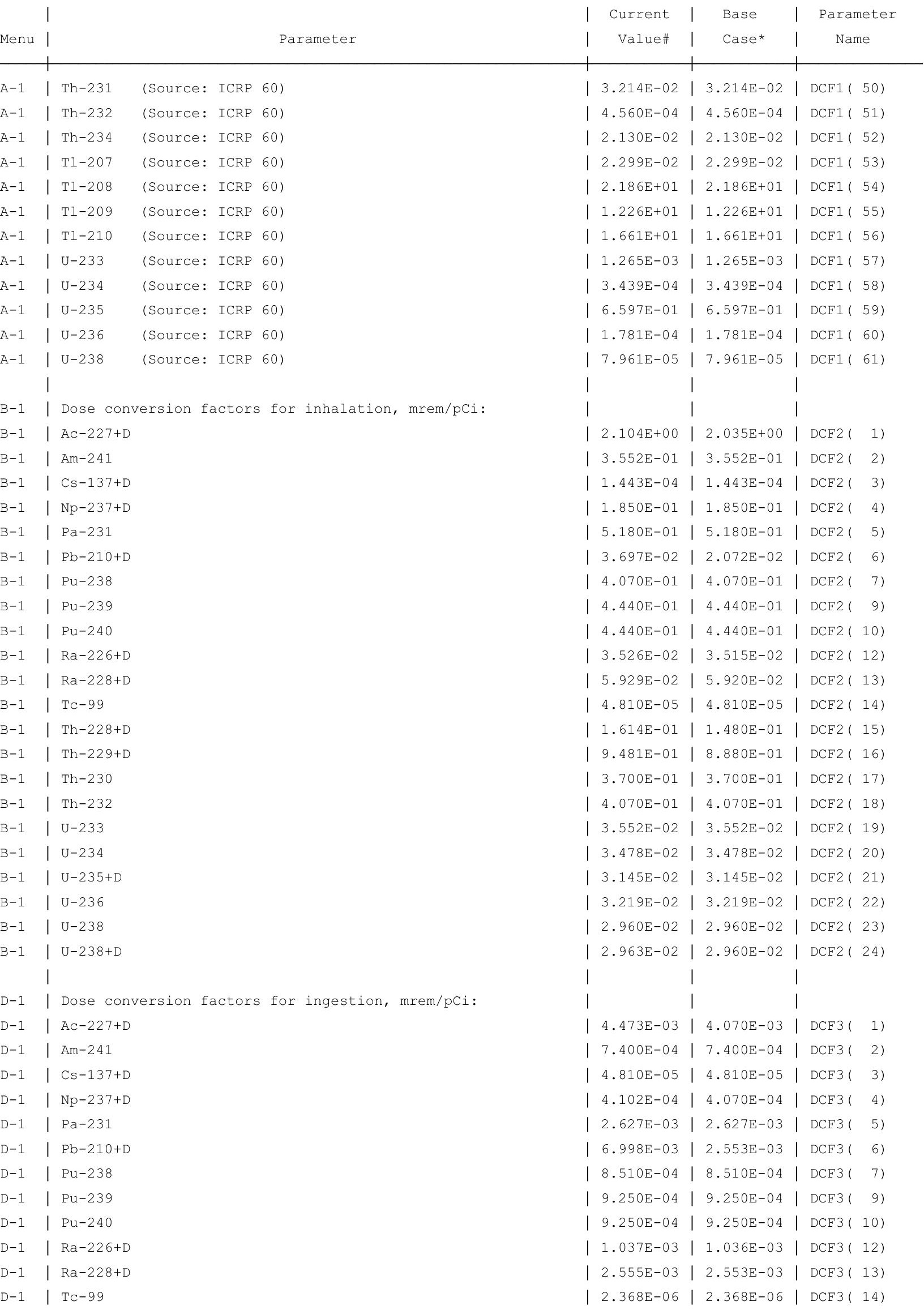


RESRAD, Version $6.5 \quad \mathrm{~T}^{1 / 2}$ Limit $=180$ days

Summary : RESRAD Parameters for U-Landfill Outdoor Worker Forward Run at Proposed ALs

File : C: \RESRAD FAMILY \RESRAD \USERFILES $\backslash Q C J U L Y 2011 \backslash$ ODW FORWARD 1050YRSALS.RAD

Dose Conversion Factor (and Related) Parameter Summary (continued) Dose Library: ICRP 60 \& ICRP 72 (Adult)

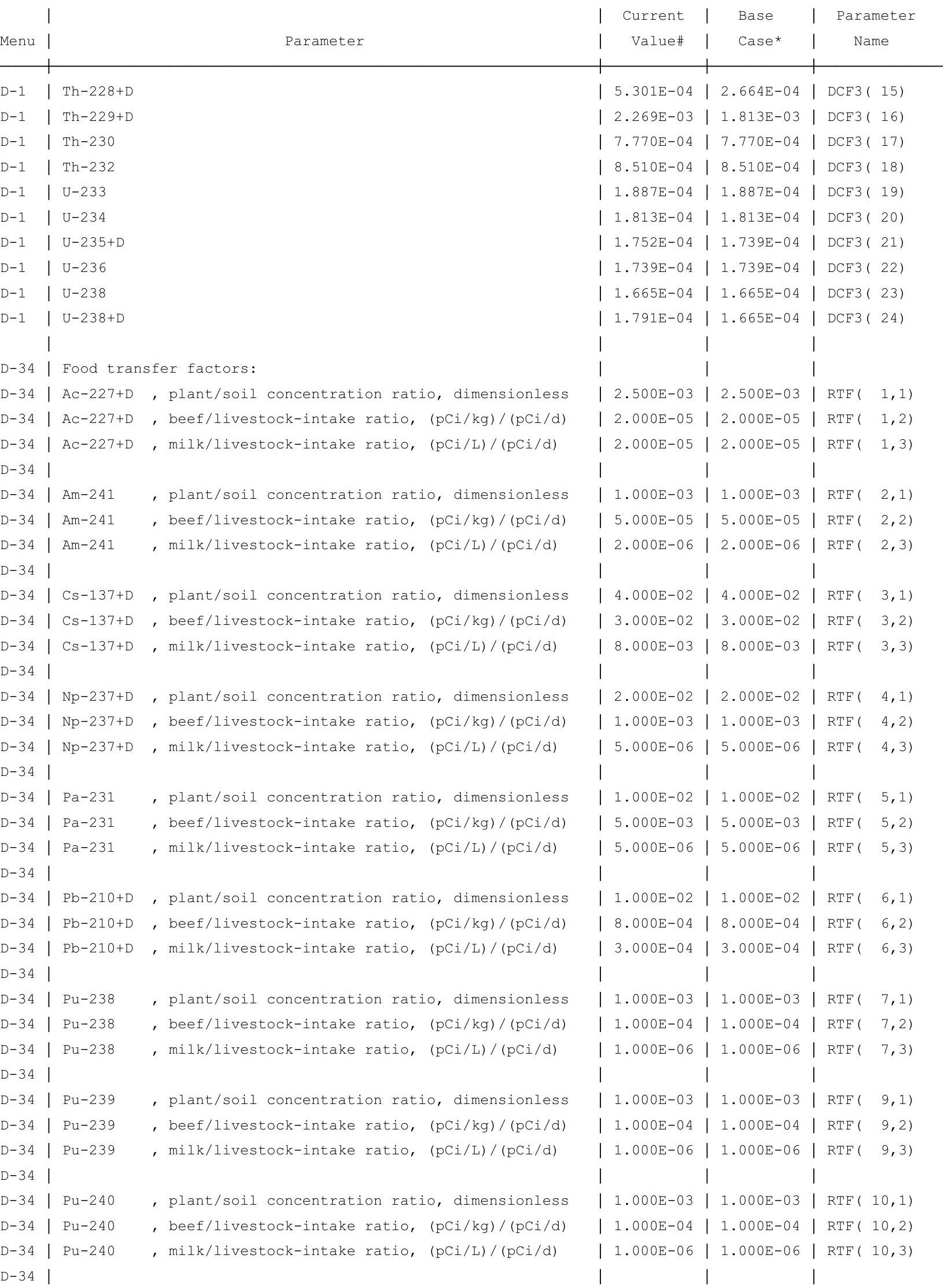


RESRAD, Version $6.5 \quad \mathrm{~T}^{1 / 2}$ Limit $=180$ days

07/20/2011 $15: 20 \quad$ Page

Summary : RESRAD Parameters for U-Landfill Outdoor Worker Forward Run at Proposed ALs

File : C:\RESRAD_FAMILY \RESRAD UUSERFILES \QCJULY2011 \ODW_FORWARD_1050YRSALS.RAD

Dose Conversion Factor (and Related) Parameter Summary (continued)

Dose Library: ICRP 60 \& ICRP 72 (Adult)

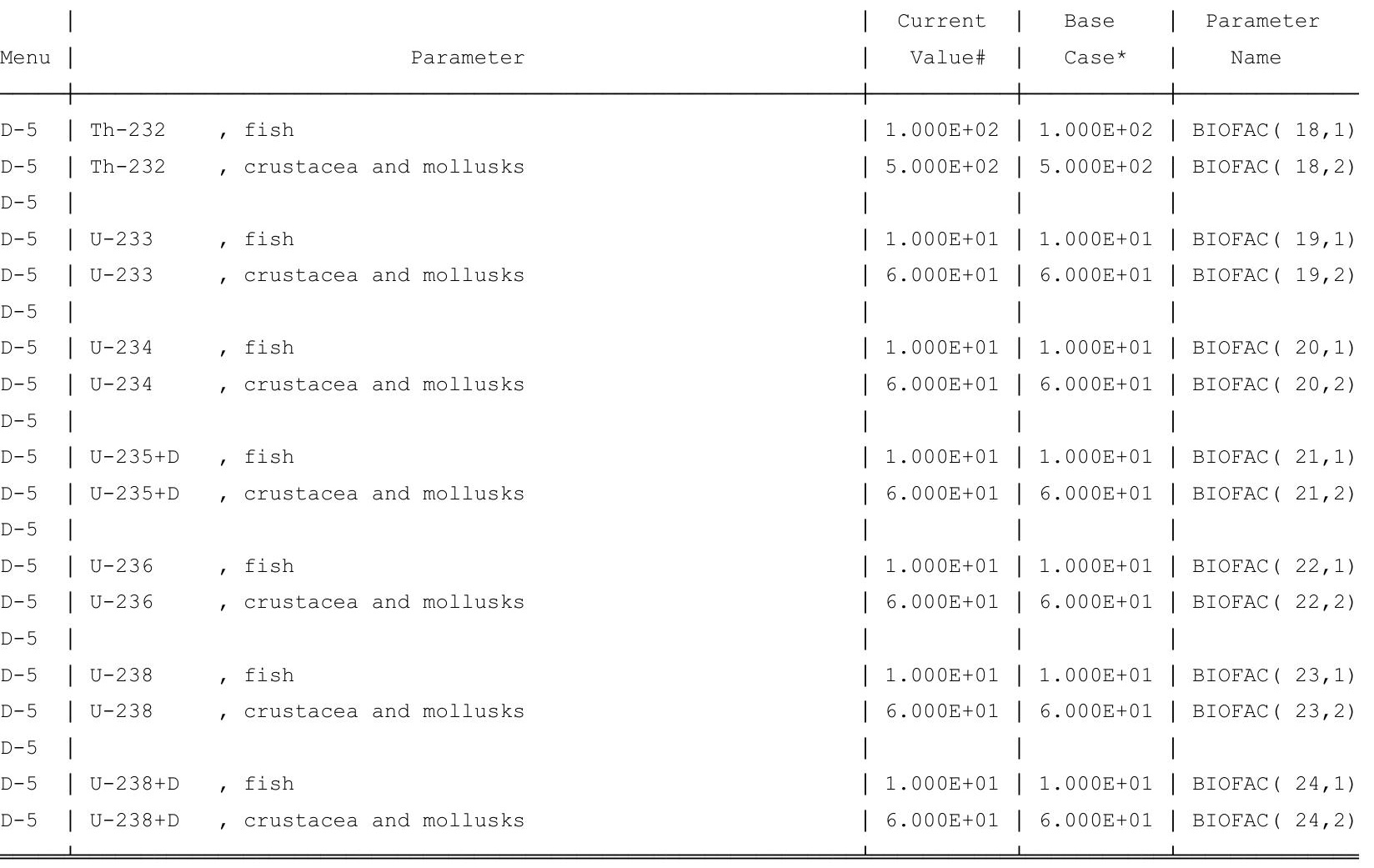

\#For DCFl(xxx) only, factors are for infinite depth \& area. See ETFG table in Ground Pathway of Detailed Report. *Base Case means Default.Lib w/o Associate Nuclide contributions. 
RESRAD, Version $6.5 \quad T^{1 / 2}$ Limit $=180$ days

07/20/2011 15:20 Page 10

Summary : RESRAD Parameters for U-Landfill Outdoor Worker Forward Run at Proposed ALs

File : C: \RESRAD FAMILY \RESRAD \USERFILES $\backslash Q C J U L Y 2011 \backslash$ ODW FORWARD 1050YRSALS.RAD

Site-Specific Parameter Summary (continued)

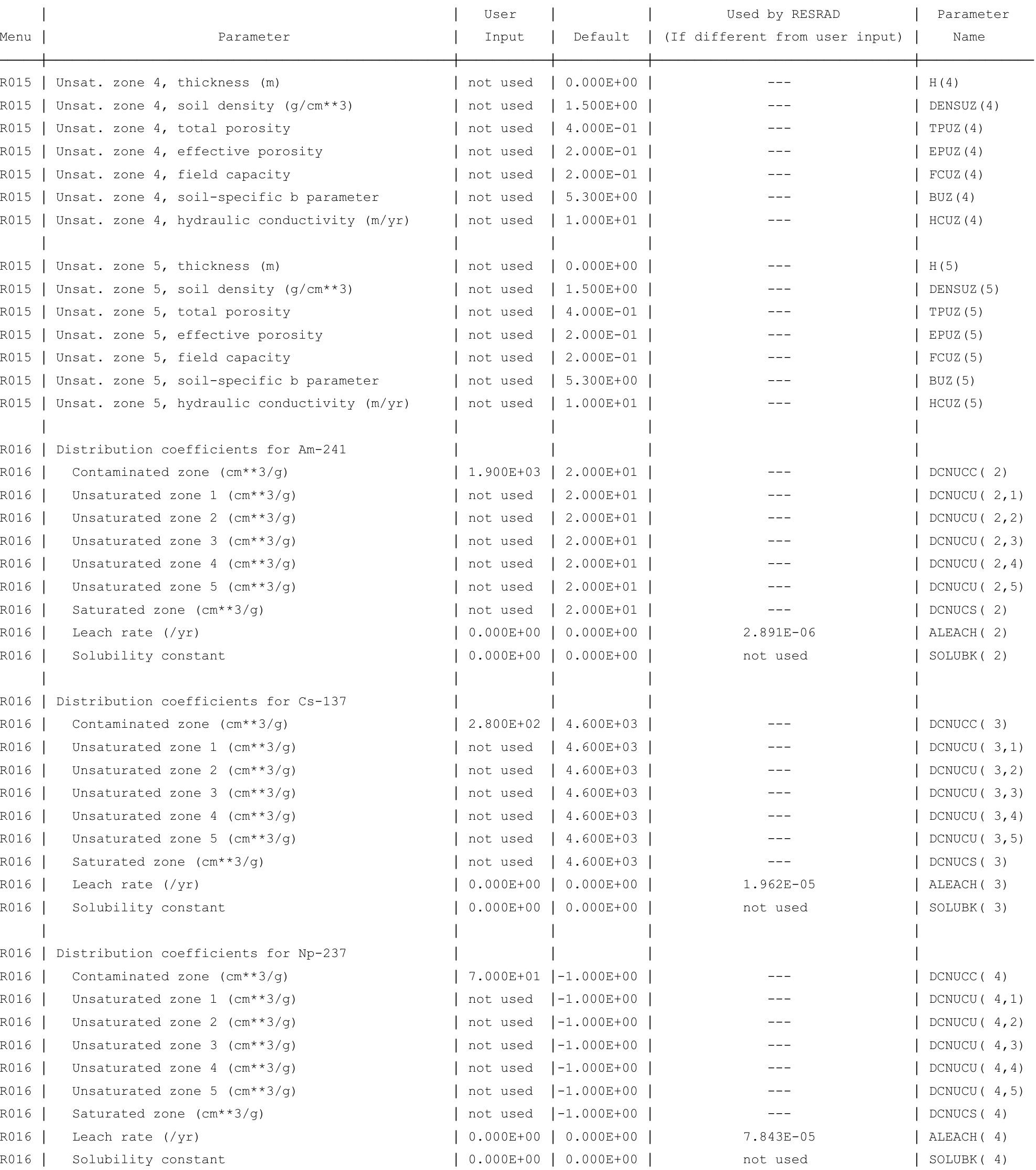


RESRAD, Version $6.5 \quad \mathrm{~T}^{1 / 2}$ Limit $=180$ days

Summary : RESRAD Parameters for U-Landfill Outdoor Worker Forward Run at Proposed ALs

File : C: \RESRAD_FAMILY \RESRAD \USERFILES \QCJULY2011 \ODW_FORWARD_1050YRSALS.RAD

Site-Specific Parameter Summary (continued)

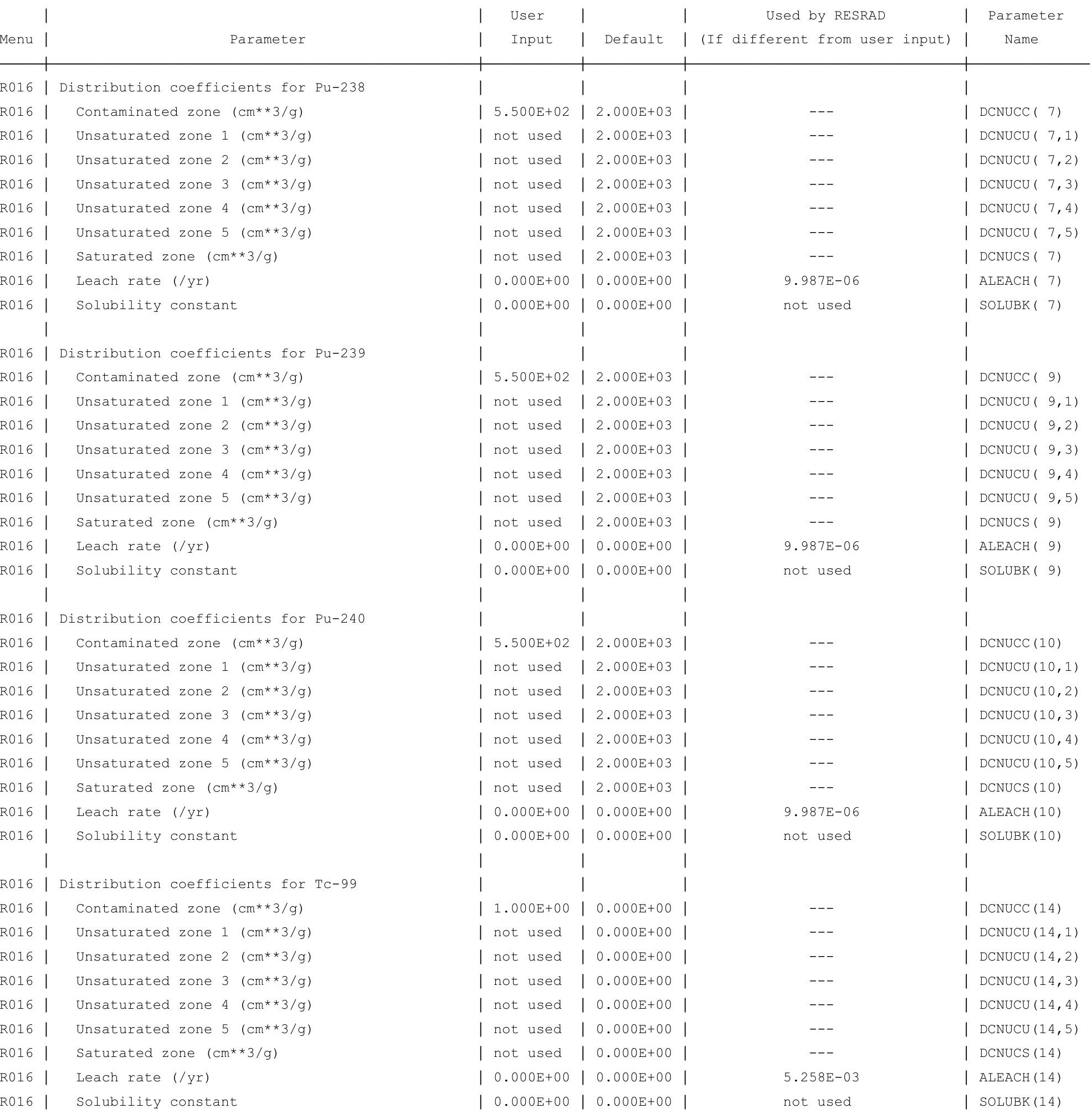


RESRAD, Version $6.5 \quad T^{1 / 2}$ Limit $=180$ days

Summary : RESRAD Parameters for U-Landfill Outdoor Worker Forward Run at Proposed ALs

File : C: \RESRAD_FAMILY \RESRAD \USERFILES \QCJULY2011 \ODW_FORWARD_1050YRSALS.RAD

Site-Specific Parameter Summary (continued)

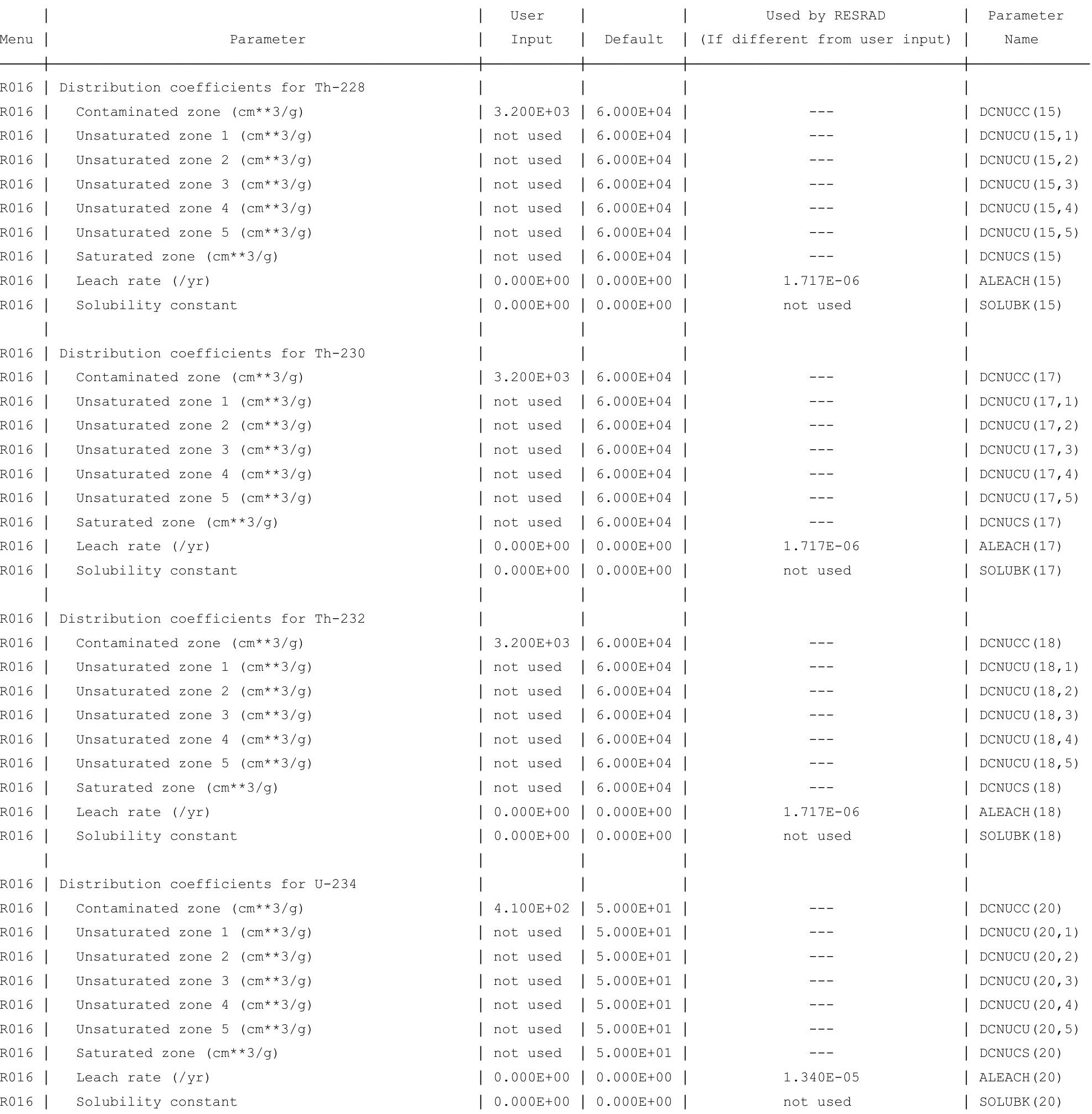


RESRAD, Version $6.5 \quad \mathrm{~T}^{1 / 2}$ Limit $=180$ days

Summary : RESRAD Parameters for U-Landfill Outdoor Worker Forward Run at Proposed ALs

File : C: \RESRAD_FAMILY \RESRAD \USERFILES \QCJULY2011 \ODW_FORWARD_1050YRSALS.RAD

Site-Specific Parameter Summary (continued)

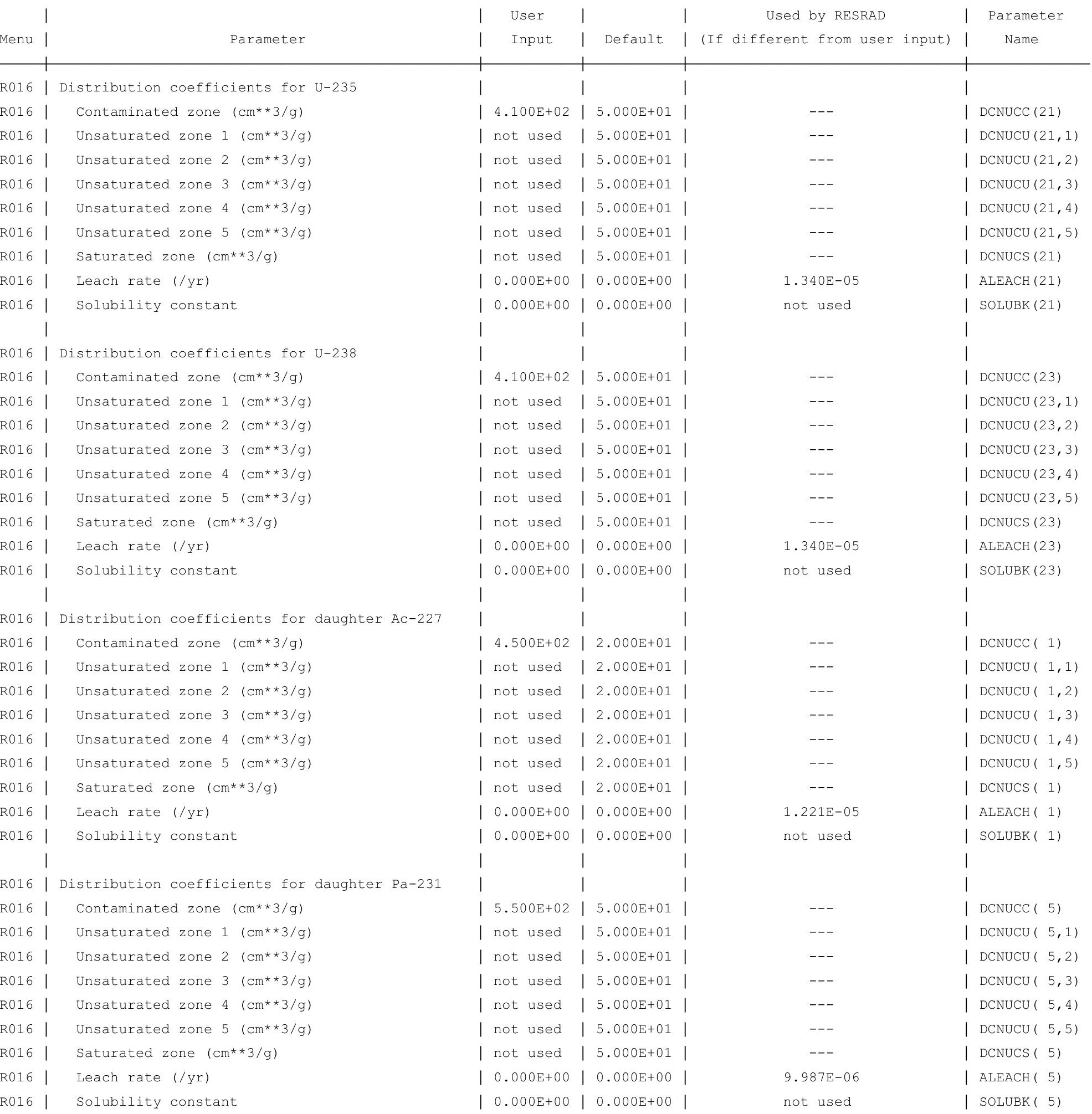


RESRAD, Version $6.5 \quad T^{1 / 2}$ Limit $=180$ days

Summary : RESRAD Parameters for U-Landfill Outdoor Worker Forward Run at Proposed ALs

File : C: \RESRAD_FAMILY \RESRAD \USERFILES \QCJULY2011 \ODW_FORWARD_1050YRSALS.RAD

Site-Specific Parameter Summary (continued)

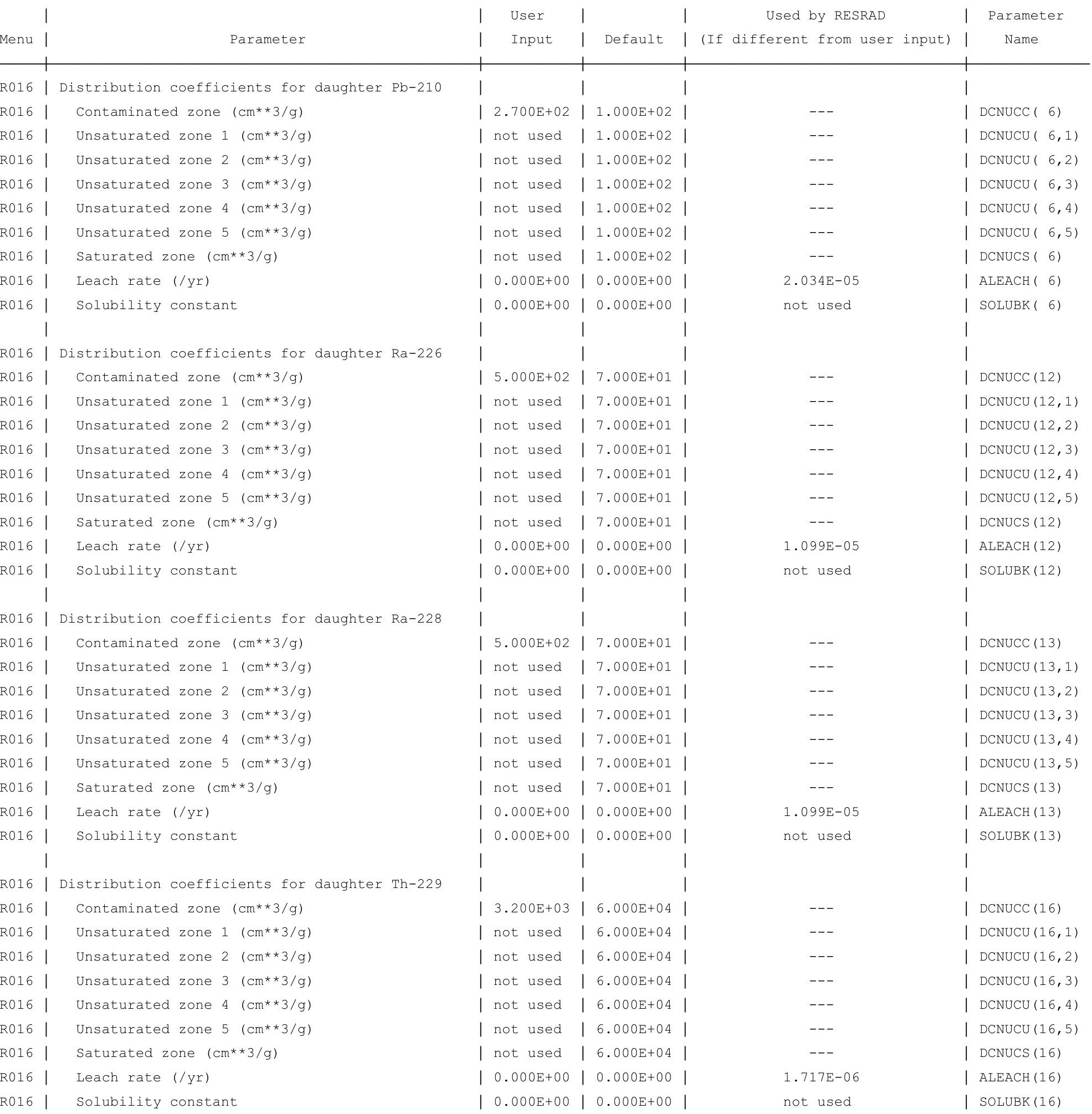


RESRAD, Version $6.5 \quad \mathrm{~T}^{\mathbb{1} 1 / 2}$ Limit $=180$ days

Summary : RESRAD Parameters for U-Landfill Outdoor Worker Forward Run at Proposed ALs

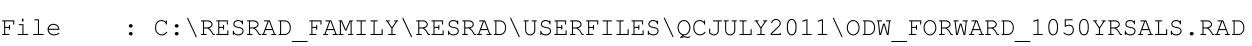

Site-Specific Parameter Summary (continued)

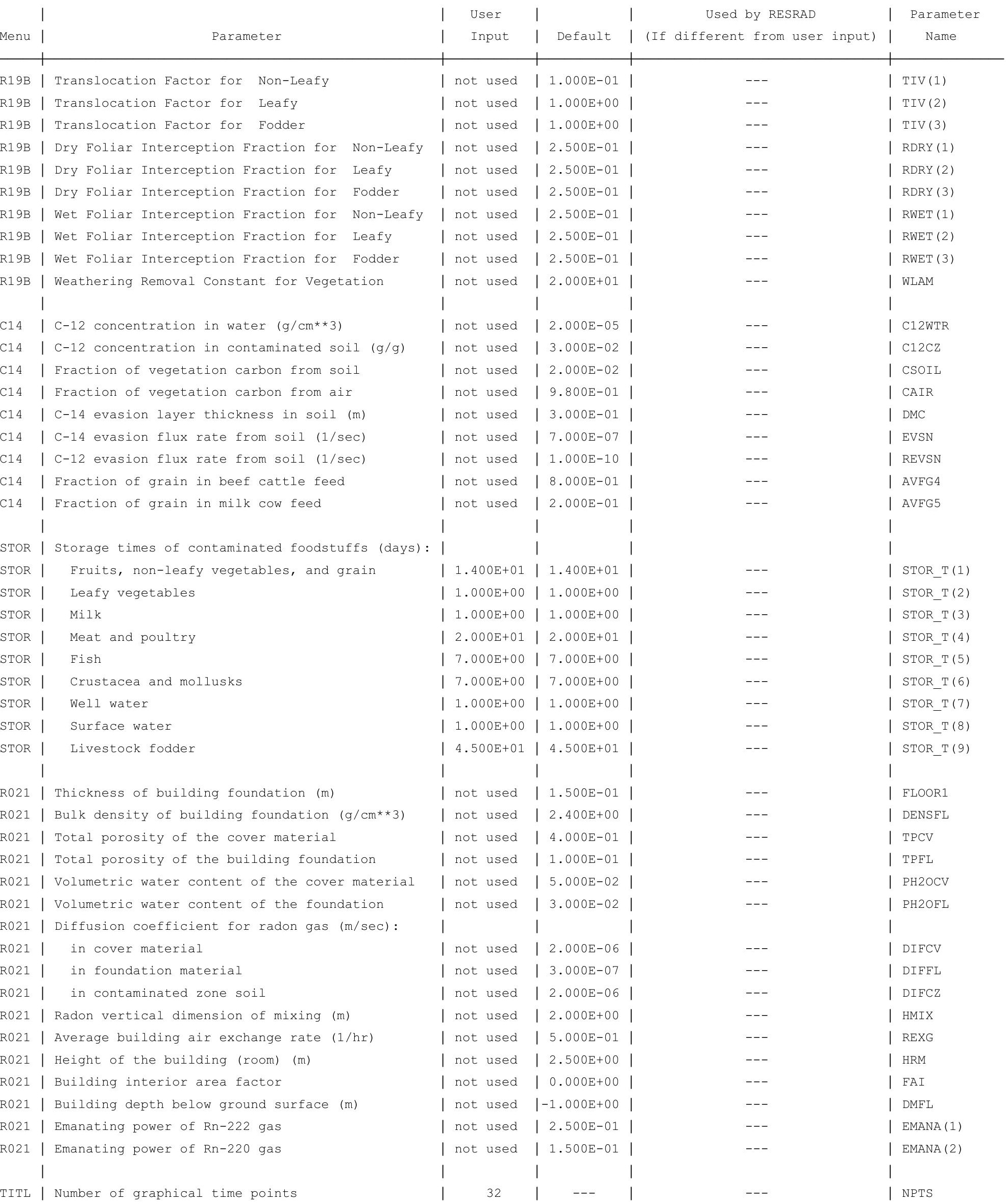

TITL | Number of graphical time points 
RESRAD, Version $6.5 \quad \mathrm{~T}^{1 / 2}$ Limit $=180$ days

Summary : RESRAD Parameters for U-Landfill Outdoor Worker Forward Run at Proposed ALs

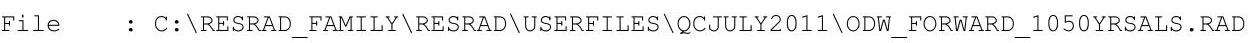

Contaminated Zone Dimensions

Area: $\quad 89436.00$ square meters

Thickness:

Cover Depth:

\begin{abstract}
13.40 meters
1.52 meters
\end{abstract}

Initial Soil Concentrations, pci/g

$\begin{array}{ll}\mathrm{Am}-241 & 7.000 \mathrm{E}+01 \\ \mathrm{Cs}-137 & 3.800 \mathrm{E}+01 \\ \mathrm{~Np}-237 & 1.100 \mathrm{E}+01 \\ \mathrm{Pu}-238 & 7.800 \mathrm{E}+01 \\ \mathrm{Pu}-239 & 7.200 \mathrm{E}+01 \\ \mathrm{Pu}-240 & 7.200 \mathrm{E}+01 \\ \mathrm{TC}-99 & 1.040 \mathrm{E}+02 \\ \mathrm{Th}-228 & 8.000 \mathrm{E}+00 \\ \mathrm{Th}-230 & 2.000 \mathrm{E}+02 \\ \mathrm{Th}-232 & 8.000 \mathrm{E}+00 \\ \mathrm{U}-234 & 3.200 \mathrm{E}+02 \\ \mathrm{U}-235 & 1.300 \mathrm{E}+01 \\ \mathrm{U}-238 & 3.200 \mathrm{E}+02\end{array}$

Total Dose TDOSE(t), mrem/yr

Basic Radiation Dose Limit $=1.000 \mathrm{E}+00 \mathrm{mrem} / \mathrm{yr}$

Total Mixture Sum $M(t)$ = Fraction of Basic Dose Limit Received at Time (t)
$t$ (years) :
1.000E+00 2.500E+01
$5.000 \mathrm{E}+01$
$1.000 \mathrm{E}+02 \quad 5.000 \mathrm{E}+02 \quad 1.050 \mathrm{E}+03$
TDOSE $(t): 2.300 \mathrm{E}-06$
1.719E-06 3.058E-06
3. $899 \mathrm{E}-06$
$5.586 \mathrm{E}-06$
$9.914 \mathrm{E}-05 \quad 5.265 \mathrm{E}-03$
$M(t): \quad 2.300 E-06$
1.719E-06 3.058E-06
3. $899 \mathrm{E}-06$
$5.586 \mathrm{E}-06$
$9.914 \mathrm{E}-05 \quad 5.265 \mathrm{E}-03$

Maximum TDOSE $(t): 5.265 \mathrm{E}-03 \mathrm{mrem} / \mathrm{yr}$ at $t=1.050 \mathrm{E}+03$ years 
RESRAD, Version $6.5 \quad$ T1/2 Limit $=180$ days
Summary : RESRAD Parameters for U-Landfill Outdoor Worker Forward Run at Proposed ALs

File : C: \RESRAD_FAMILY \RESRAD \USERFILES \QCJULY2011 \ODW_FORWARD_1050YRSALS.RAD

Total Dose Contributions TDOSE(i,p,t) for Individual Radionuclides (i) and Pathways (p) As mrem/yr and Fraction of Total Dose At $t=0.000 \mathrm{E}+00$ years

Water Independent Pathways (Inhalation excludes radon)

\begin{tabular}{|c|c|c|c|c|c|c|c|c|c|c|c|c|c|c|}
\hline \multirow{2}{*}{ Nuclide } & \multicolumn{2}{|c|}{ Ground } & \multicolumn{2}{|c|}{ Inhalation } & \multicolumn{2}{|c|}{ Radon } & \multicolumn{2}{|c|}{ Plant } & \multicolumn{2}{|c|}{ Meat } & \multicolumn{2}{|c|}{ Milk } & \multicolumn{2}{|c|}{ Soil } \\
\hline & mrem/yr & fract. & mrem/yr & fract. & mrem/yr & fract. & mrem/yr & fract. & mrem/yr & fract. & mrem/yr & fract. & mrem/yr & fract. \\
\hline-241 & 2. $212 \mathrm{E}-18$ & 0.0000 & $0.000 \mathrm{E}+00$ & 0.0000 & $0.000 \mathrm{E}+00$ & 0.0000 & $0.000 \mathrm{E}+00$ & 0.0000 & $0.000 \mathrm{E}+00$ & 0.0000 & $0.000 \mathrm{E}+00$ & 0.0000 & $0.000 \mathrm{E}+00$ & 0.0000 \\
\hline-137 & $9.797 \mathrm{E}-09$ & 0.0043 & $0.000 \mathrm{E}+00$ & 0.0000 & $0.000 \mathrm{E}+00$ & 0.0000 & $0.000 \mathrm{E}+00$ & 0.0000 & $0.000 \mathrm{E}+00$ & 0.0000 & $0.000 \mathrm{E}+00$ & 0.0000 & $0.000 \mathrm{E}+00$ & 0.0000 \\
\hline-237 & $2.143 E-12$ & 0.0000 & $0.000 \mathrm{E}+00$ & 0.0000 & $0.000 \mathrm{E}+00$ & 0.0000 & $0.000 \mathrm{E}+00$ & 0.0000 & $0.000 \mathrm{E}+00$ & 0.0000 & $0.000 \mathrm{E}+00$ & 0.0000 & $0.000 \mathrm{E}+00$ & 0.0000 \\
\hline-238 & $1.297 \mathrm{E}-21$ & 0.0000 & $0.000 \mathrm{E}+00$ & 0.0000 & $0.000 \mathrm{E}+00$ & 0.0000 & $0.000 \mathrm{E}+00$ & 0.0000 & $0.000 \mathrm{E}+00$ & 0.0000 & $0.000 \mathrm{E}+00$ & 0.0000 & $0.000 \mathrm{E}+00$ & 0.0000 \\
\hline-239 & $1.769 \mathrm{E}-16$ & 0.0000 & $0.000 \mathrm{E}+00$ & 0.0000 & $0.000 \mathrm{E}+00$ & 0.0000 & $0.000 \mathrm{E}+00$ & 0.0000 & $0.000 \mathrm{E}+00$ & 0.0000 & $0.000 \mathrm{E}+00$ & 0.0000 & $0.000 \mathrm{E}+00$ & 0.0000 \\
\hline-240 & $1.682 \mathrm{E}-23$ & 0.0000 & $0.000 \mathrm{E}+00$ & 0.0000 & $0.000 \mathrm{E}+00$ & 0.0000 & $0.000 \mathrm{E}+00$ & 0.0000 & $0.000 \mathrm{E}+00$ & 0.0000 & $0.000 \mathrm{E}+00$ & 0.0000 & $0.000 \mathrm{E}+00$ & 0.0000 \\
\hline 99 & 1. $226 \mathrm{E}-24$ & 0.0000 & $0.000 \mathrm{E}+00$ & 0.0000 & $0.000 \mathrm{E}+00$ & 0.0000 & $0.000 \mathrm{E}+00$ & 0.0000 & $0.000 \mathrm{E}+00$ & 0.0000 & $0.000 \mathrm{E}+00$ & 0.0000 & $0.000 \mathrm{E}+00$ & 0.0000 \\
\hline-228 & $2.260 \mathrm{E}-06$ & 0.9827 & $0.000 \mathrm{E}+00$ & 0.0000 & $0.000 \mathrm{E}+00$ & 0.0000 & $0.000 \mathrm{E}+00$ & 0.0000 & $0.000 \mathrm{E}+00$ & 0.0000 & $0.000 \mathrm{E}+00$ & 0.0000 & $0.000 \mathrm{E}+00$ & 0.0000 \\
\hline-230 & $1.542 \mathrm{E}-09$ & 0.0007 & $0.000 \mathrm{E}+00$ & 0.0000 & $0.000 \mathrm{E}+00$ & 0.0000 & $0.000 \mathrm{E}+00$ & 0.0000 & $0.000 \mathrm{E}+00$ & 0.0000 & $0.000 \mathrm{E}+00$ & 0.0000 & $0.000 \mathrm{E}+00$ & 0.0000 \\
\hline-232 & $1.926 \mathrm{E}-08$ & 0.0084 & $0.000 \mathrm{E}+00$ & 0.0000 & $0.000 \mathrm{E}+00$ & 0.0000 & $0.000 \mathrm{E}+00$ & 0.0000 & $0.000 \mathrm{E}+00$ & 0.0000 & $0.000 \mathrm{E}+00$ & 0.0000 & $0.000 \mathrm{E}+00$ & 0.0000 \\
\hline 234 & $7.409 \mathrm{E}-15$ & 0.0000 & $0.000 \mathrm{E}+00$ & 0.0000 & $0.000 \mathrm{E}+00$ & 0.0000 & $0.000 \mathrm{E}+00$ & 0.0000 & $0.000 \mathrm{E}+00$ & 0.0000 & $0.000 \mathrm{E}+00$ & 0.0000 & $0.000 \mathrm{E}+00$ & 0.0000 \\
\hline 35 & $3.306 \mathrm{E}-14$ & 0.0000 & $0.000 \mathrm{E}+00$ & 0.0000 & $0.000 \mathrm{E}+00$ & 0.0000 & $0.000 \mathrm{E}+00$ & 0.0000 & $0.000 \mathrm{E}+00$ & 0.0000 & $0.000 \mathrm{E}+00$ & 0.0000 & $0.000 \mathrm{E}+00$ & 0.0000 \\
\hline 38 & $9.282 \mathrm{E}-09$ & 0.0040 & $0.000 \mathrm{E}+00$ & 0.0000 & $0.000 \mathrm{E}+00$ & 0.0000 & $0.000 \mathrm{E}+00$ & 0.0000 & $0.000 \mathrm{E}+00$ & 0.0000 & $0.000 \mathrm{E}+00$ & 0.0000 & $0.000 \mathrm{E}+00$ & 0.0000 \\
\hline & $2.300 E-06$ & 1.0000 & $0.000 \mathrm{E}+00$ & 0.0000 & $0.000 \mathrm{E}+00$ & 0.0000 & $0.000 \mathrm{E}+00$ & 0.0000 & $0.000 \mathrm{E}+00$ & 0.0000 & $0.000 \mathrm{E}+00$ & 0.0000 & $0.000 \mathrm{E}+00$ & 0.0000 \\
\hline
\end{tabular}

Total Dose Contributions TDOSE(i,p,t) for Individual Radionuclides (i) and Pathways (p) As mrem/yr and Fraction of Total Dose At $t=0.000 \mathrm{E}+00$ years

Water Dependent Pathways

\begin{tabular}{|c|c|c|c|c|c|c|c|c|c|c|c|c|c|c|}
\hline \multirow{2}{*}{$\begin{array}{l}\text { Radio- } \\
\text { Nuclide }\end{array}$} & \multicolumn{2}{|c|}{ Water } & \multicolumn{2}{|c|}{ Fish } & \multicolumn{2}{|c|}{ Radon } & \multicolumn{2}{|c|}{ Plant } & \multicolumn{2}{|c|}{ Meat } & \multicolumn{2}{|c|}{ Milk } & \multicolumn{2}{|c|}{ All Pathways* } \\
\hline & mrem/yr & fract. & mrem/yr & fract. & mrem/yr & fract. & mrem/yr & fract. & mrem/yr & fract. & mrem/yr & fract. & mrem/yr & fract. \\
\hline 241 & $0.000 \mathrm{E}+00$ & 0.0000 & $0.000 \mathrm{E}+00$ & 0.0000 & $0.000 \mathrm{E}+00$ & 0.0000 & $0.000 \mathrm{E}+00$ & 0.0000 & $0.000 \mathrm{E}+00$ & 0.0000 & $0.000 \mathrm{E}+00$ & 0.0000 & $2.212 \mathrm{E}-18$ & 0.0000 \\
\hline-137 & $0.000 \mathrm{E}+00$ & 0.0000 & $0.000 \mathrm{E}+00$ & 0.0000 & $0.000 \mathrm{E}+00$ & 0.0000 & $0.000 \mathrm{E}+00$ & 0.0000 & $0.000 \mathrm{E}+00$ & 0.0000 & $0.000 \mathrm{E}+00$ & 0.0000 & $9.797 \mathrm{E}-09$ & 0.0043 \\
\hline-237 & $0.000 \mathrm{E}+00$ & 0.0000 & $0.000 \mathrm{E}+00$ & 0.0000 & $0.000 \mathrm{E}+00$ & 0.0000 & $0.000 \mathrm{E}+00$ & 0.0000 & $0.000 \mathrm{E}+00$ & 0.0000 & $0.000 \mathrm{E}+00$ & 0.0000 & $2.143 E-12$ & 0.0000 \\
\hline-238 & $0.000 \mathrm{E}+00$ & 0.0000 & $0.000 \mathrm{E}+00$ & 0.0000 & $0.000 \mathrm{E}+00$ & 0.0000 & $0.000 \mathrm{E}+00$ & 0.0000 & $0.000 \mathrm{E}+00$ & 0.0000 & $0.000 \mathrm{E}+00$ & 0.0000 & $1.297 \mathrm{E}-21$ & 0.0000 \\
\hline-239 & $0.000 \mathrm{E}+00$ & 0.0000 & $0.000 \mathrm{E}+00$ & 0.0000 & $0.000 \mathrm{E}+00$ & 0.0000 & $0.000 \mathrm{E}+00$ & 0.0000 & $0.000 \mathrm{E}+00$ & 0.0000 & $0.000 E+00$ & 0.0000 & $1.769 \mathrm{E}-16$ & 0.0000 \\
\hline-240 & $0.000 \mathrm{E}+00$ & 0.0000 & $0.000 \mathrm{E}+00$ & 0.0000 & $0.000 \mathrm{E}+00$ & 0.0000 & $0.000 \mathrm{E}+00$ & 0.0000 & $0.000 \mathrm{E}+00$ & 0.0000 & $0.000 E+00$ & 0.0000 & $1.682 \mathrm{E}-23$ & 0.0000 \\
\hline 99 & $0.000 \mathrm{E}+00$ & 0.0000 & $0.000 \mathrm{E}+00$ & 0.0000 & $0.000 \mathrm{E}+00$ & 0.0000 & $0.000 \mathrm{E}+00$ & 0.0000 & $0.000 \mathrm{E}+00$ & 0.0000 & $0.000 \mathrm{E}+00$ & 0.0000 & $1.226 \mathrm{E}-24$ & 0.0000 \\
\hline-228 & $0.000 \mathrm{E}+00$ & 0.0000 & $0.000 \mathrm{E}+00$ & 0.0000 & $0.000 \mathrm{E}+00$ & 0.0000 & $0.000 \mathrm{E}+00$ & 0.0000 & $0.000 \mathrm{E}+00$ & 0.0000 & $0.000 \mathrm{E}+00$ & 0.0000 & $2.260 \mathrm{E}-06$ & 0.9827 \\
\hline-230 & $0.000 \mathrm{E}+00$ & 0.0000 & $0.000 \mathrm{E}+00$ & 0.0000 & $0.000 \mathrm{E}+00$ & 0.0000 & $0.000 \mathrm{E}+00$ & 0.0000 & $0.000 \mathrm{E}+00$ & 0.0000 & $0.000 E+00$ & 0.0000 & $1.542 \mathrm{E}-09$ & 0.0007 \\
\hline-232 & $0.000 \mathrm{E}+00$ & 0.0000 & $0.000 \mathrm{E}+00$ & 0.0000 & $0.000 \mathrm{E}+00$ & 0.0000 & $0.000 \mathrm{E}+00$ & 0.0000 & $0.000 \mathrm{E}+00$ & 0.0000 & $0.000 \mathrm{E}+00$ & 0.0000 & $1.926 \mathrm{E}-08$ & 0.0084 \\
\hline 34 & $0.000 \mathrm{E}+00$ & 0.0000 & $0.000 \mathrm{E}+00$ & 0.0000 & $0.000 \mathrm{E}+00$ & 0.0000 & $0.000 \mathrm{E}+00$ & 0.0000 & $0.000 \mathrm{E}+00$ & 0.0000 & $0.000 \mathrm{E}+00$ & 0.0000 & 7. $409 \mathrm{E}-15$ & 0.0000 \\
\hline 35 & $0.000 \mathrm{E}+00$ & 0.0000 & $0.000 \mathrm{E}+00$ & 0.0000 & $0.000 \mathrm{E}+00$ & 0.0000 & $0.000 \mathrm{E}+00$ & 0.0000 & $0.000 \mathrm{E}+00$ & 0.0000 & $0.000 \mathrm{E}+00$ & 0.0000 & $3.306 \mathrm{E}-14$ & 0.0000 \\
\hline 38 & $0.000 \mathrm{E}+00$ & 0.0000 & $0.000 \mathrm{E}+00$ & 0.0000 & $0.000 \mathrm{E}+00$ & 0.0000 & $0.000 \mathrm{E}+00$ & 0.0000 & $0.000 \mathrm{E}+00$ & 0.0000 & $0.000 \mathrm{E}+00$ & 0.0000 & $9.282 \mathrm{E}-09$ & 0.0040 \\
\hline & $0.000 \mathrm{E}+00$ & 0.0000 & $0.000 \mathrm{E}+00$ & 0.0000 & $0.000 \mathrm{E}+00$ & 0.0000 & $0.000 \mathrm{E}+00$ & 0.0000 & $0.000 \mathrm{E}+00$ & 0.0000 & $0.000 \mathrm{E}+00$ & 0.0000 & $0 E-06$ & 1. \\
\hline
\end{tabular}

* Sum of all water independent and dependent pathways. 
RESRAD, Version $6.5 \quad$ T1/2 Limit $=180$ days
Summary : RESRAD Parameters for U-Landfill Outdoor Worker Forward Run at Proposed ALs

File : C: \RESRAD_FAMILY \RESRAD \USERFILES \QCJULY2011 \ODW_FORWARD_1050YRSALS.RAD

Total Dose Contributions TDOSE(i,p,t) for Individual Radionuclides (i) and Pathways (p) As mrem/yr and Fraction of Total Dose At $t=1.000 \mathrm{E}+00$ years

Water Independent Pathways (Inhalation excludes radon)

\begin{tabular}{|c|c|c|c|c|c|c|c|c|c|c|c|c|c|c|}
\hline \multirow{2}{*}{ Nuclide } & \multicolumn{2}{|c|}{ Ground } & \multicolumn{2}{|c|}{ Inhalation } & \multicolumn{2}{|c|}{ Radon } & \multicolumn{2}{|c|}{ Plant } & \multicolumn{2}{|c|}{ Meat } & \multicolumn{2}{|c|}{ Milk } & \multicolumn{2}{|c|}{ Soil } \\
\hline & mrem/yr & fract. & mrem/yr & fract. & mrem/yr & fract. & mrem/yr & fract. & mrem/yr & fract. & mrem/yr & fract. & mrem/yr & fract. \\
\hline-241 & $6.694 \mathrm{E}-18$ & 0.0000 & $0.000 \mathrm{E}+00$ & 0.0000 & $0.000 \mathrm{E}+00$ & 0.0000 & $0.000 \mathrm{E}+00$ & 0.0000 & $0.000 \mathrm{E}+00$ & 0.0000 & $0.000 \mathrm{E}+00$ & 0.0000 & $0.000 \mathrm{E}+00$ & 0.0000 \\
\hline-137 & $9.654 \mathrm{E}-09$ & 0.0056 & $0.000 \mathrm{E}+00$ & 0.0000 & $0.000 \mathrm{E}+00$ & 0.0000 & $0.000 \mathrm{E}+00$ & 0.0000 & $0.000 \mathrm{E}+00$ & 0.0000 & $0.000 \mathrm{E}+00$ & 0.0000 & $0.000 \mathrm{E}+00$ & 0.0000 \\
\hline-237 & $2.166 \mathrm{E}-12$ & 0.0000 & $0.000 \mathrm{E}+00$ & 0.0000 & $0.000 \mathrm{E}+00$ & 0.0000 & $0.000 \mathrm{E}+00$ & 0.0000 & $0.000 \mathrm{E}+00$ & 0.0000 & $0.000 \mathrm{E}+00$ & 0.0000 & $0.000 \mathrm{E}+00$ & 0.0000 \\
\hline-238 & $1.927 \mathrm{E}-20$ & 0.0000 & $0.000 \mathrm{E}+00$ & 0.0000 & $0.000 \mathrm{E}+00$ & 0.0000 & $0.000 \mathrm{E}+00$ & 0.0000 & $0.000 \mathrm{E}+00$ & 0.0000 & $0.000 \mathrm{E}+00$ & 0.0000 & $0.000 \mathrm{E}+00$ & 0.0000 \\
\hline-239 & $1.790 \mathrm{E}-16$ & 0.0000 & $0.000 \mathrm{E}+00$ & 0.0000 & $0.000 \mathrm{E}+00$ & 0.0000 & $0.000 \mathrm{E}+00$ & 0.0000 & $0.000 \mathrm{E}+00$ & 0.0000 & $0.000 \mathrm{E}+00$ & 0.0000 & $0.000 \mathrm{E}+00$ & 0.0000 \\
\hline-240 & $1.747 \mathrm{E}-23$ & 0.0000 & $0.000 \mathrm{E}+00$ & 0.0000 & $0.000 \mathrm{E}+00$ & 0.0000 & $0.000 \mathrm{E}+00$ & 0.0000 & $0.000 \mathrm{E}+00$ & 0.0000 & $0.000 \mathrm{E}+00$ & 0.0000 & $0.000 \mathrm{E}+00$ & 0.0000 \\
\hline 99 & $1.243 E-24$ & 0.0000 & $0.000 \mathrm{E}+00$ & 0.0000 & $0.000 \mathrm{E}+00$ & 0.0000 & $0.000 \mathrm{E}+00$ & 0.0000 & $0.000 \mathrm{E}+00$ & 0.0000 & $0.000 \mathrm{E}+00$ & 0.0000 & $0.000 \mathrm{E}+00$ & 0.0000 \\
\hline-228 & $1.582 \mathrm{E}-06$ & 0.9206 & $0.000 \mathrm{E}+00$ & 0.0000 & $0.000 \mathrm{E}+00$ & 0.0000 & $0.000 \mathrm{E}+00$ & 0.0000 & $0.000 \mathrm{E}+00$ & 0.0000 & $0.000 \mathrm{E}+00$ & 0.0000 & $0.000 \mathrm{E}+00$ & 0.0000 \\
\hline-230 & $4.655 E-09$ & 0.0027 & $0.000 \mathrm{E}+00$ & 0.0000 & $0.000 \mathrm{E}+00$ & 0.0000 & $0.000 \mathrm{E}+00$ & 0.0000 & $0.000 \mathrm{E}+00$ & 0.0000 & $0.000 \mathrm{E}+00$ & 0.0000 & $0.000 \mathrm{E}+00$ & 0.0000 \\
\hline-232 & $1.128 \mathrm{E}-07$ & 0.0656 & $0.000 \mathrm{E}+00$ & 0.0000 & $0.000 \mathrm{E}+00$ & 0.0000 & $0.000 \mathrm{E}+00$ & 0.0000 & $0.000 \mathrm{E}+00$ & 0.0000 & $0.000 \mathrm{E}+00$ & 0.0000 & $0.000 \mathrm{E}+00$ & 0.0000 \\
\hline 234 & $5.217 \mathrm{E}-14$ & 0.0000 & $0.000 \mathrm{E}+00$ & 0.0000 & $0.000 \mathrm{E}+00$ & 0.0000 & $0.000 \mathrm{E}+00$ & 0.0000 & $0.000 \mathrm{E}+00$ & 0.0000 & $0.000 \mathrm{E}+00$ & 0.0000 & $0.000 \mathrm{E}+00$ & 0.0000 \\
\hline 35 & $3.363 E-14$ & 0.0000 & $0.000 \mathrm{E}+00$ & 0.0000 & $0.000 \mathrm{E}+00$ & 0.0000 & $0.000 \mathrm{E}+00$ & 0.0000 & $0.000 \mathrm{E}+00$ & 0.0000 & $0.000 \mathrm{E}+00$ & 0.0000 & $0.000 \mathrm{E}+00$ & 0.0000 \\
\hline 38 & $9.357 \mathrm{E}-09$ & 0.0054 & $0.000 \mathrm{E}+00$ & 0.0000 & $0.000 \mathrm{E}+00$ & 0.0000 & $0.000 \mathrm{E}+00$ & 0.0000 & $0.000 \mathrm{E}+00$ & 0.0000 & $0.000 \mathrm{E}+00$ & 0.0000 & $0.000 \mathrm{E}+00$ & 0.0000 \\
\hline & $1.719 \mathrm{E}-06$ & 1.0000 & $0.000 \mathrm{E}+00$ & 0.0000 & $0.000 \mathrm{E}+00$ & 0.0000 & $0.000 \mathrm{E}+00$ & 0.0000 & $0.000 \mathrm{E}+00$ & 0.0000 & $0.000 \mathrm{E}+00$ & 0.0000 & $.000 \mathrm{E}+00$ & 0.0000 \\
\hline
\end{tabular}

Total Dose Contributions TDOSE(i,p,t) for Individual Radionuclides (i) and Pathways (p) As mrem/yr and Fraction of Total Dose At $t=1.000 \mathrm{E}+00$ years

Water Dependent Pathways

\begin{tabular}{|c|c|c|c|c|c|c|c|c|c|c|c|c|c|c|}
\hline \multirow{2}{*}{ Nuclide } & \multicolumn{2}{|c|}{ Water } & \multicolumn{2}{|c|}{ Fish } & \multicolumn{2}{|c|}{ Radon } & \multicolumn{2}{|c|}{ Plant } & \multicolumn{2}{|c|}{ Meat } & \multicolumn{2}{|c|}{ Milk } & \multicolumn{2}{|c|}{ All Pathways* } \\
\hline & mrem/yr & fract. & mrem/yr & fract. & mrem/yr & fract. & mrem/yr & fract. & mrem/yr & fract. & mrem/yr & fract. & mrem/yr & fract. \\
\hline-241 & $0.000 \mathrm{E}+00$ & 0.0000 & $0.000 \mathrm{E}+00$ & 0.0000 & $0.000 \mathrm{E}+00$ & 0.0000 & $0.000 \mathrm{E}+00$ & 0.0000 & $0.000 \mathrm{E}+00$ & 0.0000 & $0.000 \mathrm{E}+00$ & 0.0000 & $6.694 \mathrm{E}-18$ & 0.0000 \\
\hline-137 & $0.000 \mathrm{E}+00$ & 0.0000 & $0.000 \mathrm{E}+00$ & 0.0000 & $0.000 \mathrm{E}+00$ & 0.0000 & $0.000 \mathrm{E}+00$ & 0.0000 & $0.000 \mathrm{E}+00$ & 0.0000 & $0.000 \mathrm{E}+00$ & 0.0000 & $9.654 \mathrm{E}-09$ & 0.0056 \\
\hline-237 & $0.000 \mathrm{E}+00$ & 0.0000 & $0.000 \mathrm{E}+00$ & 0.0000 & $0.000 \mathrm{E}+00$ & 0.0000 & $0.000 \mathrm{E}+00$ & 0.0000 & $0.000 \mathrm{E}+00$ & 0.0000 & $0.000 \mathrm{E}+00$ & 0.0000 & $2.166 \mathrm{E}-12$ & 0.0000 \\
\hline-238 & $0.000 \mathrm{E}+00$ & 0.0000 & $0.000 \mathrm{E}+00$ & 0.0000 & $0.000 \mathrm{E}+00$ & 0.0000 & $0.000 \mathrm{E}+00$ & 0.0000 & $0.000 \mathrm{E}+00$ & 0.0000 & $0.000 \mathrm{E}+00$ & 0.0000 & $1.927 \mathrm{E}-20$ & 0.0000 \\
\hline-239 & $0.000 \mathrm{E}+00$ & 0.0000 & $0.000 \mathrm{E}+00$ & 0.0000 & $0.000 \mathrm{E}+00$ & 0.0000 & $0.000 \mathrm{E}+00$ & 0.0000 & $0.000 \mathrm{E}+00$ & 0.0000 & $0.000 \mathrm{E}+00$ & 0.0000 & $1.790 \mathrm{E}-16$ & 0.0000 \\
\hline-240 & $0.000 \mathrm{E}+00$ & 0.0000 & $0.000 \mathrm{E}+00$ & 0.0000 & $0.000 \mathrm{E}+00$ & 0.0000 & $0.000 \mathrm{E}+00$ & 0.0000 & $0.000 \mathrm{E}+00$ & 0.0000 & $0.000 \mathrm{E}+00$ & 0.0000 & $1.747 \mathrm{E}-23$ & 0.0000 \\
\hline-99 & $0.000 \mathrm{E}+00$ & 0.0000 & $0.000 \mathrm{E}+00$ & 0.0000 & $0.000 \mathrm{E}+00$ & 0.0000 & $0.000 \mathrm{E}+00$ & 0.0000 & $0.000 \mathrm{E}+00$ & 0.0000 & $0.000 \mathrm{E}+00$ & 0.0000 & $1.243 E-24$ & 0.0000 \\
\hline-228 & $0.000 \mathrm{E}+00$ & 0.0000 & $0.000 \mathrm{E}+00$ & 0.0000 & $0.000 \mathrm{E}+00$ & 0.0000 & $0.000 \mathrm{E}+00$ & 0.0000 & $0.000 \mathrm{E}+00$ & 0.0000 & $0.000 \mathrm{E}+00$ & 0.0000 & $1.582 \mathrm{E}-06$ & 0.9206 \\
\hline-230 & $0.000 \mathrm{E}+00$ & 0.0000 & $0.000 \mathrm{E}+00$ & 0.0000 & $0.000 \mathrm{E}+00$ & 0.0000 & $0.000 \mathrm{E}+00$ & 0.0000 & $0.000 \mathrm{E}+00$ & 0.0000 & $0.000 \mathrm{E}+00$ & 0.0000 & $4.655 E-09$ & 0.0027 \\
\hline 232 & $0.000 \mathrm{E}+00$ & 0.0000 & $0.000 \mathrm{E}+00$ & 0.0000 & $0.000 \mathrm{E}+00$ & 0.0000 & $0.000 \mathrm{E}+00$ & 0.0000 & $0.000 \mathrm{E}+00$ & 0.0000 & $0.000 \mathrm{E}+00$ & 0.0000 & $1.128 \mathrm{E}-07$ & 0.0656 \\
\hline 34 & $0.000 \mathrm{E}+00$ & 0.0000 & $0.000 \mathrm{E}+00$ & 0.0000 & $0.000 \mathrm{E}+00$ & 0.0000 & $0.000 \mathrm{E}+00$ & 0.0000 & $0.000 \mathrm{E}+00$ & 0.0000 & $0.000 \mathrm{E}+00$ & 0.0000 & $5.217 \mathrm{E}-14$ & 0.0000 \\
\hline 35 & $0.000 \mathrm{E}+00$ & 0.0000 & $0.000 \mathrm{E}+00$ & 0.0000 & $0.000 \mathrm{E}+00$ & 0.0000 & $0.000 \mathrm{E}+00$ & 0.0000 & $0.000 \mathrm{E}+00$ & 0.0000 & $0.000 \mathrm{E}+00$ & 0.0000 & $3.363 \mathrm{E}-14$ & 0.0000 \\
\hline 38 & $0.000 \mathrm{E}+00$ & 0.0000 & $0.000 \mathrm{E}+00$ & 0.0000 & $0.000 \mathrm{E}+00$ & 0.0000 & $0.000 \mathrm{E}+00$ & 0.0000 & $0.000 \mathrm{E}+00$ & 0.0000 & $0.000 \mathrm{E}+00$ & 0.0000 & $9.357 \mathrm{E}-09$ & 0.0054 \\
\hline & $0.000 \mathrm{E}+00$ & 0.0000 & $0.000 \mathrm{E}+00$ & 0.0000 & $0.000 \mathrm{E}+00$ & 0.0000 & $0.000 \mathrm{E}+00$ & 0.0000 & $0.000 \mathrm{E}+00$ & 0.0000 & $0.000 \mathrm{E}+00$ & 0.0000 & $9 E-06$ & 1.0000 \\
\hline
\end{tabular}

* Sum of all water independent and dependent pathways. 
RESRAD, Version $6.5 \quad$ T1/2 Limit $=180$ days
Summary : RESRAD Parameters for U-Landfill Outdoor Worker Forward Run at Proposed ALs

File : C: \RESRAD_FAMILY \RESRAD \USERFILES \QCJULY2011 \ODW_FORWARD_1050YRSALS.RAD

Total Dose Contributions TDOSE(i,p,t) for Individual Radionuclides (i) and Pathways (p) As mrem/yr and Fraction of Total Dose At $t=2.500 \mathrm{E}+01$ years

Water Independent Pathways (Inhalation excludes radon)

\begin{tabular}{|c|c|c|c|c|c|c|c|c|c|c|c|c|c|c|}
\hline \multirow{2}{*}{ Nuclide } & \multicolumn{2}{|c|}{ Ground } & \multicolumn{2}{|c|}{ Inhalation } & \multicolumn{2}{|c|}{ Radon } & \multicolumn{2}{|c|}{ Plant } & \multicolumn{2}{|c|}{ Meat } & \multicolumn{2}{|c|}{ Milk } & \multicolumn{2}{|c|}{ Soil } \\
\hline & mrem/yr & fract. & mrem/yr & fract. & mrem/yr & fract. & mrem/yr & fract. & mrem/yr & fract. & mrem/yr & fract. & mrem/yr & fract. \\
\hline-241 & $1.445 \mathrm{E}-16$ & 0.0000 & $0.000 \mathrm{E}+00$ & 0.0000 & $0.000 \mathrm{E}+00$ & 0.0000 & $0.000 \mathrm{E}+00$ & 0.0000 & $0.000 \mathrm{E}+00$ & 0.0000 & $0.000 \mathrm{E}+00$ & 0.0000 & $0.000 \mathrm{E}+00$ & 0.0000 \\
\hline-137 & $6.786 E-09$ & 0.0022 & $0.000 \mathrm{E}+00$ & 0.0000 & $0.000 \mathrm{E}+00$ & 0.0000 & $0.000 \mathrm{E}+00$ & 0.0000 & $0.000 \mathrm{E}+00$ & 0.0000 & $0.000 \mathrm{E}+00$ & 0.0000 & $0.000 \mathrm{E}+00$ & 0.0000 \\
\hline-237 & $2.804 \mathrm{E}-12$ & 0.0000 & $0.000 \mathrm{E}+00$ & 0.0000 & $0.000 \mathrm{E}+00$ & 0.0000 & $0.000 \mathrm{E}+00$ & 0.0000 & $0.000 \mathrm{E}+00$ & 0.0000 & $0.000 \mathrm{E}+00$ & 0.0000 & $0.000 \mathrm{E}+00$ & 0.0000 \\
\hline-238 & $9.563 \mathrm{E}-17$ & 0.0000 & $0.000 \mathrm{E}+00$ & 0.0000 & $0.000 \mathrm{E}+00$ & 0.0000 & $0.000 \mathrm{E}+00$ & 0.0000 & $0.000 \mathrm{E}+00$ & 0.0000 & $0.000 \mathrm{E}+00$ & 0.0000 & $0.000 \mathrm{E}+00$ & 0.0000 \\
\hline-239 & $2.384 \mathrm{E}-16$ & 0.0000 & $0.000 \mathrm{E}+00$ & 0.0000 & $0.000 \mathrm{E}+00$ & 0.0000 & $0.000 \mathrm{E}+00$ & 0.0000 & $0.000 \mathrm{E}+00$ & 0.0000 & $0.000 \mathrm{E}+00$ & 0.0000 & $0.000 \mathrm{E}+00$ & 0.0000 \\
\hline-240 & $5.775 \mathrm{E}-21$ & 0.0000 & $0.000 \mathrm{E}+00$ & 0.0000 & $0.000 \mathrm{E}+00$ & 0.0000 & $0.000 \mathrm{E}+00$ & 0.0000 & $0.000 \mathrm{E}+00$ & 0.0000 & $0.000 \mathrm{E}+00$ & 0.0000 & $0.000 \mathrm{E}+00$ & 0.0000 \\
\hline 99 & $1.736 \mathrm{E}-24$ & 0.0000 & $0.000 \mathrm{E}+00$ & 0.0000 & $0.000 \mathrm{E}+00$ & 0.0000 & $0.000 \mathrm{E}+00$ & 0.0000 & $0.000 \mathrm{E}+00$ & 0.0000 & $0.000 \mathrm{E}+00$ & 0.0000 & $0.000 \mathrm{E}+00$ & 0.0000 \\
\hline-228 & $3.055 \mathrm{E}-10$ & 0.0001 & $0.000 \mathrm{E}+00$ & 0.0000 & $0.000 \mathrm{E}+00$ & 0.0000 & $0.000 \mathrm{E}+00$ & 0.0000 & $0.000 \mathrm{E}+00$ & 0.0000 & $0.000 \mathrm{E}+00$ & 0.0000 & $0.000 \mathrm{E}+00$ & 0.0000 \\
\hline-230 & $9.288 \mathrm{E}-08$ & 0.0304 & $0.000 \mathrm{E}+00$ & 0.0000 & $0.000 \mathrm{E}+00$ & 0.0000 & $0.000 \mathrm{E}+00$ & 0.0000 & $0.000 \mathrm{E}+00$ & 0.0000 & $0.000 \mathrm{E}+00$ & 0.0000 & $0.000 \mathrm{E}+00$ & 0.0000 \\
\hline-232 & $2.947 E-06$ & 0.9636 & $0.000 \mathrm{E}+00$ & 0.0000 & $0.000 \mathrm{E}+00$ & 0.0000 & $0.000 \mathrm{E}+00$ & 0.0000 & $0.000 \mathrm{E}+00$ & 0.0000 & $0.000 \mathrm{E}+00$ & 0.0000 & $0.000 \mathrm{E}+00$ & 0.0000 \\
\hline 234 & 1. $709 \mathrm{E}-11$ & 0.0000 & $0.000 \mathrm{E}+00$ & 0.0000 & $0.000 \mathrm{E}+00$ & 0.0000 & $0.000 \mathrm{E}+00$ & 0.0000 & $0.000 \mathrm{E}+00$ & 0.0000 & $0.000 \mathrm{E}+00$ & 0.0000 & $0.000 \mathrm{E}+00$ & 0.0000 \\
\hline 35 & $9.212 \mathrm{E}-14$ & 0.0000 & $0.000 \mathrm{E}+00$ & 0.0000 & $0.000 \mathrm{E}+00$ & 0.0000 & $0.000 \mathrm{E}+00$ & 0.0000 & $0.000 \mathrm{E}+00$ & 0.0000 & $0.000 \mathrm{E}+00$ & 0.0000 & $0.000 \mathrm{E}+00$ & 0.0000 \\
\hline 38 & $1.133 E-08$ & 0.0037 & $0.000 \mathrm{E}+00$ & 0.0000 & $0.000 \mathrm{E}+00$ & 0.0000 & $0.000 \mathrm{E}+00$ & 0.0000 & $0.000 \mathrm{E}+00$ & 0.0000 & $0.000 \mathrm{E}+00$ & 0.0000 & $0.000 \mathrm{E}+00$ & 0.0000 \\
\hline & $3.058 E-06$ & 1.0000 & $0.000 \mathrm{E}+00$ & 0.0000 & $0.000 \mathrm{E}+00$ & 0.0000 & $0.000 \mathrm{E}+00$ & 0.0000 & $0.000 \mathrm{E}+00$ & 0.0000 & $0.000 \mathrm{E}+00$ & 0.0000 & $0.000 \mathrm{E}+00$ & 0.0000 \\
\hline
\end{tabular}

Total Dose Contributions TDOSE(i,p,t) for Individual Radionuclides (i) and Pathways (p) As mrem/yr and Fraction of Total Dose At $t=2.500 \mathrm{E}+01$ years

Water Dependent Pathways

\begin{tabular}{|c|c|c|c|c|c|c|c|c|c|c|c|c|c|c|}
\hline \multirow{2}{*}{$\begin{array}{l}\text { Radio- } \\
\text { Nuclide }\end{array}$} & \multicolumn{2}{|c|}{ Water } & \multicolumn{2}{|c|}{ Fish } & \multicolumn{2}{|c|}{ Radon } & \multicolumn{2}{|c|}{ Plant } & \multicolumn{2}{|c|}{ Meat } & \multicolumn{2}{|c|}{ Milk } & \multicolumn{2}{|c|}{ All Pathways* } \\
\hline & mrem/yr & fract. & mrem/yr & fract. & mrem/yr & fract. & mrem/yr & fract. & mrem/yr & fract. & mrem/yr & fract. & mrem/yr & fract. \\
\hline 241 & $0.000 \mathrm{E}+00$ & 0.0000 & $0.000 \mathrm{E}+00$ & 0.0000 & $0.000 \mathrm{E}+00$ & 0.0000 & $0.000 \mathrm{E}+00$ & 0.0000 & $0.000 \mathrm{E}+00$ & 0.0000 & $0.000 \mathrm{E}+00$ & 0.0000 & $1.445 \mathrm{E}-16$ & 0.0000 \\
\hline-137 & $0.000 \mathrm{E}+00$ & 0.0000 & $0.000 \mathrm{E}+00$ & 0.0000 & $0.000 \mathrm{E}+00$ & 0.0000 & $0.000 \mathrm{E}+00$ & 0.0000 & $0.000 \mathrm{E}+00$ & 0.0000 & $0.000 \mathrm{E}+00$ & 0.0000 & $6.786 \mathrm{E}-09$ & 0.0022 \\
\hline-237 & $0.000 \mathrm{E}+00$ & 0.0000 & $0.000 \mathrm{E}+00$ & 0.0000 & $0.000 \mathrm{E}+00$ & 0.0000 & $0.000 \mathrm{E}+00$ & 0.0000 & $0.000 \mathrm{E}+00$ & 0.0000 & $0.000 \mathrm{E}+00$ & 0.0000 & $2.804 \mathrm{E}-12$ & 0.0000 \\
\hline-238 & $0.000 \mathrm{E}+00$ & 0.0000 & $0.000 \mathrm{E}+00$ & 0.0000 & $0.000 \mathrm{E}+00$ & 0.0000 & $0.000 \mathrm{E}+00$ & 0.0000 & $0.000 \mathrm{E}+00$ & 0.0000 & $0.000 \mathrm{E}+00$ & 0.0000 & $9.563 \mathrm{E}-17$ & 0.0000 \\
\hline-239 & $0.000 \mathrm{E}+00$ & 0.0000 & $0.000 \mathrm{E}+00$ & 0.0000 & $0.000 \mathrm{E}+00$ & 0.0000 & $0.000 \mathrm{E}+00$ & 0.0000 & $0.000 \mathrm{E}+00$ & 0.0000 & $0.000 E+00$ & 0.0000 & $2.384 \mathrm{E}-16$ & 0.0000 \\
\hline-240 & $0.000 \mathrm{E}+00$ & 0.0000 & $0.000 \mathrm{E}+00$ & 0.0000 & $0.000 \mathrm{E}+00$ & 0.0000 & $0.000 \mathrm{E}+00$ & 0.0000 & $0.000 \mathrm{E}+00$ & 0.0000 & $0.000 E+00$ & 0.0000 & $5.775 E-21$ & 0.0000 \\
\hline 99 & $0.000 \mathrm{E}+00$ & 0.0000 & $0.000 \mathrm{E}+00$ & 0.0000 & $0.000 \mathrm{E}+00$ & 0.0000 & $0.000 \mathrm{E}+00$ & 0.0000 & $0.000 \mathrm{E}+00$ & 0.0000 & $0.000 \mathrm{E}+00$ & 0.0000 & $1.736 \mathrm{E}-24$ & 0.0000 \\
\hline-228 & $0.000 \mathrm{E}+00$ & 0.0000 & $0.000 \mathrm{E}+00$ & 0.0000 & $0.000 \mathrm{E}+00$ & 0.0000 & $0.000 \mathrm{E}+00$ & 0.0000 & $0.000 \mathrm{E}+00$ & 0.0000 & $0.000 \mathrm{E}+00$ & 0.0000 & $3.055 \mathrm{E}-10$ & 0.0001 \\
\hline-230 & $0.000 \mathrm{E}+00$ & 0.0000 & $0.000 \mathrm{E}+00$ & 0.0000 & $0.000 \mathrm{E}+00$ & 0.0000 & $0.000 \mathrm{E}+00$ & 0.0000 & $0.000 \mathrm{E}+00$ & 0.0000 & $0.000 E+00$ & 0.0000 & $9.288 \mathrm{E}-08$ & 0.0304 \\
\hline 232 & $0.000 \mathrm{E}+00$ & 0.0000 & $0.000 \mathrm{E}+00$ & 0.0000 & $0.000 \mathrm{E}+00$ & 0.0000 & $0.000 \mathrm{E}+00$ & 0.0000 & $0.000 \mathrm{E}+00$ & 0.0000 & $0.000 \mathrm{E}+00$ & 0.0000 & $2.947 \mathrm{E}-06$ & 0.9636 \\
\hline 34 & $0.000 \mathrm{E}+00$ & 0.0000 & $0.000 \mathrm{E}+00$ & 0.0000 & $0.000 \mathrm{E}+00$ & 0.0000 & $0.000 \mathrm{E}+00$ & 0.0000 & $0.000 \mathrm{E}+00$ & 0.0000 & $0.000 \mathrm{E}+00$ & 0.0000 & 1. $709 \mathrm{E}-11$ & 0.0000 \\
\hline 35 & $0.000 \mathrm{E}+00$ & 0.0000 & $0.000 \mathrm{E}+00$ & 0.0000 & $0.000 \mathrm{E}+00$ & 0.0000 & $0.000 \mathrm{E}+00$ & 0.0000 & $0.000 \mathrm{E}+00$ & 0.0000 & $0.000 \mathrm{E}+00$ & 0.0000 & $9.212 \mathrm{E}-14$ & 0.0000 \\
\hline 38 & $0.000 \mathrm{E}+00$ & 0.0000 & $0.000 \mathrm{E}+00$ & 0.0000 & $0.000 \mathrm{E}+00$ & 0.0000 & $0.000 \mathrm{E}+00$ & 0.0000 & $0.000 \mathrm{E}+00$ & 0.0000 & $0.000 \mathrm{E}+00$ & 0.0000 & $1.133 \mathrm{E}-08$ & 0.0037 \\
\hline & $0.000 \mathrm{E}+00$ & 0.0000 & $0.000 \mathrm{E}+00$ & 0.0000 & $0.000 \mathrm{E}+00$ & 0.0000 & $0.000 \mathrm{E}+00$ & 0.0000 & $0.000 \mathrm{E}+00$ & 0.0000 & $0.000 \mathrm{E}+00$ & 0.0000 & $3 E-06$ & 1. \\
\hline
\end{tabular}

* Sum of all water independent and dependent pathways. 
RESRAD, Version $6.5 \quad$ T1/2 Limit $=180$ days
Summary : RESRAD Parameters for U-Landfill Outdoor Worker Forward Run at Proposed ALs

File : C: \RESRAD_FAMILY \RESRAD \USERFILES \QCJULY2011 \ODW_FORWARD_1050YRSALS.RAD

Total Dose Contributions TDOSE(i,p,t) for Individual Radionuclides (i) and Pathways (p) As mrem/yr and Fraction of Total Dose At $t=5.000 \mathrm{E}+01$ years

Water Independent Pathways (Inhalation excludes radon)

\begin{tabular}{|c|c|c|c|c|c|c|c|c|c|c|c|c|c|c|}
\hline \multirow{2}{*}{ Nuclide } & \multicolumn{2}{|c|}{ Ground } & \multicolumn{2}{|c|}{ Inhalation } & \multicolumn{2}{|c|}{ Radon } & \multicolumn{2}{|c|}{ Plant } & \multicolumn{2}{|c|}{ Meat } & \multicolumn{2}{|c|}{ Milk } & \multicolumn{2}{|c|}{ Soil } \\
\hline & mrem/yr & fract. & mrem/yr & fract. & mrem/yr & fract. & mrem/yr & fract. & mrem/yr & fract. & mrem/yr & fract. & mrem/yr & fract. \\
\hline-241 & $3.672 \mathrm{E}-16$ & 0.0000 & $0.000 \mathrm{E}+00$ & 0.0000 & $0.000 \mathrm{E}+00$ & 0.0000 & $0.000 \mathrm{E}+00$ & 0.0000 & $0.000 \mathrm{E}+00$ & 0.0000 & $0.000 \mathrm{E}+00$ & 0.0000 & $0.000 \mathrm{E}+00$ & 0.0000 \\
\hline-137 & $4.701 E-09$ & 0.0012 & $0.000 \mathrm{E}+00$ & 0.0000 & $0.000 \mathrm{E}+00$ & 0.0000 & $0.000 \mathrm{E}+00$ & 0.0000 & $0.000 \mathrm{E}+00$ & 0.0000 & $0.000 \mathrm{E}+00$ & 0.0000 & $0.000 \mathrm{E}+00$ & 0.0000 \\
\hline-237 & $3.671 \mathrm{E}-12$ & 0.0000 & $0.000 \mathrm{E}+00$ & 0.0000 & $0.000 \mathrm{E}+00$ & 0.0000 & $0.000 \mathrm{E}+00$ & 0.0000 & $0.000 \mathrm{E}+00$ & 0.0000 & $0.000 \mathrm{E}+00$ & 0.0000 & $0.000 \mathrm{E}+00$ & 0.0000 \\
\hline-238 & $8.395 E-16$ & 0.0000 & $0.000 \mathrm{E}+00$ & 0.0000 & $0.000 \mathrm{E}+00$ & 0.0000 & $0.000 \mathrm{E}+00$ & 0.0000 & $0.000 \mathrm{E}+00$ & 0.0000 & $0.000 \mathrm{E}+00$ & 0.0000 & $0.000 \mathrm{E}+00$ & 0.0000 \\
\hline-239 & $3.213 E-16$ & 0.0000 & $0.000 \mathrm{E}+00$ & 0.0000 & $0.000 \mathrm{E}+00$ & 0.0000 & $0.000 \mathrm{E}+00$ & 0.0000 & $0.000 \mathrm{E}+00$ & 0.0000 & $0.000 \mathrm{E}+00$ & 0.0000 & $0.000 \mathrm{E}+00$ & 0.0000 \\
\hline-240 & $3.946 \mathrm{E}-20$ & 0.0000 & $0.000 \mathrm{E}+00$ & 0.0000 & $0.000 \mathrm{E}+00$ & 0.0000 & $0.000 \mathrm{E}+00$ & 0.0000 & $0.000 \mathrm{E}+00$ & 0.0000 & $0.000 \mathrm{E}+00$ & 0.0000 & $0.000 \mathrm{E}+00$ & 0.0000 \\
\hline 99 & $2.459 E-24$ & 0.0000 & $0.000 \mathrm{E}+00$ & 0.0000 & $0.000 \mathrm{E}+00$ & 0.0000 & $0.000 \mathrm{E}+00$ & 0.0000 & $0.000 \mathrm{E}+00$ & 0.0000 & $0.000 \mathrm{E}+00$ & 0.0000 & $0.000 \mathrm{E}+00$ & 0.0000 \\
\hline-228 & $4.130 \mathrm{E}-14$ & 0.0000 & $0.000 \mathrm{E}+00$ & 0.0000 & $0.000 \mathrm{E}+00$ & 0.0000 & $0.000 \mathrm{E}+00$ & 0.0000 & $0.000 \mathrm{E}+00$ & 0.0000 & $0.000 \mathrm{E}+00$ & 0.0000 & $0.000 \mathrm{E}+00$ & 0.0000 \\
\hline-230 & $2.174 \mathrm{E}-07$ & 0.0558 & $0.000 \mathrm{E}+00$ & 0.0000 & $0.000 \mathrm{E}+00$ & 0.0000 & $0.000 \mathrm{E}+00$ & 0.0000 & $0.000 \mathrm{E}+00$ & 0.0000 & $0.000 \mathrm{E}+00$ & 0.0000 & $0.000 \mathrm{E}+00$ & 0.0000 \\
\hline-232 & $3.663 E-06$ & 0.9395 & $0.000 \mathrm{E}+00$ & 0.0000 & $0.000 \mathrm{E}+00$ & 0.0000 & $0.000 \mathrm{E}+00$ & 0.0000 & $0.000 \mathrm{E}+00$ & 0.0000 & $0.000 \mathrm{E}+00$ & 0.0000 & $0.000 \mathrm{E}+00$ & 0.0000 \\
\hline 234 & $7.936 \mathrm{E}-11$ & 0.0000 & $0.000 \mathrm{E}+00$ & 0.0000 & $0.000 \mathrm{E}+00$ & 0.0000 & $0.000 \mathrm{E}+00$ & 0.0000 & $0.000 \mathrm{E}+00$ & 0.0000 & $0.000 \mathrm{E}+00$ & 0.0000 & $0.000 \mathrm{E}+00$ & 0.0000 \\
\hline 35 & $2.455 E-13$ & 0.0000 & $0.000 \mathrm{E}+00$ & 0.0000 & $0.000 \mathrm{E}+00$ & 0.0000 & $0.000 \mathrm{E}+00$ & 0.0000 & $0.000 \mathrm{E}+00$ & 0.0000 & $0.000 \mathrm{E}+00$ & 0.0000 & $0.000 \mathrm{E}+00$ & 0.0000 \\
\hline 38 & $1.384 \mathrm{E}-08$ & 0.0035 & $0.000 \mathrm{E}+00$ & 0.0000 & $0.000 \mathrm{E}+00$ & 0.0000 & $0.000 \mathrm{E}+00$ & 0.0000 & $0.000 \mathrm{E}+00$ & 0.0000 & $0.000 \mathrm{E}+00$ & 0.0000 & $0.000 \mathrm{E}+00$ & 0.0000 \\
\hline & $3.899 \mathrm{E}-06$ & 1.0000 & $0.000 \mathrm{E}+00$ & 0.0000 & $0.000 \mathrm{E}+00$ & 0.0000 & $0.000 \mathrm{E}+00$ & 0.0000 & $0.000 \mathrm{E}+00$ & 0.0000 & $0.000 \mathrm{E}+00$ & 0.0000 & $0.000 \mathrm{E}+00$ & 0.0000 \\
\hline
\end{tabular}

Total Dose Contributions TDOSE(i,p,t) for Individual Radionuclides (i) and Pathways (p) As mrem/yr and Fraction of Total Dose At $t=5.000 \mathrm{E}+01$ years

Water Dependent Pathways

\begin{tabular}{|c|c|c|c|c|c|c|c|c|c|c|c|c|c|c|}
\hline \multirow{2}{*}{$\begin{array}{l}\text { Radio- } \\
\text { Nuclide }\end{array}$} & \multicolumn{2}{|c|}{ Water } & \multicolumn{2}{|c|}{ Fish } & \multicolumn{2}{|c|}{ Radon } & \multicolumn{2}{|c|}{ Plant } & \multicolumn{2}{|c|}{ Meat } & \multicolumn{2}{|c|}{ Milk } & \multicolumn{2}{|c|}{ All Pathways* } \\
\hline & mrem/yr & fract. & mrem/yr & fract. & mrem/yr & fract. & mrem/yr & fract. & mrem/yr & fract. & mrem/yr & fract. & mrem/yr & fract. \\
\hline 241 & $0.000 \mathrm{E}+00$ & 0.0000 & $0.000 \mathrm{E}+00$ & 0.0000 & $0.000 \mathrm{E}+00$ & 0.0000 & $0.000 \mathrm{E}+00$ & 0.0000 & $0.000 \mathrm{E}+00$ & 0.0000 & $0.000 \mathrm{E}+00$ & 0.0000 & $3.672 \mathrm{E}-16$ & 0.0000 \\
\hline-137 & $0.000 \mathrm{E}+00$ & 0.0000 & $0.000 \mathrm{E}+00$ & 0.0000 & $0.000 \mathrm{E}+00$ & 0.0000 & $0.000 \mathrm{E}+00$ & 0.0000 & $0.000 \mathrm{E}+00$ & 0.0000 & $0.000 \mathrm{E}+00$ & 0.0000 & $4.701 \mathrm{E}-09$ & 0.0012 \\
\hline-237 & $0.000 \mathrm{E}+00$ & 0.0000 & $0.000 \mathrm{E}+00$ & 0.0000 & $0.000 \mathrm{E}+00$ & 0.0000 & $0.000 \mathrm{E}+00$ & 0.0000 & $0.000 \mathrm{E}+00$ & 0.0000 & $0.000 \mathrm{E}+00$ & 0.0000 & $3.671 E-12$ & 0.0000 \\
\hline-238 & $0.000 \mathrm{E}+00$ & 0.0000 & $0.000 \mathrm{E}+00$ & 0.0000 & $0.000 \mathrm{E}+00$ & 0.0000 & $0.000 \mathrm{E}+00$ & 0.0000 & $0.000 \mathrm{E}+00$ & 0.0000 & $0.000 \mathrm{E}+00$ & 0.0000 & $8.395 \mathrm{E}-16$ & 0.0000 \\
\hline-239 & $0.000 \mathrm{E}+00$ & 0.0000 & $0.000 \mathrm{E}+00$ & 0.0000 & $0.000 \mathrm{E}+00$ & 0.0000 & $0.000 \mathrm{E}+00$ & 0.0000 & $0.000 \mathrm{E}+00$ & 0.0000 & $0.000 E+00$ & 0.0000 & $3.213 \mathrm{E}-16$ & 0.0000 \\
\hline-240 & $0.000 \mathrm{E}+00$ & 0.0000 & $0.000 \mathrm{E}+00$ & 0.0000 & $0.000 \mathrm{E}+00$ & 0.0000 & $0.000 \mathrm{E}+00$ & 0.0000 & $0.000 \mathrm{E}+00$ & 0.0000 & $0.000 E+00$ & 0.0000 & $3.946 \mathrm{E}-20$ & 0.0000 \\
\hline-99 & $0.000 \mathrm{E}+00$ & 0.0000 & $0.000 \mathrm{E}+00$ & 0.0000 & $0.000 \mathrm{E}+00$ & 0.0000 & $0.000 \mathrm{E}+00$ & 0.0000 & $0.000 \mathrm{E}+00$ & 0.0000 & $0.000 \mathrm{E}+00$ & 0.0000 & $2.459 E-24$ & 0.0000 \\
\hline-228 & $0.000 \mathrm{E}+00$ & 0.0000 & $0.000 \mathrm{E}+00$ & 0.0000 & $0.000 \mathrm{E}+00$ & 0.0000 & $0.000 \mathrm{E}+00$ & 0.0000 & $0.000 \mathrm{E}+00$ & 0.0000 & $0.000 \mathrm{E}+00$ & 0.0000 & $4.130 \mathrm{E}-14$ & 0.0000 \\
\hline-230 & $0.000 \mathrm{E}+00$ & 0.0000 & $0.000 \mathrm{E}+00$ & 0.0000 & $0.000 \mathrm{E}+00$ & 0.0000 & $0.000 \mathrm{E}+00$ & 0.0000 & $0.000 \mathrm{E}+00$ & 0.0000 & $0.000 E+00$ & 0.0000 & $2.174 \mathrm{E}-07$ & 0.0558 \\
\hline 232 & $0.000 \mathrm{E}+00$ & 0.0000 & $0.000 \mathrm{E}+00$ & 0.0000 & $0.000 \mathrm{E}+00$ & 0.0000 & $0.000 \mathrm{E}+00$ & 0.0000 & $0.000 \mathrm{E}+00$ & 0.0000 & $0.000 \mathrm{E}+00$ & 0.0000 & $3.663 \mathrm{E}-06$ & 0.9395 \\
\hline 34 & $0.000 \mathrm{E}+00$ & 0.0000 & $0.000 \mathrm{E}+00$ & 0.0000 & $0.000 \mathrm{E}+00$ & 0.0000 & $0.000 \mathrm{E}+00$ & 0.0000 & $0.000 \mathrm{E}+00$ & 0.0000 & $0.000 \mathrm{E}+00$ & 0.0000 & 7. $936 \mathrm{E}-11$ & 0.0000 \\
\hline 35 & $0.000 \mathrm{E}+00$ & 0.0000 & $0.000 \mathrm{E}+00$ & 0.0000 & $0.000 \mathrm{E}+00$ & 0.0000 & $0.000 \mathrm{E}+00$ & 0.0000 & $0.000 \mathrm{E}+00$ & 0.0000 & $0.000 \mathrm{E}+00$ & 0.0000 & $2.455 E-13$ & 0.0000 \\
\hline 38 & $0.000 \mathrm{E}+00$ & 0.0000 & $0.000 \mathrm{E}+00$ & 0.0000 & $0.000 \mathrm{E}+00$ & 0.0000 & $0.000 \mathrm{E}+00$ & 0.0000 & $0.000 \mathrm{E}+00$ & 0.0000 & $0.000 \mathrm{E}+00$ & 0.0000 & $1.384 \mathrm{E}-08$ & 0.0035 \\
\hline & $0.000 \mathrm{E}+00$ & 0.0000 & $0.000 \mathrm{E}+00$ & 0.0000 & $0.000 \mathrm{E}+00$ & 0.0000 & $0.000 \mathrm{E}+00$ & 0.0000 & $0.000 \mathrm{E}+00$ & 0.0000 & $0.000 \mathrm{E}+00$ & 0.0000 & $9 \mathrm{E}-06$ & 1. \\
\hline
\end{tabular}

* Sum of all water independent and dependent pathways. 
RESRAD, Version $6.5 \quad$ T1/2 Limit $=180$ days
Summary : RESRAD Parameters for U-Landfill Outdoor Worker Forward Run at Proposed ALs

File : C: \RESRAD_FAMILY \RESRAD \USERFILES \QCJULY2011 \ODW_FORWARD_1050YRSALS.RAD

Total Dose Contributions TDOSE(i,p,t) for Individual Radionuclides (i) and Pathways (p) As mrem/yr and Fraction of Total Dose At $t=1.000 \mathrm{E}+02$ years

Water Independent Pathways (Inhalation excludes radon)

\begin{tabular}{|c|c|c|c|c|c|c|c|c|c|c|c|c|c|c|}
\hline \multirow{2}{*}{ Nuclide } & \multicolumn{2}{|c|}{ Ground } & \multicolumn{2}{|c|}{ Inhalation } & \multicolumn{2}{|c|}{ Radon } & \multicolumn{2}{|c|}{ Plant } & \multicolumn{2}{|c|}{ Meat } & \multicolumn{2}{|c|}{ Milk } & \multicolumn{2}{|c|}{ Soil } \\
\hline & mrem/yr & fract. & mrem/yr & fract. & mrem/yr & fract. & mrem/yr & fract. & mrem/yr & fract. & mrem/yr & fract. & mrem/yr & fract. \\
\hline-241 & 1. $205 \mathrm{E}-15$ & 0.0000 & $0.000 \mathrm{E}+00$ & 0.0000 & $0.000 \mathrm{E}+00$ & 0.0000 & $0.000 \mathrm{E}+00$ & 0.0000 & $0.000 \mathrm{E}+00$ & 0.0000 & $0.000 \mathrm{E}+00$ & 0.0000 & $0.000 \mathrm{E}+00$ & 0.0000 \\
\hline-137 & $2.255 E-09$ & 0.0004 & $0.000 \mathrm{E}+00$ & 0.0000 & $0.000 \mathrm{E}+00$ & 0.0000 & $0.000 \mathrm{E}+00$ & 0.0000 & $0.000 \mathrm{E}+00$ & 0.0000 & $0.000 \mathrm{E}+00$ & 0.0000 & $0.000 \mathrm{E}+00$ & 0.0000 \\
\hline-237 & $6.302 \mathrm{E}-12$ & 0.0000 & $0.000 \mathrm{E}+00$ & 0.0000 & $0.000 \mathrm{E}+00$ & 0.0000 & $0.000 \mathrm{E}+00$ & 0.0000 & $0.000 \mathrm{E}+00$ & 0.0000 & $0.000 \mathrm{E}+00$ & 0.0000 & $0.000 \mathrm{E}+00$ & 0.0000 \\
\hline-238 & $8.489 E-15$ & 0.0000 & $0.000 \mathrm{E}+00$ & 0.0000 & $0.000 \mathrm{E}+00$ & 0.0000 & $0.000 \mathrm{E}+00$ & 0.0000 & $0.000 \mathrm{E}+00$ & 0.0000 & $0.000 \mathrm{E}+00$ & 0.0000 & $0.000 \mathrm{E}+00$ & 0.0000 \\
\hline-239 & $5.839 \mathrm{E}-16$ & 0.0000 & $0.000 \mathrm{E}+00$ & 0.0000 & $0.000 \mathrm{E}+00$ & 0.0000 & $0.000 \mathrm{E}+00$ & 0.0000 & $0.000 \mathrm{E}+00$ & 0.0000 & $0.000 \mathrm{E}+00$ & 0.0000 & $0.000 \mathrm{E}+00$ & 0.0000 \\
\hline-240 & $2.625 E-19$ & 0.0000 & $0.000 \mathrm{E}+00$ & 0.0000 & $0.000 \mathrm{E}+00$ & 0.0000 & $0.000 \mathrm{E}+00$ & 0.0000 & $0.000 \mathrm{E}+00$ & 0.0000 & $0.000 \mathrm{E}+00$ & 0.0000 & $0.000 \mathrm{E}+00$ & 0.0000 \\
\hline 99 & $4.931 E-24$ & 0.0000 & $0.000 \mathrm{E}+00$ & 0.0000 & $0.000 \mathrm{E}+00$ & 0.0000 & $0.000 \mathrm{E}+00$ & 0.0000 & $0.000 \mathrm{E}+00$ & 0.0000 & $0.000 \mathrm{E}+00$ & 0.0000 & $0.000 \mathrm{E}+00$ & 0.0000 \\
\hline-228 & 7. $549 \mathrm{E}-22$ & 0.0000 & $0.000 \mathrm{E}+00$ & 0.0000 & $0.000 \mathrm{E}+00$ & 0.0000 & $0.000 \mathrm{E}+00$ & 0.0000 & $0.000 \mathrm{E}+00$ & 0.0000 & $0.000 \mathrm{E}+00$ & 0.0000 & $0.000 \mathrm{E}+00$ & 0.0000 \\
\hline-230 & $6.047 \mathrm{E}-07$ & 0.1082 & $0.000 \mathrm{E}+00$ & 0.0000 & $0.000 \mathrm{E}+00$ & 0.0000 & $0.000 \mathrm{E}+00$ & 0.0000 & $0.000 \mathrm{E}+00$ & 0.0000 & $0.000 \mathrm{E}+00$ & 0.0000 & $0.000 \mathrm{E}+00$ & 0.0000 \\
\hline-232 & $4.958 E-06$ & 0.8876 & $0.000 \mathrm{E}+00$ & 0.0000 & $0.000 \mathrm{E}+00$ & 0.0000 & $0.000 \mathrm{E}+00$ & 0.0000 & $0.000 \mathrm{E}+00$ & 0.0000 & $0.000 \mathrm{E}+00$ & 0.0000 & $0.000 \mathrm{E}+00$ & 0.0000 \\
\hline 234 & $4.408 \mathrm{E}-10$ & 0.0001 & $0.000 \mathrm{E}+00$ & 0.0000 & $0.000 \mathrm{E}+00$ & 0.0000 & $0.000 \mathrm{E}+00$ & 0.0000 & $0.000 \mathrm{E}+00$ & 0.0000 & $0.000 \mathrm{E}+00$ & 0.0000 & $0.000 \mathrm{E}+00$ & 0.0000 \\
\hline 35 & $9.007 \mathrm{E}-13$ & 0.0000 & $0.000 \mathrm{E}+00$ & 0.0000 & $0.000 \mathrm{E}+00$ & 0.0000 & $0.000 \mathrm{E}+00$ & 0.0000 & $0.000 \mathrm{E}+00$ & 0.0000 & $0.000 \mathrm{E}+00$ & 0.0000 & $0.000 \mathrm{E}+00$ & 0.0000 \\
\hline 38 & $2.064 \mathrm{E}-08$ & 0.0037 & $0.000 \mathrm{E}+00$ & 0.0000 & $0.000 \mathrm{E}+00$ & 0.0000 & $0.000 \mathrm{E}+00$ & 0.0000 & $0.000 \mathrm{E}+00$ & 0.0000 & $0.000 \mathrm{E}+00$ & 0.0000 & $0.000 \mathrm{E}+00$ & 0.0000 \\
\hline & $5.586 \mathrm{E}-06$ & 1.0000 & $0.000 \mathrm{E}+00$ & 0.0000 & $0.000 \mathrm{E}+00$ & 0.0000 & $0.000 \mathrm{E}+00$ & 0.0000 & $0.000 \mathrm{E}+00$ & 0.0000 & $0.000 \mathrm{E}+00$ & 0.0000 & $0.000 \mathrm{E}+00$ & 0.0000 \\
\hline
\end{tabular}

Total Dose Contributions TDOSE(i,p,t) for Individual Radionuclides (i) and Pathways (p) As mrem/yr and Fraction of Total Dose At $t=1.000 \mathrm{E}+02$ years

Water Dependent Pathways

\begin{tabular}{|c|c|c|c|c|c|c|c|c|c|c|c|c|c|c|}
\hline \multirow{2}{*}{ Nuclide } & \multicolumn{2}{|c|}{ Water } & \multicolumn{2}{|c|}{ Fish } & \multicolumn{2}{|c|}{ Radon } & \multicolumn{2}{|c|}{ Plant } & \multicolumn{2}{|c|}{ Meat } & \multicolumn{2}{|c|}{ Milk } & \multicolumn{2}{|c|}{ All Pathways* } \\
\hline & mrem/yr & fract. & mrem/yr & fract. & mrem/yr & fract. & mrem/yr & fract. & mrem/yr & fract. & mrem/yr & fract. & mrem/yr & fract. \\
\hline-241 & $0.000 \mathrm{E}+00$ & 0.0000 & $0.000 \mathrm{E}+00$ & 0.0000 & $0.000 \mathrm{E}+00$ & 0.0000 & $0.000 \mathrm{E}+00$ & 0.0000 & $0.000 \mathrm{E}+00$ & 0.0000 & $0.000 E+00$ & 0.0000 & $1.205 \mathrm{E}-15$ & 0.0000 \\
\hline-137 & $0.000 \mathrm{E}+00$ & 0.0000 & $0.000 \mathrm{E}+00$ & 0.0000 & $0.000 \mathrm{E}+00$ & 0.0000 & $0.000 \mathrm{E}+00$ & 0.0000 & $0.000 \mathrm{E}+00$ & 0.0000 & $0.000 \mathrm{E}+00$ & 0.0000 & $2.255 E-09$ & 0.0004 \\
\hline-237 & $0.000 \mathrm{E}+00$ & 0.0000 & $0.000 \mathrm{E}+00$ & 0.0000 & $0.000 \mathrm{E}+00$ & 0.0000 & $0.000 \mathrm{E}+00$ & 0.0000 & $0.000 \mathrm{E}+00$ & 0.0000 & $0.000 \mathrm{E}+00$ & 0.0000 & $6.302 \mathrm{E}-12$ & 0.0000 \\
\hline-238 & $0.000 \mathrm{E}+00$ & 0.0000 & $0.000 \mathrm{E}+00$ & 0.0000 & $0.000 \mathrm{E}+00$ & 0.0000 & $0.000 \mathrm{E}+00$ & 0.0000 & $0.000 \mathrm{E}+00$ & 0.0000 & $0.000 \mathrm{E}+00$ & 0.0000 & $8.489 \mathrm{E}-15$ & 0.0000 \\
\hline-239 & $0.000 \mathrm{E}+00$ & 0.0000 & $0.000 \mathrm{E}+00$ & 0.0000 & $0.000 \mathrm{E}+00$ & 0.0000 & $0.000 \mathrm{E}+00$ & 0.0000 & $0.000 \mathrm{E}+00$ & 0.0000 & $0.000 \mathrm{E}+00$ & 0.0000 & $5.839 \mathrm{E}-16$ & 0.0000 \\
\hline-240 & $0.000 \mathrm{E}+00$ & 0.0000 & $0.000 \mathrm{E}+00$ & 0.0000 & $0.000 \mathrm{E}+00$ & 0.0000 & $0.000 \mathrm{E}+00$ & 0.0000 & $0.000 \mathrm{E}+00$ & 0.0000 & $0.000 \mathrm{E}+00$ & 0.0000 & $2.625 E-19$ & 0.0000 \\
\hline 99 & $0.000 \mathrm{E}+00$ & 0.0000 & $0.000 \mathrm{E}+00$ & 0.0000 & $0.000 \mathrm{E}+00$ & 0.0000 & $0.000 \mathrm{E}+00$ & 0.0000 & $0.000 \mathrm{E}+00$ & 0.0000 & $0.000 \mathrm{E}+00$ & 0.0000 & $4.931 \mathrm{E}-24$ & 0.0000 \\
\hline-228 & $0.000 \mathrm{E}+00$ & 0.0000 & $0.000 \mathrm{E}+00$ & 0.0000 & $0.000 \mathrm{E}+00$ & 0.0000 & $0.000 \mathrm{E}+00$ & 0.0000 & $0.000 \mathrm{E}+00$ & 0.0000 & $0.000 \mathrm{E}+00$ & 0.0000 & $7.549 \mathrm{E}-22$ & 0.0000 \\
\hline-230 & $0.000 \mathrm{E}+00$ & 0.0000 & $0.000 \mathrm{E}+00$ & 0.0000 & $0.000 \mathrm{E}+00$ & 0.0000 & $0.000 \mathrm{E}+00$ & 0.0000 & $0.000 \mathrm{E}+00$ & 0.0000 & $0.000 \mathrm{E}+00$ & 0.0000 & $6.047 \mathrm{E}-07$ & 0.1082 \\
\hline-232 & $0.000 \mathrm{E}+00$ & 0.0000 & $0.000 \mathrm{E}+00$ & 0.0000 & $0.000 \mathrm{E}+00$ & 0.0000 & $0.000 \mathrm{E}+00$ & 0.0000 & $0.000 \mathrm{E}+00$ & 0.0000 & $0.000 \mathrm{E}+00$ & 0.0000 & $4.958 E-06$ & 0.8876 \\
\hline 234 & $0.000 \mathrm{E}+00$ & 0.0000 & $0.000 \mathrm{E}+00$ & 0.0000 & $0.000 \mathrm{E}+00$ & 0.0000 & $0.000 \mathrm{E}+00$ & 0.0000 & $0.000 \mathrm{E}+00$ & 0.0000 & $0.000 \mathrm{E}+00$ & 0.0000 & $4.408 \mathrm{E}-10$ & 0.0001 \\
\hline 35 & $0.000 \mathrm{E}+00$ & 0.0000 & $0.000 \mathrm{E}+00$ & 0.0000 & $0.000 \mathrm{E}+00$ & 0.0000 & $0.000 \mathrm{E}+00$ & 0.0000 & $0.000 \mathrm{E}+00$ & 0.0000 & $0.000 \mathrm{E}+00$ & 0.0000 & $9.007 \mathrm{E}-13$ & 0.0000 \\
\hline 38 & $0.000 \mathrm{E}+00$ & 0.0000 & $0.000 \mathrm{E}+00$ & 0.0000 & $0.000 \mathrm{E}+00$ & 0.0000 & $0.000 \mathrm{E}+00$ & 0.0000 & $0.000 \mathrm{E}+00$ & 0.0000 & $0.000 \mathrm{E}+00$ & 0.0000 & $2.064 \mathrm{E}-08$ & 0.0037 \\
\hline & $0.000 \mathrm{E}+00$ & 0.0000 & $0.000 \mathrm{E}+00$ & 0.0000 & $0.000 \mathrm{E}+00$ & 0.0000 & $0.000 \mathrm{E}+00$ & 0.0000 & $0.000 \mathrm{E}+00$ & 0.0000 & $0.000 \mathrm{E}+00$ & 0.0000 & $36 E-06$ & 1.0000 \\
\hline
\end{tabular}

* Sum of all water independent and dependent pathways. 
RESRAD, Version $6.5 \quad$ T1/2 Limit $=180$ days
Summary : RESRAD Parameters for U-Landfill Outdoor Worker Forward Run at Proposed ALs

File : C: \RESRAD_FAMILY \RESRAD \USERFILES \QCJULY2011 \ODW_FORWARD_1050YRSALS.RAD

Total Dose Contributions TDOSE(i,p,t) for Individual Radionuclides (i) and Pathways (p) As mrem/yr and Fraction of Total Dose At $t=5.000 \mathrm{E}+02$ years

Water Independent Pathways (Inhalation excludes radon)

\begin{tabular}{|c|c|c|c|c|c|c|c|c|c|c|c|c|c|c|}
\hline \multirow{2}{*}{ Nuclide } & \multicolumn{2}{|c|}{ Ground } & \multicolumn{2}{|c|}{ Inhalation } & \multicolumn{2}{|c|}{ Radon } & \multicolumn{2}{|c|}{ Plant } & \multicolumn{2}{|c|}{ Meat } & \multicolumn{2}{|c|}{ Milk } & \multicolumn{2}{|c|}{ Soil } \\
\hline & mrem/yr & fract. & mrem/yr & fract. & mrem/yr & fract. & mrem/yr & fract. & mrem/yr & fract. & mrem/yr & fract. & mrem/yr & fract. \\
\hline-241 & $3.336 \mathrm{E}-13$ & 0.0000 & $0.000 \mathrm{E}+00$ & 0.0000 & $0.000 \mathrm{E}+00$ & 0.0000 & $0.000 \mathrm{E}+00$ & 0.0000 & $0.000 \mathrm{E}+00$ & 0.0000 & $0.000 \mathrm{E}+00$ & 0.0000 & $0.000 \mathrm{E}+00$ & 0.0000 \\
\hline-137 & $6.336 \mathrm{E}-12$ & 0.0000 & $0.000 \mathrm{E}+00$ & 0.0000 & $0.000 \mathrm{E}+00$ & 0.0000 & $0.000 \mathrm{E}+00$ & 0.0000 & $0.000 \mathrm{E}+00$ & 0.0000 & $0.000 \mathrm{E}+00$ & 0.0000 & $0.000 \mathrm{E}+00$ & 0.0000 \\
\hline-237 & 4. $723 E-10$ & 0.0000 & $0.000 \mathrm{E}+00$ & 0.0000 & $0.000 \mathrm{E}+00$ & 0.0000 & $0.000 \mathrm{E}+00$ & 0.0000 & $0.000 \mathrm{E}+00$ & 0.0000 & $0.000 \mathrm{E}+00$ & 0.0000 & $0.000 \mathrm{E}+00$ & 0.0000 \\
\hline-238 & $8.964 \mathrm{E}-12$ & 0.0000 & $0.000 \mathrm{E}+00$ & 0.0000 & $0.000 \mathrm{E}+00$ & 0.0000 & $0.000 \mathrm{E}+00$ & 0.0000 & $0.000 \mathrm{E}+00$ & 0.0000 & $0.000 \mathrm{E}+00$ & 0.0000 & $0.000 \mathrm{E}+00$ & 0.0000 \\
\hline-239 & $6.951 \mathrm{E}-14$ & 0.0000 & $0.000 \mathrm{E}+00$ & 0.0000 & $0.000 \mathrm{E}+00$ & 0.0000 & $0.000 \mathrm{E}+00$ & 0.0000 & $0.000 \mathrm{E}+00$ & 0.0000 & $0.000 \mathrm{E}+00$ & 0.0000 & $0.000 \mathrm{E}+00$ & 0.0000 \\
\hline-240 & $8.438 \mathrm{E}-17$ & 0.0000 & $0.000 \mathrm{E}+00$ & 0.0000 & $0.000 \mathrm{E}+00$ & 0.0000 & $0.000 \mathrm{E}+00$ & 0.0000 & $0.000 \mathrm{E}+00$ & 0.0000 & $0.000 \mathrm{E}+00$ & 0.0000 & $0.000 \mathrm{E}+00$ & 0.0000 \\
\hline 99 & 1. $290 \mathrm{E}-21$ & 0.0000 & $0.000 \mathrm{E}+00$ & 0.0000 & $0.000 \mathrm{E}+00$ & 0.0000 & $0.000 \mathrm{E}+00$ & 0.0000 & $0.000 \mathrm{E}+00$ & 0.0000 & $0.000 \mathrm{E}+00$ & 0.0000 & $0.000 \mathrm{E}+00$ & 0.0000 \\
\hline-228 & $0.000 \mathrm{E}+00$ & 0.0000 & $0.000 \mathrm{E}+00$ & 0.0000 & $0.000 \mathrm{E}+00$ & 0.0000 & $0.000 \mathrm{E}+00$ & 0.0000 & $0.000 \mathrm{E}+00$ & 0.0000 & $0.000 \mathrm{E}+00$ & 0.0000 & $0.000 \mathrm{E}+00$ & 0.0000 \\
\hline-230 & $4.387 \mathrm{E}-05$ & 0.4425 & $0.000 \mathrm{E}+00$ & 0.0000 & $0.000 \mathrm{E}+00$ & 0.0000 & $0.000 \mathrm{E}+00$ & 0.0000 & $0.000 \mathrm{E}+00$ & 0.0000 & $0.000 \mathrm{E}+00$ & 0.0000 & $0.000 \mathrm{E}+00$ & 0.0000 \\
\hline-232 & $5.460 E-05$ & 0.5508 & $0.000 \mathrm{E}+00$ & 0.0000 & $0.000 \mathrm{E}+00$ & 0.0000 & $0.000 \mathrm{E}+00$ & 0.0000 & $0.000 \mathrm{E}+00$ & 0.0000 & $0.000 \mathrm{E}+00$ & 0.0000 & $0.000 \mathrm{E}+00$ & 0.0000 \\
\hline 234 & $1.637 \mathrm{E}-07$ & 0.0017 & $0.000 \mathrm{E}+00$ & 0.0000 & $0.000 \mathrm{E}+00$ & 0.0000 & $0.000 \mathrm{E}+00$ & 0.0000 & $0.000 \mathrm{E}+00$ & 0.0000 & $0.000 \mathrm{E}+00$ & 0.0000 & $0.000 \mathrm{E}+00$ & 0.0000 \\
\hline 35 & $1.876 \mathrm{E}-10$ & 0.0000 & $0.000 \mathrm{E}+00$ & 0.0000 & $0.000 \mathrm{E}+00$ & 0.0000 & $0.000 \mathrm{E}+00$ & 0.0000 & $0.000 \mathrm{E}+00$ & 0.0000 & $0.000 \mathrm{E}+00$ & 0.0000 & $0.000 \mathrm{E}+00$ & 0.0000 \\
\hline 38 & $5.045 E-07$ & 0.0051 & $0.000 \mathrm{E}+00$ & 0.0000 & $0.000 \mathrm{E}+00$ & 0.0000 & $0.000 \mathrm{E}+00$ & 0.0000 & $0.000 \mathrm{E}+00$ & 0.0000 & $0.000 \mathrm{E}+00$ & 0.0000 & $0.000 \mathrm{E}+00$ & 0.0000 \\
\hline & $9.914 \mathrm{E}-05$ & 1.0000 & $0.000 \mathrm{E}+00$ & 0.0000 & $0.000 \mathrm{E}+00$ & 0.0000 & $0.000 \mathrm{E}+00$ & 0.0000 & $0.000 \mathrm{E}+00$ & 0.0000 & $0.000 \mathrm{E}+00$ & 0.0000 & $.000 \mathrm{E}+00$ & 0.0000 \\
\hline
\end{tabular}

Total Dose Contributions TDOSE(i,p,t) for Individual Radionuclides (i) and Pathways (p) As mrem/yr and Fraction of Total Dose At $t=5.000 \mathrm{E}+02$ years

Water Dependent Pathways

\begin{tabular}{|c|c|c|c|c|c|c|c|c|c|c|c|c|c|c|}
\hline \multirow{2}{*}{ Nuclide } & \multicolumn{2}{|c|}{ Water } & \multicolumn{2}{|c|}{ Fish } & \multicolumn{2}{|c|}{ Radon } & \multicolumn{2}{|c|}{ Plant } & \multicolumn{2}{|c|}{ Meat } & \multicolumn{2}{|c|}{ Milk } & \multicolumn{2}{|c|}{ All Pathways* } \\
\hline & mrem/yr & fract. & mrem/yr & fract. & mrem/yr & fract. & mrem/yr & fract. & mrem/yr & fract. & mrem/yr & fract. & mrem/yr & fract. \\
\hline-241 & $0.000 \mathrm{E}+00$ & 0.0000 & $0.000 \mathrm{E}+00$ & 0.0000 & $0.000 \mathrm{E}+00$ & 0.0000 & $0.000 \mathrm{E}+00$ & 0.0000 & $0.000 \mathrm{E}+00$ & 0.0000 & $0.000 \mathrm{E}+00$ & 0.0000 & $3.336 \mathrm{E}-13$ & 0.0000 \\
\hline-137 & $0.000 \mathrm{E}+00$ & 0.0000 & $0.000 \mathrm{E}+00$ & 0.0000 & $0.000 \mathrm{E}+00$ & 0.0000 & $0.000 \mathrm{E}+00$ & 0.0000 & $0.000 \mathrm{E}+00$ & 0.0000 & $0.000 \mathrm{E}+00$ & 0.0000 & $6.336 \mathrm{E}-12$ & 0.0000 \\
\hline-237 & $0.000 \mathrm{E}+00$ & 0.0000 & $0.000 \mathrm{E}+00$ & 0.0000 & $0.000 \mathrm{E}+00$ & 0.0000 & $0.000 \mathrm{E}+00$ & 0.0000 & $0.000 \mathrm{E}+00$ & 0.0000 & $0.000 \mathrm{E}+00$ & 0.0000 & $4.723 E-10$ & 0.0000 \\
\hline-238 & $0.000 \mathrm{E}+00$ & 0.0000 & $0.000 \mathrm{E}+00$ & 0.0000 & $0.000 \mathrm{E}+00$ & 0.0000 & $0.000 \mathrm{E}+00$ & 0.0000 & $0.000 \mathrm{E}+00$ & 0.0000 & $0.000 \mathrm{E}+00$ & 0.0000 & $8.964 \mathrm{E}-12$ & 0.0000 \\
\hline 239 & $0.000 \mathrm{E}+00$ & 0.0000 & $0.000 \mathrm{E}+00$ & 0.0000 & $0.000 \mathrm{E}+00$ & 0.0000 & $0.000 \mathrm{E}+00$ & 0.0000 & $0.000 \mathrm{E}+00$ & 0.0000 & $0.000 \mathrm{E}+00$ & 0.0000 & $6.951 \mathrm{E}-14$ & 0.0000 \\
\hline-240 & $0.000 \mathrm{E}+00$ & 0.0000 & $0.000 \mathrm{E}+00$ & 0.0000 & $0.000 \mathrm{E}+00$ & 0.0000 & $0.000 \mathrm{E}+00$ & 0.0000 & $0.000 \mathrm{E}+00$ & 0.0000 & $0.000 \mathrm{E}+00$ & 0.0000 & $8.438 E-17$ & 0.0000 \\
\hline 99 & $0.000 \mathrm{E}+00$ & 0.0000 & $0.000 \mathrm{E}+00$ & 0.0000 & $0.000 \mathrm{E}+00$ & 0.0000 & $0.000 \mathrm{E}+00$ & 0.0000 & $0.000 \mathrm{E}+00$ & 0.0000 & $0.000 \mathrm{E}+00$ & 0.0000 & $1.290 \mathrm{E}-21$ & 0.0000 \\
\hline-228 & $0.000 \mathrm{E}+00$ & 0.0000 & $0.000 \mathrm{E}+00$ & 0.0000 & $0.000 \mathrm{E}+00$ & 0.0000 & $0.000 \mathrm{E}+00$ & 0.0000 & $0.000 \mathrm{E}+00$ & 0.0000 & $0.000 \mathrm{E}+00$ & 0.0000 & $0.000 \mathrm{E}+00$ & 0.0000 \\
\hline-230 & $0.000 \mathrm{E}+00$ & 0.0000 & $0.000 \mathrm{E}+00$ & 0.0000 & $0.000 \mathrm{E}+00$ & 0.0000 & $0.000 \mathrm{E}+00$ & 0.0000 & $0.000 \mathrm{E}+00$ & 0.0000 & $0.000 \mathrm{E}+00$ & 0.0000 & $4.387 \mathrm{E}-05$ & 0.4425 \\
\hline-232 & $0.000 \mathrm{E}+00$ & 0.0000 & $0.000 \mathrm{E}+00$ & 0.0000 & $0.000 \mathrm{E}+00$ & 0.0000 & $0.000 \mathrm{E}+00$ & 0.0000 & $0.000 \mathrm{E}+00$ & 0.0000 & $0.000 \mathrm{E}+00$ & 0.0000 & $5.460 \mathrm{E}-05$ & 0.5508 \\
\hline 234 & $0.000 \mathrm{E}+00$ & 0.0000 & $0.000 \mathrm{E}+00$ & 0.0000 & $0.000 \mathrm{E}+00$ & 0.0000 & $0.000 \mathrm{E}+00$ & 0.0000 & $0.000 \mathrm{E}+00$ & 0.0000 & $0.000 \mathrm{E}+00$ & 0.0000 & $1.637 \mathrm{E}-07$ & 0.0017 \\
\hline 35 & $0.000 \mathrm{E}+00$ & 0.0000 & $0.000 \mathrm{E}+00$ & 0.0000 & $0.000 \mathrm{E}+00$ & 0.0000 & $0.000 \mathrm{E}+00$ & 0.0000 & $0.000 \mathrm{E}+00$ & 0.0000 & $0.000 \mathrm{E}+00$ & 0.0000 & $1.876 \mathrm{E}-10$ & 0.0000 \\
\hline 38 & $0.000 \mathrm{E}+00$ & 0.0000 & $0.000 \mathrm{E}+00$ & 0.0000 & $0.000 \mathrm{E}+00$ & 0.0000 & $0.000 \mathrm{E}+00$ & 0.0000 & $0.000 \mathrm{E}+00$ & 0.0000 & $0.000 \mathrm{E}+00$ & 0.0000 & $5.045 \mathrm{E}-07$ & 0.0051 \\
\hline & $0.000 \mathrm{E}+00$ & 0.0000 & $0.000 \mathrm{E}+00$ & 0.0000 & $0.000 \mathrm{E}+00$ & 0.0000 & $0.000 \mathrm{E}+00$ & 0.0000 & $0.000 \mathrm{E}+00$ & 0.0000 & $0.000 \mathrm{E}+00$ & 0.0000 & $9.914 \mathrm{E}-05$ & 1.0000 \\
\hline
\end{tabular}

* Sum of all water independent and dependent pathways. 
RESRAD, Version $6.5 \quad$ T1/2 Limit $=180$ days
Summary : RESRAD Parameters for U-Landfill Outdoor Worker Forward Run at Proposed ALs

File : C: \RESRAD_FAMILY \RESRAD \USERFILES \QCJULY2011 \ODW_FORWARD_1050YRSALS.RAD

Total Dose Contributions TDOSE(i,p,t) for Individual Radionuclides (i) and Pathways (p) As mrem/yr and Fraction of Total Dose At $t=1.050 \mathrm{E}+03$ years

Water Independent Pathways (Inhalation excludes radon)

\begin{tabular}{|c|c|c|c|c|c|c|c|c|c|c|c|c|c|c|}
\hline \multirow{2}{*}{ Nuclide } & \multicolumn{2}{|c|}{ Ground } & \multicolumn{2}{|c|}{ Inhalation } & \multicolumn{2}{|c|}{ Radon } & \multicolumn{2}{|c|}{ Plant } & \multicolumn{2}{|c|}{ Meat } & \multicolumn{2}{|c|}{ Milk } & \multicolumn{2}{|c|}{ Soil } \\
\hline & mrem/yr & fract. & mrem/yr & fract. & mrem/yr & fract. & mrem/yr & fract. & mrem/yr & fract. & mrem/yr & fract. & mrem/yr & fract. \\
\hline-241 & $1.806 \mathrm{E}-10$ & 0.0000 & $0.000 \mathrm{E}+00$ & 0.0000 & $0.000 \mathrm{E}+00$ & 0.0000 & $0.000 \mathrm{E}+00$ & 0.0000 & $0.000 \mathrm{E}+00$ & 0.0000 & $0.000 \mathrm{E}+00$ & 0.0000 & $0.000 \mathrm{E}+00$ & 0.0000 \\
\hline-137 & $1.966 \mathrm{E}-15$ & 0.0000 & $0.000 \mathrm{E}+00$ & 0.0000 & $0.000 \mathrm{E}+00$ & 0.0000 & $0.000 \mathrm{E}+00$ & 0.0000 & $0.000 \mathrm{E}+00$ & 0.0000 & $0.000 \mathrm{E}+00$ & 0.0000 & $0.000 \mathrm{E}+00$ & 0.0000 \\
\hline-237 & $1.694 \mathrm{E}-07$ & 0.0000 & $0.000 \mathrm{E}+00$ & 0.0000 & $0.000 \mathrm{E}+00$ & 0.0000 & $0.000 \mathrm{E}+00$ & 0.0000 & $0.000 \mathrm{E}+00$ & 0.0000 & $0.000 \mathrm{E}+00$ & 0.0000 & $0.000 \mathrm{E}+00$ & 0.0000 \\
\hline-238 & $2.088 E-09$ & 0.0000 & $0.000 \mathrm{E}+00$ & 0.0000 & $0.000 \mathrm{E}+00$ & 0.0000 & $0.000 \mathrm{E}+00$ & 0.0000 & $0.000 \mathrm{E}+00$ & 0.0000 & $0.000 \mathrm{E}+00$ & 0.0000 & $0.000 \mathrm{E}+00$ & 0.0000 \\
\hline-239 & $4.947 E-11$ & 0.0000 & $0.000 \mathrm{E}+00$ & 0.0000 & $0.000 \mathrm{E}+00$ & 0.0000 & $0.000 \mathrm{E}+00$ & 0.0000 & $0.000 \mathrm{E}+00$ & 0.0000 & $0.000 \mathrm{E}+00$ & 0.0000 & $0.000 \mathrm{E}+00$ & 0.0000 \\
\hline-240 & $1.199 \mathrm{E}-14$ & 0.0000 & $0.000 \mathrm{E}+00$ & 0.0000 & $0.000 \mathrm{E}+00$ & 0.0000 & $0.000 \mathrm{E}+00$ & 0.0000 & $0.000 \mathrm{E}+00$ & 0.0000 & $0.000 \mathrm{E}+00$ & 0.0000 & $0.000 \mathrm{E}+00$ & 0.0000 \\
\hline 99 & $2.724 \mathrm{E}-18$ & 0.0000 & $0.000 \mathrm{E}+00$ & 0.0000 & $0.000 \mathrm{E}+00$ & 0.0000 & $0.000 \mathrm{E}+00$ & 0.0000 & $0.000 \mathrm{E}+00$ & 0.0000 & $0.000 \mathrm{E}+00$ & 0.0000 & $0.000 \mathrm{E}+00$ & 0.0000 \\
\hline-228 & $0.000 \mathrm{E}+00$ & 0.0000 & $0.000 \mathrm{E}+00$ & 0.0000 & $0.000 \mathrm{E}+00$ & 0.0000 & $0.000 \mathrm{E}+00$ & 0.0000 & $0.000 \mathrm{E}+00$ & 0.0000 & $0.000 \mathrm{E}+00$ & 0.0000 & $0.000 \mathrm{E}+00$ & 0.0000 \\
\hline-230 & $3.681 \mathrm{E}-03$ & 0.6991 & $0.000 \mathrm{E}+00$ & 0.0000 & $0.000 \mathrm{E}+00$ & 0.0000 & $0.000 \mathrm{E}+00$ & 0.0000 & $0.000 \mathrm{E}+00$ & 0.0000 & $0.000 \mathrm{E}+00$ & 0.0000 & $0.000 \mathrm{E}+00$ & 0.0000 \\
\hline-232 & $1.513 E-03$ & 0.2874 & $0.000 \mathrm{E}+00$ & 0.0000 & $0.000 \mathrm{E}+00$ & 0.0000 & $0.000 \mathrm{E}+00$ & 0.0000 & $0.000 \mathrm{E}+00$ & 0.0000 & $0.000 \mathrm{E}+00$ & 0.0000 & $0.000 \mathrm{E}+00$ & 0.0000 \\
\hline 234 & $2.989 \mathrm{E}-05$ & 0.0057 & $0.000 \mathrm{E}+00$ & 0.0000 & $0.000 \mathrm{E}+00$ & 0.0000 & $0.000 \mathrm{E}+00$ & 0.0000 & $0.000 \mathrm{E}+00$ & 0.0000 & $0.000 \mathrm{E}+00$ & 0.0000 & $0.000 \mathrm{E}+00$ & 0.0000 \\
\hline 35 & $6.296 \mathrm{E}-08$ & 0.0000 & $0.000 \mathrm{E}+00$ & 0.0000 & $0.000 \mathrm{E}+00$ & 0.0000 & $0.000 \mathrm{E}+00$ & 0.0000 & $0.000 \mathrm{E}+00$ & 0.0000 & $0.000 \mathrm{E}+00$ & 0.0000 & $0.000 \mathrm{E}+00$ & 0.0000 \\
\hline 38 & $4.095 E-05$ & 0.0078 & $0.000 \mathrm{E}+00$ & 0.0000 & $0.000 \mathrm{E}+00$ & 0.0000 & $0.000 \mathrm{E}+00$ & 0.0000 & $0.000 \mathrm{E}+00$ & 0.0000 & $0.000 \mathrm{E}+00$ & 0.0000 & $0.000 \mathrm{E}+00$ & 0.0000 \\
\hline & $5.265 E-03$ & 1.0000 & $0.000 \mathrm{E}+00$ & 0.0000 & $0.000 \mathrm{E}+00$ & 0.0000 & $0.000 \mathrm{E}+00$ & 0.0000 & $0.000 \mathrm{E}+00$ & 0.0000 & $0.000 \mathrm{E}+00$ & 0.0000 & $0.000 \mathrm{E}+00$ & 0.0000 \\
\hline
\end{tabular}

Total Dose Contributions TDOSE(i,p,t) for Individual Radionuclides (i) and Pathways (p) As mrem/yr and Fraction of Total Dose At $t=1.050 \mathrm{E}+03$ years

Water Dependent Pathways

\begin{tabular}{|c|c|c|c|c|c|c|c|c|c|c|c|c|c|c|}
\hline \multirow{2}{*}{ Nuclide } & \multicolumn{2}{|c|}{ Water } & \multicolumn{2}{|c|}{ Fish } & \multicolumn{2}{|c|}{ Radon } & \multicolumn{2}{|c|}{ Plant } & \multicolumn{2}{|c|}{ Meat } & \multicolumn{2}{|c|}{ Milk } & \multicolumn{2}{|c|}{ All Pathways* } \\
\hline & mrem/yr & fract. & mrem/yr & fract. & mrem/yr & fract. & mrem/yr & fract. & mrem/yr & fract. & mrem/yr & fract. & mrem/yr & fract. \\
\hline-241 & $0.000 \mathrm{E}+00$ & 0.0000 & $0.000 \mathrm{E}+00$ & 0.0000 & $0.000 \mathrm{E}+00$ & 0.0000 & $0.000 \mathrm{E}+00$ & 0.0000 & $0.000 \mathrm{E}+00$ & 0.0000 & $0.000 E+00$ & 0.0000 & $1.806 \mathrm{E}-10$ & 0.0000 \\
\hline-137 & $0.000 \mathrm{E}+00$ & 0.0000 & $0.000 \mathrm{E}+00$ & 0.0000 & $0.000 \mathrm{E}+00$ & 0.0000 & $0.000 \mathrm{E}+00$ & 0.0000 & $0.000 \mathrm{E}+00$ & 0.0000 & $0.000 \mathrm{E}+00$ & 0.0000 & $1.966 \mathrm{E}-15$ & 0.0000 \\
\hline-237 & $0.000 \mathrm{E}+00$ & 0.0000 & $0.000 \mathrm{E}+00$ & 0.0000 & $0.000 \mathrm{E}+00$ & 0.0000 & $0.000 \mathrm{E}+00$ & 0.0000 & $0.000 \mathrm{E}+00$ & 0.0000 & $0.000 \mathrm{E}+00$ & 0.0000 & $1.694 \mathrm{E}-07$ & 0.0000 \\
\hline-238 & $0.000 \mathrm{E}+00$ & 0.0000 & $0.000 \mathrm{E}+00$ & 0.0000 & $0.000 \mathrm{E}+00$ & 0.0000 & $0.000 \mathrm{E}+00$ & 0.0000 & $0.000 \mathrm{E}+00$ & 0.0000 & $0.000 \mathrm{E}+00$ & 0.0000 & $2.088 E-09$ & 0.0000 \\
\hline-239 & $0.000 \mathrm{E}+00$ & 0.0000 & $0.000 \mathrm{E}+00$ & 0.0000 & $0.000 \mathrm{E}+00$ & 0.0000 & $0.000 \mathrm{E}+00$ & 0.0000 & $0.000 \mathrm{E}+00$ & 0.0000 & $0.000 \mathrm{E}+00$ & 0.0000 & $4.947 \mathrm{E}-11$ & 0.0000 \\
\hline-240 & $0.000 \mathrm{E}+00$ & 0.0000 & $0.000 \mathrm{E}+00$ & 0.0000 & $0.000 \mathrm{E}+00$ & 0.0000 & $0.000 \mathrm{E}+00$ & 0.0000 & $0.000 \mathrm{E}+00$ & 0.0000 & $0.000 \mathrm{E}+00$ & 0.0000 & $1.199 \mathrm{E}-14$ & 0.0000 \\
\hline-99 & $0.000 \mathrm{E}+00$ & 0.0000 & $0.000 \mathrm{E}+00$ & 0.0000 & $0.000 \mathrm{E}+00$ & 0.0000 & $0.000 \mathrm{E}+00$ & 0.0000 & $0.000 \mathrm{E}+00$ & 0.0000 & $0.000 \mathrm{E}+00$ & 0.0000 & $2.724 \mathrm{E}-18$ & 0.0000 \\
\hline-228 & $0.000 \mathrm{E}+00$ & 0.0000 & $0.000 \mathrm{E}+00$ & 0.0000 & $0.000 \mathrm{E}+00$ & 0.0000 & $0.000 \mathrm{E}+00$ & 0.0000 & $0.000 \mathrm{E}+00$ & 0.0000 & $0.000 \mathrm{E}+00$ & 0.0000 & $0.000 \mathrm{E}+00$ & 0.0000 \\
\hline 230 & $0.000 \mathrm{E}+00$ & 0.0000 & $0.000 \mathrm{E}+00$ & 0.0000 & $0.000 \mathrm{E}+00$ & 0.0000 & $0.000 \mathrm{E}+00$ & 0.0000 & $0.000 \mathrm{E}+00$ & 0.0000 & $0.000 \mathrm{E}+00$ & 0.0000 & $3.681 \mathrm{E}-03$ & 0.6991 \\
\hline 232 & $0.000 \mathrm{E}+00$ & 0.0000 & $0.000 \mathrm{E}+00$ & 0.0000 & $0.000 \mathrm{E}+00$ & 0.0000 & $0.000 \mathrm{E}+00$ & 0.0000 & $0.000 \mathrm{E}+00$ & 0.0000 & $0.000 \mathrm{E}+00$ & 0.0000 & $1.513 \mathrm{E}-03$ & 0.2874 \\
\hline 34 & $0.000 \mathrm{E}+00$ & 0.0000 & $0.000 \mathrm{E}+00$ & 0.0000 & $0.000 \mathrm{E}+00$ & 0.0000 & $0.000 \mathrm{E}+00$ & 0.0000 & $0.000 \mathrm{E}+00$ & 0.0000 & $0.000 \mathrm{E}+00$ & 0.0000 & $2.989 \mathrm{E}-05$ & 0.0057 \\
\hline 35 & $0.000 \mathrm{E}+00$ & 0.0000 & $0.000 \mathrm{E}+00$ & 0.0000 & $0.000 \mathrm{E}+00$ & 0.0000 & $0.000 \mathrm{E}+00$ & 0.0000 & $0.000 \mathrm{E}+00$ & 0.0000 & $0.000 \mathrm{E}+00$ & 0.0000 & $6.296 \mathrm{E}-08$ & 0.0000 \\
\hline 38 & $0.000 \mathrm{E}+00$ & 0.0000 & $0.000 \mathrm{E}+00$ & 0.0000 & $0.000 \mathrm{E}+00$ & 0.0000 & $0.000 \mathrm{E}+00$ & 0.0000 & $0.000 \mathrm{E}+00$ & 0.0000 & $0.000 \mathrm{E}+00$ & 0.0000 & $4.095 \mathrm{E}-05$ & 0.0078 \\
\hline & $0.000 \mathrm{E}+00$ & 0.0000 & $0.000 \mathrm{E}+00$ & 0.0000 & $0.000 \mathrm{E}+00$ & 0.0000 & $0.000 \mathrm{E}+00$ & 0.0000 & $0.000 \mathrm{E}+00$ & 0.0000 & $0.000 \mathrm{E}+00$ & 0.0000 & $5 E-03$ & 1.0000 \\
\hline
\end{tabular}

* Sum of all water independent and dependent pathways. 
RESRAD, Version 6.5

Summary : RESRAD Parameters for U-Landfill Outdoor Worker Forward Run at Proposed ALs

File : C: \RESRAD FAMILY \RESRAD \USERFILES \QCJULY2011 \ODW FORWARD 1050YRSALS.RAD

Dose/Source Ratios Summed Over All Pathways

Parent and Progeny Principal Radionuclide Contributions Indicated

Parent Product Thread DSR $(j, t)$ At Time in Years (mrem/yr)/(pCi/g)

(i)

(j)

$\begin{array}{ll}\mathrm{Am}-241 & 1.000 \mathrm{E}+00 \\ \mathrm{~Np}-237+\mathrm{D} & 1.000 \mathrm{E}+00 \\ \mathrm{U}-233 & 1.000 \mathrm{E}+00 \\ \mathrm{Th}-229+\mathrm{D} & 1.000 \mathrm{E}+00 \\ \operatorname{\sum DSR}(j) & \end{array}$

Cs $-137+D$

$\mathrm{Np}-237+\mathrm{D}$

U-233

Th-229+D

$\sum \operatorname{DSR}(j)$

$\mathrm{Pu}-238$

$\mathrm{Pu}-238$

U-234

Th-230

Ra-226+D

$\mathrm{Pb}-210+\mathrm{D}$

$\sum \operatorname{DSR}(j)$

Pu-239

U-235+D

$\mathrm{Pa}-231$

Ac-227+D

$\sum \operatorname{DSR}(j)$

$\mathrm{Pu}-240$

$\mathrm{Pu}-240$

U-236

Th-232

$\mathrm{Ra}-228+\mathrm{D}$

Th-228+D

$\sum \operatorname{DSR}(j)$

TC-99

Th-228+D

Th-230

Ra-226+D

$\mathrm{Pb}-210+\mathrm{D}$

$\sum \operatorname{DSR}(j)$ $\begin{array}{lllllllll}1.000 \mathrm{E}+00 & 2.578 \mathrm{E}-10 & 2.541 \mathrm{E}-10 & 1.786 \mathrm{E}-10 & 1.237 \mathrm{E}-10 & 5.936 \mathrm{E}-11 & 1.667 \mathrm{E}-13 & 5.175 \mathrm{E}-17\end{array}$

$\begin{array}{llllllll}1.000 \mathrm{E}+00 & 1.948 \mathrm{E}-13 & 1.969 \mathrm{E}-13 & 2.547 \mathrm{E}-13 & 3.330 \mathrm{E}-13 & 5.693 \mathrm{E}-13 & 4.147 \mathrm{E}-11 & 1.509 \mathrm{E}-08\end{array}$ $\begin{array}{lllllllll}1.000 \mathrm{E}+00 & 6.631 \mathrm{E}-24 & 2.011 \mathrm{E}-23 & 4.612 \mathrm{E}-22 & 1.248 \mathrm{E}-21 & 4.641 \mathrm{E}-21 & 3.427 \mathrm{E}-18 & 6.954 \mathrm{E}-15\end{array}$ $1.000 \mathrm{E}+00 \quad 6.053 \mathrm{E}-20 \quad 4.262 \mathrm{E}-19 \quad 1.402 \mathrm{E}-16 \quad 6.537 \mathrm{E}-16 \quad 3.662 \mathrm{E}-15 \quad 1.463 \mathrm{E}-12 \quad 3.066 \mathrm{E}-10$ $\begin{array}{lllllll}1.948 \mathrm{E}-13 & 1.969 \mathrm{E}-13 & 2.549 \mathrm{E}-13 & 3.337 \mathrm{E}-13 & 5.729 \mathrm{E}-13 & 4.294 \mathrm{E}-11 & 1.540 \mathrm{E}-08\end{array}$

$1.840 \mathrm{E}-09 \quad 4.417 \mathrm{E}-34 \quad 4.460 \mathrm{E}-34 \quad 5.637 \mathrm{E}-34 \quad 7.195 \mathrm{E}-34 \quad 1.172 \mathrm{E}-33 \quad 5.806 \mathrm{E}-32 \quad 1.243 \mathrm{E}-29$

$1.000 \mathrm{E}+00 \quad 2.401 \mathrm{E}-25 \quad 2.424 \mathrm{E}-25 \quad 3.064 \mathrm{E}-25 \quad 3.910 \mathrm{E}-25 \quad 6.369 \mathrm{E}-25 \quad 3.155 \mathrm{E}-23 \quad 6.755 \mathrm{E}-21$ $\begin{array}{llllllll}1.000 \mathrm{E}+00 & 1.998 \mathrm{E}-30 & 6.068 \mathrm{E}-30 & 1.436 \mathrm{E}-28 & 4.032 \mathrm{E}-28 & 1.628 \mathrm{E}-27 & 3.470 \mathrm{E}-24 & 5.993 \mathrm{E}-20\end{array}$ $\begin{array}{lllllllll}1.000 \mathrm{E}+00 & 2.101 \mathrm{E}-34 & 1.489 \mathrm{E}-33 & 5.829 \mathrm{E}-31 & 3.268 \mathrm{E}-30 & 2.663 \mathrm{E}-29 & 2.676 \mathrm{E}-25 & 6.795 \mathrm{E}-21\end{array}$ $\begin{array}{llllllllll}1.000 \mathrm{E}+00 & 1.639 \mathrm{E}-23 & 2.469 \mathrm{E}-22 & 1.226 \mathrm{E}-18 & 1.076 \mathrm{E}-17 & 1.088 \mathrm{E}-16 & 1.149 \mathrm{E}-13 & 2.677 \mathrm{E}-11\end{array}$ $\begin{array}{lllllllll}1.000 \mathrm{E}+00 \quad 4.753 \mathrm{E}-32 & 1.473 \mathrm{E}-30 & 1.013 \mathrm{E}-25 & 1.589 \mathrm{E}-24 & 2.687 \mathrm{E}-23 & 7.527 \mathrm{E}-20 & 3.536 \mathrm{E}-17\end{array}$ $\begin{array}{lllllll}1.663 \mathrm{E}-23 & 2.471 \mathrm{E}-22 & 1.226 \mathrm{E}-18 & 1.076 \mathrm{E}-17 & 1.088 \mathrm{E}-16 & 1.149 \mathrm{E}-13 & 2.677 \mathrm{E}-11\end{array}$

$1.000 \mathrm{E}+00 \quad 2.456 \mathrm{E}-18 \quad 2.486 \mathrm{E}-18 \quad 3.311 \mathrm{E}-18 \quad 4.463 \mathrm{E}-18 \quad 8.107 \mathrm{E}-18 \quad 9.618 \mathrm{E}-16 \quad 6.841 \mathrm{E}-13$ $\begin{array}{llllllll}1.000 \mathrm{E}+00 & 1.254 \mathrm{E}-24 & 3.802 \mathrm{E}-24 & 8.688 \mathrm{E}-23 & 2.343 \mathrm{E}-22 & 8.645 \mathrm{E}-22 & 6.015 \mathrm{E}-19 & 1.124 \mathrm{E}-15\end{array}$ $\begin{array}{lllllllll}1.000 \mathrm{E}+00 & 1.972 \mathrm{E}-28 & 1.393 \mathrm{E}-27 & 5.002 \mathrm{E}-25 & 2.557 \mathrm{E}-24 & 1.721 \mathrm{E}-23 & 2.963 \mathrm{E}-20 & 4.446 \mathrm{E}-17\end{array}$ $\begin{array}{lllllllll}1.000 \mathrm{E}+00 & 4.675 \mathrm{E}-28 & 7.017 \mathrm{E}-27 & 3.194 \mathrm{E}-23 & 2.608 \mathrm{E}-22 & 2.391 \mathrm{E}-21 & 3.028 \mathrm{E}-18 & 1.826 \mathrm{E}-15\end{array}$ $2.456 \mathrm{E}-18 \quad 2.486 \mathrm{E}-18 \quad 3.311 \mathrm{E}-18 \quad 4.463 \mathrm{E}-18 \quad 8.110 \mathrm{E}-18 \quad 9.655 \mathrm{E}-16 \quad 6.871 \mathrm{E}-13$

4.950E-08 1.155E-32 $1.176 \mathrm{E}-32 \quad 1.791 \mathrm{E}-32 \quad 2.778 \mathrm{E}-32 \quad 6.681 \mathrm{E}-32 \quad 7.478 \mathrm{E}-29 \quad 1.164 \mathrm{E}-24$

$\begin{array}{llllllll}1.000 \mathrm{E}+00 & 2.334 \mathrm{E}-25 & 2.375 \mathrm{E}-25 & 3.619 \mathrm{E}-25 & 5.612 \mathrm{E}-25 & 1.350 \mathrm{E}-24 & 1.511 \mathrm{E}-21 & 2.352 \mathrm{E}-17\end{array}$ $\begin{array}{llllllll}1.000 \mathrm{E}+00 \quad 4.417 \mathrm{E}-33 & 1.347 \mathrm{E}-32 & 3.517 \mathrm{E}-31 & 1.091 \mathrm{E}-30 & 5.321 \mathrm{E}-30 & 3.459 \mathrm{E}-26 & 1.397 \mathrm{E}-21\end{array}$ $\begin{array}{lllllllll}1.000 \mathrm{E}+00 \quad 5.745 \mathrm{E}-44 & 4.148 \mathrm{E}-43 & 1.798 \mathrm{E}-40 & 1.120 \mathrm{E}-39 & 1.120 \mathrm{E}-38 & 4.587 \mathrm{E}-34 & 5.372 \mathrm{E}-29\end{array}$ $\begin{array}{llllllll}1.000 \mathrm{E}+00 & 2.801 \mathrm{E}-29 & 4.123 \mathrm{E}-28 & 1.234 \mathrm{E}-24 & 7.689 \mathrm{E}-24 & 5.197 \mathrm{E}-23 & 3.012 \mathrm{E}-20 & 8.590 \mathrm{E}-18\end{array}$ $1.000 \mathrm{E}+00 \quad 1.657 \mathrm{E}-28 \quad 4.769 \mathrm{E}-27 \quad 7.862 \mathrm{E}-23 \quad 5.398 \mathrm{E}-22 \quad 3.593 \mathrm{E}-21 \quad 1.140 \mathrm{E}-18 \quad 1.344 \mathrm{E}-16$ $2.335 \mathrm{E}-25 \quad 2.427 \mathrm{E}-25 \quad 8.021 \mathrm{E}-23 \quad 5.480 \mathrm{E}-22 \quad 3.646 \mathrm{E}-21 \quad 1.172 \mathrm{E}-18 \quad 1.665 \mathrm{E}-16$

$\begin{array}{llllllll}1.000 \mathrm{E}+00 & 1.179 \mathrm{E}-26 & 1.195 \mathrm{E}-26 & 1.669 \mathrm{E}-26 & 2.364 \mathrm{E}-26 & 4.741 \mathrm{E}-26 & 1.241 \mathrm{E}-23 & 2.619 \mathrm{E}-20\end{array}$ $\begin{array}{llllllll}1.000 \mathrm{E}+00 & 2.825 \mathrm{E}-07 & 1.978 \mathrm{E}-07 & 3.819 \mathrm{E}-11 & 5.163 \mathrm{E}-15 & 9.437 \mathrm{E}-23 & 0.000 \mathrm{E}+00 & 0.000 \mathrm{E}+00\end{array}$

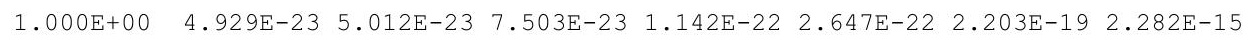
$\begin{array}{lllllllll}1.000 \mathrm{E}+00 \quad 7.712 \mathrm{E}-12 & 2.327 \mathrm{E}-11 & 4.644 \mathrm{E}-10 & 1.087 \mathrm{E}-09 & 3.024 \mathrm{E}-09 & 2.193 \mathrm{E}-07 & 1.840 \mathrm{E}-05\end{array}$ $\begin{array}{lllllllll}1.000 \mathrm{E}+00 & 3.717 \mathrm{E}-20 & 2.596 \mathrm{E}-19 & 6.907 \mathrm{E}-17 & 2.655 \mathrm{E}-16 & 1.087 \mathrm{E}-15 & 1.573 \mathrm{E}-13 & 2.528 \mathrm{E}-11\end{array}$ $\begin{array}{llllllll}7.712 \mathrm{E}-12 & 2.327 \mathrm{E}-11 & 4.644 \mathrm{E}-10 & 1.087 \mathrm{E}-09 & 3.024 \mathrm{E}-09 & 2.193 \mathrm{E}-07 & 1.840 \mathrm{E}-05\end{array}$ 
RESRAD, Version 6.5

Summary : RESRAD Parameters for U-Landfill Outdoor Worker Forward Run at Proposed ALs

File : C: $\backslash$ RESRAD_FAMILY \RESRAD \USERFILES \QCJULY2011 \ODW_FORWARD_1050YRSALS.RAD

Dose/Source Ratios Summed Over All Pathways

Parent and Progeny Principal Radionuclide Contributions Indicated

\begin{tabular}{|c|c|c|c|c|c|c|c|c|c|}
\hline Parent & Product & Thread & & $\operatorname{DSR}(j, t)$ & At Time in & Years & (mrem/yr) / & $(\mathrm{pCi} / \mathrm{g})$ & \\
\hline (i) & (j) & Fraction & $0.000 \mathrm{E}+00$ & $1.000 \mathrm{E}+00$ & $2.500 \mathrm{E}+01$ & $5.000 \mathrm{E}+01$ & $1.000 \mathrm{E}+02$ & $5.000 \mathrm{E}+02$ & $1.050 \mathrm{E}+03$ \\
\hline-232 & $\mathrm{Th}-232$ & $1.000 \mathrm{E}+00$ & $2.382 \mathrm{E}-25$ & $2.427 E-25$ & $3.789 \mathrm{E}-25$ & $6.027 \mathrm{E}-25$ & $1.525 \mathrm{E}-24$ & $2.561 \mathrm{E}-21$ & $6.965 \mathrm{E}-17$ \\
\hline $1-232$ & $\mathrm{Ra}-228+\mathrm{D}$ & $1.000 \mathrm{E}+00$ & $2.263 E-10$ & $6.486 \mathrm{E}-10$ & $4.499 \mathrm{E}-09$ & $5.690 \mathrm{E}-09$ & $8.336 \mathrm{E}-09$ & $1.737 \mathrm{E}-07$ & $1.131 \mathrm{E}-05$ \\
\hline$h-232$ & $\mathrm{Th}-228+\mathrm{D}$ & $1.000 \mathrm{E}+00$ & $2.181 E-09$ & $1.345 \mathrm{E}-08$ & $3.638 E-07$ & $4.522 \mathrm{E}-07$ & $6.114 \mathrm{E}-07$ & $6.652 \mathrm{E}-06$ & $1.778 \mathrm{E}-04$ \\
\hline$h-232$ & $\sum \operatorname{DSR}(j)$ & & $2.407 E-09$ & $1.410 \mathrm{E}-08$ & $3.683 \mathrm{E}-07$ & $4.579 \mathrm{E}-07$ & $6.198 \mathrm{E}-07$ & $6.825 \mathrm{E}-06$ & $1.891 \mathrm{E}-04$ \\
\hline-234 & $\mathrm{U}-234$ & $1.000 \mathrm{E}+00$ & $1.409 \mathrm{E}-24$ & $1.434 \mathrm{E}-24$ & $2.194 \mathrm{E}-24$ & $3.415 E-24$ & $8.276 \mathrm{E}-24$ & $9.851 \mathrm{E}-21$ & $1.669 \mathrm{E}-16$ \\
\hline-234 & Th-230 & $1.000 \mathrm{E}+00$ & $2.225 E-28$ & $6.774 \mathrm{E}-28$ & $1.722 \mathrm{E}-26$ & $5.192 \mathrm{E}-26$ & $2.394 \mathrm{E}-25$ & $9.912 \mathrm{E}-22$ & $2.152 \mathrm{E}-17$ \\
\hline-234 & $\mathrm{Ra}-226+\mathrm{D}$ & $1.000 \mathrm{E}+00$ & $2.315 E-17$ & $1.630 \mathrm{E}-16$ & $5.341 \mathrm{E}-14$ & $2.480 \mathrm{E}-13$ & 1. $377 \mathrm{E}-12$ & $5.115 \mathrm{E}-10$ & $9.341 \mathrm{E}-08$ \\
\hline-234 & $\mathrm{~Pb}-210+\mathrm{D}$ & $1.000 \mathrm{E}+00$ & $8.381 E-26$ & $1.257 \mathrm{E}-24$ & $5.622 \mathrm{E}-21$ & $4.500 \mathrm{E}-20$ & $3.956 \mathrm{E}-19$ & $3.440 \mathrm{E}-16$ & 1. $243 \mathrm{E}-13$ \\
\hline-234 & $\sum \operatorname{DSR}(j)$ & & $2.315 \mathrm{E}-17$ & $1.630 \mathrm{E}-16$ & $5.341 \mathrm{E}-14$ & $2.480 \mathrm{E}-13$ & 1. $377 \mathrm{E}-12$ & $5.115 \mathrm{E}-10$ & $9.341 \mathrm{E}-08$ \\
\hline$-235+D$ & $\mathrm{U}-235+\mathrm{D}$ & $1.000 \mathrm{E}+00$ & $2.540 \mathrm{E}-15$ & $2.572 \mathrm{E}-15$ & $3.460 \mathrm{E}-15$ & $4.713 E-15$ & $8.745 E-15$ & 1. $228 \mathrm{E}-12$ & $1.101 \mathrm{E}-09$ \\
\hline$-235+D$ & $\mathrm{~Pa}-231$ & $1.000 \mathrm{E}+00$ & $6.002 \mathrm{E}-19$ & $1.818 \mathrm{E}-18$ & $3.984 \mathrm{E}-17$ & $1.028 \mathrm{E}-16$ & $3.478 \mathrm{E}-16$ & 1. $206 \mathrm{E}-13$ & $8.644 \mathrm{E}-11$ \\
\hline$-235+D$ & $A C-227+D$ & $1.000 \mathrm{E}+00$ & $1.895 \mathrm{E}-18$ & 1. $324 \mathrm{E}-17$ & $3.586 \mathrm{E}-15$ & $1.407 \mathrm{E}-14$ & $6.019 \mathrm{E}-14$ & 1. $308 \mathrm{E}-11$ & $3.655 \mathrm{E}-09$ \\
\hline$-235+D$ & $\sum \operatorname{DSR}(j)$ & & $2.543 E-15$ & $2.587 \mathrm{E}-15$ & $7.086 \mathrm{E}-15$ & $1.888 \mathrm{E}-14$ & $6.928 \mathrm{E}-14$ & $1.443 \mathrm{E}-11$ & $4.843 E-09$ \\
\hline-238 & $\mathrm{U}-238$ & $5.400 \mathrm{E}-05$ & $0.000 \mathrm{E}+00$ & $0.000 \mathrm{E}+00$ & $0.000 \mathrm{E}+00$ & $0.000 \mathrm{E}+00$ & $0.000 \mathrm{E}+00$ & $0.000 \mathrm{E}+00$ & $3.476 \mathrm{E}-39$ \\
\hline$-238+D$ & $\mathrm{U}-238+\mathrm{D}$ & $9.999 \mathrm{E}-01$ & $2.901 \mathrm{E}-11$ & $2.924 \mathrm{E}-11$ & $3.542 \mathrm{E}-11$ & 4. $325 \mathrm{E}-11$ & $6.449 \mathrm{E}-11$ & $1.576 \mathrm{E}-09$ & $1.279 \mathrm{E}-07$ \\
\hline$-238+D$ & $\mathrm{U}-234$ & $9.999 E-01$ & $2.003 E-30$ & $6.105 E-30$ & $1.586 \mathrm{E}-28$ & $4.889 E-28$ & $2.358 E-27$ & $1.399 \mathrm{E}-23$ & 4. $978 \mathrm{E}-19$ \\
\hline$J-238+D$ & $\mathrm{Th}-230$ & $9.999 E-01$ & $2.105 E-34$ & $1.495 \mathrm{E}-33$ & $6.226 \mathrm{E}-31$ & $3.717 \mathrm{E}-30$ & $3.411 \mathrm{E}-29$ & $7.032 \mathrm{E}-25$ & $3.204 \mathrm{E}-20$ \\
\hline$J-238+D$ & $\mathrm{Ra}-226+\mathrm{D}$ & $9.999 \mathrm{E}-01$ & $1.642 \mathrm{E}-23$ & $2.477 \mathrm{E}-22$ & $1.288 \mathrm{E}-18$ & $1.186 \mathrm{E}-17$ & $1.313 E-16$ & $2.462 \mathrm{E}-13$ & $9.612 \mathrm{E}-11$ \\
\hline$J-238+D$ & $\mathrm{~Pb}-210+\mathrm{D}$ & $9.999 E-01$ & $4.759 E-32$ & $1.477 \mathrm{E}-30$ & $1.055 \mathrm{E}-25$ & $1.723 E-24$ & $3.161 \mathrm{E}-23$ & $1.561 \mathrm{E}-19$ & 1. $240 \mathrm{E}-16$ \\
\hline$-238+D$ & $\sum \operatorname{DSR}(j)$ & & $2.901 \mathrm{E}-11$ & $2.924 \mathrm{E}-11$ & $3.542 \mathrm{E}-11$ & $4.325 \mathrm{E}-11$ & $6.449 \mathrm{E}-11$ & $1.577 \mathrm{E}-09$ & $1.280 \mathrm{E}-07$ \\
\hline
\end{tabular}

The DSR includes contributions from associated (half-life $\leq 180$ days) daughters. 
RESRAD, Version $6.5 \quad \mathrm{~T}^{1 / 2}$ Limit $=180$ days

07/20/2011 $15: 20 \quad$ Page 29

ummary : RESRAD Parameters for U-Landfill Outdoor Worker Forward Run at Proposed ALs

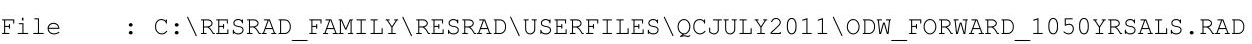

Single Radionuclide Soil Guidelines $\mathrm{G}(i, t)$ in $\mathrm{pCi} / \mathrm{g}$

Basic Radiation Dose Limit $=1.000 \mathrm{E}+00 \mathrm{mrem} / \mathrm{yr}$

Nuclide

\begin{tabular}{|c|c|c|c|c|c|c|c|}
\hline (i) & $t=0.000 \mathrm{E}+00$ & $1.000 \mathrm{E}+00$ & $2.500 \mathrm{E}+01$ & $5.000 \mathrm{E}+01$ & $1.000 \mathrm{E}+02$ & $5.000 \mathrm{E}+02$ & $1.050 \mathrm{E}+03$ \\
\hline-241 & $\star 3.431 \mathrm{E}+12$ & $\star 3.431 \mathrm{E}+12$ & $\star 3.431 \mathrm{E}+12$ & $\star 3.431 \mathrm{E}+12$ & $* 3.431 \mathrm{E}+12$ & $* 3.431 \mathrm{E}+12$ & $3.875 E+11$ \\
\hline-137 & $3.879 E+09$ & $3.936 \mathrm{E}+09$ & $5.600 \mathrm{E}+09$ & $8.084 E+09$ & $1.685 E+10$ & $5.997 \mathrm{E}+12$ & $\star 8.704 \mathrm{E}+13$ \\
\hline-237 & $\star 7.047 \mathrm{E}+08$ & $\star 7.047 \mathrm{E}+08$ & $\star 7.047 \mathrm{E}+08$ & $\star 7.047 \mathrm{E}+08$ & $\star 7.047 \mathrm{E}+08$ & $\star 7.047 \mathrm{E}+08$ & $6.495 \mathrm{E}+07$ \\
\hline-238 & $\star 1.712 \mathrm{E}+13$ & $\star 1.712 \mathrm{E}+13$ & $\star 1.712 \mathrm{E}+13$ & $\star 1.712 \mathrm{E}+13$ & $* 1.712 \mathrm{E}+13$ & $8.701 \mathrm{E}+12$ & $3.735 \mathrm{E}+1 \mathrm{C}$ \\
\hline-239 & $\star 6.214 \mathrm{E}+10$ & $* 6.214 \mathrm{E}+10$ & $* 6.214 \mathrm{E}+10$ & $* 6.214 \mathrm{E}+10$ & $\star 6.214 \mathrm{E}+10$ & $* 6.214 \mathrm{E}+10$ & $* 6.214 \mathrm{E}+1 \mathrm{C}$ \\
\hline-240 & $\star 2.278 \mathrm{E}+11$ & $\star 2.278 \mathrm{E}+11$ & $\star 2.278 \mathrm{E}+11$ & $\star 2.278 \mathrm{E}+11$ & $\star 2.278 \mathrm{E}+11$ & $\star 2.278 \mathrm{E}+11$ & $\star 2.278 \mathrm{E}+1$ \\
\hline$=-99$ & $\star 1.697 \mathrm{E}+10$ & $\star 1.697 \mathrm{E}+10$ & $\star 1.697 \mathrm{E}+10$ & $* 1.697 \mathrm{E}+10$ & $\star 1.697 \mathrm{E}+10$ & $\star 1.697 \mathrm{E}+10$ & $* 1.697 \mathrm{E}+10$ \\
\hline-228 & $3.540 \mathrm{E}+06$ & $5.056 \mathrm{E}+06$ & $2.619 \mathrm{E}+10$ & $1.937 \mathrm{E}+14$ & $\star 8.195 \mathrm{E}+14$ & $\star 8.195 \mathrm{E}+14$ & $\star 8.195 \mathrm{E}+14$ \\
\hline-230 & $\star 2.018 \mathrm{E}+10$ & $\star 2.018 \mathrm{E}+10$ & $2.153 \mathrm{E}+09$ & $9.198 \mathrm{E}+08$ & $3.307 \mathrm{E}+08$ & $4.559 \mathrm{E}+06$ & $5.434 \mathrm{E}+0$ \\
\hline$h-232$ & $* 1.097 \mathrm{E}+05$ & $\star 1.097 \mathrm{E}+05$ & $\star 1.097 \mathrm{E}+05$ & $\star 1.097 \mathrm{E}+05$ & $* 1.097 \mathrm{E}+05$ & $* 1.097 \mathrm{E}+05$ & $5.287 \mathrm{E}+03$ \\
\hline 234 & $* 6.247 \mathrm{E}+09$ & $\star 6.247 \mathrm{E}+09$ & $\star 6.247 \mathrm{E}+09$ & $\star 6.247 \mathrm{E}+09$ & $* 6.247 \mathrm{E}+09$ & $1.955 \mathrm{E}+09$ & $1.071 \mathrm{E}+07$ \\
\hline 35 & $\star 2.161 \mathrm{E}+06$ & $\star 2.161 \mathrm{E}+06$ & $\star 2.161 \mathrm{E}+06$ & $\star 2.161 \mathrm{E}+06$ & $\star 2.161 \mathrm{E}+06$ & $\star 2.161 \mathrm{E}+06$ & $\star 2.161 \mathrm{E}+06$ \\
\hline 38 & $\star 3.361 \mathrm{E}+05$ & $\star 3.361 \mathrm{E}+05$ & $\star 3.361 \mathrm{E}+05$ & $\star 3.361 \mathrm{E}+05$ & $\star 3.361 \mathrm{E}+05$ & $\star 3.361 \mathrm{E}+05$ & $\star 3.361 \mathrm{E}+05$ \\
\hline
\end{tabular}

*At specific activity limit

Summed Dose/Source Ratios DSR(i,t) in (mrem/yr)/(pCi/g)

and Single Radionuclide Soil Guidelines $\mathrm{G}(i, \mathrm{t})$ in $\mathrm{pCi} / \mathrm{g}$

at tmin = time of minimum single radionuclide soil guideline

and at tmax $=$ time of maximum total dose $=1.050 \mathrm{E}+03$ years

\begin{tabular}{|c|c|c|c|c|c|c|}
\hline $\begin{array}{l}\text { liclide } \\
\text { (i) }\end{array}$ & $\begin{array}{l}\text { Initial } \\
(\mathrm{pCi} / \mathrm{g})\end{array}$ & $\begin{array}{c}\text { tmin } \\
\text { (years) }\end{array}$ & $\operatorname{DSR}(i, \operatorname{tmin})$ & $\begin{array}{c}G(i, \operatorname{tmin}) \\
(\mathrm{pCi} / \mathrm{g})\end{array}$ & $\operatorname{DSR}(i, \operatorname{tmax})$ & $\begin{array}{c}G(i, t \max ) \\
(\mathrm{pCi} / \mathrm{g})\end{array}$ \\
\hline-241 & $7.000 \mathrm{E}+01$ & $1.050 \mathrm{E}+03$ & $2.581 \mathrm{E}-12$ & $3.875 E+11$ & $2.581 \mathrm{E}-12$ & $3.875 E+11$ \\
\hline 137 & $3.800 E+01$ & $0.000 \mathrm{E}+00$ & $2.578 \mathrm{E}-10$ & $3.879 E+09$ & $5.175 \mathrm{E}-17$ & $\star 8.704 \mathrm{E}+13$ \\
\hline 237 & $1.100 \mathrm{E}+01$ & $1.050 \mathrm{E}+03$ & $1.540 \mathrm{E}-08$ & $6.495 E+07$ & $1.540 \mathrm{E}-08$ & $6.495 \mathrm{E}+07$ \\
\hline-238 & $7.800 \mathrm{E}+01$ & $1.050 \mathrm{E}+03$ & $2.677 \mathrm{E}-11$ & $3.735 E+10$ & $2.677 \mathrm{E}-11$ & $3.735 \mathrm{E}+10$ \\
\hline-239 & $7.200 \mathrm{E}+01$ & $1.050 \mathrm{E}+03$ & $6.871 \mathrm{E}-13$ & $\star 6.214 \mathrm{E}+10$ & $6.871 E-13$ & $\star 6.214 \mathrm{E}+10$ \\
\hline-240 & $7.200 \mathrm{E}+01$ & $1.050 \mathrm{E}+03$ & $1.665 \mathrm{E}-16$ & $\star 2.278 \mathrm{E}+11$ & $1.665 \mathrm{E}-16$ & $\star 2.278 \mathrm{E}+11$ \\
\hline-99 & $1.040 \mathrm{E}+02$ & $1.050 \mathrm{E}+03$ & $2.619 \mathrm{E}-20$ & $\star 1.697 \mathrm{E}+10$ & $2.619 \mathrm{E}-20$ & $* 1.697 \mathrm{E}+10$ \\
\hline-228 & $8.000 \mathrm{E}+00$ & $0.000 \mathrm{E}+00$ & $2.825 \mathrm{E}-07$ & $3.540 \mathrm{E}+06$ & $0.000 \mathrm{E}+00$ & $\star 8.195 \mathrm{E}+14$ \\
\hline-230 & $2.000 \mathrm{E}+02$ & $1.050 \mathrm{E}+03$ & $1.840 \mathrm{E}-05$ & $5.434 \mathrm{E}+04$ & $1.840 \mathrm{E}-05$ & $5.434 \mathrm{E}+04$ \\
\hline-232 & $8.000 \mathrm{E}+00$ & $1.050 \mathrm{E}+03$ & $1.891 \mathrm{E}-04$ & $5.287 E+03$ & $1.891 \mathrm{E}-04$ & $5.287 \mathrm{E}+03$ \\
\hline 34 & $3.200 \mathrm{E}+02$ & $1.050 \mathrm{E}+03$ & $9.341 \mathrm{E}-08$ & $1.071 \mathrm{E}+07$ & $9.341 \mathrm{E}-08$ & $1.071 \mathrm{E}+07$ \\
\hline 35 & $1.300 \mathrm{E}+01$ & $1.050 \mathrm{E}+03$ & $4.843 \mathrm{E}-09$ & $\star 2.161 \mathrm{E}+06$ & $4.843 \mathrm{E}-09$ & $\star 2.161 \mathrm{E}+06$ \\
\hline 238 & $3.200 \mathrm{E}+02$ & $1.050 \mathrm{E}+03$ & $1.280 \mathrm{E}-07$ & $\star 3.361 E+05$ & $1.280 \mathrm{E}-07$ & $* 3.361 \mathrm{E}+05$ \\
\hline
\end{tabular}

*At specific activity limit 
RESRAD, Version 6.5

Summary : RESRAD Parameters for U-Landfill Outdoor Worker Forward Run at Proposed ALs

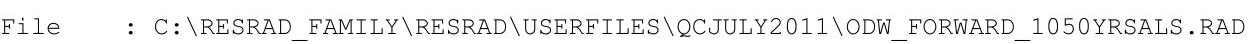

Individual Nuclide Dose Summed Over All Pathways

Parent Nuclide and Branch Fraction Indicated

Nuclide Parent THF(i) DOSE $(j, t), \mathrm{mrem} / \mathrm{yr}$

\begin{tabular}{|c|c|c|}
\hline$(j)$ & (i) & \\
\hline$m-241$ & $A m-241$ & $1.000 \mathrm{E}+00$ \\
\hline$p-237$ & $A m-241$ & $1.000 \mathrm{E}+00$ \\
\hline-237 & $N p-237$ & $1.000 \mathrm{E}+00$ \\
\hline$p-237$ & $\sum \mathrm{DOSE}$ & \\
\hline
\end{tabular}

$\mathrm{U}-233 \mathrm{Am}-241 \quad 1.000 \mathrm{E}+00$

$\mathrm{U}-233 \quad \mathrm{~Np}-237 \quad 1.000 \mathrm{E}+00$

U-233 $\quad$ DOSE $(j)$

Th-229 Am-241 1.000E+00

Th-229 Np-237 1.000E+00

Th-229 $\sum \operatorname{DOSE}(j)$

Cs-137 Cs $-137 \quad 1.000 \mathrm{E}+00$

$\mathrm{Pu}-238 \mathrm{Pu}-238 \quad 1.840 \mathrm{E}-09$

$\mathrm{Pu}-238 \quad \mathrm{Pu}-238 \quad 1.000 \mathrm{E}+00$

$\mathrm{Pu}-238 \quad \sum \mathrm{DOSE}(j)$

$\mathrm{U}-234$

$\mathrm{U}-234$

$\mathrm{U}-234$

$\mathrm{U}-234$

$\mathrm{Th}-230$

$\mathrm{Th}-230$

$\mathrm{Th}-230$

$\mathrm{Th}-230$

$\mathrm{Th}-230$

$\mathrm{Ra}-226$

$\mathrm{Ra}-226$

$\mathrm{Ra}-226$

$\mathrm{Ra}-226$

$\mathrm{Ra}-226$

$\mathrm{Pb}-210$

$\mathrm{Pb}-210$

$\mathrm{Pb}-210$

$\mathrm{Pb}-210$

$\mathrm{Pb}-210$

Pu-239

$\mathrm{Pu}-238 \quad 1.000 \mathrm{E}+00$

$\mathrm{U}-234 \quad 1.000 \mathrm{E}+00$

U-238 9.999E-01

$\sum \operatorname{DOSE}(j)$

$\mathrm{Pu}-238 \quad 1.000 \mathrm{E}+00$

Th-230 1.000E+00

$\mathrm{U}-234 \quad 1.000 \mathrm{E}+00$

U-238 9.999E-01

$\sum \operatorname{DOSE}(j)$

$\mathrm{Pu}-238 \quad 1.000 \mathrm{E}+00$

Th-230 1.000E+00

$\mathrm{U}-234 \quad 1.000 \mathrm{E}+00$

U-238 9.999E-01

$\sum \operatorname{DOSE}(j)$

$\mathrm{Pu}-238 \quad 1.000 \mathrm{E}+00$

Th-230 1.000E+00

$\mathrm{U}-234 \quad 1.000 \mathrm{E}+00$

$\mathrm{U}-2389.999 \mathrm{E}-01$

$\sum \operatorname{DOSE}(j)$

$\mathrm{Pu}-239 \quad 1.000 \mathrm{E}+00$

Pu-239 1.000E+00

U-235 $1.000 \mathrm{E}+00$

$\sum \operatorname{DOSE}(j)$
$=0.000 \mathrm{E}+00 \quad 1.000 \mathrm{E}+00 \quad 2.500 \mathrm{E}+01 \quad 5.000 \mathrm{E}+01 \quad 1.000 \mathrm{E}+02 \quad 5.000 \mathrm{E}+02 \quad 1.050 \mathrm{E}+03$

$\begin{array}{lllllll}0.000 \mathrm{E}+00 & 0.000 \mathrm{E}+00 & 0.000 \mathrm{E}+00 & 0.000 \mathrm{E}+00 & 0.000 \mathrm{E}+00 & 1.729 \mathrm{E}-26 & 4.102 \mathrm{E}-20\end{array}$

$2.212 \mathrm{E}-18 \quad 6.694 \mathrm{E}-18 \quad 1.445 \mathrm{E}-16 \quad 3.670 \mathrm{E}-16 \quad 1.202 \mathrm{E}-15 \quad 3.290 \mathrm{E}-13 \quad 1.789 \mathrm{E}-10$

$2.143 \mathrm{E}-12 \quad 2.166 \mathrm{E}-12 \quad 2.802 \mathrm{E}-12 \quad 3.663 \mathrm{E}-12 \quad 6.262 \mathrm{E}-12 \quad 4.562 \mathrm{E}-10 \quad 1.660 \mathrm{E}-07$

$2.143 \mathrm{E}-12 \quad 2.166 \mathrm{E}-12 \quad 2.802 \mathrm{E}-12 \quad 3.664 \mathrm{E}-12 \quad 6.263 \mathrm{E}-12 \quad 4.565 \mathrm{E}-10 \quad 1.662 \mathrm{E}-07$

$0.000 \mathrm{E}+00 \quad 3.546 \mathrm{E}-28 \quad 1.316 \mathrm{E}-25 \quad 6.964 \mathrm{E}-25 \quad 5.022 \mathrm{E}-24 \quad 1.524 \mathrm{E}-20 \quad 5.139 \mathrm{E}-17$

$\begin{array}{lllllll}7.294 \mathrm{E}-23 & 2.213 \mathrm{E}-22 & 5.074 \mathrm{E}-21 & 1.373 \mathrm{E}-20 & 5.105 \mathrm{E}-20 & 3.770 \mathrm{E}-17 & 7.650 \mathrm{E}-14\end{array}$

$\begin{array}{lllllll}7.294 \mathrm{E}-23 & 2.213 \mathrm{E}-22 & 5.074 \mathrm{E}-21 & 1.373 \mathrm{E}-20 & 5.106 \mathrm{E}-20 & 3.772 \mathrm{E}-17 & 7.655 \mathrm{E}-14\end{array}$

$\begin{array}{lllllll}3.431 \mathrm{E}-25 & 5.175 \mathrm{E}-24 & 2.676 \mathrm{E}-20 & 2.447 \mathrm{E}-19 & 2.677 \mathrm{E}-18 & 4.611 \mathrm{E}-15 & 1.698 \mathrm{E}-12\end{array}$

$6.658 \mathrm{E}-19 \quad 4.688 \mathrm{E}-18 \quad 1.542 \mathrm{E}-15 \quad 7.191 \mathrm{E}-15 \quad 4.028 \mathrm{E}-14 \quad 1.609 \mathrm{E}-11 \quad 3.373 \mathrm{E}-09$

$6.658 \mathrm{E}-19 \quad 4.688 \mathrm{E}-18 \quad 1.542 \mathrm{E}-15 \quad 7.191 \mathrm{E}-15 \quad 4.028 \mathrm{E}-14 \quad 1.610 \mathrm{E}-11 \quad 3.375 \mathrm{E}-09$

$\begin{array}{lllllll}9.797 \mathrm{E}-09 & 9.654 \mathrm{E}-09 & 6.786 \mathrm{E}-09 & 4.701 \mathrm{E}-09 & 2.255 \mathrm{E}-09 & 6.336 \mathrm{E}-12 & 1.966 \mathrm{E}-15\end{array}$

$\begin{array}{lllllll}0.000 \mathrm{E}+00 & 0.000 \mathrm{E}+00 & 0.000 \mathrm{E}+00 & 0.000 \mathrm{E}+00 & 0.000 \mathrm{E}+00 & 0.000 \mathrm{E}+00 & 9.694 \mathrm{E}-28\end{array}$

$\begin{array}{lllllll}1.872 E-23 & 1.891 E-23 & 2.390 E-23 & 3.050 E-23 & 4.968 E-23 & 2.461 E-21 & 5.269 E-19\end{array}$

$\begin{array}{lllllll}1.872 E-23 & 1.891 E-23 & 2.390 E-23 & 3.050 E-23 & 4.968 E-23 & 2.461 E-21 & 5.269 E-19\end{array}$

$\begin{array}{lllllll}1.558 \mathrm{E}-28 & 4.733 \mathrm{E}-28 & 1.120 \mathrm{E}-26 & 3.145 \mathrm{E}-26 & 1.270 \mathrm{E}-25 & 2.706 \mathrm{E}-22 & 4.674 \mathrm{E}-18\end{array}$

$\begin{array}{lllllll}4.509 \mathrm{E}-22 & 4.589 \mathrm{E}-22 & 7.019 \mathrm{E}-22 & 1.093 \mathrm{E}-21 & 2.648 \mathrm{E}-21 & 3.152 \mathrm{E}-18 & 5.341 \mathrm{E}-14\end{array}$

$6.410 \mathrm{E}-28 \quad 1.953 \mathrm{E}-27 \quad 5.075 \mathrm{E}-26 \quad 1.565 \mathrm{E}-25 \quad 7.546 \mathrm{E}-25 \quad 4.476 \mathrm{E}-21 \quad 1.593 \mathrm{E}-16$

$\begin{array}{lllllll}4.509 \mathrm{E}-22 & 4.589 \mathrm{E}-22 & 7.020 \mathrm{E}-22 & 1.093 \mathrm{E}-21 & 2.649 \mathrm{E}-21 & 3.157 \mathrm{E}-18 & 5.357 \mathrm{E}-14\end{array}$

$0.000 \mathrm{E}+00 \quad 0.000 \mathrm{E}+00 \quad 0.000 \mathrm{E}+00 \quad 2.549 \mathrm{E}-28 \quad 2.077 \mathrm{E}-27 \quad 2.087 \mathrm{E}-23 \quad 5.300 \mathrm{E}-19$ $\begin{array}{lllllll}9.857 \mathrm{E}-21 & 1.002 \mathrm{E}-20 & 1.501 \mathrm{E}-20 & 2.284 \mathrm{E}-20 & 5.294 \mathrm{E}-20 & 4.406 \mathrm{E}-17 & 4.565 \mathrm{E}-13\end{array}$ $\begin{array}{lllllll}7.119 \mathrm{E}-26 & 2.168 \mathrm{E}-25 & 5.511 \mathrm{E}-24 & 1.661 \mathrm{E}-23 & 7.662 \mathrm{E}-23 & 3.172 \mathrm{E}-19 & 6.886 \mathrm{E}-15\end{array}$ $\begin{array}{lllllll}0.000 \mathrm{E}+00 & 0.000 \mathrm{E}+00 & 0.000 \mathrm{E}+00 & 1.189 \mathrm{E}-27 & 1.091 \mathrm{E}-26 & 2.250 \mathrm{E}-22 & 1.025 \mathrm{E}-17\end{array}$ $\begin{array}{lllllll}9.857 \mathrm{E}-21 & 1.002 \mathrm{E}-20 & 1.501 \mathrm{E}-20 & 2.286 \mathrm{E}-20 & 5.302 \mathrm{E}-20 & 4.438 \mathrm{E}-17 & 4.634 \mathrm{E}-13\end{array}$

$\begin{array}{llllll}1.278 \mathrm{E}-21 & 1.926 \mathrm{E}-20 & 9.563 \mathrm{E}-17 & 8.395 \mathrm{E}-16 \quad 8.489 \mathrm{E}-15 & 8.964 \mathrm{E}-12 & 2.088 \mathrm{E}-09\end{array}$ $\begin{array}{lllllll}1.542 \mathrm{E}-09 & 4.655 \mathrm{E}-09 & 9.288 \mathrm{E}-08 & 2.174 \mathrm{E}-07 & 6.047 \mathrm{E}-07 & 4.387 \mathrm{E}-05 & 3.681 \mathrm{E}-03\end{array}$ $\begin{array}{llllllll}7.409 \mathrm{E}-15 & 5.217 \mathrm{E}-14 & 1.709 \mathrm{E}-11 & 7.936 \mathrm{E}-11 & 4.408 \mathrm{E}-10 & 1.637 \mathrm{E}-07 & 2.989 \mathrm{E}-05\end{array}$ $\begin{array}{llllllll}5.253 \mathrm{E}-21 & 7.925 \mathrm{E}-20 & 4.123 \mathrm{E}-16 & 3.794 \mathrm{E}-15 & 4.201 \mathrm{E}-14 & 7.878 \mathrm{E}-11 & 3.076 \mathrm{E}-08\end{array}$ 1.542E-09 4.655E-09 9.290E-08 2.175E-07 6.052E-07 4.403E-05 3.711E-03

$0.000 \mathrm{E}+00 \quad 1.149 \mathrm{E}-28 \quad 7.898 \mathrm{E}-24 \quad 1.239 \mathrm{E}-22 \quad 2.096 \mathrm{E}-21 \quad 5.871 \mathrm{E}-18 \quad 2.758 \mathrm{E}-15$ $\begin{array}{lllllll}7.434 \mathrm{E}-18 & 5.192 \mathrm{E}-17 & 1.381 \mathrm{E}-14 & 5.310 \mathrm{E}-14 & 2.173 \mathrm{E}-13 & 3.146 \mathrm{E}-11 & 5.057 \mathrm{E}-09\end{array}$ $2.682 \mathrm{E}-23 \quad 4.023 \mathrm{E}-22 \quad 1.799 \mathrm{E}-18 \quad 1.440 \mathrm{E}-17 \quad 1.266 \mathrm{E}-16 \quad 1.101 \mathrm{E}-13 \quad 3.976 \mathrm{E}-11$ $0.000 \mathrm{E}+00 \quad 4.727 \mathrm{E}-28 \quad 3.375 \mathrm{E}-23 \quad 5.514 \mathrm{E}-22 \quad 1.012 \mathrm{E}-20 \quad 4.996 \mathrm{E}-17 \quad 3.969 \mathrm{E}-14$ $\begin{array}{lllllll}7.434 \mathrm{E}-18 & 5.192 \mathrm{E}-17 & 1.381 \mathrm{E}-14 & 5.311 \mathrm{E}-14 & 2.174 \mathrm{E}-13 & 3.157 \mathrm{E}-11 & 5.096 \mathrm{E}-09\end{array}$ $\begin{array}{lllllll}1.769 \mathrm{E}-16 & 1.790 \mathrm{E}-16 & 2.384 \mathrm{E}-16 & 3.213 \mathrm{E}-16 & 5.837 \mathrm{E}-16 & 6.925 \mathrm{E}-14 & 4.926 \mathrm{E}-11\end{array}$

$\begin{array}{lllllll}9.025 \mathrm{E}-23 & 2.738 \mathrm{E}-22 & 6.255 \mathrm{E}-21 & 1.687 \mathrm{E}-20 & 6.224 \mathrm{E}-20 & 4.331 \mathrm{E}-17 & 8.095 \mathrm{E}-14\end{array}$ $\begin{array}{lllllllll}3.302 \mathrm{E}-14 & 3.344 \mathrm{E}-14 & 4.498 \mathrm{E}-14 & 6.127 \mathrm{E}-14 & 1.137 \mathrm{E}-13 & 1.596 \mathrm{E}-11 & 1.432 \mathrm{E}-08\end{array}$ $\begin{array}{llllllll}3.302 \mathrm{E}-14 & 3.344 \mathrm{E}-14 & 4.498 \mathrm{E}-14 & 6.127 \mathrm{E}-14 & 1.137 \mathrm{E}-13 & 1.596 \mathrm{E}-11 & 1.432 \mathrm{E}-08\end{array}$ 
RESRAD, Version 6.5

Summary : RESRAD Parameters for U-Landfill Outdoor Worker Forward Run at Proposed ALs

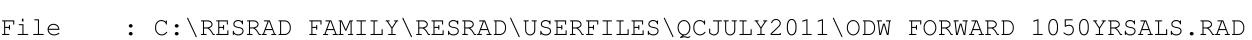

Individual Nuclide Soil Concentration

Parent Nuclide and Branch Fraction Indicated

Nuclide Parent THF(
(j)

(i)

Am-241

$\mathrm{Am}-241 \quad 1.000 \mathrm{E}+00$

Np-237

Np-237

Np-237

Am-241 $1.000 \mathrm{E}+00$

Np-237 1.000E+00

$\sum S(j):$

Am-241 $1.000 \mathrm{E}+00$

Np-237 1.000E+00

$\sum S(j):$

Am-241 1.000E+00

Np-237 1.000E+00

Th-229 $\sum \mathrm{S}(j):$

Cs -137

Cs-137 1.000E+00

$\mathrm{Pu}-238 \quad 1.840 \mathrm{E}-09$

$\mathrm{Pu}-238 \quad 1.000 \mathrm{E}+00$

$\sum S(j):$

$\mathrm{Pu}-238 \quad 1.000 \mathrm{E}+00$

U-234 $1.000 \mathrm{E}+00$

U-238 $9.999 \mathrm{E}-01$

$\sum S(j):$

$\mathrm{Pu}-238 \quad 1.000 \mathrm{E}+00$

Th-230 1.000E+00

U-234 $1.000 \mathrm{E}+00$

$\mathrm{U}-238 \quad 9.999 \mathrm{E}-01$

Th-230 $\sum S(j):$

$\mathrm{Ra}-226$

$\mathrm{Ra}-226$

$\mathrm{Ra}-226$

$\mathrm{Ra}-226$

$\mathrm{Ra}-226$

Pu-238 $1.000 \mathrm{E}+00$

Th-230 $1.000 \mathrm{E}+00$

$\mathrm{U}-2341.000 \mathrm{E}+00$

U-238 9.999E-01

$\sum S(j):$

$\mathrm{Pu}-238 \quad 1.000 \mathrm{E}+00$

Th-230 1.000E+00

$\mathrm{U}-234 \quad 1.000 \mathrm{E}+00$

$\mathrm{U}-238 \quad 9.999 \mathrm{E}-01$

$\sum S(j):$

Pu-239 1.000E+00

Pu-239 1.000E+00

$\mathrm{U}-2351.000 \mathrm{E}+00$

$\sum S(j):$
$\mathrm{S}(j, t), \mathrm{pCi} / \mathrm{g}$

$\mathrm{t}=0.000 \mathrm{E}+00 \quad 1.000 \mathrm{E}+00 \quad 2.500 \mathrm{E}+01 \quad 5.000 \mathrm{E}+01 \quad 1.000 \mathrm{E}+02 \quad 5.000 \mathrm{E}+02 \quad 1.050 \mathrm{E}+03$

$\begin{array}{lllllllll}7.000 \mathrm{E}+01 & 6.989 \mathrm{E}+01 & 6.724 \mathrm{E}+01 & 6.460 \mathrm{E}+01 & 5.961 \mathrm{E}+01 & 3.135 \mathrm{E}+01 & 1.296 \mathrm{E}+01\end{array}$

$0.000 \mathrm{E}+00 \quad 2.265 \mathrm{E}-05 \quad 5.550 \mathrm{E}-04 \quad 1.087 \mathrm{E}-03 \quad 2.086 \mathrm{E}-03 \quad 7.621 \mathrm{E}-03 \quad 1.092 \mathrm{E}-02$

$\begin{array}{lllllll}1.100 \mathrm{E}+01 & 1.100 \mathrm{E}+01 & 1.098 \mathrm{E}+01 & 1.096 \mathrm{E}+01 & 1.091 \mathrm{E}+01 & 1.058 \mathrm{E}+01 & 1.013 \mathrm{E}+01\end{array}$

$\begin{array}{llllllll}1.100 \mathrm{E}+01 & 1.100 \mathrm{E}+01 & 1.098 \mathrm{E}+01 & 1.096 \mathrm{E}+01 & 1.092 \mathrm{E}+01 & 1.058 \mathrm{E}+01 & 1.014 \mathrm{E}+01\end{array}$

$0.000 \mathrm{E}+00 \quad 4.955 \mathrm{E}-11 \quad 3.055 \mathrm{E}-08 \quad 1.205 \mathrm{E}-07 \quad 4.687 \mathrm{E}-07 \quad 9.484 \mathrm{E}-06 \quad 3.225 \mathrm{E}-05$

$\begin{array}{lllllll}0.000 \mathrm{E}+00 & 4.810 \mathrm{E}-05 & 1.201 \mathrm{E}-03 & 2.399 \mathrm{E}-03 & 4.787 \mathrm{E}-03 & 2.348 \mathrm{E}-02 & 4.802 \mathrm{E}-02\end{array}$

$\begin{array}{lllllll}0.000 \mathrm{E}+00 & 4.810 \mathrm{E}-05 & 1.201 \mathrm{E}-03 & 2.400 \mathrm{E}-03 & 4.788 \mathrm{E}-03 & 2.349 \mathrm{E}-02 & 4.805 \mathrm{E}-02\end{array}$

$0.000 \mathrm{E}+00 \quad 1.560 \mathrm{E}-15 \quad 2.411 \mathrm{E}-11 \quad 1.908 \mathrm{E}-10 \quad 1.493 \mathrm{E}-09 \quad 1.575 \mathrm{E}-07 \quad 1.178 \mathrm{E}-06$

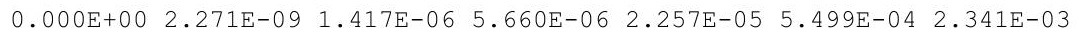

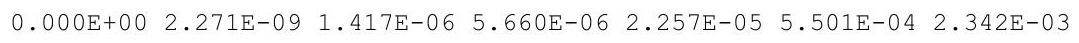

$\begin{array}{lllllll}3.800 \mathrm{E}+01 & 3.713 \mathrm{E}+01 & 2.132 \mathrm{E}+01 & 1.196 \mathrm{E}+01 & 3.763 \mathrm{E}+00 & 3.617 \mathrm{E}-04 & 1.083 \mathrm{E}-09\end{array}$

$\begin{array}{lllllll}1.435 \mathrm{E}-07 & 1.424 \mathrm{E}-07 & 1.178 \mathrm{E}-07 & 9.664 \mathrm{E}-08 & 6.507 \mathrm{E}-08 & 2.750 \mathrm{E}-09 & 3.547 \mathrm{E}-11\end{array}$

$\begin{array}{llllllllll}7.800 \mathrm{E}+01 & 7.739 \mathrm{E}+01 & 6.400 \mathrm{E}+01 & 5.252 \mathrm{E}+01 & 3.536 \mathrm{E}+01 & 1.494 \mathrm{E}+00 & 1.928 \mathrm{E}-02\end{array}$

$\begin{array}{lllllllll}7.800 \mathrm{E}+01 & 7.739 \mathrm{E}+01 & 6.400 \mathrm{E}+01 & 5.252 \mathrm{E}+01 & 3.536 \mathrm{E}+01 & 1.494 \mathrm{E}+00 & 1.928 \mathrm{E}-02\end{array}$

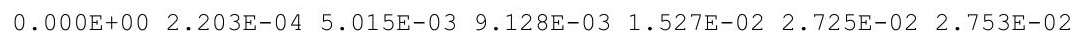

$\begin{array}{lllllll}3.200 \mathrm{E}+02 & 3.200 \mathrm{E}+02 & 3.199 \mathrm{E}+02 & 3.197 \mathrm{E}+02 & 3.195 \mathrm{E}+02 & 3.174 \mathrm{E}+02 & 3.146 \mathrm{E}+02\end{array}$

$\begin{array}{lllllllll}0.000 \mathrm{E}+00 & 9.071 \mathrm{E}-04 & 2.267 \mathrm{E}-02 & 4.532 \mathrm{E}-02 & 9.058 \mathrm{E}-02 & 4.502 \mathrm{E}-01 & 9.378 \mathrm{E}-01\end{array}$

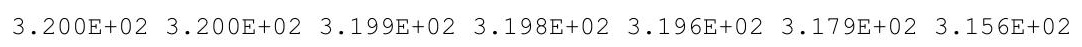

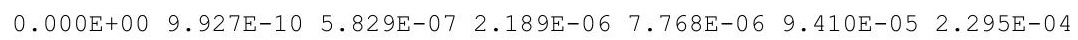

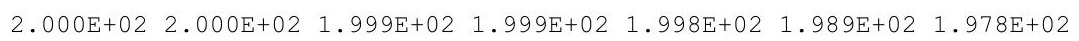
$\begin{array}{llllllll}0.000 \mathrm{E}+00 & 2.881 \mathrm{E}-03 & 7.199 \mathrm{E}-02 & 1.439 \mathrm{E}-01 & 2.877 \mathrm{E}-01 & 1.431 \mathrm{E}+00 & 2.982 \mathrm{E}+00\end{array}$ $0.000 \mathrm{E}+00 \quad 4.083 \mathrm{E}-09 \quad 2.551 \mathrm{E}-06 \quad 1.020 \mathrm{E}-05 \quad 4.077 \mathrm{E}-05 \quad 1.014 \mathrm{E}-03 \quad 4.438 \mathrm{E}-03$

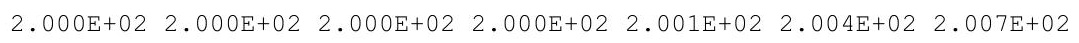

$0.000 \mathrm{E}+00 \quad 1.434 \mathrm{E}-13 \quad 2.133 \mathrm{E}-09 \quad 1.622 \mathrm{E}-08 \quad 1.178 \mathrm{E}-07 \quad 7.905 \mathrm{E}-06 \quad 4.098 \mathrm{E}-05$ $\begin{array}{lllllllll}0.000 \mathrm{E}+00 & 8.662 \mathrm{E}-02 & 2.154 \mathrm{E}+00 & 4.283 \mathrm{E}+00 & 8.470 \mathrm{E}+00 & 3.874 \mathrm{E}+01 & 7.227 \mathrm{E}+01\end{array}$ $\begin{array}{lllllll}0.000 \mathrm{E}+00 & 6.239 \mathrm{E}-07 & 3.885 \mathrm{E}-04 & 1.548 \mathrm{E}-03 & 6.143 \mathrm{E}-03 & 1.444 \mathrm{E}-01 & 5.866 \mathrm{E}-01\end{array}$ $\begin{array}{lllllll}0.000 \mathrm{E}+00 & 5.895 \mathrm{E}-13 & 9.185 \mathrm{E}-09 & 7.326 \mathrm{E}-08 & 5.825 \mathrm{E}-07 & 6.943 \mathrm{E}-05 & 6.033 \mathrm{E}-04\end{array}$ $\begin{array}{lllllll}0.000 \mathrm{E}+00 & 8.662 \mathrm{E}-02 & 2.154 \mathrm{E}+00 & 4.285 \mathrm{E}+00 & 8.476 \mathrm{E}+00 & 3.888 \mathrm{E}+01 & 7.285 \mathrm{E}+01\end{array}$

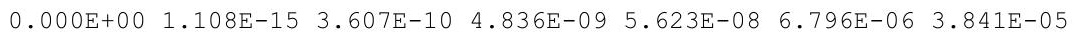
$\begin{array}{llllllll}0.000 \mathrm{E}+00 & 1.333 \mathrm{E}-03 & 6.574 \mathrm{E}-01 & 2.115 \mathrm{E}+00 & 5.891 \mathrm{E}+00 & 3.647 \mathrm{E}+01 & 7.047 \mathrm{E}+01\end{array}$ $\begin{array}{lllllll}0.000 \mathrm{E}+00 & 6.414 \mathrm{E}-09 & 8.382 \mathrm{E}-05 & 5.674 \mathrm{E}-04 & 3.412 \mathrm{E}-03 & 1.275 \mathrm{E}-01 & 5.539 \mathrm{E}-01\end{array}$ $\begin{array}{lllllll}0.000 \mathrm{E}+00 & 4.553 \mathrm{E}-15 & 1.540 \mathrm{E}-09 & 2.150 \mathrm{E}-08 & 2.712 \mathrm{E}-07 & 5.779 \mathrm{E}-05 & 5.526 \mathrm{E}-04\end{array}$ $\begin{array}{lllllll}0.000 \mathrm{E}+00 & 1.333 \mathrm{E}-03 \quad 6.575 \mathrm{E}-01 & 2.116 \mathrm{E}+00 & 5.894 \mathrm{E}+00 & 3.659 \mathrm{E}+01 & 7.103 \mathrm{E}+01\end{array}$ $\begin{array}{lllllll}7.200 \mathrm{E}+01 & 7.200 \mathrm{E}+01 & 7.193 \mathrm{E}+01 & 7.186 \mathrm{E}+01 & 7.172 \mathrm{E}+01 & 7.062 \mathrm{E}+01 & 6.913 \mathrm{E}+01\end{array}$ $0.000 \mathrm{E}+00 \quad 7.091 \mathrm{E}-08 \quad 1.772 \mathrm{E}-06 \quad 3.541 \mathrm{E}-06 \quad 7.073 \mathrm{E}-06 \quad 3.500 \mathrm{E}-05 \quad 7.245 \mathrm{E}-05$ $\begin{array}{llllllllll}1.300 \mathrm{E}+01 & 1.300 \mathrm{E}+01 & 1.300 \mathrm{E}+01 & 1.299 \mathrm{E}+01 & 1.298 \mathrm{E}+01 & 1.291 \mathrm{E}+01 & 1.282 \mathrm{E}+01\end{array}$ $\begin{array}{llllllll}1.300 \mathrm{E}+01 & 1.300 \mathrm{E}+01 & 1.300 \mathrm{E}+01 & 1.299 \mathrm{E}+01 & 1.298 \mathrm{E}+01 & 1.291 \mathrm{E}+01 & 1.282 \mathrm{E}+01\end{array}$ 
RESRAD, Version 6.5

Summary : RESRAD Parameters for U-Landfill Outdoor Worker Forward Run at Proposed ALs

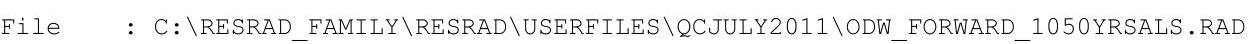

Individual Nuclide Soil Concentration

Parent Nuclide and Branch Fraction Indicated

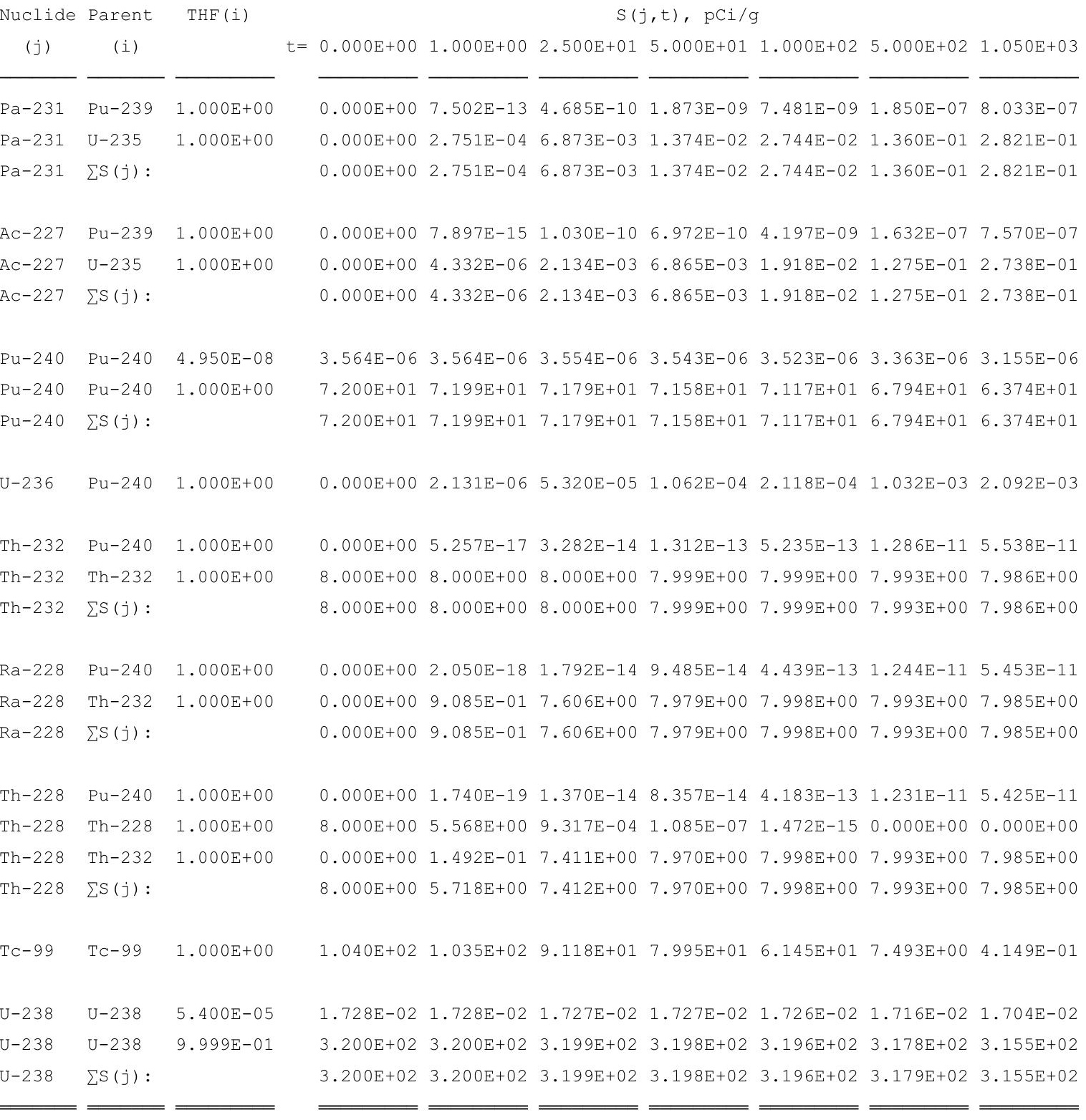

THF (i) is the thread fraction of the parent nuclide.

RESCALC.EXE execution time $=6.17$ seconds 
Summary : RESRAD Parameters for U-Landfill Outdoor Worker Forward Run 10,000

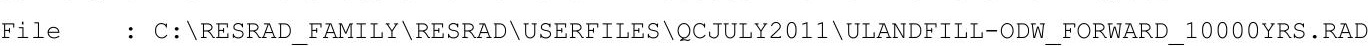

Dose Conversion Factor (and Related) Parameter Summary

Dose Library: ICRP 60 \& ICRP 72 (Adult)

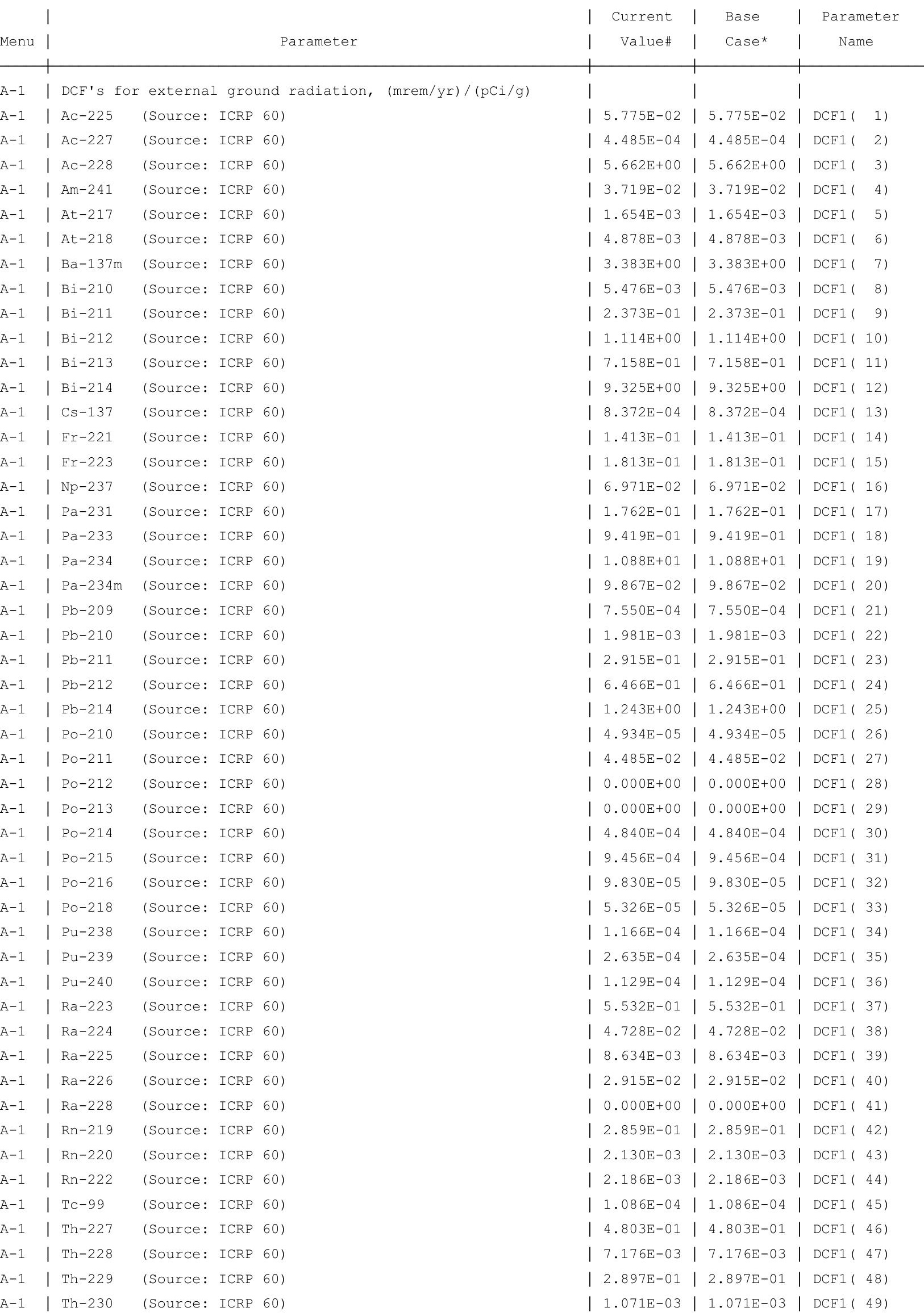


Summary : RESRAD Parameters for U-Landfill Outdoor Worker Forward Run 10,000

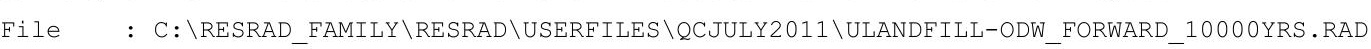

Dose Conversion Factor (and Related) Parameter Summary (continued)

Dose Library: ICRP 60 \& ICRP 72 (Adult)

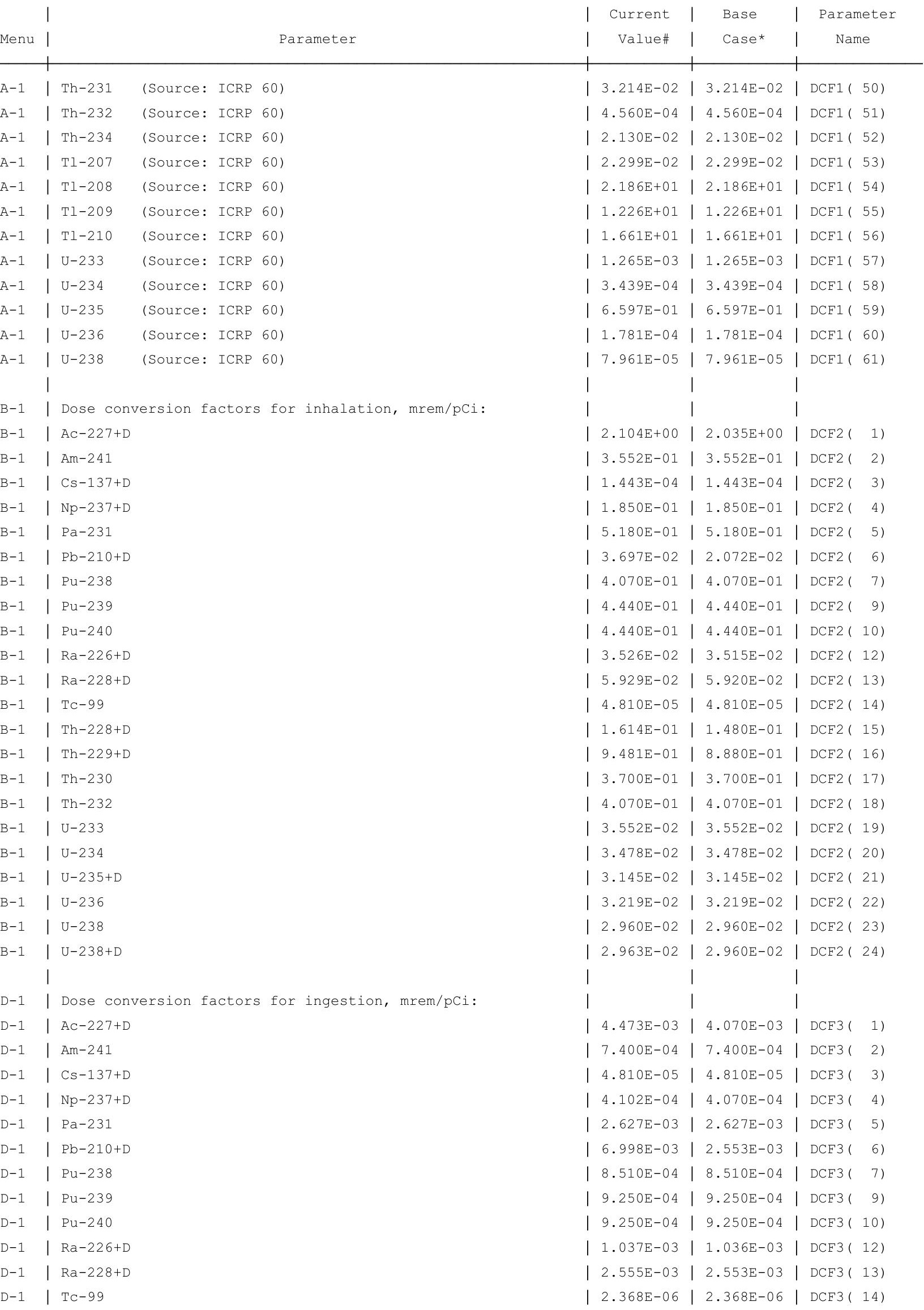


RESRAD, Version $6.5 \quad \mathrm{~T}^{1 / 2}$ Limit $=180$ days

Summary : RESRAD Parameters for U-Landfill Outdoor Worker Forward Run 10,000

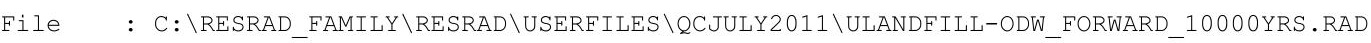

Contaminated Zone Dimensions

Area: 89436.00 square meters

Thickness:

Cover Depth:

13.40 meters

1.52 meters
Initial Soil Concentrations, pCi/g

$\begin{array}{ll}\mathrm{Am}-241 & 3.500 \mathrm{E}+01 \\ \mathrm{Cs}-137 & 1.900 \mathrm{E}+01 \\ \mathrm{~Np}-237 & 5.500 \mathrm{E}+00 \\ \mathrm{Pu}-238 & 3.900 \mathrm{E}+01 \\ \mathrm{Pu}-239 & 3.600 \mathrm{E}+01 \\ \mathrm{Pu}-240 & 3.600 \mathrm{E}+01 \\ \mathrm{TC}-99 & 5.200 \mathrm{E}+01 \\ \mathrm{Th}-228 & 4.000 \mathrm{E}+00 \\ \mathrm{Th}-230 & 1.000 \mathrm{E}+02 \\ \mathrm{Th}-232 & 4.000 \mathrm{E}+00 \\ \mathrm{U}-234 & 1.600 \mathrm{E}+02 \\ \mathrm{U}-235 & 6.500 \mathrm{E}+00 \\ \mathrm{U}-238 & 1.600 \mathrm{E}+02\end{array}$

Total Dose TDOSE(t), mrem/yr

Basic Radiation Dose Limit $=1.000 \mathrm{E}+00 \mathrm{mrem} / \mathrm{yr}$

Total Mixture Sum $M(t)$ = Fraction of Basic Dose Limit Received at Time (t)

$\begin{array}{rllllllll}t \text { (years) }: & 0.000 \mathrm{E}+00 & 1.000 \mathrm{E}+00 & 2.500 \mathrm{E}+01 & 5.000 \mathrm{E}+01 & 1.000 \mathrm{E}+02 & 5.000 \mathrm{E}+02 & 1.050 \mathrm{E}+03 & 1.000 \mathrm{E}+04 \\ \text { TDOSE }(\mathrm{t}): & 1.150 \mathrm{E}-06 & 8.594 \mathrm{E}-07 & 1.529 \mathrm{E}-06 & 1.950 \mathrm{E}-06 & 2.793 \mathrm{E}-06 & 4.957 \mathrm{E}-05 & 2.632 \mathrm{E}-03 & 2.178 \mathrm{E}+02 \\ \mathrm{M}(\mathrm{t}): & 1.150 \mathrm{E}-06 & 8.594 \mathrm{E}-07 & 1.529 \mathrm{E}-06 & 1.950 \mathrm{E}-06 & 2.793 \mathrm{E}-06 & 4.957 \mathrm{E}-05 & 2.632 \mathrm{E}-03 & 2.178 \mathrm{E}+02\end{array}$

Maximum TDOSE(t): $2.178 \mathrm{E}+02 \mathrm{mrem} / \mathrm{yr}$ at $t=1.000 \mathrm{E}+04$ years 
RESRAD, Version 6.5

mmary : RESRAD Parameters for U-Landfill Outdoor Worker Forward Run 10,000

File : C: $\backslash$ RESRAD_FAMILY \RESRAD \USERFILES $\backslash Q C J U L Y 2011 \backslash U L A N D F I L L-O D W$ FORWARD 10000 YRS.RAD

Individual Nuclide Dose Summed Over All Pathways

Parent Nuclide and Branch Fraction Indicated

Nuclide Parent THF(i) DOSE $(j, t), \mathrm{mrem} / \mathrm{yr}$

\begin{tabular}{|c|c|c|}
\hline$(j)$ & (i) & \\
\hline$n-241$ & $A m-241$ & $1.000 \mathrm{E}+00$ \\
\hline-237 & $A m-241$ & $1.000 \mathrm{E}+00$ \\
\hline $\mathrm{Np}-237$ & $\mathrm{~Np}-237$ & $1.000 \mathrm{E}+00$ \\
\hline $\mathrm{Np}-237$ & $\sum \operatorname{DOSE}(j$ & \\
\hline
\end{tabular}

$\mathrm{U}-233 \quad \mathrm{Am}-241 \quad 1.000 \mathrm{E}+00$

$\mathrm{U}-233 \quad \mathrm{~Np}-237 \quad 1.000 \mathrm{E}+00$

U-233 $\quad$ DOSE $(j)$

Th-229 Am-241 $1.000 \mathrm{E}+00$

Th-229 Np-237 $1.000 \mathrm{E}+00$

Th-229 $\sum \operatorname{DOSE}(j)$

Cs $-137 \quad$ Cs $-137 \quad 1.000 E+00$

Pu-238 Pu-238 $1.840 \mathrm{E}-09$

$\mathrm{Pu}-238 \mathrm{Pu}-238 \quad 1.000 \mathrm{E}+00$

$\mathrm{Pu}-238 \quad \sum \operatorname{DOSE}(j)$

$\mathrm{U}-234$

$\mathrm{U}-234$

$\mathrm{U}-234$

$\mathrm{U}-234$

Th-230

Th -230

Th-230

Th-230

Th-230

$\mathrm{Ra}-226$

$\mathrm{Ra}-226$

$\mathrm{Ra}-226$

$\mathrm{Ra}-226$

$\mathrm{Ra}-226$

$\mathrm{Pb}-210$

$\mathrm{Pb}-210$

$\mathrm{Pb}-210$

$\mathrm{Pb}-210$

$\mathrm{Pb}-210$

$\mathrm{Pu}-239$

Pu-238 1.000E+00 $\mathrm{U}-234 \quad 1.000 \mathrm{E}+00$ U-238 9.999E-01 $\sum \operatorname{DOSE}(j)$

Pu-238 1.000E+00 Th-230 1.000E+00 U-234 $1.000 \mathrm{E}+00$ $\mathrm{U}-238 \quad 9.999 \mathrm{E}-01$ $\sum \operatorname{DOSE}(j)$

$\mathrm{Pu}-238 \quad 1.000 \mathrm{E}+00$ Th-230 1.000E+00 $\mathrm{U}-234 \quad 1.000 \mathrm{E}+00$ $\mathrm{U}-238 \quad 9.999 \mathrm{E}-01$ ¿DOSE (j)

$\mathrm{Pu}-238 \quad 1.000 \mathrm{E}+00$ Th-230 1.000E+00 $\mathrm{U}-234 \quad 1.000 \mathrm{E}+00$ $\mathrm{U}-238 \quad 9.999 \mathrm{E}-01$ $\sum \operatorname{DOSE}(j)$

$\mathrm{Pu}-239 \quad 1.000 \mathrm{E}+00$

$\mathrm{Pu}-239 \quad 1.000 \mathrm{E}+00$ $\mathrm{U}-235 \quad 1.000 \mathrm{E}+00$ $\sum \operatorname{DOSE}(j)$ $\mathrm{t}=0.000 \mathrm{E}+00 \quad 1.000 \mathrm{E}+00 \quad 2.500 \mathrm{E}+01 \quad 5.000 \mathrm{E}+01 \quad 1.000 \mathrm{E}+02 \quad 5.000 \mathrm{E}+02 \quad 1.050 \mathrm{E}+03 \quad 1.000 \mathrm{E}+04$

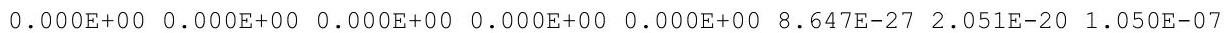

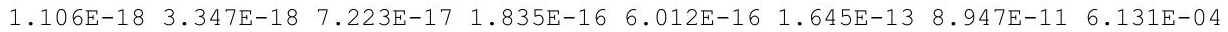

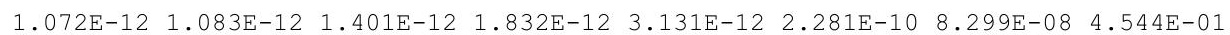

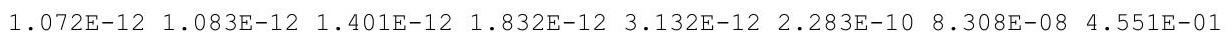

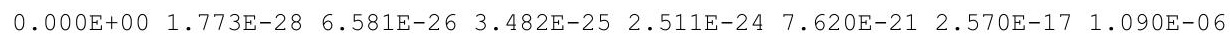
$\begin{array}{llllllll}3.647 \mathrm{E}-23 & 1.106 \mathrm{E}-22 & 2.537 \mathrm{E}-21 & 6.866 \mathrm{E}-21 & 2.553 \mathrm{E}-20 & 1.885 \mathrm{E}-17 & 3.825 \mathrm{E}-14 & 8.821 \mathrm{E}-04\end{array}$ $\begin{array}{llllllll}3.647 \mathrm{E}-23 & 1.106 \mathrm{E}-22 & 2.537 \mathrm{E}-21 & 6.867 \mathrm{E}-21 & 2.553 \mathrm{E}-20 & 1.886 \mathrm{E}-17 & 3.827 \mathrm{E}-14 & 8.832 \mathrm{E}-04\end{array}$

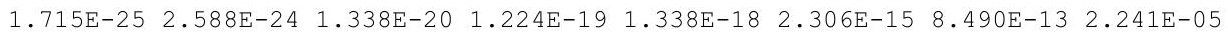

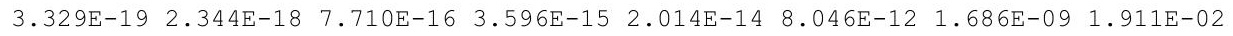

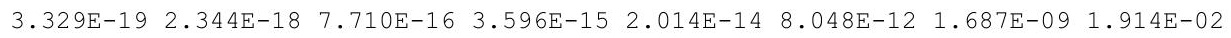

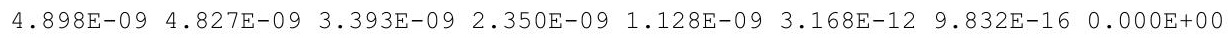

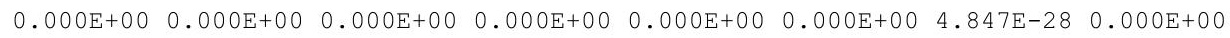
$\begin{array}{lllllllll}9.362 \mathrm{E}-24 & 9.454 \mathrm{E}-24 & 1.195 \mathrm{E}-23 & 1.525 \mathrm{E}-23 & 2.484 \mathrm{E}-23 & 1.231 \mathrm{E}-21 & 2.634 \mathrm{E}-19 & 0.000 \mathrm{E}+00\end{array}$ $\begin{array}{llllllll}9.362 \mathrm{E}-24 & 9.454 \mathrm{E}-24 & 1.195 \mathrm{E}-23 & 1.525 \mathrm{E}-23 & 2.484 \mathrm{E}-23 & 1.231 \mathrm{E}-21 & 2.634 \mathrm{E}-19 & 0.000 \mathrm{E}+00\end{array}$

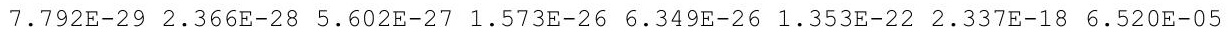
$\begin{array}{lllllllll}2.254 \mathrm{E}-22 & 2.295 \mathrm{E}-22 & 3.510 \mathrm{E}-22 & 5.464 \mathrm{E}-22 & 1.324 \mathrm{E}-21 & 1.576 \mathrm{E}-18 & 2.670 \mathrm{E}-14 & 7.448 \mathrm{E}-01\end{array}$

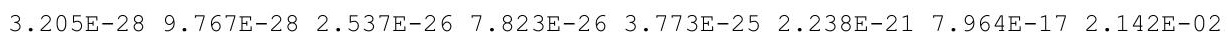
$\begin{array}{llllllll}2.254 \mathrm{E}-22 & 2.295 \mathrm{E}-22 & 3.510 \mathrm{E}-22 & 5.465 \mathrm{E}-22 & 1.325 \mathrm{E}-21 & 1.578 \mathrm{E}-18 & 2.679 \mathrm{E}-14 & 7.663 \mathrm{E}-01\end{array}$

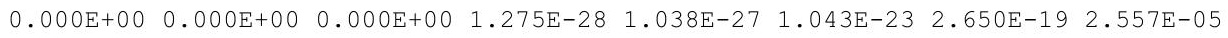
$\begin{array}{lllllllll}4.929 \mathrm{E}-21 & 5.012 \mathrm{E}-21 & 7.503 \mathrm{E}-21 & 1.142 \mathrm{E}-20 & 2.647 \mathrm{E}-20 & 2.203 \mathrm{E}-17 & 2.282 \mathrm{E}-13 & 2.112 \mathrm{E}+0\end{array}$

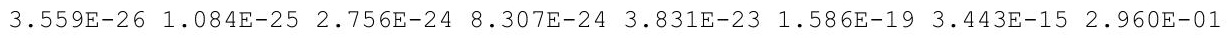
$0.000 \mathrm{E}+00 \quad 0.000 \mathrm{E}+00 \quad 0.000 \mathrm{E}+00 \quad 5.947 \mathrm{E}-28 \quad 5.457 \mathrm{E}-27 \quad 1.125 \mathrm{E}-22 \quad 5.127 \mathrm{E}-18 \quad 4.196 \mathrm{E}-03$ $\begin{array}{llllllll}4.929 \mathrm{E}-21 & 5.012 \mathrm{E}-21 & 7.506 \mathrm{E}-21 & 1.143 \mathrm{E}-20 & 2.651 \mathrm{E}-20 & 2.219 \mathrm{E}-17 & 2.317 \mathrm{E}-13 & 2.412 \mathrm{E}+00\end{array}$ 6.392E-22 9.628E-21 4.782E-17 4.197E-16 4.245E-15 4.482E-12 $1.044 \mathrm{E}-09 \quad 1.505 \mathrm{E}-03$

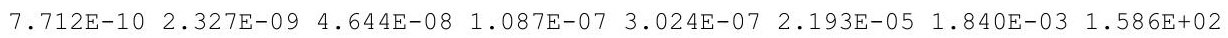

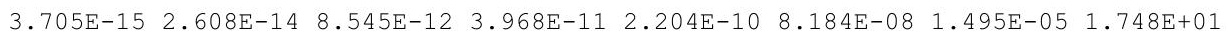
$2.626 \mathrm{E}-21 \quad 3.963 \mathrm{E}-20 \quad 2.061 \mathrm{E}-16 \quad 1.897 \mathrm{E}-15 \quad 2.100 \mathrm{E}-14 \quad 3.939 \mathrm{E}-11 \quad 1.538 \mathrm{E}-08 \quad 2.064 \mathrm{E}-01$ $\begin{array}{llllllll}7.712 \mathrm{E}-10 & 2.327 \mathrm{E}-09 & 4.645 \mathrm{E}-0 & 1.088 \mathrm{E}-07 & 3.026 \mathrm{E}-07 & 2.202 \mathrm{E}-05 & 1.855 \mathrm{E}-03 & 1.763 \mathrm{E}+02\end{array}$

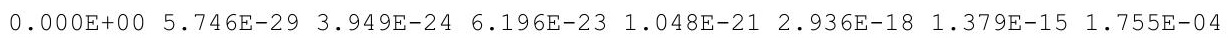
$\begin{array}{llllllll}3.717 \mathrm{E}-18 & 2.596 \mathrm{E}-17 & 6.907 \mathrm{E}-15 & 2.655 \mathrm{E}-14 & 1.087 \mathrm{E}-13 & 1.573 \mathrm{E}-11 & 2.528 \mathrm{E}-09 & 1.857 \mathrm{E}+01\end{array}$ $\begin{array}{lllllllll}1.341 \mathrm{E}-23 & 2.012 \mathrm{E}-22 & 8.994 \mathrm{E}-19 & 7.200 \mathrm{E}-18 & 6.329 \mathrm{E}-17 & 5.505 \mathrm{E}-14 & 1.988 \mathrm{E}-11 & 2.038 \mathrm{E}+00\end{array}$ $\begin{array}{llllllll}0.000 \mathrm{E}+00 & 2.363 \mathrm{E}-28 & 1.687 \mathrm{E}-23 & 2.757 \mathrm{E}-22 & 5.058 \mathrm{E}-21 & 2.498 \mathrm{E}-17 & 1.985 \mathrm{E}-14 & 2.398 \mathrm{E}-02\end{array}$ $\begin{array}{lllllllll}3.717 \mathrm{E}-18 & 2.596 \mathrm{E}-17 & 6.907 \mathrm{E}-15 & 2.655 \mathrm{E}-14 & 1.087 \mathrm{E}-13 & 1.578 \mathrm{E}-11 & 2.548 \mathrm{E}-09 & 2.063 \mathrm{E}+01\end{array}$

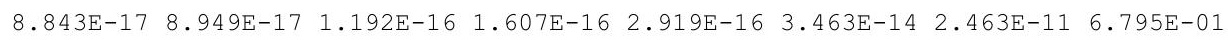
$\begin{array}{llllllll}4.513 \mathrm{E}-23 & 1.369 \mathrm{E}-22 & 3.128 \mathrm{E}-21 & 8.434 \mathrm{E}-21 & 3.112 \mathrm{E}-20 & 2.165 \mathrm{E}-17 & 4.048 \mathrm{E}-14 & 3.323 \mathrm{E}-05\end{array}$ $\begin{array}{lllllllll}1.651 \mathrm{E}-14 & 1.672 \mathrm{E}-14 & 2.249 \mathrm{E}-14 & 3.064 \mathrm{E}-14 & 5.684 \mathrm{E}-14 & 7.982 \mathrm{E}-12 & 7.159 \mathrm{E}-09 & 6.898 \mathrm{E}-01\end{array}$ $\begin{array}{llllllll}1.651 \mathrm{E}-14 & 1.672 \mathrm{E}-14 & 2.249 \mathrm{E}-14 & 3.064 \mathrm{E}-14 & 5.684 \mathrm{E}-14 & 7.982 \mathrm{E}-12 & 7.159 \mathrm{E}-09 & 6.899 \mathrm{E}-01\end{array}$ 
RESRAD, Version 6.5

Summary : RESRAD Parameters for U-Landfill Outdoor Worker Forward Run 10,000

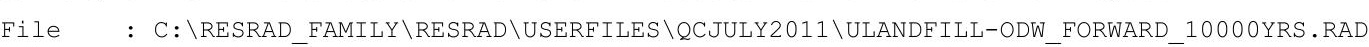

Individual Nuclide Dose Summed Over All Pathways

Parent Nuclide and Branch Fraction Indicated

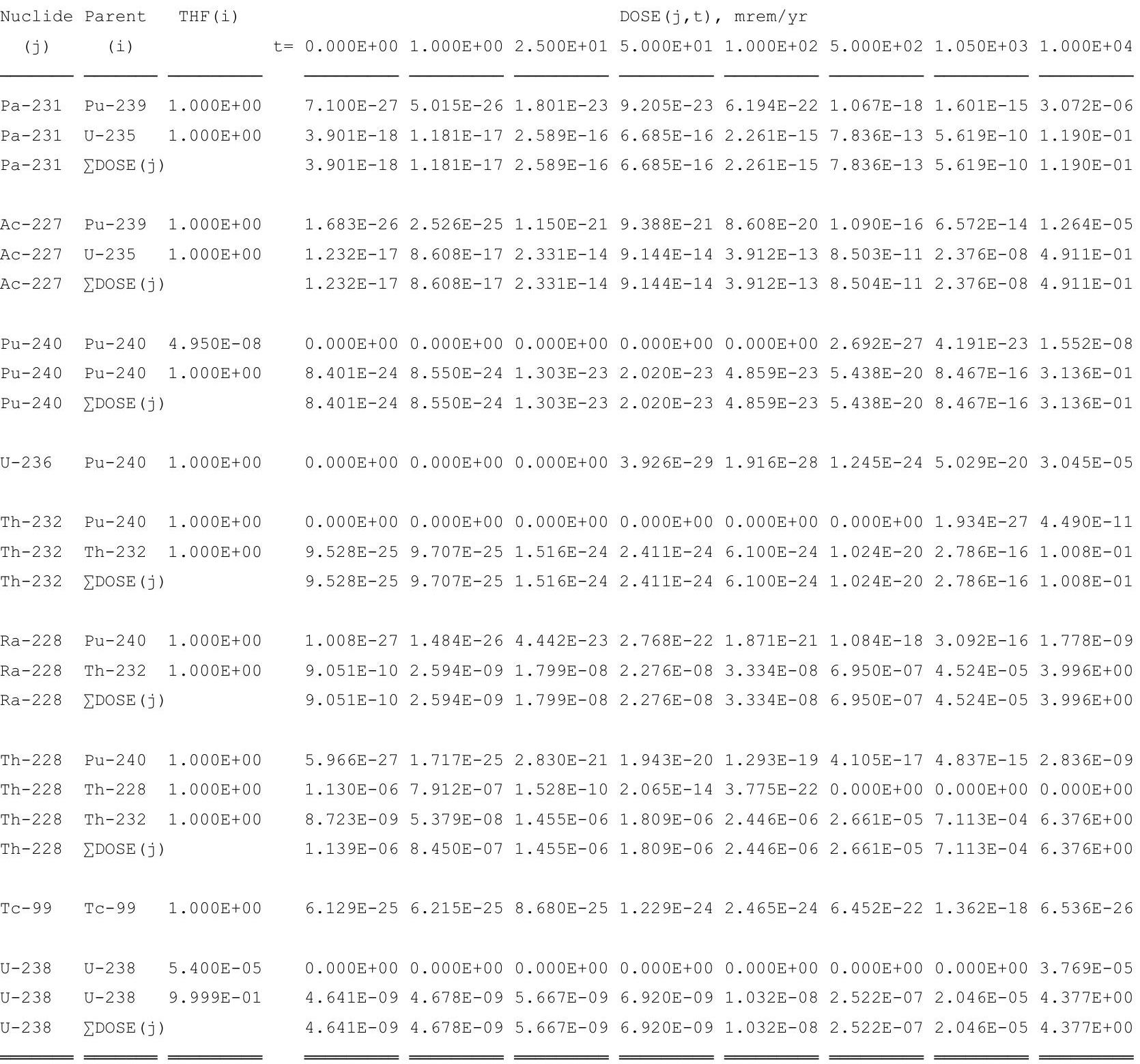

THF (i) is the thread fraction of the parent nuclide. 
RESRAD, Version 6.5

Summary : RESRAD Parameters for U-Landfill Outdoor Worker Forward Run 10,000

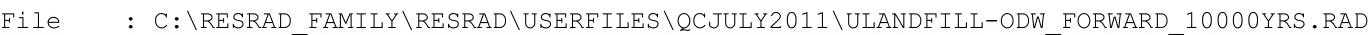

Individual Nuclide Soil Concentration

Parent Nuclide and Branch Fraction Indicated

Nuclide Parent THF(

(j) (i)

Am-241 Am-241 1.000E+00

Np-237 Am-241 $1.000 E+00$

$\mathrm{Np}-237 \quad \mathrm{~Np}-237 \quad 1.000 \mathrm{E}+00$

Np-237 $\sum S(j):$

$\mathrm{U}-233 \quad \mathrm{Am}-241 \quad 1.000 \mathrm{E}+00$

$\mathrm{U}-233 \quad \mathrm{~Np}-237 \quad 1.000 \mathrm{E}+00$

U-233 $\sum S(j):$

Th-229 Am-241 $1.000 \mathrm{E}+00$

Th-229 Np-237 1.000E+00

Th-229 $\sum \mathrm{S}(j):$

Cs-137 Cs-137 1.000E+00

$\mathrm{Pu}-238$

$\mathrm{Pu}-238$

Pu-238

$\mathrm{U}-234$

$\mathrm{U}-234$

$\mathrm{U}-234$

$\mathrm{U}-234$

Th-230

Th -230

Th-230

Th-230

$\mathrm{Th}-230$

$\mathrm{Ra}-226$

$\mathrm{Ra}-226$

$\mathrm{Ra}-226$

$\mathrm{Ra}-226$

$\mathrm{Ra}-226$

$\mathrm{Pb}-210$

$\mathrm{Pb}-210$

$\mathrm{Pb}-210$

$\mathrm{Pb}-210$

$\mathrm{Pb}-210$

$\mathrm{Pu}-239$

Pu-239 1.000E+00 $\mathrm{U}-2351.000 \mathrm{E}+00$

$\sum S(j):$
$S(j, t), p C i / g$

$\mathrm{t}=0.000 \mathrm{E}+00 \quad 1.000 \mathrm{E}+00 \quad 2.500 \mathrm{E}+01 \quad 5.000 \mathrm{E}+01 \quad 1.000 \mathrm{E}+02 \quad 5.000 \mathrm{E}+02 \quad 1.050 \mathrm{E}+03 \quad 1.000 \mathrm{E}+04$

$\begin{array}{llllllllll}3.500 \mathrm{E}+01 & 3.494 \mathrm{E}+01 & 3.362 \mathrm{E}+01 & 3.230 \mathrm{E}+01 & 2.981 \mathrm{E}+01 & 1.567 \mathrm{E}+01 & 6.478 \mathrm{E}+00 & 3.685 \mathrm{E}-06\end{array}$

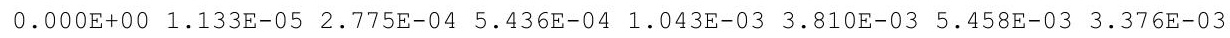

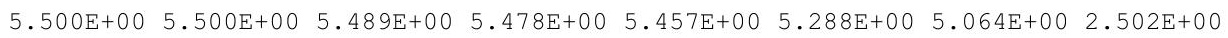

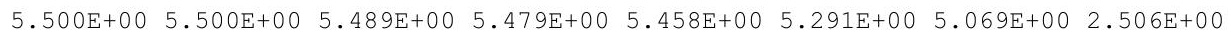

$0.000 \mathrm{E}+00 \quad 2.477 \mathrm{E}-11 \quad 1.527 \mathrm{E}-08 \quad 6.025 \mathrm{E}-08 \quad 2.344 \mathrm{E}-07 \quad 4.742 \mathrm{E}-06 \quad 1.613 \mathrm{E}-05 \quad 1.863 \mathrm{E}-04$ $\begin{array}{llllllll}0.000 \mathrm{E}+00 & 2.405 \mathrm{E}-05 & 6.006 \mathrm{E}-04 & 1.200 \mathrm{E}-03 & 2.394 \mathrm{E}-03 & 1.174 \mathrm{E}-02 & 2.401 \mathrm{E}-02 & 1.508 \mathrm{E}-01\end{array}$

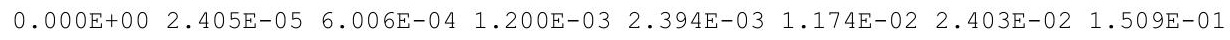

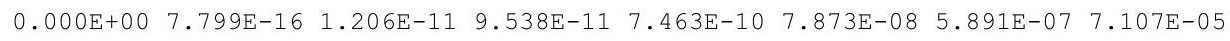

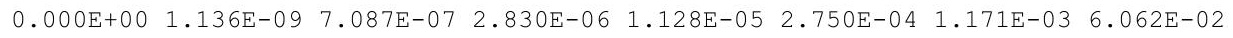
$\begin{array}{llllllll}0.000 \mathrm{E}+00 & 1.136 \mathrm{E}-09 & 7.087 \mathrm{E}-07 & 2.830 \mathrm{E}-06 & 1.128 \mathrm{E}-05 & 2.750 \mathrm{E}-04 & 1.171 \mathrm{E}-03 & 6.069 \mathrm{E}-02\end{array}$

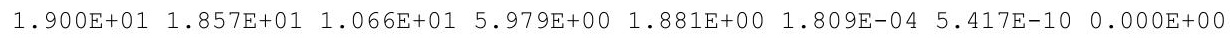

$\begin{array}{llllllll}7.176 \mathrm{E}-08 & 7.119 \mathrm{E}-08 & 5.888 \mathrm{E}-08 & 4.832 \mathrm{E}-08 & 3.254 \mathrm{E}-08 & 1.375 \mathrm{E}-09 & 1.774 \mathrm{E}-11 & 3.170 \mathrm{E}-42\end{array}$ $\begin{array}{lllllllllllll}3.900 \mathrm{E}+01 & 3.869 \mathrm{E}+01 & 3.200 \mathrm{E}+01 & 2.626 \mathrm{E}+01 & 1.768 \mathrm{E}+01 & 7.472 \mathrm{E}-01 & 9.639 \mathrm{E}-03 & 1.731 \mathrm{E}-33\end{array}$ $\begin{array}{llllllllllllll}3.900 \mathrm{E}+01 & 3.869 \mathrm{E}+01 & 3.200 \mathrm{E}+01 & 2.626 \mathrm{E}+01 & 1.768 \mathrm{E}+01 & 7.472 \mathrm{E}-01 & 9.639 \mathrm{E}-03 & 1.731 \mathrm{E}-33\end{array}$

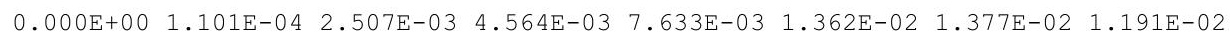

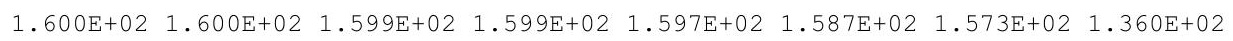
$\begin{array}{llllllllll}0.000 \mathrm{E}+00 & 4.536 \mathrm{E}-04 & 1.134 \mathrm{E}-02 & 2.266 \mathrm{E}-02 & 4.529 \mathrm{E}-02 & 2.251 \mathrm{E}-01 & 4.689 \mathrm{E}-01 & 3.911 \mathrm{E}+00\end{array}$ $\begin{array}{llllllll}1.600 \mathrm{E}+02 & 1.600 \mathrm{E}+02 & 1.599 \mathrm{E}+02 & 1.599 \mathrm{E}+02 & 1.598 \mathrm{E}+02 & 1.589 \mathrm{E}+02 & 1.578 \mathrm{E}+02 & 1.399 \mathrm{E}+02\end{array}$

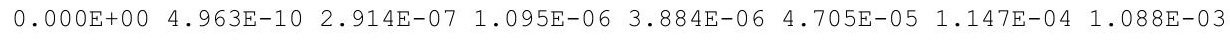
$\begin{array}{llllllllll}1.000 \mathrm{E}+02 & 1.000 \mathrm{E}+02 & 9.997 \mathrm{E}+01 & 9.995 \mathrm{E}+01 & 9.989 \mathrm{E}+01 & 9.947 \mathrm{E}+01 & 9.888 \mathrm{E}+01 & 8.984 \mathrm{E}+01\end{array}$ $\begin{array}{lllllllll}0.000 \mathrm{E}+00 & 1.440 \mathrm{E}-03 & 3.600 \mathrm{E}-02 & 7.197 \mathrm{E}-02 & 1.438 \mathrm{E}-01 & 7.153 \mathrm{E}-01 & 1.491 \mathrm{E}+00 & 1.259 \mathrm{E}+01\end{array}$

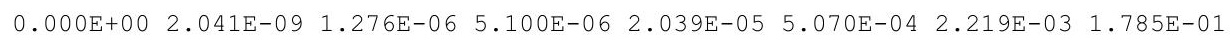

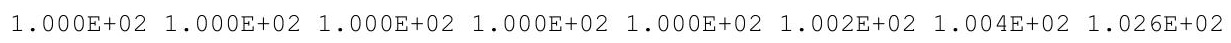

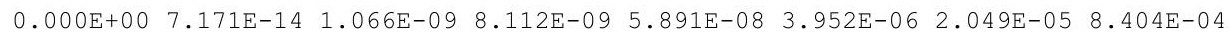
$\begin{array}{lllllllll}0.000 \mathrm{E}+00 & 4.331 \mathrm{E}-02 & 1.077 \mathrm{E}+00 & 2.142 \mathrm{E}+00 & 4.235 \mathrm{E}+00 & 1.937 \mathrm{E}+01 & 3.613 \mathrm{E}+01 & 8.860 \mathrm{E}+01\end{array}$ $\begin{array}{lllllllll}0.000 \mathrm{E}+00 & 3.119 \mathrm{E}-07 & 1.942 \mathrm{E}-04 & 7.739 \mathrm{E}-04 & 3.071 \mathrm{E}-03 & 7.220 \mathrm{E}-02 & 2.933 \mathrm{E}-01 & 9.761 \mathrm{E}+00\end{array}$ $0.000 \mathrm{E}+00 \quad 2.948 \mathrm{E}-13 \quad 4.592 \mathrm{E}-09 \quad 3.663 \mathrm{E}-08 \quad 2.913 \mathrm{E}-07 \quad 3.471 \mathrm{E}-05 \quad 3.016 \mathrm{E}-04 \quad 1.152 \mathrm{E}-01$ $\begin{array}{llllllll}0.000 \mathrm{E}+00 & 4.331 \mathrm{E}-02 & 1.077 \mathrm{E}+00 & 2.142 \mathrm{E}+00 & 4.238 \mathrm{E}+00 & 1.944 \mathrm{E}+01 & 3.643 \mathrm{E}+01 & 9.848 \mathrm{E}+01\end{array}$

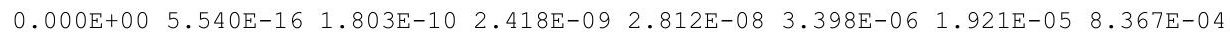
$\begin{array}{lllllllll}0.000 \mathrm{E}+00 & 6.663 \mathrm{E}-04 & 3.287 \mathrm{E}-01 & 1.058 \mathrm{E}+00 & 2.946 \mathrm{E}+00 & 1.823 \mathrm{E}+01 & 3.524 \mathrm{E}+01 & 8.856 \mathrm{E}+01\end{array}$ $\begin{array}{lllllllll}0.000 \mathrm{E}+00 & 3.207 \mathrm{E}-09 & 4.191 \mathrm{E}-05 & 2.837 \mathrm{E}-04 & 1.706 \mathrm{E}-03 & 6.374 \mathrm{E}-02 & 2.769 \mathrm{E}-01 & 9.719 \mathrm{E}+00\end{array}$ $0.000 \mathrm{E}+00 \quad 2.276 \mathrm{E}-15 \quad 7.700 \mathrm{E}-10 \quad 1.075 \mathrm{E}-08 \quad 1.356 \mathrm{E}-07 \quad 2.889 \mathrm{E}-05 \quad 2.763 \mathrm{E}-04 \quad 1.143 \mathrm{E}-01$ $\begin{array}{llllllllll}0.000 \mathrm{E}+00 & 6.663 \mathrm{E}-04 & 3.287 \mathrm{E}-01 & 1.058 \mathrm{E}+00 & 2.947 \mathrm{E}+00 & 1.830 \mathrm{E}+01 & 3.551 \mathrm{E}+01 & 9.839 \mathrm{E}+01\end{array}$ $\begin{array}{lllllllll}3.600 \mathrm{E}+01 & 3.600 \mathrm{E}+01 & 3.597 \mathrm{E}+01 & 3.593 \mathrm{E}+01 & 3.586 \mathrm{E}+01 & 3.531 \mathrm{E}+01 & 3.456 \mathrm{E}+01 & 2.443 \mathrm{E}+01\end{array}$

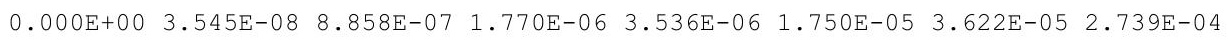

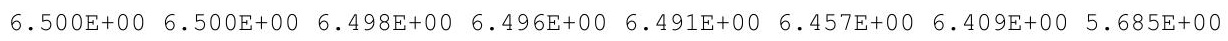

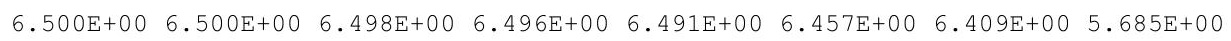


RESRAD, Version $6.5 \quad$ T1/2 Limit $=180$ days $\quad 07 / 21 / 2011 \quad 12: 52$ Page

Summary : RESRAD Parameters for U-Landfill Outdoor Worker Forward Run 100,000

File : C: \RESRAD_FAMILY \RESRAD \USERFILES \QCJULY2011 \ULANDFILL-ODW_FORWARD_100000YRS.RAD

Table of Contents

Part I: Mixture Sums and Single Radionuclide Guidelines

Dose Conversion Factor (and Related) Parameter Summary ... 2

Site-Specific Parameter Summary ................ 8

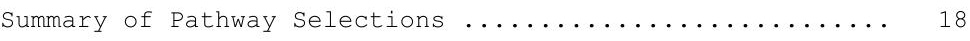

Contaminated Zone and Total Dose Summary ............. 19

Total Dose Components

Time $=0.000 \mathrm{E}+00 \ldots \ldots \ldots \ldots \ldots \ldots \ldots \ldots \ldots \ldots \ldots \ldots \ldots \ldots \ldots \ldots \ldots \ldots$

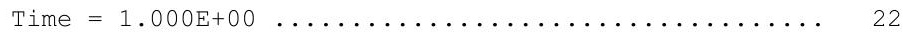

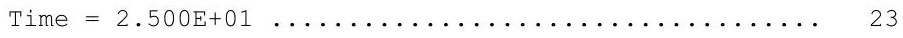

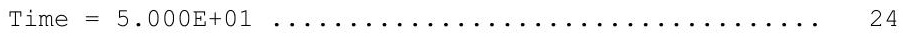

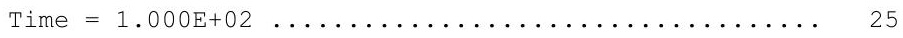

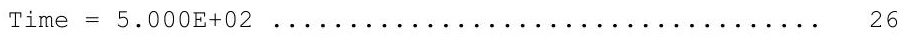

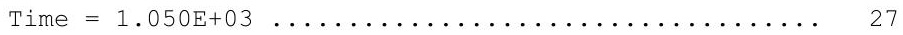

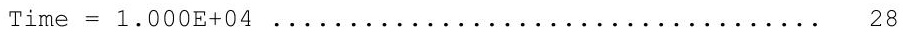

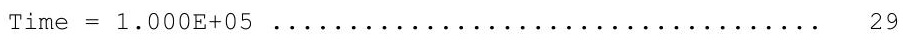

Dose/Source Ratios Summed Over All Pathways .......... 30

Single Radionuclide Soil Guidelines .............. 32

Dose Per Nuclide Summed Over All Pathways ........... 33

Soil Concentration Per Nuclide .................... 35 
Summary : RESRAD Parameters for U-Landfill Outdoor Worker Forward Run 100,000

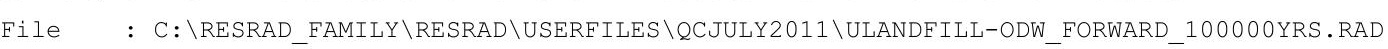

Dose Conversion Factor (and Related) Parameter Summary

Dose Library: ICRP 60 \& ICRP 72 (Adult)

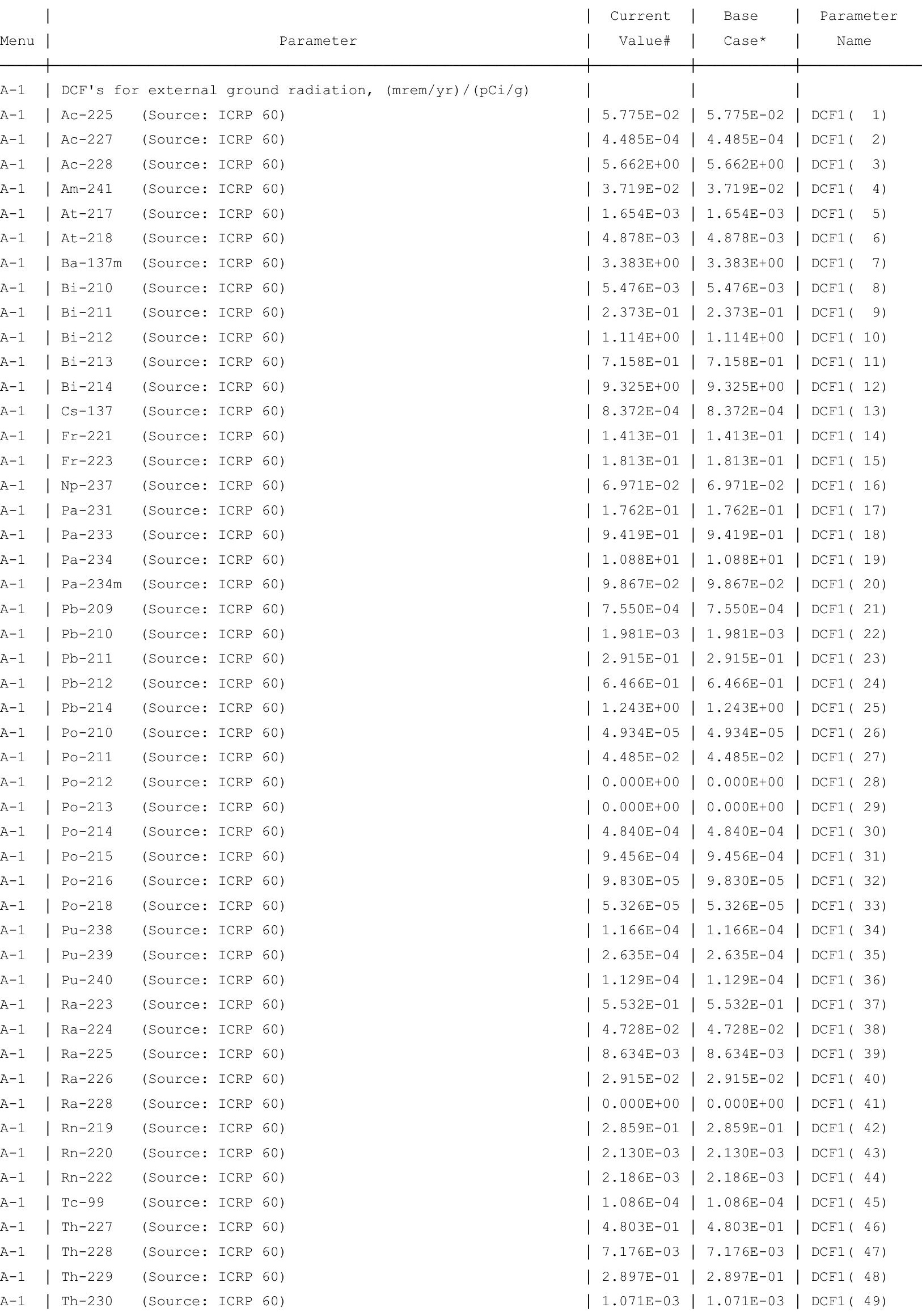


Summary : RESRAD Parameters for U-Landfill Outdoor Worker Forward Run 100,000

File : C: \RESRAD_FAMILY \RESRAD \USERFILES \QCJULY2011 \ULANDFILL-ODW_FORWARD_100000YRS.RAD

Dose Conversion Factor (and Related) Parameter Summary (continued)

Dose Library: ICRP 60 \& ICRP 72 (Adult)

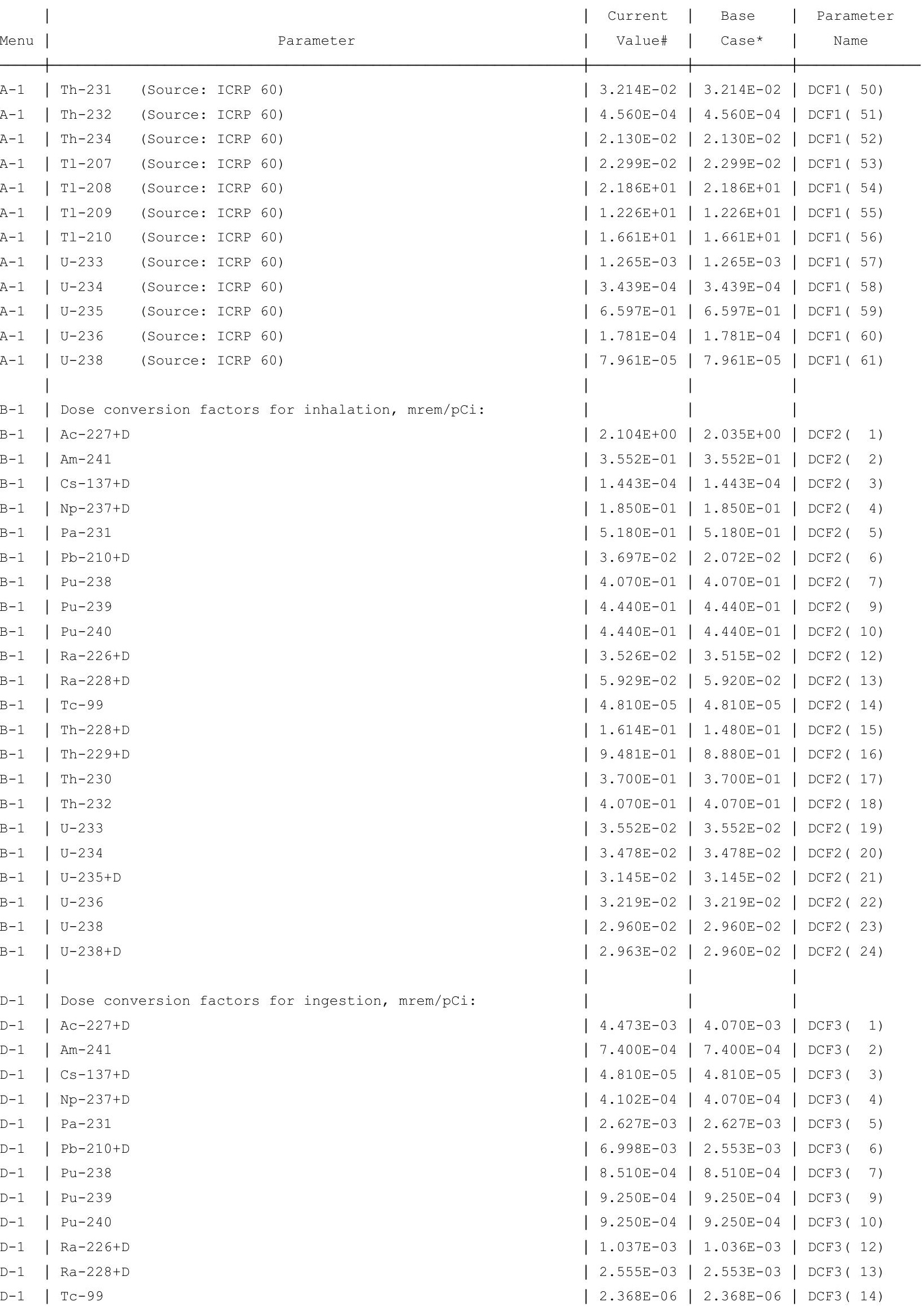


RESRAD, Version $6.5 \quad T^{1 / 2}$ Limit $=180$ days $\quad 07 / 21 / 2011 \quad 12: 52$ Page

Summary : RESRAD Parameters for U-Landfill Outdoor Worker Forward Run 100,000

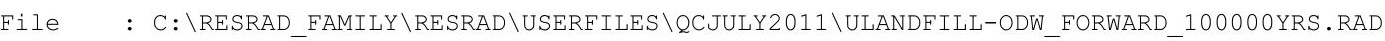

Dose Conversion Factor (and Related) Parameter Summary (continued) Dose Library: ICRP 60 \& ICRP 72 (Adult)

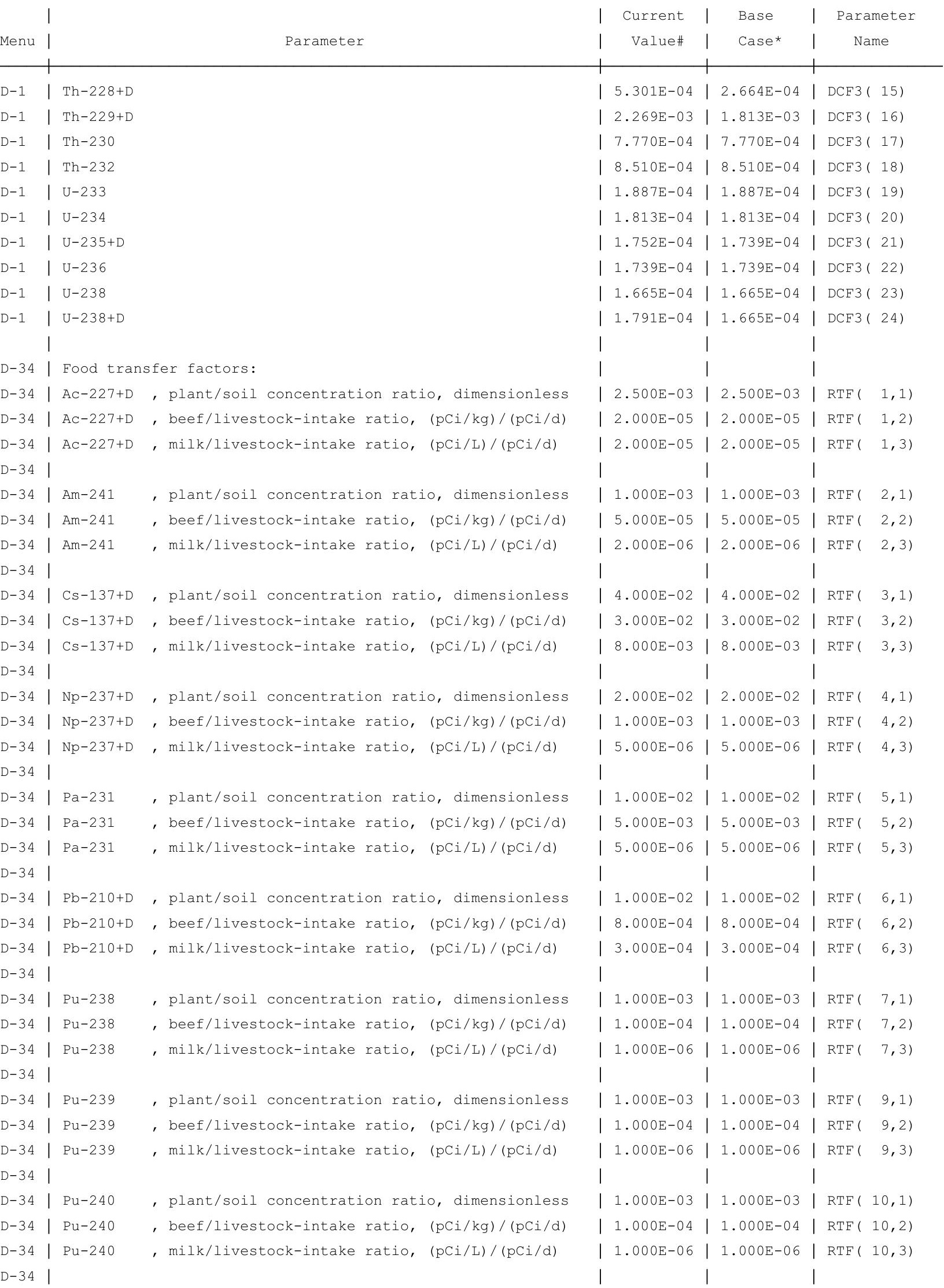


RESRAD, Version $6.5 \quad$ T1/2 Limit $=180$ days $\quad 07 / 21 / 2011 \quad 12: 52$ Page

Summary : RESRAD Parameters for U-Landfill Outdoor Worker Forward Run 100,000

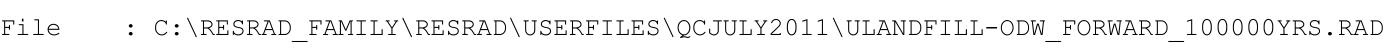

Dose Conversion Factor (and Related) Parameter Summary (continued)

Dose Library: ICRP 60 \& ICRP 72 (Adult)

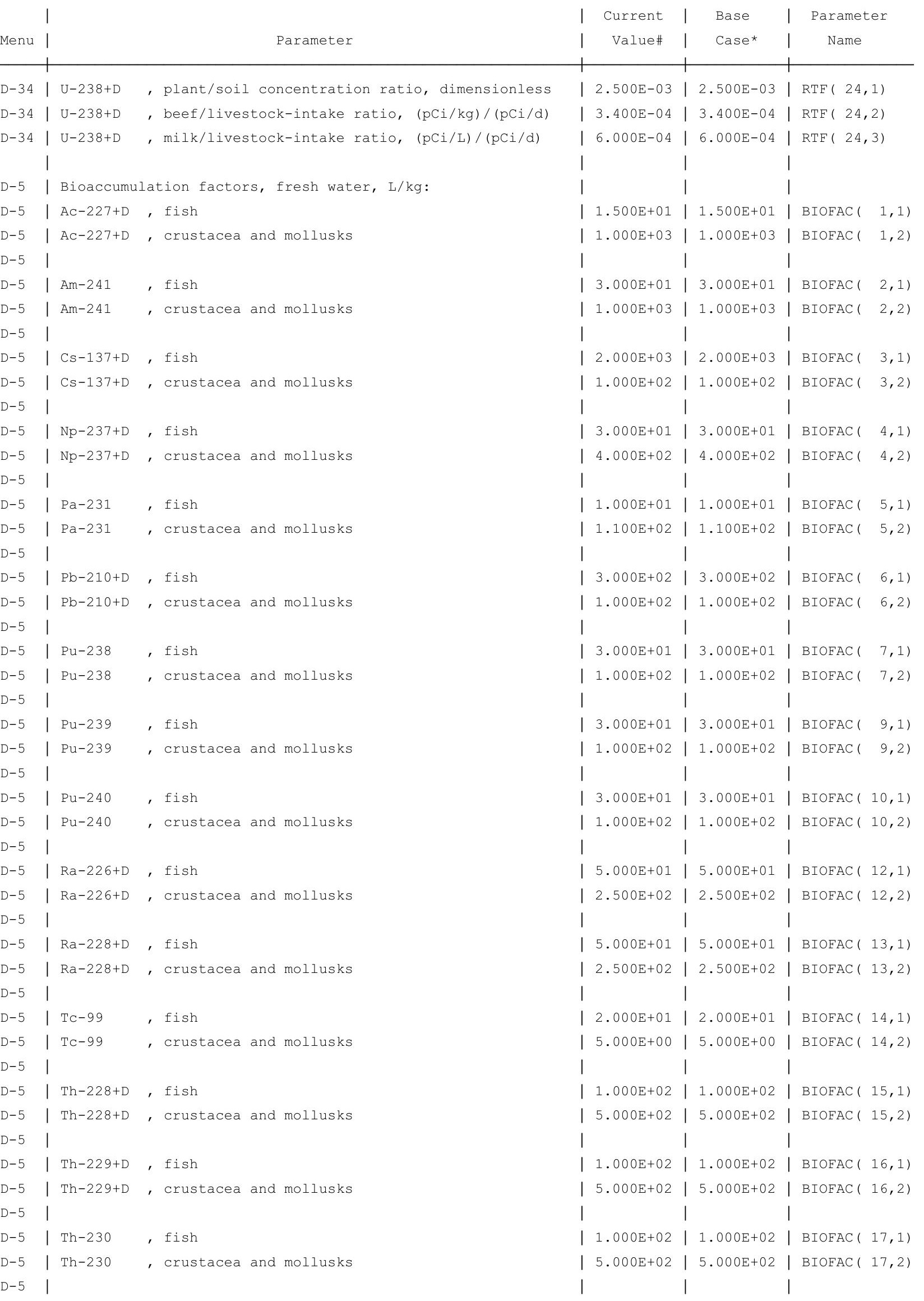

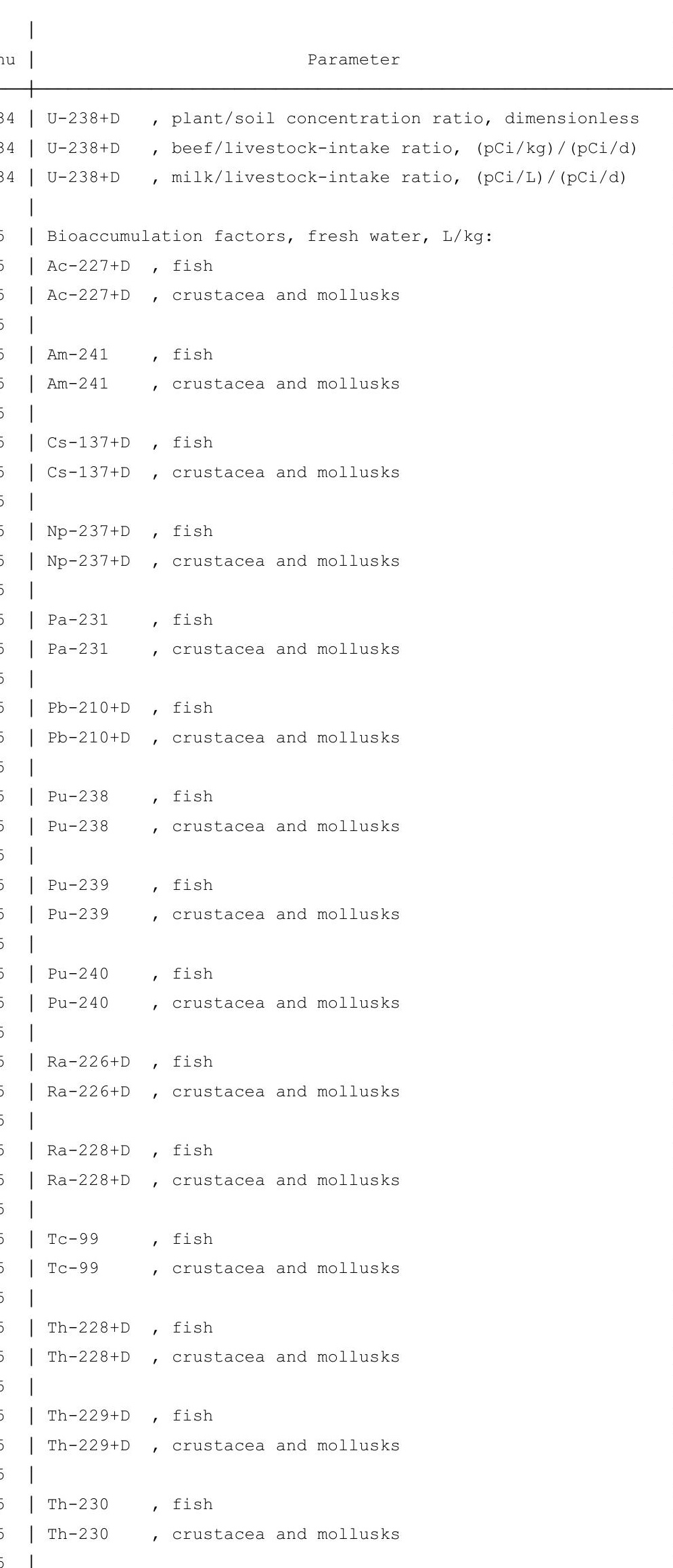

\begin{tabular}{|l|l|}
$2.500 \mathrm{E}-03$ & $2.500 \mathrm{E}-03$ \\
$\mid$ & $\operatorname{RTF}(24,1)$
\end{tabular}

\begin{tabular}{l|l}
$6,000 \mathrm{RTF}(24,3)$ \\
\hline
\end{tabular}

\begin{tabular}{l|l|l|}
$1.500 \mathrm{E}+01$ & $1.500 \mathrm{E}+01 \mid \operatorname{BIOFAC}(1,1)$
\end{tabular}

$1.000 \mathrm{E}+03|1.000 \mathrm{E}+03| \operatorname{BIOFAC}(1,2)$

\begin{tabular}{l|l|l}
$3.000 \mathrm{E}+01 \mid 3.000 \mathrm{E}+01$ & $\operatorname{BIOFAC}(2,1)$
\end{tabular}

\begin{tabular}{l|l|l}
$1.000 \mathrm{E}+03$ & $1.000 \mathrm{E}+03$ & $\operatorname{BIOFAC}(2,2)$
\end{tabular}

\begin{tabular}{l|l|l}
$2.000 \mathrm{E}+03$ & $2.000 \mathrm{E}+03$ & $\operatorname{BIOFAC}(3,1)$
\end{tabular}

\begin{tabular}{l|l|l|l}
$1.000 \mathrm{E}+02$ & $1.000 \mathrm{E}+02$ & $\operatorname{BIOFAC}(3,2)$
\end{tabular}

\begin{tabular}{l|l|l}
$3.000 \mathrm{E}+01|3.000 \mathrm{E}+01| \operatorname{BIOFAC}(4,1)$ \\
$0.000 \mathrm{E}+02$
\end{tabular}

\begin{tabular}{l|l|l}
$4.000 \mathrm{E}+02$ & $4.000 \mathrm{E}+02$ & $\operatorname{BIOFAC}(4,2)$
\end{tabular}

\begin{tabular}{l|l||}
$1.000 \mathrm{E}+01 \mid 1.000 \mathrm{E}+01$ & $\operatorname{BIOFAC}(5,1)$
\end{tabular}

\begin{tabular}{l|l|l|}
$1.100 \mathrm{E}+02$ & $1.100 \mathrm{E}+02$ & $\operatorname{BIOFAC}(5,2)$
\end{tabular}

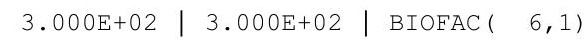

\begin{tabular}{l|l|l|}
$1.000 \mathrm{E}+02$ & $1.000 \mathrm{E}+02$ & $\operatorname{BIOFAC}(6,2)$
\end{tabular}

$3.000 \mathrm{E}+01|3.000 \mathrm{E}+01| \operatorname{BIOFAC}(7,1)$

\begin{tabular}{l|l|l}
$1.000 \mathrm{E}+02$ & $1.000 \mathrm{E}+02$ & $\operatorname{BIOFAC}(7,2)$
\end{tabular}

\begin{tabular}{l|l|l}
$3.000 \mathrm{E}+01$ & $3.000 \mathrm{E}+01$ & $\operatorname{BIOFAC}(9,1)$
\end{tabular}

\begin{tabular}{l|l|l}
$1.000 \mathrm{E}+02$ & $1.000 \mathrm{E}+02$ & $\operatorname{BIOFAC}(9,2)$
\end{tabular}

\begin{tabular}{l|l|l}
$3.000 \mathrm{E}+01|3.000 \mathrm{E}+01| \operatorname{BIOFAC}(10,1)$
\end{tabular}

\begin{tabular}{l|l|l}
$1.000 \mathrm{E}+02$ & $1.000 \mathrm{E}+02$ & $\operatorname{BIOFAC}(10,2)$
\end{tabular}

\begin{tabular}{l|l|l}
$5.000 \mathrm{E}+01|5.000 \mathrm{E}+01| \operatorname{BIOFAC}(12,1)$ & 1
\end{tabular}

\begin{tabular}{l|l|}
$2.500 \mathrm{E}+02$ & $2.500 \mathrm{E}+02$ \\
$\operatorname{BIOFAC}(12,2)$
\end{tabular}

\begin{tabular}{l|l|l}
$5.000 \mathrm{E}+01$ & $5.000 \mathrm{E}+01 \mid \operatorname{BIOFAC}(13,1)$
\end{tabular}

\begin{tabular}{l|l|}
$2.500 \mathrm{E}+02$ & $2.500 \mathrm{E}+02$ \\
$\operatorname{BIOFAC}(13,2)$
\end{tabular}

\begin{tabular}{l|l|l|l|}
$2.000 \mathrm{E}+01$ & $2.000 \mathrm{E}+01$ & $\operatorname{BIOFAC}(14,1)$
\end{tabular}

|5.000E+00 | 5.000E+00| $\operatorname{BIOFAC}(14,2)$

\begin{tabular}{l|l|l}
$1.000 \mathrm{E}+02$ & $1.000 \mathrm{E}+02$ & $\operatorname{BIOFAC}(15,1)$
\end{tabular}

\begin{tabular}{l|l|l|}
$5.000 \mathrm{E}+02|5.000 \mathrm{E}+02| \operatorname{BIOFAC}(15,2)$
\end{tabular}

\begin{tabular}{l|l|l|l|}
$1.000 \mathrm{E}+02$ & $1.000 \mathrm{E}+02$ & $\operatorname{BIOFAC}(16,1)$
\end{tabular}

\begin{tabular}{l|l|l|}
$5.000 \mathrm{E}+02$ & $5.000 \mathrm{E}+02$ & $\operatorname{BIOFAC}(16,2)$
\end{tabular}

\begin{tabular}{l|l|l|l|}
$1.000 \mathrm{E}+02$ & $1.000 \mathrm{E}+02$ & $\operatorname{BIOFAC}(17,1)$
\end{tabular}

\begin{tabular}{|l|l|l|l|}
$5.000 \mathrm{E}+02$ & $5.000 \mathrm{E}+02$ & $\operatorname{BIOFAC}(17,2)$
\end{tabular}

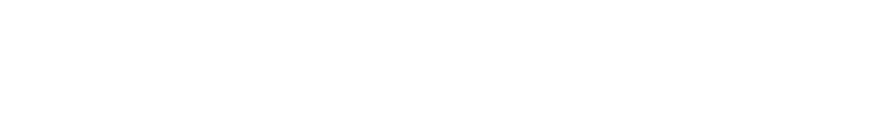


RESRAD, Version $6.5 \quad$ T1/2 Limit $=180$ days $\quad$ 07/21/2011 $12: 52$ Page

Summary : RESRAD Parameters for U-Landfill Outdoor Worker Forward Run 100,000

File : C: \RESRAD_FAMILY \RESRAD \USERFILES \QCJULY2011 \ULANDFILL-ODW_FORWARD_100000YRS.RAD

Dose Conversion Factor (and Related) Parameter Summary (continued)

Dose Library: ICRP 60 \& ICRP 72 (Adult)

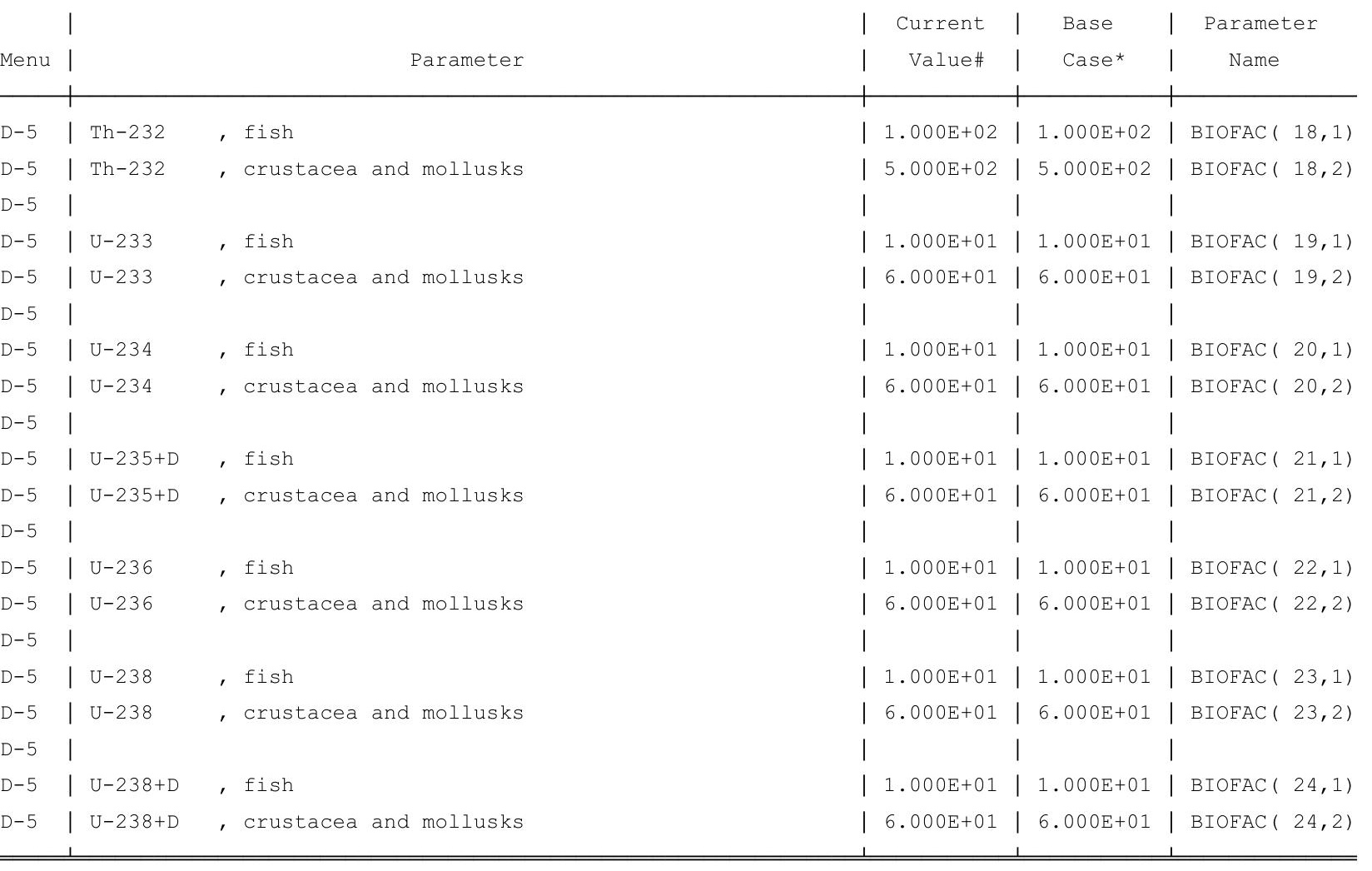

\#For DCF1(xxx) only, factors are for infinite depth \& area. See ETFG table in Ground Pathway of Detailed Report. *Base Case means Default.Lib w/o Associate Nuclide contributions. 
RESRAD, Version $6.5 \quad$ T1/2 Limit $=180$ days $\quad 07 / 21 / 2011 \quad 12: 52$ Page 10

Summary : RESRAD Parameters for U-Landfill Outdoor Worker Forward Run 100,000

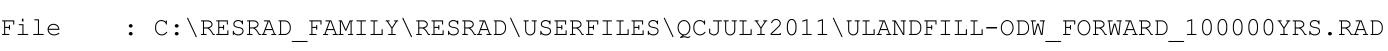

Site-Specific Parameter Summary (continued)

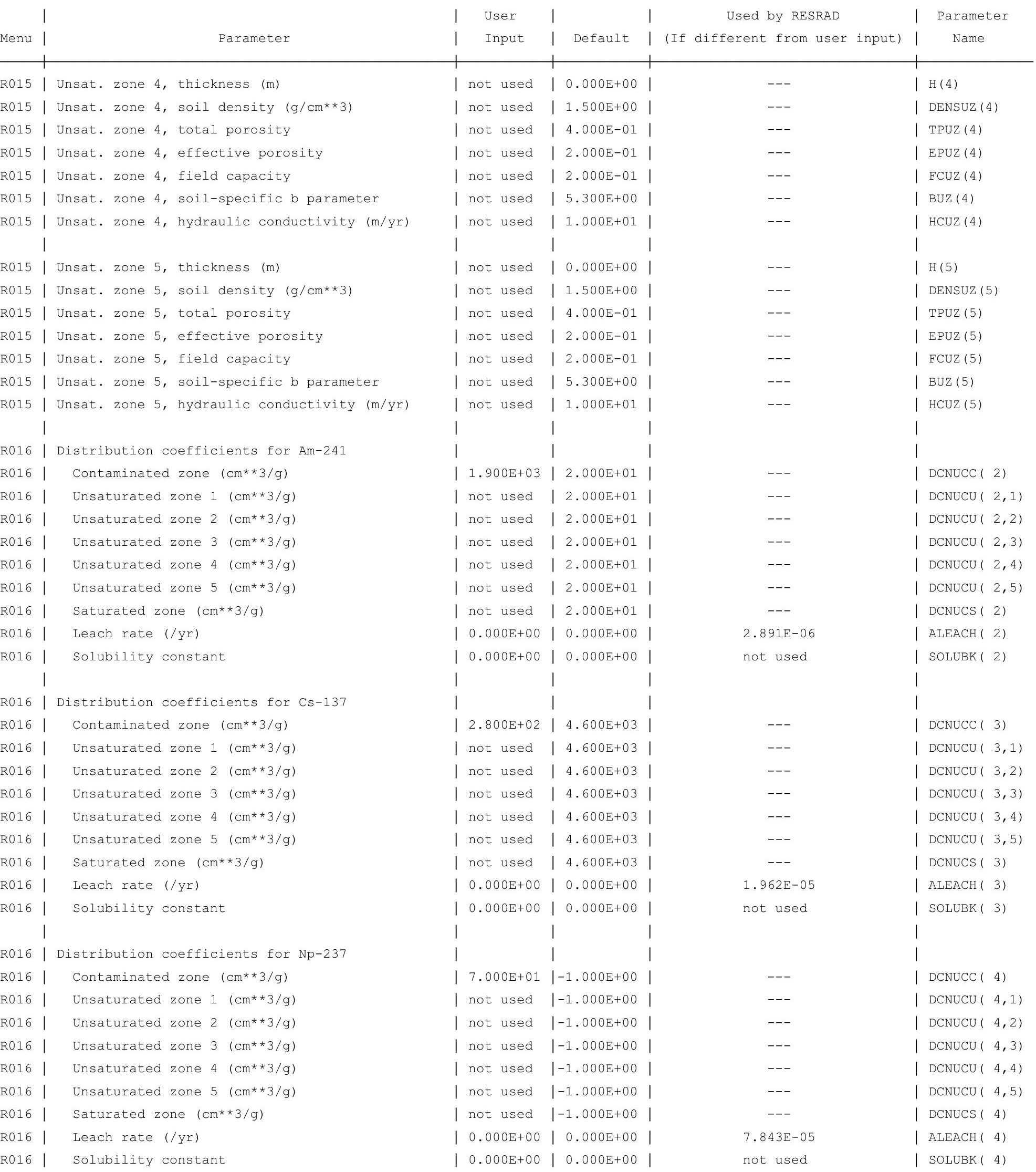

R016 Solubility constant

\begin{tabular}{|l|l|}
$\mid 0.000 \mathrm{E}+00$ & $0.000 \mathrm{E}+00$ \\
$\mid 0.000 \mathrm{E}+00$ & $0.000 \mathrm{E}+00$
\end{tabular} \mid

| SOLUBK ( 4) 
RESRAD, Version $6.5 \quad T^{1 / 2}$ Limit $=180$ days $\quad 07 / 21 / 2011 \quad 12: 52$ Page 12

Summary : RESRAD Parameters for U-Landfill Outdoor Worker Forward Run 100,000

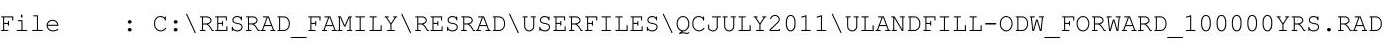

Site-Specific Parameter Summary (continued)

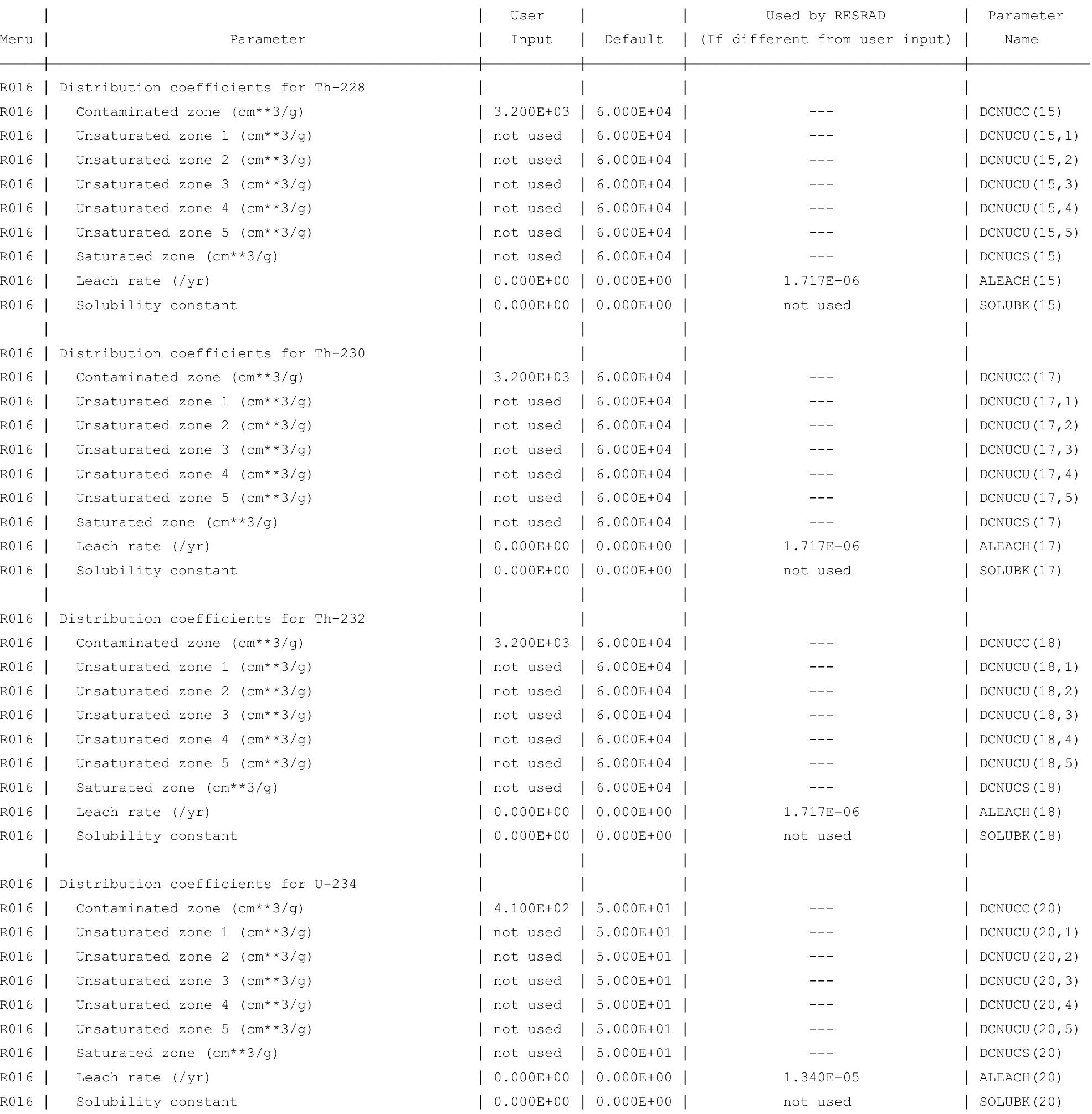


RESRAD, Version $6.5 \quad T^{1 / 2}$ Limit $=180$ days $\quad 07 / 21 / 2011 \quad 12: 52$ Page 13

Summary : RESRAD Parameters for U-Landfill Outdoor Worker Forward Run 100,000

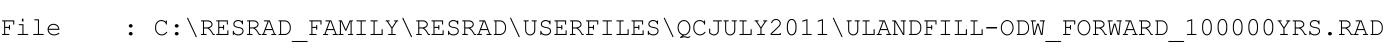

Site-Specific Parameter Summary (continued)

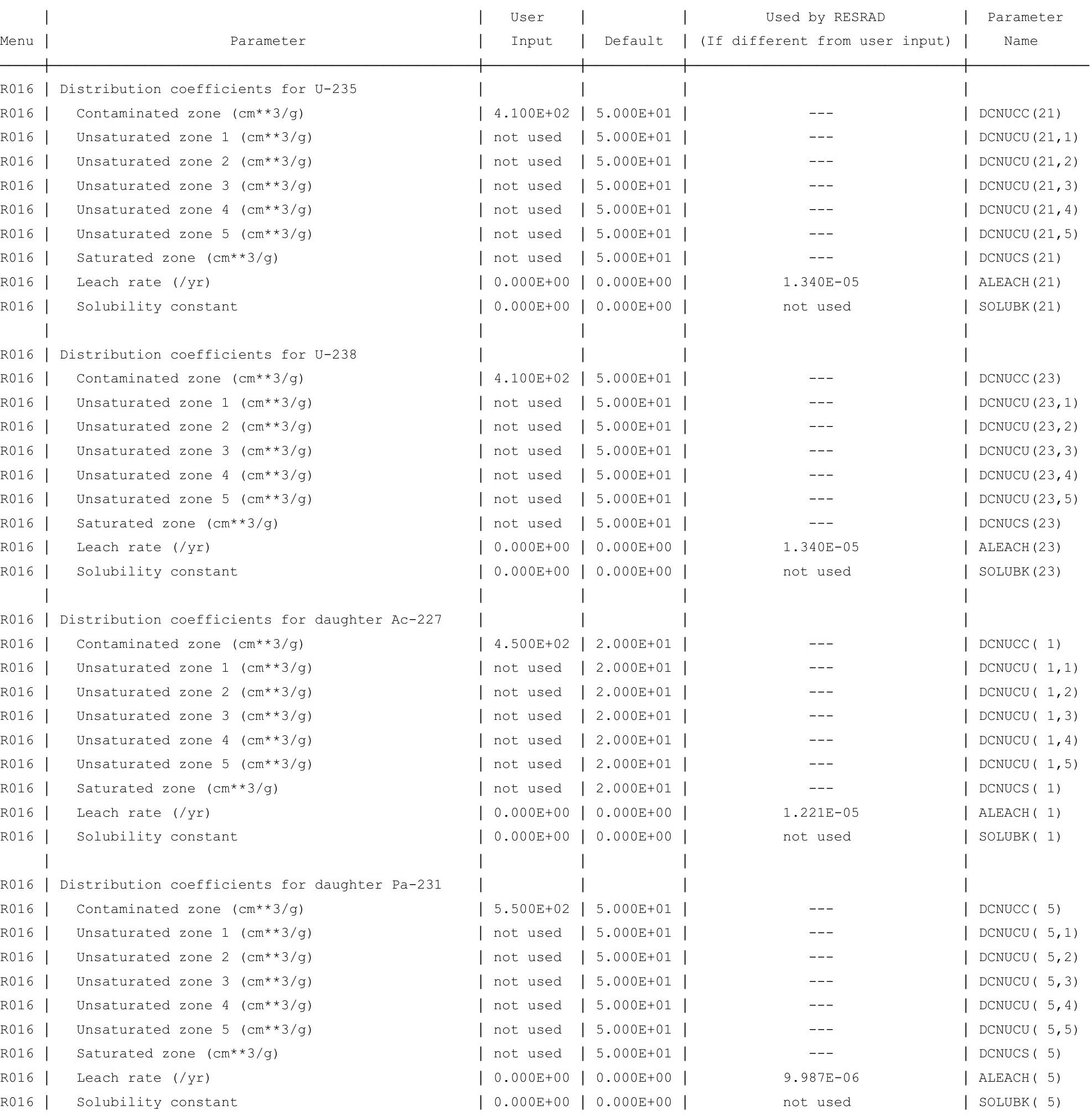

R016 | Solubility constant

| $0.000 \mathrm{E}+00 \mid 0.000 \mathrm{E}+00$

\begin{tabular}{l|l}
$0.000 \mathrm{E}+00$ & $0.000 \mathrm{E}+00$
\end{tabular}

| SOLUBK( 5) 
RESRAD, Version $6.5 \quad$ T1/2 Limit $=180$ days $\quad 07 / 21 / 2011 \quad 12: 52$ Page 14

Summary : RESRAD Parameters for U-Landfill Outdoor Worker Forward Run 100,000

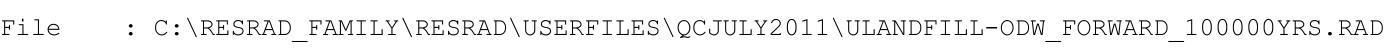

Site-Specific Parameter Summary (continued)

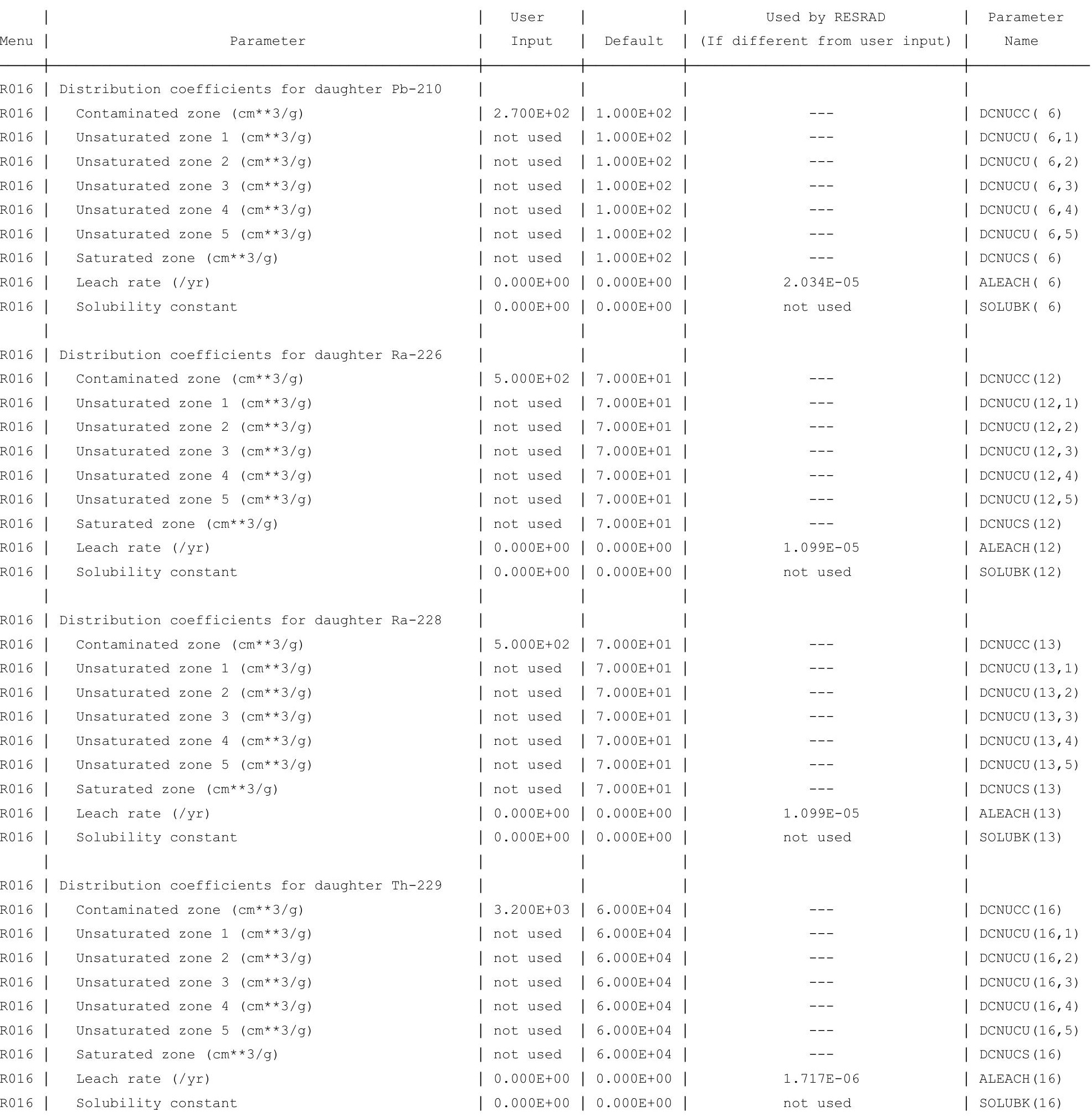


RESRAD, Version $6.5 \quad$ T1/2 Limit $=180$ days $\quad 07 / 21 / 2011 \quad 12: 52$ Page 19

Summary : RESRAD Parameters for U-Landfill Outdoor Worker Forward Run 100,000

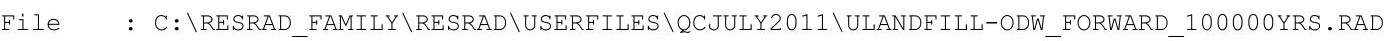

Contaminated Zone Dimensions

Area: 89436.00 square meters

Thickness:

Cover Depth:

$$
\begin{array}{r}
13.40 \text { meters } \\
1.52 \text { meters }
\end{array}
$$

Initial Soil Concentrations, pCi/g

$\begin{array}{ll}\mathrm{Am}-241 & 3.500 \mathrm{E}+01 \\ \mathrm{Cs}-137 & 1.900 \mathrm{E}+01 \\ \mathrm{~Np}-237 & 5.500 \mathrm{E}+00 \\ \mathrm{Pu}-238 & 3.900 \mathrm{E}+01 \\ \mathrm{Pu}-239 & 3.600 \mathrm{E}+01 \\ \mathrm{Pu}-240 & 3.600 \mathrm{E}+01 \\ \mathrm{TC}-99 & 5.200 \mathrm{E}+01 \\ \mathrm{Th}-228 & 4.000 \mathrm{E}+00 \\ \mathrm{Th}-230 & 1.000 \mathrm{E}+02 \\ \mathrm{Th}-232 & 4.000 \mathrm{E}+00 \\ \mathrm{U}-234 & 1.600 \mathrm{E}+02 \\ \mathrm{U}-235 & 6.500 \mathrm{E}+00 \\ \mathrm{U}-238 & 1.600 \mathrm{E}+02\end{array}$

Total Dose TDOSE(t), mrem/yr

Basic Radiation Dose Limit $=1.000 \mathrm{E}+00 \mathrm{mrem} / \mathrm{yr}$

Total Mixture Sum $M(t)=$ Fraction of Basic Dose Limit Received at Time (t)

$\begin{array}{rllllllllll}t \text { (years) }: & 0.000 \mathrm{E}+00 & 1.000 \mathrm{E}+00 & 2.500 \mathrm{E}+01 & 5.000 \mathrm{E}+01 & 1.000 \mathrm{E}+02 & 5.000 \mathrm{E}+02 & 1.050 \mathrm{E}+03 & 1.000 \mathrm{E}+04 & 1.000 \mathrm{E}+05 \\ \text { TDOSE }(\mathrm{t}): & 1.150 \mathrm{E}-06 & 8.594 \mathrm{E}-07 & 1.529 \mathrm{E}-06 & 1.950 \mathrm{E}-06 & 2.793 \mathrm{E}-06 & 4.957 \mathrm{E}-05 & 2.632 \mathrm{E}-03 & 2.178 \mathrm{E}+02 & 0.000 \mathrm{E}+00 \\ \mathrm{M}(\mathrm{t}): & 1.150 \mathrm{E}-06 & 8.594 \mathrm{E}-07 & 1.529 \mathrm{E}-06 & 1.950 \mathrm{E}-06 & 2.793 \mathrm{E}-06 & 4.957 \mathrm{E}-05 & 2.632 \mathrm{E}-03 & 2.178 \mathrm{E}+02 & 0.000 \mathrm{E}+00\end{array}$

Maximum TDOSE (t): $2.211 \mathrm{E}+02 \mathrm{mrem} / \mathrm{yr}$ at $t=19046 \pm$ * years

Total Dose Contributions TDOSE(i,p,t) for Individual Radionuclides (i) and Pathways (p) As mrem/yr and Fraction of Total Dose At $t=1.905 \mathrm{E}+04$ years

\begin{tabular}{|c|c|c|c|c|c|c|c|c|c|c|c|c|c|c|}
\hline & \multicolumn{2}{|c|}{ Ground } & \multicolumn{2}{|c|}{ Inhalation } & \multicolumn{2}{|c|}{ Radon } & \multicolumn{2}{|c|}{ Plant } & \multicolumn{2}{|c|}{ Meat } & \multicolumn{2}{|c|}{ Milk } & \multicolumn{2}{|c|}{ Soil } \\
\hline clide & mrem/yr & fract. & mrem/yr & fract. & mrem/yr & fract. & mrem/yr & fract. & mrem/yr & fract. & mrem/yr & fract. & mrem/yr & fract. \\
\hline 241 & $3.197 E-04$ & 0.0000 & $2.370 \mathrm{E}-07$ & 0.0000 & $0.000 \mathrm{E}+00$ & 0.0000 & $0.000 \mathrm{E}+00$ & 0.0000 & $0.000 \mathrm{E}+00$ & 0.0000 & $0.000 \mathrm{E}+00$ & 0.0000 & $3.237 \mathrm{E}-05$ & 0.0000 \\
\hline-137 & $0.000 \mathrm{E}+00$ & 0.0000 & $0.000 \mathrm{E}+00$ & 0.0000 & $0.000 \mathrm{E}+00$ & 0.0000 & $0.000 \mathrm{E}+00$ & 0.0000 & $0.000 \mathrm{E}+00$ & 0.0000 & $0.000 \mathrm{E}+00$ & 0.0000 & $0.000 \mathrm{E}+00$ & 0.0000 \\
\hline-237 & $2.394 \mathrm{E}-01$ & 0.0011 & $1.807 \mathrm{E}-04$ & 0.0000 & $0.000 \mathrm{E}+00$ & 0.0000 & $0.000 \mathrm{E}+00$ & 0.0000 & $0.000 \mathrm{E}+00$ & 0.0000 & $0.000 \mathrm{E}+00$ & 0.0000 & $2.472 E-02$ & 0.0001 \\
\hline-238 & $2.868 E-03$ & 0.0000 & $5.891 \mathrm{E}-07$ & 0.0000 & $0.000 \mathrm{E}+00$ & 0.0000 & $0.000 \mathrm{E}+00$ & 0.0000 & $0.000 \mathrm{E}+00$ & 0.0000 & $0.000 \mathrm{E}+00$ & 0.0000 & $4.872 \mathrm{E}-04$ & 0.0000 \\
\hline-239 & $8.361 E-04$ & 0.0000 & $3.884 \mathrm{E}-03$ & 0.0000 & $0.000 \mathrm{E}+00$ & 0.0000 & $0.000 \mathrm{E}+00$ & 0.0000 & $0.000 \mathrm{E}+00$ & 0.0000 & $0.000 \mathrm{E}+00$ & 0.0000 & $4.738 E-01$ & 0.0021 \\
\hline-240 & $7.581 E-05$ & 0.0000 & $8.923 E-04$ & 0.0000 & $0.000 \mathrm{E}+00$ & 0.0000 & $0.000 \mathrm{E}+00$ & 0.0000 & $0.000 \mathrm{E}+00$ & 0.0000 & $0.000 \mathrm{E}+00$ & 0.0000 & $1.089 \mathrm{E}-01$ & 0.0005 \\
\hline 99 & $0.000 \mathrm{E}+00$ & 0.0000 & $0.000 \mathrm{E}+00$ & 0.0000 & $0.000 \mathrm{E}+00$ & 0.0000 & $0.000 \mathrm{E}+00$ & 0.0000 & $0.000 \mathrm{E}+00$ & 0.0000 & $0.000 \mathrm{E}+00$ & 0.0000 & $0.000 \mathrm{E}+00$ & 0.0000 \\
\hline-228 & $0.000 \mathrm{E}+00$ & 0.0000 & $0.000 \mathrm{E}+00$ & 0.0000 & $0.000 \mathrm{E}+00$ & 0.0000 & $0.000 \mathrm{E}+00$ & 0.0000 & $0.000 \mathrm{E}+00$ & 0.0000 & $0.000 \mathrm{E}+00$ & 0.0000 & $0.000 \mathrm{E}+00$ & 0.0000 \\
\hline-230 & $1.435 E+02$ & 0.6490 & $1.834 \mathrm{E}-02$ & 0.0001 & $0.000 \mathrm{E}+00$ & 0.0000 & $0.000 \mathrm{E}+00$ & 0.0000 & $0.000 \mathrm{E}+00$ & 0.0000 & $0.000 \mathrm{E}+00$ & 0.0000 & $2.138 \mathrm{E}+01$ & 0.0967 \\
\hline 232 & $9.857 \mathrm{E}+00$ & 0.0446 & $1.236 \mathrm{E}-03$ & 0.0000 & $0.000 \mathrm{E}+00$ & 0.0000 & $0.000 \mathrm{E}+00$ & 0.0000 & $0.000 \mathrm{E}+00$ & 0.0000 & $0.000 \mathrm{E}+00$ & 0.0000 & $4.538 E-01$ & 0.0021 \\
\hline 34 & $3.303 E+01$ & 0.1494 & $6.763 E-03$ & 0.0000 & $0.000 \mathrm{E}+00$ & 0.0000 & $0.000 \mathrm{E}+00$ & 0.0000 & $0.000 \mathrm{E}+00$ & 0.0000 & $0.000 E+00$ & 0.0000 & $5.605 \mathrm{E}+00$ & 0.0254 \\
\hline 35 & $1.173 \mathrm{E}+00$ & 0.0053 & $2.375 E-03$ & 0.0000 & $0.000 \mathrm{E}+00$ & 0.0000 & $0.000 \mathrm{E}+00$ & 0.0000 & $0.000 \mathrm{E}+00$ & 0.0000 & $0.000 \mathrm{E}+00$ & 0.0000 & $3.901 E-01$ & 0.0018 \\
\hline 38 & $4.012 \mathrm{E}+00$ & 0.0182 & $2.108 \mathrm{E}-03$ & 0.0000 & $0.000 \mathrm{E}+00$ & 0.0000 & $0.000 \mathrm{E}+00$ & 0.0000 & $0.000 \mathrm{E}+00$ & 0.0000 & $0.000 \mathrm{E}+00$ & 0.0000 & $8.177 \mathrm{E}-01$ & 0.0037 \\
\hline & $8 \mathrm{E}+02$ & 0. & $.578 \mathrm{E}-02$ & 0.0002 & $0.000 \mathrm{E}+00$ & 0.0000 & $0.000 \mathrm{E}+00$ & 000 & $0.000 \mathrm{E}+00$ & 000 & $0.000 \mathrm{E}+00$ & 00 & +01 & 0 . \\
\hline
\end{tabular}

Water Independent Pathways (Inhalation excludes radon) 
RESRAD, Version $6.5 \quad T^{1 / 2}$ Limit $=180$ days $\quad 07 / 21 / 2011 \quad 12: 52$ Page 20

Summary : RESRAD Parameters for U-Landfill Outdoor Worker Forward Run 100,000

File : C: \RESRAD_FAMILY \RESRAD \USERFILES \QCJULY2011 \ULANDFILL-ODW_FORWARD_100000YRS.RAD

Total Dose Contributions TDOSE(i,p,t) for Individual Radionuclides (i) and Pathways (p)

As mrem/yr and Fraction of Total Dose At $t=1.905 \mathrm{E}+04$ years

Water Dependent Pathways

\begin{tabular}{|c|c|c|c|c|c|c|c|c|c|c|c|c|c|c|}
\hline & \multicolumn{2}{|c|}{ Water } & \multicolumn{2}{|c|}{ Fish } & \multicolumn{2}{|c|}{ Radon } & \multicolumn{2}{|c|}{ Plant } & \multicolumn{2}{|c|}{ Meat } & \multicolumn{2}{|c|}{ Milk } & \multicolumn{2}{|c|}{ All Pathways* } \\
\hline clide & mrem/yr & fract. & mrem/yr & fract. & mrem/yr & fract. & mrem/yr & fract. & mrem/yr & fract. & mrem/yr & fract. & mrem/yr & fract. \\
\hline-241 & $0.000 \mathrm{E}+00$ & 0.0000 & $0.000 \mathrm{E}+00$ & 0.0000 & $0.000 \mathrm{E}+00$ & 0.0000 & $0.000 \mathrm{E}+00$ & 0.0000 & $0.000 \mathrm{E}+00$ & 0.0000 & $0.000 \mathrm{E}+00$ & 0.0000 & $3.523 E-04$ & 0.0000 \\
\hline-137 & $0.000 \mathrm{E}+00$ & 0.0000 & $0.000 \mathrm{E}+00$ & 0.0000 & $0.000 \mathrm{E}+00$ & 0.0000 & $0.000 \mathrm{E}+00$ & 0.0000 & $0.000 \mathrm{E}+00$ & 0.0000 & $0.000 \mathrm{E}+00$ & 0.0000 & $0.000 \mathrm{E}+00$ & 0.0000 \\
\hline-237 & $0.000 \mathrm{E}+00$ & 0.0000 & $0.000 \mathrm{E}+00$ & 0.0000 & $0.000 \mathrm{E}+00$ & 0.0000 & $0.000 \mathrm{E}+00$ & 0.0000 & $0.000 \mathrm{E}+00$ & 0.0000 & $0.000 \mathrm{E}+00$ & 0.0000 & $2.643 \mathrm{E}-01$ & 0.0012 \\
\hline-238 & $0.000 \mathrm{E}+00$ & 0.0000 & $0.000 \mathrm{E}+00$ & 0.0000 & $0.000 \mathrm{E}+00$ & 0.0000 & $0.000 \mathrm{E}+00$ & 0.0000 & $0.000 \mathrm{E}+00$ & 0.0000 & $0.000 \mathrm{E}+00$ & 0.0000 & $3.356 \mathrm{E}-03$ & 0.0000 \\
\hline 239 & $0.000 \mathrm{E}+00$ & 0.0000 & $0.000 \mathrm{E}+00$ & 0.0000 & $0.000 \mathrm{E}+00$ & 0.0000 & $0.000 \mathrm{E}+00$ & 0.0000 & $0.000 \mathrm{E}+00$ & 0.0000 & $0.000 \mathrm{E}+00$ & 0.0000 & $4.785 E-01$ & 0.0022 \\
\hline-240 & $0.000 \mathrm{E}+00$ & 0.0000 & $0.000 \mathrm{E}+00$ & 0.0000 & $0.000 \mathrm{E}+00$ & 0.0000 & $0.000 \mathrm{E}+00$ & 0.0000 & $0.000 \mathrm{E}+00$ & 0.0000 & $0.000 \mathrm{E}+00$ & 0.0000 & $1.098 \mathrm{E}-01$ & 0.0005 \\
\hline-99 & $0.000 \mathrm{E}+00$ & 0.0000 & $0.000 \mathrm{E}+00$ & 0.0000 & $0.000 \mathrm{E}+00$ & 0.0000 & $0.000 \mathrm{E}+00$ & 0.0000 & $0.000 \mathrm{E}+00$ & 0.0000 & $0.000 \mathrm{E}+00$ & 0.0000 & $0.000 \mathrm{E}+00$ & 0.0000 \\
\hline-228 & $0.000 \mathrm{E}+00$ & 0.0000 & $0.000 \mathrm{E}+00$ & 0.0000 & $0.000 \mathrm{E}+00$ & 0.0000 & $0.000 \mathrm{E}+00$ & 0.0000 & $0.000 \mathrm{E}+00$ & 0.0000 & $0.000 \mathrm{E}+00$ & 0.0000 & $0.000 \mathrm{E}+00$ & 0.0000 \\
\hline-230 & $0.000 \mathrm{E}+00$ & 0.0000 & $0.000 \mathrm{E}+00$ & 0.0000 & $0.000 \mathrm{E}+00$ & 0.0000 & $0.000 \mathrm{E}+00$ & 0.0000 & $0.000 \mathrm{E}+00$ & 0.0000 & $0.000 \mathrm{E}+00$ & 0.0000 & $1.648 \mathrm{E}+02$ & 0.7457 \\
\hline-232 & $0.000 \mathrm{E}+00$ & 0.0000 & $0.000 \mathrm{E}+00$ & 0.0000 & $0.000 \mathrm{E}+00$ & 0.0000 & $0.000 \mathrm{E}+00$ & 0.0000 & $0.000 \mathrm{E}+00$ & 0.0000 & $0.000 \mathrm{E}+00$ & 0.0000 & $1.031 \mathrm{E}+01$ & 0.0466 \\
\hline 34 & $0.000 \mathrm{E}+00$ & 0.0000 & $0.000 \mathrm{E}+00$ & 0.0000 & $0.000 \mathrm{E}+00$ & 0.0000 & $0.000 \mathrm{E}+00$ & 0.0000 & $0.000 \mathrm{E}+00$ & 0.0000 & $0.000 \mathrm{E}+00$ & 0.0000 & $3.864 \mathrm{E}+01$ & 0.1748 \\
\hline 35 & $0.000 \mathrm{E}+00$ & 0.0000 & $0.000 \mathrm{E}+00$ & 0.0000 & $0.000 \mathrm{E}+00$ & 0.0000 & $0.000 \mathrm{E}+00$ & 0.0000 & $0.000 \mathrm{E}+00$ & 0.0000 & $0.000 \mathrm{E}+00$ & 0.0000 & $1.565 \mathrm{E}+00$ & 0.0071 \\
\hline 00 & $0.000 \mathrm{E}+00$ & 0.0000 & $0.000 \mathrm{E}+00$ & 0.0000 & $0.000 \mathrm{E}+00$ & 0.0000 & $0.000 \mathrm{E}+00$ & 0.0000 & $0.000 \mathrm{E}+00$ & 0.0000 & $0.000 \mathrm{E}+00$ & 0.0000 & $4.832 \mathrm{E}+00$ & 0.0219 \\
\hline & $0.000 \mathrm{E}+00$ & 0.0000 & $0.000 \mathrm{E}+00$ & 0.0000 & $0.000 \mathrm{E}+00$ & 0.0000 & $0.000 \mathrm{E}+00$ & 0.0000 & $0.000 \mathrm{E}+00$ & 0.0000 & $0.000 \mathrm{E}+00$ & 0.0000 & $1 E+02$ & 1.0 \\
\hline
\end{tabular}

*Sum of all water independent and dependent pathways. 
RESRAD, Version $6.5 \quad$ T1/2 Limit $=180$ days $\quad 07 / 21 / 2011 \quad 12: 52 \quad$ Page 21

Summary : RESRAD Parameters for U-Landfill Outdoor Worker Forward Run 100,000

File : C: \RESRAD_FAMILY \RESRAD \USERFILES \QCJULY2011 \ULANDFILL-ODW_FORWARD_100000YRS.RAD

Total Dose Contributions TDOSE(i,p,t) for Individual Radionuclides (i) and Pathways (p) As mrem/yr and Fraction of Total Dose At $t=0.000 \mathrm{E}+00$ years

Water Independent Pathways (Inhalation excludes radon)

\begin{tabular}{|c|c|c|c|c|c|c|c|c|c|c|c|c|c|c|}
\hline & \multicolumn{2}{|c|}{ Ground } & \multicolumn{2}{|c|}{ Inhalation } & \multicolumn{2}{|c|}{ Radon } & \multicolumn{2}{|c|}{ Plant } & \multicolumn{2}{|c|}{ Meat } & \multicolumn{2}{|c|}{ Milk } & \multicolumn{2}{|c|}{ Soil } \\
\hline Lide & mrem/yr & fract. & mrem/yr & fract. & mrem/yr & fract. & mrem/yr & fract. & mrem/yr & fract. & mrem/yr & fract. & mrem/yr & fract. \\
\hline-241 & $1.106 \mathrm{E}-18$ & 0.0000 & $0.000 \mathrm{E}+00$ & 0.0000 & $0.000 \mathrm{E}+00$ & 0.0000 & $0.000 \mathrm{E}+00$ & 0.0000 & $0.000 \mathrm{E}+00$ & 0.0000 & $0.000 \mathrm{E}+00$ & 0.0000 & $0.000 \mathrm{E}+00$ & 0.0000 \\
\hline-137 & $4.898 E-09$ & 0.0043 & $0.000 \mathrm{E}+00$ & 0.0000 & $0.000 \mathrm{E}+00$ & 0.0000 & $0.000 \mathrm{E}+00$ & 0.0000 & $0.000 \mathrm{E}+00$ & 0.0000 & $0.000 \mathrm{E}+00$ & 0.0000 & $0.000 \mathrm{E}+00$ & 0.0000 \\
\hline-237 & $1.072 \mathrm{E}-12$ & 0.0000 & $0.000 \mathrm{E}+00$ & 0.0000 & $0.000 \mathrm{E}+00$ & 0.0000 & $0.000 \mathrm{E}+00$ & 0.0000 & $0.000 \mathrm{E}+00$ & 0.0000 & $0.000 \mathrm{E}+00$ & 0.0000 & $0.000 \mathrm{E}+00$ & 0.0000 \\
\hline 238 & $6.486 \mathrm{E}-22$ & 0.0000 & $0.000 \mathrm{E}+00$ & 0.0000 & $0.000 \mathrm{E}+00$ & 0.0000 & $0.000 \mathrm{E}+00$ & 0.0000 & $0.000 \mathrm{E}+00$ & 0.0000 & $0.000 \mathrm{E}+00$ & 0.0000 & $0.000 \mathrm{E}+00$ & 0.0000 \\
\hline 239 & $8.843 E-17$ & 0.0000 & $0.000 \mathrm{E}+00$ & 0.0000 & $0.000 \mathrm{E}+00$ & 0.0000 & $0.000 \mathrm{E}+00$ & 0.0000 & $0.000 \mathrm{E}+00$ & 0.0000 & $0.000 \mathrm{E}+00$ & 0.0000 & $0.000 \mathrm{E}+00$ & 0.0000 \\
\hline 240 & $8.408 E-24$ & 0.0000 & $0.000 \mathrm{E}+00$ & 0.0000 & $0.000 \mathrm{E}+00$ & 0.0000 & $0.000 \mathrm{E}+00$ & 0.0000 & $0.000 \mathrm{E}+00$ & 0.0000 & $0.000 \mathrm{E}+00$ & 0.0000 & $0.000 \mathrm{E}+00$ & 0.0000 \\
\hline 99 & $6.129 \mathrm{E}-25$ & 0.0000 & $0.000 \mathrm{E}+00$ & 0.0000 & $0.000 \mathrm{E}+00$ & 0.0000 & $0.000 \mathrm{E}+00$ & 0.0000 & $0.000 \mathrm{E}+00$ & 0.0000 & $0.000 \mathrm{E}+00$ & 0.0000 & $0.000 \mathrm{E}+00$ & 0.0000 \\
\hline 228 & $1.130 \mathrm{E}-06$ & 0.9827 & $0.000 \mathrm{E}+00$ & 0.0000 & $0.000 \mathrm{E}+00$ & 0.0000 & $0.000 \mathrm{E}+00$ & 0.0000 & $0.000 \mathrm{E}+00$ & 0.0000 & $0.000 \mathrm{E}+00$ & 0.0000 & $0.000 \mathrm{E}+00$ & 0.0000 \\
\hline 230 & 7. $712 \mathrm{E}-10$ & 0.0007 & $0.000 \mathrm{E}+00$ & 0.0000 & $0.000 \mathrm{E}+00$ & 0.0000 & $0.000 \mathrm{E}+00$ & 0.0000 & $0.000 \mathrm{E}+00$ & 0.0000 & $0.000 \mathrm{E}+00$ & 0.0000 & $0.000 \mathrm{E}+00$ & 0.0000 \\
\hline 232 & $9.628 \mathrm{E}-09$ & 0.0084 & $0.000 \mathrm{E}+00$ & 0.0000 & $0.000 \mathrm{E}+00$ & 0.0000 & $0.000 \mathrm{E}+00$ & 0.0000 & $0.000 \mathrm{E}+00$ & 0.0000 & $0.000 \mathrm{E}+00$ & 0.0000 & $0.000 \mathrm{E}+00$ & 0.0000 \\
\hline 34 & $3.705 E-15$ & 0.0000 & $0.000 \mathrm{E}+00$ & 0.0000 & $0.000 \mathrm{E}+00$ & 0.0000 & $0.000 \mathrm{E}+00$ & 0.0000 & $0.000 \mathrm{E}+00$ & 0.0000 & $0.000 \mathrm{E}+00$ & 0.0000 & $0.000 \mathrm{E}+00$ & 0.0000 \\
\hline 35 & $1.653 E-14$ & 0.0000 & $0.000 \mathrm{E}+00$ & 0.0000 & $0.000 \mathrm{E}+00$ & 0.0000 & $0.000 \mathrm{E}+00$ & 0.0000 & $0.000 \mathrm{E}+00$ & 0.0000 & $0.000 \mathrm{E}+00$ & 0.0000 & $0.000 \mathrm{E}+00$ & 0.0000 \\
\hline 38 & $4.641 E-09$ & 0.0040 & $0.000 \mathrm{E}+00$ & 0.0000 & $0.000 \mathrm{E}+00$ & 0.0000 & $0.000 \mathrm{E}+00$ & 0.0000 & $0.000 \mathrm{E}+00$ & 0.0000 & $0.000 \mathrm{E}+00$ & 0.0000 & $0.000 \mathrm{E}+00$ & 0.0000 \\
\hline & $1.150 \mathrm{E}-06$ & 1.0000 & $0.000 \mathrm{E}+00$ & 0.0000 & $0.000 \mathrm{E}+00$ & 0.0000 & $0.000 \mathrm{E}+00$ & 0.0000 & $0.000 \mathrm{E}+00$ & 0.0000 & $0.000 \mathrm{E}+00$ & 0.0000 & $.000 \mathrm{E}+00$ & 0.0000 \\
\hline
\end{tabular}

Total Dose Contributions TDOSE(i,p,t) for Individual Radionuclides (i) and Pathways (p) As mrem/yr and Fraction of Total Dose At $t=0.000 \mathrm{E}+00$ years

Water Dependent Pathways

\begin{tabular}{|c|c|c|c|c|c|c|c|c|c|c|c|c|c|c|}
\hline \multirow{2}{*}{ Nuclide } & \multicolumn{2}{|c|}{ Water } & \multicolumn{2}{|c|}{ Fish } & \multicolumn{2}{|c|}{ Radon } & \multicolumn{2}{|c|}{ Plant } & \multicolumn{2}{|c|}{ Meat } & \multicolumn{2}{|c|}{ Milk } & \multicolumn{2}{|c|}{ All Pathways* } \\
\hline & mrem/yr & fract. & mrem/yr & fract. & mrem/yr & fract. & mrem/yr & fract. & mrem/yr & fract. & mrem/yr & fract. & mrem/yr & fract. \\
\hline-241 & $0.000 \mathrm{E}+00$ & 0.0000 & $0.000 \mathrm{E}+00$ & 0.0000 & $0.000 \mathrm{E}+00$ & 0.0000 & $0.000 \mathrm{E}+00$ & 0.0000 & $0.000 \mathrm{E}+00$ & 0.0000 & $0.000 \mathrm{E}+00$ & 0.0000 & $1.106 \mathrm{E}-18$ & 0.0000 \\
\hline-137 & $0.000 \mathrm{E}+00$ & 0.0000 & $0.000 \mathrm{E}+00$ & 0.0000 & $0.000 \mathrm{E}+00$ & 0.0000 & $0.000 \mathrm{E}+00$ & 0.0000 & $0.000 \mathrm{E}+00$ & 0.0000 & $0.000 \mathrm{E}+00$ & 0.0000 & $4.898 \mathrm{E}-09$ & 0.0043 \\
\hline-237 & $0.000 \mathrm{E}+00$ & 0.0000 & $0.000 \mathrm{E}+00$ & 0.0000 & $0.000 \mathrm{E}+00$ & 0.0000 & $0.000 \mathrm{E}+00$ & 0.0000 & $0.000 \mathrm{E}+00$ & 0.0000 & $0.000 \mathrm{E}+00$ & 0.0000 & $1.072 \mathrm{E}-12$ & 0.0000 \\
\hline-238 & $0.000 \mathrm{E}+00$ & 0.0000 & $0.000 \mathrm{E}+00$ & 0.0000 & $0.000 \mathrm{E}+00$ & 0.0000 & $0.000 \mathrm{E}+00$ & 0.0000 & $0.000 \mathrm{E}+00$ & 0.0000 & $0.000 \mathrm{E}+00$ & 0.0000 & $6.486 \mathrm{E}-22$ & 0.0000 \\
\hline 239 & $0.000 \mathrm{E}+00$ & 0.0000 & $0.000 \mathrm{E}+00$ & 0.0000 & $0.000 \mathrm{E}+00$ & 0.0000 & $0.000 \mathrm{E}+00$ & 0.0000 & $0.000 \mathrm{E}+00$ & 0.0000 & $0.000 \mathrm{E}+00$ & 0.0000 & $8.843 E-17$ & 0.0000 \\
\hline-240 & $0.000 \mathrm{E}+00$ & 0.0000 & $0.000 \mathrm{E}+00$ & 0.0000 & $0.000 \mathrm{E}+00$ & 0.0000 & $0.000 \mathrm{E}+00$ & 0.0000 & $0.000 \mathrm{E}+00$ & 0.0000 & $0.000 \mathrm{E}+00$ & 0.0000 & $8.408 E-24$ & 0.0000 \\
\hline 99 & $0.000 \mathrm{E}+00$ & 0.0000 & $0.000 \mathrm{E}+00$ & 0.0000 & $0.000 \mathrm{E}+00$ & 0.0000 & $0.000 \mathrm{E}+00$ & 0.0000 & $0.000 \mathrm{E}+00$ & 0.0000 & $0.000 \mathrm{E}+00$ & 0.0000 & $6.129 \mathrm{E}-25$ & 0.0000 \\
\hline-228 & $0.000 \mathrm{E}+00$ & 0.0000 & $0.000 \mathrm{E}+00$ & 0.0000 & $0.000 \mathrm{E}+00$ & 0.0000 & $0.000 \mathrm{E}+00$ & 0.0000 & $0.000 \mathrm{E}+00$ & 0.0000 & $0.000 \mathrm{E}+00$ & 0.0000 & $1.130 \mathrm{E}-06$ & 0.9827 \\
\hline-230 & $0.000 \mathrm{E}+00$ & 0.0000 & $0.000 \mathrm{E}+00$ & 0.0000 & $0.000 \mathrm{E}+00$ & 0.0000 & $0.000 \mathrm{E}+00$ & 0.0000 & $0.000 \mathrm{E}+00$ & 0.0000 & $0.000 \mathrm{E}+00$ & 0.0000 & 7. $712 \mathrm{E}-10$ & 0.0007 \\
\hline-232 & $0.000 \mathrm{E}+00$ & 0.0000 & $0.000 \mathrm{E}+00$ & 0.0000 & $0.000 \mathrm{E}+00$ & 0.0000 & $0.000 \mathrm{E}+00$ & 0.0000 & $0.000 \mathrm{E}+00$ & 0.0000 & $0.000 \mathrm{E}+00$ & 0.0000 & $9.628 \mathrm{E}-09$ & 0.0084 \\
\hline 234 & $0.000 \mathrm{E}+00$ & 0.0000 & $0.000 \mathrm{E}+00$ & 0.0000 & $0.000 \mathrm{E}+00$ & 0.0000 & $0.000 \mathrm{E}+00$ & 0.0000 & $0.000 \mathrm{E}+00$ & 0.0000 & $0.000 \mathrm{E}+00$ & 0.0000 & $3.705 E-15$ & 0.0000 \\
\hline 35 & $0.000 \mathrm{E}+00$ & 0.0000 & $0.000 \mathrm{E}+00$ & 0.0000 & $0.000 \mathrm{E}+00$ & 0.0000 & $0.000 \mathrm{E}+00$ & 0.0000 & $0.000 \mathrm{E}+00$ & 0.0000 & $0.000 \mathrm{E}+00$ & 0.0000 & $1.653 \mathrm{E}-14$ & 0.0000 \\
\hline 38 & $0.000 \mathrm{E}+00$ & 0.0000 & $0.000 \mathrm{E}+00$ & 0.0000 & $0.000 \mathrm{E}+00$ & 0.0000 & $0.000 \mathrm{E}+00$ & 0.0000 & $0.000 \mathrm{E}+00$ & 0.0000 & $0.000 \mathrm{E}+00$ & 0.0000 & $4.641 \mathrm{E}-09$ & 0.0040 \\
\hline & $0.000 \mathrm{E}+00$ & 0.0000 & $0.000 \mathrm{E}+00$ & 0.0000 & $0.000 \mathrm{E}+00$ & 0.0000 & $0.000 \mathrm{E}+00$ & 0.0000 & $0.000 \mathrm{E}+00$ & 0.0000 & $0.000 \mathrm{E}+00$ & 0.0000 & $1.150 \mathrm{E}-06$ & 1.0000 \\
\hline
\end{tabular}

* Sum of all water independent and dependent pathways. 
RESRAD, Version $6.5 \quad T^{1 / 2}$ Limit $=180$ days $\quad 07 / 21 / 2011 \quad 12: 52$ Page 22

Summary : RESRAD Parameters for U-Landfill Outdoor Worker Forward Run 100,000

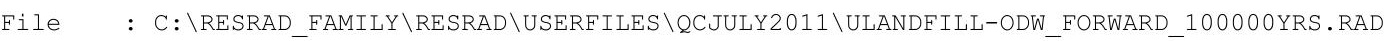

Total Dose Contributions TDOSE (i,p,t) for Individual Radionuclides (i) and Pathways (p) As mrem/yr and Fraction of Total Dose At $t=1.000 \mathrm{E}+00$ years

Water Independent Pathways (Inhalation excludes radon)

\begin{tabular}{|c|c|c|c|c|c|c|c|c|c|c|c|c|c|c|}
\hline & \multicolumn{2}{|c|}{ Ground } & \multicolumn{2}{|c|}{ Inhalation } & \multicolumn{2}{|c|}{ Radon } & \multicolumn{2}{|c|}{ Plant } & \multicolumn{2}{|c|}{ Meat } & \multicolumn{2}{|c|}{ Milk } & \multicolumn{2}{|c|}{ Soil } \\
\hline clide & mrem/yr & fract. & mrem/yr & fract. & mrem/yr & fract. & mrem/yr & fract. & mrem/yr & fract. & mrem/yr & fract. & mrem/yr & fract. \\
\hline 241 & $3.347 E-18$ & 0.0000 & $0.000 \mathrm{E}+00$ & 0.0000 & $0.000 \mathrm{E}+00$ & 0.0000 & $0.000 \mathrm{E}+00$ & 0.0000 & $0.000 \mathrm{E}+00$ & 0.0000 & $0.000 \mathrm{E}+00$ & 0.0000 & $0.000 \mathrm{E}+00$ & 0.0000 \\
\hline-137 & $4.827 E-09$ & 0.0056 & $0.000 \mathrm{E}+00$ & 0.0000 & $0.000 \mathrm{E}+00$ & 0.0000 & $0.000 \mathrm{E}+00$ & 0.0000 & $0.000 \mathrm{E}+00$ & 0.0000 & $0.000 \mathrm{E}+00$ & 0.0000 & $0.000 \mathrm{E}+00$ & 0.0000 \\
\hline-237 & $1.083 E-12$ & 0.0000 & $0.000 \mathrm{E}+00$ & 0.0000 & $0.000 \mathrm{E}+00$ & 0.0000 & $0.000 \mathrm{E}+00$ & 0.0000 & $0.000 \mathrm{E}+00$ & 0.0000 & $0.000 \mathrm{E}+00$ & 0.0000 & $0.000 \mathrm{E}+00$ & 0.0000 \\
\hline-238 & $9.637 \mathrm{E}-21$ & 0.0000 & $0.000 \mathrm{E}+00$ & 0.0000 & $0.000 \mathrm{E}+00$ & 0.0000 & $0.000 \mathrm{E}+00$ & 0.0000 & $0.000 \mathrm{E}+00$ & 0.0000 & $0.000 \mathrm{E}+00$ & 0.0000 & $0.000 \mathrm{E}+00$ & 0.0000 \\
\hline-239 & 8. $949 \mathrm{E}-17$ & 0.0000 & $0.000 \mathrm{E}+00$ & 0.0000 & $0.000 \mathrm{E}+00$ & 0.0000 & $0.000 \mathrm{E}+00$ & 0.0000 & $0.000 \mathrm{E}+00$ & 0.0000 & $0.000 \mathrm{E}+00$ & 0.0000 & $0.000 \mathrm{E}+00$ & 0.0000 \\
\hline-240 & $8.736 E-24$ & 0.0000 & $0.000 \mathrm{E}+00$ & 0.0000 & $0.000 \mathrm{E}+00$ & 0.0000 & $0.000 \mathrm{E}+00$ & 0.0000 & $0.000 \mathrm{E}+00$ & 0.0000 & $0.000 \mathrm{E}+00$ & 0.0000 & $0.000 \mathrm{E}+00$ & 0.0000 \\
\hline 99 & $6.215 E-25$ & 0.0000 & $0.000 \mathrm{E}+00$ & 0.0000 & $0.000 \mathrm{E}+00$ & 0.0000 & $0.000 \mathrm{E}+00$ & 0.0000 & $0.000 \mathrm{E}+00$ & 0.0000 & $0.000 \mathrm{E}+00$ & 0.0000 & $0.000 \mathrm{E}+00$ & 0.0000 \\
\hline-228 & 7. $912 \mathrm{E}-07$ & 0.9206 & $0.000 \mathrm{E}+00$ & 0.0000 & $0.000 \mathrm{E}+00$ & 0.0000 & $0.000 \mathrm{E}+00$ & 0.0000 & $0.000 \mathrm{E}+00$ & 0.0000 & $0.000 \mathrm{E}+00$ & 0.0000 & $0.000 \mathrm{E}+00$ & 0.0000 \\
\hline-230 & $2.327 \mathrm{E}-09$ & 0.0027 & $0.000 \mathrm{E}+00$ & 0.0000 & $0.000 \mathrm{E}+00$ & 0.0000 & $0.000 \mathrm{E}+00$ & 0.0000 & $0.000 \mathrm{E}+00$ & 0.0000 & $0.000 \mathrm{E}+00$ & 0.0000 & $0.000 \mathrm{E}+00$ & 0.0000 \\
\hline 232 & $5.638 E-08$ & 0.0656 & $0.000 \mathrm{E}+00$ & 0.0000 & $0.000 \mathrm{E}+00$ & 0.0000 & $0.000 \mathrm{E}+00$ & 0.0000 & $0.000 \mathrm{E}+00$ & 0.0000 & $0.000 \mathrm{E}+00$ & 0.0000 & $0.000 \mathrm{E}+00$ & 0.0000 \\
\hline 234 & $2.608 E-14$ & 0.0000 & $0.000 \mathrm{E}+00$ & 0.0000 & $0.000 \mathrm{E}+00$ & 0.0000 & $0.000 \mathrm{E}+00$ & 0.0000 & $0.000 \mathrm{E}+00$ & 0.0000 & $0.000 \mathrm{E}+00$ & 0.0000 & $0.000 \mathrm{E}+00$ & 0.0000 \\
\hline 235 & $1.682 \mathrm{E}-14$ & 0.0000 & $0.000 \mathrm{E}+00$ & 0.0000 & $0.000 \mathrm{E}+00$ & 0.0000 & $0.000 \mathrm{E}+00$ & 0.0000 & $0.000 \mathrm{E}+00$ & 0.0000 & $0.000 \mathrm{E}+00$ & 0.0000 & $0.000 \mathrm{E}+00$ & 0.0000 \\
\hline 38 & $4.678 E-09$ & 0.0054 & $0.000 \mathrm{E}+00$ & 0.0000 & $0.000 \mathrm{E}+00$ & 0.0000 & $0.000 \mathrm{E}+00$ & 0.0000 & $0.000 \mathrm{E}+00$ & 0.0000 & $0.000 \mathrm{E}+00$ & 0.0000 & $0.000 \mathrm{E}+00$ & 0.0000 \\
\hline & $8.594 \mathrm{E}-07$ & 1.0000 & $0.000 \mathrm{E}+00$ & 0.0000 & $0.000 \mathrm{E}+00$ & 0.0000 & $0.000 \mathrm{E}+00$ & 0.0000 & $0.000 \mathrm{E}+00$ & 0.0000 & $0.000 \mathrm{E}+00$ & 0.0000 & $0.000 \mathrm{E}+00$ & 0.0000 \\
\hline
\end{tabular}

Total Dose Contributions TDOSE(i,p,t) for Individual Radionuclides (i) and Pathways (p) As mrem/yr and Fraction of Total Dose At $t=1.000 \mathrm{E}+00$ years

Water Dependent Pathways

\begin{tabular}{|c|c|c|c|c|c|c|c|c|c|c|c|c|c|c|}
\hline \multirow{2}{*}{ Nuclide } & \multicolumn{2}{|c|}{ Water } & \multicolumn{2}{|c|}{ Fish } & \multicolumn{2}{|c|}{ Radon } & \multicolumn{2}{|c|}{ Plant } & \multicolumn{2}{|c|}{ Meat } & \multicolumn{2}{|c|}{ Milk } & \multicolumn{2}{|c|}{ All Pathways* } \\
\hline & mrem/yr & fract. & mrem/yr & fract. & mrem/yr & fract. & mrem/yr & fract. & mrem/yr & fract. & mrem/yr & fract. & mrem/yr & fract. \\
\hline-241 & $0.000 \mathrm{E}+00$ & 0.0000 & $0.000 \mathrm{E}+00$ & 0.0000 & $0.000 \mathrm{E}+00$ & 0.0000 & $0.000 \mathrm{E}+00$ & 0.0000 & $0.000 \mathrm{E}+00$ & 0.0000 & $0.000 \mathrm{E}+00$ & 0.0000 & $3.347 \mathrm{E}-18$ & 0.0000 \\
\hline-137 & $0.000 \mathrm{E}+00$ & 0.0000 & $0.000 \mathrm{E}+00$ & 0.0000 & $0.000 \mathrm{E}+00$ & 0.0000 & $0.000 \mathrm{E}+00$ & 0.0000 & $0.000 \mathrm{E}+00$ & 0.0000 & $0.000 \mathrm{E}+00$ & 0.0000 & $4.827 E-09$ & 0.0056 \\
\hline-237 & $0.000 \mathrm{E}+00$ & 0.0000 & $0.000 \mathrm{E}+00$ & 0.0000 & $0.000 \mathrm{E}+00$ & 0.0000 & $0.000 \mathrm{E}+00$ & 0.0000 & $0.000 \mathrm{E}+00$ & 0.0000 & $0.000 \mathrm{E}+00$ & 0.0000 & $1.083 \mathrm{E}-12$ & 0.0000 \\
\hline-238 & $0.000 \mathrm{E}+00$ & 0.0000 & $0.000 \mathrm{E}+00$ & 0.0000 & $0.000 \mathrm{E}+00$ & 0.0000 & $0.000 \mathrm{E}+00$ & 0.0000 & $0.000 \mathrm{E}+00$ & 0.0000 & $0.000 \mathrm{E}+00$ & 0.0000 & $9.637 \mathrm{E}-21$ & 0.0000 \\
\hline 239 & $0.000 \mathrm{E}+00$ & 0.0000 & $0.000 \mathrm{E}+00$ & 0.0000 & $0.000 \mathrm{E}+00$ & 0.0000 & $0.000 \mathrm{E}+00$ & 0.0000 & $0.000 \mathrm{E}+00$ & 0.0000 & $0.000 \mathrm{E}+00$ & 0.0000 & $8.949 \mathrm{E}-17$ & 0.0000 \\
\hline-240 & $0.000 \mathrm{E}+00$ & 0.0000 & $0.000 \mathrm{E}+00$ & 0.0000 & $0.000 \mathrm{E}+00$ & 0.0000 & $0.000 \mathrm{E}+00$ & 0.0000 & $0.000 \mathrm{E}+00$ & 0.0000 & $0.000 \mathrm{E}+00$ & 0.0000 & $8.736 \mathrm{E}-24$ & 0.0000 \\
\hline 99 & $0.000 \mathrm{E}+00$ & 0.0000 & $0.000 \mathrm{E}+00$ & 0.0000 & $0.000 \mathrm{E}+00$ & 0.0000 & $0.000 \mathrm{E}+00$ & 0.0000 & $0.000 \mathrm{E}+00$ & 0.0000 & $0.000 \mathrm{E}+00$ & 0.0000 & $6.215 \mathrm{E}-25$ & 0.0000 \\
\hline-228 & $0.000 \mathrm{E}+00$ & 0.0000 & $0.000 \mathrm{E}+00$ & 0.0000 & $0.000 \mathrm{E}+00$ & 0.0000 & $0.000 \mathrm{E}+00$ & 0.0000 & $0.000 \mathrm{E}+00$ & 0.0000 & $0.000 \mathrm{E}+00$ & 0.0000 & $7.912 \mathrm{E}-07$ & 0.9206 \\
\hline-230 & $0.000 \mathrm{E}+00$ & 0.0000 & $0.000 \mathrm{E}+00$ & 0.0000 & $0.000 \mathrm{E}+00$ & 0.0000 & $0.000 \mathrm{E}+00$ & 0.0000 & $0.000 \mathrm{E}+00$ & 0.0000 & $0.000 \mathrm{E}+00$ & 0.0000 & $2.327 \mathrm{E}-09$ & 0.0027 \\
\hline-232 & $0.000 \mathrm{E}+00$ & 0.0000 & $0.000 \mathrm{E}+00$ & 0.0000 & $0.000 \mathrm{E}+00$ & 0.0000 & $0.000 \mathrm{E}+00$ & 0.0000 & $0.000 \mathrm{E}+00$ & 0.0000 & $0.000 \mathrm{E}+00$ & 0.0000 & $5.638 \mathrm{E}-08$ & 0.0656 \\
\hline 234 & $0.000 \mathrm{E}+00$ & 0.0000 & $0.000 \mathrm{E}+00$ & 0.0000 & $0.000 \mathrm{E}+00$ & 0.0000 & $0.000 \mathrm{E}+00$ & 0.0000 & $0.000 \mathrm{E}+00$ & 0.0000 & $0.000 \mathrm{E}+00$ & 0.0000 & $2.608 \mathrm{E}-14$ & 0.0000 \\
\hline 35 & $0.000 \mathrm{E}+00$ & 0.0000 & $0.000 \mathrm{E}+00$ & 0.0000 & $0.000 \mathrm{E}+00$ & 0.0000 & $0.000 \mathrm{E}+00$ & 0.0000 & $0.000 \mathrm{E}+00$ & 0.0000 & $0.000 \mathrm{E}+00$ & 0.0000 & $1.682 \mathrm{E}-14$ & 0.0000 \\
\hline 38 & $0.000 \mathrm{E}+00$ & 0.0000 & $0.000 \mathrm{E}+00$ & 0.0000 & $0.000 \mathrm{E}+00$ & 0.0000 & $0.000 \mathrm{E}+00$ & 0.0000 & $0.000 \mathrm{E}+00$ & 0.0000 & $0.000 \mathrm{E}+00$ & 0.0000 & $4.678 \mathrm{E}-09$ & 0.0054 \\
\hline & $0.000 \mathrm{E}+00$ & 0.0000 & $0.000 \mathrm{E}+00$ & 0.0000 & $0.000 \mathrm{E}+00$ & 0.0000 & $0.000 \mathrm{E}+00$ & 0.0000 & $0.000 \mathrm{E}+00$ & 0.0000 & $0.000 \mathrm{E}+00$ & 0.0000 & $8.594 \mathrm{E}-07$ & 1.0000 \\
\hline
\end{tabular}

* Sum of all water independent and dependent pathways. 
RESRAD, Version $6.5 \quad T^{1 / 2}$ Limit $=180$ days $\quad 07 / 21 / 2011 \quad 12: 52$ Page 23

Summary : RESRAD Parameters for U-Landfill Outdoor Worker Forward Run 100,000

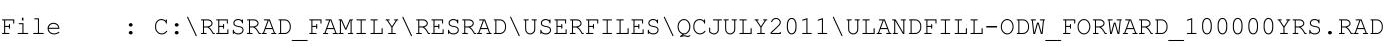

Total Dose Contributions TDOSE(i,p,t) for Individual Radionuclides (i) and Pathways (p) As mrem/yr and Fraction of Total Dose At $t=2.500 \mathrm{E}+01$ years

Water Independent Pathways (Inhalation excludes radon)

\begin{tabular}{|c|c|c|c|c|c|c|c|c|c|c|c|c|c|c|}
\hline & \multicolumn{2}{|c|}{ Ground } & \multicolumn{2}{|c|}{ Inhalation } & \multicolumn{2}{|c|}{ Radon } & \multicolumn{2}{|c|}{ Plant } & \multicolumn{2}{|c|}{ Meat } & \multicolumn{2}{|c|}{ Milk } & \multicolumn{2}{|c|}{ Soil } \\
\hline ide & mrem/yr & fract. & mrem/yr & fract. & mrem/yr & fract. & mrem/yr & fract. & mrem/yr & fract. & mrem/yr & fract. & mrem/yr & fract. \\
\hline-241 & $7.224 \mathrm{E}-17$ & 0.0000 & $0.000 \mathrm{E}+00$ & 0.0000 & $0.000 \mathrm{E}+00$ & 0.0000 & $0.000 \mathrm{E}+00$ & 0.0000 & $0.000 \mathrm{E}+00$ & 0.0000 & $0.000 \mathrm{E}+00$ & 0.0000 & $0.000 \mathrm{E}+00$ & 0.0000 \\
\hline-137 & $3.393 E-09$ & 0.0022 & $0.000 \mathrm{E}+00$ & 0.0000 & $0.000 \mathrm{E}+00$ & 0.0000 & $0.000 \mathrm{E}+00$ & 0.0000 & $0.000 \mathrm{E}+00$ & 0.0000 & $0.000 \mathrm{E}+00$ & 0.0000 & $0.000 \mathrm{E}+00$ & 0.0000 \\
\hline-237 & $1.402 \mathrm{E}-12$ & 0.0000 & $0.000 \mathrm{E}+00$ & 0.0000 & $0.000 \mathrm{E}+00$ & 0.0000 & $0.000 \mathrm{E}+00$ & 0.0000 & $0.000 \mathrm{E}+00$ & 0.0000 & $0.000 \mathrm{E}+00$ & 0.0000 & $0.000 \mathrm{E}+00$ & 0.0000 \\
\hline 238 & 4. $782 \mathrm{E}-17$ & 0.0000 & $0.000 \mathrm{E}+00$ & 0.0000 & $0.000 \mathrm{E}+00$ & 0.0000 & $0.000 \mathrm{E}+00$ & 0.0000 & $0.000 \mathrm{E}+00$ & 0.0000 & $0.000 \mathrm{E}+00$ & 0.0000 & $0.000 \mathrm{E}+00$ & 0.0000 \\
\hline 239 & $1.192 \mathrm{E}-16$ & 0.0000 & $0.000 \mathrm{E}+00$ & 0.0000 & $0.000 \mathrm{E}+00$ & 0.0000 & $0.000 \mathrm{E}+00$ & 0.0000 & $0.000 \mathrm{E}+00$ & 0.0000 & $0.000 \mathrm{E}+00$ & 0.0000 & $0.000 \mathrm{E}+00$ & 0.0000 \\
\hline 240 & $2.888 E-21$ & 0.0000 & $0.000 \mathrm{E}+00$ & 0.0000 & $0.000 \mathrm{E}+00$ & 0.0000 & $0.000 \mathrm{E}+00$ & 0.0000 & $0.000 \mathrm{E}+00$ & 0.0000 & $0.000 \mathrm{E}+00$ & 0.0000 & $0.000 \mathrm{E}+00$ & 0.0000 \\
\hline 99 & $8.680 \mathrm{E}-25$ & 0.0000 & $0.000 \mathrm{E}+00$ & 0.0000 & $0.000 \mathrm{E}+00$ & 0.0000 & $0.000 \mathrm{E}+00$ & 0.0000 & $0.000 \mathrm{E}+00$ & 0.0000 & $0.000 \mathrm{E}+00$ & 0.0000 & $0.000 \mathrm{E}+00$ & 0.0000 \\
\hline 228 & 1. $528 \mathrm{E}-10$ & 0.0001 & $0.000 \mathrm{E}+00$ & 0.0000 & $0.000 \mathrm{E}+00$ & 0.0000 & $0.000 \mathrm{E}+00$ & 0.0000 & $0.000 \mathrm{E}+00$ & 0.0000 & $0.000 \mathrm{E}+00$ & 0.0000 & $0.000 \mathrm{E}+00$ & 0.0000 \\
\hline 230 & $4.644 \mathrm{E}-08$ & 0.0304 & $0.000 \mathrm{E}+00$ & 0.0000 & $0.000 \mathrm{E}+00$ & 0.0000 & $0.000 \mathrm{E}+00$ & 0.0000 & $0.000 \mathrm{E}+00$ & 0.0000 & $0.000 \mathrm{E}+00$ & 0.0000 & $0.000 \mathrm{E}+00$ & 0.0000 \\
\hline 232 & $1.473 E-06$ & 0.9636 & $0.000 \mathrm{E}+00$ & 0.0000 & $0.000 \mathrm{E}+00$ & 0.0000 & $0.000 \mathrm{E}+00$ & 0.0000 & $0.000 \mathrm{E}+00$ & 0.0000 & $0.000 \mathrm{E}+00$ & 0.0000 & $0.000 \mathrm{E}+00$ & 0.0000 \\
\hline 34 & $8.545 E-12$ & 0.0000 & $0.000 \mathrm{E}+00$ & 0.0000 & $0.000 \mathrm{E}+00$ & 0.0000 & $0.000 \mathrm{E}+00$ & 0.0000 & $0.000 \mathrm{E}+00$ & 0.0000 & $0.000 \mathrm{E}+00$ & 0.0000 & $0.000 \mathrm{E}+00$ & 0.0000 \\
\hline 35 & $4.606 \mathrm{E}-14$ & 0.0000 & $0.000 \mathrm{E}+00$ & 0.0000 & $0.000 \mathrm{E}+00$ & 0.0000 & $0.000 \mathrm{E}+00$ & 0.0000 & $0.000 \mathrm{E}+00$ & 0.0000 & $0.000 \mathrm{E}+00$ & 0.0000 & $0.000 \mathrm{E}+00$ & 0.0000 \\
\hline 38 & $5.667 \mathrm{E}-09$ & 0.0037 & $0.000 \mathrm{E}+00$ & 0.0000 & $0.000 \mathrm{E}+00$ & 0.0000 & $0.000 \mathrm{E}+00$ & 0.0000 & $0.000 \mathrm{E}+00$ & 0.0000 & $0.000 \mathrm{E}+00$ & 0.0000 & $0.000 \mathrm{E}+00$ & 0.0000 \\
\hline & $1.529 \mathrm{E}-06$ & 1.0000 & $0.000 \mathrm{E}+00$ & 0.0000 & $0.000 \mathrm{E}+00$ & 0.0000 & $0.000 \mathrm{E}+00$ & 0.0000 & $0.000 \mathrm{E}+00$ & 0.0000 & $0.000 \mathrm{E}+00$ & 0.0000 & $.000 \mathrm{E}+00$ & 0.0000 \\
\hline
\end{tabular}

Total Dose Contributions TDOSE(i,p,t) for Individual Radionuclides (i) and Pathways (p) As mrem/yr and Fraction of Total Dose At $t=2.500 \mathrm{E}+01$ years

Water Dependent Pathways

\begin{tabular}{|c|c|c|c|c|c|c|c|c|c|c|c|c|c|c|}
\hline \multirow{2}{*}{ Nuclide } & \multicolumn{2}{|c|}{ Water } & \multicolumn{2}{|c|}{ Fish } & \multicolumn{2}{|c|}{ Radon } & \multicolumn{2}{|c|}{ Plant } & \multicolumn{2}{|c|}{ Meat } & \multicolumn{2}{|c|}{ Milk } & \multicolumn{2}{|c|}{ All Pathways* } \\
\hline & mrem/yr & fract. & mrem/yr & fract. & mrem/yr & fract. & mrem/yr & fract. & mrem/yr & fract. & mrem/yr & fract. & mrem/yr & fract. \\
\hline-241 & $0.000 \mathrm{E}+00$ & 0.0000 & $0.000 \mathrm{E}+00$ & 0.0000 & $0.000 \mathrm{E}+00$ & 0.0000 & $0.000 \mathrm{E}+00$ & 0.0000 & $0.000 \mathrm{E}+00$ & 0.0000 & $0.000 \mathrm{E}+00$ & 0.0000 & $7.224 \mathrm{E}-17$ & 0.0000 \\
\hline-137 & $0.000 \mathrm{E}+00$ & 0.0000 & $0.000 \mathrm{E}+00$ & 0.0000 & $0.000 \mathrm{E}+00$ & 0.0000 & $0.000 \mathrm{E}+00$ & 0.0000 & $0.000 \mathrm{E}+00$ & 0.0000 & $0.000 \mathrm{E}+00$ & 0.0000 & $3.393 E-09$ & 0.0022 \\
\hline-237 & $0.000 \mathrm{E}+00$ & 0.0000 & $0.000 \mathrm{E}+00$ & 0.0000 & $0.000 \mathrm{E}+00$ & 0.0000 & $0.000 \mathrm{E}+00$ & 0.0000 & $0.000 \mathrm{E}+00$ & 0.0000 & $0.000 \mathrm{E}+00$ & 0.0000 & $1.402 \mathrm{E}-12$ & 0.0000 \\
\hline-238 & $0.000 \mathrm{E}+00$ & 0.0000 & $0.000 \mathrm{E}+00$ & 0.0000 & $0.000 \mathrm{E}+00$ & 0.0000 & $0.000 \mathrm{E}+00$ & 0.0000 & $0.000 \mathrm{E}+00$ & 0.0000 & $0.000 \mathrm{E}+00$ & 0.0000 & $4.782 \mathrm{E}-17$ & 0.0000 \\
\hline 239 & $0.000 \mathrm{E}+00$ & 0.0000 & $0.000 \mathrm{E}+00$ & 0.0000 & $0.000 \mathrm{E}+00$ & 0.0000 & $0.000 \mathrm{E}+00$ & 0.0000 & $0.000 \mathrm{E}+00$ & 0.0000 & $0.000 \mathrm{E}+00$ & 0.0000 & $1.192 \mathrm{E}-16$ & 0.0000 \\
\hline-240 & $0.000 \mathrm{E}+00$ & 0.0000 & $0.000 \mathrm{E}+00$ & 0.0000 & $0.000 \mathrm{E}+00$ & 0.0000 & $0.000 \mathrm{E}+00$ & 0.0000 & $0.000 \mathrm{E}+00$ & 0.0000 & $0.000 \mathrm{E}+00$ & 0.0000 & $2.888 E-21$ & 0.0000 \\
\hline 99 & $0.000 \mathrm{E}+00$ & 0.0000 & $0.000 \mathrm{E}+00$ & 0.0000 & $0.000 \mathrm{E}+00$ & 0.0000 & $0.000 \mathrm{E}+00$ & 0.0000 & $0.000 \mathrm{E}+00$ & 0.0000 & $0.000 \mathrm{E}+00$ & 0.0000 & $8.680 \mathrm{E}-25$ & 0.0000 \\
\hline-228 & $0.000 \mathrm{E}+00$ & 0.0000 & $0.000 \mathrm{E}+00$ & 0.0000 & $0.000 \mathrm{E}+00$ & 0.0000 & $0.000 \mathrm{E}+00$ & 0.0000 & $0.000 \mathrm{E}+00$ & 0.0000 & $0.000 \mathrm{E}+00$ & 0.0000 & $1.528 \mathrm{E}-10$ & 0.0001 \\
\hline-230 & $0.000 \mathrm{E}+00$ & 0.0000 & $0.000 \mathrm{E}+00$ & 0.0000 & $0.000 \mathrm{E}+00$ & 0.0000 & $0.000 \mathrm{E}+00$ & 0.0000 & $0.000 \mathrm{E}+00$ & 0.0000 & $0.000 \mathrm{E}+00$ & 0.0000 & $4.644 \mathrm{E}-08$ & 0.0304 \\
\hline-232 & $0.000 \mathrm{E}+00$ & 0.0000 & $0.000 \mathrm{E}+00$ & 0.0000 & $0.000 \mathrm{E}+00$ & 0.0000 & $0.000 \mathrm{E}+00$ & 0.0000 & $0.000 \mathrm{E}+00$ & 0.0000 & $0.000 \mathrm{E}+00$ & 0.0000 & $1.473 E-06$ & 0.9636 \\
\hline 234 & $0.000 \mathrm{E}+00$ & 0.0000 & $0.000 \mathrm{E}+00$ & 0.0000 & $0.000 \mathrm{E}+00$ & 0.0000 & $0.000 \mathrm{E}+00$ & 0.0000 & $0.000 \mathrm{E}+00$ & 0.0000 & $0.000 \mathrm{E}+00$ & 0.0000 & $8.545 \mathrm{E}-12$ & 0.0000 \\
\hline 35 & $0.000 \mathrm{E}+00$ & 0.0000 & $0.000 \mathrm{E}+00$ & 0.0000 & $0.000 \mathrm{E}+00$ & 0.0000 & $0.000 \mathrm{E}+00$ & 0.0000 & $0.000 \mathrm{E}+00$ & 0.0000 & $0.000 \mathrm{E}+00$ & 0.0000 & $4.606 \mathrm{E}-14$ & 0.0000 \\
\hline 38 & $0.000 \mathrm{E}+00$ & 0.0000 & $0.000 \mathrm{E}+00$ & 0.0000 & $0.000 \mathrm{E}+00$ & 0.0000 & $0.000 \mathrm{E}+00$ & 0.0000 & $0.000 \mathrm{E}+00$ & 0.0000 & $0.000 \mathrm{E}+00$ & 0.0000 & $5.667 \mathrm{E}-09$ & 0.0037 \\
\hline & $0.000 \mathrm{E}+00$ & 0.0000 & $0.000 \mathrm{E}+00$ & 0.0000 & $0.000 \mathrm{E}+00$ & 0.0000 & $0.000 \mathrm{E}+00$ & 0.0000 & $0.000 \mathrm{E}+00$ & 0.0000 & $0.000 \mathrm{E}+00$ & 0.0000 & $29 E-06$ & 1.0000 \\
\hline
\end{tabular}

* Sum of all water independent and dependent pathways. 
RESRAD, Version $6.5 \quad$ T1/2 Limit = 180 days $\quad 07 / 21 / 2011 \quad 12: 52$ Page 24

Summary : RESRAD Parameters for U-Landfill Outdoor Worker Forward Run 100,000

File : C: \RESRAD_FAMILY \RESRAD \USERFILES \QCJULY2011 \ULANDFILL-ODW_FORWARD_100000YRS.RAD

Total Dose Contributions TDOSE (i,p,t) for Individual Radionuclides (i) and Pathways (p) As mrem/yr and Fraction of Total Dose At $t=5.000 \mathrm{E}+01$ years

Water Independent Pathways (Inhalation excludes radon)

\begin{tabular}{|c|c|c|c|c|c|c|c|c|c|c|c|c|c|c|}
\hline \multirow{2}{*}{$\begin{array}{l}\text { Radio- } \\
\text { Nuclide }\end{array}$} & \multicolumn{2}{|c|}{ Ground } & \multicolumn{2}{|c|}{ Inhalation } & \multicolumn{2}{|c|}{ Radon } & \multicolumn{2}{|c|}{ Plant } & \multicolumn{2}{|c|}{ Meat } & \multicolumn{2}{|c|}{ Milk } & \multicolumn{2}{|c|}{ Soil } \\
\hline & mrem/yr & fract. & mrem/yr & fract. & mrem/yr & fract. & mrem/yr & fract. & mrem/yr & fract. & mrem/yr & fract. & mrem/yr & fract. \\
\hline $1-241$ & $1.836 \mathrm{E}-16$ & 0.0000 & $0.000 \mathrm{E}+00$ & 0.0000 & $0.000 \mathrm{E}+00$ & 0.0000 & $0.000 \mathrm{E}+00$ & 0.0000 & $0.000 E+00$ & 0.0000 & $0.000 \mathrm{E}+00$ & 0.0000 & $0.000 \mathrm{E}+00$ & 0.0000 \\
\hline-137 & $2.350 \mathrm{E}-09$ & 0.0012 & $0.000 \mathrm{E}+00$ & 0.0000 & $0.000 \mathrm{E}+00$ & 0.0000 & $0.000 \mathrm{E}+00$ & 0.0000 & $0.000 \mathrm{E}+00$ & 0.0000 & $0.000 \mathrm{E}+00$ & 0.0000 & $0.000 \mathrm{E}+00$ & 0.0000 \\
\hline-237 & $1.835 \mathrm{E}-12$ & 0.0000 & $0.000 \mathrm{E}+00$ & 0.0000 & $0.000 \mathrm{E}+00$ & 0.0000 & $0.000 \mathrm{E}+00$ & 0.0000 & $0.000 \mathrm{E}+00$ & 0.0000 & $0.000 \mathrm{E}+00$ & 0.0000 & $0.000 \mathrm{E}+00$ & 0.0000 \\
\hline-238 & $4.197 \mathrm{E}-16$ & 0.0000 & $0.000 \mathrm{E}+00$ & 0.0000 & $0.000 \mathrm{E}+00$ & 0.0000 & $0.000 \mathrm{E}+00$ & 0.0000 & $0.000 \mathrm{E}+00$ & 0.0000 & $0.000 \mathrm{E}+00$ & 0.0000 & $0.000 \mathrm{E}+00$ & 0.0000 \\
\hline-239 & $1.607 \mathrm{E}-16$ & 0.0000 & $0.000 \mathrm{E}+00$ & 0.0000 & $0.000 \mathrm{E}+00$ & 0.0000 & $0.000 \mathrm{E}+00$ & 0.0000 & $0.000 \mathrm{E}+00$ & 0.0000 & $0.000 \mathrm{E}+00$ & 0.0000 & $0.000 \mathrm{E}+00$ & 0.0000 \\
\hline-240 & $1.973 \mathrm{E}-20$ & 0.0000 & $0.000 \mathrm{E}+00$ & 0.0000 & $0.000 \mathrm{E}+00$ & 0.0000 & $0.000 \mathrm{E}+00$ & 0.0000 & $0.000 \mathrm{E}+00$ & 0.0000 & $0.000 \mathrm{E}+00$ & 0.0000 & $0.000 \mathrm{E}+00$ & 0.0000 \\
\hline-99 & 1. $229 \mathrm{E}-24$ & 0.0000 & $0.000 \mathrm{E}+00$ & 0.0000 & $0.000 \mathrm{E}+00$ & 0.0000 & $0.000 \mathrm{E}+00$ & 0.0000 & $0.000 \mathrm{E}+00$ & 0.0000 & $0.000 \mathrm{E}+00$ & 0.0000 & $0.000 \mathrm{E}+00$ & 0.0000 \\
\hline-228 & $2.065 \mathrm{E}-14$ & 0.0000 & $0.000 \mathrm{E}+00$ & 0.0000 & $0.000 \mathrm{E}+00$ & 0.0000 & $0.000 \mathrm{E}+00$ & 0.0000 & $0.000 \mathrm{E}+00$ & 0.0000 & $0.000 \mathrm{E}+00$ & 0.0000 & $0.000 \mathrm{E}+00$ & 0.0000 \\
\hline-230 & $1.087 \mathrm{E}-07$ & 0.0558 & $0.000 \mathrm{E}+00$ & 0.0000 & $0.000 \mathrm{E}+00$ & 0.0000 & $0.000 \mathrm{E}+00$ & 0.0000 & $0.000 \mathrm{E}+00$ & 0.0000 & $0.000 \mathrm{E}+00$ & 0.0000 & $0.000 \mathrm{E}+00$ & 0.0000 \\
\hline-232 & $1.832 \mathrm{E}-06$ & 0.9395 & $0.000 \mathrm{E}+00$ & 0.0000 & $0.000 \mathrm{E}+00$ & 0.0000 & $0.000 \mathrm{E}+00$ & 0.0000 & $0.000 \mathrm{E}+00$ & 0.0000 & $0.000 \mathrm{E}+00$ & 0.0000 & $0.000 \mathrm{E}+00$ & 0.0000 \\
\hline 34 & $3.968 \mathrm{E}-11$ & 0.0000 & $0.000 \mathrm{E}+00$ & 0.0000 & $0.000 \mathrm{E}+00$ & 0.0000 & $0.000 \mathrm{E}+00$ & 0.0000 & $0.000 \mathrm{E}+00$ & 0.0000 & $0.000 \mathrm{E}+00$ & 0.0000 & $0.000 \mathrm{E}+00$ & 0.0000 \\
\hline 35 & $1.227 \mathrm{E}-13$ & 0.0000 & $0.000 \mathrm{E}+00$ & 0.0000 & $0.000 \mathrm{E}+00$ & 0.0000 & $0.000 \mathrm{E}+00$ & 0.0000 & $0.000 \mathrm{E}+00$ & 0.0000 & $0.000 \mathrm{E}+00$ & 0.0000 & $0.000 \mathrm{E}+00$ & 0.0000 \\
\hline 38 & $6.920 \mathrm{E}-09$ & 0.0035 & $0.000 \mathrm{E}+00$ & 0.0000 & $0.000 \mathrm{E}+00$ & 0.0000 & $0.000 \mathrm{E}+00$ & 0.0000 & $0.000 \mathrm{E}+00$ & 0.0000 & $0.000 \mathrm{E}+00$ & 0.0000 & $0.000 \mathrm{E}+00$ & 0.0000 \\
\hline & $0 E-06$ & 000 & $0.000 \mathrm{E}+00$ & 0.0000 & $0.000 \mathrm{E}+00$ & 0.0000 & $0.000 \mathrm{E}+00$ & 0.0000 & $0.000 \mathrm{E}+00$ & 000 & $0.000 \mathrm{E}+00$ & 00 & $E+00$ & 000 \\
\hline
\end{tabular}

Total Dose Contributions TDOSE(i,p,t) for Individual Radionuclides (i) and Pathways (p) As mrem/yr and Fraction of Total Dose At $t=5.000 \mathrm{E}+01$ years

Water Dependent Pathways

\begin{tabular}{|c|c|c|c|c|c|c|c|c|c|c|c|c|c|c|}
\hline \multirow{2}{*}{$\begin{array}{l}\text { Radio- } \\
\text { Nuclide }\end{array}$} & \multicolumn{2}{|c|}{ Water } & \multicolumn{2}{|c|}{ Fish } & \multicolumn{2}{|c|}{ Radon } & \multicolumn{2}{|c|}{ Plant } & \multicolumn{2}{|c|}{ Meat } & \multicolumn{2}{|c|}{ Milk } & \multicolumn{2}{|c|}{ All Pathways* } \\
\hline & mrem/yr & fract. & mrem/yr & fract. & mrem/yr & fract. & mrem/yr & fract. & mrem/yr & fract. & mrem/yr & fract. & mrem/yr & fract. \\
\hline 241 & $0.000 \mathrm{E}+00$ & 0.0000 & $0.000 \mathrm{E}+00$ & 0.0000 & $0.000 \mathrm{E}+00$ & 0.0000 & $0.000 \mathrm{E}+00$ & 0.0000 & $0.000 \mathrm{E}+00$ & 0.0000 & $0.000 \mathrm{E}+00$ & 0.0000 & $1.836 \mathrm{E}-16$ & 0.0000 \\
\hline-137 & $0.000 \mathrm{E}+00$ & 0.0000 & $0.000 \mathrm{E}+00$ & 0.0000 & $0.000 \mathrm{E}+00$ & 0.0000 & $0.000 \mathrm{E}+00$ & 0.0000 & $0.000 \mathrm{E}+00$ & 0.0000 & $0.000 \mathrm{E}+00$ & 0.0000 & $2.350 \mathrm{E}-09$ & 0.0012 \\
\hline-237 & $0.000 \mathrm{E}+00$ & 0.0000 & $0.000 \mathrm{E}+00$ & 0.0000 & $0.000 \mathrm{E}+00$ & 0.0000 & $0.000 \mathrm{E}+00$ & 0.0000 & $0.000 \mathrm{E}+00$ & 0.0000 & $0.000 \mathrm{E}+00$ & 0.0000 & $1.835 \mathrm{E}-12$ & 0.0000 \\
\hline-238 & $0.000 \mathrm{E}+00$ & 0.0000 & $0.000 \mathrm{E}+00$ & 0.0000 & $0.000 \mathrm{E}+00$ & 0.0000 & $0.000 \mathrm{E}+00$ & 0.0000 & $0.000 \mathrm{E}+00$ & 0.0000 & $0.000 \mathrm{E}+00$ & 0.0000 & $4.197 \mathrm{E}-16$ & 0.0000 \\
\hline-239 & $0.000 \mathrm{E}+00$ & 0.0000 & $0.000 \mathrm{E}+00$ & 0.0000 & $0.000 \mathrm{E}+00$ & 0.0000 & $0.000 \mathrm{E}+00$ & 0.0000 & $0.000 \mathrm{E}+00$ & 0.0000 & $0.000 E+00$ & 0.0000 & $1.607 \mathrm{E}-16$ & 0.0000 \\
\hline-240 & $0.000 \mathrm{E}+00$ & 0.0000 & $0.000 \mathrm{E}+00$ & 0.0000 & $0.000 \mathrm{E}+00$ & 0.0000 & $0.000 \mathrm{E}+00$ & 0.0000 & $0.000 \mathrm{E}+00$ & 0.0000 & $0.000 E+00$ & 0.0000 & $1.973 \mathrm{E}-20$ & 0.0000 \\
\hline-99 & $0.000 \mathrm{E}+00$ & 0.0000 & $0.000 \mathrm{E}+00$ & 0.0000 & $0.000 \mathrm{E}+00$ & 0.0000 & $0.000 \mathrm{E}+00$ & 0.0000 & $0.000 \mathrm{E}+00$ & 0.0000 & $0.000 \mathrm{E}+00$ & 0.0000 & $1.229 \mathrm{E}-24$ & 0.0000 \\
\hline-228 & $0.000 \mathrm{E}+00$ & 0.0000 & $0.000 \mathrm{E}+00$ & 0.0000 & $0.000 \mathrm{E}+00$ & 0.0000 & $0.000 \mathrm{E}+00$ & 0.0000 & $0.000 \mathrm{E}+00$ & 0.0000 & $0.000 \mathrm{E}+00$ & 0.0000 & $2.065 E-14$ & 0.0000 \\
\hline-230 & $0.000 \mathrm{E}+00$ & 0.0000 & $0.000 \mathrm{E}+00$ & 0.0000 & $0.000 \mathrm{E}+00$ & 0.0000 & $0.000 \mathrm{E}+00$ & 0.0000 & $0.000 \mathrm{E}+00$ & 0.0000 & $0.000 E+00$ & 0.0000 & $1.087 \mathrm{E}-07$ & 0.0558 \\
\hline 232 & $0.000 \mathrm{E}+00$ & 0.0000 & $0.000 \mathrm{E}+00$ & 0.0000 & $0.000 \mathrm{E}+00$ & 0.0000 & $0.000 \mathrm{E}+00$ & 0.0000 & $0.000 \mathrm{E}+00$ & 0.0000 & $0.000 \mathrm{E}+00$ & 0.0000 & $1.832 \mathrm{E}-06$ & 0.9395 \\
\hline 34 & $0.000 \mathrm{E}+00$ & 0.0000 & $0.000 \mathrm{E}+00$ & 0.0000 & $0.000 \mathrm{E}+00$ & 0.0000 & $0.000 \mathrm{E}+00$ & 0.0000 & $0.000 \mathrm{E}+00$ & 0.0000 & $0.000 \mathrm{E}+00$ & 0.0000 & $3.968 \mathrm{E}-11$ & 0.0000 \\
\hline 35 & $0.000 \mathrm{E}+00$ & 0.0000 & $0.000 \mathrm{E}+00$ & 0.0000 & $0.000 \mathrm{E}+00$ & 0.0000 & $0.000 \mathrm{E}+00$ & 0.0000 & $0.000 \mathrm{E}+00$ & 0.0000 & $0.000 \mathrm{E}+00$ & 0.0000 & $1.227 \mathrm{E}-13$ & 0.0000 \\
\hline 38 & $0.000 \mathrm{E}+00$ & 0.0000 & $0.000 \mathrm{E}+00$ & 0.0000 & $0.000 \mathrm{E}+00$ & 0.0000 & $0.000 \mathrm{E}+00$ & 0.0000 & $0.000 \mathrm{E}+00$ & 0.0000 & $0.000 \mathrm{E}+00$ & 0.0000 & $6.920 \mathrm{E}-09$ & 0.0035 \\
\hline & $0.000 \mathrm{E}+00$ & 0.0000 & $0.000 \mathrm{E}+00$ & 0.0000 & $0.000 \mathrm{E}+00$ & 0.0000 & $0.000 \mathrm{E}+00$ & 0.0000 & $0.000 \mathrm{E}+00$ & 0.0000 & $0.000 \mathrm{E}+00$ & 0.0000 & $50 E-06$ & 1. \\
\hline
\end{tabular}

* Sum of all water independent and dependent pathways. 
RESRAD, Version $6.5 \quad$ T1/2 Limit = 180 days $\quad 07 / 21 / 2011 \quad 12: 52$ Page 25

Summary : RESRAD Parameters for U-Landfill Outdoor Worker Forward Run 100,000

File : C: $\backslash$ RESRAD_FAMILY \RESRAD \USERFILES \QCJULY2011 \ULANDFILL-ODW_FORWARD_100000YRS.RAD

Total Dose Contributions TDOSE(i,p,t) for Individual Radionuclides (i) and Pathways (p) As mrem/yr and Fraction of Total Dose At $t=1.000 \mathrm{E}+02$ years

Water Independent Pathways (Inhalation excludes radon)

\begin{tabular}{|c|c|c|c|c|c|c|c|c|c|c|c|c|c|c|}
\hline & \multicolumn{2}{|c|}{ Ground } & \multicolumn{2}{|c|}{ Inhalation } & \multicolumn{2}{|c|}{ Radon } & \multicolumn{2}{|c|}{ Plant } & \multicolumn{2}{|c|}{ Meat } & \multicolumn{2}{|c|}{ Milk } & \multicolumn{2}{|c|}{ Soil } \\
\hline clide & mrem/yr & fract. & mrem/yr & fract. & mrem/yr & fract. & mrem/yr & fract. & mrem/yr & fract. & mrem/yr & fract. & mrem/yr & fract. \\
\hline 241 & $6.026 E-16$ & 0.0000 & $0.000 \mathrm{E}+00$ & 0.0000 & $0.000 \mathrm{E}+00$ & 0.0000 & $0.000 \mathrm{E}+00$ & 0.0000 & $0.000 \mathrm{E}+00$ & 0.0000 & $0.000 \mathrm{E}+00$ & 0.0000 & $0.000 \mathrm{E}+00$ & 0.0000 \\
\hline-137 & $1.128 \mathrm{E}-09$ & 0.0004 & $0.000 \mathrm{E}+00$ & 0.0000 & $0.000 \mathrm{E}+00$ & 0.0000 & $0.000 \mathrm{E}+00$ & 0.0000 & $0.000 \mathrm{E}+00$ & 0.0000 & $0.000 \mathrm{E}+00$ & 0.0000 & $0.000 \mathrm{E}+00$ & 0.0000 \\
\hline-237 & $3.151 E-12$ & 0.0000 & $0.000 \mathrm{E}+00$ & 0.0000 & $0.000 \mathrm{E}+00$ & 0.0000 & $0.000 \mathrm{E}+00$ & 0.0000 & $0.000 \mathrm{E}+00$ & 0.0000 & $0.000 \mathrm{E}+00$ & 0.0000 & $0.000 \mathrm{E}+00$ & 0.0000 \\
\hline-238 & 4. $245 E-15$ & 0.0000 & $0.000 \mathrm{E}+00$ & 0.0000 & $0.000 \mathrm{E}+00$ & 0.0000 & $0.000 \mathrm{E}+00$ & 0.0000 & $0.000 \mathrm{E}+00$ & 0.0000 & $0.000 \mathrm{E}+00$ & 0.0000 & $0.000 \mathrm{E}+00$ & 0.0000 \\
\hline-239 & $2.920 \mathrm{E}-16$ & 0.0000 & $0.000 \mathrm{E}+00$ & 0.0000 & $0.000 \mathrm{E}+00$ & 0.0000 & $0.000 \mathrm{E}+00$ & 0.0000 & $0.000 \mathrm{E}+00$ & 0.0000 & $0.000 \mathrm{E}+00$ & 0.0000 & $0.000 \mathrm{E}+00$ & 0.0000 \\
\hline-240 & 1. $313 E-19$ & 0.0000 & $0.000 \mathrm{E}+00$ & 0.0000 & $0.000 \mathrm{E}+00$ & 0.0000 & $0.000 \mathrm{E}+00$ & 0.0000 & $0.000 \mathrm{E}+00$ & 0.0000 & $0.000 \mathrm{E}+00$ & 0.0000 & $0.000 \mathrm{E}+00$ & 0.0000 \\
\hline-99 & $2.465 E-24$ & 0.0000 & $0.000 \mathrm{E}+00$ & 0.0000 & $0.000 \mathrm{E}+00$ & 0.0000 & $0.000 \mathrm{E}+00$ & 0.0000 & $0.000 \mathrm{E}+00$ & 0.0000 & $0.000 \mathrm{E}+00$ & 0.0000 & $0.000 \mathrm{E}+00$ & 0.0000 \\
\hline-228 & $3.775 E-22$ & 0.0000 & $0.000 \mathrm{E}+00$ & 0.0000 & $0.000 \mathrm{E}+00$ & 0.0000 & $0.000 \mathrm{E}+00$ & 0.0000 & $0.000 \mathrm{E}+00$ & 0.0000 & $0.000 \mathrm{E}+00$ & 0.0000 & $0.000 \mathrm{E}+00$ & 0.0000 \\
\hline-230 & $3.024 \mathrm{E}-07$ & 0.1082 & $0.000 \mathrm{E}+00$ & 0.0000 & $0.000 \mathrm{E}+00$ & 0.0000 & $0.000 \mathrm{E}+00$ & 0.0000 & $0.000 \mathrm{E}+00$ & 0.0000 & $0.000 \mathrm{E}+00$ & 0.0000 & $0.000 \mathrm{E}+00$ & 0.0000 \\
\hline-232 & $2.479 E-06$ & 0.8876 & $0.000 \mathrm{E}+00$ & 0.0000 & $0.000 \mathrm{E}+00$ & 0.0000 & $0.000 \mathrm{E}+00$ & 0.0000 & $0.000 \mathrm{E}+00$ & 0.0000 & $0.000 \mathrm{E}+00$ & 0.0000 & $0.000 \mathrm{E}+00$ & 0.0000 \\
\hline 234 & $2.204 \mathrm{E}-10$ & 0.0001 & $0.000 \mathrm{E}+00$ & 0.0000 & $0.000 \mathrm{E}+00$ & 0.0000 & $0.000 \mathrm{E}+00$ & 0.0000 & $0.000 \mathrm{E}+00$ & 0.0000 & $0.000 \mathrm{E}+00$ & 0.0000 & $0.000 \mathrm{E}+00$ & 0.0000 \\
\hline 35 & $4.503 E-13$ & 0.0000 & $0.000 \mathrm{E}+00$ & 0.0000 & $0.000 \mathrm{E}+00$ & 0.0000 & $0.000 \mathrm{E}+00$ & 0.0000 & $0.000 \mathrm{E}+00$ & 0.0000 & $0.000 \mathrm{E}+00$ & 0.0000 & $0.000 \mathrm{E}+00$ & 0.0000 \\
\hline 38 & $1.032 \mathrm{E}-08$ & 0.0037 & $0.000 \mathrm{E}+00$ & 0.0000 & $0.000 \mathrm{E}+00$ & 0.0000 & $0.000 \mathrm{E}+00$ & 0.0000 & $0.000 \mathrm{E}+00$ & 0.0000 & $0.000 \mathrm{E}+00$ & 0.0000 & $0.000 \mathrm{E}+00$ & 0.0000 \\
\hline & $2.793 E-06$ & 1.0000 & $0.000 \mathrm{E}+00$ & 0.0000 & $0.000 \mathrm{E}+00$ & 0.0000 & $0.000 \mathrm{E}+00$ & 0.0000 & $0.000 \mathrm{E}+00$ & 0.0000 & $0.000 \mathrm{E}+00$ & 0.0000 & $.000 \mathrm{E}+00$ & \\
\hline
\end{tabular}

Total Dose Contributions TDOSE(i,p,t) for Individual Radionuclides (i) and Pathways (p) As mrem/yr and Fraction of Total Dose At $t=1.000 \mathrm{E}+02$ years

Water Dependent Pathways

\begin{tabular}{|c|c|c|c|c|c|c|c|c|c|c|c|c|c|c|}
\hline & \multicolumn{2}{|c|}{ Water } & \multicolumn{2}{|c|}{ Fish } & \multicolumn{2}{|c|}{ Radon } & \multicolumn{2}{|c|}{ Plant } & \multicolumn{2}{|c|}{ Meat } & \multicolumn{2}{|c|}{ Milk } & \multicolumn{2}{|c|}{ All Pathways* } \\
\hline clide & mrem/yr & fract. & mrem/yr & fract. & mrem/yr & fract. & mrem/yr & fract. & mrem/yr & fract. & mrem/yr & fract. & mrem/yr & fract. \\
\hline-241 & $0.000 \mathrm{E}+00$ & 0.0000 & $0.000 \mathrm{E}+00$ & 0.0000 & $0.000 \mathrm{E}+00$ & 0.0000 & $0.000 \mathrm{E}+00$ & 0.0000 & $0.000 \mathrm{E}+00$ & 0.0000 & $0.000 \mathrm{E}+00$ & 0.0000 & $6.026 \mathrm{E}-16$ & 0.0000 \\
\hline-137 & $0.000 \mathrm{E}+00$ & 0.0000 & $0.000 \mathrm{E}+00$ & 0.0000 & $0.000 \mathrm{E}+00$ & 0.0000 & $0.000 \mathrm{E}+00$ & 0.0000 & $0.000 \mathrm{E}+00$ & 0.0000 & $0.000 \mathrm{E}+00$ & 0.0000 & $1.128 \mathrm{E}-09$ & 0.0004 \\
\hline-237 & $0.000 \mathrm{E}+00$ & 0.0000 & $0.000 \mathrm{E}+00$ & 0.0000 & $0.000 \mathrm{E}+00$ & 0.0000 & $0.000 \mathrm{E}+00$ & 0.0000 & $0.000 \mathrm{E}+00$ & 0.0000 & $0.000 \mathrm{E}+00$ & 0.0000 & $3.151 \mathrm{E}-12$ & 0.0000 \\
\hline 238 & $0.000 \mathrm{E}+00$ & 0.0000 & $0.000 \mathrm{E}+00$ & 0.0000 & $0.000 \mathrm{E}+00$ & 0.0000 & $0.000 \mathrm{E}+00$ & 0.0000 & $0.000 \mathrm{E}+00$ & 0.0000 & $0.000 \mathrm{E}+00$ & 0.0000 & $4.245 E-15$ & 0.0000 \\
\hline 239 & $0.000 \mathrm{E}+00$ & 0.0000 & $0.000 \mathrm{E}+00$ & 0.0000 & $0.000 \mathrm{E}+00$ & 0.0000 & $0.000 \mathrm{E}+00$ & 0.0000 & $0.000 \mathrm{E}+00$ & 0.0000 & $0.000 \mathrm{E}+00$ & 0.0000 & $2.920 \mathrm{E}-16$ & 0.0000 \\
\hline 240 & $0.000 \mathrm{E}+00$ & 0.0000 & $0.000 \mathrm{E}+00$ & 0.0000 & $0.000 \mathrm{E}+00$ & 0.0000 & $0.000 \mathrm{E}+00$ & 0.0000 & $0.000 \mathrm{E}+00$ & 0.0000 & $0.000 \mathrm{E}+00$ & 0.0000 & 1. $313 \mathrm{E}-19$ & 0.0000 \\
\hline 99 & $0.000 \mathrm{E}+00$ & 0.0000 & $0.000 \mathrm{E}+00$ & 0.0000 & $0.000 \mathrm{E}+00$ & 0.0000 & $0.000 \mathrm{E}+00$ & 0.0000 & $0.000 \mathrm{E}+00$ & 0.0000 & $0.000 \mathrm{E}+00$ & 0.0000 & $2.465 \mathrm{E}-24$ & 0.0000 \\
\hline 228 & $0.000 \mathrm{E}+00$ & 0.0000 & $0.000 \mathrm{E}+00$ & 0.0000 & $0.000 \mathrm{E}+00$ & 0.0000 & $0.000 \mathrm{E}+00$ & 0.0000 & $0.000 \mathrm{E}+00$ & 0.0000 & $0.000 \mathrm{E}+00$ & 0.0000 & $3.775 E-22$ & 0.0000 \\
\hline 230 & $0.000 \mathrm{E}+00$ & 0.0000 & $0.000 \mathrm{E}+00$ & 0.0000 & $0.000 \mathrm{E}+00$ & 0.0000 & $0.000 \mathrm{E}+00$ & 0.0000 & $0.000 \mathrm{E}+00$ & 0.0000 & $0.000 \mathrm{E}+00$ & 0.0000 & $3.024 \mathrm{E}-07$ & 0.1082 \\
\hline 232 & $0.000 \mathrm{E}+00$ & 0.0000 & $0.000 \mathrm{E}+00$ & 0.0000 & $0.000 \mathrm{E}+00$ & 0.0000 & $0.000 \mathrm{E}+00$ & 0.0000 & $0.000 \mathrm{E}+00$ & 0.0000 & $0.000 \mathrm{E}+00$ & 0.0000 & $2.479 E-06$ & 0.8876 \\
\hline & $0.000 \mathrm{E}+00$ & 0.0000 & $0.000 \mathrm{E}+00$ & 0.0000 & $0.000 \mathrm{E}+00$ & 0.0000 & $0.000 \mathrm{E}+00$ & 0.0000 & $0.000 \mathrm{E}+00$ & 0.0000 & $0.000 \mathrm{E}+00$ & 0.0000 & $2.204 \mathrm{E}-10$ & 0.0001 \\
\hline 35 & $0.000 \mathrm{E}+00$ & 0.0000 & $0.000 \mathrm{E}+00$ & 0.0000 & $0.000 \mathrm{E}+00$ & 0.0000 & $0.000 \mathrm{E}+00$ & 0.0000 & $0.000 \mathrm{E}+00$ & 0.0000 & $0.000 \mathrm{E}+00$ & 0.0000 & $4.503 E-13$ & 0.0000 \\
\hline 38 & $0.000 \mathrm{E}+00$ & 0.0000 & $0.000 \mathrm{E}+00$ & 0.0000 & $0.000 \mathrm{E}+00$ & 0.0000 & $0.000 \mathrm{E}+00$ & 0.0000 & $0.000 \mathrm{E}+00$ & 0.0000 & $0.000 \mathrm{E}+00$ & 0.0000 & $1.032 \mathrm{E}-08$ & 0.0037 \\
\hline & $0.000 \mathrm{E}+00$ & 0.0000 & $0.000 \mathrm{E}+00$ & 0.0000 & $0.000 \mathrm{E}+00$ & 0.0000 & $0.000 \mathrm{E}+00$ & 0.0000 & $0.000 \mathrm{E}+00$ & 0.0000 & $0.000 E+00$ & 000 & -06 & 1.0000 \\
\hline
\end{tabular}

* Sum of all water independent and dependent pathways. 
RESRAD, Version $6.5 \quad T^{1} \frac{1}{2}$ Limit $=180$ days $\quad 07 / 21 / 2011 \quad 12: 52$ Page 26

ummary : RESRAD Parameters for U-Landfill Outdoor Worker Forward Run 100,000

File : C: $\backslash$ RESRAD_FAMILY \RESRAD \USERFILES \QCJULY2011 \ULANDFILL-ODW_FORWARD_100000YRS.RAD

Total Dose Contributions TDOSE (i,p,t) for Individual Radionuclides (i) and Pathways (p) As mrem/yr and Fraction of Total Dose At $t=5.000 \mathrm{E}+02$ years

Water Independent Pathways (Inhalation excludes radon)

\begin{tabular}{|c|c|c|c|c|c|c|c|c|c|c|c|c|c|c|}
\hline & \multicolumn{2}{|c|}{ Ground } & \multicolumn{2}{|c|}{ Inhalation } & \multicolumn{2}{|c|}{ Radon } & \multicolumn{2}{|c|}{ Plant } & \multicolumn{2}{|c|}{ Meat } & \multicolumn{2}{|c|}{ Milk } & \multicolumn{2}{|c|}{ Soil } \\
\hline clide & mrem/yr & fract. & mrem/yr & fract. & mrem/yr & fract. & mrem/yr & fract. & mrem/yr & fract. & mrem/yr & fract. & mrem/yr & fract. \\
\hline-241 & 1. $668 \mathrm{E}-13$ & 0.0000 & $0.000 \mathrm{E}+00$ & 0.0000 & $0.000 \mathrm{E}+00$ & 0.0000 & $0.000 \mathrm{E}+00$ & 0.0000 & $0.000 \mathrm{E}+00$ & 0.0000 & $0.000 \mathrm{E}+00$ & 0.0000 & $0.000 \mathrm{E}+00$ & 0.0000 \\
\hline-137 & $3.168 \mathrm{E}-12$ & 0.0000 & $0.000 \mathrm{E}+00$ & 0.0000 & $0.000 \mathrm{E}+00$ & 0.0000 & $0.000 \mathrm{E}+00$ & 0.0000 & $0.000 \mathrm{E}+00$ & 0.0000 & $0.000 \mathrm{E}+00$ & 0.0000 & $0.000 \mathrm{E}+00$ & 0.0000 \\
\hline-237 & $2.362 E-10$ & 0.0000 & $0.000 \mathrm{E}+00$ & 0.0000 & $0.000 \mathrm{E}+00$ & 0.0000 & $0.000 \mathrm{E}+00$ & 0.0000 & $0.000 \mathrm{E}+00$ & 0.0000 & $0.000 \mathrm{E}+00$ & 0.0000 & $0.000 \mathrm{E}+00$ & 0.0000 \\
\hline 238 & $4.482 \mathrm{E}-12$ & 0.0000 & $0.000 \mathrm{E}+00$ & 0.0000 & $0.000 \mathrm{E}+00$ & 0.0000 & $0.000 \mathrm{E}+00$ & 0.0000 & $0.000 \mathrm{E}+00$ & 0.0000 & $0.000 \mathrm{E}+00$ & 0.0000 & $0.000 \mathrm{E}+00$ & 0.0000 \\
\hline 239 & $3.476 \mathrm{E}-14$ & 0.0000 & $0.000 \mathrm{E}+00$ & 0.0000 & $0.000 \mathrm{E}+00$ & 0.0000 & $0.000 \mathrm{E}+00$ & 0.0000 & $0.000 \mathrm{E}+00$ & 0.0000 & $0.000 \mathrm{E}+00$ & 0.0000 & $0.000 \mathrm{E}+00$ & 0.0000 \\
\hline 240 & $4.219 \mathrm{E}-17$ & 0.0000 & $0.000 \mathrm{E}+00$ & 0.0000 & $0.000 \mathrm{E}+00$ & 0.0000 & $0.000 \mathrm{E}+00$ & 0.0000 & $0.000 \mathrm{E}+00$ & 0.0000 & $0.000 \mathrm{E}+00$ & 0.0000 & $0.000 \mathrm{E}+00$ & 0.0000 \\
\hline 99 & $6.452 \mathrm{E}-22$ & 0.0000 & $0.000 \mathrm{E}+00$ & 0.0000 & $0.000 \mathrm{E}+00$ & 0.0000 & $0.000 \mathrm{E}+00$ & 0.0000 & $0.000 \mathrm{E}+00$ & 0.0000 & $0.000 \mathrm{E}+00$ & 0.0000 & $0.000 \mathrm{E}+00$ & 0.0000 \\
\hline 228 & $0.000 \mathrm{E}+00$ & 0.0000 & $0.000 \mathrm{E}+00$ & 0.0000 & $0.000 \mathrm{E}+00$ & 0.0000 & $0.000 \mathrm{E}+00$ & 0.0000 & $0.000 \mathrm{E}+00$ & 0.0000 & $0.000 \mathrm{E}+00$ & 0.0000 & $0.000 \mathrm{E}+00$ & 0.0000 \\
\hline 230 & $2.193 E-05$ & 0.4425 & $0.000 \mathrm{E}+00$ & 0.0000 & $0.000 \mathrm{E}+00$ & 0.0000 & $0.000 \mathrm{E}+00$ & 0.0000 & $0.000 \mathrm{E}+00$ & 0.0000 & $0.000 \mathrm{E}+00$ & 0.0000 & $0.000 \mathrm{E}+00$ & 0.0000 \\
\hline 232 & $2.730 E-05$ & 0.5508 & $0.000 \mathrm{E}+00$ & 0.0000 & $0.000 \mathrm{E}+00$ & 0.0000 & $0.000 \mathrm{E}+00$ & 0.0000 & $0.000 \mathrm{E}+00$ & 0.0000 & $0.000 \mathrm{E}+00$ & 0.0000 & $0.000 \mathrm{E}+00$ & 0.0000 \\
\hline 34 & $8.184 \mathrm{E}-08$ & 0.0017 & $0.000 \mathrm{E}+00$ & 0.0000 & $0.000 \mathrm{E}+00$ & 0.0000 & $0.000 \mathrm{E}+00$ & 0.0000 & $0.000 \mathrm{E}+00$ & 0.0000 & $0.000 \mathrm{E}+00$ & 0.0000 & $0.000 \mathrm{E}+00$ & 0.0000 \\
\hline 35 & $9.380 \mathrm{E}-11$ & 0.0000 & $0.000 \mathrm{E}+00$ & 0.0000 & $0.000 \mathrm{E}+00$ & 0.0000 & $0.000 \mathrm{E}+00$ & 0.0000 & $0.000 \mathrm{E}+00$ & 0.0000 & $0.000 \mathrm{E}+00$ & 0.0000 & $0.000 \mathrm{E}+00$ & 0.0000 \\
\hline 38 & $2.523 E-07$ & 0.0051 & $0.000 \mathrm{E}+00$ & 0.0000 & $0.000 \mathrm{E}+00$ & 0.0000 & $0.000 \mathrm{E}+00$ & 0.0000 & $0.000 \mathrm{E}+00$ & 0.0000 & $0.000 \mathrm{E}+00$ & 0.0000 & $0.000 \mathrm{E}+00$ & 0.0000 \\
\hline & $4.957 \mathrm{E}-05$ & 1.0000 & $0.000 \mathrm{E}+00$ & 0.0000 & $0.000 \mathrm{E}+00$ & 0.0000 & $0.000 \mathrm{E}+00$ & 0.0000 & $0.000 \mathrm{E}+00$ & 0.0000 & $0.000 \mathrm{E}+00$ & 000 & +00 & 0.0000 \\
\hline
\end{tabular}

Total Dose Contributions TDOSE(i,p,t) for Individual Radionuclides (i) and Pathways (p) As mrem/yr and Fraction of Total Dose At $t=5.000 \mathrm{E}+02$ years

Water Dependent Pathways

\begin{tabular}{|c|c|c|c|c|c|c|c|c|c|c|c|c|c|c|}
\hline \multirow[b]{2}{*}{ Nuclide } & \multicolumn{2}{|c|}{ Water } & \multicolumn{2}{|c|}{ Fish } & \multicolumn{2}{|c|}{ Radon } & \multicolumn{2}{|c|}{ Plant } & \multicolumn{2}{|c|}{ Meat } & \multicolumn{2}{|c|}{ Milk } & \multicolumn{2}{|c|}{ All Pathways* } \\
\hline & mrem/yr & fract. & mrem/yr & fract. & mrem/yr & fract. & mrem/yr & fract. & mrem/yr & fract. & mrem/yr & fract. & mrem/yr & fract. \\
\hline-241 & $0.000 \mathrm{E}+00$ & 0.0000 & $0.000 \mathrm{E}+00$ & 0.0000 & $0.000 \mathrm{E}+00$ & 0.0000 & $0.000 \mathrm{E}+00$ & 0.0000 & $0.000 \mathrm{E}+00$ & 0.0000 & $0.000 \mathrm{E}+00$ & 0.0000 & $1.668 \mathrm{E}-13$ & 0.0000 \\
\hline-137 & $0.000 \mathrm{E}+00$ & 0.0000 & $0.000 \mathrm{E}+00$ & 0.0000 & $0.000 \mathrm{E}+00$ & 0.0000 & $0.000 \mathrm{E}+00$ & 0.0000 & $0.000 \mathrm{E}+00$ & 0.0000 & $0.000 \mathrm{E}+00$ & 0.0000 & $3.168 \mathrm{E}-12$ & 0.0000 \\
\hline-237 & $0.000 \mathrm{E}+00$ & 0.0000 & $0.000 \mathrm{E}+00$ & 0.0000 & $0.000 \mathrm{E}+00$ & 0.0000 & $0.000 \mathrm{E}+00$ & 0.0000 & $0.000 E+00$ & 0.0000 & $0.000 \mathrm{E}+00$ & 0.0000 & $2.362 \mathrm{E}-10$ & 0.0000 \\
\hline-238 & $0.000 \mathrm{E}+00$ & 0.0000 & $0.000 \mathrm{E}+00$ & 0.0000 & $0.000 \mathrm{E}+00$ & 0.0000 & $0.000 \mathrm{E}+00$ & 0.0000 & $0.000 \mathrm{E}+00$ & 0.0000 & $0.000 \mathrm{E}+00$ & 0.0000 & $4.482 \mathrm{E}-12$ & 0.0000 \\
\hline-239 & $0.000 \mathrm{E}+00$ & 0.0000 & $0.000 \mathrm{E}+00$ & 0.0000 & $0.000 \mathrm{E}+00$ & 0.0000 & $0.000 \mathrm{E}+00$ & 0.0000 & $0.000 \mathrm{E}+00$ & 0.0000 & $0.000 \mathrm{E}+00$ & 0.0000 & $3.476 \mathrm{E}-14$ & 0.0000 \\
\hline 240 & $0.000 \mathrm{E}+00$ & 0.0000 & $0.000 \mathrm{E}+00$ & 0.0000 & $0.000 \mathrm{E}+00$ & 0.0000 & $0.000 \mathrm{E}+00$ & 0.0000 & $0.000 \mathrm{E}+00$ & 0.0000 & $0.000 \mathrm{E}+00$ & 0.0000 & $4.219 \mathrm{E}-17$ & 0.0000 \\
\hline 99 & $0.000 \mathrm{E}+00$ & 0.0000 & $0.000 \mathrm{E}+00$ & 0.0000 & $0.000 \mathrm{E}+00$ & 0.0000 & $0.000 \mathrm{E}+00$ & 0.0000 & $0.000 \mathrm{E}+00$ & 0.0000 & $0.000 \mathrm{E}+00$ & 0.0000 & $6.452 \mathrm{E}-22$ & 0.0000 \\
\hline-228 & $0.000 \mathrm{E}+00$ & 0.0000 & $0.000 \mathrm{E}+00$ & 0.0000 & $0.000 \mathrm{E}+00$ & 0.0000 & $0.000 \mathrm{E}+00$ & 0.0000 & $0.000 \mathrm{E}+00$ & 0.0000 & $0.000 \mathrm{E}+00$ & 0.0000 & $0.000 \mathrm{E}+00$ & 0.0000 \\
\hline 230 & $0.000 \mathrm{E}+00$ & 0.0000 & $0.000 \mathrm{E}+00$ & 0.0000 & $0.000 \mathrm{E}+00$ & 0.0000 & $0.000 \mathrm{E}+00$ & 0.0000 & $0.000 \mathrm{E}+00$ & 0.0000 & $0.000 \mathrm{E}+00$ & 0.0000 & $2.193 \mathrm{E}-05$ & 0.4425 \\
\hline 232 & $0.000 \mathrm{E}+00$ & 0.0000 & $0.000 \mathrm{E}+00$ & 0.0000 & $0.000 \mathrm{E}+00$ & 0.0000 & $0.000 \mathrm{E}+00$ & 0.0000 & $0.000 \mathrm{E}+00$ & 0.0000 & $0.000 \mathrm{E}+00$ & 0.0000 & $2.730 E-05$ & 0.5508 \\
\hline & $0.000 \mathrm{E}+00$ & 0.0000 & $0.000 \mathrm{E}+00$ & 0.0000 & $0.000 \mathrm{E}+00$ & 0.0000 & $0.000 \mathrm{E}+00$ & 0.0000 & $0.000 \mathrm{E}+00$ & 0.0000 & $0.000 \mathrm{E}+00$ & 0.0000 & $8.184 \mathrm{E}-08$ & 0.0017 \\
\hline 235 & $0.000 \mathrm{E}+00$ & 0.0000 & $0.000 \mathrm{E}+00$ & 0.0000 & $0.000 \mathrm{E}+00$ & 0.0000 & $0.000 \mathrm{E}+00$ & 0.0000 & $0.000 \mathrm{E}+00$ & 0.0000 & $0.000 \mathrm{E}+00$ & 0.0000 & $9.380 \mathrm{E}-11$ & 0.0000 \\
\hline 38 & $0.000 \mathrm{E}+00$ & 0.0000 & $0.000 \mathrm{E}+00$ & 0.0000 & $0.000 \mathrm{E}+00$ & 0.0000 & $0.000 \mathrm{E}+00$ & 0.0000 & $0.000 \mathrm{E}+00$ & 0.0000 & $0.000 \mathrm{E}+00$ & 0.0000 & $2.523 E-07$ & 0.0051 \\
\hline & $0.000 \mathrm{E}+00$ & 0.0000 & $0.000 \mathrm{E}+00$ & 0.0000 & $0.000 \mathrm{E}+00$ & 0.0000 & $0.000 \mathrm{E}+00$ & 0.0000 & $0.000 \mathrm{E}+00$ & 0.0000 & $0.000 \mathrm{E}+00$ & 000 & -05 & 1.0000 \\
\hline
\end{tabular}

* Sum of all water independent and dependent pathways. 
RESRAD, Version $6.5 \quad T^{1 / 2}$ Limit $=180$ days $\quad 07 / 21 / 2011 \quad 12: 52 \quad$ Page 27

Summary : RESRAD Parameters for U-Landfill Outdoor Worker Forward Run 100,000

File : C: \RESRAD_FAMILY \RESRAD \USERFILES \QCJULY2011 \ULANDFILL-ODW_FORWARD_100000YRS.RAD

Total Dose Contributions TDOSE(i,p,t) for Individual Radionuclides (i) and Pathways (p) As mrem/yr and Fraction of Total Dose At $t=1.050 \mathrm{E}+03$ years

Water Independent Pathways (Inhalation excludes radon)

\begin{tabular}{|c|c|c|c|c|c|c|c|c|c|c|c|c|c|c|}
\hline & \multicolumn{2}{|c|}{ Ground } & \multicolumn{2}{|c|}{ Inhalation } & \multicolumn{2}{|c|}{ Radon } & \multicolumn{2}{|c|}{ Plant } & \multicolumn{2}{|c|}{ Meat } & \multicolumn{2}{|c|}{ Milk } & \multicolumn{2}{|c|}{ Soil } \\
\hline Lide & mrem/yr & fract. & mrem/yr & fract. & mrem/yr & fract. & mrem/yr & fract. & mrem/yr & fract. & mrem/yr & fract. & mrem/yr & fract. \\
\hline-241 & $9.032 \mathrm{E}-11$ & 0.0000 & $0.000 \mathrm{E}+00$ & 0.0000 & $0.000 \mathrm{E}+00$ & 0.0000 & $0.000 \mathrm{E}+00$ & 0.0000 & $0.000 \mathrm{E}+00$ & 0.0000 & $0.000 \mathrm{E}+00$ & 0.0000 & $0.000 \mathrm{E}+00$ & 0.0000 \\
\hline-137 & $9.832 \mathrm{E}-16$ & 0.0000 & $0.000 \mathrm{E}+00$ & 0.0000 & $0.000 \mathrm{E}+00$ & 0.0000 & $0.000 \mathrm{E}+00$ & 0.0000 & $0.000 \mathrm{E}+00$ & 0.0000 & $0.000 \mathrm{E}+00$ & 0.0000 & $0.000 \mathrm{E}+00$ & 0.0000 \\
\hline 237 & $8.468 E-08$ & 0.0000 & $0.000 \mathrm{E}+00$ & 0.0000 & $0.000 \mathrm{E}+00$ & 0.0000 & $0.000 \mathrm{E}+00$ & 0.0000 & $0.000 \mathrm{E}+00$ & 0.0000 & $0.000 \mathrm{E}+00$ & 0.0000 & $0.000 \mathrm{E}+00$ & 0.0000 \\
\hline 238 & $1.044 \mathrm{E}-09$ & 0.0000 & $0.000 \mathrm{E}+00$ & 0.0000 & $0.000 \mathrm{E}+00$ & 0.0000 & $0.000 \mathrm{E}+00$ & 0.0000 & $0.000 \mathrm{E}+00$ & 0.0000 & $0.000 \mathrm{E}+00$ & 0.0000 & $0.000 \mathrm{E}+00$ & 0.0000 \\
\hline 239 & $2.474 E-11$ & 0.0000 & $0.000 \mathrm{E}+00$ & 0.0000 & $0.000 \mathrm{E}+00$ & 0.0000 & $0.000 \mathrm{E}+00$ & 0.0000 & $0.000 \mathrm{E}+00$ & 0.0000 & $0.000 \mathrm{E}+00$ & 0.0000 & $0.000 \mathrm{E}+00$ & 0.0000 \\
\hline 240 & $5.993 E-15$ & 0.0000 & $0.000 \mathrm{E}+00$ & 0.0000 & $0.000 \mathrm{E}+00$ & 0.0000 & $0.000 \mathrm{E}+00$ & 0.0000 & $0.000 \mathrm{E}+00$ & 0.0000 & $0.000 \mathrm{E}+00$ & 0.0000 & $0.000 \mathrm{E}+00$ & 0.0000 \\
\hline 99 & $1.362 \mathrm{E}-18$ & 0.0000 & $0.000 \mathrm{E}+00$ & 0.0000 & $0.000 \mathrm{E}+00$ & 0.0000 & $0.000 \mathrm{E}+00$ & 0.0000 & $0.000 \mathrm{E}+00$ & 0.0000 & $0.000 \mathrm{E}+00$ & 0.0000 & $0.000 \mathrm{E}+00$ & 0.0000 \\
\hline 228 & $0.000 \mathrm{E}+00$ & 0.0000 & $0.000 \mathrm{E}+00$ & 0.0000 & $0.000 \mathrm{E}+00$ & 0.0000 & $0.000 \mathrm{E}+00$ & 0.0000 & $0.000 \mathrm{E}+00$ & 0.0000 & $0.000 \mathrm{E}+00$ & 0.0000 & $0.000 \mathrm{E}+00$ & 0.0000 \\
\hline 230 & $1.840 \mathrm{E}-03$ & 0.6991 & $0.000 \mathrm{E}+00$ & 0.0000 & $0.000 \mathrm{E}+00$ & 0.0000 & $0.000 \mathrm{E}+00$ & 0.0000 & $0.000 \mathrm{E}+00$ & 0.0000 & $0.000 \mathrm{E}+00$ & 0.0000 & $0.000 \mathrm{E}+00$ & 0.0000 \\
\hline 232 & $7.565 E-04$ & 0.2874 & $0.000 \mathrm{E}+00$ & 0.0000 & $0.000 \mathrm{E}+00$ & 0.0000 & $0.000 \mathrm{E}+00$ & 0.0000 & $0.000 \mathrm{E}+00$ & 0.0000 & $0.000 \mathrm{E}+00$ & 0.0000 & $0.000 \mathrm{E}+00$ & 0.0000 \\
\hline 34 & 1. $495 \mathrm{E}-05$ & 0.0057 & $0.000 \mathrm{E}+00$ & 0.0000 & $0.000 \mathrm{E}+00$ & 0.0000 & $0.000 \mathrm{E}+00$ & 0.0000 & $0.000 \mathrm{E}+00$ & 0.0000 & $0.000 \mathrm{E}+00$ & 0.0000 & $0.000 \mathrm{E}+00$ & 0.0000 \\
\hline 35 & $3.148 E-08$ & 0.0000 & $0.000 \mathrm{E}+00$ & 0.0000 & $0.000 \mathrm{E}+00$ & 0.0000 & $0.000 \mathrm{E}+00$ & 0.0000 & $0.000 \mathrm{E}+00$ & 0.0000 & $0.000 \mathrm{E}+00$ & 0.0000 & $0.000 \mathrm{E}+00$ & 0.0000 \\
\hline 38 & $2.047 E-05$ & 0.0078 & $0.000 \mathrm{E}+00$ & 0.0000 & $0.000 \mathrm{E}+00$ & 0.0000 & $0.000 \mathrm{E}+00$ & 0.0000 & $0.000 \mathrm{E}+00$ & 0.0000 & $0.000 \mathrm{E}+00$ & 0.0000 & $0.000 \mathrm{E}+00$ & 0.0000 \\
\hline & $2.632 \mathrm{E}-03$ & 1.0000 & $0.000 \mathrm{E}+00$ & 0.0000 & $0.000 \mathrm{E}+00$ & 0.0000 & $0.000 \mathrm{E}+00$ & 0.0000 & $0.000 \mathrm{E}+00$ & 0.0000 & $0.000 \mathrm{E}+00$ & 0.0000 & $.000 \mathrm{E}+00$ & 0.0000 \\
\hline
\end{tabular}

Total Dose Contributions TDOSE(i,p,t) for Individual Radionuclides (i) and Pathways (p) As mrem/yr and Fraction of Total Dose At $t=1.050 \mathrm{E}+03$ years

Water Dependent Pathways

\begin{tabular}{|c|c|c|c|c|c|c|c|c|c|c|c|c|c|c|}
\hline \multirow{2}{*}{ Nuclide } & \multicolumn{2}{|c|}{ Water } & \multicolumn{2}{|c|}{ Fish } & \multicolumn{2}{|c|}{ Radon } & \multicolumn{2}{|c|}{ Plant } & \multicolumn{2}{|c|}{ Meat } & \multicolumn{2}{|c|}{ Milk } & \multicolumn{2}{|c|}{ All Pathways* } \\
\hline & mrem/yr & fract. & mrem/yr & fract. & mrem/yr & fract. & mrem/yr & fract. & mrem/yr & fract. & mrem/yr & fract. & mrem/yr & fract. \\
\hline-241 & $0.000 \mathrm{E}+00$ & 0.0000 & $0.000 \mathrm{E}+00$ & 0.0000 & $0.000 \mathrm{E}+00$ & 0.0000 & $0.000 \mathrm{E}+00$ & 0.0000 & $0.000 \mathrm{E}+00$ & 0.0000 & $0.000 \mathrm{E}+00$ & 0.0000 & $9.032 \mathrm{E}-11$ & 0.0000 \\
\hline-137 & $0.000 \mathrm{E}+00$ & 0.0000 & $0.000 \mathrm{E}+00$ & 0.0000 & $0.000 \mathrm{E}+00$ & 0.0000 & $0.000 \mathrm{E}+00$ & 0.0000 & $0.000 \mathrm{E}+00$ & 0.0000 & $0.000 \mathrm{E}+00$ & 0.0000 & $9.832 \mathrm{E}-16$ & 0.0000 \\
\hline-237 & $0.000 \mathrm{E}+00$ & 0.0000 & $0.000 \mathrm{E}+00$ & 0.0000 & $0.000 \mathrm{E}+00$ & 0.0000 & $0.000 \mathrm{E}+00$ & 0.0000 & $0.000 \mathrm{E}+00$ & 0.0000 & $0.000 \mathrm{E}+00$ & 0.0000 & $8.468 E-08$ & 0.0000 \\
\hline-238 & $0.000 \mathrm{E}+00$ & 0.0000 & $0.000 \mathrm{E}+00$ & 0.0000 & $0.000 \mathrm{E}+00$ & 0.0000 & $0.000 \mathrm{E}+00$ & 0.0000 & $0.000 \mathrm{E}+00$ & 0.0000 & $0.000 \mathrm{E}+00$ & 0.0000 & $1.044 \mathrm{E}-09$ & 0.0000 \\
\hline 239 & $0.000 \mathrm{E}+00$ & 0.0000 & $0.000 \mathrm{E}+00$ & 0.0000 & $0.000 \mathrm{E}+00$ & 0.0000 & $0.000 \mathrm{E}+00$ & 0.0000 & $0.000 \mathrm{E}+00$ & 0.0000 & $0.000 \mathrm{E}+00$ & 0.0000 & $2.474 \mathrm{E}-11$ & 0.0000 \\
\hline-240 & $0.000 \mathrm{E}+00$ & 0.0000 & $0.000 \mathrm{E}+00$ & 0.0000 & $0.000 \mathrm{E}+00$ & 0.0000 & $0.000 \mathrm{E}+00$ & 0.0000 & $0.000 \mathrm{E}+00$ & 0.0000 & $0.000 \mathrm{E}+00$ & 0.0000 & $5.993 E-15$ & 0.0000 \\
\hline 99 & $0.000 \mathrm{E}+00$ & 0.0000 & $0.000 \mathrm{E}+00$ & 0.0000 & $0.000 \mathrm{E}+00$ & 0.0000 & $0.000 \mathrm{E}+00$ & 0.0000 & $0.000 \mathrm{E}+00$ & 0.0000 & $0.000 \mathrm{E}+00$ & 0.0000 & 1. $362 \mathrm{E}-18$ & 0.0000 \\
\hline-228 & $0.000 \mathrm{E}+00$ & 0.0000 & $0.000 \mathrm{E}+00$ & 0.0000 & $0.000 \mathrm{E}+00$ & 0.0000 & $0.000 \mathrm{E}+00$ & 0.0000 & $0.000 \mathrm{E}+00$ & 0.0000 & $0.000 \mathrm{E}+00$ & 0.0000 & $0.000 \mathrm{E}+00$ & 0.0000 \\
\hline-230 & $0.000 \mathrm{E}+00$ & 0.0000 & $0.000 \mathrm{E}+00$ & 0.0000 & $0.000 \mathrm{E}+00$ & 0.0000 & $0.000 \mathrm{E}+00$ & 0.0000 & $0.000 \mathrm{E}+00$ & 0.0000 & $0.000 \mathrm{E}+00$ & 0.0000 & $1.840 \mathrm{E}-03$ & 0.6991 \\
\hline-232 & $0.000 \mathrm{E}+00$ & 0.0000 & $0.000 \mathrm{E}+00$ & 0.0000 & $0.000 \mathrm{E}+00$ & 0.0000 & $0.000 \mathrm{E}+00$ & 0.0000 & $0.000 \mathrm{E}+00$ & 0.0000 & $0.000 \mathrm{E}+00$ & 0.0000 & $7.565 \mathrm{E}-04$ & 0.2874 \\
\hline 234 & $0.000 \mathrm{E}+00$ & 0.0000 & $0.000 \mathrm{E}+00$ & 0.0000 & $0.000 \mathrm{E}+00$ & 0.0000 & $0.000 \mathrm{E}+00$ & 0.0000 & $0.000 \mathrm{E}+00$ & 0.0000 & $0.000 \mathrm{E}+00$ & 0.0000 & $1.495 \mathrm{E}-05$ & 0.0057 \\
\hline 35 & $0.000 \mathrm{E}+00$ & 0.0000 & $0.000 \mathrm{E}+00$ & 0.0000 & $0.000 \mathrm{E}+00$ & 0.0000 & $0.000 \mathrm{E}+00$ & 0.0000 & $0.000 \mathrm{E}+00$ & 0.0000 & $0.000 \mathrm{E}+00$ & 0.0000 & $3.148 \mathrm{E}-08$ & 0.0000 \\
\hline 38 & $0.000 \mathrm{E}+00$ & 0.0000 & $0.000 \mathrm{E}+00$ & 0.0000 & $0.000 \mathrm{E}+00$ & 0.0000 & $0.000 \mathrm{E}+00$ & 0.0000 & $0.000 \mathrm{E}+00$ & 0.0000 & $0.000 \mathrm{E}+00$ & 0.0000 & $2.047 \mathrm{E}-05$ & 0.0078 \\
\hline & $0.000 \mathrm{E}+00$ & 0.0000 & $0.000 \mathrm{E}+00$ & 0.0000 & $0.000 \mathrm{E}+00$ & 0.0000 & $0.000 \mathrm{E}+00$ & 0.0000 & $0.000 \mathrm{E}+00$ & 0.0000 & $0.000 \mathrm{E}+00$ & 0.0000 & $.632 E-03$ & 1.0000 \\
\hline
\end{tabular}

* Sum of all water independent and dependent pathways. 
RESRAD, Version $6.5 \quad$ T1/2 Limit $=180$ days $\quad 07 / 21 / 2011 \quad 12: 52$ Page 28

ummary : RESRAD Parameters for U-Landfill Outdoor Worker Forward Run 100,000

File : C: $\backslash$ RESRAD_FAMILY \RESRAD \USERFILES \QCJULY2011 \ULANDFILL-ODW_FORWARD_100000YRS.RAD

Total Dose Contributions TDOSE(i,p,t) for Individual Radionuclides (i) and Pathways (p) As mrem/yr and Fraction of Total Dose At $t=1.000 \mathrm{E}+04$ years

Water Independent Pathways (Inhalation excludes radon)

\begin{tabular}{|c|c|c|c|c|c|c|c|c|c|c|c|c|c|c|}
\hline & \multicolumn{2}{|c|}{ Ground } & \multicolumn{2}{|c|}{ Inhalation } & \multicolumn{2}{|c|}{ Radon } & \multicolumn{2}{|c|}{ Plant } & \multicolumn{2}{|c|}{ Meat } & \multicolumn{2}{|c|}{ Milk } & \multicolumn{2}{|c|}{ Soil } \\
\hline ide & mrem/yr & fract. & mrem/yr & fract. & mrem/yr & fract. & mrem/yr & fract. & mrem/yr & fract. & mrem/yr & fract. & mrem/yr & fract. \\
\hline-241 & $5.891 \mathrm{E}-04$ & 0.0000 & $3.560 \mathrm{E}-07$ & 0.0000 & $0.000 \mathrm{E}+00$ & 0.0000 & $0.000 \mathrm{E}+00$ & 0.0000 & $0.000 \mathrm{E}+00$ & 0.0000 & $0.000 \mathrm{E}+00$ & 0.0000 & $4.717 \mathrm{E}-05$ & 0.0000 \\
\hline-137 & $0.000 \mathrm{E}+00$ & 0.0000 & $0.000 \mathrm{E}+00$ & 0.0000 & $0.000 \mathrm{E}+00$ & 0.0000 & $0.000 \mathrm{E}+00$ & 0.0000 & $0.000 \mathrm{E}+00$ & 0.0000 & $0.000 \mathrm{E}+00$ & 0.0000 & $0.000 \mathrm{E}+00$ & 0.0000 \\
\hline-237 & $4.387 \mathrm{E}-01$ & 0.0020 & $2.675 E-04$ & 0.0000 & $0.000 \mathrm{E}+00$ & 0.0000 & $0.000 \mathrm{E}+00$ & 0.0000 & $0.000 \mathrm{E}+00$ & 0.0000 & $0.000 \mathrm{E}+00$ & 0.0000 & $3.552 \mathrm{E}-02$ & 0.0002 \\
\hline 238 & $1.481 E-03$ & 0.0000 & $4.462 E-07$ & 0.0000 & $0.000 \mathrm{E}+00$ & 0.0000 & $0.000 \mathrm{E}+00$ & 0.0000 & $0.000 \mathrm{E}+00$ & 0.0000 & $0.000 \mathrm{E}+00$ & 0.0000 & $2.898 E-04$ & 0.0000 \\
\hline 239 & $1.122 \mathrm{E}-03$ & 0.0000 & $5.517 \mathrm{E}-03$ & 0.0000 & $0.000 \mathrm{E}+00$ & 0.0000 & $0.000 \mathrm{E}+00$ & 0.0000 & $0.000 \mathrm{E}+00$ & 0.0000 & $0.000 \mathrm{E}+00$ & 0.0000 & $6.729 \mathrm{E}-01$ & 0.0031 \\
\hline 240 & $2.161 \mathrm{E}-04$ & 0.0000 & $2.548 \mathrm{E}-03$ & 0.0000 & $0.000 \mathrm{E}+00$ & 0.0000 & $0.000 \mathrm{E}+00$ & 0.0000 & $0.000 \mathrm{E}+00$ & 0.0000 & $0.000 \mathrm{E}+00$ & 0.0000 & $3.109 \mathrm{E}-01$ & 0.0014 \\
\hline 99 & $1.346 E-26$ & 0.0000 & $0.000 \mathrm{E}+00$ & 0.0000 & $0.000 \mathrm{E}+00$ & 0.0000 & $0.000 \mathrm{E}+00$ & 0.0000 & $0.000 \mathrm{E}+00$ & 0.0000 & $0.000 \mathrm{E}+00$ & 0.0000 & $5.190 \mathrm{E}-26$ & 0.0000 \\
\hline 228 & $0.000 \mathrm{E}+00$ & 0.0000 & $0.000 \mathrm{E}+00$ & 0.0000 & $0.000 \mathrm{E}+00$ & 0.0000 & $0.000 \mathrm{E}+00$ & 0.0000 & $0.000 \mathrm{E}+00$ & 0.0000 & $0.000 \mathrm{E}+00$ & 0.0000 & $0.000 \mathrm{E}+00$ & 0.0000 \\
\hline 230 & $1.560 \mathrm{E}+02$ & 0.7165 & $2.016 \mathrm{E}-02$ & 0.0001 & $0.000 \mathrm{E}+00$ & 0.0000 & $0.000 \mathrm{E}+00$ & 0.0000 & $0.000 \mathrm{E}+00$ & 0.0000 & $0.000 \mathrm{E}+00$ & 0.0000 & $2.327 \mathrm{E}+01$ & 0.1069 \\
\hline 232 & $1.001 E+01$ & 0.0460 & $1.256 \mathrm{E}-03$ & 0.0000 & $0.000 \mathrm{E}+00$ & 0.0000 & $0.000 \mathrm{E}+00$ & 0.0000 & $0.000 \mathrm{E}+00$ & 0.0000 & $0.000 \mathrm{E}+00$ & 0.0000 & $4.609 \mathrm{E}-01$ & 0.0021 \\
\hline 34 & $1.720 \mathrm{E}+01$ & 0.0790 & $5.134 \mathrm{E}-03$ & 0.0000 & $0.000 \mathrm{E}+00$ & 0.0000 & $0.000 \mathrm{E}+00$ & 0.0000 & $0.000 \mathrm{E}+00$ & 0.0000 & $0.000 \mathrm{E}+00$ & 0.0000 & $3.353 \mathrm{E}+00$ & 0.0154 \\
\hline 35 & $1.036 \mathrm{E}+00$ & 0.0048 & $1.558 \mathrm{E}-03$ & 0.0000 & $0.000 \mathrm{E}+00$ & 0.0000 & $0.000 \mathrm{E}+00$ & 0.0000 & $0.000 \mathrm{E}+00$ & 0.0000 & $0.000 \mathrm{E}+00$ & 0.0000 & $2.623 \mathrm{E}-01$ & 0.0012 \\
\hline 38 & $3.831 E+00$ & 0.0176 & $2.216 \mathrm{E}-03$ & 0.0000 & $0.000 \mathrm{E}+00$ & 0.0000 & $0.000 \mathrm{E}+00$ & 0.0000 & $0.000 \mathrm{E}+00$ & 0.0000 & $0.000 \mathrm{E}+00$ & 0.0000 & $7.990 \mathrm{E}-01$ & 0.0037 \\
\hline & $1.885 E+02$ & 0.8659 & $3.866 \mathrm{E}-02$ & 0.0002 & $0.000 \mathrm{E}+00$ & 0.0000 & $0.000 \mathrm{E}+00$ & 0.0000 & $0.000 \mathrm{E}+00$ & 0.0000 & $0.000 \mathrm{E}+00$ & 0.0000 & +01 & 0.1339 \\
\hline
\end{tabular}

Total Dose Contributions TDOSE(i,p,t) for Individual Radionuclides (i) and Pathways (p) As mrem/yr and Fraction of Total Dose At $t=1.000 \mathrm{E}+04$ years

Water Dependent Pathways

\begin{tabular}{|c|c|c|c|c|c|c|c|c|c|c|c|c|c|c|}
\hline \multirow{2}{*}{ Nuclide } & \multicolumn{2}{|c|}{ Water } & \multicolumn{2}{|c|}{ Fish } & \multicolumn{2}{|c|}{ Radon } & \multicolumn{2}{|c|}{ Plant } & \multicolumn{2}{|c|}{ Meat } & \multicolumn{2}{|c|}{ Milk } & \multicolumn{2}{|c|}{ All Pathways* } \\
\hline & mrem/yr & fract. & mrem/yr & fract. & mrem/yr & fract. & mrem/yr & fract. & mrem/yr & fract. & mrem/yr & fract. & mrem/yr & fract. \\
\hline-241 & $0.000 \mathrm{E}+00$ & 0.0000 & $0.000 \mathrm{E}+00$ & 0.0000 & $0.000 \mathrm{E}+00$ & 0.0000 & $0.000 \mathrm{E}+00$ & 0.0000 & $0.000 \mathrm{E}+00$ & 0.0000 & $0.000 \mathrm{E}+00$ & 0.0000 & $6.367 \mathrm{E}-04$ & 0.0000 \\
\hline-137 & $0.000 \mathrm{E}+00$ & 0.0000 & $0.000 \mathrm{E}+00$ & 0.0000 & $0.000 \mathrm{E}+00$ & 0.0000 & $0.000 \mathrm{E}+00$ & 0.0000 & $0.000 \mathrm{E}+00$ & 0.0000 & $0.000 \mathrm{E}+00$ & 0.0000 & $0.000 \mathrm{E}+00$ & 0.0000 \\
\hline-237 & $0.000 \mathrm{E}+00$ & 0.0000 & $0.000 \mathrm{E}+00$ & 0.0000 & $0.000 \mathrm{E}+00$ & 0.0000 & $0.000 \mathrm{E}+00$ & 0.0000 & $0.000 \mathrm{E}+00$ & 0.0000 & $0.000 \mathrm{E}+00$ & 0.0000 & $4.744 \mathrm{E}-01$ & 0.0022 \\
\hline-238 & $0.000 \mathrm{E}+00$ & 0.0000 & $0.000 \mathrm{E}+00$ & 0.0000 & $0.000 \mathrm{E}+00$ & 0.0000 & $0.000 \mathrm{E}+00$ & 0.0000 & $0.000 \mathrm{E}+00$ & 0.0000 & $0.000 \mathrm{E}+00$ & 0.0000 & $1.771 \mathrm{E}-03$ & 0.0000 \\
\hline 239 & $0.000 \mathrm{E}+00$ & 0.0000 & $0.000 \mathrm{E}+00$ & 0.0000 & $0.000 \mathrm{E}+00$ & 0.0000 & $0.000 \mathrm{E}+00$ & 0.0000 & $0.000 \mathrm{E}+00$ & 0.0000 & $0.000 \mathrm{E}+00$ & 0.0000 & $6.796 \mathrm{E}-01$ & 0.0031 \\
\hline-240 & $0.000 \mathrm{E}+00$ & 0.0000 & $0.000 \mathrm{E}+00$ & 0.0000 & $0.000 \mathrm{E}+00$ & 0.0000 & $0.000 \mathrm{E}+00$ & 0.0000 & $0.000 \mathrm{E}+00$ & 0.0000 & $0.000 \mathrm{E}+00$ & 0.0000 & $3.136 \mathrm{E}-01$ & 0.0014 \\
\hline 99 & $0.000 \mathrm{E}+00$ & 0.0000 & $0.000 \mathrm{E}+00$ & 0.0000 & $0.000 \mathrm{E}+00$ & 0.0000 & $0.000 \mathrm{E}+00$ & 0.0000 & $0.000 \mathrm{E}+00$ & 0.0000 & $0.000 \mathrm{E}+00$ & 0.0000 & $6.536 \mathrm{E}-26$ & 0.0000 \\
\hline-228 & $0.000 \mathrm{E}+00$ & 0.0000 & $0.000 \mathrm{E}+00$ & 0.0000 & $0.000 \mathrm{E}+00$ & 0.0000 & $0.000 \mathrm{E}+00$ & 0.0000 & $0.000 \mathrm{E}+00$ & 0.0000 & $0.000 \mathrm{E}+00$ & 0.0000 & $0.000 \mathrm{E}+00$ & 0.0000 \\
\hline-230 & $0.000 \mathrm{E}+00$ & 0.0000 & $0.000 \mathrm{E}+00$ & 0.0000 & $0.000 \mathrm{E}+00$ & 0.0000 & $0.000 \mathrm{E}+00$ & 0.0000 & $0.000 \mathrm{E}+00$ & 0.0000 & $0.000 \mathrm{E}+00$ & 0.0000 & $1.793 E+02$ & 0.8235 \\
\hline-232 & $0.000 \mathrm{E}+00$ & 0.0000 & $0.000 \mathrm{E}+00$ & 0.0000 & $0.000 \mathrm{E}+00$ & 0.0000 & $0.000 \mathrm{E}+00$ & 0.0000 & $0.000 \mathrm{E}+00$ & 0.0000 & $0.000 \mathrm{E}+00$ & 0.0000 & $1.047 \mathrm{E}+01$ & 0.0481 \\
\hline 234 & $0.000 \mathrm{E}+00$ & 0.0000 & $0.000 \mathrm{E}+00$ & 0.0000 & $0.000 \mathrm{E}+00$ & 0.0000 & $0.000 \mathrm{E}+00$ & 0.0000 & $0.000 \mathrm{E}+00$ & 0.0000 & $0.000 \mathrm{E}+00$ & 0.0000 & $2.056 \mathrm{E}+01$ & 0.0944 \\
\hline 35 & $0.000 \mathrm{E}+00$ & 0.0000 & $0.000 \mathrm{E}+00$ & 0.0000 & $0.000 \mathrm{E}+00$ & 0.0000 & $0.000 \mathrm{E}+00$ & 0.0000 & $0.000 \mathrm{E}+00$ & 0.0000 & $0.000 \mathrm{E}+00$ & 0.0000 & $1.300 \mathrm{E}+00$ & 0.0060 \\
\hline 38 & $0.000 \mathrm{E}+00$ & 0.0000 & $0.000 \mathrm{E}+00$ & 0.0000 & $0.000 \mathrm{E}+00$ & 0.0000 & $0.000 \mathrm{E}+00$ & 0.0000 & $0.000 \mathrm{E}+00$ & 0.0000 & $0.000 \mathrm{E}+00$ & 0.0000 & $4.633 E+00$ & 0.0213 \\
\hline & $0.000 \mathrm{E}+00$ & 0.0000 & $0.000 \mathrm{E}+00$ & 0.0000 & $0.000 \mathrm{E}+00$ & 0.0000 & $0.000 \mathrm{E}+00$ & 0.0000 & $0.000 \mathrm{E}+00$ & 0.0000 & $0.000 \mathrm{E}+00$ & 0.0000 & $78 E+02$ & 1.0000 \\
\hline
\end{tabular}

* Sum of all water independent and dependent pathways. 
RESRAD, Version $6.5 \quad$ T1/2 Limit = 180 days $\quad 07 / 21 / 2011 \quad 12: 52$ Page 29

Summary : RESRAD Parameters for U-Landfill Outdoor Worker Forward Run 100,000

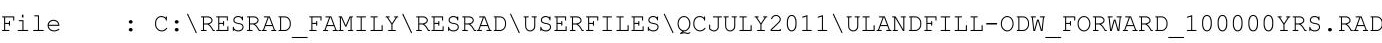

Total Dose Contributions TDOSE(i,p,t) for Individual Radionuclides (i) and Pathways (p) As mrem/yr and Fraction of Total Dose At $t=1.000 \mathrm{E}+05$ years

Water Independent Pathways (Inhalation excludes radon)

\begin{tabular}{|c|c|c|c|c|c|c|c|c|c|c|c|c|c|c|}
\hline \multirow{2}{*}{ Nuclide } & \multicolumn{2}{|c|}{ Ground } & \multicolumn{2}{|c|}{ Inhalation } & \multicolumn{2}{|c|}{ Radon } & \multicolumn{2}{|c|}{ Plant } & \multicolumn{2}{|c|}{ Meat } & \multicolumn{2}{|c|}{ Milk } & \multicolumn{2}{|c|}{ Soil } \\
\hline & mrem/yr & fract. & mrem/yr & fract. & mrem/yr & fract. & mrem/yr & fract. & mrem/yr & fract. & mrem/yr & fract. & mrem/yr & fract. \\
\hline-241 & $0.000 \mathrm{E}+00$ & 0.0000 & $0.000 \mathrm{E}+00$ & 0.0000 & $0.000 \mathrm{E}+00$ & 0.0000 & $0.000 \mathrm{E}+00$ & 0.0000 & $0.000 \mathrm{E}+00$ & 0.0000 & $0.000 \mathrm{E}+00$ & 0.0000 & $0.000 \mathrm{E}+00$ & 0.0000 \\
\hline-137 & $0.000 \mathrm{E}+00$ & 0.0000 & $0.000 \mathrm{E}+00$ & 0.0000 & $0.000 \mathrm{E}+00$ & 0.0000 & $0.000 \mathrm{E}+00$ & 0.0000 & $0.000 \mathrm{E}+00$ & 0.0000 & $0.000 \mathrm{E}+00$ & 0.0000 & $0.000 \mathrm{E}+00$ & 0.0000 \\
\hline 237 & $0.000 \mathrm{E}+00$ & 0.0000 & $0.000 \mathrm{E}+00$ & 0.0000 & $0.000 \mathrm{E}+00$ & 0.0000 & $0.000 \mathrm{E}+00$ & 0.0000 & $0.000 \mathrm{E}+00$ & 0.0000 & $0.000 \mathrm{E}+00$ & 0.0000 & $0.000 \mathrm{E}+00$ & 0.0000 \\
\hline-238 & $0.000 \mathrm{E}+00$ & 0.0000 & $0.000 \mathrm{E}+00$ & 0.0000 & $0.000 \mathrm{E}+00$ & 0.0000 & $0.000 \mathrm{E}+00$ & 0.0000 & $0.000 \mathrm{E}+00$ & 0.0000 & $0.000 \mathrm{E}+00$ & 0.0000 & $0.000 \mathrm{E}+00$ & 0.0000 \\
\hline-239 & $0.000 \mathrm{E}+00$ & 0.0000 & $0.000 \mathrm{E}+00$ & 0.0000 & $0.000 \mathrm{E}+00$ & 0.0000 & $0.000 \mathrm{E}+00$ & 0.0000 & $0.000 \mathrm{E}+00$ & 0.0000 & $0.000 \mathrm{E}+00$ & 0.0000 & $0.000 \mathrm{E}+00$ & 0.0000 \\
\hline-240 & $0.000 \mathrm{E}+00$ & 0.0000 & $0.000 \mathrm{E}+00$ & 0.0000 & $0.000 \mathrm{E}+00$ & 0.0000 & $0.000 \mathrm{E}+00$ & 0.0000 & $0.000 \mathrm{E}+00$ & 0.0000 & $0.000 \mathrm{E}+00$ & 0.0000 & $0.000 \mathrm{E}+00$ & 0.0000 \\
\hline 99 & $0.000 \mathrm{E}+00$ & 0.0000 & $0.000 \mathrm{E}+00$ & 0.0000 & $0.000 \mathrm{E}+00$ & 0.0000 & $0.000 \mathrm{E}+00$ & 0.0000 & $0.000 \mathrm{E}+00$ & 0.0000 & $0.000 \mathrm{E}+00$ & 0.0000 & $0.000 \mathrm{E}+00$ & 0.0000 \\
\hline-228 & $0.000 \mathrm{E}+00$ & 0.0000 & $0.000 \mathrm{E}+00$ & 0.0000 & $0.000 \mathrm{E}+00$ & 0.0000 & $0.000 \mathrm{E}+00$ & 0.0000 & $0.000 \mathrm{E}+00$ & 0.0000 & $0.000 \mathrm{E}+00$ & 0.0000 & $0.000 \mathrm{E}+00$ & 0.0000 \\
\hline 230 & $0.000 \mathrm{E}+00$ & 0.0000 & $0.000 \mathrm{E}+00$ & 0.0000 & $0.000 \mathrm{E}+00$ & 0.0000 & $0.000 \mathrm{E}+00$ & 0.0000 & $0.000 \mathrm{E}+00$ & 0.0000 & $0.000 \mathrm{E}+00$ & 0.0000 & $0.000 \mathrm{E}+00$ & 0.0000 \\
\hline-232 & $0.000 \mathrm{E}+00$ & 0.0000 & $0.000 \mathrm{E}+00$ & 0.0000 & $0.000 \mathrm{E}+00$ & 0.0000 & $0.000 \mathrm{E}+00$ & 0.0000 & $0.000 \mathrm{E}+00$ & 0.0000 & $0.000 \mathrm{E}+00$ & 0.0000 & $0.000 \mathrm{E}+00$ & 0.0000 \\
\hline 34 & $0.000 \mathrm{E}+00$ & 0.0000 & $0.000 \mathrm{E}+00$ & 0.0000 & $0.000 \mathrm{E}+00$ & 0.0000 & $0.000 \mathrm{E}+00$ & 0.0000 & $0.000 \mathrm{E}+00$ & 0.0000 & $0.000 \mathrm{E}+00$ & 0.0000 & $0.000 \mathrm{E}+00$ & 0.0000 \\
\hline 35 & $0.000 \mathrm{E}+00$ & 0.0000 & $0.000 \mathrm{E}+00$ & 0.0000 & $0.000 \mathrm{E}+00$ & 0.0000 & $0.000 \mathrm{E}+00$ & 0.0000 & $0.000 \mathrm{E}+00$ & 0.0000 & $0.000 \mathrm{E}+00$ & 0.0000 & $0.000 \mathrm{E}+00$ & 0.0000 \\
\hline 38 & $0.000 \mathrm{E}+00$ & 0.0000 & $0.000 \mathrm{E}+00$ & 0.0000 & $0.000 \mathrm{E}+00$ & 0.0000 & $0.000 \mathrm{E}+00$ & 0.0000 & $0.000 \mathrm{E}+00$ & 0.0000 & $0.000 \mathrm{E}+00$ & 0.0000 & $0.000 \mathrm{E}+00$ & 0.0000 \\
\hline & $0.000 \mathrm{E}+00$ & 0.0000 & $0.000 \mathrm{E}+00$ & 0.0000 & $0.000 \mathrm{E}+00$ & 0.0000 & $0.000 \mathrm{E}+00$ & 0.0000 & $0.000 \mathrm{E}+00$ & 0.0000 & $0.000 \mathrm{E}+00$ & 0.0000 & $.000 \mathrm{E}+00$ & 0.0000 \\
\hline
\end{tabular}

Total Dose Contributions TDOSE(i,p,t) for Individual Radionuclides (i) and Pathways (p) As mrem/yr and Fraction of Total Dose At $t=1.000 \mathrm{E}+05$ years

Water Dependent Pathways

\begin{tabular}{|c|c|c|c|c|c|c|c|c|c|c|c|c|c|c|}
\hline \multirow{2}{*}{$\begin{array}{l}\text { Radio- } \\
\text { Nuclide }\end{array}$} & \multicolumn{2}{|c|}{ Water } & \multicolumn{2}{|c|}{ Fish } & \multicolumn{2}{|c|}{ Radon } & \multicolumn{2}{|c|}{ Plant } & \multicolumn{2}{|c|}{ Meat } & \multicolumn{2}{|c|}{ Milk } & \multicolumn{2}{|c|}{ All Pathways* } \\
\hline & mrem/yr & fract. & mrem/yr & fract. & mrem/yr & fract. & mrem/yr & fract. & mrem/yr & fract. & mrem/yr & fract. & mrem/yr & fract. \\
\hline 241 & $0.000 \mathrm{E}+00$ & 0.0000 & $0.000 \mathrm{E}+00$ & 0.0000 & $0.000 \mathrm{E}+00$ & 0.0000 & $0.000 \mathrm{E}+00$ & 0.0000 & $0.000 \mathrm{E}+00$ & 0.0000 & $0.000 \mathrm{E}+00$ & 0.0000 & $0.000 \mathrm{E}+00$ & 0.0000 \\
\hline-137 & $0.000 \mathrm{E}+00$ & 0.0000 & $0.000 \mathrm{E}+00$ & 0.0000 & $0.000 \mathrm{E}+00$ & 0.0000 & $0.000 \mathrm{E}+00$ & 0.0000 & $0.000 \mathrm{E}+00$ & 0.0000 & $0.000 \mathrm{E}+00$ & 0.0000 & $0.000 \mathrm{E}+00$ & 0.0000 \\
\hline-237 & $0.000 \mathrm{E}+00$ & 0.0000 & $0.000 \mathrm{E}+00$ & 0.0000 & $0.000 \mathrm{E}+00$ & 0.0000 & $0.000 \mathrm{E}+00$ & 0.0000 & $0.000 \mathrm{E}+00$ & 0.0000 & $0.000 \mathrm{E}+00$ & 0.0000 & $0.000 \mathrm{E}+00$ & 0.0000 \\
\hline-238 & $0.000 \mathrm{E}+00$ & 0.0000 & $0.000 \mathrm{E}+00$ & 0.0000 & $0.000 \mathrm{E}+00$ & 0.0000 & $0.000 \mathrm{E}+00$ & 0.0000 & $0.000 \mathrm{E}+00$ & 0.0000 & $0.000 \mathrm{E}+00$ & 0.0000 & $0.000 \mathrm{E}+00$ & 0.0000 \\
\hline-239 & $0.000 \mathrm{E}+00$ & 0.0000 & $0.000 \mathrm{E}+00$ & 0.0000 & $0.000 \mathrm{E}+00$ & 0.0000 & $0.000 \mathrm{E}+00$ & 0.0000 & $0.000 \mathrm{E}+00$ & 0.0000 & $0.000 E+00$ & 0.0000 & $0.000 \mathrm{E}+00$ & 0.0000 \\
\hline-240 & $0.000 \mathrm{E}+00$ & 0.0000 & $0.000 \mathrm{E}+00$ & 0.0000 & $0.000 \mathrm{E}+00$ & 0.0000 & $0.000 \mathrm{E}+00$ & 0.0000 & $0.000 \mathrm{E}+00$ & 0.0000 & $0.000 E+00$ & 0.0000 & $0.000 \mathrm{E}+00$ & 0.0000 \\
\hline 99 & $0.000 \mathrm{E}+00$ & 0.0000 & $0.000 \mathrm{E}+00$ & 0.0000 & $0.000 \mathrm{E}+00$ & 0.0000 & $0.000 \mathrm{E}+00$ & 0.0000 & $0.000 \mathrm{E}+00$ & 0.0000 & $0.000 \mathrm{E}+00$ & 0.0000 & $0.000 \mathrm{E}+00$ & 0.0000 \\
\hline-228 & $0.000 \mathrm{E}+00$ & 0.0000 & $0.000 \mathrm{E}+00$ & 0.0000 & $0.000 \mathrm{E}+00$ & 0.0000 & $0.000 \mathrm{E}+00$ & 0.0000 & $0.000 \mathrm{E}+00$ & 0.0000 & $0.000 \mathrm{E}+00$ & 0.0000 & $0.000 \mathrm{E}+00$ & 0.0000 \\
\hline-230 & $0.000 \mathrm{E}+00$ & 0.0000 & $0.000 \mathrm{E}+00$ & 0.0000 & $0.000 \mathrm{E}+00$ & 0.0000 & $0.000 \mathrm{E}+00$ & 0.0000 & $0.000 \mathrm{E}+00$ & 0.0000 & $0.000 E+00$ & 0.0000 & $0.000 \mathrm{E}+00$ & 0.0000 \\
\hline-232 & $0.000 \mathrm{E}+00$ & 0.0000 & $0.000 \mathrm{E}+00$ & 0.0000 & $0.000 \mathrm{E}+00$ & 0.0000 & $0.000 \mathrm{E}+00$ & 0.0000 & $0.000 \mathrm{E}+00$ & 0.0000 & $0.000 \mathrm{E}+00$ & 0.0000 & $0.000 \mathrm{E}+00$ & 0.0000 \\
\hline 34 & $0.000 \mathrm{E}+00$ & 0.0000 & $0.000 \mathrm{E}+00$ & 0.0000 & $0.000 \mathrm{E}+00$ & 0.0000 & $0.000 \mathrm{E}+00$ & 0.0000 & $0.000 \mathrm{E}+00$ & 0.0000 & $0.000 \mathrm{E}+00$ & 0.0000 & $0.000 \mathrm{E}+00$ & 0.0000 \\
\hline 35 & $0.000 \mathrm{E}+00$ & 0.0000 & $0.000 \mathrm{E}+00$ & 0.0000 & $0.000 \mathrm{E}+00$ & 0.0000 & $0.000 \mathrm{E}+00$ & 0.0000 & $0.000 \mathrm{E}+00$ & 0.0000 & $0.000 \mathrm{E}+00$ & 0.0000 & $0.000 \mathrm{E}+00$ & 0.0000 \\
\hline 38 & $0.000 \mathrm{E}+00$ & 0.0000 & $0.000 \mathrm{E}+00$ & 0.0000 & $0.000 \mathrm{E}+00$ & 0.0000 & $0.000 \mathrm{E}+00$ & 0.0000 & $0.000 \mathrm{E}+00$ & 0.0000 & $0.000 \mathrm{E}+00$ & 0.0000 & $0.000 \mathrm{E}+00$ & 0.0000 \\
\hline & $0.000 \mathrm{E}+00$ & 0.0000 & $0.000 \mathrm{E}+00$ & 0.0000 & $0.000 \mathrm{E}+00$ & 0.0000 & $0.000 \mathrm{E}+00$ & 0.0000 & $0.000 \mathrm{E}+00$ & 0.0000 & $0.000 \mathrm{E}+00$ & 0.0000 & $0.000 \mathrm{E}+00$ & 0.0000 \\
\hline
\end{tabular}

* Sum of all water independent and dependent pathways. 
RESRAD, Version $6.5 \quad$ T1/2 Limit $=180$ days $\quad 07 / 21 / 2011 \quad 12: 52$ Page 30

Summary : RESRAD Parameters for U-Landfill Outdoor Worker Forward Run 100,000

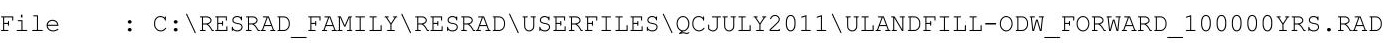

Dose/Source Ratios Summed Over All Pathways

Parent and Progeny Principal Radionuclide Contributions Indicated

Parent Product Thread DSR $(j, t)$ At Time in Years (mrem/yr)/(pCi/g)

(i)

(j)

\section{Am-241}

Fraction

Np-237+D

U-233

Th-229+D

$\sum \operatorname{DSR}(j)$

Cs $-137+D$

Np $-237+D$

U-233

Th-229+D

$\operatorname{\sum DSR}(j)$

Pu-238

$\mathrm{Pu}-238$

U-234

Th-230

Ra-226+D

$\mathrm{Pb}-210+\mathrm{D}$

$\operatorname{\sum DSR}(j)$

Pu-239

U-235+D

$\mathrm{Pa}-231$

AC-227+D

$\sum \operatorname{DSR}(j)$

Pu-240

$\mathrm{Pu}-240$

U-236

Th-232

Ra-228+D

Th-228+D

$\sum \operatorname{DSR}(j)$

TC-99

Th-228+D

Th-230

Ra-226+D

$\mathrm{Pb}-210+\mathrm{D}$

$\operatorname{\sum DSR}(j)$

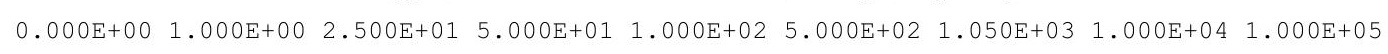

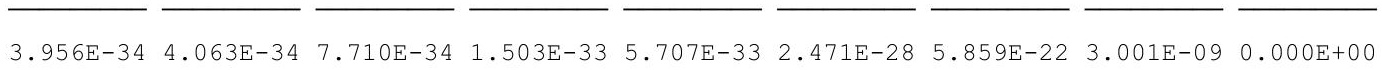
$\begin{array}{lllllllllll}3.160 \mathrm{E}-20 & 9.563 \mathrm{E}-20 & 2.064 \mathrm{E}-18 & 5.243 \mathrm{E}-18 & 1.718 \mathrm{E}-17 & 4.700 \mathrm{E}-15 & 2.556 \mathrm{E}-12 & 1.752 \mathrm{E}-05 & 0.000 \mathrm{E}+00\end{array}$ $\begin{array}{lllllllll}7.164 \mathrm{E}-31 & 5.066 \mathrm{E}-30 & 1.880 \mathrm{E}-27 & 9.948 \mathrm{E}-27 & 7.175 \mathrm{E}-26 & 2.177 \mathrm{E}-22 & 7.342 \mathrm{E}-19 & 3.114 \mathrm{E}-08 & 0.000 \mathrm{E}+00\end{array}$ $\begin{array}{llllllllll}4.901 \mathrm{E}-27 & 7.393 \mathrm{E}-26 & 3.823 \mathrm{E}-22 & 3.496 \mathrm{E}-21 & 3.824 \mathrm{E}-20 & 6.587 \mathrm{E}-17 & 2.426 \mathrm{E}-14 & 6.403 \mathrm{E}-07 & 0.000 \mathrm{E}+00\end{array}$ $\begin{array}{lllllllll}3.160 \mathrm{E}-20 & 9.563 \mathrm{E}-20 & 2.064 \mathrm{E}-18 & 5.246 \mathrm{E}-18 & 1.722 \mathrm{E}-17 & 4.766 \mathrm{E}-15 & 2.581 \mathrm{E}-12 & 1.819 \mathrm{E}-05 & 0.000 \mathrm{E}+00\end{array}$

$\begin{array}{llllllllll}1.000 \mathrm{E}+00 & 2.578 \mathrm{E}-10 & 2.541 \mathrm{E}-10 & 1.786 \mathrm{E}-10 & 1.237 \mathrm{E}-10 & 5.936 \mathrm{E}-11 & 1.667 \mathrm{E}-13 & 5.175 \mathrm{E}-17 & 0.000 \mathrm{E}+00 & 0.000 \mathrm{E}+00\end{array}$

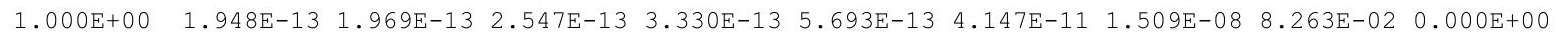
$\begin{array}{llllllllllll}1.000 \mathrm{E}+00 & 6.631 \mathrm{E}-24 & 2.011 \mathrm{E}-23 & 4.612 \mathrm{E}-22 & 1.248 \mathrm{E}-21 & 4.641 \mathrm{E}-21 & 3.427 \mathrm{E}-18 & 6.954 \mathrm{E}-15 & 1.604 \mathrm{E}-04 & 0.000 \mathrm{E}+00\end{array}$ $\begin{array}{llllllllll}1.000 \mathrm{E}+00 & 6.053 \mathrm{E}-20 & 4.262 \mathrm{E}-19 & 1.402 \mathrm{E}-16 & 6.537 \mathrm{E}-16 & 3.662 \mathrm{E}-15 & 1.463 \mathrm{E}-12 & 3.066 \mathrm{E}-10 & 3.475 \mathrm{E}-03 & 0.000 \mathrm{E}+00\end{array}$ $\begin{array}{lllllllll}1.948 \mathrm{E}-13 & 1.969 \mathrm{E}-13 & 2.549 \mathrm{E}-13 & 3.337 \mathrm{E}-13 & 5.729 \mathrm{E}-13 & 4.294 \mathrm{E}-11 & 1.540 \mathrm{E}-08 & 8.626 \mathrm{E}-02 & 0.000 \mathrm{E}+00\end{array}$

1.840E-09 4.417E-34 4.460E-34 5.637E-34 $\quad 7.195 \mathrm{E}-34 \quad 1.172 \mathrm{E}-33 \quad 5.806 \mathrm{E}-32 \quad 1.243 \mathrm{E}-29 \quad 1.401 \mathrm{E}-45 \quad 0.000 \mathrm{E}+00$

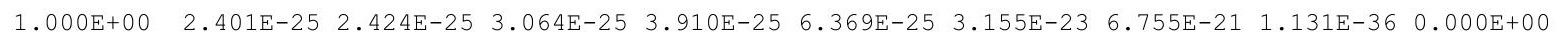
$\begin{array}{lllllllllll}1.000 \mathrm{E}+00 & 1.998 \mathrm{E}-30 & 6.068 \mathrm{E}-30 & 1.436 \mathrm{E}-28 & 4.032 \mathrm{E}-28 & 1.628 \mathrm{E}-27 & 3.470 \mathrm{E}-24 & 5.993 \mathrm{E}-20 & 1.672 \mathrm{E}-06 & 0.000 \mathrm{E}+00\end{array}$ $\begin{array}{llllllllllll}1.000 \mathrm{E}+00 & 2.101 \mathrm{E}-34 & 1.489 \mathrm{E}-33 & 5.829 \mathrm{E}-31 & 3.268 \mathrm{E}-30 & 2.663 \mathrm{E}-29 & 2.676 \mathrm{E}-25 & 6.795 \mathrm{E}-21 & 6.557 \mathrm{E}-07 & 0.000 \mathrm{E}+00\end{array}$ $\begin{array}{lllllllllll}1.000 \mathrm{E}+00 & 1.639 \mathrm{E}-23 & 2.469 \mathrm{E}-22 & 1.226 \mathrm{E}-18 & 1.076 \mathrm{E}-17 & 1.088 \mathrm{E}-16 & 1.149 \mathrm{E}-13 & 2.677 \mathrm{E}-11 & 3.858 \mathrm{E}-05 & 0.000 \mathrm{E}+00\end{array}$ $\begin{array}{lllllllllll}1.000 \mathrm{E}+00 & 4.753 \mathrm{E}-32 & 1.473 \mathrm{E}-30 & 1.013 \mathrm{E}-25 & 1.589 \mathrm{E}-24 & 2.687 \mathrm{E}-23 & 7.527 \mathrm{E}-20 & 3.536 \mathrm{E}-17 & 4.499 \mathrm{E}-06 & 0.000 \mathrm{E}+00\end{array}$ $\begin{array}{llllllllll}1.663 \mathrm{E}-23 & 2.471 \mathrm{E}-22 & 1.226 \mathrm{E}-18 & 1.076 \mathrm{E}-17 & 1.088 \mathrm{E}-16 & 1.149 \mathrm{E}-13 & 2.677 \mathrm{E}-11 & 4.541 \mathrm{E}-05 & 0.000 \mathrm{E}+00\end{array}$

$\begin{array}{llllllllll}1.000 \mathrm{E}+00 & 2.456 \mathrm{E}-18 & 2.486 \mathrm{E}-18 & 3.311 \mathrm{E}-18 & 4.463 \mathrm{E}-18 & 8.107 \mathrm{E}-18 & 9.618 \mathrm{E}-16 & 6.841 \mathrm{E}-13 & 1.888 \mathrm{E}-02 & 0.000 \mathrm{E}+00\end{array}$ $\begin{array}{lllllllllll}1.000 \mathrm{E}+00 & 1.254 \mathrm{E}-24 & 3.802 \mathrm{E}-24 & 8.688 \mathrm{E}-23 & 2.343 \mathrm{E}-22 & 8.645 \mathrm{E}-22 & 6.015 \mathrm{E}-19 & 1.124 \mathrm{E}-15 & 9.231 \mathrm{E}-07 & 0.000 \mathrm{E}+00\end{array}$ $\begin{array}{lllllllllll}1.000 \mathrm{E}+00 & 1.972 \mathrm{E}-28 & 1.393 \mathrm{E}-27 & 5.002 \mathrm{E}-25 & 2.557 \mathrm{E}-24 & 1.721 \mathrm{E}-23 & 2.963 \mathrm{E}-20 & 4.446 \mathrm{E}-17 & 8.533 \mathrm{E}-08 & 0.000 \mathrm{E}+00\end{array}$ $\begin{array}{llllllllllll}1.000 \mathrm{E}+00 & 4.675 \mathrm{E}-28 & 7.017 \mathrm{E}-27 & 3.194 \mathrm{E}-23 & 2.608 \mathrm{E}-22 & 2.391 \mathrm{E}-21 & 3.028 \mathrm{E}-18 & 1.826 \mathrm{E}-15 & 3.511 \mathrm{E}-07 & 0.000 \mathrm{E}+00\end{array}$ $\begin{array}{llllllllll}2.456 \mathrm{E}-18 & 2.486 \mathrm{E}-18 & 3.311 \mathrm{E}-18 & 4.463 \mathrm{E}-18 & 8.110 \mathrm{E}-18 & 9.655 \mathrm{E}-16 & 6.871 \mathrm{E}-13 & 1.888 \mathrm{E}-02 & 0.000 \mathrm{E}+00\end{array}$

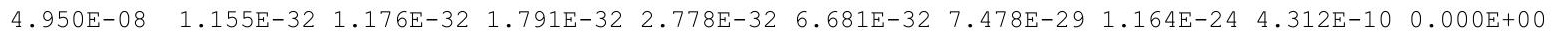

$\begin{array}{llllllllllll}1.000 \mathrm{E}+00 & 2.334 \mathrm{E}-25 & 2.375 \mathrm{E}-25 & 3.619 \mathrm{E}-25 & 5.612 \mathrm{E}-25 & 1.350 \mathrm{E}-24 & 1.511 \mathrm{E}-21 & 2.352 \mathrm{E}-17 & 8.711 \mathrm{E}-03 & 0.000 \mathrm{E}+00\end{array}$ $\begin{array}{lllllllllll}1.000 \mathrm{E}+00 & 4.417 \mathrm{E}-33 & 1.347 \mathrm{E}-32 & 3.517 \mathrm{E}-31 & 1.091 \mathrm{E}-30 & 5.321 \mathrm{E}-30 & 3.459 \mathrm{E}-26 & 1.397 \mathrm{E}-21 & 8.458 \mathrm{E}-07 & 0.000 \mathrm{E}+00\end{array}$ $\begin{array}{llllllllll}1.000 \mathrm{E}+00 & 5.745 \mathrm{E}-44 & 4.148 \mathrm{E}-43 & 1.798 \mathrm{E}-40 & 1.120 \mathrm{E}-39 & 1.120 \mathrm{E}-38 & 4.587 \mathrm{E}-34 & 5.372 \mathrm{E}-29 & 1.247 \mathrm{E}-12 & 0.000 \mathrm{E}+00\end{array}$ $\begin{array}{llllllllll}1.000 \mathrm{E}+00 & 2.801 \mathrm{E}-29 & 4.123 \mathrm{E}-28 & 1.234 \mathrm{E}-24 & 7.689 \mathrm{E}-24 & 5.197 \mathrm{E}-23 & 3.012 \mathrm{E}-20 & 8.590 \mathrm{E}-18 & 4.940 \mathrm{E}-11 & 0.000 \mathrm{E}+00\end{array}$ $\begin{array}{lllllllllll}1.000 \mathrm{E}+00 & 1.657 \mathrm{E}-28 & 4.769 \mathrm{E}-27 & 7.862 \mathrm{E}-23 & 5.398 \mathrm{E}-22 & 3.593 \mathrm{E}-21 & 1.140 \mathrm{E}-18 & 1.344 \mathrm{E}-16 & 7.877 \mathrm{E}-11 & 0.000 \mathrm{E}+00\end{array}$ $2.335 \mathrm{E}-25 \quad 2.427 \mathrm{E}-25 \quad 8.021 \mathrm{E}-23 \quad 5.480 \mathrm{E}-22 \quad 3.646 \mathrm{E}-21 \quad 1.172 \mathrm{E}-18 \quad 1.665 \mathrm{E}-16 \quad 8.712 \mathrm{E}-03 \quad 0.000 \mathrm{E}+00$

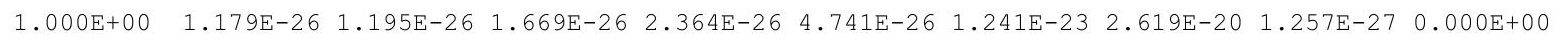
$\begin{array}{lllllllll}1.000 \mathrm{E}+00 & 2.825 \mathrm{E}-07 & 1.978 \mathrm{E}-07 & 3.819 \mathrm{E}-11 & 5.163 \mathrm{E}-15 & 9.437 \mathrm{E}-23 & 0.000 \mathrm{E}+00 & 0.000 \mathrm{E}+00 & 0.000 \mathrm{E}+00 \quad 0.000 \mathrm{E}+00\end{array}$ $\begin{array}{llllllllll}1.000 \mathrm{E}+00 & 4.929 \mathrm{E}-23 & 5.012 \mathrm{E}-23 & 7.503 \mathrm{E}-23 & 1.142 \mathrm{E}-22 & 2.647 \mathrm{E}-22 & 2.203 \mathrm{E}-19 & 2.282 \mathrm{E}-15 & 2.112 \mathrm{E}-02 & 0.000 \mathrm{E}+00\end{array}$ $\begin{array}{lllllllllllllll}1.000 \mathrm{E}+00 & 7.712 \mathrm{E}-12 & 2.327 \mathrm{E}-11 & 4.644 \mathrm{E}-10 & 1.087 \mathrm{E}-09 & 3.024 \mathrm{E}-09 & 2.193 \mathrm{E}-07 & 1.840 \mathrm{E}-05 & 1.586 \mathrm{E}+00 & 0.000 \mathrm{E}+00\end{array}$ $1.000 \mathrm{E}+00 \quad 3.717 \mathrm{E}-20 \quad 2.596 \mathrm{E}-19 \quad 6.907 \mathrm{E}-17 \quad 2.655 \mathrm{E}-16 \quad 1.087 \mathrm{E}-15 \quad 1.573 \mathrm{E}-13 \quad 2.528 \mathrm{E}-11 \quad 1.857 \mathrm{E}-01 \quad 0.000 \mathrm{E}+00$

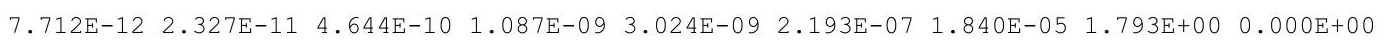


RESRAD, Version 6.5

Summary : RESRAD Parameters for U-Landfill Outdoor Worker Forward Run 100,000

File : C: \RESRAD_FAMILY \RESRAD \USERFILES QQCJULY2011 \ULANDFILL-ODW_FORWARD_100000YRS.RAD

Dose/Source Ratios Summed Over All Pathways

Parent and Progeny Principal Radionuclide Contributions Indicated

\begin{tabular}{|c|c|c|c|c|c|c|c|c|c|c|c|}
\hline $\begin{array}{c}\text { Parent } \\
\text { (i) }\end{array}$ & $\begin{array}{l}\text { Product } \\
(j)\end{array}$ & $\begin{array}{l}\text { Thread } \\
\text { Fraction }\end{array}$ & $0.000 \mathrm{E}+00$ & $1.000 \mathrm{E}+00$ & $\begin{array}{r}\operatorname{DSR}(j, t) \\
2.500 E+01\end{array}$ & $\begin{array}{l}\text { At Time in } \\
5.000 \mathrm{E}+01\end{array}$ & $\begin{array}{l}\text { Years } \\
1.000 \mathrm{E}+02\end{array}$ & $\begin{array}{l}(\text { mrem/yr) } \\
5.000 \mathrm{E}+02\end{array}$ & $\begin{array}{l}(\mathrm{pCi} / \mathrm{g}) \\
1.050 \mathrm{E}+03\end{array}$ & $1.000 \mathrm{E}+04$ & $1.000 \mathrm{E}+05$ \\
\hline-232 & $\mathrm{Th}-232$ & $1.000 \mathrm{E}+00$ & $2.382 E-25$ & $2.427 E-25$ & $3.789 \mathrm{E}-25$ & $6.027 \mathrm{E}-25$ & $1.525 \mathrm{E}-24$ & $2.561 \mathrm{E}-21$ & $6.965 \mathrm{E}-17$ & $2.519 \mathrm{E}-02$ & $0.000 \mathrm{E}+00$ \\
\hline-232 & $\mathrm{Ra}-228+\mathrm{D}$ & $1.000 \mathrm{E}+00$ & $2.263 E-10$ & $6.486 \mathrm{E}-10$ & 4. $499 \mathrm{E}-09$ & $5.690 \mathrm{E}-09$ & $8.336 \mathrm{E}-09$ & $1.737 \mathrm{E}-07$ & $1.131 \mathrm{E}-05$ & $9.991 \mathrm{E}-01$ & $0.000 \mathrm{E}+00$ \\
\hline$h-232$ & $T h-228+D$ & $1.000 \mathrm{E}+00$ & $2.181 \mathrm{E}-09$ & $1.345 \mathrm{E}-08$ & $3.638 \mathrm{E}-07$ & $4.522 \mathrm{E}-07$ & $6.114 \mathrm{E}-07$ & $6.652 \mathrm{E}-06$ & $1.778 \mathrm{E}-04$ & $1.594 \mathrm{E}+00$ & $0.000 \mathrm{E}+00$ \\
\hline-232 & $\sum \operatorname{DSR}(j)$ & & $2.407 E-09$ & 1. $410 \mathrm{E}-08$ & $3.683 \mathrm{E}-07$ & $4.579 \mathrm{E}-07$ & $6.198 E-07$ & $6.825 E-06$ & $1.891 \mathrm{E}-04$ & $2.618 \mathrm{E}+00$ & $0.000 \mathrm{E}+00$ \\
\hline-234 & $U-234$ & $1.000 \mathrm{E}+00$ & 1. $409 \mathrm{E}-24$ & $1.434 \mathrm{E}-24$ & $2.194 \mathrm{E}-24$ & $3.415 \mathrm{E}-24$ & $8.276 \mathrm{E}-24$ & $9.851 \mathrm{E}-21$ & $1.669 \mathrm{E}-16$ & $4.655 \mathrm{E}-03$ & $0.000 \mathrm{E}+00$ \\
\hline-234 & $\mathrm{Th}-230$ & $1.000 \mathrm{E}+00$ & $2.225 E-28$ & $6.774 \mathrm{E}-28$ & $1.722 \mathrm{E}-26$ & $5.192 \mathrm{E}-26$ & $2.394 \mathrm{E}-25$ & $9.912 \mathrm{E}-22$ & $2.152 \mathrm{E}-17$ & $1.850 \mathrm{E}-03$ & $0.000 \mathrm{E}+00$ \\
\hline-234 & $\mathrm{Ra}-226+\mathrm{D}$ & $1.000 \mathrm{E}+00$ & $2.315 E-17$ & $1.630 \mathrm{E}-16$ & $5.341 \mathrm{E}-14$ & $2.480 \mathrm{E}-13$ & 1. $377 \mathrm{E}-12$ & $5.115 \mathrm{E}-10$ & $9.341 \mathrm{E}-08$ & $1.092 \mathrm{E}-01$ & $0.000 \mathrm{E}+00$ \\
\hline-234 & $\mathrm{~Pb}-210+\mathrm{D}$ & $1.000 \mathrm{E}+00$ & $8.381 E-26$ & $1.257 \mathrm{E}-24$ & $5.622 \mathrm{E}-21$ & $4.500 \mathrm{E}-20$ & $3.956 \mathrm{E}-19$ & $3.440 \mathrm{E}-16$ & $1.243 \mathrm{E}-13$ & $1.274 \mathrm{E}-02$ & $0.000 \mathrm{E}+00$ \\
\hline-234 & $\sum \operatorname{DSR}(j)$ & & $2.315 E-17$ & $1.630 \mathrm{E}-16$ & $5.341 \mathrm{E}-14$ & $2.480 \mathrm{E}-13$ & 1. $377 \mathrm{E}-12$ & $5.115 \mathrm{E}-10$ & $9.341 \mathrm{E}-08$ & 1. $285 \mathrm{E}-01$ & $0.000 \mathrm{E}+00$ \\
\hline$-235+D$ & $\mathrm{U}-235+\mathrm{D}$ & $1.000 \mathrm{E}+00$ & $2.540 \mathrm{E}-15$ & $2.572 \mathrm{E}-15$ & $3.460 \mathrm{E}-15$ & $4.713 \mathrm{E}-15$ & $8.745 \mathrm{E}-15$ & $1.228 \mathrm{E}-12$ & $1.101 \mathrm{E}-09$ & $1.061 \mathrm{E}-01$ & $0.000 \mathrm{E}+00$ \\
\hline$-235+D$ & $\mathrm{~Pa}-231$ & $1.000 \mathrm{E}+00$ & $6.002 \mathrm{E}-19$ & $1.818 \mathrm{E}-18$ & $3.984 \mathrm{E}-17$ & $1.028 \mathrm{E}-16$ & $3.478 \mathrm{E}-16$ & 1. $206 \mathrm{E}-13$ & $8.644 \mathrm{E}-11$ & $1.831 \mathrm{E}-02$ & $0.000 \mathrm{E}+00$ \\
\hline$-235+D$ & $A C-227+D$ & $1.000 \mathrm{E}+00$ & $1.895 \mathrm{E}-18$ & 1. $324 \mathrm{E}-17$ & $3.586 \mathrm{E}-15$ & $1.407 \mathrm{E}-14$ & $6.019 \mathrm{E}-14$ & 1. $308 \mathrm{E}-11$ & $3.655 \mathrm{E}-09$ & 7. $555 \mathrm{E}-02$ & $0.000 \mathrm{E}+00$ \\
\hline$-235+D$ & $\sum \operatorname{DSR}(j)$ & & $2.543 E-15$ & $2.587 \mathrm{E}-15$ & $7.086 \mathrm{E}-15$ & $1.888 \mathrm{E}-14$ & $6.928 E-14$ & $1.443 \mathrm{E}-11$ & $4.843 E-09$ & $2.000 \mathrm{E}-01$ & $0.000 \mathrm{E}+00$ \\
\hline-238 & $\mathrm{U}-238$ & $5.400 \mathrm{E}-05$ & $0.000 \mathrm{E}+00$ & $0.000 \mathrm{E}+00$ & $0.000 \mathrm{E}+00$ & $0.000 \mathrm{E}+00$ & $0.000 \mathrm{E}+00$ & $0.000 \mathrm{E}+00$ & $3.476 \mathrm{E}-39$ & $2.356 \mathrm{E}-07$ & $0.000 \mathrm{E}+00$ \\
\hline$-238+D$ & $\mathrm{U}-238+\mathrm{D}$ & $9.999 \mathrm{E}-01$ & $2.901 \mathrm{E}-11$ & $2.924 \mathrm{E}-11$ & $3.542 \mathrm{E}-11$ & $4.325 E-11$ & $6.449 \mathrm{E}-11$ & $1.576 \mathrm{E}-09$ & $1.279 \mathrm{E}-07$ & $2.735 E-02$ & $0.000 \mathrm{E}+00$ \\
\hline$-238+D$ & $\mathrm{U}-234$ & $9.999 \mathrm{E}-01$ & $2.003 E-30$ & $6.105 \mathrm{E}-30$ & $1.586 \mathrm{E}-28$ & $4.889 \mathrm{E}-28$ & $2.358 E-27$ & $1.399 \mathrm{E}-23$ & $4.978 \mathrm{E}-19$ & $1.339 \mathrm{E}-04$ & $0.000 \mathrm{E}+00$ \\
\hline$-238+D$ & $\mathrm{Th}-230$ & $9.999 \mathrm{E}-01$ & $2.105 E-34$ & 1. $495 \mathrm{E}-33$ & $6.226 \mathrm{E}-31$ & $3.717 \mathrm{E}-30$ & $3.411 \mathrm{E}-29$ & $7.032 \mathrm{E}-25$ & $3.204 \mathrm{E}-20$ & $2.623 E-05$ & $0.000 \mathrm{E}+00$ \\
\hline$-238+D$ & $\mathrm{Ra}-226+\mathrm{D}$ & $9.999 \mathrm{E}-01$ & $1.642 \mathrm{E}-23$ & $2.477 \mathrm{E}-22$ & 1. $288 \mathrm{E}-18$ & $1.186 \mathrm{E}-17$ & 1. $313 \mathrm{E}-16$ & $2.462 \mathrm{E}-13$ & $9.612 \mathrm{E}-11$ & $1.290 \mathrm{E}-03$ & $0.000 \mathrm{E}+00$ \\
\hline$-238+D$ & $\mathrm{~Pb}-210+\mathrm{D}$ & $9.999 \mathrm{E}-01$ & $4.759 E-32$ & $1.477 \mathrm{E}-30$ & $1.055 \mathrm{E}-25$ & $1.723 \mathrm{E}-24$ & $3.161 \mathrm{E}-23$ & $1.561 \mathrm{E}-19$ & $1.240 \mathrm{E}-16$ & $1.499 \mathrm{E}-04$ & $0.000 \mathrm{E}+00$ \\
\hline$-238+D$ & $\sum \operatorname{DSR}(j)$ & & $2.901 \mathrm{E}-11$ & $2.924 \mathrm{E}-11$ & $3.542 \mathrm{E}-11$ & 4. $325 \mathrm{E}-11$ & $6.449 \mathrm{E}-11$ & $1.577 \mathrm{E}-09$ & $1.280 \mathrm{E}-07$ & $2.895 \mathrm{E}-02$ & $0.000 \mathrm{E}+00$ \\
\hline
\end{tabular}

The DSR includes contributions from associated (half-life $\leq 180$ days) daughters. 
RESRAD, Version $6.5 \quad T^{1 / 2}$ Limit $=180$ days $\quad 07 / 21 / 2011 \quad 12: 52$ Page 32

Summary : RESRAD Parameters for U-Landfill Outdoor Worker Forward Run 100,000

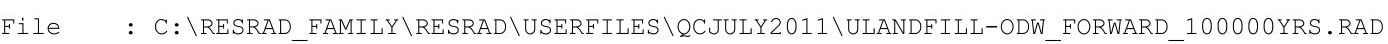

Single Radionuclide Soil Guidelines G(i,t) in pCi/g

Basic Radiation Dose Limit $=1.000 \mathrm{E}+00 \mathrm{mrem} / \mathrm{yr}$

Nuclide

\begin{tabular}{|c|c|c|c|c|c|c|c|c|c|}
\hline (i) & $t=0.000 \mathrm{E}+00$ & $1.000 \mathrm{E}+00$ & $2.500 \mathrm{E}+01$ & $5.000 \mathrm{E}+01$ & $1.000 \mathrm{E}+02$ & $5.000 \mathrm{E}+02$ & $1.050 \mathrm{E}+03$ & $1.000 \mathrm{E}+04$ & $1.000 \mathrm{E}+05$ \\
\hline-241 & $\star 3.431 \mathrm{E}+12$ & $\star 3.431 \mathrm{E}+12$ & $\star 3.431 \mathrm{E}+12$ & $\star 3.431 \mathrm{E}+12$ & $\star 3.431 \mathrm{E}+12$ & $\star 3.431 \mathrm{E}+12$ & $3.875 \mathrm{E}+11$ & $5.497 \mathrm{E}+04$ & $* 3.431 \mathrm{E}+12$ \\
\hline-137 & $3.879 \mathrm{E}+09$ & $3.936 \mathrm{E}+09$ & $5.600 \mathrm{E}+09$ & $8.084 \mathrm{E}+09$ & $1.685 E+10$ & $5.997 \mathrm{E}+12$ & $\star 8.704 \mathrm{E}+13$ & $\star 8.704 \mathrm{E}+13$ & $\star 8.704 \mathrm{E}+13$ \\
\hline-237 & $\star 7.047 \mathrm{E}+08$ & $\star 7.047 \mathrm{E}+08$ & $\star 7.047 \mathrm{E}+08$ & $\star 7.047 \mathrm{E}+08$ & $\star 7.047 \mathrm{E}+08$ & $\star 7.047 \mathrm{E}+08$ & $6.495 \mathrm{E}+07$ & $1.159 \mathrm{E}+01$ & $* 7.047 \mathrm{E}+08$ \\
\hline-238 & $\star 1.712 \mathrm{E}+13$ & $\star 1.712 \mathrm{E}+13$ & $\star 1.712 \mathrm{E}+13$ & $\star 1.712 \mathrm{E}+13$ & $\star 1.712 \mathrm{E}+13$ & $8.701 \mathrm{E}+12$ & $3.735 \mathrm{E}+10$ & $2.202 \mathrm{E}+04$ & $* 1.712 \mathrm{E}+13$ \\
\hline-239 & $\star 6.214 \mathrm{E}+10$ & $* 6.214 \mathrm{E}+10$ & $* 6.214 \mathrm{E}+10$ & $* 6.214 \mathrm{E}+10$ & $* 6.214 \mathrm{E}+10$ & $* 6.214 \mathrm{E}+10$ & $* 6.214 \mathrm{E}+10$ & $5.298 \mathrm{E}+01$ & $* 6.214 \mathrm{E}+10$ \\
\hline-228 & $3.540 \mathrm{E}+06$ & $5.056 \mathrm{E}+06$ & $2.619 \mathrm{E}+10$ & $1.937 \mathrm{E}+14$ & $\star 8.195 \mathrm{E}+14$ & $* 8.195 \mathrm{E}+14$ & $\star 8.195 \mathrm{E}+14$ & $\star 8.195 \mathrm{E}+14$ & $\star 8.195 \mathrm{E}+14$ \\
\hline $1-230$ & $\star 2.018 \mathrm{E}+10$ & $\star 2.018 \mathrm{E}+10$ & $2.153 \mathrm{E}+09$ & $9.198 \mathrm{E}+08$ & $3.307 \mathrm{E}+08$ & $4.559 \mathrm{E}+06$ & $5.434 \mathrm{E}+04$ & $5.576 \mathrm{E}-01$ & $\star 2.018 \mathrm{E}+10$ \\
\hline$h-232$ & $\star 1.097 \mathrm{E}+05$ & $\star 1.097 \mathrm{E}+05$ & $\star 1.097 \mathrm{E}+05$ & $\star 1.097 \mathrm{E}+05$ & $\star 1.097 \mathrm{E}+05$ & $\star 1.097 \mathrm{E}+05$ & $5.287 \mathrm{E}+03$ & $3.819 \mathrm{E}-01$ & $\star 1.097 \mathrm{E}+05$ \\
\hline-234 & $\star 6.247 \mathrm{E}+09$ & $* 6.247 \mathrm{E}+09$ & $* 6.247 \mathrm{E}+09$ & $* 6.247 \mathrm{E}+09$ & $* 6.247 \mathrm{E}+09$ & $1.955 \mathrm{E}+09$ & $1.071 \mathrm{E}+07$ & $7.783 \mathrm{E}+00$ & $\star 6.247 \mathrm{E}+09$ \\
\hline
\end{tabular}

*At specific activity limit

Summed Dose/Source Ratios DSR(i,t) in (mrem/yr)/(pCi/g)

and Single Radionuclide Soil Guidelines $G(i, t)$ in pCi/g

at $\operatorname{tmin}=$ time of minimum single radionuclide soil guideline

and at $\operatorname{tmax}=$ time of maximum total dose $=19046 \pm *$ years

\begin{tabular}{|c|c|c|c|c|c|c|}
\hline $\begin{array}{l}\text { uclide } \\
\text { (i) }\end{array}$ & $\begin{array}{l}\text { Initial } \\
(\mathrm{pCi} / \mathrm{g})\end{array}$ & $\begin{array}{c}\text { tmin } \\
\text { (years) }\end{array}$ & $\operatorname{DSR}(i, \operatorname{tmin})$ & $\begin{array}{c}\mathrm{G}(\mathrm{i}, \mathrm{tmin}) \\
(\mathrm{pCi} / \mathrm{g})\end{array}$ & $\operatorname{DSR}(i, t \max )$ & $\begin{array}{c}G(i, t \max ) \\
(\mathrm{pCi} / \mathrm{g})\end{array}$ \\
\hline $1-241$ & $3.500 \mathrm{E}+01$ & $2534 \pm 5$ & $5.174 \mathrm{E}-04$ & $1.933 E+03$ & $1.007 \mathrm{E}-05$ & $9.935 E+04$ \\
\hline-137 & $1.900 \mathrm{E}+01$ & $0.000 \mathrm{E}+00$ & $2.578 \mathrm{E}-10$ & $3.879 \mathrm{E}+09$ & $0.000 \mathrm{E}+00$ & $\star 8.704 \mathrm{E}+13$ \\
\hline-237 & $5.500 \mathrm{E}+00$ & $2535 \pm 5$ & $1.492 \mathrm{E}-01$ & $6.705 \mathrm{E}+00$ & $4.806 \mathrm{E}-02$ & $2.081 E+01$ \\
\hline-238 & $3.900 \mathrm{E}+01$ & $24332 \pm *$ & $1.052 \mathrm{E}-04$ & $9.508 \mathrm{E}+03$ & $8.606 \mathrm{E}-05$ & $1.162 \mathrm{E}+04$ \\
\hline-239 & $3.600 \mathrm{E}+01$ & $2538 \pm 5$ & $2.521 E-02$ & $3.966 \mathrm{E}+01$ & $1.329 E-02$ & $7.523 E+01$ \\
\hline-240 & $3.600 \mathrm{E}+01$ & $2536 \pm 5$ & $2.071 \mathrm{E}-02$ & $4.828 E+01$ & $3.051 E-03$ & $3.278 E+02$ \\
\hline-99 & $5.200 \mathrm{E}+01$ & $2535 \pm 5$ & $1.434 \mathrm{E}-10$ & $6.975 \mathrm{E}+09$ & $0.000 \mathrm{E}+00$ & $\star 1.697 \mathrm{E}+10$ \\
\hline-228 & $4.000 \mathrm{E}+00$ & $0.000 \mathrm{E}+00$ & $2.825 E-07$ & $3.540 \mathrm{E}+06$ & $0.000 \mathrm{E}+00$ & $\star 8.195 \mathrm{E}+14$ \\
\hline-230 & $1.000 \mathrm{E}+02$ & $8566 \pm *$ & $1.800 \mathrm{E}+00$ & $5.554 \mathrm{E}-01$ & $1.648 \mathrm{E}+00$ & $6.066 \mathrm{E}-01$ \\
\hline-232 & $4.000 \mathrm{E}+00$ & $2536 \pm 5$ & $2.652 \mathrm{E}+00$ & $3.771 E-01$ & $2.578 E+00$ & $3.879 \mathrm{E}-01$ \\
\hline 234 & $1.600 \mathrm{E}+02$ & $24307 \pm *$ & $2.946 E-01$ & $3.394 E+00$ & $2.415 E-01$ & $4.141 E+00$ \\
\hline 35 & $6.500 \mathrm{E}+00$ & $24405 \pm *$ & $2.557 E-01$ & $3.911 E+00$ & $2.408 E-01$ & $4.152 \mathrm{E}+00$ \\
\hline-238 & $1.600 \mathrm{E}+02$ & $2536 \pm 5$ & $3.032 \mathrm{E}-02$ & $3.299 \mathrm{E}+01$ & $3.020 \mathrm{E}-02$ & $3.311 \mathrm{E}+01$ \\
\hline
\end{tabular}

*At specific activity limit 
RESRAD, Version 6.5

mmary : RESRAD Parameters for U-Landfill Outdoor Worker Forward Run 100,000

File : C: $\backslash$ RESRAD_FAMILY \RESRAD \USERFILES \QCJULY2011 \ULANDFILL-ODW_FORWARD_100000YRS.RAD

Individual Nuclide Dose Summed Over All Pathways

Parent Nuclide and Branch Fraction Indicated

Nuclide Parent THF(i) DOSE $(j, t), \mathrm{mrem} / \mathrm{yr}$

\begin{tabular}{|c|c|c|}
\hline (j) & (i) & \\
\hline$A m-241$ & Am-241 & $1.000 \mathrm{E}+0$ \\
\hline $\mathrm{Jp}-237$ & Am-241 & $1.000 \mathrm{E}+0$ \\
\hline $\mathrm{Np}-237$ & $N p-237$ & $1.000 \mathrm{E}+0$ \\
\hline 237 & $\sum \operatorname{DOSE}(j$ & \\
\hline
\end{tabular}

Am-241 1.000E+00 $\mathrm{Np}-237 \quad 1.000 \mathrm{E}+00$ $\sum \operatorname{DOSE}(j)$

Am-241 1.000E+00 $\mathrm{Np}-237 \quad 1.000 \mathrm{E}+00$ $\sum \operatorname{DOSE}(j)$

Cs-137 1.000E+00

$\mathrm{Pu}-238 \quad 1.840 \mathrm{E}-09$ $\mathrm{Pu}-238 \quad 1.000 \mathrm{E}+00$ $\sum \operatorname{DOSE}(j)$

$\mathrm{Pu}-238 \quad 1.000 \mathrm{E}+00$ $\mathrm{U}-234 \quad 1.000 \mathrm{E}+00$ U-238 9.999E-01 $\sum \operatorname{DOSE}(j)$

Pu-238 1.000E+00 Th-230 1.000E+00 $\mathrm{U}-234 \quad 1.000 \mathrm{E}+00$ U-238 9.999E-01 $\sum \operatorname{DOSE}(j)$

$\mathrm{Pu}-238 \quad 1.000 \mathrm{E}+00$ Th-230 1.000E+00 $\mathrm{U}-234 \quad 1.000 \mathrm{E}+00$ $\mathrm{U}-238 \quad 9.999 \mathrm{E}-01$ $\sum \operatorname{DOSE}(j)$

$\mathrm{Pu}-238 \quad 1.000 \mathrm{E}+00$ Th-230 1.000E+00 $\mathrm{U}-234 \quad 1.000 \mathrm{E}+00$ U-238 9.999E-01 $\sum \operatorname{DOSE}(j)$

$\mathrm{Pu}-239$ 1.000E+00

$\mathrm{Pu}-239 \quad 1.000 \mathrm{E}+00$ U-235 1.000E+00 $\sum \operatorname{DOSE}(j)$ $t=0.000 \mathrm{E}+00 \quad 1.000 \mathrm{E}+00 \quad 2.500 \mathrm{E}+01 \quad 5.000 \mathrm{E}+01 \quad 1.000 \mathrm{E}+02 \quad 5.000 \mathrm{E}+02 \quad 1.050 \mathrm{E}+03 \quad 1.000 \mathrm{E}+04 \quad 1.000 \mathrm{E}+05$

$\begin{array}{lllllllllllll}0.000 \mathrm{E}+00 & 0.000 \mathrm{E}+00 & 0.000 \mathrm{E}+00 & 0.000 \mathrm{E}+00 & 0.000 \mathrm{E}+00 & 8.647 \mathrm{E}-27 & 2.051 \mathrm{E}-20 & 1.050 \mathrm{E}-07 & 0.000 \mathrm{E}+00\end{array}$

$\begin{array}{llllllllll}1.106 \mathrm{E}-18 & 3.347 \mathrm{E}-18 & 7.223 \mathrm{E}-17 & 1.835 \mathrm{E}-16 & 6.012 \mathrm{E}-16 & 1.645 \mathrm{E}-13 & 8.947 \mathrm{E}-11 & 6.131 \mathrm{E}-04 & 0.000 \mathrm{E}+00\end{array}$ 1.072E-12 1.083E-12 1.401E-12 $1.832 \mathrm{E}-12 \quad 3.131 \mathrm{E}-12 \quad 2.281 \mathrm{E}-10 \quad 8.299 \mathrm{E}-08 \quad 4.544 \mathrm{E}-01 \quad 0.000 \mathrm{E}+00$

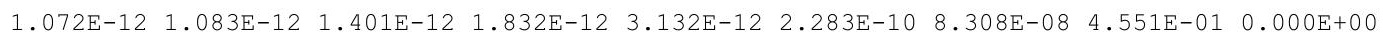

$0.000 \mathrm{E}+00 \quad 1.773 \mathrm{E}-28 \quad 6.581 \mathrm{E}-26 \quad 3.482 \mathrm{E}-25 \quad 2.511 \mathrm{E}-24 \quad 7.620 \mathrm{E}-21 \quad 2.570 \mathrm{E}-17 \quad 1.090 \mathrm{E}-06 \quad 0.000 \mathrm{E}+00$ $\begin{array}{lllllllll}3.647 \mathrm{E}-23 & 1.106 \mathrm{E}-22 & 2.537 \mathrm{E}-21 & 6.866 \mathrm{E}-21 & 2.553 \mathrm{E}-20 & 1.885 \mathrm{E}-17 & 3.825 \mathrm{E}-14 & 8.821 \mathrm{E}-04 \quad 0.000 \mathrm{E}+00\end{array}$ $\begin{array}{llllllll}3.647 \mathrm{E}-23 & 1.106 \mathrm{E}-22 & 2.537 \mathrm{E}-21 & 6.867 \mathrm{E}-21 & 2.553 \mathrm{E}-20 & 1.886 \mathrm{E}-17 & 3.827 \mathrm{E}-14 & 8.832 \mathrm{E}-04 \quad 0.000 \mathrm{E}+00\end{array}$

$\begin{array}{lllllllll}1.715 \mathrm{E}-25 & 2.588 \mathrm{E}-24 & 1.338 \mathrm{E}-20 & 1.224 \mathrm{E}-19 & 1.338 \mathrm{E}-18 & 2.306 \mathrm{E}-15 & 8.490 \mathrm{E}-13 & 2.241 \mathrm{E}-05 \quad 0.000 \mathrm{E}+00\end{array}$ $\begin{array}{llllllllll}3.329 \mathrm{E}-19 & 2.344 \mathrm{E}-18 & 7.710 \mathrm{E}-16 & 3.596 \mathrm{E}-15 & 2.014 \mathrm{E}-14 & 8.046 \mathrm{E}-12 & 1.686 \mathrm{E}-09 & 1.911 \mathrm{E}-02 \quad 0.000 \mathrm{E}+00\end{array}$ $\begin{array}{llllllll}3.329 \mathrm{E}-19 & 2.344 \mathrm{E}-18 & 7.710 \mathrm{E}-16 & 3.596 \mathrm{E}-15 & 2.014 \mathrm{E}-14 & 8.048 \mathrm{E}-12 & 1.687 \mathrm{E}-09 & 1.914 \mathrm{E}-02 \quad 0.000 \mathrm{E}+00\end{array}$

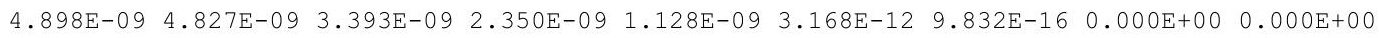

$\begin{array}{llllllllll}0.000 \mathrm{E}+00 & 0.000 \mathrm{E}+00 & 0.000 \mathrm{E}+00 & 0.000 \mathrm{E}+00 & 0.000 \mathrm{E}+00 & 0.000 \mathrm{E}+00 \quad 4.847 \mathrm{E}-28 & 0.000 \mathrm{E}+00 \quad 0.000 \mathrm{E}+00\end{array}$ $\begin{array}{llllllllll}9.362 \mathrm{E}-24 & 9.454 \mathrm{E}-24 & 1.195 \mathrm{E}-23 & 1.525 \mathrm{E}-23 & 2.484 \mathrm{E}-23 & 1.231 \mathrm{E}-21 & 2.634 \mathrm{E}-19 & 0.000 \mathrm{E}+00 \quad 0.000 \mathrm{E}+00\end{array}$ $\begin{array}{lllllllll}9.362 \mathrm{E}-24 & 9.454 \mathrm{E}-24 & 1.195 \mathrm{E}-23 & 1.525 \mathrm{E}-23 & 2.484 \mathrm{E}-23 & 1.231 \mathrm{E}-21 & 2.634 \mathrm{E}-19 & 0.000 \mathrm{E}+00 \quad 0.000 \mathrm{E}+00\end{array}$

$\begin{array}{lllllllll}7.792 E-29 & 2.366 E-28 & 5.602 E-27 & 1.573 E-26 & 6.349 E-26 & 1.353 E-22 & 2.337 E-18 & 6.520 E-05 & 0.000 E+00\end{array}$ $2.254 \mathrm{E}-22 \quad 2.295 \mathrm{E}-22 \quad 3.510 \mathrm{E}-22 \quad 5.464 \mathrm{E}-22 \quad 1.324 \mathrm{E}-21 \quad 1.576 \mathrm{E}-18 \quad 2.670 \mathrm{E}-14 \quad 7.448 \mathrm{E}-01 \quad 0.000 \mathrm{E}+00$ $\begin{array}{lllllllll}3.205 \mathrm{E}-28 & 9.767 \mathrm{E}-28 & 2.537 \mathrm{E}-26 & 7.823 \mathrm{E}-26 & 3.773 \mathrm{E}-25 & 2.238 \mathrm{E}-21 & 7.964 \mathrm{E}-17 & 2.142 \mathrm{E}-02 & 0.000 \mathrm{E}+00\end{array}$ $\begin{array}{lllllllll}2.254 \mathrm{E}-22 & 2.295 \mathrm{E}-22 & 3.510 \mathrm{E}-22 & 5.465 \mathrm{E}-22 & 1.325 \mathrm{E}-21 & 1.578 \mathrm{E}-18 & 2.679 \mathrm{E}-14 & 7.663 \mathrm{E}-01 & 0.000 \mathrm{E}+00\end{array}$

$\begin{array}{lllllllll}0.000 \mathrm{E}+00 & 0.000 \mathrm{E}+00 & 0.000 \mathrm{E}+00 & 1.275 \mathrm{E}-28 & 1.038 \mathrm{E}-27 & 1.043 \mathrm{E}-23 & 2.650 \mathrm{E}-19 & 2.557 \mathrm{E}-05 \quad 0.000 \mathrm{E}+00\end{array}$ $\begin{array}{llllllllll}4.929 \mathrm{E}-21 & 5.012 \mathrm{E}-21 & 7.503 \mathrm{E}-21 & 1.142 \mathrm{E}-20 & 2.647 \mathrm{E}-20 & 2.203 \mathrm{E}-17 & 2.282 \mathrm{E}-13 & 2.112 \mathrm{E}+00 \quad 0.000 \mathrm{E}+00\end{array}$ $\begin{array}{llllllllll}3.559 \mathrm{E}-26 & 1.084 \mathrm{E}-25 & 2.756 \mathrm{E}-24 & 8.307 \mathrm{E}-24 & 3.831 \mathrm{E}-23 & 1.586 \mathrm{E}-19 & 3.443 \mathrm{E}-15 & 2.960 \mathrm{E}-01 \quad 0.000 \mathrm{E}+00\end{array}$ $0.000 \mathrm{E}+00 \quad 0.000 \mathrm{E}+00 \quad 0.000 \mathrm{E}+00 \quad 5.947 \mathrm{E}-28 \quad 5.457 \mathrm{E}-27 \quad 1.125 \mathrm{E}-22 \quad 5.127 \mathrm{E}-18 \quad 4.196 \mathrm{E}-03 \quad 0.000 \mathrm{E}+00$ $\begin{array}{lllllllll}4.929 \mathrm{E}-21 & 5.012 \mathrm{E}-21 & 7.506 \mathrm{E}-21 & 1.143 \mathrm{E}-20 & 2.651 \mathrm{E}-20 & 2.219 \mathrm{E}-17 & 2.317 \mathrm{E}-13 & 2.412 \mathrm{E}+00 \quad 0.000 \mathrm{E}+00\end{array}$

$\begin{array}{llllllllllll}6.392 \mathrm{E}-22 & 9.628 \mathrm{E}-21 & 4.782 \mathrm{E}-17 & 4.197 \mathrm{E}-16 & 4.245 \mathrm{E}-15 & 4.482 \mathrm{E}-12 & 1.044 \mathrm{E}-09 & 1.505 \mathrm{E}-03 \quad 0.000 \mathrm{E}+00\end{array}$ $\begin{array}{llllllllll}7.712 \mathrm{E}-10 & 2.327 \mathrm{E}-09 & 4.644 \mathrm{E}-08 & 1.087 \mathrm{E}-07 & 3.024 \mathrm{E}-07 & 2.193 \mathrm{E}-05 & 1.840 \mathrm{E}-03 & 1.586 \mathrm{E}+02 & 0.000 \mathrm{E}+00\end{array}$ $\begin{array}{lllllllllll}3.705 \mathrm{E}-15 & 2.608 \mathrm{E}-14 & 8.545 \mathrm{E}-12 & 3.968 \mathrm{E}-11 & 2.204 \mathrm{E}-10 & 8.184 \mathrm{E}-08 & 1.495 \mathrm{E}-05 & 1.748 \mathrm{E}+01 & 0.000 \mathrm{E}+00\end{array}$ $\begin{array}{lllllllll}2.626 \mathrm{E}-21 & 3.963 \mathrm{E}-20 & 2.061 \mathrm{E}-16 & 1.897 \mathrm{E}-15 & 2.100 \mathrm{E}-14 & 3.939 \mathrm{E}-11 & 1.538 \mathrm{E}-08 & 2.064 \mathrm{E}-01 & 0.000 \mathrm{E}+00\end{array}$ $\begin{array}{llllllllll}7.712 \mathrm{E}-10 & 2.327 \mathrm{E}-09 & 4.645 \mathrm{E}-08 & 1.088 \mathrm{E}-07 & 3.026 \mathrm{E}-07 & 2.202 \mathrm{E}-05 & 1.855 \mathrm{E}-03 & 1.763 \mathrm{E}+02 & 0.000 \mathrm{E}+00\end{array}$

$0.000 \mathrm{E}+00 \quad 5.746 \mathrm{E}-29 \quad 3.949 \mathrm{E}-24 \quad 6.196 \mathrm{E}-23 \quad 1.048 \mathrm{E}-21 \quad 2.936 \mathrm{E}-18 \quad 1.379 \mathrm{E}-15 \quad 1.755 \mathrm{E}-04 \quad 0.000 \mathrm{E}+00$ $\begin{array}{llllllllll}3.717 \mathrm{E}-18 & 2.596 \mathrm{E}-17 & 6.907 \mathrm{E}-15 & 2.655 \mathrm{E}-14 & 1.087 \mathrm{E}-13 & 1.573 \mathrm{E}-11 & 2.528 \mathrm{E}-09 & 1.857 \mathrm{E}+01 & 0.000 \mathrm{E}+00\end{array}$ $\begin{array}{lllllllllll}1.341 \mathrm{E}-23 & 2.012 \mathrm{E}-22 & 8.994 \mathrm{E}-19 & 7.200 \mathrm{E}-18 & 6.329 \mathrm{E}-17 & 5.505 \mathrm{E}-14 & 1.988 \mathrm{E}-11 & 2.038 \mathrm{E}+00 \quad 0.000 \mathrm{E}+00\end{array}$ $\begin{array}{lllllllllll}0.000 \mathrm{E}+00 & 2.363 \mathrm{E}-28 & 1.687 \mathrm{E}-23 & 2.757 \mathrm{E}-22 & 5.058 \mathrm{E}-21 & 2.498 \mathrm{E}-17 & 1.985 \mathrm{E}-14 & 2.398 \mathrm{E}-02 & 0.000 \mathrm{E}+00\end{array}$ $\begin{array}{lllllllllll}3.717 \mathrm{E}-18 & 2.596 \mathrm{E}-17 & 6.907 \mathrm{E}-15 & 2.655 \mathrm{E}-14 & 1.087 \mathrm{E}-13 & 1.578 \mathrm{E}-11 & 2.548 \mathrm{E}-09 & 2.063 \mathrm{E}+01 \quad 0.000 \mathrm{E}+00\end{array}$

$\begin{array}{lllllllllll}8.843 E-17 & 8.949 E-17 & 1.192 E-16 & 1.607 E-16 & 2.919 E-16 & 3.463 E-14 & 2.463 E-11 & 6.795 E-01 & 0.000 E+00\end{array}$

$\begin{array}{lllllllll}4.513 E-23 & 1.369 \mathrm{E}-22 & 3.128 \mathrm{E}-21 & 8.434 \mathrm{E}-21 & 3.112 \mathrm{E}-20 & 2.165 \mathrm{E}-17 & 4.048 \mathrm{E}-14 & 3.323 \mathrm{E}-05 \quad 0.000 \mathrm{E}+00\end{array}$ $\begin{array}{lllllllll}1.651 \mathrm{E}-14 & 1.672 \mathrm{E}-14 & 2.249 \mathrm{E}-14 & 3.064 \mathrm{E}-14 & 5.684 \mathrm{E}-14 & 7.982 \mathrm{E}-12 & 7.159 \mathrm{E}-09 & 6.898 \mathrm{E}-01 \quad 0.000 \mathrm{E}+00\end{array}$ $\begin{array}{lllllllll}1.651 \mathrm{E}-14 & 1.672 \mathrm{E}-14 & 2.249 \mathrm{E}-14 & 3.064 \mathrm{E}-14 & 5.684 \mathrm{E}-14 & 7.982 \mathrm{E}-12 & 7.159 \mathrm{E}-09 & 6.899 \mathrm{E}-01 \quad 0.000 \mathrm{E}+00\end{array}$ 
RESRAD, Version $6.5 \quad T^{1 / 2}$ Limit $=180$ days $\quad 07 / 21 / 2011 \quad 12: 52$ Page 34

Summary : RESRAD Parameters for U-Landfill Outdoor Worker Forward Run 100,000

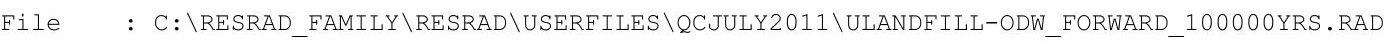

Individual Nuclide Dose Summed Over All Pathways

Parent Nuclide and Branch Fraction Indicated

Nuclide Parent THF(i) DOSE $(j, t)$, mrem/yr

\begin{tabular}{|c|c|c|c|c|c|c|c|c|c|c|c|}
\hline (j) & (i) & & $t=0.000 \mathrm{E}+00$ & $1.000 \mathrm{E}+00$ & $2.500 \mathrm{E}+01$ & $5.000 \mathrm{E}+01$ & $1.000 \mathrm{E}+02$ & $5.000 \mathrm{E}+02$ & $1.050 \mathrm{E}+03$ & $1.000 \mathrm{E}+04$ & $1.000 \mathrm{E}+05$ \\
\hline-231 & $\mathrm{Pu}-239$ & $1.000 \mathrm{E}+00$ & $7.100 \mathrm{E}-27$ & $5.015 \mathrm{E}-26$ & $1.801 E-23$ & $9.205 E-23$ & $6.194 \mathrm{E}-22$ & $1.067 \mathrm{E}-18$ & $1.601 \mathrm{E}-15$ & $3.072 E-06$ & $0.000 \mathrm{E}+00$ \\
\hline-231 & $\mathrm{U}-235$ & $1.000 \mathrm{E}+00$ & $3.901 \mathrm{E}-18$ & $1.181 \mathrm{E}-17$ & $2.589 E-16$ & $6.685 E-16$ & $2.261 \mathrm{E}-15$ & $7.836 \mathrm{E}-13$ & $5.619 \mathrm{E}-10$ & $1.190 \mathrm{E}-01$ & $0.000 \mathrm{E}+00$ \\
\hline-231 & $\sum \operatorname{DOSE}(j)$ & & $3.901 \mathrm{E}-18$ & $1.181 \mathrm{E}-17$ & $2.589 \mathrm{E}-16$ & $6.685 E-16$ & $2.261 \mathrm{E}-15$ & $7.836 \mathrm{E}-13$ & $5.619 \mathrm{E}-10$ & $1.190 \mathrm{E}-01$ & $0.000 \mathrm{E}+00$ \\
\hline-227 & $\mathrm{Pu}-239$ & $1.000 \mathrm{E}+00$ & $1.683 \mathrm{E}-26$ & $2.526 \mathrm{E}-25$ & $1.150 \mathrm{E}-21$ & $9.388 E-21$ & $8.608 \mathrm{E}-20$ & $1.090 \mathrm{E}-16$ & $6.572 \mathrm{E}-14$ & $1.264 \mathrm{E}-05$ & $0.000 \mathrm{E}+00$ \\
\hline-227 & $\mathrm{U}-235$ & $1.000 \mathrm{E}+00$ & $1.232 \mathrm{E}-17$ & $8.608 \mathrm{E}-17$ & $2.331 E-14$ & $9.144 \mathrm{E}-14$ & $3.912 \mathrm{E}-13$ & $8.503 E-11$ & $2.376 \mathrm{E}-08$ & $4.911 \mathrm{E}-01$ & $0.000 \mathrm{E}+00$ \\
\hline-227 & $\sum \operatorname{DOSE}(j)$ & & $1.232 \mathrm{E}-17$ & $8.608 \mathrm{E}-17$ & $2.331 \mathrm{E}-14$ & $9.144 \mathrm{E}-14$ & $3.912 \mathrm{E}-13$ & $8.504 \mathrm{E}-11$ & $2.376 \mathrm{E}-08$ & $4.911 \mathrm{E}-01$ & $0.000 \mathrm{E}+00$ \\
\hline 240 & $\mathrm{Pu}-240$ & $4.950 \mathrm{E}-08$ & $0.000 \mathrm{E}+00$ & $0.000 \mathrm{E}+00$ & $0.000 \mathrm{E}+00$ & $0.000 \mathrm{E}+00$ & $0.000 \mathrm{E}+00$ & $2.692 \mathrm{E}-27$ & $4.191 \mathrm{E}-23$ & $1.552 \mathrm{E}-08$ & $0.000 \mathrm{E}+00$ \\
\hline-240 & $\mathrm{Pu}-240$ & $1.000 \mathrm{E}+00$ & $8.401 \mathrm{E}-24$ & $8.550 \mathrm{E}-24$ & $1.303 E-23$ & $2.020 E-23$ & $4.859 \mathrm{E}-23$ & $5.438 \mathrm{E}-20$ & $8.467 E-16$ & $3.136 \mathrm{E}-01$ & $0.000 \mathrm{E}+00$ \\
\hline $1-240$ & $\sum \operatorname{DOSE}(j)$ & & $8.401 \mathrm{E}-24$ & $8.550 \mathrm{E}-24$ & $1.303 \mathrm{E}-23$ & $2.020 \mathrm{E}-23$ & $4.859 \mathrm{E}-23$ & $5.438 \mathrm{E}-20$ & $8.467 \mathrm{E}-16$ & $3.136 \mathrm{E}-01$ & $0.000 \mathrm{E}+00$ \\
\hline 236 & $\mathrm{Pu}-240$ & $1.000 \mathrm{E}+00$ & $0.000 \mathrm{E}+00$ & $0.000 \mathrm{E}+00$ & $0.000 \mathrm{E}+00$ & $3.926 \mathrm{E}-29$ & $1.916 \mathrm{E}-28$ & $1.245 \mathrm{E}-24$ & $5.029 \mathrm{E}-20$ & $3.045 \mathrm{E}-05$ & $0.000 \mathrm{E}+00$ \\
\hline$h-232$ & $\mathrm{Pu}-240$ & $1.000 \mathrm{E}+00$ & $0.000 \mathrm{E}+00$ & $0.000 \mathrm{E}+00$ & $0.000 \mathrm{E}+00$ & $0.000 \mathrm{E}+00$ & $0.000 \mathrm{E}+00$ & $0.000 \mathrm{E}+00$ & $1.934 \mathrm{E}-27$ & $4.490 \mathrm{E}-11$ & $0.000 \mathrm{E}+00$ \\
\hline$h-232$ & Th-232 & $1.000 \mathrm{E}+00$ & $9.528 \mathrm{E}-25$ & $9.707 \mathrm{E}-25$ & $1.516 \mathrm{E}-24$ & $2.411 E-24$ & $6.100 \mathrm{E}-24$ & $1.024 \mathrm{E}-20$ & $2.786 \mathrm{E}-16$ & $1.008 \mathrm{E}-01$ & $0.000 \mathrm{E}+00$ \\
\hline $1-232$ & $\sum \operatorname{DOSE}(j)$ & & $9.528 \mathrm{E}-25$ & $9.707 \mathrm{E}-25$ & $1.516 \mathrm{E}-24$ & $2.411 \mathrm{E}-24$ & $6.100 \mathrm{E}-24$ & $1.024 \mathrm{E}-20$ & $2.786 \mathrm{E}-16$ & $1.008 \mathrm{E}-01$ & $0.000 \mathrm{E}+00$ \\
\hline-228 & $\mathrm{Pu}-240$ & $1.000 \mathrm{E}+00$ & $1.008 \mathrm{E}-27$ & $1.484 \mathrm{E}-26$ & $4.442 \mathrm{E}-23$ & $2.768 E-22$ & $1.871 \mathrm{E}-21$ & $1.084 \mathrm{E}-18$ & $3.092 \mathrm{E}-16$ & $1.778 \mathrm{E}-09$ & $0.000 \mathrm{E}+00$ \\
\hline$a-228$ & Th-232 & $1.000 \mathrm{E}+00$ & $9.051 \mathrm{E}-10$ & $2.594 \mathrm{E}-09$ & $1.799 \mathrm{E}-08$ & $2.276 \mathrm{E}-08$ & $3.334 \mathrm{E}-08$ & $6.950 \mathrm{E}-07$ & $4.524 \mathrm{E}-05$ & $3.996 \mathrm{E}+00$ & $0.000 \mathrm{E}+00$ \\
\hline$a-228$ & $\sum \operatorname{DOSE}(j)$ & & $9.051 \mathrm{E}-10$ & $2.594 \mathrm{E}-09$ & $1.799 \mathrm{E}-08$ & $2.276 \mathrm{E}-08$ & $3.334 \mathrm{E}-08$ & $6.950 \mathrm{E}-07$ & $4.524 \mathrm{E}-05$ & $3.996 \mathrm{E}+00$ & $0.000 \mathrm{E}+00$ \\
\hline-228 & $\mathrm{Pu}-240$ & $1.000 \mathrm{E}+00$ & $5.966 \mathrm{E}-27$ & $1.717 \mathrm{E}-25$ & $2.830 E-21$ & $1.943 \mathrm{E}-20$ & $1.293 \mathrm{E}-19$ & $4.105 \mathrm{E}-17$ & $4.837 E-15$ & $2.836 \mathrm{E}-09$ & $0.000 \mathrm{E}+00$ \\
\hline Th-228 & Th-228 & $1.000 \mathrm{E}+00$ & $1.130 \mathrm{E}-06$ & $7.912 \mathrm{E}-07$ & $1.528 \mathrm{E}-10$ & $2.065 E-14$ & $3.775 \mathrm{E}-22$ & $0.000 \mathrm{E}+00$ & $0.000 \mathrm{E}+00$ & $0.000 \mathrm{E}+00$ & $0.000 \mathrm{E}+00$ \\
\hline Th-228 & Th-232 & $1.000 \mathrm{E}+00$ & $8.723 \mathrm{E}-09$ & $5.379 \mathrm{E}-08$ & $1.455 \mathrm{E}-06$ & $1.809 \mathrm{E}-06$ & $2.446 \mathrm{E}-06$ & $2.661 \mathrm{E}-05$ & $7.113 \mathrm{E}-04$ & $6.376 \mathrm{E}+00$ & $0.000 \mathrm{E}+00$ \\
\hline-228 & $\sum \operatorname{DOSE}(j)$ & & $1.139 \mathrm{E}-06$ & $8.450 \mathrm{E}-07$ & $1.455 \mathrm{E}-06$ & $1.809 \mathrm{E}-06$ & $2.446 \mathrm{E}-06$ & $2.661 \mathrm{E}-05$ & $7.113 \mathrm{E}-04$ & $6.376 \mathrm{E}+00$ & $0.000 \mathrm{E}+00$ \\
\hline-99 & TC-99 & $1.000 \mathrm{E}+00$ & $6.129 \mathrm{E}-25$ & $6.215 \mathrm{E}-25$ & $8.680 \mathrm{E}-25$ & $1.229 \mathrm{E}-24$ & $2.465 \mathrm{E}-24$ & $6.452 \mathrm{E}-22$ & $1.362 \mathrm{E}-18$ & $6.536 \mathrm{E}-26$ & $0.000 \mathrm{E}+00$ \\
\hline $\mathrm{U}-238$ & $\mathrm{U}-238$ & $5.400 \mathrm{E}-05$ & $0.000 \mathrm{E}+00$ & $0.000 \mathrm{E}+00$ & $0.000 \mathrm{E}+00$ & $0.000 \mathrm{E}+00$ & $0.000 \mathrm{E}+00$ & $0.000 \mathrm{E}+00$ & $0.000 \mathrm{E}+00$ & $3.769 \mathrm{E}-05$ & $0.000 \mathrm{E}+00$ \\
\hline $\mathrm{U}-238$ & $\mathrm{U}-238$ & $9.999 \mathrm{E}-01$ & $4.641 \mathrm{E}-09$ & $4.678 \mathrm{E}-09$ & $5.667 \mathrm{E}-09$ & $6.920 \mathrm{E}-09$ & $1.032 \mathrm{E}-08$ & $2.522 \mathrm{E}-07$ & $2.046 \mathrm{E}-05$ & $4.377 \mathrm{E}+00$ & $0.000 \mathrm{E}+00$ \\
\hline-238 & $\sum \operatorname{DOSE}(j)$ & & $4.641 \mathrm{E}-09$ & $4.678 \mathrm{E}-09$ & $5.667 \mathrm{E}-09$ & $6.920 \mathrm{E}-09$ & $1.032 \mathrm{E}-08$ & $2.522 \mathrm{E}-07$ & $2.046 \mathrm{E}-05$ & $4.377 \mathrm{E}+00$ & $0.000 \mathrm{E}+00$ \\
\hline
\end{tabular}

THF (i) is the thread fraction of the parent nuclide. 
RESRAD, Version 6.5

Summary : RESRAD Parameters for U-Landfill Outdoor Worker Forward Run 100,000

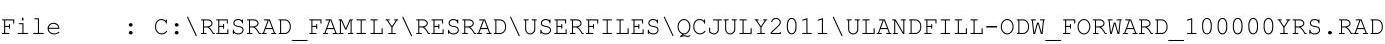

Individual Nuclide Soil Concentration

Parent Nuclide and Branch Fraction Indicated

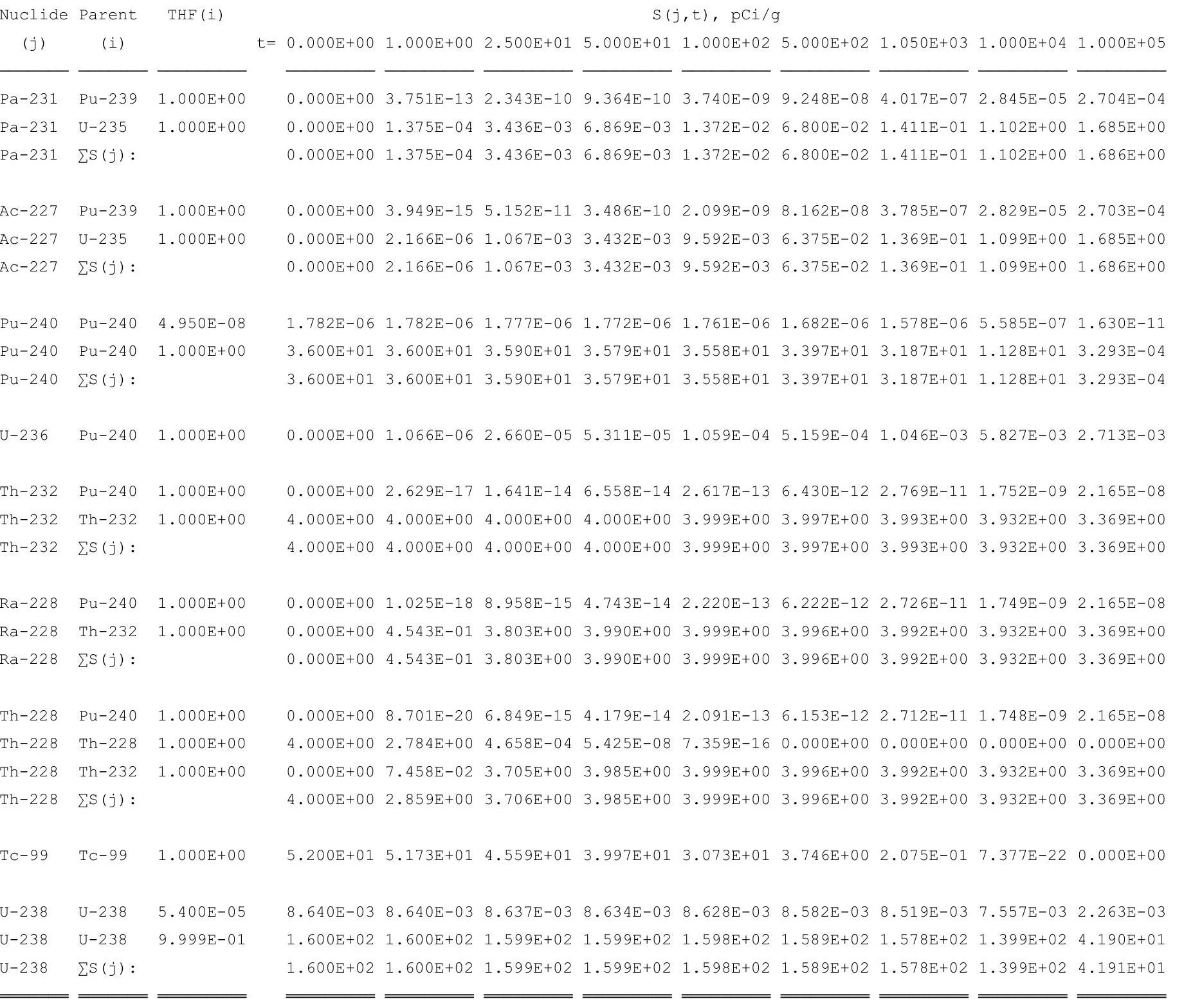

THF (i) is the thread fraction of the parent nuclide.

RESCALC.EXE execution time $=6.96$ seconds 
RESRAD, Version $6.5 \quad T^{1 / 2}$ Limit $=180$ days

Summary : RESRAD Parameters for U-Landfill Recreational User Foward Run

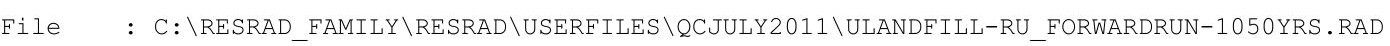

Table of Contents

Part I: Mixture Sums and Single Radionuclide Guidelines

Dose Conversion Factor (and Related) Parameter Summary ... 2

Site-Specific Parameter Summary ................ 8

Summary of Pathway Selections .................... 18

Contaminated Zone and Total Dose Summary ............. 19

Total Dose Components

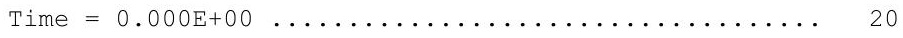

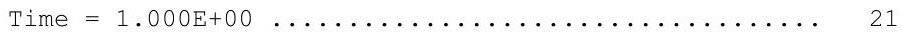

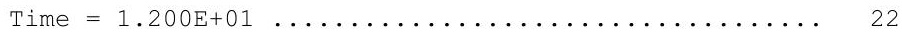

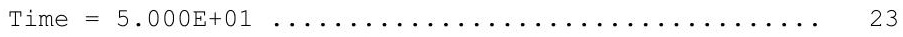

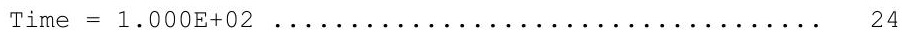

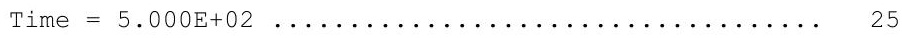

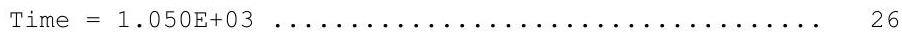

Dose/Source Ratios Summed Over All Pathways .......... 27

Single Radionuclide Soil Guidelines ............... 29

Dose Per Nuclide Summed Over All Pathways ........... 30

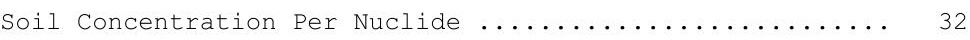


Summary : RESRAD Parameters for U-Landfill Recreational User Foward Run

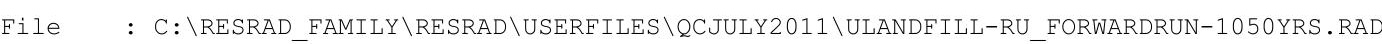

Dose Conversion Factor (and Related) Parameter Summary

Dose Library: RU for U-Landfill Plus ICRP 60 \& ICRP 72 (Age 15)

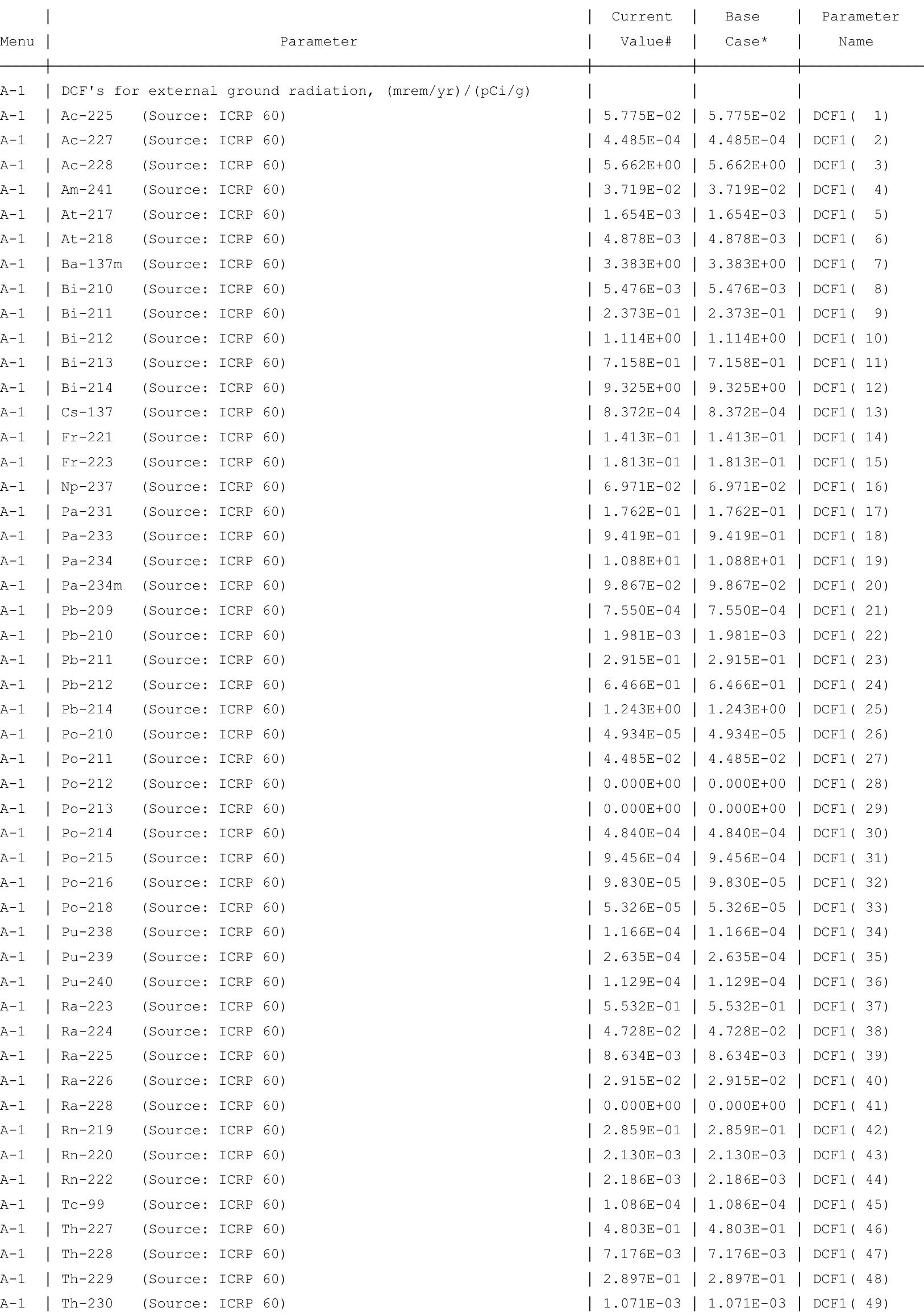


Summary : RESRAD Parameters for U-Landfill Recreational User Foward Run

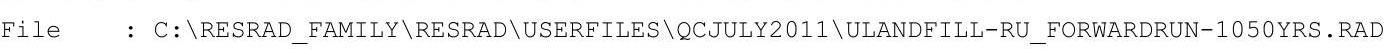

Dose Conversion Factor (and Related) Parameter Summary (continued)

Dose Library: RU for U-Landfill Plus ICRP 60 \& ICRP 72 (Age 15)

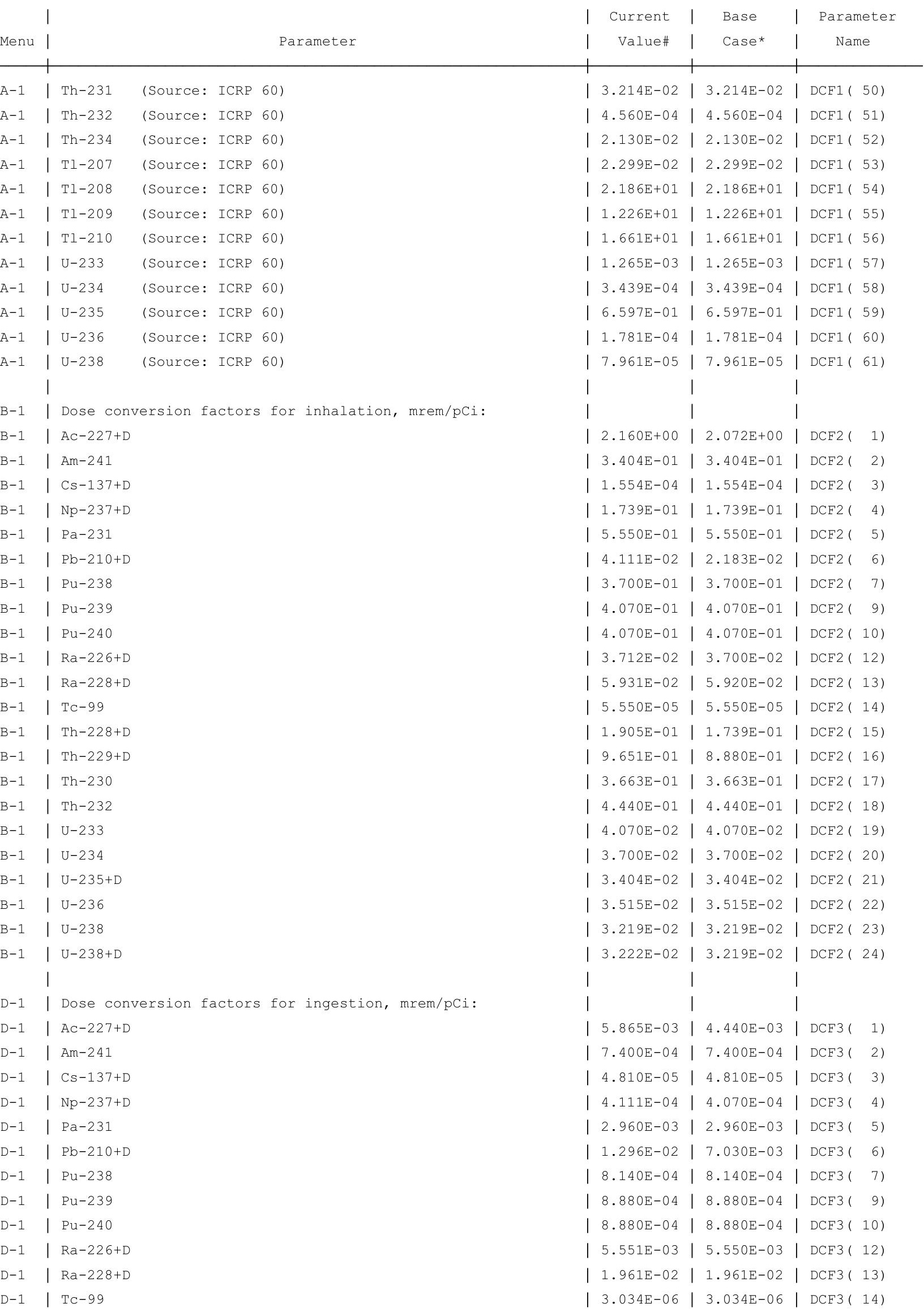


RESRAD, Version $6.5 \quad$ T1/2 Limit $=180$ days $\quad$ 07/20/2011 15:05 Page

Summary : RESRAD Parameters for U-Landfill Recreational User Foward Run

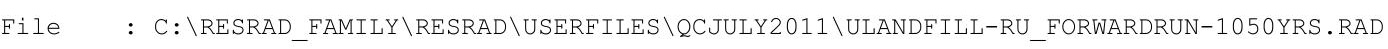

Dose Conversion Factor (and Related) Parameter Summary (continued)

Dose Library: RU for U-Landfill Plus ICRP 60 \& ICRP 72 (Age 15)

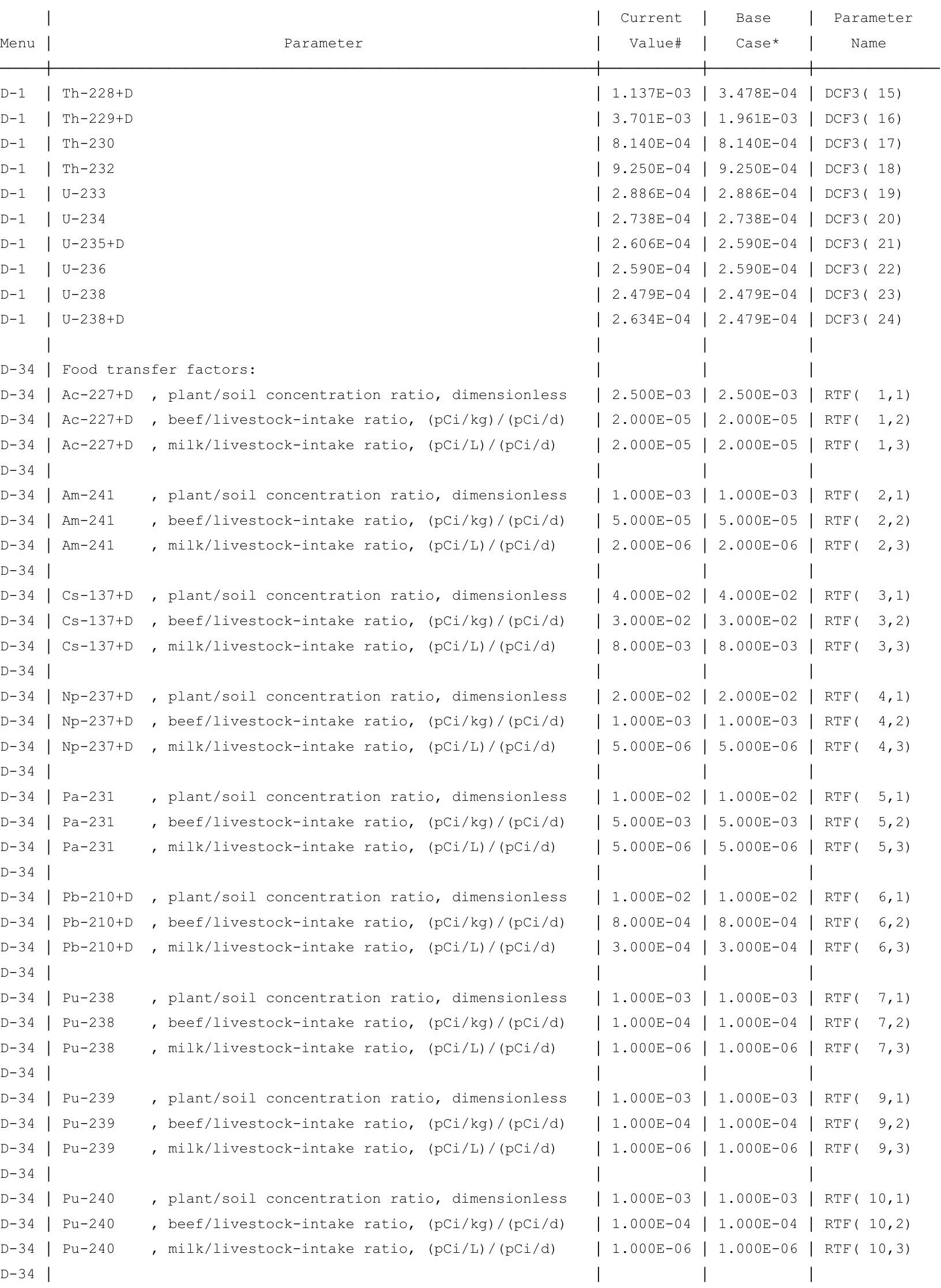

, plant/soil concentration ratio, dimensionless beef/livestock-intake ratio, (pCi/kg)/(pCi/d) , plant/soil concentration ratio, dimensionless , beef/livestock-intake ratio, (pCi/kg)/(pCi/d)

, plant/soil concentration ratio, dimensionless , beef/livestock-intake ratio, (pCi/kg)/(pCi/d) plant/soil concentration ratio, dimensionless , beef/livestock-intake ratio, $(\mathrm{pCi} / \mathrm{kg}) /(\mathrm{pCi} / \mathrm{d})$ , plant/soil concentration ratio, dimensionless , beef/livestock-intake ratio, (pCi/kg)/(pCi/d)

plant/soil concentration ratio, dimensionles , beef/livestock-intake ratio, (pCi/kg)/(pCi/d) , plant/soil concentration ratio, dimensionless , beef/livestock-intake ratio, (pCi/kg)/(pCi/d) , milk/livestock-intake ratio, (pCi/L)/(pCi/d)

, plant/soil concentration ratio, dimensionless , beef/livestock-intake ratio, $(\mathrm{pCi} / \mathrm{kg}) /(\mathrm{pCi} / \mathrm{d}$ , milk/livestock-intake ratio, (pCi/L)/(pCi/d)

, plant/soil concentration ratio, dimensionless \begin{tabular}{|l|l|l}
$1.137 \mathrm{E}-03$ & $3.478 \mathrm{E}-04$ & $\mathrm{DCF} 3(15)$
\end{tabular}

\begin{tabular}{l|l|l|l|}
$9.250 \mathrm{E}-04$ & $9.250 \mathrm{E}-04$ & $\mathrm{DCF} 3(18)$
\end{tabular}

\begin{tabular}{|l|l|l|}
$2.606 \mathrm{E}-04$ & $2.590 \mathrm{E}-04$ & $\mathrm{DCF} 3(21)$
\end{tabular}

\begin{tabular}{l|l|l}
$2.590 \mathrm{E}-04$ & $2.590 \mathrm{E}-04$ & $\mathrm{DCF} 3(22$
\end{tabular}

\begin{tabular}{l|l|l}
$2.634 \mathrm{E}-04$ & $2.479 \mathrm{E}-04$ & $\mathrm{DCF} 3(24)$
\end{tabular}

\begin{tabular}{l|l|l|}
$2.500 \mathrm{E}-03$ & $2.500 \mathrm{E}-03$ & $\operatorname{RTF}(1,1)$
\end{tabular}

\begin{tabular}{l|l|l}
$2.000 \mathrm{E}-05$ & $2.000 \mathrm{E}-05$ & $\operatorname{RTF}(1,2)$
\end{tabular}

\begin{tabular}{l|l|l}
$2.000 \mathrm{E}-05$ & $2.000 \mathrm{E}-05$ & $\operatorname{RTF}(1,3)$
\end{tabular}

\begin{tabular}{|l|l|l|}
$1.000 \mathrm{E}-03$ & $1.000 \mathrm{E}-03$ & $\operatorname{RTF}(2,1)$
\end{tabular}

\begin{tabular}{l|l|l|}
$5.000 \mathrm{E}-05$ & $5.000 \mathrm{E}-05$ & $\operatorname{RTF}(2,2)$
\end{tabular}

\begin{tabular}{l|l|l|}
$2.000 \mathrm{E}-06$ & $2.000 \mathrm{E}-06$ & $\operatorname{RTF}(2,3)$
\end{tabular}

\begin{tabular}{|l|l|l|}
$4.000 \mathrm{E}-02$ & $4.000 \mathrm{E}-02$ & $\operatorname{RTF}(3,1)$
\end{tabular}

\begin{tabular}{l|l|l}
$3.000 \mathrm{E}-02$ & $3.000 \mathrm{E}-02$ & $\operatorname{RTF}(3,2)$
\end{tabular}

\begin{tabular}{l|l|l|}
$8.000 \mathrm{E}-03$ & $8.000 \mathrm{E}-03$ & $\operatorname{RTF}(3,3)$
\end{tabular}

\begin{tabular}{|l|l|l|}
$2.000 \mathrm{E}-02$ & $2.000 \mathrm{E}-02$ & $\operatorname{RTF}(4,1)$
\end{tabular}

1.000E-03 | 1.000E-03 | RTF(4,2)

5.000E-06 5.000E-06 $\mid \operatorname{RTF}(4,3)$

\begin{tabular}{|l|l|l|}
$1.000 \mathrm{E}-02$ & $1.000 \mathrm{E}-02$ & $\operatorname{RTF}(5,1)$
\end{tabular}

\begin{tabular}{|l|l|l|}
$5.000 \mathrm{E}-03$ & $5.000 \mathrm{E}-03$ & $\operatorname{RTF}(5,2)$
\end{tabular}

\begin{tabular}{|l|l|l|}
$5.000 \mathrm{E}-06$ & $5.000 \mathrm{E}-06$ & $\operatorname{RTF}(5,3)$
\end{tabular}

\begin{tabular}{|l|l|l|}
$1.000 \mathrm{E}-02$ & $1.000 \mathrm{E}-02$ & $\operatorname{RTF}(6,1)$
\end{tabular}

\begin{tabular}{|l|l|l|}
$8.000 \mathrm{E}-04$ & $8.000 \mathrm{E}-04$ & $\operatorname{RTF}(6,2)$
\end{tabular}

\begin{tabular}{|l|l|l|}
$3.000 \mathrm{E}-04$ & $3.000 \mathrm{E}-04$ & $\operatorname{RTF}(6,3)$
\end{tabular}

1.000E-03 | 1.000E-03 | $\operatorname{RTF}(7,1)$

\begin{tabular}{|l|l|l|}
$1.000 \mathrm{E}-04$ & $1.000 \mathrm{E}-04$ & $\operatorname{RTF}(7,2)$
\end{tabular}

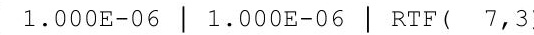

1.000E-03 | 1.000E-03 | $\operatorname{RTF}(9,1)$

\begin{tabular}{|l|l|l|l|}
$1.000 \mathrm{E}-04$ & $1.000 \mathrm{E}-04 \mid \operatorname{RTE}(9,2)$
\end{tabular}

\begin{tabular}{|l|l|l|}
$1.000 \mathrm{E}-06$ & $1.000 \mathrm{E}-06$ & $\operatorname{RTF}(9,3)$
\end{tabular}

\begin{tabular}{r|r|r|}
$1.000 \mathrm{E}-03$ & $1.000 \mathrm{E}-03$ & $\operatorname{RTF}(10,1)$
\end{tabular}

\begin{tabular}{|l|l|l|}
$1.000 \mathrm{E}-04$ & $1.000 \mathrm{E}-04$ & $\operatorname{RTF}(10,2)$
\end{tabular}

| 1.000E-06 | 1.000E-06 | $\operatorname{RTE}(10,3)$ 
RESRAD, Version $6.5 \quad$ T1/2 Limit $=180$ days $\quad$ 07/20/2011 15:05 Page

Summary : RESRAD Parameters for U-Landfill Recreational User Foward Run

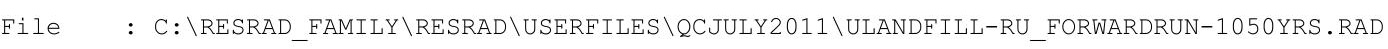

Dose Conversion Factor (and Related) Parameter Summary (continued)

Dose Library: RU for U-Landfill Plus ICRP 60 \& ICRP 72 (Age 15)

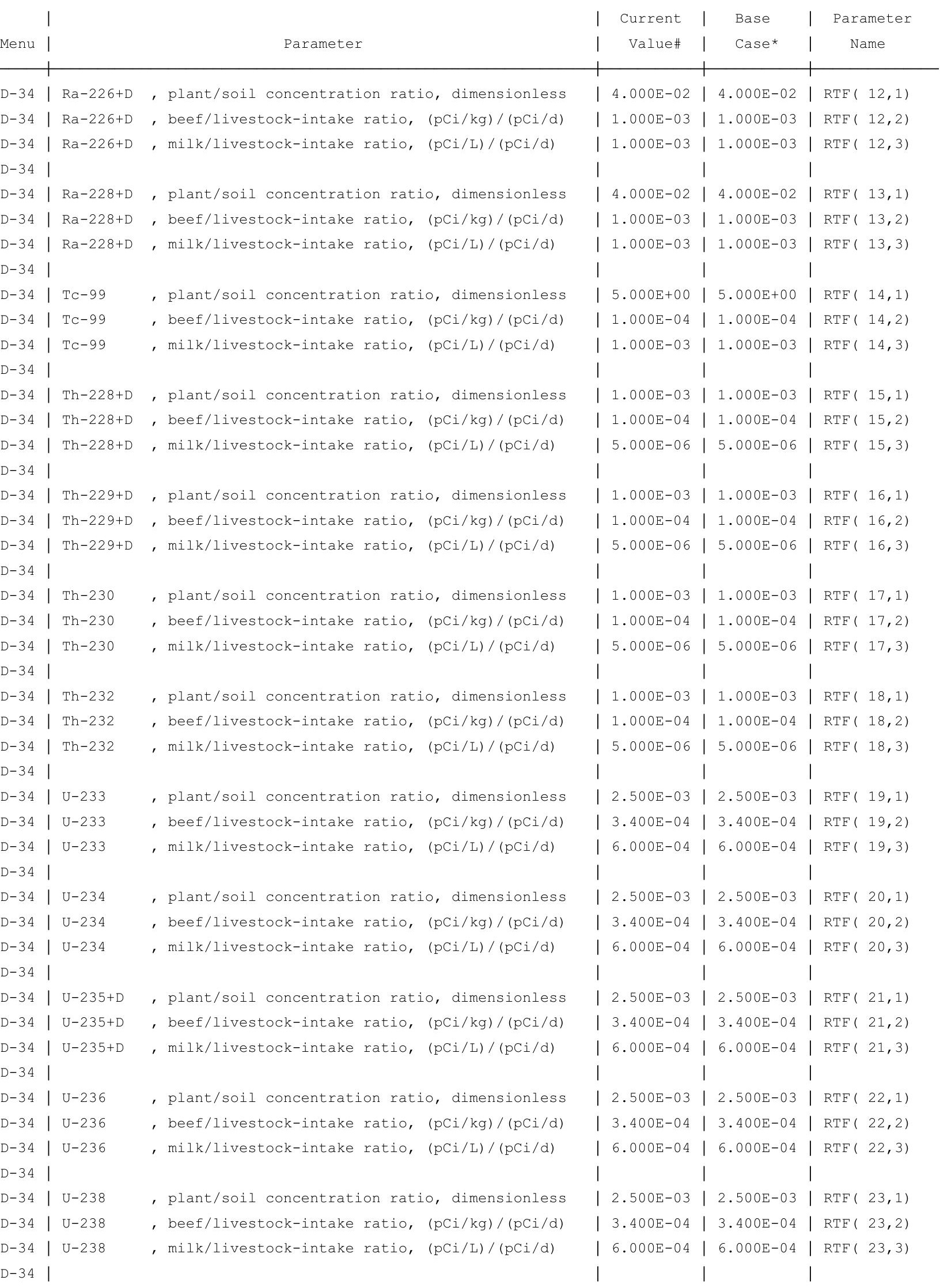


RESRAD, Version $6.5 \quad \mathrm{~T}^{1 / 2}$ Limit $=180$ days

Summary : RESRAD Parameters for U-Landfill Recreational User Foward Run

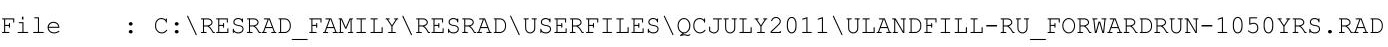

Dose Conversion Factor (and Related) Parameter Summary (continued)

Dose Library: RU for U-Landfill Plus ICRP 60 \& ICRP 72 (Age 15)

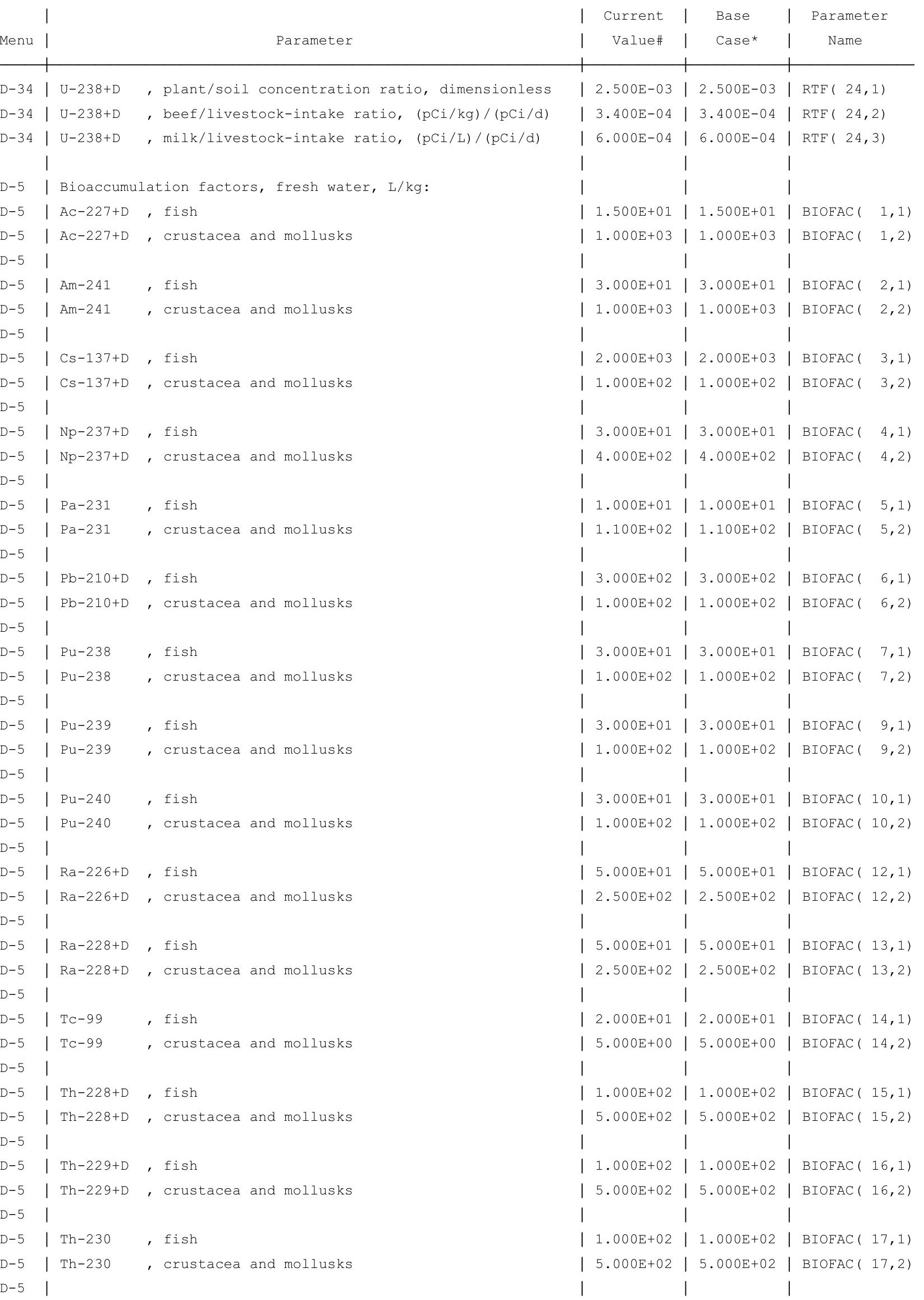


RESRAD, Version $6.5 \quad \mathrm{~T}^{1 / 2}$ Limit $=180$ days

Summary : RESRAD Parameters for U-Landfill Recreational User Foward Run

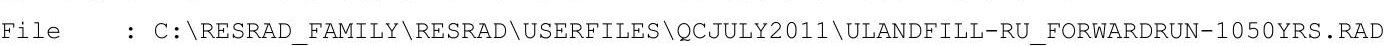

Site-Specific Parameter Summary (continued)

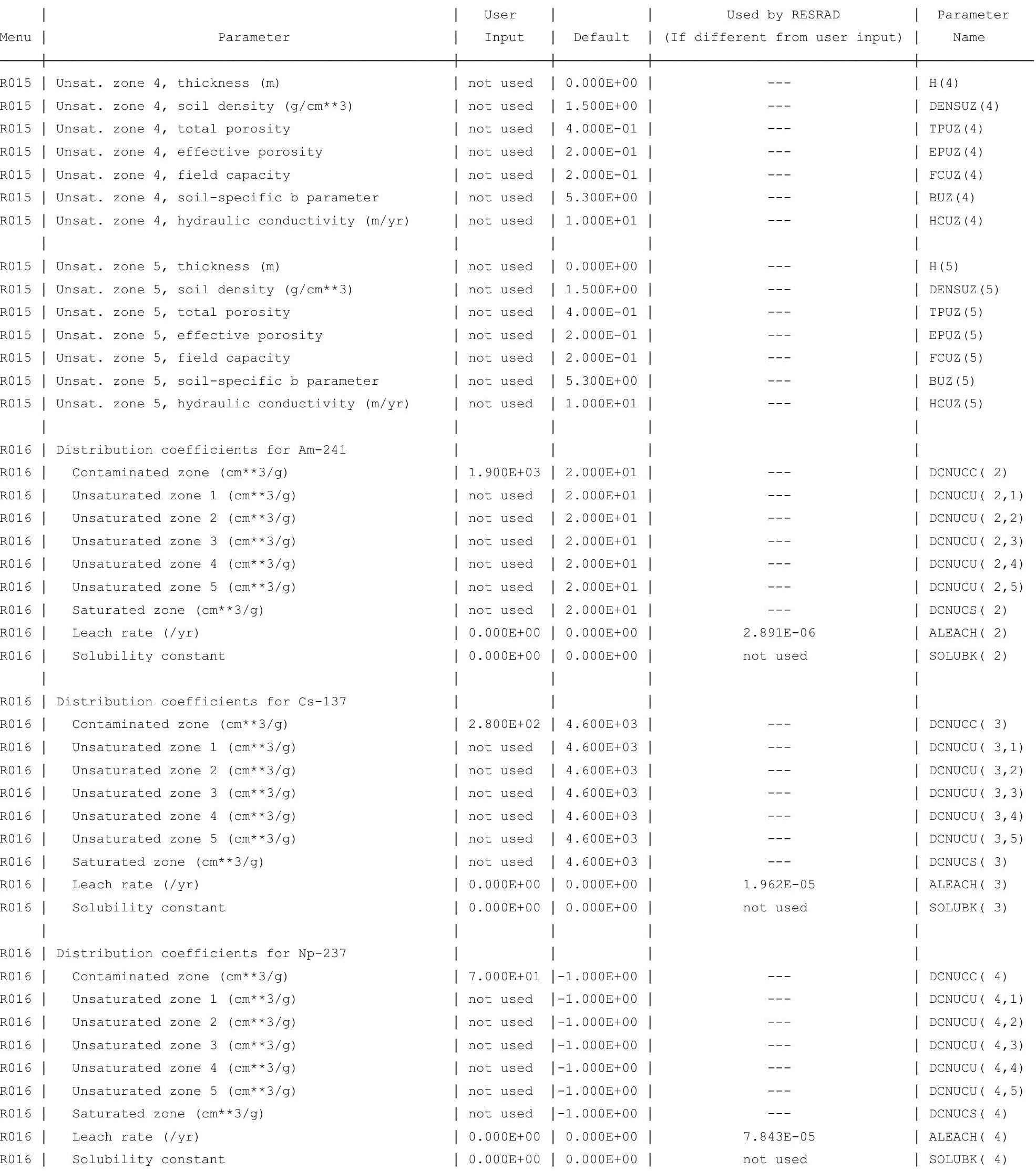


RESRAD, Version $6.5 \quad \mathrm{~T}^{1 / 2}$ Limit $=180$ days

Summary : RESRAD Parameters for U-Landfill Recreational User Foward Run

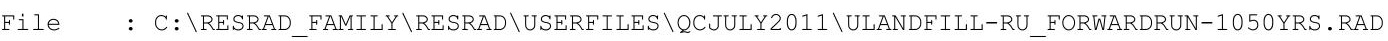

Site-Specific Parameter Summary (continued)

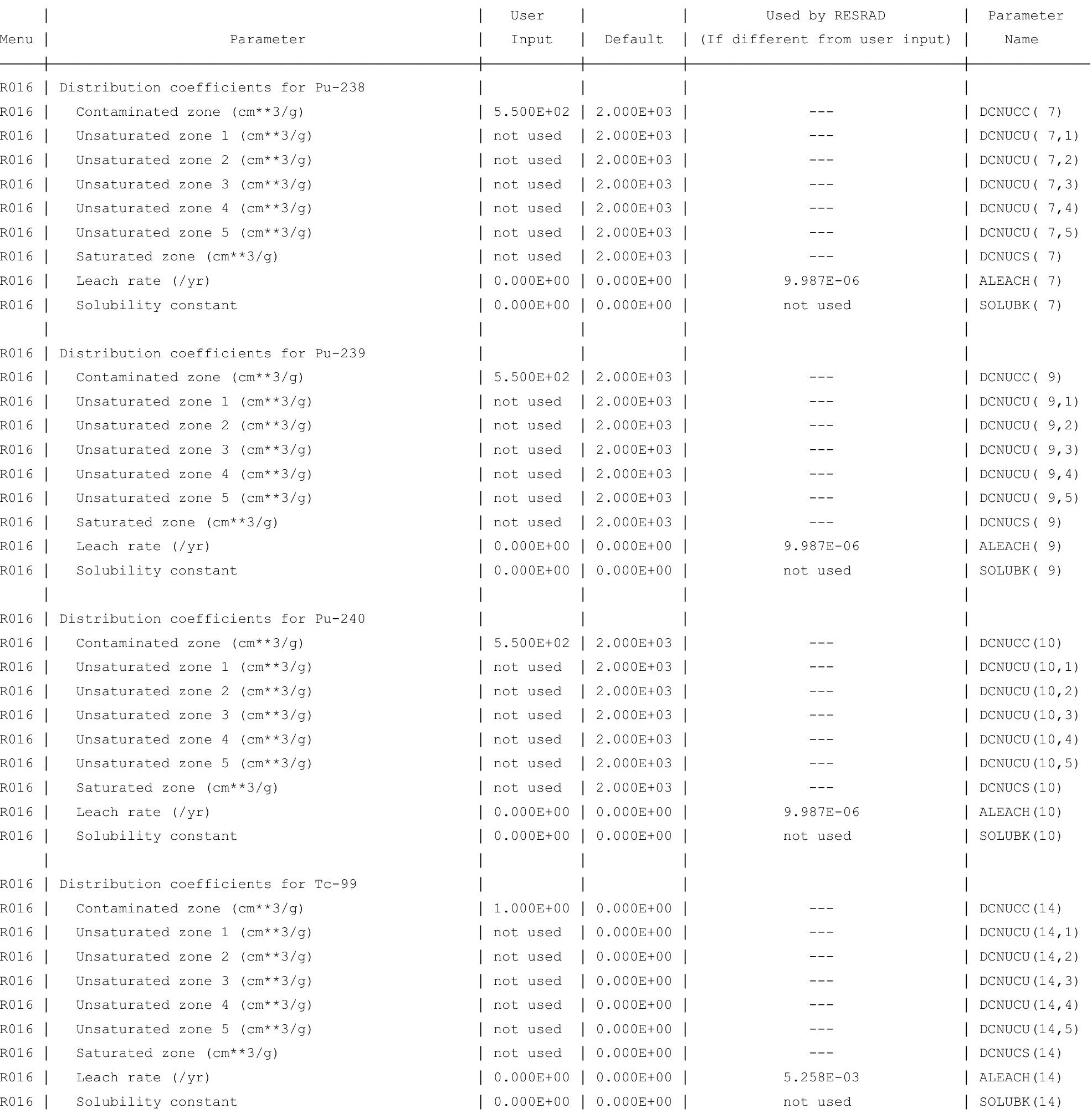


RESRAD, Version $6.5 \quad \mathrm{~T}^{1 / 2}$ Limit $=180$ days

Summary : RESRAD Parameters for U-Landfill Recreational User Foward Run

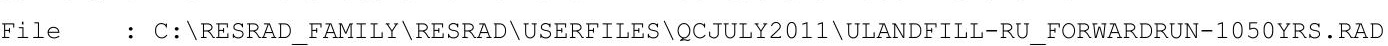

Site-Specific Parameter Summary (continued)

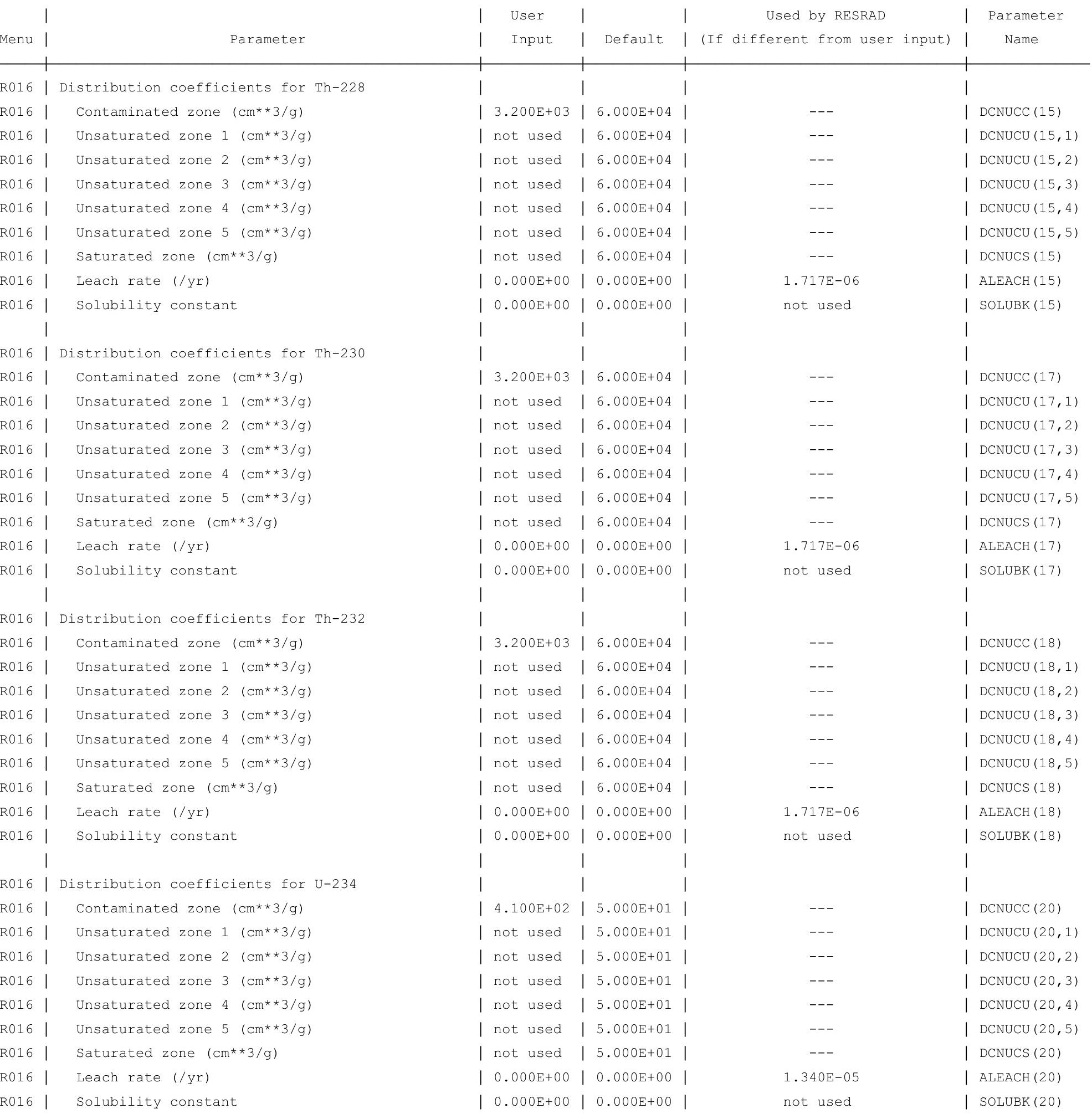


RESRAD, Version $6.5 \quad \mathrm{~T}^{1 / 2}$ Limit $=180$ days

Summary : RESRAD Parameters for U-Landfill Recreational User Foward Run

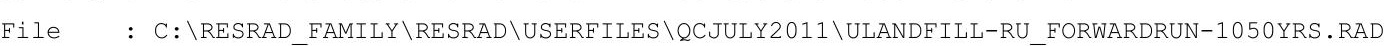

Site-Specific Parameter Summary (continued)

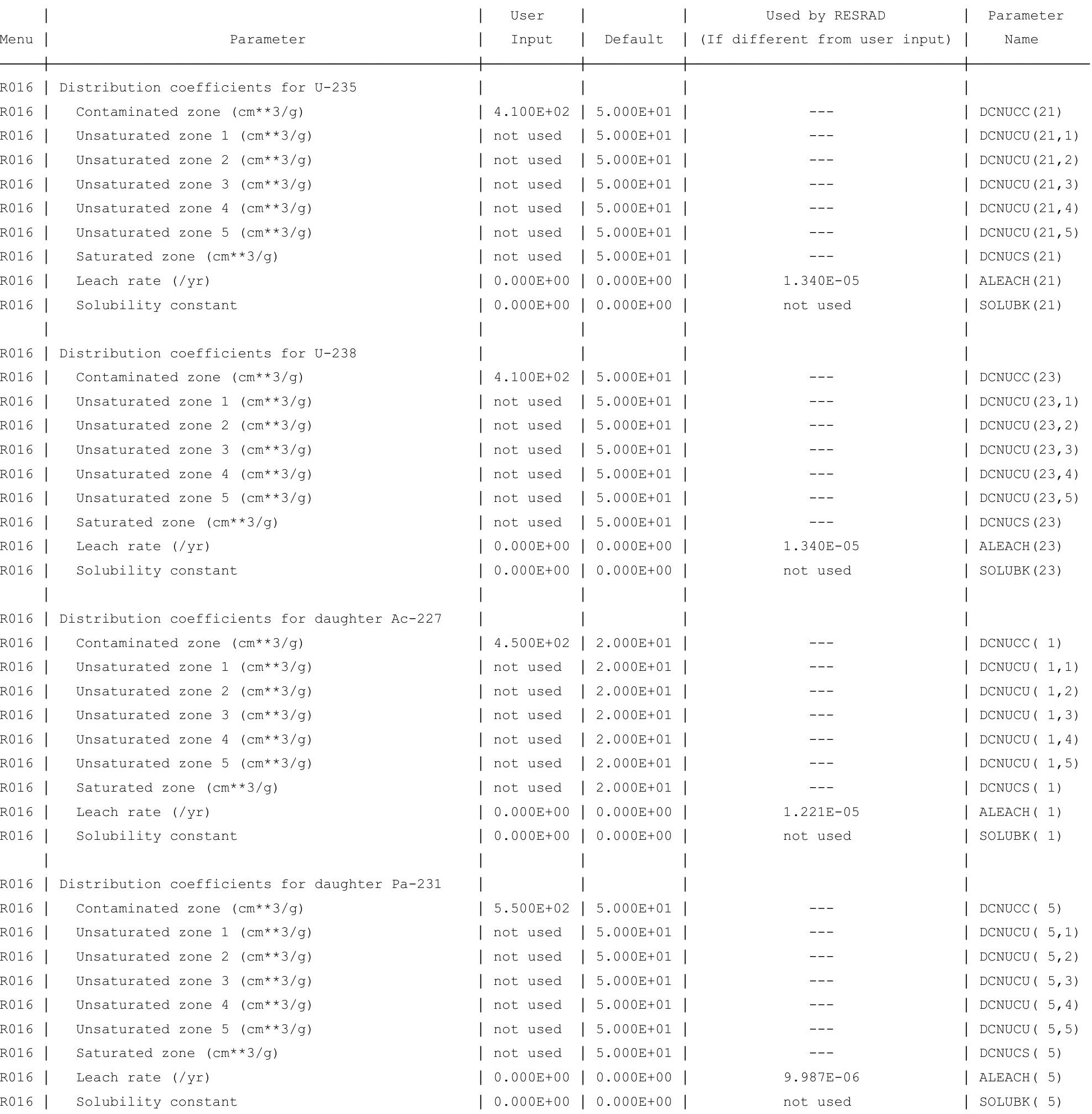


RESRAD, Version $6.5 \quad \mathrm{~T}^{1 / 2}$ Limit $=180$ days

Summary : RESRAD Parameters for U-Landfill Recreational User Foward Run

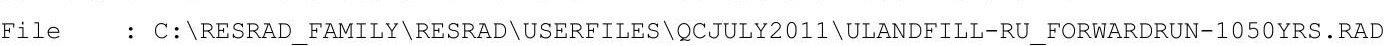

Site-Specific Parameter Summary (continued)

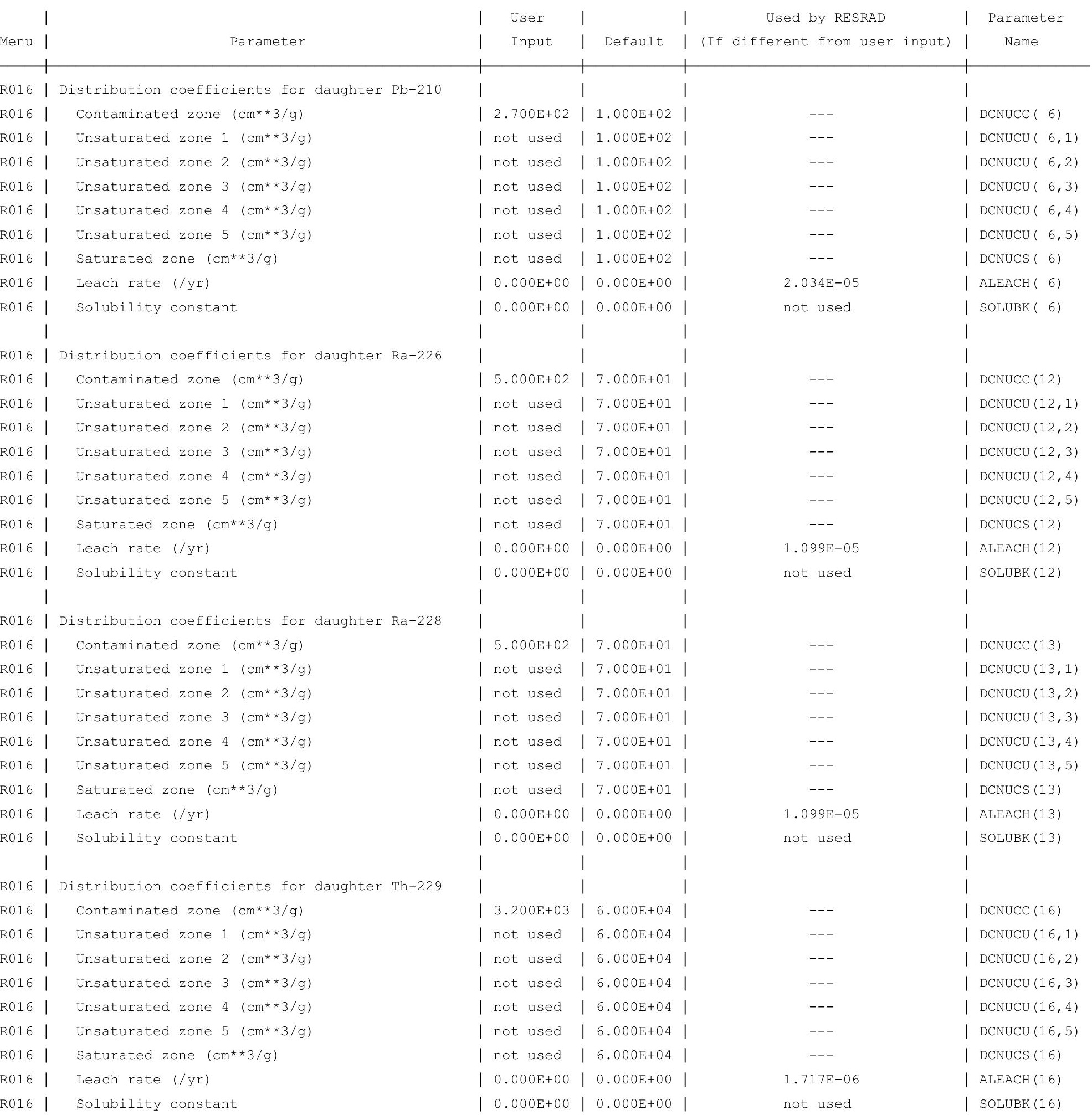


RESRAD, Version $6.5 \quad \mathrm{~T}^{1 / 2}$ Limit $=180$ days

Summary : RESRAD Parameters for U-Landfill Recreational User Foward Run

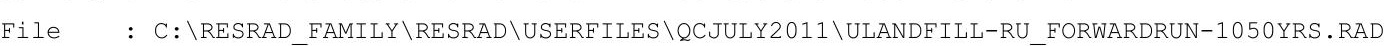

Site-Specific Parameter Summary (continued)

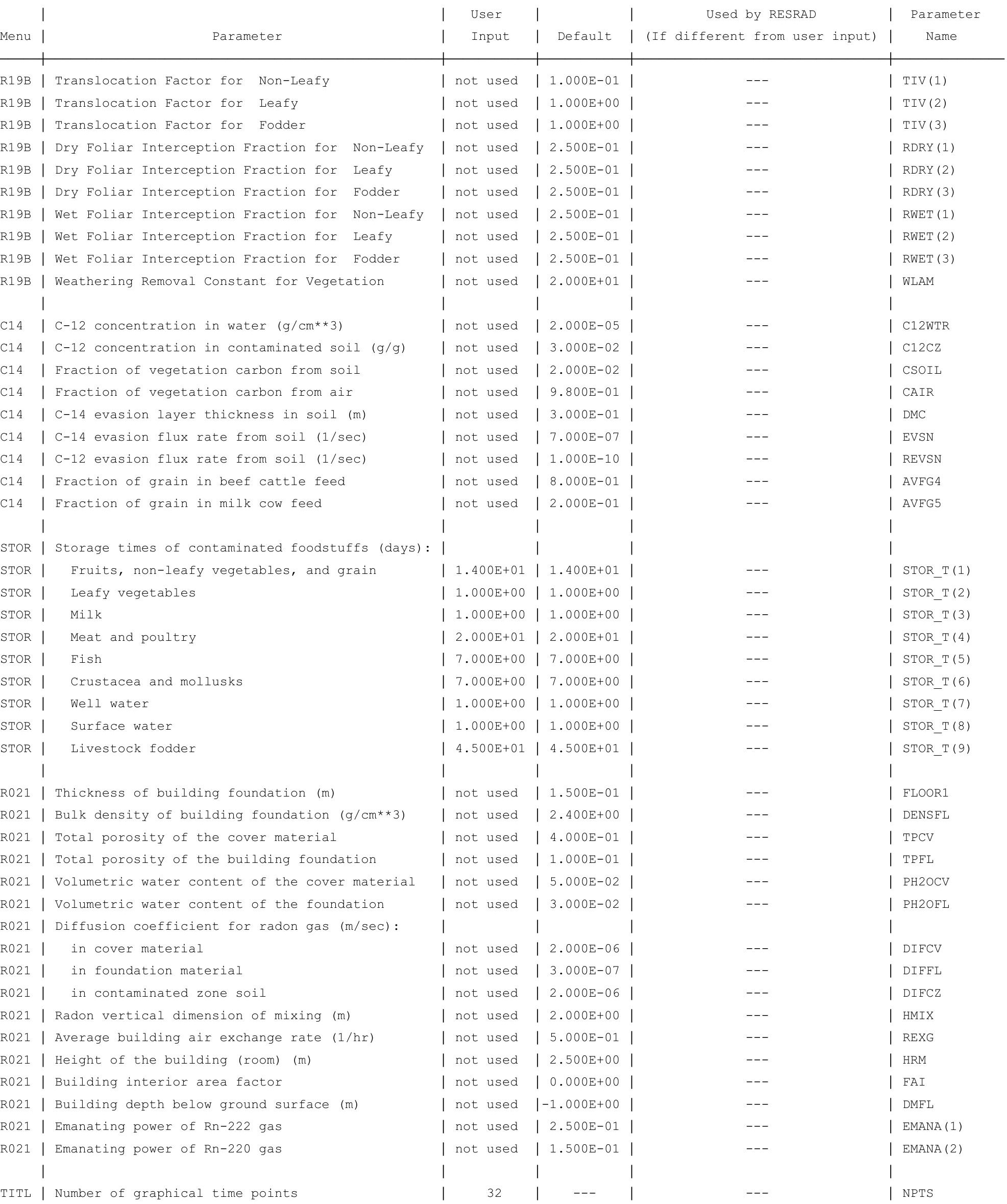

TITL | Number of graphical time points 
RESRAD, Version $6.5 \quad T^{11 / 2}$ Limit $=180$ days

Summary : RESRAD Parameters for U-Landfill Recreational User Foward Run

File : C:\RESRAD_FAMILY \RESRAD \USERFILES \QCJULY2011 \ULANDFILL-RU_FORWARDRUN-1050YRS.RAD

Contaminated Zone Dimensions

Area: 89436.00 square meters

Thickness:

Cover Depth:

\begin{abstract}
13.40 meters
1.52 meters
\end{abstract}

Initial Soil Concentrations, pci/g

$\begin{array}{ll}\text { Am-241 } & 3.500 \mathrm{E}+01 \\ \mathrm{Cs}-137 & 1.900 \mathrm{E}+01 \\ \mathrm{~Np}-237 & 5.500 \mathrm{E}+00 \\ \mathrm{Pu}-238 & 3.900 \mathrm{E}+01 \\ \mathrm{Pu}-239 & 3.600 \mathrm{E}+01 \\ \mathrm{Pu}-240 & 3.600 \mathrm{E}+01 \\ \mathrm{Tc}-99 & 5.200 \mathrm{E}+01 \\ \mathrm{Th}-228 & 4.000 \mathrm{E}+00 \\ \text { Th-230 } & 1.000 \mathrm{E}+02 \\ \text { Th-232 } & 4.000 \mathrm{E}+00 \\ \mathrm{U}-234 & 1.600 \mathrm{E}+02 \\ \mathrm{U}-235 & 6.500 \mathrm{E}+00 \\ \mathrm{U}-238 & 1.600 \mathrm{E}+02\end{array}$

Total Dose TDOSE(t), mrem/yr

Basic Radiation Dose Limit $=1.000 \mathrm{E}+00 \mathrm{mrem} / \mathrm{yr}$

Total Mixture Sum $M(t)$ = Fraction of Basic Dose Limit Received at Time (t)

$\begin{array}{rllllllll}t \text { (years) }: & 0.000 \mathrm{E}+00 & 1.000 \mathrm{E}+00 & 1.200 \mathrm{E}+01 & 5.000 \mathrm{E}+01 & 1.000 \mathrm{E}+02 & 5.000 \mathrm{E}+02 & 1.050 \mathrm{E}+03 \\ \mathrm{TDOSE}(\mathrm{t}): & 5.411 \mathrm{E}-07 & 4.044 \mathrm{E}-07 & 4.862 \mathrm{E}-07 & 9.175 \mathrm{E}-07 & 1.314 \mathrm{E}-06 & 2.333 \mathrm{E}-05 & 1.239 \mathrm{E}-03 \\ \mathrm{M}(\mathrm{t}): & 5.411 \mathrm{E}-07 & 4.044 \mathrm{E}-07 & 4.862 \mathrm{E}-07 & 9.175 \mathrm{E}-07 & 1.314 \mathrm{E}-06 & 2.333 \mathrm{E}-05 & 1.239 \mathrm{E}-03\end{array}$

Maximum TDOSE(t): $1.239 \mathrm{E}-03 \mathrm{mrem} / \mathrm{yr}$ at $t=1.050 \mathrm{E}+03$ years 
RESRAD, Version 6.5

ummary : RESRAD Parameters for U-Landfill Recreational User Foward Run

: C: $\backslash$ RESRAD FAMILY \RESRAD \USERFILES \QCJULY2011 \ULANDFILL-RU FORWARDRUN-1050YRS.RAD

Total Dose Contributions TDOSE(i,p,t) for Individual Radionuclides (i) and Pathways (p) As mrem/yr and Fraction of Total Dose At $t=0.000 \mathrm{E}+00$ years

Water Independent Pathways (Inhalation excludes radon)

\begin{tabular}{|c|c|c|c|c|c|c|c|c|c|c|c|c|c|c|}
\hline \multirow{2}{*}{ Nuclide } & \multicolumn{2}{|c|}{ Ground } & \multicolumn{2}{|c|}{ Inhalation } & \multicolumn{2}{|c|}{ Radon } & \multicolumn{2}{|c|}{ Plant } & \multicolumn{2}{|c|}{ Meat } & \multicolumn{2}{|c|}{ Milk } & \multicolumn{2}{|c|}{ Soil } \\
\hline & mrem/yr & fract. & mrem/yr & fract. & mrem/yr & fract. & mrem/yr & fract. & mrem/yr & fract. & mrem/yr & fract. & mrem/yr & fract. \\
\hline-241 & $5.204 \mathrm{E}-19$ & 0.0000 & $0.000 \mathrm{E}+00$ & 0.0000 & $0.000 \mathrm{E}+00$ & 0.0000 & $0.000 \mathrm{E}+00$ & 0.0000 & $0.000 \mathrm{E}+00$ & 0.0000 & $0.000 \mathrm{E}+00$ & 0.0000 & $0.000 \mathrm{E}+00$ & 0.0000 \\
\hline-137 & $2.305 E-09$ & 0.0043 & $0.000 \mathrm{E}+00$ & 0.0000 & $0.000 \mathrm{E}+00$ & 0.0000 & $0.000 \mathrm{E}+00$ & 0.0000 & $0.000 \mathrm{E}+00$ & 0.0000 & $0.000 \mathrm{E}+00$ & 0.0000 & $0.000 \mathrm{E}+00$ & 0.0000 \\
\hline-237 & $5.043 E-13$ & 0.0000 & $0.000 \mathrm{E}+00$ & 0.0000 & $0.000 \mathrm{E}+00$ & 0.0000 & $0.000 \mathrm{E}+00$ & 0.0000 & $0.000 \mathrm{E}+00$ & 0.0000 & $0.000 \mathrm{E}+00$ & 0.0000 & $0.000 \mathrm{E}+00$ & 0.0000 \\
\hline-238 & $3.052 \mathrm{E}-22$ & 0.0000 & $0.000 \mathrm{E}+00$ & 0.0000 & $0.000 \mathrm{E}+00$ & 0.0000 & $0.000 \mathrm{E}+00$ & 0.0000 & $0.000 \mathrm{E}+00$ & 0.0000 & $0.000 \mathrm{E}+00$ & 0.0000 & $0.000 \mathrm{E}+00$ & 0.0000 \\
\hline-239 & $4.161 \mathrm{E}-17$ & 0.0000 & $0.000 \mathrm{E}+00$ & 0.0000 & $0.000 \mathrm{E}+00$ & 0.0000 & $0.000 \mathrm{E}+00$ & 0.0000 & $0.000 \mathrm{E}+00$ & 0.0000 & $0.000 \mathrm{E}+00$ & 0.0000 & $0.000 \mathrm{E}+00$ & 0.0000 \\
\hline-240 & $3.957 \mathrm{E}-24$ & 0.0000 & $0.000 \mathrm{E}+00$ & 0.0000 & $0.000 \mathrm{E}+00$ & 0.0000 & $0.000 \mathrm{E}+00$ & 0.0000 & $0.000 \mathrm{E}+00$ & 0.0000 & $0.000 \mathrm{E}+00$ & 0.0000 & $0.000 \mathrm{E}+00$ & 0.0000 \\
\hline 99 & $2.884 \mathrm{E}-25$ & 0.0000 & $0.000 \mathrm{E}+00$ & 0.0000 & $0.000 \mathrm{E}+00$ & 0.0000 & $0.000 \mathrm{E}+00$ & 0.0000 & $0.000 \mathrm{E}+00$ & 0.0000 & $0.000 \mathrm{E}+00$ & 0.0000 & $0.000 \mathrm{E}+00$ & 0.0000 \\
\hline-228 & $5.317 \mathrm{E}-07$ & 0.9827 & $0.000 \mathrm{E}+00$ & 0.0000 & $0.000 \mathrm{E}+00$ & 0.0000 & $0.000 \mathrm{E}+00$ & 0.0000 & $0.000 \mathrm{E}+00$ & 0.0000 & $0.000 \mathrm{E}+00$ & 0.0000 & $0.000 \mathrm{E}+00$ & 0.0000 \\
\hline-230 & $3.629 \mathrm{E}-10$ & 0.0007 & $0.000 \mathrm{E}+00$ & 0.0000 & $0.000 \mathrm{E}+00$ & 0.0000 & $0.000 \mathrm{E}+00$ & 0.0000 & $0.000 \mathrm{E}+00$ & 0.0000 & $0.000 \mathrm{E}+00$ & 0.0000 & $0.000 \mathrm{E}+00$ & 0.0000 \\
\hline-232 & $4.531 E-09$ & 0.0084 & $0.000 \mathrm{E}+00$ & 0.0000 & $0.000 \mathrm{E}+00$ & 0.0000 & $0.000 \mathrm{E}+00$ & 0.0000 & $0.000 \mathrm{E}+00$ & 0.0000 & $0.000 \mathrm{E}+00$ & 0.0000 & $0.000 \mathrm{E}+00$ & 0.0000 \\
\hline 234 & $1.743 E-15$ & 0.0000 & $0.000 \mathrm{E}+00$ & 0.0000 & $0.000 \mathrm{E}+00$ & 0.0000 & $0.000 \mathrm{E}+00$ & 0.0000 & $0.000 \mathrm{E}+00$ & 0.0000 & $0.000 E+00$ & 0.0000 & $0.000 \mathrm{E}+00$ & 0.0000 \\
\hline 35 & $7.778 \mathrm{E}-15$ & 0.0000 & $0.000 \mathrm{E}+00$ & 0.0000 & $0.000 \mathrm{E}+00$ & 0.0000 & $0.000 \mathrm{E}+00$ & 0.0000 & $0.000 \mathrm{E}+00$ & 0.0000 & $0.000 \mathrm{E}+00$ & 0.0000 & $0.000 \mathrm{E}+00$ & 0.0000 \\
\hline 38 & $2.184 \mathrm{E}-09$ & 0.0040 & $0.000 \mathrm{E}+00$ & 0.0000 & $0.000 \mathrm{E}+00$ & 0.0000 & $0.000 \mathrm{E}+00$ & 0.0000 & $0.000 \mathrm{E}+00$ & 0.0000 & $0.000 \mathrm{E}+00$ & 0.0000 & $0.000 \mathrm{E}+00$ & 0.0000 \\
\hline & $5.411 \mathrm{E}-07$ & 1.0000 & $0.000 \mathrm{E}+00$ & 0.0000 & $0.000 \mathrm{E}+00$ & 0.0000 & $0.000 \mathrm{E}+00$ & 0.0000 & $0.000 \mathrm{E}+00$ & 0.0000 & $0.000 \mathrm{E}+00$ & 0.0000 & $0.000 \mathrm{E}+00$ & 0.0000 \\
\hline
\end{tabular}

Total Dose Contributions TDOSE(i,p,t) for Individual Radionuclides (i) and Pathways (p) As mrem/yr and Fraction of Total Dose At $t=0.000 \mathrm{E}+00$ years

Water Dependent Pathways

\begin{tabular}{|c|c|c|c|c|c|c|c|c|c|c|c|c|c|c|}
\hline \multirow{2}{*}{$\begin{array}{l}\text { Radio- } \\
\text { Nuclide }\end{array}$} & \multicolumn{2}{|c|}{ Water } & \multicolumn{2}{|c|}{ Fish } & \multicolumn{2}{|c|}{ Radon } & \multicolumn{2}{|c|}{ Plant } & \multicolumn{2}{|c|}{ Meat } & \multicolumn{2}{|c|}{ Milk } & \multicolumn{2}{|c|}{ All Pathways* } \\
\hline & mrem/yr & fract. & mrem/yr & fract. & mrem/yr & fract. & mrem/yr & fract. & mrem/yr & fract. & mrem/yr & fract. & mrem/yr & fract. \\
\hline 241 & $0.000 \mathrm{E}+00$ & 0.0000 & $0.000 \mathrm{E}+00$ & 0.0000 & $0.000 \mathrm{E}+00$ & 0.0000 & $0.000 \mathrm{E}+00$ & 0.0000 & $0.000 \mathrm{E}+00$ & 0.0000 & $0.000 \mathrm{E}+00$ & 0.0000 & $5.204 \mathrm{E}-19$ & 0.0000 \\
\hline-137 & $0.000 \mathrm{E}+00$ & 0.0000 & $0.000 \mathrm{E}+00$ & 0.0000 & $0.000 \mathrm{E}+00$ & 0.0000 & $0.000 \mathrm{E}+00$ & 0.0000 & $0.000 \mathrm{E}+00$ & 0.0000 & $0.000 \mathrm{E}+00$ & 0.0000 & $2.305 E-09$ & 0.0043 \\
\hline-237 & $0.000 \mathrm{E}+00$ & 0.0000 & $0.000 \mathrm{E}+00$ & 0.0000 & $0.000 \mathrm{E}+00$ & 0.0000 & $0.000 \mathrm{E}+00$ & 0.0000 & $0.000 \mathrm{E}+00$ & 0.0000 & $0.000 \mathrm{E}+00$ & 0.0000 & $5.043 E-13$ & 0.0000 \\
\hline-238 & $0.000 \mathrm{E}+00$ & 0.0000 & $0.000 \mathrm{E}+00$ & 0.0000 & $0.000 \mathrm{E}+00$ & 0.0000 & $0.000 \mathrm{E}+00$ & 0.0000 & $0.000 \mathrm{E}+00$ & 0.0000 & $0.000 \mathrm{E}+00$ & 0.0000 & $3.052 \mathrm{E}-22$ & 0.0000 \\
\hline-239 & $0.000 \mathrm{E}+00$ & 0.0000 & $0.000 \mathrm{E}+00$ & 0.0000 & $0.000 \mathrm{E}+00$ & 0.0000 & $0.000 \mathrm{E}+00$ & 0.0000 & $0.000 \mathrm{E}+00$ & 0.0000 & $0.000 E+00$ & 0.0000 & $4.161 \mathrm{E}-17$ & 0.0000 \\
\hline-240 & $0.000 \mathrm{E}+00$ & 0.0000 & $0.000 \mathrm{E}+00$ & 0.0000 & $0.000 \mathrm{E}+00$ & 0.0000 & $0.000 \mathrm{E}+00$ & 0.0000 & $0.000 \mathrm{E}+00$ & 0.0000 & $0.000 E+00$ & 0.0000 & $3.957 \mathrm{E}-24$ & 0.0000 \\
\hline 99 & $0.000 \mathrm{E}+00$ & 0.0000 & $0.000 \mathrm{E}+00$ & 0.0000 & $0.000 \mathrm{E}+00$ & 0.0000 & $0.000 \mathrm{E}+00$ & 0.0000 & $0.000 \mathrm{E}+00$ & 0.0000 & $0.000 \mathrm{E}+00$ & 0.0000 & $2.884 \mathrm{E}-25$ & 0.0000 \\
\hline-228 & $0.000 \mathrm{E}+00$ & 0.0000 & $0.000 \mathrm{E}+00$ & 0.0000 & $0.000 \mathrm{E}+00$ & 0.0000 & $0.000 \mathrm{E}+00$ & 0.0000 & $0.000 \mathrm{E}+00$ & 0.0000 & $0.000 \mathrm{E}+00$ & 0.0000 & $5.317 \mathrm{E}-07$ & 0.9827 \\
\hline-230 & $0.000 \mathrm{E}+00$ & 0.0000 & $0.000 \mathrm{E}+00$ & 0.0000 & $0.000 \mathrm{E}+00$ & 0.0000 & $0.000 \mathrm{E}+00$ & 0.0000 & $0.000 \mathrm{E}+00$ & 0.0000 & $0.000 E+00$ & 0.0000 & $3.629 \mathrm{E}-10$ & 0.0007 \\
\hline 232 & $0.000 \mathrm{E}+00$ & 0.0000 & $0.000 \mathrm{E}+00$ & 0.0000 & $0.000 \mathrm{E}+00$ & 0.0000 & $0.000 \mathrm{E}+00$ & 0.0000 & $0.000 \mathrm{E}+00$ & 0.0000 & $0.000 \mathrm{E}+00$ & 0.0000 & $4.531 E-09$ & 0.0084 \\
\hline 34 & $0.000 \mathrm{E}+00$ & 0.0000 & $0.000 \mathrm{E}+00$ & 0.0000 & $0.000 \mathrm{E}+00$ & 0.0000 & $0.000 \mathrm{E}+00$ & 0.0000 & $0.000 \mathrm{E}+00$ & 0.0000 & $0.000 \mathrm{E}+00$ & 0.0000 & $1.743 \mathrm{E}-15$ & 0.0000 \\
\hline 35 & $0.000 \mathrm{E}+00$ & 0.0000 & $0.000 \mathrm{E}+00$ & 0.0000 & $0.000 \mathrm{E}+00$ & 0.0000 & $0.000 \mathrm{E}+00$ & 0.0000 & $0.000 \mathrm{E}+00$ & 0.0000 & $0.000 \mathrm{E}+00$ & 0.0000 & 7. $778 \mathrm{E}-15$ & 0.0000 \\
\hline 38 & $0.000 \mathrm{E}+00$ & 0.0000 & $0.000 \mathrm{E}+00$ & 0.0000 & $0.000 \mathrm{E}+00$ & 0.0000 & $0.000 \mathrm{E}+00$ & 0.0000 & $0.000 \mathrm{E}+00$ & 0.0000 & $0.000 \mathrm{E}+00$ & 0.0000 & $2.184 \mathrm{E}-09$ & 0.0040 \\
\hline & $0.000 \mathrm{E}+00$ & 0.0000 & $0.000 \mathrm{E}+00$ & 0.0000 & $0.000 \mathrm{E}+00$ & 0.0000 & $0.000 \mathrm{E}+00$ & 0.0000 & $0.000 \mathrm{E}+00$ & 0.0000 & $0.000 \mathrm{E}+00$ & 0.0000 & $11 \mathrm{E}-07$ & 1.0000 \\
\hline
\end{tabular}

* Sum of all water independent and dependent pathways. 
RESRAD, Version 6.5

ummary : RESRAD Parameters for U-Landfill Recreational User Foward Run

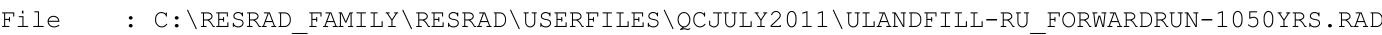

Total Dose Contributions TDOSE (i,p,t) for Individual Radionuclides (i) and Pathways (p) As mrem/yr and Fraction of Total Dose At $t=1.000 \mathrm{E}+00$ years

Water Independent Pathways (Inhalation excludes radon)

\begin{tabular}{|c|c|c|c|c|c|c|c|c|c|c|c|c|c|c|}
\hline \multirow[b]{2}{*}{ Nuclide } & \multicolumn{2}{|c|}{ Ground } & \multicolumn{2}{|c|}{ Inhalation } & \multicolumn{2}{|c|}{ Radon } & \multicolumn{2}{|c|}{ Plant } & \multicolumn{2}{|c|}{ Meat } & \multicolumn{2}{|c|}{ Milk } & \multicolumn{2}{|c|}{ Soil } \\
\hline & mrem/yr & fract. & mrem/yr & fract. & mrem/yr & fract. & mrem/yr & fract. & mrem/yr & fract. & mrem/yr & fract. & mrem/yr & fract. \\
\hline-241 & $1.575 E-18$ & 0.0000 & $0.000 \mathrm{E}+00$ & 0.0000 & $0.000 \mathrm{E}+00$ & 0.0000 & $0.000 \mathrm{E}+00$ & 0.0000 & $0.000 \mathrm{E}+00$ & 0.0000 & $0.000 \mathrm{E}+00$ & 0.0000 & $0.000 \mathrm{E}+00$ & 0.0000 \\
\hline-137 & $2.272 E-09$ & 0.0056 & $0.000 \mathrm{E}+00$ & 0.0000 & $0.000 \mathrm{E}+00$ & 0.0000 & $0.000 \mathrm{E}+00$ & 0.0000 & $0.000 \mathrm{E}+00$ & 0.0000 & $0.000 \mathrm{E}+00$ & 0.0000 & $0.000 \mathrm{E}+00$ & 0.0000 \\
\hline-237 & $5.097 \mathrm{E}-13$ & 0.0000 & $0.000 \mathrm{E}+00$ & 0.0000 & $0.000 \mathrm{E}+00$ & 0.0000 & $0.000 \mathrm{E}+00$ & 0.0000 & $0.000 \mathrm{E}+00$ & 0.0000 & $0.000 \mathrm{E}+00$ & 0.0000 & $0.000 \mathrm{E}+00$ & 0.0000 \\
\hline-238 & $4.535 E-21$ & 0.0000 & $0.000 \mathrm{E}+00$ & 0.0000 & $0.000 \mathrm{E}+00$ & 0.0000 & $0.000 \mathrm{E}+00$ & 0.0000 & $0.000 \mathrm{E}+00$ & 0.0000 & $0.000 \mathrm{E}+00$ & 0.0000 & $0.000 \mathrm{E}+00$ & 0.0000 \\
\hline-239 & $4.211 E-17$ & 0.0000 & $0.000 \mathrm{E}+00$ & 0.0000 & $0.000 \mathrm{E}+00$ & 0.0000 & $0.000 \mathrm{E}+00$ & 0.0000 & $0.000 \mathrm{E}+00$ & 0.0000 & $0.000 \mathrm{E}+00$ & 0.0000 & $0.000 \mathrm{E}+00$ & 0.0000 \\
\hline-240 & $4.111 \mathrm{E}-24$ & 0.0000 & $0.000 \mathrm{E}+00$ & 0.0000 & $0.000 \mathrm{E}+00$ & 0.0000 & $0.000 \mathrm{E}+00$ & 0.0000 & $0.000 \mathrm{E}+00$ & 0.0000 & $0.000 \mathrm{E}+00$ & 0.0000 & $0.000 \mathrm{E}+00$ & 0.0000 \\
\hline 99 & $2.925 E-25$ & 0.0000 & $0.000 \mathrm{E}+00$ & 0.0000 & $0.000 \mathrm{E}+00$ & 0.0000 & $0.000 \mathrm{E}+00$ & 0.0000 & $0.000 \mathrm{E}+00$ & 0.0000 & $0.000 \mathrm{E}+00$ & 0.0000 & $0.000 \mathrm{E}+00$ & 0.0000 \\
\hline 228 & $3.723 E-07$ & 0.9206 & $0.000 \mathrm{E}+00$ & 0.0000 & $0.000 \mathrm{E}+00$ & 0.0000 & $0.000 \mathrm{E}+00$ & 0.0000 & $0.000 \mathrm{E}+00$ & 0.0000 & $0.000 \mathrm{E}+00$ & 0.0000 & $0.000 \mathrm{E}+00$ & 0.0000 \\
\hline 230 & $1.095 \mathrm{E}-09$ & 0.0027 & $0.000 \mathrm{E}+00$ & 0.0000 & $0.000 \mathrm{E}+00$ & 0.0000 & $0.000 \mathrm{E}+00$ & 0.0000 & $0.000 \mathrm{E}+00$ & 0.0000 & $0.000 \mathrm{E}+00$ & 0.0000 & $0.000 \mathrm{E}+00$ & 0.0000 \\
\hline-232 & $2.653 E-08$ & 0.0656 & $0.000 \mathrm{E}+00$ & 0.0000 & $0.000 \mathrm{E}+00$ & 0.0000 & $0.000 \mathrm{E}+00$ & 0.0000 & $0.000 \mathrm{E}+00$ & 0.0000 & $0.000 \mathrm{E}+00$ & 0.0000 & $0.000 \mathrm{E}+00$ & 0.0000 \\
\hline 34 & $1.227 \mathrm{E}-14$ & 0.0000 & $0.000 \mathrm{E}+00$ & 0.0000 & $0.000 \mathrm{E}+00$ & 0.0000 & $0.000 \mathrm{E}+00$ & 0.0000 & $0.000 \mathrm{E}+00$ & 0.0000 & $0.000 \mathrm{E}+00$ & 0.0000 & $0.000 \mathrm{E}+00$ & 0.0000 \\
\hline 35 & 7. $913 \mathrm{E}-15$ & 0.0000 & $0.000 \mathrm{E}+00$ & 0.0000 & $0.000 \mathrm{E}+00$ & 0.0000 & $0.000 \mathrm{E}+00$ & 0.0000 & $0.000 \mathrm{E}+00$ & 0.0000 & $0.000 \mathrm{E}+00$ & 0.0000 & $0.000 \mathrm{E}+00$ & 0.0000 \\
\hline 38 & $2.202 \mathrm{E}-09$ & 0.0054 & $0.000 \mathrm{E}+00$ & 0.0000 & $0.000 \mathrm{E}+00$ & 0.0000 & $0.000 \mathrm{E}+00$ & 0.0000 & $0.000 \mathrm{E}+00$ & 0.0000 & $0.000 \mathrm{E}+00$ & 0.0000 & $0.000 \mathrm{E}+00$ & 0.0000 \\
\hline & $4.044 \mathrm{E}-07$ & 0 & $.000 \mathrm{E}+00$ & 0.0 & $0.000 \mathrm{E}+00$ & 0 . & $0.000 \mathrm{E}+00$ & 00 & +00 & 0 & 100 & & +00 & \\
\hline
\end{tabular}

Total Dose Contributions TDOSE(i,p,t) for Individual Radionuclides (i) and Pathways (p) As mrem/yr and Fraction of Total Dose At $t=1.000 \mathrm{E}+00$ years

Water Dependent Pathways

\begin{tabular}{|c|c|c|c|c|c|c|c|c|c|c|c|c|c|c|}
\hline \multirow{2}{*}{$\begin{array}{l}\text { Radio- } \\
\text { Nuclide }\end{array}$} & \multicolumn{2}{|c|}{ Water } & \multicolumn{2}{|c|}{ Fish } & \multicolumn{2}{|c|}{ Radon } & \multicolumn{2}{|c|}{ Plant } & \multicolumn{2}{|c|}{ Meat } & \multicolumn{2}{|c|}{ Milk } & \multicolumn{2}{|c|}{ All Pathways* } \\
\hline & mrem/yr & fract. & mrem/yr & fract. & mrem/yr & fract. & mrem/yr & fract. & mrem/yr & fract. & mrem/yr & fract. & mrem/yr & fract. \\
\hline 241 & $0.000 \mathrm{E}+00$ & 0.0000 & $0.000 \mathrm{E}+00$ & 0.0000 & $0.000 \mathrm{E}+00$ & 0.0000 & $0.000 \mathrm{E}+00$ & 0.0000 & $0.000 \mathrm{E}+00$ & 0.0000 & $0.000 \mathrm{E}+00$ & 0.0000 & $1.575 \mathrm{E}-18$ & 0.0000 \\
\hline-137 & $0.000 \mathrm{E}+00$ & 0.0000 & $0.000 \mathrm{E}+00$ & 0.0000 & $0.000 \mathrm{E}+00$ & 0.0000 & $0.000 \mathrm{E}+00$ & 0.0000 & $0.000 \mathrm{E}+00$ & 0.0000 & $0.000 \mathrm{E}+00$ & 0.0000 & $2.272 \mathrm{E}-09$ & 0.0056 \\
\hline-237 & $0.000 \mathrm{E}+00$ & 0.0000 & $0.000 \mathrm{E}+00$ & 0.0000 & $0.000 \mathrm{E}+00$ & 0.0000 & $0.000 \mathrm{E}+00$ & 0.0000 & $0.000 \mathrm{E}+00$ & 0.0000 & $0.000 \mathrm{E}+00$ & 0.0000 & $5.097 \mathrm{E}-13$ & 0.0000 \\
\hline-238 & $0.000 \mathrm{E}+00$ & 0.0000 & $0.000 \mathrm{E}+00$ & 0.0000 & $0.000 \mathrm{E}+00$ & 0.0000 & $0.000 \mathrm{E}+00$ & 0.0000 & $0.000 \mathrm{E}+00$ & 0.0000 & $0.000 \mathrm{E}+00$ & 0.0000 & $4.535 \mathrm{E}-21$ & 0.0000 \\
\hline-239 & $0.000 \mathrm{E}+00$ & 0.0000 & $0.000 \mathrm{E}+00$ & 0.0000 & $0.000 \mathrm{E}+00$ & 0.0000 & $0.000 \mathrm{E}+00$ & 0.0000 & $0.000 \mathrm{E}+00$ & 0.0000 & $0.000 E+00$ & 0.0000 & $4.211 \mathrm{E}-17$ & 0.0000 \\
\hline-240 & $0.000 \mathrm{E}+00$ & 0.0000 & $0.000 \mathrm{E}+00$ & 0.0000 & $0.000 \mathrm{E}+00$ & 0.0000 & $0.000 \mathrm{E}+00$ & 0.0000 & $0.000 \mathrm{E}+00$ & 0.0000 & $0.000 E+00$ & 0.0000 & $4.111 \mathrm{E}-24$ & 0.0000 \\
\hline-99 & $0.000 \mathrm{E}+00$ & 0.0000 & $0.000 \mathrm{E}+00$ & 0.0000 & $0.000 \mathrm{E}+00$ & 0.0000 & $0.000 \mathrm{E}+00$ & 0.0000 & $0.000 \mathrm{E}+00$ & 0.0000 & $0.000 \mathrm{E}+00$ & 0.0000 & $2.925 E-25$ & 0.0000 \\
\hline-228 & $0.000 \mathrm{E}+00$ & 0.0000 & $0.000 \mathrm{E}+00$ & 0.0000 & $0.000 \mathrm{E}+00$ & 0.0000 & $0.000 \mathrm{E}+00$ & 0.0000 & $0.000 \mathrm{E}+00$ & 0.0000 & $0.000 \mathrm{E}+00$ & 0.0000 & $3.723 E-07$ & 0.9206 \\
\hline-230 & $0.000 \mathrm{E}+00$ & 0.0000 & $0.000 \mathrm{E}+00$ & 0.0000 & $0.000 \mathrm{E}+00$ & 0.0000 & $0.000 \mathrm{E}+00$ & 0.0000 & $0.000 \mathrm{E}+00$ & 0.0000 & $0.000 E+00$ & 0.0000 & $1.095 \mathrm{E}-09$ & 0.0027 \\
\hline 232 & $0.000 \mathrm{E}+00$ & 0.0000 & $0.000 \mathrm{E}+00$ & 0.0000 & $0.000 \mathrm{E}+00$ & 0.0000 & $0.000 \mathrm{E}+00$ & 0.0000 & $0.000 \mathrm{E}+00$ & 0.0000 & $0.000 \mathrm{E}+00$ & 0.0000 & $2.653 E-08$ & 0.0656 \\
\hline 34 & $0.000 \mathrm{E}+00$ & 0.0000 & $0.000 \mathrm{E}+00$ & 0.0000 & $0.000 \mathrm{E}+00$ & 0.0000 & $0.000 \mathrm{E}+00$ & 0.0000 & $0.000 \mathrm{E}+00$ & 0.0000 & $0.000 \mathrm{E}+00$ & 0.0000 & 1. $227 \mathrm{E}-14$ & 0.0000 \\
\hline 35 & $0.000 \mathrm{E}+00$ & 0.0000 & $0.000 \mathrm{E}+00$ & 0.0000 & $0.000 \mathrm{E}+00$ & 0.0000 & $0.000 \mathrm{E}+00$ & 0.0000 & $0.000 \mathrm{E}+00$ & 0.0000 & $0.000 \mathrm{E}+00$ & 0.0000 & 7. $913 \mathrm{E}-15$ & 0.0000 \\
\hline 38 & $0.000 \mathrm{E}+00$ & 0.0000 & $0.000 \mathrm{E}+00$ & 0.0000 & $0.000 \mathrm{E}+00$ & 0.0000 & $0.000 \mathrm{E}+00$ & 0.0000 & $0.000 \mathrm{E}+00$ & 0.0000 & $0.000 \mathrm{E}+00$ & 0.0000 & $2.202 E-09$ & 0.0054 \\
\hline & $0.000 \mathrm{E}+00$ & 0.0000 & $0.000 \mathrm{E}+00$ & 0.0000 & $0.000 \mathrm{E}+00$ & 0.0000 & $0.000 \mathrm{E}+00$ & 0.0000 & $0.000 \mathrm{E}+00$ & 0.0000 & $0.000 \mathrm{E}+00$ & 0.0000 & $44 \mathrm{E}-07$ & 1.0000 \\
\hline
\end{tabular}

* Sum of all water independent and dependent pathways. 
RESRAD, Version 6.5

ummary : RESRAD Parameters for U-Landfill Recreational User Foward Run

: C: $\backslash$ RESRAD FAMILY \RESRAD \USERFILES \QCJULY2011 \ULANDFILL-RU FORWARDRUN-1050YRS.RAD

Total Dose Contributions TDOSE(i,p,t) for Individual Radionuclides (i) and Pathways (p) As mrem/yr and Fraction of Total Dose At $t=1.200 \mathrm{E}+01$ years

Water Independent Pathways (Inhalation excludes radon)

\begin{tabular}{|c|c|c|c|c|c|c|c|c|c|c|c|c|c|c|}
\hline \multirow[b]{2}{*}{ Nuclide } & \multicolumn{2}{|c|}{ Ground } & \multicolumn{2}{|c|}{ Inhalation } & \multicolumn{2}{|c|}{ Radon } & \multicolumn{2}{|c|}{ Plant } & \multicolumn{2}{|c|}{ Meat } & \multicolumn{2}{|c|}{ Milk } & \multicolumn{2}{|c|}{ Soil } \\
\hline & mrem/yr & fract. & mrem/yr & fract. & mrem/yr & fract. & mrem/yr & fract. & mrem/yr & fract. & mrem/yr & fract. & mrem/yr & fract. \\
\hline-241 & 1. $464 \mathrm{E}-17$ & 0.0000 & $0.000 \mathrm{E}+00$ & 0.0000 & $0.000 \mathrm{E}+00$ & 0.0000 & $0.000 \mathrm{E}+00$ & 0.0000 & $0.000 \mathrm{E}+00$ & 0.0000 & $0.000 \mathrm{E}+00$ & 0.0000 & $0.000 \mathrm{E}+00$ & 0.0000 \\
\hline-137 & $1.933 E-09$ & 0.0040 & $0.000 \mathrm{E}+00$ & 0.0000 & $0.000 \mathrm{E}+00$ & 0.0000 & $0.000 \mathrm{E}+00$ & 0.0000 & $0.000 \mathrm{E}+00$ & 0.0000 & $0.000 \mathrm{E}+00$ & 0.0000 & $0.000 \mathrm{E}+00$ & 0.0000 \\
\hline-237 & $5.736 E-13$ & 0.0000 & $0.000 \mathrm{E}+00$ & 0.0000 & $0.000 \mathrm{E}+00$ & 0.0000 & $0.000 \mathrm{E}+00$ & 0.0000 & $0.000 \mathrm{E}+00$ & 0.0000 & $0.000 \mathrm{E}+00$ & 0.0000 & $0.000 \mathrm{E}+00$ & 0.0000 \\
\hline-238 & $2.491 \mathrm{E}-18$ & 0.0000 & $0.000 \mathrm{E}+00$ & 0.0000 & $0.000 \mathrm{E}+00$ & 0.0000 & $0.000 \mathrm{E}+00$ & 0.0000 & $0.000 \mathrm{E}+00$ & 0.0000 & $0.000 \mathrm{E}+00$ & 0.0000 & $0.000 \mathrm{E}+00$ & 0.0000 \\
\hline-239 & $4.803 E-17$ & 0.0000 & $0.000 \mathrm{E}+00$ & 0.0000 & $0.000 \mathrm{E}+00$ & 0.0000 & $0.000 \mathrm{E}+00$ & 0.0000 & $0.000 \mathrm{E}+00$ & 0.0000 & $0.000 \mathrm{E}+00$ & 0.0000 & $0.000 \mathrm{E}+00$ & 0.0000 \\
\hline-240 & $1.553 \mathrm{E}-22$ & 0.0000 & $0.000 \mathrm{E}+00$ & 0.0000 & $0.000 \mathrm{E}+00$ & 0.0000 & $0.000 \mathrm{E}+00$ & 0.0000 & $0.000 \mathrm{E}+00$ & 0.0000 & $0.000 \mathrm{E}+00$ & 0.0000 & $0.000 \mathrm{E}+00$ & 0.0000 \\
\hline 99 & $3.409 E-25$ & 0.0000 & $0.000 \mathrm{E}+00$ & 0.0000 & $0.000 \mathrm{E}+00$ & 0.0000 & $0.000 \mathrm{E}+00$ & 0.0000 & $0.000 \mathrm{E}+00$ & 0.0000 & $0.000 \mathrm{E}+00$ & 0.0000 & $0.000 \mathrm{E}+00$ & 0.0000 \\
\hline-228 & $7.388 E-09$ & 0.0152 & $0.000 \mathrm{E}+00$ & 0.0000 & $0.000 \mathrm{E}+00$ & 0.0000 & $0.000 \mathrm{E}+00$ & 0.0000 & $0.000 \mathrm{E}+00$ & 0.0000 & $0.000 \mathrm{E}+00$ & 0.0000 & $0.000 \mathrm{E}+00$ & 0.0000 \\
\hline 230 & $9.820 \mathrm{E}-09$ & 0.0202 & $0.000 \mathrm{E}+00$ & 0.0000 & $0.000 \mathrm{E}+00$ & 0.0000 & $0.000 \mathrm{E}+00$ & 0.0000 & $0.000 \mathrm{E}+00$ & 0.0000 & $0.000 \mathrm{E}+00$ & 0.0000 & $0.000 \mathrm{E}+00$ & 0.0000 \\
\hline-232 & $4.646 E-07$ & 0.9557 & $0.000 \mathrm{E}+00$ & 0.0000 & $0.000 \mathrm{E}+00$ & 0.0000 & $0.000 \mathrm{E}+00$ & 0.0000 & $0.000 \mathrm{E}+00$ & 0.0000 & $0.000 \mathrm{E}+00$ & 0.0000 & $0.000 \mathrm{E}+00$ & 0.0000 \\
\hline 4 & $8.853 E-13$ & 0.0000 & $0.000 \mathrm{E}+00$ & 0.0000 & $0.000 \mathrm{E}+00$ & 0.0000 & $0.000 \mathrm{E}+00$ & 0.0000 & $0.000 \mathrm{E}+00$ & 0.0000 & $0.000 \mathrm{E}+00$ & 0.0000 & $0.000 \mathrm{E}+00$ & 0.0000 \\
\hline 35 & $1.173 \mathrm{E}-14$ & 0.0000 & $0.000 \mathrm{E}+00$ & 0.0000 & $0.000 \mathrm{E}+00$ & 0.0000 & $0.000 \mathrm{E}+00$ & 0.0000 & $0.000 \mathrm{E}+00$ & 0.0000 & $0.000 \mathrm{E}+00$ & 0.0000 & $0.000 \mathrm{E}+00$ & 0.0000 \\
\hline 38 & $2.404 \mathrm{E}-09$ & 0.0049 & $0.000 \mathrm{E}+00$ & 0.0000 & $0.000 \mathrm{E}+00$ & 0.0000 & $0.000 \mathrm{E}+00$ & 0.0000 & $0.000 \mathrm{E}+00$ & 0.0000 & $0.000 \mathrm{E}+00$ & 0.0000 & $0.000 \mathrm{E}+00$ & 0.0000 \\
\hline & $2 E-07$ & 1 . & $.000 \mathrm{E}+00$ & 0.0 & $0.000 \mathrm{E}+00$ & 0 . & $0.000 \mathrm{E}+00$ & 0 . & +00 & 0 & +00 & & +00 & \\
\hline
\end{tabular}

Total Dose Contributions TDOSE(i,p,t) for Individual Radionuclides (i) and Pathways (p) As mrem/yr and Fraction of Total Dose At $t=1.200 \mathrm{E}+01$ years

Water Dependent Pathways

\begin{tabular}{|c|c|c|c|c|c|c|c|c|c|c|c|c|c|c|}
\hline & \multicolumn{2}{|c|}{ Water } & \multicolumn{2}{|c|}{ Fish } & \multicolumn{2}{|c|}{ Radon } & \multicolumn{2}{|c|}{ Plant } & \multicolumn{2}{|c|}{ Meat } & \multicolumn{2}{|c|}{ Milk } & \multicolumn{2}{|c|}{ All Pathways* } \\
\hline clide & mrem/yr & fract. & mrem/yr & fract. & mrem/yr & fract. & mrem/yr & fract. & mrem/yr & fract. & mrem/yr & fract. & mrem/yr & fract. \\
\hline-241 & $0.000 \mathrm{E}+00$ & 0.0000 & $0.000 \mathrm{E}+00$ & 0.0000 & $0.000 \mathrm{E}+00$ & 0.0000 & $0.000 \mathrm{E}+00$ & 0.0000 & $0.000 \mathrm{E}+00$ & 0.0000 & $0.000 \mathrm{E}+00$ & 0.0000 & $1.464 \mathrm{E}-17$ & 0.0000 \\
\hline-137 & $0.000 \mathrm{E}+00$ & 0.0000 & $0.000 \mathrm{E}+00$ & 0.0000 & $0.000 \mathrm{E}+00$ & 0.0000 & $0.000 \mathrm{E}+00$ & 0.0000 & $0.000 \mathrm{E}+00$ & 0.0000 & $0.000 \mathrm{E}+00$ & 0.0000 & $1.933 \mathrm{E}-09$ & 0.0040 \\
\hline-237 & $0.000 \mathrm{E}+00$ & 0.0000 & $0.000 \mathrm{E}+00$ & 0.0000 & $0.000 \mathrm{E}+00$ & 0.0000 & $0.000 \mathrm{E}+00$ & 0.0000 & $0.000 \mathrm{E}+00$ & 0.0000 & $0.000 \mathrm{E}+00$ & 0.0000 & $5.736 \mathrm{E}-13$ & 0.0000 \\
\hline 238 & $0.000 \mathrm{E}+00$ & 0.0000 & $0.000 \mathrm{E}+00$ & 0.0000 & $0.000 \mathrm{E}+00$ & 0.0000 & $0.000 \mathrm{E}+00$ & 0.0000 & $0.000 \mathrm{E}+00$ & 0.0000 & $0.000 \mathrm{E}+00$ & 0.0000 & $2.491 \mathrm{E}-18$ & 0.0000 \\
\hline 239 & $0.000 \mathrm{E}+00$ & 0.0000 & $0.000 \mathrm{E}+00$ & 0.0000 & $0.000 \mathrm{E}+00$ & 0.0000 & $0.000 \mathrm{E}+00$ & 0.0000 & $0.000 \mathrm{E}+00$ & 0.0000 & $0.000 \mathrm{E}+00$ & 0.0000 & $4.803 E-17$ & 0.0000 \\
\hline 240 & $0.000 \mathrm{E}+00$ & 0.0000 & $0.000 \mathrm{E}+00$ & 0.0000 & $0.000 \mathrm{E}+00$ & 0.0000 & $0.000 \mathrm{E}+00$ & 0.0000 & $0.000 \mathrm{E}+00$ & 0.0000 & $0.000 \mathrm{E}+00$ & 0.0000 & $1.553 \mathrm{E}-22$ & 0.0000 \\
\hline 99 & $0.000 \mathrm{E}+00$ & 0.0000 & $0.000 \mathrm{E}+00$ & 0.0000 & $0.000 \mathrm{E}+00$ & 0.0000 & $0.000 \mathrm{E}+00$ & 0.0000 & $0.000 \mathrm{E}+00$ & 0.0000 & $0.000 \mathrm{E}+00$ & 0.0000 & $3.409 \mathrm{E}-25$ & 0.0000 \\
\hline 228 & $0.000 \mathrm{E}+00$ & 0.0000 & $0.000 \mathrm{E}+00$ & 0.0000 & $0.000 \mathrm{E}+00$ & 0.0000 & $0.000 \mathrm{E}+00$ & 0.0000 & $0.000 \mathrm{E}+00$ & 0.0000 & $0.000 \mathrm{E}+00$ & 0.0000 & $7.388 E-09$ & 0.0152 \\
\hline 230 & $0.000 \mathrm{E}+00$ & 0.0000 & $0.000 \mathrm{E}+00$ & 0.0000 & $0.000 \mathrm{E}+00$ & 0.0000 & $0.000 \mathrm{E}+00$ & 0.0000 & $0.000 \mathrm{E}+00$ & 0.0000 & $0.000 \mathrm{E}+00$ & 0.0000 & $9.820 \mathrm{E}-09$ & 0.0202 \\
\hline 232 & $0.000 \mathrm{E}+00$ & 0.0000 & $0.000 \mathrm{E}+00$ & 0.0000 & $0.000 \mathrm{E}+00$ & 0.0000 & $0.000 \mathrm{E}+00$ & 0.0000 & $0.000 \mathrm{E}+00$ & 0.0000 & $0.000 \mathrm{E}+00$ & 0.0000 & $4.646 \mathrm{E}-07$ & 0.9557 \\
\hline & $0.000 \mathrm{E}+00$ & 0.0000 & $0.000 \mathrm{E}+00$ & 0.0000 & $0.000 \mathrm{E}+00$ & 0.0000 & $0.000 \mathrm{E}+00$ & 0.0000 & $0.000 \mathrm{E}+00$ & 0.0000 & $0.000 \mathrm{E}+00$ & 0.0000 & $8.853 E-13$ & 0.0000 \\
\hline 35 & $0.000 \mathrm{E}+00$ & 0.0000 & $0.000 \mathrm{E}+00$ & 0.0000 & $0.000 \mathrm{E}+00$ & 0.0000 & $0.000 \mathrm{E}+00$ & 0.0000 & $0.000 \mathrm{E}+00$ & 0.0000 & $0.000 \mathrm{E}+00$ & 0.0000 & $1.173 \mathrm{E}-14$ & 0.0000 \\
\hline 38 & $0.000 \mathrm{E}+00$ & 0.0000 & $0.000 \mathrm{E}+00$ & 0.0000 & $0.000 \mathrm{E}+00$ & 0.0000 & $0.000 \mathrm{E}+00$ & 0.0000 & $0.000 \mathrm{E}+00$ & 0.0000 & $0.000 \mathrm{E}+00$ & 0.0000 & $2.404 \mathrm{E}-09$ & 0.0049 \\
\hline & $0.000 \mathrm{E}+00$ & 0.0000 & $0.000 \mathrm{E}+00$ & 0.0000 & $0.000 \mathrm{E}+00$ & 0.0000 & $0.000 \mathrm{E}+00$ & 0.0000 & $0.000 \mathrm{E}+00$ & 0.0000 & $0.000 E+00$ & 000 & -07 & 1.0000 \\
\hline
\end{tabular}

* Sum of all water independent and dependent pathways. 
RESRAD, Version 6.5

ummary : RESRAD Parameters for U-Landfill Recreational User Foward Run

: C: $\backslash$ RESRAD FAMILY \RESRAD \USERFILES \QCJULY2011 \ULANDFILL-RU FORWARDRUN-1050YRS.RAD

Total Dose Contributions TDOSE(i,p,t) for Individual Radionuclides (i) and Pathways (p) As mrem/yr and Fraction of Total Dose At $t=5.000 \mathrm{E}+01$ years

Water Independent Pathways (Inhalation excludes radon)

\begin{tabular}{|c|c|c|c|c|c|c|c|c|c|c|c|c|c|c|}
\hline \multirow{2}{*}{ Nuclide } & \multicolumn{2}{|c|}{ Ground } & \multicolumn{2}{|c|}{ Inhalation } & \multicolumn{2}{|c|}{ Radon } & \multicolumn{2}{|c|}{ Plant } & \multicolumn{2}{|c|}{ Meat } & \multicolumn{2}{|c|}{ Milk } & \multicolumn{2}{|c|}{ Soil } \\
\hline & mrem/yr & fract. & mrem/yr & fract. & mrem/yr & fract. & mrem/yr & fract. & mrem/yr & fract. & mrem/yr & fract. & mrem/yr & fract. \\
\hline-241 & $8.641 \mathrm{E}-17$ & 0.0000 & $0.000 \mathrm{E}+00$ & 0.0000 & $0.000 \mathrm{E}+00$ & 0.0000 & $0.000 \mathrm{E}+00$ & 0.0000 & $0.000 \mathrm{E}+00$ & 0.0000 & $0.000 \mathrm{E}+00$ & 0.0000 & $0.000 \mathrm{E}+00$ & 0.0000 \\
\hline-137 & $1.106 \mathrm{E}-09$ & 0.0012 & $0.000 \mathrm{E}+00$ & 0.0000 & $0.000 \mathrm{E}+00$ & 0.0000 & $0.000 \mathrm{E}+00$ & 0.0000 & $0.000 \mathrm{E}+00$ & 0.0000 & $0.000 \mathrm{E}+00$ & 0.0000 & $0.000 \mathrm{E}+00$ & 0.0000 \\
\hline-237 & $8.637 E-13$ & 0.0000 & $0.000 \mathrm{E}+00$ & 0.0000 & $0.000 \mathrm{E}+00$ & 0.0000 & $0.000 \mathrm{E}+00$ & 0.0000 & $0.000 \mathrm{E}+00$ & 0.0000 & $0.000 \mathrm{E}+00$ & 0.0000 & $0.000 \mathrm{E}+00$ & 0.0000 \\
\hline-238 & $1.975 E-16$ & 0.0000 & $0.000 \mathrm{E}+00$ & 0.0000 & $0.000 \mathrm{E}+00$ & 0.0000 & $0.000 \mathrm{E}+00$ & 0.0000 & $0.000 \mathrm{E}+00$ & 0.0000 & $0.000 \mathrm{E}+00$ & 0.0000 & $0.000 \mathrm{E}+00$ & 0.0000 \\
\hline-239 & 7. $561 \mathrm{E}-17$ & 0.0000 & $0.000 \mathrm{E}+00$ & 0.0000 & $0.000 \mathrm{E}+00$ & 0.0000 & $0.000 \mathrm{E}+00$ & 0.0000 & $0.000 \mathrm{E}+00$ & 0.0000 & $0.000 \mathrm{E}+00$ & 0.0000 & $0.000 \mathrm{E}+00$ & 0.0000 \\
\hline-240 & $9.285 \mathrm{E}-21$ & 0.0000 & $0.000 \mathrm{E}+00$ & 0.0000 & $0.000 \mathrm{E}+00$ & 0.0000 & $0.000 \mathrm{E}+00$ & 0.0000 & $0.000 \mathrm{E}+00$ & 0.0000 & $0.000 \mathrm{E}+00$ & 0.0000 & $0.000 \mathrm{E}+00$ & 0.0000 \\
\hline 99 & $5.785 E-25$ & 0.0000 & $0.000 \mathrm{E}+00$ & 0.0000 & $0.000 \mathrm{E}+00$ & 0.0000 & $0.000 \mathrm{E}+00$ & 0.0000 & $0.000 \mathrm{E}+00$ & 0.0000 & $0.000 \mathrm{E}+00$ & 0.0000 & $0.000 \mathrm{E}+00$ & 0.0000 \\
\hline-228 & $9.718 \mathrm{E}-15$ & 0.0000 & $0.000 \mathrm{E}+00$ & 0.0000 & $0.000 \mathrm{E}+00$ & 0.0000 & $0.000 \mathrm{E}+00$ & 0.0000 & $0.000 \mathrm{E}+00$ & 0.0000 & $0.000 \mathrm{E}+00$ & 0.0000 & $0.000 \mathrm{E}+00$ & 0.0000 \\
\hline 230 & $5.116 \mathrm{E}-08$ & 0.0558 & $0.000 \mathrm{E}+00$ & 0.0000 & $0.000 \mathrm{E}+00$ & 0.0000 & $0.000 \mathrm{E}+00$ & 0.0000 & $0.000 \mathrm{E}+00$ & 0.0000 & $0.000 \mathrm{E}+00$ & 0.0000 & $0.000 \mathrm{E}+00$ & 0.0000 \\
\hline-232 & $8.620 E-07$ & 0.9395 & $0.000 \mathrm{E}+00$ & 0.0000 & $0.000 \mathrm{E}+00$ & 0.0000 & $0.000 \mathrm{E}+00$ & 0.0000 & $0.000 \mathrm{E}+00$ & 0.0000 & $0.000 \mathrm{E}+00$ & 0.0000 & $0.000 \mathrm{E}+00$ & 0.0000 \\
\hline 34 & $1.867 \mathrm{E}-11$ & 0.0000 & $0.000 \mathrm{E}+00$ & 0.0000 & $0.000 \mathrm{E}+00$ & 0.0000 & $0.000 \mathrm{E}+00$ & 0.0000 & $0.000 \mathrm{E}+00$ & 0.0000 & $0.000 \mathrm{E}+00$ & 0.0000 & $0.000 \mathrm{E}+00$ & 0.0000 \\
\hline 35 & $5.776 \mathrm{E}-14$ & 0.0000 & $0.000 \mathrm{E}+00$ & 0.0000 & $0.000 \mathrm{E}+00$ & 0.0000 & $0.000 \mathrm{E}+00$ & 0.0000 & $0.000 \mathrm{E}+00$ & 0.0000 & $0.000 \mathrm{E}+00$ & 0.0000 & $0.000 \mathrm{E}+00$ & 0.0000 \\
\hline 38 & $3.257 \mathrm{E}-09$ & 0.0035 & $0.000 \mathrm{E}+00$ & 0.0000 & $0.000 \mathrm{E}+00$ & 0.0000 & $0.000 \mathrm{E}+00$ & 0.0000 & $0.000 \mathrm{E}+00$ & 0.0000 & $0.000 \mathrm{E}+00$ & 0.0000 & $0.000 \mathrm{E}+00$ & 0.0000 \\
\hline & $9.175 E-07$ & 1.0000 & $0.000 \mathrm{E}+00$ & 0.0000 & $0.000 \mathrm{E}+00$ & 0.0000 & $0.000 \mathrm{E}+00$ & 0.0000 & $0.000 \mathrm{E}+00$ & 0.0000 & $0.000 \mathrm{E}+00$ & 0.0000 & $.000 \mathrm{E}+00$ & 0.0000 \\
\hline
\end{tabular}

Total Dose Contributions TDOSE(i,p,t) for Individual Radionuclides (i) and Pathways (p) As mrem/yr and Fraction of Total Dose At $t=5.000 \mathrm{E}+01$ years

Water Dependent Pathways

\begin{tabular}{|c|c|c|c|c|c|c|c|c|c|c|c|c|c|c|}
\hline \multirow{2}{*}{ Nuclide } & \multicolumn{2}{|c|}{ Water } & \multicolumn{2}{|c|}{ Fish } & \multicolumn{2}{|c|}{ Radon } & \multicolumn{2}{|c|}{ Plant } & \multicolumn{2}{|c|}{ Meat } & \multicolumn{2}{|c|}{ Milk } & \multicolumn{2}{|c|}{ All Pathways* } \\
\hline & mrem/yr & fract. & mrem/yr & fract. & mrem/yr & fract. & mrem/yr & fract. & mrem/yr & fract. & mrem/yr & fract. & mrem/yr & fract. \\
\hline-241 & $0.000 \mathrm{E}+00$ & 0.0000 & $0.000 \mathrm{E}+00$ & 0.0000 & $0.000 \mathrm{E}+00$ & 0.0000 & $0.000 \mathrm{E}+00$ & 0.0000 & $0.000 \mathrm{E}+00$ & 0.0000 & $0.000 \mathrm{E}+00$ & 0.0000 & $8.641 \mathrm{E}-17$ & 0.0000 \\
\hline-137 & $0.000 \mathrm{E}+00$ & 0.0000 & $0.000 \mathrm{E}+00$ & 0.0000 & $0.000 \mathrm{E}+00$ & 0.0000 & $0.000 \mathrm{E}+00$ & 0.0000 & $0.000 \mathrm{E}+00$ & 0.0000 & $0.000 \mathrm{E}+00$ & 0.0000 & $1.106 \mathrm{E}-09$ & 0.0012 \\
\hline-237 & $0.000 \mathrm{E}+00$ & 0.0000 & $0.000 \mathrm{E}+00$ & 0.0000 & $0.000 \mathrm{E}+00$ & 0.0000 & $0.000 \mathrm{E}+00$ & 0.0000 & $0.000 \mathrm{E}+00$ & 0.0000 & $0.000 \mathrm{E}+00$ & 0.0000 & $8.637 \mathrm{E}-13$ & 0.0000 \\
\hline 238 & $0.000 \mathrm{E}+00$ & 0.0000 & $0.000 \mathrm{E}+00$ & 0.0000 & $0.000 \mathrm{E}+00$ & 0.0000 & $0.000 \mathrm{E}+00$ & 0.0000 & $0.000 \mathrm{E}+00$ & 0.0000 & $0.000 \mathrm{E}+00$ & 0.0000 & $1.975 \mathrm{E}-16$ & 0.0000 \\
\hline 239 & $0.000 \mathrm{E}+00$ & 0.0000 & $0.000 \mathrm{E}+00$ & 0.0000 & $0.000 \mathrm{E}+00$ & 0.0000 & $0.000 \mathrm{E}+00$ & 0.0000 & $0.000 \mathrm{E}+00$ & 0.0000 & $0.000 \mathrm{E}+00$ & 0.0000 & $7.561 \mathrm{E}-17$ & 0.0000 \\
\hline 240 & $0.000 \mathrm{E}+00$ & 0.0000 & $0.000 \mathrm{E}+00$ & 0.0000 & $0.000 \mathrm{E}+00$ & 0.0000 & $0.000 \mathrm{E}+00$ & 0.0000 & $0.000 \mathrm{E}+00$ & 0.0000 & $0.000 \mathrm{E}+00$ & 0.0000 & $9.285 \mathrm{E}-21$ & 0.0000 \\
\hline 99 & $0.000 \mathrm{E}+00$ & 0.0000 & $0.000 \mathrm{E}+00$ & 0.0000 & $0.000 \mathrm{E}+00$ & 0.0000 & $0.000 \mathrm{E}+00$ & 0.0000 & $0.000 \mathrm{E}+00$ & 0.0000 & $0.000 \mathrm{E}+00$ & 0.0000 & $5.785 \mathrm{E}-25$ & 0.0000 \\
\hline 228 & $0.000 \mathrm{E}+00$ & 0.0000 & $0.000 \mathrm{E}+00$ & 0.0000 & $0.000 \mathrm{E}+00$ & 0.0000 & $0.000 \mathrm{E}+00$ & 0.0000 & $0.000 \mathrm{E}+00$ & 0.0000 & $0.000 \mathrm{E}+00$ & 0.0000 & $9.718 \mathrm{E}-15$ & 0.0000 \\
\hline 230 & $0.000 \mathrm{E}+00$ & 0.0000 & $0.000 \mathrm{E}+00$ & 0.0000 & $0.000 \mathrm{E}+00$ & 0.0000 & $0.000 \mathrm{E}+00$ & 0.0000 & $0.000 \mathrm{E}+00$ & 0.0000 & $0.000 \mathrm{E}+00$ & 0.0000 & $5.116 \mathrm{E}-08$ & 0.0558 \\
\hline 232 & $0.000 \mathrm{E}+00$ & 0.0000 & $0.000 \mathrm{E}+00$ & 0.0000 & $0.000 \mathrm{E}+00$ & 0.0000 & $0.000 \mathrm{E}+00$ & 0.0000 & $0.000 \mathrm{E}+00$ & 0.0000 & $0.000 \mathrm{E}+00$ & 0.0000 & $8.620 \mathrm{E}-07$ & 0.9395 \\
\hline & $0.000 \mathrm{E}+00$ & 0.0000 & $0.000 \mathrm{E}+00$ & 0.0000 & $0.000 \mathrm{E}+00$ & 0.0000 & $0.000 \mathrm{E}+00$ & 0.0000 & $0.000 \mathrm{E}+00$ & 0.0000 & $0.000 \mathrm{E}+00$ & 0.0000 & $1.867 \mathrm{E}-11$ & 0.0000 \\
\hline 35 & $0.000 \mathrm{E}+00$ & 0.0000 & $0.000 \mathrm{E}+00$ & 0.0000 & $0.000 \mathrm{E}+00$ & 0.0000 & $0.000 \mathrm{E}+00$ & 0.0000 & $0.000 \mathrm{E}+00$ & 0.0000 & $0.000 \mathrm{E}+00$ & 0.0000 & $5.776 \mathrm{E}-14$ & 0.0000 \\
\hline 38 & $0.000 \mathrm{E}+00$ & 0.0000 & $0.000 \mathrm{E}+00$ & 0.0000 & $0.000 \mathrm{E}+00$ & 0.0000 & $0.000 \mathrm{E}+00$ & 0.0000 & $0.000 \mathrm{E}+00$ & 0.0000 & $0.000 \mathrm{E}+00$ & 0.0000 & $3.257 \mathrm{E}-09$ & 0.0035 \\
\hline & $0.000 \mathrm{E}+00$ & 0.0000 & $0.000 \mathrm{E}+00$ & 0.0000 & $0.000 \mathrm{E}+00$ & 0.0000 & $0.000 \mathrm{E}+00$ & 0.0000 & $0.000 \mathrm{E}+00$ & 0.0000 & $0.000 \mathrm{E}+00$ & 000 & -07 & 1.0000 \\
\hline
\end{tabular}

* Sum of all water independent and dependent pathways. 
RESRAD, Version 6.5

ummary : RESRAD Parameters for U-Landfill Recreational User Foward Run

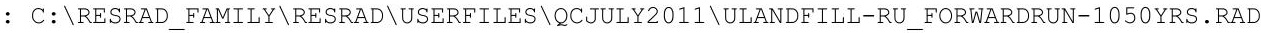

Total Dose Contributions TDOSE(i,p,t) for Individual Radionuclides (i) and Pathways (p) As mrem/yr and Fraction of Total Dose At $t=1.000 \mathrm{E}+02$ years

Water Independent Pathways (Inhalation excludes radon)

\begin{tabular}{|c|c|c|c|c|c|c|c|c|c|c|c|c|c|c|}
\hline \multirow{2}{*}{ Nuclide } & \multicolumn{2}{|c|}{ Ground } & \multicolumn{2}{|c|}{ Inhalation } & \multicolumn{2}{|c|}{ Radon } & \multicolumn{2}{|c|}{ Plant } & \multicolumn{2}{|c|}{ Meat } & \multicolumn{2}{|c|}{ Milk } & \multicolumn{2}{|c|}{ Soil } \\
\hline & mrem/yr & fract. & mrem/yr & fract. & mrem/yr & fract. & mrem/yr & fract. & mrem/yr & fract. & mrem/yr & fract. & mrem/yr & fract. \\
\hline-241 & $2.836 \mathrm{E}-16$ & 0.0000 & $0.000 \mathrm{E}+00$ & 0.0000 & $0.000 \mathrm{E}+00$ & 0.0000 & $0.000 \mathrm{E}+00$ & 0.0000 & $0.000 \mathrm{E}+00$ & 0.0000 & $0.000 \mathrm{E}+00$ & 0.0000 & $0.000 \mathrm{E}+00$ & 0.0000 \\
\hline-137 & $5.307 E-10$ & 0.0004 & $0.000 \mathrm{E}+00$ & 0.0000 & $0.000 \mathrm{E}+00$ & 0.0000 & $0.000 \mathrm{E}+00$ & 0.0000 & $0.000 \mathrm{E}+00$ & 0.0000 & $0.000 \mathrm{E}+00$ & 0.0000 & $0.000 \mathrm{E}+00$ & 0.0000 \\
\hline-237 & $1.483 \mathrm{E}-12$ & 0.0000 & $0.000 \mathrm{E}+00$ & 0.0000 & $0.000 \mathrm{E}+00$ & 0.0000 & $0.000 \mathrm{E}+00$ & 0.0000 & $0.000 \mathrm{E}+00$ & 0.0000 & $0.000 \mathrm{E}+00$ & 0.0000 & $0.000 \mathrm{E}+00$ & 0.0000 \\
\hline-238 & $1.997 \mathrm{E}-15$ & 0.0000 & $0.000 \mathrm{E}+00$ & 0.0000 & $0.000 \mathrm{E}+00$ & 0.0000 & $0.000 \mathrm{E}+00$ & 0.0000 & $0.000 \mathrm{E}+00$ & 0.0000 & $0.000 \mathrm{E}+00$ & 0.0000 & $0.000 \mathrm{E}+00$ & 0.0000 \\
\hline-239 & $1.374 \mathrm{E}-16$ & 0.0000 & $0.000 \mathrm{E}+00$ & 0.0000 & $0.000 \mathrm{E}+00$ & 0.0000 & $0.000 \mathrm{E}+00$ & 0.0000 & $0.000 \mathrm{E}+00$ & 0.0000 & $0.000 \mathrm{E}+00$ & 0.0000 & $0.000 \mathrm{E}+00$ & 0.0000 \\
\hline-240 & $6.177 \mathrm{E}-20$ & 0.0000 & $0.000 \mathrm{E}+00$ & 0.0000 & $0.000 \mathrm{E}+00$ & 0.0000 & $0.000 \mathrm{E}+00$ & 0.0000 & $0.000 \mathrm{E}+00$ & 0.0000 & $0.000 \mathrm{E}+00$ & 0.0000 & $0.000 \mathrm{E}+00$ & 0.0000 \\
\hline 99 & $1.160 \mathrm{E}-24$ & 0.0000 & $0.000 \mathrm{E}+00$ & 0.0000 & $0.000 \mathrm{E}+00$ & 0.0000 & $0.000 \mathrm{E}+00$ & 0.0000 & $0.000 \mathrm{E}+00$ & 0.0000 & $0.000 \mathrm{E}+00$ & 0.0000 & $0.000 \mathrm{E}+00$ & 0.0000 \\
\hline-228 & $1.776 \mathrm{E}-22$ & 0.0000 & $0.000 \mathrm{E}+00$ & 0.0000 & $0.000 \mathrm{E}+00$ & 0.0000 & $0.000 \mathrm{E}+00$ & 0.0000 & $0.000 \mathrm{E}+00$ & 0.0000 & $0.000 \mathrm{E}+00$ & 0.0000 & $0.000 \mathrm{E}+00$ & 0.0000 \\
\hline 230 & 1. $423 \mathrm{E}-07$ & 0.1082 & $0.000 \mathrm{E}+00$ & 0.0000 & $0.000 \mathrm{E}+00$ & 0.0000 & $0.000 \mathrm{E}+00$ & 0.0000 & $0.000 \mathrm{E}+00$ & 0.0000 & $0.000 \mathrm{E}+00$ & 0.0000 & $0.000 \mathrm{E}+00$ & 0.0000 \\
\hline-232 & $1.167 \mathrm{E}-06$ & 0.8876 & $0.000 \mathrm{E}+00$ & 0.0000 & $0.000 \mathrm{E}+00$ & 0.0000 & $0.000 \mathrm{E}+00$ & 0.0000 & $0.000 \mathrm{E}+00$ & 0.0000 & $0.000 \mathrm{E}+00$ & 0.0000 & $0.000 \mathrm{E}+00$ & 0.0000 \\
\hline 34 & $1.037 \mathrm{E}-10$ & 0.0001 & $0.000 \mathrm{E}+00$ & 0.0000 & $0.000 \mathrm{E}+00$ & 0.0000 & $0.000 \mathrm{E}+00$ & 0.0000 & $0.000 \mathrm{E}+00$ & 0.0000 & $0.000 \mathrm{E}+00$ & 0.0000 & $0.000 \mathrm{E}+00$ & 0.0000 \\
\hline 35 & $2.119 \mathrm{E}-13$ & 0.0000 & $0.000 \mathrm{E}+00$ & 0.0000 & $0.000 \mathrm{E}+00$ & 0.0000 & $0.000 \mathrm{E}+00$ & 0.0000 & $0.000 \mathrm{E}+00$ & 0.0000 & $0.000 \mathrm{E}+00$ & 0.0000 & $0.000 \mathrm{E}+00$ & 0.0000 \\
\hline 38 & $4.856 E-09$ & 0.0037 & $0.000 \mathrm{E}+00$ & 0.0000 & $0.000 \mathrm{E}+00$ & 0.0000 & $0.000 \mathrm{E}+00$ & 0.0000 & $0.000 \mathrm{E}+00$ & 0.0000 & $0.000 \mathrm{E}+00$ & 0.0000 & $0.000 \mathrm{E}+00$ & 0.0000 \\
\hline & $1.314 \mathrm{E}-06$ & 1.0000 & $0.000 \mathrm{E}+00$ & 0.0000 & $0.000 \mathrm{E}+00$ & 0.0000 & $0.000 \mathrm{E}+00$ & 0.0000 & $0.000 \mathrm{E}+00$ & 0.0000 & $0.000 \mathrm{E}+00$ & 0.0000 & $.000 \mathrm{E}+00$ & 0.0000 \\
\hline
\end{tabular}

Total Dose Contributions TDOSE(i,p,t) for Individual Radionuclides (i) and Pathways (p) As mrem/yr and Fraction of Total Dose At $t=1.000 \mathrm{E}+02$ years

Water Dependent Pathways

\begin{tabular}{|c|c|c|c|c|c|c|c|c|c|c|c|c|c|c|}
\hline & \multicolumn{2}{|c|}{ Water } & \multicolumn{2}{|c|}{ Fish } & \multicolumn{2}{|c|}{ Radon } & \multicolumn{2}{|c|}{ Plant } & \multicolumn{2}{|c|}{ Meat } & \multicolumn{2}{|c|}{ Milk } & \multicolumn{2}{|c|}{ All Pathways* } \\
\hline clide & mrem/yr & fract. & mrem/yr & fract. & mrem/yr & fract. & mrem/yr & fract. & mrem/yr & fract. & mrem/yr & fract. & mrem/yr & fract. \\
\hline-241 & $0.000 \mathrm{E}+00$ & 0.0000 & $0.000 \mathrm{E}+00$ & 0.0000 & $0.000 \mathrm{E}+00$ & 0.0000 & $0.000 \mathrm{E}+00$ & 0.0000 & $0.000 \mathrm{E}+00$ & 0.0000 & $0.000 \mathrm{E}+00$ & 0.0000 & $2.836 \mathrm{E}-16$ & 0.0000 \\
\hline-137 & $0.000 \mathrm{E}+00$ & 0.0000 & $0.000 \mathrm{E}+00$ & 0.0000 & $0.000 \mathrm{E}+00$ & 0.0000 & $0.000 \mathrm{E}+00$ & 0.0000 & $0.000 \mathrm{E}+00$ & 0.0000 & $0.000 \mathrm{E}+00$ & 0.0000 & $5.307 \mathrm{E}-10$ & 0.0004 \\
\hline-237 & $0.000 \mathrm{E}+00$ & 0.0000 & $0.000 \mathrm{E}+00$ & 0.0000 & $0.000 \mathrm{E}+00$ & 0.0000 & $0.000 \mathrm{E}+00$ & 0.0000 & $0.000 \mathrm{E}+00$ & 0.0000 & $0.000 \mathrm{E}+00$ & 0.0000 & $1.483 \mathrm{E}-12$ & 0.0000 \\
\hline 238 & $0.000 \mathrm{E}+00$ & 0.0000 & $0.000 \mathrm{E}+00$ & 0.0000 & $0.000 \mathrm{E}+00$ & 0.0000 & $0.000 \mathrm{E}+00$ & 0.0000 & $0.000 \mathrm{E}+00$ & 0.0000 & $0.000 \mathrm{E}+00$ & 0.0000 & $1.997 \mathrm{E}-15$ & 0.0000 \\
\hline 239 & $0.000 \mathrm{E}+00$ & 0.0000 & $0.000 \mathrm{E}+00$ & 0.0000 & $0.000 \mathrm{E}+00$ & 0.0000 & $0.000 \mathrm{E}+00$ & 0.0000 & $0.000 \mathrm{E}+00$ & 0.0000 & $0.000 \mathrm{E}+00$ & 0.0000 & $1.374 \mathrm{E}-16$ & 0.0000 \\
\hline 240 & $0.000 \mathrm{E}+00$ & 0.0000 & $0.000 \mathrm{E}+00$ & 0.0000 & $0.000 \mathrm{E}+00$ & 0.0000 & $0.000 \mathrm{E}+00$ & 0.0000 & $0.000 \mathrm{E}+00$ & 0.0000 & $0.000 \mathrm{E}+00$ & 0.0000 & $6.177 \mathrm{E}-20$ & 0.0000 \\
\hline 99 & $0.000 \mathrm{E}+00$ & 0.0000 & $0.000 \mathrm{E}+00$ & 0.0000 & $0.000 \mathrm{E}+00$ & 0.0000 & $0.000 \mathrm{E}+00$ & 0.0000 & $0.000 \mathrm{E}+00$ & 0.0000 & $0.000 \mathrm{E}+00$ & 0.0000 & $1.160 \mathrm{E}-24$ & 0.0000 \\
\hline 228 & $0.000 \mathrm{E}+00$ & 0.0000 & $0.000 \mathrm{E}+00$ & 0.0000 & $0.000 \mathrm{E}+00$ & 0.0000 & $0.000 \mathrm{E}+00$ & 0.0000 & $0.000 \mathrm{E}+00$ & 0.0000 & $0.000 \mathrm{E}+00$ & 0.0000 & $1.776 \mathrm{E}-22$ & 0.0000 \\
\hline 230 & $0.000 \mathrm{E}+00$ & 0.0000 & $0.000 \mathrm{E}+00$ & 0.0000 & $0.000 \mathrm{E}+00$ & 0.0000 & $0.000 \mathrm{E}+00$ & 0.0000 & $0.000 \mathrm{E}+00$ & 0.0000 & $0.000 \mathrm{E}+00$ & 0.0000 & $1.423 E-07$ & 0.1082 \\
\hline 232 & $0.000 \mathrm{E}+00$ & 0.0000 & $0.000 \mathrm{E}+00$ & 0.0000 & $0.000 \mathrm{E}+00$ & 0.0000 & $0.000 \mathrm{E}+00$ & 0.0000 & $0.000 \mathrm{E}+00$ & 0.0000 & $0.000 \mathrm{E}+00$ & 0.0000 & $1.167 \mathrm{E}-06$ & 0.8876 \\
\hline & $0.000 \mathrm{E}+00$ & 0.0000 & $0.000 \mathrm{E}+00$ & 0.0000 & $0.000 \mathrm{E}+00$ & 0.0000 & $0.000 \mathrm{E}+00$ & 0.0000 & $0.000 \mathrm{E}+00$ & 0.0000 & $0.000 \mathrm{E}+00$ & 0.0000 & $1.037 \mathrm{E}-10$ & 0.0001 \\
\hline 35 & $0.000 \mathrm{E}+00$ & 0.0000 & $0.000 \mathrm{E}+00$ & 0.0000 & $0.000 \mathrm{E}+00$ & 0.0000 & $0.000 \mathrm{E}+00$ & 0.0000 & $0.000 \mathrm{E}+00$ & 0.0000 & $0.000 \mathrm{E}+00$ & 0.0000 & $2.119 \mathrm{E}-13$ & 0.0000 \\
\hline 38 & $0.000 \mathrm{E}+00$ & 0.0000 & $0.000 \mathrm{E}+00$ & 0.0000 & $0.000 \mathrm{E}+00$ & 0.0000 & $0.000 \mathrm{E}+00$ & 0.0000 & $0.000 \mathrm{E}+00$ & 0.0000 & $0.000 \mathrm{E}+00$ & 0.0000 & $4.856 \mathrm{E}-09$ & 0.0037 \\
\hline & $0.000 \mathrm{E}+00$ & 0.0000 & $0.000 \mathrm{E}+00$ & 0.0000 & $0.000 \mathrm{E}+00$ & 0.0000 & $0.000 \mathrm{E}+00$ & 0.0000 & $0.000 \mathrm{E}+00$ & 0.0000 & $0.000 \mathrm{E}+00$ & 000 & -06 & 1.0000 \\
\hline
\end{tabular}

* Sum of all water independent and dependent pathways. 
RESRAD, Version 6.5

ummary : RESRAD Parameters for U-Landfill Recreational User Foward Run

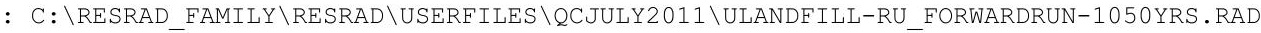

Total Dose Contributions TDOSE(i,p,t) for Individual Radionuclides (i) and Pathways (p) As mrem/yr and Fraction of Total Dose At $t=5.000 \mathrm{E}+02$ years

Water Independent Pathways (Inhalation excludes radon)

\begin{tabular}{|c|c|c|c|c|c|c|c|c|c|c|c|c|c|c|}
\hline \multirow[b]{2}{*}{ Nuclide } & \multicolumn{2}{|c|}{ Ground } & \multicolumn{2}{|c|}{ Inhalation } & \multicolumn{2}{|c|}{ Radon } & \multicolumn{2}{|c|}{ Plant } & \multicolumn{2}{|c|}{ Meat } & \multicolumn{2}{|c|}{ Milk } & \multicolumn{2}{|c|}{ Soil } \\
\hline & mrem/yr & fract. & mrem/yr & fract. & mrem/yr & fract. & mrem/yr & fract. & mrem/yr & fract. & mrem/yr & fract. & mrem/yr & fract. \\
\hline-241 & $7.849 E-14$ & 0.0000 & $0.000 \mathrm{E}+00$ & 0.0000 & $0.000 \mathrm{E}+00$ & 0.0000 & $0.000 \mathrm{E}+00$ & 0.0000 & $0.000 \mathrm{E}+00$ & 0.0000 & $0.000 \mathrm{E}+00$ & 0.0000 & $0.000 \mathrm{E}+00$ & 0.0000 \\
\hline-137 & 1. $491 \mathrm{E}-12$ & 0.0000 & $0.000 \mathrm{E}+00$ & 0.0000 & $0.000 \mathrm{E}+00$ & 0.0000 & $0.000 \mathrm{E}+00$ & 0.0000 & $0.000 \mathrm{E}+00$ & 0.0000 & $0.000 \mathrm{E}+00$ & 0.0000 & $0.000 \mathrm{E}+00$ & 0.0000 \\
\hline-237 & $1.111 \mathrm{E}-10$ & 0.0000 & $0.000 \mathrm{E}+00$ & 0.0000 & $0.000 \mathrm{E}+00$ & 0.0000 & $0.000 \mathrm{E}+00$ & 0.0000 & $0.000 \mathrm{E}+00$ & 0.0000 & $0.000 \mathrm{E}+00$ & 0.0000 & $0.000 \mathrm{E}+00$ & 0.0000 \\
\hline-238 & $2.109 \mathrm{E}-12$ & 0.0000 & $0.000 \mathrm{E}+00$ & 0.0000 & $0.000 \mathrm{E}+00$ & 0.0000 & $0.000 \mathrm{E}+00$ & 0.0000 & $0.000 \mathrm{E}+00$ & 0.0000 & $0.000 \mathrm{E}+00$ & 0.0000 & $0.000 \mathrm{E}+00$ & 0.0000 \\
\hline-239 & $1.636 \mathrm{E}-14$ & 0.0000 & $0.000 \mathrm{E}+00$ & 0.0000 & $0.000 \mathrm{E}+00$ & 0.0000 & $0.000 \mathrm{E}+00$ & 0.0000 & $0.000 \mathrm{E}+00$ & 0.0000 & $0.000 \mathrm{E}+00$ & 0.0000 & $0.000 \mathrm{E}+00$ & 0.0000 \\
\hline-240 & $1.985 \mathrm{E}-17$ & 0.0000 & $0.000 \mathrm{E}+00$ & 0.0000 & $0.000 \mathrm{E}+00$ & 0.0000 & $0.000 \mathrm{E}+00$ & 0.0000 & $0.000 \mathrm{E}+00$ & 0.0000 & $0.000 \mathrm{E}+00$ & 0.0000 & $0.000 \mathrm{E}+00$ & 0.0000 \\
\hline 99 & $3.036 E-22$ & 0.0000 & $0.000 \mathrm{E}+00$ & 0.0000 & $0.000 \mathrm{E}+00$ & 0.0000 & $0.000 \mathrm{E}+00$ & 0.0000 & $0.000 \mathrm{E}+00$ & 0.0000 & $0.000 \mathrm{E}+00$ & 0.0000 & $0.000 \mathrm{E}+00$ & 0.0000 \\
\hline-228 & $0.000 \mathrm{E}+00$ & 0.0000 & $0.000 \mathrm{E}+00$ & 0.0000 & $0.000 \mathrm{E}+00$ & 0.0000 & $0.000 \mathrm{E}+00$ & 0.0000 & $0.000 \mathrm{E}+00$ & 0.0000 & $0.000 \mathrm{E}+00$ & 0.0000 & $0.000 \mathrm{E}+00$ & 0.0000 \\
\hline 230 & $1.032 \mathrm{E}-05$ & 0.4425 & $0.000 \mathrm{E}+00$ & 0.0000 & $0.000 \mathrm{E}+00$ & 0.0000 & $0.000 \mathrm{E}+00$ & 0.0000 & $0.000 \mathrm{E}+00$ & 0.0000 & $0.000 \mathrm{E}+00$ & 0.0000 & $0.000 \mathrm{E}+00$ & 0.0000 \\
\hline-232 & $1.285 E-05$ & 0.5508 & $0.000 \mathrm{E}+00$ & 0.0000 & $0.000 \mathrm{E}+00$ & 0.0000 & $0.000 \mathrm{E}+00$ & 0.0000 & $0.000 \mathrm{E}+00$ & 0.0000 & $0.000 \mathrm{E}+00$ & 0.0000 & $0.000 \mathrm{E}+00$ & 0.0000 \\
\hline 34 & $3.851 E-08$ & 0.0017 & $0.000 \mathrm{E}+00$ & 0.0000 & $0.000 \mathrm{E}+00$ & 0.0000 & $0.000 \mathrm{E}+00$ & 0.0000 & $0.000 \mathrm{E}+00$ & 0.0000 & $0.000 \mathrm{E}+00$ & 0.0000 & $0.000 \mathrm{E}+00$ & 0.0000 \\
\hline 35 & $4.414 \mathrm{E}-11$ & 0.0000 & $0.000 \mathrm{E}+00$ & 0.0000 & $0.000 \mathrm{E}+00$ & 0.0000 & $0.000 \mathrm{E}+00$ & 0.0000 & $0.000 \mathrm{E}+00$ & 0.0000 & $0.000 \mathrm{E}+00$ & 0.0000 & $0.000 \mathrm{E}+00$ & 0.0000 \\
\hline 38 & $1.187 \mathrm{E}-07$ & 0.0051 & $0.000 \mathrm{E}+00$ & 0.0000 & $0.000 \mathrm{E}+00$ & 0.0000 & $0.000 \mathrm{E}+00$ & 0.0000 & $0.000 \mathrm{E}+00$ & 0.0000 & $0.000 \mathrm{E}+00$ & 0.0000 & $0.000 \mathrm{E}+00$ & 0.0000 \\
\hline & 5 & & $E+00$ & 0.0 & $0.000 \mathrm{E}+00$ & 0 . & $0.000 \mathrm{E}+00$ & 0 . & +00 & 0 & 100 & & +00 & \\
\hline
\end{tabular}

Total Dose Contributions TDOSE(i,p,t) for Individual Radionuclides (i) and Pathways (p) As mrem/yr and Fraction of Total Dose At $t=5.000 \mathrm{E}+02$ years

Water Dependent Pathways

\begin{tabular}{|c|c|c|c|c|c|c|c|c|c|c|c|c|c|c|}
\hline \multirow{2}{*}{$\begin{array}{l}\text { Radio- } \\
\text { Nuclide }\end{array}$} & \multicolumn{2}{|c|}{ Water } & \multicolumn{2}{|c|}{ Fish } & \multicolumn{2}{|c|}{ Radon } & \multicolumn{2}{|c|}{ Plant } & \multicolumn{2}{|c|}{ Meat } & \multicolumn{2}{|c|}{ Milk } & \multicolumn{2}{|c|}{ All Pathways* } \\
\hline & mrem/yr & fract. & mrem/yr & fract. & mrem/yr & fract. & mrem/yr & fract. & mrem/yr & fract. & mrem/yr & fract. & mrem/yr & fract. \\
\hline 241 & $0.000 \mathrm{E}+00$ & 0.0000 & $0.000 \mathrm{E}+00$ & 0.0000 & $0.000 \mathrm{E}+00$ & 0.0000 & $0.000 \mathrm{E}+00$ & 0.0000 & $0.000 \mathrm{E}+00$ & 0.0000 & $0.000 \mathrm{E}+00$ & 0.0000 & $7.849 \mathrm{E}-14$ & 0.0000 \\
\hline-137 & $0.000 \mathrm{E}+00$ & 0.0000 & $0.000 \mathrm{E}+00$ & 0.0000 & $0.000 \mathrm{E}+00$ & 0.0000 & $0.000 \mathrm{E}+00$ & 0.0000 & $0.000 \mathrm{E}+00$ & 0.0000 & $0.000 \mathrm{E}+00$ & 0.0000 & 1. $491 \mathrm{E}-12$ & 0.0000 \\
\hline-237 & $0.000 \mathrm{E}+00$ & 0.0000 & $0.000 \mathrm{E}+00$ & 0.0000 & $0.000 \mathrm{E}+00$ & 0.0000 & $0.000 \mathrm{E}+00$ & 0.0000 & $0.000 \mathrm{E}+00$ & 0.0000 & $0.000 \mathrm{E}+00$ & 0.0000 & $1.111 \mathrm{E}-10$ & 0.0000 \\
\hline-238 & $0.000 \mathrm{E}+00$ & 0.0000 & $0.000 \mathrm{E}+00$ & 0.0000 & $0.000 \mathrm{E}+00$ & 0.0000 & $0.000 \mathrm{E}+00$ & 0.0000 & $0.000 \mathrm{E}+00$ & 0.0000 & $0.000 \mathrm{E}+00$ & 0.0000 & $2.109 \mathrm{E}-12$ & 0.0000 \\
\hline-239 & $0.000 \mathrm{E}+00$ & 0.0000 & $0.000 \mathrm{E}+00$ & 0.0000 & $0.000 \mathrm{E}+00$ & 0.0000 & $0.000 \mathrm{E}+00$ & 0.0000 & $0.000 \mathrm{E}+00$ & 0.0000 & $0.000 E+00$ & 0.0000 & $1.636 \mathrm{E}-14$ & 0.0000 \\
\hline-240 & $0.000 \mathrm{E}+00$ & 0.0000 & $0.000 \mathrm{E}+00$ & 0.0000 & $0.000 \mathrm{E}+00$ & 0.0000 & $0.000 \mathrm{E}+00$ & 0.0000 & $0.000 \mathrm{E}+00$ & 0.0000 & $0.000 E+00$ & 0.0000 & $1.985 \mathrm{E}-17$ & 0.0000 \\
\hline 99 & $0.000 \mathrm{E}+00$ & 0.0000 & $0.000 \mathrm{E}+00$ & 0.0000 & $0.000 \mathrm{E}+00$ & 0.0000 & $0.000 \mathrm{E}+00$ & 0.0000 & $0.000 \mathrm{E}+00$ & 0.0000 & $0.000 \mathrm{E}+00$ & 0.0000 & $3.036 \mathrm{E}-22$ & 0.0000 \\
\hline-228 & $0.000 \mathrm{E}+00$ & 0.0000 & $0.000 \mathrm{E}+00$ & 0.0000 & $0.000 \mathrm{E}+00$ & 0.0000 & $0.000 \mathrm{E}+00$ & 0.0000 & $0.000 \mathrm{E}+00$ & 0.0000 & $0.000 \mathrm{E}+00$ & 0.0000 & $0.000 \mathrm{E}+00$ & 0.0000 \\
\hline-230 & $0.000 \mathrm{E}+00$ & 0.0000 & $0.000 \mathrm{E}+00$ & 0.0000 & $0.000 \mathrm{E}+00$ & 0.0000 & $0.000 \mathrm{E}+00$ & 0.0000 & $0.000 \mathrm{E}+00$ & 0.0000 & $0.000 E+00$ & 0.0000 & $1.032 \mathrm{E}-05$ & 0.4425 \\
\hline 232 & $0.000 \mathrm{E}+00$ & 0.0000 & $0.000 \mathrm{E}+00$ & 0.0000 & $0.000 \mathrm{E}+00$ & 0.0000 & $0.000 \mathrm{E}+00$ & 0.0000 & $0.000 \mathrm{E}+00$ & 0.0000 & $0.000 \mathrm{E}+00$ & 0.0000 & 1. $285 \mathrm{E}-05$ & 0.5508 \\
\hline 34 & $0.000 \mathrm{E}+00$ & 0.0000 & $0.000 \mathrm{E}+00$ & 0.0000 & $0.000 \mathrm{E}+00$ & 0.0000 & $0.000 \mathrm{E}+00$ & 0.0000 & $0.000 \mathrm{E}+00$ & 0.0000 & $0.000 \mathrm{E}+00$ & 0.0000 & $3.851 \mathrm{E}-08$ & 0.0017 \\
\hline 35 & $0.000 \mathrm{E}+00$ & 0.0000 & $0.000 \mathrm{E}+00$ & 0.0000 & $0.000 \mathrm{E}+00$ & 0.0000 & $0.000 \mathrm{E}+00$ & 0.0000 & $0.000 \mathrm{E}+00$ & 0.0000 & $0.000 \mathrm{E}+00$ & 0.0000 & $4.414 \mathrm{E}-11$ & 0.0000 \\
\hline 38 & $0.000 \mathrm{E}+00$ & 0.0000 & $0.000 \mathrm{E}+00$ & 0.0000 & $0.000 \mathrm{E}+00$ & 0.0000 & $0.000 \mathrm{E}+00$ & 0.0000 & $0.000 \mathrm{E}+00$ & 0.0000 & $0.000 \mathrm{E}+00$ & 0.0000 & $1.187 \mathrm{E}-07$ & 0.0051 \\
\hline & $0.000 \mathrm{E}+00$ & 0.0000 & $0.000 \mathrm{E}+00$ & 0.0000 & $0.000 \mathrm{E}+00$ & 0.0000 & $0.000 \mathrm{E}+00$ & 0.0000 & $0.000 \mathrm{E}+00$ & 0.0000 & $0.000 \mathrm{E}+00$ & 0.0000 & $3 E-05$ & 1. \\
\hline
\end{tabular}

* Sum of all water independent and dependent pathways. 
RESRAD, Version 6.5

ummary : RESRAD Parameters for U-Landfill Recreational User Foward Run

: C: $\backslash$ RESRAD FAMILY \RESRAD \USERFILES \QCJULY2011 \ULANDFILL-RU FORWARDRUN-1050YRS.RAD

Total Dose Contributions TDOSE(i,p,t) for Individual Radionuclides (i) and Pathways (p) As mrem/yr and Fraction of Total Dose At $t=1.050 \mathrm{E}+03$ years

Water Independent Pathways (Inhalation excludes radon)

\begin{tabular}{|c|c|c|c|c|c|c|c|c|c|c|c|c|c|c|}
\hline \multirow{2}{*}{ Nuclide } & \multicolumn{2}{|c|}{ Ground } & \multicolumn{2}{|c|}{ Inhalation } & \multicolumn{2}{|c|}{ Radon } & \multicolumn{2}{|c|}{ Plant } & \multicolumn{2}{|c|}{ Meat } & \multicolumn{2}{|c|}{ Milk } & \multicolumn{2}{|c|}{ Soil } \\
\hline & mrem/yr & fract. & mrem/yr & fract. & mrem/yr & fract. & mrem/yr & fract. & mrem/yr & fract. & mrem/yr & fract. & mrem/yr & fract. \\
\hline-241 & $4.250 \mathrm{E}-11$ & 0.0000 & $0.000 \mathrm{E}+00$ & 0.0000 & $0.000 \mathrm{E}+00$ & 0.0000 & $0.000 \mathrm{E}+00$ & 0.0000 & $0.000 \mathrm{E}+00$ & 0.0000 & $0.000 \mathrm{E}+00$ & 0.0000 & $0.000 \mathrm{E}+00$ & 0.0000 \\
\hline-137 & $4.627 E-16$ & 0.0000 & $0.000 \mathrm{E}+00$ & 0.0000 & $0.000 \mathrm{E}+00$ & 0.0000 & $0.000 \mathrm{E}+00$ & 0.0000 & $0.000 \mathrm{E}+00$ & 0.0000 & $0.000 \mathrm{E}+00$ & 0.0000 & $0.000 \mathrm{E}+00$ & 0.0000 \\
\hline-237 & $3.985 E-08$ & 0.0000 & $0.000 \mathrm{E}+00$ & 0.0000 & $0.000 \mathrm{E}+00$ & 0.0000 & $0.000 \mathrm{E}+00$ & 0.0000 & $0.000 \mathrm{E}+00$ & 0.0000 & $0.000 \mathrm{E}+00$ & 0.0000 & $0.000 \mathrm{E}+00$ & 0.0000 \\
\hline-238 & $4.914 \mathrm{E}-10$ & 0.0000 & $0.000 \mathrm{E}+00$ & 0.0000 & $0.000 \mathrm{E}+00$ & 0.0000 & $0.000 \mathrm{E}+00$ & 0.0000 & $0.000 \mathrm{E}+00$ & 0.0000 & $0.000 \mathrm{E}+00$ & 0.0000 & $0.000 \mathrm{E}+00$ & 0.0000 \\
\hline-239 & $1.164 \mathrm{E}-11$ & 0.0000 & $0.000 \mathrm{E}+00$ & 0.0000 & $0.000 \mathrm{E}+00$ & 0.0000 & $0.000 \mathrm{E}+00$ & 0.0000 & $0.000 \mathrm{E}+00$ & 0.0000 & $0.000 \mathrm{E}+00$ & 0.0000 & $0.000 \mathrm{E}+00$ & 0.0000 \\
\hline-240 & $2.820 \mathrm{E}-15$ & 0.0000 & $0.000 \mathrm{E}+00$ & 0.0000 & $0.000 \mathrm{E}+00$ & 0.0000 & $0.000 \mathrm{E}+00$ & 0.0000 & $0.000 \mathrm{E}+00$ & 0.0000 & $0.000 \mathrm{E}+00$ & 0.0000 & $0.000 \mathrm{E}+00$ & 0.0000 \\
\hline 99 & $6.409 \mathrm{E}-19$ & 0.0000 & $0.000 \mathrm{E}+00$ & 0.0000 & $0.000 \mathrm{E}+00$ & 0.0000 & $0.000 \mathrm{E}+00$ & 0.0000 & $0.000 \mathrm{E}+00$ & 0.0000 & $0.000 \mathrm{E}+00$ & 0.0000 & $0.000 \mathrm{E}+00$ & 0.0000 \\
\hline-228 & $0.000 \mathrm{E}+00$ & 0.0000 & $0.000 \mathrm{E}+00$ & 0.0000 & $0.000 \mathrm{E}+00$ & 0.0000 & $0.000 \mathrm{E}+00$ & 0.0000 & $0.000 \mathrm{E}+00$ & 0.0000 & $0.000 \mathrm{E}+00$ & 0.0000 & $0.000 \mathrm{E}+00$ & 0.0000 \\
\hline-230 & $8.661 \mathrm{E}-04$ & 0.6991 & $0.000 \mathrm{E}+00$ & 0.0000 & $0.000 \mathrm{E}+00$ & 0.0000 & $0.000 \mathrm{E}+00$ & 0.0000 & $0.000 \mathrm{E}+00$ & 0.0000 & $0.000 \mathrm{E}+00$ & 0.0000 & $0.000 \mathrm{E}+00$ & 0.0000 \\
\hline-232 & $3.560 E-04$ & 0.2874 & $0.000 \mathrm{E}+00$ & 0.0000 & $0.000 \mathrm{E}+00$ & 0.0000 & $0.000 \mathrm{E}+00$ & 0.0000 & $0.000 \mathrm{E}+00$ & 0.0000 & $0.000 \mathrm{E}+00$ & 0.0000 & $0.000 \mathrm{E}+00$ & 0.0000 \\
\hline 234 & $7.034 \mathrm{E}-06$ & 0.0057 & $0.000 \mathrm{E}+00$ & 0.0000 & $0.000 \mathrm{E}+00$ & 0.0000 & $0.000 \mathrm{E}+00$ & 0.0000 & $0.000 \mathrm{E}+00$ & 0.0000 & $0.000 \mathrm{E}+00$ & 0.0000 & $0.000 \mathrm{E}+00$ & 0.0000 \\
\hline 35 & $1.481 \mathrm{E}-08$ & 0.0000 & $0.000 \mathrm{E}+00$ & 0.0000 & $0.000 \mathrm{E}+00$ & 0.0000 & $0.000 \mathrm{E}+00$ & 0.0000 & $0.000 \mathrm{E}+00$ & 0.0000 & $0.000 \mathrm{E}+00$ & 0.0000 & $0.000 \mathrm{E}+00$ & 0.0000 \\
\hline 38 & $9.634 \mathrm{E}-06$ & 0.0078 & $0.000 \mathrm{E}+00$ & 0.0000 & $0.000 \mathrm{E}+00$ & 0.0000 & $0.000 \mathrm{E}+00$ & 0.0000 & $0.000 \mathrm{E}+00$ & 0.0000 & $0.000 \mathrm{E}+00$ & 0.0000 & $0.000 \mathrm{E}+00$ & 0.0000 \\
\hline & $1.239 \mathrm{E}-03$ & 1.0000 & $0.000 \mathrm{E}+00$ & 0.0000 & $0.000 \mathrm{E}+00$ & 0.0000 & $0.000 \mathrm{E}+00$ & 0.0000 & $0.000 \mathrm{E}+00$ & 0.0000 & $0.000 \mathrm{E}+00$ & 0.0000 & $.000 \mathrm{E}+00$ & 0.0000 \\
\hline
\end{tabular}

Total Dose Contributions TDOSE(i,p,t) for Individual Radionuclides (i) and Pathways (p) As mrem/yr and Fraction of Total Dose At $t=1.050 \mathrm{E}+03$ years

Water Dependent Pathways

\begin{tabular}{|c|c|c|c|c|c|c|c|c|c|c|c|c|c|c|}
\hline \multirow{2}{*}{$\begin{array}{l}\text { Radio- } \\
\text { Nuclide }\end{array}$} & \multicolumn{2}{|c|}{ Water } & \multicolumn{2}{|c|}{ Fish } & \multicolumn{2}{|c|}{ Radon } & \multicolumn{2}{|c|}{ Plant } & \multicolumn{2}{|c|}{ Meat } & \multicolumn{2}{|c|}{ Milk } & \multicolumn{2}{|c|}{ All Pathways* } \\
\hline & mrem/yr & fract. & mrem/yr & fract. & mrem/yr & fract. & mrem/yr & fract. & mrem/yr & fract. & mrem/yr & fract. & mrem/yr & fract. \\
\hline 241 & $0.000 \mathrm{E}+00$ & 0.0000 & $0.000 \mathrm{E}+00$ & 0.0000 & $0.000 \mathrm{E}+00$ & 0.0000 & $0.000 \mathrm{E}+00$ & 0.0000 & $0.000 \mathrm{E}+00$ & 0.0000 & $0.000 \mathrm{E}+00$ & 0.0000 & $4.250 \mathrm{E}-11$ & 0.0000 \\
\hline-137 & $0.000 \mathrm{E}+00$ & 0.0000 & $0.000 \mathrm{E}+00$ & 0.0000 & $0.000 \mathrm{E}+00$ & 0.0000 & $0.000 \mathrm{E}+00$ & 0.0000 & $0.000 \mathrm{E}+00$ & 0.0000 & $0.000 \mathrm{E}+00$ & 0.0000 & $4.627 \mathrm{E}-16$ & 0.0000 \\
\hline-237 & $0.000 \mathrm{E}+00$ & 0.0000 & $0.000 \mathrm{E}+00$ & 0.0000 & $0.000 \mathrm{E}+00$ & 0.0000 & $0.000 \mathrm{E}+00$ & 0.0000 & $0.000 \mathrm{E}+00$ & 0.0000 & $0.000 \mathrm{E}+00$ & 0.0000 & $3.985 E-08$ & 0.0000 \\
\hline-238 & $0.000 \mathrm{E}+00$ & 0.0000 & $0.000 \mathrm{E}+00$ & 0.0000 & $0.000 \mathrm{E}+00$ & 0.0000 & $0.000 \mathrm{E}+00$ & 0.0000 & $0.000 \mathrm{E}+00$ & 0.0000 & $0.000 \mathrm{E}+00$ & 0.0000 & $4.914 \mathrm{E}-10$ & 0.0000 \\
\hline-239 & $0.000 \mathrm{E}+00$ & 0.0000 & $0.000 \mathrm{E}+00$ & 0.0000 & $0.000 \mathrm{E}+00$ & 0.0000 & $0.000 \mathrm{E}+00$ & 0.0000 & $0.000 \mathrm{E}+00$ & 0.0000 & $0.000 E+00$ & 0.0000 & $1.164 \mathrm{E}-11$ & 0.0000 \\
\hline-240 & $0.000 \mathrm{E}+00$ & 0.0000 & $0.000 \mathrm{E}+00$ & 0.0000 & $0.000 \mathrm{E}+00$ & 0.0000 & $0.000 \mathrm{E}+00$ & 0.0000 & $0.000 \mathrm{E}+00$ & 0.0000 & $0.000 E+00$ & 0.0000 & $2.820 \mathrm{E}-15$ & 0.0000 \\
\hline 99 & $0.000 \mathrm{E}+00$ & 0.0000 & $0.000 \mathrm{E}+00$ & 0.0000 & $0.000 \mathrm{E}+00$ & 0.0000 & $0.000 \mathrm{E}+00$ & 0.0000 & $0.000 \mathrm{E}+00$ & 0.0000 & $0.000 \mathrm{E}+00$ & 0.0000 & $6.409 \mathrm{E}-19$ & 0.0000 \\
\hline-228 & $0.000 \mathrm{E}+00$ & 0.0000 & $0.000 \mathrm{E}+00$ & 0.0000 & $0.000 \mathrm{E}+00$ & 0.0000 & $0.000 \mathrm{E}+00$ & 0.0000 & $0.000 \mathrm{E}+00$ & 0.0000 & $0.000 \mathrm{E}+00$ & 0.0000 & $0.000 \mathrm{E}+00$ & 0.0000 \\
\hline-230 & $0.000 \mathrm{E}+00$ & 0.0000 & $0.000 \mathrm{E}+00$ & 0.0000 & $0.000 \mathrm{E}+00$ & 0.0000 & $0.000 \mathrm{E}+00$ & 0.0000 & $0.000 \mathrm{E}+00$ & 0.0000 & $0.000 E+00$ & 0.0000 & $8.661 \mathrm{E}-04$ & 0.6991 \\
\hline 232 & $0.000 \mathrm{E}+00$ & 0.0000 & $0.000 \mathrm{E}+00$ & 0.0000 & $0.000 \mathrm{E}+00$ & 0.0000 & $0.000 \mathrm{E}+00$ & 0.0000 & $0.000 \mathrm{E}+00$ & 0.0000 & $0.000 \mathrm{E}+00$ & 0.0000 & $3.560 \mathrm{E}-04$ & 0.2874 \\
\hline 34 & $0.000 \mathrm{E}+00$ & 0.0000 & $0.000 \mathrm{E}+00$ & 0.0000 & $0.000 \mathrm{E}+00$ & 0.0000 & $0.000 \mathrm{E}+00$ & 0.0000 & $0.000 \mathrm{E}+00$ & 0.0000 & $0.000 \mathrm{E}+00$ & 0.0000 & $7.034 \mathrm{E}-06$ & 0.0057 \\
\hline 35 & $0.000 \mathrm{E}+00$ & 0.0000 & $0.000 \mathrm{E}+00$ & 0.0000 & $0.000 \mathrm{E}+00$ & 0.0000 & $0.000 \mathrm{E}+00$ & 0.0000 & $0.000 \mathrm{E}+00$ & 0.0000 & $0.000 \mathrm{E}+00$ & 0.0000 & $1.481 E-08$ & 0.0000 \\
\hline 38 & $0.000 \mathrm{E}+00$ & 0.0000 & $0.000 \mathrm{E}+00$ & 0.0000 & $0.000 \mathrm{E}+00$ & 0.0000 & $0.000 \mathrm{E}+00$ & 0.0000 & $0.000 \mathrm{E}+00$ & 0.0000 & $0.000 \mathrm{E}+00$ & 0.0000 & $9.634 \mathrm{E}-06$ & 0.0078 \\
\hline & $0.000 \mathrm{E}+00$ & 0.0000 & $0.000 \mathrm{E}+00$ & 0.0000 & $0.000 \mathrm{E}+00$ & 0.0000 & $0.000 \mathrm{E}+00$ & 0.0000 & $0.000 \mathrm{E}+00$ & 0.0000 & $0.000 \mathrm{E}+00$ & 0.0000 & $9 \mathrm{E}-03$ & 1. \\
\hline
\end{tabular}

* Sum of all water independent and dependent pathways. 
RESRAD, Version 6.5

Summary : RESRAD Parameters for U-Landfill Recreational User Foward Run

File : C: \RESRAD FAMILY \RESRAD \USERFILES \QCJULY2011 \ULANDFILL-RU FORWARDRUN-1050YRS.RAD

Dose/Source Ratios Summed Over All Pathways

Parent and Progeny Principal Radionuclide Contributions Indicated

Parent Product Thread DSR $(j, t)$ At Time in Years (mrem/yr)/(pCi/g)

(i)

(j)

$\begin{array}{ll}\mathrm{Am}-241 & 1.000 \mathrm{E}+00 \\ \mathrm{~Np}-237+\mathrm{D} & 1.000 \mathrm{E}+00 \\ \mathrm{U}-233 & 1.000 \mathrm{E}+00 \\ \mathrm{Th}-229+\mathrm{D} & 1.000 \mathrm{E}+00 \\ \operatorname{\sum DSR}(j) & \end{array}$

Cs $-137+D$

$\mathrm{Np}-237+\mathrm{D}$

U-233

Th-229+D

$\sum \operatorname{DSR}(j)$

$\mathrm{Pu}-238$

$\mathrm{Pu}-238$

U-234

Th-230

Ra-226+D

$\mathrm{Pb}-210+\mathrm{D}$

$\sum \operatorname{DSR}(j)$

Pu-239

U-235+D

$\mathrm{Pa}-231$

Ac $-227+D$

$\sum \operatorname{DSR}(j)$

$\mathrm{Pu}-240$

$\mathrm{Pu}-240$

U-236

Th-232

$\mathrm{Ra}-228+\mathrm{D}$

Th-228+D

$\sum \operatorname{DSR}(j)$

TC-99

Th-228+D

Th-230

$\mathrm{Ra}-226+\mathrm{D}$

$\mathrm{Pb}-210+\mathrm{D}$

$\sum \operatorname{DSR}(j)$

1. $000 \mathrm{E}+00$ $\begin{array}{lllllllll}1.000 \mathrm{E}+00 & 1.213 \mathrm{E}-10 & 1.196 \mathrm{E}-10 & 1.017 \mathrm{E}-10 & 5.821 \mathrm{E}-11 & 2.793 \mathrm{E}-11 & 7.847 \mathrm{E}-14 & 2.435 \mathrm{E}-17\end{array}$

$1.000 \mathrm{E}+00 \quad 9.169 \mathrm{E}-14 \quad 9.268 \mathrm{E}-14 \quad 1.043 \mathrm{E}-13 \quad 1.567 \mathrm{E}-13 \quad 2.679 \mathrm{E}-13 \quad 1.952 \mathrm{E}-11 \quad 7.101 \mathrm{E}-09$

$\begin{array}{lllllllll}1.000 \mathrm{E}+00 & 3.120 \mathrm{E}-24 & 9.466 \mathrm{E}-24 & 9.045 \mathrm{E}-23 & 5.875 \mathrm{E}-22 & 2.184 \mathrm{E}-21 & 1.613 \mathrm{E}-18 & 3.273 \mathrm{E}-15\end{array}$

$2.848 \mathrm{E}-20 \quad 2.006 \mathrm{E}-19 \quad 1.449 \mathrm{E}-17 \quad 3.076 \mathrm{E}-16 \quad 1.723 \mathrm{E}-15 \quad 6.884 \mathrm{E}-13 \quad 1.443 \mathrm{E}-10$ $9.169 \mathrm{E}-14 \quad 9.268 \mathrm{E}-14 \quad 1.043 \mathrm{E}-13 \quad 1.570 \mathrm{E}-13 \quad 2.696 \mathrm{E}-13 \quad 2.021 \mathrm{E}-11 \quad 7.245 \mathrm{E}-09$

$\begin{array}{llllllll}1.840 E-09 & 2.079 E-34 & 2.099 E-34 & 2.337 E-34 & 3.386 E-34 & 5.515 E-34 & 2.732 E-32 & 5.849 E-30\end{array}$

$\begin{array}{llllllll}1.000 \mathrm{E}+00 & 1.130 \mathrm{E}-25 & 1.141 \mathrm{E}-25 & 1.270 \mathrm{E}-25 & 1.840 \mathrm{E}-25 & 2.997 \mathrm{E}-25 & 1.485 \mathrm{E}-23 & 3.179 \mathrm{E}-21\end{array}$

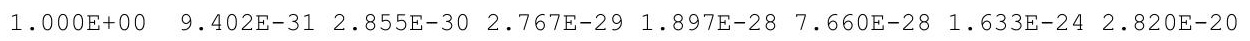
$\begin{array}{llllllll}1.000 \mathrm{E}+00 & 9.887 \mathrm{E}-35 & 7.005 \mathrm{E}-34 & 5.480 \mathrm{E}-32 & 1.538 \mathrm{E}-30 & 1.253 \mathrm{E}-29 & 1.259 \mathrm{E}-25 & 3.198 \mathrm{E}-21\end{array}$ $\begin{array}{lllllllll}1.000 \mathrm{E}+00 & 7.713 \mathrm{E}-24 & 1.162 \mathrm{E}-22 & 6.388 \mathrm{E}-20 & 5.065 \mathrm{E}-18 & 5.122 \mathrm{E}-17 & 5.408 \mathrm{E}-14 & 1.260 \mathrm{E}-11\end{array}$ $\begin{array}{lllllllll}1.000 \mathrm{E}+00 & 2.237 \mathrm{E}-32 & 6.933 \mathrm{E}-31 & 2.743 \mathrm{E}-27 & 7.476 \mathrm{E}-25 & 1.264 \mathrm{E}-23 & 3.542 \mathrm{E}-20 & 1.664 \mathrm{E}-17\end{array}$ $\begin{array}{llllllll}7.826 \mathrm{E}-24 & 1.163 \mathrm{E}-22 & 6.388 \mathrm{E}-20 & 5.065 \mathrm{E}-18 & 5.122 \mathrm{E}-17 & 5.408 \mathrm{E}-14 & 1.260 \mathrm{E}-11\end{array}$

$\begin{array}{llllllll}1.000 \mathrm{E}+00 & 1.156 \mathrm{E}-18 & 1.170 \mathrm{E}-18 & 1.334 \mathrm{E}-18 & 2.100 \mathrm{E}-18 & 3.815 \mathrm{E}-18 & 4.526 \mathrm{E}-16 & 3.220 \mathrm{E}-13\end{array}$

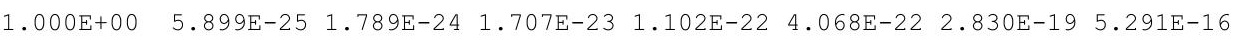
$\begin{array}{lllllllll}1.000 \mathrm{E}+00 & 9.281 \mathrm{E}-29 & 6.556 \mathrm{E}-28 & 4.931 \mathrm{E}-26 & 1.203 \mathrm{E}-24 & 8.097 \mathrm{E}-24 & 1.394 \mathrm{E}-20 & 2.092 \mathrm{E}-17\end{array}$ $\begin{array}{lllllllll}1.000 \mathrm{E}+00 & 2.200 \mathrm{E}-28 & 3.302 \mathrm{E}-27 & 1.741 \mathrm{E}-24 & 1.227 \mathrm{E}-22 & 1.125 \mathrm{E}-21 & 1.425 \mathrm{E}-18 & 8.591 \mathrm{E}-16\end{array}$ $\begin{array}{lllllll}1.156 \mathrm{E}-18 & 1.170 \mathrm{E}-18 & 1.334 \mathrm{E}-18 & 2.100 \mathrm{E}-18 & 3.817 \mathrm{E}-18 & 4.543 \mathrm{E}-16 & 3.234 \mathrm{E}-13\end{array}$

4.950E-08 5.436E-33 5.532E-33 6.710E-33 $1.307 \mathrm{E}-32 \quad 3.144 \mathrm{E}-32 \quad 3.519 \mathrm{E}-29 \quad 5.479 \mathrm{E}-25$

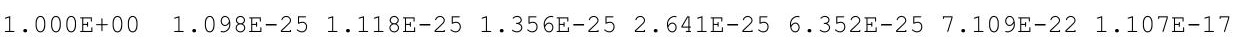
$\begin{array}{lllllllll}1.000 E+00 & 2.079 E-33 & 6.337 E-33 & 6.427 E-32 & 5.132 E-31 & 2.504 E-30 & 1.628 E-26 & 6.574 E-22\end{array}$ $\begin{array}{lllllllll}1.000 \mathrm{E}+00 & 2.803 \mathrm{E}-44 & 1.948 \mathrm{E}-43 & 1.599 \mathrm{E}-41 & 5.271 \mathrm{E}-40 & 5.270 \mathrm{E}-39 & 2.159 \mathrm{E}-34 & 2.528 \mathrm{E}-29\end{array}$ $\begin{array}{lllllllll}1.000 \mathrm{E}+00 & 1.318 \mathrm{E}-29 & 1.940 \mathrm{E}-28 & 8.230 \mathrm{E}-26 & 3.618 \mathrm{E}-24 & 2.445 \mathrm{E}-23 & 1.417 \mathrm{E}-20 & 4.042 \mathrm{E}-18\end{array}$ $\begin{array}{lllllllll}1.000 \mathrm{E}+00 \quad 7.799 \mathrm{E}-29 & 2.244 \mathrm{E}-27 & 4.095 \mathrm{E}-24 & 2.540 \mathrm{E}-22 & 1.691 \mathrm{E}-21 & 5.366 \mathrm{E}-19 & 6.323 \mathrm{E}-17\end{array}$ $\begin{array}{llllllll}1.099 \mathrm{E}-25 & 1.142 \mathrm{E}-25 & 4.313 \mathrm{E}-24 & 2.579 \mathrm{E}-22 & 1.716 \mathrm{E}-21 & 5.515 \mathrm{E}-19 & 7.834 \mathrm{E}-17\end{array}$

$\begin{array}{lllllllll}1.000 \mathrm{E}+00 & 5.547 \mathrm{E}-27 & 5.625 \mathrm{E}-27 & 6.555 \mathrm{E}-27 & 1.112 \mathrm{E}-26 & 2.231 \mathrm{E}-26 & 5.839 \mathrm{E}-24 & 1.233 \mathrm{E}-20\end{array}$ $\begin{array}{llllllll}1.000 \mathrm{E}+00 & 1.329 \mathrm{E}-07 & 9.308 \mathrm{E}-08 & 1.847 \mathrm{E}-09 & 2.430 \mathrm{E}-15 & 4.441 \mathrm{E}-23 & 0.000 \mathrm{E}+00 & 0.000 \mathrm{E}+00\end{array}$ $\begin{array}{llllllll}1.000 \mathrm{E}+00 & 2.319 \mathrm{E}-23 & 2.359 \mathrm{E}-23 & 2.838 \mathrm{E}-23 & 5.375 \mathrm{E}-23 & 1.246 \mathrm{E}-22 & 1.037 \mathrm{E}-19 & 1.074 \mathrm{E}-15\end{array}$ $\begin{array}{llllllllll}1.000 \mathrm{E}+00 & 3.629 \mathrm{E}-12 & 1.095 \mathrm{E}-11 & 9.820 \mathrm{E}-11 & 5.116 \mathrm{E}-10 & 1.423 \mathrm{E}-09 & 1.032 \mathrm{E}-07 & 8.661 \mathrm{E}-06\end{array}$ $1.000 \mathrm{E}+00 \quad 1.749 \mathrm{E}-20 \quad 1.222 \mathrm{E}-19 \quad 7.985 \mathrm{E}-18 \quad 1.249 \mathrm{E}-16 \quad 5.113 \mathrm{E}-16 \quad 7.402 \mathrm{E}-14 \quad 1.190 \mathrm{E}-11$ $\begin{array}{lllllll}3.629 \mathrm{E}-12 & 1.095 \mathrm{E}-11 & 9.820 \mathrm{E}-11 & 5.116 \mathrm{E}-10 & 1.423 \mathrm{E}-09 & 1.032 \mathrm{E}-07 & 8.661 \mathrm{E}-06\end{array}$ 
RESRAD, Version 6.5

Summary : RESRAD Parameters for U-Landfill Recreational User Foward Run

File : C: $\backslash$ RESRAD FAMILY \RESRAD \USERFILES $\backslash Q C J U L Y 2011 \backslash U L A N D F I L L-R U$ FORWARDRUN-1050YRS.RAD

Dose/Source Ratios Summed Over All Pathways

Parent and Progeny Principal Radionuclide Contributions Indicated

\begin{tabular}{|c|c|c|c|c|c|c|c|c|c|}
\hline Parent & Product & Thread & & $\operatorname{DSR}(j, t)$ & At Time in & Years & (mrem/yr) / & $(\mathrm{pCi} / \mathrm{g})$ & \\
\hline (i) & (j) & Fraction & $0.000 \mathrm{E}+00$ & $1.000 \mathrm{E}+00$ & $1.200 \mathrm{E}+01$ & $5.000 \mathrm{E}+01$ & $1.000 \mathrm{E}+02$ & $5.000 \mathrm{E}+02$ & $1.050 \mathrm{E}+03$ \\
\hline-232 & $\mathrm{Th}-232$ & $1.000 \mathrm{E}+00$ & $1.121 \mathrm{E}-25$ & $1.142 \mathrm{E}-25$ & $1.401 \mathrm{E}-25$ & $2.836 \mathrm{E}-25$ & $7.176 \mathrm{E}-25$ & 1. $205 \mathrm{E}-21$ & $3.277 \mathrm{E}-17$ \\
\hline $1-232$ & $\mathrm{Ra}-228+\mathrm{D}$ & $1.000 \mathrm{E}+00$ & 1. $065 \mathrm{E}-10$ & $3.052 \mathrm{E}-10$ & $1.565 \mathrm{E}-09$ & $2.678 \mathrm{E}-09$ & $3.923 E-09$ & $8.176 \mathrm{E}-08$ & $5.322 \mathrm{E}-06$ \\
\hline$h-232$ & $\mathrm{Th}-228+\mathrm{D}$ & $1.000 \mathrm{E}+00$ & $1.026 \mathrm{E}-09$ & $6.328 E-09$ & $1.146 \mathrm{E}-07$ & $2.128 E-07$ & $2.877 E-07$ & $3.130 \mathrm{E}-06$ & $8.368 E-05$ \\
\hline$h-232$ & $\sum \operatorname{DSR}(j)$ & & $1.133 E-09$ & $6.633 E-09$ & $1.162 \mathrm{E}-07$ & $2.155 \mathrm{E}-07$ & $2.917 \mathrm{E}-07$ & $3.212 \mathrm{E}-06$ & $8.900 \mathrm{E}-05$ \\
\hline-234 & $\mathrm{U}-234$ & $1.000 \mathrm{E}+00$ & $6.631 E-25$ & $6.749 \mathrm{E}-25$ & $8.200 \mathrm{E}-25$ & $1.607 \mathrm{E}-24$ & $3.895 E-24$ & $4.636 \mathrm{E}-21$ & $7.854 \mathrm{E}-17$ \\
\hline-234 & Th-230 & $1.000 \mathrm{E}+00$ & $1.047 \mathrm{E}-28$ & $3.188 \mathrm{E}-28$ & $3.193 E-27$ & $2.443 E-26$ & $1.127 \mathrm{E}-25$ & $4.665 \mathrm{E}-22$ & $1.013 \mathrm{E}-17$ \\
\hline-234 & $\mathrm{Ra}-226+\mathrm{D}$ & $1.000 \mathrm{E}+00$ & $1.090 \mathrm{E}-17$ & $7.671 \mathrm{E}-17$ & $5.533 \mathrm{E}-15$ & $1.167 \mathrm{E}-13$ & $6.482 \mathrm{E}-13$ & $2.407 \mathrm{E}-10$ & $4.396 \mathrm{E}-08$ \\
\hline-234 & $\mathrm{~Pb}-210+\mathrm{D}$ & $1.000 \mathrm{E}+00$ & $3.944 E-26$ & $5.916 \mathrm{E}-25$ & $3.094 \mathrm{E}-22$ & $2.118 \mathrm{E}-20$ & $1.862 \mathrm{E}-19$ & 1. $619 \mathrm{E}-16$ & $5.847 \mathrm{E}-14$ \\
\hline-234 & $\sum \operatorname{DSR}(j)$ & & $1.090 \mathrm{E}-17$ & $7.671 \mathrm{E}-17$ & $5.533 E-15$ & $1.167 \mathrm{E}-13$ & $6.482 \mathrm{E}-13$ & $2.407 \mathrm{E}-10$ & $4.396 \mathrm{E}-08$ \\
\hline$-235+D$ & $\mathrm{U}-235+\mathrm{D}$ & $1.000 \mathrm{E}+00$ & $1.195 \mathrm{E}-15$ & 1. $210 \mathrm{E}-15$ & 1. $387 \mathrm{E}-15$ & $2.218 E-15$ & $4.115 \mathrm{E}-15$ & $5.779 \mathrm{E}-13$ & $5.183 \mathrm{E}-10$ \\
\hline$-235+D$ & $\mathrm{~Pa}-231$ & $1.000 \mathrm{E}+00$ & $2.825 E-19$ & $8.554 \mathrm{E}-19$ & $8.006 \mathrm{E}-18$ & 4. $840 \mathrm{E}-17$ & $1.637 \mathrm{E}-16$ & $5.673 \mathrm{E}-14$ & $4.068 \mathrm{E}-11$ \\
\hline$-235+D$ & $A C-227+D$ & $1.000 \mathrm{E}+00$ & 8.917E-19 & $6.232 \mathrm{E}-18$ & $4.105 \mathrm{E}-16$ & $6.620 \mathrm{E}-15$ & $2.832 E-14$ & $6.156 \mathrm{E}-12$ & $1.720 \mathrm{E}-09$ \\
\hline$-235+D$ & $\sum \operatorname{DSR}(j)$ & & $1.197 \mathrm{E}-15$ & $1.217 \mathrm{E}-15$ & $1.805 \mathrm{E}-15$ & $8.886 \mathrm{E}-15$ & $3.260 \mathrm{E}-14$ & $6.791 \mathrm{E}-12$ & $2.279 \mathrm{E}-09$ \\
\hline-238 & $\mathrm{U}-238$ & $5.400 \mathrm{E}-05$ & $0.000 \mathrm{E}+00$ & $0.000 \mathrm{E}+00$ & $0.000 \mathrm{E}+00$ & $0.000 \mathrm{E}+00$ & $0.000 \mathrm{E}+00$ & $0.000 \mathrm{E}+00$ & $1.636 E-39$ \\
\hline$-238+D$ & $\mathrm{U}-238+\mathrm{D}$ & $9.999 \mathrm{E}-01$ & 1. $365 \mathrm{E}-11$ & 1. $376 \mathrm{E}-11$ & 1. $502 \mathrm{E}-11$ & $2.035 \mathrm{E}-11$ & $3.035 E-11$ & 7. $419 \mathrm{E}-10$ & $6.017 E-08$ \\
\hline$J-238+D$ & $\mathrm{U}-234$ & $9.999 E-01$ & $9.426 \mathrm{E}-31$ & $2.873 E-30$ & $2.906 \mathrm{E}-29$ & $2.301 E-28$ & $1.110 \mathrm{E}-27$ & $6.582 \mathrm{E}-24$ & $2.342 E-19$ \\
\hline$J-238+D$ & $\mathrm{Th}-230$ & $9.999 E-01$ & $9.906 \mathrm{E}-35$ & $7.035 \mathrm{E}-34$ & $5.662 \mathrm{E}-32$ & $1.749 \mathrm{E}-30$ & 1. $605 \mathrm{E}-29$ & $3.309 \mathrm{E}-25$ & $1.508 \mathrm{E}-20$ \\
\hline$J-238+D$ & $\mathrm{Ra}-226+\mathrm{D}$ & $9.999 \mathrm{E}-01$ & $7.725 E-24$ & $1.165 E-22$ & $6.546 \mathrm{E}-20$ & $5.580 \mathrm{E}-18$ & $6.178 \mathrm{E}-17$ & $1.159 \mathrm{E}-13$ & $4.523 E-11$ \\
\hline$J-238+D$ & $\mathrm{~Pb}-210+\mathrm{D}$ & $9.999 E-01$ & $2.239 E-32$ & $6.951 E-31$ & $2.798 E-27$ & $8.109 E-25$ & 1. $488 \mathrm{E}-23$ & $7.347 \mathrm{E}-20$ & $5.837 \mathrm{E}-17$ \\
\hline$-238+D$ & $\sum \operatorname{DSR}(j)$ & & $1.365 \mathrm{E}-11$ & 1. $376 \mathrm{E}-11$ & $1.502 \mathrm{E}-11$ & $2.035 \mathrm{E}-11$ & $3.035 \mathrm{E}-11$ & $7.420 \mathrm{E}-10$ & $6.021 \mathrm{E}-08$ \\
\hline
\end{tabular}

The DSR includes contributions from associated (half-life $\leq 180$ days) daughters. 
RESRAD, Version $6.5 \quad \mathrm{~T}^{1 / 2}$ Limit $=180$ days

Summary : RESRAD Parameters for U-Landfill Recreational User Foward Run

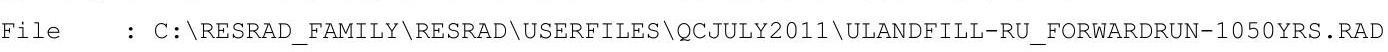

Single Radionuclide Soil Guidelines G(i,t) in pCi/g

Basic Radiation Dose Limit $=1.000 \mathrm{E}+00 \mathrm{mrem} / \mathrm{yr}$

Nuclide

\begin{tabular}{|c|c|c|c|c|c|c|c|}
\hline (i) & $t=0.000 \mathrm{E}+00$ & $1.000 \mathrm{E}+00$ & $1.200 \mathrm{E}+01$ & $5.000 \mathrm{E}+01$ & $1.000 \mathrm{E}+02$ & $5.000 \mathrm{E}+02$ & $1.050 \mathrm{E}+03$ \\
\hline $1-241$ & $\star 3.431 \mathrm{E}+12$ & $\star 3.431 \mathrm{E}+12$ & $\star 3.431 \mathrm{E}+12$ & $\star 3.431 \mathrm{E}+12$ & $\star 3.431 \mathrm{E}+12$ & $* 3.431 \mathrm{E}+12$ & $8.235 E+11$ \\
\hline$s-137$ & $8.242 \mathrm{E}+09$ & $8.364 \mathrm{E}+09$ & $9.831 \mathrm{E}+09$ & $1.718 \mathrm{E}+10$ & $3.580 \mathrm{E}+10$ & $1.274 \mathrm{E}+13$ & $\star 8.704 \mathrm{E}+13$ \\
\hline-237 & $\star 7.047 \mathrm{E}+08$ & $\star 7.047 \mathrm{E}+08$ & $\star 7.047 \mathrm{E}+08$ & $\star 7.047 \mathrm{E}+08$ & $\star 7.047 \mathrm{E}+08$ & $\star 7.047 \mathrm{E}+08$ & $1.380 \mathrm{E}+08$ \\
\hline$\lambda-238$ & $\star 1.712 \mathrm{E}+13$ & $\star 1.712 \mathrm{E}+13$ & $\star 1.712 \mathrm{E}+13$ & $\star 1.712 \mathrm{E}+13$ & $\star 1.712 \mathrm{E}+13$ & $\star 1.712 \mathrm{E}+13$ & $7.937 \mathrm{E}+10$ \\
\hline-239 & $\star 6.214 \mathrm{E}+10$ & $* 6.214 \mathrm{E}+10$ & $* 6.214 \mathrm{E}+10$ & $* 6.214 \mathrm{E}+10$ & $* 6.214 \mathrm{E}+10$ & $* 6.214 \mathrm{E}+10$ & $* 6.214 \mathrm{E}+10$ \\
\hline$\lambda-240$ & $\star 2.278 \mathrm{E}+11$ & $\star 2.278 \mathrm{E}+11$ & $\star 2.278 \mathrm{E}+11$ & $\star 2.278 \mathrm{E}+11$ & $\star 2.278 \mathrm{E}+11$ & $\star 2.278 \mathrm{E}+11$ & $\star 2.278 \mathrm{E}+11$ \\
\hline$c-99$ & $\star 1.697 \mathrm{E}+10$ & $* 1.697 \mathrm{E}+10$ & $* 1.697 \mathrm{E}+10$ & $* 1.697 \mathrm{E}+10$ & $\star 1.697 \mathrm{E}+10$ & $\star 1.697 \mathrm{E}+10$ & $* 1.697 \mathrm{E}+10$ \\
\hline$h-228$ & $7.523 \mathrm{E}+06$ & $1.074 \mathrm{E}+07$ & $5.414 \mathrm{E}+08$ & $4.116 \mathrm{E}+14$ & $\star 8.195 \mathrm{E}+14$ & $* 8.195 \mathrm{E}+14$ & $\star 8.195 \mathrm{E}+14$ \\
\hline$h-230$ & $\star 2.018 \mathrm{E}+10$ & $\star 2.018 \mathrm{E}+10$ & $1.018 \mathrm{E}+10$ & $1.955 \mathrm{E}+09$ & $7.028 \mathrm{E}+08$ & $9.688 \mathrm{E}+06$ & $1.155 \mathrm{E}+05$ \\
\hline Th-232 & $\star 1.097 \mathrm{E}+05$ & $\star 1.097 \mathrm{E}+05$ & $* 1.097 \mathrm{E}+05$ & $\star 1.097 \mathrm{E}+05$ & $* 1.097 \mathrm{E}+05$ & $* 1.097 \mathrm{E}+05$ & $1.124 \mathrm{E}+04$ \\
\hline $\mathrm{U}-234$ & $\star 6.247 \mathrm{E}+09$ & $* 6.247 \mathrm{E}+09$ & $* 6.247 \mathrm{E}+09$ & $* 6.247 \mathrm{E}+09$ & $* 6.247 \mathrm{E}+09$ & $4.154 \mathrm{E}+09$ & $2.275 \mathrm{E}+07$ \\
\hline $\mathrm{J}-235$ & $\star 2.161 \mathrm{E}+06$ & $\star 2.161 \mathrm{E}+06$ & $\star 2.161 \mathrm{E}+06$ & $\star 2.161 \mathrm{E}+06$ & $* 2.161 \mathrm{E}+06$ & $\star 2.161 \mathrm{E}+06$ & $\star 2.161 \mathrm{E}+06$ \\
\hline-238 & $* 3.361 \mathrm{E}+05$ & $\star 3.361 \mathrm{E}+05$ & $\star 3.361 \mathrm{E}+05$ & $\star 3.361 \mathrm{E}+05$ & $\star 3.361 \mathrm{E}+05$ & $\star 3.361 \mathrm{E}+05$ & $\star 3.361 \mathrm{E}+05$ \\
\hline
\end{tabular}

*At specific activity limit

Summed Dose/Source Ratios DSR(i,t) in (mrem/yr)/(pCi/g)

and Single Radionuclide Soil Guidelines G(i,t) in pCi/g

at $\operatorname{tmin}=$ time of minimum single radionuclide soil guideline

and at $\operatorname{tmax}=$ time of maximum total dose $=1.050 \mathrm{E}+03$ years

\begin{tabular}{|c|c|c|c|c|c|c|}
\hline $\begin{array}{l}\text { uclide } \\
\text { (i) }\end{array}$ & $\begin{array}{l}\text { Initial } \\
(\mathrm{pCi} / \mathrm{g})\end{array}$ & $\begin{array}{c}\text { tmin } \\
\text { (years) }\end{array}$ & $\operatorname{DSR}(i, \operatorname{tmin})$ & $\begin{array}{c}G(i, \text { tmin }) \\
(p C i / g)\end{array}$ & $\operatorname{DSR}(i, \operatorname{tmax})$ & $\begin{array}{c}G(i, \operatorname{tmax}) \\
(\mathrm{pCi} / \mathrm{g})\end{array}$ \\
\hline $1-241$ & $3.500 \mathrm{E}+01$ & $1.050 \mathrm{E}+03$ & 1. $214 \mathrm{E}-12$ & $8.235 E+11$ & 1. $214 \mathrm{E}-12$ & $8.235 E+11$ \\
\hline-137 & $1.900 \mathrm{E}+01$ & $0.000 \mathrm{E}+00$ & 1. $213 \mathrm{E}-10$ & $8.242 E+09$ & $2.435 E-17$ & $\star 8.704 \mathrm{E}+13$ \\
\hline-237 & $5.500 \mathrm{E}+00$ & $1.050 \mathrm{E}+03$ & 7. $245 \mathrm{E}-09$ & $1.380 \mathrm{E}+08$ & $7.245 \mathrm{E}-09$ & $1.380 \mathrm{E}+08$ \\
\hline-238 & $3.900 \mathrm{E}+01$ & $1.050 \mathrm{E}+03$ & 1. $260 \mathrm{E}-11$ & $7.937 E+10$ & $1.260 \mathrm{E}-11$ & $7.937 E+10$ \\
\hline-239 & $3.600 \mathrm{E}+01$ & $1.050 \mathrm{E}+03$ & $3.234 \mathrm{E}-13$ & $\star 6.214 \mathrm{E}+10$ & $3.234 \mathrm{E}-13$ & $* 6.214 \mathrm{E}+10$ \\
\hline-240 & $3.600 \mathrm{E}+01$ & $1.050 \mathrm{E}+03$ & $7.834 \mathrm{E}-17$ & $\star 2.278 \mathrm{E}+11$ & $7.834 \mathrm{E}-17$ & $\star 2.278 \mathrm{E}+11$ \\
\hline-99 & $5.200 \mathrm{E}+01$ & $1.050 \mathrm{E}+03$ & $1.233 \mathrm{E}-20$ & $\star 1.697 \mathrm{E}+10$ & 1. $233 \mathrm{E}-20$ & $\star 1.697 \mathrm{E}+10$ \\
\hline-228 & $4.000 \mathrm{E}+00$ & $0.000 \mathrm{E}+00$ & $1.329 \mathrm{E}-07$ & $7.523 E+06$ & $0.000 \mathrm{E}+00$ & $\star 8.195 \mathrm{E}+14$ \\
\hline-230 & $1.000 \mathrm{E}+02$ & $1.050 \mathrm{E}+03$ & $8.661 \mathrm{E}-06$ & $1.155 \mathrm{E}+05$ & $8.661 \mathrm{E}-06$ & $1.155 \mathrm{E}+05$ \\
\hline-232 & $4.000 \mathrm{E}+00$ & $1.050 \mathrm{E}+03$ & $8.900 \mathrm{E}-05$ & $1.124 \mathrm{E}+04$ & $8.900 \mathrm{E}-05$ & $1.124 \mathrm{E}+04$ \\
\hline 234 & $1.600 \mathrm{E}+02$ & $1.050 \mathrm{E}+03$ & $4.396 \mathrm{E}-08$ & $2.275 E+07$ & $4.396 E-08$ & $2.275 E+07$ \\
\hline 235 & $6.500 \mathrm{E}+00$ & $1.050 \mathrm{E}+03$ & $2.279 \mathrm{E}-09$ & $\star 2.161 \mathrm{E}+06$ & $2.279 \mathrm{E}-09$ & $\star 2.161 \mathrm{E}+06$ \\
\hline 238 & $1.600 \mathrm{E}+02$ & $1.050 \mathrm{E}+03$ & $6.021 \mathrm{E}-08$ & $\star 3.361 \mathrm{E}+05$ & $6.021 E-08$ & $\star 3.361 \mathrm{E}+05$ \\
\hline
\end{tabular}

*At specific activity limit 
RESRAD, Version 6.5

Summary : RESRAD Parameters for U-Landfill Recreational User Foward Run

File : C: $\backslash$ RESRAD_FAMILY \RESRAD \USERFILES $\backslash Q C J U L Y 2011 \backslash U L A N D F I L L-R U \_F O R W A R D R U N-1050 Y R S . R A D$

Individual Nuclide Dose Summed Over All Pathways

Parent Nuclide and Branch Fraction Indicated

Nuclide Parent THF(i) DOSE (j,t), mrem/yr

\begin{tabular}{|c|c|c|}
\hline$(j)$ & (i) & \\
\hline$m-241$ & $A m-241$ & $1.000 \mathrm{E}+00$ \\
\hline$p-237$ & $A m-241$ & $1.000 \mathrm{E}+00$ \\
\hline-237 & $N p-237$ & $1.000 \mathrm{E}+00$ \\
\hline$p-237$ & $\sum \mathrm{DOSE}$ & \\
\hline
\end{tabular}

$\mathrm{U}-233$ Am-241 1.000E+00

$\mathrm{U}-233 \mathrm{~Np}-237 \quad 1.000 \mathrm{E}+00$

U-233 $\sum$ DOSE $(j)$

Th-229 Am-241 1.000E+00

Th-229 Np-237 1.000E+00

Th-229 $\sum \operatorname{DOSE}(j)$

Cs-137 Cs-137 1.000E+00

$\mathrm{Pu}-238 \mathrm{Pu}-238 \quad 1.840 \mathrm{E}-09$

$\mathrm{Pu}-238 \quad \mathrm{Pu}-238 \quad 1.000 \mathrm{E}+00$

$\mathrm{Pu}-238 \quad \sum \mathrm{DOSE}(j)$

$\mathrm{U}-234$

$\mathrm{U}-234$

$\mathrm{U}-234$

$\mathrm{U}-234$

Th -230

Th -230

$\mathrm{Th}-230$

$\mathrm{Th}-230$

$\mathrm{Th}-230$

$\mathrm{Ra}-226$

$\mathrm{Ra}-226$

$\mathrm{Ra}-226$

$\mathrm{Ra}-226$

$\mathrm{Ra}-226$

$\mathrm{Pb}-210$

$\mathrm{Pb}-210$

$\mathrm{Pb}-210$

$\mathrm{Pb}-210$

$\mathrm{Pb}-210$

$\mathrm{Pu}-239$

$\mathrm{Pu}-238 \quad 1.000 \mathrm{E}+00$

$\mathrm{U}-234 \quad 1.000 \mathrm{E}+00$

U-238 9.999E-01

$\sum \operatorname{DOSE}(j)$

$\mathrm{Pu}-238 \quad 1.000 \mathrm{E}+00$

Th-230 1.000E+00

$\mathrm{U}-234 \quad 1.000 \mathrm{E}+00$

$\mathrm{U}-238 \quad 9.999 \mathrm{E}-01$

¿DOSE (j)

$\mathrm{Pu}-238 \quad 1.000 \mathrm{E}+00$

Th-230 1.000E+00

$\mathrm{U}-234 \quad 1.000 \mathrm{E}+00$

U-238 9.999E-01

$\sum \operatorname{DOSE}(j)$

$\mathrm{Pu}-238 \quad 1.000 \mathrm{E}+00$

Th-230 1.000E+00

$\mathrm{U}-234 \quad 1.000 \mathrm{E}+00$

U-238 9.999E-01

$\sum \operatorname{DOSE}(j)$

$\mathrm{Pu}-239 \quad 1.000 \mathrm{E}+00$

$\mathrm{Pu}-239 \quad 1.000 \mathrm{E}+00$

U-235 $1.000 \mathrm{E}+00$

$\sum \operatorname{DOSE}(j)$
$=0.000 \mathrm{E}+00 \quad 1.000 \mathrm{E}+00 \quad 1.200 \mathrm{E}+01 \quad 5.000 \mathrm{E}+01 \quad 1.000 \mathrm{E}+02 \quad 5.000 \mathrm{E}+02 \quad 1.050 \mathrm{E}+03$

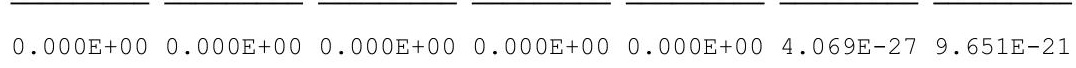

$\begin{array}{llllllll}5.204 \mathrm{E}-19 & 1.575 \mathrm{E}-18 & 1.464 \mathrm{E}-17 & 8.635 \mathrm{E}-17 & 2.829 \mathrm{E}-16 & 7.741 \mathrm{E}-14 & 4.210 \mathrm{E}-11\end{array}$

$\begin{array}{lllllll}5.043 \mathrm{E}-13 & 5.097 \mathrm{E}-13 & 5.735 \mathrm{E}-13 & 8.620 \mathrm{E}-13 & 1.473 \mathrm{E}-12 & 1.073 \mathrm{E}-10 & 3.906 \mathrm{E}-08\end{array}$

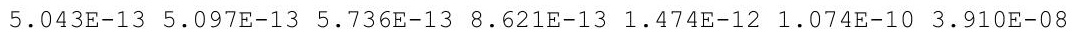

$0.000 \mathrm{E}+00 \quad 8.344 \mathrm{E}-29 \quad 6.371 \mathrm{E}-27 \quad 1.639 \mathrm{E}-25 \quad 1.182 \mathrm{E}-24 \quad 3.586 \mathrm{E}-21 \quad 1.209 \mathrm{E}-17$

$\begin{array}{lllllll}1.716 \mathrm{E}-23 & 5.206 \mathrm{E}-23 & 4.975 \mathrm{E}-22 & 3.231 \mathrm{E}-21 & 1.201 \mathrm{E}-20 & 8.871 \mathrm{E}-18 & 1.800 \mathrm{E}-14\end{array}$

$\begin{array}{lllllll}1.716 \mathrm{E}-23 & 5.206 \mathrm{E}-23 & 4.975 \mathrm{E}-22 & 3.231 \mathrm{E}-21 & 1.201 \mathrm{E}-20 & 8.874 \mathrm{E}-18 & 1.801 \mathrm{E}-14\end{array}$

$8.073 \mathrm{E}-26 \quad 1.218 \mathrm{E}-24 \quad 6.820 \mathrm{E}-22 \quad 5.759 \mathrm{E}-20 \quad 6.298 \mathrm{E}-19 \quad 1.085 \mathrm{E}-15 \quad 3.995 \mathrm{E}-13$

$1.567 \mathrm{E}-19 \quad 1.103 \mathrm{E}-18 \quad 7.971 \mathrm{E}-17 \quad 1.692 \mathrm{E}-15 \quad 9.477 \mathrm{E}-15 \quad 3.786 \mathrm{E}-12 \quad 7.936 \mathrm{E}-10$

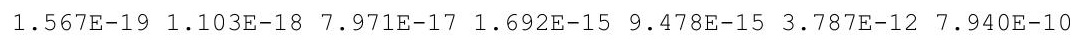

$\begin{array}{llllll}2.305 \mathrm{E}-09 & 2.272 \mathrm{E}-09 & 1.933 \mathrm{E}-09 & 1.106 \mathrm{E}-09 & 5.307 \mathrm{E}-10 & 1.491 \mathrm{E}-12 \quad 4.627 \mathrm{E}-16\end{array}$

$\begin{array}{lllllll}0.000 \mathrm{E}+00 & 0.000 \mathrm{E}+00 & 0.000 \mathrm{E}+00 & 0.000 \mathrm{E}+00 & 0.000 \mathrm{E}+00 & 0.000 \mathrm{E}+00 & 2.281 \mathrm{E}-28\end{array}$

$\begin{array}{lllllll}4.406 \mathrm{E}-24 & 4.449 \mathrm{E}-24 & 4.953 \mathrm{E}-24 & 7.176 \mathrm{E}-24 & 1.169 \mathrm{E}-23 & 5.791 \mathrm{E}-22 & 1.240 \mathrm{E}-19\end{array}$

$\begin{array}{lllllll}4.406 \mathrm{E}-24 & 4.449 \mathrm{E}-24 & 4.953 \mathrm{E}-24 & 7.176 \mathrm{E}-24 & 1.169 \mathrm{E}-23 & 5.791 \mathrm{E}-22 & 1.240 \mathrm{E}-19\end{array}$

$0.000 \mathrm{E}+00 \quad 1.114 \mathrm{E}-28 \quad 1.079 \mathrm{E}-27 \quad 7.400 \mathrm{E}-27 \quad 2.988 \mathrm{E}-26 \quad 6.368 \mathrm{E}-23 \quad 1.100 \mathrm{E}-18$

$\begin{array}{llllllll}1.061 \mathrm{E}-22 & 1.080 \mathrm{E}-22 & 1.312 \mathrm{E}-22 & 2.571 \mathrm{E}-22 & 6.232 \mathrm{E}-22 & 7.417 \mathrm{E}-19 & 1.257 \mathrm{E}-14\end{array}$

$0.000 \mathrm{E}+00 \quad 4.596 \mathrm{E}-28 \quad 4.650 \mathrm{E}-27 \quad 3.681 \mathrm{E}-26 \quad 1.776 \mathrm{E}-25 \quad 1.053 \mathrm{E}-21 \quad 3.748 \mathrm{E}-17$

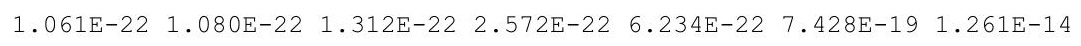

$0.000 \mathrm{E}+00 \quad 0.000 \mathrm{E}+00 \quad 0.000 \mathrm{E}+00 \quad 5.998 \mathrm{E}-29 \quad 4.887 \mathrm{E}-28 \quad 4.910 \mathrm{E}-24 \quad 1.247 \mathrm{E}-19$ $\begin{array}{lllllllll}2.319 \mathrm{E}-21 & 2.359 \mathrm{E}-21 & 2.838 \mathrm{E}-21 & 5.375 \mathrm{E}-21 & 1.246 \mathrm{E}-20 & 1.037 \mathrm{E}-17 & 1.074 \mathrm{E}-13\end{array}$ $\begin{array}{lllllll}1.675 \mathrm{E}-26 & 5.101 \mathrm{E}-26 & 5.109 \mathrm{E}-25 & 3.909 \mathrm{E}-24 & 1.803 \mathrm{E}-23 & 7.463 \mathrm{E}-20 & 1.620 \mathrm{E}-15\end{array}$ $\begin{array}{lllllll}0.000 \mathrm{E}+00 & 0.000 \mathrm{E}+00 & 0.000 \mathrm{E}+00 & 2.798 \mathrm{E}-28 & 2.568 \mathrm{E}-27 & 5.295 \mathrm{E}-23 & 2.413 \mathrm{E}-18\end{array}$ $\begin{array}{llllllll}2.319 \mathrm{E}-21 & 2.359 \mathrm{E}-21 & 2.838 \mathrm{E}-21 & 5.379 \mathrm{E}-21 & 1.248 \mathrm{E}-20 & 1.044 \mathrm{E}-17 & 1.090 \mathrm{E}-13\end{array}$

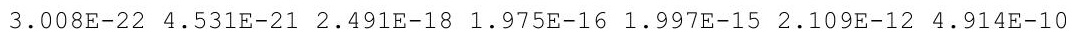
$\begin{array}{lllllll}3.629 \mathrm{E}-10 & 1.095 \mathrm{E}-09 & 9.820 \mathrm{E}-09 & 5.116 \mathrm{E}-08 & 1.423 \mathrm{E}-07 & 1.032 \mathrm{E}-05 & 8.661 \mathrm{E}-04\end{array}$ $\begin{array}{lllllll}1.743 \mathrm{E}-15 & 1.227 \mathrm{E}-14 & 8.853 \mathrm{E}-13 & 1.867 \mathrm{E}-11 & 1.037 \mathrm{E}-10 & 3.851 \mathrm{E}-08 & 7.034 \mathrm{E}-06\end{array}$ $\begin{array}{lllllll}1.236 \mathrm{E}-21 & 1.865 \mathrm{E}-20 & 1.047 \mathrm{E}-17 & 8.928 \mathrm{E}-16 & 9.885 \mathrm{E}-15 & 1.854 \mathrm{E}-11 & 7.237 \mathrm{E}-09\end{array}$

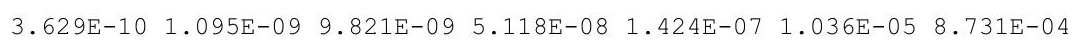

$0.000 \mathrm{E}+00 \quad 0.000 \mathrm{E}+00 \quad 1.070 \mathrm{E}-25 \quad 2.916 \mathrm{E}-23 \quad 4.931 \mathrm{E}-22 \quad 1.381 \mathrm{E}-18 \quad 6.490 \mathrm{E}-16$ $\begin{array}{llllllll}1.749 \mathrm{E}-18 & 1.222 \mathrm{E}-17 & 7.985 \mathrm{E}-16 & 1.249 \mathrm{E}-14 & 5.113 \mathrm{E}-14 & 7.402 \mathrm{E}-12 & 1.190 \mathrm{E}-09\end{array}$ $\begin{array}{llllllll}6.310 \mathrm{E}-24 & 9.466 \mathrm{E}-23 & 4.951 \mathrm{E}-20 & 3.388 \mathrm{E}-18 & 2.979 \mathrm{E}-17 & 2.590 \mathrm{E}-14 & 9.356 \mathrm{E}-12\end{array}$ $0.000 \mathrm{E}+00 \quad 0.000 \mathrm{E}+00 \quad 4.477 \mathrm{E}-25 \quad 1.297 \mathrm{E}-22 \quad 2.380 \mathrm{E}-21 \quad 1.176 \mathrm{E}-17 \quad 9.340 \mathrm{E}-15$ $\begin{array}{llllllll}1.749 \mathrm{E}-18 & 1.222 \mathrm{E}-17 & 7.985 \mathrm{E}-16 & 1.250 \mathrm{E}-14 & 5.116 \mathrm{E}-14 & 7.428 \mathrm{E}-12 & 1.199 \mathrm{E}-09\end{array}$

$4.161 \mathrm{E}-17 \quad 4.211 \mathrm{E}-17 \quad 4.803 \mathrm{E}-17 \quad 7.560 \mathrm{E}-17 \quad 1.373 \mathrm{E}-16 \quad 1.629 \mathrm{E}-14 \quad 1.159 \mathrm{E}-11$

$2.124 \mathrm{E}-23 \quad 6.441 \mathrm{E}-23 \quad 6.145 \mathrm{E}-22 \quad 3.969 \mathrm{E}-21 \quad 1.465 \mathrm{E}-20 \quad 1.019 \mathrm{E}-17 \quad 1.905 \mathrm{E}-14$ $\begin{array}{lllllllll}7.771 \mathrm{E}-15 & 7.867 \mathrm{E}-15 & 9.013 \mathrm{E}-15 & 1.442 \mathrm{E}-14 & 2.675 \mathrm{E}-14 & 3.756 \mathrm{E}-12 & 3.369 \mathrm{E}-09\end{array}$ $\begin{array}{lllllll}7.771 E-15 & 7.867 E-15 & 9.013 E-15 & 1.442 E-14 & 2.675 E-14 & 3.756 E-12 & 3.369 E-09\end{array}$ 
RESRAD, Version 6.5

Summary : RESRAD Parameters for U-Landfill Recreational User Foward Run

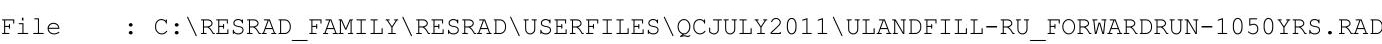

Individual Nuclide Dose Summed Over All Pathways

Parent Nuclide and Branch Fraction Indicated

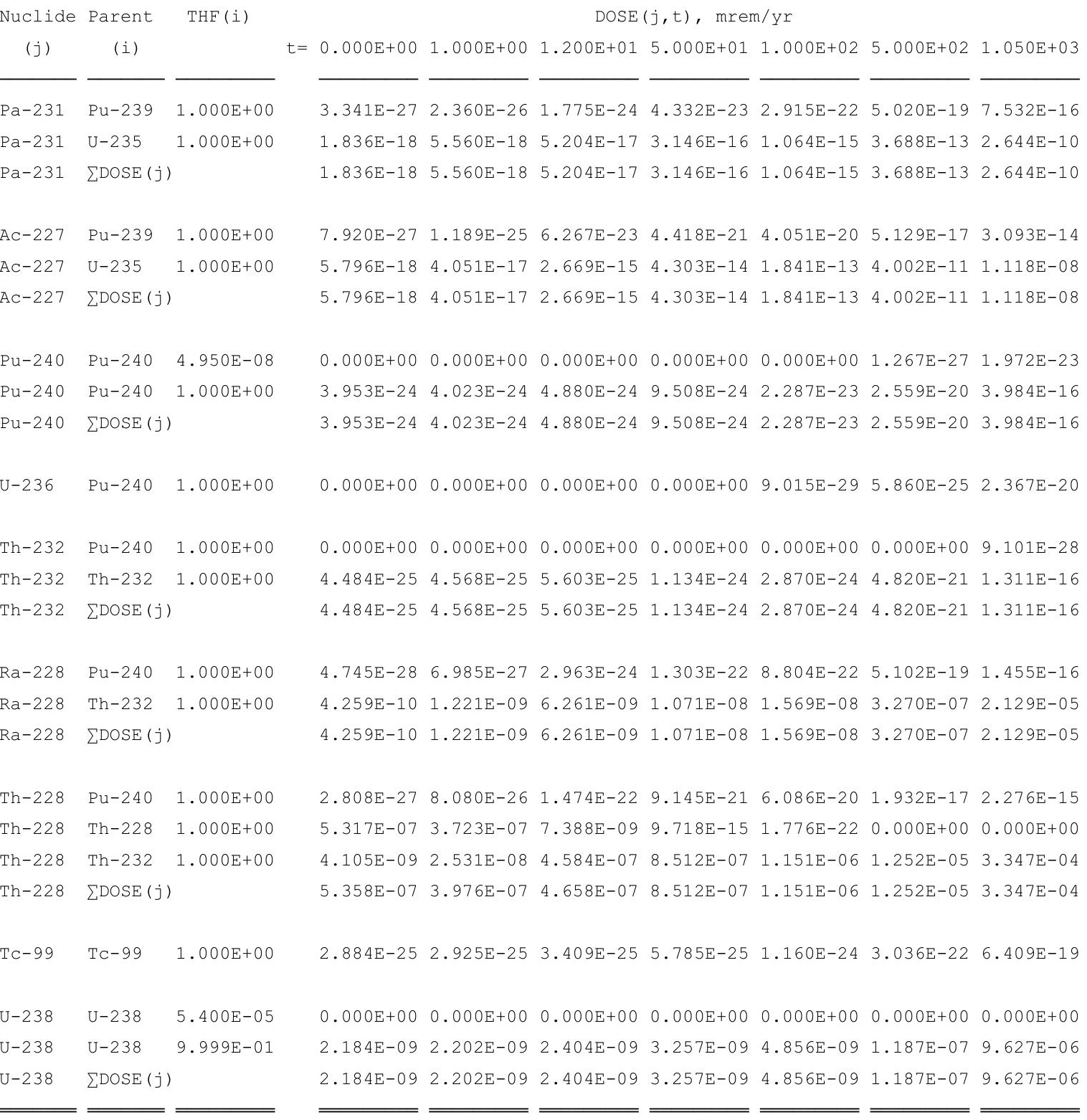

THF (i) is the thread fraction of the parent nuclide. 
RESRAD, Version 6.5

Summary : RESRAD Parameters for U-Landfill Recreational User Foward Run

File : C: $\backslash$ RESRAD_FAMILY \RESRAD \USERFILES $\backslash Q$ CJULY2011 \ULANDFILL-RU_FORWARDRUN-1050YRS.RAD

Individual Nuclide Soil Concentration

Parent Nuclide and Branch Fraction Indicated

Nuclide Parent THF(

(j)

Am-241

(i)

$\overline{A m-241} \overline{1.000 E+00}$

$\mathrm{Np}-237 \quad \mathrm{Am}-241 \quad 1.000 \mathrm{E}+00$

$\mathrm{Np}-237 \quad \mathrm{~Np}-237 \quad 1.000 \mathrm{E}+00$

Np-237 $\sum S(j):$

$\mathrm{U}-233 \quad \mathrm{Am}-241 \quad 1.000 \mathrm{E}+00$

$\mathrm{U}-233 \quad \mathrm{~Np}-237 \quad 1.000 \mathrm{E}+00$

$\mathrm{U}-233 \sum \mathrm{S}(j):$

Th-229

Th-229

Th -229

$\mathrm{Cs}-137$

$\mathrm{Pu}-238$

$\mathrm{Pu}-238$

$\mathrm{Pu}-238$

$\mathrm{U}-234$

$\mathrm{U}-234$

$\mathrm{U}-234$

$\mathrm{U}-234$

$\mathrm{Th}-230$

Th -230

$\mathrm{Th}-230$

$\mathrm{Th}-230$

$\mathrm{Th}-230$

$\mathrm{Ra}-226$

$\mathrm{Ra}-226$

$\mathrm{Ra}-226$

$\mathrm{Ra}-226$

$\mathrm{Ra}-226$

$\mathrm{Pb}-210$

$\mathrm{Pb}-210$

$\mathrm{Pb}-210$

$\mathrm{Pb}-210$

$\mathrm{Pb}-210$

$\mathrm{Pu}-239$

Am-241 1.000E+00

$\mathrm{Np}-237 \quad 1.000 \mathrm{E}+00$

$\sum S(j):$

Cs-137 1.000E+00

$\mathrm{Pu}-238$ 1.840E-09

$\mathrm{Pu}-238 \quad 1.000 \mathrm{E}+00$

$\sum S(j):$

$\mathrm{Pu}-238 \quad 1.000 \mathrm{E}+00$

$\mathrm{U}-234 \quad 1.000 \mathrm{E}+00$

$\mathrm{U}-2389.999 \mathrm{E}-01$

$\sum S(j):$

$\mathrm{Pu}-238 \quad 1.000 \mathrm{E}+00$

Th-230 1.000E+00

$\mathrm{U}-234 \quad 1.000 \mathrm{E}+00$

$\mathrm{U}-238 \quad 9.999 \mathrm{E}-01$

$\sum S(j):$

$\mathrm{Pu}-238 \quad 1.000 \mathrm{E}+00$

Th-230 1.000E+00

$\mathrm{U}-234 \quad 1.000 \mathrm{E}+00$

U-238 9.999E-01

$\sum S(j):$

$\mathrm{Pu}-238 \quad 1.000 \mathrm{E}+00$

Th-230 1.000E+00

$\mathrm{U}-234 \quad 1.000 \mathrm{E}+00$

U-238 9.999E-01

$\sum S(j):$

$\mathrm{Pu}-239 \quad 1.000 \mathrm{E}+00$

$\mathrm{Pu}-239 \quad 1.000 \mathrm{E}+00$

$\mathrm{U}-235 \quad 1.000 \mathrm{E}+00$

$\sum S(j):$
$S(j, t), p C i / g$

$t=0.000 \mathrm{E}+00 \quad 1.000 \mathrm{E}+00 \quad 1.200 \mathrm{E}+01 \quad 5.000 \mathrm{E}+01 \quad 1.000 \mathrm{E}+02 \quad 5.000 \mathrm{E}+02 \quad 1.050 \mathrm{E}+03$

$\begin{array}{llllllll}3.500 \mathrm{E}+01 & 3.494 \mathrm{E}+01 & 3.433 \mathrm{E}+01 & 3.230 \mathrm{E}+01 & 2.981 \mathrm{E}+01 & 1.567 \mathrm{E}+01 & 6.478 \mathrm{E}+00\end{array}$

$0.000 \mathrm{E}+00 \quad 1.133 \mathrm{E}-05 \quad 1.347 \mathrm{E}-04 \quad 5.436 \mathrm{E}-04 \quad 1.043 \mathrm{E}-03 \quad 3.810 \mathrm{E}-03 \quad 5.458 \mathrm{E}-03$

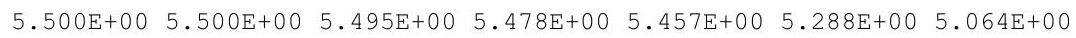

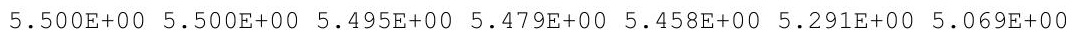

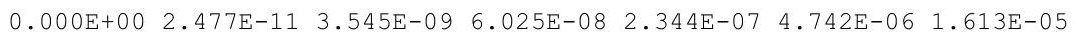

$\begin{array}{lllllll}0.000 \mathrm{E}+00 & 2.405 \mathrm{E}-05 & 2.885 \mathrm{E}-04 & 1.200 \mathrm{E}-03 & 2.394 \mathrm{E}-03 & 1.174 \mathrm{E}-02 & 2.401 \mathrm{E}-02\end{array}$

$0.000 \mathrm{E}+00 \quad 2.405 \mathrm{E}-05 \quad 2.885 \mathrm{E}-04 \quad 1.200 \mathrm{E}-03 \quad 2.394 \mathrm{E}-03 \quad 1.174 \mathrm{E}-02 \quad 2.403 \mathrm{E}-02$

$0.000 \mathrm{E}+00 \quad 7.799 \mathrm{E}-16 \quad 1.341 \mathrm{E}-12 \quad 9.538 \mathrm{E}-11 \quad 7.463 \mathrm{E}-10 \quad 7.873 \mathrm{E}-08 \quad 5.891 \mathrm{E}-07$

$\begin{array}{lllllll}0.000 \mathrm{E}+00 & 1.136 \mathrm{E}-09 & 1.634 \mathrm{E}-07 & 2.830 \mathrm{E}-06 & 1.128 \mathrm{E}-05 & 2.750 \mathrm{E}-04 & 1.171 \mathrm{E}-03\end{array}$

$\begin{array}{llllllll}0.000 \mathrm{E}+00 & 1.136 \mathrm{E}-09 & 1.634 \mathrm{E}-07 & 2.830 \mathrm{E}-06 & 1.128 \mathrm{E}-05 & 2.750 \mathrm{E}-04 & 1.171 \mathrm{E}-03\end{array}$

$\begin{array}{lllllll}1.900 \mathrm{E}+01 & 1.857 \mathrm{E}+01 & 1.440 \mathrm{E}+01 & 5.979 \mathrm{E}+00 & 1.881 \mathrm{E}+00 & 1.809 \mathrm{E}-04 & 5.417 \mathrm{E}-10\end{array}$

$\begin{array}{llllllll}7.176 \mathrm{E}-08 & 7.119 \mathrm{E}-08 & 6.526 \mathrm{E}-08 & 4.832 \mathrm{E}-08 & 3.254 \mathrm{E}-08 & 1.375 \mathrm{E}-09 & 1.774 \mathrm{E}-11\end{array}$

$\begin{array}{llllllllll}3.900 \mathrm{E}+01 & 3.869 \mathrm{E}+01 & 3.547 \mathrm{E}+01 & 2.626 \mathrm{E}+01 & 1.768 \mathrm{E}+01 & 7.472 \mathrm{E}-01 & 9.639 \mathrm{E}-03\end{array}$

$\begin{array}{lllllllll}3.900 \mathrm{E}+01 & 3.869 \mathrm{E}+01 & 3.547 \mathrm{E}+01 & 2.626 \mathrm{E}+01 & 1.768 \mathrm{E}+01 & 7.472 \mathrm{E}-01 & 9.639 \mathrm{E}-03\end{array}$

$0.000 \mathrm{E}+00 \quad 1.101 \mathrm{E}-04 \quad 1.266 \mathrm{E}-03 \quad 4.564 \mathrm{E}-03 \quad 7.633 \mathrm{E}-03 \quad 1.362 \mathrm{E}-02 \quad 1.377 \mathrm{E}-02$

$\begin{array}{llllll}1.600 \mathrm{E}+02 & 1.600 \mathrm{E}+02 & 1.600 \mathrm{E}+02 & 1.599 \mathrm{E}+02 & 1.597 \mathrm{E}+02 & 1.587 \mathrm{E}+02 \quad 1.573 \mathrm{E}+02\end{array}$

$\begin{array}{llllllll}0.000 \mathrm{E}+00 & 4.536 \mathrm{E}-04 & 5.442 \mathrm{E}-03 & 2.266 \mathrm{E}-02 & 4.529 \mathrm{E}-02 & 2.251 \mathrm{E}-01 & 4.689 \mathrm{E}-01\end{array}$

$\begin{array}{lllllll}1.600 \mathrm{E}+02 & 1.600 \mathrm{E}+02 & 1.600 \mathrm{E}+02 & 1.599 \mathrm{E}+02 & 1.598 \mathrm{E}+02 & 1.589 \mathrm{E}+02 & 1.578 \mathrm{E}+02\end{array}$

$0.000 \mathrm{E}+00 \quad 4.963 \mathrm{E}-10 \quad 6.944 \mathrm{E}-08 \quad 1.095 \mathrm{E}-06 \quad 3.884 \mathrm{E}-06 \quad 4.705 \mathrm{E}-05 \quad 1.147 \mathrm{E}-04$ $\begin{array}{lllllllll}1.000 \mathrm{E}+02 & 1.000 \mathrm{E}+02 & 9.999 \mathrm{E}+01 & 9.995 \mathrm{E}+01 & 9.989 \mathrm{E}+01 & 9.947 \mathrm{E}+01 & 9.888 \mathrm{E}+01\end{array}$ $0.000 \mathrm{E}+00 \quad 1.440 \mathrm{E}-03 \quad 1.728 \mathrm{E}-02 \quad 7.197 \mathrm{E}-02 \quad 1.438 \mathrm{E}-01 \quad 7.153 \mathrm{E}-01 \quad 1.491 \mathrm{E}+00$

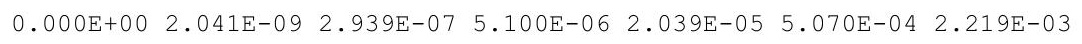

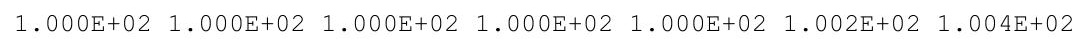

$0.000 \mathrm{E}+00 \quad 7.171 \mathrm{E}-14 \quad 1.211 \mathrm{E}-10 \quad 8.112 \mathrm{E}-09 \quad 5.891 \mathrm{E}-08 \quad 3.952 \mathrm{E}-06 \quad 2.049 \mathrm{E}-05$ $\begin{array}{lllllllll}0.000 \mathrm{E}+00 & 4.331 \mathrm{E}-02 & 5.184 \mathrm{E}-01 & 2.142 \mathrm{E}+00 & 4.235 \mathrm{E}+00 & 1.937 \mathrm{E}+01 & 3.613 \mathrm{E}+01\end{array}$ $\begin{array}{lllllll}0.000 \mathrm{E}+00 & 3.119 \mathrm{E}-07 & 4.484 \mathrm{E}-05 & 7.739 \mathrm{E}-04 & 3.071 \mathrm{E}-03 & 7.220 \mathrm{E}-02 & 2.933 \mathrm{E}-01\end{array}$ $\begin{array}{lllllll}0.000 E+00 & 2.948 E-13 & 5.087 E-10 & 3.663 E-08 & 2.913 E-07 & 3.471 E-05 & 3.016 E-04\end{array}$ $\begin{array}{lllllllll}0.000 \mathrm{E}+00 & 4.331 \mathrm{E}-02 & 5.185 \mathrm{E}-01 & 2.142 \mathrm{E}+00 & 4.238 \mathrm{E}+00 & 1.944 \mathrm{E}+01 & 3.643 \mathrm{E}+01\end{array}$

$0.000 \mathrm{E}+00 \quad 5.540 \mathrm{E}-16 \quad 1.055 \mathrm{E}-11 \quad 2.418 \mathrm{E}-09 \quad 2.812 \mathrm{E}-08 \quad 3.398 \mathrm{E}-06 \quad 1.921 \mathrm{E}-05$ $\begin{array}{llllllll}0.000 \mathrm{E}+00 & 6.663 \mathrm{E}-04 & 8.578 \mathrm{E}-02 & 1.058 \mathrm{E}+00 & 2.946 \mathrm{E}+00 & 1.823 \mathrm{E}+01 & 3.524 \mathrm{E}+01\end{array}$ $\begin{array}{lllllll}0.000 \mathrm{E}+00 & 3.207 \mathrm{E}-09 & 5.094 \mathrm{E}-06 & 2.837 \mathrm{E}-04 & 1.706 \mathrm{E}-03 & 6.374 \mathrm{E}-02 & 2.769 \mathrm{E}-01\end{array}$ $\begin{array}{llllllll}0.000 \mathrm{E}+00 & 2.276 \mathrm{E}-15 & 4.411 \mathrm{E}-11 & 1.075 \mathrm{E}-08 & 1.356 \mathrm{E}-07 & 2.889 \mathrm{E}-05 & 2.763 \mathrm{E}-04\end{array}$ $\begin{array}{lllllll}0.000 \mathrm{E}+00 & 6.663 \mathrm{E}-04 & 8.578 \mathrm{E}-02 & 1.058 \mathrm{E}+00 & 2.947 \mathrm{E}+00 & 1.830 \mathrm{E}+01 & 3.551 \mathrm{E}+01\end{array}$ $\begin{array}{lllllll}3.600 \mathrm{E}+01 & 3.600 \mathrm{E}+01 & 3.598 \mathrm{E}+01 & 3.593 \mathrm{E}+01 & 3.586 \mathrm{E}+01 & 3.531 \mathrm{E}+01 & 3.456 \mathrm{E}+01\end{array}$ $0.000 \mathrm{E}+00 \quad 3.545 \mathrm{E}-08 \quad 4.253 \mathrm{E}-07 \quad 1.770 \mathrm{E}-06 \quad 3.536 \mathrm{E}-06 \quad 1.750 \mathrm{E}-05 \quad 3.622 \mathrm{E}-05$

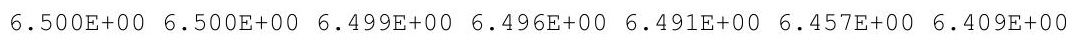

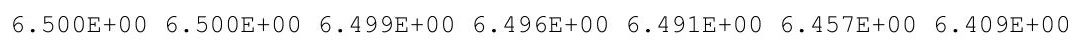


RESRAD, Version 6.5

Summary : RESRAD Parameters for U-Landfill Recreational User Foward Run

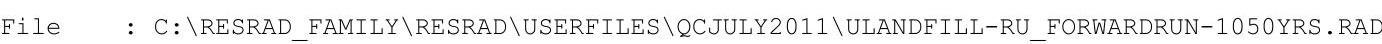

Individual Nuclide Soil Concentration

Parent Nuclide and Branch Fraction Indicated

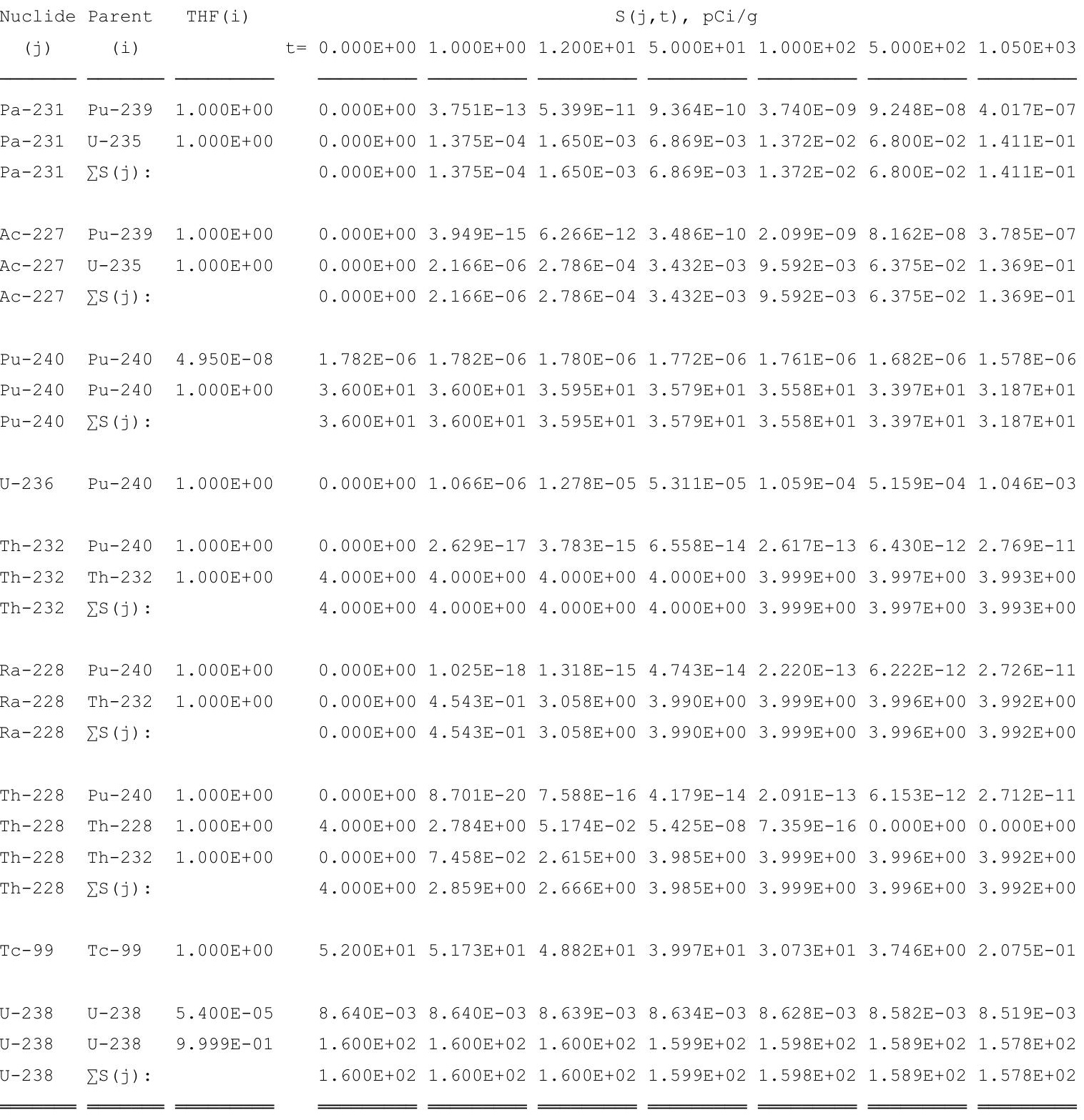

THF (i) is the thread fraction of the parent nuclide.

RESCALC.EXE execution time $=9.03$ seconds 
RESRAD, Version $6.5 \quad T^{1 / 2}$ Limit $=180$ days

07/20/2011 15:08 Page

Summary : RESRAD Parameters for U-Landfill Recreational User Foward Run at Proposed ALs

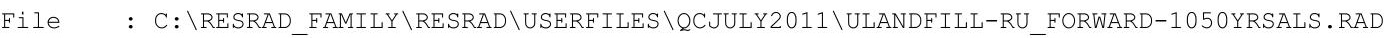

Table of Contents

Part I: Mixture Sums and Single Radionuclide Guidelines

Dose Conversion Factor (and Related) Parameter Summary ... 2

Site-Specific Parameter Summary ............... 8

Summary of Pathway Selections .................... 18

Contaminated Zone and Total Dose Summary ............. 19

Total Dose Components

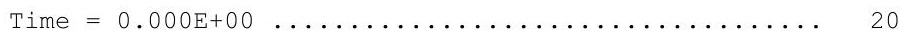

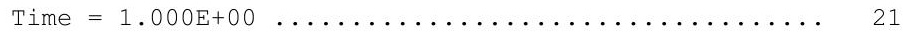

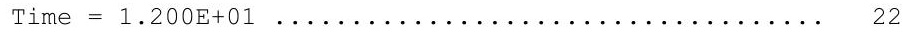

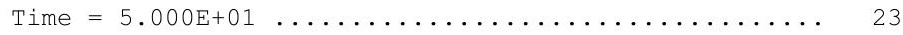

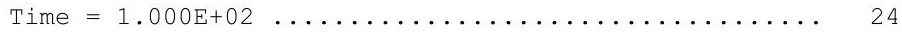

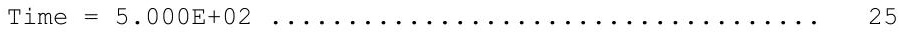

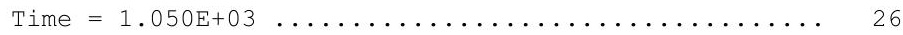

Dose/Source Ratios Summed Over All Pathways .......... 27

Single Radionuclide Soil Guidelines ................ 29

Dose Per Nuclide Summed Over All Pathways ............ 30

Soil Concentration Per Nuclide ............... 32 
Summary : RESRAD Parameters for U-Landfill Recreational User Foward Run at Proposed ALs

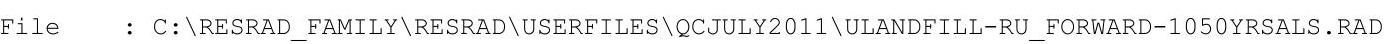

Dose Conversion Factor (and Related) Parameter Summary

Dose Library: RU for U-Landfill Plus ICRP 60 \& ICRP 72 (Age 15)

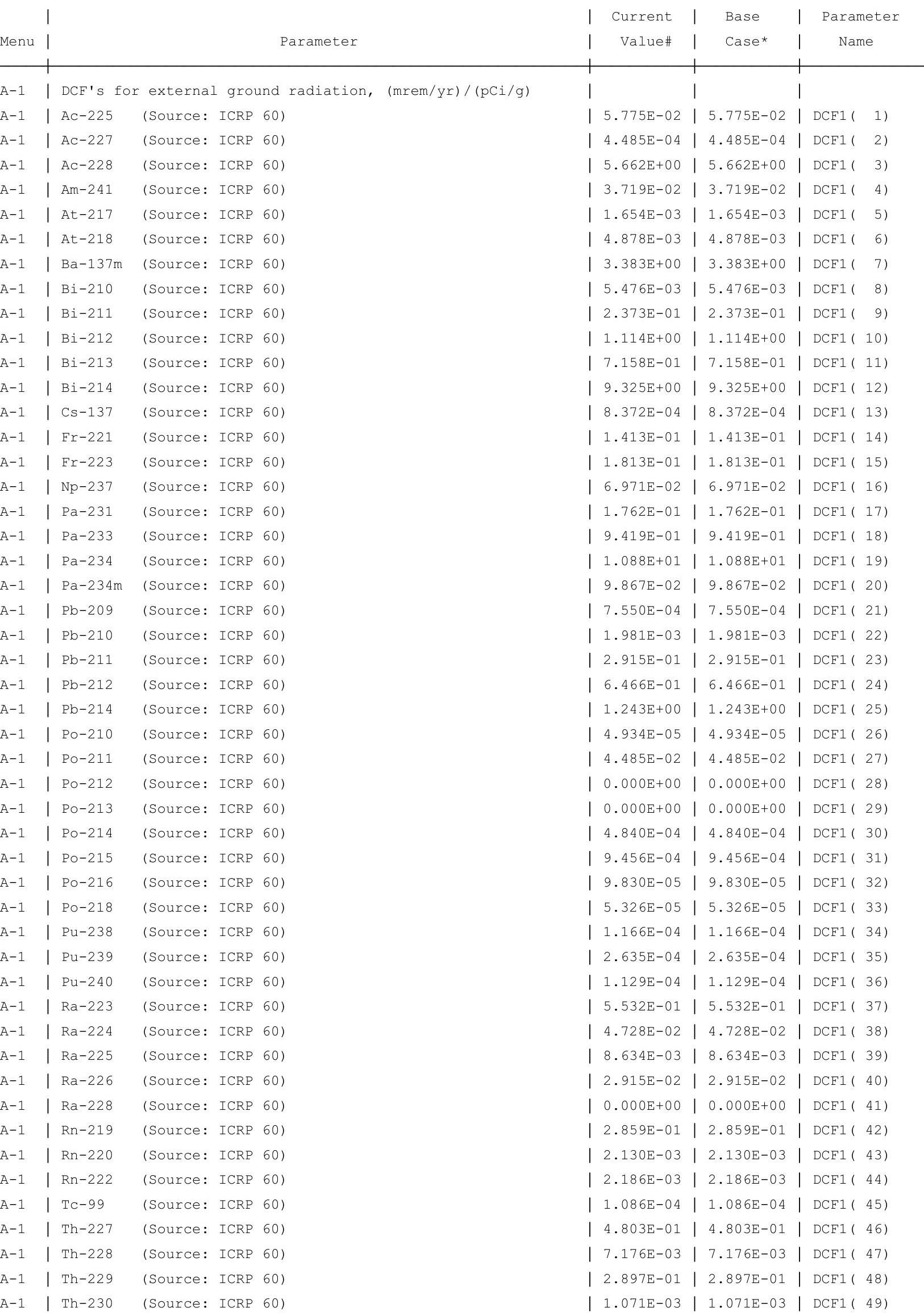


RESRAD, Version $6.5 \quad \mathrm{~T}^{1 / 2}$ Limit $=180$ days

Summary : RESRAD Parameters for U-Landfill Recreational User Foward Run at Proposed ALs

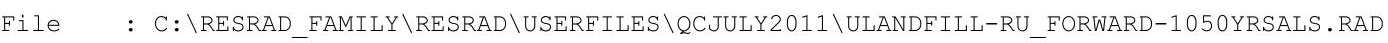

Dose Conversion Factor (and Related) Parameter Summary (continued)

Dose Library: RU for U-Landfill Plus ICRP 60 \& ICRP 72 (Age 15)

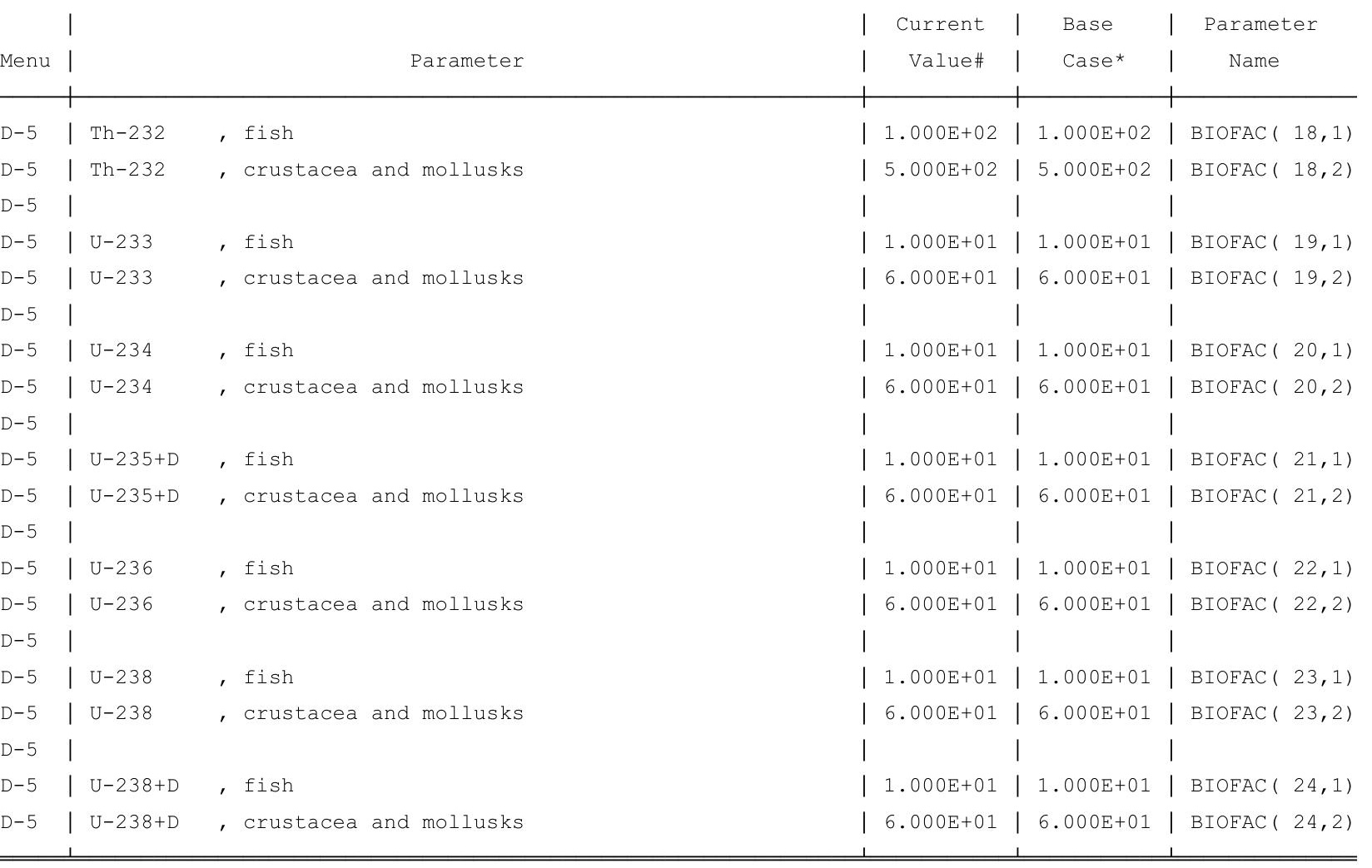

\#For DCFl(xxx) only, factors are for infinite depth \& area. See ETFG table in Ground Pathway of Detailed Report. *Base Case means Default.Lib w/o Associate Nuclide contributions. 
RESRAD, Version $6.5 \quad$ T1/2 Limit $=180$ days
Summary : RESRAD Parameters for U-Landfill Recreational User Foward Run at Proposed ALs

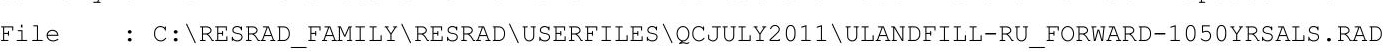

Site-Specific Parameter Summary (continued)

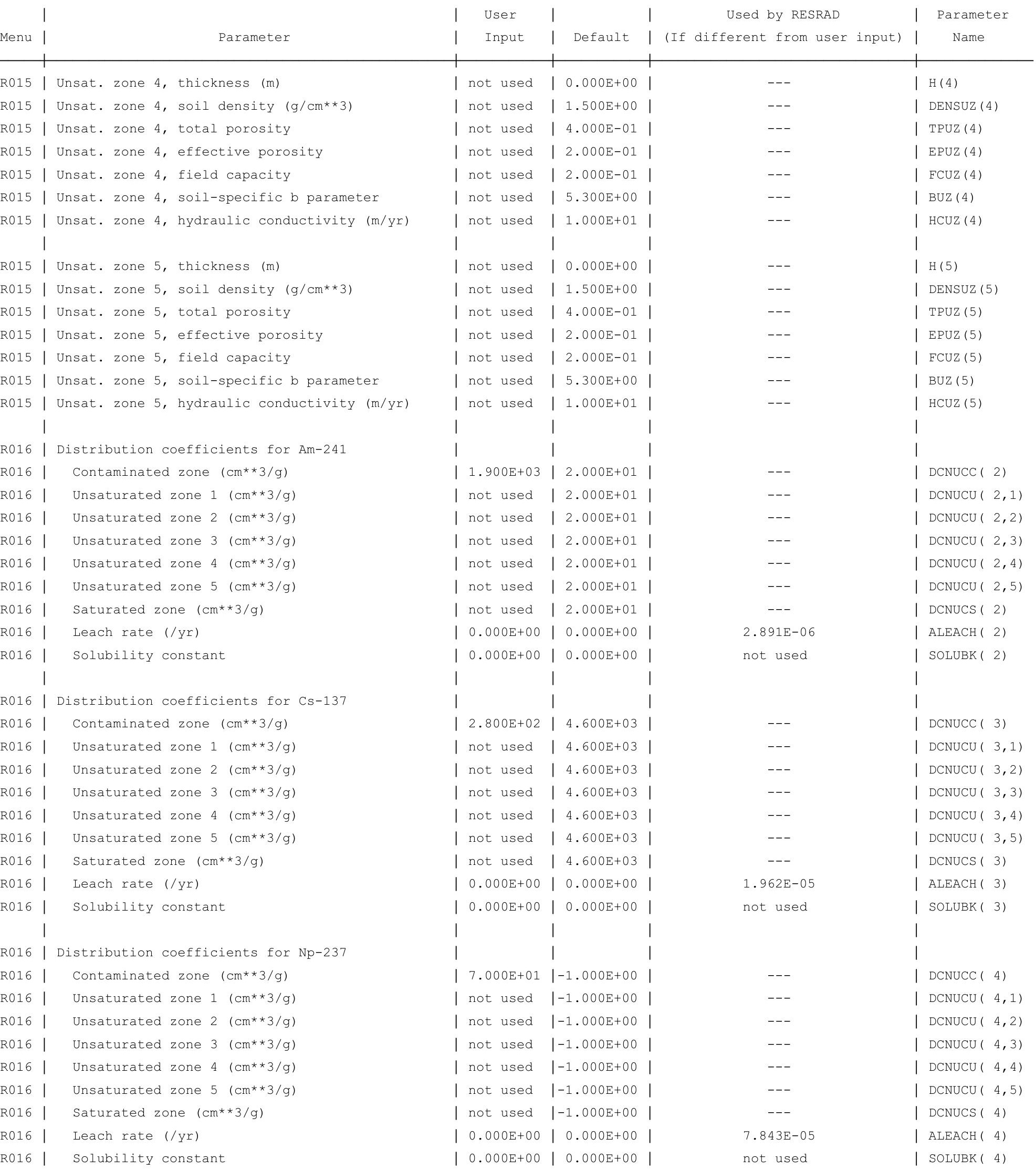


RESRAD, Version $6.5 \quad$ T1/2 Limit $=180$ days
Summary : RESRAD Parameters for U-Landfill Recreational User Foward Run at Proposed ALs

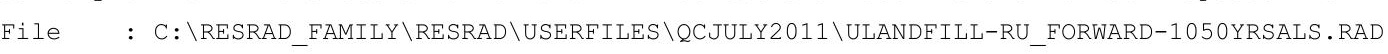

Site-Specific Parameter Summary (continued)

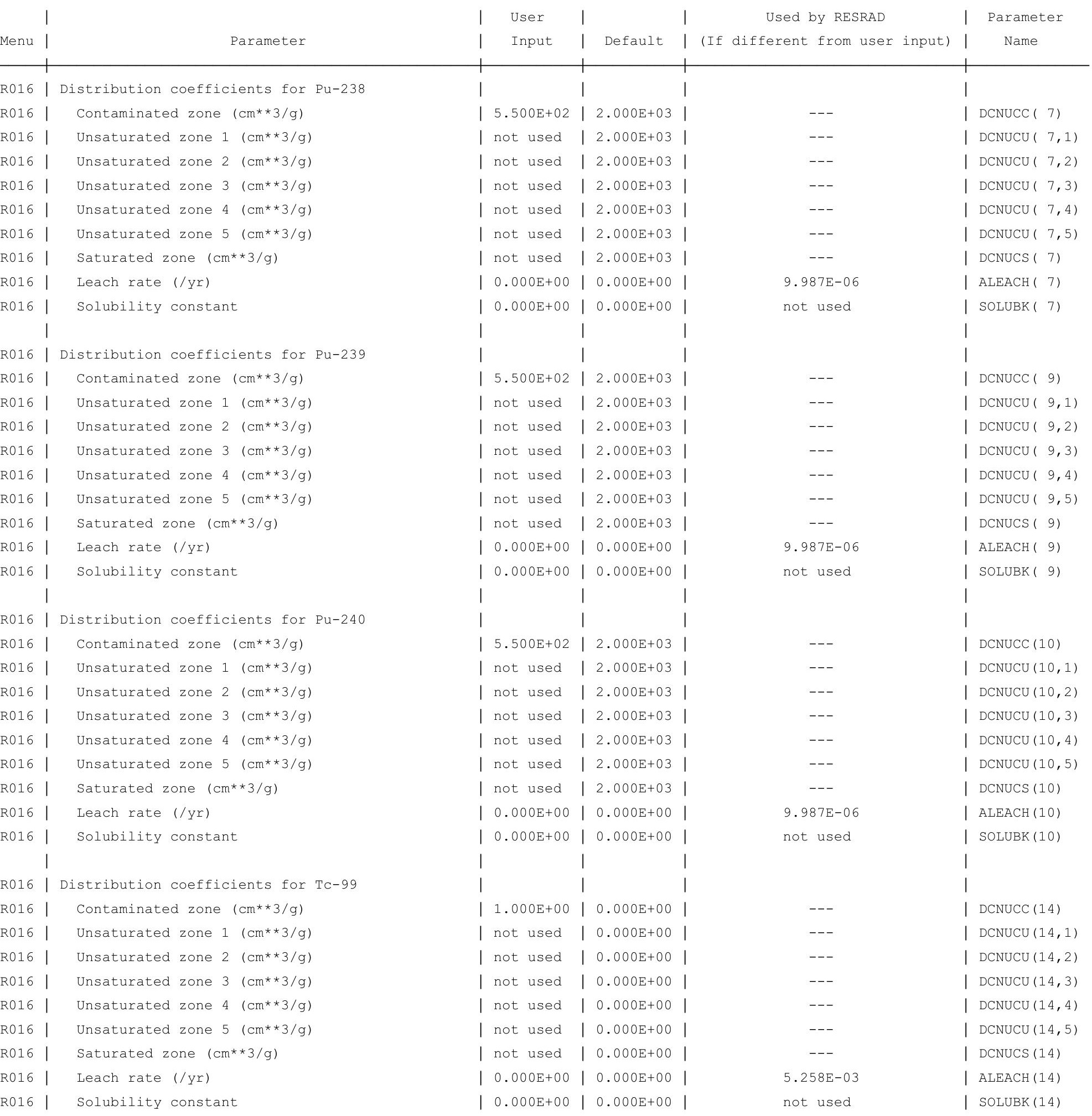


RESRAD, Version $6.5 \quad \mathrm{~T}^{1 / 2}$ Limit $=180$ days

Summary : RESRAD Parameters for U-Landfill Recreational User Foward Run at Proposed ALs

File : C: $\backslash$ RESRAD FAMILY \RESRAD \USERFILES \QCJULY2011 \ULANDFILL-RU FORWARD-1050YRSALS.RAD

Site-Specific Parameter Summary (continued)

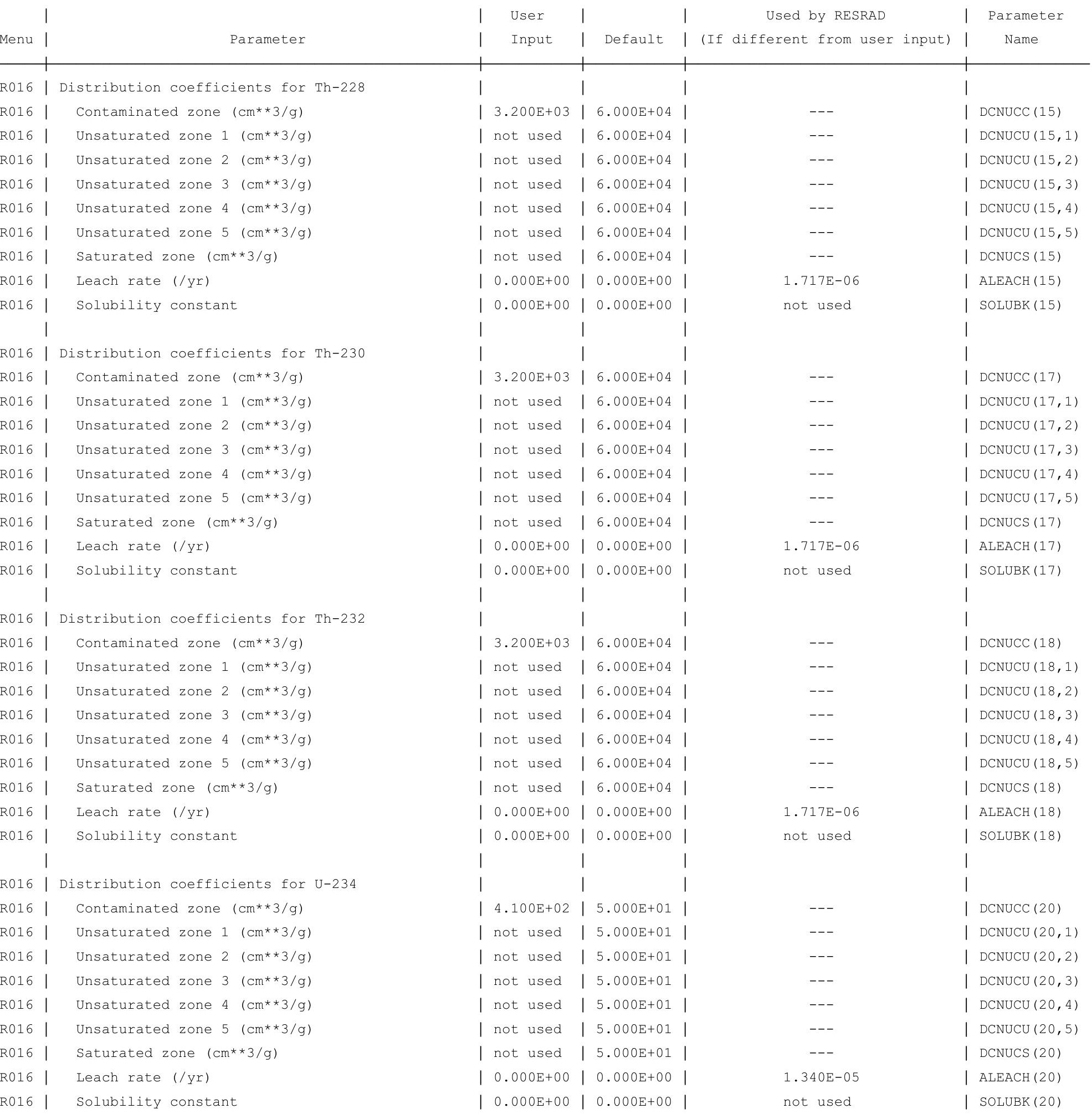


RESRAD, Version $6.5 \quad$ T1/2 Limit $=180$ days $\quad 07 / 20 / 2011 \quad 15: 08$ Page 13
Summary : RESRAD Parameters for U-Landfill Recreational User Foward Run at Proposed ALs

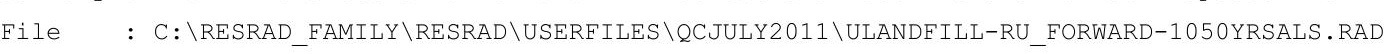

Site-Specific Parameter Summary (continued)

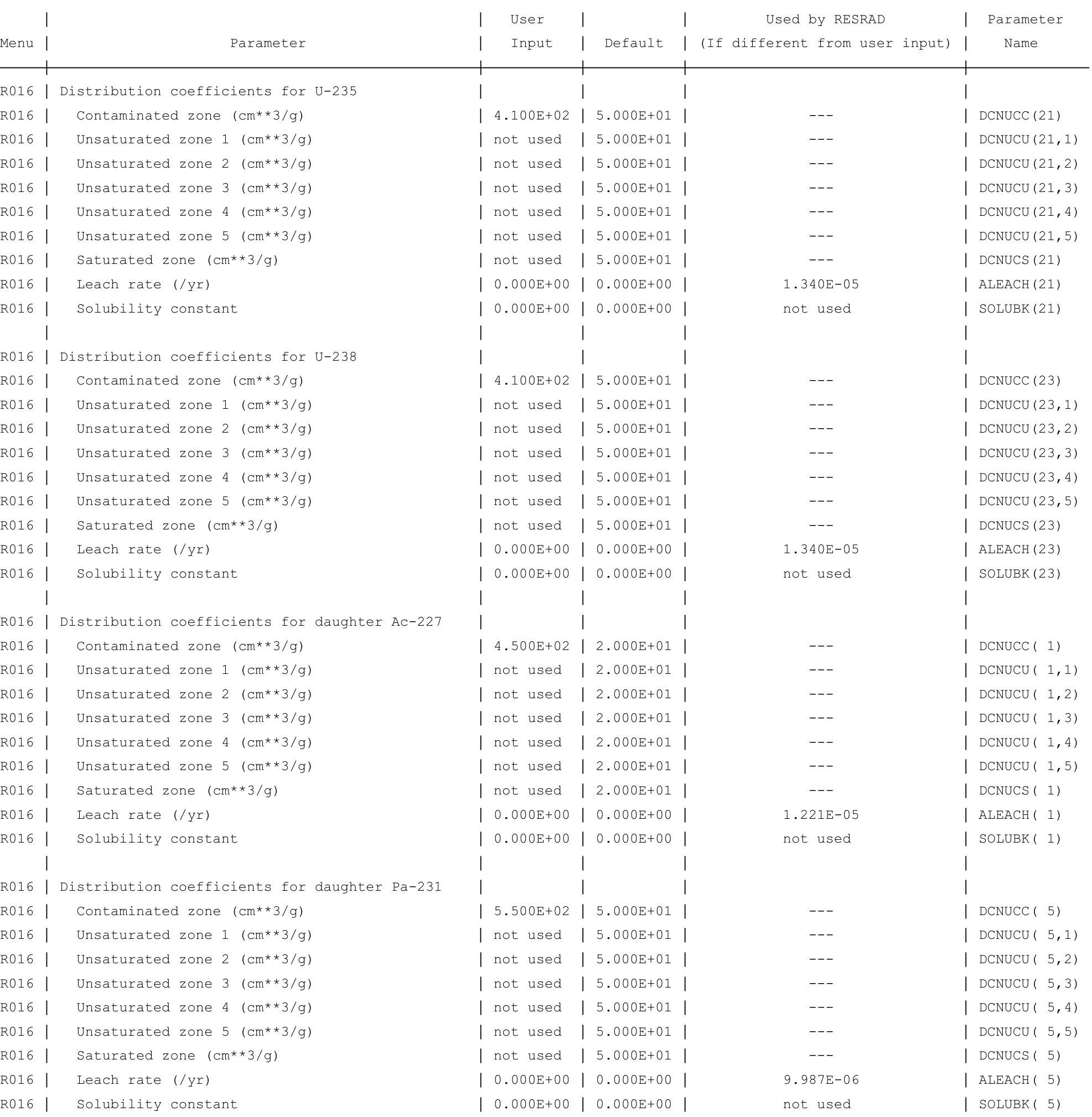


RESRAD, Version $6.5 \quad \mathrm{~T}^{1 / 2}$ Limit $=180$ days

Summary : RESRAD Parameters for U-Landfill Recreational User Foward Run at Proposed ALs

File : C: $\backslash$ RESRAD FAMILY \RESRAD \USERFILES \QCJULY2011 \ULANDFILL-RU FORWARD-1050YRSALS. RAD

Site-Specific Parameter Summary (continued)

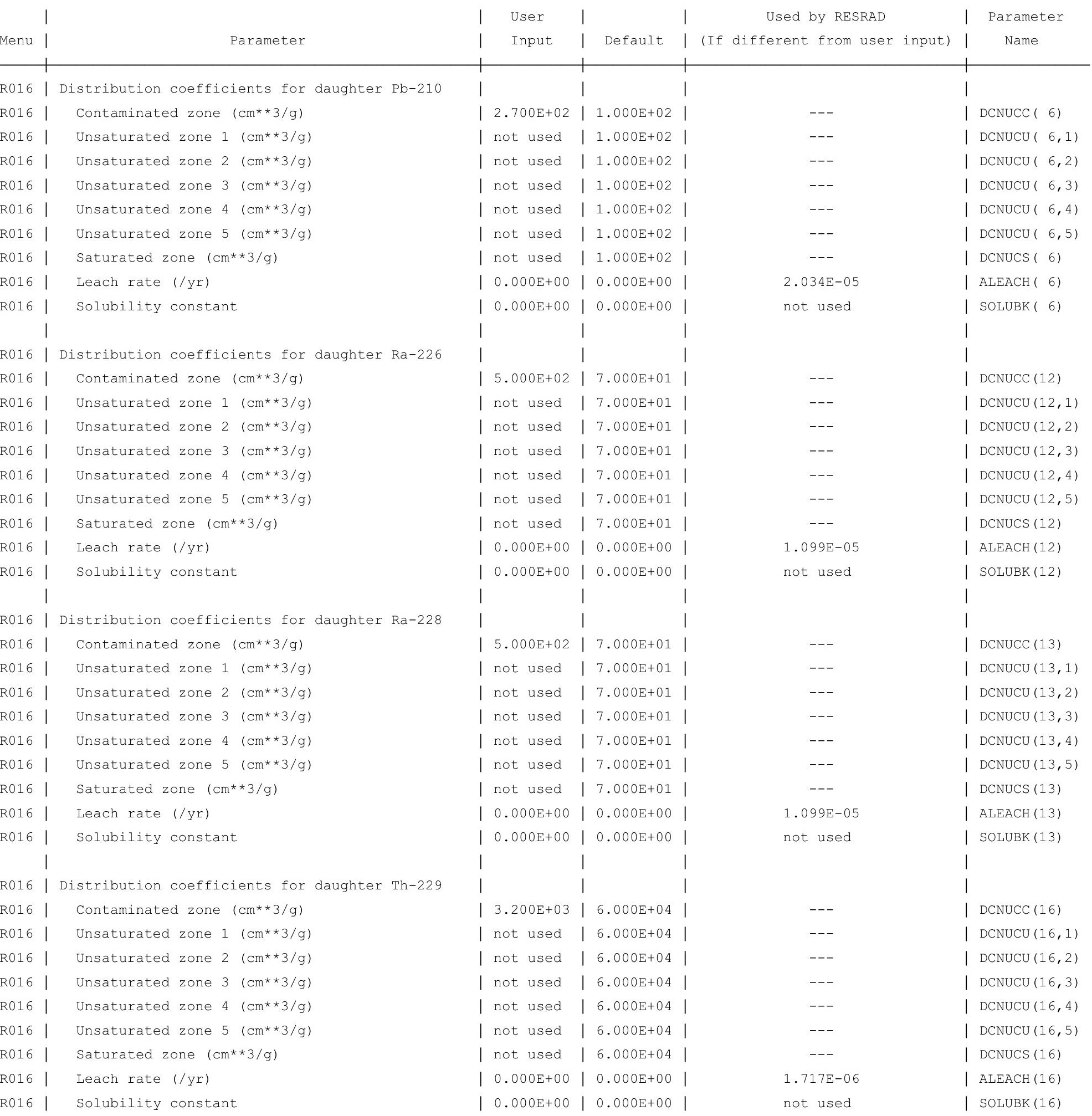


Summary : RESRAD Parameters for U-Landfill Recreational User Foward Run at Proposed ALs

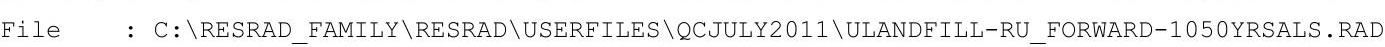

Site-Specific Parameter Summary (continued)

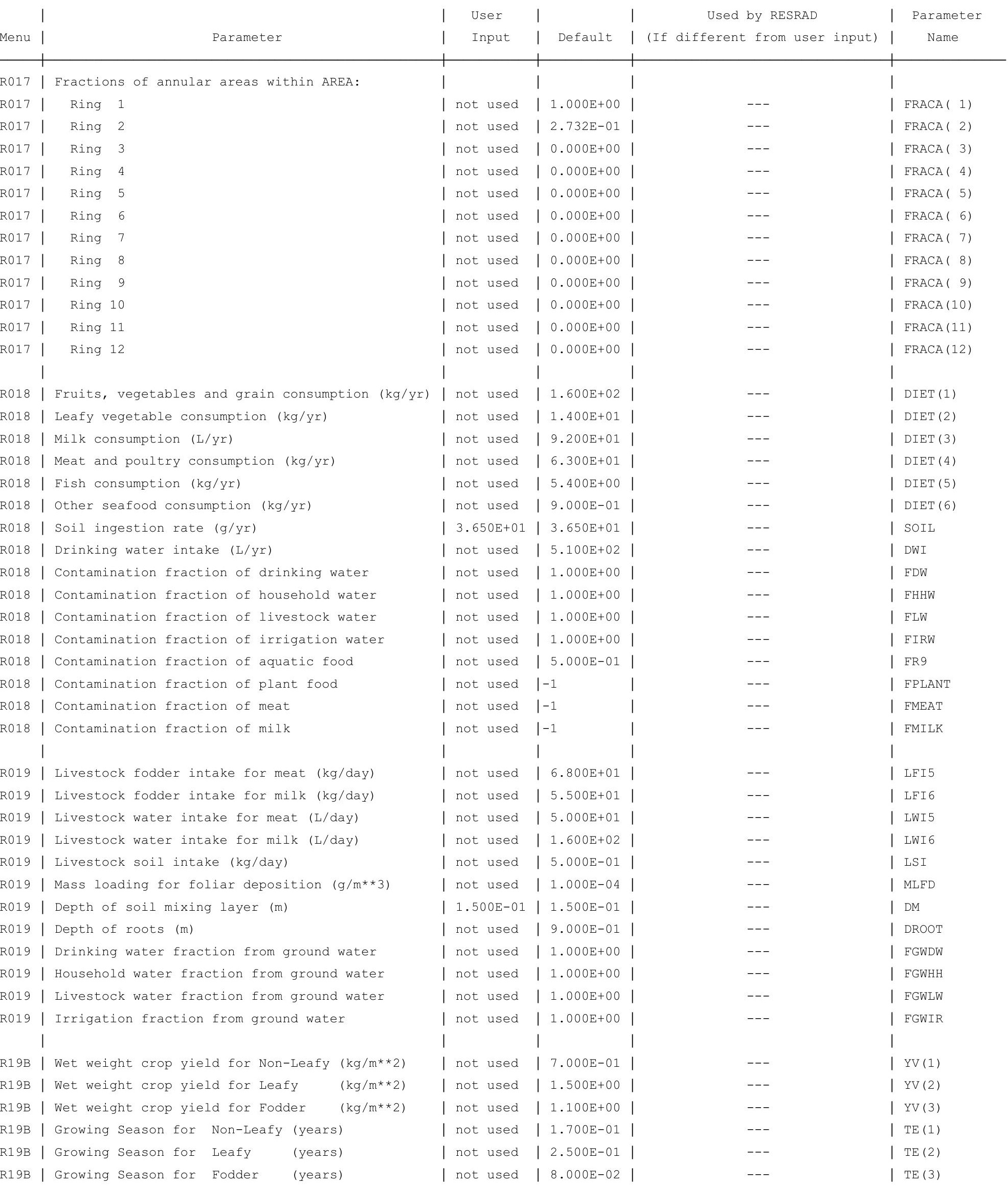


RESRAD, Version $6.5 \quad T^{13 / 2}$ Limit $=180$ days

Summary : RESRAD Parameters for U-Landfill Recreational User Foward Run at Proposed ALs

File : C:\RESRAD_FAMILY \RESRAD \USERFILES \QCJULY2011 \ULANDFILL-RU_FORWARD-1050YRSALS.RAD

Contaminated Zone Dimensions

Area: $\quad 89436.00$ square meters

Thickness:

Cover Depth:

\begin{abstract}
13.40 meters
1.52 meters
\end{abstract}

Initial Soil Concentrations, pci/g

$\begin{array}{ll}\mathrm{Am}-241 & 7.000 \mathrm{E}+01 \\ \mathrm{Cs}-137 & 3.800 \mathrm{E}+01 \\ \mathrm{~Np}-237 & 1.100 \mathrm{E}+01 \\ \mathrm{Pu}-238 & 7.800 \mathrm{E}+01 \\ \mathrm{Pu}-239 & 7.200 \mathrm{E}+01 \\ \mathrm{Pu}-240 & 7.200 \mathrm{E}+01 \\ \mathrm{TC}-99 & 1.040 \mathrm{E}+02 \\ \mathrm{Th}-228 & 8.000 \mathrm{E}+00 \\ \mathrm{Th}-230 & 2.000 \mathrm{E}+02 \\ \mathrm{Th}-232 & 8.000 \mathrm{E}+00 \\ \mathrm{U}-234 & 3.200 \mathrm{E}+02 \\ \mathrm{U}-235 & 1.300 \mathrm{E}+01 \\ \mathrm{U}-238 & 3.200 \mathrm{E}+02\end{array}$

Total Dose TDOSE(t), mrem/yr

Basic Radiation Dose Limit $=1.000 \mathrm{E}+00 \mathrm{mrem} / \mathrm{yr}$

Total Mixture Sum $M(t)$ = Fraction of Basic Dose Limit Received at Time (t)

$\begin{array}{rlllllll}t \text { (years) }: & 0.000 \mathrm{E}+00 & 1.000 \mathrm{E}+00 & 1.200 \mathrm{E}+01 & 5.000 \mathrm{E}+01 & 1.000 \mathrm{E}+02 & 5.000 \mathrm{E}+02 & 1.050 \mathrm{E}+03 \\ \mathrm{TDOSE}(\mathrm{t}): & 1.082 \mathrm{E}-06 & 8.088 \mathrm{E}-07 & 9.723 \mathrm{E}-07 & 1.835 \mathrm{E}-06 & 2.629 \mathrm{E}-06 & 4.666 \mathrm{E}-05 & 2.478 \mathrm{E}-03 \\ \mathrm{M}(\mathrm{t}): & 1.082 \mathrm{E}-06 & 8.088 \mathrm{E}-07 & 9.723 \mathrm{E}-07 & 1.835 \mathrm{E}-06 & 2.629 \mathrm{E}-06 & 4.666 \mathrm{E}-05 & 2.478 \mathrm{E}-03\end{array}$

Maximum TDOSE $(t): 2.478 \mathrm{E}-03 \mathrm{mrem} / \mathrm{yr}$ at $t=1.050 \mathrm{E}+03$ years 
RESRAD, Version $6.5 \quad$ T $1 \frac{1}{2}$ Limit $=180$ days $\quad 07 / 20 / 2011 \quad 15: 08$ Page 20
Summary : RESRAD Parameters for U-Landfill Recreational User Foward Run at Proposed ALs

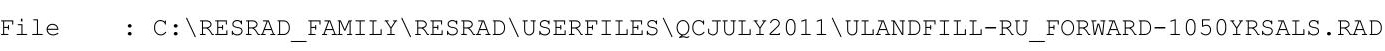

Total Dose Contributions TDOSE (i,p,t) for Individual Radionuclides (i) and Pathways (p) As mrem/yr and Fraction of Total Dose At $t=0.000 \mathrm{E}+00$ years

Water Independent Pathways (Inhalation excludes radon)

\begin{tabular}{|c|c|c|c|c|c|c|c|c|c|c|c|c|c|c|}
\hline \multirow[b]{2}{*}{ clide } & \multicolumn{2}{|c|}{ Ground } & \multicolumn{2}{|c|}{ Inhalation } & \multicolumn{2}{|c|}{ Radon } & \multicolumn{2}{|c|}{ Plant } & \multicolumn{2}{|c|}{ Meat } & \multicolumn{2}{|c|}{ Milk } & \multicolumn{2}{|l|}{ Soil } \\
\hline & mrem/yr & fract. & mrem/yr & fract. & mrem/yr & fract. & mrem/yr & fract. & mrem/yr & fract. & mrem/yr & fract. & mrem/yr & fract. \\
\hline-241 & $1.041 \mathrm{E}-18$ & 0.0000 & $0.000 \mathrm{E}+00$ & 0.0000 & $0.000 \mathrm{E}+00$ & 0.0000 & $0.000 \mathrm{E}+00$ & 0.0000 & $0.000 \mathrm{E}+00$ & 0.0000 & $0.000 \mathrm{E}+00$ & 0.0000 & $0.000 \mathrm{E}+00$ & 0000 \\
\hline 37 & $4.610 \mathrm{E}-09$ & 0.0043 & $0.000 \mathrm{E}+00$ & 0.0000 & $0.000 \mathrm{E}+00$ & 0.0000 & $0.000 \mathrm{E}+00$ & 0.0000 & $0.000 \mathrm{E}+00$ & 0.0000 & $0.000 \mathrm{E}+00$ & 0.0000 & $0.000 \mathrm{E}+00$ & .0000 \\
\hline 37 & $1.009 \mathrm{E}-12$ & 0.0000 & $0.000 \mathrm{E}+00$ & 0.0000 & $0.000 \mathrm{E}+00$ & 0.0000 & $0.000 \mathrm{E}+00$ & 0.0000 & $0.000 \mathrm{E}+00$ & 0.0000 & $0.000 \mathrm{E}+00$ & 0.0000 & $0.000 \mathrm{E}+00$ & 0.0000 \\
\hline 238 & $6.104 \mathrm{E}-22$ & 0.0000 & $0.000 \mathrm{E}+00$ & 0.0000 & $0.000 \mathrm{E}+00$ & 0.0000 & $0.000 \mathrm{E}+00$ & 0.0000 & $0.000 \mathrm{E}+00$ & 0.0000 & $0.000 \mathrm{E}+00$ & 0.0000 & $0.000 \mathrm{E}+00$ & 0.0000 \\
\hline 239 & $8.323 \mathrm{E}-17$ & 0.0000 & $0.000 \mathrm{E}+00$ & 0.0000 & $0.000 \mathrm{E}+00$ & 0.0000 & $0.000 \mathrm{E}+00$ & 0.0000 & $0.000 \mathrm{E}+00$ & 0.0000 & $0.000 \mathrm{E}+00$ & 0.0000 & $0.000 \mathrm{E}+00$ & 0.0000 \\
\hline 240 & $7.913 \mathrm{E}-24$ & 0.0000 & $0.000 \mathrm{E}+00$ & 0.0000 & $0.000 \mathrm{E}+00$ & 0.0000 & $0.000 \mathrm{E}+00$ & 0.0000 & $0.000 \mathrm{E}+00$ & 0.0000 & $0.000 \mathrm{E}+00$ & 0.0000 & $0.000 \mathrm{E}+00$ & 0.0000 \\
\hline & $5.769 \mathrm{E}-25$ & 0.0000 & $0.000 \mathrm{E}+00$ & 0.0000 & $0.000 \mathrm{E}+00$ & 0.0000 & $0.000 \mathrm{E}+00$ & 0.00 & $0.000 \mathrm{E}+00$ & 00 & $0.000 \mathrm{E}+00$ & 0.0000 & $0.000 \mathrm{E}+00$ & 0.0000 \\
\hline 8 & $1.063 \mathrm{E}-06$ & 0.9827 & $0.000 \mathrm{E}+00$ & 0.0000 & $0.000 \mathrm{E}+00$ & 0.0000 & $0.000 \mathrm{E}+00$ & 0.0000 & $0.000 \mathrm{E}+00$ & 0.0000 & $0.000 \mathrm{E}+00$ & 0.0000 & $0.000 \mathrm{E}+00$ & 0.0000 \\
\hline 30 & $7.258 \mathrm{E}-10$ & 0.0007 & $0.000 \mathrm{E}+00$ & 0.0000 & $0.000 \mathrm{E}+00$ & 0.0000 & $0.000 \mathrm{E}+00$ & 0.0000 & $0.000 \mathrm{E}+00$ & 0.0000 & $0.000 \mathrm{E}+00$ & 0.0000 & $0.000 \mathrm{E}+00$ & 0.0000 \\
\hline 2 & $9.061 \mathrm{E}-09$ & 0.0084 & $0.000 \mathrm{E}+00$ & 0.0000 & $0.000 \mathrm{E}+00$ & 0.0000 & $0.000 \mathrm{E}+00$ & 0.0000 & $0.000 \mathrm{E}+00$ & 0.0000 & $0.000 \mathrm{E}+00$ & 0.0000 & $0.000 \mathrm{E}+00$ & 0.0000 \\
\hline & $3.487 \mathrm{E}-15$ & 0.0000 & $0.000 \mathrm{E}+00$ & 0.0000 & $0.000 \mathrm{E}+00$ & 0.0000 & $0.000 \mathrm{E}+00$ & 0.0000 & $0.000 \mathrm{E}+00$ & 0.0000 & $0.000 \mathrm{E}+00$ & 0.0000 & $0.000 \mathrm{E}+00$ & 0.0000 \\
\hline & $1.556 \mathrm{E}-14$ & 0.0000 & $0.000 \mathrm{E}+00$ & 0.0000 & $0.000 \mathrm{E}+00$ & 0.0000 & $0.000 \mathrm{E}+00$ & 0.0000 & $0.000 \mathrm{E}+00$ & 0.0000 & $0.000 \mathrm{E}+00$ & 0.0000 & $0.000 \mathrm{E}+00$ & 0.0000 \\
\hline & $4.368 \mathrm{E}-09$ & 0.0040 & $0.000 \mathrm{E}+00$ & 0.0000 & $0.000 \mathrm{E}+00$ & 0.0000 & $0.000 \mathrm{E}+00$ & 0.0000 & $0.000 \mathrm{E}+00$ & 0.0000 & $0.000 \mathrm{E}+00$ & 0.0000 & $0.000 \mathrm{E}+00$ & 0.0000 \\
\hline & 0 & - & $.000 \mathrm{E}+00$ & . 000 & $.000 E+00$ & 0.0000 & $.000 \mathrm{E}+00$ & . & $0.000 \mathrm{E}+00$ & 0.0000 & . & . & $0.000 \mathrm{E}+00$ & \\
\hline
\end{tabular}

Total Dose Contributions TDOSE (i,p,t) for Individual Radionuclides (i) and Pathways (p) As mrem/yr and Fraction of Total Dose At $t=0.000 \mathrm{E}+00$ years

Water Dependent Pathways

\begin{tabular}{|c|c|c|c|c|c|c|c|c|c|c|c|c|c|c|}
\hline \multirow[b]{2}{*}{ clide } & \multicolumn{2}{|c|}{ Water } & \multicolumn{2}{|c|}{ Fish } & \multicolumn{2}{|c|}{ Radon } & \multicolumn{2}{|c|}{ Plant } & \multicolumn{2}{|c|}{ Meat } & \multicolumn{2}{|c|}{ Milk } & \multicolumn{2}{|c|}{ All Pathways* } \\
\hline & mrem/yr & fract. & mrem/yr & fract. & $\mathrm{mrem} / \mathrm{yr}$ & fract. & mrem/yr & fract. & mrem/yr & fract. & mrem/yr & fract. & mrem/yr & fract. \\
\hline 1 & $0.000 \mathrm{E}+00$ & 0.0000 & $0.000 \mathrm{E}+00$ & 0.0000 & $0.000 \mathrm{E}+00$ & 0.0000 & $0.000 \mathrm{E}+00$ & 0.0000 & $0.000 \mathrm{E}+00$ & 0.0000 & $0.000 \mathrm{E}+00$ & 0.0000 & $1.041 \mathrm{E}-18$ & 0.0000 \\
\hline 37 & $0.000 \mathrm{E}+00$ & 0.0000 & $0.000 \mathrm{E}+00$ & 0.0000 & $0.000 \mathrm{E}+00$ & 0.0000 & $0.000 \mathrm{E}+00$ & 0.0000 & $0.000 \mathrm{E}+00$ & 0.0000 & $0.000 \mathrm{E}+00$ & 0.0000 & $4.610 \mathrm{E}-09$ & 0.0043 \\
\hline 37 & $0.000 \mathrm{E}+00$ & 0.0000 & $0.000 \mathrm{E}+00$ & 0.0000 & $0.000 \mathrm{E}+00$ & 0.0000 & $0.000 \mathrm{E}+00$ & 0.0000 & $0.000 \mathrm{E}+00$ & 0.0000 & $0.000 \mathrm{E}+00$ & 0.0000 & $1.009 \mathrm{E}-12$ & 0.0000 \\
\hline 238 & $0.000 \mathrm{E}+00$ & 0.0000 & $0.000 \mathrm{E}+00$ & 0.0000 & $0.000 \mathrm{E}+00$ & 0.0000 & $0.000 \mathrm{E}+00$ & 0.0000 & $0.000 \mathrm{E}+00$ & 0.0000 & $0.000 \mathrm{E}+00$ & 0.0000 & $6.104 \mathrm{E}-22$ & 0.0000 \\
\hline 239 & $0.000 \mathrm{E}+00$ & 0.0000 & $0.000 \mathrm{E}+00$ & 0.0000 & $0.000 \mathrm{E}+00$ & 0.0000 & $0.000 \mathrm{E}+00$ & 0.0000 & $0.000 \mathrm{E}+00$ & 0.0000 & $0.000 \mathrm{E}+00$ & 0.0000 & $8.323 E-17$ & 0.0000 \\
\hline 24 & $0.000 \mathrm{E}+00$ & 0.0 & 0.00 & 0 & $0.000 \mathrm{E}+00$ & 0 & $0.000 \mathrm{E}+00$ & 0 & 0 & 0 & $0.000 \mathrm{E}+00$ & 0 & 24 & 000 \\
\hline & $0.000 \mathrm{E}+00$ & 0.0 & $0.000 \mathrm{E}+00$ & 0.0000 & $0.000 \mathrm{E}+00$ & 0.0000 & $0.000 \mathrm{E}+00$ & 0.00 & $0.000 \mathrm{E}+00$ & 0.0000 & $0.000 \mathrm{E}+00$ & 0.0 & $769 \mathrm{E}-25$ & 0000 \\
\hline 228 & $0.000 \mathrm{E}+00$ & 0.0000 & $0.000 \mathrm{E}+00$ & 0.0000 & $0.000 \mathrm{E}+00$ & 0.0000 & $0.000 \mathrm{E}+00$ & 0.0000 & $0.000 \mathrm{E}+00$ & 0.0000 & $0.000 \mathrm{E}+00$ & 0.0000 & $1.063 \mathrm{E}-06$ & 0.9827 \\
\hline & $0.000 \mathrm{E}+00$ & 0.0000 & $0.000 \mathrm{E}+00$ & 0.0000 & $0.000 \mathrm{E}+00$ & 0.0000 & $0.000 \mathrm{E}+00$ & 0.0000 & $0.000 \mathrm{E}+00$ & 0.0000 & $0.000 \mathrm{E}+00$ & 0.0000 & $7.258 \mathrm{E}-10$ & 0.0007 \\
\hline & $0.000 \mathrm{E}+00$ & 0.0000 & $0.000 \mathrm{E}+00$ & 0.0000 & $0.000 \mathrm{E}+00$ & 0.0000 & $0.000 \mathrm{E}+00$ & 0.0000 & $0.000 \mathrm{E}+00$ & 0.0000 & $0.000 \mathrm{E}+00$ & 0.0000 & $9.061 \mathrm{E}-09$ & 0.0084 \\
\hline & $0.000 \mathrm{E}+00$ & 0.0000 & $0.000 \mathrm{E}+00$ & 0.0000 & $0.000 \mathrm{E}+00$ & 0.0000 & $0.000 \mathrm{E}+00$ & 0.0000 & $0.000 \mathrm{E}+00$ & 0.0000 & $0.000 \mathrm{E}+00$ & 0.0000 & $3.487 \mathrm{E}-15$ & 0.0000 \\
\hline & $0.000 \mathrm{E}+00$ & 0.0000 & $0.000 \mathrm{E}+00$ & 0.0000 & $0.000 \mathrm{E}+00$ & 0.0000 & $0.000 \mathrm{E}+00$ & 0.0000 & $0.000 \mathrm{E}+00$ & 0.0000 & $0.000 \mathrm{E}+00$ & 0.0000 & $1.556 \mathrm{E}-14$ & 0.0000 \\
\hline & $0.000 \mathrm{E}+00$ & 0.0000 & $0.000 \mathrm{E}+00$ & 0.0000 & $0.000 \mathrm{E}+00$ & 0.0000 & $0.000 \mathrm{E}+00$ & 0.0000 & $0.000 \mathrm{E}+00$ & 0.0000 & $0.000 \mathrm{E}+00$ & 0.0000 & $4.368 \mathrm{E}-09$ & 0.0040 \\
\hline & & 00 & $0.000 \mathrm{E}+00$ & 0.0000 & $.000 \mathrm{E}+00$ & 0.0000 & $0.000 \mathrm{E}+00$ & 0.0000 & $0.000 \mathrm{E}+00$ & 0.0000 & +0 & & & 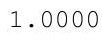 \\
\hline
\end{tabular}

* Sum of all water independent and dependent pathways. 
RESRAD, Version $6.5 \quad$ T $1 \frac{1}{2}$ Limit $=180$ days $\quad 07 / 20 / 2011 \quad 15: 08$ Page 21
Summary : RESRAD Parameters for U-Landfill Recreational User Foward Run at Proposed ALs

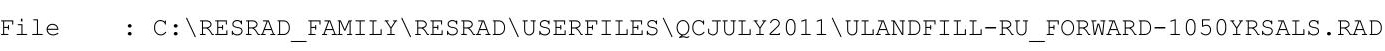

Total Dose Contributions TDOSE (i,p,t) for Individual Radionuclides (i) and Pathways (p) As mrem/yr and Fraction of Total Dose At $t=1.000 \mathrm{E}+00$ years

Water Independent Pathways (Inhalation excludes radon)

\begin{tabular}{|c|c|c|c|c|c|c|c|c|c|c|c|c|c|c|}
\hline \multirow[b]{2}{*}{ clide } & \multicolumn{2}{|c|}{ Ground } & \multicolumn{2}{|c|}{ Inhalation } & \multicolumn{2}{|c|}{ Radon } & \multicolumn{2}{|c|}{ Plant } & \multicolumn{2}{|c|}{ Meat } & \multicolumn{2}{|c|}{ Milk } & \multicolumn{2}{|c|}{ Soil } \\
\hline & mrem/yr & fract. & mrem/yr & fract. & mrem/yr & fract. & $\mathrm{mrem} / \mathrm{yr}$ & fract. & nrem/yr & fract. & mrem/yr & fract. & nrem/yr & fract. \\
\hline 1 & $3.150 \mathrm{E}-18$ & 0.0000 & $0.000 \mathrm{E}+00$ & 0.0000 & $0.000 \mathrm{E}+00$ & 0.0000 & $0.000 \mathrm{E}+00$ & 0.0000 & $0.000 \mathrm{E}+00$ & 0.0000 & $0.000 \mathrm{E}+00$ & 0.0000 & $0.000 \mathrm{E}+00$ & 0.0000 \\
\hline 7 & $4.543 \mathrm{E}-09$ & 0.0056 & $0.000 \mathrm{E}+00$ & 0.0000 & $0.000 \mathrm{E}+00$ & 0.0000 & $0.000 \mathrm{E}+00$ & 0.0000 & $0.000 \mathrm{E}+00$ & 0.0000 & $0.000 \mathrm{E}+00$ & 0.0000 & $0.000 \mathrm{E}+00$ & 0.0000 \\
\hline 37 & $1.019 \mathrm{E}-12$ & 0.0000 & $0.000 \mathrm{E}+00$ & 0.0000 & $0.000 \mathrm{E}+00$ & 0.0000 & $0.000 \mathrm{E}+00$ & 0.0000 & $0.000 \mathrm{E}+00$ & 0.0000 & $0.000 \mathrm{E}+00$ & 0.0000 & $0.000 \mathrm{E}+00$ & 0.0000 \\
\hline 238 & $9.070 \mathrm{E}-21$ & 0.0000 & $0.000 \mathrm{E}+00$ & 0.0000 & $0.000 \mathrm{E}+00$ & 0.0000 & $0.000 \mathrm{E}+00$ & 0.0000 & $0.000 \mathrm{E}+00$ & 0.0000 & $0.000 \mathrm{E}+00$ & 0.0000 & $0.000 \mathrm{E}+00$ & 0.0000 \\
\hline 39 & $8.423 \mathrm{E}-17$ & 0.0000 & $0.000 \mathrm{E}+00$ & 0.0000 & $0.000 \mathrm{E}+00$ & 0.0000 & $0.000 \mathrm{E}+00$ & 0.0000 & $0.000 \mathrm{E}+00$ & 0.0000 & $0.000 \mathrm{E}+00$ & 0.0000 & $0.000 \mathrm{E}+00$ & 0.0000 \\
\hline 240 & $8.222 \mathrm{E}-24$ & 0.0000 & $0.000 \mathrm{E}+00$ & 0.0000 & $0.000 \mathrm{E}+00$ & 0.0 & $0.000 \mathrm{E}+00$ & 0 & $0.000 \mathrm{E}+00$ & 0 & $000 \mathrm{E}+00$ & 0 & $.000 \mathrm{E}+00$ & 00 \\
\hline & $5.850 \mathrm{E}-25$ & 0.000 & $E+00$ & 0 & $0.000 \mathrm{E}+00$ & 0.0000 & $0.000 \mathrm{E}+00$ & 0.00 & $0 \mathrm{E}+00$ & 0.00 & $0.000 \mathrm{E}+00$ & 0.0000 & $0.000 \mathrm{E}+00$ & 0000 \\
\hline 228 & $7.446 \mathrm{E}-07$ & 0.9206 & $0.000 \mathrm{E}+00$ & 0.0000 & $0.000 \mathrm{E}+00$ & 0.0000 & $0.000 \mathrm{E}+00$ & 0.0000 & $0.000 \mathrm{E}+00$ & 0.0000 & $0.000 \mathrm{E}+00$ & 0.0000 & $0.000 \mathrm{E}+00$ & 0.0000 \\
\hline 230 & $2.190 \mathrm{E}-09$ & 0.0027 & $0.000 \mathrm{E}+00$ & 0.0000 & $0.000 \mathrm{E}+00$ & 0.0000 & $0.000 \mathrm{E}+00$ & 0.0000 & $0.000 \mathrm{E}+00$ & 0.0000 & $0.000 \mathrm{E}+00$ & 0.0000 & $0.000 \mathrm{E}+00$ & 0.0000 \\
\hline & $5.307 \mathrm{E}-08$ & 0.0656 & $0.000 \mathrm{E}+00$ & 0.0000 & $0.000 \mathrm{E}+00$ & 0.0000 & $0.000 \mathrm{E}+00$ & 0.0000 & $0.000 \mathrm{E}+00$ & 0.0000 & $0.000 \mathrm{E}+00$ & 0.0000 & $0.000 \mathrm{E}+00$ & 0.0000 \\
\hline & $2.455 \mathrm{E}-14$ & 0.0000 & $0.000 \mathrm{E}+00$ & 0.0000 & $0.000 \mathrm{E}+00$ & 0.0000 & $0.000 \mathrm{E}+00$ & 0.0000 & $0.000 \mathrm{E}+00$ & 0.0000 & $0.000 \mathrm{E}+00$ & 0.0000 & $0.000 \mathrm{E}+00$ & 0.0000 \\
\hline & $1.583 \mathrm{E}-14$ & 0.0000 & $0.000 \mathrm{E}+00$ & 0.0000 & $0.000 \mathrm{E}+00$ & 0.0000 & $0.000 \mathrm{E}+00$ & 0.0000 & $0.000 \mathrm{E}+00$ & 0.0000 & $0.000 \mathrm{E}+00$ & 0.0000 & $0.000 \mathrm{E}+00$ & 0.0000 \\
\hline & $4.403 E-09$ & 0.0054 & $0.000 \mathrm{E}+00$ & 0.0000 & $0.000 \mathrm{E}+00$ & 0.0000 & $0.000 \mathrm{E}+00$ & 0.0000 & $0.000 \mathrm{E}+00$ & 0.0000 & $0.000 \mathrm{E}+00$ & 0.0000 & $0.000 \mathrm{E}+00$ & 0.0000 \\
\hline & 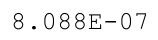 & 00 & $0.000 \mathrm{E}+00$ & 0.0000 & $0.000 \mathrm{E}+00$ & 0.0000 & $0.000 \mathrm{E}+00$ & 0.0000 & $0.000 \mathrm{E}+00$ & 0.0000 & $0.000 \mathrm{E}+00$ & 0.0000 & $E+00$ & 0.00 \\
\hline
\end{tabular}

Total Dose Contributions TDOSE (i,p,t) for Individual Radionuclides (i) and Pathways (p) As mrem/yr and Fraction of Total Dose At $t=1.000 \mathrm{E}+00$ years

Water Dependent Pathways

\begin{tabular}{|c|c|c|c|c|c|c|c|c|c|c|c|c|c|c|}
\hline \multirow[b]{2}{*}{ clide } & \multicolumn{2}{|c|}{ Water } & \multicolumn{2}{|c|}{ Fish } & \multicolumn{2}{|c|}{ Radon } & \multicolumn{2}{|c|}{ Plant } & \multicolumn{2}{|c|}{ Meat } & \multicolumn{2}{|c|}{ Milk } & \multicolumn{2}{|c|}{ All Pathways* } \\
\hline & mrem/yr & fract. & mrem/yr & fract. & mrem/yr & fract. & mrem/yr & fract. & mrem/yr & fract. & mrem/yr & fract. & mrem/yr & fract. \\
\hline 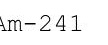 & $0.000 \mathrm{E}+00$ & 0.0000 & $0.000 \mathrm{E}+00$ & 0.0000 & $0.000 \mathrm{E}+00$ & 0.0000 & $0.000 \mathrm{E}+00$ & 0.0000 & $0.000 \mathrm{E}+00$ & 0.0000 & $0.000 \mathrm{E}+00$ & 0.0000 & $3.150 \mathrm{E}-18$ & 0.0000 \\
\hline & $0.000 \mathrm{E}+00$ & 0.0000 & $0.000 \mathrm{E}+00$ & 0.0000 & $0.000 \mathrm{E}+00$ & 0.0000 & $0.000 E+00$ & 0.0000 & $0.000 \mathrm{E}+00$ & 0.0000 & $0.000 \mathrm{E}+00$ & 0.0000 & $4.543 E-09$ & 0.0056 \\
\hline 237 & $0.000 \mathrm{E}+00$ & 0.0000 & $0.000 \mathrm{E}+00$ & 0.0000 & $0.000 \mathrm{E}+00$ & 0.0000 & $0.000 \mathrm{E}+00$ & 0.0000 & $0.000 \mathrm{E}+00$ & 0.0000 & $0.000 \mathrm{E}+00$ & 0.0000 & $1.019 \mathrm{E}-12$ & 0.0000 \\
\hline 8 & $0.000 \mathrm{E}+00$ & 0.0000 & $0.000 \mathrm{E}+00$ & 0.0000 & $0.000 \mathrm{E}+00$ & 0.0000 & $0.000 \mathrm{E}+00$ & 0.0000 & $0.000 \mathrm{E}+00$ & 0.0000 & $0.000 \mathrm{E}+00$ & 0.0000 & -21 & 000 \\
\hline & $0.000 \mathrm{E}+00$ & 0 & 0 . & 0 & $0.000 \mathrm{E}+00$ & & & 0 & & & $000 \mathrm{E}+00$ & & 17 & 00 \\
\hline 40 & $0.000 \mathrm{E}+00$ & 0. & $0.000 \mathrm{E}+00$ & 0 & $0.000 \mathrm{E}+00$ & 0.0000 & $0.000 \mathrm{E}+00$ & 0.0 & $0.000 \mathrm{E}+00$ & 0 & $0.000 \mathrm{E}+00$ & 00 & $222 \mathrm{E}-24$ & 000 \\
\hline & $0.000 \mathrm{E}+00$ & 0.0000 & $0.000 \mathrm{E}+00$ & 0.0000 & $0.000 \mathrm{E}+00$ & 0.0000 & $0.000 \mathrm{E}+00$ & 0.0000 & $0.000 \mathrm{E}+00$ & 0.0000 & $0.000 \mathrm{E}+00$ & 0.0000 & $5.850 \mathrm{E}-25$ & 0.0000 \\
\hline 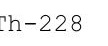 & $0.000 \mathrm{E}+00$ & 0.0000 & $0.000 \mathrm{E}+00$ & 0.0000 & $0.000 \mathrm{E}+00$ & 0.0000 & $0.000 \mathrm{E}+00$ & 0.0000 & $0.000 \mathrm{E}+00$ & 0.0000 & $0.000 \mathrm{E}+00$ & 0.0000 & $7.446 \mathrm{E}-07$ & 0.9206 \\
\hline & $0.000 \mathrm{E}+00$ & 0.0000 & $0.000 \mathrm{E}+00$ & 0.0000 & $0.000 \mathrm{E}+00$ & 0.0000 & $0.000 \mathrm{E}+00$ & 0.0000 & $0.000 \mathrm{E}+00$ & 0.0000 & $0.000 \mathrm{E}+00$ & 0.0000 & $2.190 \mathrm{E}-09$ & 0.0027 \\
\hline & $0.000 \mathrm{E}+00$ & 0.0000 & $0.000 \mathrm{E}+00$ & 0.0000 & $0.000 \mathrm{E}+00$ & 0.0000 & $0.000 \mathrm{E}+00$ & 0.0000 & $0.000 \mathrm{E}+00$ & 0.0000 & $0.000 \mathrm{E}+00$ & 0.0000 & $5.307 \mathrm{E}-08$ & 0.0656 \\
\hline & $0.000 \mathrm{E}+00$ & 0.0000 & $0.000 \mathrm{E}+00$ & 0.0000 & $0.000 \mathrm{E}+00$ & 0.0000 & $0.000 E+00$ & 0.0000 & $0.000 \mathrm{E}+00$ & 0.0000 & $0.000 \mathrm{E}+00$ & 0.0000 & $2.455 \mathrm{E}-14$ & 0.0000 \\
\hline & $0.000 \mathrm{E}+00$ & 0.0000 & $0.000 \mathrm{E}+00$ & 0.0000 & $0.000 \mathrm{E}+00$ & 0.0000 & $0.000 \mathrm{E}+00$ & 0.0000 & $0.000 \mathrm{E}+00$ & 0.0000 & $0.000 \mathrm{E}+00$ & 0.0000 & $1.583 \mathrm{E}-14$ & 0.0000 \\
\hline & $0.000 \mathrm{E}+00$ & 0.0000 & $0.000 \mathrm{E}+00$ & 0.0000 & $0.000 \mathrm{E}+00$ & 0.0000 & $0.000 \mathrm{E}+00$ & 0.0000 & $0.000 \mathrm{E}+00$ & 0.0000 & $0.000 \mathrm{E}+00$ & 0.0000 & $4.403 E-09$ & 0.0054 \\
\hline & & 00 & $.000 \mathrm{E}+00$ & 0.0000 & $0.000 \mathrm{E}+00$ & 0.0000 & $0.000 \mathrm{E}+00$ & 0.0000 & $0.000 \mathrm{E}+00$ & & +00 & & -07 & \\
\hline
\end{tabular}

* Sum of all water independent and dependent pathways. 
RESRAD, Version $6.5 \quad$ T1/2 Limit $=180$ days
Summary : RESRAD Parameters for U-Landfill Recreational User Foward Run at Proposed ALs

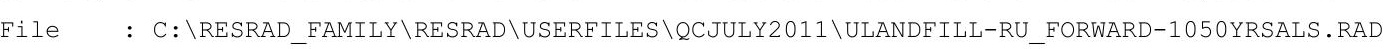

Total Dose Contributions TDOSE (i,p,t) for Individual Radionuclides (i) and Pathways (p) As mrem/yr and Fraction of Total Dose At $t=1.200 \mathrm{E}+01$ years

Water Independent Pathways (Inhalation excludes radon)

\begin{tabular}{|c|c|c|c|c|c|c|c|c|c|c|c|c|c|c|}
\hline \multirow{2}{*}{ Nuclide } & \multicolumn{2}{|c|}{ Ground } & \multicolumn{2}{|c|}{ Inhalation } & \multicolumn{2}{|c|}{ Radon } & \multicolumn{2}{|c|}{ Plant } & \multicolumn{2}{|c|}{ Meat } & \multicolumn{2}{|c|}{ Milk } & \multicolumn{2}{|c|}{ Soil } \\
\hline & mrem/yr & fract. & mrem/yr & fract. & mrem/yr & fract. & mrem/yr & fract. & mrem/yr & fract. & mrem/yr & fract. & mrem/yr & fract. \\
\hline-241 & $2.928 E-17$ & 0.0000 & $0.000 \mathrm{E}+00$ & 0.0000 & $0.000 \mathrm{E}+00$ & 0.0000 & $0.000 \mathrm{E}+00$ & 0.0000 & $0.000 \mathrm{E}+00$ & 0.0000 & $0.000 \mathrm{E}+00$ & 0.0000 & $0.000 \mathrm{E}+00$ & 0.0000 \\
\hline-137 & $3.865 E-09$ & 0.0040 & $0.000 \mathrm{E}+00$ & 0.0000 & $0.000 \mathrm{E}+00$ & 0.0000 & $0.000 \mathrm{E}+00$ & 0.0000 & $0.000 \mathrm{E}+00$ & 0.0000 & $0.000 \mathrm{E}+00$ & 0.0000 & $0.000 \mathrm{E}+00$ & 0.0000 \\
\hline-237 & $1.147 \mathrm{E}-12$ & 0.0000 & $0.000 \mathrm{E}+00$ & 0.0000 & $0.000 \mathrm{E}+00$ & 0.0000 & $0.000 \mathrm{E}+00$ & 0.0000 & $0.000 \mathrm{E}+00$ & 0.0000 & $0.000 \mathrm{E}+00$ & 0.0000 & $0.000 \mathrm{E}+00$ & 0.0000 \\
\hline-238 & $4.982 \mathrm{E}-18$ & 0.0000 & $0.000 \mathrm{E}+00$ & 0.0000 & $0.000 \mathrm{E}+00$ & 0.0000 & $0.000 \mathrm{E}+00$ & 0.0000 & $0.000 \mathrm{E}+00$ & 0.0000 & $0.000 \mathrm{E}+00$ & 0.0000 & $0.000 \mathrm{E}+00$ & 0.0000 \\
\hline-239 & $9.605 \mathrm{E}-17$ & 0.0000 & $0.000 \mathrm{E}+00$ & 0.0000 & $0.000 \mathrm{E}+00$ & 0.0000 & $0.000 \mathrm{E}+00$ & 0.0000 & $0.000 \mathrm{E}+00$ & 0.0000 & $0.000 \mathrm{E}+00$ & 0.0000 & $0.000 \mathrm{E}+00$ & 0.0000 \\
\hline-240 & $3.105 \mathrm{E}-22$ & 0.0000 & $0.000 \mathrm{E}+00$ & 0.0000 & $0.000 \mathrm{E}+00$ & 0.0000 & $0.000 \mathrm{E}+00$ & 0.0000 & $0.000 \mathrm{E}+00$ & 0.0000 & $0.000 \mathrm{E}+00$ & 0.0000 & $0.000 \mathrm{E}+00$ & 0.0000 \\
\hline 99 & $6.817 \mathrm{E}-25$ & 0.0000 & $0.000 \mathrm{E}+00$ & 0.0000 & $0.000 \mathrm{E}+00$ & 0.0000 & $0.000 \mathrm{E}+00$ & 0.0000 & $0.000 \mathrm{E}+00$ & 0.0000 & $0.000 \mathrm{E}+00$ & 0.0000 & $0.000 \mathrm{E}+00$ & 0.0000 \\
\hline-228 & $1.478 \mathrm{E}-08$ & 0.0152 & $0.000 \mathrm{E}+00$ & 0.0000 & $0.000 \mathrm{E}+00$ & 0.0000 & $0.000 \mathrm{E}+00$ & 0.0000 & $0.000 \mathrm{E}+00$ & 0.0000 & $0.000 \mathrm{E}+00$ & 0.0000 & $0.000 \mathrm{E}+00$ & 0.0000 \\
\hline 230 & $1.964 \mathrm{E}-08$ & 0.0202 & $0.000 \mathrm{E}+00$ & 0.0000 & $0.000 \mathrm{E}+00$ & 0.0000 & $0.000 \mathrm{E}+00$ & 0.0000 & $0.000 \mathrm{E}+00$ & 0.0000 & $0.000 \mathrm{E}+00$ & 0.0000 & $0.000 \mathrm{E}+00$ & 0.0000 \\
\hline-232 & $9.293 E-07$ & 0.9557 & $0.000 \mathrm{E}+00$ & 0.0000 & $0.000 \mathrm{E}+00$ & 0.0000 & $0.000 \mathrm{E}+00$ & 0.0000 & $0.000 \mathrm{E}+00$ & 0.0000 & $0.000 \mathrm{E}+00$ & 0.0000 & $0.000 \mathrm{E}+00$ & 0.0000 \\
\hline 34 & $1.771 \mathrm{E}-12$ & 0.0000 & $0.000 \mathrm{E}+00$ & 0.0000 & $0.000 \mathrm{E}+00$ & 0.0000 & $0.000 \mathrm{E}+00$ & 0.0000 & $0.000 \mathrm{E}+00$ & 0.0000 & $0.000 \mathrm{E}+00$ & 0.0000 & $0.000 \mathrm{E}+00$ & 0.0000 \\
\hline 35 & $2.347 \mathrm{E}-14$ & 0.0000 & $0.000 \mathrm{E}+00$ & 0.0000 & $0.000 \mathrm{E}+00$ & 0.0000 & $0.000 \mathrm{E}+00$ & 0.0000 & $0.000 \mathrm{E}+00$ & 0.0000 & $0.000 \mathrm{E}+00$ & 0.0000 & $0.000 \mathrm{E}+00$ & 0.0000 \\
\hline 38 & $4.808 E-09$ & 0.0049 & $0.000 \mathrm{E}+00$ & 0.0000 & $0.000 \mathrm{E}+00$ & 0.0000 & $0.000 \mathrm{E}+00$ & 0.0000 & $0.000 \mathrm{E}+00$ & 0.0000 & $0.000 \mathrm{E}+00$ & 0.0000 & $0.000 \mathrm{E}+00$ & 0.0000 \\
\hline & $9.723 E-07$ & 1.0000 & $0.000 \mathrm{E}+00$ & 0.0000 & $0.000 \mathrm{E}+00$ & 0.0000 & $0.000 \mathrm{E}+00$ & 0.0000 & $0.000 \mathrm{E}+00$ & 0.0000 & $0.000 \mathrm{E}+00$ & 0.0000 & $.000 \mathrm{E}+00$ & 0.0000 \\
\hline
\end{tabular}

Total Dose Contributions TDOSE(i,p,t) for Individual Radionuclides (i) and Pathways (p) As mrem/yr and Fraction of Total Dose At $t=1.200 \mathrm{E}+01$ years

Water Dependent Pathways

\begin{tabular}{|c|c|c|c|c|c|c|c|c|c|c|c|c|c|c|}
\hline \multirow{2}{*}{ Nuclide } & \multicolumn{2}{|c|}{ Water } & \multicolumn{2}{|c|}{ Fish } & \multicolumn{2}{|c|}{ Radon } & \multicolumn{2}{|c|}{ Plant } & \multicolumn{2}{|c|}{ Meat } & \multicolumn{2}{|c|}{ Milk } & \multicolumn{2}{|c|}{ All Pathways* } \\
\hline & mrem/yr & fract. & mrem/yr & fract. & mrem/yr & fract. & mrem/yr & fract. & mrem/yr & fract. & mrem/yr & fract. & mrem/yr & fract. \\
\hline-241 & $0.000 \mathrm{E}+00$ & 0.0000 & $0.000 \mathrm{E}+00$ & 0.0000 & $0.000 \mathrm{E}+00$ & 0.0000 & $0.000 \mathrm{E}+00$ & 0.0000 & $0.000 \mathrm{E}+00$ & 0.0000 & $0.000 E+00$ & 0.0000 & $2.928 \mathrm{E}-17$ & 0.0000 \\
\hline-137 & $0.000 \mathrm{E}+00$ & 0.0000 & $0.000 \mathrm{E}+00$ & 0.0000 & $0.000 \mathrm{E}+00$ & 0.0000 & $0.000 \mathrm{E}+00$ & 0.0000 & $0.000 \mathrm{E}+00$ & 0.0000 & $0.000 \mathrm{E}+00$ & 0.0000 & $3.865 E-09$ & 0.0040 \\
\hline-237 & $0.000 \mathrm{E}+00$ & 0.0000 & $0.000 \mathrm{E}+00$ & 0.0000 & $0.000 \mathrm{E}+00$ & 0.0000 & $0.000 \mathrm{E}+00$ & 0.0000 & $0.000 \mathrm{E}+00$ & 0.0000 & $0.000 \mathrm{E}+00$ & 0.0000 & $1.147 \mathrm{E}-12$ & 0.0000 \\
\hline-238 & $0.000 \mathrm{E}+00$ & 0.0000 & $0.000 \mathrm{E}+00$ & 0.0000 & $0.000 \mathrm{E}+00$ & 0.0000 & $0.000 \mathrm{E}+00$ & 0.0000 & $0.000 \mathrm{E}+00$ & 0.0000 & $0.000 \mathrm{E}+00$ & 0.0000 & $4.982 \mathrm{E}-18$ & 0.0000 \\
\hline-239 & $0.000 \mathrm{E}+00$ & 0.0000 & $0.000 \mathrm{E}+00$ & 0.0000 & $0.000 \mathrm{E}+00$ & 0.0000 & $0.000 \mathrm{E}+00$ & 0.0000 & $0.000 \mathrm{E}+00$ & 0.0000 & $0.000 \mathrm{E}+00$ & 0.0000 & $9.605 \mathrm{E}-17$ & 0.0000 \\
\hline-240 & $0.000 \mathrm{E}+00$ & 0.0000 & $0.000 \mathrm{E}+00$ & 0.0000 & $0.000 \mathrm{E}+00$ & 0.0000 & $0.000 \mathrm{E}+00$ & 0.0000 & $0.000 \mathrm{E}+00$ & 0.0000 & $0.000 \mathrm{E}+00$ & 0.0000 & $3.105 \mathrm{E}-22$ & 0.0000 \\
\hline-99 & $0.000 \mathrm{E}+00$ & 0.0000 & $0.000 \mathrm{E}+00$ & 0.0000 & $0.000 \mathrm{E}+00$ & 0.0000 & $0.000 \mathrm{E}+00$ & 0.0000 & $0.000 \mathrm{E}+00$ & 0.0000 & $0.000 \mathrm{E}+00$ & 0.0000 & $6.817 \mathrm{E}-25$ & 0.0000 \\
\hline-228 & $0.000 \mathrm{E}+00$ & 0.0000 & $0.000 \mathrm{E}+00$ & 0.0000 & $0.000 \mathrm{E}+00$ & 0.0000 & $0.000 \mathrm{E}+00$ & 0.0000 & $0.000 \mathrm{E}+00$ & 0.0000 & $0.000 \mathrm{E}+00$ & 0.0000 & $1.478 \mathrm{E}-08$ & 0.0152 \\
\hline-230 & $0.000 \mathrm{E}+00$ & 0.0000 & $0.000 \mathrm{E}+00$ & 0.0000 & $0.000 \mathrm{E}+00$ & 0.0000 & $0.000 \mathrm{E}+00$ & 0.0000 & $0.000 \mathrm{E}+00$ & 0.0000 & $0.000 \mathrm{E}+00$ & 0.0000 & $1.964 \mathrm{E}-08$ & 0.0202 \\
\hline 232 & $0.000 \mathrm{E}+00$ & 0.0000 & $0.000 \mathrm{E}+00$ & 0.0000 & $0.000 \mathrm{E}+00$ & 0.0000 & $0.000 \mathrm{E}+00$ & 0.0000 & $0.000 \mathrm{E}+00$ & 0.0000 & $0.000 \mathrm{E}+00$ & 0.0000 & $9.293 \mathrm{E}-07$ & 0.9557 \\
\hline 34 & $0.000 \mathrm{E}+00$ & 0.0000 & $0.000 \mathrm{E}+00$ & 0.0000 & $0.000 \mathrm{E}+00$ & 0.0000 & $0.000 \mathrm{E}+00$ & 0.0000 & $0.000 \mathrm{E}+00$ & 0.0000 & $0.000 \mathrm{E}+00$ & 0.0000 & $1.771 \mathrm{E}-12$ & 0.0000 \\
\hline 35 & $0.000 \mathrm{E}+00$ & 0.0000 & $0.000 \mathrm{E}+00$ & 0.0000 & $0.000 \mathrm{E}+00$ & 0.0000 & $0.000 \mathrm{E}+00$ & 0.0000 & $0.000 \mathrm{E}+00$ & 0.0000 & $0.000 \mathrm{E}+00$ & 0.0000 & $2.347 \mathrm{E}-14$ & 0.0000 \\
\hline 38 & $0.000 \mathrm{E}+00$ & 0.0000 & $0.000 \mathrm{E}+00$ & 0.0000 & $0.000 \mathrm{E}+00$ & 0.0000 & $0.000 \mathrm{E}+00$ & 0.0000 & $0.000 \mathrm{E}+00$ & 0.0000 & $0.000 \mathrm{E}+00$ & 0.0000 & $4.808 \mathrm{E}-09$ & 0.0049 \\
\hline & $0.000 \mathrm{E}+00$ & 0.0000 & $0.000 \mathrm{E}+00$ & 0.0000 & $0.000 \mathrm{E}+00$ & 0.0000 & $0.000 \mathrm{E}+00$ & 0.0000 & $0.000 \mathrm{E}+00$ & 0.0000 & $0.000 \mathrm{E}+00$ & 0.0000 & $3 E-07$ & 1.0000 \\
\hline
\end{tabular}

* Sum of all water independent and dependent pathways. 
RESRAD, Version $6.5 \quad$ T $1 \frac{1}{2}$ Limit $=180$ days $\quad 07 / 20 / 2011 \quad 15: 08$ Page 23
Summary : RESRAD Parameters for U-Landfill Recreational User Foward Run at Proposed ALs

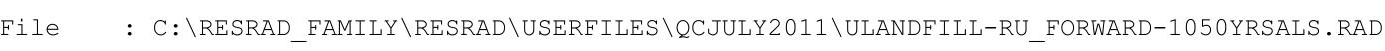

Total Dose Contributions TDOSE (i,p,t) for Individual Radionuclides (i) and Pathways (p) As mrem/yr and Fraction of Total Dose At $t=5.000 \mathrm{E}+01$ years

Water Independent Pathways (Inhalation excludes radon)

\begin{tabular}{|c|c|c|c|c|c|c|c|c|c|c|c|c|c|c|}
\hline \multirow[b]{2}{*}{ clide } & \multicolumn{2}{|c|}{ Ground } & \multicolumn{2}{|c|}{ Inhalation } & \multicolumn{2}{|c|}{ Radon } & \multicolumn{2}{|c|}{ Plant } & \multicolumn{2}{|c|}{ Meat } & \multicolumn{2}{|c|}{ Milk } & \multicolumn{2}{|l|}{ Soil } \\
\hline & mrem/yr & fract. & mrem/yr & fract. & mrem/yr & fract. & mrem/yr & fract. & mrem/yr & fract. & mrem/yr & fract. & mrem/yr & fract. \\
\hline 241 & $1.728 \mathrm{E}-16$ & 0.0000 & $0.000 \mathrm{E}+00$ & 0.0000 & $0.000 \mathrm{E}+00$ & 0.0000 & $0.000 \mathrm{E}+00$ & 0.0000 & $0.000 \mathrm{E}+00$ & 0.0000 & $0.000 \mathrm{E}+00$ & 0.0000 & $0.000 \mathrm{E}+00$ & 0000 \\
\hline 37 & $2.212 \mathrm{E}-09$ & 0.0012 & $0.000 \mathrm{E}+00$ & 0.0000 & $0.000 \mathrm{E}+00$ & 0.0000 & $0.000 \mathrm{E}+00$ & 0.0000 & $0.000 \mathrm{E}+00$ & 0.0000 & $0.000 \mathrm{E}+00$ & 0.0000 & $0.000 \mathrm{E}+00$ & 0.0000 \\
\hline 37 & $1.727 \mathrm{E}-12$ & 0.0000 & $0.000 \mathrm{E}+00$ & 0.0000 & $0.000 \mathrm{E}+00$ & 0.0000 & $0.000 \mathrm{E}+00$ & 0.0000 & $0.000 \mathrm{E}+00$ & 0.0000 & $0.000 \mathrm{E}+00$ & 0.0000 & $0.000 \mathrm{E}+00$ & 0.0000 \\
\hline 238 & $3.951 \mathrm{E}-16$ & 0.0000 & $0.000 \mathrm{E}+00$ & 0.0000 & $0.000 \mathrm{E}+00$ & 0.0000 & $0.000 \mathrm{E}+00$ & 0.0000 & $0.000 \mathrm{E}+00$ & 0.0000 & $0.000 \mathrm{E}+00$ & 0.0000 & $0.000 \mathrm{E}+00$ & 0.0000 \\
\hline 239 & $1.512 \mathrm{E}-16$ & 0.0000 & $0.000 \mathrm{E}+00$ & 0.0000 & $0.000 \mathrm{E}+00$ & 0.0000 & $0.000 \mathrm{E}+00$ & 0.0000 & $0.000 \mathrm{E}+00$ & 0.0000 & $0.000 \mathrm{E}+00$ & 0.0000 & $0.000 \mathrm{E}+00$ & 0.0000 \\
\hline 240 & $1.857 \mathrm{E}-20$ & 0.0000 & $0.000 \mathrm{E}+00$ & 0.0000 & $0.000 \mathrm{E}+00$ & 0.0000 & $0.000 \mathrm{E}+00$ & 0.0000 & $0.000 \mathrm{E}+00$ & 0.0000 & $0.000 \mathrm{E}+00$ & 0.0000 & $0.000 \mathrm{E}+00$ & 0.0000 \\
\hline & $1.157 \mathrm{E}-24$ & 0.0000 & $0.000 \mathrm{E}+00$ & 0.0000 & $0.000 \mathrm{E}+00$ & 0.0000 & $0.000 \mathrm{E}+00$ & 0.00 & $0.000 \mathrm{E}+00$ & 00 & $0.000 \mathrm{E}+00$ & 0.0000 & $0.000 \mathrm{E}+00$ & 0.0000 \\
\hline 8 & $1.944 \mathrm{E}-14$ & 0.0000 & $0.000 \mathrm{E}+00$ & 0.0000 & $0.000 \mathrm{E}+00$ & 0.0000 & $0.000 \mathrm{E}+00$ & 0.00 & $0.000 \mathrm{E}+00$ & 0.0000 & $0.000 \mathrm{E}+00$ & 0.0000 & $0.000 \mathrm{E}+00$ & 0.0000 \\
\hline 0 & $1.023 \mathrm{E}-07$ & 0.0558 & $0.000 \mathrm{E}+00$ & 0.0000 & $0.000 \mathrm{E}+00$ & 0.0000 & $0.000 \mathrm{E}+00$ & 0.0000 & $0.000 \mathrm{E}+00$ & 0.0000 & $0.000 \mathrm{E}+00$ & 0.0000 & $0.000 \mathrm{E}+00$ & 0.0000 \\
\hline 232 & $1.724 \mathrm{E}-06$ & 0.9395 & $0.000 \mathrm{E}+00$ & 0.0000 & $0.000 \mathrm{E}+00$ & 0.0000 & $0.000 \mathrm{E}+00$ & 0.0000 & $0.000 \mathrm{E}+00$ & 0.0000 & $0.000 \mathrm{E}+00$ & 0.0000 & $0.000 \mathrm{E}+00$ & 0.0000 \\
\hline & $3.735 \mathrm{E}-11$ & 0.0000 & $0.000 \mathrm{E}+00$ & 0.0000 & $0.000 \mathrm{E}+00$ & 0.0000 & $0.000 \mathrm{E}+00$ & 0.0000 & $0.000 \mathrm{E}+00$ & 0.0000 & $0.000 \mathrm{E}+00$ & 0.0000 & $0.000 \mathrm{E}+00$ & 0.0000 \\
\hline & $1.155 \mathrm{E}-13$ & 0.0000 & $0.000 \mathrm{E}+00$ & 0.0000 & $0.000 \mathrm{E}+00$ & 0.0000 & $0.000 \mathrm{E}+00$ & 0.0000 & $0.000 \mathrm{E}+00$ & 0.0000 & $0.000 \mathrm{E}+00$ & 0.0000 & $0.000 \mathrm{E}+00$ & 0.0000 \\
\hline & $6.513 \mathrm{E}-09$ & 0.0035 & $0.000 \mathrm{E}+00$ & 0.0000 & $0.000 \mathrm{E}+00$ & 0.0000 & $0.000 \mathrm{E}+00$ & 0.0000 & $0.000 \mathrm{E}+00$ & 0.0000 & $0.000 \mathrm{E}+00$ & 0.0000 & $0.000 \mathrm{E}+00$ & 0.0000 \\
\hline & 0 & - & $.000 \mathrm{E}+00$ & . 000 & $.000 E+00$ & 0.0000 & $.000 \mathrm{E}+00$ & . & $0.000 \mathrm{E}+00$ & 0.0000 & . & . & $0.000 \mathrm{E}+00$ & \\
\hline
\end{tabular}

Total Dose Contributions TDOSE (i,p,t) for Individual Radionuclides (i) and Pathways (p) As mrem/yr and Fraction of Total Dose At $t=5.000 \mathrm{E}+01$ years

Water Dependent Pathways

\begin{tabular}{|c|c|c|c|c|c|c|c|c|c|c|c|c|c|c|}
\hline \multirow[b]{2}{*}{ clide } & \multicolumn{2}{|c|}{ Water } & \multicolumn{2}{|c|}{ Fish } & \multicolumn{2}{|c|}{ Radon } & \multicolumn{2}{|c|}{ Plant } & \multicolumn{2}{|c|}{ Meat } & \multicolumn{2}{|c|}{ Milk } & \multicolumn{2}{|c|}{ All Pathways* } \\
\hline & mrem/yr & fract. & mrem/yr & fract. & $\mathrm{mrem} / \mathrm{yr}$ & fract. & mrem/yr & fract. & mrem/yr & fract. & mrem/yr & fract. & mrem/yr & fract. \\
\hline 1 & $0.000 \mathrm{E}+00$ & 0.0000 & $0.000 \mathrm{E}+00$ & 0.0000 & $0.000 \mathrm{E}+00$ & 0.0000 & $0.000 \mathrm{E}+00$ & 0.0000 & $0.000 \mathrm{E}+00$ & 0.0000 & $0.000 \mathrm{E}+00$ & 0.0000 & $1.728 \mathrm{E}-16$ & 0.0000 \\
\hline 37 & $0.000 \mathrm{E}+00$ & 0.0000 & $0.000 \mathrm{E}+00$ & 0.0000 & $0.000 \mathrm{E}+00$ & 0.0000 & $0.000 \mathrm{E}+00$ & 0.0000 & $0.000 \mathrm{E}+00$ & 0.0000 & $0.000 \mathrm{E}+00$ & 0.0000 & $2.212 \mathrm{E}-09$ & 0.0012 \\
\hline 37 & $0.000 \mathrm{E}+00$ & 0.0000 & $0.000 \mathrm{E}+00$ & 0.0000 & $0.000 \mathrm{E}+00$ & 0.0000 & $0.000 \mathrm{E}+00$ & 0.0000 & $0.000 \mathrm{E}+00$ & 0.0000 & $0.000 \mathrm{E}+00$ & 0.0000 & $1.727 \mathrm{E}-12$ & 0.0000 \\
\hline 238 & $0.000 \mathrm{E}+00$ & 0.0000 & $0.000 \mathrm{E}+00$ & 0.0000 & $0.000 \mathrm{E}+00$ & 0.0000 & $0.000 \mathrm{E}+00$ & 0.0000 & $0.000 \mathrm{E}+00$ & 0.0000 & $0.000 \mathrm{E}+00$ & 0.0000 & $3.951 \mathrm{E}-16$ & 0.0000 \\
\hline 239 & $0.000 \mathrm{E}+00$ & 0.0000 & $0.000 \mathrm{E}+00$ & 0.0000 & $0.000 \mathrm{E}+00$ & 0.0000 & $0.000 \mathrm{E}+00$ & 0.0000 & $0.000 \mathrm{E}+00$ & 0.0000 & $0.000 \mathrm{E}+00$ & 0.0000 & $1.512 \mathrm{E}-16$ & 0.0000 \\
\hline 240 & $0.000 \mathrm{E}+00$ & 0.0 & 0.00 & 0 & $0.000 \mathrm{E}+00$ & 0 & $0.000 \mathrm{E}+00$ & 0 & 0 & 0 & $0.000 \mathrm{E}+00$ & 0 & -20 & 000 \\
\hline & $0.000 \mathrm{E}+00$ & 0.0 & $0.000 \mathrm{E}+00$ & 0.0000 & $0.000 \mathrm{E}+00$ & 0.0000 & $0.000 \mathrm{E}+00$ & 0.00 & $0.000 \mathrm{E}+00$ & 0.0000 & $0.000 \mathrm{E}+00$ & 0 . & $1.157 \mathrm{E}-24$ & 0.0000 \\
\hline 228 & $0.000 \mathrm{E}+00$ & 0.0000 & $0.000 \mathrm{E}+00$ & 0.0000 & $0.000 \mathrm{E}+00$ & 0.0000 & $0.000 \mathrm{E}+00$ & 0.0000 & $0.000 \mathrm{E}+00$ & 0.0000 & $0.000 \mathrm{E}+00$ & 0.0000 & $1.944 \mathrm{E}-14$ & 0.0000 \\
\hline & $0.000 \mathrm{E}+00$ & 0.0000 & $0.000 \mathrm{E}+00$ & 0.0000 & $0.000 \mathrm{E}+00$ & 0.0000 & $0.000 \mathrm{E}+00$ & 0.0000 & $0.000 \mathrm{E}+00$ & 0.0000 & $0.000 \mathrm{E}+00$ & 0.0000 & $1.023 \mathrm{E}-07$ & 0.0558 \\
\hline & $0.000 \mathrm{E}+00$ & 0.0000 & $0.000 \mathrm{E}+00$ & 0.0000 & $0.000 \mathrm{E}+00$ & 0.0000 & $0.000 \mathrm{E}+00$ & 0.0000 & $0.000 \mathrm{E}+00$ & 0.0000 & $0.000 \mathrm{E}+00$ & 0.0000 & $1.724 \mathrm{E}-06$ & 0.9395 \\
\hline & $0.000 \mathrm{E}+00$ & 0.0000 & $0.000 \mathrm{E}+00$ & 0.0000 & $0.000 \mathrm{E}+00$ & 0.0000 & $0.000 \mathrm{E}+00$ & 0.0000 & $0.000 \mathrm{E}+00$ & 0.0000 & $0.000 \mathrm{E}+00$ & 0.0000 & $3.735 \mathrm{E}-11$ & 0.0000 \\
\hline & $0.000 \mathrm{E}+00$ & 0.0000 & $0.000 \mathrm{E}+00$ & 0.0000 & $0.000 \mathrm{E}+00$ & 0.0000 & $0.000 \mathrm{E}+00$ & 0.0000 & $0.000 \mathrm{E}+00$ & 0.0000 & $0.000 \mathrm{E}+00$ & 0.0000 & $1.155 \mathrm{E}-13$ & 0.0000 \\
\hline & $0.000 \mathrm{E}+00$ & 0.0000 & $0.000 \mathrm{E}+00$ & 0.0000 & $0.000 \mathrm{E}+00$ & 0.0000 & $0.000 \mathrm{E}+00$ & 0.0000 & $0.000 \mathrm{E}+00$ & 0.0000 & $0.000 \mathrm{E}+00$ & 0.0000 & $6.513 \mathrm{E}-09$ & 0.0035 \\
\hline & & 00 & $0.000 \mathrm{E}+00$ & 0.0000 & $.000 \mathrm{E}+00$ & 0.0000 & $0.000 \mathrm{E}+00$ & 0.0000 & $0.000 \mathrm{E}+00$ & 0.0000 & +0 & & & 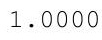 \\
\hline
\end{tabular}

* Sum of all water independent and dependent pathways. 
RESRAD, Version $6.5 \quad$ T $1 \frac{1}{2}$ Limit $=180$ days $\quad 07 / 20 / 2011 \quad 15: 08$ Page 24
Summary : RESRAD Parameters for U-Landfill Recreational User Foward Run at Proposed ALs

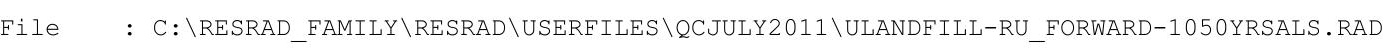

Total Dose Contributions TDOSE (i,p,t) for Individual Radionuclides (i) and Pathways (p) As mrem/yr and Fraction of Total Dose At $t=1.000 \mathrm{E}+02$ years

Water Independent Pathways (Inhalation excludes radon)

\begin{tabular}{|c|c|c|c|c|c|c|c|c|c|c|c|c|c|c|}
\hline \multirow[b]{2}{*}{ clide } & \multicolumn{2}{|c|}{ Ground } & \multicolumn{2}{|c|}{ Inhalation } & \multicolumn{2}{|c|}{ Radon } & \multicolumn{2}{|c|}{ Plant } & \multicolumn{2}{|c|}{ Meat } & \multicolumn{2}{|c|}{ Milk } & \multicolumn{2}{|l|}{ Soil } \\
\hline & mrem/yr & fract. & mrem/yr & fract. & mrem/yr & fract. & mrem/yr & fract. & mrem/yr & fract. & mrem/yr & fract. & mrem/yr & fract. \\
\hline 241 & $5.671 \mathrm{E}-16$ & 0.0000 & $0.000 \mathrm{E}+00$ & 0.0000 & $0.000 \mathrm{E}+00$ & 0.0000 & $0.000 \mathrm{E}+00$ & 0.0000 & $0.000 \mathrm{E}+00$ & 0.0000 & $0.000 \mathrm{E}+00$ & 0.0000 & $0.000 \mathrm{E}+00$ & 0000 \\
\hline 37 & $1.061 \mathrm{E}-09$ & 0.0004 & $0.000 \mathrm{E}+00$ & 0.0000 & $0.000 \mathrm{E}+00$ & 0.0000 & $0.000 \mathrm{E}+00$ & 0.0000 & $0.000 \mathrm{E}+00$ & 0.0000 & $0.000 \mathrm{E}+00$ & 0.0000 & $0.000 \mathrm{E}+00$ & .0000 \\
\hline 37 & $2.966 \mathrm{E}-12$ & 0.0000 & $0.000 \mathrm{E}+00$ & 0.0000 & $0.000 \mathrm{E}+00$ & 0.0000 & $0.000 \mathrm{E}+00$ & 0.0000 & $0.000 \mathrm{E}+00$ & 0.0000 & $0.000 \mathrm{E}+00$ & 0.0000 & $0.000 \mathrm{E}+00$ & 0.0000 \\
\hline 238 & $3.995 \mathrm{E}-15$ & 0.0000 & $0.000 \mathrm{E}+00$ & 0.0000 & $0.000 \mathrm{E}+00$ & 0.0000 & $0.000 \mathrm{E}+00$ & 0.0000 & $0.000 \mathrm{E}+00$ & 0.0000 & $0.000 \mathrm{E}+00$ & 0.0000 & $0.000 \mathrm{E}+00$ & 0.0000 \\
\hline 239 & $2.748 \mathrm{E}-16$ & 0.0000 & $0.000 \mathrm{E}+00$ & 0.0000 & $0.000 \mathrm{E}+00$ & 0.0000 & $0.000 \mathrm{E}+00$ & 0.0000 & $0.000 \mathrm{E}+00$ & 0.0000 & $0.000 \mathrm{E}+00$ & 0.0000 & $0.000 \mathrm{E}+00$ & 0.0000 \\
\hline 240 & $1.235 \mathrm{E}-19$ & 0.0000 & $0.000 \mathrm{E}+00$ & 0.0000 & $0.000 \mathrm{E}+00$ & 0.0000 & $0.000 \mathrm{E}+00$ & 0.0000 & $0.000 \mathrm{E}+00$ & 0.0000 & $0.000 \mathrm{E}+00$ & 0.0000 & $0.000 \mathrm{E}+00$ & 0.0000 \\
\hline & $2.320 \mathrm{E}-24$ & 0.0000 & $0.000 \mathrm{E}+00$ & 0.0000 & $0.000 \mathrm{E}+00$ & 0.0000 & $0.000 \mathrm{E}+00$ & 0.00 & $0.000 \mathrm{E}+00$ & 00 & $0.000 \mathrm{E}+00$ & 0.0000 & $0.000 \mathrm{E}+00$ & 0.0000 \\
\hline 8 & $3.553 \mathrm{E}-22$ & 0.0000 & $0.000 \mathrm{E}+00$ & 0.0000 & $0.000 \mathrm{E}+00$ & 0.0000 & $0.000 \mathrm{E}+00$ & 0.0000 & $0.000 \mathrm{E}+00$ & 0.0000 & $0.000 \mathrm{E}+00$ & 0.0000 & $0.000 \mathrm{E}+00$ & 0.0000 \\
\hline 0 & $2.846 \mathrm{E}-07$ & 0.1082 & $0.000 \mathrm{E}+00$ & 0.0000 & $0.000 \mathrm{E}+00$ & 0.0000 & $0.000 \mathrm{E}+00$ & 0.0000 & $0.000 \mathrm{E}+00$ & 0.0000 & $0.000 \mathrm{E}+00$ & 0.0000 & $0.000 \mathrm{E}+00$ & 0.0000 \\
\hline 2 & $2.333 \mathrm{E}-06$ & 0.8876 & $0.000 \mathrm{E}+00$ & 0.0000 & $0.000 \mathrm{E}+00$ & 0.0000 & $0.000 \mathrm{E}+00$ & 0.0000 & $0.000 \mathrm{E}+00$ & 0.0000 & $0.000 \mathrm{E}+00$ & 0.0000 & $0.000 \mathrm{E}+00$ & 0.0000 \\
\hline & $2.074 \mathrm{E}-10$ & 0.0001 & $0.000 \mathrm{E}+00$ & 0.0000 & $0.000 \mathrm{E}+00$ & 0.0000 & $0.000 \mathrm{E}+00$ & 0.0000 & $0.000 \mathrm{E}+00$ & 0.0000 & $0.000 \mathrm{E}+00$ & 0.0000 & $0.000 \mathrm{E}+00$ & 0.0000 \\
\hline & $4.238 \mathrm{E}-13$ & 0.0000 & $0.000 \mathrm{E}+00$ & 0.0000 & $0.000 \mathrm{E}+00$ & 0.0000 & $0.000 \mathrm{E}+00$ & 0.0000 & $0.000 \mathrm{E}+00$ & 0.0000 & $0.000 \mathrm{E}+00$ & 0.0000 & $0.000 \mathrm{E}+00$ & 0.0000 \\
\hline & $9.712 \mathrm{E}-09$ & 0.0037 & $0.000 \mathrm{E}+00$ & 0.0000 & $0.000 \mathrm{E}+00$ & 0.0000 & $0.000 \mathrm{E}+00$ & 0.0000 & $0.000 \mathrm{E}+00$ & 0.0000 & $0.000 \mathrm{E}+00$ & 0.0000 & $0.000 \mathrm{E}+00$ & 0.0000 \\
\hline & 0 & - & $.000 \mathrm{E}+00$ & . 000 & $.000 E+00$ & 0.0000 & $.000 \mathrm{E}+00$ & . & $0.000 \mathrm{E}+00$ & 0.0000 & . & . & $0.000 \mathrm{E}+00$ & \\
\hline
\end{tabular}

Total Dose Contributions TDOSE (i,p,t) for Individual Radionuclides (i) and Pathways (p) As mrem/yr and Fraction of Total Dose At $t=1.000 \mathrm{E}+02$ years

Water Dependent Pathways

\begin{tabular}{|c|c|c|c|c|c|c|c|c|c|c|c|c|c|c|}
\hline \multirow[b]{2}{*}{ clide } & \multicolumn{2}{|c|}{ Water } & \multicolumn{2}{|c|}{ Fish } & \multicolumn{2}{|c|}{ Radon } & \multicolumn{2}{|c|}{ Plant } & \multicolumn{2}{|c|}{ Meat } & \multicolumn{2}{|c|}{ Milk } & \multicolumn{2}{|c|}{ All Pathways* } \\
\hline & mrem/yr & fract. & mrem/yr & fract. & $\mathrm{mrem} / \mathrm{yr}$ & fract. & mrem/yr & fract. & mrem/yr & fract. & mrem/yr & fract. & mrem/yr & fract. \\
\hline 1 & $0.000 \mathrm{E}+00$ & 0.0000 & $0.000 \mathrm{E}+00$ & 0.0000 & $0.000 \mathrm{E}+00$ & 0.0000 & $0.000 \mathrm{E}+00$ & 0.0000 & $0.000 \mathrm{E}+00$ & 0.0000 & $0.000 \mathrm{E}+00$ & 0.0000 & $5.671 \mathrm{E}-16$ & 0.0000 \\
\hline 37 & $0.000 \mathrm{E}+00$ & 0.0000 & $0.000 \mathrm{E}+00$ & 0.0000 & $0.000 \mathrm{E}+00$ & 0.0000 & $0.000 \mathrm{E}+00$ & 0.0000 & $0.000 \mathrm{E}+00$ & 0.0000 & $0.000 \mathrm{E}+00$ & 0.0000 & $1.061 \mathrm{E}-09$ & 0.0004 \\
\hline 37 & $0.000 \mathrm{E}+00$ & 0.0000 & $0.000 \mathrm{E}+00$ & 0.0000 & $0.000 \mathrm{E}+00$ & 0.0000 & $0.000 \mathrm{E}+00$ & 0.0000 & $0.000 \mathrm{E}+00$ & 0.0000 & $0.000 \mathrm{E}+00$ & 0.0000 & $2.966 \mathrm{E}-12$ & 0.0000 \\
\hline 238 & $0.000 \mathrm{E}+00$ & 0.0000 & $0.000 \mathrm{E}+00$ & 0.0000 & $0.000 \mathrm{E}+00$ & 0.0000 & $0.000 \mathrm{E}+00$ & 0.0000 & $0.000 \mathrm{E}+00$ & 0.0000 & $0.000 \mathrm{E}+00$ & 0.0000 & $3.995 \mathrm{E}-15$ & 0.0000 \\
\hline 239 & $0.000 \mathrm{E}+00$ & 0.0000 & $0.000 \mathrm{E}+00$ & 0.0000 & $0.000 \mathrm{E}+00$ & 0.0000 & $0.000 \mathrm{E}+00$ & 0.0000 & $0.000 \mathrm{E}+00$ & 0.0000 & $0.000 \mathrm{E}+00$ & 0.0000 & $2.748 \mathrm{E}-16$ & 0.0000 \\
\hline 240 & $0.000 \mathrm{E}+00$ & 0.0 & 0.00 & 0 & $0.000 \mathrm{E}+00$ & 0 & $0.000 \mathrm{E}+00$ & 0 & 0 & 0 & $0.000 \mathrm{E}+00$ & 0 & 19 & 000 \\
\hline & $0.000 \mathrm{E}+00$ & 0. & $0.000 \mathrm{E}+00$ & 0.0000 & $0.000 \mathrm{E}+00$ & 0.0000 & $0.000 \mathrm{E}+00$ & 0.00 & $0.000 \mathrm{E}+00$ & 0.0000 & $0.000 \mathrm{E}+00$ & 0.0 & $2.320 \mathrm{E}-24$ & 0.0000 \\
\hline 228 & $0.000 \mathrm{E}+00$ & 0.0000 & $0.000 \mathrm{E}+00$ & 0.0000 & $0.000 \mathrm{E}+00$ & 0.0000 & $0.000 \mathrm{E}+00$ & 0.0000 & $0.000 \mathrm{E}+00$ & 0.0000 & $0.000 \mathrm{E}+00$ & 0.0000 & $3.553 E-22$ & 0.0000 \\
\hline & $0.000 \mathrm{E}+00$ & 0.0000 & $0.000 \mathrm{E}+00$ & 0.0000 & $0.000 \mathrm{E}+00$ & 0.0000 & $0.000 \mathrm{E}+00$ & 0.0000 & $0.000 \mathrm{E}+00$ & 0.0000 & $0.000 \mathrm{E}+00$ & 0.0000 & $2.846 \mathrm{E}-07$ & 0.1082 \\
\hline & $0.000 \mathrm{E}+00$ & 0.0000 & $0.000 \mathrm{E}+00$ & 0.0000 & $0.000 \mathrm{E}+00$ & 0.0000 & $0.000 \mathrm{E}+00$ & 0.0000 & $0.000 \mathrm{E}+00$ & 0.0000 & $0.000 \mathrm{E}+00$ & 0.0000 & $2.333 \mathrm{E}-06$ & 0.8876 \\
\hline & $0.000 \mathrm{E}+00$ & 0.0000 & $0.000 \mathrm{E}+00$ & 0.0000 & $0.000 \mathrm{E}+00$ & 0.0000 & $0.000 \mathrm{E}+00$ & 0.0000 & $0.000 \mathrm{E}+00$ & 0.0000 & $0.000 \mathrm{E}+00$ & 0.0000 & $2.074 \mathrm{E}-10$ & 0.0001 \\
\hline & $0.000 \mathrm{E}+00$ & 0.0000 & $0.000 \mathrm{E}+00$ & 0.0000 & $0.000 \mathrm{E}+00$ & 0.0000 & $0.000 \mathrm{E}+00$ & 0.0000 & $0.000 \mathrm{E}+00$ & 0.0000 & $0.000 \mathrm{E}+00$ & 0.0000 & $4.238 \mathrm{E}-13$ & 0.0000 \\
\hline & $0.000 \mathrm{E}+00$ & 0.0000 & $0.000 \mathrm{E}+00$ & 0.0000 & $0.000 \mathrm{E}+00$ & 0.0000 & $0.000 \mathrm{E}+00$ & 0.0000 & $0.000 \mathrm{E}+00$ & 0.0000 & $0.000 \mathrm{E}+00$ & 0.0000 & $9.712 \mathrm{E}-09$ & 0.0037 \\
\hline & & 00 & $0.000 \mathrm{E}+00$ & 0.0000 & $.000 \mathrm{E}+00$ & 0.0000 & $0.000 \mathrm{E}+00$ & 0.0000 & $0.000 \mathrm{E}+00$ & 0.0000 & +0 & & & 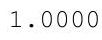 \\
\hline
\end{tabular}

* Sum of all water independent and dependent pathways. 
RESRAD, Version $6.5 \quad$ T1/2 Limit $=180$ days
Summary : RESRAD Parameters for U-Landfill Recreational User Foward Run at Proposed ALs

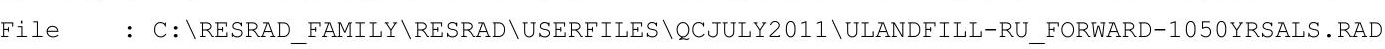

Total Dose Contributions TDOSE (i,p,t) for Individual Radionuclides (i) and Pathways (p) As mrem/yr and Fraction of Total Dose At $t=5.000 \mathrm{E}+02$ years

Water Independent Pathways (Inhalation excludes radon)

\begin{tabular}{|c|c|c|c|c|c|c|c|c|c|c|c|c|c|c|}
\hline \multirow{2}{*}{ Nuclide } & \multicolumn{2}{|c|}{ Ground } & \multicolumn{2}{|c|}{ Inhalation } & \multicolumn{2}{|c|}{ Radon } & \multicolumn{2}{|c|}{ Plant } & \multicolumn{2}{|c|}{ Meat } & \multicolumn{2}{|c|}{ Milk } & \multicolumn{2}{|c|}{ Soil } \\
\hline & mrem/yr & fract. & mrem/yr & fract. & mrem/yr & fract. & mrem/yr & fract. & mrem/yr & fract. & mrem/yr & fract. & mrem/yr & fract. \\
\hline-241 & $1.570 \mathrm{E}-13$ & 0.0000 & $0.000 \mathrm{E}+00$ & 0.0000 & $0.000 \mathrm{E}+00$ & 0.0000 & $0.000 \mathrm{E}+00$ & 0.0000 & $0.000 \mathrm{E}+00$ & 0.0000 & $0.000 \mathrm{E}+00$ & 0.0000 & $0.000 \mathrm{E}+00$ & 0.0000 \\
\hline-137 & $2.982 E-12$ & 0.0000 & $0.000 \mathrm{E}+00$ & 0.0000 & $0.000 \mathrm{E}+00$ & 0.0000 & $0.000 \mathrm{E}+00$ & 0.0000 & $0.000 \mathrm{E}+00$ & 0.0000 & $0.000 \mathrm{E}+00$ & 0.0000 & $0.000 \mathrm{E}+00$ & 0.0000 \\
\hline-237 & $2.223 E-10$ & 0.0000 & $0.000 \mathrm{E}+00$ & 0.0000 & $0.000 \mathrm{E}+00$ & 0.0000 & $0.000 \mathrm{E}+00$ & 0.0000 & $0.000 \mathrm{E}+00$ & 0.0000 & $0.000 \mathrm{E}+00$ & 0.0000 & $0.000 \mathrm{E}+00$ & 0.0000 \\
\hline-238 & $4.219 \mathrm{E}-12$ & 0.0000 & $0.000 \mathrm{E}+00$ & 0.0000 & $0.000 \mathrm{E}+00$ & 0.0000 & $0.000 \mathrm{E}+00$ & 0.0000 & $0.000 \mathrm{E}+00$ & 0.0000 & $0.000 \mathrm{E}+00$ & 0.0000 & $0.000 \mathrm{E}+00$ & 0.0000 \\
\hline-239 & $3.271 \mathrm{E}-14$ & 0.0000 & $0.000 \mathrm{E}+00$ & 0.0000 & $0.000 \mathrm{E}+00$ & 0.0000 & $0.000 \mathrm{E}+00$ & 0.0000 & $0.000 \mathrm{E}+00$ & 0.0000 & $0.000 \mathrm{E}+00$ & 0.0000 & $0.000 \mathrm{E}+00$ & 0.0000 \\
\hline-240 & $3.971 \mathrm{E}-17$ & 0.0000 & $0.000 \mathrm{E}+00$ & 0.0000 & $0.000 \mathrm{E}+00$ & 0.0000 & $0.000 \mathrm{E}+00$ & 0.0000 & $0.000 \mathrm{E}+00$ & 0.0000 & $0.000 \mathrm{E}+00$ & 0.0000 & $0.000 \mathrm{E}+00$ & 0.0000 \\
\hline 99 & $6.072 \mathrm{E}-22$ & 0.0000 & $0.000 \mathrm{E}+00$ & 0.0000 & $0.000 \mathrm{E}+00$ & 0.0000 & $0.000 \mathrm{E}+00$ & 0.0000 & $0.000 \mathrm{E}+00$ & 0.0000 & $0.000 \mathrm{E}+00$ & 0.0000 & $0.000 \mathrm{E}+00$ & 0.0000 \\
\hline-228 & $0.000 \mathrm{E}+00$ & 0.0000 & $0.000 \mathrm{E}+00$ & 0.0000 & $0.000 \mathrm{E}+00$ & 0.0000 & $0.000 \mathrm{E}+00$ & 0.0000 & $0.000 \mathrm{E}+00$ & 0.0000 & $0.000 \mathrm{E}+00$ & 0.0000 & $0.000 \mathrm{E}+00$ & 0.0000 \\
\hline-230 & $2.064 \mathrm{E}-05$ & 0.4425 & $0.000 \mathrm{E}+00$ & 0.0000 & $0.000 \mathrm{E}+00$ & 0.0000 & $0.000 \mathrm{E}+00$ & 0.0000 & $0.000 \mathrm{E}+00$ & 0.0000 & $0.000 \mathrm{E}+00$ & 0.0000 & $0.000 \mathrm{E}+00$ & 0.0000 \\
\hline-232 & $2.570 E-05$ & 0.5508 & $0.000 \mathrm{E}+00$ & 0.0000 & $0.000 \mathrm{E}+00$ & 0.0000 & $0.000 \mathrm{E}+00$ & 0.0000 & $0.000 \mathrm{E}+00$ & 0.0000 & $0.000 \mathrm{E}+00$ & 0.0000 & $0.000 \mathrm{E}+00$ & 0.0000 \\
\hline 234 & $7.703 E-08$ & 0.0017 & $0.000 \mathrm{E}+00$ & 0.0000 & $0.000 \mathrm{E}+00$ & 0.0000 & $0.000 \mathrm{E}+00$ & 0.0000 & $0.000 \mathrm{E}+00$ & 0.0000 & $0.000 \mathrm{E}+00$ & 0.0000 & $0.000 \mathrm{E}+00$ & 0.0000 \\
\hline 35 & $8.828 E-11$ & 0.0000 & $0.000 \mathrm{E}+00$ & 0.0000 & $0.000 \mathrm{E}+00$ & 0.0000 & $0.000 \mathrm{E}+00$ & 0.0000 & $0.000 \mathrm{E}+00$ & 0.0000 & $0.000 \mathrm{E}+00$ & 0.0000 & $0.000 \mathrm{E}+00$ & 0.0000 \\
\hline 38 & $2.374 \mathrm{E}-07$ & 0.0051 & $0.000 \mathrm{E}+00$ & 0.0000 & $0.000 \mathrm{E}+00$ & 0.0000 & $0.000 \mathrm{E}+00$ & 0.0000 & $0.000 \mathrm{E}+00$ & 0.0000 & $0.000 \mathrm{E}+00$ & 0.0000 & $0.000 \mathrm{E}+00$ & 0.0000 \\
\hline & $4.666 \mathrm{E}-05$ & 1.0000 & $0.000 \mathrm{E}+00$ & 0.0000 & $0.000 \mathrm{E}+00$ & 0.0000 & $0.000 \mathrm{E}+00$ & 0.0000 & $0.000 \mathrm{E}+00$ & 0.0000 & $0.000 \mathrm{E}+00$ & 0.0000 & $0.000 \mathrm{E}+00$ & 0.0000 \\
\hline
\end{tabular}

Total Dose Contributions TDOSE(i,p,t) for Individual Radionuclides (i) and Pathways (p) As mrem/yr and Fraction of Total Dose At $t=5.000 \mathrm{E}+02$ years

Water Dependent Pathways

\begin{tabular}{|c|c|c|c|c|c|c|c|c|c|c|c|c|c|c|}
\hline \multirow{2}{*}{$\begin{array}{l}\text { Radio- } \\
\text { Nuclide }\end{array}$} & \multicolumn{2}{|c|}{ Water } & \multicolumn{2}{|c|}{ Fish } & \multicolumn{2}{|c|}{ Radon } & \multicolumn{2}{|c|}{ Plant } & \multicolumn{2}{|c|}{ Meat } & \multicolumn{2}{|c|}{ Milk } & \multicolumn{2}{|c|}{ All Pathways* } \\
\hline & mrem/yr & fract. & mrem/yr & fract. & mrem/yr & fract. & mrem/yr & fract. & mrem/yr & fract. & mrem/yr & fract. & mrem/yr & fract. \\
\hline 241 & $0.000 \mathrm{E}+00$ & 0.0000 & $0.000 \mathrm{E}+00$ & 0.0000 & $0.000 \mathrm{E}+00$ & 0.0000 & $0.000 \mathrm{E}+00$ & 0.0000 & $0.000 \mathrm{E}+00$ & 0.0000 & $0.000 \mathrm{E}+00$ & 0.0000 & $1.570 \mathrm{E}-13$ & 0.0000 \\
\hline-137 & $0.000 \mathrm{E}+00$ & 0.0000 & $0.000 \mathrm{E}+00$ & 0.0000 & $0.000 \mathrm{E}+00$ & 0.0000 & $0.000 \mathrm{E}+00$ & 0.0000 & $0.000 \mathrm{E}+00$ & 0.0000 & $0.000 \mathrm{E}+00$ & 0.0000 & $2.982 \mathrm{E}-12$ & 0.0000 \\
\hline-237 & $0.000 \mathrm{E}+00$ & 0.0000 & $0.000 \mathrm{E}+00$ & 0.0000 & $0.000 \mathrm{E}+00$ & 0.0000 & $0.000 \mathrm{E}+00$ & 0.0000 & $0.000 \mathrm{E}+00$ & 0.0000 & $0.000 \mathrm{E}+00$ & 0.0000 & $2.223 E-10$ & 0.0000 \\
\hline-238 & $0.000 \mathrm{E}+00$ & 0.0000 & $0.000 \mathrm{E}+00$ & 0.0000 & $0.000 \mathrm{E}+00$ & 0.0000 & $0.000 \mathrm{E}+00$ & 0.0000 & $0.000 \mathrm{E}+00$ & 0.0000 & $0.000 \mathrm{E}+00$ & 0.0000 & $4.219 \mathrm{E}-12$ & 0.0000 \\
\hline-239 & $0.000 \mathrm{E}+00$ & 0.0000 & $0.000 \mathrm{E}+00$ & 0.0000 & $0.000 \mathrm{E}+00$ & 0.0000 & $0.000 \mathrm{E}+00$ & 0.0000 & $0.000 \mathrm{E}+00$ & 0.0000 & $0.000 E+00$ & 0.0000 & $3.271 \mathrm{E}-14$ & 0.0000 \\
\hline-240 & $0.000 \mathrm{E}+00$ & 0.0000 & $0.000 \mathrm{E}+00$ & 0.0000 & $0.000 \mathrm{E}+00$ & 0.0000 & $0.000 \mathrm{E}+00$ & 0.0000 & $0.000 \mathrm{E}+00$ & 0.0000 & $0.000 E+00$ & 0.0000 & $3.971 \mathrm{E}-17$ & 0.0000 \\
\hline-99 & $0.000 \mathrm{E}+00$ & 0.0000 & $0.000 \mathrm{E}+00$ & 0.0000 & $0.000 \mathrm{E}+00$ & 0.0000 & $0.000 \mathrm{E}+00$ & 0.0000 & $0.000 \mathrm{E}+00$ & 0.0000 & $0.000 \mathrm{E}+00$ & 0.0000 & $6.072 \mathrm{E}-22$ & 0.0000 \\
\hline-228 & $0.000 \mathrm{E}+00$ & 0.0000 & $0.000 \mathrm{E}+00$ & 0.0000 & $0.000 \mathrm{E}+00$ & 0.0000 & $0.000 \mathrm{E}+00$ & 0.0000 & $0.000 \mathrm{E}+00$ & 0.0000 & $0.000 \mathrm{E}+00$ & 0.0000 & $0.000 \mathrm{E}+00$ & 0.0000 \\
\hline-230 & $0.000 \mathrm{E}+00$ & 0.0000 & $0.000 \mathrm{E}+00$ & 0.0000 & $0.000 \mathrm{E}+00$ & 0.0000 & $0.000 \mathrm{E}+00$ & 0.0000 & $0.000 \mathrm{E}+00$ & 0.0000 & $0.000 E+00$ & 0.0000 & $2.064 \mathrm{E}-05$ & 0.4425 \\
\hline-232 & $0.000 \mathrm{E}+00$ & 0.0000 & $0.000 \mathrm{E}+00$ & 0.0000 & $0.000 \mathrm{E}+00$ & 0.0000 & $0.000 \mathrm{E}+00$ & 0.0000 & $0.000 \mathrm{E}+00$ & 0.0000 & $0.000 \mathrm{E}+00$ & 0.0000 & $2.570 \mathrm{E}-05$ & 0.5508 \\
\hline 234 & $0.000 \mathrm{E}+00$ & 0.0000 & $0.000 \mathrm{E}+00$ & 0.0000 & $0.000 \mathrm{E}+00$ & 0.0000 & $0.000 \mathrm{E}+00$ & 0.0000 & $0.000 \mathrm{E}+00$ & 0.0000 & $0.000 \mathrm{E}+00$ & 0.0000 & $7.703 E-08$ & 0.0017 \\
\hline 35 & $0.000 \mathrm{E}+00$ & 0.0000 & $0.000 \mathrm{E}+00$ & 0.0000 & $0.000 \mathrm{E}+00$ & 0.0000 & $0.000 \mathrm{E}+00$ & 0.0000 & $0.000 \mathrm{E}+00$ & 0.0000 & $0.000 \mathrm{E}+00$ & 0.0000 & $8.828 E-11$ & 0.0000 \\
\hline 38 & $0.000 \mathrm{E}+00$ & 0.0000 & $0.000 \mathrm{E}+00$ & 0.0000 & $0.000 \mathrm{E}+00$ & 0.0000 & $0.000 \mathrm{E}+00$ & 0.0000 & $0.000 \mathrm{E}+00$ & 0.0000 & $0.000 \mathrm{E}+00$ & 0.0000 & $2.374 \mathrm{E}-07$ & 0.0051 \\
\hline & $0.000 \mathrm{E}+00$ & 0.0000 & $0.000 \mathrm{E}+00$ & 0.0000 & $0.000 \mathrm{E}+00$ & 0.0000 & $0.000 \mathrm{E}+00$ & 0.0000 & $0.000 \mathrm{E}+00$ & 0.0000 & $0.000 \mathrm{E}+00$ & 0.0000 & $56 E-05$ & 1.0000 \\
\hline
\end{tabular}

* Sum of all water independent and dependent pathways. 
RESRAD, Version $6.5 \quad$ T1/2 Limit $=180$ days
Summary : RESRAD Parameters for U-Landfill Recreational User Foward Run at Proposed ALs

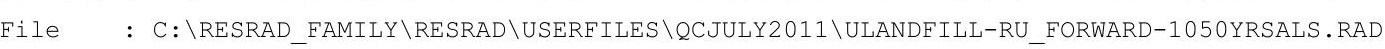

Total Dose Contributions TDOSE (i,p,t) for Individual Radionuclides (i) and Pathways (p) As mrem/yr and Fraction of Total Dose At $t=1.050 \mathrm{E}+03$ years

Water Independent Pathways (Inhalation excludes radon)

\begin{tabular}{|c|c|c|c|c|c|c|c|c|c|c|c|c|c|c|}
\hline \multirow[b]{2}{*}{ clide } & \multicolumn{2}{|c|}{ Ground } & \multicolumn{2}{|c|}{ Inhalation } & \multicolumn{2}{|c|}{ Radon } & \multicolumn{2}{|c|}{ Plant } & \multicolumn{2}{|c|}{ Meat } & \multicolumn{2}{|c|}{ Milk } & \multicolumn{2}{|c|}{ Soil } \\
\hline & mrem/yr & fract. & mrem/yr & fract. & mrem/yr & fract. & mrem/yr & fract. & $\mathrm{rem} / \mathrm{yr}$ & fract. & mrem/yr & fract. & nrem/yr & fract. \\
\hline 1 & $8.501 \mathrm{E}-11$ & 0.0000 & $0.000 \mathrm{E}+00$ & 0.0000 & $0.000 \mathrm{E}+00$ & 0.0000 & $0.000 \mathrm{E}+00$ & 0.0000 & $0.000 \mathrm{E}+00$ & 0.0000 & $0.000 \mathrm{E}+00$ & 0.0000 & $0.000 \mathrm{E}+00$ & 0.0000 \\
\hline 7 & $9.254 \mathrm{E}-16$ & 0.0000 & $0.000 \mathrm{E}+00$ & 0.0000 & $0.000 \mathrm{E}+00$ & 0.0000 & $0.000 \mathrm{E}+00$ & 0.0000 & $0.000 \mathrm{E}+00$ & 0.0000 & $0.000 \mathrm{E}+00$ & 0.0000 & $0.000 \mathrm{E}+00$ & 0.0000 \\
\hline 37 & $7.970 \mathrm{E}-08$ & 0.0000 & $0.000 \mathrm{E}+00$ & 0.0000 & $0.000 \mathrm{E}+00$ & 0.0000 & $0.000 \mathrm{E}+00$ & 0.0000 & $0.000 \mathrm{E}+00$ & 0.0000 & $0.000 \mathrm{E}+00$ & 0.0000 & $0.000 \mathrm{E}+00$ & 0.0000 \\
\hline 238 & $9.828 \mathrm{E}-10$ & 0.0000 & $0.000 \mathrm{E}+00$ & 0.0000 & $0.000 \mathrm{E}+00$ & 0.0000 & $0.000 \mathrm{E}+00$ & 0.0000 & $0.000 \mathrm{E}+00$ & 0.0000 & $0.000 \mathrm{E}+00$ & 0.0000 & $0.000 \mathrm{E}+00$ & 0.0000 \\
\hline 39 & $2.328 \mathrm{E}-11$ & 0.0000 & $0.000 \mathrm{E}+00$ & 0.0000 & $0.000 \mathrm{E}+00$ & 0.0000 & $0.000 \mathrm{E}+00$ & 0.0000 & $0.000 \mathrm{E}+00$ & 0.0000 & $0.000 \mathrm{E}+00$ & 0.0000 & $0.000 \mathrm{E}+00$ & 0.0000 \\
\hline 240 & $5.640 \mathrm{E}-15$ & 0.0 & $0.000 \mathrm{E}$ & 0. & $0 \mathrm{E}+00$ & 0 & $0.000 \mathrm{E}$ & 0 & 0 & 0 & $000 \mathrm{E}+00$ & 0 & $.000 \mathrm{E}+00$ & 00 \\
\hline 99 & $1.282 \mathrm{E}-18$ & 0.0000 & $0.000 \mathrm{E}+00$ & 0.0000 & $0.000 \mathrm{E}+00$ & 0.0000 & $0.000 \mathrm{E}+00$ & 0.0000 & $0.000 \mathrm{E}+00$ & 0.00 & $0.000 \mathrm{E}+00$ & 0.0000 & $0.000 \mathrm{E}+00$ & 0000 \\
\hline 20 & $0.000 \mathrm{E}+00$ & 0.0000 & $0.000 \mathrm{E}+00$ & 0.0000 & $0.000 \mathrm{E}+00$ & 0.0000 & $0.000 \mathrm{E}+00$ & 0.0000 & $0.000 \mathrm{E}+00$ & 0.0000 & $0.000 \mathrm{E}+00$ & 0.0000 & $0.000 \mathrm{E}+00$ & 0.0000 \\
\hline & $1.732 \mathrm{E}-03$ & 0.6991 & $0.000 \mathrm{E}+00$ & 0.0000 & $0.000 \mathrm{E}+00$ & 0.0000 & $0.000 \mathrm{E}+00$ & 0.0000 & $0.000 \mathrm{E}+00$ & 0.0000 & $0.000 \mathrm{E}+00$ & 0.0000 & $0.000 \mathrm{E}+00$ & 0.0000 \\
\hline & $7.120 \mathrm{E}-04$ & 0.2874 & $0.000 \mathrm{E}+00$ & 0.0000 & $0.000 \mathrm{E}+00$ & 0.0000 & $0.000 \mathrm{E}+00$ & 0.0000 & $0.000 \mathrm{E}+00$ & 0.0000 & $0.000 \mathrm{E}+00$ & 0.0000 & $0.000 \mathrm{E}+00$ & 0.0000 \\
\hline & $1.407 \mathrm{E}-05$ & 0.0057 & $0.000 \mathrm{E}+00$ & 0.0000 & $0.000 \mathrm{E}+00$ & 0.0000 & $0.000 \mathrm{E}+00$ & 0.0000 & $0.000 \mathrm{E}+00$ & 0.0000 & $0.000 \mathrm{E}+00$ & 0.0000 & $0.000 \mathrm{E}+00$ & 0.0000 \\
\hline & $2.963 \mathrm{E}-08$ & 0.0000 & $0.000 \mathrm{E}+00$ & 0.0000 & $0.000 \mathrm{E}+00$ & 0.0000 & $0.000 \mathrm{E}+00$ & 0.0000 & $0.000 \mathrm{E}+00$ & 0.0000 & $0.000 \mathrm{E}+00$ & 0.0000 & $0.000 \mathrm{E}+00$ & 0.0000 \\
\hline & $1.927 \mathrm{E}-05$ & 0.0078 & $0.000 \mathrm{E}+00$ & 0.0000 & $0.000 \mathrm{E}+00$ & 0.0000 & $0.000 \mathrm{E}+00$ & 0.0000 & $0.000 \mathrm{E}+00$ & 0.0000 & $0.000 \mathrm{E}+00$ & 0.0000 & $0.000 \mathrm{E}+00$ & 0.0000 \\
\hline & 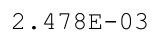 & 00 & $0.000 \mathrm{E}+00$ & 0.0000 & $0.000 \mathrm{E}+00$ & 0.0000 & $0.000 \mathrm{E}+00$ & 0.0000 & $0.000 \mathrm{E}+00$ & 0.0000 & $0.000 \mathrm{E}+00$ & 0.0000 & $E+00$ & 0.00 \\
\hline
\end{tabular}

Total Dose Contributions TDOSE (i,p,t) for Individual Radionuclides (i) and Pathways (p) As mrem/yr and Fraction of Total Dose At $t=1.050 \mathrm{E}+03$ years

Water Dependent Pathways

\begin{tabular}{|c|c|c|c|c|c|c|c|c|c|c|c|c|c|c|}
\hline \multirow[b]{2}{*}{ clide } & \multicolumn{2}{|c|}{ Water } & \multicolumn{2}{|c|}{ Fish } & \multicolumn{2}{|c|}{ Radon } & \multicolumn{2}{|c|}{ Plant } & \multicolumn{2}{|c|}{ Meat } & \multicolumn{2}{|c|}{ Milk } & \multicolumn{2}{|c|}{ All Pathways* } \\
\hline & mrem/yr & fract. & mrem/yr & fract. & $\mathrm{mrem} / \mathrm{yr}$ & fract. & mrem/yr & fract. & mrem/yr & fract. & mrem/yr & fract. & mrem/yr & fract. \\
\hline 241 & $0.000 \mathrm{E}+00$ & 0.0000 & $0.000 \mathrm{E}+00$ & 0.0000 & $0.000 \mathrm{E}+00$ & 0.0000 & $0.000 \mathrm{E}+00$ & 0.0000 & $0.000 \mathrm{E}+00$ & 0.0000 & $0.000 \mathrm{E}+00$ & 0.0000 & $8.501 \mathrm{E}-11$ & 0.0000 \\
\hline 37 & $0.000 \mathrm{E}+00$ & 0.0000 & $0.000 \mathrm{E}+00$ & 0.0000 & $0.000 \mathrm{E}+00$ & 0.0000 & $0.000 \mathrm{E}+00$ & 0.0000 & $0.000 \mathrm{E}+00$ & 0.0000 & $0.000 \mathrm{E}+00$ & 0.0000 & $9.254 \mathrm{E}-16$ & 0.0000 \\
\hline 37 & $0.000 \mathrm{E}+00$ & 0.0000 & $0.000 \mathrm{E}+00$ & 0.0000 & $0.000 \mathrm{E}+00$ & 0.0000 & $0.000 \mathrm{E}+00$ & 0.0000 & $0.000 \mathrm{E}+00$ & 0.0000 & $0.000 \mathrm{E}+00$ & 0.0000 & $7.970 \mathrm{E}-08$ & 0.0000 \\
\hline 238 & $0.000 \mathrm{E}+00$ & 0.0000 & $0.000 \mathrm{E}+00$ & 0.0000 & $0.000 \mathrm{E}+00$ & 0.0000 & $0.000 \mathrm{E}+00$ & 0.0000 & $0.000 \mathrm{E}+00$ & 0.0000 & $0.000 \mathrm{E}+00$ & 0.0000 & $9.828 \mathrm{E}-10$ & 0.0000 \\
\hline 239 & $0.000 \mathrm{E}+00$ & 0.0000 & $0.000 \mathrm{E}+00$ & 0.0000 & $0.000 \mathrm{E}+00$ & 0.0000 & $0.000 \mathrm{E}+00$ & 0.0000 & $0.000 \mathrm{E}+00$ & 0.0000 & $0.000 \mathrm{E}+00$ & 0.0000 & $2.328 \mathrm{E}-11$ & 0.0000 \\
\hline 240 & $0.000 \mathrm{E}+00$ & 0.0 & $0.000 \mathrm{E}+00$ & 0 & $0.000 \mathrm{E}+00$ & 0 & $0.000 \mathrm{E}+00$ & 0 & 00 & 0 & $0.000 \mathrm{E}+00$ & 0 & -15 & 0000 \\
\hline 99 & $0.000 \mathrm{E}+00$ & 0.00 & $0.000 \mathrm{E}+00$ & 0 & $0.000 \mathrm{E}+00$ & 0 & $0.000 \mathrm{E}+00$ & 0.00 & $000 \mathrm{E}+00$ & 0000 & $0.000 \mathrm{E}+00$ & 0 & $1.282 \mathrm{E}-18$ & 0.0000 \\
\hline 228 & $0.000 \mathrm{E}+00$ & 0.0000 & $0.000 \mathrm{E}+00$ & 0.0000 & $0.000 \mathrm{E}+00$ & 0.0000 & $0.000 \mathrm{E}+00$ & 0.0000 & $0.000 \mathrm{E}+00$ & 0.0000 & $0.000 \mathrm{E}+00$ & 0.0000 & $0.000 \mathrm{E}+00$ & 0.0000 \\
\hline 230 & $0.000 \mathrm{E}+00$ & 0.0000 & $0.000 \mathrm{E}+00$ & 0.0000 & $0.000 \mathrm{E}+00$ & 0.0000 & $0.000 \mathrm{E}+00$ & 0.0000 & $0.000 \mathrm{E}+00$ & 0.0000 & $0.000 \mathrm{E}+00$ & 0.0000 & $1.732 \mathrm{E}-03$ & 0.6991 \\
\hline & $0.000 \mathrm{E}+00$ & 0.0000 & $0.000 \mathrm{E}+00$ & 0.0000 & $0.000 \mathrm{E}+00$ & 0.0000 & $0.000 \mathrm{E}+00$ & 0.0000 & $0.000 \mathrm{E}+00$ & 0.0000 & $0.000 \mathrm{E}+00$ & 0.0000 & $7.120 \mathrm{E}-04$ & 0.2874 \\
\hline & $0.000 \mathrm{E}+00$ & 0.0000 & $0.000 \mathrm{E}+00$ & 0.0000 & $0.000 \mathrm{E}+00$ & 0.0000 & $0.000 \mathrm{E}+00$ & 0.0000 & $0.000 \mathrm{E}+00$ & 0.0000 & $0.000 \mathrm{E}+00$ & 0.0000 & $1.407 \mathrm{E}-05$ & 0.0057 \\
\hline & $0.000 \mathrm{E}+00$ & 0.0000 & $0.000 \mathrm{E}+00$ & 0.0000 & $0.000 \mathrm{E}+00$ & 0.0000 & $0.000 \mathrm{E}+00$ & 0.0000 & $0.000 \mathrm{E}+00$ & 0.0000 & $0.000 \mathrm{E}+00$ & 0.0000 & $2.963 E-08$ & 0.0000 \\
\hline & $0.000 \mathrm{E}+00$ & 0.0000 & $0.000 \mathrm{E}+00$ & 0.0000 & $0.000 \mathrm{E}+00$ & 0.0000 & $0.000 \mathrm{E}+00$ & 0.0000 & $0.000 \mathrm{E}+00$ & 0.0000 & $0.000 \mathrm{E}+00$ & 0.0000 & $1.927 \mathrm{E}-05$ & 0.0078 \\
\hline & & 0 & $.000 \mathrm{E}+00$ & 000 & $E+00$ & 0.0000 & $.000 \mathrm{E}+00$ & .0000 & $.000 \mathrm{E}+00$ & 0 & $E+C$ & & $2.4 / 8 \mathrm{E}-0$ & \\
\hline
\end{tabular}

*Sum of all water independent and dependent pathways. 
RESRAD, Version 6.5

Summary : RESRAD Parameters for U-Landfill Recreational User Foward Run at Proposed ALs

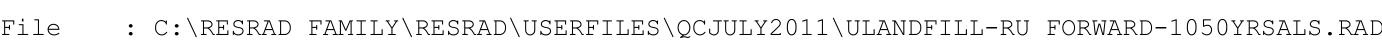

Dose/Source Ratios Summed Over All Pathways

Parent and Progeny Principal Radionuclide Contributions Indicated

Parent Product Thread DSR $(j, t)$ At Time in Years (mrem/yr)/(pCi/g)

(i)

(j)

$\begin{array}{ll}\mathrm{Am}-241 & 1.000 \mathrm{E}+00 \\ \mathrm{~Np}-237+\mathrm{D} & 1.000 \mathrm{E}+00 \\ \mathrm{U}-233 & 1.000 \mathrm{E}+00 \\ \mathrm{Th}-229+\mathrm{D} & 1.000 \mathrm{E}+00 \\ \operatorname{\sum DSR}(j) & \end{array}$

$\mathrm{Cs}-137+\mathrm{D}$

$\mathrm{Np}-237+\mathrm{D}$

U-233

Th-229+D

$\sum \operatorname{DSR}(j)$

$\mathrm{Pu}-238$

$\mathrm{Pu}-238$

U-234

Th-230

Ra-226+D

$\mathrm{Pb}-210+\mathrm{D}$

$\sum \operatorname{DSR}(j)$

Pu-239

U-235+D

$\mathrm{Pa}-231$

Ac-227+D

$\sum \operatorname{DSR}(j)$

Pu-240

Pu-240

$\mathrm{U}-236$

Th-232

$\mathrm{Ra}-228+\mathrm{D}$

Th-228+D

$\sum \operatorname{DSR}(j)$

TC-99

Th-228+D

Th-230

Ra-226+D

$\mathrm{Pb}-210+\mathrm{D}$

$\sum \operatorname{DSR}(j)$
$1.000 \mathrm{E}+00 \quad 1.213 \mathrm{E}-10 \quad 1.196 \mathrm{E}-10 \quad 1.017 \mathrm{E}-10 \quad 5.821 \mathrm{E}-11 \quad 2.793 \mathrm{E}-11 \quad 7.847 \mathrm{E}-14 \quad 2.435 \mathrm{E}-17$

$\begin{array}{lllllllll}1.000 \mathrm{E}+00 & 9.169 \mathrm{E}-14 & 9.268 \mathrm{E}-14 & 1.043 \mathrm{E}-13 & 1.567 \mathrm{E}-13 & 2.679 \mathrm{E}-13 & 1.952 \mathrm{E}-11 & 7.101 \mathrm{E}-09\end{array}$

$\begin{array}{lllllllll}1.000 \mathrm{E}+00 & 3.120 \mathrm{E}-24 & 9.466 \mathrm{E}-24 & 9.045 \mathrm{E}-23 & 5.875 \mathrm{E}-22 & 2.184 \mathrm{E}-21 & 1.613 \mathrm{E}-18 & 3.273 \mathrm{E}-15\end{array}$

$\begin{array}{llllllll}1.000 \mathrm{E}+00 & 2.848 \mathrm{E}-20 & 2.006 \mathrm{E}-19 & 1.449 \mathrm{E}-17 & 3.076 \mathrm{E}-16 & 1.723 \mathrm{E}-15 & 6.884 \mathrm{E}-13 & 1.443 \mathrm{E}-10\end{array}$ $9.169 \mathrm{E}-14 \quad 9.268 \mathrm{E}-14 \quad 1.043 \mathrm{E}-13 \quad 1.570 \mathrm{E}-13 \quad 2.696 \mathrm{E}-13 \quad 2.021 \mathrm{E}-11 \quad 7.245 \mathrm{E}-09$

$\begin{array}{llllllll}1.840 E-09 & 2.079 E-34 & 2.099 E-34 & 2.337 E-34 & 3.386 E-34 & 5.515 E-34 & 2.732 E-32 & 5.849 E-30\end{array}$

$\begin{array}{llllllll}1.000 \mathrm{E}+00 & 1.130 \mathrm{E}-25 & 1.141 \mathrm{E}-25 & 1.270 \mathrm{E}-25 & 1.840 \mathrm{E}-25 & 2.997 \mathrm{E}-25 & 1.485 \mathrm{E}-23 & 3.179 \mathrm{E}-21\end{array}$

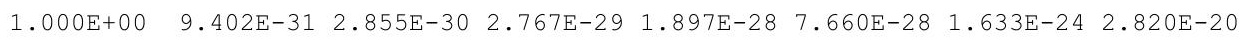
$\begin{array}{llllllll}1.000 \mathrm{E}+00 & 9.887 \mathrm{E}-35 & 7.005 \mathrm{E}-34 & 5.480 \mathrm{E}-32 & 1.538 \mathrm{E}-30 & 1.253 \mathrm{E}-29 & 1.259 \mathrm{E}-25 & 3.198 \mathrm{E}-21\end{array}$ $\begin{array}{lllllllll}1.000 \mathrm{E}+00 & 7.713 \mathrm{E}-24 & 1.162 \mathrm{E}-22 & 6.388 \mathrm{E}-20 & 5.065 \mathrm{E}-18 & 5.122 \mathrm{E}-17 & 5.408 \mathrm{E}-14 & 1.260 \mathrm{E}-11\end{array}$ $\begin{array}{lllllllll}1.000 \mathrm{E}+00 & 2.237 \mathrm{E}-32 & 6.933 \mathrm{E}-31 & 2.743 \mathrm{E}-27 & 7.476 \mathrm{E}-25 & 1.264 \mathrm{E}-23 & 3.542 \mathrm{E}-20 & 1.664 \mathrm{E}-17\end{array}$ $\begin{array}{llllllll}7.826 \mathrm{E}-24 & 1.163 \mathrm{E}-22 & 6.388 \mathrm{E}-20 & 5.065 \mathrm{E}-18 & 5.122 \mathrm{E}-17 & 5.408 \mathrm{E}-14 & 1.260 \mathrm{E}-11\end{array}$

$\begin{array}{llllllll}1.000 \mathrm{E}+00 & 1.156 \mathrm{E}-18 & 1.170 \mathrm{E}-18 & 1.334 \mathrm{E}-18 & 2.100 \mathrm{E}-18 & 3.815 \mathrm{E}-18 & 4.526 \mathrm{E}-16 & 3.220 \mathrm{E}-13\end{array}$

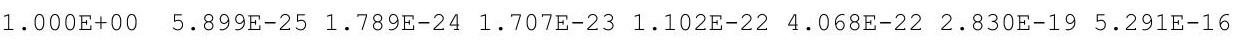
$\begin{array}{lllllllll}1.000 \mathrm{E}+00 & 9.281 \mathrm{E}-29 & 6.556 \mathrm{E}-28 & 4.931 \mathrm{E}-26 & 1.203 \mathrm{E}-24 & 8.097 \mathrm{E}-24 & 1.394 \mathrm{E}-20 & 2.092 \mathrm{E}-17\end{array}$ $\begin{array}{llllllll}1.000 \mathrm{E}+00 & 2.200 \mathrm{E}-28 & 3.302 \mathrm{E}-27 & 1.741 \mathrm{E}-24 & 1.227 \mathrm{E}-22 & 1.125 \mathrm{E}-21 & 1.425 \mathrm{E}-18 & 8.591 \mathrm{E}-16\end{array}$ $\begin{array}{lllllll}1.156 \mathrm{E}-18 & 1.170 \mathrm{E}-18 & 1.334 \mathrm{E}-18 & 2.100 \mathrm{E}-18 & 3.817 \mathrm{E}-18 & 4.543 \mathrm{E}-16 & 3.234 \mathrm{E}-13\end{array}$

4.950E-08 5.436E-33 5.532E-33 6.710E-33 $1.307 \mathrm{E}-32 \quad 3.144 \mathrm{E}-32 \quad 3.519 \mathrm{E}-29 \quad 5.479 \mathrm{E}-25$

$\begin{array}{llllllll}1.000 \mathrm{E}+00 & 1.098 \mathrm{E}-25 & 1.118 \mathrm{E}-25 & 1.356 \mathrm{E}-25 & 2.641 \mathrm{E}-25 & 6.352 \mathrm{E}-25 & 7.109 \mathrm{E}-22 & 1.107 \mathrm{E}-17\end{array}$ $\begin{array}{lllllllll}1.000 E+00 & 2.079 E-33 & 6.337 E-33 & 6.427 E-32 & 5.132 E-31 & 2.504 E-30 & 1.628 E-26 & 6.574 E-22\end{array}$ $\begin{array}{lllllllll}1.000 \mathrm{E}+00 & 2.803 \mathrm{E}-44 & 1.948 \mathrm{E}-43 & 1.599 \mathrm{E}-41 & 5.271 \mathrm{E}-40 & 5.270 \mathrm{E}-39 & 2.159 \mathrm{E}-34 & 2.528 \mathrm{E}-29\end{array}$ $\begin{array}{lllllllll}1.000 \mathrm{E}+00 & 1.318 \mathrm{E}-29 & 1.940 \mathrm{E}-28 & 8.230 \mathrm{E}-26 & 3.618 \mathrm{E}-24 & 2.445 \mathrm{E}-23 & 1.417 \mathrm{E}-20 & 4.042 \mathrm{E}-18\end{array}$ $\begin{array}{lllllllll}1.000 \mathrm{E}+00 \quad 7.799 \mathrm{E}-29 & 2.244 \mathrm{E}-27 & 4.095 \mathrm{E}-24 & 2.540 \mathrm{E}-22 & 1.691 \mathrm{E}-21 & 5.366 \mathrm{E}-19 & 6.323 \mathrm{E}-17\end{array}$ $\begin{array}{llllllll}1.099 \mathrm{E}-25 & 1.142 \mathrm{E}-25 & 4.313 \mathrm{E}-24 & 2.579 \mathrm{E}-22 & 1.716 \mathrm{E}-21 & 5.515 \mathrm{E}-19 & 7.834 \mathrm{E}-17\end{array}$

$\begin{array}{llllllll}1.000 \mathrm{E}+00 & 5.547 \mathrm{E}-27 & 5.625 \mathrm{E}-27 & 6.555 \mathrm{E}-27 & 1.112 \mathrm{E}-26 & 2.231 \mathrm{E}-26 & 5.839 \mathrm{E}-24 & 1.233 \mathrm{E}-20\end{array}$ $\begin{array}{llllllll}1.000 \mathrm{E}+00 & 1.329 \mathrm{E}-07 & 9.308 \mathrm{E}-08 & 1.847 \mathrm{E}-09 & 2.430 \mathrm{E}-15 & 4.441 \mathrm{E}-23 & 0.000 \mathrm{E}+00 & 0.000 \mathrm{E}+00\end{array}$ $\begin{array}{llllllll}1.000 \mathrm{E}+00 & 2.319 \mathrm{E}-23 & 2.359 \mathrm{E}-23 & 2.838 \mathrm{E}-23 & 5.375 \mathrm{E}-23 & 1.246 \mathrm{E}-22 & 1.037 \mathrm{E}-19 & 1.074 \mathrm{E}-15\end{array}$ $\begin{array}{llllllllll}1.000 \mathrm{E}+00 & 3.629 \mathrm{E}-12 & 1.095 \mathrm{E}-11 & 9.820 \mathrm{E}-11 & 5.116 \mathrm{E}-10 & 1.423 \mathrm{E}-09 & 1.032 \mathrm{E}-07 & 8.661 \mathrm{E}-06\end{array}$ $1.000 \mathrm{E}+00 \quad 1.749 \mathrm{E}-20 \quad 1.222 \mathrm{E}-19 \quad 7.985 \mathrm{E}-18 \quad 1.249 \mathrm{E}-16 \quad 5.113 \mathrm{E}-16 \quad 7.402 \mathrm{E}-14 \quad 1.190 \mathrm{E}-11$ $\begin{array}{lllllll}3.629 \mathrm{E}-12 & 1.095 \mathrm{E}-11 & 9.820 \mathrm{E}-11 & 5.116 \mathrm{E}-10 & 1.423 \mathrm{E}-09 & 1.032 \mathrm{E}-07 & 8.661 \mathrm{E}-06\end{array}$ 
RESRAD, Version $6.5 \quad T^{1 / 2}$ Limit $=180$ days

Summary : RESRAD Parameters for U-Landfill Recreational User Foward Run at Proposed ALs File : C: $\backslash$ RESRAD_FAMILY $\backslash$ RESRAD \USERFILES $\backslash Q C J U L Y 2011 \backslash U L A N D F I L L-R U \_F O R W A R D-1050 Y R S A L S . R A D$

Single Radionuclide Soil Guidelines G(i,t) in pCi/g

Basic Radiation Dose Limit $=1.000 \mathrm{E}+00 \mathrm{mrem} / \mathrm{yr}$

Nuclide

\begin{tabular}{|c|c|c|c|c|c|c|c|}
\hline (i) & $t=0.000 \mathrm{E}+00$ & $1.000 \mathrm{E}+00$ & $1.200 \mathrm{E}+01$ & $5.000 \mathrm{E}+01$ & $1.000 \mathrm{E}+02$ & $5.000 \mathrm{E}+02$ & $1.050 \mathrm{E}+03$ \\
\hline-241 & $\star 3.431 \mathrm{E}+12$ & $\star 3.431 \mathrm{E}+12$ & $\star 3.431 \mathrm{E}+12$ & $\star 3.431 \mathrm{E}+12$ & $* 3.431 \mathrm{E}+12$ & $* 3.431 \mathrm{E}+12$ & $8.235 E+11$ \\
\hline-137 & $8.242 E+09$ & $8.364 \mathrm{E}+09$ & $9.831 E+09$ & $1.718 \mathrm{E}+10$ & $3.580 \mathrm{E}+10$ & $1.274 \mathrm{E}+13$ & $\star 8.704 \mathrm{E}+13$ \\
\hline-237 & $\star 7.047 \mathrm{E}+08$ & $\star 7.047 \mathrm{E}+08$ & $\star 7.047 \mathrm{E}+08$ & $\star 7.047 \mathrm{E}+08$ & $\star 7.047 \mathrm{E}+08$ & $\star 7.047 \mathrm{E}+08$ & $1.380 \mathrm{E}+08$ \\
\hline-238 & $\star 1.712 \mathrm{E}+13$ & $\star 1.712 \mathrm{E}+13$ & $\star 1.712 \mathrm{E}+13$ & $\star 1.712 \mathrm{E}+13$ & $\star 1.712 \mathrm{E}+13$ & $\star 1.712 \mathrm{E}+13$ & $7.937 \mathrm{E}+10$ \\
\hline-239 & $\star 6.214 \mathrm{E}+10$ & $* 6.214 \mathrm{E}+10$ & $* 6.214 \mathrm{E}+10$ & $* 6.214 \mathrm{E}+10$ & $\star 6.214 \mathrm{E}+10$ & $* 6.214 \mathrm{E}+10$ & $* 6.214 \mathrm{E}+1 \mathrm{C}$ \\
\hline-240 & $\star 2.278 \mathrm{E}+11$ & $\star 2.278 \mathrm{E}+11$ & $\star 2.278 \mathrm{E}+11$ & $\star 2.278 \mathrm{E}+11$ & $\star 2.278 \mathrm{E}+11$ & $\star 2.278 \mathrm{E}+11$ & $\star 2.278 \mathrm{E}+1$ \\
\hline-99 & $\star 1.697 \mathrm{E}+10$ & $\star 1.697 \mathrm{E}+10$ & $\star 1.697 \mathrm{E}+10$ & $* 1.697 \mathrm{E}+10$ & $\star 1.697 \mathrm{E}+10$ & $\star 1.697 \mathrm{E}+10$ & $* 1.697 \mathrm{E}+10$ \\
\hline-228 & $7.523 \mathrm{E}+06$ & $1.074 \mathrm{E}+07$ & $5.414 \mathrm{E}+08$ & $4.116 \mathrm{E}+14$ & $\star 8.195 \mathrm{E}+14$ & $\star 8.195 \mathrm{E}+14$ & $\star 8.195 \mathrm{E}+14$ \\
\hline-230 & $\star 2.018 \mathrm{E}+10$ & $\star 2.018 \mathrm{E}+10$ & $1.018 \mathrm{E}+10$ & $1.955 \mathrm{E}+09$ & $7.028 \mathrm{E}+08$ & $9.688 \mathrm{E}+06$ & $1.155 \mathrm{E}+0$ \\
\hline$h-232$ & $* 1.097 \mathrm{E}+05$ & $\star 1.097 \mathrm{E}+05$ & $\star 1.097 \mathrm{E}+05$ & $\star 1.097 \mathrm{E}+05$ & $* 1.097 \mathrm{E}+05$ & $* 1.097 \mathrm{E}+05$ & $1.124 \mathrm{E}+04$ \\
\hline 234 & $* 6.247 \mathrm{E}+09$ & $\star 6.247 \mathrm{E}+09$ & $\star 6.247 \mathrm{E}+09$ & $\star 6.247 \mathrm{E}+09$ & $* 6.247 \mathrm{E}+09$ & $4.154 \mathrm{E}+09$ & $2.275 \mathrm{E}+07$ \\
\hline 35 & $\star 2.161 \mathrm{E}+06$ & $\star 2.161 \mathrm{E}+06$ & $\star 2.161 \mathrm{E}+06$ & $\star 2.161 \mathrm{E}+06$ & $\star 2.161 \mathrm{E}+06$ & $\star 2.161 \mathrm{E}+06$ & $\star 2.161 \mathrm{E}+06$ \\
\hline 38 & $\star 3.361 \mathrm{E}+05$ & $\star 3.361 \mathrm{E}+05$ & $\star 3.361 \mathrm{E}+05$ & $\star 3.361 \mathrm{E}+05$ & $\star 3.361 \mathrm{E}+05$ & $\star 3.361 \mathrm{E}+05$ & $\star 3.361 \mathrm{E}+05$ \\
\hline
\end{tabular}

*At specific activity limit

Summed Dose/Source Ratios DSR(i,t) in (mrem/yr)/(pCi/g)

and Single Radionuclide Soil Guidelines $\mathrm{G}(i, t)$ in $\mathrm{pCi} / \mathrm{g}$

at $\operatorname{tmin}=$ time of minimum single radionuclide soil guideline

and at tmax $=$ time of maximum total dose $=1.050 \mathrm{E}+03$ years

\begin{tabular}{|c|c|c|c|c|c|c|}
\hline $\begin{array}{l}\text { Tuclide } \\
\text { (i) }\end{array}$ & $\begin{array}{l}\text { Initial } \\
(\mathrm{pCi} / \mathrm{g})\end{array}$ & $\begin{array}{c}\text { tmin } \\
\text { (years) }\end{array}$ & $\operatorname{DSR}(i, \operatorname{tmin})$ & $\begin{array}{c}\mathrm{G}(\mathrm{i}, \mathrm{tmin}) \\
(\mathrm{pCi} / \mathrm{g})\end{array}$ & $\operatorname{DSR}(i, \operatorname{tmax})$ & $\begin{array}{c}\text { G }(i, \text { tmax }) \\
(\mathrm{pCi} / \mathrm{g})\end{array}$ \\
\hline-241 & $7.000 \mathrm{E}+01$ & $1.050 \mathrm{E}+03$ & $1.214 \mathrm{E}-12$ & $8.235 E+11$ & $1.214 \mathrm{E}-12$ & $8.235 \mathrm{E}+11$ \\
\hline-137 & $3.800 \mathrm{E}+01$ & $0.000 \mathrm{E}+00$ & $1.213 \mathrm{E}-10$ & $8.242 E+09$ & $2.435 \mathrm{E}-17$ & $\star 8.704 \mathrm{E}+13$ \\
\hline 237 & $1.100 \mathrm{E}+01$ & $1.050 \mathrm{E}+03$ & $7.245 \mathrm{E}-09$ & $1.380 \mathrm{E}+08$ & $7.245 \mathrm{E}-09$ & $1.380 \mathrm{E}+08$ \\
\hline-238 & $7.800 \mathrm{E}+01$ & $1.050 \mathrm{E}+03$ & $1.260 \mathrm{E}-11$ & $7.937 \mathrm{E}+10$ & $1.260 \mathrm{E}-11$ & $7.937 \mathrm{E}+10$ \\
\hline $\mathrm{Pu}-239$ & $7.200 \mathrm{E}+01$ & $1.050 \mathrm{E}+03$ & $3.234 \mathrm{E}-13$ & $* 6.214 \mathrm{E}+10$ & $3.234 \mathrm{E}-13$ & $\star 6.214 \mathrm{E}+10$ \\
\hline $1-240$ & $7.200 \mathrm{E}+01$ & $1.050 \mathrm{E}+03$ & $7.834 \mathrm{E}-17$ & $\star 2.278 \mathrm{E}+11$ & $7.834 \mathrm{E}-17$ & $\star 2.278 \mathrm{E}+11$ \\
\hline TC-99 & $1.040 \mathrm{E}+02$ & $1.050 \mathrm{E}+03$ & $1.233 \mathrm{E}-20$ & $\star 1.697 \mathrm{E}+10$ & $1.233 \mathrm{E}-20$ & $\star 1.697 \mathrm{E}+10$ \\
\hline Th-228 & $8.000 \mathrm{E}+00$ & $0.000 \mathrm{E}+00$ & $1.329 \mathrm{E}-07$ & $7.523 \mathrm{E}+06$ & $0.000 \mathrm{E}+00$ & $\star 8.195 \mathrm{E}+14$ \\
\hline$T h-230$ & $2.000 E+02$ & $1.050 \mathrm{E}+03$ & $8.661 \mathrm{E}-06$ & $1.155 \mathrm{E}+05$ & $8.661 \mathrm{E}-06$ & $1.155 \mathrm{E}+05$ \\
\hline 232 & $8.000 \mathrm{E}+00$ & $1.050 \mathrm{E}+03$ & $8.900 \mathrm{E}-05$ & $1.124 \mathrm{E}+04$ & $8.900 \mathrm{E}-05$ & $1.124 \mathrm{E}+04$ \\
\hline 34 & $3.200 \mathrm{E}+02$ & $1.050 \mathrm{E}+03$ & $4.396 \mathrm{E}-08$ & $2.275 \mathrm{E}+07$ & $4.396 \mathrm{E}-08$ & $2.275 E+07$ \\
\hline 35 & $1.300 \mathrm{E}+01$ & $1.050 \mathrm{E}+03$ & $2.279 \mathrm{E}-09$ & $\star 2.161 \mathrm{E}+06$ & $2.279 \mathrm{E}-09$ & $\star 2.161 \mathrm{E}+06$ \\
\hline 238 & $3.200 \mathrm{E}+02$ & $1.050 \mathrm{E}+03$ & $6.021 \mathrm{E}-08$ & $\star 3.361 \mathrm{E}+05$ & $6.021 \mathrm{E}-08$ & $\star 3.361 \mathrm{E}+05$ \\
\hline
\end{tabular}

*At specific activity limit 
RESRAD, Version 6.5

Summary : RESRAD Parameters for U-Landfill Recreational User Foward Run at Proposed ALs

File : C: \RESRAD FAMILY \RESRAD \USERFILES \QCJULY2011 \ULANDFILL-RU FORWARD-1050YRSALS.RAD

Individual Nuclide Dose Summed Over All Pathways

Parent Nuclide and Branch Fraction Indicated

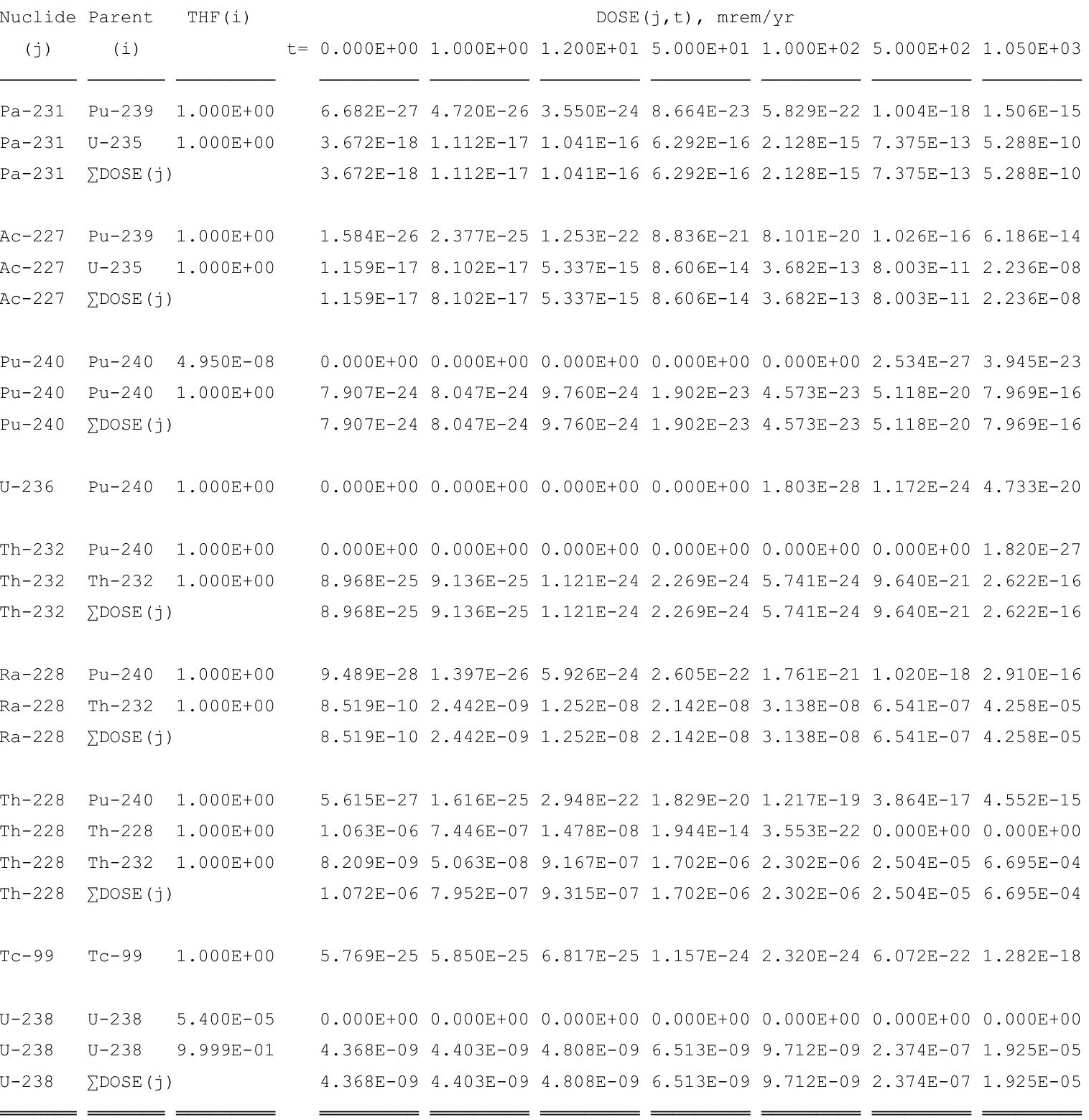

THF (i) is the thread fraction of the parent nuclide. 
RESRAD, Version 6.5

Summary : RESRAD Parameters for U-Landfill Recreational User Foward Run at Proposed ALs

File : C: $\backslash$ RESRAD_FAMILY \RESRAD \USERFILES $\backslash Q C J U L Y 2011 \backslash U L A N D F I L L-R U \_F O R W A R D-1050 Y R S A L S . R A D$

Individual Nuclide Soil Concentration

Parent Nuclide and Branch Fraction Indicated

Nuclide Parent THF(

(j)

Am-241

(i)

$\overline{A m-241} \overline{1.000 E+00}$

$\mathrm{Np}-237 \quad \mathrm{Am}-241 \quad 1.000 \mathrm{E}+00$

$\mathrm{Np}-237 \quad \mathrm{~Np}-237 \quad 1.000 \mathrm{E}+00$

Np-237 $\sum S(j):$

$\mathrm{U}-233 \quad \mathrm{Am}-241 \quad 1.000 \mathrm{E}+00$

$\mathrm{U}-233 \quad \mathrm{~Np}-237 \quad 1.000 \mathrm{E}+00$

$\mathrm{U}-233 \sum \mathrm{S}(j):$

Th-229

Th-229

Th -229

$\mathrm{Cs}-137$

$\mathrm{Pu}-238$

$\mathrm{Pu}-238$

$\mathrm{Pu}-238$

$\mathrm{U}-234$

$\mathrm{U}-234$

$\mathrm{U}-234$

$\mathrm{U}-234$

$\mathrm{Th}-230$

Th -230

$\mathrm{Th}-230$

$\mathrm{Th}-230$

Th -230

$\mathrm{Ra}-226$

$\mathrm{Ra}-226$

$\mathrm{Ra}-226$

$\mathrm{Ra}-226$

$\mathrm{Ra}-226$

$\mathrm{Pb}-210$

$\mathrm{Pb}-210$

$\mathrm{Pb}-210$

$\mathrm{Pb}-210$

$\mathrm{Pb}-210$

$\mathrm{Pu}-239$

Am-241 1.000E+00

$\mathrm{Np}-237 \quad 1.000 \mathrm{E}+00$

$\sum S(j):$

Cs-137 1.000E+00

$\mathrm{Pu}-238$ 1.840E-09

$\mathrm{Pu}-238 \quad 1.000 \mathrm{E}+00$

$\sum S(j):$

$\mathrm{Pu}-238 \quad 1.000 \mathrm{E}+00$

$\mathrm{U}-234 \quad 1.000 \mathrm{E}+00$

$\mathrm{U}-2389.999 \mathrm{E}-01$

$\sum S(j):$

$\mathrm{Pu}-238 \quad 1.000 \mathrm{E}+00$

Th-230 1.000E+00

$\mathrm{U}-234 \quad 1.000 \mathrm{E}+00$

$\mathrm{U}-2389.999 \mathrm{E}-01$

$\sum S(j):$

$\mathrm{Pu}-238 \quad 1.000 \mathrm{E}+00$

Th-230 1.000E+00

$\mathrm{U}-234 \quad 1.000 \mathrm{E}+00$

U-238 9.999E-01

$\sum S(j):$

$\mathrm{Pu}-238 \quad 1.000 \mathrm{E}+00$

Th-230 1.000E+00

$\mathrm{U}-234 \quad 1.000 \mathrm{E}+00$

U-238 9.999E-01

$\sum S(j):$

$\mathrm{Pu}-239 \quad 1.000 \mathrm{E}+00$

$\mathrm{Pu}-239 \quad 1.000 \mathrm{E}+00$

$\mathrm{U}-235 \quad 1.000 \mathrm{E}+00$

$\sum S(j):$
$S(j, t), p C i / g$

$t=0.000 \mathrm{E}+00 \quad 1.000 \mathrm{E}+00 \quad 1.200 \mathrm{E}+01 \quad 5.000 \mathrm{E}+01 \quad 1.000 \mathrm{E}+02 \quad 5.000 \mathrm{E}+02 \quad 1.050 \mathrm{E}+03$

$\begin{array}{llllllll}7.000 \mathrm{E}+01 & 6.989 \mathrm{E}+01 & 6.866 \mathrm{E}+01 & 6.460 \mathrm{E}+01 & 5.961 \mathrm{E}+01 & 3.135 \mathrm{E}+01 & 1.296 \mathrm{E}+01\end{array}$

$0.000 \mathrm{E}+00 \quad 2.265 \mathrm{E}-05 \quad 2.693 \mathrm{E}-04 \quad 1.087 \mathrm{E}-03 \quad 2.086 \mathrm{E}-03 \quad 7.621 \mathrm{E}-03 \quad 1.092 \mathrm{E}-02$

$\begin{array}{llllllllll}1.100 \mathrm{E}+01 & 1.100 \mathrm{E}+01 & 1.099 \mathrm{E}+01 & 1.096 \mathrm{E}+01 & 1.091 \mathrm{E}+01 & 1.058 \mathrm{E}+01 & 1.013 \mathrm{E}+01\end{array}$

$\begin{array}{lllllllll}1.100 \mathrm{E}+01 & 1.100 \mathrm{E}+01 & 1.099 \mathrm{E}+01 & 1.096 \mathrm{E}+01 & 1.092 \mathrm{E}+01 & 1.058 \mathrm{E}+01 & 1.014 \mathrm{E}+01\end{array}$

$0.000 \mathrm{E}+00 \quad 4.955 \mathrm{E}-11 \quad 7.091 \mathrm{E}-09 \quad 1.205 \mathrm{E}-07 \quad 4.687 \mathrm{E}-07 \quad 9.484 \mathrm{E}-06 \quad 3.225 \mathrm{E}-05$

$0.000 \mathrm{E}+00 \quad 4.810 \mathrm{E}-05 \quad 5.769 \mathrm{E}-04 \quad 2.399 \mathrm{E}-03 \quad 4.787 \mathrm{E}-03 \quad 2.348 \mathrm{E}-02 \quad 4.802 \mathrm{E}-02$

$0.000 \mathrm{E}+00 \quad 4.810 \mathrm{E}-05 \quad 5.769 \mathrm{E}-04 \quad 2.400 \mathrm{E}-03 \quad 4.788 \mathrm{E}-03 \quad 2.349 \mathrm{E}-02 \quad 4.805 \mathrm{E}-02$

$0.000 \mathrm{E}+00 \quad 1.560 \mathrm{E}-15 \quad 2.682 \mathrm{E}-12 \quad 1.908 \mathrm{E}-10 \quad 1.493 \mathrm{E}-09 \quad 1.575 \mathrm{E}-07 \quad 1.178 \mathrm{E}-06$

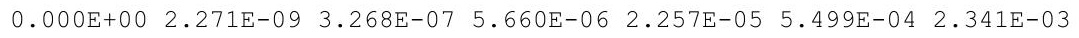

$\begin{array}{lllllll}0.000 \mathrm{E}+00 & 2.271 \mathrm{E}-09 & 3.268 \mathrm{E}-07 & 5.660 \mathrm{E}-06 & 2.257 \mathrm{E}-05 & 5.501 \mathrm{E}-04 & 2.342 \mathrm{E}-03\end{array}$

$\begin{array}{lllllll}3.800 \mathrm{E}+01 & 3.713 \mathrm{E}+01 & 2.879 \mathrm{E}+01 & 1.196 \mathrm{E}+01 & 3.763 \mathrm{E}+00 & 3.617 \mathrm{E}-04 & 1.083 \mathrm{E}-09\end{array}$

$\begin{array}{llllllll}1.435 \mathrm{E}-07 & 1.424 \mathrm{E}-07 & 1.305 \mathrm{E}-07 & 9.664 \mathrm{E}-08 & 6.507 \mathrm{E}-08 & 2.750 \mathrm{E}-09 & 3.547 \mathrm{E}-11\end{array}$

$\begin{array}{lllllllll}7.800 \mathrm{E}+01 & 7.739 \mathrm{E}+01 & 7.094 \mathrm{E}+01 & 5.252 \mathrm{E}+01 & 3.536 \mathrm{E}+01 & 1.494 \mathrm{E}+00 & 1.928 \mathrm{E}-02\end{array}$

$\begin{array}{llllllll}7.800 \mathrm{E}+01 & 7.739 \mathrm{E}+01 & 7.094 \mathrm{E}+01 & 5.252 \mathrm{E}+01 & 3.536 \mathrm{E}+01 & 1.494 \mathrm{E}+00 & 1.928 \mathrm{E}-02\end{array}$

$\begin{array}{lllllllll}0.000 \mathrm{E}+00 & 2.203 \mathrm{E}-04 & 2.531 \mathrm{E}-03 & 9.128 \mathrm{E}-03 & 1.527 \mathrm{E}-02 & 2.725 \mathrm{E}-02 & 2.753 \mathrm{E}-02\end{array}$

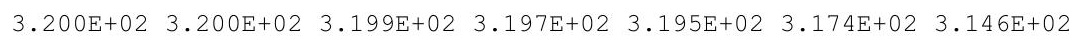

$0.000 \mathrm{E}+00 \quad 9.071 \mathrm{E}-04 \quad 1.088 \mathrm{E}-02 \quad 4.532 \mathrm{E}-02 \quad 9.058 \mathrm{E}-02 \quad 4.502 \mathrm{E}-01 \quad 9.378 \mathrm{E}-01$

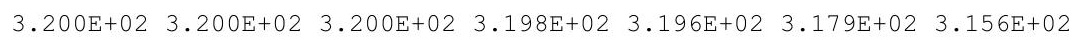

$\begin{array}{lllllll}0.000 \mathrm{E}+00 & 9.927 \mathrm{E}-10 & 1.389 \mathrm{E}-07 & 2.189 \mathrm{E}-06 & 7.768 \mathrm{E}-06 & 9.410 \mathrm{E}-05 & 2.295 \mathrm{E}-04\end{array}$

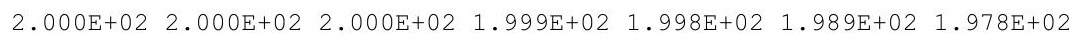
$\begin{array}{llllllllll}0.000 \mathrm{E}+00 & 2.881 \mathrm{E}-03 & 3.456 \mathrm{E}-02 & 1.439 \mathrm{E}-01 & 2.877 \mathrm{E}-01 & 1.431 \mathrm{E}+00 & 2.982 \mathrm{E}+00\end{array}$ $0.000 \mathrm{E}+00 \quad 4.083 \mathrm{E}-09 \quad 5.879 \mathrm{E}-07 \quad 1.020 \mathrm{E}-05 \quad 4.077 \mathrm{E}-05 \quad 1.014 \mathrm{E}-03 \quad 4.438 \mathrm{E}-03$

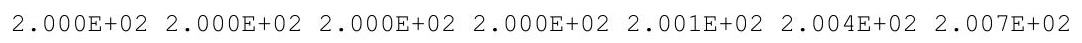

$0.000 \mathrm{E}+00 \quad 1.434 \mathrm{E}-13 \quad 2.422 \mathrm{E}-10 \quad 1.622 \mathrm{E}-08 \quad 1.178 \mathrm{E}-07 \quad 7.905 \mathrm{E}-06 \quad 4.098 \mathrm{E}-05$ $\begin{array}{llllllll}0.000 \mathrm{E}+00 & 8.662 \mathrm{E}-02 & 1.037 \mathrm{E}+00 & 4.283 \mathrm{E}+00 & 8.470 \mathrm{E}+00 & 3.874 \mathrm{E}+01 & 7.227 \mathrm{E}+01\end{array}$ $\begin{array}{llllllll}0.000 \mathrm{E}+00 & 6.239 \mathrm{E}-07 & 8.968 \mathrm{E}-05 & 1.548 \mathrm{E}-03 & 6.143 \mathrm{E}-03 & 1.444 \mathrm{E}-01 & 5.866 \mathrm{E}-01\end{array}$ $0.000 \mathrm{E}+00 \quad 5.895 \mathrm{E}-13 \quad 1.017 \mathrm{E}-09 \quad 7.326 \mathrm{E}-08 \quad 5.825 \mathrm{E}-07 \quad 6.943 \mathrm{E}-05 \quad 6.033 \mathrm{E}-04$ $\begin{array}{lllllll}0.000 \mathrm{E}+00 & 8.662 \mathrm{E}-02 & 1.037 \mathrm{E}+00 & 4.285 \mathrm{E}+00 & 8.476 \mathrm{E}+00 & 3.888 \mathrm{E}+01 & 7.285 \mathrm{E}+01\end{array}$

$0.000 \mathrm{E}+00 \quad 1.108 \mathrm{E}-15 \quad 2.110 \mathrm{E}-11 \quad 4.836 \mathrm{E}-09 \quad 5.623 \mathrm{E}-08 \quad 6.796 \mathrm{E}-06 \quad 3.841 \mathrm{E}-05$ $\begin{array}{llllllll}0.000 \mathrm{E}+00 & 1.333 \mathrm{E}-03 & 1.716 \mathrm{E}-01 & 2.115 \mathrm{E}+00 & 5.891 \mathrm{E}+00 & 3.647 \mathrm{E}+01 & 7.047 \mathrm{E}+01\end{array}$ $\begin{array}{llllllll}0.000 \mathrm{E}+00 & 6.414 \mathrm{E}-09 & 1.019 \mathrm{E}-05 & 5.674 \mathrm{E}-04 & 3.412 \mathrm{E}-03 & 1.275 \mathrm{E}-01 & 5.539 \mathrm{E}-01\end{array}$ $0.000 \mathrm{E}+00 \quad 4.553 \mathrm{E}-15 \quad 8.823 \mathrm{E}-11 \quad 2.150 \mathrm{E}-08 \quad 2.712 \mathrm{E}-07 \quad 5.779 \mathrm{E}-05 \quad 5.526 \mathrm{E}-04$ $\begin{array}{lllllll}0.000 \mathrm{E}+00 & 1.333 \mathrm{E}-03 & 1.716 \mathrm{E}-01 & 2.116 \mathrm{E}+00 & 5.894 \mathrm{E}+00 & 3.659 \mathrm{E}+01 & 7.103 \mathrm{E}+01\end{array}$

$\begin{array}{lllllll}7.200 \mathrm{E}+01 & 7.200 \mathrm{E}+01 & 7.197 \mathrm{E}+01 & 7.186 \mathrm{E}+01 & 7.172 \mathrm{E}+01 & 7.062 \mathrm{E}+01 & 6.913 \mathrm{E}+01\end{array}$

$0.000 \mathrm{E}+00 \quad 7.091 \mathrm{E}-08 \quad 8.507 \mathrm{E}-07 \quad 3.541 \mathrm{E}-06 \quad 7.073 \mathrm{E}-06 \quad 3.500 \mathrm{E}-05 \quad 7.245 \mathrm{E}-05$ $\begin{array}{lllllllllll}1.300 \mathrm{E}+01 & 1.300 \mathrm{E}+01 & 1.300 \mathrm{E}+01 & 1.299 \mathrm{E}+01 & 1.298 \mathrm{E}+01 & 1.291 \mathrm{E}+01 & 1.282 \mathrm{E}+01\end{array}$ $\begin{array}{lllllllll}1.300 \mathrm{E}+01 & 1.300 \mathrm{E}+01 & 1.300 \mathrm{E}+01 & 1.299 \mathrm{E}+01 & 1.298 \mathrm{E}+01 & 1.291 \mathrm{E}+01 & 1.282 \mathrm{E}+01\end{array}$ 
RESRAD, Version 6.5

Summary : RESRAD Parameters for U-Landfill Recreational User Foward Run at Proposed ALs

File : C: $\backslash$ RESRAD FAMILY \RESRAD \USERFILES \QCJULY2011 \ULANDFILL-RU FORWARD-1050YRSALS. RAD

Individual Nuclide Soil Concentration

Parent Nuclide and Branch Fraction Indicated

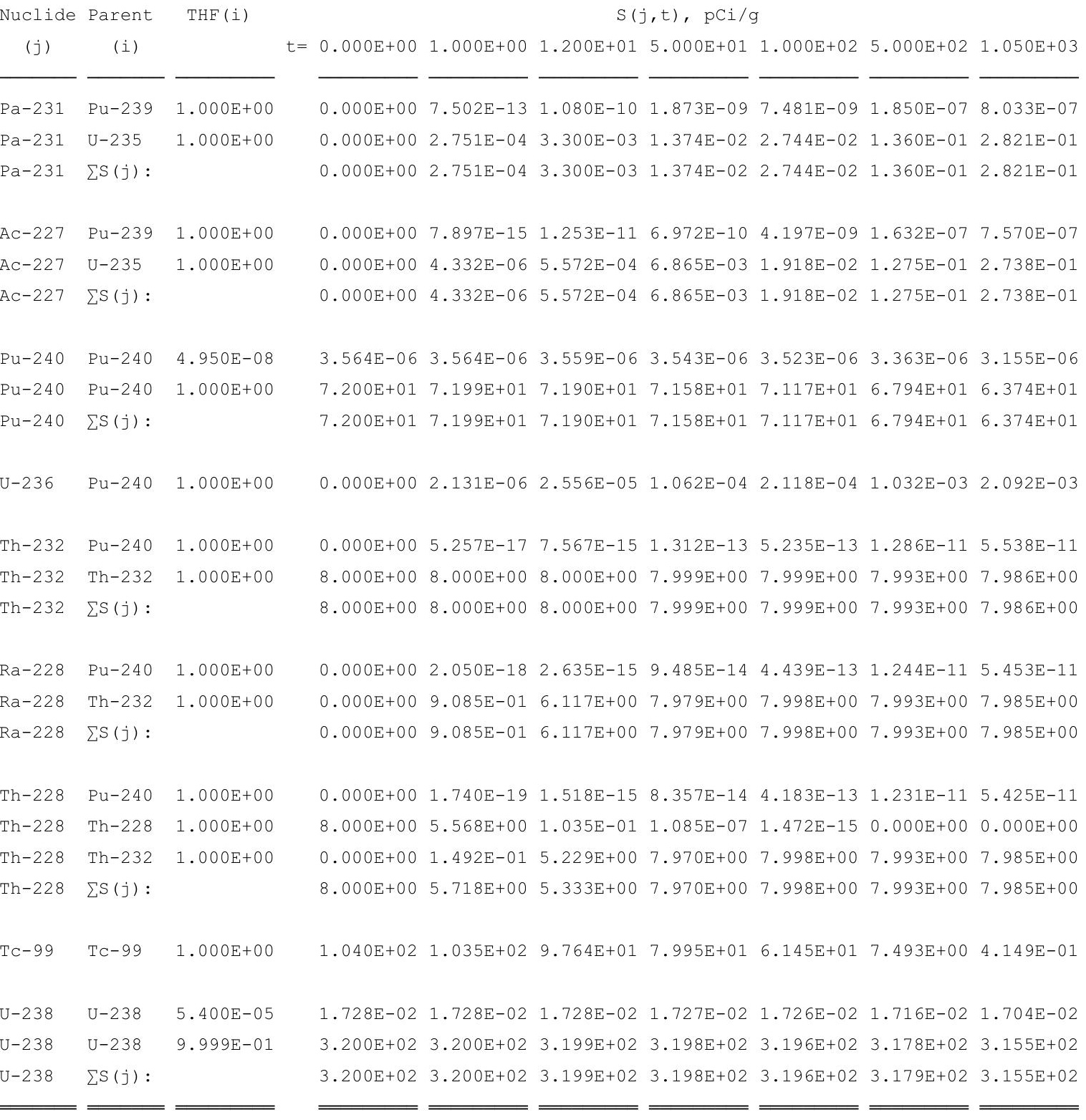

THF (i) is the thread fraction of the parent nuclide.

RESCALC.EXE execution time $=\quad 8.85$ seconds 
RESRAD, Version $6.5 \quad T^{13 / 2}$ Limit $=180$ days

07/21/2011 $12: 35$ Page

Summary : RESRAD Parameters for U-Landfill Recreational User Foward Run

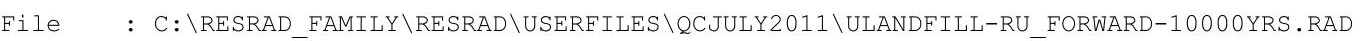

Table of Contents

Part I: Mixture Sums and Single Radionuclide Guidelines

Dose Conversion Factor (and Related) Parameter Summary ... 2

Site-Specific Parameter Summary ................ 8

Summary of Pathway Selections .................. 18

Contaminated Zone and Total Dose Summary ............. 19

Total Dose Components

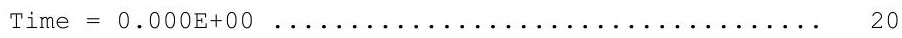

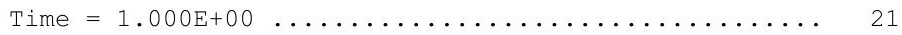

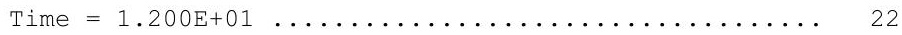

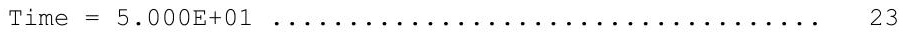

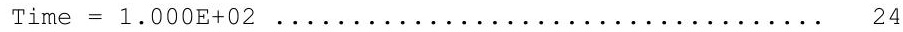

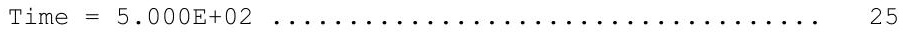

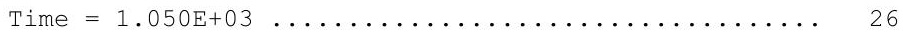

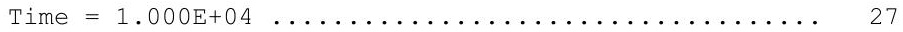

Dose/Source Ratios Summed Over All Pathways ........... 28

Single Radionuclide Soil Guidelines .............. 30

Dose Per Nuclide Summed Over All Pathways ............ 31

Soil Concentration Per Nuclide ............... 33 
Summary : RESRAD Parameters for U-Landfill Recreational User Foward Run

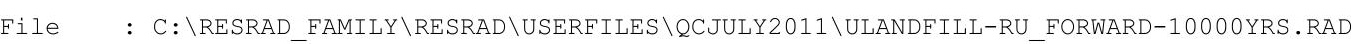

Dose Conversion Factor (and Related) Parameter Summary

Dose Library: RU for U-Landfill Plus ICRP 60 \& ICRP 72 (Age 15)

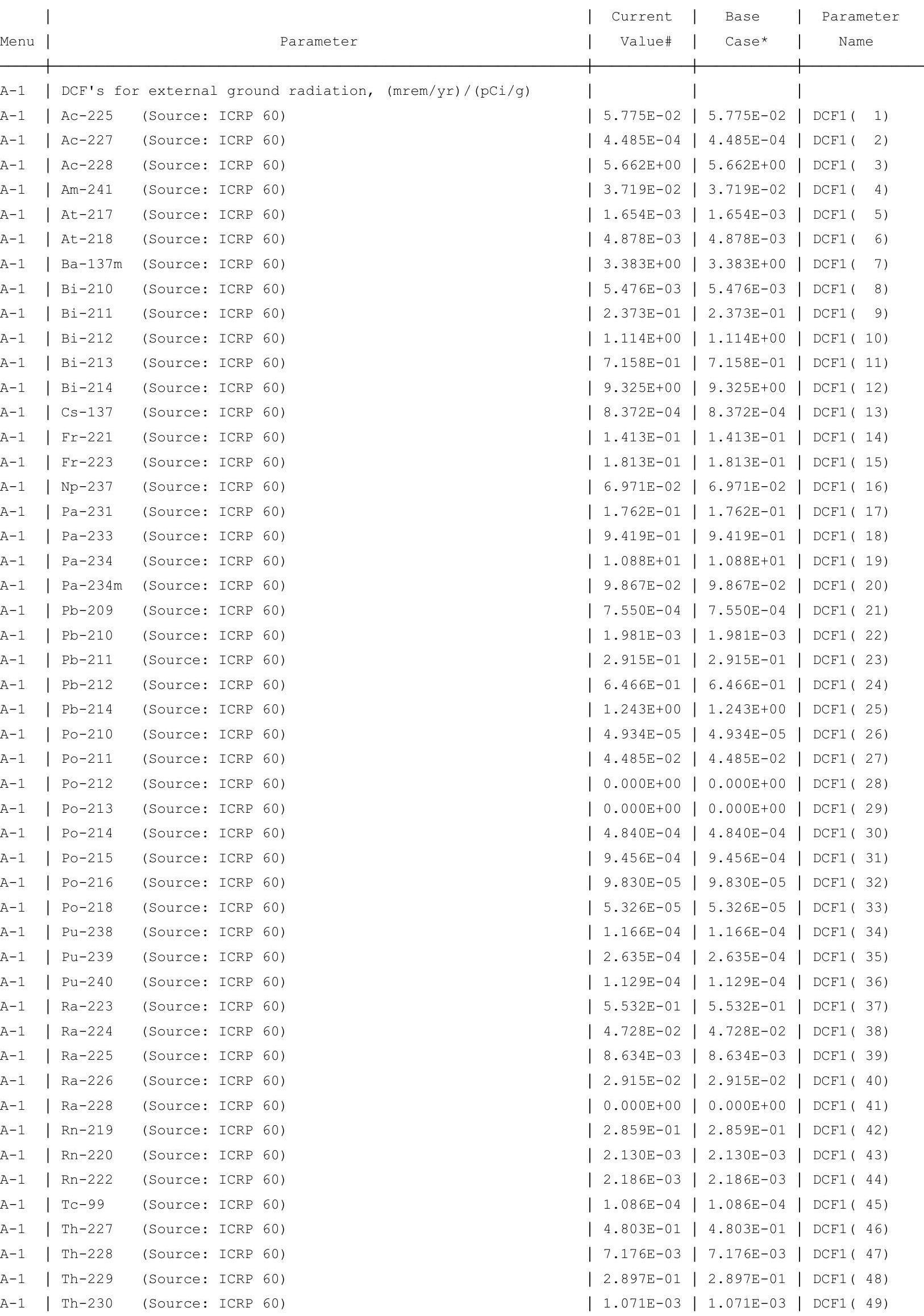


Summary : RESRAD Parameters for U-Landfill Recreational User Foward Run

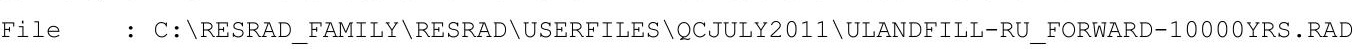

Dose Conversion Factor (and Related) Parameter Summary (continued)

Dose Library: RU for U-Landfill Plus ICRP 60 \& ICRP 72 (Age 15)

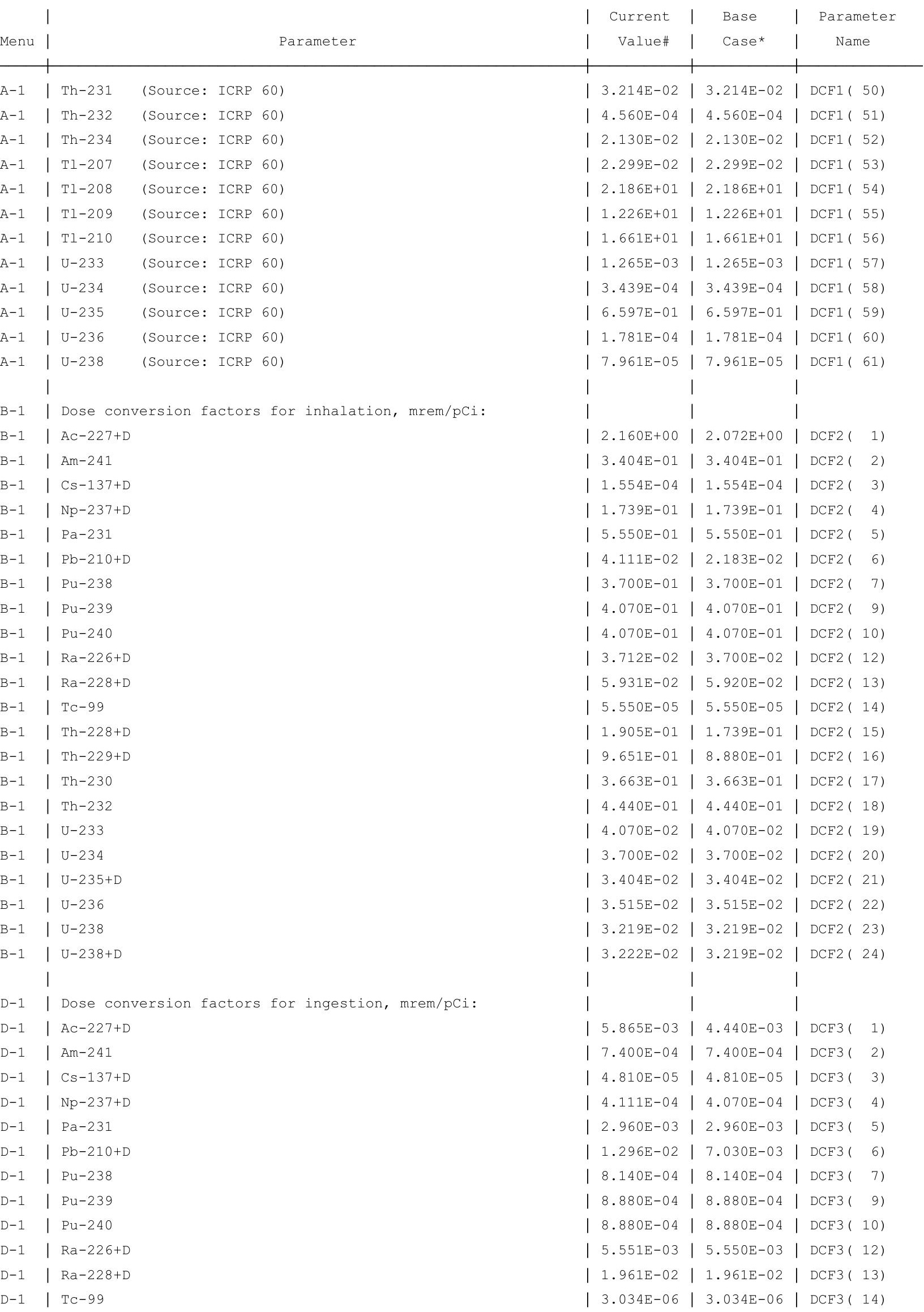


RESRAD, Version $6.5 \quad$ T1/2 Limit $=180$ days $\quad 07 / 21 / 2011 \quad 12: 35$ Page

Summary : RESRAD Parameters for U-Landfill Recreational User Foward Run

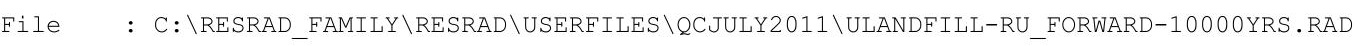

Dose Conversion Factor (and Related) Parameter Summary (continued)

Dose Library: RU for U-Landfill Plus ICRP 60 \& ICRP 72 (Age 15)

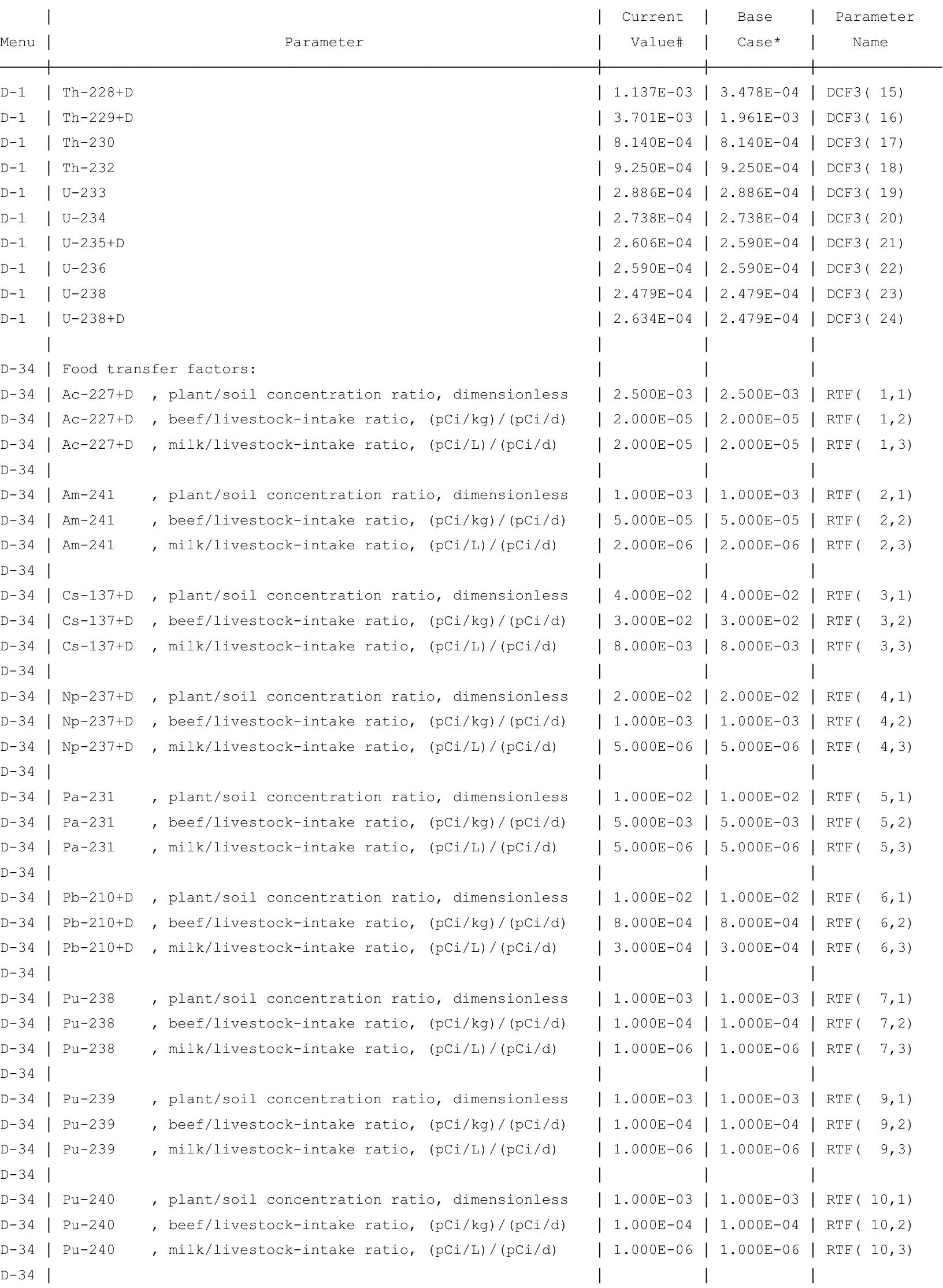

, plant/soil concentration ratio, dimensionless beef/livestock-intake ratio, (pCi/kg)/(pCi/d) , plant/soil concentration ratio, dimensionless , beef/livestock-intake ratio, (pCi/kg)/(pCi/d)

, plant/soil concentration ratio, dimensionless , beef/livestock-intake ratio, (pCi/kg)/(pCi/d) plant/soil concentration ratio, dimensionless , beef/livestock-intake ratio, $(\mathrm{pCi} / \mathrm{kg}) /(\mathrm{pCi} / \mathrm{d})$ , plant/soil concentration ratio, dimensionless , beef/livestock-intake ratio, (pCi/kg)/(pCi/d)

plant/soil concentration ratio, dimensionles , beef/livestock-intake ratio, $(\mathrm{pCi} / \mathrm{kg}) /(\mathrm{pCi} / \mathrm{d})$ , plant/soil concentration ratio, dimensionless , beef/livestock-intake ratio, (pCi/kg)/(pCi/d) , milk/livestock-intake ratio, (pCi/L)/(pCi/d)

, plant/soil concentration ratio, dimensionless , beef/livestock-intake ratio, $(\mathrm{pCi} / \mathrm{kg}) /(\mathrm{pCi} / \mathrm{d}$ , milk/livestock-intake ratio, (pCi/L)/(pCi/d)

, plant/soil concentration ratio, dimensionless \begin{tabular}{|l|l|l}
$1.137 \mathrm{E}-03$ & $3.478 \mathrm{E}-04$ & $\mathrm{DCF} 3(15)$
\end{tabular}

\begin{tabular}{l|l|l|l|}
$9.250 \mathrm{E}-04$ & $9.250 \mathrm{E}-04$ & $\mathrm{DCF} 3(18)$
\end{tabular}

\begin{tabular}{|l|l|l|}
$2.606 \mathrm{E}-04$ & $2.590 \mathrm{E}-04$ & $\mathrm{DCF} 3(21)$
\end{tabular}

\begin{tabular}{l|l|l}
$2.590 \mathrm{E}-04$ & $2.590 \mathrm{E}-04$ & $\mathrm{DCF} 3(22$
\end{tabular}

\begin{tabular}{l|l|l|l}
$2.634 \mathrm{E}-04$ & $2.479 \mathrm{E}-04$ & $\mathrm{DCF} 3(24)$
\end{tabular}

\begin{tabular}{|l|l|l|}
$2.500 \mathrm{E}-03$ & $2.500 \mathrm{E}-03$ & $\operatorname{RTF}(1,1)$
\end{tabular}

\begin{tabular}{l|l|l}
$2.000 \mathrm{E}-05$ & $2.000 \mathrm{E}-05$ & $\operatorname{RTF}(1,2)$
\end{tabular}

\begin{tabular}{l|l|l}
$2.000 \mathrm{E}-05$ & $2.000 \mathrm{E}-05$ & $\operatorname{RTF}(1,3)$
\end{tabular}

\begin{tabular}{|l|l|l|}
$1.000 \mathrm{E}-03$ & $1.000 \mathrm{E}-03$ & $\operatorname{RTF}(2,1)$
\end{tabular}

\begin{tabular}{l|l|l|}
$5.000 \mathrm{E}-05$ & $5.000 \mathrm{E}-05$ & $\operatorname{RTF}(2,2)$
\end{tabular}

\begin{tabular}{l|l|l|}
$2.000 \mathrm{E}-06$ & $2.000 \mathrm{E}-06$ & $\operatorname{RTF}(2,3)$
\end{tabular}

\begin{tabular}{|l|l|l|}
$4.000 \mathrm{E}-02$ & $4.000 \mathrm{E}-02$ & $\operatorname{RTF}(3,1)$
\end{tabular}

\begin{tabular}{l|l|l}
$3.000 \mathrm{E}-02$ & $3.000 \mathrm{E}-02$ & $\operatorname{RTF}(3,2)$
\end{tabular}

\begin{tabular}{l|l|l|}
$8.000 \mathrm{E}-03$ & $8.000 \mathrm{E}-03$ & $\operatorname{RTF}(3,3)$
\end{tabular}

\begin{tabular}{|l|l|l|}
$2.000 \mathrm{E}-02$ & $2.000 \mathrm{E}-02$ & $\operatorname{RTF}(4,1)$
\end{tabular}

1.000E-03 | 1.000E-03 | RTF(4,2)

\begin{tabular}{l|l|l|}
$5.000 \mathrm{E}-06$ & $5.000 \mathrm{E}-06$ & $\operatorname{RTF}(4,3)$
\end{tabular}

\begin{tabular}{|l|l|l|}
$1.000 \mathrm{E}-02$ & $1.000 \mathrm{E}-02$ & $\operatorname{RTF}(5,1)$
\end{tabular}

\begin{tabular}{|l|l|l|}
$5.000 \mathrm{E}-03$ & $5.000 \mathrm{E}-03$ & $\operatorname{RTF}(5,2)$
\end{tabular}

\begin{tabular}{|l|l|l|}
$5.000 \mathrm{E}-06$ & $5.000 \mathrm{E}-06$ & $\operatorname{RTF}(5,3)$
\end{tabular}

\begin{tabular}{|l|l|l|}
$1.000 \mathrm{E}-02$ & $1.000 \mathrm{E}-02$ & $\operatorname{RTF}(6,1)$
\end{tabular}

\begin{tabular}{|l|l|l|}
$8.000 \mathrm{E}-04$ & $8.000 \mathrm{E}-04$ & $\operatorname{RTF}(6,2)$
\end{tabular}

\begin{tabular}{|l|l|l|}
$3.000 \mathrm{E}-04$ & $3.000 \mathrm{E}-04$ & $\operatorname{RTF}(6,3)$
\end{tabular}

1.000E-03 | 1.000E-03 | $\operatorname{RTF}(7,1)$

\begin{tabular}{|l|l|l|}
$1.000 \mathrm{E}-04$ & $1.000 \mathrm{E}-04$ & $\operatorname{RTF}(7,2)$
\end{tabular}

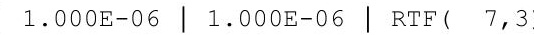

1.000E-03 | 1.000E-03 | $\operatorname{RTF}(9,1)$

\begin{tabular}{|l|l|l|l|}
$1.000 \mathrm{E}-04$ & $1.000 \mathrm{E}-04 \mid \operatorname{RTE}(9,2)$
\end{tabular}

\begin{tabular}{|l|l|l|}
$1.000 \mathrm{E}-06$ & $1.000 \mathrm{E}-06$ & $\operatorname{RTF}(9,3)$
\end{tabular}

\begin{tabular}{r|r|r|}
$1.000 \mathrm{E}-03$ & $1.000 \mathrm{E}-03$ & $\operatorname{RTF}(10,1)$
\end{tabular}

\begin{tabular}{|l|l|l|}
$1.000 \mathrm{E}-04$ & $1.000 \mathrm{E}-04$ & $\operatorname{RTF}(10,2)$
\end{tabular}

| 1.000E-06 | 1.000E-06 | $\operatorname{RTE}(10,3)$ 
RESRAD, Version $6.5 \quad \mathrm{~T}^{1 / 2}$ Limit $=180$ days

Summary : RESRAD Parameters for U-Landfill Recreational User Foward Run

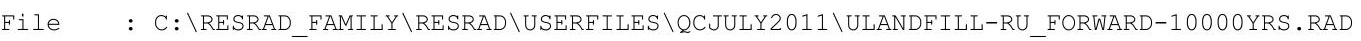

Dose Conversion Factor (and Related) Parameter Summary (continued)

Dose Library: RU for U-Landfill Plus ICRP 60 \& ICRP 72 (Age 15)

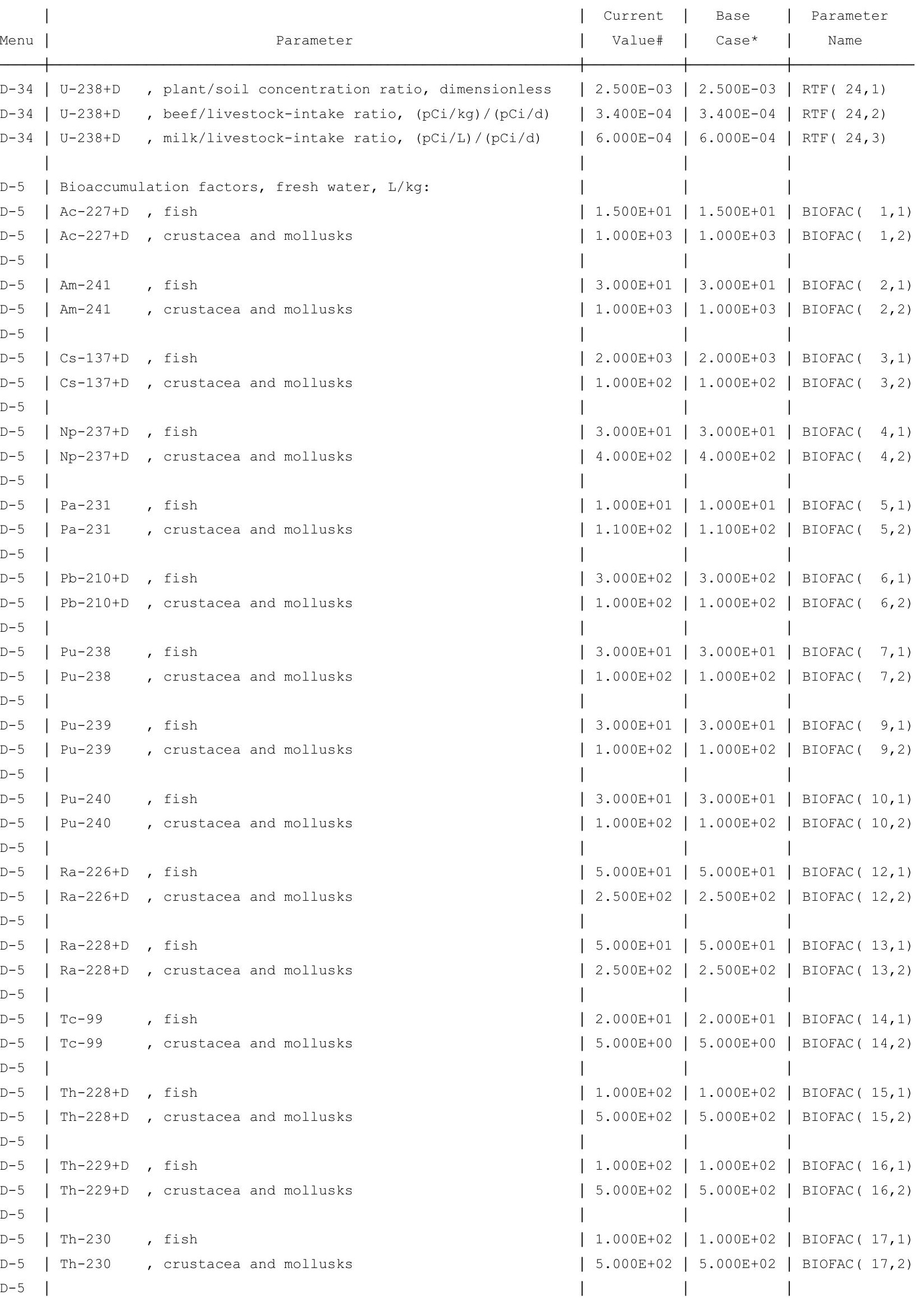


RESRAD, Version $6.5 \quad \mathrm{~T}^{1 / 2}$ Limit $=180$ days

Summary : RESRAD Parameters for U-Landfill Recreational User Foward Run

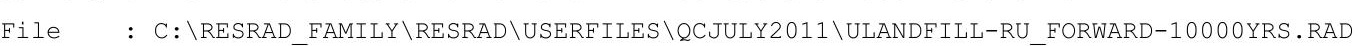

Site-Specific Parameter Summary (continued)

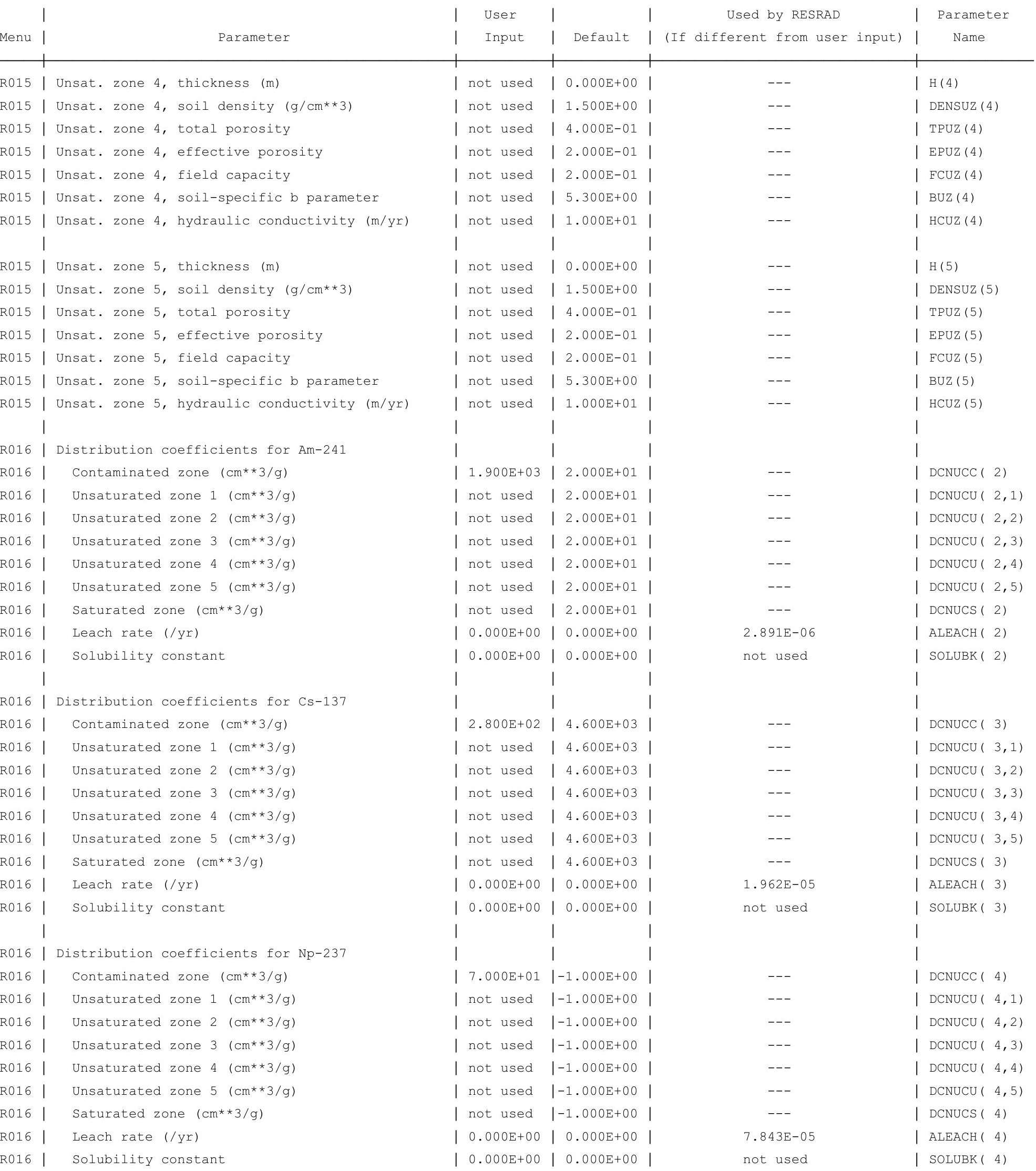


RESRAD, Version $6.5 \quad \mathrm{~T}^{1 / 2}$ Limit $=180$ days

Summary : RESRAD Parameters for U-Landfill Recreational User Foward Run

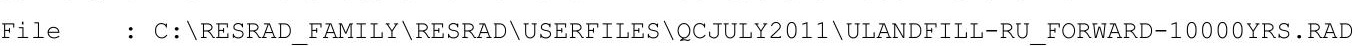

Site-Specific Parameter Summary (continued)

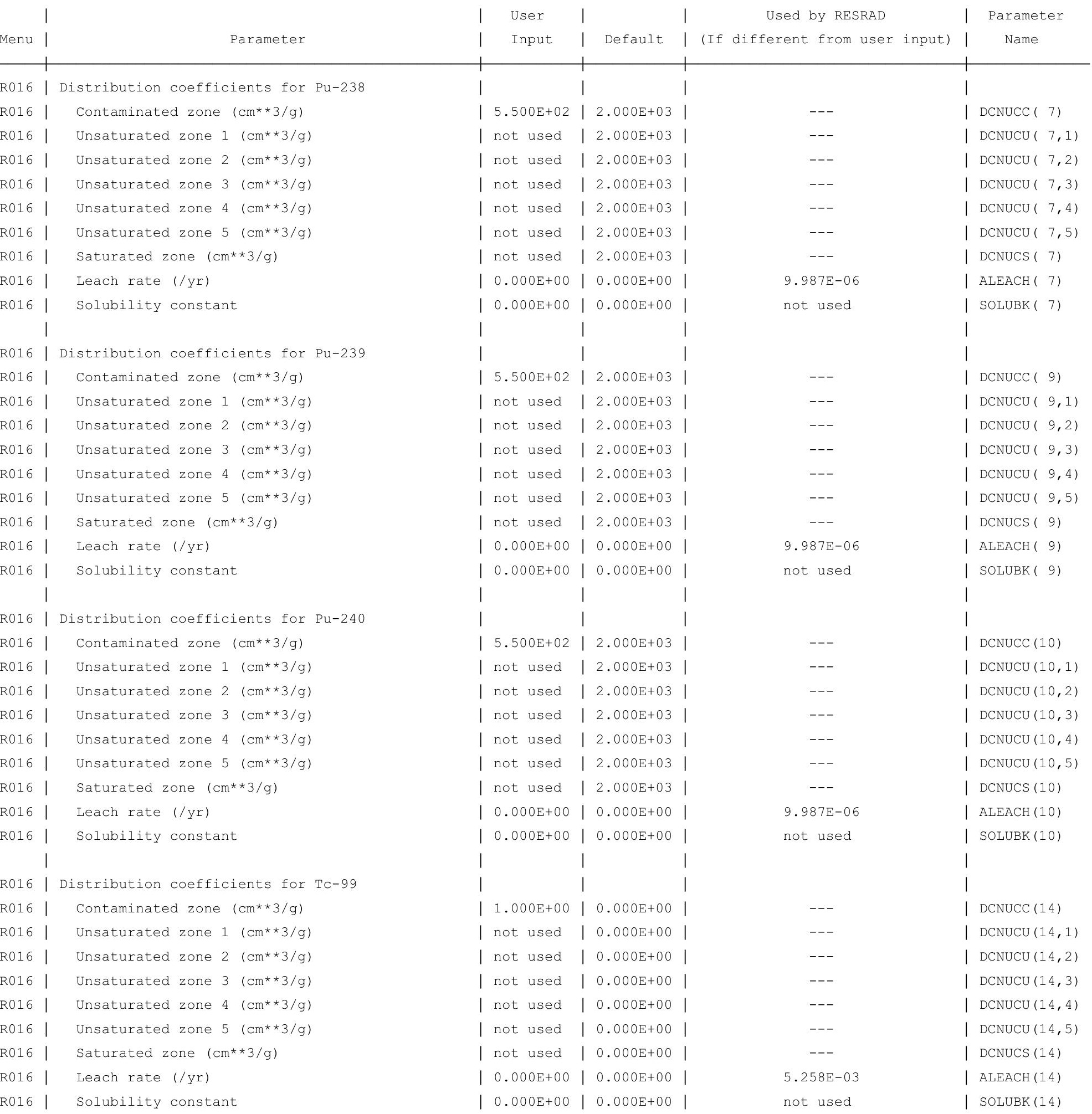


RESRAD, Version $6.5 \quad \mathrm{~T}^{1 / 2}$ Limit $=180$ days

Summary : RESRAD Parameters for U-Landfill Recreational User Foward Run

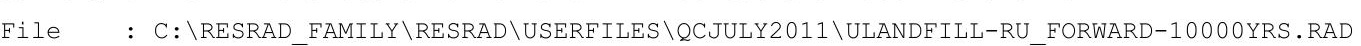

Site-Specific Parameter Summary (continued)

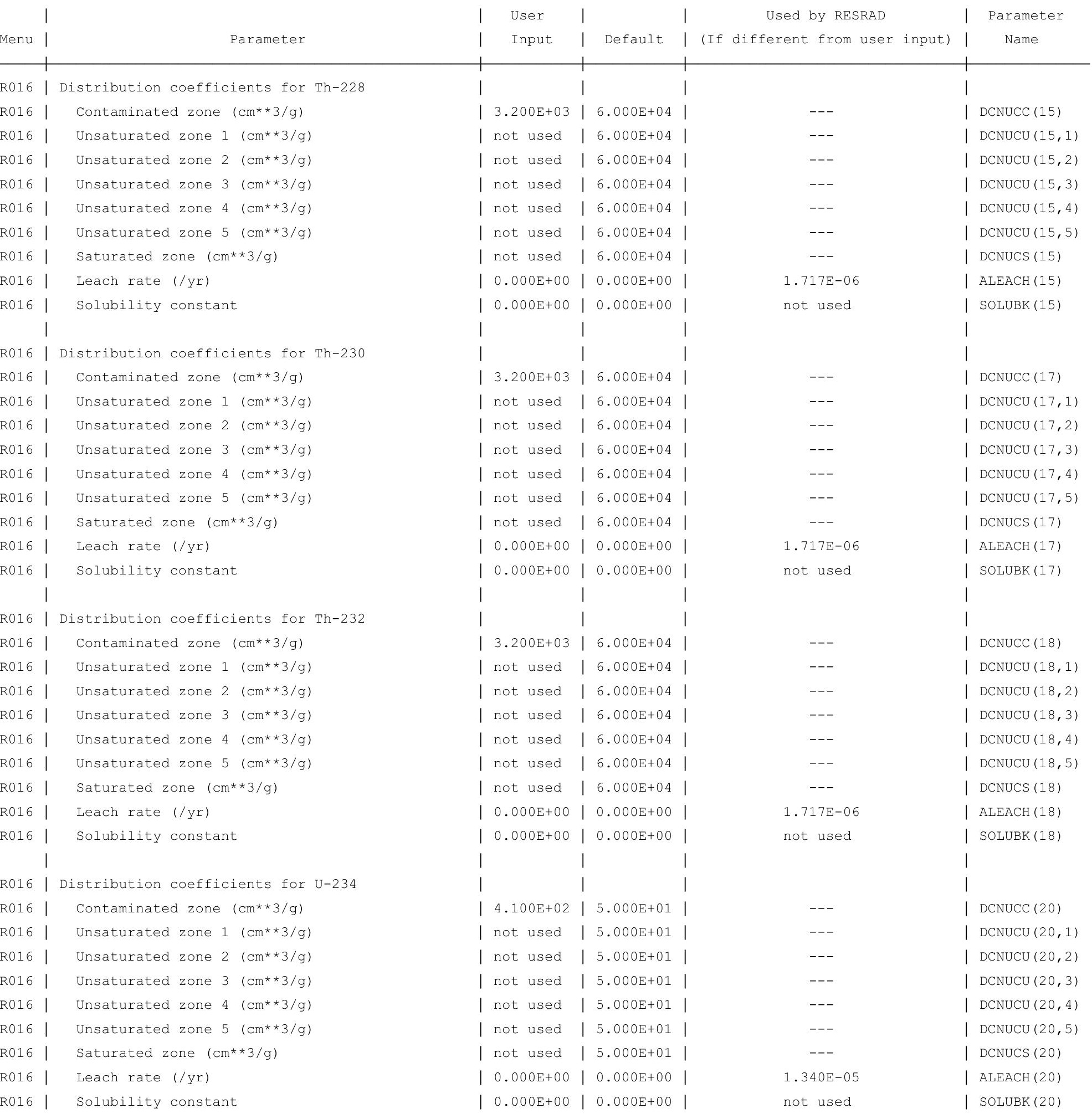


RESRAD, Version $6.5 \quad \mathrm{~T}^{1 / 2}$ Limit $=180$ days

Summary : RESRAD Parameters for U-Landfill Recreational User Foward Run

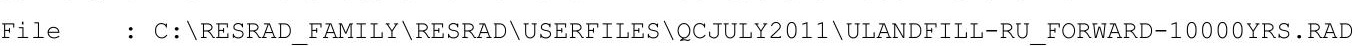

Site-Specific Parameter Summary (continued)

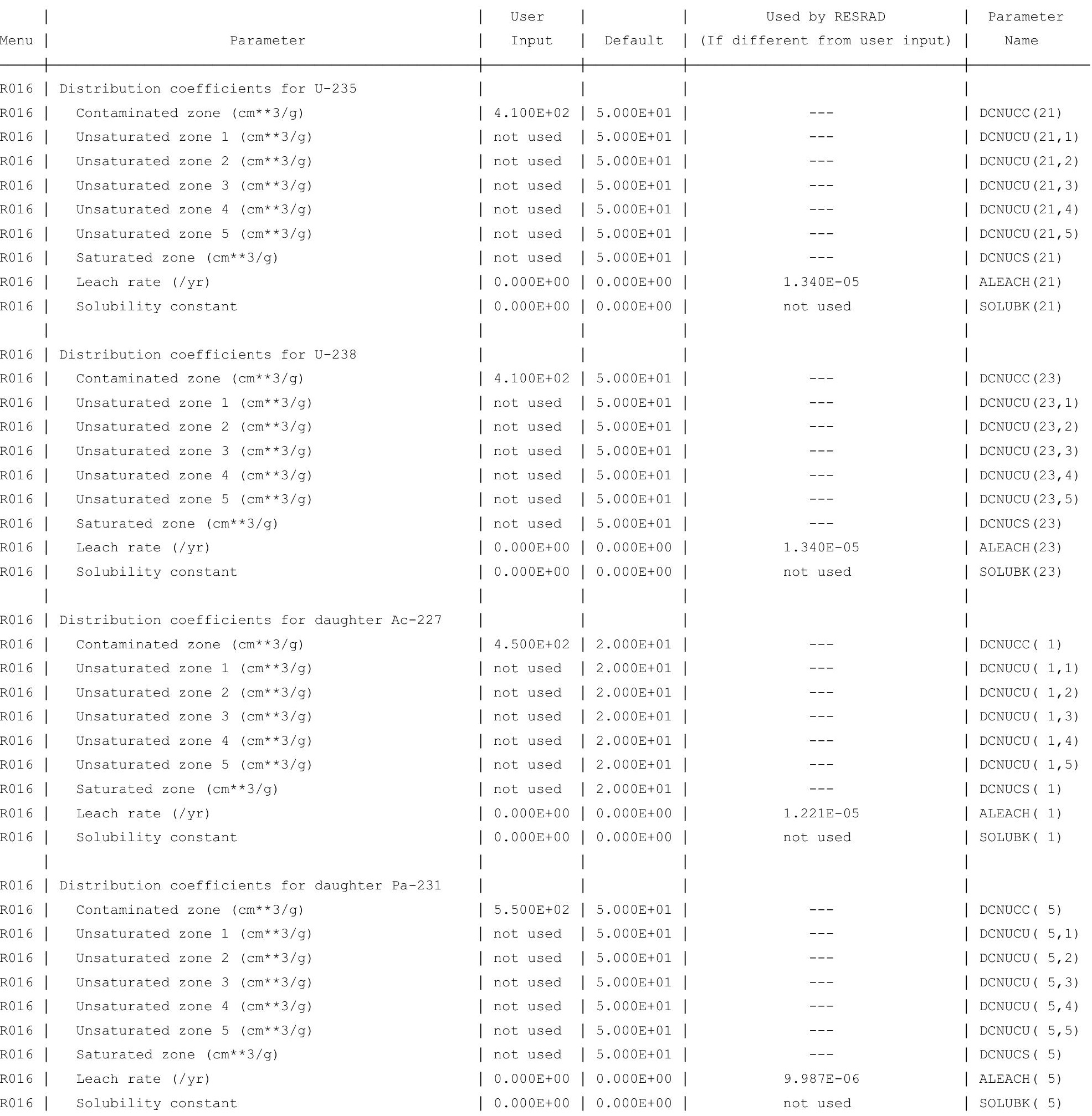


RESRAD, Version $6.5 \quad \mathrm{~T}^{1 / 2}$ Limit $=180$ days

Summary : RESRAD Parameters for U-Landfill Recreational User Foward Run

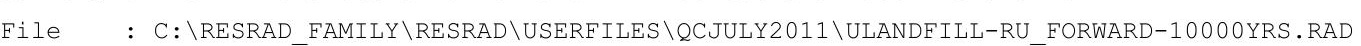

Site-Specific Parameter Summary (continued)

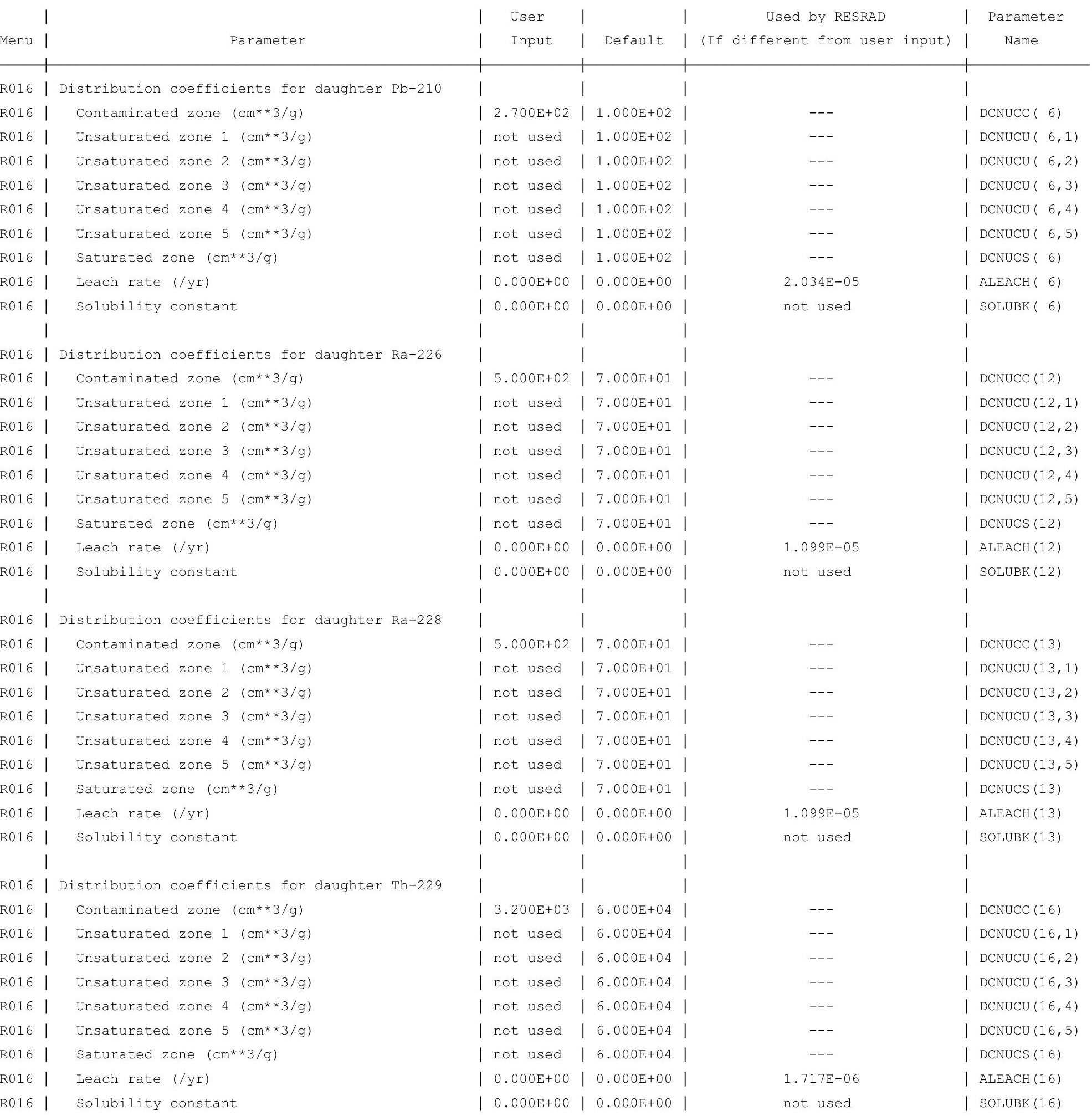


RESRAD, Version $6.5 \quad \mathrm{~T}^{1 / 2}$ Limit $=180$ days

Summary : RESRAD Parameters for U-Landfill Recreational User Foward Run

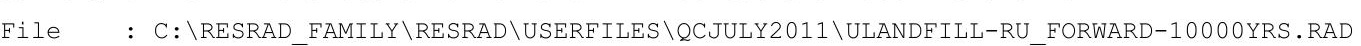

Site-Specific Parameter Summary (continued)

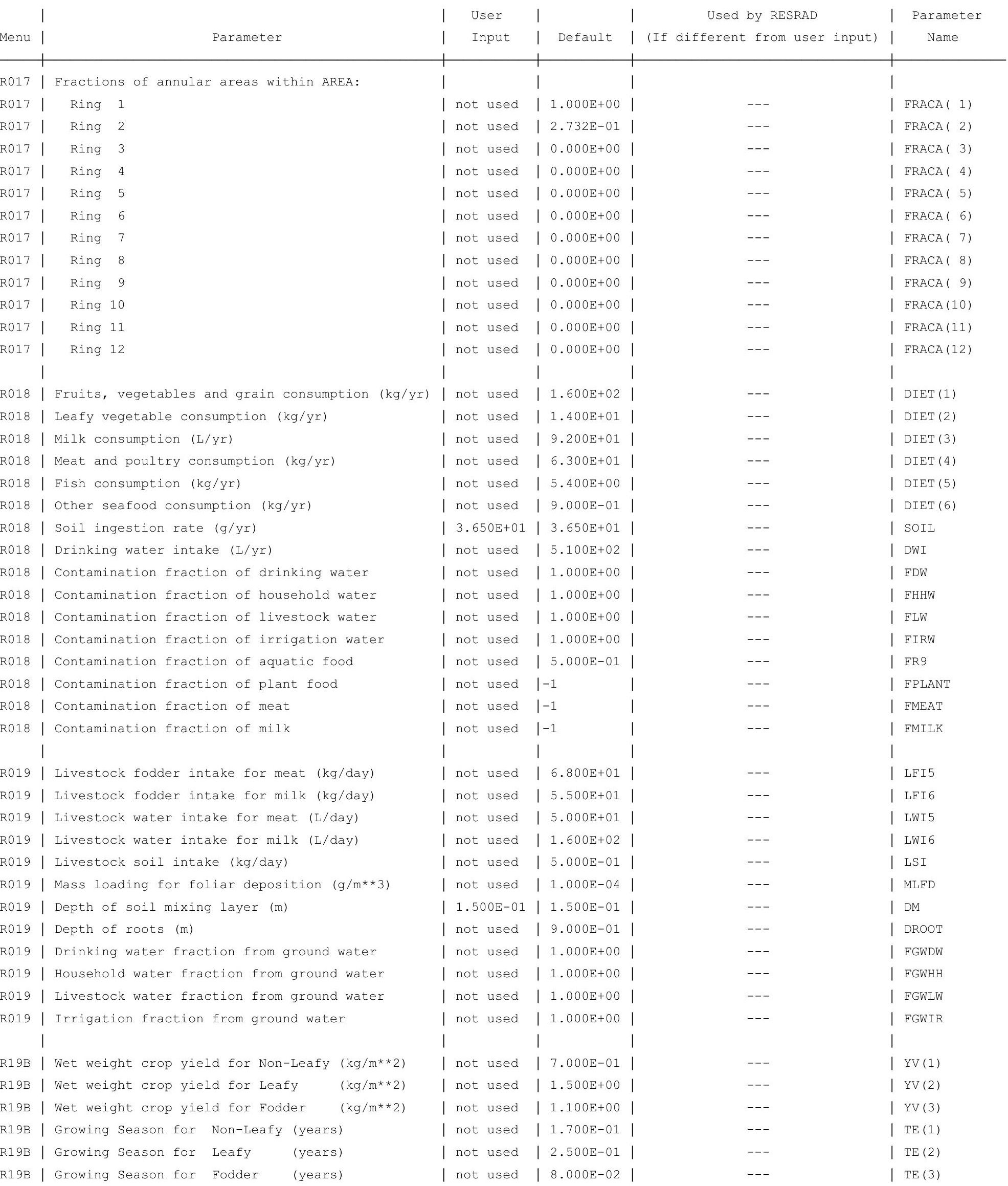


RESRAD, Version $6.5 \quad \mathrm{~T}^{1 / 2}$ Limit $=180$ days

Summary : RESRAD Parameters for U-Landfill Recreational User Foward Run

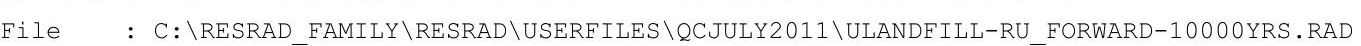

Site-Specific Parameter Summary (continued)

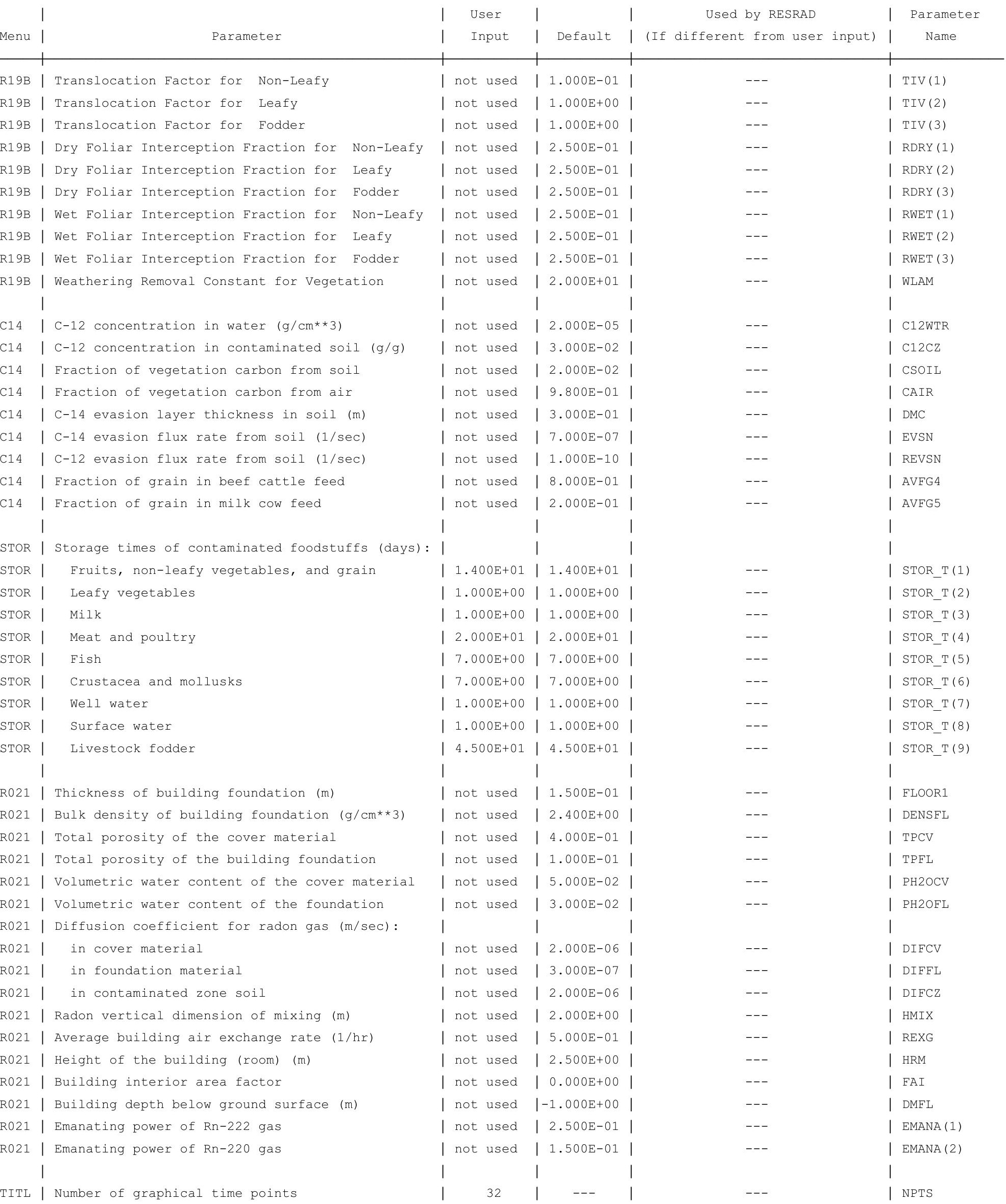

TITL | Number of graphical time points 
RESRAD, Version $6.5 \quad T^{1 / 2}$ Limit $=180$ days

Summary : RESRAD Parameters for U-Landfill Recreational User Foward Run

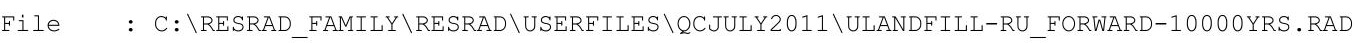

Contaminated Zone Dimensions

Area: 89436.00 square meters

Thickness:

Cover Depth:

13.40 meters

1.52 meters
Initial Soil Concentrations, pCi/g

$\begin{array}{ll}\mathrm{Am}-241 & 3.500 \mathrm{E}+01 \\ \mathrm{Cs}-137 & 1.900 \mathrm{E}+01 \\ \mathrm{~Np}-237 & 5.500 \mathrm{E}+00 \\ \mathrm{Pu}-238 & 3.900 \mathrm{E}+01 \\ \mathrm{Pu}-239 & 3.600 \mathrm{E}+01 \\ \mathrm{Pu}-240 & 3.600 \mathrm{E}+01 \\ \mathrm{TC}-99 & 5.200 \mathrm{E}+01 \\ \mathrm{Th}-228 & 4.000 \mathrm{E}+00 \\ \mathrm{Th}-230 & 1.000 \mathrm{E}+02 \\ \mathrm{Th}-232 & 4.000 \mathrm{E}+00 \\ \mathrm{U}-234 & 1.600 \mathrm{E}+02 \\ \mathrm{U}-235 & 6.500 \mathrm{E}+00 \\ \mathrm{U}-238 & 1.600 \mathrm{E}+02\end{array}$

Total Dose TDOSE(t), mrem/yr

Basic Radiation Dose Limit $=1.000 \mathrm{E}+00 \mathrm{mrem} / \mathrm{yr}$

Total Mixture Sum $M(t)$ = Fraction of Basic Dose Limit Received at Time (t)

$\begin{array}{rlllllllll}t \text { (years) }: & 0.000 \mathrm{E}+00 & 1.000 \mathrm{E}+00 & 1.200 \mathrm{E}+01 & 5.000 \mathrm{E}+01 & 1.000 \mathrm{E}+02 & 5.000 \mathrm{E}+02 & 1.050 \mathrm{E}+03 & 1.000 \mathrm{E}+04 \\ \mathrm{TDOSE}(\mathrm{t}): & 5.411 \mathrm{E}-07 & 4.044 \mathrm{E}-07 & 4.862 \mathrm{E}-07 & 9.175 \mathrm{E}-07 & 1.314 \mathrm{E}-06 & 2.333 \mathrm{E}-05 & 1.239 \mathrm{E}-03 & 9.490 \mathrm{E}+01 \\ \mathrm{M}(\mathrm{t}): & 5.411 \mathrm{E}-07 & 4.044 \mathrm{E}-07 & 4.862 \mathrm{E}-07 & 9.175 \mathrm{E}-07 & 1.314 \mathrm{E}-06 & 2.333 \mathrm{E}-05 & 1.239 \mathrm{E}-03 & 9.490 \mathrm{E}+01\end{array}$

Maximum TDOSE $(t): 9.490 \mathrm{E}+01 \mathrm{mrem} / \mathrm{yr}$ at $t=1.000 \mathrm{E}+04$ years 
RESRAD, Version 6.5

ummary : RESRAD Parameters for U-Landfill Recreational User Foward Run

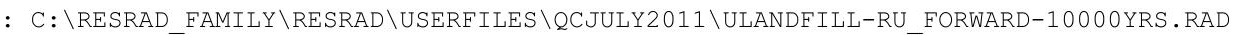

Total Dose Contributions TDOSE(i,p,t) for Individual Radionuclides (i) and Pathways (p) As mrem/yr and Fraction of Total Dose At $t=0.000 \mathrm{E}+00$ years

Water Independent Pathways (Inhalation excludes radon)

\begin{tabular}{|c|c|c|c|c|c|c|c|c|c|c|c|c|c|c|}
\hline \multirow{2}{*}{ Nuclide } & \multicolumn{2}{|c|}{ Ground } & \multicolumn{2}{|c|}{ Inhalation } & \multicolumn{2}{|c|}{ Radon } & \multicolumn{2}{|c|}{ Plant } & \multicolumn{2}{|c|}{ Meat } & \multicolumn{2}{|c|}{ Milk } & \multicolumn{2}{|c|}{ Soil } \\
\hline & mrem/yr & fract. & mrem/yr & fract. & mrem/yr & fract. & mrem/yr & fract. & mrem/yr & fract. & mrem/yr & fract. & mrem/yr & fract. \\
\hline-241 & $5.204 \mathrm{E}-19$ & 0.0000 & $0.000 \mathrm{E}+00$ & 0.0000 & $0.000 \mathrm{E}+00$ & 0.0000 & $0.000 \mathrm{E}+00$ & 0.0000 & $0.000 \mathrm{E}+00$ & 0.0000 & $0.000 \mathrm{E}+00$ & 0.0000 & $0.000 \mathrm{E}+00$ & 0.0000 \\
\hline-137 & $2.305 E-09$ & 0.0043 & $0.000 \mathrm{E}+00$ & 0.0000 & $0.000 \mathrm{E}+00$ & 0.0000 & $0.000 \mathrm{E}+00$ & 0.0000 & $0.000 \mathrm{E}+00$ & 0.0000 & $0.000 \mathrm{E}+00$ & 0.0000 & $0.000 \mathrm{E}+00$ & 0.0000 \\
\hline-237 & $5.043 E-13$ & 0.0000 & $0.000 \mathrm{E}+00$ & 0.0000 & $0.000 \mathrm{E}+00$ & 0.0000 & $0.000 \mathrm{E}+00$ & 0.0000 & $0.000 \mathrm{E}+00$ & 0.0000 & $0.000 \mathrm{E}+00$ & 0.0000 & $0.000 \mathrm{E}+00$ & 0.0000 \\
\hline-238 & $3.052 \mathrm{E}-22$ & 0.0000 & $0.000 \mathrm{E}+00$ & 0.0000 & $0.000 \mathrm{E}+00$ & 0.0000 & $0.000 \mathrm{E}+00$ & 0.0000 & $0.000 \mathrm{E}+00$ & 0.0000 & $0.000 \mathrm{E}+00$ & 0.0000 & $0.000 \mathrm{E}+00$ & 0.0000 \\
\hline-239 & $4.161 \mathrm{E}-17$ & 0.0000 & $0.000 \mathrm{E}+00$ & 0.0000 & $0.000 \mathrm{E}+00$ & 0.0000 & $0.000 \mathrm{E}+00$ & 0.0000 & $0.000 \mathrm{E}+00$ & 0.0000 & $0.000 \mathrm{E}+00$ & 0.0000 & $0.000 \mathrm{E}+00$ & 0.0000 \\
\hline-240 & $3.957 \mathrm{E}-24$ & 0.0000 & $0.000 \mathrm{E}+00$ & 0.0000 & $0.000 \mathrm{E}+00$ & 0.0000 & $0.000 \mathrm{E}+00$ & 0.0000 & $0.000 \mathrm{E}+00$ & 0.0000 & $0.000 \mathrm{E}+00$ & 0.0000 & $0.000 \mathrm{E}+00$ & 0.0000 \\
\hline 99 & $2.884 \mathrm{E}-25$ & 0.0000 & $0.000 \mathrm{E}+00$ & 0.0000 & $0.000 \mathrm{E}+00$ & 0.0000 & $0.000 \mathrm{E}+00$ & 0.0000 & $0.000 \mathrm{E}+00$ & 0.0000 & $0.000 \mathrm{E}+00$ & 0.0000 & $0.000 \mathrm{E}+00$ & 0.0000 \\
\hline-228 & $5.317 \mathrm{E}-07$ & 0.9827 & $0.000 \mathrm{E}+00$ & 0.0000 & $0.000 \mathrm{E}+00$ & 0.0000 & $0.000 \mathrm{E}+00$ & 0.0000 & $0.000 \mathrm{E}+00$ & 0.0000 & $0.000 \mathrm{E}+00$ & 0.0000 & $0.000 \mathrm{E}+00$ & 0.0000 \\
\hline-230 & $3.629 \mathrm{E}-10$ & 0.0007 & $0.000 \mathrm{E}+00$ & 0.0000 & $0.000 \mathrm{E}+00$ & 0.0000 & $0.000 \mathrm{E}+00$ & 0.0000 & $0.000 \mathrm{E}+00$ & 0.0000 & $0.000 \mathrm{E}+00$ & 0.0000 & $0.000 \mathrm{E}+00$ & 0.0000 \\
\hline-232 & $4.531 E-09$ & 0.0084 & $0.000 \mathrm{E}+00$ & 0.0000 & $0.000 \mathrm{E}+00$ & 0.0000 & $0.000 \mathrm{E}+00$ & 0.0000 & $0.000 \mathrm{E}+00$ & 0.0000 & $0.000 \mathrm{E}+00$ & 0.0000 & $0.000 \mathrm{E}+00$ & 0.0000 \\
\hline 234 & $1.743 E-15$ & 0.0000 & $0.000 \mathrm{E}+00$ & 0.0000 & $0.000 \mathrm{E}+00$ & 0.0000 & $0.000 \mathrm{E}+00$ & 0.0000 & $0.000 \mathrm{E}+00$ & 0.0000 & $0.000 E+00$ & 0.0000 & $0.000 \mathrm{E}+00$ & 0.0000 \\
\hline 35 & $7.778 \mathrm{E}-15$ & 0.0000 & $0.000 \mathrm{E}+00$ & 0.0000 & $0.000 \mathrm{E}+00$ & 0.0000 & $0.000 \mathrm{E}+00$ & 0.0000 & $0.000 \mathrm{E}+00$ & 0.0000 & $0.000 \mathrm{E}+00$ & 0.0000 & $0.000 \mathrm{E}+00$ & 0.0000 \\
\hline 38 & $2.184 \mathrm{E}-09$ & 0.0040 & $0.000 \mathrm{E}+00$ & 0.0000 & $0.000 \mathrm{E}+00$ & 0.0000 & $0.000 \mathrm{E}+00$ & 0.0000 & $0.000 \mathrm{E}+00$ & 0.0000 & $0.000 \mathrm{E}+00$ & 0.0000 & $0.000 \mathrm{E}+00$ & 0.0000 \\
\hline & $5.411 \mathrm{E}-07$ & 1.0000 & $0.000 \mathrm{E}+00$ & 0.0000 & $0.000 \mathrm{E}+00$ & 0.0000 & $0.000 \mathrm{E}+00$ & 0.0000 & $0.000 \mathrm{E}+00$ & 0.0000 & $0.000 \mathrm{E}+00$ & 0.0000 & $0.000 \mathrm{E}+00$ & 0.0000 \\
\hline
\end{tabular}

Total Dose Contributions TDOSE(i,p,t) for Individual Radionuclides (i) and Pathways (p) As mrem/yr and Fraction of Total Dose At $t=0.000 \mathrm{E}+00$ years

Water Dependent Pathways

\begin{tabular}{|c|c|c|c|c|c|c|c|c|c|c|c|c|c|c|}
\hline \multirow{2}{*}{$\begin{array}{l}\text { Radio- } \\
\text { Nuclide }\end{array}$} & \multicolumn{2}{|c|}{ Water } & \multicolumn{2}{|c|}{ Fish } & \multicolumn{2}{|c|}{ Radon } & \multicolumn{2}{|c|}{ Plant } & \multicolumn{2}{|c|}{ Meat } & \multicolumn{2}{|c|}{ Milk } & \multicolumn{2}{|c|}{ All Pathways* } \\
\hline & mrem/yr & fract. & mrem/yr & fract. & mrem/yr & fract. & mrem/yr & fract. & mrem/yr & fract. & mrem/yr & fract. & mrem/yr & fract. \\
\hline 241 & $0.000 \mathrm{E}+00$ & 0.0000 & $0.000 \mathrm{E}+00$ & 0.0000 & $0.000 \mathrm{E}+00$ & 0.0000 & $0.000 \mathrm{E}+00$ & 0.0000 & $0.000 \mathrm{E}+00$ & 0.0000 & $0.000 \mathrm{E}+00$ & 0.0000 & $5.204 \mathrm{E}-19$ & 0.0000 \\
\hline-137 & $0.000 \mathrm{E}+00$ & 0.0000 & $0.000 \mathrm{E}+00$ & 0.0000 & $0.000 \mathrm{E}+00$ & 0.0000 & $0.000 \mathrm{E}+00$ & 0.0000 & $0.000 \mathrm{E}+00$ & 0.0000 & $0.000 \mathrm{E}+00$ & 0.0000 & $2.305 E-09$ & 0.0043 \\
\hline-237 & $0.000 \mathrm{E}+00$ & 0.0000 & $0.000 \mathrm{E}+00$ & 0.0000 & $0.000 \mathrm{E}+00$ & 0.0000 & $0.000 \mathrm{E}+00$ & 0.0000 & $0.000 \mathrm{E}+00$ & 0.0000 & $0.000 \mathrm{E}+00$ & 0.0000 & $5.043 E-13$ & 0.0000 \\
\hline-238 & $0.000 \mathrm{E}+00$ & 0.0000 & $0.000 \mathrm{E}+00$ & 0.0000 & $0.000 \mathrm{E}+00$ & 0.0000 & $0.000 \mathrm{E}+00$ & 0.0000 & $0.000 \mathrm{E}+00$ & 0.0000 & $0.000 \mathrm{E}+00$ & 0.0000 & $3.052 \mathrm{E}-22$ & 0.0000 \\
\hline-239 & $0.000 \mathrm{E}+00$ & 0.0000 & $0.000 \mathrm{E}+00$ & 0.0000 & $0.000 \mathrm{E}+00$ & 0.0000 & $0.000 \mathrm{E}+00$ & 0.0000 & $0.000 \mathrm{E}+00$ & 0.0000 & $0.000 E+00$ & 0.0000 & $4.161 \mathrm{E}-17$ & 0.0000 \\
\hline-240 & $0.000 \mathrm{E}+00$ & 0.0000 & $0.000 \mathrm{E}+00$ & 0.0000 & $0.000 \mathrm{E}+00$ & 0.0000 & $0.000 \mathrm{E}+00$ & 0.0000 & $0.000 \mathrm{E}+00$ & 0.0000 & $0.000 E+00$ & 0.0000 & $3.957 \mathrm{E}-24$ & 0.0000 \\
\hline 99 & $0.000 \mathrm{E}+00$ & 0.0000 & $0.000 \mathrm{E}+00$ & 0.0000 & $0.000 \mathrm{E}+00$ & 0.0000 & $0.000 \mathrm{E}+00$ & 0.0000 & $0.000 \mathrm{E}+00$ & 0.0000 & $0.000 \mathrm{E}+00$ & 0.0000 & $2.884 \mathrm{E}-25$ & 0.0000 \\
\hline-228 & $0.000 \mathrm{E}+00$ & 0.0000 & $0.000 \mathrm{E}+00$ & 0.0000 & $0.000 \mathrm{E}+00$ & 0.0000 & $0.000 \mathrm{E}+00$ & 0.0000 & $0.000 \mathrm{E}+00$ & 0.0000 & $0.000 \mathrm{E}+00$ & 0.0000 & $5.317 \mathrm{E}-07$ & 0.9827 \\
\hline-230 & $0.000 \mathrm{E}+00$ & 0.0000 & $0.000 \mathrm{E}+00$ & 0.0000 & $0.000 \mathrm{E}+00$ & 0.0000 & $0.000 \mathrm{E}+00$ & 0.0000 & $0.000 \mathrm{E}+00$ & 0.0000 & $0.000 E+00$ & 0.0000 & $3.629 \mathrm{E}-10$ & 0.0007 \\
\hline 232 & $0.000 \mathrm{E}+00$ & 0.0000 & $0.000 \mathrm{E}+00$ & 0.0000 & $0.000 \mathrm{E}+00$ & 0.0000 & $0.000 \mathrm{E}+00$ & 0.0000 & $0.000 \mathrm{E}+00$ & 0.0000 & $0.000 \mathrm{E}+00$ & 0.0000 & $4.531 E-09$ & 0.0084 \\
\hline 34 & $0.000 \mathrm{E}+00$ & 0.0000 & $0.000 \mathrm{E}+00$ & 0.0000 & $0.000 \mathrm{E}+00$ & 0.0000 & $0.000 \mathrm{E}+00$ & 0.0000 & $0.000 \mathrm{E}+00$ & 0.0000 & $0.000 \mathrm{E}+00$ & 0.0000 & $1.743 \mathrm{E}-15$ & 0.0000 \\
\hline 35 & $0.000 \mathrm{E}+00$ & 0.0000 & $0.000 \mathrm{E}+00$ & 0.0000 & $0.000 \mathrm{E}+00$ & 0.0000 & $0.000 \mathrm{E}+00$ & 0.0000 & $0.000 \mathrm{E}+00$ & 0.0000 & $0.000 \mathrm{E}+00$ & 0.0000 & 7. $778 \mathrm{E}-15$ & 0.0000 \\
\hline 38 & $0.000 \mathrm{E}+00$ & 0.0000 & $0.000 \mathrm{E}+00$ & 0.0000 & $0.000 \mathrm{E}+00$ & 0.0000 & $0.000 \mathrm{E}+00$ & 0.0000 & $0.000 \mathrm{E}+00$ & 0.0000 & $0.000 \mathrm{E}+00$ & 0.0000 & $2.184 \mathrm{E}-09$ & 0.0040 \\
\hline & $0.000 \mathrm{E}+00$ & 0.0000 & $0.000 \mathrm{E}+00$ & 0.0000 & $0.000 \mathrm{E}+00$ & 0.0000 & $0.000 \mathrm{E}+00$ & 0.0000 & $0.000 \mathrm{E}+00$ & 0.0000 & $0.000 \mathrm{E}+00$ & 0.0000 & $11 \mathrm{E}-07$ & 1.0000 \\
\hline
\end{tabular}

* Sum of all water independent and dependent pathways. 
RESRAD, Version 6.5

ummary : RESRAD Parameters for U-Landfill Recreational User Foward Run

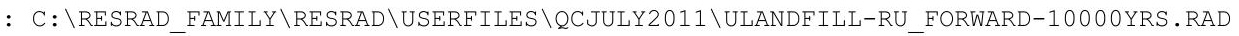

Total Dose Contributions TDOSE (i,p,t) for Individual Radionuclides (i) and Pathways (p) As mrem/yr and Fraction of Total Dose At $t=1.000 \mathrm{E}+00$ years

Water Independent Pathways (Inhalation excludes radon)

\begin{tabular}{|c|c|c|c|c|c|c|c|c|c|c|c|c|c|c|}
\hline \multirow{2}{*}{ Nuclide } & \multicolumn{2}{|c|}{ Ground } & \multicolumn{2}{|c|}{ Inhalation } & \multicolumn{2}{|c|}{ Radon } & \multicolumn{2}{|c|}{ Plant } & \multicolumn{2}{|c|}{ Meat } & \multicolumn{2}{|c|}{ Milk } & \multicolumn{2}{|c|}{ Soil } \\
\hline & mrem/yr & fract. & mrem/yr & fract. & mrem/yr & fract. & mrem/yr & fract. & mrem/yr & fract. & mrem/yr & fract. & mrem/yr & fract. \\
\hline-241 & $1.575 \mathrm{E}-18$ & 0.0000 & $0.000 \mathrm{E}+00$ & 0.0000 & $0.000 \mathrm{E}+00$ & 0.0000 & $0.000 \mathrm{E}+00$ & 0.0000 & $0.000 \mathrm{E}+00$ & 0.0000 & $0.000 \mathrm{E}+00$ & 0.0000 & $0.000 \mathrm{E}+00$ & 0.0000 \\
\hline-137 & $2.272 E-09$ & 0.0056 & $0.000 \mathrm{E}+00$ & 0.0000 & $0.000 \mathrm{E}+00$ & 0.0000 & $0.000 \mathrm{E}+00$ & 0.0000 & $0.000 \mathrm{E}+00$ & 0.0000 & $0.000 \mathrm{E}+00$ & 0.0000 & $0.000 \mathrm{E}+00$ & 0.0000 \\
\hline-237 & $5.097 \mathrm{E}-13$ & 0.0000 & $0.000 \mathrm{E}+00$ & 0.0000 & $0.000 \mathrm{E}+00$ & 0.0000 & $0.000 \mathrm{E}+00$ & 0.0000 & $0.000 \mathrm{E}+00$ & 0.0000 & $0.000 \mathrm{E}+00$ & 0.0000 & $0.000 \mathrm{E}+00$ & 0.0000 \\
\hline-238 & $4.535 E-21$ & 0.0000 & $0.000 \mathrm{E}+00$ & 0.0000 & $0.000 \mathrm{E}+00$ & 0.0000 & $0.000 \mathrm{E}+00$ & 0.0000 & $0.000 \mathrm{E}+00$ & 0.0000 & $0.000 \mathrm{E}+00$ & 0.0000 & $0.000 \mathrm{E}+00$ & 0.0000 \\
\hline-239 & $4.211 \mathrm{E}-17$ & 0.0000 & $0.000 \mathrm{E}+00$ & 0.0000 & $0.000 \mathrm{E}+00$ & 0.0000 & $0.000 \mathrm{E}+00$ & 0.0000 & $0.000 \mathrm{E}+00$ & 0.0000 & $0.000 \mathrm{E}+00$ & 0.0000 & $0.000 \mathrm{E}+00$ & 0.0000 \\
\hline-240 & $4.111 \mathrm{E}-24$ & 0.0000 & $0.000 \mathrm{E}+00$ & 0.0000 & $0.000 \mathrm{E}+00$ & 0.0000 & $0.000 \mathrm{E}+00$ & 0.0000 & $0.000 \mathrm{E}+00$ & 0.0000 & $0.000 \mathrm{E}+00$ & 0.0000 & $0.000 \mathrm{E}+00$ & 0.0000 \\
\hline 99 & $2.925 E-25$ & 0.0000 & $0.000 \mathrm{E}+00$ & 0.0000 & $0.000 \mathrm{E}+00$ & 0.0000 & $0.000 \mathrm{E}+00$ & 0.0000 & $0.000 \mathrm{E}+00$ & 0.0000 & $0.000 \mathrm{E}+00$ & 0.0000 & $0.000 \mathrm{E}+00$ & 0.0000 \\
\hline-228 & $3.723 E-07$ & 0.9206 & $0.000 \mathrm{E}+00$ & 0.0000 & $0.000 \mathrm{E}+00$ & 0.0000 & $0.000 \mathrm{E}+00$ & 0.0000 & $0.000 \mathrm{E}+00$ & 0.0000 & $0.000 \mathrm{E}+00$ & 0.0000 & $0.000 \mathrm{E}+00$ & 0.0000 \\
\hline 230 & $1.095 E-09$ & 0.0027 & $0.000 \mathrm{E}+00$ & 0.0000 & $0.000 \mathrm{E}+00$ & 0.0000 & $0.000 \mathrm{E}+00$ & 0.0000 & $0.000 \mathrm{E}+00$ & 0.0000 & $0.000 \mathrm{E}+00$ & 0.0000 & $0.000 \mathrm{E}+00$ & 0.0000 \\
\hline-232 & $2.653 E-08$ & 0.0656 & $0.000 \mathrm{E}+00$ & 0.0000 & $0.000 \mathrm{E}+00$ & 0.0000 & $0.000 \mathrm{E}+00$ & 0.0000 & $0.000 \mathrm{E}+00$ & 0.0000 & $0.000 \mathrm{E}+00$ & 0.0000 & $0.000 \mathrm{E}+00$ & 0.0000 \\
\hline 34 & $1.227 \mathrm{E}-14$ & 0.0000 & $0.000 \mathrm{E}+00$ & 0.0000 & $0.000 \mathrm{E}+00$ & 0.0000 & $0.000 \mathrm{E}+00$ & 0.0000 & $0.000 \mathrm{E}+00$ & 0.0000 & $0.000 \mathrm{E}+00$ & 0.0000 & $0.000 \mathrm{E}+00$ & 0.0000 \\
\hline 35 & 7. $913 \mathrm{E}-15$ & 0.0000 & $0.000 \mathrm{E}+00$ & 0.0000 & $0.000 \mathrm{E}+00$ & 0.0000 & $0.000 \mathrm{E}+00$ & 0.0000 & $0.000 \mathrm{E}+00$ & 0.0000 & $0.000 \mathrm{E}+00$ & 0.0000 & $0.000 \mathrm{E}+00$ & 0.0000 \\
\hline 38 & $2.202 E-09$ & 0.0054 & $0.000 \mathrm{E}+00$ & 0.0000 & $0.000 \mathrm{E}+00$ & 0.0000 & $0.000 \mathrm{E}+00$ & 0.0000 & $0.000 \mathrm{E}+00$ & 0.0000 & $0.000 \mathrm{E}+00$ & 0.0000 & $0.000 \mathrm{E}+00$ & 0.0000 \\
\hline & $4.044 \mathrm{E}-07$ & 1.0000 & $0.000 \mathrm{E}+00$ & 0.0000 & $0.000 \mathrm{E}+00$ & 0.0000 & $0.000 \mathrm{E}+00$ & 0.0000 & $0.000 \mathrm{E}+00$ & 0.0000 & $0.000 \mathrm{E}+00$ & 0.0000 & $.000 \mathrm{E}+00$ & 0.0000 \\
\hline
\end{tabular}

Total Dose Contributions TDOSE(i,p,t) for Individual Radionuclides (i) and Pathways (p) As mrem/yr and Fraction of Total Dose At $t=1.000 \mathrm{E}+00$ years

Water Dependent Pathways

\begin{tabular}{|c|c|c|c|c|c|c|c|c|c|c|c|c|c|c|}
\hline \multirow{2}{*}{$\begin{array}{l}\text { Radio- } \\
\text { Nuclide }\end{array}$} & \multicolumn{2}{|c|}{ Water } & \multicolumn{2}{|c|}{ Fish } & \multicolumn{2}{|c|}{ Radon } & \multicolumn{2}{|c|}{ Plant } & \multicolumn{2}{|c|}{ Meat } & \multicolumn{2}{|c|}{ Milk } & \multicolumn{2}{|c|}{ All Pathways* } \\
\hline & mrem/yr & fract. & mrem/yr & fract. & mrem/yr & fract. & mrem/yr & fract. & mrem/yr & fract. & mrem/yr & fract. & mrem/yr & fract. \\
\hline 241 & $0.000 \mathrm{E}+00$ & 0.0000 & $0.000 \mathrm{E}+00$ & 0.0000 & $0.000 \mathrm{E}+00$ & 0.0000 & $0.000 \mathrm{E}+00$ & 0.0000 & $0.000 \mathrm{E}+00$ & 0.0000 & $0.000 \mathrm{E}+00$ & 0.0000 & $1.575 \mathrm{E}-18$ & 0.0000 \\
\hline-137 & $0.000 \mathrm{E}+00$ & 0.0000 & $0.000 \mathrm{E}+00$ & 0.0000 & $0.000 \mathrm{E}+00$ & 0.0000 & $0.000 \mathrm{E}+00$ & 0.0000 & $0.000 \mathrm{E}+00$ & 0.0000 & $0.000 \mathrm{E}+00$ & 0.0000 & $2.272 \mathrm{E}-09$ & 0.0056 \\
\hline-237 & $0.000 \mathrm{E}+00$ & 0.0000 & $0.000 \mathrm{E}+00$ & 0.0000 & $0.000 \mathrm{E}+00$ & 0.0000 & $0.000 \mathrm{E}+00$ & 0.0000 & $0.000 \mathrm{E}+00$ & 0.0000 & $0.000 \mathrm{E}+00$ & 0.0000 & $5.097 \mathrm{E}-13$ & 0.0000 \\
\hline-238 & $0.000 \mathrm{E}+00$ & 0.0000 & $0.000 \mathrm{E}+00$ & 0.0000 & $0.000 \mathrm{E}+00$ & 0.0000 & $0.000 \mathrm{E}+00$ & 0.0000 & $0.000 \mathrm{E}+00$ & 0.0000 & $0.000 \mathrm{E}+00$ & 0.0000 & $4.535 \mathrm{E}-21$ & 0.0000 \\
\hline-239 & $0.000 \mathrm{E}+00$ & 0.0000 & $0.000 \mathrm{E}+00$ & 0.0000 & $0.000 \mathrm{E}+00$ & 0.0000 & $0.000 \mathrm{E}+00$ & 0.0000 & $0.000 \mathrm{E}+00$ & 0.0000 & $0.000 E+00$ & 0.0000 & $4.211 \mathrm{E}-17$ & 0.0000 \\
\hline-240 & $0.000 \mathrm{E}+00$ & 0.0000 & $0.000 \mathrm{E}+00$ & 0.0000 & $0.000 \mathrm{E}+00$ & 0.0000 & $0.000 \mathrm{E}+00$ & 0.0000 & $0.000 \mathrm{E}+00$ & 0.0000 & $0.000 E+00$ & 0.0000 & $4.111 \mathrm{E}-24$ & 0.0000 \\
\hline-99 & $0.000 \mathrm{E}+00$ & 0.0000 & $0.000 \mathrm{E}+00$ & 0.0000 & $0.000 \mathrm{E}+00$ & 0.0000 & $0.000 \mathrm{E}+00$ & 0.0000 & $0.000 \mathrm{E}+00$ & 0.0000 & $0.000 \mathrm{E}+00$ & 0.0000 & $2.925 E-25$ & 0.0000 \\
\hline-228 & $0.000 \mathrm{E}+00$ & 0.0000 & $0.000 \mathrm{E}+00$ & 0.0000 & $0.000 \mathrm{E}+00$ & 0.0000 & $0.000 \mathrm{E}+00$ & 0.0000 & $0.000 \mathrm{E}+00$ & 0.0000 & $0.000 \mathrm{E}+00$ & 0.0000 & $3.723 E-07$ & 0.9206 \\
\hline-230 & $0.000 \mathrm{E}+00$ & 0.0000 & $0.000 \mathrm{E}+00$ & 0.0000 & $0.000 \mathrm{E}+00$ & 0.0000 & $0.000 \mathrm{E}+00$ & 0.0000 & $0.000 \mathrm{E}+00$ & 0.0000 & $0.000 E+00$ & 0.0000 & $1.095 \mathrm{E}-09$ & 0.0027 \\
\hline 232 & $0.000 \mathrm{E}+00$ & 0.0000 & $0.000 \mathrm{E}+00$ & 0.0000 & $0.000 \mathrm{E}+00$ & 0.0000 & $0.000 \mathrm{E}+00$ & 0.0000 & $0.000 \mathrm{E}+00$ & 0.0000 & $0.000 \mathrm{E}+00$ & 0.0000 & $2.653 E-08$ & 0.0656 \\
\hline 34 & $0.000 \mathrm{E}+00$ & 0.0000 & $0.000 \mathrm{E}+00$ & 0.0000 & $0.000 \mathrm{E}+00$ & 0.0000 & $0.000 \mathrm{E}+00$ & 0.0000 & $0.000 \mathrm{E}+00$ & 0.0000 & $0.000 \mathrm{E}+00$ & 0.0000 & 1. $227 \mathrm{E}-14$ & 0.0000 \\
\hline 35 & $0.000 \mathrm{E}+00$ & 0.0000 & $0.000 \mathrm{E}+00$ & 0.0000 & $0.000 \mathrm{E}+00$ & 0.0000 & $0.000 \mathrm{E}+00$ & 0.0000 & $0.000 \mathrm{E}+00$ & 0.0000 & $0.000 \mathrm{E}+00$ & 0.0000 & 7. $913 \mathrm{E}-15$ & 0.0000 \\
\hline 38 & $0.000 \mathrm{E}+00$ & 0.0000 & $0.000 \mathrm{E}+00$ & 0.0000 & $0.000 \mathrm{E}+00$ & 0.0000 & $0.000 \mathrm{E}+00$ & 0.0000 & $0.000 \mathrm{E}+00$ & 0.0000 & $0.000 \mathrm{E}+00$ & 0.0000 & $2.202 E-09$ & 0.0054 \\
\hline & $0.000 \mathrm{E}+00$ & 0.0000 & $0.000 \mathrm{E}+00$ & 0.0000 & $0.000 \mathrm{E}+00$ & 0.0000 & $0.000 \mathrm{E}+00$ & 0.0000 & $0.000 \mathrm{E}+00$ & 0.0000 & $0.000 \mathrm{E}+00$ & 0.0000 & $44 \mathrm{E}-07$ & 1.0000 \\
\hline
\end{tabular}

* Sum of all water independent and dependent pathways. 
RESRAD, Version 6.5

ummary : RESRAD Parameters for U-Landfill Recreational User Foward Run

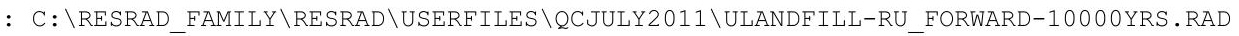

Total Dose Contributions TDOSE (i,p,t) for Individual Radionuclides (i) and Pathways (p) As mrem/yr and Fraction of Total Dose At $t=1.200 \mathrm{E}+01$ years

Water Independent Pathways (Inhalation excludes radon)

\begin{tabular}{|c|c|c|c|c|c|c|c|c|c|c|c|c|c|c|}
\hline \multirow{2}{*}{ Nuclide } & \multicolumn{2}{|c|}{ Ground } & \multicolumn{2}{|c|}{ Inhalation } & \multicolumn{2}{|c|}{ Radon } & \multicolumn{2}{|c|}{ Plant } & \multicolumn{2}{|c|}{ Meat } & \multicolumn{2}{|c|}{ Milk } & \multicolumn{2}{|c|}{ Soil } \\
\hline & mrem/yr & fract. & mrem/yr & fract. & mrem/yr & fract. & mrem/yr & fract. & mrem/yr & fract. & mrem/yr & fract. & mrem/yr & fract. \\
\hline-241 & $1.464 \mathrm{E}-17$ & 0.0000 & $0.000 \mathrm{E}+00$ & 0.0000 & $0.000 \mathrm{E}+00$ & 0.0000 & $0.000 \mathrm{E}+00$ & 0.0000 & $0.000 \mathrm{E}+00$ & 0.0000 & $0.000 \mathrm{E}+00$ & 0.0000 & $0.000 \mathrm{E}+00$ & 0.0000 \\
\hline-137 & $1.933 E-09$ & 0.0040 & $0.000 \mathrm{E}+00$ & 0.0000 & $0.000 \mathrm{E}+00$ & 0.0000 & $0.000 \mathrm{E}+00$ & 0.0000 & $0.000 \mathrm{E}+00$ & 0.0000 & $0.000 \mathrm{E}+00$ & 0.0000 & $0.000 \mathrm{E}+00$ & 0.0000 \\
\hline-237 & $5.736 \mathrm{E}-13$ & 0.0000 & $0.000 \mathrm{E}+00$ & 0.0000 & $0.000 \mathrm{E}+00$ & 0.0000 & $0.000 \mathrm{E}+00$ & 0.0000 & $0.000 \mathrm{E}+00$ & 0.0000 & $0.000 \mathrm{E}+00$ & 0.0000 & $0.000 \mathrm{E}+00$ & 0.0000 \\
\hline-238 & $2.491 \mathrm{E}-18$ & 0.0000 & $0.000 \mathrm{E}+00$ & 0.0000 & $0.000 \mathrm{E}+00$ & 0.0000 & $0.000 \mathrm{E}+00$ & 0.0000 & $0.000 \mathrm{E}+00$ & 0.0000 & $0.000 \mathrm{E}+00$ & 0.0000 & $0.000 \mathrm{E}+00$ & 0.0000 \\
\hline-239 & $4.803 E-17$ & 0.0000 & $0.000 \mathrm{E}+00$ & 0.0000 & $0.000 \mathrm{E}+00$ & 0.0000 & $0.000 \mathrm{E}+00$ & 0.0000 & $0.000 \mathrm{E}+00$ & 0.0000 & $0.000 \mathrm{E}+00$ & 0.0000 & $0.000 \mathrm{E}+00$ & 0.0000 \\
\hline-240 & $1.553 \mathrm{E}-22$ & 0.0000 & $0.000 \mathrm{E}+00$ & 0.0000 & $0.000 \mathrm{E}+00$ & 0.0000 & $0.000 \mathrm{E}+00$ & 0.0000 & $0.000 \mathrm{E}+00$ & 0.0000 & $0.000 \mathrm{E}+00$ & 0.0000 & $0.000 \mathrm{E}+00$ & 0.0000 \\
\hline 99 & $3.409 E-25$ & 0.0000 & $0.000 \mathrm{E}+00$ & 0.0000 & $0.000 \mathrm{E}+00$ & 0.0000 & $0.000 \mathrm{E}+00$ & 0.0000 & $0.000 \mathrm{E}+00$ & 0.0000 & $0.000 \mathrm{E}+00$ & 0.0000 & $0.000 \mathrm{E}+00$ & 0.0000 \\
\hline-228 & $7.388 \mathrm{E}-09$ & 0.0152 & $0.000 \mathrm{E}+00$ & 0.0000 & $0.000 \mathrm{E}+00$ & 0.0000 & $0.000 \mathrm{E}+00$ & 0.0000 & $0.000 \mathrm{E}+00$ & 0.0000 & $0.000 \mathrm{E}+00$ & 0.0000 & $0.000 \mathrm{E}+00$ & 0.0000 \\
\hline-230 & $9.820 \mathrm{E}-09$ & 0.0202 & $0.000 \mathrm{E}+00$ & 0.0000 & $0.000 \mathrm{E}+00$ & 0.0000 & $0.000 \mathrm{E}+00$ & 0.0000 & $0.000 \mathrm{E}+00$ & 0.0000 & $0.000 \mathrm{E}+00$ & 0.0000 & $0.000 \mathrm{E}+00$ & 0.0000 \\
\hline-232 & $4.646 E-07$ & 0.9557 & $0.000 \mathrm{E}+00$ & 0.0000 & $0.000 \mathrm{E}+00$ & 0.0000 & $0.000 \mathrm{E}+00$ & 0.0000 & $0.000 \mathrm{E}+00$ & 0.0000 & $0.000 \mathrm{E}+00$ & 0.0000 & $0.000 \mathrm{E}+00$ & 0.0000 \\
\hline 234 & $8.853 E-13$ & 0.0000 & $0.000 \mathrm{E}+00$ & 0.0000 & $0.000 \mathrm{E}+00$ & 0.0000 & $0.000 \mathrm{E}+00$ & 0.0000 & $0.000 \mathrm{E}+00$ & 0.0000 & $0.000 \mathrm{E}+00$ & 0.0000 & $0.000 \mathrm{E}+00$ & 0.0000 \\
\hline 35 & $1.173 \mathrm{E}-14$ & 0.0000 & $0.000 \mathrm{E}+00$ & 0.0000 & $0.000 \mathrm{E}+00$ & 0.0000 & $0.000 \mathrm{E}+00$ & 0.0000 & $0.000 \mathrm{E}+00$ & 0.0000 & $0.000 \mathrm{E}+00$ & 0.0000 & $0.000 \mathrm{E}+00$ & 0.0000 \\
\hline 38 & $2.404 \mathrm{E}-09$ & 0.0049 & $0.000 \mathrm{E}+00$ & 0.0000 & $0.000 \mathrm{E}+00$ & 0.0000 & $0.000 \mathrm{E}+00$ & 0.0000 & $0.000 \mathrm{E}+00$ & 0.0000 & $0.000 \mathrm{E}+00$ & 0.0000 & $0.000 \mathrm{E}+00$ & 0.0000 \\
\hline & $4.862 \mathrm{E}-07$ & 1.0000 & $0.000 \mathrm{E}+00$ & 0.0000 & $0.000 \mathrm{E}+00$ & 0.0000 & $0.000 \mathrm{E}+00$ & 0.0000 & $0.000 \mathrm{E}+00$ & 0.0000 & $0.000 \mathrm{E}+00$ & 0.0000 & $0.000 \mathrm{E}+00$ & 0.0000 \\
\hline
\end{tabular}

Total Dose Contributions TDOSE(i,p,t) for Individual Radionuclides (i) and Pathways (p) As mrem/yr and Fraction of Total Dose At $t=1.200 \mathrm{E}+01$ years

Water Dependent Pathways

\begin{tabular}{|c|c|c|c|c|c|c|c|c|c|c|c|c|c|c|}
\hline \multirow{2}{*}{$\begin{array}{l}\text { Radio- } \\
\text { Nuclide }\end{array}$} & \multicolumn{2}{|c|}{ Water } & \multicolumn{2}{|c|}{ Fish } & \multicolumn{2}{|c|}{ Radon } & \multicolumn{2}{|c|}{ Plant } & \multicolumn{2}{|c|}{ Meat } & \multicolumn{2}{|c|}{ Milk } & \multicolumn{2}{|c|}{ All Pathways* } \\
\hline & mrem/yr & fract. & mrem/yr & fract. & mrem/yr & fract. & mrem/yr & fract. & mrem/yr & fract. & mrem/yr & fract. & mrem/yr & fract. \\
\hline 241 & $0.000 \mathrm{E}+00$ & 0.0000 & $0.000 \mathrm{E}+00$ & 0.0000 & $0.000 \mathrm{E}+00$ & 0.0000 & $0.000 \mathrm{E}+00$ & 0.0000 & $0.000 \mathrm{E}+00$ & 0.0000 & $0.000 \mathrm{E}+00$ & 0.0000 & $1.464 \mathrm{E}-17$ & 0.0000 \\
\hline-137 & $0.000 \mathrm{E}+00$ & 0.0000 & $0.000 \mathrm{E}+00$ & 0.0000 & $0.000 \mathrm{E}+00$ & 0.0000 & $0.000 \mathrm{E}+00$ & 0.0000 & $0.000 \mathrm{E}+00$ & 0.0000 & $0.000 \mathrm{E}+00$ & 0.0000 & $1.933 \mathrm{E}-09$ & 0.0040 \\
\hline-237 & $0.000 \mathrm{E}+00$ & 0.0000 & $0.000 \mathrm{E}+00$ & 0.0000 & $0.000 \mathrm{E}+00$ & 0.0000 & $0.000 \mathrm{E}+00$ & 0.0000 & $0.000 \mathrm{E}+00$ & 0.0000 & $0.000 \mathrm{E}+00$ & 0.0000 & $5.736 \mathrm{E}-13$ & 0.0000 \\
\hline-238 & $0.000 \mathrm{E}+00$ & 0.0000 & $0.000 \mathrm{E}+00$ & 0.0000 & $0.000 \mathrm{E}+00$ & 0.0000 & $0.000 \mathrm{E}+00$ & 0.0000 & $0.000 \mathrm{E}+00$ & 0.0000 & $0.000 \mathrm{E}+00$ & 0.0000 & $2.491 \mathrm{E}-18$ & 0.0000 \\
\hline-239 & $0.000 \mathrm{E}+00$ & 0.0000 & $0.000 \mathrm{E}+00$ & 0.0000 & $0.000 \mathrm{E}+00$ & 0.0000 & $0.000 \mathrm{E}+00$ & 0.0000 & $0.000 \mathrm{E}+00$ & 0.0000 & $0.000 E+00$ & 0.0000 & $4.803 E-17$ & 0.0000 \\
\hline-240 & $0.000 \mathrm{E}+00$ & 0.0000 & $0.000 \mathrm{E}+00$ & 0.0000 & $0.000 \mathrm{E}+00$ & 0.0000 & $0.000 \mathrm{E}+00$ & 0.0000 & $0.000 \mathrm{E}+00$ & 0.0000 & $0.000 E+00$ & 0.0000 & $1.553 \mathrm{E}-22$ & 0.0000 \\
\hline-99 & $0.000 \mathrm{E}+00$ & 0.0000 & $0.000 \mathrm{E}+00$ & 0.0000 & $0.000 \mathrm{E}+00$ & 0.0000 & $0.000 \mathrm{E}+00$ & 0.0000 & $0.000 \mathrm{E}+00$ & 0.0000 & $0.000 \mathrm{E}+00$ & 0.0000 & $3.409 E-25$ & 0.0000 \\
\hline-228 & $0.000 \mathrm{E}+00$ & 0.0000 & $0.000 \mathrm{E}+00$ & 0.0000 & $0.000 \mathrm{E}+00$ & 0.0000 & $0.000 \mathrm{E}+00$ & 0.0000 & $0.000 \mathrm{E}+00$ & 0.0000 & $0.000 \mathrm{E}+00$ & 0.0000 & $7.388 E-09$ & 0.0152 \\
\hline-230 & $0.000 \mathrm{E}+00$ & 0.0000 & $0.000 \mathrm{E}+00$ & 0.0000 & $0.000 \mathrm{E}+00$ & 0.0000 & $0.000 \mathrm{E}+00$ & 0.0000 & $0.000 \mathrm{E}+00$ & 0.0000 & $0.000 E+00$ & 0.0000 & $9.820 \mathrm{E}-09$ & 0.0202 \\
\hline-232 & $0.000 \mathrm{E}+00$ & 0.0000 & $0.000 \mathrm{E}+00$ & 0.0000 & $0.000 \mathrm{E}+00$ & 0.0000 & $0.000 \mathrm{E}+00$ & 0.0000 & $0.000 \mathrm{E}+00$ & 0.0000 & $0.000 \mathrm{E}+00$ & 0.0000 & $4.646 \mathrm{E}-07$ & 0.9557 \\
\hline 34 & $0.000 \mathrm{E}+00$ & 0.0000 & $0.000 \mathrm{E}+00$ & 0.0000 & $0.000 \mathrm{E}+00$ & 0.0000 & $0.000 \mathrm{E}+00$ & 0.0000 & $0.000 \mathrm{E}+00$ & 0.0000 & $0.000 \mathrm{E}+00$ & 0.0000 & $8.853 E-13$ & 0.0000 \\
\hline 35 & $0.000 \mathrm{E}+00$ & 0.0000 & $0.000 \mathrm{E}+00$ & 0.0000 & $0.000 \mathrm{E}+00$ & 0.0000 & $0.000 \mathrm{E}+00$ & 0.0000 & $0.000 \mathrm{E}+00$ & 0.0000 & $0.000 \mathrm{E}+00$ & 0.0000 & $1.173 \mathrm{E}-14$ & 0.0000 \\
\hline 38 & $0.000 \mathrm{E}+00$ & 0.0000 & $0.000 \mathrm{E}+00$ & 0.0000 & $0.000 \mathrm{E}+00$ & 0.0000 & $0.000 \mathrm{E}+00$ & 0.0000 & $0.000 \mathrm{E}+00$ & 0.0000 & $0.000 \mathrm{E}+00$ & 0.0000 & $2.404 \mathrm{E}-09$ & 0.0049 \\
\hline & $0.000 \mathrm{E}+00$ & 0.0000 & $0.000 \mathrm{E}+00$ & 0.0000 & $0.000 \mathrm{E}+00$ & 0.0000 & $0.000 \mathrm{E}+00$ & 0.0000 & $0.000 \mathrm{E}+00$ & 0.0000 & $0.000 \mathrm{E}+00$ & 0.0000 & $52 E-07$ & 1.0000 \\
\hline
\end{tabular}

* Sum of all water independent and dependent pathways. 
RESRAD, Version 6.5

ummary : RESRAD Parameters for U-Landfill Recreational User Foward Run

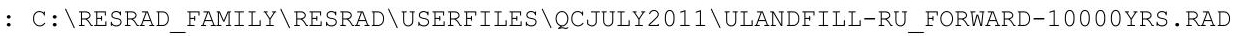

Total Dose Contributions TDOSE(i,p,t) for Individual Radionuclides (i) and Pathways (p) As mrem/yr and Fraction of Total Dose At $t=5.000 \mathrm{E}+01$ years

Water Independent Pathways (Inhalation excludes radon)

\begin{tabular}{|c|c|c|c|c|c|c|c|c|c|c|c|c|c|c|}
\hline \multirow[b]{2}{*}{ Nuclide } & \multicolumn{2}{|c|}{ Ground } & \multicolumn{2}{|c|}{ Inhalation } & \multicolumn{2}{|c|}{ Radon } & \multicolumn{2}{|c|}{ Plant } & \multicolumn{2}{|c|}{ Meat } & \multicolumn{2}{|c|}{ Milk } & \multicolumn{2}{|c|}{ Soil } \\
\hline & mrem/yr & fract. & mrem/yr & fract. & mrem/yr & fract. & mrem/yr & fract. & mrem/yr & fract. & mrem/yr & fract. & mrem/yr & fract. \\
\hline-241 & $8.641 E-17$ & 0.0000 & $0.000 \mathrm{E}+00$ & 0.0000 & $0.000 \mathrm{E}+00$ & 0.0000 & $0.000 \mathrm{E}+00$ & 0.0000 & $0.000 \mathrm{E}+00$ & 0.0000 & $0.000 \mathrm{E}+00$ & 0.0000 & $0.000 \mathrm{E}+00$ & 0.0000 \\
\hline-137 & $1.106 \mathrm{E}-09$ & 0.0012 & $0.000 \mathrm{E}+00$ & 0.0000 & $0.000 \mathrm{E}+00$ & 0.0000 & $0.000 \mathrm{E}+00$ & 0.0000 & $0.000 \mathrm{E}+00$ & 0.0000 & $0.000 \mathrm{E}+00$ & 0.0000 & $0.000 \mathrm{E}+00$ & 0.0000 \\
\hline-237 & $8.637 E-13$ & 0.0000 & $0.000 \mathrm{E}+00$ & 0.0000 & $0.000 \mathrm{E}+00$ & 0.0000 & $0.000 \mathrm{E}+00$ & 0.0000 & $0.000 \mathrm{E}+00$ & 0.0000 & $0.000 \mathrm{E}+00$ & 0.0000 & $0.000 \mathrm{E}+00$ & 0.0000 \\
\hline-238 & $1.975 E-16$ & 0.0000 & $0.000 \mathrm{E}+00$ & 0.0000 & $0.000 \mathrm{E}+00$ & 0.0000 & $0.000 \mathrm{E}+00$ & 0.0000 & $0.000 \mathrm{E}+00$ & 0.0000 & $0.000 \mathrm{E}+00$ & 0.0000 & $0.000 \mathrm{E}+00$ & 0.0000 \\
\hline-239 & $7.561 \mathrm{E}-17$ & 0.0000 & $0.000 \mathrm{E}+00$ & 0.0000 & $0.000 \mathrm{E}+00$ & 0.0000 & $0.000 \mathrm{E}+00$ & 0.0000 & $0.000 \mathrm{E}+00$ & 0.0000 & $0.000 \mathrm{E}+00$ & 0.0000 & $0.000 \mathrm{E}+00$ & 0.0000 \\
\hline-240 & $9.285 \mathrm{E}-21$ & 0.0000 & $0.000 \mathrm{E}+00$ & 0.0000 & $0.000 \mathrm{E}+00$ & 0.0000 & $0.000 \mathrm{E}+00$ & 0.0000 & $0.000 \mathrm{E}+00$ & 0.0000 & $0.000 \mathrm{E}+00$ & 0.0000 & $0.000 \mathrm{E}+00$ & 0.0000 \\
\hline 99 & $5.785 E-25$ & 0.0000 & $0.000 \mathrm{E}+00$ & 0.0000 & $0.000 \mathrm{E}+00$ & 0.0000 & $0.000 \mathrm{E}+00$ & 0.0000 & $0.000 \mathrm{E}+00$ & 0.0000 & $0.000 \mathrm{E}+00$ & 0.0000 & $0.000 \mathrm{E}+00$ & 0.0000 \\
\hline-228 & $9.718 \mathrm{E}-15$ & 0.0000 & $0.000 \mathrm{E}+00$ & 0.0000 & $0.000 \mathrm{E}+00$ & 0.0000 & $0.000 \mathrm{E}+00$ & 0.0000 & $0.000 \mathrm{E}+00$ & 0.0000 & $0.000 \mathrm{E}+00$ & 0.0000 & $0.000 \mathrm{E}+00$ & 0.0000 \\
\hline 230 & $5.116 \mathrm{E}-08$ & 0.0558 & $0.000 \mathrm{E}+00$ & 0.0000 & $0.000 \mathrm{E}+00$ & 0.0000 & $0.000 \mathrm{E}+00$ & 0.0000 & $0.000 \mathrm{E}+00$ & 0.0000 & $0.000 \mathrm{E}+00$ & 0.0000 & $0.000 \mathrm{E}+00$ & 0.0000 \\
\hline-232 & $8.620 E-07$ & 0.9395 & $0.000 \mathrm{E}+00$ & 0.0000 & $0.000 \mathrm{E}+00$ & 0.0000 & $0.000 \mathrm{E}+00$ & 0.0000 & $0.000 \mathrm{E}+00$ & 0.0000 & $0.000 \mathrm{E}+00$ & 0.0000 & $0.000 \mathrm{E}+00$ & 0.0000 \\
\hline 34 & $1.867 \mathrm{E}-11$ & 0.0000 & $0.000 \mathrm{E}+00$ & 0.0000 & $0.000 \mathrm{E}+00$ & 0.0000 & $0.000 \mathrm{E}+00$ & 0.0000 & $0.000 \mathrm{E}+00$ & 0.0000 & $0.000 \mathrm{E}+00$ & 0.0000 & $0.000 \mathrm{E}+00$ & 0.0000 \\
\hline 35 & $5.776 \mathrm{E}-14$ & 0.0000 & $0.000 \mathrm{E}+00$ & 0.0000 & $0.000 \mathrm{E}+00$ & 0.0000 & $0.000 \mathrm{E}+00$ & 0.0000 & $0.000 \mathrm{E}+00$ & 0.0000 & $0.000 \mathrm{E}+00$ & 0.0000 & $0.000 \mathrm{E}+00$ & 0.0000 \\
\hline 38 & $3.257 \mathrm{E}-09$ & 0.0035 & $0.000 \mathrm{E}+00$ & 0.0000 & $0.000 \mathrm{E}+00$ & 0.0000 & $0.000 \mathrm{E}+00$ & 0.0000 & $0.000 \mathrm{E}+00$ & 0.0000 & $0.000 \mathrm{E}+00$ & 0.0000 & $0.000 \mathrm{E}+00$ & 0.0000 \\
\hline & $9.175 E-07$ & 1.0 & $0.000 \mathrm{E}+00$ & 0.0000 & $0.000 \mathrm{E}+00$ & 0.0000 & $0.000 \mathrm{E}+00$ & 0.0000 & $0.000 \mathrm{E}+00$ & 0.0000 & $0.000 \mathrm{E}+00$ & 000 & $0.000 \mathrm{E}+00$ & 000 \\
\hline
\end{tabular}

Total Dose Contributions TDOSE(i,p,t) for Individual Radionuclides (i) and Pathways (p) As mrem/yr and Fraction of Total Dose At $t=5.000 \mathrm{E}+01$ years

Water Dependent Pathways

\begin{tabular}{|c|c|c|c|c|c|c|c|c|c|c|c|c|c|c|}
\hline \multirow{2}{*}{$\begin{array}{l}\text { Radio- } \\
\text { Nuclide }\end{array}$} & \multicolumn{2}{|c|}{ Water } & \multicolumn{2}{|c|}{ Fish } & \multicolumn{2}{|c|}{ Radon } & \multicolumn{2}{|c|}{ Plant } & \multicolumn{2}{|c|}{ Meat } & \multicolumn{2}{|c|}{ Milk } & \multicolumn{2}{|c|}{ All Pathways* } \\
\hline & mrem/yr & fract. & mrem/yr & fract. & mrem/yr & fract. & mrem/yr & fract. & mrem/yr & fract. & mrem/yr & fract. & mrem/yr & fract. \\
\hline 241 & $0.000 \mathrm{E}+00$ & 0.0000 & $0.000 \mathrm{E}+00$ & 0.0000 & $0.000 \mathrm{E}+00$ & 0.0000 & $0.000 \mathrm{E}+00$ & 0.0000 & $0.000 \mathrm{E}+00$ & 0.0000 & $0.000 \mathrm{E}+00$ & 0.0000 & $8.641 \mathrm{E}-17$ & 0.0000 \\
\hline-137 & $0.000 \mathrm{E}+00$ & 0.0000 & $0.000 \mathrm{E}+00$ & 0.0000 & $0.000 \mathrm{E}+00$ & 0.0000 & $0.000 \mathrm{E}+00$ & 0.0000 & $0.000 \mathrm{E}+00$ & 0.0000 & $0.000 \mathrm{E}+00$ & 0.0000 & $1.106 \mathrm{E}-09$ & 0.0012 \\
\hline-237 & $0.000 \mathrm{E}+00$ & 0.0000 & $0.000 \mathrm{E}+00$ & 0.0000 & $0.000 \mathrm{E}+00$ & 0.0000 & $0.000 \mathrm{E}+00$ & 0.0000 & $0.000 \mathrm{E}+00$ & 0.0000 & $0.000 \mathrm{E}+00$ & 0.0000 & $8.637 \mathrm{E}-13$ & 0.0000 \\
\hline-238 & $0.000 \mathrm{E}+00$ & 0.0000 & $0.000 \mathrm{E}+00$ & 0.0000 & $0.000 \mathrm{E}+00$ & 0.0000 & $0.000 \mathrm{E}+00$ & 0.0000 & $0.000 \mathrm{E}+00$ & 0.0000 & $0.000 \mathrm{E}+00$ & 0.0000 & $1.975 \mathrm{E}-16$ & 0.0000 \\
\hline-239 & $0.000 \mathrm{E}+00$ & 0.0000 & $0.000 \mathrm{E}+00$ & 0.0000 & $0.000 \mathrm{E}+00$ & 0.0000 & $0.000 \mathrm{E}+00$ & 0.0000 & $0.000 \mathrm{E}+00$ & 0.0000 & $0.000 E+00$ & 0.0000 & $7.561 \mathrm{E}-17$ & 0.0000 \\
\hline-240 & $0.000 \mathrm{E}+00$ & 0.0000 & $0.000 \mathrm{E}+00$ & 0.0000 & $0.000 \mathrm{E}+00$ & 0.0000 & $0.000 \mathrm{E}+00$ & 0.0000 & $0.000 \mathrm{E}+00$ & 0.0000 & $0.000 E+00$ & 0.0000 & $9.285 \mathrm{E}-21$ & 0.0000 \\
\hline-99 & $0.000 \mathrm{E}+00$ & 0.0000 & $0.000 \mathrm{E}+00$ & 0.0000 & $0.000 \mathrm{E}+00$ & 0.0000 & $0.000 \mathrm{E}+00$ & 0.0000 & $0.000 \mathrm{E}+00$ & 0.0000 & $0.000 \mathrm{E}+00$ & 0.0000 & $5.785 \mathrm{E}-25$ & 0.0000 \\
\hline-228 & $0.000 \mathrm{E}+00$ & 0.0000 & $0.000 \mathrm{E}+00$ & 0.0000 & $0.000 \mathrm{E}+00$ & 0.0000 & $0.000 \mathrm{E}+00$ & 0.0000 & $0.000 \mathrm{E}+00$ & 0.0000 & $0.000 \mathrm{E}+00$ & 0.0000 & $9.718 \mathrm{E}-15$ & 0.0000 \\
\hline-230 & $0.000 \mathrm{E}+00$ & 0.0000 & $0.000 \mathrm{E}+00$ & 0.0000 & $0.000 \mathrm{E}+00$ & 0.0000 & $0.000 \mathrm{E}+00$ & 0.0000 & $0.000 \mathrm{E}+00$ & 0.0000 & $0.000 E+00$ & 0.0000 & $5.116 \mathrm{E}-08$ & 0.0558 \\
\hline 232 & $0.000 \mathrm{E}+00$ & 0.0000 & $0.000 \mathrm{E}+00$ & 0.0000 & $0.000 \mathrm{E}+00$ & 0.0000 & $0.000 \mathrm{E}+00$ & 0.0000 & $0.000 \mathrm{E}+00$ & 0.0000 & $0.000 \mathrm{E}+00$ & 0.0000 & $8.620 \mathrm{E}-07$ & 0.9395 \\
\hline 34 & $0.000 \mathrm{E}+00$ & 0.0000 & $0.000 \mathrm{E}+00$ & 0.0000 & $0.000 \mathrm{E}+00$ & 0.0000 & $0.000 \mathrm{E}+00$ & 0.0000 & $0.000 \mathrm{E}+00$ & 0.0000 & $0.000 \mathrm{E}+00$ & 0.0000 & $1.867 \mathrm{E}-11$ & 0.0000 \\
\hline 35 & $0.000 \mathrm{E}+00$ & 0.0000 & $0.000 \mathrm{E}+00$ & 0.0000 & $0.000 \mathrm{E}+00$ & 0.0000 & $0.000 \mathrm{E}+00$ & 0.0000 & $0.000 \mathrm{E}+00$ & 0.0000 & $0.000 \mathrm{E}+00$ & 0.0000 & $5.776 \mathrm{E}-14$ & 0.0000 \\
\hline 38 & $0.000 \mathrm{E}+00$ & 0.0000 & $0.000 \mathrm{E}+00$ & 0.0000 & $0.000 \mathrm{E}+00$ & 0.0000 & $0.000 \mathrm{E}+00$ & 0.0000 & $0.000 \mathrm{E}+00$ & 0.0000 & $0.000 \mathrm{E}+00$ & 0.0000 & $3.257 \mathrm{E}-09$ & 0.0035 \\
\hline & $0.000 \mathrm{E}+00$ & 0.0000 & $0.000 \mathrm{E}+00$ & 0.0000 & $0.000 \mathrm{E}+00$ & 0.0000 & $0.000 \mathrm{E}+00$ & 0.0000 & $0.000 \mathrm{E}+00$ & 0.0000 & $0.000 \mathrm{E}+00$ & 0.0000 & $9.175 \mathrm{E}-07$ & 1.0000 \\
\hline
\end{tabular}

* Sum of all water independent and dependent pathways. 
RESRAD, Version 6.5

ummary : RESRAD Parameters for U-Landfill Recreational User Foward Run

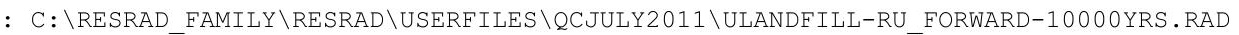

Total Dose Contributions TDOSE(i,p,t) for Individual Radionuclides (i) and Pathways (p) As mrem/yr and Fraction of Total Dose At $t=1.000 \mathrm{E}+02$ years

Water Independent Pathways (Inhalation excludes radon)

\begin{tabular}{|c|c|c|c|c|c|c|c|c|c|c|c|c|c|c|}
\hline \multirow[b]{2}{*}{ uclide } & \multicolumn{2}{|c|}{ Ground } & \multicolumn{2}{|c|}{ Inhalation } & \multicolumn{2}{|c|}{ Radon } & \multicolumn{2}{|c|}{ Plant } & \multicolumn{2}{|c|}{ Meat } & \multicolumn{2}{|c|}{ Milk } & \multicolumn{2}{|c|}{ Soil } \\
\hline & mrem/yr & fract. & mrem/yr & fract. & mrem/yr & fract. & mrem/yr & fract. & mrem/yr & fract. & mrem/yr & fract. & mrem/yr & fract. \\
\hline-241 & $2.836 \mathrm{E}-16$ & 0.0000 & $0.000 \mathrm{E}+00$ & 0.0000 & $0.000 \mathrm{E}+00$ & 0.0000 & $0.000 \mathrm{E}+00$ & 0.0000 & $0.000 \mathrm{E}+00$ & 0.0000 & $0.000 \mathrm{E}+00$ & 0.0000 & $0.000 \mathrm{E}+00$ & 0.0000 \\
\hline-137 & $5.307 E-10$ & 0.0004 & $0.000 \mathrm{E}+00$ & 0.0000 & $0.000 \mathrm{E}+00$ & 0.0000 & $0.000 \mathrm{E}+00$ & 0.0000 & $0.000 \mathrm{E}+00$ & 0.0000 & $0.000 \mathrm{E}+00$ & 0.0000 & $0.000 \mathrm{E}+00$ & 0.0000 \\
\hline-237 & $1.483 \mathrm{E}-12$ & 0.0000 & $0.000 \mathrm{E}+00$ & 0.0000 & $0.000 \mathrm{E}+00$ & 0.0000 & $0.000 \mathrm{E}+00$ & 0.0000 & $0.000 \mathrm{E}+00$ & 0.0000 & $0.000 \mathrm{E}+00$ & 0.0000 & $0.000 \mathrm{E}+00$ & 0.0000 \\
\hline 238 & $1.997 \mathrm{E}-15$ & 0.0000 & $0.000 \mathrm{E}+00$ & 0.0000 & $0.000 \mathrm{E}+00$ & 0.0000 & $0.000 \mathrm{E}+00$ & 0.0000 & $0.000 \mathrm{E}+00$ & 0.0000 & $0.000 \mathrm{E}+00$ & 0.0000 & $0.000 \mathrm{E}+00$ & 0.0000 \\
\hline 239 & $1.374 \mathrm{E}-16$ & 0.0000 & $0.000 \mathrm{E}+00$ & 0.0000 & $0.000 \mathrm{E}+00$ & 0.0000 & $0.000 \mathrm{E}+00$ & 0.0000 & $0.000 \mathrm{E}+00$ & 0.0000 & $0.000 \mathrm{E}+00$ & 0.0000 & $0.000 \mathrm{E}+00$ & 0.0000 \\
\hline 240 & $6.177 \mathrm{E}-20$ & 0.0000 & $0.000 \mathrm{E}+00$ & 0.0000 & $0.000 \mathrm{E}+00$ & 0.0000 & $0.000 \mathrm{E}+00$ & 0.0000 & $0.000 \mathrm{E}+00$ & 0.0000 & $0.000 \mathrm{E}+00$ & 0.0000 & $0.000 \mathrm{E}+00$ & 0.0000 \\
\hline 99 & $1.160 \mathrm{E}-24$ & 0.0000 & $0.000 \mathrm{E}+00$ & 0.0000 & $0.000 \mathrm{E}+00$ & 0.0000 & $0.000 \mathrm{E}+00$ & 0.0000 & $0.000 \mathrm{E}+00$ & 0.0000 & $0.000 \mathrm{E}+00$ & 0.0000 & $0.000 \mathrm{E}+00$ & 0.0000 \\
\hline 228 & $1.776 \mathrm{E}-22$ & 0.0000 & $0.000 \mathrm{E}+00$ & 0.0000 & $0.000 \mathrm{E}+00$ & 0.0000 & $0.000 \mathrm{E}+00$ & 0.0000 & $0.000 \mathrm{E}+00$ & 0.0000 & $0.000 \mathrm{E}+00$ & 0.0000 & $0.000 \mathrm{E}+00$ & 0.0000 \\
\hline 230 & 1. $423 \mathrm{E}-07$ & 0.1082 & $0.000 \mathrm{E}+00$ & 0.0000 & $0.000 \mathrm{E}+00$ & 0.0000 & $0.000 \mathrm{E}+00$ & 0.0000 & $0.000 \mathrm{E}+00$ & 0.0000 & $0.000 \mathrm{E}+00$ & 0.0000 & $0.000 \mathrm{E}+00$ & 0.0000 \\
\hline 232 & $1.167 \mathrm{E}-06$ & 0.8876 & $0.000 \mathrm{E}+00$ & 0.0000 & $0.000 \mathrm{E}+00$ & 0.0000 & $0.000 \mathrm{E}+00$ & 0.0000 & $0.000 \mathrm{E}+00$ & 0.0000 & $0.000 \mathrm{E}+00$ & 0.0000 & $0.000 \mathrm{E}+00$ & 0.0000 \\
\hline 34 & $1.037 \mathrm{E}-10$ & 0.0001 & $0.000 \mathrm{E}+00$ & 0.0000 & $0.000 \mathrm{E}+00$ & 0.0000 & $0.000 \mathrm{E}+00$ & 0.0000 & $0.000 \mathrm{E}+00$ & 0.0000 & $0.000 \mathrm{E}+00$ & 0.0000 & $0.000 \mathrm{E}+00$ & 0.0000 \\
\hline 35 & $2.119 \mathrm{E}-13$ & 0.0000 & $0.000 \mathrm{E}+00$ & 0.0000 & $0.000 \mathrm{E}+00$ & 0.0000 & $0.000 \mathrm{E}+00$ & 0.0000 & $0.000 \mathrm{E}+00$ & 0.0000 & $0.000 \mathrm{E}+00$ & 0.0000 & $0.000 \mathrm{E}+00$ & 0.0000 \\
\hline 38 & $4.856 E-09$ & 0.0037 & $0.000 \mathrm{E}+00$ & 0.0000 & $0.000 \mathrm{E}+00$ & 0.0000 & $0.000 \mathrm{E}+00$ & 0.0000 & $0.000 \mathrm{E}+00$ & 0.0000 & $0.000 \mathrm{E}+00$ & 0.0000 & $0.000 \mathrm{E}+00$ & 0.0000 \\
\hline & $1.314 \mathrm{E}-06$ & 1.0000 & $0.000 \mathrm{E}+00$ & 0.0000 & $0.000 \mathrm{E}+00$ & 0.0000 & $0.000 \mathrm{E}+00$ & 0.0000 & $0.000 \mathrm{E}+00$ & 0.0000 & $0.000 \mathrm{E}+00$ & 0.0000 & $.000 \mathrm{E}+00$ & 0.0000 \\
\hline
\end{tabular}

Total Dose Contributions TDOSE(i,p,t) for Individual Radionuclides (i) and Pathways (p) As mrem/yr and Fraction of Total Dose At $t=1.000 \mathrm{E}+02$ years

Water Dependent Pathways

\begin{tabular}{|c|c|c|c|c|c|c|c|c|c|c|c|c|c|c|}
\hline \multirow{2}{*}{$\begin{array}{l}\text { Radio- } \\
\text { Nuclide }\end{array}$} & \multicolumn{2}{|c|}{ Water } & \multicolumn{2}{|c|}{ Fish } & \multicolumn{2}{|c|}{ Radon } & \multicolumn{2}{|c|}{ Plant } & \multicolumn{2}{|c|}{ Meat } & \multicolumn{2}{|c|}{ Milk } & \multicolumn{2}{|c|}{ All Pathways* } \\
\hline & mrem/yr & fract. & mrem/yr & fract. & mrem/yr & fract. & mrem/yr & fract. & mrem/yr & fract. & mrem/yr & fract. & mrem/yr & fract. \\
\hline 241 & $0.000 \mathrm{E}+00$ & 0.0000 & $0.000 \mathrm{E}+00$ & 0.0000 & $0.000 \mathrm{E}+00$ & 0.0000 & $0.000 \mathrm{E}+00$ & 0.0000 & $0.000 \mathrm{E}+00$ & 0.0000 & $0.000 \mathrm{E}+00$ & 0.0000 & $2.836 \mathrm{E}-16$ & 0.0000 \\
\hline-137 & $0.000 \mathrm{E}+00$ & 0.0000 & $0.000 \mathrm{E}+00$ & 0.0000 & $0.000 \mathrm{E}+00$ & 0.0000 & $0.000 \mathrm{E}+00$ & 0.0000 & $0.000 \mathrm{E}+00$ & 0.0000 & $0.000 \mathrm{E}+00$ & 0.0000 & $5.307 \mathrm{E}-10$ & 0.0004 \\
\hline-237 & $0.000 \mathrm{E}+00$ & 0.0000 & $0.000 \mathrm{E}+00$ & 0.0000 & $0.000 \mathrm{E}+00$ & 0.0000 & $0.000 \mathrm{E}+00$ & 0.0000 & $0.000 \mathrm{E}+00$ & 0.0000 & $0.000 \mathrm{E}+00$ & 0.0000 & $1.483 \mathrm{E}-12$ & 0.0000 \\
\hline-238 & $0.000 \mathrm{E}+00$ & 0.0000 & $0.000 \mathrm{E}+00$ & 0.0000 & $0.000 \mathrm{E}+00$ & 0.0000 & $0.000 \mathrm{E}+00$ & 0.0000 & $0.000 \mathrm{E}+00$ & 0.0000 & $0.000 \mathrm{E}+00$ & 0.0000 & $1.997 \mathrm{E}-15$ & 0.0000 \\
\hline-239 & $0.000 \mathrm{E}+00$ & 0.0000 & $0.000 \mathrm{E}+00$ & 0.0000 & $0.000 \mathrm{E}+00$ & 0.0000 & $0.000 \mathrm{E}+00$ & 0.0000 & $0.000 \mathrm{E}+00$ & 0.0000 & $0.000 E+00$ & 0.0000 & $1.374 \mathrm{E}-16$ & 0.0000 \\
\hline-240 & $0.000 \mathrm{E}+00$ & 0.0000 & $0.000 \mathrm{E}+00$ & 0.0000 & $0.000 \mathrm{E}+00$ & 0.0000 & $0.000 \mathrm{E}+00$ & 0.0000 & $0.000 \mathrm{E}+00$ & 0.0000 & $0.000 E+00$ & 0.0000 & $6.177 \mathrm{E}-20$ & 0.0000 \\
\hline 99 & $0.000 \mathrm{E}+00$ & 0.0000 & $0.000 \mathrm{E}+00$ & 0.0000 & $0.000 \mathrm{E}+00$ & 0.0000 & $0.000 \mathrm{E}+00$ & 0.0000 & $0.000 \mathrm{E}+00$ & 0.0000 & $0.000 \mathrm{E}+00$ & 0.0000 & $1.160 \mathrm{E}-24$ & 0.0000 \\
\hline-228 & $0.000 \mathrm{E}+00$ & 0.0000 & $0.000 \mathrm{E}+00$ & 0.0000 & $0.000 \mathrm{E}+00$ & 0.0000 & $0.000 \mathrm{E}+00$ & 0.0000 & $0.000 \mathrm{E}+00$ & 0.0000 & $0.000 \mathrm{E}+00$ & 0.0000 & $1.776 \mathrm{E}-22$ & 0.0000 \\
\hline-230 & $0.000 \mathrm{E}+00$ & 0.0000 & $0.000 \mathrm{E}+00$ & 0.0000 & $0.000 \mathrm{E}+00$ & 0.0000 & $0.000 \mathrm{E}+00$ & 0.0000 & $0.000 \mathrm{E}+00$ & 0.0000 & $0.000 E+00$ & 0.0000 & $1.423 \mathrm{E}-07$ & 0.1082 \\
\hline 232 & $0.000 \mathrm{E}+00$ & 0.0000 & $0.000 \mathrm{E}+00$ & 0.0000 & $0.000 \mathrm{E}+00$ & 0.0000 & $0.000 \mathrm{E}+00$ & 0.0000 & $0.000 \mathrm{E}+00$ & 0.0000 & $0.000 \mathrm{E}+00$ & 0.0000 & $1.167 \mathrm{E}-06$ & 0.8876 \\
\hline 34 & $0.000 \mathrm{E}+00$ & 0.0000 & $0.000 \mathrm{E}+00$ & 0.0000 & $0.000 \mathrm{E}+00$ & 0.0000 & $0.000 \mathrm{E}+00$ & 0.0000 & $0.000 \mathrm{E}+00$ & 0.0000 & $0.000 \mathrm{E}+00$ & 0.0000 & $1.037 \mathrm{E}-10$ & 0.0001 \\
\hline 35 & $0.000 \mathrm{E}+00$ & 0.0000 & $0.000 \mathrm{E}+00$ & 0.0000 & $0.000 \mathrm{E}+00$ & 0.0000 & $0.000 \mathrm{E}+00$ & 0.0000 & $0.000 \mathrm{E}+00$ & 0.0000 & $0.000 \mathrm{E}+00$ & 0.0000 & $2.119 \mathrm{E}-13$ & 0.0000 \\
\hline 38 & $0.000 \mathrm{E}+00$ & 0.0000 & $0.000 \mathrm{E}+00$ & 0.0000 & $0.000 \mathrm{E}+00$ & 0.0000 & $0.000 \mathrm{E}+00$ & 0.0000 & $0.000 \mathrm{E}+00$ & 0.0000 & $0.000 \mathrm{E}+00$ & 0.0000 & $4.856 \mathrm{E}-09$ & 0.0037 \\
\hline & $0.000 \mathrm{E}+00$ & 0.0000 & $0.000 \mathrm{E}+00$ & 0.0000 & $0.000 \mathrm{E}+00$ & 0.0000 & $0.000 \mathrm{E}+00$ & 0.0000 & $0.000 \mathrm{E}+00$ & 0.0000 & $0.000 \mathrm{E}+00$ & 0.0000 & $4 E-06$ & 1. \\
\hline
\end{tabular}

* Sum of all water independent and dependent pathways. 
RESRAD, Version 6.5

ummary : RESRAD Parameters for U-Landfill Recreational User Foward Run

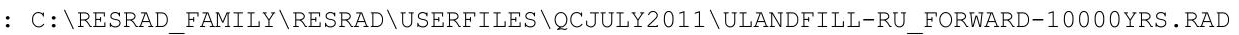

Total Dose Contributions TDOSE (i,p,t) for Individual Radionuclides (i) and Pathways (p) As mrem/yr and Fraction of Total Dose At $t=5.000 \mathrm{E}+02$ years

Water Independent Pathways (Inhalation excludes radon)

\begin{tabular}{|c|c|c|c|c|c|c|c|c|c|c|c|c|c|c|}
\hline \multirow[b]{2}{*}{ uclide } & \multicolumn{2}{|c|}{ Ground } & \multicolumn{2}{|c|}{ Inhalation } & \multicolumn{2}{|c|}{ Radon } & \multicolumn{2}{|c|}{ Plant } & \multicolumn{2}{|c|}{ Meat } & \multicolumn{2}{|c|}{ Milk } & \multicolumn{2}{|c|}{ Soil } \\
\hline & mrem/yr & fract. & mrem/yr & fract. & mrem/yr & fract. & mrem/yr & fract. & mrem/yr & fract. & mrem/yr & fract. & mrem/yr & fract. \\
\hline-241 & $7.849 \mathrm{E}-14$ & 0.0000 & $0.000 \mathrm{E}+00$ & 0.0000 & $0.000 \mathrm{E}+00$ & 0.0000 & $0.000 \mathrm{E}+00$ & 0.0000 & $0.000 \mathrm{E}+00$ & 0.0000 & $0.000 \mathrm{E}+00$ & 0.0000 & $0.000 \mathrm{E}+00$ & 0.0000 \\
\hline-137 & 1. $491 \mathrm{E}-12$ & 0.0000 & $0.000 \mathrm{E}+00$ & 0.0000 & $0.000 \mathrm{E}+00$ & 0.0000 & $0.000 \mathrm{E}+00$ & 0.0000 & $0.000 \mathrm{E}+00$ & 0.0000 & $0.000 \mathrm{E}+00$ & 0.0000 & $0.000 \mathrm{E}+00$ & 0.0000 \\
\hline-237 & $1.111 \mathrm{E}-10$ & 0.0000 & $0.000 \mathrm{E}+00$ & 0.0000 & $0.000 \mathrm{E}+00$ & 0.0000 & $0.000 \mathrm{E}+00$ & 0.0000 & $0.000 \mathrm{E}+00$ & 0.0000 & $0.000 \mathrm{E}+00$ & 0.0000 & $0.000 \mathrm{E}+00$ & 0.0000 \\
\hline 238 & $2.109 \mathrm{E}-12$ & 0.0000 & $0.000 \mathrm{E}+00$ & 0.0000 & $0.000 \mathrm{E}+00$ & 0.0000 & $0.000 \mathrm{E}+00$ & 0.0000 & $0.000 \mathrm{E}+00$ & 0.0000 & $0.000 \mathrm{E}+00$ & 0.0000 & $0.000 \mathrm{E}+00$ & 0.0000 \\
\hline 239 & $1.636 \mathrm{E}-14$ & 0.0000 & $0.000 \mathrm{E}+00$ & 0.0000 & $0.000 \mathrm{E}+00$ & 0.0000 & $0.000 \mathrm{E}+00$ & 0.0000 & $0.000 \mathrm{E}+00$ & 0.0000 & $0.000 \mathrm{E}+00$ & 0.0000 & $0.000 \mathrm{E}+00$ & 0.0000 \\
\hline 240 & 1. $985 \mathrm{E}-17$ & 0.0000 & $0.000 \mathrm{E}+00$ & 0.0000 & $0.000 \mathrm{E}+00$ & 0.0000 & $0.000 \mathrm{E}+00$ & 0.0000 & $0.000 \mathrm{E}+00$ & 0.0000 & $0.000 \mathrm{E}+00$ & 0.0000 & $0.000 \mathrm{E}+00$ & 0.0000 \\
\hline 99 & $3.036 E-22$ & 0.0000 & $0.000 \mathrm{E}+00$ & 0.0000 & $0.000 \mathrm{E}+00$ & 0.0000 & $0.000 \mathrm{E}+00$ & 0.0000 & $0.000 \mathrm{E}+00$ & 0.0000 & $0.000 \mathrm{E}+00$ & 0.0000 & $0.000 \mathrm{E}+00$ & 0.0000 \\
\hline 228 & $0.000 \mathrm{E}+00$ & 0.0000 & $0.000 \mathrm{E}+00$ & 0.0000 & $0.000 \mathrm{E}+00$ & 0.0000 & $0.000 \mathrm{E}+00$ & 0.0000 & $0.000 \mathrm{E}+00$ & 0.0000 & $0.000 \mathrm{E}+00$ & 0.0000 & $0.000 \mathrm{E}+00$ & 0.0000 \\
\hline 230 & $1.032 \mathrm{E}-05$ & 0.4425 & $0.000 \mathrm{E}+00$ & 0.0000 & $0.000 \mathrm{E}+00$ & 0.0000 & $0.000 \mathrm{E}+00$ & 0.0000 & $0.000 \mathrm{E}+00$ & 0.0000 & $0.000 \mathrm{E}+00$ & 0.0000 & $0.000 \mathrm{E}+00$ & 0.0000 \\
\hline 232 & $1.285 E-05$ & 0.5508 & $0.000 \mathrm{E}+00$ & 0.0000 & $0.000 \mathrm{E}+00$ & 0.0000 & $0.000 \mathrm{E}+00$ & 0.0000 & $0.000 \mathrm{E}+00$ & 0.0000 & $0.000 \mathrm{E}+00$ & 0.0000 & $0.000 \mathrm{E}+00$ & 0.0000 \\
\hline 34 & $3.851 \mathrm{E}-08$ & 0.0017 & $0.000 \mathrm{E}+00$ & 0.0000 & $0.000 \mathrm{E}+00$ & 0.0000 & $0.000 \mathrm{E}+00$ & 0.0000 & $0.000 \mathrm{E}+00$ & 0.0000 & $0.000 \mathrm{E}+00$ & 0.0000 & $0.000 \mathrm{E}+00$ & 0.0000 \\
\hline 35 & $4.414 \mathrm{E}-11$ & 0.0000 & $0.000 \mathrm{E}+00$ & 0.0000 & $0.000 \mathrm{E}+00$ & 0.0000 & $0.000 \mathrm{E}+00$ & 0.0000 & $0.000 \mathrm{E}+00$ & 0.0000 & $0.000 \mathrm{E}+00$ & 0.0000 & $0.000 \mathrm{E}+00$ & 0.0000 \\
\hline 38 & $1.187 \mathrm{E}-07$ & 0.0051 & $0.000 \mathrm{E}+00$ & 0.0000 & $0.000 \mathrm{E}+00$ & 0.0000 & $0.000 \mathrm{E}+00$ & 0.0000 & $0.000 \mathrm{E}+00$ & 0.0000 & $0.000 \mathrm{E}+00$ & 0.0000 & $0.000 \mathrm{E}+00$ & 0.0000 \\
\hline & $2.333 E-05$ & 1.0000 & $0.000 \mathrm{E}+00$ & 0.0000 & $0.000 \mathrm{E}+00$ & 0.0000 & $0.000 \mathrm{E}+00$ & 0.0000 & $0.000 \mathrm{E}+00$ & 0.0000 & $0.000 \mathrm{E}+00$ & 0.0000 & $.000 \mathrm{E}+00$ & 0.0000 \\
\hline
\end{tabular}

Total Dose Contributions TDOSE(i,p,t) for Individual Radionuclides (i) and Pathways (p) As mrem/yr and Fraction of Total Dose At $t=5.000 \mathrm{E}+02$ years

Water Dependent Pathways

\begin{tabular}{|c|c|c|c|c|c|c|c|c|c|c|c|c|c|c|}
\hline & \multicolumn{2}{|c|}{ Water } & \multicolumn{2}{|c|}{ Fish } & \multicolumn{2}{|c|}{ Radon } & \multicolumn{2}{|c|}{ Plant } & \multicolumn{2}{|c|}{ Meat } & \multicolumn{2}{|c|}{ Milk } & \multicolumn{2}{|c|}{ All Pathways* } \\
\hline clide & mrem/yr & fract. & mrem/yr & fract. & mrem/yr & fract. & mrem/yr & fract. & mrem/yr & fract. & mrem/yr & fract. & mrem/yr & fract. \\
\hline-241 & $0.000 \mathrm{E}+00$ & 0.0000 & $0.000 \mathrm{E}+00$ & 0.0000 & $0.000 \mathrm{E}+00$ & 0.0000 & $0.000 \mathrm{E}+00$ & 0.0000 & $0.000 \mathrm{E}+00$ & 0.0000 & $0.000 \mathrm{E}+00$ & 0.0000 & $7.849 \mathrm{E}-14$ & 0.0000 \\
\hline-137 & $0.000 \mathrm{E}+00$ & 0.0000 & $0.000 \mathrm{E}+00$ & 0.0000 & $0.000 \mathrm{E}+00$ & 0.0000 & $0.000 \mathrm{E}+00$ & 0.0000 & $0.000 \mathrm{E}+00$ & 0.0000 & $0.000 \mathrm{E}+00$ & 0.0000 & $1.491 \mathrm{E}-12$ & 0.0000 \\
\hline-237 & $0.000 \mathrm{E}+00$ & 0.0000 & $0.000 \mathrm{E}+00$ & 0.0000 & $0.000 \mathrm{E}+00$ & 0.0000 & $0.000 \mathrm{E}+00$ & 0.0000 & $0.000 \mathrm{E}+00$ & 0.0000 & $0.000 \mathrm{E}+00$ & 0.0000 & $1.111 \mathrm{E}-10$ & 0.0000 \\
\hline 238 & $0.000 \mathrm{E}+00$ & 0.0000 & $0.000 \mathrm{E}+00$ & 0.0000 & $0.000 \mathrm{E}+00$ & 0.0000 & $0.000 \mathrm{E}+00$ & 0.0000 & $0.000 \mathrm{E}+00$ & 0.0000 & $0.000 \mathrm{E}+00$ & 0.0000 & $2.109 \mathrm{E}-12$ & 0.0000 \\
\hline 239 & $0.000 \mathrm{E}+00$ & 0.0000 & $0.000 \mathrm{E}+00$ & 0.0000 & $0.000 \mathrm{E}+00$ & 0.0000 & $0.000 \mathrm{E}+00$ & 0.0000 & $0.000 \mathrm{E}+00$ & 0.0000 & $0.000 \mathrm{E}+00$ & 0.0000 & $1.636 \mathrm{E}-14$ & 0.0000 \\
\hline 240 & $0.000 \mathrm{E}+00$ & 0.0000 & $0.000 \mathrm{E}+00$ & 0.0000 & $0.000 \mathrm{E}+00$ & 0.0000 & $0.000 \mathrm{E}+00$ & 0.0000 & $0.000 \mathrm{E}+00$ & 0.0000 & $0.000 \mathrm{E}+00$ & 0.0000 & $1.985 \mathrm{E}-17$ & 0.0000 \\
\hline 99 & $0.000 \mathrm{E}+00$ & 0.0000 & $0.000 \mathrm{E}+00$ & 0.0000 & $0.000 \mathrm{E}+00$ & 0.0000 & $0.000 \mathrm{E}+00$ & 0.0000 & $0.000 \mathrm{E}+00$ & 0.0000 & $0.000 \mathrm{E}+00$ & 0.0000 & $3.036 \mathrm{E}-22$ & 0.0000 \\
\hline 228 & $0.000 \mathrm{E}+00$ & 0.0000 & $0.000 \mathrm{E}+00$ & 0.0000 & $0.000 \mathrm{E}+00$ & 0.0000 & $0.000 \mathrm{E}+00$ & 0.0000 & $0.000 \mathrm{E}+00$ & 0.0000 & $0.000 \mathrm{E}+00$ & 0.0000 & $0.000 \mathrm{E}+00$ & 0.0000 \\
\hline 230 & $0.000 \mathrm{E}+00$ & 0.0000 & $0.000 \mathrm{E}+00$ & 0.0000 & $0.000 \mathrm{E}+00$ & 0.0000 & $0.000 \mathrm{E}+00$ & 0.0000 & $0.000 \mathrm{E}+00$ & 0.0000 & $0.000 \mathrm{E}+00$ & 0.0000 & $1.032 \mathrm{E}-05$ & 0.4425 \\
\hline 232 & $0.000 \mathrm{E}+00$ & 0.0000 & $0.000 \mathrm{E}+00$ & 0.0000 & $0.000 \mathrm{E}+00$ & 0.0000 & $0.000 \mathrm{E}+00$ & 0.0000 & $0.000 \mathrm{E}+00$ & 0.0000 & $0.000 \mathrm{E}+00$ & 0.0000 & $1.285 \mathrm{E}-05$ & 0.5508 \\
\hline & $0.000 \mathrm{E}+00$ & 0.0000 & $0.000 \mathrm{E}+00$ & 0.0000 & $0.000 \mathrm{E}+00$ & 0.0000 & $0.000 \mathrm{E}+00$ & 0.0000 & $0.000 \mathrm{E}+00$ & 0.0000 & $0.000 \mathrm{E}+00$ & 0.0000 & $3.851 \mathrm{E}-08$ & 0.0017 \\
\hline 35 & $0.000 \mathrm{E}+00$ & 0.0000 & $0.000 \mathrm{E}+00$ & 0.0000 & $0.000 \mathrm{E}+00$ & 0.0000 & $0.000 \mathrm{E}+00$ & 0.0000 & $0.000 \mathrm{E}+00$ & 0.0000 & $0.000 \mathrm{E}+00$ & 0.0000 & $4.414 \mathrm{E}-11$ & 0.0000 \\
\hline 38 & $0.000 \mathrm{E}+00$ & 0.0000 & $0.000 \mathrm{E}+00$ & 0.0000 & $0.000 \mathrm{E}+00$ & 0.0000 & $0.000 \mathrm{E}+00$ & 0.0000 & $0.000 \mathrm{E}+00$ & 0.0000 & $0.000 \mathrm{E}+00$ & 0.0000 & $1.187 \mathrm{E}-07$ & 0.0051 \\
\hline & $0.000 \mathrm{E}+00$ & 0.0000 & $0.000 \mathrm{E}+00$ & 0.0000 & $0.000 \mathrm{E}+00$ & 0.0000 & $0.000 \mathrm{E}+00$ & 0.0000 & $0.000 \mathrm{E}+00$ & 0.0000 & $0.000 E+00$ & 000 & -05 & 1.0000 \\
\hline
\end{tabular}

* Sum of all water independent and dependent pathways. 
RESRAD, Version 6.5

ummary : RESRAD Parameters for U-Landfill Recreational User Foward Run

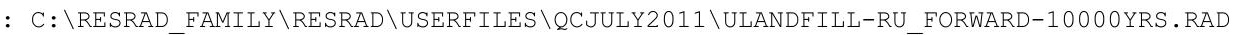

Total Dose Contributions TDOSE(i,p,t) for Individual Radionuclides (i) and Pathways (p) As mrem/yr and Fraction of Total Dose At $t=1.050 \mathrm{E}+03$ years

Water Independent Pathways (Inhalation excludes radon)

\begin{tabular}{|c|c|c|c|c|c|c|c|c|c|c|c|c|c|c|}
\hline & \multicolumn{2}{|c|}{ Ground } & \multicolumn{2}{|c|}{ Inhalation } & \multicolumn{2}{|c|}{ Radon } & \multicolumn{2}{|c|}{ Plant } & \multicolumn{2}{|c|}{ Meat } & \multicolumn{2}{|c|}{ Milk } & \multicolumn{2}{|c|}{ Soil } \\
\hline Lide & mrem/yr & fract. & mrem/yr & fract. & mrem/yr & fract. & mrem/yr & fract. & mrem/yr & fract. & mrem/yr & fract. & mrem/yr & fract. \\
\hline-241 & $4.250 \mathrm{E}-11$ & 0.0000 & $0.000 \mathrm{E}+00$ & 0.0000 & $0.000 \mathrm{E}+00$ & 0.0000 & $0.000 \mathrm{E}+00$ & 0.0000 & $0.000 \mathrm{E}+00$ & 0.0000 & $0.000 \mathrm{E}+00$ & 0.0000 & $0.000 \mathrm{E}+00$ & 0.0000 \\
\hline-137 & $4.627 E-16$ & 0.0000 & $0.000 \mathrm{E}+00$ & 0.0000 & $0.000 \mathrm{E}+00$ & 0.0000 & $0.000 \mathrm{E}+00$ & 0.0000 & $0.000 \mathrm{E}+00$ & 0.0000 & $0.000 \mathrm{E}+00$ & 0.0000 & $0.000 \mathrm{E}+00$ & 0.0000 \\
\hline-237 & $3.985 E-08$ & 0.0000 & $0.000 \mathrm{E}+00$ & 0.0000 & $0.000 \mathrm{E}+00$ & 0.0000 & $0.000 \mathrm{E}+00$ & 0.0000 & $0.000 \mathrm{E}+00$ & 0.0000 & $0.000 \mathrm{E}+00$ & 0.0000 & $0.000 \mathrm{E}+00$ & 0.0000 \\
\hline 238 & 4. $914 \mathrm{E}-10$ & 0.0000 & $0.000 \mathrm{E}+00$ & 0.0000 & $0.000 \mathrm{E}+00$ & 0.0000 & $0.000 \mathrm{E}+00$ & 0.0000 & $0.000 \mathrm{E}+00$ & 0.0000 & $0.000 \mathrm{E}+00$ & 0.0000 & $0.000 \mathrm{E}+00$ & 0.0000 \\
\hline 239 & $1.164 \mathrm{E}-11$ & 0.0000 & $0.000 \mathrm{E}+00$ & 0.0000 & $0.000 \mathrm{E}+00$ & 0.0000 & $0.000 \mathrm{E}+00$ & 0.0000 & $0.000 \mathrm{E}+00$ & 0.0000 & $0.000 \mathrm{E}+00$ & 0.0000 & $0.000 \mathrm{E}+00$ & 0.0000 \\
\hline 240 & $2.820 E-15$ & 0.0000 & $0.000 \mathrm{E}+00$ & 0.0000 & $0.000 \mathrm{E}+00$ & 0.0000 & $0.000 \mathrm{E}+00$ & 0.0000 & $0.000 \mathrm{E}+00$ & 0.0000 & $0.000 \mathrm{E}+00$ & 0.0000 & $0.000 \mathrm{E}+00$ & 0.0000 \\
\hline 99 & $6.409 \mathrm{E}-19$ & 0.0000 & $0.000 \mathrm{E}+00$ & 0.0000 & $0.000 \mathrm{E}+00$ & 0.0000 & $0.000 \mathrm{E}+00$ & 0.0000 & $0.000 \mathrm{E}+00$ & 0.0000 & $0.000 \mathrm{E}+00$ & 0.0000 & $0.000 \mathrm{E}+00$ & 0.0000 \\
\hline 228 & $0.000 \mathrm{E}+00$ & 0.0000 & $0.000 \mathrm{E}+00$ & 0.0000 & $0.000 \mathrm{E}+00$ & 0.0000 & $0.000 \mathrm{E}+00$ & 0.0000 & $0.000 \mathrm{E}+00$ & 0.0000 & $0.000 \mathrm{E}+00$ & 0.0000 & $0.000 \mathrm{E}+00$ & 0.0000 \\
\hline 230 & $8.661 \mathrm{E}-04$ & 0.6991 & $0.000 \mathrm{E}+00$ & 0.0000 & $0.000 \mathrm{E}+00$ & 0.0000 & $0.000 \mathrm{E}+00$ & 0.0000 & $0.000 \mathrm{E}+00$ & 0.0000 & $0.000 \mathrm{E}+00$ & 0.0000 & $0.000 \mathrm{E}+00$ & 0.0000 \\
\hline 232 & $3.560 \mathrm{E}-04$ & 0.2874 & $0.000 \mathrm{E}+00$ & 0.0000 & $0.000 \mathrm{E}+00$ & 0.0000 & $0.000 \mathrm{E}+00$ & 0.0000 & $0.000 \mathrm{E}+00$ & 0.0000 & $0.000 \mathrm{E}+00$ & 0.0000 & $0.000 \mathrm{E}+00$ & 0.0000 \\
\hline 34 & $7.034 \mathrm{E}-06$ & 0.0057 & $0.000 \mathrm{E}+00$ & 0.0000 & $0.000 \mathrm{E}+00$ & 0.0000 & $0.000 \mathrm{E}+00$ & 0.0000 & $0.000 \mathrm{E}+00$ & 0.0000 & $0.000 \mathrm{E}+00$ & 0.0000 & $0.000 \mathrm{E}+00$ & 0.0000 \\
\hline 35 & $1.481 E-08$ & 0.0000 & $0.000 \mathrm{E}+00$ & 0.0000 & $0.000 \mathrm{E}+00$ & 0.0000 & $0.000 \mathrm{E}+00$ & 0.0000 & $0.000 \mathrm{E}+00$ & 0.0000 & $0.000 \mathrm{E}+00$ & 0.0000 & $0.000 \mathrm{E}+00$ & 0.0000 \\
\hline 38 & $9.634 \mathrm{E}-06$ & 0.0078 & $0.000 \mathrm{E}+00$ & 0.0000 & $0.000 \mathrm{E}+00$ & 0.0000 & $0.000 \mathrm{E}+00$ & 0.0000 & $0.000 \mathrm{E}+00$ & 0.0000 & $0.000 \mathrm{E}+00$ & 0.0000 & $0.000 \mathrm{E}+00$ & 0.0000 \\
\hline & $1.239 \mathrm{E}-03$ & 1.0000 & $0.000 \mathrm{E}+00$ & 0.0000 & $0.000 \mathrm{E}+00$ & 0.0000 & $0.000 \mathrm{E}+00$ & 0.0000 & $0.000 \mathrm{E}+00$ & 0.0000 & $0.000 \mathrm{E}+00$ & 0.0000 & $.000 \mathrm{E}+00$ & 0.0000 \\
\hline
\end{tabular}

Total Dose Contributions TDOSE(i,p,t) for Individual Radionuclides (i) and Pathways (p) As mrem/yr and Fraction of Total Dose At $t=1.050 \mathrm{E}+03$ years

Water Dependent Pathways

\begin{tabular}{|c|c|c|c|c|c|c|c|c|c|c|c|c|c|c|}
\hline & \multicolumn{2}{|c|}{ Water } & \multicolumn{2}{|c|}{ Fish } & \multicolumn{2}{|c|}{ Radon } & \multicolumn{2}{|c|}{ Plant } & \multicolumn{2}{|c|}{ Meat } & \multicolumn{2}{|c|}{ Milk } & \multicolumn{2}{|c|}{ All Pathways* } \\
\hline clide & mrem/yr & fract. & mrem/yr & fract. & mrem/yr & fract. & mrem/yr & fract. & mrem/yr & fract. & mrem/yr & fract. & mrem/yr & fract. \\
\hline-241 & $0.000 \mathrm{E}+00$ & 0.0000 & $0.000 \mathrm{E}+00$ & 0.0000 & $0.000 \mathrm{E}+00$ & 0.0000 & $0.000 \mathrm{E}+00$ & 0.0000 & $0.000 \mathrm{E}+00$ & 0.0000 & $0.000 \mathrm{E}+00$ & 0.0000 & $4.250 \mathrm{E}-11$ & 0.0000 \\
\hline-137 & $0.000 \mathrm{E}+00$ & 0.0000 & $0.000 \mathrm{E}+00$ & 0.0000 & $0.000 \mathrm{E}+00$ & 0.0000 & $0.000 \mathrm{E}+00$ & 0.0000 & $0.000 \mathrm{E}+00$ & 0.0000 & $0.000 \mathrm{E}+00$ & 0.0000 & $4.627 \mathrm{E}-16$ & 0.0000 \\
\hline-237 & $0.000 \mathrm{E}+00$ & 0.0000 & $0.000 \mathrm{E}+00$ & 0.0000 & $0.000 \mathrm{E}+00$ & 0.0000 & $0.000 \mathrm{E}+00$ & 0.0000 & $0.000 \mathrm{E}+00$ & 0.0000 & $0.000 \mathrm{E}+00$ & 0.0000 & $3.985 E-08$ & 0.0000 \\
\hline 238 & $0.000 \mathrm{E}+00$ & 0.0000 & $0.000 \mathrm{E}+00$ & 0.0000 & $0.000 \mathrm{E}+00$ & 0.0000 & $0.000 \mathrm{E}+00$ & 0.0000 & $0.000 \mathrm{E}+00$ & 0.0000 & $0.000 \mathrm{E}+00$ & 0.0000 & $4.914 \mathrm{E}-10$ & 0.0000 \\
\hline 239 & $0.000 \mathrm{E}+00$ & 0.0000 & $0.000 \mathrm{E}+00$ & 0.0000 & $0.000 \mathrm{E}+00$ & 0.0000 & $0.000 \mathrm{E}+00$ & 0.0000 & $0.000 \mathrm{E}+00$ & 0.0000 & $0.000 \mathrm{E}+00$ & 0.0000 & $1.164 \mathrm{E}-11$ & 0.0000 \\
\hline 240 & $0.000 \mathrm{E}+00$ & 0.0000 & $0.000 \mathrm{E}+00$ & 0.0000 & $0.000 \mathrm{E}+00$ & 0.0000 & $0.000 \mathrm{E}+00$ & 0.0000 & $0.000 \mathrm{E}+00$ & 0.0000 & $0.000 \mathrm{E}+00$ & 0.0000 & $2.820 \mathrm{E}-15$ & 0.0000 \\
\hline 99 & $0.000 \mathrm{E}+00$ & 0.0000 & $0.000 \mathrm{E}+00$ & 0.0000 & $0.000 \mathrm{E}+00$ & 0.0000 & $0.000 \mathrm{E}+00$ & 0.0000 & $0.000 \mathrm{E}+00$ & 0.0000 & $0.000 \mathrm{E}+00$ & 0.0000 & $6.409 \mathrm{E}-19$ & 0.0000 \\
\hline 228 & $0.000 \mathrm{E}+00$ & 0.0000 & $0.000 \mathrm{E}+00$ & 0.0000 & $0.000 \mathrm{E}+00$ & 0.0000 & $0.000 \mathrm{E}+00$ & 0.0000 & $0.000 \mathrm{E}+00$ & 0.0000 & $0.000 \mathrm{E}+00$ & 0.0000 & $0.000 \mathrm{E}+00$ & 0.0000 \\
\hline 230 & $0.000 \mathrm{E}+00$ & 0.0000 & $0.000 \mathrm{E}+00$ & 0.0000 & $0.000 \mathrm{E}+00$ & 0.0000 & $0.000 \mathrm{E}+00$ & 0.0000 & $0.000 \mathrm{E}+00$ & 0.0000 & $0.000 \mathrm{E}+00$ & 0.0000 & $8.661 E-04$ & 0.6991 \\
\hline 232 & $0.000 \mathrm{E}+00$ & 0.0000 & $0.000 \mathrm{E}+00$ & 0.0000 & $0.000 \mathrm{E}+00$ & 0.0000 & $0.000 \mathrm{E}+00$ & 0.0000 & $0.000 \mathrm{E}+00$ & 0.0000 & $0.000 \mathrm{E}+00$ & 0.0000 & $3.560 \mathrm{E}-04$ & 0.2874 \\
\hline 34 & $0.000 \mathrm{E}+00$ & 0.0000 & $0.000 \mathrm{E}+00$ & 0.0000 & $0.000 \mathrm{E}+00$ & 0.0000 & $0.000 \mathrm{E}+00$ & 0.0000 & $0.000 \mathrm{E}+00$ & 0.0000 & $0.000 \mathrm{E}+00$ & 0.0000 & $7.034 \mathrm{E}-06$ & 0.0057 \\
\hline 35 & $0.000 \mathrm{E}+00$ & 0.0000 & $0.000 \mathrm{E}+00$ & 0.0000 & $0.000 \mathrm{E}+00$ & 0.0000 & $0.000 \mathrm{E}+00$ & 0.0000 & $0.000 \mathrm{E}+00$ & 0.0000 & $0.000 \mathrm{E}+00$ & 0.0000 & $1.481 \mathrm{E}-08$ & 0.0000 \\
\hline 38 & $0.000 \mathrm{E}+00$ & 0.0000 & $0.000 \mathrm{E}+00$ & 0.0000 & $0.000 \mathrm{E}+00$ & 0.0000 & $0.000 \mathrm{E}+00$ & 0.0000 & $0.000 \mathrm{E}+00$ & 0.0000 & $0.000 \mathrm{E}+00$ & 0.0000 & $9.634 \mathrm{E}-06$ & 0.0078 \\
\hline & $0.000 \mathrm{E}+00$ & 0.0000 & $0.000 \mathrm{E}+00$ & 0.0000 & $0.000 \mathrm{E}+00$ & 0.0000 & $0.000 \mathrm{E}+00$ & 0.0000 & $0.000 \mathrm{E}+00$ & 0.0000 & $0.000 E+00$ & 000 & -03 & 000 \\
\hline
\end{tabular}

* Sum of all water independent and dependent pathways. 
RESRAD, Version 6.5

ummary : RESRAD Parameters for U-Landfill Recreational User Foward Run

: C: \RESRAD_FAMILY \RESRAD \USERFILES \QCJULY2011 \ULANDFILL-RU_FORWARD-10000YRS.RAD

Total Dose Contributions TDOSE(i,p,t) for Individual Radionuclides (i) and Pathways (p) As mrem/yr and Fraction of Total Dose At $t=1.000 \mathrm{E}+04$ years

Water Independent Pathways (Inhalation excludes radon)

\begin{tabular}{|c|c|c|c|c|c|c|c|c|c|c|c|c|c|c|}
\hline \multirow{2}{*}{ Nuclide } & \multicolumn{2}{|c|}{ Ground } & \multicolumn{2}{|c|}{ Inhalation } & \multicolumn{2}{|c|}{ Radon } & \multicolumn{2}{|c|}{ Plant } & \multicolumn{2}{|c|}{ Meat } & \multicolumn{2}{|c|}{ Milk } & \multicolumn{2}{|c|}{ Soil } \\
\hline & mrem/yr & fract. & mrem/yr & fract. & mrem/yr & fract. & mrem/yr & fract. & mrem/yr & fract. & mrem/yr & fract. & mrem/yr & fract. \\
\hline-241 & $2.772 \mathrm{E}-04$ & 0.0000 & $1.067 \mathrm{E}-07$ & 0.0000 & $0.000 \mathrm{E}+00$ & 0.0000 & $0.000 \mathrm{E}+00$ & 0.0000 & $0.000 \mathrm{E}+00$ & 0.0000 & $0.000 \mathrm{E}+00$ & 0.0000 & $4.985 \mathrm{E}-06$ & 0.0000 \\
\hline-137 & $0.000 \mathrm{E}+00$ & 0.0000 & $0.000 \mathrm{E}+00$ & 0.0000 & $0.000 \mathrm{E}+00$ & 0.0000 & $0.000 \mathrm{E}+00$ & 0.0000 & $0.000 \mathrm{E}+00$ & 0.0000 & $0.000 \mathrm{E}+00$ & 0.0000 & $0.000 \mathrm{E}+00$ & 0.0000 \\
\hline-237 & $2.064 \mathrm{E}-01$ & 0.0022 & $8.027 \mathrm{E}-05$ & 0.0000 & $0.000 \mathrm{E}+00$ & 0.0000 & $0.000 \mathrm{E}+00$ & 0.0000 & $0.000 \mathrm{E}+00$ & 0.0000 & $0.000 \mathrm{E}+00$ & 0.0000 & $3.786 \mathrm{E}-03$ & 0.0000 \\
\hline-238 & $6.968 E-04$ & 0.0000 & $1.453 E-07$ & 0.0000 & $0.000 \mathrm{E}+00$ & 0.0000 & $0.000 \mathrm{E}+00$ & 0.0000 & $0.000 \mathrm{E}+00$ & 0.0000 & $0.000 \mathrm{E}+00$ & 0.0000 & $5.738 E-05$ & 0.0000 \\
\hline-239 & $5.278 \mathrm{E}-04$ & 0.0000 & $1.596 \mathrm{E}-03$ & 0.0000 & $0.000 \mathrm{E}+00$ & 0.0000 & $0.000 \mathrm{E}+00$ & 0.0000 & $0.000 \mathrm{E}+00$ & 0.0000 & $0.000 \mathrm{E}+00$ & 0.0000 & $6.333 E-02$ & 0.0007 \\
\hline-240 & $1.017 \mathrm{E}-04$ & 0.0000 & $7.375 \mathrm{E}-04$ & 0.0000 & $0.000 \mathrm{E}+00$ & 0.0000 & $0.000 \mathrm{E}+00$ & 0.0000 & $0.000 \mathrm{E}+00$ & 0.0000 & $0.000 \mathrm{E}+00$ & 0.0000 & $2.926 \mathrm{E}-02$ & 0.0003 \\
\hline 99 & $6.336 E-27$ & 0.0000 & $0.000 \mathrm{E}+00$ & 0.0000 & $0.000 \mathrm{E}+00$ & 0.0000 & $0.000 \mathrm{E}+00$ & 0.0000 & $0.000 \mathrm{E}+00$ & 0.0000 & $0.000 \mathrm{E}+00$ & 0.0000 & $6.519 \mathrm{E}-27$ & 0.0000 \\
\hline-228 & $0.000 \mathrm{E}+00$ & 0.0000 & $0.000 \mathrm{E}+00$ & 0.0000 & $0.000 \mathrm{E}+00$ & 0.0000 & $0.000 \mathrm{E}+00$ & 0.0000 & $0.000 \mathrm{E}+00$ & 0.0000 & $0.000 \mathrm{E}+00$ & 0.0000 & $0.000 \mathrm{E}+00$ & 0.0000 \\
\hline-230 & 7. $343 \mathrm{E}+01$ & 0.7737 & $6.397 \mathrm{E}-03$ & 0.0001 & $0.000 \mathrm{E}+00$ & 0.0000 & $0.000 \mathrm{E}+00$ & 0.0000 & $0.000 \mathrm{E}+00$ & 0.0000 & $0.000 \mathrm{E}+00$ & 0.0000 & $5.000 \mathrm{E}+00$ & 0.0527 \\
\hline-232 & $4.711 E+00$ & 0.0496 & $4.381 E-04$ & 0.0000 & $0.000 \mathrm{E}+00$ & 0.0000 & $0.000 \mathrm{E}+00$ & 0.0000 & $0.000 \mathrm{E}+00$ & 0.0000 & $0.000 \mathrm{E}+00$ & 0.0000 & $2.488 \mathrm{E}-01$ & 0.0026 \\
\hline 234 & $8.094 \mathrm{E}+00$ & 0.0853 & $1.671 \mathrm{E}-03$ & 0.0000 & $0.000 \mathrm{E}+00$ & 0.0000 & $0.000 \mathrm{E}+00$ & 0.0000 & $0.000 \mathrm{E}+00$ & 0.0000 & $0.000 \mathrm{E}+00$ & 0.0000 & $6.646 \mathrm{E}-01$ & 0.0070 \\
\hline 35 & $4.875 E-01$ & 0.0051 & $5.106 \mathrm{E}-04$ & 0.0000 & $0.000 \mathrm{E}+00$ & 0.0000 & $0.000 \mathrm{E}+00$ & 0.0000 & $0.000 \mathrm{E}+00$ & 0.0000 & $0.000 \mathrm{E}+00$ & 0.0000 & $3.267 \mathrm{E}-02$ & 0.0003 \\
\hline 38 & $1.803 E+00$ & 0.0190 & $7.593 E-04$ & 0.0000 & $0.000 \mathrm{E}+00$ & 0.0000 & $0.000 \mathrm{E}+00$ & 0.0000 & $0.000 \mathrm{E}+00$ & 0.0000 & $0.000 \mathrm{E}+00$ & 0.0000 & $1.174 \mathrm{E}-01$ & 0.0012 \\
\hline & $8.873 E+01$ & 0.9350 & $1.219 \mathrm{E}-02$ & 0.0001 & $0.000 \mathrm{E}+00$ & 0.0000 & $0.000 \mathrm{E}+00$ & 0.0000 & $0.000 \mathrm{E}+00$ & 0.0000 & $0.000 \mathrm{E}+00$ & 0.0000 & $6.160 \mathrm{E}+00$ & 0.0649 \\
\hline
\end{tabular}

Total Dose Contributions TDOSE(i,p,t) for Individual Radionuclides (i) and Pathways (p) As mrem/yr and Fraction of Total Dose At $t=1.000 \mathrm{E}+04$ years

Water Dependent Pathways

\begin{tabular}{|c|c|c|c|c|c|c|c|c|c|c|c|c|c|c|}
\hline & \multicolumn{2}{|c|}{ Water } & \multicolumn{2}{|c|}{ Fish } & \multicolumn{2}{|c|}{ Radon } & \multicolumn{2}{|c|}{ Plant } & \multicolumn{2}{|c|}{ Meat } & \multicolumn{2}{|c|}{ Milk } & \multicolumn{2}{|c|}{ All Pathways* } \\
\hline clide & mrem/yr & fract. & mrem/yr & fract. & mrem/yr & fract. & mrem/yr & fract. & mrem/yr & fract. & mrem/yr & fract. & mrem/yr & fract. \\
\hline-241 & $0.000 \mathrm{E}+00$ & 0.0000 & $0.000 \mathrm{E}+00$ & 0.0000 & $0.000 \mathrm{E}+00$ & 0.0000 & $0.000 \mathrm{E}+00$ & 0.0000 & $0.000 \mathrm{E}+00$ & 0.0000 & $0.000 \mathrm{E}+00$ & 0.0000 & $2.823 E-04$ & 0.0000 \\
\hline-137 & $0.000 \mathrm{E}+00$ & 0.0000 & $0.000 \mathrm{E}+00$ & 0.0000 & $0.000 \mathrm{E}+00$ & 0.0000 & $0.000 \mathrm{E}+00$ & 0.0000 & $0.000 \mathrm{E}+00$ & 0.0000 & $0.000 \mathrm{E}+00$ & 0.0000 & $0.000 \mathrm{E}+00$ & 0.0000 \\
\hline-237 & $0.000 \mathrm{E}+00$ & 0.0000 & $0.000 \mathrm{E}+00$ & 0.0000 & $0.000 \mathrm{E}+00$ & 0.0000 & $0.000 \mathrm{E}+00$ & 0.0000 & $0.000 \mathrm{E}+00$ & 0.0000 & $0.000 \mathrm{E}+00$ & 0.0000 & $2.103 E-01$ & 0.0022 \\
\hline 238 & $0.000 \mathrm{E}+00$ & 0.0000 & $0.000 \mathrm{E}+00$ & 0.0000 & $0.000 \mathrm{E}+00$ & 0.0000 & $0.000 \mathrm{E}+00$ & 0.0000 & $0.000 \mathrm{E}+00$ & 0.0000 & $0.000 \mathrm{E}+00$ & 0.0000 & $7.543 E-04$ & 0.0000 \\
\hline 239 & $0.000 \mathrm{E}+00$ & 0.0000 & $0.000 \mathrm{E}+00$ & 0.0000 & $0.000 \mathrm{E}+00$ & 0.0000 & $0.000 \mathrm{E}+00$ & 0.0000 & $0.000 \mathrm{E}+00$ & 0.0000 & $0.000 \mathrm{E}+00$ & 0.0000 & $6.546 \mathrm{E}-02$ & 0.0007 \\
\hline 240 & $0.000 \mathrm{E}+00$ & 0.0000 & $0.000 \mathrm{E}+00$ & 0.0000 & $0.000 \mathrm{E}+00$ & 0.0000 & $0.000 \mathrm{E}+00$ & 0.0000 & $0.000 \mathrm{E}+00$ & 0.0000 & $0.000 \mathrm{E}+00$ & 0.0000 & $3.010 \mathrm{E}-02$ & 0.0003 \\
\hline 99 & $0.000 \mathrm{E}+00$ & 0.0000 & $0.000 \mathrm{E}+00$ & 0.0000 & $0.000 \mathrm{E}+00$ & 0.0000 & $0.000 \mathrm{E}+00$ & 0.0000 & $0.000 \mathrm{E}+00$ & 0.0000 & $0.000 \mathrm{E}+00$ & 0.0000 & 1. $285 \mathrm{E}-26$ & 0.0000 \\
\hline 228 & $0.000 \mathrm{E}+00$ & 0.0000 & $0.000 \mathrm{E}+00$ & 0.0000 & $0.000 \mathrm{E}+00$ & 0.0000 & $0.000 \mathrm{E}+00$ & 0.0000 & $0.000 \mathrm{E}+00$ & 0.0000 & $0.000 \mathrm{E}+00$ & 0.0000 & $0.000 \mathrm{E}+00$ & 0.0000 \\
\hline 230 & $0.000 \mathrm{E}+00$ & 0.0000 & $0.000 \mathrm{E}+00$ & 0.0000 & $0.000 \mathrm{E}+00$ & 0.0000 & $0.000 \mathrm{E}+00$ & 0.0000 & $0.000 \mathrm{E}+00$ & 0.0000 & $0.000 \mathrm{E}+00$ & 0.0000 & $7.843 E+01$ & 0.8265 \\
\hline 232 & $0.000 \mathrm{E}+00$ & 0.0000 & $0.000 \mathrm{E}+00$ & 0.0000 & $0.000 \mathrm{E}+00$ & 0.0000 & $0.000 \mathrm{E}+00$ & 0.0000 & $0.000 \mathrm{E}+00$ & 0.0000 & $0.000 \mathrm{E}+00$ & 0.0000 & $4.960 \mathrm{E}+00$ & 0.0523 \\
\hline & $0.000 \mathrm{E}+00$ & 0.0000 & $0.000 \mathrm{E}+00$ & 0.0000 & $0.000 \mathrm{E}+00$ & 0.0000 & $0.000 \mathrm{E}+00$ & 0.0000 & $0.000 \mathrm{E}+00$ & 0.0000 & $0.000 \mathrm{E}+00$ & 0.0000 & $8.760 \mathrm{E}+00$ & 0.0923 \\
\hline 35 & $0.000 \mathrm{E}+00$ & 0.0000 & $0.000 \mathrm{E}+00$ & 0.0000 & $0.000 \mathrm{E}+00$ & 0.0000 & $0.000 \mathrm{E}+00$ & 0.0000 & $0.000 \mathrm{E}+00$ & 0.0000 & $0.000 \mathrm{E}+00$ & 0.0000 & $5.207 \mathrm{E}-01$ & 0.0055 \\
\hline 38 & $0.000 \mathrm{E}+00$ & 0.0000 & $0.000 \mathrm{E}+00$ & 0.0000 & $0.000 \mathrm{E}+00$ & 0.0000 & $0.000 \mathrm{E}+00$ & 0.0000 & $0.000 \mathrm{E}+00$ & 0.0000 & $0.000 \mathrm{E}+00$ & 0.0000 & $1.921 \mathrm{E}+00$ & 0.0202 \\
\hline & $0.000 \mathrm{E}+00$ & 0.0000 & $0.000 \mathrm{E}+00$ & 0.0000 & $0.000 \mathrm{E}+00$ & 0.0000 & $0.000 \mathrm{E}+00$ & 0.0000 & $0.000 \mathrm{E}+00$ & 0.0000 & $.000 E+00$ & 000 & -01 & 1.0000 \\
\hline
\end{tabular}

* Sum of all water independent and dependent pathways. 
RESRAD, Version 6.5

$\mathrm{T}^{1 / 2}$ Limit $=180$ days

07/21/2011 12:35 Page

28

ummary : RESRAD Parameters for U-Landfill Recreational User Foward Run

File : C: \RESRAD_FAMILY \RESRAD \USERFILES \QCJULY2011 \ULANDFILL-RU_FORWARD-10000YRS.RAD

Dose/Source Ratios Summed Over All Pathways

Parent and Progeny Principal Radionuclide Contributions Indicated

Parent Product Thread DSR $(j, t)$ At Time in Years (mrem/yr)/(pCi/g)

(i)

(j)

\section{Am-241}

$\mathrm{Np}-237+\mathrm{D}$

$\mathrm{U}-233$

Th-229+D

$\sum \mathrm{DSR}(\mathrm{j})$

Cs $-137+D$

$\mathrm{Np}-237+\mathrm{D}$

U-233

Th-229+D

$\sum \mathrm{DSR}(j)$

$\mathrm{Pu}-238$

$\mathrm{Pu}-238$

U-234

Th-230

$\mathrm{Ra}-226+\mathrm{D}$

$\mathrm{Pb}-210+\mathrm{D}$

$\sum \operatorname{DSR}(j)$

$\mathrm{Pu}-239$

$\mathrm{U}-235+\mathrm{D}$

$\mathrm{Pa}-231$

Ac-227+D

$\sum \operatorname{DSR}(j)$

$\mathrm{Pu}-240$

$\mathrm{Pu}-240$

U-236

Th-232

$\mathrm{Ra}-228+\mathrm{D}$

Th-228+D

$\sum \operatorname{DSR}(j)$

TC-99

Th $-228+\mathrm{D}$

Th-230

Ra-226+D

$\mathrm{Pb}-210+\mathrm{D}$

$\sum \operatorname{DSR}(j)$ $\begin{array}{llllllll}0.000 \mathrm{E}+00 & 1.000 \mathrm{E}+00 & 1.200 \mathrm{E}+01 & 5.000 \mathrm{E}+01 & 1.000 \mathrm{E}+02 & 5.000 \mathrm{E}+02 & 1.050 \mathrm{E}+03 & 1.000 \mathrm{E}+04\end{array}$

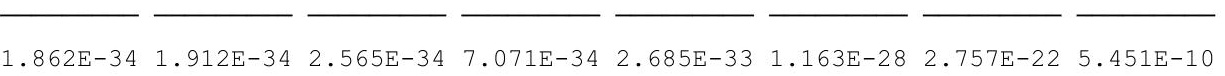

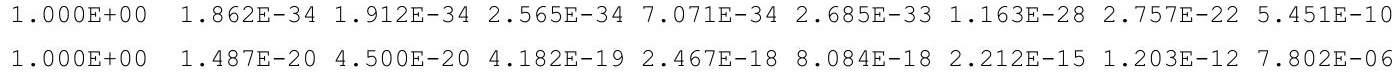

$\begin{array}{lllllllll}1.000 \mathrm{E}+00 & 3.371 \mathrm{E}-31 & 2.384 \mathrm{E}-30 & 1.820 \mathrm{E}-28 & 4.682 \mathrm{E}-27 & 3.376 \mathrm{E}-26 & 1.025 \mathrm{E}-22 & 3.455 \mathrm{E}-19 & 5.052 \mathrm{E}-09\end{array}$

$\begin{array}{llllllllll}1.000 \mathrm{E}+00 & 2.306 \mathrm{E}-27 & 3.479 \mathrm{E}-26 & 1.949 \mathrm{E}-23 & 1.645 \mathrm{E}-21 & 1.799 \mathrm{E}-20 & 3.100 \mathrm{E}-17 & 1.142 \mathrm{E}-14 & 2.585 \mathrm{E}-07\end{array}$

$\begin{array}{llllllll}1.487 \mathrm{E}-20 & 4.500 \mathrm{E}-20 & 4.182 \mathrm{E}-19 & 2.469 \mathrm{E}-18 & 8.102 \mathrm{E}-18 & 2.243 \mathrm{E}-15 & 1.214 \mathrm{E}-12 & 8.067 \mathrm{E}-06\end{array}$

$\begin{array}{lllllllll}1.000 \mathrm{E}+00 & 1.213 \mathrm{E}-10 & 1.196 \mathrm{E}-10 & 1.017 \mathrm{E}-10 & 5.821 \mathrm{E}-11 & 2.793 \mathrm{E}-11 & 7.847 \mathrm{E}-14 & 2.435 \mathrm{E}-17 & 0.000 \mathrm{E}+00\end{array}$

$\begin{array}{lllllllllll}1.000 \mathrm{E}+00 & 9.169 \mathrm{E}-14 & 9.268 \mathrm{E}-14 & 1.043 \mathrm{E}-13 & 1.567 \mathrm{E}-13 & 2.679 \mathrm{E}-13 & 1.952 \mathrm{E}-11 & 7.101 \mathrm{E}-09 & 3.681 \mathrm{E}-02\end{array}$

$\begin{array}{llllllllll}1.000 \mathrm{E}+00 & 3.120 \mathrm{E}-24 & 9.466 \mathrm{E}-24 & 9.045 \mathrm{E}-23 & 5.875 \mathrm{E}-22 & 2.184 \mathrm{E}-21 & 1.613 \mathrm{E}-18 & 3.273 \mathrm{E}-15 & 2.602 \mathrm{E}-05\end{array}$

$\begin{array}{llllllllll}1.000 \mathrm{E}+00 & 2.848 \mathrm{E}-20 & 2.006 \mathrm{E}-19 & 1.449 \mathrm{E}-17 & 3.076 \mathrm{E}-16 & 1.723 \mathrm{E}-15 & 6.884 \mathrm{E}-13 & 1.443 \mathrm{E}-10 & 1.403 \mathrm{E}-03\end{array}$

$9.169 \mathrm{E}-14 \quad 9.268 \mathrm{E}-14 \quad 1.043 \mathrm{E}-13 \quad 1.570 \mathrm{E}-13 \quad 2.696 \mathrm{E}-13 \quad 2.021 \mathrm{E}-11 \quad 7.245 \mathrm{E}-09 \quad 3.824 \mathrm{E}-02$

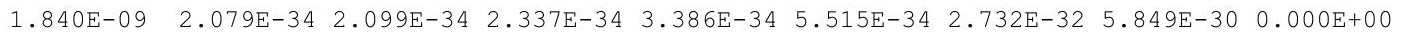

$\begin{array}{lllllllll}1.000 \mathrm{E}+00 & 1.130 \mathrm{E}-25 & 1.141 \mathrm{E}-25 & 1.270 \mathrm{E}-25 & 1.840 \mathrm{E}-25 & 2.997 \mathrm{E}-25 & 1.485 \mathrm{E}-23 & 3.179 \mathrm{E}-21 & 1.081 \mathrm{E}-37\end{array}$ $\begin{array}{llllllllll}1.000 E+00 & 9.402 E-31 & 2.855 E-30 & 2.767 E-29 & 1.897 E-28 & 7.660 E-28 & 1.633 E-24 & 2.820 E-20 & 2.543 E-07\end{array}$ $\begin{array}{lllllllll}1.000 \mathrm{E}+00 & 9.887 \mathrm{E}-35 & 7.005 \mathrm{E}-34 & 5.480 \mathrm{E}-32 & 1.538 \mathrm{E}-30 & 1.253 \mathrm{E}-29 & 1.259 \mathrm{E}-25 & 3.198 \mathrm{E}-21 & 7.030 \mathrm{E}-08\end{array}$ $\begin{array}{llllllllll}1.000 \mathrm{E}+00 & 7.713 \mathrm{E}-24 & 1.162 \mathrm{E}-22 & 6.388 \mathrm{E}-20 & 5.065 \mathrm{E}-18 & 5.122 \mathrm{E}-17 & 5.408 \mathrm{E}-14 & 1.260 \mathrm{E}-11 & 1.819 \mathrm{E}-05\end{array}$ $\begin{array}{lllllllll}1.000 \mathrm{E}+00 & 2.237 \mathrm{E}-32 & 6.933 \mathrm{E}-31 & 2.743 \mathrm{E}-27 & 7.476 \mathrm{E}-25 & 1.264 \mathrm{E}-23 & 3.542 \mathrm{E}-20 & 1.664 \mathrm{E}-17 & 8.245 \mathrm{E}-07\end{array}$ $\begin{array}{llllllll}7.826 \mathrm{E}-24 & 1.163 \mathrm{E}-22 & 6.388 \mathrm{E}-20 & 5.065 \mathrm{E}-18 & 5.122 \mathrm{E}-17 & 5.408 \mathrm{E}-14 & 1.260 \mathrm{E}-11 & 1.934 \mathrm{E}-05\end{array}$

$\begin{array}{lllllllll}1.000 \mathrm{E}+00 & 1.156 \mathrm{E}-18 & 1.170 \mathrm{E}-18 & 1.334 \mathrm{E}-18 & 2.100 \mathrm{E}-18 & 3.815 \mathrm{E}-18 & 4.526 \mathrm{E}-16 & 3.220 \mathrm{E}-13 & 1.818 \mathrm{E}-03\end{array}$ $\begin{array}{llllllll}1.000 \mathrm{E}+00 & 5.899 \mathrm{E}-25 & 1.789 \mathrm{E}-24 & 1.707 \mathrm{E}-23 & 1.102 \mathrm{E}-22 & 4.068 \mathrm{E}-22 & 2.830 \mathrm{E}-19 & 5.291 \mathrm{E}-16 \quad 4.215 \mathrm{E}-07\end{array}$ $\begin{array}{lllllllll}1.000 \mathrm{E}+00 & 9.281 \mathrm{E}-29 & 6.556 \mathrm{E}-28 & 4.931 \mathrm{E}-26 & 1.203 \mathrm{E}-24 & 8.097 \mathrm{E}-24 & 1.394 \mathrm{E}-20 & 2.092 \mathrm{E}-17 & 1.785 \mathrm{E}-08\end{array}$ $\begin{array}{llllllllll}1.000 \mathrm{E}+00 & 2.200 \mathrm{E}-28 & 3.302 \mathrm{E}-27 & 1.741 \mathrm{E}-24 & 1.227 \mathrm{E}-22 & 1.125 \mathrm{E}-21 & 1.425 \mathrm{E}-18 & 8.591 \mathrm{E}-16 & 1.293 \mathrm{E}-07\end{array}$ $\begin{array}{llllllll}1.156 \mathrm{E}-18 & 1.170 \mathrm{E}-18 & 1.334 \mathrm{E}-18 & 2.100 \mathrm{E}-18 & 3.817 \mathrm{E}-18 & 4.543 \mathrm{E}-16 & 3.234 \mathrm{E}-13 & 1.818 \mathrm{E}-03\end{array}$

4.950E-08 5.436E-33 5.532E-33 6.710E-33 $1.307 \mathrm{E}-32 \quad 3.144 \mathrm{E}-32 \quad 3.519 \mathrm{E}-29 \quad 5.479 \mathrm{E}-25 \quad 4.138 \mathrm{E}-11$

$\begin{array}{lllllllll}1.000 \mathrm{E}+00 & 1.098 \mathrm{E}-25 & 1.118 \mathrm{E}-25 & 1.356 \mathrm{E}-25 & 2.641 \mathrm{E}-25 & 6.352 \mathrm{E}-25 & 7.109 \mathrm{E}-22 & 1.107 \mathrm{E}-17 \quad 8.359 \mathrm{E}-04\end{array}$ $\begin{array}{llllllllll}1.000 E+00 & 2.079 E-33 & 6.337 E-33 & 6.427 E-32 & 5.132 E-31 & 2.504 E-30 & 1.628 E-26 & 6.574 E-22 & 1.256 E-07\end{array}$ $\begin{array}{llllllllll}1.000 \mathrm{E}+00 & 2.803 \mathrm{E}-44 & 1.948 \mathrm{E}-43 & 1.599 \mathrm{E}-41 & 5.271 \mathrm{E}-40 & 5.270 \mathrm{E}-39 & 2.159 \mathrm{E}-34 & 2.528 \mathrm{E}-29 & 1.367 \mathrm{E}-13\end{array}$ $\begin{array}{llllllllll}1.000 \mathrm{E}+00 & 1.318 \mathrm{E}-29 & 1.940 \mathrm{E}-28 & 8.230 \mathrm{E}-26 & 3.618 \mathrm{E}-24 & 2.445 \mathrm{E}-23 & 1.417 \mathrm{E}-20 & 4.042 \mathrm{E}-18 & 2.429 \mathrm{E}-11\end{array}$ $\begin{array}{lllllllll}1.000 E+00 \quad 7.799 E-29 & 2.244 E-27 & 4.095 E-24 & 2.540 E-22 & 1.691 E-21 & 5.366 E-19 & 6.323 E-17 & 3.687 \mathrm{E}-11\end{array}$ $\begin{array}{llllllll}1.099 \mathrm{E}-25 & 1.142 \mathrm{E}-25 & 4.313 \mathrm{E}-24 & 2.579 \mathrm{E}-22 & 1.716 \mathrm{E}-21 & 5.515 \mathrm{E}-19 & 7.834 \mathrm{E}-17 & 8.361 \mathrm{E}-04\end{array}$

$\begin{array}{lllllllll}1.000 \mathrm{E}+00 \quad 5.547 \mathrm{E}-27 & 5.625 \mathrm{E}-27 & 6.555 \mathrm{E}-27 & 1.112 \mathrm{E}-26 & 2.231 \mathrm{E}-26 & 5.839 \mathrm{E}-24 & 1.233 \mathrm{E}-20 & 2.473 \mathrm{E}-28\end{array}$

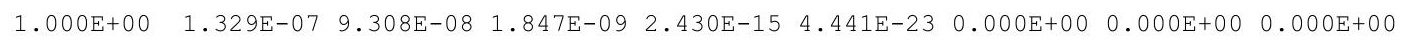

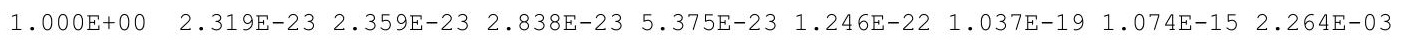
$\begin{array}{llllllllll}1.000 \mathrm{E}+00 & 3.629 \mathrm{E}-12 & 1.095 \mathrm{E}-11 & 9.820 \mathrm{E}-11 & 5.116 \mathrm{E}-10 & 1.423 \mathrm{E}-09 & 1.032 \mathrm{E}-07 & 8.661 \mathrm{E}-06 & 7.480 \mathrm{E}-01\end{array}$ $\begin{array}{llllllll}1.000 \mathrm{E}+00 & 1.749 \mathrm{E}-20 & 1.222 \mathrm{E}-19 & 7.985 \mathrm{E}-18 & 1.249 \mathrm{E}-16 & 5.113 \mathrm{E}-16 & 7.402 \mathrm{E}-14 & 1.190 \mathrm{E}-11 \quad 3.403 \mathrm{E}-02\end{array}$ $\begin{array}{lllllllll}3.629 \mathrm{E}-12 & 1.095 \mathrm{E}-11 & 9.820 \mathrm{E}-11 & 5.116 \mathrm{E}-10 & 1.423 \mathrm{E}-09 & 1.032 \mathrm{E}-07 & 8.661 \mathrm{E}-06 & 7.843 \mathrm{E}-01\end{array}$ 
RESRAD, Version 6.5

Summary : RESRAD Parameters for U-Landfill Recreational User Foward Run

File : C: \RESRAD_FAMILY \RESRAD \USERFILES \QCJULY2011 \ULANDFILL-RU_FORWARD-10000YRS.RAD

Dose/Source Ratios Summed Over All Pathways

Parent and Progeny Principal Radionuclide Contributions Indicated

\begin{tabular}{|c|c|c|c|c|c|c|c|c|c|c|}
\hline Parent & Product & Thread & & DSR & $(j, t)$ At & ime in Yea & (mrem) & $/ \mathrm{yr}) /(\mathrm{pCi} / \mathrm{g}$ & & \\
\hline (i) & $(j)$ & Fraction & $0.000 \mathrm{E}+00$ & $1.000 \mathrm{E}+00$ & $1.200 \mathrm{E}+01$ & $5.000 \mathrm{E}+01$ & $1.000 \mathrm{E}+02$ & $5.000 \mathrm{E}+02$ & $1.050 \mathrm{E}+03$ & $1.000 \mathrm{E}+04$ \\
\hline-232 & $\mathrm{Th}-232$ & $1.000 \mathrm{E}+00$ & $1.121 \mathrm{E}-25$ & $1.142 \mathrm{E}-25$ & $1.401 \mathrm{E}-25$ & $2.836 \mathrm{E}-25$ & $7.176 \mathrm{E}-25$ & $1.205 E-21$ & $3.277 \mathrm{E}-17$ & $2.761 \mathrm{E}-03$ \\
\hline-232 & $\mathrm{Ra}-228+\mathrm{D}$ & $1.000 \mathrm{E}+00$ & 1. $065 \mathrm{E}-10$ & $3.052 \mathrm{E}-10$ & $1.565 \mathrm{E}-09$ & $2.678 E-09$ & $3.923 E-09$ & $8.176 \mathrm{E}-08$ & $5.322 \mathrm{E}-06$ & 4. $913 \mathrm{E}-01$ \\
\hline$h-232$ & $\mathrm{Th}-228+\mathrm{D}$ & $1.000 \mathrm{E}+00$ & $1.026 \mathrm{E}-09$ & $6.328 E-09$ & $1.146 \mathrm{E}-07$ & $2.128 E-07$ & $2.877 E-07$ & $3.130 E-06$ & $8.368 E-05$ & $7.461 \mathrm{E}-01$ \\
\hline-232 & $\sum \operatorname{DSR}(j)$ & & $1.133 E-09$ & $6.633 E-09$ & $1.162 \mathrm{E}-07$ & $2.155 \mathrm{E}-07$ & $2.917 \mathrm{E}-07$ & $3.212 \mathrm{E}-06$ & $8.900 \mathrm{E}-05$ & $1.240 \mathrm{E}+00$ \\
\hline-234 & $\mathrm{U}-234$ & $1.000 \mathrm{E}+00$ & $6.631 E-25$ & $6.749 \mathrm{E}-25$ & $8.200 \mathrm{E}-25$ & $1.607 \mathrm{E}-24$ & $3.895 E-24$ & $4.636 \mathrm{E}-21$ & $7.854 \mathrm{E}-17$ & $7.080 \mathrm{E}-04$ \\
\hline-234 & Th-230 & $1.000 \mathrm{E}+00$ & $1.047 \mathrm{E}-28$ & $3.188 \mathrm{E}-28$ & $3.193 \mathrm{E}-27$ & $2.443 E-26$ & $1.127 \mathrm{E}-25$ & $4.665 E-22$ & $1.013 \mathrm{E}-17$ & $1.983 \mathrm{E}-04$ \\
\hline-234 & $\mathrm{Ra}-226+\mathrm{D}$ & $1.000 \mathrm{E}+00$ & $1.090 \mathrm{E}-17$ & $7.671 \mathrm{E}-17$ & $5.533 E-15$ & $1.167 \mathrm{E}-13$ & $6.482 \mathrm{E}-13$ & $2.407 E-10$ & $4.396 E-08$ & $5.151 \mathrm{E}-02$ \\
\hline-234 & $\mathrm{~Pb}-210+\mathrm{D}$ & $1.000 \mathrm{E}+00$ & $3.944 E-26$ & $5.916 \mathrm{E}-25$ & $3.094 \mathrm{E}-22$ & $2.118 \mathrm{E}-20$ & $1.862 \mathrm{E}-19$ & $1.619 \mathrm{E}-16$ & $5.847 \mathrm{E}-14$ & $2.335 \mathrm{E}-03$ \\
\hline-234 & $\sum \operatorname{DSR}(j)$ & & $1.090 \mathrm{E}-17$ & $7.671 \mathrm{E}-17$ & $5.533 \mathrm{E}-15$ & $1.167 \mathrm{E}-13$ & $6.482 \mathrm{E}-13$ & $2.407 \mathrm{E}-10$ & $4.396 \mathrm{E}-08$ & $5.475 \mathrm{E}-02$ \\
\hline$-235+D$ & $\mathrm{U}-235+\mathrm{D}$ & $1.000 \mathrm{E}+00$ & $1.195 \mathrm{E}-15$ & 1. $210 \mathrm{E}-15$ & 1. $387 \mathrm{E}-15$ & $2.218 E-15$ & $4.115 E-15$ & $5.779 \mathrm{E}-13$ & $5.183 E-10$ & $4.846 \mathrm{E}-02$ \\
\hline$-235+D$ & $\mathrm{~Pa}-231$ & $1.000 \mathrm{E}+00$ & $2.825 E-19$ & $8.554 \mathrm{E}-19$ & $8.006 \mathrm{E}-18$ & $4.840 \mathrm{E}-17$ & $1.637 \mathrm{E}-16$ & $5.673 E-14$ & $4.068 \mathrm{E}-11$ & $3.830 \mathrm{E}-03$ \\
\hline$-235+D$ & $A C-227+D$ & $1.000 \mathrm{E}+00$ & $8.917 \mathrm{E}-19$ & $6.232 \mathrm{E}-18$ & $4.105 \mathrm{E}-16$ & $6.620 \mathrm{E}-15$ & $2.832 \mathrm{E}-14$ & $6.156 \mathrm{E}-12$ & $1.720 \mathrm{E}-09$ & $2.782 \mathrm{E}-02$ \\
\hline$-235+D$ & $\sum \operatorname{DSR}(j)$ & & $1.197 \mathrm{E}-15$ & 1. $217 \mathrm{E}-15$ & $1.805 \mathrm{E}-15$ & $8.886 E-15$ & $3.260 E-14$ & $6.791 E-12$ & $2.279 E-09$ & $8.011 \mathrm{E}-02$ \\
\hline-238 & $\mathrm{U}-238$ & $5.400 \mathrm{E}-05$ & $0.000 \mathrm{E}+00$ & $0.000 \mathrm{E}+00$ & $0.000 \mathrm{E}+00$ & $0.000 \mathrm{E}+00$ & $0.000 \mathrm{E}+00$ & $0.000 \mathrm{E}+00$ & $1.636 \mathrm{E}-39$ & $3.473 E-08$ \\
\hline$-238+D$ & $\mathrm{U}-238+\mathrm{D}$ & $9.999 \mathrm{E}-01$ & $1.365 \mathrm{E}-11$ & $1.376 \mathrm{E}-11$ & $1.502 \mathrm{E}-11$ & $2.035 E-11$ & $3.035 E-11$ & $7.419 \mathrm{E}-10$ & $6.017 \mathrm{E}-08$ & $1.135 \mathrm{E}-02$ \\
\hline$-238+D$ & $\mathrm{U}-234$ & $9.999 \mathrm{E}-01$ & $9.426 \mathrm{E}-31$ & $2.873 E-30$ & $2.906 \mathrm{E}-29$ & $2.301 \mathrm{E}-28$ & $1.110 \mathrm{E}-27$ & $6.582 E-24$ & $2.342 E-19$ & $2.036 \mathrm{E}-05$ \\
\hline$J-238+D$ & $\mathrm{Th}-230$ & $9.999 E-01$ & $9.906 \mathrm{E}-35$ & $7.035 \mathrm{E}-34$ & $5.662 E-32$ & $1.749 \mathrm{E}-30$ & $1.605 \mathrm{E}-29$ & $3.309 \mathrm{E}-25$ & $1.508 \mathrm{E}-20$ & $2.812 \mathrm{E}-06$ \\
\hline$J-238+D$ & $\mathrm{Ra}-226+\mathrm{D}$ & $9.999 \mathrm{E}-01$ & $7.725 E-24$ & $1.165 E-22$ & $6.546 \mathrm{E}-20$ & $5.580 \mathrm{E}-18$ & $6.178 \mathrm{E}-17$ & $1.159 \mathrm{E}-13$ & $4.523 E-11$ & $6.081 \mathrm{E}-04$ \\
\hline$J-238+D$ & $\mathrm{~Pb}-210+\mathrm{D}$ & $9.999 E-01$ & $2.239 E-32$ & $6.951 E-31$ & $2.798 \mathrm{E}-27$ & $8.109 E-25$ & $1.488 \mathrm{E}-23$ & $7.347 E-20$ & $5.837 \mathrm{E}-17$ & $2.746 \mathrm{E}-05$ \\
\hline$-238+D$ & $\sum \operatorname{DSR}(j)$ & & $1.365 \mathrm{E}-11$ & 1. $376 \mathrm{E}-11$ & $1.502 \mathrm{E}-11$ & $2.035 \mathrm{E}-11$ & $3.035 \mathrm{E}-11$ & $7.420 \mathrm{E}-10$ & $6.021 \mathrm{E}-08$ & $1.201 \mathrm{E}-02$ \\
\hline
\end{tabular}

The DSR includes contributions from associated (half-life $\leq 180$ days) daughters. 
RESRAD, Version $6.5 \quad \mathrm{~T}^{1 / 2}$ Limit $=180$ days

Summary : RESRAD Parameters for U-Landfill Recreational User Foward Run

File : C: $\backslash$ RESRAD_FAMILY \RESRAD UUSERFILES \QCJULY2011 \ULANDFILL-RU_FORWARD-10000YRS.RAD

Single Radionuclide Soil Guidelines $G(i, t)$ in $\mathrm{pCi} / \mathrm{g}$

Basic Radiation Dose Limit $=1.000 \mathrm{E}+00 \mathrm{mrem} / \mathrm{yr}$

Nuclide

\begin{tabular}{|c|c|c|c|c|c|c|c|c|}
\hline (i) & $t=0.000 \mathrm{E}+00$ & $1.000 \mathrm{E}+00$ & $1.200 \mathrm{E}+01$ & $5.000 \mathrm{E}+01$ & $1.000 \mathrm{E}+02$ & $5.000 \mathrm{E}+02$ & $1.050 \mathrm{E}+03$ & $1.000 \mathrm{E}+04$ \\
\hline $1-241$ & $\star 3.431 \mathrm{E}+12$ & $\star 3.431 \mathrm{E}+12$ & $\star 3.431 \mathrm{E}+12$ & $\star 3.431 \mathrm{E}+12$ & $\star 3.431 \mathrm{E}+12$ & $* 3.431 \mathrm{E}+12$ & $8.235 E+11$ & $1.240 \mathrm{E}+05$ \\
\hline-137 & $8.242 E+09$ & $8.364 \mathrm{E}+09$ & $9.831 E+09$ & $1.718 \mathrm{E}+10$ & $3.580 \mathrm{E}+10$ & $1.274 \mathrm{E}+13$ & $\star 8.704 \mathrm{E}+13$ & $\star 8.704 \mathrm{E}+13$ \\
\hline-237 & $\star 7.047 \mathrm{E}+08$ & $\star 7.047 \mathrm{E}+08$ & $\star 7.047 \mathrm{E}+08$ & $\star 7.047 \mathrm{E}+08$ & $\star 7.047 \mathrm{E}+08$ & $\star 7.047 \mathrm{E}+08$ & $1.380 \mathrm{E}+08$ & $2.615 E+01$ \\
\hline $1-238$ & $* 1.712 \mathrm{E}+13$ & $\star 1.712 \mathrm{E}+13$ & $\star 1.712 \mathrm{E}+13$ & $* 1.712 \mathrm{E}+13$ & $\star 1.712 \mathrm{E}+13$ & $* 1.712 \mathrm{E}+13$ & $7.937 \mathrm{E}+10$ & $5.170 E+04$ \\
\hline-239 & $\star 6.214 \mathrm{E}+10$ & $* 6.214 \mathrm{E}+10$ & $* 6.214 \mathrm{E}+10$ & $\star 6.214 \mathrm{E}+10$ & $\star 6.214 \mathrm{E}+10$ & $* 6.214 \mathrm{E}+10$ & $* 6.214 \mathrm{E}+10$ & $5.500 \mathrm{E}+02$ \\
\hline-240 & $\star 2.278 \mathrm{E}+11$ & $\star 2.278 \mathrm{E}+11$ & $\star 2.278 \mathrm{E}+11$ & $\star 2.278 \mathrm{E}+11$ & $\star 2.278 \mathrm{E}+11$ & $\star 2.278 \mathrm{E}+11$ & $\star 2.278 \mathrm{E}+11$ & $1.196 \mathrm{E}+03$ \\
\hline$c-99$ & $\star 1.697 \mathrm{E}+10$ & $\star 1.697 \mathrm{E}+10$ & $\star 1.697 \mathrm{E}+10$ & $* 1.697 \mathrm{E}+10$ & $\star 1.697 \mathrm{E}+10$ & $\star 1.697 \mathrm{E}+10$ & $\star 1.697 \mathrm{E}+10$ & $\star 1.697 \mathrm{E}+10$ \\
\hline$h-228$ & $7.523 \mathrm{E}+06$ & $1.074 \mathrm{E}+07$ & $5.414 \mathrm{E}+08$ & $4.116 \mathrm{E}+14$ & $\star 8.195 \mathrm{E}+14$ & $\star 8.195 \mathrm{E}+14$ & $\star 8.195 \mathrm{E}+14$ & $\star 8.195 \mathrm{E}+14$ \\
\hline$h-230$ & $\star 2.018 \mathrm{E}+10$ & $\star 2.018 \mathrm{E}+10$ & $1.018 \mathrm{E}+10$ & $1.955 \mathrm{E}+09$ & $7.028 \mathrm{E}+08$ & $9.688 \mathrm{E}+06$ & $1.155 \mathrm{E}+05$ & $1.275 \mathrm{E}+00$ \\
\hline$h-232$ & $* 1.097 \mathrm{E}+05$ & $\star 1.097 \mathrm{E}+05$ & $\star 1.097 \mathrm{E}+05$ & $\star 1.097 \mathrm{E}+05$ & $\star 1.097 \mathrm{E}+05$ & $* 1.097 \mathrm{E}+05$ & $1.124 \mathrm{E}+04$ & $8.064 \mathrm{E}-01$ \\
\hline$J-234$ & $* 6.247 \mathrm{E}+09$ & $\star 6.247 \mathrm{E}+09$ & $\star 6.247 \mathrm{E}+09$ & $\star 6.247 \mathrm{E}+09$ & $\star 6.247 \mathrm{E}+09$ & $4.154 \mathrm{E}+09$ & $2.275 \mathrm{E}+07$ & $1.827 \mathrm{E}+01$ \\
\hline 35 & $\star 2.161 \mathrm{E}+06$ & $\star 2.161 \mathrm{E}+06$ & $\star 2.161 \mathrm{E}+06$ & $\star 2.161 \mathrm{E}+06$ & $\star 2.161 \mathrm{E}+06$ & $\star 2.161 \mathrm{E}+06$ & $\star 2.161 \mathrm{E}+06$ & $1.248 \mathrm{E}+01$ \\
\hline 38 & $\star 3.361 \mathrm{E}+05$ & $\star 3.361 \mathrm{E}+05$ & $\star 3.361 \mathrm{E}+05$ & $\star 3.361 \mathrm{E}+05$ & $\star 3.361 \mathrm{E}+05$ & $\star 3.361 \mathrm{E}+05$ & $* 3.361 \mathrm{E}+05$ & $8.328 \mathrm{E}+01$ \\
\hline
\end{tabular}

*At specific activity limit

Summed Dose/Source Ratios DSR(i,t) in (mrem/yr)/(pCi/g)

and Single Radionuclide Soil Guidelines $\mathrm{G}(\mathrm{i}, \mathrm{t})$ in $\mathrm{pCi} / \mathrm{g}$

at tmin = time of minimum single radionuclide soil guideline

and at $\operatorname{tmax}=$ time of maximum total dose $=1.000 \mathrm{E}+04$ years

\begin{tabular}{|c|c|c|c|c|c|c|}
\hline $\begin{array}{l}\text { Tuclide } \\
\text { (i) }\end{array}$ & $\begin{array}{l}\text { Initial } \\
(\mathrm{pCi} / \mathrm{g})\end{array}$ & $\begin{array}{c}\text { tmin } \\
\text { (years) }\end{array}$ & $\operatorname{DSR}(i, \operatorname{tmin})$ & $\begin{array}{c}\mathrm{G}(\mathrm{i}, \mathrm{tmin}) \\
(\mathrm{pCi} / \mathrm{g})\end{array}$ & $\operatorname{DSR}(i, \operatorname{tmax})$ & $\begin{array}{c}\text { G }(i, \text { tmax }) \\
(\mathrm{pCi} / \mathrm{g})\end{array}$ \\
\hline-241 & $3.500 \mathrm{E}+01$ & $2534 \pm 5$ & $1.020 \mathrm{E}-04$ & $9.802 \mathrm{E}+03$ & $8.067 \mathrm{E}-06$ & $1.240 \mathrm{E}+05$ \\
\hline-137 & $1.900 \mathrm{E}+01$ & $0.000 \mathrm{E}+00$ & $1.213 \mathrm{E}-10$ & $8.242 E+09$ & $0.000 \mathrm{E}+00$ & $\star 8.704 \mathrm{E}+13$ \\
\hline 237 & $5.500 \mathrm{E}+00$ & $2534 \pm 5$ & $6.642 \mathrm{E}-02$ & $1.506 \mathrm{E}+01$ & $3.824 \mathrm{E}-02$ & $2.615 \mathrm{E}+01$ \\
\hline-238 & $3.900 \mathrm{E}+01$ & $1.000 \mathrm{E}+04$ & $1.934 \mathrm{E}-05$ & $5.170 \mathrm{E}+04$ & $1.934 \mathrm{E}-05$ & $5.170 \mathrm{E}+04$ \\
\hline $\mathrm{Pu}-239$ & $3.600 \mathrm{E}+01$ & $2534 \pm 5$ & $2.428 \mathrm{E}-03$ & $4.118 \mathrm{E}+02$ & $1.818 \mathrm{E}-03$ & $5.500 \mathrm{E}+02$ \\
\hline$u-240$ & $3.600 \mathrm{E}+01$ & $2534 \pm 5$ & $1.988 \mathrm{E}-03$ & $5.030 \mathrm{E}+02$ & $8.361 \mathrm{E}-04$ & $1.196 \mathrm{E}+03$ \\
\hline TC-99 & $5.200 \mathrm{E}+01$ & $2534 \pm 5$ & $2.825 \mathrm{E}-11$ & $\star 1.697 \mathrm{E}+10$ & $2.472 \mathrm{E}-28$ & $* 1.697 \mathrm{E}+10$ \\
\hline$T h-228$ & $4.000 \mathrm{E}+00$ & $0.000 \mathrm{E}+00$ & $1.329 \mathrm{E}-07$ & $7.523 E+06$ & $0.000 \mathrm{E}+00$ & $\star 8.195 \mathrm{E}+14$ \\
\hline$T h-230$ & $1.000 \mathrm{E}+02$ & $1.000 \mathrm{E}+04$ & $7.843 \mathrm{E}-01$ & $1.275 \mathrm{E}+00$ & $7.843 \mathrm{E}-01$ & $1.275 \mathrm{E}+00$ \\
\hline 232 & $4.000 \mathrm{E}+00$ & $2534 \pm 5$ & $1.256 \mathrm{E}+00$ & $7.961 \mathrm{E}-01$ & $1.240 \mathrm{E}+00$ & $8.064 \mathrm{E}-01$ \\
\hline 34 & $1.600 \mathrm{E}+02$ & $1.000 \mathrm{E}+04$ & $5.475 \mathrm{E}-02$ & $1.827 \mathrm{E}+01$ & $5.475 \mathrm{E}-02$ & $1.827 \mathrm{E}+01$ \\
\hline 35 & $6.500 \mathrm{E}+00$ & $1.000 \mathrm{E}+04$ & $8.011 \mathrm{E}-02$ & $1.248 \mathrm{E}+01$ & $8.011 \mathrm{E}-02$ & $1.248 \mathrm{E}+01$ \\
\hline 238 & $1.600 \mathrm{E}+02$ & $2534 \pm 5$ & $1.257 \mathrm{E}-02$ & $7.957 \mathrm{E}+01$ & $1.201 \mathrm{E}-02$ & $8.328 E+01$ \\
\hline
\end{tabular}

*At specific activity limit 
RESRAD, Version 6.5

Summary : RESRAD Parameters for U-Landfill Recreational User Foward Run

File : C: \RESRAD_FAMILY \RESRAD \USERFILES \QCJULY2011 \ULANDFILL-RU_FORWARD-10000YRS.RAD

Individual Nuclide Dose Summed Over All Pathways

Parent Nuclide and Branch Fraction Indicated

Nuclide Parent THF(i) DOSE $(j, t), \mathrm{mrem} / \mathrm{yr}$

\begin{tabular}{|c|c|c|}
\hline$(j)$ & (i) & \\
\hline$m-241$ & $A m-241$ & $1.000 \mathrm{E}+00$ \\
\hline$p-237$ & Am-241 & $1.000 \mathrm{E}+00$ \\
\hline-237 & $N p-237$ & $1.000 \mathrm{E}+00$ \\
\hline 237 & $\sum \mathrm{DOSE}$ & \\
\hline
\end{tabular}

U-233 Am-241 1.000E+00

$\mathrm{U}-233 \quad \mathrm{~Np}-237 \quad 1.000 \mathrm{E}+00$

U-233 $\quad$ DOSE $(j)$

Th-229 Am-241 1.000E+00

Th-229 Np-237 1.000E+00

Th-229 $\sum \operatorname{DOSE}(j)$

Cs-137 Cs $-137 \quad 1.000 \mathrm{E}+00$

$\mathrm{Pu}-238 \mathrm{Pu}-238 \quad 1.840 \mathrm{E}-09$

$\mathrm{Pu}-238 \quad \mathrm{Pu}-238 \quad 1.000 \mathrm{E}+00$

$\mathrm{Pu}-238 \quad \sum \mathrm{DOSE}(j)$

$\mathrm{U}-234$

$\mathrm{U}-234$

$\mathrm{U}-234$

$\mathrm{U}-234$

$\mathrm{Th}-230$

$\mathrm{Th}-230$

$\mathrm{Th}-230$

$\mathrm{Th}-230$

$\mathrm{Th}-230$

$\mathrm{Ra}-226$

$\mathrm{Ra}-226$

$\mathrm{Ra}-226$

$\mathrm{Ra}-226$

$\mathrm{Ra}-226$

$\mathrm{Pb}-210$

$\mathrm{Pb}-210$

$\mathrm{Pb}-210$

$\mathrm{Pb}-210$

$\mathrm{Pb}-210$

Pu-239

$\mathrm{Pu}-238 \quad 1.000 \mathrm{E}+00$ $\mathrm{U}-234 \quad 1.000 \mathrm{E}+00$ U-238 9.999E-01 $\sum \operatorname{DOSE}(j)$

$\mathrm{Pu}-238 \quad 1.000 \mathrm{E}+00$ Th-230 1.000E+00 U-234 $1.000 \mathrm{E}+00$ U-238 9.999E-01 $\sum \operatorname{DOSE}(j)$

$\mathrm{Pu}-238 \quad 1.000 \mathrm{E}+00$ $\mathrm{Th}-230 \quad 1.000 \mathrm{E}+00$ $\mathrm{U}-234 \quad 1.000 \mathrm{E}+00$ U-238 9.999E-01 $\sum \operatorname{DOSE}(j)$

$\mathrm{Pu}-238 \quad 1.000 \mathrm{E}+00$ Th-230 1.000E+00 $\mathrm{U}-234 \quad 1.000 \mathrm{E}+00$ U-238 9.999E-01 $\sum \operatorname{DOSE}(j)$

$\mathrm{Pu}-239 \quad 1.000 \mathrm{E}+00$

$\mathrm{Pu}-239$ 1.000E+00 U-235 $1.000 \mathrm{E}+00$ $\sum \operatorname{DOSE}(j)$ $t=0.000 \mathrm{E}+00 \quad 1.000 \mathrm{E}+00 \quad 1.200 \mathrm{E}+01 \quad 5.000 \mathrm{E}+01 \quad 1.000 \mathrm{E}+02 \quad 5.000 \mathrm{E}+02 \quad 1.050 \mathrm{E}+03 \quad 1.000 \mathrm{E}+04$

$\begin{array}{lllllllll}0.000 \mathrm{E}+00 & 0.000 \mathrm{E}+00 & 0.000 \mathrm{E}+00 & 0.000 \mathrm{E}+00 & 0.000 \mathrm{E}+00 & 4.069 \mathrm{E}-27 & 9.651 \mathrm{E}-21 & 1.908 \mathrm{E}-08\end{array}$

$5.204 \mathrm{E}-19 \quad 1.575 \mathrm{E}-18 \quad 1.464 \mathrm{E}-17 \quad 8.635 \mathrm{E}-17 \quad 2.829 \mathrm{E}-16 \quad 7.741 \mathrm{E}-14 \quad 4.210 \mathrm{E}-11 \quad 2.731 \mathrm{E}-04$ 5.043E-13 5.097 E-13 5.735E-13 8.620E-13 $1.473 \mathrm{E}-12 \quad 1.073 \mathrm{E}-10 \quad 3.906 \mathrm{E}-08 \quad 2.024 \mathrm{E}-01$ $\begin{array}{lllllllll}5.043 E-13 & 5.097 \mathrm{E}-13 & 5.736 \mathrm{E}-13 & 8.621 \mathrm{E}-13 & 1.474 \mathrm{E}-12 & 1.074 \mathrm{E}-10 & 3.910 \mathrm{E}-08 & 2.027 \mathrm{E}-01\end{array}$

$\begin{array}{llllllllll}0.000 \mathrm{E}+00 & 8.344 \mathrm{E}-29 & 6.371 \mathrm{E}-27 & 1.639 \mathrm{E}-25 & 1.182 \mathrm{E}-24 & 3.586 \mathrm{E}-21 & 1.209 \mathrm{E}-17 & 1.768 \mathrm{E}-07\end{array}$ $\begin{array}{llllllll}1.716 \mathrm{E}-23 & 5.206 \mathrm{E}-23 & 4.975 \mathrm{E}-22 & 3.231 \mathrm{E}-21 & 1.201 \mathrm{E}-20 & 8.871 \mathrm{E}-18 & 1.800 \mathrm{E}-14 & 1.431 \mathrm{E}-04\end{array}$ $\begin{array}{lllllllll}1.716 \mathrm{E}-23 & 5.206 \mathrm{E}-23 & 4.975 \mathrm{E}-22 & 3.231 \mathrm{E}-21 & 1.201 \mathrm{E}-20 & 8.874 \mathrm{E}-18 & 1.801 \mathrm{E}-14 & 1.433 \mathrm{E}-04\end{array}$

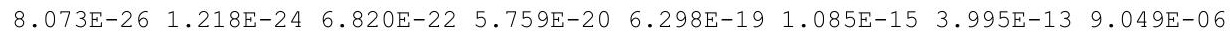
$\begin{array}{llllllll}1.567 \mathrm{E}-19 & 1.103 \mathrm{E}-18 & 7.971 \mathrm{E}-17 & 1.692 \mathrm{E}-15 & 9.477 \mathrm{E}-15 & 3.786 \mathrm{E}-12 & 7.936 \mathrm{E}-10 & 7.718 \mathrm{E}-03\end{array}$ $\begin{array}{llllllll}1.567 \mathrm{E}-19 & 1.103 \mathrm{E}-18 & 7.971 \mathrm{E}-17 & 1.692 \mathrm{E}-15 & 9.478 \mathrm{E}-15 & 3.787 \mathrm{E}-12 & 7.940 \mathrm{E}-10 & 7.727 \mathrm{E}-03\end{array}$

2.305E-09 2.272E-09 1.933E-09 1.106E-09 5.307E-10 1.491E-12 4.627E-16 0.000E+00

$\begin{array}{lllllllll}0.000 \mathrm{E}+00 & 0.000 \mathrm{E}+00 & 0.000 \mathrm{E}+00 & 0.000 \mathrm{E}+00 & 0.000 \mathrm{E}+00 & 0.000 \mathrm{E}+00 & 2.281 \mathrm{E}-28 & 0.000 \mathrm{E}+00\end{array}$ $\begin{array}{llllllll}4.406 \mathrm{E}-24 & 4.449 \mathrm{E}-24 & 4.953 \mathrm{E}-24 & 7.176 \mathrm{E}-24 & 1.169 \mathrm{E}-23 & 5.791 \mathrm{E}-22 & 1.240 \mathrm{E}-19 & 0.000 \mathrm{E}+00\end{array}$

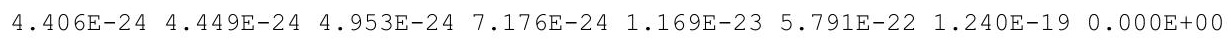

$0.000 \mathrm{E}+00 \quad 1.114 \mathrm{E}-28 \quad 1.079 \mathrm{E}-27 \quad 7.400 \mathrm{E}-27 \quad 2.988 \mathrm{E}-26 \quad 6.368 \mathrm{E}-23 \quad 1.100 \mathrm{E}-18 \quad 9.916 \mathrm{E}-06$ $\begin{array}{lllllllll}1.061 \mathrm{E}-22 & 1.080 \mathrm{E}-22 & 1.312 \mathrm{E}-22 & 2.571 \mathrm{E}-22 & 6.232 \mathrm{E}-22 & 7.417 \mathrm{E}-19 & 1.257 \mathrm{E}-14 & 1.133 \mathrm{E}-01\end{array}$ $0.000 \mathrm{E}+00 \quad 4.596 \mathrm{E}-28 \quad 4.650 \mathrm{E}-27 \quad 3.681 \mathrm{E}-26 \quad 1.776 \mathrm{E}-25 \quad 1.053 \mathrm{E}-21 \quad 3.748 \mathrm{E}-17 \quad 3.257 \mathrm{E}-03$ $\begin{array}{llllllllll}1.061 \mathrm{E}-22 & 1.080 \mathrm{E}-22 & 1.312 \mathrm{E}-22 & 2.572 \mathrm{E}-22 & 6.234 \mathrm{E}-22 & 7.428 \mathrm{E}-19 & 1.261 \mathrm{E}-14 & 1.165 \mathrm{E}-01\end{array}$

$0.000 \mathrm{E}+00 \quad 0.000 \mathrm{E}+00 \quad 0.000 \mathrm{E}+00 \quad 5.998 \mathrm{E}-29 \quad 4.887 \mathrm{E}-28 \quad 4.910 \mathrm{E}-24 \quad 1.247 \mathrm{E}-19 \quad 2.742 \mathrm{E}-06$ $\begin{array}{lllllllllll}2.319 \mathrm{E}-21 & 2.359 \mathrm{E}-21 & 2.838 \mathrm{E}-21 & 5.375 \mathrm{E}-21 & 1.246 \mathrm{E}-20 & 1.037 \mathrm{E}-17 & 1.074 \mathrm{E}-13 & 2.264 \mathrm{E}-01\end{array}$ $\begin{array}{llllllllll}1.675 \mathrm{E}-26 & 5.101 \mathrm{E}-26 & 5.109 \mathrm{E}-25 & 3.909 \mathrm{E}-24 & 1.803 \mathrm{E}-23 & 7.463 \mathrm{E}-20 & 1.620 \mathrm{E}-15 & 3.173 \mathrm{E}-02\end{array}$ $\begin{array}{llllllll}0.000 \mathrm{E}+00 & 0.000 \mathrm{E}+00 & 0.000 \mathrm{E}+00 & 2.798 \mathrm{E}-28 & 2.568 \mathrm{E}-27 & 5.295 \mathrm{E}-23 & 2.413 \mathrm{E}-18 & 4.499 \mathrm{E}-04\end{array}$ $\begin{array}{lllllllll}2.319 \mathrm{E}-21 & 2.359 \mathrm{E}-21 & 2.838 \mathrm{E}-21 & 5.379 \mathrm{E}-21 & 1.248 \mathrm{E}-20 & 1.044 \mathrm{E}-17 & 1.090 \mathrm{E}-13 & 2.586 \mathrm{E}-01\end{array}$

$3.008 \mathrm{E}-22 \quad 4.531 \mathrm{E}-21 \quad 2.491 \mathrm{E}-18 \quad 1.975 \mathrm{E}-16 \quad 1.997 \mathrm{E}-15 \quad 2.109 \mathrm{E}-12 \quad 4.914 \mathrm{E}-10 \quad 7.095 \mathrm{E}-04$ $\begin{array}{llllllll}3.629 \mathrm{E}-10 & 1.095 \mathrm{E}-09 & 9.820 \mathrm{E}-09 & 5.116 \mathrm{E}-08 & 1.423 \mathrm{E}-07 & 1.032 \mathrm{E}-05 & 8.661 \mathrm{E}-04 & 7.480 \mathrm{E}+01\end{array}$

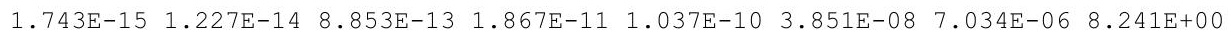
$\begin{array}{llllllll}1.236 \mathrm{E}-21 & 1.865 \mathrm{E}-20 & 1.047 \mathrm{E}-17 & 8.928 \mathrm{E}-16 & 9.885 \mathrm{E}-15 & 1.854 \mathrm{E}-11 & 7.237 \mathrm{E}-09 & 9.730 \mathrm{E}-02\end{array}$

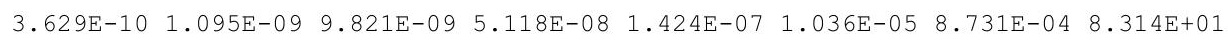

$0.000 \mathrm{E}+00 \quad 0.000 \mathrm{E}+00 \quad 1.070 \mathrm{E}-25 \quad 2.916 \mathrm{E}-23 \quad 4.931 \mathrm{E}-22 \quad 1.381 \mathrm{E}-18 \quad 6.490 \mathrm{E}-16 \quad 3.216 \mathrm{E}-05$ $\begin{array}{lllllllll}1.749 \mathrm{E}-18 & 1.222 \mathrm{E}-17 & 7.985 \mathrm{E}-16 & 1.249 \mathrm{E}-14 & 5.113 \mathrm{E}-14 & 7.402 \mathrm{E}-12 & 1.190 \mathrm{E}-09 & 3.403 \mathrm{E}+00\end{array}$ $\begin{array}{llllllllll}6.310 \mathrm{E}-24 & 9.466 \mathrm{E}-23 & 4.951 \mathrm{E}-20 & 3.388 \mathrm{E}-18 & 2.979 \mathrm{E}-17 & 2.590 \mathrm{E}-14 & 9.356 \mathrm{E}-12 & 3.735 \mathrm{E}-01\end{array}$ $0.000 \mathrm{E}+00 \quad 0.000 \mathrm{E}+00 \quad 4.477 \mathrm{E}-25 \quad 1.297 \mathrm{E}-22 \quad 2.380 \mathrm{E}-21 \quad 1.176 \mathrm{E}-17 \quad 9.340 \mathrm{E}-15 \quad 4.394 \mathrm{E}-03$ $\begin{array}{lllllllll}1.749 \mathrm{E}-18 & 1.222 \mathrm{E}-17 & 7.985 \mathrm{E}-16 & 1.250 \mathrm{E}-14 & 5.116 \mathrm{E}-14 & 7.428 \mathrm{E}-12 & 1.199 \mathrm{E}-09 & 3.781 \mathrm{E}+00\end{array}$ $\begin{array}{lllllllll}461 \mathrm{E}-17 & 4.211 \mathrm{E}-17 & 4.803 \mathrm{E}-17 & 7.560 \mathrm{E}-17 & 1.373 \mathrm{E}-16 & 1.629 \mathrm{E}-14 & 1.159 \mathrm{E}-11 & 6.544 \mathrm{E}-02\end{array}$ $2.124 \mathrm{E}-23 \quad 6.441 \mathrm{E}-23 \quad 6.145 \mathrm{E}-22 \quad 3.969 \mathrm{E}-21 \quad 1.465 \mathrm{E}-20 \quad 1.019 \mathrm{E}-17 \quad 1.905 \mathrm{E}-14 \quad 1.517 \mathrm{E}-05$ $\begin{array}{llllllllll}7.771 E-15 & 7.867 \mathrm{E}-15 & 9.013 \mathrm{E}-15 & 1.442 \mathrm{E}-14 & 2.675 \mathrm{E}-14 & 3.756 \mathrm{E}-12 & 3.369 \mathrm{E}-09 & 3.150 \mathrm{E}-01\end{array}$ $\begin{array}{llllllll}7.771 E-15 & 7.867 E-15 & 9.013 E-15 & 1.442 \mathrm{E}-14 & 2.675 \mathrm{E}-14 & 3.756 \mathrm{E}-12 & 3.369 \mathrm{E}-09 & 3.150 \mathrm{E}-01\end{array}$ 
RESRAD, Version 6.5

Summary : RESRAD Parameters for U-Landfill Recreational User Foward Run

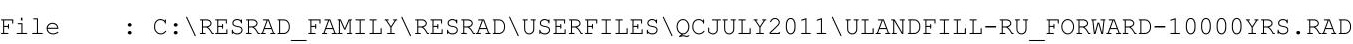

Individual Nuclide Dose Summed Over All Pathways

Parent Nuclide and Branch Fraction Indicated

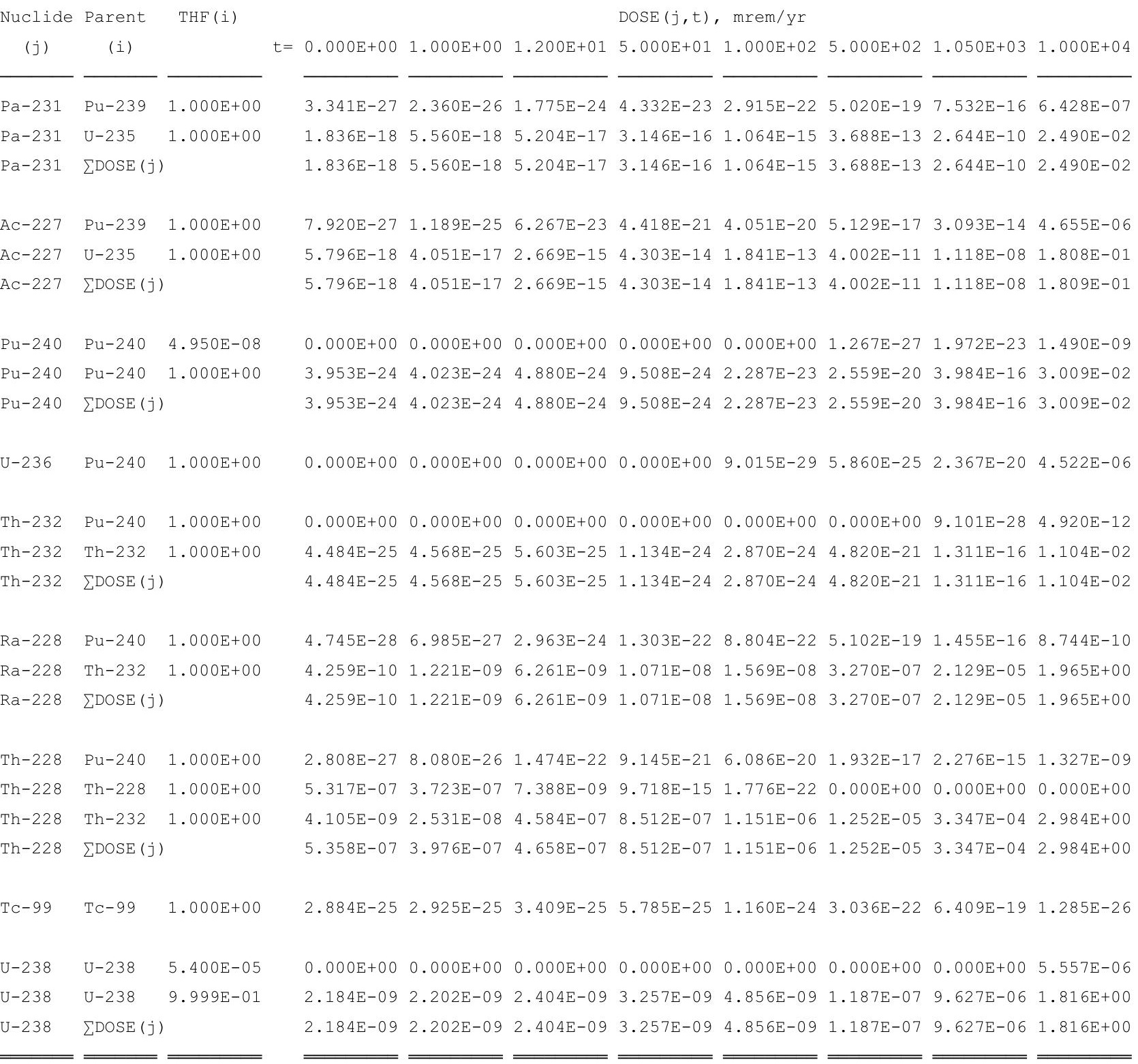

THF (i) is the thread fraction of the parent nuclide. 
RESRAD, Version 6.5

Summary : RESRAD Parameters for U-Landfill Recreational User Foward Run

File : C: $\backslash$ RESRAD FAMILY \RESRAD \USERFILES \QCJULY2011 \ULANDFILL-RU FORWARD-10000YRS.RAD

Individual Nuclide Soil Concentration

Parent Nuclide and Branch Fraction Indicated

Nuclide Parent THF(

(j) (i)

Am-241 Am-241 $1.000 \mathrm{E}+00$

Np-237 Am-241 1.000E+00

$\mathrm{Np}-237 \quad \mathrm{~Np}-237 \quad 1.000 \mathrm{E}+00$

Np-237 $\sum S(j):$

$\mathrm{U}-233 \quad \mathrm{Am}-241 \quad 1.000 \mathrm{E}+00$

$\mathrm{U}-233 \quad \mathrm{~Np}-237 \quad 1.000 \mathrm{E}+00$

U-233 $\sum S(j):$

Th-229 Am-241 $1.000 \mathrm{E}+00$

Th-229 Np-237 1.000E+00

Th-229 $\sum \mathrm{S}(j):$

Cs-137 Cs-137 1.000E+00

$\mathrm{Pu}-238$

$\mathrm{Pu}-238$

$\mathrm{Pu}-238$

$\mathrm{U}-234$

$\mathrm{U}-234$

$\mathrm{U}-234$

$\mathrm{U}-234$

Th-230

Th -230

Th-230

Th-230

$\mathrm{Th}-230$

$\mathrm{Ra}-226$

$\mathrm{Ra}-226$

Ra-226

$\mathrm{Ra}-226$

Ra-226

$\mathrm{Pb}-210$

$\mathrm{Pb}-210$

$\mathrm{Pb}-210$

$\mathrm{Pb}-210$

$\mathrm{Pb}-210$

$\mathrm{Pu}-239$

$\mathrm{Pu}-239 \quad 1.000 \mathrm{E}+00$ $\mathrm{U}-2351.000 \mathrm{E}+00$

$\sum S(j):$
$S(j, t), p C i / g$

$t=0.000 \mathrm{E}+00 \quad 1.000 \mathrm{E}+00 \quad 1.200 \mathrm{E}+01 \quad 5.000 \mathrm{E}+01 \quad 1.000 \mathrm{E}+02 \quad 5.000 \mathrm{E}+02 \quad 1.050 \mathrm{E}+03 \quad 1.000 \mathrm{E}+04$

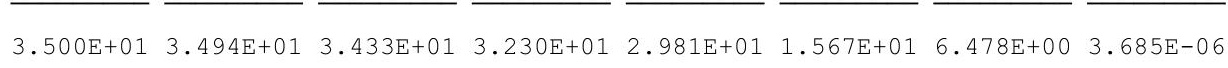

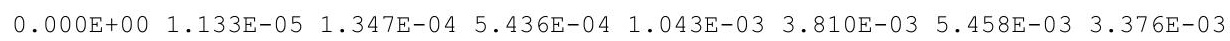

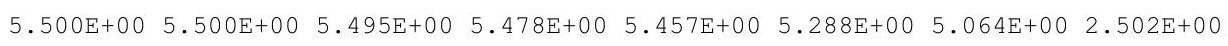

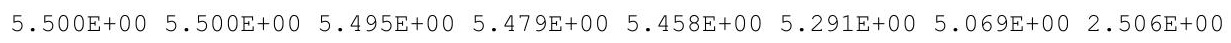

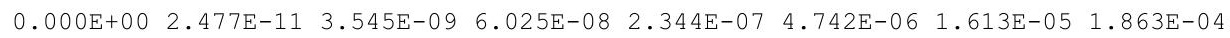

$\begin{array}{llllllll}0.000 \mathrm{E}+00 & 2.405 \mathrm{E}-05 & 2.885 \mathrm{E}-04 & 1.200 \mathrm{E}-03 & 2.394 \mathrm{E}-03 & 1.174 \mathrm{E}-02 & 2.401 \mathrm{E}-02 & 1.508 \mathrm{E}-01\end{array}$

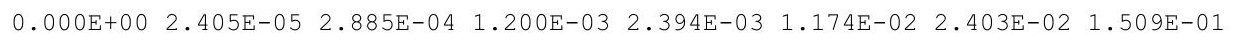

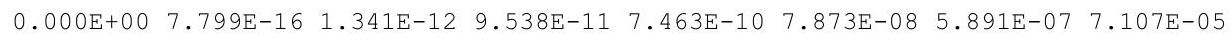

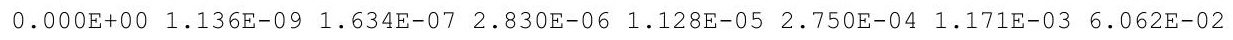

$\begin{array}{llllllll}0.000 \mathrm{E}+00 & 1.136 \mathrm{E}-09 & 1.634 \mathrm{E}-07 & 2.830 \mathrm{E}-06 & 1.128 \mathrm{E}-05 & 2.750 \mathrm{E}-04 & 1.171 \mathrm{E}-03 & 6.069 \mathrm{E}-02\end{array}$

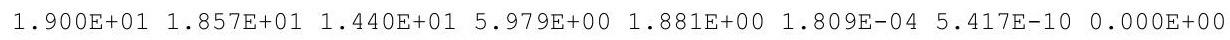

$\begin{array}{llllllll}7.176 \mathrm{E}-08 & 7.119 \mathrm{E}-08 & 6.526 \mathrm{E}-08 & 4.832 \mathrm{E}-08 & 3.254 \mathrm{E}-08 & 1.375 \mathrm{E}-09 & 1.774 \mathrm{E}-11 & 3.170 \mathrm{E}-42\end{array}$

$\begin{array}{llllllllllll}3.900 \mathrm{E}+01 & 3.869 \mathrm{E}+01 & 3.547 \mathrm{E}+01 & 2.626 \mathrm{E}+01 & 1.768 \mathrm{E}+01 & 7.472 \mathrm{E}-01 & 9.639 \mathrm{E}-03 & 1.731 \mathrm{E}-33\end{array}$

$\begin{array}{llllllllllll}3.900 \mathrm{E}+01 & 3.869 \mathrm{E}+01 & 3.547 \mathrm{E}+01 & 2.626 \mathrm{E}+01 & 1.768 \mathrm{E}+01 & 7.472 \mathrm{E}-01 & 9.639 \mathrm{E}-03 & 1.731 \mathrm{E}-33\end{array}$

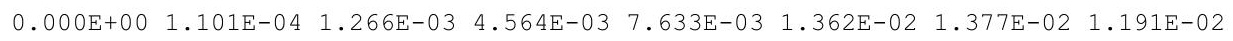

$\begin{array}{llllllll}1.600 \mathrm{E}+02 & 1.600 \mathrm{E}+02 & 1.600 \mathrm{E}+02 & 1.599 \mathrm{E}+02 & 1.597 \mathrm{E}+02 & 1.587 \mathrm{E}+02 & 1.573 \mathrm{E}+02 & 1.360 \mathrm{E}+02\end{array}$

$\begin{array}{llllllllll}0.000 \mathrm{E}+00 & 4.536 \mathrm{E}-04 & 5.442 \mathrm{E}-03 & 2.266 \mathrm{E}-02 & 4.529 \mathrm{E}-02 & 2.251 \mathrm{E}-01 & 4.689 \mathrm{E}-01 & 3.911 \mathrm{E}+00\end{array}$

$\begin{array}{llllllll}1.600 \mathrm{E}+02 & 1.600 \mathrm{E}+02 & 1.600 \mathrm{E}+02 & 1.599 \mathrm{E}+02 & 1.598 \mathrm{E}+02 & 1.589 \mathrm{E}+02 & 1.578 \mathrm{E}+02 & 1.399 \mathrm{E}+02\end{array}$

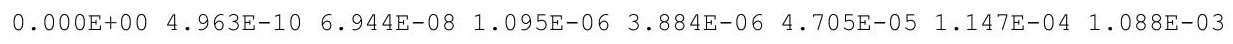
$\begin{array}{llllllllll}1.000 \mathrm{E}+02 & 1.000 \mathrm{E}+02 & 9.999 \mathrm{E}+01 & 9.995 \mathrm{E}+01 & 9.989 \mathrm{E}+01 & 9.947 \mathrm{E}+01 & 9.888 \mathrm{E}+01 & 8.984 \mathrm{E}+01\end{array}$ $\begin{array}{lllllllll}0.000 \mathrm{E}+00 & 1.440 \mathrm{E}-03 & 1.728 \mathrm{E}-02 & 7.197 \mathrm{E}-02 & 1.438 \mathrm{E}-01 & 7.153 \mathrm{E}-01 & 1.491 \mathrm{E}+00 & 1.259 \mathrm{E}+01\end{array}$ $\begin{array}{llllllll}0.000 \mathrm{E}+00 & 2.041 \mathrm{E}-09 & 2.939 \mathrm{E}-07 & 5.100 \mathrm{E}-06 & 2.039 \mathrm{E}-05 & 5.070 \mathrm{E}-04 & 2.219 \mathrm{E}-03 & 1.785 \mathrm{E}-01\end{array}$

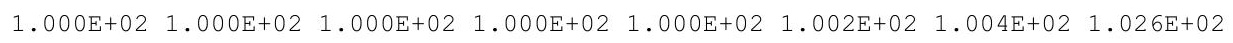

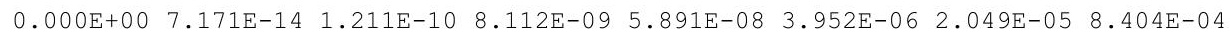
$\begin{array}{lllllllll}0.000 \mathrm{E}+00 & 4.331 \mathrm{E}-02 & 5.184 \mathrm{E}-01 & 2.142 \mathrm{E}+00 & 4.235 \mathrm{E}+00 & 1.937 \mathrm{E}+01 & 3.613 \mathrm{E}+01 & 8.860 \mathrm{E}+01\end{array}$ $\begin{array}{lllllllll}0.000 \mathrm{E}+00 & 3.119 \mathrm{E}-07 & 4.484 \mathrm{E}-05 & 7.739 \mathrm{E}-04 & 3.071 \mathrm{E}-03 & 7.220 \mathrm{E}-02 & 2.933 \mathrm{E}-01 & 9.761 \mathrm{E}+00\end{array}$ $\begin{array}{llllllll}0.000 \mathrm{E}+00 & 2.948 \mathrm{E}-13 & 5.087 \mathrm{E}-10 & 3.663 \mathrm{E}-08 & 2.913 \mathrm{E}-07 & 3.471 \mathrm{E}-05 & 3.016 \mathrm{E}-04 & 1.152 \mathrm{E}-01\end{array}$ $\begin{array}{llllllll}0.000 \mathrm{E}+00 & 4.331 \mathrm{E}-02 & 5.185 \mathrm{E}-01 & 2.142 \mathrm{E}+00 & 4.238 \mathrm{E}+00 & 1.944 \mathrm{E}+01 & 3.643 \mathrm{E}+01 & 9.848 \mathrm{E}+01\end{array}$

$\begin{array}{llllllll}0.000 \mathrm{E}+00 & 5.540 \mathrm{E}-16 & 1.055 \mathrm{E}-11 & 2.418 \mathrm{E}-09 & 2.812 \mathrm{E}-08 & 3.398 \mathrm{E}-06 & 1.921 \mathrm{E}-05 & 8.367 \mathrm{E}-04\end{array}$ $\begin{array}{lllllllll}0.000 \mathrm{E}+00 & 6.663 \mathrm{E}-04 & 8.578 \mathrm{E}-02 & 1.058 \mathrm{E}+00 & 2.946 \mathrm{E}+00 & 1.823 \mathrm{E}+01 & 3.524 \mathrm{E}+01 & 8.856 \mathrm{E}+01\end{array}$ $\begin{array}{lllllllll}0.000 \mathrm{E}+00 & 3.207 \mathrm{E}-09 & 5.094 \mathrm{E}-06 & 2.837 \mathrm{E}-04 & 1.706 \mathrm{E}-03 & 6.374 \mathrm{E}-02 & 2.769 \mathrm{E}-01 & 9.719 \mathrm{E}+00\end{array}$ $\begin{array}{llllllll}0.000 \mathrm{E}+00 & 2.276 \mathrm{E}-15 & 4.411 \mathrm{E}-11 & 1.075 \mathrm{E}-08 & 1.356 \mathrm{E}-07 & 2.889 \mathrm{E}-05 & 2.763 \mathrm{E}-04 & 1.143 \mathrm{E}-01\end{array}$ $\begin{array}{lllllllll}0.000 \mathrm{E}+00 & 6.663 \mathrm{E}-04 & 8.578 \mathrm{E}-02 & 1.058 \mathrm{E}+00 & 2.947 \mathrm{E}+00 & 1.830 \mathrm{E}+01 & 3.551 \mathrm{E}+01 & 9.839 \mathrm{E}+01\end{array}$

$\begin{array}{llllllll}3.600 \mathrm{E}+01 & 3.600 \mathrm{E}+01 & 3.598 \mathrm{E}+01 & 3.593 \mathrm{E}+01 & 3.586 \mathrm{E}+01 & 3.531 \mathrm{E}+01 & 3.456 \mathrm{E}+01 & 2.443 \mathrm{E}+01\end{array}$

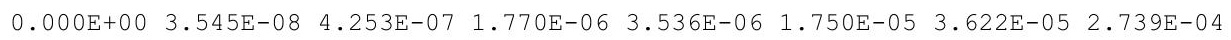
$\begin{array}{llllllll}6.500 \mathrm{E}+00 & 6.500 \mathrm{E}+00 & 6.499 \mathrm{E}+00 & 6.496 \mathrm{E}+00 & 6.491 \mathrm{E}+00 & 6.457 \mathrm{E}+00 & 6.409 \mathrm{E}+00 & 5.685 \mathrm{E}+00\end{array}$

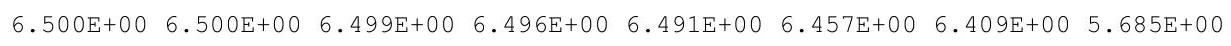


Summary : RESRAD Parameters for U-Landfill Recreational User Foward Run 100,000 years

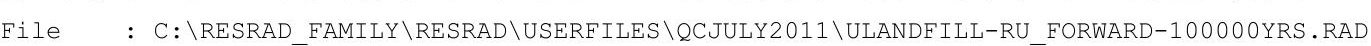

Dose Conversion Factor (and Related) Parameter Summary

Dose Library: RU for U-Landfill Plus ICRP 60 \& ICRP 72 (Age 15)

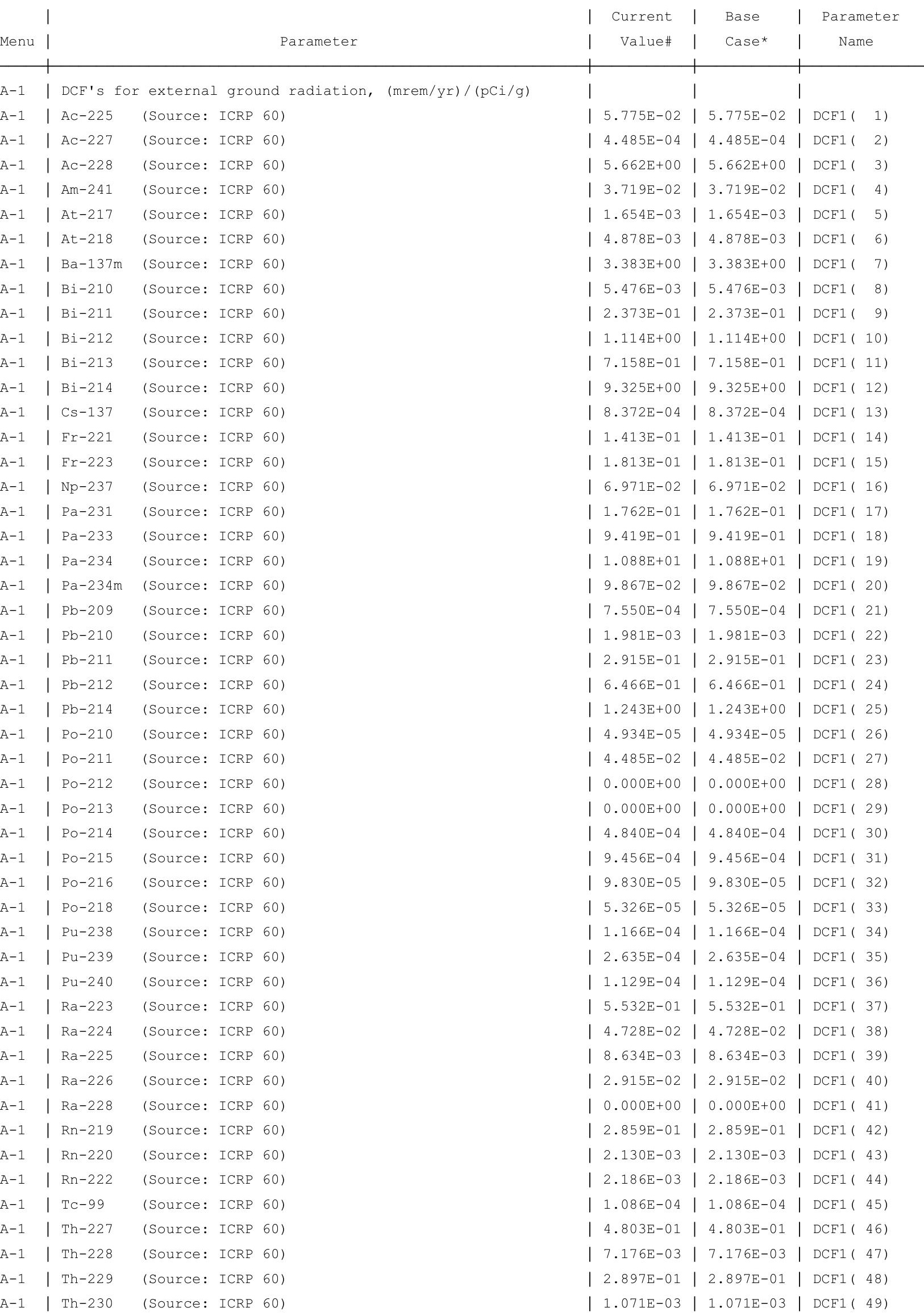


Summary : RESRAD Parameters for U-Landfill Recreational User Foward Run 100,000 years

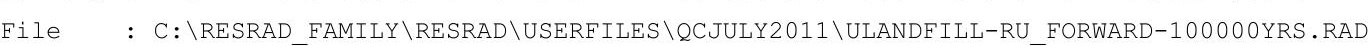

Dose Conversion Factor (and Related) Parameter Summary (continued)

Dose Library: RU for U-Landfill Plus ICRP 60 \& ICRP 72 (Age 15)

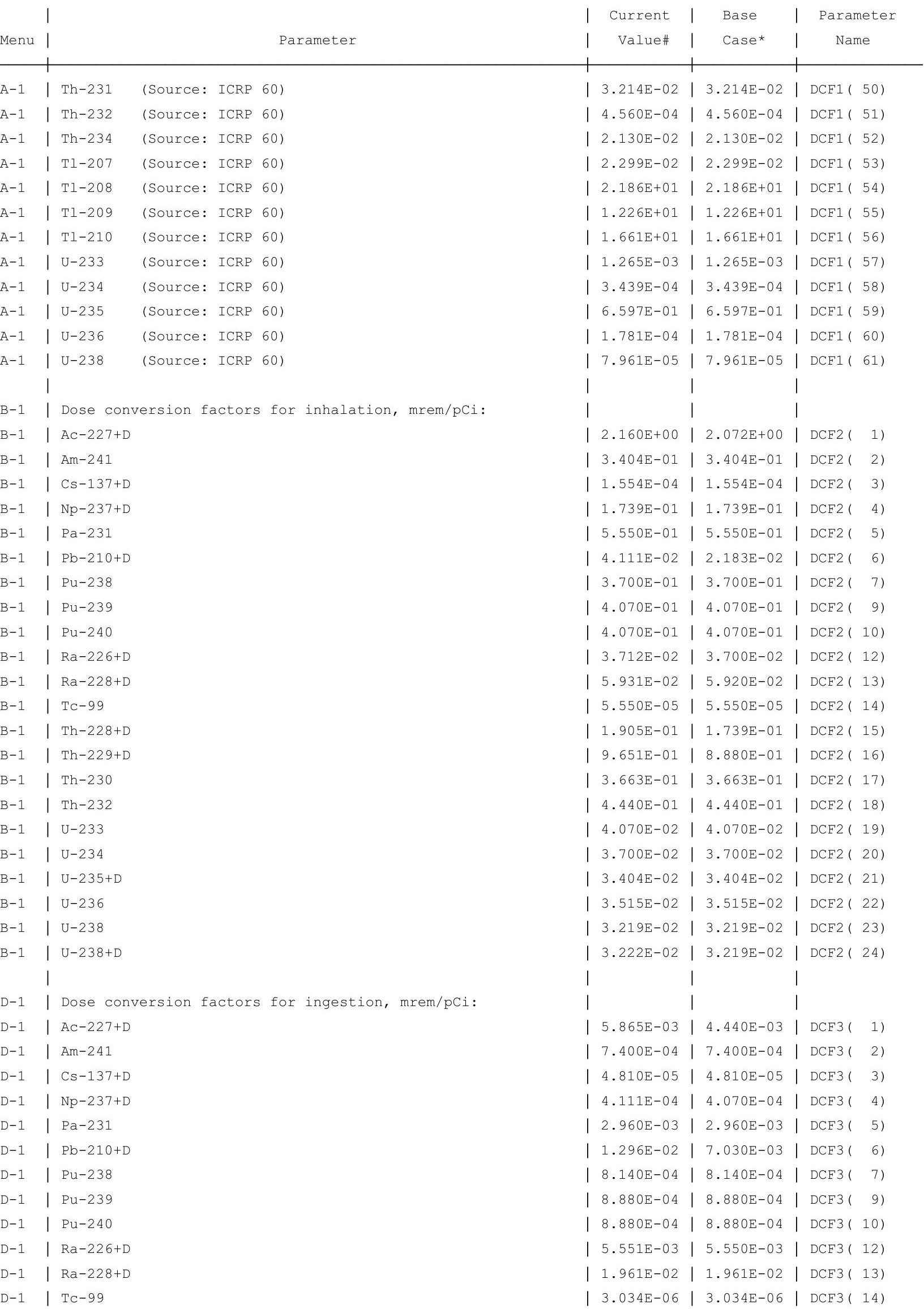


RESRAD, Version $6.5 \quad \mathrm{~T}^{1 / 2}$ Limit $=180$ days

Summary : RESRAD Parameters for U-Landfill Recreational User Foward Run 100,000 years

File : C: $\backslash$ RESRAD FAMILY \RESRAD \USERFILES $\backslash Q C J U L Y 2011 \backslash U L A N D F I L L-R U$ FORWARD-100000YRS.RAD

Dose Conversion Factor (and Related) Parameter Summary (continued)

Dose Library: RU for U-Landfill Plus ICRP 60 \& ICRP 72 (Age 15)

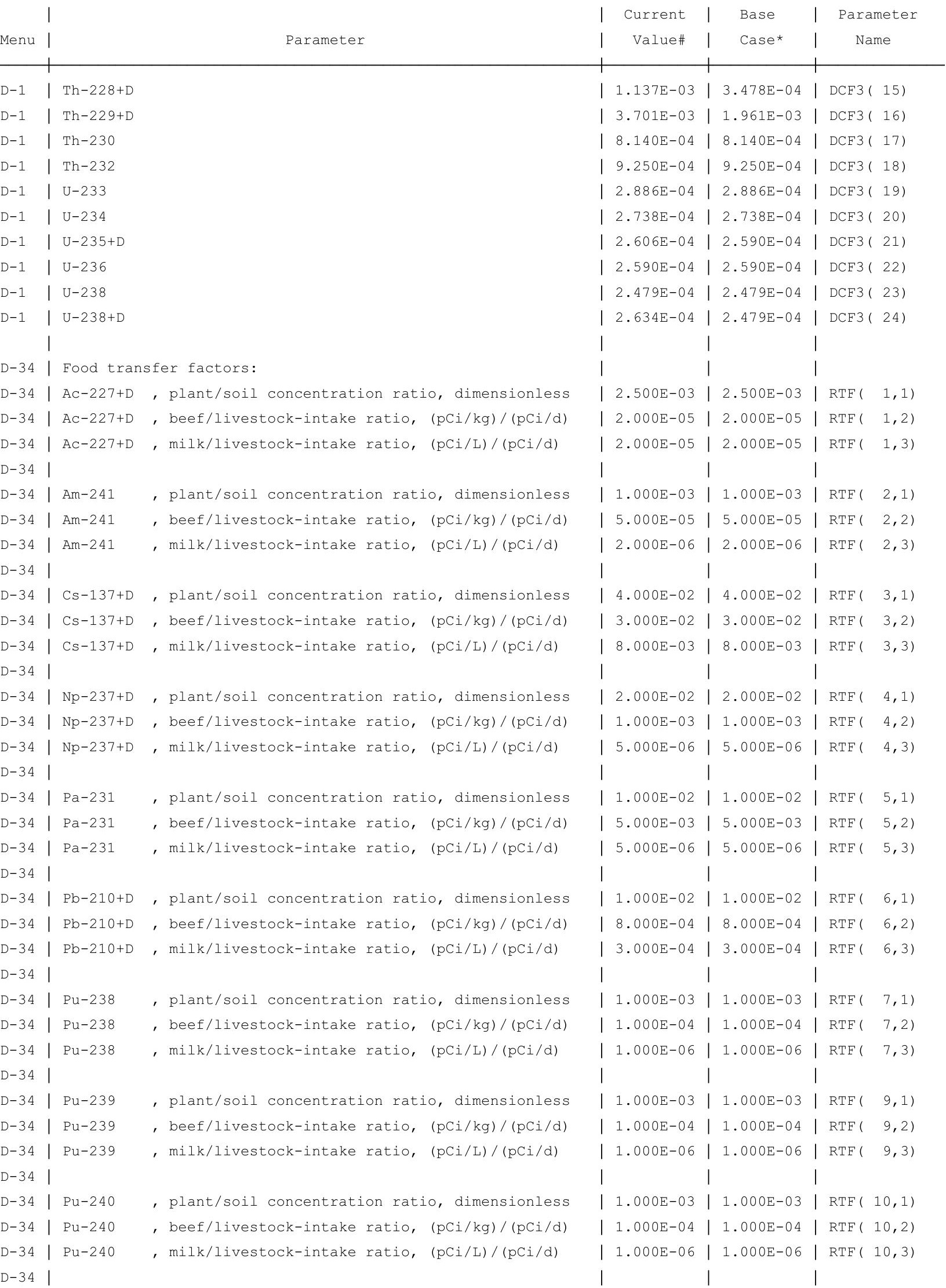


RESRAD, Version $6.5 \quad T^{13 / 2}$ Limit $=180$ days

Summary : RESRAD Parameters for U-Landfill Recreational User Foward Run 100,000 years

File : C: $\backslash$ RESRAD_FAMILY \RESRAD \USERFILES \QCJULY2011 \ULANDFILL-RU_FORWARD-100000YRS.RAD

Dose Conversion Factor (and Related) Parameter Summary (continued)

Dose Library: RU for U-Landfill Plus ICRP 60 \& ICRP 72 (Age 15)

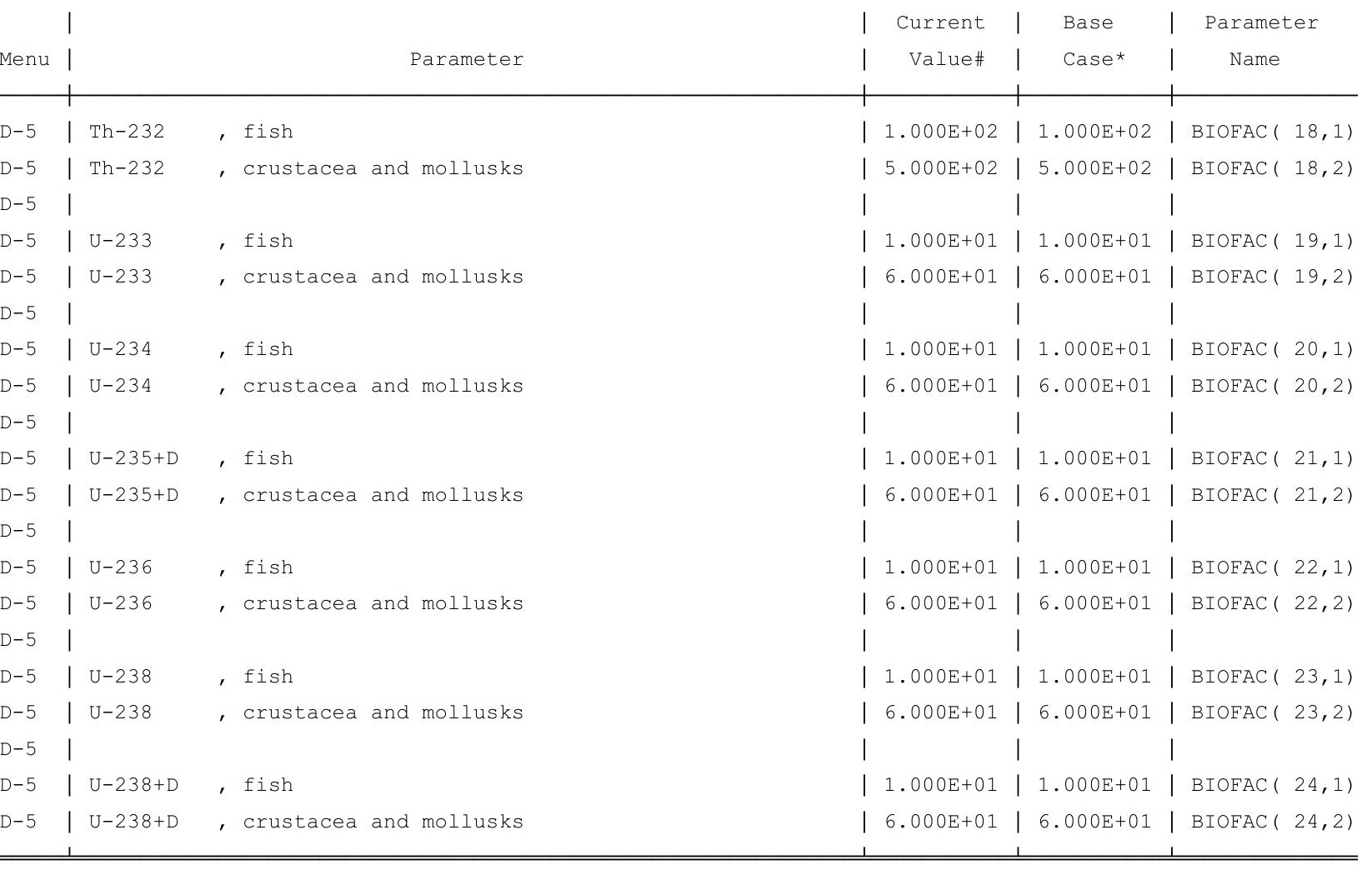

\#For DCFl(xxx) only, factors are for infinite depth \& area. See ETFG table in Ground Pathway of Detailed Report. *Base Case means Default.Lib w/o Associate Nuclide contributions. 
RESRAD, Version $6.5 \quad \mathrm{~T}^{1 / 2}$ Limit $=180$ days

Summary : RESRAD Parameters for U-Landfill Recreational User Foward Run 100,000 years

File : C: $\backslash$ RESRAD_FAMILY \RESRAD \USERFILES \QCJULY2011 \ULANDFILL-RU_FORWARD-100000YRS.RAD

Site-Specific Parameter Summary (continued)

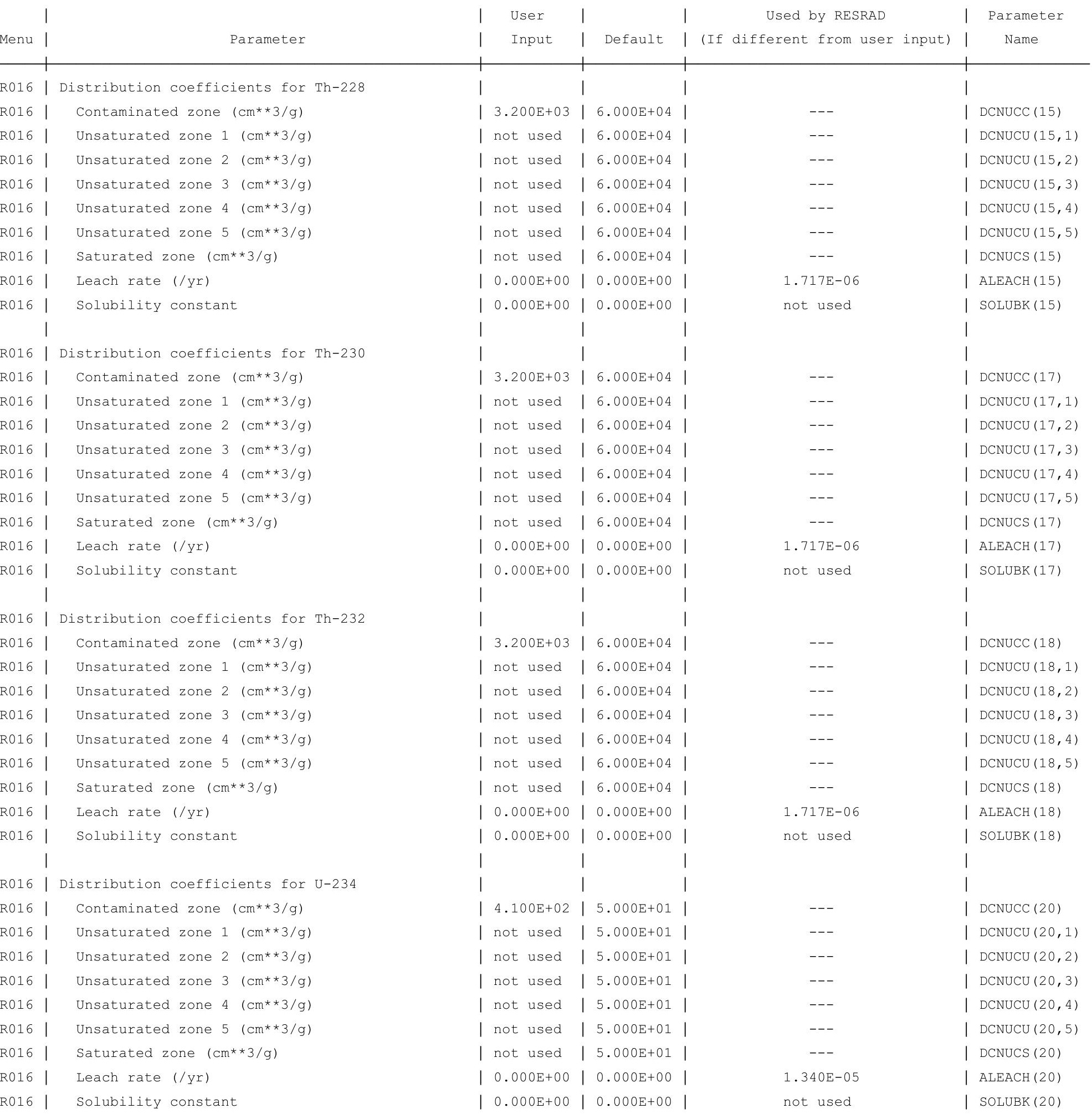


RESRAD, Version 6.5

ummary : RESRAD Parameters for U-Landfill Recreational User Foward Run 100,000 years

File : C: \RESRAD FAMILY \RESRAD \USERFILES \QCJULY2011 \ULANDFILL-RU FORWARD-100000YRS.RAD

Total Dose Contributions TDOSE (i,p,t) for Individual Radionuclides (i) and Pathways (p) As mrem/yr and Fraction of Total Dose At $t=5.000 \mathrm{E}+02$ years

Water Independent Pathways (Inhalation excludes radon)

\begin{tabular}{|c|c|c|c|c|c|c|c|c|c|c|c|c|c|c|}
\hline \multirow{2}{*}{ Nuclide } & \multicolumn{2}{|c|}{ Ground } & \multicolumn{2}{|c|}{ Inhalation } & \multicolumn{2}{|c|}{ Radon } & \multicolumn{2}{|c|}{ Plant } & \multicolumn{2}{|c|}{ Meat } & \multicolumn{2}{|c|}{ Milk } & \multicolumn{2}{|c|}{ Soil } \\
\hline & mrem/yr & fract. & mrem/yr & fract. & mrem/yr & fract. & mrem/yr & fract. & mrem/yr & fract. & mrem/yr & fract. & mrem/yr & fract. \\
\hline-241 & $7.849 \mathrm{E}-14$ & 0.0000 & $0.000 \mathrm{E}+00$ & 0.0000 & $0.000 \mathrm{E}+00$ & 0.0000 & $0.000 \mathrm{E}+00$ & 0.0000 & $0.000 \mathrm{E}+00$ & 0.0000 & $0.000 \mathrm{E}+00$ & 0.0000 & $0.000 \mathrm{E}+00$ & 0.0000 \\
\hline-137 & 1. $491 \mathrm{E}-12$ & 0.0000 & $0.000 \mathrm{E}+00$ & 0.0000 & $0.000 \mathrm{E}+00$ & 0.0000 & $0.000 \mathrm{E}+00$ & 0.0000 & $0.000 \mathrm{E}+00$ & 0.0000 & $0.000 \mathrm{E}+00$ & 0.0000 & $0.000 \mathrm{E}+00$ & 0.0000 \\
\hline-237 & $1.111 \mathrm{E}-10$ & 0.0000 & $0.000 \mathrm{E}+00$ & 0.0000 & $0.000 \mathrm{E}+00$ & 0.0000 & $0.000 \mathrm{E}+00$ & 0.0000 & $0.000 \mathrm{E}+00$ & 0.0000 & $0.000 \mathrm{E}+00$ & 0.0000 & $0.000 \mathrm{E}+00$ & 0.0000 \\
\hline-238 & $2.109 \mathrm{E}-12$ & 0.0000 & $0.000 \mathrm{E}+00$ & 0.0000 & $0.000 \mathrm{E}+00$ & 0.0000 & $0.000 \mathrm{E}+00$ & 0.0000 & $0.000 \mathrm{E}+00$ & 0.0000 & $0.000 \mathrm{E}+00$ & 0.0000 & $0.000 \mathrm{E}+00$ & 0.0000 \\
\hline-239 & $1.636 \mathrm{E}-14$ & 0.0000 & $0.000 \mathrm{E}+00$ & 0.0000 & $0.000 \mathrm{E}+00$ & 0.0000 & $0.000 \mathrm{E}+00$ & 0.0000 & $0.000 \mathrm{E}+00$ & 0.0000 & $0.000 \mathrm{E}+00$ & 0.0000 & $0.000 \mathrm{E}+00$ & 0.0000 \\
\hline-240 & $1.985 \mathrm{E}-17$ & 0.0000 & $0.000 \mathrm{E}+00$ & 0.0000 & $0.000 \mathrm{E}+00$ & 0.0000 & $0.000 \mathrm{E}+00$ & 0.0000 & $0.000 \mathrm{E}+00$ & 0.0000 & $0.000 \mathrm{E}+00$ & 0.0000 & $0.000 \mathrm{E}+00$ & 0.0000 \\
\hline 99 & $3.036 E-22$ & 0.0000 & $0.000 \mathrm{E}+00$ & 0.0000 & $0.000 \mathrm{E}+00$ & 0.0000 & $0.000 \mathrm{E}+00$ & 0.0000 & $0.000 \mathrm{E}+00$ & 0.0000 & $0.000 \mathrm{E}+00$ & 0.0000 & $0.000 \mathrm{E}+00$ & 0.0000 \\
\hline-228 & $0.000 \mathrm{E}+00$ & 0.0000 & $0.000 \mathrm{E}+00$ & 0.0000 & $0.000 \mathrm{E}+00$ & 0.0000 & $0.000 \mathrm{E}+00$ & 0.0000 & $0.000 \mathrm{E}+00$ & 0.0000 & $0.000 \mathrm{E}+00$ & 0.0000 & $0.000 \mathrm{E}+00$ & 0.0000 \\
\hline-230 & $1.032 \mathrm{E}-05$ & 0.4425 & $0.000 \mathrm{E}+00$ & 0.0000 & $0.000 \mathrm{E}+00$ & 0.0000 & $0.000 \mathrm{E}+00$ & 0.0000 & $0.000 \mathrm{E}+00$ & 0.0000 & $0.000 \mathrm{E}+00$ & 0.0000 & $0.000 \mathrm{E}+00$ & 0.0000 \\
\hline-232 & $1.285 E-05$ & 0.5508 & $0.000 \mathrm{E}+00$ & 0.0000 & $0.000 \mathrm{E}+00$ & 0.0000 & $0.000 \mathrm{E}+00$ & 0.0000 & $0.000 \mathrm{E}+00$ & 0.0000 & $0.000 \mathrm{E}+00$ & 0.0000 & $0.000 \mathrm{E}+00$ & 0.0000 \\
\hline 234 & $3.851 E-08$ & 0.0017 & $0.000 \mathrm{E}+00$ & 0.0000 & $0.000 \mathrm{E}+00$ & 0.0000 & $0.000 \mathrm{E}+00$ & 0.0000 & $0.000 \mathrm{E}+00$ & 0.0000 & $0.000 \mathrm{E}+00$ & 0.0000 & $0.000 \mathrm{E}+00$ & 0.0000 \\
\hline 35 & $4.414 \mathrm{E}-11$ & 0.0000 & $0.000 \mathrm{E}+00$ & 0.0000 & $0.000 \mathrm{E}+00$ & 0.0000 & $0.000 \mathrm{E}+00$ & 0.0000 & $0.000 \mathrm{E}+00$ & 0.0000 & $0.000 \mathrm{E}+00$ & 0.0000 & $0.000 \mathrm{E}+00$ & 0.0000 \\
\hline 38 & $1.187 \mathrm{E}-07$ & 0.0051 & $0.000 \mathrm{E}+00$ & 0.0000 & $0.000 \mathrm{E}+00$ & 0.0000 & $0.000 \mathrm{E}+00$ & 0.0000 & $0.000 \mathrm{E}+00$ & 0.0000 & $0.000 \mathrm{E}+00$ & 0.0000 & $0.000 \mathrm{E}+00$ & 0.0000 \\
\hline & $2.333 E-05$ & 1.0000 & $0.000 \mathrm{E}+00$ & 0.0000 & $0.000 \mathrm{E}+00$ & 0.0000 & $0.000 \mathrm{E}+00$ & 0.0000 & $0.000 \mathrm{E}+00$ & 0.0000 & $0.000 \mathrm{E}+00$ & 0.0000 & $.000 \mathrm{E}+00$ & 0.0000 \\
\hline
\end{tabular}

Total Dose Contributions TDOSE(i,p,t) for Individual Radionuclides (i) and Pathways (p) As mrem/yr and Fraction of Total Dose At $t=5.000 \mathrm{E}+02$ years

Water Dependent Pathways

\begin{tabular}{|c|c|c|c|c|c|c|c|c|c|c|c|c|c|c|}
\hline \multirow{2}{*}{$\begin{array}{l}\text { Radio- } \\
\text { Nuclide }\end{array}$} & \multicolumn{2}{|c|}{ Water } & \multicolumn{2}{|c|}{ Fish } & \multicolumn{2}{|c|}{ Radon } & \multicolumn{2}{|c|}{ Plant } & \multicolumn{2}{|c|}{ Meat } & \multicolumn{2}{|c|}{ Milk } & \multicolumn{2}{|c|}{ All Pathways* } \\
\hline & mrem/yr & fract. & mrem/yr & fract. & mrem/yr & fract. & mrem/yr & fract. & mrem/yr & fract. & mrem/yr & fract. & mrem/yr & fract. \\
\hline 241 & $0.000 \mathrm{E}+00$ & 0.0000 & $0.000 \mathrm{E}+00$ & 0.0000 & $0.000 \mathrm{E}+00$ & 0.0000 & $0.000 \mathrm{E}+00$ & 0.0000 & $0.000 \mathrm{E}+00$ & 0.0000 & $0.000 \mathrm{E}+00$ & 0.0000 & $7.849 \mathrm{E}-14$ & 0.0000 \\
\hline-137 & $0.000 \mathrm{E}+00$ & 0.0000 & $0.000 \mathrm{E}+00$ & 0.0000 & $0.000 \mathrm{E}+00$ & 0.0000 & $0.000 \mathrm{E}+00$ & 0.0000 & $0.000 \mathrm{E}+00$ & 0.0000 & $0.000 \mathrm{E}+00$ & 0.0000 & 1. $491 \mathrm{E}-12$ & 0.0000 \\
\hline-237 & $0.000 \mathrm{E}+00$ & 0.0000 & $0.000 \mathrm{E}+00$ & 0.0000 & $0.000 \mathrm{E}+00$ & 0.0000 & $0.000 \mathrm{E}+00$ & 0.0000 & $0.000 \mathrm{E}+00$ & 0.0000 & $0.000 \mathrm{E}+00$ & 0.0000 & $1.111 \mathrm{E}-10$ & 0.0000 \\
\hline-238 & $0.000 \mathrm{E}+00$ & 0.0000 & $0.000 \mathrm{E}+00$ & 0.0000 & $0.000 \mathrm{E}+00$ & 0.0000 & $0.000 \mathrm{E}+00$ & 0.0000 & $0.000 \mathrm{E}+00$ & 0.0000 & $0.000 \mathrm{E}+00$ & 0.0000 & $2.109 \mathrm{E}-12$ & 0.0000 \\
\hline-239 & $0.000 \mathrm{E}+00$ & 0.0000 & $0.000 \mathrm{E}+00$ & 0.0000 & $0.000 \mathrm{E}+00$ & 0.0000 & $0.000 \mathrm{E}+00$ & 0.0000 & $0.000 \mathrm{E}+00$ & 0.0000 & $0.000 E+00$ & 0.0000 & $1.636 \mathrm{E}-14$ & 0.0000 \\
\hline-240 & $0.000 \mathrm{E}+00$ & 0.0000 & $0.000 \mathrm{E}+00$ & 0.0000 & $0.000 \mathrm{E}+00$ & 0.0000 & $0.000 \mathrm{E}+00$ & 0.0000 & $0.000 \mathrm{E}+00$ & 0.0000 & $0.000 E+00$ & 0.0000 & $1.985 \mathrm{E}-17$ & 0.0000 \\
\hline 99 & $0.000 \mathrm{E}+00$ & 0.0000 & $0.000 \mathrm{E}+00$ & 0.0000 & $0.000 \mathrm{E}+00$ & 0.0000 & $0.000 \mathrm{E}+00$ & 0.0000 & $0.000 \mathrm{E}+00$ & 0.0000 & $0.000 \mathrm{E}+00$ & 0.0000 & $3.036 \mathrm{E}-22$ & 0.0000 \\
\hline-228 & $0.000 \mathrm{E}+00$ & 0.0000 & $0.000 \mathrm{E}+00$ & 0.0000 & $0.000 \mathrm{E}+00$ & 0.0000 & $0.000 \mathrm{E}+00$ & 0.0000 & $0.000 \mathrm{E}+00$ & 0.0000 & $0.000 \mathrm{E}+00$ & 0.0000 & $0.000 \mathrm{E}+00$ & 0.0000 \\
\hline-230 & $0.000 \mathrm{E}+00$ & 0.0000 & $0.000 \mathrm{E}+00$ & 0.0000 & $0.000 \mathrm{E}+00$ & 0.0000 & $0.000 \mathrm{E}+00$ & 0.0000 & $0.000 \mathrm{E}+00$ & 0.0000 & $0.000 E+00$ & 0.0000 & $1.032 \mathrm{E}-05$ & 0.4425 \\
\hline 232 & $0.000 \mathrm{E}+00$ & 0.0000 & $0.000 \mathrm{E}+00$ & 0.0000 & $0.000 \mathrm{E}+00$ & 0.0000 & $0.000 \mathrm{E}+00$ & 0.0000 & $0.000 \mathrm{E}+00$ & 0.0000 & $0.000 \mathrm{E}+00$ & 0.0000 & 1. $285 \mathrm{E}-05$ & 0.5508 \\
\hline 34 & $0.000 \mathrm{E}+00$ & 0.0000 & $0.000 \mathrm{E}+00$ & 0.0000 & $0.000 \mathrm{E}+00$ & 0.0000 & $0.000 \mathrm{E}+00$ & 0.0000 & $0.000 \mathrm{E}+00$ & 0.0000 & $0.000 \mathrm{E}+00$ & 0.0000 & $3.851 \mathrm{E}-08$ & 0.0017 \\
\hline 35 & $0.000 \mathrm{E}+00$ & 0.0000 & $0.000 \mathrm{E}+00$ & 0.0000 & $0.000 \mathrm{E}+00$ & 0.0000 & $0.000 \mathrm{E}+00$ & 0.0000 & $0.000 \mathrm{E}+00$ & 0.0000 & $0.000 \mathrm{E}+00$ & 0.0000 & $4.414 \mathrm{E}-11$ & 0.0000 \\
\hline 38 & $0.000 \mathrm{E}+00$ & 0.0000 & $0.000 \mathrm{E}+00$ & 0.0000 & $0.000 \mathrm{E}+00$ & 0.0000 & $0.000 \mathrm{E}+00$ & 0.0000 & $0.000 \mathrm{E}+00$ & 0.0000 & $0.000 \mathrm{E}+00$ & 0.0000 & $1.187 \mathrm{E}-07$ & 0.0051 \\
\hline & $0.000 \mathrm{E}+00$ & 0.0000 & $0.000 \mathrm{E}+00$ & 0.0000 & $0.000 \mathrm{E}+00$ & 0.0000 & $0.000 \mathrm{E}+00$ & 0.0000 & $0.000 \mathrm{E}+00$ & 0.0000 & $0.000 \mathrm{E}+00$ & 0.0000 & $3 E-05$ & 1. \\
\hline
\end{tabular}

* Sum of all water independent and dependent pathways. 
RESRAD, Version 6.5

ummary : RESRAD Parameters for U-Landfill Recreational User Foward Run 100,000 years

File : C: \RESRAD FAMILY \RESRAD \USERFILES \QCJULY2011 \ULANDFILL-RU FORWARD-100000YRS.RAD

Total Dose Contributions TDOSE (i,p,t) for Individual Radionuclides (i) and Pathways (p) As mrem/yr and Fraction of Total Dose At $t=1.050 \mathrm{E}+03$ years

Water Independent Pathways (Inhalation excludes radon)

\begin{tabular}{|c|c|c|c|c|c|c|c|c|c|c|c|c|c|c|}
\hline \multirow{2}{*}{ Nuclide } & \multicolumn{2}{|c|}{ Ground } & \multicolumn{2}{|c|}{ Inhalation } & \multicolumn{2}{|c|}{ Radon } & \multicolumn{2}{|c|}{ Plant } & \multicolumn{2}{|c|}{ Meat } & \multicolumn{2}{|c|}{ Milk } & \multicolumn{2}{|c|}{ Soil } \\
\hline & mrem/yr & fract. & mrem/yr & fract. & mrem/yr & fract. & mrem/yr & fract. & mrem/yr & fract. & mrem/yr & fract. & mrem/yr & fract. \\
\hline-241 & $4.250 \mathrm{E}-11$ & 0.0000 & $0.000 \mathrm{E}+00$ & 0.0000 & $0.000 \mathrm{E}+00$ & 0.0000 & $0.000 \mathrm{E}+00$ & 0.0000 & $0.000 \mathrm{E}+00$ & 0.0000 & $0.000 \mathrm{E}+00$ & 0.0000 & $0.000 \mathrm{E}+00$ & 0.0000 \\
\hline-137 & $4.627 E-16$ & 0.0000 & $0.000 \mathrm{E}+00$ & 0.0000 & $0.000 \mathrm{E}+00$ & 0.0000 & $0.000 \mathrm{E}+00$ & 0.0000 & $0.000 \mathrm{E}+00$ & 0.0000 & $0.000 \mathrm{E}+00$ & 0.0000 & $0.000 \mathrm{E}+00$ & 0.0000 \\
\hline-237 & $3.985 E-08$ & 0.0000 & $0.000 \mathrm{E}+00$ & 0.0000 & $0.000 \mathrm{E}+00$ & 0.0000 & $0.000 \mathrm{E}+00$ & 0.0000 & $0.000 \mathrm{E}+00$ & 0.0000 & $0.000 \mathrm{E}+00$ & 0.0000 & $0.000 \mathrm{E}+00$ & 0.0000 \\
\hline-238 & $4.914 \mathrm{E}-10$ & 0.0000 & $0.000 \mathrm{E}+00$ & 0.0000 & $0.000 \mathrm{E}+00$ & 0.0000 & $0.000 \mathrm{E}+00$ & 0.0000 & $0.000 \mathrm{E}+00$ & 0.0000 & $0.000 \mathrm{E}+00$ & 0.0000 & $0.000 \mathrm{E}+00$ & 0.0000 \\
\hline-239 & $1.164 \mathrm{E}-11$ & 0.0000 & $0.000 \mathrm{E}+00$ & 0.0000 & $0.000 \mathrm{E}+00$ & 0.0000 & $0.000 \mathrm{E}+00$ & 0.0000 & $0.000 \mathrm{E}+00$ & 0.0000 & $0.000 \mathrm{E}+00$ & 0.0000 & $0.000 \mathrm{E}+00$ & 0.0000 \\
\hline-240 & $2.820 \mathrm{E}-15$ & 0.0000 & $0.000 \mathrm{E}+00$ & 0.0000 & $0.000 \mathrm{E}+00$ & 0.0000 & $0.000 \mathrm{E}+00$ & 0.0000 & $0.000 \mathrm{E}+00$ & 0.0000 & $0.000 \mathrm{E}+00$ & 0.0000 & $0.000 \mathrm{E}+00$ & 0.0000 \\
\hline 99 & $6.409 \mathrm{E}-19$ & 0.0000 & $0.000 \mathrm{E}+00$ & 0.0000 & $0.000 \mathrm{E}+00$ & 0.0000 & $0.000 \mathrm{E}+00$ & 0.0000 & $0.000 \mathrm{E}+00$ & 0.0000 & $0.000 \mathrm{E}+00$ & 0.0000 & $0.000 \mathrm{E}+00$ & 0.0000 \\
\hline-228 & $0.000 \mathrm{E}+00$ & 0.0000 & $0.000 \mathrm{E}+00$ & 0.0000 & $0.000 \mathrm{E}+00$ & 0.0000 & $0.000 \mathrm{E}+00$ & 0.0000 & $0.000 \mathrm{E}+00$ & 0.0000 & $0.000 \mathrm{E}+00$ & 0.0000 & $0.000 \mathrm{E}+00$ & 0.0000 \\
\hline-230 & $8.661 \mathrm{E}-04$ & 0.6991 & $0.000 \mathrm{E}+00$ & 0.0000 & $0.000 \mathrm{E}+00$ & 0.0000 & $0.000 \mathrm{E}+00$ & 0.0000 & $0.000 \mathrm{E}+00$ & 0.0000 & $0.000 \mathrm{E}+00$ & 0.0000 & $0.000 \mathrm{E}+00$ & 0.0000 \\
\hline-232 & $3.560 E-04$ & 0.2874 & $0.000 \mathrm{E}+00$ & 0.0000 & $0.000 \mathrm{E}+00$ & 0.0000 & $0.000 \mathrm{E}+00$ & 0.0000 & $0.000 \mathrm{E}+00$ & 0.0000 & $0.000 \mathrm{E}+00$ & 0.0000 & $0.000 \mathrm{E}+00$ & 0.0000 \\
\hline 234 & $7.034 \mathrm{E}-06$ & 0.0057 & $0.000 \mathrm{E}+00$ & 0.0000 & $0.000 \mathrm{E}+00$ & 0.0000 & $0.000 \mathrm{E}+00$ & 0.0000 & $0.000 \mathrm{E}+00$ & 0.0000 & $0.000 \mathrm{E}+00$ & 0.0000 & $0.000 \mathrm{E}+00$ & 0.0000 \\
\hline 35 & $1.481 \mathrm{E}-08$ & 0.0000 & $0.000 \mathrm{E}+00$ & 0.0000 & $0.000 \mathrm{E}+00$ & 0.0000 & $0.000 \mathrm{E}+00$ & 0.0000 & $0.000 \mathrm{E}+00$ & 0.0000 & $0.000 \mathrm{E}+00$ & 0.0000 & $0.000 \mathrm{E}+00$ & 0.0000 \\
\hline 38 & $9.634 \mathrm{E}-06$ & 0.0078 & $0.000 \mathrm{E}+00$ & 0.0000 & $0.000 \mathrm{E}+00$ & 0.0000 & $0.000 \mathrm{E}+00$ & 0.0000 & $0.000 \mathrm{E}+00$ & 0.0000 & $0.000 \mathrm{E}+00$ & 0.0000 & $0.000 \mathrm{E}+00$ & 0.0000 \\
\hline & $1.239 \mathrm{E}-03$ & 1.0000 & $0.000 \mathrm{E}+00$ & 0.0000 & $0.000 \mathrm{E}+00$ & 0.0000 & $0.000 \mathrm{E}+00$ & 0.0000 & $0.000 \mathrm{E}+00$ & 0.0000 & $0.000 \mathrm{E}+00$ & 0.0000 & $.000 \mathrm{E}+00$ & 0.0000 \\
\hline
\end{tabular}

Total Dose Contributions TDOSE(i,p,t) for Individual Radionuclides (i) and Pathways (p) As mrem/yr and Fraction of Total Dose At $t=1.050 \mathrm{E}+03$ years

Water Dependent Pathways

\begin{tabular}{|c|c|c|c|c|c|c|c|c|c|c|c|c|c|c|}
\hline \multirow{2}{*}{$\begin{array}{l}\text { Radio- } \\
\text { Nuclide }\end{array}$} & \multicolumn{2}{|c|}{ Water } & \multicolumn{2}{|c|}{ Fish } & \multicolumn{2}{|c|}{ Radon } & \multicolumn{2}{|c|}{ Plant } & \multicolumn{2}{|c|}{ Meat } & \multicolumn{2}{|c|}{ Milk } & \multicolumn{2}{|c|}{ All Pathways* } \\
\hline & mrem/yr & fract. & mrem/yr & fract. & mrem/yr & fract. & mrem/yr & fract. & mrem/yr & fract. & mrem/yr & fract. & mrem/yr & fract. \\
\hline 241 & $0.000 \mathrm{E}+00$ & 0.0000 & $0.000 \mathrm{E}+00$ & 0.0000 & $0.000 \mathrm{E}+00$ & 0.0000 & $0.000 \mathrm{E}+00$ & 0.0000 & $0.000 \mathrm{E}+00$ & 0.0000 & $0.000 \mathrm{E}+00$ & 0.0000 & $4.250 \mathrm{E}-11$ & 0.0000 \\
\hline-137 & $0.000 \mathrm{E}+00$ & 0.0000 & $0.000 \mathrm{E}+00$ & 0.0000 & $0.000 \mathrm{E}+00$ & 0.0000 & $0.000 \mathrm{E}+00$ & 0.0000 & $0.000 \mathrm{E}+00$ & 0.0000 & $0.000 \mathrm{E}+00$ & 0.0000 & $4.627 \mathrm{E}-16$ & 0.0000 \\
\hline-237 & $0.000 \mathrm{E}+00$ & 0.0000 & $0.000 \mathrm{E}+00$ & 0.0000 & $0.000 \mathrm{E}+00$ & 0.0000 & $0.000 \mathrm{E}+00$ & 0.0000 & $0.000 \mathrm{E}+00$ & 0.0000 & $0.000 \mathrm{E}+00$ & 0.0000 & $3.985 E-08$ & 0.0000 \\
\hline-238 & $0.000 \mathrm{E}+00$ & 0.0000 & $0.000 \mathrm{E}+00$ & 0.0000 & $0.000 \mathrm{E}+00$ & 0.0000 & $0.000 \mathrm{E}+00$ & 0.0000 & $0.000 \mathrm{E}+00$ & 0.0000 & $0.000 \mathrm{E}+00$ & 0.0000 & $4.914 \mathrm{E}-10$ & 0.0000 \\
\hline-239 & $0.000 \mathrm{E}+00$ & 0.0000 & $0.000 \mathrm{E}+00$ & 0.0000 & $0.000 \mathrm{E}+00$ & 0.0000 & $0.000 \mathrm{E}+00$ & 0.0000 & $0.000 \mathrm{E}+00$ & 0.0000 & $0.000 E+00$ & 0.0000 & $1.164 \mathrm{E}-11$ & 0.0000 \\
\hline-240 & $0.000 \mathrm{E}+00$ & 0.0000 & $0.000 \mathrm{E}+00$ & 0.0000 & $0.000 \mathrm{E}+00$ & 0.0000 & $0.000 \mathrm{E}+00$ & 0.0000 & $0.000 \mathrm{E}+00$ & 0.0000 & $0.000 E+00$ & 0.0000 & $2.820 \mathrm{E}-15$ & 0.0000 \\
\hline 99 & $0.000 \mathrm{E}+00$ & 0.0000 & $0.000 \mathrm{E}+00$ & 0.0000 & $0.000 \mathrm{E}+00$ & 0.0000 & $0.000 \mathrm{E}+00$ & 0.0000 & $0.000 \mathrm{E}+00$ & 0.0000 & $0.000 \mathrm{E}+00$ & 0.0000 & $6.409 \mathrm{E}-19$ & 0.0000 \\
\hline-228 & $0.000 \mathrm{E}+00$ & 0.0000 & $0.000 \mathrm{E}+00$ & 0.0000 & $0.000 \mathrm{E}+00$ & 0.0000 & $0.000 \mathrm{E}+00$ & 0.0000 & $0.000 \mathrm{E}+00$ & 0.0000 & $0.000 \mathrm{E}+00$ & 0.0000 & $0.000 \mathrm{E}+00$ & 0.0000 \\
\hline-230 & $0.000 \mathrm{E}+00$ & 0.0000 & $0.000 \mathrm{E}+00$ & 0.0000 & $0.000 \mathrm{E}+00$ & 0.0000 & $0.000 \mathrm{E}+00$ & 0.0000 & $0.000 \mathrm{E}+00$ & 0.0000 & $0.000 E+00$ & 0.0000 & $8.661 \mathrm{E}-04$ & 0.6991 \\
\hline 232 & $0.000 \mathrm{E}+00$ & 0.0000 & $0.000 \mathrm{E}+00$ & 0.0000 & $0.000 \mathrm{E}+00$ & 0.0000 & $0.000 \mathrm{E}+00$ & 0.0000 & $0.000 \mathrm{E}+00$ & 0.0000 & $0.000 \mathrm{E}+00$ & 0.0000 & $3.560 \mathrm{E}-04$ & 0.2874 \\
\hline 34 & $0.000 \mathrm{E}+00$ & 0.0000 & $0.000 \mathrm{E}+00$ & 0.0000 & $0.000 \mathrm{E}+00$ & 0.0000 & $0.000 \mathrm{E}+00$ & 0.0000 & $0.000 \mathrm{E}+00$ & 0.0000 & $0.000 \mathrm{E}+00$ & 0.0000 & $7.034 \mathrm{E}-06$ & 0.0057 \\
\hline 35 & $0.000 \mathrm{E}+00$ & 0.0000 & $0.000 \mathrm{E}+00$ & 0.0000 & $0.000 \mathrm{E}+00$ & 0.0000 & $0.000 \mathrm{E}+00$ & 0.0000 & $0.000 \mathrm{E}+00$ & 0.0000 & $0.000 \mathrm{E}+00$ & 0.0000 & $1.481 E-08$ & 0.0000 \\
\hline 38 & $0.000 \mathrm{E}+00$ & 0.0000 & $0.000 \mathrm{E}+00$ & 0.0000 & $0.000 \mathrm{E}+00$ & 0.0000 & $0.000 \mathrm{E}+00$ & 0.0000 & $0.000 \mathrm{E}+00$ & 0.0000 & $0.000 \mathrm{E}+00$ & 0.0000 & $9.634 \mathrm{E}-06$ & 0.0078 \\
\hline & $0.000 \mathrm{E}+00$ & 0.0000 & $0.000 \mathrm{E}+00$ & 0.0000 & $0.000 \mathrm{E}+00$ & 0.0000 & $0.000 \mathrm{E}+00$ & 0.0000 & $0.000 \mathrm{E}+00$ & 0.0000 & $0.000 \mathrm{E}+00$ & 0.0000 & $9 \mathrm{E}-03$ & 1. \\
\hline
\end{tabular}

* Sum of all water independent and dependent pathways. 
RESRAD, Version 6.5

ummary : RESRAD Parameters for U-Landfill Recreational User Foward Run 100,000 years

File : C: $\backslash$ RESRAD_FAMILY \RESRAD \USERFILES \QCJULY2011 \ULANDFILL-RU_FORWARD-100000YRS.RAD

Dose/Source Ratios Summed Over All Pathways

Parent and Progeny Principal Radionuclide Contributions Indicated

Parent Product Thread DSR(j,t) At Time in Years (mrem/yr)/(pCi/g)

(i)

(j)

\section{Am-241}

$\mathrm{Np}-237+\mathrm{D}$

$\mathrm{U}-233$

Th-229+D

$\sum \operatorname{DSR}(j)$

$\mathrm{Cs}-137+\mathrm{D}$

$\mathrm{Np}-237+\mathrm{D}$

$\mathrm{U}-233$

Th-229+D

$\sum \operatorname{DSR}(j)$

$\mathrm{Pu}-238$

$\mathrm{Pu}-238$

$\mathrm{U}-234$

Th-230

Ra-226+D

$\mathrm{Pb}-210+\mathrm{D}$

$\sum \operatorname{DSR}(j)$

$\mathrm{Pu}-239$

U-235+D

$\mathrm{Pa}-231$

Ac $-227+D$

$\sum \operatorname{DSR}(j)$

Pu-240

Pu-240

$\mathrm{U}-236$

Th-232

$\mathrm{Ra}-228+\mathrm{D}$

Th-228+D

$\sum \operatorname{DSR}(j)$

TC-99

Th $-228+\mathrm{D}$

Th-230

$\mathrm{Ra}-226+\mathrm{D}$

$\mathrm{Pb}-210+\mathrm{D}$

$\sum \operatorname{DSR}(j)$
Fraction

1. $000 \mathrm{E}+00$

1. $000 \mathrm{E}+00$

1. $000 \mathrm{E}+00$

$1.000 \mathrm{E}+00$

$1.000 \mathrm{E}+00$

1. $000 \mathrm{E}+00$

$1.000 \mathrm{E}+00$

$1.000 \mathrm{E}+00$

$1.840 \mathrm{E}-09$

1. $000 \mathrm{E}+00$

1. $000 \mathrm{E}+00$

1. $000 \mathrm{E}+00$

1. $000 \mathrm{E}+00$

1. $000 \mathrm{E}+00$

1. $000 \mathrm{E}+0$

1. $000 \mathrm{E}+00$

1. $000 \mathrm{E}+00$

1. $000 \mathrm{E}+00$

4. $950 \mathrm{E}-0$

1. $000 \mathrm{E}+00$

1. $000 \mathrm{E}+00$

1. $000 \mathrm{E}+00$

1. $000 \mathrm{E}+00$

1. $000 \mathrm{E}+00$

1. $000 \mathrm{E}+00$

1. $000 \mathrm{E}+00$

1. $000 \mathrm{E}+00$

1. $000 \mathrm{E}+00$

1. $000 \mathrm{E}+00$

3 $\begin{array}{llllllllll}.319 \mathrm{E}-23 & 2.359 \mathrm{E}-23 & 2.838 \mathrm{E}-23 & 5.375 \mathrm{E}-23 & 1.246 \mathrm{E}-22 & 1.037 \mathrm{E}-19 & 1.074 \mathrm{E}-15 & 2.264 \mathrm{E}-03 & 0.000 \mathrm{E}+00 \\ .629 \mathrm{E}-12 & 1.095 \mathrm{E}-11 & 9.820 \mathrm{E}-11 & 5.116 \mathrm{E}-10 & 1.423 \mathrm{E}-09 & 1.032 \mathrm{E}-07 & 8.661 \mathrm{E}-06 & 7.480 \mathrm{E}-01 & 0.000 \mathrm{E}+00 \\ .749 \mathrm{E}-20 & 1.222 \mathrm{E}-19 & 7.985 \mathrm{E}-18 & 1.249 \mathrm{E}-16 & 5.113 \mathrm{E}-16 & 7.402 \mathrm{E}-14 & 1.190 \mathrm{E}-11 & 3.403 \mathrm{E}-02 & 0.000 \mathrm{E}+00 \\ .629 \mathrm{E}-12 & 1.095 \mathrm{E}-11 & 9.820 \mathrm{E}-11 & 5.116 \mathrm{E}-10 & 1.423 \mathrm{E}-09 & 1.032 \mathrm{E}-07 & 8.661 \mathrm{E}-06 & 7.843 \mathrm{E}-01 & 0.000 \mathrm{E}+00\end{array}$ $\begin{array}{llllllllll}2.319 \mathrm{E}-23 & 2.359 \mathrm{E}-23 & 2.838 \mathrm{E}-23 & 5.375 \mathrm{E}-23 & 1.246 \mathrm{E}-22 & 1.037 \mathrm{E}-19 & 1.074 \mathrm{E}-15 & 2.264 \mathrm{E}-03 & 0.000 \mathrm{E}+00 \\ 3.629 \mathrm{E}-12 & 1.095 \mathrm{E}-11 & 9.820 \mathrm{E}-11 & 5.116 \mathrm{E}-10 & 1.423 \mathrm{E}-09 & 1.032 \mathrm{E}-07 & 8.661 \mathrm{E}-06 & 7.480 \mathrm{E}-01 & 0.000 \mathrm{E}+00 \\ 1.749 \mathrm{E}-20 & 1.222 \mathrm{E}-19 & 7.985 \mathrm{E}-18 & 1.249 \mathrm{E}-16 & 5.113 \mathrm{E}-16 & 7.402 \mathrm{E}-14 & 1.190 \mathrm{E}-11 & 3.403 \mathrm{E}-02 & 0.000 \mathrm{E}+00 \\ 3.629 \mathrm{E}-12 & 1.095 \mathrm{E}-11 & 9.820 \mathrm{E}-11 & 5.116 \mathrm{E}-10 & 1.423 \mathrm{E}-09 & 1.032 \mathrm{E}-07 & 8.661 \mathrm{E}-06 & 7.843 \mathrm{E}-01 & 0.000 \mathrm{E}+00\end{array}$ $\begin{array}{llllllllll}2.319 \mathrm{E}-23 & 2.359 \mathrm{E}-23 & 2.838 \mathrm{E}-23 & 5.375 \mathrm{E}-23 & 1.246 \mathrm{E}-22 & 1.037 \mathrm{E}-19 & 1.074 \mathrm{E}-15 & 2.264 \mathrm{E}-03 & 0.000 \mathrm{E}+00 \\ 3.629 \mathrm{E}-12 & 1.095 \mathrm{E}-11 & 9.820 \mathrm{E}-11 & 5.116 \mathrm{E}-10 & 1.423 \mathrm{E}-09 & 1.032 \mathrm{E}-07 & 8.661 \mathrm{E}-06 & 7.480 \mathrm{E}-01 & 0.000 \mathrm{E}+00 \\ 1.749 \mathrm{E}-20 & 1.222 \mathrm{E}-19 & 7.985 \mathrm{E}-18 & 1.249 \mathrm{E}-16 & 5.113 \mathrm{E}-16 & 7.402 \mathrm{E}-14 & 1.190 \mathrm{E}-11 & 3.403 \mathrm{E}-02 & 0.000 \mathrm{E}+00 \\ 3.629 \mathrm{E}-12 & 1.095 \mathrm{E}-11 & 9.820 \mathrm{E}-11 & 5.116 \mathrm{E}-10 & 1.423 \mathrm{E}-09 & 1.032 \mathrm{E}-07 & 8.661 \mathrm{E}-06 & 7.843 \mathrm{E}-01 & 0.000 \mathrm{E}+00\end{array}$

$0.000 \mathrm{E}+00 \quad 1.000 \mathrm{E}+00 \quad 1.200 \mathrm{E}+01 \quad 5.000 \mathrm{E}+01 \quad 1.000 \mathrm{E}+02 \quad 5.000 \mathrm{E}+02 \quad 1.050 \mathrm{E}+03 \quad 1.000 \mathrm{E}+04 \quad 1.000 \mathrm{E}+05$

$\begin{array}{lllllllll}1.862 \mathrm{E}-34 & 1.912 \mathrm{E}-34 & 2.565 \mathrm{E}-34 & 7.071 \mathrm{E}-34 & 2.685 \mathrm{E}-33 & 1.163 \mathrm{E}-28 & 2.757 \mathrm{E}-22 & 5.451 \mathrm{E}-10 \quad 0.000 \mathrm{E}+00\end{array}$ $\begin{array}{lllllllll}1.487 \mathrm{E}-20 & 4.500 \mathrm{E}-20 & 4.182 \mathrm{E}-19 & 2.467 \mathrm{E}-18 & 8.084 \mathrm{E}-18 & 2.212 \mathrm{E}-15 & 1.203 \mathrm{E}-12 & 7.802 \mathrm{E}-06 & 0.000 \mathrm{E}+00\end{array}$ $3.371 \mathrm{E}-31 \quad 2.384 \mathrm{E}-30 \quad 1.820 \mathrm{E}-28 \quad 4.682 \mathrm{E}-27 \quad 3.376 \mathrm{E}-26 \quad 1.025 \mathrm{E}-22 \quad 3.455 \mathrm{E}-19 \quad 5.052 \mathrm{E}-09 \quad 0.000 \mathrm{E}+00$ $2.306 \mathrm{E}-27 \quad 3.479 \mathrm{E}-26 \quad 1.949 \mathrm{E}-23 \quad 1.645 \mathrm{E}-21 \quad 1.799 \mathrm{E}-20 \quad 3.100 \mathrm{E}-17 \quad 1.142 \mathrm{E}-14 \quad 2.585 \mathrm{E}-07 \quad 0.000 \mathrm{E}+00$ $1.487 \mathrm{E}-20 \quad 4.500 \mathrm{E}-20 \quad 4.182 \mathrm{E}-19 \quad 2.469 \mathrm{E}-18 \quad 8.102 \mathrm{E}-18 \quad 2.243 \mathrm{E}-15 \quad 1.214 \mathrm{E}-12 \quad 8.067 \mathrm{E}-06 \quad 0.000 \mathrm{E}+00$

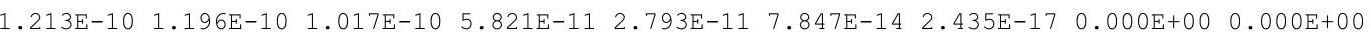

$9.169 \mathrm{E}-14 \quad 9.268 \mathrm{E}-14 \quad 1.043 \mathrm{E}-13 \quad 1.567 \mathrm{E}-13 \quad 2.679 \mathrm{E}-13 \quad 1.952 \mathrm{E}-11 \quad 7.101 \mathrm{E}-09 \quad 3.681 \mathrm{E}-02 \quad 0.000 \mathrm{E}+00$ $3.120 \mathrm{E}-249.466 \mathrm{E}-24 \quad 9.045 \mathrm{E}-23 \quad 5.875 \mathrm{E}-22 \quad 2.184 \mathrm{E}-21 \quad 1.613 \mathrm{E}-18 \quad 3.273 \mathrm{E}-15 \quad 2.602 \mathrm{E}-05 \quad 0.000 \mathrm{E}+00$ $9.169 \mathrm{E}-14 \quad 9.268 \mathrm{E}-14 \quad 1.043 \mathrm{E}-13 \quad 1.570 \mathrm{E}-13 \quad 2.696 \mathrm{E}-13 \quad 2.021 \mathrm{E}-11 \quad 7.245 \mathrm{E}-09 \quad 3.824 \mathrm{E}-02 \quad 0.000 \mathrm{E}+00$

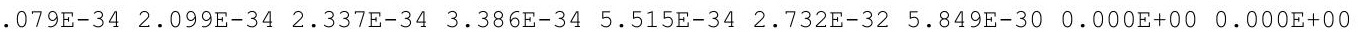

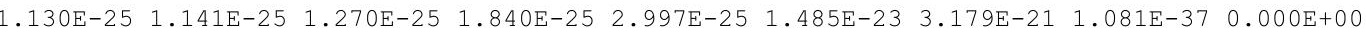
$\begin{array}{llllllllll}9.402 \mathrm{E}-31 & 2.855 \mathrm{E}-30 & 2.767 \mathrm{E}-29 & 1.897 \mathrm{E}-28 & 7.660 \mathrm{E}-28 & 1.633 \mathrm{E}-24 & 2.820 \mathrm{E}-20 & 2.543 \mathrm{E}-07 & 0.000 \mathrm{E}+00\end{array}$ $9.887 \mathrm{E}-35 \quad 7.005 \mathrm{E}-34 \quad 5.480 \mathrm{E}-32 \quad 1.538 \mathrm{E}-30 \quad 1.253 \mathrm{E}-29 \quad 1.259 \mathrm{E}-25 \quad 3.198 \mathrm{E}-21 \quad 7.030 \mathrm{E}-08 \quad 0.000 \mathrm{E}+00$ $7.713 \mathrm{E}-24 \quad 1.162 \mathrm{E}-22 \quad 6.388 \mathrm{E}-20 \quad 5.065 \mathrm{E}-18 \quad 5.122 \mathrm{E}-17 \quad 5.408 \mathrm{E}-14 \quad 1.260 \mathrm{E}-11 \quad 1.819 \mathrm{E}-05 \quad 0.000 \mathrm{E}+00$ $2.237 \mathrm{E}-32 \quad 6.933 \mathrm{E}-31 \quad 2.743 \mathrm{E}-27 \quad 7.476 \mathrm{E}-25 \quad 1.264 \mathrm{E}-23 \quad 3.542 \mathrm{E}-20 \quad 1.664 \mathrm{E}-17 \quad 8.245 \mathrm{E}-07 \quad 0.000 \mathrm{E}+00$ $\begin{array}{lllllllll}7.826 \mathrm{E}-24 & 1.163 \mathrm{E}-22 & 6.388 \mathrm{E}-20 & 5.065 \mathrm{E}-18 & 5.122 \mathrm{E}-17 & 5.408 \mathrm{E}-14 & 1.260 \mathrm{E}-11 & 1.934 \mathrm{E}-05 & 0.000 \mathrm{E}+00\end{array}$

$\begin{array}{lllllllll}.156 \mathrm{E}-18 & 1.170 \mathrm{E}-18 & 1.334 \mathrm{E}-18 & 2.100 \mathrm{E}-18 & 3.815 \mathrm{E}-18 & 4.526 \mathrm{E}-16 & 3.220 \mathrm{E}-13 & 1.818 \mathrm{E}-03 & 0.000 \mathrm{E}+00\end{array}$ $5.899 \mathrm{E}-25 \quad 1.789 \mathrm{E}-24 \quad 1.707 \mathrm{E}-23 \quad 1.102 \mathrm{E}-22 \quad 4.068 \mathrm{E}-22 \quad 2.830 \mathrm{E}-19 \quad 5.291 \mathrm{E}-16 \quad 4.215 \mathrm{E}-07 \quad 0.000 \mathrm{E}+00$ $9.281 \mathrm{E}-29 \quad 6.556 \mathrm{E}-28 \quad 4.931 \mathrm{E}-26 \quad 1.203 \mathrm{E}-24 \quad 8.097 \mathrm{E}-24 \quad 1.394 \mathrm{E}-20 \quad 2.092 \mathrm{E}-17 \quad 1.785 \mathrm{E}-08 \quad 0.000 \mathrm{E}+00$ $2.200 \mathrm{E}-28 \quad 3.302 \mathrm{E}-27 \quad 1.741 \mathrm{E}-24 \quad 1.227 \mathrm{E}-22 \quad 1.125 \mathrm{E}-21 \quad 1.425 \mathrm{E}-18 \quad 8.591 \mathrm{E}-16 \quad 1.293 \mathrm{E}-07 \quad 0.000 \mathrm{E}+00$ $\begin{array}{lllllllll}1.156 \mathrm{E}-18 & 1.170 \mathrm{E}-18 & 1.334 \mathrm{E}-18 & 2.100 \mathrm{E}-18 & 3.817 \mathrm{E}-18 & 4.543 \mathrm{E}-16 & 3.234 \mathrm{E}-13 & 1.818 \mathrm{E}-03 \quad 0.000 \mathrm{E}+00\end{array}$ $5.436 \mathrm{E}-33 \quad 5.532 \mathrm{E}-33 \quad 6.710 \mathrm{E}-33 \quad 1.307 \mathrm{E}-32 \quad 3.144 \mathrm{E}-32 \quad 3.519 \mathrm{E}-29 \quad 5.479 \mathrm{E}-25 \quad 4.138 \mathrm{E}-11 \quad 0.000 \mathrm{E}+00$ $\begin{array}{lllllllll}1.098 \mathrm{E}-25 & 1.118 \mathrm{E}-25 & 1.356 \mathrm{E}-25 & 2.641 \mathrm{E}-25 & 6.352 \mathrm{E}-25 & 7.109 \mathrm{E}-22 & 1.107 \mathrm{E}-17 & 8.359 \mathrm{E}-04 \quad 0.000 \mathrm{E}+00\end{array}$ $\begin{array}{llllllllll}33 & 6.337 \mathrm{E}-33 & 6.427 \mathrm{E}-32 & 5.132 \mathrm{E}-31 & 2.504 \mathrm{E}-30 & 1.628 \mathrm{E}-26 & 6.574 \mathrm{E}-22 & 1.256 \mathrm{E}-07 & 0.000 \mathrm{E}+00\end{array}$ $2.803 \mathrm{E}-44 \quad 1.948 \mathrm{E}-43 \quad 1.599 \mathrm{E}-41 \quad 5.271 \mathrm{E}-40 \quad 5.270 \mathrm{E}-39 \quad 2.159 \mathrm{E}-34 \quad 2.528 \mathrm{E}-29 \quad 1.367 \mathrm{E}-13 \quad 0.000 \mathrm{E}+00$

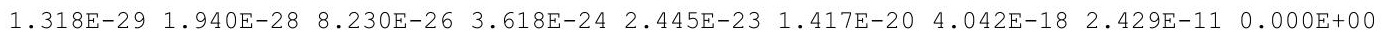
$\begin{array}{lllllllll}7.799 \mathrm{E}-29 & 2.244 \mathrm{E}-27 & 4.095 \mathrm{E}-24 & 2.540 \mathrm{E}-22 & 1.691 \mathrm{E}-21 & 5.366 \mathrm{E}-19 & 6.323 \mathrm{E}-17 & 3.687 \mathrm{E}-11 & 0.000 \mathrm{E}+00\end{array}$ $\begin{array}{lllllllll}1.099 \mathrm{E}-25 & 1.142 \mathrm{E}-25 & 4.313 \mathrm{E}-24 & 2.579 \mathrm{E}-22 & 1.716 \mathrm{E}-21 & 5.515 \mathrm{E}-19 & 7.834 \mathrm{E}-17 & 8.361 \mathrm{E}-04 \quad 0.000 \mathrm{E}+00\end{array}$ $\begin{array}{lllllllll}5.547 \mathrm{E}-27 & 5.625 \mathrm{E}-27 & 6.555 \mathrm{E}-27 & 1.112 \mathrm{E}-26 & 2.231 \mathrm{E}-26 & 5.839 \mathrm{E}-24 & 1.233 \mathrm{E}-20 & 2.473 \mathrm{E}-28 & 0.000 \mathrm{E}+00\end{array}$

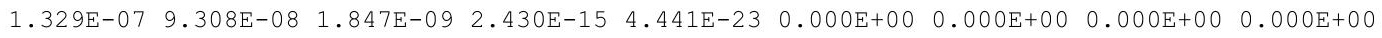


RESRAD, Version 6.5

Summary : RESRAD Parameters for U-Landfill Recreational User Foward Run 100,000 years

File : C: $\backslash$ RESRAD FAMILY \RESRAD \USERFILES $\backslash Q C J U L Y 2011 \backslash U L A N D F I L L-R U$ FORWARD-100000YRS.RAD

Individual Nuclide Dose Summed Over All Pathways

Parent Nuclide and Branch Fraction Indicated

Nuclide Parent THF(i) DOSE $(j, t), \mathrm{mrem} / \mathrm{yr}$

\begin{tabular}{|c|c|c|}
\hline (j) & (i) & \\
\hline$A m-241$ & Am-241 & $1.000 \mathrm{E}+0$ \\
\hline$N p-237$ & Am-241 & $1.000 \mathrm{E}+0$ \\
\hline$N p-237$ & $N p-237$ & $1.000 \mathrm{E}+0$ \\
\hline $\mathrm{Jp}-237$ & $\sum \operatorname{DOSE}(j$ & \\
\hline
\end{tabular}

Am-241 1.000E+00 $\mathrm{Np}-237 \quad 1.000 \mathrm{E}+00$ $\sum \operatorname{DOSE}(j)$

Am-241 1.000E+00 $\mathrm{Np}-237 \quad 1.000 \mathrm{E}+00$ $\sum \operatorname{DOSE}(j)$

Cs-137 1.000E+00

Pu-238 1.840E-09 $\mathrm{Pu}-238 \quad 1.000 \mathrm{E}+00$ $\sum \operatorname{DOSE}(j)$

$\mathrm{Pu}-238 \quad 1.000 \mathrm{E}+00$ $\mathrm{U}-234 \quad 1.000 \mathrm{E}+00$ U-238 9.999E-01 $\sum \operatorname{DOSE}(j)$

Pu-238 1.000E+00 Th-230 1.000E+00 $\mathrm{U}-234 \quad 1.000 \mathrm{E}+00$ $\mathrm{U}-238 \quad 9.999 \mathrm{E}-01$ $\sum \operatorname{DOSE}(j)$

$\mathrm{Pu}-238 \quad 1.000 \mathrm{E}+00$ Th-230 1.000E+00 $\mathrm{U}-234 \quad 1.000 \mathrm{E}+00$ $\mathrm{U}-238 \quad 9.999 \mathrm{E}-01$ $\sum \operatorname{DOSE}(j)$

$\mathrm{Pu}-238 \quad 1.000 \mathrm{E}+00$ Th-230 1.000E+00 $\mathrm{U}-234 \quad 1.000 \mathrm{E}+00$ U-238 9.999E-01 $\sum \operatorname{DOSE}(j)$

$\mathrm{Pu}-239 \quad 1.000 \mathrm{E}+00$

$\mathrm{Pu}-239 \quad 1.000 \mathrm{E}+00$ U-235 1.000E+00 $\sum \operatorname{DOSE}(j)$ $\mathrm{t}=0.000 \mathrm{E}+00 \quad 1.000 \mathrm{E}+00 \quad 1.200 \mathrm{E}+01 \quad 5.000 \mathrm{E}+01 \quad 1.000 \mathrm{E}+02 \quad 5.000 \mathrm{E}+02 \quad 1.050 \mathrm{E}+03 \quad 1.000 \mathrm{E}+04 \quad 1.000 \mathrm{E}+05$

$\begin{array}{lllllllllllllll}0.000 \mathrm{E}+00 & 0.000 \mathrm{E}+00 & 0.000 \mathrm{E}+00 & 0.000 \mathrm{E}+00 & 0.000 \mathrm{E}+00 & 4.069 \mathrm{E}-27 & 9.651 \mathrm{E}-21 & 1.908 \mathrm{E}-08 & 0.000 \mathrm{E}+00\end{array}$

$\begin{array}{lllllllllll}5.204 \mathrm{E}-19 & 1.575 \mathrm{E}-18 & 1.464 \mathrm{E}-17 & 8.635 \mathrm{E}-17 & 2.829 \mathrm{E}-16 & 7.741 \mathrm{E}-14 & 4.210 \mathrm{E}-11 & 2.731 \mathrm{E}-04 \quad 0.000 \mathrm{E}+00\end{array}$ $\begin{array}{lllllllll}5.043 \mathrm{E}-13 & 5.097 \mathrm{E}-13 & 5.735 \mathrm{E}-13 & 8.620 \mathrm{E}-13 & 1.473 \mathrm{E}-12 & 1.073 \mathrm{E}-10 & 3.906 \mathrm{E}-08 & 2.024 \mathrm{E}-01 \quad 0.000 \mathrm{E}+00\end{array}$ $\begin{array}{lllllllll}5.043 E-13 & 5.097 \mathrm{E}-13 & 5.736 \mathrm{E}-13 & 8.621 \mathrm{E}-13 & 1.474 \mathrm{E}-12 & 1.074 \mathrm{E}-10 & 3.910 \mathrm{E}-08 & 2.027 \mathrm{E}-01 \quad 0.000 \mathrm{E}+00\end{array}$

$\begin{array}{llllllllll}0.000 \mathrm{E}+00 & 8.344 \mathrm{E}-29 & 6.371 \mathrm{E}-27 & 1.639 \mathrm{E}-25 & 1.182 \mathrm{E}-24 & 3.586 \mathrm{E}-21 & 1.209 \mathrm{E}-17 & 1.768 \mathrm{E}-07 & 0.000 \mathrm{E}+00\end{array}$ $\begin{array}{lllllllll}1.716 \mathrm{E}-23 & 5.206 \mathrm{E}-23 & 4.975 \mathrm{E}-22 & 3.231 \mathrm{E}-21 & 1.201 \mathrm{E}-20 & 8.871 \mathrm{E}-18 & 1.800 \mathrm{E}-14 & 1.431 \mathrm{E}-04 & 0.000 \mathrm{E}+00\end{array}$ $\begin{array}{lllllllll}1.716 \mathrm{E}-23 & 5.206 \mathrm{E}-23 & 4.975 \mathrm{E}-22 & 3.231 \mathrm{E}-21 & 1.201 \mathrm{E}-20 & 8.874 \mathrm{E}-18 & 1.801 \mathrm{E}-14 & 1.433 \mathrm{E}-04 \quad 0.000 \mathrm{E}+00\end{array}$

$\begin{array}{lllllllll}8.073 \mathrm{E}-26 & 1.218 \mathrm{E}-24 & 6.820 \mathrm{E}-22 & 5.759 \mathrm{E}-20 & 6.298 \mathrm{E}-19 & 1.085 \mathrm{E}-15 & 3.995 \mathrm{E}-13 & 9.049 \mathrm{E}-06 \quad 0.000 \mathrm{E}+00\end{array}$ $\begin{array}{lllllllll}1.567 \mathrm{E}-19 & 1.103 \mathrm{E}-18 & 7.971 \mathrm{E}-17 & 1.692 \mathrm{E}-15 & 9.477 \mathrm{E}-15 & 3.786 \mathrm{E}-12 & 7.936 \mathrm{E}-10 & 7.718 \mathrm{E}-03 \quad 0.000 \mathrm{E}+00\end{array}$ $\begin{array}{lllllll}1.567 \mathrm{E}-19 & 1.103 \mathrm{E}-18 & 7.971 \mathrm{E}-17 & 1.692 \mathrm{E}-15 & 9.478 \mathrm{E}-15 & 3.787 \mathrm{E}-12 & 7.940 \mathrm{E}-10 \quad 7.727 \mathrm{E}-03 \quad 0.000 \mathrm{E}+00\end{array}$

2.305E-09 2.272E-09 1.933E-09 1.106E-09 5.307E-10 1.491E-12 4.627E-16 $0.000 \mathrm{E}+00 \quad 0.000 \mathrm{E}+00$

$\begin{array}{llllllllll}0.000 \mathrm{E}+00 & 0.000 \mathrm{E}+00 & 0.000 \mathrm{E}+00 & 0.000 \mathrm{E}+00 & 0.000 \mathrm{E}+00 & 0.000 \mathrm{E}+00 & 2.281 \mathrm{E}-28 & 0.000 \mathrm{E}+00 \quad 0.000 \mathrm{E}+00\end{array}$ $\begin{array}{lllllllll}4.406 \mathrm{E}-24 & 4.449 \mathrm{E}-24 & 4.953 \mathrm{E}-24 & 7.176 \mathrm{E}-24 & 1.169 \mathrm{E}-23 & 5.791 \mathrm{E}-22 & 1.240 \mathrm{E}-19 & 0.000 \mathrm{E}+00 \quad 0.000 \mathrm{E}+00\end{array}$ $\begin{array}{llllllll}4.406 \mathrm{E}-24 & 4.449 \mathrm{E}-24 & 4.953 \mathrm{E}-24 & 7.176 \mathrm{E}-24 & 1.169 \mathrm{E}-23 & 5.791 \mathrm{E}-22 & 1.240 \mathrm{E}-19 & 0.000 \mathrm{E}+00 \quad 0.000 \mathrm{E}+00\end{array}$

$0.000 \mathrm{E}+00 \quad 1.114 \mathrm{E}-28 \quad 1.079 \mathrm{E}-27 \quad 7.400 \mathrm{E}-27 \quad 2.988 \mathrm{E}-26 \quad 6.368 \mathrm{E}-23 \quad 1.100 \mathrm{E}-18 \quad 9.916 \mathrm{E}-06 \quad 0.000 \mathrm{E}+00$ $\begin{array}{lllllllll}1.061 \mathrm{E}-22 & 1.080 \mathrm{E}-22 & 1.312 \mathrm{E}-22 & 2.571 \mathrm{E}-22 & 6.232 \mathrm{E}-22 & 7.417 \mathrm{E}-19 & 1.257 \mathrm{E}-14 & 1.133 \mathrm{E}-01 \quad 0.000 \mathrm{E}+00\end{array}$ $\begin{array}{llllllllll}0.000 \mathrm{E}+00 & 4.596 \mathrm{E}-28 & 4.650 \mathrm{E}-27 & 3.681 \mathrm{E}-26 & 1.776 \mathrm{E}-25 & 1.053 \mathrm{E}-21 & 3.748 \mathrm{E}-17 & 3.257 \mathrm{E}-03 & 0.000 \mathrm{E}+00\end{array}$ $\begin{array}{lllllllll}1.061 \mathrm{E}-22 & 1.080 \mathrm{E}-22 & 1.312 \mathrm{E}-22 & 2.572 \mathrm{E}-22 & 6.234 \mathrm{E}-22 & 7.428 \mathrm{E}-19 & 1.261 \mathrm{E}-14 & 1.165 \mathrm{E}-01 \quad 0.000 \mathrm{E}+00\end{array}$

$\begin{array}{llllllll}0.000 \mathrm{E}+00 & 0.000 \mathrm{E}+00 & 0.000 \mathrm{E}+00 & 5.998 \mathrm{E}-29 & 4.887 \mathrm{E}-28 & 4.910 \mathrm{E}-24 & 1.247 \mathrm{E}-19 & 2.742 \mathrm{E}-06 \quad 0.000 \mathrm{E}+00\end{array}$ $\begin{array}{llllllllllllllllll}2.319 \mathrm{E}-21 & 2.359 \mathrm{E}-21 & 2.838 \mathrm{E}-21 & 5.375 \mathrm{E}-21 & 1.246 \mathrm{E}-20 & 1.037 \mathrm{E}-17 & 1.074 \mathrm{E}-13 & 2.264 \mathrm{E}-01 & 0.000 \mathrm{E}+00\end{array}$ $\begin{array}{lllllllll}1.675 \mathrm{E}-26 & 5.101 \mathrm{E}-26 & 5.109 \mathrm{E}-25 & 3.909 \mathrm{E}-24 & 1.803 \mathrm{E}-23 & 7.463 \mathrm{E}-20 & 1.620 \mathrm{E}-15 & 3.173 \mathrm{E}-02 \quad 0.000 \mathrm{E}+00\end{array}$ $\begin{array}{lllllllll}0.000 \mathrm{E}+00 & 0.000 \mathrm{E}+00 & 0.000 \mathrm{E}+00 & 2.798 \mathrm{E}-28 & 2.568 \mathrm{E}-27 & 5.295 \mathrm{E}-23 & 2.413 \mathrm{E}-18 & 4.499 \mathrm{E}-04 & 0.000 \mathrm{E}+00\end{array}$ $\begin{array}{lllllllll}2.319 \mathrm{E}-21 & 2.359 \mathrm{E}-21 & 2.838 \mathrm{E}-21 & 5.379 \mathrm{E}-21 & 1.248 \mathrm{E}-20 & 1.044 \mathrm{E}-17 & 1.090 \mathrm{E}-13 & 2.586 \mathrm{E}-01 & 0.000 \mathrm{E}+00\end{array}$

$3.008 \mathrm{E}-22 \quad 4.531 \mathrm{E}-21 \quad 2.491 \mathrm{E}-18 \quad 1.975 \mathrm{E}-16 \quad 1.997 \mathrm{E}-15 \quad 2.109 \mathrm{E}-12 \quad 4.914 \mathrm{E}-10 \quad 7.095 \mathrm{E}-04 \quad 0.000 \mathrm{E}+00$ $\begin{array}{lllllllll}3.629 \mathrm{E}-10 & 1.095 \mathrm{E}-09 & 9.820 \mathrm{E}-09 & 5.116 \mathrm{E}-08 & 1.423 \mathrm{E}-07 & 1.032 \mathrm{E}-05 & 8.661 \mathrm{E}-04 & 7.480 \mathrm{E}+01 \quad 0.000 \mathrm{E}+00\end{array}$ $\begin{array}{lllllllll}1.743 \mathrm{E}-15 & 1.227 \mathrm{E}-14 & 8.853 \mathrm{E}-13 & 1.867 \mathrm{E}-11 & 1.037 \mathrm{E}-10 & 3.851 \mathrm{E}-08 & 7.034 \mathrm{E}-06 & 8.241 \mathrm{E}+00 \quad 0.000 \mathrm{E}+00\end{array}$ $\begin{array}{lllllllll}1.236 \mathrm{E}-21 & 1.865 \mathrm{E}-20 & 1.047 \mathrm{E}-17 & 8.928 \mathrm{E}-16 & 9.885 \mathrm{E}-15 & 1.854 \mathrm{E}-11 & 7.237 \mathrm{E}-09 & 9.730 \mathrm{E}-02 & 0.000 \mathrm{E}+00\end{array}$

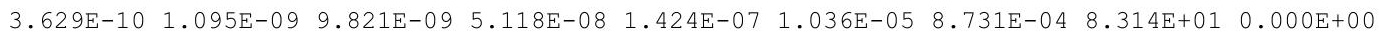

$0.000 \mathrm{E}+00 \quad 0.000 \mathrm{E}+00 \quad 1.070 \mathrm{E}-25 \quad 2.916 \mathrm{E}-23 \quad 4.931 \mathrm{E}-22 \quad 1.381 \mathrm{E}-18 \quad 6.490 \mathrm{E}-16 \quad 3.216 \mathrm{E}-05 \quad 0.000 \mathrm{E}+00$ $\begin{array}{llllllllll}1.749 \mathrm{E}-18 & 1.222 \mathrm{E}-17 & 7.985 \mathrm{E}-16 & 1.249 \mathrm{E}-14 & 5.113 \mathrm{E}-14 & 7.402 \mathrm{E}-12 & 1.190 \mathrm{E}-09 & 3.403 \mathrm{E}+00 \quad 0.000 \mathrm{E}+00\end{array}$ $\begin{array}{lllllllllllllll}6.310 \mathrm{E}-24 & 9.466 \mathrm{E}-23 & 4.951 \mathrm{E}-20 & 3.388 \mathrm{E}-18 & 2.979 \mathrm{E}-17 & 2.590 \mathrm{E}-14 & 9.356 \mathrm{E}-12 & 3.735 \mathrm{E}-01 & 0.000 \mathrm{E}+00\end{array}$ $0.000 \mathrm{E}+00 \quad 0.000 \mathrm{E}+00 \quad 4.477 \mathrm{E}-25 \quad 1.297 \mathrm{E}-22 \quad 2.380 \mathrm{E}-21 \quad 1.176 \mathrm{E}-17 \quad 9.340 \mathrm{E}-15 \quad 4.394 \mathrm{E}-03 \quad 0.000 \mathrm{E}+00$ $\begin{array}{lllllllll}1.749 \mathrm{E}-18 & 1.222 \mathrm{E}-17 & 7.985 \mathrm{E}-16 & 1.250 \mathrm{E}-14 & 5.116 \mathrm{E}-14 & 7.428 \mathrm{E}-12 & 1.199 \mathrm{E}-09 & 3.781 \mathrm{E}+00 \quad 0.000 \mathrm{E}+00\end{array}$

$\begin{array}{llllllllll}461 \mathrm{E}-17 & 4.211 \mathrm{E}-17 & 4.803 \mathrm{E}-17 & 7.560 \mathrm{E}-17 & 1.373 \mathrm{E}-16 & 1.629 \mathrm{E}-14 & 1.159 \mathrm{E}-11 & 6.544 \mathrm{E}-02 & 0.000 \mathrm{E}+00\end{array}$

$2.124 \mathrm{E}-23 \quad 6.441 \mathrm{E}-23 \quad 6.145 \mathrm{E}-22 \quad 3.969 \mathrm{E}-21 \quad 1.465 \mathrm{E}-20 \quad 1.019 \mathrm{E}-17 \quad 1.905 \mathrm{E}-14 \quad 1.517 \mathrm{E}-05 \quad 0.000 \mathrm{E}+00$ $\begin{array}{lllllllllll}7.771 \mathrm{E}-15 & 7.867 \mathrm{E}-15 & 9.013 \mathrm{E}-15 & 1.442 \mathrm{E}-14 & 2.675 \mathrm{E}-14 & 3.756 \mathrm{E}-12 & 3.369 \mathrm{E}-09 & 3.150 \mathrm{E}-01 & 0.000 \mathrm{E}+00\end{array}$ $\begin{array}{lllllllll}7.771 E-15 & 7.867 \mathrm{E}-15 & 9.013 \mathrm{E}-15 & 1.442 \mathrm{E}-14 & 2.675 \mathrm{E}-14 & 3.756 \mathrm{E}-12 & 3.369 \mathrm{E}-09 & 3.150 \mathrm{E}-01 & 0.000 \mathrm{E}+00\end{array}$ 
RESRAD, Version 6.5

Summary : RESRAD Parameters for U-Landfill Recreational User Foward Run 100,000 years

File : C: $\backslash$ RESRAD FAMILY \RESRAD \USERFILES $\backslash Q C J U L Y 2011 \backslash U L A N D F I L L-R U$ FORWARD-100000YRS.RAD

Individual Nuclide Soil Concentration

Parent Nuclide and Branch Fraction Indicated

Nuclide Parent THF(

\section{(j)}

(i)

Am-241

$\overline{A m-241} \overline{1.000 E+00}$

$\mathrm{Np}-237$

Np-237

Np-237

$\mathrm{Am}-241 \quad 1.000 \mathrm{E}+00$

$\mathrm{Np}-237 \quad 1.000 \mathrm{E}+00$

$\sum S(j):$

$\mathrm{Am}-241 \quad 1.000 \mathrm{E}+00$

Np-237 1.000E+00

$\sum S(j):$

Am-241 $1.000 \mathrm{E}+00$

Np-237 1.000E+00

Th-229

Th-229

Cs-137

$\mathrm{Pu}-238$

$\mathrm{Pu}-238$

Pu-238

$\mathrm{U}-234$

$\mathrm{U}-234$

$\mathrm{U}-234$

$\mathrm{U}-234$

Th-230

Th -230

Th -230

Th-230

$\mathrm{Th}-23 \mathrm{C}$

$\mathrm{Ra}-226$

$\mathrm{Ra}-226$

$\mathrm{Ra}-226$

$\mathrm{Ra}-226$

$\mathrm{Ra}-226$

$\mathrm{Pb}-210$

$\mathrm{Pb}-210$

$\mathrm{Pb}-210$

$\mathrm{Pb}-210$

$\mathrm{Pb}-210$

$\mathrm{Pu}-239$

Pu-239 1.000E+00 $\mathrm{U}-2351.000 \mathrm{E}+00$

$\sum S(j):$
$\mathrm{S}(j, \mathrm{t}), \mathrm{pCi} / \mathrm{g}$

$\mathrm{t}=0.000 \mathrm{E}+00 \quad 1.000 \mathrm{E}+00 \quad 1.200 \mathrm{E}+01 \quad 5.000 \mathrm{E}+01 \quad 1.000 \mathrm{E}+02 \quad 5.000 \mathrm{E}+02 \quad 1.050 \mathrm{E}+03 \quad 1.000 \mathrm{E}+04 \quad 1.000 \mathrm{E}+05$

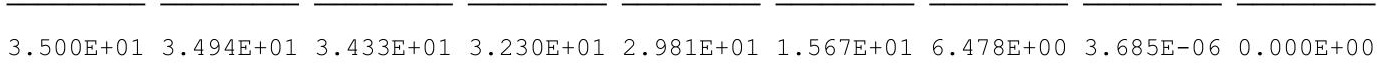

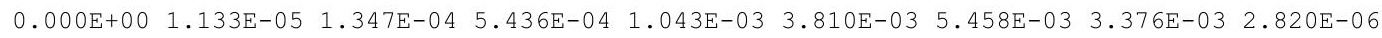

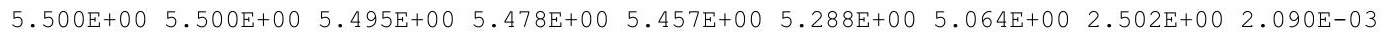
$\begin{array}{lllllllll}5.500 \mathrm{E}+00 & 5.500 \mathrm{E}+00 & 5.495 \mathrm{E}+00 & 5.479 \mathrm{E}+00 & 5.458 \mathrm{E}+00 & 5.291 \mathrm{E}+00 & 5.069 \mathrm{E}+00 & 2.506 \mathrm{E}+00 & 2.093 \mathrm{E}-03\end{array}$

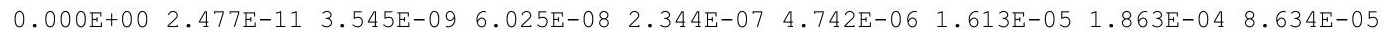
$\begin{array}{llllllllll}0.000 \mathrm{E}+00 & 2.405 \mathrm{E}-05 & 2.885 \mathrm{E}-04 & 1.200 \mathrm{E}-03 & 2.394 \mathrm{E}-03 & 1.174 \mathrm{E}-02 & 2.401 \mathrm{E}-02 & 1.508 \mathrm{E}-01 & 6.656 \mathrm{E}-02\end{array}$ $\begin{array}{lllllllll}0.000 \mathrm{E}+00 & 2.405 \mathrm{E}-05 & 2.885 \mathrm{E}-04 & 1.200 \mathrm{E}-03 & 2.394 \mathrm{E}-03 & 1.174 \mathrm{E}-02 & 2.403 \mathrm{E}-02 & 1.509 \mathrm{E}-01 & 6.665 \mathrm{E}-02\end{array}$

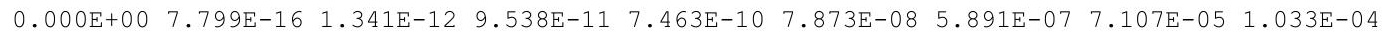

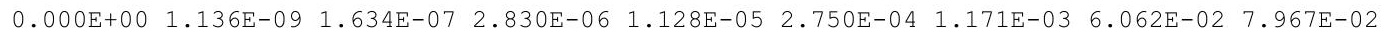

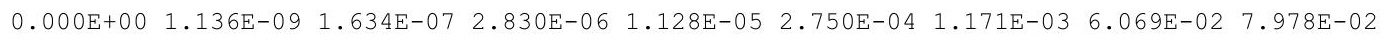

$\begin{array}{lllllllll}1.900 \mathrm{E}+01 & 1.857 \mathrm{E}+01 & 1.440 \mathrm{E}+01 & 5.979 \mathrm{E}+00 & 1.881 \mathrm{E}+00 & 1.809 \mathrm{E}-04 & 5.417 \mathrm{E}-10 & 0.000 \mathrm{E}+00 & 0.000 \mathrm{E}+00\end{array}$

$\begin{array}{lllllllll}7.176 \mathrm{E}-08 & 7.119 \mathrm{E}-08 & 6.526 \mathrm{E}-08 & 4.832 \mathrm{E}-08 & 3.254 \mathrm{E}-08 & 1.375 \mathrm{E}-09 & 1.774 \mathrm{E}-11 & 3.170 \mathrm{E}-42 & 0.000 \mathrm{E}+00\end{array}$

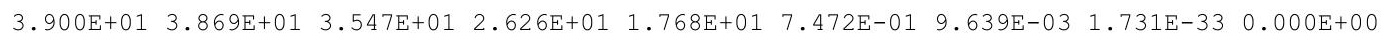
$\begin{array}{lllllllllllllllll}3.900 \mathrm{E}+01 & 3.869 \mathrm{E}+01 & 3.547 \mathrm{E}+01 & 2.626 \mathrm{E}+01 & 1.768 \mathrm{E}+01 & 7.472 \mathrm{E}-01 & 9.639 \mathrm{E}-03 & 1.731 \mathrm{E}-33 & 0.000 \mathrm{E}+00\end{array}$

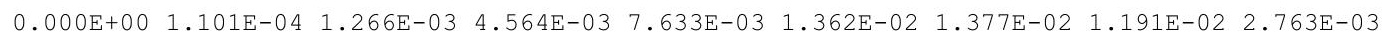
$\begin{array}{llllllllll}1.600 \mathrm{E}+02 & 1.600 \mathrm{E}+02 & 1.600 \mathrm{E}+02 & 1.599 \mathrm{E}+02 & 1.597 \mathrm{E}+02 & 1.587 \mathrm{E}+02 & 1.573 \mathrm{E}+02 & 1.360 \mathrm{E}+02 & 3.156 \mathrm{E}+01\end{array}$ $\begin{array}{lllllllllllll}0.000 \mathrm{E}+00 & 4.536 \mathrm{E}-04 & 5.442 \mathrm{E}-03 & 2.266 \mathrm{E}-02 & 4.529 \mathrm{E}-02 & 2.251 \mathrm{E}-01 & 4.689 \mathrm{E}-01 & 3.911 \mathrm{E}+00 & 1.034 \mathrm{E}+01\end{array}$ $\begin{array}{llllllllll}1.600 \mathrm{E}+02 & 1.600 \mathrm{E}+02 & 1.600 \mathrm{E}+02 & 1.599 \mathrm{E}+02 & 1.598 \mathrm{E}+02 & 1.589 \mathrm{E}+02 & 1.578 \mathrm{E}+02 & 1.399 \mathrm{E}+02 & 4.191 \mathrm{E}+01\end{array}$

$\begin{array}{lllllllll}0.000 \mathrm{E}+00 & 4.963 \mathrm{E}-10 & 6.944 \mathrm{E}-08 & 1.095 \mathrm{E}-06 & 3.884 \mathrm{E}-06 & 4.705 \mathrm{E}-05 & 1.147 \mathrm{E}-04 & 1.088 \mathrm{E}-03 & 3.313 \mathrm{E}-03\end{array}$ $\begin{array}{lllllllllllllllll}1.000 \mathrm{E}+02 & 1.000 \mathrm{E}+02 & 9.999 \mathrm{E}+01 & 9.995 \mathrm{E}+01 & 9.989 \mathrm{E}+01 & 9.947 \mathrm{E}+01 & 9.888 \mathrm{E}+01 & 8.984 \mathrm{E}+01 & 3.424 \mathrm{E}+01\end{array}$ $\begin{array}{lllllllllll}0.000 \mathrm{E}+00 & 1.440 \mathrm{E}-03 & 1.728 \mathrm{E}-02 & 7.197 \mathrm{E}-02 & 1.438 \mathrm{E}-01 & 7.153 \mathrm{E}-01 & 1.491 \mathrm{E}+00 & 1.259 \mathrm{E}+01 & 3.791 \mathrm{E}+01\end{array}$ $\begin{array}{llllllllllll}0.000 \mathrm{E}+00 & 2.041 \mathrm{E}-09 & 2.939 \mathrm{E}-07 & 5.100 \mathrm{E}-06 & 2.039 \mathrm{E}-05 & 5.070 \mathrm{E}-04 & 2.219 \mathrm{E}-03 & 1.785 \mathrm{E}-01 & 5.353 \mathrm{E}+00\end{array}$

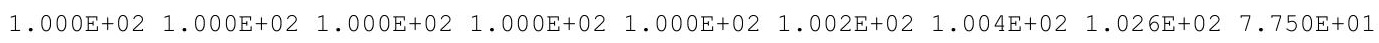

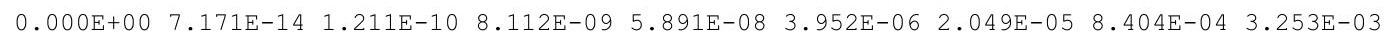
$\begin{array}{lllllllllllll}0.000 \mathrm{E}+00 & 4.331 \mathrm{E}-02 & 5.184 \mathrm{E}-01 & 2.142 \mathrm{E}+00 & 4.235 \mathrm{E}+00 & 1.937 \mathrm{E}+01 & 3.613 \mathrm{E}+01 & 8.860 \mathrm{E}+01 & 3.422 \mathrm{E}+01\end{array}$ $\begin{array}{llllllllllll}0.000 \mathrm{E}+00 & 3.119 \mathrm{E}-07 & 4.484 \mathrm{E}-0 & 7.739 \mathrm{E}-04 & 3.071 \mathrm{E}-03 & 7.220 \mathrm{E}-02 & 2.933 \mathrm{E}-01 & 9.761 \mathrm{E}+00 & 3.722 \mathrm{E}+01\end{array}$ $\begin{array}{lllllllll}0.000 \mathrm{E}+00 & 2.948 \mathrm{E}-13 & 5.087 \mathrm{E}-10 & 3.663 \mathrm{E}-08 & 2.913 \mathrm{E}-07 & 3.471 \mathrm{E}-05 & 3.016 \mathrm{E}-04 & 1.152 \mathrm{E}-01 & 5.138 \mathrm{E}+00\end{array}$ $\begin{array}{lllllllllllllllll}0.000 \mathrm{E}+00 & 4.331 \mathrm{E}-02 & 5.185 \mathrm{E}-01 & 2.142 \mathrm{E}+00 & 4.238 \mathrm{E}+00 & 1.944 \mathrm{E}+01 & 3.643 \mathrm{E}+01 & 9.848 \mathrm{E}+01 & 7.658 \mathrm{E}+01\end{array}$

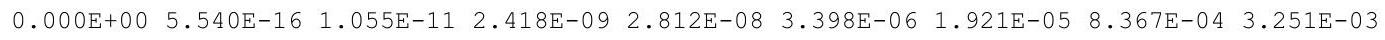
$\begin{array}{lllllllllllll}0.000 \mathrm{E}+00 & 6.663 \mathrm{E}-04 & 8.578 \mathrm{E}-02 & 1.058 \mathrm{E}+00 & 2.946 \mathrm{E}+00 & 1.823 \mathrm{E}+01 & 3.524 \mathrm{E}+01 & 8.856 \mathrm{E}+01 & 3.421 \mathrm{E}+01\end{array}$ $\begin{array}{llllllllll}0.000 \mathrm{E}+00 & 3.207 \mathrm{E}-09 & 5.094 \mathrm{E}-06 & 2.837 \mathrm{E}-04 & 1.706 \mathrm{E}-03 & 6.374 \mathrm{E}-02 & 2.769 \mathrm{E}-01 & 9.719 \mathrm{E}+00 & 3.720 \mathrm{E}+01\end{array}$

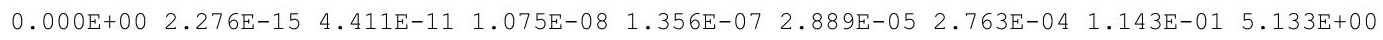
$\begin{array}{lllllllllllllll}0.000 \mathrm{E}+00 & 6.663 \mathrm{E}-04 & 8.578 \mathrm{E}-02 & 1.058 \mathrm{E}+00 & 2.947 \mathrm{E}+00 & 1.830 \mathrm{E}+01 & 3.551 \mathrm{E}+01 & 9.839 \mathrm{E}+01 & 7.654 \mathrm{E}+01\end{array}$

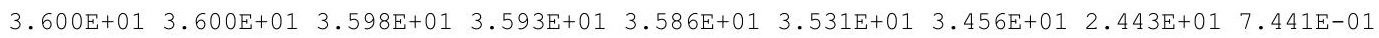

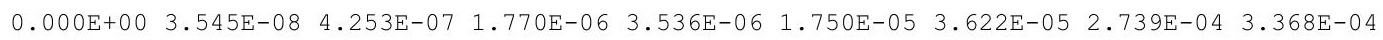
$\begin{array}{lllllllll}6.500 \mathrm{E}+00 & 6.500 \mathrm{E}+00 & 6.499 \mathrm{E}+00 & 6.496 \mathrm{E}+00 & 6.491 \mathrm{E}+00 & 6.457 \mathrm{E}+00 & 6.409 \mathrm{E}+00 & 5.685 \mathrm{E}+00 & 1.702 \mathrm{E}+00\end{array}$

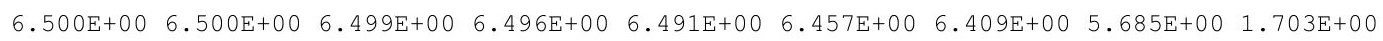


Parent Dose Report

Title : RESRAD-OFFSITE Parameters for Offsite Resident Farmer Forward Run 1,050 Years File : OFFSITE-RF_FORWARD-7-11.ROF

Table of Contents

Part I: Mixture Sums and Single Radionuclide Guidelines

Dose Conversion Factor (and Related) Parameter Summary ... 2

Site-Specific Parameter Summary ................ 11

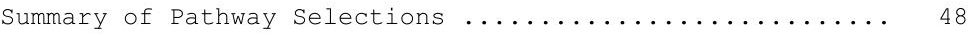

Contaminated Zone and Total Dose Summary ............ 49

Total Dose Components

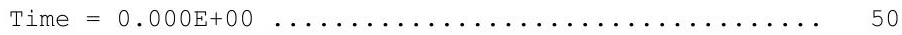

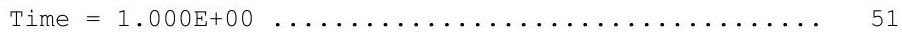

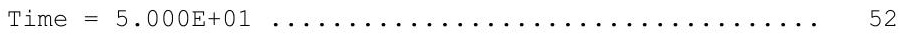

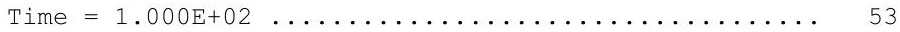

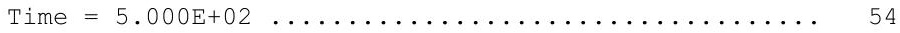

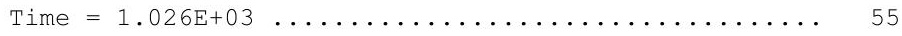

Dose/Source Ratios Summed Over All Pathways .......... 56

Single Radionuclide Soil Guidelines ............... 58

Dose Per Nuclide Summed Over All Pathways ............ 59

Soil Concentration Per Nuclide ................. 61

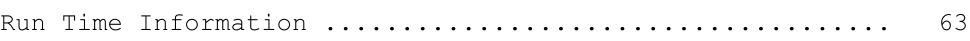


RESRAD-OFFSITE, Version 2.5

Parent Dose Report

Title : RESRAD-OFFSITE Parameters for Offsite Resident Farmer Forward Run 1,050 Years

File : OFFSITE-RF FORWARD-7-11.ROF

Dose Conversion Factor (and Related) Parameter Summary

Current Library: ICRP 60

Default Library: ICRP 60

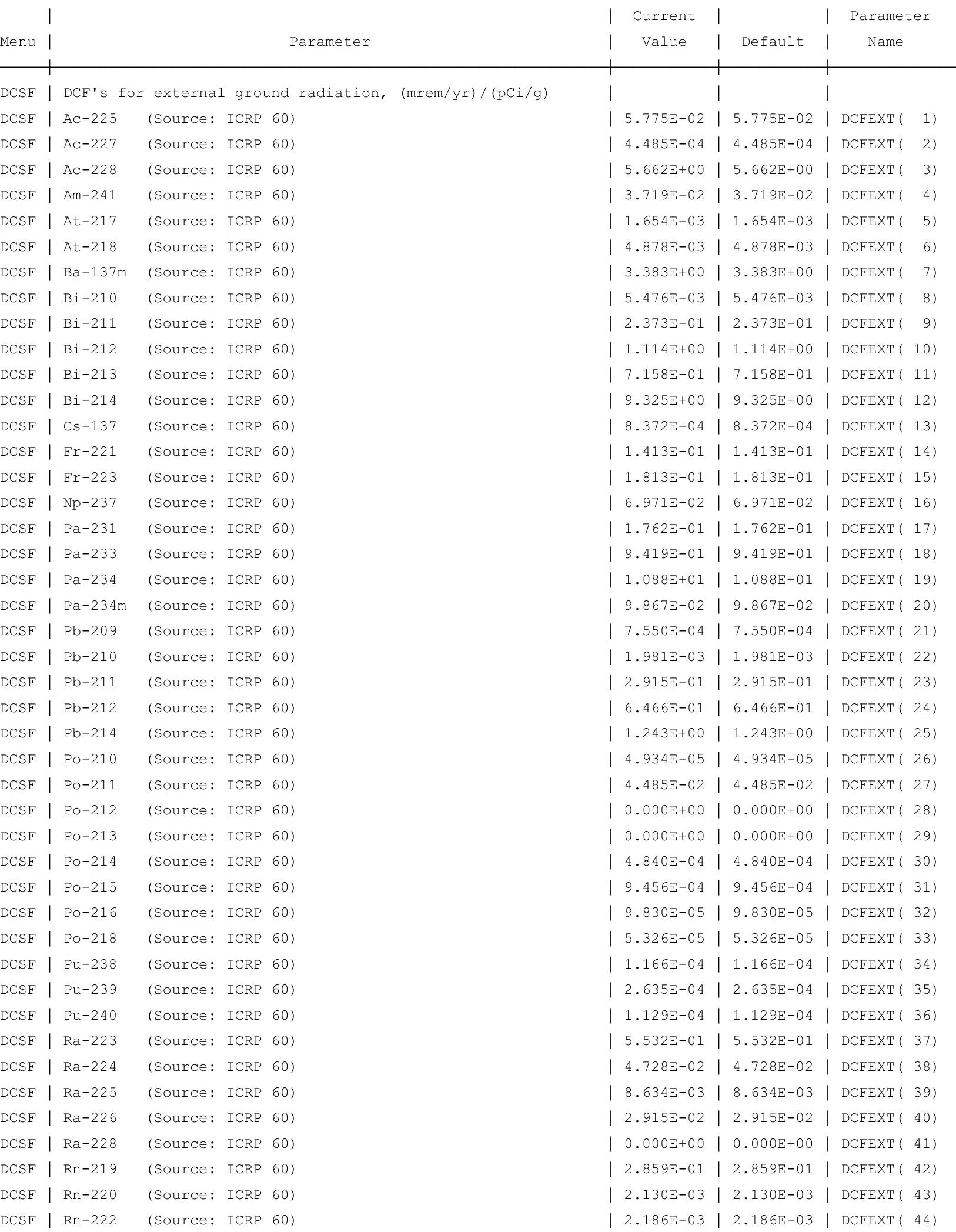


RESRAD-OFFSITE, Version $2.5 \quad \mathrm{~T}^{1 / 2}$ Limit $=180$ days

Parent Dose Report

Title : RESRAD-OFFSITE Parameters for Offsite Resident Farmer Forward Run 1,050 Years

File : OFFSITE-RF_FORWARD-7-11.ROF

Dose Conversion Factor (and Related) Parameter Summary (continued)

Current Library: ICRP 60

Default Library: ICRP 60

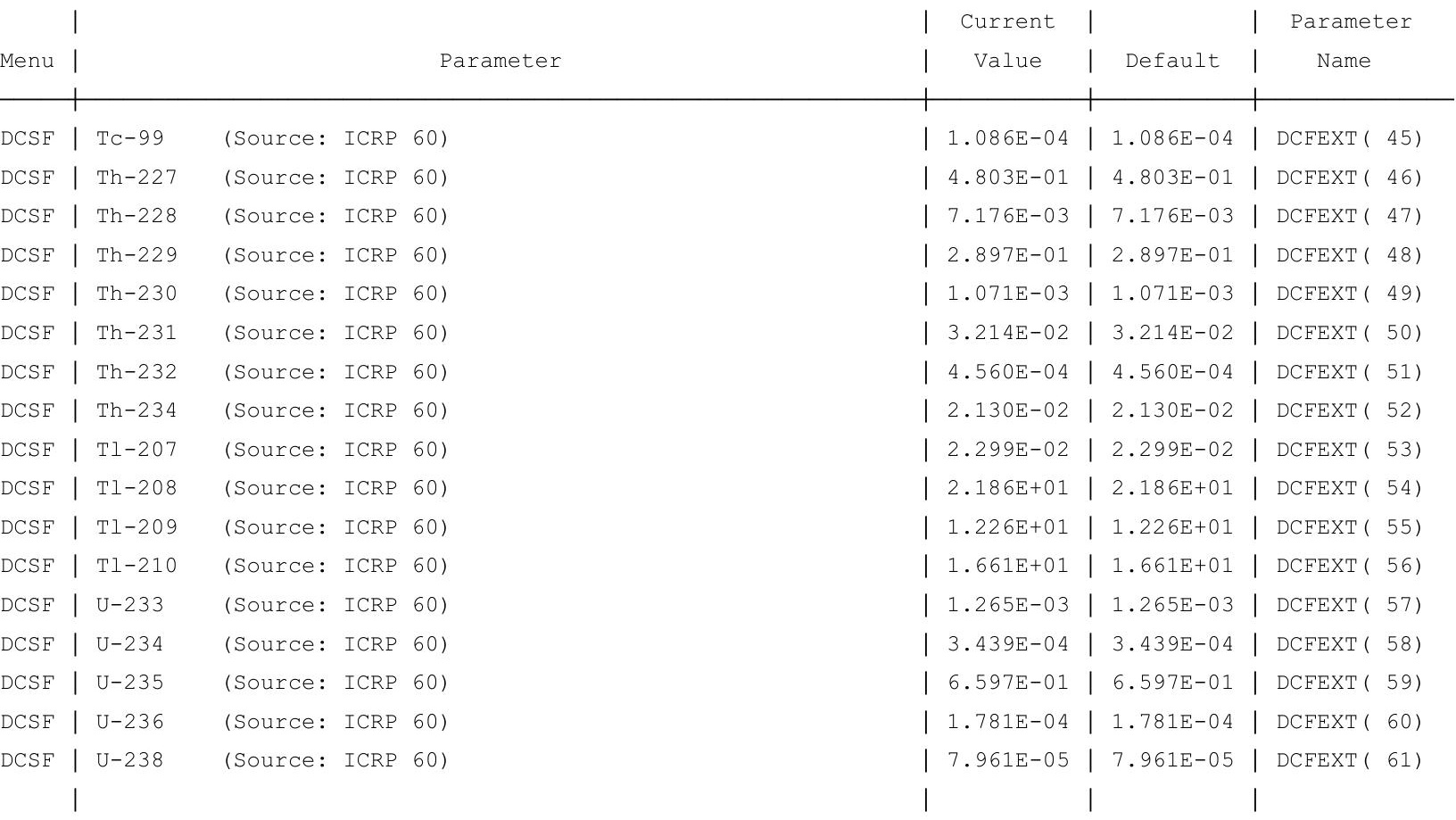

Current Library: ICRP 72 (Adult)

Default Library: ICRP 72 (Adult)

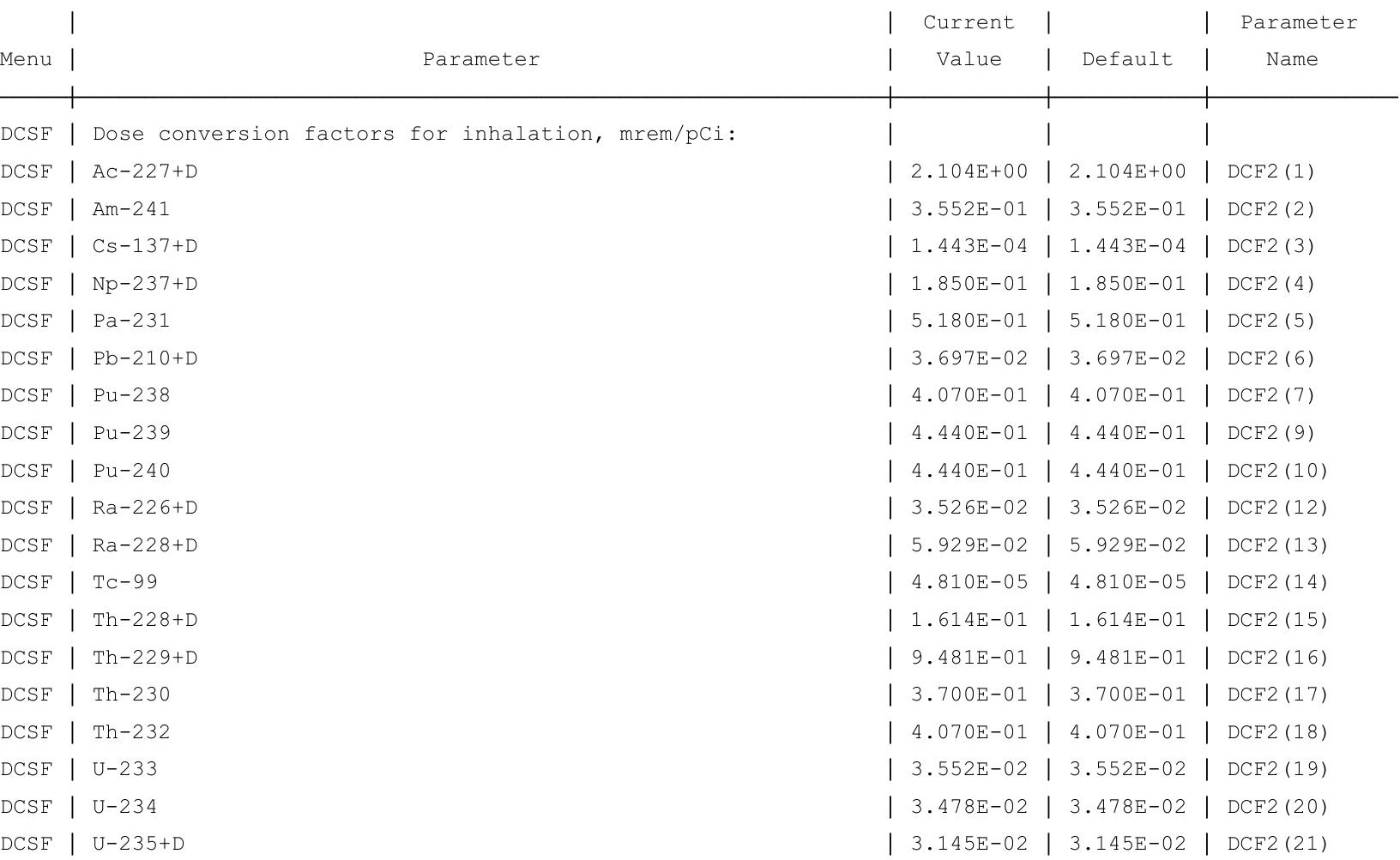


RESRAD-OFFSITE, Version 2.9

Parent Dose Report

Title : RESRAD-OFFSITE Parameters for Offsite Resident Farmer Forward Run 1,050 Years

File : OFFSITE-RF_FORWARD-7-11.ROF

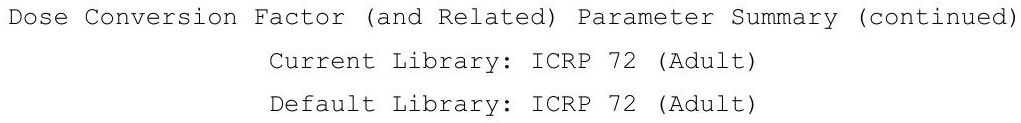

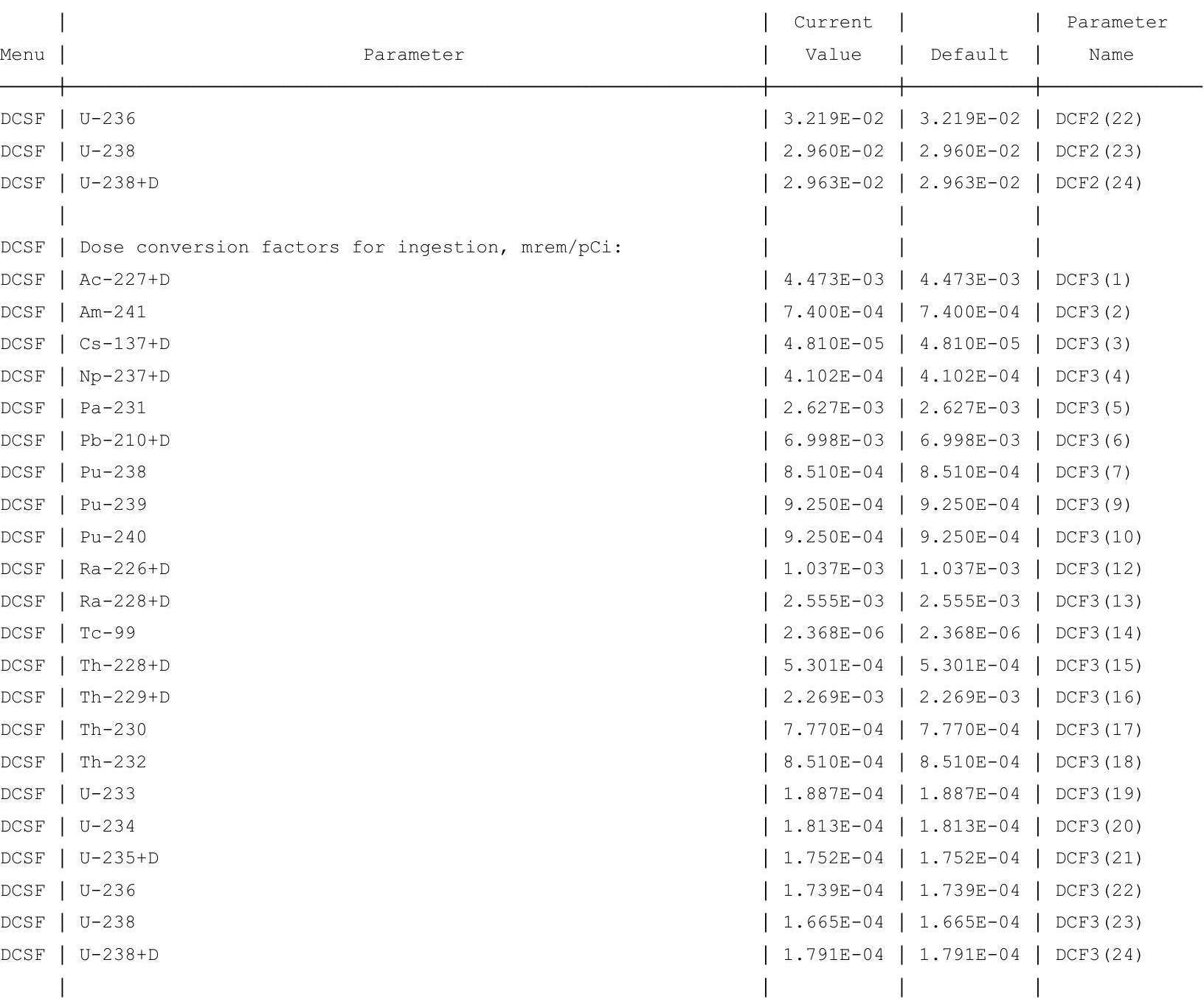


RESRAD-OFFSITE, Version 2.5

Parent Dose Report

Title : RESRAD-OFFSITE Parameters for Offsite Resident Farmer Forward Run 1,050 Years

File : OFFSITE-RF FORWARD-7-11.ROF

Dose Conversion Factor (and Related) Parameter Summary (continued)

Current Library: RESRAD Default Transfer factors

Default Library: RESRAD Default Transfer factors

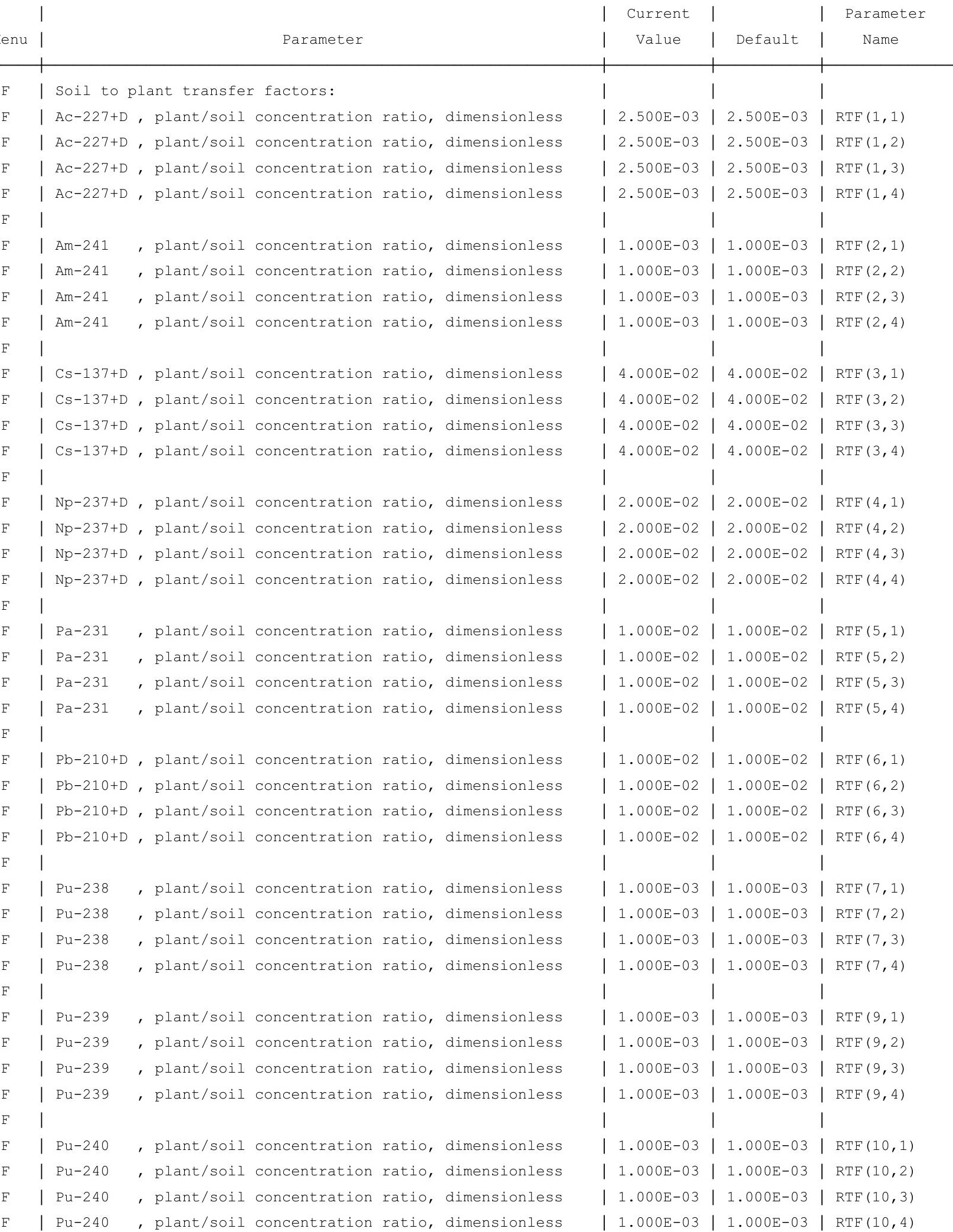


RESRAD-OFFSITE, Version 2.5

Parent Dose Report

Title : RESRAD-OFFSITE Parameters for Offsite Resident Farmer Forward Run 1,050 Years

File : OFFSITE-RF FORWARD-7-11.ROF

Dose Conversion Factor (and Related) Parameter Summary (continued)

Current Library: RESRAD Default Transfer factors

Default Library: RESRAD Default Transfer factors

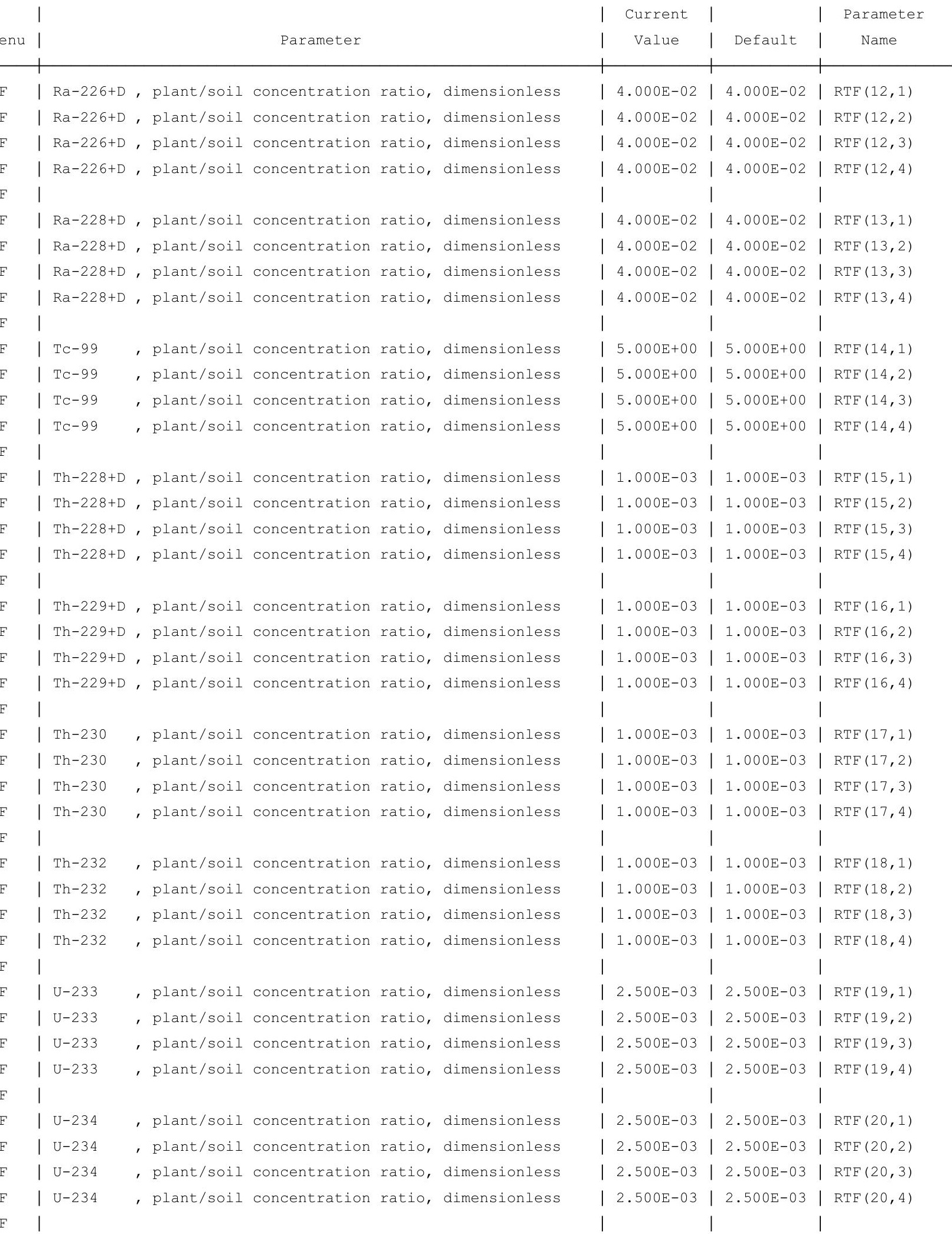


RESRAD-OFFSITE, Version 2.5

Parent Dose Report

Title : RESRAD-OFFSITE Parameters for Offsite Resident Farmer Forward Run 1,050 Years

File : OFFSITE-RF_FORWARD-7-11.ROF

Dose Conversion Factor (and Related) Parameter Summary (continued)

Current Library: RESRAD Default Transfer factors

Default Library: RESRAD Default Transfer factors

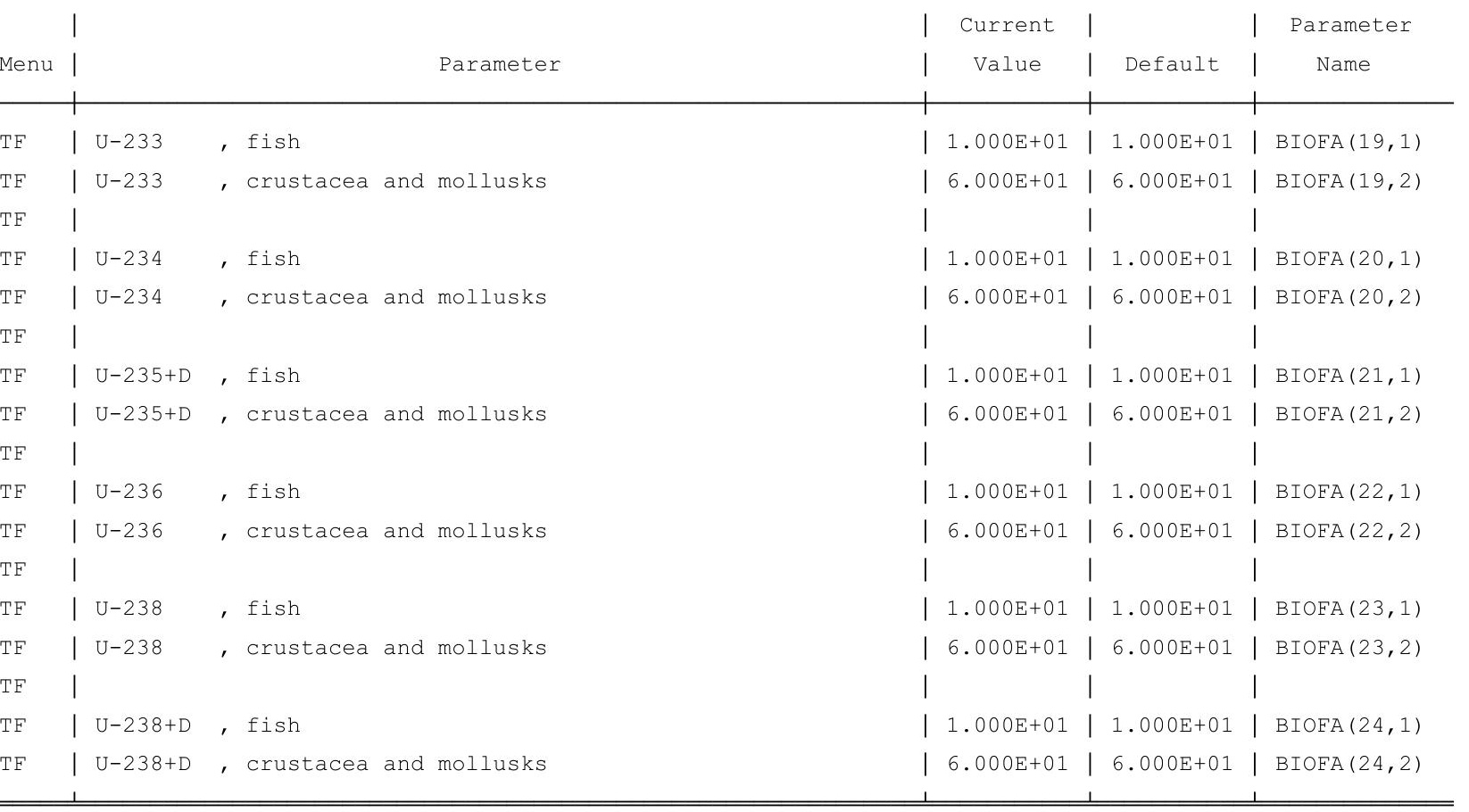


RESRAD-OFFSITE, Version $2.5 \quad$ T1/2 Limit $=180$ days $\quad$ 07/21/2011 $10: 27 \quad$ Page

Parent Dose Report

Title : RESRAD-OFFSITE Parameters for Offsite Resident Farmer Forward Run 1,050 Years

File : OFFSITE-RF_FORWARD-7-11.ROF

Site-Specific Parameter Summary

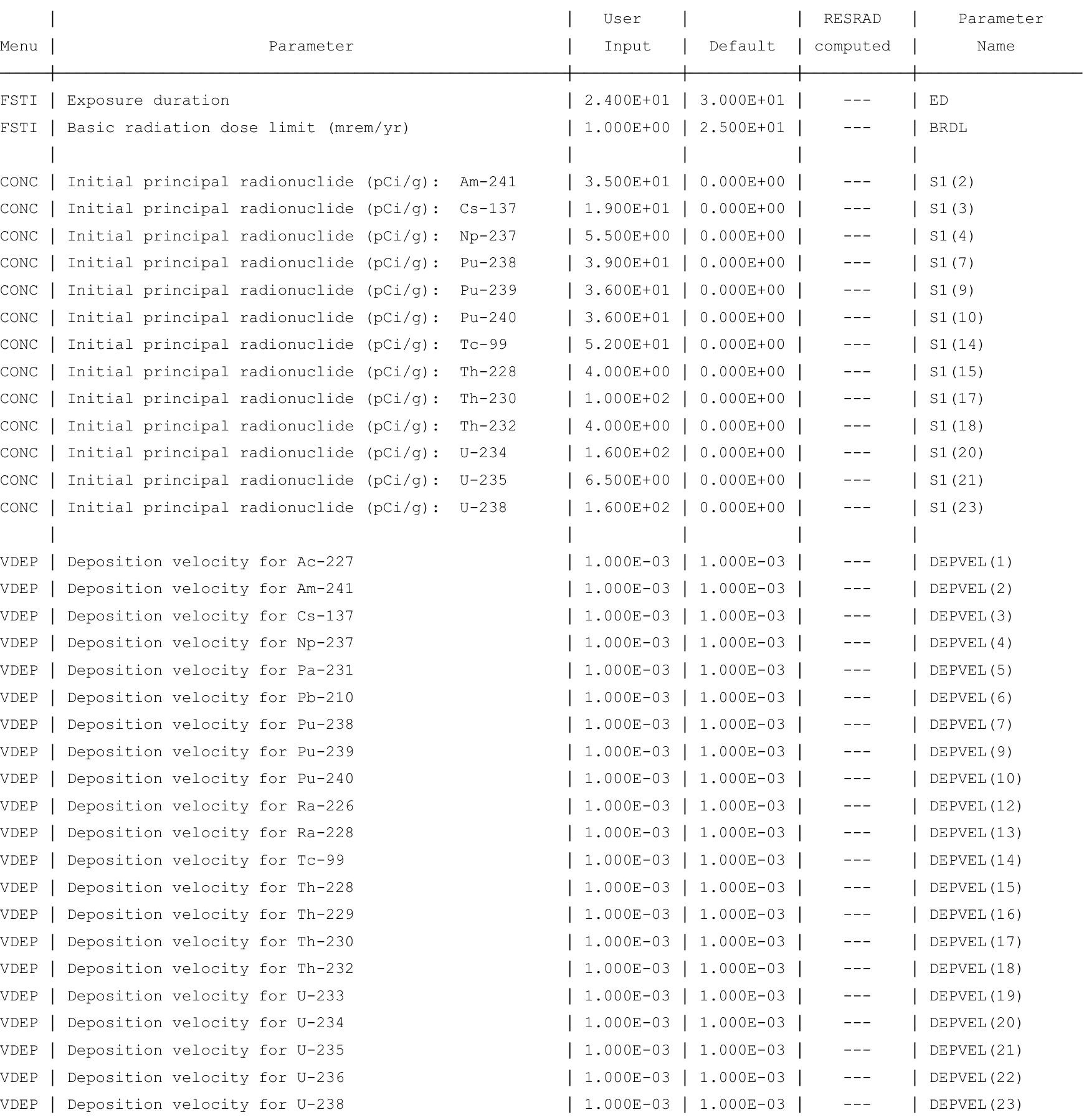

DEP Deposition velocity for U-238 
RESRAD-OFFSITE, Version $2.5 \quad T^{1 / 3}$ Limit $=180$ days $\quad 07 / 21 / 2011 \quad 10: 27 \quad$ Page

Parent Dose Report

Title : RESRAD-OFFSITE Parameters for Offsite Resident Farmer Forward Run 1,050 Years

File : OFFSITE-RF_FORWARD-7-11.ROF

Site-Specific Parameter Summary (continued)

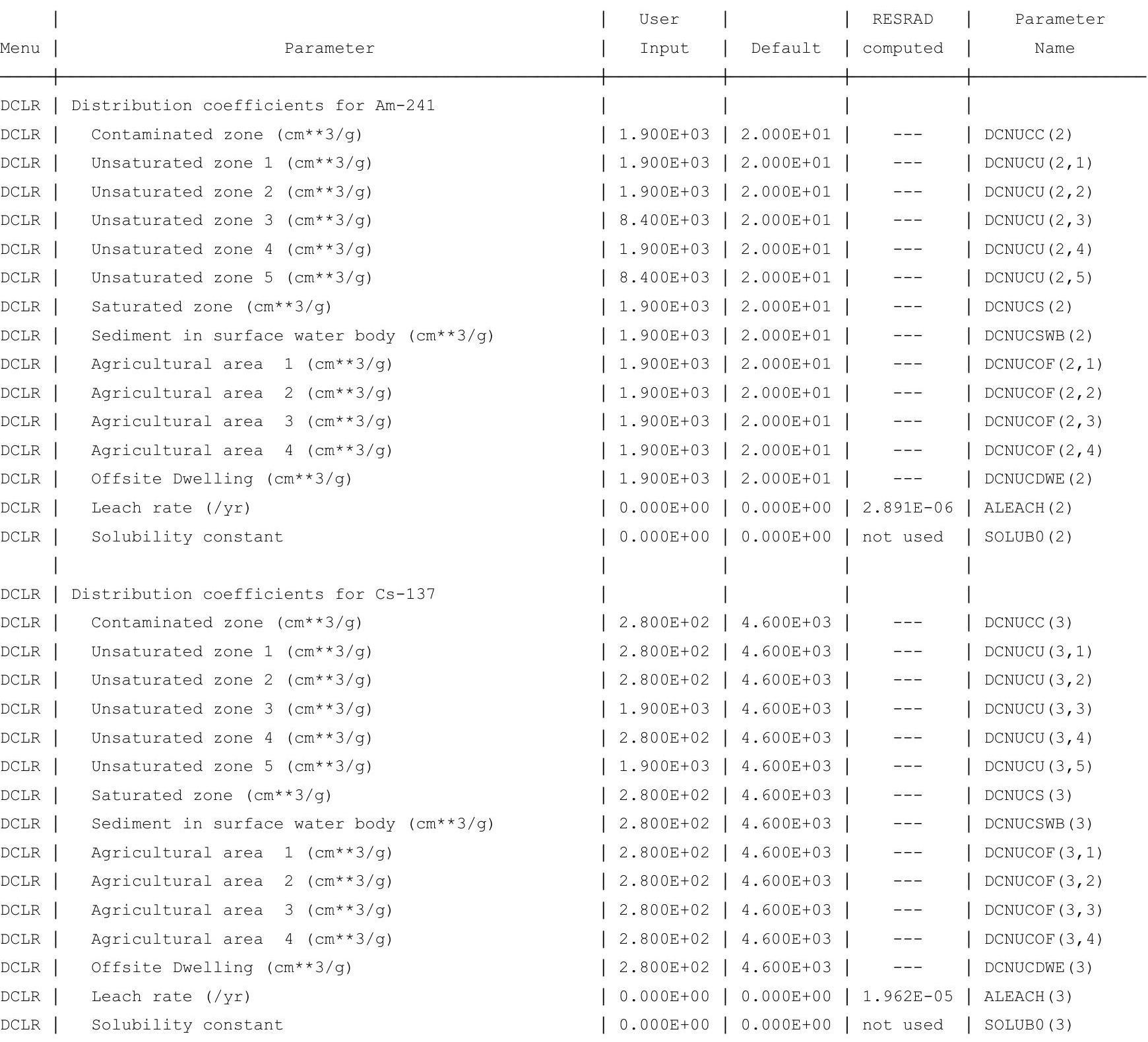


RESRAD-OFFSITE, Version $2.5 \quad T^{1 / 2}$ Limit $=180$ days $\quad 07 / 21 / 2011 \quad 10: 27$ Page

Parent Dose Report

Title : RESRAD-OFFSITE Parameters for Offsite Resident Farmer Forward Run 1,050 Years

File : OFFSITE-RF_FORWARD-7-11.ROF

Site-Specific Parameter Summary (continued)

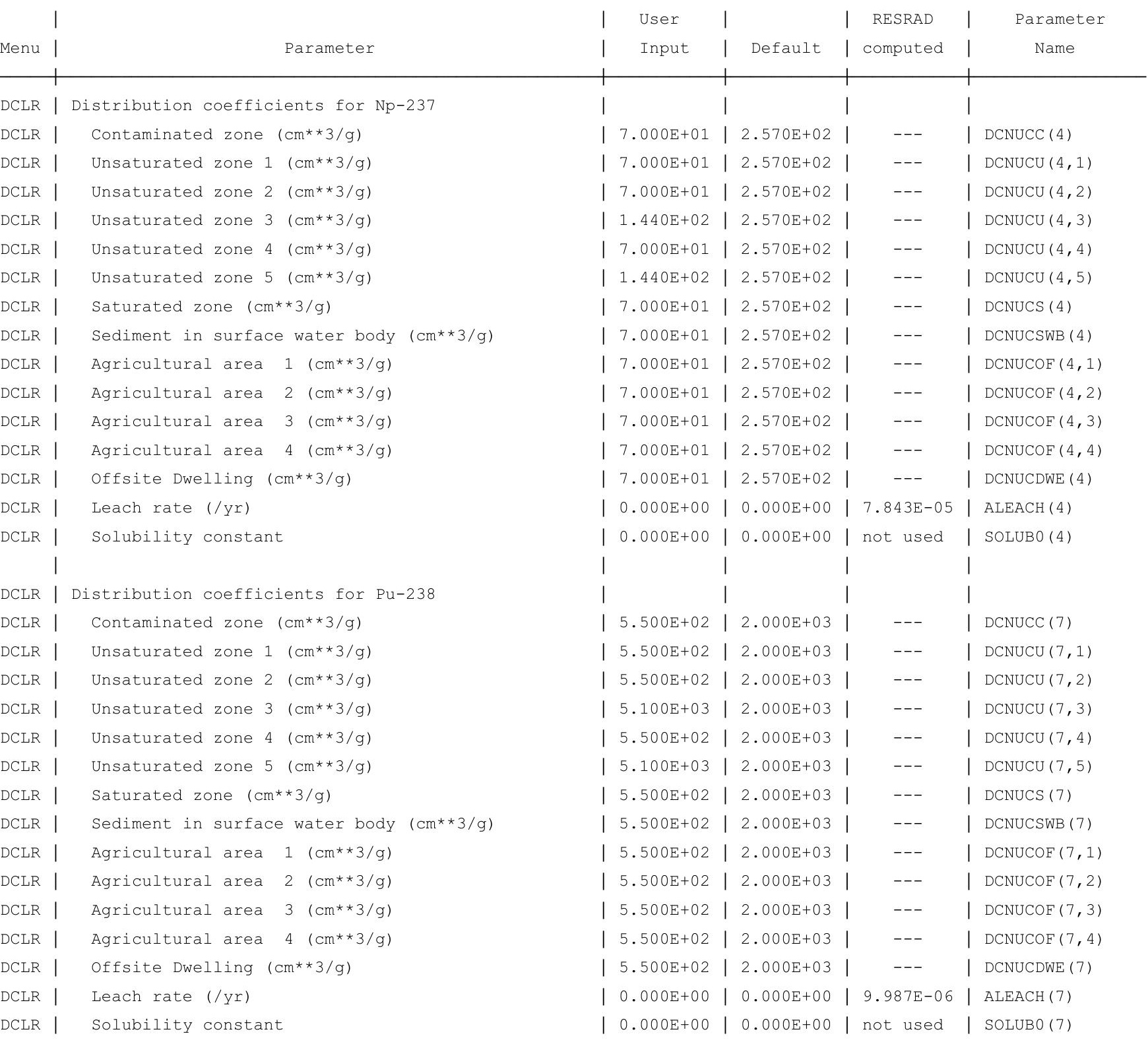


RESRAD-OFFSITE, Version $2.5 \quad T^{1 / 3}$ Limit $=180$ days $\quad 07 / 21 / 2011 \quad 10: 27 \quad$ Page

Parent Dose Report

Title : RESRAD-OFFSITE Parameters for Offsite Resident Farmer Forward Run 1,050 Years

File : OFFSITE-RF_FORWARD-7-11.ROF

Site-Specific Parameter Summary (continued)

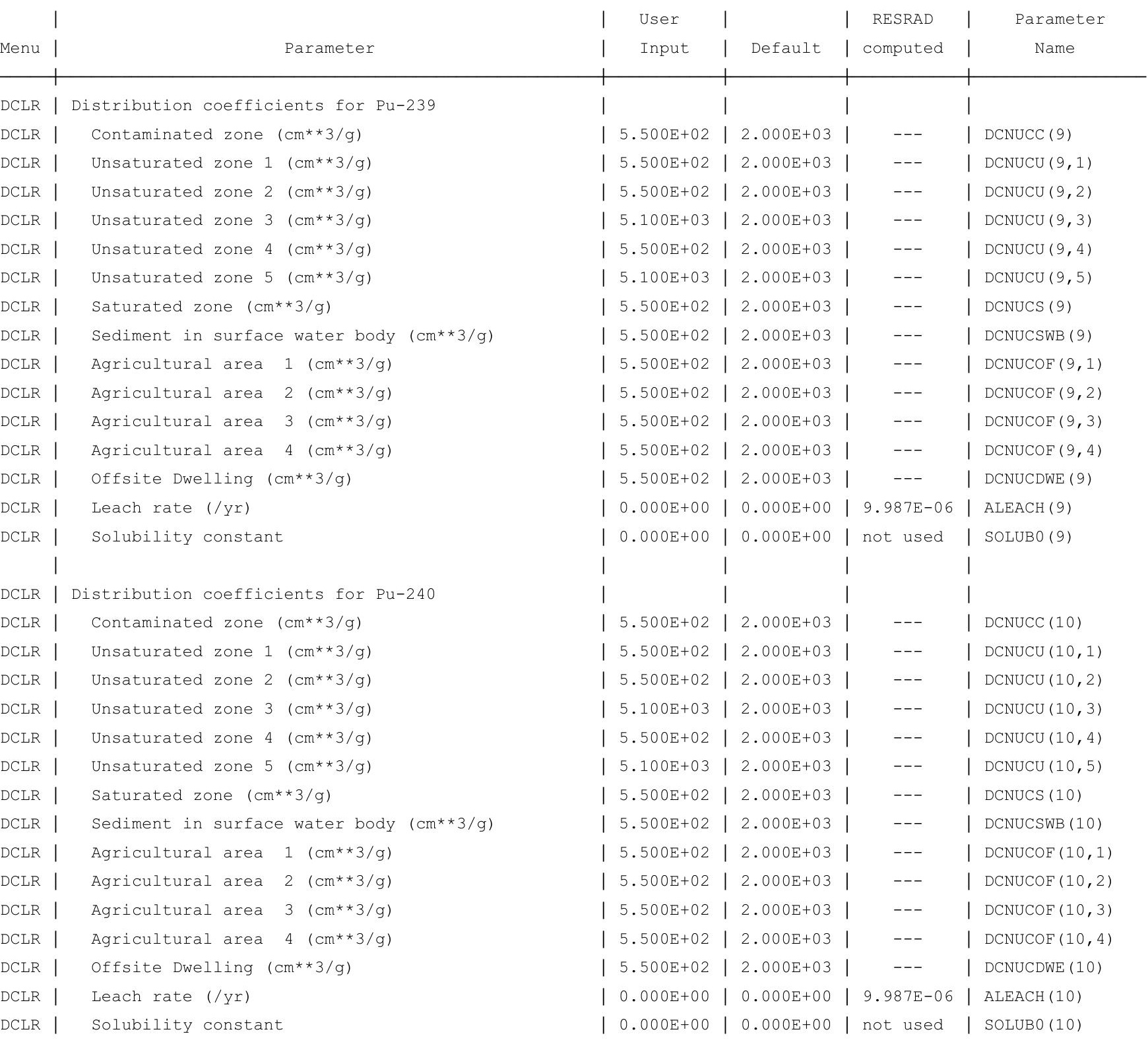


RESRAD-OFFSITE, Version $2.5 \quad T^{1 / 2}$ Limit $=180$ days $\quad 07 / 21 / 2011 \quad 10: 27$ Page

Parent Dose Report

Title : RESRAD-OFFSITE Parameters for Offsite Resident Farmer Forward Run 1,050 Years

File : OFFSITE-RF_FORWARD-7-11.ROF

Site-Specific Parameter Summary (continued)

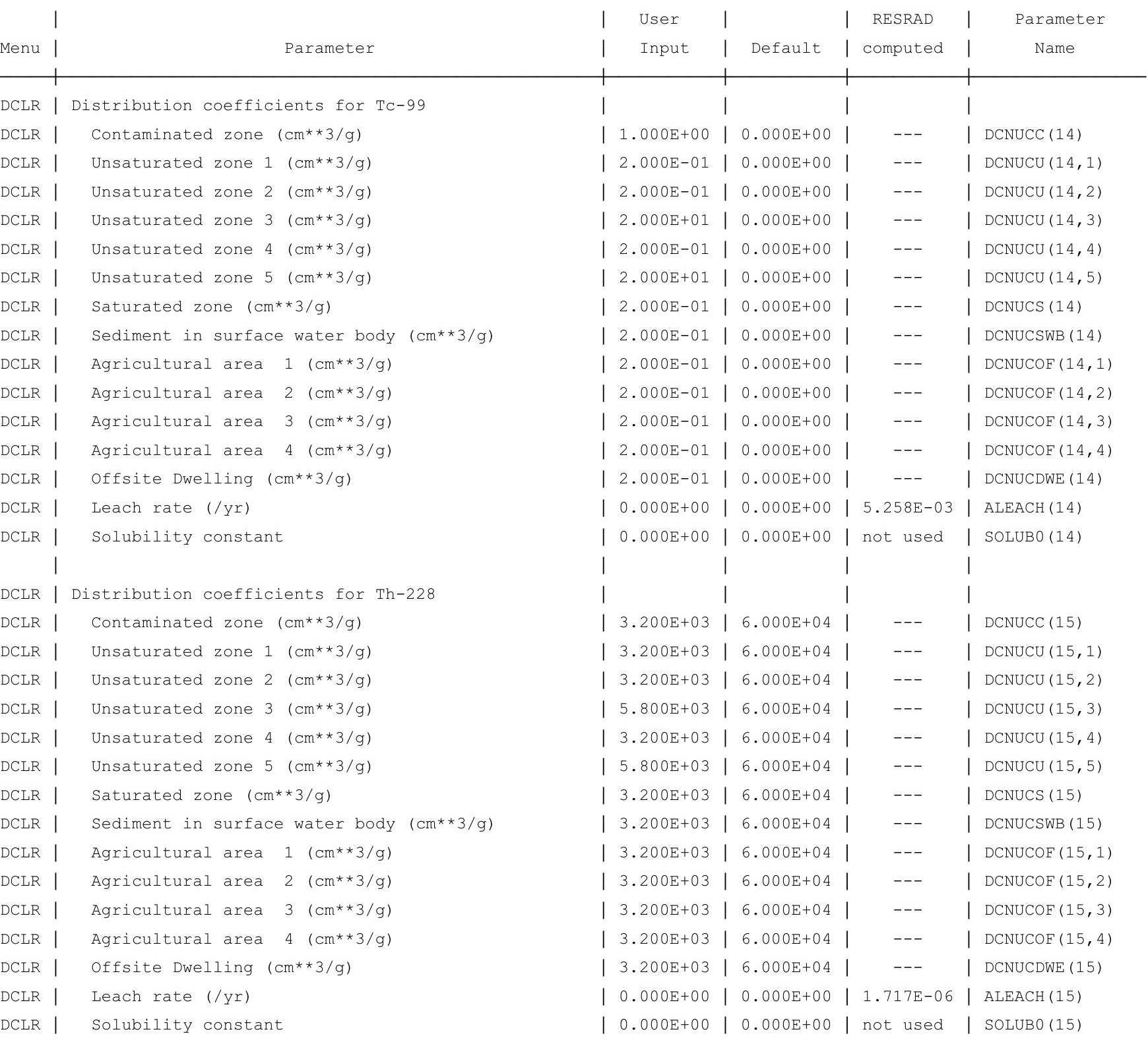


RESRAD-OFFSITE, Version $2.5 \quad T^{1 / 3}$ Limit $=180$ days $\quad 07 / 21 / 2011 \quad 10: 27 \quad$ Page

Parent Dose Report

Title : RESRAD-OFFSITE Parameters for Offsite Resident Farmer Forward Run 1,050 Years

File : OFFSITE-RF_FORWARD-7-11.ROF

Site-Specific Parameter Summary (continued)

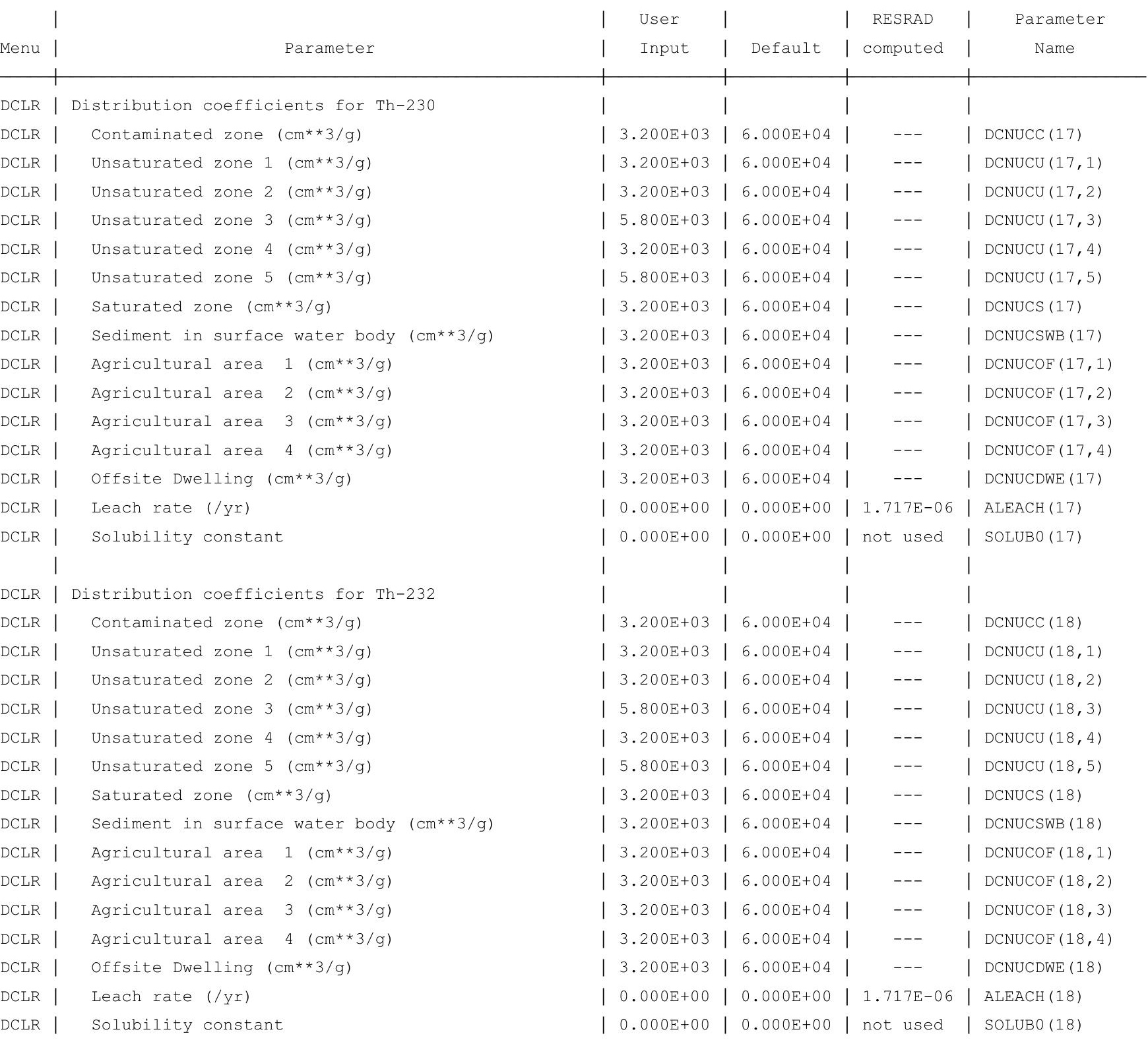


RESRAD-OFFSITE, Version $2.5 \quad T^{1 / 2}$ Limit $=180$ days $\quad 07 / 21 / 2011 \quad 10: 27$ Page

Parent Dose Report

Title : RESRAD-OFFSITE Parameters for Offsite Resident Farmer Forward Run 1,050 Years

File : OFFSITE-RF_FORWARD-7-11.ROF

Site-Specific Parameter Summary (continued)

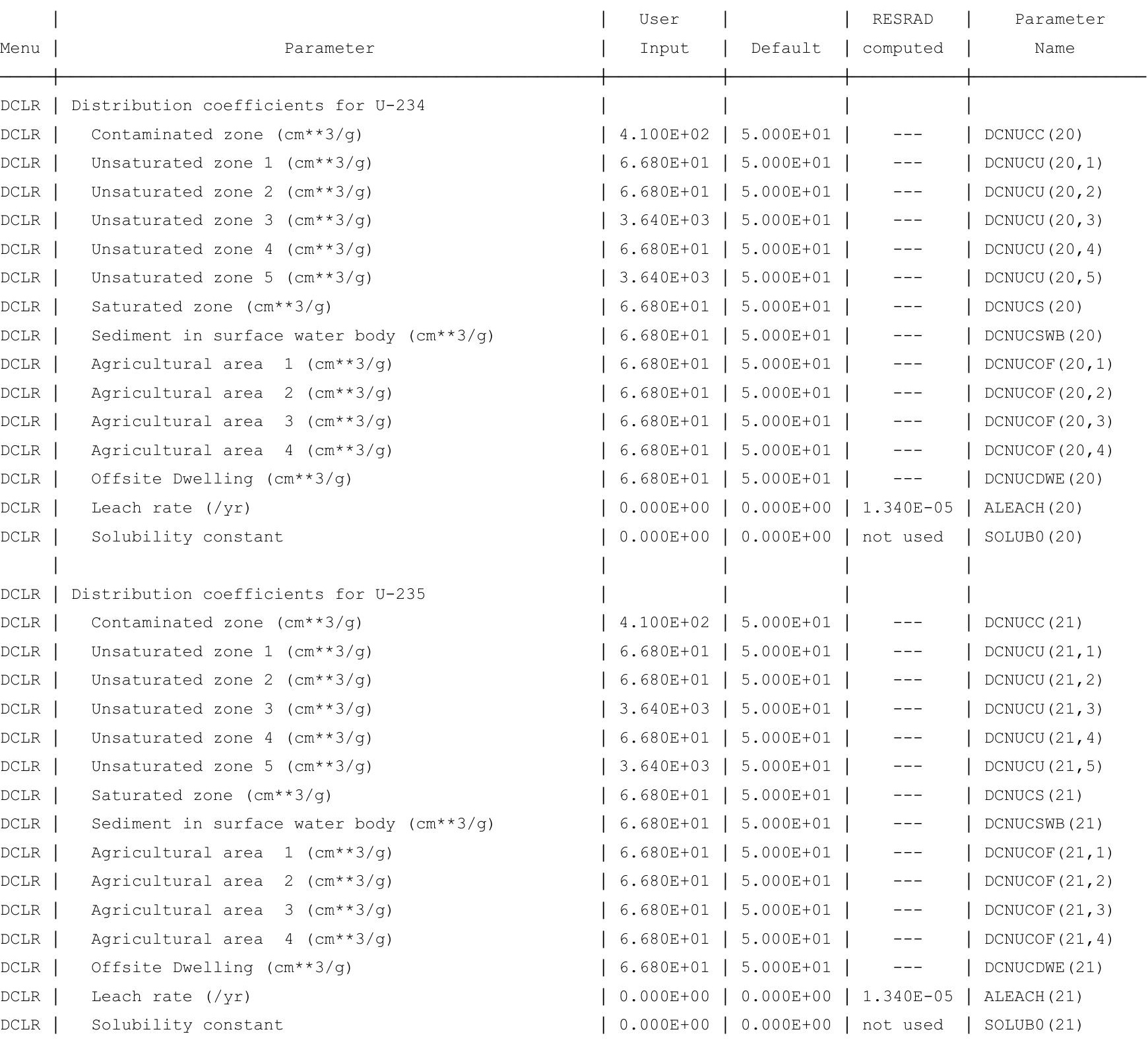


RESRAD-OFFSITE, Version $2.5 \quad T^{1 / 2}$ Limit $=180$ days $\quad 07 / 21 / 2011 \quad 10: 27$ Page

Parent Dose Report

Title : RESRAD-OFFSITE Parameters for Offsite Resident Farmer Forward Run 1,050 Years

File : OFFSITE-RF_FORWARD-7-11.ROF

Site-Specific Parameter Summary (continued)

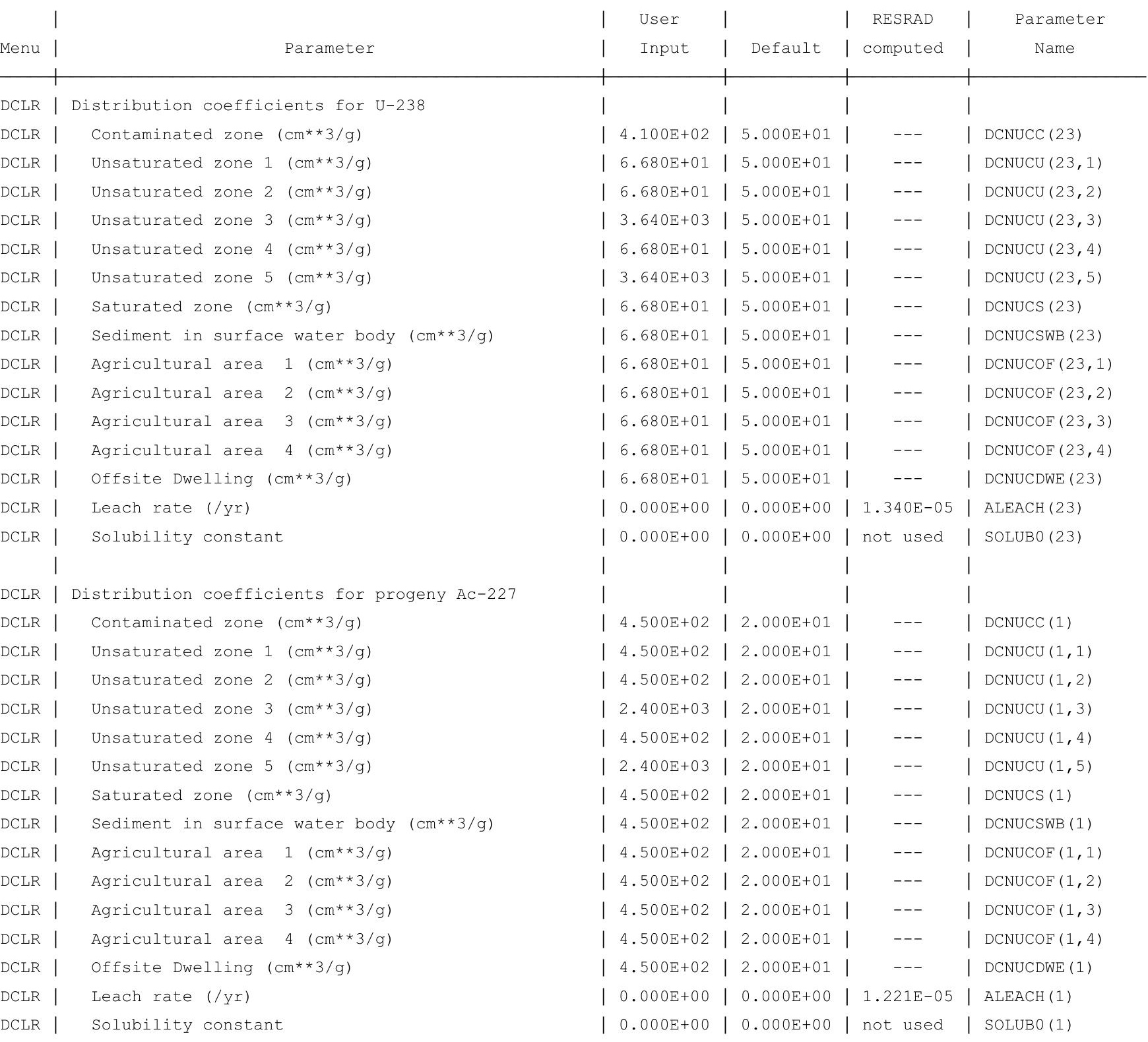


RESRAD-OFFSITE, Version $2.5 \quad T^{1 / 2}$ Limit $=180$ days $\quad 07 / 21 / 2011 \quad 10: 27$ Page

Parent Dose Report

Title : RESRAD-OFFSITE Parameters for Offsite Resident Farmer Forward Run 1,050 Years

File : OFFSITE-RF_FORWARD-7-11.ROF

Site-Specific Parameter Summary (continued)

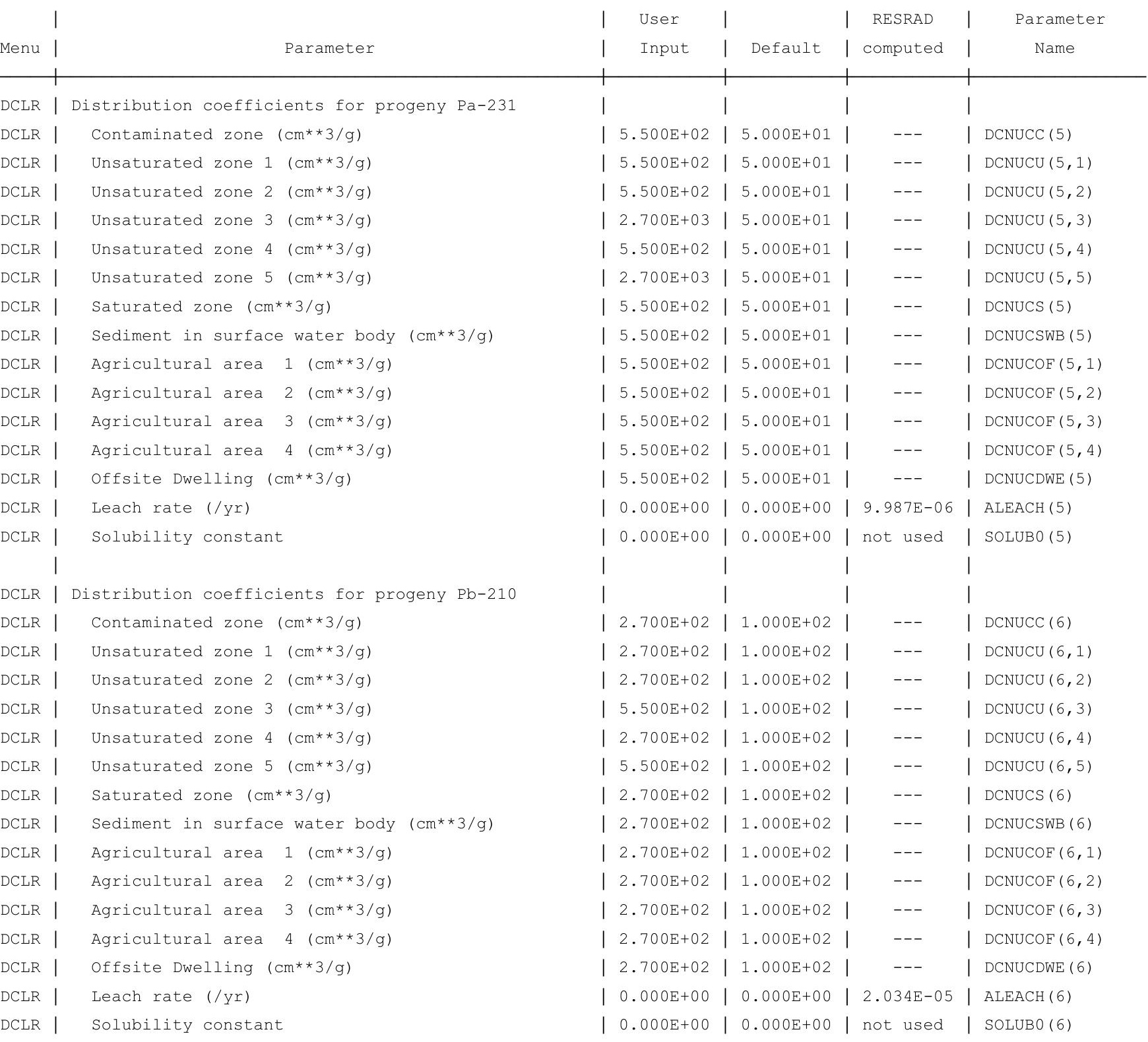


RESRAD-OFFSITE, Version 2.5

Parent Dose Report

Title : RESRAD-OFFSITE Parameters for Offsite Resident Farmer Forward Run 1,050 Years

File : OFFSITE-RF_FORWARD-7-11.ROF

Site-Specific Parameter Summary (continued)

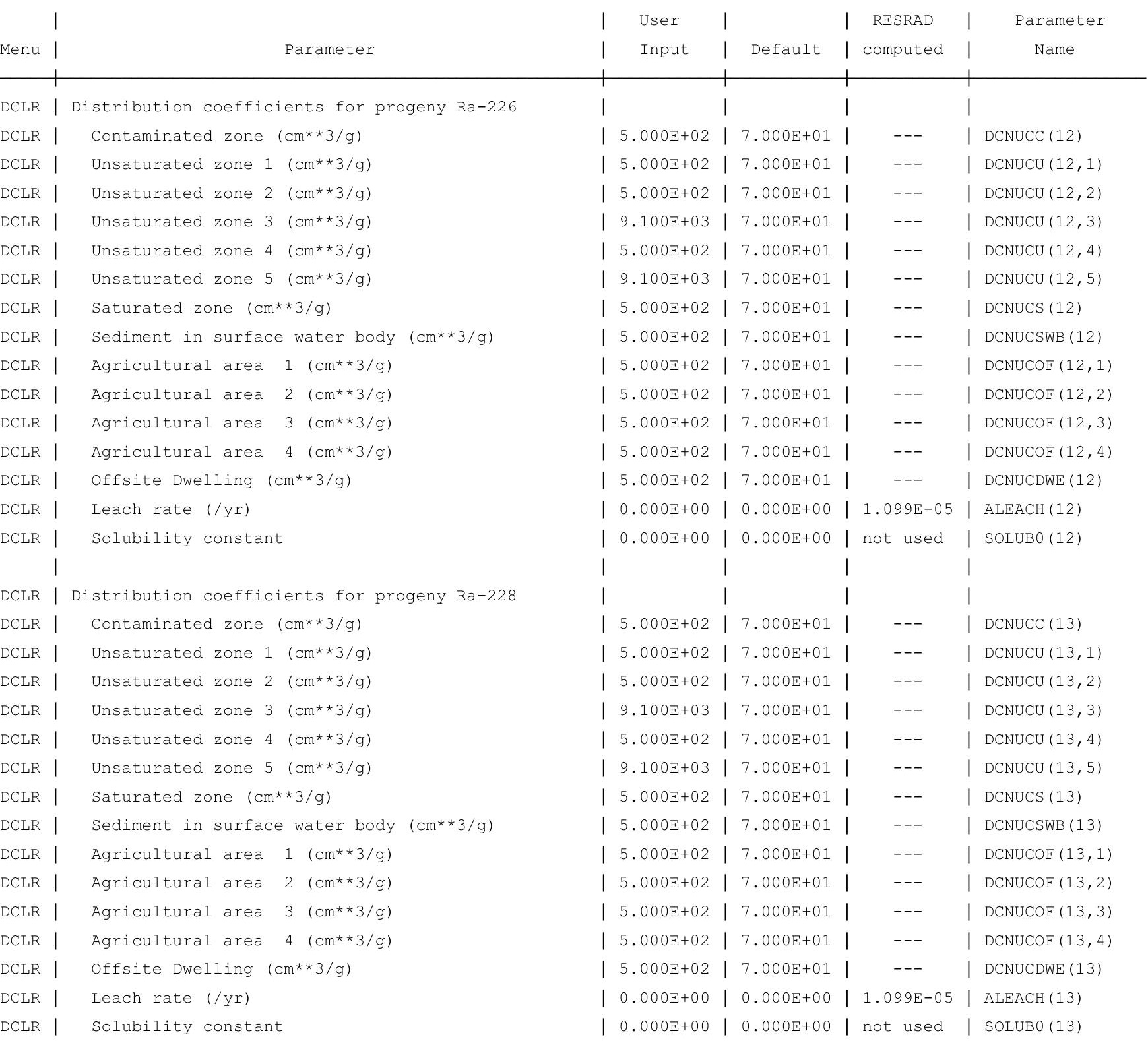


RESRAD-OFFSITE, Version $2.5 \quad$ T⿱11/2 Limit $=180$ days $\quad 07 / 21 / 2011 \quad 10: 27 \quad$ Page

Parent Dose Report

Title : RESRAD-OFFSITE Parameters for Offsite Resident Farmer Forward Run 1,050 Years

File : OFFSITE-RF_FORWARD-7-11.ROF

Site-Specific Parameter Summary (continued)

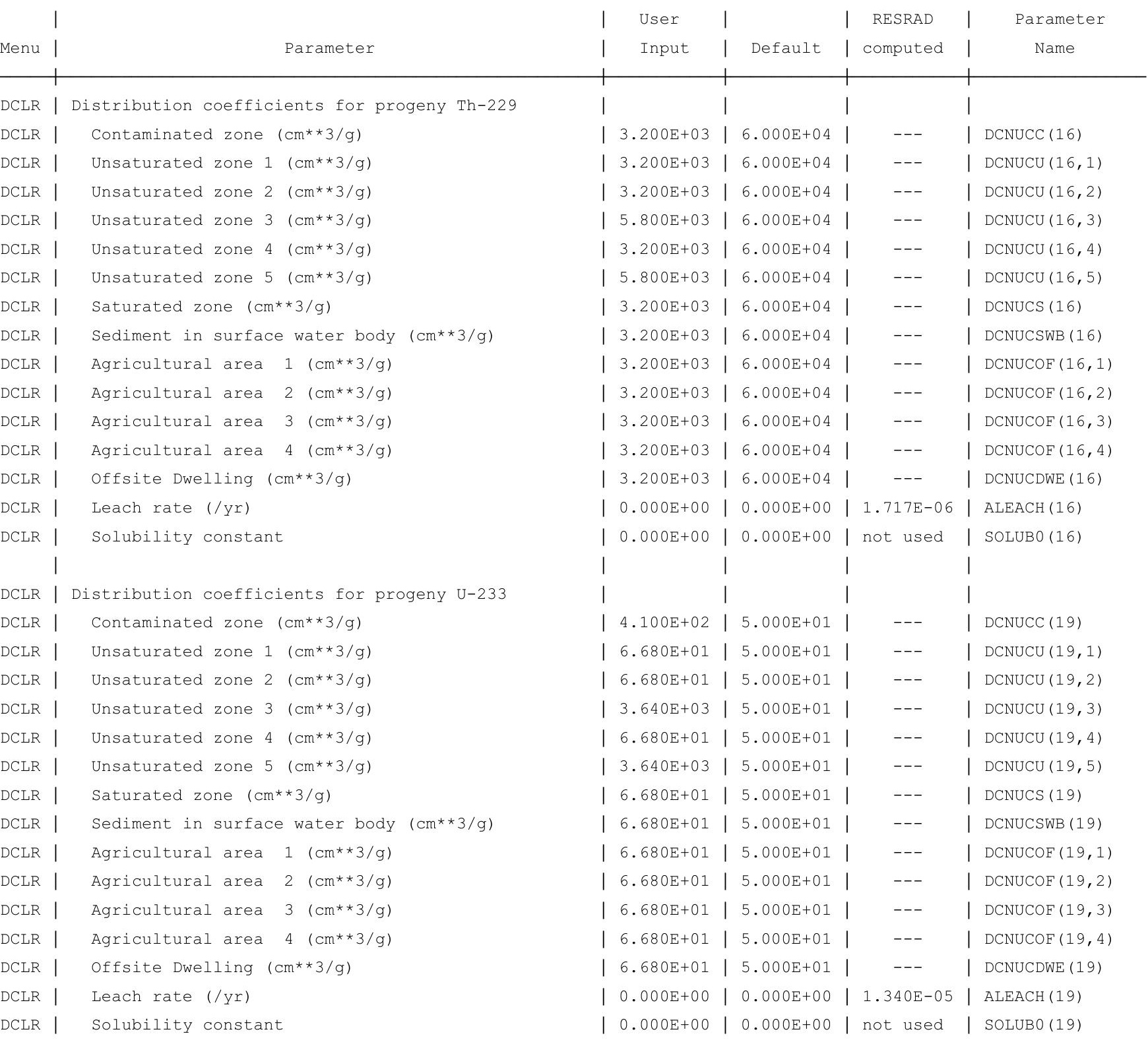


RESRAD-OFFSITE, Version $2.5 \quad \mathrm{~T}^{1 / 2}$ Limit $=180$ days $\quad$ 07/21/2011 $10: 27 \quad \mathrm{Page}$

Parent Dose Report

Title : RESRAD-OFFSITE Parameters for Offsite Resident Farmer Forward Run 1,050 Years

File : OFFSITE-RF_FORWARD-7-11.ROF

Site-Specific Parameter Summary (continued)

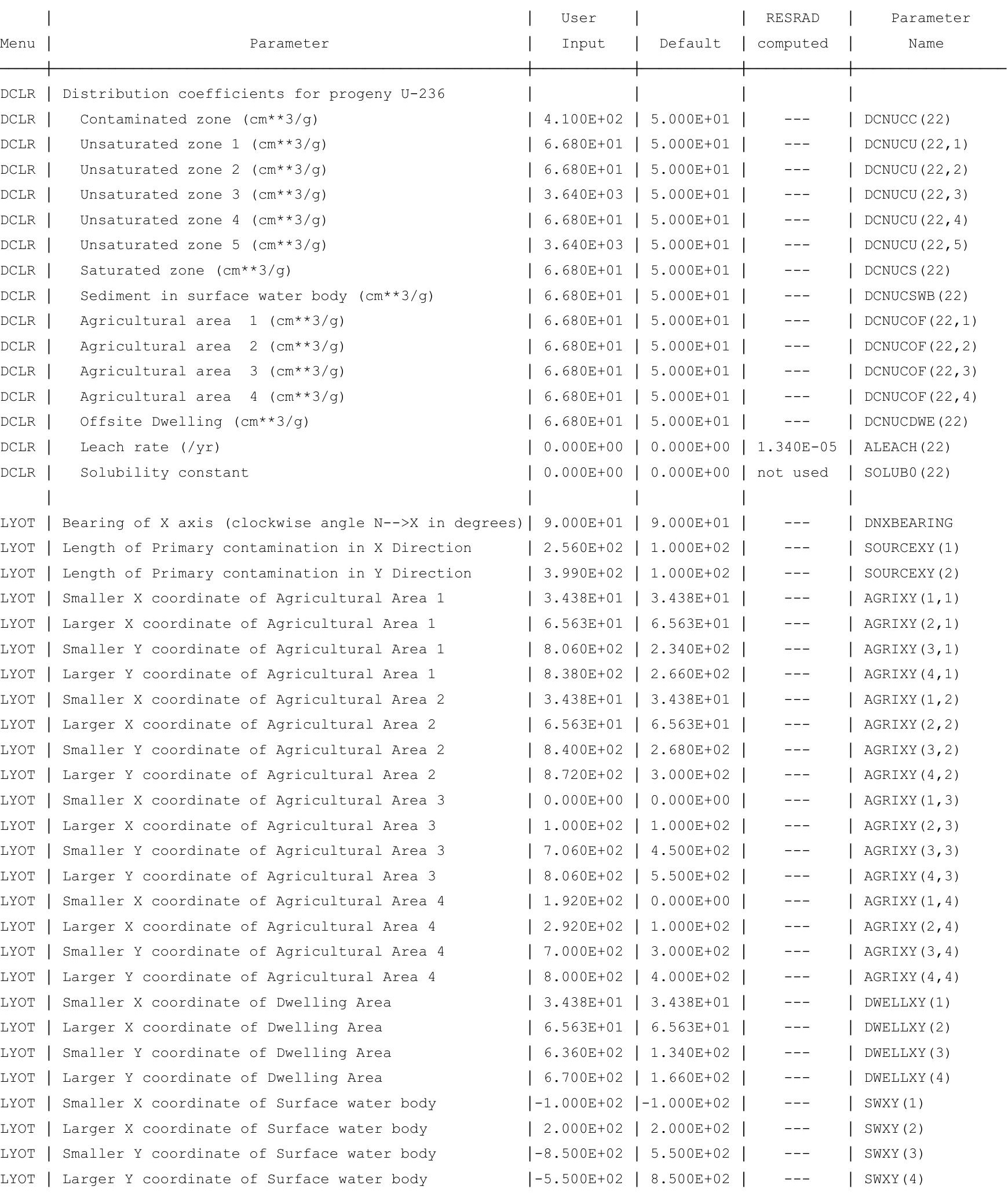

LYOT | Larger Y coordinate of Surface water body

\begin{tabular}{l|l|l|l|l|}
$\mid-5.500 \mathrm{E}+02$ & $\mathbf{8} .500 \mathrm{E}+02$ & --- & $\operatorname{SWXY}(4)$
\end{tabular} 
RESRAD-OFFSITE, Version 2.

Parent Dose Report

Title : RESRAD-OFFSITE Parameters for Offsite Resident Farmer Forward Run 1,050 Years

File : OFFSITE-RF FORWARD-7-11.ROF

Site-Specific Parameter Summary (continued)

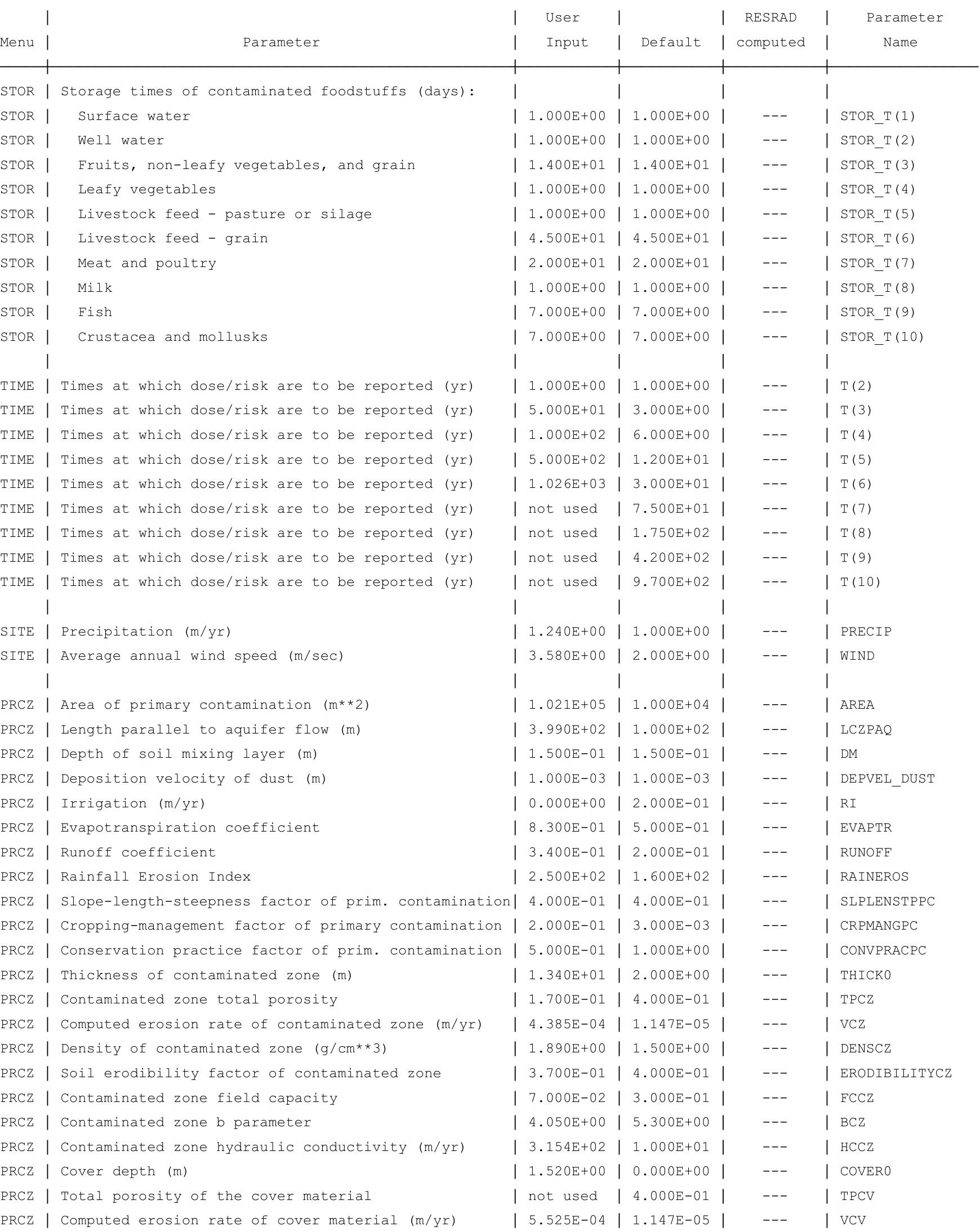


RESRAD-OFFSITE, Version 2.

Parent Dose Report

Title : RESRAD-OFFSITE Parameters for Offsite Resident Farmer Forward Run 1,050 Years

File : OFFSITE-RF FORWARD-7-11.ROF

Site-Specific Parameter Summary (continued)

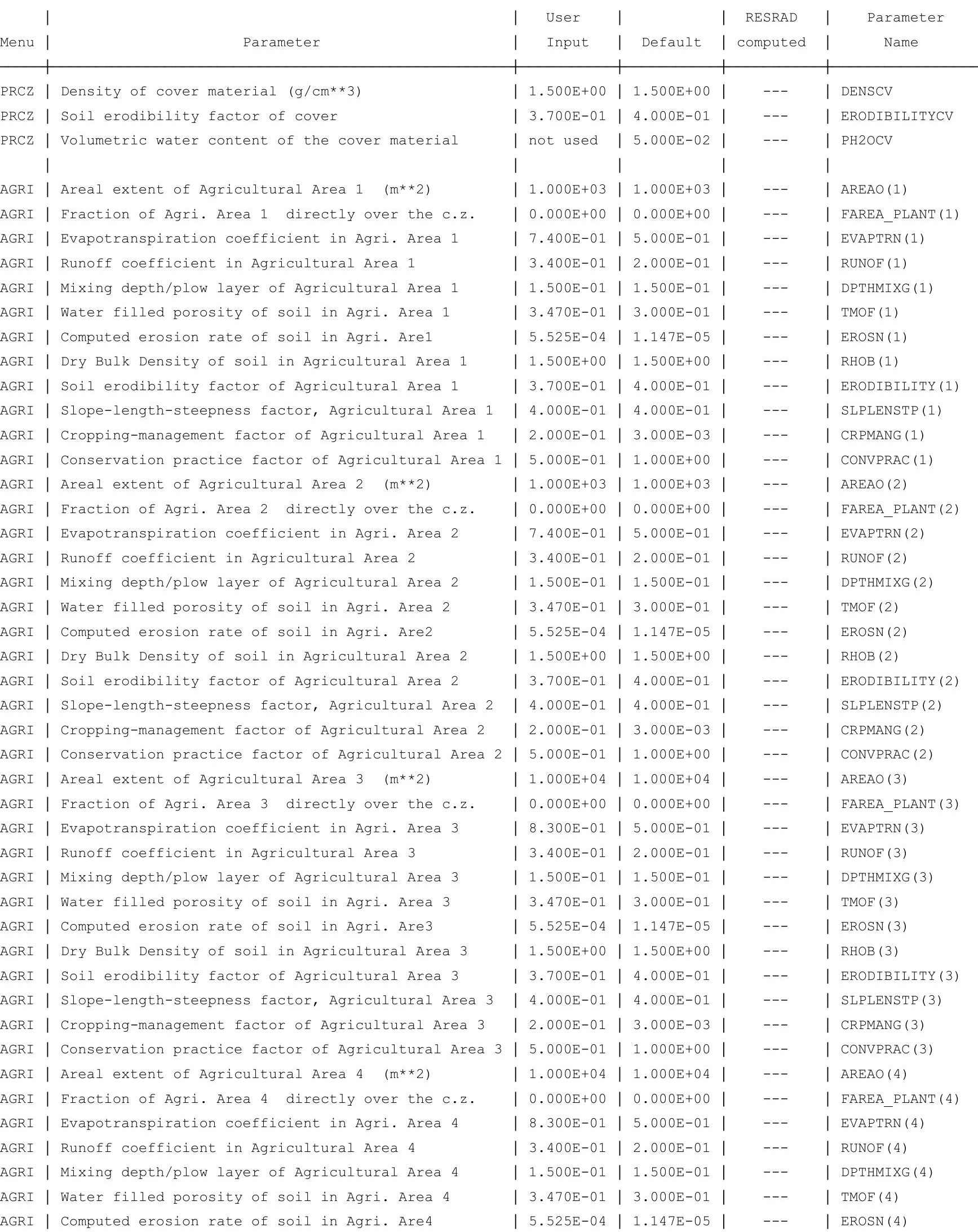


RESRAD-OFFSITE, Version 2.5

Parent Dose Report

Title : RESRAD-OFFSITE Parameters for Offsite Resident Farmer Forward Run 1,050 Years

File : OFFSITE-RF_FORWARD-7-11.ROF

Site-Specific Parameter Summary (continued)

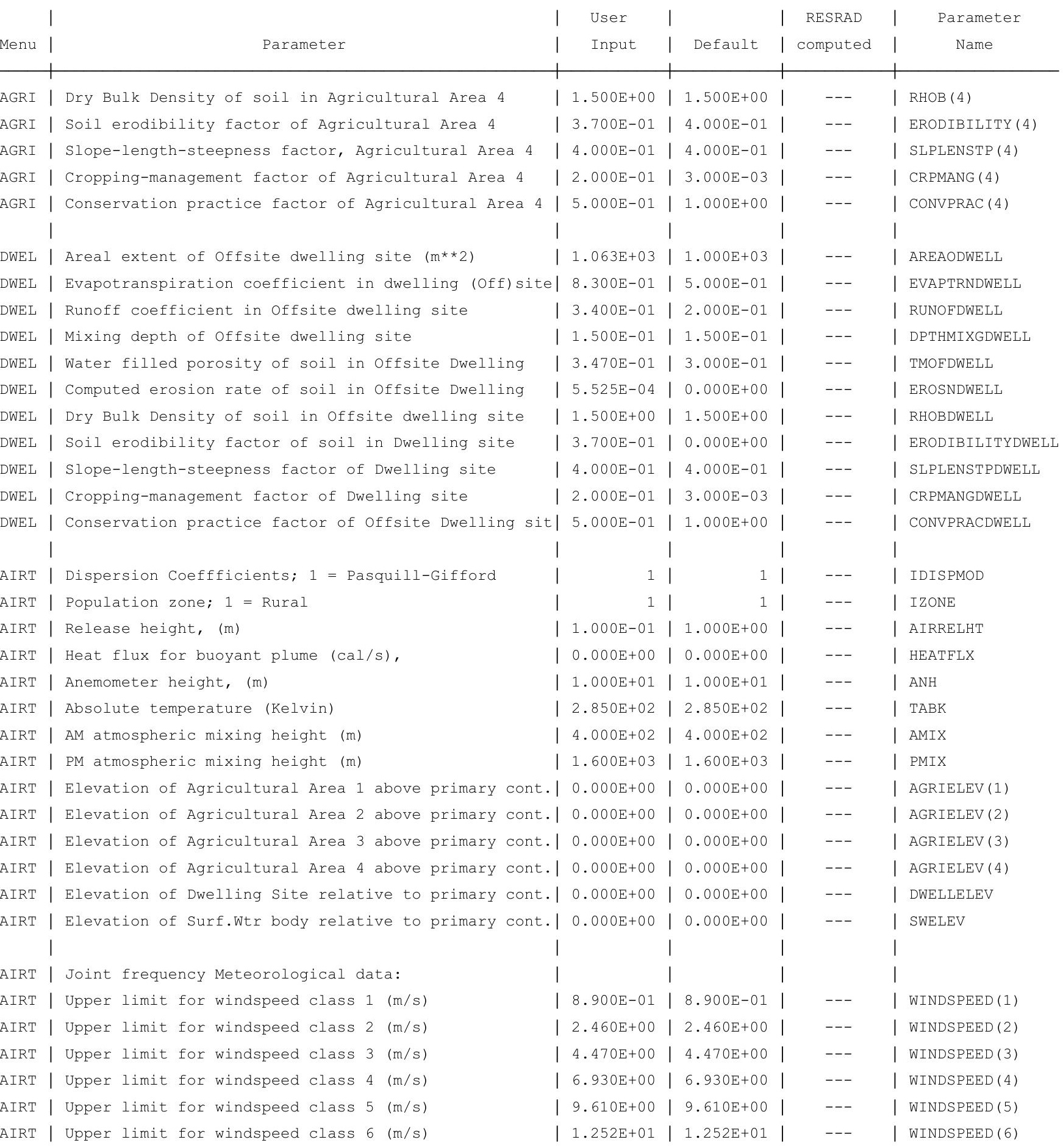


RESRAD-OFFSITE, Version 2.

Parent Dose Report

Title : RESRAD-OFFSITE Parameters for Offsite Resident Farmer Forward Run 1,050 Years

File : OFFSITE-RF FORWARD-7-11.ROF

Site-Specific Parameter Summary (continued)

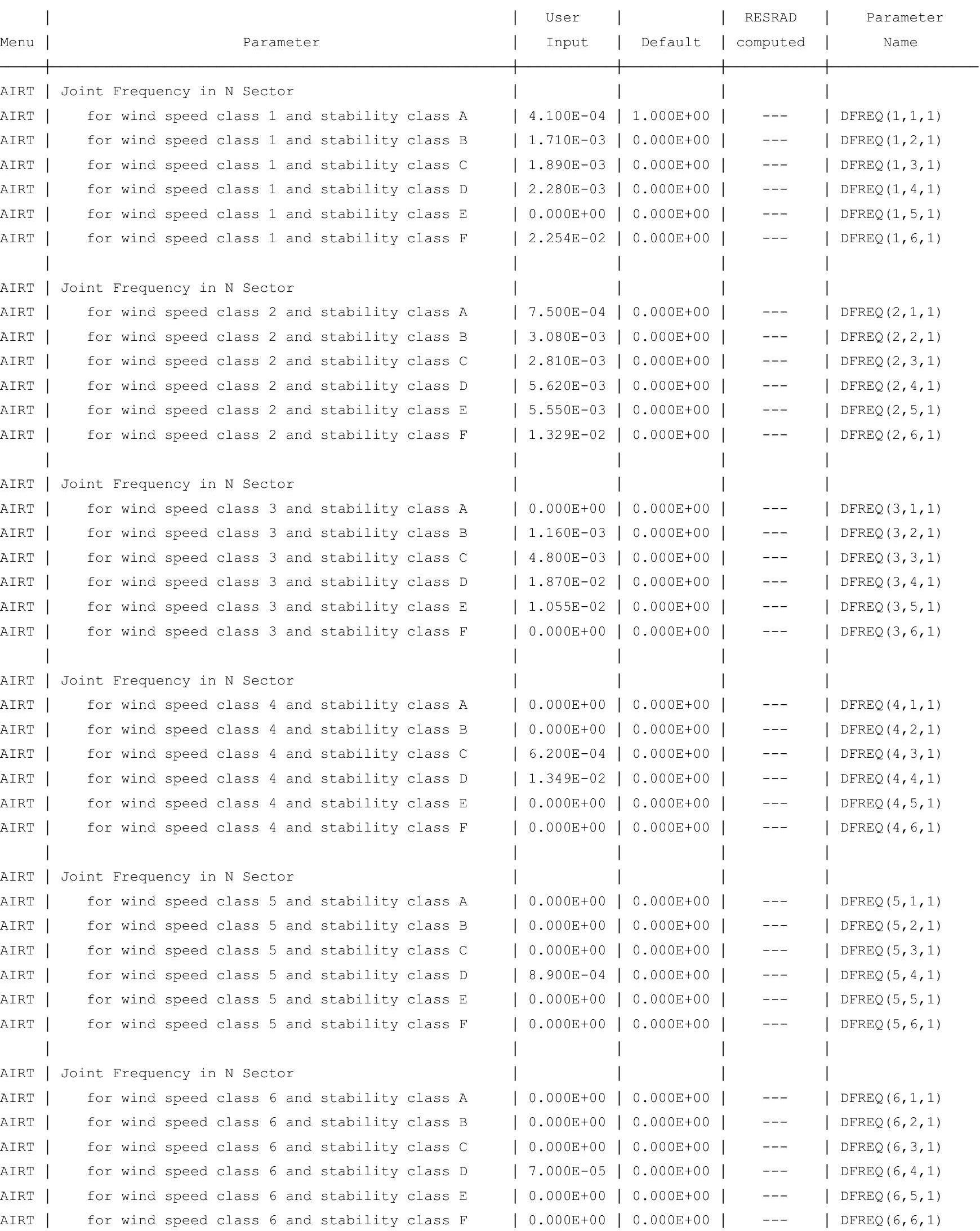


RESRAD-OFFSITE, Version 2.

Parent Dose Report

Title : RESRAD-OFFSITE Parameters for Offsite Resident Farmer Forward Run 1,050 Years

File : OFFSITE-RF FORWARD-7-11.ROF

Site-Specific Parameter Summary (continued)

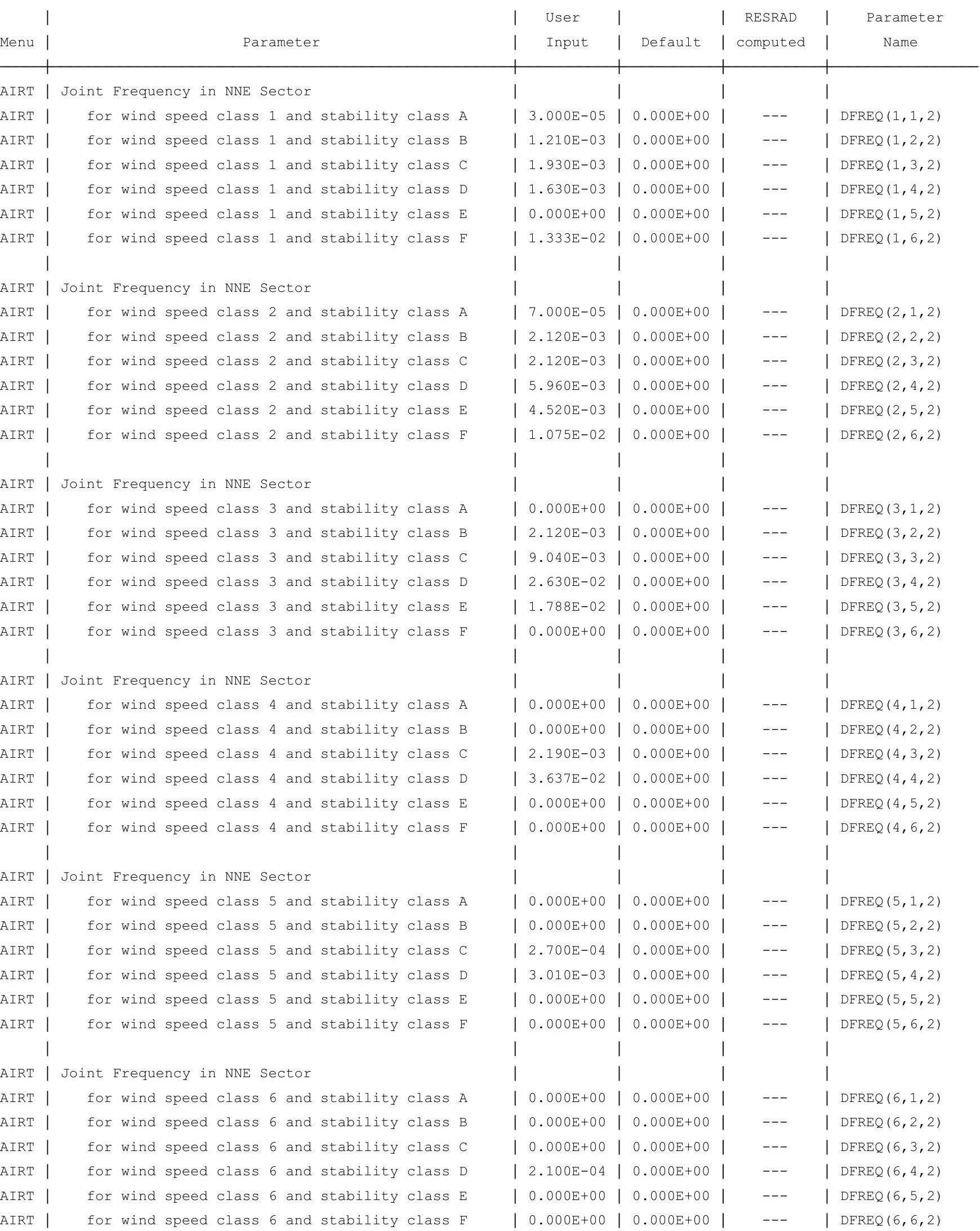


RESRAD-OFFSITE, Version 2.

Parent Dose Report

Title : RESRAD-OFFSITE Parameters for Offsite Resident Farmer Forward Run 1,050 Years

File : OFFSITE-RF FORWARD-7-11.ROF

Site-Specific Parameter Summary (continued)

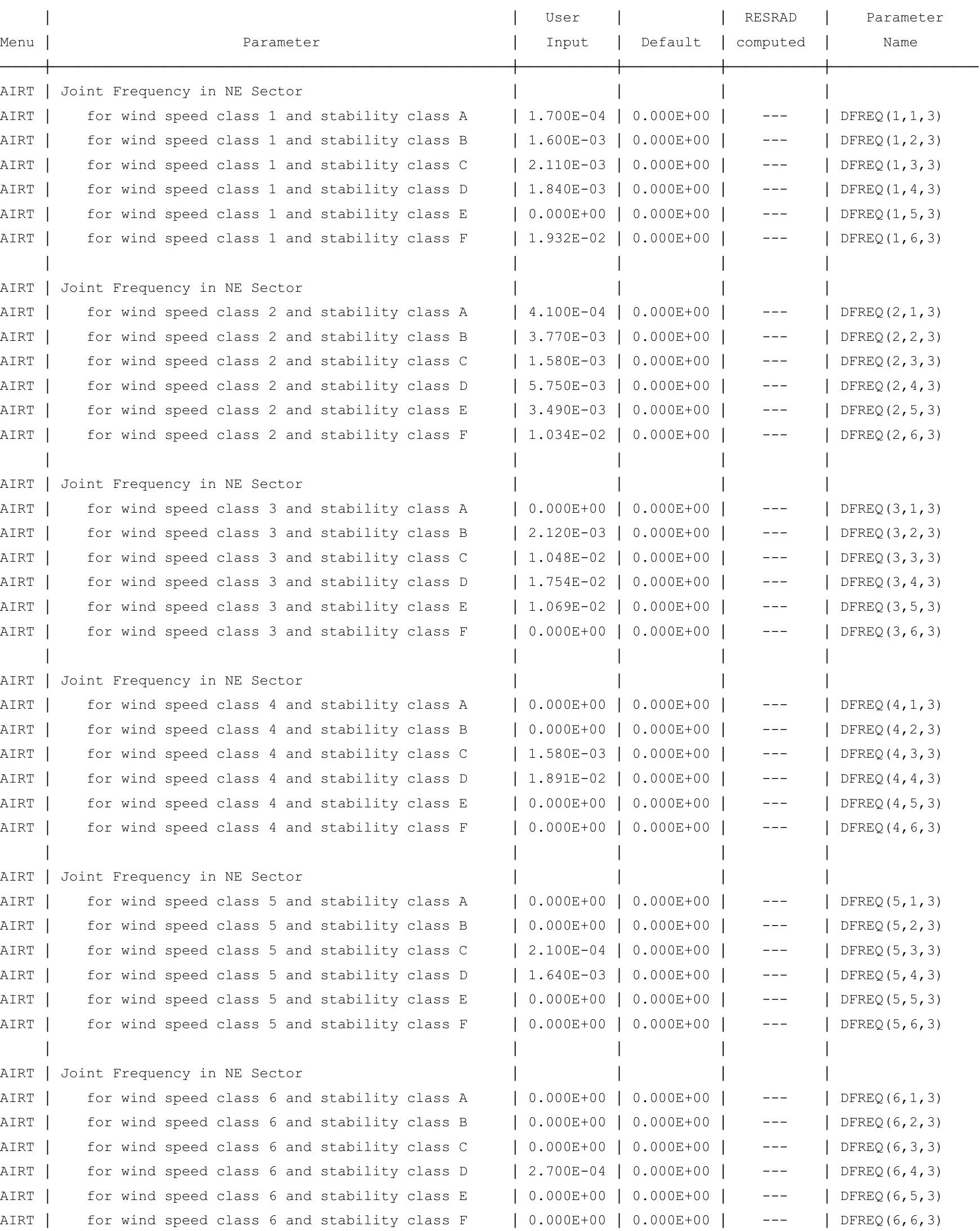


RESRAD-OFFSITE, Version 2.

Parent Dose Report

Title : RESRAD-OFFSITE Parameters for Offsite Resident Farmer Forward Run 1,050 Years

File : OFFSITE-RF FORWARD-7-11.ROF

Site-Specific Parameter Summary (continued)

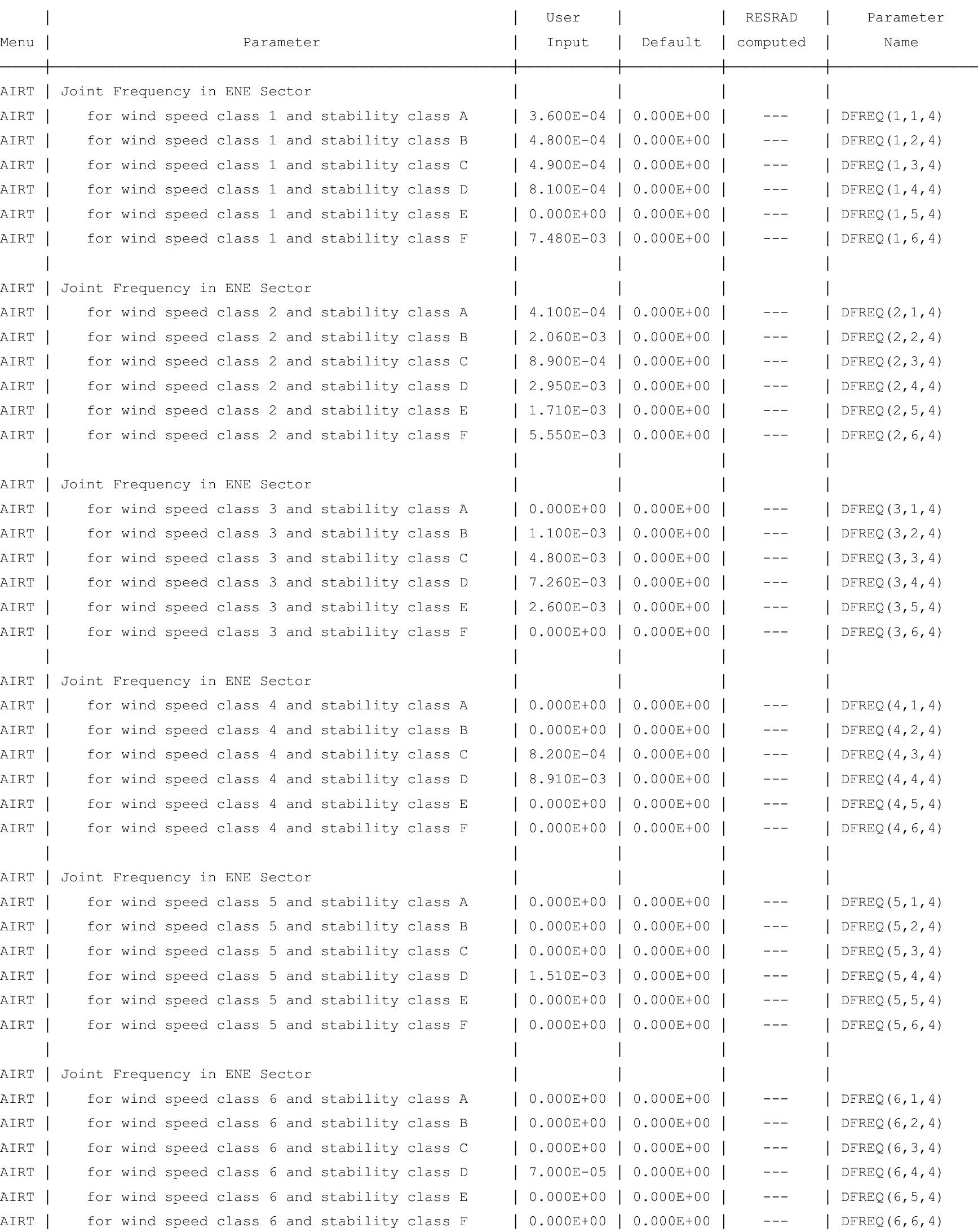


RESRAD-OFFSITE, Version 2.

Parent Dose Report

Title : RESRAD-OFFSITE Parameters for Offsite Resident Farmer Forward Run 1,050 Years

File : OFFSITE-RF FORWARD-7-11.ROF

Site-Specific Parameter Summary (continued)

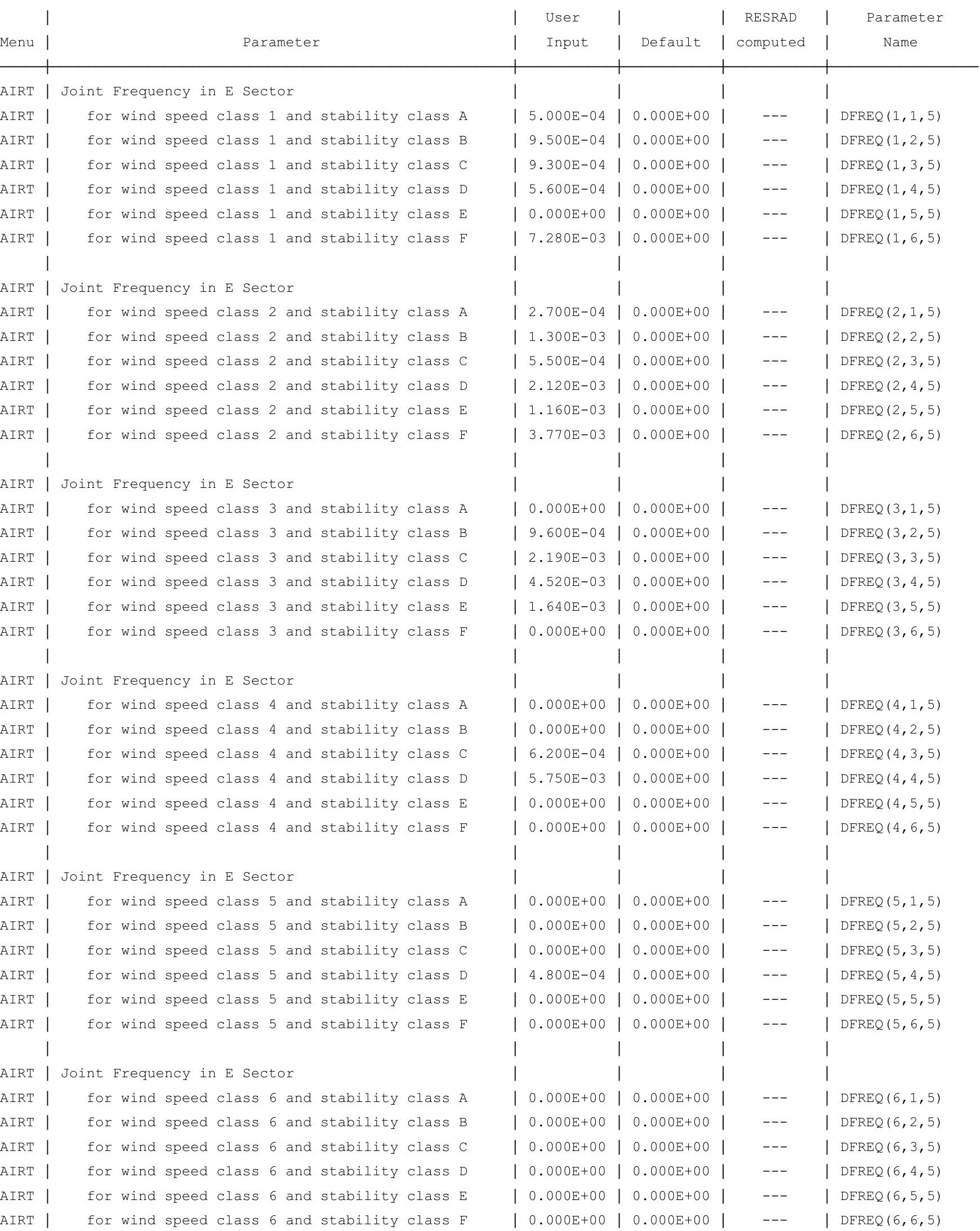


RESRAD-OFFSITE, Version 2.

Parent Dose Report

Title : RESRAD-OFFSITE Parameters for Offsite Resident Farmer Forward Run 1,050 Years

File : OFFSITE-RF FORWARD-7-11.ROF

Site-Specific Parameter Summary (continued)

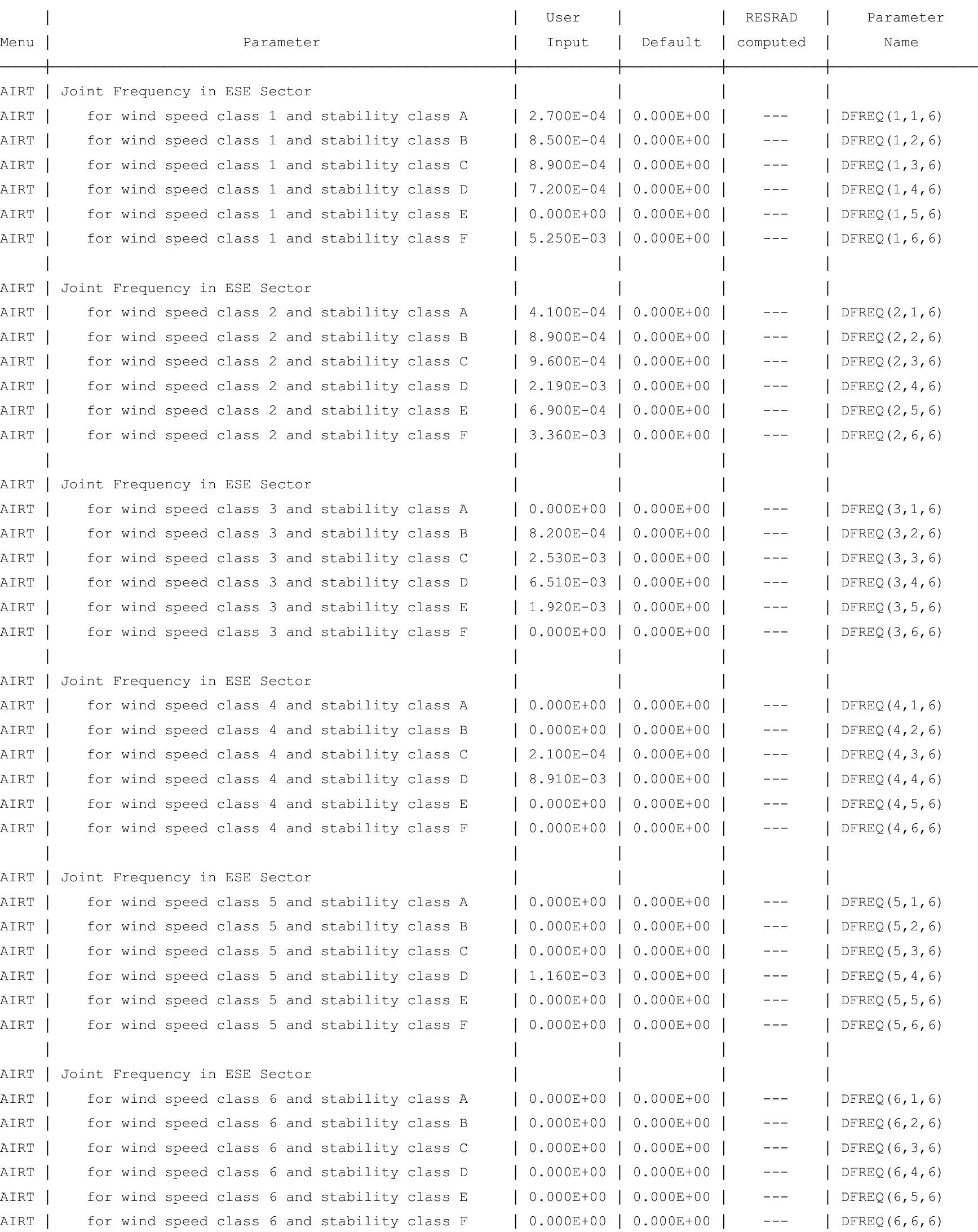


RESRAD-OFFSITE, Version 2.

Parent Dose Report

Title : RESRAD-OFFSITE Parameters for Offsite Resident Farmer Forward Run 1,050 Years

File : OFFSITE-RF FORWARD-7-11.ROF

Site-Specific Parameter Summary (continued)

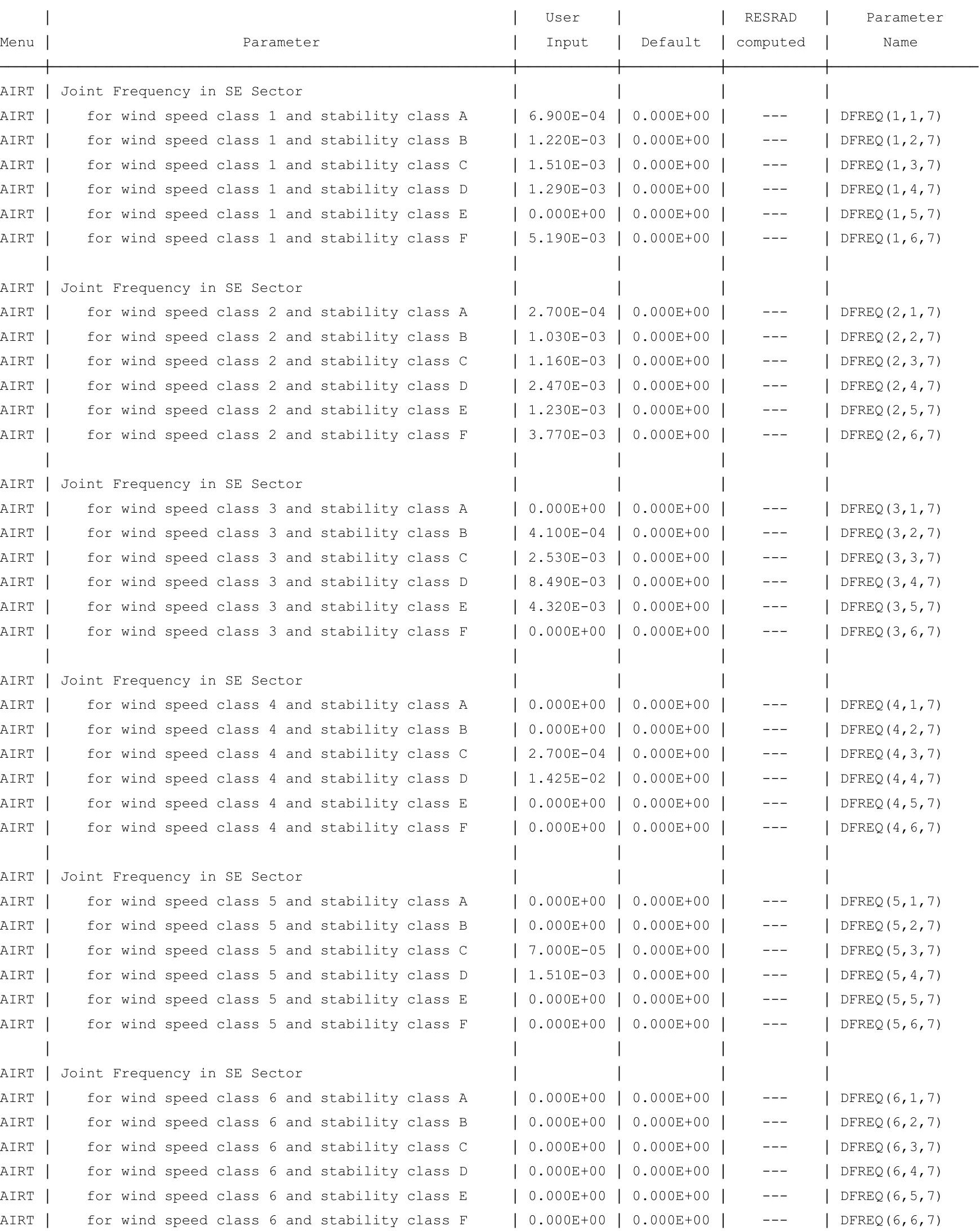


RESRAD-OFFSITE, Version 2.

Parent Dose Report

Title : RESRAD-OFFSITE Parameters for Offsite Resident Farmer Forward Run 1,050 Years

File : OFFSITE-RF FORWARD-7-11.ROF

Site-Specific Parameter Summary (continued)

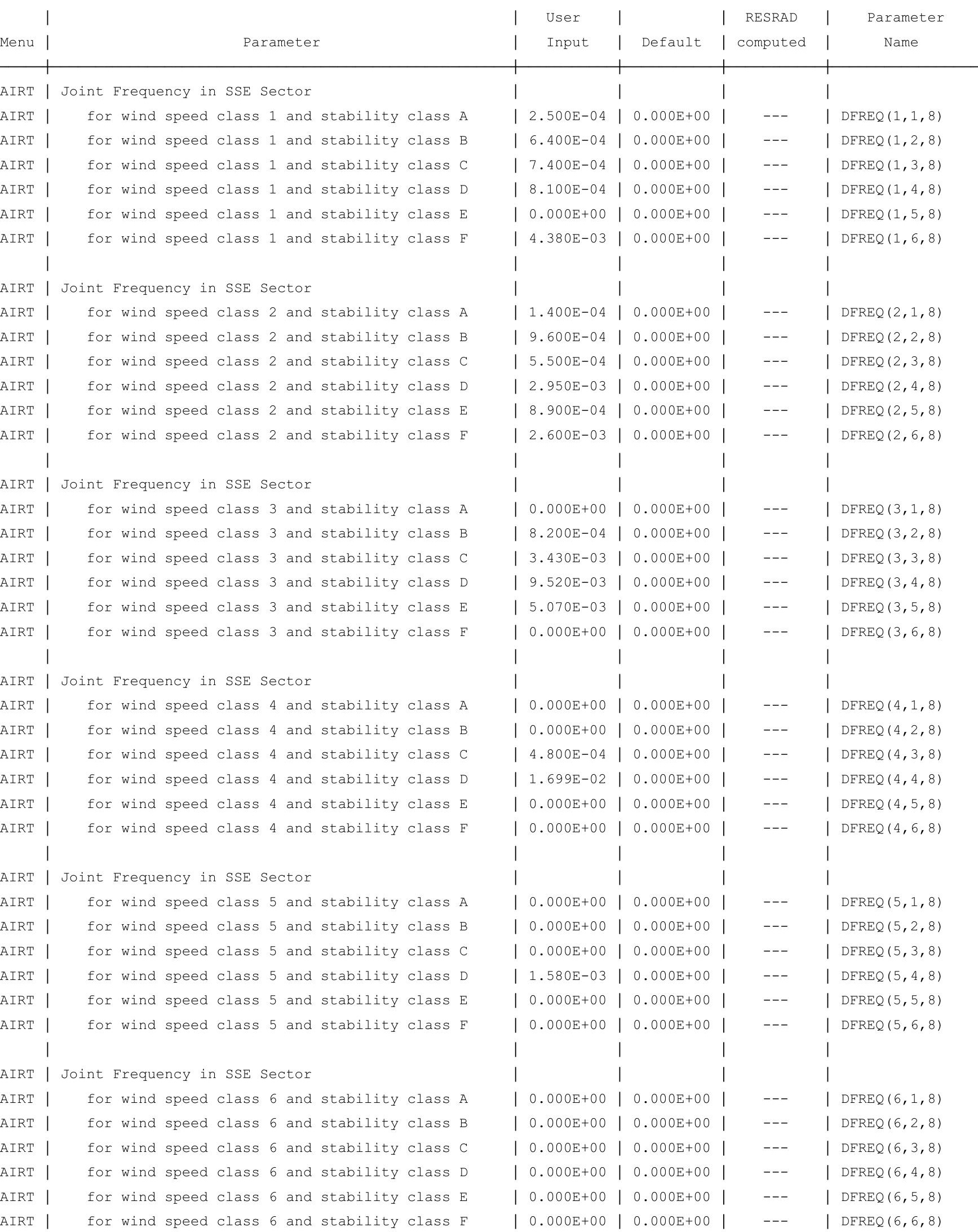


RESRAD-OFFSITE, Version 2.

Parent Dose Report

Title : RESRAD-OFFSITE Parameters for Offsite Resident Farmer Forward Run 1,050 Years

File : OFFSITE-RF FORWARD-7-11.ROF

Site-Specific Parameter Summary (continued)

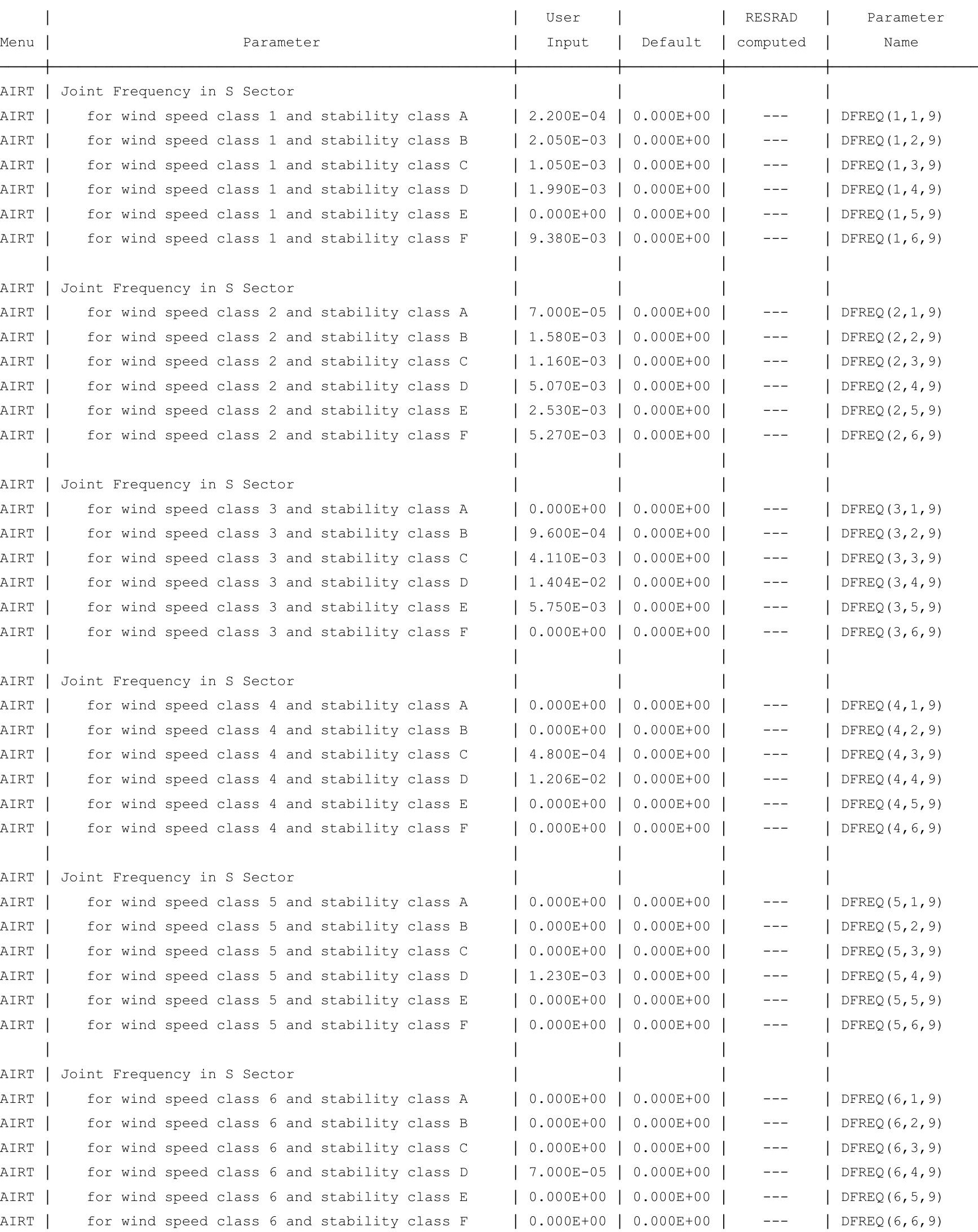


RESRAD-OFFSITE, Version 2.

Parent Dose Report

Title : RESRAD-OFFSITE Parameters for Offsite Resident Farmer Forward Run 1,050 Years

File : OFFSITE-RF FORWARD-7-11.ROF

Site-Specific Parameter Summary (continued)

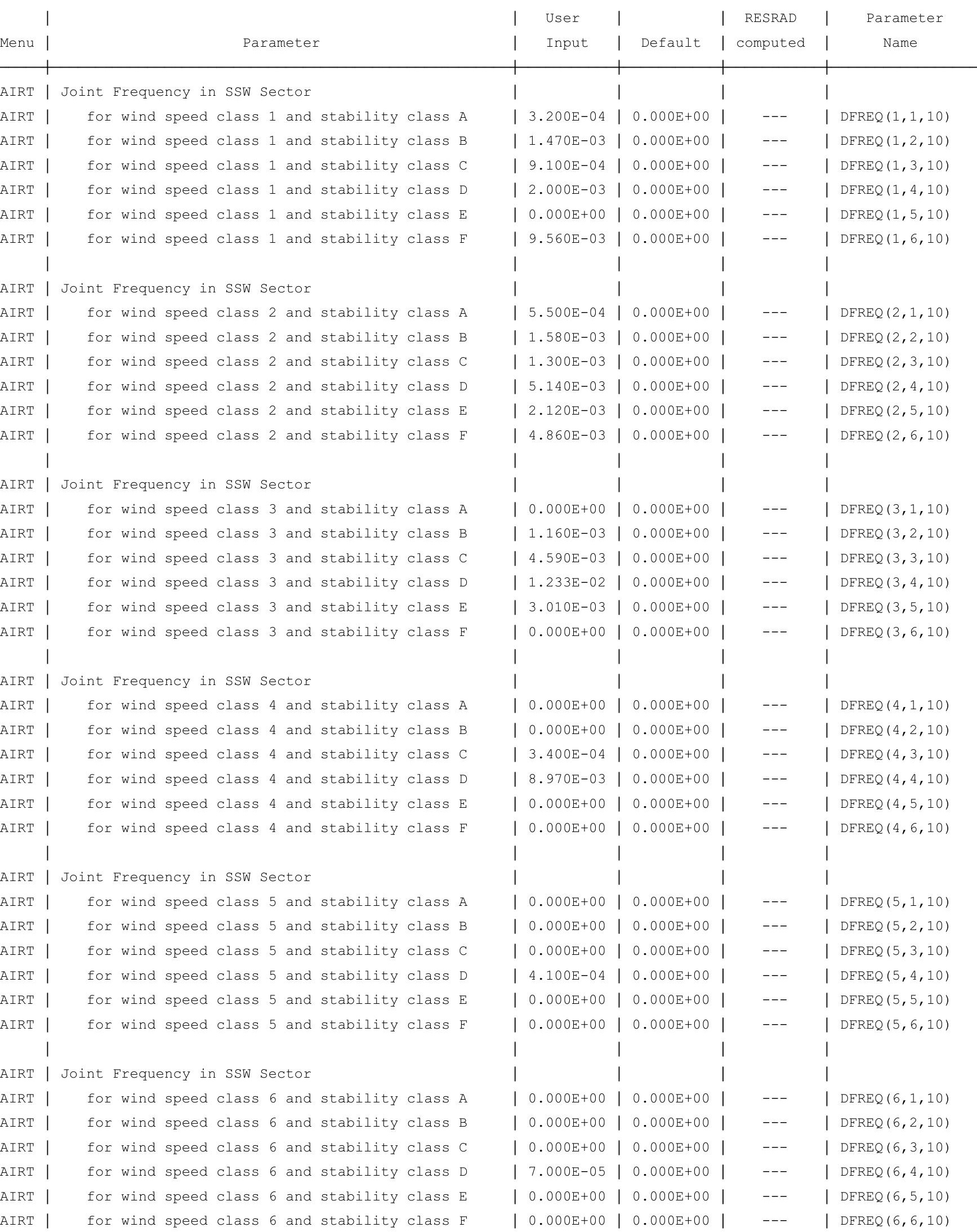


RESRAD-OFFSITE, Version 2.

Parent Dose Report

Title : RESRAD-OFFSITE Parameters for Offsite Resident Farmer Forward Run 1,050 Years

File : OFFSITE-RF FORWARD-7-11.ROF

Site-Specific Parameter Summary (continued)

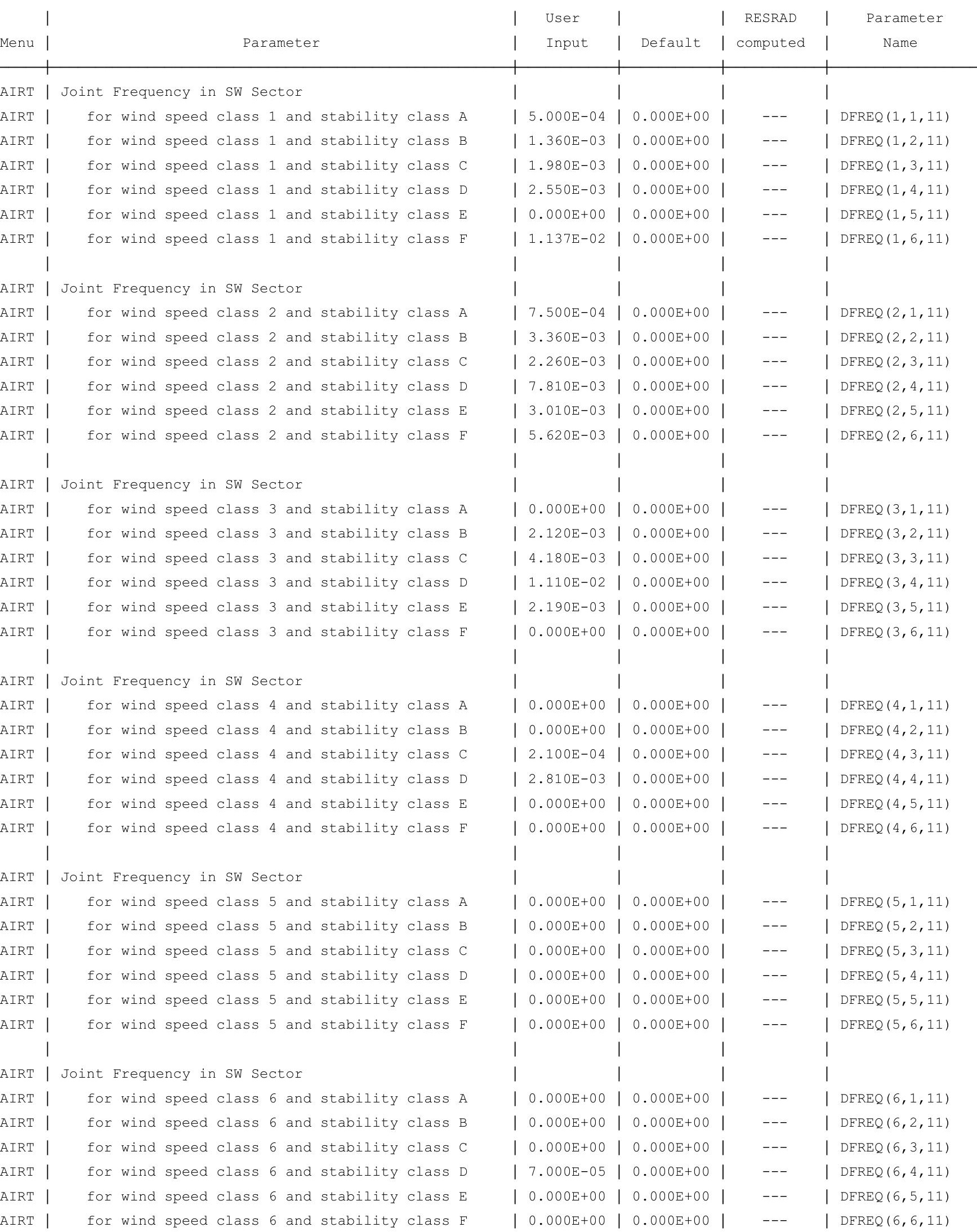


RESRAD-OFFSITE, Version $2.5 \quad \mathrm{~T}^{1 / 1} / 2$ Limit $=180$ days $\quad$ 07/21/2011 $10: 27$ Page

Parent Dose Report

Title : RESRAD-OFFSITE Parameters for Offsite Resident Farmer Forward Run 1,050 Years

File : OFFSITE-RF_FORWARD-7-11.ROF

Site-Specific Parameter Summary (continued)

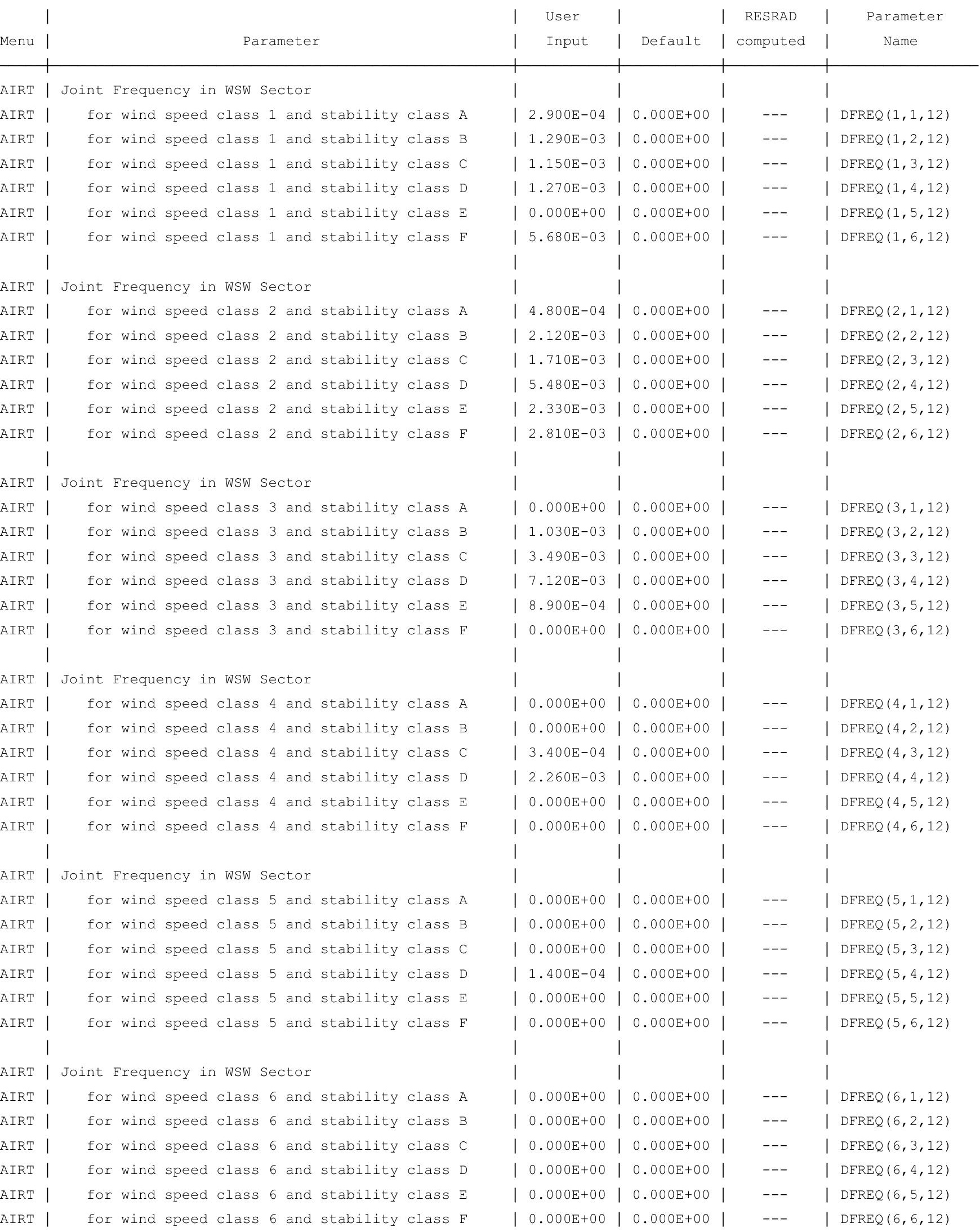


RESRAD-OFFSITE, Version 2.

Parent Dose Report

Title : RESRAD-OFFSITE Parameters for Offsite Resident Farmer Forward Run 1,050 Years

File : OFFSITE-RF FORWARD-7-11.ROF

Site-Specific Parameter Summary (continued)

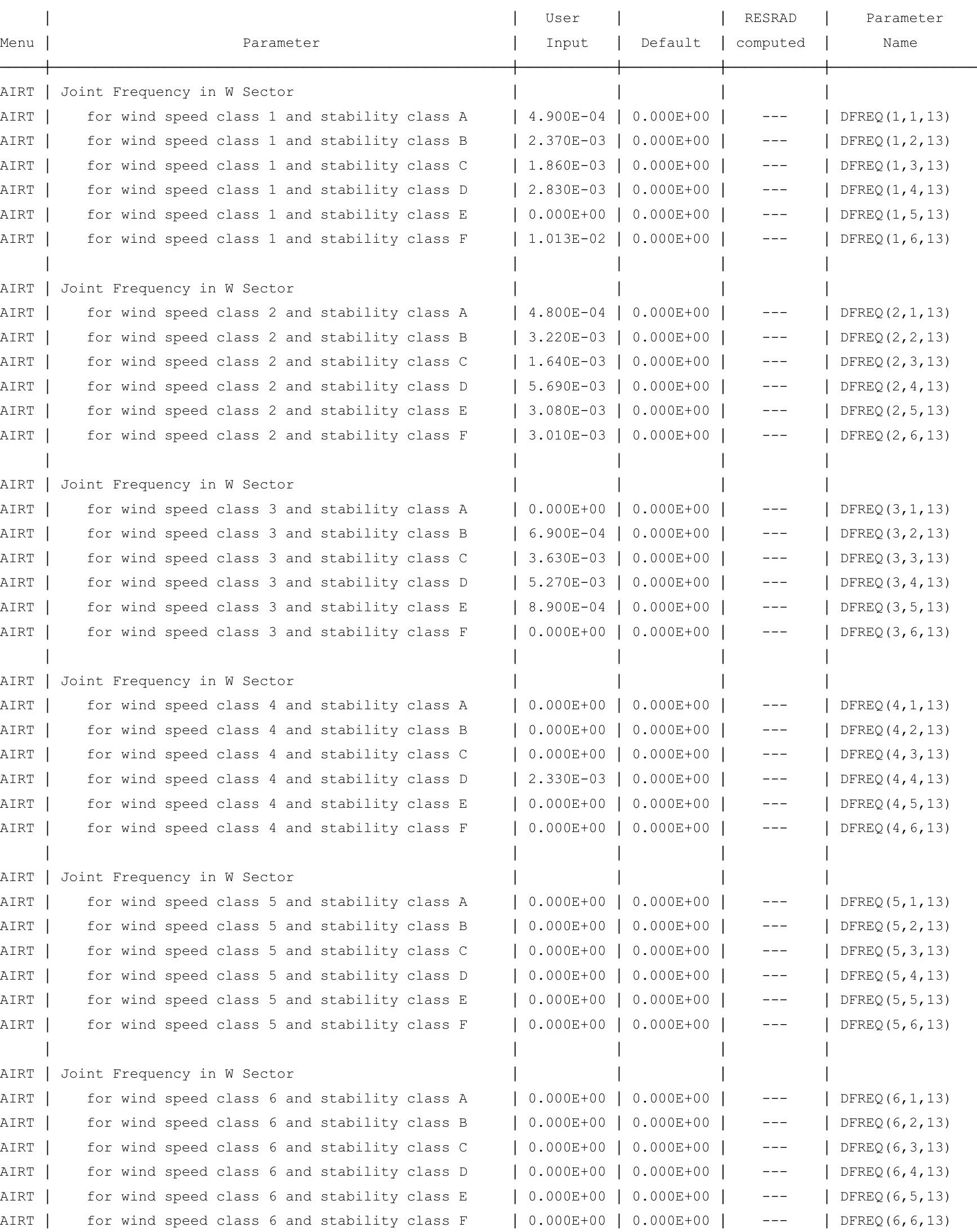


RESRAD-OFFSITE, Version $2.5 \quad \mathrm{~T}^{1 / 1} / 2$ Limit $=180$ days $\quad$ 07/21/2011 $10: 27$ Page

Parent Dose Report

Title : RESRAD-OFFSITE Parameters for Offsite Resident Farmer Forward Run 1,050 Years

File : OFFSITE-RF_FORWARD-7-11.ROF

Site-Specific Parameter Summary (continued)

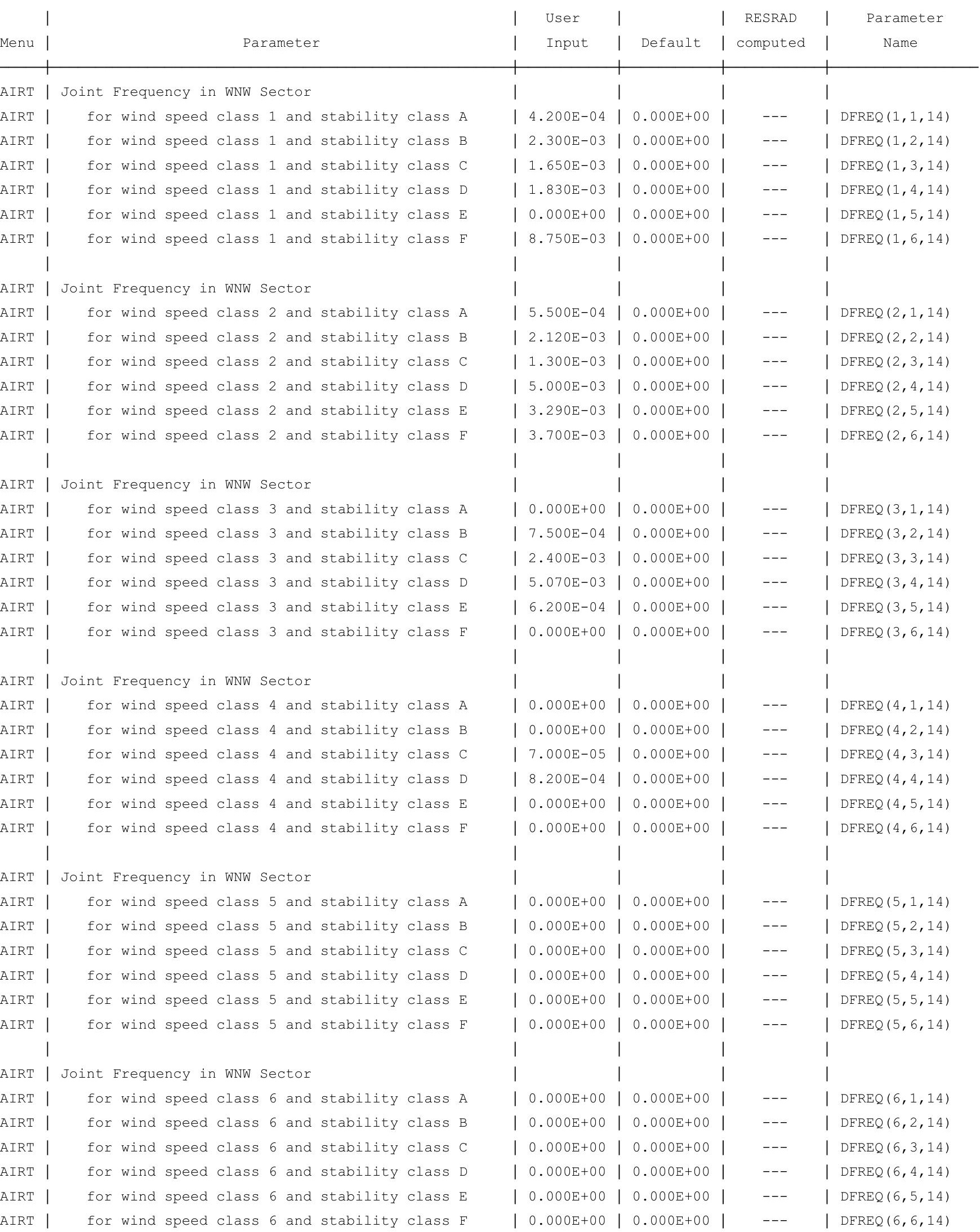


RESRAD-OFFSITE, Version 2.

Parent Dose Report

Title : RESRAD-OFFSITE Parameters for Offsite Resident Farmer Forward Run 1,050 Years

File : OFFSITE-RF FORWARD-7-11.ROF

Site-Specific Parameter Summary (continued)

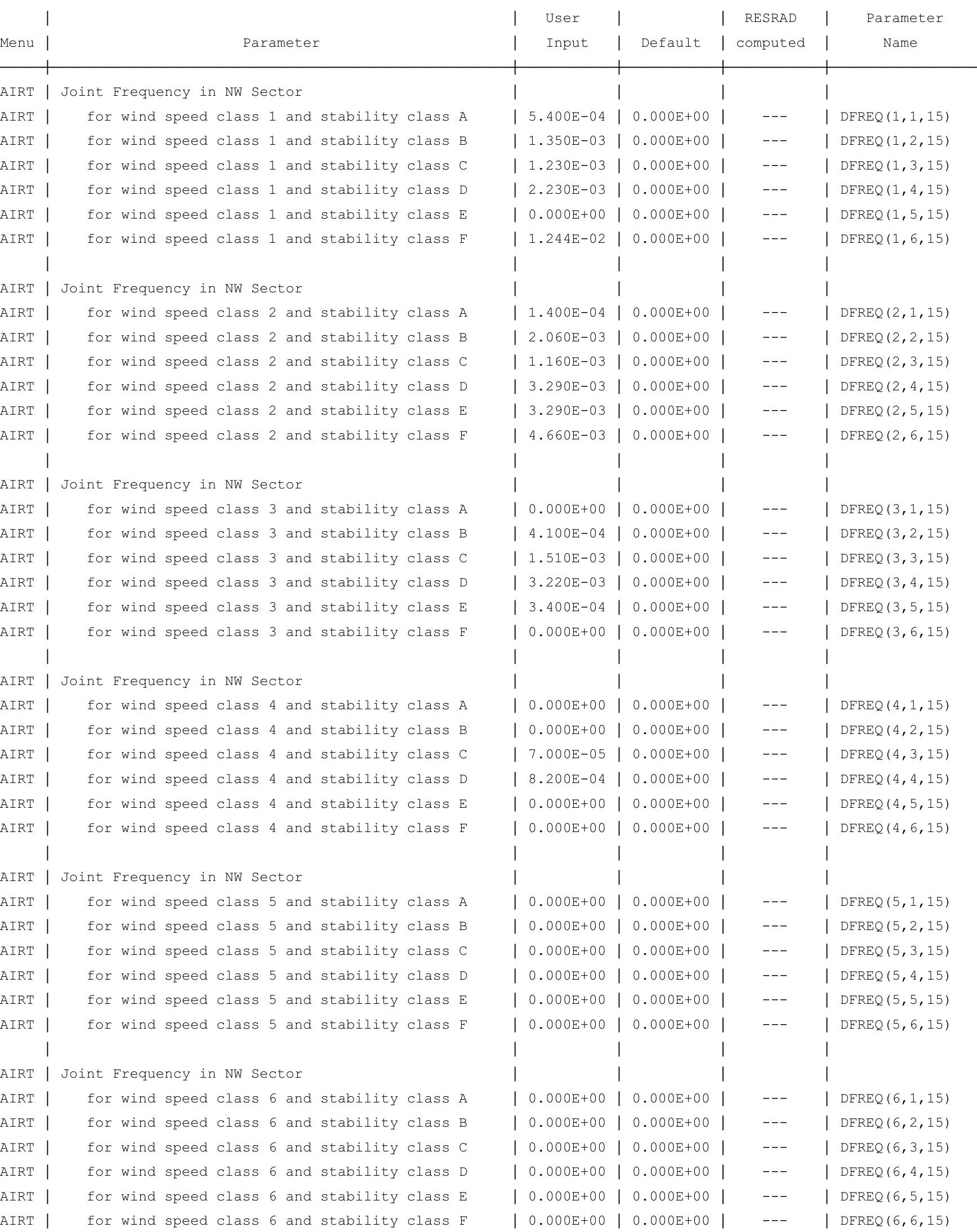


RESRAD-OFFSITE, Version $2.5 \quad T^{1 / 2}$ Limit $=180$ days $\quad 07 / 21 / 2011 \quad 10: 27 \quad \mathrm{Page}$

Parent Dose Report

Title : RESRAD-OFFSITE Parameters for Offsite Resident Farmer Forward Run 1,050 Years

File : OFFSITE-RF_FORWARD-7-11.ROF

Site-Specific Parameter Summary (continued)

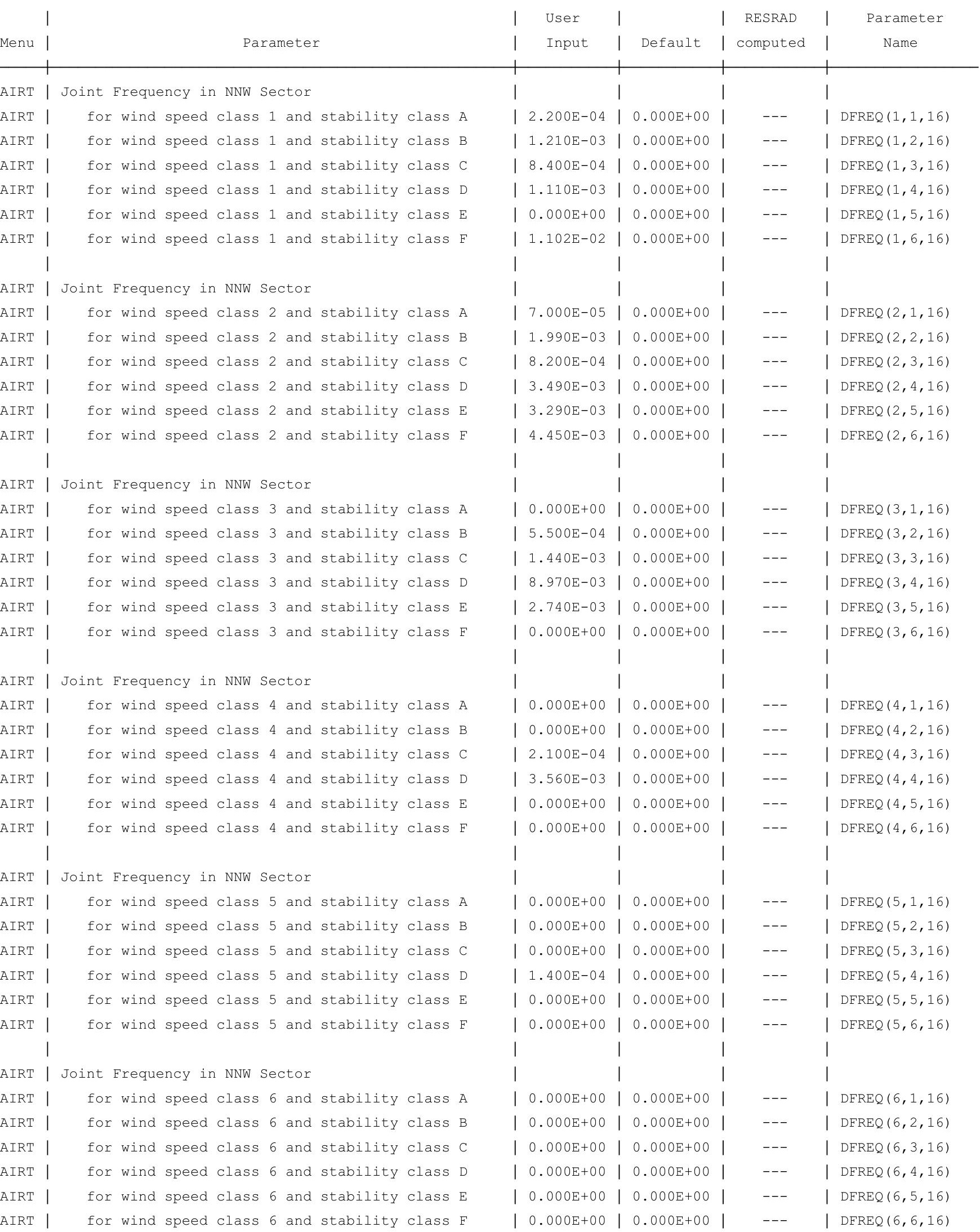


RESRAD-OFFSITE, Version 2.

Parent Dose Report

Title : RESRAD-OFFSITE Parameters for Offsite Resident Farmer Forward Run 1,050 Years

File : OFFSITE-RF_FORWARD-7-11.ROF

Site-Specific Parameter Summary (continued)

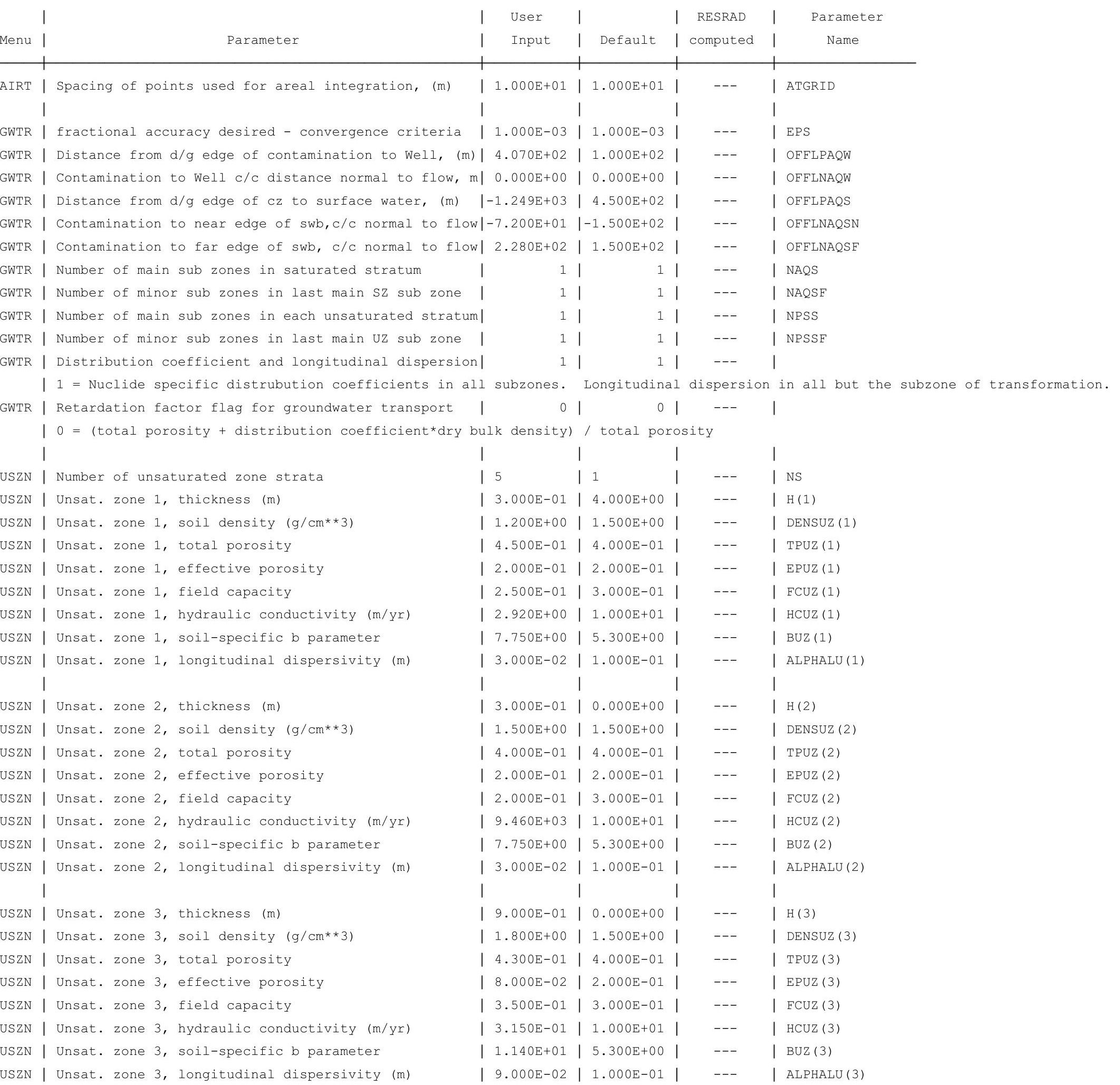


RESRAD-OFFSITE, Version 2.

Parent Dose Report

Title : RESRAD-OFFSITE Parameters for Offsite Resident Farmer Forward Run 1,050 Years

File : OFFSITE-RF FORWARD-7-11.ROF

Site-Specific Parameter Summary (continued)

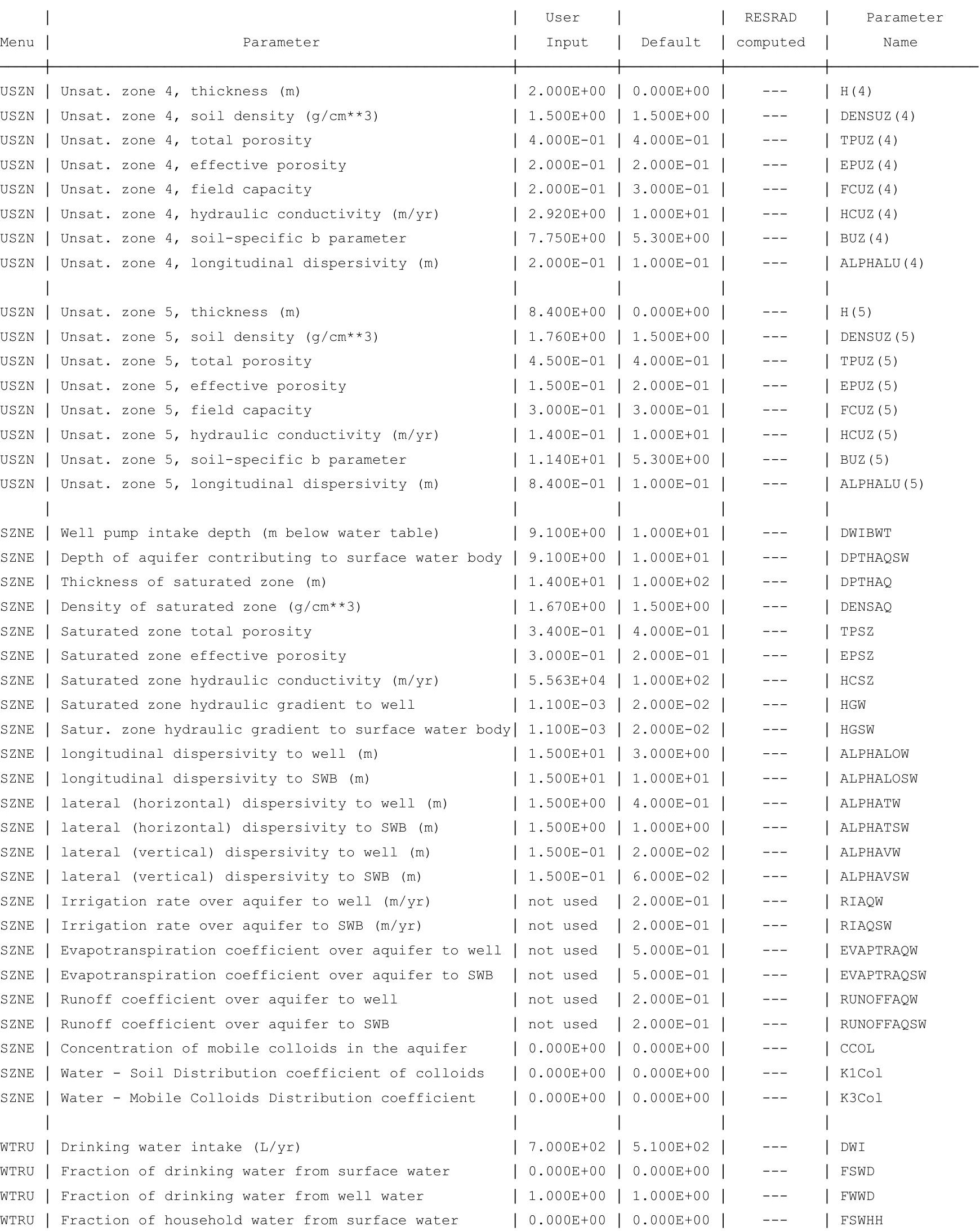


RESRAD-OFFSITE, Version 2.

Parent Dose Report

Title : RESRAD-OFFSITE Parameters for Offsite Resident Farmer Forward Run 1,050 Years

File : OFFSITE-RF FORWARD-7-11.ROF

Site-Specific Parameter Summary (continued)

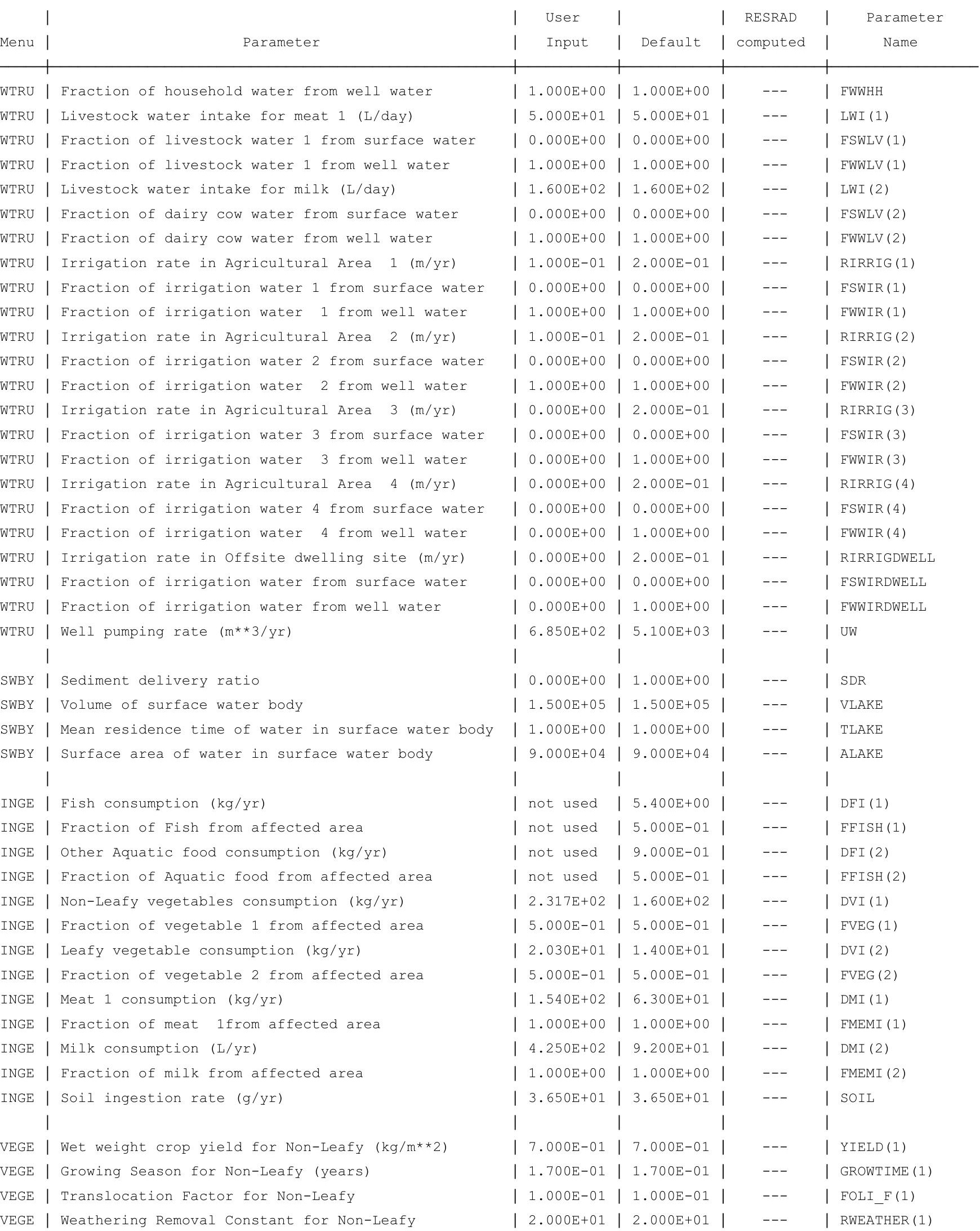


RESRAD-OFFSITE, Version 2.

Parent Dose Report

Title : RESRAD-OFFSITE Parameters for Offsite Resident Farmer Forward Run 1,050 Years

File : OFFSITE-RF_FORWARD-7-11.ROF

Site-Specific Parameter Summary (continued)

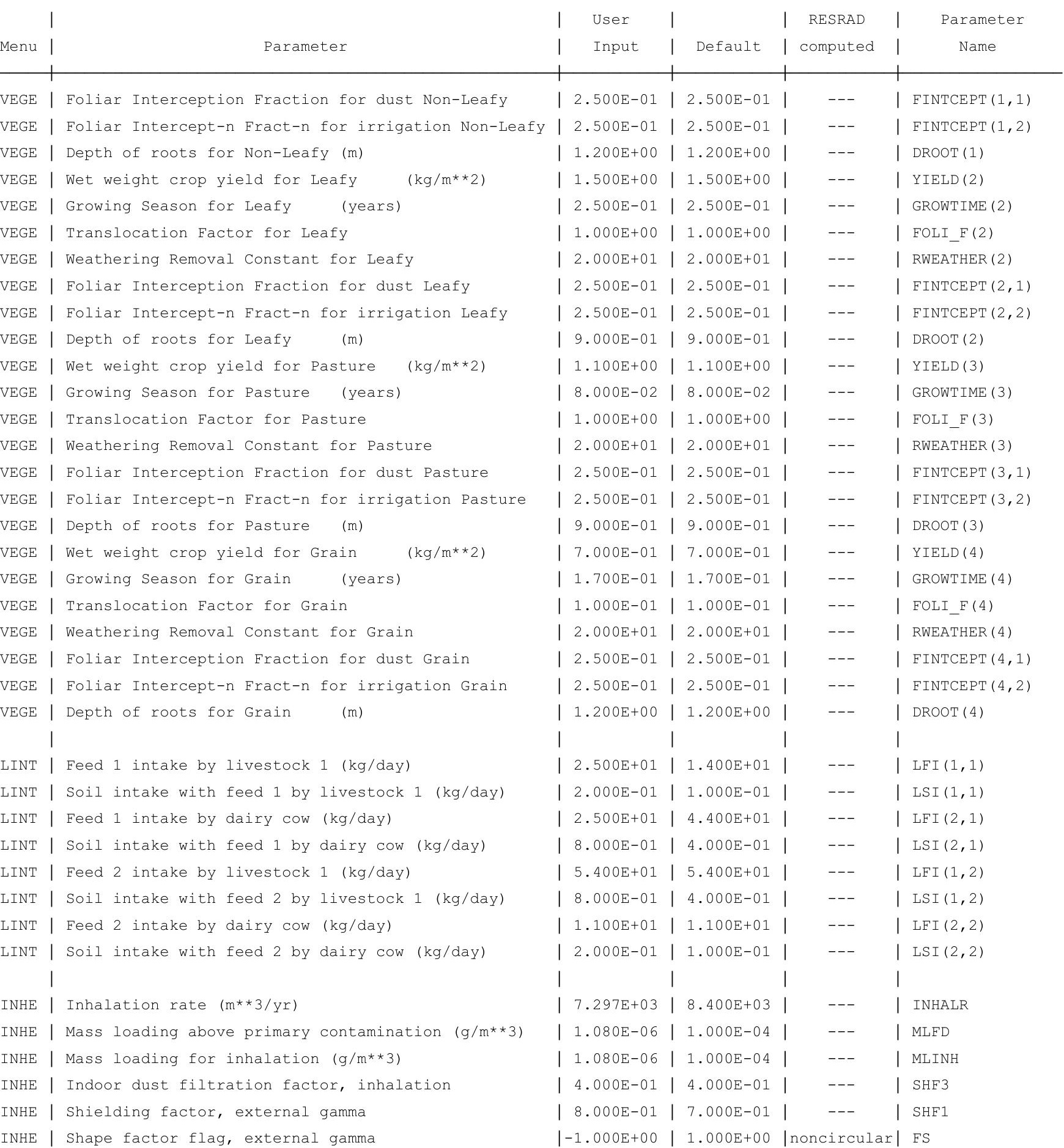


RESRAD-OFFSITE, Version 2.5

Parent Dose Report

Title : RESRAD-OFFSITE Parameters for Offsite Resident Farmer Forward Run 1,050 Years

File : OFFSITE-RF FORWARD-7-11.ROF

Site-Specific Parameter Summary (continued)

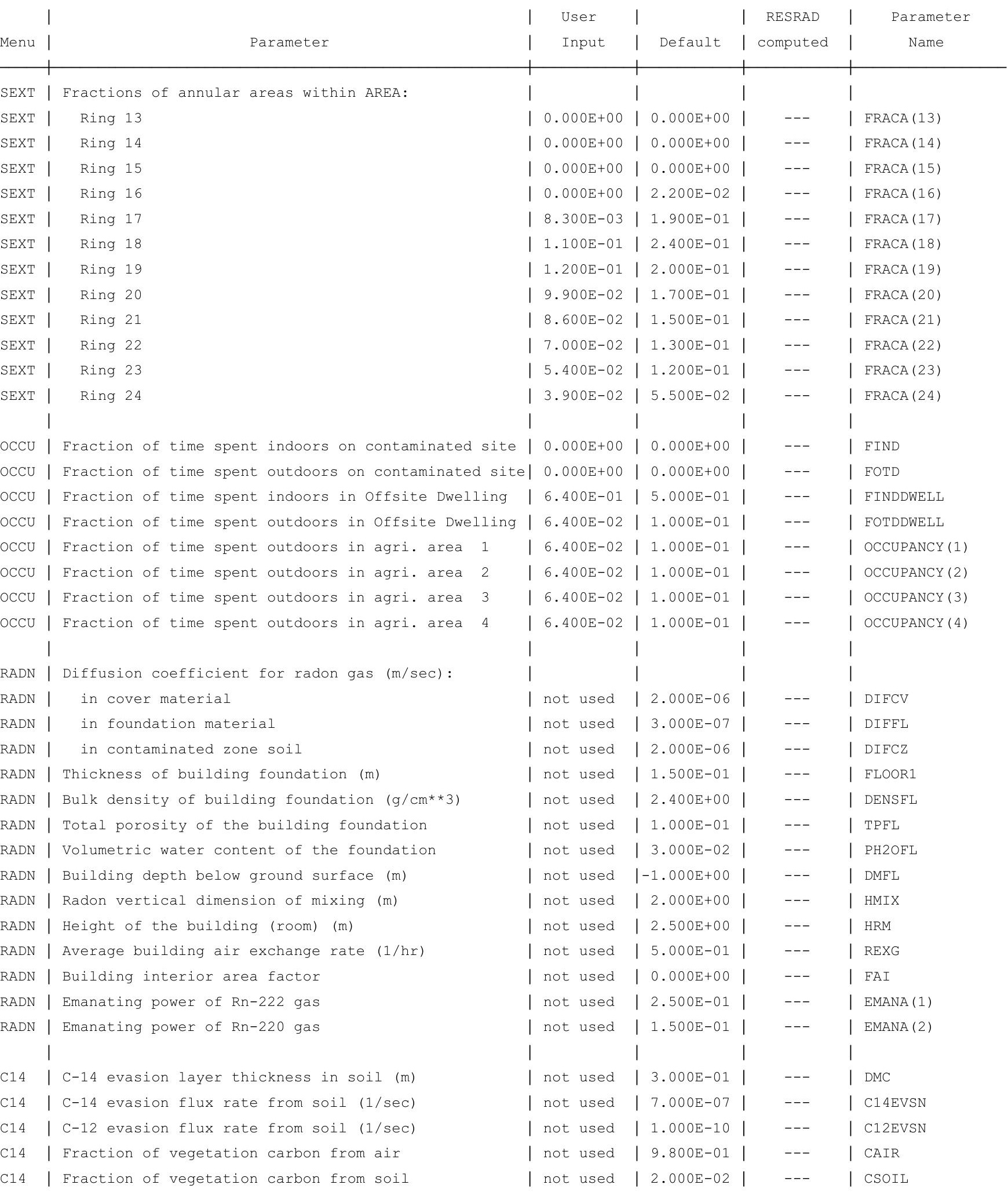


RESRAD-OFFSITE, Version 2.5

Parent Dose Report

Title : RESRAD-OFFSITE Parameters for Offsite Resident Farmer Forward Run 1,050 Years

File : OFFSITE-RF_FORWARD-7-11.ROF

Site-Specific Parameter Summary (continued)

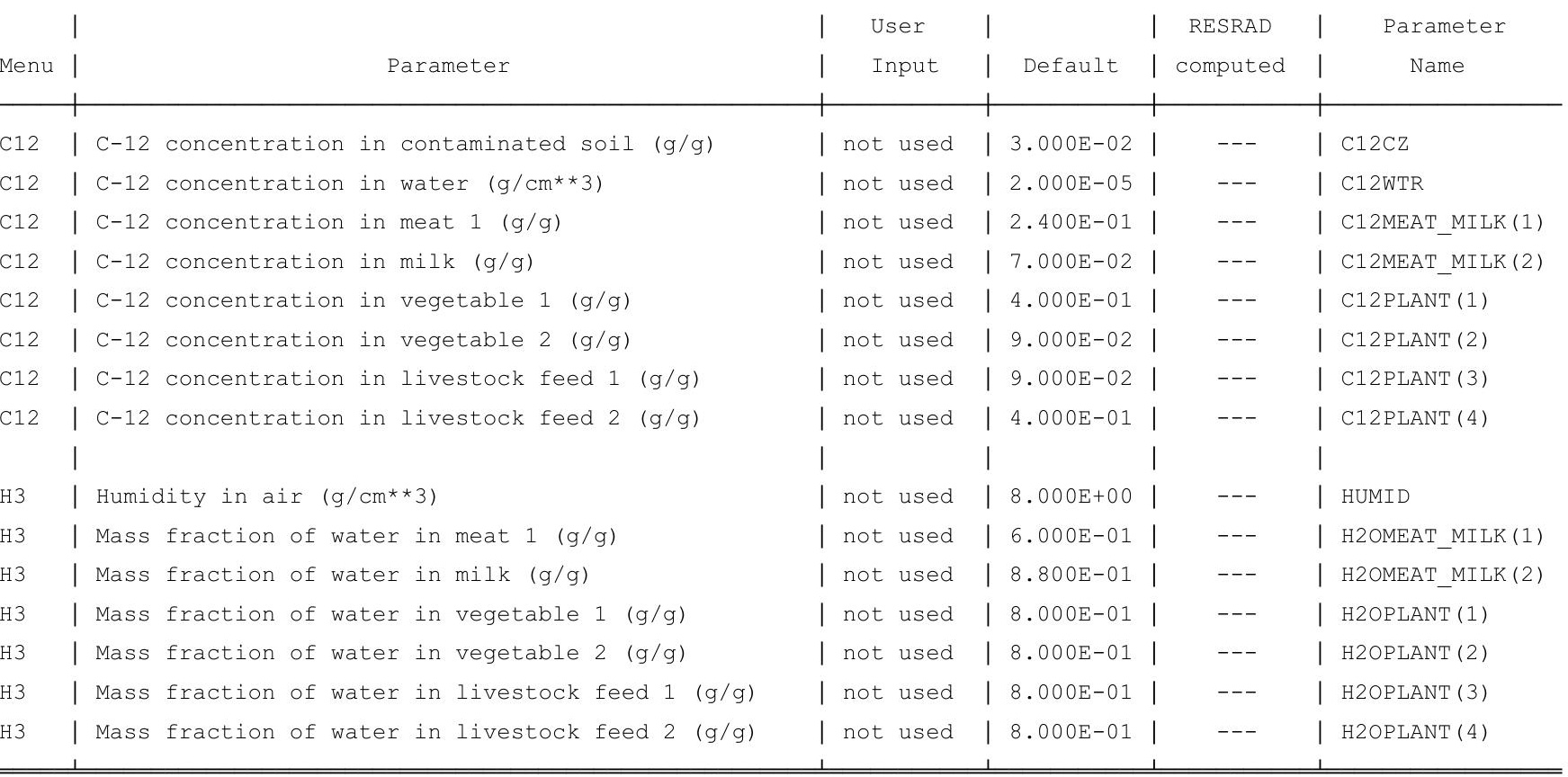

Summary of Pathway Selections

\begin{tabular}{|c|c|c|}
\hline & Pathway & User Selection \\
\hline 1 & -- external gamma & active \\
\hline 2 & -- inhalation (w/o radon) & active \\
\hline 3 & -- plant ingestion & active \\
\hline 4 & -- meat ingestion & active \\
\hline 5 & -- milk ingestion & active \\
\hline 6 & -- aquatic foods & suppressed \\
\hline 7 & -- drinking water & active \\
\hline 8 & -- soil ingestion & active \\
\hline 9 & -- radon & suppressed \\
\hline
\end{tabular}


RESRAD-OFFSITE, Version $2.5 \quad \mathrm{~T}^{1 / 2}$ Limit $=180$ days

Parent Dose Report

Title : RESRAD-OFFSITE Parameters for Offsite Resident Farmer Forward Run 1,050 Years

File : OFFSITE-RF_FORWARD-7-11.ROF

Contaminated Zone Dimensions

Area: 102144.00 square meters

Thickness:

Cover Depth:

\begin{abstract}
13.40 meters
1.52 meters
\end{abstract}

Initial Soil Concentrations, pCi/g

$\begin{array}{ll}\text { Am-241 } & 3.500 \mathrm{E}+01 \\ \mathrm{Cs}-137 & 1.900 \mathrm{E}+01 \\ \mathrm{~Np}-237 & 5.500 \mathrm{E}+00 \\ \mathrm{Pu}-238 & 3.900 \mathrm{E}+01 \\ \mathrm{Pu}-239 & 3.600 \mathrm{E}+01 \\ \mathrm{Pu}-240 & 3.600 \mathrm{E}+01 \\ \mathrm{TC}-99 & 5.200 \mathrm{E}+01 \\ \mathrm{Th}-228 & 4.000 \mathrm{E}+00 \\ \text { Th-230 } & 1.000 \mathrm{E}+02 \\ \text { Th-232 } & 4.000 \mathrm{E}+00 \\ \mathrm{U}-234 & 1.600 \mathrm{E}+02 \\ \mathrm{U}-235 & 6.500 \mathrm{E}+00 \\ \mathrm{U}-238 & 1.600 \mathrm{E}+02\end{array}$

Total Dose TDOSE(t), mrem/yr

Basic Radiation Dose Limit $=1.000 \mathrm{E}+00 \mathrm{mrem} / \mathrm{yr}$

Total Mixture Sum $\mathrm{M}(\mathrm{t})$ = Fraction of Basic Dose Limit Received at Time (t)

$\begin{array}{rllllll}t \text { (years) }: & 0.000 \mathrm{E}+00 & 1.000 \mathrm{E}+00 & 5.000 \mathrm{E}+01 & 1.000 \mathrm{E}+02 & 5.000 \mathrm{E}+02 & 1.026 \mathrm{E}+03 \\ \text { TDOSE }(\mathrm{t}): & 2.774 \mathrm{E}-14 & 2.073 \mathrm{E}-14 & 4.593 \mathrm{E}-14 & 6.422 \mathrm{E}-14 & 9.910 \mathrm{E}-01 & 1.436 \mathrm{E}+00 \\ \mathrm{M}(\mathrm{t}): & 2.774 \mathrm{E}-14 & 2.073 \mathrm{E}-14 & 4.593 \mathrm{E}-14 & 6.422 \mathrm{E}-14 & 9.910 \mathrm{E}-01 & 1.436 \mathrm{E}+00\end{array}$

Maximum TDOSE(t): $1.869 \mathrm{E}+00 \mathrm{mrem} / \mathrm{yr}$ at $t=772$ years 
RESRAD-OFFSITE, Version 2.

Parent Dose Report

Title : RESRAD-OFFSITE Parameters for Offsite Resident Farmer Forward Run 1,050 Years

File : OFFSITE-RF FORWARD-7-11.ROF

Total Dose Contributions TDOSE (i,p,t) for Individual Radionuclides (i) and Pathways (p) in mrem/yr and as a Percentage of Total Dose at $t=0$ years

From releases to ground water and to surface water

\begin{tabular}{|c|c|c|c|c|c|c|c|c|c|c|c|c|c|c|c|c|}
\hline & \multicolumn{2}{|c|}{ Ground } & \multicolumn{2}{|l|}{ Fish } & \multicolumn{2}{|c|}{ Radon } & \multicolumn{2}{|c|}{ Plant } & \multicolumn{2}{|l|}{ Meat } & \multicolumn{2}{|l|}{ Milk } & \multicolumn{2}{|l|}{ Soil } & \multicolumn{2}{|c|}{ Water } \\
\hline clide & Dose & \% & Dose & $\%$ & Dose & \% & Dose & \% & Dose & \% & Dose & \% & Dose & \% & Dose & $\%$ \\
\hline-241 & $0.00 \mathrm{E}+00$ & 0 & $0.00 \mathrm{E}+00$ & 0 & $0.00 \mathrm{E}+00$ & 0 & $0.00 \mathrm{E}+00$ & 0 & $0.00 \mathrm{E}+00$ & 0 & $0.00 \mathrm{E}+00$ & 0 & $0.00 \mathrm{E}+00$ & 0 & $0.00 \mathrm{E}+00$ & 0 \\
\hline-137 & $0.00 \mathrm{E}+00$ & 0 & $0.00 \mathrm{E}+00$ & 0 & $0.00 \mathrm{E}+00$ & 0 & $0.00 \mathrm{E}+00$ & 0 & $0.00 \mathrm{E}+00$ & 0 & $0.00 \mathrm{E}+00$ & 0 & $0.00 \mathrm{E}+00$ & 0 & $0.00 \mathrm{E}+00$ & 0 \\
\hline-237 & $0.00 \mathrm{E}+00$ & 0 & $0.00 \mathrm{E}+00$ & 0 & $0.00 \mathrm{E}+00$ & 0 & $0.00 \mathrm{E}+00$ & 0 & $0.00 \mathrm{E}+00$ & 0 & $0.00 \mathrm{E}+00$ & 0 & $0.00 \mathrm{E}+00$ & 0 & $0.00 \mathrm{E}+00$ & 0 \\
\hline-238 & $0.00 \mathrm{E}+00$ & 0 & $0.00 \mathrm{E}+00$ & 0 & $0.00 \mathrm{E}+00$ & 0 & $0.00 \mathrm{E}+00$ & 0 & $0.00 \mathrm{E}+00$ & 0 & $0.00 \mathrm{E}+00$ & 0 & $0.00 \mathrm{E}+00$ & 0 & $0.00 \mathrm{E}+00$ & 0 \\
\hline-239 & $0.00 \mathrm{E}+00$ & 0 & $0.00 \mathrm{E}+00$ & 0 & $0.00 \mathrm{E}+00$ & 0 & $0.00 \mathrm{E}+00$ & 0 & $0.00 \mathrm{E}+00$ & 0 & $0.00 \mathrm{E}+00$ & 0 & $0.00 \mathrm{E}+00$ & 0 & $0.00 \mathrm{E}+00$ & 0 \\
\hline-240 & $0.00 \mathrm{E}+00$ & 0 & $0.00 \mathrm{E}+00$ & 0 & $0.00 \mathrm{E}+00$ & 0 & $0.00 \mathrm{E}+00$ & 0 & $0.00 \mathrm{E}+00$ & 0 & $0.00 \mathrm{E}+00$ & 0 & $0.00 \mathrm{E}+00$ & 0 & $0.00 \mathrm{E}+00$ & 0 \\
\hline-99 & $0.00 \mathrm{E}+00$ & 0 & $0.00 E+00$ & 0 & $0.00 E+00$ & 0 & $0.00 \mathrm{E}+00$ & 0 & $0.00 \mathrm{E}+00$ & 0 & $0.00 E+00$ & 0 & $0.00 \mathrm{E}+00$ & 0 & $0.00 \mathrm{E}+00$ & 0 \\
\hline-228 & $0.00 \mathrm{E}+00$ & 0 & $0.00 \mathrm{E}+00$ & 0 & $0.00 \mathrm{E}+00$ & 0 & $0.00 \mathrm{E}+00$ & 0 & $0.00 \mathrm{E}+00$ & 0 & $0.00 \mathrm{E}+00$ & 0 & $0.00 \mathrm{E}+00$ & 0 & $0.00 \mathrm{E}+00$ & 0 \\
\hline-230 & $0.00 \mathrm{E}+00$ & 0 & $0.00 \mathrm{E}+00$ & 0 & $0.00 \mathrm{E}+00$ & 0 & $0.00 \mathrm{E}+00$ & 0 & $0.00 \mathrm{E}+00$ & 0 & $0.00 \mathrm{E}+00$ & 0 & $0.00 \mathrm{E}+00$ & 0 & $0.00 \mathrm{E}+00$ & 0 \\
\hline-232 & $0.00 \mathrm{E}+00$ & 0 & $0.00 E+00$ & 0 & $0.00 \mathrm{E}+00$ & 0 & $0.00 \mathrm{E}+00$ & 0 & $0.00 \mathrm{E}+00$ & 0 & $0.00 \mathrm{E}+00$ & 0 & $0.00 \mathrm{E}+00$ & 0 & $0.00 \mathrm{E}+00$ & 0 \\
\hline 234 & $0.00 \mathrm{E}+00$ & 0 & $0.00 \mathrm{E}+00$ & 0 & $0.00 \mathrm{E}+00$ & 0 & $0.00 \mathrm{E}+00$ & 0 & $0.00 \mathrm{E}+00$ & 0 & $0.00 \mathrm{E}+00$ & 0 & $0.00 \mathrm{E}+00$ & 0 & $0.00 \mathrm{E}+00$ & 0 \\
\hline 235 & $0.00 \mathrm{E}+00$ & 0 & $0.00 \mathrm{E}+00$ & 0 & $0.00 \mathrm{E}+00$ & 0 & $0.00 \mathrm{E}+00$ & 0 & $0.00 \mathrm{E}+00$ & 0 & $0.00 \mathrm{E}+00$ & 0 & $0.00 \mathrm{E}+00$ & 0 & $0.00 \mathrm{E}+00$ & 0 \\
\hline 38 & $0.00 \mathrm{E}+00$ & 0 & $0.00 E+00$ & 0 & $0.00 \mathrm{E}+00$ & 0 & $0.00 \mathrm{E}+00$ & 0 & $0.00 \mathrm{E}+00$ & 0 & $0.00 \mathrm{E}+00$ & 0 & $0.00 \mathrm{E}+00$ & 0 & $0.00 \mathrm{E}+00$ & 0 \\
\hline & $0.00 \mathrm{E}+00$ & 0 & $0.00 \mathrm{E}+00$ & 0 & $0.00 \mathrm{E}+00$ & 0 & $0.00 \mathrm{E}+00$ & 0 & $0.00 \mathrm{E}+00$ & 0 & $0.00 \mathrm{E}+00$ & 0 & $0.00 \mathrm{E}+00$ & 0 & $.00 \mathrm{E}+00$ & 0 \\
\hline
\end{tabular}

Total Dose Contributions TDOSE(i,p,t) for Individual Radionuclides (i) and Pathways (p)

in mrem/yr and as a Percentage of Total Dose at $t=0$ years

Directly from primary contamination and from release to atmosphere (Inhalation excludes radon)

\begin{tabular}{|c|c|c|c|c|c|c|c|c|c|c|c|c|c|c|c|c|}
\hline & \multicolumn{2}{|c|}{ Ground } & \multicolumn{2}{|c|}{ Inhalation } & \multicolumn{2}{|l|}{ Radon } & \multicolumn{2}{|c|}{ Plant } & \multicolumn{2}{|l|}{ Meat } & \multicolumn{2}{|l|}{ Milk } & \multicolumn{2}{|l|}{ Soil } & \multicolumn{2}{|c|}{ All Pathways* } \\
\hline clide & Dose & $\frac{\circ}{0}$ & Dose & $\%$ & Dose & $\%$ & Dose & $\frac{\circ}{0}$ & Dose & $\%$ & Dose & 응 & Dose & $\frac{\circ}{0}$ & Dose & $\frac{\circ}{0}$ \\
\hline $1-241$ & $2.67 E-26$ & 0 & $0.00 \mathrm{E}+00$ & 0 & $0.00 \mathrm{E}+00$ & 0 & $0.00 \mathrm{E}+00$ & 0 & $0.00 \mathrm{E}+00$ & 0 & $0.00 \mathrm{E}+00$ & 0 & $0.00 \mathrm{E}+00$ & 0 & $2.67 E-26$ & 0 \\
\hline-137 & $1.18 \mathrm{E}-16$ & 0 & $0.00 \mathrm{E}+00$ & 0 & $0.00 \mathrm{E}+00$ & 0 & $0.00 \mathrm{E}+00$ & 0 & $0.00 \mathrm{E}+00$ & 0 & $0.00 \mathrm{E}+00$ & 0 & $0.00 \mathrm{E}+00$ & 0 & $1.18 \mathrm{E}-16$ & 0 \\
\hline-237 & $2.59 E-20$ & 0 & $0.00 \mathrm{E}+00$ & 0 & $0.00 \mathrm{E}+00$ & 0 & $0.00 \mathrm{E}+00$ & 0 & $0.00 \mathrm{E}+00$ & 0 & $0.00 \mathrm{E}+00$ & 0 & $0.00 \mathrm{E}+00$ & 0 & $2.59 \mathrm{E}-20$ & 0 \\
\hline-238 & $1.57 E-29$ & 0 & $0.00 \mathrm{E}+00$ & 0 & $0.00 \mathrm{E}+00$ & 0 & $0.00 \mathrm{E}+00$ & 0 & $0.00 \mathrm{E}+00$ & 0 & $0.00 \mathrm{E}+00$ & 0 & $0.00 \mathrm{E}+00$ & 0 & $1.57 E-29$ & 0 \\
\hline-239 & $2.13 E-24$ & 0 & $0.00 \mathrm{E}+00$ & 0 & $0.00 \mathrm{E}+00$ & 0 & $0.00 \mathrm{E}+00$ & 0 & $0.00 \mathrm{E}+00$ & 0 & $0.00 \mathrm{E}+00$ & 0 & $0.00 \mathrm{E}+00$ & 0 & $2.13 E-24$ & 0 \\
\hline-240 & $2.03 E-31$ & 0 & $0.00 \mathrm{E}+00$ & 0 & $0.00 \mathrm{E}+00$ & 0 & $0.00 \mathrm{E}+00$ & 0 & $0.00 \mathrm{E}+00$ & 0 & $0.00 \mathrm{E}+00$ & 0 & $0.00 \mathrm{E}+00$ & 0 & $2.03 E-31$ & 0 \\
\hline-99 & $1.48 \mathrm{E}-32$ & 0 & $0.00 \mathrm{E}+00$ & 0 & $0.00 \mathrm{E}+00$ & 0 & $0.00 \mathrm{E}+00$ & 0 & $0.00 \mathrm{E}+00$ & 0 & $0.00 \mathrm{E}+00$ & 0 & $0.00 \mathrm{E}+00$ & 0 & $1.48 \mathrm{E}-32$ & 0 \\
\hline-228 & $2.73 \mathrm{E}-14$ & 98 & $0.00 \mathrm{E}+00$ & 0 & $0.00 \mathrm{E}+00$ & 0 & $0.00 \mathrm{E}+00$ & 0 & $0.00 \mathrm{E}+00$ & 0 & $0.00 \mathrm{E}+00$ & 0 & $0.00 \mathrm{E}+00$ & 0 & $2.73 E-14$ & 98 \\
\hline-230 & $1.86 \mathrm{E}-17$ & 0 & $0.00 \mathrm{E}+00$ & 0 & $0.00 \mathrm{E}+00$ & 0 & $0.00 \mathrm{E}+00$ & 0 & $0.00 \mathrm{E}+00$ & 0 & $0.00 \mathrm{E}+00$ & 0 & $0.00 \mathrm{E}+00$ & 0 & $1.86 \mathrm{E}-17$ & 0 \\
\hline-232 & $2.33 E-16$ & 1 & $0.00 \mathrm{E}+00$ & 0 & $0.00 \mathrm{E}+00$ & 0 & $0.00 \mathrm{E}+00$ & 0 & $0.00 \mathrm{E}+00$ & 0 & $0.00 \mathrm{E}+00$ & 0 & $0.00 \mathrm{E}+00$ & 0 & $2.33 E-16$ & 1 \\
\hline 234 & $8.95 E-23$ & 0 & $0.00 \mathrm{E}+00$ & 0 & $0.00 \mathrm{E}+00$ & 0 & $0.00 \mathrm{E}+00$ & 0 & $0.00 \mathrm{E}+00$ & 0 & $0.00 \mathrm{E}+00$ & 0 & $0.00 \mathrm{E}+00$ & 0 & $8.95 E-23$ & 0 \\
\hline 235 & $3.99 \mathrm{E}-22$ & 0 & $0.00 \mathrm{E}+00$ & 0 & $0.00 \mathrm{E}+00$ & 0 & $0.00 \mathrm{E}+00$ & 0 & $0.00 \mathrm{E}+00$ & 0 & $0.00 \mathrm{E}+00$ & 0 & $0.00 \mathrm{E}+00$ & 0 & $3.99 \mathrm{E}-22$ & 0 \\
\hline 238 & $1.12 \mathrm{E}-16$ & 0 & $0.00 \mathrm{E}+00$ & 0 & $0.00 \mathrm{E}+00$ & 0 & $0.00 \mathrm{E}+00$ & 0 & $0.00 \mathrm{E}+00$ & 0 & $0.00 \mathrm{E}+00$ & 0 & $0.00 \mathrm{E}+00$ & 0 & 1. $12 \mathrm{E}-16$ & 0 \\
\hline & $2.77 \mathrm{E}-14$ & 100 & $0.00 \mathrm{E}+00$ & 0 & $0.00 \mathrm{E}+00$ & 0 & $0.00 \mathrm{E}+00$ & 0 & $0.00 E+00$ & 0 & $0.00 \mathrm{E}+00$ & 0 & $0.00 \mathrm{E}+00$ & 0 & $2.77 \mathrm{E}-14$ & 100 \\
\hline
\end{tabular}

* Sum of dose from all releases and from primary contamination. 
RESRAD-OFFSITE, Version 2.

Parent Dose Report

Title : RESRAD-OFFSITE Parameters for Offsite Resident Farmer Forward Run 1,050 Years

File : OFFSITE-RF FORWARD-7-11.ROF

Total Dose Contributions TDOSE (i,p,t) for Individual Radionuclides (i) and Pathways (p) in mrem/yr and as a Percentage of Total Dose at $t=1$ years

From releases to ground water and to surface water

\begin{tabular}{|c|c|c|c|c|c|c|c|c|c|c|c|c|c|c|c|c|}
\hline & \multicolumn{2}{|c|}{ Ground } & \multicolumn{2}{|l|}{ Fish } & \multicolumn{2}{|c|}{ Radon } & \multicolumn{2}{|c|}{ Plant } & \multicolumn{2}{|l|}{ Meat } & \multicolumn{2}{|l|}{ Milk } & \multicolumn{2}{|l|}{ Soil } & \multicolumn{2}{|c|}{ Water } \\
\hline clide & Dose & \% & Dose & $\%$ & Dose & \% & Dose & \% & Dose & \% & Dose & \% & Dose & \% & Dose & $\%$ \\
\hline-241 & $0.00 \mathrm{E}+00$ & 0 & $0.00 \mathrm{E}+00$ & 0 & $0.00 \mathrm{E}+00$ & 0 & $0.00 \mathrm{E}+00$ & 0 & $0.00 \mathrm{E}+00$ & 0 & $0.00 \mathrm{E}+00$ & 0 & $0.00 \mathrm{E}+00$ & 0 & $0.00 \mathrm{E}+00$ & 0 \\
\hline-137 & $0.00 \mathrm{E}+00$ & 0 & $0.00 \mathrm{E}+00$ & 0 & $0.00 \mathrm{E}+00$ & 0 & $0.00 \mathrm{E}+00$ & 0 & $0.00 \mathrm{E}+00$ & 0 & $0.00 \mathrm{E}+00$ & 0 & $0.00 \mathrm{E}+00$ & 0 & $0.00 \mathrm{E}+00$ & 0 \\
\hline-237 & $0.00 \mathrm{E}+00$ & 0 & $0.00 \mathrm{E}+00$ & 0 & $0.00 \mathrm{E}+00$ & 0 & $0.00 \mathrm{E}+00$ & 0 & $0.00 \mathrm{E}+00$ & 0 & $0.00 \mathrm{E}+00$ & 0 & $0.00 \mathrm{E}+00$ & 0 & $0.00 \mathrm{E}+00$ & 0 \\
\hline-238 & $0.00 \mathrm{E}+00$ & 0 & $0.00 \mathrm{E}+00$ & 0 & $0.00 \mathrm{E}+00$ & 0 & $0.00 \mathrm{E}+00$ & 0 & $0.00 \mathrm{E}+00$ & 0 & $0.00 \mathrm{E}+00$ & 0 & $0.00 \mathrm{E}+00$ & 0 & $0.00 \mathrm{E}+00$ & 0 \\
\hline-239 & $0.00 \mathrm{E}+00$ & 0 & $0.00 \mathrm{E}+00$ & 0 & $0.00 \mathrm{E}+00$ & 0 & $0.00 \mathrm{E}+00$ & 0 & $0.00 \mathrm{E}+00$ & 0 & $0.00 \mathrm{E}+00$ & 0 & $0.00 \mathrm{E}+00$ & 0 & $0.00 \mathrm{E}+00$ & 0 \\
\hline-240 & $0.00 \mathrm{E}+00$ & 0 & $0.00 \mathrm{E}+00$ & 0 & $0.00 \mathrm{E}+00$ & 0 & $0.00 \mathrm{E}+00$ & 0 & $0.00 \mathrm{E}+00$ & 0 & $0.00 \mathrm{E}+00$ & 0 & $0.00 \mathrm{E}+00$ & 0 & $0.00 \mathrm{E}+00$ & 0 \\
\hline-99 & $0.00 \mathrm{E}+00$ & 0 & $0.00 E+00$ & 0 & $0.00 E+00$ & 0 & $0.00 \mathrm{E}+00$ & 0 & $0.00 \mathrm{E}+00$ & 0 & $0.00 E+00$ & 0 & $0.00 \mathrm{E}+00$ & 0 & $0.00 \mathrm{E}+00$ & 0 \\
\hline-228 & $0.00 \mathrm{E}+00$ & 0 & $0.00 \mathrm{E}+00$ & 0 & $0.00 \mathrm{E}+00$ & 0 & $0.00 \mathrm{E}+00$ & 0 & $0.00 \mathrm{E}+00$ & 0 & $0.00 \mathrm{E}+00$ & 0 & $0.00 \mathrm{E}+00$ & 0 & $0.00 \mathrm{E}+00$ & 0 \\
\hline-230 & $0.00 \mathrm{E}+00$ & 0 & $0.00 \mathrm{E}+00$ & 0 & $0.00 \mathrm{E}+00$ & 0 & $0.00 \mathrm{E}+00$ & 0 & $0.00 \mathrm{E}+00$ & 0 & $0.00 \mathrm{E}+00$ & 0 & $0.00 \mathrm{E}+00$ & 0 & $0.00 \mathrm{E}+00$ & 0 \\
\hline-232 & $0.00 \mathrm{E}+00$ & 0 & $0.00 E+00$ & 0 & $0.00 \mathrm{E}+00$ & 0 & $0.00 \mathrm{E}+00$ & 0 & $0.00 \mathrm{E}+00$ & 0 & $0.00 \mathrm{E}+00$ & 0 & $0.00 \mathrm{E}+00$ & 0 & $0.00 \mathrm{E}+00$ & 0 \\
\hline 234 & $0.00 \mathrm{E}+00$ & 0 & $0.00 \mathrm{E}+00$ & 0 & $0.00 \mathrm{E}+00$ & 0 & $0.00 \mathrm{E}+00$ & 0 & $0.00 \mathrm{E}+00$ & 0 & $0.00 \mathrm{E}+00$ & 0 & $0.00 \mathrm{E}+00$ & 0 & $0.00 \mathrm{E}+00$ & 0 \\
\hline 235 & $0.00 \mathrm{E}+00$ & 0 & $0.00 \mathrm{E}+00$ & 0 & $0.00 \mathrm{E}+00$ & 0 & $0.00 \mathrm{E}+00$ & 0 & $0.00 \mathrm{E}+00$ & 0 & $0.00 \mathrm{E}+00$ & 0 & $0.00 \mathrm{E}+00$ & 0 & $0.00 \mathrm{E}+00$ & 0 \\
\hline 38 & $0.00 \mathrm{E}+00$ & 0 & $0.00 E+00$ & 0 & $0.00 \mathrm{E}+00$ & 0 & $0.00 \mathrm{E}+00$ & 0 & $0.00 \mathrm{E}+00$ & 0 & $0.00 \mathrm{E}+00$ & 0 & $0.00 \mathrm{E}+00$ & 0 & $0.00 \mathrm{E}+00$ & 0 \\
\hline & $0.00 \mathrm{E}+00$ & 0 & $0.00 \mathrm{E}+00$ & 0 & $0.00 \mathrm{E}+00$ & 0 & $0.00 \mathrm{E}+00$ & 0 & $0.00 \mathrm{E}+00$ & 0 & $0.00 \mathrm{E}+00$ & 0 & $0.00 \mathrm{E}+00$ & 0 & $.00 \mathrm{E}+00$ & 0 \\
\hline
\end{tabular}

Total Dose Contributions TDOSE(i,p,t) for Individual Radionuclides (i) and Pathways (p)

in mrem/yr and as a Percentage of Total Dose at $t=1$ years

Directly from primary contamination and from release to atmosphere (Inhalation excludes radon)

\begin{tabular}{|c|c|c|c|c|c|c|c|c|c|c|c|c|c|c|c|c|}
\hline & \multicolumn{2}{|c|}{ Ground } & \multicolumn{2}{|c|}{ Inhalation } & \multicolumn{2}{|c|}{ Radon } & \multicolumn{2}{|c|}{ Plant } & \multicolumn{2}{|l|}{ Meat } & \multicolumn{2}{|l|}{ Milk } & \multicolumn{2}{|l|}{ Soil } & \multicolumn{2}{|c|}{ All Pathways* } \\
\hline clide & Dose & $\%$ & Dose & $\%$ & Dose & $\%$ & Dose & 음 & Dose & $\%$ & Dose & 음 & Dose & $\%$ & Dose & $\%$ \\
\hline-241 & $8.07 E-26$ & 0 & $0.00 \mathrm{E}+00$ & 0 & $0.00 E+00$ & 0 & $0.00 \mathrm{E}+00$ & 0 & $0.00 \mathrm{E}+00$ & 0 & $0.00 \mathrm{E}+00$ & 0 & $0.00 \mathrm{E}+00$ & 0 & $8.07 \mathrm{E}-26$ & 0 \\
\hline-137 & $1.16 \mathrm{E}-16$ & 1 & $0.00 E+00$ & 0 & $0.00 E+00$ & 0 & $0.00 \mathrm{E}+00$ & 0 & $0.00 \mathrm{E}+00$ & 0 & $0.00 E+00$ & 0 & $0.00 \mathrm{E}+00$ & 0 & $1.16 \mathrm{E}-16$ & 1 \\
\hline-237 & $2.61 E-20$ & 0 & $0.00 \mathrm{E}+00$ & 0 & $0.00 E+00$ & 0 & $0.00 \mathrm{E}+00$ & 0 & $0.00 \mathrm{E}+00$ & 0 & $0.00 E+00$ & 0 & $0.00 \mathrm{E}+00$ & 0 & $2.61 E-20$ & 0 \\
\hline-238 & $2.33 E-28$ & 0 & $0.00 \mathrm{E}+00$ & 0 & $0.00 \mathrm{E}+00$ & 0 & $0.00 \mathrm{E}+00$ & 0 & $0.00 \mathrm{E}+00$ & 0 & $0.00 \mathrm{E}+00$ & 0 & $0.00 \mathrm{E}+00$ & 0 & $2.33 E-28$ & 0 \\
\hline-239 & $2.16 \mathrm{E}-24$ & 0 & $0.00 \mathrm{E}+00$ & 0 & $0.00 \mathrm{E}+00$ & 0 & $0.00 \mathrm{E}+00$ & 0 & $0.00 \mathrm{E}+00$ & 0 & $0.00 \mathrm{E}+00$ & 0 & $0.00 \mathrm{E}+00$ & 0 & $2.16 \mathrm{E}-24$ & 0 \\
\hline-240 & $2.10 E-31$ & 0 & $0.00 \mathrm{E}+00$ & 0 & $0.00 E+00$ & 0 & $0.00 \mathrm{E}+00$ & 0 & $0.00 \mathrm{E}+00$ & 0 & $0.00 E+00$ & 0 & $0.00 \mathrm{E}+00$ & 0 & $2.10 E-31$ & 0 \\
\hline-99 & $1.50 \mathrm{E}-32$ & 0 & $0.00 \mathrm{E}+00$ & 0 & $0.00 \mathrm{E}+00$ & 0 & $0.00 \mathrm{E}+00$ & 0 & $0.00 \mathrm{E}+00$ & 0 & $0.00 E+00$ & 0 & $0.00 \mathrm{E}+00$ & 0 & $1.50 \mathrm{E}-32$ & 0 \\
\hline-228 & 1. $91 \mathrm{E}-14$ & 92 & $0.00 \mathrm{E}+00$ & 0 & $0.00 \mathrm{E}+00$ & 0 & $0.00 \mathrm{E}+00$ & 0 & $0.00 \mathrm{E}+00$ & 0 & $0.00 \mathrm{E}+00$ & 0 & $0.00 \mathrm{E}+00$ & 0 & 1. $91 \mathrm{E}-14$ & 92 \\
\hline-230 & $5.61 E-17$ & 0 & $0.00 E+00$ & 0 & $0.00 \mathrm{E}+00$ & 0 & $0.00 \mathrm{E}+00$ & 0 & $0.00 \mathrm{E}+00$ & 0 & $0.00 E+00$ & 0 & $0.00 \mathrm{E}+00$ & 0 & $5.61 \mathrm{E}-17$ & 0 \\
\hline-232 & $1.36 \mathrm{E}-15$ & 7 & $0.00 \mathrm{E}+00$ & 0 & $0.00 \mathrm{E}+00$ & 0 & $0.00 \mathrm{E}+00$ & 0 & $0.00 \mathrm{E}+00$ & 0 & $0.00 \mathrm{E}+00$ & 0 & $0.00 \mathrm{E}+00$ & 0 & $1.36 \mathrm{E}-15$ & 7 \\
\hline 34 & $6.29 \mathrm{E}-22$ & 0 & $0.00 \mathrm{E}+00$ & 0 & $0.00 \mathrm{E}+00$ & 0 & $0.00 \mathrm{E}+00$ & 0 & $0.00 \mathrm{E}+00$ & 0 & $0.00 \mathrm{E}+00$ & 0 & $0.00 \mathrm{E}+00$ & 0 & $6.29 \mathrm{E}-22$ & 0 \\
\hline 35 & $4.05 E-22$ & 0 & $0.00 \mathrm{E}+00$ & 0 & $0.00 E+00$ & 0 & $0.00 \mathrm{E}+00$ & 0 & $0.00 \mathrm{E}+00$ & 0 & $0.00 E+00$ & 0 & $0.00 \mathrm{E}+00$ & 0 & $4.05 E-22$ & 0 \\
\hline 38 & $1.13 E-16$ & 1 & $0.00 \mathrm{E}+00$ & 0 & $0.00 \mathrm{E}+00$ & 0 & $0.00 \mathrm{E}+00$ & 0 & $0.00 \mathrm{E}+00$ & 0 & $0.00 E+00$ & 0 & $0.00 \mathrm{E}+00$ & 0 & 1. $13 \mathrm{E}-16$ & 1 \\
\hline & $2.07 E-14$ & 100 & $0.00 \mathrm{E}+00$ & 0 & $0.00 \mathrm{E}+00$ & 0 & $0.00 \mathrm{E}+00$ & 0 & $0.00 \mathrm{E}+00$ & 0 & $0.00 \mathrm{E}+00$ & 0 & $0.00 \mathrm{E}+00$ & 0 & $2.07 E-14$ & 100 \\
\hline
\end{tabular}

* Sum of dose from all releases and from primary contamination. 
RESRAD-OFFSITE, Version 2.

Parent Dose Report

Title : RESRAD-OFFSITE Parameters for Offsite Resident Farmer Forward Run 1,050 Years

File : OFFSITE-RF FORWARD-7-11.ROF

Total Dose Contributions TDOSE (i,p,t) for Individual Radionuclides (i) and Pathways (p) in mrem/yr and as a Percentage of Total Dose at $t=50$ years

From releases to ground water and to surface water

\begin{tabular}{|c|c|c|c|c|c|c|c|c|c|c|c|c|c|c|c|c|}
\hline & \multicolumn{2}{|c|}{ Ground } & \multicolumn{2}{|l|}{ Fish } & \multicolumn{2}{|c|}{ Radon } & \multicolumn{2}{|c|}{ Plant } & \multicolumn{2}{|l|}{ Meat } & \multicolumn{2}{|l|}{ Milk } & \multicolumn{2}{|l|}{ Soil } & \multicolumn{2}{|c|}{ Water } \\
\hline ide & Dose & $\%$ & Dose & $\%$ & Dose & 응 & Dose & $\frac{\circ}{0}$ & Dose & \% & Dose & 응 & Dose & $\%$ & Dose & $\%$ \\
\hline-241 & $0.00 \mathrm{E}+00$ & 0 & $0.00 E+00$ & 0 & $0.00 \mathrm{E}+00$ & 0 & $0.00 \mathrm{E}+00$ & 0 & $0.00 \mathrm{E}+00$ & 0 & $0.00 \mathrm{E}+00$ & 0 & $0.00 \mathrm{E}+00$ & 0 & $0.00 \mathrm{E}+00$ & 0 \\
\hline-137 & $0.00 \mathrm{E}+00$ & 0 & $0.00 \mathrm{E}+00$ & 0 & $0.00 \mathrm{E}+00$ & 0 & $0.00 \mathrm{E}+00$ & 0 & $0.00 \mathrm{E}+00$ & 0 & $0.00 \mathrm{E}+00$ & 0 & $0.00 \mathrm{E}+00$ & 0 & $0.00 \mathrm{E}+00$ & 0 \\
\hline-237 & $0.00 \mathrm{E}+00$ & 0 & $0.00 \mathrm{E}+00$ & 0 & $0.00 \mathrm{E}+00$ & 0 & $0.00 \mathrm{E}+00$ & 0 & $0.00 \mathrm{E}+00$ & 0 & $0.00 \mathrm{E}+00$ & 0 & $0.00 \mathrm{E}+00$ & 0 & $0.00 \mathrm{E}+00$ & 0 \\
\hline-238 & $0.00 \mathrm{E}+00$ & 0 & $0.00 \mathrm{E}+00$ & 0 & $0.00 E+00$ & 0 & $0.00 \mathrm{E}+00$ & 0 & $0.00 \mathrm{E}+00$ & 0 & $0.00 E+00$ & 0 & $0.00 \mathrm{E}+00$ & 0 & $0.00 \mathrm{E}+00$ & 0 \\
\hline-239 & $0.00 \mathrm{E}+00$ & 0 & $0.00 \mathrm{E}+00$ & 0 & $0.00 \mathrm{E}+00$ & 0 & $0.00 \mathrm{E}+00$ & 0 & $0.00 \mathrm{E}+00$ & 0 & $0.00 \mathrm{E}+00$ & 0 & $0.00 \mathrm{E}+00$ & 0 & $0.00 \mathrm{E}+00$ & 0 \\
\hline-240 & $0.00 \mathrm{E}+00$ & 0 & $0.00 \mathrm{E}+00$ & 0 & $0.00 \mathrm{E}+00$ & 0 & $0.00 \mathrm{E}+00$ & 0 & $0.00 \mathrm{E}+00$ & 0 & $0.00 \mathrm{E}+00$ & 0 & $0.00 \mathrm{E}+00$ & 0 & $0.00 \mathrm{E}+00$ & 0 \\
\hline-99 & $0.00 \mathrm{E}+00$ & 0 & $0.00 \mathrm{E}+00$ & 0 & $0.00 \mathrm{E}+00$ & 0 & $0.00 \mathrm{E}+00$ & 0 & $0.00 \mathrm{E}+00$ & 0 & $0.00 E+00$ & 0 & $0.00 \mathrm{E}+00$ & 0 & $0.00 \mathrm{E}+00$ & 0 \\
\hline-228 & $0.00 \mathrm{E}+00$ & 0 & $0.00 \mathrm{E}+00$ & 0 & $0.00 \mathrm{E}+00$ & 0 & $0.00 \mathrm{E}+00$ & 0 & $0.00 \mathrm{E}+00$ & 0 & $0.00 \mathrm{E}+00$ & 0 & $0.00 \mathrm{E}+00$ & 0 & $0.00 \mathrm{E}+00$ & 0 \\
\hline-230 & $0.00 \mathrm{E}+00$ & 0 & $0.00 \mathrm{E}+00$ & 0 & $0.00 \mathrm{E}+00$ & 0 & $0.00 \mathrm{E}+00$ & 0 & $0.00 \mathrm{E}+00$ & 0 & $0.00 \mathrm{E}+00$ & 0 & $0.00 \mathrm{E}+00$ & 0 & $0.00 \mathrm{E}+00$ & 0 \\
\hline-232 & $0.00 \mathrm{E}+00$ & 0 & $0.00 \mathrm{E}+00$ & 0 & $0.00 \mathrm{E}+00$ & 0 & $0.00 \mathrm{E}+00$ & 0 & $0.00 \mathrm{E}+00$ & 0 & $0.00 \mathrm{E}+00$ & 0 & $0.00 \mathrm{E}+00$ & 0 & $0.00 \mathrm{E}+00$ & 0 \\
\hline 4 & $0.00 \mathrm{E}+00$ & 0 & $0.00 \mathrm{E}+00$ & 0 & $0.00 \mathrm{E}+00$ & 0 & $0.00 \mathrm{E}+00$ & 0 & $0.00 \mathrm{E}+00$ & 0 & $0.00 \mathrm{E}+00$ & 0 & $0.00 \mathrm{E}+00$ & 0 & $0.00 \mathrm{E}+00$ & 0 \\
\hline 35 & $0.00 \mathrm{E}+00$ & 0 & $0.00 \mathrm{E}+00$ & 0 & $0.00 \mathrm{E}+00$ & 0 & $0.00 \mathrm{E}+00$ & 0 & $0.00 \mathrm{E}+00$ & 0 & $0.00 \mathrm{E}+00$ & 0 & $0.00 \mathrm{E}+00$ & 0 & $0.00 \mathrm{E}+00$ & 0 \\
\hline 38 & $0.00 \mathrm{E}+00$ & 0 & $0.00 \mathrm{E}+00$ & 0 & $0.00 \mathrm{E}+00$ & 0 & $0.00 \mathrm{E}+00$ & 0 & $0.00 \mathrm{E}+00$ & 0 & $0.00 \mathrm{E}+00$ & 0 & $0.00 \mathrm{E}+00$ & 0 & $0.00 \mathrm{E}+00$ & 0 \\
\hline & $0.00 \mathrm{E}+00$ & 0 & $0.00 E+00$ & 0 & $0.00 \mathrm{E}+00$ & 0 & $0.00 \mathrm{E}+00$ & 0 & $0.00 \mathrm{E}+00$ & 0 & $0.00 \mathrm{E}+00$ & 0 & $0.00 \mathrm{E}+00$ & 0 & $0.00 \mathrm{E}+00$ & \\
\hline
\end{tabular}

Total Dose Contributions TDOSE(i,p,t) for Individual Radionuclides (i) and Pathways (p) in mrem/yr and as a Percentage of Total Dose at $t=50$ years

Directly from primary contamination and from release to atmosphere (Inhalation excludes radon)

\begin{tabular}{|c|c|c|c|c|c|c|c|c|c|c|c|c|c|c|c|c|}
\hline & \multicolumn{2}{|c|}{ Ground } & \multicolumn{2}{|c|}{ Inhalation } & \multicolumn{2}{|c|}{ Radon } & \multicolumn{2}{|c|}{ Plant } & \multicolumn{2}{|l|}{ Meat } & \multicolumn{2}{|l|}{ Milk } & \multicolumn{2}{|l|}{ Soil } & \multicolumn{2}{|c|}{ All Pathways* } \\
\hline clide & Dose & $\%$ & Dose & $\%$ & Dose & $\%$ & Dose & \% & Dose & $\%$ & Dose & \% & Dose & \% & Dose & $\%$ \\
\hline-241 & $4.24 \mathrm{E}-24$ & 0 & $0.00 \mathrm{E}+00$ & 0 & $0.00 \mathrm{E}+00$ & 0 & $0.00 \mathrm{E}+00$ & 0 & $0.00 \mathrm{E}+00$ & 0 & $0.00 \mathrm{E}+00$ & 0 & $0.00 \mathrm{E}+00$ & 0 & $4.24 \mathrm{E}-24$ & 0 \\
\hline-137 & $5.48 \mathrm{E}-17$ & 0 & $0.00 \mathrm{E}+00$ & 0 & $0.00 \mathrm{E}+00$ & 0 & $0.00 \mathrm{E}+00$ & 0 & $0.00 \mathrm{E}+00$ & 0 & $0.00 \mathrm{E}+00$ & 0 & $0.00 \mathrm{E}+00$ & 0 & $5.48 \mathrm{E}-17$ & 0 \\
\hline-237 & $4.24 \mathrm{E}-20$ & 0 & $0.00 \mathrm{E}+00$ & 0 & $0.00 \mathrm{E}+00$ & 0 & $0.00 \mathrm{E}+00$ & 0 & $0.00 \mathrm{E}+00$ & 0 & $0.00 \mathrm{E}+00$ & 0 & $0.00 \mathrm{E}+00$ & 0 & $4.24 \mathrm{E}-20$ & 0 \\
\hline-238 & $9.85 E-24$ & 0 & $0.00 \mathrm{E}+00$ & 0 & $0.00 \mathrm{E}+00$ & 0 & $0.00 \mathrm{E}+00$ & 0 & $0.00 \mathrm{E}+00$ & 0 & $0.00 \mathrm{E}+00$ & 0 & $0.00 \mathrm{E}+00$ & 0 & $9.85 E-24$ & 0 \\
\hline-239 & $3.70 \mathrm{E}-24$ & 0 & $0.00 \mathrm{E}+00$ & 0 & $0.00 \mathrm{E}+00$ & 0 & $0.00 \mathrm{E}+00$ & 0 & $0.00 \mathrm{E}+00$ & 0 & $0.00 \mathrm{E}+00$ & 0 & $0.00 \mathrm{E}+00$ & 0 & $3.70 \mathrm{E}-24$ & 0 \\
\hline-240 & $4.65 E-28$ & 0 & $0.00 \mathrm{E}+00$ & 0 & $0.00 \mathrm{E}+00$ & 0 & $0.00 \mathrm{E}+00$ & 0 & $0.00 \mathrm{E}+00$ & 0 & $0.00 \mathrm{E}+00$ & 0 & $0.00 \mathrm{E}+00$ & 0 & 4. $65 \mathrm{E}-28$ & 0 \\
\hline-99 & $2.75 E-32$ & 0 & $0.00 \mathrm{E}+00$ & 0 & $0.00 \mathrm{E}+00$ & 0 & $0.00 \mathrm{E}+00$ & 0 & $0.00 \mathrm{E}+00$ & 0 & $0.00 \mathrm{E}+00$ & 0 & $0.00 \mathrm{E}+00$ & 0 & $2.75 E-32$ & 0 \\
\hline-228 & $4.87 E-22$ & 0 & $0.00 E+00$ & 0 & $0.00 \mathrm{E}+00$ & 0 & $0.00 \mathrm{E}+00$ & 0 & $0.00 \mathrm{E}+00$ & 0 & $0.00 \mathrm{E}+00$ & 0 & $0.00 \mathrm{E}+00$ & 0 & $4.87 E-22$ & 0 \\
\hline-230 & $2.55 \mathrm{E}-15$ & 6 & $0.00 \mathrm{E}+00$ & 0 & $0.00 \mathrm{E}+00$ & 0 & $0.00 \mathrm{E}+00$ & 0 & $0.00 \mathrm{E}+00$ & 0 & $0.00 \mathrm{E}+00$ & 0 & $0.00 \mathrm{E}+00$ & 0 & $2.55 \mathrm{E}-15$ & 6 \\
\hline-232 & $4.32 E-14$ & 94 & $0.00 \mathrm{E}+00$ & 0 & $0.00 \mathrm{E}+00$ & 0 & $0.00 \mathrm{E}+00$ & 0 & $0.00 \mathrm{E}+00$ & 0 & $0.00 \mathrm{E}+00$ & 0 & $0.00 \mathrm{E}+00$ & 0 & $4.32 \mathrm{E}-14$ & 94 \\
\hline 234 & $9.31 \mathrm{E}-19$ & 0 & $0.00 \mathrm{E}+00$ & 0 & $0.00 \mathrm{E}+00$ & 0 & $0.00 \mathrm{E}+00$ & 0 & $0.00 \mathrm{E}+00$ & 0 & $0.00 \mathrm{E}+00$ & 0 & $0.00 \mathrm{E}+00$ & 0 & $9.31 \mathrm{E}-19$ & 0 \\
\hline 235 & $2.85 E-21$ & 0 & $0.00 \mathrm{E}+00$ & 0 & $0.00 \mathrm{E}+00$ & 0 & $0.00 \mathrm{E}+00$ & 0 & $0.00 \mathrm{E}+00$ & 0 & $0.00 \mathrm{E}+00$ & 0 & $0.00 \mathrm{E}+00$ & 0 & $2.85 E-21$ & 0 \\
\hline 38 & $1.62 \mathrm{E}-16$ & 0 & $0.00 \mathrm{E}+00$ & 0 & $0.00 \mathrm{E}+00$ & 0 & $0.00 \mathrm{E}+00$ & 0 & $0.00 \mathrm{E}+00$ & 0 & $0.00 \mathrm{E}+00$ & 0 & $0.00 \mathrm{E}+00$ & 0 & $1.62 \mathrm{E}-16$ & 0 \\
\hline al & $4.59 E-14$ & 100 & $0.00 \mathrm{E}+00$ & 0 & $0.00 \mathrm{E}+00$ & 0 & $0.00 \mathrm{E}+00$ & 0 & $0.00 \mathrm{E}+00$ & 0 & $0.00 \mathrm{E}+00$ & 0 & $0.00 \mathrm{E}+00$ & 0 & $4.59 \mathrm{E}-14$ & 00 \\
\hline
\end{tabular}

* Sum of dose from all releases and from primary contamination. 
RESRAD-OFFSITE, Version 2.

Parent Dose Report

Title : RESRAD-OFFSITE Parameters for Offsite Resident Farmer Forward Run 1,050 Years

File : OFFSITE-RF FORWARD-7-11.ROF

Total Dose Contributions TDOSE (i,p,t) for Individual Radionuclides (i) and Pathways (p) in mrem/yr and as a Percentage of Total Dose at $t=100$ years

From releases to ground water and to surface water

\begin{tabular}{|c|c|c|c|c|c|c|c|c|c|c|c|c|c|c|c|c|}
\hline & \multicolumn{2}{|c|}{ Ground } & \multicolumn{2}{|l|}{ Fish } & \multicolumn{2}{|c|}{ Radon } & \multicolumn{2}{|c|}{ Plant } & \multicolumn{2}{|l|}{ Meat } & \multicolumn{2}{|l|}{ Milk } & \multicolumn{2}{|l|}{ Soil } & \multicolumn{2}{|c|}{ Water } \\
\hline ide & Dose & $\%$ & Dose & $\%$ & Dose & 응 & Dose & $\frac{\circ}{0}$ & Dose & \% & Dose & 응 & Dose & $\%$ & Dose & $\%$ \\
\hline-241 & $0.00 \mathrm{E}+00$ & 0 & $0.00 E+00$ & 0 & $0.00 \mathrm{E}+00$ & 0 & $0.00 \mathrm{E}+00$ & 0 & $0.00 \mathrm{E}+00$ & 0 & $0.00 \mathrm{E}+00$ & 0 & $0.00 \mathrm{E}+00$ & 0 & $0.00 \mathrm{E}+00$ & 0 \\
\hline-137 & $0.00 \mathrm{E}+00$ & 0 & $0.00 \mathrm{E}+00$ & 0 & $0.00 \mathrm{E}+00$ & 0 & $0.00 \mathrm{E}+00$ & 0 & $0.00 \mathrm{E}+00$ & 0 & $0.00 \mathrm{E}+00$ & 0 & $0.00 \mathrm{E}+00$ & 0 & $0.00 \mathrm{E}+00$ & 0 \\
\hline-237 & $0.00 \mathrm{E}+00$ & 0 & $0.00 \mathrm{E}+00$ & 0 & $0.00 \mathrm{E}+00$ & 0 & $0.00 \mathrm{E}+00$ & 0 & $0.00 \mathrm{E}+00$ & 0 & $0.00 \mathrm{E}+00$ & 0 & $0.00 \mathrm{E}+00$ & 0 & $0.00 \mathrm{E}+00$ & 0 \\
\hline-238 & $0.00 \mathrm{E}+00$ & 0 & $0.00 \mathrm{E}+00$ & 0 & $0.00 E+00$ & 0 & $0.00 \mathrm{E}+00$ & 0 & $0.00 \mathrm{E}+00$ & 0 & $0.00 E+00$ & 0 & $0.00 \mathrm{E}+00$ & 0 & $0.00 \mathrm{E}+00$ & 0 \\
\hline-239 & $0.00 \mathrm{E}+00$ & 0 & $0.00 \mathrm{E}+00$ & 0 & $0.00 \mathrm{E}+00$ & 0 & $0.00 \mathrm{E}+00$ & 0 & $0.00 \mathrm{E}+00$ & 0 & $0.00 \mathrm{E}+00$ & 0 & $0.00 \mathrm{E}+00$ & 0 & $0.00 \mathrm{E}+00$ & 0 \\
\hline-240 & $0.00 \mathrm{E}+00$ & 0 & $0.00 \mathrm{E}+00$ & 0 & $0.00 \mathrm{E}+00$ & 0 & $0.00 \mathrm{E}+00$ & 0 & $0.00 \mathrm{E}+00$ & 0 & $0.00 \mathrm{E}+00$ & 0 & $0.00 \mathrm{E}+00$ & 0 & $0.00 \mathrm{E}+00$ & 0 \\
\hline-99 & $0.00 \mathrm{E}+00$ & 0 & $0.00 \mathrm{E}+00$ & 0 & $0.00 \mathrm{E}+00$ & 0 & $0.00 \mathrm{E}+00$ & 0 & $0.00 \mathrm{E}+00$ & 0 & $0.00 E+00$ & 0 & $0.00 \mathrm{E}+00$ & 0 & $0.00 \mathrm{E}+00$ & 0 \\
\hline-228 & $0.00 \mathrm{E}+00$ & 0 & $0.00 \mathrm{E}+00$ & 0 & $0.00 \mathrm{E}+00$ & 0 & $0.00 \mathrm{E}+00$ & 0 & $0.00 \mathrm{E}+00$ & 0 & $0.00 \mathrm{E}+00$ & 0 & $0.00 \mathrm{E}+00$ & 0 & $0.00 \mathrm{E}+00$ & 0 \\
\hline-230 & $0.00 \mathrm{E}+00$ & 0 & $0.00 \mathrm{E}+00$ & 0 & $0.00 \mathrm{E}+00$ & 0 & $0.00 \mathrm{E}+00$ & 0 & $0.00 \mathrm{E}+00$ & 0 & $0.00 \mathrm{E}+00$ & 0 & $0.00 \mathrm{E}+00$ & 0 & $0.00 \mathrm{E}+00$ & 0 \\
\hline-232 & $0.00 \mathrm{E}+00$ & 0 & $0.00 \mathrm{E}+00$ & 0 & $0.00 \mathrm{E}+00$ & 0 & $0.00 \mathrm{E}+00$ & 0 & $0.00 \mathrm{E}+00$ & 0 & $0.00 \mathrm{E}+00$ & 0 & $0.00 \mathrm{E}+00$ & 0 & $0.00 \mathrm{E}+00$ & 0 \\
\hline 4 & $0.00 \mathrm{E}+00$ & 0 & $0.00 \mathrm{E}+00$ & 0 & $0.00 \mathrm{E}+00$ & 0 & $0.00 \mathrm{E}+00$ & 0 & $0.00 \mathrm{E}+00$ & 0 & $0.00 \mathrm{E}+00$ & 0 & $0.00 \mathrm{E}+00$ & 0 & $0.00 \mathrm{E}+00$ & 0 \\
\hline 35 & $0.00 \mathrm{E}+00$ & 0 & $0.00 \mathrm{E}+00$ & 0 & $0.00 \mathrm{E}+00$ & 0 & $0.00 \mathrm{E}+00$ & 0 & $0.00 \mathrm{E}+00$ & 0 & $0.00 \mathrm{E}+00$ & 0 & $0.00 \mathrm{E}+00$ & 0 & $0.00 \mathrm{E}+00$ & 0 \\
\hline 38 & $0.00 \mathrm{E}+00$ & 0 & $0.00 \mathrm{E}+00$ & 0 & $0.00 \mathrm{E}+00$ & 0 & $0.00 \mathrm{E}+00$ & 0 & $0.00 \mathrm{E}+00$ & 0 & $0.00 \mathrm{E}+00$ & 0 & $0.00 \mathrm{E}+00$ & 0 & $0.00 \mathrm{E}+00$ & 0 \\
\hline & $0.00 \mathrm{E}+00$ & 0 & $0.00 E+00$ & 0 & $0.00 \mathrm{E}+00$ & 0 & $0.00 \mathrm{E}+00$ & 0 & $0.00 \mathrm{E}+00$ & 0 & $0.00 \mathrm{E}+00$ & 0 & $0.00 \mathrm{E}+00$ & 0 & $0.00 \mathrm{E}+00$ & \\
\hline
\end{tabular}

Total Dose Contributions TDOSE(i,p,t) for Individual Radionuclides (i) and Pathways (p) in mrem/yr and as a Percentage of Total Dose at $t=100$ years

Directly from primary contamination and from release to atmosphere (Inhalation excludes radon)

\begin{tabular}{|c|c|c|c|c|c|c|c|c|c|c|c|c|c|c|c|c|}
\hline & \multicolumn{2}{|c|}{ Ground } & \multicolumn{2}{|c|}{ Inhalation } & \multicolumn{2}{|c|}{ Radon } & \multicolumn{2}{|c|}{ Plant } & \multicolumn{2}{|l|}{ Meat } & \multicolumn{2}{|l|}{ Milk } & \multicolumn{2}{|l|}{ Soil } & \multicolumn{2}{|c|}{ All Pathways* } \\
\hline clide & Dose & $\%$ & Dose & $\%$ & Dose & $\%$ & Dose & 음 & Dose & $\%$ & Dose & 음 & Dose & $\%$ & Dose & $\%$ \\
\hline-241 & $1.33 E-23$ & 0 & $0.00 E+00$ & 0 & $0.00 E+00$ & 0 & $0.00 \mathrm{E}+00$ & 0 & $0.00 \mathrm{E}+00$ & 0 & $0.00 \mathrm{E}+00$ & 0 & $0.00 \mathrm{E}+00$ & 0 & 1. $33 \mathrm{E}-23$ & 0 \\
\hline-137 & $2.55 E-17$ & 0 & $0.00 E+00$ & 0 & $0.00 E+00$ & 0 & $0.00 \mathrm{E}+00$ & 0 & $0.00 \mathrm{E}+00$ & 0 & $0.00 E+00$ & 0 & $0.00 \mathrm{E}+00$ & 0 & $2.55 E-17$ & 0 \\
\hline-237 & $6.98 E-20$ & 0 & $0.00 E+00$ & 0 & $0.00 E+00$ & 0 & $0.00 \mathrm{E}+00$ & 0 & $0.00 \mathrm{E}+00$ & 0 & $0.00 E+00$ & 0 & $0.00 \mathrm{E}+00$ & 0 & $6.98 E-20$ & 0 \\
\hline-238 & $9.69 E-23$ & 0 & $0.00 E+00$ & 0 & $0.00 \mathrm{E}+00$ & 0 & $0.00 \mathrm{E}+00$ & 0 & $0.00 \mathrm{E}+00$ & 0 & $0.00 \mathrm{E}+00$ & 0 & $0.00 \mathrm{E}+00$ & 0 & $9.69 \mathrm{E}-23$ & 0 \\
\hline-239 & $6.41 E-24$ & 0 & $0.00 \mathrm{E}+00$ & 0 & $0.00 \mathrm{E}+00$ & 0 & $0.00 \mathrm{E}+00$ & 0 & $0.00 \mathrm{E}+00$ & 0 & $0.00 \mathrm{E}+00$ & 0 & $0.00 \mathrm{E}+00$ & 0 & $6.41 \mathrm{E}-24$ & 0 \\
\hline-240 & $3.02 \mathrm{E}-27$ & 0 & $0.00 \mathrm{E}+00$ & 0 & $0.00 \mathrm{E}+00$ & 0 & $0.00 \mathrm{E}+00$ & 0 & $0.00 \mathrm{E}+00$ & 0 & $0.00 \mathrm{E}+00$ & 0 & $0.00 \mathrm{E}+00$ & 0 & $3.02 \mathrm{E}-27$ & 0 \\
\hline-99 & $5.11 E-32$ & 0 & $0.00 E+00$ & 0 & $0.00 \mathrm{E}+00$ & 0 & $0.00 \mathrm{E}+00$ & 0 & $0.00 \mathrm{E}+00$ & 0 & $0.00 E+00$ & 0 & $0.00 \mathrm{E}+00$ & 0 & $5.11 E-32$ & 0 \\
\hline-228 & $8.69 \mathrm{E}-30$ & 0 & $0.00 \mathrm{E}+00$ & 0 & $0.00 \mathrm{E}+00$ & 0 & $0.00 \mathrm{E}+00$ & 0 & $0.00 \mathrm{E}+00$ & 0 & $0.00 \mathrm{E}+00$ & 0 & $0.00 \mathrm{E}+00$ & 0 & $8.69 \mathrm{E}-30$ & 0 \\
\hline-230 & $6.90 \mathrm{E}-15$ & 11 & $0.00 E+00$ & 0 & $0.00 \mathrm{E}+00$ & 0 & $0.00 \mathrm{E}+00$ & 0 & $0.00 \mathrm{E}+00$ & 0 & $0.00 E+00$ & 0 & $0.00 \mathrm{E}+00$ & 0 & $6.90 \mathrm{E}-15$ & 11 \\
\hline-232 & $5.70 \mathrm{E}-14$ & 89 & $0.00 E+00$ & 0 & $0.00 \mathrm{E}+00$ & 0 & $0.00 \mathrm{E}+00$ & 0 & $0.00 \mathrm{E}+00$ & 0 & $0.00 \mathrm{E}+00$ & 0 & $0.00 \mathrm{E}+00$ & 0 & $5.70 \mathrm{E}-14$ & 89 \\
\hline 34 & $5.03 E-18$ & 0 & $0.00 \mathrm{E}+00$ & 0 & $0.00 \mathrm{E}+00$ & 0 & $0.00 \mathrm{E}+00$ & 0 & $0.00 \mathrm{E}+00$ & 0 & $0.00 \mathrm{E}+00$ & 0 & $0.00 \mathrm{E}+00$ & 0 & $5.03 E-18$ & 0 \\
\hline 35 & $1.01 E-20$ & 0 & $0.00 E+00$ & 0 & $0.00 E+00$ & 0 & $0.00 \mathrm{E}+00$ & 0 & $0.00 \mathrm{E}+00$ & 0 & $0.00 E+00$ & 0 & $0.00 \mathrm{E}+00$ & 0 & 1. $01 \mathrm{E}-20$ & 0 \\
\hline 38 & $2.34 E-16$ & 0 & $0.00 E+00$ & 0 & $0.00 \mathrm{E}+00$ & 0 & $0.00 \mathrm{E}+00$ & 0 & $0.00 \mathrm{E}+00$ & 0 & $0.00 E+00$ & 0 & $0.00 \mathrm{E}+00$ & 0 & $2.34 \mathrm{E}-16$ & 0 \\
\hline & $6.42 \mathrm{E}-14$ & 100 & $0.00 \mathrm{E}+00$ & 0 & $0.00 \mathrm{E}+00$ & 0 & $0.00 \mathrm{E}+00$ & 0 & $0.00 \mathrm{E}+00$ & 0 & $0.00 \mathrm{E}+00$ & 0 & $0.00 \mathrm{E}+00$ & 0 & $6.42 \mathrm{E}-14$ & 100 \\
\hline
\end{tabular}

* Sum of dose from all releases and from primary contamination. 
RESRAD-OFFSITE, Version 2.

Parent Dose Report

Title : RESRAD-OFFSITE Parameters for Offsite Resident Farmer Forward Run 1,050 Years

File : OFFSITE-RF FORWARD-7-11.ROF

Total Dose Contributions TDOSE (i,p,t) for Individual Radionuclides (i) and Pathways (p) in mrem/yr and as a Percentage of Total Dose at $t=500$ years

From releases to ground water and to surface water

\begin{tabular}{|c|c|c|c|c|c|c|c|c|c|c|c|c|c|c|c|c|}
\hline & \multicolumn{2}{|c|}{ Ground } & \multicolumn{2}{|l|}{ Fish } & \multicolumn{2}{|c|}{ Radon } & \multicolumn{2}{|c|}{ Plant } & \multicolumn{2}{|l|}{ Meat } & \multicolumn{2}{|l|}{ Milk } & \multicolumn{2}{|l|}{ Soil } & \multicolumn{2}{|c|}{ Water } \\
\hline clide & Dose & \% & Dose & $\%$ & Dose & \% & Dose & \% & Dose & \% & Dose & \% & Dose & \% & Dose & $\%$ \\
\hline-241 & $0.00 \mathrm{E}+00$ & 0 & $0.00 \mathrm{E}+00$ & 0 & $0.00 \mathrm{E}+00$ & 0 & $0.00 \mathrm{E}+00$ & 0 & $0.00 E+00$ & 0 & $0.00 \mathrm{E}+00$ & 0 & $0.00 \mathrm{E}+00$ & 0 & $0.00 \mathrm{E}+00$ & 0 \\
\hline-137 & $0.00 \mathrm{E}+00$ & 0 & $0.00 \mathrm{E}+00$ & 0 & $0.00 \mathrm{E}+00$ & 0 & $0.00 \mathrm{E}+00$ & 0 & $0.00 \mathrm{E}+00$ & 0 & $0.00 \mathrm{E}+00$ & 0 & $0.00 \mathrm{E}+00$ & 0 & $0.00 \mathrm{E}+00$ & 0 \\
\hline-237 & $0.00 \mathrm{E}+00$ & 0 & $0.00 \mathrm{E}+00$ & 0 & $0.00 \mathrm{E}+00$ & 0 & $0.00 \mathrm{E}+00$ & 0 & $0.00 \mathrm{E}+00$ & 0 & $0.00 \mathrm{E}+00$ & 0 & $0.00 \mathrm{E}+00$ & 0 & $0.00 \mathrm{E}+00$ & 0 \\
\hline-238 & $0.00 \mathrm{E}+00$ & 0 & $0.00 \mathrm{E}+00$ & 0 & $0.00 \mathrm{E}+00$ & 0 & $0.00 \mathrm{E}+00$ & 0 & $0.00 E+00$ & 0 & $0.00 \mathrm{E}+00$ & 0 & $0.00 \mathrm{E}+00$ & 0 & $0.00 \mathrm{E}+00$ & 0 \\
\hline-239 & $0.00 \mathrm{E}+00$ & 0 & $0.00 \mathrm{E}+00$ & 0 & $0.00 \mathrm{E}+00$ & 0 & $0.00 \mathrm{E}+00$ & 0 & $0.00 \mathrm{E}+00$ & 0 & $0.00 \mathrm{E}+00$ & 0 & $0.00 \mathrm{E}+00$ & 0 & $0.00 \mathrm{E}+00$ & 0 \\
\hline-240 & $0.00 \mathrm{E}+00$ & 0 & $0.00 \mathrm{E}+00$ & 0 & $0.00 \mathrm{E}+00$ & 0 & $0.00 \mathrm{E}+00$ & 0 & $0.00 \mathrm{E}+00$ & 0 & $0.00 \mathrm{E}+00$ & 0 & $0.00 \mathrm{E}+00$ & 0 & $0.00 \mathrm{E}+00$ & 0 \\
\hline-99 & $9.04 \mathrm{E}-07$ & 0 & $0.00 \mathrm{E}+00$ & 0 & $0.00 \mathrm{E}+00$ & 0 & $2.48 \mathrm{E}-01$ & 25 & $7.44 E-04$ & 0 & $6.57 E-02$ & 7 & $7.63 \mathrm{E}-07$ & 0 & $6.77 \mathrm{E}-01$ & 68 \\
\hline-228 & $0.00 \mathrm{E}+00$ & 0 & $0.00 \mathrm{E}+00$ & 0 & $0.00 \mathrm{E}+00$ & 0 & $0.00 \mathrm{E}+00$ & 0 & $0.00 \mathrm{E}+00$ & 0 & $0.00 \mathrm{E}+00$ & 0 & $0.00 \mathrm{E}+00$ & 0 & $0.00 \mathrm{E}+00$ & 0 \\
\hline-230 & $0.00 \mathrm{E}+00$ & 0 & $0.00 \mathrm{E}+00$ & 0 & $0.00 \mathrm{E}+00$ & 0 & $0.00 \mathrm{E}+00$ & 0 & $0.00 \mathrm{E}+00$ & 0 & $0.00 \mathrm{E}+00$ & 0 & $0.00 \mathrm{E}+00$ & 0 & $0.00 \mathrm{E}+00$ & 0 \\
\hline-232 & $0.00 \mathrm{E}+00$ & 0 & $0.00 \mathrm{E}+00$ & 0 & $0.00 \mathrm{E}+00$ & 0 & $0.00 \mathrm{E}+00$ & 0 & $0.00 \mathrm{E}+00$ & 0 & $0.00 \mathrm{E}+00$ & 0 & $0.00 \mathrm{E}+00$ & 0 & $0.00 \mathrm{E}+00$ & 0 \\
\hline 234 & $0.00 \mathrm{E}+00$ & 0 & $0.00 \mathrm{E}+00$ & 0 & $0.00 \mathrm{E}+00$ & 0 & $0.00 \mathrm{E}+00$ & 0 & $0.00 \mathrm{E}+00$ & 0 & $0.00 \mathrm{E}+00$ & 0 & $0.00 \mathrm{E}+00$ & 0 & $0.00 \mathrm{E}+00$ & 0 \\
\hline 235 & $0.00 \mathrm{E}+00$ & 0 & $0.00 \mathrm{E}+00$ & 0 & $0.00 \mathrm{E}+00$ & 0 & $0.00 \mathrm{E}+00$ & 0 & $0.00 \mathrm{E}+00$ & 0 & $0.00 \mathrm{E}+00$ & 0 & $0.00 \mathrm{E}+00$ & 0 & $0.00 \mathrm{E}+00$ & 0 \\
\hline 38 & $0.00 \mathrm{E}+00$ & 0 & $0.00 \mathrm{E}+00$ & 0 & $0.00 \mathrm{E}+00$ & 0 & $0.00 \mathrm{E}+00$ & 0 & $0.00 \mathrm{E}+00$ & 0 & $0.00 \mathrm{E}+00$ & 0 & $0.00 \mathrm{E}+00$ & 0 & $0.00 \mathrm{E}+00$ & 0 \\
\hline & $9.04 \mathrm{E}-07$ & 0 & $0.00 \mathrm{E}+00$ & 0 & $0.00 \mathrm{E}+00$ & 0 & $2.48 \mathrm{E}-01$ & 25 & $7.44 \mathrm{E}-04$ & 0 & $6.57 \mathrm{E}-02$ & 7 & $7.63 \mathrm{E}-07$ & 0 & $6.77 \mathrm{E}-01$ & 68 \\
\hline
\end{tabular}

Total Dose Contributions TDOSE(i,p,t) for Individual Radionuclides (i) and Pathways (p) in mrem/yr and as a Percentage of Total Dose at $t=500$ years

Directly from primary contamination and from release to atmosphere (Inhalation excludes radon)

\begin{tabular}{|c|c|c|c|c|c|c|c|c|c|c|c|c|c|c|c|c|}
\hline & \multicolumn{2}{|c|}{ Ground } & \multicolumn{2}{|c|}{ Inhalation } & \multicolumn{2}{|c|}{ Radon } & \multicolumn{2}{|c|}{ Plant } & \multicolumn{2}{|l|}{ Meat } & \multicolumn{2}{|l|}{ Milk } & \multicolumn{2}{|l|}{ Soil } & \multicolumn{2}{|c|}{ All Pathways* } \\
\hline clide & Dose & $\%$ & Dose & $\%$ & Dose & $\%$ & Dose & 음 & Dose & $\%$ & Dose & 음 & Dose & $\%$ & Dose & $\%$ \\
\hline-241 & $2.63 E-21$ & 0 & $0.00 E+00$ & 0 & $0.00 E+00$ & 0 & $0.00 \mathrm{E}+00$ & 0 & $0.00 \mathrm{E}+00$ & 0 & $0.00 \mathrm{E}+00$ & 0 & $0.00 \mathrm{E}+00$ & 0 & 2. $63 E-21$ & 0 \\
\hline-137 & $5.47 E-20$ & 0 & $0.00 E+00$ & 0 & $0.00 E+00$ & 0 & $0.00 \mathrm{E}+00$ & 0 & $0.00 \mathrm{E}+00$ & 0 & $0.00 E+00$ & 0 & $0.00 \mathrm{E}+00$ & 0 & $5.47 E-20$ & 0 \\
\hline-237 & $3.74 E-18$ & 0 & $0.00 E+00$ & 0 & $0.00 E+00$ & 0 & $0.00 \mathrm{E}+00$ & 0 & $0.00 \mathrm{E}+00$ & 0 & $0.00 E+00$ & 0 & $0.00 \mathrm{E}+00$ & 0 & $3.74 \mathrm{E}-18$ & 0 \\
\hline-238 & $8.22 E-20$ & 0 & $0.00 E+00$ & 0 & $0.00 \mathrm{E}+00$ & 0 & $0.00 \mathrm{E}+00$ & 0 & $0.00 \mathrm{E}+00$ & 0 & $0.00 \mathrm{E}+00$ & 0 & $0.00 \mathrm{E}+00$ & 0 & $8.22 \mathrm{E}-20$ & 0 \\
\hline-239 & $5.22 \mathrm{E}-22$ & 0 & $0.00 \mathrm{E}+00$ & 0 & $0.00 \mathrm{E}+00$ & 0 & $0.00 \mathrm{E}+00$ & 0 & $0.00 \mathrm{E}+00$ & 0 & $0.00 \mathrm{E}+00$ & 0 & $0.00 \mathrm{E}+00$ & 0 & $5.22 \mathrm{E}-22$ & 0 \\
\hline-240 & $8.02 E-25$ & 0 & $0.00 \mathrm{E}+00$ & 0 & $0.00 \mathrm{E}+00$ & 0 & $0.00 \mathrm{E}+00$ & 0 & $0.00 \mathrm{E}+00$ & 0 & $0.00 \mathrm{E}+00$ & 0 & $0.00 \mathrm{E}+00$ & 0 & $8.02 \mathrm{E}-25$ & 0 \\
\hline-99 & 7. $29 \mathrm{E}-30$ & 0 & $0.00 E+00$ & 0 & $0.00 \mathrm{E}+00$ & 0 & $0.00 \mathrm{E}+00$ & 0 & $0.00 \mathrm{E}+00$ & 0 & $0.00 E+00$ & 0 & $0.00 \mathrm{E}+00$ & 0 & $9.91 \mathrm{E}-01$ & 100 \\
\hline-228 & $0.00 \mathrm{E}+00$ & 0 & $0.00 \mathrm{E}+00$ & 0 & $0.00 \mathrm{E}+00$ & 0 & $0.00 \mathrm{E}+00$ & 0 & $0.00 \mathrm{E}+00$ & 0 & $0.00 \mathrm{E}+00$ & 0 & $0.00 \mathrm{E}+00$ & 0 & $0.00 \mathrm{E}+00$ & 0 \\
\hline-230 & $4.02 E-13$ & 0 & $0.00 E+00$ & 0 & $0.00 \mathrm{E}+00$ & 0 & $0.00 \mathrm{E}+00$ & 0 & $0.00 \mathrm{E}+00$ & 0 & $0.00 E+00$ & 0 & $0.00 \mathrm{E}+00$ & 0 & $4.02 \mathrm{E}-13$ & 0 \\
\hline-232 & $5.19 \mathrm{E}-13$ & 0 & $0.00 E+00$ & 0 & $0.00 \mathrm{E}+00$ & 0 & $0.00 \mathrm{E}+00$ & 0 & $0.00 \mathrm{E}+00$ & 0 & $0.00 \mathrm{E}+00$ & 0 & $0.00 \mathrm{E}+00$ & 0 & $5.19 \mathrm{E}-13$ & 0 \\
\hline 34 & $1.50 \mathrm{E}-15$ & 0 & $0.00 \mathrm{E}+00$ & 0 & $0.00 \mathrm{E}+00$ & 0 & $0.00 \mathrm{E}+00$ & 0 & $0.00 \mathrm{E}+00$ & 0 & $0.00 \mathrm{E}+00$ & 0 & $0.00 \mathrm{E}+00$ & 0 & 1. $50 \mathrm{E}-15$ & 0 \\
\hline 35 & 1. $58 \mathrm{E}-18$ & 0 & $0.00 \mathrm{E}+00$ & 0 & $0.00 \mathrm{E}+00$ & 0 & $0.00 \mathrm{E}+00$ & 0 & $0.00 \mathrm{E}+00$ & 0 & $0.00 \mathrm{E}+00$ & 0 & $0.00 \mathrm{E}+00$ & 0 & 1. $58 \mathrm{E}-18$ & 0 \\
\hline 38 & 4. $43 E-15$ & 0 & $0.00 E+00$ & 0 & $0.00 \mathrm{E}+00$ & 0 & $0.00 \mathrm{E}+00$ & 0 & $0.00 \mathrm{E}+00$ & 0 & $0.00 E+00$ & 0 & $0.00 \mathrm{E}+00$ & 0 & 4. $43 E-15$ & 0 \\
\hline & $9.28 \mathrm{E}-13$ & 0 & $0.00 \mathrm{E}+00$ & 0 & $0.00 \mathrm{E}+00$ & 0 & $0.00 \mathrm{E}+00$ & 0 & $0.00 \mathrm{E}+00$ & 0 & $0.00 \mathrm{E}+00$ & 0 & $0.00 \mathrm{E}+00$ & 0 & $9.91 \mathrm{E}-01$ & 100 \\
\hline
\end{tabular}


RESRAD-OFFSITE, Version 2.

Parent Dose Report

Title : RESRAD-OFFSITE Parameters for Offsite Resident Farmer Forward Run 1,050 Years

File : OFFSITE-RF FORWARD-7-11.ROF

Total Dose Contributions TDOSE (i,p,t) for Individual Radionuclides (i) and Pathways (p) in mrem/yr and as a Percentage of Total Dose at $t=1026$ years

From releases to ground water and to surface water

\begin{tabular}{|c|c|c|c|c|c|c|c|c|c|c|c|c|c|c|c|c|}
\hline & \multicolumn{2}{|c|}{ Ground } & \multicolumn{2}{|l|}{ Fish } & \multicolumn{2}{|c|}{ Radon } & \multicolumn{2}{|c|}{ Plant } & \multicolumn{2}{|l|}{ Meat } & \multicolumn{2}{|l|}{ Milk } & \multicolumn{2}{|l|}{ Soil } & \multicolumn{2}{|c|}{ Water } \\
\hline clide & Dose & \% & Dose & $\%$ & Dose & $\%$ & Dose & \% & Dose & $\%$ & Dose & $\%$ & Dose & \% & Dose & $\%$ \\
\hline-241 & $0.00 \mathrm{E}+00$ & 0 & $0.00 \mathrm{E}+00$ & 0 & $0.00 \mathrm{E}+00$ & 0 & $0.00 \mathrm{E}+00$ & 0 & $0.00 E+00$ & 0 & $0.00 \mathrm{E}+00$ & 0 & $0.00 \mathrm{E}+00$ & 0 & $0.00 \mathrm{E}+00$ & 0 \\
\hline-137 & $0.00 \mathrm{E}+00$ & 0 & $0.00 \mathrm{E}+00$ & 0 & $0.00 \mathrm{E}+00$ & 0 & $0.00 \mathrm{E}+00$ & 0 & $0.00 \mathrm{E}+00$ & 0 & $0.00 \mathrm{E}+00$ & 0 & $0.00 \mathrm{E}+00$ & 0 & $0.00 \mathrm{E}+00$ & 0 \\
\hline-237 & $0.00 \mathrm{E}+00$ & 0 & $0.00 \mathrm{E}+00$ & 0 & $0.00 \mathrm{E}+00$ & 0 & $0.00 \mathrm{E}+00$ & 0 & $0.00 \mathrm{E}+00$ & 0 & $0.00 \mathrm{E}+00$ & 0 & $0.00 \mathrm{E}+00$ & 0 & $0.00 \mathrm{E}+00$ & 0 \\
\hline-238 & $0.00 \mathrm{E}+00$ & 0 & $0.00 \mathrm{E}+00$ & 0 & $0.00 \mathrm{E}+00$ & 0 & $0.00 \mathrm{E}+00$ & 0 & $0.00 E+00$ & 0 & $0.00 \mathrm{E}+00$ & 0 & $0.00 \mathrm{E}+00$ & 0 & $0.00 \mathrm{E}+00$ & 0 \\
\hline-239 & $0.00 \mathrm{E}+00$ & 0 & $0.00 \mathrm{E}+00$ & 0 & $0.00 \mathrm{E}+00$ & 0 & $0.00 \mathrm{E}+00$ & 0 & $0.00 \mathrm{E}+00$ & 0 & $0.00 \mathrm{E}+00$ & 0 & $0.00 \mathrm{E}+00$ & 0 & $0.00 \mathrm{E}+00$ & 0 \\
\hline-240 & $0.00 \mathrm{E}+00$ & 0 & $0.00 \mathrm{E}+00$ & 0 & $0.00 \mathrm{E}+00$ & 0 & $0.00 \mathrm{E}+00$ & 0 & $0.00 \mathrm{E}+00$ & 0 & $0.00 \mathrm{E}+00$ & 0 & $0.00 \mathrm{E}+00$ & 0 & $0.00 \mathrm{E}+00$ & 0 \\
\hline-99 & $1.31 E-06$ & 0 & $0.00 \mathrm{E}+00$ & 0 & $0.00 \mathrm{E}+00$ & 0 & $3.60 \mathrm{E}-01$ & 25 & $1.08 E-03$ & 0 & $9.52 E-02$ & 7 & $1.11 \mathrm{E}-06$ & 0 & $9.80 \mathrm{E}-01$ & 68 \\
\hline-228 & $0.00 \mathrm{E}+00$ & 0 & $0.00 \mathrm{E}+00$ & 0 & $0.00 \mathrm{E}+00$ & 0 & $0.00 \mathrm{E}+00$ & 0 & $0.00 \mathrm{E}+00$ & 0 & $0.00 \mathrm{E}+00$ & 0 & $0.00 \mathrm{E}+00$ & 0 & $0.00 \mathrm{E}+00$ & 0 \\
\hline-230 & $0.00 \mathrm{E}+00$ & 0 & $0.00 \mathrm{E}+00$ & 0 & $0.00 \mathrm{E}+00$ & 0 & $0.00 \mathrm{E}+00$ & 0 & $0.00 \mathrm{E}+00$ & 0 & $0.00 \mathrm{E}+00$ & 0 & $0.00 \mathrm{E}+00$ & 0 & $0.00 \mathrm{E}+00$ & 0 \\
\hline-232 & $0.00 \mathrm{E}+00$ & 0 & $0.00 \mathrm{E}+00$ & 0 & $0.00 \mathrm{E}+00$ & 0 & $0.00 \mathrm{E}+00$ & 0 & $0.00 \mathrm{E}+00$ & 0 & $0.00 \mathrm{E}+00$ & 0 & $0.00 \mathrm{E}+00$ & 0 & $0.00 \mathrm{E}+00$ & 0 \\
\hline 234 & $0.00 \mathrm{E}+00$ & 0 & $0.00 \mathrm{E}+00$ & 0 & $0.00 \mathrm{E}+00$ & 0 & $0.00 \mathrm{E}+00$ & 0 & $0.00 \mathrm{E}+00$ & 0 & $0.00 \mathrm{E}+00$ & 0 & $0.00 \mathrm{E}+00$ & 0 & $0.00 \mathrm{E}+00$ & 0 \\
\hline 235 & $0.00 \mathrm{E}+00$ & 0 & $0.00 \mathrm{E}+00$ & 0 & $0.00 \mathrm{E}+00$ & 0 & $0.00 \mathrm{E}+00$ & 0 & $0.00 \mathrm{E}+00$ & 0 & $0.00 \mathrm{E}+00$ & 0 & $0.00 \mathrm{E}+00$ & 0 & $0.00 \mathrm{E}+00$ & 0 \\
\hline 38 & $0.00 \mathrm{E}+00$ & 0 & $0.00 \mathrm{E}+00$ & 0 & $0.00 \mathrm{E}+00$ & 0 & $0.00 \mathrm{E}+00$ & 0 & $0.00 \mathrm{E}+00$ & 0 & $0.00 \mathrm{E}+00$ & 0 & $0.00 \mathrm{E}+00$ & 0 & $0.00 \mathrm{E}+00$ & 0 \\
\hline & $1.31 \mathrm{E}-06$ & 0 & $0.00 \mathrm{E}+00$ & 0 & $0.00 \mathrm{E}+00$ & 0 & $3.60 \mathrm{E}-01$ & 25 & $1.08 \mathrm{E}-03$ & 0 & $9.52 \mathrm{E}-02$ & 7 & $1.11 \mathrm{E}-06$ & 0 & $9.80 \mathrm{E}-01$ & 68 \\
\hline
\end{tabular}

Total Dose Contributions TDOSE(i,p,t) for Individual Radionuclides (i) and Pathways (p) in mrem/yr and as a Percentage of Total Dose at $t=1026$ years

Directly from primary contamination and from release to atmosphere (Inhalation excludes radon)

\begin{tabular}{|c|c|c|c|c|c|c|c|c|c|c|c|c|c|c|c|c|}
\hline & \multicolumn{2}{|c|}{ Ground } & \multicolumn{2}{|c|}{ Inhalation } & \multicolumn{2}{|c|}{ Radon } & \multicolumn{2}{|c|}{ Plant } & \multicolumn{2}{|l|}{ Meat } & \multicolumn{2}{|l|}{ Milk } & \multicolumn{2}{|l|}{ Soil } & \multicolumn{2}{|c|}{ All Pathways* } \\
\hline clide & Dose & $\%$ & Dose & $\%$ & Dose & $\%$ & Dose & 음 & Dose & $\%$ & Dose & 음 & Dose & $\%$ & Dose & $\%$ \\
\hline-241 & $6.97 \mathrm{E}-19$ & 0 & $0.00 \mathrm{E}+00$ & 0 & $0.00 \mathrm{E}+00$ & 0 & $0.00 \mathrm{E}+00$ & 0 & $0.00 \mathrm{E}+00$ & 0 & $0.00 \mathrm{E}+00$ & 0 & $0.00 \mathrm{E}+00$ & 0 & $6.97 \mathrm{E}-19$ & 0 \\
\hline-137 & $1.70 \mathrm{E}-23$ & 0 & $0.00 E+00$ & 0 & $0.00 E+00$ & 0 & $0.00 \mathrm{E}+00$ & 0 & $0.00 \mathrm{E}+00$ & 0 & $0.00 E+00$ & 0 & $0.00 \mathrm{E}+00$ & 0 & $1.70 E-23$ & 0 \\
\hline-237 & $6.63 E-16$ & 0 & $0.00 E+00$ & 0 & $0.00 E+00$ & 0 & $0.00 \mathrm{E}+00$ & 0 & $0.00 \mathrm{E}+00$ & 0 & $0.00 E+00$ & 0 & $0.00 \mathrm{E}+00$ & 0 & $6.63 E-16$ & 0 \\
\hline-238 & $1.16 \mathrm{E}-17$ & 0 & $0.00 E+00$ & 0 & $0.00 \mathrm{E}+00$ & 0 & $0.00 \mathrm{E}+00$ & 0 & $0.00 \mathrm{E}+00$ & 0 & $0.00 \mathrm{E}+00$ & 0 & $0.00 \mathrm{E}+00$ & 0 & $1.16 \mathrm{E}-17$ & 0 \\
\hline-239 & 1. $70 \mathrm{E}-19$ & 0 & $0.00 \mathrm{E}+00$ & 0 & $0.00 \mathrm{E}+00$ & 0 & $0.00 \mathrm{E}+00$ & 0 & $0.00 \mathrm{E}+00$ & 0 & $0.00 \mathrm{E}+00$ & 0 & $0.00 \mathrm{E}+00$ & 0 & 1. $70 \mathrm{E}-19$ & 0 \\
\hline-240 & $6.58 E-23$ & 0 & $0.00 E+00$ & 0 & $0.00 \mathrm{E}+00$ & 0 & $0.00 \mathrm{E}+00$ & 0 & $0.00 \mathrm{E}+00$ & 0 & $0.00 E+00$ & 0 & $0.00 \mathrm{E}+00$ & 0 & $6.58 E-23$ & 0 \\
\hline-99 & $4.96 \mathrm{E}-27$ & 0 & $0.00 E+00$ & 0 & $0.00 \mathrm{E}+00$ & 0 & $0.00 \mathrm{E}+00$ & 0 & $0.00 \mathrm{E}+00$ & 0 & $0.00 E+00$ & 0 & $0.00 \mathrm{E}+00$ & 0 & 1. $44 \mathrm{E}+00$ & 100 \\
\hline-228 & $0.00 \mathrm{E}+00$ & 0 & $0.00 \mathrm{E}+00$ & 0 & $0.00 \mathrm{E}+00$ & 0 & $0.00 \mathrm{E}+00$ & 0 & $0.00 \mathrm{E}+00$ & 0 & $0.00 \mathrm{E}+00$ & 0 & $0.00 \mathrm{E}+00$ & 0 & $0.00 \mathrm{E}+00$ & 0 \\
\hline-230 & $2.11 E-11$ & 0 & $0.00 E+00$ & 0 & $0.00 \mathrm{E}+00$ & 0 & $0.00 \mathrm{E}+00$ & 0 & $0.00 \mathrm{E}+00$ & 0 & $0.00 E+00$ & 0 & $0.00 \mathrm{E}+00$ & 0 & $2.11 \mathrm{E}-11$ & 0 \\
\hline-232 & $9.64 \mathrm{E}-12$ & 0 & $0.00 E+00$ & 0 & $0.00 E+00$ & 0 & $0.00 \mathrm{E}+00$ & 0 & $0.00 \mathrm{E}+00$ & 0 & $0.00 E+00$ & 0 & $0.00 \mathrm{E}+00$ & 0 & $9.64 \mathrm{E}-12$ & 0 \\
\hline 234 & $1.67 \mathrm{E}-13$ & 0 & $0.00 \mathrm{E}+00$ & 0 & $0.00 \mathrm{E}+00$ & 0 & $0.00 \mathrm{E}+00$ & 0 & $0.00 \mathrm{E}+00$ & 0 & $0.00 \mathrm{E}+00$ & 0 & $0.00 \mathrm{E}+00$ & 0 & $1.67 \mathrm{E}-13$ & 0 \\
\hline 235 & $2.70 \mathrm{E}-16$ & 0 & $0.00 \mathrm{E}+00$ & 0 & $0.00 \mathrm{E}+00$ & 0 & $0.00 \mathrm{E}+00$ & 0 & $0.00 \mathrm{E}+00$ & 0 & $0.00 \mathrm{E}+00$ & 0 & $0.00 \mathrm{E}+00$ & 0 & $2.70 \mathrm{E}-16$ & 0 \\
\hline 38 & $2.13 E-13$ & 0 & $0.00 E+00$ & 0 & $0.00 \mathrm{E}+00$ & 0 & $0.00 \mathrm{E}+00$ & 0 & $0.00 \mathrm{E}+00$ & 0 & $0.00 E+00$ & 0 & $0.00 \mathrm{E}+00$ & 0 & $2.13 E-13$ & 0 \\
\hline & $3.11 \mathrm{E}-11$ & 0 & $0.00 \mathrm{E}+00$ & 0 & $0.00 \mathrm{E}+00$ & 0 & $0.00 \mathrm{E}+00$ & 0 & $0.00 \mathrm{E}+00$ & 0 & $0.00 \mathrm{E}+00$ & 0 & $0.00 \mathrm{E}+00$ & 0 & $1.44 \mathrm{E}+00$ & 100 \\
\hline
\end{tabular}


RESRAD-OFFSITE, Version 2.

Parent Dose Report

Title : RESRAD-OFFSITE Parameters for Offsite Resident Farmer Forward Run 1,050 Years File : OFFSITE-RF FORWARD-7-11.ROF

Dose/Source Ratios Summed Over All Pathways

Parent and Progeny Principal Radionuclide Contributions Indicated

Parent Product Thread DSR $(j, \mathrm{t}) \quad(\mathrm{mrem} / \mathrm{yr}) /(\mathrm{pCi} / \mathrm{g})$

(i)

(j)

$\begin{array}{ll}\mathrm{Am}-241 & 1.000 \mathrm{E}+00 \\ \mathrm{~Np}-237+\mathrm{D} & 1.000 \mathrm{E}+00 \\ \mathrm{U}-233 & 1.000 \mathrm{E}+00 \\ \mathrm{Th}-229+\mathrm{D} & 1.000 \mathrm{E}+00 \\ \operatorname{\sum DSR}(j) & \end{array}$

Cs $-137+D$

$\mathrm{Np}-237+\mathrm{D}$

$\mathrm{U}-233$

1. $000 \mathrm{E}+00$

$0.000 \mathrm{E}+00 \quad 1.000 \mathrm{E}+00 \quad 5.000 \mathrm{E}+01 \quad 1.000 \mathrm{E}+02 \quad 5.000 \mathrm{E}+02 \quad 1.026 \mathrm{E}+03$

$\begin{array}{llllll}9.537 \mathrm{E}-42 & 9.773 \mathrm{E}-42 & 3.239 \mathrm{E}-41 & 1.100 \mathrm{E}-40 & 1.945 \mathrm{E}-36 & 7.488 \mathrm{E}-31\end{array}$

$\begin{array}{llllll}7.621 \mathrm{E}-28 & 2.305 \mathrm{E}-27 & 1.212 \mathrm{E}-25 & 3.805 \mathrm{E}-25 & 7.396 \mathrm{E}-23 & 1.966 \mathrm{E}-20\end{array}$

$\begin{array}{lllllll}1.731 E-38 & 1.222 \mathrm{E}-37 & 2.283 \mathrm{E}-34 & 1.567 \mathrm{E}-33 & 3.197 \mathrm{E}-30 & 4.568 \mathrm{E}-27\end{array}$

$\begin{array}{llllll}1.187 \mathrm{E}-34 & 1.786 \mathrm{E}-33 & 8.205 \mathrm{E}-29 & 8.729 \mathrm{E}-28 & 1.204 \mathrm{E}-24 & 2.598 \mathrm{E}-22\end{array}$

$\begin{array}{llllll}7.621 \mathrm{E}-28 & 2.305 \mathrm{E}-27 & 1.213 \mathrm{E}-25 & 3.813 \mathrm{E}-25 & 7.516 \mathrm{E}-23 & 1.992 \mathrm{E}-20\end{array}$

Th $-229+$

$1.000 \mathrm{E}+00$

$\sum \operatorname{DSR}(j)$

$\mathrm{Pu}-238$

$\begin{array}{lllllllll}1.840 E-09 & 1.065 E-41 & 1.074 E-41 & 1.618 E-41 & 2.458 E-41 & 6.961 E-40 & 5.653 E-38\end{array}$

$1.000 \mathrm{E}+00 \quad 5.790 \mathrm{E}-33 \quad 5.838 \mathrm{E}-33 \quad 8.794 \mathrm{E}-33 \quad 1.336 \mathrm{E}-32 \quad 3.783 \mathrm{E}-31 \quad 3.072 \mathrm{E}-29$

$\mathrm{U}-234$

$1.000 \mathrm{E}+00$

Th-230

1. $000 \mathrm{E}+00$

Ra $-226+D$

1. $000 \mathrm{E}+00$

$\mathrm{Pb}-210+\mathrm{D}$

1. $000 \mathrm{E}+00$

$\sum \operatorname{DSR}(j)$

$\begin{array}{llllllll}\mathrm{Pu}-239 & 1.000 \mathrm{E}+00 & 5.925 \mathrm{E}-26 & 5.991 \mathrm{E}-26 & 1.027 \mathrm{E}-25 & 1.779 \mathrm{E}-25 & 1.445 \mathrm{E}-23 & 4.686 \mathrm{E}-21\end{array}$

$\begin{array}{llllllll}\mathrm{U}-235+\mathrm{D} & 1.000 \mathrm{E}+00 & 3.023 \mathrm{E}-32 & 9.162 \mathrm{E}-32 & 5.381 \mathrm{E}-30 & 1.891 \mathrm{E}-29 & 8.893 \mathrm{E}-27 & 7.217 \mathrm{E}-24\end{array}$

$\mathrm{Pa}-231 \quad 1.000 \mathrm{E}+00$

$\mathrm{AC}-227+\mathrm{D} \quad 1.000 \mathrm{E}+00$

$\sum \operatorname{DSR}(j)$

$\mathrm{Pu}-240$

$4.950 \mathrm{E}-08$

$\begin{array}{llllll}4.766 \mathrm{E}-36 & 3.360 \mathrm{E}-35 & 5.914 \mathrm{E}-32 & 3.816 \mathrm{E}-31 & 4.695 \mathrm{E}-28 & 3.351 \mathrm{E}-25\end{array}$

$\mathrm{Pu}-239$

$\mathrm{Pu}-239$

$\mathrm{Pu}-240$

$\mathrm{Pu}-240$

$\mathrm{Pu}-240$

$\mathrm{Pu}-240$

$\mathrm{Pu}-240$

$\mathrm{Pu}-240$

$\mathrm{Pu}-240$

$\mathrm{TC}-9 \mathrm{~g}$

\section{$\mathrm{Pu}-240$}

U-236

1. $000 \mathrm{E}+0$

Th-232

1. $000 \mathrm{E}+00$

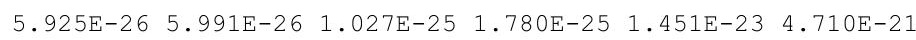

$\mathrm{Ra}-228+\mathrm{D}$

$1.000 \mathrm{E}+00$

$\mathrm{Th}-228+\mathrm{D}$

1. $000 \mathrm{E}+00$

$\sum \operatorname{DSR}(j)$

TC-99

1. $000 \mathrm{E}+00$

$2.786 \mathrm{E}-40 \quad 2.831 \mathrm{E}-40 \quad 6.247 \mathrm{E}-40 \quad 1.401 \mathrm{E}-39 \quad 8.966 \mathrm{E}-37 \quad 4.392 \mathrm{E}-33$

Th $-228+\mathrm{D}$
$1.000 \mathrm{E}+00$

$\begin{array}{lllllll}5.632 \mathrm{E}-33 & 5.845 \mathrm{E}-33 & 1.291 \mathrm{E}-29 & 8.389 \mathrm{E}-29 & 2.228 \mathrm{E}-26 & 1.829 \mathrm{E}-24\end{array}$
Th-228+D 1.000E+00 6.816E-15 4.771E-15 $1.217 \mathrm{E}-22 \quad 2.172 \mathrm{E}-30 \quad 0.000 \mathrm{E}+00 \quad 0.000 \mathrm{E}+00$ 
RESRAD-OFFSITE, Version 2.

Parent Dose Report

Title : RESRAD-OFFSITE Parameters for Offsite Resident Farmer Forward Run 1,050 Years File : OFFSITE-RF_FORWARD-7-11.ROF

Dose/Source Ratios Summed Over All Pathways

Parent and Progeny Principal Radionuclide Contributions Indicated

\begin{tabular}{|c|c|c|c|c|c|c|c|c|}
\hline Parent & Product & Thread & & $\operatorname{DSR}(j$, & t) $\quad(\mathrm{mrem} / \mathrm{y}$ & $/(\mathrm{pCi} / \mathrm{g})$ & & \\
\hline (i) & $(j)$ & Fraction & $0.000 \mathrm{E}+00$ & $1.000 \mathrm{E}+00$ & $5.000 \mathrm{E}+01$ & $1.000 \mathrm{E}+02$ & $5.000 \mathrm{E}+02$ & $1.026 \mathrm{E}+03$ \\
\hline-230 & $T h-230$ & $1.000 \mathrm{E}+00$ & $1.189 \mathrm{E}-30$ & $1.207 \mathrm{E}-30$ & $2.577 \mathrm{E}-30$ & $5.589 \mathrm{E}-30$ & $2.731 E-27$ & $9.387 \mathrm{E}-24$ \\
\hline-230 & $\mathrm{Ra}-226+\mathrm{D}$ & $1.000 \mathrm{E}+00$ & $1.860 \mathrm{E}-19$ & 5. $610 \mathrm{E}-19$ & $2.552 \mathrm{E}-17$ & $6.905 \mathrm{E}-17$ & $4.024 \mathrm{E}-15$ & $2.105 \mathrm{E}-13$ \\
\hline-230 & $\mathrm{~Pb}-210+\mathrm{D}$ & $1.000 \mathrm{E}+00$ & $8.984 \mathrm{E}-28$ & $6.263 \mathrm{E}-27$ & $6.208 E-24$ & $2.463 E-23$ & $2.775 E-21$ & $2.524 \mathrm{E}-19$ \\
\hline-230 & $\sum \operatorname{DSR}(j)$ & & $1.860 \mathrm{E}-19$ & $5.610 \mathrm{E}-19$ & $2.552 \mathrm{E}-17$ & $6.905 E-17$ & $4.024 E-15$ & $2.105 E-13$ \\
\hline-232 & Th-232 & $1.000 \mathrm{E}+00$ & $5.745 E-33$ & $5.844 \mathrm{E}-33$ & $1.351 \mathrm{E}-32$ & $3.175 E-32$ & $2.963 E-29$ & $2.383 E-25$ \\
\hline-232 & $\mathrm{Ra}-228+\mathrm{D}$ & $1.000 \mathrm{E}+00$ & $5.458 \mathrm{E}-18$ & $1.564 \mathrm{E}-17$ & 1. $332 \mathrm{E}-16$ & $1.894 \mathrm{E}-16$ & $3.104 \mathrm{E}-15$ & 1.228E-13 \\
\hline-232 & $\mathrm{Th}-228+\mathrm{D}$ & $1.000 \mathrm{E}+00$ & $5.270 \mathrm{E}-17$ & $3.244 \mathrm{E}-16$ & $1.066 \mathrm{E}-14$ & $1.407 \mathrm{E}-14$ & $1.267 \mathrm{E}-13$ & $2.287 \mathrm{E}-12$ \\
\hline-232 & $\sum \operatorname{DSR}(j)$ & & $5.816 \mathrm{E}-17$ & $3.401 \mathrm{E}-16$ & $1.079 \mathrm{E}-14$ & $1.426 \mathrm{E}-14$ & $1.298 E-13$ & $2.410 \mathrm{E}-12$ \\
\hline 234 & $\mathrm{U}-234$ & $1.000 \mathrm{E}+00$ & $3.398 E-32$ & $3.454 \mathrm{E}-32$ & $7.678 E-32$ & $1.735 E-31$ & $1.179 \mathrm{E}-28$ & $6.245 E-25$ \\
\hline-234 & $T h-230$ & $1.000 \mathrm{E}+00$ & $5.364 \mathrm{E}-36$ & $1.631 \mathrm{E}-35$ & $1.172 \mathrm{E}-33$ & $5.055 E-33$ & $1.229 E-29$ & $8.650 \mathrm{E}-26$ \\
\hline-234 & $\mathrm{Ra}-226+\mathrm{D}$ & $1.000 \mathrm{E}+00$ & $5.596 \mathrm{E}-25$ & $3.933 E-24$ & $5.821 \mathrm{E}-21$ & $3.145 E-20$ & $9.384 \mathrm{E}-18$ & $1.042 E-15$ \\
\hline-234 & $\mathrm{~Pb}-210+\mathrm{D}$ & $1.000 \mathrm{E}+00$ & $2.030 E-33$ & $3.037 E-32$ & $1.052 \mathrm{E}-27$ & $8.967 \mathrm{E}-27$ & $6.069 \mathrm{E}-24$ & 1.209E-21 \\
\hline 234 & $\sum \operatorname{DSR}(j)$ & & $5.596 \mathrm{E}-25$ & $3.933 E-24$ & $5.821 \mathrm{E}-21$ & $3.145 E-20$ & $9.384 \mathrm{E}-18$ & $1.042 E-15$ \\
\hline$-235+D$ & $\mathrm{U}-235+\mathrm{D}$ & $1.000 \mathrm{E}+00$ & $6.128 E-23$ & $6.198 E-23$ & $1.083 E-22$ & $1.913 E-22$ & $1.816 \mathrm{E}-20$ & $7.232 E-18$ \\
\hline$-235+D$ & $\mathrm{~Pa}-231$ & $1.000 \mathrm{E}+00$ & $1.448 \mathrm{E}-26$ & $4.381 \mathrm{E}-26$ & $2.379 E-24$ & $7.714 \mathrm{E}-24$ & 1. $910 \mathrm{E}-21$ & $6.667 \mathrm{E}-19$ \\
\hline$-235+D$ & $A C-227+D$ & $1.000 \mathrm{E}+00$ & $4.580 \mathrm{E}-26$ & $3.195 E-25$ & $3.279 \mathrm{E}-22$ & $1.355 E-21$ & $2.231 E-19$ & $3.366 E-17$ \\
\hline 235 & $\sum \operatorname{DSR}(j)$ & & $6.134 \mathrm{E}-23$ & $6.234 \mathrm{E}-23$ & $4.385 E-22$ & $1.554 \mathrm{E}-21$ & $2.432 E-19$ & $4.156 \mathrm{E}-17$ \\
\hline-238 & $\mathrm{U}-238$ & $5.400 \mathrm{E}-05$ & $0.000 \mathrm{E}+00$ & $0.000 \mathrm{E}+00$ & $0.000 \mathrm{E}+00$ & $0.000 \mathrm{E}+00$ & $0.000 \mathrm{E}+00$ & $0.000 \mathrm{E}+00$ \\
\hline$-238+D$ & $\mathrm{U}-238+\mathrm{D}$ & $9.999 E-01$ & $6.998 \mathrm{E}-19$ & $7.050 \mathrm{E}-19$ & $1.011 \mathrm{E}-18$ & $1.460 \mathrm{E}-18$ & $2.771 \mathrm{E}-17$ & 1. $329 \mathrm{E}-15$ \\
\hline$-238+D$ & $\mathrm{U}-234$ & $9.999 \mathrm{E}-01$ & $4.830 E-38$ & $1.470 \mathrm{E}-37$ & $1.099 \mathrm{E}-35$ & $4.943 E-35$ & $1.673 E-31$ & $1.820 \mathrm{E}-27$ \\
\hline$-238+D$ & Th-230 & $9.999 \mathrm{E}-01$ & $5.085 E-42$ & $3.603 E-41$ & $8.386 \mathrm{E}-38$ & $7.201 \mathrm{E}-37$ & $8.719 E-33$ & $1.259 \mathrm{E}-28$ \\
\hline$-238+D$ & $\mathrm{Ra}-226+\mathrm{D}$ & $9.999 \mathrm{E}-01$ & $3.792 \mathrm{E}-31$ & $5.970 \mathrm{E}-30$ & $2.783 E-25$ & $2.998 E-24$ & $4.516 \mathrm{E}-21$ & $1.047 E-18$ \\
\hline$-238+D$ & $\mathrm{~Pb}-210+\mathrm{D}$ & $9.999 \mathrm{E}-01$ & $1.122 \mathrm{E}-38$ & $4.009 E-38$ & $4.030 E-32$ & $7.166 \mathrm{E}-31$ & $2.754 \mathrm{E}-27$ & $1.178 \mathrm{E}-24$ \\
\hline-238 & $\sum \operatorname{DSR}(j)$ & & $6.998 \mathrm{E}-19$ & $7.050 \mathrm{E}-19$ & $1.011 \mathrm{E}-18$ & $1.460 \mathrm{E}-18$ & $2.772 \mathrm{E}-17$ & $1.331 E-15$ \\
\hline
\end{tabular}

The DSR includes contributions from associated (half-life $\leq 180$ days) daughters. 
RESRAD-OFFSITE, Version 2.

Parent Dose Report

Title : RESRAD-OFFSITE Parameters for Offsite Resident Farmer Forward Run 1,050 Years File : OFFSITE-RF_FORWARD-7-11.ROF

Single Radionuclide Soil Guidelines $G(i, t)$ in pCi/g

Basic Radiation Dose Limit $=1.000 \mathrm{E}+00 \mathrm{mrem} / \mathrm{yr}$

Nuclide

\begin{tabular}{|c|c|c|c|c|c|c|}
\hline (i) & $t=0.000 \mathrm{E}+00$ & $1.000 \mathrm{E}+00$ & $5.000 \mathrm{E}+01$ & $1.000 \mathrm{E}+02$ & $5.000 \mathrm{E}+02$ & $1.026 \mathrm{E}+03$ \\
\hline $1-241$ & $\star 3.431 \mathrm{E}+12$ & $\star 3.431 \mathrm{E}+12$ & $\star 3.431 \mathrm{E}+12$ & $\star 3.431 E+12$ & $\star 3.431 \mathrm{E}+12$ & $\star 3.431 E+12$ \\
\hline-137 & $\star 8.704 \mathrm{E}+13$ & $\star 8.704 \mathrm{E}+13$ & $\star 8.704 \mathrm{E}+13$ & $\star 8.704 \mathrm{E}+13$ & $\star 8.704 \mathrm{E}+13$ & $\star 8.704 \mathrm{E}+13$ \\
\hline-237 & $\star 7.047 \mathrm{E}+08$ & $\star 7.047 \mathrm{E}+08$ & $\star 7.047 \mathrm{E}+08$ & $\star 7.047 \mathrm{E}+08$ & $\star 7.047 \mathrm{E}+08$ & $\star 7.047 \mathrm{E}+08$ \\
\hline-238 & $\star 1.712 \mathrm{E}+13$ & $\star 1.712 \mathrm{E}+13$ & $\star 1.712 \mathrm{E}+13$ & $\star 1.712 \mathrm{E}+13$ & $\star 1.712 \mathrm{E}+13$ & $\star 1.712 \mathrm{E}+13$ \\
\hline-239 & $\star 6.214 \mathrm{E}+10$ & $\star 6.214 \mathrm{E}+10$ & $* 6.214 \mathrm{E}+10$ & $\star 6.214 \mathrm{E}+10$ & $\star 6.214 \mathrm{E}+10$ & $\star 6.214 \mathrm{E}+10$ \\
\hline-240 & $\star 2.278 \mathrm{E}+11$ & $\star 2.278 \mathrm{E}+11$ & $\star 2.278 \mathrm{E}+11$ & $\star 2.278 \mathrm{E}+11$ & $\star 2.278 \mathrm{E}+11$ & $E+11$ \\
\hline-99 & $\star 1.697 \mathrm{E}+10$ & $\star 1.697 \mathrm{E}+10$ & $\star 1.697 \mathrm{E}+10$ & $\star 1.697 \mathrm{E}+10$ & $5.247 E+01$ & $3.621 \mathrm{E}+01$ \\
\hline-228 & $1.467 \mathrm{E}+14$ & $2.096 \mathrm{E}+14$ & $\star 8.195 \mathrm{E}+14$ & $\star 8.195 \mathrm{E}+14$ & $\star 8.195 \mathrm{E}+14$ & $\star 8.195 \mathrm{E}+14$ \\
\hline $1-230$ & $\star 2.018 \mathrm{E}+10$ & $\star 2.018 \mathrm{E}+10$ & $\star 2.018 \mathrm{E}+10$ & $\star 2.018 \mathrm{E}+10$ & $\star 2.018 \mathrm{E}+10$ & $\star 2.018 E+10$ \\
\hline-232 & $* 1.097 \mathrm{E}+05$ & $\star 1.097 \mathrm{E}+05$ & $\star 1.097 \mathrm{E}+05$ & $\star 1.097 \mathrm{E}+05$ & $\star 1.097 \mathrm{E}+05$ & $\star 1.097 \mathrm{E}+05$ \\
\hline 234 & $\star 6.247 \mathrm{E}+09$ & $\star 6.247 \mathrm{E}+09$ & $\star 6.247 \mathrm{E}+09$ & $\star 6.247 \mathrm{E}+09$ & $\star 6.247 \mathrm{E}+09$ & $\star 6.247 \mathrm{E}+09$ \\
\hline 235 & $\star 2.161 \mathrm{E}+06$ & $\star 2.161 \mathrm{E}+06$ & $\star 2.161 \mathrm{E}+06$ & $\star 2.161 \mathrm{E}+06$ & $\star 2.161 \mathrm{E}+06$ & $\star 2.161 \mathrm{E}+06$ \\
\hline 38 & $\star 3.361 \mathrm{E}+05$ & $\star 3.361 \mathrm{E}+05$ & $* 3.361 \mathrm{E}+05$ & $\star 3.361 \mathrm{E}+05$ & $\star 3.361 \mathrm{E}+05$ & $\star 3.361 E+05$ \\
\hline
\end{tabular}

*At specific activity limit

Summed Dose/Source Ratios DSR(i,t) in (mrem/yr)/(pCi/g)

and Single Radionuclide Soil Guidelines $G(i, t)$ in pCi/g

at tmin = time of minimum single radionuclide soil guideline

and at $\operatorname{tmax}=$ time of maximum total dose $=772$ years

\begin{tabular}{|c|c|c|c|c|c|c|}
\hline $\begin{array}{l}\text { Juclide } \\
\text { (i) }\end{array}$ & $\begin{array}{l}\text { Initial } \\
(\mathrm{pCi} / \mathrm{g})\end{array}$ & $\begin{array}{c}\text { tmin } \\
\text { (years) }\end{array}$ & $\operatorname{DSR}(i, \operatorname{tmin})$ & $\begin{array}{c}G(i, \operatorname{tmin}) \\
(\mathrm{pCi} / \mathrm{g})\end{array}$ & $\operatorname{DSR}(i, \operatorname{tmax})$ & $\begin{array}{c}G(i, t \max ) \\
(\mathrm{pCi} / \mathrm{g})\end{array}$ \\
\hline-241 & $3.500 \mathrm{E}+01$ & 1050 & $2.534 \mathrm{E}-20$ & $\star 3.431 \mathrm{E}+12$ & $1.422 \mathrm{E}-21$ & $\star 3.431 \mathrm{E}+12$ \\
\hline$s-137$ & $1.900 \mathrm{E}+01$ & 0 & $6.220 \mathrm{E}-18$ & $\star 8.704 \mathrm{E}+13$ & $4.446 \mathrm{E}-23$ & $\star 8.704 \mathrm{E}+13$ \\
\hline$p-237$ & $5.500 \mathrm{E}+00$ & 1050 & $1.518 \mathrm{E}-16$ & $\star 7.047 \mathrm{E}+08$ & $9.888 \mathrm{E}-18$ & $\star 7.047 \mathrm{E}+08$ \\
\hline$x-238$ & $3.900 \mathrm{E}+01$ & 1050 & 3. $619 \mathrm{E}-19$ & $\star 1.712 \mathrm{E}+13$ & $3.193 E-20$ & $* 1.712 \mathrm{E}+13$ \\
\hline$x-239$ & $3.600 \mathrm{E}+01$ & 1050 & $6.099 \mathrm{E}-21$ & $\star 6.214 \mathrm{E}+10$ & $2.877 \mathrm{E}-22$ & $\star 6.214 \mathrm{E}+10$ \\
\hline$x-240$ & $3.600 \mathrm{E}+01$ & 1050 & $2.205 E-24$ & $\star 2.278 \mathrm{E}+11$ & $2.413 E-25$ & $\star 2.278 \mathrm{E}+11$ \\
\hline$=-99$ & $5.200 \mathrm{E}+01$ & 772 & $3.594 \mathrm{E}-02$ & $2.783 E+01$ & $3.594 \mathrm{E}-02$ & $2.783 \mathrm{E}+01$ \\
\hline-228 & $4.000 E+00$ & 0 & $6.816 \mathrm{E}-15$ & $1.467 \mathrm{E}+14$ & $0.000 \mathrm{E}+00$ & $\star 8.195 \mathrm{E}+14$ \\
\hline $1-230$ & $1.000 \mathrm{E}+02$ & 1050 & $2.489 \mathrm{E}-13$ & $4.018 \mathrm{E}+12$ & $3.305 E-14$ & $\star 2.018 \mathrm{E}+10$ \\
\hline-232 & $4.000 \mathrm{E}+00$ & 1050 & $2.748 \mathrm{E}-12$ & $* 1.097 \mathrm{E}+05$ & $5.851 \mathrm{E}-13$ & $\star 1.097 \mathrm{E}+05$ \\
\hline-234 & $1.600 \mathrm{E}+02$ & 1050 & 1. $263 \mathrm{E}-15$ & $\star 6.247 \mathrm{E}+09$ & 1. $211 \mathrm{E}-16$ & $* 6.247 \mathrm{E}+09$ \\
\hline 235 & $6.500 \mathrm{E}+00$ & 1050 & $5.208 \mathrm{E}-17$ & $\star 2.161 \mathrm{E}+06$ & $3.601 \mathrm{E}-18$ & $\star 2.161 \mathrm{E}+06$ \\
\hline 238 & $1.600 \mathrm{E}+02$ & 1050 & $1.582 \mathrm{E}-15$ & $\star 3.361 \mathrm{E}+05$ & $2.047 \mathrm{E}-16$ & $\star 3.361 \mathrm{E}+05$ \\
\hline
\end{tabular}

*At specific activity limit 
RESRAD-OFFSITE, Version 2.

Parent Dose Report

Title : RESRAD-OFFSITE Parameters for Offsite Resident Farmer Forward Run 1,050 Years File : OFFSITE-RF FORWARD-7-11.ROF

Individual Nuclide Dose Summed Over All Pathways

Parent Nuclide and Thread Fraction Indicated

Nuclide Parent THF(i) DOSE $(j, t)$, mrem/yr

\begin{tabular}{|c|c|c|}
\hline (j) & (i) & \\
\hline$A m-241$ & $A m-241$ & $1.000 \mathrm{E}+00$ \\
\hline-237 & $A m-241$ & $1.000 \mathrm{E}+00$ \\
\hline $\mathrm{Jp}-237$ & $\mathrm{~Np}-237$ & $1.000 \mathrm{E}+00$ \\
\hline 237 & $\sum \operatorname{DOSE}(j$ & ): \\
\hline
\end{tabular}

$\mathrm{U}-233 \quad \mathrm{Am}-241 \quad 1.000 \mathrm{E}+00$

$\mathrm{U}-233 \quad \mathrm{~Np}-237 \quad 1.000 \mathrm{E}+00$

U-233 $\operatorname{LDOSE}(j):$

Th-229 Am-241 $1.000 \mathrm{E}+00$

Th-229 Np-237 $1.000 \mathrm{E}+00$

Th-229 $\operatorname{DDOSE}(j)$ :

Cs-137 Cs-137 1.000E+00

$\mathrm{Pu}-238$

$\mathrm{Pu}-238$

$\mathrm{Pu}-238$

$\mathrm{U}-234$

$\mathrm{U}-234$

$\mathrm{U}-234$

$\mathrm{U}-234$

Th -230

Th -230

Th-230

Th -230

Th -230

$\mathrm{Ra}-226$

$\mathrm{Ra}-226$

$\mathrm{Ra}-226$

$\mathrm{Ra}-226$

$\mathrm{Ra}-226$

$\mathrm{Pb}-210 \quad \mathrm{Pu}-238 \quad 1.000 \mathrm{E}+00$

$\mathrm{Pb}-210 \quad \mathrm{Th}-230 \quad 1.000 \mathrm{E}+00$

$\mathrm{Pb}-210 \quad \mathrm{U}-234 \quad 1.000 \mathrm{E}+00$

$\mathrm{Pb}-210 \quad \mathrm{U}-238 \quad 9.999 \mathrm{E}-01$

$\mathrm{Pb}-210 \quad \mathrm{DOSE}(j):$

Pu-239 Pu-239 $1.000 E+00$ $\mathrm{t}=0.000 \mathrm{E}+00 \quad 1.000 \mathrm{E}+00 \quad 5.000 \mathrm{E}+01 \quad 1.000 \mathrm{E}+02 \quad 5.000 \mathrm{E}+02 \quad 1.026 \mathrm{E}+03$

$\begin{array}{llllll}3.338 \mathrm{E}-40 & 3.420 \mathrm{E}-40 & 1.133 \mathrm{E}-39 & 3.849 \mathrm{E}-39 & 6.806 \mathrm{E}-35 & 2.621 \mathrm{E}-29\end{array}$

$2.667 \mathrm{E}-26 \quad 8.067 \mathrm{E}-26 \quad 4.241 \mathrm{E}-24 \quad 1.332 \mathrm{E}-23 \quad 2.588 \mathrm{E}-21 \quad 6.880 \mathrm{E}-19$

$2.585 \mathrm{E}-20 \quad 2.611 \mathrm{E}-20 \quad 4.234 \mathrm{E}-20 \quad 6.934 \mathrm{E}-20 \quad 3.590 \mathrm{E}-18 \quad 6.442 \mathrm{E}-16$

$\begin{array}{llllll}2.585 \mathrm{E}-20 & 2.611 \mathrm{E}-20 & 4.234 \mathrm{E}-20 & 6.936 \mathrm{E}-20 & 3.592 \mathrm{E}-18 & 6.449 \mathrm{E}-16\end{array}$

$6.059 \mathrm{E}-37 \quad 4.276 \mathrm{E}-36 \quad 7.992 \mathrm{E}-33 \quad 5.485 \mathrm{E}-32 \quad 1.119 \mathrm{E}-28 \quad 1.599 \mathrm{E}-25$

$\begin{array}{llllll}8.796 \mathrm{E}-31 & 2.666 \mathrm{E}-30 & 1.576 \mathrm{E}-28 & 5.576 \mathrm{E}-28 & 2.768 \mathrm{E}-25 & 2.412 \mathrm{E}-22\end{array}$

$\begin{array}{llllll}8.796 \mathrm{E}-31 & 2.666 \mathrm{E}-30 & 1.576 \mathrm{E}-28 & 5.576 \mathrm{E}-28 & 2.769 \mathrm{E}-25 & 2.414 \mathrm{E}-22\end{array}$

$\begin{array}{llllll}4.155 E-33 & 6.252 E-32 & 2.872 E-27 & 3.055 E-26 & 4.212 E-23 & 9.094 E-21\end{array}$

$8.047 \mathrm{E}-27 \quad 5.656 \mathrm{E}-26 \quad 8.438 \mathrm{E}-23 \quad 4.597 \mathrm{E}-22 \quad 1.470 \mathrm{E}-19 \quad 1.835 \mathrm{E}-17$

$8.047 \mathrm{E}-27 \quad 5.656 \mathrm{E}-26 \quad 8.438 \mathrm{E}-23 \quad 4.598 \mathrm{E}-22 \quad 1.470 \mathrm{E}-19 \quad 1.836 \mathrm{E}-17$

$\begin{array}{llllll}1.182 \mathrm{E}-16 & 1.164 \mathrm{E}-16 & 5.484 \mathrm{E}-17 & 2.545 \mathrm{E}-17 & 5.475 \mathrm{E}-20 & 1.701 \mathrm{E}-23\end{array}$

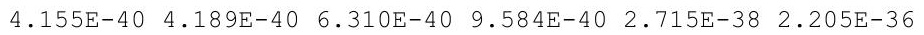

$2.258 \mathrm{E}-31 \quad 2.277 \mathrm{E}-31 \quad 3.429 \mathrm{E}-31 \quad 5.209 \mathrm{E}-31 \quad 1.475 \mathrm{E}-29 \quad 1.198 \mathrm{E}-27$

$\begin{array}{llllll}2.258 \mathrm{E}-31 & 2.277 \mathrm{E}-31 & 3.429 \mathrm{E}-31 & 5.209 \mathrm{E}-31 & 1.475 \mathrm{E}-29 & 1.198 \mathrm{E}-27\end{array}$

$1.879 \mathrm{E}-36 \quad 5.698 \mathrm{E}-36 \quad 3.536 \mathrm{E}-34 \quad 1.331 \mathrm{E}-33 \quad 1.619 \mathrm{E}-30 \quad 8.745 \mathrm{E}-27$

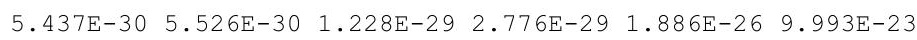

$\begin{array}{llllll}7.728 \mathrm{E}-36 & 2.352 \mathrm{E}-35 & 1.759 \mathrm{E}-33 & 7.909 \mathrm{E}-33 & 2.677 \mathrm{E}-29 & 2.912 \mathrm{E}-25\end{array}$

$\begin{array}{llllll}5.437 \mathrm{E}-30 & 5.526 \mathrm{E}-30 & 1.229 \mathrm{E}-29 & 2.777 \mathrm{E}-29 & 1.889 \mathrm{E}-26 & 1.002 \mathrm{E}-22\end{array}$

$1.980 \mathrm{E}-40 \quad 1.399 \mathrm{E}-39 \quad 2.876 \mathrm{E}-36 \quad 2.192 \mathrm{E}-35 \quad 1.294 \mathrm{E}-31 \quad 1.062 \mathrm{E}-27$

$\begin{array}{llllll}1.189 \mathrm{E}-28 & 1.207 \mathrm{E}-28 & 2.577 \mathrm{E}-28 & 5.589 \mathrm{E}-28 & 2.731 \mathrm{E}-25 & 9.387 \mathrm{E}-22\end{array}$

$\begin{array}{llllll}8.582 \mathrm{E}-34 & 2.610 \mathrm{E}-33 & 1.875 \mathrm{E}-31 & 8.088 \mathrm{E}-31 & 1.966 \mathrm{E}-27 & 1.384 \mathrm{E}-23\end{array}$

$\begin{array}{llllll}8.137 \mathrm{E}-40 & 5.764 \mathrm{E}-39 & 1.342 \mathrm{E}-35 & 1.152 \mathrm{E}-34 & 1.395 \mathrm{E}-30 & 2.014 \mathrm{E}-26\end{array}$

$\begin{array}{llllll}1.189 \mathrm{E}-28 & 1.207 \mathrm{E}-28 & 2.579 \mathrm{E}-28 & 5.597 \mathrm{E}-28 & 2.751 \mathrm{E}-25 & 9.526 \mathrm{E}-22\end{array}$

$\begin{array}{llllll}1.548 \mathrm{E}-29 & 2.326 \mathrm{E}-28 & 9.851 \mathrm{E}-24 & 9.693 \mathrm{E}-23 & 8.223 \mathrm{E}-20 & 1.159 \mathrm{E}-17\end{array}$

$\begin{array}{llllll}1.860 \mathrm{E}-17 & 5.610 \mathrm{E}-17 & 2.552 \mathrm{E}-15 & 6.905 \mathrm{E}-15 & 4.024 \mathrm{E}-13 & 2.105 \mathrm{E}-11\end{array}$

$\begin{array}{llllll}8.953 \mathrm{E}-23 & 6.292 \mathrm{E}-22 & 9.313 \mathrm{E}-19 & 5.033 \mathrm{E}-18 & 1.501 \mathrm{E}-15 & 1.668 \mathrm{E}-13\end{array}$

$\begin{array}{llllll}6.068 \mathrm{E}-29 & 9.551 \mathrm{E}-28 & 4.453 \mathrm{E}-23 & 4.797 \mathrm{E}-22 & 7.226 \mathrm{E}-19 & 1.676 \mathrm{E}-16\end{array}$

$\begin{array}{llllll}1.860 \mathrm{E}-17 & 5.611 \mathrm{E}-17 & 2.553 \mathrm{E}-15 & 6.910 \mathrm{E}-15 & 4.039 \mathrm{E}-13 & 2.122 \mathrm{E}-11\end{array}$

$\begin{array}{llllll}4.525 \mathrm{E}-38 & 1.390 \mathrm{E}-36 & 1.449 \mathrm{E}-30 & 2.375 \mathrm{E}-29 & 5.179 \mathrm{E}-26 & 1.334 \mathrm{E}-23\end{array}$ $\begin{array}{lllllllll}8.984 \mathrm{E}-26 & 6.263 \mathrm{E}-25 & 6.208 \mathrm{E}-22 & 2.463 \mathrm{E}-21 & 2.775 \mathrm{E}-19 & 2.524 \mathrm{E}-17\end{array}$

$\begin{array}{llllll}3.248 \mathrm{E}-31 & 4.859 \mathrm{E}-30 & 1.684 \mathrm{E}-25 & 1.435 \mathrm{E}-24 & 9.711 \mathrm{E}-22 & 1.935 \mathrm{E}-19\end{array}$

$\begin{array}{llllll}1.795 \mathrm{E}-36 & 6.414 \mathrm{E}-36 & 6.448 \mathrm{E}-30 & 1.147 \mathrm{E}-28 & 4.407 \mathrm{E}-25 & 1.885 \mathrm{E}-22\end{array}$

$\begin{array}{lllllll}8.984 \mathrm{E}-26 & 6.263 \mathrm{E}-25 & 6.210 \mathrm{E}-22 & 2.464 \mathrm{E}-21 & 2.785 \mathrm{E}-19 & 2.543 \mathrm{E}-17\end{array}$

$2.133 \mathrm{E}-24 \quad 2.157 \mathrm{E}-24 \quad 3.696 \mathrm{E}-24 \quad 6.404 \mathrm{E}-24 \quad 5.200 \mathrm{E}-22 \quad 1.687 \mathrm{E}-19$ 
RESRAD-OFFSITE, Version 2.

Parent Dose Report

Title : RESRAD-OFFSITE Parameters for Offsite Resident Farmer Forward Run 1,050 Years File : OFFSITE-RF_FORWARD-7-11.ROF

Individual Nuclide Dose Summed Over All Pathways

Parent Nuclide and Thread Fraction Indicated

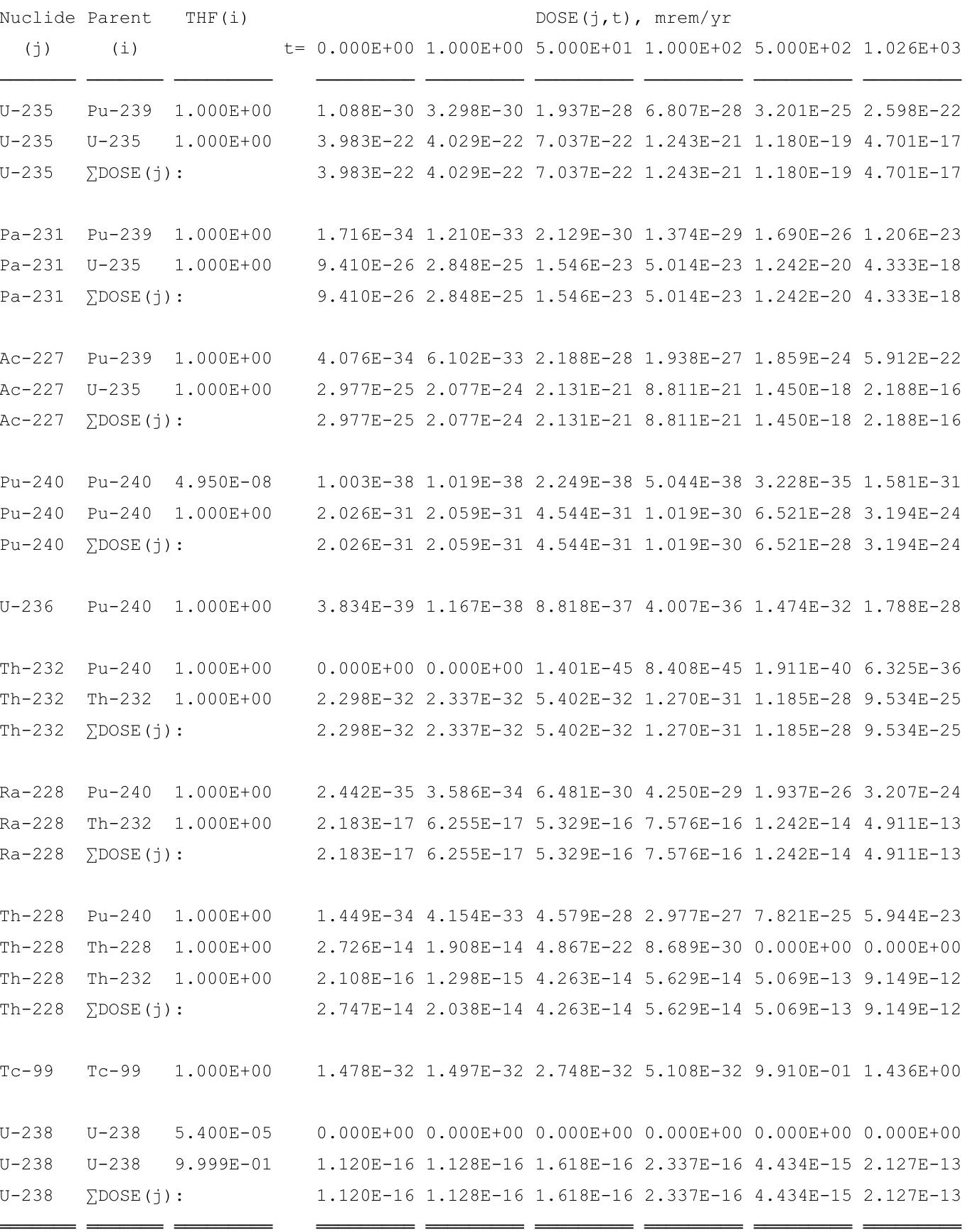

THF (i) is the thread fraction of the parent nuclide. 
RESRAD-OFFSITE, Version 2.

Parent Dose Report

Title : RESRAD-OFFSITE Parameters for Offsite Resident Farmer Forward Run 1,050 Years File : OFFSITE-RF FORWARD-7-11.ROF

Individual Nuclide Soil Concentration

Parent Nuclide and Thread Fraction Indicated

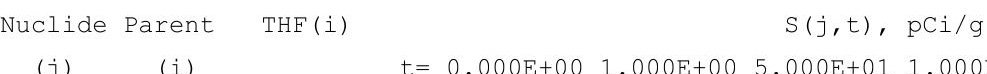

\section{(j)}

Am-241 Am-241 1.000E+00

Np-237 Am-241 $1.000 \mathrm{E}+00$

$\mathrm{Np}-237 \quad \mathrm{~Np}-237 \quad 1.000 \mathrm{E}+00$

Np-237 $\sum S(j):$

$\mathrm{U}-233 \mathrm{Am}-241 \quad 1.000 \mathrm{E}+00$

$\mathrm{U}-233 \mathrm{~Np}-237 \quad 1.000 \mathrm{E}+00$

$\mathrm{U}-233 \sum \mathrm{S}(j)$ :

Th-229 Am-241 1.000E+00

$\mathrm{Th}-229 \quad \mathrm{~Np}-237 \quad 1.000 \mathrm{E}+00$

Th-229 $\sum S(j):$

Cs-137 Cs-137 1.000E+00

$\mathrm{Pu}-238$

$\mathrm{Pu}-238$

$\mathrm{Pu}-238$

$\mathrm{U}-234$

$\mathrm{U}-234$

$\mathrm{U}-234$

$\mathrm{U}-234$

Th -230

$\mathrm{Th}-230$

$\mathrm{Th}-230$

Th-230

$\mathrm{Th}-230$

$\mathrm{Ra}-226$

$\mathrm{Ra}-226$

$\mathrm{Ra}-226$

$\mathrm{Ra}-226$

$\mathrm{Ra}-226$

$\mathrm{Pb}-210$

$\mathrm{Pb}-210$

$\mathrm{Pb}-210$

$\mathrm{Pb}-210$

$\mathrm{Pb}-210$

Pu-239 Pu-239 1.000E+00
$=0.000 \mathrm{E}+001.000 \mathrm{E}+00 \quad 5.000 \mathrm{E}+01 \quad 1.000 \mathrm{E}+02 \quad 5.000 \mathrm{E}+02 \quad 1.026 \mathrm{E}+03$

$\begin{array}{lllllll}3.500 \mathrm{E}+01 & 3.494 \mathrm{E}+01 & 3.230 \mathrm{E}+01 & 2.981 \mathrm{E}+01 & 1.567 \mathrm{E}+01 & 6.732 \mathrm{E}+00\end{array}$

$0.000 \mathrm{E}+00$ 1.133E-05 5.436E-04 1.043E-03 3.810E-03 5.417E-03

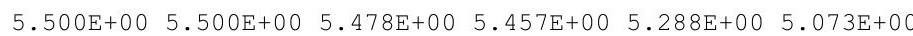

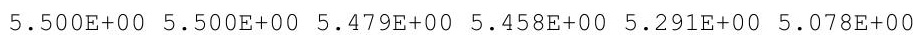

$\begin{array}{lllllll}0.000 \mathrm{E}+00 & 2.480 \mathrm{E}-11 & 6.025 \mathrm{E}-08 & 2.344 \mathrm{E}-07 & 4.742 \mathrm{E}-06 & 1.556 \mathrm{E}-05\end{array}$

$0.000 \mathrm{E}+00 \quad 2.405 \mathrm{E}-05 \quad 1.200 \mathrm{E}-03 \quad 2.394 \mathrm{E}-03 \quad 1.174 \mathrm{E}-02 \quad 2.349 \mathrm{E}-02$

$\begin{array}{llllll}0.000 \mathrm{E}+00 & 2.405 \mathrm{E}-05 & 1.200 \mathrm{E}-03 & 2.394 \mathrm{E}-03 & 1.174 \mathrm{E}-02 & 2.350 \mathrm{E}-02\end{array}$

$0.000 \mathrm{E}+00 \quad 7.822 \mathrm{E}-16 \quad 9.538 \mathrm{E}-11 \quad 7.463 \mathrm{E}-10 \quad 7.873 \mathrm{E}-08 \quad 5.545 \mathrm{E}-07$

$0.000 \mathrm{E}+00 \quad 1.137 \mathrm{E}-09 \quad 2.830 \mathrm{E}-06 \quad 1.128 \mathrm{E}-05 \quad 2.750 \mathrm{E}-04 \quad 1.119 \mathrm{E}-03$

$0.000 \mathrm{E}+00 \quad 1.137 \mathrm{E}-09 \quad 2.830 \mathrm{E}-06 \quad 1.128 \mathrm{E}-05 \quad 2.750 \mathrm{E}-04 \quad 1.120 \mathrm{E}-03$

$\begin{array}{llllll}1.900 \mathrm{E}+01 & 1.857 \mathrm{E}+01 & 5.979 \mathrm{E}+00 & 1.881 \mathrm{E}+00 & 1.809 \mathrm{E}-04 & 9.436 \mathrm{E}-10\end{array}$

$\begin{array}{llllll}7.176 \mathrm{E}-08 & 7.119 \mathrm{E}-08 & 4.832 \mathrm{E}-08 & 3.254 \mathrm{E}-08 & 1.375 \mathrm{E}-09 & 2.144 \mathrm{E}-11\end{array}$

$\begin{array}{llllllll}3.900 \mathrm{E}+01 & 3.869 \mathrm{E}+01 & 2.626 \mathrm{E}+01 & 1.768 \mathrm{E}+01 & 7.472 \mathrm{E}-01 & 1.165 \mathrm{E}-02\end{array}$

$\begin{array}{lllllll}3.900 \mathrm{E}+01 & 3.869 \mathrm{E}+01 & 2.626 \mathrm{E}+01 & 1.768 \mathrm{E}+01 & 7.472 \mathrm{E}-01 & 1.165 \mathrm{E}-02\end{array}$

$0.000 \mathrm{E}+00 \quad 1.101 \mathrm{E}-04 \quad 4.564 \mathrm{E}-03 \quad 7.633 \mathrm{E}-03 \quad 1.362 \mathrm{E}-02 \quad 1.377 \mathrm{E}-02$

$\begin{array}{llllll}1.600 \mathrm{E}+02 & 1.600 \mathrm{E}+02 & 1.599 \mathrm{E}+02 & 1.597 \mathrm{E}+02 & 1.587 \mathrm{E}+02 & 1.574 \mathrm{E}+02\end{array}$

$\begin{array}{llllllll}0.000 \mathrm{E}+00 & 4.536 \mathrm{E}-04 & 2.266 \mathrm{E}-02 & 4.529 \mathrm{E}-02 & 2.251 \mathrm{E}-01 & 4.583 \mathrm{E}-01\end{array}$

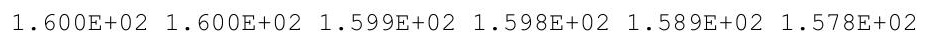

$0.000 \mathrm{E}+00 \quad 4.968 \mathrm{E}-10 \quad 1.095 \mathrm{E}-06 \quad 3.884 \mathrm{E}-06 \quad 4.705 \mathrm{E}-05 \quad 1.118 \mathrm{E}-04$ $\begin{array}{llllllll}1.000 \mathrm{E}+02 & 1.000 \mathrm{E}+02 & 9.995 \mathrm{E}+01 & 9.989 \mathrm{E}+01 & 9.947 \mathrm{E}+01 & 9.891 \mathrm{E}+01\end{array}$ $0.000 \mathrm{E}+001.440 \mathrm{E}-03 \quad 7.197 \mathrm{E}-02 \quad 1.438 \mathrm{E}-01 \quad 7.153 \mathrm{E}-01 \quad 1.457 \mathrm{E}+00$ $0.000 \mathrm{E}+00 \quad 2.043 \mathrm{E}-09 \quad 5.100 \mathrm{E}-06 \quad 2.039 \mathrm{E}-05 \quad 5.070 \mathrm{E}-04 \quad 2.120 \mathrm{E}-03$ $\begin{array}{lll}1.000 \mathrm{E}+02 & 1.000 \mathrm{E}+02 \quad 1.000 \mathrm{E}+02 \quad 1.000 \mathrm{E}+02 \quad 1.002 \mathrm{E}+02 \quad 1.004 \mathrm{E}+02\end{array}$

$0.000 \mathrm{E}+00 \quad 7.192 \mathrm{E}-14 \quad 8.112 \mathrm{E}-09 \quad 5.891 \mathrm{E}-08 \quad 3.952 \mathrm{E}-06 \quad 1.952 \mathrm{E}-05$ $0.000 \mathrm{E}+00 \quad 4.331 \mathrm{E}-02 \quad 2.142 \mathrm{E}+00 \quad 4.235 \mathrm{E}+00 \quad 1.937 \mathrm{E}+01 \quad 3.549 \mathrm{E}+01$ $\begin{array}{llllll}0.000 \mathrm{E}+00 & 3.122 \mathrm{E}-07 & 7.739 \mathrm{E}-04 & 3.071 \mathrm{E}-03 & 7.220 \mathrm{E}-02 & 2.810 \mathrm{E}-01\end{array}$ $0.000 \mathrm{E}+00 \quad 3.025 \mathrm{E}-13 \quad 3.663 \mathrm{E}-08 \quad 2.913 \mathrm{E}-07 \quad 3.471 \mathrm{E}-05 \quad 2.822 \mathrm{E}-04$ $\begin{array}{lllllll}0.000 \mathrm{E}+00 & 4.331 \mathrm{E}-02 & 2.142 \mathrm{E}+00 & 4.238 \mathrm{E}+00 & 1.944 \mathrm{E}+01 & 3.577 \mathrm{E}+01\end{array}$

$0.000 \mathrm{E}+00 \quad 5.579 \mathrm{E}-16 \quad 2.418 \mathrm{E}-09 \quad 2.812 \mathrm{E}-08 \quad 3.398 \mathrm{E}-06 \quad 1.827 \mathrm{E}-05$ $\begin{array}{llllllll}0.000 \mathrm{E}+00 & 6.669 \mathrm{E}-04 & 1.058 \mathrm{E}+00 & 2.946 \mathrm{E}+00 & 1.823 \mathrm{E}+01 & 3.458 \mathrm{E}+01\end{array}$ $\begin{array}{llllll}0.000 \mathrm{E}+00 & 3.216 \mathrm{E}-09 & 2.837 \mathrm{E}-04 & 1.706 \mathrm{E}-03 & 6.374 \mathrm{E}-02 & 2.650 \mathrm{E}-01\end{array}$ $\begin{array}{llllll}0.000 \mathrm{E}+00 & 9.289 \mathrm{E}-15 & 1.075 \mathrm{E}-08 & 1.356 \mathrm{E}-07 & 2.889 \mathrm{E}-05 & 2.580 \mathrm{E}-04\end{array}$ $\begin{array}{lllllll}0.000 \mathrm{E}+00 & 6.669 \mathrm{E}-04 & 1.058 \mathrm{E}+00 & 2.947 \mathrm{E}+00 & 1.830 \mathrm{E}+01 & 3.485 \mathrm{E}+01\end{array}$ $\begin{array}{lllllll}3.600 E+01 & 3.600 E+01 & 3.593 E+01 & 3.586 E+01 & 3.531 E+01 & 3.460 E+01\end{array}$ 
RESRAD-OFFSITE, Version 2.

Parent Dose Report

Title : RESRAD-OFFSITE Parameters for Offsite Resident Farmer Forward Run 1,050 Years File : OFFSITE-RF_FORWARD-7-11.ROF

Individual Nuclide Soil Concentration

Parent Nuclide and Thread Fraction Indicated

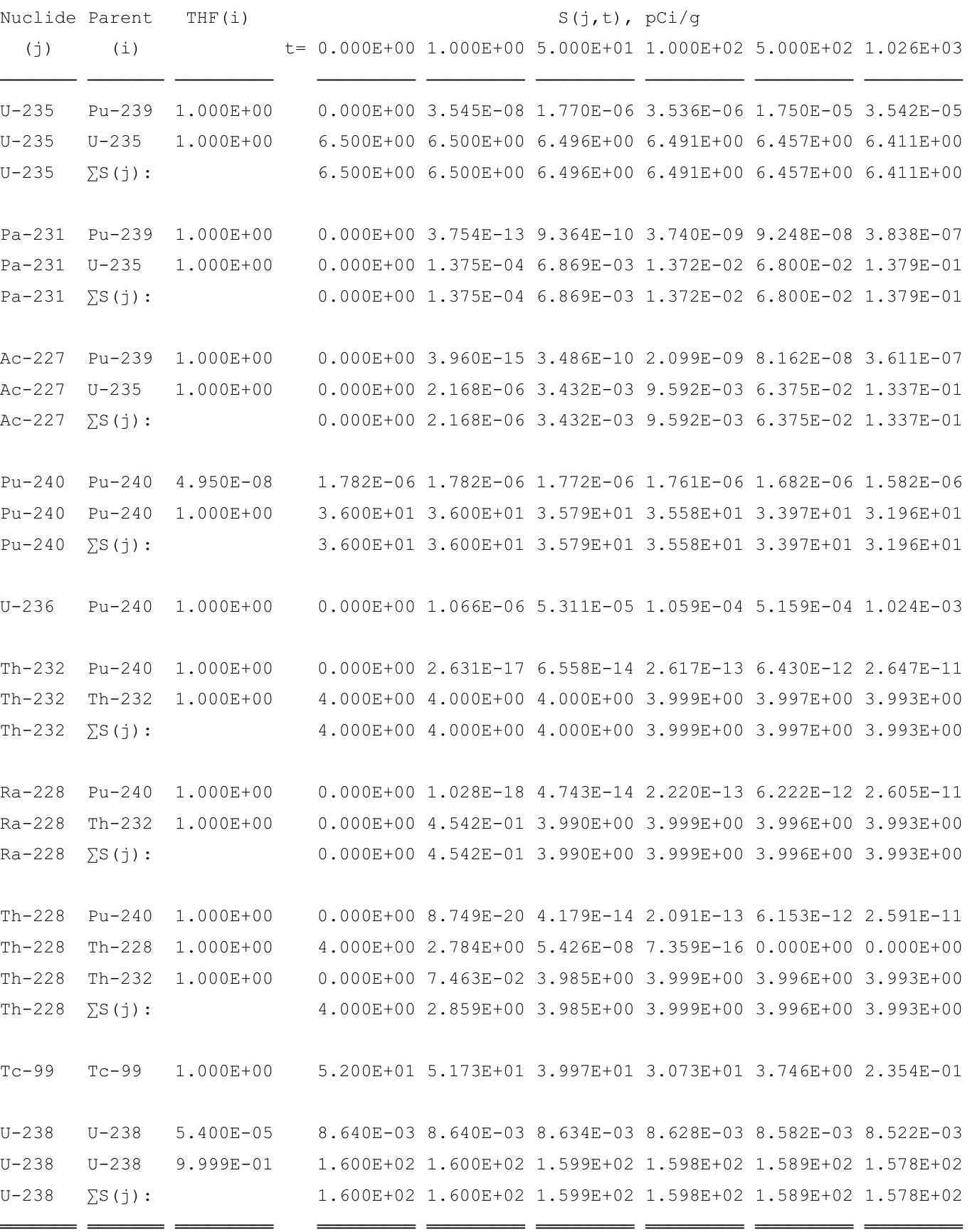

THF (i) is the thread fraction of the parent nuclide. 
RESRAD-OFFSITE, Version $2.5 \quad \mathrm{~T}^{1 / 2}$ Limit $=180$ days

Parent Dose Report

Title : RESRAD-OFFSITE Parameters for Offsite Resident Farmer Forward Run 1,050 Years

File : OFFSITE-RF_FORWARD-7-11.ROF

Run Time Information

ResOCalc.EXE execution began at 10:27 on 07/21/2011

ResOCalc.EXE execution ended at 10:42 on 07/21/2011

ResOCalc.EXE execution time 14 minutes 55 seconds 
Parent Dose Report

Title : RESRAD-OFFSITE Parameters for Offsite Resident Farmer Forward Run 1,050 Years File : OFFSITE-RF_FORWARD-7-11ALS.ROF

Table of Contents

Part I: Mixture Sums and Single Radionuclide Guidelines

Dose Conversion Factor (and Related) Parameter Summary ... 2

Site-Specific Parameter Summary ................ 11

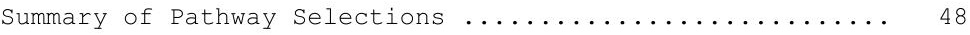

Contaminated Zone and Total Dose Summary ............ 49

Total Dose Components

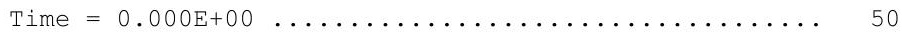

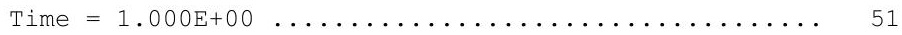

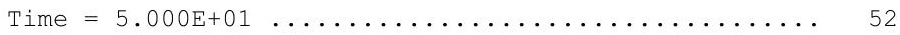

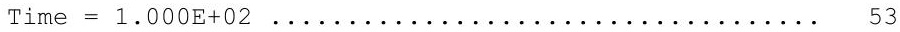

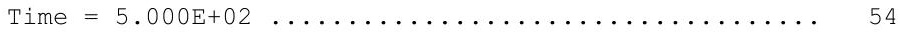

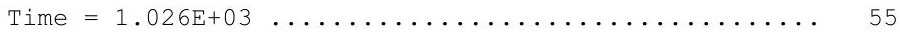

Dose/Source Ratios Summed Over All Pathways .......... 56

Single Radionuclide Soil Guidelines ............... 58

Dose Per Nuclide Summed Over All Pathways ............ 59

Soil Concentration Per Nuclide ................. 61

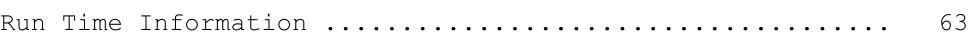


RESRAD-OFFSITE, Version 2.5

Parent Dose Report

Title : RESRAD-OFFSITE Parameters for Offsite Resident Farmer Forward Run 1,050 Years

File : OFFSITE-RF_FORWARD-7-11ALS.ROF

Dose Conversion Factor (and Related) Parameter Summary

Current Library: ICRP 60

Default Library: ICRP 60

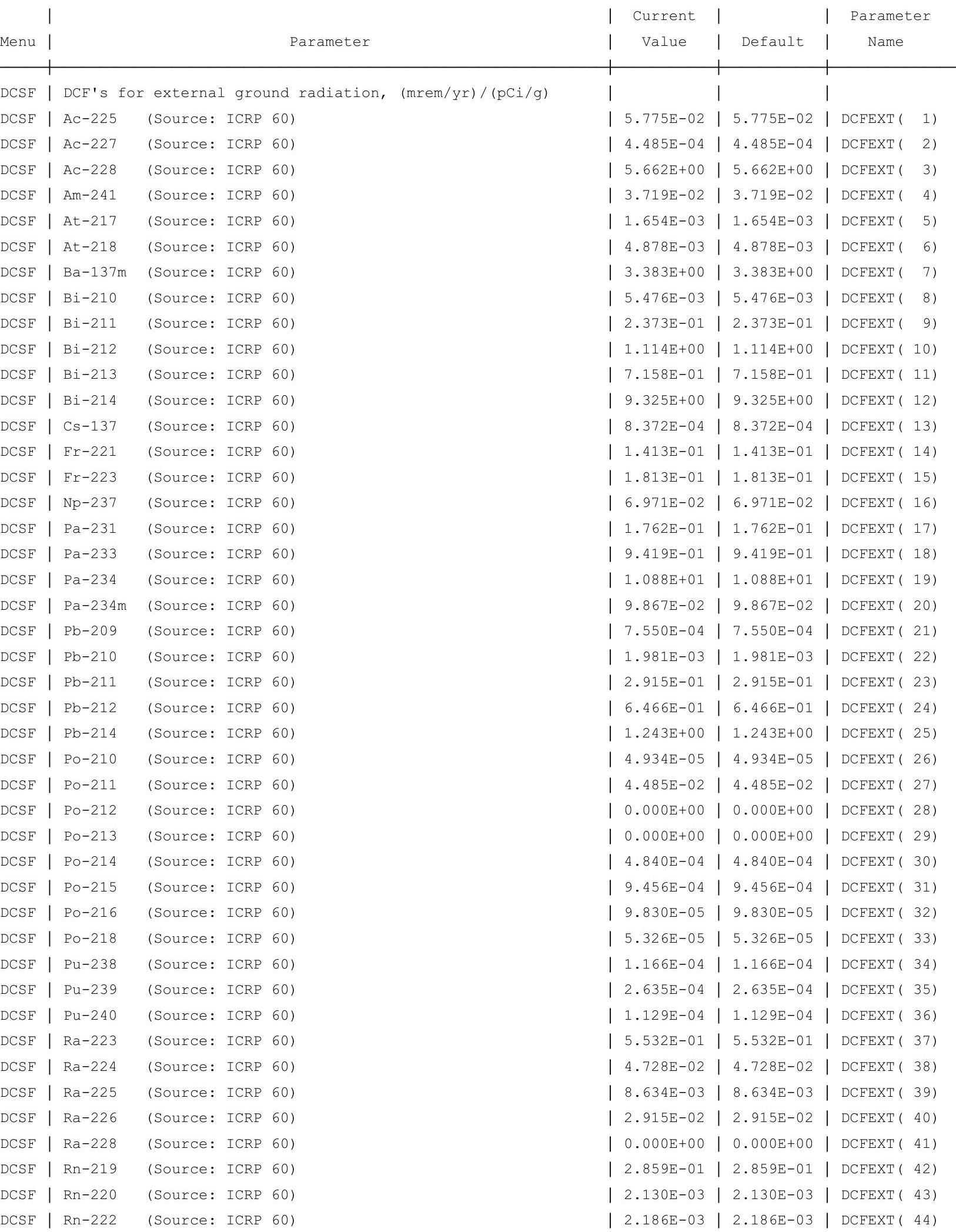


RESRAD-OFFSITE, Version $2.5 \quad \mathrm{~T}^{1 / 2}$ Limit $=180$ days

Parent Dose Report

Title : RESRAD-OFFSITE Parameters for Offsite Resident Farmer Forward Run 1,050 Years

File : OFFSITE-RF_FORWARD-7-11ALS.ROF

Dose Conversion Factor (and Related) Parameter Summary (continued)

Current Library: ICRP 60

Default Library: ICRP 60

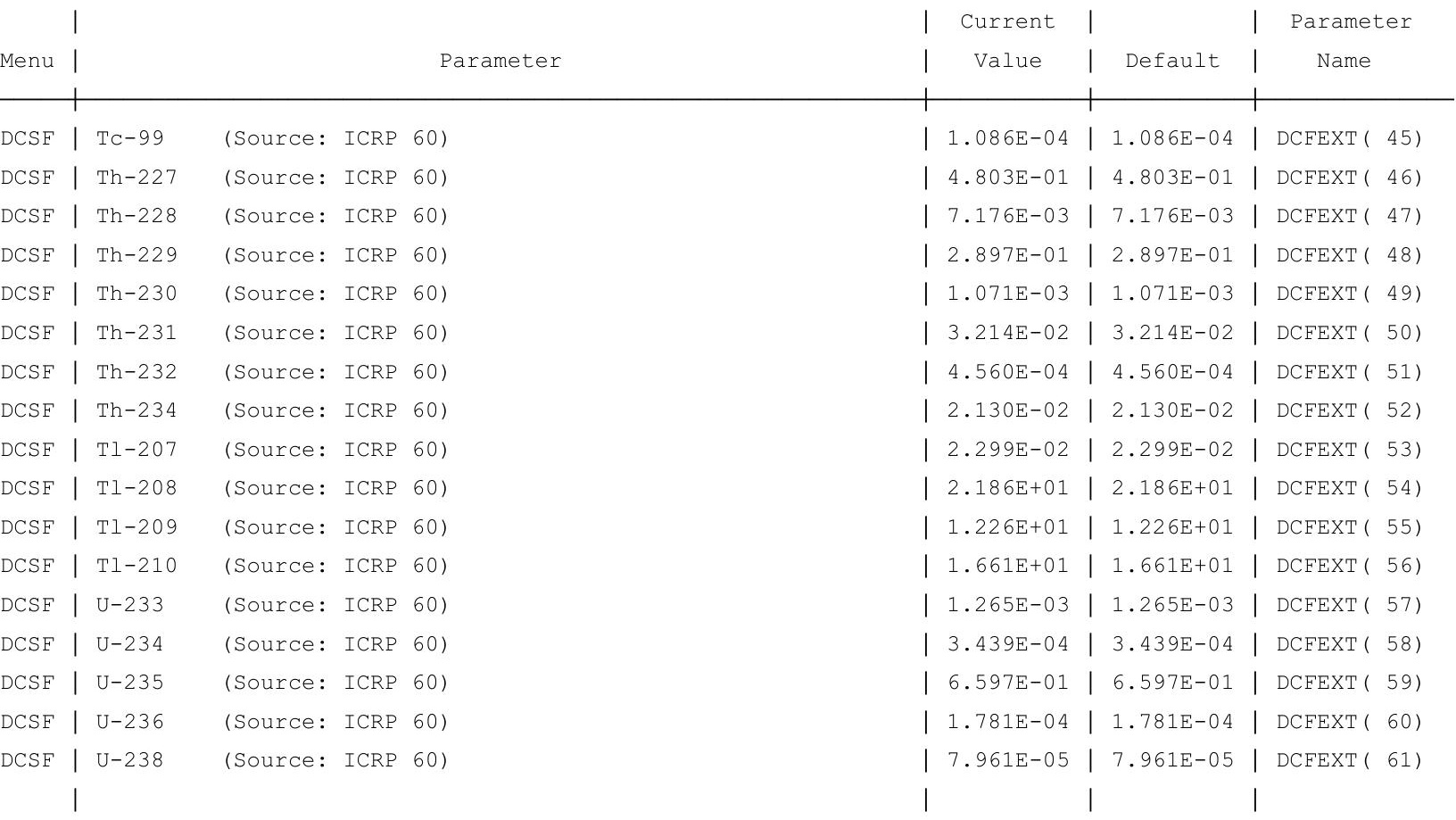

Current Library: ICRP 72 (Adult)

Default Library: ICRP 72 (Adult)

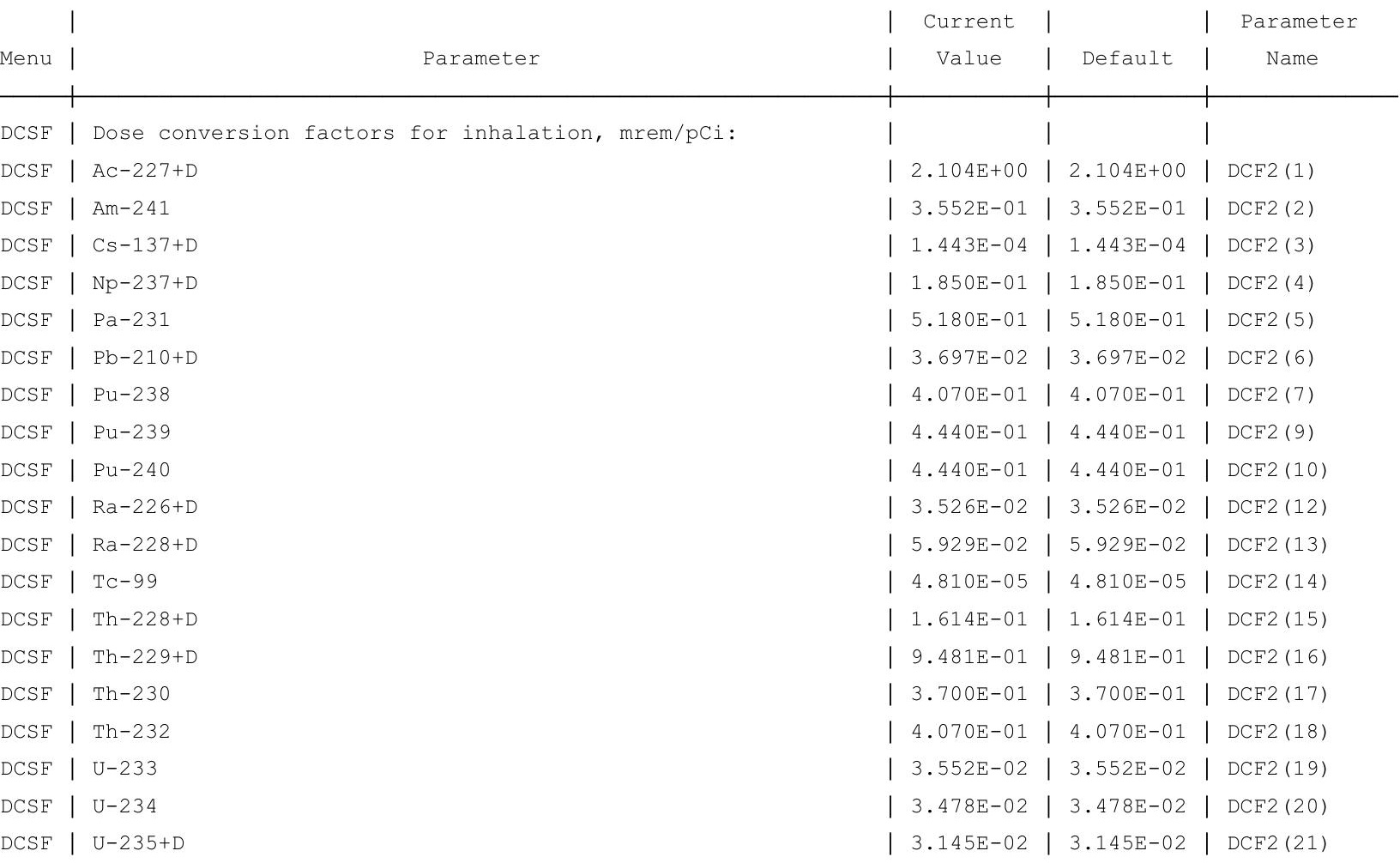


RESRAD-OFFSITE, Version 2.9

Parent Dose Report

Title : RESRAD-OFFSITE Parameters for Offsite Resident Farmer Forward Run 1,050 Years

File : OFFSITE-RF_FORWARD-7-11ALS.ROF

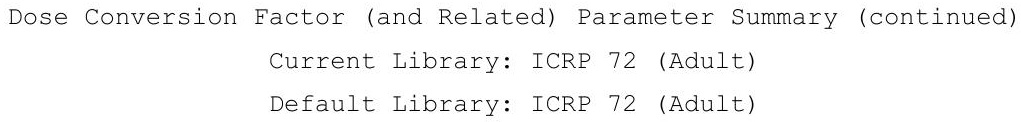

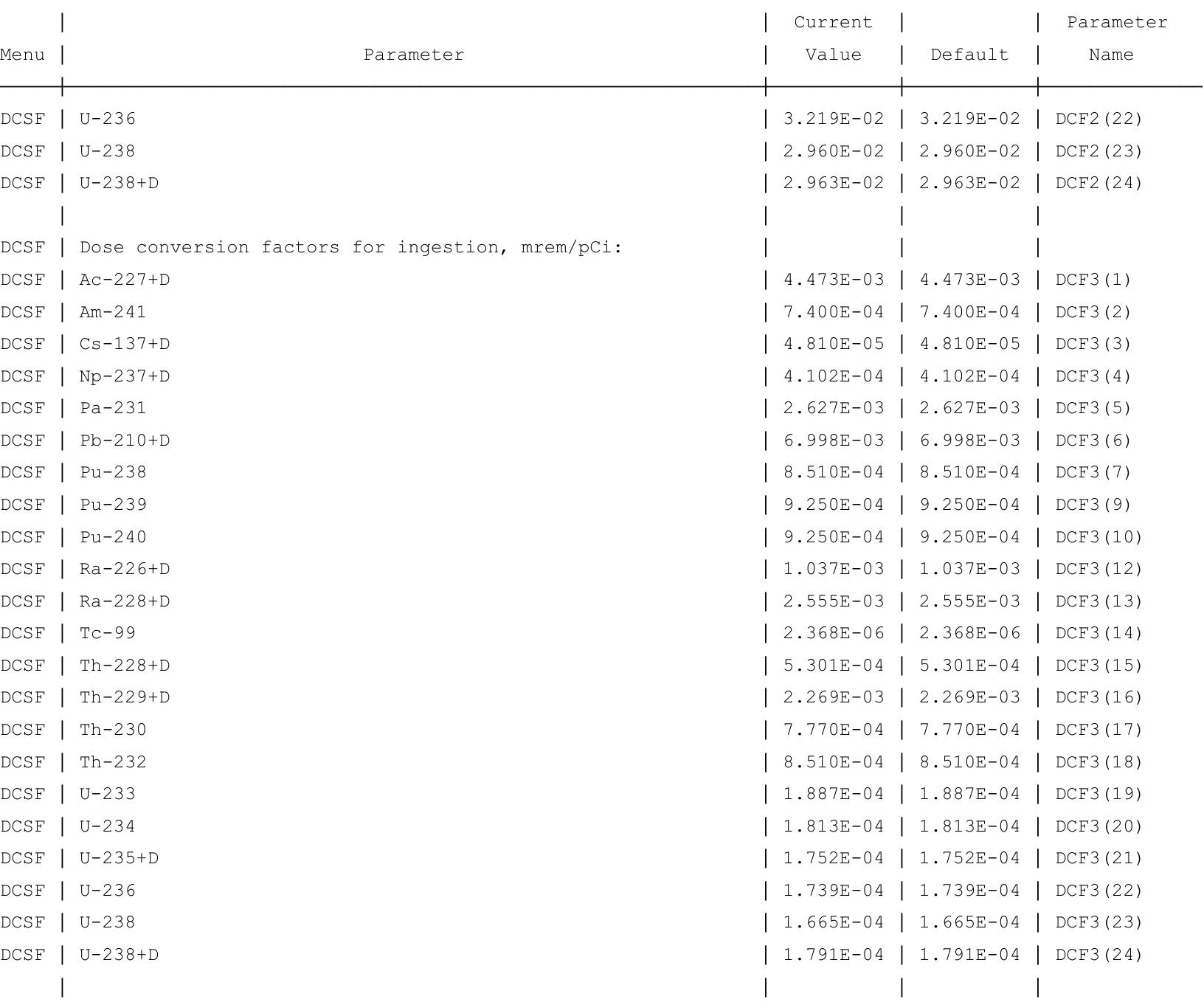


RESRAD-OFFSITE, Version 2.5

Parent Dose Report

Title : RESRAD-OFFSITE Parameters for Offsite Resident Farmer Forward Run 1,050 Years

File : OFFSITE-RF_FORWARD-7-11ALS.ROF

Dose Conversion Factor (and Related) Parameter Summary (continued)

Current Library: RESRAD Default Transfer factors

Default Library: RESRAD Default Transfer factors

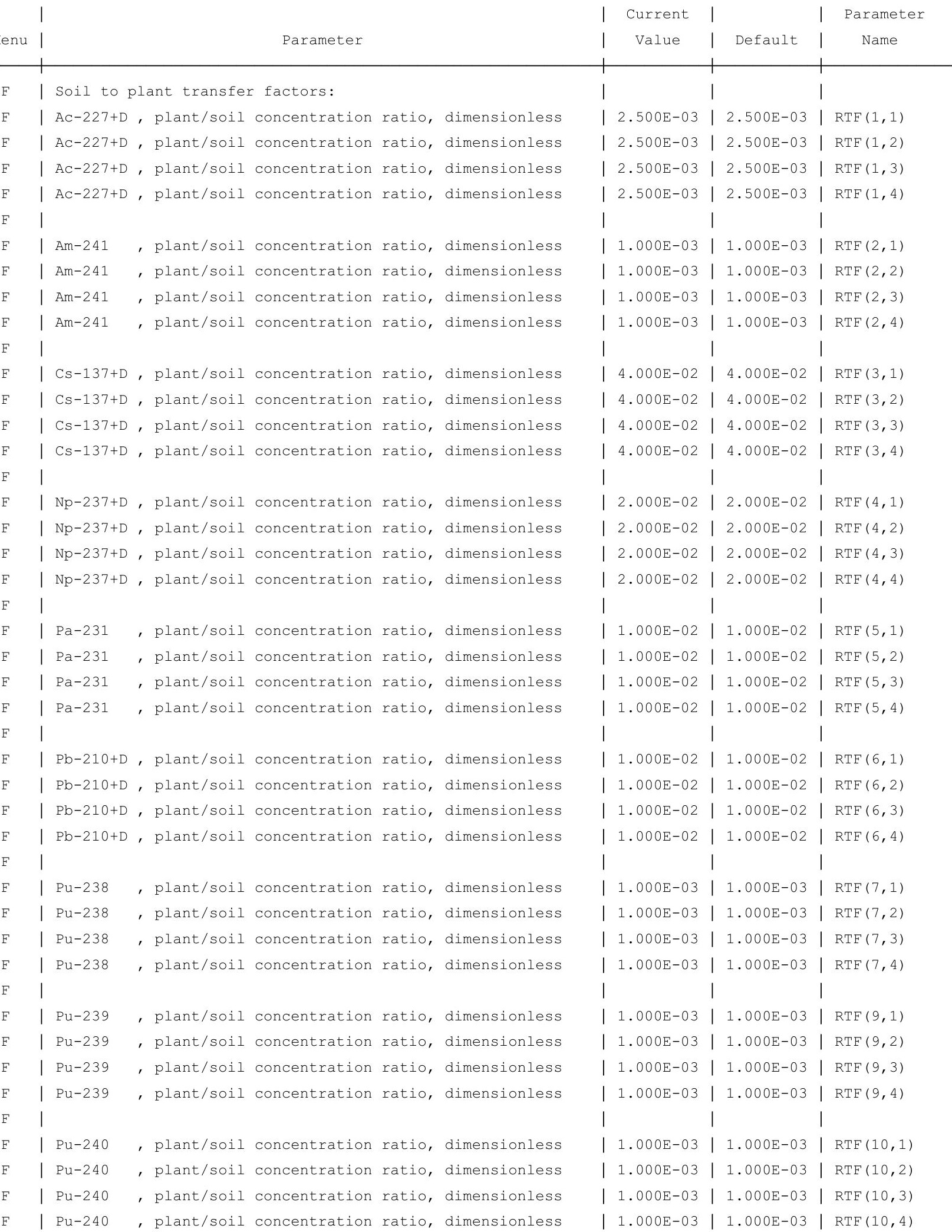


RESRAD-OFFSITE, Version 2.5

Parent Dose Report

Title : RESRAD-OFFSITE Parameters for Offsite Resident Farmer Forward Run 1,050 Years

File : OFFSITE-RF_FORWARD-7-11ALS.ROF

Dose Conversion Factor (and Related) Parameter Summary (continued)

Current Library: RESRAD Default Transfer factors

Default Library: RESRAD Default Transfer factors

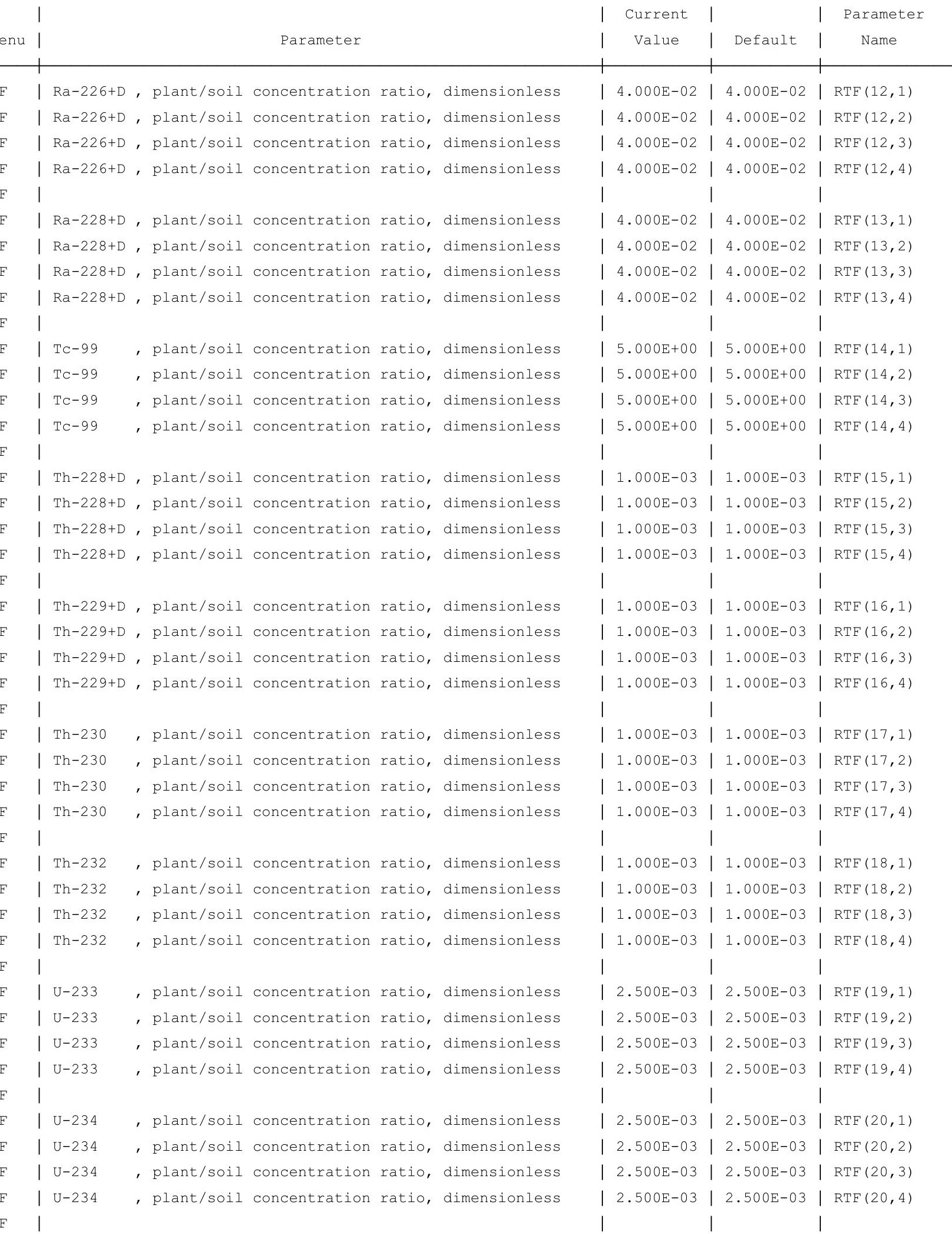


RESRAD-OFFSITE, Version 2.5

Parent Dose Report

Title : RESRAD-OFFSITE Parameters for Offsite Resident Farmer Forward Run 1,050 Years

File : OFFSITE-RF_FORWARD-7-11ALS.ROF

Dose Conversion Factor (and Related) Parameter Summary (continued)

Current Library: RESRAD Default Transfer factors

Default Library: RESRAD Default Transfer factors

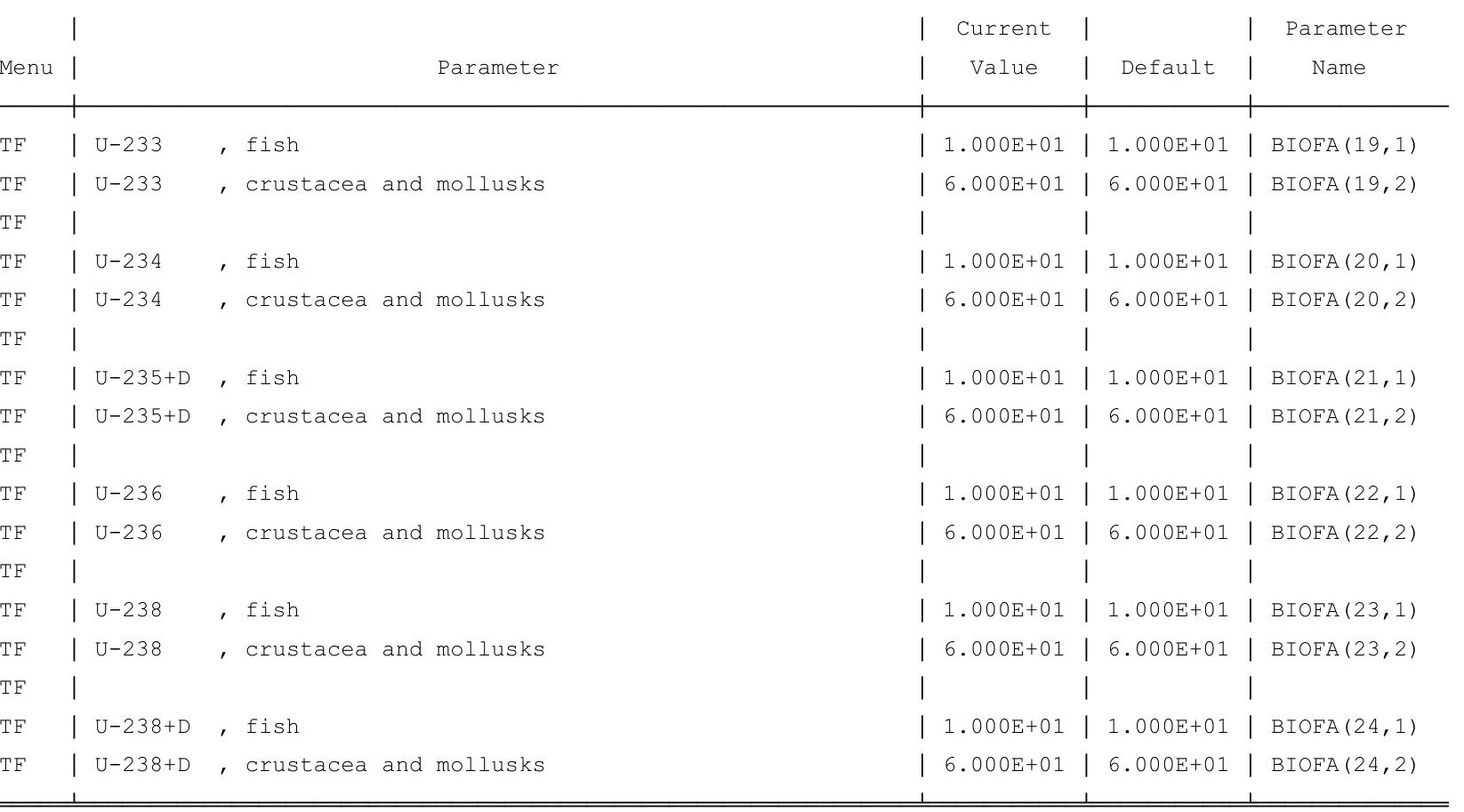


RESRAD-OFFSITE, Version $2.5 \quad$ T1/2 Limit $=180$ days $\quad$ 07/21/2011 $11: 14$ Page

Parent Dose Report

Title : RESRAD-OFFSITE Parameters for Offsite Resident Farmer Forward Run 1,050 Years

File : OFFSITE-RF_FORWARD-7-11ALS.ROF

Site-Specific Parameter Summary

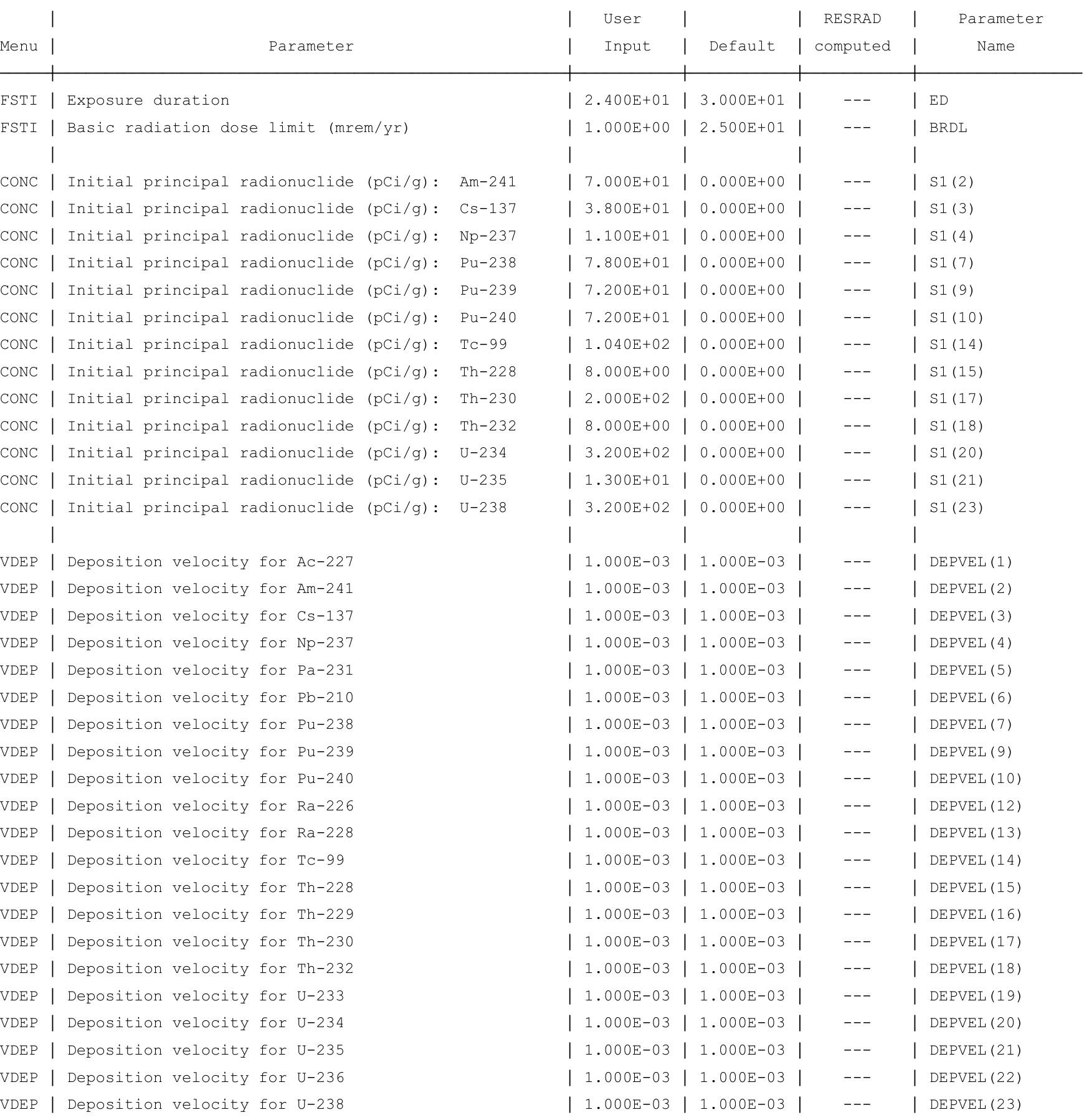

DEP Deposition velocity for U-238 
RESRAD-OFFSITE, Version $2.5 \quad \mathrm{~T}^{1 / 2}$ Limit $=180$ days $\quad$ 07/21/2011 $11: 14$ Page

Parent Dose Report

Title : RESRAD-OFFSITE Parameters for Offsite Resident Farmer Forward Run 1,050 Years

File : OFFSITE-RF_FORWARD-7-11ALS.ROF

Site-Specific Parameter Summary (continued)

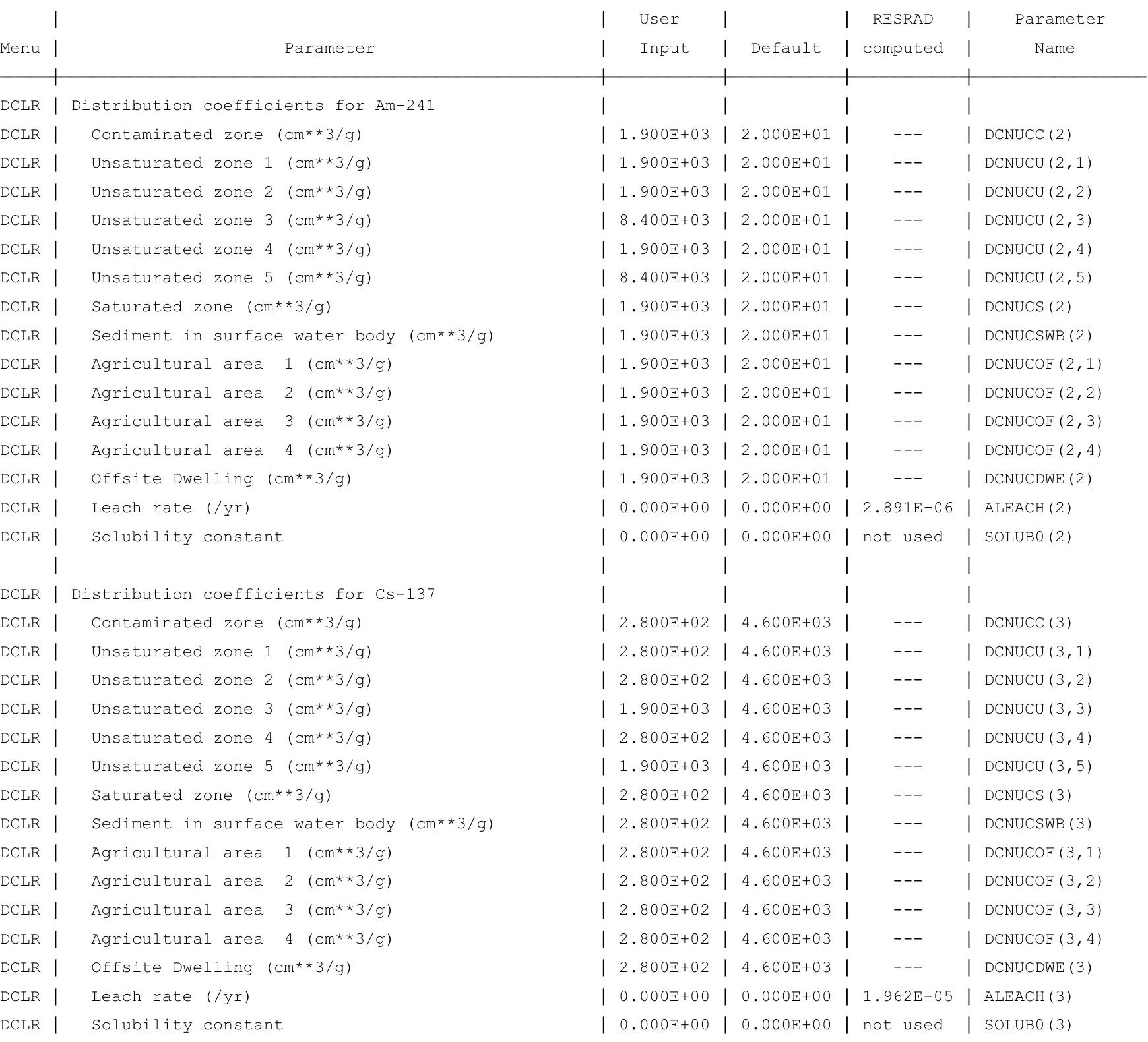


RESRAD-OFFSITE, Version $2.5 \quad \mathrm{~T}^{1 / 2}$ Limit $=180$ days $\quad$ 07/21/2011 $11: 14$ Page

Parent Dose Report

Title : RESRAD-OFFSITE Parameters for Offsite Resident Farmer Forward Run 1,050 Years

File : OFFSITE-RF_FORWARD-7-11ALS.ROF

Site-Specific Parameter Summary (continued)

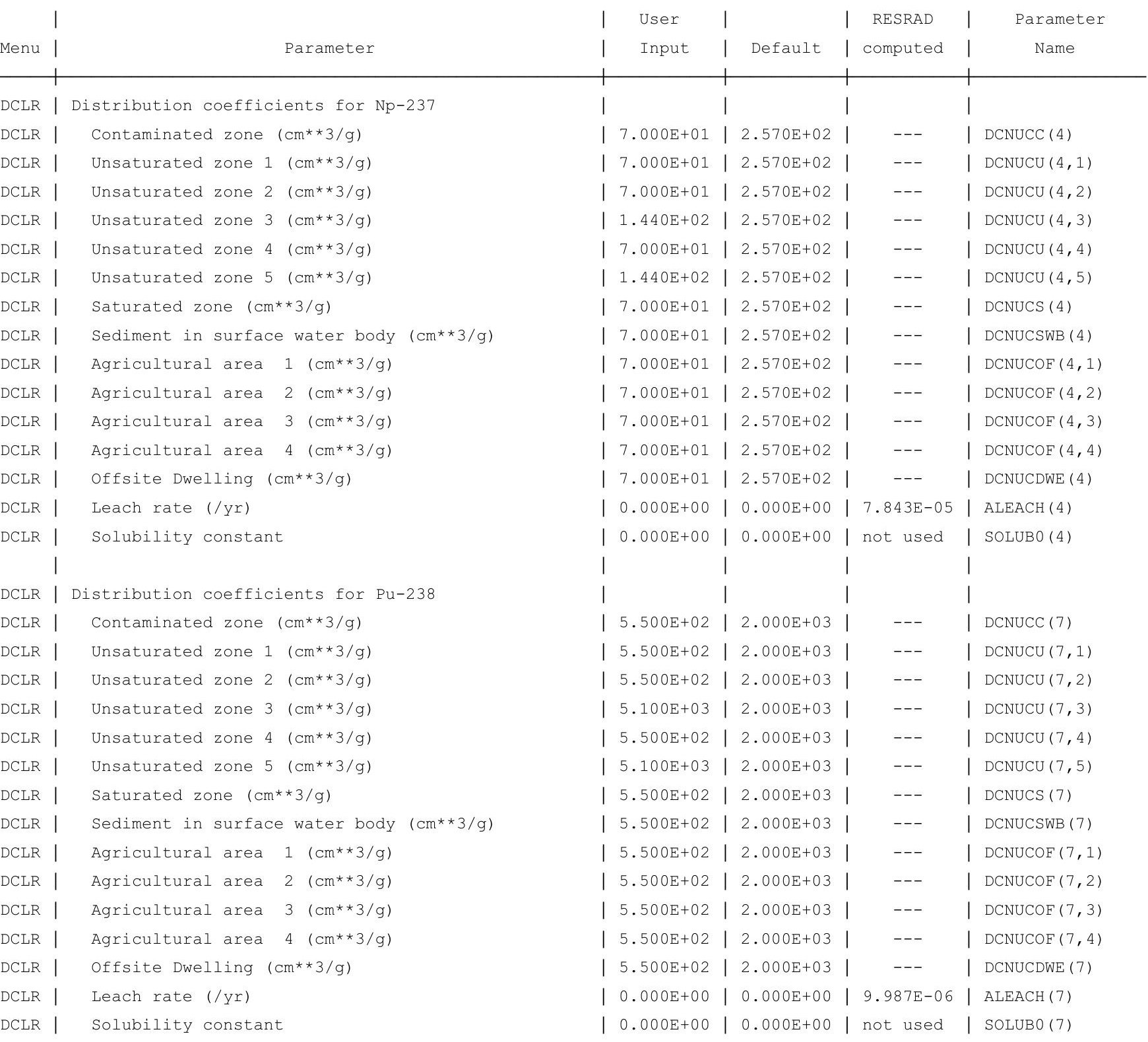


RESRAD-OFFSITE, Version $2.5 \quad \mathrm{~T}^{1 / 2}$ Limit $=180$ days $\quad$ 07/21/2011 $11: 14$ Page

Parent Dose Report

Title : RESRAD-OFFSITE Parameters for Offsite Resident Farmer Forward Run 1,050 Years

File : OFFSITE-RF_FORWARD-7-11ALS.ROF

Site-Specific Parameter Summary (continued)

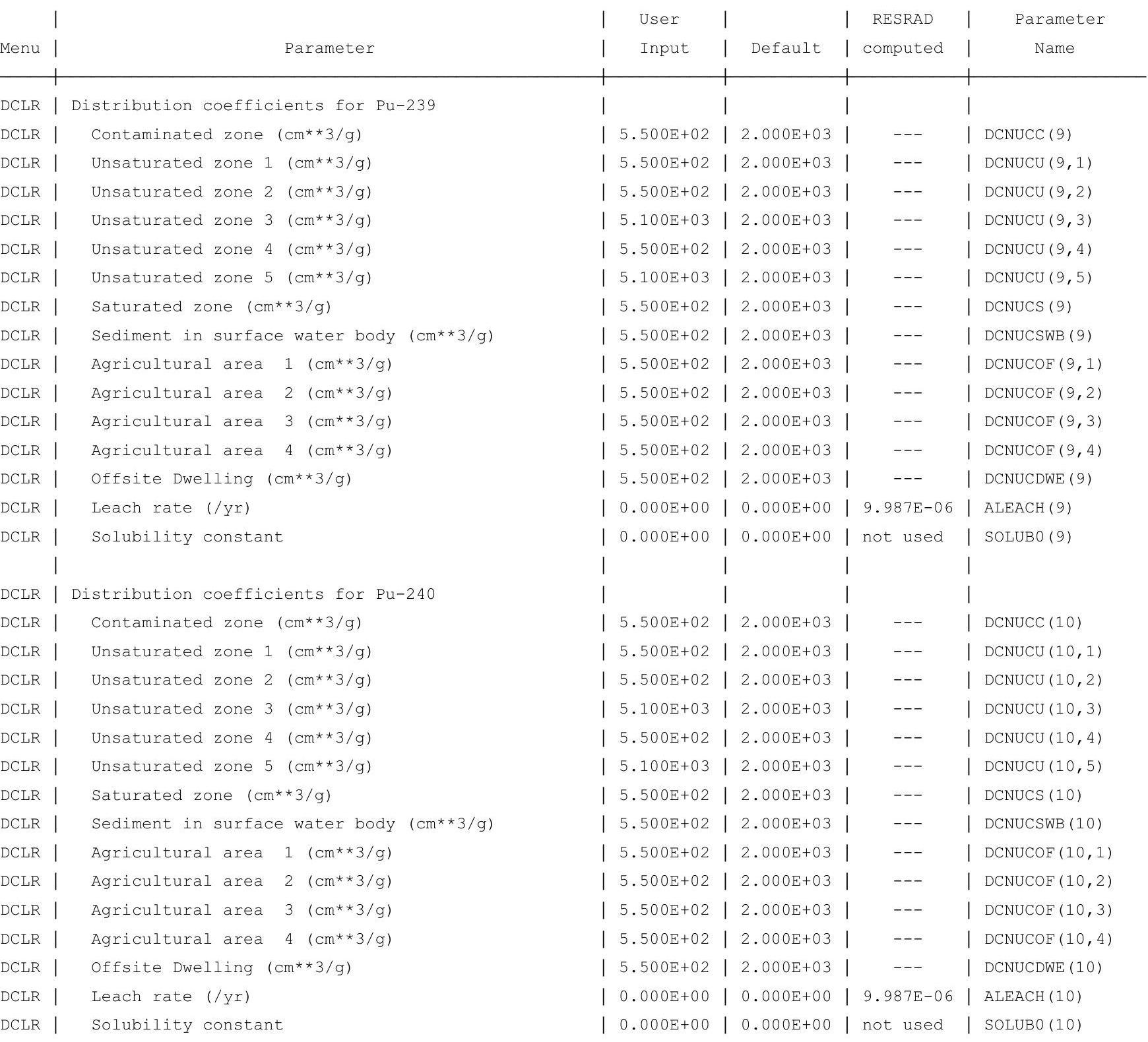


RESRAD-OFFSITE, Version $2.5 \quad$ T1/2 Limit = 180 days $\quad$ 07/21/2011 $11: 14 \quad$ Page

Parent Dose Report

Title : RESRAD-OFFSITE Parameters for Offsite Resident Farmer Forward Run 1,050 Years

File : OFFSITE-RF_FORWARD-7-11ALS.ROF

Site-Specific Parameter Summary (continued)

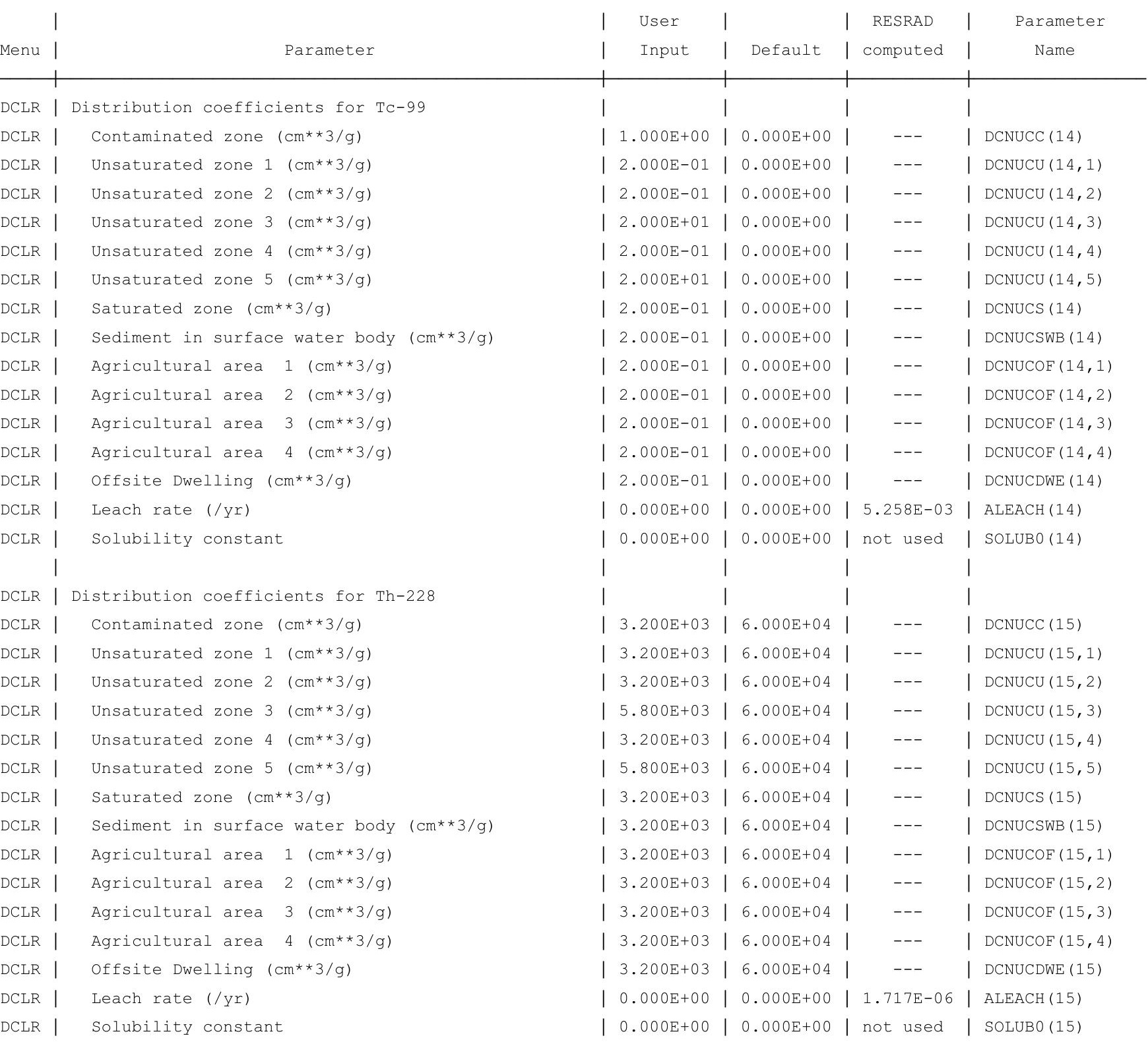


RESRAD-OFFSITE, Version $2.5 \quad$ T⿱11/2 Limit $=180$ days $\quad$ 07/21/2011 $11: 14$ Page

Parent Dose Report

Title : RESRAD-OFFSITE Parameters for Offsite Resident Farmer Forward Run 1,050 Years

File : OFFSITE-RF_FORWARD-7-11ALS.ROF

Site-Specific Parameter Summary (continued)

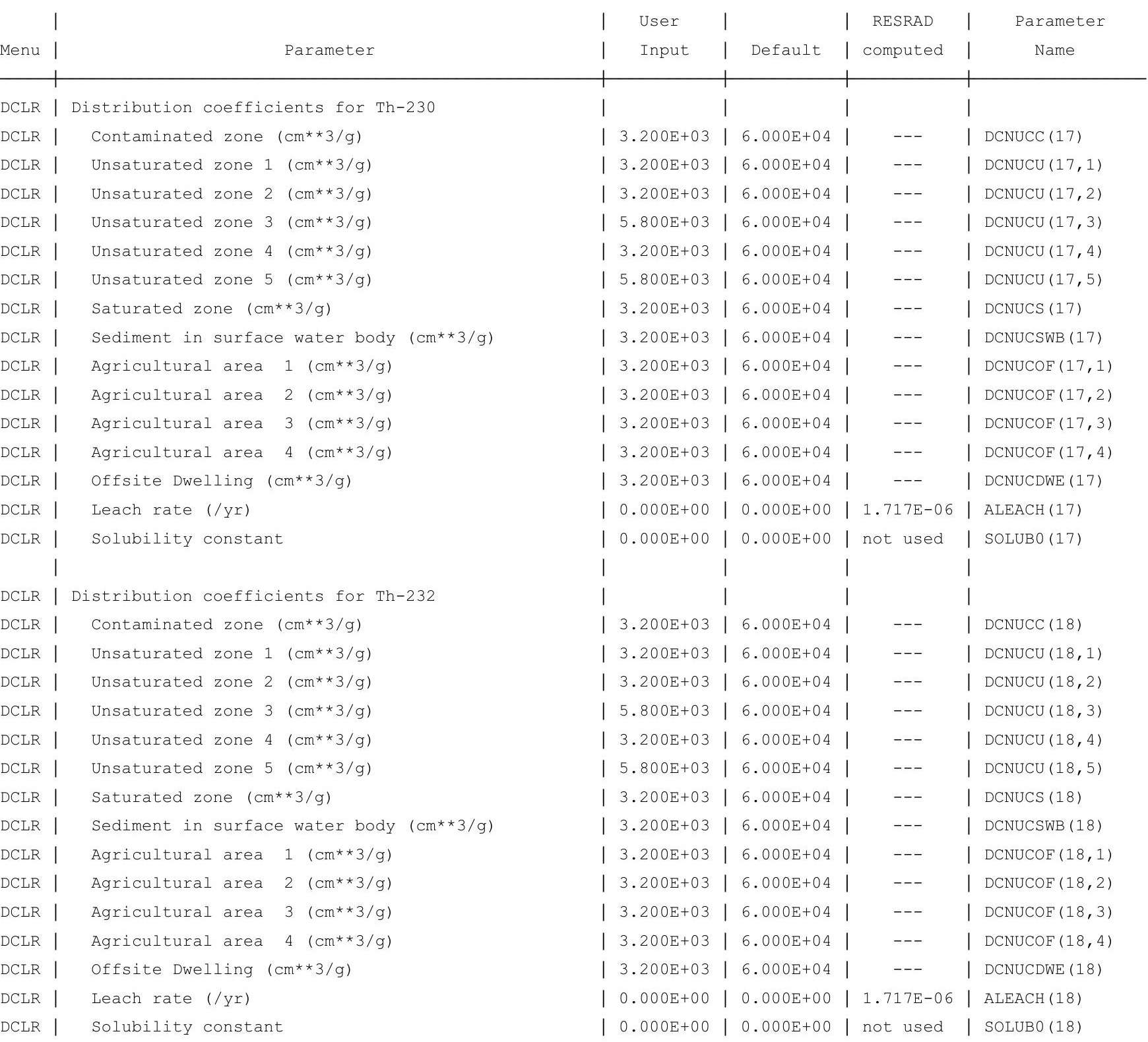


RESRAD-OFFSITE, Version 2.5

Parent Dose Report

Title : RESRAD-OFFSITE Parameters for Offsite Resident Farmer Forward Run 1,050 Years

File : OFFSITE-RF_FORWARD-7-11ALS.ROF

Site-Specific Parameter Summary (continued)

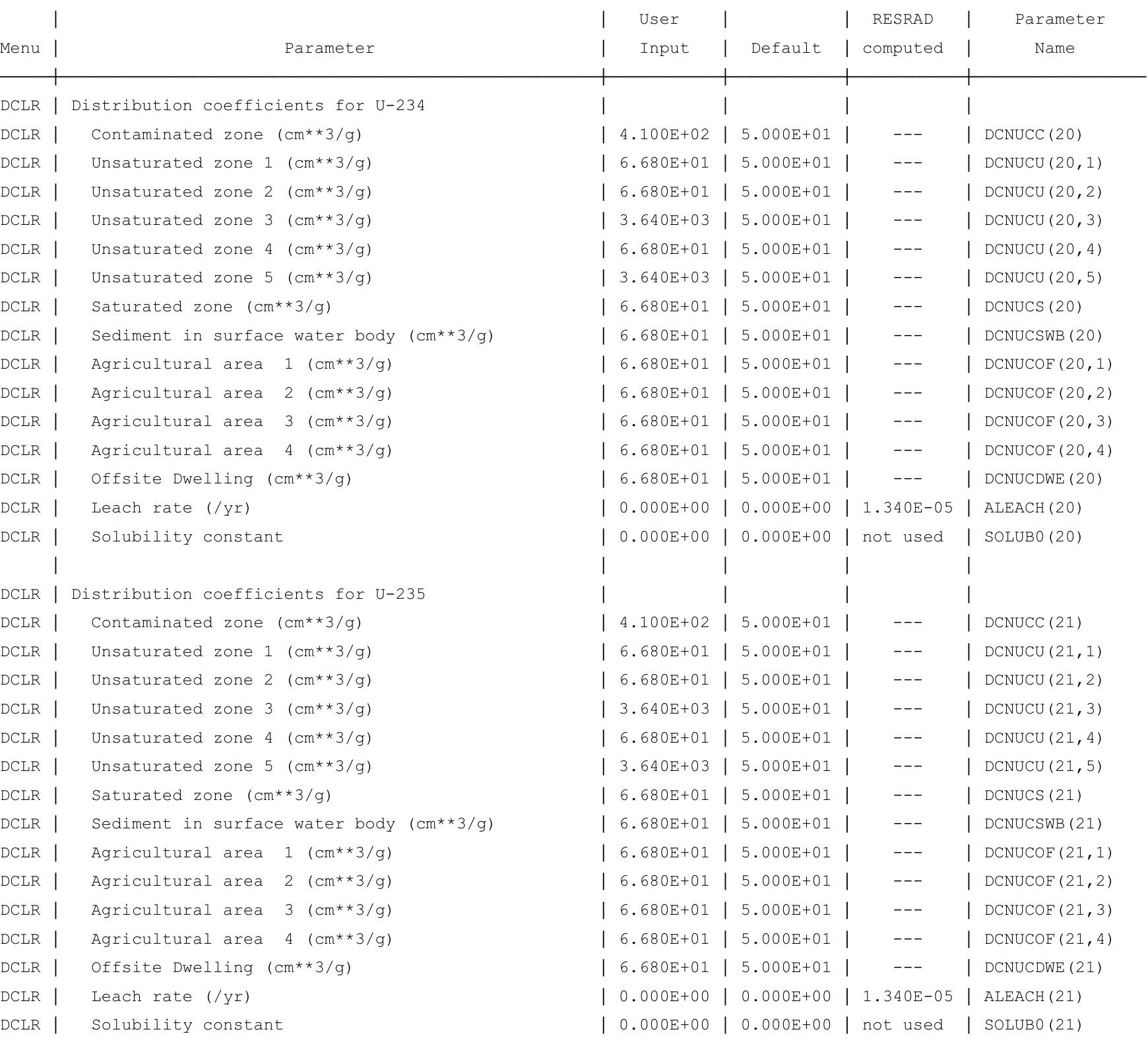


RESRAD-OFFSITE, Version $2.5 \quad T^{1 / 3}$ Limit $=180$ days $\quad 07 / 21 / 2011 \quad 11: 14$ Page

Parent Dose Report

Title : RESRAD-OFFSITE Parameters for Offsite Resident Farmer Forward Run 1,050 Years

File : OFFSITE-RF_FORWARD-7-11ALS.ROF

Site-Specific Parameter Summary (continued)

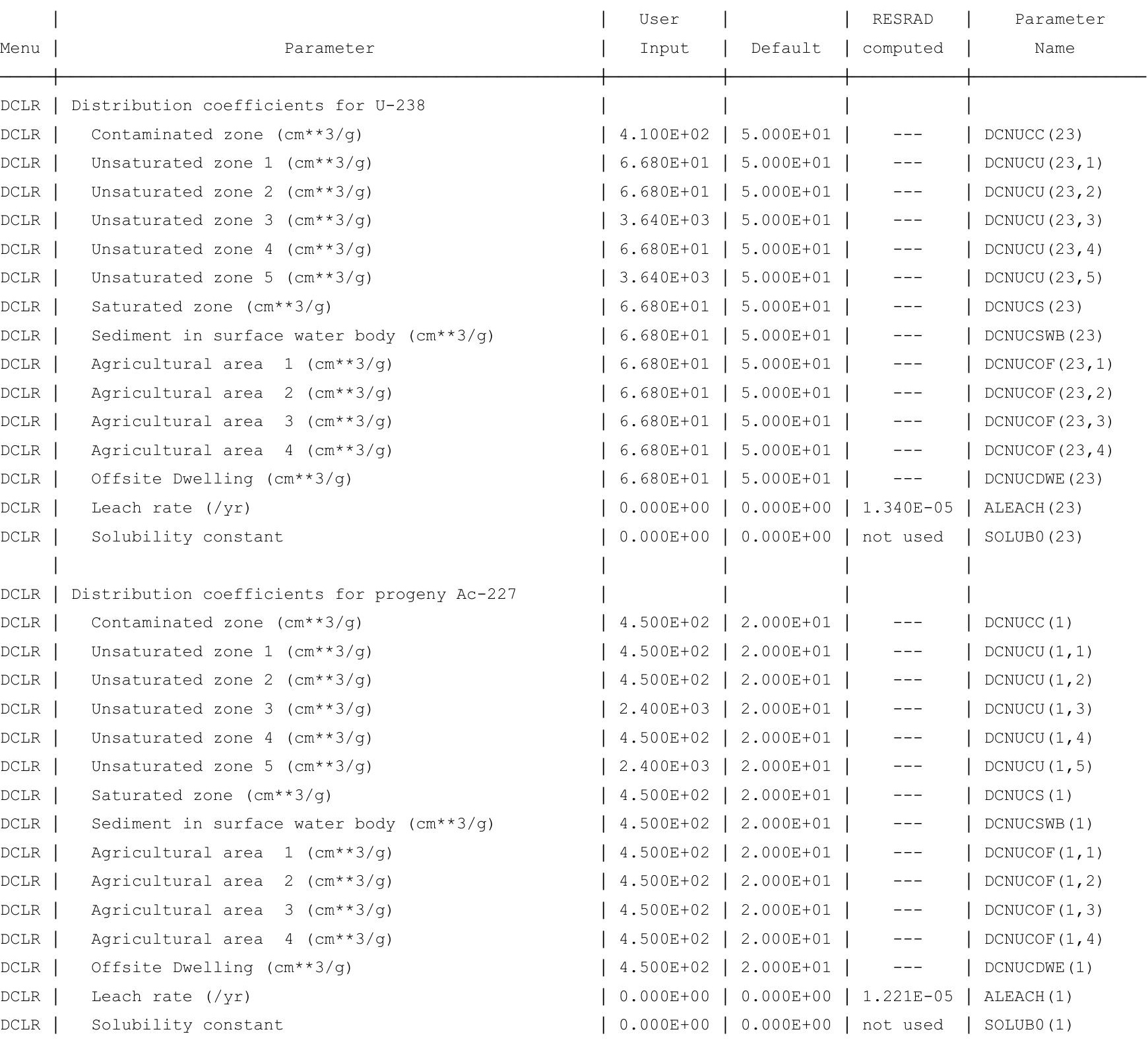


RESRAD-OFFSITE, Version $2.5 \quad$ T1/2 Limit = 180 days $\quad$ 07/21/2011 $11: 14 \quad$ Page

Parent Dose Report

Title : RESRAD-OFFSITE Parameters for Offsite Resident Farmer Forward Run 1,050 Years

File : OFFSITE-RF_FORWARD-7-11ALS.ROF

Site-Specific Parameter Summary (continued)

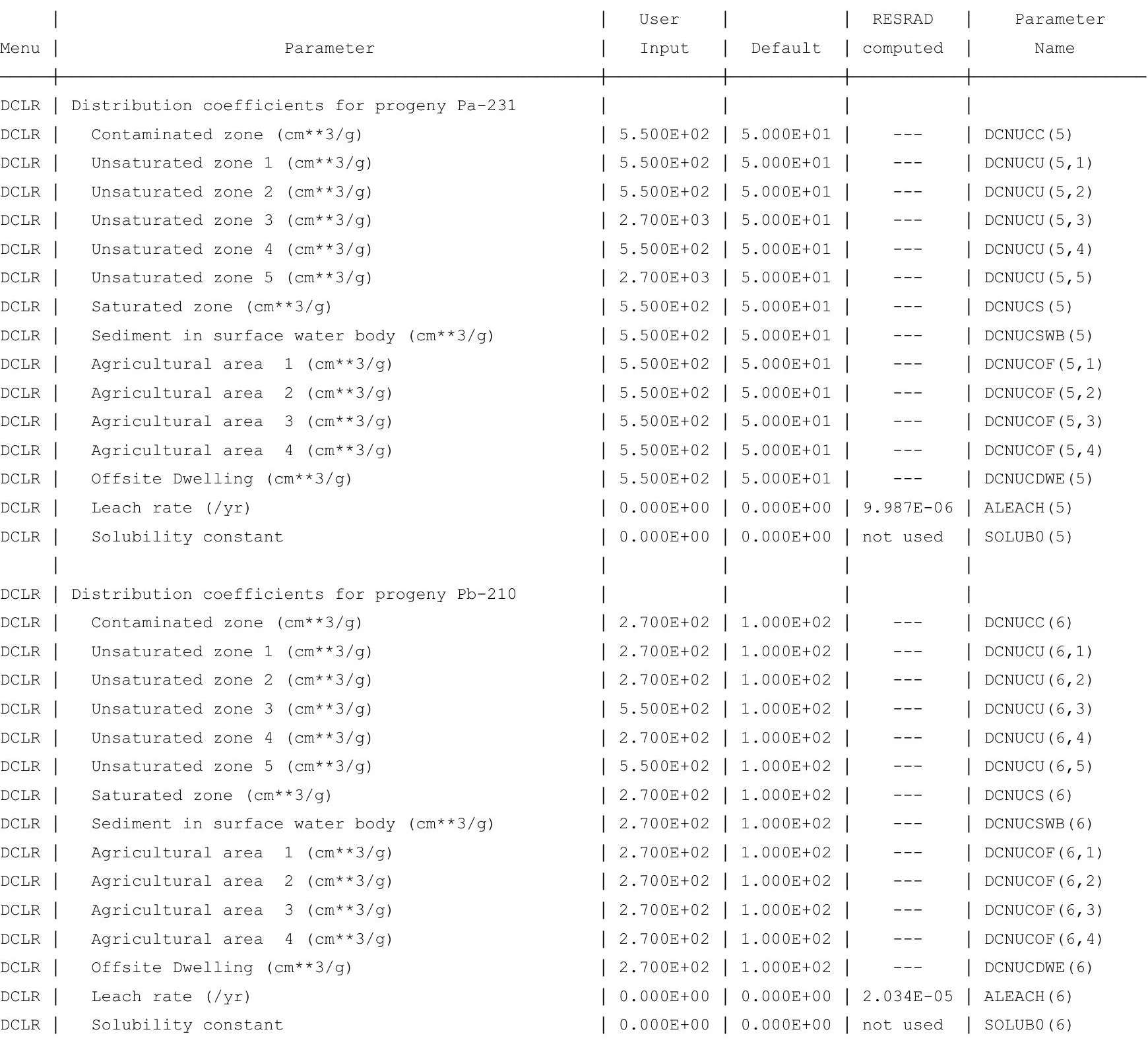


RESRAD-OFFSITE, Version 2.5

Parent Dose Report

Title : RESRAD-OFFSITE Parameters for Offsite Resident Farmer Forward Run 1,050 Years

File : OFFSITE-RF_FORWARD-7-11ALS.ROF

Site-Specific Parameter Summary (continued)

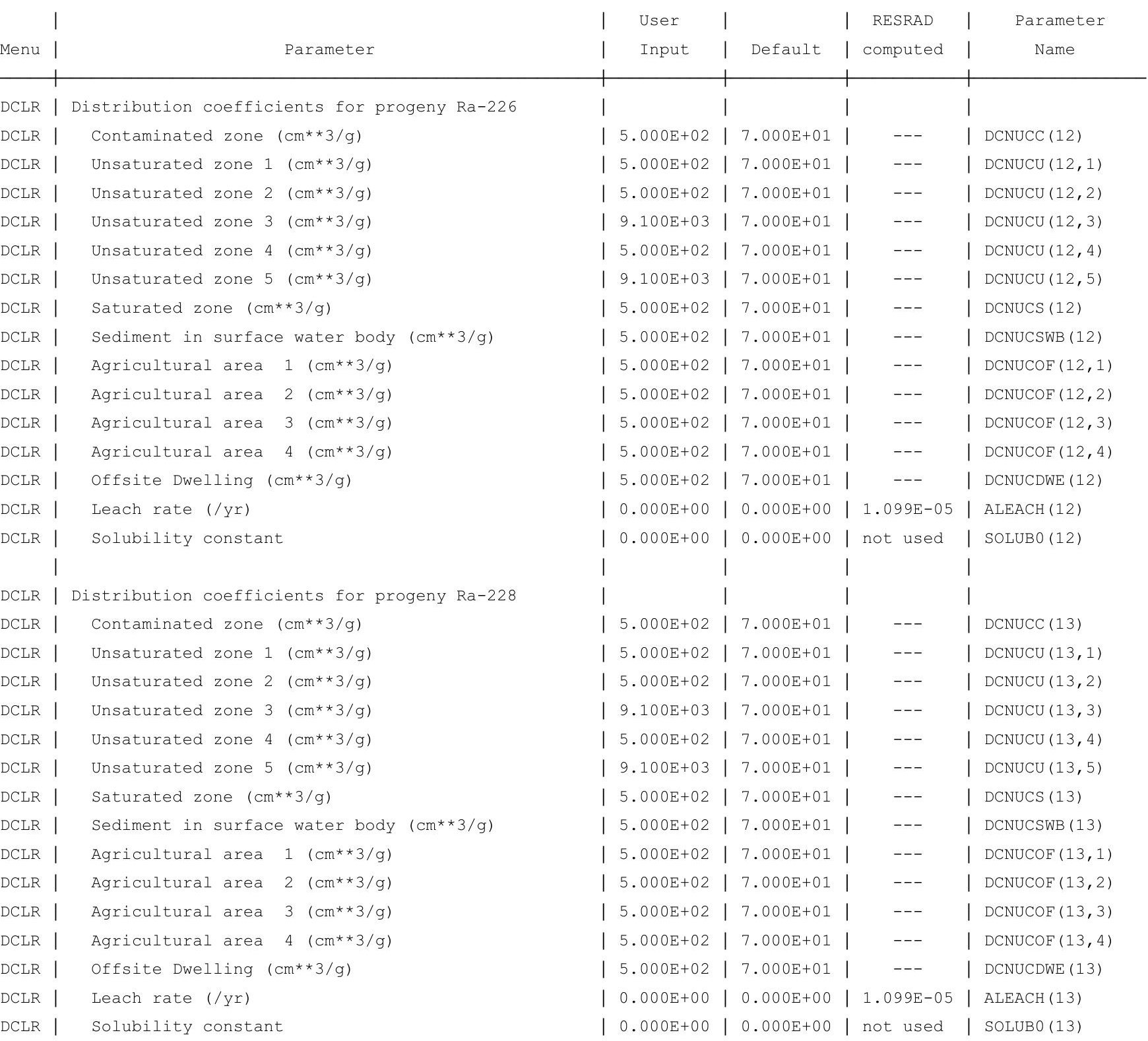


RESRAD-OFFSITE, Version 2.5

Parent Dose Report

Title : RESRAD-OFFSITE Parameters for Offsite Resident Farmer Forward Run 1,050 Years

File : OFFSITE-RF_FORWARD-7-11ALS.ROF

Site-Specific Parameter Summary (continued)

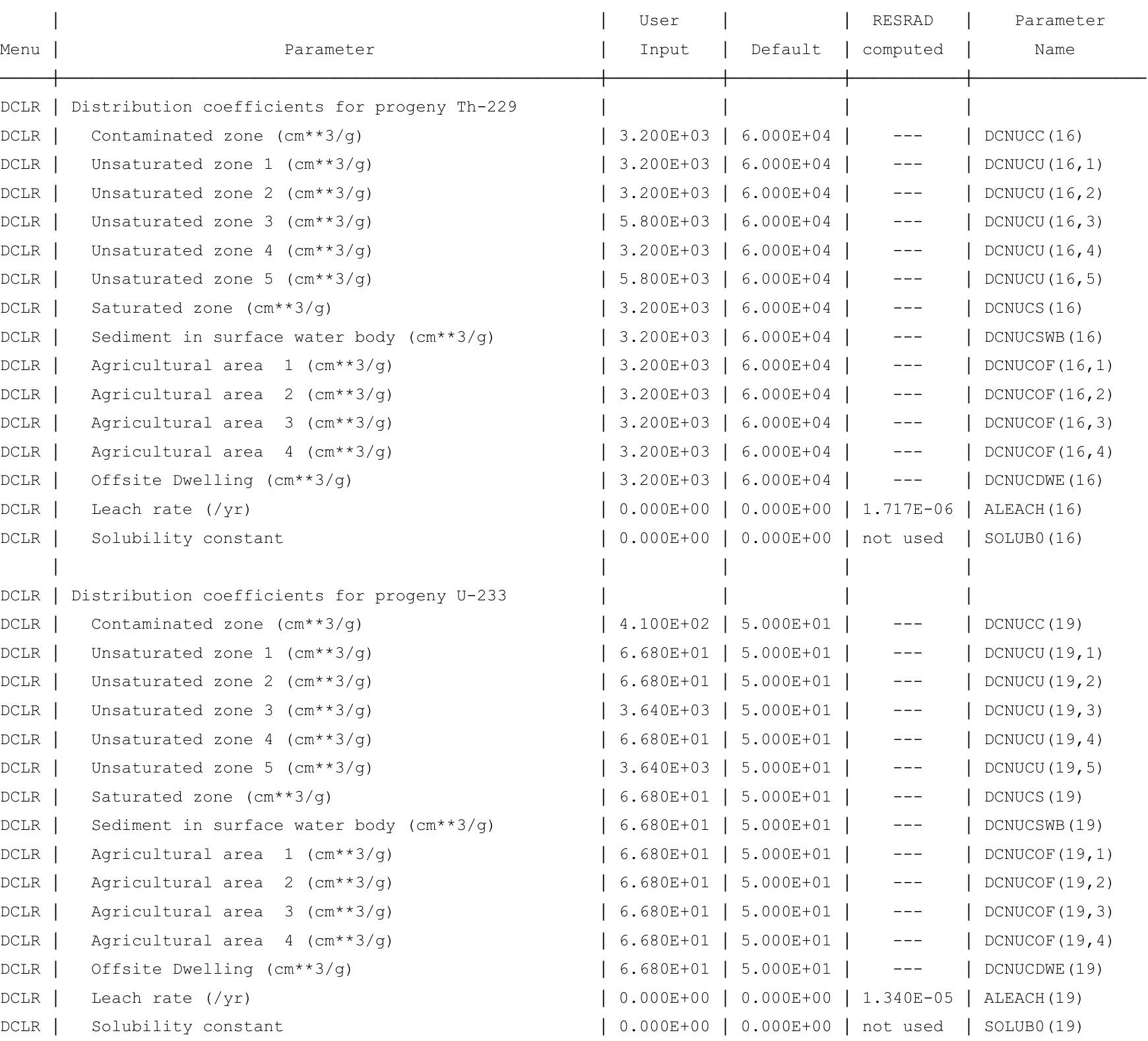


RESRAD-OFFSITE, Version $2.5 \quad \mathrm{~T}^{1 / 2} / 2$ Limit $=180$ days $\quad$ 07/21/2011 $11: 14 \quad \mathrm{Page}$

Parent Dose Report

Title : RESRAD-OFFSITE Parameters for Offsite Resident Farmer Forward Run 1,050 Years

File : OFFSITE-RF_FORWARD-7-11ALS.ROF

Site-Specific Parameter Summary (continued)

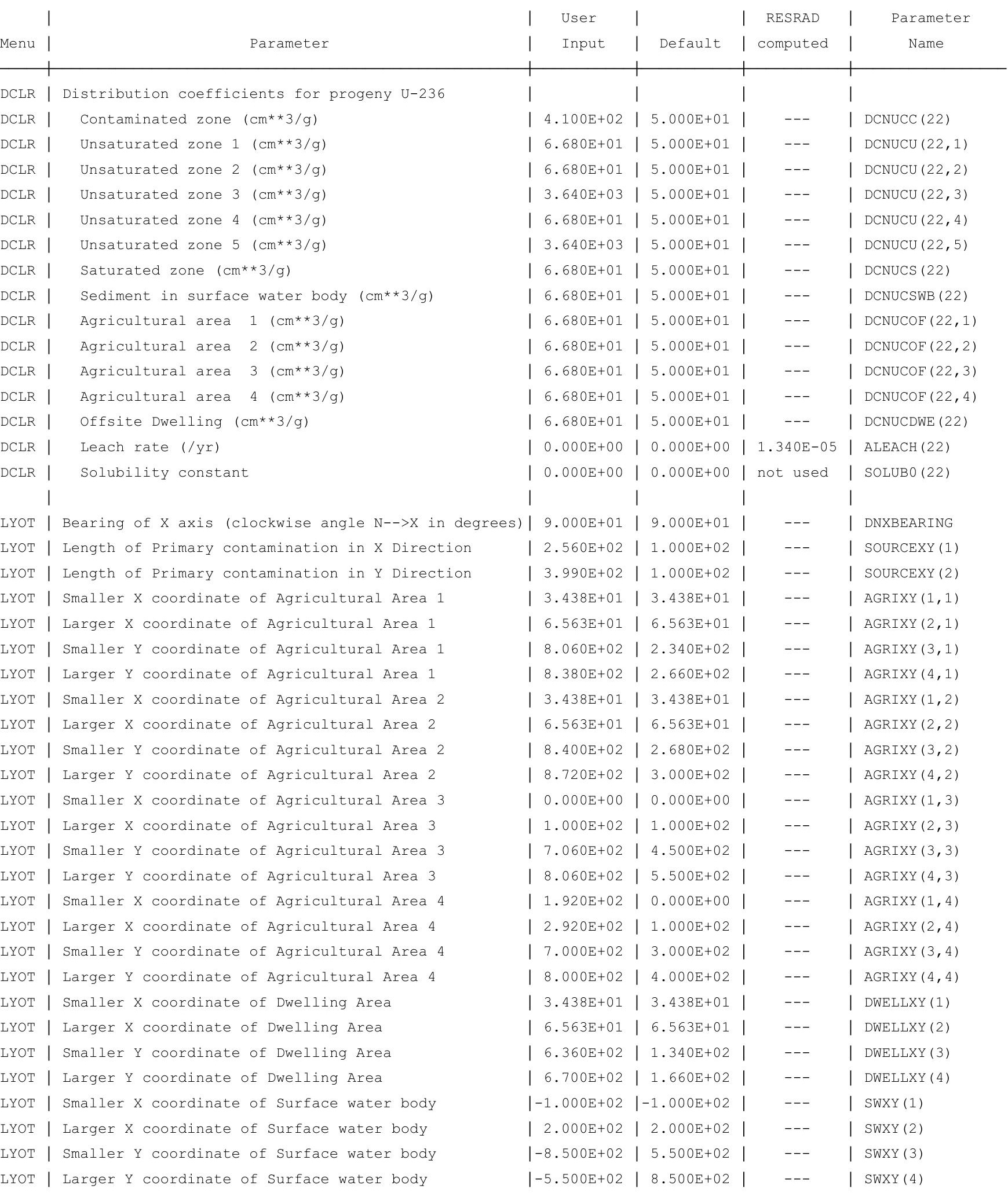

LYOT | Larger Y coordinate of Surface water body

\begin{tabular}{l|l|l|l|l|}
$\mid-5.500 \mathrm{E}+02$ & $8.500 \mathrm{E}+02$ & -- & $\operatorname{SWXY}(4)$
\end{tabular} 
RESRAD-OFFSITE, Version 2.

Parent Dose Report

Title : RESRAD-OFFSITE Parameters for Offsite Resident Farmer Forward Run 1,050 Years

File : OFFSITE-RF FORWARD-7-11ALS.ROF

Site-Specific Parameter Summary (continued)

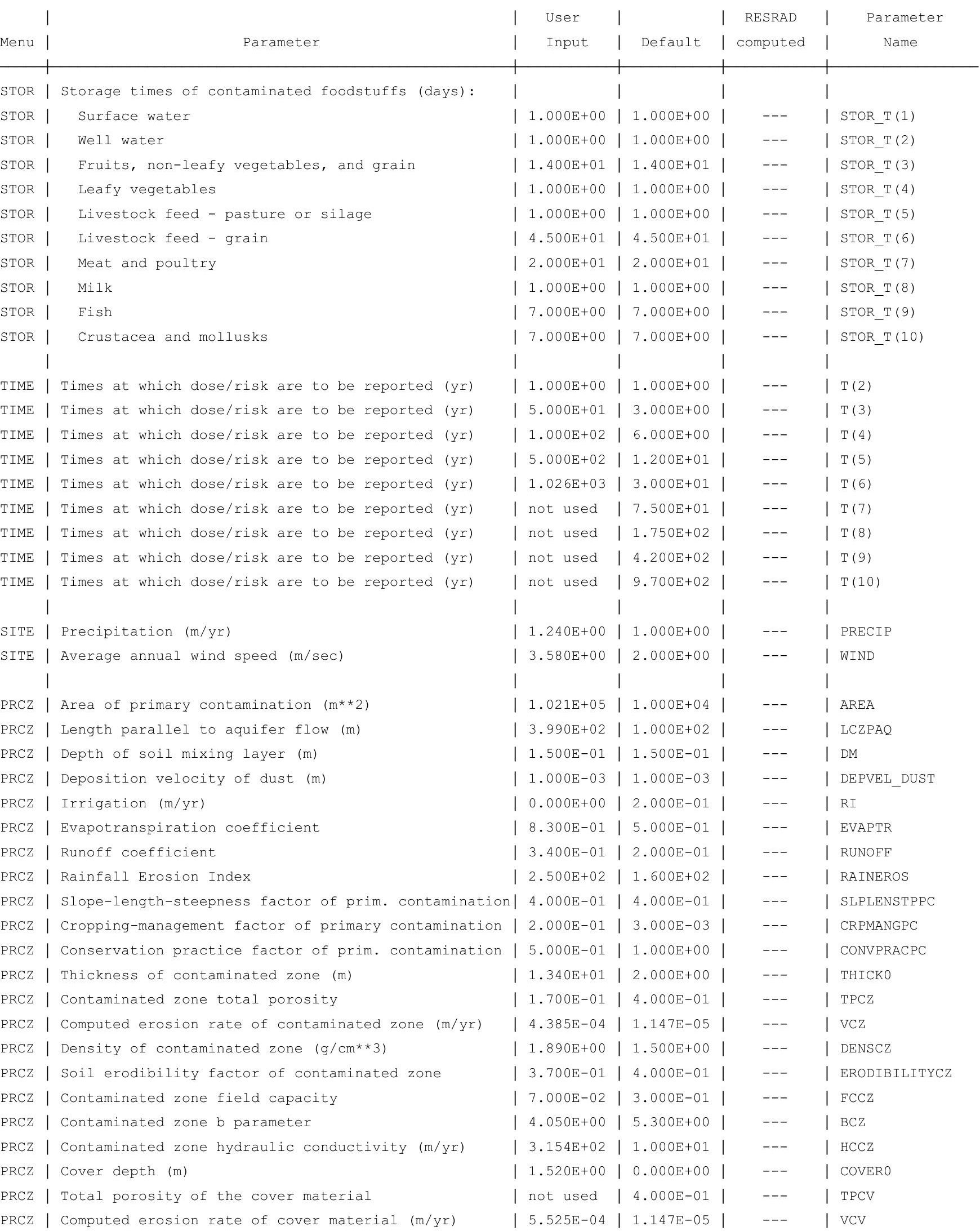


RESRAD-OFFSITE, Version 2.

Parent Dose Report

Title : RESRAD-OFFSITE Parameters for Offsite Resident Farmer Forward Run 1,050 Years

File : OFFSITE-RF FORWARD-7-11ALS.ROF

Site-Specific Parameter Summary (continued)

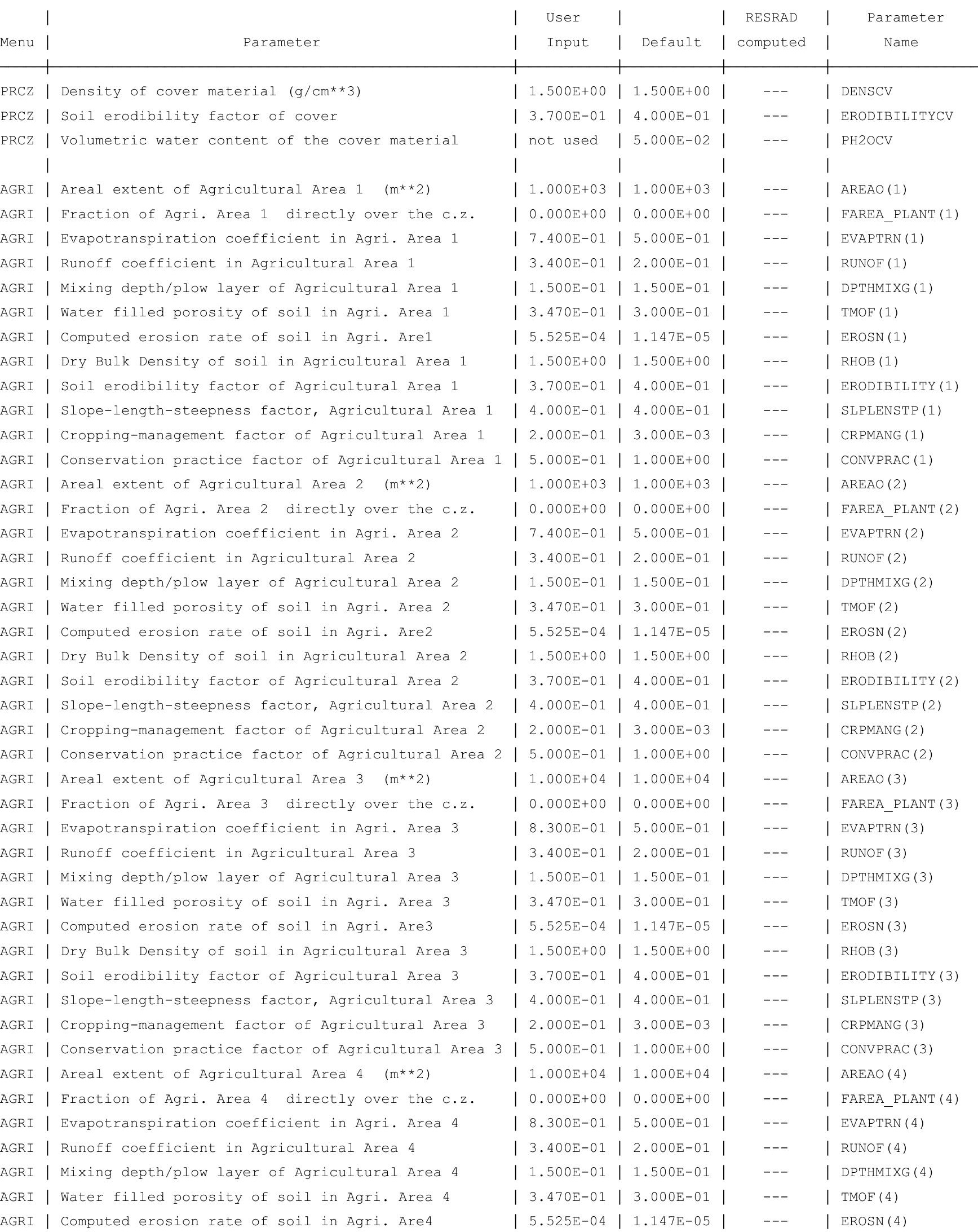


RESRAD-OFFSITE, Version 2.

Parent Dose Report

Title : RESRAD-OFFSITE Parameters for Offsite Resident Farmer Forward Run 1,050 Years

File : OFFSITE-RF FORWARD-7-11ALS.ROF

Site-Specific Parameter Summary (continued)

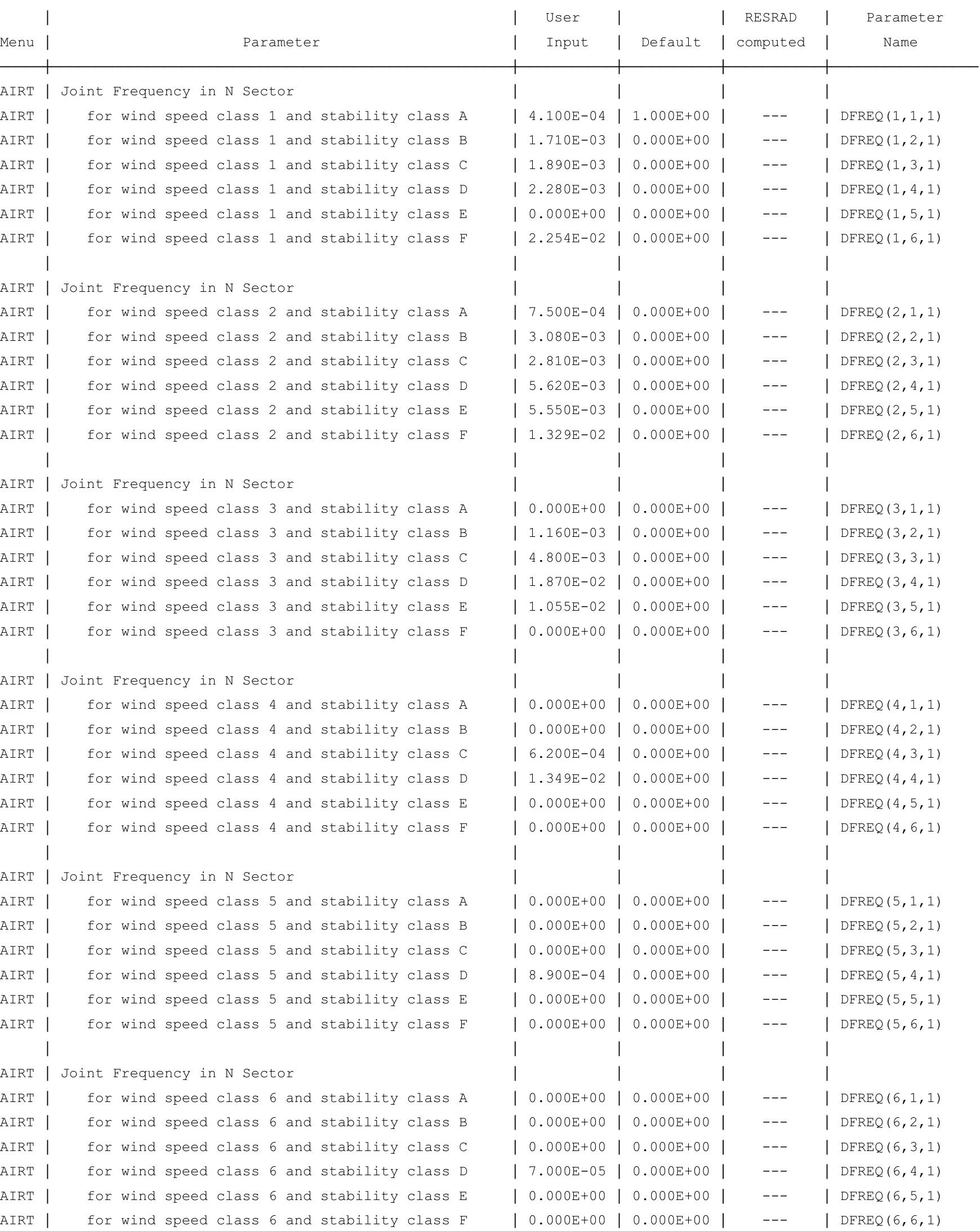


RESRAD-OFFSITE, Version 2.

Parent Dose Report

Title : RESRAD-OFFSITE Parameters for Offsite Resident Farmer Forward Run 1,050 Years

File : OFFSITE-RF FORWARD-7-11ALS.ROF

Site-Specific Parameter Summary (continued)

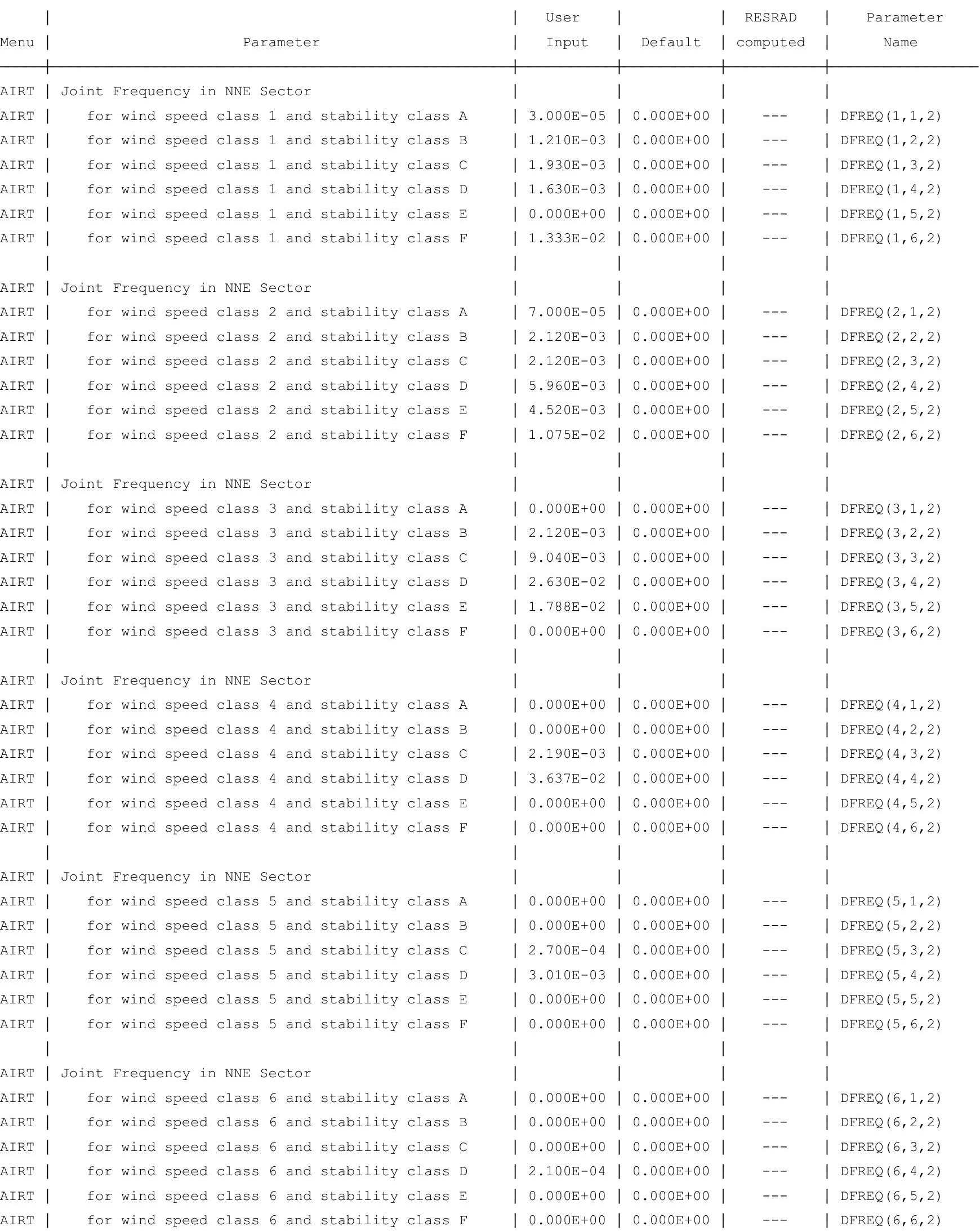


RESRAD-OFFSITE, Version 2.

Parent Dose Report

Title : RESRAD-OFFSITE Parameters for Offsite Resident Farmer Forward Run 1,050 Years

File : OFFSITE-RF FORWARD-7-11ALS.ROF

Site-Specific Parameter Summary (continued)

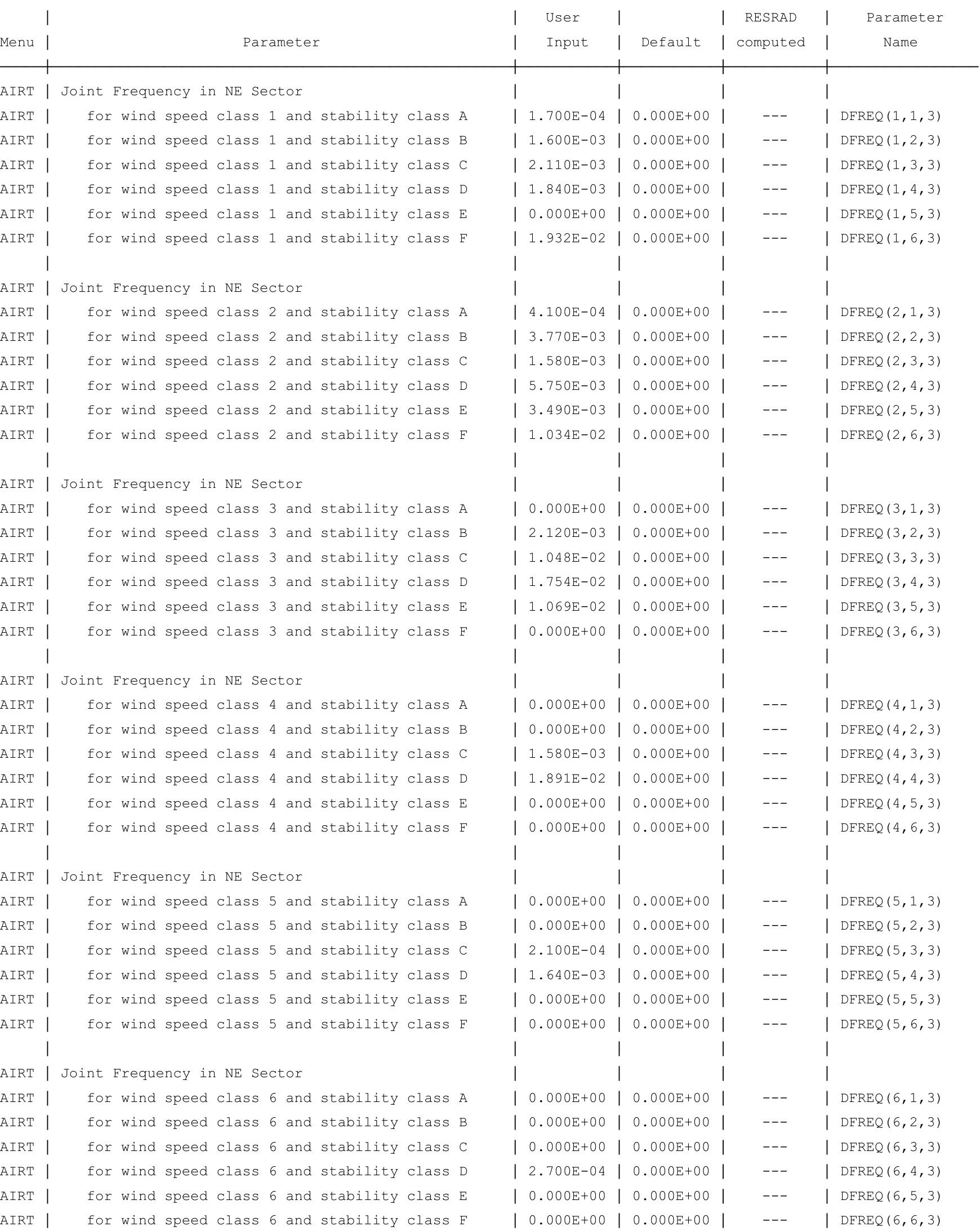


RESRAD-OFFSITE, Version 2.

Parent Dose Report

Title : RESRAD-OFFSITE Parameters for Offsite Resident Farmer Forward Run 1,050 Years

File : OFFSITE-RF FORWARD-7-11ALS.ROF

Site-Specific Parameter Summary (continued)

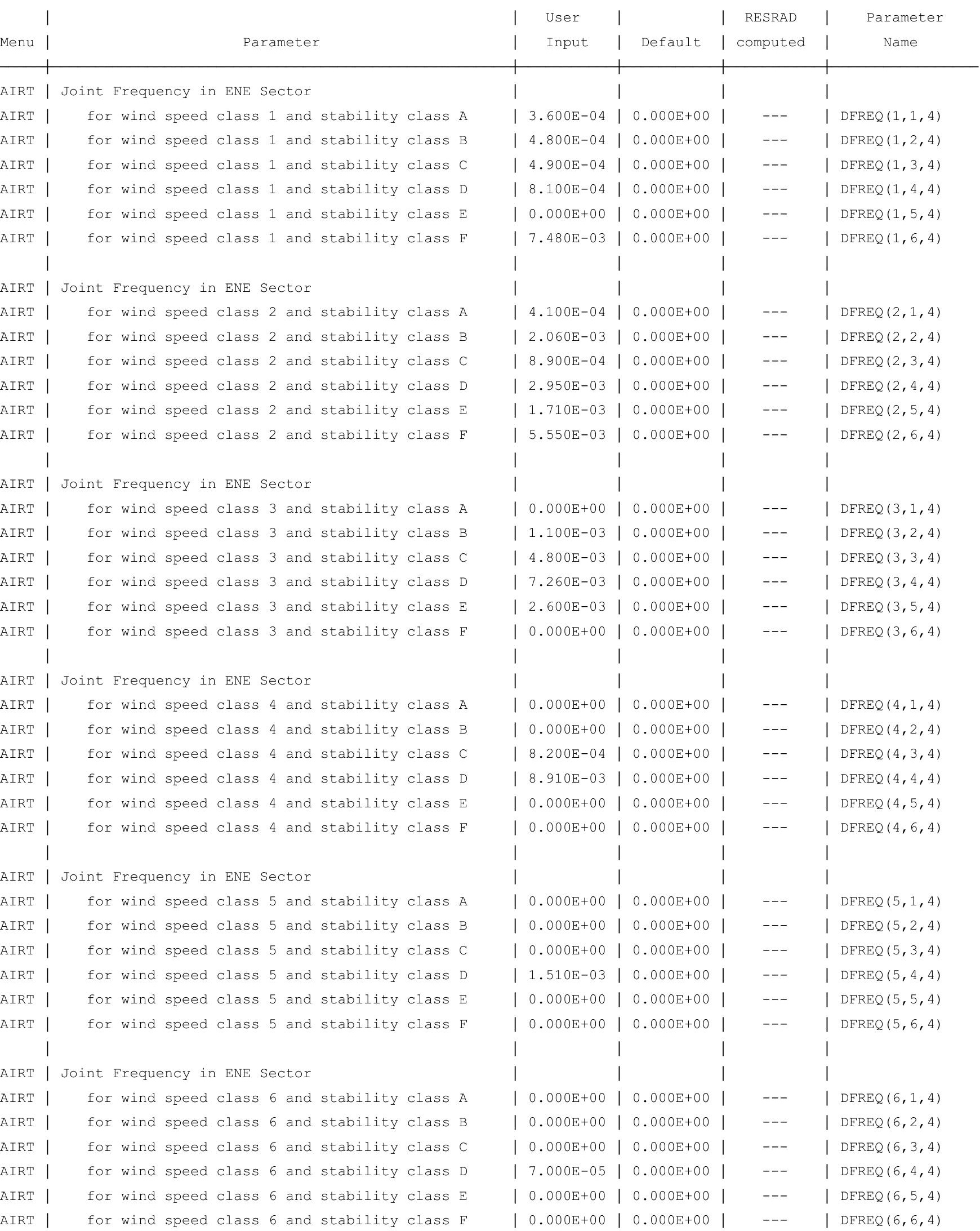


RESRAD-OFFSITE, Version 2.

Parent Dose Report

Title : RESRAD-OFFSITE Parameters for Offsite Resident Farmer Forward Run 1,050 Years

File : OFFSITE-RF FORWARD-7-11ALS.ROF

Site-Specific Parameter Summary (continued)

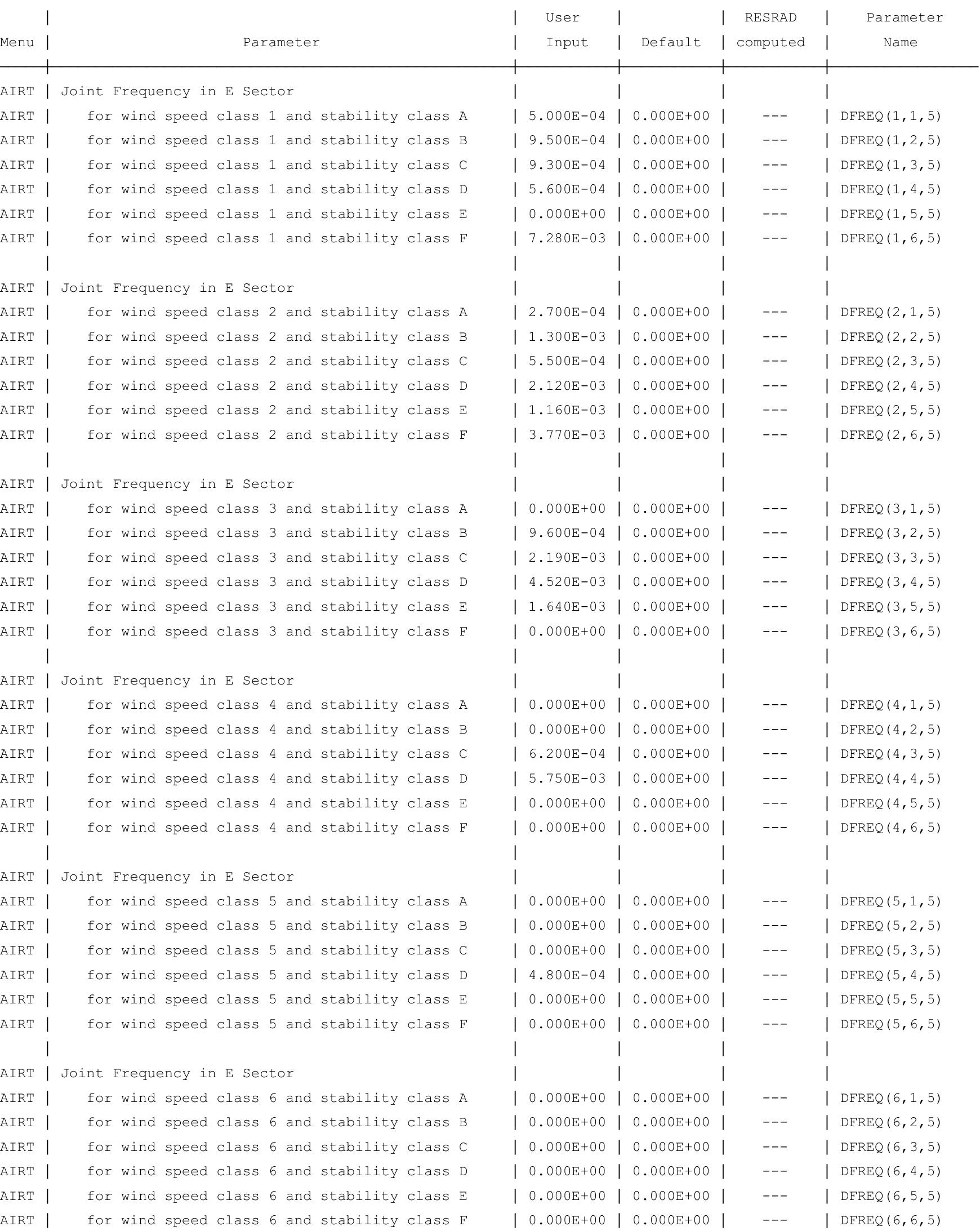


RESRAD-OFFSITE, Version 2.

Parent Dose Report

Title : RESRAD-OFFSITE Parameters for Offsite Resident Farmer Forward Run 1,050 Years

File : OFFSITE-RF FORWARD-7-11ALS.ROF

Site-Specific Parameter Summary (continued)

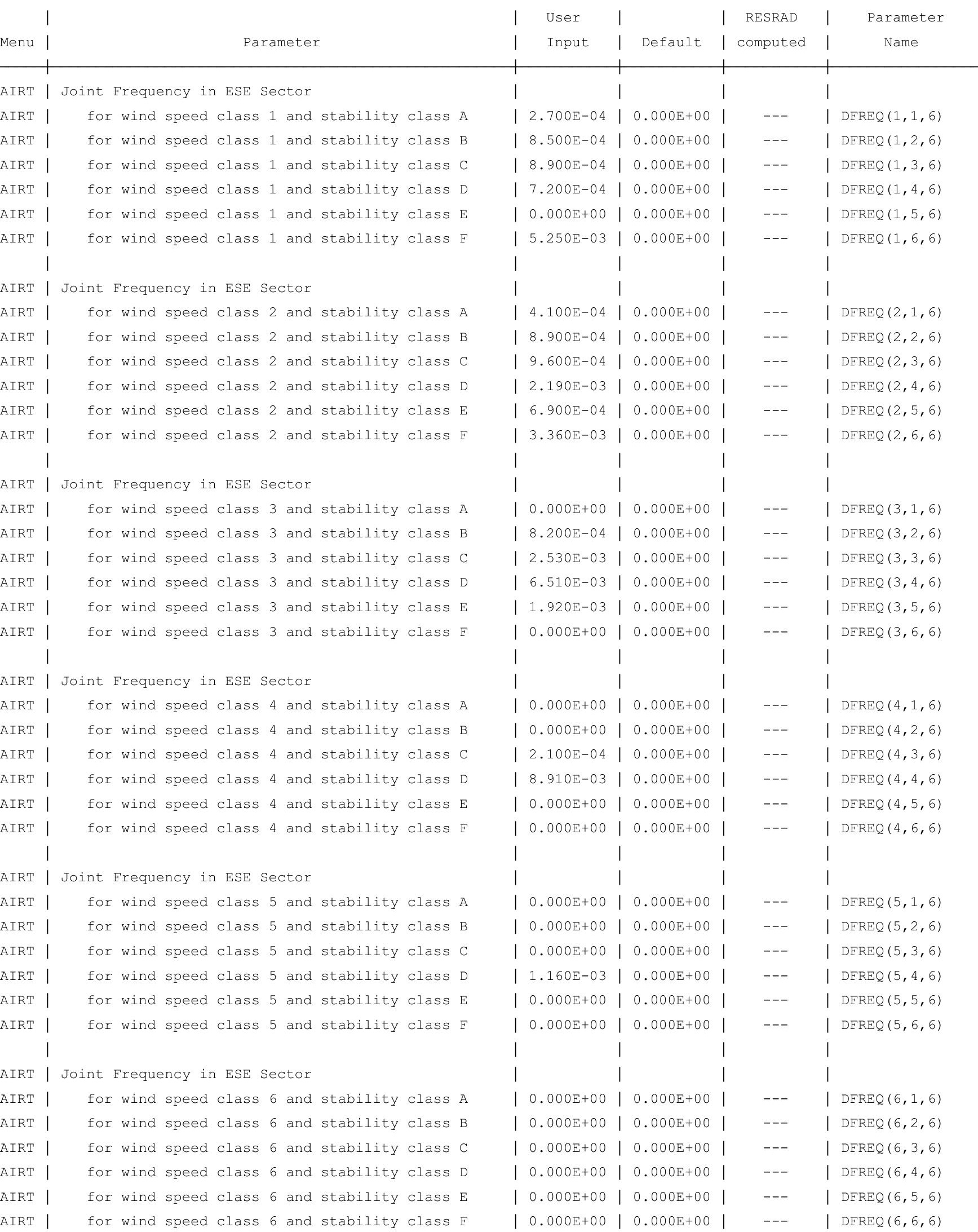


RESRAD-OFFSITE, Version 2.

Parent Dose Report

Title : RESRAD-OFFSITE Parameters for Offsite Resident Farmer Forward Run 1,050 Years

File : OFFSITE-RF FORWARD-7-11ALS.ROF

Site-Specific Parameter Summary (continued)

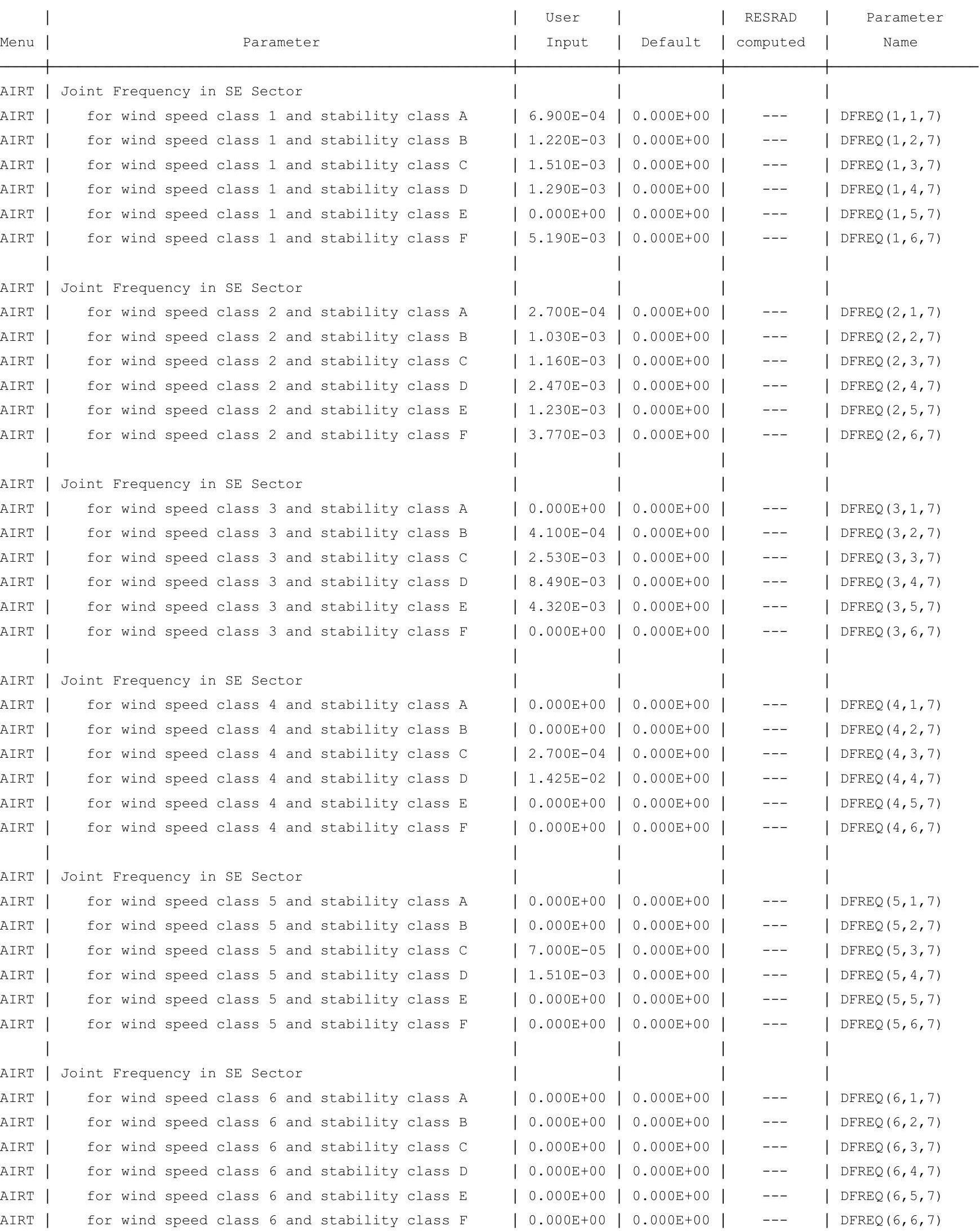


RESRAD-OFFSITE, Version $2.5 \quad \mathrm{~T}^{1 / 2} / 2$ Limit $=180$ days $\quad$ 07/21/2011 $11: 14 \quad \mathrm{Page}$

Parent Dose Report

Title : RESRAD-OFFSITE Parameters for Offsite Resident Farmer Forward Run 1,050 Years

File : OFFSITE-RF_FORWARD-7-11ALS.ROF

Site-Specific Parameter Summary (continued)

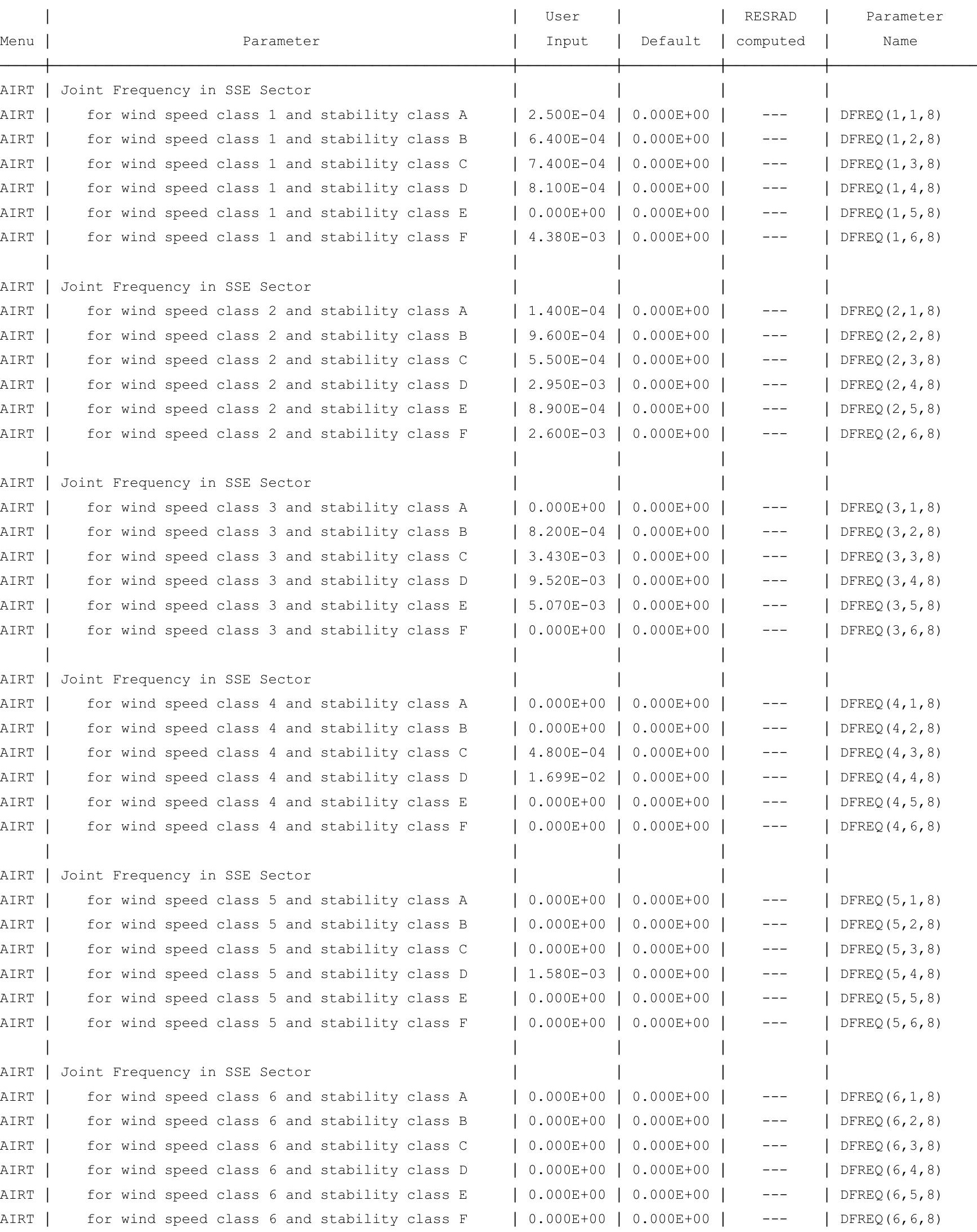


RESRAD-OFFSITE, Version 2.

Parent Dose Report

Title : RESRAD-OFFSITE Parameters for Offsite Resident Farmer Forward Run 1,050 Years

File : OFFSITE-RF FORWARD-7-11ALS.ROF

Site-Specific Parameter Summary (continued)

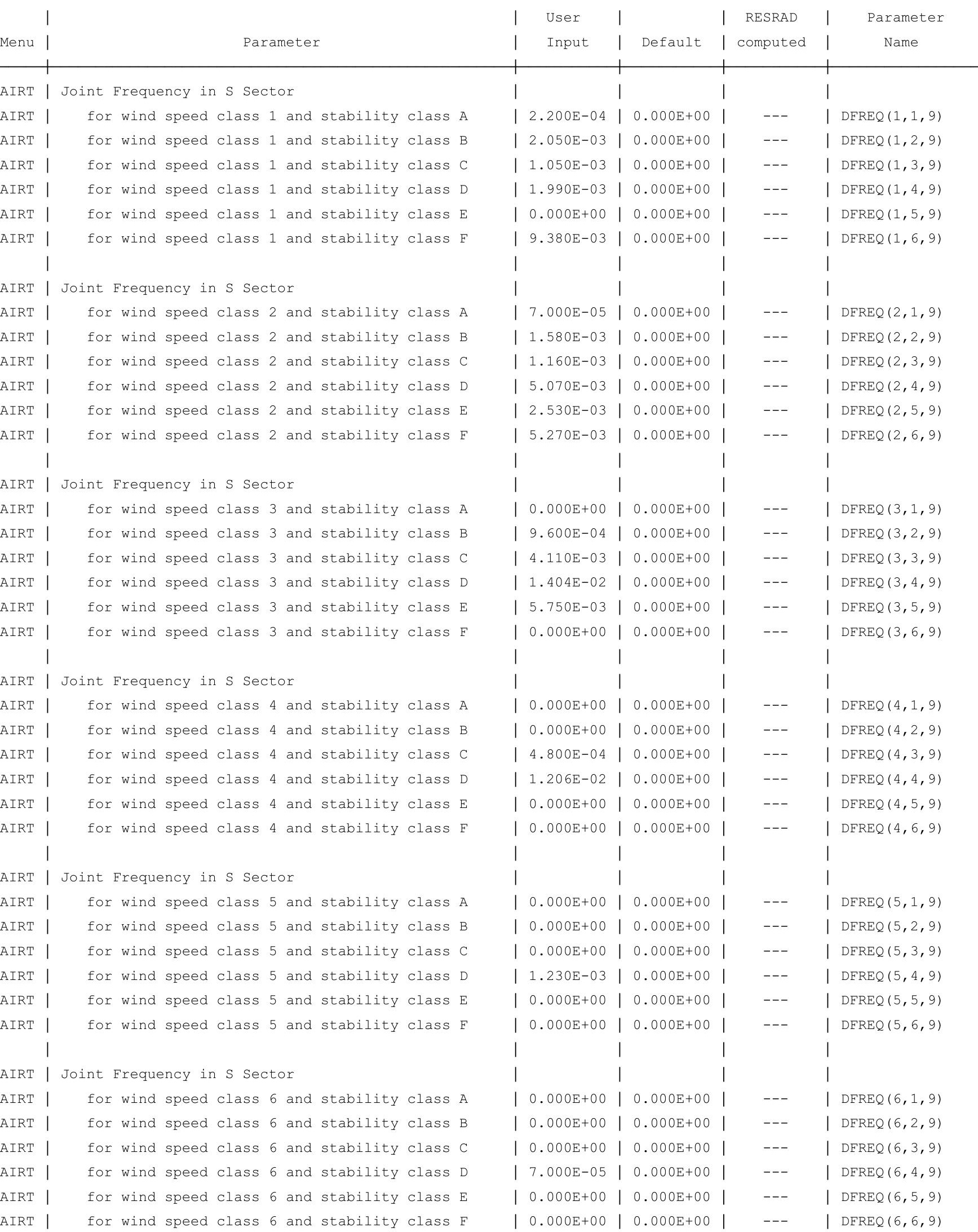


RESRAD-OFFSITE, Version 2.

Parent Dose Report

Title : RESRAD-OFFSITE Parameters for Offsite Resident Farmer Forward Run 1,050 Years

File : OFFSITE-RF FORWARD-7-11ALS.ROF

Site-Specific Parameter Summary (continued)

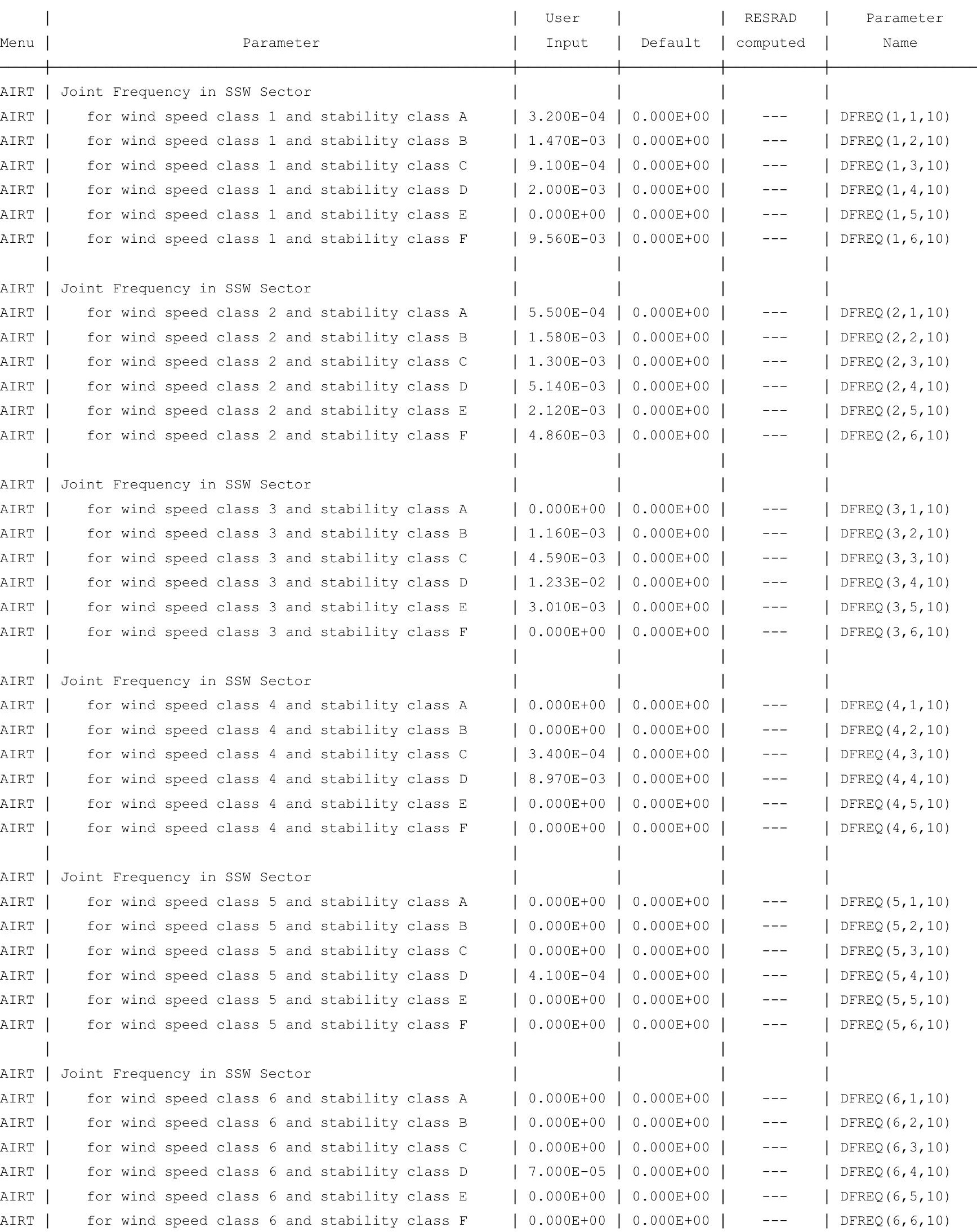


RESRAD-OFFSITE, Version 2.

Parent Dose Report

Title : RESRAD-OFFSITE Parameters for Offsite Resident Farmer Forward Run 1,050 Years

File : OFFSITE-RF FORWARD-7-11ALS.ROF

Site-Specific Parameter Summary (continued)

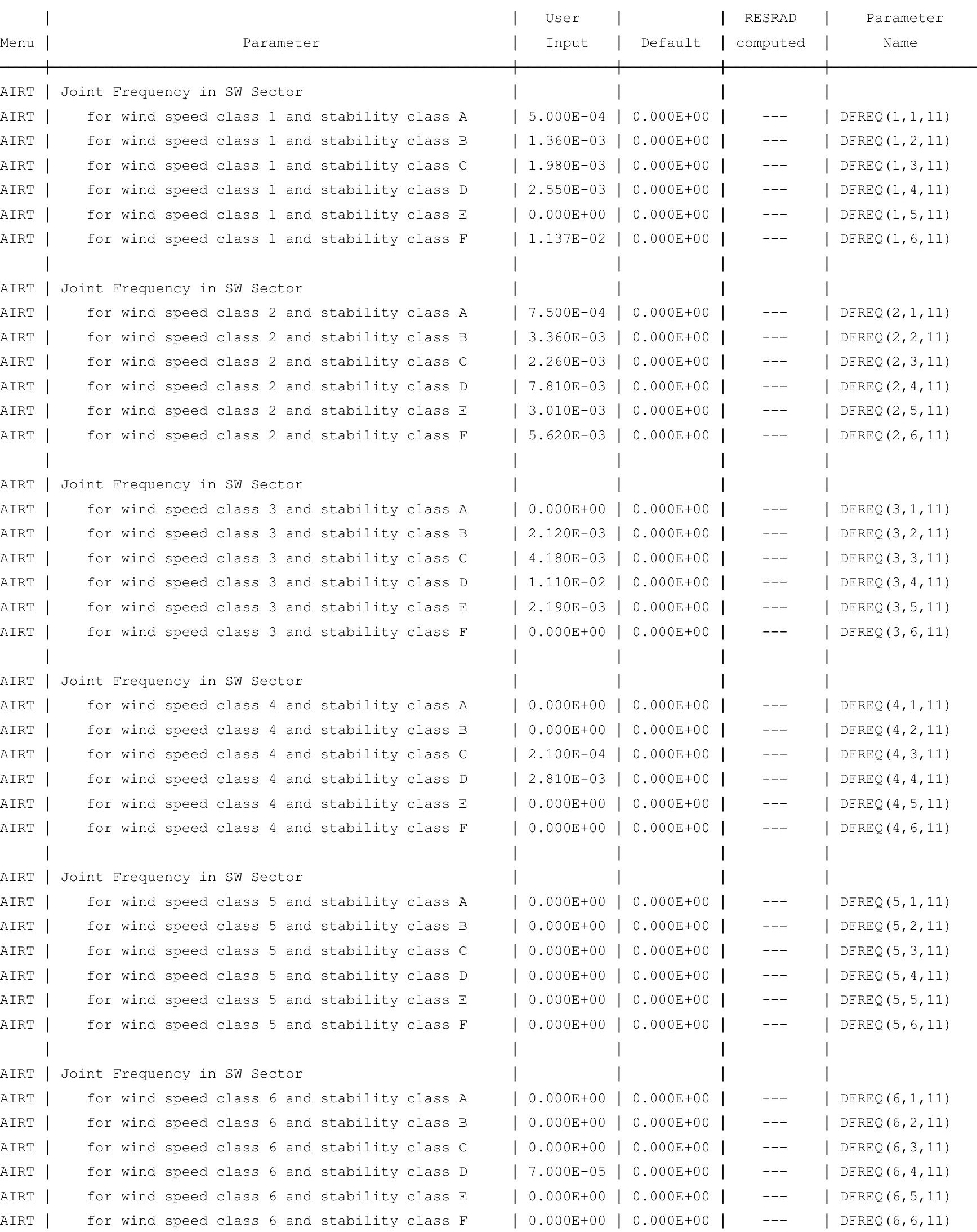


RESRAD-OFFSITE, Version $2.5 \quad \mathrm{~T}^{1 / 1} / 2$ Limit $=180$ days $\quad$ 07/21/2011 $11: 14$ Page

Parent Dose Report

Title : RESRAD-OFFSITE Parameters for Offsite Resident Farmer Forward Run 1,050 Years

File : OFFSITE-RF_FORWARD-7-11ALS.ROF

Site-Specific Parameter Summary (continued)

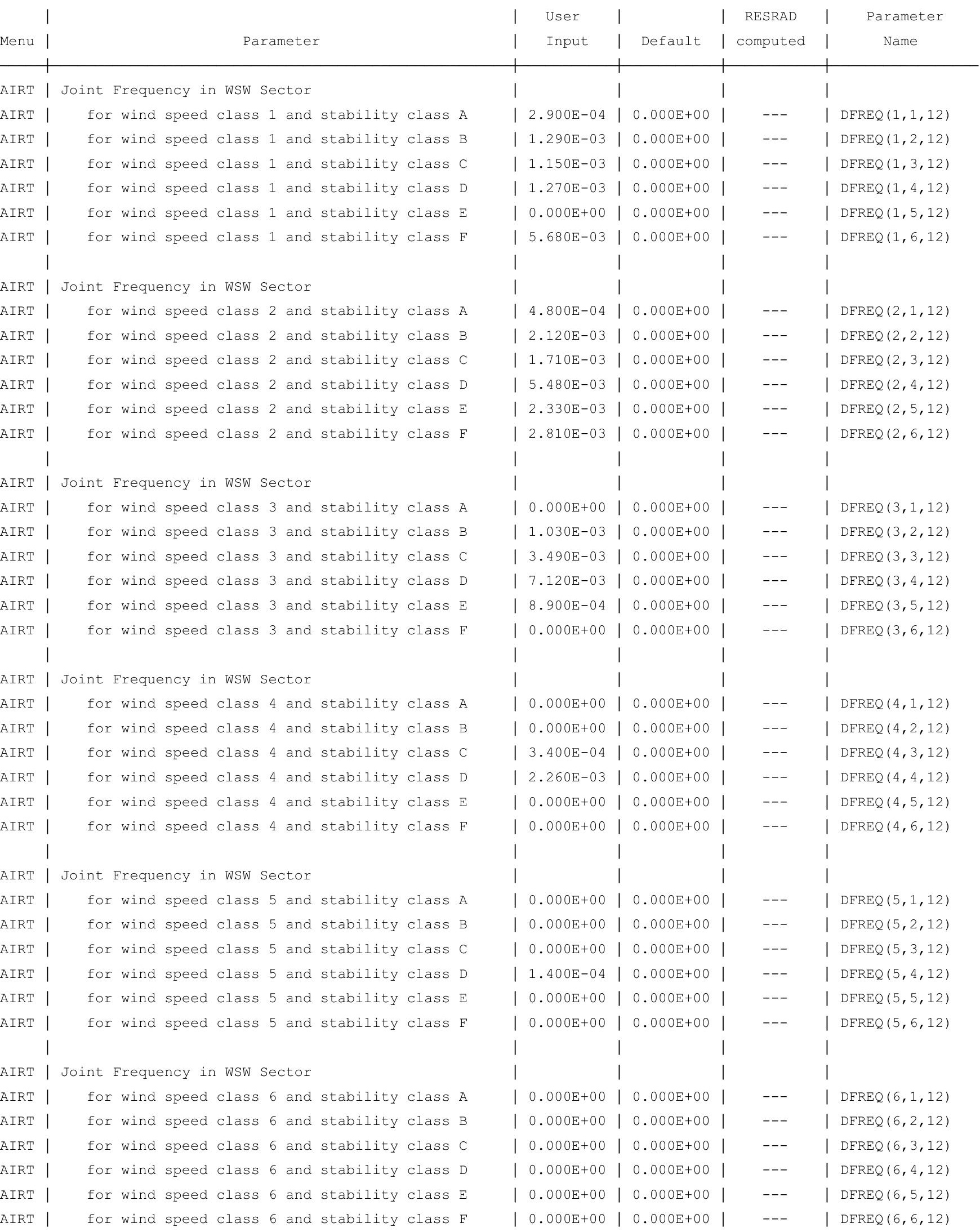


RESRAD-OFFSITE, Version $2.5 \quad \mathrm{~T}^{1 / 1} / 2$ Limit $=180$ days $\quad$ 07/21/2011 $11: 14$ Page

Parent Dose Report

Title : RESRAD-OFFSITE Parameters for Offsite Resident Farmer Forward Run 1,050 Years

File : OFFSITE-RF_FORWARD-7-11ALS.ROF

Site-Specific Parameter Summary (continued)

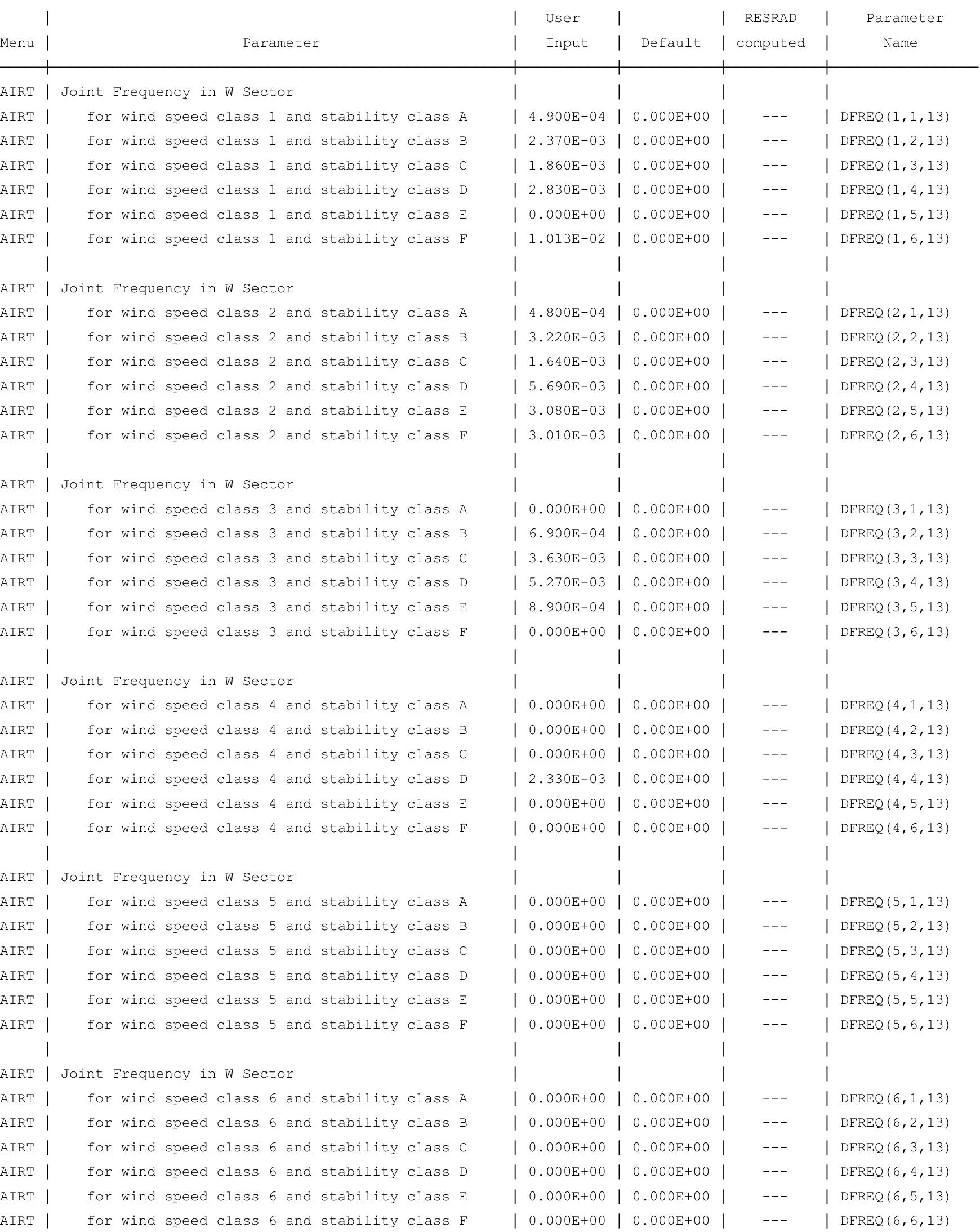


RESRAD-OFFSITE, Version $2.5 \quad \mathrm{~T}^{1 / 1} / 2$ Limit $=180$ days $\quad$ 07/21/2011 $11: 14$ Page

Parent Dose Report

Title : RESRAD-OFFSITE Parameters for Offsite Resident Farmer Forward Run 1,050 Years

File : OFFSITE-RF_FORWARD-7-11ALS.ROF

Site-Specific Parameter Summary (continued)

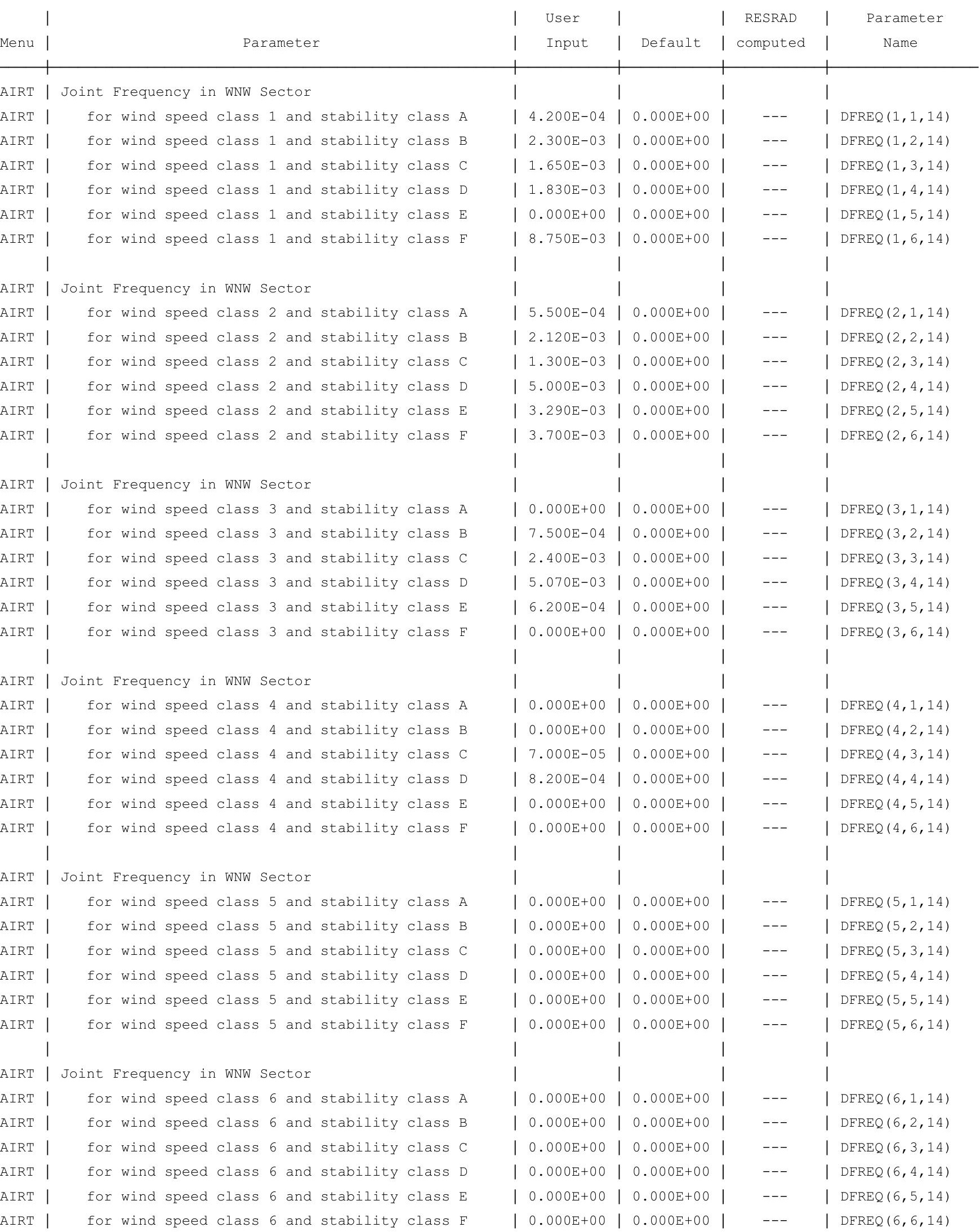


RESRAD-OFFSITE, Version 2.

Parent Dose Report

Title : RESRAD-OFFSITE Parameters for Offsite Resident Farmer Forward Run 1,050 Years

File : OFFSITE-RF FORWARD-7-11ALS.ROF

Site-Specific Parameter Summary (continued)

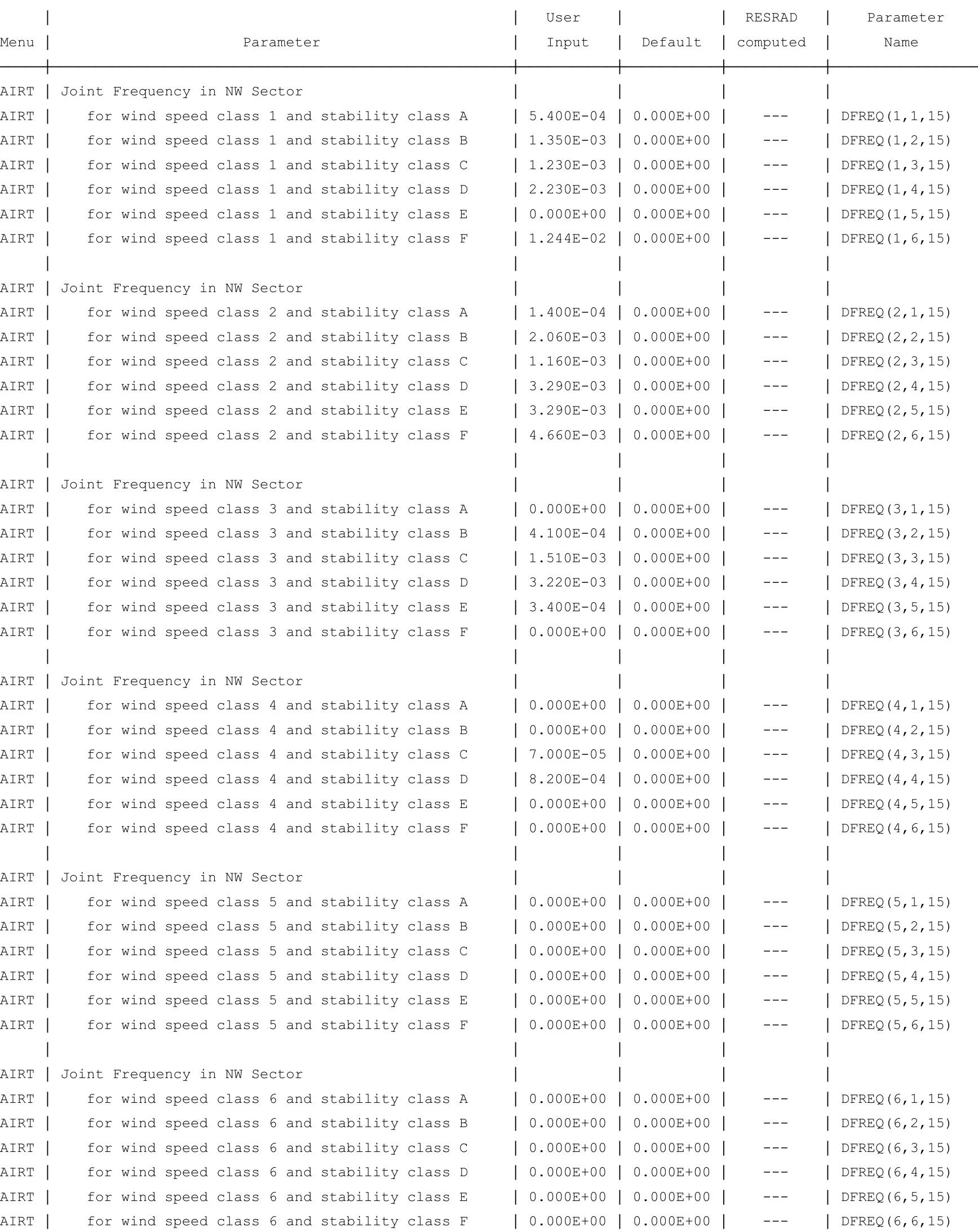


RESRAD-OFFSITE, Version $2.5 \quad \mathrm{~T}^{1 / 2} / 2$ Limit $=180$ days $\quad$ 07/21/2011 $11: 14 \quad \mathrm{Page}$

Parent Dose Report

Title : RESRAD-OFFSITE Parameters for Offsite Resident Farmer Forward Run 1,050 Years

File : OFFSITE-RF_FORWARD-7-11ALS.ROF

Site-Specific Parameter Summary (continued)

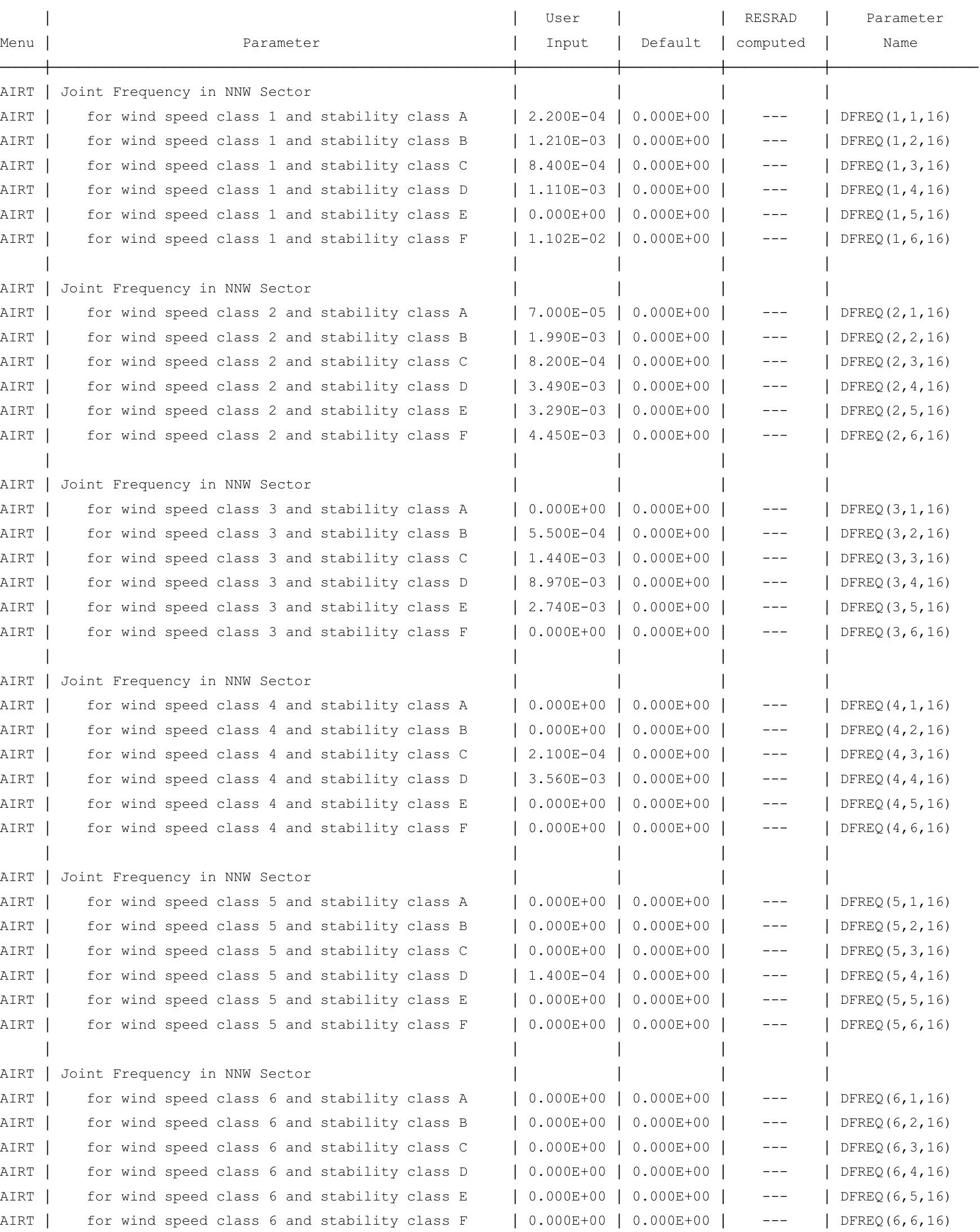


RESRAD-OFFSITE, Version 2.

Parent Dose Report

Title : RESRAD-OFFSITE Parameters for Offsite Resident Farmer Forward Run 1,050 Years

File : OFFSITE-RF_FORWARD-7-11ALS.ROF

Site-Specific Parameter Summary (continued)

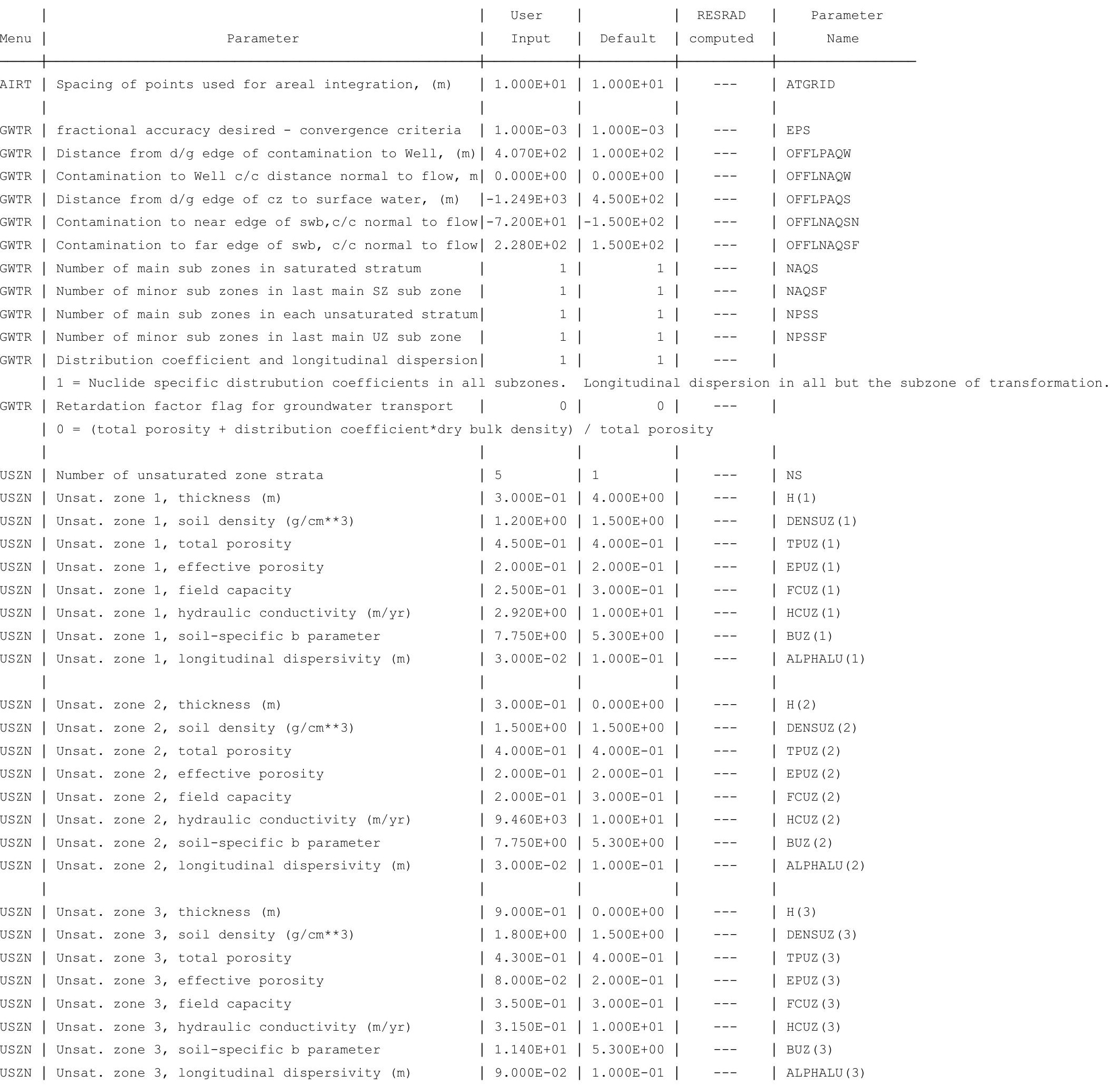


RESRAD-OFFSITE, Version 2.

Parent Dose Report

Title : RESRAD-OFFSITE Parameters for Offsite Resident Farmer Forward Run 1,050 Years

File : OFFSITE-RF FORWARD-7-11ALS.ROF

Site-Specific Parameter Summary (continued)

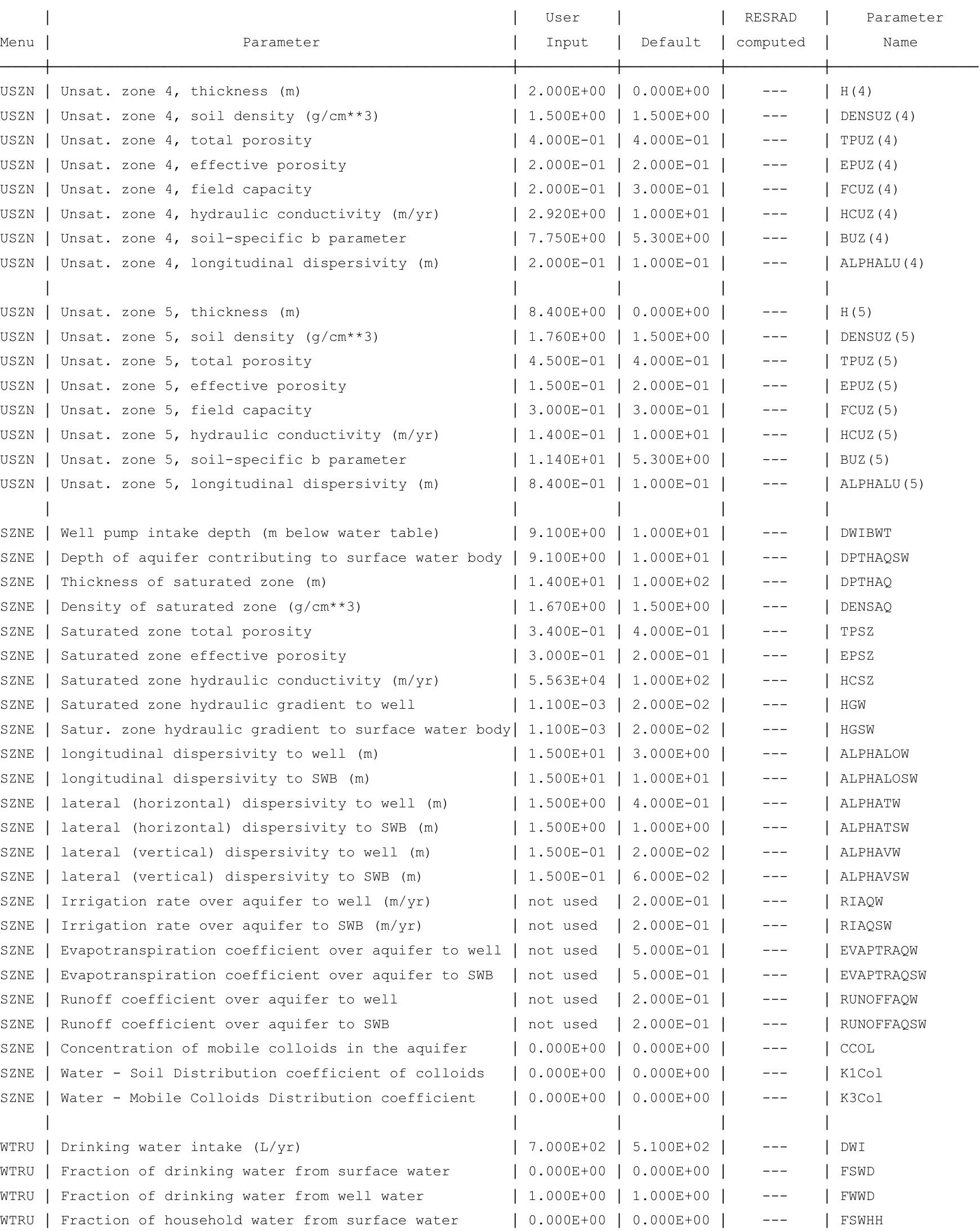


RESRAD-OFFSITE, Version 2.

Parent Dose Report

Title : RESRAD-OFFSITE Parameters for Offsite Resident Farmer Forward Run 1,050 Years

File : OFFSITE-RF FORWARD-7-11ALS.ROF

Site-Specific Parameter Summary (continued)

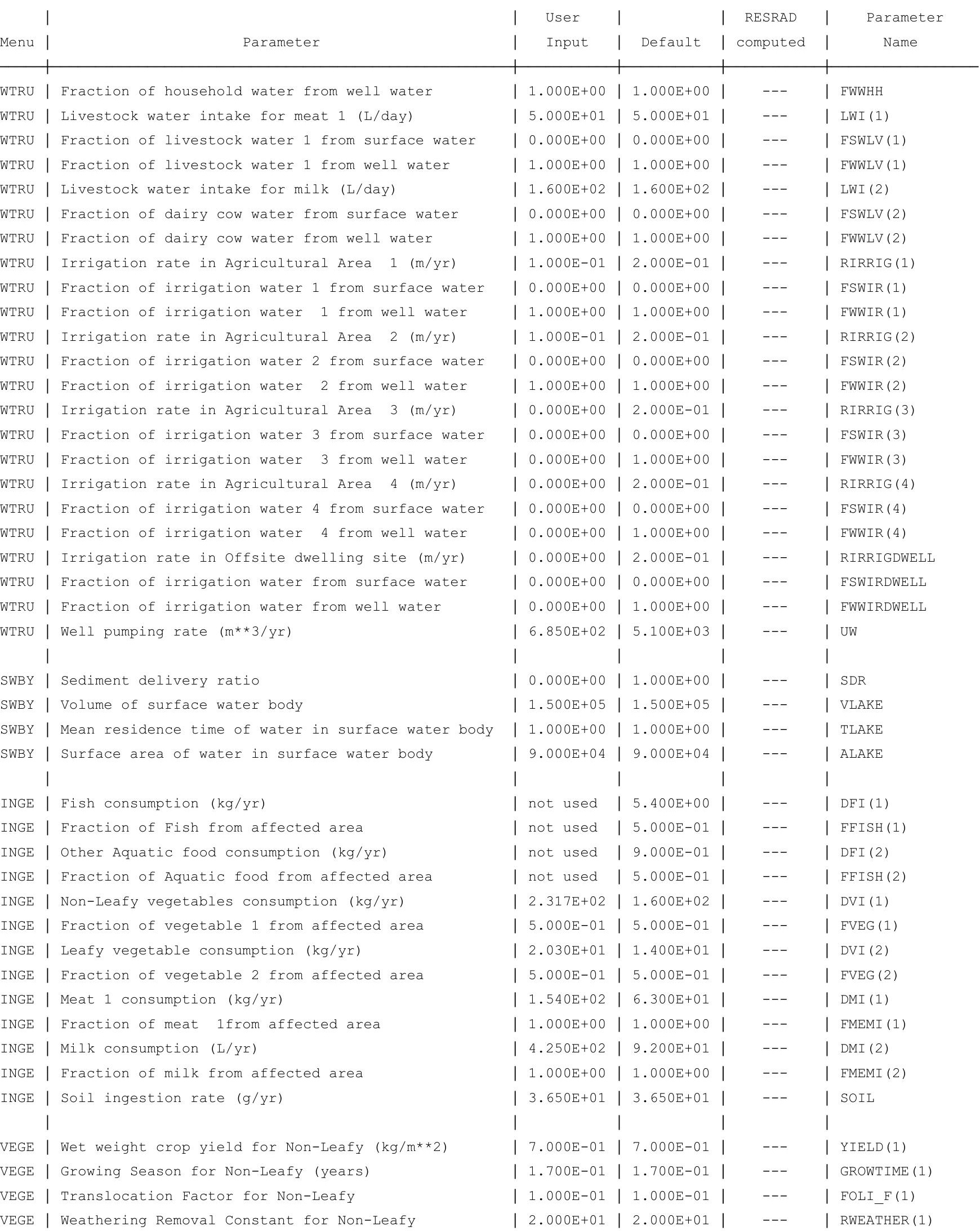


RESRAD-OFFSITE, Version 2.5

Parent Dose Report

Title : RESRAD-OFFSITE Parameters for Offsite Resident Farmer Forward Run 1,050 Years

File : OFFSITE-RF_FORWARD-7-11ALS.ROF

Site-Specific Parameter Summary (continued)

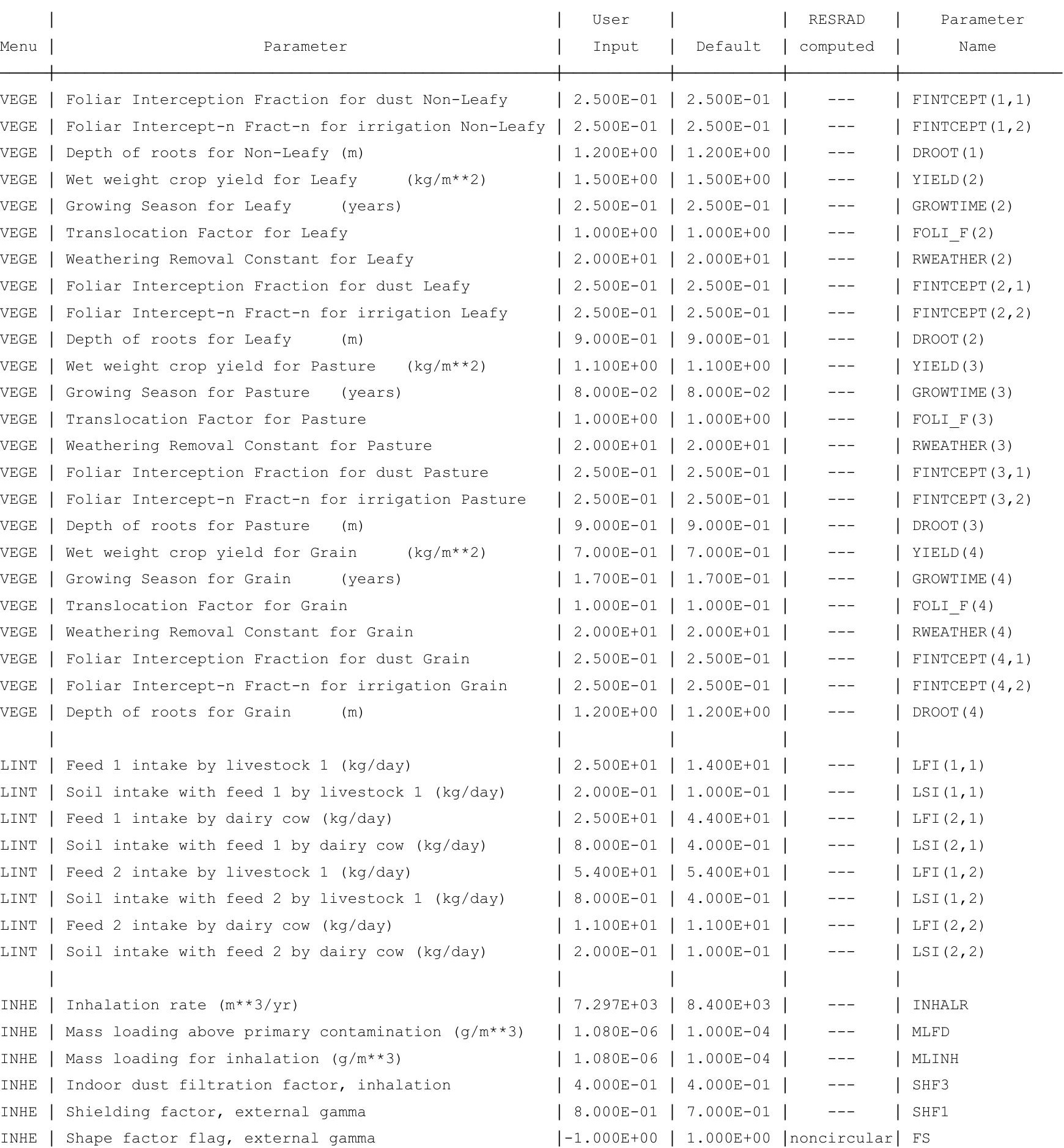


RESRAD-OFFSITE, Version 2.5

Parent Dose Report

Title : RESRAD-OFFSITE Parameters for Offsite Resident Farmer Forward Run 1,050 Years

File : OFFSITE-RF_FORWARD-7-11ALS.ROF

Site-Specific Parameter Summary (continued)

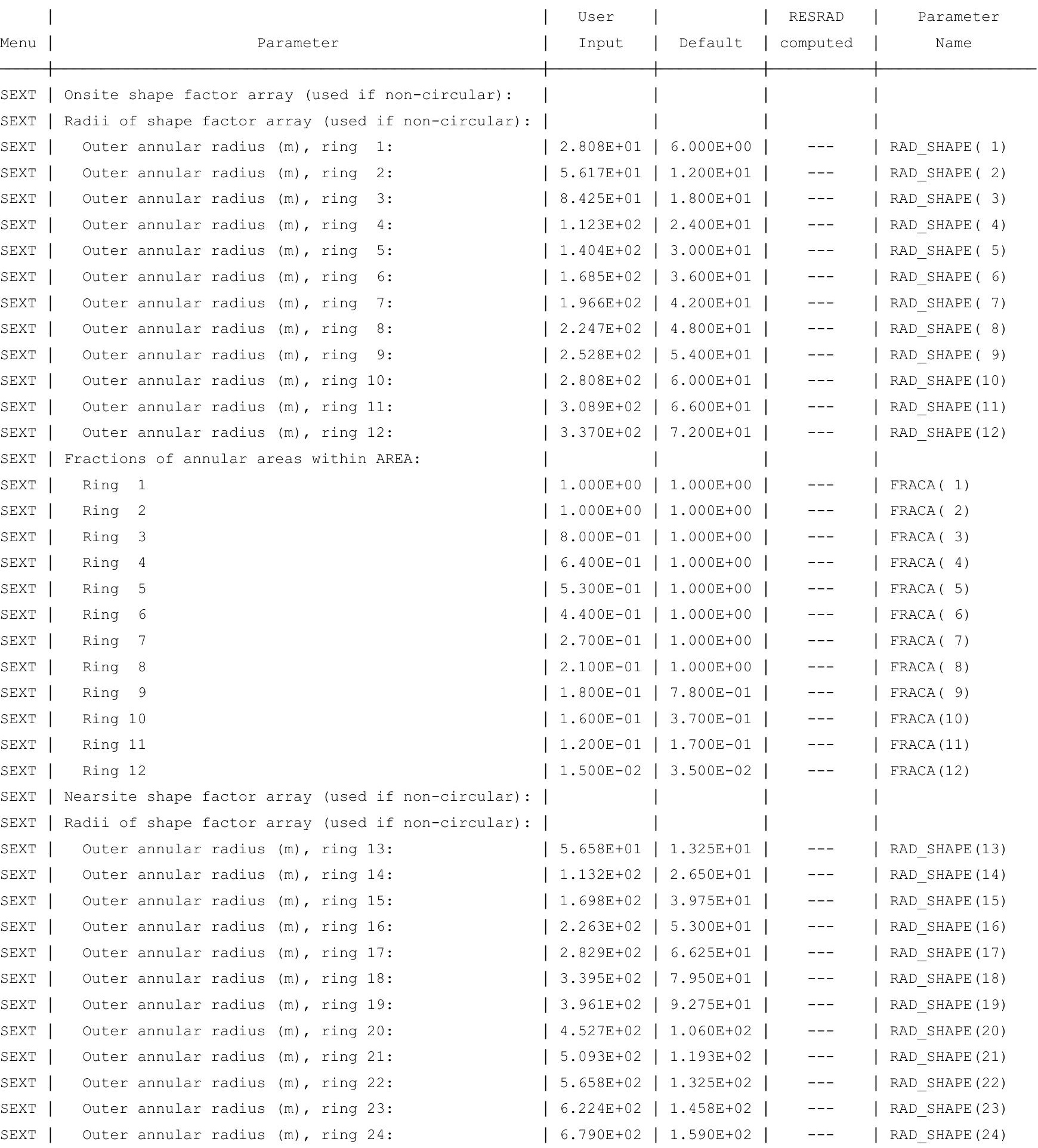


RESRAD-OFFSITE, Version 2.5

Parent Dose Report

Title : RESRAD-OFFSITE Parameters for Offsite Resident Farmer Forward Run 1,050 Years

File : OFFSITE-RF_FORWARD-7-11ALS.ROF

Site-Specific Parameter Summary (continued)

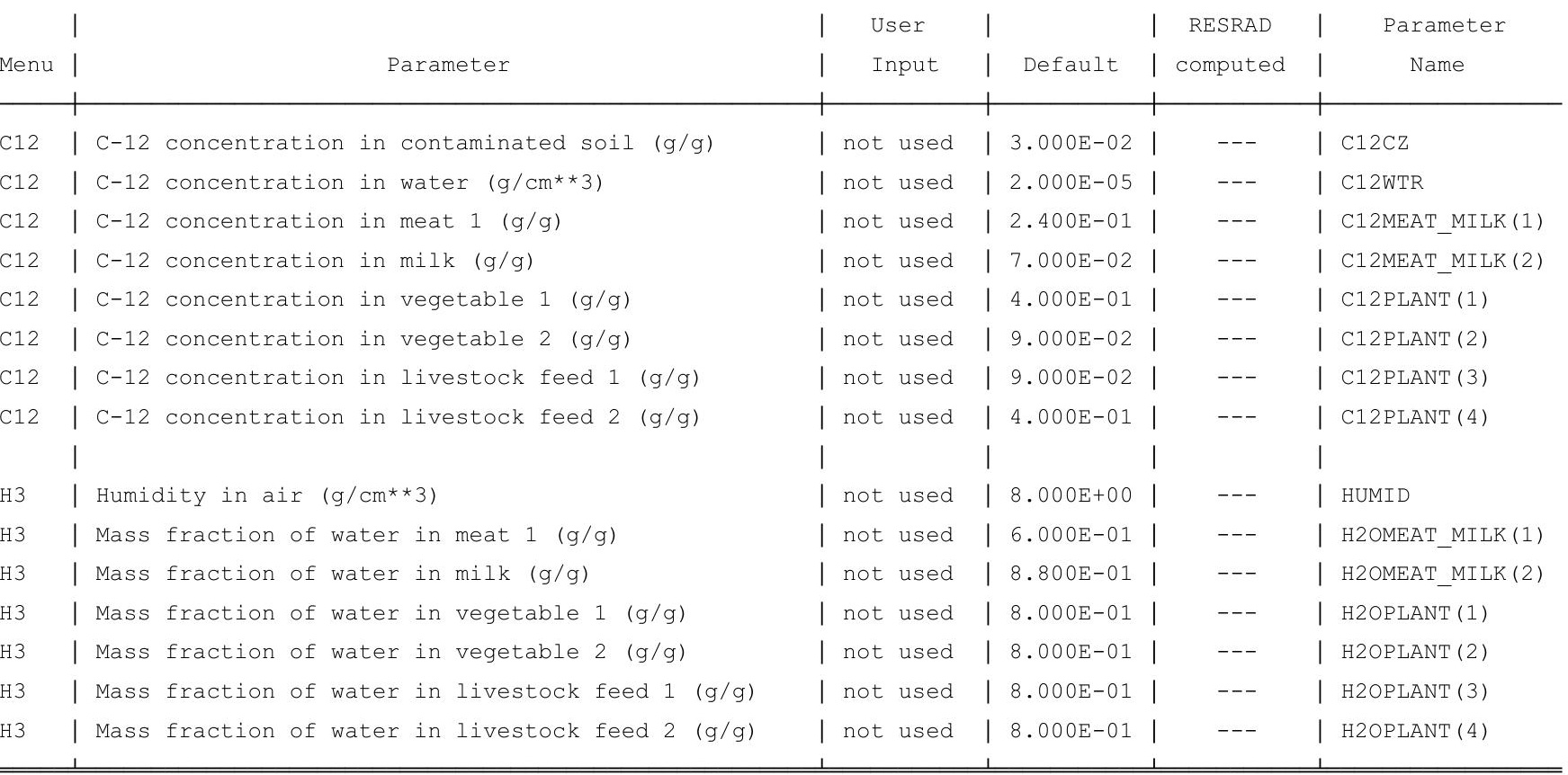

Summary of Pathway Selections

\begin{tabular}{|c|c|c|}
\hline & Pathway & User Selection \\
\hline 1 & -- external gamma & active \\
\hline 2 & -- inhalation (w/o radon) & active \\
\hline 3 & -- plant ingestion & active \\
\hline 4 & -- meat ingestion & active \\
\hline 5 & -- milk ingestion & active \\
\hline 6 & -- aquatic foods & suppressed \\
\hline 7 & -- drinking water & active \\
\hline 8 & -- soil ingestion & active \\
\hline 9 & -- radon & suppressed \\
\hline
\end{tabular}


RESRAD-OFFSITE, Version $2.5 \quad \mathrm{~T}^{1 / 2}$ Limit $=180$ days

Parent Dose Report

Title : RESRAD-OFFSITE Parameters for Offsite Resident Farmer Forward Run 1,050 Years

File : OFFSITE-RF_FORWARD-7-11ALS.ROF

Contaminated Zone Dimensions

Area: 102144.00 square meters

Thickness:

Cover Depth:

\begin{abstract}
13.40 meters
1.52 meters
\end{abstract}

Initial Soil Concentrations, pCi/g

$\begin{array}{ll}\text { Am-241 } & 7.000 \mathrm{E}+01 \\ \mathrm{Cs}-137 & 3.800 \mathrm{E}+01 \\ \mathrm{~Np}-237 & 1.100 \mathrm{E}+01 \\ \mathrm{Pu}-238 & 7.800 \mathrm{E}+01 \\ \mathrm{Pu}-239 & 7.200 \mathrm{E}+01 \\ \mathrm{Pu}-240 & 7.200 \mathrm{E}+01 \\ \mathrm{TC}-99 & 1.040 \mathrm{E}+02 \\ \mathrm{Th}-228 & 8.000 \mathrm{E}+00 \\ \text { Th-230 } & 2.000 \mathrm{E}+02 \\ \text { Th-232 } & 8.000 \mathrm{E}+00 \\ \mathrm{U}-234 & 3.200 \mathrm{E}+02 \\ \mathrm{U}-235 & 1.300 \mathrm{E}+01 \\ \mathrm{U}-238 & 3.200 \mathrm{E}+02\end{array}$

Total Dose TDOSE(t), mrem/yr

Basic Radiation Dose Limit $=1.000 \mathrm{E}+00 \mathrm{mrem} / \mathrm{yr}$

Total Mixture Sum $M(t)$ = Fraction of Basic Dose Limit Received at Time (t)

$\begin{array}{rllllll}t \text { (years }): & 0.000 \mathrm{E}+00 & 1.000 \mathrm{E}+00 & 5.000 \mathrm{E}+01 & 1.000 \mathrm{E}+02 & 5.000 \mathrm{E}+02 & 1.026 \mathrm{E}+03 \\ \text { TDOSE }(\mathrm{t}): & 5.549 \mathrm{E}-14 & 4.146 \mathrm{E}-14 & 9.186 \mathrm{E}-14 & 1.284 \mathrm{E}-13 & 1.982 \mathrm{E}+00 & 2.872 \mathrm{E}+00 \\ \mathrm{M}(\mathrm{t}): & 5.549 \mathrm{E}-14 & 4.146 \mathrm{E}-14 & 9.186 \mathrm{E}-14 & 1.284 \mathrm{E}-13 & 1.982 \mathrm{E}+00 & 2.872 \mathrm{E}+00\end{array}$

Maximum TDOSE(t): $\quad 3.737 \mathrm{E}+00 \mathrm{mrem} / \mathrm{yr}$ at $t=772$ years 
RESRAD-OFFSITE, Version 2.

Parent Dose Report

Title : RESRAD-OFFSITE Parameters for Offsite Resident Farmer Forward Run 1,050 Years

File : OFFSITE-RF FORWARD-7-11ALS.ROF

Total Dose Contributions TDOSE (i,p,t) for Individual Radionuclides (i) and Pathways (p) in mrem/yr and as a Percentage of Total Dose at $t=0$ years

From releases to ground water and to surface water

\begin{tabular}{|c|c|c|c|c|c|c|c|c|c|c|c|c|c|c|c|c|}
\hline & \multicolumn{2}{|c|}{ Ground } & \multicolumn{2}{|l|}{ Fish } & \multicolumn{2}{|c|}{ Radon } & \multicolumn{2}{|c|}{ Plant } & \multicolumn{2}{|l|}{ Meat } & \multicolumn{2}{|l|}{ Milk } & \multicolumn{2}{|l|}{ Soil } & \multicolumn{2}{|c|}{ Water } \\
\hline ide & Dose & $\%$ & Dose & $\%$ & Dose & 응 & Dose & $\frac{\circ}{0}$ & Dose & \% & Dose & 응 & Dose & $\%$ & Dose & $\%$ \\
\hline-241 & $0.00 \mathrm{E}+00$ & 0 & $0.00 E+00$ & 0 & $0.00 \mathrm{E}+00$ & 0 & $0.00 \mathrm{E}+00$ & 0 & $0.00 \mathrm{E}+00$ & 0 & $0.00 \mathrm{E}+00$ & 0 & $0.00 \mathrm{E}+00$ & 0 & $0.00 \mathrm{E}+00$ & 0 \\
\hline-137 & $0.00 \mathrm{E}+00$ & 0 & $0.00 \mathrm{E}+00$ & 0 & $0.00 \mathrm{E}+00$ & 0 & $0.00 \mathrm{E}+00$ & 0 & $0.00 \mathrm{E}+00$ & 0 & $0.00 \mathrm{E}+00$ & 0 & $0.00 \mathrm{E}+00$ & 0 & $0.00 \mathrm{E}+00$ & 0 \\
\hline-237 & $0.00 \mathrm{E}+00$ & 0 & $0.00 \mathrm{E}+00$ & 0 & $0.00 \mathrm{E}+00$ & 0 & $0.00 \mathrm{E}+00$ & 0 & $0.00 \mathrm{E}+00$ & 0 & $0.00 \mathrm{E}+00$ & 0 & $0.00 \mathrm{E}+00$ & 0 & $0.00 \mathrm{E}+00$ & 0 \\
\hline-238 & $0.00 \mathrm{E}+00$ & 0 & $0.00 \mathrm{E}+00$ & 0 & $0.00 E+00$ & 0 & $0.00 \mathrm{E}+00$ & 0 & $0.00 \mathrm{E}+00$ & 0 & $0.00 E+00$ & 0 & $0.00 \mathrm{E}+00$ & 0 & $0.00 \mathrm{E}+00$ & 0 \\
\hline-239 & $0.00 \mathrm{E}+00$ & 0 & $0.00 \mathrm{E}+00$ & 0 & $0.00 \mathrm{E}+00$ & 0 & $0.00 \mathrm{E}+00$ & 0 & $0.00 \mathrm{E}+00$ & 0 & $0.00 \mathrm{E}+00$ & 0 & $0.00 \mathrm{E}+00$ & 0 & $0.00 \mathrm{E}+00$ & 0 \\
\hline-240 & $0.00 \mathrm{E}+00$ & 0 & $0.00 \mathrm{E}+00$ & 0 & $0.00 \mathrm{E}+00$ & 0 & $0.00 \mathrm{E}+00$ & 0 & $0.00 \mathrm{E}+00$ & 0 & $0.00 \mathrm{E}+00$ & 0 & $0.00 \mathrm{E}+00$ & 0 & $0.00 \mathrm{E}+00$ & 0 \\
\hline-99 & $0.00 \mathrm{E}+00$ & 0 & $0.00 \mathrm{E}+00$ & 0 & $0.00 \mathrm{E}+00$ & 0 & $0.00 \mathrm{E}+00$ & 0 & $0.00 \mathrm{E}+00$ & 0 & $0.00 E+00$ & 0 & $0.00 \mathrm{E}+00$ & 0 & $0.00 \mathrm{E}+00$ & 0 \\
\hline-228 & $0.00 \mathrm{E}+00$ & 0 & $0.00 \mathrm{E}+00$ & 0 & $0.00 \mathrm{E}+00$ & 0 & $0.00 \mathrm{E}+00$ & 0 & $0.00 \mathrm{E}+00$ & 0 & $0.00 \mathrm{E}+00$ & 0 & $0.00 \mathrm{E}+00$ & 0 & $0.00 \mathrm{E}+00$ & 0 \\
\hline-230 & $0.00 \mathrm{E}+00$ & 0 & $0.00 \mathrm{E}+00$ & 0 & $0.00 \mathrm{E}+00$ & 0 & $0.00 \mathrm{E}+00$ & 0 & $0.00 \mathrm{E}+00$ & 0 & $0.00 \mathrm{E}+00$ & 0 & $0.00 \mathrm{E}+00$ & 0 & $0.00 \mathrm{E}+00$ & 0 \\
\hline-232 & $0.00 \mathrm{E}+00$ & 0 & $0.00 \mathrm{E}+00$ & 0 & $0.00 \mathrm{E}+00$ & 0 & $0.00 \mathrm{E}+00$ & 0 & $0.00 \mathrm{E}+00$ & 0 & $0.00 \mathrm{E}+00$ & 0 & $0.00 \mathrm{E}+00$ & 0 & $0.00 \mathrm{E}+00$ & 0 \\
\hline 4 & $0.00 \mathrm{E}+00$ & 0 & $0.00 \mathrm{E}+00$ & 0 & $0.00 \mathrm{E}+00$ & 0 & $0.00 \mathrm{E}+00$ & 0 & $0.00 \mathrm{E}+00$ & 0 & $0.00 \mathrm{E}+00$ & 0 & $0.00 \mathrm{E}+00$ & 0 & $0.00 \mathrm{E}+00$ & 0 \\
\hline 35 & $0.00 \mathrm{E}+00$ & 0 & $0.00 \mathrm{E}+00$ & 0 & $0.00 \mathrm{E}+00$ & 0 & $0.00 \mathrm{E}+00$ & 0 & $0.00 \mathrm{E}+00$ & 0 & $0.00 \mathrm{E}+00$ & 0 & $0.00 \mathrm{E}+00$ & 0 & $0.00 \mathrm{E}+00$ & 0 \\
\hline 38 & $0.00 \mathrm{E}+00$ & 0 & $0.00 \mathrm{E}+00$ & 0 & $0.00 \mathrm{E}+00$ & 0 & $0.00 \mathrm{E}+00$ & 0 & $0.00 \mathrm{E}+00$ & 0 & $0.00 \mathrm{E}+00$ & 0 & $0.00 \mathrm{E}+00$ & 0 & $0.00 \mathrm{E}+00$ & 0 \\
\hline & $0.00 \mathrm{E}+00$ & 0 & $0.00 E+00$ & 0 & $0.00 \mathrm{E}+00$ & 0 & $0.00 \mathrm{E}+00$ & 0 & $0.00 \mathrm{E}+00$ & 0 & $0.00 \mathrm{E}+00$ & 0 & $0.00 \mathrm{E}+00$ & 0 & $0.00 \mathrm{E}+00$ & \\
\hline
\end{tabular}

Total Dose Contributions TDOSE(i,p,t) for Individual Radionuclides (i) and Pathways (p)

in mrem/yr and as a Percentage of Total Dose at $t=0$ years

Directly from primary contamination and from release to atmosphere (Inhalation excludes radon)

\begin{tabular}{|c|c|c|c|c|c|c|c|c|c|c|c|c|c|c|c|c|}
\hline & \multicolumn{2}{|c|}{ Ground } & \multicolumn{2}{|c|}{ Inhalation } & \multicolumn{2}{|c|}{ Radon } & \multicolumn{2}{|c|}{ Plant } & \multicolumn{2}{|l|}{ Meat } & \multicolumn{2}{|l|}{ Milk } & \multicolumn{2}{|l|}{ Soil } & \multicolumn{2}{|c|}{ All Pathways* } \\
\hline clide & Dose & $\%$ & Dose & $\%$ & Dose & $\%$ & Dose & 음 & Dose & $\%$ & Dose & 음 & Dose & $\%$ & Dose & $\%$ \\
\hline-241 & $5.33 E-26$ & 0 & $0.00 \mathrm{E}+00$ & 0 & $0.00 E+00$ & 0 & $0.00 \mathrm{E}+00$ & 0 & $0.00 \mathrm{E}+00$ & 0 & $0.00 \mathrm{E}+00$ & 0 & $0.00 \mathrm{E}+00$ & 0 & $5.33 E-26$ & 0 \\
\hline-137 & $2.36 E-16$ & 0 & $0.00 E+00$ & 0 & $0.00 E+00$ & 0 & $0.00 \mathrm{E}+00$ & 0 & $0.00 \mathrm{E}+00$ & 0 & $0.00 E+00$ & 0 & $0.00 \mathrm{E}+00$ & 0 & $2.36 \mathrm{E}-16$ & 0 \\
\hline-237 & $5.17 E-20$ & 0 & $0.00 \mathrm{E}+00$ & 0 & $0.00 E+00$ & 0 & $0.00 \mathrm{E}+00$ & 0 & $0.00 \mathrm{E}+00$ & 0 & $0.00 E+00$ & 0 & $0.00 \mathrm{E}+00$ & 0 & $5.17 E-20$ & 0 \\
\hline-238 & $3.14 \mathrm{E}-29$ & 0 & $0.00 \mathrm{E}+00$ & 0 & $0.00 \mathrm{E}+00$ & 0 & $0.00 \mathrm{E}+00$ & 0 & $0.00 \mathrm{E}+00$ & 0 & $0.00 \mathrm{E}+00$ & 0 & $0.00 \mathrm{E}+00$ & 0 & $3.14 \mathrm{E}-29$ & 0 \\
\hline-239 & $4.27 E-24$ & 0 & $0.00 \mathrm{E}+00$ & 0 & $0.00 \mathrm{E}+00$ & 0 & $0.00 \mathrm{E}+00$ & 0 & $0.00 \mathrm{E}+00$ & 0 & $0.00 \mathrm{E}+00$ & 0 & $0.00 \mathrm{E}+00$ & 0 & $4.27 E-24$ & 0 \\
\hline-240 & $4.06 E-31$ & 0 & $0.00 \mathrm{E}+00$ & 0 & $0.00 \mathrm{E}+00$ & 0 & $0.00 \mathrm{E}+00$ & 0 & $0.00 \mathrm{E}+00$ & 0 & $0.00 E+00$ & 0 & $0.00 \mathrm{E}+00$ & 0 & $4.06 E-31$ & 0 \\
\hline-99 & $2.96 E-32$ & 0 & $0.00 \mathrm{E}+00$ & 0 & $0.00 \mathrm{E}+00$ & 0 & $0.00 \mathrm{E}+00$ & 0 & $0.00 \mathrm{E}+00$ & 0 & $0.00 E+00$ & 0 & $0.00 \mathrm{E}+00$ & 0 & $2.96 \mathrm{E}-32$ & 0 \\
\hline-228 & $5.45 \mathrm{E}-14$ & 98 & $0.00 \mathrm{E}+00$ & 0 & $0.00 \mathrm{E}+00$ & 0 & $0.00 \mathrm{E}+00$ & 0 & $0.00 \mathrm{E}+00$ & 0 & $0.00 \mathrm{E}+00$ & 0 & $0.00 \mathrm{E}+00$ & 0 & $5.45 \mathrm{E}-14$ & 98 \\
\hline-230 & $3.72 E-17$ & 0 & $0.00 E+00$ & 0 & $0.00 \mathrm{E}+00$ & 0 & $0.00 \mathrm{E}+00$ & 0 & $0.00 \mathrm{E}+00$ & 0 & $0.00 E+00$ & 0 & $0.00 \mathrm{E}+00$ & 0 & $3.72 \mathrm{E}-17$ & 0 \\
\hline-232 & $4.65 E-16$ & 1 & $0.00 \mathrm{E}+00$ & 0 & $0.00 \mathrm{E}+00$ & 0 & $0.00 \mathrm{E}+00$ & 0 & $0.00 \mathrm{E}+00$ & 0 & $0.00 \mathrm{E}+00$ & 0 & $0.00 \mathrm{E}+00$ & 0 & $4.65 E-16$ & 1 \\
\hline 34 & $1.79 \mathrm{E}-22$ & 0 & $0.00 \mathrm{E}+00$ & 0 & $0.00 \mathrm{E}+00$ & 0 & $0.00 \mathrm{E}+00$ & 0 & $0.00 \mathrm{E}+00$ & 0 & $0.00 \mathrm{E}+00$ & 0 & $0.00 \mathrm{E}+00$ & 0 & 1. $79 \mathrm{E}-22$ & 0 \\
\hline 35 & $7.97 \mathrm{E}-22$ & 0 & $0.00 \mathrm{E}+00$ & 0 & $0.00 \mathrm{E}+00$ & 0 & $0.00 \mathrm{E}+00$ & 0 & $0.00 \mathrm{E}+00$ & 0 & $0.00 \mathrm{E}+00$ & 0 & $0.00 \mathrm{E}+00$ & 0 & $7.97 \mathrm{E}-22$ & 0 \\
\hline 38 & $2.24 E-16$ & 0 & $0.00 \mathrm{E}+00$ & 0 & $0.00 \mathrm{E}+00$ & 0 & $0.00 \mathrm{E}+00$ & 0 & $0.00 \mathrm{E}+00$ & 0 & $0.00 E+00$ & 0 & $0.00 \mathrm{E}+00$ & 0 & $2.24 \mathrm{E}-16$ & 0 \\
\hline & $5.55 \mathrm{E}-14$ & 100 & $0.00 \mathrm{E}+00$ & 0 & $0.00 \mathrm{E}+00$ & 0 & $0.00 \mathrm{E}+00$ & 0 & $0.00 \mathrm{E}+00$ & 0 & $0.00 \mathrm{E}+00$ & 0 & $0.00 \mathrm{E}+00$ & 0 & $5.55 \mathrm{E}-14$ & 100 \\
\hline
\end{tabular}

* Sum of dose from all releases and from primary contamination. 
RESRAD-OFFSITE, Version 2.

Parent Dose Report

Title : RESRAD-OFFSITE Parameters for Offsite Resident Farmer Forward Run 1,050 Years

File : OFFSITE-RF FORWARD-7-11ALS.ROF

Total Dose Contributions TDOSE (i,p,t) for Individual Radionuclides (i) and Pathways (p) in mrem/yr and as a Percentage of Total Dose at $t=1$ years

From releases to ground water and to surface water

\begin{tabular}{|c|c|c|c|c|c|c|c|c|c|c|c|c|c|c|c|c|}
\hline & \multicolumn{2}{|c|}{ Ground } & \multicolumn{2}{|l|}{ Fish } & \multicolumn{2}{|c|}{ Radon } & \multicolumn{2}{|c|}{ Plant } & \multicolumn{2}{|l|}{ Meat } & \multicolumn{2}{|l|}{ Milk } & \multicolumn{2}{|l|}{ Soil } & \multicolumn{2}{|c|}{ Water } \\
\hline ide & Dose & $\%$ & Dose & $\%$ & Dose & 응 & Dose & $\frac{\circ}{0}$ & Dose & \% & Dose & 응 & Dose & $\%$ & Dose & $\%$ \\
\hline-241 & $0.00 \mathrm{E}+00$ & 0 & $0.00 E+00$ & 0 & $0.00 \mathrm{E}+00$ & 0 & $0.00 \mathrm{E}+00$ & 0 & $0.00 \mathrm{E}+00$ & 0 & $0.00 \mathrm{E}+00$ & 0 & $0.00 \mathrm{E}+00$ & 0 & $0.00 \mathrm{E}+00$ & 0 \\
\hline-137 & $0.00 \mathrm{E}+00$ & 0 & $0.00 \mathrm{E}+00$ & 0 & $0.00 \mathrm{E}+00$ & 0 & $0.00 \mathrm{E}+00$ & 0 & $0.00 \mathrm{E}+00$ & 0 & $0.00 \mathrm{E}+00$ & 0 & $0.00 \mathrm{E}+00$ & 0 & $0.00 \mathrm{E}+00$ & 0 \\
\hline-237 & $0.00 \mathrm{E}+00$ & 0 & $0.00 \mathrm{E}+00$ & 0 & $0.00 \mathrm{E}+00$ & 0 & $0.00 \mathrm{E}+00$ & 0 & $0.00 \mathrm{E}+00$ & 0 & $0.00 \mathrm{E}+00$ & 0 & $0.00 \mathrm{E}+00$ & 0 & $0.00 \mathrm{E}+00$ & 0 \\
\hline-238 & $0.00 \mathrm{E}+00$ & 0 & $0.00 \mathrm{E}+00$ & 0 & $0.00 E+00$ & 0 & $0.00 \mathrm{E}+00$ & 0 & $0.00 \mathrm{E}+00$ & 0 & $0.00 E+00$ & 0 & $0.00 \mathrm{E}+00$ & 0 & $0.00 \mathrm{E}+00$ & 0 \\
\hline-239 & $0.00 \mathrm{E}+00$ & 0 & $0.00 \mathrm{E}+00$ & 0 & $0.00 \mathrm{E}+00$ & 0 & $0.00 \mathrm{E}+00$ & 0 & $0.00 \mathrm{E}+00$ & 0 & $0.00 \mathrm{E}+00$ & 0 & $0.00 \mathrm{E}+00$ & 0 & $0.00 \mathrm{E}+00$ & 0 \\
\hline-240 & $0.00 \mathrm{E}+00$ & 0 & $0.00 \mathrm{E}+00$ & 0 & $0.00 \mathrm{E}+00$ & 0 & $0.00 \mathrm{E}+00$ & 0 & $0.00 \mathrm{E}+00$ & 0 & $0.00 \mathrm{E}+00$ & 0 & $0.00 \mathrm{E}+00$ & 0 & $0.00 \mathrm{E}+00$ & 0 \\
\hline-99 & $0.00 \mathrm{E}+00$ & 0 & $0.00 \mathrm{E}+00$ & 0 & $0.00 \mathrm{E}+00$ & 0 & $0.00 \mathrm{E}+00$ & 0 & $0.00 \mathrm{E}+00$ & 0 & $0.00 E+00$ & 0 & $0.00 \mathrm{E}+00$ & 0 & $0.00 \mathrm{E}+00$ & 0 \\
\hline-228 & $0.00 \mathrm{E}+00$ & 0 & $0.00 \mathrm{E}+00$ & 0 & $0.00 \mathrm{E}+00$ & 0 & $0.00 \mathrm{E}+00$ & 0 & $0.00 \mathrm{E}+00$ & 0 & $0.00 \mathrm{E}+00$ & 0 & $0.00 \mathrm{E}+00$ & 0 & $0.00 \mathrm{E}+00$ & 0 \\
\hline-230 & $0.00 \mathrm{E}+00$ & 0 & $0.00 \mathrm{E}+00$ & 0 & $0.00 \mathrm{E}+00$ & 0 & $0.00 \mathrm{E}+00$ & 0 & $0.00 \mathrm{E}+00$ & 0 & $0.00 \mathrm{E}+00$ & 0 & $0.00 \mathrm{E}+00$ & 0 & $0.00 \mathrm{E}+00$ & 0 \\
\hline-232 & $0.00 \mathrm{E}+00$ & 0 & $0.00 \mathrm{E}+00$ & 0 & $0.00 \mathrm{E}+00$ & 0 & $0.00 \mathrm{E}+00$ & 0 & $0.00 \mathrm{E}+00$ & 0 & $0.00 \mathrm{E}+00$ & 0 & $0.00 \mathrm{E}+00$ & 0 & $0.00 \mathrm{E}+00$ & 0 \\
\hline 4 & $0.00 \mathrm{E}+00$ & 0 & $0.00 \mathrm{E}+00$ & 0 & $0.00 \mathrm{E}+00$ & 0 & $0.00 \mathrm{E}+00$ & 0 & $0.00 \mathrm{E}+00$ & 0 & $0.00 \mathrm{E}+00$ & 0 & $0.00 \mathrm{E}+00$ & 0 & $0.00 \mathrm{E}+00$ & 0 \\
\hline 35 & $0.00 \mathrm{E}+00$ & 0 & $0.00 \mathrm{E}+00$ & 0 & $0.00 \mathrm{E}+00$ & 0 & $0.00 \mathrm{E}+00$ & 0 & $0.00 \mathrm{E}+00$ & 0 & $0.00 \mathrm{E}+00$ & 0 & $0.00 \mathrm{E}+00$ & 0 & $0.00 \mathrm{E}+00$ & 0 \\
\hline 38 & $0.00 \mathrm{E}+00$ & 0 & $0.00 \mathrm{E}+00$ & 0 & $0.00 \mathrm{E}+00$ & 0 & $0.00 \mathrm{E}+00$ & 0 & $0.00 \mathrm{E}+00$ & 0 & $0.00 \mathrm{E}+00$ & 0 & $0.00 \mathrm{E}+00$ & 0 & $0.00 \mathrm{E}+00$ & 0 \\
\hline & $0.00 \mathrm{E}+00$ & 0 & $0.00 E+00$ & 0 & $0.00 \mathrm{E}+00$ & 0 & $0.00 \mathrm{E}+00$ & 0 & $0.00 \mathrm{E}+00$ & 0 & $0.00 \mathrm{E}+00$ & 0 & $0.00 \mathrm{E}+00$ & 0 & $0.00 \mathrm{E}+00$ & \\
\hline
\end{tabular}

Total Dose Contributions TDOSE(i,p,t) for Individual Radionuclides (i) and Pathways (p)

in mrem/yr and as a Percentage of Total Dose at $t=1$ years

Directly from primary contamination and from release to atmosphere (Inhalation excludes radon)

\begin{tabular}{|c|c|c|c|c|c|c|c|c|c|c|c|c|c|c|c|c|}
\hline & \multicolumn{2}{|c|}{ Ground } & \multicolumn{2}{|c|}{ Inhalation } & \multicolumn{2}{|c|}{ Radon } & \multicolumn{2}{|c|}{ Plant } & \multicolumn{2}{|l|}{ Meat } & \multicolumn{2}{|l|}{ Milk } & \multicolumn{2}{|l|}{ Soil } & \multicolumn{2}{|c|}{ All Pathways* } \\
\hline clide & Dose & $\%$ & Dose & $\%$ & Dose & $\%$ & Dose & 음 & Dose & $\%$ & Dose & 음 & Dose & $\%$ & Dose & $\%$ \\
\hline-241 & $1.61 \mathrm{E}-25$ & 0 & $0.00 \mathrm{E}+00$ & 0 & $0.00 E+00$ & 0 & $0.00 \mathrm{E}+00$ & 0 & $0.00 \mathrm{E}+00$ & 0 & $0.00 \mathrm{E}+00$ & 0 & $0.00 \mathrm{E}+00$ & 0 & 1. $61 \mathrm{E}-25$ & 0 \\
\hline-137 & $2.33 E-16$ & 1 & $0.00 E+00$ & 0 & $0.00 E+00$ & 0 & $0.00 \mathrm{E}+00$ & 0 & $0.00 \mathrm{E}+00$ & 0 & $0.00 E+00$ & 0 & $0.00 \mathrm{E}+00$ & 0 & $2.33 E-16$ & 1 \\
\hline-237 & $5.22 E-20$ & 0 & $0.00 \mathrm{E}+00$ & 0 & $0.00 E+00$ & 0 & $0.00 \mathrm{E}+00$ & 0 & $0.00 \mathrm{E}+00$ & 0 & $0.00 E+00$ & 0 & $0.00 \mathrm{E}+00$ & 0 & $5.22 \mathrm{E}-20$ & 0 \\
\hline-238 & 4. $66 \mathrm{E}-28$ & 0 & $0.00 \mathrm{E}+00$ & 0 & $0.00 \mathrm{E}+00$ & 0 & $0.00 \mathrm{E}+00$ & 0 & $0.00 \mathrm{E}+00$ & 0 & $0.00 \mathrm{E}+00$ & 0 & $0.00 \mathrm{E}+00$ & 0 & 4. $66 \mathrm{E}-28$ & 0 \\
\hline-239 & 4. $31 E-24$ & 0 & $0.00 \mathrm{E}+00$ & 0 & $0.00 \mathrm{E}+00$ & 0 & $0.00 \mathrm{E}+00$ & 0 & $0.00 \mathrm{E}+00$ & 0 & $0.00 \mathrm{E}+00$ & 0 & $0.00 \mathrm{E}+00$ & 0 & $4.31 E-24$ & 0 \\
\hline-240 & $4.21 E-31$ & 0 & $0.00 \mathrm{E}+00$ & 0 & $0.00 \mathrm{E}+00$ & 0 & $0.00 \mathrm{E}+00$ & 0 & $0.00 \mathrm{E}+00$ & 0 & $0.00 E+00$ & 0 & $0.00 \mathrm{E}+00$ & 0 & $4.21 E-31$ & 0 \\
\hline-99 & $2.99 E-32$ & 0 & $0.00 \mathrm{E}+00$ & 0 & $0.00 \mathrm{E}+00$ & 0 & $0.00 \mathrm{E}+00$ & 0 & $0.00 \mathrm{E}+00$ & 0 & $0.00 E+00$ & 0 & $0.00 \mathrm{E}+00$ & 0 & $2.99 E-32$ & 0 \\
\hline-228 & $3.82 \mathrm{E}-14$ & 92 & $0.00 \mathrm{E}+00$ & 0 & $0.00 \mathrm{E}+00$ & 0 & $0.00 \mathrm{E}+00$ & 0 & $0.00 \mathrm{E}+00$ & 0 & $0.00 \mathrm{E}+00$ & 0 & $0.00 \mathrm{E}+00$ & 0 & $3.82 \mathrm{E}-14$ & 92 \\
\hline-230 & $1.12 \mathrm{E}-16$ & 0 & $0.00 E+00$ & 0 & $0.00 \mathrm{E}+00$ & 0 & $0.00 \mathrm{E}+00$ & 0 & $0.00 \mathrm{E}+00$ & 0 & $0.00 E+00$ & 0 & $0.00 \mathrm{E}+00$ & 0 & 1. $12 \mathrm{E}-16$ & 0 \\
\hline-232 & $2.72 E-15$ & 7 & $0.00 \mathrm{E}+00$ & 0 & $0.00 \mathrm{E}+00$ & 0 & $0.00 \mathrm{E}+00$ & 0 & $0.00 \mathrm{E}+00$ & 0 & $0.00 \mathrm{E}+00$ & 0 & $0.00 \mathrm{E}+00$ & 0 & $2.72 \mathrm{E}-15$ & 7 \\
\hline 34 & $1.26 \mathrm{E}-21$ & 0 & $0.00 \mathrm{E}+00$ & 0 & $0.00 \mathrm{E}+00$ & 0 & $0.00 \mathrm{E}+00$ & 0 & $0.00 \mathrm{E}+00$ & 0 & $0.00 \mathrm{E}+00$ & 0 & $0.00 \mathrm{E}+00$ & 0 & 1. $26 \mathrm{E}-21$ & 0 \\
\hline 35 & $8.10 \mathrm{E}-22$ & 0 & $0.00 \mathrm{E}+00$ & 0 & $0.00 \mathrm{E}+00$ & 0 & $0.00 \mathrm{E}+00$ & 0 & $0.00 \mathrm{E}+00$ & 0 & $0.00 \mathrm{E}+00$ & 0 & $0.00 \mathrm{E}+00$ & 0 & $8.10 \mathrm{E}-22$ & 0 \\
\hline 38 & $2.26 E-16$ & 1 & $0.00 \mathrm{E}+00$ & 0 & $0.00 \mathrm{E}+00$ & 0 & $0.00 \mathrm{E}+00$ & 0 & $0.00 \mathrm{E}+00$ & 0 & $0.00 E+00$ & 0 & $0.00 \mathrm{E}+00$ & 0 & $2.26 \mathrm{E}-16$ & 1 \\
\hline & $4.15 \mathrm{E}-14$ & 100 & $0.00 \mathrm{E}+00$ & 0 & $0.00 \mathrm{E}+00$ & 0 & $0.00 \mathrm{E}+00$ & 0 & $0.00 \mathrm{E}+00$ & 0 & $0.00 \mathrm{E}+00$ & 0 & $0.00 \mathrm{E}+00$ & 0 & $4.15 \mathrm{E}-14$ & 100 \\
\hline
\end{tabular}

* Sum of dose from all releases and from primary contamination. 
RESRAD-OFFSITE, Version 2.

Parent Dose Report

Title : RESRAD-OFFSITE Parameters for Offsite Resident Farmer Forward Run 1,050 Years

File : OFFSITE-RF FORWARD-7-11ALS.ROF

Total Dose Contributions TDOSE (i,p,t) for Individual Radionuclides (i) and Pathways (p) in mrem/yr and as a Percentage of Total Dose at $t=50$ years

From releases to ground water and to surface water

\begin{tabular}{|c|c|c|c|c|c|c|c|c|c|c|c|c|c|c|c|c|}
\hline & \multicolumn{2}{|c|}{ Ground } & \multicolumn{2}{|l|}{ Fish } & \multicolumn{2}{|c|}{ Radon } & \multicolumn{2}{|c|}{ Plant } & \multicolumn{2}{|l|}{ Meat } & \multicolumn{2}{|l|}{ Milk } & \multicolumn{2}{|l|}{ Soil } & \multicolumn{2}{|c|}{ Water } \\
\hline clide & Dose & \% & Dose & $\%$ & Dose & \% & Dose & \% & Dose & \% & Dose & \% & Dose & \% & Dose & $\%$ \\
\hline-241 & $0.00 \mathrm{E}+00$ & 0 & $0.00 \mathrm{E}+00$ & 0 & $0.00 \mathrm{E}+00$ & 0 & $0.00 \mathrm{E}+00$ & 0 & $0.00 \mathrm{E}+00$ & 0 & $0.00 \mathrm{E}+00$ & 0 & $0.00 \mathrm{E}+00$ & 0 & $0.00 \mathrm{E}+00$ & 0 \\
\hline-137 & $0.00 \mathrm{E}+00$ & 0 & $0.00 \mathrm{E}+00$ & 0 & $0.00 \mathrm{E}+00$ & 0 & $0.00 \mathrm{E}+00$ & 0 & $0.00 \mathrm{E}+00$ & 0 & $0.00 \mathrm{E}+00$ & 0 & $0.00 \mathrm{E}+00$ & 0 & $0.00 \mathrm{E}+00$ & 0 \\
\hline-237 & $0.00 \mathrm{E}+00$ & 0 & $0.00 \mathrm{E}+00$ & 0 & $0.00 \mathrm{E}+00$ & 0 & $0.00 \mathrm{E}+00$ & 0 & $0.00 \mathrm{E}+00$ & 0 & $0.00 \mathrm{E}+00$ & 0 & $0.00 \mathrm{E}+00$ & 0 & $0.00 \mathrm{E}+00$ & 0 \\
\hline-238 & $0.00 \mathrm{E}+00$ & 0 & $0.00 \mathrm{E}+00$ & 0 & $0.00 \mathrm{E}+00$ & 0 & $0.00 \mathrm{E}+00$ & 0 & $0.00 \mathrm{E}+00$ & 0 & $0.00 \mathrm{E}+00$ & 0 & $0.00 \mathrm{E}+00$ & 0 & $0.00 \mathrm{E}+00$ & 0 \\
\hline-239 & $0.00 \mathrm{E}+00$ & 0 & $0.00 \mathrm{E}+00$ & 0 & $0.00 \mathrm{E}+00$ & 0 & $0.00 \mathrm{E}+00$ & 0 & $0.00 \mathrm{E}+00$ & 0 & $0.00 \mathrm{E}+00$ & 0 & $0.00 \mathrm{E}+00$ & 0 & $0.00 \mathrm{E}+00$ & 0 \\
\hline-240 & $0.00 \mathrm{E}+00$ & 0 & $0.00 \mathrm{E}+00$ & 0 & $0.00 \mathrm{E}+00$ & 0 & $0.00 \mathrm{E}+00$ & 0 & $0.00 \mathrm{E}+00$ & 0 & $0.00 \mathrm{E}+00$ & 0 & $0.00 \mathrm{E}+00$ & 0 & $0.00 \mathrm{E}+00$ & 0 \\
\hline-99 & $0.00 \mathrm{E}+00$ & 0 & $0.00 E+00$ & 0 & $0.00 E+00$ & 0 & $0.00 \mathrm{E}+00$ & 0 & $0.00 \mathrm{E}+00$ & 0 & $0.00 E+00$ & 0 & $0.00 \mathrm{E}+00$ & 0 & $0.00 \mathrm{E}+00$ & 0 \\
\hline-228 & $0.00 \mathrm{E}+00$ & 0 & $0.00 \mathrm{E}+00$ & 0 & $0.00 \mathrm{E}+00$ & 0 & $0.00 \mathrm{E}+00$ & 0 & $0.00 \mathrm{E}+00$ & 0 & $0.00 \mathrm{E}+00$ & 0 & $0.00 \mathrm{E}+00$ & 0 & $0.00 \mathrm{E}+00$ & 0 \\
\hline-230 & $0.00 \mathrm{E}+00$ & 0 & $0.00 \mathrm{E}+00$ & 0 & $0.00 \mathrm{E}+00$ & 0 & $0.00 \mathrm{E}+00$ & 0 & $0.00 \mathrm{E}+00$ & 0 & $0.00 \mathrm{E}+00$ & 0 & $0.00 \mathrm{E}+00$ & 0 & $0.00 \mathrm{E}+00$ & 0 \\
\hline-232 & $0.00 \mathrm{E}+00$ & 0 & $0.00 E+00$ & 0 & $0.00 \mathrm{E}+00$ & 0 & $0.00 \mathrm{E}+00$ & 0 & $0.00 \mathrm{E}+00$ & 0 & $0.00 \mathrm{E}+00$ & 0 & $0.00 \mathrm{E}+00$ & 0 & $0.00 \mathrm{E}+00$ & 0 \\
\hline 234 & $0.00 \mathrm{E}+00$ & 0 & $0.00 \mathrm{E}+00$ & 0 & $0.00 \mathrm{E}+00$ & 0 & $0.00 \mathrm{E}+00$ & 0 & $0.00 \mathrm{E}+00$ & 0 & $0.00 \mathrm{E}+00$ & 0 & $0.00 \mathrm{E}+00$ & 0 & $0.00 \mathrm{E}+00$ & 0 \\
\hline 235 & $0.00 \mathrm{E}+00$ & 0 & $0.00 \mathrm{E}+00$ & 0 & $0.00 \mathrm{E}+00$ & 0 & $0.00 \mathrm{E}+00$ & 0 & $0.00 \mathrm{E}+00$ & 0 & $0.00 \mathrm{E}+00$ & 0 & $0.00 \mathrm{E}+00$ & 0 & $0.00 \mathrm{E}+00$ & 0 \\
\hline 38 & $0.00 \mathrm{E}+00$ & 0 & $0.00 E+00$ & 0 & $0.00 \mathrm{E}+00$ & 0 & $0.00 \mathrm{E}+00$ & 0 & $0.00 \mathrm{E}+00$ & 0 & $0.00 \mathrm{E}+00$ & 0 & $0.00 \mathrm{E}+00$ & 0 & $0.00 \mathrm{E}+00$ & 0 \\
\hline & $0.00 \mathrm{E}+00$ & 0 & $0.00 \mathrm{E}+00$ & 0 & $0.00 \mathrm{E}+00$ & 0 & $0.00 \mathrm{E}+00$ & 0 & $0.00 \mathrm{E}+00$ & 0 & $0.00 \mathrm{E}+00$ & 0 & $0.00 \mathrm{E}+00$ & 0 & $.00 \mathrm{E}+00$ & 0 \\
\hline
\end{tabular}

Total Dose Contributions TDOSE(i,p,t) for Individual Radionuclides (i) and Pathways (p) in mrem/yr and as a Percentage of Total Dose at $t=50$ years

Directly from primary contamination and from release to atmosphere (Inhalation excludes radon)

\begin{tabular}{|c|c|c|c|c|c|c|c|c|c|c|c|c|c|c|c|c|}
\hline & \multicolumn{2}{|c|}{ Ground } & \multicolumn{2}{|c|}{ Inhalation } & \multicolumn{2}{|c|}{ Radon } & \multicolumn{2}{|c|}{ Plant } & \multicolumn{2}{|l|}{ Meat } & \multicolumn{2}{|l|}{ Milk } & \multicolumn{2}{|l|}{ Soil } & \multicolumn{2}{|c|}{ All Pathways* } \\
\hline clide & Dose & $\%$ & Dose & $\%$ & Dose & $\%$ & Dose & \% & Dose & $\%$ & Dose & \% & Dose & \% & Dose & $\%$ \\
\hline-241 & $8.49 \mathrm{E}-24$ & 0 & $0.00 \mathrm{E}+00$ & 0 & $0.00 \mathrm{E}+00$ & 0 & $0.00 \mathrm{E}+00$ & 0 & $0.00 \mathrm{E}+00$ & 0 & $0.00 \mathrm{E}+00$ & 0 & $0.00 \mathrm{E}+00$ & 0 & $8.49 \mathrm{E}-24$ & 0 \\
\hline-137 & $1.10 \mathrm{E}-16$ & 0 & $0.00 \mathrm{E}+00$ & 0 & $0.00 \mathrm{E}+00$ & 0 & $0.00 \mathrm{E}+00$ & 0 & $0.00 \mathrm{E}+00$ & 0 & $0.00 \mathrm{E}+00$ & 0 & $0.00 \mathrm{E}+00$ & 0 & $1.10 \mathrm{E}-16$ & 0 \\
\hline-237 & $8.48 \mathrm{E}-20$ & 0 & $0.00 \mathrm{E}+00$ & 0 & $0.00 \mathrm{E}+00$ & 0 & $0.00 \mathrm{E}+00$ & 0 & $0.00 \mathrm{E}+00$ & 0 & $0.00 \mathrm{E}+00$ & 0 & $0.00 \mathrm{E}+00$ & 0 & $8.48 \mathrm{E}-20$ & 0 \\
\hline-238 & $1.97 \mathrm{E}-23$ & 0 & $0.00 \mathrm{E}+00$ & 0 & $0.00 \mathrm{E}+00$ & 0 & $0.00 \mathrm{E}+00$ & 0 & $0.00 \mathrm{E}+00$ & 0 & $0.00 \mathrm{E}+00$ & 0 & $0.00 \mathrm{E}+00$ & 0 & $1.97 \mathrm{E}-23$ & 0 \\
\hline-239 & $7.39 \mathrm{E}-24$ & 0 & $0.00 \mathrm{E}+00$ & 0 & $0.00 \mathrm{E}+00$ & 0 & $0.00 \mathrm{E}+00$ & 0 & $0.00 \mathrm{E}+00$ & 0 & $0.00 \mathrm{E}+00$ & 0 & $0.00 \mathrm{E}+00$ & 0 & $7.39 \mathrm{E}-24$ & 0 \\
\hline-240 & $9.30 \mathrm{E}-28$ & 0 & $0.00 \mathrm{E}+00$ & 0 & $0.00 \mathrm{E}+00$ & 0 & $0.00 \mathrm{E}+00$ & 0 & $0.00 \mathrm{E}+00$ & 0 & $0.00 \mathrm{E}+00$ & 0 & $0.00 \mathrm{E}+00$ & 0 & $9.30 \mathrm{E}-28$ & 0 \\
\hline-99 & $5.50 \mathrm{E}-32$ & 0 & $0.00 \mathrm{E}+00$ & 0 & $0.00 \mathrm{E}+00$ & 0 & $0.00 \mathrm{E}+00$ & 0 & $0.00 \mathrm{E}+00$ & 0 & $0.00 \mathrm{E}+00$ & 0 & $0.00 \mathrm{E}+00$ & 0 & $5.50 \mathrm{E}-32$ & 0 \\
\hline-228 & $9.73 E-22$ & 0 & $0.00 \mathrm{E}+00$ & 0 & $0.00 \mathrm{E}+00$ & 0 & $0.00 \mathrm{E}+00$ & 0 & $0.00 \mathrm{E}+00$ & 0 & $0.00 \mathrm{E}+00$ & 0 & $0.00 \mathrm{E}+00$ & 0 & $9.73 E-22$ & 0 \\
\hline-230 & $5.10 \mathrm{E}-15$ & 6 & $0.00 \mathrm{E}+00$ & 0 & $0.00 \mathrm{E}+00$ & 0 & $0.00 \mathrm{E}+00$ & 0 & $0.00 \mathrm{E}+00$ & 0 & $0.00 \mathrm{E}+00$ & 0 & $0.00 \mathrm{E}+00$ & 0 & $5.10 \mathrm{E}-15$ & 6 \\
\hline-232 & $8.63 E-14$ & 94 & $0.00 \mathrm{E}+00$ & 0 & $0.00 \mathrm{E}+00$ & 0 & $0.00 \mathrm{E}+00$ & 0 & $0.00 \mathrm{E}+00$ & 0 & $0.00 \mathrm{E}+00$ & 0 & $0.00 \mathrm{E}+00$ & 0 & $8.63 E-14$ & 94 \\
\hline 234 & $1.86 \mathrm{E}-18$ & 0 & $0.00 \mathrm{E}+00$ & 0 & $0.00 \mathrm{E}+00$ & 0 & $0.00 \mathrm{E}+00$ & 0 & $0.00 \mathrm{E}+00$ & 0 & $0.00 \mathrm{E}+00$ & 0 & $0.00 \mathrm{E}+00$ & 0 & $1.86 \mathrm{E}-18$ & 0 \\
\hline 235 & $5.70 \mathrm{E}-21$ & 0 & $0.00 \mathrm{E}+00$ & 0 & $0.00 \mathrm{E}+00$ & 0 & $0.00 \mathrm{E}+00$ & 0 & $0.00 \mathrm{E}+00$ & 0 & $0.00 \mathrm{E}+00$ & 0 & $0.00 \mathrm{E}+00$ & 0 & $5.70 \mathrm{E}-21$ & 0 \\
\hline 38 & $3.24 \mathrm{E}-16$ & 0 & $0.00 \mathrm{E}+00$ & 0 & $0.00 \mathrm{E}+00$ & 0 & $0.00 \mathrm{E}+00$ & 0 & $0.00 \mathrm{E}+00$ & 0 & $0.00 \mathrm{E}+00$ & 0 & $0.00 \mathrm{E}+00$ & 0 & $3.24 \mathrm{E}-16$ & 0 \\
\hline & $9.19 \mathrm{E}-14$ & 100 & $0.00 \mathrm{E}+00$ & 0 & $0.00 \mathrm{E}+00$ & 0 & $0.00 \mathrm{E}+00$ & 0 & $0.00 \mathrm{E}+00$ & 0 & $0.00 \mathrm{E}+00$ & 0 & $0.00 \mathrm{E}+00$ & 0 & $9.19 \mathrm{E}-14$ & 00 \\
\hline
\end{tabular}

* Sum of dose from all releases and from primary contamination. 
RESRAD-OFFSITE, Version 2.

Parent Dose Report

Title : RESRAD-OFFSITE Parameters for Offsite Resident Farmer Forward Run 1,050 Years

File : OFFSITE-RF FORWARD-7-11ALS.ROF

Total Dose Contributions TDOSE (i,p,t) for Individual Radionuclides (i) and Pathways (p) in mrem/yr and as a Percentage of Total Dose at $t=100$ years

From releases to ground water and to surface water

\begin{tabular}{|c|c|c|c|c|c|c|c|c|c|c|c|c|c|c|c|c|}
\hline & \multicolumn{2}{|c|}{ Ground } & \multicolumn{2}{|l|}{ Fish } & \multicolumn{2}{|c|}{ Radon } & \multicolumn{2}{|c|}{ Plant } & \multicolumn{2}{|l|}{ Meat } & \multicolumn{2}{|l|}{ Milk } & \multicolumn{2}{|l|}{ Soil } & \multicolumn{2}{|c|}{ Water } \\
\hline ide & Dose & $\%$ & Dose & $\%$ & Dose & 응 & Dose & $\frac{\circ}{0}$ & Dose & \% & Dose & 응 & Dose & $\%$ & Dose & $\%$ \\
\hline-241 & $0.00 \mathrm{E}+00$ & 0 & $0.00 E+00$ & 0 & $0.00 \mathrm{E}+00$ & 0 & $0.00 \mathrm{E}+00$ & 0 & $0.00 \mathrm{E}+00$ & 0 & $0.00 \mathrm{E}+00$ & 0 & $0.00 \mathrm{E}+00$ & 0 & $0.00 \mathrm{E}+00$ & 0 \\
\hline-137 & $0.00 \mathrm{E}+00$ & 0 & $0.00 \mathrm{E}+00$ & 0 & $0.00 \mathrm{E}+00$ & 0 & $0.00 \mathrm{E}+00$ & 0 & $0.00 \mathrm{E}+00$ & 0 & $0.00 \mathrm{E}+00$ & 0 & $0.00 \mathrm{E}+00$ & 0 & $0.00 \mathrm{E}+00$ & 0 \\
\hline-237 & $0.00 \mathrm{E}+00$ & 0 & $0.00 \mathrm{E}+00$ & 0 & $0.00 \mathrm{E}+00$ & 0 & $0.00 \mathrm{E}+00$ & 0 & $0.00 \mathrm{E}+00$ & 0 & $0.00 \mathrm{E}+00$ & 0 & $0.00 \mathrm{E}+00$ & 0 & $0.00 \mathrm{E}+00$ & 0 \\
\hline-238 & $0.00 \mathrm{E}+00$ & 0 & $0.00 \mathrm{E}+00$ & 0 & $0.00 E+00$ & 0 & $0.00 \mathrm{E}+00$ & 0 & $0.00 \mathrm{E}+00$ & 0 & $0.00 E+00$ & 0 & $0.00 \mathrm{E}+00$ & 0 & $0.00 \mathrm{E}+00$ & 0 \\
\hline-239 & $0.00 \mathrm{E}+00$ & 0 & $0.00 \mathrm{E}+00$ & 0 & $0.00 \mathrm{E}+00$ & 0 & $0.00 \mathrm{E}+00$ & 0 & $0.00 \mathrm{E}+00$ & 0 & $0.00 \mathrm{E}+00$ & 0 & $0.00 \mathrm{E}+00$ & 0 & $0.00 \mathrm{E}+00$ & 0 \\
\hline-240 & $0.00 \mathrm{E}+00$ & 0 & $0.00 \mathrm{E}+00$ & 0 & $0.00 \mathrm{E}+00$ & 0 & $0.00 \mathrm{E}+00$ & 0 & $0.00 \mathrm{E}+00$ & 0 & $0.00 \mathrm{E}+00$ & 0 & $0.00 \mathrm{E}+00$ & 0 & $0.00 \mathrm{E}+00$ & 0 \\
\hline-99 & $0.00 \mathrm{E}+00$ & 0 & $0.00 \mathrm{E}+00$ & 0 & $0.00 \mathrm{E}+00$ & 0 & $0.00 \mathrm{E}+00$ & 0 & $0.00 \mathrm{E}+00$ & 0 & $0.00 E+00$ & 0 & $0.00 \mathrm{E}+00$ & 0 & $0.00 \mathrm{E}+00$ & 0 \\
\hline-228 & $0.00 \mathrm{E}+00$ & 0 & $0.00 \mathrm{E}+00$ & 0 & $0.00 \mathrm{E}+00$ & 0 & $0.00 \mathrm{E}+00$ & 0 & $0.00 \mathrm{E}+00$ & 0 & $0.00 \mathrm{E}+00$ & 0 & $0.00 \mathrm{E}+00$ & 0 & $0.00 \mathrm{E}+00$ & 0 \\
\hline-230 & $0.00 \mathrm{E}+00$ & 0 & $0.00 \mathrm{E}+00$ & 0 & $0.00 \mathrm{E}+00$ & 0 & $0.00 \mathrm{E}+00$ & 0 & $0.00 \mathrm{E}+00$ & 0 & $0.00 \mathrm{E}+00$ & 0 & $0.00 \mathrm{E}+00$ & 0 & $0.00 \mathrm{E}+00$ & 0 \\
\hline-232 & $0.00 \mathrm{E}+00$ & 0 & $0.00 \mathrm{E}+00$ & 0 & $0.00 \mathrm{E}+00$ & 0 & $0.00 \mathrm{E}+00$ & 0 & $0.00 \mathrm{E}+00$ & 0 & $0.00 \mathrm{E}+00$ & 0 & $0.00 \mathrm{E}+00$ & 0 & $0.00 \mathrm{E}+00$ & 0 \\
\hline 4 & $0.00 \mathrm{E}+00$ & 0 & $0.00 \mathrm{E}+00$ & 0 & $0.00 \mathrm{E}+00$ & 0 & $0.00 \mathrm{E}+00$ & 0 & $0.00 \mathrm{E}+00$ & 0 & $0.00 \mathrm{E}+00$ & 0 & $0.00 \mathrm{E}+00$ & 0 & $0.00 \mathrm{E}+00$ & 0 \\
\hline 35 & $0.00 \mathrm{E}+00$ & 0 & $0.00 \mathrm{E}+00$ & 0 & $0.00 \mathrm{E}+00$ & 0 & $0.00 \mathrm{E}+00$ & 0 & $0.00 \mathrm{E}+00$ & 0 & $0.00 \mathrm{E}+00$ & 0 & $0.00 \mathrm{E}+00$ & 0 & $0.00 \mathrm{E}+00$ & 0 \\
\hline 38 & $0.00 \mathrm{E}+00$ & 0 & $0.00 \mathrm{E}+00$ & 0 & $0.00 \mathrm{E}+00$ & 0 & $0.00 \mathrm{E}+00$ & 0 & $0.00 \mathrm{E}+00$ & 0 & $0.00 \mathrm{E}+00$ & 0 & $0.00 \mathrm{E}+00$ & 0 & $0.00 \mathrm{E}+00$ & 0 \\
\hline & $0.00 \mathrm{E}+00$ & 0 & $0.00 E+00$ & 0 & $0.00 \mathrm{E}+00$ & 0 & $0.00 \mathrm{E}+00$ & 0 & $0.00 \mathrm{E}+00$ & 0 & $0.00 \mathrm{E}+00$ & 0 & $0.00 \mathrm{E}+00$ & 0 & $0.00 \mathrm{E}+00$ & \\
\hline
\end{tabular}

Total Dose Contributions TDOSE(i,p,t) for Individual Radionuclides (i) and Pathways (p) in mrem/yr and as a Percentage of Total Dose at $t=100$ years

Directly from primary contamination and from release to atmosphere (Inhalation excludes radon)

\begin{tabular}{|c|c|c|c|c|c|c|c|c|c|c|c|c|c|c|c|c|}
\hline & \multicolumn{2}{|c|}{ Ground } & \multicolumn{2}{|c|}{ Inhalation } & \multicolumn{2}{|c|}{ Radon } & \multicolumn{2}{|c|}{ Plant } & \multicolumn{2}{|l|}{ Meat } & \multicolumn{2}{|l|}{ Milk } & \multicolumn{2}{|l|}{ Soil } & \multicolumn{2}{|c|}{ All Pathways* } \\
\hline ide & Dose & $\%$ & Dose & $\%$ & Dose & $\%$ & Dose & 음 & Dose & $\%$ & Dose & 음 & Dose & $\%$ & Dose & $\%$ \\
\hline-241 & $2.67 E-23$ & 0 & $0.00 E+00$ & 0 & $0.00 E+00$ & 0 & $0.00 \mathrm{E}+00$ & 0 & $0.00 \mathrm{E}+00$ & 0 & $0.00 \mathrm{E}+00$ & 0 & $0.00 \mathrm{E}+00$ & 0 & 2. $67 \mathrm{E}-23$ & 0 \\
\hline-137 & $5.09 \mathrm{E}-17$ & 0 & $0.00 E+00$ & 0 & $0.00 E+00$ & 0 & $0.00 \mathrm{E}+00$ & 0 & $0.00 \mathrm{E}+00$ & 0 & $0.00 E+00$ & 0 & $0.00 \mathrm{E}+00$ & 0 & $5.09 \mathrm{E}-17$ & 0 \\
\hline-237 & 1. $40 \mathrm{E}-19$ & 0 & $0.00 E+00$ & 0 & $0.00 E+00$ & 0 & $0.00 \mathrm{E}+00$ & 0 & $0.00 \mathrm{E}+00$ & 0 & $0.00 E+00$ & 0 & $0.00 \mathrm{E}+00$ & 0 & 1. $40 \mathrm{E}-19$ & 0 \\
\hline-238 & 1. $94 \mathrm{E}-22$ & 0 & $0.00 E+00$ & 0 & $0.00 \mathrm{E}+00$ & 0 & $0.00 \mathrm{E}+00$ & 0 & $0.00 \mathrm{E}+00$ & 0 & $0.00 \mathrm{E}+00$ & 0 & $0.00 \mathrm{E}+00$ & 0 & 1. $94 \mathrm{E}-22$ & 0 \\
\hline-239 & $1.28 E-23$ & 0 & $0.00 \mathrm{E}+00$ & 0 & $0.00 \mathrm{E}+00$ & 0 & $0.00 \mathrm{E}+00$ & 0 & $0.00 \mathrm{E}+00$ & 0 & $0.00 \mathrm{E}+00$ & 0 & $0.00 \mathrm{E}+00$ & 0 & 1. $28 \mathrm{E}-23$ & 0 \\
\hline-240 & $6.04 E-27$ & 0 & $0.00 E+00$ & 0 & $0.00 \mathrm{E}+00$ & 0 & $0.00 \mathrm{E}+00$ & 0 & $0.00 \mathrm{E}+00$ & 0 & $0.00 E+00$ & 0 & $0.00 \mathrm{E}+00$ & 0 & $6.04 \mathrm{E}-27$ & 0 \\
\hline-99 & $1.02 \mathrm{E}-31$ & 0 & $0.00 \mathrm{E}+00$ & 0 & $0.00 \mathrm{E}+00$ & 0 & $0.00 \mathrm{E}+00$ & 0 & $0.00 \mathrm{E}+00$ & 0 & $0.00 \mathrm{E}+00$ & 0 & $0.00 \mathrm{E}+00$ & 0 & $1.02 \mathrm{E}-31$ & 0 \\
\hline-228 & $1.74 \mathrm{E}-29$ & 0 & $0.00 \mathrm{E}+00$ & 0 & $0.00 \mathrm{E}+00$ & 0 & $0.00 \mathrm{E}+00$ & 0 & $0.00 \mathrm{E}+00$ & 0 & $0.00 \mathrm{E}+00$ & 0 & $0.00 \mathrm{E}+00$ & 0 & $1.74 \mathrm{E}-29$ & 0 \\
\hline-230 & $1.38 E-14$ & 11 & $0.00 E+00$ & 0 & $0.00 \mathrm{E}+00$ & 0 & $0.00 \mathrm{E}+00$ & 0 & $0.00 \mathrm{E}+00$ & 0 & $0.00 E+00$ & 0 & $0.00 \mathrm{E}+00$ & 0 & $1.38 E-14$ & 11 \\
\hline-232 & $1.14 \mathrm{E}-13$ & 89 & $0.00 E+00$ & 0 & $0.00 \mathrm{E}+00$ & 0 & $0.00 \mathrm{E}+00$ & 0 & $0.00 \mathrm{E}+00$ & 0 & $0.00 \mathrm{E}+00$ & 0 & $0.00 \mathrm{E}+00$ & 0 & $1.14 \mathrm{E}-13$ & 89 \\
\hline 34 & $1.01 \mathrm{E}-17$ & 0 & $0.00 \mathrm{E}+00$ & 0 & $0.00 \mathrm{E}+00$ & 0 & $0.00 \mathrm{E}+00$ & 0 & $0.00 \mathrm{E}+00$ & 0 & $0.00 \mathrm{E}+00$ & 0 & $0.00 \mathrm{E}+00$ & 0 & 1.01E-17 & 0 \\
\hline 35 & $2.02 E-20$ & 0 & $0.00 \mathrm{E}+00$ & 0 & $0.00 \mathrm{E}+00$ & 0 & $0.00 \mathrm{E}+00$ & 0 & $0.00 \mathrm{E}+00$ & 0 & $0.00 \mathrm{E}+00$ & 0 & $0.00 \mathrm{E}+00$ & 0 & $2.02 \mathrm{E}-20$ & 0 \\
\hline 38 & 4. $67 \mathrm{E}-16$ & 0 & $0.00 E+00$ & 0 & $0.00 \mathrm{E}+00$ & 0 & $0.00 \mathrm{E}+00$ & 0 & $0.00 \mathrm{E}+00$ & 0 & $0.00 \mathrm{E}+00$ & 0 & $0.00 E+00$ & 0 & $4.67 \mathrm{E}-16$ & 0 \\
\hline & 1. $28 \mathrm{E}-13$ & 100 & $0.00 \mathrm{E}+00$ & 0 & $0.00 \mathrm{E}+00$ & 0 & $0.00 \mathrm{E}+00$ & 0 & $0.00 \mathrm{E}+00$ & 0 & $0.00 \mathrm{E}+00$ & 0 & $0.00 \mathrm{E}+00$ & 0 & 1. $28 \mathrm{E}-13$ & 100 \\
\hline
\end{tabular}


RESRAD-OFFSITE, Version 2.

Parent Dose Report

Title : RESRAD-OFFSITE Parameters for Offsite Resident Farmer Forward Run 1,050 Years

File : OFFSITE-RF FORWARD-7-11ALS.ROF

Total Dose Contributions TDOSE (i,p,t) for Individual Radionuclides (i) and Pathways (p) in mrem/yr and as a Percentage of Total Dose at $t=500$ years

From releases to ground water and to surface water

\begin{tabular}{|c|c|c|c|c|c|c|c|c|c|c|c|c|c|c|c|c|}
\hline & \multicolumn{2}{|c|}{ Ground } & \multicolumn{2}{|l|}{ Fish } & \multicolumn{2}{|c|}{ Radon } & \multicolumn{2}{|c|}{ Plant } & \multicolumn{2}{|l|}{ Meat } & \multicolumn{2}{|l|}{ Milk } & \multicolumn{2}{|l|}{ Soil } & \multicolumn{2}{|c|}{ Water } \\
\hline clide & Dose & \% & Dose & $\%$ & Dose & $\%$ & Dose & \% & Dose & $\%$ & Dose & $\%$ & Dose & \% & Dose & $\%$ \\
\hline-241 & $0.00 \mathrm{E}+00$ & 0 & $0.00 \mathrm{E}+00$ & 0 & $0.00 \mathrm{E}+00$ & 0 & $0.00 \mathrm{E}+00$ & 0 & $0.00 E+00$ & 0 & $0.00 \mathrm{E}+00$ & 0 & $0.00 \mathrm{E}+00$ & 0 & $0.00 \mathrm{E}+00$ & 0 \\
\hline-137 & $0.00 \mathrm{E}+00$ & 0 & $0.00 \mathrm{E}+00$ & 0 & $0.00 \mathrm{E}+00$ & 0 & $0.00 \mathrm{E}+00$ & 0 & $0.00 \mathrm{E}+00$ & 0 & $0.00 \mathrm{E}+00$ & 0 & $0.00 \mathrm{E}+00$ & 0 & $0.00 \mathrm{E}+00$ & 0 \\
\hline-237 & $0.00 \mathrm{E}+00$ & 0 & $0.00 \mathrm{E}+00$ & 0 & $0.00 \mathrm{E}+00$ & 0 & $0.00 \mathrm{E}+00$ & 0 & $0.00 \mathrm{E}+00$ & 0 & $0.00 \mathrm{E}+00$ & 0 & $0.00 \mathrm{E}+00$ & 0 & $0.00 \mathrm{E}+00$ & 0 \\
\hline-238 & $0.00 \mathrm{E}+00$ & 0 & $0.00 \mathrm{E}+00$ & 0 & $0.00 \mathrm{E}+00$ & 0 & $0.00 \mathrm{E}+00$ & 0 & $0.00 E+00$ & 0 & $0.00 \mathrm{E}+00$ & 0 & $0.00 \mathrm{E}+00$ & 0 & $0.00 \mathrm{E}+00$ & 0 \\
\hline-239 & $0.00 \mathrm{E}+00$ & 0 & $0.00 \mathrm{E}+00$ & 0 & $0.00 \mathrm{E}+00$ & 0 & $0.00 \mathrm{E}+00$ & 0 & $0.00 \mathrm{E}+00$ & 0 & $0.00 \mathrm{E}+00$ & 0 & $0.00 \mathrm{E}+00$ & 0 & $0.00 \mathrm{E}+00$ & 0 \\
\hline-240 & $0.00 \mathrm{E}+00$ & 0 & $0.00 \mathrm{E}+00$ & 0 & $0.00 \mathrm{E}+00$ & 0 & $0.00 \mathrm{E}+00$ & 0 & $0.00 \mathrm{E}+00$ & 0 & $0.00 \mathrm{E}+00$ & 0 & $0.00 \mathrm{E}+00$ & 0 & $0.00 \mathrm{E}+00$ & 0 \\
\hline-99 & $1.81 \mathrm{E}-06$ & 0 & $0.00 \mathrm{E}+00$ & 0 & $0.00 \mathrm{E}+00$ & 0 & $4.96 \mathrm{E}-01$ & 25 & $1.49 E-03$ & 0 & $1.31 E-01$ & 7 & $1.53 \mathrm{E}-06$ & 0 & $1.35 \mathrm{E}+00$ & 68 \\
\hline-228 & $0.00 \mathrm{E}+00$ & 0 & $0.00 \mathrm{E}+00$ & 0 & $0.00 \mathrm{E}+00$ & 0 & $0.00 \mathrm{E}+00$ & 0 & $0.00 \mathrm{E}+00$ & 0 & $0.00 \mathrm{E}+00$ & 0 & $0.00 \mathrm{E}+00$ & 0 & $0.00 \mathrm{E}+00$ & 0 \\
\hline-230 & $0.00 \mathrm{E}+00$ & 0 & $0.00 \mathrm{E}+00$ & 0 & $0.00 \mathrm{E}+00$ & 0 & $0.00 \mathrm{E}+00$ & 0 & $0.00 \mathrm{E}+00$ & 0 & $0.00 \mathrm{E}+00$ & 0 & $0.00 \mathrm{E}+00$ & 0 & $0.00 \mathrm{E}+00$ & 0 \\
\hline-232 & $0.00 \mathrm{E}+00$ & 0 & $0.00 \mathrm{E}+00$ & 0 & $0.00 \mathrm{E}+00$ & 0 & $0.00 \mathrm{E}+00$ & 0 & $0.00 \mathrm{E}+00$ & 0 & $0.00 \mathrm{E}+00$ & 0 & $0.00 \mathrm{E}+00$ & 0 & $0.00 \mathrm{E}+00$ & 0 \\
\hline 234 & $0.00 \mathrm{E}+00$ & 0 & $0.00 \mathrm{E}+00$ & 0 & $0.00 \mathrm{E}+00$ & 0 & $0.00 \mathrm{E}+00$ & 0 & $0.00 \mathrm{E}+00$ & 0 & $0.00 \mathrm{E}+00$ & 0 & $0.00 \mathrm{E}+00$ & 0 & $0.00 \mathrm{E}+00$ & 0 \\
\hline 235 & $0.00 \mathrm{E}+00$ & 0 & $0.00 \mathrm{E}+00$ & 0 & $0.00 \mathrm{E}+00$ & 0 & $0.00 \mathrm{E}+00$ & 0 & $0.00 \mathrm{E}+00$ & 0 & $0.00 \mathrm{E}+00$ & 0 & $0.00 \mathrm{E}+00$ & 0 & $0.00 \mathrm{E}+00$ & 0 \\
\hline 38 & $0.00 \mathrm{E}+00$ & 0 & $0.00 \mathrm{E}+00$ & 0 & $0.00 \mathrm{E}+00$ & 0 & $0.00 \mathrm{E}+00$ & 0 & $0.00 \mathrm{E}+00$ & 0 & $0.00 \mathrm{E}+00$ & 0 & $0.00 \mathrm{E}+00$ & 0 & $0.00 \mathrm{E}+00$ & 0 \\
\hline & $1.81 \mathrm{E}-06$ & 0 & $0.00 \mathrm{E}+00$ & 0 & $0.00 \mathrm{E}+00$ & 0 & $4.96 \mathrm{E}-01$ & 25 & 1. $49 \mathrm{E}-03$ & 0 & 1. $31 \mathrm{E}-01$ & 7 & $1.53 \mathrm{E}-06$ & 0 & $1.35 \mathrm{E}+00$ & 68 \\
\hline
\end{tabular}

Total Dose Contributions TDOSE(i,p,t) for Individual Radionuclides (i) and Pathways (p) in mrem/yr and as a Percentage of Total Dose at $t=500$ years

Directly from primary contamination and from release to atmosphere (Inhalation excludes radon)

\begin{tabular}{|c|c|c|c|c|c|c|c|c|c|c|c|c|c|c|c|c|}
\hline & \multicolumn{2}{|c|}{ Ground } & \multicolumn{2}{|c|}{ Inhalation } & \multicolumn{2}{|c|}{ Radon } & \multicolumn{2}{|c|}{ Plant } & \multicolumn{2}{|l|}{ Meat } & \multicolumn{2}{|l|}{ Milk } & \multicolumn{2}{|l|}{ Soil } & \multicolumn{2}{|c|}{ All Pathways* } \\
\hline clide & Dose & $\%$ & Dose & $\%$ & Dose & $\%$ & Dose & \% & Dose & $\%$ & Dose & \% & Dose & \% & Dose & $\%$ \\
\hline-241 & $5.26 \mathrm{E}-21$ & 0 & $0.00 \mathrm{E}+00$ & 0 & $0.00 \mathrm{E}+00$ & 0 & $0.00 \mathrm{E}+00$ & 0 & $0.00 \mathrm{E}+00$ & 0 & $0.00 \mathrm{E}+00$ & 0 & $0.00 \mathrm{E}+00$ & 0 & $5.26 \mathrm{E}-21$ & 0 \\
\hline-137 & 1.09E-19 & 0 & $0.00 \mathrm{E}+00$ & 0 & $0.00 \mathrm{E}+00$ & 0 & $0.00 \mathrm{E}+00$ & 0 & $0.00 \mathrm{E}+00$ & 0 & $0.00 \mathrm{E}+00$ & 0 & $0.00 \mathrm{E}+00$ & 0 & $1.09 \mathrm{E}-19$ & 0 \\
\hline-237 & $7.47 \mathrm{E}-18$ & 0 & $0.00 \mathrm{E}+00$ & 0 & $0.00 \mathrm{E}+00$ & 0 & $0.00 \mathrm{E}+00$ & 0 & $0.00 \mathrm{E}+00$ & 0 & $0.00 \mathrm{E}+00$ & 0 & $0.00 \mathrm{E}+00$ & 0 & $7.47 \mathrm{E}-18$ & 0 \\
\hline-238 & $1.64 \mathrm{E}-19$ & 0 & $0.00 \mathrm{E}+00$ & 0 & $0.00 \mathrm{E}+00$ & 0 & $0.00 \mathrm{E}+00$ & 0 & $0.00 \mathrm{E}+00$ & 0 & $0.00 \mathrm{E}+00$ & 0 & $0.00 \mathrm{E}+00$ & 0 & $1.64 \mathrm{E}-19$ & 0 \\
\hline-239 & $1.04 \mathrm{E}-21$ & 0 & $0.00 \mathrm{E}+00$ & 0 & $0.00 \mathrm{E}+00$ & 0 & $0.00 \mathrm{E}+00$ & 0 & $0.00 \mathrm{E}+00$ & 0 & $0.00 \mathrm{E}+00$ & 0 & $0.00 \mathrm{E}+00$ & 0 & $1.04 \mathrm{E}-21$ & 0 \\
\hline-240 & 1. $60 \mathrm{E}-24$ & 0 & $0.00 \mathrm{E}+00$ & 0 & $0.00 \mathrm{E}+00$ & 0 & $0.00 \mathrm{E}+00$ & 0 & $0.00 \mathrm{E}+00$ & 0 & $0.00 \mathrm{E}+00$ & 0 & $0.00 \mathrm{E}+00$ & 0 & $1.60 \mathrm{E}-24$ & 0 \\
\hline-99 & 1. $46 \mathrm{E}-29$ & 0 & $0.00 \mathrm{E}+00$ & 0 & $0.00 \mathrm{E}+00$ & 0 & $0.00 \mathrm{E}+00$ & 0 & $0.00 \mathrm{E}+00$ & 0 & $0.00 \mathrm{E}+00$ & 0 & $0.00 \mathrm{E}+00$ & 0 & $1.98 \mathrm{E}+00$ & 100 \\
\hline-228 & $0.00 \mathrm{E}+00$ & 0 & $0.00 \mathrm{E}+00$ & 0 & $0.00 \mathrm{E}+00$ & 0 & $0.00 \mathrm{E}+00$ & 0 & $0.00 \mathrm{E}+00$ & 0 & $0.00 \mathrm{E}+00$ & 0 & $0.00 \mathrm{E}+00$ & 0 & $0.00 \mathrm{E}+00$ & 0 \\
\hline-230 & $8.05 E-13$ & 0 & $0.00 \mathrm{E}+00$ & 0 & $0.00 \mathrm{E}+00$ & 0 & $0.00 \mathrm{E}+00$ & 0 & $0.00 \mathrm{E}+00$ & 0 & $0.00 \mathrm{E}+00$ & 0 & $0.00 \mathrm{E}+00$ & 0 & $8.05 \mathrm{E}-13$ & 0 \\
\hline-232 & $1.04 \mathrm{E}-12$ & 0 & $0.00 \mathrm{E}+00$ & 0 & $0.00 E+00$ & 0 & $0.00 \mathrm{E}+00$ & 0 & $0.00 \mathrm{E}+00$ & 0 & $0.00 E+00$ & 0 & $0.00 \mathrm{E}+00$ & 0 & 1. $04 \mathrm{E}-12$ & 0 \\
\hline 234 & $3.00 \mathrm{E}-15$ & 0 & $0.00 \mathrm{E}+00$ & 0 & $0.00 \mathrm{E}+00$ & 0 & $0.00 \mathrm{E}+00$ & 0 & $0.00 \mathrm{E}+00$ & 0 & $0.00 \mathrm{E}+00$ & 0 & $0.00 \mathrm{E}+00$ & 0 & $3.00 E-15$ & 0 \\
\hline 235 & $3.16 \mathrm{E}-18$ & 0 & $0.00 \mathrm{E}+00$ & 0 & $0.00 \mathrm{E}+00$ & 0 & $0.00 \mathrm{E}+00$ & 0 & $0.00 \mathrm{E}+00$ & 0 & $0.00 \mathrm{E}+00$ & 0 & $0.00 \mathrm{E}+00$ & 0 & $3.16 \mathrm{E}-18$ & 0 \\
\hline 38 & $8.87 E-15$ & 0 & $0.00 \mathrm{E}+00$ & 0 & $0.00 \mathrm{E}+00$ & 0 & $0.00 \mathrm{E}+00$ & 0 & $0.00 \mathrm{E}+00$ & 0 & $0.00 \mathrm{E}+00$ & 0 & $0.00 \mathrm{E}+00$ & 0 & $8.87 E-15$ & 0 \\
\hline & $1.86 \mathrm{E}-12$ & 0 & $0.00 \mathrm{E}+00$ & 0 & $0.00 \mathrm{E}+00$ & 0 & $0.00 \mathrm{E}+00$ & 0 & $0.00 \mathrm{E}+00$ & 0 & $0.00 \mathrm{E}+00$ & 0 & $0.00 \mathrm{E}+00$ & 0 & 1. $98 \mathrm{E}+00$ & 100 \\
\hline
\end{tabular}


RESRAD-OFFSITE, Version 2.

Parent Dose Report

Title : RESRAD-OFFSITE Parameters for Offsite Resident Farmer Forward Run 1,050 Years

File : OFFSITE-RF FORWARD-7-11ALS.ROF

Total Dose Contributions TDOSE (i,p,t) for Individual Radionuclides (i) and Pathways (p) in mrem/yr and as a Percentage of Total Dose at $t=1026$ years

From releases to ground water and to surface water

\begin{tabular}{|c|c|c|c|c|c|c|c|c|c|c|c|c|c|c|c|c|}
\hline & \multicolumn{2}{|c|}{ Ground } & \multicolumn{2}{|l|}{ Fish } & \multicolumn{2}{|c|}{ Radon } & \multicolumn{2}{|c|}{ Plant } & \multicolumn{2}{|l|}{ Meat } & \multicolumn{2}{|l|}{ Milk } & \multicolumn{2}{|l|}{ Soil } & \multicolumn{2}{|c|}{ Water } \\
\hline clide & Dose & $\%$ & Dose & $\%$ & Dose & 응 & Dose & 웅 & Dose & \% & Dose & $\frac{\circ}{0}$ & Dose & $\frac{\circ}{0}$ & Dose & \% \\
\hline $1-241$ & $0.00 \mathrm{E}+00$ & 0 & $0.00 \mathrm{E}+00$ & 0 & $0.00 \mathrm{E}+00$ & 0 & $0.00 \mathrm{E}+00$ & 0 & $0.00 \mathrm{E}+00$ & 0 & $0.00 \mathrm{E}+00$ & 0 & $0.00 \mathrm{E}+00$ & 0 & $0.00 E+00$ & 0 \\
\hline-137 & $0.00 \mathrm{E}+00$ & 0 & $0.00 \mathrm{E}+00$ & 0 & $0.00 \mathrm{E}+00$ & 0 & $0.00 \mathrm{E}+00$ & 0 & $0.00 \mathrm{E}+00$ & 0 & $0.00 \mathrm{E}+00$ & 0 & $0.00 \mathrm{E}+00$ & 0 & $0.00 \mathrm{E}+00$ & 0 \\
\hline-237 & $0.00 \mathrm{E}+00$ & 0 & $0.00 \mathrm{E}+00$ & 0 & $0.00 \mathrm{E}+00$ & 0 & $0.00 \mathrm{E}+00$ & 0 & $0.00 \mathrm{E}+00$ & 0 & $0.00 \mathrm{E}+00$ & 0 & $0.00 \mathrm{E}+00$ & 0 & $0.00 \mathrm{E}+00$ & 0 \\
\hline-238 & $0.00 \mathrm{E}+00$ & 0 & $0.00 \mathrm{E}+00$ & 0 & $0.00 \mathrm{E}+00$ & 0 & $0.00 \mathrm{E}+00$ & 0 & $0.00 \mathrm{E}+00$ & 0 & $0.00 \mathrm{E}+00$ & 0 & $0.00 \mathrm{E}+00$ & 0 & $0.00 \mathrm{E}+00$ & 0 \\
\hline-239 & $0.00 \mathrm{E}+00$ & 0 & $0.00 \mathrm{E}+00$ & 0 & $0.00 \mathrm{E}+00$ & 0 & $0.00 \mathrm{E}+00$ & 0 & $0.00 \mathrm{E}+00$ & 0 & $0.00 \mathrm{E}+00$ & 0 & $0.00 \mathrm{E}+00$ & 0 & $0.00 \mathrm{E}+00$ & 0 \\
\hline-240 & $0.00 \mathrm{E}+00$ & 0 & $0.00 \mathrm{E}+00$ & 0 & $0.00 \mathrm{E}+00$ & 0 & $0.00 \mathrm{E}+00$ & 0 & $0.00 \mathrm{E}+00$ & 0 & $0.00 \mathrm{E}+00$ & 0 & $0.00 \mathrm{E}+00$ & 0 & $0.00 \mathrm{E}+00$ & 0 \\
\hline-99 & $2.63 E-06$ & 0 & $0.00 \mathrm{E}+00$ & 0 & $0.00 \mathrm{E}+00$ & 0 & 7. $20 \mathrm{E}-01$ & 25 & $2.16 \mathrm{E}-03$ & 0 & $1.90 \mathrm{E}-01$ & 7 & $2.22 \mathrm{E}-06$ & 0 & $1.96 \mathrm{E}+00$ & 68 \\
\hline-228 & $0.00 \mathrm{E}+00$ & 0 & $0.00 \mathrm{E}+00$ & 0 & $0.00 \mathrm{E}+00$ & 0 & $0.00 \mathrm{E}+00$ & 0 & $0.00 \mathrm{E}+00$ & 0 & $0.00 \mathrm{E}+00$ & 0 & $0.00 \mathrm{E}+00$ & 0 & $0.00 \mathrm{E}+00$ & 0 \\
\hline-230 & $0.00 \mathrm{E}+00$ & 0 & $0.00 \mathrm{E}+00$ & 0 & $0.00 \mathrm{E}+00$ & 0 & $0.00 \mathrm{E}+00$ & 0 & $0.00 \mathrm{E}+00$ & 0 & $0.00 \mathrm{E}+00$ & 0 & $0.00 \mathrm{E}+00$ & 0 & $0.00 \mathrm{E}+00$ & 0 \\
\hline-232 & $0.00 \mathrm{E}+00$ & 0 & $0.00 \mathrm{E}+00$ & 0 & $0.00 \mathrm{E}+00$ & 0 & $0.00 \mathrm{E}+00$ & 0 & $0.00 \mathrm{E}+00$ & 0 & $0.00 \mathrm{E}+00$ & 0 & $0.00 \mathrm{E}+00$ & 0 & $0.00 \mathrm{E}+00$ & 0 \\
\hline 234 & $0.00 \mathrm{E}+00$ & 0 & $0.00 \mathrm{E}+00$ & 0 & $0.00 \mathrm{E}+00$ & 0 & $0.00 \mathrm{E}+00$ & 0 & $0.00 \mathrm{E}+00$ & 0 & $0.00 \mathrm{E}+00$ & 0 & $0.00 \mathrm{E}+00$ & 0 & $0.00 \mathrm{E}+00$ & 0 \\
\hline 235 & $0.00 \mathrm{E}+00$ & 0 & $0.00 \mathrm{E}+00$ & 0 & $0.00 \mathrm{E}+00$ & 0 & $0.00 \mathrm{E}+00$ & 0 & $0.00 \mathrm{E}+00$ & 0 & $0.00 \mathrm{E}+00$ & 0 & $0.00 \mathrm{E}+00$ & 0 & $0.00 \mathrm{E}+00$ & 0 \\
\hline 238 & $0.00 \mathrm{E}+00$ & 0 & $0.00 E+00$ & 0 & $0.00 \mathrm{E}+00$ & 0 & $0.00 E+00$ & 0 & $0.00 \mathrm{E}+00$ & 0 & $0.00 \mathrm{E}+00$ & 0 & $0.00 \mathrm{E}+00$ & 0 & $0.00 \mathrm{E}+00$ & 0 \\
\hline & $2.63 E-06$ & 0 & $0.00 \mathrm{E}+00$ & 0 & $0.00 \mathrm{E}+00$ & 0 & 7. $20 \mathrm{E}-01$ & 25 & $2.16 \mathrm{E}-03$ & 0 & $1.90 \mathrm{E}-01$ & 7 & $2.22 E-06$ & 0 & L. $96 \mathrm{E}+00$ & 68 \\
\hline
\end{tabular}

Total Dose Contributions TDOSE(i,p,t) for Individual Radionuclides (i) and Pathways (p) in mrem/yr and as a Percentage of Total Dose at $t=1026$ years

Directly from primary contamination and from release to atmosphere (Inhalation excludes radon)

\begin{tabular}{|c|c|c|c|c|c|c|c|c|c|c|c|c|c|c|c|c|}
\hline & \multicolumn{2}{|c|}{ Ground } & \multicolumn{2}{|c|}{ Inhalation } & \multicolumn{2}{|c|}{ Radon } & \multicolumn{2}{|c|}{ Plant } & \multicolumn{2}{|l|}{ Meat } & \multicolumn{2}{|l|}{ Milk } & \multicolumn{2}{|l|}{ Soil } & \multicolumn{2}{|c|}{ All Pathways* } \\
\hline clide & Dose & $\%$ & Dose & $\%$ & Dose & $\%$ & Dose & 음 & Dose & $\%$ & Dose & 음 & Dose & $\%$ & Dose & $\%$ \\
\hline-241 & 1. $39 \mathrm{E}-18$ & 0 & $0.00 E+00$ & 0 & $0.00 E+00$ & 0 & $0.00 \mathrm{E}+00$ & 0 & $0.00 \mathrm{E}+00$ & 0 & $0.00 \mathrm{E}+00$ & 0 & $0.00 \mathrm{E}+00$ & 0 & 1. $39 \mathrm{E}-18$ & 0 \\
\hline-137 & $3.40 E-23$ & 0 & $0.00 E+00$ & 0 & $0.00 E+00$ & 0 & $0.00 \mathrm{E}+00$ & 0 & $0.00 \mathrm{E}+00$ & 0 & $0.00 E+00$ & 0 & $0.00 \mathrm{E}+00$ & 0 & $3.40 E-23$ & 0 \\
\hline-237 & $1.33 E-15$ & 0 & $0.00 E+00$ & 0 & $0.00 E+00$ & 0 & $0.00 \mathrm{E}+00$ & 0 & $0.00 \mathrm{E}+00$ & 0 & $0.00 E+00$ & 0 & $0.00 \mathrm{E}+00$ & 0 & $1.33 E-15$ & 0 \\
\hline-238 & $2.32 E-17$ & 0 & $0.00 E+00$ & 0 & $0.00 \mathrm{E}+00$ & 0 & $0.00 \mathrm{E}+00$ & 0 & $0.00 \mathrm{E}+00$ & 0 & $0.00 \mathrm{E}+00$ & 0 & $0.00 \mathrm{E}+00$ & 0 & $2.32 \mathrm{E}-17$ & 0 \\
\hline-239 & $3.39 E-19$ & 0 & $0.00 \mathrm{E}+00$ & 0 & $0.00 \mathrm{E}+00$ & 0 & $0.00 \mathrm{E}+00$ & 0 & $0.00 \mathrm{E}+00$ & 0 & $0.00 \mathrm{E}+00$ & 0 & $0.00 \mathrm{E}+00$ & 0 & $3.39 \mathrm{E}-19$ & 0 \\
\hline-240 & 1. $32 \mathrm{E}-22$ & 0 & $0.00 E+00$ & 0 & $0.00 \mathrm{E}+00$ & 0 & $0.00 \mathrm{E}+00$ & 0 & $0.00 \mathrm{E}+00$ & 0 & $0.00 E+00$ & 0 & $0.00 \mathrm{E}+00$ & 0 & 1. $32 \mathrm{E}-22$ & 0 \\
\hline-99 & $9.92 E-27$ & 0 & $0.00 E+00$ & 0 & $0.00 \mathrm{E}+00$ & 0 & $0.00 \mathrm{E}+00$ & 0 & $0.00 \mathrm{E}+00$ & 0 & $0.00 E+00$ & 0 & $0.00 \mathrm{E}+00$ & 0 & $2.87 \mathrm{E}+00$ & 100 \\
\hline-228 & $0.00 \mathrm{E}+00$ & 0 & $0.00 \mathrm{E}+00$ & 0 & $0.00 \mathrm{E}+00$ & 0 & $0.00 \mathrm{E}+00$ & 0 & $0.00 \mathrm{E}+00$ & 0 & $0.00 \mathrm{E}+00$ & 0 & $0.00 \mathrm{E}+00$ & 0 & $0.00 \mathrm{E}+00$ & 0 \\
\hline-230 & $4.21 E-11$ & 0 & $0.00 E+00$ & 0 & $0.00 \mathrm{E}+00$ & 0 & $0.00 \mathrm{E}+00$ & 0 & $0.00 \mathrm{E}+00$ & 0 & $0.00 E+00$ & 0 & $0.00 \mathrm{E}+00$ & 0 & 4. $21 \mathrm{E}-11$ & 0 \\
\hline-232 & 1. $93 \mathrm{E}-11$ & 0 & $0.00 E+00$ & 0 & $0.00 \mathrm{E}+00$ & 0 & $0.00 \mathrm{E}+00$ & 0 & $0.00 \mathrm{E}+00$ & 0 & $0.00 \mathrm{E}+00$ & 0 & $0.00 \mathrm{E}+00$ & 0 & 1. $93 \mathrm{E}-11$ & 0 \\
\hline 34 & $3.34 \mathrm{E}-13$ & 0 & $0.00 \mathrm{E}+00$ & 0 & $0.00 \mathrm{E}+00$ & 0 & $0.00 \mathrm{E}+00$ & 0 & $0.00 \mathrm{E}+00$ & 0 & $0.00 \mathrm{E}+00$ & 0 & $0.00 \mathrm{E}+00$ & 0 & $3.34 \mathrm{E}-13$ & 0 \\
\hline 35 & $5.40 \mathrm{E}-16$ & 0 & $0.00 \mathrm{E}+00$ & 0 & $0.00 \mathrm{E}+00$ & 0 & $0.00 \mathrm{E}+00$ & 0 & $0.00 \mathrm{E}+00$ & 0 & $0.00 \mathrm{E}+00$ & 0 & $0.00 \mathrm{E}+00$ & 0 & $5.40 \mathrm{E}-16$ & 0 \\
\hline 38 & 4. $26 E-13$ & 0 & $0.00 E+00$ & 0 & $0.00 \mathrm{E}+00$ & 0 & $0.00 \mathrm{E}+00$ & 0 & $0.00 \mathrm{E}+00$ & 0 & $0.00 E+00$ & 0 & $0.00 \mathrm{E}+00$ & 0 & 4. $26 \mathrm{E}-13$ & 0 \\
\hline & $6.21 \mathrm{E}-11$ & 0 & $0.00 \mathrm{E}+00$ & 0 & $0.00 \mathrm{E}+00$ & 0 & $0.00 \mathrm{E}+00$ & 0 & $0.00 \mathrm{E}+00$ & 0 & $0.00 \mathrm{E}+00$ & 0 & $0.00 \mathrm{E}+00$ & 0 & $2.87 \mathrm{E}+00$ & 100 \\
\hline
\end{tabular}


RESRAD-OFFSITE, Version 2.

Parent Dose Report

Title : RESRAD-OFFSITE Parameters for Offsite Resident Farmer Forward Run 1,050 Years

File : OFFSITE-RF_FORWARD-7-11ALS.ROF

Dose/Source Ratios Summed Over All Pathways

Parent and Progeny Principal Radionuclide Contributions Indicated

Parent Product Thread DSR $(j, \mathrm{t}) \quad(\mathrm{mrem} / \mathrm{yr}) /(\mathrm{pCi} / \mathrm{g})$

(i)

(j)

$\begin{array}{ll}\operatorname{Am}-241 & 1.000 \mathrm{E}+00 \\ \mathrm{~Np}-237+\mathrm{D} & 1.000 \mathrm{E}+00 \\ \mathrm{U}-233 & 1.000 \mathrm{E}+00 \\ \operatorname{Th}-229+\mathrm{D} & 1.000 \mathrm{E}+00 \\ \operatorname{\sum DSR}(j) & \end{array}$

Cs $-137+D$

$\mathrm{Np}-237+\mathrm{D}$

$\mathrm{U}-233$

1. $000 \mathrm{E}+00$

$9.537 \mathrm{E}-42 \quad 9.773 \mathrm{E}-42 \quad 3.239 \mathrm{E}-41 \quad 1.100 \mathrm{E}-40 \quad 1.945 \mathrm{E}-36 \quad 7.488 \mathrm{E}-31$

$\begin{array}{llllll}.621 \mathrm{E}-28 & 2.305 \mathrm{E}-27 & 1.212 \mathrm{E}-25 & 3.805 \mathrm{E}-25 & 7.396 \mathrm{E}-23 & 1.966 \mathrm{E}-20\end{array}$

$\begin{array}{lllllll}1.731 E-38 & 1.222 \mathrm{E}-37 & 2.283 \mathrm{E}-34 & 1.567 \mathrm{E}-33 & 3.197 \mathrm{E}-30 & 4.568 \mathrm{E}-27\end{array}$

$\begin{array}{llllll}1.187 \mathrm{E}-34 & 1.786 \mathrm{E}-33 & 8.205 \mathrm{E}-29 & 8.729 \mathrm{E}-28 & 1.204 \mathrm{E}-24 & 2.598 \mathrm{E}-22\end{array}$

$\begin{array}{llllll}7.621 \mathrm{E}-28 & 2.305 \mathrm{E}-27 & 1.213 \mathrm{E}-25 & 3.813 \mathrm{E}-25 & 7.516 \mathrm{E}-23 & 1.992 \mathrm{E}-20\end{array}$

$\mathrm{Th}-229+\mathrm{D}$

1. $000 \mathrm{E}+00$

$\begin{array}{llllll}6.220 E-18 & 6.125 E-18 & 2.886 E-18 & 1.340 E-18 & 2.881 E-21 & 8.954 E-25\end{array}$

$\sum \operatorname{DSR}(j)$

1. $000 \mathrm{E}+00$

$\begin{array}{llllll}4.700 \mathrm{E}-21 & 4.747 \mathrm{E}-21 & 7.698 \mathrm{E}-21 & 1.261 \mathrm{E}-20 & 6.527 \mathrm{E}-19 & 1.171 \mathrm{E}-16\end{array}$

$\mathrm{Np}-237+\mathrm{D}$

$\mathrm{Np}-237+\mathrm{D}$

$\mathrm{Np}-237$

$\mathrm{Pu}-238$

Pu-238

1. $840 \mathrm{E}-0$

$\mathrm{Pu}-238$

1. $000 \mathrm{E}+00$

$\mathrm{U}-234$

1. $000 \mathrm{E}+00$

Th-230

1. $000 \mathrm{E}+00$

Ra $-226+D$

1. $000 \mathrm{E}+00$

$\mathrm{Pb}-210+\mathrm{D}$

1. $000 \mathrm{E}+00$

$\sum \operatorname{DSR}(j)$

$\begin{array}{llllllll}\mathrm{Pu}-239 & 1.000 \mathrm{E}+00 & 5.925 \mathrm{E}-26 & 5.991 \mathrm{E}-26 & 1.027 \mathrm{E}-25 & 1.779 \mathrm{E}-25 & 1.445 \mathrm{E}-23 & 4.686 \mathrm{E}-21\end{array}$

$1.000 \mathrm{E}+00$

$\mathrm{Pa}-231$

1. $000 \mathrm{E}+00$

$\mathrm{AC}-227+\mathrm{D}$

$1.000 \mathrm{E}+00$

$\sum \operatorname{DSR}(j)$

$\mathrm{Pu}-240$

4. $950 \mathrm{E}-08$

$3.023 \mathrm{E}-32 \quad 9.162 \mathrm{E}-32 \quad 5.381 \mathrm{E}-30 \quad 1.891 \mathrm{E}-29 \quad 8.893 \mathrm{E}-27 \quad 7.217 \mathrm{E}-24$

$\begin{array}{llllll}4.766 E-36 & 3.360 E-35 & 5.914 E-32 & 3.816 E-31 & 4.695 E-28 & 3.351 E-25\end{array}$

$\begin{array}{llllll}1.132 \mathrm{E}-35 & 1.695 \mathrm{E}-34 & 6.079 \mathrm{E}-30 & 5.385 \mathrm{E}-29 & 5.164 \mathrm{E}-26 & 1.642 \mathrm{E}-23\end{array}$

\begin{tabular}{l}
$5.925 \mathrm{E}-26 \quad 5.991 \mathrm{E}-26 \quad 1.027 \mathrm{E}-25 \quad 1.780 \mathrm{E}-25 \quad 1.451 \mathrm{E}-23 \quad 4.710 \mathrm{E}-21$ \\
\hline
\end{tabular}

$\begin{array}{llllllll}\mathrm{Pu}-240 & 1.000 \mathrm{E}+00 & 5.628 \mathrm{E}-33 & 5.719 \mathrm{E}-33 & 1.262 \mathrm{E}-32 & 2.831 \mathrm{E}-32 & 1.811 \mathrm{E}-29 & 8.872 \mathrm{E}-26\end{array}$

$\begin{array}{lllllllll}\mathrm{U}-236 & 1.000 \mathrm{E}+00 & 1.065 \mathrm{E}-40 & 3.243 \mathrm{E}-40 & 2.449 \mathrm{E}-38 & 1.113 \mathrm{E}-37 & 4.093 \mathrm{E}-34 & 4.966 \mathrm{E}-30\end{array}$

$\begin{array}{llllllllll}\mathrm{Th}-232 & 1.000 \mathrm{E}+00 & 0.000 \mathrm{E}+00 & 0.000 \mathrm{E}+00 & 0.000 \mathrm{E}+00 & 0.000 \mathrm{E}+00 & 5.307 \mathrm{E}-42 & 1.757 \mathrm{E}-37\end{array}$

$\mathrm{Ra}-228+\mathrm{D} \quad 1.000 \mathrm{E}+00 \quad 6.783 \mathrm{E}-37 \quad 9.960 \mathrm{E}-36 \quad 1.800 \mathrm{E}-31 \quad 1.181 \mathrm{E}-30 \quad 5.381 \mathrm{E}-28 \quad 8.909 \mathrm{E}-26$

$\begin{array}{lllllllll}\mathrm{Th}-228+\mathrm{D} & 1.000 \mathrm{E}+00 & 4.024 \mathrm{E}-36 & 1.154 \mathrm{E}-34 & 1.272 \mathrm{E}-29 & 8.268 \mathrm{E}-29 & 2.173 \mathrm{E}-26 & 1.651 \mathrm{E}-24\end{array}$

$\sum \operatorname{DSR}(j)$

$\begin{array}{llllll}5.632 \mathrm{E}-33 & 5.845 \mathrm{E}-33 & 1.291 \mathrm{E}-29 & 8.389 \mathrm{E}-29 & 2.228 \mathrm{E}-26 & 1.829 \mathrm{E}-24\end{array}$

$\begin{array}{lllllllll}\text { TC-99 } 1.000 E+00 & 2.843 E-34 & 2.878 E-34 & 5.284 E-34 & 9.823 E-34 & 1.906 E-02 & 2.762 E-02\end{array}$

Th-228+D Th-228+D 1.000E+00 6.816E-15 4.771E-15 1.217E-22 2.172E-30 $0.000 \mathrm{E}+00 \quad 0.000 \mathrm{E}+00$ 
RESRAD-OFFSITE, Version 2.

Parent Dose Report

Title : RESRAD-OFFSITE Parameters for Offsite Resident Farmer Forward Run 1,050 Years

File : OFFSITE-RF_FORWARD-7-11ALS.ROF

Dose/Source Ratios Summed Over All Pathways

Parent and Progeny Principal Radionuclide Contributions Indicated

\begin{tabular}{|c|c|c|c|c|c|c|c|c|}
\hline Parent & Product & Thread & & $\operatorname{DSR}(j$, & t) $\quad($ mrem $/ y$ & r) / ( $\mathrm{pCi} / \mathrm{g})$ & & \\
\hline (i) & $(j)$ & Fraction & $0.000 \mathrm{E}+00$ & $1.000 \mathrm{E}+00$ & $5.000 \mathrm{E}+01$ & $1.000 \mathrm{E}+02$ & $5.000 \mathrm{E}+02$ & $1.026 \mathrm{E}+03$ \\
\hline-230 & $T h-230$ & $1.000 \mathrm{E}+00$ & $1.189 \mathrm{E}-30$ & $1.207 E-30$ & $2.577 E-30$ & $5.589 \mathrm{E}-30$ & $2.731 \mathrm{E}-27$ & $9.387 \mathrm{E}-24$ \\
\hline-230 & $\mathrm{Ra}-226+\mathrm{D}$ & $1.000 \mathrm{E}+00$ & $1.860 \mathrm{E}-19$ & $5.610 \mathrm{E}-19$ & $2.552 \mathrm{E}-17$ & $6.905 \mathrm{E}-17$ & $4.024 \mathrm{E}-15$ & $2.105 E-13$ \\
\hline-230 & $\mathrm{~Pb}-210+\mathrm{D}$ & $1.000 \mathrm{E}+00$ & $8.984 \mathrm{E}-28$ & $6.263 E-27$ & $6.208 E-24$ & $2.463 E-23$ & $2.775 E-21$ & $2.524 \mathrm{E}-19$ \\
\hline-230 & $\sum \operatorname{DSR}(j)$ & & $1.860 \mathrm{E}-19$ & $5.610 \mathrm{E}-19$ & $2.552 \mathrm{E}-17$ & $6.905 \mathrm{E}-17$ & $4.024 \mathrm{E}-15$ & $2.105 E-13$ \\
\hline-232 & Th-232 & $1.000 \mathrm{E}+00$ & $5.745 E-33$ & $5.844 \mathrm{E}-33$ & $1.351 \mathrm{E}-32$ & $3.175 \mathrm{E}-32$ & $2.963 E-29$ & $2.383 E-25$ \\
\hline-232 & $\mathrm{Ra}-228+\mathrm{D}$ & $1.000 \mathrm{E}+00$ & $5.458 \mathrm{E}-18$ & $1.564 \mathrm{E}-17$ & $1.332 \mathrm{E}-16$ & $1.894 \mathrm{E}-16$ & $3.104 \mathrm{E}-15$ & $1.228 \mathrm{E}-13$ \\
\hline-232 & $T h-228+D$ & $1.000 \mathrm{E}+00$ & $5.270 \mathrm{E}-17$ & $3.244 \mathrm{E}-16$ & $1.066 \mathrm{E}-14$ & $1.407 \mathrm{E}-14$ & $1.267 \mathrm{E}-13$ & $2.287 \mathrm{E}-12$ \\
\hline-232 & $\sum \operatorname{DSR}(j)$ & & $5.816 \mathrm{E}-17$ & $3.401 \mathrm{E}-16$ & $1.079 \mathrm{E}-14$ & $1.426 \mathrm{E}-14$ & $1.298 \mathrm{E}-13$ & $2.410 \mathrm{E}-12$ \\
\hline 234 & $\mathrm{U}-234$ & $1.000 \mathrm{E}+00$ & $3.398 E-32$ & $3.454 \mathrm{E}-32$ & $7.678 E-32$ & $1.735 \mathrm{E}-31$ & $1.179 \mathrm{E}-28$ & $6.245 E-25$ \\
\hline-234 & $T h-230$ & $1.000 \mathrm{E}+00$ & $5.364 \mathrm{E}-36$ & $1.631 \mathrm{E}-35$ & $1.172 \mathrm{E}-33$ & $5.055 \mathrm{E}-33$ & $1.229 \mathrm{E}-29$ & $8.650 \mathrm{E}-26$ \\
\hline 234 & $\mathrm{Ra}-226+\mathrm{D}$ & $1.000 \mathrm{E}+00$ & $5.596 \mathrm{E}-25$ & $3.933 E-24$ & $5.821 \mathrm{E}-21$ & $3.145 \mathrm{E}-20$ & $9.384 \mathrm{E}-18$ & $1.042 \mathrm{E}-15$ \\
\hline-234 & $\mathrm{~Pb}-210+\mathrm{D}$ & $1.000 \mathrm{E}+00$ & $2.030 \mathrm{E}-33$ & $3.037 \mathrm{E}-32$ & $1.052 \mathrm{E}-27$ & $8.967 \mathrm{E}-27$ & $6.069 \mathrm{E}-24$ & $1.209 \mathrm{E}-21$ \\
\hline 234 & $\sum \operatorname{DSR}(j)$ & & $5.596 \mathrm{E}-25$ & $3.933 E-24$ & $5.821 \mathrm{E}-21$ & $3.145 \mathrm{E}-20$ & $9.384 \mathrm{E}-18$ & $1.042 \mathrm{E}-15$ \\
\hline$-235+D$ & $\mathrm{U}-235+\mathrm{D}$ & $1.000 \mathrm{E}+00$ & $6.128 E-23$ & $6.198 \mathrm{E}-23$ & $1.083 E-22$ & 1. $913 \mathrm{E}-22$ & $1.816 \mathrm{E}-20$ & $7.232 \mathrm{E}-18$ \\
\hline$-235+D$ & $\mathrm{~Pa}-231$ & $1.000 \mathrm{E}+00$ & $1.448 \mathrm{E}-26$ & $4.381 \mathrm{E}-26$ & $2.379 E-24$ & $7.714 \mathrm{E}-24$ & $1.910 \mathrm{E}-21$ & $6.667 \mathrm{E}-19$ \\
\hline$-235+D$ & $A c-227+D$ & $1.000 \mathrm{E}+00$ & $4.580 \mathrm{E}-26$ & $3.195 \mathrm{E}-25$ & $3.279 \mathrm{E}-22$ & 1. $355 \mathrm{E}-21$ & $2.231 \mathrm{E}-19$ & $3.366 \mathrm{E}-17$ \\
\hline 235 & $\sum \operatorname{DSR}(j)$ & & $6.134 \mathrm{E}-23$ & $6.234 \mathrm{E}-23$ & $4.385 E-22$ & $1.554 \mathrm{E}-21$ & $2.432 \mathrm{E}-19$ & $4.156 \mathrm{E}-17$ \\
\hline-238 & $\mathrm{U}-238$ & $5.400 \mathrm{E}-05$ & $0.000 \mathrm{E}+00$ & $0.000 \mathrm{E}+00$ & $0.000 \mathrm{E}+00$ & $0.000 \mathrm{E}+00$ & $0.000 \mathrm{E}+00$ & $0.000 \mathrm{E}+00$ \\
\hline$-238+D$ & $\mathrm{U}-238+\mathrm{D}$ & $9.999 \mathrm{E}-01$ & $6.998 \mathrm{E}-19$ & $7.050 \mathrm{E}-19$ & $1.011 \mathrm{E}-18$ & 1. $460 \mathrm{E}-18$ & $2.771 \mathrm{E}-17$ & 1. $329 \mathrm{E}-15$ \\
\hline$-238+D$ & $\mathrm{U}-234$ & $9.999 \mathrm{E}-01$ & $4.830 \mathrm{E}-38$ & $1.470 \mathrm{E}-37$ & $1.099 \mathrm{E}-35$ & $4.943 E-35$ & $1.673 E-31$ & $1.820 \mathrm{E}-27$ \\
\hline$-238+D$ & Th-230 & $9.999 \mathrm{E}-01$ & $5.085 E-42$ & 3. $603 E-41$ & $8.386 \mathrm{E}-38$ & $7.201 \mathrm{E}-37$ & $8.719 \mathrm{E}-33$ & $1.259 \mathrm{E}-28$ \\
\hline$-238+D$ & $\mathrm{Ra}-226+\mathrm{D}$ & $9.999 \mathrm{E}-01$ & $3.792 \mathrm{E}-31$ & $5.970 \mathrm{E}-30$ & $2.783 \mathrm{E}-25$ & $2.998 \mathrm{E}-24$ & $4.516 \mathrm{E}-21$ & $1.047 \mathrm{E}-18$ \\
\hline $38+D$ & $\mathrm{~Pb}-210+\mathrm{D}$ & $9.999 \mathrm{E}-01$ & $1.122 \mathrm{E}-38$ & $4.009 \mathrm{E}-38$ & $4.030 \mathrm{E}-32$ & $7.166 \mathrm{E}-31$ & $2.754 \mathrm{E}-27$ & $1.178 \mathrm{E}-24$ \\
\hline-238 & $\sum \operatorname{DSR}(j)$ & & $6.998 \mathrm{E}-19$ & $7.050 \mathrm{E}-19$ & $1.011 \mathrm{E}-18$ & $1.460 \mathrm{E}-18$ & $2.772 \mathrm{E}-17$ & $1.331 \mathrm{E}-15$ \\
\hline
\end{tabular}

The DSR includes contributions from associated (half-life $\leq 180$ days) daughters. 
RESRAD-OFFSITE, Version 2.

Parent Dose Report

Title : RESRAD-OFFSITE Parameters for Offsite Resident Farmer Forward Run 1,050 Years File : OFFSITE-RF_FORWARD-7-11ALS.ROF

Single Radionuclide Soil Guidelines $G(i, t)$ in pCi/g

Basic Radiation Dose Limit $=1.000 \mathrm{E}+00 \mathrm{mrem} / \mathrm{yr}$

Nuclide

\begin{tabular}{|c|c|c|c|c|c|c|}
\hline (i) & $t=0.000 \mathrm{E}+00$ & $1.000 \mathrm{E}+00$ & $5.000 \mathrm{E}+01$ & $1.000 \mathrm{E}+02$ & $5.000 \mathrm{E}+02$ & $1.026 \mathrm{E}+03$ \\
\hline $1-241$ & $\star 3.431 \mathrm{E}+12$ & $\star 3.431 \mathrm{E}+12$ & $\star 3.431 \mathrm{E}+12$ & $\star 3.431 E+12$ & $\star 3.431 \mathrm{E}+12$ & $\star 3.431 E+12$ \\
\hline-137 & $\star 8.704 \mathrm{E}+13$ & $\star 8.704 \mathrm{E}+13$ & $\star 8.704 \mathrm{E}+13$ & $\star 8.704 \mathrm{E}+13$ & $\star 8.704 \mathrm{E}+13$ & $\star 8.704 \mathrm{E}+13$ \\
\hline-237 & $\star 7.047 \mathrm{E}+08$ & $\star 7.047 \mathrm{E}+08$ & $\star 7.047 \mathrm{E}+08$ & $\star 7.047 \mathrm{E}+08$ & $\star 7.047 \mathrm{E}+08$ & $\star 7.047 \mathrm{E}+08$ \\
\hline-238 & $\star 1.712 \mathrm{E}+13$ & $\star 1.712 \mathrm{E}+13$ & $\star 1.712 \mathrm{E}+13$ & $\star 1.712 \mathrm{E}+13$ & $\star 1.712 \mathrm{E}+13$ & $\star 1.712 \mathrm{E}+13$ \\
\hline-239 & $\star 6.214 \mathrm{E}+10$ & $\star 6.214 \mathrm{E}+10$ & $* 6.214 \mathrm{E}+10$ & $\star 6.214 \mathrm{E}+10$ & $\star 6.214 \mathrm{E}+10$ & $\star 6.214 \mathrm{E}+10$ \\
\hline-240 & $\star 2.278 \mathrm{E}+11$ & $\star 2.278 \mathrm{E}+11$ & $\star 2.278 \mathrm{E}+11$ & $\star 2.278 \mathrm{E}+11$ & $\star 2.278 \mathrm{E}+11$ & $E+11$ \\
\hline-99 & $\star 1.697 \mathrm{E}+10$ & $\star 1.697 \mathrm{E}+10$ & $\star 1.697 \mathrm{E}+10$ & $\star 1.697 \mathrm{E}+10$ & $5.247 E+01$ & $3.621 \mathrm{E}+01$ \\
\hline-228 & $1.467 \mathrm{E}+14$ & $2.096 \mathrm{E}+14$ & $\star 8.195 \mathrm{E}+14$ & $\star 8.195 \mathrm{E}+14$ & $\star 8.195 \mathrm{E}+14$ & $\star 8.195 \mathrm{E}+14$ \\
\hline $1-230$ & $\star 2.018 \mathrm{E}+10$ & $\star 2.018 \mathrm{E}+10$ & $\star 2.018 \mathrm{E}+10$ & $\star 2.018 \mathrm{E}+10$ & $\star 2.018 \mathrm{E}+10$ & $\star 2.018 E+10$ \\
\hline-232 & $* 1.097 \mathrm{E}+05$ & $\star 1.097 \mathrm{E}+05$ & $\star 1.097 \mathrm{E}+05$ & $\star 1.097 \mathrm{E}+05$ & $\star 1.097 \mathrm{E}+05$ & $\star 1.097 \mathrm{E}+05$ \\
\hline 234 & $\star 6.247 \mathrm{E}+09$ & $\star 6.247 \mathrm{E}+09$ & $\star 6.247 \mathrm{E}+09$ & $\star 6.247 \mathrm{E}+09$ & $\star 6.247 \mathrm{E}+09$ & $\star 6.247 \mathrm{E}+09$ \\
\hline 235 & $\star 2.161 \mathrm{E}+06$ & $\star 2.161 \mathrm{E}+06$ & $\star 2.161 \mathrm{E}+06$ & $\star 2.161 \mathrm{E}+06$ & $\star 2.161 \mathrm{E}+06$ & $\star 2.161 \mathrm{E}+06$ \\
\hline 38 & $\star 3.361 \mathrm{E}+05$ & $\star 3.361 \mathrm{E}+05$ & $* 3.361 \mathrm{E}+05$ & $\star 3.361 \mathrm{E}+05$ & $\star 3.361 \mathrm{E}+05$ & $\star 3.361 E+05$ \\
\hline
\end{tabular}

*At specific activity limit

Summed Dose/Source Ratios DSR(i,t) in (mrem/yr)/(pCi/g)

and Single Radionuclide Soil Guidelines $G(i, t)$ in pCi/g

at tmin = time of minimum single radionuclide soil guideline

and at $\operatorname{tmax}=$ time of maximum total dose $=772$ years

\begin{tabular}{|c|c|c|c|c|c|c|}
\hline $\begin{array}{l}\text { Juclide } \\
\text { (i) }\end{array}$ & $\begin{array}{l}\text { Initial } \\
(\mathrm{pCi} / \mathrm{g})\end{array}$ & $\begin{array}{c}\text { tmin } \\
\text { (years) }\end{array}$ & $\operatorname{DSR}(i, \operatorname{tmin})$ & $\begin{array}{c}G(i, \operatorname{tmin}) \\
(\mathrm{pCi} / \mathrm{g})\end{array}$ & $\operatorname{DSR}(i, \operatorname{tmax})$ & $\begin{array}{c}G(i, t \max ) \\
(\mathrm{pCi} / \mathrm{g})\end{array}$ \\
\hline-241 & $7.000 \mathrm{E}+01$ & 1050 & $2.534 \mathrm{E}-20$ & $\star 3.431 \mathrm{E}+12$ & $1.422 \mathrm{E}-21$ & $\star 3.431 \mathrm{E}+12$ \\
\hline$s-137$ & $3.800 \mathrm{E}+01$ & 0 & $6.220 \mathrm{E}-18$ & $\star 8.704 \mathrm{E}+13$ & $4.446 \mathrm{E}-23$ & $\star 8.704 \mathrm{E}+13$ \\
\hline$p-237$ & $1.100 \mathrm{E}+01$ & 1050 & $1.518 \mathrm{E}-16$ & $\star 7.047 \mathrm{E}+08$ & $9.888 \mathrm{E}-18$ & $\star 7.047 \mathrm{E}+08$ \\
\hline$x-238$ & $7.800 \mathrm{E}+01$ & 1050 & 3. $619 \mathrm{E}-19$ & $\star 1.712 \mathrm{E}+13$ & $3.193 E-20$ & $\star 1.712 \mathrm{E}+13$ \\
\hline-239 & $7.200 E+01$ & 1050 & $6.099 \mathrm{E}-21$ & $\star 6.214 \mathrm{E}+10$ & $2.877 \mathrm{E}-22$ & $\star 6.214 \mathrm{E}+10$ \\
\hline$x-240$ & $7.200 \mathrm{E}+01$ & 1050 & $2.205 E-24$ & $\star 2.278 \mathrm{E}+11$ & $2.413 E-25$ & $\star 2.278 \mathrm{E}+11$ \\
\hline$=-99$ & $1.040 \mathrm{E}+02$ & 772 & $3.594 \mathrm{E}-02$ & $2.783 E+01$ & $3.594 \mathrm{E}-02$ & $2.783 E+01$ \\
\hline $1-228$ & $8.000 \mathrm{E}+00$ & 0 & $6.816 \mathrm{E}-15$ & $1.467 \mathrm{E}+14$ & $0.000 \mathrm{E}+00$ & $\star 8.195 \mathrm{E}+14$ \\
\hline $1-230$ & $2.000 E+02$ & 1050 & $2.489 \mathrm{E}-13$ & $4.018 \mathrm{E}+12$ & $3.305 E-14$ & $\star 2.018 \mathrm{E}+10$ \\
\hline $1-232$ & $8.000 \mathrm{E}+00$ & 1050 & $2.748 \mathrm{E}-12$ & $* 1.097 \mathrm{E}+05$ & $5.851 \mathrm{E}-13$ & $\star 1.097 \mathrm{E}+05$ \\
\hline-234 & $3.200 \mathrm{E}+02$ & 1050 & 1. $263 \mathrm{E}-15$ & $\star 6.247 \mathrm{E}+09$ & 1. $211 \mathrm{E}-16$ & $* 6.247 \mathrm{E}+09$ \\
\hline 235 & $1.300 \mathrm{E}+01$ & 1050 & $5.208 \mathrm{E}-17$ & $\star 2.161 \mathrm{E}+06$ & $3.601 \mathrm{E}-18$ & $\star 2.161 \mathrm{E}+06$ \\
\hline 238 & $3.200 \mathrm{E}+02$ & 1050 & $1.582 \mathrm{E}-15$ & $\star 3.361 \mathrm{E}+05$ & $2.047 \mathrm{E}-16$ & $\star 3.361 \mathrm{E}+05$ \\
\hline
\end{tabular}

*At specific activity limit 
RESRAD-OFFSITE, Version 2.

Parent Dose Report

Title : RESRAD-OFFSITE Parameters for Offsite Resident Farmer Forward Run 1,050 Years File : OFFSITE-RF FORWARD-7-11ALS.ROF

Individual Nuclide Dose Summed Over All Pathways

Parent Nuclide and Thread Fraction Indicated

Nuclide Parent THF(i) DOSE $(j, t)$, mrem/yr

\begin{tabular}{|c|c|c|}
\hline (j) & (i) & \\
\hline-241 & $A m-241$ & $1.000 \mathrm{E}+00$ \\
\hline $0-237$ & $A m-241$ & $1.000 \mathrm{E}+00$ \\
\hline $\mathrm{Np}-237$ & $\mathrm{~Np}-237$ & $1.000 \mathrm{E}+00$ \\
\hline $\mathrm{Np}-237$ & $\sum \operatorname{DOSE}(j$ & \\
\hline
\end{tabular}

$\mathrm{U}-233 \quad \mathrm{Am}-241 \quad 1.000 \mathrm{E}+00$

$\mathrm{U}-233 \quad \mathrm{~Np}-237 \quad 1.000 \mathrm{E}+00$

U-233 $\operatorname{LDOSE}(j):$

Th-229 Am-241 $1.000 \mathrm{E}+00$

Th-229 Np-237 $1.000 \mathrm{E}+00$

Th-229 $\operatorname{DOSE}(j):$

Cs-137 Cs $-137 \quad 1.000 \mathrm{E}+00$

$\mathrm{Pu}-238$

$\mathrm{Pu}-238$

$\mathrm{Pu}-238$

$\mathrm{U}-234$

$\mathrm{U}-234$

$\mathrm{U}-234$

$\mathrm{U}-234$

Th -230

Th -230

Th -230

Th -230

Th -230

$\mathrm{Ra}-226$

$\mathrm{Ra}-226$

$\mathrm{Ra}-226$

$\mathrm{Ra}-226$

$\mathrm{Ra}-226$

$\mathrm{Pb}-210 \quad \mathrm{Pu}-238 \quad 1.000 \mathrm{E}+00$

$\mathrm{Pb}-210 \quad \mathrm{Th}-230 \quad 1.000 \mathrm{E}+00$

$\mathrm{Pb}-210 \quad \mathrm{U}-234 \quad 1.000 \mathrm{E}+00$

$\mathrm{Pb}-210 \quad \mathrm{U}-238 \quad 9.999 \mathrm{E}-01$

$\mathrm{Pb}-210 \quad \sum \operatorname{DOSE}(j)$ :

$\mathrm{Pu}-239 \mathrm{Pu}-239 \quad 1.000 \mathrm{E}+00$ $\mathrm{t}=0.000 \mathrm{E}+00 \quad 1.000 \mathrm{E}+00 \quad 5.000 \mathrm{E}+01 \quad 1.000 \mathrm{E}+02 \quad 5.000 \mathrm{E}+02 \quad 1.026 \mathrm{E}+03$

$\begin{array}{llllll}6.676 \mathrm{E}-40 & 6.841 \mathrm{E}-40 & 2.267 \mathrm{E}-39 & 7.698 \mathrm{E}-39 & 1.361 \mathrm{E}-34 & 5.241 \mathrm{E}-29\end{array}$

$\begin{array}{llllll}5.335 E-26 & 1.613 E-25 & 8.483 E-24 & 2.663 E-23 & 5.177 E-21 & 1.376 E-18\end{array}$

$\begin{array}{llllll}5.170 \mathrm{E}-20 & 5.222 \mathrm{E}-20 & 8.468 \mathrm{E}-20 & 1.387 \mathrm{E}-19 & 7.179 \mathrm{E}-18 & 1.288 \mathrm{E}-15\end{array}$

$\begin{array}{llllll}5.170 \mathrm{E}-20 & 5.222 \mathrm{E}-20 & 8.469 \mathrm{E}-20 & 1.387 \mathrm{E}-19 & 7.184 \mathrm{E}-18 & 1.290 \mathrm{E}-15\end{array}$

$\begin{array}{llllll}1.212 \mathrm{E}-36 & 8.551 \mathrm{E}-36 & 1.598 \mathrm{E}-32 & 1.097 \mathrm{E}-31 & 2.238 \mathrm{E}-28 & 3.198 \mathrm{E}-25\end{array}$

$\begin{array}{llllll}1.759 \mathrm{E}-30 & 5.332 \mathrm{E}-30 & 3.152 \mathrm{E}-28 & 1.115 \mathrm{E}-27 & 5.536 \mathrm{E}-25 & 4.825 \mathrm{E}-22\end{array}$

$\begin{array}{llllll}1.759 \mathrm{E}-30 & 5.332 \mathrm{E}-30 & 3.152 \mathrm{E}-28 & 1.115 \mathrm{E}-27 & 5.539 \mathrm{E}-25 & 4.828 \mathrm{E}-22\end{array}$

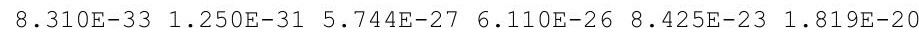

$\begin{array}{llllll}1.609 \mathrm{E}-26 & 1.131 \mathrm{E}-25 & 1.688 \mathrm{E}-22 & 9.194 \mathrm{E}-22 & 2.940 \mathrm{E}-19 & 3.670 \mathrm{E}-17\end{array}$

$\begin{array}{lllllll}1.609 \mathrm{E}-26 & 1.131 \mathrm{E}-25 & 1.688 \mathrm{E}-22 & 9.195 \mathrm{E}-22 & 2.941 \mathrm{E}-19 & 3.672 \mathrm{E}-17\end{array}$

$2.364 \mathrm{E}-16 \quad 2.328 \mathrm{E}-16 \quad 1.097 \mathrm{E}-16 \quad 5.090 \mathrm{E}-17 \quad 1.095 \mathrm{E}-19 \quad 3.403 \mathrm{E}-23$

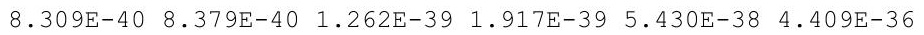

$\begin{array}{lllllll}4.516 \mathrm{E}-31 & 4.554 \mathrm{E}-31 & 6.859 \mathrm{E}-31 & 1.042 \mathrm{E}-30 & 2.951 \mathrm{E}-29 & 2.396 \mathrm{E}-27\end{array}$

$\begin{array}{lllllll}4.516 \mathrm{E}-31 & 4.554 \mathrm{E}-31 & 6.859 \mathrm{E}-31 & 1.042 \mathrm{E}-30 & 2.951 \mathrm{E}-29 & 2.396 \mathrm{E}-27\end{array}$

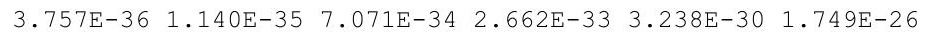

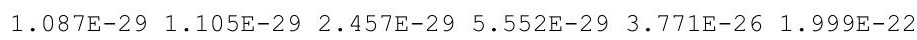

$\begin{array}{llllll}1.546 \mathrm{E}-35 & 4.704 \mathrm{E}-35 & 3.518 \mathrm{E}-33 & 1.582 \mathrm{E}-32 & 5.355 \mathrm{E}-29 & 5.824 \mathrm{E}-25\end{array}$

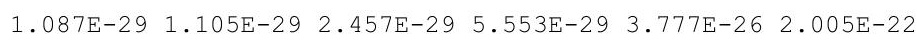

$\begin{array}{llllll}3.959 E-40 & 2.798 E-39 & 5.752 E-36 & 4.385 E-35 & 2.587 E-31 & 2.123 E-27\end{array}$

$2.377 \mathrm{E}-28 \quad 2.414 \mathrm{E}-28 \quad 5.155 \mathrm{E}-28 \quad 1.118 \mathrm{E}-27 \quad 5.463 \mathrm{E}-25 \quad 1.877 \mathrm{E}-21$

$\begin{array}{llllll}1.716 \mathrm{E}-33 & 5.221 \mathrm{E}-33 & 3.749 \mathrm{E}-31 & 1.618 \mathrm{E}-30 & 3.933 \mathrm{E}-27 & 2.768 \mathrm{E}-23\end{array}$

$\begin{array}{llllll}1.627 \mathrm{E}-39 & 1.153 \mathrm{E}-38 & 2.684 \mathrm{E}-35 & 2.304 \mathrm{E}-34 & 2.790 \mathrm{E}-30 & 4.027 \mathrm{E}-26\end{array}$

$2.377 \mathrm{E}-28 \quad 2.414 \mathrm{E}-28 \quad 5.159 \mathrm{E}-28 \quad 1.119 \mathrm{E}-27 \quad 5.502 \mathrm{E}-25 \quad 1.905 \mathrm{E}-21$

$\begin{array}{llllll}3.096 \mathrm{E}-29 & 4.651 \mathrm{E}-28 & 1.970 \mathrm{E}-23 & 1.939 \mathrm{E}-22 & 1.645 \mathrm{E}-19 & 2.318 \mathrm{E}-17\end{array}$

$3.720 \mathrm{E}-17 \quad 1.122 \mathrm{E}-16 \quad 5.103 \mathrm{E}-15 \quad 1.381 \mathrm{E}-14 \quad 8.048 \mathrm{E}-13 \quad 4.210 \mathrm{E}-11$

$\begin{array}{llllll}1.791 \mathrm{E}-22 & 1.258 \mathrm{E}-21 & 1.863 \mathrm{E}-18 & 1.007 \mathrm{E}-17 & 3.003 \mathrm{E}-15 & 3.336 \mathrm{E}-13\end{array}$

$\begin{array}{llllll}1.214 \mathrm{E}-28 & 1.910 \mathrm{E}-27 & 8.905 \mathrm{E}-23 & 9.593 \mathrm{E}-22 & 1.445 \mathrm{E}-18 & 3.351 \mathrm{E}-16\end{array}$

$\begin{array}{llllll}3.720 \mathrm{E}-17 & 1.122 \mathrm{E}-16 & 5.105 \mathrm{E}-15 & 1.382 \mathrm{E}-14 & 8.078 \mathrm{E}-13 & 4.244 \mathrm{E}-11\end{array}$

$9.050 \mathrm{E}-38 \quad 2.780 \mathrm{E}-36 \quad 2.898 \mathrm{E}-30 \quad 4.750 \mathrm{E}-29 \quad 1.036 \mathrm{E}-25 \quad 2.669 \mathrm{E}-23$ $\begin{array}{llllll}1.797 \mathrm{E}-25 & 1.253 \mathrm{E}-24 & 1.242 \mathrm{E}-21 & 4.926 \mathrm{E}-21 & 5.550 \mathrm{E}-19 & 5.048 \mathrm{E}-17\end{array}$ $\begin{array}{llllll}6.496 \mathrm{E}-31 & 9.718 \mathrm{E}-30 & 3.367 \mathrm{E}-25 & 2.869 \mathrm{E}-24 & 1.942 \mathrm{E}-21 & 3.870 \mathrm{E}-19\end{array}$ $\begin{array}{llllll}3.590 \mathrm{E}-36 & 1.283 \mathrm{E}-35 & 1.290 \mathrm{E}-29 & 2.293 \mathrm{E}-28 & 8.814 \mathrm{E}-25 & 3.770 \mathrm{E}-22\end{array}$ $\begin{array}{llllll}1.797 \mathrm{E}-25 & 1.253 \mathrm{E}-24 & 1.242 \mathrm{E}-21 & 4.929 \mathrm{E}-21 & 5.569 \mathrm{E}-19 & 5.087 \mathrm{E}-17\end{array}$

$\begin{array}{llllll}4.266 \mathrm{E}-24 & 4.313 \mathrm{E}-24 & 7.392 \mathrm{E}-24 & 1.281 \mathrm{E}-23 & 1.040 \mathrm{E}-21 & 3.374 \mathrm{E}-19\end{array}$ 
RESRAD-OFFSITE, Version 2.

Parent Dose Report

Title : RESRAD-OFFSITE Parameters for Offsite Resident Farmer Forward Run 1,050 Years File : OFFSITE-RF_FORWARD-7-11ALS.ROF

Individual Nuclide Dose Summed Over All Pathways

Parent Nuclide and Thread Fraction Indicated

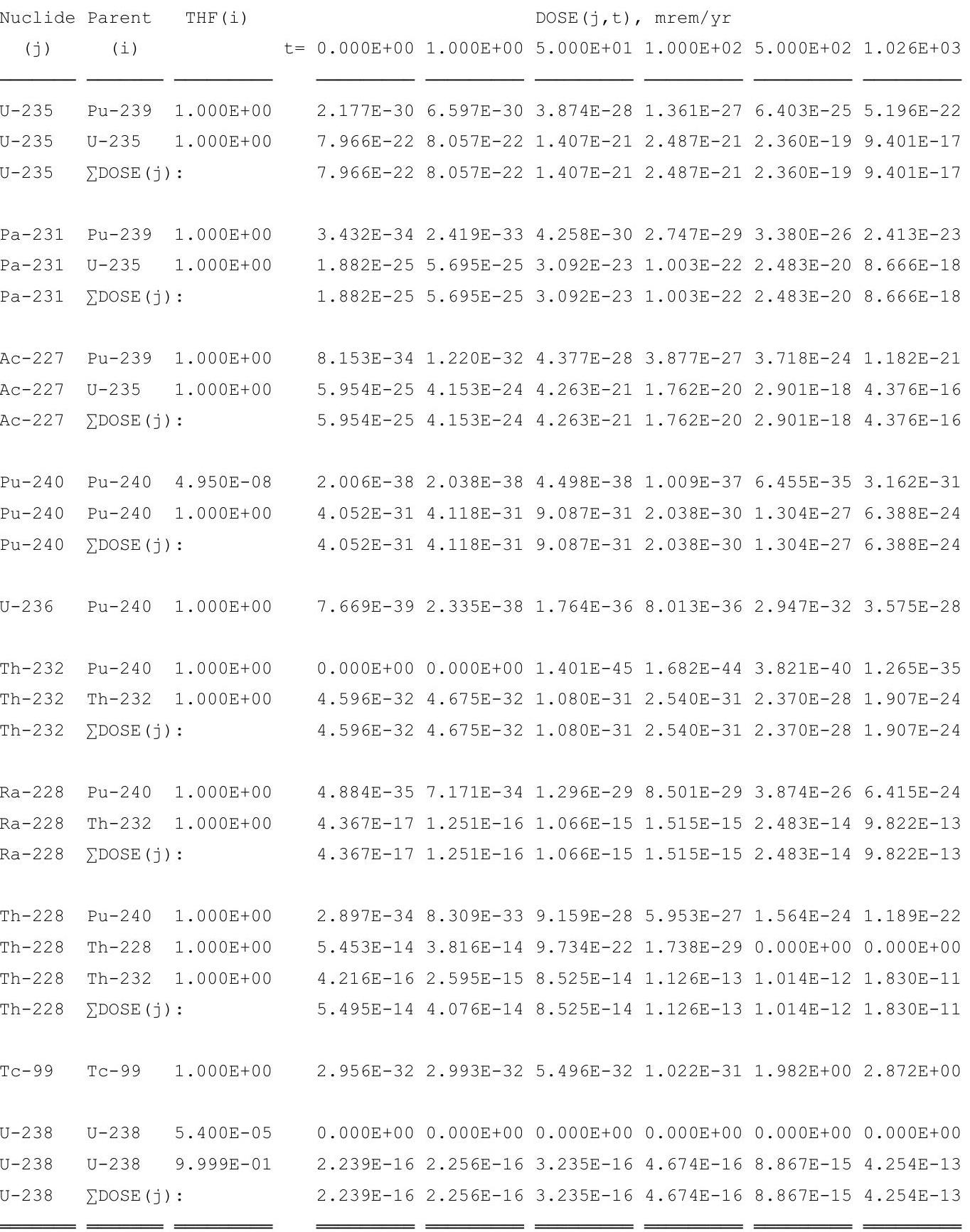

THF (i) is the thread fraction of the parent nuclide. 
RESRAD-OFFSITE, Version 2.

Parent Dose Report

Title : RESRAD-OFFSITE Parameters for Offsite Resident Farmer Forward Run 1,050 Years File : OFFSITE-RF_FORWARD-7-11ALS.ROF

Individual Nuclide Soil Concentration

Parent Nuclide and Thread Fraction Indicated

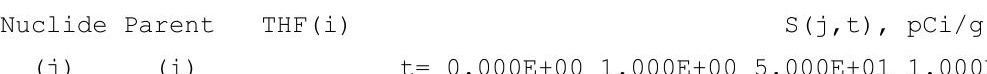

\section{(j)}

(i)

Am-241 Am-241 1.000E+00

$\mathrm{Np}-237 \quad \mathrm{Am}-241 \quad 1.000 \mathrm{E}+00$

$\mathrm{Np}-237 \quad \mathrm{~Np}-237 \quad 1.000 \mathrm{E}+00$

Np-237 $\sum S(j):$

$\mathrm{U}-233 \mathrm{Am}-241 \quad 1.000 \mathrm{E}+00$

$\mathrm{U}-233 \mathrm{~Np}-237 \quad 1.000 \mathrm{E}+00$

$\mathrm{U}-233 \sum \mathrm{S}(j)$ :

Th-229 Am-241 1.000E+00

Th-229 Np-237 1.000E+00

Th-229 $\sum S(j):$

CS-137 Cs $-137 \quad 1.000 E+00$

$\mathrm{Pu}-238$

$\mathrm{Pu}-238$

$\mathrm{Pu}-238$

$\mathrm{U}-234$

$\mathrm{U}-234$

$\mathrm{U}-234$

$\mathrm{U}-234$

Th-230

Th-230

$\mathrm{Th}-230$

Th-230

$\mathrm{Th}-230$

$\mathrm{Ra}-226$

$\mathrm{Ra}-226$

$\mathrm{Ra}-226$

$\mathrm{Ra}-226$

$\mathrm{Ra}-226$

$\mathrm{Pb}-210$

$\mathrm{Pb}-210$

$\mathrm{Pb}-210$

$\mathrm{Pb}-210$

$\mathrm{Pb}-210$

Pu-239 Pu-239 1.000E+00
$=0.000 \mathrm{E}+001.000 \mathrm{E}+00 \quad 5.000 \mathrm{E}+01 \quad 1.000 \mathrm{E}+02 \quad 5.000 \mathrm{E}+02 \quad 1.026 \mathrm{E}+03$

$\begin{array}{lllllll}7.000 \mathrm{E}+01 & 6.989 \mathrm{E}+01 & 6.460 \mathrm{E}+01 & 5.961 \mathrm{E}+01 & 3.135 \mathrm{E}+01 & 1.346 \mathrm{E}+01\end{array}$

$0.000 E+00 \quad 2.265 E-05 \quad 1.087 E-03 \quad 2.086 E-03 \quad 7.621 E-03 \quad 1.083 E-02$

$\begin{array}{lllllll}1.100 \mathrm{E}+01 & 1.100 \mathrm{E}+01 & 1.096 \mathrm{E}+01 & 1.091 \mathrm{E}+01 & 1.058 \mathrm{E}+01 & 1.015 \mathrm{E}+01\end{array}$

$\begin{array}{lllllll}1.100 \mathrm{E}+01 & 1.100 \mathrm{E}+01 & 1.096 \mathrm{E}+01 & 1.092 \mathrm{E}+01 & 1.058 \mathrm{E}+01 & 1.016 \mathrm{E}+01\end{array}$

$0.000 \mathrm{E}+00 \quad 4.960 \mathrm{E}-11 \quad 1.205 \mathrm{E}-07 \quad 4.687 \mathrm{E}-07 \quad 9.484 \mathrm{E}-06 \quad 3.113 \mathrm{E}-05$

$0.000 \mathrm{E}+00 \quad 4.810 \mathrm{E}-05 \quad 2.399 \mathrm{E}-03 \quad 4.787 \mathrm{E}-03 \quad 2.348 \mathrm{E}-02 \quad 4.698 \mathrm{E}-02$

$0.000 \mathrm{E}+00 \quad 4.810 \mathrm{E}-05 \quad 2.400 \mathrm{E}-03 \quad 4.788 \mathrm{E}-03 \quad 2.349 \mathrm{E}-02 \quad 4.701 \mathrm{E}-02$

$0.000 \mathrm{E}+00 \quad 1.564 \mathrm{E}-15 \quad 1.908 \mathrm{E}-10 \quad 1.493 \mathrm{E}-09 \quad 1.575 \mathrm{E}-07 \quad 1.109 \mathrm{E}-06$

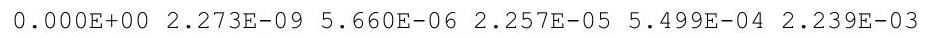

$0.000 \mathrm{E}+00 \quad 2.273 \mathrm{E}-09 \quad 5.660 \mathrm{E}-06 \quad 2.257 \mathrm{E}-05 \quad 5.501 \mathrm{E}-04 \quad 2.240 \mathrm{E}-03$

$\begin{array}{lllllll}3.800 E+01 & 3.713 E+01 & 1.196 E+01 & 3.763 E+00 & 3.617 E-04 & 1.887 E-09\end{array}$

$\begin{array}{lllllll}1.435 \mathrm{E}-07 & 1.424 \mathrm{E}-07 & 9.664 \mathrm{E}-08 & 6.507 \mathrm{E}-08 & 2.750 \mathrm{E}-09 & 4.289 \mathrm{E}-11\end{array}$

$\begin{array}{llllllll}7.800 \mathrm{E}+01 & 7.739 \mathrm{E}+01 & 5.252 \mathrm{E}+01 & 3.536 \mathrm{E}+01 & 1.494 \mathrm{E}+00 & 2.331 \mathrm{E}-02\end{array}$

$\begin{array}{lllllll}7.800 \mathrm{E}+01 & 7.739 \mathrm{E}+01 & 5.252 \mathrm{E}+01 & 3.536 \mathrm{E}+01 & 1.494 \mathrm{E}+00 & 2.331 \mathrm{E}-02\end{array}$

$\begin{array}{lllllll}0.000 \mathrm{E}+00 & 2.203 \mathrm{E}-04 & 9.128 \mathrm{E}-03 & 1.527 \mathrm{E}-02 & 2.725 \mathrm{E}-02 & 2.754 \mathrm{E}-02\end{array}$

$\begin{array}{lllll}3.200 \mathrm{E}+02 & 3.200 \mathrm{E}+02 \quad 3.197 \mathrm{E}+02 & 3.195 \mathrm{E}+02 & 3.174 \mathrm{E}+02 & 3.147 \mathrm{E}+02\end{array}$

$0.000 \mathrm{E}+00 \quad 9.071 \mathrm{E}-04 \quad 4.532 \mathrm{E}-02 \quad 9.058 \mathrm{E}-02 \quad 4.502 \mathrm{E}-01 \quad 9.167 \mathrm{E}-01$

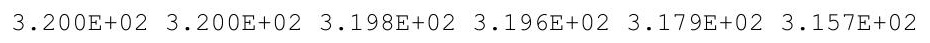

$\begin{array}{llllll}0.000 \mathrm{E}+00 & 9.936 \mathrm{E}-10 & 2.189 \mathrm{E}-06 & 7.768 \mathrm{E}-06 & 9.410 \mathrm{E}-05 & 2.236 \mathrm{E}-04\end{array}$ $\begin{array}{llllll}2.000 \mathrm{E}+02 & 2.000 \mathrm{E}+02 & 1.999 \mathrm{E}+02 & 1.998 \mathrm{E}+02 & 1.989 \mathrm{E}+02 & 1.978 \mathrm{E}+02\end{array}$ $\begin{array}{lllllll}0.000 \mathrm{E}+00 & 2.881 \mathrm{E}-03 & 1.439 \mathrm{E}-01 & 2.877 \mathrm{E}-01 & 1.431 \mathrm{E}+00 & 2.915 \mathrm{E}+00\end{array}$ $0.000 \mathrm{E}+00 \quad 4.087 \mathrm{E}-09 \quad 1.020 \mathrm{E}-05 \quad 4.077 \mathrm{E}-05 \quad 1.014 \mathrm{E}-03 \quad 4.239 \mathrm{E}-03$

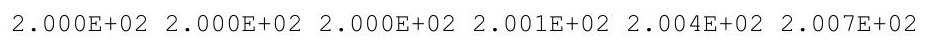

$0.000 \mathrm{E}+00 \quad 1.438 \mathrm{E}-13 \quad 1.622 \mathrm{E}-08 \quad 1.178 \mathrm{E}-07 \quad 7.905 \mathrm{E}-06 \quad 3.905 \mathrm{E}-05$ $0.000 \mathrm{E}+00 \quad 8.662 \mathrm{E}-02 \quad 4.283 \mathrm{E}+00 \quad 8.470 \mathrm{E}+00 \quad 3.874 \mathrm{E}+01 \quad 7.097 \mathrm{E}+01$ $0.000 \mathrm{E}+00 \quad 6.245 \mathrm{E}-07 \quad 1.548 \mathrm{E}-03 \quad 6.143 \mathrm{E}-03 \quad 1.444 \mathrm{E}-01 \quad 5.621 \mathrm{E}-01$ $0.000 \mathrm{E}+00 \quad 6.051 \mathrm{E}-13 \quad 7.326 \mathrm{E}-08 \quad 5.825 \mathrm{E}-07 \quad 6.943 \mathrm{E}-05 \quad 5.644 \mathrm{E}-04$ $0.000 \mathrm{E}+00 \quad 8.662 \mathrm{E}-02 \quad 4.285 \mathrm{E}+00 \quad 8.476 \mathrm{E}+00 \quad 3.888 \mathrm{E}+01 \quad 7.154 \mathrm{E}+01$

$0.000 \mathrm{E}+00 \quad 1.116 \mathrm{E}-15 \quad 4.836 \mathrm{E}-09 \quad 5.623 \mathrm{E}-08 \quad 6.796 \mathrm{E}-06 \quad 3.654 \mathrm{E}-05$ $\begin{array}{llllll}0.000 \mathrm{E}+00 & 1.334 \mathrm{E}-03 & 2.115 \mathrm{E}+00 & 5.891 \mathrm{E}+00 & 3.647 \mathrm{E}+01 & 6.916 \mathrm{E}+01\end{array}$ $\begin{array}{lllllll}0.000 \mathrm{E}+00 & 6.433 \mathrm{E}-09 & 5.674 \mathrm{E}-04 & 3.412 \mathrm{E}-03 & 1.275 \mathrm{E}-01 & 5.299 \mathrm{E}-01\end{array}$ $\begin{array}{llllll}0.000 \mathrm{E}+00 & 1.858 \mathrm{E}-14 & 2.150 \mathrm{E}-08 & 2.712 \mathrm{E}-07 & 5.779 \mathrm{E}-05 & 5.159 \mathrm{E}-04\end{array}$ $\begin{array}{llllll}0.000 \mathrm{E}+00 & 1.334 \mathrm{E}-03 \quad 2.116 \mathrm{E}+00 & 5.894 \mathrm{E}+00 & 3.659 \mathrm{E}+01 & 6.969 \mathrm{E}+01\end{array}$

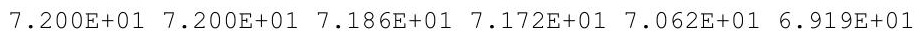


RESRAD-OFFSITE, Version 2.

Parent Dose Report

Title : RESRAD-OFFSITE Parameters for Offsite Resident Farmer Forward Run 1,050 Years File : OFFSITE-RF_FORWARD-7-11ALS.ROF

Individual Nuclide Soil Concentration

Parent Nuclide and Thread Fraction Indicated

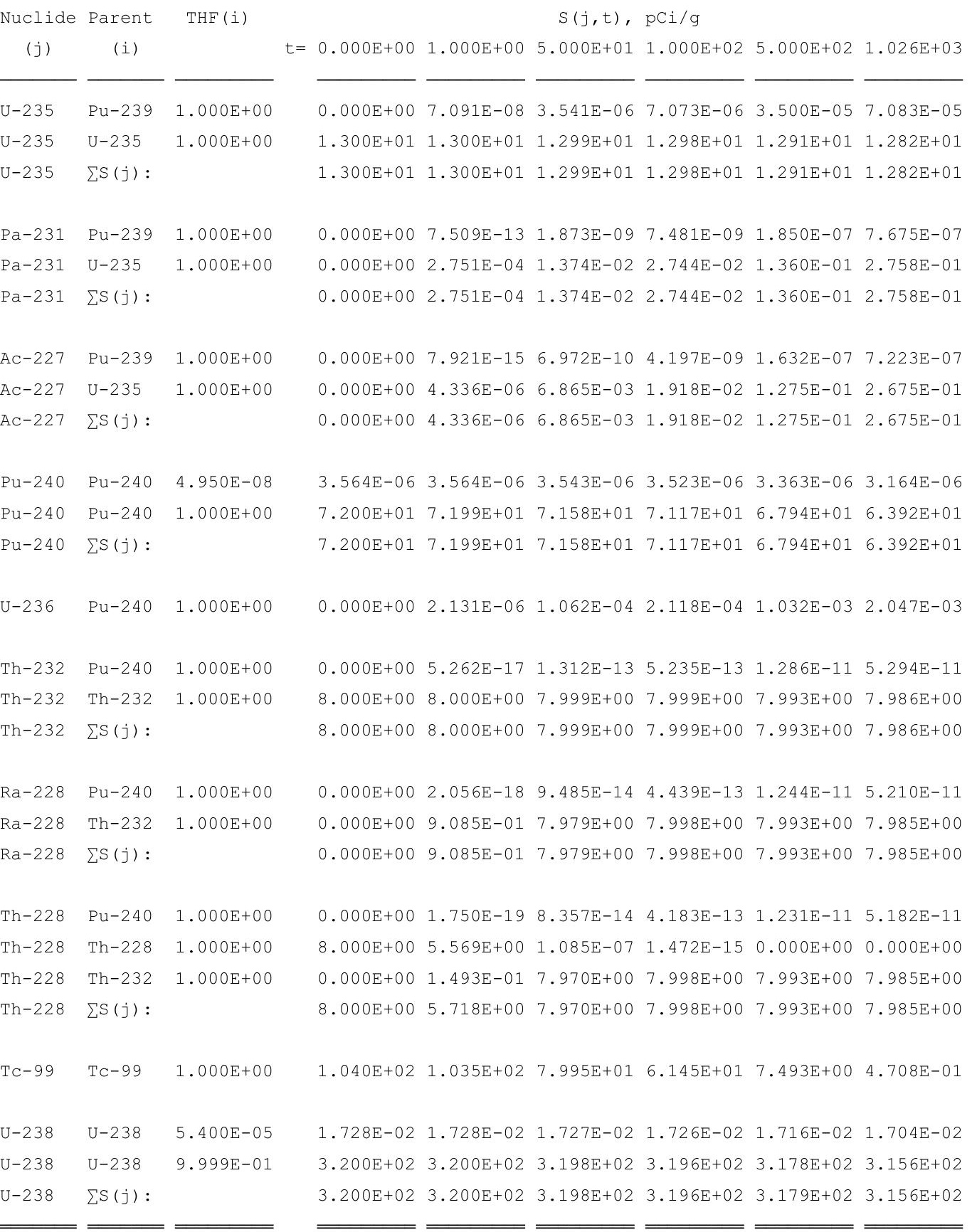

THF (i) is the thread fraction of the parent nuclide. 
RESRAD-OFFSITE, Version $2.5 \quad \mathrm{~T}^{1 / 2}$ Limit $=180$ days

Parent Dose Report

Title : RESRAD-OFFSITE Parameters for Offsite Resident Farmer Forward Run 1,050 Years

File : OFFSITE-RF_FORWARD-7-11ALS.ROF

Run Time Information

ResOCalc.EXE execution began at 11:14 on 07/21/2011

ResOCalc.EXE execution ended at 11:29 on 07/21/2011

ResOCalc.EXE execution time 14 minutes 57 seconds 
RESRAD-OFFSITE, Version 2.5

Parent Dose Report

Title : RESRAD-OFFSITE Parameters for Offsite Resident Farmer Forward Run 10,000 Years

File : OFFSITE-RF_FORWARD-7-11-10000yr.ROF

Table of Contents

Part I: Mixture Sums and Single Radionuclide Guidelines

Dose Conversion Factor (and Related) Parameter Summary ... 2

Site-Specific Parameter Summary $\ldots \ldots \ldots \ldots \ldots \ldots \ldots \ldots \ldots, 11$

Summary of Pathway Selections $\ldots \ldots \ldots \ldots \ldots \ldots \ldots \ldots \ldots \ldots \ldots \ldots$

Contaminated Zone and Total Dose Summary ............. 49

Total Dose Components

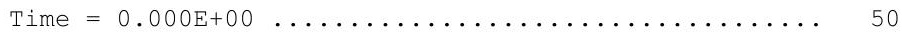

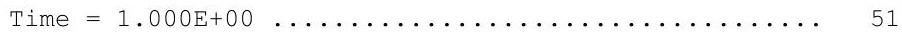

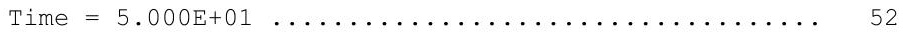

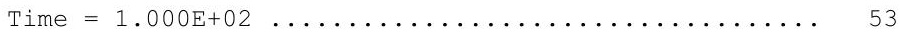

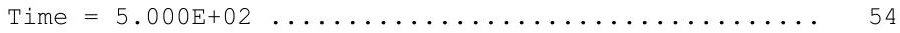

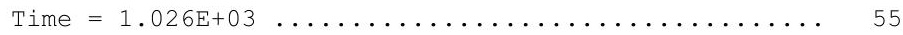

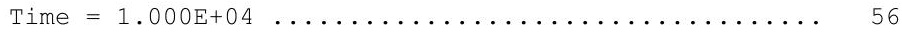

Dose/Source Ratios Summed Over All Pathways ............ 57

Single Radionuclide Soil Guidelines ................ 59

Dose Per Nuclide Summed Over All Pathways ............ 60

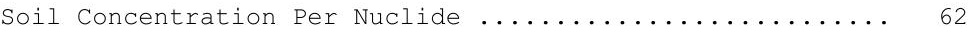

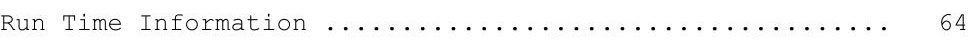


RESRAD-OFFSITE, Version 2.5

Parent Dose Report

Title : RESRAD-OFFSITE Parameters for Offsite Resident Farmer Forward Run 10,000 Years

File : OFFSITE-RF FORWARD-7-11-10000yr.ROF

Dose Conversion Factor (and Related) Parameter Summary

Current Library: ICRP 60

Default Library: ICRP 60

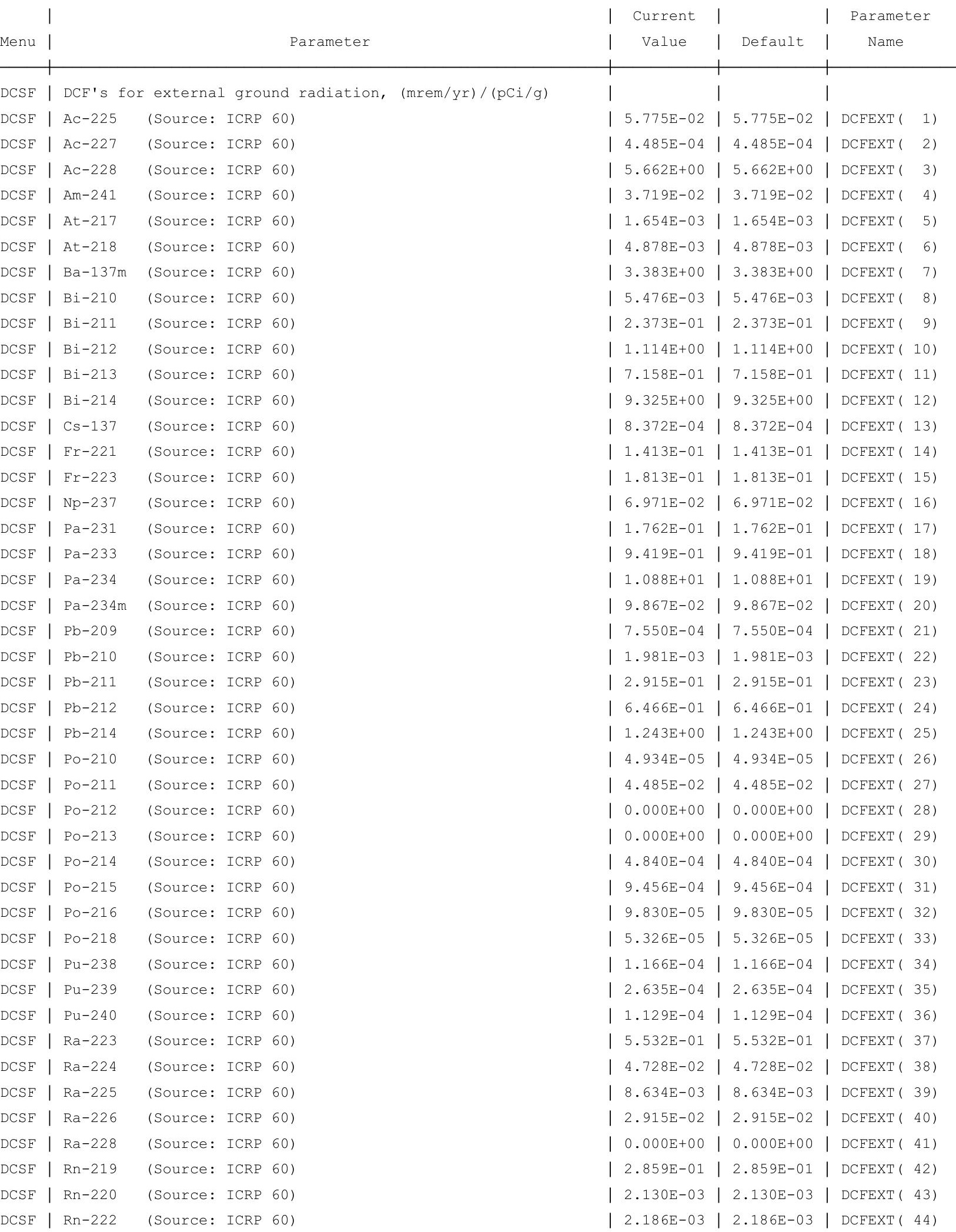


RESRAD-OFFSITE, Version $2.5 \quad \mathrm{~T}^{1 / 2}$ Limit $=180$ days

Parent Dose Report

Title : RESRAD-OFFSITE Parameters for Offsite Resident Farmer Forward Run 10,000 Years

File : OFFSITE-RF_FORWARD-7-11-10000yr.ROF

Dose Conversion Factor (and Related) Parameter Summary (continued)

Current Library: ICRP 60

Default Library: ICRP 60

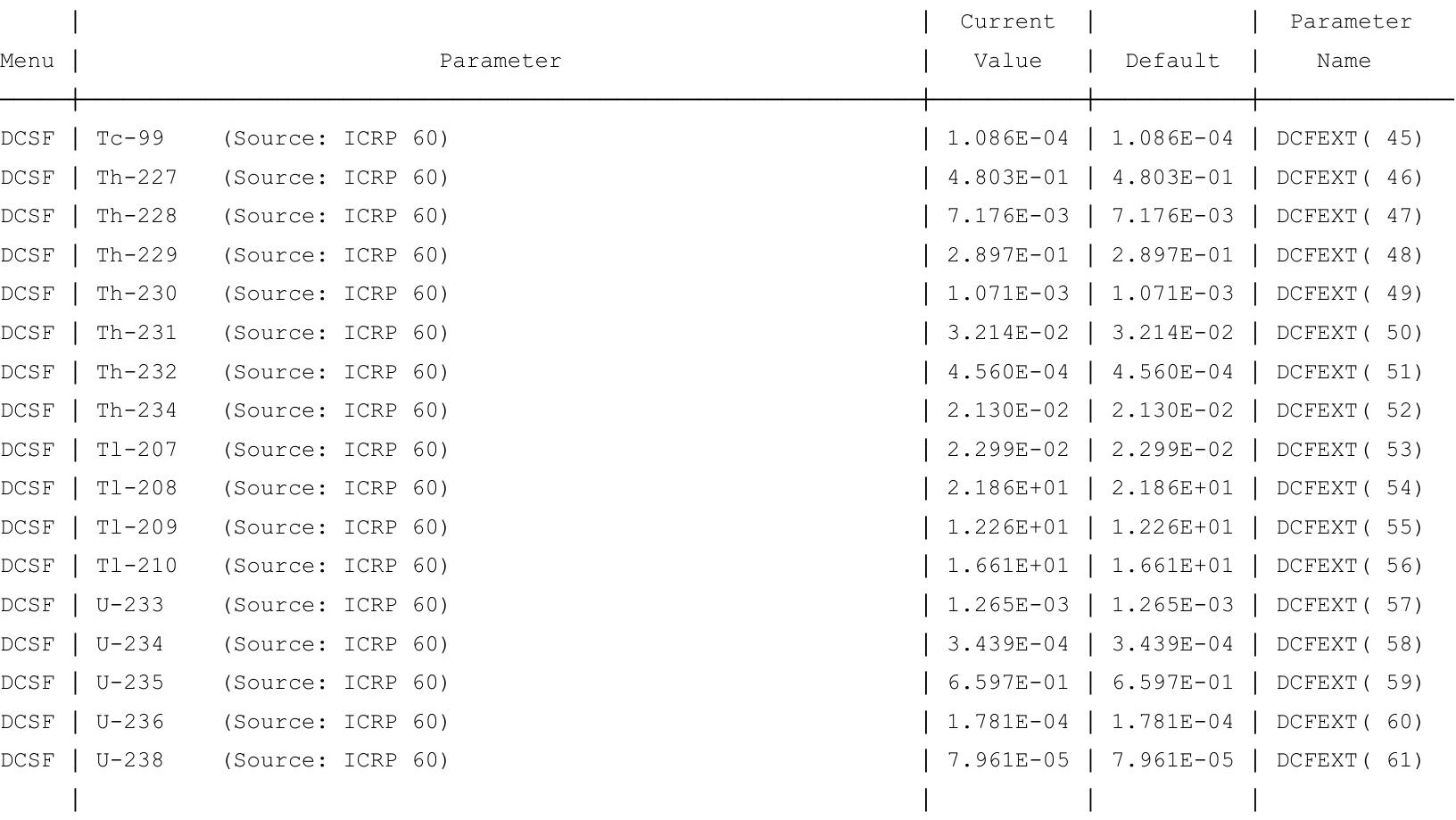

Current Library: ICRP 72 (Adult)

Default Library: ICRP 72 (Adult)

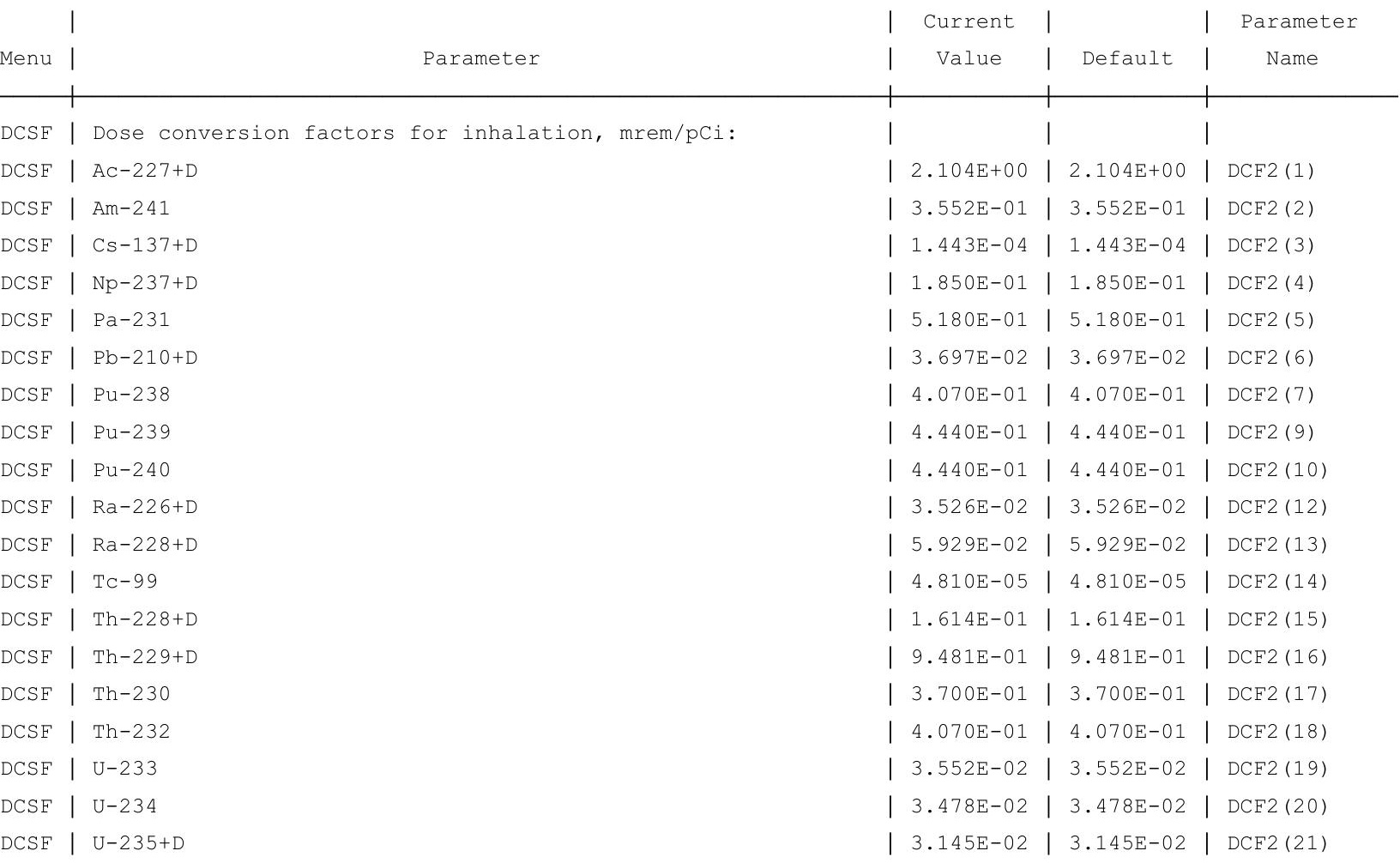


RESRAD-OFFSITE, Version 2.9

Parent Dose Report

Title : RESRAD-OFFSITE Parameters for Offsite Resident Farmer Forward Run 10,000 Years

File : OFFSITE-RF_FORWARD-7-11-10000yr.ROF

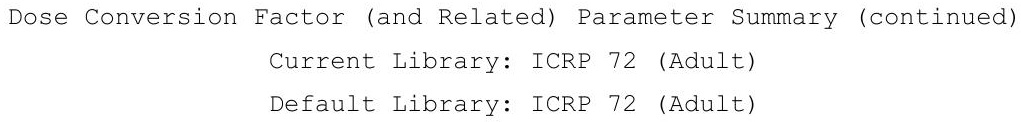

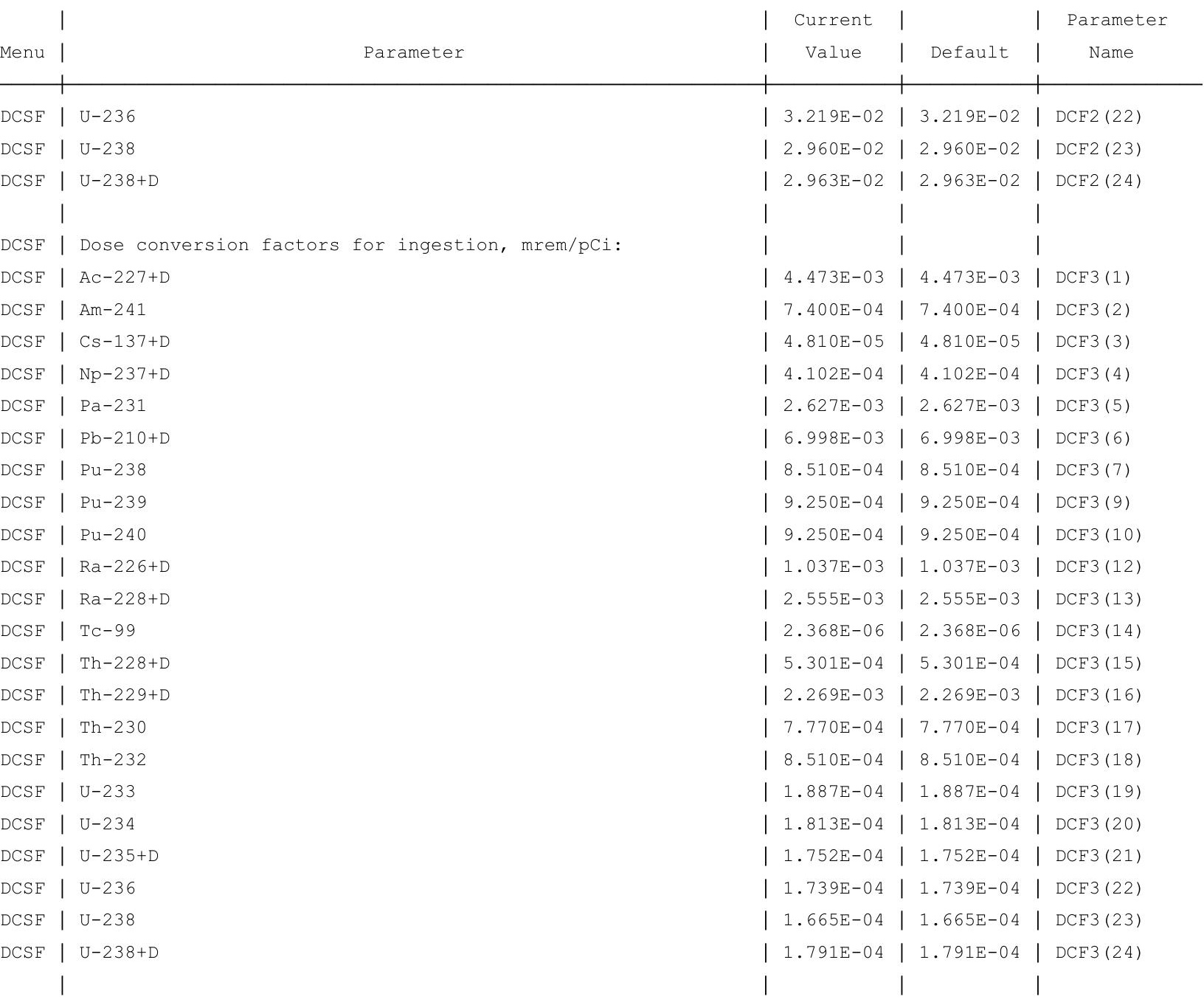


RESRAD-OFFSITE, Version 2.5

arent Dose Report

Title : RESRAD-OFFSITE Parameters for Offsite Resident Farmer Forward Run 10,000 Years File : OFFSITE-RF_FORWARD-7-11-10000yr.ROF

Dose Conversion Factor (and Related) Parameter Summary (continued) Current Library: RESRAD Default Transfer factors Default Library: RESRAD Default Transfer factors

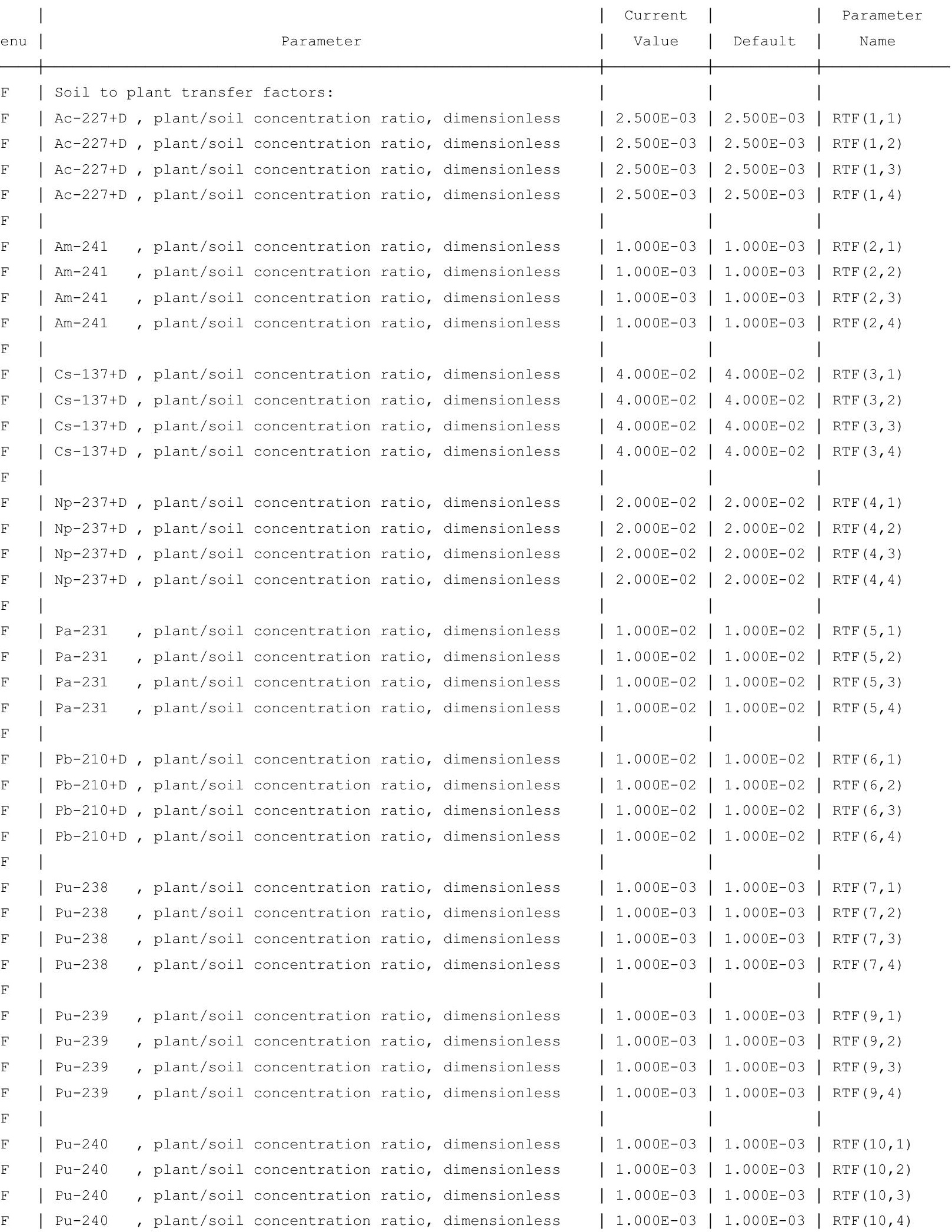


Parent Dose Report

Title : RESRAD-OFFSITE Parameters for Offsite Resident Farmer Forward Run 10,000 Years File : OFFSITE-RF_FORWARD-7-11-10000yr.ROF

Dose Conversion Factor (and Related) Parameter Summary (continued) Current Library: RESRAD Default Transfer factors Default Library: RESRAD Default Transfer factors

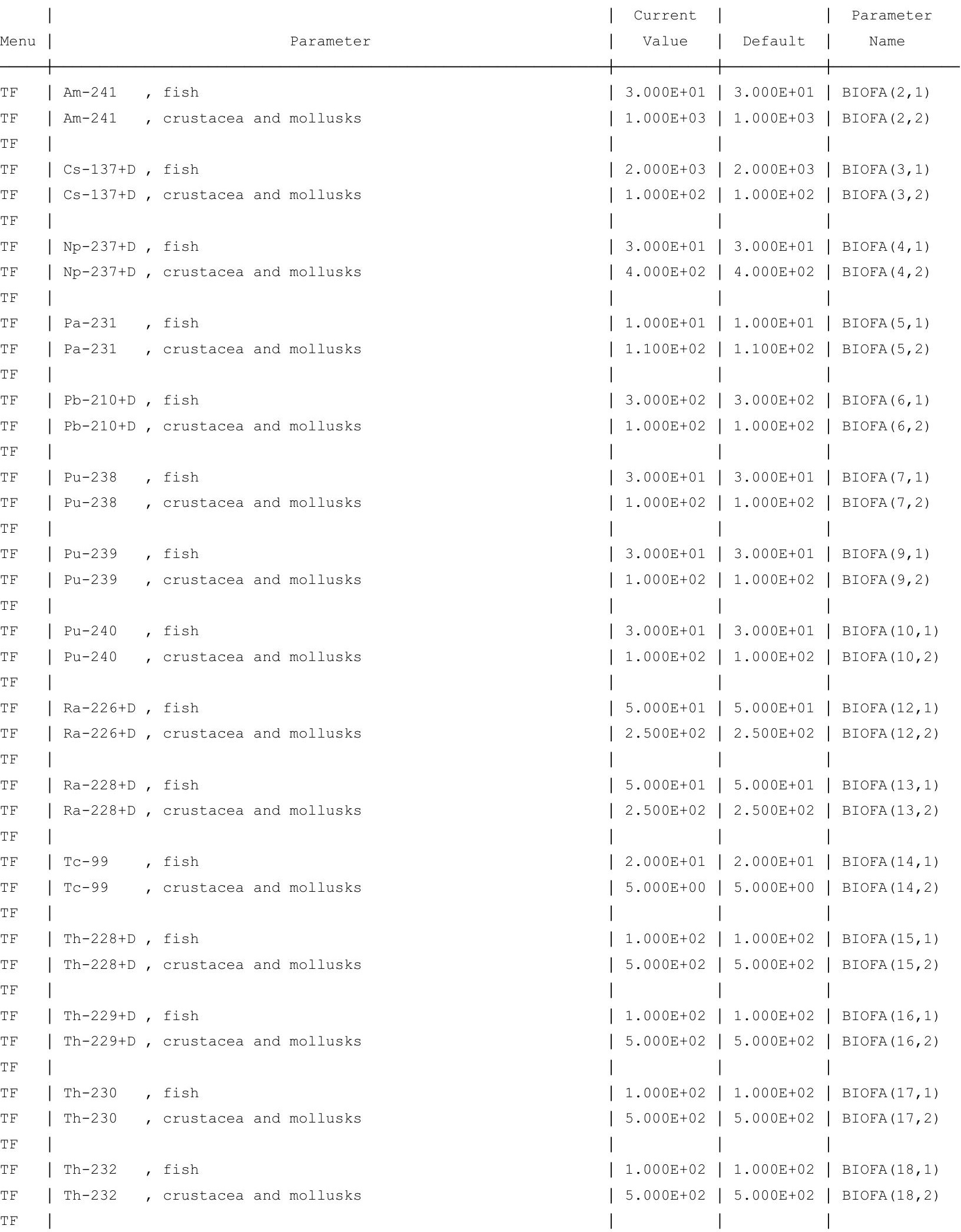


RESRAD-OFFSITE, Version 2.5

Parent Dose Report

Title : RESRAD-OFFSITE Parameters for Offsite Resident Farmer Forward Run 10,000 Years

File : OFFSITE-RF_FORWARD-7-11-10000yr.ROF

Dose Conversion Factor (and Related) Parameter Summary (continued)

Current Library: RESRAD Default Transfer factors

Default Library: RESRAD Default Transfer factors

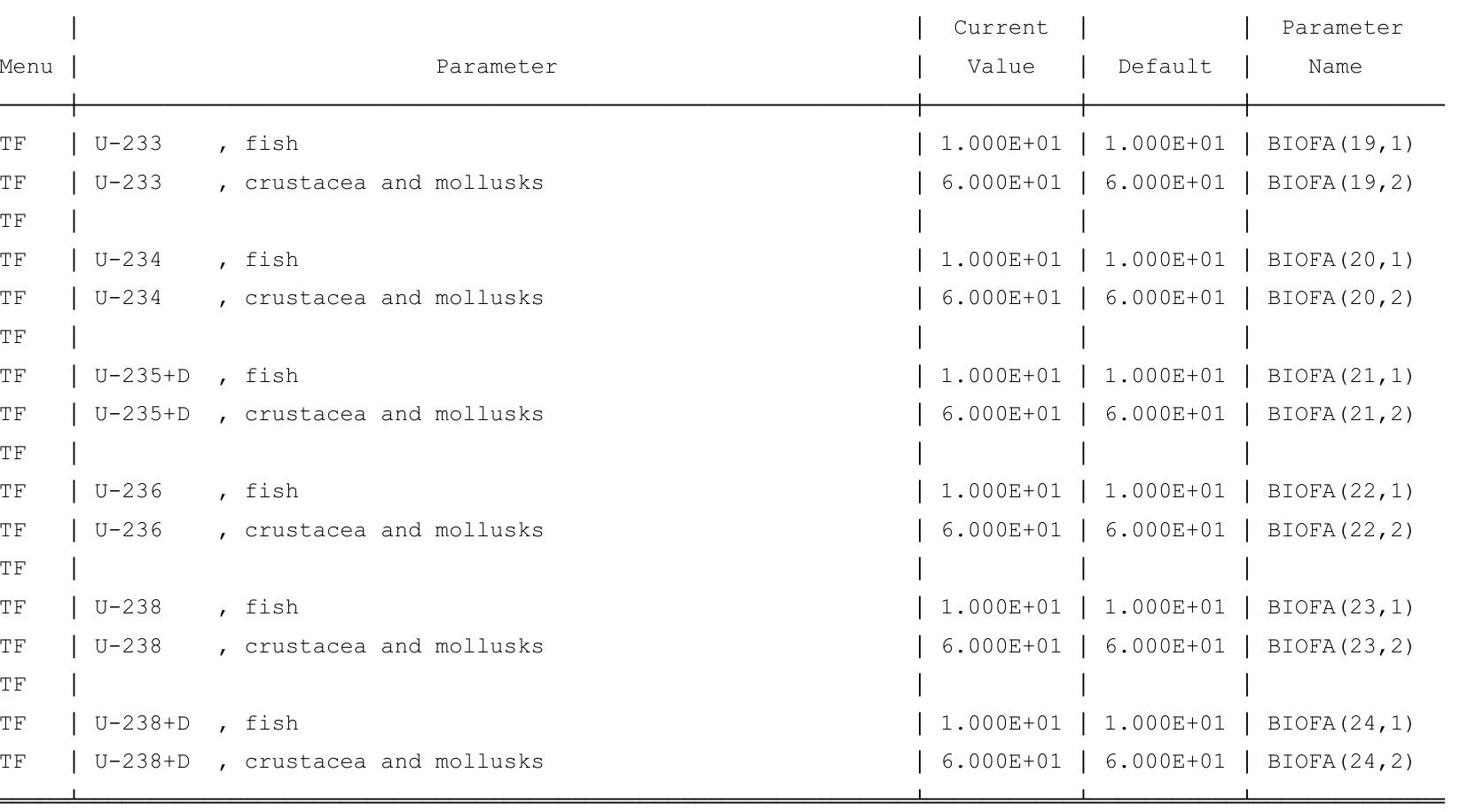


RESRAD-OFFSITE, Version 2.5 TT1/2 Limit = 180 days $\quad$ 07/21/2011 $12: 59$ Page

Parent Dose Report

Title : RESRAD-OFFSITE Parameters for Offsite Resident Farmer Forward Run 10,000 Years

File : OFFSITE-RF_FORWARD-7-11-10000yr.ROF

Site-Specific Parameter Summary

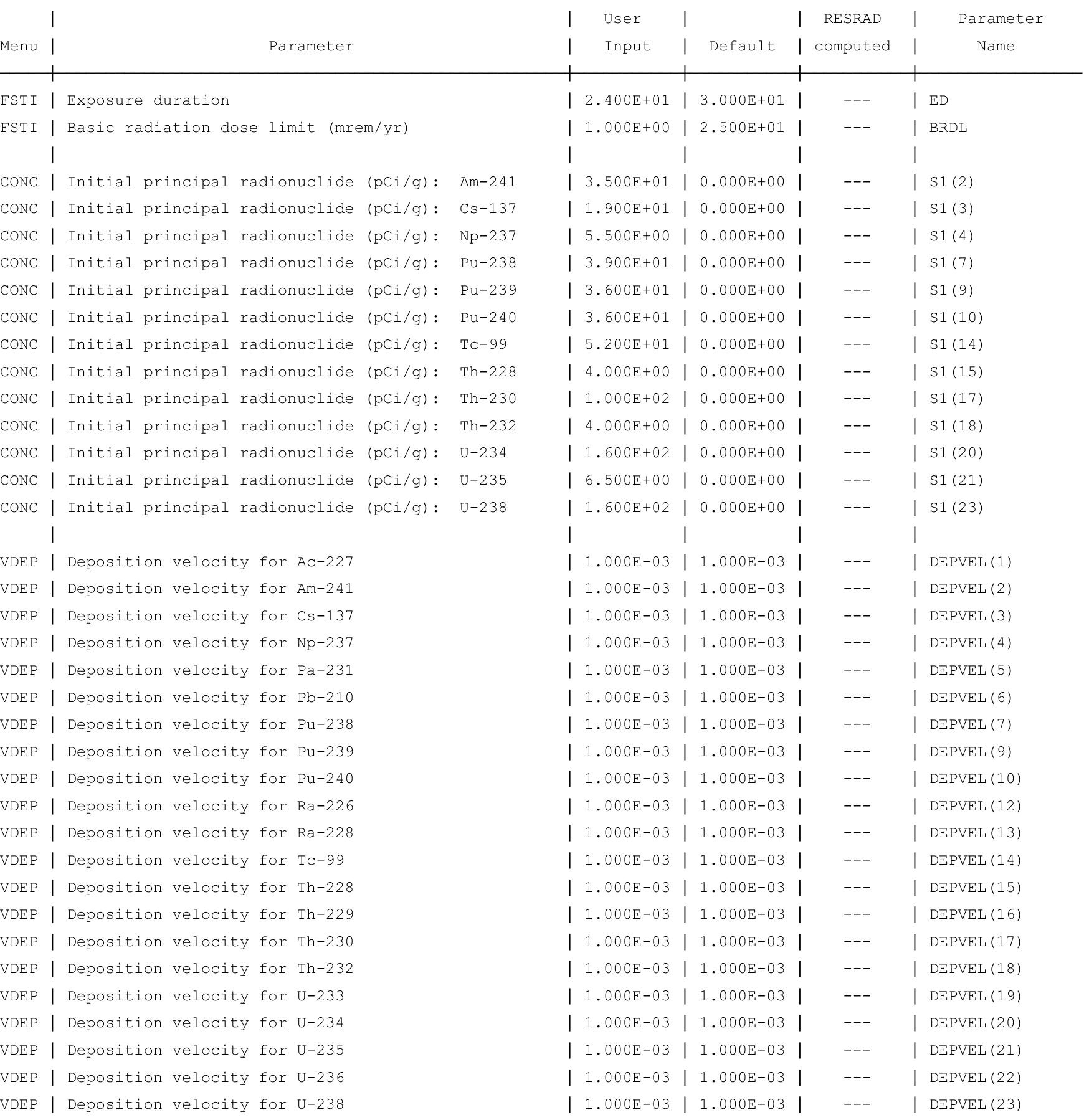

DEP Deposition velocity for U-238 
RESRAD-OFFSITE, Version $2.5 \quad T^{1 / 3}$ Limit $=180$ days $\quad 07 / 21 / 2011 \quad 12: 59$ Page

Parent Dose Report

Title : RESRAD-OFFSITE Parameters for Offsite Resident Farmer Forward Run 10,000 Years

File : OFFSITE-RF_FORWARD-7-11-10000yr.ROF

Site-Specific Parameter Summary (continued)

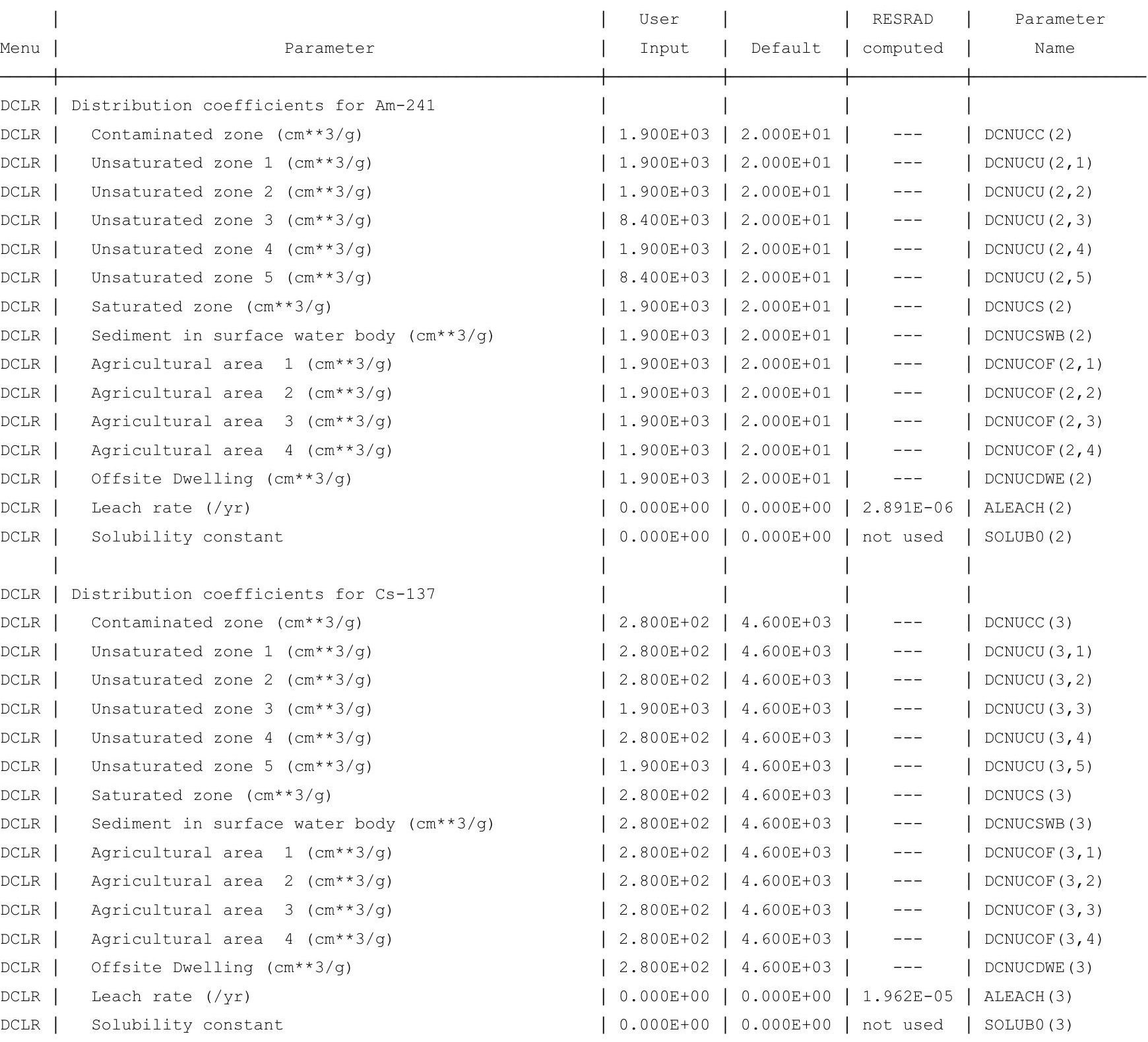


RESRAD-OFFSITE, Version 2.5

Parent Dose Report

Title : RESRAD-OFFSITE Parameters for Offsite Resident Farmer Forward Run 10,000 Years

File : OFFSITE-RF_FORWARD-7-11-10000yr.ROF

Site-Specific Parameter Summary (continued)

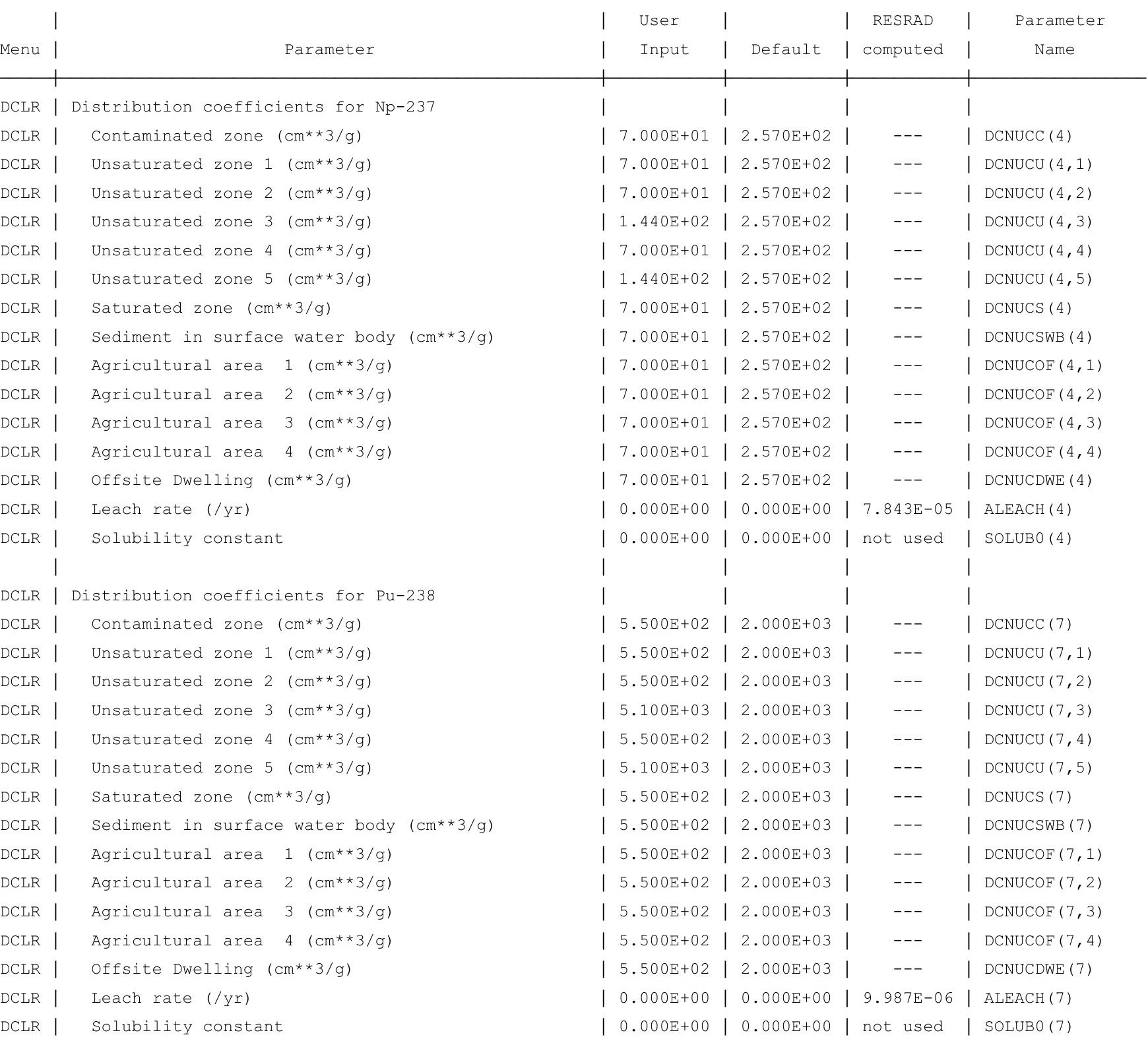


RESRAD-OFFSITE, Version 2.5

Parent Dose Report

Title : RESRAD-OFFSITE Parameters for Offsite Resident Farmer Forward Run 10,000 Years

File : OFFSITE-RF_FORWARD-7-11-10000yr.ROF

Site-Specific Parameter Summary (continued)

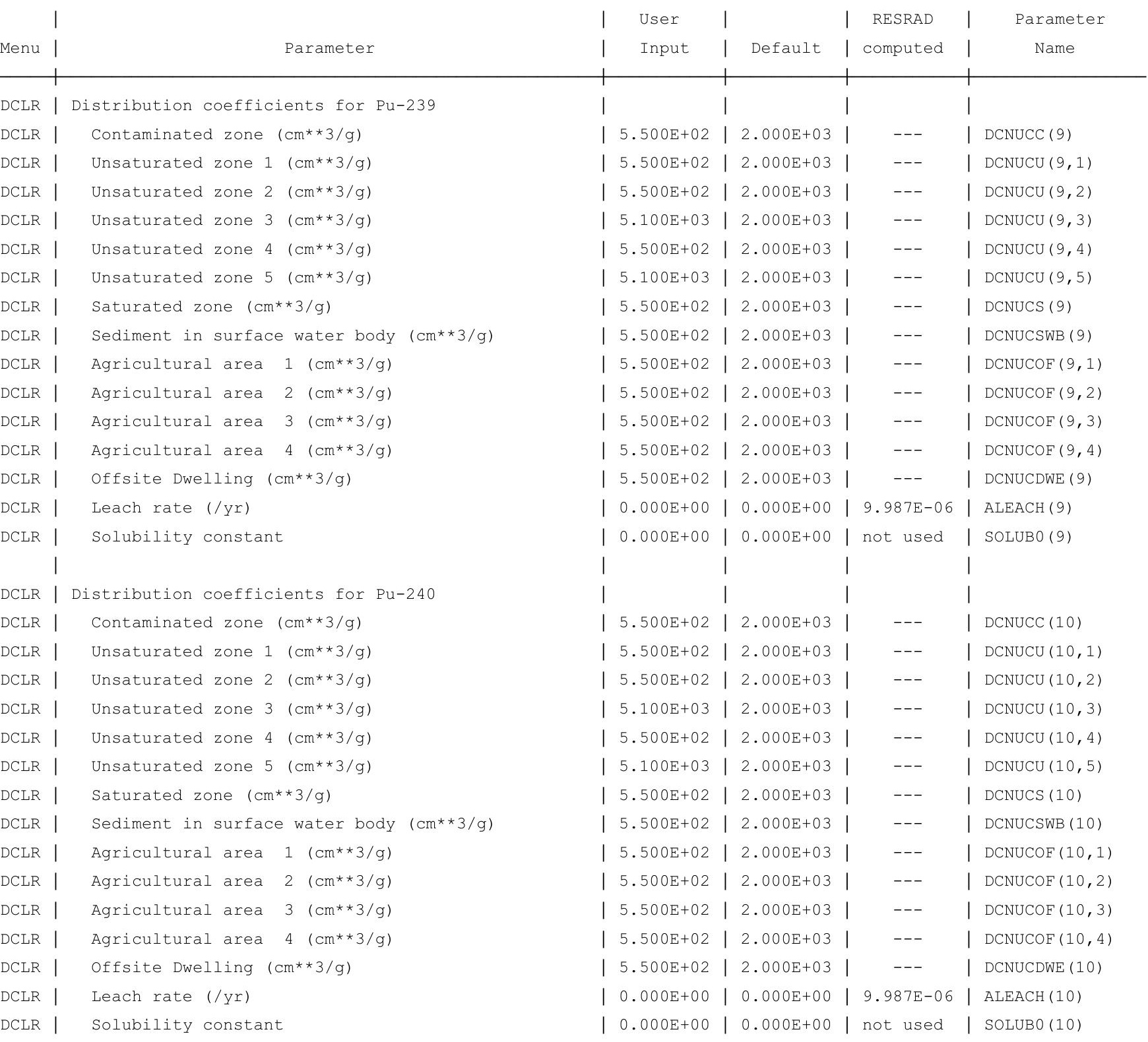


RESRAD-OFFSITE, Version $2.5 \quad$ T1/2 Limit $=180$ days $\quad$ 07/21/2011 $12: 59$ Page

Parent Dose Report

Title : RESRAD-OFFSITE Parameters for Offsite Resident Farmer Forward Run 10,000 Years

File : OFFSITE-RF_FORWARD-7-11-10000yr.ROF

Site-Specific Parameter Summary (continued)

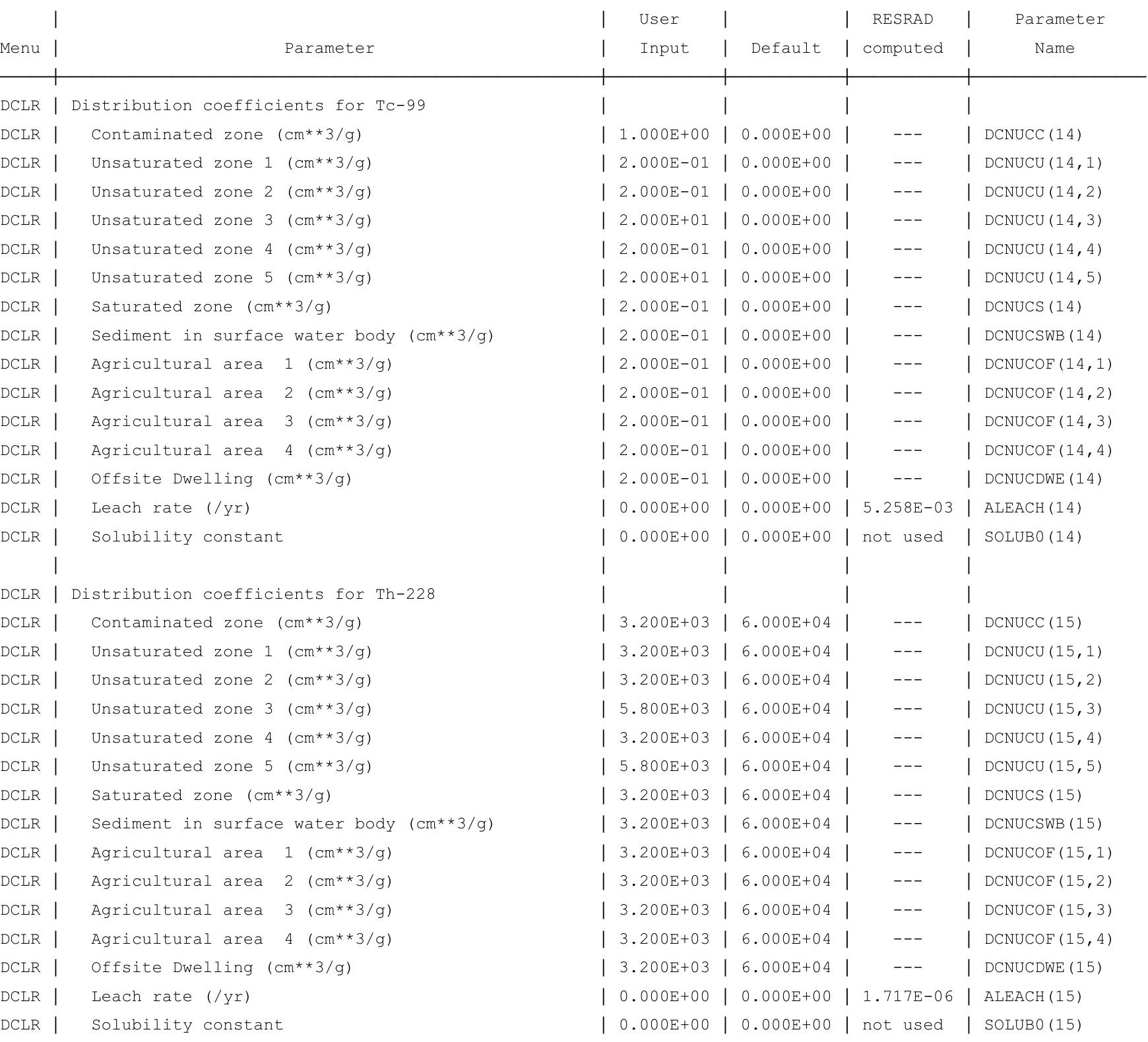


RESRAD-OFFSITE, Version 2.5

Parent Dose Report

Title : RESRAD-OFFSITE Parameters for Offsite Resident Farmer Forward Run 10,000 Years

File : OFFSITE-RF_FORWARD-7-11-10000yr.ROF

Site-Specific Parameter Summary (continued)

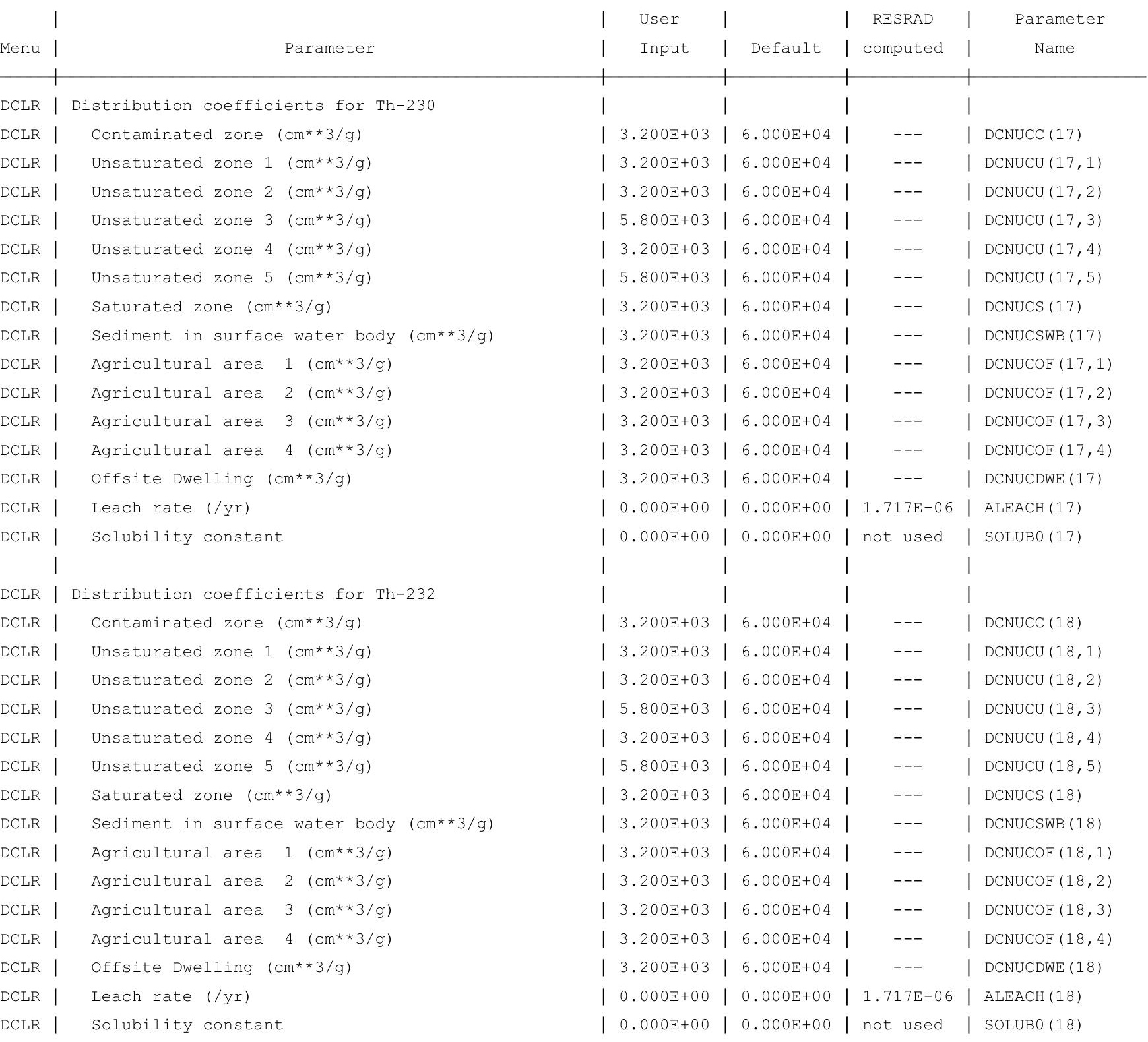


RESRAD-OFFSITE, Version 2.5

Parent Dose Report

Title : RESRAD-OFFSITE Parameters for Offsite Resident Farmer Forward Run 10,000 Years

File : OFFSITE-RF_FORWARD-7-11-10000yr.ROF

Site-Specific Parameter Summary (continued)

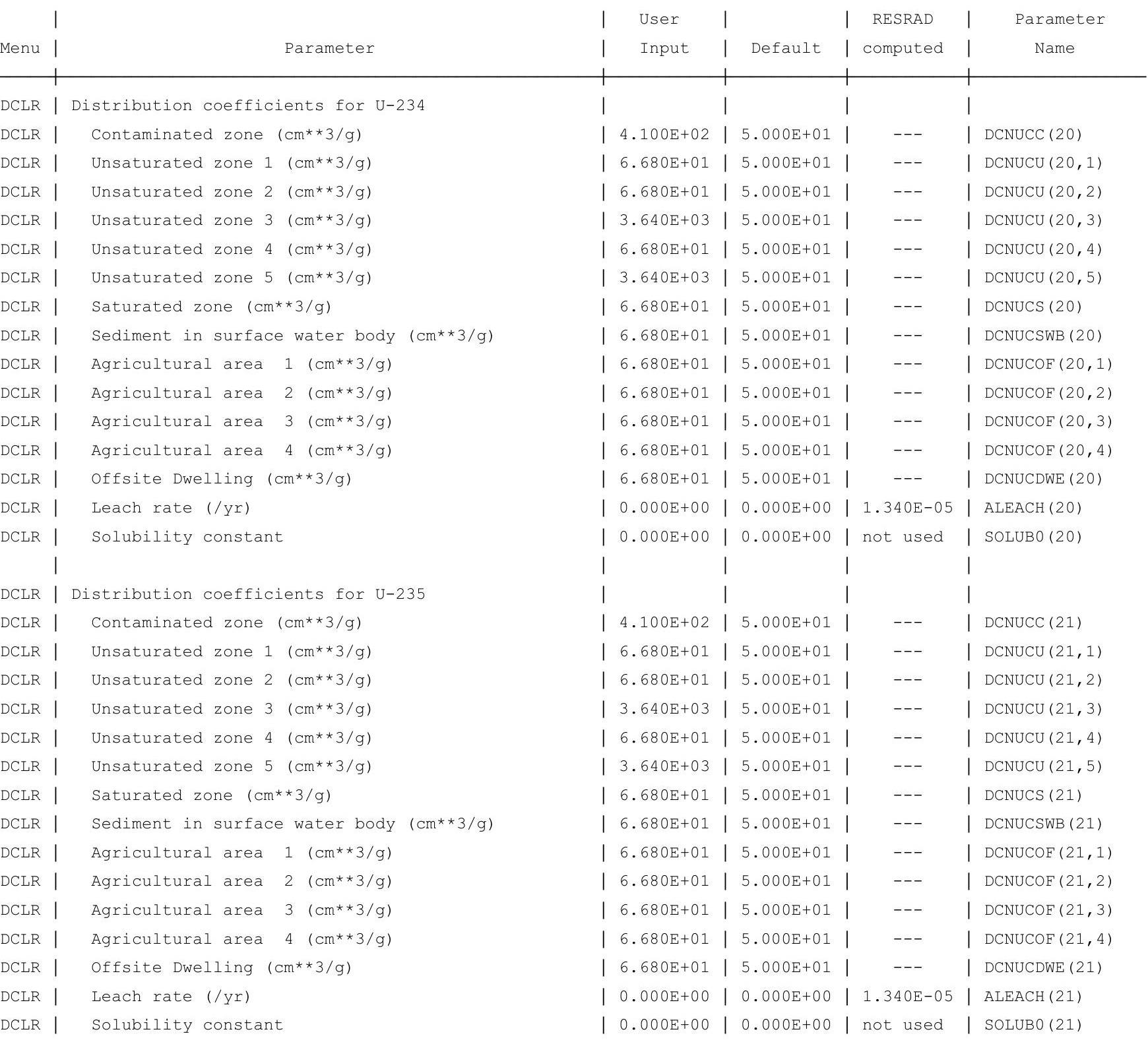


RESRAD-OFFSITE, Version $2.5 \quad T^{1 / 2}$ Limit $=180$ days $\quad$ 07/21/2011 $12: 59$ Page

Parent Dose Report

Title : RESRAD-OFFSITE Parameters for Offsite Resident Farmer Forward Run 10,000 Years

File : OFFSITE-RF_FORWARD-7-11-10000yr.ROF

Site-Specific Parameter Summary (continued)

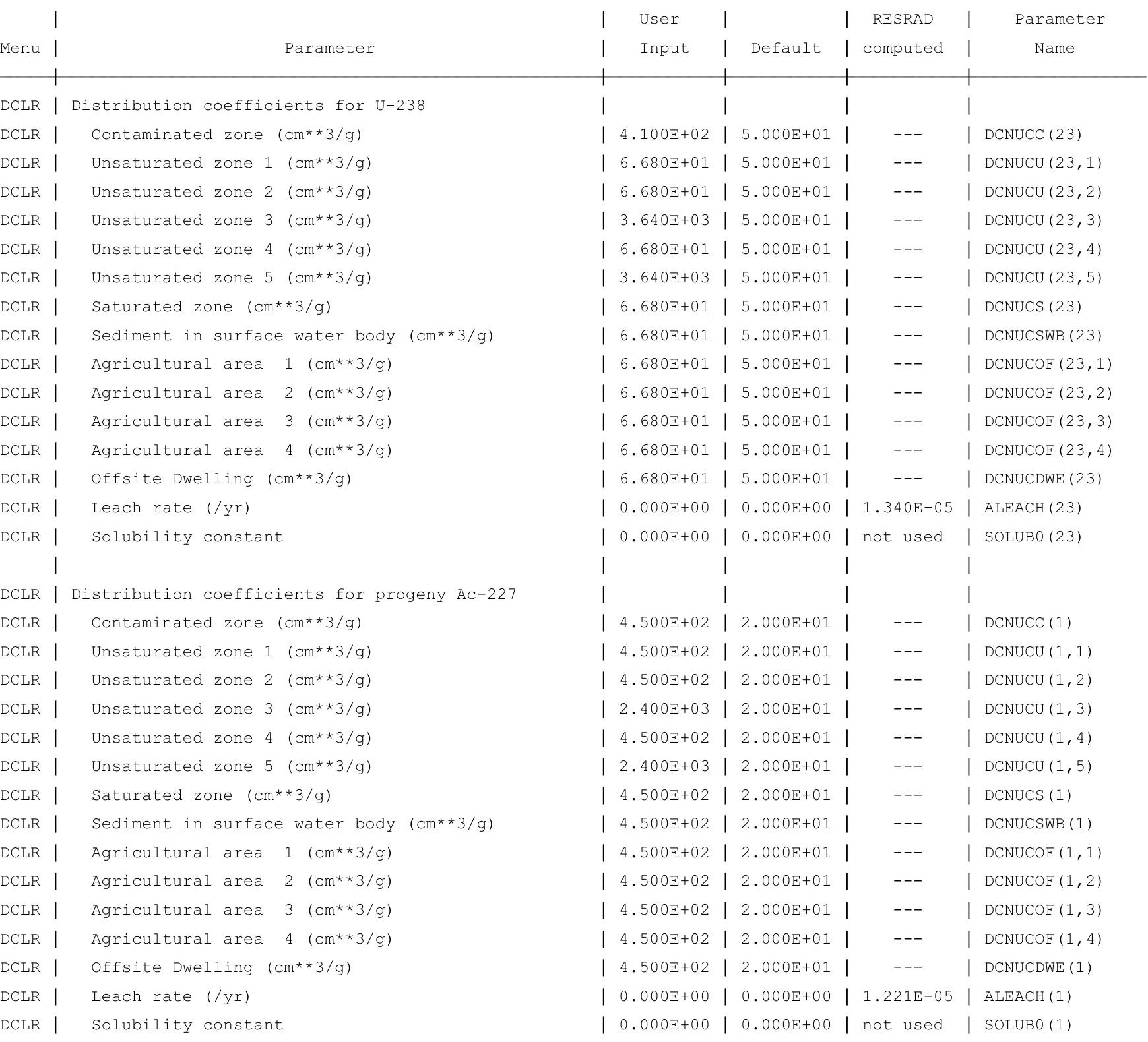


RESRAD-OFFSITE, Version $2.5 \quad$ T1/2 Limit $=180$ days $\quad$ 07/21/2011 $12: 59$ Page

Parent Dose Report

Title : RESRAD-OFFSITE Parameters for Offsite Resident Farmer Forward Run 10,000 Years

File : OFFSITE-RF_FORWARD-7-11-10000yr.ROF

Site-Specific Parameter Summary (continued)

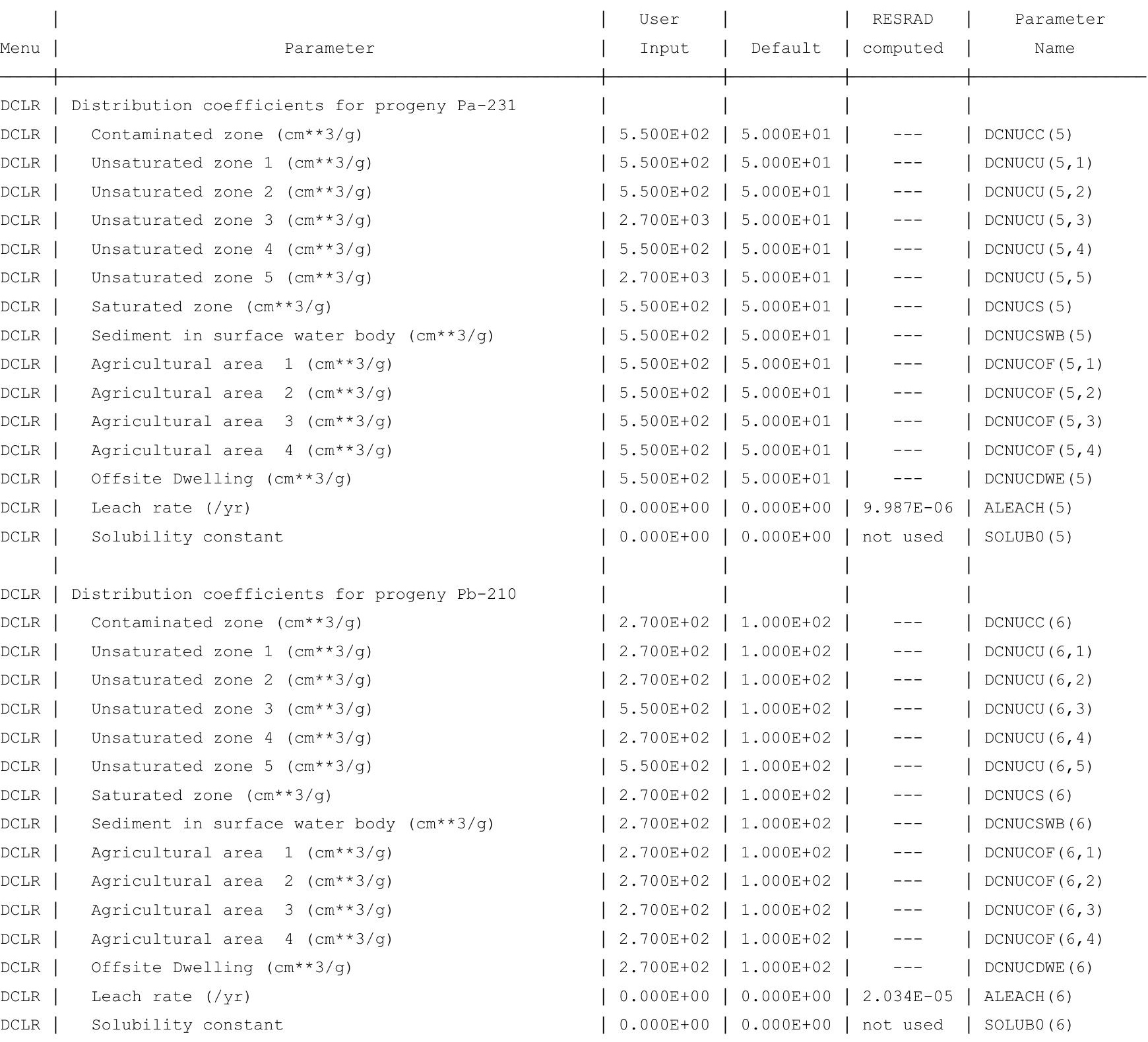


RESRAD-OFFSITE, Version 2.5

Parent Dose Report

Title : RESRAD-OFFSITE Parameters for Offsite Resident Farmer Forward Run 10,000 Years

File : OFFSITE-RF_FORWARD-7-11-10000yr.ROF

Site-Specific Parameter Summary (continued)

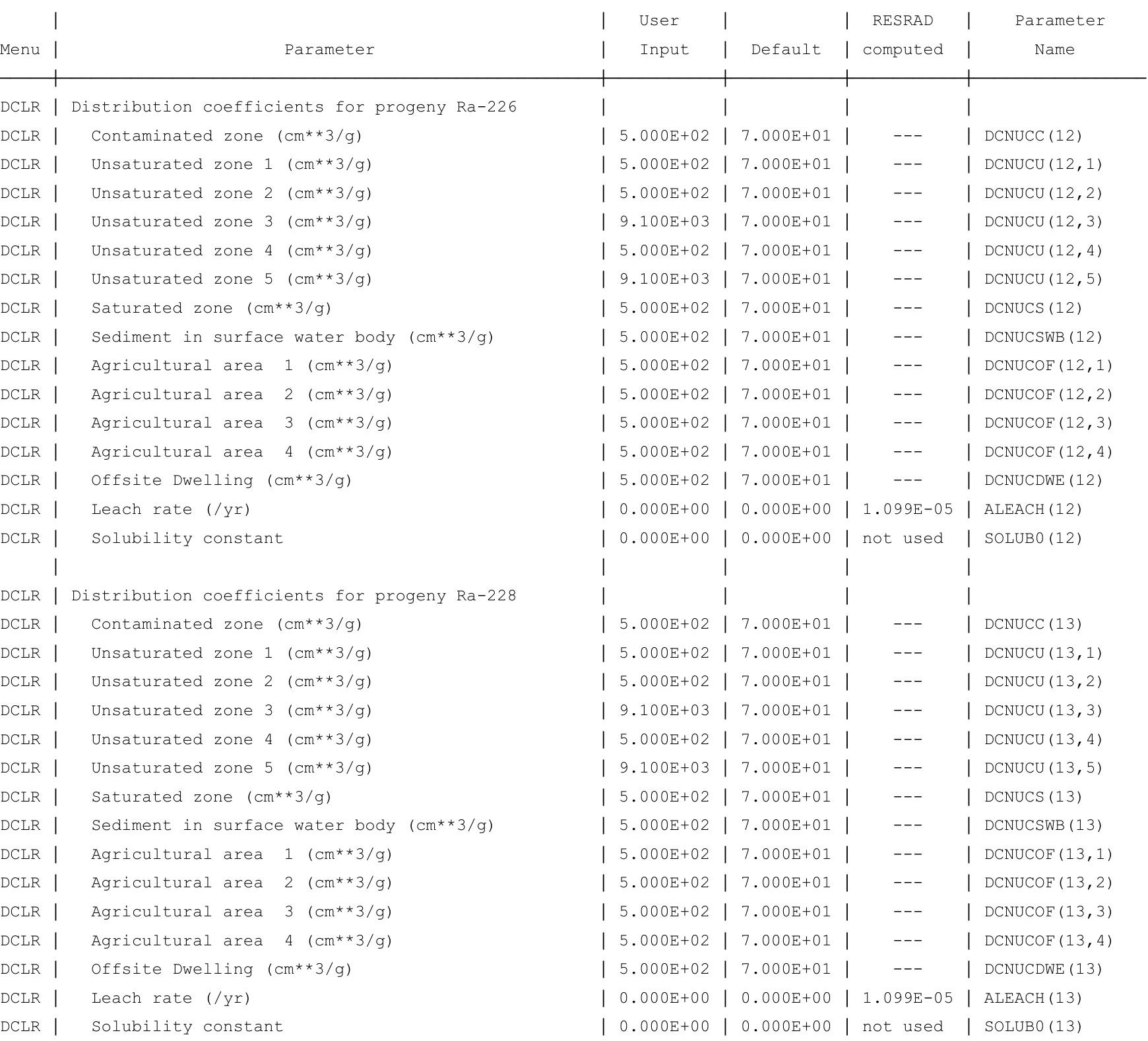


RESRAD-OFFSITE, Version 2.5

Parent Dose Report

Title : RESRAD-OFFSITE Parameters for Offsite Resident Farmer Forward Run 10,000 Years

File : OFFSITE-RF_FORWARD-7-11-10000yr.ROF

Site-Specific Parameter Summary (continued)

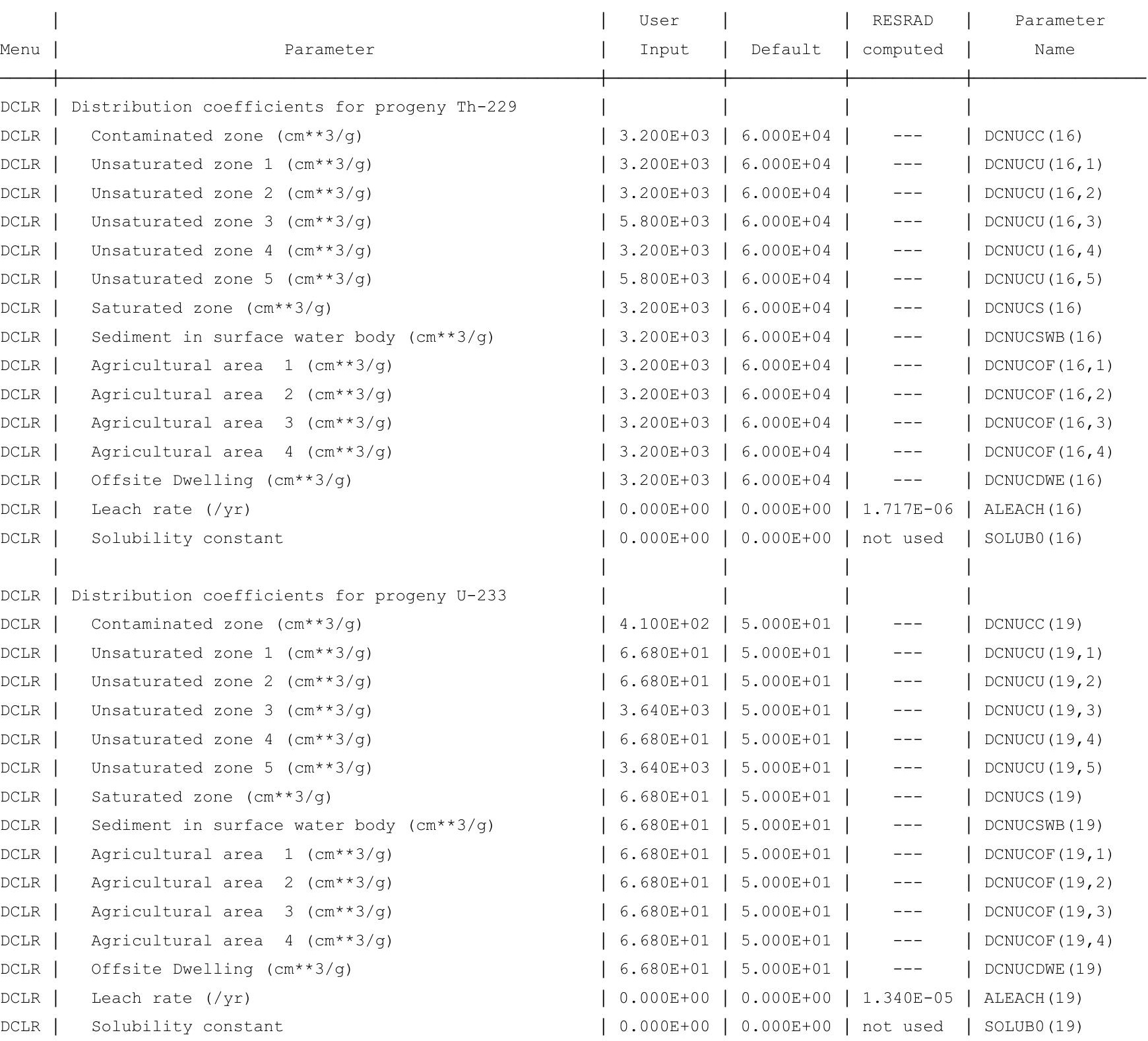


RESRAD-OFFSITE, Version $2.5 \quad$ T1/2 Limit $=180$ days $\quad$ 07/21/2011 $12: 59$ Page

Parent Dose Report

Title : RESRAD-OFFSITE Parameters for Offsite Resident Farmer Forward Run 10,000 Years

File : OFFSITE-RF_FORWARD-7-11-10000yr.ROF

Site-Specific Parameter Summary (continued)

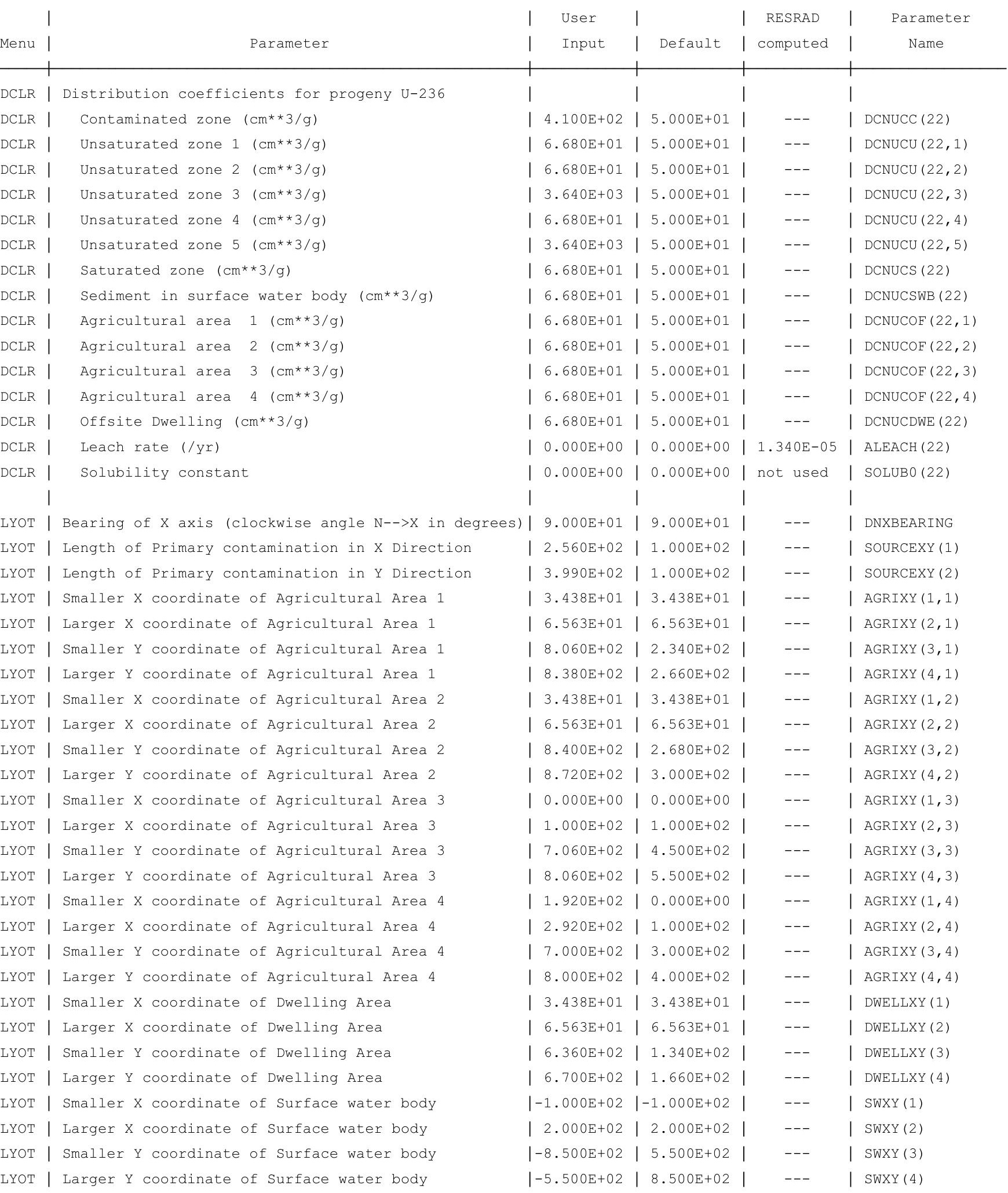

LYOT | Larger Y coordinate of Surface water body

\begin{tabular}{l|l|l|l|l|}
$\mid-5.500 \mathrm{E}+02$ & $\mathbf{8} .500 \mathrm{E}+02$ & --- & $\operatorname{SWXY}(4)$
\end{tabular} 
RESRAD-OFFSITE, Version 2.

Parent Dose Report

Title : RESRAD-OFFSITE Parameters for Offsite Resident Farmer Forward Run 10,000 Years

File : OFFSITE-RF FORWARD-7-11-10000yr.ROF

Site-Specific Parameter Summary (continued)

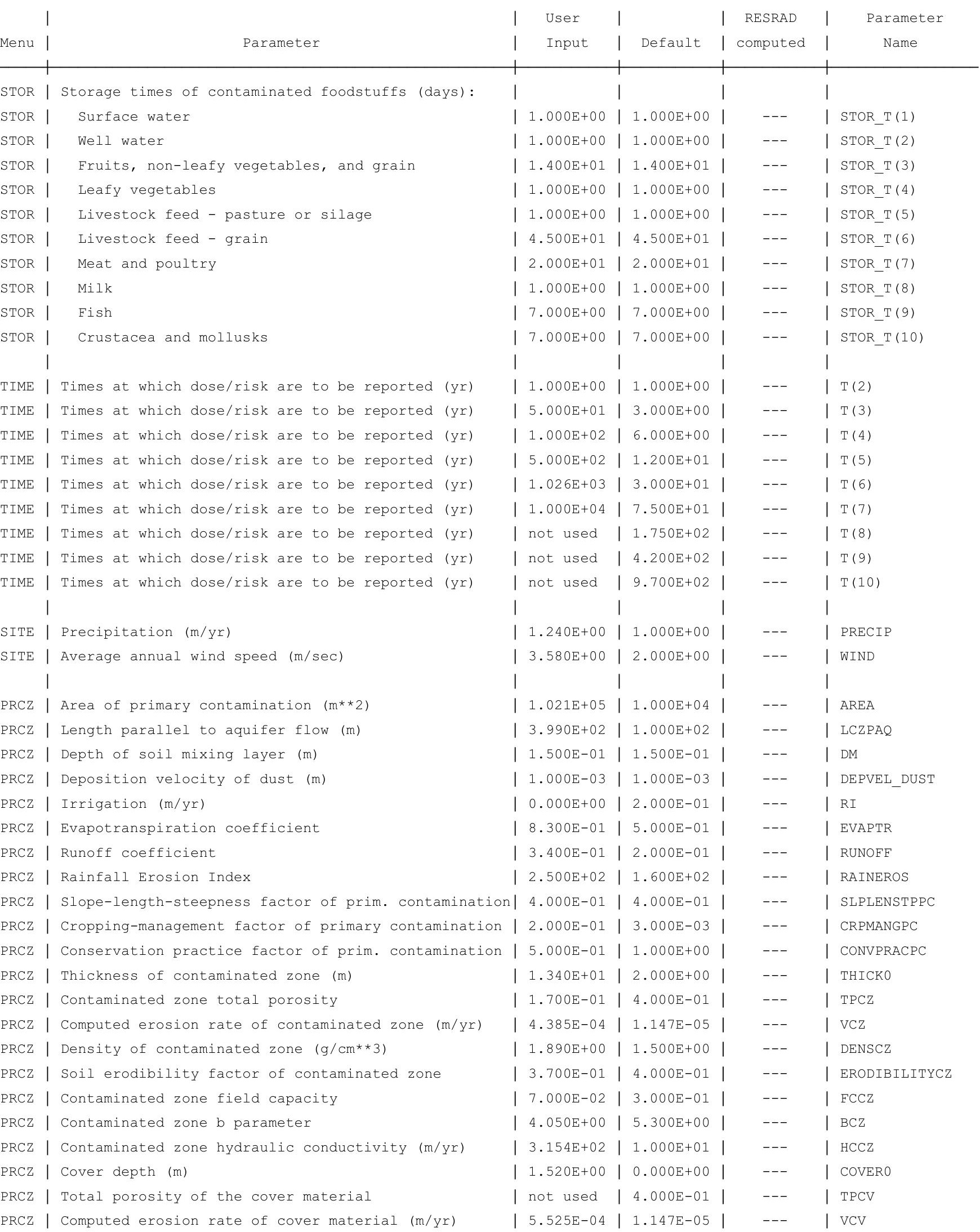


RESRAD-OFFSITE, Version 2.

Parent Dose Report

Title : RESRAD-OFFSITE Parameters for Offsite Resident Farmer Forward Run 10,000 Years

File : OFFSITE-RF_FORWARD-7-11-10000yr.ROF

Site-Specific Parameter Summary (continued)

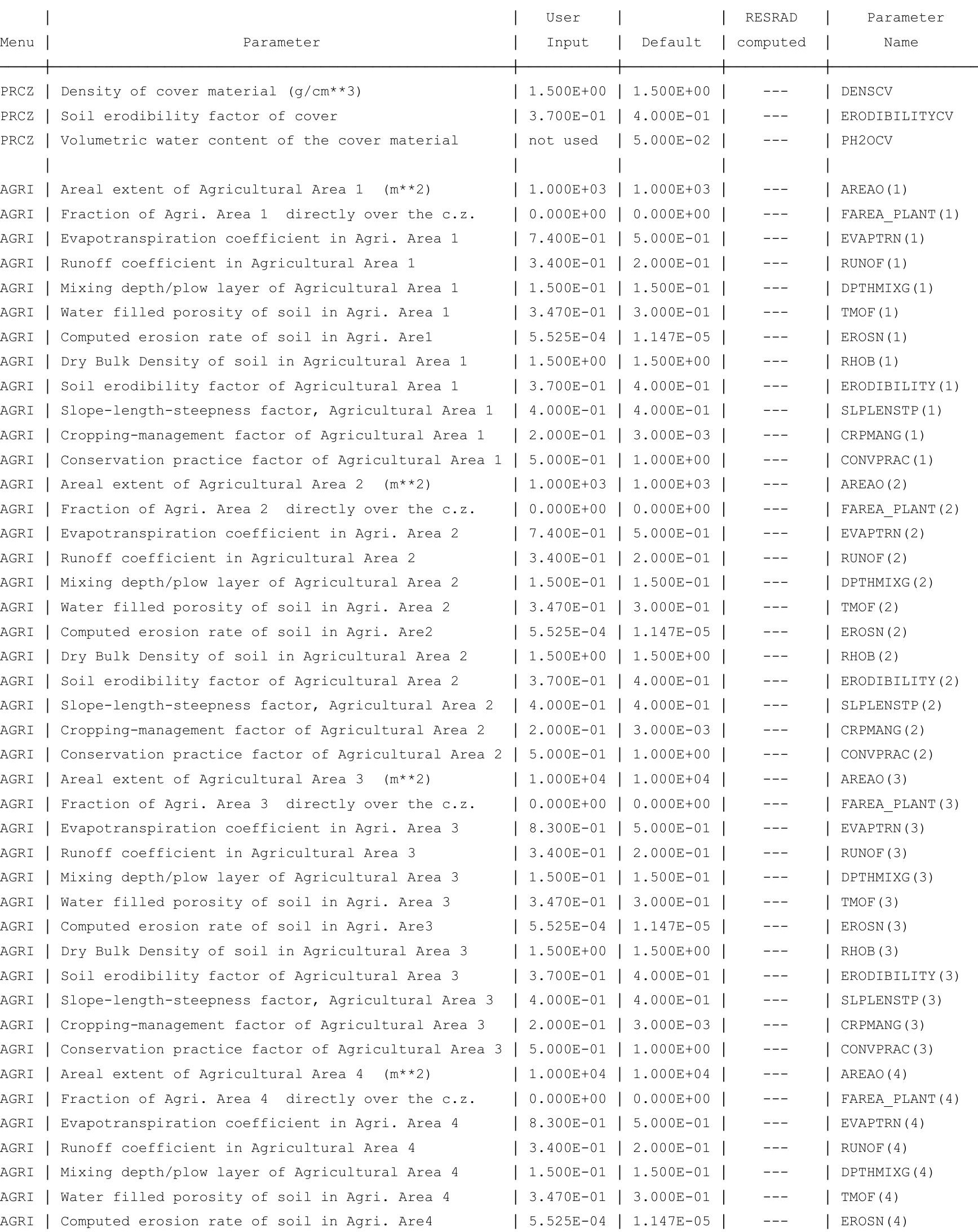


RESRAD-OFFSITE, Version $2.5 \quad \mathrm{~T}^{1 / 2}$ Limit $=180$ days $\quad$ 07/21/2011 $12: 59$ Page

Parent Dose Report

Title : RESRAD-OFFSITE Parameters for Offsite Resident Farmer Forward Run 10,000 Years

File : OFFSITE-RF_FORWARD-7-11-10000yr.ROF

Site-Specific Parameter Summary (continued)

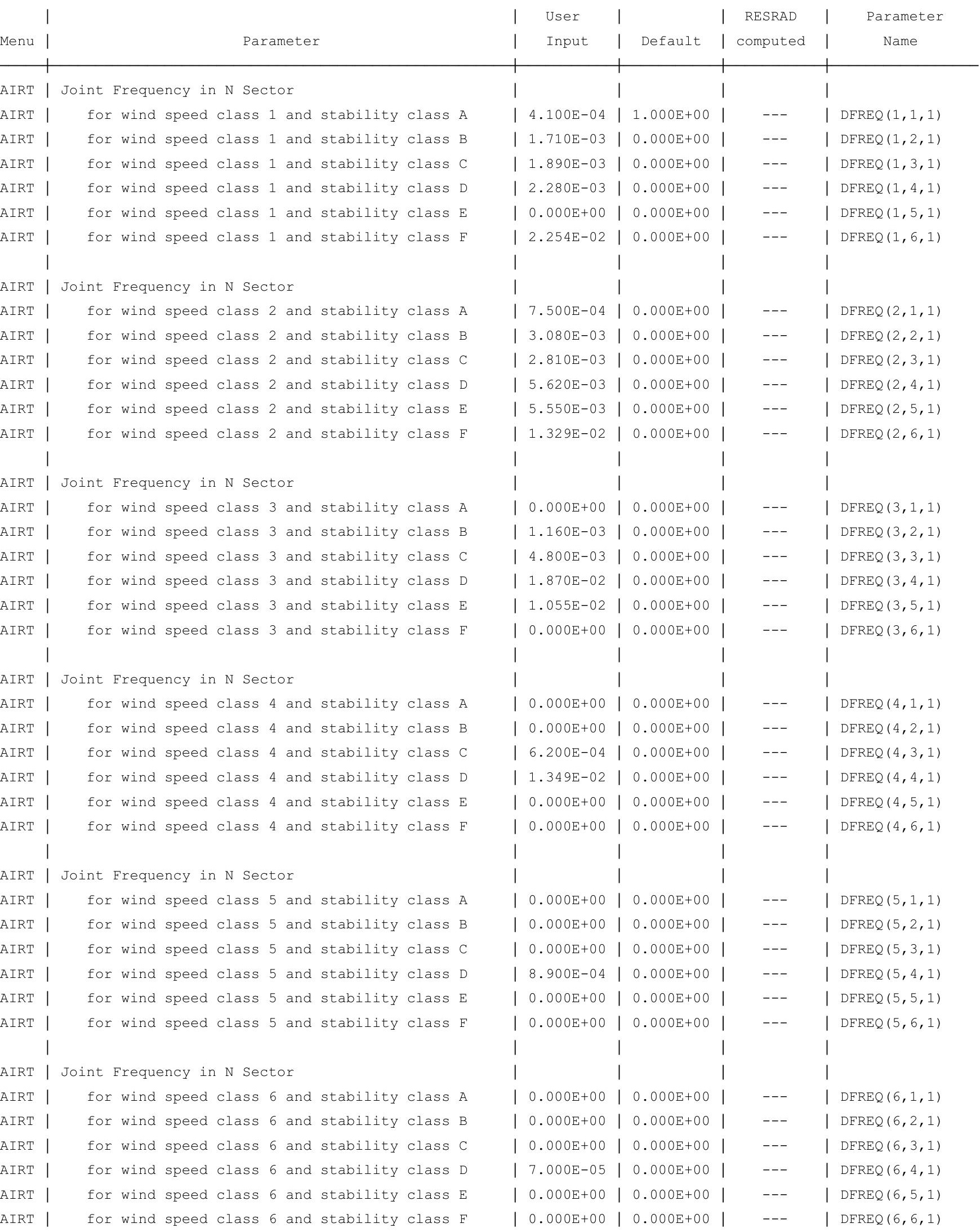


RESRAD-OFFSITE, Version $2.5 \quad T^{1 / 2}$ Limit $=180$ days $\quad$ 07/21/2011 12:59 Page

Parent Dose Report

Title : RESRAD-OFFSITE Parameters for Offsite Resident Farmer Forward Run 10,000 Years

File : OFFSITE-RF_FORWARD-7-11-10000yr.ROF

Site-Specific Parameter Summary (continued)

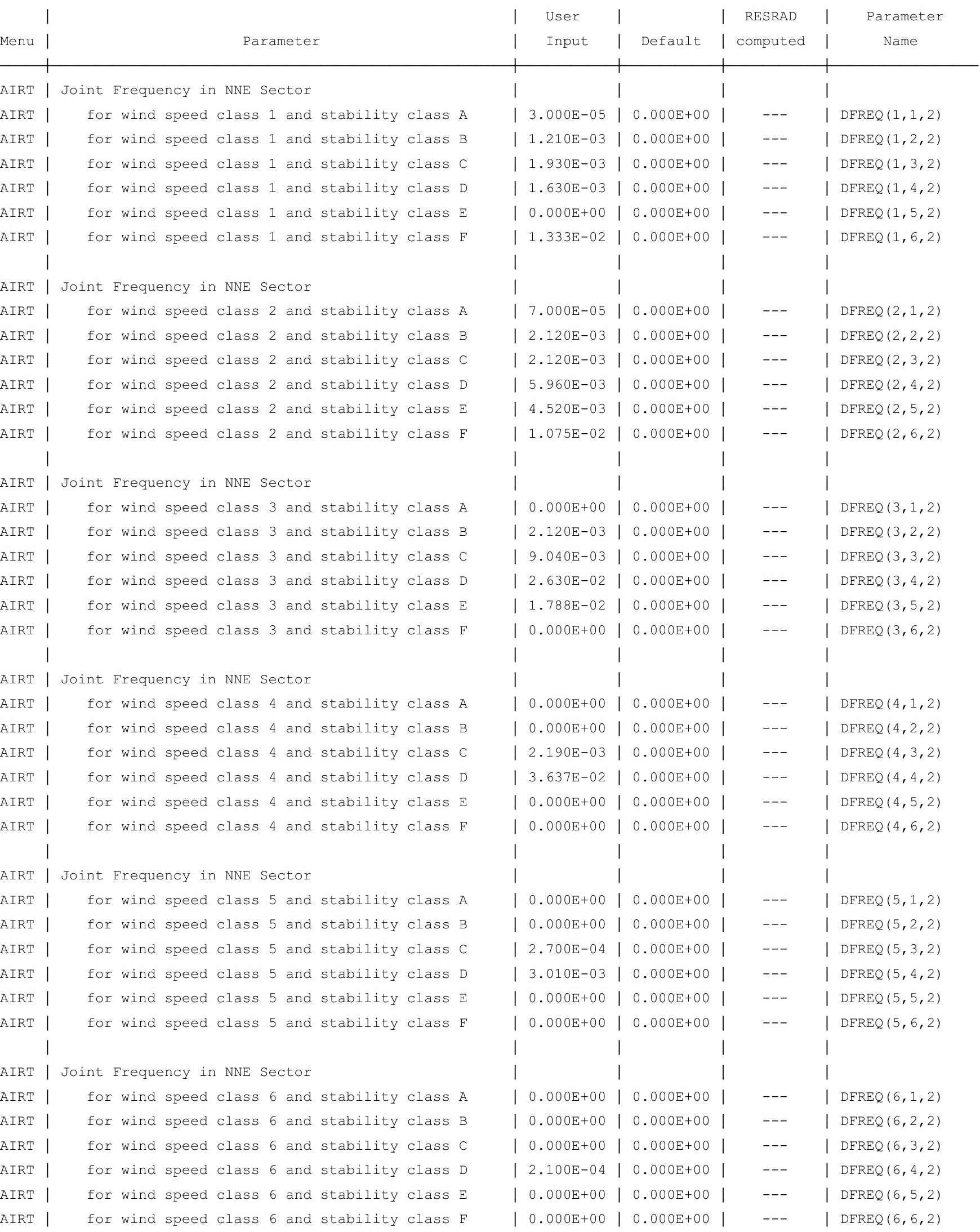


RESRAD-OFFSITE, Version $2.5 \quad$ T1/2 Limit $=180$ days $\quad$ 07/21/2011 $12: 59$ Page

Parent Dose Report

Title : RESRAD-OFFSITE Parameters for Offsite Resident Farmer Forward Run 10,000 Years

File : OFFSITE-RF_FORWARD-7-11-10000yr.ROF

Site-Specific Parameter Summary (continued)

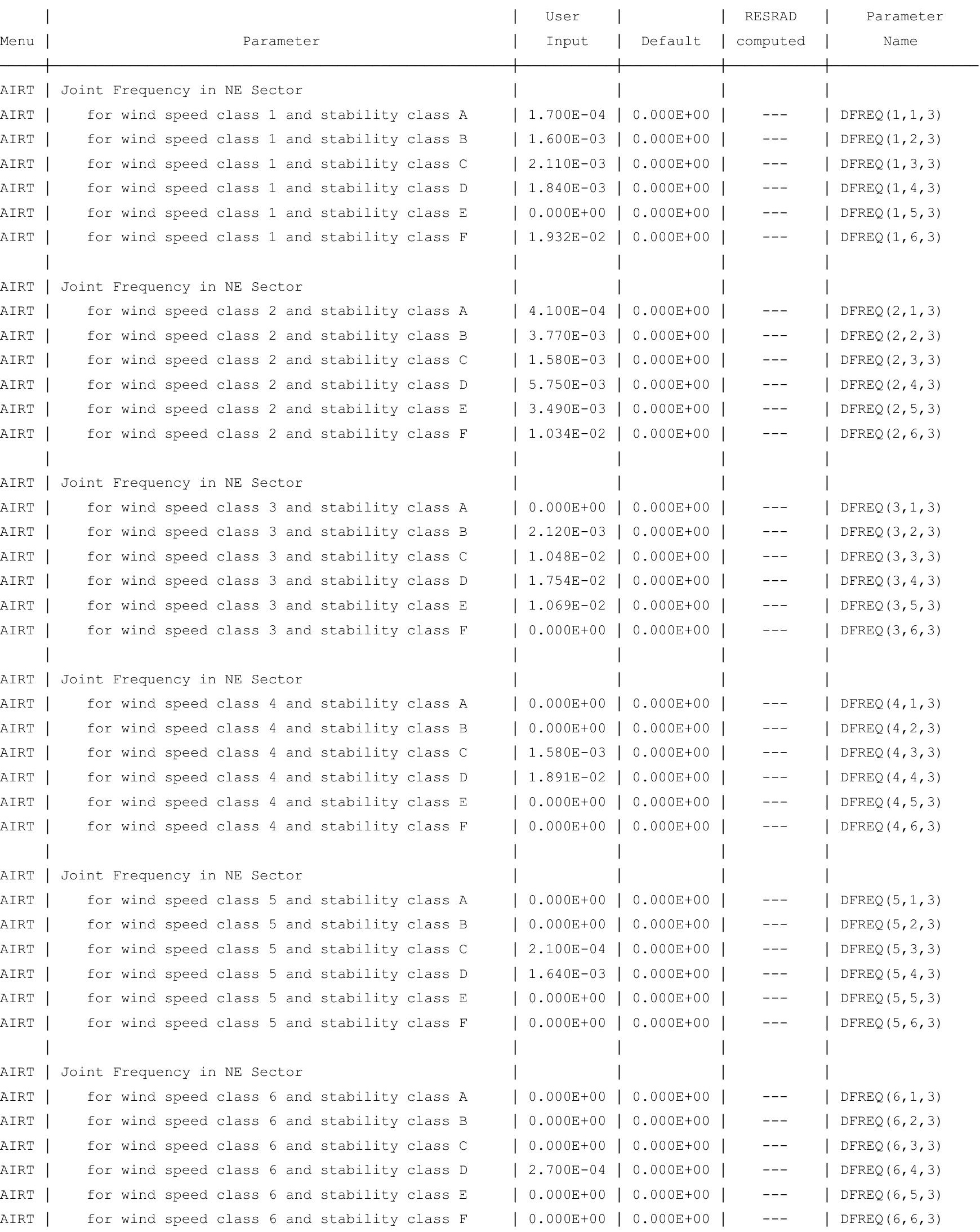


RESRAD-OFFSITE, Version $2.5 \quad T^{1 / 2}$ Limit $=180$ days $\quad$ 07/21/2011 12:59 Page

Parent Dose Report

Title : RESRAD-OFFSITE Parameters for Offsite Resident Farmer Forward Run 10,000 Years

File : OFFSITE-RF_FORWARD-7-11-10000yr.ROF

Site-Specific Parameter Summary (continued)

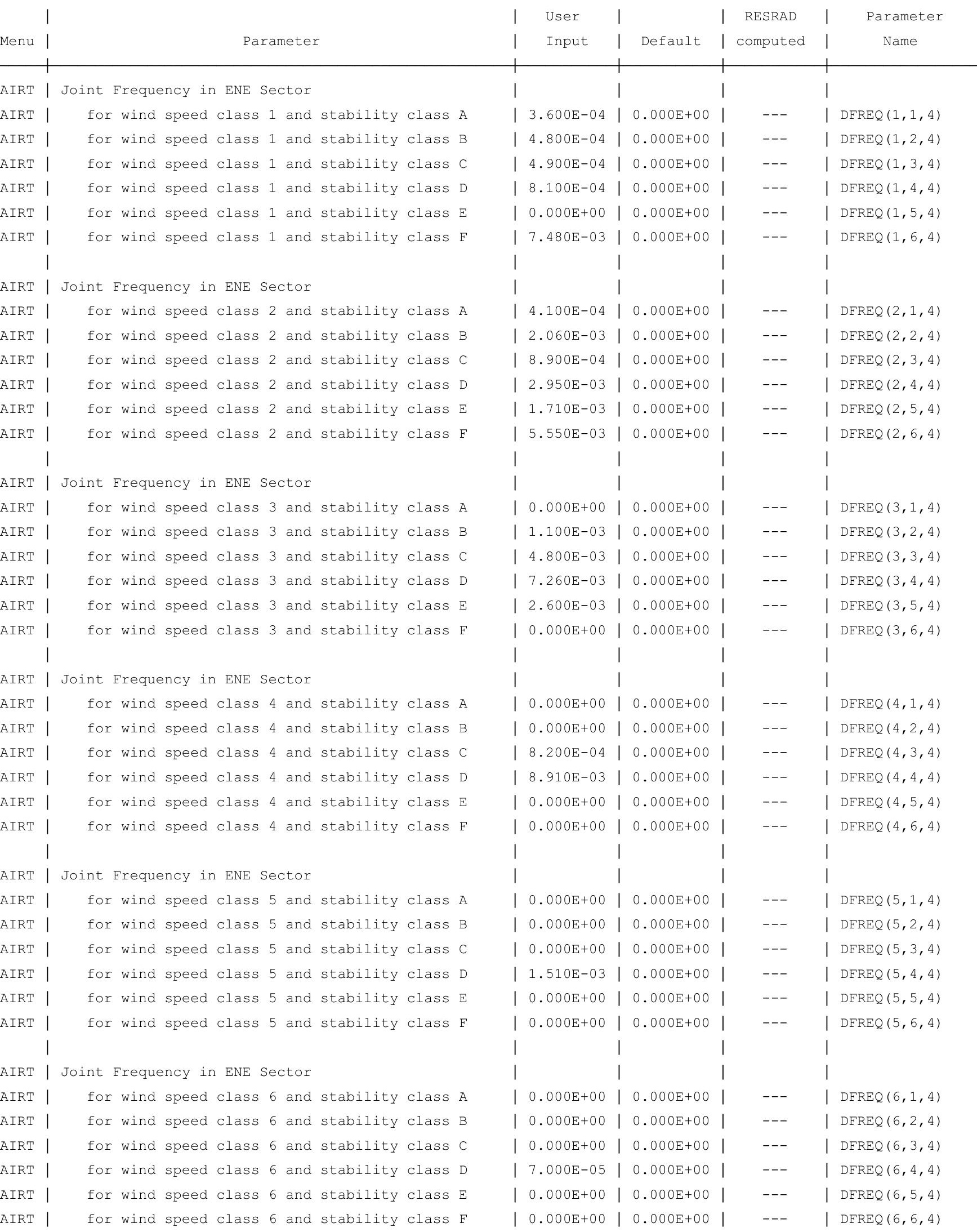


RESRAD-OFFSITE, Version $2.5 \quad T^{1 / 2}$ Limit $=180$ days $\quad$ 07/21/2011 $12: 59$ Page

Parent Dose Report

Title : RESRAD-OFFSITE Parameters for Offsite Resident Farmer Forward Run 10,000 Years

File : OFFSITE-RF_FORWARD-7-11-10000yr.ROF

Site-Specific Parameter Summary (continued)

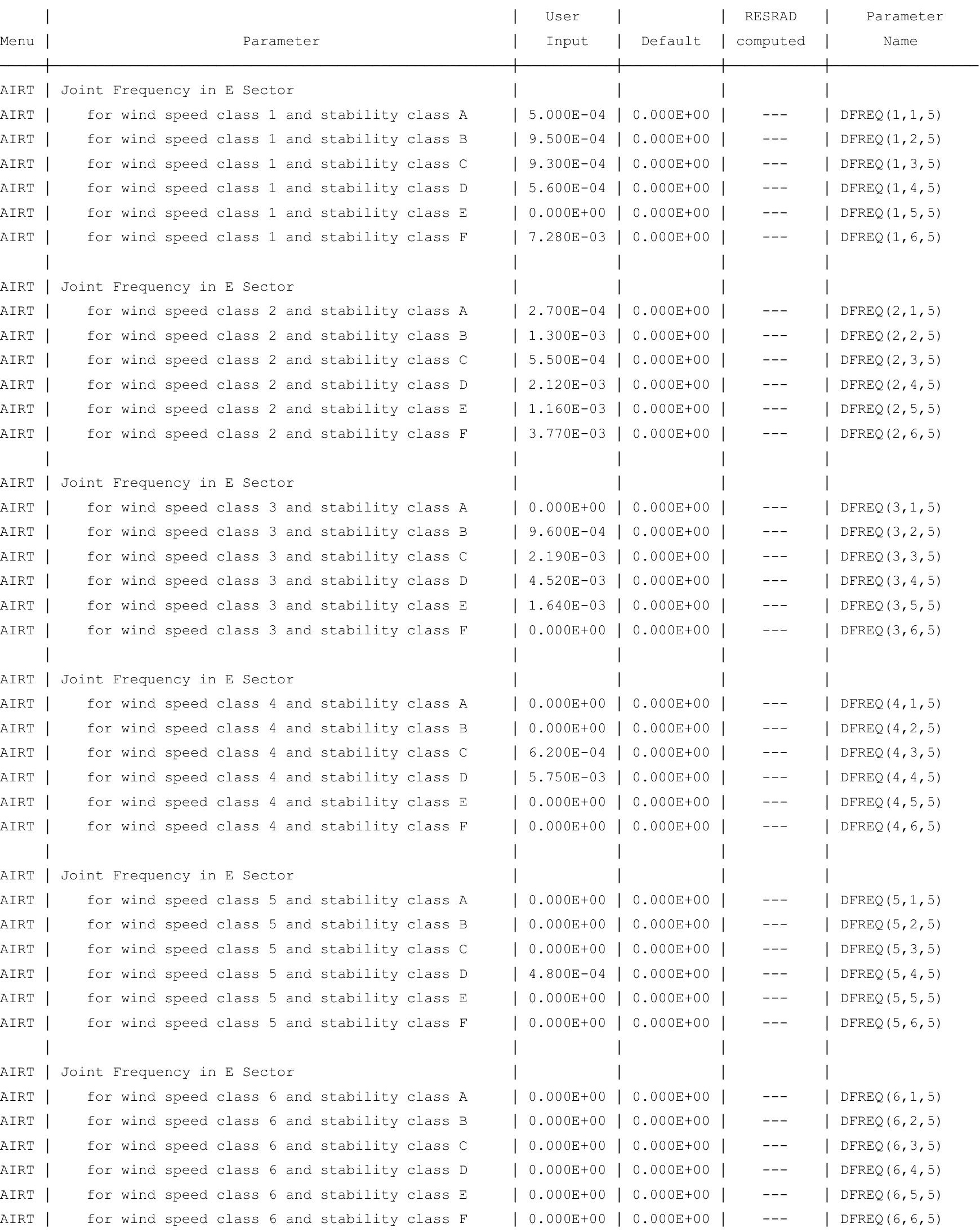


RESRAD-OFFSITE, Version $2.5 \quad T^{1 / 2}$ Limit $=180$ days $\quad 07 / 21 / 2011 \quad 12: 59$ Page

Parent Dose Report

Title : RESRAD-OFFSITE Parameters for Offsite Resident Farmer Forward Run 10,000 Years

File : OFFSITE-RF_FORWARD-7-11-10000yr.ROF

Site-Specific Parameter Summary (continued)

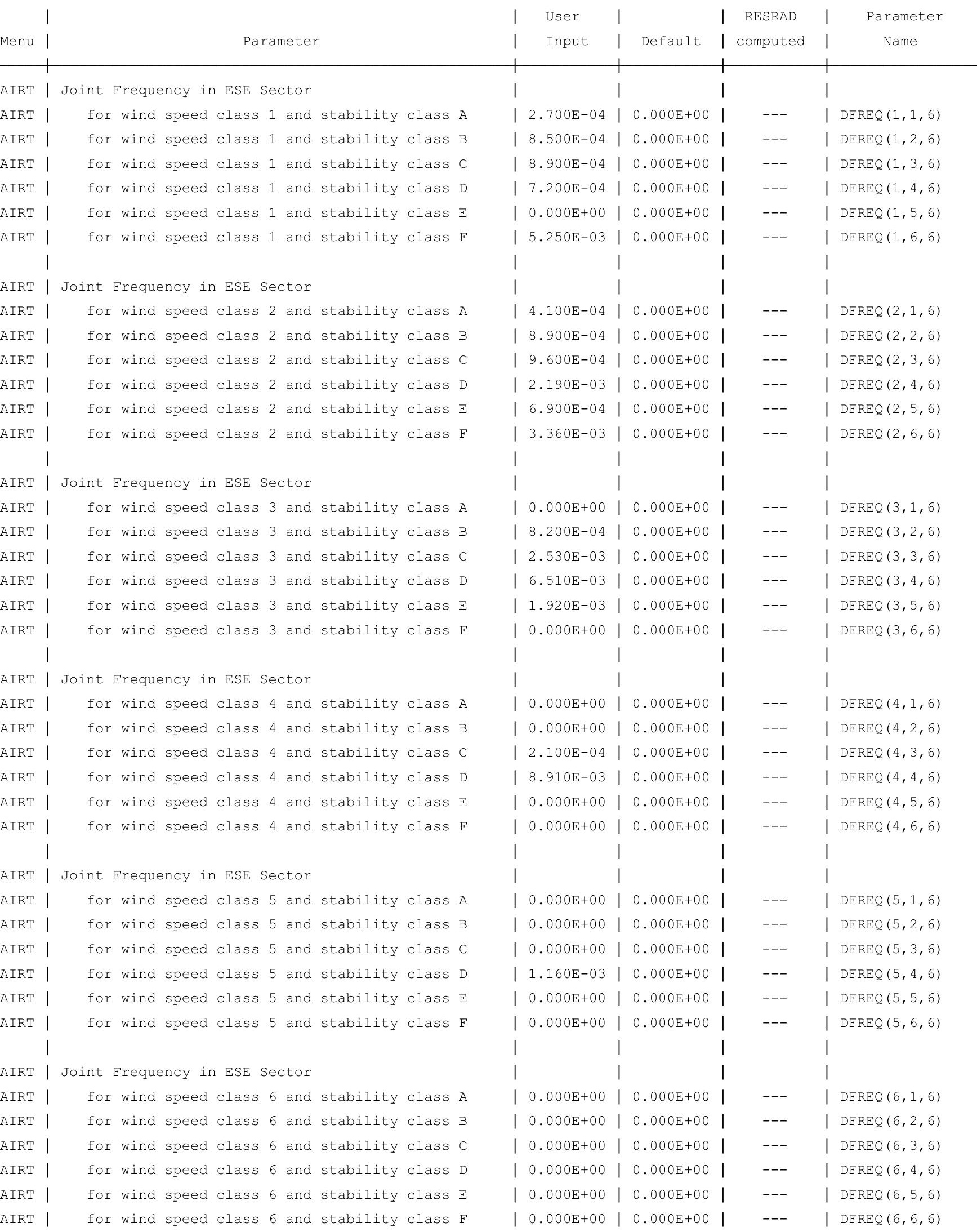


RESRAD-OFFSITE, Version $2.5 \quad$ T1/2 Limit $=180$ days $\quad$ 07/21/2011 $12: 59$ Page

Parent Dose Report

Title : RESRAD-OFFSITE Parameters for Offsite Resident Farmer Forward Run 10,000 Years

File : OFFSITE-RF_FORWARD-7-11-10000yr.ROF

Site-Specific Parameter Summary (continued)

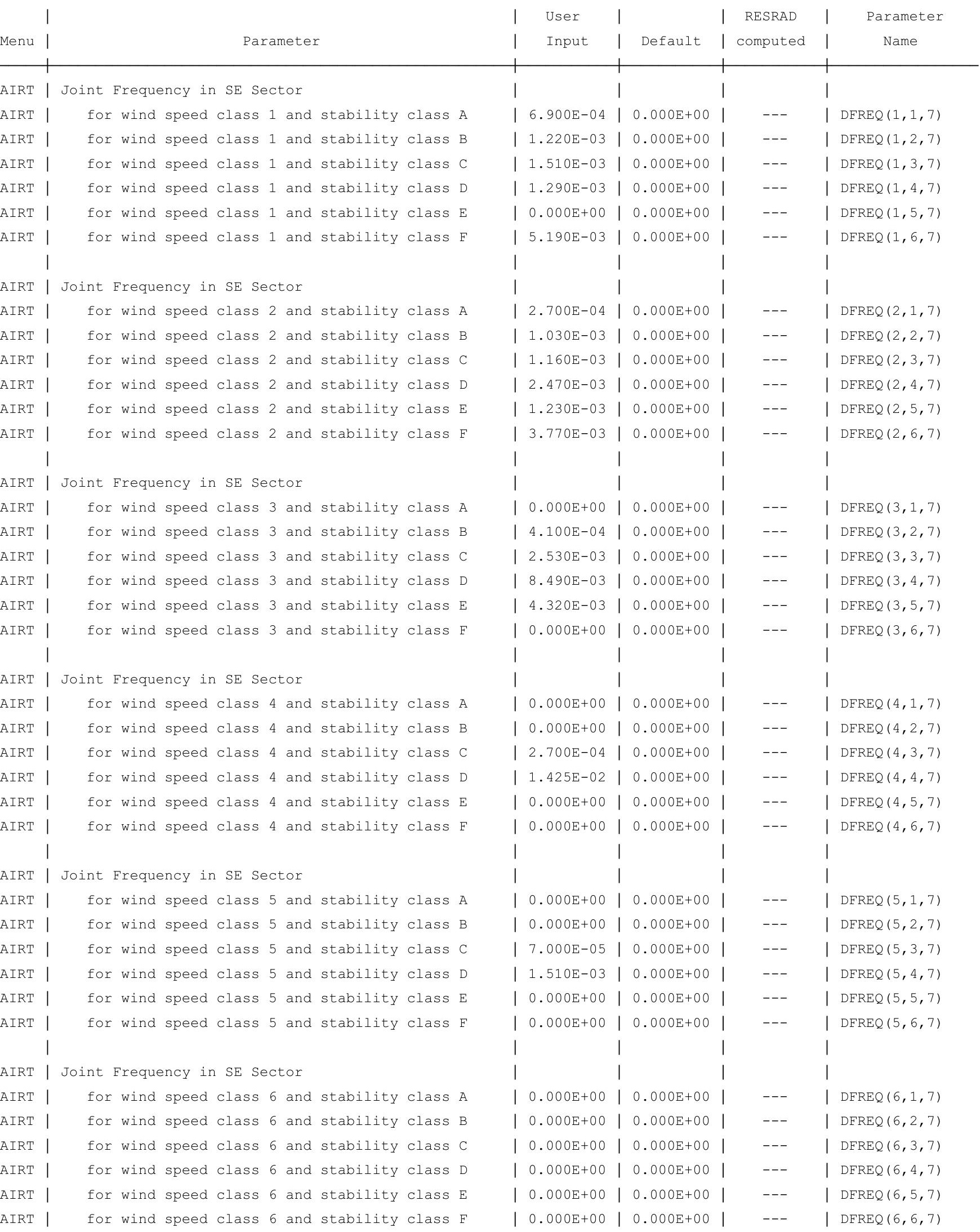


RESRAD-OFFSITE, Version $2.5 \quad \mathrm{~T}^{1 / 2}$ Limit $=180$ days $\quad$ 07/21/2011 $12: 59$ Page

Parent Dose Report

Title : RESRAD-OFFSITE Parameters for Offsite Resident Farmer Forward Run 10,000 Years

File : OFFSITE-RF_FORWARD-7-11-10000yr.ROF

Site-Specific Parameter Summary (continued)

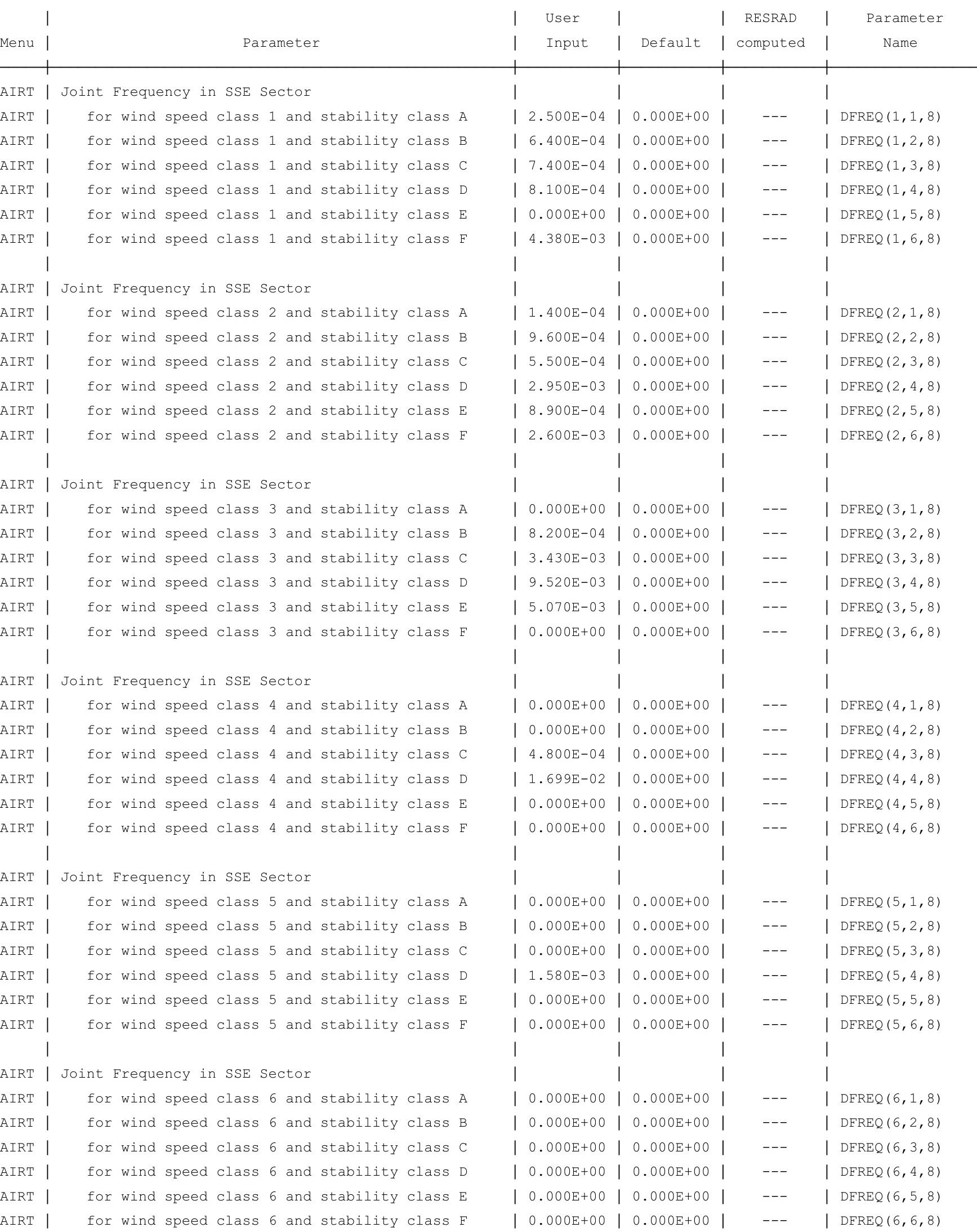


RESRAD-OFFSITE, Version $2.5 \quad$ T⿱11/2 Limit $=180$ days $\quad 07 / 21 / 2011 \quad 12: 59$ Page

Parent Dose Report

Title : RESRAD-OFFSITE Parameters for Offsite Resident Farmer Forward Run 10,000 Years

File : OFFSITE-RF_FORWARD-7-11-10000yr.ROF

Site-Specific Parameter Summary (continued)

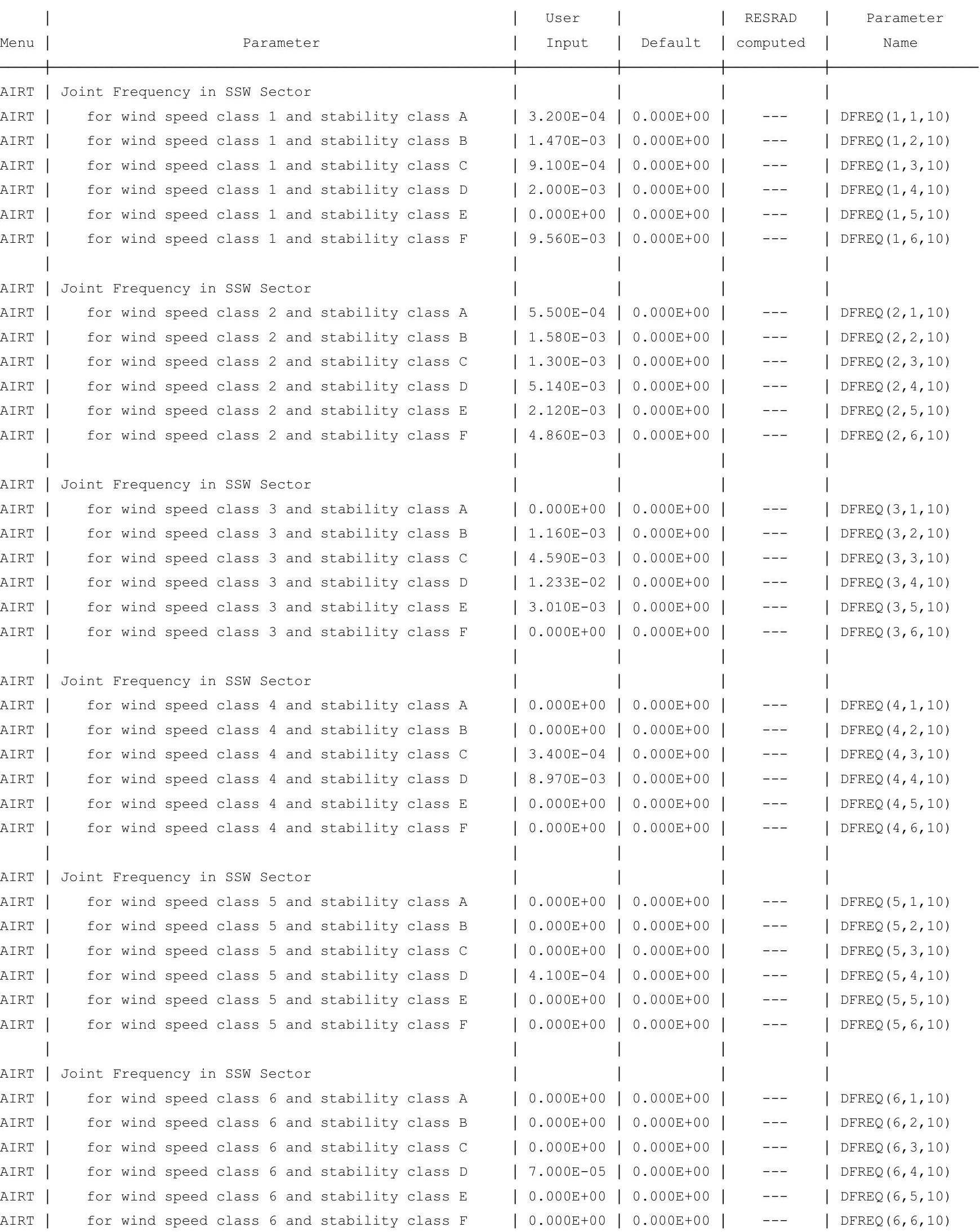


RESRAD-OFFSITE, Version $2.5 \quad$ T1/2 Limit $=180$ days $\quad$ 07/21/2011 $12: 59$ Page

Parent Dose Report

Title : RESRAD-OFFSITE Parameters for Offsite Resident Farmer Forward Run 10,000 Years

File : OFFSITE-RF_FORWARD-7-11-10000yr.ROF

Site-Specific Parameter Summary (continued)

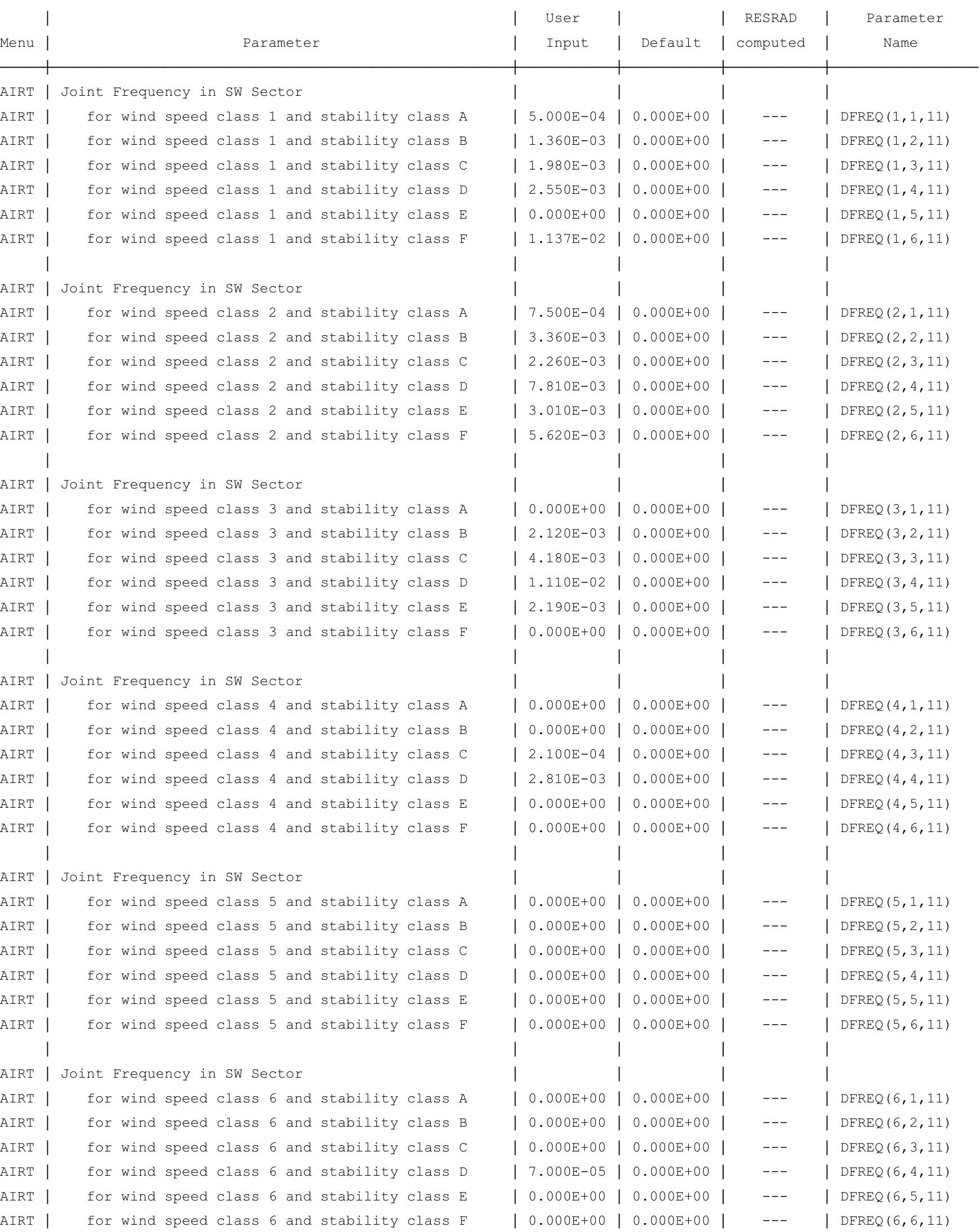


RESRAD-OFFSITE, Version $2.5 \quad$ T⿱11/2 Limit $=180$ days $\quad$ 07/21/2011 12:59 Page

Parent Dose Report

Title : RESRAD-OFFSITE Parameters for Offsite Resident Farmer Forward Run 10,000 Years

File : OFFSITE-RF_FORWARD-7-11-10000yr.ROF

Site-Specific Parameter Summary (continued)

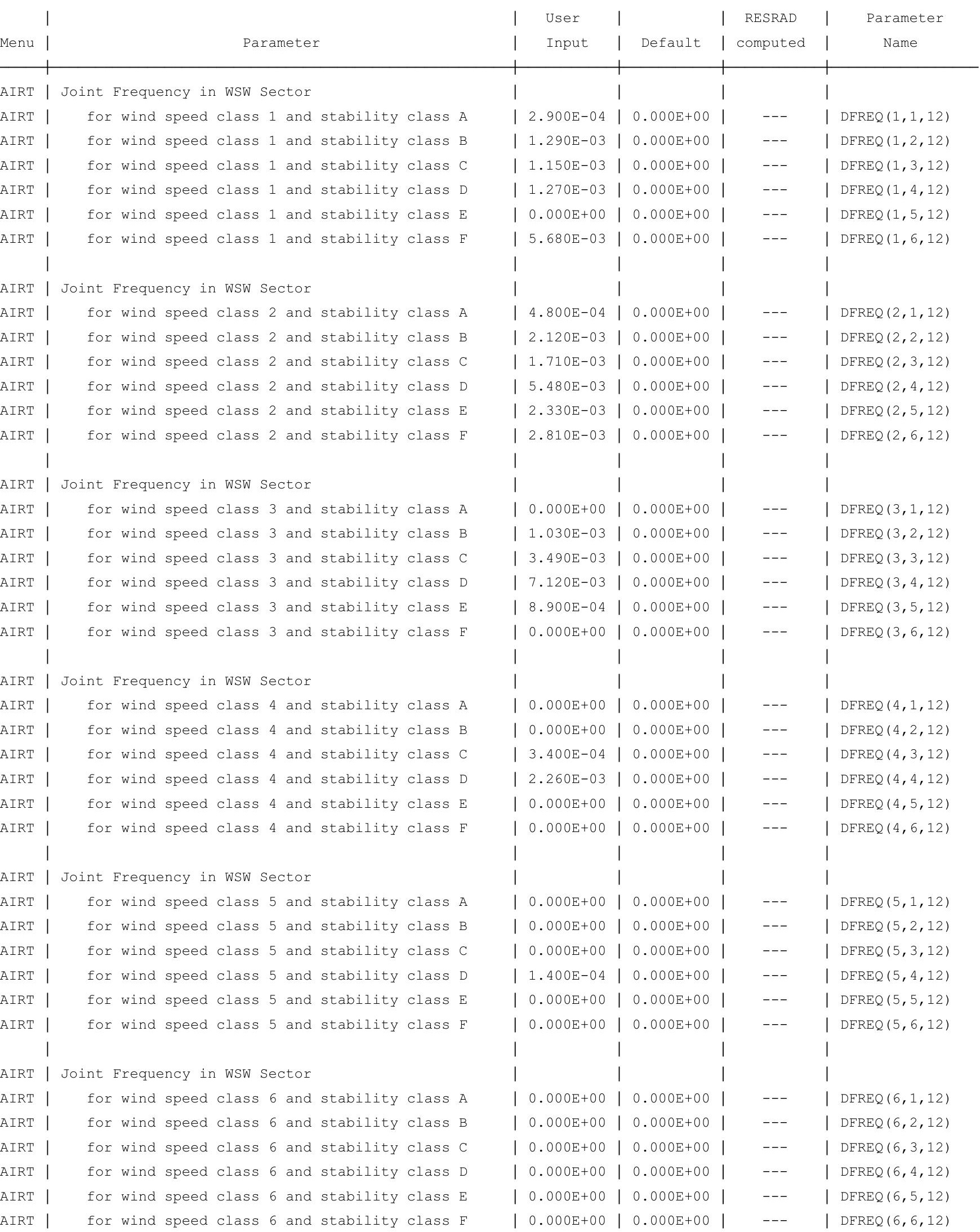


RESRAD-OFFSITE, Version $2.5 \quad$ T1/2 Limit $=180$ days $\quad$ 07/21/2011 $12: 59$ Page

Parent Dose Report

Title : RESRAD-OFFSITE Parameters for Offsite Resident Farmer Forward Run 10,000 Years

File : OFFSITE-RF_FORWARD-7-11-10000yr.ROF

Site-Specific Parameter Summary (continued)

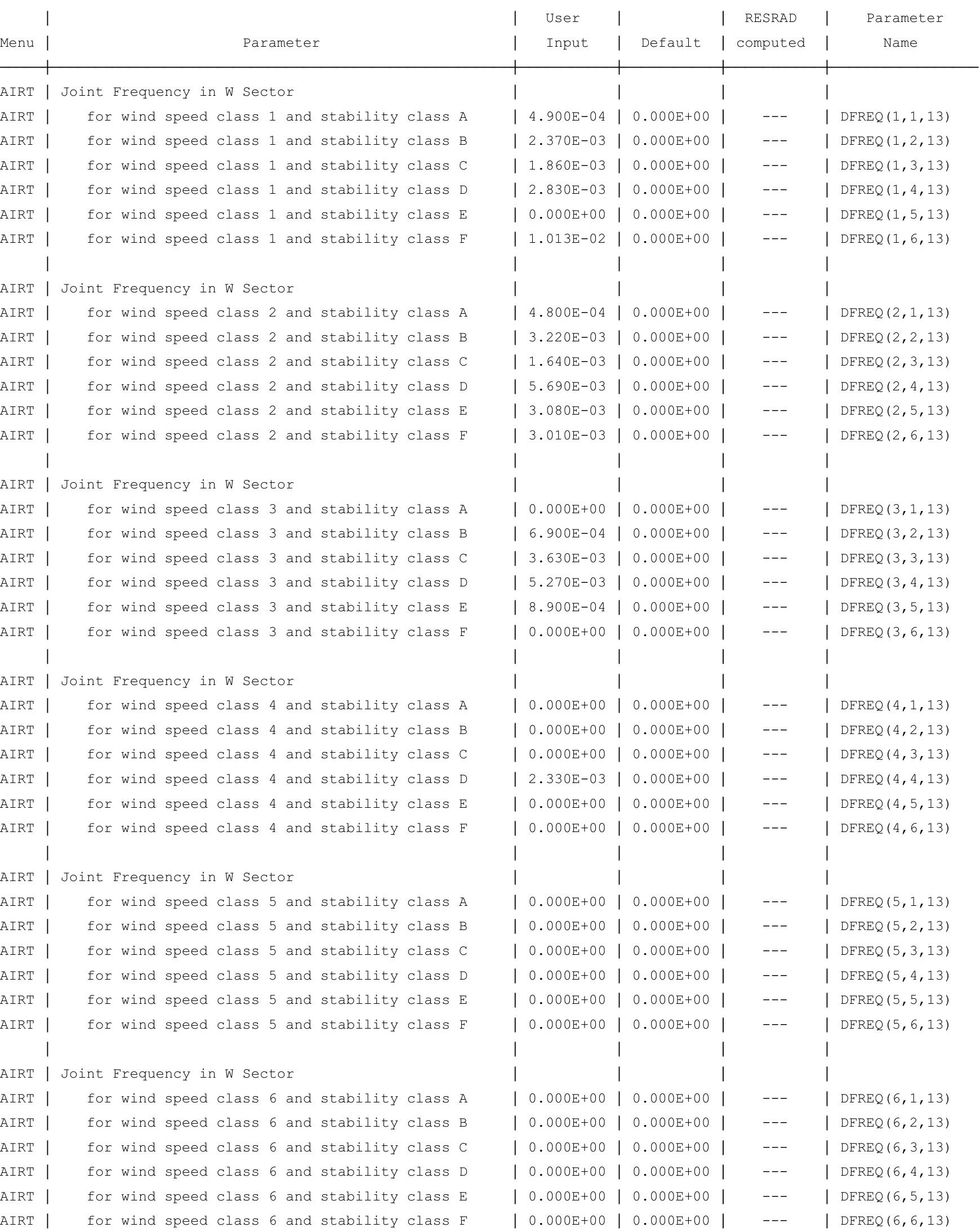


RESRAD-OFFSITE, Version $2.5 \quad$ T1/2 Limit $=180$ days $\quad$ 07/21/2011 $12: 59$ Page

Parent Dose Report

Title : RESRAD-OFFSITE Parameters for Offsite Resident Farmer Forward Run 10,000 Years

File : OFFSITE-RF_FORWARD-7-11-10000yr.ROF

Site-Specific Parameter Summary (continued)

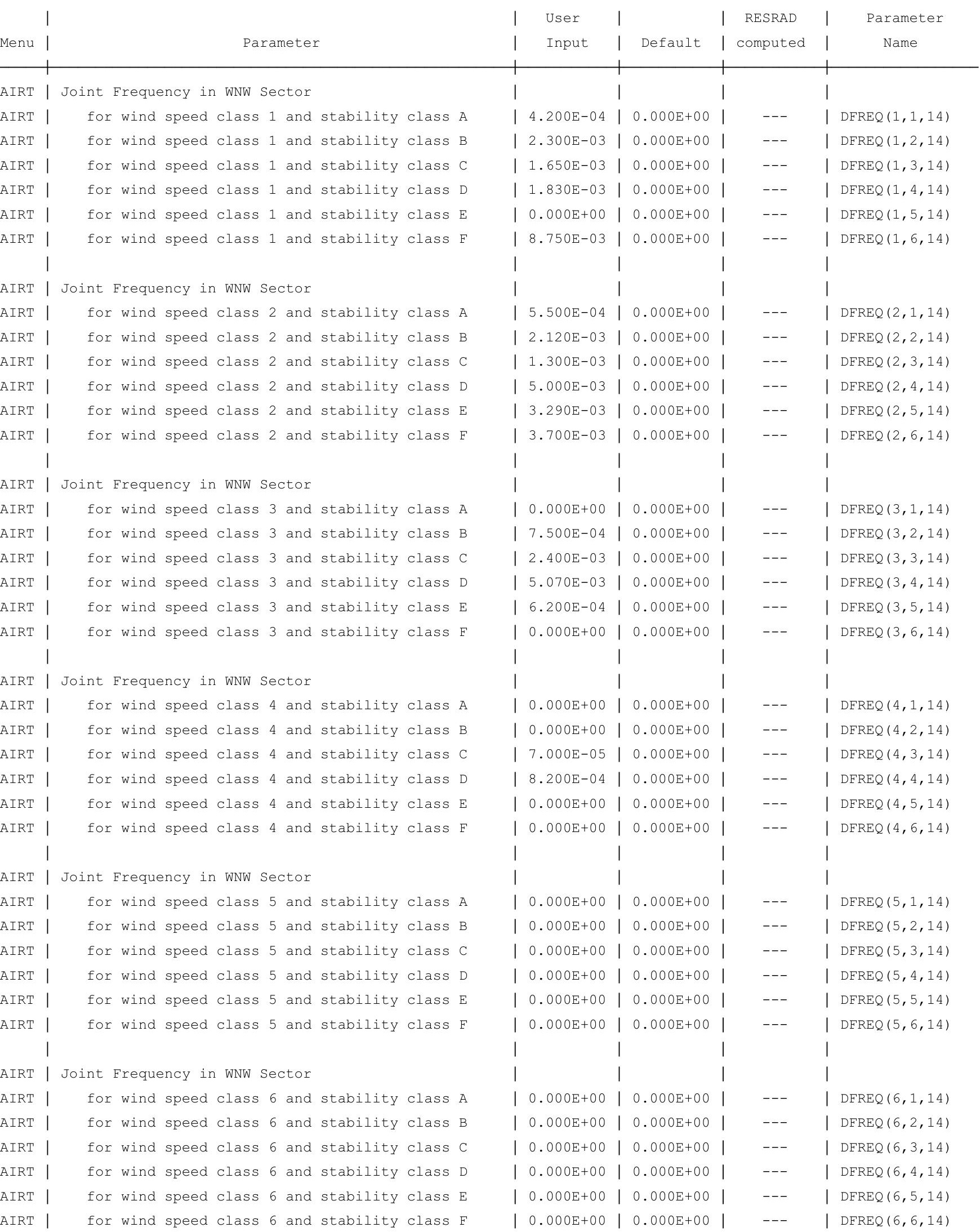


RESRAD-OFFSITE, Version 2.5 TT1/2 Limit = 180 days $\quad$ 07/21/2011 $12: 59$ Page

Parent Dose Report

Title : RESRAD-OFFSITE Parameters for Offsite Resident Farmer Forward Run 10,000 Years

File : OFFSITE-RF_FORWARD-7-11-10000yr.ROF

Site-Specific Parameter Summary (continued)

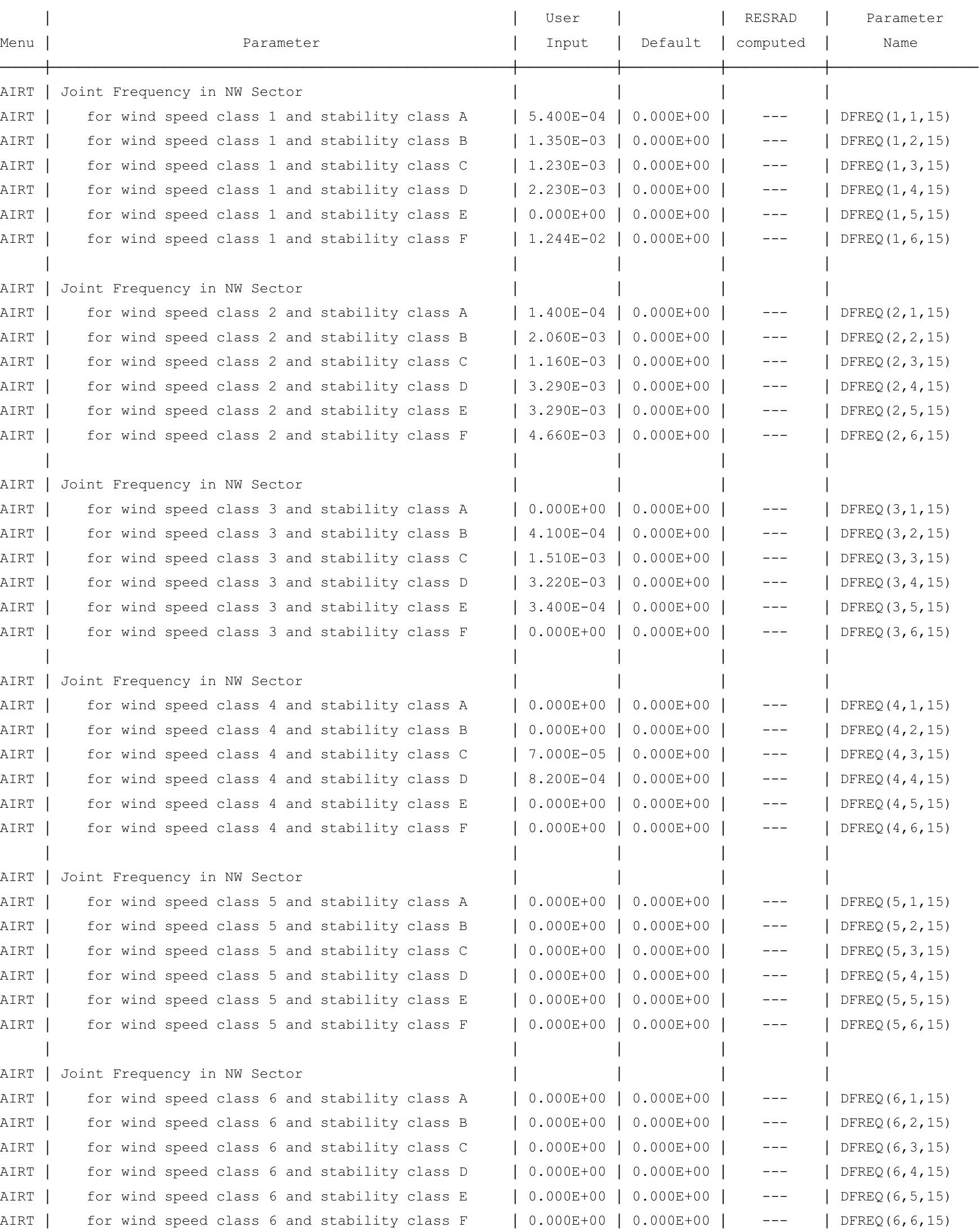


RESRAD-OFFSITE, Version $2.5 \quad T^{1 / 2}$ Limit $=180$ days $\quad 07 / 21 / 2011 \quad 12: 59$ Page

Parent Dose Report

Title : RESRAD-OFFSITE Parameters for Offsite Resident Farmer Forward Run 10,000 Years

File : OFFSITE-RF_FORWARD-7-11-10000yr.ROF

Site-Specific Parameter Summary (continued)

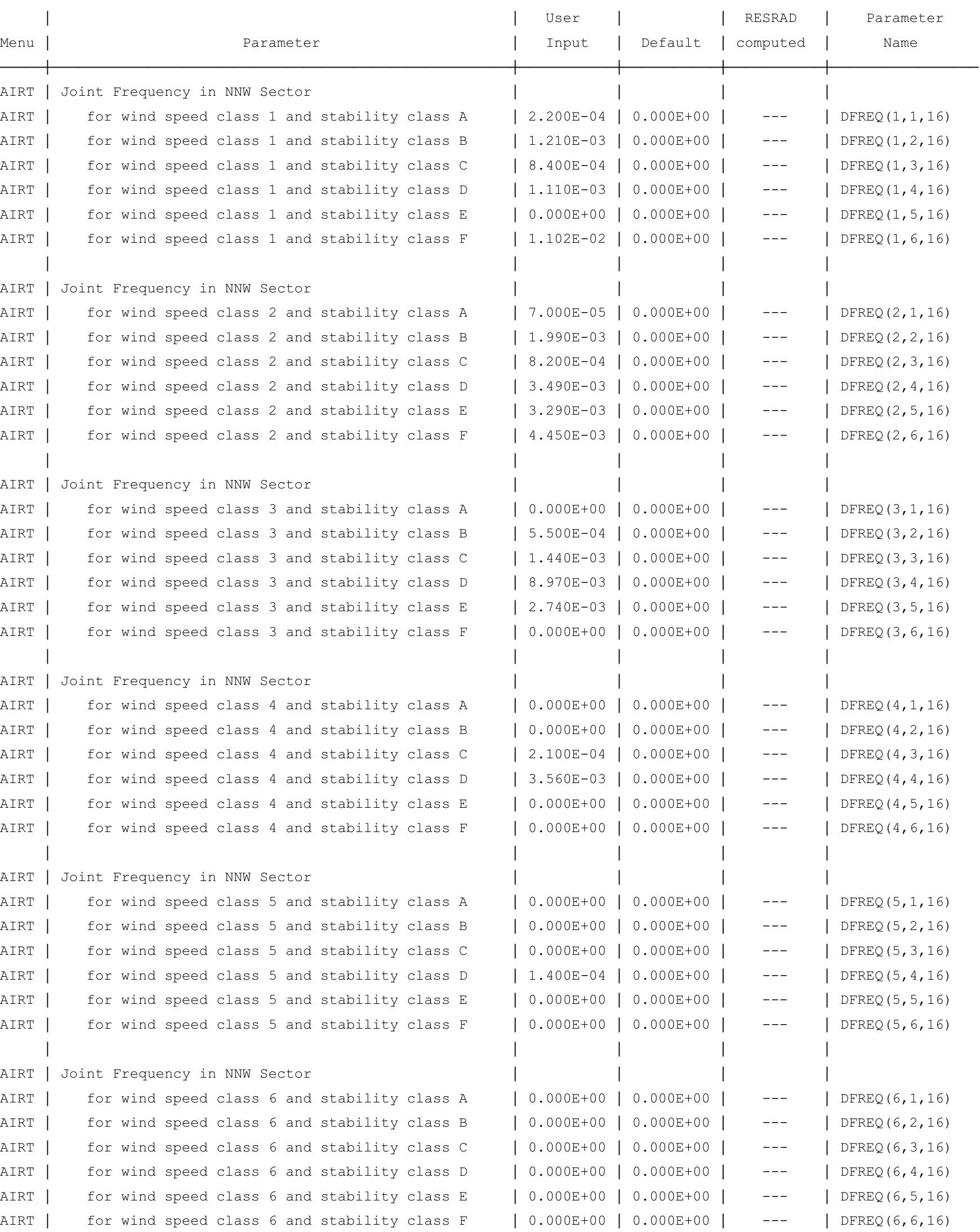


RESRAD-OFFSITE, Version 2.

Parent Dose Report

Title : RESRAD-OFFSITE Parameters for Offsite Resident Farmer Forward Run 10,000 Years

File : OFFSITE-RF FORWARD-7-11-10000yr.ROF

Site-Specific Parameter Summary (continued)

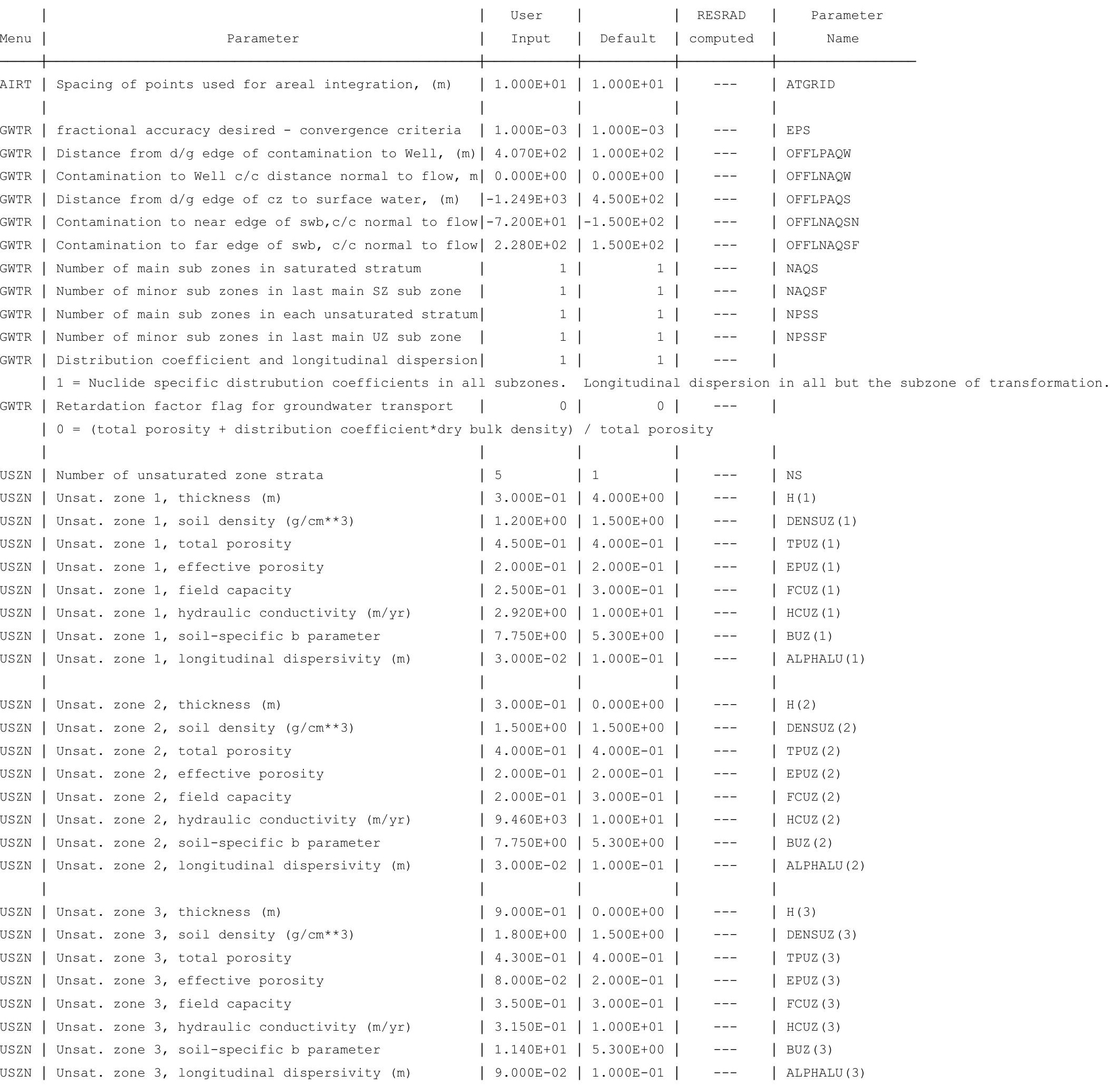


RESRAD-OFFSITE, Version 2.

Parent Dose Report

Title : RESRAD-OFFSITE Parameters for Offsite Resident Farmer Forward Run 10,000 Years

File : OFFSITE-RF FORWARD-7-11-10000yr.ROF

Site-Specific Parameter Summary (continued)

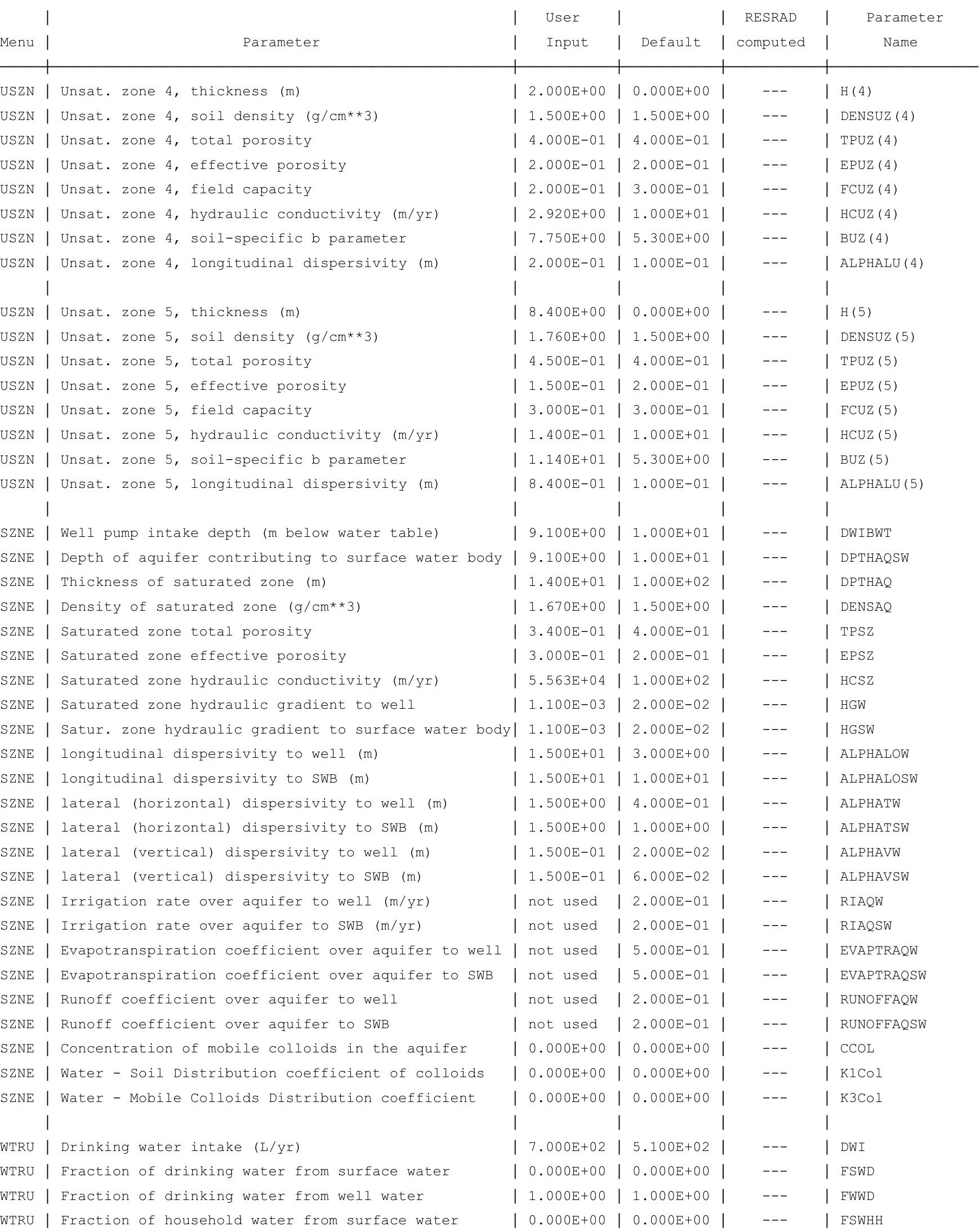


RESRAD-OFFSITE, Version $2.5 \quad \mathrm{~T}^{1 / 2}$ Limit $=180$ days $\quad$ 07/21/2011 $12: 59$ Page

Parent Dose Report

Title : RESRAD-OFFSITE Parameters for Offsite Resident Farmer Forward Run 10,000 Years

File : OFFSITE-RF_FORWARD-7-11-10000yr.ROF

Site-Specific Parameter Summary (continued)

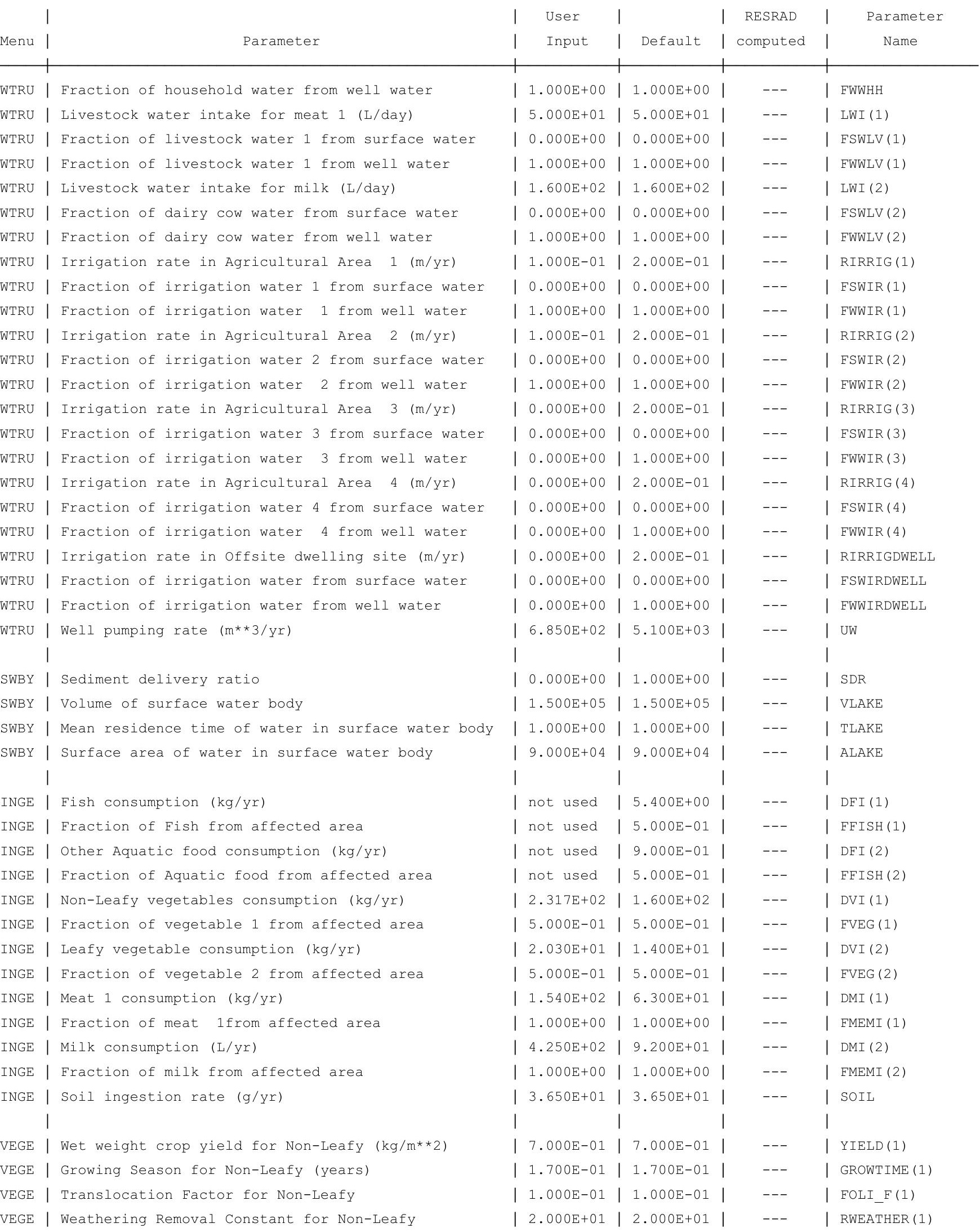

VEGE | Weathering Removal Constant for Non-Leafy

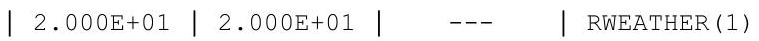


RESRAD-OFFSITE, Version 2.

Parent Dose Report

Title : RESRAD-OFFSITE Parameters for Offsite Resident Farmer Forward Run 10,000 Years

File : OFFSITE-RF_FORWARD-7-11-10000yr.ROF

Site-Specific Parameter Summary (continued)

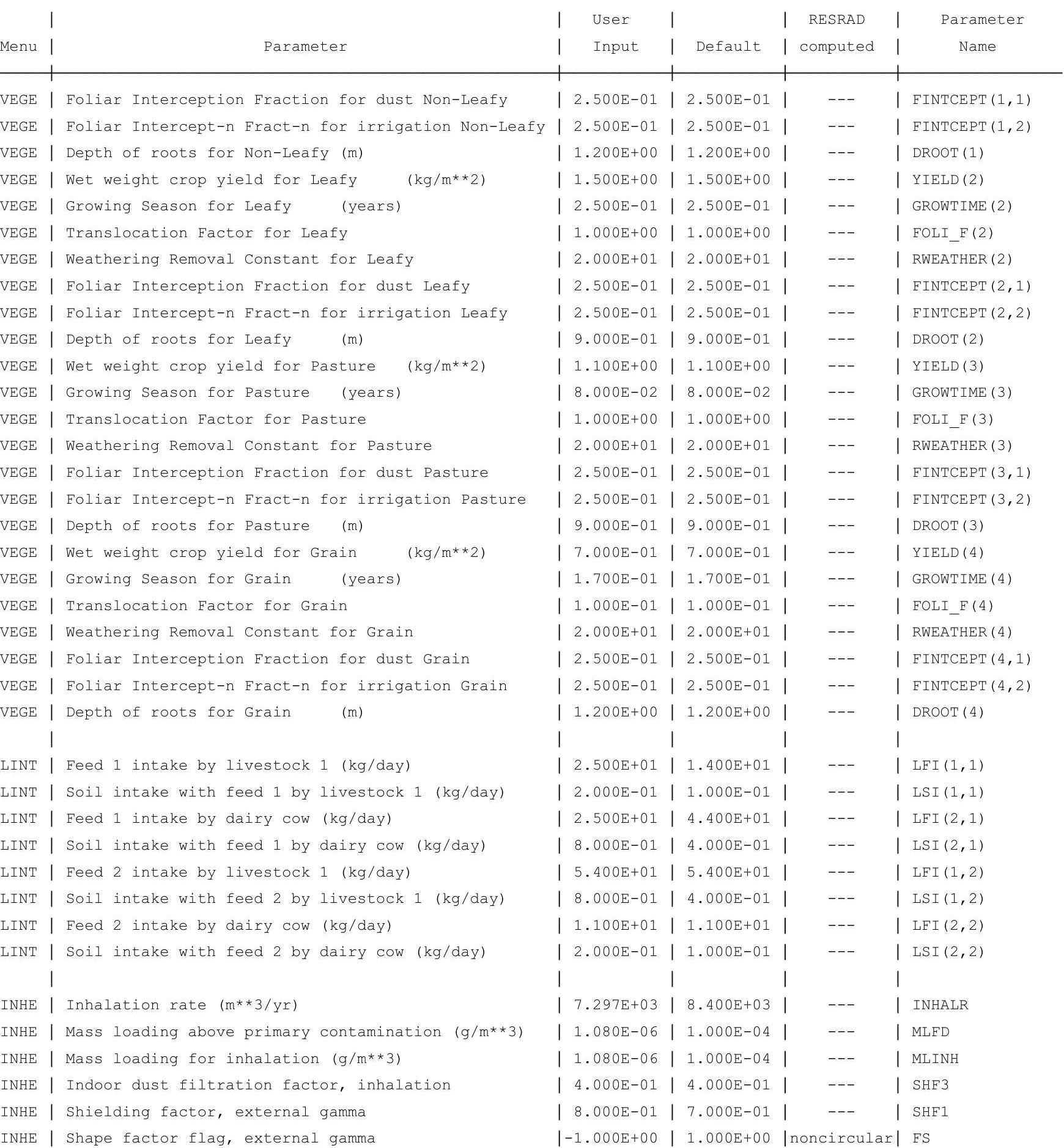


RESRAD-OFFSITE, Version 2.5

Parent Dose Report

Title : RESRAD-OFFSITE Parameters for Offsite Resident Farmer Forward Run 10,000 Years

File : OFFSITE-RF_FORWARD-7-11-10000yr.ROF

Site-Specific Parameter Summary (continued)

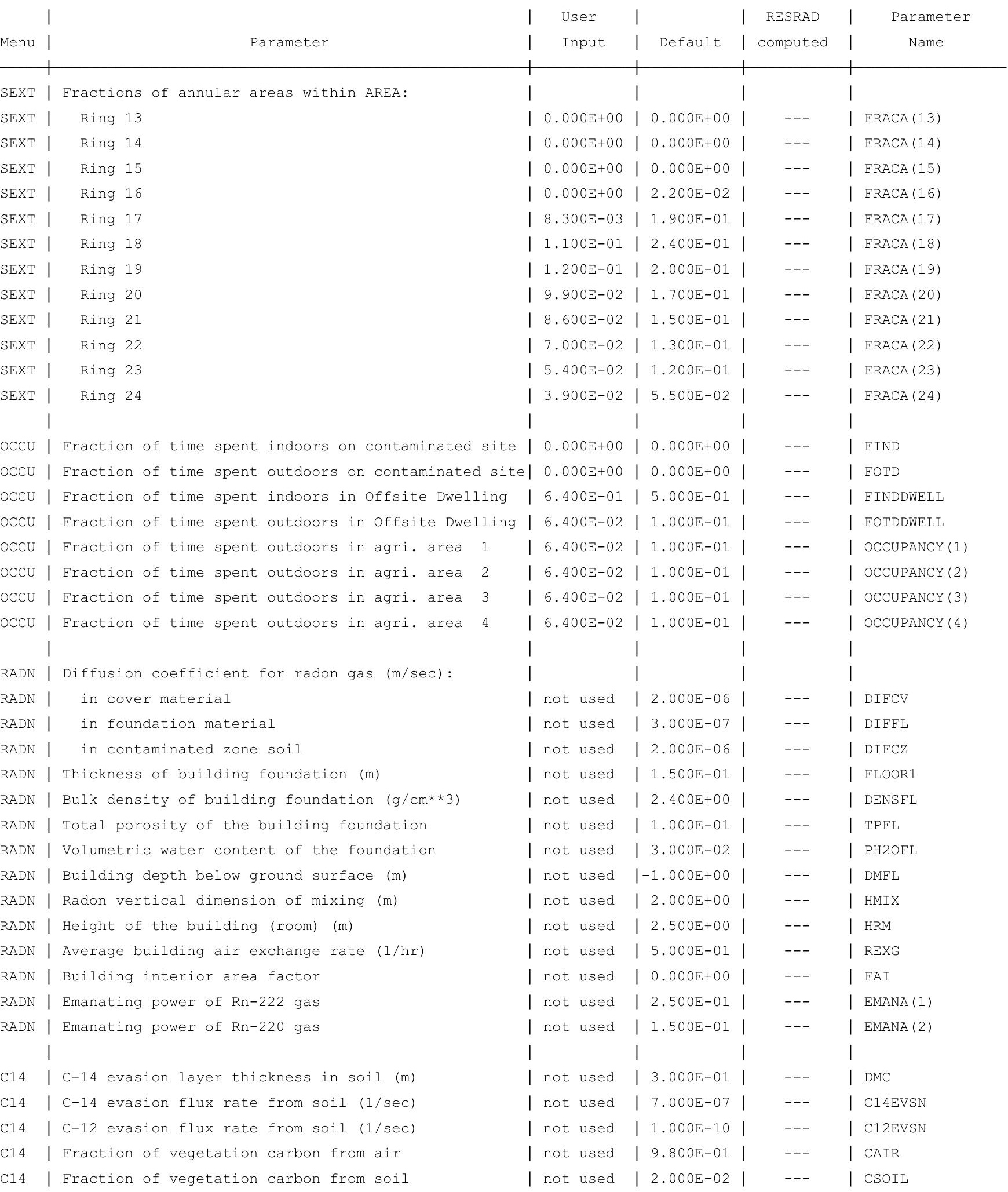


RESRAD-OFFSITE, Version 2.5

Parent Dose Report

Title : RESRAD-OFFSITE Parameters for Offsite Resident Farmer Forward Run 10,000 Years

File : OFFSITE-RF_FORWARD-7-11-10000yr.ROF

Site-Specific Parameter Summary (continued)

Parameter
Menu

Summary of Pathway Selections

\begin{tabular}{|c|c|c|}
\hline & Pathway & User Selection \\
\hline 1 & -- external gamma & active \\
\hline 2 & -- inhalation (w/o radon) & active \\
\hline 3 & -- plant ingestion & active \\
\hline 4 & -- meat ingestion & active \\
\hline 5 & -- milk ingestion & active \\
\hline 6 & -- aquatic foods & suppressed \\
\hline 7 & -- drinking water & active \\
\hline 8 & -- soil ingestion & active \\
\hline 9 & -- radon & suppressed \\
\hline
\end{tabular}


RESRAD-OFFSITE, Version $2.5 \quad \mathrm{~T}^{1 / 2}$ Limit $=180$ days

Parent Dose Report

Title : RESRAD-OFFSITE Parameters for Offsite Resident Farmer Forward Run 10,000 Years

File : OFFSITE-RF_FORWARD-7-11-10000yr.ROF

Contaminated Zone Dimensions

Area: 102144.00 square meters

Thickness: $\quad 13.40$ meters

Cover Depth: $\quad 1.52$ meters
Initial Soil Concentrations, pci/g

$\begin{array}{ll}\text { Am-241 } & 3.500 \mathrm{E}+01 \\ \mathrm{Cs}-137 & 1.900 \mathrm{E}+01 \\ \mathrm{~Np}-237 & 5.500 \mathrm{E}+00 \\ \mathrm{Pu}-238 & 3.900 \mathrm{E}+01 \\ \mathrm{Pu}-239 & 3.600 \mathrm{E}+01 \\ \mathrm{Pu}-240 & 3.600 \mathrm{E}+01 \\ \mathrm{TC}-99 & 5.200 \mathrm{E}+01 \\ \mathrm{Th}-228 & 4.000 \mathrm{E}+00 \\ \mathrm{Th}-230 & 1.000 \mathrm{E}+02 \\ \mathrm{Th}-232 & 4.000 \mathrm{E}+00 \\ \mathrm{U}-234 & 1.600 \mathrm{E}+02 \\ \mathrm{U}-235 & 6.500 \mathrm{E}+00 \\ \mathrm{U}-238 & 1.600 \mathrm{E}+02\end{array}$

Total Dose TDOSE(t), mrem/yr

Basic Radiation Dose Limit $=1.000 \mathrm{E}+00 \mathrm{mrem} / \mathrm{yr}$

Total Mixture Sum $M(t)$ = Fraction of Basic Dose Limit Received at Time (t)

$\begin{array}{rlllllll}t \text { (years) : } & 0.000 \mathrm{E}+00 & 1.000 \mathrm{E}+00 & 5.000 \mathrm{E}+01 & 1.000 \mathrm{E}+02 & 5.000 \mathrm{E}+02 & 1.026 \mathrm{E}+03 & 1.000 \mathrm{E}+04 \\ \mathrm{TDOSE}(\mathrm{t}): & 2.789 \mathrm{E}-14 & 2.096 \mathrm{E}-14 & 4.593 \mathrm{E}-14 & 6.422 \mathrm{E}-14 & 9.915 \mathrm{E}-01 & 1.436 \mathrm{E}+00 & 2.180 \mathrm{E}+00 \\ \mathrm{M}(\mathrm{t}): & 2.789 \mathrm{E}-14 & 2.096 \mathrm{E}-14 & 4.593 \mathrm{E}-14 & 6.422 \mathrm{E}-14 & 9.915 \mathrm{E}-01 & 1.436 \mathrm{E}+00 & 2.180 \mathrm{E}+00\end{array}$

Maximum TDOSE(t): $2.180 \mathrm{E}+00 \mathrm{mrem} / \mathrm{yr}$ at $t=10024$ years 
RESRAD-OFFSITE, Version 2.

Parent Dose Report

Title : RESRAD-OFFSITE Parameters for Offsite Resident Farmer Forward Run 10,000 Years

File : OFFSITE-RF FORWARD-7-11-10000yr.ROF

Total Dose Contributions TDOSE (i,p,t) for Individual Radionuclides (i) and Pathways (p) in mrem/yr and as a Percentage of Total Dose at $t=0$ years

From releases to ground water and to surface water

\begin{tabular}{|c|c|c|c|c|c|c|c|c|c|c|c|c|c|c|c|c|}
\hline & \multicolumn{2}{|c|}{ Ground } & \multicolumn{2}{|l|}{ Fish } & \multicolumn{2}{|c|}{ Radon } & \multicolumn{2}{|c|}{ Plant } & \multicolumn{2}{|l|}{ Meat } & \multicolumn{2}{|l|}{ Milk } & \multicolumn{2}{|l|}{ Soil } & \multicolumn{2}{|c|}{ Water } \\
\hline ide & Dose & $\%$ & Dose & $\%$ & Dose & 응 & Dose & $\frac{\circ}{0}$ & Dose & \% & Dose & 응 & Dose & $\%$ & Dose & $\%$ \\
\hline-241 & $0.00 \mathrm{E}+00$ & 0 & $0.00 E+00$ & 0 & $0.00 \mathrm{E}+00$ & 0 & $0.00 \mathrm{E}+00$ & 0 & $0.00 \mathrm{E}+00$ & 0 & $0.00 \mathrm{E}+00$ & 0 & $0.00 \mathrm{E}+00$ & 0 & $0.00 \mathrm{E}+00$ & 0 \\
\hline-137 & $0.00 \mathrm{E}+00$ & 0 & $0.00 \mathrm{E}+00$ & 0 & $0.00 \mathrm{E}+00$ & 0 & $0.00 \mathrm{E}+00$ & 0 & $0.00 \mathrm{E}+00$ & 0 & $0.00 \mathrm{E}+00$ & 0 & $0.00 \mathrm{E}+00$ & 0 & $0.00 \mathrm{E}+00$ & 0 \\
\hline-237 & $0.00 \mathrm{E}+00$ & 0 & $0.00 \mathrm{E}+00$ & 0 & $0.00 \mathrm{E}+00$ & 0 & $0.00 \mathrm{E}+00$ & 0 & $0.00 \mathrm{E}+00$ & 0 & $0.00 \mathrm{E}+00$ & 0 & $0.00 \mathrm{E}+00$ & 0 & $0.00 \mathrm{E}+00$ & 0 \\
\hline-238 & $0.00 \mathrm{E}+00$ & 0 & $0.00 \mathrm{E}+00$ & 0 & $0.00 E+00$ & 0 & $0.00 \mathrm{E}+00$ & 0 & $0.00 \mathrm{E}+00$ & 0 & $0.00 E+00$ & 0 & $0.00 \mathrm{E}+00$ & 0 & $0.00 \mathrm{E}+00$ & 0 \\
\hline-239 & $0.00 \mathrm{E}+00$ & 0 & $0.00 \mathrm{E}+00$ & 0 & $0.00 \mathrm{E}+00$ & 0 & $0.00 \mathrm{E}+00$ & 0 & $0.00 \mathrm{E}+00$ & 0 & $0.00 \mathrm{E}+00$ & 0 & $0.00 \mathrm{E}+00$ & 0 & $0.00 \mathrm{E}+00$ & 0 \\
\hline-240 & $0.00 \mathrm{E}+00$ & 0 & $0.00 \mathrm{E}+00$ & 0 & $0.00 \mathrm{E}+00$ & 0 & $0.00 \mathrm{E}+00$ & 0 & $0.00 \mathrm{E}+00$ & 0 & $0.00 \mathrm{E}+00$ & 0 & $0.00 \mathrm{E}+00$ & 0 & $0.00 \mathrm{E}+00$ & 0 \\
\hline-99 & $0.00 \mathrm{E}+00$ & 0 & $0.00 \mathrm{E}+00$ & 0 & $0.00 \mathrm{E}+00$ & 0 & $0.00 \mathrm{E}+00$ & 0 & $0.00 \mathrm{E}+00$ & 0 & $0.00 E+00$ & 0 & $0.00 \mathrm{E}+00$ & 0 & $0.00 \mathrm{E}+00$ & 0 \\
\hline-228 & $0.00 \mathrm{E}+00$ & 0 & $0.00 \mathrm{E}+00$ & 0 & $0.00 \mathrm{E}+00$ & 0 & $0.00 \mathrm{E}+00$ & 0 & $0.00 \mathrm{E}+00$ & 0 & $0.00 \mathrm{E}+00$ & 0 & $0.00 \mathrm{E}+00$ & 0 & $0.00 \mathrm{E}+00$ & 0 \\
\hline-230 & $0.00 \mathrm{E}+00$ & 0 & $0.00 \mathrm{E}+00$ & 0 & $0.00 \mathrm{E}+00$ & 0 & $0.00 \mathrm{E}+00$ & 0 & $0.00 \mathrm{E}+00$ & 0 & $0.00 \mathrm{E}+00$ & 0 & $0.00 \mathrm{E}+00$ & 0 & $0.00 \mathrm{E}+00$ & 0 \\
\hline-232 & $0.00 \mathrm{E}+00$ & 0 & $0.00 \mathrm{E}+00$ & 0 & $0.00 \mathrm{E}+00$ & 0 & $0.00 \mathrm{E}+00$ & 0 & $0.00 \mathrm{E}+00$ & 0 & $0.00 \mathrm{E}+00$ & 0 & $0.00 \mathrm{E}+00$ & 0 & $0.00 \mathrm{E}+00$ & 0 \\
\hline 4 & $0.00 \mathrm{E}+00$ & 0 & $0.00 \mathrm{E}+00$ & 0 & $0.00 \mathrm{E}+00$ & 0 & $0.00 \mathrm{E}+00$ & 0 & $0.00 \mathrm{E}+00$ & 0 & $0.00 \mathrm{E}+00$ & 0 & $0.00 \mathrm{E}+00$ & 0 & $0.00 \mathrm{E}+00$ & 0 \\
\hline 35 & $0.00 \mathrm{E}+00$ & 0 & $0.00 \mathrm{E}+00$ & 0 & $0.00 \mathrm{E}+00$ & 0 & $0.00 \mathrm{E}+00$ & 0 & $0.00 \mathrm{E}+00$ & 0 & $0.00 \mathrm{E}+00$ & 0 & $0.00 \mathrm{E}+00$ & 0 & $0.00 \mathrm{E}+00$ & 0 \\
\hline 38 & $0.00 \mathrm{E}+00$ & 0 & $0.00 \mathrm{E}+00$ & 0 & $0.00 \mathrm{E}+00$ & 0 & $0.00 \mathrm{E}+00$ & 0 & $0.00 \mathrm{E}+00$ & 0 & $0.00 \mathrm{E}+00$ & 0 & $0.00 \mathrm{E}+00$ & 0 & $0.00 \mathrm{E}+00$ & 0 \\
\hline & $0.00 \mathrm{E}+00$ & 0 & $0.00 E+00$ & 0 & $0.00 \mathrm{E}+00$ & 0 & $0.00 \mathrm{E}+00$ & 0 & $0.00 \mathrm{E}+00$ & 0 & $0.00 \mathrm{E}+00$ & 0 & $0.00 \mathrm{E}+00$ & 0 & $0.00 \mathrm{E}+00$ & \\
\hline
\end{tabular}

Total Dose Contributions TDOSE (i,p,t) for Individual Radionuclides (i) and Pathways (p)

in mrem/yr and as a Percentage of Total Dose at $t=0$ years

Directly from primary contamination and from release to atmosphere (Inhalation excludes radon)

\begin{tabular}{|c|c|c|c|c|c|c|c|c|c|c|c|c|c|c|c|c|}
\hline & \multicolumn{2}{|c|}{ Ground } & \multicolumn{2}{|c|}{ Inhalation } & \multicolumn{2}{|c|}{ Radon } & \multicolumn{2}{|c|}{ Plant } & \multicolumn{2}{|l|}{ Meat } & \multicolumn{2}{|l|}{ Milk } & \multicolumn{2}{|l|}{ Soil } & \multicolumn{2}{|c|}{ All Pathways* } \\
\hline clide & Dose & \% & Dose & \% & Dose & \% & Dose & $\frac{\circ}{0}$ & Dose & $\%$ & Dose & $\frac{\circ}{0}$ & Dose & $\frac{\circ}{0}$ & Dose & $\frac{\circ}{0}$ \\
\hline $1-241$ & $2.67 E-26$ & 0 & $0.00 \mathrm{E}+00$ & 0 & $0.00 \mathrm{E}+00$ & 0 & $0.00 \mathrm{E}+00$ & 0 & $0.00 \mathrm{E}+00$ & 0 & $0.00 \mathrm{E}+00$ & 0 & $0.00 \mathrm{E}+00$ & 0 & $2.67 E-26$ & 0 \\
\hline-137 & 1. $18 \mathrm{E}-16$ & 0 & $0.00 \mathrm{E}+00$ & 0 & $0.00 \mathrm{E}+00$ & 0 & $0.00 \mathrm{E}+00$ & 0 & $0.00 \mathrm{E}+00$ & 0 & $0.00 \mathrm{E}+00$ & 0 & $0.00 \mathrm{E}+00$ & 0 & $1.18 \mathrm{E}-16$ & 0 \\
\hline-237 & $2.59 \mathrm{E}-20$ & 0 & $0.00 \mathrm{E}+00$ & 0 & $0.00 \mathrm{E}+00$ & 0 & $0.00 \mathrm{E}+00$ & 0 & $0.00 \mathrm{E}+00$ & 0 & $0.00 \mathrm{E}+00$ & 0 & $0.00 \mathrm{E}+00$ & 0 & $2.59 \mathrm{E}-20$ & 0 \\
\hline-238 & 2. $22 E-29$ & 0 & $0.00 \mathrm{E}+00$ & 0 & $0.00 \mathrm{E}+00$ & 0 & $0.00 \mathrm{E}+00$ & 0 & $0.00 \mathrm{E}+00$ & 0 & $0.00 \mathrm{E}+00$ & 0 & $0.00 \mathrm{E}+00$ & 0 & $2.22 E-29$ & 0 \\
\hline-239 & $2.13 E-24$ & 0 & $0.00 \mathrm{E}+00$ & 0 & $0.00 \mathrm{E}+00$ & 0 & $0.00 \mathrm{E}+00$ & 0 & $0.00 \mathrm{E}+00$ & 0 & $0.00 \mathrm{E}+00$ & 0 & $0.00 \mathrm{E}+00$ & 0 & $2.13 E-24$ & 0 \\
\hline-240 & $2.03 E-31$ & 0 & $0.00 \mathrm{E}+00$ & 0 & $0.00 \mathrm{E}+00$ & 0 & $0.00 \mathrm{E}+00$ & 0 & $0.00 \mathrm{E}+00$ & 0 & $0.00 \mathrm{E}+00$ & 0 & $0.00 \mathrm{E}+00$ & 0 & $2.03 E-31$ & 0 \\
\hline-99 & $1.48 \mathrm{E}-32$ & 0 & $0.00 \mathrm{E}+00$ & 0 & $0.00 \mathrm{E}+00$ & 0 & $0.00 \mathrm{E}+00$ & 0 & $0.00 \mathrm{E}+00$ & 0 & $0.00 \mathrm{E}+00$ & 0 & $0.00 \mathrm{E}+00$ & 0 & $1.48 \mathrm{E}-32$ & 0 \\
\hline-228 & $2.74 \mathrm{E}-14$ & 98 & $0.00 \mathrm{E}+00$ & 0 & $0.00 \mathrm{E}+00$ & 0 & $0.00 \mathrm{E}+00$ & 0 & $0.00 \mathrm{E}+00$ & 0 & $0.00 \mathrm{E}+00$ & 0 & $0.00 \mathrm{E}+00$ & 0 & $2.74 \mathrm{E}-14$ & 98 \\
\hline-230 & $1.86 \mathrm{E}-17$ & 0 & $0.00 \mathrm{E}+00$ & 0 & $0.00 \mathrm{E}+00$ & 0 & $0.00 \mathrm{E}+00$ & 0 & $0.00 \mathrm{E}+00$ & 0 & $0.00 \mathrm{E}+00$ & 0 & $0.00 \mathrm{E}+00$ & 0 & $1.86 \mathrm{E}-17$ & 0 \\
\hline-232 & $2.68 E-16$ & 1 & $0.00 \mathrm{E}+00$ & 0 & $0.00 \mathrm{E}+00$ & 0 & $0.00 \mathrm{E}+00$ & 0 & $0.00 \mathrm{E}+00$ & 0 & $0.00 \mathrm{E}+00$ & 0 & $0.00 \mathrm{E}+00$ & 0 & $2.68 E-16$ & 1 \\
\hline 234 & $1.07 \mathrm{E}-22$ & 0 & $0.00 \mathrm{E}+00$ & 0 & $0.00 \mathrm{E}+00$ & 0 & $0.00 \mathrm{E}+00$ & 0 & $0.00 \mathrm{E}+00$ & 0 & $0.00 \mathrm{E}+00$ & 0 & $0.00 \mathrm{E}+00$ & 0 & 1. $07 \mathrm{E}-22$ & 0 \\
\hline 235 & $3.99 \mathrm{E}-22$ & 0 & $0.00 \mathrm{E}+00$ & 0 & $0.00 \mathrm{E}+00$ & 0 & $0.00 \mathrm{E}+00$ & 0 & $0.00 \mathrm{E}+00$ & 0 & $0.00 \mathrm{E}+00$ & 0 & $0.00 \mathrm{E}+00$ & 0 & $3.99 \mathrm{E}-22$ & 0 \\
\hline 238 & $1.12 \mathrm{E}-16$ & 0 & $0.00 \mathrm{E}+00$ & 0 & $0.00 \mathrm{E}+00$ & 0 & $0.00 \mathrm{E}+00$ & 0 & $0.00 \mathrm{E}+00$ & 0 & $0.00 \mathrm{E}+00$ & 0 & $0.00 \mathrm{E}+00$ & 0 & $1.12 \mathrm{E}-16$ & 0 \\
\hline & $2.79 \mathrm{E}-14$ & 100 & $0.00 \mathrm{E}+00$ & 0 & $0.00 \mathrm{E}+00$ & 0 & $0.00 \mathrm{E}+00$ & 0 & $0.00 \mathrm{E}+00$ & 0 & $0.00 \mathrm{E}+00$ & 0 & $0.00 \mathrm{E}+00$ & 0 & $2.79 \mathrm{E}-14$ & 100 \\
\hline
\end{tabular}

* Sum of dose from all releases and from primary contamination. 
RESRAD-OFFSITE, Version 2.

Parent Dose Report

Title : RESRAD-OFFSITE Parameters for Offsite Resident Farmer Forward Run 10,000 Years

File : OFFSITE-RF_FORWARD-7-11-10000yr.ROF

Total Dose Contributions TDOSE (i,p,t) for Individual Radionuclides (i) and Pathways (p) in mrem/yr and as a Percentage of Total Dose at $t=1$ years

From releases to ground water and to surface water

\begin{tabular}{|c|c|c|c|c|c|c|c|c|c|c|c|c|c|c|c|c|}
\hline & \multicolumn{2}{|c|}{ Ground } & \multicolumn{2}{|l|}{ Fish } & \multicolumn{2}{|c|}{ Radon } & \multicolumn{2}{|c|}{ Plant } & \multicolumn{2}{|l|}{ Meat } & \multicolumn{2}{|l|}{ Milk } & \multicolumn{2}{|l|}{ Soil } & \multicolumn{2}{|c|}{ Water } \\
\hline ide & Dose & $\%$ & Dose & $\%$ & Dose & 응 & Dose & $\frac{\circ}{0}$ & Dose & \% & Dose & 응 & Dose & $\%$ & Dose & $\%$ \\
\hline-241 & $0.00 \mathrm{E}+00$ & 0 & $0.00 E+00$ & 0 & $0.00 \mathrm{E}+00$ & 0 & $0.00 \mathrm{E}+00$ & 0 & $0.00 \mathrm{E}+00$ & 0 & $0.00 \mathrm{E}+00$ & 0 & $0.00 \mathrm{E}+00$ & 0 & $0.00 \mathrm{E}+00$ & 0 \\
\hline-137 & $0.00 \mathrm{E}+00$ & 0 & $0.00 \mathrm{E}+00$ & 0 & $0.00 \mathrm{E}+00$ & 0 & $0.00 \mathrm{E}+00$ & 0 & $0.00 \mathrm{E}+00$ & 0 & $0.00 \mathrm{E}+00$ & 0 & $0.00 \mathrm{E}+00$ & 0 & $0.00 \mathrm{E}+00$ & 0 \\
\hline-237 & $0.00 \mathrm{E}+00$ & 0 & $0.00 \mathrm{E}+00$ & 0 & $0.00 \mathrm{E}+00$ & 0 & $0.00 \mathrm{E}+00$ & 0 & $0.00 \mathrm{E}+00$ & 0 & $0.00 \mathrm{E}+00$ & 0 & $0.00 \mathrm{E}+00$ & 0 & $0.00 \mathrm{E}+00$ & 0 \\
\hline-238 & $0.00 \mathrm{E}+00$ & 0 & $0.00 \mathrm{E}+00$ & 0 & $0.00 E+00$ & 0 & $0.00 \mathrm{E}+00$ & 0 & $0.00 \mathrm{E}+00$ & 0 & $0.00 E+00$ & 0 & $0.00 \mathrm{E}+00$ & 0 & $0.00 \mathrm{E}+00$ & 0 \\
\hline-239 & $0.00 \mathrm{E}+00$ & 0 & $0.00 \mathrm{E}+00$ & 0 & $0.00 \mathrm{E}+00$ & 0 & $0.00 \mathrm{E}+00$ & 0 & $0.00 \mathrm{E}+00$ & 0 & $0.00 \mathrm{E}+00$ & 0 & $0.00 \mathrm{E}+00$ & 0 & $0.00 \mathrm{E}+00$ & 0 \\
\hline-240 & $0.00 \mathrm{E}+00$ & 0 & $0.00 \mathrm{E}+00$ & 0 & $0.00 \mathrm{E}+00$ & 0 & $0.00 \mathrm{E}+00$ & 0 & $0.00 \mathrm{E}+00$ & 0 & $0.00 \mathrm{E}+00$ & 0 & $0.00 \mathrm{E}+00$ & 0 & $0.00 \mathrm{E}+00$ & 0 \\
\hline-99 & $0.00 \mathrm{E}+00$ & 0 & $0.00 \mathrm{E}+00$ & 0 & $0.00 \mathrm{E}+00$ & 0 & $0.00 \mathrm{E}+00$ & 0 & $0.00 \mathrm{E}+00$ & 0 & $0.00 E+00$ & 0 & $0.00 \mathrm{E}+00$ & 0 & $0.00 \mathrm{E}+00$ & 0 \\
\hline-228 & $0.00 \mathrm{E}+00$ & 0 & $0.00 \mathrm{E}+00$ & 0 & $0.00 \mathrm{E}+00$ & 0 & $0.00 \mathrm{E}+00$ & 0 & $0.00 \mathrm{E}+00$ & 0 & $0.00 \mathrm{E}+00$ & 0 & $0.00 \mathrm{E}+00$ & 0 & $0.00 \mathrm{E}+00$ & 0 \\
\hline-230 & $0.00 \mathrm{E}+00$ & 0 & $0.00 \mathrm{E}+00$ & 0 & $0.00 \mathrm{E}+00$ & 0 & $0.00 \mathrm{E}+00$ & 0 & $0.00 \mathrm{E}+00$ & 0 & $0.00 \mathrm{E}+00$ & 0 & $0.00 \mathrm{E}+00$ & 0 & $0.00 \mathrm{E}+00$ & 0 \\
\hline-232 & $0.00 \mathrm{E}+00$ & 0 & $0.00 \mathrm{E}+00$ & 0 & $0.00 \mathrm{E}+00$ & 0 & $0.00 \mathrm{E}+00$ & 0 & $0.00 \mathrm{E}+00$ & 0 & $0.00 \mathrm{E}+00$ & 0 & $0.00 \mathrm{E}+00$ & 0 & $0.00 \mathrm{E}+00$ & 0 \\
\hline 4 & $0.00 \mathrm{E}+00$ & 0 & $0.00 \mathrm{E}+00$ & 0 & $0.00 \mathrm{E}+00$ & 0 & $0.00 \mathrm{E}+00$ & 0 & $0.00 \mathrm{E}+00$ & 0 & $0.00 \mathrm{E}+00$ & 0 & $0.00 \mathrm{E}+00$ & 0 & $0.00 \mathrm{E}+00$ & 0 \\
\hline 35 & $0.00 \mathrm{E}+00$ & 0 & $0.00 \mathrm{E}+00$ & 0 & $0.00 \mathrm{E}+00$ & 0 & $0.00 \mathrm{E}+00$ & 0 & $0.00 \mathrm{E}+00$ & 0 & $0.00 \mathrm{E}+00$ & 0 & $0.00 \mathrm{E}+00$ & 0 & $0.00 \mathrm{E}+00$ & 0 \\
\hline 38 & $0.00 \mathrm{E}+00$ & 0 & $0.00 \mathrm{E}+00$ & 0 & $0.00 \mathrm{E}+00$ & 0 & $0.00 \mathrm{E}+00$ & 0 & $0.00 \mathrm{E}+00$ & 0 & $0.00 \mathrm{E}+00$ & 0 & $0.00 \mathrm{E}+00$ & 0 & $0.00 \mathrm{E}+00$ & 0 \\
\hline & $0.00 \mathrm{E}+00$ & 0 & $0.00 E+00$ & 0 & $0.00 \mathrm{E}+00$ & 0 & $0.00 \mathrm{E}+00$ & 0 & $0.00 \mathrm{E}+00$ & 0 & $0.00 \mathrm{E}+00$ & 0 & $0.00 \mathrm{E}+00$ & 0 & $0.00 \mathrm{E}+00$ & \\
\hline
\end{tabular}

Total Dose Contributions TDOSE (i,p,t) for Individual Radionuclides (i) and Pathways (p)

in mrem/yr and as a Percentage of Total Dose at $t=1$ years

Directly from primary contamination and from release to atmosphere (Inhalation excludes radon)

\begin{tabular}{|c|c|c|c|c|c|c|c|c|c|c|c|c|c|c|c|c|}
\hline & \multicolumn{2}{|c|}{ Ground } & \multicolumn{2}{|c|}{ Inhalation } & \multicolumn{2}{|c|}{ Radon } & \multicolumn{2}{|c|}{ Plant } & \multicolumn{2}{|l|}{ Meat } & \multicolumn{2}{|l|}{ Milk } & \multicolumn{2}{|l|}{ Soil } & \multicolumn{2}{|c|}{ All Pathways* } \\
\hline clide & Dose & \% & Dose & $\%$ & Dose & $\%$ & Dose & 음 & Dose & $\%$ & Dose & $\%$ & Dose & \% & Dose & $\frac{\circ}{0}$ \\
\hline-241 & $8.07 E-26$ & 0 & $0.00 E+00$ & 0 & $0.00 \mathrm{E}+00$ & 0 & $0.00 \mathrm{E}+00$ & 0 & $0.00 \mathrm{E}+00$ & 0 & $0.00 \mathrm{E}+00$ & 0 & $0.00 \mathrm{E}+00$ & 0 & $8.07 E-26$ & 0 \\
\hline-137 & $1.16 \mathrm{E}-16$ & 1 & $0.00 \mathrm{E}+00$ & 0 & $0.00 \mathrm{E}+00$ & 0 & $0.00 \mathrm{E}+00$ & 0 & $0.00 \mathrm{E}+00$ & 0 & $0.00 \mathrm{E}+00$ & 0 & $0.00 \mathrm{E}+00$ & 0 & $1.16 \mathrm{E}-16$ & 1 \\
\hline-237 & $2.61 \mathrm{E}-20$ & 0 & $0.00 \mathrm{E}+00$ & 0 & $0.00 \mathrm{E}+00$ & 0 & $0.00 \mathrm{E}+00$ & 0 & $0.00 \mathrm{E}+00$ & 0 & $0.00 \mathrm{E}+00$ & 0 & $0.00 \mathrm{E}+00$ & 0 & $2.61 E-20$ & 0 \\
\hline-238 & $2.74 \mathrm{E}-28$ & 0 & $0.00 \mathrm{E}+00$ & 0 & $0.00 \mathrm{E}+00$ & 0 & $0.00 \mathrm{E}+00$ & 0 & $0.00 \mathrm{E}+00$ & 0 & $0.00 \mathrm{E}+00$ & 0 & $0.00 \mathrm{E}+00$ & 0 & $2.74 \mathrm{E}-28$ & 0 \\
\hline-239 & $2.16 \mathrm{E}-24$ & 0 & $0.00 \mathrm{E}+00$ & 0 & $0.00 \mathrm{E}+00$ & 0 & $0.00 \mathrm{E}+00$ & 0 & $0.00 \mathrm{E}+00$ & 0 & $0.00 \mathrm{E}+00$ & 0 & $0.00 \mathrm{E}+00$ & 0 & $2.16 \mathrm{E}-24$ & 0 \\
\hline-240 & $2.12 E-31$ & 0 & $0.00 \mathrm{E}+00$ & 0 & $0.00 \mathrm{E}+00$ & 0 & $0.00 \mathrm{E}+00$ & 0 & $0.00 \mathrm{E}+00$ & 0 & $0.00 \mathrm{E}+00$ & 0 & $0.00 \mathrm{E}+00$ & 0 & $2.12 E-31$ & 0 \\
\hline-99 & $1.50 \mathrm{E}-32$ & 0 & $0.00 \mathrm{E}+00$ & 0 & $0.00 \mathrm{E}+00$ & 0 & $0.00 \mathrm{E}+00$ & 0 & $0.00 \mathrm{E}+00$ & 0 & $0.00 \mathrm{E}+00$ & 0 & $0.00 \mathrm{E}+00$ & 0 & $1.50 \mathrm{E}-32$ & 0 \\
\hline-228 & 1. $93 \mathrm{E}-14$ & 92 & $0.00 \mathrm{E}+00$ & 0 & $0.00 \mathrm{E}+00$ & 0 & $0.00 \mathrm{E}+00$ & 0 & $0.00 \mathrm{E}+00$ & 0 & $0.00 \mathrm{E}+00$ & 0 & $0.00 \mathrm{E}+00$ & 0 & 1. $93 \mathrm{E}-14$ & 92 \\
\hline-230 & $5.61 \mathrm{E}-17$ & 0 & $0.00 \mathrm{E}+00$ & 0 & $0.00 \mathrm{E}+00$ & 0 & $0.00 \mathrm{E}+00$ & 0 & $0.00 \mathrm{E}+00$ & 0 & $0.00 \mathrm{E}+00$ & 0 & $0.00 \mathrm{E}+00$ & 0 & $5.61 \mathrm{E}-17$ & 0 \\
\hline-232 & 1. $41 \mathrm{E}-15$ & 7 & $0.00 \mathrm{E}+00$ & 0 & $0.00 \mathrm{E}+00$ & 0 & $0.00 \mathrm{E}+00$ & 0 & $0.00 \mathrm{E}+00$ & 0 & $0.00 \mathrm{E}+00$ & 0 & $0.00 \mathrm{E}+00$ & 0 & $1.41 \mathrm{E}-15$ & 7 \\
\hline 234 & $6.70 \mathrm{E}-22$ & 0 & $0.00 \mathrm{E}+00$ & 0 & $0.00 \mathrm{E}+00$ & 0 & $0.00 \mathrm{E}+00$ & 0 & $0.00 \mathrm{E}+00$ & 0 & $0.00 \mathrm{E}+00$ & 0 & $0.00 \mathrm{E}+00$ & 0 & $6.70 \mathrm{E}-22$ & 0 \\
\hline 235 & $4.05 E-22$ & 0 & $0.00 \mathrm{E}+00$ & 0 & $0.00 \mathrm{E}+00$ & 0 & $0.00 \mathrm{E}+00$ & 0 & $0.00 \mathrm{E}+00$ & 0 & $0.00 \mathrm{E}+00$ & 0 & $0.00 \mathrm{E}+00$ & 0 & $4.05 E-22$ & 0 \\
\hline 38 & $1.13 \mathrm{E}-16$ & 1 & $0.00 \mathrm{E}+00$ & 0 & $0.00 \mathrm{E}+00$ & 0 & $0.00 \mathrm{E}+00$ & 0 & $0.00 \mathrm{E}+00$ & 0 & $0.00 \mathrm{E}+00$ & 0 & $0.00 \mathrm{E}+00$ & 0 & $1.13 \mathrm{E}-16$ & 1 \\
\hline & $2.10 \mathrm{E}-14$ & 100 & $0.00 \mathrm{E}+00$ & 0 & $0.00 \mathrm{E}+00$ & 0 & $0.00 \mathrm{E}+00$ & 0 & $0.00 \mathrm{E}+00$ & 0 & $0.00 \mathrm{E}+00$ & 0 & $0.00 \mathrm{E}+00$ & 0 & $2.10 \mathrm{E}-14$ & 100 \\
\hline
\end{tabular}

* Sum of dose from all releases and from primary contamination. 
RESRAD-OFFSITE, Version 2.

Parent Dose Report

Title : RESRAD-OFFSITE Parameters for Offsite Resident Farmer Forward Run 10,000 Years

File : OFFSITE-RF FORWARD-7-11-10000yr.ROF

Total Dose Contributions TDOSE (i,p,t) for Individual Radionuclides (i) and Pathways (p) in mrem/yr and as a Percentage of Total Dose at $t=50$ years

From releases to ground water and to surface water

\begin{tabular}{|c|c|c|c|c|c|c|c|c|c|c|c|c|c|c|c|c|}
\hline & \multicolumn{2}{|c|}{ Ground } & \multicolumn{2}{|l|}{ Fish } & \multicolumn{2}{|c|}{ Radon } & \multicolumn{2}{|c|}{ Plant } & \multicolumn{2}{|l|}{ Meat } & \multicolumn{2}{|l|}{ Milk } & \multicolumn{2}{|l|}{ Soil } & \multicolumn{2}{|c|}{ Water } \\
\hline ide & Dose & $\%$ & Dose & $\%$ & Dose & 응 & Dose & $\frac{\circ}{0}$ & Dose & \% & Dose & 응 & Dose & $\%$ & Dose & $\%$ \\
\hline-241 & $0.00 \mathrm{E}+00$ & 0 & $0.00 E+00$ & 0 & $0.00 \mathrm{E}+00$ & 0 & $0.00 \mathrm{E}+00$ & 0 & $0.00 \mathrm{E}+00$ & 0 & $0.00 \mathrm{E}+00$ & 0 & $0.00 \mathrm{E}+00$ & 0 & $0.00 \mathrm{E}+00$ & 0 \\
\hline-137 & $0.00 \mathrm{E}+00$ & 0 & $0.00 \mathrm{E}+00$ & 0 & $0.00 \mathrm{E}+00$ & 0 & $0.00 \mathrm{E}+00$ & 0 & $0.00 \mathrm{E}+00$ & 0 & $0.00 \mathrm{E}+00$ & 0 & $0.00 \mathrm{E}+00$ & 0 & $0.00 \mathrm{E}+00$ & 0 \\
\hline-237 & $0.00 \mathrm{E}+00$ & 0 & $0.00 \mathrm{E}+00$ & 0 & $0.00 \mathrm{E}+00$ & 0 & $0.00 \mathrm{E}+00$ & 0 & $0.00 \mathrm{E}+00$ & 0 & $0.00 \mathrm{E}+00$ & 0 & $0.00 \mathrm{E}+00$ & 0 & $0.00 \mathrm{E}+00$ & 0 \\
\hline-238 & $0.00 \mathrm{E}+00$ & 0 & $0.00 \mathrm{E}+00$ & 0 & $0.00 E+00$ & 0 & $0.00 \mathrm{E}+00$ & 0 & $0.00 \mathrm{E}+00$ & 0 & $0.00 E+00$ & 0 & $0.00 \mathrm{E}+00$ & 0 & $0.00 \mathrm{E}+00$ & 0 \\
\hline-239 & $0.00 \mathrm{E}+00$ & 0 & $0.00 \mathrm{E}+00$ & 0 & $0.00 \mathrm{E}+00$ & 0 & $0.00 \mathrm{E}+00$ & 0 & $0.00 \mathrm{E}+00$ & 0 & $0.00 \mathrm{E}+00$ & 0 & $0.00 \mathrm{E}+00$ & 0 & $0.00 \mathrm{E}+00$ & 0 \\
\hline-240 & $0.00 \mathrm{E}+00$ & 0 & $0.00 \mathrm{E}+00$ & 0 & $0.00 \mathrm{E}+00$ & 0 & $0.00 \mathrm{E}+00$ & 0 & $0.00 \mathrm{E}+00$ & 0 & $0.00 \mathrm{E}+00$ & 0 & $0.00 \mathrm{E}+00$ & 0 & $0.00 \mathrm{E}+00$ & 0 \\
\hline-99 & $0.00 \mathrm{E}+00$ & 0 & $0.00 \mathrm{E}+00$ & 0 & $0.00 \mathrm{E}+00$ & 0 & $0.00 \mathrm{E}+00$ & 0 & $0.00 \mathrm{E}+00$ & 0 & $0.00 E+00$ & 0 & $0.00 \mathrm{E}+00$ & 0 & $0.00 \mathrm{E}+00$ & 0 \\
\hline-228 & $0.00 \mathrm{E}+00$ & 0 & $0.00 \mathrm{E}+00$ & 0 & $0.00 \mathrm{E}+00$ & 0 & $0.00 \mathrm{E}+00$ & 0 & $0.00 \mathrm{E}+00$ & 0 & $0.00 \mathrm{E}+00$ & 0 & $0.00 \mathrm{E}+00$ & 0 & $0.00 \mathrm{E}+00$ & 0 \\
\hline-230 & $0.00 \mathrm{E}+00$ & 0 & $0.00 \mathrm{E}+00$ & 0 & $0.00 \mathrm{E}+00$ & 0 & $0.00 \mathrm{E}+00$ & 0 & $0.00 \mathrm{E}+00$ & 0 & $0.00 \mathrm{E}+00$ & 0 & $0.00 \mathrm{E}+00$ & 0 & $0.00 \mathrm{E}+00$ & 0 \\
\hline-232 & $0.00 \mathrm{E}+00$ & 0 & $0.00 \mathrm{E}+00$ & 0 & $0.00 \mathrm{E}+00$ & 0 & $0.00 \mathrm{E}+00$ & 0 & $0.00 \mathrm{E}+00$ & 0 & $0.00 \mathrm{E}+00$ & 0 & $0.00 \mathrm{E}+00$ & 0 & $0.00 \mathrm{E}+00$ & 0 \\
\hline 4 & $0.00 \mathrm{E}+00$ & 0 & $0.00 \mathrm{E}+00$ & 0 & $0.00 \mathrm{E}+00$ & 0 & $0.00 \mathrm{E}+00$ & 0 & $0.00 \mathrm{E}+00$ & 0 & $0.00 \mathrm{E}+00$ & 0 & $0.00 \mathrm{E}+00$ & 0 & $0.00 \mathrm{E}+00$ & 0 \\
\hline 35 & $0.00 \mathrm{E}+00$ & 0 & $0.00 \mathrm{E}+00$ & 0 & $0.00 \mathrm{E}+00$ & 0 & $0.00 \mathrm{E}+00$ & 0 & $0.00 \mathrm{E}+00$ & 0 & $0.00 \mathrm{E}+00$ & 0 & $0.00 \mathrm{E}+00$ & 0 & $0.00 \mathrm{E}+00$ & 0 \\
\hline 38 & $0.00 \mathrm{E}+00$ & 0 & $0.00 \mathrm{E}+00$ & 0 & $0.00 \mathrm{E}+00$ & 0 & $0.00 \mathrm{E}+00$ & 0 & $0.00 \mathrm{E}+00$ & 0 & $0.00 \mathrm{E}+00$ & 0 & $0.00 \mathrm{E}+00$ & 0 & $0.00 \mathrm{E}+00$ & 0 \\
\hline & $0.00 \mathrm{E}+00$ & 0 & $0.00 E+00$ & 0 & $0.00 \mathrm{E}+00$ & 0 & $0.00 \mathrm{E}+00$ & 0 & $0.00 \mathrm{E}+00$ & 0 & $0.00 \mathrm{E}+00$ & 0 & $0.00 \mathrm{E}+00$ & 0 & $0.00 \mathrm{E}+00$ & \\
\hline
\end{tabular}

Total Dose Contributions TDOSE (i,p,t) for Individual Radionuclides (i) and Pathways (p) in mrem/yr and as a Percentage of Total Dose at $t=50$ years

Directly from primary contamination and from release to atmosphere (Inhalation excludes radon)

\begin{tabular}{|c|c|c|c|c|c|c|c|c|c|c|c|c|c|c|c|c|}
\hline & \multicolumn{2}{|c|}{ Ground } & \multicolumn{2}{|c|}{ Inhalation } & \multicolumn{2}{|c|}{ Radon } & \multicolumn{2}{|c|}{ Plant } & \multicolumn{2}{|l|}{ Meat } & \multicolumn{2}{|l|}{ Milk } & \multicolumn{2}{|l|}{ Soil } & \multicolumn{2}{|c|}{ All Pathways* } \\
\hline clide & Dose & $\%$ & Dose & $\%$ & Dose & $\%$ & Dose & 음 & Dose & $\%$ & Dose & 음 & Dose & $\%$ & Dose & $\%$ \\
\hline-241 & $4.24 E-24$ & 0 & $0.00 \mathrm{E}+00$ & 0 & $0.00 E+00$ & 0 & $0.00 \mathrm{E}+00$ & 0 & $0.00 \mathrm{E}+00$ & 0 & $0.00 \mathrm{E}+00$ & 0 & $0.00 \mathrm{E}+00$ & 0 & 4. $24 \mathrm{E}-24$ & 0 \\
\hline-137 & $5.48 E-17$ & 0 & $0.00 E+00$ & 0 & $0.00 E+00$ & 0 & $0.00 \mathrm{E}+00$ & 0 & $0.00 \mathrm{E}+00$ & 0 & $0.00 E+00$ & 0 & $0.00 \mathrm{E}+00$ & 0 & $5.48 \mathrm{E}-17$ & 0 \\
\hline-237 & $4.24 E-20$ & 0 & $0.00 \mathrm{E}+00$ & 0 & $0.00 E+00$ & 0 & $0.00 \mathrm{E}+00$ & 0 & $0.00 \mathrm{E}+00$ & 0 & $0.00 E+00$ & 0 & $0.00 \mathrm{E}+00$ & 0 & $4.24 E-20$ & 0 \\
\hline-238 & $9.85 E-24$ & 0 & $0.00 \mathrm{E}+00$ & 0 & $0.00 \mathrm{E}+00$ & 0 & $0.00 \mathrm{E}+00$ & 0 & $0.00 \mathrm{E}+00$ & 0 & $0.00 \mathrm{E}+00$ & 0 & $0.00 \mathrm{E}+00$ & 0 & $9.85 E-24$ & 0 \\
\hline-239 & $3.70 E-24$ & 0 & $0.00 \mathrm{E}+00$ & 0 & $0.00 \mathrm{E}+00$ & 0 & $0.00 \mathrm{E}+00$ & 0 & $0.00 \mathrm{E}+00$ & 0 & $0.00 \mathrm{E}+00$ & 0 & $0.00 \mathrm{E}+00$ & 0 & $3.70 \mathrm{E}-24$ & 0 \\
\hline-240 & 4. $65 \mathrm{E}-28$ & 0 & $0.00 \mathrm{E}+00$ & 0 & $0.00 \mathrm{E}+00$ & 0 & $0.00 \mathrm{E}+00$ & 0 & $0.00 \mathrm{E}+00$ & 0 & $0.00 \mathrm{E}+00$ & 0 & $0.00 \mathrm{E}+00$ & 0 & 4. $65 \mathrm{E}-28$ & 0 \\
\hline-99 & $2.75 E-32$ & 0 & $0.00 \mathrm{E}+00$ & 0 & $0.00 \mathrm{E}+00$ & 0 & $0.00 \mathrm{E}+00$ & 0 & $0.00 \mathrm{E}+00$ & 0 & $0.00 E+00$ & 0 & $0.00 \mathrm{E}+00$ & 0 & $2.75 E-32$ & 0 \\
\hline-228 & 4. $91 \mathrm{E}-22$ & 0 & $0.00 \mathrm{E}+00$ & 0 & $0.00 \mathrm{E}+00$ & 0 & $0.00 \mathrm{E}+00$ & 0 & $0.00 \mathrm{E}+00$ & 0 & $0.00 \mathrm{E}+00$ & 0 & $0.00 \mathrm{E}+00$ & 0 & $4.91 \mathrm{E}-22$ & 0 \\
\hline-230 & $2.55 E-15$ & 6 & $0.00 E+00$ & 0 & $0.00 \mathrm{E}+00$ & 0 & $0.00 \mathrm{E}+00$ & 0 & $0.00 \mathrm{E}+00$ & 0 & $0.00 E+00$ & 0 & $0.00 \mathrm{E}+00$ & 0 & $2.55 E-15$ & 6 \\
\hline-232 & $4.32 E-14$ & 94 & $0.00 \mathrm{E}+00$ & 0 & $0.00 \mathrm{E}+00$ & 0 & $0.00 \mathrm{E}+00$ & 0 & $0.00 \mathrm{E}+00$ & 0 & $0.00 \mathrm{E}+00$ & 0 & $0.00 \mathrm{E}+00$ & 0 & $4.32 \mathrm{E}-14$ & 94 \\
\hline 34 & $9.31 E-19$ & 0 & $0.00 \mathrm{E}+00$ & 0 & $0.00 \mathrm{E}+00$ & 0 & $0.00 \mathrm{E}+00$ & 0 & $0.00 \mathrm{E}+00$ & 0 & $0.00 \mathrm{E}+00$ & 0 & $0.00 \mathrm{E}+00$ & 0 & $9.31 \mathrm{E}-19$ & 0 \\
\hline 35 & $2.85 E-21$ & 0 & $0.00 \mathrm{E}+00$ & 0 & $0.00 E+00$ & 0 & $0.00 \mathrm{E}+00$ & 0 & $0.00 \mathrm{E}+00$ & 0 & $0.00 E+00$ & 0 & $0.00 \mathrm{E}+00$ & 0 & $2.85 E-21$ & 0 \\
\hline 38 & 1. $62 \mathrm{E}-16$ & 0 & $0.00 \mathrm{E}+00$ & 0 & $0.00 \mathrm{E}+00$ & 0 & $0.00 \mathrm{E}+00$ & 0 & $0.00 \mathrm{E}+00$ & 0 & $0.00 E+00$ & 0 & $0.00 \mathrm{E}+00$ & 0 & 1. $62 \mathrm{E}-16$ & 0 \\
\hline & $4.59 \mathrm{E}-14$ & 100 & $0.00 \mathrm{E}+00$ & 0 & $0.00 \mathrm{E}+00$ & 0 & $0.00 \mathrm{E}+00$ & 0 & $0.00 \mathrm{E}+00$ & 0 & $0.00 \mathrm{E}+00$ & 0 & $0.00 \mathrm{E}+00$ & 0 & $4.59 \mathrm{E}-14$ & 100 \\
\hline
\end{tabular}

* Sum of dose from all releases and from primary contamination. 
RESRAD-OFFSITE, Version 2.

Parent Dose Report

Title : RESRAD-OFFSITE Parameters for Offsite Resident Farmer Forward Run 10,000 Years

File : OFFSITE-RF_FORWARD-7-11-10000yr.ROF

Total Dose Contributions TDOSE (i,p,t) for Individual Radionuclides (i) and Pathways (p) in mrem/yr and as a Percentage of Total Dose at $t=100$ years

From releases to ground water and to surface water

\begin{tabular}{|c|c|c|c|c|c|c|c|c|c|c|c|c|c|c|c|c|}
\hline & \multicolumn{2}{|c|}{ Ground } & \multicolumn{2}{|l|}{ Fish } & \multicolumn{2}{|c|}{ Radon } & \multicolumn{2}{|c|}{ Plant } & \multicolumn{2}{|l|}{ Meat } & \multicolumn{2}{|l|}{ Milk } & \multicolumn{2}{|l|}{ Soil } & \multicolumn{2}{|c|}{ Water } \\
\hline ide & Dose & $\%$ & Dose & $\%$ & Dose & 응 & Dose & $\frac{\circ}{0}$ & Dose & \% & Dose & 응 & Dose & $\%$ & Dose & $\%$ \\
\hline-241 & $0.00 \mathrm{E}+00$ & 0 & $0.00 E+00$ & 0 & $0.00 \mathrm{E}+00$ & 0 & $0.00 \mathrm{E}+00$ & 0 & $0.00 \mathrm{E}+00$ & 0 & $0.00 \mathrm{E}+00$ & 0 & $0.00 \mathrm{E}+00$ & 0 & $0.00 \mathrm{E}+00$ & 0 \\
\hline-137 & $0.00 \mathrm{E}+00$ & 0 & $0.00 \mathrm{E}+00$ & 0 & $0.00 \mathrm{E}+00$ & 0 & $0.00 \mathrm{E}+00$ & 0 & $0.00 \mathrm{E}+00$ & 0 & $0.00 \mathrm{E}+00$ & 0 & $0.00 \mathrm{E}+00$ & 0 & $0.00 \mathrm{E}+00$ & 0 \\
\hline-237 & $0.00 \mathrm{E}+00$ & 0 & $0.00 \mathrm{E}+00$ & 0 & $0.00 \mathrm{E}+00$ & 0 & $0.00 \mathrm{E}+00$ & 0 & $0.00 \mathrm{E}+00$ & 0 & $0.00 \mathrm{E}+00$ & 0 & $0.00 \mathrm{E}+00$ & 0 & $0.00 \mathrm{E}+00$ & 0 \\
\hline-238 & $0.00 \mathrm{E}+00$ & 0 & $0.00 \mathrm{E}+00$ & 0 & $0.00 E+00$ & 0 & $0.00 \mathrm{E}+00$ & 0 & $0.00 \mathrm{E}+00$ & 0 & $0.00 E+00$ & 0 & $0.00 \mathrm{E}+00$ & 0 & $0.00 \mathrm{E}+00$ & 0 \\
\hline-239 & $0.00 \mathrm{E}+00$ & 0 & $0.00 \mathrm{E}+00$ & 0 & $0.00 \mathrm{E}+00$ & 0 & $0.00 \mathrm{E}+00$ & 0 & $0.00 \mathrm{E}+00$ & 0 & $0.00 \mathrm{E}+00$ & 0 & $0.00 \mathrm{E}+00$ & 0 & $0.00 \mathrm{E}+00$ & 0 \\
\hline-240 & $0.00 \mathrm{E}+00$ & 0 & $0.00 \mathrm{E}+00$ & 0 & $0.00 \mathrm{E}+00$ & 0 & $0.00 \mathrm{E}+00$ & 0 & $0.00 \mathrm{E}+00$ & 0 & $0.00 \mathrm{E}+00$ & 0 & $0.00 \mathrm{E}+00$ & 0 & $0.00 \mathrm{E}+00$ & 0 \\
\hline-99 & $0.00 \mathrm{E}+00$ & 0 & $0.00 \mathrm{E}+00$ & 0 & $0.00 \mathrm{E}+00$ & 0 & $0.00 \mathrm{E}+00$ & 0 & $0.00 \mathrm{E}+00$ & 0 & $0.00 E+00$ & 0 & $0.00 \mathrm{E}+00$ & 0 & $0.00 \mathrm{E}+00$ & 0 \\
\hline-228 & $0.00 \mathrm{E}+00$ & 0 & $0.00 \mathrm{E}+00$ & 0 & $0.00 \mathrm{E}+00$ & 0 & $0.00 \mathrm{E}+00$ & 0 & $0.00 \mathrm{E}+00$ & 0 & $0.00 \mathrm{E}+00$ & 0 & $0.00 \mathrm{E}+00$ & 0 & $0.00 \mathrm{E}+00$ & 0 \\
\hline-230 & $0.00 \mathrm{E}+00$ & 0 & $0.00 \mathrm{E}+00$ & 0 & $0.00 \mathrm{E}+00$ & 0 & $0.00 \mathrm{E}+00$ & 0 & $0.00 \mathrm{E}+00$ & 0 & $0.00 \mathrm{E}+00$ & 0 & $0.00 \mathrm{E}+00$ & 0 & $0.00 \mathrm{E}+00$ & 0 \\
\hline-232 & $0.00 \mathrm{E}+00$ & 0 & $0.00 \mathrm{E}+00$ & 0 & $0.00 \mathrm{E}+00$ & 0 & $0.00 \mathrm{E}+00$ & 0 & $0.00 \mathrm{E}+00$ & 0 & $0.00 \mathrm{E}+00$ & 0 & $0.00 \mathrm{E}+00$ & 0 & $0.00 \mathrm{E}+00$ & 0 \\
\hline 4 & $0.00 \mathrm{E}+00$ & 0 & $0.00 \mathrm{E}+00$ & 0 & $0.00 \mathrm{E}+00$ & 0 & $0.00 \mathrm{E}+00$ & 0 & $0.00 \mathrm{E}+00$ & 0 & $0.00 \mathrm{E}+00$ & 0 & $0.00 \mathrm{E}+00$ & 0 & $0.00 \mathrm{E}+00$ & 0 \\
\hline 35 & $0.00 \mathrm{E}+00$ & 0 & $0.00 \mathrm{E}+00$ & 0 & $0.00 \mathrm{E}+00$ & 0 & $0.00 \mathrm{E}+00$ & 0 & $0.00 \mathrm{E}+00$ & 0 & $0.00 \mathrm{E}+00$ & 0 & $0.00 \mathrm{E}+00$ & 0 & $0.00 \mathrm{E}+00$ & 0 \\
\hline 38 & $0.00 \mathrm{E}+00$ & 0 & $0.00 \mathrm{E}+00$ & 0 & $0.00 \mathrm{E}+00$ & 0 & $0.00 \mathrm{E}+00$ & 0 & $0.00 \mathrm{E}+00$ & 0 & $0.00 \mathrm{E}+00$ & 0 & $0.00 \mathrm{E}+00$ & 0 & $0.00 \mathrm{E}+00$ & 0 \\
\hline & $0.00 \mathrm{E}+00$ & 0 & $0.00 E+00$ & 0 & $0.00 \mathrm{E}+00$ & 0 & $0.00 \mathrm{E}+00$ & 0 & $0.00 \mathrm{E}+00$ & 0 & $0.00 \mathrm{E}+00$ & 0 & $0.00 \mathrm{E}+00$ & 0 & $0.00 \mathrm{E}+00$ & \\
\hline
\end{tabular}

Total Dose Contributions TDOSE (i,p,t) for Individual Radionuclides (i) and Pathways (p) in mrem/yr and as a Percentage of Total Dose at $t=100$ years

Directly from primary contamination and from release to atmosphere (Inhalation excludes radon)

\begin{tabular}{|c|c|c|c|c|c|c|c|c|c|c|c|c|c|c|c|c|}
\hline & \multicolumn{2}{|c|}{ Ground } & \multicolumn{2}{|c|}{ Inhalation } & \multicolumn{2}{|c|}{ Radon } & \multicolumn{2}{|c|}{ Plant } & \multicolumn{2}{|l|}{ Meat } & \multicolumn{2}{|l|}{ Milk } & \multicolumn{2}{|l|}{ Soil } & \multicolumn{2}{|c|}{ All Pathways* } \\
\hline clide & Dose & \% & Dose & $\%$ & Dose & $\%$ & Dose & 음 & Dose & $\%$ & Dose & $\%$ & Dose & \% & Dose & $\frac{\circ}{0}$ \\
\hline-241 & $1.33 E-23$ & 0 & $0.00 \mathrm{E}+00$ & 0 & $0.00 \mathrm{E}+00$ & 0 & $0.00 \mathrm{E}+00$ & 0 & $0.00 \mathrm{E}+00$ & 0 & $0.00 \mathrm{E}+00$ & 0 & $0.00 \mathrm{E}+00$ & 0 & 1. $33 \mathrm{E}-23$ & 0 \\
\hline-137 & $2.55 E-17$ & 0 & $0.00 \mathrm{E}+00$ & 0 & $0.00 \mathrm{E}+00$ & 0 & $0.00 \mathrm{E}+00$ & 0 & $0.00 \mathrm{E}+00$ & 0 & $0.00 \mathrm{E}+00$ & 0 & $0.00 \mathrm{E}+00$ & 0 & $2.55 \mathrm{E}-17$ & 0 \\
\hline-237 & $6.98 \mathrm{E}-20$ & 0 & $0.00 \mathrm{E}+00$ & 0 & $0.00 \mathrm{E}+00$ & 0 & $0.00 \mathrm{E}+00$ & 0 & $0.00 \mathrm{E}+00$ & 0 & $0.00 \mathrm{E}+00$ & 0 & $0.00 \mathrm{E}+00$ & 0 & $6.98 E-20$ & 0 \\
\hline-238 & $9.69 \mathrm{E}-23$ & 0 & $0.00 \mathrm{E}+00$ & 0 & $0.00 \mathrm{E}+00$ & 0 & $0.00 \mathrm{E}+00$ & 0 & $0.00 \mathrm{E}+00$ & 0 & $0.00 \mathrm{E}+00$ & 0 & $0.00 \mathrm{E}+00$ & 0 & $9.69 \mathrm{E}-23$ & 0 \\
\hline-239 & $6.41 \mathrm{E}-24$ & 0 & $0.00 \mathrm{E}+00$ & 0 & $0.00 \mathrm{E}+00$ & 0 & $0.00 \mathrm{E}+00$ & 0 & $0.00 \mathrm{E}+00$ & 0 & $0.00 \mathrm{E}+00$ & 0 & $0.00 \mathrm{E}+00$ & 0 & $6.41 \mathrm{E}-24$ & 0 \\
\hline-240 & $3.02 E-27$ & 0 & $0.00 \mathrm{E}+00$ & 0 & $0.00 \mathrm{E}+00$ & 0 & $0.00 \mathrm{E}+00$ & 0 & $0.00 \mathrm{E}+00$ & 0 & $0.00 \mathrm{E}+00$ & 0 & $0.00 \mathrm{E}+00$ & 0 & $3.02 E-27$ & 0 \\
\hline-99 & $5.11 \mathrm{E}-32$ & 0 & $0.00 \mathrm{E}+00$ & 0 & $0.00 \mathrm{E}+00$ & 0 & $0.00 \mathrm{E}+00$ & 0 & $0.00 \mathrm{E}+00$ & 0 & $0.00 \mathrm{E}+00$ & 0 & $0.00 \mathrm{E}+00$ & 0 & $5.11 \mathrm{E}-32$ & 0 \\
\hline-228 & $8.77 \mathrm{E}-30$ & 0 & $0.00 \mathrm{E}+00$ & 0 & $0.00 \mathrm{E}+00$ & 0 & $0.00 \mathrm{E}+00$ & 0 & $0.00 \mathrm{E}+00$ & 0 & $0.00 \mathrm{E}+00$ & 0 & $0.00 \mathrm{E}+00$ & 0 & $8.77 \mathrm{E}-30$ & 0 \\
\hline-230 & $6.90 \mathrm{E}-15$ & 11 & $0.00 \mathrm{E}+00$ & 0 & $0.00 \mathrm{E}+00$ & 0 & $0.00 \mathrm{E}+00$ & 0 & $0.00 \mathrm{E}+00$ & 0 & $0.00 \mathrm{E}+00$ & 0 & $0.00 \mathrm{E}+00$ & 0 & $6.90 \mathrm{E}-15$ & 11 \\
\hline-232 & $5.70 \mathrm{E}-14$ & 89 & $0.00 \mathrm{E}+00$ & 0 & $0.00 \mathrm{E}+00$ & 0 & $0.00 \mathrm{E}+00$ & 0 & $0.00 \mathrm{E}+00$ & 0 & $0.00 \mathrm{E}+00$ & 0 & $0.00 \mathrm{E}+00$ & 0 & $5.70 \mathrm{E}-14$ & 89 \\
\hline 234 & $5.03 E-18$ & 0 & $0.00 \mathrm{E}+00$ & 0 & $0.00 \mathrm{E}+00$ & 0 & $0.00 \mathrm{E}+00$ & 0 & $0.00 \mathrm{E}+00$ & 0 & $0.00 \mathrm{E}+00$ & 0 & $0.00 \mathrm{E}+00$ & 0 & $5.03 E-18$ & 0 \\
\hline 235 & $1.01 \mathrm{E}-20$ & 0 & $0.00 \mathrm{E}+00$ & 0 & $0.00 \mathrm{E}+00$ & 0 & $0.00 \mathrm{E}+00$ & 0 & $0.00 \mathrm{E}+00$ & 0 & $0.00 \mathrm{E}+00$ & 0 & $0.00 \mathrm{E}+00$ & 0 & $1.01 \mathrm{E}-20$ & 0 \\
\hline 38 & $2.34 \mathrm{E}-16$ & 0 & $0.00 \mathrm{E}+00$ & 0 & $0.00 \mathrm{E}+00$ & 0 & $0.00 \mathrm{E}+00$ & 0 & $0.00 \mathrm{E}+00$ & 0 & $0.00 \mathrm{E}+00$ & 0 & $0.00 \mathrm{E}+00$ & 0 & $2.34 \mathrm{E}-16$ & 0 \\
\hline & $6.42 \mathrm{E}-14$ & 100 & $0.00 \mathrm{E}+00$ & 0 & $0.00 \mathrm{E}+00$ & 0 & $0.00 \mathrm{E}+00$ & 0 & $0.00 \mathrm{E}+00$ & 0 & $0.00 \mathrm{E}+00$ & 0 & $0.00 \mathrm{E}+00$ & 0 & $6.42 \mathrm{E}-14$ & 100 \\
\hline
\end{tabular}

* Sum of dose from all releases and from primary contamination. 
RESRAD-OFFSITE, Version 2.

Parent Dose Report

Title : RESRAD-OFFSITE Parameters for Offsite Resident Farmer Forward Run 10,000 Years

File : OFFSITE-RF_FORWARD-7-11-10000yr.ROF

Total Dose Contributions TDOSE (i,p,t) for Individual Radionuclides (i) and Pathways (p) in mrem/yr and as a Percentage of Total Dose at $t=500$ years

From releases to ground water and to surface water

\begin{tabular}{|c|c|c|c|c|c|c|c|c|c|c|c|c|c|c|c|c|}
\hline \multirow{2}{*}{$\begin{array}{l}\text { Radio- } \\
\text { Nuclide }\end{array}$} & \multicolumn{2}{|c|}{ Ground } & \multicolumn{2}{|l|}{ Fish } & \multicolumn{2}{|c|}{ Radon } & \multicolumn{2}{|c|}{ Plant } & \multicolumn{2}{|l|}{ Meat } & \multicolumn{2}{|l|}{ Milk } & \multicolumn{2}{|l|}{ Soil } & \multicolumn{2}{|c|}{ Water } \\
\hline & Dose & \% & Dose & $\%$ & Dose & $\%$ & Dose & 음 & Dose & $\%$ & Dose & 응 & Dose & \% & Dose & $\%$ \\
\hline-241 & $0.00 E+00$ & 0 & $0.00 \mathrm{E}+00$ & 0 & $0.00 \mathrm{E}+00$ & 0 & $0.00 \mathrm{E}+00$ & 0 & $0.00 \mathrm{E}+00$ & 0 & $0.00 E+00$ & 0 & $0.00 \mathrm{E}+00$ & 0 & $0.00 \mathrm{E}+00$ & 0 \\
\hline-137 & $0.00 \mathrm{E}+00$ & 0 & $0.00 \mathrm{E}+00$ & 0 & $0.00 \mathrm{E}+00$ & 0 & $0.00 \mathrm{E}+00$ & 0 & $0.00 \mathrm{E}+00$ & 0 & $0.00 \mathrm{E}+00$ & 0 & $0.00 \mathrm{E}+00$ & 0 & $0.00 \mathrm{E}+00$ & 0 \\
\hline-237 & $0.00 \mathrm{E}+00$ & 0 & $0.00 \mathrm{E}+00$ & 0 & $0.00 \mathrm{E}+00$ & 0 & $0.00 \mathrm{E}+00$ & 0 & $0.00 \mathrm{E}+00$ & 0 & $0.00 \mathrm{E}+00$ & 0 & $0.00 \mathrm{E}+00$ & 0 & $0.00 \mathrm{E}+00$ & 0 \\
\hline-238 & $0.00 \mathrm{E}+00$ & 0 & $0.00 \mathrm{E}+00$ & 0 & $0.00 E+00$ & 0 & $0.00 \mathrm{E}+00$ & 0 & $0.00 \mathrm{E}+00$ & 0 & $0.00 E+00$ & 0 & $0.00 \mathrm{E}+00$ & 0 & $0.00 \mathrm{E}+00$ & 0 \\
\hline-239 & $0.00 \mathrm{E}+00$ & 0 & $0.00 \mathrm{E}+00$ & 0 & $0.00 \mathrm{E}+00$ & 0 & $0.00 \mathrm{E}+00$ & 0 & $0.00 \mathrm{E}+00$ & 0 & $0.00 \mathrm{E}+00$ & 0 & $0.00 \mathrm{E}+00$ & 0 & $0.00 \mathrm{E}+00$ & 0 \\
\hline-240 & $0.00 \mathrm{E}+00$ & 0 & $0.00 \mathrm{E}+00$ & 0 & $0.00 \mathrm{E}+00$ & 0 & $0.00 \mathrm{E}+00$ & 0 & $0.00 \mathrm{E}+00$ & 0 & $0.00 \mathrm{E}+00$ & 0 & $0.00 \mathrm{E}+00$ & 0 & $0.00 \mathrm{E}+00$ & 0 \\
\hline-99 & $9.05 \mathrm{E}-07$ & 0 & $0.00 \mathrm{E}+00$ & 0 & $0.00 \mathrm{E}+00$ & 0 & $2.48 \mathrm{E}-01$ & 25 & $7.44 \mathrm{E}-04$ & 0 & $6.57 E-02$ & 7 & $7.64 \mathrm{E}-07$ & 0 & $6.77 \mathrm{E}-01$ & 68 \\
\hline-228 & $0.00 \mathrm{E}+00$ & 0 & $0.00 \mathrm{E}+00$ & 0 & $0.00 \mathrm{E}+00$ & 0 & $0.00 \mathrm{E}+00$ & 0 & $0.00 \mathrm{E}+00$ & 0 & $0.00 \mathrm{E}+00$ & 0 & $0.00 \mathrm{E}+00$ & 0 & $0.00 \mathrm{E}+00$ & 0 \\
\hline-230 & $0.00 \mathrm{E}+00$ & 0 & $0.00 \mathrm{E}+00$ & 0 & $0.00 \mathrm{E}+00$ & 0 & $0.00 \mathrm{E}+00$ & 0 & $0.00 \mathrm{E}+00$ & 0 & $0.00 \mathrm{E}+00$ & 0 & $0.00 \mathrm{E}+00$ & 0 & $0.00 \mathrm{E}+00$ & 0 \\
\hline-232 & $0.00 \mathrm{E}+00$ & 0 & $0.00 \mathrm{E}+00$ & 0 & $0.00 \mathrm{E}+00$ & 0 & $0.00 \mathrm{E}+00$ & 0 & $0.00 \mathrm{E}+00$ & 0 & $0.00 \mathrm{E}+00$ & 0 & $0.00 \mathrm{E}+00$ & 0 & $0.00 \mathrm{E}+00$ & 0 \\
\hline 234 & $0.00 \mathrm{E}+00$ & 0 & $0.00 \mathrm{E}+00$ & 0 & $0.00 \mathrm{E}+00$ & 0 & $0.00 \mathrm{E}+00$ & 0 & $0.00 \mathrm{E}+00$ & 0 & $0.00 \mathrm{E}+00$ & 0 & $0.00 \mathrm{E}+00$ & 0 & $0.00 \mathrm{E}+00$ & 0 \\
\hline 235 & $0.00 \mathrm{E}+00$ & 0 & $0.00 \mathrm{E}+00$ & 0 & $0.00 \mathrm{E}+00$ & 0 & $0.00 \mathrm{E}+00$ & 0 & $0.00 \mathrm{E}+00$ & 0 & $0.00 \mathrm{E}+00$ & 0 & $0.00 \mathrm{E}+00$ & 0 & $0.00 \mathrm{E}+00$ & 0 \\
\hline 38 & $0.00 \mathrm{E}+00$ & 0 & $0.00 \mathrm{E}+00$ & 0 & $0.00 \mathrm{E}+00$ & 0 & $0.00 \mathrm{E}+00$ & 0 & $0.00 \mathrm{E}+00$ & 0 & $0.00 \mathrm{E}+00$ & 0 & $0.00 \mathrm{E}+00$ & 0 & $0.00 \mathrm{E}+00$ & 0 \\
\hline$a_{1}$ & $9.05 \mathrm{E}-07$ & 0 & $0.00 \mathrm{E}+00$ & 0 & $0.00 \mathrm{E}+00$ & 0 & $2.48 \mathrm{E}-01$ & 25 & $7.44 \mathrm{E}-04$ & 0 & $6.57 \mathrm{E}-02$ & 7 & $7.64 \mathrm{E}-07$ & 0 & $6.77 \mathrm{E}-01$ & 68 \\
\hline
\end{tabular}

Total Dose Contributions TDOSE (i,p,t) for Individual Radionuclides (i) and Pathways (p) in mrem/yr and as a Percentage of Total Dose at $t=500$ years

Directly from primary contamination and from release to atmosphere (Inhalation excludes radon)

\begin{tabular}{|c|c|c|c|c|c|c|c|c|c|c|c|c|c|c|c|c|}
\hline & \multicolumn{2}{|c|}{ Ground } & \multicolumn{2}{|c|}{ Inhalation } & \multicolumn{2}{|c|}{ Radon } & \multicolumn{2}{|c|}{ Plant } & \multicolumn{2}{|l|}{ Meat } & \multicolumn{2}{|l|}{ Milk } & \multicolumn{2}{|l|}{ Soil } & \multicolumn{2}{|c|}{ All Pathways* } \\
\hline clide & Dose & $\%$ & Dose & 응 & Dose & $\%$ & Dose & 응 & Dose & 응 & Dose & $\%$ & Dose & 웅 & Dose & $\frac{\circ}{0}$ \\
\hline $1-241$ & $2.63 E-21$ & 0 & $0.00 \mathrm{E}+00$ & 0 & $0.00 \mathrm{E}+00$ & 0 & $0.00 \mathrm{E}+00$ & 0 & $0.00 \mathrm{E}+00$ & 0 & $0.00 \mathrm{E}+00$ & 0 & $0.00 \mathrm{E}+00$ & 0 & $2.63 E-21$ & 0 \\
\hline-137 & $5.47 E-20$ & 0 & $0.00 \mathrm{E}+00$ & 0 & $0.00 \mathrm{E}+00$ & 0 & $0.00 \mathrm{E}+00$ & 0 & $0.00 \mathrm{E}+00$ & 0 & $0.00 \mathrm{E}+00$ & 0 & $0.00 \mathrm{E}+00$ & 0 & $5.47 E-20$ & 0 \\
\hline-237 & $3.74 \mathrm{E}-18$ & 0 & $0.00 \mathrm{E}+00$ & 0 & $0.00 \mathrm{E}+00$ & 0 & $0.00 \mathrm{E}+00$ & 0 & $0.00 \mathrm{E}+00$ & 0 & $0.00 \mathrm{E}+00$ & 0 & $0.00 \mathrm{E}+00$ & 0 & $3.74 \mathrm{E}-18$ & 0 \\
\hline-238 & 8. $22 E-20$ & 0 & $0.00 \mathrm{E}+00$ & 0 & $0.00 \mathrm{E}+00$ & 0 & $0.00 \mathrm{E}+00$ & 0 & $0.00 \mathrm{E}+00$ & 0 & $0.00 \mathrm{E}+00$ & 0 & $0.00 \mathrm{E}+00$ & 0 & $8.22 E-20$ & 0 \\
\hline-239 & $5.22 \mathrm{E}-22$ & 0 & $0.00 \mathrm{E}+00$ & 0 & $0.00 \mathrm{E}+00$ & 0 & $0.00 \mathrm{E}+00$ & 0 & $0.00 \mathrm{E}+00$ & 0 & $0.00 \mathrm{E}+00$ & 0 & $0.00 \mathrm{E}+00$ & 0 & 5. $22 \mathrm{E}-22$ & 0 \\
\hline-240 & $8.02 E-25$ & 0 & $0.00 \mathrm{E}+00$ & 0 & $0.00 \mathrm{E}+00$ & 0 & $0.00 \mathrm{E}+00$ & 0 & $0.00 \mathrm{E}+00$ & 0 & $0.00 \mathrm{E}+00$ & 0 & $0.00 \mathrm{E}+00$ & 0 & $8.02 E-25$ & 0 \\
\hline-99 & $7.29 \mathrm{E}-30$ & 0 & $0.00 \mathrm{E}+00$ & 0 & $0.00 \mathrm{E}+00$ & 0 & $0.00 \mathrm{E}+00$ & 0 & $0.00 \mathrm{E}+00$ & 0 & $0.00 \mathrm{E}+00$ & 0 & $0.00 \mathrm{E}+00$ & 0 & $9.91 \mathrm{E}-01$ & 100 \\
\hline-228 & $0.00 \mathrm{E}+00$ & 0 & $0.00 \mathrm{E}+00$ & 0 & $0.00 \mathrm{E}+00$ & 0 & $0.00 \mathrm{E}+00$ & 0 & $0.00 \mathrm{E}+00$ & 0 & $0.00 \mathrm{E}+00$ & 0 & $0.00 \mathrm{E}+00$ & 0 & $0.00 \mathrm{E}+00$ & 0 \\
\hline-230 & $4.02 \mathrm{E}-13$ & 0 & $0.00 \mathrm{E}+00$ & 0 & $0.00 \mathrm{E}+00$ & 0 & $0.00 \mathrm{E}+00$ & 0 & $0.00 \mathrm{E}+00$ & 0 & $0.00 \mathrm{E}+00$ & 0 & $0.00 \mathrm{E}+00$ & 0 & $4.02 \mathrm{E}-13$ & 0 \\
\hline-232 & $5.19 \mathrm{E}-13$ & 0 & $0.00 \mathrm{E}+00$ & 0 & $0.00 \mathrm{E}+00$ & 0 & $0.00 \mathrm{E}+00$ & 0 & $0.00 \mathrm{E}+00$ & 0 & $0.00 \mathrm{E}+00$ & 0 & $0.00 \mathrm{E}+00$ & 0 & $5.19 \mathrm{E}-13$ & 0 \\
\hline 234 & $1.50 \mathrm{E}-15$ & 0 & $0.00 \mathrm{E}+00$ & 0 & $0.00 \mathrm{E}+00$ & 0 & $0.00 \mathrm{E}+00$ & 0 & $0.00 \mathrm{E}+00$ & 0 & $0.00 \mathrm{E}+00$ & 0 & $0.00 \mathrm{E}+00$ & 0 & $1.50 \mathrm{E}-15$ & 0 \\
\hline 235 & $1.58 \mathrm{E}-18$ & 0 & $0.00 \mathrm{E}+00$ & 0 & $0.00 \mathrm{E}+00$ & 0 & $0.00 \mathrm{E}+00$ & 0 & $0.00 \mathrm{E}+00$ & 0 & $0.00 \mathrm{E}+00$ & 0 & $0.00 \mathrm{E}+00$ & 0 & 1. $58 \mathrm{E}-18$ & 0 \\
\hline 238 & $4.43 E-15$ & 0 & $0.00 \mathrm{E}+00$ & 0 & $0.00 \mathrm{E}+00$ & 0 & $0.00 \mathrm{E}+00$ & 0 & $0.00 \mathrm{E}+00$ & 0 & $0.00 \mathrm{E}+00$ & 0 & $0.00 E+00$ & 0 & $4.43 E-15$ & 0 \\
\hline & $9.28 \mathrm{E}-13$ & 0 & $0.00 \mathrm{E}+00$ & 0 & $0.00 \mathrm{E}+00$ & 0 & $0.00 \mathrm{E}+00$ & 0 & $0.00 \mathrm{E}+00$ & 0 & $0.00 \mathrm{E}+00$ & 0 & $0.00 \mathrm{E}+00$ & 0 & $9.91 \mathrm{E}-01$ & 100 \\
\hline
\end{tabular}

* Sum of dose from all releases and from primary contamination. 
RESRAD-OFFSITE, Version 2.

Parent Dose Report

Title : RESRAD-OFFSITE Parameters for Offsite Resident Farmer Forward Run 10,000 Years

File : OFFSITE-RF FORWARD-7-11-10000yr.ROF

Total Dose Contributions TDOSE (i,p,t) for Individual Radionuclides (i) and Pathways (p) in mrem/yr and as a Percentage of Total Dose at $t=1026$ years

From releases to ground water and to surface water

\begin{tabular}{|c|c|c|c|c|c|c|c|c|c|c|c|c|c|c|c|c|}
\hline \multirow{2}{*}{$\begin{array}{l}\text { Radio- } \\
\text { Nuclide }\end{array}$} & \multicolumn{2}{|c|}{ Ground } & \multicolumn{2}{|l|}{ Fish } & \multicolumn{2}{|c|}{ Radon } & \multicolumn{2}{|c|}{ Plant } & \multicolumn{2}{|l|}{ Meat } & \multicolumn{2}{|l|}{ Milk } & \multicolumn{2}{|l|}{ Soil } & \multicolumn{2}{|c|}{ Water } \\
\hline & Dose & \% & Dose & $\%$ & Dose & $\%$ & Dose & 음 & Dose & $\%$ & Dose & 응 & Dose & \% & Dose & $\frac{\circ}{0}$ \\
\hline-241 & $0.00 E+00$ & 0 & $0.00 \mathrm{E}+00$ & 0 & $0.00 \mathrm{E}+00$ & 0 & $0.00 \mathrm{E}+00$ & 0 & $0.00 \mathrm{E}+00$ & 0 & $0.00 E+00$ & 0 & $0.00 \mathrm{E}+00$ & 0 & $0.00 \mathrm{E}+00$ & 0 \\
\hline-137 & $0.00 \mathrm{E}+00$ & 0 & $0.00 \mathrm{E}+00$ & 0 & $0.00 \mathrm{E}+00$ & 0 & $0.00 \mathrm{E}+00$ & 0 & $0.00 \mathrm{E}+00$ & 0 & $0.00 \mathrm{E}+00$ & 0 & $0.00 \mathrm{E}+00$ & 0 & $0.00 \mathrm{E}+00$ & 0 \\
\hline-237 & $0.00 \mathrm{E}+00$ & 0 & $0.00 \mathrm{E}+00$ & 0 & $0.00 \mathrm{E}+00$ & 0 & $0.00 \mathrm{E}+00$ & 0 & $0.00 \mathrm{E}+00$ & 0 & $0.00 \mathrm{E}+00$ & 0 & $0.00 \mathrm{E}+00$ & 0 & $0.00 \mathrm{E}+00$ & 0 \\
\hline-238 & $0.00 \mathrm{E}+00$ & 0 & $0.00 \mathrm{E}+00$ & 0 & $0.00 E+00$ & 0 & $0.00 \mathrm{E}+00$ & 0 & $0.00 \mathrm{E}+00$ & 0 & $0.00 E+00$ & 0 & $0.00 \mathrm{E}+00$ & 0 & $0.00 \mathrm{E}+00$ & 0 \\
\hline-239 & $0.00 \mathrm{E}+00$ & 0 & $0.00 \mathrm{E}+00$ & 0 & $0.00 \mathrm{E}+00$ & 0 & $0.00 \mathrm{E}+00$ & 0 & $0.00 \mathrm{E}+00$ & 0 & $0.00 \mathrm{E}+00$ & 0 & $0.00 \mathrm{E}+00$ & 0 & $0.00 \mathrm{E}+00$ & 0 \\
\hline-240 & $0.00 \mathrm{E}+00$ & 0 & $0.00 \mathrm{E}+00$ & 0 & $0.00 \mathrm{E}+00$ & 0 & $0.00 \mathrm{E}+00$ & 0 & $0.00 \mathrm{E}+00$ & 0 & $0.00 \mathrm{E}+00$ & 0 & $0.00 \mathrm{E}+00$ & 0 & $0.00 \mathrm{E}+00$ & 0 \\
\hline-99 & $1.31 \mathrm{E}-06$ & 0 & $0.00 \mathrm{E}+00$ & 0 & $0.00 \mathrm{E}+00$ & 0 & $3.60 \mathrm{E}-01$ & 25 & $1.08 \mathrm{E}-03$ & 0 & $9.52 E-02$ & 7 & $1.11 \mathrm{E}-06$ & 0 & $9.80 \mathrm{E}-01$ & 68 \\
\hline-228 & $0.00 \mathrm{E}+00$ & 0 & $0.00 \mathrm{E}+00$ & 0 & $0.00 \mathrm{E}+00$ & 0 & $0.00 \mathrm{E}+00$ & 0 & $0.00 \mathrm{E}+00$ & 0 & $0.00 \mathrm{E}+00$ & 0 & $0.00 \mathrm{E}+00$ & 0 & $0.00 \mathrm{E}+00$ & 0 \\
\hline-230 & $0.00 \mathrm{E}+00$ & 0 & $0.00 \mathrm{E}+00$ & 0 & $0.00 \mathrm{E}+00$ & 0 & $0.00 \mathrm{E}+00$ & 0 & $0.00 \mathrm{E}+00$ & 0 & $0.00 \mathrm{E}+00$ & 0 & $0.00 \mathrm{E}+00$ & 0 & $0.00 \mathrm{E}+00$ & 0 \\
\hline-232 & $0.00 \mathrm{E}+00$ & 0 & $0.00 \mathrm{E}+00$ & 0 & $0.00 \mathrm{E}+00$ & 0 & $0.00 \mathrm{E}+00$ & 0 & $0.00 \mathrm{E}+00$ & 0 & $0.00 \mathrm{E}+00$ & 0 & $0.00 \mathrm{E}+00$ & 0 & $0.00 \mathrm{E}+00$ & 0 \\
\hline 234 & $0.00 \mathrm{E}+00$ & 0 & $0.00 \mathrm{E}+00$ & 0 & $0.00 \mathrm{E}+00$ & 0 & $0.00 \mathrm{E}+00$ & 0 & $0.00 \mathrm{E}+00$ & 0 & $0.00 \mathrm{E}+00$ & 0 & $0.00 \mathrm{E}+00$ & 0 & $0.00 \mathrm{E}+00$ & 0 \\
\hline 235 & $0.00 \mathrm{E}+00$ & 0 & $0.00 \mathrm{E}+00$ & 0 & $0.00 \mathrm{E}+00$ & 0 & $0.00 \mathrm{E}+00$ & 0 & $0.00 \mathrm{E}+00$ & 0 & $0.00 \mathrm{E}+00$ & 0 & $0.00 \mathrm{E}+00$ & 0 & $0.00 \mathrm{E}+00$ & 0 \\
\hline 38 & $0.00 \mathrm{E}+00$ & 0 & $0.00 \mathrm{E}+00$ & 0 & $0.00 \mathrm{E}+00$ & 0 & $0.00 \mathrm{E}+00$ & 0 & $0.00 \mathrm{E}+00$ & 0 & $0.00 \mathrm{E}+00$ & 0 & $0.00 \mathrm{E}+00$ & 0 & $0.00 \mathrm{E}+00$ & 0 \\
\hline$a_{1}$ & 1. $31 \mathrm{E}-06$ & 0 & $0.00 \mathrm{E}+00$ & 0 & $0.00 \mathrm{E}+00$ & 0 & $3.60 \mathrm{E}-01$ & 25 & $1.08 \mathrm{E}-03$ & 0 & $9.52 \mathrm{E}-02$ & 7 & $1.11 \mathrm{E}-06$ & 0 & $9.80 \mathrm{E}-01$ & 68 \\
\hline
\end{tabular}

Total Dose Contributions TDOSE (i,p,t) for Individual Radionuclides (i) and Pathways (p) in mrem/yr and as a Percentage of Total Dose at $t=1026$ years

Directly from primary contamination and from release to atmosphere (Inhalation excludes radon)

\begin{tabular}{|c|c|c|c|c|c|c|c|c|c|c|c|c|c|c|c|c|}
\hline & \multicolumn{2}{|c|}{ Ground } & \multicolumn{2}{|c|}{ Inhalation } & \multicolumn{2}{|c|}{ Radon } & \multicolumn{2}{|c|}{ Plant } & \multicolumn{2}{|l|}{ Meat } & \multicolumn{2}{|l|}{ Milk } & \multicolumn{2}{|l|}{ Soil } & \multicolumn{2}{|c|}{ All Pathways* } \\
\hline clide & Dose & $\%$ & Dose & $\%$ & Dose & $\%$ & Dose & 음 & Dose & $\%$ & Dose & $\%$ & Dose & \% & Dose & $\%$ \\
\hline-241 & $6.97 E-19$ & 0 & $0.00 \mathrm{E}+00$ & 0 & $0.00 \mathrm{E}+00$ & 0 & $0.00 \mathrm{E}+00$ & 0 & $0.00 \mathrm{E}+00$ & 0 & $0.00 E+00$ & 0 & $0.00 E+00$ & 0 & $6.97 E-19$ & 0 \\
\hline-137 & $1.70 \mathrm{E}-23$ & 0 & $0.00 \mathrm{E}+00$ & 0 & $0.00 \mathrm{E}+00$ & 0 & $0.00 \mathrm{E}+00$ & 0 & $0.00 \mathrm{E}+00$ & 0 & $0.00 \mathrm{E}+00$ & 0 & $0.00 \mathrm{E}+00$ & 0 & 1. $70 \mathrm{E}-23$ & 0 \\
\hline-237 & $6.63 \mathrm{E}-16$ & 0 & $0.00 \mathrm{E}+00$ & 0 & $0.00 \mathrm{E}+00$ & 0 & $0.00 \mathrm{E}+00$ & 0 & $0.00 \mathrm{E}+00$ & 0 & $0.00 \mathrm{E}+00$ & 0 & $0.00 \mathrm{E}+00$ & 0 & $6.63 E-16$ & 0 \\
\hline-238 & $1.16 \mathrm{E}-17$ & 0 & $0.00 \mathrm{E}+00$ & 0 & $0.00 \mathrm{E}+00$ & 0 & $0.00 \mathrm{E}+00$ & 0 & $0.00 \mathrm{E}+00$ & 0 & $0.00 \mathrm{E}+00$ & 0 & $0.00 \mathrm{E}+00$ & 0 & $1.16 \mathrm{E}-17$ & 0 \\
\hline-239 & 1. $70 \mathrm{E}-19$ & 0 & $0.00 \mathrm{E}+00$ & 0 & $0.00 \mathrm{E}+00$ & 0 & $0.00 \mathrm{E}+00$ & 0 & $0.00 \mathrm{E}+00$ & 0 & $0.00 \mathrm{E}+00$ & 0 & $0.00 \mathrm{E}+00$ & 0 & $1.70 \mathrm{E}-19$ & 0 \\
\hline-240 & $6.58 E-23$ & 0 & $0.00 \mathrm{E}+00$ & 0 & $0.00 \mathrm{E}+00$ & 0 & $0.00 \mathrm{E}+00$ & 0 & $0.00 \mathrm{E}+00$ & 0 & $0.00 \mathrm{E}+00$ & 0 & $0.00 \mathrm{E}+00$ & 0 & $6.58 E-23$ & 0 \\
\hline-99 & $4.96 \mathrm{E}-27$ & 0 & $0.00 \mathrm{E}+00$ & 0 & $0.00 \mathrm{E}+00$ & 0 & $0.00 \mathrm{E}+00$ & 0 & $0.00 \mathrm{E}+00$ & 0 & $0.00 \mathrm{E}+00$ & 0 & $0.00 \mathrm{E}+00$ & 0 & 1. $44 \mathrm{E}+00$ & 100 \\
\hline-228 & $0.00 \mathrm{E}+00$ & 0 & $0.00 \mathrm{E}+00$ & 0 & $0.00 \mathrm{E}+00$ & 0 & $0.00 \mathrm{E}+00$ & 0 & $0.00 \mathrm{E}+00$ & 0 & $0.00 \mathrm{E}+00$ & 0 & $0.00 \mathrm{E}+00$ & 0 & $0.00 \mathrm{E}+00$ & 0 \\
\hline-230 & $2.11 \mathrm{E}-11$ & 0 & $0.00 \mathrm{E}+00$ & 0 & $0.00 \mathrm{E}+00$ & 0 & $0.00 \mathrm{E}+00$ & 0 & $0.00 \mathrm{E}+00$ & 0 & $0.00 \mathrm{E}+00$ & 0 & $0.00 \mathrm{E}+00$ & 0 & $2.11 \mathrm{E}-11$ & 0 \\
\hline-232 & $9.64 \mathrm{E}-12$ & 0 & $0.00 \mathrm{E}+00$ & 0 & $0.00 \mathrm{E}+00$ & 0 & $0.00 \mathrm{E}+00$ & 0 & $0.00 \mathrm{E}+00$ & 0 & $0.00 \mathrm{E}+00$ & 0 & $0.00 \mathrm{E}+00$ & 0 & $9.64 \mathrm{E}-12$ & 0 \\
\hline 234 & $1.67 \mathrm{E}-13$ & 0 & $0.00 \mathrm{E}+00$ & 0 & $0.00 \mathrm{E}+00$ & 0 & $0.00 \mathrm{E}+00$ & 0 & $0.00 \mathrm{E}+00$ & 0 & $0.00 \mathrm{E}+00$ & 0 & $0.00 \mathrm{E}+00$ & 0 & 1. $67 \mathrm{E}-13$ & 0 \\
\hline 235 & $2.70 \mathrm{E}-16$ & 0 & $0.00 \mathrm{E}+00$ & 0 & $0.00 \mathrm{E}+00$ & 0 & $0.00 \mathrm{E}+00$ & 0 & $0.00 \mathrm{E}+00$ & 0 & $0.00 \mathrm{E}+00$ & 0 & $0.00 \mathrm{E}+00$ & 0 & $2.70 \mathrm{E}-16$ & 0 \\
\hline 238 & $2.13 E-13$ & 0 & $0.00 \mathrm{E}+00$ & 0 & $0.00 \mathrm{E}+00$ & 0 & $0.00 \mathrm{E}+00$ & 0 & $0.00 \mathrm{E}+00$ & 0 & $0.00 \mathrm{E}+00$ & 0 & $0.00 \mathrm{E}+00$ & 0 & $2.13 \mathrm{E}-13$ & 0 \\
\hline$a$ & $3.11 \mathrm{E}-11$ & 0 & $0.00 \mathrm{E}+00$ & 0 & $0.00 \mathrm{E}+00$ & 0 & $0.00 \mathrm{E}+00$ & 0 & $0.00 \mathrm{E}+00$ & 0 & $0.00 \mathrm{E}+00$ & 0 & $0.00 \mathrm{E}+00$ & 0 & $1.44 \mathrm{E}+00$ & 100 \\
\hline
\end{tabular}

* Sum of dose from all releases and from primary contamination. 
RESRAD-OFFSITE, Version 2.

Parent Dose Report

Title : RESRAD-OFFSITE Parameters for Offsite Resident Farmer Forward Run 10,000 Years

File : OFFSITE-RF_FORWARD-7-11-10000yr.ROF

Total Dose Contributions TDOSE (i,p,t) for Individual Radionuclides (i) and Pathways (p) in mrem/yr and as a Percentage of Total Dose at $t=10000$ years

From releases to ground water and to surface water

\begin{tabular}{|c|c|c|c|c|c|c|c|c|c|c|c|c|c|c|c|c|}
\hline \multirow{2}{*}{$\begin{array}{l}\text { Radio- } \\
\text { Nuclide }\end{array}$} & \multicolumn{2}{|c|}{ Ground } & \multicolumn{2}{|l|}{ Fish } & \multicolumn{2}{|c|}{ Radon } & \multicolumn{2}{|c|}{ Plant } & \multicolumn{2}{|l|}{ Meat } & \multicolumn{2}{|l|}{ Milk } & \multicolumn{2}{|l|}{ Soil } & \multicolumn{2}{|c|}{ Water } \\
\hline & Dose & \% & Dose & $\%$ & Dose & $\%$ & Dose & \% & Dose & $\%$ & Dose & 응 & Dose & \% & Dose & $\%$ \\
\hline-241 & $1.21 E-05$ & 0 & $0.00 \mathrm{E}+00$ & 0 & $0.00 \mathrm{E}+00$ & 0 & $4.01 E-04$ & 0 & 1. $49 E-05$ & 0 & $8.55 E-07$ & 0 & $2.01 E-07$ & 0 & $1.36 \mathrm{E}-03$ & 0 \\
\hline-137 & $0.00 \mathrm{E}+00$ & 0 & $0.00 \mathrm{E}+00$ & 0 & $0.00 \mathrm{E}+00$ & 0 & $0.00 \mathrm{E}+00$ & 0 & $0.00 \mathrm{E}+00$ & 0 & $0.00 \mathrm{E}+00$ & 0 & $0.00 \mathrm{E}+00$ & 0 & $0.00 \mathrm{E}+00$ & 0 \\
\hline-237 & $8.70 \mathrm{E}-03$ & 0 & $0.00 \mathrm{E}+00$ & 0 & $0.00 \mathrm{E}+00$ & 0 & $2.89 \mathrm{E}-01$ & 13 & $1.07 \mathrm{E}-02$ & 0 & $6.59 \mathrm{E}-04$ & 0 & 1. $45 \mathrm{E}-04$ & 0 & $9.79 \mathrm{E}-01$ & 45 \\
\hline-238 & $0.00 \mathrm{E}+00$ & 0 & $0.00 \mathrm{E}+00$ & 0 & $0.00 E+00$ & 0 & $0.00 \mathrm{E}+00$ & 0 & $0.00 \mathrm{E}+00$ & 0 & $0.00 E+00$ & 0 & $0.00 \mathrm{E}+00$ & 0 & $0.00 \mathrm{E}+00$ & 0 \\
\hline-239 & $0.00 \mathrm{E}+00$ & 0 & $0.00 \mathrm{E}+00$ & 0 & $0.00 \mathrm{E}+00$ & 0 & $0.00 \mathrm{E}+00$ & 0 & $0.00 \mathrm{E}+00$ & 0 & $0.00 \mathrm{E}+00$ & 0 & $0.00 \mathrm{E}+00$ & 0 & $0.00 \mathrm{E}+00$ & 0 \\
\hline-240 & $0.00 \mathrm{E}+00$ & 0 & $0.00 \mathrm{E}+00$ & 0 & $0.00 \mathrm{E}+00$ & 0 & $0.00 \mathrm{E}+00$ & 0 & $0.00 \mathrm{E}+00$ & 0 & $0.00 \mathrm{E}+00$ & 0 & $0.00 \mathrm{E}+00$ & 0 & $0.00 \mathrm{E}+00$ & 0 \\
\hline-99 & 4. $61 \mathrm{E}-25$ & 0 & $0.00 \mathrm{E}+00$ & 0 & $0.00 \mathrm{E}+00$ & 0 & 1. $26 \mathrm{E}-19$ & 0 & $3.77 E-22$ & 0 & 3. $33 E-20$ & 0 & $3.89 \mathrm{E}-25$ & 0 & $3.43 E-19$ & 0 \\
\hline-228 & $0.00 \mathrm{E}+00$ & 0 & $0.00 \mathrm{E}+00$ & 0 & $0.00 \mathrm{E}+00$ & 0 & $0.00 \mathrm{E}+00$ & 0 & $0.00 \mathrm{E}+00$ & 0 & $0.00 \mathrm{E}+00$ & 0 & $0.00 \mathrm{E}+00$ & 0 & $0.00 \mathrm{E}+00$ & 0 \\
\hline-230 & $0.00 \mathrm{E}+00$ & 0 & $0.00 \mathrm{E}+00$ & 0 & $0.00 \mathrm{E}+00$ & 0 & $0.00 \mathrm{E}+00$ & 0 & $0.00 E+00$ & 0 & $0.00 \mathrm{E}+00$ & 0 & $0.00 \mathrm{E}+00$ & 0 & $0.00 \mathrm{E}+00$ & 0 \\
\hline-232 & $0.00 \mathrm{E}+00$ & 0 & $0.00 \mathrm{E}+00$ & 0 & $0.00 \mathrm{E}+00$ & 0 & $0.00 \mathrm{E}+00$ & 0 & $0.00 \mathrm{E}+00$ & 0 & $0.00 \mathrm{E}+00$ & 0 & $0.00 \mathrm{E}+00$ & 0 & $0.00 \mathrm{E}+00$ & 0 \\
\hline 234 & $0.00 \mathrm{E}+00$ & 0 & $0.00 \mathrm{E}+00$ & 0 & $0.00 \mathrm{E}+00$ & 0 & $0.00 \mathrm{E}+00$ & 0 & $0.00 \mathrm{E}+00$ & 0 & $0.00 \mathrm{E}+00$ & 0 & $0.00 \mathrm{E}+00$ & 0 & $0.00 \mathrm{E}+00$ & 0 \\
\hline 235 & $0.00 \mathrm{E}+00$ & 0 & $0.00 \mathrm{E}+00$ & 0 & $0.00 \mathrm{E}+00$ & 0 & $0.00 \mathrm{E}+00$ & 0 & $0.00 \mathrm{E}+00$ & 0 & $0.00 \mathrm{E}+00$ & 0 & $0.00 \mathrm{E}+00$ & 0 & $0.00 \mathrm{E}+00$ & 0 \\
\hline 38 & $0.00 \mathrm{E}+00$ & 0 & $0.00 \mathrm{E}+00$ & 0 & $0.00 \mathrm{E}+00$ & 0 & $0.00 \mathrm{E}+00$ & 0 & $0.00 \mathrm{E}+00$ & 0 & $0.00 \mathrm{E}+00$ & 0 & $0.00 \mathrm{E}+00$ & 0 & $0.00 \mathrm{E}+00$ & 0 \\
\hline a & $8.71 \mathrm{E}-03$ & 0 & $0.00 \mathrm{E}+00$ & 0 & $0.00 \mathrm{E}+00$ & 0 & $2.89 \mathrm{E}-01$ & 13 & $1.08 \mathrm{E}-02$ & 0 & $6.60 \mathrm{E}-04$ & 0 & $1.46 \mathrm{E}-04$ & 0 & $9.80 \mathrm{E}-01$ & 45 \\
\hline
\end{tabular}

Total Dose Contributions TDOSE (i,p,t) for Individual Radionuclides (i) and Pathways (p) in mrem/yr and as a Percentage of Total Dose at $t=10000$ years

Directly from primary contamination and from release to atmosphere (Inhalation excludes radon)

\begin{tabular}{|c|c|c|c|c|c|c|c|c|c|c|c|c|c|c|c|c|}
\hline & \multicolumn{2}{|c|}{ Ground } & \multicolumn{2}{|c|}{ Inhalation } & \multicolumn{2}{|c|}{ Radon } & \multicolumn{2}{|c|}{ Plant } & \multicolumn{2}{|l|}{ Meat } & \multicolumn{2}{|l|}{ Milk } & \multicolumn{2}{|l|}{ Soil } & \multicolumn{2}{|c|}{ All Pathways* } \\
\hline clide & Dose & $\%$ & Dose & $\%$ & Dose & \% & Dose & $\frac{\circ}{0}$ & Dose & 응 & Dose & $\%$ & Dose & $\%$ & Dose & 응 \\
\hline $1-241$ & $1.81 E-06$ & 0 & $4.76 E-09$ & 0 & $0.00 \mathrm{E}+00$ & 0 & $4.46 \mathrm{E}-11$ & 0 & 1. $23 E-11$ & 0 & $3.69 \mathrm{E}-13$ & 0 & 1. $29 \mathrm{E}-12$ & 0 & $1.79 E-03$ & 0 \\
\hline-137 & $9.95 E-44$ & 0 & $0.00 E+00$ & 0 & $0.00 \mathrm{E}+00$ & 0 & $8.41 E-45$ & 0 & $3.64 E-44$ & 0 & $1.54 \mathrm{E}-44$ & 0 & $0.00 \mathrm{E}+00$ & 0 & 1. $60 E-43$ & 0 \\
\hline-237 & 1. $35 \mathrm{E}-03$ & 0 & $3.57 E-06$ & 0 & $0.00 \mathrm{E}+00$ & 0 & $3.33 E-08$ & 0 & $9.15 E-09$ & 0 & $2.92 \mathrm{E}-10$ & 0 & $9.92 \mathrm{E}-10$ & 0 & $1.29 \mathrm{E}+00$ & 59 \\
\hline-238 & $7.03 E-06$ & 0 & $5.96 E-09$ & 0 & $0.00 \mathrm{E}+00$ & 0 & $4.14 \mathrm{E}-10$ & 0 & $9.45 E-11$ & 0 & $1.02 \mathrm{E}-10$ & 0 & $1.47 \mathrm{E}-11$ & 0 & $7.03 E-06$ & 0 \\
\hline-239 & $2.76 \mathrm{E}-06$ & 0 & $7.37 \mathrm{E}-05$ & 0 & $0.00 \mathrm{E}+00$ & 0 & $2.96 \mathrm{E}-07$ & 0 & $2.10 \mathrm{E}-08$ & 0 & 4. $98 \mathrm{E}-10$ & 0 & $3.96 \mathrm{E}-08$ & 0 & $7.68 \mathrm{E}-05$ & 0 \\
\hline-240 & $9.79 \mathrm{E}-08$ & 0 & $3.40 E-05$ & 0 & $0.00 \mathrm{E}+00$ & 0 & $1.37 \mathrm{E}-07$ & 0 & $9.72 \mathrm{E}-09$ & 0 & $2.37 \mathrm{E}-10$ & 0 & $1.83 \mathrm{E}-08$ & 0 & $3.43 E-05$ & 0 \\
\hline-99 & $1.99 \mathrm{E}-29$ & 0 & $2.41 E-31$ & 0 & $0.00 \mathrm{E}+00$ & 0 & $8.49 E-32$ & 0 & $1.89 \mathrm{E}-33$ & 0 & $2.59 E-32$ & 0 & $1.00 \mathrm{E}-35$ & 0 & $5.03 E-19$ & 0 \\
\hline-228 & $0.00 \mathrm{E}+00$ & 0 & $0.00 \mathrm{E}+00$ & 0 & $0.00 \mathrm{E}+00$ & 0 & $0.00 \mathrm{E}+00$ & 0 & $0.00 \mathrm{E}+00$ & 0 & $0.00 \mathrm{E}+00$ & 0 & $0.00 \mathrm{E}+00$ & 0 & $0.00 \mathrm{E}+00$ & 0 \\
\hline-230 & $7.41 \mathrm{E}-01$ & 34 & $2.69 \mathrm{E}-04$ & 0 & $0.00 \mathrm{E}+00$ & 0 & $4.06 \mathrm{E}-05$ & 0 & $9.55 E-06$ & 0 & $9.24 \mathrm{E}-06$ & 0 & $1.36 \mathrm{E}-06$ & 0 & $7.41 \mathrm{E}-01$ & 34 \\
\hline-232 & $4.56 \mathrm{E}-02$ & 2 & $1.68 E-05$ & 0 & $0.00 \mathrm{E}+00$ & 0 & $2.07 E-06$ & 0 & $3.61 E-07$ & 0 & $5.58 E-07$ & 0 & $3.37 E-08$ & 0 & $4.56 \mathrm{E}-02$ & 2 \\
\hline 234 & $8.16 \mathrm{E}-02$ & 4 & $6.86 \mathrm{E}-05$ & 0 & $0.00 \mathrm{E}+00$ & 0 & $4.81 \mathrm{E}-06$ & 0 & $1.10 \mathrm{E}-06$ & 0 & $1.19 \mathrm{E}-06$ & 0 & $1.70 \mathrm{E}-07$ & 0 & $8.17 \mathrm{E}-02$ & 4 \\
\hline 235 & $2.81 \mathrm{E}-03$ & 0 & $2.08 E-05$ & 0 & $0.00 \mathrm{E}+00$ & 0 & $2.27 \mathrm{E}-07$ & 0 & $2.03 E-07$ & 0 & $9.39 \mathrm{E}-09$ & 0 & $1.41 \mathrm{E}-08$ & 0 & $2.83 E-03$ & 0 \\
\hline 238 & $1.67 \mathrm{E}-02$ & 1 & $2.96 E-05$ & 0 & $0.00 \mathrm{E}+00$ & 0 & $3.66 \mathrm{E}-07$ & 0 & $5.73 E-08$ & 0 & $1.87 \mathrm{E}-07$ & 0 & $1.84 \mathrm{E}-08$ & 0 & 1. $68 \mathrm{E}-02$ & 1 \\
\hline & $8.89 \mathrm{E}-01$ & 41 & $5.16 E-04$ & 0 & $0.00 \mathrm{E}+00$ & 0 & $4.85 E-05$ & 0 & 1.13E-05 & 0 & 1. $12 \mathrm{E}-05$ & 0 & $1.66 \mathrm{E}-06$ & 0 & $2.18 \mathrm{E}+00$ & 100 \\
\hline
\end{tabular}

* Sum of dose from all releases and from primary contamination. 
RESRAD-OFFSITE, Version 2.

Parent Dose Report

Title : RESRAD-OFFSITE Parameters for Offsite Resident Farmer Forward Run 10,000 Years

File : OFFSITE-RF_FORWARD-7-11-10000yr.ROF

Dose/Source Ratios Summed Over All Pathways

Parent and Progeny Principal Radionuclide Contributions Indicated

Parent Product Thread DSR $(j, \mathrm{t}) \quad(\mathrm{mrem} / \mathrm{yr}) /(\mathrm{pCi} / \mathrm{g})$

(i)

(j)

$\begin{array}{ll}\mathrm{Am}-241 & 1.000 \mathrm{E}+00 \\ \mathrm{~Np}-237+\mathrm{D} & 1.000 \mathrm{E}+00 \\ \mathrm{U}-233 & 1.000 \mathrm{E}+00 \\ \mathrm{Th}-229+\mathrm{D} & 1.000 \mathrm{E}+00 \\ \operatorname{\sum DSR}(j) & \end{array}$

$\mathrm{Np}-237+\mathrm{D}$

$\mathrm{U}-233$

$\mathrm{Th}-229+\mathrm{D}$

$\sum \operatorname{DSR}(j)$

Pu-238

$\mathrm{Pu}-238$

$\mathrm{U}-234$

Th-230

$\mathrm{Ra}-226+\mathrm{D}$

$\mathrm{Pb}-210+\mathrm{D}$

$\sum \operatorname{DSR}(j)$

$\mathrm{Pu}-239$

$\mathrm{U}-235+\mathrm{D}$

$\mathrm{Pa}-231$

$A C-227+D$

$\sum \operatorname{DSR}(j)$

$\mathrm{Pu}-240$

Pu-240

U-236

Th-232

$\mathrm{Ra}-228+\mathrm{D}$

Th-228+D

$\sum \mathrm{DSR}(\mathrm{j})$

TC-99

1. $000 \mathrm{E}+00$

1. $000 \mathrm{E}+00$

$1.000 \mathrm{E}+00$

1. $000 \mathrm{E}+00$

1. $000 \mathrm{E}+00$

1. $000 \mathrm{E}+00$

1. $000 \mathrm{E}+00$

1. $000 \mathrm{E}+00$

1. $000 \mathrm{E}+00$

4. $950 \mathrm{E}-08$

1. $000 \mathrm{E}+00$

1. $000 \mathrm{E}+00$

1. $000 \mathrm{E}+00$

1. $000 \mathrm{E}+00$

1. $000 \mathrm{E}+00$

Th-228+D Th-228+D $1.000 \mathrm{E}+00 \quad 6.843 \mathrm{E}-15 \quad 4.816 \mathrm{E}-15 \quad 1.228 \mathrm{E}-22 \quad 2.194 \mathrm{E}-30 \quad 0.000 \mathrm{E}+00 \quad 0.000 \mathrm{E}+00 \quad 0.000 \mathrm{E}+00$

$0.000 \mathrm{E}+00 \quad 1.000 \mathrm{E}+00 \quad 5.000 \mathrm{E}+01 \quad 1.000 \mathrm{E}+02 \quad 5.000 \mathrm{E}+02 \quad 1.026 \mathrm{E}+03 \quad 1.000 \mathrm{E}+04$

$\begin{array}{cccccccc}9.537 \mathrm{E}-42 & 9.774 \mathrm{E}-42 & 3.239 \mathrm{E}-41 & 1.100 \mathrm{E}-40 & 1.945 \mathrm{E}-36 & 7.488 \mathrm{E}-31 & 4.155 \mathrm{E}-13\end{array}$

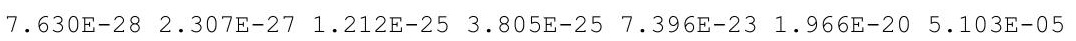

$2.067 \mathrm{E}-38 \quad 1.303 \mathrm{E}-37 \quad 2.284 \mathrm{E}-34 \quad 1.567 \mathrm{E}-33 \quad 3.197 \mathrm{E}-30 \quad 4.568 \mathrm{E}-27 \quad 1.239 \mathrm{E}-07$

$\begin{array}{lllllll}1.687 \mathrm{E}-34 & 2.107 \mathrm{E}-33 & 8.207 \mathrm{E}-29 & 8.730 \mathrm{E}-28 & 1.204 \mathrm{E}-24 & 2.598 \mathrm{E}-22 & 8.417 \mathrm{E}-09\end{array}$

$\begin{array}{lllllll}7.630 \mathrm{E}-28 & 2.307 \mathrm{E}-27 & 1.213 \mathrm{E}-25 & 3.813 \mathrm{E}-25 & 7.516 \mathrm{E}-23 & 1.992 \mathrm{E}-20 & 5.116 \mathrm{E}-05\end{array}$

$\begin{array}{lllllll}.220 E-18 & 6.125 E-18 & 2.887 E-18 & 1.340 E-18 & 2.881 E-21 & 8.954 E-25 & 8.408 E-45\end{array}$

$\begin{array}{llllllll}4.700 E-21 & 4.747 E-21 & 7.698 E-21 & 1.261 E-20 & 6.527 E-19 & 1.171 E-16 & 2.337 E-01\end{array}$

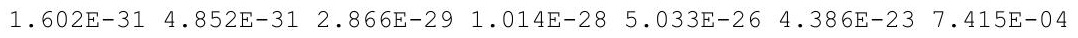

$\begin{array}{lllllll}1.745 \mathrm{E}-27 & 1.096 \mathrm{E}-26 & 1.534 \mathrm{E}-23 & 8.359 \mathrm{E}-23 & 2.673 \mathrm{E}-20 & 3.337 \mathrm{E}-18 & 4.489 \mathrm{E}-05\end{array}$

$\begin{array}{llllllll}4.700 \mathrm{E}-21 & 4.747 \mathrm{E}-21 & 7.713 \mathrm{E}-21 & 1.269 \mathrm{E}-20 & 6.794 \mathrm{E}-19 & 1.205 \mathrm{E}-16 & 2.345 \mathrm{E}-01\end{array}$

$\begin{array}{lllllll}.065 E-41 & 1.074 E-41 & 1.618 E-41 & 2.458 E-41 & 6.961 E-40 & 5.653 E-38 & 0.000 E+00\end{array}$

$5.790 \mathrm{E}-33 \quad 5.838 \mathrm{E}-33 \quad 8.794 \mathrm{E}-33 \quad 1.336 \mathrm{E}-32 \quad 3.783 \mathrm{E}-31 \quad 3.072 \mathrm{E}-29 \quad 1.230 \mathrm{E}-40$

$\begin{array}{lllllll}4.825 E-38 & 1.463 E-37 & 9.066 E-36 & 3.412 E-35 & 4.151 E-32 & 2.242 E-28 & 9.220 E-11\end{array}$

$\begin{array}{lllllll}6.061 E-42 & 3.827 \mathrm{E}-41 & 7.376 \mathrm{E}-38 & 5.622 \mathrm{E}-37 & 3.317 \mathrm{E}-33 & 2.722 \mathrm{E}-29 & 7.814 \mathrm{E}-11\end{array}$

$\begin{array}{lllllllll}5.640 \mathrm{E}-31 & 7.032 \mathrm{E}-30 & 2.526 \mathrm{E}-25 & 2.486 \mathrm{E}-24 & 2.108 \mathrm{E}-21 & 2.972 \mathrm{E}-19 & 1.801 \mathrm{E}-07\end{array}$

$2.042 \mathrm{E}-39 \quad 4.778 \mathrm{E}-38 \quad 3.717 \mathrm{E}-32 \quad 6.091 \mathrm{E}-31 \quad 1.328 \mathrm{E}-27 \quad 3.422 \mathrm{E}-25 \quad 8.401 \mathrm{E}-11$

$\begin{array}{lllllllll}5.698 \mathrm{E}-31 & 7.038 \mathrm{E}-30 & 2.526 \mathrm{E}-25 & 2.486 \mathrm{E}-24 & 2.108 \mathrm{E}-21 & 2.972 \mathrm{E}-19 & 1.804 \mathrm{E}-07\end{array}$

$5.925 \mathrm{E}-26 \quad 5.991 \mathrm{E}-26 \quad 1.027 \mathrm{E}-25 \quad 1.779 \mathrm{E}-25 \quad 1.445 \mathrm{E}-23 \quad 4.686 \mathrm{E}-21 \quad 2.131 \mathrm{E}-06$

$3.028 \mathrm{E}-32 \quad 9.172 \mathrm{E}-32 \quad 5.381 \mathrm{E}-30 \quad 1.891 \mathrm{E}-29 \quad 8.893 \mathrm{E}-27 \quad 7.217 \mathrm{E}-24 \quad 2.135 \mathrm{E}-09$

$\begin{array}{lllllll}5.689 \mathrm{E}-36 & 3.582 \mathrm{E}-35 & 5.915 \mathrm{E}-32 & 3.816 \mathrm{E}-31 & 4.695 \mathrm{E}-28 & 3.351 \mathrm{E}-25 & 8.226 \mathrm{E}-11\end{array}$

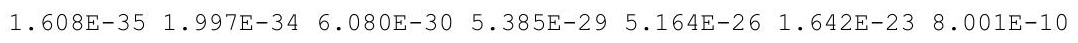
$5.925 \mathrm{E}-26 \quad 5.991 \mathrm{E}-26 \quad 1.027 \mathrm{E}-25 \quad 1.780 \mathrm{E}-25 \quad 1.451 \mathrm{E}-23 \quad 4.710 \mathrm{E}-21 \quad 2.134 \mathrm{E}-06$

$2.786 E-40 \quad 2.831 E-40 \quad 6.248 E-40 \quad 1.401 E-39 \quad 8.966 E-37 \quad 4.392 E-33 \quad 4.717 E-14$

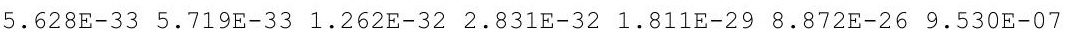

$\begin{array}{lllllll}1.067 \mathrm{E}-40 & 3.248 \mathrm{E}-40 & 2.450 \mathrm{E}-38 & 1.113 \mathrm{E}-37 & 4.093 \mathrm{E}-34 & 4.966 \mathrm{E}-30 & 4.001 \mathrm{E}-11\end{array}$

$\begin{array}{llllllll}0.000 \mathrm{E}+00 & 0.000 \mathrm{E}+00 & 0.000 \mathrm{E}+00 & 0.000 \mathrm{E}+00 & 5.307 \mathrm{E}-42 & 1.757 \mathrm{E}-37 & 1.389 \mathrm{E}-16\end{array}$

$\begin{array}{lllllll}9.587 \mathrm{E}-37 & 1.168 \mathrm{E}-35 & 1.800 \mathrm{E}-31 & 1.181 \mathrm{E}-30 & 5.381 \mathrm{E}-28 & 8.909 \mathrm{E}-26 & 2.184 \mathrm{E}-13\end{array}$

$\begin{array}{llllllll}6.962 \mathrm{E}-36 & 1.512 \mathrm{E}-34 & 1.272 \mathrm{E}-29 & 8.269 \mathrm{E}-29 & 2.173 \mathrm{E}-26 & 1.651 \mathrm{E}-24 & 3.453 \mathrm{E}-13\end{array}$

$\begin{array}{lllllll}5.636 \mathrm{E}-33 & 5.882 \mathrm{E}-33 & 1.291 \mathrm{E}-29 & 8.390 \mathrm{E}-29 & 2.228 \mathrm{E}-26 & 1.829 \mathrm{E}-24 & 9.530 \mathrm{E}-07\end{array}$

$2.843 \mathrm{E}-34 \quad 2.878 \mathrm{E}-34 \quad 5.284 \mathrm{E}-34 \quad 9.824 \mathrm{E}-34 \quad 1.907 \mathrm{E}-02 \quad 2.762 \mathrm{E}-02 \quad 9.668 \mathrm{E}-21$ 
RESRAD-OFFSITE, Version 2.

Parent Dose Report

Title : RESRAD-OFFSITE Parameters for Offsite Resident Farmer Forward Run 10,000 Years File : OFFSITE-RF_FORWARD-7-11-10000yr.ROF

Dose/Source Ratios Summed Over All Pathways

Parent and Progeny Principal Radionuclide Contributions Indicated

\begin{tabular}{|c|c|c|c|c|c|c|c|c|c|}
\hline Parent & Product & Thread & & & $\operatorname{SR}(j, t) \quad(m$ & $\mathrm{rem} / \mathrm{yr}) /(\mathrm{r}$ & Ci/g) & & \\
\hline (i) & $(j)$ & Fraction & $0.000 \mathrm{E}+00$ & $1.000 \mathrm{E}+00$ & $5.000 \mathrm{E}+01$ & $1.000 \mathrm{E}+02$ & $5.000 \mathrm{E}+02$ & $1.026 E+03$ & $1.000 \mathrm{E}+04$ \\
\hline-230 & $\mathrm{Th}-230$ & $1.000 \mathrm{E}+00$ & $1.189 \mathrm{E}-30$ & $1.207 \mathrm{E}-30$ & $2.577 \mathrm{E}-30$ & $5.589 \mathrm{E}-30$ & $2.732 \mathrm{E}-27$ & $9.387 \mathrm{E}-24$ & $2.517 \mathrm{E}-06$ \\
\hline-230 & $\mathrm{Ra}-226+\mathrm{D}$ & $1.000 \mathrm{E}+00$ & $1.861 \mathrm{E}-19$ & $5.614 \mathrm{E}-19$ & $2.552 \mathrm{E}-17$ & $6.905 \mathrm{E}-17$ & $4.024 \mathrm{E}-15$ & $2.105 E-13$ & $7.405 E-03$ \\
\hline-230 & $\mathrm{~Pb}-210+\mathrm{D}$ & $1.000 \mathrm{E}+00$ & $1.070 \mathrm{E}-27$ & $6.662 E-27$ & $6.209 E-24$ & $2.463 E-23$ & $2.775 E-21$ & $2.524 \mathrm{E}-19$ & $3.467 E-06$ \\
\hline-230 & $\sum \operatorname{DSR}(j)$ & & $1.861 \mathrm{E}-19$ & 5. $614 \mathrm{E}-19$ & $2.552 \mathrm{E}-17$ & $6.905 \mathrm{E}-17$ & $4.024 \mathrm{E}-15$ & $2.105 E-13$ & $7.411 \mathrm{E}-03$ \\
\hline-232 & $T h-232$ & $1.000 \mathrm{E}+00$ & $5.745 E-33$ & $5.844 E-33$ & $1.351 \mathrm{E}-32$ & $3.175 \mathrm{E}-32$ & $2.963 E-29$ & $2.383 E-25$ & $2.805 E-06$ \\
\hline-232 & $\mathrm{Ra}-228+\mathrm{D}$ & $1.000 \mathrm{E}+00$ & $5.422 \mathrm{E}-18$ & $1.556 \mathrm{E}-17$ & $1.332 \mathrm{E}-16$ & $1.894 \mathrm{E}-16$ & $3.104 \mathrm{E}-15$ & $1.228 \mathrm{E}-13$ & $4.417 E-03$ \\
\hline-232 & $\mathrm{Th}-228+\mathrm{D}$ & $1.000 \mathrm{E}+00$ & $6.152 \mathrm{E}-17$ & $3.372 E-16$ & $1.066 \mathrm{E}-14$ & $1.407 \mathrm{E}-14$ & 1. $267 \mathrm{E}-13$ & $2.287 \mathrm{E}-12$ & $6.987 E-03$ \\
\hline-232 & $\sum \operatorname{DSR}(j)$ & & $6.694 \mathrm{E}-17$ & $3.527 \mathrm{E}-16$ & $1.079 \mathrm{E}-14$ & 1. $426 \mathrm{E}-14$ & 1. $298 \mathrm{E}-13$ & 2. $410 \mathrm{E}-12$ & $1.141 \mathrm{E}-02$ \\
\hline-234 & $\mathrm{U}-234$ & $1.000 \mathrm{E}+00$ & $3.398 E-32$ & $3.454 E-32$ & 7. $678 E-32$ & $1.735 \mathrm{E}-31$ & $1.179 E-28$ & $6.245 E-25$ & $2.567 E-07$ \\
\hline-234 & $\mathrm{Th}-230$ & $1.000 \mathrm{E}+00$ & $5.375 E-36$ & $1.634 \mathrm{E}-35$ & $1.172 \mathrm{E}-33$ & $5.055 \mathrm{E}-33$ & $1.229 \mathrm{E}-29$ & $8.650 \mathrm{E}-26$ & $2.204 \mathrm{E}-07$ \\
\hline-234 & $\mathrm{Ra}-226+\mathrm{D}$ & $1.000 \mathrm{E}+00$ & $6.675 E-25$ & $4.190 \mathrm{E}-24$ & $5.821 \mathrm{E}-21$ & $3.146 \mathrm{E}-20$ & $9.384 \mathrm{E}-18$ & $1.042 \mathrm{E}-15$ & $5.099 E-04$ \\
\hline-234 & $\mathrm{~Pb}-210+\mathrm{D}$ & $1.000 \mathrm{E}+00$ & $2.882 E-33$ & $3.578 E-32$ & $1.052 \mathrm{E}-27$ & $8.968 E-27$ & $6.069 \mathrm{E}-24$ & $1.209 \mathrm{E}-21$ & $2.379 E-07$ \\
\hline-234 & $\sum \operatorname{DSR}(j)$ & & $6.675 \mathrm{E}-25$ & $4.190 \mathrm{E}-24$ & $5.821 \mathrm{E}-21$ & $3.146 \mathrm{E}-20$ & $9.384 \mathrm{E}-18$ & $1.042 \mathrm{E}-15$ & $5.106 \mathrm{E}-04$ \\
\hline$-235+D$ & $\mathrm{U}-235+\mathrm{D}$ & $1.000 \mathrm{E}+00$ & $6.128 E-23$ & $6.198 E-23$ & $1.083 E-22$ & $1.913 \mathrm{E}-22$ & $1.816 \mathrm{E}-20$ & $7.232 \mathrm{E}-18$ & $2.455 E-04$ \\
\hline$-235+D$ & $\mathrm{~Pa}-231$ & $1.000 \mathrm{E}+00$ & $1.450 \mathrm{E}-26$ & $4.385 E-26$ & $2.379 E-24$ & $7.715 \mathrm{E}-24$ & 1. $910 \mathrm{E}-21$ & $6.667 \mathrm{E}-19$ & $1.765 \mathrm{E}-05$ \\
\hline$-235+D$ & $A C-227+D$ & $1.000 \mathrm{E}+00$ & $5.457 \mathrm{E}-26$ & $3.398 E-25$ & $3.279 \mathrm{E}-22$ & 1. $356 \mathrm{E}-21$ & $2.231 \mathrm{E}-19$ & $3.366 \mathrm{E}-17$ & $1.722 \mathrm{E}-04$ \\
\hline-235 & $\sum \operatorname{DSR}(j)$ & & $6.135 E-23$ & $6.236 \mathrm{E}-23$ & $4.386 \mathrm{E}-22$ & $1.555 \mathrm{E}-21$ & $2.432 E-19$ & $4.156 \mathrm{E}-17$ & $4.353 E-04$ \\
\hline-238 & $\mathrm{U}-238$ & $5.400 \mathrm{E}-05$ & $0.000 \mathrm{E}+00$ & $0.000 \mathrm{E}+00$ & $0.000 \mathrm{E}+00$ & $0.000 \mathrm{E}+00$ & $0.000 \mathrm{E}+00$ & $0.000 \mathrm{E}+00$ & $9.669 \mathrm{E}-12$ \\
\hline $238+D$ & $U-238+D$ & $9.999 \mathrm{E}-01$ & $6.998 E-19$ & $7.050 \mathrm{E}-19$ & $1.011 \mathrm{E}-18$ & 1. $460 \mathrm{E}-18$ & $2.771 \mathrm{E}-17$ & $1.329 \mathrm{E}-15$ & $9.867 E-05$ \\
\hline$-238+D$ & $\mathrm{U}-234$ & $9.999 \mathrm{E}-01$ & $4.840 E-38$ & $1.472 \mathrm{E}-37$ & $1.099 \mathrm{E}-35$ & $4.944 \mathrm{E}-35$ & $1.673 E-31$ & $1.820 \mathrm{E}-27$ & $7.382 \mathrm{E}-09$ \\
\hline$-238+D$ & $T h-230$ & $9.999 \mathrm{E}-01$ & $6.075 E-42$ & $3.844 E-41$ & $8.388 E-38$ & $7.201 \mathrm{E}-37$ & $8.719 E-33$ & 1.259E-28 & $3.125 E-09$ \\
\hline$-238+D$ & $\mathrm{Ra}-226+\mathrm{D}$ & $9.999 \mathrm{E}-01$ & $5.569 \mathrm{E}-31$ & $7.109 \mathrm{E}-30$ & $2.783 \mathrm{E}-25$ & $2.998 \mathrm{E}-24$ & 4. $516 \mathrm{E}-21$ & $1.047 \mathrm{E}-18$ & $6.020 E-06$ \\
\hline$-238+D$ & $\mathrm{~Pb}-210+\mathrm{D}$ & $9.999 \mathrm{E}-01$ & $2.828 E-40$ & $7.237 E-38$ & $4.031 E-32$ & $7.167 \mathrm{E}-31$ & $2.754 \mathrm{E}-27$ & $1.178 E-24$ & $2.799 E-09$ \\
\hline-238 & $\sum \operatorname{DSR}(j)$ & & $6.998 \mathrm{E}-19$ & $7.050 \mathrm{E}-19$ & $1.011 \mathrm{E}-18$ & 1. $460 \mathrm{E}-18$ & $2.772 \mathrm{E}-17$ & $1.331 \mathrm{E}-15$ & $1.047 \mathrm{E}-04$ \\
\hline
\end{tabular}

The DSR includes contributions from associated (half-life $\leq 180$ days) daughters. 
RESRAD-OFFSITE, Version 2.

Parent Dose Report

Title : RESRAD-OFFSITE Parameters for Offsite Resident Farmer Forward Run 10,000 Years File : OFFSITE-RF_FORWARD-7-11-10000yr.ROF

Single Radionuclide Soil Guidelines $G(i, t)$ in $\mathrm{pCi} / \mathrm{g}$

Basic Radiation Dose Limit $=1.000 \mathrm{E}+00 \mathrm{mrem} / \mathrm{yr}$

Nuclide

\begin{tabular}{|c|c|c|c|c|c|c|c|}
\hline (i) & $t=0.000 \mathrm{E}+00$ & $1.000 \mathrm{E}+00$ & $5.000 \mathrm{E}+01$ & $1.000 \mathrm{E}+02$ & $5.000 \mathrm{E}+02$ & $1.026 \mathrm{E}+03$ & 1. $000 \mathrm{E}+04$ \\
\hline 241 & $\star 3.431 \mathrm{E}+12$ & $\star 3.431 \mathrm{E}+12$ & $\star 3.431 \mathrm{E}+12$ & $\star 3.431 \mathrm{E}+12$ & $\star 3.431 \mathrm{E}+12$ & $\star 3.431 \mathrm{E}+12$ & 1. $955 \mathrm{E}+04$ \\
\hline 137 & $\star 8.704 \mathrm{E}+13$ & $\star 8.704 \mathrm{E}+13$ & $\star 8.704 \mathrm{E}+13$ & $\star 8.704 \mathrm{E}+13$ & $* 8.704 \mathrm{E}+13$ & $* 8.704 \mathrm{E}+13$ & $\star 8.704 \mathrm{E}+13$ \\
\hline-237 & $\star 7.047 \mathrm{E}+08$ & $\star 7.047 \mathrm{E}+08$ & $\star 7.047 \mathrm{E}+08$ & $\star 7.047 \mathrm{E}+08$ & $\star 7.047 \mathrm{E}+08$ & $\star 7.047 \mathrm{E}+08$ & $4.265 \mathrm{E}+00$ \\
\hline-238 & $\star 1.712 \mathrm{E}+13$ & $\star 1.712 \mathrm{E}+13$ & $\star 1.712 \mathrm{E}+13$ & $\star 1.712 \mathrm{E}+13$ & $\star 1.712 \mathrm{E}+13$ & $\star 1.712 \mathrm{E}+13$ & $5.545 \mathrm{E}+06$ \\
\hline-239 & $* 6.214 \mathrm{E}+10$ & $\star 6.214 \mathrm{E}+10$ & $\star 6.214 \mathrm{E}+10$ & $\star 6.214 \mathrm{E}+10$ & $* 6.214 \mathrm{E}+10$ & $\star 6.214 \mathrm{E}+10$ & $4.686 \mathrm{E}+05$ \\
\hline-240 & $\star 2.278 \mathrm{E}+11$ & $\star 2.278 \mathrm{E}+11$ & $\star 2.278 \mathrm{E}+11$ & $\star 2.278 \mathrm{E}+11$ & $* 2.278 \mathrm{E}+11$ & $\star 2.278 \mathrm{E}+11$ & $1.049 \mathrm{E}+06$ \\
\hline-99 & $\star 1.697 \mathrm{E}+10$ & $\star 1.697 \mathrm{E}+10$ & $\star 1.697 \mathrm{E}+10$ & $\star 1.697 \mathrm{E}+10$ & $5.245 \mathrm{E}+01$ & $3.620 \mathrm{E}+01$ & $\star 1.697 \mathrm{E}+10$ \\
\hline-228 & $1.461 \mathrm{E}+14$ & $2.076 \mathrm{E}+14$ & $\star 8.195 \mathrm{E}+14$ & $\star 8.195 \mathrm{E}+14$ & $* 8.195 \mathrm{E}+14$ & $\star 8.195 E+14$ & $\star 8.195 \mathrm{E}+14$ \\
\hline $1-230$ & $* 2.018 \mathrm{E}+10$ & $\star 2.018 \mathrm{E}+10$ & $\star 2.018 \mathrm{E}+10$ & $\star 2.018 \mathrm{E}+10$ & $\star 2.018 \mathrm{E}+10$ & $\star 2.018 \mathrm{E}+10$ & $1.349 \mathrm{E}+02$ \\
\hline $1-232$ & $\star 1.097 \mathrm{E}+05$ & $\star 1.097 \mathrm{E}+05$ & $\star 1.097 \mathrm{E}+05$ & $\star 1.097 \mathrm{E}+05$ & $\star 1.097 \mathrm{E}+05$ & $\star 1.097 \mathrm{E}+05$ & $8.766 \mathrm{E}+01$ \\
\hline-234 & $\star 6.247 \mathrm{E}+09$ & $\star 6.247 \mathrm{E}+09$ & $\star 6.247 \mathrm{E}+09$ & $\star 6.247 \mathrm{E}+09$ & $\star 6.247 \mathrm{E}+09$ & $\star 6.247 \mathrm{E}+09$ & $1.958 \mathrm{E}+03$ \\
\hline נת & $\star 2.161 \mathrm{E}+06$ & $\star 2.161 \mathrm{E}+06$ & $\star 2.161 \mathrm{E}+06$ & $\star 2.161 \mathrm{E}+06$ & $\star 2.161 \mathrm{E}+06$ & $\star 2.161 \mathrm{E}+06$ & $2.297 \mathrm{E}+03$ \\
\hline 30 & $\star 3.361 \mathrm{E}+05$ & $\star 3.361 \mathrm{E}+05$ & $* 3.361 \mathrm{E}+05$ & $\star 3.361 \mathrm{E}+05$ & $\star 3.361 \mathrm{E}+05$ & $* 3.361 \mathrm{E}+05$ & $9.551 \mathrm{E}+03$ \\
\hline
\end{tabular}

*At specific activity limit

Summed Dose/Source Ratios DSR(i,t) in (mrem/yr)/(pCi/g)

and Single Radionuclide Soil Guidelines $G(i, t)$ in pCi/g

at tmin $=$ time of minimum single radionuclide soil guideline

and at $\operatorname{tmax}=$ time of maximum total dose $=10024$ years

\begin{tabular}{|c|c|c|c|c|c|c|}
\hline $\begin{array}{l}\text { Juclide } \\
\text { (i) }\end{array}$ & $\begin{array}{l}\text { Initial } \\
(\mathrm{pCi} / \mathrm{g})\end{array}$ & $\begin{array}{c}\text { tmin } \\
\text { (years) }\end{array}$ & $\operatorname{DSR}(i, \operatorname{tmin})$ & $\begin{array}{c}G(i, \operatorname{tmin}) \\
(\mathrm{pCi} / \mathrm{g})\end{array}$ & $\operatorname{DSR}(i, \operatorname{tmax})$ & $\begin{array}{c}G(i, t \max ) \\
(\mathrm{pCi} / \mathrm{g})\end{array}$ \\
\hline-241 & $3.500 \mathrm{E}+01$ & 10024 & $5.120 E-05$ & $1.953 E+04$ & $5.120 E-05$ & $1.953 E+04$ \\
\hline$s-137$ & $1.900 \mathrm{E}+01$ & 0 & $6.220 \mathrm{E}-18$ & $\star 8.704 \mathrm{E}+13$ & $8.408 E-45$ & $\star 8.704 \mathrm{E}+13$ \\
\hline$p-237$ & $5.500 \mathrm{E}+00$ & 10024 & $2.345 \mathrm{E}-01$ & $4.264 \mathrm{E}+00$ & $2.345 E-01$ & $4.264 \mathrm{E}+00$ \\
\hline$x-238$ & $3.900 \mathrm{E}+01$ & 10024 & $1.808 \mathrm{E}-07$ & $5.529 \mathrm{E}+06$ & $1.808 \mathrm{E}-07$ & $5.529 E+06$ \\
\hline-239 & $3.600 \mathrm{E}+01$ & 3804 & $2.676 \mathrm{E}-06$ & $3.737 \mathrm{E}+05$ & $2.132 \mathrm{E}-06$ & $4.690 \mathrm{E}+05$ \\
\hline$x-240$ & $3.600 \mathrm{E}+01$ & 3452 & $1.960 \mathrm{E}-06$ & $5.102 E+05$ & $9.504 \mathrm{E}-07$ & $1.052 \mathrm{E}+06$ \\
\hline$=-99$ & $5.200 \mathrm{E}+01$ & 772 & $3.595 \mathrm{E}-02$ & $2.782 \mathrm{E}+01$ & $8.536 \mathrm{E}-21$ & $* 1.697 \mathrm{E}+10$ \\
\hline $1-228$ & $4.000 \mathrm{E}+00$ & 0 & $6.843 \mathrm{E}-15$ & $1.461 \mathrm{E}+14$ & $0.000 \mathrm{E}+00$ & $\star 8.195 \mathrm{E}+14$ \\
\hline $1-230$ & $1.000 \mathrm{E}+02$ & 8586 & $7.440 \mathrm{E}-03$ & $1.344 \mathrm{E}+02$ & $7.410 \mathrm{E}-03$ & $1.349 \mathrm{E}+02$ \\
\hline-232 & $4.000 \mathrm{E}+00$ & 2751 & $1.155 \mathrm{E}-02$ & $8.660 \mathrm{E}+01$ & $1.141 \mathrm{E}-02$ & $8.767 \mathrm{E}+01$ \\
\hline-234 & $1.600 \mathrm{E}+02$ & 10024 & $5.120 \mathrm{E}-04$ & $1.953 \mathrm{E}+03$ & $5.120 \mathrm{E}-04$ & $1.953 \mathrm{E}+03$ \\
\hline 235 & $6.500 \mathrm{E}+00$ & 10024 & $4.355 E-04$ & $2.296 E+03$ & $4.355 \mathrm{E}-04$ & $2.296 E+03$ \\
\hline 238 & $1.600 \mathrm{E}+02$ & 2751 & $1.089 \mathrm{E}-04$ & $9.182 \mathrm{E}+03$ & $1.047 \mathrm{E}-04$ & $9.551 E+03$ \\
\hline
\end{tabular}

*At specific activity limit 
RESRAD-OFFSITE, Version 2.

Parent Dose Report

Title : RESRAD-OFFSITE Parameters for Offsite Resident Farmer Forward Run 10,000 Years

File : OFFSITE-RF FORWARD-7-11-10000yr.ROF

Individual Nuclide Dose Summed Over All Pathways

Parent Nuclide and Thread Fraction Indicated

Nuclide Parent THF(i) DOSE $(j, t)$, mrem/yr

\begin{tabular}{|c|c|c|}
\hline (j) & (i) & \\
\hline$A m-241$ & $A m-241$ & $1.000 \mathrm{E}+00$ \\
\hline$p-237$ & $A m-241$ & $1.000 \mathrm{E}+00$ \\
\hline Np-237 & $\mathrm{Np}-237$ & $1.000 \mathrm{E}+00$ \\
\hline-237 & $\sum \operatorname{DOSE}(j$ & : \\
\hline
\end{tabular}

$\mathrm{U}-233 \quad \mathrm{Am}-241 \quad 1.000 \mathrm{E}+00$

$\mathrm{U}-233 \quad \mathrm{~Np}-237 \quad 1.000 \mathrm{E}+00$

U-233 $\operatorname{DOSE}(j):$

Th-229 Am-241 $1.000 \mathrm{E}+00$

Th-229 Np-237 $1.000 \mathrm{E}+00$

Th-229 $\operatorname{DDOSE}(j):$

Cs-137 Cs-137 1.000E+00

$\mathrm{Pu}-238$

$\mathrm{Pu}-238$

$\mathrm{Pu}-238$

$\mathrm{U}-234$

$\mathrm{U}-234$

$\mathrm{U}-234$

$\mathrm{U}-234$

Th -230

Th-230

Th-230

Th-230

Th-230

$\mathrm{Ra}-226$

$\mathrm{Ra}-226$

$\mathrm{Ra}-226$

$\mathrm{Ra}-226$

$\mathrm{Ra}-226$

$\mathrm{Pb}-210 \mathrm{Pu}-238 \quad 1.000 \mathrm{E}+00$

$\mathrm{Pb}-210 \mathrm{Th}-230 \quad 1.000 \mathrm{E}+00$

$\mathrm{Pb}-210 \quad \mathrm{U}-234 \quad 1.000 \mathrm{E}+00$

$\mathrm{Pb}-210 \quad \mathrm{U}-238 \quad 9.999 \mathrm{E}-01$

$\mathrm{Pb}-210 \quad \sum \operatorname{DOSE}(j):$

Pu-239 Pu-239 1.000E+00 $t=0.000 \mathrm{E}+00 \quad 1.000 \mathrm{E}+00 \quad 5.000 \mathrm{E}+01 \quad 1.000 \mathrm{E}+02 \quad 5.000 \mathrm{E}+02 \quad 1.026 \mathrm{E}+03 \quad 1.000 \mathrm{E}+04$

$\begin{array}{lllllll}3.338 \mathrm{E}-40 & 3.421 \mathrm{E}-40 & 1.134 \mathrm{E}-39 & 3.849 \mathrm{E}-39 & 6.806 \mathrm{E}-35 & 2.621 \mathrm{E}-29 & 1.454 \mathrm{E}-11\end{array}$

$2.670 \mathrm{E}-26 \quad 8.074 \mathrm{E}-26 \quad 4.242 \mathrm{E}-24 \quad 1.332 \mathrm{E}-23 \quad 2.588 \mathrm{E}-21 \quad 6.880 \mathrm{E}-19 \quad 1.786 \mathrm{E}-03$

$2.585 \mathrm{E}-20 \quad 2.611 \mathrm{E}-20 \quad 4.234 \mathrm{E}-20 \quad 6.934 \mathrm{E}-20 \quad 3.590 \mathrm{E}-18 \quad 6.442 \mathrm{E}-16 \quad 1.285 \mathrm{E}+00$

$\begin{array}{lllllll}2.585 \mathrm{E}-20 & 2.611 \mathrm{E}-20 & 4.234 \mathrm{E}-20 & 6.936 \mathrm{E}-20 & 3.592 \mathrm{E}-18 & 6.449 \mathrm{E}-16 & 1.287 \mathrm{E}+00\end{array}$

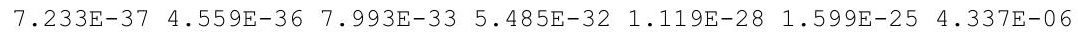

$\begin{array}{lllllll}8.809 \mathrm{E}-31 & 2.669 \mathrm{E}-30 & 1.576 \mathrm{E}-28 & 5.576 \mathrm{E}-28 & 2.768 \mathrm{E}-25 & 2.412 \mathrm{E}-22 & 4.078 \mathrm{E}-03\end{array}$

$\begin{array}{lllllll}8.809 \mathrm{E}-31 & 2.669 \mathrm{E}-30 & 1.576 \mathrm{E}-28 & 5.576 \mathrm{E}-28 & 2.769 \mathrm{E}-25 & 2.414 \mathrm{E}-22 & 4.083 \mathrm{E}-03\end{array}$

$\begin{array}{lllllll}5.905 \mathrm{E}-33 & 7.376 \mathrm{E}-32 & 2.872 \mathrm{E}-27 & 3.055 \mathrm{E}-26 & 4.212 \mathrm{E}-23 & 9.094 \mathrm{E}-21 & 2.946 \mathrm{E}-07\end{array}$

$9.600 \mathrm{E}-27 \quad 6.026 \mathrm{E}-26 \quad 8.439 \mathrm{E}-23 \quad 4.597 \mathrm{E}-22 \quad 1.470 \mathrm{E}-19 \quad 1.835 \mathrm{E}-17 \quad 2.469 \mathrm{E}-04$

$\begin{array}{lllllll}9.600 \mathrm{E}-27 & 6.026 \mathrm{E}-26 & 8.439 \mathrm{E}-23 & 4.598 \mathrm{E}-22 & 1.470 \mathrm{E}-19 & 1.836 \mathrm{E}-17 & 2.472 \mathrm{E}-04\end{array}$

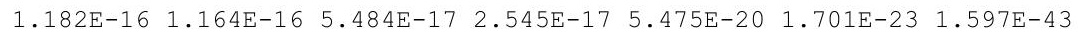

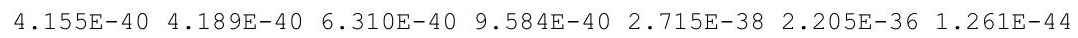

$\begin{array}{lllllll}2.258 \mathrm{E}-31 & 2.277 \mathrm{E}-31 & 3.429 \mathrm{E}-31 & 5.209 \mathrm{E}-31 & 1.475 \mathrm{E}-29 & 1.198 \mathrm{E}-27 & 4.796 \mathrm{E}-39\end{array}$

$\begin{array}{lllllll}2.258 \mathrm{E}-31 & 2.277 \mathrm{E}-31 & 3.429 \mathrm{E}-31 & 5.209 \mathrm{E}-31 & 1.475 \mathrm{E}-29 & 1.198 \mathrm{E}-27 & 4.796 \mathrm{E}-39\end{array}$

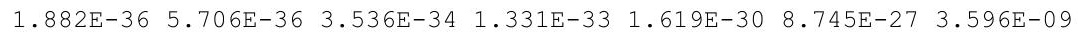

$\begin{array}{lllllll}5.437 \mathrm{E}-30 & 5.526 \mathrm{E}-30 & 1.229 \mathrm{E}-29 & 2.776 \mathrm{E}-29 & 1.886 \mathrm{E}-26 & 9.993 \mathrm{E}-23 & 4.108 \mathrm{E}-05\end{array}$

$\begin{array}{lllllll}7.744 \mathrm{E}-36 & 2.356 \mathrm{E}-35 & 1.759 \mathrm{E}-33 & 7.910 \mathrm{E}-33 & 2.677 \mathrm{E}-29 & 2.912 \mathrm{E}-25 & 1.181 \mathrm{E}-06\end{array}$

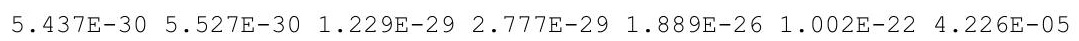

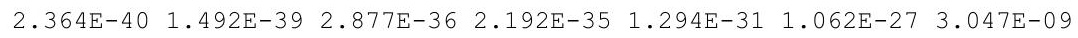

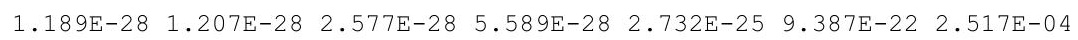
$\begin{array}{lllllll}8.599 \mathrm{E}-34 & 2.614 \mathrm{E}-33 & 1.875 \mathrm{E}-31 & 8.088 \mathrm{E}-31 & 1.966 \mathrm{E}-27 & 1.384 \mathrm{E}-23 & 3.527 \mathrm{E}-05\end{array}$ $\begin{array}{lllllll}9.720 \mathrm{E}-40 & 6.151 \mathrm{E}-39 & 1.342 \mathrm{E}-35 & 1.152 \mathrm{E}-34 & 1.395 \mathrm{E}-30 & 2.014 \mathrm{E}-26 & 5.000 \mathrm{E}-07\end{array}$ $\begin{array}{lllllll}1.189 \mathrm{E}-28 & 1.207 \mathrm{E}-28 & 2.579 \mathrm{E}-28 & 5.597 \mathrm{E}-28 & 2.751 \mathrm{E}-25 & 9.526 \mathrm{E}-22 & 2.875 \mathrm{E}-04\end{array}$

$\begin{array}{lllllll}2.199 \mathrm{E}-29 & 2.743 \mathrm{E}-28 & 9.853 \mathrm{E}-24 & 9.694 \mathrm{E}-23 & 8.223 \mathrm{E}-20 & 1.159 \mathrm{E}-17 & 7.024 \mathrm{E}-06\end{array}$ $\begin{array}{llllllll}1.861 \mathrm{E}-17 & 5.614 \mathrm{E}-17 & 2.552 \mathrm{E}-15 & 6.905 \mathrm{E}-15 & 4.024 \mathrm{E}-13 & 2.105 \mathrm{E}-11 & 7.405 \mathrm{E}-01\end{array}$ $\begin{array}{lllllll}1.068 \mathrm{E}-22 & 6.703 \mathrm{E}-22 & 9.314 \mathrm{E}-19 & 5.033 \mathrm{E}-18 & 1.501 \mathrm{E}-15 & 1.668 \mathrm{E}-13 & 8.159 \mathrm{E}-02\end{array}$ $\begin{array}{lllllll}8.911 \mathrm{E}-29 & 1.137 \mathrm{E}-27 & 4.454 \mathrm{E}-23 & 4.797 \mathrm{E}-22 & 7.226 \mathrm{E}-19 & 1.676 \mathrm{E}-16 & 9.632 \mathrm{E}-04\end{array}$ $\begin{array}{lllllll}1.861 \mathrm{E}-17 & 5.614 \mathrm{E}-17 & 2.553 \mathrm{E}-15 & 6.910 \mathrm{E}-15 & 4.039 \mathrm{E}-13 & 2.122 \mathrm{E}-11 & 8.231 \mathrm{E}-01\end{array}$

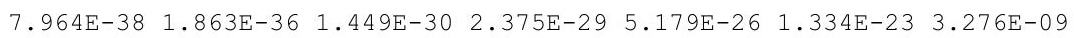
$\begin{array}{llllllllll}1.070 \mathrm{E}-25 & 6.662 \mathrm{E}-25 & 6.209 \mathrm{E}-22 & 2.463 \mathrm{E}-21 & 2.775 \mathrm{E}-19 & 2.524 \mathrm{E}-17 & 3.467 \mathrm{E}-04\end{array}$

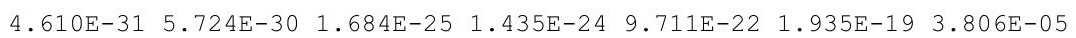
$\begin{array}{lllllll}4.525 \mathrm{E}-38 & 1.158 \mathrm{E}-35 & 6.450 \mathrm{E}-30 & 1.147 \mathrm{E}-28 & 4.407 \mathrm{E}-25 & 1.885 \mathrm{E}-22 & 4.478 \mathrm{E}-07\end{array}$ $\begin{array}{lllllll}1.070 \mathrm{E}-25 & 6.662 \mathrm{E}-25 & 6.210 \mathrm{E}-22 & 2.464 \mathrm{E}-21 & 2.785 \mathrm{E}-19 & 2.543 \mathrm{E}-17 & 3.852 \mathrm{E}-04\end{array}$ $2.133 \mathrm{E}-24 \quad 2.157 \mathrm{E}-24 \quad 3.696 \mathrm{E}-24 \quad 6.404 \mathrm{E}-24 \quad 5.200 \mathrm{E}-22 \quad 1.687 \mathrm{E}-19 \quad 7.671 \mathrm{E}-05$ 
RESRAD-OFFSITE, Version 2.

Parent Dose Report

Title : RESRAD-OFFSITE Parameters for Offsite Resident Farmer Forward Run 10,000 Years

File : OFFSITE-RF_FORWARD-7-11-10000yr.ROF

Individual Nuclide Dose Summed Over All Pathways

Parent Nuclide and Thread Fraction Indicated

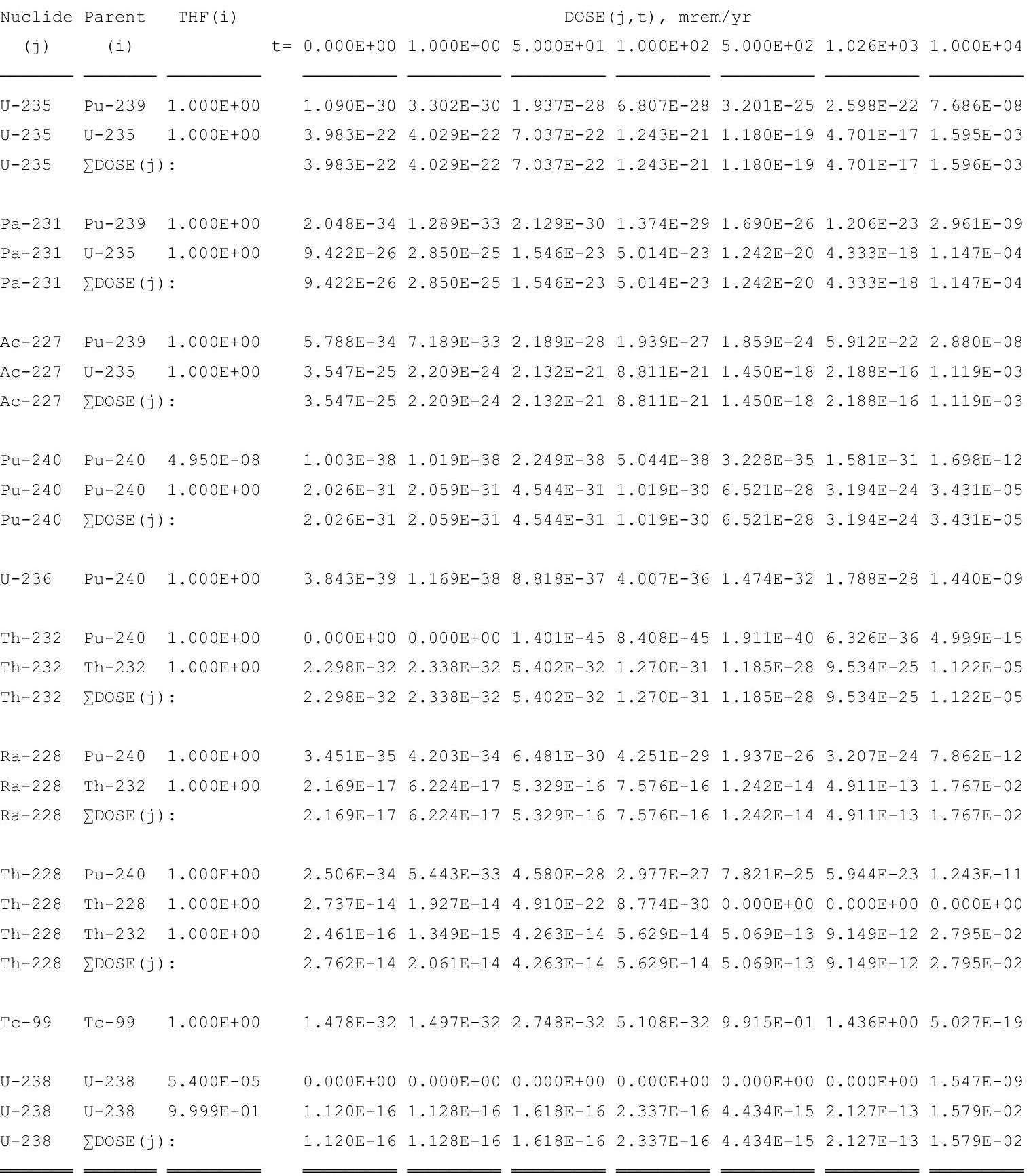

THF (i) is the thread fraction of the parent nuclide. 
RESRAD-OFFSITE, Version 2.

Parent Dose Report

Title : RESRAD-OFFSITE Parameters for Offsite Resident Farmer Forward Run 10,000 Years File : OFFSITE-RF_FORWARD-7-11-10000yr.ROF

Individual Nuclide Soil Concentration

Parent Nuclide and Thread Fraction Indicated

Nuclide Parent THF(

(j)

(i)

Am-241

$\mathrm{Np}-237$

$\mathrm{Np}-237$

$\mathrm{Np}-237$

$\mathrm{U}-233$

$\mathrm{U}-233$

$\mathrm{U}-233$

$\mathrm{Th}-229$

$\mathrm{Th}-229$

$\mathrm{Th}-229$

$\mathrm{Cs}-137$

$\mathrm{Pu}-238$

$\mathrm{Pu}-238$

$\mathrm{Pu}-238$

$\mathrm{U}-234$

$\mathrm{U}-234$

$\mathrm{U}-234$

$\mathrm{U}-234$

$\mathrm{Th}-230$

$\mathrm{Th}-230$

$\mathrm{Th}-230$

$\mathrm{Th}-230$

$\mathrm{Th}-23 \mathrm{C}$

$\mathrm{Ra}-226$

$\mathrm{Ra}-226$

$\mathrm{Ra}-226$

$\mathrm{Ra}-226$

$\mathrm{Ra}-226$

$\mathrm{Pb}-210$

$\mathrm{Pb}-210$

$\mathrm{Pb}-210$

$\mathrm{Pb}-210$

$\mathrm{Pb}-210$

Pu-239 Pu-239 1.000E+00
$S(j, t), p C i / g$

$t=0.000 \mathrm{E}+00 \quad 1.000 \mathrm{E}+00 \quad 5.000 \mathrm{E}+01 \quad 1.000 \mathrm{E}+02 \quad 5.000 \mathrm{E}+02 \quad 1.026 \mathrm{E}+03 \quad 1.000 \mathrm{E}+04$

$\begin{array}{lllllll}3.500 \mathrm{E}+01 & 3.494 \mathrm{E}+01 & 3.230 \mathrm{E}+01 & 2.981 \mathrm{E}+01 & 1.567 \mathrm{E}+01 & 6.732 \mathrm{E}+00 & 3.685 \mathrm{E}-06\end{array}$

$0.000 \mathrm{E}+00 \quad 1.133 \mathrm{E}-05 \quad 5.436 \mathrm{E}-04 \quad 1.043 \mathrm{E}-03 \quad 3.810 \mathrm{E}-03 \quad 5.417 \mathrm{E}-03 \quad 3.376 \mathrm{E}-03$

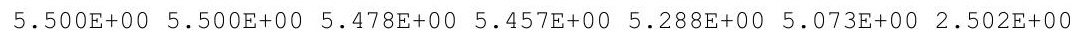

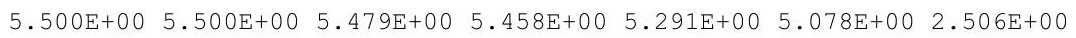

$0.000 \mathrm{E}+00 \quad 2.692 \mathrm{E}-11 \quad 6.025 \mathrm{E}-08 \quad 2.344 \mathrm{E}-07 \quad 4.742 \mathrm{E}-06 \quad 1.556 \mathrm{E}-05 \quad 1.863 \mathrm{E}-04$

$\begin{array}{lllllll}0.000 \mathrm{E}+00 & 2.405 \mathrm{E}-05 & 1.200 \mathrm{E}-03 & 2.394 \mathrm{E}-03 & 1.174 \mathrm{E}-02 & 2.349 \mathrm{E}-02 & 1.508 \mathrm{E}-01\end{array}$

$\begin{array}{lllllll}0.000 \mathrm{E}+00 & 2.405 \mathrm{E}-05 & 1.200 \mathrm{E}-03 & 2.394 \mathrm{E}-03 & 1.174 \mathrm{E}-02 & 2.350 \mathrm{E}-02 & 1.509 \mathrm{E}-01\end{array}$

$0.000 \mathrm{E}+00 \quad 9.718 \mathrm{E}-16 \quad 9.539 \mathrm{E}-11 \quad 7.463 \mathrm{E}-10 \quad 7.873 \mathrm{E}-08 \quad 5.545 \mathrm{E}-07 \quad 7.107 \mathrm{E}-05$

$\begin{array}{lllllll}0.000 \mathrm{E}+00 & 1.234 \mathrm{E}-09 & 2.830 \mathrm{E}-06 & 1.128 \mathrm{E}-05 & 2.750 \mathrm{E}-04 & 1.119 \mathrm{E}-03 & 6.062 \mathrm{E}-02\end{array}$

$\begin{array}{lllllll}0.000 \mathrm{E}+00 & 1.234 \mathrm{E}-09 & 2.830 \mathrm{E}-06 & 1.129 \mathrm{E}-05 & 2.750 \mathrm{E}-04 & 1.120 \mathrm{E}-03 & 6.069 \mathrm{E}-02\end{array}$

$\begin{array}{lllllll}1.900 \mathrm{E}+01 & 1.857 \mathrm{E}+01 & 5.979 \mathrm{E}+00 & 1.881 \mathrm{E}+00 & 1.809 \mathrm{E}-04 & 9.436 \mathrm{E}-10 & 0.000 \mathrm{E}+00\end{array}$

$\begin{array}{lllllll}7.176 \mathrm{E}-08 & 7.119 \mathrm{E}-08 & 4.832 \mathrm{E}-08 & 3.254 \mathrm{E}-08 & 1.375 \mathrm{E}-09 & 2.144 \mathrm{E}-11 & 3.185 \mathrm{E}-42\end{array}$

$\begin{array}{llllllllll}3.900 \mathrm{E}+01 & 3.869 \mathrm{E}+01 & 2.626 \mathrm{E}+01 & 1.768 \mathrm{E}+01 & 7.472 \mathrm{E}-01 & 1.165 \mathrm{E}-02 & 1.731 \mathrm{E}-33\end{array}$

$\begin{array}{llllllll}3.900 E+01 & 3.869 E+01 & 2.626 E+01 & 1.768 E+01 & 7.472 E-01 & 1.165 E-02 & 1.731 E-33\end{array}$

$0.000 \mathrm{E}+00 \quad 1.101 \mathrm{E}-04 \quad 4.564 \mathrm{E}-03 \quad 7.633 \mathrm{E}-03 \quad 1.362 \mathrm{E}-02 \quad 1.377 \mathrm{E}-02 \quad 1.191 \mathrm{E}-02$

$\begin{array}{lllllll}1.600 \mathrm{E}+02 & 1.600 \mathrm{E}+02 & 1.599 \mathrm{E}+02 & 1.597 \mathrm{E}+02 & 1.587 \mathrm{E}+02 & 1.574 \mathrm{E}+02 & 1.360 \mathrm{E}+02\end{array}$

$\begin{array}{lllllll}0.000 \mathrm{E}+00 & 4.536 \mathrm{E}-04 & 2.266 \mathrm{E}-02 & 4.529 \mathrm{E}-02 & 2.251 \mathrm{E}-01 \quad 4.583 \mathrm{E}-01 & 3.911 \mathrm{E}+00\end{array}$

$\begin{array}{lllllll}1.600 \mathrm{E}+02 & 1.600 \mathrm{E}+02 & 1.599 \mathrm{E}+02 & 1.598 \mathrm{E}+02 & 1.589 \mathrm{E}+02 & 1.578 \mathrm{E}+02 & 1.399 \mathrm{E}+02\end{array}$

$0.000 \mathrm{E}+00 \quad 5.392 \mathrm{E}-10 \quad 1.095 \mathrm{E}-06 \quad 3.884 \mathrm{E}-06 \quad 4.705 \mathrm{E}-05 \quad 1.118 \mathrm{E}-04 \quad 1.088 \mathrm{E}-03$ $\begin{array}{lllllllll}1.000 \mathrm{E}+02 & 1.000 \mathrm{E}+02 & 9.995 \mathrm{E}+01 & 9.989 \mathrm{E}+01 & 9.947 \mathrm{E}+01 & 9.891 \mathrm{E}+01 & 8.984 \mathrm{E}+01\end{array}$ $\begin{array}{lllllllllll}0.000 \mathrm{E}+00 & 1.440 \mathrm{E}-03 & 7.197 \mathrm{E}-02 & 1.438 \mathrm{E}-01 & 7.153 \mathrm{E}-01 & 1.457 \mathrm{E}+00 & 1.259 \mathrm{E}+01\end{array}$ $\begin{array}{llllllll}0.000 \mathrm{E}+00 & 2.219 \mathrm{E}-09 & 5.100 \mathrm{E}-06 & 2.039 \mathrm{E}-05 & 5.070 \mathrm{E}-04 & 2.120 \mathrm{E}-03 & 1.785 \mathrm{E}-01\end{array}$

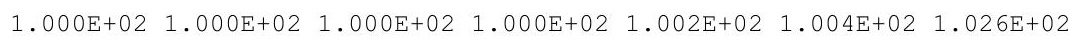

$0.000 \mathrm{E}+00 \quad 8.933 \mathrm{E}-14 \quad 8.112 \mathrm{E}-09 \quad 5.891 \mathrm{E}-08 \quad 3.952 \mathrm{E}-06 \quad 1.952 \mathrm{E}-05 \quad 8.404 \mathrm{E}-04$ $\begin{array}{llllllll}0.000 \mathrm{E}+00 & 4.331 \mathrm{E}-02 & 2.142 \mathrm{E}+00 \quad 4.235 \mathrm{E}+00 & 1.937 \mathrm{E}+01 & 3.549 \mathrm{E}+01 & 8.860 \mathrm{E}+01\end{array}$ $\begin{array}{lllllll}0.000 \mathrm{E}+00 & 3.390 \mathrm{E}-07 & 7.739 \mathrm{E}-04 & 3.071 \mathrm{E}-03 & 7.220 \mathrm{E}-02 & 2.810 \mathrm{E}-01 & 9.761 \mathrm{E}+00\end{array}$ $0.000 \mathrm{E}+00 \quad 3.640 \mathrm{E}-13 \quad 3.663 \mathrm{E}-08 \quad 2.913 \mathrm{E}-07 \quad 3.471 \mathrm{E}-05 \quad 2.822 \mathrm{E}-04 \quad 1.152 \mathrm{E}-01$ $0.000 \mathrm{E}+00 \quad 4.331 \mathrm{E}-02 \quad 2.142 \mathrm{E}+00 \quad 4.238 \mathrm{E}+00 \quad 1.944 \mathrm{E}+01 \quad 3.577 \mathrm{E}+01 \quad 9.848 \mathrm{E}+01$

$0.000 \mathrm{E}+00 \quad 8.147 \mathrm{E}-16 \quad 2.418 \mathrm{E}-09 \quad 2.812 \mathrm{E}-08 \quad 3.398 \mathrm{E}-06 \quad 1.827 \mathrm{E}-05 \quad 8.367 \mathrm{E}-04$ $0.000 \mathrm{E}+00 \quad 7.230 \mathrm{E}-04 \quad 1.058 \mathrm{E}+00 \quad 2.946 \mathrm{E}+00 \quad 1.823 \mathrm{E}+01 \quad 3.458 \mathrm{E}+01 \quad 8.856 \mathrm{E}+01$ $\begin{array}{llllllll}0.000 \mathrm{E}+00 & 3.991 \mathrm{E}-09 & 2.837 \mathrm{E}-04 & 1.706 \mathrm{E}-03 & 6.374 \mathrm{E}-02 & 2.650 \mathrm{E}-01 & 9.719 \mathrm{E}+00\end{array}$ $\begin{array}{llllllll}0.000 \mathrm{E}+00 & 5.770 \mathrm{E}-16 & 1.075 \mathrm{E}-08 & 1.356 \mathrm{E}-07 & 2.889 \mathrm{E}-05 & 2.580 \mathrm{E}-04 & 1.143 \mathrm{E}-01\end{array}$ $\begin{array}{lllllll}0.000 \mathrm{E}+00 & 7.230 \mathrm{E}-04 & 1.058 \mathrm{E}+00 & 2.947 \mathrm{E}+00 & 1.830 \mathrm{E}+01 & 3.485 \mathrm{E}+01 & 9.839 \mathrm{E}+01\end{array}$

$\begin{array}{lllllll}3.600 \mathrm{E}+01 & 3.600 \mathrm{E}+01 & 3.593 \mathrm{E}+01 & 3.586 \mathrm{E}+01 & 3.531 \mathrm{E}+01 & 3.460 \mathrm{E}+01 & 2.443 \mathrm{E}+01\end{array}$ 
RESRAD-OFFSITE, Version $2.5 \quad \mathrm{~T}^{1 / 2}$ Limit $=180$ days

Parent Dose Report

Title : RESRAD-OFFSITE Parameters for Offsite Resident Farmer Forward Run 10,000 Years

File : OFFSITE-RF_FORWARD-7-11-10000yr.ROF

Run Time Information

ResOCalc.EXE execution began at 12:59 on 07/21/2011

ResOCalc.EXE execution ended at 13:26 on 07/21/2011

ResOCalc.EXE execution time 26 minutes 47 seconds 
RESRAD-OFFSITE, Version 2.5

Parent Dose Report

Title : RESRAD-OFFSITE Parameters for Offsite Resident Farmer Forward Run 100,000 Years

File : OFFSITE-RF_FORWARD-7-11-100000yr.ROF

Table of Contents

Part I: Mixture Sums and Single Radionuclide Guidelines

Dose Conversion Factor (and Related) Parameter Summary ... 2

Site-Specific Parameter Summary ................ 11

Summary of Pathway Selections ................ 48

Contaminated Zone and Total Dose Summary ............ 49

Total Dose Components

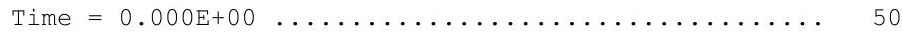

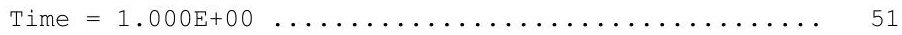

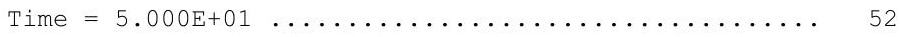

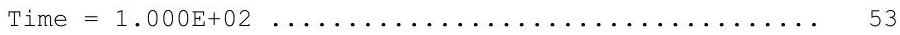

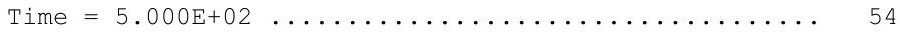

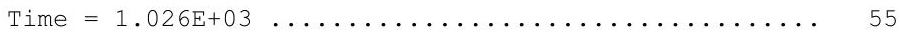

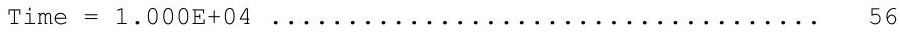

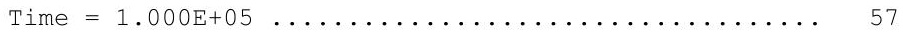

Dose/Source Ratios Summed Over All Pathways ........... 58

Single Radionuclide Soil Guidelines ............... 60

Dose Per Nuclide Summed Over All Pathways ............. 61

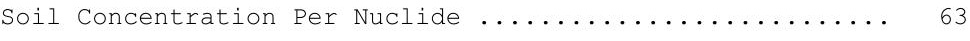

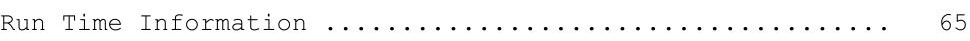


RESRAD-OFFSITE, Version 2.5

Parent Dose Report

Title : RESRAD-OFFSITE Parameters for Offsite Resident Farmer Forward Run 100,000 Years

File : OFFSITE-RF FORWARD-7-11-100000yr.ROF

Dose Conversion Factor (and Related) Parameter Summary

Current Library: ICRP 60

Default Library: ICRP 60

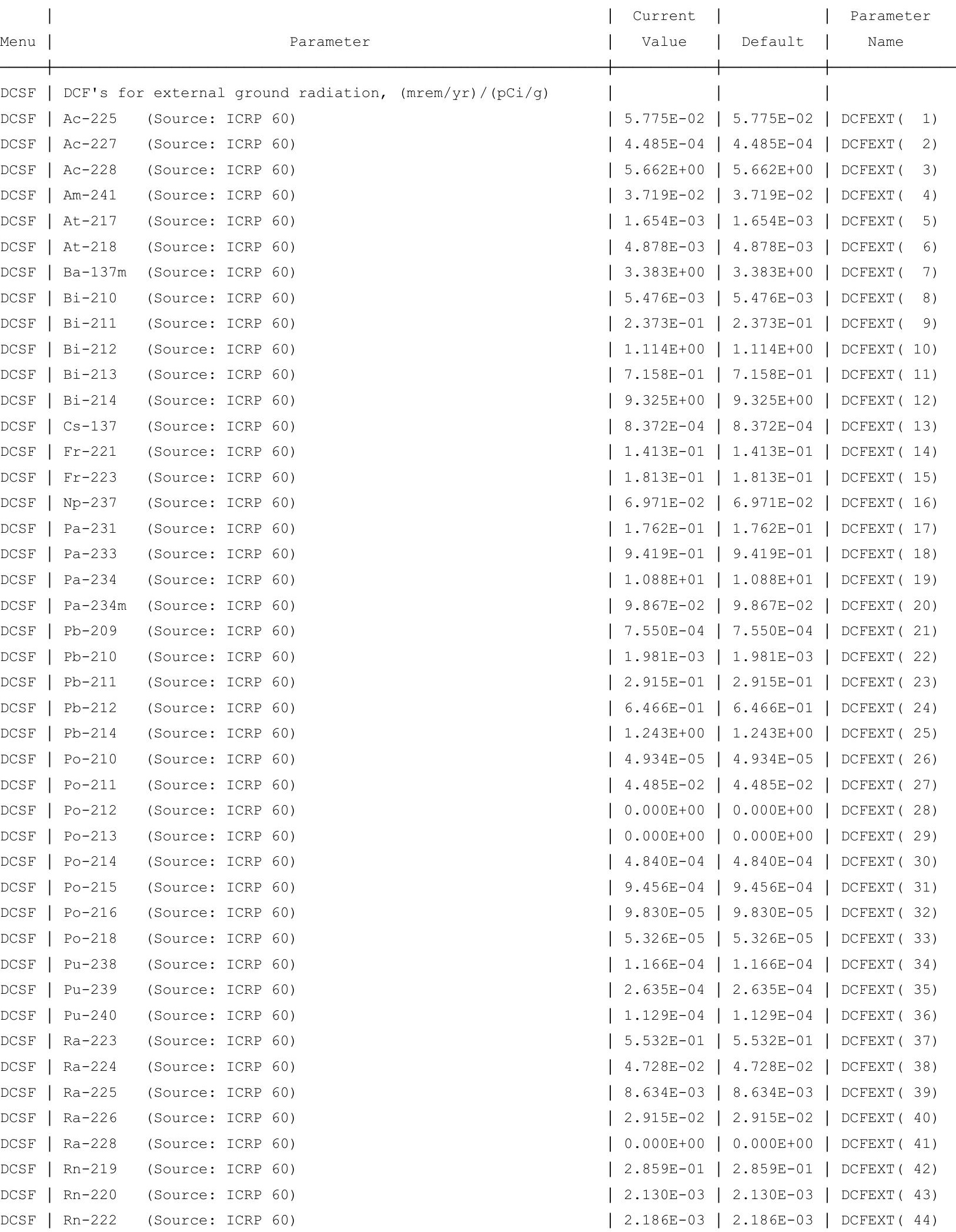


RESRAD-OFFSITE, Version $2.5 \quad \mathrm{~T}^{1 / 2}$ Limit $=180$ days

Parent Dose Report

Title : RESRAD-OFFSITE Parameters for Offsite Resident Farmer Forward Run 100,000 Years

File : OFFSITE-RF_FORWARD-7-11-100000yr.ROF

Dose Conversion Factor (and Related) Parameter Summary (continued)

Current Library: ICRP 60

Default Library: ICRP 60

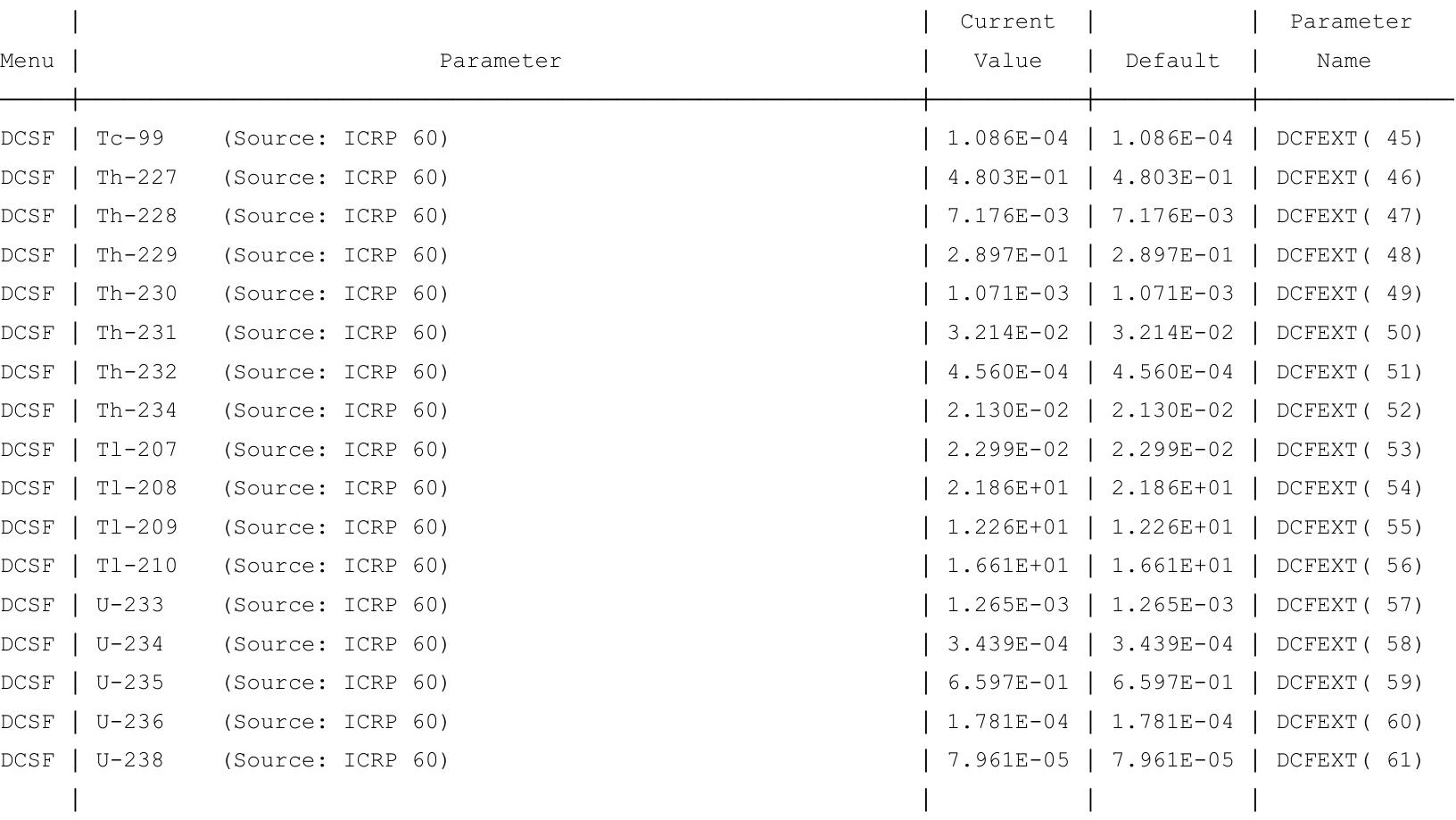

Current Library: ICRP 72 (Adult)

Default Library: ICRP 72 (Adult)

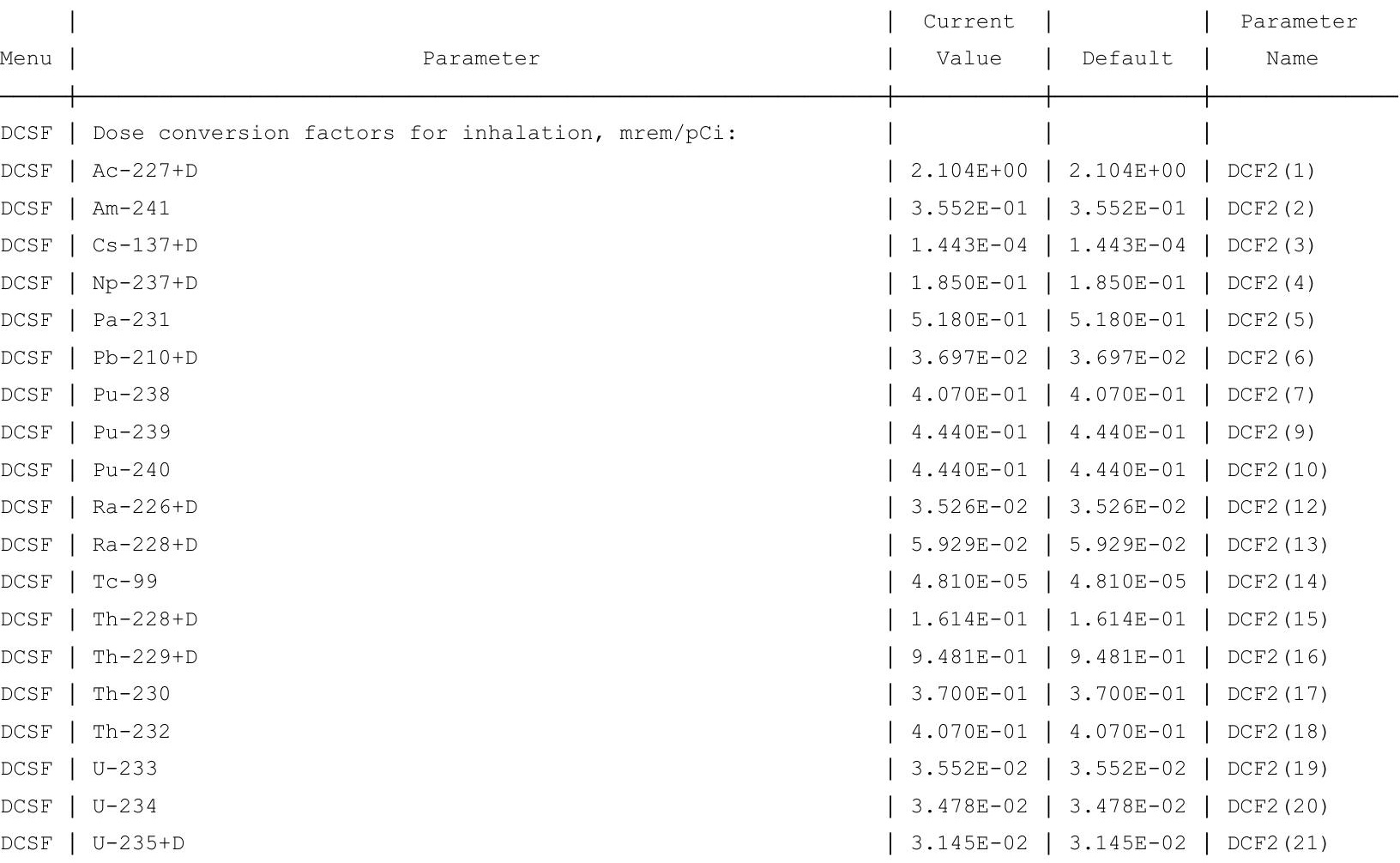


RESRAD-OFFSITE, Version 2.5

Parent Dose Report

Title : RESRAD-OFFSITE Parameters for Offsite Resident Farmer Forward Run 100,000 Years

File : OFFSITE-RF_FORWARD-7-11-100000yr.ROF

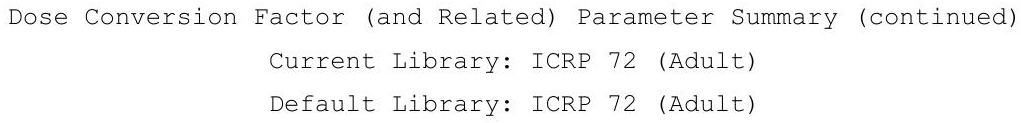

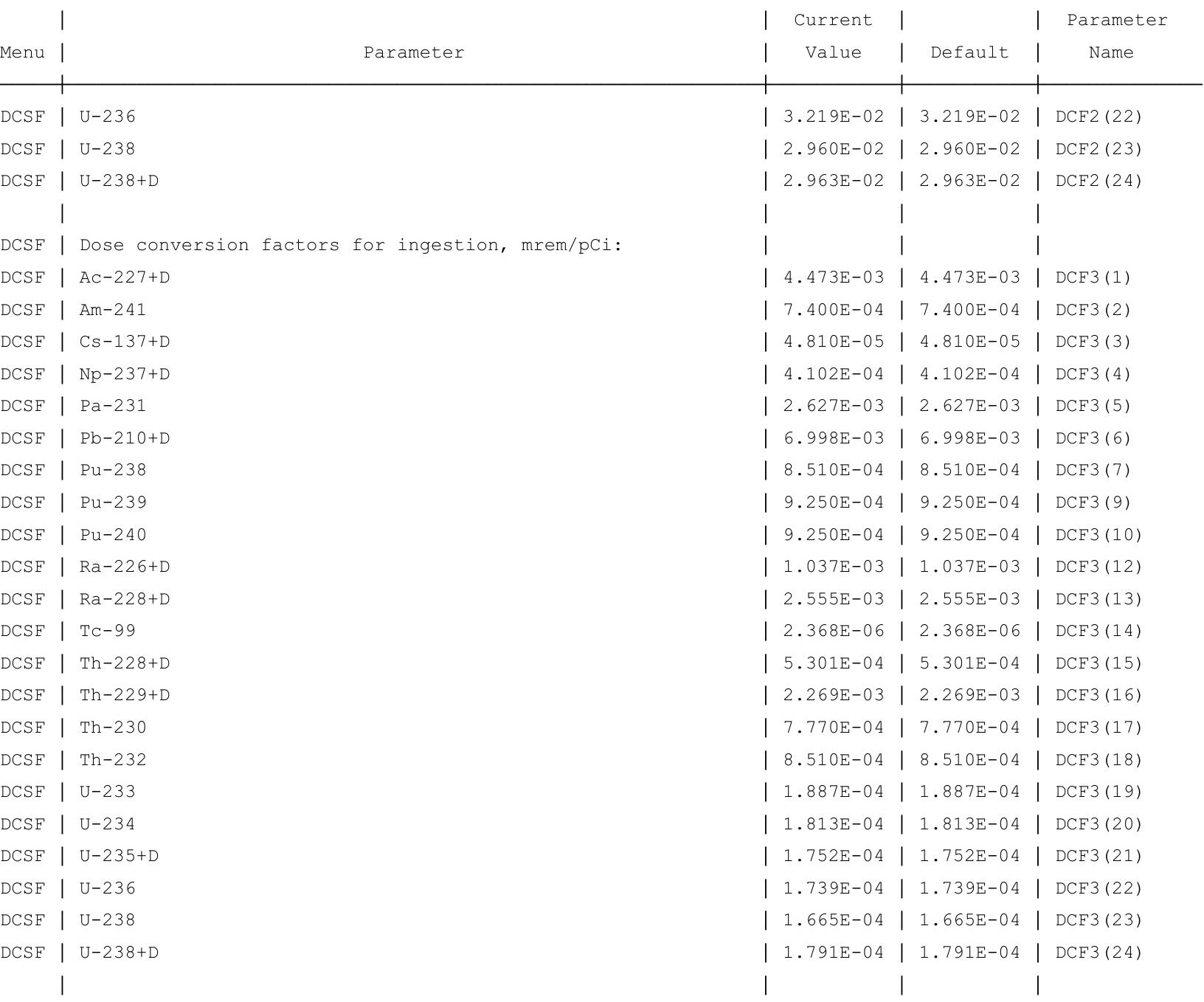


RESRAD-OFFSITE, Version 2.5

arent Dose Report

Title : RESRAD-OFFSITE Parameters for Offsite Resident Farmer Forward Run 100,000 Years

File : OFFSITE-RF_FORWARD-7-11-100000yr.ROF

Dose Conversion Factor (and Related) Parameter Summary (continued)

Current Library: RESRAD Default Transfer factors

Default Library: RESRAD Default Transfer factors

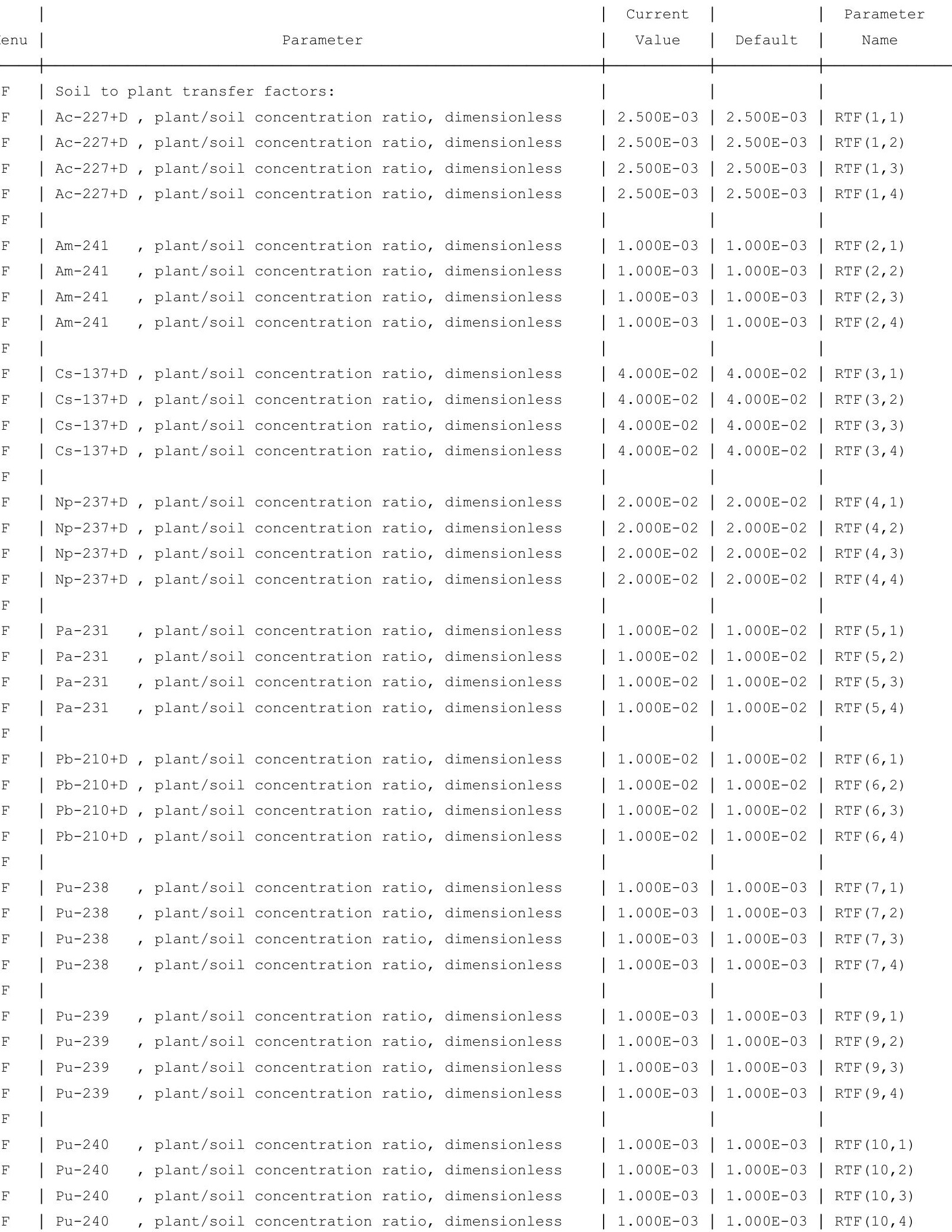


RESRAD-OFFSITE, Version 2.

Parent Dose Report

Title : RESRAD-OFFSITE Parameters for Offsite Resident Farmer Forward Run 100,000 Years

File : OFFSITE-RF_FORWARD-7-11-100000yr.ROF

Dose Conversion Factor (and Related) Parameter Summary (continued)

Current Library: RESRAD Default Transfer factors

Default Library: RESRAD Default Transfer factors

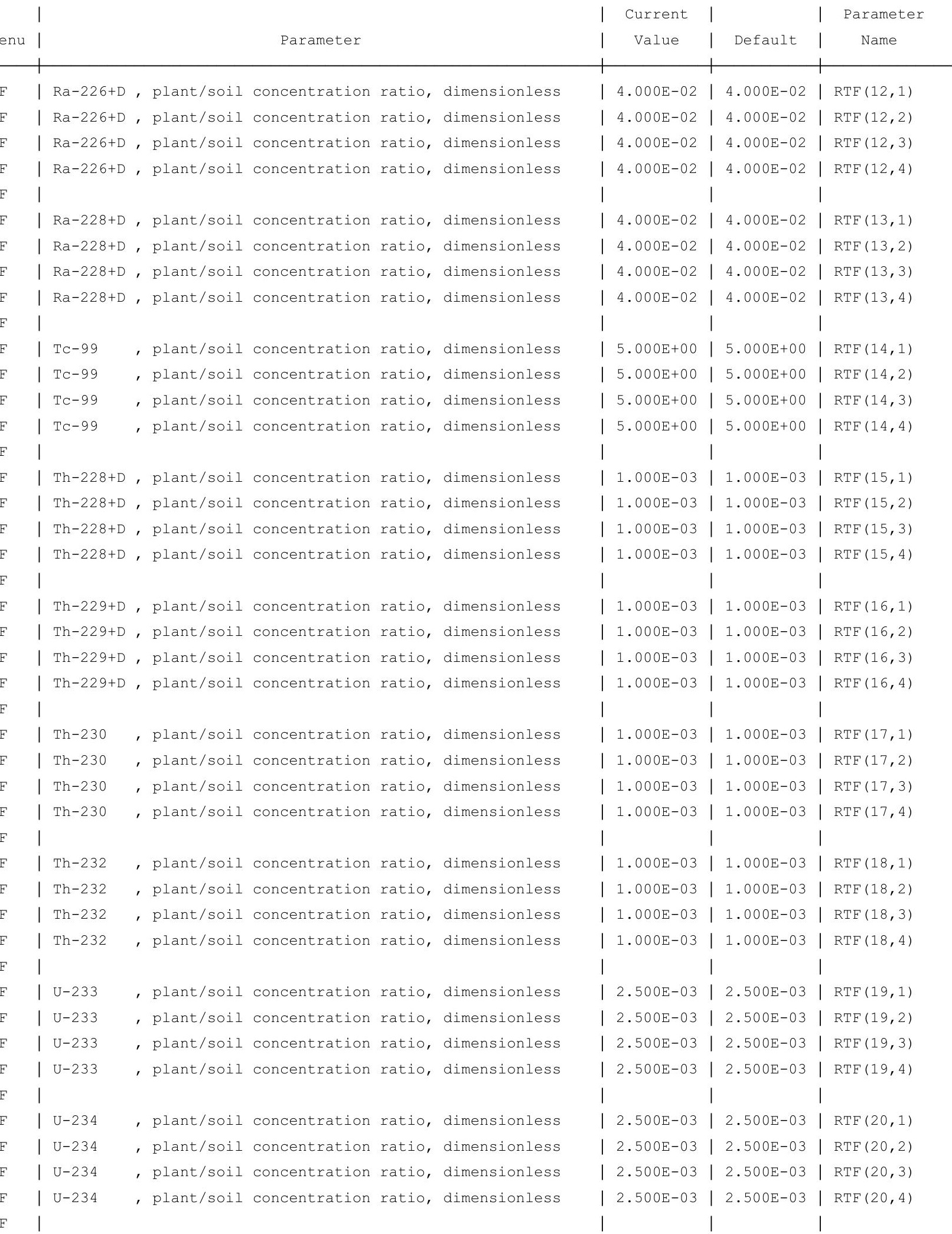


RESRAD-OFFSITE, Version 2.5

Parent Dose Report

Title : RESRAD-OFFSITE Parameters for Offsite Resident Farmer Forward Run 100,000 Years

File : OFFSITE-RF_FORWARD-7-11-100000yr.ROF

Dose Conversion Factor (and Related) Parameter Summary (continued)

Current Library: RESRAD Default Transfer factors

Default Library: RESRAD Default Transfer factors

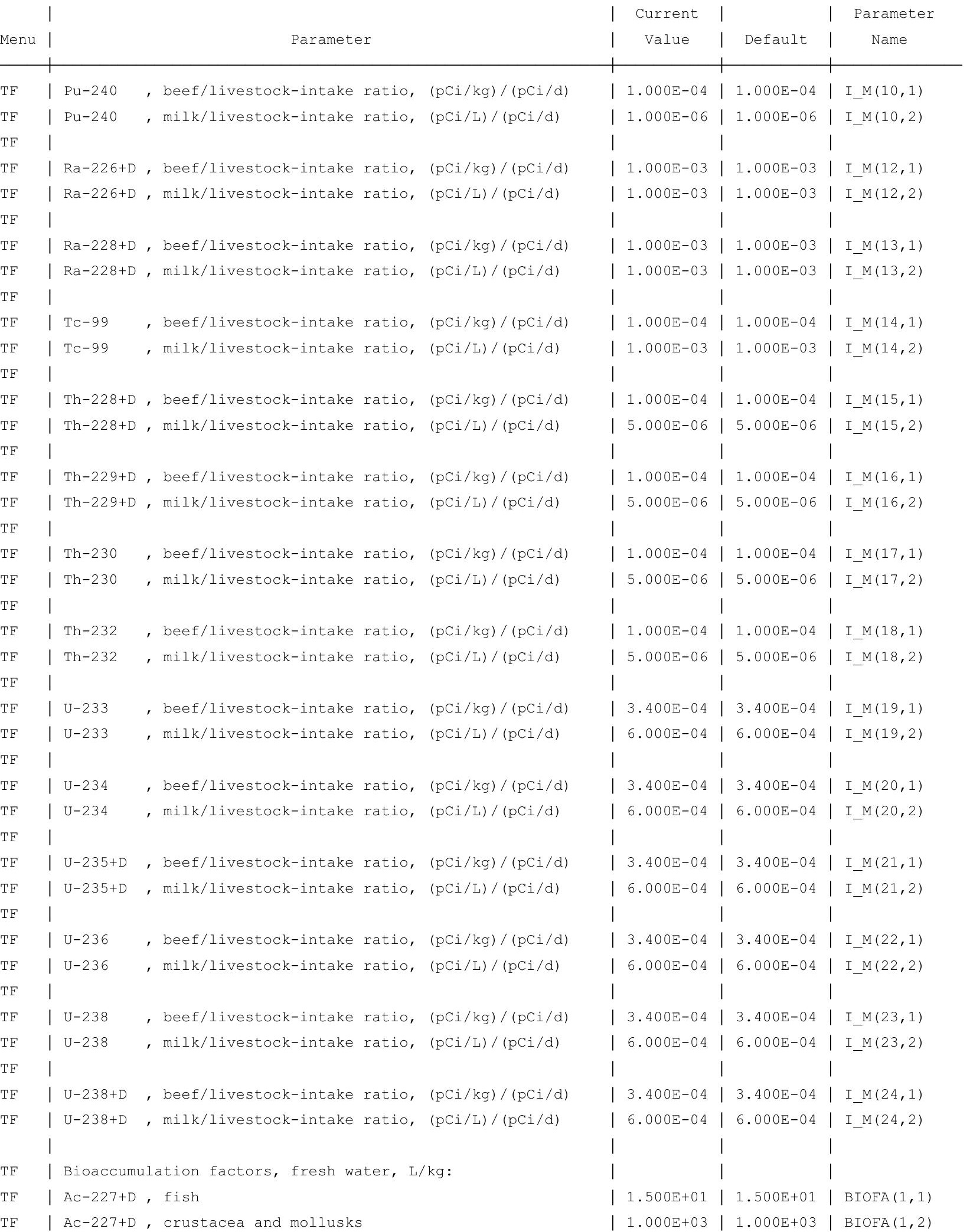


RESRAD-OFFSITE, Version 2.5

Parent Dose Report

Title : RESRAD-OFFSITE Parameters for Offsite Resident Farmer Forward Run 100,000 Years

File : OFFSITE-RF_FORWARD-7-11-100000yr.ROF

Dose Conversion Factor (and Related) Parameter Summary (continued)

Current Library: RESRAD Default Transfer factors

Default Library: RESRAD Default Transfer factors

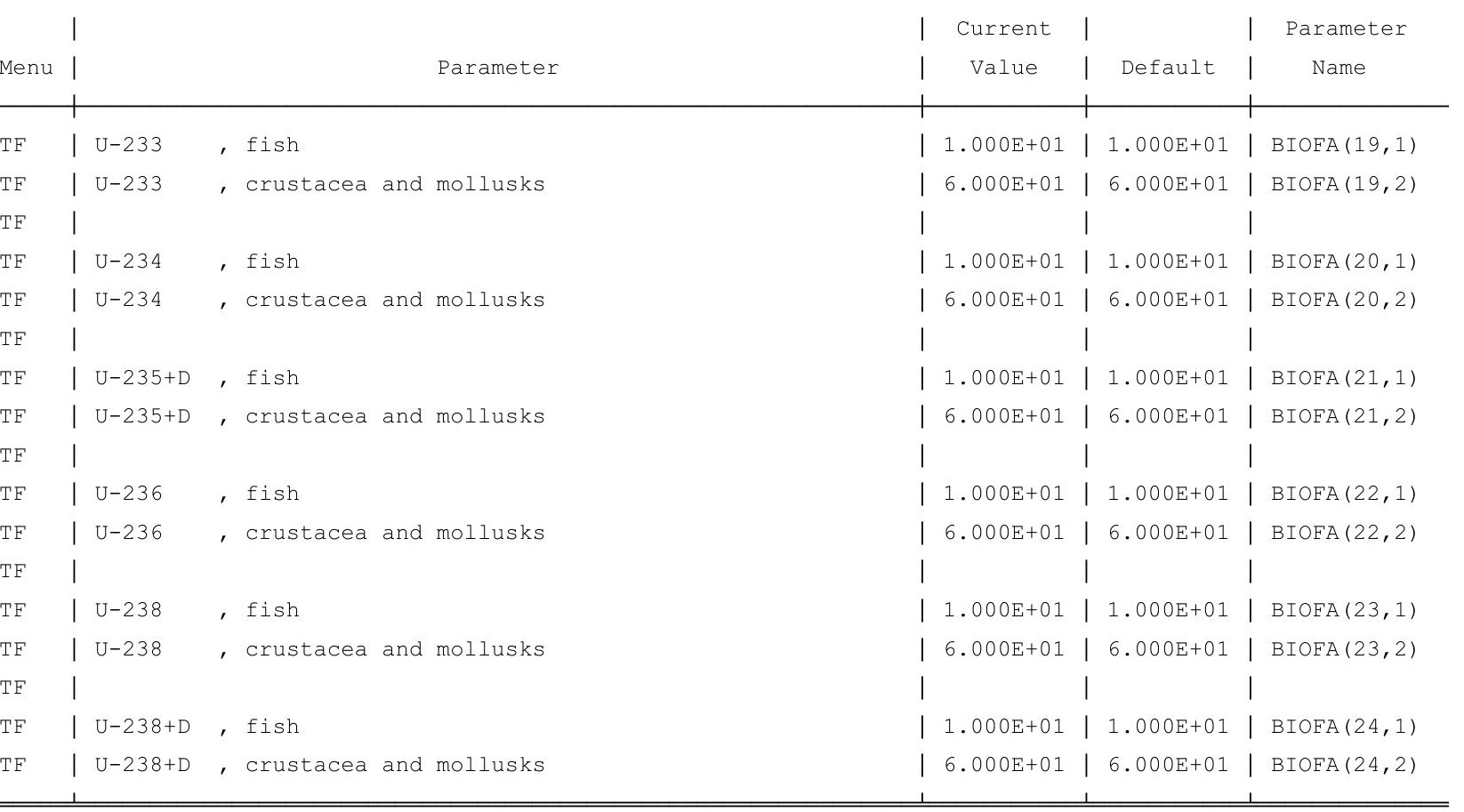


RESRAD-OFFSITE, Version $2.5 \quad$ T1/2 Limit $=180$ days $\quad$ 07/21/2011 $13: 36$ Page

Parent Dose Report

Title : RESRAD-OFFSITE Parameters for Offsite Resident Farmer Forward Run 100,000 Years

File : OFFSITE-RF_FORWARD-7-11-100000yr.ROF

Site-Specific Parameter Summary

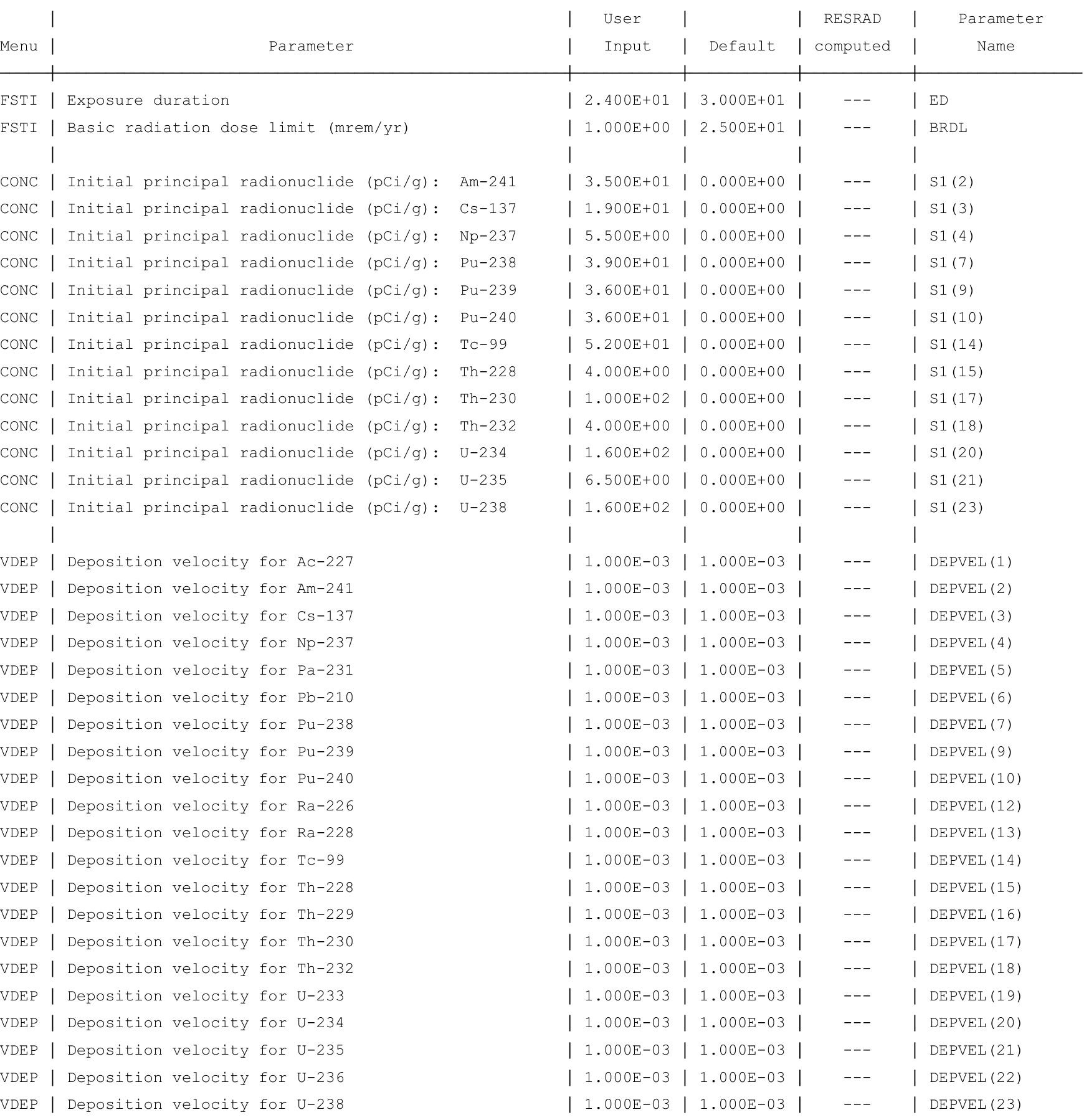

DEP I Deposition velocity for U-238 
RESRAD-OFFSITE, Version $2.5 \quad$ T1/2 Limit $=180$ days $\quad$ 07/21/2011 13:36 Page

Parent Dose Report

Title : RESRAD-OFFSITE Parameters for Offsite Resident Farmer Forward Run 100,000 Years

File : OFFSITE-RF_FORWARD-7-11-100000yr.ROF

Site-Specific Parameter Summary (continued)

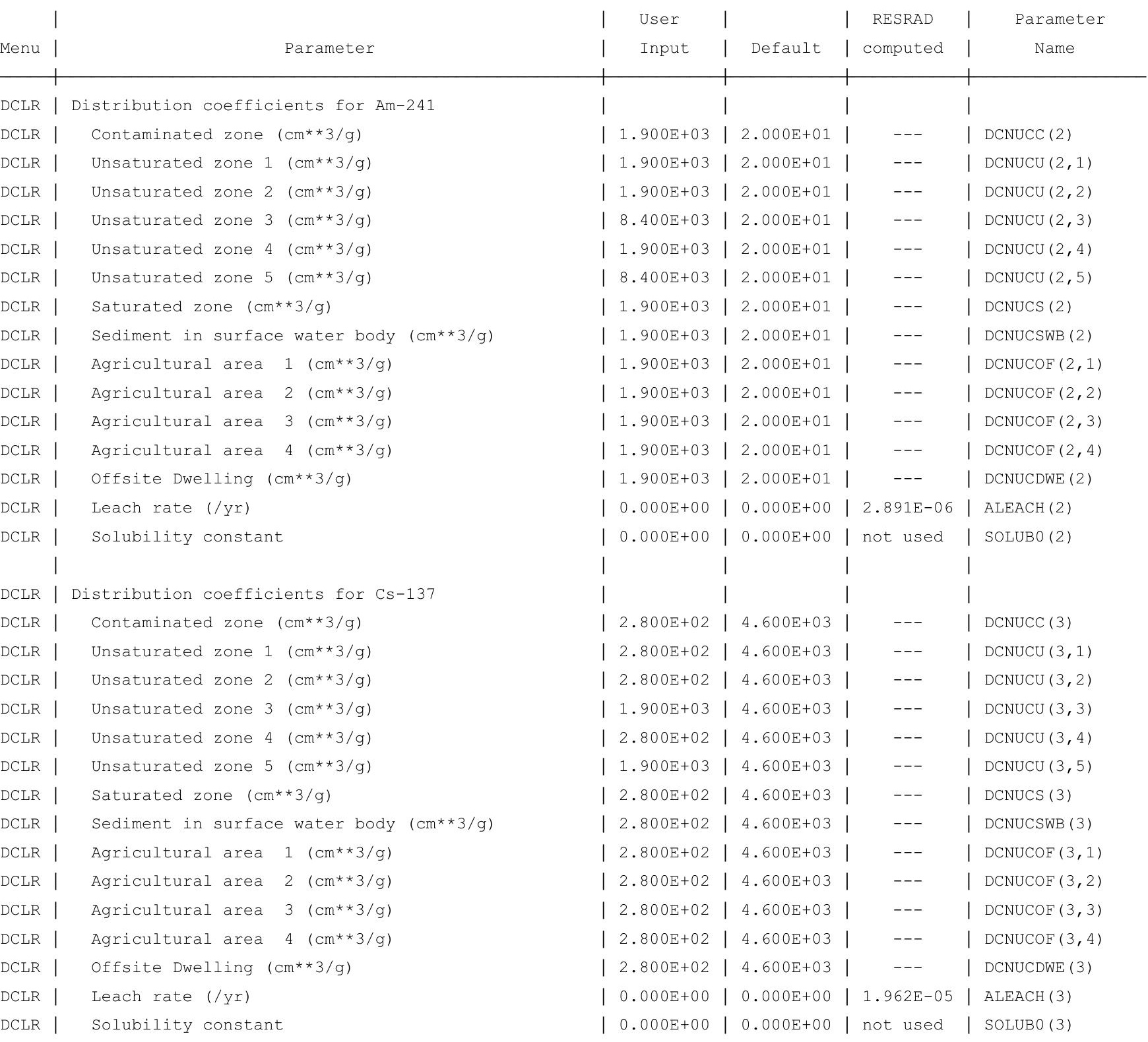


RESRAD-OFFSITE, Version $2.5 \quad T^{1 / 2}$ Limit $=180$ days $\quad 07 / 21 / 2011 \quad 13: 36$ Page

Parent Dose Report

Title : RESRAD-OFFSITE Parameters for Offsite Resident Farmer Forward Run 100,000 Years

File : OFFSITE-RF_FORWARD-7-11-100000yr.ROF

Site-Specific Parameter Summary (continued)

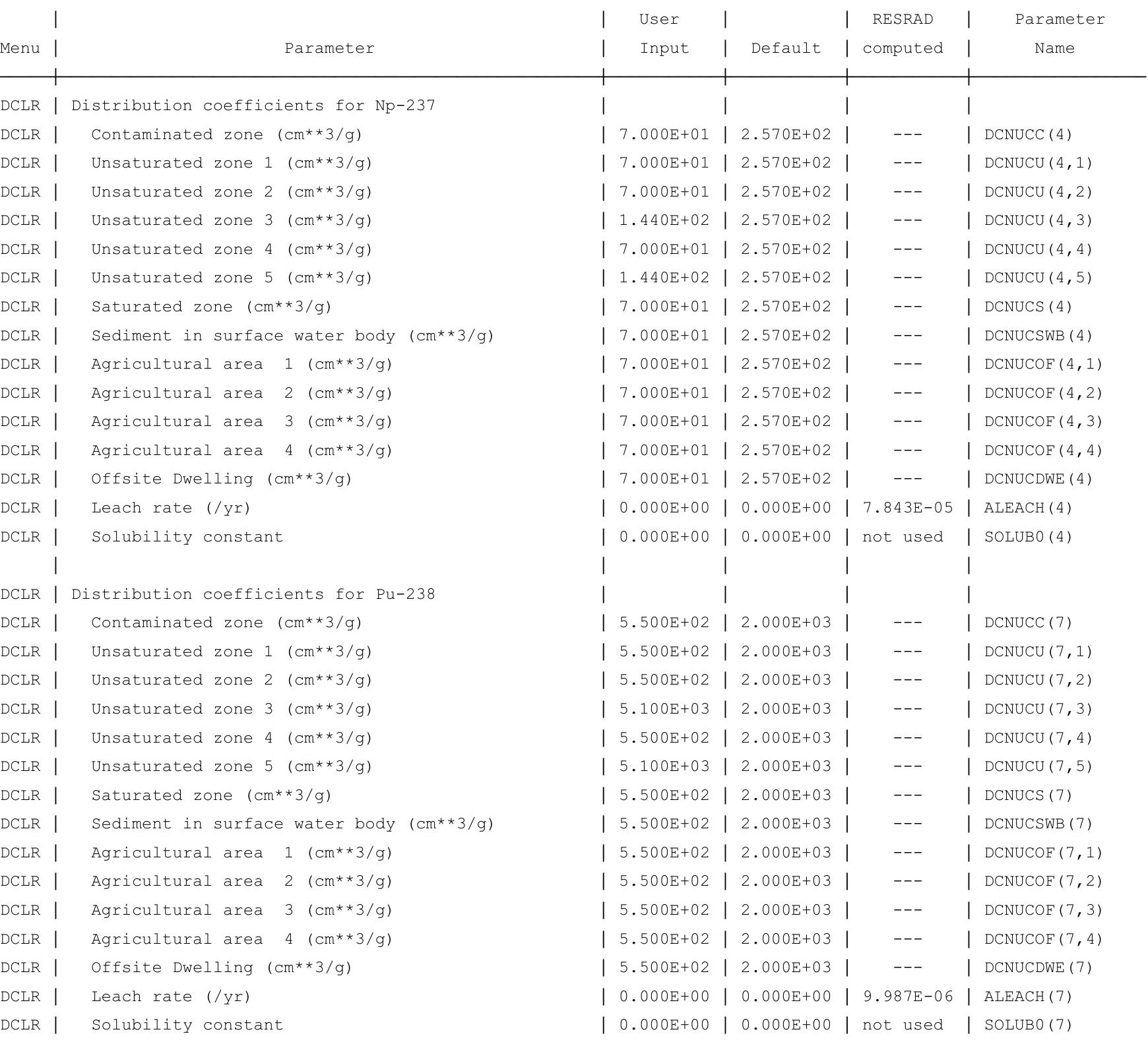


RESRAD-OFFSITE, Version $2.5 \quad$ T1/2 Limit $=180$ days $\quad$ 07/21/2011 13:36 Page

Parent Dose Report

Title : RESRAD-OFFSITE Parameters for Offsite Resident Farmer Forward Run 100,000 Years

File : OFFSITE-RF_FORWARD-7-11-100000yr.ROF

Site-Specific Parameter Summary (continued)

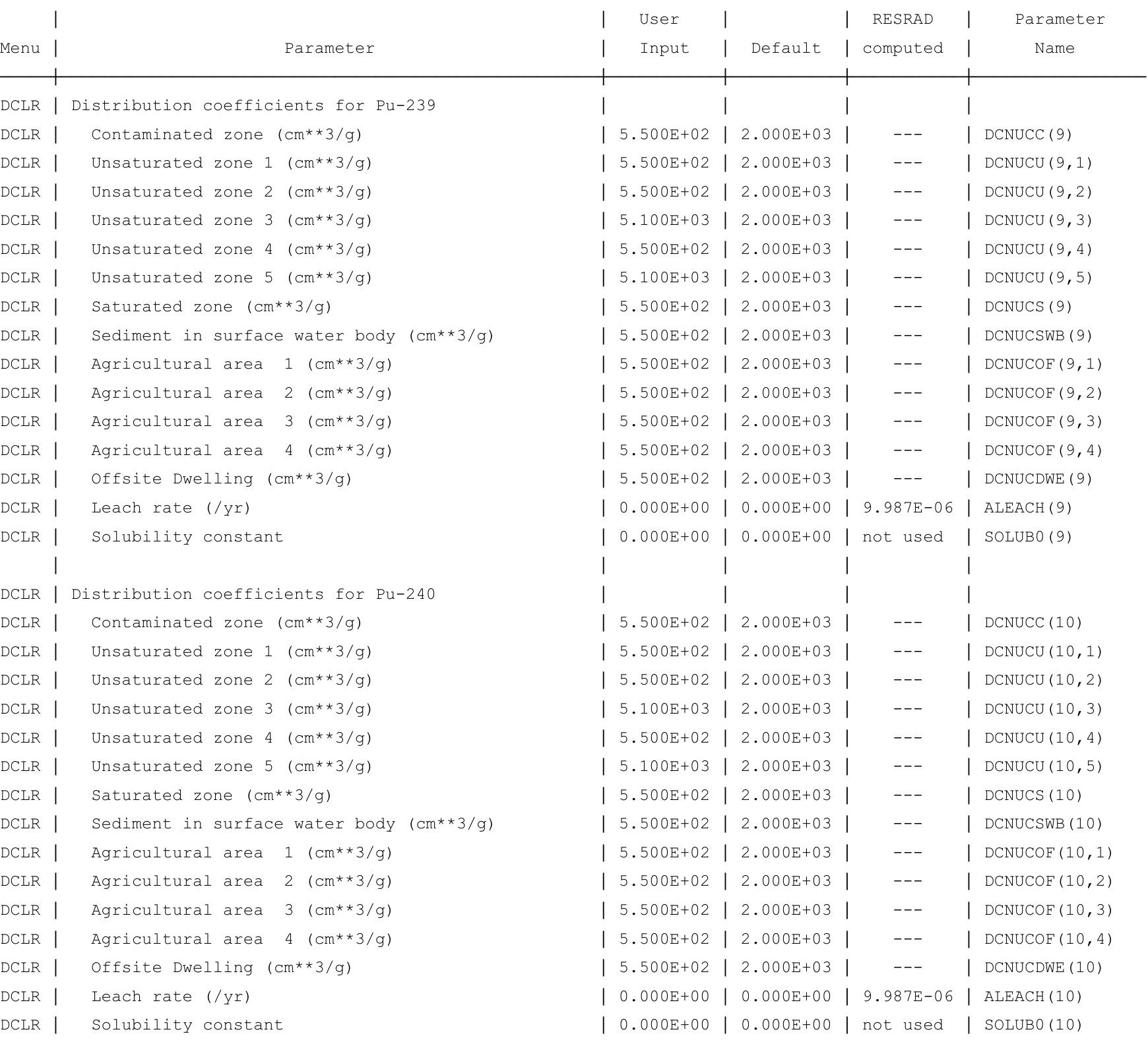


RESRAD-OFFSITE, Version $2.5 \quad T^{1 / 2}$ Limit $=180$ days $\quad 07 / 21 / 2011 \quad 13: 36$ Page

Parent Dose Report

Title : RESRAD-OFFSITE Parameters for Offsite Resident Farmer Forward Run 100,000 Years

File : OFFSITE-RF_FORWARD-7-11-100000yr.ROF

Site-Specific Parameter Summary (continued)

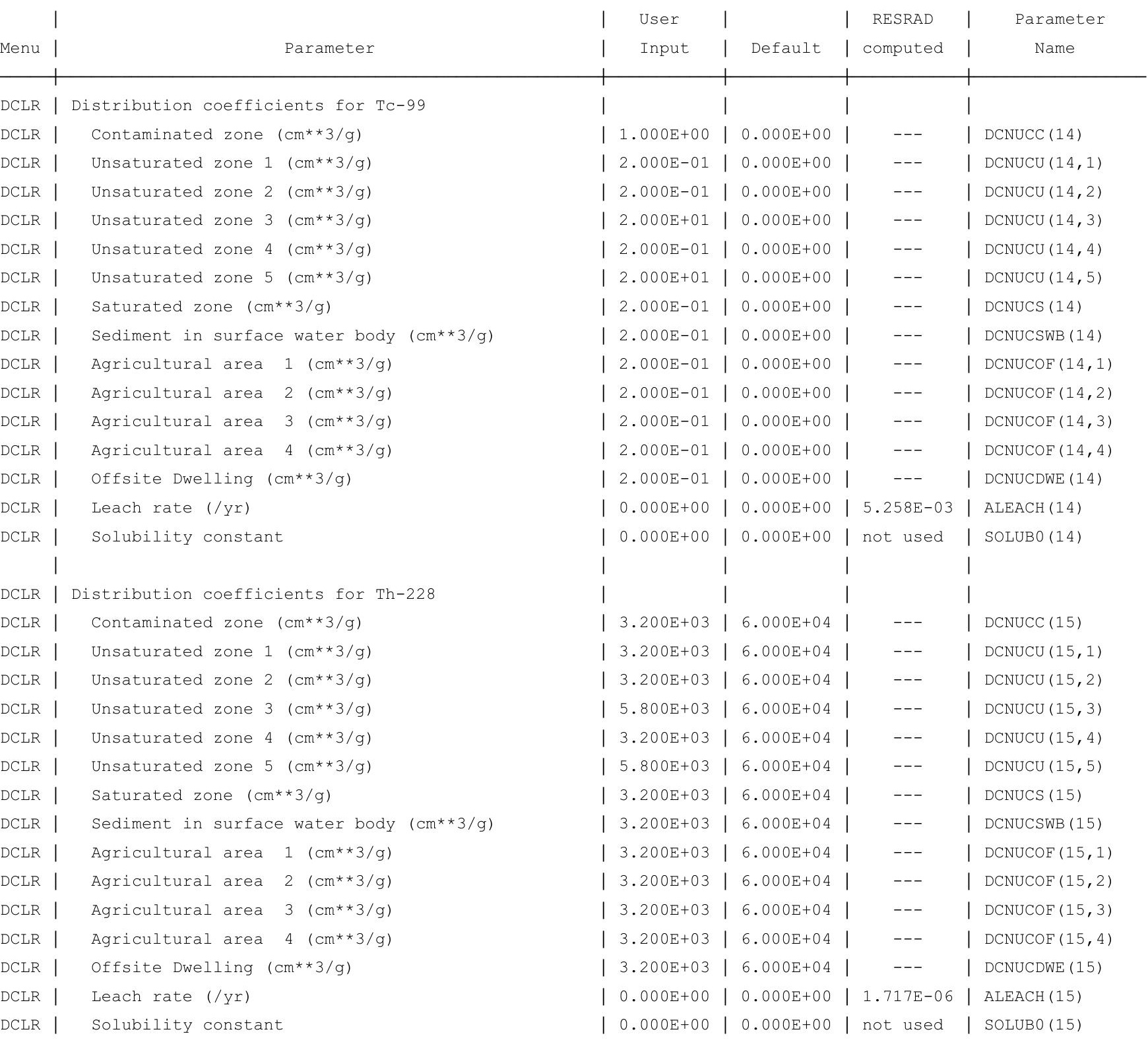


RESRAD-OFFSITE, Version $2.5 \quad T^{1 / 2}$ Limit $=180$ days $\quad 07 / 21 / 2011 \quad 13: 36$ Page

Parent Dose Report

Title : RESRAD-OFFSITE Parameters for Offsite Resident Farmer Forward Run 100,000 Years

File : OFFSITE-RF_FORWARD-7-11-100000yr.ROF

Site-Specific Parameter Summary (continued)

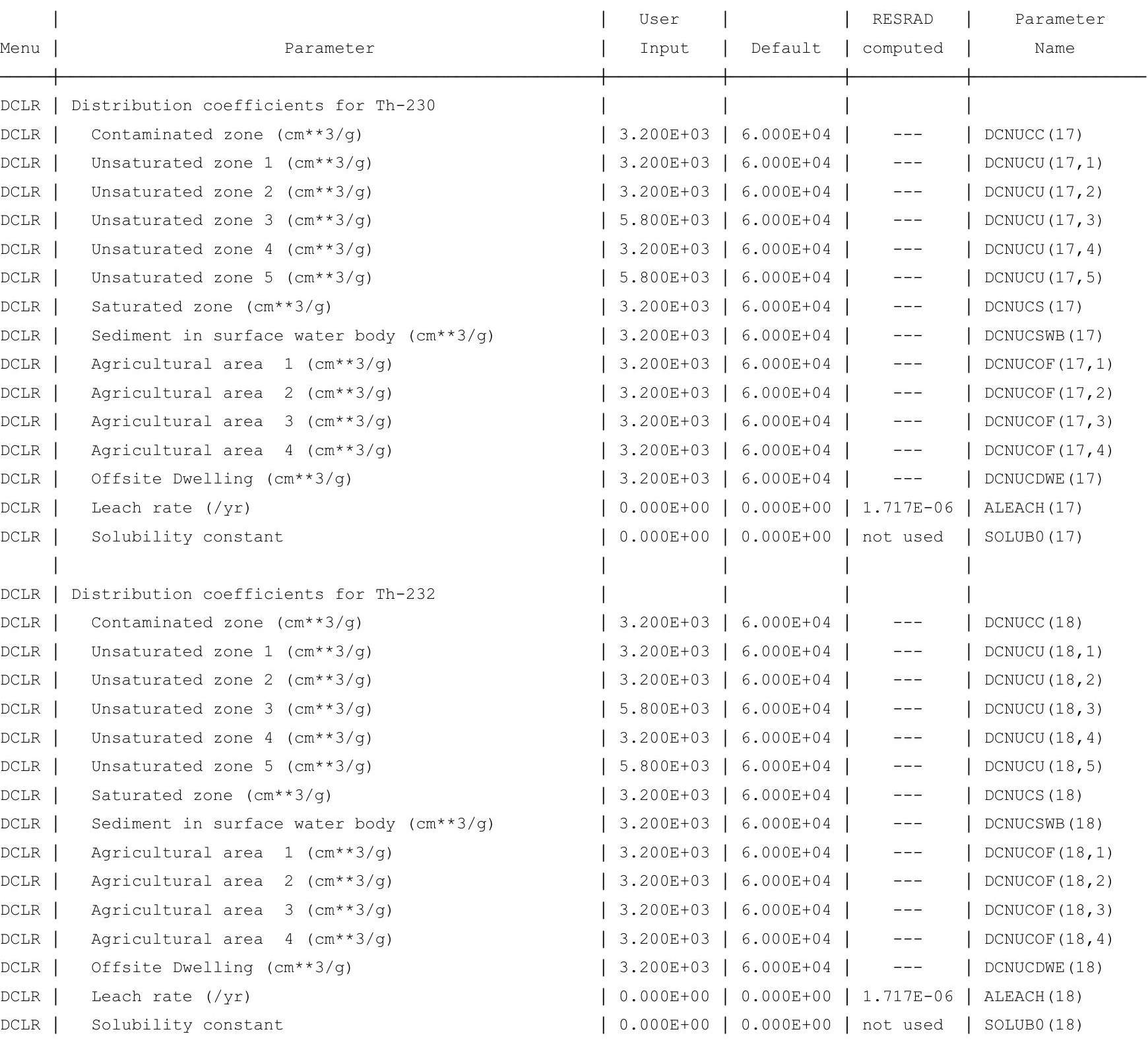


RESRAD-OFFSITE, Version $2.5 \quad T^{1 / 2}$ Limit $=180$ days $\quad 07 / 21 / 2011 \quad 13: 36$ Page

Parent Dose Report

Title : RESRAD-OFFSITE Parameters for Offsite Resident Farmer Forward Run 100,000 Years

File : OFFSITE-RF_FORWARD-7-11-100000yr.ROF

Site-Specific Parameter Summary (continued)

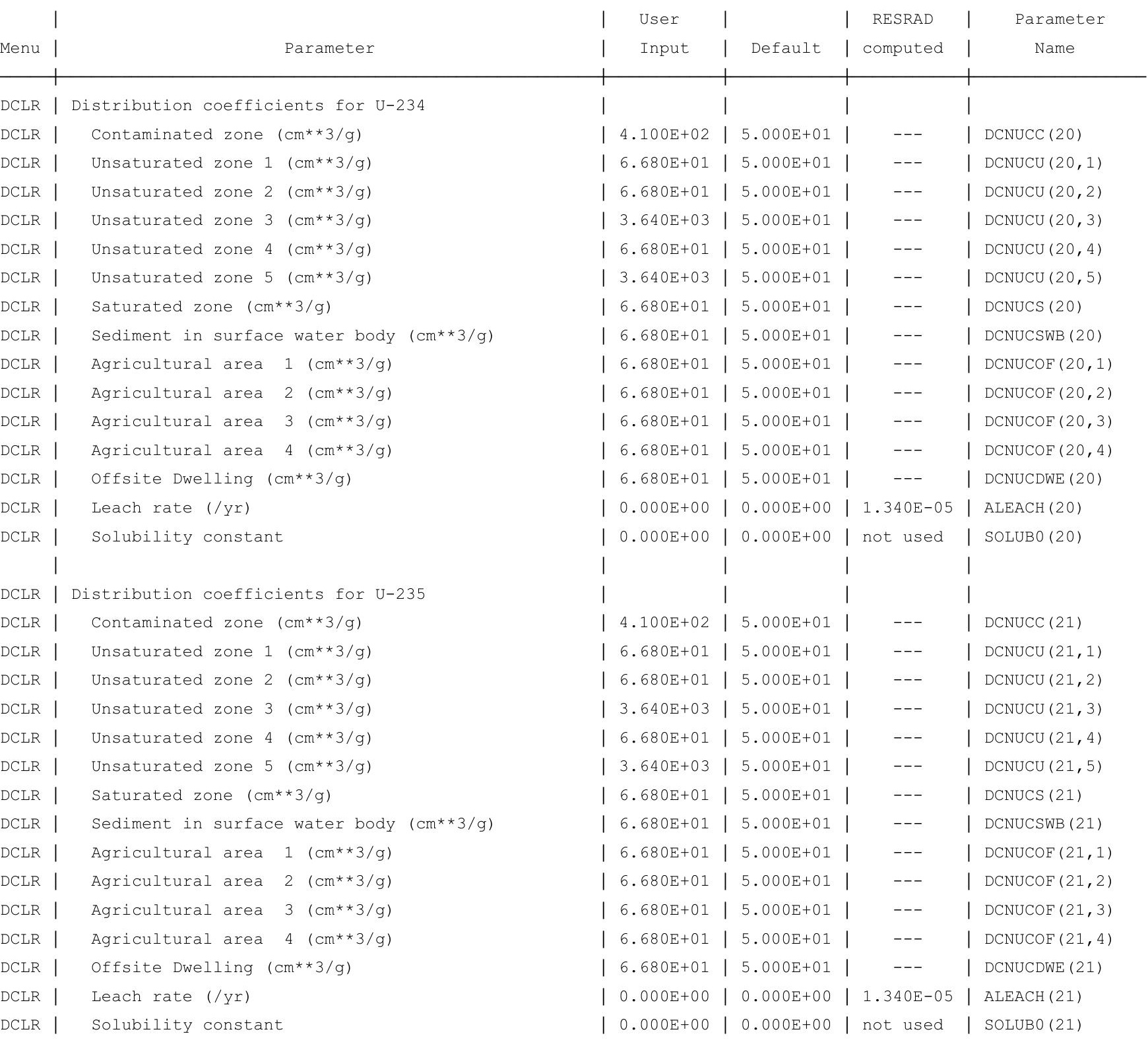


RESRAD-OFFSITE, Version $2.5 \quad T^{1 / 2}$ Limit $=180$ days $\quad 07 / 21 / 2011 \quad 13: 36$ Page

Parent Dose Report

Title : RESRAD-OFFSITE Parameters for Offsite Resident Farmer Forward Run 100,000 Years

File : OFFSITE-RF_FORWARD-7-11-100000yr.ROF

Site-Specific Parameter Summary (continued)

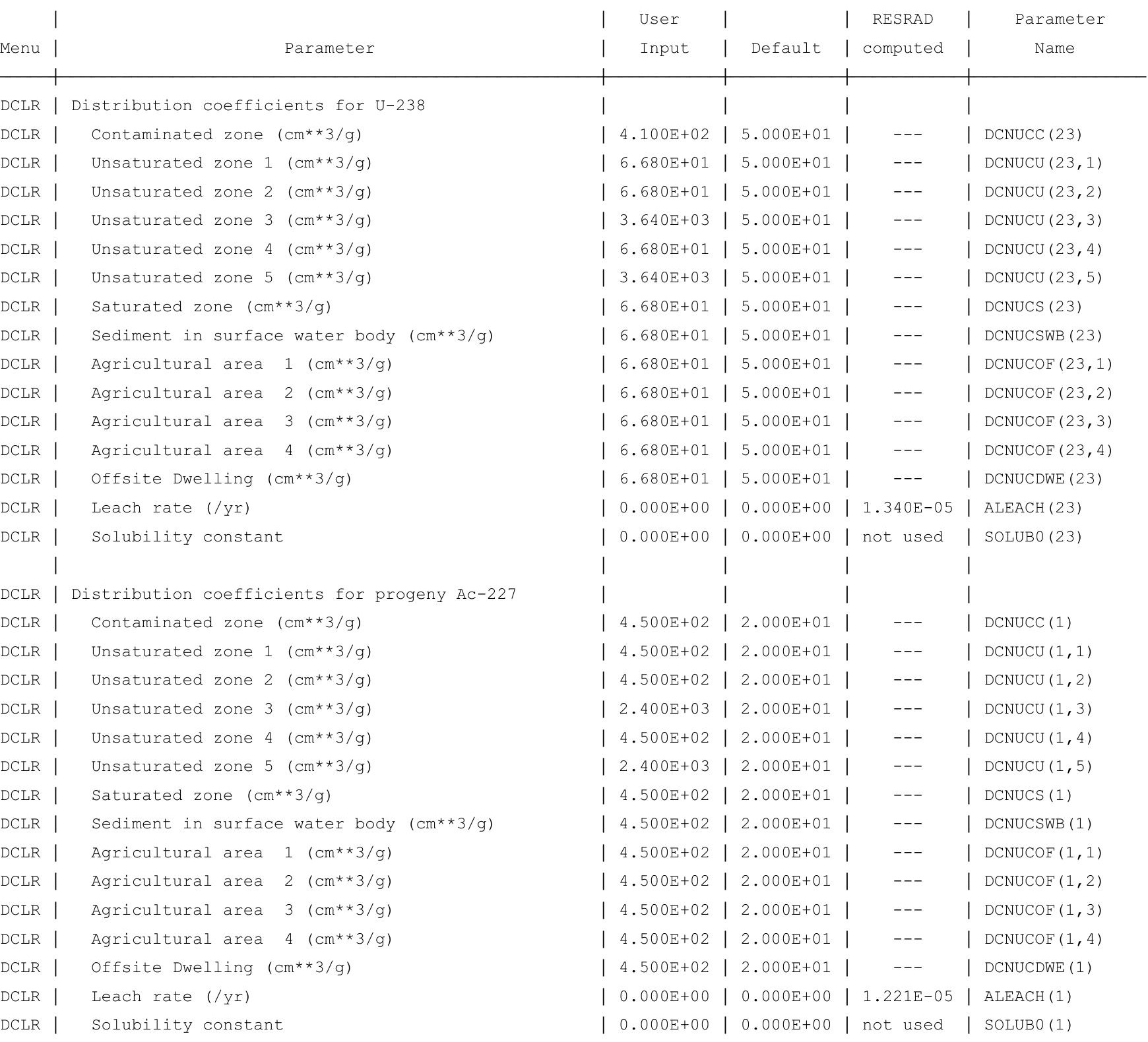


RESRAD-OFFSITE, Version $2.5 \quad T^{1 / 2}$ Limit $=180$ days $\quad 07 / 21 / 2011 \quad 13: 36$ Page

Parent Dose Report

Title : RESRAD-OFFSITE Parameters for Offsite Resident Farmer Forward Run 100,000 Years

File : OFFSITE-RF_FORWARD-7-11-100000yr.ROF

Site-Specific Parameter Summary (continued)

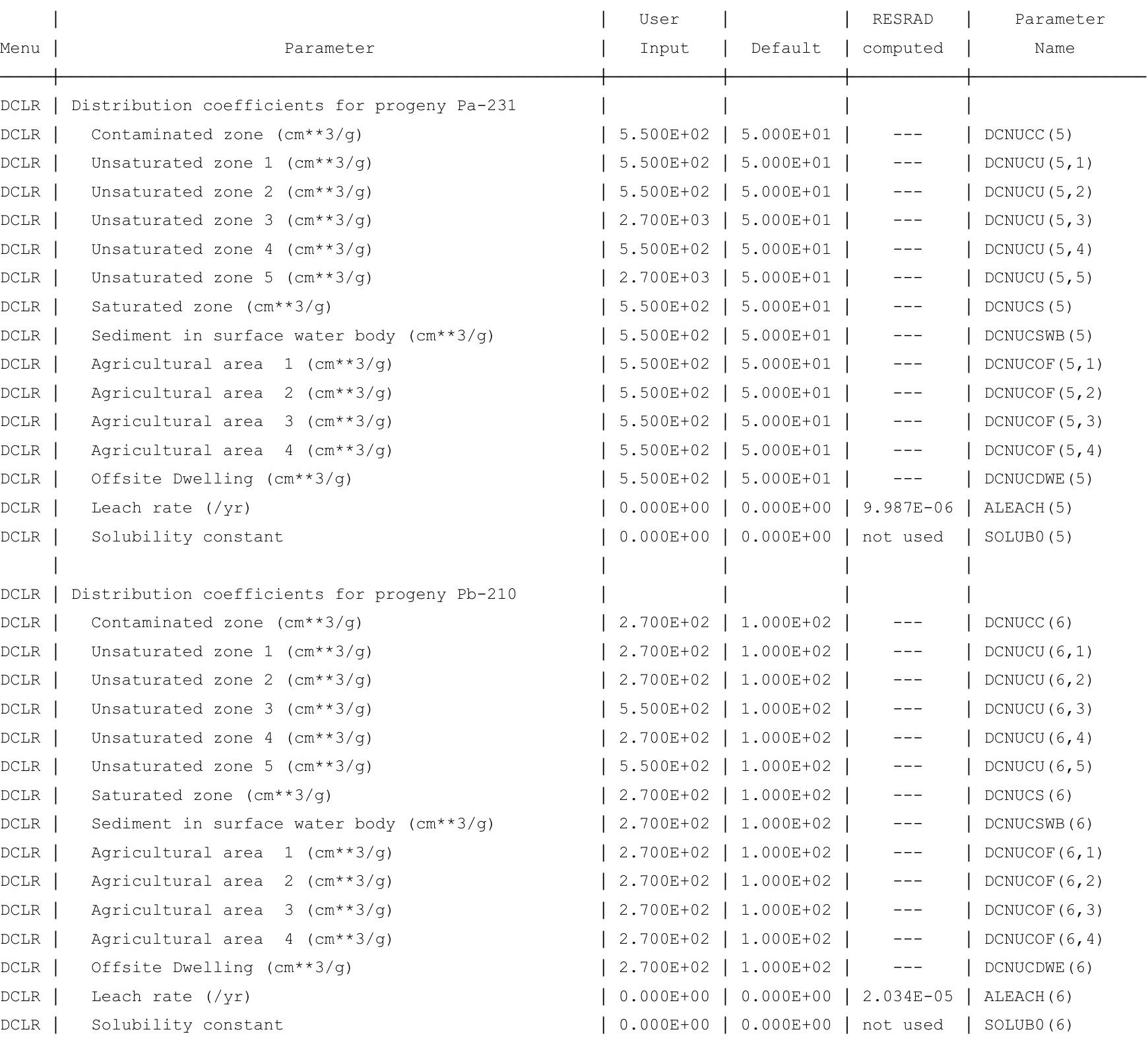


RESRAD-OFFSITE, Version 2.5

Parent Dose Report

Title : RESRAD-OFFSITE Parameters for Offsite Resident Farmer Forward Run 100,000 Years

File : OFFSITE-RF FORWARD-7-11-100000yr.ROF

Site-Specific Parameter Summary (continued)

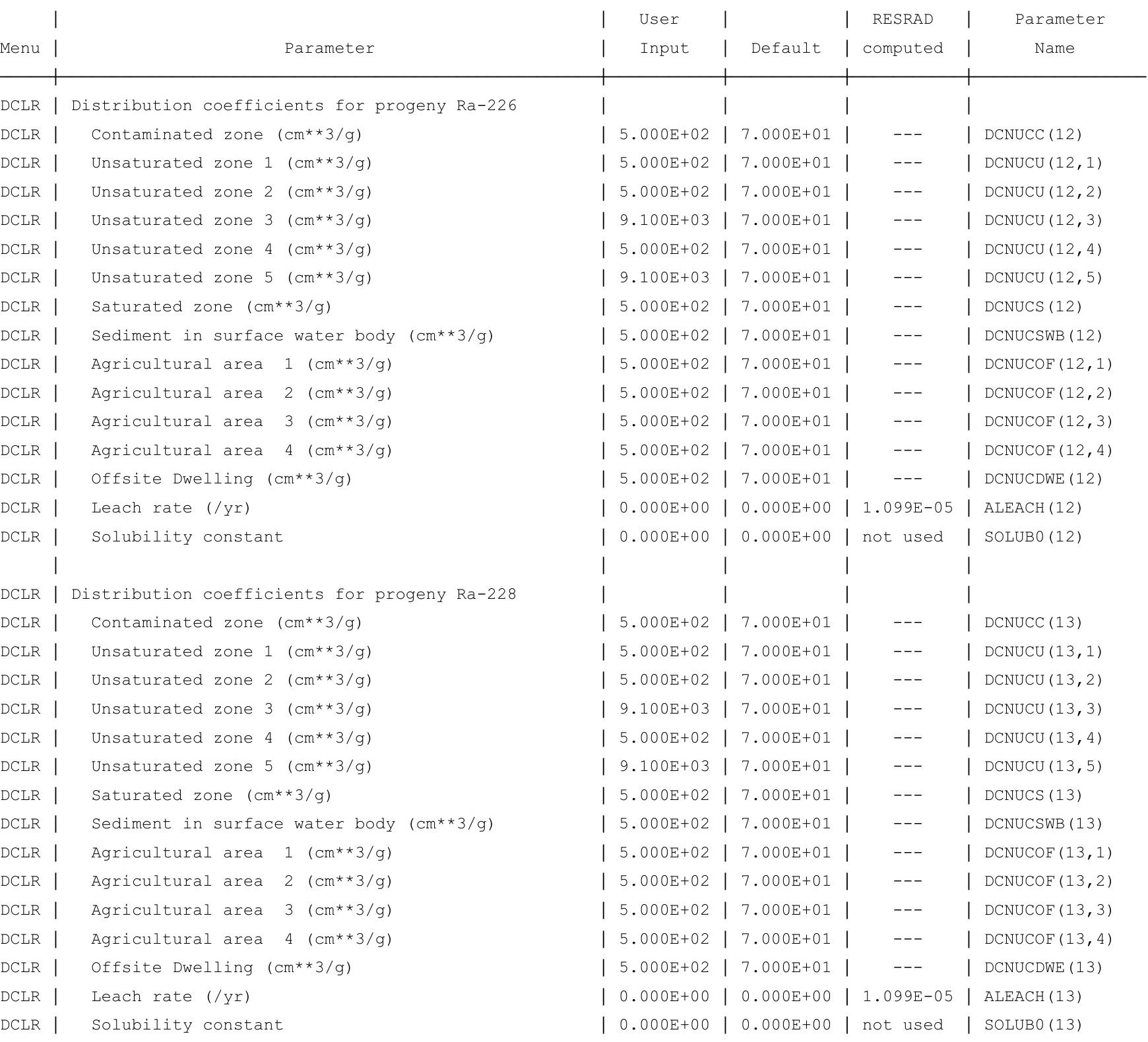


RESRAD-OFFSITE, Version 2.5

Parent Dose Report

Title : RESRAD-OFFSITE Parameters for Offsite Resident Farmer Forward Run 100,000 Years

File : OFFSITE-RF FORWARD-7-11-100000yr.ROF

Site-Specific Parameter Summary (continued)

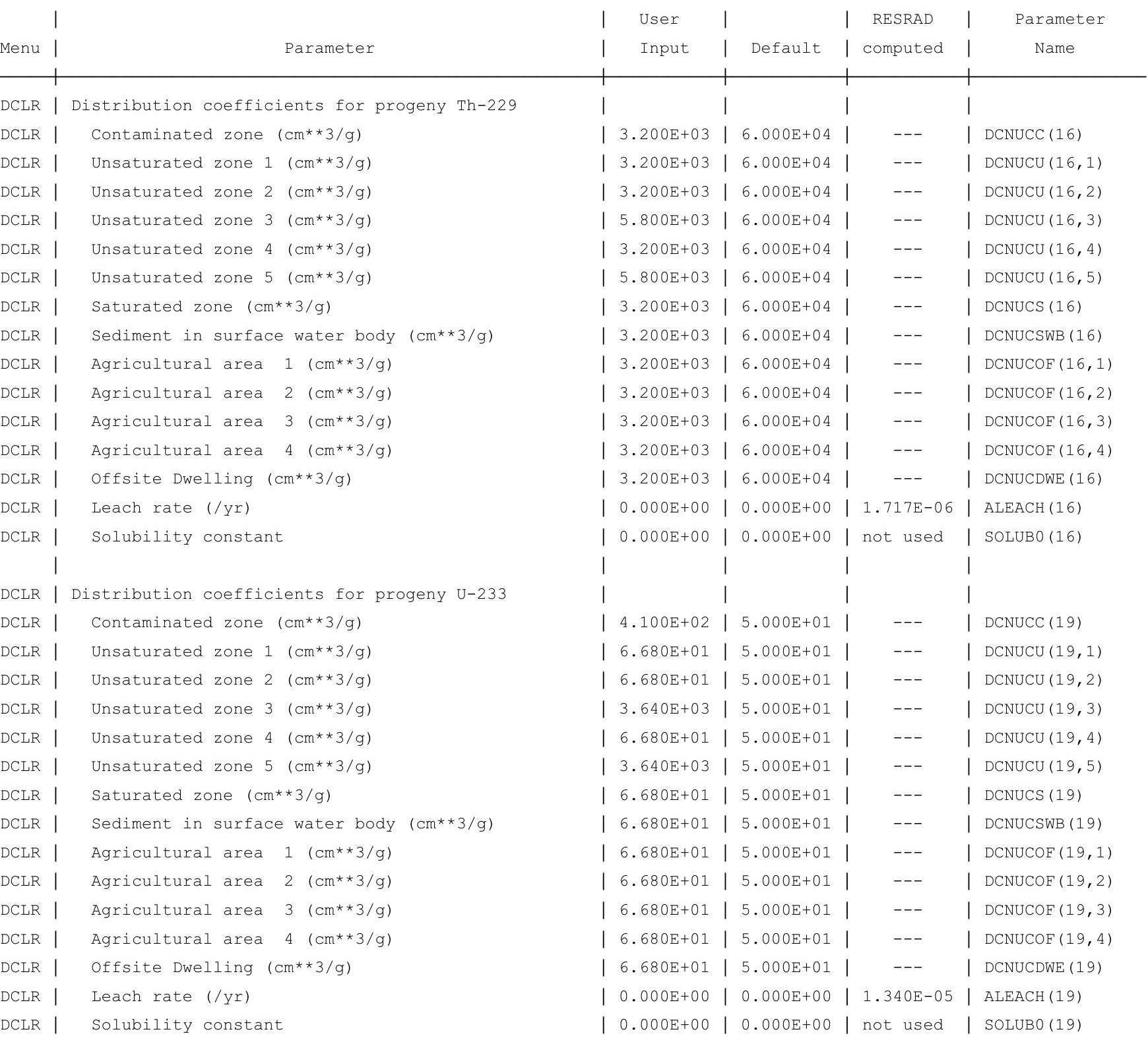


RESRAD-OFFSITE, Version 2.

Parent Dose Report

Title : RESRAD-OFFSITE Parameters for Offsite Resident Farmer Forward Run 100,000 Years

File : OFFSITE-RF_FORWARD-7-11-100000yr.ROF

Site-Specific Parameter Summary (continued)

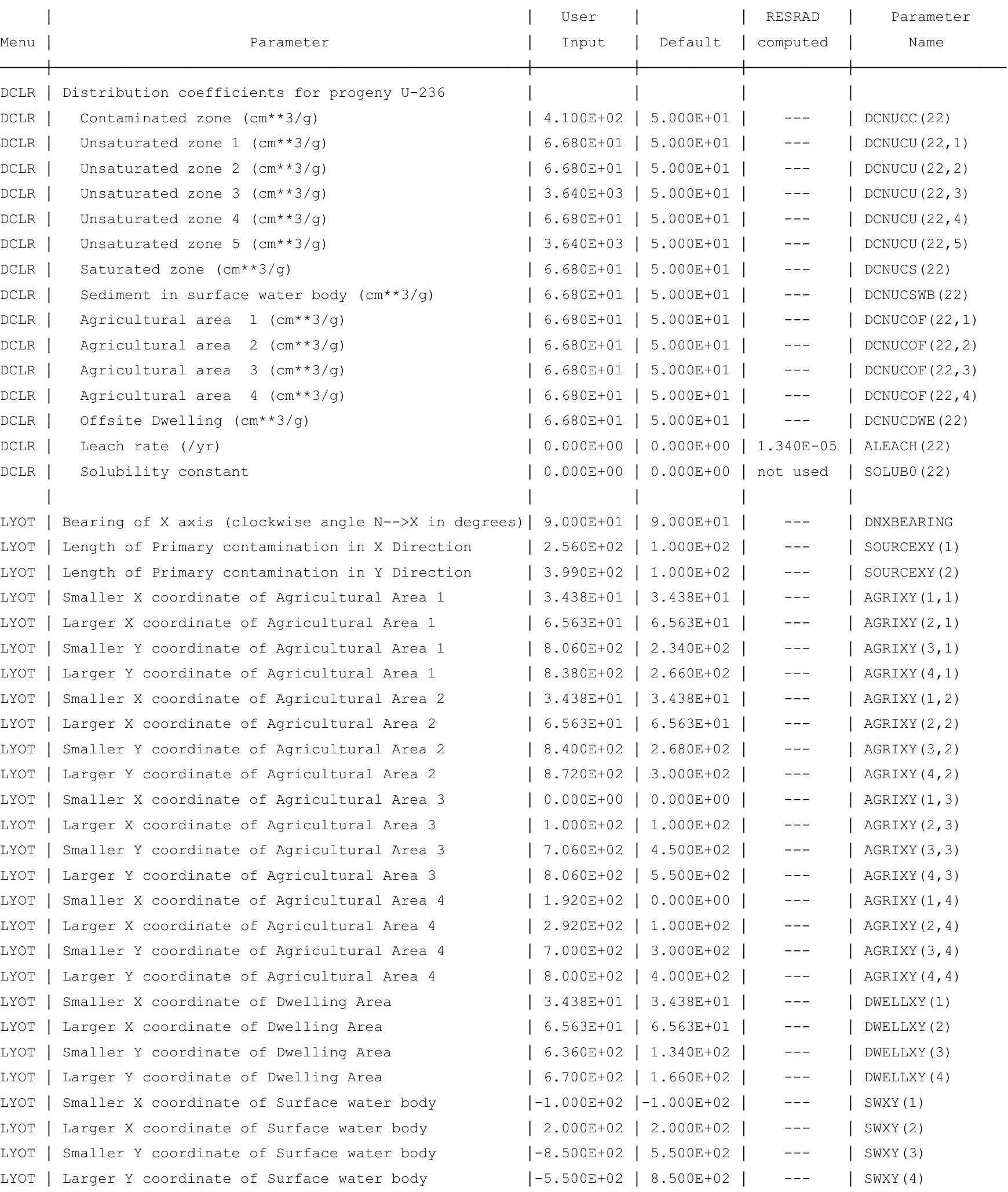


RESRAD-OFFSITE, Version 2.

Parent Dose Report

Title : RESRAD-OFFSITE Parameters for Offsite Resident Farmer Forward Run 100,000 Years

File : OFFSITE-RF FORWARD-7-11-100000yr.ROF

Site-Specific Parameter Summary (continued)

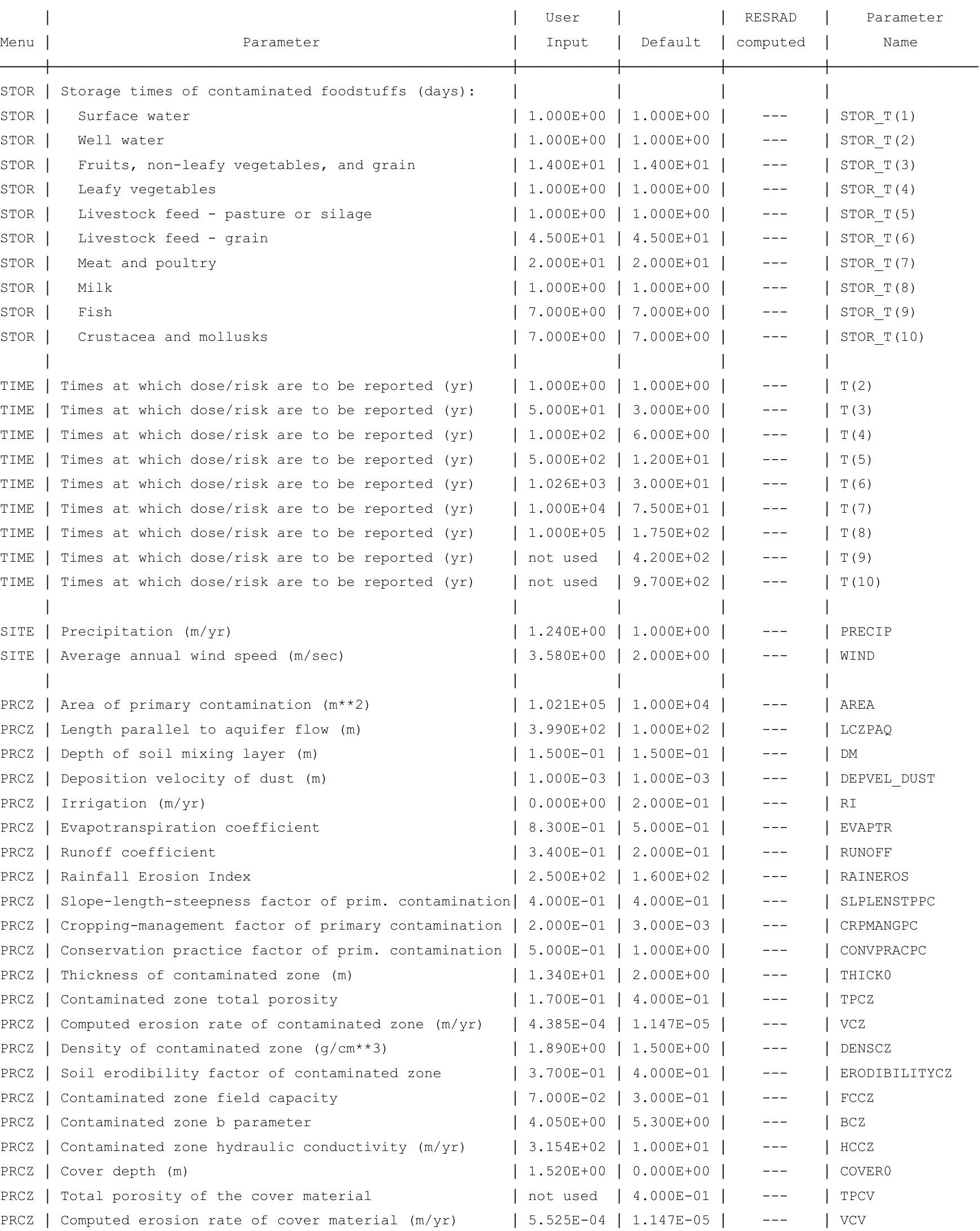


RESRAD-OFFSITE, Version 2.

Parent Dose Report

Title : RESRAD-OFFSITE Parameters for Offsite Resident Farmer Forward Run 100,000 Years

File : OFFSITE-RF_FORWARD-7-11-100000yr.ROF

Site-Specific Parameter Summary (continued)

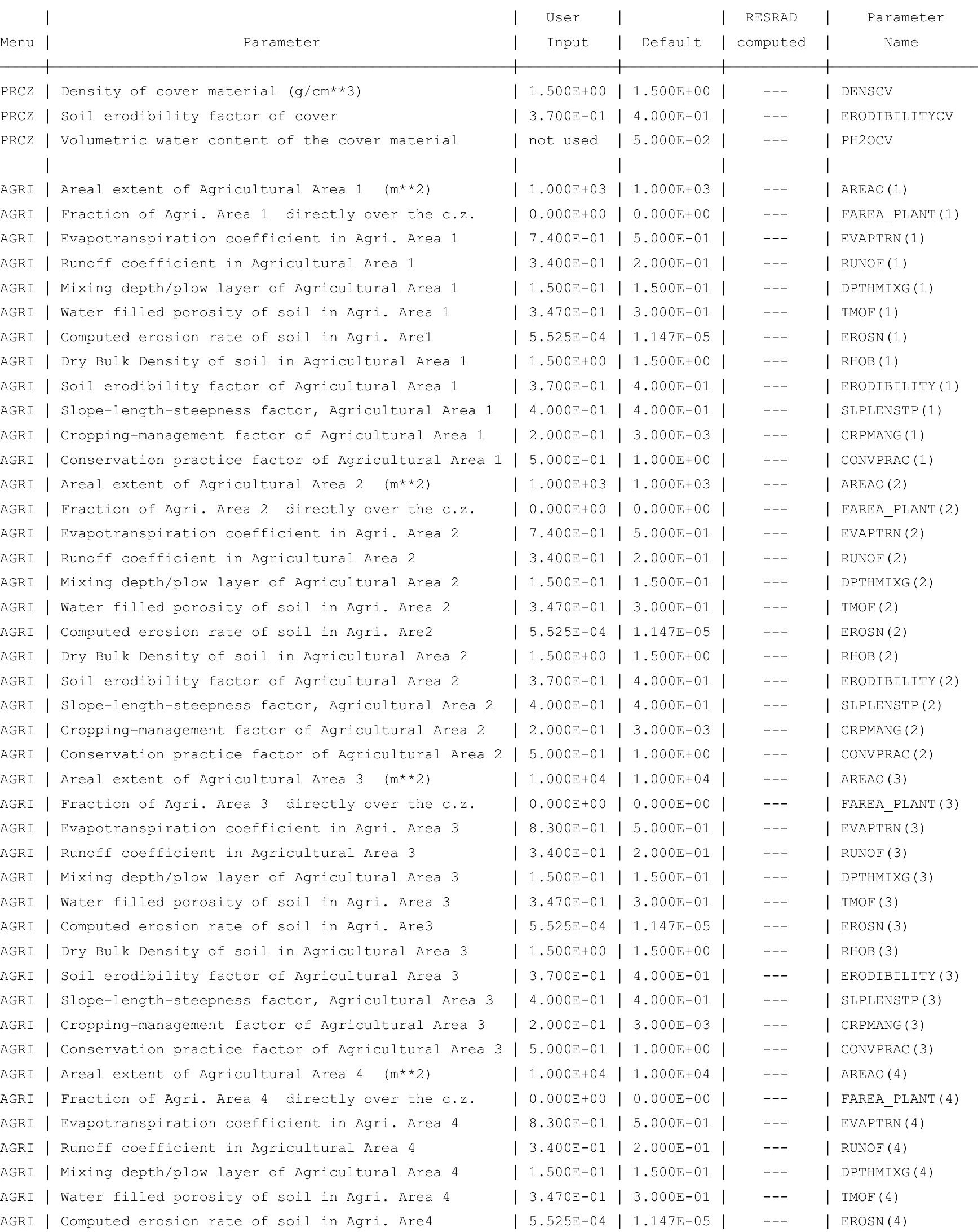


RESRAD-OFFSITE, Version $2.5 \quad T^{1 / 2}$ Limit $=180$ days

Parent Dose Report

Title : RESRAD-OFFSITE Parameters for Offsite Resident Farmer Forward Run 100,000 Years

File : OFFSITE-RF_FORWARD-7-11-100000yr.ROF

Site-Specific Parameter Summary (continued)

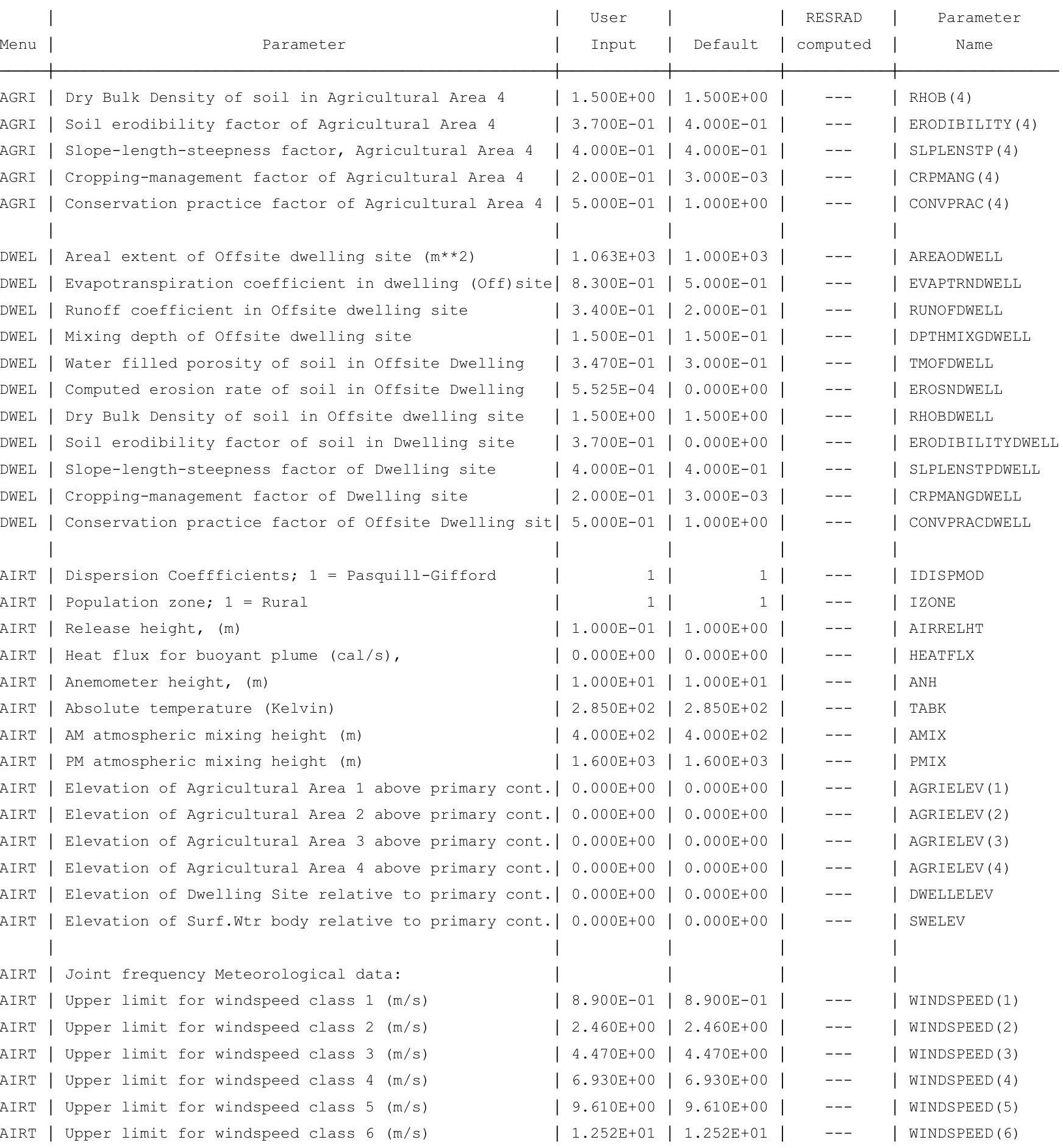


RESRAD-OFFSITE, Version 2.

Parent Dose Report

Title : RESRAD-OFFSITE Parameters for Offsite Resident Farmer Forward Run 100,000 Years

File : OFFSITE-RF FORWARD-7-11-100000yr.ROF

Site-Specific Parameter Summary (continued)

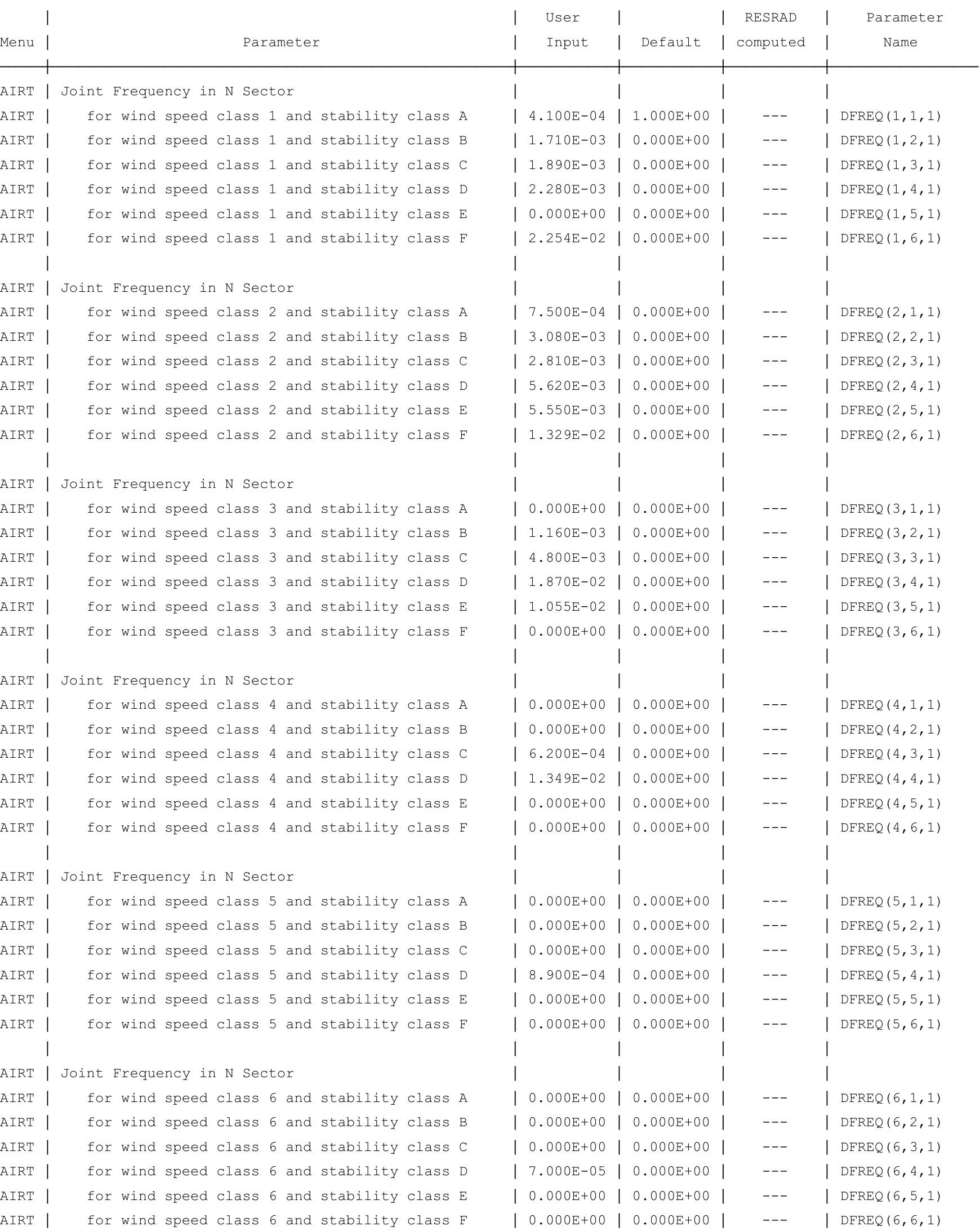


RESRAD-OFFSITE, Version 2.

Parent Dose Report

Title : RESRAD-OFFSITE Parameters for Offsite Resident Farmer Forward Run 100,000 Years

File : OFFSITE-RF FORWARD-7-11-100000yr.ROF

Site-Specific Parameter Summary (continued)

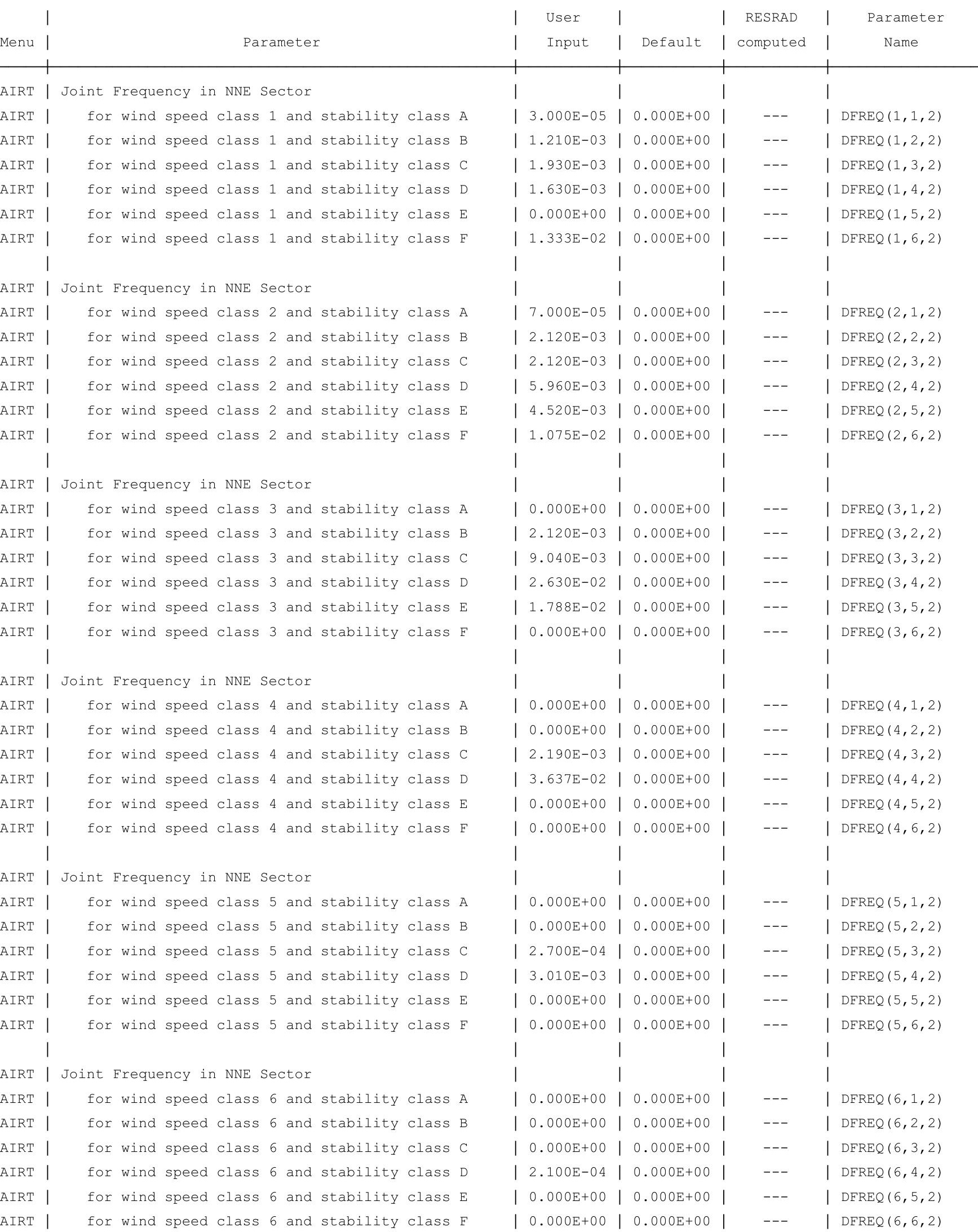


RESRAD-OFFSITE, Version 2.

Parent Dose Report

Title : RESRAD-OFFSITE Parameters for Offsite Resident Farmer Forward Run 100,000 Years

File : OFFSITE-RF FORWARD-7-11-100000yr.ROF

Site-Specific Parameter Summary (continued)

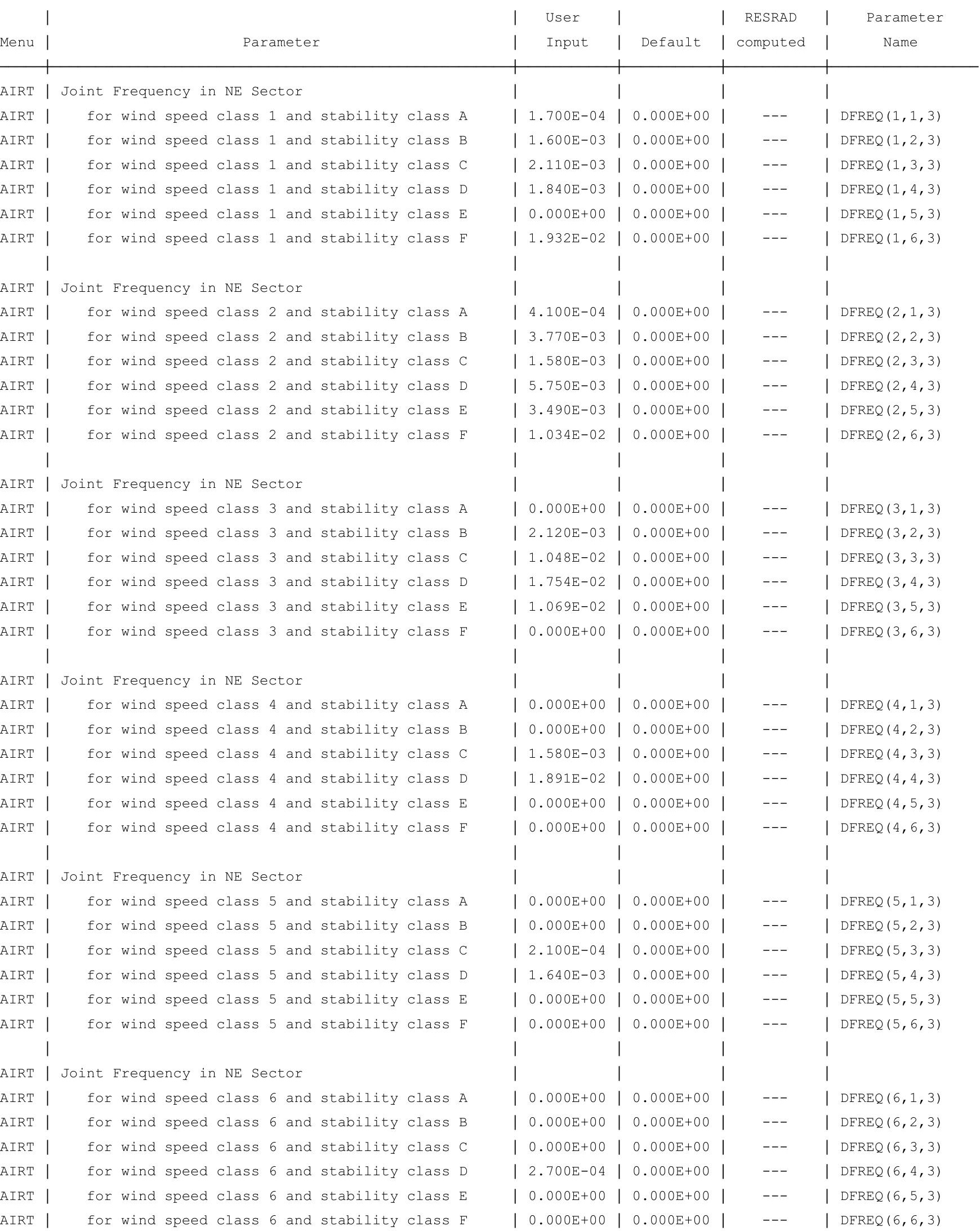


RESRAD-OFFSITE, Version 2.

Parent Dose Report

Title : RESRAD-OFFSITE Parameters for Offsite Resident Farmer Forward Run 100,000 Years

File : OFFSITE-RF FORWARD-7-11-100000yr.ROF

Site-Specific Parameter Summary (continued)

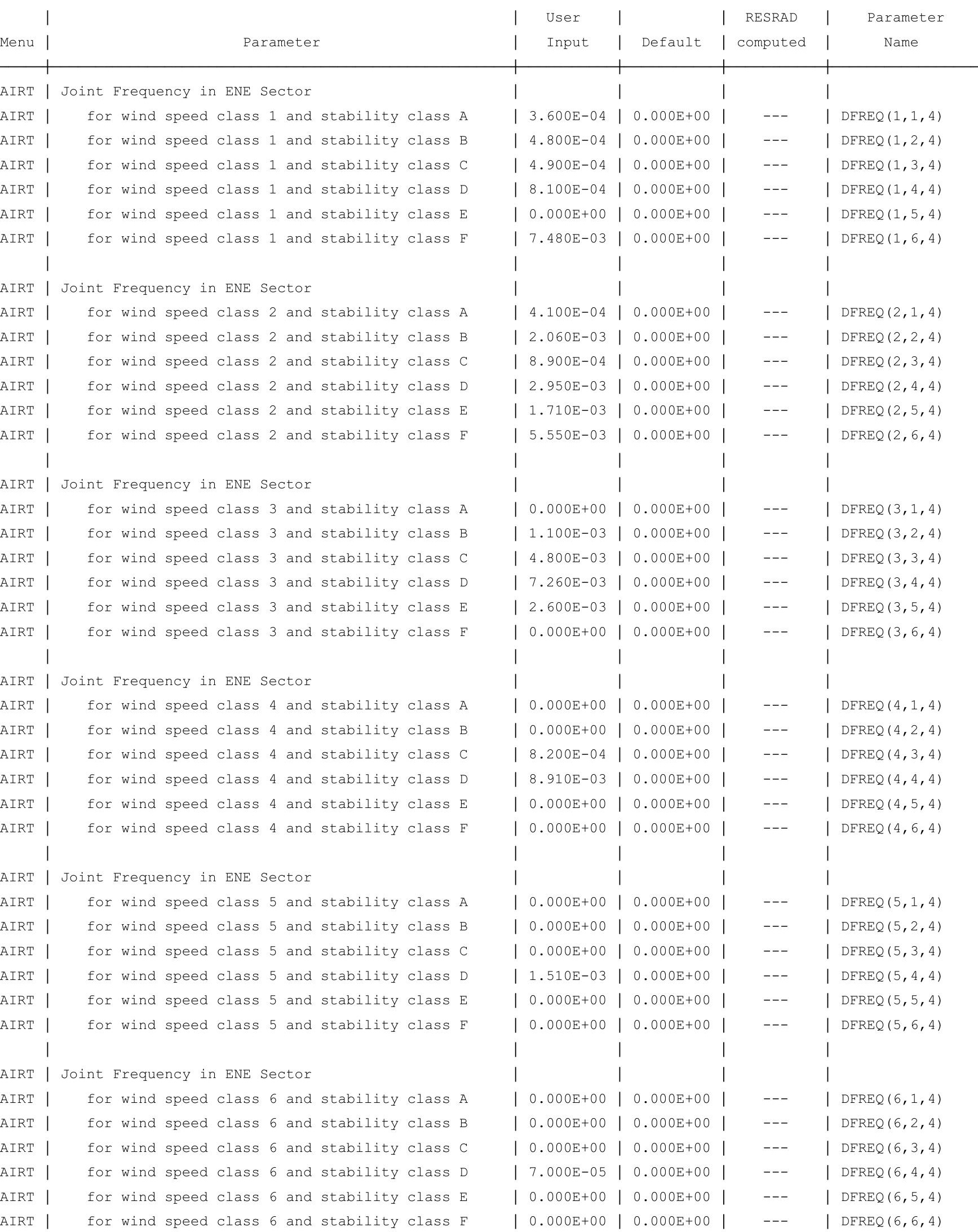


RESRAD-OFFSITE, Version 2.

Parent Dose Report

Title : RESRAD-OFFSITE Parameters for Offsite Resident Farmer Forward Run 100,000 Years

File : OFFSITE-RF FORWARD-7-11-100000yr.ROF

Site-Specific Parameter Summary (continued)

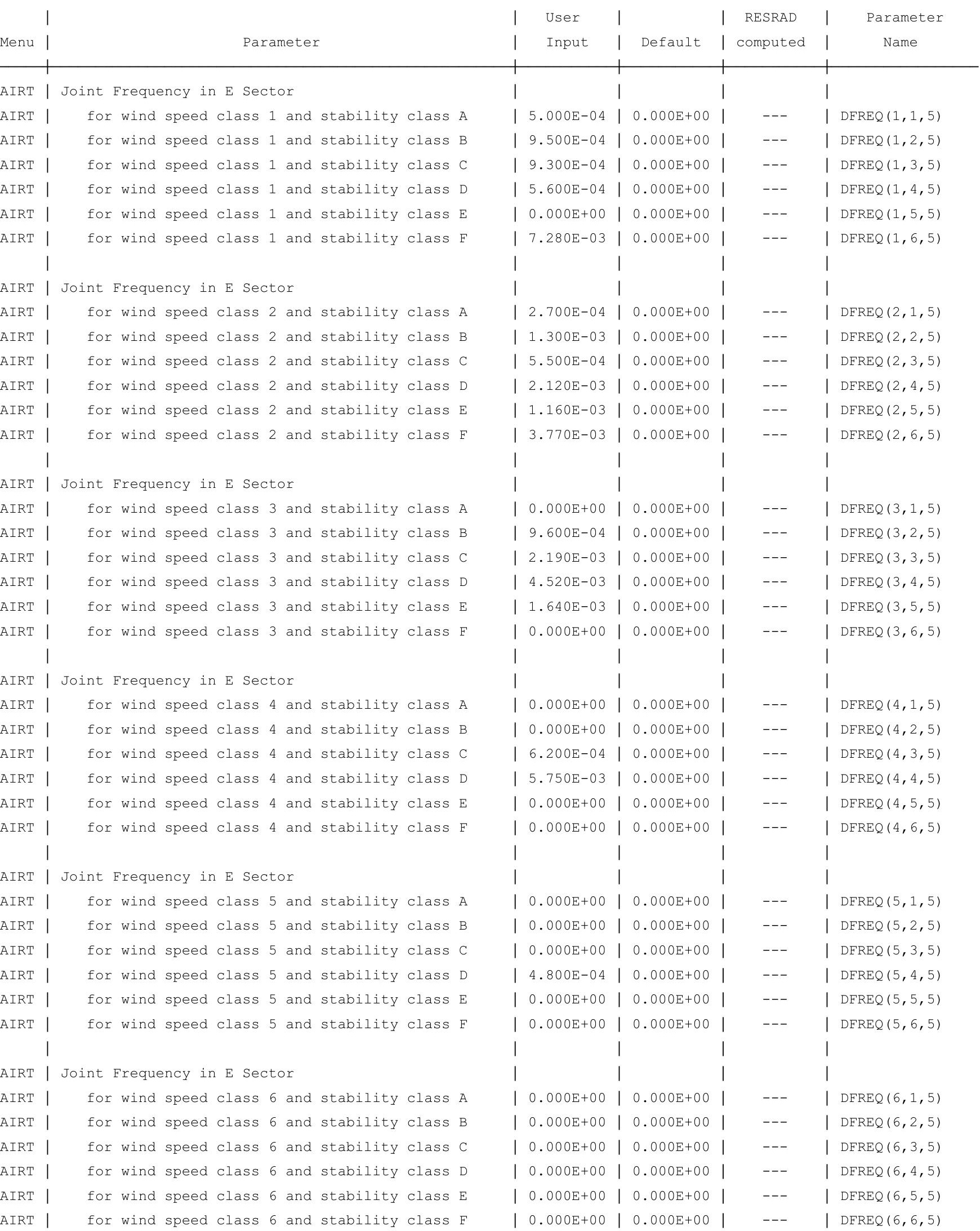


RESRAD-OFFSITE, Version 2.

Parent Dose Report

Title : RESRAD-OFFSITE Parameters for Offsite Resident Farmer Forward Run 100,000 Years

File : OFFSITE-RF FORWARD-7-11-100000yr.ROF

Site-Specific Parameter Summary (continued)

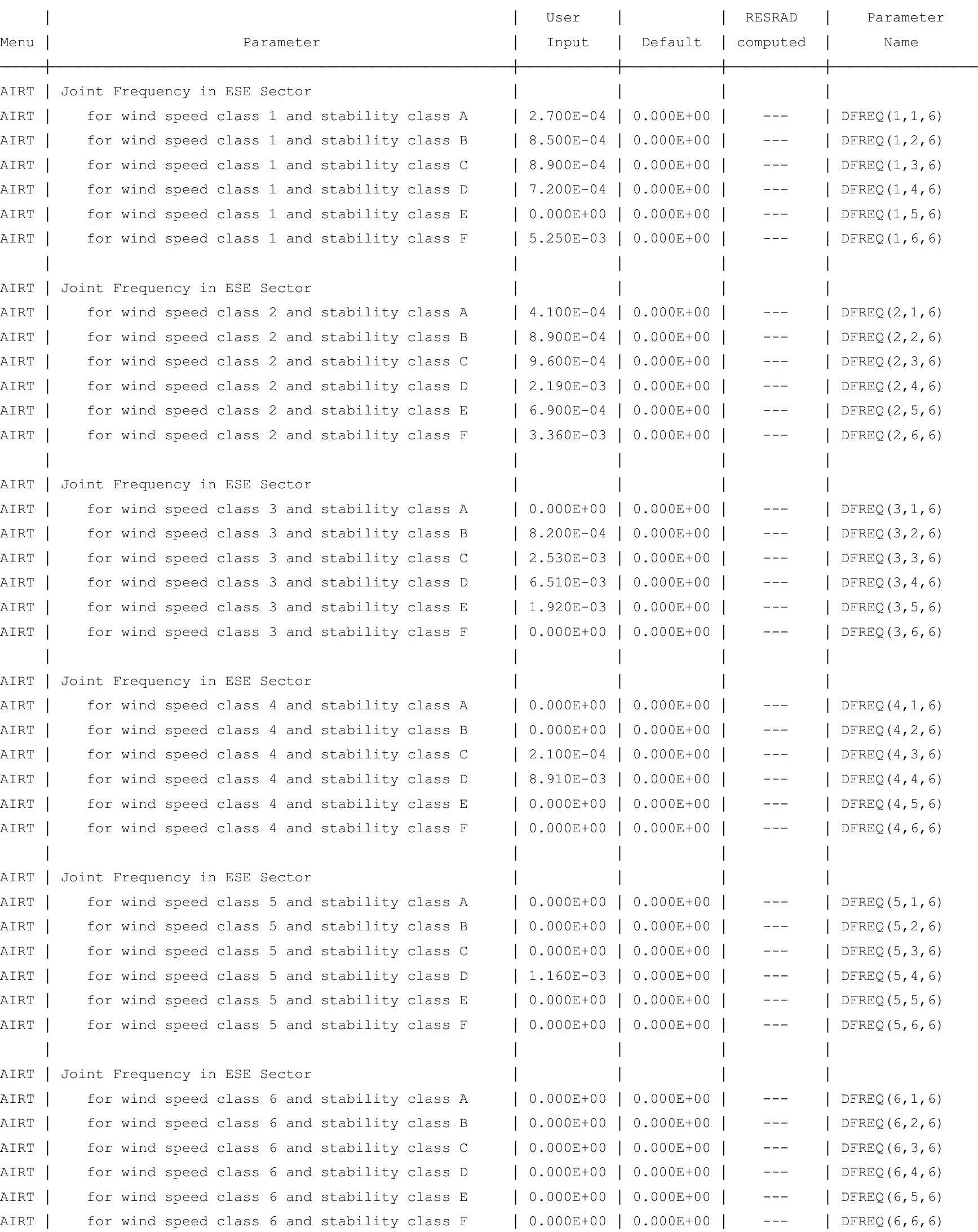


RESRAD-OFFSITE, Version 2.

Parent Dose Report

Title : RESRAD-OFFSITE Parameters for Offsite Resident Farmer Forward Run 100,000 Years

File : OFFSITE-RF FORWARD-7-11-100000yr.ROF

Site-Specific Parameter Summary (continued)

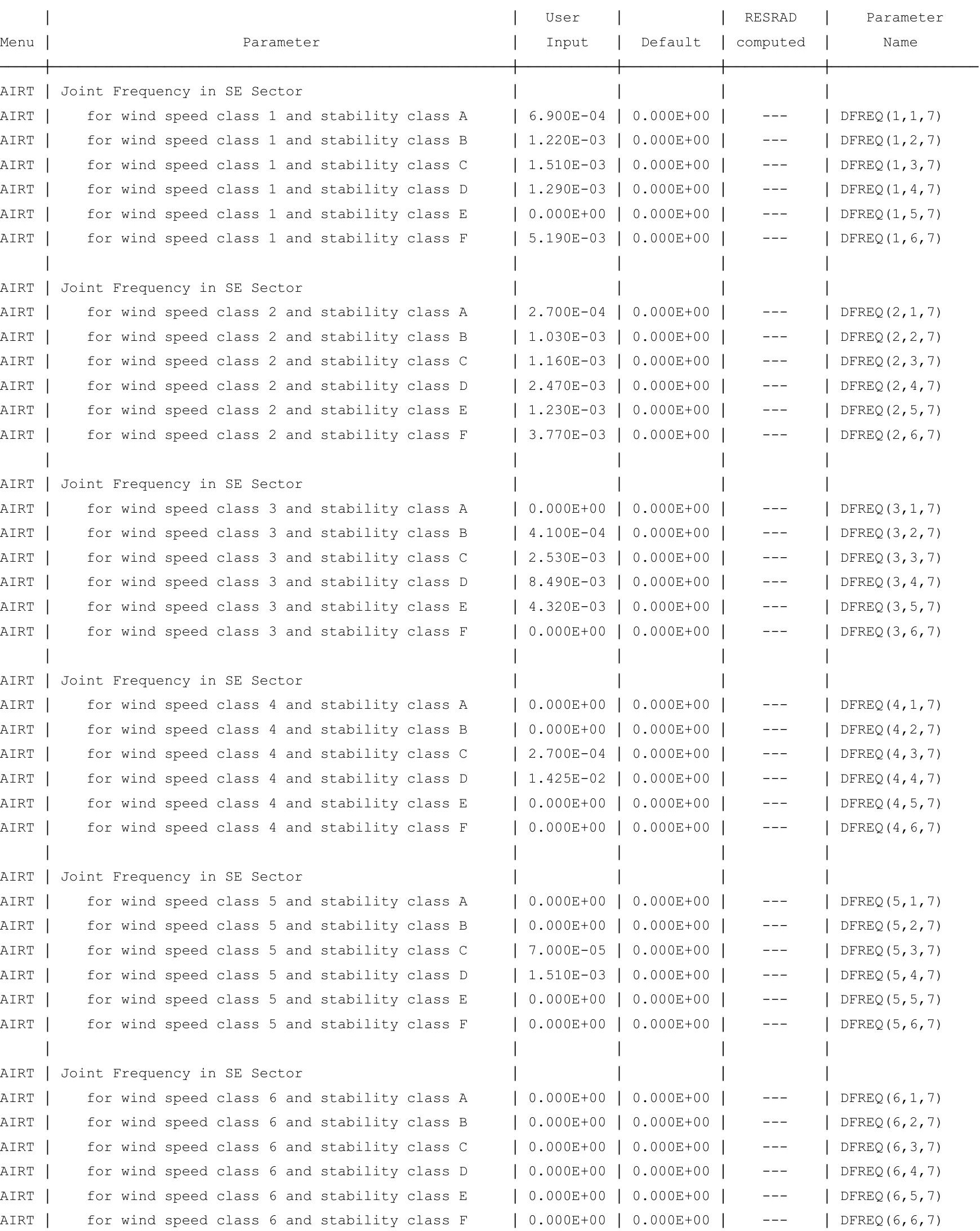


RESRAD-OFFSITE, Version 2.

Parent Dose Report

Title : RESRAD-OFFSITE Parameters for Offsite Resident Farmer Forward Run 100,000 Years

File : OFFSITE-RF FORWARD-7-11-100000yr.ROF

Site-Specific Parameter Summary (continued)

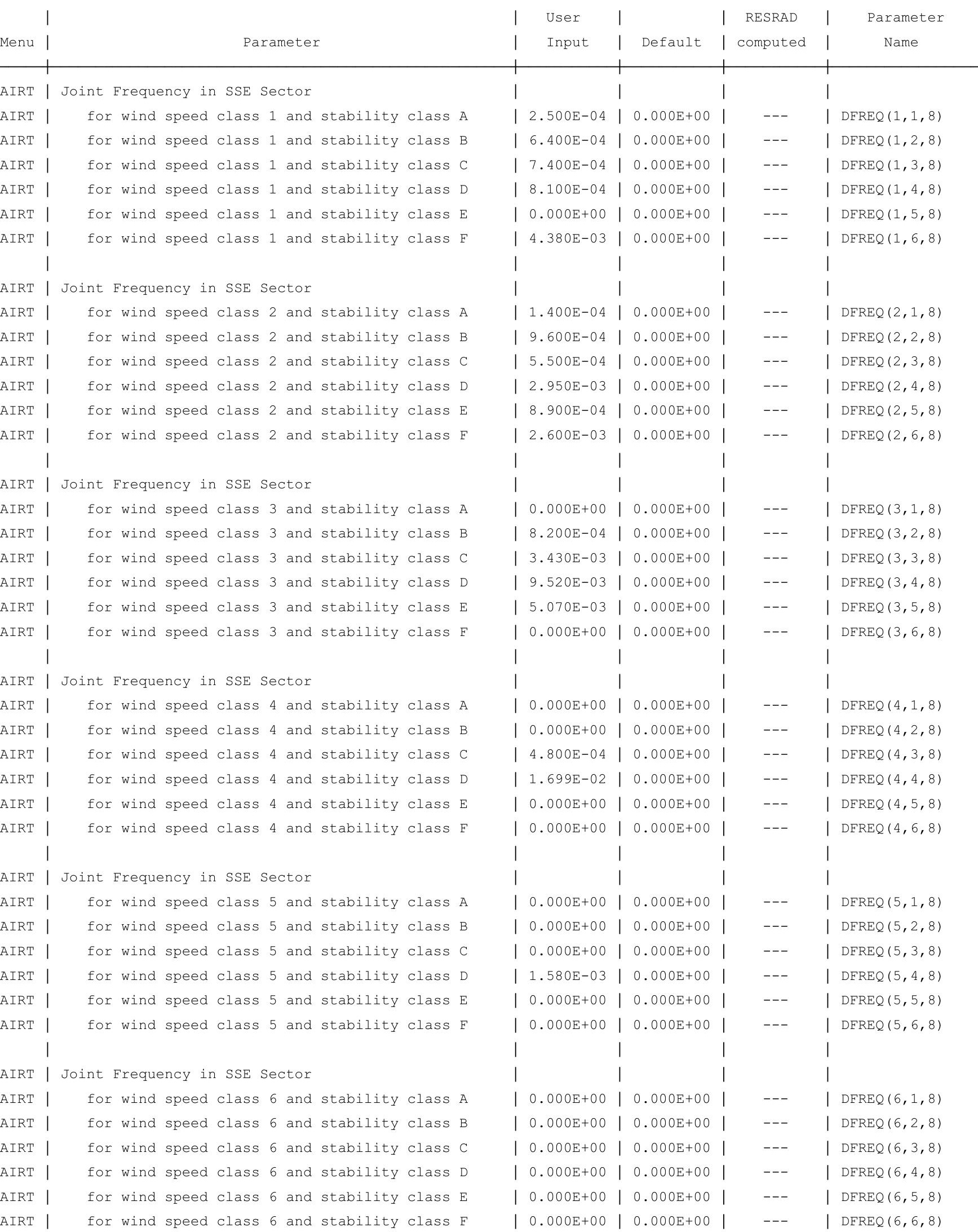


RESRAD-OFFSITE, Version 2.

Parent Dose Report

Title : RESRAD-OFFSITE Parameters for Offsite Resident Farmer Forward Run 100,000 Years

File : OFFSITE-RF FORWARD-7-11-100000yr.ROF

Site-Specific Parameter Summary (continued)

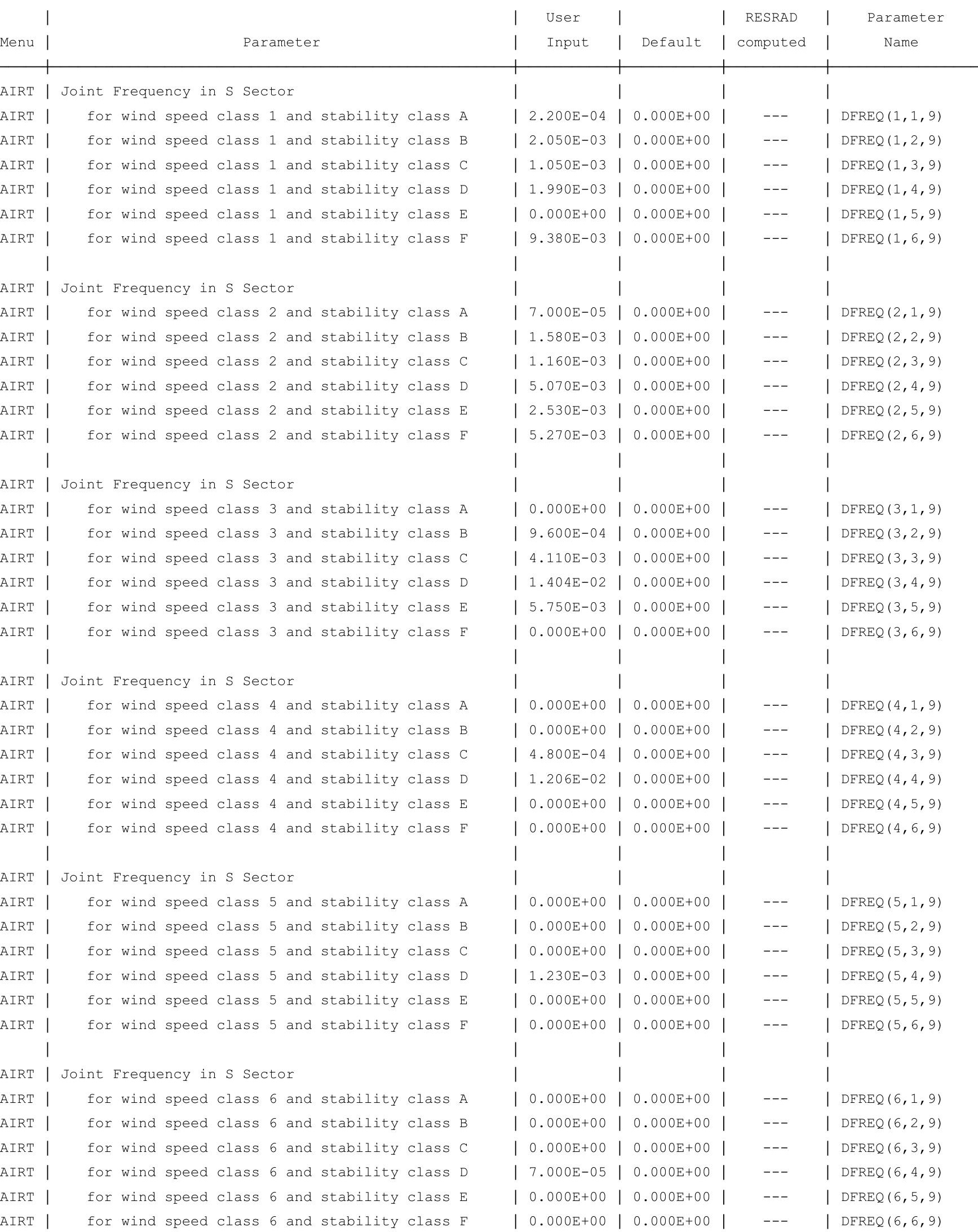


RESRAD-OFFSITE, Version 2.

Parent Dose Report

Title : RESRAD-OFFSITE Parameters for Offsite Resident Farmer Forward Run 100,000 Years

File : OFFSITE-RF FORWARD-7-11-100000yr.ROF

Site-Specific Parameter Summary (continued)

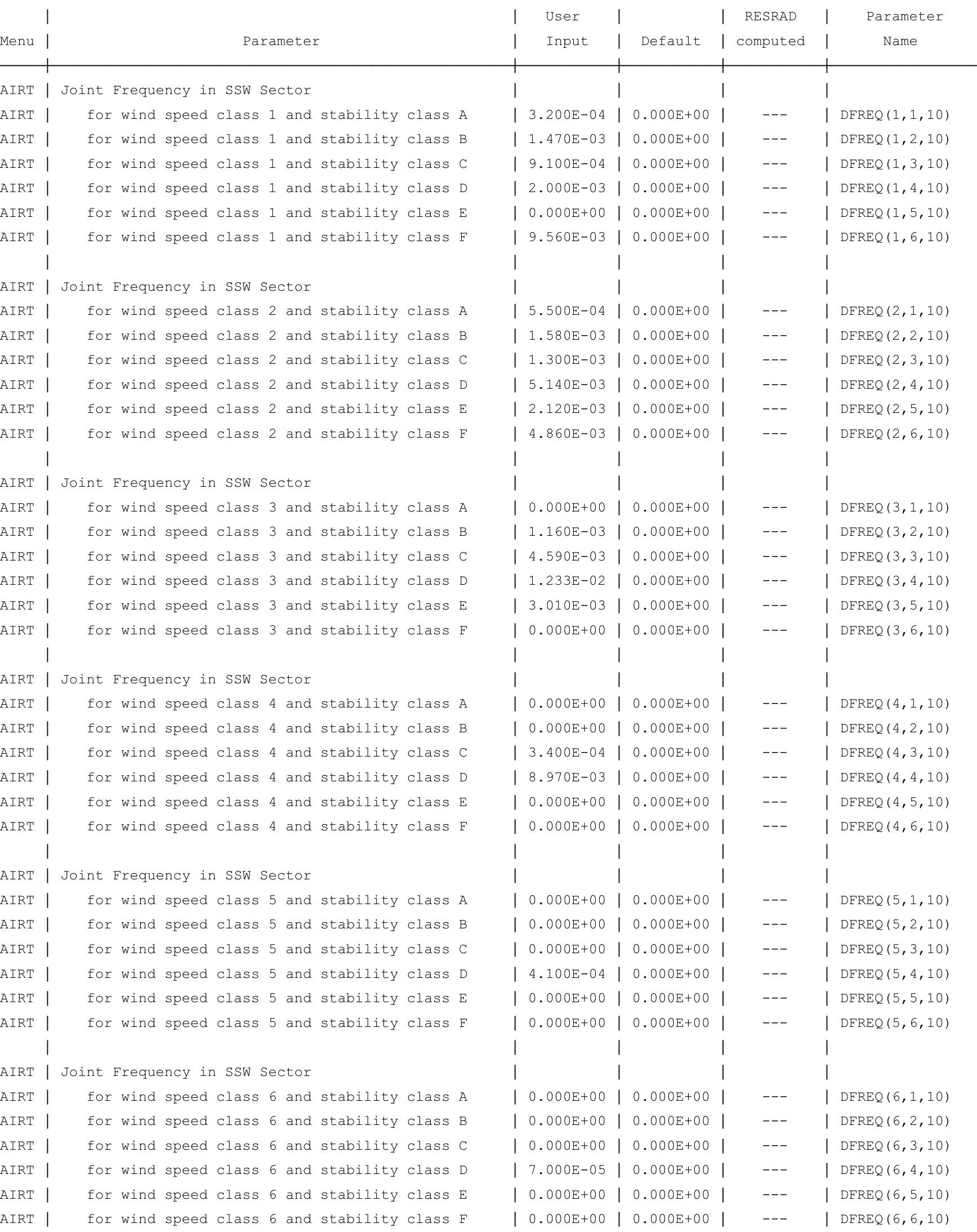


RESRAD-OFFSITE, Version 2.

Parent Dose Report

Title : RESRAD-OFFSITE Parameters for Offsite Resident Farmer Forward Run 100,000 Years

File : OFFSITE-RF FORWARD-7-11-100000yr.ROF

Site-Specific Parameter Summary (continued)

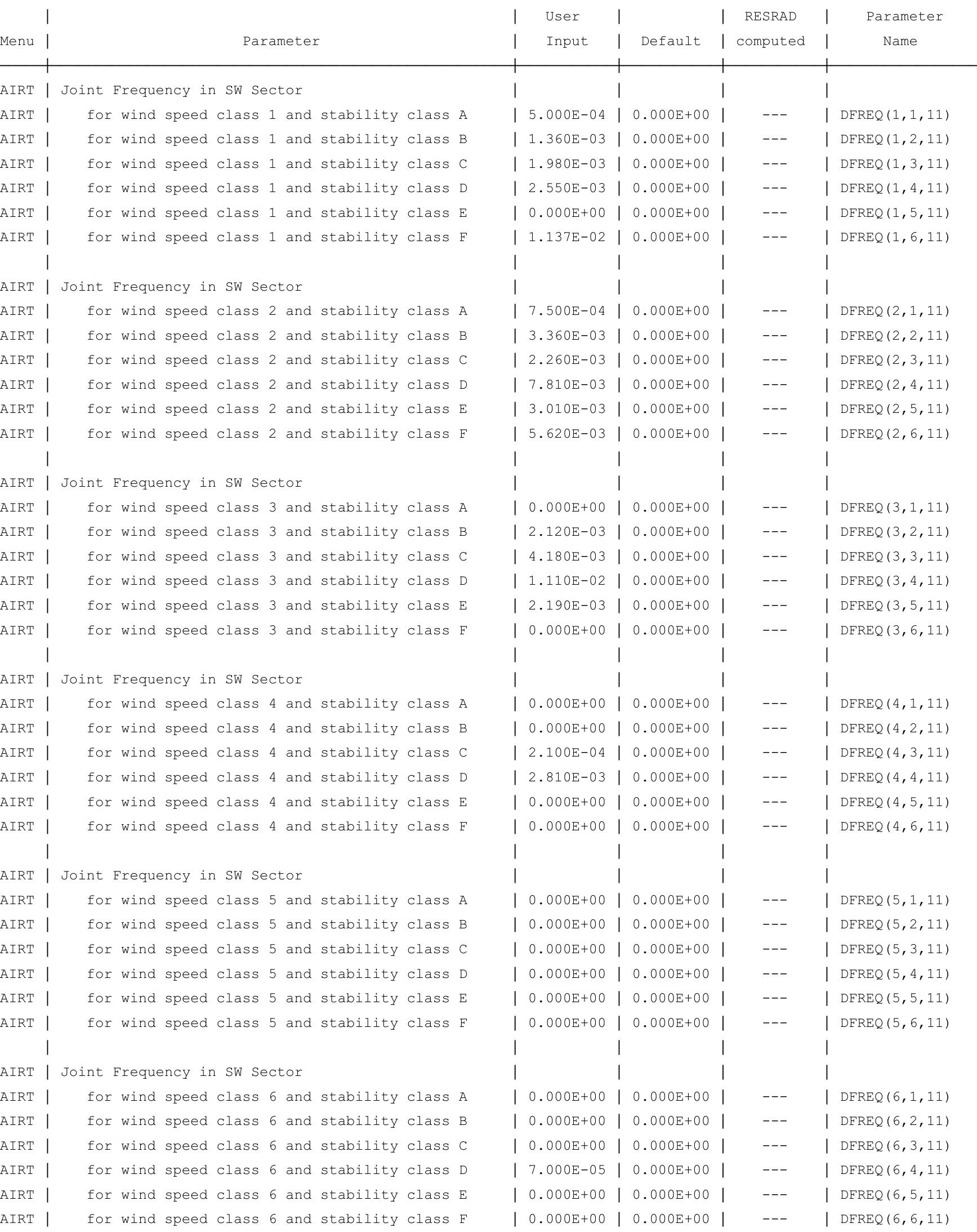


RESRAD-OFFSITE, Version 2.

Parent Dose Report

Title : RESRAD-OFFSITE Parameters for Offsite Resident Farmer Forward Run 100,000 Years

File : OFFSITE-RF FORWARD-7-11-100000yr.ROF

Site-Specific Parameter Summary (continued)

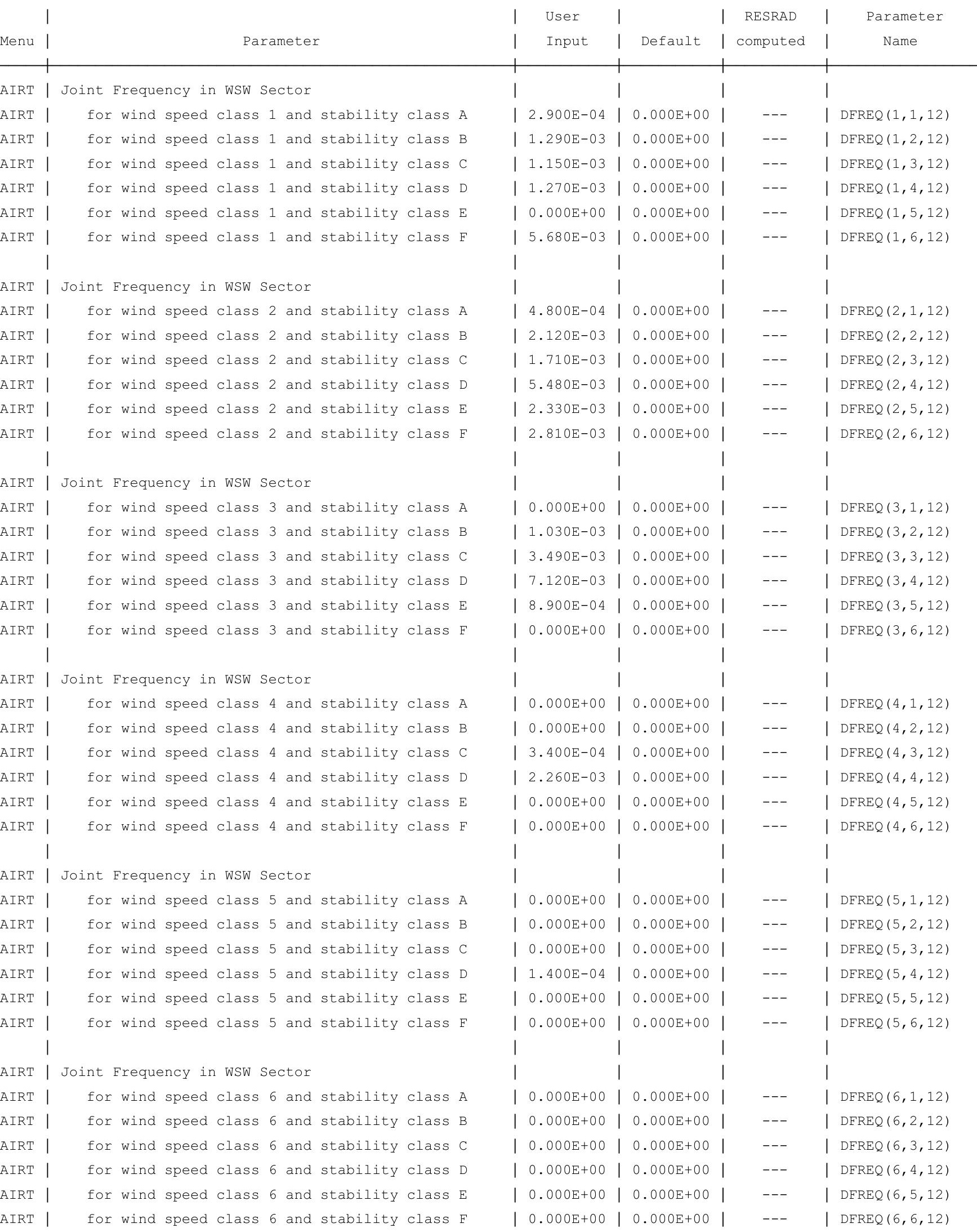


RESRAD-OFFSITE, Version 2.

Parent Dose Report

Title : RESRAD-OFFSITE Parameters for Offsite Resident Farmer Forward Run 100,000 Years

File : OFFSITE-RF FORWARD-7-11-100000yr.ROF

Site-Specific Parameter Summary (continued)

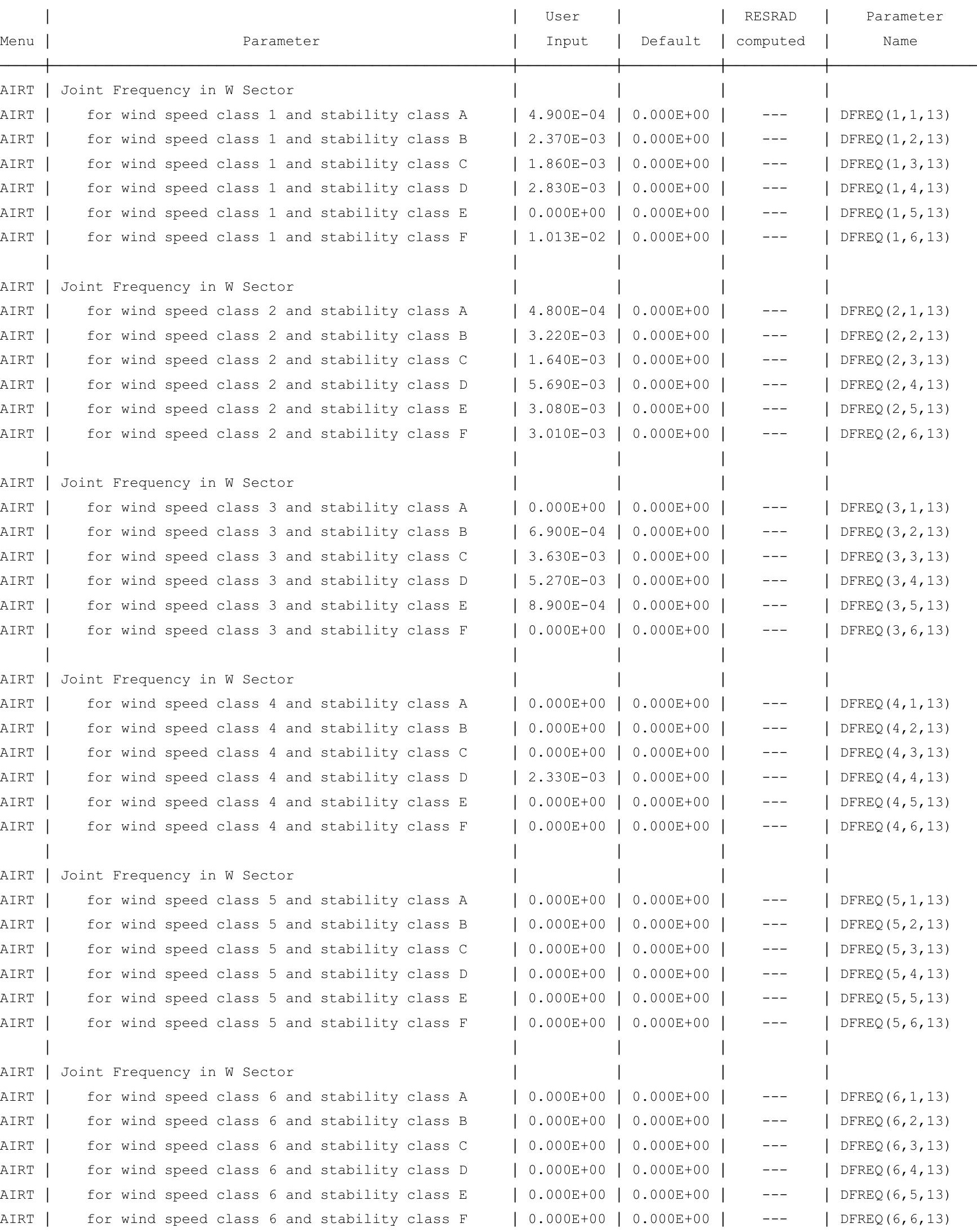


RESRAD-OFFSITE, Version 2.

Parent Dose Report

Title : RESRAD-OFFSITE Parameters for Offsite Resident Farmer Forward Run 100,000 Years

File : OFFSITE-RF FORWARD-7-11-100000yr.ROF

Site-Specific Parameter Summary (continued)

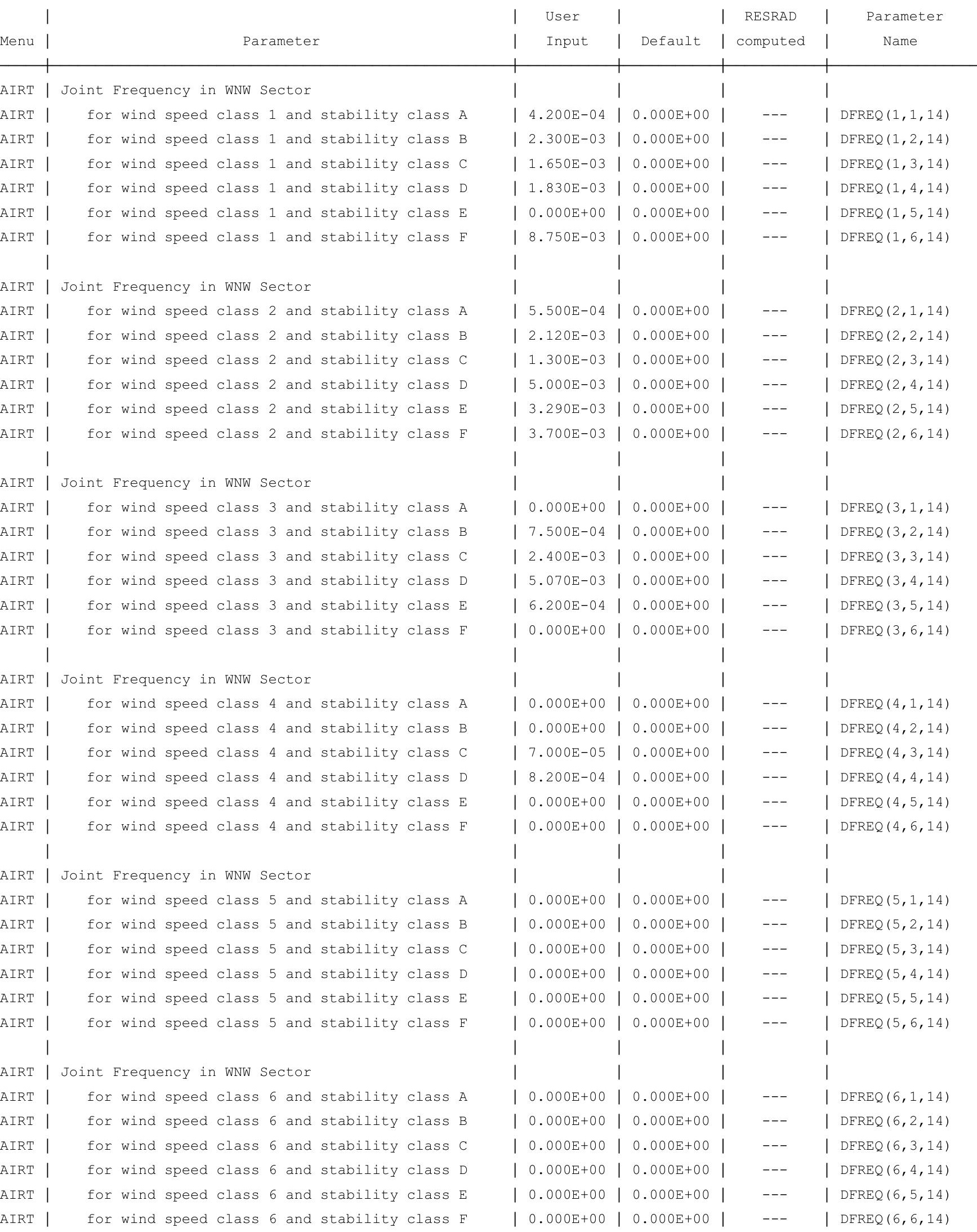


RESRAD-OFFSITE, Version 2.

Parent Dose Report

Title : RESRAD-OFFSITE Parameters for Offsite Resident Farmer Forward Run 100,000 Years

File : OFFSITE-RF FORWARD-7-11-100000yr.ROF

Site-Specific Parameter Summary (continued)

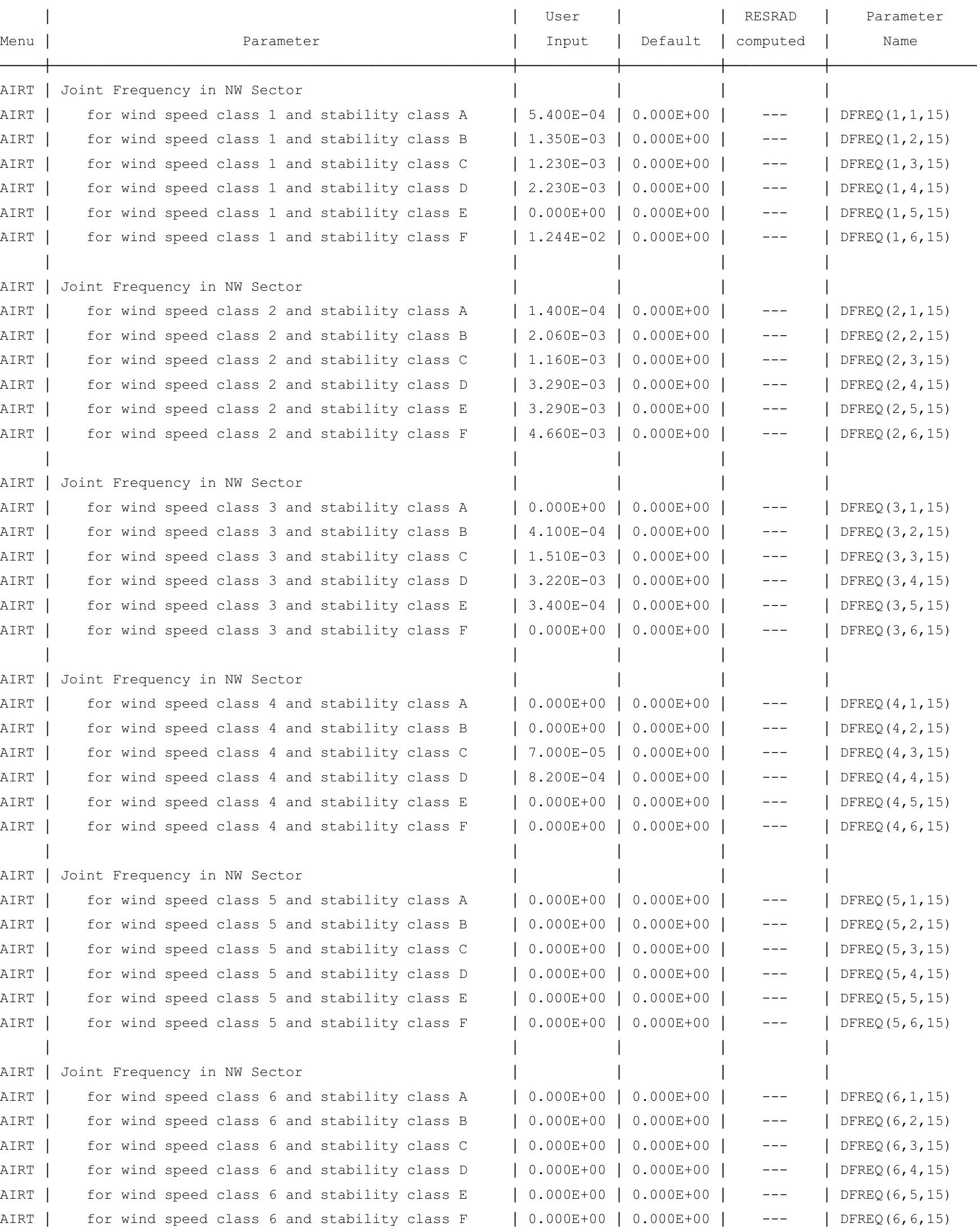


RESRAD-OFFSITE, Version 2.

Parent Dose Report

Title : RESRAD-OFFSITE Parameters for Offsite Resident Farmer Forward Run 100,000 Years

File : OFFSITE-RF FORWARD-7-11-100000yr.ROF

Site-Specific Parameter Summary (continued)

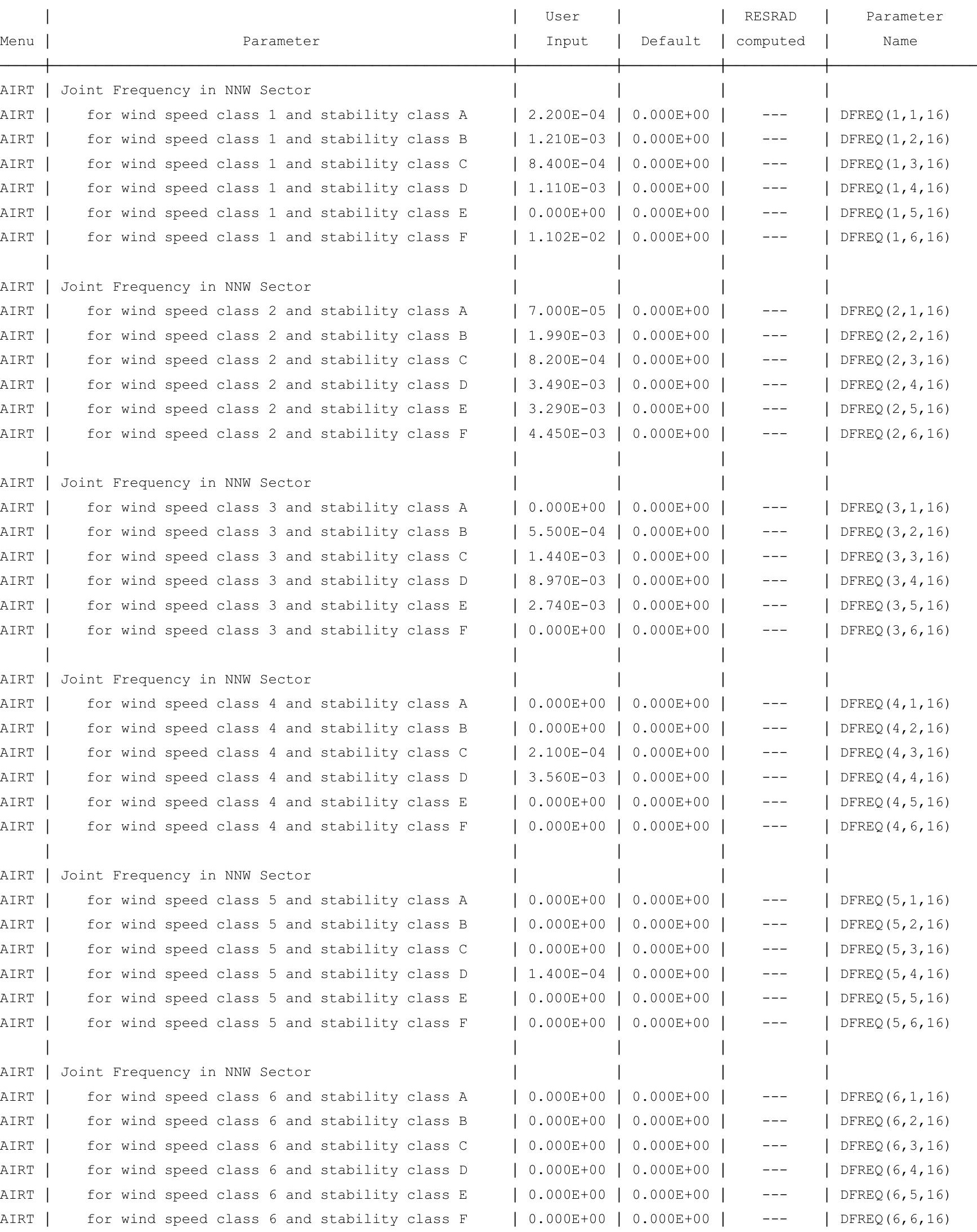


RESRAD-OFFSITE, Version 2.

Parent Dose Report

Title : RESRAD-OFFSITE Parameters for Offsite Resident Farmer Forward Run 100,000 Years

File : OFFSITE-RF_FORWARD-7-11-100000yr.ROF

Site-Specific Parameter Summary (continued)

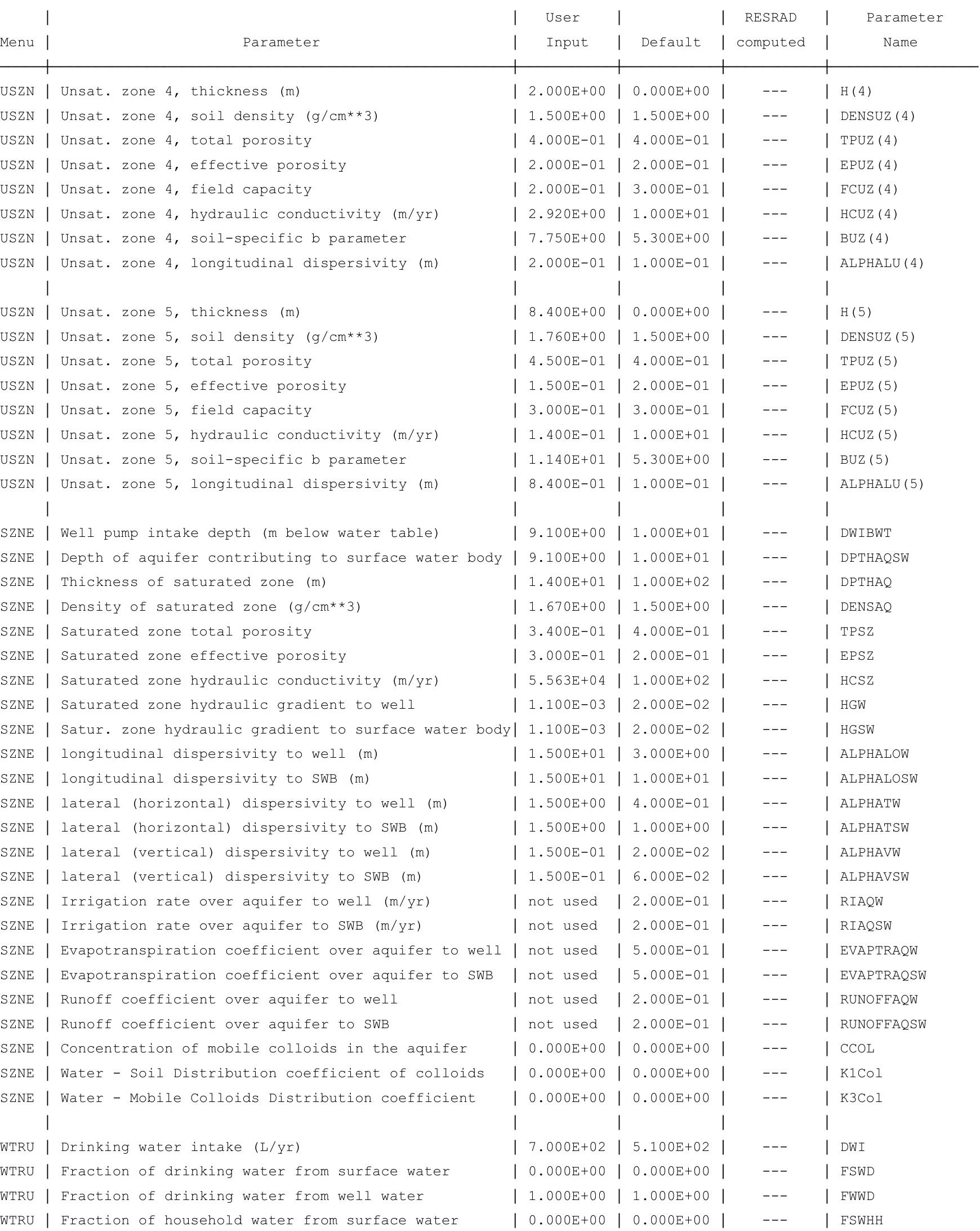


RESRAD-OFFSITE, Version 2.

Parent Dose Report

Title : RESRAD-OFFSITE Parameters for Offsite Resident Farmer Forward Run 100,000 Years

File : OFFSITE-RF_FORWARD-7-11-100000yr.ROF

Site-Specific Parameter Summary (continued)

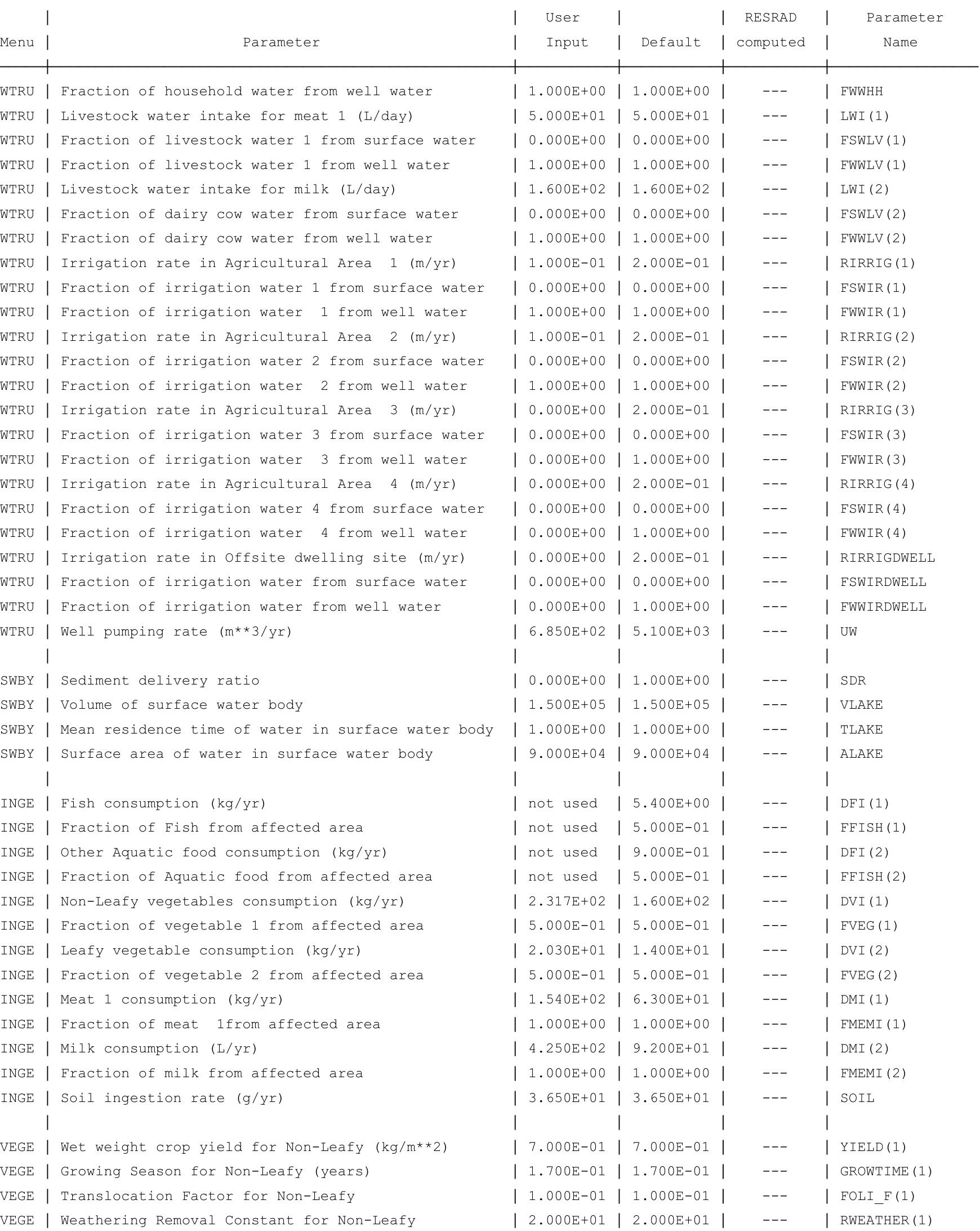


RESRAD-OFFSITE, Version 2.

Parent Dose Report

Title : RESRAD-OFFSITE Parameters for Offsite Resident Farmer Forward Run 100,000 Years

File : OFFSITE-RF FORWARD-7-11-100000yr.ROF

Site-Specific Parameter Summary (continued)

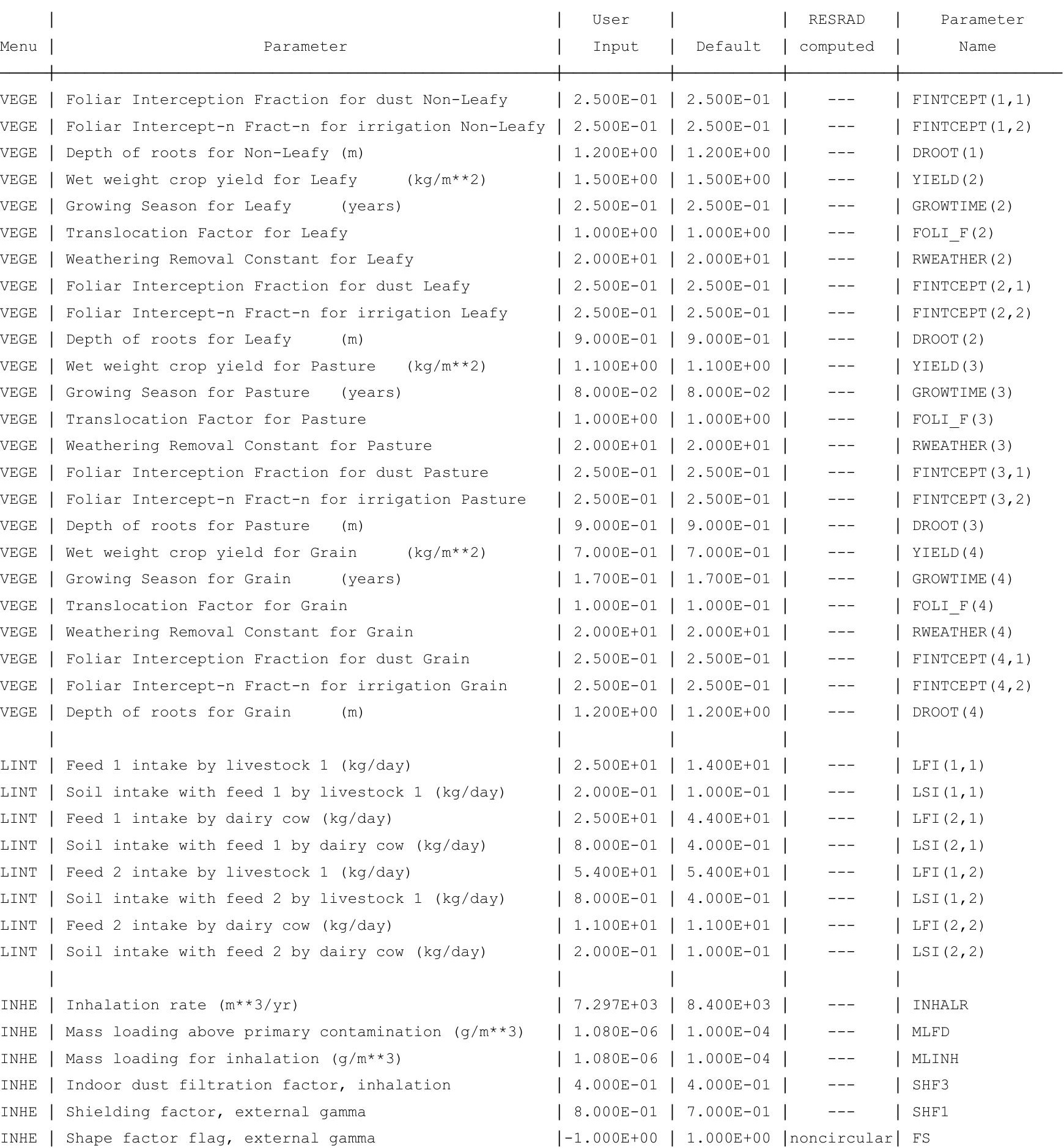


RESRAD-OFFSITE, Version 2.5

Parent Dose Report

Title : RESRAD-OFFSITE Parameters for Offsite Resident Farmer Forward Run 100,000 Years

File : OFFSITE-RF_FORWARD-7-11-100000yr.ROF

Site-Specific Parameter Summary (continued)

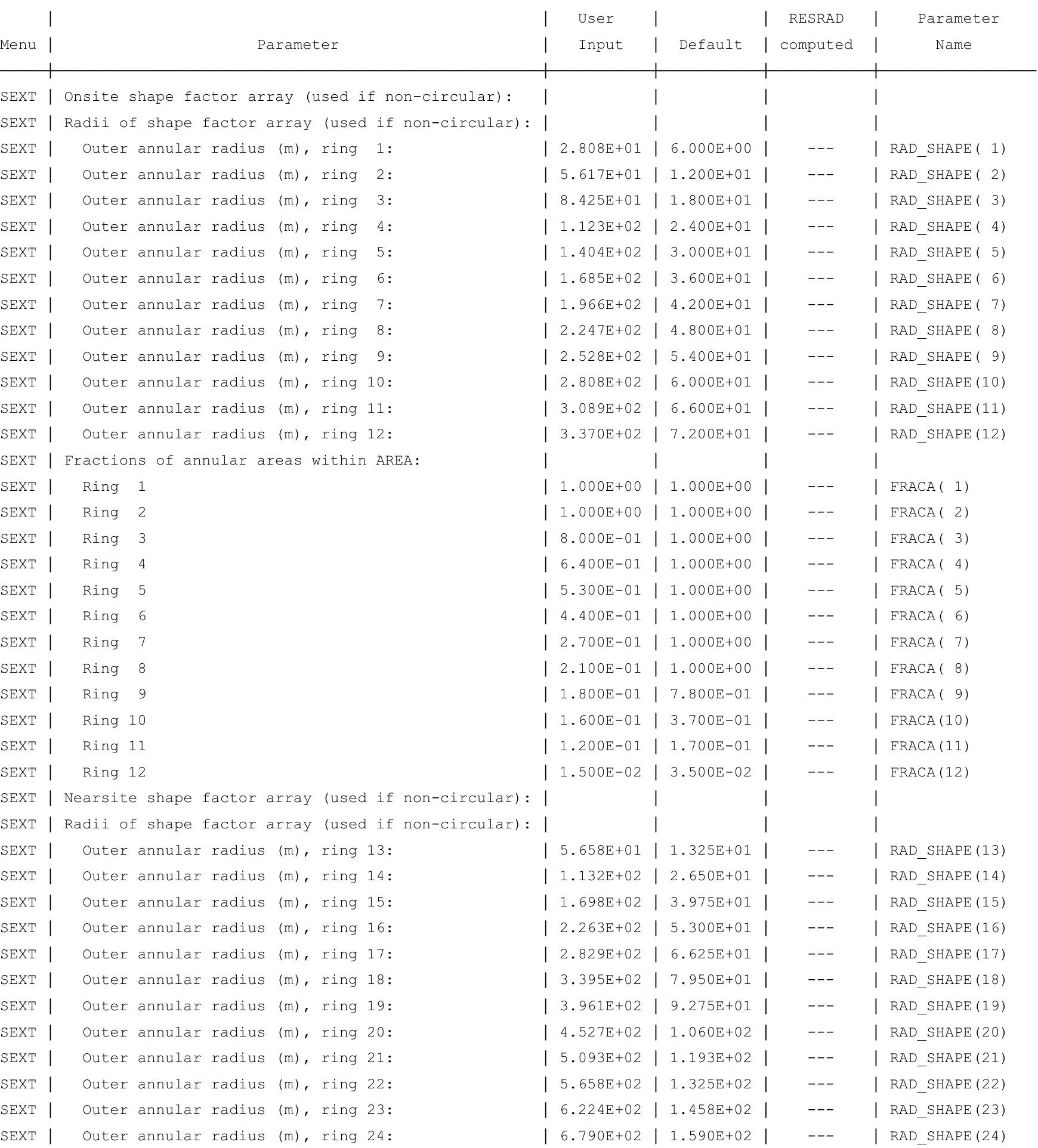


RESRAD-OFFSITE, Version 2.5

Parent Dose Report

Title : RESRAD-OFFSITE Parameters for Offsite Resident Farmer Forward Run 100,000 Years

File : OFFSITE-RF_FORWARD-7-11-100000yr.ROF

Site-Specific Parameter Summary (continued)

\begin{tabular}{|c|c|c|c|c|c|}
\hline | & & User & | & RESRAD & Parameter \\
\hline enu $\mid$ & Parameter & Input & Default & | computed & Name \\
\hline $\mathrm{XT}$ & Fractions of annular areas within AREA: & | & | & | & | \\
\hline $\mathrm{XT}$ & Ring 13 & $0.000 \mathrm{E}+00$ & $0.000 \mathrm{E}+00$ & --- & | FRACA (13) \\
\hline $\mathrm{XT}$ & Ring 14 & $0.000 \mathrm{E}+00$ & $0.000 \mathrm{E}+00$ & --- & | FRACA (14) \\
\hline $\mathrm{XT}$ & Ring 15 & $0.000 \mathrm{E}+00$ & $0.000 \mathrm{E}+00$ & --- & | FRACA (15) \\
\hline $\mathrm{XT}$ & Ring 16 & $0.000 \mathrm{E}+00$ & | $2.200 \mathrm{E}-02$ & --- & | FRACA (16) \\
\hline $\mathrm{XT}$ & Ring 17 & | $8.300 E-03$ & | $1.900 \mathrm{E}-01$ & --- & | FRACA (17) \\
\hline XT | & Ring 18 & | $1.100 \mathrm{E}-01$ & | 2.400E-01 & --- & | FRACA (18) \\
\hline $\mathrm{XT}$ & Ring 19 & | $1.200 \mathrm{E}-01$ & | $2.000 \mathrm{E}-01$ & --- & | FRACA (19) \\
\hline $\mathrm{XT}$ & Ring 20 & | $9.900 \mathrm{E}-02$ & | $1.700 \mathrm{E}-01$ & --- & | FRACA (20) \\
\hline $\mathrm{XT}$ & Ring 21 & $18.600 \mathrm{E}-02$ & | $1.500 \mathrm{E}-01$ & --- & | FRACA (21) \\
\hline $\mathrm{XT}$ & Ring 22 & $17.000 \mathrm{E}-02$ & | $1.300 \mathrm{E}-01$ & --- & | FRACA (22) \\
\hline $\mathrm{XT}$ & Ring 23 & | $5.400 \mathrm{E}-02$ & | $1.200 \mathrm{E}-01$ & --- & | FRACA (23) \\
\hline XT | & Ring 24 & $13.900 \mathrm{E}-02$ & | $5.500 \mathrm{E}-02$ & --- & | FRACA (24) \\
\hline | & & | & | & | & | \\
\hline $\mathrm{CU} \mid$ & Fraction of time spent indoors on contaminated site & $0.000 \mathrm{E}+00$ & $0.000 \mathrm{E}+00$ & --- & | FIND \\
\hline $\mathrm{CU}$ & Fraction of time spent outdoors on contaminated site & el $0.000 \mathrm{E}+00$ & $0.000 \mathrm{E}+00$ & --- & | FOTD \\
\hline $\mathrm{CU}$ & Fraction of time spent indoors in offsite Dwelling & | $6.400 \mathrm{E}-01$ & | $5.000 \mathrm{E}-01$ & --- & | FINDDWELL \\
\hline $\mathrm{CU}$ & Fraction of time spent outdoors in offsite Dwelling & $6.400 \mathrm{E}-02$ & | $1.000 \mathrm{E}-01$ & --- & | FOTDDWELL \\
\hline $\mathrm{CU} \mid$ & Fraction of time spent outdoors in agri. area 1 & $6.400 \mathrm{E}-02$ & | $1.000 \mathrm{E}-01$ & --- & | OCCUPANCY (1) \\
\hline $\mathrm{CU}$ & Fraction of time spent outdoors in agri. area 2 & $6.400 \mathrm{E}-02$ & | $1.000 \mathrm{E}-01$ & --- & | OCCUPANCY (2) \\
\hline $\mathrm{CU} \mid$ & Fraction of time spent outdoors in agri. area 3 & $6.400 \mathrm{E}-02$ & | $1.000 \mathrm{E}-01$ & --- & | OCCUPANCY (3) \\
\hline & Fraction of time spent outdoors in agri. area 4 & $6.400 \mathrm{E}-02$ & | $1.000 \mathrm{E}-01$ & --- & | OCCUPANCY (4) \\
\hline | & & | & | & | & | \\
\hline & Diffusion coefficient for radon gas $(\mathrm{m} / \mathrm{sec})$ : & | & | & | & | \\
\hline $\mathrm{DN} \mid$ & in cover material & I not used & $2.000 \mathrm{E}-06$ & --- & I DIFCV \\
\hline $\mathrm{DN} \mid$ & in foundation material & I not used & | $3.000 \mathrm{E}-07$ & --- & | DIFFL \\
\hline $\mathrm{DN} \mid$ & in contaminated zone soil & I not used & | 2.000E-06 & --- & | DIFCZ \\
\hline $\mathrm{DN} \mid$ & Thickness of building foundation (m) & I not used & $1.500 \mathrm{E}-01$ & --- & | FLOOR1 \\
\hline DN & Bulk density of building foundation $(\mathrm{g} / \mathrm{cm} \star \star 3)$ & I not used & $2.400 \mathrm{E}+00$ & --- & | DENSFL \\
\hline $\mathrm{DN}$ & Total porosity of the building foundation & I not used & $1.000 \mathrm{E}-01$ & --- & I TPFL \\
\hline $\mathrm{ADN} \mid$ & Volumetric water content of the foundation & I not used & $3.000 \mathrm{E}-02$ & --- & | PH2OFL \\
\hline DN & Building depth below ground surface (m) & I not used & $\mid-1.000 \mathrm{E}+00$ & --- & | DMFL \\
\hline DN & Radon vertical dimension of mixing (m) & I not used & $2.000 \mathrm{E}+00$ & --- & | HMIX \\
\hline $\mathrm{N}$ & Height of the building (room) (m) & I not used & | $2.500 \mathrm{E}+00$ & --- & | HRM \\
\hline DN $\mid$ & Average building air exchange rate $(1 / \mathrm{hr})$ & I not used & | $5.000 \mathrm{E}-01$ & --- & | REXG \\
\hline $\mathrm{N}$ & Building interior area factor & I not used & $0.000 \mathrm{E}+00$ & --- & | FAI \\
\hline $\mathrm{DN}$ & Emanating power of $\mathrm{Rn}-222$ gas & I not used & | $2.500 \mathrm{E}-01$ & --- & | EMANA (1) \\
\hline DN 1 & Emanating power of $\mathrm{Rn}-220$ gas & I not used & | $1.500 \mathrm{E}-01$ & --- & | EMANA (2) \\
\hline । & & | & | & | & । \\
\hline & C-14 evasion layer thickness in soil (m) & I not used & $3.000 \mathrm{E}-01$ & --- & | $\mathrm{DMC}$ \\
\hline & C-14 evasion flux rate from soil ( $1 / \mathrm{sec})$ & I not used & | $7.000 \mathrm{E}-07$ & --- & | C14EVSN \\
\hline & C-12 evasion flux rate from soil ( $1 / \mathrm{sec})$ & I not used & $1.000 \mathrm{E}-10$ & --- & | C12EVSN \\
\hline & Fraction of vegetation carbon from air & I not used & | $9.800 \mathrm{E}-01$ & --- & | CAIR \\
\hline | & Fraction of vegetation carbon from soil & I not used & | $2.000 \mathrm{E}-02$ & --- & I CSOIL \\
\hline
\end{tabular}


RESRAD-OFFSITE, Version 2.5

Parent Dose Report

Title : RESRAD-OFFSITE Parameters for Offsite Resident Farmer Forward Run 100,000 Years

File : OFFSITE-RF_FORWARD-7-11-100000yr.ROF

Site-Specific Parameter Summary (continued)

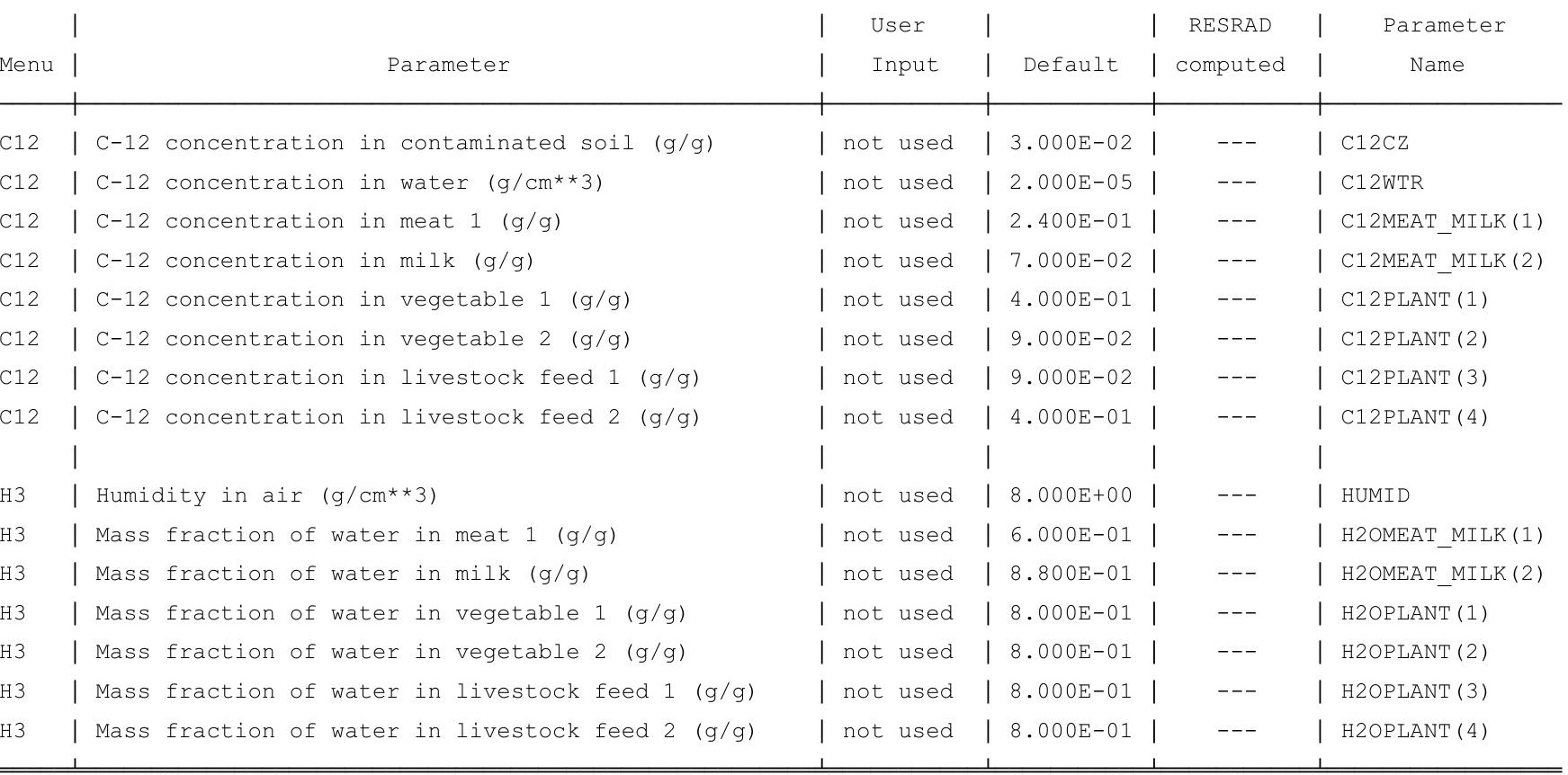

Summary of Pathway Selections

\begin{tabular}{l|c} 
Pathway & User Selection \\
\hline 1 -- external gamma & active \\
2 -- inhalation (w/o radon) & active \\
3 -- plant ingestion & active \\
4 -- meat ingestion & active \\
5 -- milk ingestion & active \\
6 -- aquatic foods & suppressed \\
7 -- drinking water & active \\
8 -- soil ingestion & active \\
9 -- radon & suppressed \\
\hline \hline
\end{tabular}


RESRAD-OFFSITE, Version $2.5 \quad \mathrm{~T}^{1 / 2}$ Limit $=180$ days

Parent Dose Report

Title : RESRAD-OFFSITE Parameters for Offsite Resident Farmer Forward Run 100,000 Years

File : OFFSITE-RF_FORWARD-7-11-100000yr.ROF

Contaminated Zone Dimensions

Area: 102144.00 square meters

Thickness:

Cover Depth:
Initial Soil Concentrations, pCi/g

$\begin{array}{ll}\text { Am-241 } & 3.500 \mathrm{E}+01 \\ \mathrm{Cs}-137 & 1.900 \mathrm{E}+01 \\ \mathrm{~Np}-237 & 5.500 \mathrm{E}+00 \\ \mathrm{Pu}-238 & 3.900 \mathrm{E}+01 \\ \mathrm{Pu}-239 & 3.600 \mathrm{E}+01 \\ \mathrm{Pu}-240 & 3.600 \mathrm{E}+01 \\ \mathrm{TC}-99 & 5.200 \mathrm{E}+01 \\ \mathrm{Th}-228 & 4.000 \mathrm{E}+00 \\ \mathrm{Th}-230 & 1.000 \mathrm{E}+02 \\ \mathrm{Th}-232 & 4.000 \mathrm{E}+00 \\ \mathrm{U}-234 & 1.600 \mathrm{E}+02 \\ \mathrm{U}-235 & 6.500 \mathrm{E}+00 \\ \mathrm{U}-238 & 1.600 \mathrm{E}+02\end{array}$

Total Dose TDOSE(t), mrem/yr

Basic Radiation Dose Limit $=1.000 \mathrm{E}+00 \mathrm{mrem} / \mathrm{yr}$

Total Mixture Sum $M(t)$ = Fraction of Basic Dose Limit Received at Time (t)
$t($ years) :
$0.000 \mathrm{E}+00 \quad 1.000 \mathrm{E}+00 \quad 5.000 \mathrm{E}+01$
$1.000 \mathrm{E}+02$
5. $000 \mathrm{E}+02$
$1.026 \mathrm{E}+03 \quad 1.000 \mathrm{E}+04 \quad 1.000 \mathrm{E}+05$
TDOSE $(t)$
M $(t)$
$3.125 \mathrm{E}-14 \quad 2.881 \mathrm{E}-14 \quad 4.593 \mathrm{E}-14$
$6.423 \mathrm{E}-14$
$9.278 \mathrm{E}-13$
$3.108 \mathrm{E}-112.179 \mathrm{E}+00$
1. $987 \mathrm{E}+00$
$M(t): \quad 3.125 E-14 \quad 2.881 E-14$
4.593E-14 6.423E-14
$9.278 \mathrm{E}-13$
$3.108 \mathrm{E}-11$
$2.179 \mathrm{E}+00$
1. $987 \mathrm{E}+00$

Maximum TDOSE $(t): 2.179 \mathrm{E}+00 \mathrm{mrem} / \mathrm{yr}$ at $t=10061$ years 
RESRAD-OFFSITE, Version 2.

Parent Dose Report

Title : RESRAD-OFFSITE Parameters for Offsite Resident Farmer Forward Run 100,000 Years

File : OFFSITE-RF_FORWARD-7-11-100000yr.ROF

Total Dose Contributions TDOSE (i,p,t) for Individual Radionuclides (i) and Pathways (p) in mrem/yr and as a Percentage of Total Dose at $t=0$ years

From releases to ground water and to surface water

\begin{tabular}{|c|c|c|c|c|c|c|c|c|c|c|c|c|c|c|c|c|}
\hline & \multicolumn{2}{|c|}{ Ground } & \multicolumn{2}{|l|}{ Fish } & \multicolumn{2}{|c|}{ Radon } & \multicolumn{2}{|c|}{ Plant } & \multicolumn{2}{|l|}{ Meat } & \multicolumn{2}{|l|}{ Milk } & \multicolumn{2}{|l|}{ Soil } & \multicolumn{2}{|c|}{ Water } \\
\hline ide & Dose & $\%$ & Dose & $\%$ & Dose & 응 & Dose & $\frac{\circ}{0}$ & Dose & \% & Dose & 응 & Dose & $\%$ & Dose & $\%$ \\
\hline-241 & $0.00 \mathrm{E}+00$ & 0 & $0.00 E+00$ & 0 & $0.00 \mathrm{E}+00$ & 0 & $0.00 \mathrm{E}+00$ & 0 & $0.00 \mathrm{E}+00$ & 0 & $0.00 \mathrm{E}+00$ & 0 & $0.00 \mathrm{E}+00$ & 0 & $0.00 \mathrm{E}+00$ & 0 \\
\hline-137 & $0.00 \mathrm{E}+00$ & 0 & $0.00 \mathrm{E}+00$ & 0 & $0.00 \mathrm{E}+00$ & 0 & $0.00 \mathrm{E}+00$ & 0 & $0.00 \mathrm{E}+00$ & 0 & $0.00 \mathrm{E}+00$ & 0 & $0.00 \mathrm{E}+00$ & 0 & $0.00 \mathrm{E}+00$ & 0 \\
\hline-237 & $0.00 \mathrm{E}+00$ & 0 & $0.00 \mathrm{E}+00$ & 0 & $0.00 \mathrm{E}+00$ & 0 & $0.00 \mathrm{E}+00$ & 0 & $0.00 \mathrm{E}+00$ & 0 & $0.00 \mathrm{E}+00$ & 0 & $0.00 \mathrm{E}+00$ & 0 & $0.00 \mathrm{E}+00$ & 0 \\
\hline-238 & $0.00 \mathrm{E}+00$ & 0 & $0.00 \mathrm{E}+00$ & 0 & $0.00 E+00$ & 0 & $0.00 \mathrm{E}+00$ & 0 & $0.00 \mathrm{E}+00$ & 0 & $0.00 E+00$ & 0 & $0.00 \mathrm{E}+00$ & 0 & $0.00 \mathrm{E}+00$ & 0 \\
\hline-239 & $0.00 \mathrm{E}+00$ & 0 & $0.00 \mathrm{E}+00$ & 0 & $0.00 \mathrm{E}+00$ & 0 & $0.00 \mathrm{E}+00$ & 0 & $0.00 \mathrm{E}+00$ & 0 & $0.00 \mathrm{E}+00$ & 0 & $0.00 \mathrm{E}+00$ & 0 & $0.00 \mathrm{E}+00$ & 0 \\
\hline-240 & $0.00 \mathrm{E}+00$ & 0 & $0.00 \mathrm{E}+00$ & 0 & $0.00 \mathrm{E}+00$ & 0 & $0.00 \mathrm{E}+00$ & 0 & $0.00 \mathrm{E}+00$ & 0 & $0.00 \mathrm{E}+00$ & 0 & $0.00 \mathrm{E}+00$ & 0 & $0.00 \mathrm{E}+00$ & 0 \\
\hline-99 & $0.00 \mathrm{E}+00$ & 0 & $0.00 \mathrm{E}+00$ & 0 & $0.00 \mathrm{E}+00$ & 0 & $0.00 \mathrm{E}+00$ & 0 & $0.00 \mathrm{E}+00$ & 0 & $0.00 E+00$ & 0 & $0.00 \mathrm{E}+00$ & 0 & $0.00 \mathrm{E}+00$ & 0 \\
\hline-228 & $0.00 \mathrm{E}+00$ & 0 & $0.00 \mathrm{E}+00$ & 0 & $0.00 \mathrm{E}+00$ & 0 & $0.00 \mathrm{E}+00$ & 0 & $0.00 \mathrm{E}+00$ & 0 & $0.00 \mathrm{E}+00$ & 0 & $0.00 \mathrm{E}+00$ & 0 & $0.00 \mathrm{E}+00$ & 0 \\
\hline-230 & $0.00 \mathrm{E}+00$ & 0 & $0.00 \mathrm{E}+00$ & 0 & $0.00 \mathrm{E}+00$ & 0 & $0.00 \mathrm{E}+00$ & 0 & $0.00 \mathrm{E}+00$ & 0 & $0.00 \mathrm{E}+00$ & 0 & $0.00 \mathrm{E}+00$ & 0 & $0.00 \mathrm{E}+00$ & 0 \\
\hline-232 & $0.00 \mathrm{E}+00$ & 0 & $0.00 \mathrm{E}+00$ & 0 & $0.00 \mathrm{E}+00$ & 0 & $0.00 \mathrm{E}+00$ & 0 & $0.00 \mathrm{E}+00$ & 0 & $0.00 \mathrm{E}+00$ & 0 & $0.00 \mathrm{E}+00$ & 0 & $0.00 \mathrm{E}+00$ & 0 \\
\hline 4 & $0.00 \mathrm{E}+00$ & 0 & $0.00 \mathrm{E}+00$ & 0 & $0.00 \mathrm{E}+00$ & 0 & $0.00 \mathrm{E}+00$ & 0 & $0.00 \mathrm{E}+00$ & 0 & $0.00 \mathrm{E}+00$ & 0 & $0.00 \mathrm{E}+00$ & 0 & $0.00 \mathrm{E}+00$ & 0 \\
\hline 35 & $0.00 \mathrm{E}+00$ & 0 & $0.00 \mathrm{E}+00$ & 0 & $0.00 \mathrm{E}+00$ & 0 & $0.00 \mathrm{E}+00$ & 0 & $0.00 \mathrm{E}+00$ & 0 & $0.00 \mathrm{E}+00$ & 0 & $0.00 \mathrm{E}+00$ & 0 & $0.00 \mathrm{E}+00$ & 0 \\
\hline 38 & $0.00 \mathrm{E}+00$ & 0 & $0.00 \mathrm{E}+00$ & 0 & $0.00 \mathrm{E}+00$ & 0 & $0.00 \mathrm{E}+00$ & 0 & $0.00 \mathrm{E}+00$ & 0 & $0.00 \mathrm{E}+00$ & 0 & $0.00 \mathrm{E}+00$ & 0 & $0.00 \mathrm{E}+00$ & 0 \\
\hline & $0.00 \mathrm{E}+00$ & 0 & $0.00 E+00$ & 0 & $0.00 \mathrm{E}+00$ & 0 & $0.00 \mathrm{E}+00$ & 0 & $0.00 \mathrm{E}+00$ & 0 & $0.00 \mathrm{E}+00$ & 0 & $0.00 \mathrm{E}+00$ & 0 & $0.00 \mathrm{E}+00$ & \\
\hline
\end{tabular}

Total Dose Contributions TDOSE (i,p,t) for Individual Radionuclides (i) and Pathways (p)

in mrem/yr and as a Percentage of Total Dose at $t=0$ years

Directly from primary contamination and from release to atmosphere (Inhalation excludes radon)

\begin{tabular}{|c|c|c|c|c|c|c|c|c|c|c|c|c|c|c|c|c|}
\hline & \multicolumn{2}{|c|}{ Ground } & \multicolumn{2}{|c|}{ Inhalation } & \multicolumn{2}{|c|}{ Radon } & \multicolumn{2}{|c|}{ Plant } & \multicolumn{2}{|l|}{ Meat } & \multicolumn{2}{|l|}{ Milk } & \multicolumn{2}{|l|}{ Soil } & \multicolumn{2}{|c|}{ All Pathways* } \\
\hline clide & Dose & $\%$ & Dose & $\%$ & Dose & $\%$ & Dose & 음 & Dose & $\%$ & Dose & 음 & Dose & $\%$ & Dose & $\%$ \\
\hline-241 & $2.80 E-26$ & 0 & $0.00 \mathrm{E}+00$ & 0 & $0.00 E+00$ & 0 & $0.00 \mathrm{E}+00$ & 0 & $0.00 \mathrm{E}+00$ & 0 & $0.00 \mathrm{E}+00$ & 0 & $0.00 \mathrm{E}+00$ & 0 & $2.80 E-26$ & 0 \\
\hline-137 & $1.18 \mathrm{E}-16$ & 0 & $0.00 E+00$ & 0 & $0.00 E+00$ & 0 & $0.00 \mathrm{E}+00$ & 0 & $0.00 \mathrm{E}+00$ & 0 & $0.00 E+00$ & 0 & $0.00 \mathrm{E}+00$ & 0 & 1. $18 \mathrm{E}-16$ & 0 \\
\hline-237 & $2.59 E-20$ & 0 & $0.00 E+00$ & 0 & $0.00 E+00$ & 0 & $0.00 \mathrm{E}+00$ & 0 & $0.00 \mathrm{E}+00$ & 0 & $0.00 E+00$ & 0 & $0.00 \mathrm{E}+00$ & 0 & $2.59 E-20$ & 0 \\
\hline-238 & $1.18 E-27$ & 0 & $0.00 E+00$ & 0 & $0.00 \mathrm{E}+00$ & 0 & $0.00 \mathrm{E}+00$ & 0 & $0.00 \mathrm{E}+00$ & 0 & $0.00 \mathrm{E}+00$ & 0 & $0.00 \mathrm{E}+00$ & 0 & 1. $18 \mathrm{E}-27$ & 0 \\
\hline-239 & $2.13 E-24$ & 0 & $0.00 \mathrm{E}+00$ & 0 & $0.00 \mathrm{E}+00$ & 0 & $0.00 \mathrm{E}+00$ & 0 & $0.00 \mathrm{E}+00$ & 0 & $0.00 \mathrm{E}+00$ & 0 & $0.00 \mathrm{E}+00$ & 0 & $2.13 E-24$ & 0 \\
\hline-240 & $2.58 E-31$ & 0 & $0.00 E+00$ & 0 & $0.00 \mathrm{E}+00$ & 0 & $0.00 \mathrm{E}+00$ & 0 & $0.00 \mathrm{E}+00$ & 0 & $0.00 E+00$ & 0 & $0.00 \mathrm{E}+00$ & 0 & $2.58 E-31$ & 0 \\
\hline-99 & 1. $48 E-32$ & 0 & $0.00 E+00$ & 0 & $0.00 \mathrm{E}+00$ & 0 & $0.00 \mathrm{E}+00$ & 0 & $0.00 \mathrm{E}+00$ & 0 & $0.00 E+00$ & 0 & $0.00 \mathrm{E}+00$ & 0 & 1. $48 \mathrm{E}-32$ & 0 \\
\hline-228 & $3.01 \mathrm{E}-14$ & 96 & $0.00 \mathrm{E}+00$ & 0 & $0.00 \mathrm{E}+00$ & 0 & $0.00 \mathrm{E}+00$ & 0 & $0.00 \mathrm{E}+00$ & 0 & $0.00 \mathrm{E}+00$ & 0 & $0.00 \mathrm{E}+00$ & 0 & $3.01 \mathrm{E}-14$ & 96 \\
\hline-230 & $1.92 \mathrm{E}-17$ & 0 & $0.00 E+00$ & 0 & $0.00 \mathrm{E}+00$ & 0 & $0.00 \mathrm{E}+00$ & 0 & $0.00 \mathrm{E}+00$ & 0 & $0.00 E+00$ & 0 & $0.00 \mathrm{E}+00$ & 0 & 1. $92 \mathrm{E}-17$ & 0 \\
\hline-232 & $9.41 \mathrm{E}-16$ & 3 & $0.00 E+00$ & 0 & $0.00 \mathrm{E}+00$ & 0 & $0.00 \mathrm{E}+00$ & 0 & $0.00 \mathrm{E}+00$ & 0 & $0.00 \mathrm{E}+00$ & 0 & $0.00 \mathrm{E}+00$ & 0 & $9.41 \mathrm{E}-16$ & 3 \\
\hline 34 & $8.46 \mathrm{E}-22$ & 0 & $0.00 \mathrm{E}+00$ & 0 & $0.00 \mathrm{E}+00$ & 0 & $0.00 \mathrm{E}+00$ & 0 & $0.00 \mathrm{E}+00$ & 0 & $0.00 \mathrm{E}+00$ & 0 & $0.00 \mathrm{E}+00$ & 0 & $8.46 \mathrm{E}-22$ & 0 \\
\hline 35 & $4.01 E-22$ & 0 & $0.00 E+00$ & 0 & $0.00 E+00$ & 0 & $0.00 \mathrm{E}+00$ & 0 & $0.00 \mathrm{E}+00$ & 0 & $0.00 E+00$ & 0 & $0.00 \mathrm{E}+00$ & 0 & $4.01 E-22$ & 0 \\
\hline 38 & $1.12 \mathrm{E}-16$ & 0 & $0.00 E+00$ & 0 & $0.00 \mathrm{E}+00$ & 0 & $0.00 \mathrm{E}+00$ & 0 & $0.00 \mathrm{E}+00$ & 0 & $0.00 E+00$ & 0 & $0.00 \mathrm{E}+00$ & 0 & 1. $12 \mathrm{E}-16$ & 0 \\
\hline & $3.13 \mathrm{E}-14$ & 100 & $0.00 \mathrm{E}+00$ & 0 & $0.00 \mathrm{E}+00$ & 0 & $0.00 \mathrm{E}+00$ & 0 & $0.00 \mathrm{E}+00$ & 0 & $0.00 \mathrm{E}+00$ & 0 & $0.00 \mathrm{E}+00$ & 0 & $3.13 \mathrm{E}-14$ & 100 \\
\hline
\end{tabular}

* Sum of dose from all releases and from primary contamination. 
RESRAD-OFFSITE, Version 2.

Parent Dose Report

Title : RESRAD-OFFSITE Parameters for Offsite Resident Farmer Forward Run 100,000 Years

File : OFFSITE-RF_FORWARD-7-11-100000yr.ROF

Total Dose Contributions TDOSE (i,p,t) for Individual Radionuclides (i) and Pathways (p) in mrem/yr and as a Percentage of Total Dose at $t=1$ years

From releases to ground water and to surface water

\begin{tabular}{|c|c|c|c|c|c|c|c|c|c|c|c|c|c|c|c|c|}
\hline & \multicolumn{2}{|c|}{ Ground } & \multicolumn{2}{|l|}{ Fish } & \multicolumn{2}{|c|}{ Radon } & \multicolumn{2}{|c|}{ Plant } & \multicolumn{2}{|l|}{ Meat } & \multicolumn{2}{|l|}{ Milk } & \multicolumn{2}{|l|}{ Soil } & \multicolumn{2}{|c|}{ Water } \\
\hline ide & Dose & $\%$ & Dose & $\%$ & Dose & 응 & Dose & $\frac{\circ}{0}$ & Dose & \% & Dose & 응 & Dose & $\%$ & Dose & $\%$ \\
\hline-241 & $0.00 \mathrm{E}+00$ & 0 & $0.00 E+00$ & 0 & $0.00 \mathrm{E}+00$ & 0 & $0.00 \mathrm{E}+00$ & 0 & $0.00 \mathrm{E}+00$ & 0 & $0.00 \mathrm{E}+00$ & 0 & $0.00 \mathrm{E}+00$ & 0 & $0.00 \mathrm{E}+00$ & 0 \\
\hline-137 & $0.00 \mathrm{E}+00$ & 0 & $0.00 \mathrm{E}+00$ & 0 & $0.00 \mathrm{E}+00$ & 0 & $0.00 \mathrm{E}+00$ & 0 & $0.00 \mathrm{E}+00$ & 0 & $0.00 \mathrm{E}+00$ & 0 & $0.00 \mathrm{E}+00$ & 0 & $0.00 \mathrm{E}+00$ & 0 \\
\hline-237 & $0.00 \mathrm{E}+00$ & 0 & $0.00 \mathrm{E}+00$ & 0 & $0.00 \mathrm{E}+00$ & 0 & $0.00 \mathrm{E}+00$ & 0 & $0.00 \mathrm{E}+00$ & 0 & $0.00 \mathrm{E}+00$ & 0 & $0.00 \mathrm{E}+00$ & 0 & $0.00 \mathrm{E}+00$ & 0 \\
\hline-238 & $0.00 \mathrm{E}+00$ & 0 & $0.00 \mathrm{E}+00$ & 0 & $0.00 E+00$ & 0 & $0.00 \mathrm{E}+00$ & 0 & $0.00 \mathrm{E}+00$ & 0 & $0.00 E+00$ & 0 & $0.00 \mathrm{E}+00$ & 0 & $0.00 \mathrm{E}+00$ & 0 \\
\hline-239 & $0.00 \mathrm{E}+00$ & 0 & $0.00 \mathrm{E}+00$ & 0 & $0.00 \mathrm{E}+00$ & 0 & $0.00 \mathrm{E}+00$ & 0 & $0.00 \mathrm{E}+00$ & 0 & $0.00 \mathrm{E}+00$ & 0 & $0.00 \mathrm{E}+00$ & 0 & $0.00 \mathrm{E}+00$ & 0 \\
\hline-240 & $0.00 \mathrm{E}+00$ & 0 & $0.00 \mathrm{E}+00$ & 0 & $0.00 \mathrm{E}+00$ & 0 & $0.00 \mathrm{E}+00$ & 0 & $0.00 \mathrm{E}+00$ & 0 & $0.00 \mathrm{E}+00$ & 0 & $0.00 \mathrm{E}+00$ & 0 & $0.00 \mathrm{E}+00$ & 0 \\
\hline-99 & $0.00 \mathrm{E}+00$ & 0 & $0.00 \mathrm{E}+00$ & 0 & $0.00 \mathrm{E}+00$ & 0 & $0.00 \mathrm{E}+00$ & 0 & $0.00 \mathrm{E}+00$ & 0 & $0.00 E+00$ & 0 & $0.00 \mathrm{E}+00$ & 0 & $0.00 \mathrm{E}+00$ & 0 \\
\hline-228 & $0.00 \mathrm{E}+00$ & 0 & $0.00 \mathrm{E}+00$ & 0 & $0.00 \mathrm{E}+00$ & 0 & $0.00 \mathrm{E}+00$ & 0 & $0.00 \mathrm{E}+00$ & 0 & $0.00 \mathrm{E}+00$ & 0 & $0.00 \mathrm{E}+00$ & 0 & $0.00 \mathrm{E}+00$ & 0 \\
\hline-230 & $0.00 \mathrm{E}+00$ & 0 & $0.00 \mathrm{E}+00$ & 0 & $0.00 \mathrm{E}+00$ & 0 & $0.00 \mathrm{E}+00$ & 0 & $0.00 \mathrm{E}+00$ & 0 & $0.00 \mathrm{E}+00$ & 0 & $0.00 \mathrm{E}+00$ & 0 & $0.00 \mathrm{E}+00$ & 0 \\
\hline-232 & $0.00 \mathrm{E}+00$ & 0 & $0.00 \mathrm{E}+00$ & 0 & $0.00 \mathrm{E}+00$ & 0 & $0.00 \mathrm{E}+00$ & 0 & $0.00 \mathrm{E}+00$ & 0 & $0.00 \mathrm{E}+00$ & 0 & $0.00 \mathrm{E}+00$ & 0 & $0.00 \mathrm{E}+00$ & 0 \\
\hline 4 & $0.00 \mathrm{E}+00$ & 0 & $0.00 \mathrm{E}+00$ & 0 & $0.00 \mathrm{E}+00$ & 0 & $0.00 \mathrm{E}+00$ & 0 & $0.00 \mathrm{E}+00$ & 0 & $0.00 \mathrm{E}+00$ & 0 & $0.00 \mathrm{E}+00$ & 0 & $0.00 \mathrm{E}+00$ & 0 \\
\hline 35 & $0.00 \mathrm{E}+00$ & 0 & $0.00 \mathrm{E}+00$ & 0 & $0.00 \mathrm{E}+00$ & 0 & $0.00 \mathrm{E}+00$ & 0 & $0.00 \mathrm{E}+00$ & 0 & $0.00 \mathrm{E}+00$ & 0 & $0.00 \mathrm{E}+00$ & 0 & $0.00 \mathrm{E}+00$ & 0 \\
\hline 38 & $0.00 \mathrm{E}+00$ & 0 & $0.00 \mathrm{E}+00$ & 0 & $0.00 \mathrm{E}+00$ & 0 & $0.00 \mathrm{E}+00$ & 0 & $0.00 \mathrm{E}+00$ & 0 & $0.00 \mathrm{E}+00$ & 0 & $0.00 \mathrm{E}+00$ & 0 & $0.00 \mathrm{E}+00$ & 0 \\
\hline & $0.00 \mathrm{E}+00$ & 0 & $0.00 E+00$ & 0 & $0.00 \mathrm{E}+00$ & 0 & $0.00 \mathrm{E}+00$ & 0 & $0.00 \mathrm{E}+00$ & 0 & $0.00 \mathrm{E}+00$ & 0 & $0.00 \mathrm{E}+00$ & 0 & $0.00 \mathrm{E}+00$ & \\
\hline
\end{tabular}

Total Dose Contributions TDOSE (i,p,t) for Individual Radionuclides (i) and Pathways (p)

in mrem/yr and as a Percentage of Total Dose at $t=1$ years

Directly from primary contamination and from release to atmosphere (Inhalation excludes radon)

\begin{tabular}{|c|c|c|c|c|c|c|c|c|c|c|c|c|c|c|c|c|}
\hline & \multicolumn{2}{|c|}{ Ground } & \multicolumn{2}{|c|}{ Inhalation } & \multicolumn{2}{|c|}{ Radon } & \multicolumn{2}{|c|}{ Plant } & \multicolumn{2}{|l|}{ Meat } & \multicolumn{2}{|l|}{ Milk } & \multicolumn{2}{|l|}{ Soil } & \multicolumn{2}{|c|}{ All Pathways* } \\
\hline clide & Dose & \% & Dose & $\%$ & Dose & $\%$ & Dose & 음 & Dose & $\%$ & Dose & $\%$ & Dose & \% & Dose & $\frac{\circ}{0}$ \\
\hline-241 & $8.46 E-26$ & 0 & $0.00 E+00$ & 0 & $0.00 \mathrm{E}+00$ & 0 & $0.00 \mathrm{E}+00$ & 0 & $0.00 \mathrm{E}+00$ & 0 & $0.00 \mathrm{E}+00$ & 0 & $0.00 \mathrm{E}+00$ & 0 & $8.46 \mathrm{E}-26$ & 0 \\
\hline-137 & $1.16 \mathrm{E}-16$ & 0 & $0.00 \mathrm{E}+00$ & 0 & $0.00 \mathrm{E}+00$ & 0 & $0.00 \mathrm{E}+00$ & 0 & $0.00 \mathrm{E}+00$ & 0 & $0.00 \mathrm{E}+00$ & 0 & $0.00 \mathrm{E}+00$ & 0 & $1.16 \mathrm{E}-16$ & 0 \\
\hline-237 & $2.61 \mathrm{E}-20$ & 0 & $0.00 \mathrm{E}+00$ & 0 & $0.00 \mathrm{E}+00$ & 0 & $0.00 \mathrm{E}+00$ & 0 & $0.00 \mathrm{E}+00$ & 0 & $0.00 \mathrm{E}+00$ & 0 & $0.00 \mathrm{E}+00$ & 0 & $2.61 E-20$ & 0 \\
\hline-238 & $4.72 E-27$ & 0 & $0.00 \mathrm{E}+00$ & 0 & $0.00 \mathrm{E}+00$ & 0 & $0.00 \mathrm{E}+00$ & 0 & $0.00 \mathrm{E}+00$ & 0 & $0.00 \mathrm{E}+00$ & 0 & $0.00 \mathrm{E}+00$ & 0 & $4.72 \mathrm{E}-27$ & 0 \\
\hline-239 & $2.16 \mathrm{E}-24$ & 0 & $0.00 \mathrm{E}+00$ & 0 & $0.00 \mathrm{E}+00$ & 0 & $0.00 \mathrm{E}+00$ & 0 & $0.00 \mathrm{E}+00$ & 0 & $0.00 \mathrm{E}+00$ & 0 & $0.00 \mathrm{E}+00$ & 0 & $2.16 \mathrm{E}-24$ & 0 \\
\hline-240 & 4. $49 \mathrm{E}-31$ & 0 & $0.00 \mathrm{E}+00$ & 0 & $0.00 \mathrm{E}+00$ & 0 & $0.00 \mathrm{E}+00$ & 0 & $0.00 \mathrm{E}+00$ & 0 & $0.00 \mathrm{E}+00$ & 0 & $0.00 \mathrm{E}+00$ & 0 & $4.49 E-31$ & 0 \\
\hline-99 & $1.50 \mathrm{E}-32$ & 0 & $0.00 \mathrm{E}+00$ & 0 & $0.00 \mathrm{E}+00$ & 0 & $0.00 \mathrm{E}+00$ & 0 & $0.00 \mathrm{E}+00$ & 0 & $0.00 \mathrm{E}+00$ & 0 & $0.00 \mathrm{E}+00$ & 0 & $1.50 \mathrm{E}-32$ & 0 \\
\hline-228 & $2.57 \mathrm{E}-14$ & 89 & $0.00 \mathrm{E}+00$ & 0 & $0.00 \mathrm{E}+00$ & 0 & $0.00 \mathrm{E}+00$ & 0 & $0.00 \mathrm{E}+00$ & 0 & $0.00 \mathrm{E}+00$ & 0 & $0.00 \mathrm{E}+00$ & 0 & $2.57 \mathrm{E}-14$ & 89 \\
\hline-230 & $5.79 \mathrm{E}-17$ & 0 & $0.00 \mathrm{E}+00$ & 0 & $0.00 \mathrm{E}+00$ & 0 & $0.00 \mathrm{E}+00$ & 0 & $0.00 \mathrm{E}+00$ & 0 & $0.00 \mathrm{E}+00$ & 0 & $0.00 \mathrm{E}+00$ & 0 & $5.79 \mathrm{E}-17$ & 0 \\
\hline-232 & $2.83 E-15$ & 10 & $0.00 \mathrm{E}+00$ & 0 & $0.00 \mathrm{E}+00$ & 0 & $0.00 \mathrm{E}+00$ & 0 & $0.00 \mathrm{E}+00$ & 0 & $0.00 \mathrm{E}+00$ & 0 & $0.00 \mathrm{E}+00$ & 0 & $2.83 E-15$ & 10 \\
\hline 234 & $2.84 \mathrm{E}-21$ & 0 & $0.00 E+00$ & 0 & $0.00 \mathrm{E}+00$ & 0 & $0.00 \mathrm{E}+00$ & 0 & $0.00 \mathrm{E}+00$ & 0 & $0.00 \mathrm{E}+00$ & 0 & $0.00 \mathrm{E}+00$ & 0 & $2.84 \mathrm{E}-21$ & 0 \\
\hline 235 & $4.12 \mathrm{E}-22$ & 0 & $0.00 \mathrm{E}+00$ & 0 & $0.00 \mathrm{E}+00$ & 0 & $0.00 \mathrm{E}+00$ & 0 & $0.00 \mathrm{E}+00$ & 0 & $0.00 \mathrm{E}+00$ & 0 & $0.00 \mathrm{E}+00$ & 0 & $4.12 \mathrm{E}-22$ & 0 \\
\hline 38 & $1.13 \mathrm{E}-16$ & 0 & $0.00 \mathrm{E}+00$ & 0 & $0.00 \mathrm{E}+00$ & 0 & $0.00 \mathrm{E}+00$ & 0 & $0.00 \mathrm{E}+00$ & 0 & $0.00 \mathrm{E}+00$ & 0 & $0.00 \mathrm{E}+00$ & 0 & $1.13 \mathrm{E}-16$ & 0 \\
\hline & $2.88 \mathrm{E}-14$ & 100 & $0.00 \mathrm{E}+00$ & 0 & $0.00 \mathrm{E}+00$ & 0 & $0.00 \mathrm{E}+00$ & 0 & $0.00 \mathrm{E}+00$ & 0 & $0.00 \mathrm{E}+00$ & 0 & $0.00 \mathrm{E}+00$ & 0 & $2.88 \mathrm{E}-14$ & 100 \\
\hline
\end{tabular}

* Sum of dose from all releases and from primary contamination. 
RESRAD-OFFSITE, Version 2.

Parent Dose Report

Title : RESRAD-OFFSITE Parameters for Offsite Resident Farmer Forward Run 100,000 Years

File : OFFSITE-RF_FORWARD-7-11-100000yr.ROF

Total Dose Contributions TDOSE (i,p,t) for Individual Radionuclides (i) and Pathways (p) in mrem/yr and as a Percentage of Total Dose at $t=50$ years

From releases to ground water and to surface water

\begin{tabular}{|c|c|c|c|c|c|c|c|c|c|c|c|c|c|c|c|c|}
\hline & \multicolumn{2}{|c|}{ Ground } & \multicolumn{2}{|l|}{ Fish } & \multicolumn{2}{|c|}{ Radon } & \multicolumn{2}{|c|}{ Plant } & \multicolumn{2}{|l|}{ Meat } & \multicolumn{2}{|l|}{ Milk } & \multicolumn{2}{|l|}{ Soil } & \multicolumn{2}{|c|}{ Water } \\
\hline ide & Dose & $\%$ & Dose & $\%$ & Dose & 응 & Dose & $\frac{\circ}{0}$ & Dose & \% & Dose & 응 & Dose & $\%$ & Dose & $\%$ \\
\hline-241 & $0.00 \mathrm{E}+00$ & 0 & $0.00 E+00$ & 0 & $0.00 \mathrm{E}+00$ & 0 & $0.00 \mathrm{E}+00$ & 0 & $0.00 \mathrm{E}+00$ & 0 & $0.00 \mathrm{E}+00$ & 0 & $0.00 \mathrm{E}+00$ & 0 & $0.00 \mathrm{E}+00$ & 0 \\
\hline-137 & $0.00 \mathrm{E}+00$ & 0 & $0.00 \mathrm{E}+00$ & 0 & $0.00 \mathrm{E}+00$ & 0 & $0.00 \mathrm{E}+00$ & 0 & $0.00 \mathrm{E}+00$ & 0 & $0.00 \mathrm{E}+00$ & 0 & $0.00 \mathrm{E}+00$ & 0 & $0.00 \mathrm{E}+00$ & 0 \\
\hline-237 & $0.00 \mathrm{E}+00$ & 0 & $0.00 \mathrm{E}+00$ & 0 & $0.00 \mathrm{E}+00$ & 0 & $0.00 \mathrm{E}+00$ & 0 & $0.00 \mathrm{E}+00$ & 0 & $0.00 \mathrm{E}+00$ & 0 & $0.00 \mathrm{E}+00$ & 0 & $0.00 \mathrm{E}+00$ & 0 \\
\hline-238 & $0.00 \mathrm{E}+00$ & 0 & $0.00 \mathrm{E}+00$ & 0 & $0.00 E+00$ & 0 & $0.00 \mathrm{E}+00$ & 0 & $0.00 \mathrm{E}+00$ & 0 & $0.00 E+00$ & 0 & $0.00 \mathrm{E}+00$ & 0 & $0.00 \mathrm{E}+00$ & 0 \\
\hline-239 & $0.00 \mathrm{E}+00$ & 0 & $0.00 \mathrm{E}+00$ & 0 & $0.00 \mathrm{E}+00$ & 0 & $0.00 \mathrm{E}+00$ & 0 & $0.00 \mathrm{E}+00$ & 0 & $0.00 \mathrm{E}+00$ & 0 & $0.00 \mathrm{E}+00$ & 0 & $0.00 \mathrm{E}+00$ & 0 \\
\hline-240 & $0.00 \mathrm{E}+00$ & 0 & $0.00 \mathrm{E}+00$ & 0 & $0.00 \mathrm{E}+00$ & 0 & $0.00 \mathrm{E}+00$ & 0 & $0.00 \mathrm{E}+00$ & 0 & $0.00 \mathrm{E}+00$ & 0 & $0.00 \mathrm{E}+00$ & 0 & $0.00 \mathrm{E}+00$ & 0 \\
\hline-99 & $0.00 \mathrm{E}+00$ & 0 & $0.00 \mathrm{E}+00$ & 0 & $0.00 \mathrm{E}+00$ & 0 & $0.00 \mathrm{E}+00$ & 0 & $0.00 \mathrm{E}+00$ & 0 & $0.00 E+00$ & 0 & $0.00 \mathrm{E}+00$ & 0 & $0.00 \mathrm{E}+00$ & 0 \\
\hline-228 & $0.00 \mathrm{E}+00$ & 0 & $0.00 \mathrm{E}+00$ & 0 & $0.00 \mathrm{E}+00$ & 0 & $0.00 \mathrm{E}+00$ & 0 & $0.00 \mathrm{E}+00$ & 0 & $0.00 \mathrm{E}+00$ & 0 & $0.00 \mathrm{E}+00$ & 0 & $0.00 \mathrm{E}+00$ & 0 \\
\hline-230 & $0.00 \mathrm{E}+00$ & 0 & $0.00 \mathrm{E}+00$ & 0 & $0.00 \mathrm{E}+00$ & 0 & $0.00 \mathrm{E}+00$ & 0 & $0.00 \mathrm{E}+00$ & 0 & $0.00 \mathrm{E}+00$ & 0 & $0.00 \mathrm{E}+00$ & 0 & $0.00 \mathrm{E}+00$ & 0 \\
\hline-232 & $0.00 \mathrm{E}+00$ & 0 & $0.00 \mathrm{E}+00$ & 0 & $0.00 \mathrm{E}+00$ & 0 & $0.00 \mathrm{E}+00$ & 0 & $0.00 \mathrm{E}+00$ & 0 & $0.00 \mathrm{E}+00$ & 0 & $0.00 \mathrm{E}+00$ & 0 & $0.00 \mathrm{E}+00$ & 0 \\
\hline 4 & $0.00 \mathrm{E}+00$ & 0 & $0.00 \mathrm{E}+00$ & 0 & $0.00 \mathrm{E}+00$ & 0 & $0.00 \mathrm{E}+00$ & 0 & $0.00 \mathrm{E}+00$ & 0 & $0.00 \mathrm{E}+00$ & 0 & $0.00 \mathrm{E}+00$ & 0 & $0.00 \mathrm{E}+00$ & 0 \\
\hline 35 & $0.00 \mathrm{E}+00$ & 0 & $0.00 \mathrm{E}+00$ & 0 & $0.00 \mathrm{E}+00$ & 0 & $0.00 \mathrm{E}+00$ & 0 & $0.00 \mathrm{E}+00$ & 0 & $0.00 \mathrm{E}+00$ & 0 & $0.00 \mathrm{E}+00$ & 0 & $0.00 \mathrm{E}+00$ & 0 \\
\hline 38 & $0.00 \mathrm{E}+00$ & 0 & $0.00 \mathrm{E}+00$ & 0 & $0.00 \mathrm{E}+00$ & 0 & $0.00 \mathrm{E}+00$ & 0 & $0.00 \mathrm{E}+00$ & 0 & $0.00 \mathrm{E}+00$ & 0 & $0.00 \mathrm{E}+00$ & 0 & $0.00 \mathrm{E}+00$ & 0 \\
\hline & $0.00 \mathrm{E}+00$ & 0 & $0.00 E+00$ & 0 & $0.00 \mathrm{E}+00$ & 0 & $0.00 \mathrm{E}+00$ & 0 & $0.00 \mathrm{E}+00$ & 0 & $0.00 \mathrm{E}+00$ & 0 & $0.00 \mathrm{E}+00$ & 0 & $0.00 \mathrm{E}+00$ & \\
\hline
\end{tabular}

Total Dose Contributions TDOSE (i,p,t) for Individual Radionuclides (i) and Pathways (p) in mrem/yr and as a Percentage of Total Dose at $t=50$ years

Directly from primary contamination and from release to atmosphere (Inhalation excludes radon)

\begin{tabular}{|c|c|c|c|c|c|c|c|c|c|c|c|c|c|c|c|c|}
\hline & \multicolumn{2}{|c|}{ Ground } & \multicolumn{2}{|c|}{ Inhalation } & \multicolumn{2}{|c|}{ Radon } & \multicolumn{2}{|c|}{ Plant } & \multicolumn{2}{|l|}{ Meat } & \multicolumn{2}{|l|}{ Milk } & \multicolumn{2}{|l|}{ Soil } & \multicolumn{2}{|c|}{ All Pathways* } \\
\hline clide & Dose & $\%$ & Dose & $\%$ & Dose & $\%$ & Dose & \% & Dose & $\%$ & Dose & \% & Dose & \% & Dose & $\%$ \\
\hline-241 & $4.25 E-24$ & 0 & $0.00 \mathrm{E}+00$ & 0 & $0.00 \mathrm{E}+00$ & 0 & $0.00 \mathrm{E}+00$ & 0 & $0.00 \mathrm{E}+00$ & 0 & $0.00 \mathrm{E}+00$ & 0 & $0.00 \mathrm{E}+00$ & 0 & 4. $25 \mathrm{E}-24$ & 0 \\
\hline-137 & $5.49 \mathrm{E}-17$ & 0 & $0.00 \mathrm{E}+00$ & 0 & $0.00 \mathrm{E}+00$ & 0 & $0.00 \mathrm{E}+00$ & 0 & $0.00 \mathrm{E}+00$ & 0 & $0.00 \mathrm{E}+00$ & 0 & $0.00 \mathrm{E}+00$ & 0 & $5.49 \mathrm{E}-17$ & 0 \\
\hline-237 & $4.24 \mathrm{E}-20$ & 0 & $0.00 \mathrm{E}+00$ & 0 & $0.00 \mathrm{E}+00$ & 0 & $0.00 \mathrm{E}+00$ & 0 & $0.00 \mathrm{E}+00$ & 0 & $0.00 \mathrm{E}+00$ & 0 & $0.00 \mathrm{E}+00$ & 0 & $4.24 \mathrm{E}-20$ & 0 \\
\hline-238 & $9.98 E-24$ & 0 & $0.00 \mathrm{E}+00$ & 0 & $0.00 \mathrm{E}+00$ & 0 & $0.00 \mathrm{E}+00$ & 0 & $0.00 \mathrm{E}+00$ & 0 & $0.00 \mathrm{E}+00$ & 0 & $0.00 \mathrm{E}+00$ & 0 & $9.98 \mathrm{E}-24$ & 0 \\
\hline-239 & $3.70 \mathrm{E}-24$ & 0 & $0.00 \mathrm{E}+00$ & 0 & $0.00 \mathrm{E}+00$ & 0 & $0.00 \mathrm{E}+00$ & 0 & $0.00 \mathrm{E}+00$ & 0 & $0.00 \mathrm{E}+00$ & 0 & $0.00 \mathrm{E}+00$ & 0 & $3.70 \mathrm{E}-24$ & 0 \\
\hline-240 & $4.68 E-28$ & 0 & $0.00 \mathrm{E}+00$ & 0 & $0.00 \mathrm{E}+00$ & 0 & $0.00 \mathrm{E}+00$ & 0 & $0.00 \mathrm{E}+00$ & 0 & $0.00 \mathrm{E}+00$ & 0 & $0.00 \mathrm{E}+00$ & 0 & $4.68 \mathrm{E}-28$ & 0 \\
\hline-99 & $2.75 E-32$ & 0 & $0.00 \mathrm{E}+00$ & 0 & $0.00 \mathrm{E}+00$ & 0 & $0.00 \mathrm{E}+00$ & 0 & $0.00 \mathrm{E}+00$ & 0 & $0.00 \mathrm{E}+00$ & 0 & $0.00 \mathrm{E}+00$ & 0 & $2.75 E-32$ & 0 \\
\hline-228 & $6.75 E-22$ & 0 & $0.00 \mathrm{E}+00$ & 0 & $0.00 \mathrm{E}+00$ & 0 & $0.00 \mathrm{E}+00$ & 0 & $0.00 \mathrm{E}+00$ & 0 & $0.00 \mathrm{E}+00$ & 0 & $0.00 \mathrm{E}+00$ & 0 & $6.75 E-22$ & 0 \\
\hline-230 & $2.55 \mathrm{E}-15$ & 6 & $0.00 \mathrm{E}+00$ & 0 & $0.00 \mathrm{E}+00$ & 0 & $0.00 \mathrm{E}+00$ & 0 & $0.00 \mathrm{E}+00$ & 0 & $0.00 \mathrm{E}+00$ & 0 & $0.00 \mathrm{E}+00$ & 0 & $2.55 \mathrm{E}-15$ & 6 \\
\hline-232 & $4.32 E-14$ & 94 & $0.00 \mathrm{E}+00$ & 0 & $0.00 \mathrm{E}+00$ & 0 & $0.00 \mathrm{E}+00$ & 0 & $0.00 \mathrm{E}+00$ & 0 & $0.00 \mathrm{E}+00$ & 0 & $0.00 \mathrm{E}+00$ & 0 & $4.32 \mathrm{E}-14$ & 94 \\
\hline 234 & $9.37 \mathrm{E}-19$ & 0 & $0.00 \mathrm{E}+00$ & 0 & $0.00 \mathrm{E}+00$ & 0 & $0.00 \mathrm{E}+00$ & 0 & $0.00 \mathrm{E}+00$ & 0 & $0.00 \mathrm{E}+00$ & 0 & $0.00 \mathrm{E}+00$ & 0 & $9.37 \mathrm{E}-19$ & 0 \\
\hline 235 & $2.86 \mathrm{E}-21$ & 0 & $0.00 \mathrm{E}+00$ & 0 & $0.00 \mathrm{E}+00$ & 0 & $0.00 \mathrm{E}+00$ & 0 & $0.00 \mathrm{E}+00$ & 0 & $0.00 \mathrm{E}+00$ & 0 & $0.00 \mathrm{E}+00$ & 0 & $2.86 \mathrm{E}-21$ & 0 \\
\hline 38 & $1.62 \mathrm{E}-16$ & 0 & $0.00 \mathrm{E}+00$ & 0 & $0.00 \mathrm{E}+00$ & 0 & $0.00 \mathrm{E}+00$ & 0 & $0.00 \mathrm{E}+00$ & 0 & $0.00 \mathrm{E}+00$ & 0 & $0.00 \mathrm{E}+00$ & 0 & $1.62 \mathrm{E}-16$ & 0 \\
\hline al & $4.59 E-14$ & 100 & $0.00 \mathrm{E}+00$ & 0 & $0.00 \mathrm{E}+00$ & 0 & $0.00 \mathrm{E}+00$ & 0 & $0.00 \mathrm{E}+00$ & 0 & $0.00 \mathrm{E}+00$ & 0 & $0.00 \mathrm{E}+00$ & 0 & $4.59 \mathrm{E}-14$ & 00 \\
\hline
\end{tabular}

* Sum of dose from all releases and from primary contamination. 
RESRAD-OFFSITE, Version 2.

Parent Dose Report

Title : RESRAD-OFFSITE Parameters for Offsite Resident Farmer Forward Run 100,000 Years

File : OFFSITE-RF_FORWARD-7-11-100000yr.ROF

Total Dose Contributions TDOSE (i,p,t) for Individual Radionuclides (i) and Pathways (p) in mrem/yr and as a Percentage of Total Dose at $t=100$ years

From releases to ground water and to surface water

\begin{tabular}{|c|c|c|c|c|c|c|c|c|c|c|c|c|c|c|c|c|}
\hline & \multicolumn{2}{|c|}{ Ground } & \multicolumn{2}{|l|}{ Fish } & \multicolumn{2}{|c|}{ Radon } & \multicolumn{2}{|c|}{ Plant } & \multicolumn{2}{|l|}{ Meat } & \multicolumn{2}{|l|}{ Milk } & \multicolumn{2}{|l|}{ Soil } & \multicolumn{2}{|c|}{ Water } \\
\hline ide & Dose & $\%$ & Dose & $\%$ & Dose & 응 & Dose & $\frac{\circ}{0}$ & Dose & \% & Dose & 응 & Dose & $\%$ & Dose & $\%$ \\
\hline-241 & $0.00 \mathrm{E}+00$ & 0 & $0.00 E+00$ & 0 & $0.00 \mathrm{E}+00$ & 0 & $0.00 \mathrm{E}+00$ & 0 & $0.00 \mathrm{E}+00$ & 0 & $0.00 \mathrm{E}+00$ & 0 & $0.00 \mathrm{E}+00$ & 0 & $0.00 \mathrm{E}+00$ & 0 \\
\hline-137 & $0.00 \mathrm{E}+00$ & 0 & $0.00 \mathrm{E}+00$ & 0 & $0.00 \mathrm{E}+00$ & 0 & $0.00 \mathrm{E}+00$ & 0 & $0.00 \mathrm{E}+00$ & 0 & $0.00 \mathrm{E}+00$ & 0 & $0.00 \mathrm{E}+00$ & 0 & $0.00 \mathrm{E}+00$ & 0 \\
\hline-237 & $0.00 \mathrm{E}+00$ & 0 & $0.00 \mathrm{E}+00$ & 0 & $0.00 \mathrm{E}+00$ & 0 & $0.00 \mathrm{E}+00$ & 0 & $0.00 \mathrm{E}+00$ & 0 & $0.00 \mathrm{E}+00$ & 0 & $0.00 \mathrm{E}+00$ & 0 & $0.00 \mathrm{E}+00$ & 0 \\
\hline-238 & $0.00 \mathrm{E}+00$ & 0 & $0.00 \mathrm{E}+00$ & 0 & $0.00 E+00$ & 0 & $0.00 \mathrm{E}+00$ & 0 & $0.00 \mathrm{E}+00$ & 0 & $0.00 E+00$ & 0 & $0.00 \mathrm{E}+00$ & 0 & $0.00 \mathrm{E}+00$ & 0 \\
\hline-239 & $0.00 \mathrm{E}+00$ & 0 & $0.00 \mathrm{E}+00$ & 0 & $0.00 \mathrm{E}+00$ & 0 & $0.00 \mathrm{E}+00$ & 0 & $0.00 \mathrm{E}+00$ & 0 & $0.00 \mathrm{E}+00$ & 0 & $0.00 \mathrm{E}+00$ & 0 & $0.00 \mathrm{E}+00$ & 0 \\
\hline-240 & $0.00 \mathrm{E}+00$ & 0 & $0.00 \mathrm{E}+00$ & 0 & $0.00 \mathrm{E}+00$ & 0 & $0.00 \mathrm{E}+00$ & 0 & $0.00 \mathrm{E}+00$ & 0 & $0.00 \mathrm{E}+00$ & 0 & $0.00 \mathrm{E}+00$ & 0 & $0.00 \mathrm{E}+00$ & 0 \\
\hline-99 & $0.00 \mathrm{E}+00$ & 0 & $0.00 \mathrm{E}+00$ & 0 & $0.00 \mathrm{E}+00$ & 0 & $0.00 \mathrm{E}+00$ & 0 & $0.00 \mathrm{E}+00$ & 0 & $0.00 E+00$ & 0 & $0.00 \mathrm{E}+00$ & 0 & $0.00 \mathrm{E}+00$ & 0 \\
\hline-228 & $0.00 \mathrm{E}+00$ & 0 & $0.00 \mathrm{E}+00$ & 0 & $0.00 \mathrm{E}+00$ & 0 & $0.00 \mathrm{E}+00$ & 0 & $0.00 \mathrm{E}+00$ & 0 & $0.00 \mathrm{E}+00$ & 0 & $0.00 \mathrm{E}+00$ & 0 & $0.00 \mathrm{E}+00$ & 0 \\
\hline-230 & $0.00 \mathrm{E}+00$ & 0 & $0.00 \mathrm{E}+00$ & 0 & $0.00 \mathrm{E}+00$ & 0 & $0.00 \mathrm{E}+00$ & 0 & $0.00 \mathrm{E}+00$ & 0 & $0.00 \mathrm{E}+00$ & 0 & $0.00 \mathrm{E}+00$ & 0 & $0.00 \mathrm{E}+00$ & 0 \\
\hline-232 & $0.00 \mathrm{E}+00$ & 0 & $0.00 \mathrm{E}+00$ & 0 & $0.00 \mathrm{E}+00$ & 0 & $0.00 \mathrm{E}+00$ & 0 & $0.00 \mathrm{E}+00$ & 0 & $0.00 \mathrm{E}+00$ & 0 & $0.00 \mathrm{E}+00$ & 0 & $0.00 \mathrm{E}+00$ & 0 \\
\hline 4 & $0.00 \mathrm{E}+00$ & 0 & $0.00 \mathrm{E}+00$ & 0 & $0.00 \mathrm{E}+00$ & 0 & $0.00 \mathrm{E}+00$ & 0 & $0.00 \mathrm{E}+00$ & 0 & $0.00 \mathrm{E}+00$ & 0 & $0.00 \mathrm{E}+00$ & 0 & $0.00 \mathrm{E}+00$ & 0 \\
\hline 35 & $0.00 \mathrm{E}+00$ & 0 & $0.00 \mathrm{E}+00$ & 0 & $0.00 \mathrm{E}+00$ & 0 & $0.00 \mathrm{E}+00$ & 0 & $0.00 \mathrm{E}+00$ & 0 & $0.00 \mathrm{E}+00$ & 0 & $0.00 \mathrm{E}+00$ & 0 & $0.00 \mathrm{E}+00$ & 0 \\
\hline 38 & $0.00 \mathrm{E}+00$ & 0 & $0.00 \mathrm{E}+00$ & 0 & $0.00 \mathrm{E}+00$ & 0 & $0.00 \mathrm{E}+00$ & 0 & $0.00 \mathrm{E}+00$ & 0 & $0.00 \mathrm{E}+00$ & 0 & $0.00 \mathrm{E}+00$ & 0 & $0.00 \mathrm{E}+00$ & 0 \\
\hline & $0.00 \mathrm{E}+00$ & 0 & $0.00 E+00$ & 0 & $0.00 \mathrm{E}+00$ & 0 & $0.00 \mathrm{E}+00$ & 0 & $0.00 \mathrm{E}+00$ & 0 & $0.00 \mathrm{E}+00$ & 0 & $0.00 \mathrm{E}+00$ & 0 & $0.00 \mathrm{E}+00$ & \\
\hline
\end{tabular}

Total Dose Contributions TDOSE (i,p,t) for Individual Radionuclides (i) and Pathways (p) in mrem/yr and as a Percentage of Total Dose at $t=100$ years

Directly from primary contamination and from release to atmosphere (Inhalation excludes radon)

\begin{tabular}{|c|c|c|c|c|c|c|c|c|c|c|c|c|c|c|c|c|}
\hline & \multicolumn{2}{|c|}{ Ground } & \multicolumn{2}{|c|}{ Inhalation } & \multicolumn{2}{|c|}{ Radon } & \multicolumn{2}{|c|}{ Plant } & \multicolumn{2}{|l|}{ Meat } & \multicolumn{2}{|l|}{ Milk } & \multicolumn{2}{|l|}{ Soil } & \multicolumn{2}{|c|}{ All Pathways* } \\
\hline clide & Dose & $\%$ & Dose & $\%$ & Dose & $\%$ & Dose & 음 & Dose & $\%$ & Dose & 음 & Dose & $\%$ & Dose & $\%$ \\
\hline-241 & $1.34 \mathrm{E}-23$ & 0 & $0.00 E+00$ & 0 & $0.00 E+00$ & 0 & $0.00 \mathrm{E}+00$ & 0 & $0.00 \mathrm{E}+00$ & 0 & $0.00 \mathrm{E}+00$ & 0 & $0.00 \mathrm{E}+00$ & 0 & 1. $34 \mathrm{E}-23$ & 0 \\
\hline-137 & $2.55 E-17$ & 0 & $0.00 E+00$ & 0 & $0.00 E+00$ & 0 & $0.00 \mathrm{E}+00$ & 0 & $0.00 \mathrm{E}+00$ & 0 & $0.00 E+00$ & 0 & $0.00 \mathrm{E}+00$ & 0 & $2.55 E-17$ & 0 \\
\hline-237 & $6.98 E-20$ & 0 & $0.00 E+00$ & 0 & $0.00 E+00$ & 0 & $0.00 \mathrm{E}+00$ & 0 & $0.00 \mathrm{E}+00$ & 0 & $0.00 E+00$ & 0 & $0.00 \mathrm{E}+00$ & 0 & $6.98 E-20$ & 0 \\
\hline-238 & $9.74 E-23$ & 0 & $0.00 E+00$ & 0 & $0.00 \mathrm{E}+00$ & 0 & $0.00 \mathrm{E}+00$ & 0 & $0.00 \mathrm{E}+00$ & 0 & $0.00 \mathrm{E}+00$ & 0 & $0.00 \mathrm{E}+00$ & 0 & $9.74 \mathrm{E}-23$ & 0 \\
\hline-239 & $6.41 E-24$ & 0 & $0.00 \mathrm{E}+00$ & 0 & $0.00 \mathrm{E}+00$ & 0 & $0.00 \mathrm{E}+00$ & 0 & $0.00 \mathrm{E}+00$ & 0 & $0.00 \mathrm{E}+00$ & 0 & $0.00 \mathrm{E}+00$ & 0 & $6.41 \mathrm{E}-24$ & 0 \\
\hline-240 & $3.03 E-27$ & 0 & $0.00 E+00$ & 0 & $0.00 \mathrm{E}+00$ & 0 & $0.00 \mathrm{E}+00$ & 0 & $0.00 \mathrm{E}+00$ & 0 & $0.00 E+00$ & 0 & $0.00 \mathrm{E}+00$ & 0 & $3.03 E-27$ & 0 \\
\hline-99 & $5.11 E-32$ & 0 & $0.00 E+00$ & 0 & $0.00 \mathrm{E}+00$ & 0 & $0.00 \mathrm{E}+00$ & 0 & $0.00 \mathrm{E}+00$ & 0 & $0.00 E+00$ & 0 & $0.00 \mathrm{E}+00$ & 0 & $5.11 E-32$ & 0 \\
\hline-228 & 1. $45 \mathrm{E}-29$ & 0 & $0.00 \mathrm{E}+00$ & 0 & $0.00 \mathrm{E}+00$ & 0 & $0.00 \mathrm{E}+00$ & 0 & $0.00 \mathrm{E}+00$ & 0 & $0.00 \mathrm{E}+00$ & 0 & $0.00 \mathrm{E}+00$ & 0 & 1. $45 \mathrm{E}-29$ & 0 \\
\hline-230 & $6.91 E-15$ & 11 & $0.00 E+00$ & 0 & $0.00 \mathrm{E}+00$ & 0 & $0.00 \mathrm{E}+00$ & 0 & $0.00 \mathrm{E}+00$ & 0 & $0.00 E+00$ & 0 & $0.00 \mathrm{E}+00$ & 0 & $6.91 \mathrm{E}-15$ & 11 \\
\hline-232 & $5.71 E-14$ & 89 & $0.00 E+00$ & 0 & $0.00 \mathrm{E}+00$ & 0 & $0.00 \mathrm{E}+00$ & 0 & $0.00 \mathrm{E}+00$ & 0 & $0.00 \mathrm{E}+00$ & 0 & $0.00 \mathrm{E}+00$ & 0 & $5.71 \mathrm{E}-14$ & 89 \\
\hline 34 & $5.05 E-18$ & 0 & $0.00 \mathrm{E}+00$ & 0 & $0.00 \mathrm{E}+00$ & 0 & $0.00 \mathrm{E}+00$ & 0 & $0.00 \mathrm{E}+00$ & 0 & $0.00 \mathrm{E}+00$ & 0 & $0.00 \mathrm{E}+00$ & 0 & $5.05 \mathrm{E}-18$ & 0 \\
\hline 35 & $1.01 E-20$ & 0 & $0.00 E+00$ & 0 & $0.00 E+00$ & 0 & $0.00 \mathrm{E}+00$ & 0 & $0.00 \mathrm{E}+00$ & 0 & $0.00 E+00$ & 0 & $0.00 \mathrm{E}+00$ & 0 & 1. $01 \mathrm{E}-20$ & 0 \\
\hline 38 & $2.34 E-16$ & 0 & $0.00 E+00$ & 0 & $0.00 \mathrm{E}+00$ & 0 & $0.00 \mathrm{E}+00$ & 0 & $0.00 \mathrm{E}+00$ & 0 & $0.00 E+00$ & 0 & $0.00 \mathrm{E}+00$ & 0 & $2.34 \mathrm{E}-16$ & 0 \\
\hline & $6.42 \mathrm{E}-14$ & 100 & $0.00 \mathrm{E}+00$ & 0 & $0.00 \mathrm{E}+00$ & 0 & $0.00 \mathrm{E}+00$ & 0 & $0.00 \mathrm{E}+00$ & 0 & $0.00 \mathrm{E}+00$ & 0 & $0.00 \mathrm{E}+00$ & 0 & $6.42 \mathrm{E}-14$ & 100 \\
\hline
\end{tabular}


RESRAD-OFFSITE, Version 2.

Parent Dose Report

Title : RESRAD-OFFSITE Parameters for Offsite Resident Farmer Forward Run 100,000 Years

File : OFFSITE-RF_FORWARD-7-11-100000yr.ROF

Total Dose Contributions TDOSE (i,p,t) for Individual Radionuclides (i) and Pathways (p) in mrem/yr and as a Percentage of Total Dose at $t=500$ years

From releases to ground water and to surface water

\begin{tabular}{|c|c|c|c|c|c|c|c|c|c|c|c|c|c|c|c|c|}
\hline & \multicolumn{2}{|c|}{ Ground } & \multicolumn{2}{|l|}{ Fish } & \multicolumn{2}{|c|}{ Radon } & \multicolumn{2}{|c|}{ Plant } & \multicolumn{2}{|l|}{ Meat } & \multicolumn{2}{|l|}{ Milk } & \multicolumn{2}{|l|}{ Soil } & \multicolumn{2}{|c|}{ Water } \\
\hline ide & Dose & $\%$ & Dose & $\%$ & Dose & 응 & Dose & $\frac{\circ}{0}$ & Dose & \% & Dose & 응 & Dose & $\%$ & Dose & $\%$ \\
\hline-241 & $0.00 \mathrm{E}+00$ & 0 & $0.00 E+00$ & 0 & $0.00 \mathrm{E}+00$ & 0 & $0.00 \mathrm{E}+00$ & 0 & $0.00 \mathrm{E}+00$ & 0 & $0.00 \mathrm{E}+00$ & 0 & $0.00 \mathrm{E}+00$ & 0 & $0.00 \mathrm{E}+00$ & 0 \\
\hline-137 & $0.00 \mathrm{E}+00$ & 0 & $0.00 \mathrm{E}+00$ & 0 & $0.00 \mathrm{E}+00$ & 0 & $0.00 \mathrm{E}+00$ & 0 & $0.00 \mathrm{E}+00$ & 0 & $0.00 \mathrm{E}+00$ & 0 & $0.00 \mathrm{E}+00$ & 0 & $0.00 \mathrm{E}+00$ & 0 \\
\hline-237 & $0.00 \mathrm{E}+00$ & 0 & $0.00 \mathrm{E}+00$ & 0 & $0.00 \mathrm{E}+00$ & 0 & $0.00 \mathrm{E}+00$ & 0 & $0.00 \mathrm{E}+00$ & 0 & $0.00 \mathrm{E}+00$ & 0 & $0.00 \mathrm{E}+00$ & 0 & $0.00 \mathrm{E}+00$ & 0 \\
\hline-238 & $0.00 \mathrm{E}+00$ & 0 & $0.00 \mathrm{E}+00$ & 0 & $0.00 E+00$ & 0 & $0.00 \mathrm{E}+00$ & 0 & $0.00 \mathrm{E}+00$ & 0 & $0.00 E+00$ & 0 & $0.00 \mathrm{E}+00$ & 0 & $0.00 \mathrm{E}+00$ & 0 \\
\hline-239 & $0.00 \mathrm{E}+00$ & 0 & $0.00 \mathrm{E}+00$ & 0 & $0.00 \mathrm{E}+00$ & 0 & $0.00 \mathrm{E}+00$ & 0 & $0.00 \mathrm{E}+00$ & 0 & $0.00 \mathrm{E}+00$ & 0 & $0.00 \mathrm{E}+00$ & 0 & $0.00 \mathrm{E}+00$ & 0 \\
\hline-240 & $0.00 \mathrm{E}+00$ & 0 & $0.00 \mathrm{E}+00$ & 0 & $0.00 \mathrm{E}+00$ & 0 & $0.00 \mathrm{E}+00$ & 0 & $0.00 \mathrm{E}+00$ & 0 & $0.00 \mathrm{E}+00$ & 0 & $0.00 \mathrm{E}+00$ & 0 & $0.00 \mathrm{E}+00$ & 0 \\
\hline-99 & $0.00 \mathrm{E}+00$ & 0 & $0.00 \mathrm{E}+00$ & 0 & $0.00 \mathrm{E}+00$ & 0 & $0.00 \mathrm{E}+00$ & 0 & $0.00 \mathrm{E}+00$ & 0 & $0.00 E+00$ & 0 & $0.00 \mathrm{E}+00$ & 0 & $0.00 \mathrm{E}+00$ & 0 \\
\hline-228 & $0.00 \mathrm{E}+00$ & 0 & $0.00 \mathrm{E}+00$ & 0 & $0.00 \mathrm{E}+00$ & 0 & $0.00 \mathrm{E}+00$ & 0 & $0.00 \mathrm{E}+00$ & 0 & $0.00 \mathrm{E}+00$ & 0 & $0.00 \mathrm{E}+00$ & 0 & $0.00 \mathrm{E}+00$ & 0 \\
\hline-230 & $0.00 \mathrm{E}+00$ & 0 & $0.00 \mathrm{E}+00$ & 0 & $0.00 \mathrm{E}+00$ & 0 & $0.00 \mathrm{E}+00$ & 0 & $0.00 \mathrm{E}+00$ & 0 & $0.00 \mathrm{E}+00$ & 0 & $0.00 \mathrm{E}+00$ & 0 & $0.00 \mathrm{E}+00$ & 0 \\
\hline-232 & $0.00 \mathrm{E}+00$ & 0 & $0.00 \mathrm{E}+00$ & 0 & $0.00 \mathrm{E}+00$ & 0 & $0.00 \mathrm{E}+00$ & 0 & $0.00 \mathrm{E}+00$ & 0 & $0.00 \mathrm{E}+00$ & 0 & $0.00 \mathrm{E}+00$ & 0 & $0.00 \mathrm{E}+00$ & 0 \\
\hline 4 & $0.00 \mathrm{E}+00$ & 0 & $0.00 \mathrm{E}+00$ & 0 & $0.00 \mathrm{E}+00$ & 0 & $0.00 \mathrm{E}+00$ & 0 & $0.00 \mathrm{E}+00$ & 0 & $0.00 \mathrm{E}+00$ & 0 & $0.00 \mathrm{E}+00$ & 0 & $0.00 \mathrm{E}+00$ & 0 \\
\hline 35 & $0.00 \mathrm{E}+00$ & 0 & $0.00 \mathrm{E}+00$ & 0 & $0.00 \mathrm{E}+00$ & 0 & $0.00 \mathrm{E}+00$ & 0 & $0.00 \mathrm{E}+00$ & 0 & $0.00 \mathrm{E}+00$ & 0 & $0.00 \mathrm{E}+00$ & 0 & $0.00 \mathrm{E}+00$ & 0 \\
\hline 38 & $0.00 \mathrm{E}+00$ & 0 & $0.00 \mathrm{E}+00$ & 0 & $0.00 \mathrm{E}+00$ & 0 & $0.00 \mathrm{E}+00$ & 0 & $0.00 \mathrm{E}+00$ & 0 & $0.00 \mathrm{E}+00$ & 0 & $0.00 \mathrm{E}+00$ & 0 & $0.00 \mathrm{E}+00$ & 0 \\
\hline & $0.00 \mathrm{E}+00$ & 0 & $0.00 E+00$ & 0 & $0.00 \mathrm{E}+00$ & 0 & $0.00 \mathrm{E}+00$ & 0 & $0.00 \mathrm{E}+00$ & 0 & $0.00 \mathrm{E}+00$ & 0 & $0.00 \mathrm{E}+00$ & 0 & $0.00 \mathrm{E}+00$ & \\
\hline
\end{tabular}

Total Dose Contributions TDOSE (i,p,t) for Individual Radionuclides (i) and Pathways (p) in mrem/yr and as a Percentage of Total Dose at $t=500$ years

Directly from primary contamination and from release to atmosphere (Inhalation excludes radon)

\begin{tabular}{|c|c|c|c|c|c|c|c|c|c|c|c|c|c|c|c|c|}
\hline & \multicolumn{2}{|c|}{ Ground } & \multicolumn{2}{|c|}{ Inhalation } & \multicolumn{2}{|c|}{ Radon } & \multicolumn{2}{|c|}{ Plant } & \multicolumn{2}{|l|}{ Meat } & \multicolumn{2}{|l|}{ Milk } & \multicolumn{2}{|l|}{ Soil } & \multicolumn{2}{|c|}{ All Pathways* } \\
\hline clide & Dose & $\%$ & Dose & $\%$ & Dose & $\%$ & Dose & 음 & Dose & $\%$ & Dose & 음 & Dose & $\%$ & Dose & $\%$ \\
\hline-241 & $2.63 E-21$ & 0 & $0.00 \mathrm{E}+00$ & 0 & $0.00 \mathrm{E}+00$ & 0 & $0.00 \mathrm{E}+00$ & 0 & $0.00 \mathrm{E}+00$ & 0 & $0.00 \mathrm{E}+00$ & 0 & $0.00 \mathrm{E}+00$ & 0 & $2.63 E-21$ & 0 \\
\hline-137 & $5.48 E-20$ & 0 & $0.00 \mathrm{E}+00$ & 0 & $0.00 E+00$ & 0 & $0.00 \mathrm{E}+00$ & 0 & $0.00 \mathrm{E}+00$ & 0 & $0.00 E+00$ & 0 & $0.00 \mathrm{E}+00$ & 0 & $5.48 E-20$ & 0 \\
\hline-237 & $3.74 E-18$ & 0 & $0.00 \mathrm{E}+00$ & 0 & $0.00 E+00$ & 0 & $0.00 \mathrm{E}+00$ & 0 & $0.00 \mathrm{E}+00$ & 0 & $0.00 E+00$ & 0 & $0.00 \mathrm{E}+00$ & 0 & $3.74 \mathrm{E}-18$ & 0 \\
\hline-238 & $8.23 E-20$ & 0 & $0.00 \mathrm{E}+00$ & 0 & $0.00 \mathrm{E}+00$ & 0 & $0.00 \mathrm{E}+00$ & 0 & $0.00 \mathrm{E}+00$ & 0 & $0.00 \mathrm{E}+00$ & 0 & $0.00 \mathrm{E}+00$ & 0 & $8.23 E-20$ & 0 \\
\hline-239 & $5.22 E-22$ & 0 & $0.00 \mathrm{E}+00$ & 0 & $0.00 \mathrm{E}+00$ & 0 & $0.00 \mathrm{E}+00$ & 0 & $0.00 \mathrm{E}+00$ & 0 & $0.00 \mathrm{E}+00$ & 0 & $0.00 \mathrm{E}+00$ & 0 & $5.22 \mathrm{E}-22$ & 0 \\
\hline-240 & $8.02 E-25$ & 0 & $0.00 \mathrm{E}+00$ & 0 & $0.00 \mathrm{E}+00$ & 0 & $0.00 \mathrm{E}+00$ & 0 & $0.00 \mathrm{E}+00$ & 0 & $0.00 \mathrm{E}+00$ & 0 & $0.00 \mathrm{E}+00$ & 0 & $8.02 \mathrm{E}-25$ & 0 \\
\hline-99 & 7. $29 \mathrm{E}-30$ & 0 & $0.00 \mathrm{E}+00$ & 0 & $0.00 \mathrm{E}+00$ & 0 & $0.00 \mathrm{E}+00$ & 0 & $0.00 \mathrm{E}+00$ & 0 & $0.00 E+00$ & 0 & $0.00 \mathrm{E}+00$ & 0 & $7.29 \mathrm{E}-30$ & 0 \\
\hline-228 & $0.00 \mathrm{E}+00$ & 0 & $0.00 \mathrm{E}+00$ & 0 & $0.00 \mathrm{E}+00$ & 0 & $0.00 \mathrm{E}+00$ & 0 & $0.00 \mathrm{E}+00$ & 0 & $0.00 \mathrm{E}+00$ & 0 & $0.00 \mathrm{E}+00$ & 0 & $0.00 \mathrm{E}+00$ & 0 \\
\hline-230 & $4.02 E-13$ & 43 & $0.00 E+00$ & 0 & $0.00 \mathrm{E}+00$ & 0 & $0.00 \mathrm{E}+00$ & 0 & $0.00 \mathrm{E}+00$ & 0 & $0.00 E+00$ & 0 & $0.00 \mathrm{E}+00$ & 0 & $4.02 \mathrm{E}-13$ & 43 \\
\hline-232 & $5.19 \mathrm{E}-13$ & 56 & $0.00 \mathrm{E}+00$ & 0 & $0.00 \mathrm{E}+00$ & 0 & $0.00 \mathrm{E}+00$ & 0 & $0.00 \mathrm{E}+00$ & 0 & $0.00 \mathrm{E}+00$ & 0 & $0.00 \mathrm{E}+00$ & 0 & $5.19 \mathrm{E}-13$ & 56 \\
\hline 34 & $1.50 \mathrm{E}-15$ & 0 & $0.00 \mathrm{E}+00$ & 0 & $0.00 \mathrm{E}+00$ & 0 & $0.00 \mathrm{E}+00$ & 0 & $0.00 \mathrm{E}+00$ & 0 & $0.00 \mathrm{E}+00$ & 0 & $0.00 \mathrm{E}+00$ & 0 & 1. $50 \mathrm{E}-15$ & 0 \\
\hline 35 & 1. $58 \mathrm{E}-18$ & 0 & $0.00 \mathrm{E}+00$ & 0 & $0.00 \mathrm{E}+00$ & 0 & $0.00 \mathrm{E}+00$ & 0 & $0.00 \mathrm{E}+00$ & 0 & $0.00 \mathrm{E}+00$ & 0 & $0.00 \mathrm{E}+00$ & 0 & 1. $58 \mathrm{E}-18$ & 0 \\
\hline 38 & 4. $44 E-15$ & 0 & $0.00 \mathrm{E}+00$ & 0 & $0.00 \mathrm{E}+00$ & 0 & $0.00 \mathrm{E}+00$ & 0 & $0.00 \mathrm{E}+00$ & 0 & $0.00 E+00$ & 0 & $0.00 \mathrm{E}+00$ & 0 & 4. $44 \mathrm{E}-15$ & 0 \\
\hline & $9.28 \mathrm{E}-13$ & 100 & $0.00 \mathrm{E}+00$ & 0 & $0.00 \mathrm{E}+00$ & 0 & $0.00 \mathrm{E}+00$ & 0 & $0.00 \mathrm{E}+00$ & 0 & $0.00 \mathrm{E}+00$ & 0 & $0.00 \mathrm{E}+00$ & 0 & $9.28 \mathrm{E}-13$ & 100 \\
\hline
\end{tabular}


RESRAD-OFFSITE, Version 2.

Parent Dose Report

Title : RESRAD-OFFSITE Parameters for Offsite Resident Farmer Forward Run 100,000 Years

File : OFFSITE-RF_FORWARD-7-11-100000yr.ROF

Total Dose Contributions TDOSE (i,p,t) for Individual Radionuclides (i) and Pathways (p) in mrem/yr and as a Percentage of Total Dose at $t=1026$ years

From releases to ground water and to surface water

\begin{tabular}{|c|c|c|c|c|c|c|c|c|c|c|c|c|c|c|c|c|}
\hline & \multicolumn{2}{|c|}{ Ground } & \multicolumn{2}{|l|}{ Fish } & \multicolumn{2}{|c|}{ Radon } & \multicolumn{2}{|c|}{ Plant } & \multicolumn{2}{|l|}{ Meat } & \multicolumn{2}{|l|}{ Milk } & \multicolumn{2}{|l|}{ Soil } & \multicolumn{2}{|c|}{ Water } \\
\hline clide & Dose & \% & Dose & $\%$ & Dose & \% & Dose & \% & Dose & \% & Dose & \% & Dose & \% & Dose & $\%$ \\
\hline-241 & $0.00 \mathrm{E}+00$ & 0 & $0.00 \mathrm{E}+00$ & 0 & $0.00 \mathrm{E}+00$ & 0 & $0.00 \mathrm{E}+00$ & 0 & $0.00 \mathrm{E}+00$ & 0 & $0.00 \mathrm{E}+00$ & 0 & $0.00 \mathrm{E}+00$ & 0 & $0.00 \mathrm{E}+00$ & 0 \\
\hline-137 & $0.00 \mathrm{E}+00$ & 0 & $0.00 \mathrm{E}+00$ & 0 & $0.00 \mathrm{E}+00$ & 0 & $0.00 \mathrm{E}+00$ & 0 & $0.00 \mathrm{E}+00$ & 0 & $0.00 \mathrm{E}+00$ & 0 & $0.00 \mathrm{E}+00$ & 0 & $0.00 \mathrm{E}+00$ & 0 \\
\hline-237 & $0.00 \mathrm{E}+00$ & 0 & $0.00 \mathrm{E}+00$ & 0 & $0.00 \mathrm{E}+00$ & 0 & $0.00 \mathrm{E}+00$ & 0 & $0.00 \mathrm{E}+00$ & 0 & $0.00 \mathrm{E}+00$ & 0 & $0.00 \mathrm{E}+00$ & 0 & $0.00 \mathrm{E}+00$ & 0 \\
\hline-238 & $0.00 \mathrm{E}+00$ & 0 & $0.00 \mathrm{E}+00$ & 0 & $0.00 \mathrm{E}+00$ & 0 & $0.00 \mathrm{E}+00$ & 0 & $0.00 \mathrm{E}+00$ & 0 & $0.00 \mathrm{E}+00$ & 0 & $0.00 \mathrm{E}+00$ & 0 & $0.00 \mathrm{E}+00$ & 0 \\
\hline-239 & $0.00 \mathrm{E}+00$ & 0 & $0.00 \mathrm{E}+00$ & 0 & $0.00 \mathrm{E}+00$ & 0 & $0.00 \mathrm{E}+00$ & 0 & $0.00 \mathrm{E}+00$ & 0 & $0.00 \mathrm{E}+00$ & 0 & $0.00 \mathrm{E}+00$ & 0 & $0.00 \mathrm{E}+00$ & 0 \\
\hline-240 & $0.00 \mathrm{E}+00$ & 0 & $0.00 \mathrm{E}+00$ & 0 & $0.00 \mathrm{E}+00$ & 0 & $0.00 \mathrm{E}+00$ & 0 & $0.00 \mathrm{E}+00$ & 0 & $0.00 \mathrm{E}+00$ & 0 & $0.00 \mathrm{E}+00$ & 0 & $0.00 \mathrm{E}+00$ & 0 \\
\hline-99 & $0.00 \mathrm{E}+00$ & 0 & $0.00 E+00$ & 0 & $0.00 E+00$ & 0 & $0.00 \mathrm{E}+00$ & 0 & $0.00 \mathrm{E}+00$ & 0 & $0.00 E+00$ & 0 & $0.00 \mathrm{E}+00$ & 0 & $0.00 \mathrm{E}+00$ & 0 \\
\hline-228 & $0.00 \mathrm{E}+00$ & 0 & $0.00 \mathrm{E}+00$ & 0 & $0.00 \mathrm{E}+00$ & 0 & $0.00 \mathrm{E}+00$ & 0 & $0.00 \mathrm{E}+00$ & 0 & $0.00 \mathrm{E}+00$ & 0 & $0.00 \mathrm{E}+00$ & 0 & $0.00 \mathrm{E}+00$ & 0 \\
\hline-230 & $0.00 \mathrm{E}+00$ & 0 & $0.00 \mathrm{E}+00$ & 0 & $0.00 \mathrm{E}+00$ & 0 & $0.00 \mathrm{E}+00$ & 0 & $0.00 \mathrm{E}+00$ & 0 & $0.00 \mathrm{E}+00$ & 0 & $0.00 \mathrm{E}+00$ & 0 & $0.00 \mathrm{E}+00$ & 0 \\
\hline-232 & $0.00 \mathrm{E}+00$ & 0 & $0.00 E+00$ & 0 & $0.00 \mathrm{E}+00$ & 0 & $0.00 \mathrm{E}+00$ & 0 & $0.00 \mathrm{E}+00$ & 0 & $0.00 \mathrm{E}+00$ & 0 & $0.00 \mathrm{E}+00$ & 0 & $0.00 \mathrm{E}+00$ & 0 \\
\hline 234 & $0.00 \mathrm{E}+00$ & 0 & $0.00 \mathrm{E}+00$ & 0 & $0.00 \mathrm{E}+00$ & 0 & $0.00 \mathrm{E}+00$ & 0 & $0.00 \mathrm{E}+00$ & 0 & $0.00 \mathrm{E}+00$ & 0 & $0.00 \mathrm{E}+00$ & 0 & $0.00 \mathrm{E}+00$ & 0 \\
\hline 235 & $0.00 \mathrm{E}+00$ & 0 & $0.00 \mathrm{E}+00$ & 0 & $0.00 \mathrm{E}+00$ & 0 & $0.00 \mathrm{E}+00$ & 0 & $0.00 \mathrm{E}+00$ & 0 & $0.00 \mathrm{E}+00$ & 0 & $0.00 \mathrm{E}+00$ & 0 & $0.00 \mathrm{E}+00$ & 0 \\
\hline 38 & $0.00 \mathrm{E}+00$ & 0 & $0.00 E+00$ & 0 & $0.00 \mathrm{E}+00$ & 0 & $0.00 \mathrm{E}+00$ & 0 & $0.00 \mathrm{E}+00$ & 0 & $0.00 \mathrm{E}+00$ & 0 & $0.00 \mathrm{E}+00$ & 0 & $0.00 \mathrm{E}+00$ & 0 \\
\hline & $0.00 \mathrm{E}+00$ & 0 & $0.00 \mathrm{E}+00$ & 0 & $0.00 \mathrm{E}+00$ & 0 & $0.00 \mathrm{E}+00$ & 0 & $0.00 \mathrm{E}+00$ & 0 & $0.00 \mathrm{E}+00$ & 0 & $0.00 \mathrm{E}+00$ & 0 & $.00 \mathrm{E}+00$ & 0 \\
\hline
\end{tabular}

Total Dose Contributions TDOSE(i,p,t) for Individual Radionuclides (i) and Pathways (p) in mrem/yr and as a Percentage of Total Dose at $t=1026$ years

Directly from primary contamination and from release to atmosphere (Inhalation excludes radon)

\begin{tabular}{|c|c|c|c|c|c|c|c|c|c|c|c|c|c|c|c|c|}
\hline & \multicolumn{2}{|c|}{ Ground } & \multicolumn{2}{|c|}{ Inhalation } & \multicolumn{2}{|c|}{ Radon } & \multicolumn{2}{|c|}{ Plant } & \multicolumn{2}{|l|}{ Meat } & \multicolumn{2}{|l|}{ Milk } & \multicolumn{2}{|l|}{ Soil } & \multicolumn{2}{|c|}{ All Pathways* } \\
\hline clide & Dose & $\%$ & Dose & $\%$ & Dose & $\%$ & Dose & 음 & Dose & $\%$ & Dose & 음 & Dose & $\%$ & Dose & $\%$ \\
\hline-241 & $6.97 E-19$ & 0 & $0.00 \mathrm{E}+00$ & 0 & $0.00 E+00$ & 0 & $0.00 \mathrm{E}+00$ & 0 & $0.00 \mathrm{E}+00$ & 0 & $0.00 \mathrm{E}+00$ & 0 & $0.00 \mathrm{E}+00$ & 0 & $6.97 \mathrm{E}-19$ & 0 \\
\hline-137 & $1.70 \mathrm{E}-23$ & 0 & $0.00 \mathrm{E}+00$ & 0 & $0.00 E+00$ & 0 & $0.00 \mathrm{E}+00$ & 0 & $0.00 \mathrm{E}+00$ & 0 & $0.00 E+00$ & 0 & $0.00 \mathrm{E}+00$ & 0 & $1.70 \mathrm{E}-23$ & 0 \\
\hline-237 & $6.63 E-16$ & 0 & $0.00 \mathrm{E}+00$ & 0 & $0.00 E+00$ & 0 & $0.00 \mathrm{E}+00$ & 0 & $0.00 \mathrm{E}+00$ & 0 & $0.00 E+00$ & 0 & $0.00 \mathrm{E}+00$ & 0 & $6.63 E-16$ & 0 \\
\hline-238 & $1.16 \mathrm{E}-17$ & 0 & $0.00 \mathrm{E}+00$ & 0 & $0.00 \mathrm{E}+00$ & 0 & $0.00 \mathrm{E}+00$ & 0 & $0.00 \mathrm{E}+00$ & 0 & $0.00 \mathrm{E}+00$ & 0 & $0.00 \mathrm{E}+00$ & 0 & 1. $16 \mathrm{E}-17$ & 0 \\
\hline-239 & $1.70 \mathrm{E}-19$ & 0 & $0.00 \mathrm{E}+00$ & 0 & $0.00 \mathrm{E}+00$ & 0 & $0.00 \mathrm{E}+00$ & 0 & $0.00 \mathrm{E}+00$ & 0 & $0.00 \mathrm{E}+00$ & 0 & $0.00 \mathrm{E}+00$ & 0 & 1. $70 \mathrm{E}-19$ & 0 \\
\hline-240 & $6.58 E-23$ & 0 & $0.00 \mathrm{E}+00$ & 0 & $0.00 \mathrm{E}+00$ & 0 & $0.00 \mathrm{E}+00$ & 0 & $0.00 \mathrm{E}+00$ & 0 & $0.00 E+00$ & 0 & $0.00 \mathrm{E}+00$ & 0 & $6.58 E-23$ & 0 \\
\hline-99 & $4.96 \mathrm{E}-27$ & 0 & $0.00 \mathrm{E}+00$ & 0 & $0.00 \mathrm{E}+00$ & 0 & $0.00 \mathrm{E}+00$ & 0 & $0.00 \mathrm{E}+00$ & 0 & $0.00 E+00$ & 0 & $0.00 \mathrm{E}+00$ & 0 & $4.96 \mathrm{E}-27$ & 0 \\
\hline-228 & $0.00 \mathrm{E}+00$ & 0 & $0.00 \mathrm{E}+00$ & 0 & $0.00 \mathrm{E}+00$ & 0 & $0.00 \mathrm{E}+00$ & 0 & $0.00 \mathrm{E}+00$ & 0 & $0.00 \mathrm{E}+00$ & 0 & $0.00 \mathrm{E}+00$ & 0 & $0.00 \mathrm{E}+00$ & 0 \\
\hline-230 & $2.11 E-11$ & 68 & $0.00 E+00$ & 0 & $0.00 \mathrm{E}+00$ & 0 & $0.00 \mathrm{E}+00$ & 0 & $0.00 \mathrm{E}+00$ & 0 & $0.00 E+00$ & 0 & $0.00 \mathrm{E}+00$ & 0 & $2.11 \mathrm{E}-11$ & 68 \\
\hline-232 & $9.64 \mathrm{E}-12$ & 31 & $0.00 \mathrm{E}+00$ & 0 & $0.00 \mathrm{E}+00$ & 0 & $0.00 \mathrm{E}+00$ & 0 & $0.00 \mathrm{E}+00$ & 0 & $0.00 \mathrm{E}+00$ & 0 & $0.00 \mathrm{E}+00$ & 0 & $9.64 \mathrm{E}-12$ & 31 \\
\hline 34 & $1.67 \mathrm{E}-13$ & 1 & $0.00 \mathrm{E}+00$ & 0 & $0.00 \mathrm{E}+00$ & 0 & $0.00 \mathrm{E}+00$ & 0 & $0.00 \mathrm{E}+00$ & 0 & $0.00 \mathrm{E}+00$ & 0 & $0.00 \mathrm{E}+00$ & 0 & 1. $67 \mathrm{E}-13$ & 1 \\
\hline 35 & $2.70 \mathrm{E}-16$ & 0 & $0.00 \mathrm{E}+00$ & 0 & $0.00 \mathrm{E}+00$ & 0 & $0.00 \mathrm{E}+00$ & 0 & $0.00 \mathrm{E}+00$ & 0 & $0.00 \mathrm{E}+00$ & 0 & $0.00 \mathrm{E}+00$ & 0 & $2.70 \mathrm{E}-16$ & 0 \\
\hline 38 & $2.13 E-13$ & 1 & $0.00 \mathrm{E}+00$ & 0 & $0.00 \mathrm{E}+00$ & 0 & $0.00 \mathrm{E}+00$ & 0 & $0.00 \mathrm{E}+00$ & 0 & $0.00 E+00$ & 0 & $0.00 \mathrm{E}+00$ & 0 & $2.13 E-13$ & 1 \\
\hline & $3.11 \mathrm{E}-11$ & 100 & $0.00 \mathrm{E}+00$ & 0 & $0.00 \mathrm{E}+00$ & 0 & $0.00 \mathrm{E}+00$ & 0 & $0.00 \mathrm{E}+00$ & 0 & $0.00 \mathrm{E}+00$ & 0 & $0.00 \mathrm{E}+00$ & 0 & $3.11 \mathrm{E}-11$ & 100 \\
\hline
\end{tabular}

* Sum of dose from all releases and from primary contamination. 
RESRAD-OFFSITE, Version 2.

Parent Dose Report

Title : RESRAD-OFFSITE Parameters for Offsite Resident Farmer Forward Run 100,000 Years

File : OFFSITE-RF_FORWARD-7-11-100000yr.ROF

Total Dose Contributions TDOSE (i,p,t) for Individual Radionuclides (i) and Pathways (p) in mrem/yr and as a Percentage of Total Dose at $t=10000$ years

From releases to ground water and to surface water

\begin{tabular}{|c|c|c|c|c|c|c|c|c|c|c|c|c|c|c|c|c|}
\hline \multirow{2}{*}{$\begin{array}{l}\text { Radio- } \\
\text { Nuclide }\end{array}$} & \multicolumn{2}{|c|}{ Ground } & \multicolumn{2}{|l|}{ Fish } & \multicolumn{2}{|c|}{ Radon } & \multicolumn{2}{|c|}{ Plant } & \multicolumn{2}{|l|}{ Meat } & \multicolumn{2}{|l|}{ Milk } & \multicolumn{2}{|l|}{ Soil } & \multicolumn{2}{|c|}{ Water } \\
\hline & Dose & \% & Dose & $\%$ & Dose & $\%$ & Dose & \% & Dose & $\%$ & Dose & 응 & Dose & \% & Dose & $\%$ \\
\hline-241 & $1.21 E-05$ & 0 & $0.00 \mathrm{E}+00$ & 0 & $0.00 \mathrm{E}+00$ & 0 & $4.01 E-04$ & 0 & 1. $49 E-05$ & 0 & $8.41 E-07$ & 0 & $2.01 E-07$ & 0 & $1.36 \mathrm{E}-03$ & 0 \\
\hline-137 & $0.00 \mathrm{E}+00$ & 0 & $0.00 \mathrm{E}+00$ & 0 & $0.00 \mathrm{E}+00$ & 0 & $0.00 \mathrm{E}+00$ & 0 & $0.00 \mathrm{E}+00$ & 0 & $0.00 \mathrm{E}+00$ & 0 & $0.00 \mathrm{E}+00$ & 0 & $0.00 \mathrm{E}+00$ & 0 \\
\hline-237 & $8.70 \mathrm{E}-03$ & 0 & $0.00 \mathrm{E}+00$ & 0 & $0.00 \mathrm{E}+00$ & 0 & $2.89 \mathrm{E}-01$ & 13 & $1.07 \mathrm{E}-02$ & 0 & $6.08 \mathrm{E}-04$ & 0 & 1. $45 \mathrm{E}-04$ & 0 & $9.78 \mathrm{E}-01$ & 45 \\
\hline-238 & $0.00 \mathrm{E}+00$ & 0 & $0.00 \mathrm{E}+00$ & 0 & $0.00 E+00$ & 0 & $0.00 \mathrm{E}+00$ & 0 & $0.00 \mathrm{E}+00$ & 0 & $0.00 E+00$ & 0 & $0.00 \mathrm{E}+00$ & 0 & $0.00 \mathrm{E}+00$ & 0 \\
\hline-239 & $0.00 \mathrm{E}+00$ & 0 & $0.00 \mathrm{E}+00$ & 0 & $0.00 \mathrm{E}+00$ & 0 & $0.00 \mathrm{E}+00$ & 0 & $0.00 \mathrm{E}+00$ & 0 & $0.00 \mathrm{E}+00$ & 0 & $0.00 \mathrm{E}+00$ & 0 & $0.00 \mathrm{E}+00$ & 0 \\
\hline-240 & $0.00 \mathrm{E}+00$ & 0 & $0.00 \mathrm{E}+00$ & 0 & $0.00 \mathrm{E}+00$ & 0 & $0.00 \mathrm{E}+00$ & 0 & $0.00 \mathrm{E}+00$ & 0 & $0.00 \mathrm{E}+00$ & 0 & $0.00 \mathrm{E}+00$ & 0 & $0.00 \mathrm{E}+00$ & 0 \\
\hline-99 & $0.00 \mathrm{E}+00$ & 0 & $0.00 \mathrm{E}+00$ & 0 & $0.00 \mathrm{E}+00$ & 0 & $0.00 \mathrm{E}+00$ & 0 & $0.00 \mathrm{E}+00$ & 0 & $0.00 \mathrm{E}+00$ & 0 & $0.00 \mathrm{E}+00$ & 0 & $0.00 \mathrm{E}+00$ & 0 \\
\hline-228 & $0.00 \mathrm{E}+00$ & 0 & $0.00 \mathrm{E}+00$ & 0 & $0.00 \mathrm{E}+00$ & 0 & $0.00 \mathrm{E}+00$ & 0 & $0.00 \mathrm{E}+00$ & 0 & $0.00 \mathrm{E}+00$ & 0 & $0.00 \mathrm{E}+00$ & 0 & $0.00 \mathrm{E}+00$ & 0 \\
\hline-230 & $0.00 \mathrm{E}+00$ & 0 & $0.00 \mathrm{E}+00$ & 0 & $0.00 \mathrm{E}+00$ & 0 & $0.00 \mathrm{E}+00$ & 0 & $0.00 \mathrm{E}+00$ & 0 & $0.00 \mathrm{E}+00$ & 0 & $0.00 \mathrm{E}+00$ & 0 & $0.00 \mathrm{E}+00$ & 0 \\
\hline-232 & $0.00 \mathrm{E}+00$ & 0 & $0.00 \mathrm{E}+00$ & 0 & $0.00 \mathrm{E}+00$ & 0 & $0.00 \mathrm{E}+00$ & 0 & $0.00 \mathrm{E}+00$ & 0 & $0.00 \mathrm{E}+00$ & 0 & $0.00 \mathrm{E}+00$ & 0 & $0.00 \mathrm{E}+00$ & 0 \\
\hline 234 & $0.00 \mathrm{E}+00$ & 0 & $0.00 \mathrm{E}+00$ & 0 & $0.00 \mathrm{E}+00$ & 0 & $0.00 \mathrm{E}+00$ & 0 & $0.00 \mathrm{E}+00$ & 0 & $0.00 \mathrm{E}+00$ & 0 & $0.00 \mathrm{E}+00$ & 0 & $0.00 \mathrm{E}+00$ & 0 \\
\hline 235 & $0.00 \mathrm{E}+00$ & 0 & $0.00 \mathrm{E}+00$ & 0 & $0.00 \mathrm{E}+00$ & 0 & $0.00 \mathrm{E}+00$ & 0 & $0.00 \mathrm{E}+00$ & 0 & $0.00 \mathrm{E}+00$ & 0 & $0.00 \mathrm{E}+00$ & 0 & $0.00 \mathrm{E}+00$ & 0 \\
\hline 38 & $0.00 \mathrm{E}+00$ & 0 & $0.00 \mathrm{E}+00$ & 0 & $0.00 \mathrm{E}+00$ & 0 & $0.00 \mathrm{E}+00$ & 0 & $0.00 \mathrm{E}+00$ & 0 & $0.00 \mathrm{E}+00$ & 0 & $0.00 \mathrm{E}+00$ & 0 & $0.00 \mathrm{E}+00$ & 0 \\
\hline a & $8.71 \mathrm{E}-03$ & 0 & $0.00 \mathrm{E}+00$ & 0 & $0.00 \mathrm{E}+00$ & 0 & $2.89 \mathrm{E}-01$ & 13 & $1.08 \mathrm{E}-02$ & 0 & $6.09 \mathrm{E}-04$ & 0 & 1. $45 \mathrm{E}-04$ & 0 & $9.80 \mathrm{E}-01$ & 45 \\
\hline
\end{tabular}

Total Dose Contributions TDOSE (i,p,t) for Individual Radionuclides (i) and Pathways (p) in mrem/yr and as a Percentage of Total Dose at $t=10000$ years

Directly from primary contamination and from release to atmosphere (Inhalation excludes radon)

\begin{tabular}{|c|c|c|c|c|c|c|c|c|c|c|c|c|c|c|c|c|}
\hline & \multicolumn{2}{|c|}{ Ground } & \multicolumn{2}{|c|}{ Inhalation } & \multicolumn{2}{|c|}{ Radon } & \multicolumn{2}{|c|}{ Plant } & \multicolumn{2}{|l|}{ Meat } & \multicolumn{2}{|l|}{ Milk } & \multicolumn{2}{|l|}{ Soil } & \multicolumn{2}{|c|}{ All Pathways* } \\
\hline clide & Dose & $\%$ & Dose & $\%$ & Dose & \% & Dose & $\frac{\circ}{0}$ & Dose & 응 & Dose & $\%$ & Dose & $\%$ & Dose & 응 \\
\hline $1-241$ & $1.81 E-06$ & 0 & $4.76 E-09$ & 0 & $0.00 \mathrm{E}+00$ & 0 & $4.46 \mathrm{E}-11$ & 0 & 1. $23 E-11$ & 0 & $3.69 \mathrm{E}-13$ & 0 & 1. $29 \mathrm{E}-12$ & 0 & $1.79 E-03$ & 0 \\
\hline-137 & 1. $12 \mathrm{E}-44$ & 0 & $0.00 E+00$ & 0 & $0.00 \mathrm{E}+00$ & 0 & $0.00 \mathrm{E}+00$ & 0 & $4.20 E-45$ & 0 & 1. $40 \mathrm{E}-45$ & 0 & $0.00 \mathrm{E}+00$ & 0 & 1. $68 E-44$ & 0 \\
\hline-237 & 1. $35 \mathrm{E}-03$ & 0 & $3.57 E-06$ & 0 & $0.00 \mathrm{E}+00$ & 0 & $3.33 E-08$ & 0 & $9.15 E-09$ & 0 & $2.92 \mathrm{E}-10$ & 0 & $9.92 \mathrm{E}-10$ & 0 & $1.29 \mathrm{E}+00$ & 59 \\
\hline-238 & $7.03 E-06$ & 0 & $5.96 E-09$ & 0 & $0.00 \mathrm{E}+00$ & 0 & $4.14 \mathrm{E}-10$ & 0 & $9.45 E-11$ & 0 & $1.02 \mathrm{E}-10$ & 0 & $1.47 \mathrm{E}-11$ & 0 & $7.03 E-06$ & 0 \\
\hline-239 & $2.76 \mathrm{E}-06$ & 0 & $7.37 \mathrm{E}-05$ & 0 & $0.00 \mathrm{E}+00$ & 0 & $2.96 \mathrm{E}-07$ & 0 & $2.10 \mathrm{E}-08$ & 0 & $4.98 \mathrm{E}-10$ & 0 & $3.96 \mathrm{E}-08$ & 0 & $7.68 \mathrm{E}-05$ & 0 \\
\hline-240 & $9.79 \mathrm{E}-08$ & 0 & $3.40 E-05$ & 0 & $0.00 \mathrm{E}+00$ & 0 & $1.37 \mathrm{E}-07$ & 0 & $9.72 \mathrm{E}-09$ & 0 & $2.37 \mathrm{E}-10$ & 0 & $1.83 \mathrm{E}-08$ & 0 & $3.43 E-05$ & 0 \\
\hline-99 & $1.99 \mathrm{E}-29$ & 0 & $2.41 E-31$ & 0 & $0.00 \mathrm{E}+00$ & 0 & $8.49 E-32$ & 0 & $1.89 \mathrm{E}-33$ & 0 & $2.59 \mathrm{E}-32$ & 0 & $1.00 \mathrm{E}-35$ & 0 & $2.03 E-29$ & 0 \\
\hline-228 & $0.00 \mathrm{E}+00$ & 0 & $0.00 \mathrm{E}+00$ & 0 & $0.00 \mathrm{E}+00$ & 0 & $0.00 \mathrm{E}+00$ & 0 & $0.00 \mathrm{E}+00$ & 0 & $0.00 \mathrm{E}+00$ & 0 & $0.00 \mathrm{E}+00$ & 0 & $0.00 \mathrm{E}+00$ & 0 \\
\hline-230 & $7.41 \mathrm{E}-01$ & 34 & $2.69 \mathrm{E}-04$ & 0 & $0.00 \mathrm{E}+00$ & 0 & $4.06 \mathrm{E}-05$ & 0 & $9.55 E-06$ & 0 & $9.24 \mathrm{E}-06$ & 0 & $1.36 \mathrm{E}-06$ & 0 & $7.41 \mathrm{E}-01$ & 34 \\
\hline-232 & $4.56 \mathrm{E}-02$ & 2 & $1.68 E-05$ & 0 & $0.00 \mathrm{E}+00$ & 0 & $2.07 E-06$ & 0 & $3.61 E-07$ & 0 & $5.58 \mathrm{E}-07$ & 0 & $3.37 E-08$ & 0 & $4.56 \mathrm{E}-02$ & 2 \\
\hline 234 & $8.16 \mathrm{E}-02$ & 4 & $6.86 \mathrm{E}-05$ & 0 & $0.00 \mathrm{E}+00$ & 0 & $4.81 \mathrm{E}-06$ & 0 & $1.10 \mathrm{E}-06$ & 0 & $1.19 \mathrm{E}-06$ & 0 & $1.70 \mathrm{E}-07$ & 0 & $8.17 \mathrm{E}-02$ & 4 \\
\hline 235 & $2.81 \mathrm{E}-03$ & 0 & $2.08 E-05$ & 0 & $0.00 \mathrm{E}+00$ & 0 & $2.27 \mathrm{E}-07$ & 0 & $2.03 E-07$ & 0 & $9.39 \mathrm{E}-09$ & 0 & $1.41 \mathrm{E}-08$ & 0 & $2.83 E-03$ & 0 \\
\hline 238 & $1.67 \mathrm{E}-02$ & 1 & $2.96 E-05$ & 0 & $0.00 \mathrm{E}+00$ & 0 & $3.66 \mathrm{E}-07$ & 0 & $5.73 E-08$ & 0 & $1.87 \mathrm{E}-07$ & 0 & $1.84 \mathrm{E}-08$ & 0 & 1. $68 \mathrm{E}-02$ & 1 \\
\hline & $8.89 \mathrm{E}-01$ & 41 & $5.16 E-04$ & 0 & $0.00 \mathrm{E}+00$ & 0 & $4.85 E-05$ & 0 & 1.13E-05 & 0 & $1.12 \mathrm{E}-05$ & 0 & $1.66 \mathrm{E}-06$ & 0 & $2.18 \mathrm{E}+00$ & 100 \\
\hline
\end{tabular}

* Sum of dose from all releases and from primary contamination. 
RESRAD-OFFSITE, Version 2.

Parent Dose Report

Title : RESRAD-OFFSITE Parameters for Offsite Resident Farmer Forward Run 100,000 Years

File : OFFSITE-RF FORWARD-7-11-100000yr.ROF

Dose/Source Ratios Summed Over All Pathways

Parent and Progeny Principal Radionuclide Contributions Indicated

Parent Product Thread DSR $(j, \mathrm{t})$ (mrem/yr)/(pCi/g)

(i)

(j)

$\begin{array}{ll}\mathrm{Am}-241 & 1.000 \mathrm{E}+00 \\ \mathrm{~Np}-237+\mathrm{D} & 1.000 \mathrm{E}+00 \\ \mathrm{U}-233 & 1.000 \mathrm{E}+00 \\ \mathrm{Th}-229+\mathrm{D} & 1.000 \mathrm{E}+00 \\ \operatorname{\sum DSR}(j) & \end{array}$

Cs $-137+D$

$\mathrm{Np}-237+\mathrm{D}$

$\mathrm{U}-233$

Th-229+D

$\sum \operatorname{DSR}(j)$

Pu-238

$\mathrm{Pu}-238$

$\mathrm{U}-234$

Th-230

Ra $-226+D$

$\mathrm{Pb}-210+\mathrm{D}$

$\sum \operatorname{DSR}(j)$

$\mathrm{Pu}-239$

$\mathrm{U}-235+\mathrm{D}$

$\mathrm{Pa}-231$

$A C-227+D$

$\sum \operatorname{DSR}(j)$

$\mathrm{Pu}-240$

$\mathrm{Pu}-240$

U-236

Th-232

$\mathrm{Ra}-228+\mathrm{D}$

Th-228+D

$\sum \operatorname{DSR}(j)$

TC-99

Th-228+D

$1.000 \mathrm{E}+00$

1. $000 \mathrm{E}+00$

1. $000 \mathrm{E}+00$

1. $000 \mathrm{E}+00$ 1. $000 \mathrm{E}+00$ 1. $000 \mathrm{E}+00$
(

$9.546 \mathrm{E}-42 \quad 9.796 \mathrm{E}-42 \quad 3.247 \mathrm{E}-41 \quad 1.104 \mathrm{E}-40 \quad 1.948 \mathrm{E}-36 \quad 7.499 \mathrm{E}-31 \quad 4.155 \mathrm{E}-13 \quad 0.000 \mathrm{E}+00$

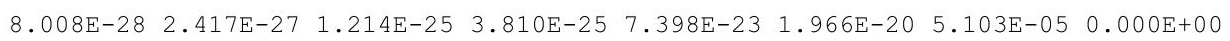
$\begin{array}{lllllllll}1.678 \mathrm{E}-37 & 5.659 \mathrm{E}-37 & 2.301 \mathrm{E}-34 & 1.574 \mathrm{E}-33 & 3.199 \mathrm{E}-30 & 4.570 \mathrm{E}-27 & 1.149 \mathrm{E}-07 & 8.968 \mathrm{E}-07\end{array}$

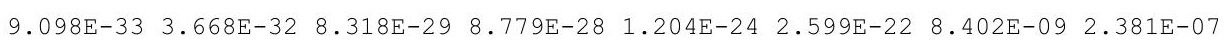
$8.008 \mathrm{E}-28 \quad 2.417 \mathrm{E}-27 \quad 1.215 \mathrm{E}-25 \quad 3.819 \mathrm{E}-25 \quad 7.519 \mathrm{E}-23 \quad 1.992 \mathrm{E}-20 \quad 5.116 \mathrm{E}-05 \quad 1.135 \mathrm{E}-06$

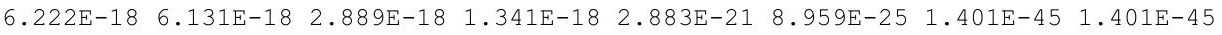

$4.701 \mathrm{E}-21 \quad 4.749 \mathrm{E}-21 \quad 7.701 \mathrm{E}-21 \quad 1.261 \mathrm{E}-20 \quad 6.528 \mathrm{E}-19 \quad 1.172 \mathrm{E}-16 \quad 2.337 \mathrm{E}-012.803 \mathrm{E}-45$ $\begin{array}{llllllll}1.702 \mathrm{E}-31 & 5.148 \mathrm{E}-31 & 2.873 \mathrm{E}-29 & 1.016 \mathrm{E}-28 & 5.036 \mathrm{E}-26 & 4.388 \mathrm{E}-23 & 5.376 \mathrm{E}-04 & 4.058 \mathrm{E}-03\end{array}$ $\begin{array}{lllllllll}1.384 \mathrm{E}-26 & 4.640 \mathrm{E}-26 & 1.543 \mathrm{E}-23 & 8.382 \mathrm{E}-23 & 2.673 \mathrm{E}-20 & 3.337 \mathrm{E}-18 & 4.441 \mathrm{E}-05 & 1.092 \mathrm{E}-03\end{array}$ $\begin{array}{llllllllll}4.701 \mathrm{E}-21 & 4.749 \mathrm{E}-21 & 7.717 \mathrm{E}-21 & 1.270 \mathrm{E}-20 & 6.796 \mathrm{E}-19 & 1.205 \mathrm{E}-16 & 2.343 \mathrm{E}-01 & 5.150 \mathrm{E}-03\end{array}$

$\begin{array}{lllllllllll}1.840 \mathrm{E}-09 & 1.065 \mathrm{E}-41 & 1.075 \mathrm{E}-41 & 1.618 \mathrm{E}-41 & 2.459 \mathrm{E}-41 & 6.962 \mathrm{E}-40 & 5.654 \mathrm{E}-38 & 0.000 \mathrm{E}+00 & 0.000 \mathrm{E}+00\end{array}$

$\begin{array}{llllllll}1.000 \mathrm{E}+00 \quad 5.790 \mathrm{E}-33 & 5.840 \mathrm{E}-33 & 8.796 \mathrm{E}-33 & 1.336 \mathrm{E}-32 & 3.784 \mathrm{E}-31 & 3.073 \mathrm{E}-29 & 1.230 \mathrm{E}-40 & 0.000 \mathrm{E}+00\end{array}$ $\begin{array}{lllllllll}1.000 \mathrm{E}+00 & 5.152 \mathrm{E}-38 & 1.559 \mathrm{E}-37 & 9.092 \mathrm{E}-36 & 3.421 \mathrm{E}-35 & 4.155 \mathrm{E}-32 & 2.244 \mathrm{E}-28 & 9.220 \mathrm{E}-11 & 9.723 \mathrm{E}-07\end{array}$ $\begin{array}{llllllllll}1.000 \mathrm{E}+00 & 4.969 \mathrm{E}-41 & 1.680 \mathrm{E}-40 & 7.439 \mathrm{E}-38 & 5.651 \mathrm{E}-37 & 3.320 \mathrm{E}-33 & 2.724 \mathrm{E}-29 & 7.814 \mathrm{E}-11 & 1.681 \mathrm{E}-08\end{array}$ $\begin{array}{lllllllllll}1.000 \mathrm{E}+00 & 3.014 \mathrm{E}-29 & 1.211 \mathrm{E}-28 & 2.558 \mathrm{E}-25 & 2.498 \mathrm{E}-24 & 2.109 \mathrm{E}-21 & 2.972 \mathrm{E}-19 & 1.801 \mathrm{E}-07 & 1.783 \mathrm{E}-07\end{array}$ $\begin{array}{llllllllll}6.501 \mathrm{E}-37 & 3.437 \mathrm{E}-36 & 3.795 \mathrm{E}-32 & 6.137 \mathrm{E}-31 & 1.329 \mathrm{E}-27 & 3.422 \mathrm{E}-25 & 8.401 \mathrm{E}-11 & 1.538 \mathrm{E}-06\end{array}$ $\begin{array}{lllllllll}3.015 E-29 & 1.211 E-28 & 2.558 E-25 & 2.498 E-24 & 2.109 E-21 & 2.972 \mathrm{E}-19 & 1.804 \mathrm{E}-07 & 2.705 \mathrm{E}-06\end{array}$

$\begin{array}{llllllllll}1.000 \mathrm{E}+00 & 5.926 \mathrm{E}-26 & 5.994 \mathrm{E}-26 & 1.027 \mathrm{E}-25 & 1.780 \mathrm{E}-25 & 1.445 \mathrm{E}-23 & 4.688 \mathrm{E}-21 & 2.131 \mathrm{E}-06 & 1.071 \mathrm{E}-04\end{array}$ $\begin{array}{lllllllll}1.000 \mathrm{E}+00 & 3.216 \mathrm{E}-32 & 9.724 \mathrm{E}-32 & 5.395 \mathrm{E}-30 & 1.895 \mathrm{E}-29 & 8.897 \mathrm{E}-27 & 7.219 \mathrm{E}-24 & 2.135 \mathrm{E}-09 & 4.871 \mathrm{E}-08\end{array}$

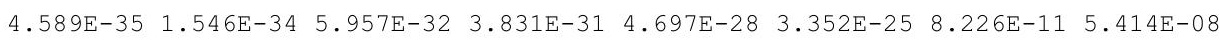
$8.412 \mathrm{E}-34 \quad 3.353 \mathrm{E}-33 \quad 6.148 \mathrm{E}-30 \quad 5.410 \mathrm{E}-29 \quad 5.166 \mathrm{E}-26 \quad 1.643 \mathrm{E}-23 \quad 8.001 \mathrm{E}-10 \quad 1.007 \mathrm{E}-07$ $\begin{array}{lllllllll}5.926 \mathrm{E}-26 & 5.994 \mathrm{E}-26 & 1.027 \mathrm{E}-25 & 1.781 \mathrm{E}-25 & 1.451 \mathrm{E}-23 & 4.712 \mathrm{E}-21 & 2.134 \mathrm{E}-06 & 1.073 \mathrm{E}-04\end{array}$

$\begin{array}{lllllllll}4.950 \mathrm{E}-08 & 2.787 \mathrm{E}-40 & 2.834 \mathrm{E}-40 & 6.255 \mathrm{E}-40 & 1.403 \mathrm{E}-39 & 8.973 \mathrm{E}-37 & 4.395 \mathrm{E}-33 & 4.717 \mathrm{E}-14 & 2.349 \mathrm{E}-15\end{array}$

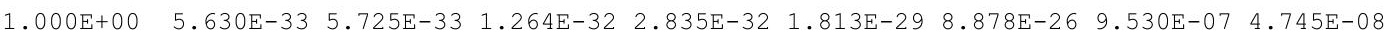
$\begin{array}{lllllllll}1.000 \mathrm{E}+00 & 1.165 \mathrm{E}-40 & 3.536 \mathrm{E}-40 & 2.459 \mathrm{E}-38 & 1.117 \mathrm{E}-37 & 4.097 \mathrm{E}-34 & 4.969 \mathrm{E}-30 & 4.001 \mathrm{E}-11 \quad 7.086 \mathrm{E}-07\end{array}$ $\begin{array}{llllllllll}1.000 \mathrm{E}+00 & 0.000 \mathrm{E}+00 & 0.000 \mathrm{E}+00 & 0.000 \mathrm{E}+00 & 0.000 \mathrm{E}+00 & 5.314 \mathrm{E}-42 & 1.759 \mathrm{E}-37 & 1.389 \mathrm{E}-16 & 8.112 \mathrm{E}-14\end{array}$ $\begin{array}{lllllllll}1.000 \mathrm{E}+00 & 4.496 \mathrm{E}-35 & 1.727 \mathrm{E}-34 & 1.814 \mathrm{E}-31 & 1.185 \mathrm{E}-30 & 5.383 \mathrm{E}-28 & 8.911 \mathrm{E}-26 & 2.184 \mathrm{E}-13 & 1.843 \mathrm{E}-12\end{array}$ $\begin{array}{llllllllll}1.000 \mathrm{E}+00 & 1.486 \mathrm{E}-33 & 6.561 \mathrm{E}-33 & 1.282 \mathrm{E}-29 & 8.293 \mathrm{E}-29 & 2.173 \mathrm{E}-26 & 1.651 \mathrm{E}-24 & 3.453 \mathrm{E}-13 & 6.505 \mathrm{E}-14\end{array}$ $\begin{array}{lllllllll}7.161 \mathrm{E}-33 & 1.246 \mathrm{E}-32 & 1.301 \mathrm{E}-29 & 8.415 \mathrm{E}-29 & 2.229 \mathrm{E}-26 & 1.829 \mathrm{E}-24 & 9.530 \mathrm{E}-07 & 7.561 \mathrm{E}-07\end{array}$

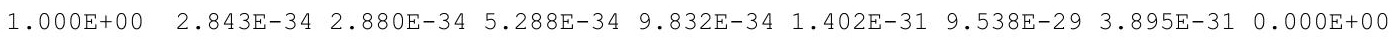


RESRAD-OFFSITE, Version 2.

Parent Dose Report

Title : RESRAD-OFFSITE Parameters for Offsite Resident Farmer Forward Run 100,000 Years

File : OFFSITE-RF_FORWARD-7-11-100000yr.ROF

Dose/Source Ratios Summed Over All Pathways

Parent and Progeny Principal Radionuclide Contributions Indicated

\begin{tabular}{|c|c|c|c|c|c|c|c|c|c|c|}
\hline Parent & Product & Thread & & & $\operatorname{DSR}(j, t$ & (mrem/s & r) /(pCi/g) & & & \\
\hline (i) & (j) & Fraction & $0.000 \mathrm{E}+00$ & $1.000 \mathrm{E}+00$ & $5.000 \mathrm{E}+01$ & $1.000 \mathrm{E}+02$ & $5.000 \mathrm{E}+02$ & $1.026 \mathrm{E}+03$ & $1.000 \mathrm{E}+04$ & $1.000 \mathrm{E}+05$ \\
\hline-230 & Th -230 & $1.000 \mathrm{E}+00$ & $1.189 \mathrm{E}-30$ & $1.208 \mathrm{E}-30$ & $2.580 \mathrm{E}-30$ & $5.597 \mathrm{E}-30$ & $2.733 E-27$ & $9.393 E-24$ & $2.517 E-06$ & $2.317 E-09$ \\
\hline $1-230$ & $\mathrm{Ra}-226+\mathrm{D}$ & $1.000 \mathrm{E}+00$ & 1.923E-19 & $5.794 \mathrm{E}-19$ & $2.555 \mathrm{E}-17$ & $6.911 \mathrm{E}-17$ & $4.025 E-15$ & $2.105 \mathrm{E}-13$ & $7.405 E-03$ & $9.722 \mathrm{E}-07$ \\
\hline$h-230$ & $\mathrm{~Pb}-210+\mathrm{D}$ & $1.000 \mathrm{E}+00$ & $8.076 E-27$ & $2.678 E-26$ & $6.228 E-24$ & $2.467 \mathrm{E}-23$ & $2.775 \mathrm{E}-21$ & $2.524 \mathrm{E}-19$ & $3.467 E-06$ & $8.796 \mathrm{E}-06$ \\
\hline$h-230$ & $\sum \operatorname{DSR}(j)$ & & 1. $923 \mathrm{E}-19$ & $5.794 \mathrm{E}-19$ & $2.555 \mathrm{E}-17$ & $6.911 \mathrm{E}-17$ & $4.025 \mathrm{E}-15$ & $2.105 \mathrm{E}-13$ & 7. $411 \mathrm{E}-03$ & $9.771 \mathrm{E}-06$ \\
\hline-232 & Th-232 & $1.000 \mathrm{E}+00$ & $5.747 E-33$ & $5.851 \mathrm{E}-33$ & 1. $352 \mathrm{E}-32$ & $3.180 \mathrm{E}-32$ & $2.965 E-29$ & $2.385 E-25$ & $2.805 E-06$ & $6.235 E-09$ \\
\hline$h-232$ & $\mathrm{Ra}-228+\mathrm{D}$ & $1.000 \mathrm{E}+00$ & $4.177 \mathrm{E}-18$ & 1.222E-17 & $1.332 \mathrm{E}-16$ & $1.894 \mathrm{E}-16$ & $3.105 E-15$ & 1. $228 \mathrm{E}-13$ & 4. $417 \mathrm{E}-03$ & 1. $489 \mathrm{E}-08$ \\
\hline$h-232$ & $\mathrm{Th}-228+\mathrm{D}$ & $1.000 \mathrm{E}+00$ & $2.311 E-16$ & $6.944 \mathrm{E}-16$ & $1.066 \mathrm{E}-14$ & $1.408 \mathrm{E}-14$ & 1. $267 \mathrm{E}-13$ & $2.288 \mathrm{E}-12$ & $6.987 \mathrm{E}-03$ & $9.427 \mathrm{E}-10$ \\
\hline$h-232$ & $\sum \operatorname{DSR}(j)$ & & $2.352 \mathrm{E}-16$ & $7.067 \mathrm{E}-16$ & $1.079 \mathrm{E}-14$ & $1.426 \mathrm{E}-14$ & 1. $298 \mathrm{E}-13$ & $2.410 \mathrm{E}-12$ & $1.141 \mathrm{E}-02$ & $2.207 \mathrm{E}-08$ \\
\hline-234 & $\mathrm{U}-234$ & $1.000 \mathrm{E}+00$ & $3.399 E-32$ & $3.458 E-32$ & 7. $687 \mathrm{E}-32$ & $1.738 \mathrm{E}-31$ & 1.180E-28 & $6.250 \mathrm{E}-25$ & $2.567 \mathrm{E}-07$ & $2.352 E-03$ \\
\hline-234 & Th-230 & $1.000 \mathrm{E}+00$ & $5.835 E-36$ & $1.769 \mathrm{E}-35$ & $1.176 \mathrm{E}-33$ & $5.071 \mathrm{E}-33$ & $1.230 \mathrm{E}-29$ & $8.655 E-26$ & $2.204 \mathrm{E}-07$ & $4.068 \mathrm{E}-05$ \\
\hline-234 & $\mathrm{Ra}-226+\mathrm{D}$ & $1.000 \mathrm{E}+00$ & $5.287 \mathrm{E}-24$ & $1.773 \mathrm{E}-23$ & $5.854 \mathrm{E}-21$ & $3.154 \mathrm{E}-20$ & $9.386 \mathrm{E}-18$ & $1.043 \mathrm{E}-15$ & $5.099 \mathrm{E}-04$ & $4.316 \mathrm{E}-04$ \\
\hline-234 & $\mathrm{~Pb}-210+\mathrm{D}$ & $1.000 \mathrm{E}+00$ & $1.503 E-31$ & $5.982 E-31$ & $1.064 \mathrm{E}-27$ & $9.006 \mathrm{E}-27$ & $6.072 E-24$ & 1.210E-21 & $2.379 \mathrm{E}-07$ & $3.721 \mathrm{E}-03$ \\
\hline-234 & $\sum \operatorname{DSR}(j)$ & & $5.287 E-24$ & $1.773 \mathrm{E}-23$ & $5.854 \mathrm{E}-21$ & $3.154 \mathrm{E}-20$ & $9.386 \mathrm{E}-18$ & $1.043 \mathrm{E}-15$ & $5.106 \mathrm{E}-04$ & $6.546 \mathrm{E}-03$ \\
\hline$-235+D$ & $\mathrm{U}-235+\mathrm{D}$ & $1.000 \mathrm{E}+00$ & $6.129 \mathrm{E}-23$ & $6.201 \mathrm{E}-23$ & $1.083 \mathrm{E}-22$ & $1.914 \mathrm{E}-22$ & $1.816 \mathrm{E}-20$ & $7.234 \mathrm{E}-18$ & $2.455 E-04$ & $3.050 \mathrm{E}-03$ \\
\hline$-235+D$ & $\mathrm{~Pa}-231$ & $1.000 \mathrm{E}+00$ & $1.527 \mathrm{E}-26$ & 4. $611 \mathrm{E}-26$ & $2.384 \mathrm{E}-24$ & $7.727 \mathrm{E}-24$ & 1. $911 \mathrm{E}-21$ & $6.668 \mathrm{E}-19$ & $1.765 \mathrm{E}-05$ & $4.726 \mathrm{E}-03$ \\
\hline$J-235+D$ & $A C-227+D$ & $1.000 \mathrm{E}+00$ & $4.131 \mathrm{E}-25$ & $1.371 \mathrm{E}-24$ & $3.290 \mathrm{E}-22$ & 1. $358 \mathrm{E}-21$ & $2.232 \mathrm{E}-19$ & $3.367 \mathrm{E}-17$ & $1.722 \mathrm{E}-04$ & $8.784 \mathrm{E}-03$ \\
\hline$J-235$ & $\sum \operatorname{DSR}(j)$ & & $6.172 \mathrm{E}-23$ & $6.343 E-23$ & $4.398 E-22$ & $1.557 \mathrm{E}-21$ & $2.433 E-19$ & $4.157 \mathrm{E}-17$ & $4.353 E-04$ & $1.656 \mathrm{E}-02$ \\
\hline$J-238$ & $\mathrm{U}-238$ & $5.400 \mathrm{E}-05$ & $0.000 \mathrm{E}+00$ & $0.000 \mathrm{E}+00$ & $0.000 \mathrm{E}+00$ & $0.000 \mathrm{E}+00$ & $0.000 \mathrm{E}+00$ & $0.000 \mathrm{E}+00$ & $9.669 \mathrm{E}-12$ & $1.549 \mathrm{E}-07$ \\
\hline$J-238+D$ & $\mathrm{U}-238+\mathrm{D}$ & $9.999 \mathrm{E}-01$ & $6.999 \mathrm{E}-19$ & $7.051 \mathrm{E}-19$ & $1.011 \mathrm{E}-18$ & 1. $461 \mathrm{E}-18$ & $2.772 \mathrm{E}-17$ & 1. $330 \mathrm{E}-15$ & $9.867 \mathrm{E}-05$ & $3.091 \mathrm{E}-03$ \\
\hline$-238+D$ & $\mathrm{U}-234$ & $9.999 \mathrm{E}-01$ & $5.277 E-38$ & $1.601 \mathrm{E}-37$ & $1.104 \mathrm{E}-35$ & $4.960 \mathrm{E}-35$ & $1.675 \mathrm{E}-31$ & $1.821 \mathrm{E}-27$ & $7.382 \mathrm{E}-09$ & $7.704 \mathrm{E}-04$ \\
\hline$-238+D$ & Th -230 & $9.999 \mathrm{E}-01$ & $5.049 \mathrm{E}-41$ & $1.713 \mathrm{E}-40$ & $8.470 \mathrm{E}-38$ & $7.245 E-37$ & $8.728 \mathrm{E}-33$ & $1.259 \mathrm{E}-28$ & $3.125 \mathrm{E}-09$ & $1.105 \mathrm{E}-05$ \\
\hline$-238+D$ & $\mathrm{Ra}-226+\mathrm{D}$ & $9.999 \mathrm{E}-01$ & $3.050 \mathrm{E}-29$ & 1.230E-28 & $2.821 E-25$ & $3.016 \mathrm{E}-24$ & $4.518 \mathrm{E}-21$ & $1.048 \mathrm{E}-18$ & $6.020 \mathrm{E}-06$ & $1.163 \mathrm{E}-04$ \\
\hline$J-238+D$ & $\mathrm{~Pb}-210+\mathrm{D}$ & $9.999 \mathrm{E}-01$ & $6.546 E-37$ & $3.482 E-36$ & $4.122 E-32$ & $7.227 E-31$ & $2.756 \mathrm{E}-27$ & $1.178 \mathrm{E}-24$ & $2.799 \mathrm{E}-09$ & $1.003 E-03$ \\
\hline$J-238$ & $\sum \operatorname{DSR}(j)$ & & $6.999 \mathrm{E}-19$ & $7.051 \mathrm{E}-19$ & $1.011 \mathrm{E}-18$ & 1. $461 \mathrm{E}-18$ & $2.772 \mathrm{E}-17$ & $1.331 \mathrm{E}-15$ & $1.047 \mathrm{E}-04$ & 4. $992 \mathrm{E}-03$ \\
\hline
\end{tabular}

The DSR includes contributions from associated (half-life $\leq 180$ days) daughters. 
RESRAD-OFFSITE, Version 2.

Parent Dose Report

Title : RESRAD-OFFSITE Parameters for Offsite Resident Farmer Forward Run 100,000 Years

File : OFFSITE-RF FORWARD-7-11-100000yr.ROF

Single Radionuclide Soil Guidelines G(i,t) in pCi/g

Basic Radiation Dose Limit $=1.000 \mathrm{E}+00 \mathrm{mrem} / \mathrm{yr}$

Nuclide

\begin{tabular}{|c|c|c|c|c|c|c|c|c|}
\hline (i) & $t=0.000 \mathrm{E}+00$ & $1.000 \mathrm{E}+00$ & $5.000 \mathrm{E}+01$ & $1.000 \mathrm{E}+02$ & $5.000 \mathrm{E}+02$ & $1.026 \mathrm{E}+03$ & $1.000 \mathrm{E}+04$ & $1.000 \mathrm{E}+05$ \\
\hline-241 & $\star 3.431 \mathrm{E}+12$ & $\star 3.431 \mathrm{E}+12$ & $\star 3.431 \mathrm{E}+12$ & $\star 3.431 \mathrm{E}+12$ & $\star 3.431 \mathrm{E}+12$ & $\star 3.431 \mathrm{E}+12$ & $1.955 \mathrm{E}+04$ & $8.812 E+05$ \\
\hline-137 & $\star 8.704 \mathrm{E}+13$ & $\star 8.704 \mathrm{E}+13$ & $\star 8.704 \mathrm{E}+13$ & $\star 8.704 \mathrm{E}+13$ & $\star 8.704 \mathrm{E}+13$ & $\star 8.704 \mathrm{E}+13$ & $\star 8.704 \mathrm{E}+13$ & $\star 8.704 \mathrm{E}+13$ \\
\hline-237 & $* 7.047 \mathrm{E}+08$ & $\star 7.047 \mathrm{E}+08$ & $\star 7.047 \mathrm{E}+08$ & $\star 7.047 \mathrm{E}+08$ & $\star 7.047 \mathrm{E}+08$ & $\star 7.047 \mathrm{E}+08$ & $4.268 \mathrm{E}+00$ & $1.942 \mathrm{E}+02$ \\
\hline-238 & $\star 1.712 \mathrm{E}+13$ & $\star 1.712 \mathrm{E}+13$ & $\star 1.712 \mathrm{E}+13$ & $\star 1.712 \mathrm{E}+13$ & $\star 1.712 \mathrm{E}+13$ & $\star 1.712 \mathrm{E}+13$ & $5.545 \mathrm{E}+06$ & $3.697 \mathrm{E}+05$ \\
\hline-239 & $\star 6.214 \mathrm{E}+10$ & $\star 6.214 \mathrm{E}+10$ & $\star 6.214 \mathrm{E}+10$ & $\star 6.214 \mathrm{E}+10$ & $\star 6.214 \mathrm{E}+10$ & $\star 6.214 \mathrm{E}+10$ & $4.686 \mathrm{E}+05$ & $9.323 E+03$ \\
\hline-240 & $\star 2.278 \mathrm{E}+11$ & $\star 2.278 \mathrm{E}+11$ & $\star 2.278 \mathrm{E}+11$ & $\star 2.278 \mathrm{E}+11$ & $\star 2.278 \mathrm{E}+11$ & $\star 2.278 \mathrm{E}+11$ & $1.049 \mathrm{E}+06$ & $1.323 E+06$ \\
\hline-99 & $\star 1.697 \mathrm{E}+10$ & $\star 1.697 \mathrm{E}+10$ & $\star 1.697 \mathrm{E}+10$ & $\star 1.697 \mathrm{E}+10$ & $\star 1.697 \mathrm{E}+10$ & $\star 1.697 \mathrm{E}+10$ & $\star 1.697 \mathrm{E}+10$ & $* 1.697 \mathrm{E}+10$ \\
\hline-228 & $1.331 \mathrm{E}+14$ & $1.557 \mathrm{E}+14$ & $\star 8.195 \mathrm{E}+14$ & $\star 8.195 \mathrm{E}+14$ & $\star 8.195 \mathrm{E}+14$ & $\star 8.195 \mathrm{E}+14$ & $\star 8.195 \mathrm{E}+14$ & $\star 8.195 E+14$ \\
\hline$h-230$ & $\star 2.018 \mathrm{E}+10$ & $\star 2.018 \mathrm{E}+10$ & $\star 2.018 \mathrm{E}+10$ & $\star 2.018 \mathrm{E}+10$ & $\star 2.018 \mathrm{E}+10$ & $\star 2.018 \mathrm{E}+10$ & $1.349 \mathrm{E}+02$ & $1.023 E+05$ \\
\hline$h-232$ & $* 1.097 \mathrm{E}+05$ & $* 1.097 \mathrm{E}+05$ & $\star 1.097 \mathrm{E}+05$ & $\star 1.097 \mathrm{E}+05$ & $\star 1.097 \mathrm{E}+05$ & $* 1.097 \mathrm{E}+05$ & $8.766 \mathrm{E}+01$ & $* 1.097 \mathrm{E}+05$ \\
\hline 34 & $\star 6.247 \mathrm{E}+09$ & $* 6.247 \mathrm{E}+09$ & $* 6.247 \mathrm{E}+09$ & $\star 6.247 \mathrm{E}+09$ & $* 6.247 \mathrm{E}+09$ & $* 6.247 \mathrm{E}+09$ & $1.958 \mathrm{E}+03$ & $1.528 \mathrm{E}+02$ \\
\hline 35 & $\star 2.161 \mathrm{E}+06$ & $\star 2.161 \mathrm{E}+06$ & $\star 2.161 \mathrm{E}+06$ & $\star 2.161 \mathrm{E}+06$ & $\star 2.161 \mathrm{E}+06$ & $\star 2.161 \mathrm{E}+06$ & $2.297 \mathrm{E}+03$ & $6.039 E+01$ \\
\hline 238 & $\star 3.361 \mathrm{E}+05$ & $\star 3.361 \mathrm{E}+05$ & $\star 3.361 \mathrm{E}+05$ & $\star 3.361 \mathrm{E}+05$ & $\star 3.361 \mathrm{E}+05$ & $\star 3.361 \mathrm{E}+05$ & $9.551 \mathrm{E}+03$ & $2.003 E+02$ \\
\hline
\end{tabular}

*At specific activity limit

Summed Dose/Source Ratios DSR(i,t) in (mrem/yr)/(pCi/g)

and Single Radionuclide Soil Guidelines G(i,t) in pCi/g

at tmin = time of minimum single radionuclide soil guideline

and at $\operatorname{tmax}=$ time of maximum total dose $=10061$ years

\begin{tabular}{|c|c|c|c|c|c|c|}
\hline $\begin{array}{l}\text { uclide } \\
\text { (i) }\end{array}$ & $\begin{array}{l}\text { Initial } \\
(\mathrm{pCi} / \mathrm{g})\end{array}$ & $\begin{array}{c}\text { tmin } \\
\text { (years) }\end{array}$ & $\operatorname{DSR}(i, \operatorname{tmin})$ & $\begin{array}{c}\mathrm{G}(\mathrm{i}, \mathrm{tmin}) \\
(\mathrm{pCi} / \mathrm{g})\end{array}$ & $\operatorname{DSR}(i, \operatorname{tmax})$ & $\begin{array}{c}G(i, t \max ) \\
(\mathrm{pCi} / \mathrm{g})\end{array}$ \\
\hline$m-241$ & $3.500 \mathrm{E}+01$ & 10586 & $5.165 \mathrm{E}-05$ & $1.936 \mathrm{E}+04$ & $5.126 \mathrm{E}-05$ & $1.951 \mathrm{E}+04$ \\
\hline-137 & $1.900 \mathrm{E}+01$ & 0 & $6.222 E-18$ & $\star 8.704 \mathrm{E}+13$ & $1.401 \mathrm{E}-45$ & $\star 8.704 \mathrm{E}+13$ \\
\hline$p-237$ & $5.500 \mathrm{E}+00$ & 9976 & $2.343 \mathrm{E}-01$ & $4.268 \mathrm{E}+00$ & $2.343 E-01$ & $4.269 \mathrm{E}+00$ \\
\hline-238 & $3.900 \mathrm{E}+01$ & 100031 & $2.707 E-06$ & $3.694 E+05$ & $1.816 \mathrm{E}-07$ & $5.506 \mathrm{E}+06$ \\
\hline-239 & $3.600 \mathrm{E}+01$ & 100031 & $1.074 \mathrm{E}-04$ & $9.313 E+03$ & $2.129 \mathrm{E}-06$ & $4.697 \mathrm{E}+05$ \\
\hline$\lambda-240$ & $3.600 \mathrm{E}+01$ & 3455 & $1.960 \mathrm{E}-06$ & $5.102 \mathrm{E}+05$ & $9.463 E-07$ & $1.057 \mathrm{E}+06$ \\
\hline-99 & $5.200 \mathrm{E}+01$ & 2753 & $1.397 \mathrm{E}-14$ & $\star 1.697 \mathrm{E}+10$ & $2.825 E-31$ & $\star 1.697 \mathrm{E}+10$ \\
\hline $1-228$ & $4.000 \mathrm{E}+00$ & 0 & $7.515 \mathrm{E}-15$ & $1.331 \mathrm{E}+14$ & $0.000 \mathrm{E}+00$ & $\star 8.195 \mathrm{E}+14$ \\
\hline-230 & $1.000 \mathrm{E}+02$ & 8590 & $7.440 \mathrm{E}-03$ & $1.344 \mathrm{E}+02$ & $7.409 \mathrm{E}-03$ & $1.350 \mathrm{E}+02$ \\
\hline-232 & $4.000 \mathrm{E}+00$ & 2753 & $1.155 \mathrm{E}-02$ & $8.660 \mathrm{E}+01$ & $1.141 \mathrm{E}-02$ & $8.767 \mathrm{E}+01$ \\
\hline 234 & $1.600 \mathrm{E}+02$ & 100031 & $6.550 \mathrm{E}-03$ & $1.527 \mathrm{E}+02$ & $5.142 \mathrm{E}-04$ & $1.945 \mathrm{E}+03$ \\
\hline-235 & $6.500 \mathrm{E}+00$ & 97259 & $1.663 \mathrm{E}-02$ & $6.012 \mathrm{E}+01$ & $4.360 \mathrm{E}-04$ & $2.294 E+03$ \\
\hline-238 & $1.600 \mathrm{E}+02$ & 100031 & $4.996 \mathrm{E}-03$ & $2.002 \mathrm{E}+02$ & $1.047 \mathrm{E}-04$ & $9.550 \mathrm{E}+03$ \\
\hline
\end{tabular}

*At specific activity limit 
RESRAD-OFFSITE, Version 2.

Parent Dose Report

Title : RESRAD-OFFSITE Parameters for Offsite Resident Farmer Forward Run 100,000 Years

File : OFFSITE-RF_FORWARD-7-11-100000yr.ROF

Individual Nuclide Dose Summed Over All Pathways

Parent Nuclide and Thread Fraction Indicated

Nuclide Parent THF(i) DOSE $(j, t)$, mrem/yr

\section{(j) \\ (i) \\ $\mathrm{Am}-241 \quad \mathrm{Am}-241 \quad 1.000 \mathrm{E}+00$ \\ $\mathrm{Np}-237 \quad \mathrm{Am}-241 \quad 1.000 \mathrm{E}+00$ \\ Np-237 Np-237 $1.000 \mathrm{E}+00$ \\ Np-237 $\operatorname{DOSE}(j):$}

$\mathrm{U}-233 \quad \mathrm{Am}-241 \quad 1.000 \mathrm{E}+00$

U-233 Np-237 1.000E+00

U-233 $\operatorname{DOSE}(j)$ :

Th-229

Th-229

Th-229

Cs-137

$\mathrm{Pu}-238$

$\mathrm{Pu}-238$

$\mathrm{Pu}-238$

$\mathrm{U}-234$

$\mathrm{U}-234$

$\mathrm{U}-234$

$\mathrm{U}-234$

Th-230

Th-230

Th-230

Th-230

Th-230

$\mathrm{Ra}-226$

$\mathrm{Ra}-226$

$\mathrm{Ra}-226$

$\mathrm{Ra}-226$

$\mathrm{Ra}-226$

$\mathrm{Pb}-210 \mathrm{Pu}-238 \quad 1.000 \mathrm{E}+00$

$\mathrm{Pb}-210 \mathrm{Th}-230 \quad 1.000 \mathrm{E}+00$

$\mathrm{Pb}-210 \mathrm{U}-234 \quad 1.000 \mathrm{E}+00$

$\mathrm{Pb}-210 \quad \mathrm{U}-238 \quad 9.999 \mathrm{E}-01$

$\mathrm{Pb}-210 \quad \sum \operatorname{DOSE}(j):$

Pu-239 Pu-239 1.000E+00 $\mathrm{t}=0.000 \mathrm{E}+00 \quad 1.000 \mathrm{E}+00 \quad 5.000 \mathrm{E}+01 \quad 1.000 \mathrm{E}+02 \quad 5.000 \mathrm{E}+02 \quad 1.026 \mathrm{E}+03 \quad 1.000 \mathrm{E}+04 \quad 1.000 \mathrm{E}+05$

$\begin{array}{llllllll}3.341 \mathrm{E}-40 & 3.429 \mathrm{E}-40 & 1.136 \mathrm{E}-39 & 3.863 \mathrm{E}-39 & 6.818 \mathrm{E}-35 & 2.625 \mathrm{E}-29 & 1.454 \mathrm{E}-11 & 1.401 \mathrm{E}-45\end{array}$

$2.803 \mathrm{E}-26 \quad 8.460 \mathrm{E}-26 \quad 4.250 \mathrm{E}-24 \quad 1.334 \mathrm{E}-23 \quad 2.589 \mathrm{E}-21 \quad 6.881 \mathrm{E}-19 \quad 1.786 \mathrm{E}-03 \quad 1.822 \mathrm{E}-44$

$2.586 \mathrm{E}-20 \quad 2.612 \mathrm{E}-20 \quad 4.236 \mathrm{E}-20 \quad 6.938 \mathrm{E}-20 \quad 3.591 \mathrm{E}-18 \quad 6.444 \mathrm{E}-16 \quad 1.285 \mathrm{E}+00 \quad 1.822 \mathrm{E}-44$

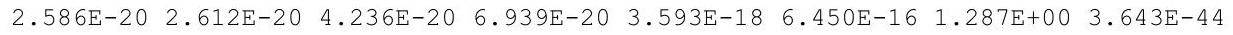

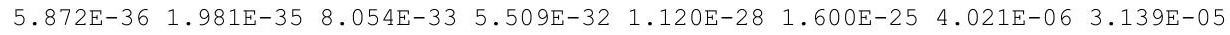

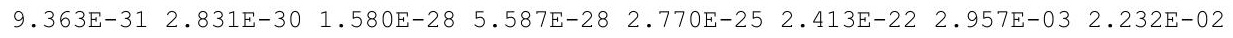

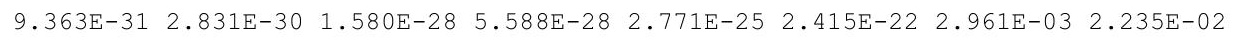

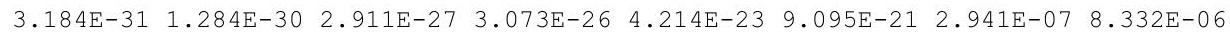

$\begin{array}{lllllllll}7.609 \mathrm{E}-26 & 2.552 \mathrm{E}-25 & 8.487 \mathrm{E}-23 & 4.610 \mathrm{E}-22 & 1.470 \mathrm{E}-19 & 1.835 \mathrm{E}-17 & 2.443 \mathrm{E}-04 & 6.006 \mathrm{E}-03\end{array}$

$\begin{array}{llllllll}7.609 \mathrm{E}-26 & 2.552 \mathrm{E}-25 & 8.487 \mathrm{E}-23 & 4.611 \mathrm{E}-22 & 1.471 \mathrm{E}-19 & 1.836 \mathrm{E}-17 & 2.446 \mathrm{E}-04 & 6.014 \mathrm{E}-03\end{array}$

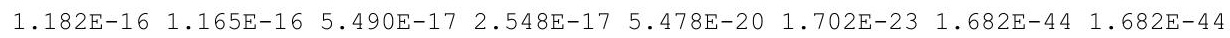

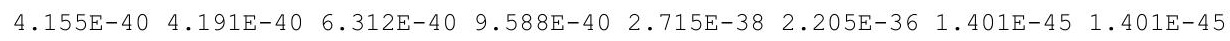
$\begin{array}{llllllll}2.258 \mathrm{E}-31 & 2.277 \mathrm{E}-31 & 3.430 \mathrm{E}-31 & 5.211 \mathrm{E}-31 & 1.476 \mathrm{E}-29 & 1.198 \mathrm{E}-27 & 4.797 \mathrm{E}-39 & 1.401 \mathrm{E}-45\end{array}$

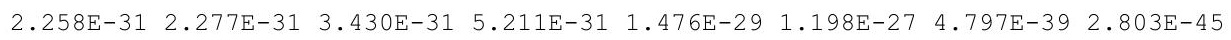

$2.009 \mathrm{E}-36 \quad 6.080 \mathrm{E}-36 \quad 3.546 \mathrm{E}-34 \quad 1.334 \mathrm{E}-33 \quad 1.620 \mathrm{E}-30 \quad 8.751 \mathrm{E}-27 \quad 3.596 \mathrm{E}-09 \quad 3.792 \mathrm{E}-05$ $\begin{array}{llllllll}5.439 \mathrm{E}-30 & 5.532 \mathrm{E}-30 & 1.230 \mathrm{E}-29 & 2.780 \mathrm{E}-29 & 1.887 \mathrm{E}-26 & 9.999 \mathrm{E}-23 & 4.108 \mathrm{E}-05 & 3.763 \mathrm{E}-01\end{array}$ $\begin{array}{llllllll}8.444 \mathrm{E}-36 & 2.562 \mathrm{E}-35 & 1.766 \mathrm{E}-33 & 7.937 \mathrm{E}-33 & 2.680 \mathrm{E}-29 & 2.914 \mathrm{E}-25 & 1.181 \mathrm{E}-06 & 1.233 \mathrm{E}-01\end{array}$

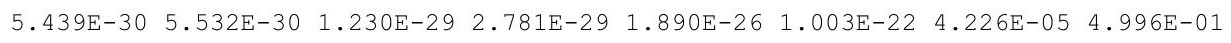

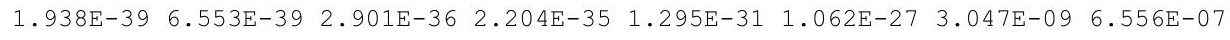
$\begin{array}{llllllll}1.189 \mathrm{E}-28 & 1.208 \mathrm{E}-28 & 2.580 \mathrm{E}-28 & 5.597 \mathrm{E}-28 & 2.733 \mathrm{E}-25 & 9.393 \mathrm{E}-22 & 2.517 \mathrm{E}-04 & 2.317 \mathrm{E}-07\end{array}$ $\begin{array}{llllllll}9.336 \mathrm{E}-34 & 2.831 \mathrm{E}-33 & 1.881 \mathrm{E}-31 & 8.114 \mathrm{E}-31 & 1.968 \mathrm{E}-27 & 1.385 \mathrm{E}-23 & 3.527 \mathrm{E}-05 & 6.509 \mathrm{E}-03\end{array}$ $\begin{array}{llllllll}8.078 \mathrm{E}-39 & 2.741 \mathrm{E}-38 & 1.355 \mathrm{E}-35 & 1.159 \mathrm{E}-34 & 1.397 \mathrm{E}-30 & 2.015 \mathrm{E}-26 & 5.000 \mathrm{E}-07 & 1.768 \mathrm{E}-03\end{array}$

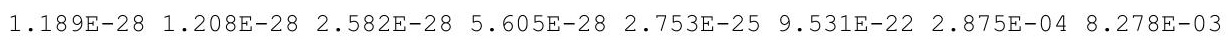

$\begin{array}{llllllll}1.176 \mathrm{E}-27 & 4.723 \mathrm{E}-27 & 9.977 \mathrm{E}-24 & 9.743 \mathrm{E}-23 & 8.225 \mathrm{E}-20 & 1.159 \mathrm{E}-17 & 7.024 \mathrm{E}-06 & 6.954 \mathrm{E}-06\end{array}$ $\begin{array}{llllllll}1.923 \mathrm{E}-17 & 5.794 \mathrm{E}-17 & 2.555 \mathrm{E}-15 & 6.911 \mathrm{E}-15 & 4.025 \mathrm{E}-13 & 2.105 \mathrm{E}-11 & 7.405 \mathrm{E}-01 & 9.722 \mathrm{E}-05\end{array}$ $\begin{array}{llllllll}8.459 \mathrm{E}-22 & 2.836 \mathrm{E}-21 & 9.366 \mathrm{E}-19 & 5.047 \mathrm{E}-18 & 1.502 \mathrm{E}-15 & 1.668 \mathrm{E}-13 & 8.159 \mathrm{E}-02 & 6.905 \mathrm{E}-02\end{array}$ $\begin{array}{llllllll}4.880 \mathrm{E}-27 & 1.969 \mathrm{E}-26 & 4.514 \mathrm{E}-23 & 4.825 \mathrm{E}-22 & 7.229 \mathrm{E}-19 & 1.676 \mathrm{E}-16 & 9.632 \mathrm{E}-04 & 1.861 \mathrm{E}-02\end{array}$ $\begin{array}{lllllllll}1.923 \mathrm{E}-17 & 5.794 \mathrm{E}-17 & 2.556 \mathrm{E}-15 & 6.916 \mathrm{E}-15 & 4.040 \mathrm{E}-13 & 2.122 \mathrm{E}-11 & 8.231 \mathrm{E}-01 & 8.777 \mathrm{E}-02\end{array}$

$2.535 \mathrm{E}-35 \quad 1.340 \mathrm{E}-34 \quad 1.480 \mathrm{E}-30 \quad 2.393 \mathrm{E}-29 \quad 5.181 \mathrm{E}-26 \quad 1.335 \mathrm{E}-23 \quad 3.276 \mathrm{E}-09 \quad 5.996 \mathrm{E}-05$ $\begin{array}{lllllllll}8.076 \mathrm{E}-25 & 2.678 \mathrm{E}-24 & 6.228 \mathrm{E}-22 & 2.467 \mathrm{E}-21 & 2.775 \mathrm{E}-19 & 2.524 \mathrm{E}-17 & 3.467 \mathrm{E}-04 & 8.796 \mathrm{E}-04\end{array}$ $2.405 \mathrm{E}-29 \quad 9.571 \mathrm{E}-29 \quad 1.702 \mathrm{E}-25 \quad 1.441 \mathrm{E}-24 \quad 9.715 \mathrm{E}-22 \quad 1.935 \mathrm{E}-19 \quad 3.806 \mathrm{E}-05 \quad 5.954 \mathrm{E}-01$ $\begin{array}{lllllllll}1.047 \mathrm{E}-34 & 5.572 \mathrm{E}-34 & 6.594 \mathrm{E}-30 & 1.156 \mathrm{E}-28 & 4.409 \mathrm{E}-25 & 1.885 \mathrm{E}-22 & 4.478 \mathrm{E}-07 & 1.605 \mathrm{E}-01\end{array}$ $\begin{array}{llllllll}8.076 \mathrm{E}-25 & 2.679 \mathrm{E}-24 & 6.230 \mathrm{E}-22 & 2.468 \mathrm{E}-21 & 2.785 \mathrm{E}-19 & 2.544 \mathrm{E}-17 & 3.852 \mathrm{E}-04 & 7.569 \mathrm{E}-01\end{array}$

$2.134 \mathrm{E}-24 \quad 2.158 \mathrm{E}-24 \quad 3.698 \mathrm{E}-24 \quad 6.408 \mathrm{E}-24 \quad 5.202 \mathrm{E}-22 \quad 1.688 \mathrm{E}-19 \quad 7.671 \mathrm{E}-05 \quad 3.854 \mathrm{E}-03$ 
RESRAD-OFFSITE, Version 2.

Parent Dose Report

Title : RESRAD-OFFSITE Parameters for Offsite Resident Farmer Forward Run 100,000 Years

File : OFFSITE-RF FORWARD-7-11-100000yr.ROF

Individual Nuclide Soil Concentration

Parent Nuclide and Thread Fraction Indicated

Nuclide Parent THF(

(j)

(i)

$\overline{A m-241} \overline{1.000 E+00}$

Am-241

Np-237

Np-237

Np-237

$\mathrm{U}-233$

$\mathrm{U}-233$

$\mathrm{U}-233$

Th-229

Th -229

Th-229

Cs-137

$\mathrm{Pu}-238$

$\mathrm{Pu}-238$

$\mathrm{Pu}-238$

$\mathrm{U}-234$

$\mathrm{U}-234$

$\mathrm{U}-234$

$\mathrm{U}-234$

Th -230

Th -230

Th-230

Th-230

Th -230

$\mathrm{Ra}-226$

$\mathrm{Ra}-226$

$\mathrm{Ra}-226$

$\mathrm{Ra}-226$

$\mathrm{Ra}-226$

$\mathrm{Pb}-210$

$\mathrm{Pb}-210$

$\mathrm{Pb}-210$

$\mathrm{Pb}-210$

$\mathrm{Pb}-210$

Pu-239 Pu-239 $1.000 E+00$
Am-241 $1.000 \mathrm{E}+00$

Np-237 1.000E+00

$\sum S(j):$

Am-241 1.000E+00

Np-237 1.000E+00

$\sum S(j):$

Am-241 $1.000 \mathrm{E}+00$

Np-237 1.000E+00

$\sum S(j):$

CS-137 1.000E+00

Pu-238 1.840E-09

Pu-238 1.000E+00

$\sum S(j):$

$\mathrm{Pu}-238 \quad 1.000 \mathrm{E}+00$

$\mathrm{U}-238 \quad 9.999 \mathrm{E}-01$

$\sum S(j):$

Pu-238 1.000E+00

Th-230 1.000E+00

$\mathrm{U}-234 \quad 1.000 \mathrm{E}+00$

$\mathrm{U}-238 \quad 9.999 \mathrm{E}-01$

$\sum S(j):$

Pu-238 1.000E+00

Th-230 1.000E+00

$\mathrm{U}-2341.000 \mathrm{E}+00$

$\mathrm{U}-238 \quad 9.999 \mathrm{E}-01$

$\sum S(j):$

$\mathrm{Pu}-238 \quad 1.000 \mathrm{E}+00$ Th-230 1.000E+00 $\mathrm{U}-2341.000 \mathrm{E}+00$ $\mathrm{U}-238 \quad 9.999 \mathrm{E}-01$ $\sum S(j):$
$\mathrm{U}-2341.000 \mathrm{E}+00$
$S(j, t), p C i / g$

$\mathrm{t}=0.000 \mathrm{E}+00 \quad 1.000 \mathrm{E}+00 \quad 5.000 \mathrm{E}+01 \quad 1.000 \mathrm{E}+02 \quad 5.000 \mathrm{E}+02 \quad 1.026 \mathrm{E}+03 \quad 1.000 \mathrm{E}+04 \quad 1.000 \mathrm{E}+05$

$\begin{array}{lllllllll}3.500 \mathrm{E}+01 & 3.494 \mathrm{E}+01 & 3.230 \mathrm{E}+01 & 2.981 \mathrm{E}+01 & 1.567 \mathrm{E}+01 & 6.732 \mathrm{E}+00 & 3.685 \mathrm{E}-06 & 0.000 \mathrm{E}+0\end{array}$

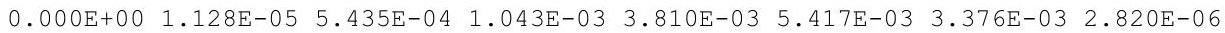

$\begin{array}{llllllll}5.500 \mathrm{E}+00 & 5.500 \mathrm{E}+00 & 5.478 \mathrm{E}+00 & 5.457 \mathrm{E}+00 & 5.288 \mathrm{E}+00 & 5.073 \mathrm{E}+00 & 2.502 \mathrm{E}+00 & 2.090 \mathrm{E}-03\end{array}$

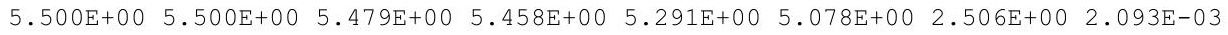

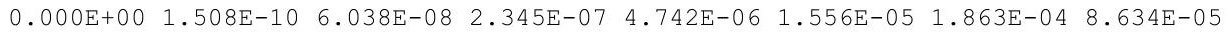

$\begin{array}{llllllll}0.000 \mathrm{E}+00 & 2.405 \mathrm{E}-05 & 1.200 \mathrm{E}-03 & 2.394 \mathrm{E}-03 & 1.174 \mathrm{E}-02 & 2.349 \mathrm{E}-02 & 1.508 \mathrm{E}-01 & 6.656 \mathrm{E}-02\end{array}$

$\begin{array}{llllllll}0.000 \mathrm{E}+00 & 2.405 \mathrm{E}-05 & 1.200 \mathrm{E}-03 & 2.394 \mathrm{E}-03 & 1.174 \mathrm{E}-02 & 2.350 \mathrm{E}-02 & 1.509 \mathrm{E}-01 & 6.665 \mathrm{E}-02\end{array}$

$0.000 \mathrm{E}+00 \quad 2.900 \mathrm{E}-14 \quad 9.603 \mathrm{E}-11 \quad 7.482 \mathrm{E}-10 \quad 7.873 \mathrm{E}-08 \quad 5.545 \mathrm{E}-07 \quad 7.107 \mathrm{E}-05 \quad 1.033 \mathrm{E}-04$

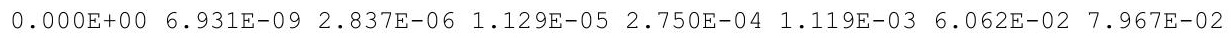

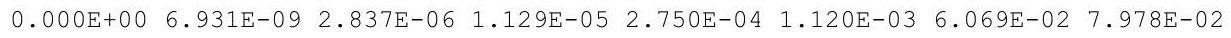

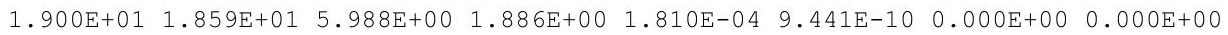

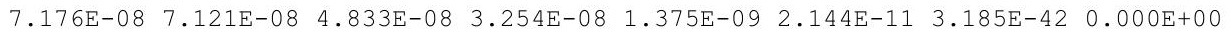

$\begin{array}{llllllllllll}3.900 \mathrm{E}+01 & 3.870 \mathrm{E}+01 & 2.627 \mathrm{E}+01 & 1.769 \mathrm{E}+01 & 7.473 \mathrm{E}-01 & 1.165 \mathrm{E}-02 & 1.731 \mathrm{E}-33 & 0.000 \mathrm{E}+00\end{array}$

$\begin{array}{lllllllllll}3.900 \mathrm{E}+01 & 3.870 \mathrm{E}+01 & 2.627 \mathrm{E}+01 & 1.769 \mathrm{E}+01 & 7.473 \mathrm{E}-01 & 1.165 \mathrm{E}-02 & 1.731 \mathrm{E}-33 & 0.000 \mathrm{E}+00\end{array}$

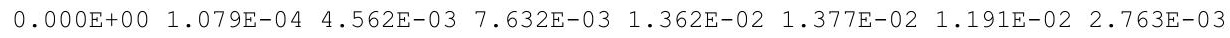

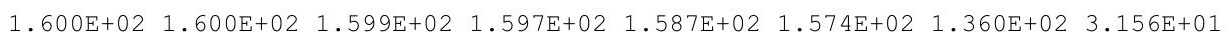

$\begin{array}{lllllllll}0.000 \mathrm{E}+00 & 4.535 \mathrm{E}-04 & 2.266 \mathrm{E}-02 & 4.529 \mathrm{E}-02 & 2.251 \mathrm{E}-01 & 4.583 \mathrm{E}-01 & 3.911 \mathrm{E}+00 & 1.034 \mathrm{E}+01\end{array}$

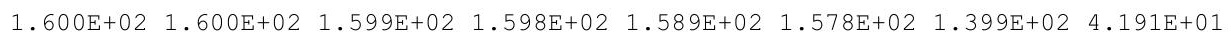

$0.000 \mathrm{E}+00 \quad 2.990 \mathrm{E}-09 \quad 1.096 \mathrm{E}-06 \quad 3.886 \mathrm{E}-06 \quad 4.705 \mathrm{E}-05 \quad 1.118 \mathrm{E}-04 \quad 1.088 \mathrm{E}-03 \quad 3.313 \mathrm{E}-03$ $\begin{array}{llllllllll}1.000 \mathrm{E}+02 & 1.000 \mathrm{E}+02 & 9.995 \mathrm{E}+01 & 9.989 \mathrm{E}+01 & 9.947 \mathrm{E}+01 & 9.891 \mathrm{E}+01 & 8.984 \mathrm{E}+01 & 3.424 \mathrm{E}+01\end{array}$ $\begin{array}{lllllllllllll}0.000 \mathrm{E}+00 & 1.440 \mathrm{E}-03 & 7.197 \mathrm{E}-02 & 1.438 \mathrm{E}-01 & 7.153 \mathrm{E}-01 & 1.457 \mathrm{E}+00 & 1.259 \mathrm{E}+01 & 3.791 \mathrm{E}+01\end{array}$ $0.000 \mathrm{E}+00 \quad 1.246 \mathrm{E}-08 \quad 5.112 \mathrm{E}-06 \quad 2.041 \mathrm{E}-05 \quad 5.070 \mathrm{E}-04 \quad 2.120 \mathrm{E}-03 \quad 1.785 \mathrm{E}-01 \quad 5.353 \mathrm{E}+00$

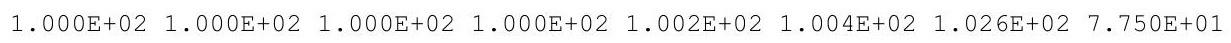

$0.000 \mathrm{E}+00 \quad 2.644 \mathrm{E}-12 \quad 8.163 \mathrm{E}-09 \quad 5.904 \mathrm{E}-08 \quad 3.952 \mathrm{E}-06 \quad 1.952 \mathrm{E}-05 \quad 8.404 \mathrm{E}-04 \quad 3.253 \mathrm{E}-03$ $\begin{array}{llllllllll}0.000 \mathrm{E}+00 & 4.326 \mathrm{E}-02 & 2.142 \mathrm{E}+00 & 4.235 \mathrm{E}+00 & 1.937 \mathrm{E}+01 & 3.549 \mathrm{E}+01 & 8.860 \mathrm{E}+01 & 3.422 \mathrm{E}+01\end{array}$ $\begin{array}{llllllllll}0.000 \mathrm{E}+00 & 1.903 \mathrm{E}-06 & 7.756 \mathrm{E}-04 & 3.074 \mathrm{E}-03 & 7.220 \mathrm{E}-02 & 2.810 \mathrm{E}-01 & 9.761 \mathrm{E}+00 & 3.722 \mathrm{E}+01\end{array}$ $\begin{array}{lllllllll}0.000 \mathrm{E}+00 & 1.098 \mathrm{E}-11 & 3.689 \mathrm{E}-0 & 2.920 \mathrm{E}-07 & 3.472 \mathrm{E}-05 & 2.822 \mathrm{E}-04 & 1.152 \mathrm{E}-01 & 5.138 \mathrm{E}+00\end{array}$ $\begin{array}{lllllllll}0.000 \mathrm{E}+00 & 4.326 \mathrm{E}-02 & 2.142 \mathrm{E}+00 & 4.238 \mathrm{E}+00 & 1.944 \mathrm{E}+01 & 3.577 \mathrm{E}+01 & 9.848 \mathrm{E}+01 & 7.658 \mathrm{E}+01\end{array}$

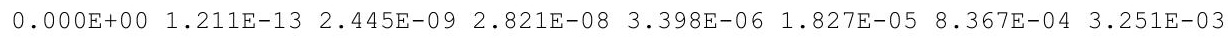
$\begin{array}{llllllllll}0.000 \mathrm{E}+00 & 3.858 \mathrm{E}-03 & 1.058 \mathrm{E}+00 & 2.946 \mathrm{E}+00 & 1.823 \mathrm{E}+01 & 3.458 \mathrm{E}+01 & 8.856 \mathrm{E}+01 & 3.421 \mathrm{E}+01\end{array}$ $\begin{array}{llllllll}0.000 \mathrm{E}+00 & 1.149 \mathrm{E}-07 & 2.851 \mathrm{E}-04 & 1.709 \mathrm{E}-03 & 6.374 \mathrm{E}-02 & 2.650 \mathrm{E}-01 & 9.719 \mathrm{E}+00 & 3.720 \mathrm{E}+01\end{array}$ $0.000 \mathrm{E}+00 \quad 5.004 \mathrm{E}-13 \quad 1.088 \mathrm{E}-08 \quad 1.362 \mathrm{E}-07 \quad 2.890 \mathrm{E}-05 \quad 2.580 \mathrm{E}-04 \quad 1.143 \mathrm{E}-01 \quad 5.133 \mathrm{E}+00$ $\begin{array}{lllllllll}0.000 \mathrm{E}+00 & 3.859 \mathrm{E}-03 & 1.059 \mathrm{E}+00 & 2.947 \mathrm{E}+00 & 1.830 \mathrm{E}+01 & 3.485 \mathrm{E}+01 & 9.839 \mathrm{E}+01 & 7.654 \mathrm{E}+01\end{array}$

$\begin{array}{llllllllll}3.600 \mathrm{E}+01 & 3.600 \mathrm{E}+01 & 3.593 \mathrm{E}+01 & 3.586 \mathrm{E}+01 & 3.531 \mathrm{E}+01 & 3.460 \mathrm{E}+01 & 2.443 \mathrm{E}+01 & 7.441 \mathrm{E}-01\end{array}$ 
RESRAD-OFFSITE, Version $2.5 \quad \mathrm{~T}^{1 / 2}$ Limit $=180$ days

Parent Dose Report

Title : RESRAD-OFFSITE Parameters for Offsite Resident Farmer Forward Run 100,000 Years

File : OFFSITE-RF_FORWARD-7-11-100000yr.ROF

Run Time Information

ResOCalc.EXE execution began at 13:36 on 07/21/2011

ResOCalc.EXE execution ended at 13:59 on 07/21/2011

ResOCalc.EXE execution time 22 minutes 37 seconds 
RESRAD, Version $6.5 \quad T^{13 / 2}$ Limit $=180$ days

Summary : RESRAD Parameters for Resident Farmer U-Landfill Forward Run 1,050 Years

File : C: $\backslash$ RESRAD_FAMILY \RESRAD \USERFILES $\backslash Q C J U L Y 2011 \backslash$ ONSITERF_FORWARD-1050-JULY11.RAD

Table of Contents

Part I: Mixture Sums and Single Radionuclide Guidelines

Dose Conversion Factor (and Related) Parameter Summary ... 2

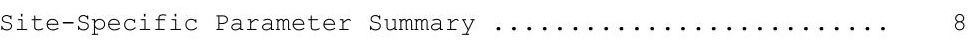

Summary of Pathway Selections .................... 18

Contaminated Zone and Total Dose Summary ............. 19

Total Dose Components

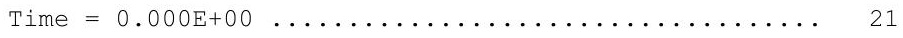

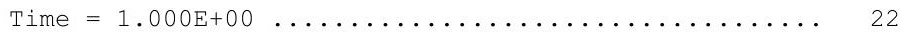

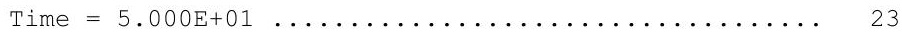

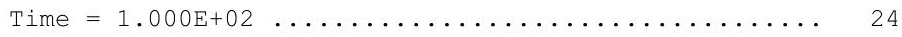

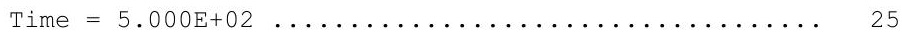

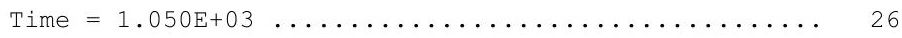

Dose/Source Ratios Summed Over All Pathways ........... 27

Single Radionuclide Soil Guidelines ............... 29

Dose Per Nuclide Summed Over All Pathways ............ 30

Soil Concentration Per Nuclide ................. 32 
Summary : RESRAD Parameters for Resident Farmer U-Landfill Forward Run 1,050 Years

File : C: $\backslash$ RESRAD_FAMILY \RESRAD \USERFILES $\backslash Q C J U L Y 2011 \backslash$ ONSITERF_FORWARD-1050-JULY11.RAD

Dose Conversion Factor (and Related) Parameter Summary

Dose Library: ICRP 60 \& ICRP 72 (Adult)

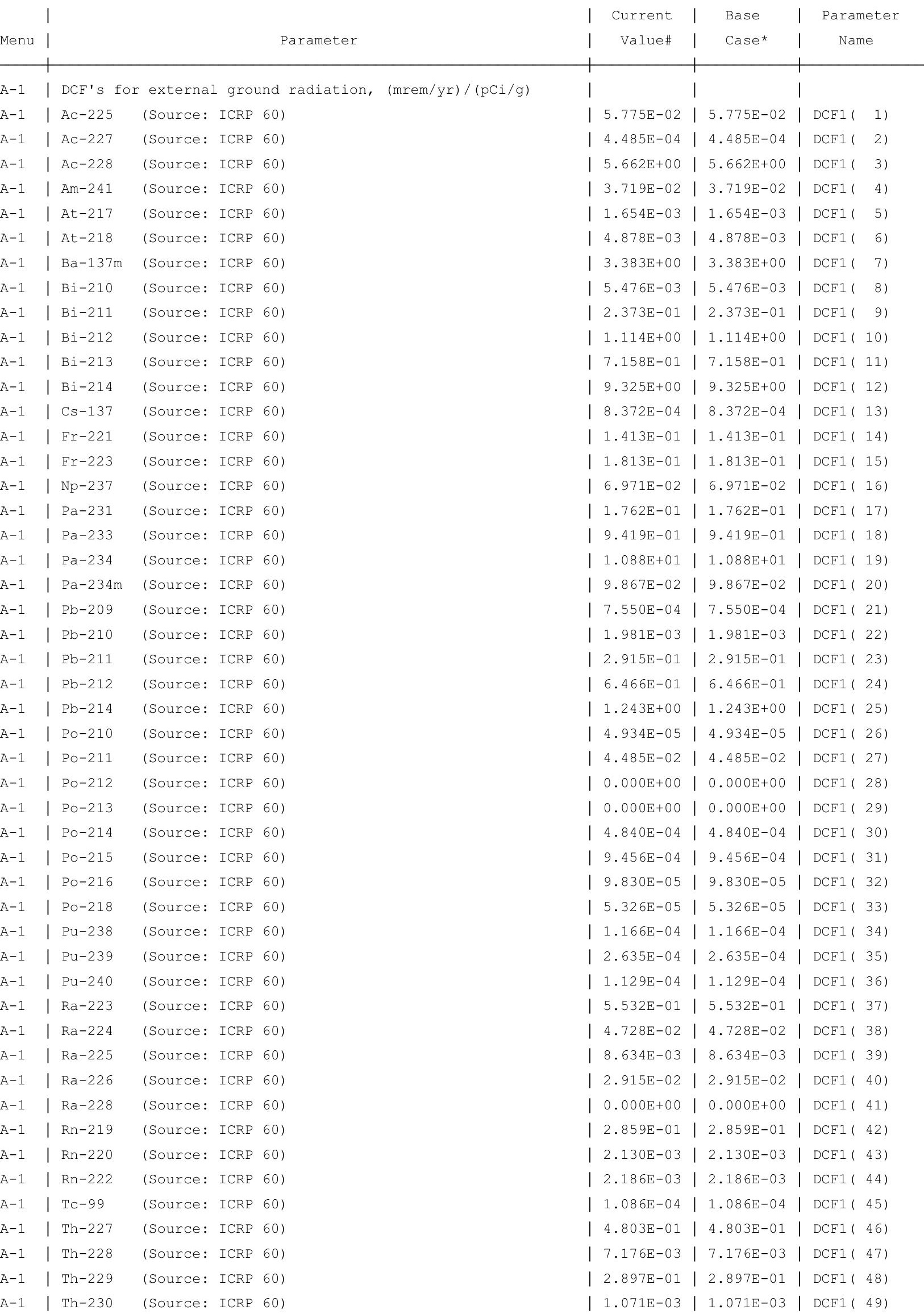


Summary : RESRAD Parameters for Resident Farmer U-Landfill Forward Run 1,050 Years

File : C: \RESRAD_FAMILY\RESRAD \USERFILES $\backslash Q C J U L Y 2011 \backslash$ ONSITERF_FORWARD-1050-JULY11.RAD

Dose Conversion Factor (and Related) Parameter Summary (continued)

Dose Library: ICRP 60 \& ICRP 72 (Adult)

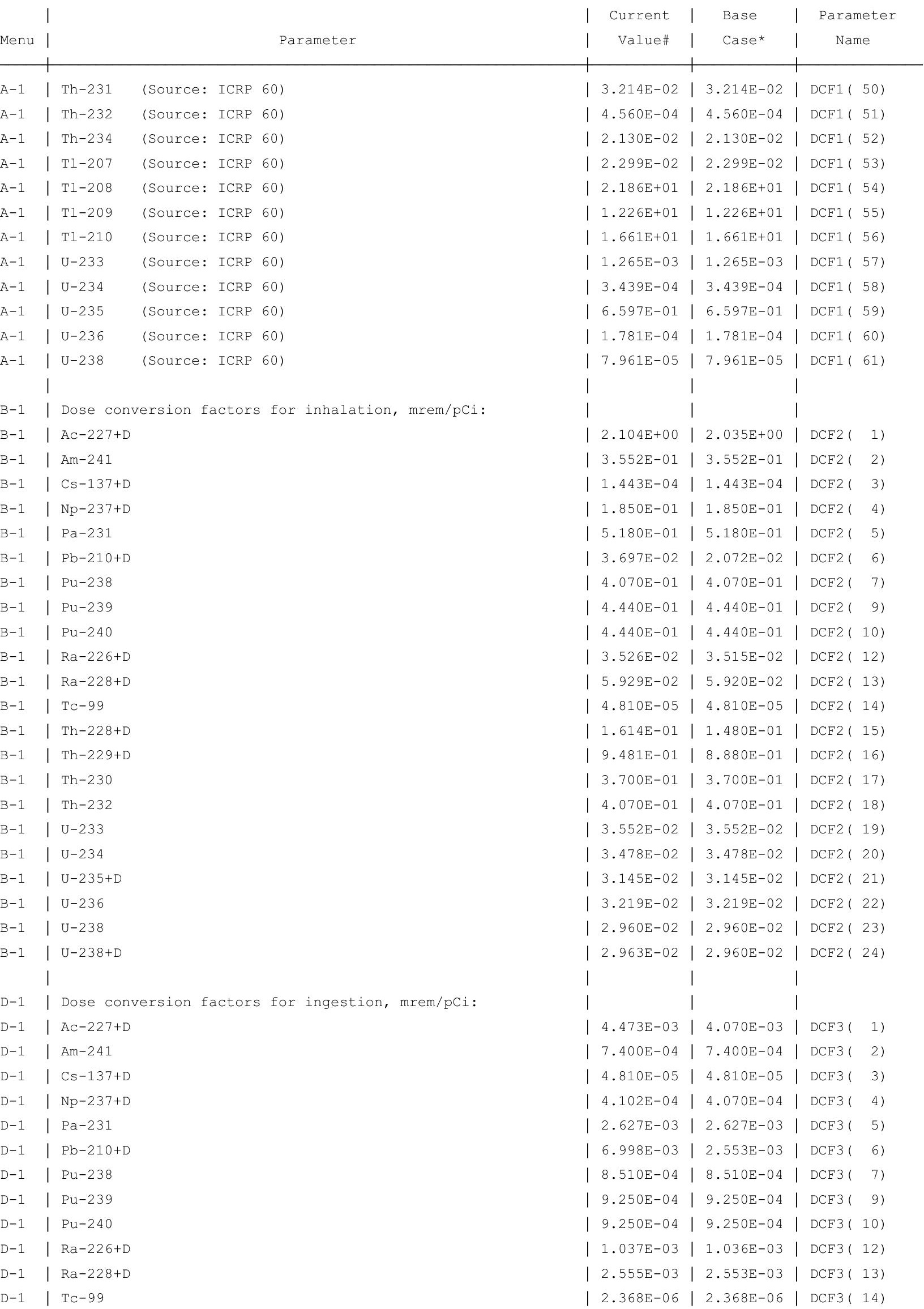


RESRAD, Version $6.5 \quad \mathrm{~T}^{1 / 2}$ Limit $=180$ days

mmary : RESRAD Parameters for Resident Farmer U-Landfill Forward Run 1,050 Years

File : C: $\backslash$ RESRAD FAMILY \RESRAD \USERFILES \QCJULY2011 \ONSITERF FORWARD-1050-JULY11.RAD

Dose Conversion Factor (and Related) Parameter Summary (continued) Dose Library: ICRP 60 \& ICRP 72 (Adult)

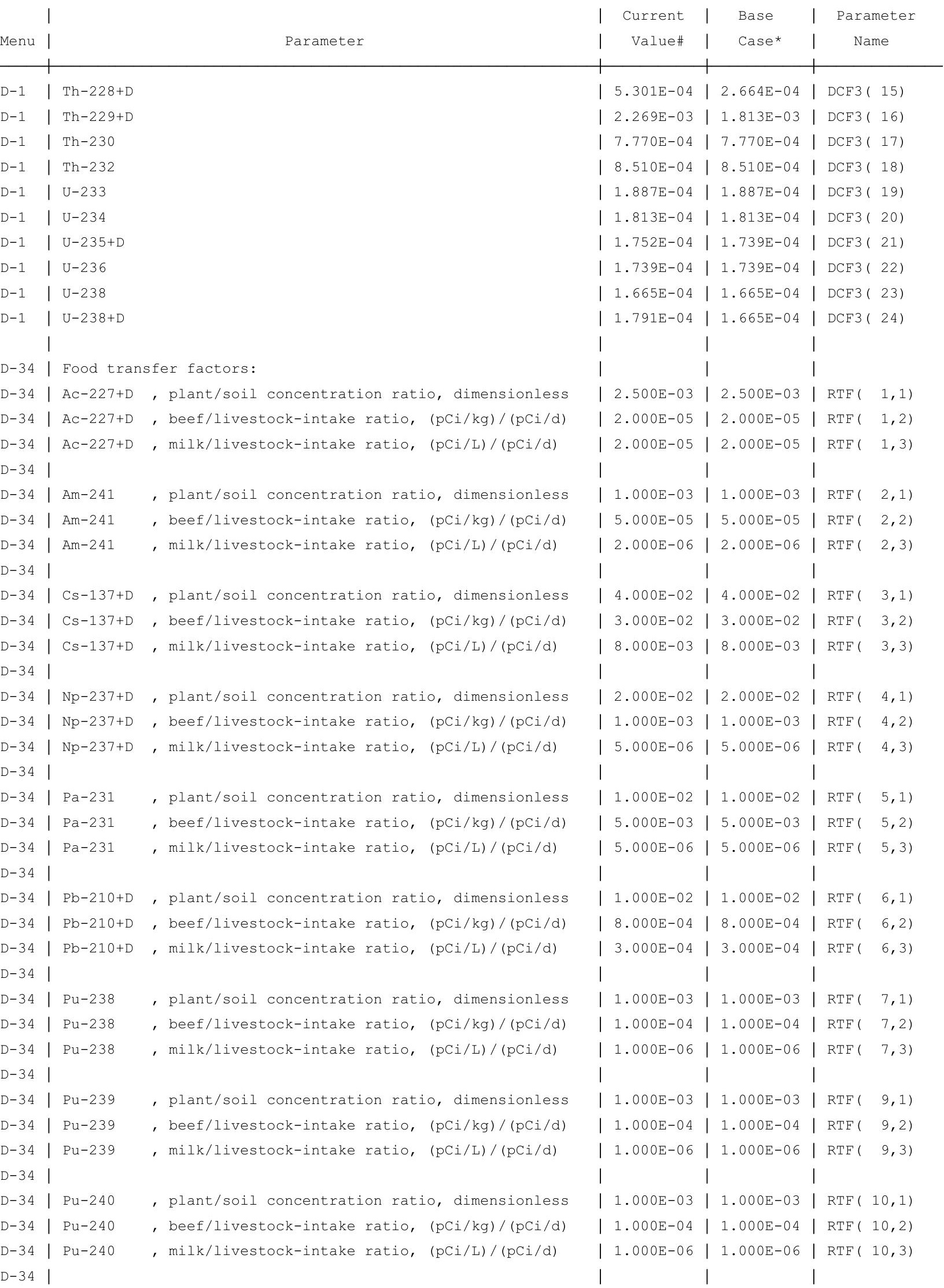


RESRAD, Version $6.5 \quad T^{1 / 2}$ Limit $=180$ days $\quad 07 / 20 / 2011 \quad 13: 54$ Page 10

Summary : RESRAD Parameters for Resident Farmer U-Landfill Forward Run 1,050 Years

File : C: $\backslash$ RESRAD_FAMILY \RESRAD \USERFILES $\backslash Q C J U L Y 2011 \backslash$ ONSITERF_FORWARD-1050-JULY11.RAD

Site-Specific Parameter Summary (continued)

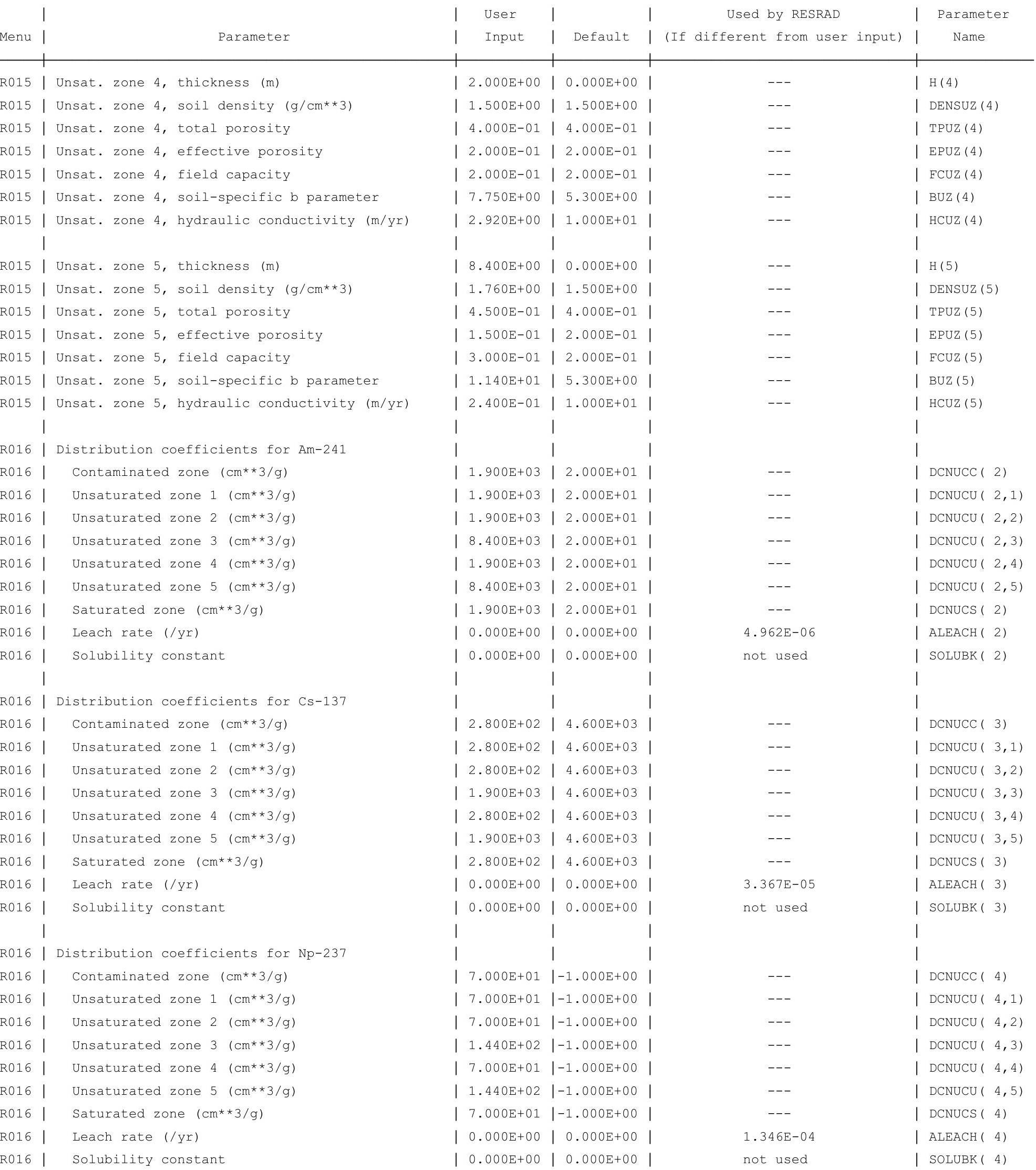


RESRAD, Version $6.5 \quad \mathrm{~T}^{1 / 2}$ Limit $=180$ days

Summary : RESRAD Parameters for Resident Farmer U-Landfill Forward Run 1,050 Years

File : C: \RESRAD FAMILY \RESRAD \USERFILES \QCJULY2011 \ONSITERF FORWARD-1050-JULY11.RAD

Site-Specific Parameter Summary (continued)

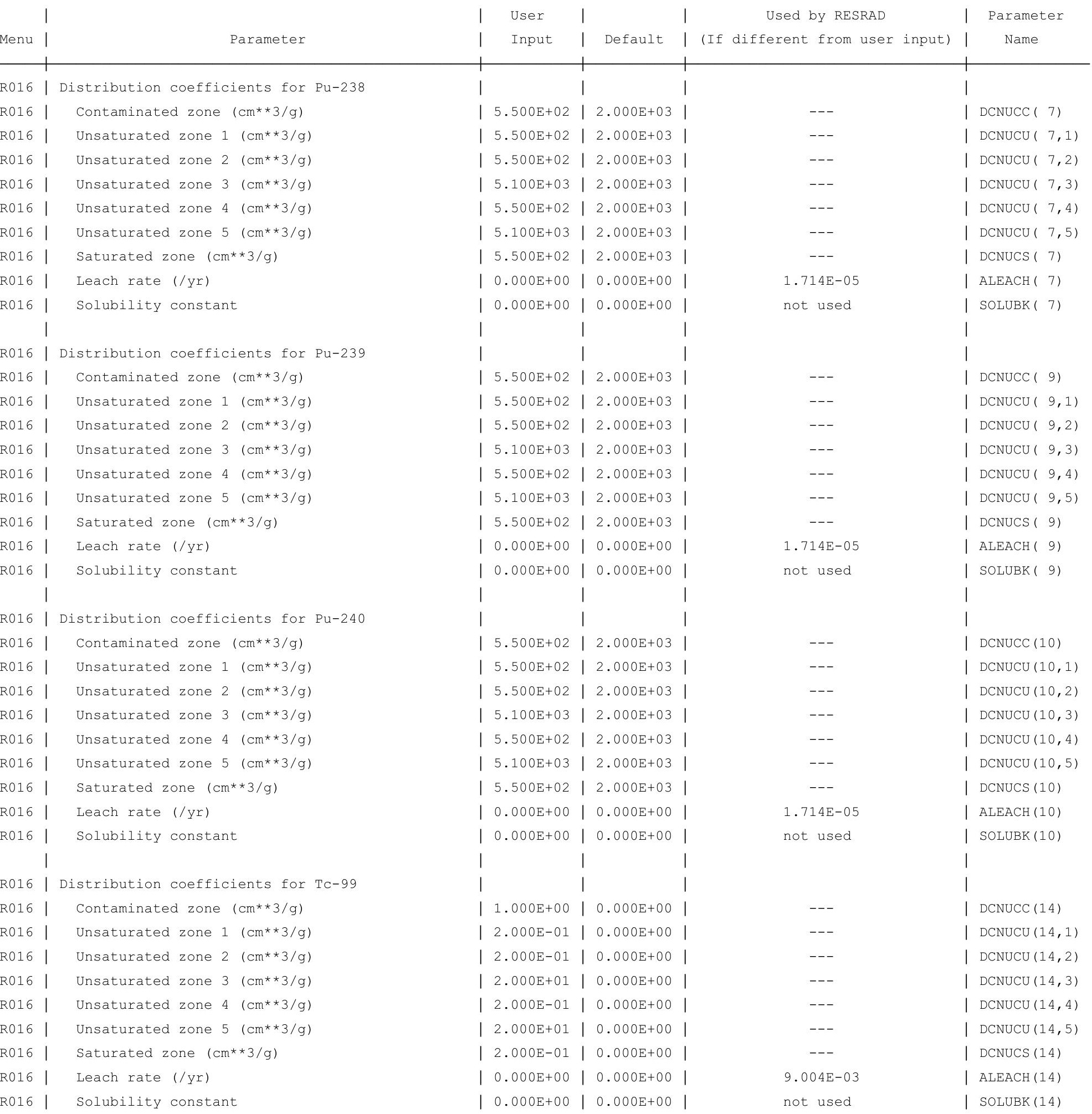


RESRAD, Version $6.5 \quad T^{1 / 2}$ Limit $=180$ days $\quad$ 07/20/2011 13:54 Page 12

Summary : RESRAD Parameters for Resident Farmer U-Landfill Forward Run 1,050 Years

File : C: $\backslash$ RESRAD_FAMILY \RESRAD \USERFILES $\backslash Q C J U L Y 2011 \backslash$ ONSITERF_FORWARD-1050-JULY11.RAD

Site-Specific Parameter Summary (continued)

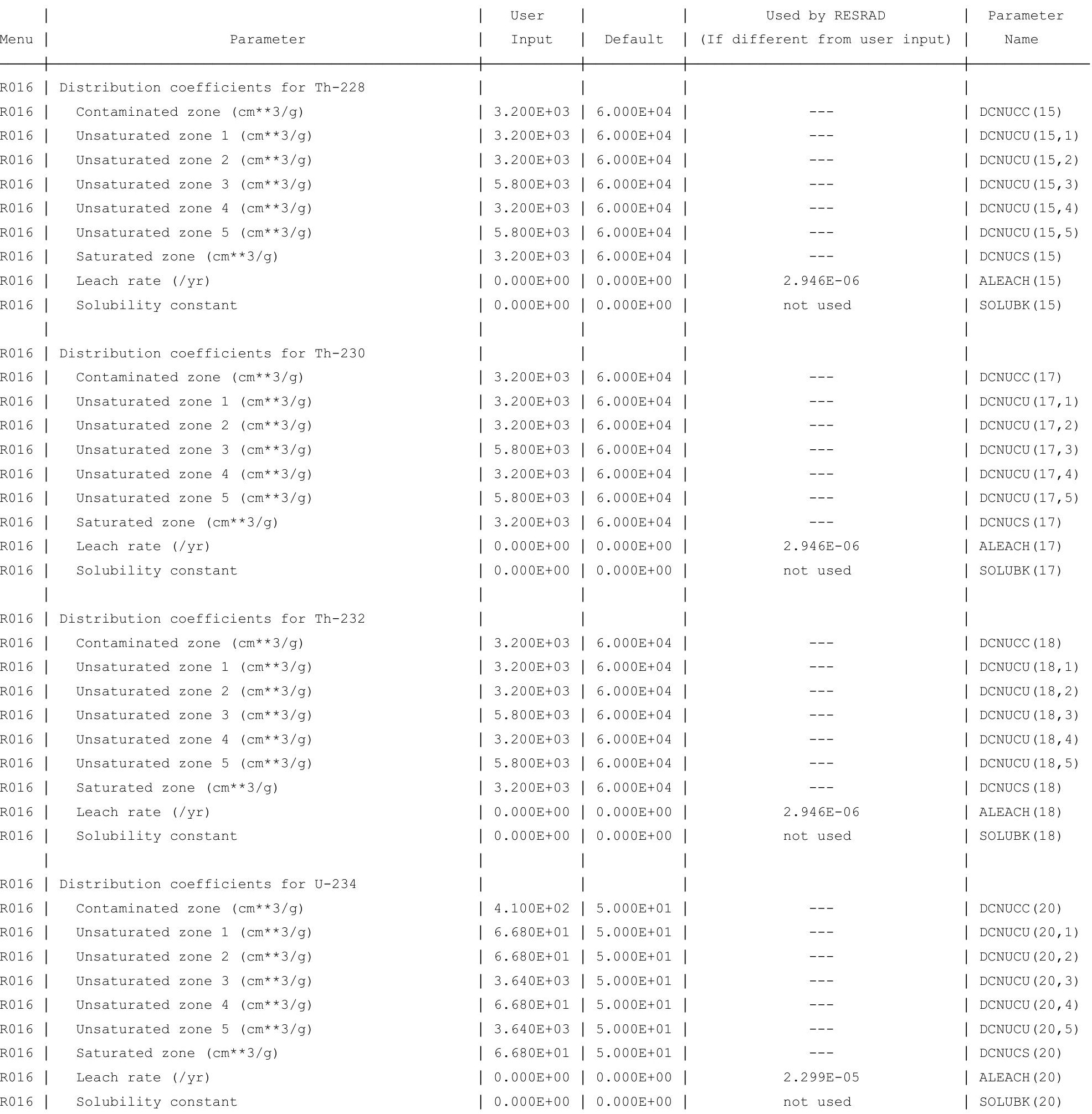


Summary : RESRAD Parameters for Resident Farmer U-Landfill Forward Run 1,050 Years

File : C: \RESRAD_FAMILY\RESRAD \USERFILES QQCJULY2011 \ONSITERF_FORWARD-1050-JULY11.RAD

Site-Specific Parameter Summary (continued)

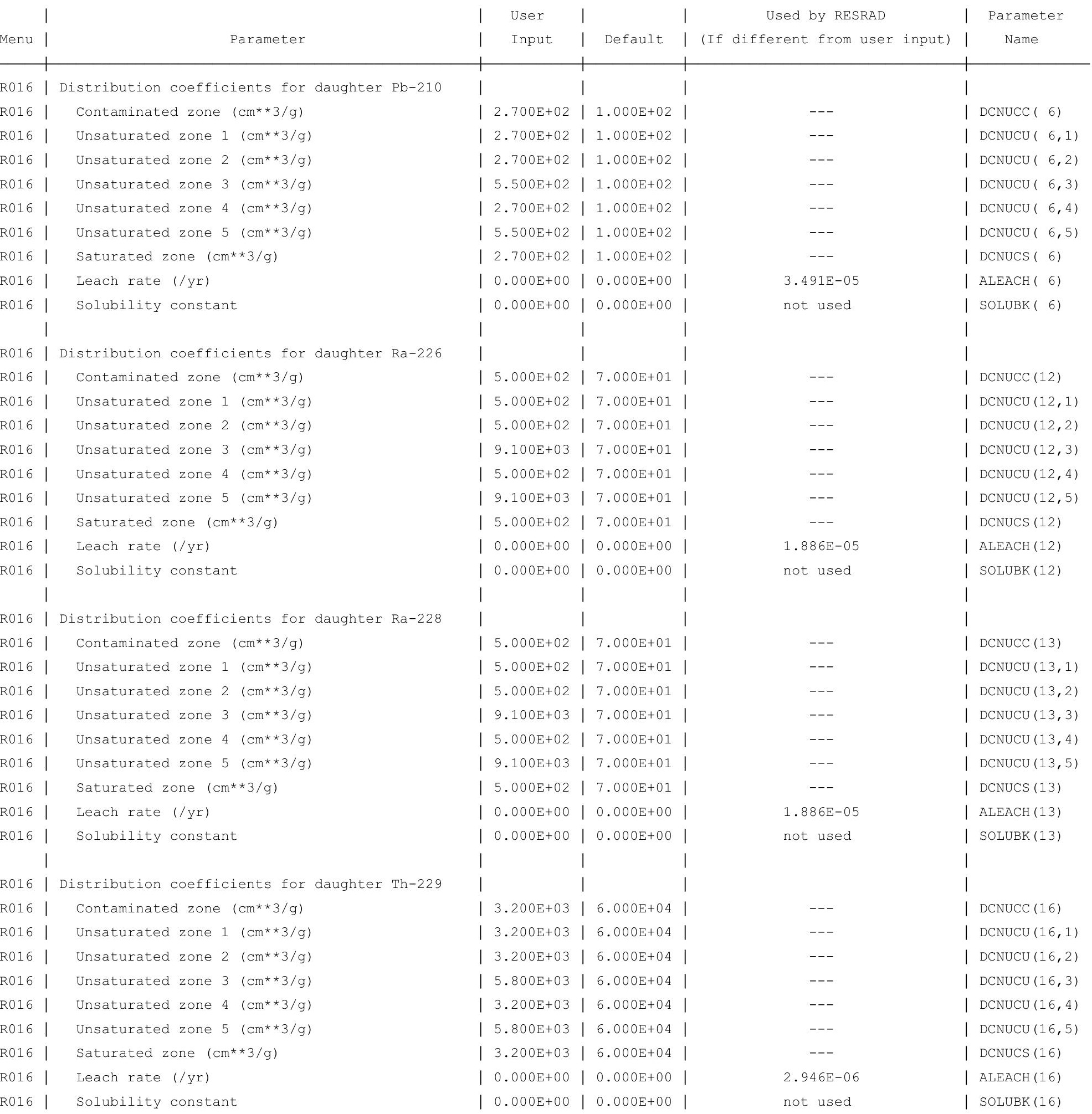


RESRAD, Version $6.5 \quad \mathrm{~T}^{\mathbb{1} 1 / 2}$ Limit $=180$ days

Summary : RESRAD Parameters for Resident Farmer U-Landfill Forward Run 1,050 Years

File : C: \RESRAD_FAMILY\RESRAD \USERFILES QQCJULY2011 ONSITERF_FORWARD-1050-JULY11.RAD

Site-Specific Parameter Summary (continued)

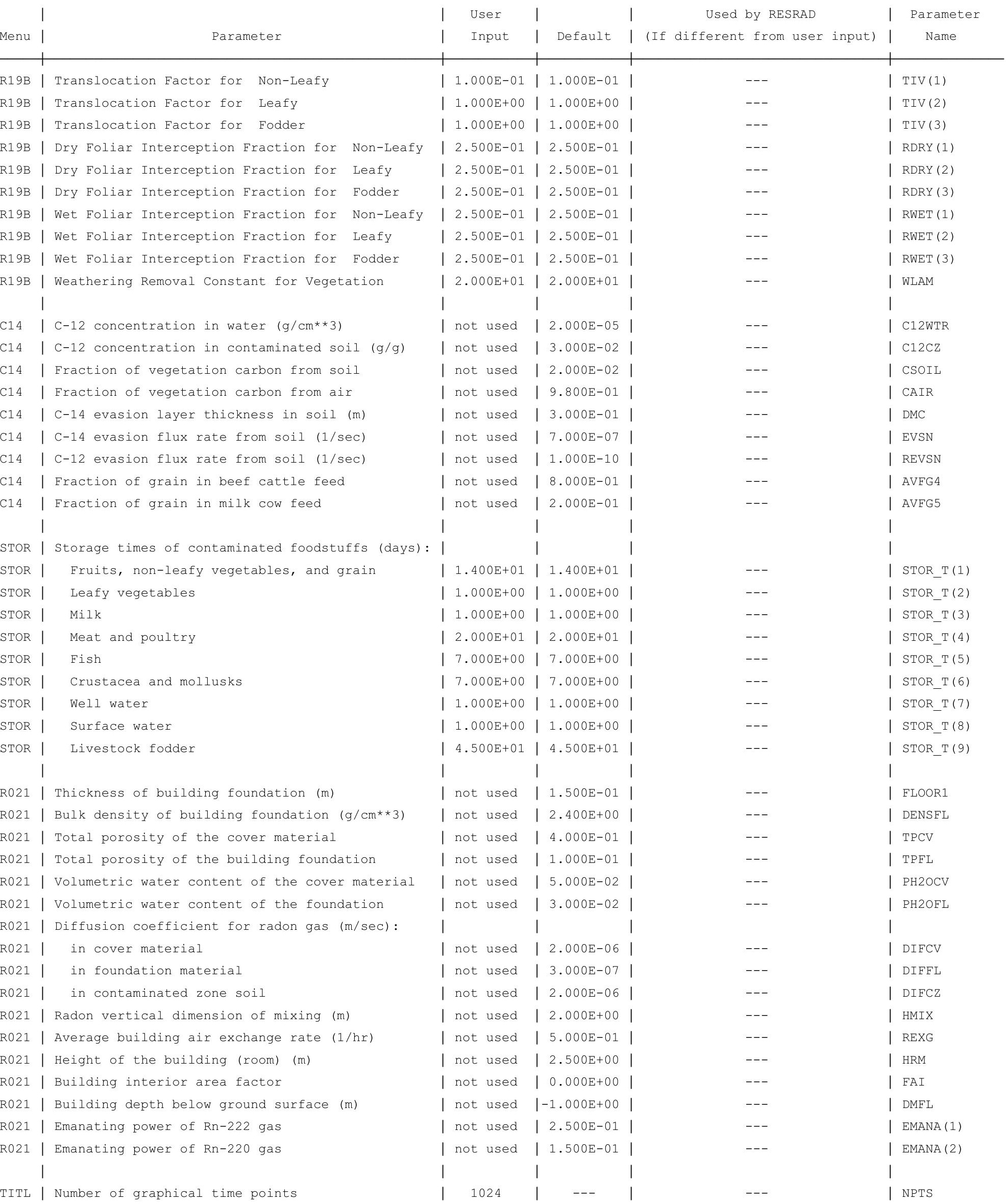

TITL | Number of graphical time points 
RESRAD, Version $6.5 \quad$ T1/2 Limit $=180$ days $\quad$ 07/20/2011 13:54 Page 19

Summary : RESRAD Parameters for Resident Farmer U-Landfill Forward Run 1,050 Years

File : C: $\backslash$ RESRAD_FAMILY \RESRAD \USERFILES $\backslash Q C J U L Y 2011 \backslash$ ONSITERF_FORWARD-1050-JULY11.RAD

Contaminated Zone Dimensions

Area: 89436.00 square meters

Thickness:

Cover Depth:

\begin{abstract}
13.40 meters
1.52 meters
\end{abstract}

Initial Soil Concentrations, pCi/g

$\begin{array}{ll}\mathrm{Am}-241 & 3.500 \mathrm{E}+01 \\ \mathrm{Cs}-137 & 1.900 \mathrm{E}+01 \\ \mathrm{~Np}-237 & 5.500 \mathrm{E}+00 \\ \mathrm{Pu}-238 & 3.900 \mathrm{E}+01 \\ \mathrm{Pu}-239 & 3.600 \mathrm{E}+01 \\ \mathrm{Pu}-240 & 3.600 \mathrm{E}+01 \\ \mathrm{TC}-99 & 5.200 \mathrm{E}+01 \\ \mathrm{Th}-228 & 4.000 \mathrm{E}+00 \\ \mathrm{Th}-230 & 1.000 \mathrm{E}+02 \\ \mathrm{Th}-232 & 4.000 \mathrm{E}+00 \\ \mathrm{U}-234 & 1.600 \mathrm{E}+02 \\ \mathrm{U}-235 & 6.500 \mathrm{E}+00 \\ \mathrm{U}-238 & 1.600 \mathrm{E}+02\end{array}$

Total Dose TDOSE(t), mrem/yr

Basic Radiation Dose Limit $=1.000 \mathrm{E}+02 \mathrm{mrem} / \mathrm{yr}$

Total Mixture Sum $M(t)=$ Fraction of Basic Dose Limit Received at Time (t)

$\begin{array}{rllllll}t \text { (years) : } & 0.000 \mathrm{E}+00 & 1.000 \mathrm{E}+00 & 5.000 \mathrm{E}+01 & 1.000 \mathrm{E}+02 & 5.000 \mathrm{E}+02 & 1.050 \mathrm{E}+03 \\ \text { TDOSE }(\mathrm{t}): & 5.627 \mathrm{E}-06 & 4.206 \mathrm{E}-06 & 9.541 \mathrm{E}-06 & 1.367 \mathrm{E}-05 & 1.076 \mathrm{E}+01 & 7.405 \mathrm{E}+00 \\ \mathrm{M}(\mathrm{t}): & 5.627 \mathrm{E}-08 & 4.206 \mathrm{E}-08 & 9.541 \mathrm{E}-08 & 1.367 \mathrm{E}-07 & 1.076 \mathrm{E}-01 & 7.405 \mathrm{E}-02\end{array}$

Maximum TDOSE(t): $2.119 \mathrm{E}+01 \mathrm{mrem} / \mathrm{yr}$ at $t=424.6 \pm 0.8$ years

Total Dose Contributions TDOSE(i,p,t) for Individual Radionuclides (i) and Pathways (p) As mrem/yr and Fraction of Total Dose At $t=4.246 \mathrm{E}+02$ years

Water Independent Pathways (Inhalation excludes radon)

\begin{tabular}{|c|c|c|c|c|c|c|c|c|c|c|c|c|c|c|}
\hline & \multicolumn{2}{|c|}{ Ground } & \multicolumn{2}{|c|}{ Inhalation } & \multicolumn{2}{|c|}{ Radon } & \multicolumn{2}{|c|}{ Plant } & \multicolumn{2}{|c|}{ Meat } & \multicolumn{2}{|c|}{ Milk } & \multicolumn{2}{|c|}{ Soil } \\
\hline clide & mrem/yr & fract. & mrem/yr & fract. & mrem/yr & fract. & mrem/yr & fract. & mrem/yr & fract. & mrem/yr & fract. & mrem/yr & fract. \\
\hline 241 & $3.203 E-13$ & 0.0000 & $0.000 \mathrm{E}+00$ & 0.0000 & $0.000 \mathrm{E}+00$ & 0.0000 & $0.000 \mathrm{E}+00$ & 0.0000 & $0.000 \mathrm{E}+00$ & 0.0000 & $0.000 \mathrm{E}+00$ & 0.0000 & $0.000 \mathrm{E}+00$ & 0.0000 \\
\hline-137 & $4.667 \mathrm{E}-11$ & 0.0000 & $0.000 \mathrm{E}+00$ & 0.0000 & $0.000 \mathrm{E}+00$ & 0.0000 & $0.000 \mathrm{E}+00$ & 0.0000 & $0.000 \mathrm{E}+00$ & 0.0000 & $0.000 \mathrm{E}+00$ & 0.0000 & $0.000 \mathrm{E}+00$ & 0.0000 \\
\hline-237 & $5.022 E-10$ & 0.0000 & $0.000 \mathrm{E}+00$ & 0.0000 & $0.000 \mathrm{E}+00$ & 0.0000 & $0.000 \mathrm{E}+00$ & 0.0000 & $0.000 \mathrm{E}+00$ & 0.0000 & $0.000 \mathrm{E}+00$ & 0.0000 & $0.000 \mathrm{E}+00$ & 0.0000 \\
\hline-238 & $8.791 E-12$ & 0.0000 & $0.000 \mathrm{E}+00$ & 0.0000 & $0.000 \mathrm{E}+00$ & 0.0000 & $0.000 \mathrm{E}+00$ & 0.0000 & $0.000 \mathrm{E}+00$ & 0.0000 & $0.000 \mathrm{E}+00$ & 0.0000 & $0.000 \mathrm{E}+00$ & 0.0000 \\
\hline-239 & $6.887 \mathrm{E}-14$ & 0.0000 & $0.000 \mathrm{E}+00$ & 0.0000 & $0.000 \mathrm{E}+00$ & 0.0000 & $0.000 \mathrm{E}+00$ & 0.0000 & $0.000 \mathrm{E}+00$ & 0.0000 & $0.000 \mathrm{E}+00$ & 0.0000 & $0.000 \mathrm{E}+00$ & 0.0000 \\
\hline-240 & $9.393 E-17$ & 0.0000 & $0.000 \mathrm{E}+00$ & 0.0000 & $0.000 \mathrm{E}+00$ & 0.0000 & $0.000 \mathrm{E}+00$ & 0.0000 & $0.000 \mathrm{E}+00$ & 0.0000 & $0.000 \mathrm{E}+00$ & 0.0000 & $0.000 \mathrm{E}+00$ & 0.0000 \\
\hline 99 & $2.248 E-22$ & 0.0000 & $0.000 \mathrm{E}+00$ & 0.0000 & $0.000 \mathrm{E}+00$ & 0.0000 & $0.000 \mathrm{E}+00$ & 0.0000 & $0.000 \mathrm{E}+00$ & 0.0000 & $0.000 \mathrm{E}+00$ & 0.0000 & $0.000 \mathrm{E}+00$ & 0.0000 \\
\hline-228 & $0.000 \mathrm{E}+00$ & 0.0000 & $0.000 \mathrm{E}+00$ & 0.0000 & $0.000 \mathrm{E}+00$ & 0.0000 & $0.000 \mathrm{E}+00$ & 0.0000 & $0.000 \mathrm{E}+00$ & 0.0000 & $0.000 \mathrm{E}+00$ & 0.0000 & $0.000 \mathrm{E}+00$ & 0.0000 \\
\hline-230 & $5.490 E-05$ & 0.0000 & $0.000 \mathrm{E}+00$ & 0.0000 & $0.000 \mathrm{E}+00$ & 0.0000 & $0.000 \mathrm{E}+00$ & 0.0000 & $0.000 \mathrm{E}+00$ & 0.0000 & $0.000 \mathrm{E}+00$ & 0.0000 & $0.000 \mathrm{E}+00$ & 0.0000 \\
\hline 232 & $8.488 E-05$ & 0.0000 & $0.000 \mathrm{E}+00$ & 0.0000 & $0.000 \mathrm{E}+00$ & 0.0000 & $0.000 \mathrm{E}+00$ & 0.0000 & $0.000 \mathrm{E}+00$ & 0.0000 & $0.000 \mathrm{E}+00$ & 0.0000 & $0.000 \mathrm{E}+00$ & 0.0000 \\
\hline 4 & $1.729 \mathrm{E}-07$ & 0.0000 & $0.000 \mathrm{E}+00$ & 0.0000 & $0.000 \mathrm{E}+00$ & 0.0000 & $0.000 \mathrm{E}+00$ & 0.0000 & $0.000 \mathrm{E}+00$ & 0.0000 & $0.000 E+00$ & 0.0000 & $0.000 \mathrm{E}+00$ & 0.0000 \\
\hline 35 & $1.968 \mathrm{E}-10$ & 0.0000 & $0.000 \mathrm{E}+00$ & 0.0000 & $0.000 \mathrm{E}+00$ & 0.0000 & $0.000 \mathrm{E}+00$ & 0.0000 & $0.000 \mathrm{E}+00$ & 0.0000 & $0.000 \mathrm{E}+00$ & 0.0000 & $0.000 \mathrm{E}+00$ & 0.0000 \\
\hline 38 & $6.729 \mathrm{E}-07$ & 0.0000 & $0.000 \mathrm{E}+00$ & 0.0000 & $0.000 \mathrm{E}+00$ & 0.0000 & $0.000 \mathrm{E}+00$ & 0.0000 & $0.000 \mathrm{E}+00$ & 0.0000 & $0.000 \mathrm{E}+00$ & 0.0000 & $0.000 \mathrm{E}+00$ & 0.0000 \\
\hline & 1.4 & 0.0 & $.000 \mathrm{E}+00$ & 0.0000 & $0.000 \mathrm{E}+00$ & 0.0000 & $0.000 \mathrm{E}+00$ & 0.0000 & $0.000 \mathrm{E}+00$ & 0.0000 & $0.000 \mathrm{E}+00$ & 000 & $0 \mathrm{E}+00$ & 00 \\
\hline
\end{tabular}


RESRAD, Version $6.5 \quad$ T1/2 Limit $=180$ days $\quad$ 07/20/2011 13:54 Page 20

Summary : RESRAD Parameters for Resident Farmer U-Landfill Forward Run 1,050 Years

File : C: $\backslash$ RESRAD_FAMILY \RESRAD \USERFILES $\backslash Q C J U L Y 2011 \backslash$ ONSITERF_FORWARD-1050-JULY11.RAD

Total Dose Contributions TDOSE (i,p,t) for Individual Radionuclides (i) and Pathways (p) As mrem/yr and Fraction of Total Dose At $t=4.246 \mathrm{E}+02$ years

Water Dependent Pathways

\begin{tabular}{|c|c|c|c|c|c|c|c|c|c|c|c|c|c|c|}
\hline & \multicolumn{2}{|c|}{ Water } & \multicolumn{2}{|c|}{ Fish } & \multicolumn{2}{|c|}{ Radon } & \multicolumn{2}{|c|}{ Plant } & \multicolumn{2}{|c|}{ Meat } & \multicolumn{2}{|c|}{ Milk } & \multicolumn{2}{|c|}{ All Pathways* } \\
\hline ide & mrem/yr & fract. & mrem/yr & fract. & mrem/yr & fract. & mrem/yr & fract. & mrem/yr & fract. & mrem/yr & fract. & mrem/yr & fract. \\
\hline-241 & $0.000 \mathrm{E}+00$ & 0.0000 & $0.000 \mathrm{E}+00$ & 0.0000 & $0.000 \mathrm{E}+00$ & 0.0000 & $0.000 \mathrm{E}+00$ & 0.0000 & $0.000 \mathrm{E}+00$ & 0.0000 & $0.000 \mathrm{E}+00$ & 0.0000 & $3.203 E-13$ & 0.0000 \\
\hline-137 & $0.000 \mathrm{E}+00$ & 0.0000 & $0.000 \mathrm{E}+00$ & 0.0000 & $0.000 \mathrm{E}+00$ & 0.0000 & $0.000 \mathrm{E}+00$ & 0.0000 & $0.000 \mathrm{E}+00$ & 0.0000 & $0.000 \mathrm{E}+00$ & 0.0000 & $4.667 \mathrm{E}-11$ & 0.0000 \\
\hline 237 & $0.000 \mathrm{E}+00$ & 0.0000 & $0.000 \mathrm{E}+00$ & 0.0000 & $0.000 \mathrm{E}+00$ & 0.0000 & $0.000 \mathrm{E}+00$ & 0.0000 & $0.000 \mathrm{E}+00$ & 0.0000 & $0.000 \mathrm{E}+00$ & 0.0000 & $5.022 \mathrm{E}-10$ & 0.0000 \\
\hline 238 & $0.000 \mathrm{E}+00$ & 0.0000 & $0.000 \mathrm{E}+00$ & 0.0000 & $0.000 \mathrm{E}+00$ & 0.0000 & $0.000 \mathrm{E}+00$ & 0.0000 & $0.000 \mathrm{E}+00$ & 0.0000 & $0.000 \mathrm{E}+00$ & 0.0000 & $8.791 \mathrm{E}-12$ & 0.0000 \\
\hline 239 & $0.000 \mathrm{E}+00$ & 0.0000 & $0.000 \mathrm{E}+00$ & 0.0000 & $0.000 \mathrm{E}+00$ & 0.0000 & $0.000 \mathrm{E}+00$ & 0.0000 & $0.000 \mathrm{E}+00$ & 0.0000 & $0.000 \mathrm{E}+00$ & 0.0000 & $6.887 \mathrm{E}-14$ & 0.0000 \\
\hline-240 & $0.000 \mathrm{E}+00$ & 0.0000 & $0.000 \mathrm{E}+00$ & 0.0000 & $0.000 \mathrm{E}+00$ & 0.0000 & $0.000 \mathrm{E}+00$ & 0.0000 & $0.000 \mathrm{E}+00$ & 0.0000 & $0.000 \mathrm{E}+00$ & 0.0000 & $9.393 \mathrm{E}-17$ & 0.0000 \\
\hline 99 & $1.754 \mathrm{E}+01$ & 0.8278 & $0.000 \mathrm{E}+00$ & 0.0000 & $0.000 \mathrm{E}+00$ & 0.0000 & $1.639 \mathrm{E}+00$ & 0.0773 & $2.931 E-02$ & 0.0014 & $1.981 \mathrm{E}+00$ & 0.0935 & $2.119 \mathrm{E}+01$ & 1.0000 \\
\hline-228 & $0.000 \mathrm{E}+00$ & 0.0000 & $0.000 \mathrm{E}+00$ & 0.0000 & $0.000 \mathrm{E}+00$ & 0.0000 & $0.000 \mathrm{E}+00$ & 0.0000 & $0.000 \mathrm{E}+00$ & 0.0000 & $0.000 \mathrm{E}+00$ & 0.0000 & $0.000 \mathrm{E}+00$ & 0.0000 \\
\hline 230 & $0.000 \mathrm{E}+00$ & 0.0000 & $0.000 \mathrm{E}+00$ & 0.0000 & $0.000 \mathrm{E}+00$ & 0.0000 & $0.000 \mathrm{E}+00$ & 0.0000 & $0.000 \mathrm{E}+00$ & 0.0000 & $0.000 \mathrm{E}+00$ & 0.0000 & $5.490 \mathrm{E}-05$ & 0.0000 \\
\hline 232 & $0.000 \mathrm{E}+00$ & 0.0000 & $0.000 \mathrm{E}+00$ & 0.0000 & $0.000 \mathrm{E}+00$ & 0.0000 & $0.000 \mathrm{E}+00$ & 0.0000 & $0.000 \mathrm{E}+00$ & 0.0000 & $0.000 \mathrm{E}+00$ & 0.0000 & $8.488 E-05$ & 0.0000 \\
\hline 34 & $0.000 \mathrm{E}+00$ & 0.0000 & $0.000 \mathrm{E}+00$ & 0.0000 & $0.000 \mathrm{E}+00$ & 0.0000 & $0.000 \mathrm{E}+00$ & 0.0000 & $0.000 \mathrm{E}+00$ & 0.0000 & $0.000 \mathrm{E}+00$ & 0.0000 & $1.729 \mathrm{E}-07$ & 0.0000 \\
\hline 35 & $0.000 \mathrm{E}+00$ & 0.0000 & $0.000 \mathrm{E}+00$ & 0.0000 & $0.000 \mathrm{E}+00$ & 0.0000 & $0.000 \mathrm{E}+00$ & 0.0000 & $0.000 \mathrm{E}+00$ & 0.0000 & $0.000 \mathrm{E}+00$ & 0.0000 & $1.968 \mathrm{E}-10$ & 0.0000 \\
\hline & $0.000 \mathrm{E}+00$ & 0.0000 & $0.000 \mathrm{E}+00$ & 0.0000 & $0.000 \mathrm{E}+00$ & 0.0000 & $0.000 \mathrm{E}+00$ & 0.0000 & $0.000 \mathrm{E}+00$ & 0.0000 & $0.000 \mathrm{E}+00$ & 0.0000 & $6.729 \mathrm{E}-07$ & 0.0000 \\
\hline & $1.754 \mathrm{E}+01$ & 0.8278 & $0.000 \mathrm{E}+00$ & 0.0000 & $0.000 \mathrm{E}+00$ & 0.0000 & $1.639 \mathrm{E}+00$ & 0.0773 & $2.931 \mathrm{E}-02$ & 0.0014 & $1.981 \mathrm{E}+00$ & 35 & -01 & 00 \\
\hline
\end{tabular}

*Sum of all water independent and dependent pathways. 
RESRAD, Version $6.5 \quad$ T1/2 Limit $=180$ days $\quad$ 07/20/2011 $13: 54 \quad$ Page 21

Summary : RESRAD Parameters for Resident Farmer U-Landfill Forward Run 1,050 Years

File : C: $\backslash$ RESRAD_FAMILY \RESRAD \USERFILES $\backslash Q C J U L Y 2011 \backslash$ ONSITERF_FORWARD-1050-JULY11.RAD

Total Dose Contributions TDOSE (i,p,t) for Individual Radionuclides (i) and Pathways (p) As mrem/yr and Fraction of Total Dose At $t=0.000 \mathrm{E}+00$ years

Water Independent Pathways (Inhalation excludes radon)

\begin{tabular}{|c|c|c|c|c|c|c|c|c|c|c|c|c|c|c|}
\hline & \multicolumn{2}{|c|}{ Ground } & \multicolumn{2}{|c|}{ Inhalation } & \multicolumn{2}{|c|}{ Radon } & \multicolumn{2}{|c|}{ Plant } & \multicolumn{2}{|c|}{ Meat } & \multicolumn{2}{|c|}{ Milk } & \multicolumn{2}{|c|}{ Soil } \\
\hline lide & mrem/yr & fract. & mrem/yr & fract. & mrem/yr & fract. & mrem/yr & fract. & mrem/yr & fract. & mrem/yr & fract. & mrem/yr & fract. \\
\hline 241 & $5.412 \mathrm{E}-18$ & 0.0000 & $0.000 \mathrm{E}+00$ & 0.0000 & $0.000 \mathrm{E}+00$ & 0.0000 & $0.000 \mathrm{E}+00$ & 0.0000 & $0.000 \mathrm{E}+00$ & 0.0000 & $0.000 \mathrm{E}+00$ & 0.0000 & $0.000 \mathrm{E}+00$ & 0.0000 \\
\hline-137 & $2.397 E-08$ & 0.0043 & $0.000 \mathrm{E}+00$ & 0.0000 & $0.000 \mathrm{E}+00$ & 0.0000 & $0.000 \mathrm{E}+00$ & 0.0000 & $0.000 \mathrm{E}+00$ & 0.0000 & $0.000 \mathrm{E}+00$ & 0.0000 & $0.000 \mathrm{E}+00$ & 0.0000 \\
\hline-237 & $5.245 E-12$ & 0.0000 & $0.000 \mathrm{E}+00$ & 0.0000 & $0.000 \mathrm{E}+00$ & 0.0000 & $0.000 \mathrm{E}+00$ & 0.0000 & $0.000 \mathrm{E}+00$ & 0.0000 & $0.000 \mathrm{E}+00$ & 0.0000 & $0.000 \mathrm{E}+00$ & 0.0000 \\
\hline-238 & $3.174 \mathrm{E}-21$ & 0.0000 & $0.000 \mathrm{E}+00$ & 0.0000 & $0.000 \mathrm{E}+00$ & 0.0000 & $0.000 \mathrm{E}+00$ & 0.0000 & $0.000 \mathrm{E}+00$ & 0.0000 & $0.000 \mathrm{E}+00$ & 0.0000 & $0.000 \mathrm{E}+00$ & 0.0000 \\
\hline-239 & 4. $328 E-16$ & 0.0000 & $0.000 \mathrm{E}+00$ & 0.0000 & $0.000 \mathrm{E}+00$ & 0.0000 & $0.000 \mathrm{E}+00$ & 0.0000 & $0.000 \mathrm{E}+00$ & 0.0000 & $0.000 \mathrm{E}+00$ & 0.0000 & $0.000 \mathrm{E}+00$ & 0.0000 \\
\hline-240 & $4.115 E-23$ & 0.0000 & $0.000 \mathrm{E}+00$ & 0.0000 & $0.000 \mathrm{E}+00$ & 0.0000 & $0.000 \mathrm{E}+00$ & 0.0000 & $0.000 \mathrm{E}+00$ & 0.0000 & $0.000 \mathrm{E}+00$ & 0.0000 & $0.000 \mathrm{E}+00$ & 0.0000 \\
\hline 99 & $2.994 \mathrm{E}-24$ & 0.0000 & $0.000 \mathrm{E}+00$ & 0.0000 & $0.000 \mathrm{E}+00$ & 0.0000 & $0.000 \mathrm{E}+00$ & 0.0000 & $0.000 \mathrm{E}+00$ & 0.0000 & $0.000 \mathrm{E}+00$ & 0.0000 & $0.000 \mathrm{E}+00$ & 0.0000 \\
\hline-228 & $5.530 \mathrm{E}-06$ & 0.9827 & $0.000 \mathrm{E}+00$ & 0.0000 & $0.000 \mathrm{E}+00$ & 0.0000 & $0.000 \mathrm{E}+00$ & 0.0000 & $0.000 \mathrm{E}+00$ & 0.0000 & $0.000 \mathrm{E}+00$ & 0.0000 & $0.000 \mathrm{E}+00$ & 0.0000 \\
\hline-230 & $3.774 \mathrm{E}-09$ & 0.0007 & $0.000 \mathrm{E}+00$ & 0.0000 & $0.000 \mathrm{E}+00$ & 0.0000 & $0.000 \mathrm{E}+00$ & 0.0000 & $0.000 \mathrm{E}+00$ & 0.0000 & $0.000 \mathrm{E}+00$ & 0.0000 & $0.000 \mathrm{E}+00$ & 0.0000 \\
\hline 232 & $4.712 \mathrm{E}-08$ & 0.0084 & $0.000 \mathrm{E}+00$ & 0.0000 & $0.000 \mathrm{E}+00$ & 0.0000 & $0.000 \mathrm{E}+00$ & 0.0000 & $0.000 \mathrm{E}+00$ & 0.0000 & $0.000 \mathrm{E}+00$ & 0.0000 & $0.000 \mathrm{E}+00$ & 0.0000 \\
\hline 234 & $1.813 \mathrm{E}-14$ & 0.0000 & $0.000 \mathrm{E}+00$ & 0.0000 & $0.000 \mathrm{E}+00$ & 0.0000 & $0.000 \mathrm{E}+00$ & 0.0000 & $0.000 \mathrm{E}+00$ & 0.0000 & $0.000 \mathrm{E}+00$ & 0.0000 & $0.000 \mathrm{E}+00$ & 0.0000 \\
\hline 235 & $8.089 \mathrm{E}-14$ & 0.0000 & $0.000 \mathrm{E}+00$ & 0.0000 & $0.000 \mathrm{E}+00$ & 0.0000 & $0.000 \mathrm{E}+00$ & 0.0000 & $0.000 \mathrm{E}+00$ & 0.0000 & $0.000 \mathrm{E}+00$ & 0.0000 & $0.000 \mathrm{E}+00$ & 0.0000 \\
\hline 38 & $2.271 E-08$ & 0.0040 & $0.000 \mathrm{E}+00$ & 0.0000 & $0.000 \mathrm{E}+00$ & 0.0000 & $0.000 \mathrm{E}+00$ & 0.0000 & $0.000 \mathrm{E}+00$ & 0.0000 & $0.000 \mathrm{E}+00$ & 0.0000 & $0.000 \mathrm{E}+00$ & 0.0000 \\
\hline & $5.627 \mathrm{E}-06$ & 1.0000 & $0.000 \mathrm{E}+00$ & 0.0000 & $0.000 \mathrm{E}+00$ & 0.0000 & $0.000 \mathrm{E}+00$ & 0.0000 & $0.000 \mathrm{E}+00$ & 0.0000 & $0.000 \mathrm{E}+00$ & 0.0000 & $0.000 \mathrm{E}+00$ & 0.0000 \\
\hline
\end{tabular}

Total Dose Contributions TDOSE(i,p,t) for Individual Radionuclides (i) and Pathways (p) As mrem/yr and Fraction of Total Dose At $t=0.000 \mathrm{E}+00$ years

Water Dependent Pathways

\begin{tabular}{|c|c|c|c|c|c|c|c|c|c|c|c|c|c|c|}
\hline \multirow{2}{*}{$\begin{array}{l}\text { Radio- } \\
\text { Nuclide }\end{array}$} & \multicolumn{2}{|c|}{ Water } & \multicolumn{2}{|c|}{ Fish } & \multicolumn{2}{|c|}{ Radon } & \multicolumn{2}{|c|}{ Plant } & \multicolumn{2}{|c|}{ Meat } & \multicolumn{2}{|c|}{ Milk } & \multicolumn{2}{|c|}{ All Pathways* } \\
\hline & mrem/yr & fract. & mrem/yr & fract. & mrem/yr & fract. & mrem/yr & fract. & mrem/yr & fract. & mrem/yr & fract. & mrem/yr & fract. \\
\hline 241 & $0.000 \mathrm{E}+00$ & 0.0000 & $0.000 \mathrm{E}+00$ & 0.0000 & $0.000 \mathrm{E}+00$ & 0.0000 & $0.000 \mathrm{E}+00$ & 0.0000 & $0.000 \mathrm{E}+00$ & 0.0000 & $0.000 \mathrm{E}+00$ & 0.0000 & $5.412 \mathrm{E}-18$ & 0.0000 \\
\hline-137 & $0.000 \mathrm{E}+00$ & 0.0000 & $0.000 \mathrm{E}+00$ & 0.0000 & $0.000 \mathrm{E}+00$ & 0.0000 & $0.000 \mathrm{E}+00$ & 0.0000 & $0.000 \mathrm{E}+00$ & 0.0000 & $0.000 \mathrm{E}+00$ & 0.0000 & $2.397 \mathrm{E}-08$ & 0.0043 \\
\hline-237 & $0.000 \mathrm{E}+00$ & 0.0000 & $0.000 \mathrm{E}+00$ & 0.0000 & $0.000 \mathrm{E}+00$ & 0.0000 & $0.000 \mathrm{E}+00$ & 0.0000 & $0.000 \mathrm{E}+00$ & 0.0000 & $0.000 \mathrm{E}+00$ & 0.0000 & $5.245 E-12$ & 0.0000 \\
\hline-238 & $0.000 \mathrm{E}+00$ & 0.0000 & $0.000 \mathrm{E}+00$ & 0.0000 & $0.000 \mathrm{E}+00$ & 0.0000 & $0.000 \mathrm{E}+00$ & 0.0000 & $0.000 \mathrm{E}+00$ & 0.0000 & $0.000 \mathrm{E}+00$ & 0.0000 & $3.174 \mathrm{E}-21$ & 0.0000 \\
\hline-239 & $0.000 \mathrm{E}+00$ & 0.0000 & $0.000 \mathrm{E}+00$ & 0.0000 & $0.000 \mathrm{E}+00$ & 0.0000 & $0.000 \mathrm{E}+00$ & 0.0000 & $0.000 \mathrm{E}+00$ & 0.0000 & $0.000 E+00$ & 0.0000 & $4.328 E-16$ & 0.0000 \\
\hline-240 & $0.000 \mathrm{E}+00$ & 0.0000 & $0.000 \mathrm{E}+00$ & 0.0000 & $0.000 \mathrm{E}+00$ & 0.0000 & $0.000 \mathrm{E}+00$ & 0.0000 & $0.000 \mathrm{E}+00$ & 0.0000 & $0.000 E+00$ & 0.0000 & $4.115 \mathrm{E}-23$ & 0.0000 \\
\hline-99 & $0.000 \mathrm{E}+00$ & 0.0000 & $0.000 \mathrm{E}+00$ & 0.0000 & $0.000 \mathrm{E}+00$ & 0.0000 & $0.000 \mathrm{E}+00$ & 0.0000 & $0.000 \mathrm{E}+00$ & 0.0000 & $0.000 \mathrm{E}+00$ & 0.0000 & $2.994 \mathrm{E}-24$ & 0.0000 \\
\hline-228 & $0.000 \mathrm{E}+00$ & 0.0000 & $0.000 \mathrm{E}+00$ & 0.0000 & $0.000 \mathrm{E}+00$ & 0.0000 & $0.000 \mathrm{E}+00$ & 0.0000 & $0.000 \mathrm{E}+00$ & 0.0000 & $0.000 \mathrm{E}+00$ & 0.0000 & $5.530 \mathrm{E}-06$ & 0.9827 \\
\hline-230 & $0.000 \mathrm{E}+00$ & 0.0000 & $0.000 \mathrm{E}+00$ & 0.0000 & $0.000 \mathrm{E}+00$ & 0.0000 & $0.000 \mathrm{E}+00$ & 0.0000 & $0.000 \mathrm{E}+00$ & 0.0000 & $0.000 E+00$ & 0.0000 & $3.774 \mathrm{E}-09$ & 0.0007 \\
\hline 232 & $0.000 \mathrm{E}+00$ & 0.0000 & $0.000 \mathrm{E}+00$ & 0.0000 & $0.000 \mathrm{E}+00$ & 0.0000 & $0.000 \mathrm{E}+00$ & 0.0000 & $0.000 \mathrm{E}+00$ & 0.0000 & $0.000 \mathrm{E}+00$ & 0.0000 & $4.712 \mathrm{E}-08$ & 0.0084 \\
\hline 34 & $0.000 \mathrm{E}+00$ & 0.0000 & $0.000 \mathrm{E}+00$ & 0.0000 & $0.000 \mathrm{E}+00$ & 0.0000 & $0.000 \mathrm{E}+00$ & 0.0000 & $0.000 \mathrm{E}+00$ & 0.0000 & $0.000 \mathrm{E}+00$ & 0.0000 & $1.813 \mathrm{E}-14$ & 0.0000 \\
\hline 35 & $0.000 \mathrm{E}+00$ & 0.0000 & $0.000 \mathrm{E}+00$ & 0.0000 & $0.000 \mathrm{E}+00$ & 0.0000 & $0.000 \mathrm{E}+00$ & 0.0000 & $0.000 \mathrm{E}+00$ & 0.0000 & $0.000 \mathrm{E}+00$ & 0.0000 & $8.089 \mathrm{E}-14$ & 0.0000 \\
\hline 38 & $0.000 \mathrm{E}+00$ & 0.0000 & $0.000 \mathrm{E}+00$ & 0.0000 & $0.000 \mathrm{E}+00$ & 0.0000 & $0.000 \mathrm{E}+00$ & 0.0000 & $0.000 \mathrm{E}+00$ & 0.0000 & $0.000 \mathrm{E}+00$ & 0.0000 & $2.271 E-08$ & 0.0040 \\
\hline & $0.000 \mathrm{E}+00$ & 0.0000 & $0.000 \mathrm{E}+00$ & 0.0000 & $0.000 \mathrm{E}+00$ & 0.0000 & $0.000 \mathrm{E}+00$ & 0.0000 & $0.000 \mathrm{E}+00$ & 0.0000 & $0.000 \mathrm{E}+00$ & 0.0000 & $7 E-06$ & 1. \\
\hline
\end{tabular}

* Sum of all water independent and dependent pathways. 
RESRAD, Version $6.5 \quad$ T1/2 Limit $=180$ days $\quad$ 07/20/2011 13:54 Page 22

Summary : RESRAD Parameters for Resident Farmer U-Landfill Forward Run 1,050 Years

File : C: $\backslash$ RESRAD_FAMILY \RESRAD \USERFILES $\backslash Q C J U L Y 2011 \backslash$ ONSITERF_FORWARD-1050-JULY11.RAD

Total Dose Contributions TDOSE (i,p,t) for Individual Radionuclides (i) and Pathways (p) As mrem/yr and Fraction of Total Dose At $t=1.000 \mathrm{E}+00$ years

Water Independent Pathways (Inhalation excludes radon)

\begin{tabular}{|c|c|c|c|c|c|c|c|c|c|c|c|c|c|c|}
\hline & \multicolumn{2}{|c|}{ Ground } & \multicolumn{2}{|c|}{ Inhalation } & \multicolumn{2}{|c|}{ Radon } & \multicolumn{2}{|c|}{ Plant } & \multicolumn{2}{|c|}{ Meat } & \multicolumn{2}{|c|}{ Milk } & \multicolumn{2}{|c|}{ Soil } \\
\hline clide & mrem/yr & fract. & mrem/yr & fract. & mrem/yr & fract. & mrem/yr & fract. & mrem/yr & fract. & mrem/yr & fract. & mrem/yr & fract. \\
\hline 241 & $1.638 \mathrm{E}-17$ & 0.0000 & $0.000 \mathrm{E}+00$ & 0.0000 & $0.000 \mathrm{E}+00$ & 0.0000 & $0.000 \mathrm{E}+00$ & 0.0000 & $0.000 \mathrm{E}+00$ & 0.0000 & $0.000 \mathrm{E}+00$ & 0.0000 & $0.000 \mathrm{E}+00$ & 0.0000 \\
\hline-137 & $2.362 E-08$ & 0.0056 & $0.000 \mathrm{E}+00$ & 0.0000 & $0.000 \mathrm{E}+00$ & 0.0000 & $0.000 \mathrm{E}+00$ & 0.0000 & $0.000 \mathrm{E}+00$ & 0.0000 & $0.000 \mathrm{E}+00$ & 0.0000 & $0.000 \mathrm{E}+00$ & 0.0000 \\
\hline-237 & $5.301 E-12$ & 0.0000 & $0.000 \mathrm{E}+00$ & 0.0000 & $0.000 \mathrm{E}+00$ & 0.0000 & $0.000 \mathrm{E}+00$ & 0.0000 & $0.000 \mathrm{E}+00$ & 0.0000 & $0.000 \mathrm{E}+00$ & 0.0000 & $0.000 \mathrm{E}+00$ & 0.0000 \\
\hline-238 & $4.717 \mathrm{E}-20$ & 0.0000 & $0.000 \mathrm{E}+00$ & 0.0000 & $0.000 \mathrm{E}+00$ & 0.0000 & $0.000 \mathrm{E}+00$ & 0.0000 & $0.000 \mathrm{E}+00$ & 0.0000 & $0.000 \mathrm{E}+00$ & 0.0000 & $0.000 \mathrm{E}+00$ & 0.0000 \\
\hline-239 & 4. $380 \mathrm{E}-16$ & 0.0000 & $0.000 \mathrm{E}+00$ & 0.0000 & $0.000 \mathrm{E}+00$ & 0.0000 & $0.000 \mathrm{E}+00$ & 0.0000 & $0.000 \mathrm{E}+00$ & 0.0000 & $0.000 \mathrm{E}+00$ & 0.0000 & $0.000 \mathrm{E}+00$ & 0.0000 \\
\hline-240 & $4.275 E-23$ & 0.0000 & $0.000 \mathrm{E}+00$ & 0.0000 & $0.000 \mathrm{E}+00$ & 0.0000 & $0.000 \mathrm{E}+00$ & 0.0000 & $0.000 \mathrm{E}+00$ & 0.0000 & $0.000 \mathrm{E}+00$ & 0.0000 & $0.000 \mathrm{E}+00$ & 0.0000 \\
\hline 99 & $3.025 E-24$ & 0.0000 & $0.000 \mathrm{E}+00$ & 0.0000 & $0.000 \mathrm{E}+00$ & 0.0000 & $0.000 \mathrm{E}+00$ & 0.0000 & $0.000 \mathrm{E}+00$ & 0.0000 & $0.000 \mathrm{E}+00$ & 0.0000 & $0.000 \mathrm{E}+00$ & 0.0000 \\
\hline-228 & $3.872 E-06$ & 0.9206 & $0.000 \mathrm{E}+00$ & 0.0000 & $0.000 \mathrm{E}+00$ & 0.0000 & $0.000 \mathrm{E}+00$ & 0.0000 & $0.000 \mathrm{E}+00$ & 0.0000 & $0.000 \mathrm{E}+00$ & 0.0000 & $0.000 \mathrm{E}+00$ & 0.0000 \\
\hline-230 & $1.139 \mathrm{E}-08$ & 0.0027 & $0.000 \mathrm{E}+00$ & 0.0000 & $0.000 \mathrm{E}+00$ & 0.0000 & $0.000 \mathrm{E}+00$ & 0.0000 & $0.000 \mathrm{E}+00$ & 0.0000 & $0.000 \mathrm{E}+00$ & 0.0000 & $0.000 \mathrm{E}+00$ & 0.0000 \\
\hline 232 & $2.759 \mathrm{E}-07$ & 0.0656 & $0.000 \mathrm{E}+00$ & 0.0000 & $0.000 \mathrm{E}+00$ & 0.0000 & $0.000 \mathrm{E}+00$ & 0.0000 & $0.000 \mathrm{E}+00$ & 0.0000 & $0.000 \mathrm{E}+00$ & 0.0000 & $0.000 \mathrm{E}+00$ & 0.0000 \\
\hline 234 & $1.277 \mathrm{E}-13$ & 0.0000 & $0.000 \mathrm{E}+00$ & 0.0000 & $0.000 \mathrm{E}+00$ & 0.0000 & $0.000 \mathrm{E}+00$ & 0.0000 & $0.000 \mathrm{E}+00$ & 0.0000 & $0.000 \mathrm{E}+00$ & 0.0000 & $0.000 \mathrm{E}+00$ & 0.0000 \\
\hline 235 & $8.230 \mathrm{E}-14$ & 0.0000 & $0.000 \mathrm{E}+00$ & 0.0000 & $0.000 \mathrm{E}+00$ & 0.0000 & $0.000 \mathrm{E}+00$ & 0.0000 & $0.000 \mathrm{E}+00$ & 0.0000 & $0.000 \mathrm{E}+00$ & 0.0000 & $0.000 \mathrm{E}+00$ & 0.0000 \\
\hline 38 & $2.290 \mathrm{E}-08$ & 0.0054 & $0.000 \mathrm{E}+00$ & 0.0000 & $0.000 \mathrm{E}+00$ & 0.0000 & $0.000 \mathrm{E}+00$ & 0.0000 & $0.000 \mathrm{E}+00$ & 0.0000 & $0.000 \mathrm{E}+00$ & 0.0000 & $0.000 \mathrm{E}+00$ & 0.0000 \\
\hline & $4.206 E-06$ & 1.0000 & $0.000 \mathrm{E}+00$ & 0.0000 & $0.000 \mathrm{E}+00$ & 0.0000 & $0.000 \mathrm{E}+00$ & 0.0000 & $0.000 \mathrm{E}+00$ & 0.0000 & $0.000 \mathrm{E}+00$ & 0.0000 & $0.000 \mathrm{E}+00$ & 0.0000 \\
\hline
\end{tabular}

Total Dose Contributions TDOSE(i,p,t) for Individual Radionuclides (i) and Pathways (p) As mrem/yr and Fraction of Total Dose At $t=1.000 \mathrm{E}+00$ years

Water Dependent Pathways

\begin{tabular}{|c|c|c|c|c|c|c|c|c|c|c|c|c|c|c|}
\hline \multirow{2}{*}{$\begin{array}{l}\text { Radio- } \\
\text { Nuclide }\end{array}$} & \multicolumn{2}{|c|}{ Water } & \multicolumn{2}{|c|}{ Fish } & \multicolumn{2}{|c|}{ Radon } & \multicolumn{2}{|c|}{ Plant } & \multicolumn{2}{|c|}{ Meat } & \multicolumn{2}{|c|}{ Milk } & \multicolumn{2}{|c|}{ All Pathways* } \\
\hline & mrem/yr & fract. & mrem/yr & fract. & mrem/yr & fract. & mrem/yr & fract. & mrem/yr & fract. & mrem/yr & fract. & mrem/yr & fract. \\
\hline 241 & $0.000 \mathrm{E}+00$ & 0.0000 & $0.000 \mathrm{E}+00$ & 0.0000 & $0.000 \mathrm{E}+00$ & 0.0000 & $0.000 \mathrm{E}+00$ & 0.0000 & $0.000 \mathrm{E}+00$ & 0.0000 & $0.000 \mathrm{E}+00$ & 0.0000 & $1.638 \mathrm{E}-17$ & 0.0000 \\
\hline-137 & $0.000 \mathrm{E}+00$ & 0.0000 & $0.000 \mathrm{E}+00$ & 0.0000 & $0.000 \mathrm{E}+00$ & 0.0000 & $0.000 \mathrm{E}+00$ & 0.0000 & $0.000 \mathrm{E}+00$ & 0.0000 & $0.000 \mathrm{E}+00$ & 0.0000 & $2.362 \mathrm{E}-08$ & 0.0056 \\
\hline-237 & $0.000 \mathrm{E}+00$ & 0.0000 & $0.000 \mathrm{E}+00$ & 0.0000 & $0.000 \mathrm{E}+00$ & 0.0000 & $0.000 \mathrm{E}+00$ & 0.0000 & $0.000 \mathrm{E}+00$ & 0.0000 & $0.000 \mathrm{E}+00$ & 0.0000 & $5.301 \mathrm{E}-12$ & 0.0000 \\
\hline-238 & $0.000 \mathrm{E}+00$ & 0.0000 & $0.000 \mathrm{E}+00$ & 0.0000 & $0.000 \mathrm{E}+00$ & 0.0000 & $0.000 \mathrm{E}+00$ & 0.0000 & $0.000 \mathrm{E}+00$ & 0.0000 & $0.000 \mathrm{E}+00$ & 0.0000 & $4.717 \mathrm{E}-20$ & 0.0000 \\
\hline-239 & $0.000 \mathrm{E}+00$ & 0.0000 & $0.000 \mathrm{E}+00$ & 0.0000 & $0.000 \mathrm{E}+00$ & 0.0000 & $0.000 \mathrm{E}+00$ & 0.0000 & $0.000 \mathrm{E}+00$ & 0.0000 & $0.000 E+00$ & 0.0000 & $4.380 \mathrm{E}-16$ & 0.0000 \\
\hline-240 & $0.000 \mathrm{E}+00$ & 0.0000 & $0.000 \mathrm{E}+00$ & 0.0000 & $0.000 \mathrm{E}+00$ & 0.0000 & $0.000 \mathrm{E}+00$ & 0.0000 & $0.000 \mathrm{E}+00$ & 0.0000 & $0.000 E+00$ & 0.0000 & $4.275 E-23$ & 0.0000 \\
\hline-99 & $0.000 \mathrm{E}+00$ & 0.0000 & $0.000 \mathrm{E}+00$ & 0.0000 & $0.000 \mathrm{E}+00$ & 0.0000 & $0.000 \mathrm{E}+00$ & 0.0000 & $0.000 \mathrm{E}+00$ & 0.0000 & $0.000 \mathrm{E}+00$ & 0.0000 & $3.025 \mathrm{E}-24$ & 0.0000 \\
\hline-228 & $0.000 \mathrm{E}+00$ & 0.0000 & $0.000 \mathrm{E}+00$ & 0.0000 & $0.000 \mathrm{E}+00$ & 0.0000 & $0.000 \mathrm{E}+00$ & 0.0000 & $0.000 \mathrm{E}+00$ & 0.0000 & $0.000 \mathrm{E}+00$ & 0.0000 & $3.872 \mathrm{E}-06$ & 0.9206 \\
\hline-230 & $0.000 \mathrm{E}+00$ & 0.0000 & $0.000 \mathrm{E}+00$ & 0.0000 & $0.000 \mathrm{E}+00$ & 0.0000 & $0.000 \mathrm{E}+00$ & 0.0000 & $0.000 \mathrm{E}+00$ & 0.0000 & $0.000 E+00$ & 0.0000 & $1.139 \mathrm{E}-08$ & 0.0027 \\
\hline-232 & $0.000 \mathrm{E}+00$ & 0.0000 & $0.000 \mathrm{E}+00$ & 0.0000 & $0.000 \mathrm{E}+00$ & 0.0000 & $0.000 \mathrm{E}+00$ & 0.0000 & $0.000 \mathrm{E}+00$ & 0.0000 & $0.000 \mathrm{E}+00$ & 0.0000 & $2.759 \mathrm{E}-07$ & 0.0656 \\
\hline 234 & $0.000 \mathrm{E}+00$ & 0.0000 & $0.000 \mathrm{E}+00$ & 0.0000 & $0.000 \mathrm{E}+00$ & 0.0000 & $0.000 \mathrm{E}+00$ & 0.0000 & $0.000 \mathrm{E}+00$ & 0.0000 & $0.000 \mathrm{E}+00$ & 0.0000 & $1.277 \mathrm{E}-13$ & 0.0000 \\
\hline 35 & $0.000 \mathrm{E}+00$ & 0.0000 & $0.000 \mathrm{E}+00$ & 0.0000 & $0.000 \mathrm{E}+00$ & 0.0000 & $0.000 \mathrm{E}+00$ & 0.0000 & $0.000 \mathrm{E}+00$ & 0.0000 & $0.000 \mathrm{E}+00$ & 0.0000 & $8.230 \mathrm{E}-14$ & 0.0000 \\
\hline 38 & $0.000 \mathrm{E}+00$ & 0.0000 & $0.000 \mathrm{E}+00$ & 0.0000 & $0.000 \mathrm{E}+00$ & 0.0000 & $0.000 \mathrm{E}+00$ & 0.0000 & $0.000 \mathrm{E}+00$ & 0.0000 & $0.000 \mathrm{E}+00$ & 0.0000 & $2.290 \mathrm{E}-08$ & 0.0054 \\
\hline & $0.000 \mathrm{E}+00$ & 0.0000 & $0.000 \mathrm{E}+00$ & 0.0000 & $0.000 \mathrm{E}+00$ & 0.0000 & $0.000 \mathrm{E}+00$ & 0.0000 & $0.000 \mathrm{E}+00$ & 0.0000 & $0.000 \mathrm{E}+00$ & 0.0000 & $6 E-06$ & 1. \\
\hline
\end{tabular}

* Sum of all water independent and dependent pathways. 
RESRAD, Version $6.5 \quad$ T1/2 Limit $=180$ days $\quad$ 07/20/2011 $13: 54 \quad$ Page 23

Summary : RESRAD Parameters for Resident Farmer U-Landfill Forward Run 1,050 Years

File : C: $\backslash$ RESRAD_FAMILY \RESRAD \USERFILES $\backslash Q C J U L Y 2011 \backslash$ ONSITERF_FORWARD-1050-JULY11.RAD

Total Dose Contributions TDOSE (i,p,t) for Individual Radionuclides (i) and Pathways (p) As mrem/yr and Fraction of Total Dose At $t=5.000 \mathrm{E}+01$ years

Water Independent Pathways (Inhalation excludes radon)

\begin{tabular}{|c|c|c|c|c|c|c|c|c|c|c|c|c|c|c|}
\hline \multirow{2}{*}{ Nuclide } & \multicolumn{2}{|c|}{ Ground } & \multicolumn{2}{|c|}{ Inhalation } & \multicolumn{2}{|c|}{ Radon } & \multicolumn{2}{|c|}{ Plant } & \multicolumn{2}{|c|}{ Meat } & \multicolumn{2}{|c|}{ Milk } & \multicolumn{2}{|c|}{ Soil } \\
\hline & mrem/yr & fract. & mrem/yr & fract. & mrem/yr & fract. & mrem/yr & fract. & mrem/yr & fract. & mrem/yr & fract. & mrem/yr & fract. \\
\hline-241 & $8.973 E-16$ & 0.0000 & $0.000 \mathrm{E}+00$ & 0.0000 & $0.000 \mathrm{E}+00$ & 0.0000 & $0.000 \mathrm{E}+00$ & 0.0000 & $0.000 \mathrm{E}+00$ & 0.0000 & $0.000 \mathrm{E}+00$ & 0.0000 & $0.000 \mathrm{E}+00$ & 0.0000 \\
\hline-137 & $1.149 \mathrm{E}-08$ & 0.0012 & $0.000 \mathrm{E}+00$ & 0.0000 & $0.000 \mathrm{E}+00$ & 0.0000 & $0.000 \mathrm{E}+00$ & 0.0000 & $0.000 \mathrm{E}+00$ & 0.0000 & $0.000 \mathrm{E}+00$ & 0.0000 & $0.000 \mathrm{E}+00$ & 0.0000 \\
\hline-237 & $8.957 \mathrm{E}-12$ & 0.0000 & $0.000 \mathrm{E}+00$ & 0.0000 & $0.000 \mathrm{E}+00$ & 0.0000 & $0.000 \mathrm{E}+00$ & 0.0000 & $0.000 \mathrm{E}+00$ & 0.0000 & $0.000 \mathrm{E}+00$ & 0.0000 & $0.000 \mathrm{E}+00$ & 0.0000 \\
\hline-238 & $2.054 \mathrm{E}-15$ & 0.0000 & $0.000 \mathrm{E}+00$ & 0.0000 & $0.000 \mathrm{E}+00$ & 0.0000 & $0.000 \mathrm{E}+00$ & 0.0000 & $0.000 \mathrm{E}+00$ & 0.0000 & $0.000 \mathrm{E}+00$ & 0.0000 & $0.000 \mathrm{E}+00$ & 0.0000 \\
\hline-239 & $7.861 \mathrm{E}-16$ & 0.0000 & $0.000 \mathrm{E}+00$ & 0.0000 & $0.000 \mathrm{E}+00$ & 0.0000 & $0.000 \mathrm{E}+00$ & 0.0000 & $0.000 \mathrm{E}+00$ & 0.0000 & $0.000 \mathrm{E}+00$ & 0.0000 & $0.000 \mathrm{E}+00$ & 0.0000 \\
\hline-240 & $9.653 \mathrm{E}-20$ & 0.0000 & $0.000 \mathrm{E}+00$ & 0.0000 & $0.000 \mathrm{E}+00$ & 0.0000 & $0.000 \mathrm{E}+00$ & 0.0000 & $0.000 \mathrm{E}+00$ & 0.0000 & $0.000 \mathrm{E}+00$ & 0.0000 & $0.000 \mathrm{E}+00$ & 0.0000 \\
\hline 99 & $4.979 E-24$ & 0.0000 & $0.000 \mathrm{E}+00$ & 0.0000 & $0.000 \mathrm{E}+00$ & 0.0000 & $0.000 \mathrm{E}+00$ & 0.0000 & $0.000 \mathrm{E}+00$ & 0.0000 & $0.000 \mathrm{E}+00$ & 0.0000 & $0.000 \mathrm{E}+00$ & 0.0000 \\
\hline-228 & 1.011E-13 & 0.0000 & $0.000 \mathrm{E}+00$ & 0.0000 & $0.000 \mathrm{E}+00$ & 0.0000 & $0.000 \mathrm{E}+00$ & 0.0000 & $0.000 \mathrm{E}+00$ & 0.0000 & $0.000 \mathrm{E}+00$ & 0.0000 & $0.000 \mathrm{E}+00$ & 0.0000 \\
\hline 230 & $5.320 \mathrm{E}-07$ & 0.0558 & $0.000 \mathrm{E}+00$ & 0.0000 & $0.000 \mathrm{E}+00$ & 0.0000 & $0.000 \mathrm{E}+00$ & 0.0000 & $0.000 \mathrm{E}+00$ & 0.0000 & $0.000 \mathrm{E}+00$ & 0.0000 & $0.000 \mathrm{E}+00$ & 0.0000 \\
\hline-232 & $8.963 E-06$ & 0.9395 & $0.000 \mathrm{E}+00$ & 0.0000 & $0.000 \mathrm{E}+00$ & 0.0000 & $0.000 \mathrm{E}+00$ & 0.0000 & $0.000 \mathrm{E}+00$ & 0.0000 & $0.000 \mathrm{E}+00$ & 0.0000 & $0.000 \mathrm{E}+00$ & 0.0000 \\
\hline 234 & 1. $941 \mathrm{E}-10$ & 0.0000 & $0.000 \mathrm{E}+00$ & 0.0000 & $0.000 \mathrm{E}+00$ & 0.0000 & $0.000 \mathrm{E}+00$ & 0.0000 & $0.000 \mathrm{E}+00$ & 0.0000 & $0.000 \mathrm{E}+00$ & 0.0000 & $0.000 \mathrm{E}+00$ & 0.0000 \\
\hline 35 & $6.005 E-13$ & 0.0000 & $0.000 \mathrm{E}+00$ & 0.0000 & $0.000 \mathrm{E}+00$ & 0.0000 & $0.000 \mathrm{E}+00$ & 0.0000 & $0.000 \mathrm{E}+00$ & 0.0000 & $0.000 \mathrm{E}+00$ & 0.0000 & $0.000 \mathrm{E}+00$ & 0.0000 \\
\hline 38 & $3.385 E-08$ & 0.0035 & $0.000 \mathrm{E}+00$ & 0.0000 & $0.000 \mathrm{E}+00$ & 0.0000 & $0.000 \mathrm{E}+00$ & 0.0000 & $0.000 \mathrm{E}+00$ & 0.0000 & $0.000 \mathrm{E}+00$ & 0.0000 & $0.000 \mathrm{E}+00$ & 0.0000 \\
\hline & $9.541 \mathrm{E}-06$ & 1.0000 & $0.000 \mathrm{E}+00$ & 0.0000 & $0.000 \mathrm{E}+00$ & 0.0000 & $0.000 \mathrm{E}+00$ & 0.0000 & $0.000 \mathrm{E}+00$ & 0.0000 & $0.000 \mathrm{E}+00$ & 0.0000 & $.000 \mathrm{E}+00$ & 0.0000 \\
\hline
\end{tabular}

Total Dose Contributions TDOSE(i,p,t) for Individual Radionuclides (i) and Pathways (p) As mrem/yr and Fraction of Total Dose At $t=5.000 \mathrm{E}+01$ years

Water Dependent Pathways

\begin{tabular}{|c|c|c|c|c|c|c|c|c|c|c|c|c|c|c|}
\hline \multirow{2}{*}{ Nuclide } & \multicolumn{2}{|c|}{ Water } & \multicolumn{2}{|c|}{ Fish } & \multicolumn{2}{|c|}{ Radon } & \multicolumn{2}{|c|}{ Plant } & \multicolumn{2}{|c|}{ Meat } & \multicolumn{2}{|c|}{ Milk } & \multicolumn{2}{|c|}{ All Pathways* } \\
\hline & mrem/yr & fract. & mrem/yr & fract. & mrem/yr & fract. & mrem/yr & fract. & mrem/yr & fract. & mrem/yr & fract. & mrem/yr & fract. \\
\hline-241 & $0.000 \mathrm{E}+00$ & 0.0000 & $0.000 \mathrm{E}+00$ & 0.0000 & $0.000 \mathrm{E}+00$ & 0.0000 & $0.000 \mathrm{E}+00$ & 0.0000 & $0.000 \mathrm{E}+00$ & 0.0000 & $0.000 \mathrm{E}+00$ & 0.0000 & $8.973 E-16$ & 0.0000 \\
\hline-137 & $0.000 \mathrm{E}+00$ & 0.0000 & $0.000 \mathrm{E}+00$ & 0.0000 & $0.000 \mathrm{E}+00$ & 0.0000 & $0.000 \mathrm{E}+00$ & 0.0000 & $0.000 \mathrm{E}+00$ & 0.0000 & $0.000 \mathrm{E}+00$ & 0.0000 & $1.149 \mathrm{E}-08$ & 0.0012 \\
\hline-237 & $0.000 \mathrm{E}+00$ & 0.0000 & $0.000 \mathrm{E}+00$ & 0.0000 & $0.000 \mathrm{E}+00$ & 0.0000 & $0.000 \mathrm{E}+00$ & 0.0000 & $0.000 \mathrm{E}+00$ & 0.0000 & $0.000 \mathrm{E}+00$ & 0.0000 & $8.957 \mathrm{E}-12$ & 0.0000 \\
\hline-238 & $0.000 \mathrm{E}+00$ & 0.0000 & $0.000 \mathrm{E}+00$ & 0.0000 & $0.000 \mathrm{E}+00$ & 0.0000 & $0.000 \mathrm{E}+00$ & 0.0000 & $0.000 \mathrm{E}+00$ & 0.0000 & $0.000 \mathrm{E}+00$ & 0.0000 & $2.054 \mathrm{E}-15$ & 0.0000 \\
\hline 239 & $0.000 \mathrm{E}+00$ & 0.0000 & $0.000 \mathrm{E}+00$ & 0.0000 & $0.000 \mathrm{E}+00$ & 0.0000 & $0.000 \mathrm{E}+00$ & 0.0000 & $0.000 \mathrm{E}+00$ & 0.0000 & $0.000 \mathrm{E}+00$ & 0.0000 & $7.861 \mathrm{E}-16$ & 0.0000 \\
\hline-240 & $0.000 \mathrm{E}+00$ & 0.0000 & $0.000 \mathrm{E}+00$ & 0.0000 & $0.000 \mathrm{E}+00$ & 0.0000 & $0.000 \mathrm{E}+00$ & 0.0000 & $0.000 \mathrm{E}+00$ & 0.0000 & $0.000 \mathrm{E}+00$ & 0.0000 & $9.653 \mathrm{E}-20$ & 0.0000 \\
\hline 99 & $0.000 \mathrm{E}+00$ & 0.0000 & $0.000 \mathrm{E}+00$ & 0.0000 & $0.000 \mathrm{E}+00$ & 0.0000 & $0.000 \mathrm{E}+00$ & 0.0000 & $0.000 \mathrm{E}+00$ & 0.0000 & $0.000 \mathrm{E}+00$ & 0.0000 & $4.979 E-24$ & 0.0000 \\
\hline-228 & $0.000 \mathrm{E}+00$ & 0.0000 & $0.000 \mathrm{E}+00$ & 0.0000 & $0.000 \mathrm{E}+00$ & 0.0000 & $0.000 \mathrm{E}+00$ & 0.0000 & $0.000 \mathrm{E}+00$ & 0.0000 & $0.000 \mathrm{E}+00$ & 0.0000 & $1.011 \mathrm{E}-13$ & 0.0000 \\
\hline-230 & $0.000 \mathrm{E}+00$ & 0.0000 & $0.000 \mathrm{E}+00$ & 0.0000 & $0.000 \mathrm{E}+00$ & 0.0000 & $0.000 \mathrm{E}+00$ & 0.0000 & $0.000 \mathrm{E}+00$ & 0.0000 & $0.000 \mathrm{E}+00$ & 0.0000 & $5.320 \mathrm{E}-07$ & 0.0558 \\
\hline-232 & $0.000 \mathrm{E}+00$ & 0.0000 & $0.000 \mathrm{E}+00$ & 0.0000 & $0.000 \mathrm{E}+00$ & 0.0000 & $0.000 \mathrm{E}+00$ & 0.0000 & $0.000 \mathrm{E}+00$ & 0.0000 & $0.000 \mathrm{E}+00$ & 0.0000 & $8.963 E-06$ & 0.9395 \\
\hline 234 & $0.000 \mathrm{E}+00$ & 0.0000 & $0.000 \mathrm{E}+00$ & 0.0000 & $0.000 \mathrm{E}+00$ & 0.0000 & $0.000 \mathrm{E}+00$ & 0.0000 & $0.000 \mathrm{E}+00$ & 0.0000 & $0.000 \mathrm{E}+00$ & 0.0000 & $1.941 \mathrm{E}-10$ & 0.0000 \\
\hline 35 & $0.000 \mathrm{E}+00$ & 0.0000 & $0.000 \mathrm{E}+00$ & 0.0000 & $0.000 \mathrm{E}+00$ & 0.0000 & $0.000 \mathrm{E}+00$ & 0.0000 & $0.000 \mathrm{E}+00$ & 0.0000 & $0.000 \mathrm{E}+00$ & 0.0000 & $6.005 E-13$ & 0.0000 \\
\hline 38 & $0.000 \mathrm{E}+00$ & 0.0000 & $0.000 \mathrm{E}+00$ & 0.0000 & $0.000 \mathrm{E}+00$ & 0.0000 & $0.000 \mathrm{E}+00$ & 0.0000 & $0.000 \mathrm{E}+00$ & 0.0000 & $0.000 \mathrm{E}+00$ & 0.0000 & $3.385 \mathrm{E}-08$ & 0.0035 \\
\hline & $0.000 \mathrm{E}+00$ & 0.0000 & $0.000 \mathrm{E}+00$ & 0.0000 & $0.000 \mathrm{E}+00$ & 0.0000 & $0.000 \mathrm{E}+00$ & 0.0000 & $0.000 \mathrm{E}+00$ & 0.0000 & $0.000 \mathrm{E}+00$ & 0.0000 & $9.541 \mathrm{E}-06$ & 1.0000 \\
\hline
\end{tabular}

* Sum of all water independent and dependent pathways. 
RESRAD, Version $6.5 \quad$ T1/2 Limit $=180$ days $\quad$ 07/20/2011 13:54 Page 24

Summary : RESRAD Parameters for Resident Farmer U-Landfill Forward Run 1,050 Years

File : C: $\backslash$ RESRAD_FAMILY \RESRAD \USERFILES $\backslash Q C J U L Y 2011 \backslash$ ONSITERF_FORWARD-1050-JULY11.RAD

Total Dose Contributions TDOSE (i,p,t) for Individual Radionuclides (i) and Pathways (p) As mrem/yr and Fraction of Total Dose At $t=1.000 \mathrm{E}+02$ years

Water Independent Pathways (Inhalation excludes radon)

\begin{tabular}{|c|c|c|c|c|c|c|c|c|c|c|c|c|c|c|}
\hline & \multicolumn{2}{|c|}{ Ground } & \multicolumn{2}{|c|}{ Inhalation } & \multicolumn{2}{|c|}{ Radon } & \multicolumn{2}{|c|}{ Plant } & \multicolumn{2}{|c|}{ Meat } & \multicolumn{2}{|c|}{ Milk } & \multicolumn{2}{|c|}{ Soil } \\
\hline clide & mrem/yr & fract. & mrem/yr & fract. & mrem/yr & fract. & mrem/yr & fract. & mrem/yr & fract. & mrem/yr & fract. & mrem/yr & fract. \\
\hline 241 & $2.940 E-15$ & 0.0000 & $0.000 \mathrm{E}+00$ & 0.0000 & $0.000 \mathrm{E}+00$ & 0.0000 & $0.000 \mathrm{E}+00$ & 0.0000 & $0.000 \mathrm{E}+00$ & 0.0000 & $0.000 \mathrm{E}+00$ & 0.0000 & $0.000 \mathrm{E}+00$ & 0.0000 \\
\hline-137 & $5.512 \mathrm{E}-09$ & 0.0004 & $0.000 \mathrm{E}+00$ & 0.0000 & $0.000 \mathrm{E}+00$ & 0.0000 & $0.000 \mathrm{E}+00$ & 0.0000 & $0.000 \mathrm{E}+00$ & 0.0000 & $0.000 \mathrm{E}+00$ & 0.0000 & $0.000 \mathrm{E}+00$ & 0.0000 \\
\hline-237 & $1.534 \mathrm{E}-11$ & 0.0000 & $0.000 \mathrm{E}+00$ & 0.0000 & $0.000 \mathrm{E}+00$ & 0.0000 & $0.000 \mathrm{E}+00$ & 0.0000 & $0.000 \mathrm{E}+00$ & 0.0000 & $0.000 \mathrm{E}+00$ & 0.0000 & $0.000 \mathrm{E}+00$ & 0.0000 \\
\hline-238 & $2.076 \mathrm{E}-14$ & 0.0000 & $0.000 \mathrm{E}+00$ & 0.0000 & $0.000 \mathrm{E}+00$ & 0.0000 & $0.000 \mathrm{E}+00$ & 0.0000 & $0.000 \mathrm{E}+00$ & 0.0000 & $0.000 \mathrm{E}+00$ & 0.0000 & $0.000 \mathrm{E}+00$ & 0.0000 \\
\hline-239 & $1.428 \mathrm{E}-15$ & 0.0000 & $0.000 \mathrm{E}+00$ & 0.0000 & $0.000 \mathrm{E}+00$ & 0.0000 & $0.000 \mathrm{E}+00$ & 0.0000 & $0.000 \mathrm{E}+00$ & 0.0000 & $0.000 \mathrm{E}+00$ & 0.0000 & $0.000 \mathrm{E}+00$ & 0.0000 \\
\hline-240 & $6.420 E-19$ & 0.0000 & $0.000 \mathrm{E}+00$ & 0.0000 & $0.000 \mathrm{E}+00$ & 0.0000 & $0.000 \mathrm{E}+00$ & 0.0000 & $0.000 \mathrm{E}+00$ & 0.0000 & $0.000 \mathrm{E}+00$ & 0.0000 & $0.000 \mathrm{E}+00$ & 0.0000 \\
\hline-99 & $8.280 E-24$ & 0.0000 & $0.000 \mathrm{E}+00$ & 0.0000 & $0.000 \mathrm{E}+00$ & 0.0000 & $0.000 \mathrm{E}+00$ & 0.0000 & $0.000 \mathrm{E}+00$ & 0.0000 & $0.000 \mathrm{E}+00$ & 0.0000 & $0.000 \mathrm{E}+00$ & 0.0000 \\
\hline-228 & $1.847 \mathrm{E}-21$ & 0.0000 & $0.000 \mathrm{E}+00$ & 0.0000 & $0.000 \mathrm{E}+00$ & 0.0000 & $0.000 \mathrm{E}+00$ & 0.0000 & $0.000 \mathrm{E}+00$ & 0.0000 & $0.000 \mathrm{E}+00$ & 0.0000 & $0.000 \mathrm{E}+00$ & 0.0000 \\
\hline-230 & $1.479 \mathrm{E}-06$ & 0.1082 & $0.000 \mathrm{E}+00$ & 0.0000 & $0.000 \mathrm{E}+00$ & 0.0000 & $0.000 \mathrm{E}+00$ & 0.0000 & $0.000 \mathrm{E}+00$ & 0.0000 & $0.000 \mathrm{E}+00$ & 0.0000 & $0.000 \mathrm{E}+00$ & 0.0000 \\
\hline-232 & $1.213 E-05$ & 0.8876 & $0.000 \mathrm{E}+00$ & 0.0000 & $0.000 \mathrm{E}+00$ & 0.0000 & $0.000 \mathrm{E}+00$ & 0.0000 & $0.000 \mathrm{E}+00$ & 0.0000 & $0.000 \mathrm{E}+00$ & 0.0000 & $0.000 \mathrm{E}+00$ & 0.0000 \\
\hline 234 & $1.078 \mathrm{E}-09$ & 0.0001 & $0.000 \mathrm{E}+00$ & 0.0000 & $0.000 \mathrm{E}+00$ & 0.0000 & $0.000 \mathrm{E}+00$ & 0.0000 & $0.000 \mathrm{E}+00$ & 0.0000 & $0.000 \mathrm{E}+00$ & 0.0000 & $0.000 \mathrm{E}+00$ & 0.0000 \\
\hline 35 & 2. $202 \mathrm{E}-12$ & 0.0000 & $0.000 \mathrm{E}+00$ & 0.0000 & $0.000 \mathrm{E}+00$ & 0.0000 & $0.000 \mathrm{E}+00$ & 0.0000 & $0.000 \mathrm{E}+00$ & 0.0000 & $0.000 \mathrm{E}+00$ & 0.0000 & $0.000 \mathrm{E}+00$ & 0.0000 \\
\hline 38 & $5.045 E-08$ & 0.0037 & $0.000 \mathrm{E}+00$ & 0.0000 & $0.000 \mathrm{E}+00$ & 0.0000 & $0.000 \mathrm{E}+00$ & 0.0000 & $0.000 \mathrm{E}+00$ & 0.0000 & $0.000 \mathrm{E}+00$ & 0.0000 & $0.000 \mathrm{E}+00$ & 0.0000 \\
\hline & $1.367 \mathrm{E}-05$ & 1.0000 & $0.000 \mathrm{E}+00$ & 0.0000 & $0.000 \mathrm{E}+00$ & 0.0000 & $0.000 \mathrm{E}+00$ & 0.0000 & $0.000 \mathrm{E}+00$ & 0.0000 & $0.000 \mathrm{E}+00$ & 0.0000 & $0.000 \mathrm{E}+00$ & 0.0000 \\
\hline
\end{tabular}

Total Dose Contributions TDOSE(i,p,t) for Individual Radionuclides (i) and Pathways (p) As mrem/yr and Fraction of Total Dose At $t=1.000 \mathrm{E}+02$ years

Water Dependent Pathways

\begin{tabular}{|c|c|c|c|c|c|c|c|c|c|c|c|c|c|c|}
\hline \multirow{2}{*}{$\begin{array}{l}\text { Radio- } \\
\text { Nuclide }\end{array}$} & \multicolumn{2}{|c|}{ Water } & \multicolumn{2}{|c|}{ Fish } & \multicolumn{2}{|c|}{ Radon } & \multicolumn{2}{|c|}{ Plant } & \multicolumn{2}{|c|}{ Meat } & \multicolumn{2}{|c|}{ Milk } & \multicolumn{2}{|c|}{ All Pathways* } \\
\hline & mrem/yr & fract. & mrem/yr & fract. & mrem/yr & fract. & mrem/yr & fract. & mrem/yr & fract. & mrem/yr & fract. & mrem/yr & fract. \\
\hline 241 & $0.000 \mathrm{E}+00$ & 0.0000 & $0.000 \mathrm{E}+00$ & 0.0000 & $0.000 \mathrm{E}+00$ & 0.0000 & $0.000 \mathrm{E}+00$ & 0.0000 & $0.000 \mathrm{E}+00$ & 0.0000 & $0.000 \mathrm{E}+00$ & 0.0000 & $2.940 \mathrm{E}-15$ & 0.0000 \\
\hline-137 & $0.000 \mathrm{E}+00$ & 0.0000 & $0.000 \mathrm{E}+00$ & 0.0000 & $0.000 \mathrm{E}+00$ & 0.0000 & $0.000 \mathrm{E}+00$ & 0.0000 & $0.000 \mathrm{E}+00$ & 0.0000 & $0.000 \mathrm{E}+00$ & 0.0000 & $5.512 \mathrm{E}-09$ & 0.0004 \\
\hline-237 & $0.000 \mathrm{E}+00$ & 0.0000 & $0.000 \mathrm{E}+00$ & 0.0000 & $0.000 \mathrm{E}+00$ & 0.0000 & $0.000 \mathrm{E}+00$ & 0.0000 & $0.000 \mathrm{E}+00$ & 0.0000 & $0.000 \mathrm{E}+00$ & 0.0000 & $1.534 \mathrm{E}-11$ & 0.0000 \\
\hline-238 & $0.000 \mathrm{E}+00$ & 0.0000 & $0.000 \mathrm{E}+00$ & 0.0000 & $0.000 \mathrm{E}+00$ & 0.0000 & $0.000 \mathrm{E}+00$ & 0.0000 & $0.000 \mathrm{E}+00$ & 0.0000 & $0.000 \mathrm{E}+00$ & 0.0000 & $2.076 \mathrm{E}-14$ & 0.0000 \\
\hline-239 & $0.000 \mathrm{E}+00$ & 0.0000 & $0.000 \mathrm{E}+00$ & 0.0000 & $0.000 \mathrm{E}+00$ & 0.0000 & $0.000 \mathrm{E}+00$ & 0.0000 & $0.000 \mathrm{E}+00$ & 0.0000 & $0.000 E+00$ & 0.0000 & 1. $428 \mathrm{E}-15$ & 0.0000 \\
\hline-240 & $0.000 \mathrm{E}+00$ & 0.0000 & $0.000 \mathrm{E}+00$ & 0.0000 & $0.000 \mathrm{E}+00$ & 0.0000 & $0.000 \mathrm{E}+00$ & 0.0000 & $0.000 \mathrm{E}+00$ & 0.0000 & $0.000 E+00$ & 0.0000 & $6.420 \mathrm{E}-19$ & 0.0000 \\
\hline-99 & $0.000 \mathrm{E}+00$ & 0.0000 & $0.000 \mathrm{E}+00$ & 0.0000 & $0.000 \mathrm{E}+00$ & 0.0000 & $0.000 \mathrm{E}+00$ & 0.0000 & $0.000 \mathrm{E}+00$ & 0.0000 & $0.000 \mathrm{E}+00$ & 0.0000 & $8.280 \mathrm{E}-24$ & 0.0000 \\
\hline-228 & $0.000 \mathrm{E}+00$ & 0.0000 & $0.000 \mathrm{E}+00$ & 0.0000 & $0.000 \mathrm{E}+00$ & 0.0000 & $0.000 \mathrm{E}+00$ & 0.0000 & $0.000 \mathrm{E}+00$ & 0.0000 & $0.000 \mathrm{E}+00$ & 0.0000 & $1.847 \mathrm{E}-21$ & 0.0000 \\
\hline-230 & $0.000 \mathrm{E}+00$ & 0.0000 & $0.000 \mathrm{E}+00$ & 0.0000 & $0.000 \mathrm{E}+00$ & 0.0000 & $0.000 \mathrm{E}+00$ & 0.0000 & $0.000 \mathrm{E}+00$ & 0.0000 & $0.000 E+00$ & 0.0000 & $1.479 \mathrm{E}-06$ & 0.1082 \\
\hline 232 & $0.000 \mathrm{E}+00$ & 0.0000 & $0.000 \mathrm{E}+00$ & 0.0000 & $0.000 \mathrm{E}+00$ & 0.0000 & $0.000 \mathrm{E}+00$ & 0.0000 & $0.000 \mathrm{E}+00$ & 0.0000 & $0.000 \mathrm{E}+00$ & 0.0000 & $1.213 E-05$ & 0.8876 \\
\hline 34 & $0.000 \mathrm{E}+00$ & 0.0000 & $0.000 \mathrm{E}+00$ & 0.0000 & $0.000 \mathrm{E}+00$ & 0.0000 & $0.000 \mathrm{E}+00$ & 0.0000 & $0.000 \mathrm{E}+00$ & 0.0000 & $0.000 \mathrm{E}+00$ & 0.0000 & $1.078 \mathrm{E}-09$ & 0.0001 \\
\hline 35 & $0.000 \mathrm{E}+00$ & 0.0000 & $0.000 \mathrm{E}+00$ & 0.0000 & $0.000 \mathrm{E}+00$ & 0.0000 & $0.000 \mathrm{E}+00$ & 0.0000 & $0.000 \mathrm{E}+00$ & 0.0000 & $0.000 \mathrm{E}+00$ & 0.0000 & 2. $202 \mathrm{E}-12$ & 0.0000 \\
\hline 38 & $0.000 \mathrm{E}+00$ & 0.0000 & $0.000 \mathrm{E}+00$ & 0.0000 & $0.000 \mathrm{E}+00$ & 0.0000 & $0.000 \mathrm{E}+00$ & 0.0000 & $0.000 \mathrm{E}+00$ & 0.0000 & $0.000 \mathrm{E}+00$ & 0.0000 & $5.045 E-08$ & 0.0037 \\
\hline & $0.000 \mathrm{E}+00$ & 0.0000 & $0.000 \mathrm{E}+00$ & 0.0000 & $0.000 \mathrm{E}+00$ & 0.0000 & $0.000 \mathrm{E}+00$ & 0.0000 & $0.000 \mathrm{E}+00$ & 0.0000 & $0.000 \mathrm{E}+00$ & 0.0000 & $7 E-05$ & 1.0000 \\
\hline
\end{tabular}

* Sum of all water independent and dependent pathways. 
RESRAD, Version $6.5 \quad$ T1/2 Limit $=180$ days $\quad$ 07/20/2011 $13: 54 \quad$ Page 25

Summary : RESRAD Parameters for Resident Farmer U-Landfill Forward Run 1,050 Years

File : C: $\backslash$ RESRAD_FAMILY \RESRAD \USERFILES $\backslash Q C J U L Y 2011 \backslash$ ONSITERF_FORWARD-1050-JULY11.RAD

Total Dose Contributions TDOSE (i,p,t) for Individual Radionuclides (i) and Pathways (p) As mrem/yr and Fraction of Total Dose At $t=5.000 \mathrm{E}+02$ years

Water Independent Pathways (Inhalation excludes radon)

\begin{tabular}{|c|c|c|c|c|c|c|c|c|c|c|c|c|c|c|}
\hline & \multicolumn{2}{|c|}{ Ground } & \multicolumn{2}{|c|}{ Inhalation } & \multicolumn{2}{|c|}{ Radon } & \multicolumn{2}{|c|}{ Plant } & \multicolumn{2}{|c|}{ Meat } & \multicolumn{2}{|c|}{ Milk } & \multicolumn{2}{|c|}{ Soil } \\
\hline clide & mrem/yr & fract. & mrem/yr & fract. & mrem/yr & fract. & mrem/yr & fract. & mrem/yr & fract. & mrem/yr & fract. & mrem/yr & fract. \\
\hline 241 & $8.032 E-13$ & 0.0000 & $0.000 \mathrm{E}+00$ & 0.0000 & $0.000 \mathrm{E}+00$ & 0.0000 & $0.000 \mathrm{E}+00$ & 0.0000 & $0.000 \mathrm{E}+00$ & 0.0000 & $0.000 \mathrm{E}+00$ & 0.0000 & $0.000 \mathrm{E}+00$ & 0.0000 \\
\hline-137 & $1.540 \mathrm{E}-11$ & 0.0000 & $0.000 \mathrm{E}+00$ & 0.0000 & $0.000 \mathrm{E}+00$ & 0.0000 & $0.000 \mathrm{E}+00$ & 0.0000 & $0.000 \mathrm{E}+00$ & 0.0000 & $0.000 \mathrm{E}+00$ & 0.0000 & $0.000 \mathrm{E}+00$ & 0.0000 \\
\hline-237 & $1.124 \mathrm{E}-09$ & 0.0000 & $0.000 \mathrm{E}+00$ & 0.0000 & $0.000 \mathrm{E}+00$ & 0.0000 & $0.000 \mathrm{E}+00$ & 0.0000 & $0.000 \mathrm{E}+00$ & 0.0000 & $0.000 \mathrm{E}+00$ & 0.0000 & $0.000 \mathrm{E}+00$ & 0.0000 \\
\hline-238 & $2.187 \mathrm{E}-11$ & 0.0000 & $0.000 \mathrm{E}+00$ & 0.0000 & $0.000 \mathrm{E}+00$ & 0.0000 & $0.000 \mathrm{E}+00$ & 0.0000 & $0.000 \mathrm{E}+00$ & 0.0000 & $0.000 \mathrm{E}+00$ & 0.0000 & $0.000 \mathrm{E}+00$ & 0.0000 \\
\hline-239 & $1.695 \mathrm{E}-13$ & 0.0000 & $0.000 \mathrm{E}+00$ & 0.0000 & $0.000 \mathrm{E}+00$ & 0.0000 & $0.000 \mathrm{E}+00$ & 0.0000 & $0.000 \mathrm{E}+00$ & 0.0000 & $0.000 \mathrm{E}+00$ & 0.0000 & $0.000 \mathrm{E}+00$ & 0.0000 \\
\hline-240 & $2.059 E-16$ & 0.0000 & $0.000 \mathrm{E}+00$ & 0.0000 & $0.000 \mathrm{E}+00$ & 0.0000 & $0.000 \mathrm{E}+00$ & 0.0000 & $0.000 \mathrm{E}+00$ & 0.0000 & $0.000 \mathrm{E}+00$ & 0.0000 & $0.000 \mathrm{E}+00$ & 0.0000 \\
\hline-99 & $4.841 E-22$ & 0.0000 & $0.000 \mathrm{E}+00$ & 0.0000 & $0.000 \mathrm{E}+00$ & 0.0000 & $0.000 \mathrm{E}+00$ & 0.0000 & $0.000 \mathrm{E}+00$ & 0.0000 & $0.000 \mathrm{E}+00$ & 0.0000 & $0.000 \mathrm{E}+00$ & 0.0000 \\
\hline-228 & $0.000 \mathrm{E}+00$ & 0.0000 & $0.000 \mathrm{E}+00$ & 0.0000 & $0.000 \mathrm{E}+00$ & 0.0000 & $0.000 \mathrm{E}+00$ & 0.0000 & $0.000 \mathrm{E}+00$ & 0.0000 & $0.000 \mathrm{E}+00$ & 0.0000 & $0.000 \mathrm{E}+00$ & 0.0000 \\
\hline-230 & $1.071 \mathrm{E}-04$ & 0.0000 & $0.000 \mathrm{E}+00$ & 0.0000 & $0.000 \mathrm{E}+00$ & 0.0000 & $0.000 \mathrm{E}+00$ & 0.0000 & $0.000 \mathrm{E}+00$ & 0.0000 & $0.000 \mathrm{E}+00$ & 0.0000 & $0.000 \mathrm{E}+00$ & 0.0000 \\
\hline-232 & $1.335 E-04$ & 0.0000 & $0.000 \mathrm{E}+00$ & 0.0000 & $0.000 \mathrm{E}+00$ & 0.0000 & $0.000 \mathrm{E}+00$ & 0.0000 & $0.000 \mathrm{E}+00$ & 0.0000 & $0.000 \mathrm{E}+00$ & 0.0000 & $0.000 \mathrm{E}+00$ & 0.0000 \\
\hline 234 & $3.993 E-07$ & 0.0000 & $0.000 \mathrm{E}+00$ & 0.0000 & $0.000 \mathrm{E}+00$ & 0.0000 & $0.000 \mathrm{E}+00$ & 0.0000 & $0.000 \mathrm{E}+00$ & 0.0000 & $0.000 \mathrm{E}+00$ & 0.0000 & $0.000 \mathrm{E}+00$ & 0.0000 \\
\hline 235 & $4.571 \mathrm{E}-10$ & 0.0000 & $0.000 \mathrm{E}+00$ & 0.0000 & $0.000 \mathrm{E}+00$ & 0.0000 & $0.000 \mathrm{E}+00$ & 0.0000 & $0.000 \mathrm{E}+00$ & 0.0000 & $0.000 \mathrm{E}+00$ & 0.0000 & $0.000 \mathrm{E}+00$ & 0.0000 \\
\hline 38 & $1.229 \mathrm{E}-06$ & 0.0000 & $0.000 \mathrm{E}+00$ & 0.0000 & $0.000 \mathrm{E}+00$ & 0.0000 & $0.000 \mathrm{E}+00$ & 0.0000 & $0.000 \mathrm{E}+00$ & 0.0000 & $0.000 \mathrm{E}+00$ & 0.0000 & $0.000 \mathrm{E}+00$ & 0.0000 \\
\hline & $2.423 E-04$ & 0.0000 & $0.000 \mathrm{E}+00$ & 0.0000 & $0.000 \mathrm{E}+00$ & 0.0000 & $0.000 \mathrm{E}+00$ & 0.0000 & $0.000 \mathrm{E}+00$ & 0.0000 & $0.000 \mathrm{E}+00$ & 0.0000 & $0.000 \mathrm{E}+00$ & 0.0000 \\
\hline
\end{tabular}

Total Dose Contributions TDOSE(i,p,t) for Individual Radionuclides (i) and Pathways (p) As mrem/yr and Fraction of Total Dose At $t=5.000 \mathrm{E}+02$ years

Water Dependent Pathways

\begin{tabular}{|c|c|c|c|c|c|c|c|c|c|c|c|c|c|c|}
\hline & \multicolumn{2}{|c|}{ Water } & \multicolumn{2}{|c|}{ Fish } & \multicolumn{2}{|c|}{ Radon } & \multicolumn{2}{|c|}{ Plant } & \multicolumn{2}{|c|}{ Meat } & \multicolumn{2}{|c|}{ Milk } & \multicolumn{2}{|c|}{ All Pathways* } \\
\hline clide & mrem/yr & fract. & mrem/yr & fract. & mrem/yr & fract. & mrem/yr & fract. & mrem/yr & fract. & mrem/yr & fract. & mrem/yr & fract. \\
\hline-241 & $0.000 \mathrm{E}+00$ & 0.0000 & $0.000 \mathrm{E}+00$ & 0.0000 & $0.000 \mathrm{E}+00$ & 0.0000 & $0.000 \mathrm{E}+00$ & 0.0000 & $0.000 \mathrm{E}+00$ & 0.0000 & $0.000 \mathrm{E}+00$ & 0.0000 & $8.032 \mathrm{E}-13$ & 0.0000 \\
\hline-137 & $0.000 \mathrm{E}+00$ & 0.0000 & $0.000 \mathrm{E}+00$ & 0.0000 & $0.000 \mathrm{E}+00$ & 0.0000 & $0.000 \mathrm{E}+00$ & 0.0000 & $0.000 \mathrm{E}+00$ & 0.0000 & $0.000 \mathrm{E}+00$ & 0.0000 & $1.540 \mathrm{E}-11$ & 0.0000 \\
\hline-237 & $0.000 \mathrm{E}+00$ & 0.0000 & $0.000 \mathrm{E}+00$ & 0.0000 & $0.000 \mathrm{E}+00$ & 0.0000 & $0.000 \mathrm{E}+00$ & 0.0000 & $0.000 \mathrm{E}+00$ & 0.0000 & $0.000 \mathrm{E}+00$ & 0.0000 & $1.124 \mathrm{E}-09$ & 0.0000 \\
\hline 238 & $0.000 \mathrm{E}+00$ & 0.0000 & $0.000 \mathrm{E}+00$ & 0.0000 & $0.000 \mathrm{E}+00$ & 0.0000 & $0.000 \mathrm{E}+00$ & 0.0000 & $0.000 \mathrm{E}+00$ & 0.0000 & $0.000 \mathrm{E}+00$ & 0.0000 & $2.187 \mathrm{E}-11$ & 0.0000 \\
\hline 239 & $0.000 \mathrm{E}+00$ & 0.0000 & $0.000 \mathrm{E}+00$ & 0.0000 & $0.000 \mathrm{E}+00$ & 0.0000 & $0.000 \mathrm{E}+00$ & 0.0000 & $0.000 \mathrm{E}+00$ & 0.0000 & $0.000 \mathrm{E}+00$ & 0.0000 & $1.695 \mathrm{E}-13$ & 0.0000 \\
\hline 240 & $0.000 \mathrm{E}+00$ & 0.0000 & $0.000 \mathrm{E}+00$ & 0.0000 & $0.000 \mathrm{E}+00$ & 0.0000 & $0.000 \mathrm{E}+00$ & 0.0000 & $0.000 \mathrm{E}+00$ & 0.0000 & $0.000 \mathrm{E}+00$ & 0.0000 & $2.059 \mathrm{E}-16$ & 0.0000 \\
\hline 99 & $8.904 \mathrm{E}+00$ & 0.8277 & $0.000 \mathrm{E}+00$ & 0.0000 & $0.000 \mathrm{E}+00$ & 0.0000 & $8.324 \mathrm{E}-01$ & 0.0774 & $1.490 \mathrm{E}-02$ & 0.0014 & $1.006 \mathrm{E}+00$ & 0.0935 & $1.076 \mathrm{E}+01$ & 1.0000 \\
\hline 228 & $0.000 \mathrm{E}+00$ & 0.0000 & $0.000 \mathrm{E}+00$ & 0.0000 & $0.000 \mathrm{E}+00$ & 0.0000 & $0.000 \mathrm{E}+00$ & 0.0000 & $0.000 \mathrm{E}+00$ & 0.0000 & $0.000 \mathrm{E}+00$ & 0.0000 & $0.000 \mathrm{E}+00$ & 0.0000 \\
\hline 230 & $0.000 \mathrm{E}+00$ & 0.0000 & $0.000 \mathrm{E}+00$ & 0.0000 & $0.000 \mathrm{E}+00$ & 0.0000 & $0.000 \mathrm{E}+00$ & 0.0000 & $0.000 \mathrm{E}+00$ & 0.0000 & $0.000 \mathrm{E}+00$ & 0.0000 & $1.071 \mathrm{E}-04$ & 0.0000 \\
\hline 232 & $0.000 \mathrm{E}+00$ & 0.0000 & $0.000 \mathrm{E}+00$ & 0.0000 & $0.000 \mathrm{E}+00$ & 0.0000 & $0.000 \mathrm{E}+00$ & 0.0000 & $0.000 \mathrm{E}+00$ & 0.0000 & $0.000 \mathrm{E}+00$ & 0.0000 & $1.335 \mathrm{E}-04$ & 0.0000 \\
\hline & $0.000 \mathrm{E}+00$ & 0.0000 & $0.000 \mathrm{E}+00$ & 0.0000 & $0.000 \mathrm{E}+00$ & 0.0000 & $0.000 \mathrm{E}+00$ & 0.0000 & $0.000 \mathrm{E}+00$ & 0.0000 & $0.000 \mathrm{E}+00$ & 0.0000 & $3.993 E-07$ & 0.0000 \\
\hline 35 & $0.000 \mathrm{E}+00$ & 0.0000 & $0.000 \mathrm{E}+00$ & 0.0000 & $0.000 \mathrm{E}+00$ & 0.0000 & $0.000 \mathrm{E}+00$ & 0.0000 & $0.000 \mathrm{E}+00$ & 0.0000 & $0.000 \mathrm{E}+00$ & 0.0000 & $4.571 \mathrm{E}-10$ & 0.0000 \\
\hline 38 & $0.000 \mathrm{E}+00$ & 0.0000 & $0.000 \mathrm{E}+00$ & 0.0000 & $0.000 \mathrm{E}+00$ & 0.0000 & $0.000 \mathrm{E}+00$ & 0.0000 & $0.000 \mathrm{E}+00$ & 0.0000 & $0.000 \mathrm{E}+00$ & 0.0000 & $1.229 \mathrm{E}-06$ & 0.0000 \\
\hline & $8.904 E+00$ & 0.8277 & $0.000 \mathrm{E}+00$ & 0.0000 & $0.000 \mathrm{E}+00$ & 0.0000 & $8.324 \mathrm{E}-01$ & 0.0774 & $1.490 \mathrm{E}-02$ & 0.0014 & $1.006 \mathrm{E}+00$ & 935 & +01 & 1.0000 \\
\hline
\end{tabular}

* Sum of all water independent and dependent pathways. 
RESRAD, Version $6.5 \quad$ T1/2 Limit $=180$ days $\quad$ 07/20/2011 $13: 54 \quad$ Page 26

Summary : RESRAD Parameters for Resident Farmer U-Landfill Forward Run 1,050 Years

File : C: $\backslash$ RESRAD_FAMILY \RESRAD \USERFILES $\backslash Q C J U L Y 2011 \backslash$ ONSITERF_FORWARD-1050-JULY11.RAD

Total Dose Contributions TDOSE (i,p,t) for Individual Radionuclides (i) and Pathways (p) As mrem/yr and Fraction of Total Dose At $t=1.050 \mathrm{E}+03$ years

Water Independent Pathways (Inhalation excludes radon)

\begin{tabular}{|c|c|c|c|c|c|c|c|c|c|c|c|c|c|c|}
\hline \multirow{2}{*}{ Nuclide } & \multicolumn{2}{|c|}{ Ground } & \multicolumn{2}{|c|}{ Inhalation } & \multicolumn{2}{|c|}{ Radon } & \multicolumn{2}{|c|}{ Plant } & \multicolumn{2}{|c|}{ Meat } & \multicolumn{2}{|c|}{ Milk } & \multicolumn{2}{|c|}{ Soil } \\
\hline & mrem/yr & fract. & mrem/yr & fract. & mrem/yr & fract. & mrem/yr & fract. & mrem/yr & fract. & mrem/yr & fract. & mrem/yr & fract. \\
\hline-241 & $4.257 \mathrm{E}-10$ & 0.0000 & $0.000 \mathrm{E}+00$ & 0.0000 & $0.000 \mathrm{E}+00$ & 0.0000 & $6.939 E-03$ & 0.0009 & $1.230 \mathrm{E}-05$ & 0.0000 & $1.180 \mathrm{E}-06$ & 0.0000 & $0.000 \mathrm{E}+00$ & 0.0000 \\
\hline-137 & $4.741 E-15$ & 0.0000 & $0.000 \mathrm{E}+00$ & 0.0000 & $0.000 \mathrm{E}+00$ & 0.0000 & $1.461 \mathrm{E}-12$ & 0.0000 & $1.328 \mathrm{E}-12$ & 0.0000 & $9.802 \mathrm{E}-13$ & 0.0000 & $0.000 \mathrm{E}+00$ & 0.0000 \\
\hline-237 & $3.910 \mathrm{E}-07$ & 0.0000 & $0.000 \mathrm{E}+00$ & 0.0000 & $0.000 \mathrm{E}+00$ & 0.0000 & $5.637 \mathrm{E}-02$ & 0.0076 & $1.708 \mathrm{E}-03$ & 0.0002 & $2.443 E-05$ & 0.0000 & $0.000 \mathrm{E}+00$ & 0.0000 \\
\hline-238 & $5.077 \mathrm{E}-09$ & 0.0000 & $0.000 \mathrm{E}+00$ & 0.0000 & $0.000 \mathrm{E}+00$ & 0.0000 & $2.383 E-05$ & 0.0000 & $2.117 \mathrm{E}-07$ & 0.0000 & $5.995 \mathrm{E}-07$ & 0.0000 & $0.000 \mathrm{E}+00$ & 0.0000 \\
\hline-239 & $1.202 \mathrm{E}-10$ & 0.0000 & $0.000 \mathrm{E}+00$ & 0.0000 & $0.000 \mathrm{E}+00$ & 0.0000 & $4.566 \mathrm{E}-02$ & 0.0062 & $1.384 \mathrm{E}-04$ & 0.0000 & $3.831 E-06$ & 0.0000 & $0.000 \mathrm{E}+00$ & 0.0000 \\
\hline-240 & $2.914 \mathrm{E}-14$ & 0.0000 & $0.000 \mathrm{E}+00$ & 0.0000 & $0.000 \mathrm{E}+00$ & 0.0000 & $4.210 \mathrm{E}-02$ & 0.0057 & $1.276 \mathrm{E}-04$ & 0.0000 & $3.564 \mathrm{E}-06$ & 0.0000 & $0.000 \mathrm{E}+00$ & 0.0000 \\
\hline 99 & 1. 302E-19 & 0.0000 & $0.000 \mathrm{E}+00$ & 0.0000 & $0.000 \mathrm{E}+00$ & 0.0000 & $6.886 \mathrm{E}-05$ & 0.0000 & $2.089 \mathrm{E}-07$ & 0.0000 & $5.781 \mathrm{E}-06$ & 0.0000 & $0.000 \mathrm{E}+00$ & 0.0000 \\
\hline-228 & $0.000 \mathrm{E}+00$ & 0.0000 & $0.000 \mathrm{E}+00$ & 0.0000 & $0.000 \mathrm{E}+00$ & 0.0000 & $0.000 \mathrm{E}+00$ & 0.0000 & $0.000 \mathrm{E}+00$ & 0.0000 & $0.000 \mathrm{E}+00$ & 0.0000 & $0.000 \mathrm{E}+00$ & 0.0000 \\
\hline-230 & $8.967 \mathrm{E}-03$ & 0.0012 & $0.000 \mathrm{E}+00$ & 0.0000 & $0.000 \mathrm{E}+00$ & 0.0000 & $5.803 E+00$ & 0.7836 & $1.526 \mathrm{E}-01$ & 0.0206 & $2.702 \mathrm{E}-01$ & 0.0365 & $0.000 \mathrm{E}+00$ & 0.0000 \\
\hline-232 & $3.698 E-03$ & 0.0005 & $0.000 \mathrm{E}+00$ & 0.0000 & $0.000 \mathrm{E}+00$ & 0.0000 & $5.933 E-01$ & 0.0801 & $1.751 \mathrm{E}-02$ & 0.0024 & $4.847 \mathrm{E}-02$ & 0.0065 & $0.000 \mathrm{E}+00$ & 0.0000 \\
\hline 34 & $7.268 E-05$ & 0.0000 & $0.000 \mathrm{E}+00$ & 0.0000 & $0.000 \mathrm{E}+00$ & 0.0000 & $1.485 \mathrm{E}-01$ & 0.0200 & $2.264 \mathrm{E}-03$ & 0.0003 & $7.279 E-03$ & 0.0010 & $0.000 \mathrm{E}+00$ & 0.0000 \\
\hline 35 & $1.527 \mathrm{E}-07$ & 0.0000 & $0.000 \mathrm{E}+00$ & 0.0000 & $0.000 \mathrm{E}+00$ & 0.0000 & $1.148 \mathrm{E}-02$ & 0.0016 & $8.461 \mathrm{E}-04$ & 0.0001 & $2.071 E-04$ & 0.0000 & $0.000 \mathrm{E}+00$ & 0.0000 \\
\hline 38 & $9.919 \mathrm{E}-05$ & 0.0000 & $0.000 \mathrm{E}+00$ & 0.0000 & $0.000 \mathrm{E}+00$ & 0.0000 & $1.010 \mathrm{E}-01$ & 0.0136 & $1.041 \mathrm{E}-03$ & 0.0001 & $5.082 \mathrm{E}-03$ & 0.0007 & $0.000 \mathrm{E}+00$ & 0.0000 \\
\hline & 1. $284 \mathrm{E}-02$ & 0.0017 & $0.000 \mathrm{E}+00$ & 0.0000 & $0.000 \mathrm{E}+00$ & 0.0000 & $6.808 \mathrm{E}+00$ & 0.9194 & $1.763 \mathrm{E}-01$ & 0.0238 & $3.313 E-01$ & 0.0447 & $0.000 \mathrm{E}+00$ & 0.0000 \\
\hline
\end{tabular}

Total Dose Contributions TDOSE(i,p,t) for Individual Radionuclides (i) and Pathways (p) As mrem/yr and Fraction of Total Dose At $t=1.050 \mathrm{E}+03$ years

Water Dependent Pathways

\begin{tabular}{|c|c|c|c|c|c|c|c|c|c|c|c|c|c|c|}
\hline \multirow{2}{*}{ Nuclide } & \multicolumn{2}{|c|}{ Water } & \multicolumn{2}{|c|}{ Fish } & \multicolumn{2}{|c|}{ Radon } & \multicolumn{2}{|c|}{ Plant } & \multicolumn{2}{|c|}{ Meat } & \multicolumn{2}{|c|}{ Milk } & \multicolumn{2}{|c|}{ All Pathways* } \\
\hline & mrem/yr & fract. & mrem/yr & fract. & mrem/yr & fract. & mrem/yr & fract. & mrem/yr & fract. & mrem/yr & fract. & mrem/yr & fract. \\
\hline-241 & $0.000 \mathrm{E}+00$ & 0.0000 & $0.000 \mathrm{E}+00$ & 0.0000 & $0.000 \mathrm{E}+00$ & 0.0000 & $0.000 \mathrm{E}+00$ & 0.0000 & $0.000 \mathrm{E}+00$ & 0.0000 & $0.000 \mathrm{E}+00$ & 0.0000 & $6.953 E-03$ & 0.0009 \\
\hline-137 & $0.000 \mathrm{E}+00$ & 0.0000 & $0.000 \mathrm{E}+00$ & 0.0000 & $0.000 \mathrm{E}+00$ & 0.0000 & $0.000 \mathrm{E}+00$ & 0.0000 & $0.000 \mathrm{E}+00$ & 0.0000 & $0.000 \mathrm{E}+00$ & 0.0000 & $3.773 \mathrm{E}-12$ & 0.0000 \\
\hline-237 & $0.000 \mathrm{E}+00$ & 0.0000 & $0.000 \mathrm{E}+00$ & 0.0000 & $0.000 \mathrm{E}+00$ & 0.0000 & $0.000 \mathrm{E}+00$ & 0.0000 & $0.000 \mathrm{E}+00$ & 0.0000 & $0.000 \mathrm{E}+00$ & 0.0000 & $5.811 \mathrm{E}-02$ & 0.0078 \\
\hline-238 & $0.000 \mathrm{E}+00$ & 0.0000 & $0.000 \mathrm{E}+00$ & 0.0000 & $0.000 \mathrm{E}+00$ & 0.0000 & $0.000 \mathrm{E}+00$ & 0.0000 & $0.000 \mathrm{E}+00$ & 0.0000 & $0.000 \mathrm{E}+00$ & 0.0000 & $2.465 E-05$ & 0.0000 \\
\hline 239 & $0.000 \mathrm{E}+00$ & 0.0000 & $0.000 \mathrm{E}+00$ & 0.0000 & $0.000 \mathrm{E}+00$ & 0.0000 & $0.000 \mathrm{E}+00$ & 0.0000 & $0.000 \mathrm{E}+00$ & 0.0000 & $0.000 \mathrm{E}+00$ & 0.0000 & $4.580 \mathrm{E}-02$ & 0.0062 \\
\hline-240 & $0.000 \mathrm{E}+00$ & 0.0000 & $0.000 \mathrm{E}+00$ & 0.0000 & $0.000 \mathrm{E}+00$ & 0.0000 & $0.000 \mathrm{E}+00$ & 0.0000 & $0.000 \mathrm{E}+00$ & 0.0000 & $0.000 \mathrm{E}+00$ & 0.0000 & $4.224 \mathrm{E}-02$ & 0.0057 \\
\hline 99 & $6.331 E-02$ & 0.0086 & $0.000 \mathrm{E}+00$ & 0.0000 & $0.000 \mathrm{E}+00$ & 0.0000 & $5.919 \mathrm{E}-03$ & 0.0008 & $1.060 \mathrm{E}-04$ & 0.0000 & $7.152 \mathrm{E}-03$ & 0.0010 & $7.657 \mathrm{E}-02$ & 0.0103 \\
\hline-228 & $0.000 \mathrm{E}+00$ & 0.0000 & $0.000 \mathrm{E}+00$ & 0.0000 & $0.000 \mathrm{E}+00$ & 0.0000 & $0.000 \mathrm{E}+00$ & 0.0000 & $0.000 \mathrm{E}+00$ & 0.0000 & $0.000 \mathrm{E}+00$ & 0.0000 & $0.000 \mathrm{E}+00$ & 0.0000 \\
\hline-230 & $0.000 \mathrm{E}+00$ & 0.0000 & $0.000 \mathrm{E}+00$ & 0.0000 & $0.000 \mathrm{E}+00$ & 0.0000 & $0.000 \mathrm{E}+00$ & 0.0000 & $0.000 \mathrm{E}+00$ & 0.0000 & $0.000 \mathrm{E}+00$ & 0.0000 & $6.234 \mathrm{E}+00$ & 0.8419 \\
\hline-232 & $0.000 \mathrm{E}+00$ & 0.0000 & $0.000 \mathrm{E}+00$ & 0.0000 & $0.000 \mathrm{E}+00$ & 0.0000 & $0.000 \mathrm{E}+00$ & 0.0000 & $0.000 \mathrm{E}+00$ & 0.0000 & $0.000 \mathrm{E}+00$ & 0.0000 & $6.630 \mathrm{E}-01$ & 0.0895 \\
\hline 234 & $0.000 \mathrm{E}+00$ & 0.0000 & $0.000 \mathrm{E}+00$ & 0.0000 & $0.000 \mathrm{E}+00$ & 0.0000 & $0.000 \mathrm{E}+00$ & 0.0000 & $0.000 \mathrm{E}+00$ & 0.0000 & $0.000 \mathrm{E}+00$ & 0.0000 & $1.581 \mathrm{E}-01$ & 0.0213 \\
\hline 35 & $0.000 \mathrm{E}+00$ & 0.0000 & $0.000 \mathrm{E}+00$ & 0.0000 & $0.000 \mathrm{E}+00$ & 0.0000 & $0.000 \mathrm{E}+00$ & 0.0000 & $0.000 \mathrm{E}+00$ & 0.0000 & $0.000 \mathrm{E}+00$ & 0.0000 & $1.253 \mathrm{E}-02$ & 0.0017 \\
\hline 38 & $0.000 \mathrm{E}+00$ & 0.0000 & $0.000 \mathrm{E}+00$ & 0.0000 & $0.000 \mathrm{E}+00$ & 0.0000 & $0.000 \mathrm{E}+00$ & 0.0000 & $0.000 \mathrm{E}+00$ & 0.0000 & $0.000 \mathrm{E}+00$ & 0.0000 & $1.072 \mathrm{E}-01$ & 0.0145 \\
\hline & $6.331 E-02$ & 0.0086 & $0.000 \mathrm{E}+00$ & 0.0000 & $0.000 \mathrm{E}+00$ & 0.0000 & $5.919 \mathrm{E}-03$ & 0.0008 & $1.060 \mathrm{E}-04$ & 0.0000 & $7.152 \mathrm{E}-03$ & 0.0010 & $05 E+00$ & 1.0000 \\
\hline
\end{tabular}

* Sum of all water independent and dependent pathways. 
RESRAD, Version 6.5

Summary : RESRAD Parameters for Resident Farmer U-Landfill Forward Run 1,050 Years

File : C: \RESRAD FAMILY \RESRAD \USERFILES QQCJULY2011 \ONSITERF FORWARD-1050-JULY11.RAD

Dose/Source Ratios Summed Over All Pathways

Parent and Progeny Principal Radionuclide Contributions Indicated

Parent Product Thread DSR $(j, t)$ At Time in Years (mrem/yr)/(pCi/g)

(i)

(j) Fraction

$0.000 \mathrm{E}+00 \quad 1.000 \mathrm{E}+00 \quad 5.000 \mathrm{E}+01 \quad 1.000 \mathrm{E}+02 \quad 5.000 \mathrm{E}+02 \quad 1.050 \mathrm{E}+03$

Am-241

$\overline{A m-241} \quad \overline{1.000 E+00}$

$\begin{array}{lllll}1.936 \mathrm{E}-33 & 1.989 \mathrm{E}-33 & 7.353 \mathrm{E}-33 & 2.792 \mathrm{E}-32 & 1.208 \mathrm{E}-27 \\ 1.968 \mathrm{E}-04\end{array}$

$\begin{array}{lllllllll}\mathrm{Np}-237+\mathrm{D} & 1.000 \mathrm{E}+00 & 1.546 \mathrm{E}-19 & 4.680 \mathrm{E}-19 & 2.562 \mathrm{E}-17 & 8.382 \mathrm{E}-17 & 2.263 \mathrm{E}-14 & 1.827 \mathrm{E}-06\end{array}$

$\begin{array}{llllllll}\mathrm{U}-233 & 1.000 \mathrm{E}+00 & 3.506 \mathrm{E}-30 & 2.479 \mathrm{E}-29 & 4.863 \mathrm{E}-26 & 3.503 \mathrm{E}-25 & 1.053 \mathrm{E}-21 & 3.236 \mathrm{E}-10\end{array}$

$\begin{array}{llllllll}\mathrm{Th}-229+\mathrm{D} & 1.000 \mathrm{E}+00 & 2.399 \mathrm{E}-26 & 3.618 \mathrm{E}-25 & 1.710 \mathrm{E}-20 & 1.868 \mathrm{E}-19 & 3.195 \mathrm{E}-16 & 5.430 \mathrm{E}-11\end{array}$

$\sum \operatorname{DSR}(j)$

$\begin{array}{lllllll}1.546 \mathrm{E}-19 & 4.680 \mathrm{E}-19 & 2.564 \mathrm{E}-17 & 8.401 \mathrm{E}-17 & 2.295 \mathrm{E}-14 & 1.987 \mathrm{E}-04\end{array}$

$\mathrm{Cs}-137+\mathrm{D} \quad 1.000 \mathrm{E}+00 \quad 1.262 \mathrm{E}-09 \quad 1.243 \mathrm{E}-09 \quad 6.050 \mathrm{E}-10 \quad 2.901 \mathrm{E}-10 \quad 8.104 \mathrm{E}-13 \quad 1.986 \mathrm{E}-13$

$\mathrm{Np}-237+\mathrm{D} \quad 1.000 \mathrm{E}+00 \quad 9.536 \mathrm{E}-13 \quad 9.638 \mathrm{E}-13 \quad 1.625 \mathrm{E}-12 \quad 2.770 \mathrm{E}-12 \quad 1.974 \mathrm{E}-10 \quad 1.056 \mathrm{E}-02$

$\begin{array}{lllllllll}\mathrm{U}-233 & 1.000 \mathrm{E}+00 & 3.245 \mathrm{E}-23 & 9.844 \mathrm{E}-23 & 6.100 \mathrm{E}-21 & 2.264 \mathrm{E}-20 & 1.650 \mathrm{E}-17 & 3.040 \mathrm{E}-06\end{array}$

$\begin{array}{llllllll}\mathrm{Th}-229+\mathrm{D} & 1.000 \mathrm{E}+00 & 2.962 \mathrm{E}-19 & 2.086 \mathrm{E}-18 & 3.196 \mathrm{E}-15 & 1.788 \mathrm{E}-14 & 7.080 \mathrm{E}-12 & 6.835 \mathrm{E}-07\end{array}$

$\sum \operatorname{DSR}(j)$

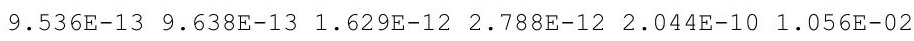

$\mathrm{Pu}-238$

$\begin{array}{lllllll}1.840 E-09 & 2.162 E-33 & 2.183 E-33 & 3.520 E-33 & 5.731 E-33 & 2.831 E-31 & 5.523 E-16\end{array}$

$\begin{array}{lllllllll}\mathrm{Pu}-238 & 1.000 \mathrm{E}+00 & 1.175 \mathrm{E}-24 & 1.186 \mathrm{E}-24 & 1.913 \mathrm{E}-24 & 3.115 \mathrm{E}-24 & 1.539 \mathrm{E}-22 & 3.001 \mathrm{E}-07\end{array}$

$\begin{array}{llllllll}\mathrm{U}-234 & 1.000 \mathrm{E}+00 & 9.778 \mathrm{E}-30 & 2.969 \mathrm{E}-29 & 1.973 \mathrm{E}-27 & 7.960 \mathrm{E}-27 & 1.690 \mathrm{E}-23 & 2.418 \mathrm{E}-07\end{array}$

$\begin{array}{llllllll}\mathrm{Th}-230 & 1.000 \mathrm{E}+00 & 1.028 \mathrm{E}-33 & 7.286 \mathrm{E}-33 & 1.599 \mathrm{E}-29 & 1.302 \mathrm{E}-28 & 1.306 \mathrm{E}-24 & 3.284 \mathrm{E}-09\end{array}$

$\mathrm{Ra}-226+\mathrm{D} \quad 1.000 \mathrm{E}+00 \quad 8.021 \mathrm{E}-23 \quad 1.208 \mathrm{E}-21 \quad 5.266 \mathrm{E}-17 \quad 5.323 \mathrm{E}-16 \quad 5.607 \mathrm{E}-13 \quad 3.487 \mathrm{E}-08$

$\mathrm{Pb}-210+\mathrm{D} \quad 1.000 \mathrm{E}+00 \quad 2.326 \mathrm{E}-31 \quad 7.210 \mathrm{E}-30 \quad 7.772 \mathrm{E}-24 \quad 1.314 \mathrm{E}-22 \quad 3.671 \mathrm{E}-19 \quad 5.196 \mathrm{E}-08$

$\operatorname{LDSR}(j) \quad 8.139 \mathrm{E}-23 \quad 1.209 \mathrm{E}-21 \quad 5.266 \mathrm{E}-17 \quad 5.323 \mathrm{E}-16 \quad 5.607 \mathrm{E}-13 \quad 6.321 \mathrm{E}-07$

Pu-239 1.000E+00 1.202E-17 $1.217 \mathrm{E}-17 \quad 2.183 \mathrm{E}-17 \quad 3.965 \mathrm{E}-17 \quad 4.690 \mathrm{E}-15 \quad 1.272 \mathrm{E}-03$

$\mathrm{U}-235+\mathrm{D} \quad 1.000 \mathrm{E}+00 \quad 6.135 \mathrm{E}-24 \quad 1.861 \mathrm{E}-23 \quad 1.146 \mathrm{E}-21 \quad 4.227 \mathrm{E}-21 \quad 2.931 \mathrm{E}-18 \quad 6.669 \mathrm{E}-10$

$\begin{array}{llllllll}\mathrm{Pa}-231 & 1.000 \mathrm{E}+00 & 9.652 \mathrm{E}-28 & 6.818 \mathrm{E}-27 & 1.251 \mathrm{E}-23 & 8.414 \mathrm{E}-23 & 1.444 \mathrm{E}-19 & 4.822 \mathrm{E}-10\end{array}$

$\mathrm{AC}-227+\mathrm{D} \quad 1.000 \mathrm{E}+00 \quad 2.288 \mathrm{E}-27 \quad 3.434 \mathrm{E}-26 \quad 1.276 \mathrm{E}-21 \quad 1.169 \mathrm{E}-20 \quad 1.476 \mathrm{E}-17 \quad 1.691 \mathrm{E}-10$

$\operatorname{EDSR}(j) \quad 1.202 \mathrm{E}-17 \quad 1.217 \mathrm{E}-17 \quad 2.183 \mathrm{E}-17 \quad 3.966 \mathrm{E}-17 \quad 4.708 \mathrm{E}-15 \quad 1.272 \mathrm{E}-03$

$\begin{array}{lllllll}\mathrm{Pu}-240 \quad 4.950 \mathrm{E}-08 & 5.653 \mathrm{E}-32 & 5.753 \mathrm{E}-32 & 1.359 \mathrm{E}-31 & 3.267 \mathrm{E}-31 & 3.647 \mathrm{E}-28 & 5.807 \mathrm{E}-11\end{array}$

$\begin{array}{lllllllll}\mathrm{Pu}-240 & 1.000 \mathrm{E}+00 & 1.142 \mathrm{E}-24 & 1.162 \mathrm{E}-24 & 2.746 \mathrm{E}-24 & 6.601 \mathrm{E}-24 & 7.367 \mathrm{E}-21 & 1.173 \mathrm{E}-03\end{array}$

$\begin{array}{llllllll}\mathrm{U}-236 & 1.000 \mathrm{E}+00 & 2.162 \mathrm{E}-32 & 6.590 \mathrm{E}-32 & 5.335 \mathrm{E}-30 & 2.602 \mathrm{E}-29 & 1.686 \mathrm{E}-25 & 1.912 \mathrm{E}-08\end{array}$

$\begin{array}{llllllll}\mathrm{Th}-232 & 1.000 \mathrm{E}+00 & 2.845 \mathrm{E}-43 & 2.028 \mathrm{E}-42 & 5.480 \mathrm{E}-39 & 5.478 \mathrm{E}-38 & 2.238 \mathrm{E}-33 & 9.403 \mathrm{E}-16\end{array}$

$\mathrm{Ra}-228+\mathrm{D} \quad 1.000 \mathrm{E}+00 \quad 1.371 \mathrm{E}-28 \quad 2.018 \mathrm{E}-27 \quad 3.762 \mathrm{E}-23 \quad 2.542 \mathrm{E}-22 \quad 1.470 \mathrm{E}-19 \quad 1.228 \mathrm{E}-13$

$\begin{array}{lllllllll}\mathrm{Th}-228+\mathrm{D} & 1.000 \mathrm{E}+00 & 8.111 \mathrm{E}-28 & 2.334 \mathrm{E}-26 & 2.641 \mathrm{E}-21 & 1.757 \mathrm{E}-20 & 5.564 \mathrm{E}-18 & 1.531 \mathrm{E}-15\end{array}$

$\operatorname{LDSR}(j) \quad 1.143 \mathrm{E}-24 \quad 1.188 \mathrm{E}-24 \quad 2.681 \mathrm{E}-21 \quad 1.783 \mathrm{E}-20 \quad 5.719 \mathrm{E}-18 \quad 1.173 \mathrm{E}-03$

$\begin{array}{llllllll}\text { TC-99 } 1.000 \mathrm{E}+00 & 5.758 \mathrm{E}-26 & 5.817 \mathrm{E}-26 & 9.575 \mathrm{E}-26 & 1.592 \mathrm{E}-25 & 2.069 \mathrm{E}-01 & 1.472 \mathrm{E}-03\end{array}$

$\mathrm{Th}-228+\mathrm{D} \quad 1.000 \mathrm{E}+00 \quad 1.382 \mathrm{E}-06 \quad 9.680 \mathrm{E}-07 \quad 2.527 \mathrm{E}-14 \quad 4.618 \mathrm{E}-22 \quad 0.000 \mathrm{E}+00 \quad 0.000 \mathrm{E}+00$

$\begin{array}{llllllll}\mathrm{Th}-230 & 1.000 \mathrm{E}+00 & 2.412 \mathrm{E}-22 & 2.453 \mathrm{E}-22 & 5.590 \mathrm{E}-22 & 1.295 \mathrm{E}-21 & 1.078 \mathrm{E}-18 & 1.108 \mathrm{E}-03\end{array}$ $\mathrm{Ra}-226+\mathrm{D} \quad 1.000 \mathrm{E}+00 \quad 3.774 \mathrm{E}-11 \quad 1.139 \mathrm{E}-10 \quad 5.320 \mathrm{E}-09 \quad 1.479 \mathrm{E}-08 \quad 1.071 \mathrm{E}-06 \quad 2.402 \mathrm{E}-02$ $\mathrm{Pb}-210+\mathrm{D} \quad 1.000 \mathrm{E}+00 \quad 1.819 \mathrm{E}-19 \quad 1.271 \mathrm{E}-18 \quad 1.299 \mathrm{E}-15 \quad 5.314 \mathrm{E}-15 \quad 7.678 \mathrm{E}-13 \quad 3.722 \mathrm{E}-02$ $\operatorname{EDSR}(j) \quad 3.774 \mathrm{E}-11 \quad 1.139 \mathrm{E}-10 \quad 5.320 \mathrm{E}-09 \quad 1.479 \mathrm{E}-08 \quad 1.071 \mathrm{E}-06 \quad 6.234 \mathrm{E}-02$ 
RESRAD, Version $6.5 \quad T^{1 / 2}$ Limit $=180$ days $\quad 07 / 20 / 2011 \quad 13: 54 \quad$ Page 28

Summary : RESRAD Parameters for Resident Farmer U-Landfill Forward Run 1,050 Years

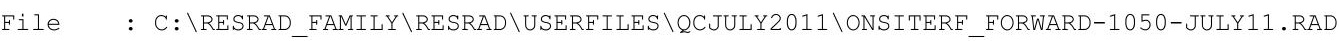

Dose/Source Ratios Summed Over All Pathways

Parent and Progeny Principal Radionuclide Contributions Indicated

\begin{tabular}{|c|c|c|c|c|c|c|c|c|}
\hline $\begin{array}{l}\text { Parent } \\
\text { (i) }\end{array}$ & $\begin{array}{l}\text { Product } \\
\text { (j) }\end{array}$ & $\begin{array}{l}\text { Thread } \\
\text { Fraction }\end{array}$ & $\begin{array}{r}\text { DSR } \\
0.000 \mathrm{E}+00\end{array}$ & $\begin{array}{l}(j, t) \text { At } T \\
1.000 E+00\end{array}$ & $\begin{array}{l}\text { Ime in Year } \\
5.000 \mathrm{E}+01\end{array}$ & $\begin{array}{l}\text { Es (mrem/ } \\
1.000 \mathrm{E}+02\end{array}$ & $\begin{array}{l}/ \mathrm{yr}) /(\mathrm{pCi} / \mathrm{g} \\
5.000 \mathrm{E}+02\end{array}$ & $1.050 \mathrm{E}+03$ \\
\hline 232 & $\mathrm{Th}-232$ & $1.000 \mathrm{E}+00$ & $1.166 \mathrm{E}-24$ & $1.188 \mathrm{E}-24$ & $2.949 E-24$ & $7.462 \mathrm{E}-24$ & 1. $252 \mathrm{E}-20$ & 1. $225 \mathrm{E}-03$ \\
\hline 232 & $\mathrm{Ra}-228+\mathrm{D}$ & $1.000 \mathrm{E}+00$ & $1.107 \mathrm{E}-09$ & $3.174 \mathrm{E}-09$ & $2.784 \mathrm{E}-08$ & $4.079 \mathrm{E}-08$ & $8.497 \mathrm{E}-07$ & $1.625 \mathrm{E}-01$ \\
\hline-232 & $\mathrm{Th}-228+\mathrm{D}$ & $1.000 \mathrm{E}+00$ & $1.067 \mathrm{E}-08$ & $6.581 \mathrm{E}-08$ & $2.213 E-06$ & $2.992 \mathrm{E}-06$ & $3.253 E-05$ & $2.034 \mathrm{E}-03$ \\
\hline-232 & $\sum \operatorname{DSR}(j)$ & & $1.178 \mathrm{E}-08$ & $6.899 \mathrm{E}-08$ & $2.241 \mathrm{E}-06$ & $3.033 E-06$ & $3.338 E-05$ & $1.657 \mathrm{E}-01$ \\
\hline-234 & $\mathrm{U}-234$ & $1.000 \mathrm{E}+00$ & $6.896 \mathrm{E}-24$ & $7.019 \mathrm{E}-24$ & $1.670 \mathrm{E}-23$ & $4.047 \mathrm{E}-23$ & $4.798 E-20$ & $6.733 E-04$ \\
\hline-234 & $T h-230$ & $1.000 \mathrm{E}+00$ & $1.089 \mathrm{E}-27$ & $3.315 E-27$ & $2.540 \mathrm{E}-25$ & $1.171 \mathrm{E}-24$ & $4.838 E-21$ & $1.040 \mathrm{E}-05$ \\
\hline 234 & $\mathrm{Ra}-226+\mathrm{D}$ & $1.000 \mathrm{E}+00$ & $1.133 \mathrm{E}-16$ & $7.978 E-16$ & $1.213 E-12$ & $6.737 E-12$ & $2.496 E-09$ & 1. $217 \mathrm{E}-04$ \\
\hline 234 & $\mathrm{~Pb}-210+\mathrm{D}$ & $1.000 \mathrm{E}+00$ & $4.102 E-25$ & $6.153 E-24$ & $2.201 \mathrm{E}-19$ & 1. $935 \mathrm{E}-18$ & $1.678 \mathrm{E}-15$ & $1.826 \mathrm{E}-04$ \\
\hline 234 & $\sum \operatorname{DSR}(j)$ & & $1.133 \mathrm{E}-16$ & 7. $978 \mathrm{E}-16$ & $1.213 \mathrm{E}-12$ & $6.737 \mathrm{E}-12$ & $2.496 \mathrm{E}-09$ & $9.879 E-04$ \\
\hline$-235+D$ & $\mathrm{U}-235+\mathrm{D}$ & $1.000 \mathrm{E}+00$ & 1. $243 \mathrm{E}-14$ & $1.259 \mathrm{E}-14$ & $2.306 \mathrm{E}-14$ & $4.276 \mathrm{E}-14$ & $5.981 \mathrm{E}-12$ & $6.524 \mathrm{E}-04$ \\
\hline$-235+D$ & $\mathrm{~Pa}-231$ & $1.000 \mathrm{E}+00$ & $2.937 \mathrm{E}-18$ & $8.896 \mathrm{E}-18$ & $5.031 \mathrm{E}-16$ & $1.701 \mathrm{E}-15$ & $5.876 \mathrm{E}-13$ & $9.372 \mathrm{E}-04$ \\
\hline$-235+D$ & $A C-227+D$ & $1.000 \mathrm{E}+00$ & $9.274 \mathrm{E}-18$ & $6.481 \mathrm{E}-17$ & $6.882 \mathrm{E}-14$ & $2.943 E-13$ & $6.376 \mathrm{E}-11$ & $3.384 \mathrm{E}-04$ \\
\hline$-235+D$ & $\sum \operatorname{DSR}(j)$ & & $1.245 \mathrm{E}-14$ & $1.266 \mathrm{E}-14$ & $9.238 \mathrm{E}-14$ & $3.388 \mathrm{E}-13$ & $7.033 E-11$ & $1.928 \mathrm{E}-03$ \\
\hline-238 & $U-238$ & $5.400 \mathrm{E}-05$ & $0.000 \mathrm{E}+00$ & $0.000 \mathrm{E}+00$ & $0.000 \mathrm{E}+00$ & $0.000 \mathrm{E}+00$ & $0.000 \mathrm{E}+00$ & $3.349 \mathrm{E}-08$ \\
\hline$-238+D$ & $\mathrm{U}-238+\mathrm{D}$ & $9.999 \mathrm{E}-01$ & $1.420 \mathrm{E}-10$ & $1.431 \mathrm{E}-10$ & $2.116 \mathrm{E}-10$ & $3.153 E-10$ & $7.678 E-09$ & $6.676 \mathrm{E}-04$ \\
\hline $238+D$ & $\mathrm{U}-234$ & $9.999 \mathrm{E}-01$ & $9.803 E-30$ & $2.988 E-29$ & $2.392 E-27$ & $1.153 E-26$ & $6.812 \mathrm{E}-23$ & $2.008 E-06$ \\
\hline$-238+D$ & $T h-230$ & $9.999 \mathrm{E}-01$ & $1.030 E-33$ & $7.316 E-33$ & $1.818 \mathrm{E}-29$ & $1.668 E-28$ & $3.430 E-24$ & $1.547 \mathrm{E}-08$ \\
\hline$-238+D$ & $\mathrm{Ra}-226+\mathrm{D}$ & $9.999 \mathrm{E}-01$ & $8.034 \mathrm{E}-23$ & 1. $212 \mathrm{E}-21$ & $5.801 \mathrm{E}-17$ & $6.420 \mathrm{E}-16$ & $1.201 \mathrm{E}-12$ & $1.251 \mathrm{E}-07$ \\
\hline$-238+D$ & $\mathrm{~Pb}-210+\mathrm{D}$ & $9.999 \mathrm{E}-01$ & $2.329 E-31$ & $7.229 E-30$ & $8.430 \mathrm{E}-24$ & $1.546 \mathrm{E}-22$ & $7.612 E-19$ & $1.821 \mathrm{E}-07$ \\
\hline$-238+D$ & $\sum \operatorname{DSR}(j)$ & & $1.420 \mathrm{E}-10$ & $1.431 \mathrm{E}-10$ & $2.116 \mathrm{E}-10$ & $3.153 \mathrm{E}-10$ & $7.680 \mathrm{E}-09$ & $6.699 \mathrm{E}-04$ \\
\hline
\end{tabular}

The DSR includes contributions from associated (half-life $\leq 180$ days) daughters. 
RESRAD, Version $6.5 \quad T^{1 / 2}$ Limit $=180$ days $\quad 07 / 20 / 2011 \quad 13: 54 \quad$ Page 29

Summary : RESRAD Parameters for Resident Farmer U-Landfill Forward Run 1,050 Years

File : C: $\backslash$ RESRAD_FAMILY \RESRAD \USERFILES $\backslash Q C J U L Y 2011 \backslash$ ONSITERF_FORWARD-1050-JULY11.RAD

Single Radionuclide Soil Guidelines $G(i, t)$ in $\mathrm{pCi} / \mathrm{g}$

Basic Radiation Dose Limit $=1.000 \mathrm{E}+02 \mathrm{mrem} / \mathrm{yr}$

Nuclide

\begin{tabular}{|c|c|c|c|c|c|c|}
\hline (i) & $t=0.000 E+00$ & $1.000 \mathrm{E}+00$ & $5.000 \mathrm{E}+01$ & $1.000 \mathrm{E}+02$ & $5.000 \mathrm{E}+02$ & $1.050 \mathrm{E}+03$ \\
\hline $1-241$ & $\star 3.431 \mathrm{E}+12$ & $\star 3.431 \mathrm{E}+12$ & $\star 3.431 \mathrm{E}+12$ & $\star 3.431 \mathrm{E}+12$ & $\star 3.431 \mathrm{E}+12$ & $5.034 \mathrm{E}+05$ \\
\hline$s-137$ & $7.925 E+10$ & $8.043 E+10$ & $1.653 \mathrm{E}+11$ & $3.447 \mathrm{E}+11$ & $\star 8.704 \mathrm{E}+13$ & $\star 8.704 \mathrm{E}+13$ \\
\hline$p-237$ & $\star 7.047 \mathrm{E}+08$ & $\star 7.047 \mathrm{E}+08$ & $\star 7.047 \mathrm{E}+08$ & $\star 7.047 \mathrm{E}+08$ & $\star 7.047 \mathrm{E}+08$ & $9.465 \mathrm{E}+03$ \\
\hline $\mathrm{Pu}-238$ & $\star 1.712 \mathrm{E}+13$ & $\star 1.712 \mathrm{E}+13$ & $\star 1.712 \mathrm{E}+13$ & $\star 1.712 \mathrm{E}+13$ & $\star 1.712 \mathrm{E}+13$ & $1.582 \mathrm{E}+08$ \\
\hline $\mathrm{Pu}-239$ & $\star 6.214 \mathrm{E}+10$ & $\star 6.214 \mathrm{E}+10$ & $* 6.214 \mathrm{E}+10$ & $\star 6.214 \mathrm{E}+10$ & $\star 6.214 \mathrm{E}+10$ & $7.860 \mathrm{E}+04$ \\
\hline $\mathrm{Pu}-240$ & $\star 2.278 E+11$ & $\star 2.278 \mathrm{E}+11$ & $\star 2.278 \mathrm{E}+11$ & $\star 2.278 \mathrm{E}+11$ & $\star 2.278 \mathrm{E}+11$ & $8.524 \mathrm{E}+04$ \\
\hline TC-99 & $* 1.697 \mathrm{E}+10$ & $* 1.697 \mathrm{E}+10$ & $\star 1.697 \mathrm{E}+10$ & $* 1.697 \mathrm{E}+10$ & $4.834 \mathrm{E}+02$ & $6.791 \mathrm{E}+04$ \\
\hline Th-228 & $7.234 \mathrm{E}+07$ & $1.033 \mathrm{E}+08$ & $\star 8.195 \mathrm{E}+14$ & $\star 8.195 \mathrm{E}+14$ & $\star 8.195 \mathrm{E}+14$ & $\star 8.195 \mathrm{E}+14$ \\
\hline Th-230 & $\star 2.018 \mathrm{E}+10$ & $\star 2.018 \mathrm{E}+10$ & $1.880 \mathrm{E}+10$ & $6.761 \mathrm{E}+09$ & $9.336 \mathrm{E}+07$ & $1.604 \mathrm{E}+03$ \\
\hline Th-232 & $\star 1.097 \mathrm{E}+05$ & $* 1.097 \mathrm{E}+05$ & $* 1.097 \mathrm{E}+05$ & $\star 1.097 \mathrm{E}+05$ & $\star 1.097 \mathrm{E}+05$ & $6.034 \mathrm{E}+02$ \\
\hline $\mathrm{U}-234$ & $\star 6.247 \mathrm{E}+09$ & $\star 6.247 \mathrm{E}+09$ & $\star 6.247 \mathrm{E}+09$ & $* 6.247 \mathrm{E}+09$ & $\star 6.247 \mathrm{E}+09$ & $1.012 \mathrm{E}+05$ \\
\hline 35 & $\star 2.161 \mathrm{E}+06$ & $\star 2.161 \mathrm{E}+06$ & $\star 2.161 \mathrm{E}+06$ & $\star 2.161 \mathrm{E}+06$ & $\star 2.161 \mathrm{E}+06$ & $5.187 \mathrm{E}+04$ \\
\hline 238 & $\star 3.361 \mathrm{E}+05$ & $\star 3.361 \mathrm{E}+05$ & $\star 3.361 \mathrm{E}+05$ & $\star 3.361 \mathrm{E}+05$ & $\star 3.361 \mathrm{E}+05$ & $1.493 \mathrm{E}+05$ \\
\hline
\end{tabular}

*At specific activity limit

Summed Dose/Source Ratios DSR(i,t) in (mrem/yr)/(pCi/g) and Single Radionuclide Soil Guidelines $\mathrm{G}(i, t)$ in $\mathrm{pCi} / \mathrm{g}$

at $\operatorname{tmin}=$ time of minimum single radionuclide soil guideline and at tmax $=$ time of maximum total dose $=424.6 \pm 0.8$ years

\begin{tabular}{|c|c|c|c|c|c|c|}
\hline $\begin{array}{l}\text { liclide } \\
\text { (i) }\end{array}$ & $\begin{array}{l}\text { Initial } \\
\text { (pCi/g) }\end{array}$ & $\begin{array}{c}\text { tmin } \\
\text { (years) }\end{array}$ & $\operatorname{DSR}(i, \operatorname{tmin})$ & $\begin{array}{c}\mathrm{G}(\mathrm{i}, \mathrm{tmin}) \\
\quad(\mathrm{pCi} / \mathrm{g})\end{array}$ & $\operatorname{DSR}(i, \operatorname{tmax})$ & $\begin{array}{c}G(i, t \max ) \\
(\mathrm{pCi} / \mathrm{g})\end{array}$ \\
\hline-241 & $3.500 \mathrm{E}+01$ & $1.050 \mathrm{E}+03$ & $1.987 \mathrm{E}-04$ & $5.034 \mathrm{E}+05$ & $9.151 \mathrm{E}-15$ & $\star 3.431 \mathrm{E}+12$ \\
\hline-137 & $1.900 \mathrm{E}+01$ & $0.000 \mathrm{E}+00$ & $1.262 \mathrm{E}-09$ & $7.925 \mathrm{E}+10$ & $2.456 \mathrm{E}-12$ & $4.071 E+13$ \\
\hline-237 & $5.500 \mathrm{E}+00$ & $1.050 \mathrm{E}+03$ & $1.056 \mathrm{E}-02$ & $9.465 \mathrm{E}+03$ & $9.131 \mathrm{E}-11$ & $* 7.047 \mathrm{E}+08$ \\
\hline-238 & $3.900 \mathrm{E}+01$ & $1.050 \mathrm{E}+03$ & $6.321 \mathrm{E}-07$ & $1.582 \mathrm{E}+08$ & $2.254 \mathrm{E}-13$ & $\star 1.712 \mathrm{E}+13$ \\
\hline$u-239$ & $3.600 \mathrm{E}+01$ & $1.050 \mathrm{E}+03$ & $1.272 \mathrm{E}-03$ & $7.860 E+04$ & $1.913 \mathrm{E}-15$ & $\star 6.214 \mathrm{E}+10$ \\
\hline$u-240$ & $3.600 \mathrm{E}+01$ & $1.050 \mathrm{E}+03$ & $1.173 \mathrm{E}-03$ & $8.524 \mathrm{E}+04$ & $2.609 \mathrm{E}-18$ & $\star 2.278 \mathrm{E}+11$ \\
\hline$c-99$ & $5.200 \mathrm{E}+01$ & $424.6 \pm 0.8$ & $4.076 \mathrm{E}-01$ & $2.453 \mathrm{E}+02$ & $4.076 \mathrm{E}-01$ & $2.453 \mathrm{E}+02$ \\
\hline$h-228$ & $4.000 \mathrm{E}+00$ & $0.000 \mathrm{E}+00$ & $1.382 \mathrm{E}-06$ & $7.234 \mathrm{E}+07$ & $0.000 \mathrm{E}+00$ & $\star 8.195 \mathrm{E}+14$ \\
\hline$T h-230$ & $1.000 \mathrm{E}+02$ & $1.050 \mathrm{E}+03$ & $6.234 \mathrm{E}-02$ & $1.604 \mathrm{E}+03$ & $5.490 \mathrm{E}-07$ & $1.822 \mathrm{E}+08$ \\
\hline 232 & $4.000 \mathrm{E}+00$ & $1.050 \mathrm{E}+03$ & $1.657 \mathrm{E}-01$ & $6.034 \mathrm{E}+02$ & $2.122 \mathrm{E}-05$ & $\star 1.097 \mathrm{E}+05$ \\
\hline 34 & $1.600 \mathrm{E}+02$ & $1.050 \mathrm{E}+03$ & $9.879 \mathrm{E}-04$ & $1.012 \mathrm{E}+05$ & $1.081 \mathrm{E}-09$ & $\star 6.247 \mathrm{E}+09$ \\
\hline 35 & $6.500 \mathrm{E}+00$ & $1.050 \mathrm{E}+03$ & $1.928 \mathrm{E}-03$ & $5.187 E+04$ & $3.027 \mathrm{E}-11$ & $\star 2.161 \mathrm{E}+06$ \\
\hline 238 & $1.600 \mathrm{E}+02$ & $1.050 \mathrm{E}+03$ & $6.700 \mathrm{E}-04$ & $1.493 \mathrm{E}+05$ & $4.206 \mathrm{E}-09$ & $* 3.361 \mathrm{E}+05$ \\
\hline
\end{tabular}

*At specific activity limit 
RESRAD, Version $6.5 \quad T^{1 / 2}$ Limit $=180$ days $\quad 07 / 20 / 2011 \quad 13: 54$ Page 30

Summary : RESRAD Parameters for Resident Farmer U-Landfill Forward Run 1,050 Years

File : C: $\backslash$ RESRAD_FAMILY \RESRAD \USERFILES $\backslash Q C J U L Y 2011 \backslash$ ONSITERF_FORWARD-1050-JULY11.RAD

Individual Nuclide Dose Summed Over All Pathways

Parent Nuclide and Branch Fraction Indicated

Nuclide Parent THF(i) DOSE $(j, t), \mathrm{mrem} / \mathrm{yr}$

\begin{tabular}{|c|c|c|}
\hline (j) & (i) & \\
\hline$n-241$ & $A m-241$ & $1.000 \mathrm{E}+00$ \\
\hline-237 & $A m-241$ & $1.000 \mathrm{E}+00$ \\
\hline$p-237$ & $\mathrm{~Np}-237$ & $1.000 \mathrm{E}+00$ \\
\hline $\mathrm{Np}-237$ & $\sum \operatorname{DOSE}(j$ & \\
\hline
\end{tabular}

$\mathrm{U}-233 \quad \mathrm{Am}-241 \quad 1.000 \mathrm{E}+00$

$\mathrm{U}-233 \quad \mathrm{~Np}-237 \quad 1.000 \mathrm{E}+00$

U-233 $\sum \operatorname{DOSE}(j)$

Th-229 Am-241 $1.000 \mathrm{E}+00$

Th-229 Np-237 $1.000 \mathrm{E}+00$

Th-229 $\sum \operatorname{DOSE}(j)$

Cs-137 Cs-137 1.000E+00

Pu-238 $\mathrm{Pu}-238 \quad 1.840 \mathrm{E}-09$

$\mathrm{Pu}-238 \mathrm{Pu}-238 \quad 1.000 \mathrm{E}+00$

$\mathrm{Pu}-238 \quad \sum \operatorname{DOSE}(j)$

$\mathrm{U}-234$

$\mathrm{U}-234$

$\mathrm{U}-234$

$\mathrm{U}-234$

Th-230

Th-230

Th -230

Th-230

Th-230

$\mathrm{Ra}-226$

$\mathrm{Ra}-226$

Ra-226

$\mathrm{Ra}-226$

Ra-226

$\mathrm{Pb}-210$

$\mathrm{Pb}-210$

$\mathrm{Pb}-210$

$\mathrm{Pb}-210$

$\mathrm{Pb}-210$

$\mathrm{Pu}-239$

$\mathrm{Pu}-238 \quad 1.000 \mathrm{E}+00$

$\mathrm{U}-234 \quad 1.000 \mathrm{E}+00$

$\mathrm{U}-238 \quad 9.999 \mathrm{E}-01$

$\sum \operatorname{DOSE}(j)$

$\begin{array}{ll}\mathrm{Pu}-238 & 1.000 \mathrm{E}+00 \\ \mathrm{Th}-230 & 1.000 \mathrm{E}+00 \\ \mathrm{U}-234 & 1.000 \mathrm{E}+00 \\ \mathrm{U}-238 & 9.999 \mathrm{E}-01 \\ \sum \operatorname{DOSE}(j)\end{array}$

$\mathrm{Pu}-238 \quad 1.000 \mathrm{E}+00$

Th-230 1.000E+00

$\mathrm{U}-234 \quad 1.000 \mathrm{E}+00$

$\mathrm{U}-238 \quad 9.999 \mathrm{E}-01$

$\sum \operatorname{DOSE}(j)$

Pu-238 1.000E+00

$\mathrm{Th}-230 \quad 1.000 \mathrm{E}+00$

U-234 $1.000 \mathrm{E}+00$

U-238 $9.999 \mathrm{E}-01$

$\operatorname{DOSE}(j)$

$\mathrm{Pu}-239 \quad 1.000 \mathrm{E}+00$

$\mathrm{Pu}-239 \quad 1.000 \mathrm{E}+00$

U-235 1.000E+00

¿DOSE (j) $\mathrm{t}=0.000 \mathrm{E}+00 \quad 1.000 \mathrm{E}+00 \quad 5.000 \mathrm{E}+01 \quad 1.000 \mathrm{E}+02 \quad 5.000 \mathrm{E}+02 \quad 1.050 \mathrm{E}+03$

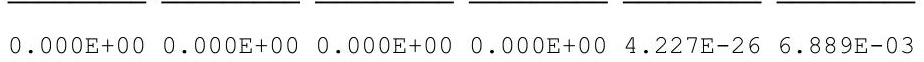

$\begin{array}{llllll}5.412 \mathrm{E}-18 & 1.638 \mathrm{E}-17 & 8.967 \mathrm{E}-16 & 2.934 \mathrm{E}-15 & 7.921 \mathrm{E}-13 & 6.396 \mathrm{E}-05\end{array}$

$\begin{array}{llllll}5.245 \mathrm{E}-12 & 5.301 \mathrm{E}-12 & 8.939 \mathrm{E}-12 & 1.524 \mathrm{E}-11 & 1.085 \mathrm{E}-09 & 5.809 \mathrm{E}-02\end{array}$

$\begin{array}{llllll}5.245 \mathrm{E}-12 & 5.301 \mathrm{E}-12 & 8.940 \mathrm{E}-12 & 1.524 \mathrm{E}-11 & 1.086 \mathrm{E}-09 & 5.815 \mathrm{E}-02\end{array}$

$\begin{array}{llllll}1.227 \mathrm{E}-28 & 8.678 \mathrm{E}-28 & 1.702 \mathrm{E}-24 & 1.226 \mathrm{E}-23 & 3.685 \mathrm{E}-20 & 1.133 \mathrm{E}-08\end{array}$

$\begin{array}{llllll}1.785 \mathrm{E}-22 & 5.414 \mathrm{E}-22 & 3.355 \mathrm{E}-20 & 1.245 \mathrm{E}-19 & 9.076 \mathrm{E}-17 & 1.672 \mathrm{E}-05\end{array}$

$\begin{array}{llllll}1.785 \mathrm{E}-22 & 5.414 \mathrm{E}-22 & 3.355 \mathrm{E}-20 & 1.245 \mathrm{E}-19 & 9.079 \mathrm{E}-17 & 1.673 \mathrm{E}-05\end{array}$

$\begin{array}{llllll}8.395 \mathrm{E}-25 & 1.266 \mathrm{E}-23 & 5.984 \mathrm{E}-19 & 6.539 \mathrm{E}-18 & 1.118 \mathrm{E}-14 & 1.900 \mathrm{E}-09\end{array}$

$\begin{array}{lllllll}1.629 \mathrm{E}-18 & 1.147 \mathrm{E}-17 & 1.758 \mathrm{E}-14 & 9.834 \mathrm{E}-14 & 3.894 \mathrm{E}-11 & 3.759 \mathrm{E}-06\end{array}$

$\begin{array}{llllll}1.629 \mathrm{E}-18 & 1.147 \mathrm{E}-17 & 1.758 \mathrm{E}-14 & 9.835 \mathrm{E}-14 & 3.895 \mathrm{E}-11 & 3.761 \mathrm{E}-06\end{array}$

$\begin{array}{llllll}2.397 \mathrm{E}-08 & 2.362 \mathrm{E}-08 & 1.149 \mathrm{E}-08 & 5.512 \mathrm{E}-09 & 1.540 \mathrm{E}-11 & 3.773 \mathrm{E}-12\end{array}$

$\begin{array}{llllll}0.000 \mathrm{E}+00 & 0.000 \mathrm{E}+00 & 0.000 \mathrm{E}+00 & 0.000 \mathrm{E}+00 & 0.000 \mathrm{E}+00 & 2.154 \mathrm{E}-14\end{array}$

$\begin{array}{lllllll}4.582 \mathrm{E}-23 & 4.627 \mathrm{E}-23 & 7.461 \mathrm{E}-23 & 1.215 \mathrm{E}-22 & 6.001 \mathrm{E}-21 & 1.171 \mathrm{E}-05\end{array}$

$\begin{array}{llllll}4.582 \mathrm{E}-23 & 4.627 \mathrm{E}-23 & 7.461 \mathrm{E}-23 & 1.215 \mathrm{E}-22 & 6.001 \mathrm{E}-21 & 1.171 \mathrm{E}-05\end{array}$

$\begin{array}{llllll}3.813 \mathrm{E}-28 & 1.158 \mathrm{E}-27 & 7.693 \mathrm{E}-26 & 3.104 \mathrm{E}-25 & 6.593 \mathrm{E}-22 & 9.431 \mathrm{E}-06\end{array}$

$\begin{array}{llllll}1.103 \mathrm{E}-21 & 1.123 \mathrm{E}-21 & 2.673 \mathrm{E}-21 & 6.475 \mathrm{E}-21 & 7.677 \mathrm{E}-18 & 1.077 \mathrm{E}-01\end{array}$

$\begin{array}{lllllll}1.569 \mathrm{E}-27 & 4.780 \mathrm{E}-27 & 3.827 \mathrm{E}-25 & 1.845 \mathrm{E}-24 & 1.090 \mathrm{E}-20 & 3.213 \mathrm{E}-04\end{array}$

$\begin{array}{llllll}1.103 \mathrm{E}-21 & 1.123 \mathrm{E}-21 & 2.673 \mathrm{E}-21 & 6.477 \mathrm{E}-21 & 7.688 \mathrm{E}-18 & 1.081 \mathrm{E}-01\end{array}$

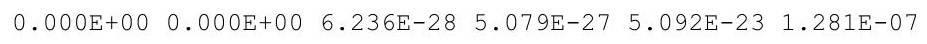

$2.412 \mathrm{E}-20 \quad 2.453 \mathrm{E}-20 \quad 5.590 \mathrm{E}-20 \quad 1.295 \mathrm{E}-19 \quad 1.078 \mathrm{E}-16 \quad 1.108 \mathrm{E}-01$

$\begin{array}{llllll}1.742 \mathrm{E}-25 & 5.304 \mathrm{E}-25 & 4.065 \mathrm{E}-23 & 1.874 \mathrm{E}-22 & 7.741 \mathrm{E}-19 & 1.664 \mathrm{E}-03\end{array}$

$\begin{array}{llllll}0.000 \mathrm{E}+00 & 0.000 \mathrm{E}+00 & 2.909 \mathrm{E}-27 & 2.669 \mathrm{E}-26 & 5.488 \mathrm{E}-22 & 2.475 \mathrm{E}-06\end{array}$

$2.412 \mathrm{E}-20 \quad 2.453 \mathrm{E}-20 \quad 5.594 \mathrm{E}-20 \quad 1.297 \mathrm{E}-19 \quad 1.085 \mathrm{E}-16 \quad 1.125 \mathrm{E}-01$

$\begin{array}{llllll}3.128 \mathrm{E}-21 & 4.712 \mathrm{E}-20 & 2.054 \mathrm{E}-15 & 2.076 \mathrm{E}-14 & 2.187 \mathrm{E}-11 & 1.360 \mathrm{E}-06\end{array}$ $\begin{array}{llllll}3.774 \mathrm{E}-09 & 1.139 \mathrm{E}-08 & 5.320 \mathrm{E}-07 & 1.479 \mathrm{E}-06 & 1.071 \mathrm{E}-04 & 2.402 \mathrm{E}+00\end{array}$ $\begin{array}{llllll}1.813 \mathrm{E}-14 & 1.277 \mathrm{E}-13 & 1.941 \mathrm{E}-10 & 1.078 \mathrm{E}-09 & 3.993 \mathrm{E}-07 & 1.947 \mathrm{E}-02\end{array}$ $\begin{array}{llllll}1.285 \mathrm{E}-20 & 1.939 \mathrm{E}-19 & 9.281 \mathrm{E}-15 & 1.027 \mathrm{E}-13 & 1.921 \mathrm{E}-10 & 2.001 \mathrm{E}-05\end{array}$

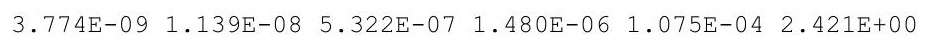

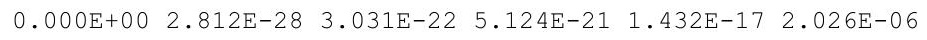
$\begin{array}{llllll}1.819 \mathrm{E}-17 & 1.271 \mathrm{E}-16 & 1.299 \mathrm{E}-13 & 5.314 \mathrm{E}-13 & 7.678 \mathrm{E}-11 & 3.722 \mathrm{E}+00\end{array}$ $\begin{array}{llllll}6.563 \mathrm{E}-23 & 9.844 \mathrm{E}-22 & 3.522 \mathrm{E}-17 & 3.095 \mathrm{E}-16 & 2.685 \mathrm{E}-13 & 2.921 \mathrm{E}-02\end{array}$ $\begin{array}{llllll}0.000 \mathrm{E}+00 & 1.157 \mathrm{E}-27 & 1.349 \mathrm{E}-21 & 2.474 \mathrm{E}-20 & 1.218 \mathrm{E}-16 & 2.914 \mathrm{E}-05\end{array}$ $\begin{array}{llllll}1.819 \mathrm{E}-17 & 1.271 \mathrm{E}-16 & 1.299 \mathrm{E}-13 & 5.317 \mathrm{E}-13 & 7.705 \mathrm{E}-11 & 3.751 \mathrm{E}+00\end{array}$

$4.328 \mathrm{E}-16 \quad 4.380 \mathrm{E}-16 \quad 7.860 \mathrm{E}-16 \quad 1.427 \mathrm{E}-15 \quad 1.689 \mathrm{E}-13 \quad 4.580 \mathrm{E}-02$

$2.209 \mathrm{E}-22 \quad 6.699 \mathrm{E}-22 \quad 4.126 \mathrm{E}-20 \quad 1.522 \mathrm{E}-19 \quad 1.055 \mathrm{E}-16 \quad 2.401 \mathrm{E}-08$ $\begin{array}{lllllll}8.081 \mathrm{E}-14 & 8.182 \mathrm{E}-14 & 1.499 \mathrm{E}-13 & 2.779 \mathrm{E}-13 & 3.888 \mathrm{E}-11 & 4.241 \mathrm{E}-03\end{array}$ $\begin{array}{lllllll}8.081 \mathrm{E}-14 & 8.182 \mathrm{E}-14 & 1.499 \mathrm{E}-13 & 2.779 \mathrm{E}-13 & 3.888 \mathrm{E}-11 & 4.241 \mathrm{E}-03\end{array}$ 
RESRAD, Version $6.5 \quad T^{1 / 2}$ Limit $=180$ days $\quad 07 / 20 / 2011 \quad 13: 54$ Page 31

Summary : RESRAD Parameters for Resident Farmer U-Landfill Forward Run 1,050 Years

File : C: $\backslash$ RESRAD_FAMILY $\backslash$ RESRAD \USERFILES $\backslash Q C J U L Y 2011 \backslash$ ONSITERF_FORWARD-1050-JULY11.RAD

Individual Nuclide Dose Summed Over All Pathways

Parent Nuclide and Branch Fraction Indicated

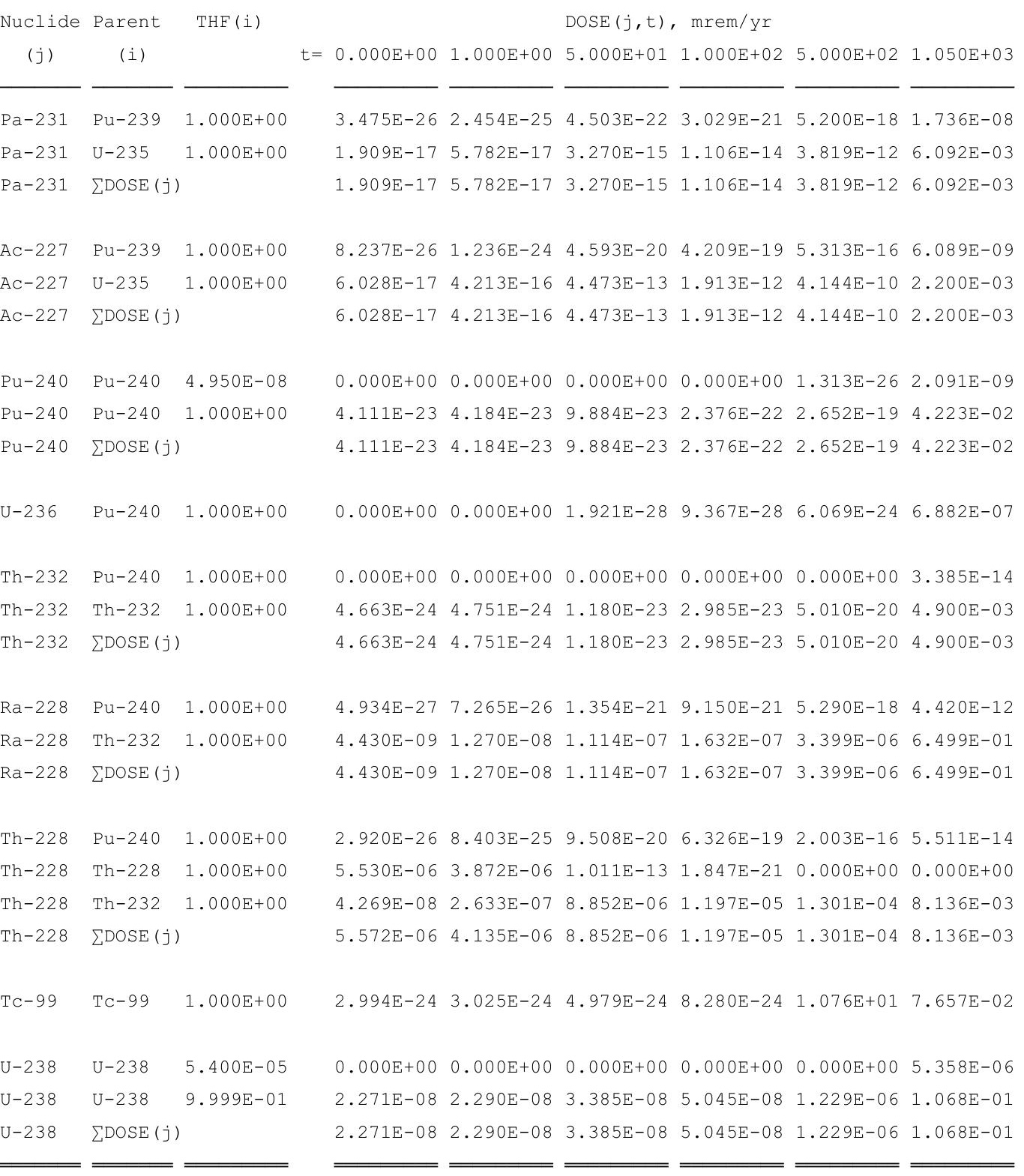

THF (i) is the thread fraction of the parent nuclide. 
RESRAD, Version $6.5 \quad T^{1 / 2}$ Limit $=180$ days $\quad 07 / 20 / 2011 \quad 13: 54 \quad$ Page 33

Summary : RESRAD Parameters for Resident Farmer U-Landfill Forward Run 1,050 Years

File : C: $\backslash$ RESRAD_FAMILY \RESRAD \USERFILES $\backslash Q C J U L Y 2011 \backslash$ ONSITERF_FORWARD-1050-JULY11.RAD

Individual Nuclide Soil Concentration

Parent Nuclide and Branch Fraction Indicated

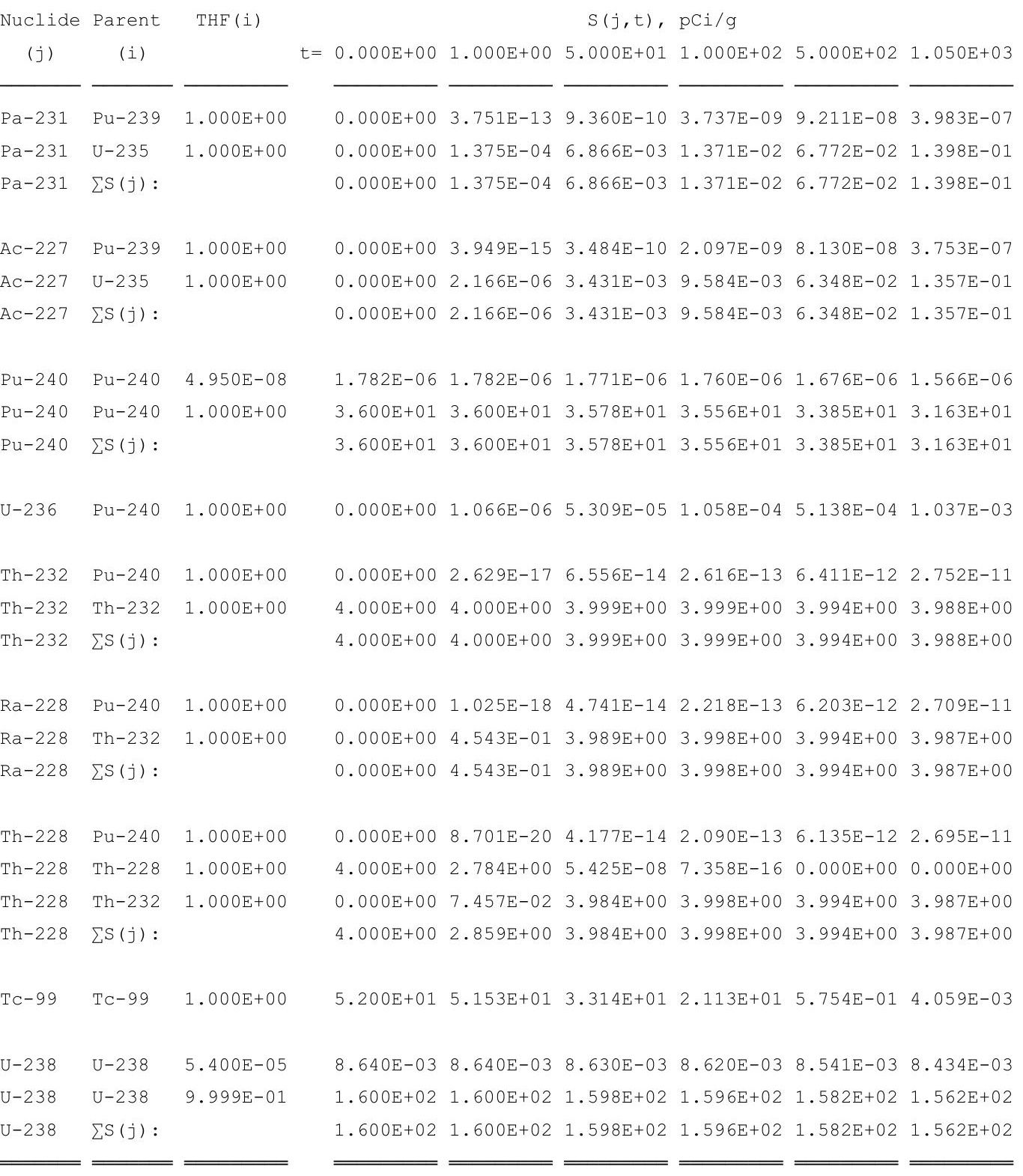

THF (i) is the thread fraction of the parent nuclide.

RESCALC.EXE execution time $=107.38$ seconds 
RESRAD, Version $6.5 \quad T^{13 / 2}$ Limit $=180$ days

Summary : RESRAD Parameters for Resident Farmer U-Landfill Forward Run 1,050 Years at ALs

File : C: \RESRAD_FAMILY \RESRAD \USERFILES $\backslash Q C J U L Y 2011 \backslash$ ONSITERF_FORWARD-1050YRALS.RAD

Table of Contents

Part I: Mixture Sums and Single Radionuclide Guidelines

Dose Conversion Factor (and Related) Parameter Summary ... 2

Site-Specific Parameter Summary ................ 8

Summary of Pathway Selections ................... 18

Contaminated Zone and Total Dose Summary ............. 19

Total Dose Components

Time $=0.000 \mathrm{E}+00 \ldots \ldots \ldots \ldots \ldots \ldots \ldots \ldots \ldots \ldots \ldots \ldots \ldots \ldots \ldots \ldots \ldots \ldots$

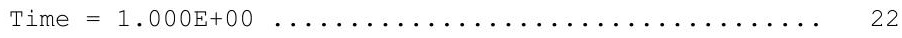

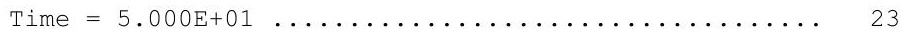

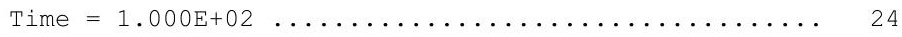

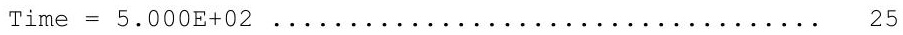

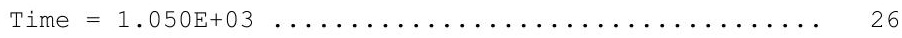

Dose/Source Ratios Summed Over All Pathways ........... 27

Single Radionuclide Soil Guidelines ............... 29

Dose Per Nuclide Summed Over All Pathways ............ 30

Soil Concentration Per Nuclide ................ 32 
Summary : RESRAD Parameters for Resident Farmer U-Landfill Forward Run 1,050 Years at ALs

File : C: \RESRAD_FAMILY \RESRAD \USERFILES $\backslash Q C J U L Y 2011 \backslash$ ONSITERF_FORWARD-1050YRALS.RAD

Dose Conversion Factor (and Related) Parameter Summary

Dose Library: ICRP 60 \& ICRP 72 (Adult)

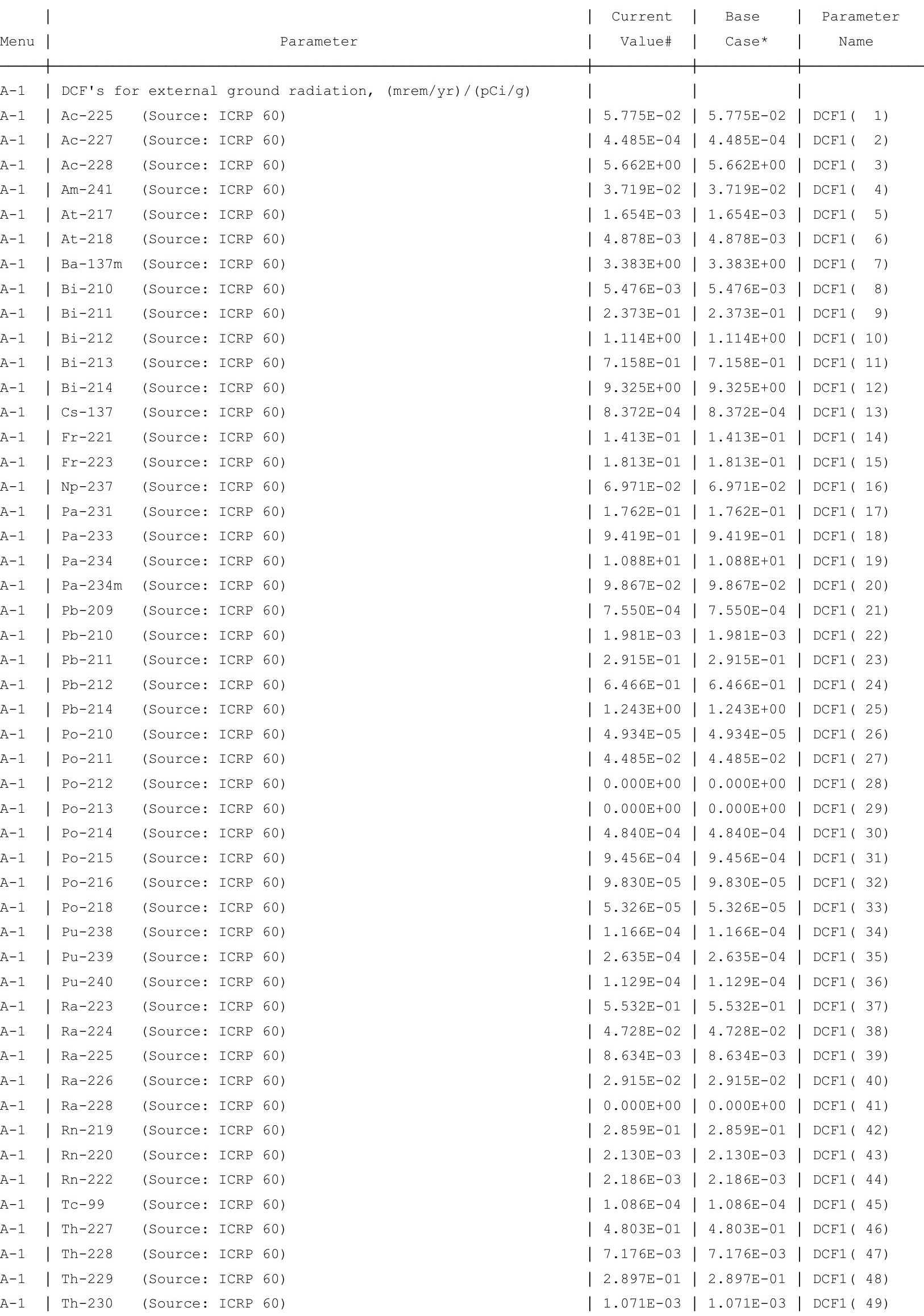


Summary : RESRAD Parameters for Resident Farmer U-Landfill Forward Run 1,050 Years at ALs File : C: \RESRAD_FAMILY \RESRAD \USERFILES $\backslash Q C J U L Y 2011 \backslash$ ONSITERF_FORWARD-1050YRALS.RAD

Dose Conversion Factor (and Related) Parameter Summary (continued)

Dose Library: ICRP 60 \& ICRP 72 (Adult)

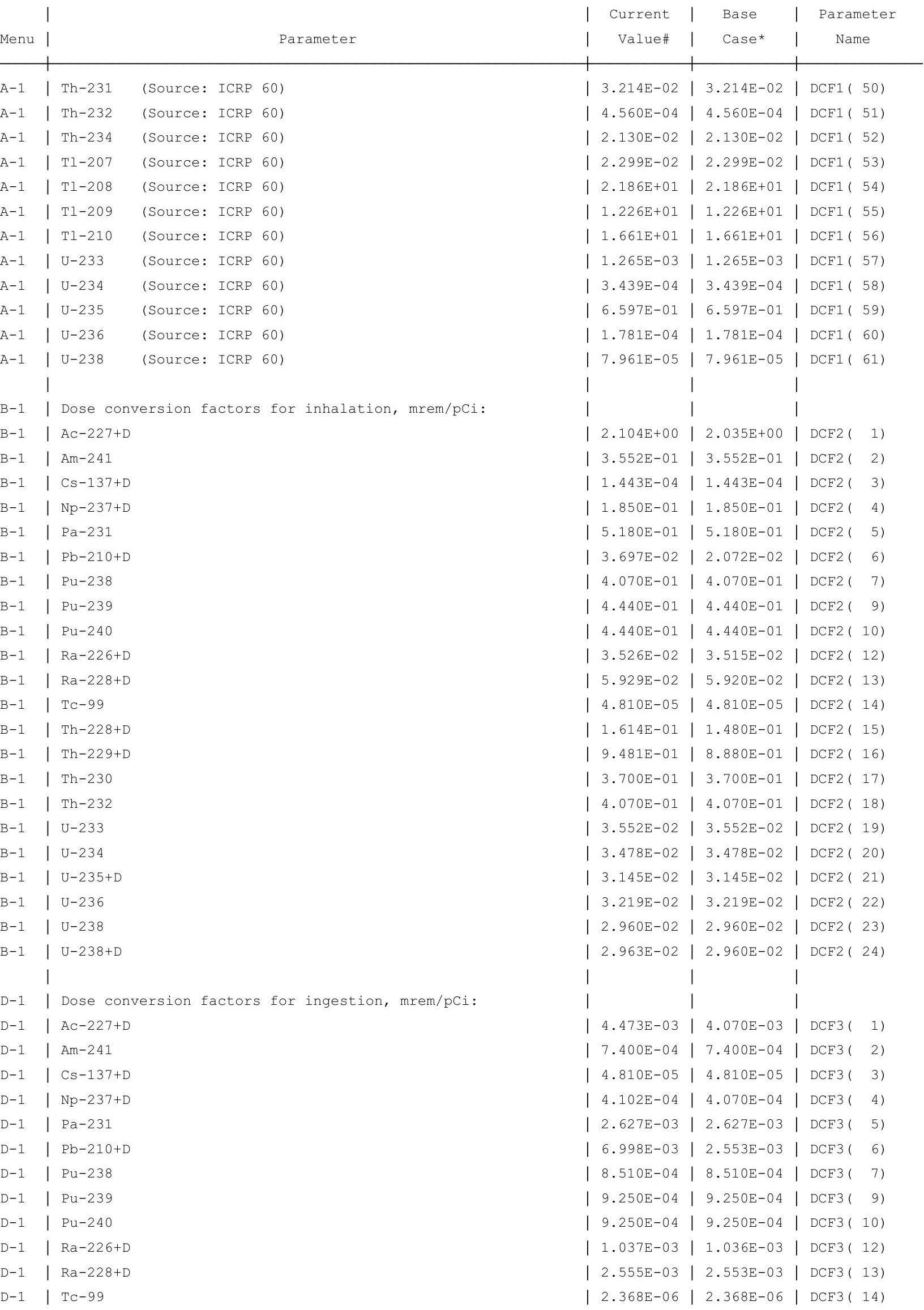


RESRAD, Version $6.5 \quad \mathrm{~T}^{1 / 2}$ Limit $=180$ days

Summary : RESRAD Parameters for Resident Farmer U-Landfill Forward Run 1,050 Years at ALs File : C: $\backslash$ RESRAD_FAMILY \RESRAD \USERFILES $\backslash Q C J U L Y 2011 \backslash$ ONSITERF_FORWARD-1050YRALS.RAD

Dose Conversion Factor (and Related) Parameter Summary (continued) Dose Library: ICRP 60 \& ICRP 72 (Adult)

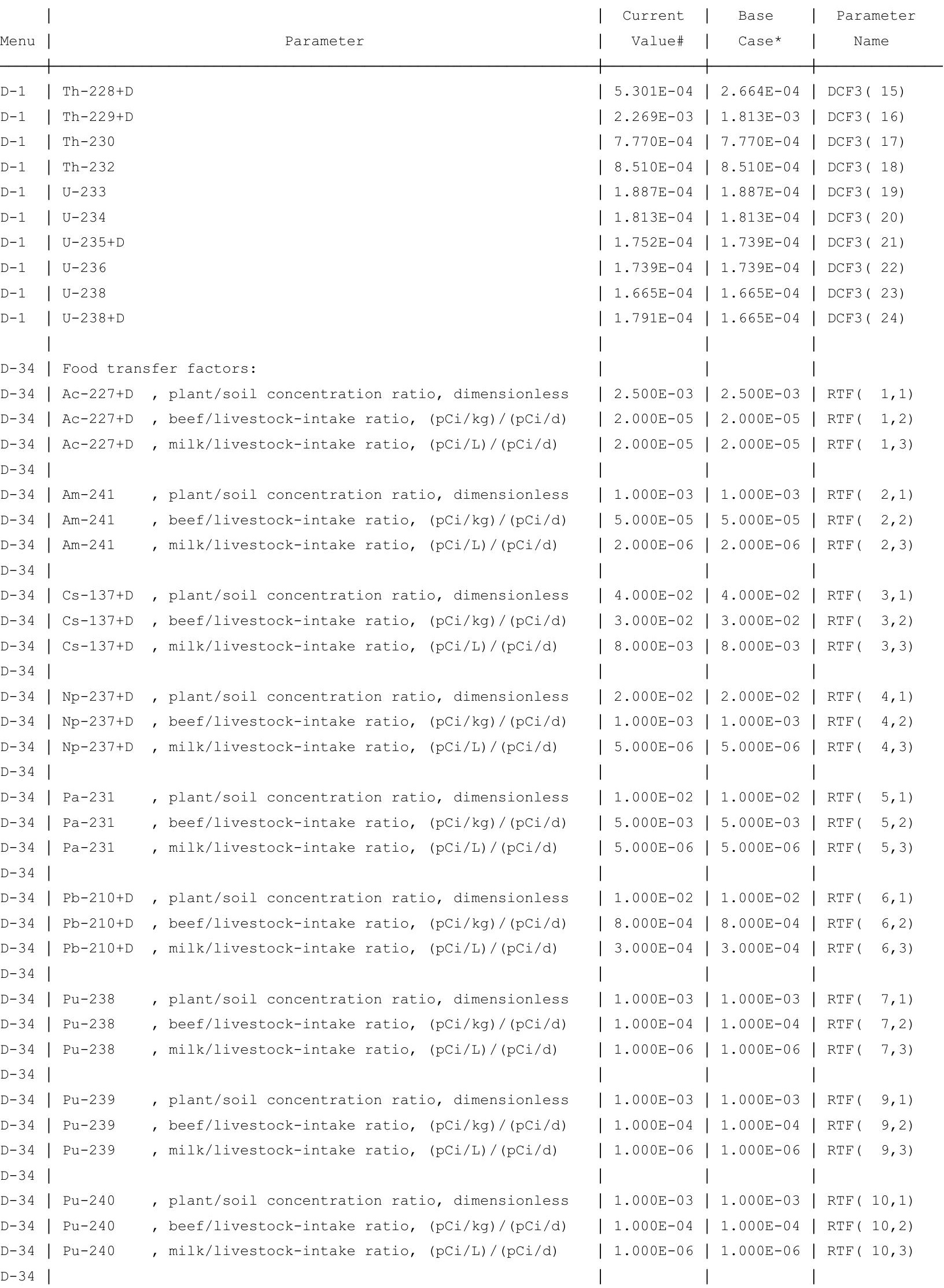


RESRAD, Version $6.5 \quad T^{1 / 2}$ Limit $=180$ days

Summary : RESRAD Parameters for Resident Farmer U-Landfill Forward Run 1,050 Years at ALs

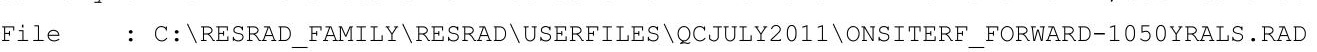

Dose Conversion Factor (and Related) Parameter Summary (continued)

Dose Library: ICRP 60 \& ICRP 72 (Adult)

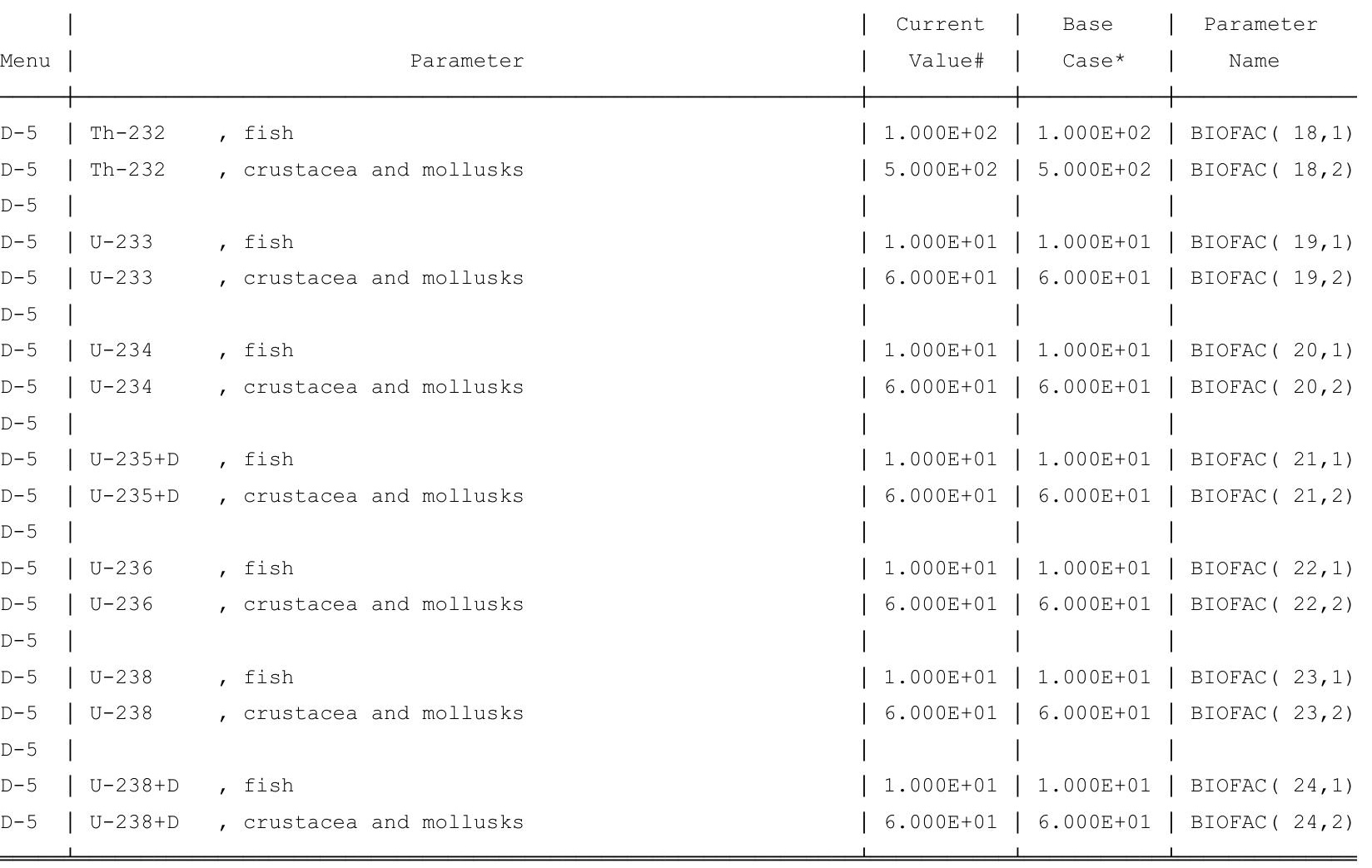

\#For DCFl(xxx) only, factors are for infinite depth \& area. See ETFG table in Ground Pathway of Detailed Report. *Base Case means Default.Lib w/o Associate Nuclide contributions. 
RESRAD, Version $6.5 \quad \mathrm{~T}^{\mathbb{1} 1 / 2}$ Limit $=180$ days

Summary : RESRAD Parameters for Resident Farmer U-Landfill Forward Run 1,050 Years at ALs

File : C: \RESRAD FAMILY\RESRAD \USERFILES \QCJULY2011 \ONSITERF FORWARD-1050YRALS.RAD

Site-Specific Parameter Summary (continued)

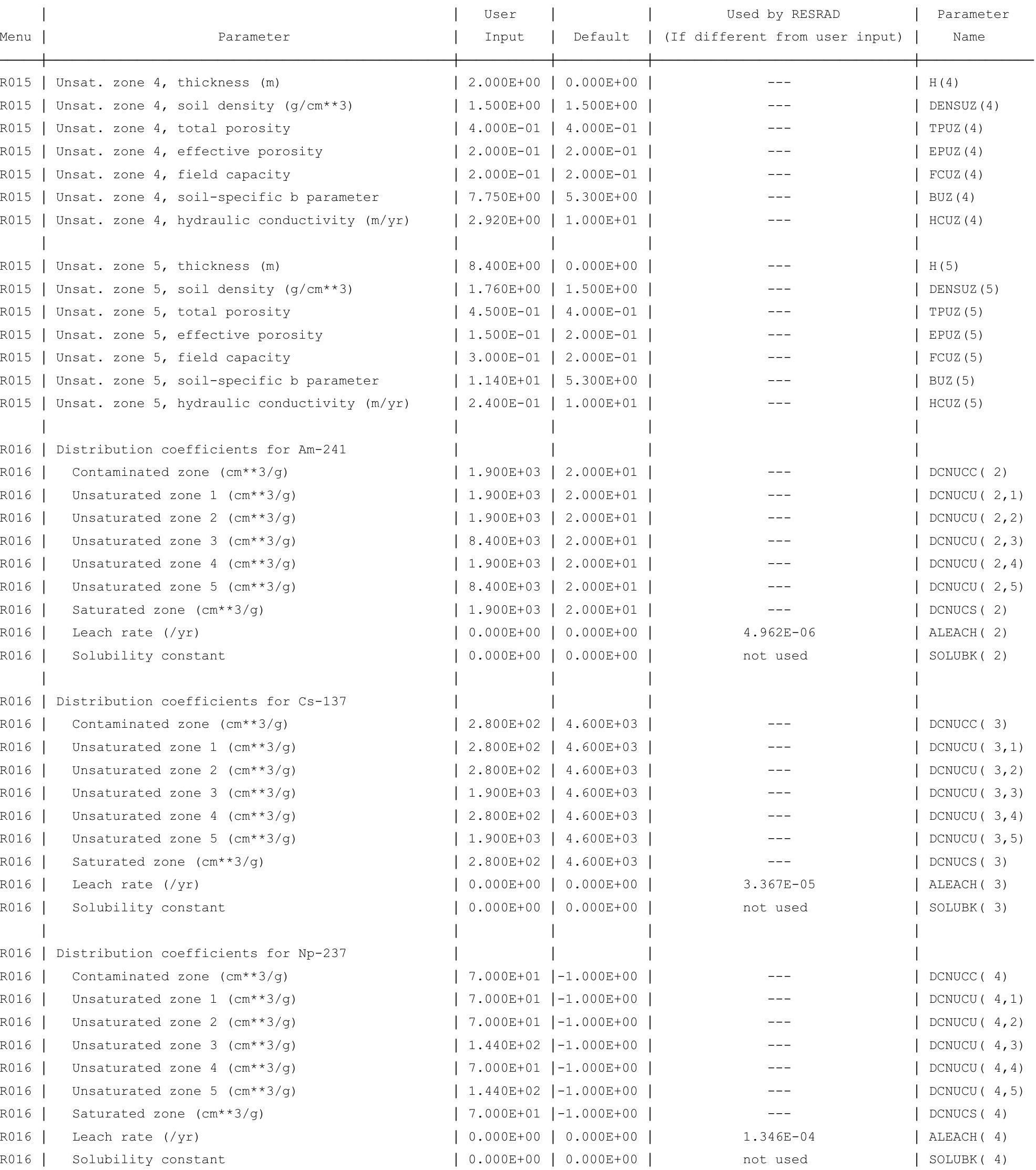


RESRAD, Version $6.5 \quad T^{1 / 2}$ Limit $=180$ days

Summary : RESRAD Parameters for Resident Farmer U-Landfill Forward Run 1,050 Years at ALs

File : C: \RESRAD_FAMILY \RESRAD \USERFILES QQCJULY2011 IONSITERF_FORWARD-1050YRALS.RAD

Site-Specific Parameter Summary (continued)

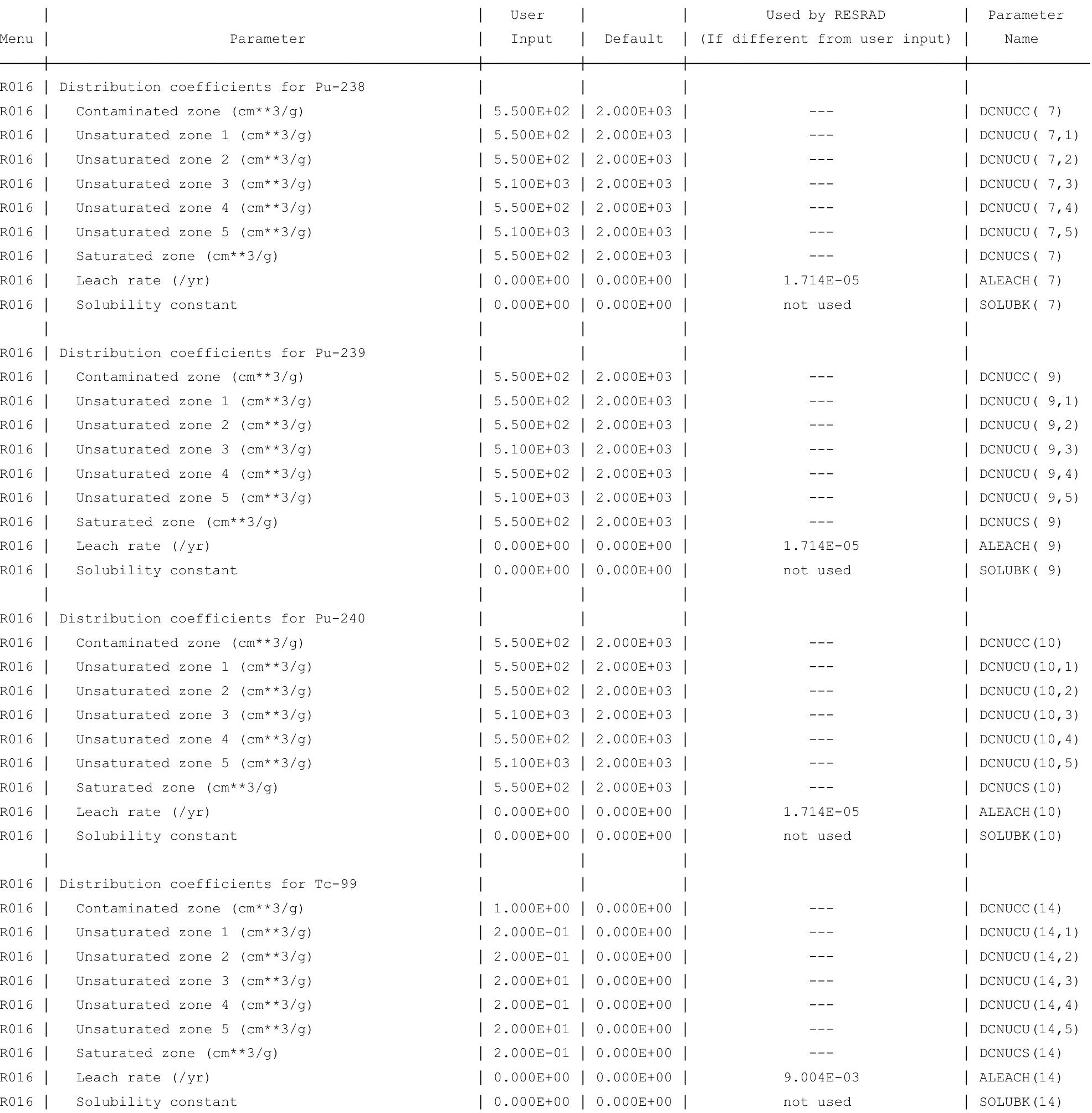


RESRAD, Version $6.5 \quad T^{1 / 2}$ Limit $=180$ days

Summary : RESRAD Parameters for Resident Farmer U-Landfill Forward Run 1,050 Years at ALs

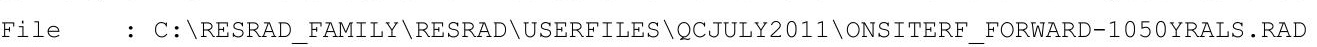

Site-Specific Parameter Summary (continued)

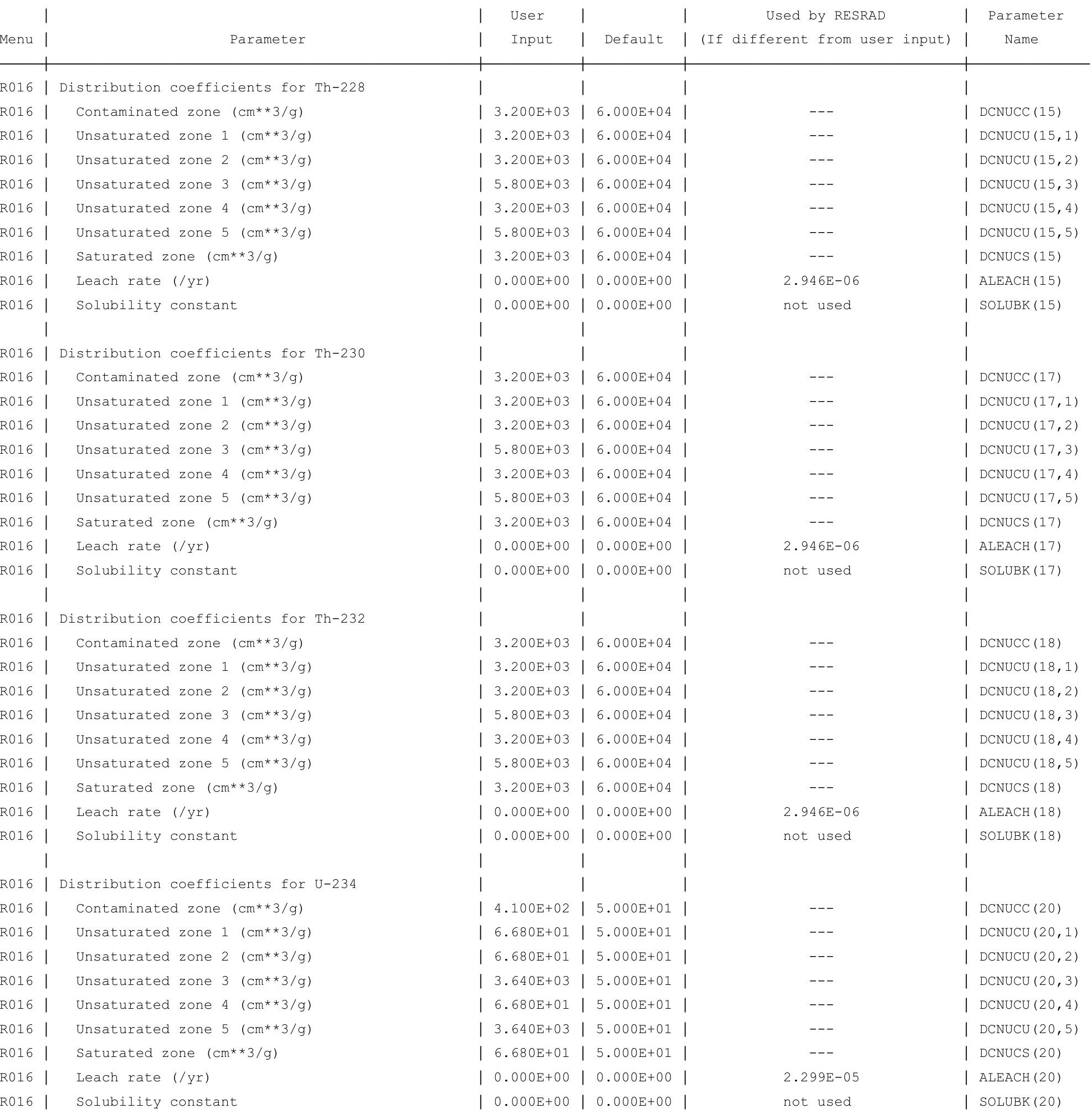


RESRAD, Version $6.5 \quad$ T1/2 Limit $=180$ days
Summary : RESRAD Parameters for Resident Farmer U-Landfill Forward Run 1,050 Years at ALs

File : C: \RESRAD_FAMILY \RESRAD \USERFILES $\backslash Q C J U L Y 2011 \backslash$ ONSITERF_FORWARD-1050YRALS.RAD

Site-Specific Parameter Summary (continued)

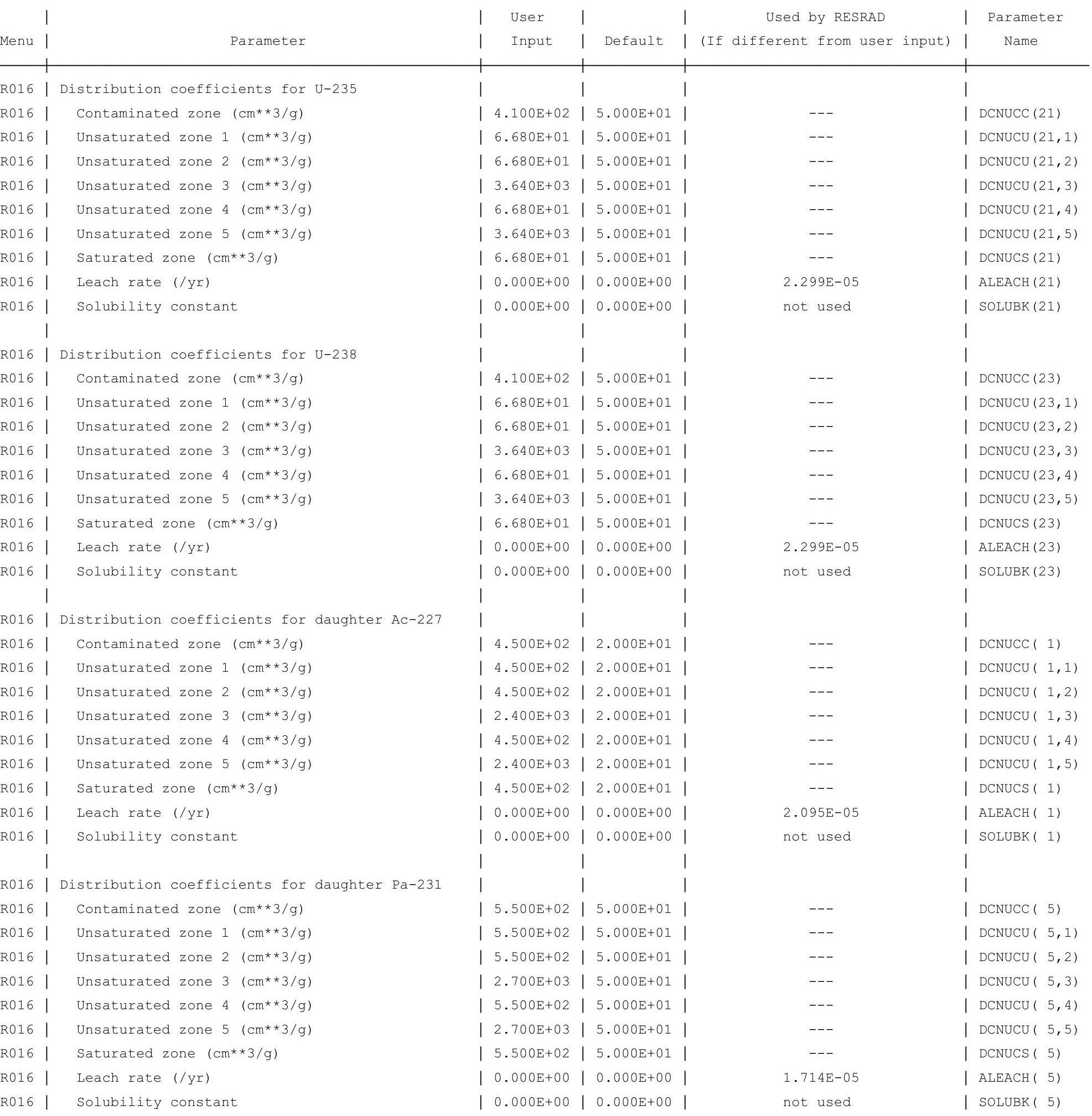


RESRAD, Version $6.5 \quad T^{1 / 2}$ Limit $=180$ days

Summary : RESRAD Parameters for Resident Farmer U-Landfill Forward Run 1,050 Years at ALs

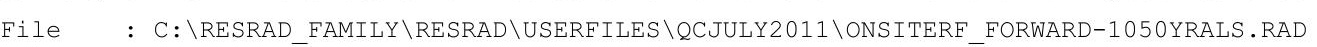

Site-Specific Parameter Summary (continued)

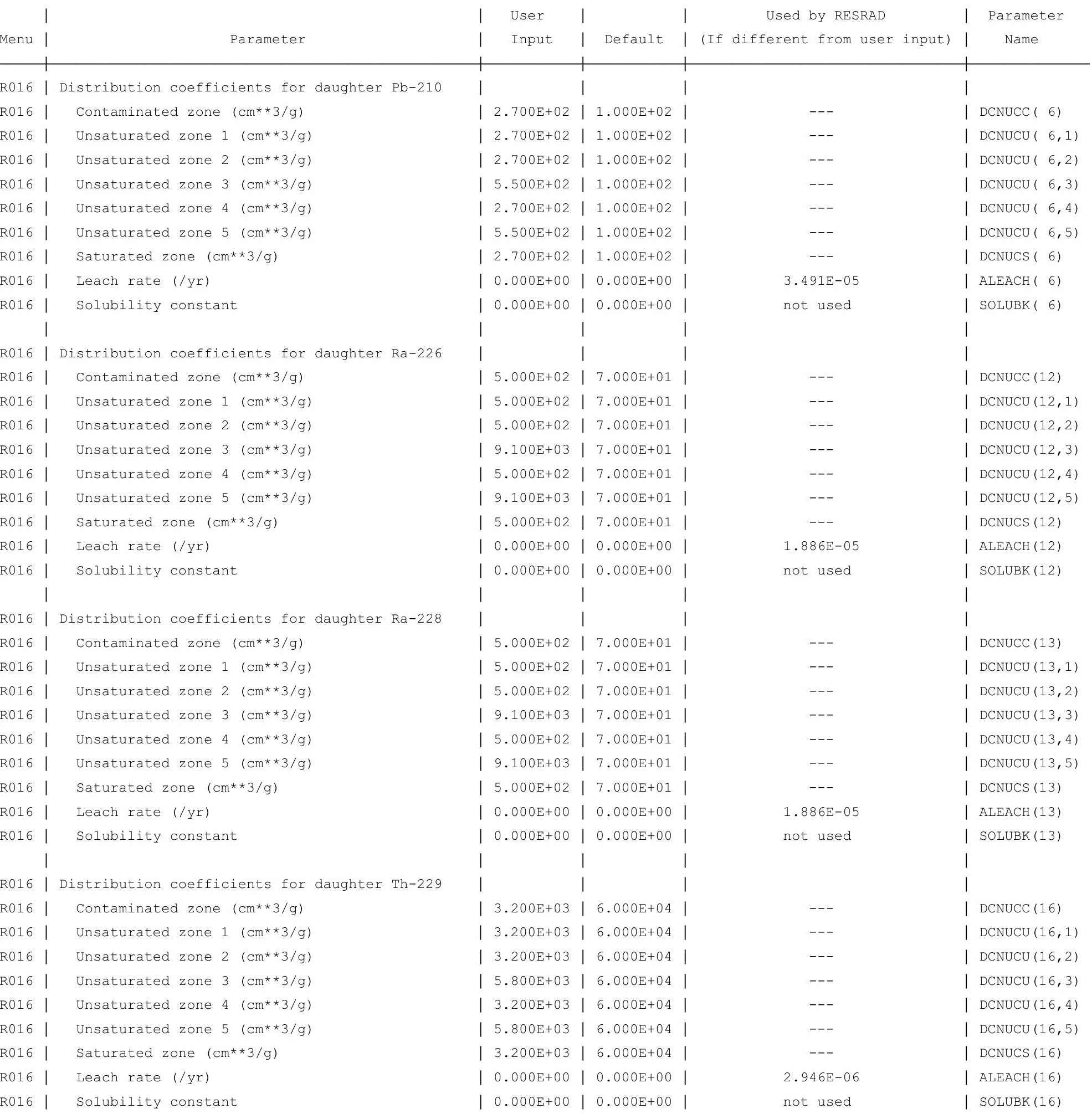


RESRAD, Version $6.5 \quad \mathrm{~T}^{\mathbb{1} 1 / 2}$ Limit $=180$ days

Summary : RESRAD Parameters for Resident Farmer U-Landfill Forward Run 1,050 Years at ALs

File : C: \RESRAD_FAMILY \RESRAD \USERFILES $Q Q C J U L Y 2011 \backslash$ ONSITERF_FORWARD-1050YRALS.RAD

Site-Specific Parameter Summary (continued)

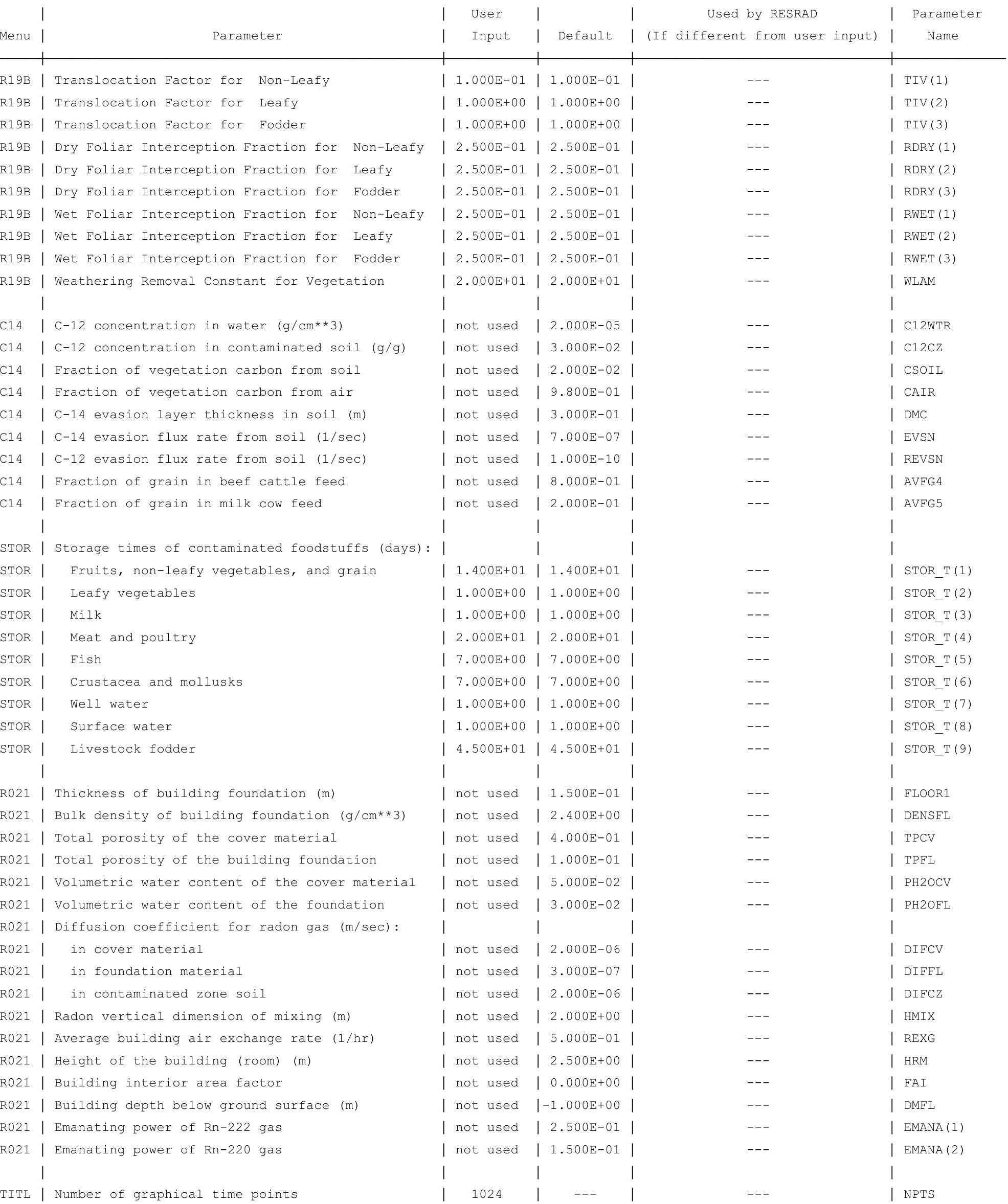

TITL | Number of graphical time points 
RESRAD, Version $6.5 \quad \mathrm{~T}^{1 / 2}$ Limit $=180$ days

Summary : RESRAD Parameters for Resident Farmer U-Landfill Forward Run 1,050 Years at ALs

File : C: \RESRAD_FAMILY \RESRAD \USERFILES \QCJULY2011 \ONSITERF_FORWARD-1050YRALS.RAD

Contaminated Zone Dimensions

Area: 89436.00 square meters

Thickness:

Cover Depth:

\begin{abstract}
13.40 meters
1.52 meters
\end{abstract}

\begin{tabular}{cr} 
Initial Soil Concentrations, pCi/g \\
\hline Am-241 & $7.000 \mathrm{E}+01$ \\
$\mathrm{Cs}-137$ & $3.800 \mathrm{E}+01$ \\
$\mathrm{~Np}-237$ & $1.100 \mathrm{E}+01$ \\
$\mathrm{Pu}-238$ & $7.800 \mathrm{E}+01$ \\
$\mathrm{Pu}-239$ & $7.200 \mathrm{E}+01$ \\
$\mathrm{Pu}-240$ & $7.200 \mathrm{E}+01$ \\
$\mathrm{TC}-99$ & $1.040 \mathrm{E}+02$ \\
$\mathrm{Th}-228$ & $8.000 \mathrm{E}+00$ \\
$\mathrm{Th}-230$ & $2.000 \mathrm{E}+02$ \\
$\mathrm{Th}-232$ & $8.000 \mathrm{E}+00$ \\
$\mathrm{U}-234$ & $3.200 \mathrm{E}+02$ \\
$\mathrm{U}-235$ & $1.300 \mathrm{E}+01$ \\
$\mathrm{U}-238$ & $3.200 \mathrm{E}+02$
\end{tabular}

Total Dose TDOSE(t), mrem/yr

Basic Radiation Dose Limit $=1.000 \mathrm{E}+02 \mathrm{mrem} / \mathrm{yr}$

Total Mixture Sum $M(t)$ = Fraction of Basic Dose Limit Received at Time (t)

$\begin{array}{rllllll}t \text { (years) }: & 0.000 \mathrm{E}+00 & 1.000 \mathrm{E}+00 & 5.000 \mathrm{E}+01 & 1.000 \mathrm{E}+02 & 5.000 \mathrm{E}+02 & 1.050 \mathrm{E}+03 \\ \mathrm{TDOSE}(\mathrm{t}): & 1.125 \mathrm{E}-05 & 8.412 \mathrm{E}-06 & 1.908 \mathrm{E}-05 & 2.733 \mathrm{E}-05 & 2.151 \mathrm{E}+01 & 1.481 \mathrm{E}+01 \\ \mathrm{M}(\mathrm{t}): & 1.125 \mathrm{E}-07 & 8.412 \mathrm{E}-08 & 1.908 \mathrm{E}-07 & 2.733 \mathrm{E}-07 & 2.151 \mathrm{E}-01 & 1.481 \mathrm{E}-01\end{array}$

Maximum TDOSE(t): $4.239 \mathrm{E}+01 \mathrm{mrem} / \mathrm{yr}$ at $t=424.6 \pm 0.8$ years

Total Dose Contributions TDOSE(i,p,t) for Individual Radionuclides (i) and Pathways (p) As mrem/yr and Fraction of Total Dose At $t=4.246 \mathrm{E}+02$ years

Water Independent Pathways (Inhalation excludes radon)

\begin{tabular}{|c|c|c|c|c|c|c|c|c|c|c|c|c|c|c|}
\hline & \multicolumn{2}{|c|}{ Ground } & \multicolumn{2}{|c|}{ Inhalation } & \multicolumn{2}{|c|}{ Radon } & \multicolumn{2}{|c|}{ Plant } & \multicolumn{2}{|c|}{ Meat } & \multicolumn{2}{|c|}{ Milk } & \multicolumn{2}{|c|}{ Soil } \\
\hline clide & mrem/yr & fract. & mrem/yr & fract. & mrem/yr & fract. & mrem/yr & fract. & mrem/yr & fract. & mrem/yr & fract. & mrem/yr & fract. \\
\hline 241 & $6.406 \mathrm{E}-13$ & 0.0000 & $0.000 \mathrm{E}+00$ & 0.0000 & $0.000 \mathrm{E}+00$ & 0.0000 & $0.000 \mathrm{E}+00$ & 0.0000 & $0.000 \mathrm{E}+00$ & 0.0000 & $0.000 \mathrm{E}+00$ & 0.0000 & $0.000 \mathrm{E}+00$ & 0.0000 \\
\hline-137 & $9.334 \mathrm{E}-11$ & 0.0000 & $0.000 \mathrm{E}+00$ & 0.0000 & $0.000 \mathrm{E}+00$ & 0.0000 & $0.000 \mathrm{E}+00$ & 0.0000 & $0.000 \mathrm{E}+00$ & 0.0000 & $0.000 \mathrm{E}+00$ & 0.0000 & $0.000 \mathrm{E}+00$ & 0.0000 \\
\hline-237 & $1.004 \mathrm{E}-09$ & 0.0000 & $0.000 \mathrm{E}+00$ & 0.0000 & $0.000 \mathrm{E}+00$ & 0.0000 & $0.000 \mathrm{E}+00$ & 0.0000 & $0.000 \mathrm{E}+00$ & 0.0000 & $0.000 \mathrm{E}+00$ & 0.0000 & $0.000 \mathrm{E}+00$ & 0.0000 \\
\hline-238 & $1.758 \mathrm{E}-11$ & 0.0000 & $0.000 \mathrm{E}+00$ & 0.0000 & $0.000 \mathrm{E}+00$ & 0.0000 & $0.000 \mathrm{E}+00$ & 0.0000 & $0.000 \mathrm{E}+00$ & 0.0000 & $0.000 \mathrm{E}+00$ & 0.0000 & $0.000 \mathrm{E}+00$ & 0.0000 \\
\hline-239 & $1.377 \mathrm{E}-13$ & 0.0000 & $0.000 \mathrm{E}+00$ & 0.0000 & $0.000 \mathrm{E}+00$ & 0.0000 & $0.000 \mathrm{E}+00$ & 0.0000 & $0.000 \mathrm{E}+00$ & 0.0000 & $0.000 \mathrm{E}+00$ & 0.0000 & $0.000 \mathrm{E}+00$ & 0.0000 \\
\hline-240 & $1.879 \mathrm{E}-16$ & 0.0000 & $0.000 \mathrm{E}+00$ & 0.0000 & $0.000 \mathrm{E}+00$ & 0.0000 & $0.000 \mathrm{E}+00$ & 0.0000 & $0.000 \mathrm{E}+00$ & 0.0000 & $0.000 \mathrm{E}+00$ & 0.0000 & $0.000 \mathrm{E}+00$ & 0.0000 \\
\hline 99 & 4. $495 \mathrm{E}-22$ & 0.0000 & $0.000 \mathrm{E}+00$ & 0.0000 & $0.000 \mathrm{E}+00$ & 0.0000 & $0.000 \mathrm{E}+00$ & 0.0000 & $0.000 \mathrm{E}+00$ & 0.0000 & $0.000 \mathrm{E}+00$ & 0.0000 & $0.000 \mathrm{E}+00$ & 0.0000 \\
\hline-228 & $0.000 \mathrm{E}+00$ & 0.0000 & $0.000 \mathrm{E}+00$ & 0.0000 & $0.000 \mathrm{E}+00$ & 0.0000 & $0.000 \mathrm{E}+00$ & 0.0000 & $0.000 \mathrm{E}+00$ & 0.0000 & $0.000 \mathrm{E}+00$ & 0.0000 & $0.000 \mathrm{E}+00$ & 0.0000 \\
\hline-230 & $1.098 E-04$ & 0.0000 & $0.000 \mathrm{E}+00$ & 0.0000 & $0.000 \mathrm{E}+00$ & 0.0000 & $0.000 \mathrm{E}+00$ & 0.0000 & $0.000 \mathrm{E}+00$ & 0.0000 & $0.000 \mathrm{E}+00$ & 0.0000 & $0.000 \mathrm{E}+00$ & 0.0000 \\
\hline 232 & $1.698 E-04$ & 0.0000 & $0.000 \mathrm{E}+00$ & 0.0000 & $0.000 \mathrm{E}+00$ & 0.0000 & $0.000 \mathrm{E}+00$ & 0.0000 & $0.000 \mathrm{E}+00$ & 0.0000 & $0.000 \mathrm{E}+00$ & 0.0000 & $0.000 \mathrm{E}+00$ & 0.0000 \\
\hline 34 & $3.459 E-07$ & 0.0000 & $0.000 \mathrm{E}+00$ & 0.0000 & $0.000 \mathrm{E}+00$ & 0.0000 & $0.000 \mathrm{E}+00$ & 0.0000 & $0.000 \mathrm{E}+00$ & 0.0000 & $0.000 \mathrm{E}+00$ & 0.0000 & $0.000 \mathrm{E}+00$ & 0.0000 \\
\hline 35 & $3.935 E-10$ & 0.0000 & $0.000 \mathrm{E}+00$ & 0.0000 & $0.000 \mathrm{E}+00$ & 0.0000 & $0.000 \mathrm{E}+00$ & 0.0000 & $0.000 \mathrm{E}+00$ & 0.0000 & $0.000 \mathrm{E}+00$ & 0.0000 & $0.000 \mathrm{E}+00$ & 0.0000 \\
\hline 38 & $1.346 \mathrm{E}-06$ & 0.0000 & $0.000 \mathrm{E}+00$ & 0.0000 & $0.000 \mathrm{E}+00$ & 0.0000 & $0.000 \mathrm{E}+00$ & 0.0000 & $0.000 \mathrm{E}+00$ & 0.0000 & $0.000 \mathrm{E}+00$ & 0.0000 & $0.000 \mathrm{E}+00$ & 0.0000 \\
\hline & $2.813 \mathrm{E}-04$ & 0.0 & $.000 \mathrm{E}+00$ & 0.0000 & $0.000 \mathrm{E}+00$ & 0.0000 & $0.000 \mathrm{E}+00$ & 0.0000 & $0.000 \mathrm{E}+00$ & 0.0000 & $0.000 \mathrm{E}+00$ & 000 & $0 \mathrm{E}+00$ & 00 \\
\hline
\end{tabular}


RESRAD, Version $6.5 \quad \mathrm{~T}^{1} \frac{1}{2}$ Limit $=180$ days

ummary : RESRAD Parameters for Resident Farmer U-Landfill Forward Run 1,050 Years at ALs

File : C: \RESRAD_FAMILY \RESRAD \USERFILES \QCJULY2011 \ONSITERF_FORWARD-1050YRALS.RAD

Total Dose Contributions TDOSE (i,p,t) for Individual Radionuclides (i) and Pathways (p) As mrem/yr and Fraction of Total Dose At $t=4.246 \mathrm{E}+02$ years

Water Dependent Pathways

\begin{tabular}{|c|c|c|c|c|c|c|c|c|c|c|c|c|c|c|}
\hline & \multicolumn{2}{|c|}{ Water } & \multicolumn{2}{|c|}{ Fish } & \multicolumn{2}{|c|}{ Radon } & \multicolumn{2}{|c|}{ Plant } & \multicolumn{2}{|c|}{ Meat } & \multicolumn{2}{|c|}{ Milk } & \multicolumn{2}{|c|}{ All Pathways* } \\
\hline clide & mrem/yr & fract. & mrem/yr & fract. & mrem/yr & fract. & mrem/yr & fract. & mrem/yr & fract. & mrem/yr & fract. & mrem/yr & fract. \\
\hline-241 & $0.000 \mathrm{E}+00$ & 0.0000 & $0.000 \mathrm{E}+00$ & 0.0000 & $0.000 \mathrm{E}+00$ & 0.0000 & $0.000 \mathrm{E}+00$ & 0.0000 & $0.000 \mathrm{E}+00$ & 0.0000 & $0.000 \mathrm{E}+00$ & 0.0000 & $6.406 \mathrm{E}-13$ & 0.0000 \\
\hline-137 & $0.000 \mathrm{E}+00$ & 0.0000 & $0.000 \mathrm{E}+00$ & 0.0000 & $0.000 \mathrm{E}+00$ & 0.0000 & $0.000 \mathrm{E}+00$ & 0.0000 & $0.000 \mathrm{E}+00$ & 0.0000 & $0.000 \mathrm{E}+00$ & 0.0000 & $9.334 \mathrm{E}-11$ & 0.0000 \\
\hline-237 & $0.000 \mathrm{E}+00$ & 0.0000 & $0.000 \mathrm{E}+00$ & 0.0000 & $0.000 \mathrm{E}+00$ & 0.0000 & $0.000 \mathrm{E}+00$ & 0.0000 & $0.000 \mathrm{E}+00$ & 0.0000 & $0.000 \mathrm{E}+00$ & 0.0000 & $1.004 \mathrm{E}-09$ & 0.0000 \\
\hline-238 & $0.000 \mathrm{E}+00$ & 0.0000 & $0.000 \mathrm{E}+00$ & 0.0000 & $0.000 \mathrm{E}+00$ & 0.0000 & $0.000 \mathrm{E}+00$ & 0.0000 & $0.000 \mathrm{E}+00$ & 0.0000 & $0.000 \mathrm{E}+00$ & 0.0000 & $1.758 \mathrm{E}-11$ & 0.0000 \\
\hline 239 & $0.000 \mathrm{E}+00$ & 0.0000 & $0.000 \mathrm{E}+00$ & 0.0000 & $0.000 \mathrm{E}+00$ & 0.0000 & $0.000 \mathrm{E}+00$ & 0.0000 & $0.000 \mathrm{E}+00$ & 0.0000 & $0.000 \mathrm{E}+00$ & 0.0000 & $1.377 \mathrm{E}-13$ & 0.0000 \\
\hline-240 & $0.000 \mathrm{E}+00$ & 0.0000 & $0.000 \mathrm{E}+00$ & 0.0000 & $0.000 \mathrm{E}+00$ & 0.0000 & $0.000 \mathrm{E}+00$ & 0.0000 & $0.000 \mathrm{E}+00$ & 0.0000 & $0.000 \mathrm{E}+00$ & 0.0000 & $1.879 \mathrm{E}-16$ & 0.0000 \\
\hline-99 & $3.509 \mathrm{E}+01$ & 0.8278 & $0.000 \mathrm{E}+00$ & 0.0000 & $0.000 \mathrm{E}+00$ & 0.0000 & $3.279 \mathrm{E}+00$ & 0.0773 & $5.862 \mathrm{E}-02$ & 0.0014 & $3.962 \mathrm{E}+00$ & 0.0935 & $4.239 \mathrm{E}+01$ & 1.0000 \\
\hline-228 & $0.000 \mathrm{E}+00$ & 0.0000 & $0.000 \mathrm{E}+00$ & 0.0000 & $0.000 \mathrm{E}+00$ & 0.0000 & $0.000 \mathrm{E}+00$ & 0.0000 & $0.000 \mathrm{E}+00$ & 0.0000 & $0.000 \mathrm{E}+00$ & 0.0000 & $0.000 \mathrm{E}+00$ & 0.0000 \\
\hline-230 & $0.000 \mathrm{E}+00$ & 0.0000 & $0.000 \mathrm{E}+00$ & 0.0000 & $0.000 \mathrm{E}+00$ & 0.0000 & $0.000 \mathrm{E}+00$ & 0.0000 & $0.000 \mathrm{E}+00$ & 0.0000 & $0.000 \mathrm{E}+00$ & 0.0000 & $1.098 \mathrm{E}-04$ & 0.0000 \\
\hline-232 & $0.000 \mathrm{E}+00$ & 0.0000 & $0.000 \mathrm{E}+00$ & 0.0000 & $0.000 \mathrm{E}+00$ & 0.0000 & $0.000 \mathrm{E}+00$ & 0.0000 & $0.000 \mathrm{E}+00$ & 0.0000 & $0.000 \mathrm{E}+00$ & 0.0000 & $1.698 \mathrm{E}-04$ & 0.0000 \\
\hline 34 & $0.000 \mathrm{E}+00$ & 0.0000 & $0.000 \mathrm{E}+00$ & 0.0000 & $0.000 \mathrm{E}+00$ & 0.0000 & $0.000 \mathrm{E}+00$ & 0.0000 & $0.000 \mathrm{E}+00$ & 0.0000 & $0.000 \mathrm{E}+00$ & 0.0000 & $3.459 \mathrm{E}-07$ & 0.0000 \\
\hline 35 & $0.000 \mathrm{E}+00$ & 0.0000 & $0.000 \mathrm{E}+00$ & 0.0000 & $0.000 \mathrm{E}+00$ & 0.0000 & $0.000 \mathrm{E}+00$ & 0.0000 & $0.000 \mathrm{E}+00$ & 0.0000 & $0.000 \mathrm{E}+00$ & 0.0000 & $3.935 \mathrm{E}-10$ & 0.0000 \\
\hline 80 & $0.000 \mathrm{E}+00$ & 0.0000 & $0.000 \mathrm{E}+00$ & 0.0000 & $0.000 \mathrm{E}+00$ & 0.0000 & $0.000 \mathrm{E}+00$ & 0.0000 & $0.000 \mathrm{E}+00$ & 0.0000 & $0.000 \mathrm{E}+00$ & 0.0000 & $1.346 \mathrm{E}-06$ & 0.0000 \\
\hline & $3.509 \mathrm{E}+01$ & 0.8278 & $0.000 \mathrm{E}+00$ & 0.0000 & $0.000 \mathrm{E}+00$ & 0.0000 & $3.279 E+00$ & 0.0773 & $5.862 E-02$ & 0.0014 & $3.962 E+00$ & 0.0935 & +01 & 00 \\
\hline
\end{tabular}

*Sum of all water independent and dependent pathways. 
RESRAD, Version $6.5 \quad \mathrm{~T}^{1} \frac{1}{2}$ Limit $=180$ days

07/20/2011 14:25 Page 21

ummary : RESRAD Parameters for Resident Farmer U-Landfill Forward Run 1,050 Years at ALs

File : C: \RESRAD_FAMILY \RESRAD \USERFILES \QCJULY2011 \ONSITERF_FORWARD-1050YRALS.RAD

Total Dose Contributions TDOSE (i,p,t) for Individual Radionuclides (i) and Pathways (p) As mrem/yr and Fraction of Total Dose At $t=0.000 \mathrm{E}+00$ years

Water Independent Pathways (Inhalation excludes radon)

\begin{tabular}{|c|c|c|c|c|c|c|c|c|c|c|c|c|c|c|}
\hline \multirow{2}{*}{ Nuclide } & \multicolumn{2}{|c|}{ Ground } & \multicolumn{2}{|c|}{ Inhalation } & \multicolumn{2}{|c|}{ Radon } & \multicolumn{2}{|c|}{ Plant } & \multicolumn{2}{|c|}{ Meat } & \multicolumn{2}{|c|}{ Milk } & \multicolumn{2}{|c|}{ Soil } \\
\hline & mrem/yr & fract. & mrem/yr & fract. & mrem/yr & fract. & mrem/yr & fract. & mrem/yr & fract. & mrem/yr & fract. & mrem/yr & fract. \\
\hline-241 & $1.082 \mathrm{E}-17$ & 0.0000 & $0.000 \mathrm{E}+00$ & 0.0000 & $0.000 \mathrm{E}+00$ & 0.0000 & $0.000 \mathrm{E}+00$ & 0.0000 & $0.000 \mathrm{E}+00$ & 0.0000 & $0.000 \mathrm{E}+00$ & 0.0000 & $0.000 \mathrm{E}+00$ & 0.0000 \\
\hline-137 & $4.795 E-08$ & 0.0043 & $0.000 \mathrm{E}+00$ & 0.0000 & $0.000 \mathrm{E}+00$ & 0.0000 & $0.000 \mathrm{E}+00$ & 0.0000 & $0.000 \mathrm{E}+00$ & 0.0000 & $0.000 \mathrm{E}+00$ & 0.0000 & $0.000 \mathrm{E}+00$ & 0.0000 \\
\hline-237 & $1.049 \mathrm{E}-11$ & 0.0000 & $0.000 \mathrm{E}+00$ & 0.0000 & $0.000 \mathrm{E}+00$ & 0.0000 & $0.000 \mathrm{E}+00$ & 0.0000 & $0.000 \mathrm{E}+00$ & 0.0000 & $0.000 \mathrm{E}+00$ & 0.0000 & $0.000 \mathrm{E}+00$ & 0.0000 \\
\hline-238 & $6.348 E-21$ & 0.0000 & $0.000 \mathrm{E}+00$ & 0.0000 & $0.000 \mathrm{E}+00$ & 0.0000 & $0.000 \mathrm{E}+00$ & 0.0000 & $0.000 \mathrm{E}+00$ & 0.0000 & $0.000 \mathrm{E}+00$ & 0.0000 & $0.000 \mathrm{E}+00$ & 0.0000 \\
\hline-239 & $8.656 \mathrm{E}-16$ & 0.0000 & $0.000 \mathrm{E}+00$ & 0.0000 & $0.000 \mathrm{E}+00$ & 0.0000 & $0.000 \mathrm{E}+00$ & 0.0000 & $0.000 \mathrm{E}+00$ & 0.0000 & $0.000 \mathrm{E}+00$ & 0.0000 & $0.000 \mathrm{E}+00$ & 0.0000 \\
\hline-240 & $8.230 \mathrm{E}-23$ & 0.0000 & $0.000 \mathrm{E}+00$ & 0.0000 & $0.000 \mathrm{E}+00$ & 0.0000 & $0.000 \mathrm{E}+00$ & 0.0000 & $0.000 \mathrm{E}+00$ & 0.0000 & $0.000 \mathrm{E}+00$ & 0.0000 & $0.000 \mathrm{E}+00$ & 0.0000 \\
\hline 99 & $5.988 E-24$ & 0.0000 & $0.000 \mathrm{E}+00$ & 0.0000 & $0.000 \mathrm{E}+00$ & 0.0000 & $0.000 \mathrm{E}+00$ & 0.0000 & $0.000 \mathrm{E}+00$ & 0.0000 & $0.000 \mathrm{E}+00$ & 0.0000 & $0.000 \mathrm{E}+00$ & 0.0000 \\
\hline-228 & $1.106 \mathrm{E}-05$ & 0.9827 & $0.000 \mathrm{E}+00$ & 0.0000 & $0.000 \mathrm{E}+00$ & 0.0000 & $0.000 \mathrm{E}+00$ & 0.0000 & $0.000 \mathrm{E}+00$ & 0.0000 & $0.000 \mathrm{E}+00$ & 0.0000 & $0.000 \mathrm{E}+00$ & 0.0000 \\
\hline-230 & $7.548 \mathrm{E}-09$ & 0.0007 & $0.000 \mathrm{E}+00$ & 0.0000 & $0.000 \mathrm{E}+00$ & 0.0000 & $0.000 \mathrm{E}+00$ & 0.0000 & $0.000 \mathrm{E}+00$ & 0.0000 & $0.000 \mathrm{E}+00$ & 0.0000 & $0.000 \mathrm{E}+00$ & 0.0000 \\
\hline-232 & $9.424 \mathrm{E}-08$ & 0.0084 & $0.000 \mathrm{E}+00$ & 0.0000 & $0.000 \mathrm{E}+00$ & 0.0000 & $0.000 \mathrm{E}+00$ & 0.0000 & $0.000 \mathrm{E}+00$ & 0.0000 & $0.000 \mathrm{E}+00$ & 0.0000 & $0.000 \mathrm{E}+00$ & 0.0000 \\
\hline 34 & $3.626 \mathrm{E}-14$ & 0.0000 & $0.000 \mathrm{E}+00$ & 0.0000 & $0.000 \mathrm{E}+00$ & 0.0000 & $0.000 \mathrm{E}+00$ & 0.0000 & $0.000 \mathrm{E}+00$ & 0.0000 & $0.000 \mathrm{E}+00$ & 0.0000 & $0.000 \mathrm{E}+00$ & 0.0000 \\
\hline 35 & 1. $618 \mathrm{E}-13$ & 0.0000 & $0.000 \mathrm{E}+00$ & 0.0000 & $0.000 \mathrm{E}+00$ & 0.0000 & $0.000 \mathrm{E}+00$ & 0.0000 & $0.000 \mathrm{E}+00$ & 0.0000 & $0.000 \mathrm{E}+00$ & 0.0000 & $0.000 \mathrm{E}+00$ & 0.0000 \\
\hline 38 & $4.543 E-08$ & 0.0040 & $0.000 \mathrm{E}+00$ & 0.0000 & $0.000 \mathrm{E}+00$ & 0.0000 & $0.000 \mathrm{E}+00$ & 0.0000 & $0.000 \mathrm{E}+00$ & 0.0000 & $0.000 \mathrm{E}+00$ & 0.0000 & $0.000 \mathrm{E}+00$ & 0.0000 \\
\hline & $1.125 E-05$ & 1.0000 & $0.000 \mathrm{E}+00$ & 0.0000 & $0.000 \mathrm{E}+00$ & 0.0000 & $0.000 \mathrm{E}+00$ & 0.0000 & $0.000 \mathrm{E}+00$ & 0.0000 & $0.000 \mathrm{E}+00$ & 0.0000 & $.000 \mathrm{E}+00$ & 0.0000 \\
\hline
\end{tabular}

Total Dose Contributions TDOSE(i,p,t) for Individual Radionuclides (i) and Pathways (p) As mrem/yr and Fraction of Total Dose At $t=0.000 \mathrm{E}+00$ years

Water Dependent Pathways

\begin{tabular}{|c|c|c|c|c|c|c|c|c|c|c|c|c|c|c|}
\hline & \multicolumn{2}{|c|}{ Water } & \multicolumn{2}{|c|}{ Fish } & \multicolumn{2}{|c|}{ Radon } & \multicolumn{2}{|c|}{ Plant } & \multicolumn{2}{|c|}{ Meat } & \multicolumn{2}{|c|}{ Milk } & \multicolumn{2}{|c|}{ All Pathways* } \\
\hline clide & mrem/yr & fract. & mrem/yr & fract. & mrem/yr & fract. & mrem/yr & fract. & mrem/yr & fract. & mrem/yr & fract. & mrem/yr & fract. \\
\hline-241 & $0.000 \mathrm{E}+00$ & 0.0000 & $0.000 \mathrm{E}+00$ & 0.0000 & $0.000 \mathrm{E}+00$ & 0.0000 & $0.000 \mathrm{E}+00$ & 0.0000 & $0.000 \mathrm{E}+00$ & 0.0000 & $0.000 \mathrm{E}+00$ & 0.0000 & $1.082 \mathrm{E}-17$ & 0.0000 \\
\hline-137 & $0.000 \mathrm{E}+00$ & 0.0000 & $0.000 \mathrm{E}+00$ & 0.0000 & $0.000 \mathrm{E}+00$ & 0.0000 & $0.000 \mathrm{E}+00$ & 0.0000 & $0.000 \mathrm{E}+00$ & 0.0000 & $0.000 \mathrm{E}+00$ & 0.0000 & $4.795 E-08$ & 0.0043 \\
\hline-237 & $0.000 \mathrm{E}+00$ & 0.0000 & $0.000 \mathrm{E}+00$ & 0.0000 & $0.000 \mathrm{E}+00$ & 0.0000 & $0.000 \mathrm{E}+00$ & 0.0000 & $0.000 \mathrm{E}+00$ & 0.0000 & $0.000 \mathrm{E}+00$ & 0.0000 & $1.049 \mathrm{E}-11$ & 0.0000 \\
\hline 238 & $0.000 \mathrm{E}+00$ & 0.0000 & $0.000 \mathrm{E}+00$ & 0.0000 & $0.000 \mathrm{E}+00$ & 0.0000 & $0.000 \mathrm{E}+00$ & 0.0000 & $0.000 \mathrm{E}+00$ & 0.0000 & $0.000 \mathrm{E}+00$ & 0.0000 & $6.348 E-21$ & 0.0000 \\
\hline 239 & $0.000 \mathrm{E}+00$ & 0.0000 & $0.000 \mathrm{E}+00$ & 0.0000 & $0.000 \mathrm{E}+00$ & 0.0000 & $0.000 \mathrm{E}+00$ & 0.0000 & $0.000 \mathrm{E}+00$ & 0.0000 & $0.000 \mathrm{E}+00$ & 0.0000 & $8.656 \mathrm{E}-16$ & 0.0000 \\
\hline 240 & $0.000 \mathrm{E}+00$ & 0.0000 & $0.000 \mathrm{E}+00$ & 0.0000 & $0.000 \mathrm{E}+00$ & 0.0000 & $0.000 \mathrm{E}+00$ & 0.0000 & $0.000 \mathrm{E}+00$ & 0.0000 & $0.000 \mathrm{E}+00$ & 0.0000 & $8.230 \mathrm{E}-23$ & 0.0000 \\
\hline 99 & $0.000 \mathrm{E}+00$ & 0.0000 & $0.000 \mathrm{E}+00$ & 0.0000 & $0.000 \mathrm{E}+00$ & 0.0000 & $0.000 \mathrm{E}+00$ & 0.0000 & $0.000 \mathrm{E}+00$ & 0.0000 & $0.000 \mathrm{E}+00$ & 0.0000 & $5.988 E-24$ & 0.0000 \\
\hline 228 & $0.000 \mathrm{E}+00$ & 0.0000 & $0.000 \mathrm{E}+00$ & 0.0000 & $0.000 \mathrm{E}+00$ & 0.0000 & $0.000 \mathrm{E}+00$ & 0.0000 & $0.000 \mathrm{E}+00$ & 0.0000 & $0.000 \mathrm{E}+00$ & 0.0000 & $1.106 \mathrm{E}-05$ & 0.9827 \\
\hline 230 & $0.000 \mathrm{E}+00$ & 0.0000 & $0.000 \mathrm{E}+00$ & 0.0000 & $0.000 \mathrm{E}+00$ & 0.0000 & $0.000 \mathrm{E}+00$ & 0.0000 & $0.000 \mathrm{E}+00$ & 0.0000 & $0.000 \mathrm{E}+00$ & 0.0000 & $7.548 \mathrm{E}-09$ & 0.0007 \\
\hline 232 & $0.000 \mathrm{E}+00$ & 0.0000 & $0.000 \mathrm{E}+00$ & 0.0000 & $0.000 \mathrm{E}+00$ & 0.0000 & $0.000 \mathrm{E}+00$ & 0.0000 & $0.000 \mathrm{E}+00$ & 0.0000 & $0.000 \mathrm{E}+00$ & 0.0000 & $9.424 \mathrm{E}-08$ & 0.0084 \\
\hline 34 & $0.000 \mathrm{E}+00$ & 0.0000 & $0.000 \mathrm{E}+00$ & 0.0000 & $0.000 \mathrm{E}+00$ & 0.0000 & $0.000 \mathrm{E}+00$ & 0.0000 & $0.000 \mathrm{E}+00$ & 0.0000 & $0.000 \mathrm{E}+00$ & 0.0000 & $3.626 \mathrm{E}-14$ & 0.0000 \\
\hline 35 & $0.000 \mathrm{E}+00$ & 0.0000 & $0.000 \mathrm{E}+00$ & 0.0000 & $0.000 \mathrm{E}+00$ & 0.0000 & $0.000 \mathrm{E}+00$ & 0.0000 & $0.000 \mathrm{E}+00$ & 0.0000 & $0.000 \mathrm{E}+00$ & 0.0000 & $1.618 \mathrm{E}-13$ & 0.0000 \\
\hline 38 & $0.000 \mathrm{E}+00$ & 0.0000 & $0.000 \mathrm{E}+00$ & 0.0000 & $0.000 \mathrm{E}+00$ & 0.0000 & $0.000 \mathrm{E}+00$ & 0.0000 & $0.000 \mathrm{E}+00$ & 0.0000 & $0.000 \mathrm{E}+00$ & 0.0000 & $4.543 E-08$ & 0.0040 \\
\hline & $0.000 \mathrm{E}+00$ & 0.0000 & $0.000 \mathrm{E}+00$ & 0.0000 & $0.000 \mathrm{E}+00$ & 0.0000 & $0.000 \mathrm{E}+00$ & 0.0000 & $0.000 \mathrm{E}+00$ & 0.0000 & $0.000 \mathrm{E}+00$ & 000 & -05 & 1.0000 \\
\hline
\end{tabular}

* Sum of all water independent and dependent pathways. 
RESRAD, Version $6.5 \quad \mathrm{~T}^{1} \frac{1}{2}$ Limit $=180$ days

07/20/2011 14:25 Page 22

ummary : RESRAD Parameters for Resident Farmer U-Landfill Forward Run 1,050 Years at ALs

File : C: \RESRAD_FAMILY \RESRAD \USERFILES \QCJULY2011 \ONSITERF_FORWARD-1050YRALS.RAD

Total Dose Contributions TDOSE (i,p,t) for Individual Radionuclides (i) and Pathways (p) As mrem/yr and Fraction of Total Dose At $t=1.000 \mathrm{E}+00$ years

Water Independent Pathways (Inhalation excludes radon)

\begin{tabular}{|c|c|c|c|c|c|c|c|c|c|c|c|c|c|c|}
\hline \multirow{2}{*}{ Nuclide } & \multicolumn{2}{|c|}{ Ground } & \multicolumn{2}{|c|}{ Inhalation } & \multicolumn{2}{|c|}{ Radon } & \multicolumn{2}{|c|}{ Plant } & \multicolumn{2}{|c|}{ Meat } & \multicolumn{2}{|c|}{ Milk } & \multicolumn{2}{|c|}{ Soil } \\
\hline & mrem/yr & fract. & mrem/yr & fract. & mrem/yr & fract. & mrem/yr & fract. & mrem/yr & fract. & mrem/yr & fract. & mrem/yr & fract. \\
\hline-241 & $3.276 \mathrm{E}-17$ & 0.0000 & $0.000 \mathrm{E}+00$ & 0.0000 & $0.000 \mathrm{E}+00$ & 0.0000 & $0.000 \mathrm{E}+00$ & 0.0000 & $0.000 \mathrm{E}+00$ & 0.0000 & $0.000 \mathrm{E}+00$ & 0.0000 & $0.000 \mathrm{E}+00$ & 0.0000 \\
\hline-137 & $4.725 E-08$ & 0.0056 & $0.000 \mathrm{E}+00$ & 0.0000 & $0.000 \mathrm{E}+00$ & 0.0000 & $0.000 \mathrm{E}+00$ & 0.0000 & $0.000 \mathrm{E}+00$ & 0.0000 & $0.000 \mathrm{E}+00$ & 0.0000 & $0.000 \mathrm{E}+00$ & 0.0000 \\
\hline-237 & $1.060 \mathrm{E}-11$ & 0.0000 & $0.000 \mathrm{E}+00$ & 0.0000 & $0.000 \mathrm{E}+00$ & 0.0000 & $0.000 \mathrm{E}+00$ & 0.0000 & $0.000 \mathrm{E}+00$ & 0.0000 & $0.000 \mathrm{E}+00$ & 0.0000 & $0.000 \mathrm{E}+00$ & 0.0000 \\
\hline-238 & $9.433 E-20$ & 0.0000 & $0.000 \mathrm{E}+00$ & 0.0000 & $0.000 \mathrm{E}+00$ & 0.0000 & $0.000 \mathrm{E}+00$ & 0.0000 & $0.000 \mathrm{E}+00$ & 0.0000 & $0.000 \mathrm{E}+00$ & 0.0000 & $0.000 \mathrm{E}+00$ & 0.0000 \\
\hline-239 & $8.760 \mathrm{E}-16$ & 0.0000 & $0.000 \mathrm{E}+00$ & 0.0000 & $0.000 \mathrm{E}+00$ & 0.0000 & $0.000 \mathrm{E}+00$ & 0.0000 & $0.000 \mathrm{E}+00$ & 0.0000 & $0.000 \mathrm{E}+00$ & 0.0000 & $0.000 \mathrm{E}+00$ & 0.0000 \\
\hline-240 & $8.551 \mathrm{E}-23$ & 0.0000 & $0.000 \mathrm{E}+00$ & 0.0000 & $0.000 \mathrm{E}+00$ & 0.0000 & $0.000 \mathrm{E}+00$ & 0.0000 & $0.000 \mathrm{E}+00$ & 0.0000 & $0.000 \mathrm{E}+00$ & 0.0000 & $0.000 \mathrm{E}+00$ & 0.0000 \\
\hline 99 & $6.050 E-24$ & 0.0000 & $0.000 \mathrm{E}+00$ & 0.0000 & $0.000 \mathrm{E}+00$ & 0.0000 & $0.000 \mathrm{E}+00$ & 0.0000 & $0.000 \mathrm{E}+00$ & 0.0000 & $0.000 \mathrm{E}+00$ & 0.0000 & $0.000 \mathrm{E}+00$ & 0.0000 \\
\hline-228 & $7.744 \mathrm{E}-06$ & 0.9206 & $0.000 \mathrm{E}+00$ & 0.0000 & $0.000 \mathrm{E}+00$ & 0.0000 & $0.000 \mathrm{E}+00$ & 0.0000 & $0.000 \mathrm{E}+00$ & 0.0000 & $0.000 \mathrm{E}+00$ & 0.0000 & $0.000 \mathrm{E}+00$ & 0.0000 \\
\hline 230 & $2.278 E-08$ & 0.0027 & $0.000 \mathrm{E}+00$ & 0.0000 & $0.000 \mathrm{E}+00$ & 0.0000 & $0.000 \mathrm{E}+00$ & 0.0000 & $0.000 \mathrm{E}+00$ & 0.0000 & $0.000 \mathrm{E}+00$ & 0.0000 & $0.000 \mathrm{E}+00$ & 0.0000 \\
\hline-232 & $5.519 \mathrm{E}-07$ & 0.0656 & $0.000 \mathrm{E}+00$ & 0.0000 & $0.000 \mathrm{E}+00$ & 0.0000 & $0.000 \mathrm{E}+00$ & 0.0000 & $0.000 \mathrm{E}+00$ & 0.0000 & $0.000 \mathrm{E}+00$ & 0.0000 & $0.000 \mathrm{E}+00$ & 0.0000 \\
\hline 234 & $2.553 E-13$ & 0.0000 & $0.000 \mathrm{E}+00$ & 0.0000 & $0.000 \mathrm{E}+00$ & 0.0000 & $0.000 \mathrm{E}+00$ & 0.0000 & $0.000 \mathrm{E}+00$ & 0.0000 & $0.000 \mathrm{E}+00$ & 0.0000 & $0.000 \mathrm{E}+00$ & 0.0000 \\
\hline 35 & $1.646 \mathrm{E}-13$ & 0.0000 & $0.000 \mathrm{E}+00$ & 0.0000 & $0.000 \mathrm{E}+00$ & 0.0000 & $0.000 \mathrm{E}+00$ & 0.0000 & $0.000 \mathrm{E}+00$ & 0.0000 & $0.000 \mathrm{E}+00$ & 0.0000 & $0.000 \mathrm{E}+00$ & 0.0000 \\
\hline 38 & $4.579 E-08$ & 0.0054 & $0.000 \mathrm{E}+00$ & 0.0000 & $0.000 \mathrm{E}+00$ & 0.0000 & $0.000 \mathrm{E}+00$ & 0.0000 & $0.000 \mathrm{E}+00$ & 0.0000 & $0.000 \mathrm{E}+00$ & 0.0000 & $0.000 \mathrm{E}+00$ & 0.0000 \\
\hline & $8.412 \mathrm{E}-06$ & 1.0000 & $0.000 \mathrm{E}+00$ & 0.0000 & $0.000 \mathrm{E}+00$ & 0.0000 & $0.000 \mathrm{E}+00$ & 0.0000 & $0.000 \mathrm{E}+00$ & 0.0000 & $0.000 \mathrm{E}+00$ & 0.0000 & $.000 \mathrm{E}+00$ & 0.0000 \\
\hline
\end{tabular}

Total Dose Contributions TDOSE(i,p,t) for Individual Radionuclides (i) and Pathways (p) As mrem/yr and Fraction of Total Dose At $t=1.000 \mathrm{E}+00$ years

Water Dependent Pathways

\begin{tabular}{|c|c|c|c|c|c|c|c|c|c|c|c|c|c|c|}
\hline \multirow{2}{*}{ Nuclide } & \multicolumn{2}{|c|}{ Water } & \multicolumn{2}{|c|}{ Fish } & \multicolumn{2}{|c|}{ Radon } & \multicolumn{2}{|c|}{ Plant } & \multicolumn{2}{|c|}{ Meat } & \multicolumn{2}{|c|}{ Milk } & \multicolumn{2}{|c|}{ All Pathways* } \\
\hline & mrem/yr & fract. & mrem/yr & fract. & mrem/yr & fract. & mrem/yr & fract. & mrem/yr & fract. & mrem/yr & fract. & mrem/yr & fract. \\
\hline-241 & $0.000 \mathrm{E}+00$ & 0.0000 & $0.000 \mathrm{E}+00$ & 0.0000 & $0.000 \mathrm{E}+00$ & 0.0000 & $0.000 \mathrm{E}+00$ & 0.0000 & $0.000 \mathrm{E}+00$ & 0.0000 & $0.000 \mathrm{E}+00$ & 0.0000 & $3.276 \mathrm{E}-17$ & 0.0000 \\
\hline-137 & $0.000 \mathrm{E}+00$ & 0.0000 & $0.000 \mathrm{E}+00$ & 0.0000 & $0.000 \mathrm{E}+00$ & 0.0000 & $0.000 \mathrm{E}+00$ & 0.0000 & $0.000 \mathrm{E}+00$ & 0.0000 & $0.000 \mathrm{E}+00$ & 0.0000 & $4.725 E-08$ & 0.0056 \\
\hline-237 & $0.000 \mathrm{E}+00$ & 0.0000 & $0.000 \mathrm{E}+00$ & 0.0000 & $0.000 \mathrm{E}+00$ & 0.0000 & $0.000 \mathrm{E}+00$ & 0.0000 & $0.000 \mathrm{E}+00$ & 0.0000 & $0.000 \mathrm{E}+00$ & 0.0000 & $1.060 \mathrm{E}-11$ & 0.0000 \\
\hline-238 & $0.000 \mathrm{E}+00$ & 0.0000 & $0.000 \mathrm{E}+00$ & 0.0000 & $0.000 \mathrm{E}+00$ & 0.0000 & $0.000 \mathrm{E}+00$ & 0.0000 & $0.000 \mathrm{E}+00$ & 0.0000 & $0.000 \mathrm{E}+00$ & 0.0000 & $9.433 E-20$ & 0.0000 \\
\hline 239 & $0.000 \mathrm{E}+00$ & 0.0000 & $0.000 \mathrm{E}+00$ & 0.0000 & $0.000 \mathrm{E}+00$ & 0.0000 & $0.000 \mathrm{E}+00$ & 0.0000 & $0.000 \mathrm{E}+00$ & 0.0000 & $0.000 \mathrm{E}+00$ & 0.0000 & $8.760 \mathrm{E}-16$ & 0.0000 \\
\hline-240 & $0.000 \mathrm{E}+00$ & 0.0000 & $0.000 \mathrm{E}+00$ & 0.0000 & $0.000 \mathrm{E}+00$ & 0.0000 & $0.000 \mathrm{E}+00$ & 0.0000 & $0.000 \mathrm{E}+00$ & 0.0000 & $0.000 \mathrm{E}+00$ & 0.0000 & $8.551 E-23$ & 0.0000 \\
\hline 99 & $0.000 \mathrm{E}+00$ & 0.0000 & $0.000 \mathrm{E}+00$ & 0.0000 & $0.000 \mathrm{E}+00$ & 0.0000 & $0.000 \mathrm{E}+00$ & 0.0000 & $0.000 \mathrm{E}+00$ & 0.0000 & $0.000 \mathrm{E}+00$ & 0.0000 & $6.050 \mathrm{E}-24$ & 0.0000 \\
\hline-228 & $0.000 \mathrm{E}+00$ & 0.0000 & $0.000 \mathrm{E}+00$ & 0.0000 & $0.000 \mathrm{E}+00$ & 0.0000 & $0.000 \mathrm{E}+00$ & 0.0000 & $0.000 \mathrm{E}+00$ & 0.0000 & $0.000 \mathrm{E}+00$ & 0.0000 & $7.744 \mathrm{E}-06$ & 0.9206 \\
\hline-230 & $0.000 \mathrm{E}+00$ & 0.0000 & $0.000 \mathrm{E}+00$ & 0.0000 & $0.000 \mathrm{E}+00$ & 0.0000 & $0.000 \mathrm{E}+00$ & 0.0000 & $0.000 \mathrm{E}+00$ & 0.0000 & $0.000 \mathrm{E}+00$ & 0.0000 & $2.278 E-08$ & 0.0027 \\
\hline-232 & $0.000 \mathrm{E}+00$ & 0.0000 & $0.000 \mathrm{E}+00$ & 0.0000 & $0.000 \mathrm{E}+00$ & 0.0000 & $0.000 \mathrm{E}+00$ & 0.0000 & $0.000 \mathrm{E}+00$ & 0.0000 & $0.000 \mathrm{E}+00$ & 0.0000 & $5.519 \mathrm{E}-07$ & 0.0656 \\
\hline 234 & $0.000 \mathrm{E}+00$ & 0.0000 & $0.000 \mathrm{E}+00$ & 0.0000 & $0.000 \mathrm{E}+00$ & 0.0000 & $0.000 \mathrm{E}+00$ & 0.0000 & $0.000 \mathrm{E}+00$ & 0.0000 & $0.000 \mathrm{E}+00$ & 0.0000 & $2.553 E-13$ & 0.0000 \\
\hline 35 & $0.000 \mathrm{E}+00$ & 0.0000 & $0.000 \mathrm{E}+00$ & 0.0000 & $0.000 \mathrm{E}+00$ & 0.0000 & $0.000 \mathrm{E}+00$ & 0.0000 & $0.000 \mathrm{E}+00$ & 0.0000 & $0.000 \mathrm{E}+00$ & 0.0000 & $1.646 \mathrm{E}-13$ & 0.0000 \\
\hline 38 & $0.000 \mathrm{E}+00$ & 0.0000 & $0.000 \mathrm{E}+00$ & 0.0000 & $0.000 \mathrm{E}+00$ & 0.0000 & $0.000 \mathrm{E}+00$ & 0.0000 & $0.000 \mathrm{E}+00$ & 0.0000 & $0.000 \mathrm{E}+00$ & 0.0000 & $4.579 \mathrm{E}-08$ & 0.0054 \\
\hline & $0.000 \mathrm{E}+00$ & 0.0000 & $0.000 \mathrm{E}+00$ & 0.0000 & $0.000 \mathrm{E}+00$ & 0.0000 & $0.000 \mathrm{E}+00$ & 0.0000 & $0.000 \mathrm{E}+00$ & 0.0000 & $0.000 \mathrm{E}+00$ & 0.0000 & $12 E-06$ & 1.0000 \\
\hline
\end{tabular}

* Sum of all water independent and dependent pathways. 
RESRAD, Version $6.5 \quad \mathrm{~T}^{1} \frac{1}{2}$ Limit $=180$ days

07/20/2011 14:25 Page 23

ummary : RESRAD Parameters for Resident Farmer U-Landfill Forward Run 1,050 Years at ALs

File : C: \RESRAD_FAMILY \RESRAD \USERFILES \QCJULY2011 \ONSITERF_FORWARD-1050YRALS.RAD

Total Dose Contributions TDOSE (i,p,t) for Individual Radionuclides (i) and Pathways (p) As mrem/yr and Fraction of Total Dose At $t=5.000 \mathrm{E}+01$ years

Water Independent Pathways (Inhalation excludes radon)

\begin{tabular}{|c|c|c|c|c|c|c|c|c|c|c|c|c|c|c|}
\hline \multirow{2}{*}{ Nuclide } & \multicolumn{2}{|c|}{ Ground } & \multicolumn{2}{|c|}{ Inhalation } & \multicolumn{2}{|c|}{ Radon } & \multicolumn{2}{|c|}{ Plant } & \multicolumn{2}{|c|}{ Meat } & \multicolumn{2}{|c|}{ Milk } & \multicolumn{2}{|c|}{ Soil } \\
\hline & mrem/yr & fract. & mrem/yr & fract. & mrem/yr & fract. & mrem/yr & fract. & mrem/yr & fract. & mrem/yr & fract. & mrem/yr & fract. \\
\hline-241 & $1.795 E-15$ & 0.0000 & $0.000 \mathrm{E}+00$ & 0.0000 & $0.000 \mathrm{E}+00$ & 0.0000 & $0.000 \mathrm{E}+00$ & 0.0000 & $0.000 \mathrm{E}+00$ & 0.0000 & $0.000 \mathrm{E}+00$ & 0.0000 & $0.000 \mathrm{E}+00$ & 0.0000 \\
\hline-137 & $2.299 \mathrm{E}-08$ & 0.0012 & $0.000 \mathrm{E}+00$ & 0.0000 & $0.000 \mathrm{E}+00$ & 0.0000 & $0.000 \mathrm{E}+00$ & 0.0000 & $0.000 \mathrm{E}+00$ & 0.0000 & $0.000 \mathrm{E}+00$ & 0.0000 & $0.000 \mathrm{E}+00$ & 0.0000 \\
\hline-237 & $1.791 \mathrm{E}-11$ & 0.0000 & $0.000 \mathrm{E}+00$ & 0.0000 & $0.000 \mathrm{E}+00$ & 0.0000 & $0.000 \mathrm{E}+00$ & 0.0000 & $0.000 \mathrm{E}+00$ & 0.0000 & $0.000 \mathrm{E}+00$ & 0.0000 & $0.000 \mathrm{E}+00$ & 0.0000 \\
\hline-238 & $4.107 \mathrm{E}-15$ & 0.0000 & $0.000 \mathrm{E}+00$ & 0.0000 & $0.000 \mathrm{E}+00$ & 0.0000 & $0.000 \mathrm{E}+00$ & 0.0000 & $0.000 \mathrm{E}+00$ & 0.0000 & $0.000 \mathrm{E}+00$ & 0.0000 & $0.000 \mathrm{E}+00$ & 0.0000 \\
\hline-239 & $1.572 \mathrm{E}-15$ & 0.0000 & $0.000 \mathrm{E}+00$ & 0.0000 & $0.000 \mathrm{E}+00$ & 0.0000 & $0.000 \mathrm{E}+00$ & 0.0000 & $0.000 \mathrm{E}+00$ & 0.0000 & $0.000 \mathrm{E}+00$ & 0.0000 & $0.000 \mathrm{E}+00$ & 0.0000 \\
\hline-240 & $1.931 \mathrm{E}-19$ & 0.0000 & $0.000 \mathrm{E}+00$ & 0.0000 & $0.000 \mathrm{E}+00$ & 0.0000 & $0.000 \mathrm{E}+00$ & 0.0000 & $0.000 \mathrm{E}+00$ & 0.0000 & $0.000 \mathrm{E}+00$ & 0.0000 & $0.000 \mathrm{E}+00$ & 0.0000 \\
\hline 99 & $9.958 E-24$ & 0.0000 & $0.000 \mathrm{E}+00$ & 0.0000 & $0.000 \mathrm{E}+00$ & 0.0000 & $0.000 \mathrm{E}+00$ & 0.0000 & $0.000 \mathrm{E}+00$ & 0.0000 & $0.000 \mathrm{E}+00$ & 0.0000 & $0.000 \mathrm{E}+00$ & 0.0000 \\
\hline-228 & $2.021 E-13$ & 0.0000 & $0.000 \mathrm{E}+00$ & 0.0000 & $0.000 \mathrm{E}+00$ & 0.0000 & $0.000 \mathrm{E}+00$ & 0.0000 & $0.000 \mathrm{E}+00$ & 0.0000 & $0.000 \mathrm{E}+00$ & 0.0000 & $0.000 \mathrm{E}+00$ & 0.0000 \\
\hline-230 & $1.064 \mathrm{E}-06$ & 0.0558 & $0.000 \mathrm{E}+00$ & 0.0000 & $0.000 \mathrm{E}+00$ & 0.0000 & $0.000 \mathrm{E}+00$ & 0.0000 & $0.000 \mathrm{E}+00$ & 0.0000 & $0.000 \mathrm{E}+00$ & 0.0000 & $0.000 \mathrm{E}+00$ & 0.0000 \\
\hline-232 & $1.793 E-05$ & 0.9395 & $0.000 \mathrm{E}+00$ & 0.0000 & $0.000 \mathrm{E}+00$ & 0.0000 & $0.000 \mathrm{E}+00$ & 0.0000 & $0.000 \mathrm{E}+00$ & 0.0000 & $0.000 \mathrm{E}+00$ & 0.0000 & $0.000 \mathrm{E}+00$ & 0.0000 \\
\hline 234 & $3.883 E-10$ & 0.0000 & $0.000 \mathrm{E}+00$ & 0.0000 & $0.000 \mathrm{E}+00$ & 0.0000 & $0.000 \mathrm{E}+00$ & 0.0000 & $0.000 \mathrm{E}+00$ & 0.0000 & $0.000 \mathrm{E}+00$ & 0.0000 & $0.000 \mathrm{E}+00$ & 0.0000 \\
\hline 35 & 1. $201 \mathrm{E}-12$ & 0.0000 & $0.000 \mathrm{E}+00$ & 0.0000 & $0.000 \mathrm{E}+00$ & 0.0000 & $0.000 \mathrm{E}+00$ & 0.0000 & $0.000 \mathrm{E}+00$ & 0.0000 & $0.000 \mathrm{E}+00$ & 0.0000 & $0.000 \mathrm{E}+00$ & 0.0000 \\
\hline 38 & $6.770 E-08$ & 0.0035 & $0.000 \mathrm{E}+00$ & 0.0000 & $0.000 \mathrm{E}+00$ & 0.0000 & $0.000 \mathrm{E}+00$ & 0.0000 & $0.000 \mathrm{E}+00$ & 0.0000 & $0.000 \mathrm{E}+00$ & 0.0000 & $0.000 \mathrm{E}+00$ & 0.0000 \\
\hline & $1.908 E-05$ & 1.0000 & $0.000 \mathrm{E}+00$ & 0.0000 & $0.000 \mathrm{E}+00$ & 0.0000 & $0.000 \mathrm{E}+00$ & 0.0000 & $0.000 \mathrm{E}+00$ & 0.0000 & $0.000 \mathrm{E}+00$ & 0.0000 & $0.000 \mathrm{E}+00$ & 0.0000 \\
\hline
\end{tabular}

Total Dose Contributions TDOSE(i,p,t) for Individual Radionuclides (i) and Pathways (p) As mrem/yr and Fraction of Total Dose At $t=5.000 \mathrm{E}+01$ years

Water Dependent Pathways

\begin{tabular}{|c|c|c|c|c|c|c|c|c|c|c|c|c|c|c|}
\hline \multirow{2}{*}{ Nuclide } & \multicolumn{2}{|c|}{ Water } & \multicolumn{2}{|c|}{ Fish } & \multicolumn{2}{|c|}{ Radon } & \multicolumn{2}{|c|}{ Plant } & \multicolumn{2}{|c|}{ Meat } & \multicolumn{2}{|c|}{ Milk } & \multicolumn{2}{|c|}{ All Pathways* } \\
\hline & mrem/yr & fract. & mrem/yr & fract. & mrem/yr & fract. & mrem/yr & fract. & mrem/yr & fract. & mrem/yr & fract. & mrem/yr & fract. \\
\hline-241 & $0.000 \mathrm{E}+00$ & 0.0000 & $0.000 \mathrm{E}+00$ & 0.0000 & $0.000 \mathrm{E}+00$ & 0.0000 & $0.000 \mathrm{E}+00$ & 0.0000 & $0.000 \mathrm{E}+00$ & 0.0000 & $0.000 \mathrm{E}+00$ & 0.0000 & $1.795 \mathrm{E}-15$ & 0.0000 \\
\hline-137 & $0.000 \mathrm{E}+00$ & 0.0000 & $0.000 \mathrm{E}+00$ & 0.0000 & $0.000 \mathrm{E}+00$ & 0.0000 & $0.000 \mathrm{E}+00$ & 0.0000 & $0.000 \mathrm{E}+00$ & 0.0000 & $0.000 \mathrm{E}+00$ & 0.0000 & $2.299 \mathrm{E}-08$ & 0.0012 \\
\hline-237 & $0.000 \mathrm{E}+00$ & 0.0000 & $0.000 \mathrm{E}+00$ & 0.0000 & $0.000 \mathrm{E}+00$ & 0.0000 & $0.000 \mathrm{E}+00$ & 0.0000 & $0.000 \mathrm{E}+00$ & 0.0000 & $0.000 \mathrm{E}+00$ & 0.0000 & $1.791 \mathrm{E}-11$ & 0.0000 \\
\hline-238 & $0.000 \mathrm{E}+00$ & 0.0000 & $0.000 \mathrm{E}+00$ & 0.0000 & $0.000 \mathrm{E}+00$ & 0.0000 & $0.000 \mathrm{E}+00$ & 0.0000 & $0.000 \mathrm{E}+00$ & 0.0000 & $0.000 \mathrm{E}+00$ & 0.0000 & $4.107 \mathrm{E}-15$ & 0.0000 \\
\hline-239 & $0.000 \mathrm{E}+00$ & 0.0000 & $0.000 \mathrm{E}+00$ & 0.0000 & $0.000 \mathrm{E}+00$ & 0.0000 & $0.000 \mathrm{E}+00$ & 0.0000 & $0.000 \mathrm{E}+00$ & 0.0000 & $0.000 \mathrm{E}+00$ & 0.0000 & $1.572 \mathrm{E}-15$ & 0.0000 \\
\hline-240 & $0.000 \mathrm{E}+00$ & 0.0000 & $0.000 \mathrm{E}+00$ & 0.0000 & $0.000 \mathrm{E}+00$ & 0.0000 & $0.000 \mathrm{E}+00$ & 0.0000 & $0.000 \mathrm{E}+00$ & 0.0000 & $0.000 \mathrm{E}+00$ & 0.0000 & $1.931 \mathrm{E}-19$ & 0.0000 \\
\hline-99 & $0.000 \mathrm{E}+00$ & 0.0000 & $0.000 \mathrm{E}+00$ & 0.0000 & $0.000 \mathrm{E}+00$ & 0.0000 & $0.000 \mathrm{E}+00$ & 0.0000 & $0.000 \mathrm{E}+00$ & 0.0000 & $0.000 \mathrm{E}+00$ & 0.0000 & $9.958 E-24$ & 0.0000 \\
\hline-228 & $0.000 \mathrm{E}+00$ & 0.0000 & $0.000 \mathrm{E}+00$ & 0.0000 & $0.000 \mathrm{E}+00$ & 0.0000 & $0.000 \mathrm{E}+00$ & 0.0000 & $0.000 \mathrm{E}+00$ & 0.0000 & $0.000 \mathrm{E}+00$ & 0.0000 & $2.021 \mathrm{E}-13$ & 0.0000 \\
\hline-230 & $0.000 \mathrm{E}+00$ & 0.0000 & $0.000 \mathrm{E}+00$ & 0.0000 & $0.000 \mathrm{E}+00$ & 0.0000 & $0.000 \mathrm{E}+00$ & 0.0000 & $0.000 \mathrm{E}+00$ & 0.0000 & $0.000 \mathrm{E}+00$ & 0.0000 & $1.064 \mathrm{E}-06$ & 0.0558 \\
\hline 232 & $0.000 \mathrm{E}+00$ & 0.0000 & $0.000 \mathrm{E}+00$ & 0.0000 & $0.000 \mathrm{E}+00$ & 0.0000 & $0.000 \mathrm{E}+00$ & 0.0000 & $0.000 \mathrm{E}+00$ & 0.0000 & $0.000 \mathrm{E}+00$ & 0.0000 & $1.793 E-05$ & 0.9395 \\
\hline 34 & $0.000 \mathrm{E}+00$ & 0.0000 & $0.000 \mathrm{E}+00$ & 0.0000 & $0.000 \mathrm{E}+00$ & 0.0000 & $0.000 \mathrm{E}+00$ & 0.0000 & $0.000 \mathrm{E}+00$ & 0.0000 & $0.000 \mathrm{E}+00$ & 0.0000 & $3.883 E-10$ & 0.0000 \\
\hline 35 & $0.000 \mathrm{E}+00$ & 0.0000 & $0.000 \mathrm{E}+00$ & 0.0000 & $0.000 \mathrm{E}+00$ & 0.0000 & $0.000 \mathrm{E}+00$ & 0.0000 & $0.000 \mathrm{E}+00$ & 0.0000 & $0.000 \mathrm{E}+00$ & 0.0000 & $1.201 \mathrm{E}-12$ & 0.0000 \\
\hline 38 & $0.000 \mathrm{E}+00$ & 0.0000 & $0.000 \mathrm{E}+00$ & 0.0000 & $0.000 \mathrm{E}+00$ & 0.0000 & $0.000 \mathrm{E}+00$ & 0.0000 & $0.000 \mathrm{E}+00$ & 0.0000 & $0.000 \mathrm{E}+00$ & 0.0000 & $6.770 \mathrm{E}-08$ & 0.0035 \\
\hline & $0.000 \mathrm{E}+00$ & 0.0000 & $0.000 \mathrm{E}+00$ & 0.0000 & $0.000 \mathrm{E}+00$ & 0.0000 & $0.000 \mathrm{E}+00$ & 0.0000 & $0.000 \mathrm{E}+00$ & 0.0000 & $0.000 \mathrm{E}+00$ & 0.0000 & $8 E-05$ & 1.0000 \\
\hline
\end{tabular}

* Sum of all water independent and dependent pathways. 
RESRAD, Version $6.5 \quad \mathrm{~T}^{1} \frac{1}{2}$ Limit $=180$ days

07/20/2011 14:25 Page 24

ummary : RESRAD Parameters for Resident Farmer U-Landfill Forward Run 1,050 Years at ALs

File : C: \RESRAD_FAMILY \RESRAD \USERFILES \QCJULY2011 \ONSITERF_FORWARD-1050YRALS.RAD

Total Dose Contributions TDOSE (i,p,t) for Individual Radionuclides (i) and Pathways (p) As mrem/yr and Fraction of Total Dose At $t=1.000 \mathrm{E}+02$ years

Water Independent Pathways (Inhalation excludes radon)

\begin{tabular}{|c|c|c|c|c|c|c|c|c|c|c|c|c|c|c|}
\hline \multirow{2}{*}{ Nuclide } & \multicolumn{2}{|c|}{ Ground } & \multicolumn{2}{|c|}{ Inhalation } & \multicolumn{2}{|c|}{ Radon } & \multicolumn{2}{|c|}{ Plant } & \multicolumn{2}{|c|}{ Meat } & \multicolumn{2}{|c|}{ Milk } & \multicolumn{2}{|c|}{ Soil } \\
\hline & mrem/yr & fract. & mrem/yr & fract. & mrem/yr & fract. & mrem/yr & fract. & mrem/yr & fract. & mrem/yr & fract. & mrem/yr & fract. \\
\hline-241 & $5.880 \mathrm{E}-15$ & 0.0000 & $0.000 \mathrm{E}+00$ & 0.0000 & $0.000 \mathrm{E}+00$ & 0.0000 & $0.000 \mathrm{E}+00$ & 0.0000 & $0.000 \mathrm{E}+00$ & 0.0000 & $0.000 \mathrm{E}+00$ & 0.0000 & $0.000 \mathrm{E}+00$ & 0.0000 \\
\hline-137 & $1.102 \mathrm{E}-08$ & 0.0004 & $0.000 \mathrm{E}+00$ & 0.0000 & $0.000 \mathrm{E}+00$ & 0.0000 & $0.000 \mathrm{E}+00$ & 0.0000 & $0.000 \mathrm{E}+00$ & 0.0000 & $0.000 \mathrm{E}+00$ & 0.0000 & $0.000 \mathrm{E}+00$ & 0.0000 \\
\hline-237 & $3.067 \mathrm{E}-11$ & 0.0000 & $0.000 \mathrm{E}+00$ & 0.0000 & $0.000 \mathrm{E}+00$ & 0.0000 & $0.000 \mathrm{E}+00$ & 0.0000 & $0.000 \mathrm{E}+00$ & 0.0000 & $0.000 \mathrm{E}+00$ & 0.0000 & $0.000 \mathrm{E}+00$ & 0.0000 \\
\hline-238 & $4.152 \mathrm{E}-14$ & 0.0000 & $0.000 \mathrm{E}+00$ & 0.0000 & $0.000 \mathrm{E}+00$ & 0.0000 & $0.000 \mathrm{E}+00$ & 0.0000 & $0.000 \mathrm{E}+00$ & 0.0000 & $0.000 \mathrm{E}+00$ & 0.0000 & $0.000 \mathrm{E}+00$ & 0.0000 \\
\hline-239 & $2.856 \mathrm{E}-15$ & 0.0000 & $0.000 \mathrm{E}+00$ & 0.0000 & $0.000 \mathrm{E}+00$ & 0.0000 & $0.000 \mathrm{E}+00$ & 0.0000 & $0.000 \mathrm{E}+00$ & 0.0000 & $0.000 \mathrm{E}+00$ & 0.0000 & $0.000 \mathrm{E}+00$ & 0.0000 \\
\hline-240 & $1.284 \mathrm{E}-18$ & 0.0000 & $0.000 \mathrm{E}+00$ & 0.0000 & $0.000 \mathrm{E}+00$ & 0.0000 & $0.000 \mathrm{E}+00$ & 0.0000 & $0.000 \mathrm{E}+00$ & 0.0000 & $0.000 \mathrm{E}+00$ & 0.0000 & $0.000 \mathrm{E}+00$ & 0.0000 \\
\hline 99 & $1.656 \mathrm{E}-23$ & 0.0000 & $0.000 \mathrm{E}+00$ & 0.0000 & $0.000 \mathrm{E}+00$ & 0.0000 & $0.000 \mathrm{E}+00$ & 0.0000 & $0.000 \mathrm{E}+00$ & 0.0000 & $0.000 \mathrm{E}+00$ & 0.0000 & $0.000 \mathrm{E}+00$ & 0.0000 \\
\hline-228 & $3.694 \mathrm{E}-21$ & 0.0000 & $0.000 \mathrm{E}+00$ & 0.0000 & $0.000 \mathrm{E}+00$ & 0.0000 & $0.000 \mathrm{E}+00$ & 0.0000 & $0.000 \mathrm{E}+00$ & 0.0000 & $0.000 \mathrm{E}+00$ & 0.0000 & $0.000 \mathrm{E}+00$ & 0.0000 \\
\hline-230 & $2.958 E-06$ & 0.1082 & $0.000 \mathrm{E}+00$ & 0.0000 & $0.000 \mathrm{E}+00$ & 0.0000 & $0.000 \mathrm{E}+00$ & 0.0000 & $0.000 \mathrm{E}+00$ & 0.0000 & $0.000 \mathrm{E}+00$ & 0.0000 & $0.000 \mathrm{E}+00$ & 0.0000 \\
\hline-232 & $2.426 E-05$ & 0.8876 & $0.000 \mathrm{E}+00$ & 0.0000 & $0.000 \mathrm{E}+00$ & 0.0000 & $0.000 \mathrm{E}+00$ & 0.0000 & $0.000 \mathrm{E}+00$ & 0.0000 & $0.000 \mathrm{E}+00$ & 0.0000 & $0.000 \mathrm{E}+00$ & 0.0000 \\
\hline 34 & $2.156 \mathrm{E}-09$ & 0.0001 & $0.000 \mathrm{E}+00$ & 0.0000 & $0.000 \mathrm{E}+00$ & 0.0000 & $0.000 \mathrm{E}+00$ & 0.0000 & $0.000 \mathrm{E}+00$ & 0.0000 & $0.000 \mathrm{E}+00$ & 0.0000 & $0.000 \mathrm{E}+00$ & 0.0000 \\
\hline 35 & $4.404 \mathrm{E}-12$ & 0.0000 & $0.000 \mathrm{E}+00$ & 0.0000 & $0.000 \mathrm{E}+00$ & 0.0000 & $0.000 \mathrm{E}+00$ & 0.0000 & $0.000 \mathrm{E}+00$ & 0.0000 & $0.000 \mathrm{E}+00$ & 0.0000 & $0.000 \mathrm{E}+00$ & 0.0000 \\
\hline 38 & $1.009 \mathrm{E}-07$ & 0.0037 & $0.000 \mathrm{E}+00$ & 0.0000 & $0.000 \mathrm{E}+00$ & 0.0000 & $0.000 \mathrm{E}+00$ & 0.0000 & $0.000 \mathrm{E}+00$ & 0.0000 & $0.000 \mathrm{E}+00$ & 0.0000 & $0.000 \mathrm{E}+00$ & 0.0000 \\
\hline & $2.733 E-05$ & 1.0000 & $0.000 \mathrm{E}+00$ & 0.0000 & $0.000 \mathrm{E}+00$ & 0.0000 & $0.000 \mathrm{E}+00$ & 0.0000 & $0.000 \mathrm{E}+00$ & 0.0000 & $0.000 \mathrm{E}+00$ & 0.0000 & $0.000 \mathrm{E}+00$ & 0.0000 \\
\hline
\end{tabular}

Total Dose Contributions TDOSE(i,p,t) for Individual Radionuclides (i) and Pathways (p) As mrem/yr and Fraction of Total Dose At $t=1.000 \mathrm{E}+02$ years

Water Dependent Pathways

\begin{tabular}{|c|c|c|c|c|c|c|c|c|c|c|c|c|c|c|}
\hline & \multicolumn{2}{|c|}{ Water } & \multicolumn{2}{|c|}{ Fish } & \multicolumn{2}{|c|}{ Radon } & \multicolumn{2}{|c|}{ Plant } & \multicolumn{2}{|c|}{ Meat } & \multicolumn{2}{|c|}{ Milk } & \multicolumn{2}{|c|}{ All Pathways* } \\
\hline clide & mrem/yr & fract. & mrem/yr & fract. & mrem/yr & fract. & mrem/yr & fract. & mrem/yr & fract. & mrem/yr & fract. & mrem/yr & fract. \\
\hline-241 & $0.000 \mathrm{E}+00$ & 0.0000 & $0.000 \mathrm{E}+00$ & 0.0000 & $0.000 \mathrm{E}+00$ & 0.0000 & $0.000 \mathrm{E}+00$ & 0.0000 & $0.000 \mathrm{E}+00$ & 0.0000 & $0.000 \mathrm{E}+00$ & 0.0000 & $5.880 \mathrm{E}-15$ & 0.0000 \\
\hline-137 & $0.000 \mathrm{E}+00$ & 0.0000 & $0.000 \mathrm{E}+00$ & 0.0000 & $0.000 \mathrm{E}+00$ & 0.0000 & $0.000 \mathrm{E}+00$ & 0.0000 & $0.000 \mathrm{E}+00$ & 0.0000 & $0.000 \mathrm{E}+00$ & 0.0000 & $1.102 \mathrm{E}-08$ & 0.0004 \\
\hline-237 & $0.000 \mathrm{E}+00$ & 0.0000 & $0.000 \mathrm{E}+00$ & 0.0000 & $0.000 \mathrm{E}+00$ & 0.0000 & $0.000 \mathrm{E}+00$ & 0.0000 & $0.000 \mathrm{E}+00$ & 0.0000 & $0.000 \mathrm{E}+00$ & 0.0000 & $3.067 \mathrm{E}-11$ & 0.0000 \\
\hline 238 & $0.000 \mathrm{E}+00$ & 0.0000 & $0.000 \mathrm{E}+00$ & 0.0000 & $0.000 \mathrm{E}+00$ & 0.0000 & $0.000 \mathrm{E}+00$ & 0.0000 & $0.000 \mathrm{E}+00$ & 0.0000 & $0.000 \mathrm{E}+00$ & 0.0000 & $4.152 \mathrm{E}-14$ & 0.0000 \\
\hline 239 & $0.000 \mathrm{E}+00$ & 0.0000 & $0.000 \mathrm{E}+00$ & 0.0000 & $0.000 \mathrm{E}+00$ & 0.0000 & $0.000 \mathrm{E}+00$ & 0.0000 & $0.000 \mathrm{E}+00$ & 0.0000 & $0.000 \mathrm{E}+00$ & 0.0000 & $2.856 \mathrm{E}-15$ & 0.0000 \\
\hline 240 & $0.000 \mathrm{E}+00$ & 0.0000 & $0.000 \mathrm{E}+00$ & 0.0000 & $0.000 \mathrm{E}+00$ & 0.0000 & $0.000 \mathrm{E}+00$ & 0.0000 & $0.000 \mathrm{E}+00$ & 0.0000 & $0.000 \mathrm{E}+00$ & 0.0000 & 1. $284 \mathrm{E}-18$ & 0.0000 \\
\hline 99 & $0.000 \mathrm{E}+00$ & 0.0000 & $0.000 \mathrm{E}+00$ & 0.0000 & $0.000 \mathrm{E}+00$ & 0.0000 & $0.000 \mathrm{E}+00$ & 0.0000 & $0.000 \mathrm{E}+00$ & 0.0000 & $0.000 \mathrm{E}+00$ & 0.0000 & $1.656 \mathrm{E}-23$ & 0.0000 \\
\hline 228 & $0.000 \mathrm{E}+00$ & 0.0000 & $0.000 \mathrm{E}+00$ & 0.0000 & $0.000 \mathrm{E}+00$ & 0.0000 & $0.000 \mathrm{E}+00$ & 0.0000 & $0.000 \mathrm{E}+00$ & 0.0000 & $0.000 \mathrm{E}+00$ & 0.0000 & $3.694 \mathrm{E}-21$ & 0.0000 \\
\hline 230 & $0.000 \mathrm{E}+00$ & 0.0000 & $0.000 \mathrm{E}+00$ & 0.0000 & $0.000 \mathrm{E}+00$ & 0.0000 & $0.000 \mathrm{E}+00$ & 0.0000 & $0.000 \mathrm{E}+00$ & 0.0000 & $0.000 \mathrm{E}+00$ & 0.0000 & $2.958 E-06$ & 0.1082 \\
\hline 232 & $0.000 \mathrm{E}+00$ & 0.0000 & $0.000 \mathrm{E}+00$ & 0.0000 & $0.000 \mathrm{E}+00$ & 0.0000 & $0.000 \mathrm{E}+00$ & 0.0000 & $0.000 \mathrm{E}+00$ & 0.0000 & $0.000 \mathrm{E}+00$ & 0.0000 & $2.426 \mathrm{E}-05$ & 0.8876 \\
\hline & $0.000 \mathrm{E}+00$ & 0.0000 & $0.000 \mathrm{E}+00$ & 0.0000 & $0.000 \mathrm{E}+00$ & 0.0000 & $0.000 \mathrm{E}+00$ & 0.0000 & $0.000 \mathrm{E}+00$ & 0.0000 & $0.000 \mathrm{E}+00$ & 0.0000 & $2.156 \mathrm{E}-09$ & 0.0001 \\
\hline 35 & $0.000 \mathrm{E}+00$ & 0.0000 & $0.000 \mathrm{E}+00$ & 0.0000 & $0.000 \mathrm{E}+00$ & 0.0000 & $0.000 \mathrm{E}+00$ & 0.0000 & $0.000 \mathrm{E}+00$ & 0.0000 & $0.000 \mathrm{E}+00$ & 0.0000 & $4.404 \mathrm{E}-12$ & 0.0000 \\
\hline 38 & $0.000 \mathrm{E}+00$ & 0.0000 & $0.000 \mathrm{E}+00$ & 0.0000 & $0.000 \mathrm{E}+00$ & 0.0000 & $0.000 \mathrm{E}+00$ & 0.0000 & $0.000 \mathrm{E}+00$ & 0.0000 & $0.000 \mathrm{E}+00$ & 0.0000 & $1.009 \mathrm{E}-07$ & 0.0037 \\
\hline & $0.000 \mathrm{E}+00$ & 0.0000 & $0.000 \mathrm{E}+00$ & 0.0000 & $0.000 \mathrm{E}+00$ & 0.0000 & $0.000 \mathrm{E}+00$ & 0.0000 & $0.000 \mathrm{E}+00$ & 0.0000 & $0.000 E+00$ & 000 & -05 & 1.0000 \\
\hline
\end{tabular}

* Sum of all water independent and dependent pathways. 
RESRAD, Version $6.5 \quad \mathrm{~T}^{1} \frac{1}{2}$ Limit $=180$ days

07/20/2011 14:25 Page 25

ummary : RESRAD Parameters for Resident Farmer U-Landfill Forward Run 1,050 Years at ALs

File : C: \RESRAD_FAMILY \RESRAD \USERFILES \QCJULY2011 \ONSITERF_FORWARD-1050YRALS.RAD

Total Dose Contributions TDOSE (i,p,t) for Individual Radionuclides (i) and Pathways (p) As mrem/yr and Fraction of Total Dose At $t=5.000 \mathrm{E}+02$ years

Water Independent Pathways (Inhalation excludes radon)

\begin{tabular}{|c|c|c|c|c|c|c|c|c|c|c|c|c|c|c|}
\hline \multirow{2}{*}{ Nuclide } & \multicolumn{2}{|c|}{ Ground } & \multicolumn{2}{|c|}{ Inhalation } & \multicolumn{2}{|c|}{ Radon } & \multicolumn{2}{|c|}{ Plant } & \multicolumn{2}{|c|}{ Meat } & \multicolumn{2}{|c|}{ Milk } & \multicolumn{2}{|c|}{ Soil } \\
\hline & mrem/yr & fract. & mrem/yr & fract. & mrem/yr & fract. & mrem/yr & fract. & mrem/yr & fract. & mrem/yr & fract. & mrem/yr & fract. \\
\hline-241 & $1.606 \mathrm{E}-12$ & 0.0000 & $0.000 \mathrm{E}+00$ & 0.0000 & $0.000 \mathrm{E}+00$ & 0.0000 & $0.000 \mathrm{E}+00$ & 0.0000 & $0.000 \mathrm{E}+00$ & 0.0000 & $0.000 \mathrm{E}+00$ & 0.0000 & $0.000 \mathrm{E}+00$ & 0.0000 \\
\hline-137 & $3.079 \mathrm{E}-11$ & 0.0000 & $0.000 \mathrm{E}+00$ & 0.0000 & $0.000 \mathrm{E}+00$ & 0.0000 & $0.000 \mathrm{E}+00$ & 0.0000 & $0.000 \mathrm{E}+00$ & 0.0000 & $0.000 \mathrm{E}+00$ & 0.0000 & $0.000 \mathrm{E}+00$ & 0.0000 \\
\hline-237 & $2.249 \mathrm{E}-09$ & 0.0000 & $0.000 \mathrm{E}+00$ & 0.0000 & $0.000 \mathrm{E}+00$ & 0.0000 & $0.000 \mathrm{E}+00$ & 0.0000 & $0.000 \mathrm{E}+00$ & 0.0000 & $0.000 \mathrm{E}+00$ & 0.0000 & $0.000 \mathrm{E}+00$ & 0.0000 \\
\hline-238 & $4.373 E-11$ & 0.0000 & $0.000 \mathrm{E}+00$ & 0.0000 & $0.000 \mathrm{E}+00$ & 0.0000 & $0.000 \mathrm{E}+00$ & 0.0000 & $0.000 \mathrm{E}+00$ & 0.0000 & $0.000 \mathrm{E}+00$ & 0.0000 & $0.000 \mathrm{E}+00$ & 0.0000 \\
\hline-239 & $3.390 \mathrm{E}-13$ & 0.0000 & $0.000 \mathrm{E}+00$ & 0.0000 & $0.000 \mathrm{E}+00$ & 0.0000 & $0.000 \mathrm{E}+00$ & 0.0000 & $0.000 \mathrm{E}+00$ & 0.0000 & $0.000 \mathrm{E}+00$ & 0.0000 & $0.000 \mathrm{E}+00$ & 0.0000 \\
\hline-240 & $4.117 \mathrm{E}-16$ & 0.0000 & $0.000 \mathrm{E}+00$ & 0.0000 & $0.000 \mathrm{E}+00$ & 0.0000 & $0.000 \mathrm{E}+00$ & 0.0000 & $0.000 \mathrm{E}+00$ & 0.0000 & $0.000 \mathrm{E}+00$ & 0.0000 & $0.000 \mathrm{E}+00$ & 0.0000 \\
\hline 99 & $9.682 \mathrm{E}-22$ & 0.0000 & $0.000 \mathrm{E}+00$ & 0.0000 & $0.000 \mathrm{E}+00$ & 0.0000 & $0.000 \mathrm{E}+00$ & 0.0000 & $0.000 \mathrm{E}+00$ & 0.0000 & $0.000 \mathrm{E}+00$ & 0.0000 & $0.000 \mathrm{E}+00$ & 0.0000 \\
\hline-228 & $0.000 \mathrm{E}+00$ & 0.0000 & $0.000 \mathrm{E}+00$ & 0.0000 & $0.000 \mathrm{E}+00$ & 0.0000 & $0.000 \mathrm{E}+00$ & 0.0000 & $0.000 \mathrm{E}+00$ & 0.0000 & $0.000 \mathrm{E}+00$ & 0.0000 & $0.000 \mathrm{E}+00$ & 0.0000 \\
\hline 230 & $2.142 \mathrm{E}-04$ & 0.0000 & $0.000 \mathrm{E}+00$ & 0.0000 & $0.000 \mathrm{E}+00$ & 0.0000 & $0.000 \mathrm{E}+00$ & 0.0000 & $0.000 \mathrm{E}+00$ & 0.0000 & $0.000 \mathrm{E}+00$ & 0.0000 & $0.000 \mathrm{E}+00$ & 0.0000 \\
\hline-232 & $2.671 E-04$ & 0.0000 & $0.000 \mathrm{E}+00$ & 0.0000 & $0.000 \mathrm{E}+00$ & 0.0000 & $0.000 \mathrm{E}+00$ & 0.0000 & $0.000 \mathrm{E}+00$ & 0.0000 & $0.000 \mathrm{E}+00$ & 0.0000 & $0.000 \mathrm{E}+00$ & 0.0000 \\
\hline 34 & $7.986 \mathrm{E}-07$ & 0.0000 & $0.000 \mathrm{E}+00$ & 0.0000 & $0.000 \mathrm{E}+00$ & 0.0000 & $0.000 \mathrm{E}+00$ & 0.0000 & $0.000 \mathrm{E}+00$ & 0.0000 & $0.000 E+00$ & 0.0000 & $0.000 \mathrm{E}+00$ & 0.0000 \\
\hline 35 & $9.142 \mathrm{E}-10$ & 0.0000 & $0.000 \mathrm{E}+00$ & 0.0000 & $0.000 \mathrm{E}+00$ & 0.0000 & $0.000 \mathrm{E}+00$ & 0.0000 & $0.000 \mathrm{E}+00$ & 0.0000 & $0.000 \mathrm{E}+00$ & 0.0000 & $0.000 \mathrm{E}+00$ & 0.0000 \\
\hline 38 & $2.457 \mathrm{E}-06$ & 0.0000 & $0.000 \mathrm{E}+00$ & 0.0000 & $0.000 \mathrm{E}+00$ & 0.0000 & $0.000 \mathrm{E}+00$ & 0.0000 & $0.000 \mathrm{E}+00$ & 0.0000 & $0.000 \mathrm{E}+00$ & 0.0000 & $0.000 \mathrm{E}+00$ & 0.0000 \\
\hline & $4.845 E-04$ & 0.0000 & $0.000 \mathrm{E}+00$ & 0.0000 & $0.000 \mathrm{E}+00$ & 0.0000 & $0.000 \mathrm{E}+00$ & 0.0000 & $0.000 \mathrm{E}+00$ & 0.0000 & $0.000 \mathrm{E}+00$ & 0.0000 & $0.000 \mathrm{E}+00$ & 0.0000 \\
\hline
\end{tabular}

Total Dose Contributions TDOSE(i,p,t) for Individual Radionuclides (i) and Pathways (p) As mrem/yr and Fraction of Total Dose At $t=5.000 \mathrm{E}+02$ years

Water Dependent Pathways

\begin{tabular}{|c|c|c|c|c|c|c|c|c|c|c|c|c|c|c|}
\hline \multirow{2}{*}{$\begin{array}{l}\text { Radio- } \\
\text { Nuclide }\end{array}$} & \multicolumn{2}{|c|}{ Water } & \multicolumn{2}{|c|}{ Fish } & \multicolumn{2}{|c|}{ Radon } & \multicolumn{2}{|c|}{ Plant } & \multicolumn{2}{|c|}{ Meat } & \multicolumn{2}{|c|}{ Milk } & \multicolumn{2}{|c|}{ All Pathways* } \\
\hline & mrem/yr & fract. & mrem/yr & fract. & mrem/yr & fract. & mrem/yr & fract. & mrem/yr & fract. & mrem/yr & fract. & mrem/yr & fract. \\
\hline 241 & $0.000 \mathrm{E}+00$ & 0.0000 & $0.000 \mathrm{E}+00$ & 0.0000 & $0.000 \mathrm{E}+00$ & 0.0000 & $0.000 \mathrm{E}+00$ & 0.0000 & $0.000 \mathrm{E}+00$ & 0.0000 & $0.000 \mathrm{E}+00$ & 0.0000 & $1.606 \mathrm{E}-12$ & 0.0000 \\
\hline-137 & $0.000 \mathrm{E}+00$ & 0.0000 & $0.000 \mathrm{E}+00$ & 0.0000 & $0.000 \mathrm{E}+00$ & 0.0000 & $0.000 \mathrm{E}+00$ & 0.0000 & $0.000 \mathrm{E}+00$ & 0.0000 & $0.000 \mathrm{E}+00$ & 0.0000 & $3.079 \mathrm{E}-11$ & 0.0000 \\
\hline-237 & $0.000 \mathrm{E}+00$ & 0.0000 & $0.000 \mathrm{E}+00$ & 0.0000 & $0.000 \mathrm{E}+00$ & 0.0000 & $0.000 \mathrm{E}+00$ & 0.0000 & $0.000 \mathrm{E}+00$ & 0.0000 & $0.000 \mathrm{E}+00$ & 0.0000 & $2.249 E-09$ & 0.0000 \\
\hline-238 & $0.000 \mathrm{E}+00$ & 0.0000 & $0.000 \mathrm{E}+00$ & 0.0000 & $0.000 \mathrm{E}+00$ & 0.0000 & $0.000 \mathrm{E}+00$ & 0.0000 & $0.000 \mathrm{E}+00$ & 0.0000 & $0.000 \mathrm{E}+00$ & 0.0000 & $4.373 E-11$ & 0.0000 \\
\hline-239 & $0.000 \mathrm{E}+00$ & 0.0000 & $0.000 \mathrm{E}+00$ & 0.0000 & $0.000 \mathrm{E}+00$ & 0.0000 & $0.000 \mathrm{E}+00$ & 0.0000 & $0.000 \mathrm{E}+00$ & 0.0000 & $0.000 E+00$ & 0.0000 & $3.390 \mathrm{E}-13$ & 0.0000 \\
\hline-240 & $0.000 \mathrm{E}+00$ & 0.0000 & $0.000 \mathrm{E}+00$ & 0.0000 & $0.000 \mathrm{E}+00$ & 0.0000 & $0.000 \mathrm{E}+00$ & 0.0000 & $0.000 \mathrm{E}+00$ & 0.0000 & $0.000 E+00$ & 0.0000 & $4.117 \mathrm{E}-16$ & 0.0000 \\
\hline 99 & $1.781 \mathrm{E}+01$ & 0.8277 & $0.000 \mathrm{E}+00$ & 0.0000 & $0.000 \mathrm{E}+00$ & 0.0000 & $1.665 \mathrm{E}+00$ & 0.0774 & $2.980 E-02$ & 0.0014 & $2.011 E+00$ & 0.0935 & $2.151 \mathrm{E}+01$ & 1.0000 \\
\hline-228 & $0.000 \mathrm{E}+00$ & 0.0000 & $0.000 \mathrm{E}+00$ & 0.0000 & $0.000 \mathrm{E}+00$ & 0.0000 & $0.000 \mathrm{E}+00$ & 0.0000 & $0.000 \mathrm{E}+00$ & 0.0000 & $0.000 E+00$ & 0.0000 & $0.000 \mathrm{E}+00$ & 0.0000 \\
\hline-230 & $0.000 \mathrm{E}+00$ & 0.0000 & $0.000 \mathrm{E}+00$ & 0.0000 & $0.000 \mathrm{E}+00$ & 0.0000 & $0.000 \mathrm{E}+00$ & 0.0000 & $0.000 \mathrm{E}+00$ & 0.0000 & $0.000 E+00$ & 0.0000 & $2.142 \mathrm{E}-04$ & 0.0000 \\
\hline 232 & $0.000 \mathrm{E}+00$ & 0.0000 & $0.000 \mathrm{E}+00$ & 0.0000 & $0.000 \mathrm{E}+00$ & 0.0000 & $0.000 \mathrm{E}+00$ & 0.0000 & $0.000 \mathrm{E}+00$ & 0.0000 & $0.000 \mathrm{E}+00$ & 0.0000 & $2.671 E-04$ & 0.0000 \\
\hline 34 & $0.000 \mathrm{E}+00$ & 0.0000 & $0.000 \mathrm{E}+00$ & 0.0000 & $0.000 \mathrm{E}+00$ & 0.0000 & $0.000 \mathrm{E}+00$ & 0.0000 & $0.000 \mathrm{E}+00$ & 0.0000 & $0.000 \mathrm{E}+00$ & 0.0000 & $7.986 \mathrm{E}-07$ & 0.0000 \\
\hline 35 & $0.000 \mathrm{E}+00$ & 0.0000 & $0.000 \mathrm{E}+00$ & 0.0000 & $0.000 \mathrm{E}+00$ & 0.0000 & $0.000 \mathrm{E}+00$ & 0.0000 & $0.000 \mathrm{E}+00$ & 0.0000 & $0.000 \mathrm{E}+00$ & 0.0000 & $9.142 \mathrm{E}-10$ & 0.0000 \\
\hline 38 & $0.000 \mathrm{E}+00$ & 0.0000 & $0.000 \mathrm{E}+00$ & 0.0000 & $0.000 \mathrm{E}+00$ & 0.0000 & $0.000 \mathrm{E}+00$ & 0.0000 & $0.000 \mathrm{E}+00$ & 0.0000 & $0.000 \mathrm{E}+00$ & 0.0000 & $2.457 \mathrm{E}-06$ & 0.0000 \\
\hline & $1.781 E+01$ & 0.8277 & $0.000 \mathrm{E}+00$ & 0.0000 & $0.000 \mathrm{E}+00$ & 0.0000 & $1.665 \mathrm{E}+00$ & 0.0774 & $2.980 \mathrm{E}-02$ & 0.0014 & $2.011 E+00$ & 0.0935 & $E+01$ & \\
\hline
\end{tabular}

* Sum of all water independent and dependent pathways. 
RESRAD, Version $6.5 \quad \mathrm{~T}^{1} \frac{1}{2}$ Limit $=180$ days

07/20/2011 14:25 Page 26

ummary : RESRAD Parameters for Resident Farmer U-Landfill Forward Run 1,050 Years at ALs

File : C: \RESRAD_FAMILY \RESRAD \USERFILES \QCJULY2011 \ONSITERF_FORWARD-1050YRALS.RAD

Total Dose Contributions TDOSE (i,p,t) for Individual Radionuclides (i) and Pathways (p) As mrem/yr and Fraction of Total Dose At $t=1.050 \mathrm{E}+03$ years

Water Independent Pathways (Inhalation excludes radon)

\begin{tabular}{|c|c|c|c|c|c|c|c|c|c|c|c|c|c|c|}
\hline \multirow{2}{*}{ Nuclide } & \multicolumn{2}{|c|}{ Ground } & \multicolumn{2}{|c|}{ Inhalation } & \multicolumn{2}{|c|}{ Radon } & \multicolumn{2}{|c|}{ Plant } & \multicolumn{2}{|c|}{ Meat } & \multicolumn{2}{|c|}{ Milk } & \multicolumn{2}{|c|}{ Soil } \\
\hline & mrem/yr & fract. & mrem/yr & fract. & mrem/yr & fract. & mrem/yr & fract. & mrem/yr & fract. & mrem/yr & fract. & mrem/yr & fract. \\
\hline-241 & $8.514 \mathrm{E}-10$ & 0.0000 & $0.000 \mathrm{E}+00$ & 0.0000 & $0.000 \mathrm{E}+00$ & 0.0000 & $1.388 \mathrm{E}-02$ & 0.0009 & $2.460 \mathrm{E}-05$ & 0.0000 & $2.361 \mathrm{E}-06$ & 0.0000 & $0.000 \mathrm{E}+00$ & 0.0000 \\
\hline-137 & $9.483 E-15$ & 0.0000 & $0.000 \mathrm{E}+00$ & 0.0000 & $0.000 \mathrm{E}+00$ & 0.0000 & $2.921 \mathrm{E}-12$ & 0.0000 & $2.656 \mathrm{E}-12$ & 0.0000 & $1.960 \mathrm{E}-12$ & 0.0000 & $0.000 \mathrm{E}+00$ & 0.0000 \\
\hline-237 & $7.819 \mathrm{E}-07$ & 0.0000 & $0.000 \mathrm{E}+00$ & 0.0000 & $0.000 \mathrm{E}+00$ & 0.0000 & $1.127 \mathrm{E}-01$ & 0.0076 & $3.416 \mathrm{E}-03$ & 0.0002 & $4.886 \mathrm{E}-05$ & 0.0000 & $0.000 \mathrm{E}+00$ & 0.0000 \\
\hline-238 & $1.015 E-08$ & 0.0000 & $0.000 \mathrm{E}+00$ & 0.0000 & $0.000 \mathrm{E}+00$ & 0.0000 & $4.767 \mathrm{E}-05$ & 0.0000 & $4.234 \mathrm{E}-07$ & 0.0000 & $1.199 \mathrm{E}-06$ & 0.0000 & $0.000 \mathrm{E}+00$ & 0.0000 \\
\hline-239 & $2.403 E-10$ & 0.0000 & $0.000 \mathrm{E}+00$ & 0.0000 & $0.000 \mathrm{E}+00$ & 0.0000 & $9.132 \mathrm{E}-02$ & 0.0062 & $2.767 \mathrm{E}-04$ & 0.0000 & $7.663 \mathrm{E}-06$ & 0.0000 & $0.000 \mathrm{E}+00$ & 0.0000 \\
\hline-240 & $5.828 \mathrm{E}-14$ & 0.0000 & $0.000 \mathrm{E}+00$ & 0.0000 & $0.000 \mathrm{E}+00$ & 0.0000 & $8.421 E-02$ & 0.0057 & $2.552 \mathrm{E}-04$ & 0.0000 & $7.129 \mathrm{E}-06$ & 0.0000 & $0.000 \mathrm{E}+00$ & 0.0000 \\
\hline 99 & $2.603 E-19$ & 0.0000 & $0.000 \mathrm{E}+00$ & 0.0000 & $0.000 \mathrm{E}+00$ & 0.0000 & $1.377 \mathrm{E}-04$ & 0.0000 & $4.179 \mathrm{E}-07$ & 0.0000 & $1.156 \mathrm{E}-05$ & 0.0000 & $0.000 \mathrm{E}+00$ & 0.0000 \\
\hline-228 & $0.000 \mathrm{E}+00$ & 0.0000 & $0.000 \mathrm{E}+00$ & 0.0000 & $0.000 \mathrm{E}+00$ & 0.0000 & $0.000 \mathrm{E}+00$ & 0.0000 & $0.000 \mathrm{E}+00$ & 0.0000 & $0.000 \mathrm{E}+00$ & 0.0000 & $0.000 \mathrm{E}+00$ & 0.0000 \\
\hline-230 & 1. $793 \mathrm{E}-02$ & 0.0012 & $0.000 \mathrm{E}+00$ & 0.0000 & $0.000 \mathrm{E}+00$ & 0.0000 & $1.161 \mathrm{E}+01$ & 0.7836 & $3.053 E-01$ & 0.0206 & $5.404 \mathrm{E}-01$ & 0.0365 & $0.000 \mathrm{E}+00$ & 0.0000 \\
\hline-232 & $7.395 E-03$ & 0.0005 & $0.000 \mathrm{E}+00$ & 0.0000 & $0.000 \mathrm{E}+00$ & 0.0000 & $1.187 \mathrm{E}+00$ & 0.0801 & $3.501 \mathrm{E}-02$ & 0.0024 & $9.694 \mathrm{E}-02$ & 0.0065 & $0.000 \mathrm{E}+00$ & 0.0000 \\
\hline 234 & $1.454 \mathrm{E}-04$ & 0.0000 & $0.000 \mathrm{E}+00$ & 0.0000 & $0.000 \mathrm{E}+00$ & 0.0000 & $2.969 \mathrm{E}-01$ & 0.0200 & $4.528 E-03$ & 0.0003 & $1.456 \mathrm{E}-02$ & 0.0010 & $0.000 \mathrm{E}+00$ & 0.0000 \\
\hline 35 & $3.053 \mathrm{E}-07$ & 0.0000 & $0.000 \mathrm{E}+00$ & 0.0000 & $0.000 \mathrm{E}+00$ & 0.0000 & $2.296 \mathrm{E}-02$ & 0.0016 & $1.692 \mathrm{E}-03$ & 0.0001 & $4.143 E-04$ & 0.0000 & $0.000 \mathrm{E}+00$ & 0.0000 \\
\hline 38 & $1.984 \mathrm{E}-04$ & 0.0000 & $0.000 \mathrm{E}+00$ & 0.0000 & $0.000 \mathrm{E}+00$ & 0.0000 & $2.019 \mathrm{E}-01$ & 0.0136 & $2.082 E-03$ & 0.0001 & $1.016 \mathrm{E}-02$ & 0.0007 & $0.000 \mathrm{E}+00$ & 0.0000 \\
\hline & $2.567 \mathrm{E}-02$ & 0.0017 & $0.000 \mathrm{E}+00$ & 0.0000 & $0.000 \mathrm{E}+00$ & 0.0000 & $1.362 \mathrm{E}+01$ & 0.9194 & $3.526 \mathrm{E}-01$ & 0.0238 & $6.626 \mathrm{E}-01$ & 0.0447 & $0.000 \mathrm{E}+00$ & 0.0000 \\
\hline
\end{tabular}

Total Dose Contributions TDOSE(i,p,t) for Individual Radionuclides (i) and Pathways (p) As mrem/yr and Fraction of Total Dose At $t=1.050 \mathrm{E}+03$ years

Water Dependent Pathways

\begin{tabular}{|c|c|c|c|c|c|c|c|c|c|c|c|c|c|c|}
\hline \multirow{2}{*}{$\begin{array}{l}\text { Radio- } \\
\text { Nuclide }\end{array}$} & \multicolumn{2}{|c|}{ Water } & \multicolumn{2}{|c|}{ Fish } & \multicolumn{2}{|c|}{ Radon } & \multicolumn{2}{|c|}{ Plant } & \multicolumn{2}{|c|}{ Meat } & \multicolumn{2}{|c|}{ Milk } & \multicolumn{2}{|c|}{ All Pathways* } \\
\hline & mrem/yr & fract. & mrem/yr & fract. & mrem/yr & fract. & mrem/yr & fract. & mrem/yr & fract. & mrem/yr & fract. & mrem/yr & fract. \\
\hline 241 & $0.000 \mathrm{E}+00$ & 0.0000 & $0.000 \mathrm{E}+00$ & 0.0000 & $0.000 \mathrm{E}+00$ & 0.0000 & $0.000 \mathrm{E}+00$ & 0.0000 & $0.000 \mathrm{E}+00$ & 0.0000 & $0.000 \mathrm{E}+00$ & 0.0000 & $1.391 \mathrm{E}-02$ & 0.0009 \\
\hline-137 & $0.000 \mathrm{E}+00$ & 0.0000 & $0.000 \mathrm{E}+00$ & 0.0000 & $0.000 \mathrm{E}+00$ & 0.0000 & $0.000 \mathrm{E}+00$ & 0.0000 & $0.000 \mathrm{E}+00$ & 0.0000 & $0.000 \mathrm{E}+00$ & 0.0000 & 7. $547 \mathrm{E}-12$ & 0.0000 \\
\hline-237 & $0.000 \mathrm{E}+00$ & 0.0000 & $0.000 \mathrm{E}+00$ & 0.0000 & $0.000 \mathrm{E}+00$ & 0.0000 & $0.000 \mathrm{E}+00$ & 0.0000 & $0.000 \mathrm{E}+00$ & 0.0000 & $0.000 \mathrm{E}+00$ & 0.0000 & $1.162 \mathrm{E}-01$ & 0.0078 \\
\hline-238 & $0.000 \mathrm{E}+00$ & 0.0000 & $0.000 \mathrm{E}+00$ & 0.0000 & $0.000 \mathrm{E}+00$ & 0.0000 & $0.000 \mathrm{E}+00$ & 0.0000 & $0.000 \mathrm{E}+00$ & 0.0000 & $0.000 \mathrm{E}+00$ & 0.0000 & $4.930 \mathrm{E}-05$ & 0.0000 \\
\hline-239 & $0.000 \mathrm{E}+00$ & 0.0000 & $0.000 \mathrm{E}+00$ & 0.0000 & $0.000 \mathrm{E}+00$ & 0.0000 & $0.000 \mathrm{E}+00$ & 0.0000 & $0.000 \mathrm{E}+00$ & 0.0000 & $0.000 E+00$ & 0.0000 & $9.161 \mathrm{E}-02$ & 0.0062 \\
\hline-240 & $0.000 \mathrm{E}+00$ & 0.0000 & $0.000 \mathrm{E}+00$ & 0.0000 & $0.000 \mathrm{E}+00$ & 0.0000 & $0.000 \mathrm{E}+00$ & 0.0000 & $0.000 \mathrm{E}+00$ & 0.0000 & $0.000 E+00$ & 0.0000 & $8.447 \mathrm{E}-02$ & 0.0057 \\
\hline 99 & $1.266 \mathrm{E}-01$ & 0.0086 & $0.000 \mathrm{E}+00$ & 0.0000 & $0.000 \mathrm{E}+00$ & 0.0000 & $1.184 \mathrm{E}-02$ & 0.0008 & $2.119 \mathrm{E}-04$ & 0.0000 & $1.430 \mathrm{E}-02$ & 0.0010 & $1.531 \mathrm{E}-01$ & 0.0103 \\
\hline-228 & $0.000 \mathrm{E}+00$ & 0.0000 & $0.000 \mathrm{E}+00$ & 0.0000 & $0.000 \mathrm{E}+00$ & 0.0000 & $0.000 \mathrm{E}+00$ & 0.0000 & $0.000 \mathrm{E}+00$ & 0.0000 & $0.000 \mathrm{E}+00$ & 0.0000 & $0.000 \mathrm{E}+00$ & 0.0000 \\
\hline-230 & $0.000 \mathrm{E}+00$ & 0.0000 & $0.000 \mathrm{E}+00$ & 0.0000 & $0.000 \mathrm{E}+00$ & 0.0000 & $0.000 \mathrm{E}+00$ & 0.0000 & $0.000 \mathrm{E}+00$ & 0.0000 & $0.000 E+00$ & 0.0000 & $1.247 \mathrm{E}+01$ & 0.8419 \\
\hline 232 & $0.000 \mathrm{E}+00$ & 0.0000 & $0.000 \mathrm{E}+00$ & 0.0000 & $0.000 \mathrm{E}+00$ & 0.0000 & $0.000 \mathrm{E}+00$ & 0.0000 & $0.000 \mathrm{E}+00$ & 0.0000 & $0.000 \mathrm{E}+00$ & 0.0000 & $1.326 \mathrm{E}+00$ & 0.0895 \\
\hline 34 & $0.000 \mathrm{E}+00$ & 0.0000 & $0.000 \mathrm{E}+00$ & 0.0000 & $0.000 \mathrm{E}+00$ & 0.0000 & $0.000 \mathrm{E}+00$ & 0.0000 & $0.000 \mathrm{E}+00$ & 0.0000 & $0.000 \mathrm{E}+00$ & 0.0000 & $3.161 \mathrm{E}-01$ & 0.0213 \\
\hline 35 & $0.000 \mathrm{E}+00$ & 0.0000 & $0.000 \mathrm{E}+00$ & 0.0000 & $0.000 \mathrm{E}+00$ & 0.0000 & $0.000 \mathrm{E}+00$ & 0.0000 & $0.000 \mathrm{E}+00$ & 0.0000 & $0.000 \mathrm{E}+00$ & 0.0000 & $2.506 \mathrm{E}-02$ & 0.0017 \\
\hline 38 & $0.000 \mathrm{E}+00$ & 0.0000 & $0.000 \mathrm{E}+00$ & 0.0000 & $0.000 \mathrm{E}+00$ & 0.0000 & $0.000 \mathrm{E}+00$ & 0.0000 & $0.000 \mathrm{E}+00$ & 0.0000 & $0.000 \mathrm{E}+00$ & 0.0000 & $2.144 \mathrm{E}-01$ & 0.0145 \\
\hline & $1.266 \mathrm{E}-01$ & 0.0086 & $0.000 \mathrm{E}+00$ & 0.0000 & $0.000 \mathrm{E}+00$ & 0.0000 & $1.184 \mathrm{E}-02$ & 0.0008 & $.119 \mathrm{E}-04$ & 0.0000 & $430 E-02$ & 0.0010 & $E+01$ & \\
\hline
\end{tabular}

* Sum of all water independent and dependent pathways. 
RESRAD, Version 6.5

Summary : RESRAD Parameters for Resident Farmer U-Landfill Forward Run 1,050 Years at ALs File : C: \RESRAD_FAMILY \RESRAD \USERFILES \QCJULY2011 \ONSITERF_FORWARD-1050YRALS.RAD

Dose/Source Ratios Summed Over All Pathways

Parent and Progeny Principal Radionuclide Contributions Indicated

Parent Product Thread DSR $(j, t)$ At Time in Years (mrem/yr)/(pCi/g)

(i)

(j)

$\begin{array}{ll}\mathrm{Am}-241 & 1.000 \mathrm{E}+00 \\ \mathrm{~Np}-237+\mathrm{D} & 1.000 \mathrm{E}+00 \\ \mathrm{U}-233 & 1.000 \mathrm{E}+00 \\ \mathrm{Th}-229+\mathrm{D} & 1.000 \mathrm{E}+00 \\ \operatorname{\sum DSR}(j) & \end{array}$

Cs $-137+D$

$\mathrm{Np}-237+\mathrm{D}$

$\mathrm{U}-233$

Th-229+D

$\sum \operatorname{DSR}(j)$

Pu-238

$\mathrm{Pu}-238$

$\mathrm{U}-234$

Th-230

Ra-226+D

$\mathrm{Pb}-210+\mathrm{D}$

$\sum \operatorname{DSR}(j)$

$\mathrm{Pu}-239$

$\mathrm{U}-235+\mathrm{D}$

$\mathrm{Pa}-231$

Ac $-227+D$

$\sum \operatorname{DSR}(j)$

Pu-240

$\mathrm{Pu}-240$

U-236

Th-232

$\mathrm{Ra}-228+\mathrm{D}$

Th-228+D

$\sum \operatorname{DSR}(j)$

Tc-99

Th $-228+\mathrm{D}$

Th-230

$\mathrm{Ra}-226+\mathrm{D}$

$\mathrm{Pb}-210+\mathrm{D}$

$\sum \operatorname{DSR}(j)$ $\begin{array}{llllllll}1.000 \mathrm{E}+00 & 1.262 \mathrm{E}-09 & 1.243 \mathrm{E}-09 & 6.050 \mathrm{E}-10 & 2.901 \mathrm{E}-10 & 8.104 \mathrm{E}-13 & 1.986 \mathrm{E}-13\end{array}$

$\begin{array}{lllllllll}1.000 \mathrm{E}+00 & 9.536 \mathrm{E}-13 & 9.638 \mathrm{E}-13 & 1.625 \mathrm{E}-12 & 2.770 \mathrm{E}-12 & 1.974 \mathrm{E}-10 & 1.056 \mathrm{E}-02\end{array}$

$\begin{array}{llllllll}1.000 \mathrm{E}+00 & 3.245 \mathrm{E}-23 & 9.844 \mathrm{E}-23 & 6.100 \mathrm{E}-21 & 2.264 \mathrm{E}-20 & 1.650 \mathrm{E}-17 & 3.040 \mathrm{E}-06\end{array}$

$\begin{array}{llllllll}1.000 \mathrm{E}+00 & 2.962 \mathrm{E}-19 & 2.086 \mathrm{E}-18 & 3.196 \mathrm{E}-15 & 1.788 \mathrm{E}-14 & 7.080 \mathrm{E}-12 & 6.835 \mathrm{E}-07\end{array}$ $9.536 \mathrm{E}-13 \quad 9.638 \mathrm{E}-13 \quad 1.629 \mathrm{E}-12 \quad 2.788 \mathrm{E}-12 \quad 2.044 \mathrm{E}-10 \quad 1.056 \mathrm{E}-02$

$\begin{array}{lllllll}1.840 E-09 & 2.162 E-33 & 2.183 E-33 & 3.520 E-33 & 5.731 E-33 & 2.831 E-31 & 5.523 E-16\end{array}$

$1.000 \mathrm{E}+00 \quad 1.175 \mathrm{E}-24 \quad 1.186 \mathrm{E}-24 \quad 1.913 \mathrm{E}-24 \quad 3.115 \mathrm{E}-24 \quad 1.539 \mathrm{E}-22 \quad 3.001 \mathrm{E}-07$ $\begin{array}{llllllll}1.000 \mathrm{E}+00 & 9.778 \mathrm{E}-30 & 2.969 \mathrm{E}-29 & 1.973 \mathrm{E}-27 & 7.960 \mathrm{E}-27 & 1.690 \mathrm{E}-23 & 2.418 \mathrm{E}-07\end{array}$ $\begin{array}{lllllll}1.000 \mathrm{E}+00 & 1.028 \mathrm{E}-33 & 7.286 \mathrm{E}-33 & 1.599 \mathrm{E}-29 & 1.302 \mathrm{E}-28 & 1.306 \mathrm{E}-24 & 3.284 \mathrm{E}-09\end{array}$ $\begin{array}{llllllll}1.000 \mathrm{E}+00 & 8.021 \mathrm{E}-23 & 1.208 \mathrm{E}-21 & 5.266 \mathrm{E}-17 & 5.323 \mathrm{E}-16 & 5.607 \mathrm{E}-13 & 3.487 \mathrm{E}-08\end{array}$ $\begin{array}{llllllll}1.000 \mathrm{E}+00 & 2.326 \mathrm{E}-31 & 7.210 \mathrm{E}-30 & 7.772 \mathrm{E}-24 & 1.314 \mathrm{E}-22 & 3.671 \mathrm{E}-19 & 5.196 \mathrm{E}-08\end{array}$ $\begin{array}{llllll}8.139 \mathrm{E}-23 & 1.209 \mathrm{E}-21 & 5.266 \mathrm{E}-17 & 5.323 \mathrm{E}-16 & 5.607 \mathrm{E}-13 & 6.321 \mathrm{E}-07\end{array}$

$\begin{array}{lllllllll}1.000 \mathrm{E}+00 & 1.202 \mathrm{E}-17 & 1.217 \mathrm{E}-17 & 2.183 \mathrm{E}-17 & 3.965 \mathrm{E}-17 & 4.690 \mathrm{E}-15 & 1.272 \mathrm{E}-03\end{array}$ $\begin{array}{llllllll}1.000 \mathrm{E}+00 & 6.135 \mathrm{E}-24 & 1.861 \mathrm{E}-23 & 1.146 \mathrm{E}-21 & 4.227 \mathrm{E}-21 & 2.931 \mathrm{E}-18 & 6.669 \mathrm{E}-10\end{array}$ $\begin{array}{lllllll}1.000 \mathrm{E}+00 & 9.652 \mathrm{E}-28 & 6.818 \mathrm{E}-27 & 1.251 \mathrm{E}-23 & 8.414 \mathrm{E}-23 & 1.444 \mathrm{E}-19 & 4.822 \mathrm{E}-10\end{array}$ $\begin{array}{llllllll}1.000 \mathrm{E}+00 & 2.288 \mathrm{E}-27 & 3.434 \mathrm{E}-26 & 1.276 \mathrm{E}-21 & 1.169 \mathrm{E}-20 & 1.476 \mathrm{E}-17 & 1.691 \mathrm{E}-10\end{array}$ $\begin{array}{lllllll}1.202 \mathrm{E}-17 & 1.217 \mathrm{E}-17 & 2.183 \mathrm{E}-17 & 3.966 \mathrm{E}-17 & 4.708 \mathrm{E}-15 & 1.272 \mathrm{E}-03\end{array}$

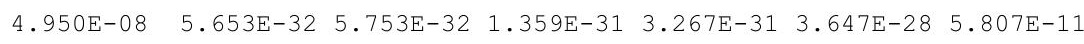

$1.000 \mathrm{E}+00 \quad 1.142 \mathrm{E}-24 \quad 1.162 \mathrm{E}-24 \quad 2.746 \mathrm{E}-24 \quad 6.601 \mathrm{E}-24 \quad 7.367 \mathrm{E}-21 \quad 1.173 \mathrm{E}-03$ $\begin{array}{llllllll}1.000 \mathrm{E}+00 & 2.162 \mathrm{E}-32 & 6.590 \mathrm{E}-32 & 5.335 \mathrm{E}-30 & 2.602 \mathrm{E}-29 & 1.686 \mathrm{E}-25 & 1.912 \mathrm{E}-08\end{array}$

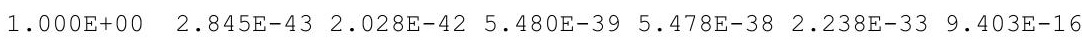
$\begin{array}{llllllll}1.000 \mathrm{E}+00 & 1.371 \mathrm{E}-28 & 2.018 \mathrm{E}-27 & 3.762 \mathrm{E}-23 & 2.542 \mathrm{E}-22 & 1.470 \mathrm{E}-19 & 1.228 \mathrm{E}-13\end{array}$ $\begin{array}{llllllll}1.000 \mathrm{E}+00 & 8.111 \mathrm{E}-28 & 2.334 \mathrm{E}-26 & 2.641 \mathrm{E}-21 & 1.757 \mathrm{E}-20 & 5.564 \mathrm{E}-18 & 1.531 \mathrm{E}-15\end{array}$ $\begin{array}{llllll}1.143 \mathrm{E}-24 & 1.188 \mathrm{E}-24 & 2.681 \mathrm{E}-21 & 1.783 \mathrm{E}-20 & 5.719 \mathrm{E}-18 & 1.173 \mathrm{E}-03\end{array}$

$\begin{array}{lllllll}1.000 \mathrm{E}+00 \quad 5.758 \mathrm{E}-26 & 5.817 \mathrm{E}-26 & 9.575 \mathrm{E}-26 & 1.592 \mathrm{E}-25 & 2.069 \mathrm{E}-01 & 1.472 \mathrm{E}-03\end{array}$ $\begin{array}{llllll}1.000 \mathrm{E}+00 & 1.382 \mathrm{E}-06 \quad 9.680 \mathrm{E}-07 & 2.527 \mathrm{E}-14 & 4.618 \mathrm{E}-22 & 0.000 \mathrm{E}+00 \quad 0.000 \mathrm{E}+00\end{array}$

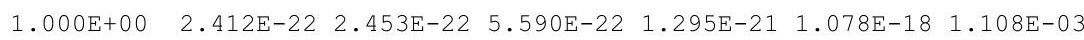
$\begin{array}{llllllll}1.000 \mathrm{E}+00 & 3.774 \mathrm{E}-11 & 1.139 \mathrm{E}-10 & 5.320 \mathrm{E}-09 & 1.479 \mathrm{E}-08 & 1.071 \mathrm{E}-06 & 2.402 \mathrm{E}-02\end{array}$ $\begin{array}{lllllll}1.000 \mathrm{E}+00 & 1.819 \mathrm{E}-19 & 1.271 \mathrm{E}-18 & 1.299 \mathrm{E}-15 & 5.314 \mathrm{E}-15 & 7.678 \mathrm{E}-13 & 3.722 \mathrm{E}-02\end{array}$ $\begin{array}{llllll}3.774 \mathrm{E}-11 & 1.139 \mathrm{E}-10 & 5.320 \mathrm{E}-09 & 1.479 \mathrm{E}-08 & 1.071 \mathrm{E}-06 & 6.234 \mathrm{E}-02\end{array}$ 
RESRAD, Version 6.5

Summary : RESRAD Parameters for Resident Farmer U-Landfill Forward Run 1,050 Years at ALs File : C: $\backslash$ RESRAD_FAMILY \RESRAD \USERFILES $\backslash Q C J U L Y 2011 \backslash$ ONSITERF_FORWARD-1050YRALS.RAD

Dose/Source Ratios Summed Over All Pathways

Parent and Progeny Principal Radionuclide Contributions Indicated

\begin{tabular}{|c|c|c|c|c|c|c|c|c|}
\hline $\begin{array}{l}\text { Parent } \\
\text { (i) }\end{array}$ & $\begin{array}{l}\text { Product } \\
\text { (j) }\end{array}$ & $\begin{array}{l}\text { Thread } \\
\text { Fraction }\end{array}$ & $\begin{array}{r}\text { DSR } \\
0.000 \mathrm{E}+00\end{array}$ & $\begin{array}{l}(j, t) \text { At } T \\
1.000 E+00\end{array}$ & $\begin{array}{l}\text { Ime in Year } \\
5.000 \mathrm{E}+01\end{array}$ & $\begin{array}{l}\text { Es (mrem/ } \\
1.000 \mathrm{E}+02\end{array}$ & $\begin{array}{l}/ \mathrm{yr}) /(\mathrm{pCi} / \mathrm{g} \\
5.000 \mathrm{E}+02\end{array}$ & $1.050 \mathrm{E}+03$ \\
\hline 232 & $\mathrm{Th}-232$ & $1.000 \mathrm{E}+00$ & $1.166 \mathrm{E}-24$ & $1.188 \mathrm{E}-24$ & $2.949 E-24$ & $7.462 \mathrm{E}-24$ & 1. $252 \mathrm{E}-20$ & 1. $225 \mathrm{E}-03$ \\
\hline 232 & $\mathrm{Ra}-228+\mathrm{D}$ & $1.000 \mathrm{E}+00$ & $1.107 \mathrm{E}-09$ & $3.174 \mathrm{E}-09$ & $2.784 \mathrm{E}-08$ & $4.079 \mathrm{E}-08$ & $8.497 \mathrm{E}-07$ & $1.625 \mathrm{E}-01$ \\
\hline-232 & $\mathrm{Th}-228+\mathrm{D}$ & $1.000 \mathrm{E}+00$ & $1.067 \mathrm{E}-08$ & $6.581 \mathrm{E}-08$ & $2.213 E-06$ & $2.992 \mathrm{E}-06$ & $3.253 E-05$ & $2.034 \mathrm{E}-03$ \\
\hline-232 & $\sum \operatorname{DSR}(j)$ & & $1.178 \mathrm{E}-08$ & $6.899 \mathrm{E}-08$ & $2.241 \mathrm{E}-06$ & $3.033 E-06$ & $3.338 E-05$ & $1.657 \mathrm{E}-01$ \\
\hline-234 & $\mathrm{U}-234$ & $1.000 \mathrm{E}+00$ & $6.896 \mathrm{E}-24$ & $7.019 \mathrm{E}-24$ & $1.670 \mathrm{E}-23$ & $4.047 \mathrm{E}-23$ & $4.798 E-20$ & $6.733 E-04$ \\
\hline-234 & $T h-230$ & $1.000 \mathrm{E}+00$ & $1.089 \mathrm{E}-27$ & $3.315 E-27$ & $2.540 \mathrm{E}-25$ & $1.171 \mathrm{E}-24$ & $4.838 E-21$ & $1.040 \mathrm{E}-05$ \\
\hline 234 & $\mathrm{Ra}-226+\mathrm{D}$ & $1.000 \mathrm{E}+00$ & $1.133 \mathrm{E}-16$ & $7.978 E-16$ & $1.213 E-12$ & $6.737 E-12$ & $2.496 E-09$ & 1. $217 \mathrm{E}-04$ \\
\hline 234 & $\mathrm{~Pb}-210+\mathrm{D}$ & $1.000 \mathrm{E}+00$ & $4.102 E-25$ & $6.153 E-24$ & $2.201 \mathrm{E}-19$ & 1. $935 \mathrm{E}-18$ & $1.678 \mathrm{E}-15$ & $1.826 \mathrm{E}-04$ \\
\hline 234 & $\sum \operatorname{DSR}(j)$ & & $1.133 \mathrm{E}-16$ & 7. $978 \mathrm{E}-16$ & $1.213 \mathrm{E}-12$ & $6.737 \mathrm{E}-12$ & $2.496 \mathrm{E}-09$ & $9.879 E-04$ \\
\hline$-235+D$ & $\mathrm{U}-235+\mathrm{D}$ & $1.000 \mathrm{E}+00$ & 1. $243 \mathrm{E}-14$ & $1.259 \mathrm{E}-14$ & $2.306 \mathrm{E}-14$ & $4.276 \mathrm{E}-14$ & $5.981 \mathrm{E}-12$ & $6.524 \mathrm{E}-04$ \\
\hline$-235+D$ & $\mathrm{~Pa}-231$ & $1.000 \mathrm{E}+00$ & $2.937 \mathrm{E}-18$ & $8.896 \mathrm{E}-18$ & $5.031 \mathrm{E}-16$ & $1.701 \mathrm{E}-15$ & $5.876 \mathrm{E}-13$ & $9.372 \mathrm{E}-04$ \\
\hline$-235+D$ & $A C-227+D$ & $1.000 \mathrm{E}+00$ & $9.274 \mathrm{E}-18$ & $6.481 \mathrm{E}-17$ & $6.882 \mathrm{E}-14$ & $2.943 E-13$ & $6.376 \mathrm{E}-11$ & $3.384 \mathrm{E}-04$ \\
\hline$-235+D$ & $\sum \operatorname{DSR}(j)$ & & $1.245 \mathrm{E}-14$ & $1.266 \mathrm{E}-14$ & $9.238 \mathrm{E}-14$ & $3.388 \mathrm{E}-13$ & $7.033 E-11$ & $1.928 \mathrm{E}-03$ \\
\hline-238 & $U-238$ & $5.400 \mathrm{E}-05$ & $0.000 \mathrm{E}+00$ & $0.000 \mathrm{E}+00$ & $0.000 \mathrm{E}+00$ & $0.000 \mathrm{E}+00$ & $0.000 \mathrm{E}+00$ & $3.349 \mathrm{E}-08$ \\
\hline$-238+D$ & $\mathrm{U}-238+\mathrm{D}$ & $9.999 \mathrm{E}-01$ & $1.420 \mathrm{E}-10$ & $1.431 \mathrm{E}-10$ & $2.116 \mathrm{E}-10$ & $3.153 E-10$ & $7.678 E-09$ & $6.676 \mathrm{E}-04$ \\
\hline $238+D$ & $\mathrm{U}-234$ & $9.999 \mathrm{E}-01$ & $9.803 E-30$ & $2.988 E-29$ & $2.392 E-27$ & $1.153 E-26$ & $6.812 \mathrm{E}-23$ & $2.008 E-06$ \\
\hline$-238+D$ & $T h-230$ & $9.999 \mathrm{E}-01$ & $1.030 E-33$ & $7.316 E-33$ & $1.818 \mathrm{E}-29$ & $1.668 E-28$ & $3.430 E-24$ & $1.547 \mathrm{E}-08$ \\
\hline$-238+D$ & $\mathrm{Ra}-226+\mathrm{D}$ & $9.999 \mathrm{E}-01$ & $8.034 \mathrm{E}-23$ & 1. $212 \mathrm{E}-21$ & $5.801 \mathrm{E}-17$ & $6.420 \mathrm{E}-16$ & $1.201 \mathrm{E}-12$ & $1.251 \mathrm{E}-07$ \\
\hline$-238+D$ & $\mathrm{~Pb}-210+\mathrm{D}$ & $9.999 \mathrm{E}-01$ & $2.329 E-31$ & $7.229 E-30$ & $8.430 \mathrm{E}-24$ & $1.546 \mathrm{E}-22$ & $7.612 E-19$ & $1.821 \mathrm{E}-07$ \\
\hline$-238+D$ & $\sum \operatorname{DSR}(j)$ & & $1.420 \mathrm{E}-10$ & $1.431 \mathrm{E}-10$ & $2.116 \mathrm{E}-10$ & $3.153 \mathrm{E}-10$ & $7.680 \mathrm{E}-09$ & $6.699 \mathrm{E}-04$ \\
\hline
\end{tabular}

The DSR includes contributions from associated (half-life $\leq 180$ days) daughters. 
RESRAD, Version 6.5

Summary : RESRAD Parameters for Resident Farmer U-Landfill Forward Run 1,050 Years at ALs File : C: \RESRAD_FAMILY \RESRAD \USERFILES \QCJULY2011 \ONSITERF_FORWARD-1050YRALS.RAD

Individual Nuclide Dose Summed Over All Pathways

Parent Nuclide and Branch Fraction Indicated

Nuclide Parent THF(i) DOSE $(j, t)$, mrem/yr

\begin{tabular}{|c|c|c|}
\hline (j) & (i) & \\
\hline$m-241$ & $A m-241$ & $1.000 \mathrm{E}+00$ \\
\hline$p-237$ & $A m-241$ & $1.000 \mathrm{E}+00$ \\
\hline$p-237$ & Np-237 & $1.000 \mathrm{E}+00$ \\
\hline $\mathrm{Np}-237$ & $\sum \operatorname{DOSE}(j$ & \\
\hline
\end{tabular}

$\mathrm{U}-233 \quad \mathrm{Am}-241 \quad 1.000 \mathrm{E}+00$

$\mathrm{U}-233 \quad \mathrm{NP}-237 \quad 1.000 \mathrm{E}+00$

U-233 $\quad$ DDOSE (j)

Th-229 Am-241 $1.000 \mathrm{~F}+00$

Th-229 Np-237 1.000E+00

Th-229 $\sum \operatorname{DOSE}(j)$

Cs-137 Cs-137 1.000E+00

Pu-238 $\mathrm{Pu}-238 \quad 1.840 \mathrm{E}-09$

$\mathrm{Pu}-238$

$\mathrm{Pu}-238$

$\mathrm{U}-234$

$\mathrm{U}-234$

$\mathrm{U}-234$

$\mathrm{U}-234$

Th-230

Th -230

Th -230

Th-230

Th-230

$\mathrm{Ra}-226$

$\mathrm{Ra}-226$

$\mathrm{Ra}-226$

$\mathrm{Ra}-226$

$\mathrm{Ra}-226$

$\mathrm{Pb}-210$

$\mathrm{Pb}-210$

$\mathrm{Pb}-210$

$\mathrm{Pb}-210$

$\mathrm{Pb}-210$

$\mathrm{Pu}-239$

$\mathrm{Pu}-239 \quad 1.000 \mathrm{E}+00$ $\mathrm{U}-2351.000 \mathrm{E}+00$ $\sum \operatorname{DOSE}(j)$ $\mathrm{t}=0.000 \mathrm{E}+00 \quad 1.000 \mathrm{E}+00 \quad 5.000 \mathrm{E}+01 \quad 1.000 \mathrm{E}+02 \quad 5.000 \mathrm{E}+02 \quad 1.050 \mathrm{E}+03$

$\begin{array}{llllll}0.000 \mathrm{E}+00 & 0.000 \mathrm{E}+00 & 0.000 \mathrm{E}+00 & 0.000 \mathrm{E}+00 & 8.455 \mathrm{E}-26 & 1.378 \mathrm{E}-02\end{array}$

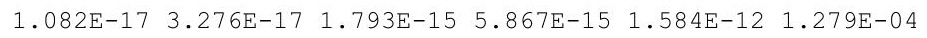

$1.049 \mathrm{E}-11 \quad 1.060 \mathrm{E}-11 \quad 1.788 \mathrm{E}-11 \quad 3.047 \mathrm{E}-11 \quad 2.171 \mathrm{E}-09 \quad 1.162 \mathrm{E}-01$

$\begin{array}{lllllll}1.049 \mathrm{E}-11 & 1.060 \mathrm{E}-11 & 1.788 \mathrm{E}-11 & 3.048 \mathrm{E}-11 & 2.172 \mathrm{E}-09 & 1.163 \mathrm{E}-01\end{array}$

$2.454 \mathrm{E}-28 \quad 1.736 \mathrm{E}-27 \quad 3.404 \mathrm{E}-24 \quad 2.452 \mathrm{E}-23 \quad 7.371 \mathrm{E}-20 \quad 2.265 \mathrm{E}-08$

$\begin{array}{llllll}3.570 \mathrm{E}-22 & 1.083 \mathrm{E}-21 & 6.710 \mathrm{E}-20 & 2.490 \mathrm{E}-19 & 1.815 \mathrm{E}-16 & 3.344 \mathrm{E}-05\end{array}$ $\begin{array}{llllll}3.570 \mathrm{E}-22 & 1.083 \mathrm{E}-21 & 6.710 \mathrm{E}-20 & 2.491 \mathrm{E}-19 & 1.816 \mathrm{E}-16 & 3.346 \mathrm{E}-05\end{array}$

$\begin{array}{llllll}1.679 \mathrm{E}-24 & 2.533 \mathrm{E}-23 & 1.197 \mathrm{E}-18 & 1.308 \mathrm{E}-17 & 2.237 \mathrm{E}-14 & 3.801 \mathrm{E}-09\end{array}$ $\begin{array}{llllll}3.258 \mathrm{E}-18 & 2.294 \mathrm{E}-17 & 3.515 \mathrm{E}-14 & 1.967 \mathrm{E}-13 & 7.788 \mathrm{E}-11 & 7.518 \mathrm{E}-06\end{array}$ $\begin{array}{lllllll}3.258 \mathrm{E}-18 & 2.294 \mathrm{E}-17 & 3.516 \mathrm{E}-14 & 1.967 \mathrm{E}-13 & 7.790 \mathrm{E}-11 & 7.522 \mathrm{E}-06\end{array}$

$\begin{array}{llllll}4.795 \mathrm{E}-08 & 4.725 \mathrm{E}-08 & 2.299 \mathrm{E}-08 & 1.102 \mathrm{E}-08 & 3.079 \mathrm{E}-11 & 7.547 \mathrm{E}-12\end{array}$

$\begin{array}{llllll}0.000 \mathrm{E}+00 & 0.000 \mathrm{E}+00 & 0.000 \mathrm{E}+00 & 0.000 \mathrm{E}+00 & 0.000 \mathrm{E}+00 & 4.308 \mathrm{E}-14\end{array}$ $\begin{array}{llllll}9.164 \mathrm{E}-23 & 9.254 \mathrm{E}-23 & 1.492 \mathrm{E}-22 & 2.430 \mathrm{E}-22 & 1.200 \mathrm{E}-20 & 2.341 \mathrm{E}-05\end{array}$ $\begin{array}{llllll}9.164 \mathrm{E}-23 & 9.254 \mathrm{E}-23 & 1.492 \mathrm{E}-22 & 2.430 \mathrm{E}-22 & 1.200 \mathrm{E}-20 & 2.341 \mathrm{E}-05\end{array}$

$\begin{array}{llllll}7.627 \mathrm{E}-28 & 2.316 \mathrm{E}-27 & 1.539 \mathrm{E}-25 & 6.209 \mathrm{E}-25 & 1.319 \mathrm{E}-21 & 1.886 \mathrm{E}-05\end{array}$ $\begin{array}{llllll}2.207 \mathrm{E}-21 & 2.246 \mathrm{E}-21 & 5.346 \mathrm{E}-21 & 1.295 \mathrm{E}-20 & 1.535 \mathrm{E}-17 & 2.154 \mathrm{E}-01\end{array}$ $\begin{array}{lllllll}3.137 \mathrm{E}-27 & 9.560 \mathrm{E}-27 & 7.653 \mathrm{E}-25 & 3.690 \mathrm{E}-24 & 2.180 \mathrm{E}-20 & 6.425 \mathrm{E}-04\end{array}$ $\begin{array}{llllll}2.207 \mathrm{E}-21 & 2.246 \mathrm{E}-21 & 5.346 \mathrm{E}-21 & 1.295 \mathrm{E}-20 & 1.538 \mathrm{E}-17 & 2.161 \mathrm{E}-01\end{array}$

$\begin{array}{llllll}0.000 \mathrm{E}+00 & 0.000 \mathrm{E}+00 & 1.247 \mathrm{E}-27 & 1.016 \mathrm{E}-26 & 1.018 \mathrm{E}-22 & 2.561 \mathrm{E}-07\end{array}$ $\begin{array}{llllll}4.824 \mathrm{E}-20 & 4.906 \mathrm{E}-20 & 1.118 \mathrm{E}-19 & 2.591 \mathrm{E}-19 & 2.155 \mathrm{E}-16 & 2.216 \mathrm{E}-01\end{array}$ $\begin{array}{llllll}3.484 \mathrm{E}-25 & 1.061 \mathrm{E}-24 & 8.129 \mathrm{E}-23 & 3.748 \mathrm{E}-22 & 1.548 \mathrm{E}-18 & 3.329 \mathrm{E}-03\end{array}$ $\begin{array}{llllll}0.000 \mathrm{E}+00 & 0.000 \mathrm{E}+00 & 5.819 \mathrm{E}-27 & 5.338 \mathrm{E}-26 & 1.098 \mathrm{E}-21 & 4.950 \mathrm{E}-06\end{array}$ $\begin{array}{llllll}4.824 \mathrm{E}-20 & 4.906 \mathrm{E}-20 & 1.119 \mathrm{E}-19 & 2.595 \mathrm{E}-19 & 2.171 \mathrm{E}-16 & 2.249 \mathrm{E}-01\end{array}$

$\begin{array}{lllllll}6.257 \mathrm{E}-21 & 9.424 \mathrm{E}-20 & 4.107 \mathrm{E}-15 & 4.152 \mathrm{E}-14 & 4.373 \mathrm{E}-11 & 2.720 \mathrm{E}-06\end{array}$ $\begin{array}{llllll}7.548 \mathrm{E}-09 & 2.278 \mathrm{E}-08 & 1.064 \mathrm{E}-06 & 2.958 \mathrm{E}-06 & 2.142 \mathrm{E}-04 & 4.804 \mathrm{E}+00\end{array}$ $\begin{array}{lllllll}3.626 \mathrm{E}-14 & 2.553 \mathrm{E}-13 & 3.883 \mathrm{E}-10 & 2.156 \mathrm{E}-09 & 7.986 \mathrm{E}-07 & 3.893 \mathrm{E}-02\end{array}$ $\begin{array}{llllll}2.571 \mathrm{E}-20 & 3.879 \mathrm{E}-19 & 1.856 \mathrm{E}-14 & 2.055 \mathrm{E}-13 & 3.842 \mathrm{E}-10 & 4.002 \mathrm{E}-05\end{array}$

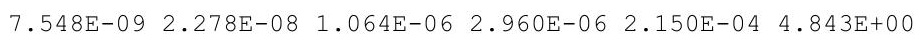

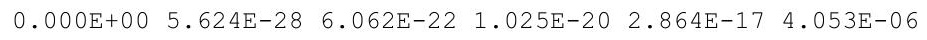
$\begin{array}{llllll}3.638 \mathrm{E}-17 & 2.541 \mathrm{E}-16 & 2.598 \mathrm{E}-13 & 1.063 \mathrm{E}-12 & 1.536 \mathrm{E}-10 & 7.444 \mathrm{E}+00\end{array}$

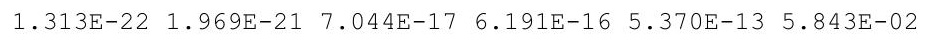
$0.000 \mathrm{E}+00 \quad 2.313 \mathrm{E}-27 \quad 2.698 \mathrm{E}-21 \quad 4.947 \mathrm{E}-20 \quad 2.436 \mathrm{E}-16 \quad 5.828 \mathrm{E}-05$ $\begin{array}{llllll}3.638 \mathrm{E}-17 & 2.541 \mathrm{E}-16 & 2.598 \mathrm{E}-13 & 1.063 \mathrm{E}-12 & 1.541 \mathrm{E}-10 & 7.502 \mathrm{E}+00\end{array}$

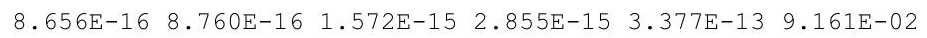

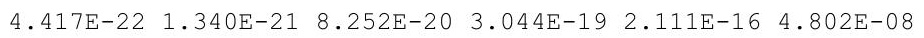
$\begin{array}{lllllll}1.616 \mathrm{E}-13 & 1.636 \mathrm{E}-13 & 2.997 \mathrm{E}-13 & 5.558 \mathrm{E}-13 & 7.775 \mathrm{E}-11 & 8.481 \mathrm{E}-03\end{array}$ $\begin{array}{llllll}1.616 \mathrm{E}-13 & 1.636 \mathrm{E}-13 & 2.997 \mathrm{E}-13 & 5.558 \mathrm{E}-13 & 7.775 \mathrm{E}-11 & 8.481 \mathrm{E}-03\end{array}$ 
RESRAD, Version $6.5 \quad \mathrm{~T}^{1 / 2}$ Limit $=180$ days

Summary : RESRAD Parameters for Resident Farmer U-Landfill Forward Run 1,050 Years at ALs File : C: \RESRAD_FAMILY \RESRAD \USERFILES $\backslash Q C J U L Y 2011 \backslash$ ONSITERF_FORWARD-1050YRALS.RAD

Individual Nuclide Dose Summed Over All Pathways

Parent Nuclide and Branch Fraction Indicated

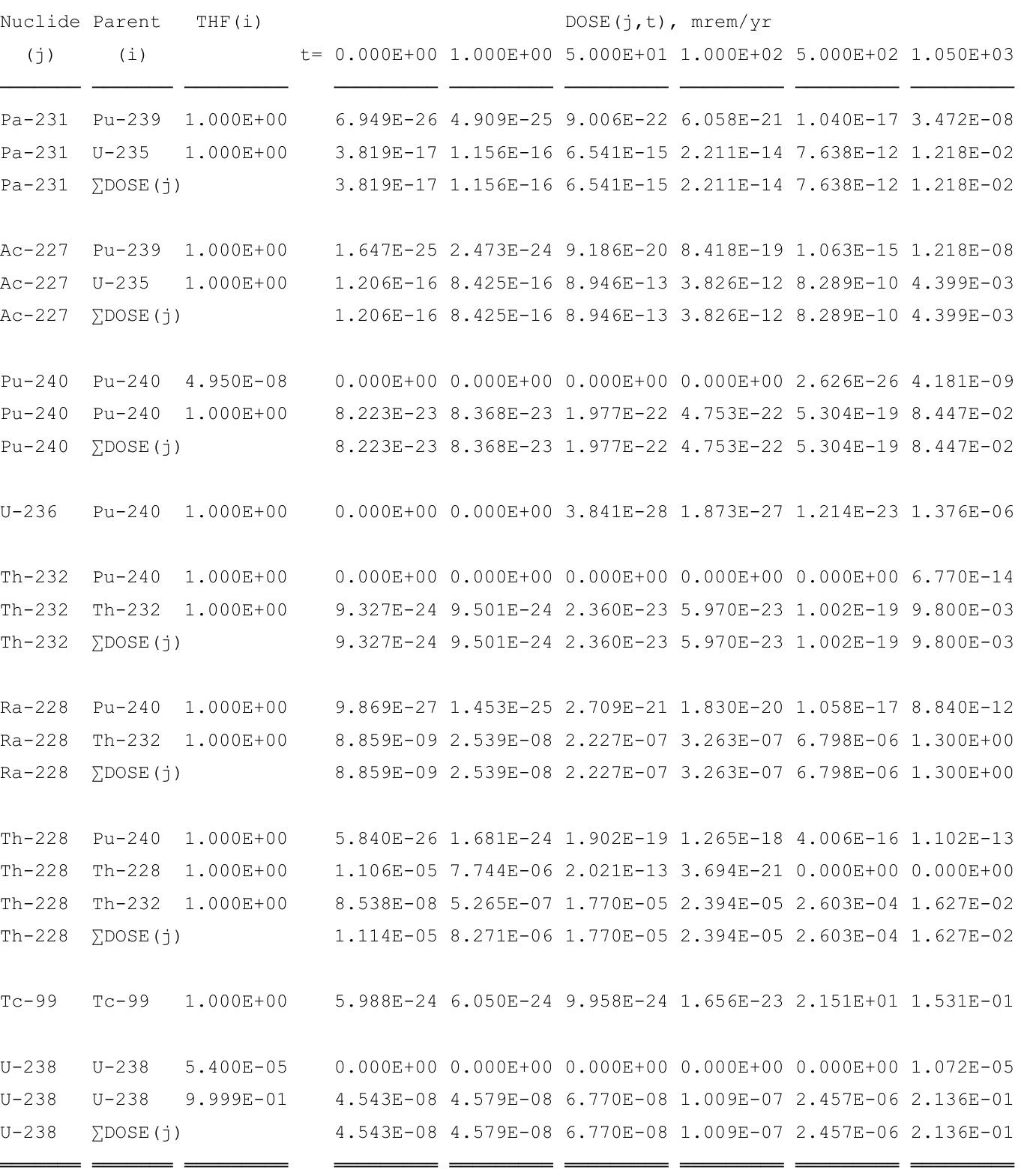

THF (i) is the thread fraction of the parent nuclide. 
RESRAD, Version 6.5

Summary : RESRAD Parameters for Resident Farmer U-Landfill Forward Run 1,050 Years at ALs File : C: \RESRAD_FAMILY \RESRAD \USERFILES $Q Q C J U L Y 2011 \backslash$ ONSITERF_FORWARD-1050YRALS.RAD

Individual Nuclide Soil Concentration

Parent Nuclide and Branch Fraction Indicated

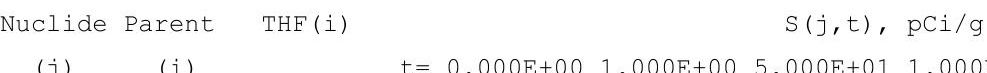

\section{(j)}

(i)

Am-241 Am-241 1.000E+00

Np-237 Am-241 1.000E+00

$\mathrm{Np}-237 \quad \mathrm{~Np}-237 \quad 1.000 \mathrm{E}+00$

Np-237 $\sum S(j):$

$\mathrm{U}-233 \quad \mathrm{Am}-241 \quad 1.000 \mathrm{E}+00$

$\mathrm{U}-233 \mathrm{~Np}-237 \quad 1.000 \mathrm{E}+00$

$\mathrm{U}-233 \sum \mathrm{S}(j)$ :

Th-229 Am-241 1.000E+00

$\mathrm{Th}-229 \mathrm{~Np}-237 \quad 1.000 \mathrm{E}+00$

Th-229 $\sum S(j):$

Cs-137 Cs-137 1.000E+00

$\mathrm{Pu}-238$

$\mathrm{Pu}-238$

$\mathrm{Pu}-238$

$\mathrm{U}-234$

$\mathrm{U}-234$

$\mathrm{U}-234$

$\mathrm{U}-234$

Th-230

$\mathrm{Th}-230$

$\mathrm{Th}-230$

$\mathrm{Th}-230$

$\mathrm{Th}-23 \mathrm{C}$

$\mathrm{Ra}-226$

$\mathrm{Ra}-226$

$\mathrm{Ra}-226$

$\mathrm{Ra}-226$

$\mathrm{Ra}-226$

$\mathrm{Pb}-210$

$\mathrm{Pb}-210$

$\mathrm{Pb}-210$

$\mathrm{Pb}-210$

$\mathrm{Pb}-210$

$\mathrm{Pu}-239$

$\mathrm{U}-235$

$\mathrm{U}-235$

$\mathrm{U}-235$ $\sum S(j)$ :

$\mathrm{Pu}-238 \quad 1.000 \mathrm{E}+00$

$\mathrm{U}-234 \quad 1.000 \mathrm{E}+00$

U-238 9.999E-01

$\sum S(j):$

$\mathrm{Pu}-238 \quad 1.000 \mathrm{E}+00$

Th-230 1.000E+00

U-234 $1.000 \mathrm{E}+00$

$\mathrm{U}-2389.999 \mathrm{E}-01$

$\sum S(j):$

$\mathrm{Pu}-238 \quad 1.000 \mathrm{E}+00$

$\mathrm{Th}-230 \quad 1.000 \mathrm{E}+00$

$\mathrm{U}-2341.000 \mathrm{E}+00$

U-238 9.999E-01

$\sum S(j):$

$\mathrm{Pu}-238 \quad 1.000 \mathrm{E}+00$

Th-230 1.000E+00

$\mathrm{U}-234 \quad 1.000 \mathrm{E}+00$

U-238 9.999E-01

$\sum S(j):$

$\mathrm{Pu}-239 \quad 1.000 \mathrm{E}+00$

$\mathrm{U}-2351.000 \mathrm{E}+00$

$\sum S(j):$
$\mathrm{Pu}-238 \quad 1.840 \mathrm{E}-09$

$\mathrm{Pu}-238 \quad 1.000 \mathrm{E}+00$

$\mathrm{Pu}-239 \quad 1.000 \mathrm{E}+00$
$=0.000 \mathrm{E}+00 \quad 1.000 \mathrm{E}+00 \quad 5.000 \mathrm{E}+01 \quad 1.000 \mathrm{E}+02 \quad 5.000 \mathrm{E}+02 \quad 1.050 \mathrm{E}+03$

$\begin{array}{llllllllll}7.000 \mathrm{E}+01 & 6.989 \mathrm{E}+01 & 6.459 \mathrm{E}+01 & 5.960 \mathrm{E}+01 & 3.132 \mathrm{E}+01 & 1.293 \mathrm{E}+01\end{array}$

$0.000 \mathrm{E}+00 \quad 2.265 \mathrm{E}-05 \quad 1.086 \mathrm{E}-03 \quad 2.080 \mathrm{E}-03 \quad 7.498 \mathrm{E}-03 \quad 1.051 \mathrm{E}-02$

$\begin{array}{lllllll}1.100 \mathrm{E}+01 & 1.100 \mathrm{E}+01 & 1.093 \mathrm{E}+01 & 1.085 \mathrm{E}+01 & 1.028 \mathrm{E}+01 & 9.547 \mathrm{E}+00\end{array}$

$\begin{array}{lllllll}1.100 \mathrm{E}+01 & 1.100 \mathrm{E}+01 & 1.093 \mathrm{E}+01 & 1.085 \mathrm{E}+01 & 1.029 \mathrm{E}+01 & 9.557 \mathrm{E}+00\end{array}$

$0.000 \mathrm{E}+00 \quad 4.955 \mathrm{E}-11 \quad 1.204 \mathrm{E}-07 \quad 4.676 \mathrm{E}-07 \quad 9.372 \mathrm{E}-06 \quad 3.142 \mathrm{E}-05$

$0.000 \mathrm{E}+00 \quad 4.810 \mathrm{E}-05 \quad 2.396 \mathrm{E}-03 \quad 4.772 \mathrm{E}-03 \quad 2.310 \mathrm{E}-02 \quad 4.641 \mathrm{E}-02$

$0.000 \mathrm{E}+00 \quad 4.810 \mathrm{E}-05 \quad 2.396 \mathrm{E}-03 \quad 4.772 \mathrm{E}-03 \quad 2.311 \mathrm{E}-02 \quad 4.644 \mathrm{E}-02$

$0.000 \mathrm{E}+00 \quad 1.560 \mathrm{E}-15 \quad 1.906 \mathrm{E}-10 \quad 1.490 \mathrm{E}-09 \quad 1.561 \mathrm{E}-07 \quad 1.156 \mathrm{E}-06$

$0.000 \mathrm{E}+00 \quad 2.271 \mathrm{E}-09 \quad 5.654 \mathrm{E}-06 \quad 2.252 \mathrm{E}-05 \quad 5.438 \mathrm{E}-04 \quad 2.287 \mathrm{E}-03$

$0.000 \mathrm{E}+00 \quad 2.271 \mathrm{E}-09 \quad 5.654 \mathrm{E}-06 \quad 2.252 \mathrm{E}-05 \quad 5.440 \mathrm{E}-04 \quad 2.288 \mathrm{E}-03$

$\begin{array}{llllll}3.800 \mathrm{E}+01 & 3.713 \mathrm{E}+01 & 1.195 \mathrm{E}+01 & 3.757 \mathrm{E}+00 & 3.592 \mathrm{E}-04 & 1.068 \mathrm{E}-09\end{array}$

$\begin{array}{llllll}1.435 \mathrm{E}-07 & 1.424 \mathrm{E}-07 & 9.660 \mathrm{E}-08 & 6.502 \mathrm{E}-08 & 2.740 \mathrm{E}-09 & 3.521 \mathrm{E}-11\end{array}$

$\begin{array}{lllllll}7.800 \mathrm{E}+01 & 7.738 \mathrm{E}+01 & 5.250 \mathrm{E}+01 & 3.534 \mathrm{E}+01 & 1.489 \mathrm{E}+00 & 1.913 \mathrm{E}-02\end{array}$

$\begin{array}{lllllll}7.800 \mathrm{E}+01 & 7.738 \mathrm{E}+01 & 5.250 \mathrm{E}+01 & 3.534 \mathrm{E}+01 & 1.489 \mathrm{E}+00 & 1.913 \mathrm{E}-02\end{array}$

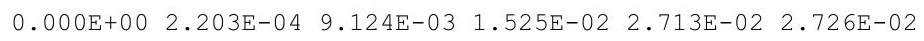

$\begin{array}{lllll}3.200 \mathrm{E}+02 & 3.200 \mathrm{E}+02 & 3.196 \mathrm{E}+02 & 3.192 \mathrm{E}+02 & 3.159 \mathrm{E}+02 \quad 3.114 \mathrm{E}+02\end{array}$

$0.000 \mathrm{E}+00 \quad 9.071 \mathrm{E}-04 \quad 4.530 \mathrm{E}-02 \quad 9.049 \mathrm{E}-02 \quad 4.481 \mathrm{E}-01 \quad 9.284 \mathrm{E}-01$

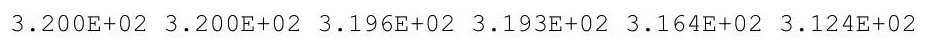

$0.000 \mathrm{E}+00 \quad 9.926 \mathrm{E}-10 \quad 2.189 \mathrm{E}-06 \quad 7.763 \mathrm{E}-06 \quad 9.383 \mathrm{E}-05 \quad 2.282 \mathrm{E}-04$ $\begin{array}{llllll}2.000 \mathrm{E}+02 & 2.000 \mathrm{E}+02 & 1.999 \mathrm{E}+02 & 1.998 \mathrm{E}+02 & 1.988 \mathrm{E}+02 & 1.975 \mathrm{E}+02\end{array}$ $\begin{array}{lllllll}0.000 \mathrm{E}+00 & 2.881 \mathrm{E}-03 & 1.439 \mathrm{E}-01 & 2.875 \mathrm{E}-01 & 1.427 \mathrm{E}+00 & 2.965 \mathrm{E}+00\end{array}$ $0.000 \mathrm{E}+00 \quad 4.083 \mathrm{E}-09 \quad 1.020 \mathrm{E}-05 \quad 4.075 \mathrm{E}-05 \quad 1.010 \mathrm{E}-03 \quad 4.407 \mathrm{E}-03$

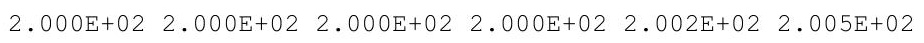

$0.000 \mathrm{E}+00 \quad 1.434 \mathrm{E}-13 \quad 1.622 \mathrm{E}-08 \quad 1.177 \mathrm{E}-07 \quad 7.880 \mathrm{E}-06 \quad 4.071 \mathrm{E}-05$ $0.000 \mathrm{E}+00 \quad 8.662 \mathrm{E}-02 \quad 4.282 \mathrm{E}+00 \quad 8.466 \mathrm{E}+00 \quad 3.865 \mathrm{E}+01 \quad 7.194 \mathrm{E}+01$ $\begin{array}{lllllll}0.000 \mathrm{E}+00 & 6.239 \mathrm{E}-07 & 1.547 \mathrm{E}-03 & 6.139 \mathrm{E}-03 & 1.439 \mathrm{E}-01 & 5.828 \mathrm{E}-01\end{array}$ $0.000 \mathrm{E}+00 \quad 5.895 \mathrm{E}-13 \quad 7.323 \mathrm{E}-08 \quad 5.821 \mathrm{E}-07 \quad 6.918 \mathrm{E}-05 \quad 5.988 \mathrm{E}-04$ $0.000 \mathrm{E}+00 \quad 8.662 \mathrm{E}-02 \quad 4.284 \mathrm{E}+00 \quad 8.472 \mathrm{E}+00 \quad 3.880 \mathrm{E}+01 \quad 7.253 \mathrm{E}+01$

$0.000 \mathrm{E}+00 \quad 1.108 \mathrm{E}-15 \quad 4.834 \mathrm{E}-09 \quad 5.619 \mathrm{E}-08 \quad 6.772 \mathrm{E}-06 \quad 3.815 \mathrm{E}-05$ $\begin{array}{llllll}0.000 \mathrm{E}+00 & 1.332 \mathrm{E}-03 & 2.115 \mathrm{E}+00 & 5.887 \mathrm{E}+00 & 3.637 \mathrm{E}+01 & 7.013 \mathrm{E}+01\end{array}$ $\begin{array}{lllllll}0.000 \mathrm{E}+00 & 6.414 \mathrm{E}-09 & 5.672 \mathrm{E}-04 & 3.410 \mathrm{E}-03 & 1.271 \mathrm{E}-01 & 5.502 \mathrm{E}-01\end{array}$ $0.000 \mathrm{E}+00 \quad 4.553 \mathrm{E}-15 \quad 2.149 \mathrm{E}-08 \quad 2.710 \mathrm{E}-07 \quad 5.757 \mathrm{E}-05 \quad 5.484 \mathrm{E}-04$ $\begin{array}{llllll}0.000 \mathrm{E}+00 & 1.333 \mathrm{E}-03 & 2.115 \mathrm{E}+00 & 5.891 \mathrm{E}+00 & 3.650 \mathrm{E}+01 & 7.068 \mathrm{E}+01\end{array}$ $\begin{array}{lllllll}7.200 \mathrm{E}+01 & 7.200 \mathrm{E}+01 & 7.183 \mathrm{E}+01 & 7.167 \mathrm{E}+01 & 7.036 \mathrm{E}+01 & 6.861 \mathrm{E}+01\end{array}$ $0.000 \mathrm{E}+00 \quad 7.091 \mathrm{E}-08 \quad 3.539 \mathrm{E}-06 \quad 7.067 \mathrm{E}-06 \quad 3.485 \mathrm{E}-05 \quad 7.181 \mathrm{E}-05$ $\begin{array}{lllllll}1.300 \mathrm{E}+01 & 1.300 \mathrm{E}+01 & 1.299 \mathrm{E}+01 & 1.297 \mathrm{E}+01 & 1.285 \mathrm{E}+01 & 1.269 \mathrm{E}+01\end{array}$ $\begin{array}{lllllll}1.300 \mathrm{E}+01 & 1.300 \mathrm{E}+01 & 1.299 \mathrm{E}+01 & 1.297 \mathrm{E}+01 & 1.285 \mathrm{E}+01 & 1.269 \mathrm{E}+01\end{array}$ 
RESRAD, Version $6.5 \quad \mathrm{~T}^{1 / 2}$ Limit $=180$ days

Summary : RESRAD Parameters for Resident Farmer U-Landfill Forward Run 1,050 Years at ALs File : C: \RESRAD_FAMILY \RESRAD \USERFILES $\backslash Q C J U L Y 2011 \backslash$ ONSITERF_FORWARD-1050YRALS.RAD

Individual Nuclide Soil Concentration

Parent Nuclide and Branch Fraction Indicated

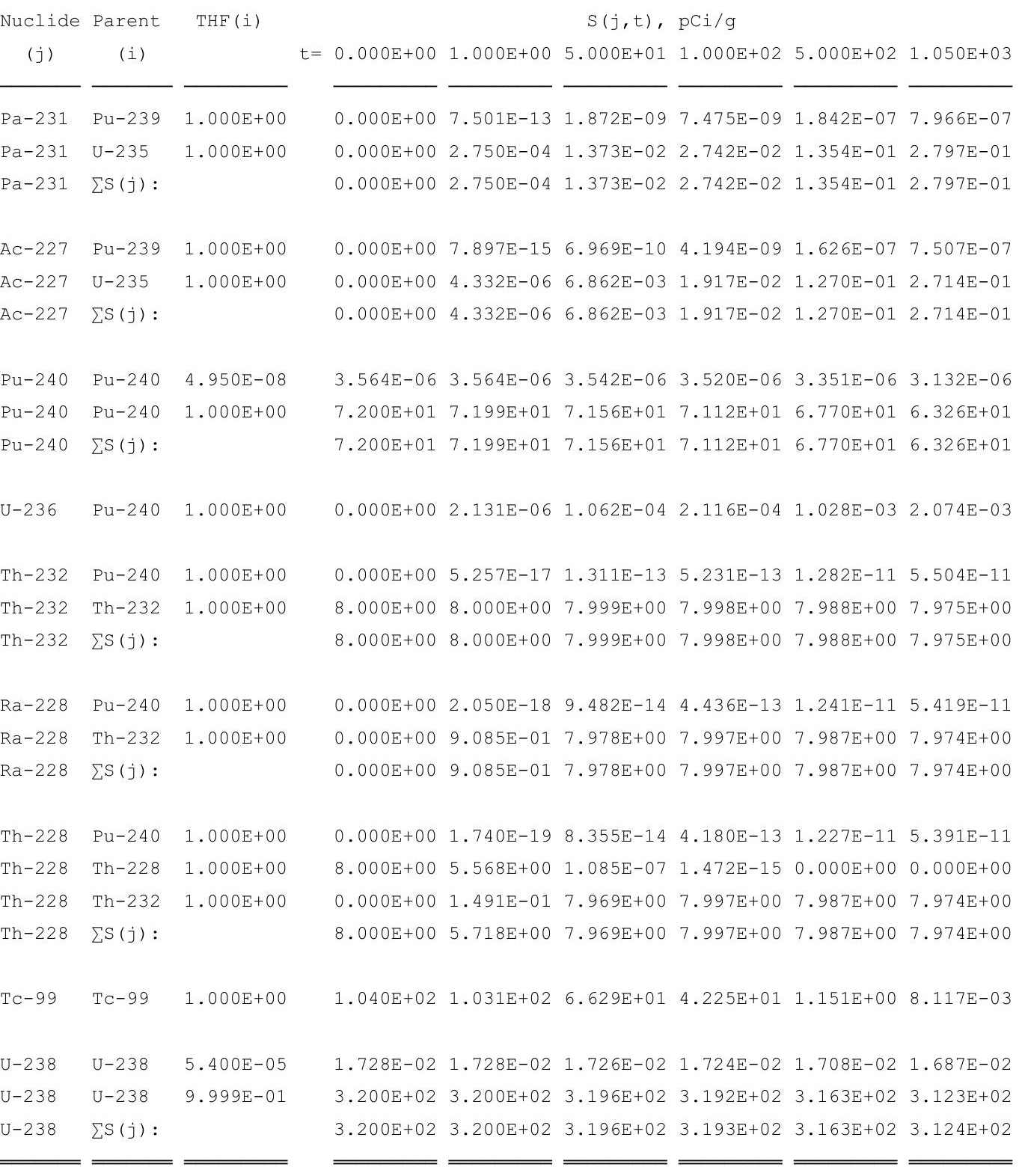

THF (i) is the thread fraction of the parent nuclide.

RESCALC.EXE execution time $=131.44$ seconds 
RESRAD, Version $6.5 \quad T^{13 / 2}$ Limit $=180$ days

Summary : RESRAD Parameters for Resident Farmer U-Landfill Forward Run 10,000 Years

File : C: $\backslash$ RESRAD_FAMILY \RESRAD UUSERFILES \QCJULY2011 \ONSITERF_FORWARD-10000-JULY11.RAD

Table of Contents

Part I: Mixture Sums and Single Radionuclide Guidelines

Dose Conversion Factor (and Related) Parameter Summary ... 2

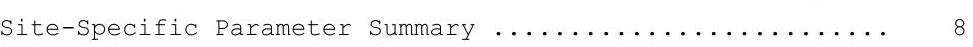

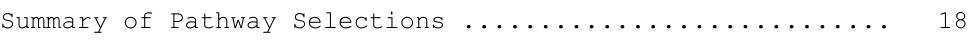

Contaminated Zone and Total Dose Summary ............. 19

Total Dose Components

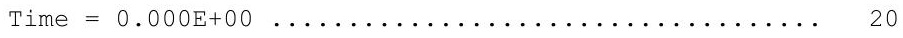

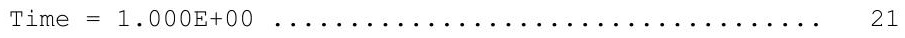

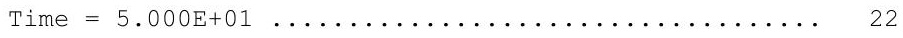

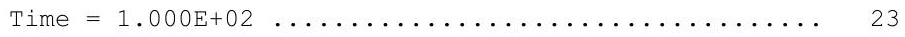

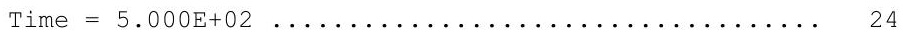

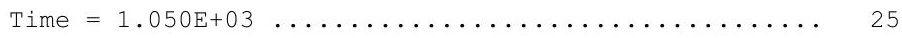

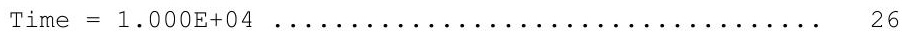

Dose/Source Ratios Summed Over All Pathways ............ 27

Single Radionuclide Soil Guidelines ............... 29

Dose Per Nuclide Summed Over All Pathways ........... 30

Soil Concentration Per Nuclide .................. 32 
Summary : RESRAD Parameters for Resident Farmer U-Landfill Forward Run 10,000 Years

File : C: \RESRAD_FAMILY \RESRAD \USERFILES QCUULY2011 ONSITERF_FORWARD-10000-JULY11.RAD

Dose Conversion Factor (and Related) Parameter Summary

Dose Library: ICRP 60 \& ICRP 72 (Adult)

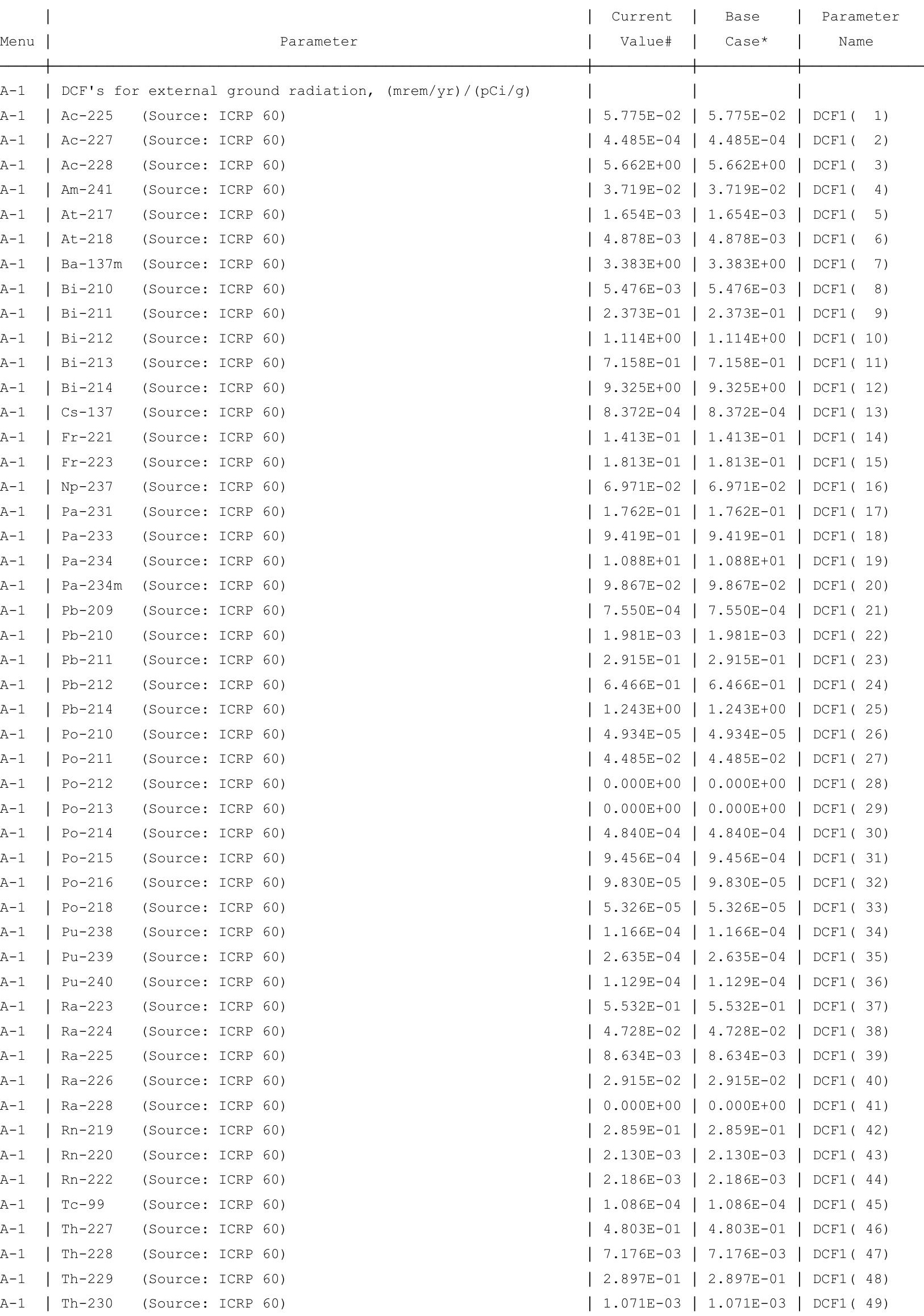


Summary : RESRAD Parameters for Resident Farmer U-Landfill Forward Run 10,000 Years

File : C: \RESRAD_FAMILY \RESRAD \USERFILES QCUULY2011 ONSITERF_FORWARD-10000-JULY11.RAD

Dose Conversion Factor (and Related) Parameter Summary (continued)

Dose Library: ICRP 60 \& ICRP 72 (Adult)

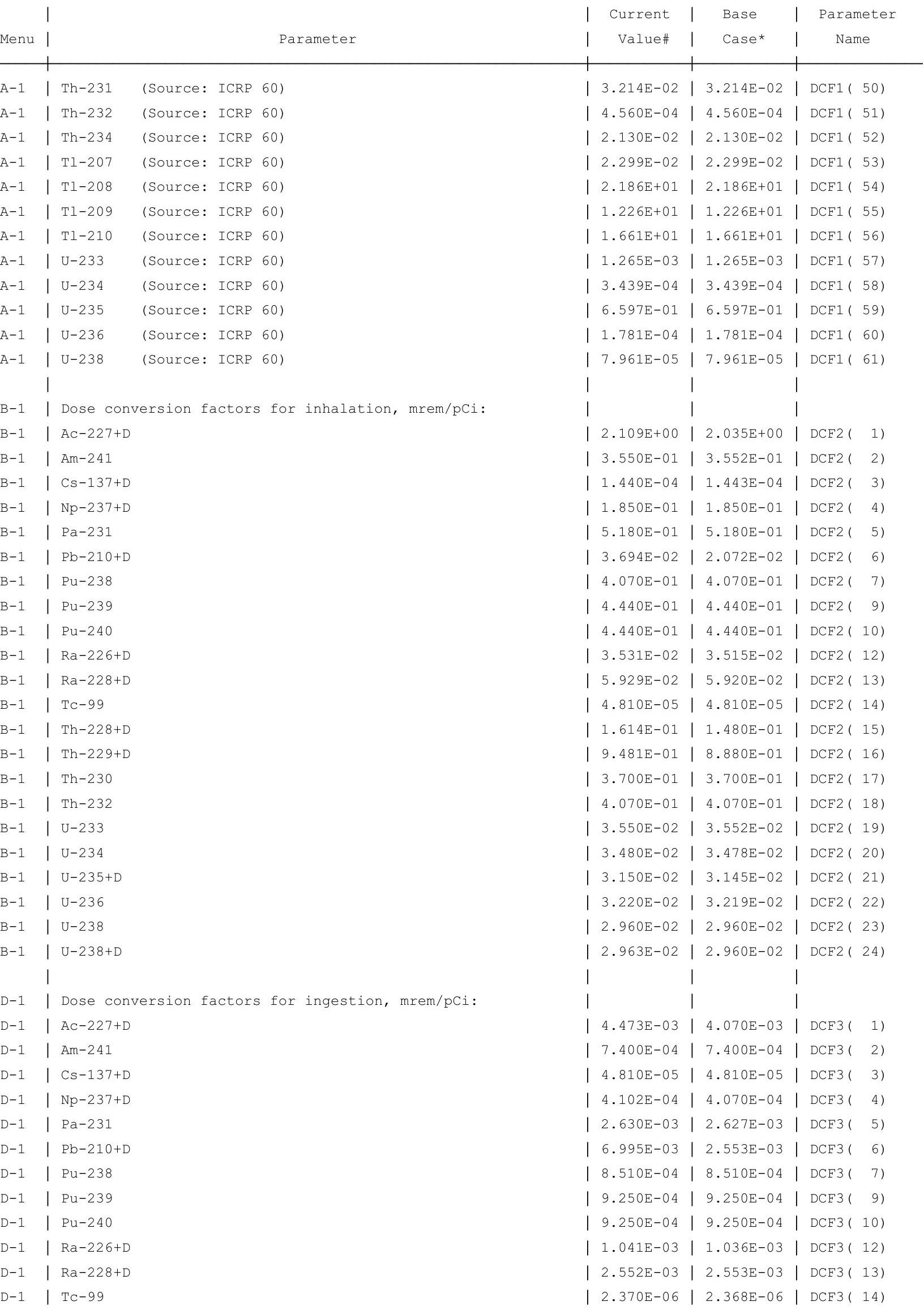


RESRAD, Version $6.5 \quad T^{1 / 2}$ Limit $=180$ days

ummary : RESRAD Parameters for Resident Farmer U-Landfill Forward Run 10,000 Years

File $\quad$ : C: $\backslash$ RESRAD FAMILY \RESRAD \USERFILES \QCJULY2011 \ONSITERF FORWARD-10000-JULY11.RAD

Dose Conversion Factor (and Related) Parameter Summary (continued) Dose Library: ICRP 60 \& ICRP 72 (Adult)

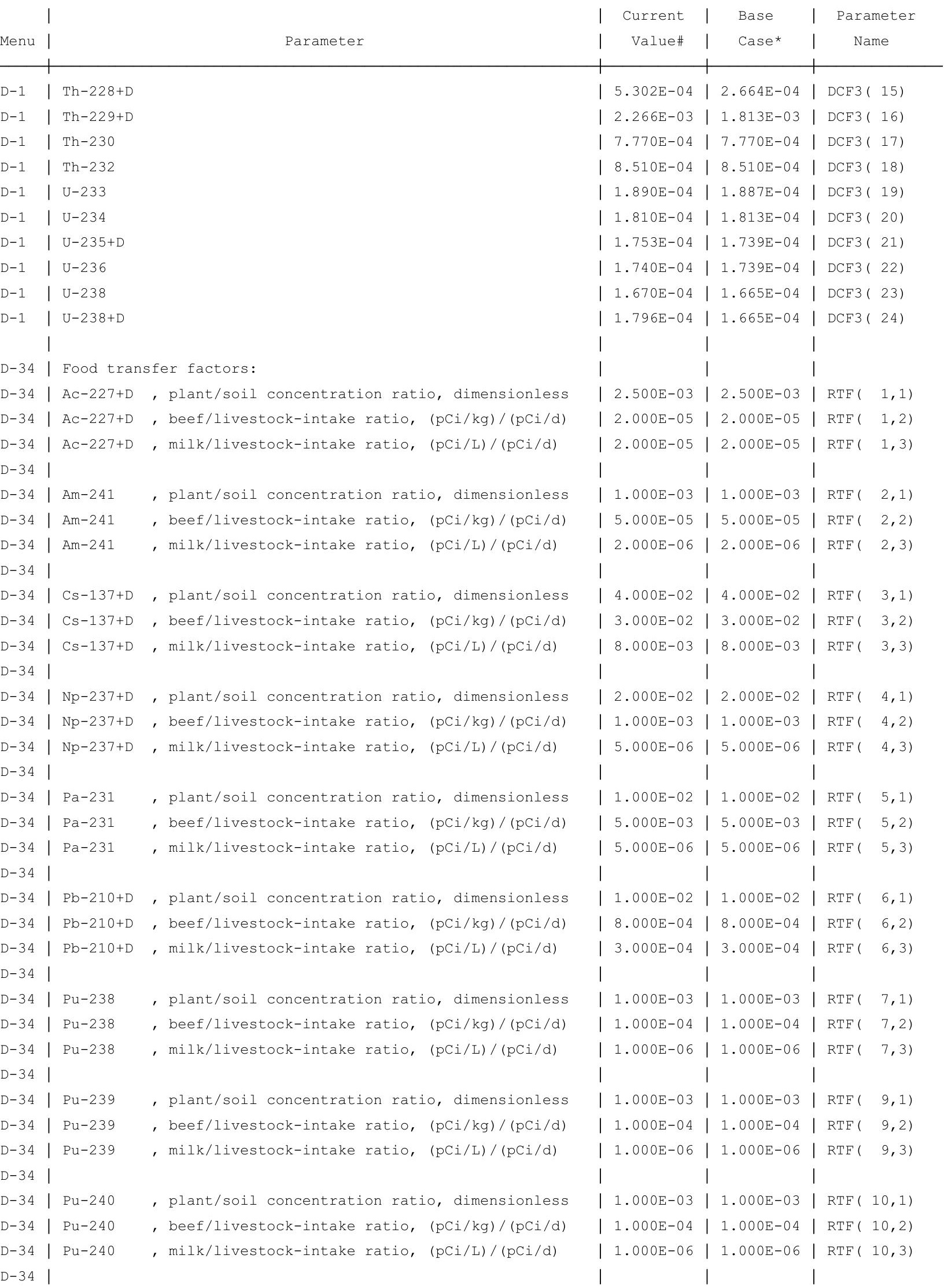


RESRAD, Version $6.5 \quad T^{1 / 2}$ Limit $=180$ days

Summary : RESRAD Parameters for Resident Farmer U-Landfill Forward Run 10,000 Years

File : C: \RESRAD_FAMILY \RESRAD \USERFILES \QCJULY2011 IONSITERF_FORWARD-10000-JULY11.RAD

Dose Conversion Factor (and Related) Parameter Summary (continued)

Dose Library: ICRP 60 \& ICRP 72 (Adult)

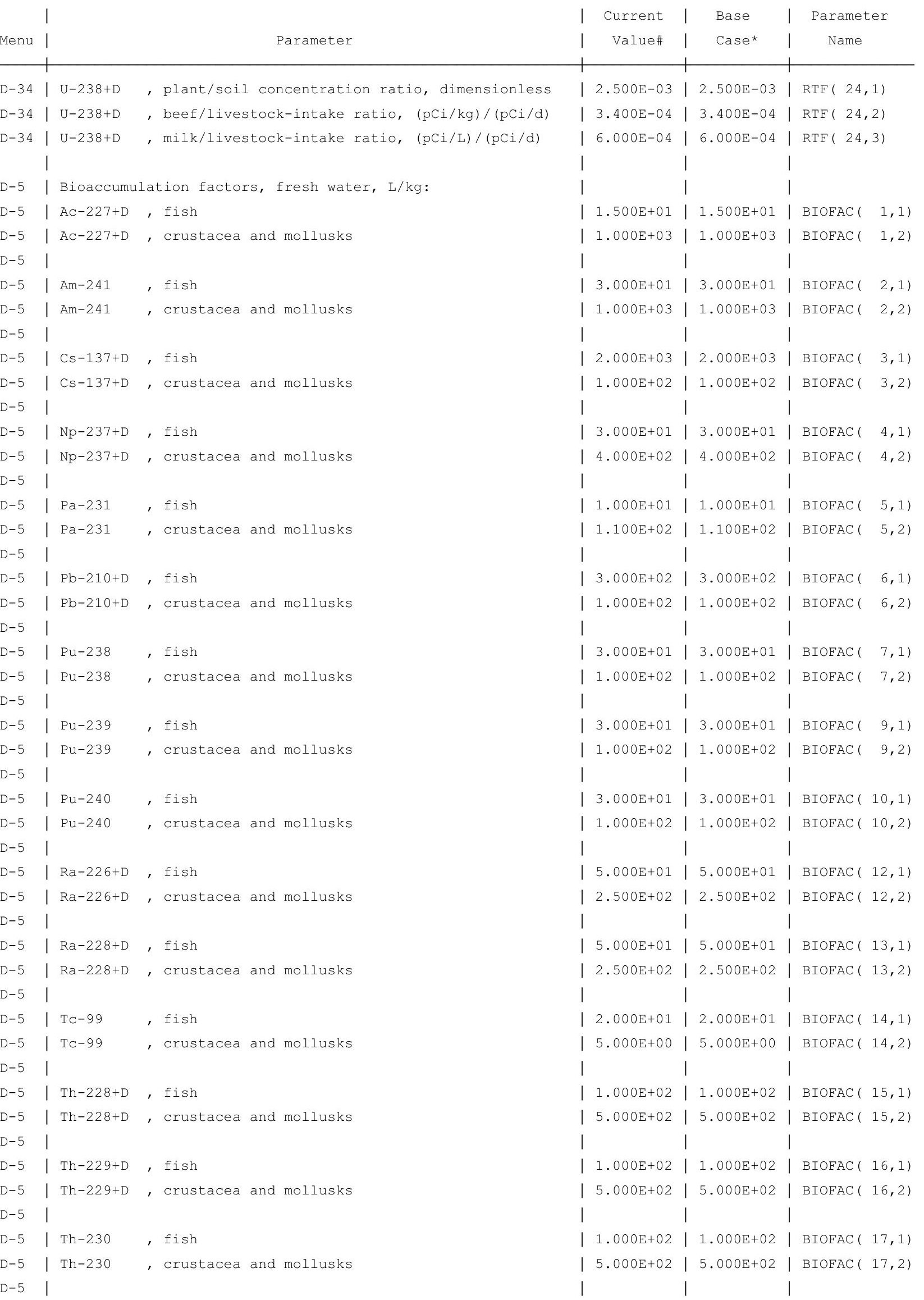


RESRAD, Version $6.5 \quad T^{1 / 2}$ Limit $=180$ days

Summary : RESRAD Parameters for Resident Farmer U-Landfill Forward Run 10,000 Years

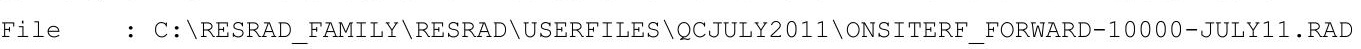

Dose Conversion Factor (and Related) Parameter Summary (continued)

Dose Library: ICRP 60 \& ICRP 72 (Adult)

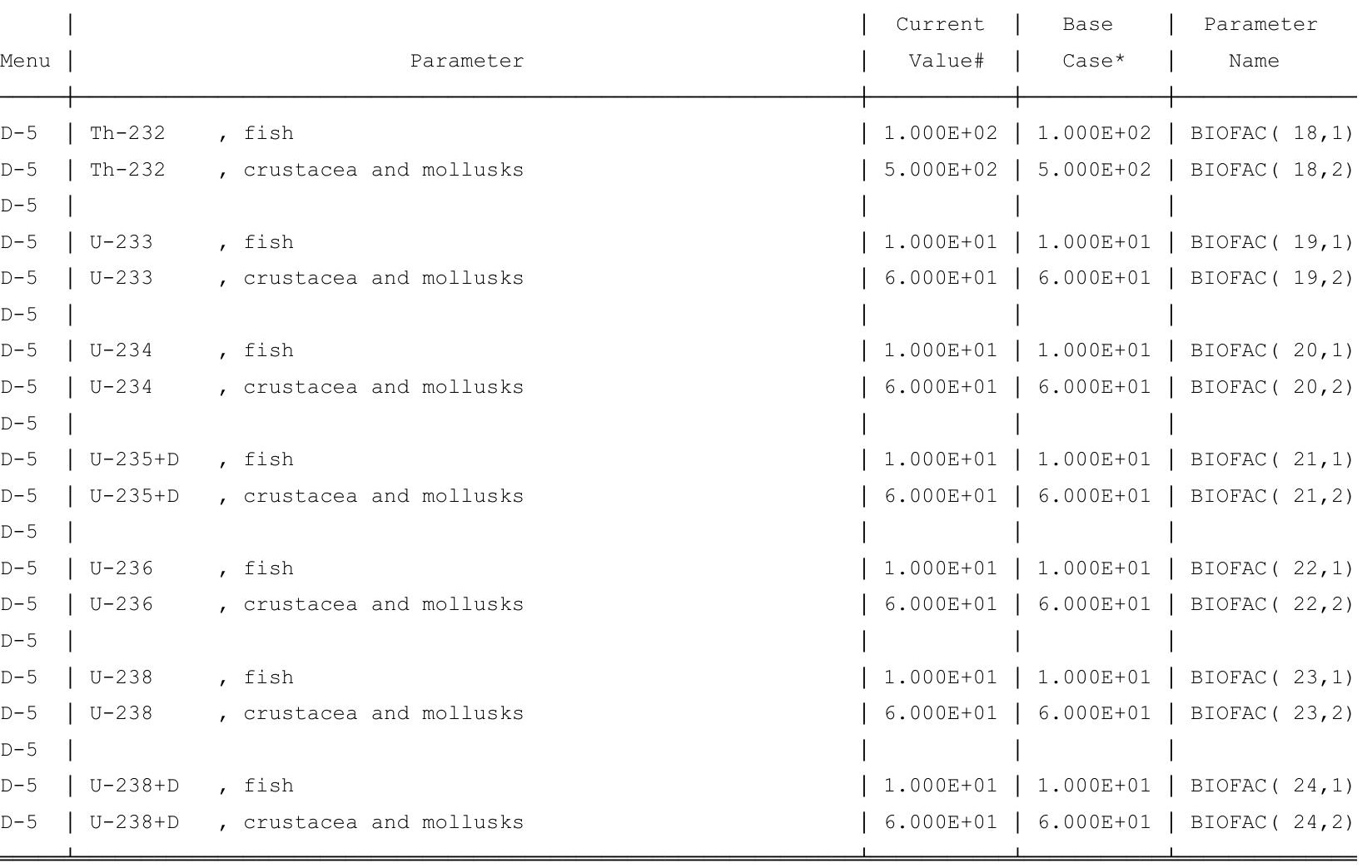

\#For DCFl(xxx) only, factors are for infinite depth \& area. See ETFG table in Ground Pathway of Detailed Report. *Base Case means Default.Lib w/o Associate Nuclide contributions. 
RESRAD, Version $6.5 \quad \mathrm{~T}^{\mathbb{1} 1 / 2}$ Limit $=180$ days

Summary : RESRAD Parameters for Resident Farmer U-Landfill Forward Run 10,000 Years

File : C: \RESRAD_FAMILY \RESRAD \USERFILES QQCJULY2011 ONSITERF_FORWARD-10000-JULY11.RAD

Site-Specific Parameter Summary (continued)

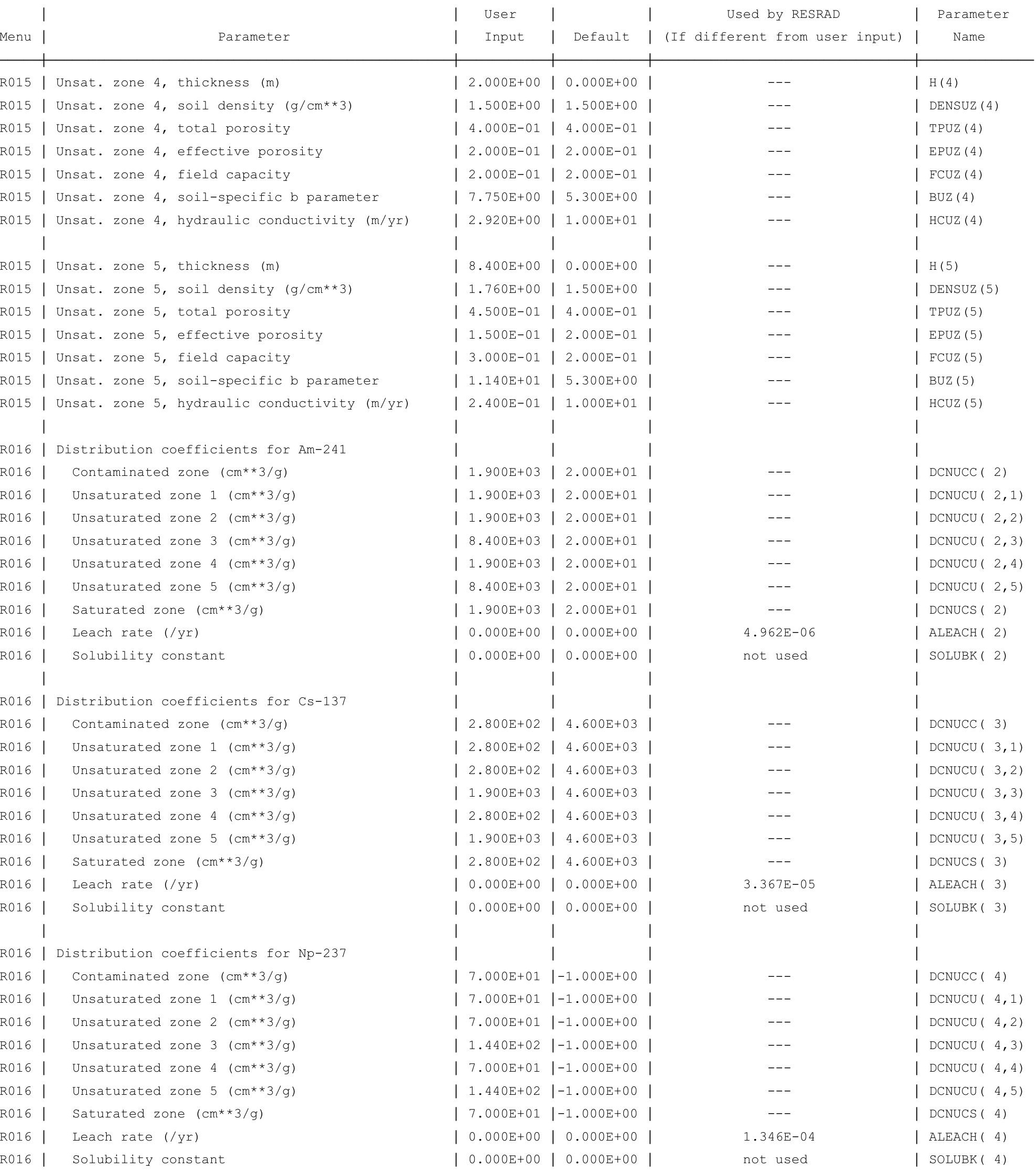


RESRAD, Version $6.5 \quad \mathrm{~T}^{1 / 2}$ Limit $=180$ days

Summary : RESRAD Parameters for Resident Farmer U-Landfill Forward Run 10,000 Years

File : C: \RESRAD_FAMILY \RESRAD \USERFILES QCUULY2011 ONSITERF_FORWARD-10000-JULY11.RAD

Site-Specific Parameter Summary (continued)

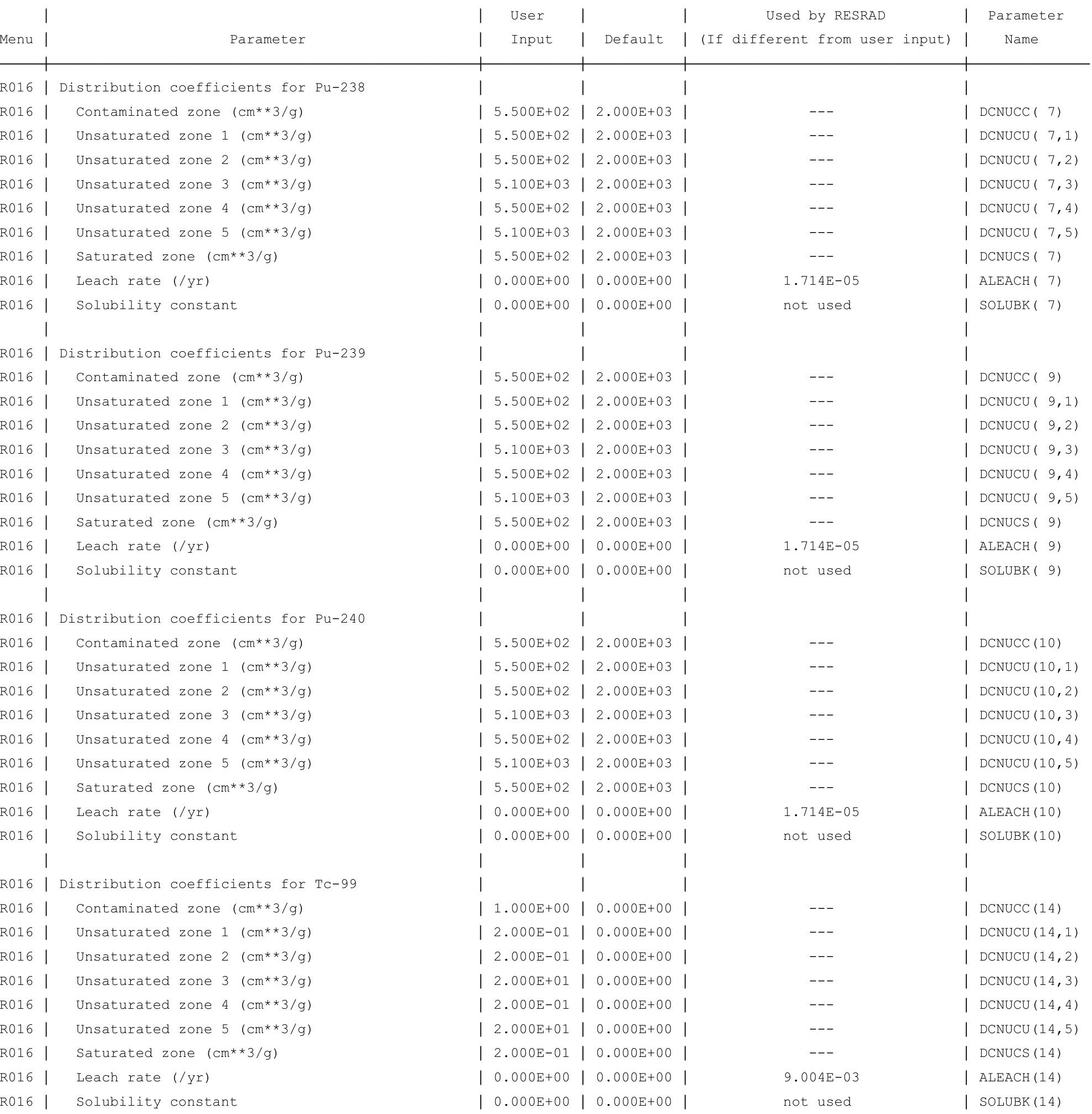


RESRAD, Version $6.5 \quad T^{1 / 2}$ Limit $=180$ days

Summary : RESRAD Parameters for Resident Farmer U-Landfill Forward Run 10,000 Years

File : C: \RESRAD_FAMILY \RESRAD \USERFILES QQCJULY2011 ONSITERF_FORWARD-10000-JULY11.RAD

Site-Specific Parameter Summary (continued)

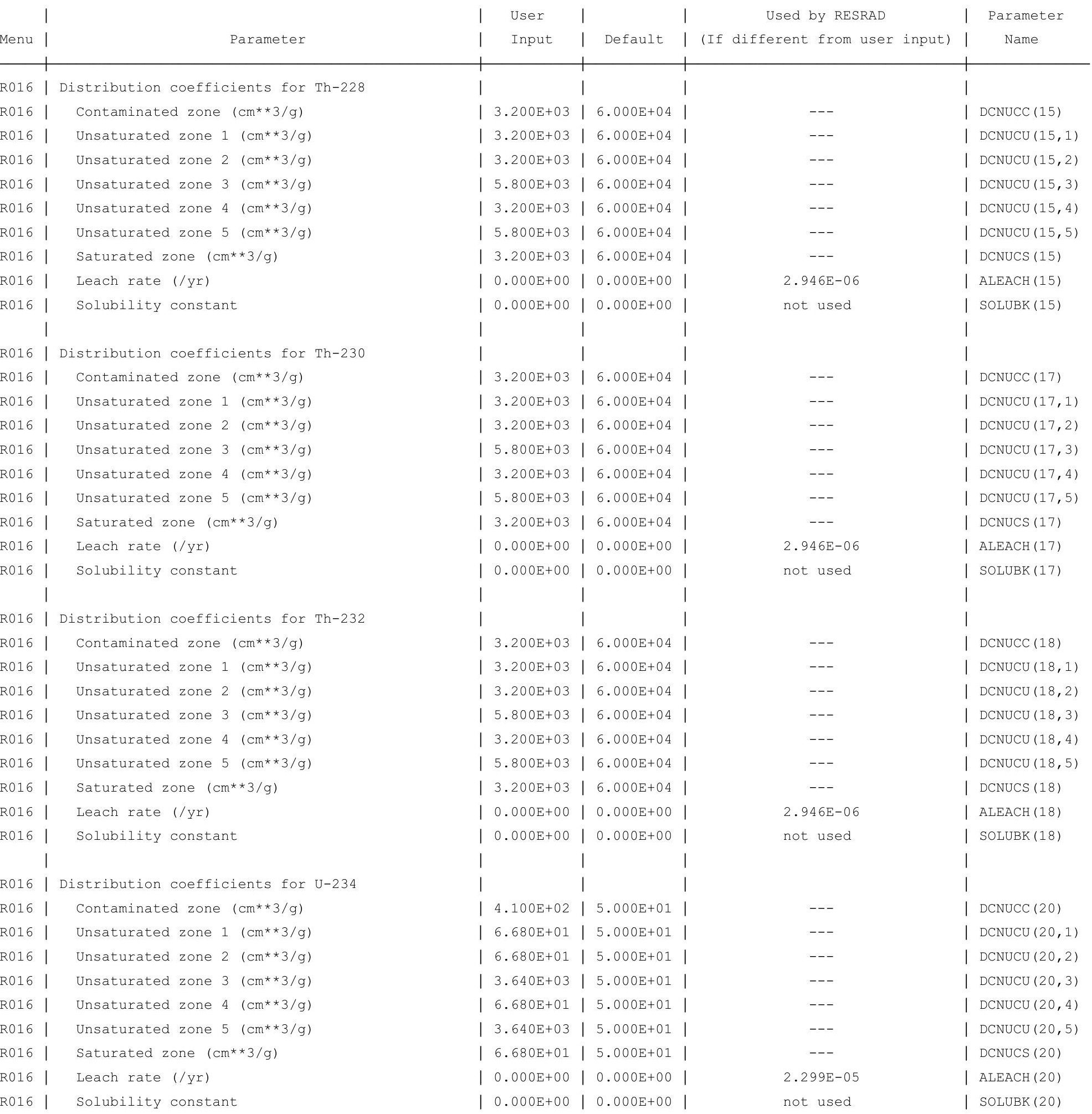


Summary : RESRAD Parameters for Resident Farmer U-Landfill Forward Run 10,000 Years

File : C: \RESRAD_FAMILY \RESRAD \USERFILES QCUULY2011 ONSITERF_FORWARD-10000-JULY11.RAD

Site-Specific Parameter Summary (continued)

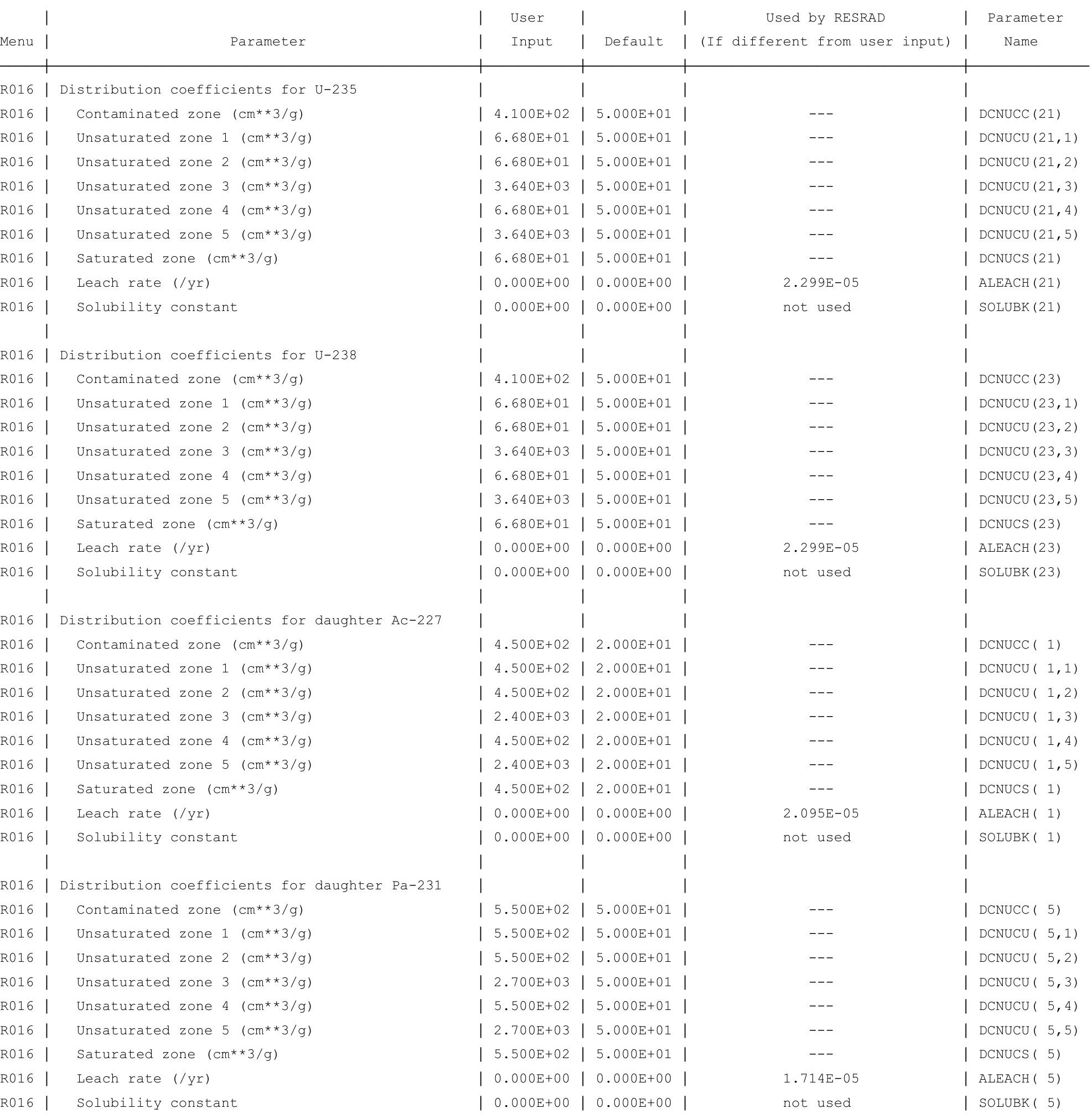


RESRAD, Version $6.5 \quad T^{1 / 2}$ Limit $=180$ days $\quad 07 / 21 / 2011 \quad 12: 03$ Page 14

Summary : RESRAD Parameters for Resident Farmer U-Landfill Forward Run 10,000 Years

File : C: $\backslash$ RESRAD_FAMILY \RESRAD \USERFILES $\backslash Q C J U L Y 2011 \backslash$ ONSITERF_FORWARD-10000-JULY11.RAD

Site-Specific Parameter Summary (continued)

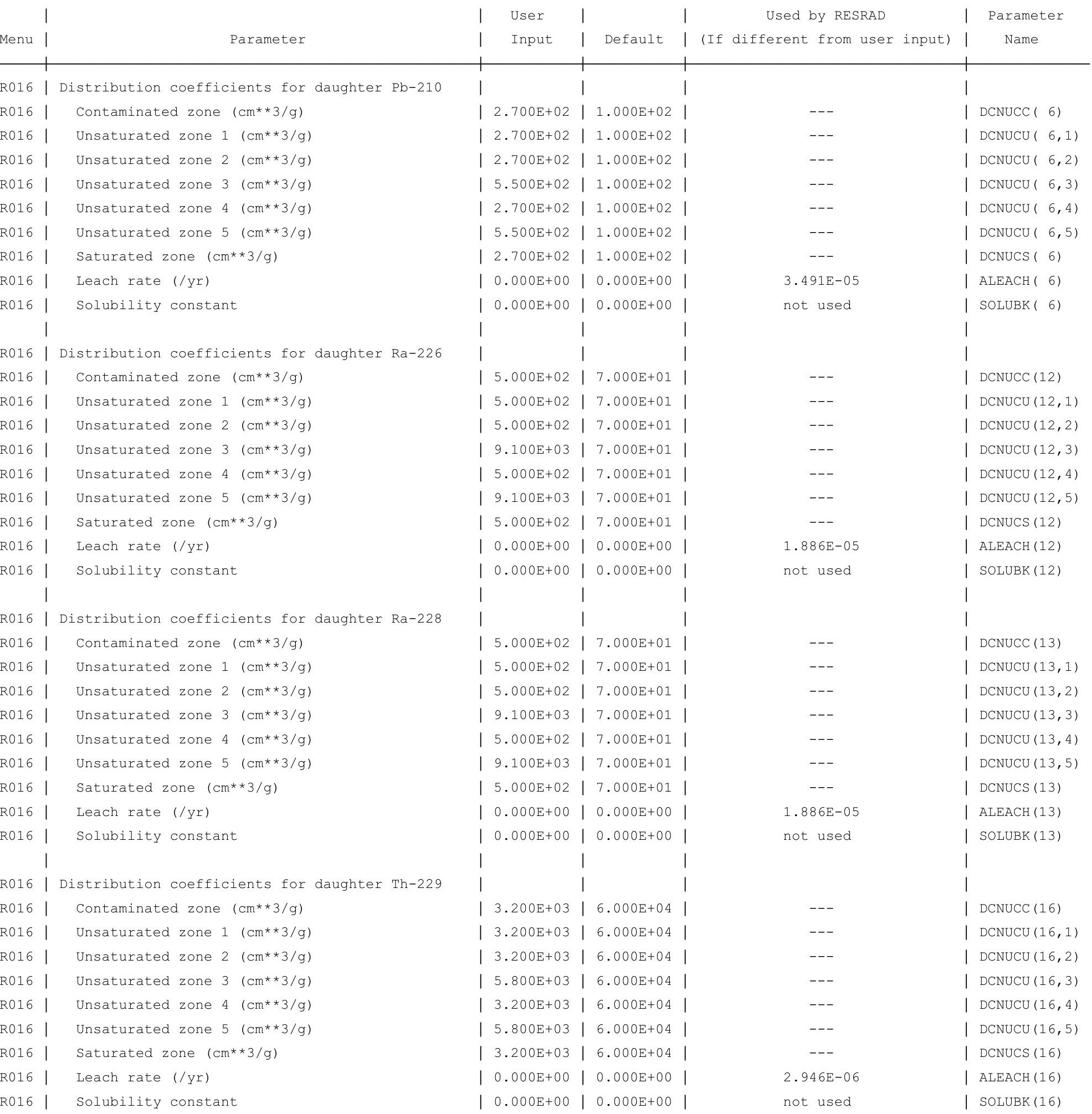


RESRAD, Version $6.5 \quad \mathrm{~T}^{\mathbb{1} 1 / 2}$ Limit $=180$ days

07/21/2011 12:03 Page 17

Summary : RESRAD Parameters for Resident Farmer U-Landfill Forward Run 10,000 Years

File : C: \RESRAD_FAMILY \RESRAD \USERFILES \QCJULY2011 \ONSITERF_FORWARD-10000-JULY11.RAD

Site-Specific Parameter Summary (continued)

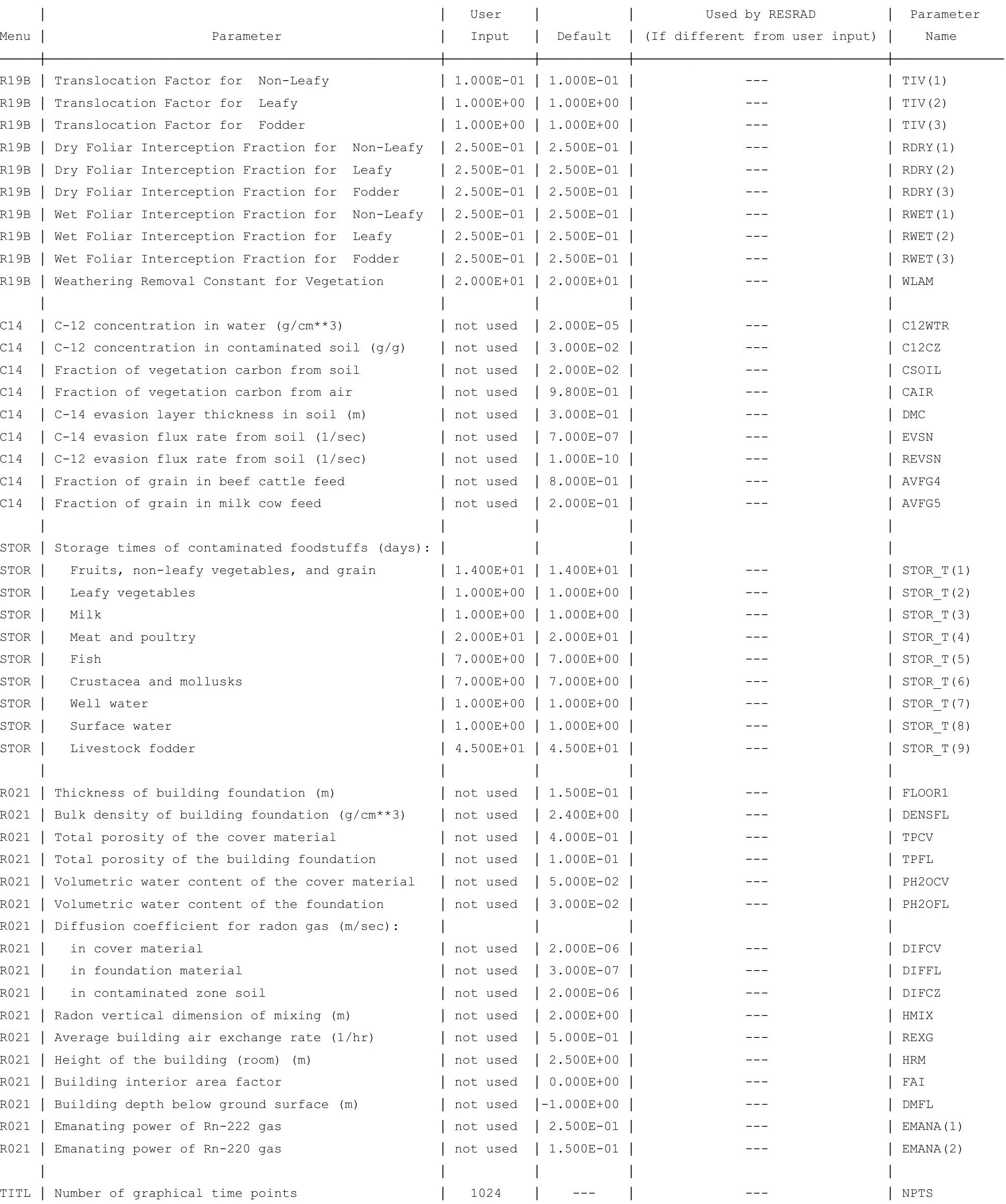


RESRAD, Version $6.5 \quad T^{1 / 2}$ Limit $=180$ days $\quad 07 / 21 / 2011 \quad 12: 03$ Page 19

Summary : RESRAD Parameters for Resident Farmer U-Landfill Forward Run 10,000 Years

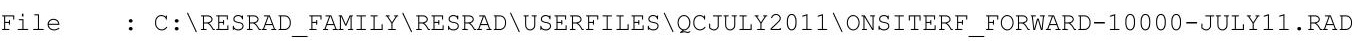

Contaminated Zone Dimensions

Area: $\quad 89436.00$ square meters

Thickness:

Cover Depth:

\begin{abstract}
13.40 meters
1.52 meters
\end{abstract}

Initial Soil Concentrations, pCi/g

$\begin{array}{ll}\mathrm{Am}-241 & 3.500 \mathrm{E}+01 \\ \mathrm{Cs}-137 & 1.900 \mathrm{E}+01 \\ \mathrm{~Np}-237 & 5.500 \mathrm{E}+00 \\ \mathrm{Pu}-238 & 3.900 \mathrm{E}+01 \\ \mathrm{Pu}-239 & 3.600 \mathrm{E}+01 \\ \mathrm{Pu}-240 & 3.600 \mathrm{E}+01 \\ \mathrm{TC}-99 & 5.200 \mathrm{E}+01 \\ \mathrm{Th}-228 & 4.000 \mathrm{E}+00 \\ \mathrm{Th}-230 & 1.000 \mathrm{E}+02 \\ \mathrm{Th}-232 & 4.000 \mathrm{E}+00 \\ \mathrm{U}-234 & 1.600 \mathrm{E}+02 \\ \mathrm{U}-235 & 6.500 \mathrm{E}+00 \\ \mathrm{U}-238 & 1.600 \mathrm{E}+02\end{array}$

Total Dose TDOSE(t), mrem/yr

Basic Radiation Dose Limit $=1.000 \mathrm{E}+02 \mathrm{mrem} / \mathrm{yr}$

Total Mixture Sum $M(t)$ = Fraction of Basic Dose Limit Received at Time (t)

$\begin{array}{rllllllll}t \text { (years) }: & 0.000 \mathrm{E}+00 & 1.000 \mathrm{E}+00 & 5.000 \mathrm{E}+01 & 1.000 \mathrm{E}+02 & 5.000 \mathrm{E}+02 & 1.050 \mathrm{E}+03 & 1.000 \mathrm{E}+04 \\ \mathrm{TDOSE}(\mathrm{t}): & 5.627 \mathrm{E}-06 & 4.206 \mathrm{E}-06 & 9.541 \mathrm{E}-06 & 1.367 \mathrm{E}-05 & 1.077 \mathrm{E}+01 & 7.412 \mathrm{E}+00 & 2.719 \mathrm{E}+03 \\ \mathrm{M}(\mathrm{t}): & 5.627 \mathrm{E}-08 & 4.206 \mathrm{E}-08 & 9.541 \mathrm{E}-08 & 1.367 \mathrm{E}-07 & 1.077 \mathrm{E}-01 & 7.412 \mathrm{E}-02 & 2.719 \mathrm{E}+01\end{array}$

Maximum TDOSE $(t): 2.719 \mathrm{E}+03 \mathrm{mrem} / \mathrm{yr}$ at $t=1.000 \mathrm{E}+04$ years 
RESRAD, Version $6.5 \quad$ T1/2 Limit $=180$ days $\quad$ 07/21/2011 12:03 Page 20

Summary : RESRAD Parameters for Resident Farmer U-Landfill Forward Run 10,000 Years

File : C: \RESRAD_FAMILY \RESRAD \USERFILES \QCJULY2011 \ONSITERF_FORWARD-10000-JULY11.RAD

Total Dose Contributions TDOSE (i,p,t) for Individual Radionuclides (i) and Pathways (p) As mrem/yr and Fraction of Total Dose At $t=0.000 \mathrm{E}+00$ years

Water Independent Pathways (Inhalation excludes radon)

\begin{tabular}{|c|c|c|c|c|c|c|c|c|c|c|c|c|c|c|}
\hline & \multicolumn{2}{|c|}{ Ground } & \multicolumn{2}{|c|}{ Inhalation } & \multicolumn{2}{|c|}{ Radon } & \multicolumn{2}{|c|}{ Plant } & \multicolumn{2}{|c|}{ Meat } & \multicolumn{2}{|c|}{ Milk } & \multicolumn{2}{|c|}{ Soil } \\
\hline lide & mrem/yr & fract. & mrem/yr & fract. & mrem/yr & fract. & mrem/yr & fract. & mrem/yr & fract. & mrem/yr & fract. & mrem/yr & fract. \\
\hline 241 & $5.412 \mathrm{E}-18$ & 0.0000 & $0.000 \mathrm{E}+00$ & 0.0000 & $0.000 \mathrm{E}+00$ & 0.0000 & $0.000 \mathrm{E}+00$ & 0.0000 & $0.000 \mathrm{E}+00$ & 0.0000 & $0.000 \mathrm{E}+00$ & 0.0000 & $0.000 \mathrm{E}+00$ & 0.0000 \\
\hline-137 & $2.397 E-08$ & 0.0043 & $0.000 \mathrm{E}+00$ & 0.0000 & $0.000 \mathrm{E}+00$ & 0.0000 & $0.000 \mathrm{E}+00$ & 0.0000 & $0.000 \mathrm{E}+00$ & 0.0000 & $0.000 \mathrm{E}+00$ & 0.0000 & $0.000 \mathrm{E}+00$ & 0.0000 \\
\hline-237 & $5.245 E-12$ & 0.0000 & $0.000 \mathrm{E}+00$ & 0.0000 & $0.000 \mathrm{E}+00$ & 0.0000 & $0.000 \mathrm{E}+00$ & 0.0000 & $0.000 \mathrm{E}+00$ & 0.0000 & $0.000 \mathrm{E}+00$ & 0.0000 & $0.000 \mathrm{E}+00$ & 0.0000 \\
\hline-238 & $3.174 \mathrm{E}-21$ & 0.0000 & $0.000 \mathrm{E}+00$ & 0.0000 & $0.000 \mathrm{E}+00$ & 0.0000 & $0.000 \mathrm{E}+00$ & 0.0000 & $0.000 \mathrm{E}+00$ & 0.0000 & $0.000 \mathrm{E}+00$ & 0.0000 & $0.000 \mathrm{E}+00$ & 0.0000 \\
\hline-239 & 4. $328 E-16$ & 0.0000 & $0.000 \mathrm{E}+00$ & 0.0000 & $0.000 \mathrm{E}+00$ & 0.0000 & $0.000 \mathrm{E}+00$ & 0.0000 & $0.000 \mathrm{E}+00$ & 0.0000 & $0.000 \mathrm{E}+00$ & 0.0000 & $0.000 \mathrm{E}+00$ & 0.0000 \\
\hline-240 & $4.115 E-23$ & 0.0000 & $0.000 \mathrm{E}+00$ & 0.0000 & $0.000 \mathrm{E}+00$ & 0.0000 & $0.000 \mathrm{E}+00$ & 0.0000 & $0.000 \mathrm{E}+00$ & 0.0000 & $0.000 \mathrm{E}+00$ & 0.0000 & $0.000 \mathrm{E}+00$ & 0.0000 \\
\hline 99 & $2.994 \mathrm{E}-24$ & 0.0000 & $0.000 \mathrm{E}+00$ & 0.0000 & $0.000 \mathrm{E}+00$ & 0.0000 & $0.000 \mathrm{E}+00$ & 0.0000 & $0.000 \mathrm{E}+00$ & 0.0000 & $0.000 \mathrm{E}+00$ & 0.0000 & $0.000 \mathrm{E}+00$ & 0.0000 \\
\hline-228 & $5.530 \mathrm{E}-06$ & 0.9827 & $0.000 \mathrm{E}+00$ & 0.0000 & $0.000 \mathrm{E}+00$ & 0.0000 & $0.000 \mathrm{E}+00$ & 0.0000 & $0.000 \mathrm{E}+00$ & 0.0000 & $0.000 \mathrm{E}+00$ & 0.0000 & $0.000 \mathrm{E}+00$ & 0.0000 \\
\hline-230 & $3.774 \mathrm{E}-09$ & 0.0007 & $0.000 \mathrm{E}+00$ & 0.0000 & $0.000 \mathrm{E}+00$ & 0.0000 & $0.000 \mathrm{E}+00$ & 0.0000 & $0.000 \mathrm{E}+00$ & 0.0000 & $0.000 \mathrm{E}+00$ & 0.0000 & $0.000 \mathrm{E}+00$ & 0.0000 \\
\hline 232 & $4.712 \mathrm{E}-08$ & 0.0084 & $0.000 \mathrm{E}+00$ & 0.0000 & $0.000 \mathrm{E}+00$ & 0.0000 & $0.000 \mathrm{E}+00$ & 0.0000 & $0.000 \mathrm{E}+00$ & 0.0000 & $0.000 \mathrm{E}+00$ & 0.0000 & $0.000 \mathrm{E}+00$ & 0.0000 \\
\hline 234 & $1.813 \mathrm{E}-14$ & 0.0000 & $0.000 \mathrm{E}+00$ & 0.0000 & $0.000 \mathrm{E}+00$ & 0.0000 & $0.000 \mathrm{E}+00$ & 0.0000 & $0.000 \mathrm{E}+00$ & 0.0000 & $0.000 \mathrm{E}+00$ & 0.0000 & $0.000 \mathrm{E}+00$ & 0.0000 \\
\hline 235 & $8.089 \mathrm{E}-14$ & 0.0000 & $0.000 \mathrm{E}+00$ & 0.0000 & $0.000 \mathrm{E}+00$ & 0.0000 & $0.000 \mathrm{E}+00$ & 0.0000 & $0.000 \mathrm{E}+00$ & 0.0000 & $0.000 \mathrm{E}+00$ & 0.0000 & $0.000 \mathrm{E}+00$ & 0.0000 \\
\hline 38 & $2.271 E-08$ & 0.0040 & $0.000 \mathrm{E}+00$ & 0.0000 & $0.000 \mathrm{E}+00$ & 0.0000 & $0.000 \mathrm{E}+00$ & 0.0000 & $0.000 \mathrm{E}+00$ & 0.0000 & $0.000 \mathrm{E}+00$ & 0.0000 & $0.000 \mathrm{E}+00$ & 0.0000 \\
\hline & $5.627 \mathrm{E}-06$ & 1.0000 & $0.000 \mathrm{E}+00$ & 0.0000 & $0.000 \mathrm{E}+00$ & 0.0000 & $0.000 \mathrm{E}+00$ & 0.0000 & $0.000 \mathrm{E}+00$ & 0.0000 & $0.000 \mathrm{E}+00$ & 0.0000 & $0.000 \mathrm{E}+00$ & 0.0000 \\
\hline
\end{tabular}

Total Dose Contributions TDOSE(i,p,t) for Individual Radionuclides (i) and Pathways (p) As mrem/yr and Fraction of Total Dose At $t=0.000 \mathrm{E}+00$ years

Water Dependent Pathways

\begin{tabular}{|c|c|c|c|c|c|c|c|c|c|c|c|c|c|c|}
\hline \multirow{2}{*}{$\begin{array}{l}\text { Radio- } \\
\text { Nuclide }\end{array}$} & \multicolumn{2}{|c|}{ Water } & \multicolumn{2}{|c|}{ Fish } & \multicolumn{2}{|c|}{ Radon } & \multicolumn{2}{|c|}{ Plant } & \multicolumn{2}{|c|}{ Meat } & \multicolumn{2}{|c|}{ Milk } & \multicolumn{2}{|c|}{ All Pathways* } \\
\hline & mrem/yr & fract. & mrem/yr & fract. & mrem/yr & fract. & mrem/yr & fract. & mrem/yr & fract. & mrem/yr & fract. & mrem/yr & fract. \\
\hline 241 & $0.000 \mathrm{E}+00$ & 0.0000 & $0.000 \mathrm{E}+00$ & 0.0000 & $0.000 \mathrm{E}+00$ & 0.0000 & $0.000 \mathrm{E}+00$ & 0.0000 & $0.000 \mathrm{E}+00$ & 0.0000 & $0.000 \mathrm{E}+00$ & 0.0000 & $5.412 \mathrm{E}-18$ & 0.0000 \\
\hline-137 & $0.000 \mathrm{E}+00$ & 0.0000 & $0.000 \mathrm{E}+00$ & 0.0000 & $0.000 \mathrm{E}+00$ & 0.0000 & $0.000 \mathrm{E}+00$ & 0.0000 & $0.000 \mathrm{E}+00$ & 0.0000 & $0.000 \mathrm{E}+00$ & 0.0000 & $2.397 \mathrm{E}-08$ & 0.0043 \\
\hline-237 & $0.000 \mathrm{E}+00$ & 0.0000 & $0.000 \mathrm{E}+00$ & 0.0000 & $0.000 \mathrm{E}+00$ & 0.0000 & $0.000 \mathrm{E}+00$ & 0.0000 & $0.000 \mathrm{E}+00$ & 0.0000 & $0.000 \mathrm{E}+00$ & 0.0000 & $5.245 E-12$ & 0.0000 \\
\hline-238 & $0.000 \mathrm{E}+00$ & 0.0000 & $0.000 \mathrm{E}+00$ & 0.0000 & $0.000 \mathrm{E}+00$ & 0.0000 & $0.000 \mathrm{E}+00$ & 0.0000 & $0.000 \mathrm{E}+00$ & 0.0000 & $0.000 \mathrm{E}+00$ & 0.0000 & $3.174 \mathrm{E}-21$ & 0.0000 \\
\hline-239 & $0.000 \mathrm{E}+00$ & 0.0000 & $0.000 \mathrm{E}+00$ & 0.0000 & $0.000 \mathrm{E}+00$ & 0.0000 & $0.000 \mathrm{E}+00$ & 0.0000 & $0.000 \mathrm{E}+00$ & 0.0000 & $0.000 E+00$ & 0.0000 & $4.328 E-16$ & 0.0000 \\
\hline-240 & $0.000 \mathrm{E}+00$ & 0.0000 & $0.000 \mathrm{E}+00$ & 0.0000 & $0.000 \mathrm{E}+00$ & 0.0000 & $0.000 \mathrm{E}+00$ & 0.0000 & $0.000 \mathrm{E}+00$ & 0.0000 & $0.000 E+00$ & 0.0000 & $4.115 \mathrm{E}-23$ & 0.0000 \\
\hline-99 & $0.000 \mathrm{E}+00$ & 0.0000 & $0.000 \mathrm{E}+00$ & 0.0000 & $0.000 \mathrm{E}+00$ & 0.0000 & $0.000 \mathrm{E}+00$ & 0.0000 & $0.000 \mathrm{E}+00$ & 0.0000 & $0.000 \mathrm{E}+00$ & 0.0000 & $2.994 \mathrm{E}-24$ & 0.0000 \\
\hline-228 & $0.000 \mathrm{E}+00$ & 0.0000 & $0.000 \mathrm{E}+00$ & 0.0000 & $0.000 \mathrm{E}+00$ & 0.0000 & $0.000 \mathrm{E}+00$ & 0.0000 & $0.000 \mathrm{E}+00$ & 0.0000 & $0.000 \mathrm{E}+00$ & 0.0000 & $5.530 \mathrm{E}-06$ & 0.9827 \\
\hline-230 & $0.000 \mathrm{E}+00$ & 0.0000 & $0.000 \mathrm{E}+00$ & 0.0000 & $0.000 \mathrm{E}+00$ & 0.0000 & $0.000 \mathrm{E}+00$ & 0.0000 & $0.000 \mathrm{E}+00$ & 0.0000 & $0.000 E+00$ & 0.0000 & $3.774 \mathrm{E}-09$ & 0.0007 \\
\hline 232 & $0.000 \mathrm{E}+00$ & 0.0000 & $0.000 \mathrm{E}+00$ & 0.0000 & $0.000 \mathrm{E}+00$ & 0.0000 & $0.000 \mathrm{E}+00$ & 0.0000 & $0.000 \mathrm{E}+00$ & 0.0000 & $0.000 \mathrm{E}+00$ & 0.0000 & $4.712 \mathrm{E}-08$ & 0.0084 \\
\hline 34 & $0.000 \mathrm{E}+00$ & 0.0000 & $0.000 \mathrm{E}+00$ & 0.0000 & $0.000 \mathrm{E}+00$ & 0.0000 & $0.000 \mathrm{E}+00$ & 0.0000 & $0.000 \mathrm{E}+00$ & 0.0000 & $0.000 \mathrm{E}+00$ & 0.0000 & $1.813 \mathrm{E}-14$ & 0.0000 \\
\hline 35 & $0.000 \mathrm{E}+00$ & 0.0000 & $0.000 \mathrm{E}+00$ & 0.0000 & $0.000 \mathrm{E}+00$ & 0.0000 & $0.000 \mathrm{E}+00$ & 0.0000 & $0.000 \mathrm{E}+00$ & 0.0000 & $0.000 \mathrm{E}+00$ & 0.0000 & $8.089 \mathrm{E}-14$ & 0.0000 \\
\hline 38 & $0.000 \mathrm{E}+00$ & 0.0000 & $0.000 \mathrm{E}+00$ & 0.0000 & $0.000 \mathrm{E}+00$ & 0.0000 & $0.000 \mathrm{E}+00$ & 0.0000 & $0.000 \mathrm{E}+00$ & 0.0000 & $0.000 \mathrm{E}+00$ & 0.0000 & $2.271 E-08$ & 0.0040 \\
\hline & $0.000 \mathrm{E}+00$ & 0.0000 & $0.000 \mathrm{E}+00$ & 0.0000 & $0.000 \mathrm{E}+00$ & 0.0000 & $0.000 \mathrm{E}+00$ & 0.0000 & $0.000 \mathrm{E}+00$ & 0.0000 & $0.000 \mathrm{E}+00$ & 0.0000 & $7 E-06$ & 1. \\
\hline
\end{tabular}

* Sum of all water independent and dependent pathways. 
RESRAD, Version 6.5

07/21/2011 12:03 Page 21

ummary : RESRAD Parameters for Resident Farmer U-Landfill Forward Run 10,000 Years

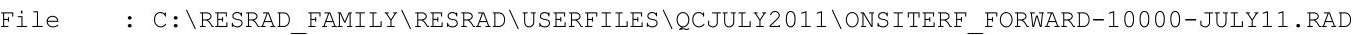

Total Dose Contributions TDOSE(i,p,t) for Individual Radionuclides (i) and Pathways (p) As mrem/yr and Fraction of Total Dose At $t=1.000 \mathrm{E}+00$ years

Water Independent Pathways (Inhalation excludes radon)

\begin{tabular}{|c|c|c|c|c|c|c|c|c|c|c|c|c|c|c|}
\hline \multirow{2}{*}{ Nuclide } & \multicolumn{2}{|c|}{ Ground } & \multicolumn{2}{|c|}{ Inhalation } & \multicolumn{2}{|c|}{ Radon } & \multicolumn{2}{|c|}{ Plant } & \multicolumn{2}{|c|}{ Meat } & \multicolumn{2}{|c|}{ Milk } & \multicolumn{2}{|c|}{ Soil } \\
\hline & mrem/yr & fract. & mrem/yr & fract. & mrem/yr & fract. & mrem/yr & fract. & mrem/yr & fract. & mrem/yr & fract. & mrem/yr & fract. \\
\hline-241 & $1.638 \mathrm{E}-17$ & 0.0000 & $0.000 \mathrm{E}+00$ & 0.0000 & $0.000 \mathrm{E}+00$ & 0.0000 & $0.000 \mathrm{E}+00$ & 0.0000 & $0.000 \mathrm{E}+00$ & 0.0000 & $0.000 \mathrm{E}+00$ & 0.0000 & $0.000 \mathrm{E}+00$ & 0.0000 \\
\hline-137 & $2.362 E-08$ & 0.0056 & $0.000 \mathrm{E}+00$ & 0.0000 & $0.000 \mathrm{E}+00$ & 0.0000 & $0.000 \mathrm{E}+00$ & 0.0000 & $0.000 \mathrm{E}+00$ & 0.0000 & $0.000 \mathrm{E}+00$ & 0.0000 & $0.000 \mathrm{E}+00$ & 0.0000 \\
\hline-237 & $5.301 \mathrm{E}-12$ & 0.0000 & $0.000 \mathrm{E}+00$ & 0.0000 & $0.000 \mathrm{E}+00$ & 0.0000 & $0.000 \mathrm{E}+00$ & 0.0000 & $0.000 \mathrm{E}+00$ & 0.0000 & $0.000 \mathrm{E}+00$ & 0.0000 & $0.000 \mathrm{E}+00$ & 0.0000 \\
\hline-238 & $4.717 \mathrm{E}-20$ & 0.0000 & $0.000 \mathrm{E}+00$ & 0.0000 & $0.000 \mathrm{E}+00$ & 0.0000 & $0.000 \mathrm{E}+00$ & 0.0000 & $0.000 \mathrm{E}+00$ & 0.0000 & $0.000 \mathrm{E}+00$ & 0.0000 & $0.000 \mathrm{E}+00$ & 0.0000 \\
\hline-239 & $4.380 \mathrm{E}-16$ & 0.0000 & $0.000 \mathrm{E}+00$ & 0.0000 & $0.000 \mathrm{E}+00$ & 0.0000 & $0.000 \mathrm{E}+00$ & 0.0000 & $0.000 \mathrm{E}+00$ & 0.0000 & $0.000 \mathrm{E}+00$ & 0.0000 & $0.000 \mathrm{E}+00$ & 0.0000 \\
\hline-240 & $4.275 E-23$ & 0.0000 & $0.000 \mathrm{E}+00$ & 0.0000 & $0.000 \mathrm{E}+00$ & 0.0000 & $0.000 \mathrm{E}+00$ & 0.0000 & $0.000 \mathrm{E}+00$ & 0.0000 & $0.000 \mathrm{E}+00$ & 0.0000 & $0.000 \mathrm{E}+00$ & 0.0000 \\
\hline 99 & $3.025 E-24$ & 0.0000 & $0.000 \mathrm{E}+00$ & 0.0000 & $0.000 \mathrm{E}+00$ & 0.0000 & $0.000 \mathrm{E}+00$ & 0.0000 & $0.000 \mathrm{E}+00$ & 0.0000 & $0.000 \mathrm{E}+00$ & 0.0000 & $0.000 \mathrm{E}+00$ & 0.0000 \\
\hline-228 & $3.872 E-06$ & 0.9206 & $0.000 \mathrm{E}+00$ & 0.0000 & $0.000 \mathrm{E}+00$ & 0.0000 & $0.000 \mathrm{E}+00$ & 0.0000 & $0.000 \mathrm{E}+00$ & 0.0000 & $0.000 \mathrm{E}+00$ & 0.0000 & $0.000 \mathrm{E}+00$ & 0.0000 \\
\hline-230 & $1.139 \mathrm{E}-08$ & 0.0027 & $0.000 \mathrm{E}+00$ & 0.0000 & $0.000 \mathrm{E}+00$ & 0.0000 & $0.000 \mathrm{E}+00$ & 0.0000 & $0.000 \mathrm{E}+00$ & 0.0000 & $0.000 \mathrm{E}+00$ & 0.0000 & $0.000 \mathrm{E}+00$ & 0.0000 \\
\hline-232 & $2.759 E-07$ & 0.0656 & $0.000 \mathrm{E}+00$ & 0.0000 & $0.000 \mathrm{E}+00$ & 0.0000 & $0.000 \mathrm{E}+00$ & 0.0000 & $0.000 \mathrm{E}+00$ & 0.0000 & $0.000 \mathrm{E}+00$ & 0.0000 & $0.000 \mathrm{E}+00$ & 0.0000 \\
\hline 234 & $1.277 \mathrm{E}-13$ & 0.0000 & $0.000 \mathrm{E}+00$ & 0.0000 & $0.000 \mathrm{E}+00$ & 0.0000 & $0.000 \mathrm{E}+00$ & 0.0000 & $0.000 \mathrm{E}+00$ & 0.0000 & $0.000 E+00$ & 0.0000 & $0.000 \mathrm{E}+00$ & 0.0000 \\
\hline 35 & $8.230 \mathrm{E}-14$ & 0.0000 & $0.000 \mathrm{E}+00$ & 0.0000 & $0.000 \mathrm{E}+00$ & 0.0000 & $0.000 \mathrm{E}+00$ & 0.0000 & $0.000 \mathrm{E}+00$ & 0.0000 & $0.000 \mathrm{E}+00$ & 0.0000 & $0.000 \mathrm{E}+00$ & 0.0000 \\
\hline 38 & $2.290 \mathrm{E}-08$ & 0.0054 & $0.000 \mathrm{E}+00$ & 0.0000 & $0.000 \mathrm{E}+00$ & 0.0000 & $0.000 \mathrm{E}+00$ & 0.0000 & $0.000 \mathrm{E}+00$ & 0.0000 & $0.000 \mathrm{E}+00$ & 0.0000 & $0.000 \mathrm{E}+00$ & 0.0000 \\
\hline & $4.206 E-06$ & 1.0000 & $0.000 \mathrm{E}+00$ & 0.0000 & $0.000 \mathrm{E}+00$ & 0.0000 & $0.000 \mathrm{E}+00$ & 0.0000 & $0.000 \mathrm{E}+00$ & 0.0000 & $0.000 \mathrm{E}+00$ & 0.0000 & $0.000 \mathrm{E}+00$ & 0.0000 \\
\hline
\end{tabular}

Total Dose Contributions TDOSE(i,p,t) for Individual Radionuclides (i) and Pathways (p) As mrem/yr and Fraction of Total Dose At $t=1.000 \mathrm{E}+00$ years

Water Dependent Pathways

\begin{tabular}{|c|c|c|c|c|c|c|c|c|c|c|c|c|c|c|}
\hline & \multicolumn{2}{|c|}{ Water } & \multicolumn{2}{|c|}{ Fish } & \multicolumn{2}{|c|}{ Radon } & \multicolumn{2}{|c|}{ Plant } & \multicolumn{2}{|c|}{ Meat } & \multicolumn{2}{|c|}{ Milk } & \multicolumn{2}{|c|}{ All Pathways* } \\
\hline clide & mrem/yr & fract. & mrem/yr & fract. & mrem/yr & fract. & mrem/yr & fract. & mrem/yr & fract. & mrem/yr & fract. & mrem/yr & fract. \\
\hline-241 & $0.000 \mathrm{E}+00$ & 0.0000 & $0.000 \mathrm{E}+00$ & 0.0000 & $0.000 \mathrm{E}+00$ & 0.0000 & $0.000 \mathrm{E}+00$ & 0.0000 & $0.000 \mathrm{E}+00$ & 0.0000 & $0.000 \mathrm{E}+00$ & 0.0000 & $1.638 \mathrm{E}-17$ & 0.0000 \\
\hline-137 & $0.000 \mathrm{E}+00$ & 0.0000 & $0.000 \mathrm{E}+00$ & 0.0000 & $0.000 \mathrm{E}+00$ & 0.0000 & $0.000 \mathrm{E}+00$ & 0.0000 & $0.000 \mathrm{E}+00$ & 0.0000 & $0.000 \mathrm{E}+00$ & 0.0000 & $2.362 \mathrm{E}-08$ & 0.0056 \\
\hline-237 & $0.000 \mathrm{E}+00$ & 0.0000 & $0.000 \mathrm{E}+00$ & 0.0000 & $0.000 \mathrm{E}+00$ & 0.0000 & $0.000 \mathrm{E}+00$ & 0.0000 & $0.000 \mathrm{E}+00$ & 0.0000 & $0.000 \mathrm{E}+00$ & 0.0000 & $5.301 \mathrm{E}-12$ & 0.0000 \\
\hline 238 & $0.000 \mathrm{E}+00$ & 0.0000 & $0.000 \mathrm{E}+00$ & 0.0000 & $0.000 \mathrm{E}+00$ & 0.0000 & $0.000 \mathrm{E}+00$ & 0.0000 & $0.000 \mathrm{E}+00$ & 0.0000 & $0.000 \mathrm{E}+00$ & 0.0000 & $4.717 \mathrm{E}-20$ & 0.0000 \\
\hline 239 & $0.000 \mathrm{E}+00$ & 0.0000 & $0.000 \mathrm{E}+00$ & 0.0000 & $0.000 \mathrm{E}+00$ & 0.0000 & $0.000 \mathrm{E}+00$ & 0.0000 & $0.000 \mathrm{E}+00$ & 0.0000 & $0.000 \mathrm{E}+00$ & 0.0000 & $4.380 \mathrm{E}-16$ & 0.0000 \\
\hline 240 & $0.000 \mathrm{E}+00$ & 0.0000 & $0.000 \mathrm{E}+00$ & 0.0000 & $0.000 \mathrm{E}+00$ & 0.0000 & $0.000 \mathrm{E}+00$ & 0.0000 & $0.000 \mathrm{E}+00$ & 0.0000 & $0.000 \mathrm{E}+00$ & 0.0000 & $4.275 E-23$ & 0.0000 \\
\hline 99 & $0.000 \mathrm{E}+00$ & 0.0000 & $0.000 \mathrm{E}+00$ & 0.0000 & $0.000 \mathrm{E}+00$ & 0.0000 & $0.000 \mathrm{E}+00$ & 0.0000 & $0.000 \mathrm{E}+00$ & 0.0000 & $0.000 \mathrm{E}+00$ & 0.0000 & $3.025 \mathrm{E}-24$ & 0.0000 \\
\hline 228 & $0.000 \mathrm{E}+00$ & 0.0000 & $0.000 \mathrm{E}+00$ & 0.0000 & $0.000 \mathrm{E}+00$ & 0.0000 & $0.000 \mathrm{E}+00$ & 0.0000 & $0.000 \mathrm{E}+00$ & 0.0000 & $0.000 \mathrm{E}+00$ & 0.0000 & $3.872 \mathrm{E}-06$ & 0.9206 \\
\hline 230 & $0.000 \mathrm{E}+00$ & 0.0000 & $0.000 \mathrm{E}+00$ & 0.0000 & $0.000 \mathrm{E}+00$ & 0.0000 & $0.000 \mathrm{E}+00$ & 0.0000 & $0.000 \mathrm{E}+00$ & 0.0000 & $0.000 \mathrm{E}+00$ & 0.0000 & $1.139 \mathrm{E}-08$ & 0.0027 \\
\hline 232 & $0.000 \mathrm{E}+00$ & 0.0000 & $0.000 \mathrm{E}+00$ & 0.0000 & $0.000 \mathrm{E}+00$ & 0.0000 & $0.000 \mathrm{E}+00$ & 0.0000 & $0.000 \mathrm{E}+00$ & 0.0000 & $0.000 \mathrm{E}+00$ & 0.0000 & $2.759 \mathrm{E}-07$ & 0.0656 \\
\hline & $0.000 \mathrm{E}+00$ & 0.0000 & $0.000 \mathrm{E}+00$ & 0.0000 & $0.000 \mathrm{E}+00$ & 0.0000 & $0.000 \mathrm{E}+00$ & 0.0000 & $0.000 \mathrm{E}+00$ & 0.0000 & $0.000 \mathrm{E}+00$ & 0.0000 & $1.277 \mathrm{E}-13$ & 0.0000 \\
\hline 35 & $0.000 \mathrm{E}+00$ & 0.0000 & $0.000 \mathrm{E}+00$ & 0.0000 & $0.000 \mathrm{E}+00$ & 0.0000 & $0.000 \mathrm{E}+00$ & 0.0000 & $0.000 \mathrm{E}+00$ & 0.0000 & $0.000 \mathrm{E}+00$ & 0.0000 & $8.230 \mathrm{E}-14$ & 0.0000 \\
\hline 38 & $0.000 \mathrm{E}+00$ & 0.0000 & $0.000 \mathrm{E}+00$ & 0.0000 & $0.000 \mathrm{E}+00$ & 0.0000 & $0.000 \mathrm{E}+00$ & 0.0000 & $0.000 \mathrm{E}+00$ & 0.0000 & $0.000 \mathrm{E}+00$ & 0.0000 & $2.290 \mathrm{E}-08$ & 0.0054 \\
\hline & $0.000 \mathrm{E}+00$ & 0.0000 & $0.000 \mathrm{E}+00$ & 0.0000 & $0.000 \mathrm{E}+00$ & 0.0000 & $0.000 \mathrm{E}+00$ & 0.0000 & $0.000 \mathrm{E}+00$ & 0.0000 & $0.000 E+00$ & 000 & -06 & 1.0000 \\
\hline
\end{tabular}

* Sum of all water independent and dependent pathways. 
RESRAD, Version $6.5 \quad \mathrm{~T}^{1 / 2}$ Limit $=180$ days

07/21/2011 12:03 Page 22

: C: $\backslash$ RESRAD_FAMILY \RESRAD \USERFILES $\backslash Q C J U L Y 2011 \backslash$ ONSITERF_FORWARD-10000-JULY11.RAD

Total Dose Contributions TDOSE(i,p,t) for Individual Radionuclides (i) and Pathways (p) As mrem/yr and Fraction of Total Dose At $t=5.000 \mathrm{E}+01$ years

Water Independent Pathways (Inhalation excludes radon)

\begin{tabular}{|c|c|c|c|c|c|c|c|c|c|c|c|c|c|c|}
\hline \multirow{2}{*}{ Nuclide } & \multicolumn{2}{|c|}{ Ground } & \multicolumn{2}{|c|}{ Inhalation } & \multicolumn{2}{|c|}{ Radon } & \multicolumn{2}{|c|}{ Plant } & \multicolumn{2}{|c|}{ Meat } & \multicolumn{2}{|c|}{ Milk } & \multicolumn{2}{|c|}{ Soil } \\
\hline & mrem/yr & fract. & mrem/yr & fract. & mrem/yr & fract. & mrem/yr & fract. & mrem/yr & fract. & mrem/yr & fract. & mrem/yr & fract. \\
\hline-241 & $8.973 E-16$ & 0.0000 & $0.000 \mathrm{E}+00$ & 0.0000 & $0.000 \mathrm{E}+00$ & 0.0000 & $0.000 \mathrm{E}+00$ & 0.0000 & $0.000 \mathrm{E}+00$ & 0.0000 & $0.000 \mathrm{E}+00$ & 0.0000 & $0.000 \mathrm{E}+00$ & 0.0000 \\
\hline-137 & $1.149 \mathrm{E}-08$ & 0.0012 & $0.000 \mathrm{E}+00$ & 0.0000 & $0.000 \mathrm{E}+00$ & 0.0000 & $0.000 \mathrm{E}+00$ & 0.0000 & $0.000 \mathrm{E}+00$ & 0.0000 & $0.000 \mathrm{E}+00$ & 0.0000 & $0.000 \mathrm{E}+00$ & 0.0000 \\
\hline-237 & $8.957 \mathrm{E}-12$ & 0.0000 & $0.000 \mathrm{E}+00$ & 0.0000 & $0.000 \mathrm{E}+00$ & 0.0000 & $0.000 \mathrm{E}+00$ & 0.0000 & $0.000 \mathrm{E}+00$ & 0.0000 & $0.000 \mathrm{E}+00$ & 0.0000 & $0.000 \mathrm{E}+00$ & 0.0000 \\
\hline-238 & $2.054 \mathrm{E}-15$ & 0.0000 & $0.000 \mathrm{E}+00$ & 0.0000 & $0.000 \mathrm{E}+00$ & 0.0000 & $0.000 \mathrm{E}+00$ & 0.0000 & $0.000 \mathrm{E}+00$ & 0.0000 & $0.000 \mathrm{E}+00$ & 0.0000 & $0.000 \mathrm{E}+00$ & 0.0000 \\
\hline-239 & $7.861 \mathrm{E}-16$ & 0.0000 & $0.000 \mathrm{E}+00$ & 0.0000 & $0.000 \mathrm{E}+00$ & 0.0000 & $0.000 \mathrm{E}+00$ & 0.0000 & $0.000 \mathrm{E}+00$ & 0.0000 & $0.000 \mathrm{E}+00$ & 0.0000 & $0.000 \mathrm{E}+00$ & 0.0000 \\
\hline-240 & $9.653 \mathrm{E}-20$ & 0.0000 & $0.000 \mathrm{E}+00$ & 0.0000 & $0.000 \mathrm{E}+00$ & 0.0000 & $0.000 \mathrm{E}+00$ & 0.0000 & $0.000 \mathrm{E}+00$ & 0.0000 & $0.000 \mathrm{E}+00$ & 0.0000 & $0.000 \mathrm{E}+00$ & 0.0000 \\
\hline 99 & $4.979 E-24$ & 0.0000 & $0.000 \mathrm{E}+00$ & 0.0000 & $0.000 \mathrm{E}+00$ & 0.0000 & $0.000 \mathrm{E}+00$ & 0.0000 & $0.000 \mathrm{E}+00$ & 0.0000 & $0.000 \mathrm{E}+00$ & 0.0000 & $0.000 \mathrm{E}+00$ & 0.0000 \\
\hline-228 & 1.011E-13 & 0.0000 & $0.000 \mathrm{E}+00$ & 0.0000 & $0.000 \mathrm{E}+00$ & 0.0000 & $0.000 \mathrm{E}+00$ & 0.0000 & $0.000 \mathrm{E}+00$ & 0.0000 & $0.000 \mathrm{E}+00$ & 0.0000 & $0.000 \mathrm{E}+00$ & 0.0000 \\
\hline 230 & $5.320 \mathrm{E}-07$ & 0.0558 & $0.000 \mathrm{E}+00$ & 0.0000 & $0.000 \mathrm{E}+00$ & 0.0000 & $0.000 \mathrm{E}+00$ & 0.0000 & $0.000 \mathrm{E}+00$ & 0.0000 & $0.000 \mathrm{E}+00$ & 0.0000 & $0.000 \mathrm{E}+00$ & 0.0000 \\
\hline-232 & $8.963 E-06$ & 0.9395 & $0.000 \mathrm{E}+00$ & 0.0000 & $0.000 \mathrm{E}+00$ & 0.0000 & $0.000 \mathrm{E}+00$ & 0.0000 & $0.000 \mathrm{E}+00$ & 0.0000 & $0.000 \mathrm{E}+00$ & 0.0000 & $0.000 \mathrm{E}+00$ & 0.0000 \\
\hline 234 & 1. $941 \mathrm{E}-10$ & 0.0000 & $0.000 \mathrm{E}+00$ & 0.0000 & $0.000 \mathrm{E}+00$ & 0.0000 & $0.000 \mathrm{E}+00$ & 0.0000 & $0.000 \mathrm{E}+00$ & 0.0000 & $0.000 \mathrm{E}+00$ & 0.0000 & $0.000 \mathrm{E}+00$ & 0.0000 \\
\hline 35 & $6.005 E-13$ & 0.0000 & $0.000 \mathrm{E}+00$ & 0.0000 & $0.000 \mathrm{E}+00$ & 0.0000 & $0.000 \mathrm{E}+00$ & 0.0000 & $0.000 \mathrm{E}+00$ & 0.0000 & $0.000 \mathrm{E}+00$ & 0.0000 & $0.000 \mathrm{E}+00$ & 0.0000 \\
\hline 38 & $3.385 E-08$ & 0.0035 & $0.000 \mathrm{E}+00$ & 0.0000 & $0.000 \mathrm{E}+00$ & 0.0000 & $0.000 \mathrm{E}+00$ & 0.0000 & $0.000 \mathrm{E}+00$ & 0.0000 & $0.000 \mathrm{E}+00$ & 0.0000 & $0.000 \mathrm{E}+00$ & 0.0000 \\
\hline & $9.541 \mathrm{E}-06$ & 1.0000 & $0.000 \mathrm{E}+00$ & 0.0000 & $0.000 \mathrm{E}+00$ & 0.0000 & $0.000 \mathrm{E}+00$ & 0.0000 & $0.000 \mathrm{E}+00$ & 0.0000 & $0.000 \mathrm{E}+00$ & 0.0000 & $.000 \mathrm{E}+00$ & 0.0000 \\
\hline
\end{tabular}

Total Dose Contributions TDOSE(i,p,t) for Individual Radionuclides (i) and Pathways (p) As mrem/yr and Fraction of Total Dose At $t=5.000 \mathrm{E}+01$ years

Water Dependent Pathways

\begin{tabular}{|c|c|c|c|c|c|c|c|c|c|c|c|c|c|c|}
\hline \multirow{2}{*}{ Nuclide } & \multicolumn{2}{|c|}{ Water } & \multicolumn{2}{|c|}{ Fish } & \multicolumn{2}{|c|}{ Radon } & \multicolumn{2}{|c|}{ Plant } & \multicolumn{2}{|c|}{ Meat } & \multicolumn{2}{|c|}{ Milk } & \multicolumn{2}{|c|}{ All Pathways* } \\
\hline & mrem/yr & fract. & mrem/yr & fract. & mrem/yr & fract. & mrem/yr & fract. & mrem/yr & fract. & mrem/yr & fract. & mrem/yr & fract. \\
\hline-241 & $0.000 \mathrm{E}+00$ & 0.0000 & $0.000 \mathrm{E}+00$ & 0.0000 & $0.000 \mathrm{E}+00$ & 0.0000 & $0.000 \mathrm{E}+00$ & 0.0000 & $0.000 \mathrm{E}+00$ & 0.0000 & $0.000 \mathrm{E}+00$ & 0.0000 & $8.973 E-16$ & 0.0000 \\
\hline-137 & $0.000 \mathrm{E}+00$ & 0.0000 & $0.000 \mathrm{E}+00$ & 0.0000 & $0.000 \mathrm{E}+00$ & 0.0000 & $0.000 \mathrm{E}+00$ & 0.0000 & $0.000 \mathrm{E}+00$ & 0.0000 & $0.000 \mathrm{E}+00$ & 0.0000 & $1.149 \mathrm{E}-08$ & 0.0012 \\
\hline-237 & $0.000 \mathrm{E}+00$ & 0.0000 & $0.000 \mathrm{E}+00$ & 0.0000 & $0.000 \mathrm{E}+00$ & 0.0000 & $0.000 \mathrm{E}+00$ & 0.0000 & $0.000 \mathrm{E}+00$ & 0.0000 & $0.000 \mathrm{E}+00$ & 0.0000 & $8.957 \mathrm{E}-12$ & 0.0000 \\
\hline-238 & $0.000 \mathrm{E}+00$ & 0.0000 & $0.000 \mathrm{E}+00$ & 0.0000 & $0.000 \mathrm{E}+00$ & 0.0000 & $0.000 \mathrm{E}+00$ & 0.0000 & $0.000 \mathrm{E}+00$ & 0.0000 & $0.000 \mathrm{E}+00$ & 0.0000 & $2.054 \mathrm{E}-15$ & 0.0000 \\
\hline 239 & $0.000 \mathrm{E}+00$ & 0.0000 & $0.000 \mathrm{E}+00$ & 0.0000 & $0.000 \mathrm{E}+00$ & 0.0000 & $0.000 \mathrm{E}+00$ & 0.0000 & $0.000 \mathrm{E}+00$ & 0.0000 & $0.000 \mathrm{E}+00$ & 0.0000 & $7.861 \mathrm{E}-16$ & 0.0000 \\
\hline-240 & $0.000 \mathrm{E}+00$ & 0.0000 & $0.000 \mathrm{E}+00$ & 0.0000 & $0.000 \mathrm{E}+00$ & 0.0000 & $0.000 \mathrm{E}+00$ & 0.0000 & $0.000 \mathrm{E}+00$ & 0.0000 & $0.000 \mathrm{E}+00$ & 0.0000 & $9.653 \mathrm{E}-20$ & 0.0000 \\
\hline 99 & $0.000 \mathrm{E}+00$ & 0.0000 & $0.000 \mathrm{E}+00$ & 0.0000 & $0.000 \mathrm{E}+00$ & 0.0000 & $0.000 \mathrm{E}+00$ & 0.0000 & $0.000 \mathrm{E}+00$ & 0.0000 & $0.000 \mathrm{E}+00$ & 0.0000 & $4.979 E-24$ & 0.0000 \\
\hline-228 & $0.000 \mathrm{E}+00$ & 0.0000 & $0.000 \mathrm{E}+00$ & 0.0000 & $0.000 \mathrm{E}+00$ & 0.0000 & $0.000 \mathrm{E}+00$ & 0.0000 & $0.000 \mathrm{E}+00$ & 0.0000 & $0.000 \mathrm{E}+00$ & 0.0000 & $1.011 \mathrm{E}-13$ & 0.0000 \\
\hline-230 & $0.000 \mathrm{E}+00$ & 0.0000 & $0.000 \mathrm{E}+00$ & 0.0000 & $0.000 \mathrm{E}+00$ & 0.0000 & $0.000 \mathrm{E}+00$ & 0.0000 & $0.000 \mathrm{E}+00$ & 0.0000 & $0.000 \mathrm{E}+00$ & 0.0000 & $5.320 \mathrm{E}-07$ & 0.0558 \\
\hline-232 & $0.000 \mathrm{E}+00$ & 0.0000 & $0.000 \mathrm{E}+00$ & 0.0000 & $0.000 \mathrm{E}+00$ & 0.0000 & $0.000 \mathrm{E}+00$ & 0.0000 & $0.000 \mathrm{E}+00$ & 0.0000 & $0.000 \mathrm{E}+00$ & 0.0000 & $8.963 E-06$ & 0.9395 \\
\hline 234 & $0.000 \mathrm{E}+00$ & 0.0000 & $0.000 \mathrm{E}+00$ & 0.0000 & $0.000 \mathrm{E}+00$ & 0.0000 & $0.000 \mathrm{E}+00$ & 0.0000 & $0.000 \mathrm{E}+00$ & 0.0000 & $0.000 \mathrm{E}+00$ & 0.0000 & $1.941 \mathrm{E}-10$ & 0.0000 \\
\hline 35 & $0.000 \mathrm{E}+00$ & 0.0000 & $0.000 \mathrm{E}+00$ & 0.0000 & $0.000 \mathrm{E}+00$ & 0.0000 & $0.000 \mathrm{E}+00$ & 0.0000 & $0.000 \mathrm{E}+00$ & 0.0000 & $0.000 \mathrm{E}+00$ & 0.0000 & $6.005 E-13$ & 0.0000 \\
\hline 38 & $0.000 \mathrm{E}+00$ & 0.0000 & $0.000 \mathrm{E}+00$ & 0.0000 & $0.000 \mathrm{E}+00$ & 0.0000 & $0.000 \mathrm{E}+00$ & 0.0000 & $0.000 \mathrm{E}+00$ & 0.0000 & $0.000 \mathrm{E}+00$ & 0.0000 & $3.385 \mathrm{E}-08$ & 0.0035 \\
\hline & $0.000 \mathrm{E}+00$ & 0.0000 & $0.000 \mathrm{E}+00$ & 0.0000 & $0.000 \mathrm{E}+00$ & 0.0000 & $0.000 \mathrm{E}+00$ & 0.0000 & $0.000 \mathrm{E}+00$ & 0.0000 & $0.000 \mathrm{E}+00$ & 0.0000 & $9.541 \mathrm{E}-06$ & 1.0000 \\
\hline
\end{tabular}

* Sum of all water independent and dependent pathways. 
RESRAD, Version 6.5

07/21/2011 12:03 Page 23

ummary : RESRAD Parameters for Resident Farmer U-Landfill Forward Run 10,000 Years

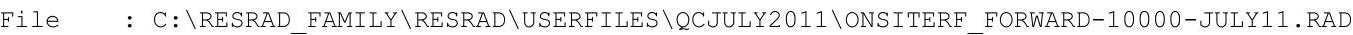

Total Dose Contributions TDOSE(i,p,t) for Individual Radionuclides (i) and Pathways (p) As mrem/yr and Fraction of Total Dose At $t=1.000 \mathrm{E}+02$ years

Water Independent Pathways (Inhalation excludes radon)

\begin{tabular}{|c|c|c|c|c|c|c|c|c|c|c|c|c|c|c|}
\hline \multirow{2}{*}{ Nuclide } & \multicolumn{2}{|c|}{ Ground } & \multicolumn{2}{|c|}{ Inhalation } & \multicolumn{2}{|c|}{ Radon } & \multicolumn{2}{|c|}{ Plant } & \multicolumn{2}{|c|}{ Meat } & \multicolumn{2}{|c|}{ Milk } & \multicolumn{2}{|c|}{ Soil } \\
\hline & mrem/yr & fract. & mrem/yr & fract. & mrem/yr & fract. & mrem/yr & fract. & mrem/yr & fract. & mrem/yr & fract. & mrem/yr & fract. \\
\hline-241 & $2.940 \mathrm{E}-15$ & 0.0000 & $0.000 \mathrm{E}+00$ & 0.0000 & $0.000 \mathrm{E}+00$ & 0.0000 & $0.000 \mathrm{E}+00$ & 0.0000 & $0.000 \mathrm{E}+00$ & 0.0000 & $0.000 \mathrm{E}+00$ & 0.0000 & $0.000 \mathrm{E}+00$ & 0.0000 \\
\hline-137 & $5.512 \mathrm{E}-09$ & 0.0004 & $0.000 \mathrm{E}+00$ & 0.0000 & $0.000 \mathrm{E}+00$ & 0.0000 & $0.000 \mathrm{E}+00$ & 0.0000 & $0.000 \mathrm{E}+00$ & 0.0000 & $0.000 \mathrm{E}+00$ & 0.0000 & $0.000 \mathrm{E}+00$ & 0.0000 \\
\hline-237 & $1.534 \mathrm{E}-11$ & 0.0000 & $0.000 \mathrm{E}+00$ & 0.0000 & $0.000 \mathrm{E}+00$ & 0.0000 & $0.000 \mathrm{E}+00$ & 0.0000 & $0.000 \mathrm{E}+00$ & 0.0000 & $0.000 \mathrm{E}+00$ & 0.0000 & $0.000 \mathrm{E}+00$ & 0.0000 \\
\hline-238 & $2.076 \mathrm{E}-14$ & 0.0000 & $0.000 \mathrm{E}+00$ & 0.0000 & $0.000 \mathrm{E}+00$ & 0.0000 & $0.000 \mathrm{E}+00$ & 0.0000 & $0.000 \mathrm{E}+00$ & 0.0000 & $0.000 \mathrm{E}+00$ & 0.0000 & $0.000 \mathrm{E}+00$ & 0.0000 \\
\hline-239 & 1. $428 \mathrm{E}-15$ & 0.0000 & $0.000 \mathrm{E}+00$ & 0.0000 & $0.000 \mathrm{E}+00$ & 0.0000 & $0.000 \mathrm{E}+00$ & 0.0000 & $0.000 \mathrm{E}+00$ & 0.0000 & $0.000 \mathrm{E}+00$ & 0.0000 & $0.000 \mathrm{E}+00$ & 0.0000 \\
\hline-240 & $6.420 \mathrm{E}-19$ & 0.0000 & $0.000 \mathrm{E}+00$ & 0.0000 & $0.000 \mathrm{E}+00$ & 0.0000 & $0.000 \mathrm{E}+00$ & 0.0000 & $0.000 \mathrm{E}+00$ & 0.0000 & $0.000 \mathrm{E}+00$ & 0.0000 & $0.000 \mathrm{E}+00$ & 0.0000 \\
\hline 99 & $8.280 E-24$ & 0.0000 & $0.000 \mathrm{E}+00$ & 0.0000 & $0.000 \mathrm{E}+00$ & 0.0000 & $0.000 \mathrm{E}+00$ & 0.0000 & $0.000 \mathrm{E}+00$ & 0.0000 & $0.000 \mathrm{E}+00$ & 0.0000 & $0.000 \mathrm{E}+00$ & 0.0000 \\
\hline-228 & $1.847 \mathrm{E}-21$ & 0.0000 & $0.000 \mathrm{E}+00$ & 0.0000 & $0.000 \mathrm{E}+00$ & 0.0000 & $0.000 \mathrm{E}+00$ & 0.0000 & $0.000 \mathrm{E}+00$ & 0.0000 & $0.000 \mathrm{E}+00$ & 0.0000 & $0.000 \mathrm{E}+00$ & 0.0000 \\
\hline-230 & $1.479 \mathrm{E}-06$ & 0.1082 & $0.000 \mathrm{E}+00$ & 0.0000 & $0.000 \mathrm{E}+00$ & 0.0000 & $0.000 \mathrm{E}+00$ & 0.0000 & $0.000 \mathrm{E}+00$ & 0.0000 & $0.000 \mathrm{E}+00$ & 0.0000 & $0.000 \mathrm{E}+00$ & 0.0000 \\
\hline-232 & $1.213 E-05$ & 0.8876 & $0.000 \mathrm{E}+00$ & 0.0000 & $0.000 \mathrm{E}+00$ & 0.0000 & $0.000 \mathrm{E}+00$ & 0.0000 & $0.000 \mathrm{E}+00$ & 0.0000 & $0.000 \mathrm{E}+00$ & 0.0000 & $0.000 \mathrm{E}+00$ & 0.0000 \\
\hline 34 & $1.078 E-09$ & 0.0001 & $0.000 \mathrm{E}+00$ & 0.0000 & $0.000 \mathrm{E}+00$ & 0.0000 & $0.000 \mathrm{E}+00$ & 0.0000 & $0.000 \mathrm{E}+00$ & 0.0000 & $0.000 \mathrm{E}+00$ & 0.0000 & $0.000 \mathrm{E}+00$ & 0.0000 \\
\hline 35 & 2. $202 \mathrm{E}-12$ & 0.0000 & $0.000 \mathrm{E}+00$ & 0.0000 & $0.000 \mathrm{E}+00$ & 0.0000 & $0.000 \mathrm{E}+00$ & 0.0000 & $0.000 \mathrm{E}+00$ & 0.0000 & $0.000 \mathrm{E}+00$ & 0.0000 & $0.000 \mathrm{E}+00$ & 0.0000 \\
\hline 38 & $5.045 E-08$ & 0.0037 & $0.000 \mathrm{E}+00$ & 0.0000 & $0.000 \mathrm{E}+00$ & 0.0000 & $0.000 \mathrm{E}+00$ & 0.0000 & $0.000 \mathrm{E}+00$ & 0.0000 & $0.000 \mathrm{E}+00$ & 0.0000 & $0.000 \mathrm{E}+00$ & 0.0000 \\
\hline & $1.367 \mathrm{E}-05$ & 1.0000 & $0.000 \mathrm{E}+00$ & 0.0000 & $0.000 \mathrm{E}+00$ & 0.0000 & $0.000 \mathrm{E}+00$ & 0.0000 & $0.000 \mathrm{E}+00$ & 0.0000 & $0.000 \mathrm{E}+00$ & 0.0000 & $0.000 \mathrm{E}+00$ & 0.0000 \\
\hline
\end{tabular}

Total Dose Contributions TDOSE(i,p,t) for Individual Radionuclides (i) and Pathways (p) As mrem/yr and Fraction of Total Dose At $t=1.000 \mathrm{E}+02$ years

Water Dependent Pathways

\begin{tabular}{|c|c|c|c|c|c|c|c|c|c|c|c|c|c|c|}
\hline \multirow{2}{*}{$\begin{array}{l}\text { Radio- } \\
\text { Nuclide }\end{array}$} & \multicolumn{2}{|c|}{ Water } & \multicolumn{2}{|c|}{ Fish } & \multicolumn{2}{|c|}{ Radon } & \multicolumn{2}{|c|}{ Plant } & \multicolumn{2}{|c|}{ Meat } & \multicolumn{2}{|c|}{ Milk } & \multicolumn{2}{|c|}{ All Pathways* } \\
\hline & mrem/yr & fract. & mrem/yr & fract. & mrem/yr & fract. & mrem/yr & fract. & mrem/yr & fract. & mrem/yr & fract. & mrem/yr & fract. \\
\hline 241 & $0.000 \mathrm{E}+00$ & 0.0000 & $0.000 \mathrm{E}+00$ & 0.0000 & $0.000 \mathrm{E}+00$ & 0.0000 & $0.000 \mathrm{E}+00$ & 0.0000 & $0.000 \mathrm{E}+00$ & 0.0000 & $0.000 \mathrm{E}+00$ & 0.0000 & $2.940 \mathrm{E}-15$ & 0.0000 \\
\hline-137 & $0.000 \mathrm{E}+00$ & 0.0000 & $0.000 \mathrm{E}+00$ & 0.0000 & $0.000 \mathrm{E}+00$ & 0.0000 & $0.000 \mathrm{E}+00$ & 0.0000 & $0.000 \mathrm{E}+00$ & 0.0000 & $0.000 \mathrm{E}+00$ & 0.0000 & $5.512 \mathrm{E}-09$ & 0.0004 \\
\hline-237 & $0.000 \mathrm{E}+00$ & 0.0000 & $0.000 \mathrm{E}+00$ & 0.0000 & $0.000 \mathrm{E}+00$ & 0.0000 & $0.000 \mathrm{E}+00$ & 0.0000 & $0.000 \mathrm{E}+00$ & 0.0000 & $0.000 \mathrm{E}+00$ & 0.0000 & $1.534 \mathrm{E}-11$ & 0.0000 \\
\hline-238 & $0.000 \mathrm{E}+00$ & 0.0000 & $0.000 \mathrm{E}+00$ & 0.0000 & $0.000 \mathrm{E}+00$ & 0.0000 & $0.000 \mathrm{E}+00$ & 0.0000 & $0.000 \mathrm{E}+00$ & 0.0000 & $0.000 \mathrm{E}+00$ & 0.0000 & $2.076 \mathrm{E}-14$ & 0.0000 \\
\hline-239 & $0.000 \mathrm{E}+00$ & 0.0000 & $0.000 \mathrm{E}+00$ & 0.0000 & $0.000 \mathrm{E}+00$ & 0.0000 & $0.000 \mathrm{E}+00$ & 0.0000 & $0.000 \mathrm{E}+00$ & 0.0000 & $0.000 E+00$ & 0.0000 & 1. $428 \mathrm{E}-15$ & 0.0000 \\
\hline-240 & $0.000 \mathrm{E}+00$ & 0.0000 & $0.000 \mathrm{E}+00$ & 0.0000 & $0.000 \mathrm{E}+00$ & 0.0000 & $0.000 \mathrm{E}+00$ & 0.0000 & $0.000 \mathrm{E}+00$ & 0.0000 & $0.000 E+00$ & 0.0000 & $6.420 \mathrm{E}-19$ & 0.0000 \\
\hline-99 & $0.000 \mathrm{E}+00$ & 0.0000 & $0.000 \mathrm{E}+00$ & 0.0000 & $0.000 \mathrm{E}+00$ & 0.0000 & $0.000 \mathrm{E}+00$ & 0.0000 & $0.000 \mathrm{E}+00$ & 0.0000 & $0.000 \mathrm{E}+00$ & 0.0000 & $8.280 \mathrm{E}-24$ & 0.0000 \\
\hline-228 & $0.000 \mathrm{E}+00$ & 0.0000 & $0.000 \mathrm{E}+00$ & 0.0000 & $0.000 \mathrm{E}+00$ & 0.0000 & $0.000 \mathrm{E}+00$ & 0.0000 & $0.000 \mathrm{E}+00$ & 0.0000 & $0.000 \mathrm{E}+00$ & 0.0000 & $1.847 \mathrm{E}-21$ & 0.0000 \\
\hline-230 & $0.000 \mathrm{E}+00$ & 0.0000 & $0.000 \mathrm{E}+00$ & 0.0000 & $0.000 \mathrm{E}+00$ & 0.0000 & $0.000 \mathrm{E}+00$ & 0.0000 & $0.000 \mathrm{E}+00$ & 0.0000 & $0.000 E+00$ & 0.0000 & $1.479 \mathrm{E}-06$ & 0.1082 \\
\hline 232 & $0.000 \mathrm{E}+00$ & 0.0000 & $0.000 \mathrm{E}+00$ & 0.0000 & $0.000 \mathrm{E}+00$ & 0.0000 & $0.000 \mathrm{E}+00$ & 0.0000 & $0.000 \mathrm{E}+00$ & 0.0000 & $0.000 \mathrm{E}+00$ & 0.0000 & $1.213 E-05$ & 0.8876 \\
\hline 34 & $0.000 \mathrm{E}+00$ & 0.0000 & $0.000 \mathrm{E}+00$ & 0.0000 & $0.000 \mathrm{E}+00$ & 0.0000 & $0.000 \mathrm{E}+00$ & 0.0000 & $0.000 \mathrm{E}+00$ & 0.0000 & $0.000 \mathrm{E}+00$ & 0.0000 & $1.078 \mathrm{E}-09$ & 0.0001 \\
\hline 35 & $0.000 \mathrm{E}+00$ & 0.0000 & $0.000 \mathrm{E}+00$ & 0.0000 & $0.000 \mathrm{E}+00$ & 0.0000 & $0.000 \mathrm{E}+00$ & 0.0000 & $0.000 \mathrm{E}+00$ & 0.0000 & $0.000 \mathrm{E}+00$ & 0.0000 & 2. $202 \mathrm{E}-12$ & 0.0000 \\
\hline 38 & $0.000 \mathrm{E}+00$ & 0.0000 & $0.000 \mathrm{E}+00$ & 0.0000 & $0.000 \mathrm{E}+00$ & 0.0000 & $0.000 \mathrm{E}+00$ & 0.0000 & $0.000 \mathrm{E}+00$ & 0.0000 & $0.000 \mathrm{E}+00$ & 0.0000 & $5.045 E-08$ & 0.0037 \\
\hline & $0.000 \mathrm{E}+00$ & 0.0000 & $0.000 \mathrm{E}+00$ & 0.0000 & $0.000 \mathrm{E}+00$ & 0.0000 & $0.000 \mathrm{E}+00$ & 0.0000 & $0.000 \mathrm{E}+00$ & 0.0000 & $0.000 \mathrm{E}+00$ & 0.0000 & $7 E-05$ & 1.0000 \\
\hline
\end{tabular}

* Sum of all water independent and dependent pathways. 
RESRAD, Version 6.5

07/21/2011 12:03 Page 24

ummary : RESRAD Parameters for Resident Farmer U-Landfill Forward Run 10,000 Years

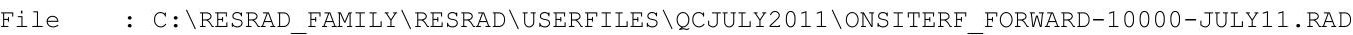

Total Dose Contributions TDOSE(i,p,t) for Individual Radionuclides (i) and Pathways (p) As mrem/yr and Fraction of Total Dose At $t=5.000 \mathrm{E}+02$ years

Water Independent Pathways (Inhalation excludes radon)

\begin{tabular}{|c|c|c|c|c|c|c|c|c|c|c|c|c|c|c|}
\hline \multirow{2}{*}{ Nuclide } & \multicolumn{2}{|c|}{ Ground } & \multicolumn{2}{|c|}{ Inhalation } & \multicolumn{2}{|c|}{ Radon } & \multicolumn{2}{|c|}{ Plant } & \multicolumn{2}{|c|}{ Meat } & \multicolumn{2}{|c|}{ Milk } & \multicolumn{2}{|c|}{ Soil } \\
\hline & mrem/yr & fract. & mrem/yr & fract. & mrem/yr & fract. & mrem/yr & fract. & mrem/yr & fract. & mrem/yr & fract. & mrem/yr & fract. \\
\hline-241 & $8.032 \mathrm{E}-13$ & 0.0000 & $0.000 \mathrm{E}+00$ & 0.0000 & $0.000 \mathrm{E}+00$ & 0.0000 & $0.000 \mathrm{E}+00$ & 0.0000 & $0.000 \mathrm{E}+00$ & 0.0000 & $0.000 \mathrm{E}+00$ & 0.0000 & $0.000 \mathrm{E}+00$ & 0.0000 \\
\hline-137 & $1.540 \mathrm{E}-11$ & 0.0000 & $0.000 \mathrm{E}+00$ & 0.0000 & $0.000 \mathrm{E}+00$ & 0.0000 & $0.000 \mathrm{E}+00$ & 0.0000 & $0.000 \mathrm{E}+00$ & 0.0000 & $0.000 \mathrm{E}+00$ & 0.0000 & $0.000 \mathrm{E}+00$ & 0.0000 \\
\hline-237 & $1.124 \mathrm{E}-09$ & 0.0000 & $0.000 \mathrm{E}+00$ & 0.0000 & $0.000 \mathrm{E}+00$ & 0.0000 & $0.000 \mathrm{E}+00$ & 0.0000 & $0.000 \mathrm{E}+00$ & 0.0000 & $0.000 \mathrm{E}+00$ & 0.0000 & $0.000 \mathrm{E}+00$ & 0.0000 \\
\hline-238 & $2.187 \mathrm{E}-11$ & 0.0000 & $0.000 \mathrm{E}+00$ & 0.0000 & $0.000 \mathrm{E}+00$ & 0.0000 & $0.000 \mathrm{E}+00$ & 0.0000 & $0.000 \mathrm{E}+00$ & 0.0000 & $0.000 \mathrm{E}+00$ & 0.0000 & $0.000 \mathrm{E}+00$ & 0.0000 \\
\hline-239 & 1. $695 \mathrm{E}-13$ & 0.0000 & $0.000 \mathrm{E}+00$ & 0.0000 & $0.000 \mathrm{E}+00$ & 0.0000 & $0.000 \mathrm{E}+00$ & 0.0000 & $0.000 \mathrm{E}+00$ & 0.0000 & $0.000 \mathrm{E}+00$ & 0.0000 & $0.000 \mathrm{E}+00$ & 0.0000 \\
\hline-240 & $2.059 \mathrm{E}-16$ & 0.0000 & $0.000 \mathrm{E}+00$ & 0.0000 & $0.000 \mathrm{E}+00$ & 0.0000 & $0.000 \mathrm{E}+00$ & 0.0000 & $0.000 \mathrm{E}+00$ & 0.0000 & $0.000 \mathrm{E}+00$ & 0.0000 & $0.000 \mathrm{E}+00$ & 0.0000 \\
\hline 99 & $4.841 E-22$ & 0.0000 & $0.000 \mathrm{E}+00$ & 0.0000 & $0.000 \mathrm{E}+00$ & 0.0000 & $0.000 \mathrm{E}+00$ & 0.0000 & $0.000 \mathrm{E}+00$ & 0.0000 & $0.000 \mathrm{E}+00$ & 0.0000 & $0.000 \mathrm{E}+00$ & 0.0000 \\
\hline-228 & $0.000 \mathrm{E}+00$ & 0.0000 & $0.000 \mathrm{E}+00$ & 0.0000 & $0.000 \mathrm{E}+00$ & 0.0000 & $0.000 \mathrm{E}+00$ & 0.0000 & $0.000 \mathrm{E}+00$ & 0.0000 & $0.000 \mathrm{E}+00$ & 0.0000 & $0.000 \mathrm{E}+00$ & 0.0000 \\
\hline-230 & $1.071 \mathrm{E}-04$ & 0.0000 & $0.000 \mathrm{E}+00$ & 0.0000 & $0.000 \mathrm{E}+00$ & 0.0000 & $0.000 \mathrm{E}+00$ & 0.0000 & $0.000 \mathrm{E}+00$ & 0.0000 & $0.000 \mathrm{E}+00$ & 0.0000 & $0.000 \mathrm{E}+00$ & 0.0000 \\
\hline-232 & $1.335 E-04$ & 0.0000 & $0.000 \mathrm{E}+00$ & 0.0000 & $0.000 \mathrm{E}+00$ & 0.0000 & $0.000 \mathrm{E}+00$ & 0.0000 & $0.000 \mathrm{E}+00$ & 0.0000 & $0.000 \mathrm{E}+00$ & 0.0000 & $0.000 \mathrm{E}+00$ & 0.0000 \\
\hline 234 & $3.993 E-07$ & 0.0000 & $0.000 \mathrm{E}+00$ & 0.0000 & $0.000 \mathrm{E}+00$ & 0.0000 & $0.000 \mathrm{E}+00$ & 0.0000 & $0.000 \mathrm{E}+00$ & 0.0000 & $0.000 \mathrm{E}+00$ & 0.0000 & $0.000 \mathrm{E}+00$ & 0.0000 \\
\hline 35 & $4.571 \mathrm{E}-10$ & 0.0000 & $0.000 \mathrm{E}+00$ & 0.0000 & $0.000 \mathrm{E}+00$ & 0.0000 & $0.000 \mathrm{E}+00$ & 0.0000 & $0.000 \mathrm{E}+00$ & 0.0000 & $0.000 \mathrm{E}+00$ & 0.0000 & $0.000 \mathrm{E}+00$ & 0.0000 \\
\hline 38 & $1.229 \mathrm{E}-06$ & 0.0000 & $0.000 \mathrm{E}+00$ & 0.0000 & $0.000 \mathrm{E}+00$ & 0.0000 & $0.000 \mathrm{E}+00$ & 0.0000 & $0.000 \mathrm{E}+00$ & 0.0000 & $0.000 \mathrm{E}+00$ & 0.0000 & $0.000 \mathrm{E}+00$ & 0.0000 \\
\hline & $2.423 E-04$ & 0.0000 & $0.000 \mathrm{E}+00$ & 0.0000 & $0.000 \mathrm{E}+00$ & 0.0000 & $0.000 \mathrm{E}+00$ & 0.0000 & $0.000 \mathrm{E}+00$ & 0.0000 & $0.000 \mathrm{E}+00$ & 0.0000 & $0.000 \mathrm{E}+00$ & 0.0000 \\
\hline
\end{tabular}

Total Dose Contributions TDOSE(i,p,t) for Individual Radionuclides (i) and Pathways (p) As mrem/yr and Fraction of Total Dose At $t=5.000 \mathrm{E}+02$ years

Water Dependent Pathways

\begin{tabular}{|c|c|c|c|c|c|c|c|c|c|c|c|c|c|c|}
\hline \multirow{2}{*}{$\begin{array}{l}\text { Radio- } \\
\text { Nuclide }\end{array}$} & \multicolumn{2}{|c|}{ Water } & \multicolumn{2}{|c|}{ Fish } & \multicolumn{2}{|c|}{ Radon } & \multicolumn{2}{|c|}{ Plant } & \multicolumn{2}{|c|}{ Meat } & \multicolumn{2}{|c|}{ Milk } & \multicolumn{2}{|c|}{ All Pathways* } \\
\hline & mrem/yr & fract. & mrem/yr & fract. & mrem/yr & fract. & mrem/yr & fract. & mrem/yr & fract. & mrem/yr & fract. & mrem/yr & fract. \\
\hline 241 & $0.000 \mathrm{E}+00$ & 0.0000 & $0.000 \mathrm{E}+00$ & 0.0000 & $0.000 \mathrm{E}+00$ & 0.0000 & $0.000 \mathrm{E}+00$ & 0.0000 & $0.000 \mathrm{E}+00$ & 0.0000 & $0.000 \mathrm{E}+00$ & 0.0000 & $8.032 \mathrm{E}-13$ & 0.0000 \\
\hline-137 & $0.000 \mathrm{E}+00$ & 0.0000 & $0.000 \mathrm{E}+00$ & 0.0000 & $0.000 \mathrm{E}+00$ & 0.0000 & $0.000 \mathrm{E}+00$ & 0.0000 & $0.000 \mathrm{E}+00$ & 0.0000 & $0.000 \mathrm{E}+00$ & 0.0000 & $1.540 \mathrm{E}-11$ & 0.0000 \\
\hline-237 & $0.000 \mathrm{E}+00$ & 0.0000 & $0.000 \mathrm{E}+00$ & 0.0000 & $0.000 \mathrm{E}+00$ & 0.0000 & $0.000 \mathrm{E}+00$ & 0.0000 & $0.000 \mathrm{E}+00$ & 0.0000 & $0.000 \mathrm{E}+00$ & 0.0000 & $1.124 \mathrm{E}-09$ & 0.0000 \\
\hline-238 & $0.000 \mathrm{E}+00$ & 0.0000 & $0.000 \mathrm{E}+00$ & 0.0000 & $0.000 \mathrm{E}+00$ & 0.0000 & $0.000 \mathrm{E}+00$ & 0.0000 & $0.000 \mathrm{E}+00$ & 0.0000 & $0.000 \mathrm{E}+00$ & 0.0000 & $2.187 \mathrm{E}-11$ & 0.0000 \\
\hline-239 & $0.000 \mathrm{E}+00$ & 0.0000 & $0.000 \mathrm{E}+00$ & 0.0000 & $0.000 \mathrm{E}+00$ & 0.0000 & $0.000 \mathrm{E}+00$ & 0.0000 & $0.000 \mathrm{E}+00$ & 0.0000 & $0.000 E+00$ & 0.0000 & $1.695 \mathrm{E}-13$ & 0.0000 \\
\hline-240 & $0.000 \mathrm{E}+00$ & 0.0000 & $0.000 \mathrm{E}+00$ & 0.0000 & $0.000 \mathrm{E}+00$ & 0.0000 & $0.000 \mathrm{E}+00$ & 0.0000 & $0.000 \mathrm{E}+00$ & 0.0000 & $0.000 E+00$ & 0.0000 & $2.059 \mathrm{E}-16$ & 0.0000 \\
\hline-99 & $8.911 E+00$ & 0.8277 & $0.000 \mathrm{E}+00$ & 0.0000 & $0.000 \mathrm{E}+00$ & 0.0000 & $8.331 E-01$ & 0.0774 & $1.491 \mathrm{E}-02$ & 0.0014 & $1.007 \mathrm{E}+00$ & 0.0935 & $1.077 \mathrm{E}+01$ & 1.0000 \\
\hline-228 & $0.000 \mathrm{E}+00$ & 0.0000 & $0.000 \mathrm{E}+00$ & 0.0000 & $0.000 \mathrm{E}+00$ & 0.0000 & $0.000 \mathrm{E}+00$ & 0.0000 & $0.000 \mathrm{E}+00$ & 0.0000 & $0.000 \mathrm{E}+00$ & 0.0000 & $0.000 \mathrm{E}+00$ & 0.0000 \\
\hline-230 & $0.000 \mathrm{E}+00$ & 0.0000 & $0.000 \mathrm{E}+00$ & 0.0000 & $0.000 \mathrm{E}+00$ & 0.0000 & $0.000 \mathrm{E}+00$ & 0.0000 & $0.000 \mathrm{E}+00$ & 0.0000 & $0.000 E+00$ & 0.0000 & $1.071 \mathrm{E}-04$ & 0.0000 \\
\hline-232 & $0.000 \mathrm{E}+00$ & 0.0000 & $0.000 \mathrm{E}+00$ & 0.0000 & $0.000 \mathrm{E}+00$ & 0.0000 & $0.000 \mathrm{E}+00$ & 0.0000 & $0.000 \mathrm{E}+00$ & 0.0000 & $0.000 \mathrm{E}+00$ & 0.0000 & $1.335 \mathrm{E}-04$ & 0.0000 \\
\hline 234 & $0.000 \mathrm{E}+00$ & 0.0000 & $0.000 \mathrm{E}+00$ & 0.0000 & $0.000 \mathrm{E}+00$ & 0.0000 & $0.000 \mathrm{E}+00$ & 0.0000 & $0.000 \mathrm{E}+00$ & 0.0000 & $0.000 \mathrm{E}+00$ & 0.0000 & $3.993 E-07$ & 0.0000 \\
\hline 35 & $0.000 \mathrm{E}+00$ & 0.0000 & $0.000 \mathrm{E}+00$ & 0.0000 & $0.000 \mathrm{E}+00$ & 0.0000 & $0.000 \mathrm{E}+00$ & 0.0000 & $0.000 \mathrm{E}+00$ & 0.0000 & $0.000 \mathrm{E}+00$ & 0.0000 & $4.571 E-10$ & 0.0000 \\
\hline 38 & $0.000 \mathrm{E}+00$ & 0.0000 & $0.000 \mathrm{E}+00$ & 0.0000 & $0.000 \mathrm{E}+00$ & 0.0000 & $0.000 \mathrm{E}+00$ & 0.0000 & $0.000 \mathrm{E}+00$ & 0.0000 & $0.000 \mathrm{E}+00$ & 0.0000 & $1.229 \mathrm{E}-06$ & 0.0000 \\
\hline & $8.911 \mathrm{E}+00$ & 0.8277 & $0.000 \mathrm{E}+00$ & 0.0000 & $0.000 \mathrm{E}+00$ & 0.0000 & $8.331 \mathrm{E}-01$ & 0.0774 & $1.491 \mathrm{E}-02$ & 0.0014 & $1.007 \mathrm{E}+00$ & 0.0935 & $7 \mathrm{E}+01$ & 1. \\
\hline
\end{tabular}

* Sum of all water independent and dependent pathways. 
RESRAD, Version 6.5

07/21/2011 12:03 Page 25

ummary : RESRAD Parameters for Resident Farmer U-Landfill Forward Run 10,000 Years

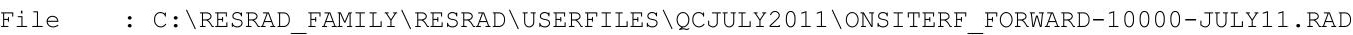

Total Dose Contributions TDOSE(i,p,t) for Individual Radionuclides (i) and Pathways (p) As mrem/yr and Fraction of Total Dose At $t=1.050 \mathrm{E}+03$ years

Water Independent Pathways (Inhalation excludes radon)

\begin{tabular}{|c|c|c|c|c|c|c|c|c|c|c|c|c|c|c|}
\hline \multirow{2}{*}{ Nuclide } & \multicolumn{2}{|c|}{ Ground } & \multicolumn{2}{|c|}{ Inhalation } & \multicolumn{2}{|c|}{ Radon } & \multicolumn{2}{|c|}{ Plant } & \multicolumn{2}{|c|}{ Meat } & \multicolumn{2}{|c|}{ Milk } & \multicolumn{2}{|c|}{ Soil } \\
\hline & mrem/yr & fract. & mrem/yr & fract. & mrem/yr & fract. & mrem/yr & fract. & mrem/yr & fract. & mrem/yr & fract. & mrem/yr & fract. \\
\hline-241 & $4.257 \mathrm{E}-10$ & 0.0000 & $0.000 \mathrm{E}+00$ & 0.0000 & $0.000 \mathrm{E}+00$ & 0.0000 & $6.939 E-03$ & 0.0009 & $1.230 \mathrm{E}-05$ & 0.0000 & $1.180 \mathrm{E}-06$ & 0.0000 & $0.000 \mathrm{E}+00$ & 0.0000 \\
\hline-137 & $4.741 E-15$ & 0.0000 & $0.000 \mathrm{E}+00$ & 0.0000 & $0.000 \mathrm{E}+00$ & 0.0000 & $1.461 \mathrm{E}-12$ & 0.0000 & $1.328 \mathrm{E}-12$ & 0.0000 & $9.802 \mathrm{E}-13$ & 0.0000 & $0.000 \mathrm{E}+00$ & 0.0000 \\
\hline-237 & $3.910 \mathrm{E}-07$ & 0.0000 & $0.000 \mathrm{E}+00$ & 0.0000 & $0.000 \mathrm{E}+00$ & 0.0000 & $5.637 \mathrm{E}-02$ & 0.0076 & $1.708 \mathrm{E}-03$ & 0.0002 & $2.443 E-05$ & 0.0000 & $0.000 \mathrm{E}+00$ & 0.0000 \\
\hline-238 & $5.077 \mathrm{E}-09$ & 0.0000 & $0.000 \mathrm{E}+00$ & 0.0000 & $0.000 \mathrm{E}+00$ & 0.0000 & $2.382 \mathrm{E}-05$ & 0.0000 & $2.117 \mathrm{E}-07$ & 0.0000 & $5.992 \mathrm{E}-07$ & 0.0000 & $0.000 \mathrm{E}+00$ & 0.0000 \\
\hline-239 & $1.202 \mathrm{E}-10$ & 0.0000 & $0.000 \mathrm{E}+00$ & 0.0000 & $0.000 \mathrm{E}+00$ & 0.0000 & $4.566 \mathrm{E}-02$ & 0.0062 & $1.384 \mathrm{E}-04$ & 0.0000 & $3.831 E-06$ & 0.0000 & $0.000 \mathrm{E}+00$ & 0.0000 \\
\hline-240 & $2.914 \mathrm{E}-14$ & 0.0000 & $0.000 \mathrm{E}+00$ & 0.0000 & $0.000 \mathrm{E}+00$ & 0.0000 & $4.210 \mathrm{E}-02$ & 0.0057 & $1.276 \mathrm{E}-04$ & 0.0000 & $3.564 \mathrm{E}-06$ & 0.0000 & $0.000 \mathrm{E}+00$ & 0.0000 \\
\hline 99 & 1. 302E-19 & 0.0000 & $0.000 \mathrm{E}+00$ & 0.0000 & $0.000 \mathrm{E}+00$ & 0.0000 & $6.892 \mathrm{E}-05$ & 0.0000 & $2.091 \mathrm{E}-07$ & 0.0000 & $5.786 \mathrm{E}-06$ & 0.0000 & $0.000 \mathrm{E}+00$ & 0.0000 \\
\hline-228 & $0.000 \mathrm{E}+00$ & 0.0000 & $0.000 \mathrm{E}+00$ & 0.0000 & $0.000 \mathrm{E}+00$ & 0.0000 & $0.000 \mathrm{E}+00$ & 0.0000 & $0.000 \mathrm{E}+00$ & 0.0000 & $0.000 \mathrm{E}+00$ & 0.0000 & $0.000 \mathrm{E}+00$ & 0.0000 \\
\hline-230 & $8.967 \mathrm{E}-03$ & 0.0012 & $0.000 \mathrm{E}+00$ & 0.0000 & $0.000 \mathrm{E}+00$ & 0.0000 & $5.809 \mathrm{E}+00$ & 0.7838 & $1.529 \mathrm{E}-01$ & 0.0206 & $2.709 \mathrm{E}-01$ & 0.0365 & $0.000 \mathrm{E}+00$ & 0.0000 \\
\hline-232 & $3.698 E-03$ & 0.0005 & $0.000 \mathrm{E}+00$ & 0.0000 & $0.000 \mathrm{E}+00$ & 0.0000 & $5.926 \mathrm{E}-01$ & 0.0800 & $1.748 \mathrm{E}-02$ & 0.0024 & $4.841 \mathrm{E}-02$ & 0.0065 & $0.000 \mathrm{E}+00$ & 0.0000 \\
\hline 34 & $7.268 E-05$ & 0.0000 & $0.000 \mathrm{E}+00$ & 0.0000 & $0.000 \mathrm{E}+00$ & 0.0000 & $1.483 \mathrm{E}-01$ & 0.0200 & $2.264 \mathrm{E}-03$ & 0.0003 & $7.276 \mathrm{E}-03$ & 0.0010 & $0.000 \mathrm{E}+00$ & 0.0000 \\
\hline 35 & $1.527 \mathrm{E}-07$ & 0.0000 & $0.000 \mathrm{E}+00$ & 0.0000 & $0.000 \mathrm{E}+00$ & 0.0000 & $1.149 \mathrm{E}-02$ & 0.0015 & $8.470 \mathrm{E}-04$ & 0.0001 & $2.073 E-04$ & 0.0000 & $0.000 \mathrm{E}+00$ & 0.0000 \\
\hline 38 & $9.919 \mathrm{E}-05$ & 0.0000 & $0.000 \mathrm{E}+00$ & 0.0000 & $0.000 \mathrm{E}+00$ & 0.0000 & $1.013 \mathrm{E}-01$ & 0.0137 & $1.044 \mathrm{E}-03$ & 0.0001 & $5.096 \mathrm{E}-03$ & 0.0007 & $0.000 \mathrm{E}+00$ & 0.0000 \\
\hline & 1. $284 \mathrm{E}-02$ & 0.0017 & $0.000 \mathrm{E}+00$ & 0.0000 & $0.000 \mathrm{E}+00$ & 0.0000 & $6.814 \mathrm{E}+00$ & 0.9194 & $1.765 \mathrm{E}-01$ & 0.0238 & $3.319 \mathrm{E}-01$ & 0.0448 & $.000 \mathrm{E}+00$ & 0.0000 \\
\hline
\end{tabular}

Total Dose Contributions TDOSE(i,p,t) for Individual Radionuclides (i) and Pathways (p) As mrem/yr and Fraction of Total Dose At $t=1.050 \mathrm{E}+03$ years

Water Dependent Pathways

\begin{tabular}{|c|c|c|c|c|c|c|c|c|c|c|c|c|c|c|}
\hline \multirow{2}{*}{$\begin{array}{l}\text { Radio- } \\
\text { Nuclide }\end{array}$} & \multicolumn{2}{|c|}{ Water } & \multicolumn{2}{|c|}{ Fish } & \multicolumn{2}{|c|}{ Radon } & \multicolumn{2}{|c|}{ Plant } & \multicolumn{2}{|c|}{ Meat } & \multicolumn{2}{|c|}{ Milk } & \multicolumn{2}{|c|}{ All Pathways* } \\
\hline & mrem/yr & fract. & mrem/yr & fract. & mrem/yr & fract. & mrem/yr & fract. & mrem/yr & fract. & mrem/yr & fract. & mrem/yr & fract. \\
\hline 241 & $0.000 \mathrm{E}+00$ & 0.0000 & $0.000 \mathrm{E}+00$ & 0.0000 & $0.000 \mathrm{E}+00$ & 0.0000 & $0.000 \mathrm{E}+00$ & 0.0000 & $0.000 \mathrm{E}+00$ & 0.0000 & $0.000 \mathrm{E}+00$ & 0.0000 & $6.953 E-03$ & 0.0009 \\
\hline-137 & $0.000 \mathrm{E}+00$ & 0.0000 & $0.000 \mathrm{E}+00$ & 0.0000 & $0.000 \mathrm{E}+00$ & 0.0000 & $0.000 \mathrm{E}+00$ & 0.0000 & $0.000 \mathrm{E}+00$ & 0.0000 & $0.000 \mathrm{E}+00$ & 0.0000 & $3.773 \mathrm{E}-12$ & 0.0000 \\
\hline-237 & $0.000 \mathrm{E}+00$ & 0.0000 & $0.000 \mathrm{E}+00$ & 0.0000 & $0.000 \mathrm{E}+00$ & 0.0000 & $0.000 \mathrm{E}+00$ & 0.0000 & $0.000 \mathrm{E}+00$ & 0.0000 & $0.000 \mathrm{E}+00$ & 0.0000 & $5.811 E-02$ & 0.0078 \\
\hline-238 & $0.000 \mathrm{E}+00$ & 0.0000 & $0.000 \mathrm{E}+00$ & 0.0000 & $0.000 \mathrm{E}+00$ & 0.0000 & $0.000 \mathrm{E}+00$ & 0.0000 & $0.000 \mathrm{E}+00$ & 0.0000 & $0.000 \mathrm{E}+00$ & 0.0000 & $2.464 \mathrm{E}-05$ & 0.0000 \\
\hline-239 & $0.000 \mathrm{E}+00$ & 0.0000 & $0.000 \mathrm{E}+00$ & 0.0000 & $0.000 \mathrm{E}+00$ & 0.0000 & $0.000 \mathrm{E}+00$ & 0.0000 & $0.000 \mathrm{E}+00$ & 0.0000 & $0.000 E+00$ & 0.0000 & $4.580 \mathrm{E}-02$ & 0.0062 \\
\hline-240 & $0.000 \mathrm{E}+00$ & 0.0000 & $0.000 \mathrm{E}+00$ & 0.0000 & $0.000 \mathrm{E}+00$ & 0.0000 & $0.000 \mathrm{E}+00$ & 0.0000 & $0.000 \mathrm{E}+00$ & 0.0000 & $0.000 E+00$ & 0.0000 & $4.224 \mathrm{E}-02$ & 0.0057 \\
\hline 99 & $6.337 \mathrm{E}-02$ & 0.0085 & $0.000 \mathrm{E}+00$ & 0.0000 & $0.000 \mathrm{E}+00$ & 0.0000 & $5.924 \mathrm{E}-03$ & 0.0008 & $1.061 \mathrm{E}-04$ & 0.0000 & $7.158 \mathrm{E}-03$ & 0.0010 & $7.663 \mathrm{E}-02$ & 0.0103 \\
\hline-228 & $0.000 \mathrm{E}+00$ & 0.0000 & $0.000 \mathrm{E}+00$ & 0.0000 & $0.000 \mathrm{E}+00$ & 0.0000 & $0.000 \mathrm{E}+00$ & 0.0000 & $0.000 \mathrm{E}+00$ & 0.0000 & $0.000 \mathrm{E}+00$ & 0.0000 & $0.000 \mathrm{E}+00$ & 0.0000 \\
\hline-230 & $0.000 \mathrm{E}+00$ & 0.0000 & $0.000 \mathrm{E}+00$ & 0.0000 & $0.000 \mathrm{E}+00$ & 0.0000 & $0.000 \mathrm{E}+00$ & 0.0000 & $0.000 \mathrm{E}+00$ & 0.0000 & $0.000 E+00$ & 0.0000 & $6.242 \mathrm{E}+00$ & 0.8422 \\
\hline 232 & $0.000 \mathrm{E}+00$ & 0.0000 & $0.000 \mathrm{E}+00$ & 0.0000 & $0.000 \mathrm{E}+00$ & 0.0000 & $0.000 \mathrm{E}+00$ & 0.0000 & $0.000 \mathrm{E}+00$ & 0.0000 & $0.000 \mathrm{E}+00$ & 0.0000 & $6.622 \mathrm{E}-01$ & 0.0893 \\
\hline 34 & $0.000 \mathrm{E}+00$ & 0.0000 & $0.000 \mathrm{E}+00$ & 0.0000 & $0.000 \mathrm{E}+00$ & 0.0000 & $0.000 \mathrm{E}+00$ & 0.0000 & $0.000 \mathrm{E}+00$ & 0.0000 & $0.000 \mathrm{E}+00$ & 0.0000 & $1.580 \mathrm{E}-01$ & 0.0213 \\
\hline 35 & $0.000 \mathrm{E}+00$ & 0.0000 & $0.000 \mathrm{E}+00$ & 0.0000 & $0.000 \mathrm{E}+00$ & 0.0000 & $0.000 \mathrm{E}+00$ & 0.0000 & $0.000 \mathrm{E}+00$ & 0.0000 & $0.000 \mathrm{E}+00$ & 0.0000 & $1.254 \mathrm{E}-02$ & 0.0017 \\
\hline 38 & $0.000 \mathrm{E}+00$ & 0.0000 & $0.000 \mathrm{E}+00$ & 0.0000 & $0.000 \mathrm{E}+00$ & 0.0000 & $0.000 \mathrm{E}+00$ & 0.0000 & $0.000 \mathrm{E}+00$ & 0.0000 & $0.000 \mathrm{E}+00$ & 0.0000 & $1.075 \mathrm{E}-01$ & 0.0145 \\
\hline & $6.337 \mathrm{E}-02$ & 0.0085 & $0.000 \mathrm{E}+00$ & 0.0000 & $0.000 \mathrm{E}+00$ & 0.0000 & $5.924 \mathrm{E}-03$ & 0.0008 & $1.061 \mathrm{E}-04$ & 0.0000 & $7.158 \mathrm{E}-03$ & 0.0010 & $7.412 \mathrm{E}+00$ & 1. \\
\hline
\end{tabular}

* Sum of all water independent and dependent pathways. 
RESRAD, Version 6.5

07/21/2011 12:03 Page 26

ummary : RESRAD Parameters for Resident Farmer U-Landfill Forward Run 10,000 Years

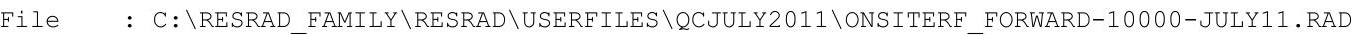

Total Dose Contributions TDOSE(i,p,t) for Individual Radionuclides (i) and Pathways (p) As mrem/yr and Fraction of Total Dose At $t=1.000 \mathrm{E}+04$ years

Water Independent Pathways (Inhalation excludes radon)

\begin{tabular}{|c|c|c|c|c|c|c|c|c|c|c|c|c|c|c|}
\hline \multirow{2}{*}{ Nuclide } & \multicolumn{2}{|c|}{ Ground } & \multicolumn{2}{|c|}{ Inhalation } & \multicolumn{2}{|c|}{ Radon } & \multicolumn{2}{|c|}{ Plant } & \multicolumn{2}{|c|}{ Meat } & \multicolumn{2}{|c|}{ Milk } & \multicolumn{2}{|c|}{ Soil } \\
\hline & mrem/yr & fract. & mrem/yr & fract. & mrem/yr & fract. & mrem/yr & fract. & mrem/yr & fract. & mrem/yr & fract. & mrem/yr & fract. \\
\hline-241 & $1.724 \mathrm{E}-03$ & 0.0000 & $1.816 \mathrm{E}-07$ & 0.0000 & $0.000 \mathrm{E}+00$ & 0.0000 & $2.088 E-03$ & 0.0000 & $1.927 \mathrm{E}-04$ & 0.0000 & $1.010 \mathrm{E}-05$ & 0.0000 & $3.432 \mathrm{E}-05$ & 0.0000 \\
\hline-137 & $0.000 \mathrm{E}+00$ & 0.0000 & $0.000 \mathrm{E}+00$ & 0.0000 & $0.000 \mathrm{E}+00$ & 0.0000 & $0.000 \mathrm{E}+00$ & 0.0000 & $0.000 \mathrm{E}+00$ & 0.0000 & $0.000 \mathrm{E}+00$ & 0.0000 & $0.000 \mathrm{E}+00$ & 0.0000 \\
\hline-237 & $1.242 \mathrm{E}+00$ & 0.0005 & 1. $326 \mathrm{E}-04$ & 0.0000 & $0.000 \mathrm{E}+00$ & 0.0000 & $1.496 \mathrm{E}+00$ & 0.0006 & $1.381 \mathrm{E}-01$ & 0.0001 & $7.847 E-03$ & 0.0000 & $2.514 \mathrm{E}-02$ & 0.0000 \\
\hline-238 & $6.839 E-03$ & 0.0000 & $3.439 \mathrm{E}-07$ & 0.0000 & $0.000 \mathrm{E}+00$ & 0.0000 & $1.186 \mathrm{E}-02$ & 0.0000 & $1.230 \mathrm{E}-03$ & 0.0000 & $2.117 \mathrm{E}-03$ & 0.0000 & $3.191 \mathrm{E}-04$ & 0.0000 \\
\hline-239 & $5.108 E-03$ & 0.0000 & $4.259 \mathrm{E}-03$ & 0.0000 & $0.000 \mathrm{E}+00$ & 0.0000 & $2.652 \mathrm{E}+00$ & 0.0010 & $3.321 \mathrm{E}-01$ & 0.0001 & $9.176 \mathrm{E}-03$ & 0.0000 & $7.370 \mathrm{E}-01$ & 0.0003 \\
\hline-240 & $9.845 \mathrm{E}-04$ & 0.0000 & $1.967 \mathrm{E}-03$ & 0.0000 & $0.000 \mathrm{E}+00$ & 0.0000 & $1.225 \mathrm{E}+00$ & 0.0005 & $1.534 \mathrm{E}-01$ & 0.0001 & $4.485 E-03$ & 0.0000 & $3.405 \mathrm{E}-01$ & 0.0001 \\
\hline 99 & $0.000 \mathrm{E}+00$ & 0.0000 & $0.000 \mathrm{E}+00$ & 0.0000 & $0.000 \mathrm{E}+00$ & 0.0000 & $0.000 \mathrm{E}+00$ & 0.0000 & $0.000 \mathrm{E}+00$ & 0.0000 & $0.000 \mathrm{E}+00$ & 0.0000 & $0.000 \mathrm{E}+00$ & 0.0000 \\
\hline-228 & $0.000 \mathrm{E}+00$ & 0.0000 & $0.000 \mathrm{E}+00$ & 0.0000 & $0.000 \mathrm{E}+00$ & 0.0000 & $0.000 \mathrm{E}+00$ & 0.0000 & $0.000 \mathrm{E}+00$ & 0.0000 & $0.000 \mathrm{E}+00$ & 0.0000 & $0.000 \mathrm{E}+00$ & 0.0000 \\
\hline 230 & $7.436 \mathrm{E}+02$ & 0.2735 & $1.648 \mathrm{E}-02$ & 0.0000 & $0.000 \mathrm{E}+00$ & 0.0000 & $1.224 \mathrm{E}+03$ & 0.4501 & 1. $220 \mathrm{E}+02$ & 0.0449 & $1.728 \mathrm{E}+02$ & 0.0636 & $2.669 \mathrm{E}+01$ & 0.0098 \\
\hline-232 & $4.839 E+01$ & 0.0178 & $1.028 E-03$ & 0.0000 & $0.000 \mathrm{E}+00$ & 0.0000 & $5.054 \mathrm{E}+01$ & 0.0186 & $3.109 \mathrm{E}+00$ & 0.0011 & $8.373 E+00$ & 0.0031 & $5.352 \mathrm{E}-01$ & 0.0002 \\
\hline 234 & $7.945 E+01$ & 0.0292 & $3.957 \mathrm{E}-03$ & 0.0000 & $0.000 \mathrm{E}+00$ & 0.0000 & $1.377 \mathrm{E}+02$ & 0.0506 & $1.426 \mathrm{E}+01$ & 0.0052 & $2.449 \mathrm{E}+01$ & 0.0090 & $3.693 \mathrm{E}+00$ & 0.0014 \\
\hline 35 & $4.626 \mathrm{E}+00$ & 0.0017 & $1.189 \mathrm{E}-03$ & 0.0000 & $0.000 \mathrm{E}+00$ & 0.0000 & $5.072 \mathrm{E}+00$ & 0.0019 & $2.638 \mathrm{E}+00$ & 0.0010 & $2.932 \mathrm{E}-01$ & 0.0001 & $2.835 \mathrm{E}-01$ & 0.0001 \\
\hline 38 & $1.706 \mathrm{E}+01$ & 0.0063 & $1.671 \mathrm{E}-03$ & 0.0000 & $0.000 \mathrm{E}+00$ & 0.0000 & $8.921 \mathrm{E}+00$ & 0.0033 & $1.458 \mathrm{E}+00$ & 0.0005 & $6.576 \mathrm{E}+00$ & 0.0024 & $8.572 \mathrm{E}-01$ & 0.0003 \\
\hline & $8.943 E+02$ & 0.3290 & $3.068 E-02$ & 0.0000 & $0.000 \mathrm{E}+00$ & 0.0000 & $1.431 \mathrm{E}+03$ & 0.5264 & $1.441 \mathrm{E}+02$ & 0.0530 & $2.126 \mathrm{E}+02$ & 0.0782 & $3.316 \mathrm{E}+01$ & 0.0122 \\
\hline
\end{tabular}

Total Dose Contributions TDOSE(i,p,t) for Individual Radionuclides (i) and Pathways (p) As mrem/yr and Fraction of Total Dose At $t=1.000 \mathrm{E}+04$ years

Water Dependent Pathways

\begin{tabular}{|c|c|c|c|c|c|c|c|c|c|c|c|c|c|c|}
\hline \multirow{2}{*}{ Nuclide } & \multicolumn{2}{|c|}{ Water } & \multicolumn{2}{|c|}{ Fish } & \multicolumn{2}{|c|}{ Radon } & \multicolumn{2}{|c|}{ Plant } & \multicolumn{2}{|c|}{ Meat } & \multicolumn{2}{|c|}{ Milk } & \multicolumn{2}{|c|}{ All Pathways* } \\
\hline & mrem/yr & fract. & mrem/yr & fract. & mrem/yr & fract. & mrem/yr & fract. & mrem/yr & fract. & mrem/yr & fract. & mrem/yr & fract. \\
\hline-241 & $4.122 \mathrm{E}-03$ & 0.0000 & $0.000 \mathrm{E}+00$ & 0.0000 & $0.000 \mathrm{E}+00$ & 0.0000 & $1.681 \mathrm{E}-04$ & 0.0000 & $6.589 E-05$ & 0.0000 & $2.364 E-06$ & 0.0000 & $8.407 \mathrm{E}-03$ & 0.0000 \\
\hline-137 & $0.000 \mathrm{E}+00$ & 0.0000 & $0.000 \mathrm{E}+00$ & 0.0000 & $0.000 \mathrm{E}+00$ & 0.0000 & $0.000 \mathrm{E}+00$ & 0.0000 & $0.000 \mathrm{E}+00$ & 0.0000 & $0.000 \mathrm{E}+00$ & 0.0000 & $0.000 \mathrm{E}+00$ & 0.0000 \\
\hline-237 & $3.092 \mathrm{E}+00$ & 0.0011 & $0.000 \mathrm{E}+00$ & 0.0000 & $0.000 \mathrm{E}+00$ & 0.0000 & $1.261 \mathrm{E}-01$ & 0.0000 & $4.943 E-02$ & 0.0000 & $1.801 \mathrm{E}-03$ & 0.0000 & $6.178 \mathrm{E}+00$ & 0.0023 \\
\hline 238 & $0.000 \mathrm{E}+00$ & 0.0000 & $0.000 \mathrm{E}+00$ & 0.0000 & $0.000 \mathrm{E}+00$ & 0.0000 & $0.000 \mathrm{E}+00$ & 0.0000 & $0.000 \mathrm{E}+00$ & 0.0000 & $0.000 \mathrm{E}+00$ & 0.0000 & $2.236 \mathrm{E}-02$ & 0.0000 \\
\hline 239 & $0.000 \mathrm{E}+00$ & 0.0000 & $0.000 \mathrm{E}+00$ & 0.0000 & $0.000 \mathrm{E}+00$ & 0.0000 & $0.000 \mathrm{E}+00$ & 0.0000 & $0.000 \mathrm{E}+00$ & 0.0000 & $0.000 \mathrm{E}+00$ & 0.0000 & $3.740 \mathrm{E}+00$ & 0.0014 \\
\hline 240 & $0.000 \mathrm{E}+00$ & 0.0000 & $0.000 \mathrm{E}+00$ & 0.0000 & $0.000 \mathrm{E}+00$ & 0.0000 & $0.000 \mathrm{E}+00$ & 0.0000 & $0.000 \mathrm{E}+00$ & 0.0000 & $0.000 \mathrm{E}+00$ & 0.0000 & $1.727 \mathrm{E}+00$ & 0.0006 \\
\hline 99 & $0.000 \mathrm{E}+00$ & 0.0000 & $0.000 \mathrm{E}+00$ & 0.0000 & $0.000 \mathrm{E}+00$ & 0.0000 & $0.000 \mathrm{E}+00$ & 0.0000 & $0.000 \mathrm{E}+00$ & 0.0000 & $0.000 \mathrm{E}+00$ & 0.0000 & $0.000 \mathrm{E}+00$ & 0.0000 \\
\hline 228 & $0.000 \mathrm{E}+00$ & 0.0000 & $0.000 \mathrm{E}+00$ & 0.0000 & $0.000 \mathrm{E}+00$ & 0.0000 & $0.000 \mathrm{E}+00$ & 0.0000 & $0.000 \mathrm{E}+00$ & 0.0000 & $0.000 \mathrm{E}+00$ & 0.0000 & $0.000 \mathrm{E}+00$ & 0.0000 \\
\hline 230 & $0.000 \mathrm{E}+00$ & 0.0000 & $0.000 \mathrm{E}+00$ & 0.0000 & $0.000 \mathrm{E}+00$ & 0.0000 & $0.000 \mathrm{E}+00$ & 0.0000 & $0.000 \mathrm{E}+00$ & 0.0000 & $0.000 \mathrm{E}+00$ & 0.0000 & $2.289 E+03$ & 0.8418 \\
\hline 232 & $0.000 \mathrm{E}+00$ & 0.0000 & $0.000 \mathrm{E}+00$ & 0.0000 & $0.000 \mathrm{E}+00$ & 0.0000 & $0.000 \mathrm{E}+00$ & 0.0000 & $0.000 \mathrm{E}+00$ & 0.0000 & $0.000 \mathrm{E}+00$ & 0.0000 & $1.109 \mathrm{E}+02$ & 0.0408 \\
\hline & $0.000 \mathrm{E}+00$ & 0.0000 & $0.000 \mathrm{E}+00$ & 0.0000 & $0.000 \mathrm{E}+00$ & 0.0000 & $0.000 \mathrm{E}+00$ & 0.0000 & $0.000 \mathrm{E}+00$ & 0.0000 & $0.000 \mathrm{E}+00$ & 0.0000 & $2.596 \mathrm{E}+02$ & 0.0955 \\
\hline 35 & $0.000 \mathrm{E}+00$ & 0.0000 & $0.000 \mathrm{E}+00$ & 0.0000 & $0.000 \mathrm{E}+00$ & 0.0000 & $0.000 \mathrm{E}+00$ & 0.0000 & $0.000 \mathrm{E}+00$ & 0.0000 & $0.000 \mathrm{E}+00$ & 0.0000 & $1.291 \mathrm{E}+01$ & 0.0048 \\
\hline 38 & $0.000 \mathrm{E}+00$ & 0.0000 & $0.000 \mathrm{E}+00$ & 0.0000 & $0.000 \mathrm{E}+00$ & 0.0000 & $0.000 \mathrm{E}+00$ & 0.0000 & $0.000 \mathrm{E}+00$ & 0.0000 & $0.000 \mathrm{E}+00$ & 0.0000 & $3.487 \mathrm{E}+01$ & 0.0128 \\
\hline & $3.096 \mathrm{E}+00$ & 0.0011 & $0.000 \mathrm{E}+00$ & 0.0000 & $0.000 \mathrm{E}+00$ & 0.0000 & $1.263 \mathrm{E}-01$ & 0.0000 & $4.950 \mathrm{E}-02$ & 0.0000 & $1.804 E-03$ & 000 & +03 & 1.0000 \\
\hline
\end{tabular}

* Sum of all water independent and dependent pathways. 
RESRAD, Version 6.5

Summary : RESRAD Parameters for Resident Farmer U-Landfill Forward Run 10,000 Years

File : C: \RESRAD FAMILY \RESRAD \USERFILES \QCJULY2011 \ONSITERF FORWARD-10000-JULY11.RAD

Dose/Source Ratios Summed Over All Pathways

Parent and Progeny Principal Radionuclide Contributions Indicated

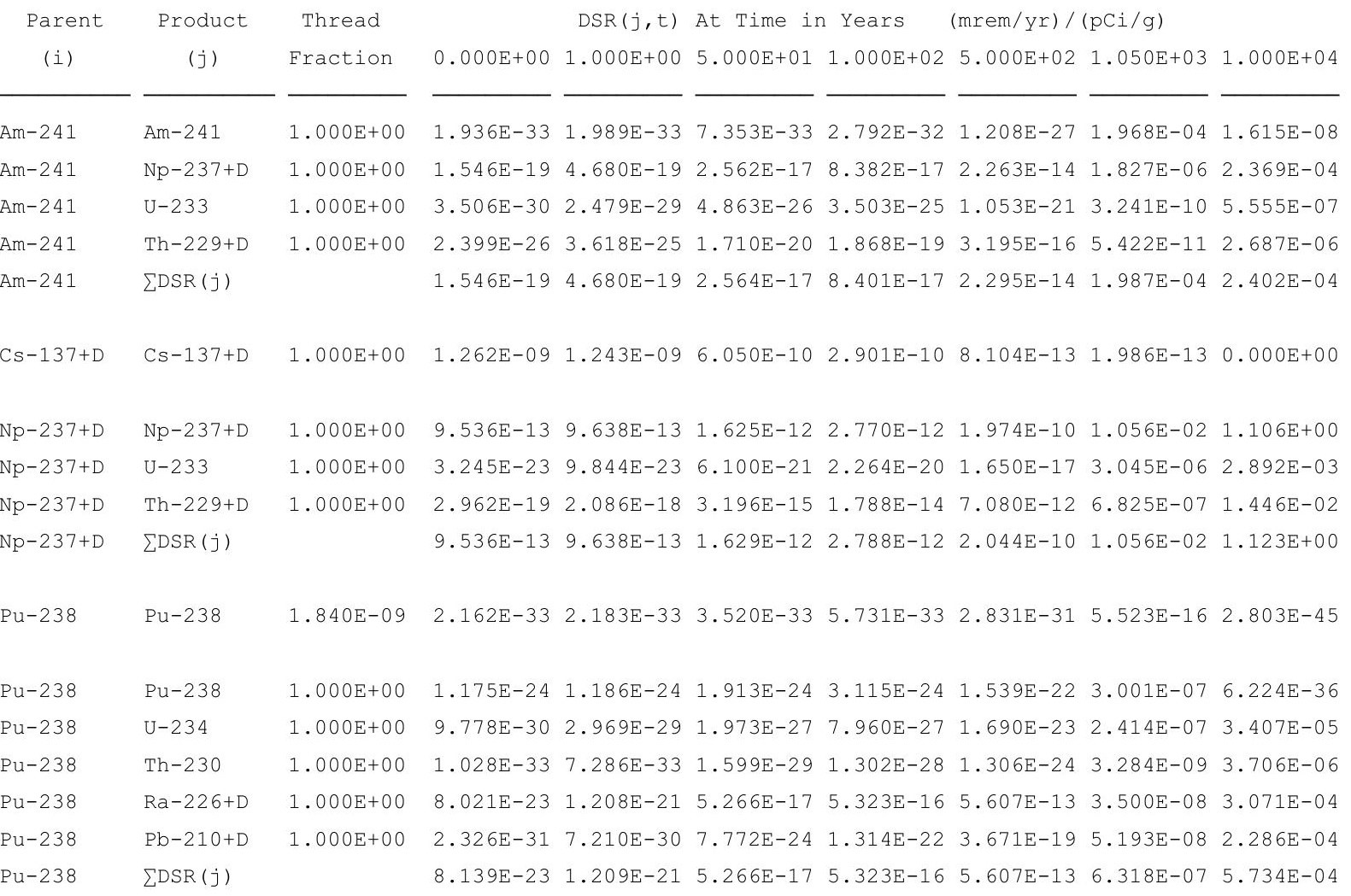

$\begin{array}{lllllllll}\mathrm{Pu}-239 & 1.000 \mathrm{E}+00 & 1.202 \mathrm{E}-17 & 1.217 \mathrm{E}-17 & 2.183 \mathrm{E}-17 & 3.965 \mathrm{E}-17 & 4.690 \mathrm{E}-15 & 1.272 \mathrm{E}-03 & 1.039 \mathrm{E}-01\end{array}$

$\begin{array}{llllllllll}\mathrm{U}-235+\mathrm{D} & 1.000 \mathrm{E}+00 & 6.135 \mathrm{E}-24 & 1.861 \mathrm{E}-23 & 1.146 \mathrm{E}-21 & 4.227 \mathrm{E}-21 & 2.931 \mathrm{E}-18 & 6.673 \mathrm{E}-10 & 4.803 \mathrm{E}-06\end{array}$

$\begin{array}{lllllllll}\mathrm{Pa}-231 & 1.000 \mathrm{E}+00 & 9.652 \mathrm{E}-28 & 6.818 \mathrm{E}-27 & 1.251 \mathrm{E}-23 & 8.414 \mathrm{E}-23 & 1.444 \mathrm{E}-19 & 4.828 \mathrm{E}-10 & 4.443 \mathrm{E}-06\end{array}$

$\mathrm{AC}-227+\mathrm{D} \quad 1.000 \mathrm{E}+00 \quad 2.288 \mathrm{E}-27 \quad 3.434 \mathrm{E}-26 \quad 1.276 \mathrm{E}-21 \quad 1.169 \mathrm{E}-20 \quad 1.476 \mathrm{E}-17 \quad 1.691 \mathrm{E}-10 \quad 2.295 \mathrm{E}-06$

$\operatorname{\sum DSR}(j) \quad 1.202 \mathrm{E}-17 \quad 1.217 \mathrm{E}-17 \quad 2.183 \mathrm{E}-17 \quad 3.966 \mathrm{E}-17 \quad 4.708 \mathrm{E}-15 \quad 1.272 \mathrm{E}-03 \quad 1.039 \mathrm{E}-01$

Pu-240 4.950E-08 5.653E-32 5.753E-32 $1.359 \mathrm{E}-31 \quad 3.267 \mathrm{E}-31 \quad 3.647 \mathrm{E}-28 \quad 5.807 \mathrm{E}-11 \quad 2.373 \mathrm{E}-09$

Pu-240 1.000E+00 1.142E-24 $1.162 \mathrm{E}-24 \quad 2.746 \mathrm{E}-24 \quad 6.601 \mathrm{E}-24 \quad 7.367 \mathrm{E}-21 \quad 1.173 \mathrm{E}-03 \quad 4.794 \mathrm{E}-02$

$\begin{array}{lllllllll}\mathrm{U}-236 & 1.000 \mathrm{E}+00 & 2.162 \mathrm{E}-32 & 6.590 \mathrm{E}-32 & 5.335 \mathrm{E}-30 & 2.602 \mathrm{E}-29 & 1.686 \mathrm{E}-25 & 1.913 \mathrm{E}-08 & 1.752 \mathrm{E}-05\end{array}$

$\begin{array}{lllllllll}\mathrm{Th}-232 & 1.000 \mathrm{E}+00 & 2.845 \mathrm{E}-43 & 2.028 \mathrm{E}-42 & 5.480 \mathrm{E}-39 & 5.478 \mathrm{E}-38 & 2.238 \mathrm{E}-33 & 9.403 \mathrm{E}-16 & 7.022 \mathrm{E}-12\end{array}$

$\mathrm{Ra}-228+\mathrm{D} \quad 1.000 \mathrm{E}+00 \quad 1.371 \mathrm{E}-28 \quad 2.018 \mathrm{E}-27 \quad 3.762 \mathrm{E}-23 \quad 2.542 \mathrm{E}-22 \quad 1.470 \mathrm{E}-19 \quad 1.226 \mathrm{E}-13 \quad 9.364 \mathrm{E}-10$

Th-228+D 1.000E+00 8.111E-28 $2.334 \mathrm{E}-26 \quad 2.641 \mathrm{E}-21 \quad 1.757 \mathrm{E}-20 \quad 5.564 \mathrm{E}-18 \quad 1.531 \mathrm{E}-15 \quad 3.662 \mathrm{E}-10$

$\operatorname{LDSR}(j) \quad 1.143 \mathrm{E}-24 \quad 1.188 \mathrm{E}-24 \quad 2.681 \mathrm{E}-21 \quad 1.783 \mathrm{E}-20 \quad 5.719 \mathrm{E}-18 \quad 1.173 \mathrm{E}-03 \quad 4.796 \mathrm{E}-02$

TC-99 1.000E+00 5.758E-26 5.817E-26 $\quad 9.575 \mathrm{E}-26 \quad 1.592 \mathrm{E}-25 \quad 2.070 \mathrm{E}-01 \quad 1.474 \mathrm{E}-03 \quad 1.242 \mathrm{E}-38$

$\mathrm{Th}-228+\mathrm{D} \quad 1.000 \mathrm{E}+00 \quad 1.382 \mathrm{E}-06 \quad 9.680 \mathrm{E}-07 \quad 2.527 \mathrm{E}-14 \quad 4.618 \mathrm{E}-22 \quad 0.000 \mathrm{E}+00 \quad 0.000 \mathrm{E}+00 \quad 0.000 \mathrm{E}+00$

Th-230 1.000E+00 2.412E-22 2.453E-22 $5.590 \mathrm{E}-22 \quad 1.295 \mathrm{E}-21 \quad 1.078 \mathrm{E}-18 \quad 1.108 \mathrm{E}-03 \quad 1.244 \mathrm{E}-01$ $\mathrm{Ra}-226+\mathrm{D} \quad 1.000 \mathrm{E}+00 \quad 3.774 \mathrm{E}-11 \quad 1.139 \mathrm{E}-10 \quad 5.320 \mathrm{E}-09 \quad 1.479 \mathrm{E}-08 \quad 1.071 \mathrm{E}-06 \quad 2.411 \mathrm{E}-02 \quad 1.303 \mathrm{E}+01$ $\mathrm{Pb}-210+\mathrm{D} \quad 1.000 \mathrm{E}+00 \quad 1.819 \mathrm{E}-19 \quad 1.271 \mathrm{E}-18 \quad 1.299 \mathrm{E}-15 \quad 5.314 \mathrm{E}-15 \quad 7.678 \mathrm{E}-13 \quad 3.720 \mathrm{E}-02 \quad 9.735 \mathrm{E}+00$ $\operatorname{EDSR}(j) \quad 3.774 \mathrm{E}-11 \quad 1.139 \mathrm{E}-10 \quad 5.320 \mathrm{E}-09 \quad 1.479 \mathrm{E}-08 \quad 1.071 \mathrm{E}-06 \quad 6.242 \mathrm{E}-02 \quad 2.289 \mathrm{E}+01$ 
RESRAD, Version $6.5 \quad T^{1 / 2}$ Limit $=180$ days $\quad 07 / 21 / 2011 \quad 12: 03$ Page 28

Summary : RESRAD Parameters for Resident Farmer U-Landfill Forward Run 10,000 Years

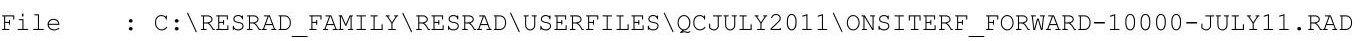

Dose/Source Ratios Summed Over All Pathways

Parent and Progeny Principal Radionuclide Contributions Indicated

\begin{tabular}{|c|c|c|c|c|c|c|c|c|c|}
\hline Parent & Product & Thread & & $\operatorname{DSR}(j, t)$ & At Time in & n Years & (mrem/yr) / & $(\mathrm{pCi} / \mathrm{g})$ & \\
\hline (i) & (j) & Fraction & $0.000 \mathrm{E}+00$ & $1.000 \mathrm{E}+00$ & $5.000 \mathrm{E}+01$ & $1.000 \mathrm{E}+02$ & $5.000 \mathrm{E}+02$ & $1.050 \mathrm{E}+03$ & $1.000 \mathrm{E}+04$ \\
\hline 232 & $T h-232$ & $1.000 \mathrm{E}+00$ & $1.166 \mathrm{E}-24$ & $1.188 \mathrm{E}-24$ & $2.949 \mathrm{E}-24$ & $7.462 \mathrm{E}-24$ & $1.252 \mathrm{E}-20$ & $1.225 \mathrm{E}-03$ & 1. $485 \mathrm{E}-01$ \\
\hline-232 & $\mathrm{Ra}-228+\mathrm{D}$ & $1.000 \mathrm{E}+00$ & $1.107 \mathrm{E}-09$ & $3.174 \mathrm{E}-09$ & $2.784 \mathrm{E}-08$ & $4.079 \mathrm{E}-08$ & $8.497 \mathrm{E}-07$ & 1. $623 \mathrm{E}-01$ & 1. $983 \mathrm{E}+01$ \\
\hline-232 & $\mathrm{Th}-228+\mathrm{D}$ & $1.000 \mathrm{E}+00$ & $1.067 \mathrm{E}-08$ & $6.581 \mathrm{E}-08$ & $2.213 \mathrm{E}-06$ & $2.992 \mathrm{E}-06$ & $3.253 E-05$ & $2.034 \mathrm{E}-03$ & $7.758 \mathrm{E}+00$ \\
\hline-232 & $\sum \operatorname{DSR}(j)$ & & $1.178 \mathrm{E}-08$ & $6.899 \mathrm{E}-08$ & $2.241 \mathrm{E}-06$ & $3.033 \mathrm{E}-06$ & $3.338 E-05$ & $1.655 \mathrm{E}-01$ & $2.774 \mathrm{E}+01$ \\
\hline-234 & $U-234$ & $1.000 \mathrm{E}+00$ & $6.896 \mathrm{E}-24$ & $7.019 \mathrm{E}-24$ & $1.670 \mathrm{E}-23$ & $4.047 \mathrm{E}-23$ & $4.798 E-20$ & $6.722 \mathrm{E}-04$ & $9.483 E-02$ \\
\hline 234 & $T h-230$ & $1.000 \mathrm{E}+00$ & $1.089 \mathrm{E}-27$ & $3.315 E-27$ & $2.540 \mathrm{E}-25$ & $1.171 \mathrm{E}-24$ & $4.838 E-21$ & $1.040 E-05$ & $1.046 \mathrm{E}-02$ \\
\hline-234 & $\mathrm{Ra}-226+\mathrm{D}$ & $1.000 \mathrm{E}+00$ & $1.133 \mathrm{E}-16$ & $7.978 \mathrm{E}-16$ & $1.213 \mathrm{E}-12$ & $6.737 \mathrm{E}-12$ & $2.496 \mathrm{E}-09$ & $1.221 \mathrm{E}-04$ & $8.696 \mathrm{E}-01$ \\
\hline-234 & $\mathrm{~Pb}-210+\mathrm{D}$ & $1.000 \mathrm{E}+00$ & $4.102 E-25$ & $6.153 E-24$ & $2.201 \mathrm{E}-19$ & $1.935 \mathrm{E}-18$ & $1.678 \mathrm{E}-15$ & $1.825 \mathrm{E}-04$ & $6.474 \mathrm{E}-01$ \\
\hline 234 & $\sum \operatorname{DSR}(j)$ & & $1.133 E-16$ & $7.978 E-16$ & 1. $213 \mathrm{E}-12$ & $6.737 \mathrm{E}-12$ & $2.496 \mathrm{E}-09$ & $9.872 \mathrm{E}-04$ & $1.622 \mathrm{E}+00$ \\
\hline$-235+D$ & $\mathrm{U}-235+\mathrm{D}$ & $1.000 \mathrm{E}+00$ & 1. $243 \mathrm{E}-14$ & 1. $259 \mathrm{E}-14$ & $2.306 \mathrm{E}-14$ & $4.276 \mathrm{E}-14$ & $5.981 \mathrm{E}-12$ & $6.528 E-04$ & $5.458 \mathrm{E}-01$ \\
\hline$-235+D$ & $\mathrm{~Pa}-231$ & $1.000 \mathrm{E}+00$ & $2.937 \mathrm{E}-18$ & $8.896 \mathrm{E}-18$ & $5.031 E-16$ & $1.701 \mathrm{E}-15$ & $5.876 \mathrm{E}-13$ & $9.383 E-04$ & $9.492 \mathrm{E}-01$ \\
\hline$-235+D$ & $A C-227+D$ & $1.000 \mathrm{E}+00$ & $9.274 \mathrm{E}-18$ & $6.481 \mathrm{E}-17$ & $6.882 \mathrm{E}-14$ & $2.943 \mathrm{E}-13$ & $6.376 \mathrm{E}-11$ & $3.384 \mathrm{E}-04$ & 4. $918 \mathrm{E}-01$ \\
\hline$-235+D$ & $\sum \operatorname{DSR}(j)$ & & $1.245 \mathrm{E}-14$ & $1.266 \mathrm{E}-14$ & $9.238 \mathrm{E}-14$ & 3. $388 \mathrm{E}-13$ & $7.033 \mathrm{E}-11$ & $1.929 \mathrm{E}-03$ & $1.987 \mathrm{E}+00$ \\
\hline-238 & $\mathrm{U}-238$ & $5.400 E-05$ & $0.000 \mathrm{E}+00$ & $0.000 \mathrm{E}+00$ & $0.000 \mathrm{E}+00$ & $0.000 \mathrm{E}+00$ & $0.000 \mathrm{E}+00$ & $3.359 E-08$ & $4.852 E-06$ \\
\hline$-238+D$ & $\mathrm{U}-238+\mathrm{D}$ & $9.999 \mathrm{E}-01$ & $1.420 \mathrm{E}-10$ & $1.431 \mathrm{E}-10$ & $2.116 \mathrm{E}-10$ & $3.153 E-10$ & $7.678 E-09$ & $6.695 E-04$ & $1.974 \mathrm{E}-01$ \\
\hline$-238+D$ & $\mathrm{U}-234$ & $9.999 \mathrm{E}-01$ & $9.803 E-30$ & $2.988 E-29$ & $2.392 E-27$ & $1.153 \mathrm{E}-26$ & $6.812 \mathrm{E}-23$ & $2.005 E-06$ & $2.727 \mathrm{E}-03$ \\
\hline$-238+D$ & Th-230 & $9.999 E-01$ & $1.030 \mathrm{E}-33$ & $7.316 \mathrm{E}-33$ & $1.818 \mathrm{E}-29$ & $1.668 \mathrm{E}-28$ & $3.430 \mathrm{E}-24$ & $1.547 \mathrm{E}-08$ & 1. $462 \mathrm{E}-04$ \\
\hline$-238+D$ & $\mathrm{Ra}-226+\mathrm{D}$ & $9.999 \mathrm{E}-01$ & $8.034 \mathrm{E}-23$ & $1.212 \mathrm{E}-21$ & $5.801 \mathrm{E}-17$ & $6.420 \mathrm{E}-16$ & $1.201 \mathrm{E}-12$ & $1.255 \mathrm{E}-07$ & $1.015 E-02$ \\
\hline$-238+D$ & $\mathrm{~Pb}-210+\mathrm{D}$ & $9.999 \mathrm{E}-01$ & $2.329 E-31$ & $7.229 \mathrm{E}-30$ & $8.430 \mathrm{E}-24$ & $1.546 \mathrm{E}-22$ & 7. $612 \mathrm{E}-19$ & $1.821 \mathrm{E}-07$ & $7.529 \mathrm{E}-03$ \\
\hline$-238+D$ & $\sum \operatorname{DSR}(j)$ & & $1.420 \mathrm{E}-10$ & $1.431 \mathrm{E}-10$ & $2.116 \mathrm{E}-10$ & $3.153 \mathrm{E}-10$ & $7.680 \mathrm{E}-09$ & $6.719 \mathrm{E}-04$ & $2.180 \mathrm{E}-01$ \\
\hline
\end{tabular}

The DSR includes contributions from associated (half-life $\leq 180$ days) daughters. 
RESRAD, Version 6.5

ummary : RESRAD Parameters for Resident Farmer U-Landfill Forward Run 10,000 Years

File : C: \RESRAD_FAMILY \RESRAD \USERFILES \QCJULY2011 IONSITERF_FORWARD-10000-JULY11.RAD

Individual Nuclide Dose Summed Over All Pathways

Parent Nuclide and Branch Fraction Indicated

Nuclide Parent THF(i) DOSE $(j, t), \mathrm{mrem} / \mathrm{yr}$

\begin{tabular}{|c|c|c|}
\hline$(j)$ & (i) & \\
\hline$m-241$ & $A m-241$ & $1.000 \mathrm{E}+00$ \\
\hline$p-237$ & $A m-241$ & $1.000 \mathrm{E}+00$ \\
\hline-237 & $N p-237$ & $1.000 \mathrm{E}+00$ \\
\hline$p-237$ & $\sum \mathrm{DOSE}$ & \\
\hline
\end{tabular}

$\mathrm{U}-233 \quad \mathrm{Am}-241 \quad 1.000 \mathrm{E}+00$

$\mathrm{U}-233 \mathrm{~Np}-237 \quad 1.000 \mathrm{E}+00$

U-233 $\quad$ DOSE $(j)$

Th-229 Am-241 1.000E+00

$\mathrm{Th}-229 \quad \mathrm{~Np}-237 \quad 1.000 \mathrm{E}+00$

Th-229 $\sum \mathrm{DOSE}(j)$

Cs-137 Cs $-137 \quad 1.000 \mathrm{E}+00$

$\mathrm{Pu}-238$

$\mathrm{Pu}-238$

$\mathrm{Pu}-238$

$\mathrm{U}-234$

$\mathrm{U}-234$

$\mathrm{U}-234$

$\mathrm{U}-234$

Th -230

$\mathrm{Th}-230$

$\mathrm{Th}-230$

$\mathrm{Th}-230$

$\mathrm{Th}-230$

$\mathrm{Ra}-226$

$\mathrm{Ra}-226$

$\mathrm{Ra}-226$

$\mathrm{Ra}-226$

$\mathrm{Ra}-226$

$\mathrm{Pb}-210$

$\mathrm{Pb}-210$

$\mathrm{Pb}-210$

$\mathrm{Pb}-210$

$\mathrm{Pb}-210$

$P u-239$

Pu-238 1.840E-09 $\mathrm{Pu}-238 \quad 1.000 \mathrm{E}+00$ $\sum \operatorname{DOSE}(j)$

Pu-238 1.000E+00 $\mathrm{U}-234 \quad 1.000 \mathrm{E}+00$ U-238 9.999E-01 $\sum \operatorname{DOSE}(j)$

$\mathrm{Pu}-238 \quad 1.000 \mathrm{E}+00$ Th-230 1.000E+00 $\mathrm{U}-234 \quad 1.000 \mathrm{E}+00$ U-238 9.999E-01 $\sum \operatorname{DOSE}(j)$

$\mathrm{Pu}-238 \quad 1.000 \mathrm{E}+00$ $\mathrm{Th}-230 \quad 1.000 \mathrm{E}+00$ $\mathrm{U}-234 \quad 1.000 \mathrm{E}+00$ U-238 9.999E-01 $\sum \operatorname{DOSE}(j)$

$\mathrm{Pu}-238 \quad 1.000 \mathrm{E}+00$ Th-230 1.000E+00 $\mathrm{U}-234 \quad 1.000 \mathrm{E}+00$ U-238 9.999E-01 $\sum \operatorname{DOSE}(j)$

$\mathrm{Pu}-239 \quad 1.000 \mathrm{E}+00$

$\mathrm{Pu}-239 \quad 1.000 \mathrm{E}+00$ U-235 1.000E+00 $\sum \operatorname{DOSE}(j)$ $t=0.000 \mathrm{E}+00 \quad 1.000 \mathrm{E}+00 \quad 5.000 \mathrm{E}+01 \quad 1.000 \mathrm{E}+02 \quad 5.000 \mathrm{E}+02 \quad 1.050 \mathrm{E}+03 \quad 1.000 \mathrm{E}+04$
5.412E-18 1.638E-17 8.967E-16 2.934E-15 $\quad 7.921 \mathrm{E}-13 \quad 6.396 \mathrm{E}-05 \quad 8.293 \mathrm{E}-03$ 5.245E-12 5.301E-12 8.939E-12 $1.524 \mathrm{E}-11 \quad 1.085 \mathrm{E}-09 \quad 5.809 \mathrm{E}-02 \quad 6.083 \mathrm{E}+00$ $5.245 \mathrm{E}-12 \quad 5.301 \mathrm{E}-12 \quad 8.940 \mathrm{E}-12 \quad 1.524 \mathrm{E}-11 \quad 1.086 \mathrm{E}-09 \quad 5.815 \mathrm{E}-02 \quad 6.091 \mathrm{E}+00$

$\begin{array}{lllllll}1.227 \mathrm{E}-28 & 8.678 \mathrm{E}-28 & 1.702 \mathrm{E}-24 & 1.226 \mathrm{E}-23 & 3.685 \mathrm{E}-20 & 1.134 \mathrm{E}-08 & 1.944 \mathrm{E}-05\end{array}$ $1.785 \mathrm{E}-22 \quad 5.414 \mathrm{E}-22 \quad 3.355 \mathrm{E}-20 \quad 1.245 \mathrm{E}-19 \quad 9.076 \mathrm{E}-17 \quad 1.675 \mathrm{E}-05 \quad 1.591 \mathrm{E}-02$ $\begin{array}{llllllll}1.785 \mathrm{E}-22 & 5.414 \mathrm{E}-22 & 3.355 \mathrm{E}-20 & 1.245 \mathrm{E}-19 & 9.079 \mathrm{E}-17 & 1.676 \mathrm{E}-05 & 1.593 \mathrm{E}-02\end{array}$

8.395E-25 1.266E-23 5.984E-19 $\quad 6.539 \mathrm{E}-18 \quad 1.118 \mathrm{E}-14 \quad 1.898 \mathrm{E}-09 \quad 9.405 \mathrm{E}-05$ $\begin{array}{llllllll}1.629 \mathrm{E}-18 & 1.147 \mathrm{E}-17 & 1.758 \mathrm{E}-14 & 9.834 \mathrm{E}-14 & 3.894 \mathrm{E}-11 & 3.754 \mathrm{E}-06 & 7.951 \mathrm{E}-02\end{array}$ $\begin{array}{lllllll}1.629 \mathrm{E}-18 & 1.147 \mathrm{E}-17 & 1.758 \mathrm{E}-14 & 9.835 \mathrm{E}-14 & 3.895 \mathrm{E}-11 & 3.755 \mathrm{E}-06 & 7.960 \mathrm{E}-02\end{array}$ $2.397 \mathrm{E}-08 \quad 2.362 \mathrm{E}-08 \quad 1.149 \mathrm{E}-08 \quad 5.512 \mathrm{E}-09 \quad 1.540 \mathrm{E}-11 \quad 3.773 \mathrm{E}-12 \quad 0.000 \mathrm{E}+00$ $\begin{array}{lllllll}0.000 \mathrm{E}+00 & 0.000 \mathrm{E}+00 & 0.000 \mathrm{E}+00 & 0.000 \mathrm{E}+00 & 0.000 \mathrm{E}+00 & 2.154 \mathrm{E}-14 & 0.000 \mathrm{E}+00\end{array}$

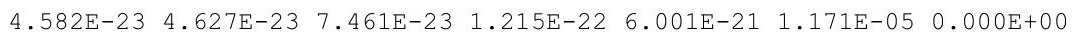
$4.582 \mathrm{E}-23 \quad 4.627 \mathrm{E}-23 \quad 7.461 \mathrm{E}-23 \quad 1.215 \mathrm{E}-22 \quad 6.001 \mathrm{E}-21 \quad 1.171 \mathrm{E}-05 \quad 0.000 \mathrm{E}+00$ $3.813 \mathrm{E}-28 \quad 1.158 \mathrm{E}-27 \quad 7.693 \mathrm{E}-26 \quad 3.104 \mathrm{E}-25 \quad 6.593 \mathrm{E}-22 \quad 9.415 \mathrm{E}-06 \quad 1.329 \mathrm{E}-03$ $\begin{array}{llllllllll}1.103 \mathrm{E}-21 & 1.123 \mathrm{E}-21 & 2.673 \mathrm{E}-21 & 6.475 \mathrm{E}-21 & 7.677 \mathrm{E}-18 & 1.075 \mathrm{E}-01 & 1.517 \mathrm{E}+01\end{array}$ $\begin{array}{lllllll}1.569 \mathrm{E}-27 & 4.780 \mathrm{E}-27 & 3.827 \mathrm{E}-25 & 1.845 \mathrm{E}-24 & 1.090 \mathrm{E}-20 & 3.207 \mathrm{E}-04 & 4.363 \mathrm{E}-01\end{array}$ $\begin{array}{llllllll}1.103 \mathrm{E}-21 & 1.123 \mathrm{E}-21 & 2.673 \mathrm{E}-21 & 6.477 \mathrm{E}-21 & 7.688 \mathrm{E}-18 & 1.079 \mathrm{E}-01 & 1.561 \mathrm{E}+01\end{array}$

$0.000 \mathrm{E}+00 \quad 0.000 \mathrm{E}+00 \quad 6.236 \mathrm{E}-28 \quad 5.079 \mathrm{E}-27 \quad 5.092 \mathrm{E}-23 \quad 1.281 \mathrm{E}-07 \quad 1.445 \mathrm{E}-04$ $2.412 \mathrm{E}-20 \quad 2.453 \mathrm{E}-20 \quad 5.590 \mathrm{E}-20 \quad 1.295 \mathrm{E}-19 \quad 1.078 \mathrm{E}-16 \quad 1.108 \mathrm{E}-01 \quad 1.244 \mathrm{E}+01$ $\begin{array}{llllllll}1.742 \mathrm{E}-25 & 5.304 \mathrm{E}-25 & 4.065 \mathrm{E}-23 & 1.874 \mathrm{E}-22 & 7.741 \mathrm{E}-19 & 1.664 \mathrm{E}-03 & 1.673 \mathrm{E}+00\end{array}$ $\begin{array}{lllllll}0.000 \mathrm{E}+00 & 0.000 \mathrm{E}+00 & 2.909 \mathrm{E}-27 & 2.669 \mathrm{E}-26 & 5.488 \mathrm{E}-22 & 2.475 \mathrm{E}-06 & 2.338 \mathrm{E}-02\end{array}$ $2.412 \mathrm{E}-20 \quad 2.453 \mathrm{E}-20 \quad 5.594 \mathrm{E}-20 \quad 1.297 \mathrm{E}-19 \quad 1.085 \mathrm{E}-16 \quad 1.125 \mathrm{E}-01 \quad 1.414 \mathrm{E}+01$

$\begin{array}{lllllll}3.128 \mathrm{E}-21 & 4.712 \mathrm{E}-20 & 2.054 \mathrm{E}-15 & 2.076 \mathrm{E}-14 & 2.187 \mathrm{E}-11 & 1.365 \mathrm{E}-06 & 1.198 \mathrm{E}-02\end{array}$ $\begin{array}{llllllll}3.774 \mathrm{E}-09 & 1.139 \mathrm{E}-08 & 5.320 \mathrm{E}-07 & 1.479 \mathrm{E}-06 & 1.071 \mathrm{E}-04 & 2.411 \mathrm{E}+00 & 1.303 \mathrm{E}+03\end{array}$ $\begin{array}{llllllll}1.813 \mathrm{E}-14 & 1.277 \mathrm{E}-13 & 1.941 \mathrm{E}-10 & 1.078 \mathrm{E}-09 & 3.993 \mathrm{E}-07 & 1.954 \mathrm{E}-02 & 1.391 \mathrm{E}+02\end{array}$ $\begin{array}{lllllll}1.285 \mathrm{E}-20 & 1.939 \mathrm{E}-19 & 9.281 \mathrm{E}-15 & 1.027 \mathrm{E}-13 & 1.921 \mathrm{E}-10 & 2.009 \mathrm{E}-05 & 1.624 \mathrm{E}+00\end{array}$ $\begin{array}{lllllll}3.774 \mathrm{E}-09 & 1.139 \mathrm{E}-08 & 5.322 \mathrm{E}-07 & 1.480 \mathrm{E}-06 & 1.075 \mathrm{E}-04 & 2.431 \mathrm{E}+00 & 1.443 \mathrm{E}+03\end{array}$

$0.000 \mathrm{E}+00 \quad 2.812 \mathrm{E}-28 \quad 3.031 \mathrm{E}-22 \quad 5.124 \mathrm{E}-21 \quad 1.432 \mathrm{E}-17 \quad 2.025 \mathrm{E}-06 \quad 8.915 \mathrm{E}-03$ $\begin{array}{lllllll}1.819 \mathrm{E}-17 & 1.271 \mathrm{E}-16 & 1.299 \mathrm{E}-13 & 5.314 \mathrm{E}-13 & 7.678 \mathrm{E}-11 & 3.720 \mathrm{E}+00 & 9.735 \mathrm{E}+02\end{array}$ $\begin{array}{llllllll}6.563 \mathrm{E}-23 & 9.844 \mathrm{E}-22 & 3.522 \mathrm{E}-17 & 3.095 \mathrm{E}-16 & 2.685 \mathrm{E}-13 & 2.920 \mathrm{E}-02 & 1.036 \mathrm{E}+02\end{array}$ $\begin{array}{lllllll}0.000 \mathrm{E}+00 & 1.157 \mathrm{E}-27 & 1.349 \mathrm{E}-21 & 2.474 \mathrm{E}-20 & 1.218 \mathrm{E}-16 & 2.913 \mathrm{E}-05 & 1.205 \mathrm{E}+00\end{array}$ $\begin{array}{llllllll}1.819 \mathrm{E}-17 & 1.271 \mathrm{E}-16 & 1.299 \mathrm{E}-13 & 5.317 \mathrm{E}-13 & 7.705 \mathrm{E}-11 & 3.749 \mathrm{E}+00 & 1.078 \mathrm{E}+03\end{array}$

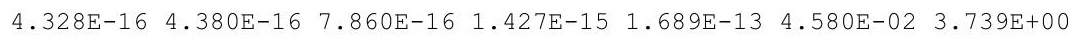

$2.209 \mathrm{E}-22 \quad 6.699 \mathrm{E}-22 \quad 4.126 \mathrm{E}-20 \quad 1.522 \mathrm{E}-19 \quad 1.055 \mathrm{E}-16 \quad 2.402 \mathrm{E}-08 \quad 1.729 \mathrm{E}-04$ $\begin{array}{llllllll}8.081 \mathrm{E}-14 & 8.182 \mathrm{E}-14 & 1.499 \mathrm{E}-13 & 2.779 \mathrm{E}-13 & 3.888 \mathrm{E}-11 & 4.243 \mathrm{E}-03 & 3.547 \mathrm{E}+00\end{array}$ $\begin{array}{llllllll}8.081 \mathrm{E}-14 & 8.182 \mathrm{E}-14 & 1.499 \mathrm{E}-13 & 2.779 \mathrm{E}-13 & 3.888 \mathrm{E}-11 & 4.243 \mathrm{E}-03 & 3.548 \mathrm{E}+00\end{array}$ 
RESRAD, Version 6.5

Summary : RESRAD Parameters for Resident Farmer U-Landfill Forward Run 10,000 Years

File : C: \RESRAD_FAMILY \RESRAD \USERFILES $\backslash Q C J U L Y 2011 \backslash$ ONSITERF_FORWARD-10000-JULY11.RAD

Individual Nuclide Dose Summed Over All Pathways

Parent Nuclide and Branch Fraction Indicated

Nuclide Parent THF(i) DOSE $(j, t), \mathrm{mrem} / \mathrm{yr}$

\begin{tabular}{|c|c|c|c|c|c|c|c|c|c|c|}
\hline (j) & (i) & & $t=$ & $0.000 \mathrm{E}+00$ & $1.000 \mathrm{E}+00$ & $5.000 \mathrm{E}+01$ & $1.000 \mathrm{E}+02$ & $5.000 \mathrm{E}+02$ & $1.050 \mathrm{E}+03$ & $1.000 \mathrm{E}+04$ \\
\hline-231 & $\mathrm{Pu}-239$ & $1.000 \mathrm{E}+00$ & & $3.475 E-26$ & $2.454 \mathrm{E}-25$ & $4.503 E-22$ & $3.029 \mathrm{E}-21$ & $5.200 \mathrm{E}-18$ & $1.738 \mathrm{E}-08$ & $1.599 \mathrm{E}-04$ \\
\hline$a-231$ & $\mathrm{U}-235$ & $1.000 \mathrm{E}+00$ & & $1.909 \mathrm{E}-17$ & $5.782 \mathrm{E}-17$ & $3.270 \mathrm{E}-15$ & $1.106 \mathrm{E}-14$ & $3.819 \mathrm{E}-12$ & $6.099 \mathrm{E}-03$ & $6.170 \mathrm{E}+00$ \\
\hline$a-231$ & $\sum \operatorname{DOSE}(j)$ & & & $1.909 \mathrm{E}-17$ & $5.782 \mathrm{E}-17$ & $3.270 \mathrm{E}-15$ & $1.106 \mathrm{E}-14$ & $3.819 \mathrm{E}-12$ & $6.099 \mathrm{E}-03$ & $6.170 \mathrm{E}+00$ \\
\hline$c-227$ & $\mathrm{Pu}-239$ & $1.000 \mathrm{E}+00$ & & $8.237 E-26$ & $1.236 \mathrm{E}-24$ & $4.593 E-20$ & 4. $209 \mathrm{E}-19$ & $5.313 \mathrm{E}-16$ & $6.089 E-09$ & $8.263 E-05$ \\
\hline$c-227$ & $\mathrm{U}-235$ & $1.000 \mathrm{E}+00$ & & $6.028 \mathrm{E}-17$ & $4.213 E-16$ & $4.473 E-13$ & 1. $913 \mathrm{E}-12$ & $4.144 \mathrm{E}-10$ & $2.200 \mathrm{E}-03$ & $3.197 \mathrm{E}+00$ \\
\hline$c-227$ & $\sum \operatorname{DOSE}(j)$ & & & $6.028 E-17$ & $4.213 E-16$ & $4.473 E-13$ & 1. $913 E-12$ & $4.144 \mathrm{E}-10$ & $2.200 \mathrm{E}-03$ & $3.197 \mathrm{E}+00$ \\
\hline$u-240$ & $\mathrm{Pu}-240$ & $4.950 \mathrm{E}-08$ & & $0.000 \mathrm{E}+00$ & $0.000 \mathrm{E}+00$ & $0.000 \mathrm{E}+00$ & $0.000 \mathrm{E}+00$ & 1. $313 \mathrm{E}-26$ & $2.091 \mathrm{E}-09$ & $8.544 \mathrm{E}-08$ \\
\hline$x-240$ & $\mathrm{Pu}-240$ & $1.000 \mathrm{E}+00$ & & $4.111 E-23$ & $4.184 E-23$ & $9.884 E-23$ & $2.376 E-22$ & $2.652 E-19$ & $4.223 E-02$ & $1.726 \mathrm{E}+00$ \\
\hline$u-240$ & $\sum \operatorname{DOSE}(j)$ & & & $4.111 \mathrm{E}-23$ & $4.184 \mathrm{E}-23$ & $9.884 \mathrm{E}-23$ & $2.376 E-22$ & $2.652 \mathrm{E}-19$ & $4.223 E-02$ & $1.726 \mathrm{E}+00$ \\
\hline-236 & $\mathrm{Pu}-240$ & $1.000 \mathrm{E}+00$ & & $0.000 \mathrm{E}+00$ & $0.000 \mathrm{E}+00$ & $1.921 E-28$ & $9.367 E-28$ & $6.069 \mathrm{E}-24$ & $6.886 \mathrm{E}-07$ & $6.306 \mathrm{E}-04$ \\
\hline$h-232$ & $\mathrm{Pu}-240$ & $1.000 \mathrm{E}+00$ & & $0.000 \mathrm{E}+00$ & $0.000 \mathrm{E}+00$ & $0.000 \mathrm{E}+00$ & $0.000 \mathrm{E}+00$ & $0.000 \mathrm{E}+00$ & $3.385 \mathrm{E}-14$ & $2.528 \mathrm{E}-10$ \\
\hline$h-232$ & $\mathrm{Th}-232$ & $1.000 \mathrm{E}+00$ & & $4.663 E-24$ & $4.751 E-24$ & $1.180 \mathrm{E}-23$ & $2.985 E-23$ & $5.010 \mathrm{E}-20$ & $4.900 E-03$ & $5.940 \mathrm{E}-01$ \\
\hline$h-232$ & $\sum \operatorname{DOSE}(j)$ & & & $4.663 E-24$ & $4.751 E-24$ & $1.180 \mathrm{E}-23$ & $2.985 E-23$ & $5.010 \mathrm{E}-20$ & $4.900 \mathrm{E}-03$ & $5.940 \mathrm{E}-01$ \\
\hline$a-228$ & $\mathrm{Pu}-240$ & $1.000 \mathrm{E}+00$ & & $4.934 \mathrm{E}-27$ & 7. $265 \mathrm{E}-26$ & 1. $354 \mathrm{E}-21$ & $9.150 \mathrm{E}-21$ & $5.290 \mathrm{E}-18$ & 4. $415 \mathrm{E}-12$ & $3.371 \mathrm{E}-08$ \\
\hline$a-228$ & $\mathrm{Th}-232$ & $1.000 \mathrm{E}+00$ & & $4.430 \mathrm{E}-09$ & $1.270 \mathrm{E}-08$ & $1.114 \mathrm{E}-07$ & $1.632 \mathrm{E}-07$ & $3.399 \mathrm{E}-06$ & $6.492 \mathrm{E}-01$ & 7. $932 \mathrm{E}+01$ \\
\hline $\mathrm{Ra}-228$ & $\sum \operatorname{DOSE}(j)$ & & & $4.430 E-09$ & $1.270 \mathrm{E}-08$ & $1.114 \mathrm{E}-07$ & $1.632 \mathrm{E}-07$ & $3.399 \mathrm{E}-06$ & $6.492 \mathrm{E}-01$ & 7. $932 \mathrm{E}+01$ \\
\hline$h-228$ & $\mathrm{Pu}-240$ & $1.000 \mathrm{E}+00$ & & $2.920 \mathrm{E}-26$ & $8.403 E-25$ & $9.508 \mathrm{E}-20$ & $6.326 \mathrm{E}-19$ & $2.003 E-16$ & $5.512 \mathrm{E}-14$ & $1.318 \mathrm{E}-08$ \\
\hline$h-228$ & Th-228 & $1.000 \mathrm{E}+00$ & & $5.530 E-06$ & $3.872 \mathrm{E}-06$ & $1.011 \mathrm{E}-13$ & $1.847 E-21$ & $0.000 \mathrm{E}+00$ & $0.000 \mathrm{E}+00$ & $0.000 \mathrm{E}+00$ \\
\hline Th-228 & $\mathrm{Th}-232$ & $1.000 \mathrm{E}+00$ & & $4.269 \mathrm{E}-08$ & $2.633 E-07$ & $8.852 E-06$ & $1.197 \mathrm{E}-05$ & $1.301 \mathrm{E}-04$ & $8.137 \mathrm{E}-03$ & $3.103 \mathrm{E}+01$ \\
\hline Th-228 & $\sum \operatorname{DOSE}(j)$ & & & $5.572 \mathrm{E}-06$ & $4.135 E-06$ & $8.852 E-06$ & $1.197 \mathrm{E}-05$ & $1.301 E-04$ & $8.137 \mathrm{E}-03$ & $3.103 E+01$ \\
\hline$\Gamma c-99$ & TC-99 & $1.000 \mathrm{E}+00$ & & $2.994 \mathrm{E}-24$ & $3.025 \mathrm{E}-24$ & $4.979 E-24$ & $8.280 \mathrm{E}-24$ & $1.077 \mathrm{E}+01$ & $7.663 \mathrm{E}-02$ & $0.000 \mathrm{E}+00$ \\
\hline$J-238$ & $\mathrm{U}-238$ & $5.400 \mathrm{E}-05$ & & $0.000 \mathrm{E}+00$ & $0.000 \mathrm{E}+00$ & $0.000 \mathrm{E}+00$ & $0.000 \mathrm{E}+00$ & $0.000 \mathrm{E}+00$ & $5.374 \mathrm{E}-06$ & $7.764 \mathrm{E}-04$ \\
\hline$J-238$ & $\mathrm{U}-238$ & $9.999 \mathrm{E}-01$ & & $2.271 E-08$ & $2.290 \mathrm{E}-08$ & $3.385 E-08$ & $5.045 E-08$ & 1. $229 \mathrm{E}-06$ & $1.071 \mathrm{E}-01$ & $3.158 \mathrm{E}+01$ \\
\hline$J-238$ & $\sum \operatorname{DOSE}(j)$ & & & $2.271 \mathrm{E}-08$ & $2.290 \mathrm{E}-08$ & $3.385 E-08$ & $5.045 E-08$ & 1. $229 \mathrm{E}-06$ & $1.071 \mathrm{E}-01$ & $3.159 \mathrm{E}+01$ \\
\hline
\end{tabular}

THF (i) is the thread fraction of the parent nuclide. 
RESRAD, Version 6.5

ummary : RESRAD Parameters for Resident Farmer U-Landfill Forward Run 10,000 Years

File : C: \RESRAD FAMILY \RESRAD \USERFILES \QCJULY2011 \ONSITERF FORWARD-10000-JULY11.RAD

Individual Nuclide Soil Concentration

Parent Nuclide and Branch Fraction Indicated

Nuclide Parent THF(

(j)

Am-241

(i)

$\overline{A m-241} \overline{1.000 E+00}$

Np-237 Am-241 $1.000 \mathrm{E}+00$

$\mathrm{Np}-237 \quad \mathrm{~Np}-237 \quad 1.000 \mathrm{E}+00$

Np-237 $\sum S(j):$

$\mathrm{U}-233 \quad \mathrm{Am}-241 \quad 1.000 \mathrm{E}+00$

$\mathrm{U}-233 \quad \mathrm{~Np}-237 \quad 1.000 \mathrm{E}+00$

U-233 $\sum S(j):$

Th -229

Th-229

Th-229

$A m-241 \quad 1.000 \mathrm{E}+00$

Np-237 1.000E+00

Cs -137

$\mathrm{Pu}-238$

$\mathrm{Pu}-238$

$\mathrm{Pu}-238$

$\mathrm{U}-234$

$\mathrm{U}-234$

$\mathrm{U}-234$

$\mathrm{U}-234$

Th-230

Th-230

Th -230

Th-230

Th-230

$\mathrm{Ra}-226$

$\mathrm{Ra}-226$

$\mathrm{Ra}-226$

$\mathrm{Ra}-226$

$\mathrm{Ra}-226$

$\mathrm{Pb}-210$

$\mathrm{Pb}-210$

$\mathrm{Pb}-210$

$\mathrm{Pb}-210$

$\mathrm{Pb}-210$

$\mathrm{Pu}-239$
$\mathrm{S}(j, \mathrm{t}), \mathrm{pCi} / \mathrm{g}$

$t=0.000 \mathrm{E}+00 \quad 1.000 \mathrm{E}+00 \quad 5.000 \mathrm{E}+01 \quad 1.000 \mathrm{E}+02 \quad 5.000 \mathrm{E}+02 \quad 1.050 \mathrm{E}+03 \quad 1.000 \mathrm{E}+04$ $\begin{array}{llllllll}3.500 \mathrm{E}+01 & 3.494 \mathrm{E}+01 & 3.229 \mathrm{E}+01 & 2.980 \mathrm{E}+01 & 1.566 \mathrm{E}+01 & 6.464 \mathrm{E}+00 & 3.610 \mathrm{E}-06\end{array}$

$0.000 \mathrm{E}+00 \quad 1.133 \mathrm{E}-05 \quad 5.428 \mathrm{E}-04 \quad 1.040 \mathrm{E}-03 \quad 3.749 \mathrm{E}-03 \quad 5.255 \mathrm{E}-03 \quad 1.996 \mathrm{E}-03$

$\begin{array}{llllllll}5.500 \mathrm{E}+00 & 5.499 \mathrm{E}+00 & 5.463 \mathrm{E}+00 & 5.426 \mathrm{E}+00 & 5.141 \mathrm{E}+00 & 4.773 \mathrm{E}+00 & 1.427 \mathrm{E}+00\end{array}$ $\begin{array}{lllllll}5.500 \mathrm{E}+00 & 5.499 \mathrm{E}+00 & 5.464 \mathrm{E}+00 & 5.427 \mathrm{E}+00 & 5.145 \mathrm{E}+00 & 4.779 \mathrm{E}+00 & 1.429 \mathrm{E}+00\end{array}$

$\begin{array}{lllllll}0.000 \mathrm{E}+00 & 2.477 \mathrm{E}-11 & 6.018 \mathrm{E}-08 & 2.338 \mathrm{E}-07 & 4.686 \mathrm{E}-06 & 1.571 \mathrm{E}-05 & 1.406 \mathrm{E}-04\end{array}$ $0.000 \mathrm{E}+00 \quad 2.405 \mathrm{E}-05 \quad 1.198 \mathrm{E}-03 \quad 2.386 \mathrm{E}-03 \quad 1.155 \mathrm{E}-02 \quad 2.320 \mathrm{E}-02 \quad 1.121 \mathrm{E}-01$ $\begin{array}{lllllllll}0.000 \mathrm{E}+00 & 2.405 \mathrm{E}-05 & 1.198 \mathrm{E}-03 & 2.386 \mathrm{E}-03 & 1.155 \mathrm{E}-02 & 2.322 \mathrm{E}-02 & 1.122 \mathrm{E}-01\end{array}$

$0.000 \mathrm{E}+00 \quad 7.799 \mathrm{E}-16 \quad 9.529 \mathrm{E}-11 \quad 7.450 \mathrm{E}-10 \quad 7.803 \mathrm{E}-08 \quad 5.780 \mathrm{E}-07 \quad 5.806 \mathrm{E}-05$ $0.000 \mathrm{E}+00 \quad 1.136 \mathrm{E}-09 \quad 2.827 \mathrm{E}-06 \quad 1.126 \mathrm{E}-05 \quad 2.719 \mathrm{E}-04 \quad 1.144 \mathrm{E}-03 \quad 4.901 \mathrm{E}-02$ $\begin{array}{lllllll}0.000 \mathrm{E}+00 & 1.136 \mathrm{E}-09 & 2.827 \mathrm{E}-06 & 1.126 \mathrm{E}-05 & 2.720 \mathrm{E}-04 & 1.144 \mathrm{E}-03 & 4.907 \mathrm{E}-02\end{array}$

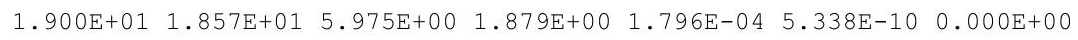

$\begin{array}{lllllll}7.176 \mathrm{E}-08 & 7.119 \mathrm{E}-08 & 4.830 \mathrm{E}-08 & 3.251 \mathrm{E}-08 & 1.370 \mathrm{E}-09 & 1.760 \mathrm{E}-11 & 2.951 \mathrm{E}-42\end{array}$ $\begin{array}{lllllllll}3.900 E+01 & 3.869 E+01 & 2.625 E+01 & 1.767 E+01 & 7.445 E-01 & 9.567 E-03 & 1.612 E-33\end{array}$ $\begin{array}{llllllll}3.900 \mathrm{E}+01 & 3.869 \mathrm{E}+01 & 2.625 \mathrm{E}+01 & 1.767 \mathrm{E}+01 & 7.445 \mathrm{E}-01 & 9.567 \mathrm{E}-03 & 1.612 \mathrm{E}-33\end{array}$

$0.000 \mathrm{E}+00 \quad 1.101 \mathrm{E}-04 \quad 4.562 \mathrm{E}-03 \quad 7.627 \mathrm{E}-03 \quad 1.356 \mathrm{E}-02 \quad 1.363 \mathrm{E}-02 \quad 1.082 \mathrm{E}-02$ $\begin{array}{lllllll}1.600 \mathrm{E}+02 & 1.600 \mathrm{E}+02 & 1.598 \mathrm{E}+02 & 1.596 \mathrm{E}+02 & 1.579 \mathrm{E}+02 & 1.557 \mathrm{E}+02 & 1.236 \mathrm{E}+02\end{array}$ $\begin{array}{lllllll}0.000 \mathrm{E}+00 & 4.536 \mathrm{E}-04 & 2.265 \mathrm{E}-02 & 4.525 \mathrm{E}-02 & 2.240 \mathrm{E}-01 & 4.642 \mathrm{E}-01 & 3.553 \mathrm{E}+00\end{array}$ $\begin{array}{lllllll}1.600 \mathrm{E}+02 & 1.600 \mathrm{E}+02 & 1.598 \mathrm{E}+02 & 1.596 \mathrm{E}+02 & 1.582 \mathrm{E}+02 & 1.562 \mathrm{E}+02 & 1.271 \mathrm{E}+02\end{array}$

$0.000 \mathrm{E}+00 \quad 4.963 \mathrm{E}-10 \quad 1.094 \mathrm{E}-06 \quad 3.882 \mathrm{E}-06 \quad 4.691 \mathrm{E}-05 \quad 1.141 \mathrm{E}-04 \quad 1.031 \mathrm{E}-03$ $\begin{array}{lllllll}1.000 \mathrm{E}+02 & 1.000 \mathrm{E}+02 & 9.994 \mathrm{E}+01 & 9.988 \mathrm{E}+01 & 9.940 \mathrm{E}+01 & 9.875 \mathrm{E}+01 \quad 8.874 \mathrm{E}+01\end{array}$ $\begin{array}{llllllllll}0.000 \mathrm{E}+00 & 1.440 \mathrm{E}-03 & 7.195 \mathrm{E}-02 & 1.438 \mathrm{E}-01 & 7.134 \mathrm{E}-01 & 1.483 \mathrm{E}+00 & 1.193 \mathrm{E}+01\end{array}$

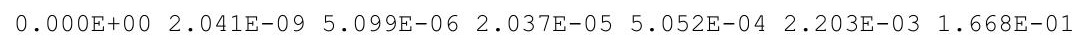

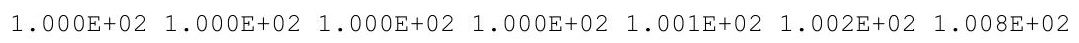

$0.000 \mathrm{E}+00 \quad 7.171 \mathrm{E}-14 \quad 8.109 \mathrm{E}-09 \quad 5.887 \mathrm{E}-08 \quad 3.940 \mathrm{E}-06 \quad 2.035 \mathrm{E}-05 \quad 7.931 \mathrm{E}-04$ $\begin{array}{llllllll}0.000 \mathrm{E}+00 & 4.331 \mathrm{E}-02 & 2.141 \mathrm{E}+00 & 4.233 \mathrm{E}+00 & 1.933 \mathrm{E}+01 & 3.597 \mathrm{E}+01 & 8.627 \mathrm{E}+01\end{array}$ $\begin{array}{lllllll}0.000 \mathrm{E}+00 & 3.119 \mathrm{E}-07 & 7.736 \mathrm{E}-04 & 3.069 \mathrm{E}-03 & 7.197 \mathrm{E}-02 & 2.914 \mathrm{E}-01 & 9.214 \mathrm{E}+00\end{array}$ $\begin{array}{lllllll}0.000 \mathrm{E}+00 & 2.948 \mathrm{E}-13 & 3.662 \mathrm{E}-08 & 2.911 \mathrm{E}-07 & 3.459 \mathrm{E}-05 & 2.994 \mathrm{E}-04 & 1.075 \mathrm{E}-01\end{array}$ $\begin{array}{lllllll}0.000 \mathrm{E}+00 & 4.331 \mathrm{E}-02 & 2.142 \mathrm{E}+00 & 4.236 \mathrm{E}+00 & 1.940 \mathrm{E}+01 & 3.626 \mathrm{E}+01 & 9.560 \mathrm{E}+01\end{array}$

$0.000 \mathrm{E}+00 \quad 5.540 \mathrm{E}-16 \quad 2.417 \mathrm{E}-09 \quad 2.809 \mathrm{E}-08 \quad 3.386 \mathrm{E}-06 \quad 1.908 \mathrm{E}-05 \quad 7.893 \mathrm{E}-04$ $\begin{array}{llllllllll}0.000 \mathrm{E}+00 & 6.662 \mathrm{E}-04 & 1.057 \mathrm{E}+00 & 2.944 \mathrm{E}+00 & 1.819 \mathrm{E}+01 & 3.507 \mathrm{E}+01 & 8.620 \mathrm{E}+01\end{array}$ $\begin{array}{llllllll}0.000 \mathrm{E}+00 & 3.207 \mathrm{E}-09 & 2.836 \mathrm{E}-04 & 1.705 \mathrm{E}-03 & 6.353 \mathrm{E}-02 & 2.751 \mathrm{E}-01 & 9.171 \mathrm{E}+00\end{array}$ $\begin{array}{llllllll}0.000 \mathrm{E}+00 & 2.276 \mathrm{E}-15 & 1.075 \mathrm{E}-08 & 1.355 \mathrm{E}-07 & 2.879 \mathrm{E}-05 & 2.742 \mathrm{E}-04 & 1.066 \mathrm{E}-01\end{array}$ $\begin{array}{llllllll}0.000 \mathrm{E}+00 & 6.663 \mathrm{E}-04 & 1.058 \mathrm{E}+00 & 2.945 \mathrm{E}+00 & 1.825 \mathrm{E}+01 & 3.534 \mathrm{E}+01 & 9.547 \mathrm{E}+01\end{array}$ $\begin{array}{lllllll}3.600 \mathrm{E}+01 & 3.600 \mathrm{E}+01 & 3.592 \mathrm{E}+01 & 3.583 \mathrm{E}+01 & 3.518 \mathrm{E}+01 & 3.430 \mathrm{E}+01 & 2.274 \mathrm{E}+01\end{array}$ $0.000 \mathrm{E}+00 \quad 3.545 \mathrm{E}-08 \quad 1.770 \mathrm{E}-06 \quad 3.533 \mathrm{E}-06 \quad 1.742 \mathrm{E}-05 \quad 3.591 \mathrm{E}-05 \quad 2.517 \mathrm{E}-04$ $\begin{array}{llllllll}6.500 \mathrm{E}+00 & 6.500 \mathrm{E}+00 & 6.493 \mathrm{E}+00 & 6.485 \mathrm{E}+00 & 6.426 \mathrm{E}+00 & 6.345 \mathrm{E}+00 & 5.165 \mathrm{E}+00\end{array}$

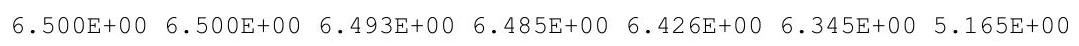


RESRAD, Version 6.5

Summary : RESRAD Parameters for Resident Farmer U-Landfill Forward Run 10,000 Years

File : C: \RESRAD_FAMILY \RESRAD \USERFILES $\backslash Q C J U L Y 2011 \backslash$ ONSITERF_FORWARD-10000-JULY11.RAD

Individual Nuclide Soil Concentration

Parent Nuclide and Branch Fraction Indicated

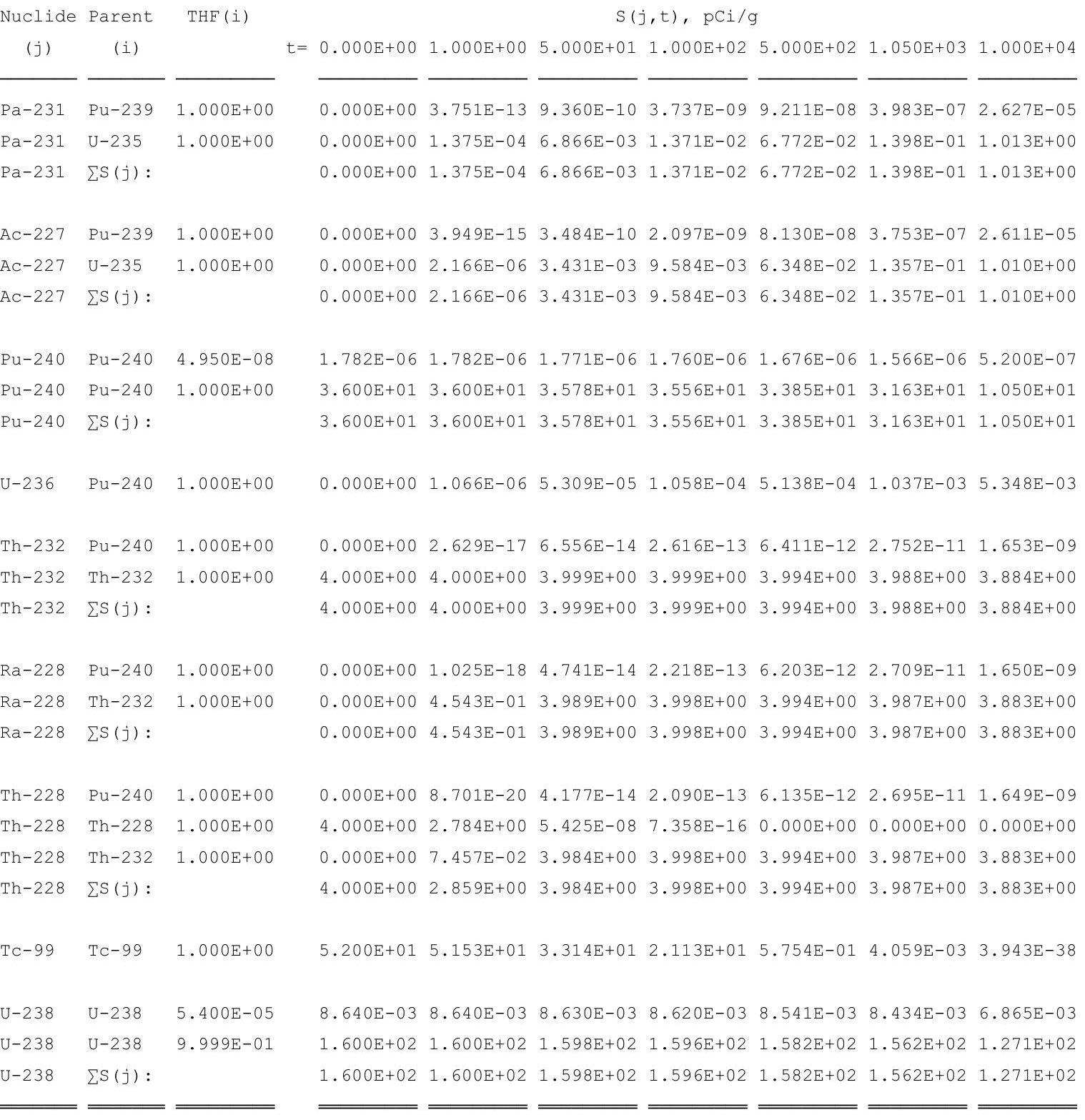

THF (i) is the thread fraction of the parent nuclide.

RESCALC.EXE execution time $=95.60$ seconds 
RESRAD, Version $6.5 \quad T^{13 / 2}$ Limit $=180$ days

Summary : RESRAD Parameters for Resident Farmer U-Landfill Forward Run 100,000 Years

File : C: $\backslash$ RESRAD_FAMILY \RESRAD \USERFILES $\backslash Q C J U L Y 2011 \backslash$ ONSITERF_FORWARD-100000-JULY11.RAD

Table of Contents

Part I: Mixture Sums and Single Radionuclide Guidelines

Dose Conversion Factor (and Related) Parameter Summary ... 2

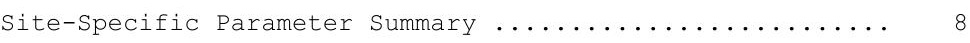

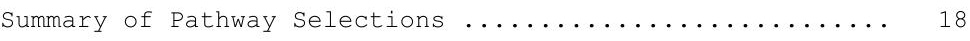

Contaminated Zone and Total Dose Summary ............. 19

Total Dose Components

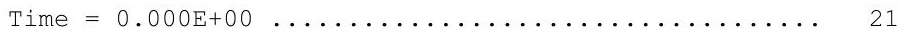

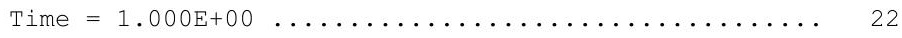

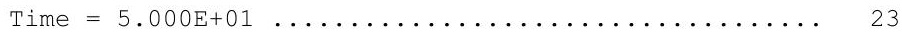

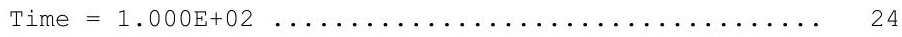

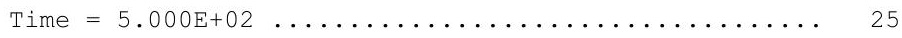

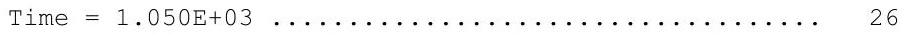

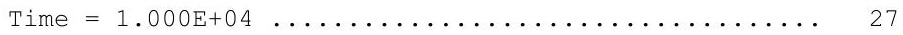

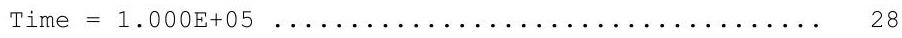

Dose/Source Ratios Summed Over All Pathways .......... 29

Single Radionuclide Soil Guidelines ................ 31

Dose Per Nuclide Summed Over All Pathways ............ 32

Soil Concentration Per Nuclide ................. 34 
Summary : RESRAD Parameters for Resident Farmer U-Landfill Forward Run 100,000 Years

File : C: \RESRAD_FAMILY \RESRAD \USERFILES \QCJULY2011 ONSITERF_FORWARD-100000-JULY11.RAD

Dose Conversion Factor (and Related) Parameter Summary

Dose Library: ICRP 60 \& ICRP 72 (Adult)

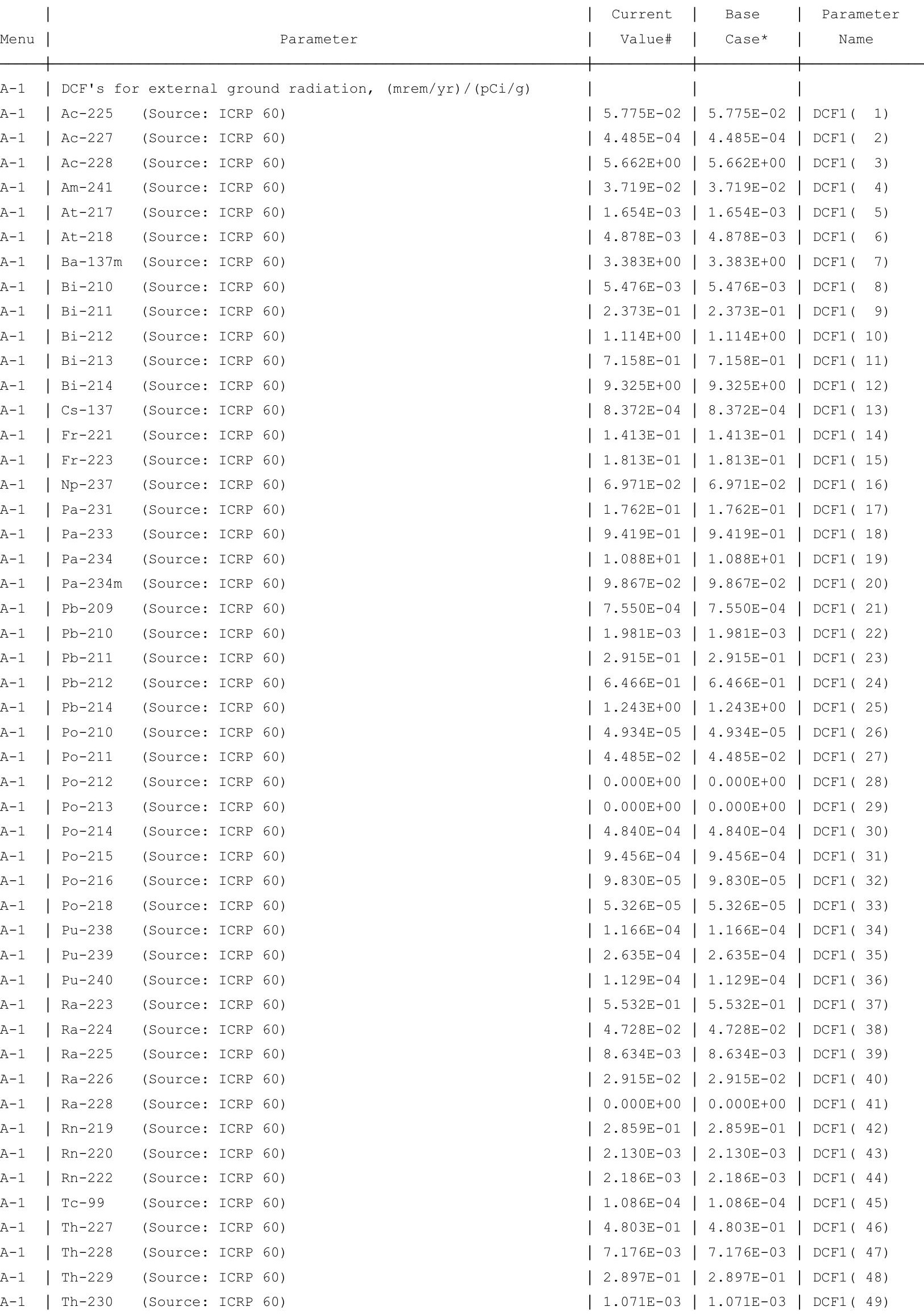


Summary : RESRAD Parameters for Resident Farmer U-Landfill Forward Run 100,000 Years

File : C: \RESRAD_FAMILY \RESRAD \USERFILES $\backslash Q C J U L Y 2011 \backslash$ ONSITERF_FORWARD-100000-JULY11.RAD

Dose Conversion Factor (and Related) Parameter Summary (continued)

Dose Library: ICRP 60 \& ICRP 72 (Adult)

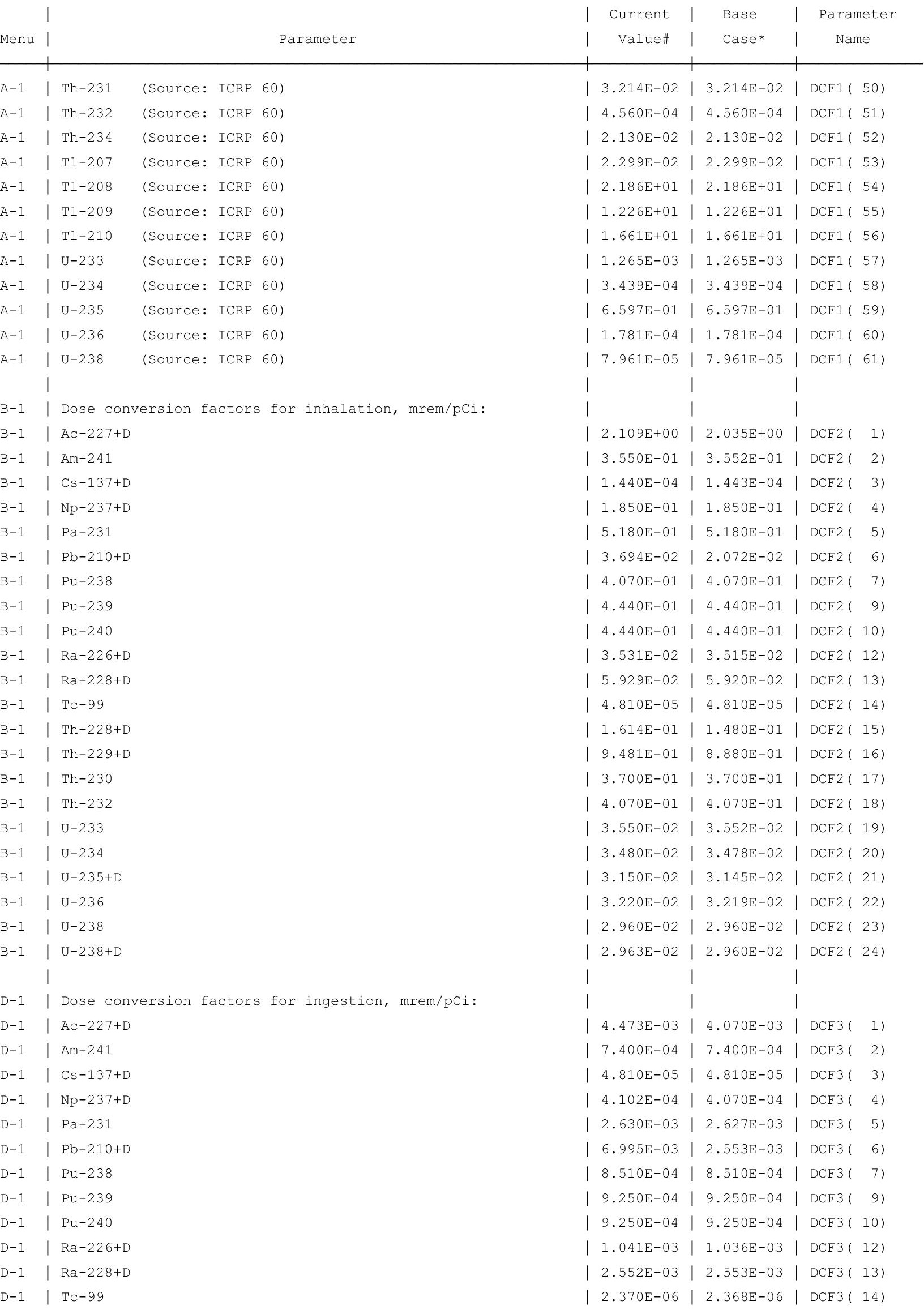


RESRAD, Version $6.5 \quad \mathrm{~T}^{1 / 2}$ Limit $=180$ days

ummary : RESRAD Parameters for Resident Farmer U-Landfill Forward Run 100,000 Years

File : C: $\backslash$ RESRAD FAMILY \RESRAD \USERFILES $\backslash Q C J U L Y 2011 \backslash$ ONSITERF FORWARD-100000-JULY11.RAD

Dose Conversion Factor (and Related) Parameter Summary (continued) Dose Library: ICRP 60 \& ICRP 72 (Adult)

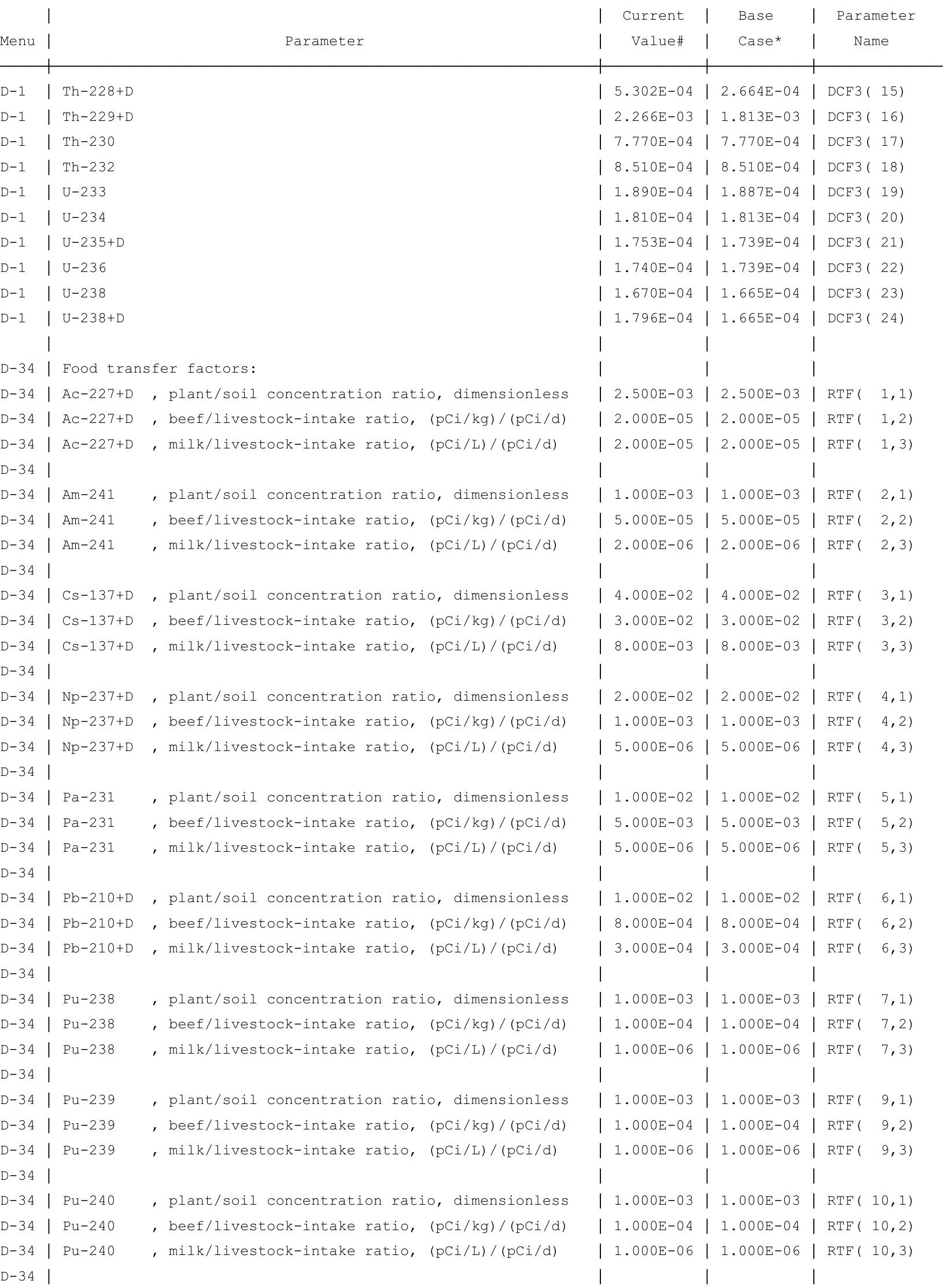


RESRAD, Version $6.5 \quad \mathrm{~T}^{\mathbb{1} 1 / 2}$ Limit $=180$ days

Summary : RESRAD Parameters for Resident Farmer U-Landfill Forward Run 100,000 Years

File : C: \RESRAD_FAMILY \RESRAD \USERFILES \QCJULY2011 ONSITERF_FORWARD-100000-JULY11.RAD

Site-Specific Parameter Summary (continued)

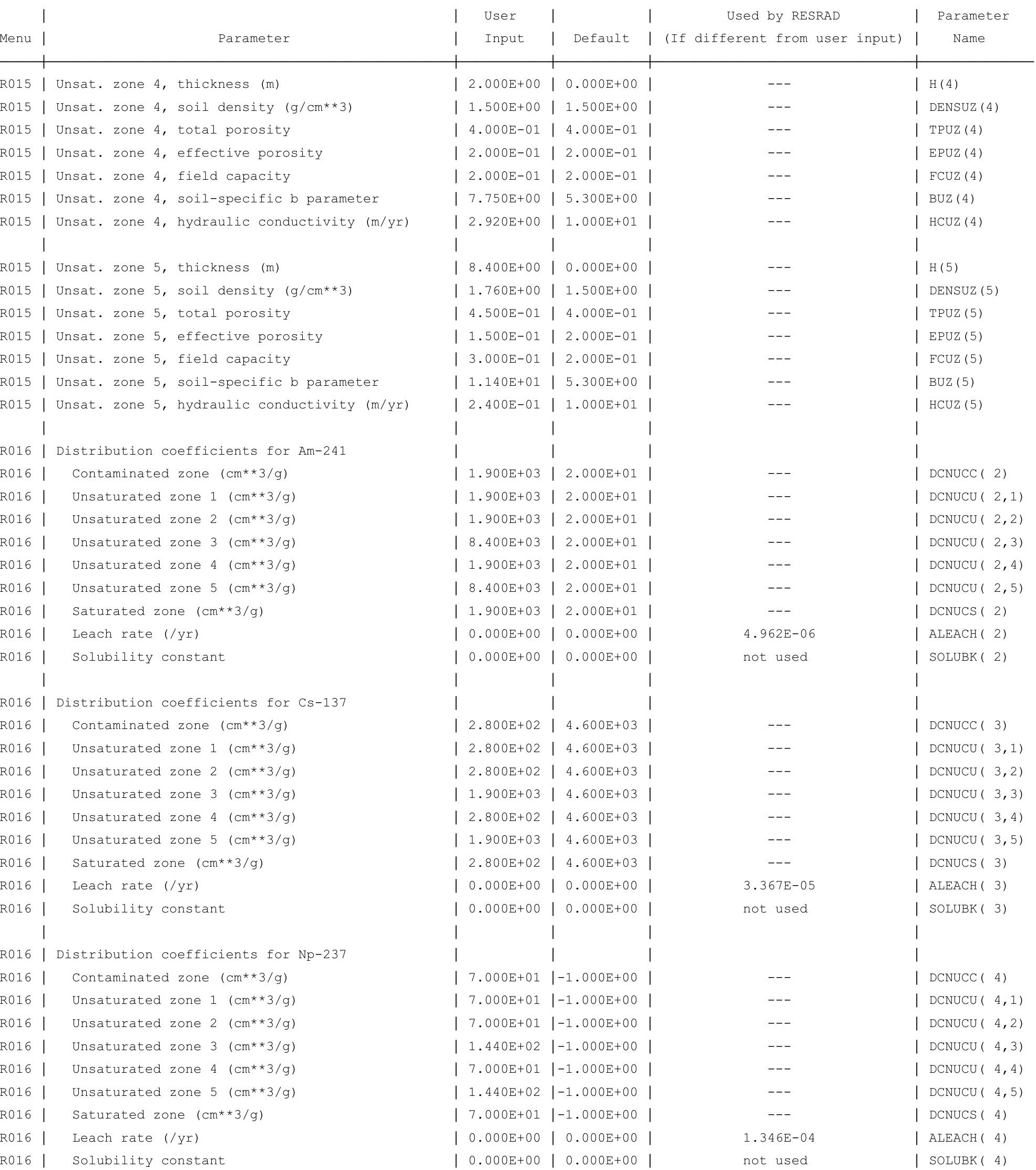


RESRAD, Version $6.5 \quad \mathrm{~T}^{1 / 2}$ Limit $=180$ days

Summary : RESRAD Parameters for Resident Farmer U-Landfill Forward Run 100,000 Years

File : C: \RESRAD_FAMILY \RESRAD \USERFILES \QCJULY2011 ONSITERF_FORWARD-100000-JULY11.RAD

Site-Specific Parameter Summary (continued)

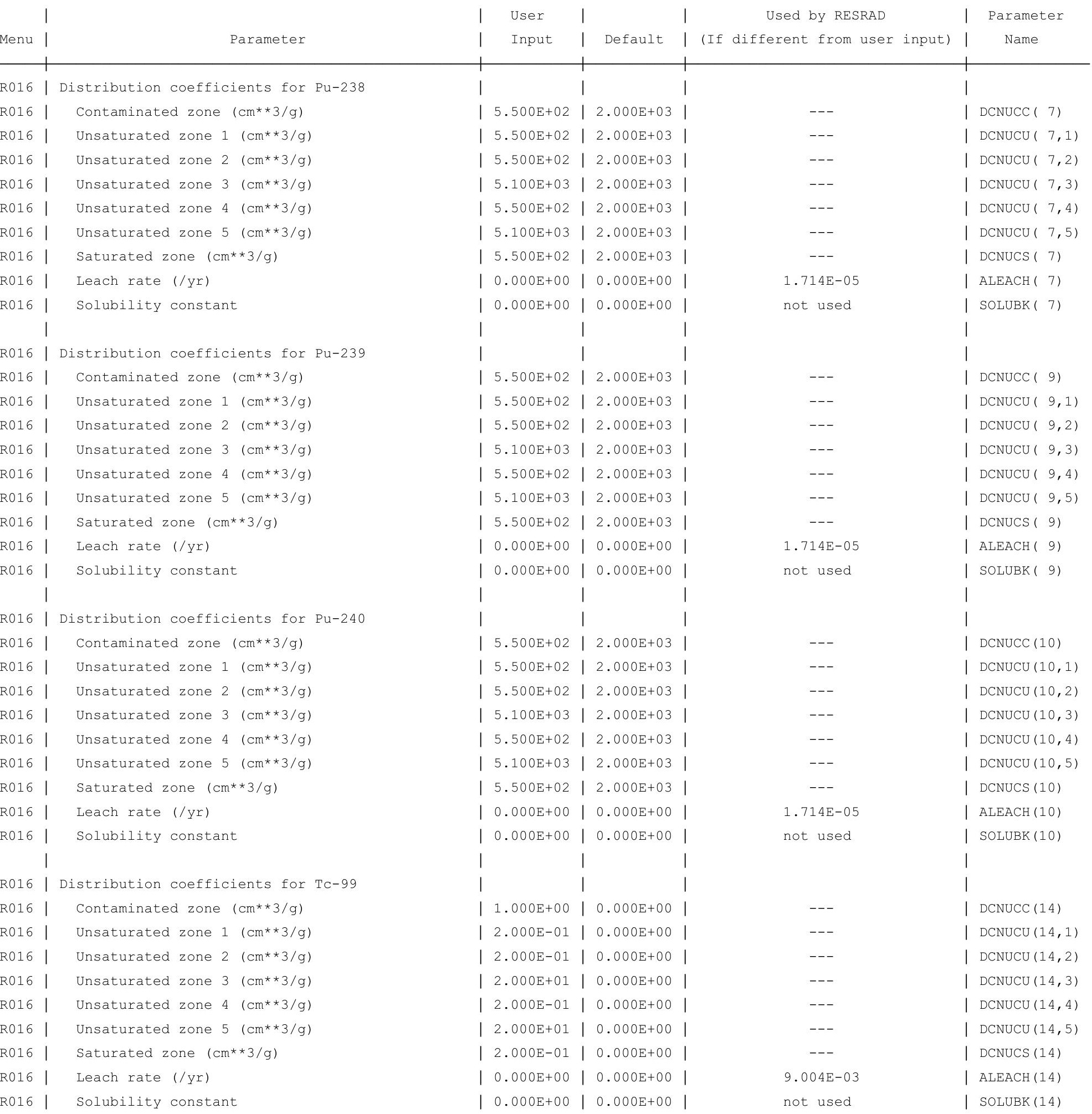


RESRAD, Version $6.5 \quad \mathrm{~T}^{1 / 2}$ Limit $=180$ days

Summary : RESRAD Parameters for Resident Farmer U-Landfill Forward Run 100,000 Years

File : C: \RESRAD_FAMILY \RESRAD \USERFILES \QCJULY2011 ONSITERF_FORWARD-100000-JULY11.RAD

Site-Specific Parameter Summary (continued)

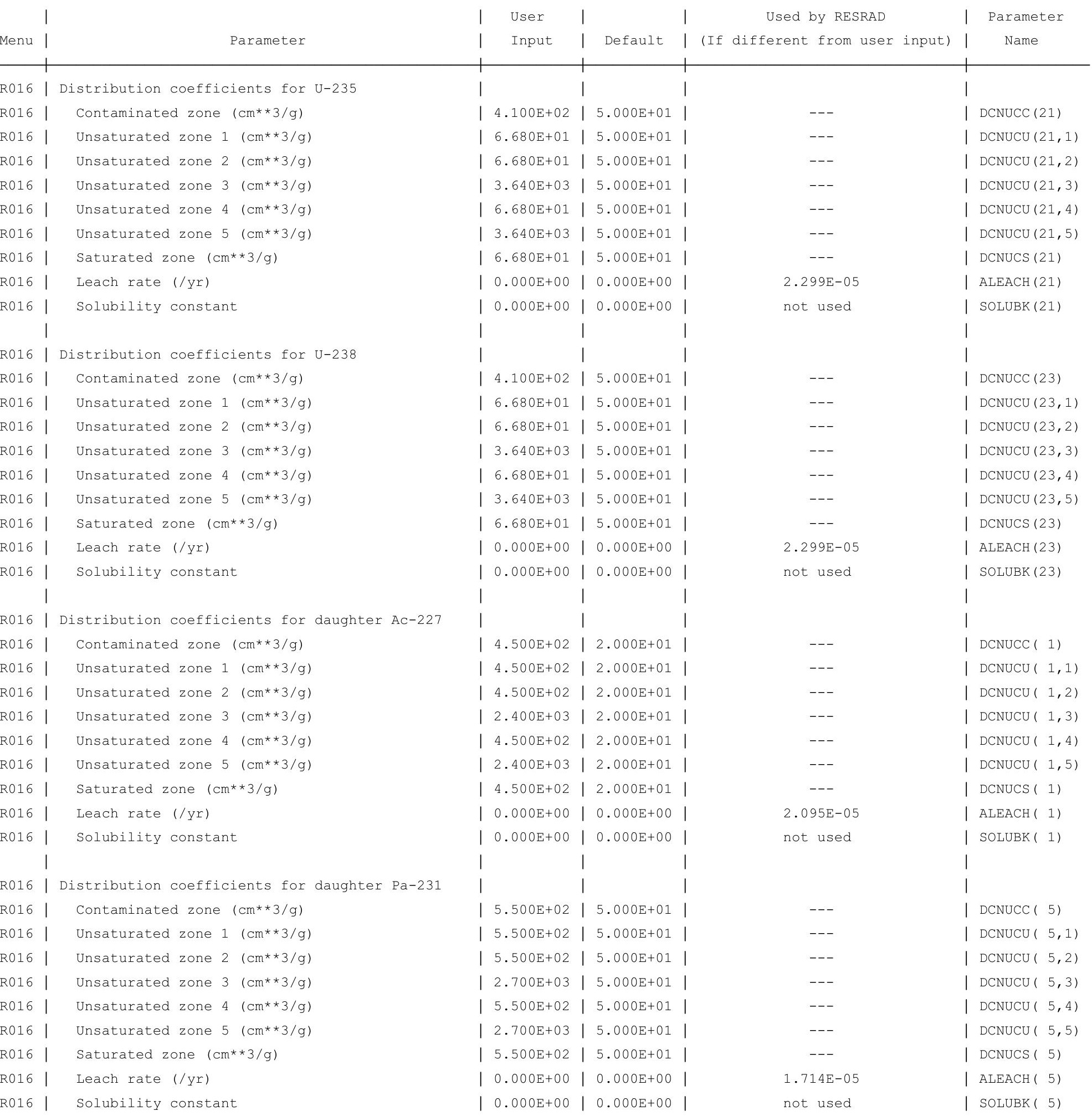


RESRAD, Version $6.5 \quad \mathrm{~T}^{1 / 2}$ Limit $=180$ days

Summary : RESRAD Parameters for Resident Farmer U-Landfill Forward Run 100,000 Years

File : C: \RESRAD_FAMILY \RESRAD \USERFILES \QCJULY2011 ONSITERF_FORWARD-100000-JULY11.RAD

Site-Specific Parameter Summary (continued)

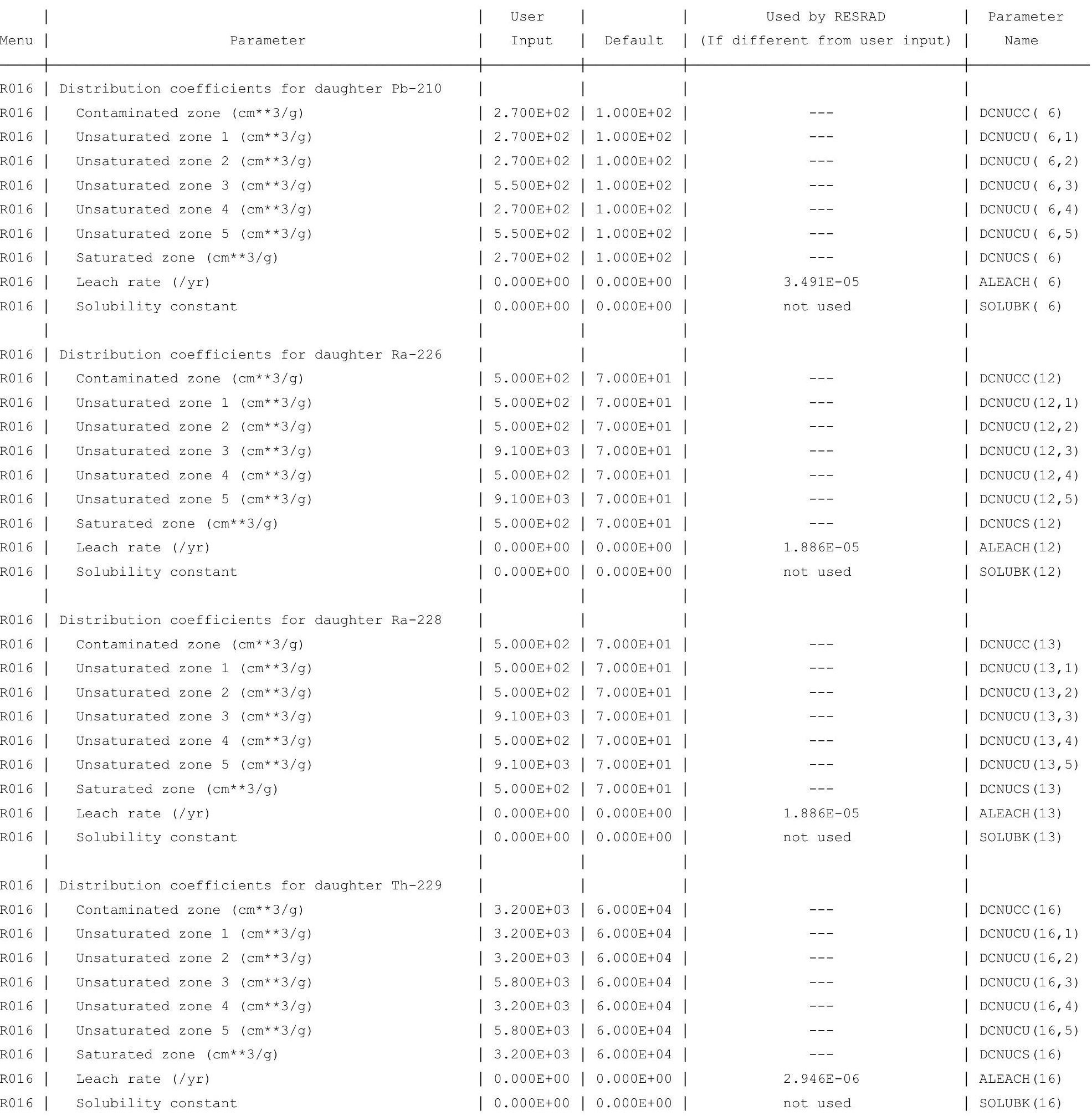


RESRAD, Version $6.5 \quad \mathrm{~T}^{1 / 2}$ Limit $=180$ days

Summary : RESRAD Parameters for Resident Farmer U-Landfill Forward Run 100,000 Years

File : C: \RESRAD_FAMILY \RESRAD \USERFILES \QCJULY2011 ONSITERF_FORWARD-100000-JULY11.RAD

Site-Specific Parameter Summary (continued)

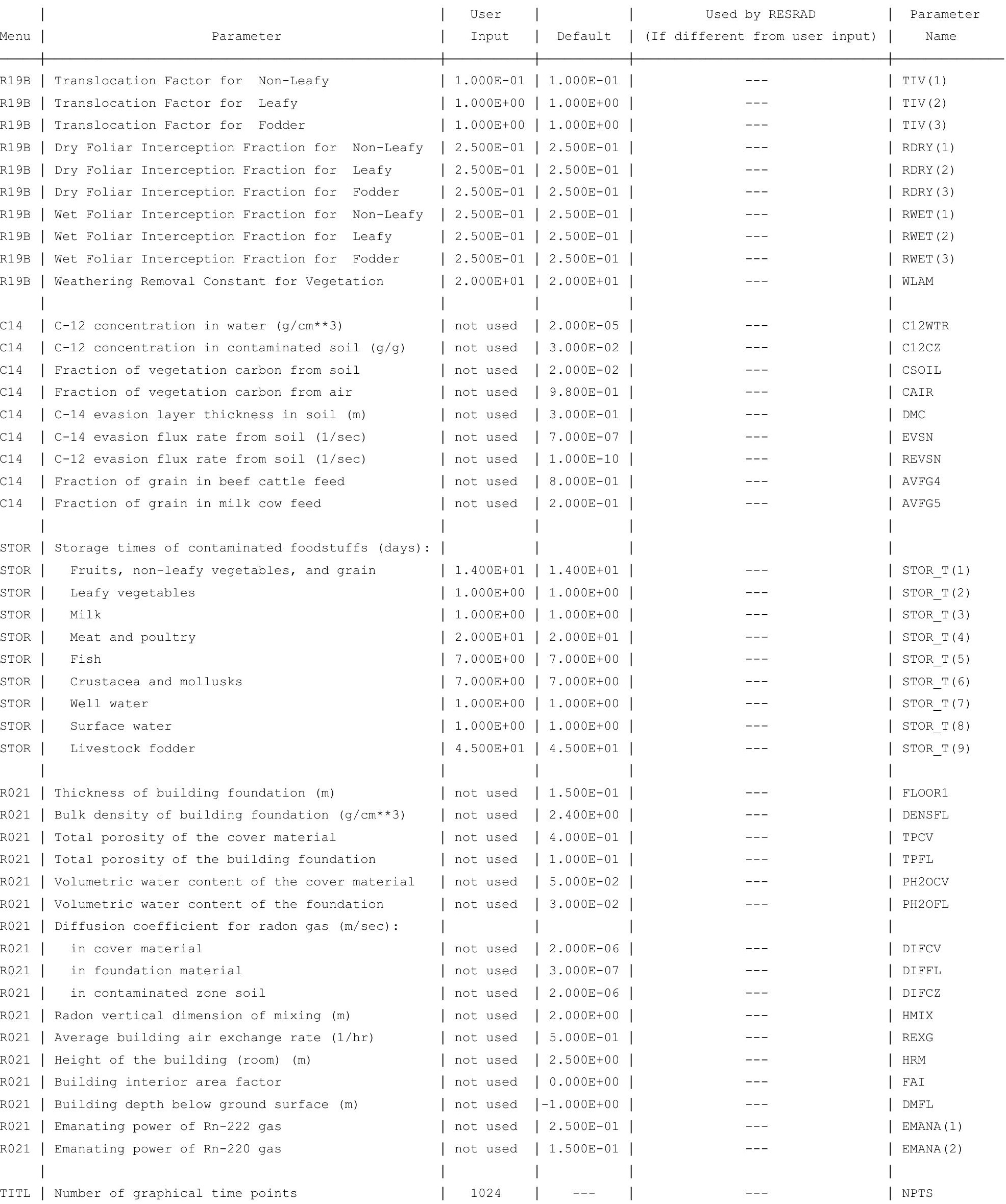

TITL | Number of graphical time points 
RESRAD, Version $6.5 \quad \mathrm{~T}^{1 / 2}$ Limit $=180$ days

07/21/2011 12:07 Page 20

ummary : RESRAD Parameters for Resident Farmer U-Landfill Forward Run 100,000 Years

File : C: \RESRAD_FAMILY \RESRAD \USERFILES $\backslash Q C J U L Y 2011 \backslash$ ONSITERF_FORWARD-100000-JULY11.RAD

Total Dose Contributions TDOSE(i,p,t) for Individual Radionuclides (i) and Pathways (p)

As mrem/yr and Fraction of Total Dose At $t=1.278 \mathrm{E}+04$ years

Water Dependent Pathways

\begin{tabular}{|c|c|c|c|c|c|c|c|c|c|c|c|c|c|c|}
\hline & \multicolumn{2}{|c|}{ Water } & \multicolumn{2}{|c|}{ Fish } & \multicolumn{2}{|c|}{ Radon } & \multicolumn{2}{|c|}{ Plant } & \multicolumn{2}{|c|}{ Meat } & \multicolumn{2}{|c|}{ Milk } & \multicolumn{2}{|c|}{ All Pathways* } \\
\hline clide & mrem/yr & fract. & mrem/yr & fract. & mrem/yr & fract. & mrem/yr & fract. & mrem/yr & fract. & mrem/yr & fract. & mrem/yr & fract. \\
\hline-241 & $3.499 E-03$ & 0.0000 & $0.000 \mathrm{E}+00$ & 0.0000 & $0.000 \mathrm{E}+00$ & 0.0000 & $1.427 \mathrm{E}-04$ & 0.0000 & $5.591 \mathrm{E}-05$ & 0.0000 & $2.135 \mathrm{E}-06$ & 0.0000 & $6.550 \mathrm{E}-03$ & 0.0000 \\
\hline-137 & $0.000 \mathrm{E}+00$ & 0.0000 & $0.000 \mathrm{E}+00$ & 0.0000 & $0.000 \mathrm{E}+00$ & 0.0000 & $0.000 \mathrm{E}+00$ & 0.0000 & $0.000 \mathrm{E}+00$ & 0.0000 & $0.000 \mathrm{E}+00$ & 0.0000 & $0.000 \mathrm{E}+00$ & 0.0000 \\
\hline-237 & $2.423 E+00$ & 0.0009 & $0.000 \mathrm{E}+00$ & 0.0000 & $0.000 \mathrm{E}+00$ & 0.0000 & $9.882 \mathrm{E}-02$ & 0.0000 & $3.871 \mathrm{E}-02$ & 0.0000 & $1.517 \mathrm{E}-03$ & 0.0000 & $4.615 \mathrm{E}+00$ & 0.0017 \\
\hline-238 & $0.000 \mathrm{E}+00$ & 0.0000 & $0.000 \mathrm{E}+00$ & 0.0000 & $0.000 \mathrm{E}+00$ & 0.0000 & $0.000 \mathrm{E}+00$ & 0.0000 & $0.000 \mathrm{E}+00$ & 0.0000 & $0.000 \mathrm{E}+00$ & 0.0000 & $2.845 \mathrm{E}-02$ & 0.0000 \\
\hline 239 & $0.000 \mathrm{E}+00$ & 0.0000 & $0.000 \mathrm{E}+00$ & 0.0000 & $0.000 \mathrm{E}+00$ & 0.0000 & $0.000 \mathrm{E}+00$ & 0.0000 & $0.000 \mathrm{E}+00$ & 0.0000 & $0.000 \mathrm{E}+00$ & 0.0000 & $3.292 \mathrm{E}+00$ & 0.0012 \\
\hline-240 & $0.000 \mathrm{E}+00$ & 0.0000 & $0.000 \mathrm{E}+00$ & 0.0000 & $0.000 \mathrm{E}+00$ & 0.0000 & $0.000 \mathrm{E}+00$ & 0.0000 & $0.000 \mathrm{E}+00$ & 0.0000 & $0.000 \mathrm{E}+00$ & 0.0000 & $1.226 \mathrm{E}+00$ & 0.0004 \\
\hline-99 & $0.000 \mathrm{E}+00$ & 0.0000 & $0.000 \mathrm{E}+00$ & 0.0000 & $0.000 \mathrm{E}+00$ & 0.0000 & $0.000 \mathrm{E}+00$ & 0.0000 & $0.000 \mathrm{E}+00$ & 0.0000 & $0.000 \mathrm{E}+00$ & 0.0000 & $0.000 \mathrm{E}+00$ & 0.0000 \\
\hline-228 & $0.000 \mathrm{E}+00$ & 0.0000 & $0.000 \mathrm{E}+00$ & 0.0000 & $0.000 \mathrm{E}+00$ & 0.0000 & $0.000 \mathrm{E}+00$ & 0.0000 & $0.000 \mathrm{E}+00$ & 0.0000 & $0.000 \mathrm{E}+00$ & 0.0000 & $0.000 \mathrm{E}+00$ & 0.0000 \\
\hline-230 & $0.000 \mathrm{E}+00$ & 0.0000 & $0.000 \mathrm{E}+00$ & 0.0000 & $0.000 \mathrm{E}+00$ & 0.0000 & $0.000 \mathrm{E}+00$ & 0.0000 & $0.000 \mathrm{E}+00$ & 0.0000 & $0.000 \mathrm{E}+00$ & 0.0000 & $2.233 E+03$ & 0.8178 \\
\hline-232 & $0.000 \mathrm{E}+00$ & 0.0000 & $0.000 \mathrm{E}+00$ & 0.0000 & $0.000 \mathrm{E}+00$ & 0.0000 & $0.000 \mathrm{E}+00$ & 0.0000 & $0.000 \mathrm{E}+00$ & 0.0000 & $0.000 \mathrm{E}+00$ & 0.0000 & $1.100 \mathrm{E}+02$ & 0.0403 \\
\hline 34 & $0.000 \mathrm{E}+00$ & 0.0000 & $0.000 \mathrm{E}+00$ & 0.0000 & $0.000 \mathrm{E}+00$ & 0.0000 & $0.000 \mathrm{E}+00$ & 0.0000 & $0.000 \mathrm{E}+00$ & 0.0000 & $0.000 \mathrm{E}+00$ & 0.0000 & $3.290 \mathrm{E}+02$ & 0.1205 \\
\hline 35 & $0.000 \mathrm{E}+00$ & 0.0000 & $0.000 \mathrm{E}+00$ & 0.0000 & $0.000 \mathrm{E}+00$ & 0.0000 & $0.000 \mathrm{E}+00$ & 0.0000 & $0.000 \mathrm{E}+00$ & 0.0000 & $0.000 \mathrm{E}+00$ & 0.0000 & $1.433 \mathrm{E}+01$ & 0.0052 \\
\hline 00 & $0.000 \mathrm{E}+00$ & 0.0000 & $0.000 \mathrm{E}+00$ & 0.0000 & $0.000 \mathrm{E}+00$ & 0.0000 & $0.000 \mathrm{E}+00$ & 0.0000 & $0.000 \mathrm{E}+00$ & 0.0000 & $0.000 \mathrm{E}+00$ & 0.0000 & $3.497 \mathrm{E}+01$ & 0.0128 \\
\hline & $2.427 E+00$ & 0.0009 & $0.000 \mathrm{E}+00$ & 0.0000 & $0.000 \mathrm{E}+00$ & 0.0000 & $9.896 \mathrm{E}-02$ & 0.0000 & $3.876 \mathrm{E}-02$ & 0.0000 & $1.519 \mathrm{E}-03$ & 0.0000 & +03 & 1.0000 \\
\hline
\end{tabular}

*Sum of all water independent and dependent pathways. 
RESRAD, Version $6.5 \quad \mathrm{~T}^{1 / 2}$ Limit $=180$ days

07/21/2011 12:07 Page 21

ummary : RESRAD Parameters for Resident Farmer U-Landfill Forward Run 100,000 Years

File : C: \RESRAD_FAMILY \RESRAD \USERFILES $\backslash Q C J U L Y 2011 \backslash$ ONSITERF_FORWARD-100000-JULY11.RAD

Total Dose Contributions TDOSE (i,p,t) for Individual Radionuclides (i) and Pathways (p) As mrem/yr and Fraction of Total Dose At $t=0.000 \mathrm{E}+00$ years

Water Independent Pathways (Inhalation excludes radon)

\begin{tabular}{|c|c|c|}
\hline clide & mrem/yr & fract. \\
\hline $1-241$ & $5.412 \mathrm{E}-18$ & 0.0000 \\
\hline-137 & $2.397 E-08$ & 0.0043 \\
\hline-237 & $5.245 E-12$ & 0.0000 \\
\hline-238 & $3.174 \mathrm{E}-21$ & 0.0000 \\
\hline-239 & $4.328 E-16$ & 0.0000 \\
\hline-240 & $4.115 E-23$ & 0.0000 \\
\hline-99 & $2.994 \mathrm{E}-24$ & 0.0000 \\
\hline-228 & $5.530 \mathrm{E}-06$ & 0.9827 \\
\hline-230 & $3.774 \mathrm{E}-09$ & 0.0007 \\
\hline-232 & $4.712 \mathrm{E}-08$ & 0.0084 \\
\hline 234 & $1.813 E-14$ & 0.0000 \\
\hline 235 & $8.089 E-14$ & 0.0000 \\
\hline 38 & $2.271 E-08$ & 0.0040 \\
\hline & & 1.0000 \\
\hline
\end{tabular}

Total $5.627 \mathrm{E}-061.0000$

\begin{abstract}
Inhalation
\end{abstract}
mrem/yr fract.

$\overline{0.000 E+00} 0.0000$

$0.000 \mathrm{E}+00 \quad 0.0000$

$0.000 \mathrm{E}+00 \quad 0.0000$

$0.000 \mathrm{E}+00 \quad 0.0000$

$0.000 \mathrm{E}+00 \quad 0.0000$

$0.000 \mathrm{E}+00 \quad 0.0000$

$0.000 \mathrm{E}+00 \quad 0.0000$

$0.000 \mathrm{E}+00 \quad 0.0000$

$0.000 \mathrm{E}+00 \quad 0.0000$

$0.000 \mathrm{E}+00 \quad 0.0000$

$0.000 \mathrm{E}+00 \quad 0.0000$

$0.000 \mathrm{E}+00 \quad 0.0000$

$0.000 \mathrm{E}+00 \quad 0.0000$

$\overline{\overline{0.000 \mathrm{E}+00}} \overline{\overline{0.0000}}$

Radon

mrem/yr fract. $\overline{0.000 E+00} \overline{0.0000}$

$0.000 E+00 \quad 0.0000$

$0.000 \mathrm{E}+00 \quad 0.0000$

$0.000 E+00 \quad 0.0000$

$0.000 E+00 \quad 0.0000$

$0.000 \mathrm{E}+00 \quad 0.0000$

$0.000 \mathrm{E}+00 \quad 0.0000$

$0.000 \mathrm{E}+00 \quad 0.0000$

$0.000 \mathrm{E}+00 \quad 0.0000$

$0.000 \mathrm{E}+00 \quad 0.0000$

$0.000 E+00 \quad 0.0000$

$0.000 E+00 \quad 0.0000$

$0.000 \mathrm{E}+00 \quad 0.0000$

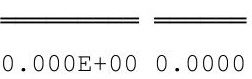

\begin{tabular}{|c|c|c|c|}
\hline \multicolumn{2}{|c|}{ Plant } & \multicolumn{2}{|c|}{ Meat } \\
\hline mrem/yr & fract. & mrem/yr & fract. \\
\hline $0.000 \mathrm{E}+00$ & 0.0000 & $0.000 \mathrm{E}+00$ & 0.0000 \\
\hline $0.000 \mathrm{E}+00$ & 0.0000 & $0.000 \mathrm{E}+00$ & 0.0000 \\
\hline $0.000 \mathrm{E}+00$ & 0.0000 & $0.000 \mathrm{E}+00$ & 0.0000 \\
\hline $0.000 \mathrm{E}+00$ & 0.0000 & $0.000 \mathrm{E}+00$ & 0.0000 \\
\hline $0.000 \mathrm{E}+00$ & 0.0000 & $0.000 \mathrm{E}+00$ & 0.0000 \\
\hline $0.000 \mathrm{E}+00$ & 0.0000 & $0.000 \mathrm{E}+00$ & 0.0000 \\
\hline $0.000 \mathrm{E}+00$ & 0.0000 & $0.000 \mathrm{E}+00$ & 0.0000 \\
\hline $0.000 \mathrm{E}+00$ & 0.0000 & $0.000 \mathrm{E}+00$ & 0.0000 \\
\hline $0.000 \mathrm{E}+00$ & 0.0000 & $0.000 \mathrm{E}+00$ & 0.0000 \\
\hline $0.000 \mathrm{E}+00$ & 0.0000 & $0.000 \mathrm{E}+00$ & 0.0000 \\
\hline $0.000 \mathrm{E}+00$ & 0.0000 & $0.000 \mathrm{E}+00$ & 0.0000 \\
\hline $0.000 \mathrm{E}+00$ & 0.0000 & $0.000 \mathrm{E}+00$ & 0.0000 \\
\hline $0.000 \mathrm{E}+00$ & 0.0000 & $0.000 \mathrm{E}+00$ & 0.0000 \\
\hline $.000 \mathrm{E}+00$ & 0.0000 & $0.000 \mathrm{E}+00$ & 0.0000 \\
\hline
\end{tabular}

\begin{tabular}{cc} 
Milk \\
\hline mrem/yr fract. \\
\cline { 1 - 2 } $0.000 \mathrm{E}+00$ & 0.0000 \\
$0.000 \mathrm{E}+00$ & 0.0000 \\
$0.000 \mathrm{E}+00$ & 0.0000 \\
$0.000 \mathrm{E}+00$ & 0.0000 \\
$0.000 \mathrm{E}+00$ & 0.0000 \\
$0.000 \mathrm{E}+00$ & 0.0000 \\
$0.000 \mathrm{E}+00$ & 0.0000 \\
$0.000 \mathrm{E}+00$ & 0.0000 \\
$0.000 \mathrm{E}+00$ & 0.0000 \\
$0.000 \mathrm{E}+00$ & 0.0000 \\
$0.000 \mathrm{E}+00$ & 0.0000 \\
$0.000 \mathrm{E}+00$ & 0.0000 \\
$0.000 \mathrm{E}+00$ & 0.0000 \\
\hline \hline $0.000 \mathrm{E}+00$ & 0.0000
\end{tabular}

Soil

mrem/yr fract.

$0.000 \mathrm{E}+00 \quad 0.0000$

$0.000 \mathrm{E}+00 \quad 0.0000$

$0.000 \mathrm{E}+00 \quad 0.0000$

$0.000 \mathrm{E}+00 \quad 0.0000$

$0.000 \mathrm{E}+00 \quad 0.0000$

$0.000 \mathrm{E}+00 \quad 0.0000$

$0.000 \mathrm{E}+00 \quad 0.0000$

$0.000 \mathrm{E}+00 \quad 0.0000$

$0.000 \mathrm{E}+00 \quad 0.0000$

$0.000 \mathrm{E}+00 \quad 0.0000$

$0.000 \mathrm{E}+00 \quad 0.0000$

$0.000 \mathrm{E}+00 \quad 0.0000$

$0.000 \mathrm{E}+00 \quad 0.0000$

$0.000 \mathrm{E}+00 \quad 0.0000$

Total Dose Contributions TDOSE (i,p,t) for Individual Radionuclides (i) and Pathways (p) As mrem/yr and Fraction of Total Dose At $t=0.000 \mathrm{E}+00$ years

Water Dependent Pathways

\begin{tabular}{|c|c|c|c|c|c|c|}
\hline & \multicolumn{2}{|c|}{ Water } & \multicolumn{2}{|c|}{ Fish } & \multicolumn{2}{|c|}{ Radon } \\
\hline clide & mrem/yr & fract. & mrem/yr & fract. & mrem/yr & fract. \\
\hline-241 & $0.000 \mathrm{E}+00$ & 0.0000 & $0.000 \mathrm{E}+00$ & 0.0000 & $0.000 \mathrm{E}+00$ & 0.0000 \\
\hline-137 & $0.000 \mathrm{E}+00$ & 0.0000 & $0.000 \mathrm{E}+00$ & 0.0000 & $0.000 \mathrm{E}+00$ & 0.0000 \\
\hline-237 & $0.000 \mathrm{E}+00$ & 0.0000 & $0.000 \mathrm{E}+00$ & 0.0000 & $0.000 \mathrm{E}+00$ & 0.0000 \\
\hline-238 & $0.000 \mathrm{E}+00$ & 0.0000 & $0.000 \mathrm{E}+00$ & 0.0000 & $0.000 \mathrm{E}+00$ & 0.0000 \\
\hline-239 & $0.000 \mathrm{E}+00$ & 0.0000 & $0.000 \mathrm{E}+00$ & 0.0000 & $0.000 \mathrm{E}+00$ & 0.0000 \\
\hline-240 & $0.000 \mathrm{E}+00$ & 0.0000 & $0.000 \mathrm{E}+00$ & 0.0000 & $0.000 \mathrm{E}+00$ & 0.0000 \\
\hline-99 & $0.000 \mathrm{E}+00$ & 0.0000 & $0.000 \mathrm{E}+00$ & 0.0000 & $0.000 \mathrm{E}+00$ & 0.0000 \\
\hline-228 & $0.000 \mathrm{E}+00$ & 0.0000 & $0.000 \mathrm{E}+00$ & 0.0000 & $0.000 \mathrm{E}+00$ & 0.0000 \\
\hline-230 & $0.000 \mathrm{E}+00$ & 0.0000 & $0.000 \mathrm{E}+00$ & 0.0000 & $0.000 \mathrm{E}+00$ & 0.0000 \\
\hline-232 & $0.000 \mathrm{E}+00$ & 0.0000 & $0.000 \mathrm{E}+00$ & 0.0000 & $0.000 \mathrm{E}+00$ & 0.0000 \\
\hline 34 & $0.000 \mathrm{E}+00$ & 0.0000 & $0.000 \mathrm{E}+00$ & 0.0000 & $0.000 \mathrm{E}+00$ & 0.0000 \\
\hline 35 & $0.000 \mathrm{E}+00$ & 0.0000 & $0.000 \mathrm{E}+00$ & 0.0000 & $0.000 \mathrm{E}+00$ & 0.0000 \\
\hline 38 & $0.000 \mathrm{E}+00$ & 0.0000 & $0.000 \mathrm{E}+00$ & 0.0000 & $0.000 \mathrm{E}+00$ & 0.0000 \\
\hline & $0.000 \mathrm{E}+00$ & 0.0000 & $0.000 \mathrm{E}+00$ & 0.0000 & $0.000 \mathrm{E}+00$ & 0.0000 \\
\hline
\end{tabular}

\begin{tabular}{|c|c|c|c|}
\hline \multicolumn{2}{|c|}{ Plant } & \multicolumn{2}{|c|}{ Meat } \\
\hline mrem/yr & fract. & mrem/yr & fract. \\
\hline $0.000 \mathrm{E}+00$ & 0.0000 & $0.000 \mathrm{E}+00$ & 0.0000 \\
\hline $0.000 \mathrm{E}+00$ & 0.0000 & $0.000 \mathrm{E}+00$ & 0.0000 \\
\hline $0.000 \mathrm{E}+00$ & 0.0000 & $0.000 \mathrm{E}+00$ & 0.0000 \\
\hline $0.000 \mathrm{E}+00$ & 0.0000 & $0.000 \mathrm{E}+00$ & 0.0000 \\
\hline $0.000 \mathrm{E}+00$ & 0.0000 & $0.000 \mathrm{E}+00$ & 0.0000 \\
\hline $0.000 \mathrm{E}+00$ & 0.0000 & $0.000 \mathrm{E}+00$ & 0.0000 \\
\hline $0.000 \mathrm{E}+00$ & 0.0000 & $0.000 \mathrm{E}+00$ & 0.0000 \\
\hline $0.000 \mathrm{E}+00$ & 0.0000 & $0.000 \mathrm{E}+00$ & 0.0000 \\
\hline $0.000 \mathrm{E}+00$ & 0.0000 & $0.000 \mathrm{E}+00$ & 0.0000 \\
\hline $0.000 \mathrm{E}+00$ & 0.0000 & $0.000 \mathrm{E}+00$ & 0.0000 \\
\hline $0.000 \mathrm{E}+00$ & 0.0000 & $0.000 \mathrm{E}+00$ & 0.0000 \\
\hline $0.000 \mathrm{E}+00$ & 0.0000 & $0.000 \mathrm{E}+00$ & 0.0000 \\
\hline $0.000 \mathrm{E}+00$ & 0.0000 & $0.000 \mathrm{E}+00$ & 0.0000 \\
\hline
\end{tabular}

$0.000 \mathrm{E}+00 \quad 0.0000$

$0.000 \mathrm{E}+00 \quad 0.0000$

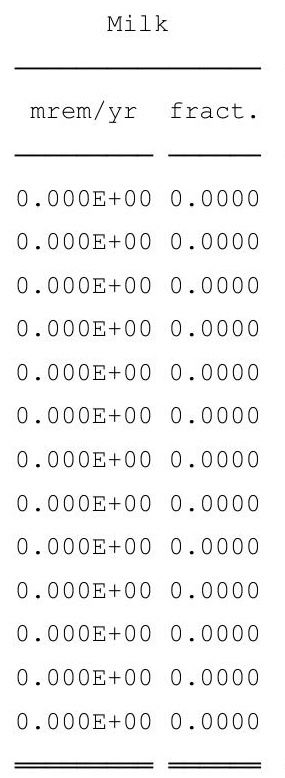

All Pathways* mrem/yr fract. $5.412 \mathrm{E}-18 \quad 0.0000$ $2.397 \mathrm{E}-08 \quad 0.0043$ $5.245 \mathrm{E}-120.0000$ $3.174 \mathrm{E}-210.0000$ $4.328 \mathrm{E}-160.0000$ $4.115 \mathrm{E}-230.0000$ $2.994 \mathrm{E}-240.0000$ $5.530 \mathrm{E}-06 \quad 0.9827$ $3.774 \mathrm{E}-09 \quad 0.0007$ $4.712 \mathrm{E}-08 \quad 0.0084$ $1.813 \mathrm{E}-14 \quad 0.0000$ $8.089 \mathrm{E}-14 \quad 0.0000$ $2.271 \mathrm{E}-08 \quad 0.0040$ $0.000 \mathrm{E}+00 \quad 0.0000 \quad 5.627 \mathrm{E}-06 \quad 1.0000$

* Sum of all water independent and dependent pathways. 
RESRAD, Version $6.5 \quad \mathrm{~T}^{1 / 2}$ Limit $=180$ days

07/21/2011 12:07 Page 22

: C: \RESRAD_FAMILY \RESRAD \USERFILES \QCJULY2011 \ONSITERF_FORWARD-100000-JULY11.RAD

Total Dose Contributions TDOSE (i,p,t) for Individual Radionuclides (i) and Pathways (p) As mrem/yr and Fraction of Total Dose At $t=1.000 \mathrm{E}+00$ years

Water Independent Pathways (Inhalation excludes radon)

\begin{tabular}{|c|c|c|c|c|c|c|c|c|c|c|c|c|c|c|}
\hline \multirow{2}{*}{ Nuclide } & \multicolumn{2}{|c|}{ Ground } & \multicolumn{2}{|c|}{ Inhalation } & \multicolumn{2}{|c|}{ Radon } & \multicolumn{2}{|c|}{ Plant } & \multicolumn{2}{|c|}{ Meat } & \multicolumn{2}{|c|}{ Milk } & \multicolumn{2}{|c|}{ Soil } \\
\hline & mrem/yr & fract. & mrem/yr & fract. & mrem/yr & fract. & mrem/yr & fract. & mrem/yr & fract. & mrem/yr & fract. & mrem/yr & fract. \\
\hline-241 & 1. $638 \mathrm{E}-17$ & 0.0000 & $0.000 \mathrm{E}+00$ & 0.0000 & $0.000 \mathrm{E}+00$ & 0.0000 & $0.000 \mathrm{E}+00$ & 0.0000 & $0.000 \mathrm{E}+00$ & 0.0000 & $0.000 \mathrm{E}+00$ & 0.0000 & $0.000 \mathrm{E}+00$ & 0.0000 \\
\hline-137 & $2.362 E-08$ & 0.0056 & $0.000 \mathrm{E}+00$ & 0.0000 & $0.000 \mathrm{E}+00$ & 0.0000 & $0.000 \mathrm{E}+00$ & 0.0000 & $0.000 \mathrm{E}+00$ & 0.0000 & $0.000 \mathrm{E}+00$ & 0.0000 & $0.000 \mathrm{E}+00$ & 0.0000 \\
\hline-237 & $5.301 E-12$ & 0.0000 & $0.000 \mathrm{E}+00$ & 0.0000 & $0.000 \mathrm{E}+00$ & 0.0000 & $0.000 \mathrm{E}+00$ & 0.0000 & $0.000 \mathrm{E}+00$ & 0.0000 & $0.000 \mathrm{E}+00$ & 0.0000 & $0.000 \mathrm{E}+00$ & 0.0000 \\
\hline-238 & $4.717 E-20$ & 0.0000 & $0.000 \mathrm{E}+00$ & 0.0000 & $0.000 \mathrm{E}+00$ & 0.0000 & $0.000 \mathrm{E}+00$ & 0.0000 & $0.000 \mathrm{E}+00$ & 0.0000 & $0.000 \mathrm{E}+00$ & 0.0000 & $0.000 \mathrm{E}+00$ & 0.0000 \\
\hline-239 & $4.380 \mathrm{E}-16$ & 0.0000 & $0.000 \mathrm{E}+00$ & 0.0000 & $0.000 \mathrm{E}+00$ & 0.0000 & $0.000 \mathrm{E}+00$ & 0.0000 & $0.000 \mathrm{E}+00$ & 0.0000 & $0.000 \mathrm{E}+00$ & 0.0000 & $0.000 \mathrm{E}+00$ & 0.0000 \\
\hline-240 & $4.275 \mathrm{E}-23$ & 0.0000 & $0.000 \mathrm{E}+00$ & 0.0000 & $0.000 \mathrm{E}+00$ & 0.0000 & $0.000 \mathrm{E}+00$ & 0.0000 & $0.000 \mathrm{E}+00$ & 0.0000 & $0.000 \mathrm{E}+00$ & 0.0000 & $0.000 \mathrm{E}+00$ & 0.0000 \\
\hline 99 & $3.025 E-24$ & 0.0000 & $0.000 \mathrm{E}+00$ & 0.0000 & $0.000 \mathrm{E}+00$ & 0.0000 & $0.000 \mathrm{E}+00$ & 0.0000 & $0.000 \mathrm{E}+00$ & 0.0000 & $0.000 \mathrm{E}+00$ & 0.0000 & $0.000 \mathrm{E}+00$ & 0.0000 \\
\hline-228 & $3.872 \mathrm{E}-06$ & 0.9206 & $0.000 \mathrm{E}+00$ & 0.0000 & $0.000 \mathrm{E}+00$ & 0.0000 & $0.000 \mathrm{E}+00$ & 0.0000 & $0.000 \mathrm{E}+00$ & 0.0000 & $0.000 \mathrm{E}+00$ & 0.0000 & $0.000 \mathrm{E}+00$ & 0.0000 \\
\hline-230 & $1.139 \mathrm{E}-08$ & 0.0027 & $0.000 \mathrm{E}+00$ & 0.0000 & $0.000 \mathrm{E}+00$ & 0.0000 & $0.000 \mathrm{E}+00$ & 0.0000 & $0.000 \mathrm{E}+00$ & 0.0000 & $0.000 \mathrm{E}+00$ & 0.0000 & $0.000 \mathrm{E}+00$ & 0.0000 \\
\hline-232 & $2.759 \mathrm{E}-07$ & 0.0656 & $0.000 \mathrm{E}+00$ & 0.0000 & $0.000 \mathrm{E}+00$ & 0.0000 & $0.000 \mathrm{E}+00$ & 0.0000 & $0.000 \mathrm{E}+00$ & 0.0000 & $0.000 \mathrm{E}+00$ & 0.0000 & $0.000 \mathrm{E}+00$ & 0.0000 \\
\hline 34 & $1.277 \mathrm{E}-13$ & 0.0000 & $0.000 \mathrm{E}+00$ & 0.0000 & $0.000 \mathrm{E}+00$ & 0.0000 & $0.000 \mathrm{E}+00$ & 0.0000 & $0.000 \mathrm{E}+00$ & 0.0000 & $0.000 \mathrm{E}+00$ & 0.0000 & $0.000 \mathrm{E}+00$ & 0.0000 \\
\hline 235 & $8.230 \mathrm{E}-14$ & 0.0000 & $0.000 \mathrm{E}+00$ & 0.0000 & $0.000 \mathrm{E}+00$ & 0.0000 & $0.000 \mathrm{E}+00$ & 0.0000 & $0.000 \mathrm{E}+00$ & 0.0000 & $0.000 \mathrm{E}+00$ & 0.0000 & $0.000 \mathrm{E}+00$ & 0.0000 \\
\hline 38 & $2.290 \mathrm{E}-08$ & 0.0054 & $0.000 \mathrm{E}+00$ & 0.0000 & $0.000 \mathrm{E}+00$ & 0.0000 & $0.000 \mathrm{E}+00$ & 0.0000 & $0.000 \mathrm{E}+00$ & 0.0000 & $0.000 \mathrm{E}+00$ & 0.0000 & $0.000 \mathrm{E}+00$ & 0.0000 \\
\hline & $4.206 \mathrm{E}-06$ & 1.0000 & $0.000 \mathrm{E}+00$ & 0.0000 & $0.000 \mathrm{E}+00$ & 0.0000 & $0.000 \mathrm{E}+00$ & 0.0000 & $0.000 \mathrm{E}+00$ & 0.0000 & $0.000 \mathrm{E}+00$ & 0.0000 & $0.000 \mathrm{E}+00$ & 0.0000 \\
\hline
\end{tabular}

Total Dose Contributions TDOSE(i,p,t) for Individual Radionuclides (i) and Pathways (p) As mrem/yr and Fraction of Total Dose At $t=1.000 \mathrm{E}+00$ years

Water Dependent Pathways

\begin{tabular}{|c|c|c|c|c|c|c|c|c|c|c|c|c|c|c|}
\hline & \multicolumn{2}{|c|}{ Water } & \multicolumn{2}{|c|}{ Fish } & \multicolumn{2}{|c|}{ Radon } & \multicolumn{2}{|c|}{ Plant } & \multicolumn{2}{|c|}{ Meat } & \multicolumn{2}{|c|}{ Milk } & \multicolumn{2}{|c|}{ All Pathways* } \\
\hline clide & mrem/yr & fract. & mrem/yr & fract. & mrem/yr & fract. & mrem/yr & fract. & mrem/yr & fract. & mrem/yr & fract. & mrem/yr & fract. \\
\hline-241 & $0.000 \mathrm{E}+00$ & 0.0000 & $0.000 \mathrm{E}+00$ & 0.0000 & $0.000 \mathrm{E}+00$ & 0.0000 & $0.000 \mathrm{E}+00$ & 0.0000 & $0.000 \mathrm{E}+00$ & 0.0000 & $0.000 \mathrm{E}+00$ & 0.0000 & $1.638 \mathrm{E}-17$ & 0.0000 \\
\hline-137 & $0.000 \mathrm{E}+00$ & 0.0000 & $0.000 \mathrm{E}+00$ & 0.0000 & $0.000 \mathrm{E}+00$ & 0.0000 & $0.000 \mathrm{E}+00$ & 0.0000 & $0.000 \mathrm{E}+00$ & 0.0000 & $0.000 \mathrm{E}+00$ & 0.0000 & $2.362 \mathrm{E}-08$ & 0.0056 \\
\hline-237 & $0.000 \mathrm{E}+00$ & 0.0000 & $0.000 \mathrm{E}+00$ & 0.0000 & $0.000 \mathrm{E}+00$ & 0.0000 & $0.000 \mathrm{E}+00$ & 0.0000 & $0.000 \mathrm{E}+00$ & 0.0000 & $0.000 \mathrm{E}+00$ & 0.0000 & $5.301 \mathrm{E}-12$ & 0.0000 \\
\hline 238 & $0.000 \mathrm{E}+00$ & 0.0000 & $0.000 \mathrm{E}+00$ & 0.0000 & $0.000 \mathrm{E}+00$ & 0.0000 & $0.000 \mathrm{E}+00$ & 0.0000 & $0.000 \mathrm{E}+00$ & 0.0000 & $0.000 \mathrm{E}+00$ & 0.0000 & $4.717 \mathrm{E}-20$ & 0.0000 \\
\hline 239 & $0.000 \mathrm{E}+00$ & 0.0000 & $0.000 \mathrm{E}+00$ & 0.0000 & $0.000 \mathrm{E}+00$ & 0.0000 & $0.000 \mathrm{E}+00$ & 0.0000 & $0.000 \mathrm{E}+00$ & 0.0000 & $0.000 \mathrm{E}+00$ & 0.0000 & $4.380 \mathrm{E}-16$ & 0.0000 \\
\hline 240 & $0.000 \mathrm{E}+00$ & 0.0000 & $0.000 \mathrm{E}+00$ & 0.0000 & $0.000 \mathrm{E}+00$ & 0.0000 & $0.000 \mathrm{E}+00$ & 0.0000 & $0.000 \mathrm{E}+00$ & 0.0000 & $0.000 \mathrm{E}+00$ & 0.0000 & $4.275 E-23$ & 0.0000 \\
\hline 99 & $0.000 \mathrm{E}+00$ & 0.0000 & $0.000 \mathrm{E}+00$ & 0.0000 & $0.000 \mathrm{E}+00$ & 0.0000 & $0.000 \mathrm{E}+00$ & 0.0000 & $0.000 \mathrm{E}+00$ & 0.0000 & $0.000 \mathrm{E}+00$ & 0.0000 & $3.025 \mathrm{E}-24$ & 0.0000 \\
\hline 228 & $0.000 \mathrm{E}+00$ & 0.0000 & $0.000 \mathrm{E}+00$ & 0.0000 & $0.000 \mathrm{E}+00$ & 0.0000 & $0.000 \mathrm{E}+00$ & 0.0000 & $0.000 \mathrm{E}+00$ & 0.0000 & $0.000 \mathrm{E}+00$ & 0.0000 & $3.872 \mathrm{E}-06$ & 0.9206 \\
\hline 230 & $0.000 \mathrm{E}+00$ & 0.0000 & $0.000 \mathrm{E}+00$ & 0.0000 & $0.000 \mathrm{E}+00$ & 0.0000 & $0.000 \mathrm{E}+00$ & 0.0000 & $0.000 \mathrm{E}+00$ & 0.0000 & $0.000 \mathrm{E}+00$ & 0.0000 & $1.139 \mathrm{E}-08$ & 0.0027 \\
\hline 232 & $0.000 \mathrm{E}+00$ & 0.0000 & $0.000 \mathrm{E}+00$ & 0.0000 & $0.000 \mathrm{E}+00$ & 0.0000 & $0.000 \mathrm{E}+00$ & 0.0000 & $0.000 \mathrm{E}+00$ & 0.0000 & $0.000 \mathrm{E}+00$ & 0.0000 & $2.759 \mathrm{E}-07$ & 0.0656 \\
\hline & $0.000 \mathrm{E}+00$ & 0.0000 & $0.000 \mathrm{E}+00$ & 0.0000 & $0.000 \mathrm{E}+00$ & 0.0000 & $0.000 \mathrm{E}+00$ & 0.0000 & $0.000 \mathrm{E}+00$ & 0.0000 & $0.000 \mathrm{E}+00$ & 0.0000 & $1.277 \mathrm{E}-13$ & 0.0000 \\
\hline 35 & $0.000 \mathrm{E}+00$ & 0.0000 & $0.000 \mathrm{E}+00$ & 0.0000 & $0.000 \mathrm{E}+00$ & 0.0000 & $0.000 \mathrm{E}+00$ & 0.0000 & $0.000 \mathrm{E}+00$ & 0.0000 & $0.000 \mathrm{E}+00$ & 0.0000 & $8.230 \mathrm{E}-14$ & 0.0000 \\
\hline 38 & $0.000 \mathrm{E}+00$ & 0.0000 & $0.000 \mathrm{E}+00$ & 0.0000 & $0.000 \mathrm{E}+00$ & 0.0000 & $0.000 \mathrm{E}+00$ & 0.0000 & $0.000 \mathrm{E}+00$ & 0.0000 & $0.000 \mathrm{E}+00$ & 0.0000 & $2.290 \mathrm{E}-08$ & 0.0054 \\
\hline & $0.000 \mathrm{E}+00$ & 0.0000 & $0.000 \mathrm{E}+00$ & 0.0000 & $0.000 \mathrm{E}+00$ & 0.0000 & $0.000 \mathrm{E}+00$ & 0.0000 & $0.000 \mathrm{E}+00$ & 0.0000 & $0.000 E+00$ & 000 & -06 & 1.0000 \\
\hline
\end{tabular}

* Sum of all water independent and dependent pathways. 
RESRAD, Version $6.5 \quad \mathrm{~T}^{1 / 2}$ Limit $=180$ days

07/21/2011 12:07 Page 23

: C: \RESRAD_FAMILY \RESRAD \USERFILES \QCJULY2011 \ONSITERF_FORWARD-100000-JULY11.RAD

Total Dose Contributions TDOSE (i,p,t) for Individual Radionuclides (i) and Pathways (p) As mrem/yr and Fraction of Total Dose At $t=5.000 \mathrm{E}+01$ years

Water Independent Pathways (Inhalation excludes radon)

\begin{tabular}{|c|c|c|c|c|c|c|c|c|c|c|c|c|c|c|}
\hline \multirow{2}{*}{ Nuclide } & \multicolumn{2}{|c|}{ Ground } & \multicolumn{2}{|c|}{ Inhalation } & \multicolumn{2}{|c|}{ Radon } & \multicolumn{2}{|c|}{ Plant } & \multicolumn{2}{|c|}{ Meat } & \multicolumn{2}{|c|}{ Milk } & \multicolumn{2}{|c|}{ Soil } \\
\hline & mrem/yr & fract. & mrem/yr & fract. & mrem/yr & fract. & mrem/yr & fract. & mrem/yr & fract. & mrem/yr & fract. & mrem/yr & fract. \\
\hline-241 & $8.973 E-16$ & 0.0000 & $0.000 \mathrm{E}+00$ & 0.0000 & $0.000 \mathrm{E}+00$ & 0.0000 & $0.000 \mathrm{E}+00$ & 0.0000 & $0.000 \mathrm{E}+00$ & 0.0000 & $0.000 \mathrm{E}+00$ & 0.0000 & $0.000 \mathrm{E}+00$ & 0.0000 \\
\hline-137 & $1.149 \mathrm{E}-08$ & 0.0012 & $0.000 \mathrm{E}+00$ & 0.0000 & $0.000 \mathrm{E}+00$ & 0.0000 & $0.000 \mathrm{E}+00$ & 0.0000 & $0.000 \mathrm{E}+00$ & 0.0000 & $0.000 \mathrm{E}+00$ & 0.0000 & $0.000 \mathrm{E}+00$ & 0.0000 \\
\hline-237 & $8.957 \mathrm{E}-12$ & 0.0000 & $0.000 \mathrm{E}+00$ & 0.0000 & $0.000 \mathrm{E}+00$ & 0.0000 & $0.000 \mathrm{E}+00$ & 0.0000 & $0.000 \mathrm{E}+00$ & 0.0000 & $0.000 \mathrm{E}+00$ & 0.0000 & $0.000 \mathrm{E}+00$ & 0.0000 \\
\hline-238 & $2.054 \mathrm{E}-15$ & 0.0000 & $0.000 \mathrm{E}+00$ & 0.0000 & $0.000 \mathrm{E}+00$ & 0.0000 & $0.000 \mathrm{E}+00$ & 0.0000 & $0.000 \mathrm{E}+00$ & 0.0000 & $0.000 \mathrm{E}+00$ & 0.0000 & $0.000 \mathrm{E}+00$ & 0.0000 \\
\hline-239 & $7.861 \mathrm{E}-16$ & 0.0000 & $0.000 \mathrm{E}+00$ & 0.0000 & $0.000 \mathrm{E}+00$ & 0.0000 & $0.000 \mathrm{E}+00$ & 0.0000 & $0.000 \mathrm{E}+00$ & 0.0000 & $0.000 \mathrm{E}+00$ & 0.0000 & $0.000 \mathrm{E}+00$ & 0.0000 \\
\hline-240 & $9.653 \mathrm{E}-20$ & 0.0000 & $0.000 \mathrm{E}+00$ & 0.0000 & $0.000 \mathrm{E}+00$ & 0.0000 & $0.000 \mathrm{E}+00$ & 0.0000 & $0.000 \mathrm{E}+00$ & 0.0000 & $0.000 \mathrm{E}+00$ & 0.0000 & $0.000 \mathrm{E}+00$ & 0.0000 \\
\hline 99 & $4.979 E-24$ & 0.0000 & $0.000 \mathrm{E}+00$ & 0.0000 & $0.000 \mathrm{E}+00$ & 0.0000 & $0.000 \mathrm{E}+00$ & 0.0000 & $0.000 \mathrm{E}+00$ & 0.0000 & $0.000 \mathrm{E}+00$ & 0.0000 & $0.000 \mathrm{E}+00$ & 0.0000 \\
\hline-228 & 1.011E-13 & 0.0000 & $0.000 \mathrm{E}+00$ & 0.0000 & $0.000 \mathrm{E}+00$ & 0.0000 & $0.000 \mathrm{E}+00$ & 0.0000 & $0.000 \mathrm{E}+00$ & 0.0000 & $0.000 \mathrm{E}+00$ & 0.0000 & $0.000 \mathrm{E}+00$ & 0.0000 \\
\hline 230 & $5.320 \mathrm{E}-07$ & 0.0558 & $0.000 \mathrm{E}+00$ & 0.0000 & $0.000 \mathrm{E}+00$ & 0.0000 & $0.000 \mathrm{E}+00$ & 0.0000 & $0.000 \mathrm{E}+00$ & 0.0000 & $0.000 \mathrm{E}+00$ & 0.0000 & $0.000 \mathrm{E}+00$ & 0.0000 \\
\hline-232 & $8.963 E-06$ & 0.9395 & $0.000 \mathrm{E}+00$ & 0.0000 & $0.000 \mathrm{E}+00$ & 0.0000 & $0.000 \mathrm{E}+00$ & 0.0000 & $0.000 \mathrm{E}+00$ & 0.0000 & $0.000 \mathrm{E}+00$ & 0.0000 & $0.000 \mathrm{E}+00$ & 0.0000 \\
\hline 234 & 1. $941 \mathrm{E}-10$ & 0.0000 & $0.000 \mathrm{E}+00$ & 0.0000 & $0.000 \mathrm{E}+00$ & 0.0000 & $0.000 \mathrm{E}+00$ & 0.0000 & $0.000 \mathrm{E}+00$ & 0.0000 & $0.000 \mathrm{E}+00$ & 0.0000 & $0.000 \mathrm{E}+00$ & 0.0000 \\
\hline 35 & $6.005 E-13$ & 0.0000 & $0.000 \mathrm{E}+00$ & 0.0000 & $0.000 \mathrm{E}+00$ & 0.0000 & $0.000 \mathrm{E}+00$ & 0.0000 & $0.000 \mathrm{E}+00$ & 0.0000 & $0.000 \mathrm{E}+00$ & 0.0000 & $0.000 \mathrm{E}+00$ & 0.0000 \\
\hline 38 & $3.385 E-08$ & 0.0035 & $0.000 \mathrm{E}+00$ & 0.0000 & $0.000 \mathrm{E}+00$ & 0.0000 & $0.000 \mathrm{E}+00$ & 0.0000 & $0.000 \mathrm{E}+00$ & 0.0000 & $0.000 \mathrm{E}+00$ & 0.0000 & $0.000 \mathrm{E}+00$ & 0.0000 \\
\hline & $9.541 \mathrm{E}-06$ & 1.0000 & $0.000 \mathrm{E}+00$ & 0.0000 & $0.000 \mathrm{E}+00$ & 0.0000 & $0.000 \mathrm{E}+00$ & 0.0000 & $0.000 \mathrm{E}+00$ & 0.0000 & $0.000 \mathrm{E}+00$ & 0.0000 & $.000 \mathrm{E}+00$ & 0.0000 \\
\hline
\end{tabular}

Total Dose Contributions TDOSE(i,p,t) for Individual Radionuclides (i) and Pathways (p) As mrem/yr and Fraction of Total Dose At $t=5.000 \mathrm{E}+01$ years

Water Dependent Pathways

\begin{tabular}{|c|c|c|c|c|c|c|c|c|c|c|c|c|c|c|}
\hline & \multicolumn{2}{|c|}{ Water } & \multicolumn{2}{|c|}{ Fish } & \multicolumn{2}{|c|}{ Radon } & \multicolumn{2}{|c|}{ Plant } & \multicolumn{2}{|c|}{ Meat } & \multicolumn{2}{|c|}{ Milk } & \multicolumn{2}{|c|}{ All Pathways* } \\
\hline clide & mrem/yr & fract. & mrem/yr & fract. & mrem/yr & fract. & mrem/yr & fract. & mrem/yr & fract. & mrem/yr & fract. & mrem/yr & fract. \\
\hline-241 & $0.000 \mathrm{E}+00$ & 0.0000 & $0.000 \mathrm{E}+00$ & 0.0000 & $0.000 \mathrm{E}+00$ & 0.0000 & $0.000 \mathrm{E}+00$ & 0.0000 & $0.000 \mathrm{E}+00$ & 0.0000 & $0.000 \mathrm{E}+00$ & 0.0000 & $8.973 E-16$ & 0.0000 \\
\hline-137 & $0.000 \mathrm{E}+00$ & 0.0000 & $0.000 \mathrm{E}+00$ & 0.0000 & $0.000 \mathrm{E}+00$ & 0.0000 & $0.000 \mathrm{E}+00$ & 0.0000 & $0.000 \mathrm{E}+00$ & 0.0000 & $0.000 \mathrm{E}+00$ & 0.0000 & $1.149 \mathrm{E}-08$ & 0.0012 \\
\hline-237 & $0.000 \mathrm{E}+00$ & 0.0000 & $0.000 \mathrm{E}+00$ & 0.0000 & $0.000 \mathrm{E}+00$ & 0.0000 & $0.000 \mathrm{E}+00$ & 0.0000 & $0.000 \mathrm{E}+00$ & 0.0000 & $0.000 \mathrm{E}+00$ & 0.0000 & $8.957 \mathrm{E}-12$ & 0.0000 \\
\hline 238 & $0.000 \mathrm{E}+00$ & 0.0000 & $0.000 \mathrm{E}+00$ & 0.0000 & $0.000 \mathrm{E}+00$ & 0.0000 & $0.000 \mathrm{E}+00$ & 0.0000 & $0.000 \mathrm{E}+00$ & 0.0000 & $0.000 \mathrm{E}+00$ & 0.0000 & $2.054 \mathrm{E}-15$ & 0.0000 \\
\hline 239 & $0.000 \mathrm{E}+00$ & 0.0000 & $0.000 \mathrm{E}+00$ & 0.0000 & $0.000 \mathrm{E}+00$ & 0.0000 & $0.000 \mathrm{E}+00$ & 0.0000 & $0.000 \mathrm{E}+00$ & 0.0000 & $0.000 \mathrm{E}+00$ & 0.0000 & $7.861 \mathrm{E}-16$ & 0.0000 \\
\hline 240 & $0.000 \mathrm{E}+00$ & 0.0000 & $0.000 \mathrm{E}+00$ & 0.0000 & $0.000 \mathrm{E}+00$ & 0.0000 & $0.000 \mathrm{E}+00$ & 0.0000 & $0.000 \mathrm{E}+00$ & 0.0000 & $0.000 \mathrm{E}+00$ & 0.0000 & $9.653 \mathrm{E}-20$ & 0.0000 \\
\hline 99 & $0.000 \mathrm{E}+00$ & 0.0000 & $0.000 \mathrm{E}+00$ & 0.0000 & $0.000 \mathrm{E}+00$ & 0.0000 & $0.000 \mathrm{E}+00$ & 0.0000 & $0.000 \mathrm{E}+00$ & 0.0000 & $0.000 \mathrm{E}+00$ & 0.0000 & $4.979 E-24$ & 0.0000 \\
\hline 228 & $0.000 \mathrm{E}+00$ & 0.0000 & $0.000 \mathrm{E}+00$ & 0.0000 & $0.000 \mathrm{E}+00$ & 0.0000 & $0.000 \mathrm{E}+00$ & 0.0000 & $0.000 \mathrm{E}+00$ & 0.0000 & $0.000 \mathrm{E}+00$ & 0.0000 & $1.011 \mathrm{E}-13$ & 0.0000 \\
\hline 230 & $0.000 \mathrm{E}+00$ & 0.0000 & $0.000 \mathrm{E}+00$ & 0.0000 & $0.000 \mathrm{E}+00$ & 0.0000 & $0.000 \mathrm{E}+00$ & 0.0000 & $0.000 \mathrm{E}+00$ & 0.0000 & $0.000 \mathrm{E}+00$ & 0.0000 & $5.320 \mathrm{E}-07$ & 0.0558 \\
\hline 232 & $0.000 \mathrm{E}+00$ & 0.0000 & $0.000 \mathrm{E}+00$ & 0.0000 & $0.000 \mathrm{E}+00$ & 0.0000 & $0.000 \mathrm{E}+00$ & 0.0000 & $0.000 \mathrm{E}+00$ & 0.0000 & $0.000 \mathrm{E}+00$ & 0.0000 & $8.963 E-06$ & 0.9395 \\
\hline & $0.000 \mathrm{E}+00$ & 0.0000 & $0.000 \mathrm{E}+00$ & 0.0000 & $0.000 \mathrm{E}+00$ & 0.0000 & $0.000 \mathrm{E}+00$ & 0.0000 & $0.000 \mathrm{E}+00$ & 0.0000 & $0.000 \mathrm{E}+00$ & 0.0000 & $1.941 \mathrm{E}-10$ & 0.0000 \\
\hline 35 & $0.000 \mathrm{E}+00$ & 0.0000 & $0.000 \mathrm{E}+00$ & 0.0000 & $0.000 \mathrm{E}+00$ & 0.0000 & $0.000 \mathrm{E}+00$ & 0.0000 & $0.000 \mathrm{E}+00$ & 0.0000 & $0.000 \mathrm{E}+00$ & 0.0000 & $6.005 E-13$ & 0.0000 \\
\hline 38 & $0.000 \mathrm{E}+00$ & 0.0000 & $0.000 \mathrm{E}+00$ & 0.0000 & $0.000 \mathrm{E}+00$ & 0.0000 & $0.000 \mathrm{E}+00$ & 0.0000 & $0.000 \mathrm{E}+00$ & 0.0000 & $0.000 \mathrm{E}+00$ & 0.0000 & $3.385 \mathrm{E}-08$ & 0.0035 \\
\hline & $0.000 \mathrm{E}+00$ & 0.0000 & $0.000 \mathrm{E}+00$ & 0.0000 & $0.000 \mathrm{E}+00$ & 0.0000 & $0.000 \mathrm{E}+00$ & 0.0000 & $0.000 \mathrm{E}+00$ & 0.0000 & $0.000 \mathrm{E}+00$ & 000 & -06 & 1.0000 \\
\hline
\end{tabular}

* Sum of all water independent and dependent pathways. 
RESRAD, Version $6.5 \quad \mathrm{~T}^{1 / 2}$ Limit $=180$ days

07/21/2011 12:07 Page 24

ummary : RESRAD Parameters for Resident Farmer U-Landfill Forward Run 100,000 Years

File : C: \RESRAD_FAMILY \RESRAD \USERFILES $\backslash Q C J U L Y 2011 \backslash$ ONSITERF_FORWARD-100000-JULY11.RAD

Total Dose Contributions TDOSE (i,p,t) for Individual Radionuclides (i) and Pathways (p) As mrem/yr and Fraction of Total Dose At $t=1.000 \mathrm{E}+02$ years

Water Independent Pathways (Inhalation excludes radon)

\begin{tabular}{|c|c|c|c|c|c|c|c|c|c|c|c|c|c|c|}
\hline \multirow{2}{*}{ Nuclide } & \multicolumn{2}{|c|}{ Ground } & \multicolumn{2}{|c|}{ Inhalation } & \multicolumn{2}{|c|}{ Radon } & \multicolumn{2}{|c|}{ Plant } & \multicolumn{2}{|c|}{ Meat } & \multicolumn{2}{|c|}{ Milk } & \multicolumn{2}{|c|}{ Soil } \\
\hline & mrem/yr & fract. & mrem/yr & fract. & mrem/yr & fract. & mrem/yr & fract. & mrem/yr & fract. & mrem/yr & fract. & mrem/yr & fract. \\
\hline-241 & $2.940 \mathrm{E}-15$ & 0.0000 & $0.000 \mathrm{E}+00$ & 0.0000 & $0.000 \mathrm{E}+00$ & 0.0000 & $0.000 \mathrm{E}+00$ & 0.0000 & $0.000 \mathrm{E}+00$ & 0.0000 & $0.000 \mathrm{E}+00$ & 0.0000 & $0.000 \mathrm{E}+00$ & 0.0000 \\
\hline-137 & $5.512 \mathrm{E}-09$ & 0.0004 & $0.000 \mathrm{E}+00$ & 0.0000 & $0.000 \mathrm{E}+00$ & 0.0000 & $0.000 \mathrm{E}+00$ & 0.0000 & $0.000 \mathrm{E}+00$ & 0.0000 & $0.000 \mathrm{E}+00$ & 0.0000 & $0.000 \mathrm{E}+00$ & 0.0000 \\
\hline-237 & $1.534 \mathrm{E}-11$ & 0.0000 & $0.000 \mathrm{E}+00$ & 0.0000 & $0.000 \mathrm{E}+00$ & 0.0000 & $0.000 \mathrm{E}+00$ & 0.0000 & $0.000 \mathrm{E}+00$ & 0.0000 & $0.000 \mathrm{E}+00$ & 0.0000 & $0.000 \mathrm{E}+00$ & 0.0000 \\
\hline-238 & $2.076 \mathrm{E}-14$ & 0.0000 & $0.000 \mathrm{E}+00$ & 0.0000 & $0.000 \mathrm{E}+00$ & 0.0000 & $0.000 \mathrm{E}+00$ & 0.0000 & $0.000 \mathrm{E}+00$ & 0.0000 & $0.000 \mathrm{E}+00$ & 0.0000 & $0.000 \mathrm{E}+00$ & 0.0000 \\
\hline-239 & $1.428 \mathrm{E}-15$ & 0.0000 & $0.000 \mathrm{E}+00$ & 0.0000 & $0.000 \mathrm{E}+00$ & 0.0000 & $0.000 \mathrm{E}+00$ & 0.0000 & $0.000 \mathrm{E}+00$ & 0.0000 & $0.000 \mathrm{E}+00$ & 0.0000 & $0.000 \mathrm{E}+00$ & 0.0000 \\
\hline-240 & $6.420 \mathrm{E}-19$ & 0.0000 & $0.000 \mathrm{E}+00$ & 0.0000 & $0.000 \mathrm{E}+00$ & 0.0000 & $0.000 \mathrm{E}+00$ & 0.0000 & $0.000 \mathrm{E}+00$ & 0.0000 & $0.000 \mathrm{E}+00$ & 0.0000 & $0.000 \mathrm{E}+00$ & 0.0000 \\
\hline 99 & $8.280 E-24$ & 0.0000 & $0.000 \mathrm{E}+00$ & 0.0000 & $0.000 \mathrm{E}+00$ & 0.0000 & $0.000 \mathrm{E}+00$ & 0.0000 & $0.000 \mathrm{E}+00$ & 0.0000 & $0.000 \mathrm{E}+00$ & 0.0000 & $0.000 \mathrm{E}+00$ & 0.0000 \\
\hline-228 & $1.847 \mathrm{E}-21$ & 0.0000 & $0.000 \mathrm{E}+00$ & 0.0000 & $0.000 \mathrm{E}+00$ & 0.0000 & $0.000 \mathrm{E}+00$ & 0.0000 & $0.000 \mathrm{E}+00$ & 0.0000 & $0.000 \mathrm{E}+00$ & 0.0000 & $0.000 \mathrm{E}+00$ & 0.0000 \\
\hline-230 & $1.479 \mathrm{E}-06$ & 0.1082 & $0.000 \mathrm{E}+00$ & 0.0000 & $0.000 \mathrm{E}+00$ & 0.0000 & $0.000 \mathrm{E}+00$ & 0.0000 & $0.000 \mathrm{E}+00$ & 0.0000 & $0.000 \mathrm{E}+00$ & 0.0000 & $0.000 \mathrm{E}+00$ & 0.0000 \\
\hline-232 & $1.213 E-05$ & 0.8876 & $0.000 \mathrm{E}+00$ & 0.0000 & $0.000 \mathrm{E}+00$ & 0.0000 & $0.000 \mathrm{E}+00$ & 0.0000 & $0.000 \mathrm{E}+00$ & 0.0000 & $0.000 \mathrm{E}+00$ & 0.0000 & $0.000 \mathrm{E}+00$ & 0.0000 \\
\hline 34 & $1.078 \mathrm{E}-09$ & 0.0001 & $0.000 \mathrm{E}+00$ & 0.0000 & $0.000 \mathrm{E}+00$ & 0.0000 & $0.000 \mathrm{E}+00$ & 0.0000 & $0.000 \mathrm{E}+00$ & 0.0000 & $0.000 \mathrm{E}+00$ & 0.0000 & $0.000 \mathrm{E}+00$ & 0.0000 \\
\hline 35 & $2.202 \mathrm{E}-12$ & 0.0000 & $0.000 \mathrm{E}+00$ & 0.0000 & $0.000 \mathrm{E}+00$ & 0.0000 & $0.000 \mathrm{E}+00$ & 0.0000 & $0.000 \mathrm{E}+00$ & 0.0000 & $0.000 \mathrm{E}+00$ & 0.0000 & $0.000 \mathrm{E}+00$ & 0.0000 \\
\hline 38 & $5.045 E-08$ & 0.0037 & $0.000 \mathrm{E}+00$ & 0.0000 & $0.000 \mathrm{E}+00$ & 0.0000 & $0.000 \mathrm{E}+00$ & 0.0000 & $0.000 \mathrm{E}+00$ & 0.0000 & $0.000 \mathrm{E}+00$ & 0.0000 & $0.000 \mathrm{E}+00$ & 0.0000 \\
\hline & $1.367 \mathrm{E}-05$ & 1.0000 & $0.000 \mathrm{E}+00$ & 0.0000 & $0.000 \mathrm{E}+00$ & 0.0000 & $0.000 \mathrm{E}+00$ & 0.0000 & $0.000 \mathrm{E}+00$ & 0.0000 & $0.000 \mathrm{E}+00$ & 0.0000 & $0.000 \mathrm{E}+00$ & 0.0000 \\
\hline
\end{tabular}

Total Dose Contributions TDOSE(i,p,t) for Individual Radionuclides (i) and Pathways (p) As mrem/yr and Fraction of Total Dose At $t=1.000 \mathrm{E}+02$ years

Water Dependent Pathways

\begin{tabular}{|c|c|c|c|c|c|c|c|c|c|c|c|c|c|c|}
\hline & \multicolumn{2}{|c|}{ Water } & \multicolumn{2}{|c|}{ Fish } & \multicolumn{2}{|c|}{ Radon } & \multicolumn{2}{|c|}{ Plant } & \multicolumn{2}{|c|}{ Meat } & \multicolumn{2}{|c|}{ Milk } & \multicolumn{2}{|c|}{ All Pathways* } \\
\hline clide & mrem/yr & fract. & mrem/yr & fract. & mrem/yr & fract. & mrem/yr & fract. & mrem/yr & fract. & mrem/yr & fract. & mrem/yr & fract. \\
\hline-241 & $0.000 \mathrm{E}+00$ & 0.0000 & $0.000 \mathrm{E}+00$ & 0.0000 & $0.000 \mathrm{E}+00$ & 0.0000 & $0.000 \mathrm{E}+00$ & 0.0000 & $0.000 \mathrm{E}+00$ & 0.0000 & $0.000 \mathrm{E}+00$ & 0.0000 & $2.940 \mathrm{E}-15$ & 0.0000 \\
\hline-137 & $0.000 \mathrm{E}+00$ & 0.0000 & $0.000 \mathrm{E}+00$ & 0.0000 & $0.000 \mathrm{E}+00$ & 0.0000 & $0.000 \mathrm{E}+00$ & 0.0000 & $0.000 \mathrm{E}+00$ & 0.0000 & $0.000 \mathrm{E}+00$ & 0.0000 & $5.512 \mathrm{E}-09$ & 0.0004 \\
\hline-237 & $0.000 \mathrm{E}+00$ & 0.0000 & $0.000 \mathrm{E}+00$ & 0.0000 & $0.000 \mathrm{E}+00$ & 0.0000 & $0.000 \mathrm{E}+00$ & 0.0000 & $0.000 \mathrm{E}+00$ & 0.0000 & $0.000 \mathrm{E}+00$ & 0.0000 & $1.534 \mathrm{E}-11$ & 0.0000 \\
\hline 238 & $0.000 \mathrm{E}+00$ & 0.0000 & $0.000 \mathrm{E}+00$ & 0.0000 & $0.000 \mathrm{E}+00$ & 0.0000 & $0.000 \mathrm{E}+00$ & 0.0000 & $0.000 \mathrm{E}+00$ & 0.0000 & $0.000 \mathrm{E}+00$ & 0.0000 & $2.076 \mathrm{E}-14$ & 0.0000 \\
\hline 239 & $0.000 \mathrm{E}+00$ & 0.0000 & $0.000 \mathrm{E}+00$ & 0.0000 & $0.000 \mathrm{E}+00$ & 0.0000 & $0.000 \mathrm{E}+00$ & 0.0000 & $0.000 \mathrm{E}+00$ & 0.0000 & $0.000 \mathrm{E}+00$ & 0.0000 & $1.428 \mathrm{E}-15$ & 0.0000 \\
\hline 240 & $0.000 \mathrm{E}+00$ & 0.0000 & $0.000 \mathrm{E}+00$ & 0.0000 & $0.000 \mathrm{E}+00$ & 0.0000 & $0.000 \mathrm{E}+00$ & 0.0000 & $0.000 \mathrm{E}+00$ & 0.0000 & $0.000 \mathrm{E}+00$ & 0.0000 & $6.420 \mathrm{E}-19$ & 0.0000 \\
\hline 99 & $0.000 \mathrm{E}+00$ & 0.0000 & $0.000 \mathrm{E}+00$ & 0.0000 & $0.000 \mathrm{E}+00$ & 0.0000 & $0.000 \mathrm{E}+00$ & 0.0000 & $0.000 \mathrm{E}+00$ & 0.0000 & $0.000 \mathrm{E}+00$ & 0.0000 & $8.280 \mathrm{E}-24$ & 0.0000 \\
\hline 228 & $0.000 \mathrm{E}+00$ & 0.0000 & $0.000 \mathrm{E}+00$ & 0.0000 & $0.000 \mathrm{E}+00$ & 0.0000 & $0.000 \mathrm{E}+00$ & 0.0000 & $0.000 \mathrm{E}+00$ & 0.0000 & $0.000 \mathrm{E}+00$ & 0.0000 & $1.847 \mathrm{E}-21$ & 0.0000 \\
\hline 230 & $0.000 \mathrm{E}+00$ & 0.0000 & $0.000 \mathrm{E}+00$ & 0.0000 & $0.000 \mathrm{E}+00$ & 0.0000 & $0.000 \mathrm{E}+00$ & 0.0000 & $0.000 \mathrm{E}+00$ & 0.0000 & $0.000 \mathrm{E}+00$ & 0.0000 & $1.479 \mathrm{E}-06$ & 0.1082 \\
\hline 232 & $0.000 \mathrm{E}+00$ & 0.0000 & $0.000 \mathrm{E}+00$ & 0.0000 & $0.000 \mathrm{E}+00$ & 0.0000 & $0.000 \mathrm{E}+00$ & 0.0000 & $0.000 \mathrm{E}+00$ & 0.0000 & $0.000 \mathrm{E}+00$ & 0.0000 & $1.213 E-05$ & 0.8876 \\
\hline & $0.000 \mathrm{E}+00$ & 0.0000 & $0.000 \mathrm{E}+00$ & 0.0000 & $0.000 \mathrm{E}+00$ & 0.0000 & $0.000 \mathrm{E}+00$ & 0.0000 & $0.000 \mathrm{E}+00$ & 0.0000 & $0.000 \mathrm{E}+00$ & 0.0000 & $1.078 \mathrm{E}-09$ & 0.0001 \\
\hline 35 & $0.000 \mathrm{E}+00$ & 0.0000 & $0.000 \mathrm{E}+00$ & 0.0000 & $0.000 \mathrm{E}+00$ & 0.0000 & $0.000 \mathrm{E}+00$ & 0.0000 & $0.000 \mathrm{E}+00$ & 0.0000 & $0.000 \mathrm{E}+00$ & 0.0000 & $2.202 \mathrm{E}-12$ & 0.0000 \\
\hline 38 & $0.000 \mathrm{E}+00$ & 0.0000 & $0.000 \mathrm{E}+00$ & 0.0000 & $0.000 \mathrm{E}+00$ & 0.0000 & $0.000 \mathrm{E}+00$ & 0.0000 & $0.000 \mathrm{E}+00$ & 0.0000 & $0.000 \mathrm{E}+00$ & 0.0000 & $5.045 \mathrm{E}-08$ & 0.0037 \\
\hline & $0.000 \mathrm{E}+00$ & 0.0000 & $0.000 \mathrm{E}+00$ & 0.0000 & $0.000 \mathrm{E}+00$ & 0.0000 & $0.000 \mathrm{E}+00$ & 0.0000 & $0.000 \mathrm{E}+00$ & 0.0000 & $0.000 \mathrm{E}+00$ & 000 & -05 & 1.0000 \\
\hline
\end{tabular}

* Sum of all water independent and dependent pathways. 
RESRAD, Version $6.5 \quad \mathrm{~T}^{1 / 2}$ Limit $=180$ days

07/21/2011 12:07 Page 25

: C: $\backslash$ RESRAD_FAMILY \RESRAD \USERFILES \QCJULY2011 \ONSITERF_FORWARD-100000-JULY11.RAD

Total Dose Contributions TDOSE (i,p,t) for Individual Radionuclides (i) and Pathways (p) As mrem/yr and Fraction of Total Dose At $t=5.000 \mathrm{E}+02$ years

Water Independent Pathways (Inhalation excludes radon)

\begin{tabular}{|c|c|c|c|c|c|c|c|c|c|c|c|c|c|c|}
\hline \multirow{2}{*}{ Nuclide } & \multicolumn{2}{|c|}{ Ground } & \multicolumn{2}{|c|}{ Inhalation } & \multicolumn{2}{|c|}{ Radon } & \multicolumn{2}{|c|}{ Plant } & \multicolumn{2}{|c|}{ Meat } & \multicolumn{2}{|c|}{ Milk } & \multicolumn{2}{|c|}{ Soil } \\
\hline & mrem/yr & fract. & mrem/yr & fract. & mrem/yr & fract. & mrem/yr & fract. & mrem/yr & fract. & mrem/yr & fract. & mrem/yr & fract. \\
\hline-241 & $8.032 \mathrm{E}-13$ & 0.0000 & $0.000 \mathrm{E}+00$ & 0.0000 & $0.000 \mathrm{E}+00$ & 0.0000 & $0.000 \mathrm{E}+00$ & 0.0000 & $0.000 \mathrm{E}+00$ & 0.0000 & $0.000 \mathrm{E}+00$ & 0.0000 & $0.000 \mathrm{E}+00$ & 0.0000 \\
\hline-137 & $1.540 \mathrm{E}-11$ & 0.0000 & $0.000 \mathrm{E}+00$ & 0.0000 & $0.000 \mathrm{E}+00$ & 0.0000 & $0.000 \mathrm{E}+00$ & 0.0000 & $0.000 \mathrm{E}+00$ & 0.0000 & $0.000 \mathrm{E}+00$ & 0.0000 & $0.000 \mathrm{E}+00$ & 0.0000 \\
\hline-237 & $1.124 \mathrm{E}-09$ & 0.0000 & $0.000 \mathrm{E}+00$ & 0.0000 & $0.000 \mathrm{E}+00$ & 0.0000 & $0.000 \mathrm{E}+00$ & 0.0000 & $0.000 \mathrm{E}+00$ & 0.0000 & $0.000 \mathrm{E}+00$ & 0.0000 & $0.000 \mathrm{E}+00$ & 0.0000 \\
\hline-238 & $2.187 \mathrm{E}-11$ & 0.0000 & $0.000 \mathrm{E}+00$ & 0.0000 & $0.000 \mathrm{E}+00$ & 0.0000 & $0.000 \mathrm{E}+00$ & 0.0000 & $0.000 \mathrm{E}+00$ & 0.0000 & $0.000 \mathrm{E}+00$ & 0.0000 & $0.000 \mathrm{E}+00$ & 0.0000 \\
\hline-239 & 1. $695 \mathrm{E}-13$ & 0.0000 & $0.000 \mathrm{E}+00$ & 0.0000 & $0.000 \mathrm{E}+00$ & 0.0000 & $0.000 \mathrm{E}+00$ & 0.0000 & $0.000 \mathrm{E}+00$ & 0.0000 & $0.000 \mathrm{E}+00$ & 0.0000 & $0.000 \mathrm{E}+00$ & 0.0000 \\
\hline-240 & $2.059 \mathrm{E}-16$ & 0.0000 & $0.000 \mathrm{E}+00$ & 0.0000 & $0.000 \mathrm{E}+00$ & 0.0000 & $0.000 \mathrm{E}+00$ & 0.0000 & $0.000 \mathrm{E}+00$ & 0.0000 & $0.000 \mathrm{E}+00$ & 0.0000 & $0.000 \mathrm{E}+00$ & 0.0000 \\
\hline 99 & $4.841 E-22$ & 0.0000 & $0.000 \mathrm{E}+00$ & 0.0000 & $0.000 \mathrm{E}+00$ & 0.0000 & $0.000 \mathrm{E}+00$ & 0.0000 & $0.000 \mathrm{E}+00$ & 0.0000 & $0.000 \mathrm{E}+00$ & 0.0000 & $0.000 \mathrm{E}+00$ & 0.0000 \\
\hline-228 & $0.000 \mathrm{E}+00$ & 0.0000 & $0.000 \mathrm{E}+00$ & 0.0000 & $0.000 \mathrm{E}+00$ & 0.0000 & $0.000 \mathrm{E}+00$ & 0.0000 & $0.000 \mathrm{E}+00$ & 0.0000 & $0.000 \mathrm{E}+00$ & 0.0000 & $0.000 \mathrm{E}+00$ & 0.0000 \\
\hline-230 & $1.071 \mathrm{E}-04$ & 0.0000 & $0.000 \mathrm{E}+00$ & 0.0000 & $0.000 \mathrm{E}+00$ & 0.0000 & $0.000 \mathrm{E}+00$ & 0.0000 & $0.000 \mathrm{E}+00$ & 0.0000 & $0.000 \mathrm{E}+00$ & 0.0000 & $0.000 \mathrm{E}+00$ & 0.0000 \\
\hline-232 & $1.335 E-04$ & 0.0000 & $0.000 \mathrm{E}+00$ & 0.0000 & $0.000 \mathrm{E}+00$ & 0.0000 & $0.000 \mathrm{E}+00$ & 0.0000 & $0.000 \mathrm{E}+00$ & 0.0000 & $0.000 \mathrm{E}+00$ & 0.0000 & $0.000 \mathrm{E}+00$ & 0.0000 \\
\hline 234 & $3.993 E-07$ & 0.0000 & $0.000 \mathrm{E}+00$ & 0.0000 & $0.000 \mathrm{E}+00$ & 0.0000 & $0.000 \mathrm{E}+00$ & 0.0000 & $0.000 \mathrm{E}+00$ & 0.0000 & $0.000 \mathrm{E}+00$ & 0.0000 & $0.000 \mathrm{E}+00$ & 0.0000 \\
\hline 35 & $4.571 \mathrm{E}-10$ & 0.0000 & $0.000 \mathrm{E}+00$ & 0.0000 & $0.000 \mathrm{E}+00$ & 0.0000 & $0.000 \mathrm{E}+00$ & 0.0000 & $0.000 \mathrm{E}+00$ & 0.0000 & $0.000 \mathrm{E}+00$ & 0.0000 & $0.000 \mathrm{E}+00$ & 0.0000 \\
\hline 38 & $1.229 \mathrm{E}-06$ & 0.0000 & $0.000 \mathrm{E}+00$ & 0.0000 & $0.000 \mathrm{E}+00$ & 0.0000 & $0.000 \mathrm{E}+00$ & 0.0000 & $0.000 \mathrm{E}+00$ & 0.0000 & $0.000 \mathrm{E}+00$ & 0.0000 & $0.000 \mathrm{E}+00$ & 0.0000 \\
\hline & $2.423 E-04$ & 0.0000 & $0.000 \mathrm{E}+00$ & 0.0000 & $0.000 \mathrm{E}+00$ & 0.0000 & $0.000 \mathrm{E}+00$ & 0.0000 & $0.000 \mathrm{E}+00$ & 0.0000 & $0.000 \mathrm{E}+00$ & 0.0000 & $0.000 \mathrm{E}+00$ & 0.0000 \\
\hline
\end{tabular}

Total Dose Contributions TDOSE(i,p,t) for Individual Radionuclides (i) and Pathways (p) As mrem/yr and Fraction of Total Dose At $t=5.000 \mathrm{E}+02$ years

Water Dependent Pathways

\begin{tabular}{|c|c|c|c|c|c|c|c|c|c|c|c|c|c|c|}
\hline & \multicolumn{2}{|c|}{ Water } & \multicolumn{2}{|c|}{ Fish } & \multicolumn{2}{|c|}{ Radon } & \multicolumn{2}{|c|}{ Plant } & \multicolumn{2}{|c|}{ Meat } & \multicolumn{2}{|c|}{ Milk } & \multicolumn{2}{|c|}{ All Pathways* } \\
\hline clide & mrem/yr & fract. & mrem/yr & fract. & mrem/yr & fract. & mrem/yr & fract. & mrem/yr & fract. & mrem/yr & fract. & mrem/yr & fract. \\
\hline-241 & $0.000 \mathrm{E}+00$ & 0.0000 & $0.000 \mathrm{E}+00$ & 0.0000 & $0.000 \mathrm{E}+00$ & 0.0000 & $0.000 \mathrm{E}+00$ & 0.0000 & $0.000 \mathrm{E}+00$ & 0.0000 & $0.000 \mathrm{E}+00$ & 0.0000 & $8.032 \mathrm{E}-13$ & 0.0000 \\
\hline-137 & $0.000 \mathrm{E}+00$ & 0.0000 & $0.000 \mathrm{E}+00$ & 0.0000 & $0.000 \mathrm{E}+00$ & 0.0000 & $0.000 \mathrm{E}+00$ & 0.0000 & $0.000 \mathrm{E}+00$ & 0.0000 & $0.000 \mathrm{E}+00$ & 0.0000 & $1.540 \mathrm{E}-11$ & 0.0000 \\
\hline-237 & $0.000 \mathrm{E}+00$ & 0.0000 & $0.000 \mathrm{E}+00$ & 0.0000 & $0.000 \mathrm{E}+00$ & 0.0000 & $0.000 \mathrm{E}+00$ & 0.0000 & $0.000 \mathrm{E}+00$ & 0.0000 & $0.000 \mathrm{E}+00$ & 0.0000 & $1.124 \mathrm{E}-09$ & 0.0000 \\
\hline 238 & $0.000 \mathrm{E}+00$ & 0.0000 & $0.000 \mathrm{E}+00$ & 0.0000 & $0.000 \mathrm{E}+00$ & 0.0000 & $0.000 \mathrm{E}+00$ & 0.0000 & $0.000 \mathrm{E}+00$ & 0.0000 & $0.000 \mathrm{E}+00$ & 0.0000 & $2.187 \mathrm{E}-11$ & 0.0000 \\
\hline 239 & $0.000 \mathrm{E}+00$ & 0.0000 & $0.000 \mathrm{E}+00$ & 0.0000 & $0.000 \mathrm{E}+00$ & 0.0000 & $0.000 \mathrm{E}+00$ & 0.0000 & $0.000 \mathrm{E}+00$ & 0.0000 & $0.000 \mathrm{E}+00$ & 0.0000 & $1.695 \mathrm{E}-13$ & 0.0000 \\
\hline 240 & $0.000 \mathrm{E}+00$ & 0.0000 & $0.000 \mathrm{E}+00$ & 0.0000 & $0.000 \mathrm{E}+00$ & 0.0000 & $0.000 \mathrm{E}+00$ & 0.0000 & $0.000 \mathrm{E}+00$ & 0.0000 & $0.000 \mathrm{E}+00$ & 0.0000 & $2.059 \mathrm{E}-16$ & 0.0000 \\
\hline 99 & $8.911 E+00$ & 0.8277 & $0.000 \mathrm{E}+00$ & 0.0000 & $0.000 \mathrm{E}+00$ & 0.0000 & $8.331 \mathrm{E}-01$ & 0.0774 & $1.491 \mathrm{E}-02$ & 0.0014 & $1.007 \mathrm{E}+00$ & 0.0935 & $1.077 \mathrm{E}+01$ & 1.0000 \\
\hline 228 & $0.000 \mathrm{E}+00$ & 0.0000 & $0.000 \mathrm{E}+00$ & 0.0000 & $0.000 \mathrm{E}+00$ & 0.0000 & $0.000 \mathrm{E}+00$ & 0.0000 & $0.000 \mathrm{E}+00$ & 0.0000 & $0.000 \mathrm{E}+00$ & 0.0000 & $0.000 \mathrm{E}+00$ & 0.0000 \\
\hline 230 & $0.000 \mathrm{E}+00$ & 0.0000 & $0.000 \mathrm{E}+00$ & 0.0000 & $0.000 \mathrm{E}+00$ & 0.0000 & $0.000 \mathrm{E}+00$ & 0.0000 & $0.000 \mathrm{E}+00$ & 0.0000 & $0.000 \mathrm{E}+00$ & 0.0000 & $1.071 \mathrm{E}-04$ & 0.0000 \\
\hline 232 & $0.000 \mathrm{E}+00$ & 0.0000 & $0.000 \mathrm{E}+00$ & 0.0000 & $0.000 \mathrm{E}+00$ & 0.0000 & $0.000 \mathrm{E}+00$ & 0.0000 & $0.000 \mathrm{E}+00$ & 0.0000 & $0.000 \mathrm{E}+00$ & 0.0000 & $1.335 \mathrm{E}-04$ & 0.0000 \\
\hline & $0.000 \mathrm{E}+00$ & 0.0000 & $0.000 \mathrm{E}+00$ & 0.0000 & $0.000 \mathrm{E}+00$ & 0.0000 & $0.000 \mathrm{E}+00$ & 0.0000 & $0.000 \mathrm{E}+00$ & 0.0000 & $0.000 \mathrm{E}+00$ & 0.0000 & $3.993 E-07$ & 0.0000 \\
\hline 35 & $0.000 \mathrm{E}+00$ & 0.0000 & $0.000 \mathrm{E}+00$ & 0.0000 & $0.000 \mathrm{E}+00$ & 0.0000 & $0.000 \mathrm{E}+00$ & 0.0000 & $0.000 \mathrm{E}+00$ & 0.0000 & $0.000 \mathrm{E}+00$ & 0.0000 & $4.571 \mathrm{E}-10$ & 0.0000 \\
\hline 38 & $0.000 \mathrm{E}+00$ & 0.0000 & $0.000 \mathrm{E}+00$ & 0.0000 & $0.000 \mathrm{E}+00$ & 0.0000 & $0.000 \mathrm{E}+00$ & 0.0000 & $0.000 \mathrm{E}+00$ & 0.0000 & $0.000 \mathrm{E}+00$ & 0.0000 & $1.229 \mathrm{E}-06$ & 0.0000 \\
\hline & $8.911 E+00$ & 0.8277 & $0.000 \mathrm{E}+00$ & 0.0000 & $0.000 \mathrm{E}+00$ & 0.0000 & $8.331 \mathrm{E}-01$ & 0.0774 & $1.491 \mathrm{E}-02$ & 0.0014 & $.007 E+00$ & 935 & +01 & 1.0000 \\
\hline
\end{tabular}

* Sum of all water independent and dependent pathways. 
RESRAD, Version $6.5 \quad \mathrm{~T}^{1 / 2}$ Limit $=180$ days

07/21/2011 12:07 Page 26

ummary : RESRAD Parameters for Resident Farmer U-Landfill Forward Run 100,000 Years

File : C: \RESRAD_FAMILY \RESRAD \USERFILES $\backslash Q C J U L Y 2011 \backslash$ ONSITERF_FORWARD-100000-JULY11.RAD

Total Dose Contributions TDOSE (i,p,t) for Individual Radionuclides (i) and Pathways (p) As mrem/yr and Fraction of Total Dose At $t=1.050 \mathrm{E}+03$ years

Water Independent Pathways (Inhalation excludes radon)

\begin{tabular}{|c|c|c|c|c|c|c|c|c|c|c|c|c|c|c|}
\hline \multirow{2}{*}{$\begin{array}{l}\text { Radio- } \\
\text { Nuclide }\end{array}$} & \multicolumn{2}{|c|}{ Ground } & \multicolumn{2}{|c|}{ Inhalation } & \multicolumn{2}{|c|}{ Radon } & \multicolumn{2}{|c|}{ Plant } & \multicolumn{2}{|c|}{ Meat } & \multicolumn{2}{|c|}{ Milk } & \multicolumn{2}{|c|}{ Soil } \\
\hline & mrem/yr & fract. & mrem/yr & fract. & mrem/yr & fract. & mrem/yr & fract. & mrem/yr & fract. & mrem/yr & fract. & mrem/yr & fract. \\
\hline $1-241$ & $4.257 \mathrm{E}-10$ & 0.0000 & $0.000 \mathrm{E}+00$ & 0.0000 & $0.000 \mathrm{E}+00$ & 0.0000 & $6.939 E-03$ & 0.0009 & $1.230 E-05$ & 0.0000 & $1.180 \mathrm{E}-06$ & 0.0000 & $0.000 \mathrm{E}+00$ & 0.0000 \\
\hline-137 & $4.741 \mathrm{E}-15$ & 0.0000 & $0.000 \mathrm{E}+00$ & 0.0000 & $0.000 \mathrm{E}+00$ & 0.0000 & $1.461 \mathrm{E}-12$ & 0.0000 & 1. $328 \mathrm{E}-12$ & 0.0000 & $9.802 \mathrm{E}-13$ & 0.0000 & $0.000 \mathrm{E}+00$ & 0.0000 \\
\hline-237 & $3.910 \mathrm{E}-07$ & 0.0000 & $0.000 \mathrm{E}+00$ & 0.0000 & $0.000 \mathrm{E}+00$ & 0.0000 & $5.637 \mathrm{E}-02$ & 0.0076 & $1.708 \mathrm{E}-03$ & 0.0002 & $2.443 E-05$ & 0.0000 & $0.000 \mathrm{E}+00$ & 0.0000 \\
\hline-238 & $5.077 \mathrm{E}-09$ & 0.0000 & $0.000 \mathrm{E}+00$ & 0.0000 & $0.000 \mathrm{E}+00$ & 0.0000 & $2.382 E-05$ & 0.0000 & $2.117 \mathrm{E}-07$ & 0.0000 & $5.992 \mathrm{E}-07$ & 0.0000 & $0.000 \mathrm{E}+00$ & 0.0000 \\
\hline-239 & $1.202 \mathrm{E}-10$ & 0.0000 & $0.000 \mathrm{E}+00$ & 0.0000 & $0.000 \mathrm{E}+00$ & 0.0000 & $4.566 \mathrm{E}-02$ & 0.0062 & $1.384 \mathrm{E}-04$ & 0.0000 & $3.831 \mathrm{E}-06$ & 0.0000 & $0.000 \mathrm{E}+00$ & 0.0000 \\
\hline-240 & $2.914 \mathrm{E}-14$ & 0.0000 & $0.000 \mathrm{E}+00$ & 0.0000 & $0.000 \mathrm{E}+00$ & 0.0000 & $4.210 \mathrm{E}-02$ & 0.0057 & $1.276 \mathrm{E}-04$ & 0.0000 & $3.564 \mathrm{E}-06$ & 0.0000 & $0.000 \mathrm{E}+00$ & 0.0000 \\
\hline-99 & 1. $302 \mathrm{E}-19$ & 0.0000 & $0.000 \mathrm{E}+00$ & 0.0000 & $0.000 \mathrm{E}+00$ & 0.0000 & $6.892 \mathrm{E}-05$ & 0.0000 & $2.091 \mathrm{E}-07$ & 0.0000 & $5.786 \mathrm{E}-06$ & 0.0000 & $0.000 \mathrm{E}+00$ & 0.0000 \\
\hline-228 & $0.000 \mathrm{E}+00$ & 0.0000 & $0.000 \mathrm{E}+00$ & 0.0000 & $0.000 \mathrm{E}+00$ & 0.0000 & $0.000 \mathrm{E}+00$ & 0.0000 & $0.000 \mathrm{E}+00$ & 0.0000 & $0.000 \mathrm{E}+00$ & 0.0000 & $0.000 \mathrm{E}+00$ & 0.0000 \\
\hline-230 & $8.967 \mathrm{E}-03$ & 0.0012 & $0.000 \mathrm{E}+00$ & 0.0000 & $0.000 \mathrm{E}+00$ & 0.0000 & $5.809 \mathrm{E}+00$ & 0.7838 & $1.529 \mathrm{E}-01$ & 0.0206 & $2.709 \mathrm{E}-01$ & 0.0365 & $0.000 \mathrm{E}+00$ & 0.0000 \\
\hline-232 & $3.698 \mathrm{E}-03$ & 0.0005 & $0.000 \mathrm{E}+00$ & 0.0000 & $0.000 \mathrm{E}+00$ & 0.0000 & $5.926 \mathrm{E}-01$ & 0.0800 & $1.748 \mathrm{E}-02$ & 0.0024 & $4.841 E-02$ & 0.0065 & $0.000 \mathrm{E}+00$ & 0.0000 \\
\hline 34 & $7.268 E-05$ & 0.0000 & $0.000 \mathrm{E}+00$ & 0.0000 & $0.000 \mathrm{E}+00$ & 0.0000 & $1.483 \mathrm{E}-01$ & 0.0200 & $2.264 \mathrm{E}-03$ & 0.0003 & $7.276 \mathrm{E}-03$ & 0.0010 & $0.000 \mathrm{E}+00$ & 0.0000 \\
\hline 35 & $1.527 \mathrm{E}-07$ & 0.0000 & $0.000 \mathrm{E}+00$ & 0.0000 & $0.000 \mathrm{E}+00$ & 0.0000 & $1.149 \mathrm{E}-02$ & 0.0015 & $8.470 \mathrm{E}-04$ & 0.0001 & $2.073 E-04$ & 0.0000 & $0.000 \mathrm{E}+00$ & 0.0000 \\
\hline 38 & $9.919 \mathrm{E}-05$ & 0.0000 & $0.000 \mathrm{E}+00$ & 0.0000 & $0.000 \mathrm{E}+00$ & 0.0000 & $1.013 \mathrm{E}-01$ & 0.0137 & $1.044 \mathrm{E}-03$ & 0.0001 & $5.096 \mathrm{E}-03$ & 0.0007 & $0.000 \mathrm{E}+00$ & 0.0000 \\
\hline & $1.284 \mathrm{E}-02$ & 0.0017 & $0.000 \mathrm{E}+00$ & 0.0000 & $0.000 \mathrm{E}+00$ & 0.0000 & $6.814 \mathrm{E}+00$ & 0.9194 & $E-01$ & 238 & $E-01$ & 48 & +00 & 000 \\
\hline
\end{tabular}

Total Dose Contributions TDOSE(i,p,t) for Individual Radionuclides (i) and Pathways (p) As mrem/yr and Fraction of Total Dose At $t=1.050 \mathrm{E}+03$ years

Water Dependent Pathways

\begin{tabular}{|c|c|c|c|c|c|c|c|c|c|c|c|c|c|c|}
\hline \multirow{2}{*}{ Nuclide } & \multicolumn{2}{|c|}{ Water } & \multicolumn{2}{|c|}{ Fish } & \multicolumn{2}{|c|}{ Radon } & \multicolumn{2}{|c|}{ Plant } & \multicolumn{2}{|c|}{ Meat } & \multicolumn{2}{|c|}{ Milk } & \multicolumn{2}{|c|}{ All Pathways* } \\
\hline & mrem/yr & fract. & mrem/yr & fract. & mrem/yr & fract. & mrem/yr & fract. & mrem/yr & fract. & mrem/yr & fract. & mrem/yr & fract. \\
\hline-241 & $0.000 \mathrm{E}+00$ & 0.0000 & $0.000 \mathrm{E}+00$ & 0.0000 & $0.000 \mathrm{E}+00$ & 0.0000 & $0.000 \mathrm{E}+00$ & 0.0000 & $0.000 \mathrm{E}+00$ & 0.0000 & $0.000 E+00$ & 0.0000 & $6.953 E-03$ & 0.0009 \\
\hline-137 & $0.000 \mathrm{E}+00$ & 0.0000 & $0.000 \mathrm{E}+00$ & 0.0000 & $0.000 \mathrm{E}+00$ & 0.0000 & $0.000 \mathrm{E}+00$ & 0.0000 & $0.000 \mathrm{E}+00$ & 0.0000 & $0.000 \mathrm{E}+00$ & 0.0000 & $3.773 \mathrm{E}-12$ & 0.0000 \\
\hline-237 & $0.000 \mathrm{E}+00$ & 0.0000 & $0.000 \mathrm{E}+00$ & 0.0000 & $0.000 \mathrm{E}+00$ & 0.0000 & $0.000 \mathrm{E}+00$ & 0.0000 & $0.000 \mathrm{E}+00$ & 0.0000 & $0.000 \mathrm{E}+00$ & 0.0000 & $5.811 \mathrm{E}-02$ & 0.0078 \\
\hline-238 & $0.000 \mathrm{E}+00$ & 0.0000 & $0.000 \mathrm{E}+00$ & 0.0000 & $0.000 \mathrm{E}+00$ & 0.0000 & $0.000 \mathrm{E}+00$ & 0.0000 & $0.000 \mathrm{E}+00$ & 0.0000 & $0.000 \mathrm{E}+00$ & 0.0000 & $2.464 \mathrm{E}-05$ & 0.0000 \\
\hline-239 & $0.000 \mathrm{E}+00$ & 0.0000 & $0.000 \mathrm{E}+00$ & 0.0000 & $0.000 \mathrm{E}+00$ & 0.0000 & $0.000 \mathrm{E}+00$ & 0.0000 & $0.000 \mathrm{E}+00$ & 0.0000 & $0.000 \mathrm{E}+00$ & 0.0000 & $4.580 \mathrm{E}-02$ & 0.0062 \\
\hline-240 & $0.000 \mathrm{E}+00$ & 0.0000 & $0.000 \mathrm{E}+00$ & 0.0000 & $0.000 \mathrm{E}+00$ & 0.0000 & $0.000 \mathrm{E}+00$ & 0.0000 & $0.000 \mathrm{E}+00$ & 0.0000 & $0.000 \mathrm{E}+00$ & 0.0000 & $4.224 \mathrm{E}-02$ & 0.0057 \\
\hline-99 & $6.337 \mathrm{E}-02$ & 0.0085 & $0.000 \mathrm{E}+00$ & 0.0000 & $0.000 \mathrm{E}+00$ & 0.0000 & $5.924 \mathrm{E}-03$ & 0.0008 & $1.061 \mathrm{E}-04$ & 0.0000 & $7.158 \mathrm{E}-03$ & 0.0010 & 7. $663 \mathrm{E}-02$ & 0.0103 \\
\hline-228 & $0.000 \mathrm{E}+00$ & 0.0000 & $0.000 \mathrm{E}+00$ & 0.0000 & $0.000 \mathrm{E}+00$ & 0.0000 & $0.000 \mathrm{E}+00$ & 0.0000 & $0.000 \mathrm{E}+00$ & 0.0000 & $0.000 \mathrm{E}+00$ & 0.0000 & $0.000 \mathrm{E}+00$ & 0.0000 \\
\hline-230 & $0.000 \mathrm{E}+00$ & 0.0000 & $0.000 \mathrm{E}+00$ & 0.0000 & $0.000 \mathrm{E}+00$ & 0.0000 & $0.000 \mathrm{E}+00$ & 0.0000 & $0.000 \mathrm{E}+00$ & 0.0000 & $0.000 \mathrm{E}+00$ & 0.0000 & $6.242 \mathrm{E}+00$ & 0.8422 \\
\hline 232 & $0.000 \mathrm{E}+00$ & 0.0000 & $0.000 \mathrm{E}+00$ & 0.0000 & $0.000 \mathrm{E}+00$ & 0.0000 & $0.000 \mathrm{E}+00$ & 0.0000 & $0.000 \mathrm{E}+00$ & 0.0000 & $0.000 \mathrm{E}+00$ & 0.0000 & $6.622 \mathrm{E}-01$ & 0.0893 \\
\hline 34 & $0.000 \mathrm{E}+00$ & 0.0000 & $0.000 \mathrm{E}+00$ & 0.0000 & $0.000 \mathrm{E}+00$ & 0.0000 & $0.000 \mathrm{E}+00$ & 0.0000 & $0.000 \mathrm{E}+00$ & 0.0000 & $0.000 \mathrm{E}+00$ & 0.0000 & $1.580 \mathrm{E}-01$ & 0.0213 \\
\hline 35 & $0.000 \mathrm{E}+00$ & 0.0000 & $0.000 \mathrm{E}+00$ & 0.0000 & $0.000 \mathrm{E}+00$ & 0.0000 & $0.000 \mathrm{E}+00$ & 0.0000 & $0.000 \mathrm{E}+00$ & 0.0000 & $0.000 \mathrm{E}+00$ & 0.0000 & $1.254 \mathrm{E}-02$ & 0.0017 \\
\hline 38 & $0.000 \mathrm{E}+00$ & 0.0000 & $0.000 \mathrm{E}+00$ & 0.0000 & $0.000 \mathrm{E}+00$ & 0.0000 & $0.000 \mathrm{E}+00$ & 0.0000 & $0.000 \mathrm{E}+00$ & 0.0000 & $0.000 \mathrm{E}+00$ & 0.0000 & $1.075 \mathrm{E}-01$ & 0.0145 \\
\hline & $6.337 E-02$ & 0.0085 & $0.000 \mathrm{E}+00$ & 0.0000 & $0.000 \mathrm{E}+00$ & 0.0000 & $5.924 \mathrm{E}-03$ & 0.0008 & $1.061 \mathrm{E}-04$ & 0.0000 & $7.158 \mathrm{E}-03$ & 0.0010 & $2 E+00$ & 1.0000 \\
\hline
\end{tabular}

* Sum of all water independent and dependent pathways. 
RESRAD, Version $6.5 \quad \mathrm{~T}^{1 / 2}$ Limit $=180$ days

07/21/2011 12:07 Page 27

: C: \RESRAD_FAMILY \RESRAD \USERFILES \QCJULY2011 \ONSITERF_FORWARD-100000-JULY11.RAD

Total Dose Contributions TDOSE (i,p,t) for Individual Radionuclides (i) and Pathways (p) As mrem/yr and Fraction of Total Dose At $t=1.000 \mathrm{E}+04$ years

Water Independent Pathways (Inhalation excludes radon)

\begin{tabular}{|c|c|c|c|c|c|c|c|c|c|c|c|c|c|c|}
\hline \multirow{2}{*}{ Nuclide } & \multicolumn{2}{|c|}{ Ground } & \multicolumn{2}{|c|}{ Inhalation } & \multicolumn{2}{|c|}{ Radon } & \multicolumn{2}{|c|}{ Plant } & \multicolumn{2}{|c|}{ Meat } & \multicolumn{2}{|c|}{ Milk } & \multicolumn{2}{|c|}{ Soil } \\
\hline & mrem/yr & fract. & mrem/yr & fract. & mrem/yr & fract. & mrem/yr & fract. & mrem/yr & fract. & mrem/yr & fract. & mrem/yr & fract. \\
\hline-241 & $1.724 \mathrm{E}-03$ & 0.0000 & $1.816 \mathrm{E}-07$ & 0.0000 & $0.000 \mathrm{E}+00$ & 0.0000 & $2.088 E-03$ & 0.0000 & $1.927 \mathrm{E}-04$ & 0.0000 & $1.010 \mathrm{E}-05$ & 0.0000 & $3.432 \mathrm{E}-05$ & 0.0000 \\
\hline-137 & $0.000 \mathrm{E}+00$ & 0.0000 & $0.000 \mathrm{E}+00$ & 0.0000 & $0.000 \mathrm{E}+00$ & 0.0000 & $0.000 \mathrm{E}+00$ & 0.0000 & $0.000 \mathrm{E}+00$ & 0.0000 & $0.000 \mathrm{E}+00$ & 0.0000 & $0.000 \mathrm{E}+00$ & 0.0000 \\
\hline-237 & $1.242 \mathrm{E}+00$ & 0.0005 & 1. $326 \mathrm{E}-04$ & 0.0000 & $0.000 \mathrm{E}+00$ & 0.0000 & $1.496 \mathrm{E}+00$ & 0.0006 & $1.381 \mathrm{E}-01$ & 0.0001 & $7.847 E-03$ & 0.0000 & $2.514 \mathrm{E}-02$ & 0.0000 \\
\hline-238 & $6.839 E-03$ & 0.0000 & $3.439 \mathrm{E}-07$ & 0.0000 & $0.000 \mathrm{E}+00$ & 0.0000 & $1.186 \mathrm{E}-02$ & 0.0000 & $1.230 \mathrm{E}-03$ & 0.0000 & $2.117 \mathrm{E}-03$ & 0.0000 & $3.191 \mathrm{E}-04$ & 0.0000 \\
\hline-239 & $5.108 E-03$ & 0.0000 & $4.259 \mathrm{E}-03$ & 0.0000 & $0.000 \mathrm{E}+00$ & 0.0000 & $2.652 \mathrm{E}+00$ & 0.0010 & $3.321 \mathrm{E}-01$ & 0.0001 & $9.176 \mathrm{E}-03$ & 0.0000 & $7.370 \mathrm{E}-01$ & 0.0003 \\
\hline-240 & $9.845 \mathrm{E}-04$ & 0.0000 & $1.967 \mathrm{E}-03$ & 0.0000 & $0.000 \mathrm{E}+00$ & 0.0000 & $1.225 \mathrm{E}+00$ & 0.0005 & $1.534 \mathrm{E}-01$ & 0.0001 & $4.485 E-03$ & 0.0000 & $3.405 \mathrm{E}-01$ & 0.0001 \\
\hline 99 & $0.000 \mathrm{E}+00$ & 0.0000 & $0.000 \mathrm{E}+00$ & 0.0000 & $0.000 \mathrm{E}+00$ & 0.0000 & $0.000 \mathrm{E}+00$ & 0.0000 & $0.000 \mathrm{E}+00$ & 0.0000 & $0.000 \mathrm{E}+00$ & 0.0000 & $0.000 \mathrm{E}+00$ & 0.0000 \\
\hline-228 & $0.000 \mathrm{E}+00$ & 0.0000 & $0.000 \mathrm{E}+00$ & 0.0000 & $0.000 \mathrm{E}+00$ & 0.0000 & $0.000 \mathrm{E}+00$ & 0.0000 & $0.000 \mathrm{E}+00$ & 0.0000 & $0.000 \mathrm{E}+00$ & 0.0000 & $0.000 \mathrm{E}+00$ & 0.0000 \\
\hline 230 & $7.436 \mathrm{E}+02$ & 0.2735 & $1.648 \mathrm{E}-02$ & 0.0000 & $0.000 \mathrm{E}+00$ & 0.0000 & $1.224 \mathrm{E}+03$ & 0.4501 & 1. $220 \mathrm{E}+02$ & 0.0449 & $1.728 \mathrm{E}+02$ & 0.0636 & $2.669 \mathrm{E}+01$ & 0.0098 \\
\hline-232 & $4.839 E+01$ & 0.0178 & $1.028 E-03$ & 0.0000 & $0.000 \mathrm{E}+00$ & 0.0000 & $5.054 \mathrm{E}+01$ & 0.0186 & $3.109 \mathrm{E}+00$ & 0.0011 & $8.373 E+00$ & 0.0031 & $5.352 \mathrm{E}-01$ & 0.0002 \\
\hline 234 & $7.945 E+01$ & 0.0292 & $3.957 \mathrm{E}-03$ & 0.0000 & $0.000 \mathrm{E}+00$ & 0.0000 & $1.377 \mathrm{E}+02$ & 0.0506 & $1.426 \mathrm{E}+01$ & 0.0052 & $2.449 \mathrm{E}+01$ & 0.0090 & $3.693 \mathrm{E}+00$ & 0.0014 \\
\hline 35 & $4.626 \mathrm{E}+00$ & 0.0017 & $1.189 \mathrm{E}-03$ & 0.0000 & $0.000 \mathrm{E}+00$ & 0.0000 & $5.072 \mathrm{E}+00$ & 0.0019 & $2.638 \mathrm{E}+00$ & 0.0010 & $2.932 \mathrm{E}-01$ & 0.0001 & $2.835 \mathrm{E}-01$ & 0.0001 \\
\hline 38 & $1.706 \mathrm{E}+01$ & 0.0063 & $1.671 \mathrm{E}-03$ & 0.0000 & $0.000 \mathrm{E}+00$ & 0.0000 & $8.921 \mathrm{E}+00$ & 0.0033 & $1.458 \mathrm{E}+00$ & 0.0005 & $6.576 \mathrm{E}+00$ & 0.0024 & $8.572 \mathrm{E}-01$ & 0.0003 \\
\hline & $8.943 E+02$ & 0.3290 & $3.068 E-02$ & 0.0000 & $0.000 \mathrm{E}+00$ & 0.0000 & $1.431 \mathrm{E}+03$ & 0.5264 & $1.441 \mathrm{E}+02$ & 0.0530 & $2.126 \mathrm{E}+02$ & 0.0782 & $3.316 \mathrm{E}+01$ & 0.0122 \\
\hline
\end{tabular}

Total Dose Contributions TDOSE(i,p,t) for Individual Radionuclides (i) and Pathways (p) As mrem/yr and Fraction of Total Dose At $t=1.000 \mathrm{E}+04$ years

Water Dependent Pathways

\begin{tabular}{|c|c|c|c|c|c|c|c|c|c|c|c|c|c|c|}
\hline \multirow{2}{*}{$\begin{array}{l}\text { Radio- } \\
\text { Nuclide }\end{array}$} & \multicolumn{2}{|c|}{ Water } & \multicolumn{2}{|c|}{ Fish } & \multicolumn{2}{|c|}{ Radon } & \multicolumn{2}{|c|}{ Plant } & \multicolumn{2}{|c|}{ Meat } & \multicolumn{2}{|c|}{ Milk } & \multicolumn{2}{|c|}{ All Pathways* } \\
\hline & mrem/yr & fract. & mrem/yr & fract. & mrem/yr & fract. & mrem/yr & fract. & mrem/yr & fract. & mrem/yr & fract. & mrem/yr & fract. \\
\hline 241 & $4.122 \mathrm{E}-03$ & 0.0000 & $0.000 \mathrm{E}+00$ & 0.0000 & $0.000 \mathrm{E}+00$ & 0.0000 & $1.681 \mathrm{E}-04$ & 0.0000 & $6.589 E-05$ & 0.0000 & $2.364 E-06$ & 0.0000 & $8.407 \mathrm{E}-03$ & 0.0000 \\
\hline-137 & $0.000 \mathrm{E}+00$ & 0.0000 & $0.000 \mathrm{E}+00$ & 0.0000 & $0.000 \mathrm{E}+00$ & 0.0000 & $0.000 \mathrm{E}+00$ & 0.0000 & $0.000 \mathrm{E}+00$ & 0.0000 & $0.000 \mathrm{E}+00$ & 0.0000 & $0.000 \mathrm{E}+00$ & 0.0000 \\
\hline-237 & $3.092 \mathrm{E}+00$ & 0.0011 & $0.000 \mathrm{E}+00$ & 0.0000 & $0.000 \mathrm{E}+00$ & 0.0000 & $1.261 \mathrm{E}-01$ & 0.0000 & $4.943 E-02$ & 0.0000 & $1.801 E-03$ & 0.0000 & $6.178 \mathrm{E}+00$ & 0.0023 \\
\hline-238 & $0.000 \mathrm{E}+00$ & 0.0000 & $0.000 \mathrm{E}+00$ & 0.0000 & $0.000 \mathrm{E}+00$ & 0.0000 & $0.000 \mathrm{E}+00$ & 0.0000 & $0.000 \mathrm{E}+00$ & 0.0000 & $0.000 \mathrm{E}+00$ & 0.0000 & $2.236 \mathrm{E}-02$ & 0.0000 \\
\hline-239 & $0.000 \mathrm{E}+00$ & 0.0000 & $0.000 \mathrm{E}+00$ & 0.0000 & $0.000 \mathrm{E}+00$ & 0.0000 & $0.000 \mathrm{E}+00$ & 0.0000 & $0.000 \mathrm{E}+00$ & 0.0000 & $0.000 \mathrm{E}+00$ & 0.0000 & $3.740 \mathrm{E}+00$ & 0.0014 \\
\hline-240 & $0.000 \mathrm{E}+00$ & 0.0000 & $0.000 \mathrm{E}+00$ & 0.0000 & $0.000 \mathrm{E}+00$ & 0.0000 & $0.000 \mathrm{E}+00$ & 0.0000 & $0.000 \mathrm{E}+00$ & 0.0000 & $0.000 E+00$ & 0.0000 & $1.727 \mathrm{E}+00$ & 0.0006 \\
\hline 99 & $0.000 \mathrm{E}+00$ & 0.0000 & $0.000 \mathrm{E}+00$ & 0.0000 & $0.000 \mathrm{E}+00$ & 0.0000 & $0.000 \mathrm{E}+00$ & 0.0000 & $0.000 \mathrm{E}+00$ & 0.0000 & $0.000 \mathrm{E}+00$ & 0.0000 & $0.000 \mathrm{E}+00$ & 0.0000 \\
\hline-228 & $0.000 \mathrm{E}+00$ & 0.0000 & $0.000 \mathrm{E}+00$ & 0.0000 & $0.000 \mathrm{E}+00$ & 0.0000 & $0.000 \mathrm{E}+00$ & 0.0000 & $0.000 \mathrm{E}+00$ & 0.0000 & $0.000 \mathrm{E}+00$ & 0.0000 & $0.000 \mathrm{E}+00$ & 0.0000 \\
\hline-230 & $0.000 \mathrm{E}+00$ & 0.0000 & $0.000 \mathrm{E}+00$ & 0.0000 & $0.000 \mathrm{E}+00$ & 0.0000 & $0.000 \mathrm{E}+00$ & 0.0000 & $0.000 \mathrm{E}+00$ & 0.0000 & $0.000 E+00$ & 0.0000 & $2.289 \mathrm{E}+03$ & 0.8418 \\
\hline-232 & $0.000 \mathrm{E}+00$ & 0.0000 & $0.000 \mathrm{E}+00$ & 0.0000 & $0.000 \mathrm{E}+00$ & 0.0000 & $0.000 \mathrm{E}+00$ & 0.0000 & $0.000 \mathrm{E}+00$ & 0.0000 & $0.000 \mathrm{E}+00$ & 0.0000 & $1.109 \mathrm{E}+02$ & 0.0408 \\
\hline 34 & $0.000 \mathrm{E}+00$ & 0.0000 & $0.000 \mathrm{E}+00$ & 0.0000 & $0.000 \mathrm{E}+00$ & 0.0000 & $0.000 \mathrm{E}+00$ & 0.0000 & $0.000 \mathrm{E}+00$ & 0.0000 & $0.000 \mathrm{E}+00$ & 0.0000 & $2.596 \mathrm{E}+02$ & 0.0955 \\
\hline 35 & $0.000 \mathrm{E}+00$ & 0.0000 & $0.000 \mathrm{E}+00$ & 0.0000 & $0.000 \mathrm{E}+00$ & 0.0000 & $0.000 \mathrm{E}+00$ & 0.0000 & $0.000 \mathrm{E}+00$ & 0.0000 & $0.000 \mathrm{E}+00$ & 0.0000 & $1.291 \mathrm{E}+01$ & 0.0048 \\
\hline 38 & $0.000 \mathrm{E}+00$ & 0.0000 & $0.000 \mathrm{E}+00$ & 0.0000 & $0.000 \mathrm{E}+00$ & 0.0000 & $0.000 \mathrm{E}+00$ & 0.0000 & $0.000 \mathrm{E}+00$ & 0.0000 & $0.000 \mathrm{E}+00$ & 0.0000 & $3.487 \mathrm{E}+01$ & 0.0128 \\
\hline & $3.096 \mathrm{E}+00$ & 0.0011 & $0.000 \mathrm{E}+00$ & 0.0000 & $0.000 \mathrm{E}+00$ & 0.0000 & $1.263 \mathrm{E}-01$ & 0.0000 & $4.950 \mathrm{E}-02$ & 0.0000 & $1.804 \mathrm{E}-03$ & 0.0000 & $.719 \mathrm{E}+03$ & 1. \\
\hline
\end{tabular}

* Sum of all water independent and dependent pathways. 
RESRAD, Version $6.5 \quad \mathrm{~T}^{1 / 2}$ Limit $=180$ days

07/21/2011 12:07 Page 28

: C: \RESRAD_FAMILY \RESRAD \USERFILES \QCJULY2011 \ONSITERF_FORWARD-100000-JULY11.RAD

Total Dose Contributions TDOSE (i,p,t) for Individual Radionuclides (i) and Pathways (p) As mrem/yr and Fraction of Total Dose At $t=1.000 \mathrm{E}+05$ years

Water Independent Pathways (Inhalation excludes radon)

\begin{tabular}{|c|c|c|c|c|c|c|c|c|c|c|c|c|c|c|}
\hline \multirow{2}{*}{ Nuclide } & \multicolumn{2}{|c|}{ Ground } & \multicolumn{2}{|c|}{ Inhalation } & \multicolumn{2}{|c|}{ Radon } & \multicolumn{2}{|c|}{ Plant } & \multicolumn{2}{|c|}{ Meat } & \multicolumn{2}{|c|}{ Milk } & \multicolumn{2}{|c|}{ Soil } \\
\hline & mrem/yr & fract. & mrem/yr & fract. & mrem/yr & fract. & mrem/yr & fract. & mrem/yr & fract. & mrem/yr & fract. & mrem/yr & fract. \\
\hline-241 & $0.000 \mathrm{E}+00$ & 0.0000 & $0.000 \mathrm{E}+00$ & 0.0000 & $0.000 \mathrm{E}+00$ & 0.0000 & $0.000 \mathrm{E}+00$ & 0.0000 & $0.000 \mathrm{E}+00$ & 0.0000 & $0.000 \mathrm{E}+00$ & 0.0000 & $0.000 \mathrm{E}+00$ & 0.0000 \\
\hline-137 & $0.000 \mathrm{E}+00$ & 0.0000 & $0.000 \mathrm{E}+00$ & 0.0000 & $0.000 \mathrm{E}+00$ & 0.0000 & $0.000 \mathrm{E}+00$ & 0.0000 & $0.000 \mathrm{E}+00$ & 0.0000 & $0.000 \mathrm{E}+00$ & 0.0000 & $0.000 \mathrm{E}+00$ & 0.0000 \\
\hline 237 & $0.000 \mathrm{E}+00$ & 0.0000 & $0.000 \mathrm{E}+00$ & 0.0000 & $0.000 \mathrm{E}+00$ & 0.0000 & $0.000 \mathrm{E}+00$ & 0.0000 & $0.000 \mathrm{E}+00$ & 0.0000 & $0.000 \mathrm{E}+00$ & 0.0000 & $0.000 \mathrm{E}+00$ & 0.0000 \\
\hline-238 & $0.000 \mathrm{E}+00$ & 0.0000 & $0.000 \mathrm{E}+00$ & 0.0000 & $0.000 \mathrm{E}+00$ & 0.0000 & $0.000 \mathrm{E}+00$ & 0.0000 & $0.000 \mathrm{E}+00$ & 0.0000 & $0.000 \mathrm{E}+00$ & 0.0000 & $0.000 \mathrm{E}+00$ & 0.0000 \\
\hline-239 & $0.000 \mathrm{E}+00$ & 0.0000 & $0.000 \mathrm{E}+00$ & 0.0000 & $0.000 \mathrm{E}+00$ & 0.0000 & $0.000 \mathrm{E}+00$ & 0.0000 & $0.000 \mathrm{E}+00$ & 0.0000 & $0.000 \mathrm{E}+00$ & 0.0000 & $0.000 \mathrm{E}+00$ & 0.0000 \\
\hline-240 & $0.000 \mathrm{E}+00$ & 0.0000 & $0.000 \mathrm{E}+00$ & 0.0000 & $0.000 \mathrm{E}+00$ & 0.0000 & $0.000 \mathrm{E}+00$ & 0.0000 & $0.000 \mathrm{E}+00$ & 0.0000 & $0.000 \mathrm{E}+00$ & 0.0000 & $0.000 \mathrm{E}+00$ & 0.0000 \\
\hline 99 & $0.000 \mathrm{E}+00$ & 0.0000 & $0.000 \mathrm{E}+00$ & 0.0000 & $0.000 \mathrm{E}+00$ & 0.0000 & $0.000 \mathrm{E}+00$ & 0.0000 & $0.000 \mathrm{E}+00$ & 0.0000 & $0.000 \mathrm{E}+00$ & 0.0000 & $0.000 \mathrm{E}+00$ & 0.0000 \\
\hline-228 & $0.000 \mathrm{E}+00$ & 0.0000 & $0.000 \mathrm{E}+00$ & 0.0000 & $0.000 \mathrm{E}+00$ & 0.0000 & $0.000 \mathrm{E}+00$ & 0.0000 & $0.000 \mathrm{E}+00$ & 0.0000 & $0.000 \mathrm{E}+00$ & 0.0000 & $0.000 \mathrm{E}+00$ & 0.0000 \\
\hline 230 & $0.000 \mathrm{E}+00$ & 0.0000 & $0.000 \mathrm{E}+00$ & 0.0000 & $0.000 \mathrm{E}+00$ & 0.0000 & $0.000 \mathrm{E}+00$ & 0.0000 & $0.000 \mathrm{E}+00$ & 0.0000 & $0.000 \mathrm{E}+00$ & 0.0000 & $0.000 \mathrm{E}+00$ & 0.0000 \\
\hline-232 & $0.000 \mathrm{E}+00$ & 0.0000 & $0.000 \mathrm{E}+00$ & 0.0000 & $0.000 \mathrm{E}+00$ & 0.0000 & $0.000 \mathrm{E}+00$ & 0.0000 & $0.000 \mathrm{E}+00$ & 0.0000 & $0.000 \mathrm{E}+00$ & 0.0000 & $0.000 \mathrm{E}+00$ & 0.0000 \\
\hline 34 & $0.000 \mathrm{E}+00$ & 0.0000 & $0.000 \mathrm{E}+00$ & 0.0000 & $0.000 \mathrm{E}+00$ & 0.0000 & $0.000 \mathrm{E}+00$ & 0.0000 & $0.000 \mathrm{E}+00$ & 0.0000 & $0.000 \mathrm{E}+00$ & 0.0000 & $0.000 \mathrm{E}+00$ & 0.0000 \\
\hline 35 & $0.000 \mathrm{E}+00$ & 0.0000 & $0.000 \mathrm{E}+00$ & 0.0000 & $0.000 \mathrm{E}+00$ & 0.0000 & $0.000 \mathrm{E}+00$ & 0.0000 & $0.000 \mathrm{E}+00$ & 0.0000 & $0.000 \mathrm{E}+00$ & 0.0000 & $0.000 \mathrm{E}+00$ & 0.0000 \\
\hline 38 & $0.000 \mathrm{E}+00$ & 0.0000 & $0.000 \mathrm{E}+00$ & 0.0000 & $0.000 \mathrm{E}+00$ & 0.0000 & $0.000 \mathrm{E}+00$ & 0.0000 & $0.000 \mathrm{E}+00$ & 0.0000 & $0.000 \mathrm{E}+00$ & 0.0000 & $0.000 \mathrm{E}+00$ & 0.0000 \\
\hline & $0.000 \mathrm{E}+00$ & 0.0000 & $0.000 \mathrm{E}+00$ & 0.0000 & $0.000 \mathrm{E}+00$ & 0.0000 & $0.000 \mathrm{E}+00$ & 0.0000 & $0.000 \mathrm{E}+00$ & 0.0000 & $0.000 \mathrm{E}+00$ & 0.0000 & $.000 \mathrm{E}+00$ & 0.0000 \\
\hline
\end{tabular}

Total Dose Contributions TDOSE(i,p,t) for Individual Radionuclides (i) and Pathways (p) As mrem/yr and Fraction of Total Dose At $t=1.000 \mathrm{E}+05$ years

Water Dependent Pathways

\begin{tabular}{|c|c|c|c|c|c|c|c|c|c|c|c|c|c|c|}
\hline \multirow{2}{*}{$\begin{array}{l}\text { Radio- } \\
\text { Nuclide }\end{array}$} & \multicolumn{2}{|c|}{ Water } & \multicolumn{2}{|c|}{ Fish } & \multicolumn{2}{|c|}{ Radon } & \multicolumn{2}{|c|}{ Plant } & \multicolumn{2}{|c|}{ Meat } & \multicolumn{2}{|c|}{ Milk } & \multicolumn{2}{|c|}{ All Pathways* } \\
\hline & mrem/yr & fract. & mrem/yr & fract. & mrem/yr & fract. & mrem/yr & fract. & mrem/yr & fract. & mrem/yr & fract. & mrem/yr & fract. \\
\hline 241 & $4.511 E-05$ & 0.0012 & $0.000 \mathrm{E}+00$ & 0.0000 & $0.000 \mathrm{E}+00$ & 0.0000 & $1.831 \mathrm{E}-06$ & 0.0000 & $1.728 \mathrm{E}-07$ & 0.0000 & $1.756 \mathrm{E}-06$ & 0.0000 & $4.887 \mathrm{E}-05$ & 0.0013 \\
\hline-137 & $0.000 \mathrm{E}+00$ & 0.0000 & $0.000 \mathrm{E}+00$ & 0.0000 & $0.000 \mathrm{E}+00$ & 0.0000 & $0.000 \mathrm{E}+00$ & 0.0000 & $0.000 \mathrm{E}+00$ & 0.0000 & $0.000 \mathrm{E}+00$ & 0.0000 & $0.000 \mathrm{E}+00$ & 0.0000 \\
\hline-237 & $3.478 E-02$ & 0.9219 & $0.000 \mathrm{E}+00$ & 0.0000 & $0.000 \mathrm{E}+00$ & 0.0000 & $1.412 \mathrm{E}-03$ & 0.0374 & $1.332 \mathrm{E}-04$ & 0.0035 & $1.354 \mathrm{E}-03$ & 0.0359 & $3.768 E-02$ & 0.9987 \\
\hline-238 & $0.000 \mathrm{E}+00$ & 0.0000 & $0.000 \mathrm{E}+00$ & 0.0000 & $0.000 \mathrm{E}+00$ & 0.0000 & $0.000 \mathrm{E}+00$ & 0.0000 & $0.000 \mathrm{E}+00$ & 0.0000 & $0.000 \mathrm{E}+00$ & 0.0000 & $0.000 \mathrm{E}+00$ & 0.0000 \\
\hline-239 & $0.000 \mathrm{E}+00$ & 0.0000 & $0.000 \mathrm{E}+00$ & 0.0000 & $0.000 \mathrm{E}+00$ & 0.0000 & $0.000 \mathrm{E}+00$ & 0.0000 & $0.000 \mathrm{E}+00$ & 0.0000 & $0.000 E+00$ & 0.0000 & $0.000 \mathrm{E}+00$ & 0.0000 \\
\hline-240 & $0.000 \mathrm{E}+00$ & 0.0000 & $0.000 \mathrm{E}+00$ & 0.0000 & $0.000 \mathrm{E}+00$ & 0.0000 & $0.000 \mathrm{E}+00$ & 0.0000 & $0.000 \mathrm{E}+00$ & 0.0000 & $0.000 E+00$ & 0.0000 & $0.000 \mathrm{E}+00$ & 0.0000 \\
\hline 99 & $0.000 \mathrm{E}+00$ & 0.0000 & $0.000 \mathrm{E}+00$ & 0.0000 & $0.000 \mathrm{E}+00$ & 0.0000 & $0.000 \mathrm{E}+00$ & 0.0000 & $0.000 \mathrm{E}+00$ & 0.0000 & $0.000 \mathrm{E}+00$ & 0.0000 & $0.000 \mathrm{E}+00$ & 0.0000 \\
\hline-228 & $0.000 \mathrm{E}+00$ & 0.0000 & $0.000 \mathrm{E}+00$ & 0.0000 & $0.000 \mathrm{E}+00$ & 0.0000 & $0.000 \mathrm{E}+00$ & 0.0000 & $0.000 \mathrm{E}+00$ & 0.0000 & $0.000 \mathrm{E}+00$ & 0.0000 & $0.000 \mathrm{E}+00$ & 0.0000 \\
\hline-230 & $0.000 \mathrm{E}+00$ & 0.0000 & $0.000 \mathrm{E}+00$ & 0.0000 & $0.000 \mathrm{E}+00$ & 0.0000 & $0.000 \mathrm{E}+00$ & 0.0000 & $0.000 \mathrm{E}+00$ & 0.0000 & $0.000 E+00$ & 0.0000 & $0.000 \mathrm{E}+00$ & 0.0000 \\
\hline-232 & $0.000 \mathrm{E}+00$ & 0.0000 & $0.000 \mathrm{E}+00$ & 0.0000 & $0.000 \mathrm{E}+00$ & 0.0000 & $0.000 \mathrm{E}+00$ & 0.0000 & $0.000 \mathrm{E}+00$ & 0.0000 & $0.000 \mathrm{E}+00$ & 0.0000 & $0.000 \mathrm{E}+00$ & 0.0000 \\
\hline 234 & $0.000 \mathrm{E}+00$ & 0.0000 & $0.000 \mathrm{E}+00$ & 0.0000 & $0.000 \mathrm{E}+00$ & 0.0000 & $0.000 \mathrm{E}+00$ & 0.0000 & $0.000 \mathrm{E}+00$ & 0.0000 & $0.000 \mathrm{E}+00$ & 0.0000 & $0.000 \mathrm{E}+00$ & 0.0000 \\
\hline 35 & $0.000 \mathrm{E}+00$ & 0.0000 & $0.000 \mathrm{E}+00$ & 0.0000 & $0.000 \mathrm{E}+00$ & 0.0000 & $0.000 \mathrm{E}+00$ & 0.0000 & $0.000 \mathrm{E}+00$ & 0.0000 & $0.000 \mathrm{E}+00$ & 0.0000 & $0.000 \mathrm{E}+00$ & 0.0000 \\
\hline 38 & $0.000 \mathrm{E}+00$ & 0.0000 & $0.000 \mathrm{E}+00$ & 0.0000 & $0.000 \mathrm{E}+00$ & 0.0000 & $0.000 \mathrm{E}+00$ & 0.0000 & $0.000 \mathrm{E}+00$ & 0.0000 & $0.000 \mathrm{E}+00$ & 0.0000 & $0.000 \mathrm{E}+00$ & 0.0000 \\
\hline & $3.483 E-02$ & 0.9231 & $0.000 \mathrm{E}+00$ & 0.0000 & $0.000 \mathrm{E}+00$ & 0.0000 & $1.414 \mathrm{E}-03$ & 0.0375 & $1.334 \mathrm{E}-04$ & 0.0035 & $1.355 \mathrm{E}-03$ & 0.0359 & $3 E-02$ & 1.0000 \\
\hline
\end{tabular}

* Sum of all water independent and dependent pathways. 
RESRAD, Version 6.5

ummary : RESRAD Parameters for Resident Farmer U-Landfill Forward Run 100,000 Years

File : C: \RESRAD FAMILY \RESRAD \USERFILES QCJULY2011 \ONSITERF FORWARD-100000-JULY11.RAD

Dose/Source Ratios Summed Over All Pathways

Parent and Progeny Principal Radionuclide Contributions Indicated

\section{Parent}

(i)

Am-241

Am-241

Am-241

Am-241

Am-241

$\mathrm{Cs}-137+\mathrm{D}$

$\mathrm{Np}-237+\mathrm{D}$

$\mathrm{Np}-237+\mathrm{D}$

$\mathrm{Np}-237+\mathrm{D}$

$\mathrm{Np}-237+\mathrm{D}$

$\mathrm{Pu}-238$

$\mathrm{Pu}-238$

$\mathrm{Pu}-238$

$\mathrm{Pu}-238$

$\mathrm{Pu}-238$

$\mathrm{Pu}-238$

$\mathrm{Pu}-238$

$\mathrm{Pu}-239$

$\mathrm{Pu}-239$

$\mathrm{Pu}-239$

$\mathrm{Pu}-239$

Pu-239

Pu-240

$\mathrm{Pu}-240$

$\mathrm{Pu}-240$

$\mathrm{Pu}-240$

$\mathrm{Pu}-240$

$\mathrm{Pu}-240$

$\mathrm{Pu}-240$

TC-99

Th $-228+D$

$\mathrm{Th}-230$

$\mathrm{Th}-230$

$\mathrm{Th}-230$

Th-230
Product Thread

(j) Fraction

$\overline{A m-241} 1.000 \mathrm{E}+00$

$\mathrm{Np}-237+\mathrm{D} \quad 1.000 \mathrm{E}+00$

$\mathrm{U}-233 \quad 1.000 \mathrm{E}+00$

Th-229+D 1.000E+00

$\sum \operatorname{DSR}(j)$

Cs $-137+D$

$\mathrm{Np}-237+\mathrm{D}$

$\mathrm{U}-233$

Th-229+D

$\sum \operatorname{DSR}(j)$

$\mathrm{Pu}-238$

$\mathrm{Pu}-238$

$\mathrm{U}-234$

Th -230

$\mathrm{Ra}-226+\mathrm{D}$

$\mathrm{Pb}-210+\mathrm{D}$

$\sum \operatorname{DSR}(j)$

$\mathrm{Pu}-239$

$\mathrm{U}-235+\mathrm{D}$

$\mathrm{Pa}-231$

AC $-227+D$

$\sum \operatorname{DSR}(j)$

$\mathrm{Pu}-240$

$\mathrm{Pu}-240$

U-236

Th-232

$\mathrm{Ra}-228+\mathrm{D}$

Th-228+D

$\sum \operatorname{DSR}(j)$

TC-99

Th $-228+D$

Th-230

Ra-226+D

$\mathrm{Pb}-210+\mathrm{D}$

$\sum \operatorname{DSR}(j)$ 1. $000 \mathrm{E}+00$ 1. $000 \mathrm{E}+00$
$\operatorname{DSR}(j, t)$ At Time in Years (mrem/yr)/(pCi/g)

$0.000 \mathrm{E}+00 \quad 1.000 \mathrm{E}+00 \quad 5.000 \mathrm{E}+01 \quad 1.000 \mathrm{E}+02 \quad 5.000 \mathrm{E}+02 \quad 1.050 \mathrm{E}+03 \quad 1.000 \mathrm{E}+04 \quad 1.000 \mathrm{E}+05$

$\begin{array}{llllllll}1.936 \mathrm{E}-33 & 1.989 \mathrm{E}-33 & 7.353 \mathrm{E}-33 & 2.792 \mathrm{E}-32 & 1.208 \mathrm{E}-27 & 1.968 \mathrm{E}-04 & 1.615 \mathrm{E}-08 & 0.000 \mathrm{E}+00\end{array}$ $\begin{array}{lllllllll}1.546 \mathrm{E}-19 & 4.680 \mathrm{E}-19 & 2.562 \mathrm{E}-17 & 8.382 \mathrm{E}-17 & 2.263 \mathrm{E}-14 & 1.827 \mathrm{E}-06 & 2.369 \mathrm{E}-04 & 0.000 \mathrm{E}+00\end{array}$ $3.506 \mathrm{E}-30 \quad 2.479 \mathrm{E}-29 \quad 4.863 \mathrm{E}-26 \quad 3.503 \mathrm{E}-25 \quad 1.053 \mathrm{E}-21 \quad 3.241 \mathrm{E}-10 \quad 5.555 \mathrm{E}-07 \quad 8.337 \mathrm{E}-07$ $2.399 \mathrm{E}-26 \quad 3.618 \mathrm{E}-25 \quad 1.710 \mathrm{E}-20 \quad 1.868 \mathrm{E}-19 \quad 3.195 \mathrm{E}-16 \quad 5.422 \mathrm{E}-11 \quad 2.687 \mathrm{E}-06 \quad 5.625 \mathrm{E}-07$ $\begin{array}{llllllll}1.546 \mathrm{E}-19 & 4.680 \mathrm{E}-19 & 2.564 \mathrm{E}-17 & 8.401 \mathrm{E}-17 & 2.295 \mathrm{E}-14 & 1.987 \mathrm{E}-04 & 2.402 \mathrm{E}-04 & 1.396 \mathrm{E}-06\end{array}$

$\begin{array}{llllllll}1.000 \mathrm{E}+00 & 1.262 \mathrm{E}-09 & 1.243 \mathrm{E}-09 & 6.050 \mathrm{E}-10 & 2.901 \mathrm{E}-10 & 8.104 \mathrm{E}-13 & 1.986 \mathrm{E}-13 & 0.000 \mathrm{E}+00 \quad 0.000 \mathrm{E}+00\end{array}$

$1.000 \mathrm{E}+00 \quad 9.536 \mathrm{E}-13 \quad 9.638 \mathrm{E}-13 \quad 1.625 \mathrm{E}-12 \quad 2.770 \mathrm{E}-12 \quad 1.974 \mathrm{E}-10 \quad 1.056 \mathrm{E}-02 \quad 1.106 \mathrm{E}+00 \quad 0.000 \mathrm{E}+00$ $\begin{array}{llllllllll}1.000 \mathrm{E}+00 & 3.245 \mathrm{E}-23 & 9.844 \mathrm{E}-23 & 6.100 \mathrm{E}-21 & 2.264 \mathrm{E}-20 & 1.650 \mathrm{E}-17 & 3.045 \mathrm{E}-06 & 2.892 \mathrm{E}-03 & 4.090 \mathrm{E}-03\end{array}$ $\begin{array}{lllllllllll}1.000 \mathrm{E}+00 & 2.962 \mathrm{E}-19 & 2.086 \mathrm{E}-18 & 3.196 \mathrm{E}-15 & 1.788 \mathrm{E}-14 & 7.080 \mathrm{E}-12 & 6.825 \mathrm{E}-07 & 1.446 \mathrm{E}-02 & 2.761 \mathrm{E}-03\end{array}$ $9.536 \mathrm{E}-13 \quad 9.638 \mathrm{E}-13 \quad 1.629 \mathrm{E}-12 \quad 2.788 \mathrm{E}-12 \quad 2.044 \mathrm{E}-10 \quad 1.056 \mathrm{E}-02 \quad 1.123 \mathrm{E}+00 \quad 6.851 \mathrm{E}-03$

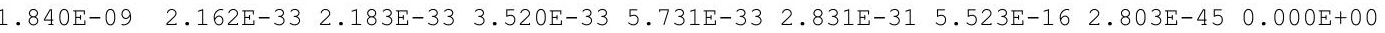

$\begin{array}{llllllll}1.000 \mathrm{E}+00 & 1.175 \mathrm{E}-24 & 1.186 \mathrm{E}-24 & 1.913 \mathrm{E}-24 & 3.115 \mathrm{E}-24 & 1.539 \mathrm{E}-22 & 3.001 \mathrm{E}-07 \quad 6.224 \mathrm{E}-36 \quad 0.000 \mathrm{E}+00\end{array}$ $\begin{array}{llllllllll}1.000 \mathrm{E}+00 & 9.778 \mathrm{E}-30 & 2.969 \mathrm{E}-29 & 1.973 \mathrm{E}-27 & 7.960 \mathrm{E}-27 & 1.690 \mathrm{E}-23 & 2.414 \mathrm{E}-07 & 3.407 \mathrm{E}-05 & 0.000 \mathrm{E}+00\end{array}$ $1.000 \mathrm{E}+00 \quad 1.028 \mathrm{E}-33 \quad 7.286 \mathrm{E}-33 \quad 1.599 \mathrm{E}-29 \quad 1.302 \mathrm{E}-28 \quad 1.306 \mathrm{E}-24 \quad 3.284 \mathrm{E}-09 \quad 3.706 \mathrm{E}-06 \quad 0.000 \mathrm{E}+00$ $1.000 \mathrm{E}+00 \quad 8.021 \mathrm{E}-23 \quad 1.208 \mathrm{E}-21 \quad 5.266 \mathrm{E}-17 \quad 5.323 \mathrm{E}-16 \quad 5.607 \mathrm{E}-13 \quad 3.500 \mathrm{E}-08 \quad 3.071 \mathrm{E}-04 \quad 0.000 \mathrm{E}+00$ $\begin{array}{lllllllll}1.000 \mathrm{E}+00 & 2.326 \mathrm{E}-31 & 7.210 \mathrm{E}-30 & 7.772 \mathrm{E}-24 & 1.314 \mathrm{E}-22 & 3.671 \mathrm{E}-19 & 5.193 \mathrm{E}-08 & 2.286 \mathrm{E}-04 & 0.000 \mathrm{E}+00\end{array}$ $\begin{array}{llllllll}8.139 \mathrm{E}-23 & 1.209 \mathrm{E}-21 & 5.266 \mathrm{E}-17 & 5.323 \mathrm{E}-16 & 5.607 \mathrm{E}-13 & 6.318 \mathrm{E}-07 & 5.734 \mathrm{E}-04 & 0.000 \mathrm{E}+00\end{array}$

$\begin{array}{lllllllllll}1.000 \mathrm{E}+00 & 1.202 \mathrm{E}-17 & 1.217 \mathrm{E}-17 & 2.183 \mathrm{E}-17 & 3.965 \mathrm{E}-17 & 4.690 \mathrm{E}-15 & 1.272 \mathrm{E}-03 & 1.039 \mathrm{E}-01 & 0.000 \mathrm{E}+00\end{array}$ $1.000 \mathrm{E}+00 \quad 6.135 \mathrm{E}-24 \quad 1.861 \mathrm{E}-23 \quad 1.146 \mathrm{E}-21 \quad 4.227 \mathrm{E}-21 \quad 2.931 \mathrm{E}-18 \quad 6.673 \mathrm{E}-10 \quad 4.803 \mathrm{E}-06 \quad 0.000 \mathrm{E}+00$ $1.000 \mathrm{E}+00 \quad 9.652 \mathrm{E}-28 \quad 6.818 \mathrm{E}-27 \quad 1.251 \mathrm{E}-23 \quad 8.414 \mathrm{E}-23 \quad 1.444 \mathrm{E}-19 \quad 4.828 \mathrm{E}-10 \quad 4.443 \mathrm{E}-06 \quad 0.000 \mathrm{E}+00$ $2.288 \mathrm{E}-27 \quad 3.434 \mathrm{E}-26 \quad 1.276 \mathrm{E}-21 \quad 1.169 \mathrm{E}-20 \quad 1.476 \mathrm{E}-17 \quad 1.691 \mathrm{E}-10 \quad 2.295 \mathrm{E}-06 \quad 0.000 \mathrm{E}+00$ $\begin{array}{llllllll}1.202 \mathrm{E}-17 & 1.217 \mathrm{E}-17 & 2.183 \mathrm{E}-17 & 3.966 \mathrm{E}-17 & 4.708 \mathrm{E}-15 & 1.272 \mathrm{E}-03 & 1.039 \mathrm{E}-01 & 0.000 \mathrm{E}+00\end{array}$

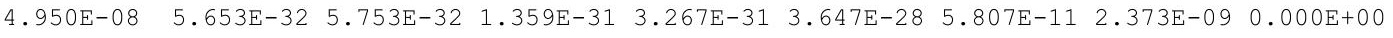

1.000E+00 1.142E-24 1.162E-24 2.746E-24 6.601E-24 7.367E-21 $1.173 \mathrm{E}-03 \quad 4.794 \mathrm{E}-02 \quad 0.000 \mathrm{E}+00$ $\begin{array}{lllllllll}1.000 \mathrm{E}+00 & 2.162 \mathrm{E}-32 & 6.590 \mathrm{E}-32 & 5.335 \mathrm{E}-30 & 2.602 \mathrm{E}-29 & 1.686 \mathrm{E}-25 & 1.913 \mathrm{E}-08 & 1.752 \mathrm{E}-05 & 0.000 \mathrm{E}+00\end{array}$ $\begin{array}{llllllll}1.000 \mathrm{E}+00 & 2.845 \mathrm{E}-43 & 2.028 \mathrm{E}-42 & 5.480 \mathrm{E}-39 & 5.478 \mathrm{E}-38 & 2.238 \mathrm{E}-33 & 9.403 \mathrm{E}-16 & 7.022 \mathrm{E}-12 \quad 0.000 \mathrm{E}+00\end{array}$ $\begin{array}{lllllllll}1.000 \mathrm{E}+00 & 1.371 \mathrm{E}-28 & 2.018 \mathrm{E}-27 & 3.762 \mathrm{E}-23 & 2.542 \mathrm{E}-22 & 1.470 \mathrm{E}-19 & 1.226 \mathrm{E}-13 & 9.364 \mathrm{E}-10 & 0.000 \mathrm{E}+00\end{array}$ $\begin{array}{lllllllll}8.111 \mathrm{E}-28 & 2.334 \mathrm{E}-26 & 2.641 \mathrm{E}-21 & 1.757 \mathrm{E}-20 & 5.564 \mathrm{E}-18 & 1.531 \mathrm{E}-15 & 3.662 \mathrm{E}-10 & 0.000 \mathrm{E}+00\end{array}$ $1.143 \mathrm{E}-24 \quad 1.188 \mathrm{E}-24 \quad 2.681 \mathrm{E}-21 \quad 1.783 \mathrm{E}-20 \quad 5.719 \mathrm{E}-18 \quad 1.173 \mathrm{E}-03 \quad 4.796 \mathrm{E}-02 \quad 0.000 \mathrm{E}+00$ $\begin{array}{llllllllll}1.000 \mathrm{E}+00 \quad 5.758 \mathrm{E}-26 & 5.817 \mathrm{E}-26 & 9.575 \mathrm{E}-26 & 1.592 \mathrm{E}-25 & 2.070 \mathrm{E}-01 & 1.474 \mathrm{E}-03 & 1.242 \mathrm{E}-38 & 0.000 \mathrm{E}+00\end{array}$ $1.000 \mathrm{E}+00 \quad 1.382 \mathrm{E}-06 \quad 9.680 \mathrm{E}-07 \quad 2.527 \mathrm{E}-14 \quad 4.618 \mathrm{E}-22 \quad 0.000 \mathrm{E}+00 \quad 0.000 \mathrm{E}+00 \quad 0.000 \mathrm{E}+00 \quad 0.000 \mathrm{E}+00$ $\begin{array}{lllllllll}1.000 \mathrm{E}+00 & 2.412 \mathrm{E}-22 & 2.453 \mathrm{E}-22 & 5.590 \mathrm{E}-22 & 1.295 \mathrm{E}-21 & 1.078 \mathrm{E}-18 & 1.108 \mathrm{E}-03 & 1.244 \mathrm{E}-01 \quad 0.000 \mathrm{E}+00\end{array}$ $\begin{array}{llllllllll}1.000 \mathrm{E}+00 & 3.774 \mathrm{E}-11 & 1.139 \mathrm{E}-10 & 5.320 \mathrm{E}-09 & 1.479 \mathrm{E}-08 & 1.071 \mathrm{E}-06 & 2.411 \mathrm{E}-02 & 1.303 \mathrm{E}+01 \quad 0.000 \mathrm{E}+00\end{array}$ $\begin{array}{lllllllll}1.000 \mathrm{E}+00 & 1.819 \mathrm{E}-19 & 1.271 \mathrm{E}-18 & 1.299 \mathrm{E}-15 & 5.314 \mathrm{E}-15 & 7.678 \mathrm{E}-13 & 3.720 \mathrm{E}-02 & 9.735 \mathrm{E}+00 \quad 0.000 \mathrm{E}+00\end{array}$ $\begin{array}{llllllll}3.774 \mathrm{E}-11 & 1.139 \mathrm{E}-10 & 5.320 \mathrm{E}-09 & 1.479 \mathrm{E}-08 & 1.071 \mathrm{E}-06 & 6.242 \mathrm{E}-02 & 2.289 \mathrm{E}+01 & 0.000 \mathrm{E}+00\end{array}$ 
RESRAD, Version $6.5 \quad T^{1 / 2}$ Limit $=180$ days $\quad 07 / 21 / 2011 \quad 12: 07$ Page 30

Summary : RESRAD Parameters for Resident Farmer U-Landfill Forward Run 100,000 Years

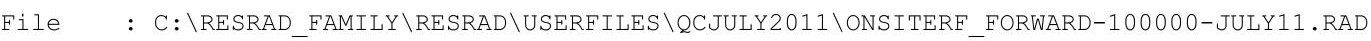

Dose/Source Ratios Summed Over All Pathways

Parent and Progeny Principal Radionuclide Contributions Indicated

\begin{tabular}{|c|c|c|c|c|c|c|c|c|c|c|}
\hline Parent & Product & Thread & & DSR & $(j, t)$ At & ime in Yea & (mrem) & $/ \mathrm{yr}) /(\mathrm{pCi} / \mathrm{g}$ & & \\
\hline (i) & (j) & Fraction & $0.000 \mathrm{E}+00$ & $1.000 \mathrm{E}+00$ & $5.000 \mathrm{E}+01$ & $1.000 \mathrm{E}+02$ & $5.000 \mathrm{E}+02$ & $1.050 \mathrm{E}+03$ & $1.000 \mathrm{E}+04$ & $1.000 \mathrm{E}+05$ \\
\hline-232 & $\mathrm{Th}-232$ & $1.000 \mathrm{E}+00$ & $1.166 \mathrm{E}-24$ & 1. $188 \mathrm{E}-24$ & $2.949 \mathrm{E}-24$ & $7.462 \mathrm{E}-24$ & $1.252 \mathrm{E}-20$ & $1.225 E-03$ & $1.485 \mathrm{E}-01$ & $0.000 \mathrm{E}+00$ \\
\hline-232 & $\mathrm{Ra}-228+\mathrm{D}$ & $1.000 \mathrm{E}+00$ & $1.107 \mathrm{E}-09$ & $3.174 \mathrm{E}-09$ & $2.784 \mathrm{E}-08$ & $4.079 \mathrm{E}-08$ & $8.497 \mathrm{E}-07$ & $1.623 E-01$ & 1. $983 \mathrm{E}+01$ & $0.000 \mathrm{E}+00$ \\
\hline $1-232$ & $\mathrm{Th}-228+\mathrm{D}$ & $1.000 \mathrm{E}+00$ & $1.067 \mathrm{E}-08$ & $6.581 \mathrm{E}-08$ & $2.213 E-06$ & $2.992 E-06$ & $3.253 E-05$ & $2.034 \mathrm{E}-03$ & $7.758 \mathrm{E}+00$ & $0.000 \mathrm{E}+00$ \\
\hline$h-232$ & $\sum \operatorname{DSR}(j)$ & & $1.178 \mathrm{E}-08$ & $6.899 \mathrm{E}-08$ & $2.241 \mathrm{E}-06$ & $3.033 E-06$ & $3.338 E-05$ & $1.655 \mathrm{E}-01$ & $2.774 \mathrm{E}+01$ & $0.000 \mathrm{E}+00$ \\
\hline-234 & $\mathrm{U}-234$ & $1.000 \mathrm{E}+00$ & $6.896 \mathrm{E}-24$ & $7.019 \mathrm{E}-24$ & $1.670 \mathrm{E}-23$ & $4.047 \mathrm{E}-23$ & $4.798 \mathrm{E}-20$ & $6.722 \mathrm{E}-04$ & $9.483 \mathrm{E}-02$ & $0.000 \mathrm{E}+00$ \\
\hline-234 & Th-230 & $1.000 \mathrm{E}+00$ & $1.089 E-27$ & $3.315 E-27$ & $2.540 \mathrm{E}-25$ & $1.171 \mathrm{E}-24$ & $4.838 E-21$ & $1.040 E-05$ & $1.046 \mathrm{E}-02$ & $0.000 \mathrm{E}+00$ \\
\hline-234 & $\mathrm{Ra}-226+\mathrm{D}$ & $1.000 \mathrm{E}+00$ & $1.133 \mathrm{E}-16$ & $7.978 \mathrm{E}-16$ & 1. $213 \mathrm{E}-12$ & $6.737 \mathrm{E}-12$ & $2.496 \mathrm{E}-09$ & 1.221E-04 & $8.696 \mathrm{E}-01$ & $0.000 \mathrm{E}+00$ \\
\hline-234 & $\mathrm{~Pb}-210+\mathrm{D}$ & $1.000 \mathrm{E}+00$ & $4.102 E-25$ & $6.153 \mathrm{E}-24$ & $2.201 \mathrm{E}-19$ & $1.935 \mathrm{E}-18$ & $1.678 \mathrm{E}-15$ & $1.825 E-04$ & $6.474 \mathrm{E}-01$ & $0.000 \mathrm{E}+00$ \\
\hline-234 & $\sum \operatorname{DSR}(j)$ & & $1.133 E-16$ & $7.978 \mathrm{E}-16$ & $1.213 E-12$ & $6.737 E-12$ & $2.496 \mathrm{E}-09$ & $9.872 E-04$ & $1.622 \mathrm{E}+00$ & $0.000 \mathrm{E}+00$ \\
\hline$-235+D$ & $\mathrm{U}-235+\mathrm{D}$ & $1.000 \mathrm{E}+00$ & 1. $243 \mathrm{E}-14$ & 1. $259 \mathrm{E}-14$ & $2.306 \mathrm{E}-14$ & $4.276 \mathrm{E}-14$ & $5.981 \mathrm{E}-12$ & $6.528 E-04$ & $5.458 \mathrm{E}-01$ & $0.000 \mathrm{E}+00$ \\
\hline$-235+D$ & $\mathrm{~Pa}-231$ & $1.000 \mathrm{E}+00$ & $2.937 \mathrm{E}-18$ & $8.896 \mathrm{E}-18$ & $5.031 E-16$ & $1.701 \mathrm{E}-15$ & $5.876 \mathrm{E}-13$ & $9.383 E-04$ & $9.492 \mathrm{E}-01$ & $0.000 \mathrm{E}+00$ \\
\hline$-235+D$ & $A C-227+D$ & $1.000 \mathrm{E}+00$ & $9.274 \mathrm{E}-18$ & $6.481 \mathrm{E}-17$ & $6.882 \mathrm{E}-14$ & $2.943 E-13$ & $6.376 \mathrm{E}-11$ & $3.384 \mathrm{E}-04$ & 4. $918 \mathrm{E}-01$ & $0.000 \mathrm{E}+00$ \\
\hline$-235+D$ & $\sum \operatorname{DSR}(j)$ & & $1.245 \mathrm{E}-14$ & $1.266 \mathrm{E}-14$ & $9.238 \mathrm{E}-14$ & $3.388 \mathrm{E}-13$ & 7.033E-11 & $1.929 \mathrm{E}-03$ & $1.987 \mathrm{E}+00$ & $0.000 \mathrm{E}+00$ \\
\hline-238 & $\mathrm{U}-238$ & $5.400 \mathrm{E}-05$ & $0.000 \mathrm{E}+00$ & $0.000 \mathrm{E}+00$ & $0.000 \mathrm{E}+00$ & $0.000 \mathrm{E}+00$ & $0.000 \mathrm{E}+00$ & $3.359 \mathrm{E}-08$ & $4.852 \mathrm{E}-06$ & $0.000 \mathrm{E}+00$ \\
\hline$-238+D$ & $\mathrm{U}-238+\mathrm{D}$ & $9.999 \mathrm{E}-01$ & $1.420 \mathrm{E}-10$ & 1. $431 \mathrm{E}-10$ & $2.116 \mathrm{E}-10$ & $3.153 \mathrm{E}-10$ & $7.678 E-09$ & $6.695 E-04$ & $1.974 \mathrm{E}-01$ & $0.000 \mathrm{E}+00$ \\
\hline$-238+D$ & $\mathrm{U}-234$ & $9.999 \mathrm{E}-01$ & $9.803 E-30$ & $2.988 E-29$ & $2.392 \mathrm{E}-27$ & $1.153 \mathrm{E}-26$ & $6.812 \mathrm{E}-23$ & $2.005 E-06$ & $2.727 \mathrm{E}-03$ & $0.000 \mathrm{E}+00$ \\
\hline$-238+D$ & Th-230 & $9.999 E-01$ & $1.030 \mathrm{E}-33$ & $7.316 \mathrm{E}-33$ & $1.818 \mathrm{E}-29$ & $1.668 \mathrm{E}-28$ & $3.430 \mathrm{E}-24$ & $1.547 \mathrm{E}-08$ & $1.462 \mathrm{E}-04$ & $0.000 \mathrm{E}+00$ \\
\hline$-238+D$ & $\mathrm{Ra}-226+\mathrm{D}$ & $9.999 \mathrm{E}-01$ & $8.034 E-23$ & 1. $212 \mathrm{E}-21$ & $5.801 \mathrm{E}-17$ & $6.420 \mathrm{E}-16$ & 1. $201 \mathrm{E}-12$ & $1.255 \mathrm{E}-07$ & 1. $015 \mathrm{E}-02$ & $0.000 \mathrm{E}+00$ \\
\hline$-238+D$ & $\mathrm{~Pb}-210+\mathrm{D}$ & $9.999 \mathrm{E}-01$ & $2.329 E-31$ & $7.229 \mathrm{E}-30$ & $8.430 \mathrm{E}-24$ & $1.546 \mathrm{E}-22$ & 7. $612 \mathrm{E}-19$ & $1.821 E-07$ & $7.529 \mathrm{E}-03$ & $0.000 \mathrm{E}+00$ \\
\hline$-238+D$ & $\sum \operatorname{DSR}(j)$ & & $1.420 \mathrm{E}-10$ & $1.431 \mathrm{E}-10$ & $2.116 \mathrm{E}-10$ & $3.153 \mathrm{E}-10$ & $7.680 \mathrm{E}-09$ & $6.719 \mathrm{E}-04$ & $2.180 \mathrm{E}-01$ & $0.000 \mathrm{E}+00$ \\
\hline
\end{tabular}

The DSR includes contributions from associated (half-life $\leq 180$ days) daughters. 
RESRAD, Version $6.5 \quad T^{1 / 2}$ Limit $=180$ days

07/21/2011 12:07 Page 31

ummary : RESRAD Parameters for Resident Farmer U-Landfill Forward Run 100,000 Years

File : C: \RESRAD FAMILY \RESRAD \USERFILES \QCJULY2011 ONSITERF FORWARD-100000-JULY11.RAD

Single Radionuclide Soil Guidelines G(i,t) in pCi/g

Basic Radiation Dose Limit $=1.000 \mathrm{E}+02 \mathrm{mrem} / \mathrm{yr}$

Nuclide

\begin{tabular}{|c|c|c|c|c|c|c|c|c|}
\hline (i) & $t=0.000 \mathrm{E}+00$ & $1.000 \mathrm{E}+00$ & $5.000 \mathrm{E}+01$ & $1.000 \mathrm{E}+02$ & $5.000 \mathrm{E}+02$ & $1.050 \mathrm{E}+03$ & $1.000 \mathrm{E}+04$ & $1.000 \mathrm{E}+05$ \\
\hline $1-241$ & $\star 3.431 \mathrm{E}+12$ & $\star 3.431 \mathrm{E}+12$ & $\star 3.431 \mathrm{E}+12$ & $\star 3.431 \mathrm{E}+12$ & $\star 3.431 \mathrm{E}+12$ & $5.034 \mathrm{E}+05$ & $4.163 \mathrm{E}+05$ & $7.162 \mathrm{E}+07$ \\
\hline-137 & $7.925 \mathrm{E}+10$ & $8.043 E+10$ & $1.653 E+11$ & $3.447 E+11$ & $\star 8.704 \mathrm{E}+13$ & $\star 8.704 \mathrm{E}+13$ & $\star 8.704 \mathrm{E}+13$ & $\star 8.704 \mathrm{E}+13$ \\
\hline-237 & $\star 7.047 \mathrm{E}+08$ & $* 7.047 \mathrm{E}+08$ & $\star 7.047 \mathrm{E}+08$ & $\star 7.047 \mathrm{E}+08$ & $\star 7.047 \mathrm{E}+08$ & $9.465 \mathrm{E}+03$ & $8.902 \mathrm{E}+01$ & $1.460 \mathrm{E}+04$ \\
\hline-238 & $\star 1.712 \mathrm{E}+13$ & $\star 1.712 \mathrm{E}+13$ & $\star 1.712 \mathrm{E}+13$ & $\star 1.712 \mathrm{E}+13$ & $\star 1.712 \mathrm{E}+13$ & $1.583 \mathrm{E}+08$ & $1.744 \mathrm{E}+05$ & $\star 1.712 \mathrm{E}+13$ \\
\hline-239 & $\star 6.214 \mathrm{E}+10$ & $* 6.214 \mathrm{E}+10$ & $* 6.214 \mathrm{E}+10$ & $* 6.214 \mathrm{E}+10$ & $\star 6.214 \mathrm{E}+10$ & $7.860 \mathrm{E}+04$ & $9.626 \mathrm{E}+02$ & $* 6.214 \mathrm{E}+10$ \\
\hline-240 & $\star 2.278 \mathrm{E}+11$ & $\star 2.278 \mathrm{E}+11$ & $\star 2.278 \mathrm{E}+11$ & $\star 2.278 \mathrm{E}+11$ & $\star 2.278 \mathrm{E}+11$ & $8.524 \mathrm{E}+04$ & $2.085 E+03$ & $\star 2.278 \mathrm{E}+11$ \\
\hline$c-99$ & $\star 1.697 \mathrm{E}+10$ & $* 1.697 \mathrm{E}+10$ & $\star 1.697 \mathrm{E}+10$ & $* 1.697 \mathrm{E}+10$ & $4.830 \mathrm{E}+02$ & $6.786 \mathrm{E}+04$ & $\star 1.697 \mathrm{E}+10$ & $* 1.697 \mathrm{E}+10$ \\
\hline$h-228$ & $7.234 \mathrm{E}+07$ & $1.033 \mathrm{E}+08$ & $\star 8.195 \mathrm{E}+14$ & $\star 8.195 E+14$ & $\star 8.195 \mathrm{E}+14$ & $\star 8.195 \mathrm{E}+14$ & $\star 8.195 \mathrm{E}+14$ & $\star 8.195 \mathrm{E}+14$ \\
\hline Th-230 & $\star 2.018 \mathrm{E}+10$ & $\star 2.018 \mathrm{E}+10$ & $1.880 \mathrm{E}+10$ & $6.761 \mathrm{E}+09$ & $9.336 \mathrm{E}+07$ & $1.602 \mathrm{E}+03$ & $4.369 \mathrm{E}+00$ & $* 2.018 \mathrm{E}+10$ \\
\hline$h-232$ & $* 1.097 \mathrm{E}+05$ & $* 1.097 \mathrm{E}+05$ & $\star 1.097 \mathrm{E}+05$ & $* 1.097 \mathrm{E}+05$ & $* 1.097 \mathrm{E}+05$ & $6.041 \mathrm{E}+02$ & $3.605 \mathrm{E}+00$ & $* 1.097 \mathrm{E}+05$ \\
\hline$J-234$ & $* 6.247 \mathrm{E}+09$ & $* 6.247 \mathrm{E}+09$ & $\star 6.247 \mathrm{E}+09$ & $\star 6.247 \mathrm{E}+09$ & $* 6.247 \mathrm{E}+09$ & $1.013 \mathrm{E}+05$ & $6.164 \mathrm{E}+01$ & $* 6.247 \mathrm{E}+09$ \\
\hline 35 & $\star 2.161 \mathrm{E}+06$ & $\star 2.161 \mathrm{E}+06$ & $\star 2.161 \mathrm{E}+06$ & $\star 2.161 \mathrm{E}+06$ & $\star 2.161 \mathrm{E}+06$ & $5.183 \mathrm{E}+04$ & $5.033 E+01$ & $\star 2.161 \mathrm{E}+06$ \\
\hline 38 & $\star 3.361 \mathrm{E}+05$ & $\star 3.361 \mathrm{E}+05$ & $\star 3.361 \mathrm{E}+05$ & $\star 3.361 E+05$ & $\star 3.361 \mathrm{E}+05$ & $1.488 \mathrm{E}+05$ & $4.588 E+02$ & $\star 3.361 \mathrm{E}+05$ \\
\hline
\end{tabular}

*At specific activity limit

Summed Dose/Source Ratios DSR(i,t) in (mrem/yr)/(pCi/g)

and Single Radionuclide Soil Guidelines $G(i, t)$ in pCi/g

at $\operatorname{tmin}=$ time of minimum single radionuclide soil guideline and at $\operatorname{tmax}=$ time of maximum total dose $=12780 \pm *$ years

\begin{tabular}{|c|c|c|c|c|c|c|}
\hline $\begin{array}{l}\text { uclide } \\
\text { (i) }\end{array}$ & $\begin{array}{l}\text { Initial } \\
(\mathrm{pCi} / \mathrm{g})\end{array}$ & $\begin{array}{c}\text { tmin } \\
\text { (years) }\end{array}$ & $\operatorname{DSR}(i, \operatorname{tmin})$ & $\begin{array}{c}\mathrm{G}(\mathrm{i}, \mathrm{tmin}) \\
(\mathrm{pCi} / \mathrm{g})\end{array}$ & $\operatorname{DSR}(i, t \max )$ & $\begin{array}{c}G(i, t \max ) \\
(\mathrm{pCi} / \mathrm{g})\end{array}$ \\
\hline $1-241$ & $3.500 \mathrm{E}+01$ & $2534 \pm 5$ & $2.960 E-03$ & $3.379 E+04$ & $1.872 \mathrm{E}-04$ & $5.343 E+05$ \\
\hline-137 & $1.900 \mathrm{E}+01$ & $0.000 \mathrm{E}+00$ & $1.262 E-09$ & $7.925 E+10$ & $0.000 \mathrm{E}+00$ & $\star 8.704 \mathrm{E}+13$ \\
\hline-237 & $5.500 \mathrm{E}+00$ & $7684 \pm *$ & $1.422 \mathrm{E}+00$ & $7.033 E+01$ & $8.391 \mathrm{E}-01$ & $1.192 \mathrm{E}+02$ \\
\hline-238 & $3.900 \mathrm{E}+01$ & $23350 \pm *$ & $1.182 \mathrm{E}-03$ & $8.462 \mathrm{E}+04$ & $7.295 E-04$ & $1.371 \mathrm{E}+05$ \\
\hline-239 & $3.600 \mathrm{E}+01$ & $2534 \pm 5$ & $1.464 \mathrm{E}-01$ & $6.832 \mathrm{E}+02$ & $9.143 E-02$ & $1.094 \mathrm{E}+03$ \\
\hline-240 & $3.600 \mathrm{E}+01$ & $2534 \pm 5$ & $1.203 E-01$ & $8.314 \mathrm{E}+02$ & $3.406 \mathrm{E}-02$ & $2.936 E+03$ \\
\hline-99 & $5.200 \mathrm{E}+01$ & $424.8 \pm 0.8$ & $4.073 E-01$ & $2.455 \mathrm{E}+02$ & $0.000 \mathrm{E}+00$ & $\star 1.697 \mathrm{E}+10$ \\
\hline-228 & $4.000 \mathrm{E}+00$ & $0.000 \mathrm{E}+00$ & $1.382 E-06$ & $7.234 \mathrm{E}+07$ & $0.000 \mathrm{E}+00$ & $\star 8.195 \mathrm{E}+14$ \\
\hline-230 & $1.000 \mathrm{E}+02$ & $8257 \pm *$ & $2.303 E+01$ & $4.342 \mathrm{E}+00$ & $2.233 E+01$ & $4.478 E+00$ \\
\hline 232 & $4.000 \mathrm{E}+00$ & $2534 \pm 5$ & $2.835 E+01$ & $3.527 \mathrm{E}+00$ & $2.751 \mathrm{E}+01$ & $3.635 \mathrm{E}+00$ \\
\hline 234 & $1.600 \mathrm{E}+02$ & $23350 \pm \star$ & $3.312 \mathrm{E}+00$ & $3.019 \mathrm{E}+01$ & $2.056 \mathrm{E}+00$ & $4.863 E+01$ \\
\hline 35 & $6.500 \mathrm{E}+00$ & $23350 \pm \star$ & $2.648 \mathrm{E}+00$ & $3.777 \mathrm{E}+01$ & $2.205 E+00$ & $4.536 \mathrm{E}+01$ \\
\hline 238 & $1.600 \mathrm{E}+02$ & $23350 \pm *$ & $2.448 \mathrm{E}-01$ & $4.085 E+02$ & $2.185 \mathrm{E}-01$ & $4.576 \mathrm{E}+02$ \\
\hline
\end{tabular}

*At specific activity limit 
RESRAD, Version 6.5

ummary : RESRAD Parameters for Resident Farmer U-Landfill Forward Run 100,000 Years

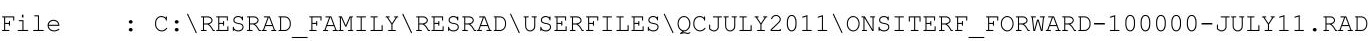

Individual Nuclide Dose Summed Over All Pathways

Parent Nuclide and Branch Fraction Indicated

Nuclide Parent THF(i) DOSE $(j, t), \mathrm{mrem} / \mathrm{yr}$

\begin{tabular}{|c|c|c|}
\hline (j) & (i) & \\
\hline $1-241$ & $A m-241$ & $1.000 \mathrm{E}+0$ \\
\hline $\mathrm{Np}-237$ & $A m-241$ & $1.000 \mathrm{E}+0 \mathrm{C}$ \\
\hline $\mathrm{Np}-237$ & $\mathrm{~Np}-237$ & $1.000 \mathrm{E}+0 \mathrm{C}$ \\
\hline $\mathrm{Np}-237$ & $\sum \operatorname{DOSE}(j$ & \\
\hline
\end{tabular}

$\mathrm{U}-233 \quad \mathrm{Am}-241 \quad 1.000 \mathrm{E}+00$

$\mathrm{U}-233 \quad \mathrm{~Np}-237 \quad 1.000 \mathrm{E}+00$

U-233 $\quad$ DOSE $(j)$

Th-229 Am-241 $1.000 \mathrm{E}+00$

Th-229 Np-237 $1.000 \mathrm{E}+00$

Th-229 $\sum \operatorname{DOSE}(j)$

Cs-137 Cs-137 1.000E+00

Pu-238 Pu-238 $1.840 \mathrm{E}-09$

$\mathrm{Pu}-238 \mathrm{Pu}-238 \quad 1.000 \mathrm{E}+00$

$\mathrm{Pu}-238 \quad \sum \operatorname{DOSE}(j)$

$\mathrm{U}-234$

$\mathrm{U}-234$

$\mathrm{U}-234$

$\mathrm{U}-234$

Th-230

Th -230

Th-230

Th-230

Th-230

$\mathrm{Ra}-226$

$\mathrm{Ra}-226$

$\mathrm{Ra}-226$

$\mathrm{Ra}-226$

$\mathrm{Ra}-226$

$\mathrm{Pb}-210$

$\mathrm{Pb}-210$

$\mathrm{Pb}-210$

$\mathrm{Pb}-210$

$\mathrm{Pb}-210$

$\mathrm{Pu}-239$

$\mathrm{Pu}-238 \quad 1.000 \mathrm{E}+00$ $\mathrm{U}-234 \quad 1.000 \mathrm{E}+00$ U-238 $9.999 \mathrm{E}-01$ $\sum \operatorname{DOSE}(j)$

$\mathrm{Pu}-238 \quad 1.000 \mathrm{E}+00$ Th-230 1.000E+00 U-234 $1.000 \mathrm{E}+00$ $\mathrm{U}-238 \quad 9.999 \mathrm{E}-01$ $\sum \operatorname{DOSE}(j)$

$\mathrm{Pu}-238 \quad 1.000 \mathrm{E}+00$ Th-230 1.000E+00 $\mathrm{U}-234 \quad 1.000 \mathrm{E}+00$ $\mathrm{U}-238 \quad 9.999 \mathrm{E}-01$ ¿DOSE (j)

$\mathrm{Pu}-238 \quad 1.000 \mathrm{E}+00$ Th-230 1.000E+00 $\mathrm{U}-234 \quad 1.000 \mathrm{E}+00$ $\mathrm{U}-238 \quad 9.999 \mathrm{E}-01$ $\sum \operatorname{DOSE}(j)$

Pu-239 1.000E+00

Pu-239 1.000E+00 $\mathrm{U}-235 \quad 1.000 \mathrm{E}+00$ ¿DOSE $(j)$ $t=0.000 \mathrm{E}+00 \quad 1.000 \mathrm{E}+00 \quad 5.000 \mathrm{E}+01 \quad 1.000 \mathrm{E}+02 \quad 5.000 \mathrm{E}+02 \quad 1.050 \mathrm{E}+03 \quad 1.000 \mathrm{E}+04 \quad 1.000 \mathrm{E}+05$

$\begin{array}{llllllll}0.000 \mathrm{E}+00 & 0.000 \mathrm{E}+00 & 0.000 \mathrm{E}+00 & 0.000 \mathrm{E}+00 & 4.227 \mathrm{E}-26 & 6.889 \mathrm{E}-03 & 5.652 \mathrm{E}-07 & 0.000 \mathrm{E}+00\end{array}$

5.412E-18 $1.638 \mathrm{E}-17 \quad 8.967 \mathrm{E}-16 \quad 2.934 \mathrm{E}-15 \quad 7.921 \mathrm{E}-13 \quad 6.396 \mathrm{E}-05 \quad 8.293 \mathrm{E}-03 \quad 0.000 \mathrm{E}+00$ $\begin{array}{llllllll}5.245 \mathrm{E}-12 & 5.301 \mathrm{E}-12 & 8.939 \mathrm{E}-12 & 1.524 \mathrm{E}-11 & 1.085 \mathrm{E}-09 & 5.809 \mathrm{E}-02 & 6.083 \mathrm{E}+00 & 0.000 \mathrm{E}+00\end{array}$

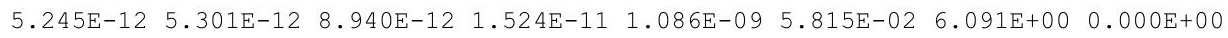

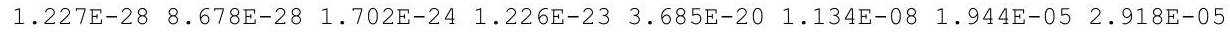

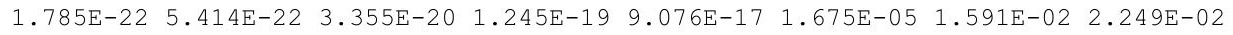

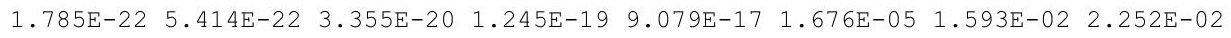

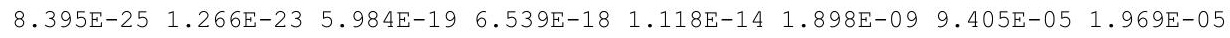
$\begin{array}{llllllll}1.629 \mathrm{E}-18 & 1.147 \mathrm{E}-17 & 1.758 \mathrm{E}-14 & 9.834 \mathrm{E}-14 & 3.894 \mathrm{E}-11 & 3.754 \mathrm{E}-06 & 7.951 \mathrm{E}-02 & 1.519 \mathrm{E}-02\end{array}$ $\begin{array}{llllllll}1.629 \mathrm{E}-18 & 1.147 \mathrm{E}-17 & 1.758 \mathrm{E}-14 & 9.835 \mathrm{E}-14 & 3.895 \mathrm{E}-11 & 3.755 \mathrm{E}-06 & 7.960 \mathrm{E}-02 & 1.521 \mathrm{E}-02\end{array}$

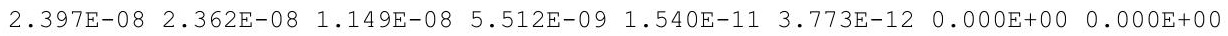
$\begin{array}{lllllllll}0.000 \mathrm{E}+00 & 0.000 \mathrm{E}+00 & 0.000 \mathrm{E}+00 & 0.000 \mathrm{E}+00 & 0.000 \mathrm{E}+00 & 2.154 \mathrm{E}-14 & 0.000 \mathrm{E}+00 & 0.000 \mathrm{E}+00\end{array}$

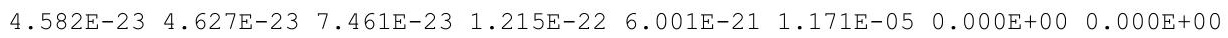
$\begin{array}{llllllll}4.582 \mathrm{E}-23 & 4.627 \mathrm{E}-23 & 7.461 \mathrm{E}-23 & 1.215 \mathrm{E}-22 & 6.001 \mathrm{E}-21 & 1.171 \mathrm{E}-05 & 0.000 \mathrm{E}+00 & 0.000 \mathrm{E}+00\end{array}$

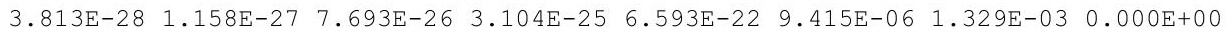
$\begin{array}{llllllllll}1.103 \mathrm{E}-21 & 1.123 \mathrm{E}-21 & 2.673 \mathrm{E}-21 & 6.475 \mathrm{E}-21 & 7.677 \mathrm{E}-18 & 1.075 \mathrm{E}-01 & 1.517 \mathrm{E}+01 & 0.000 \mathrm{E}+00\end{array}$ $\begin{array}{llllllll}1.569 \mathrm{E}-27 & 4.780 \mathrm{E}-27 & 3.827 \mathrm{E}-25 & 1.845 \mathrm{E}-24 & 1.090 \mathrm{E}-20 & 3.207 \mathrm{E}-04 & 4.363 \mathrm{E}-01 & 0.000 \mathrm{E}+00\end{array}$ $\begin{array}{lllllllll}1.103 \mathrm{E}-21 & 1.123 \mathrm{E}-21 & 2.673 \mathrm{E}-21 & 6.477 \mathrm{E}-21 & 7.688 \mathrm{E}-18 & 1.079 \mathrm{E}-01 & 1.561 \mathrm{E}+01 & 0.000 \mathrm{E}+00\end{array}$

$\begin{array}{llllllll}0.000 \mathrm{E}+00 & 0.000 \mathrm{E}+00 & 6.236 \mathrm{E}-28 & 5.079 \mathrm{E}-27 & 5.092 \mathrm{E}-23 & 1.281 \mathrm{E}-07 & 1.445 \mathrm{E}-04 & 0.000 \mathrm{E}+00\end{array}$ $\begin{array}{llllllll}2.412 \mathrm{E}-20 & 2.453 \mathrm{E}-20 & 5.590 \mathrm{E}-20 & 1.295 \mathrm{E}-19 & 1.078 \mathrm{E}-16 & 1.108 \mathrm{E}-01 & 1.244 \mathrm{E}+01 & 0.000 \mathrm{E}+00\end{array}$

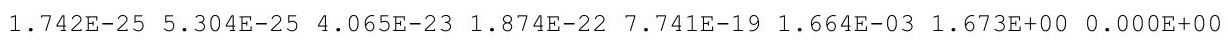

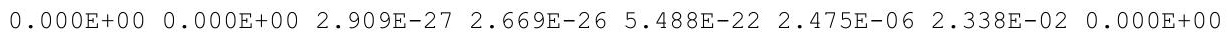
$\begin{array}{llllllll}2.412 \mathrm{E}-20 & 2.453 \mathrm{E}-20 & 5.594 \mathrm{E}-20 & 1.297 \mathrm{E}-19 & 1.085 \mathrm{E}-16 & 1.125 \mathrm{E}-01 & 1.414 \mathrm{E}+01 & 0.000 \mathrm{E}+00\end{array}$

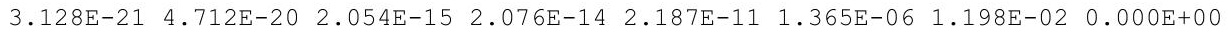

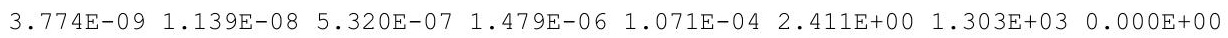
$\begin{array}{llllllll}1.813 \mathrm{E}-14 & 1.277 \mathrm{E}-13 & 1.941 \mathrm{E}-10 & 1.078 \mathrm{E}-09 & 3.993 \mathrm{E}-07 & 1.954 \mathrm{E}-02 & 1.391 \mathrm{E}+02 & 0.000 \mathrm{E}+00\end{array}$

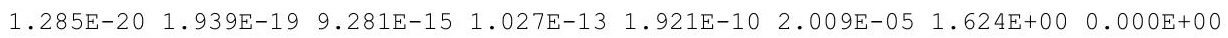

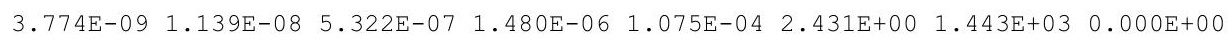

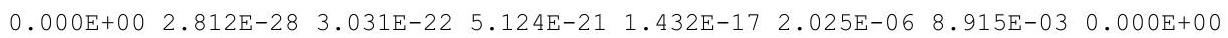
$\begin{array}{lllllllll}1.819 \mathrm{E}-17 & 1.271 \mathrm{E}-16 & 1.299 \mathrm{E}-13 & 5.314 \mathrm{E}-13 & 7.678 \mathrm{E}-11 & 3.720 \mathrm{E}+00 & 9.735 \mathrm{E}+02 & 0.000 \mathrm{E}+00\end{array}$ $\begin{array}{llllllll}6.563 \mathrm{E}-23 & 9.844 \mathrm{E}-22 & 3.522 \mathrm{E}-17 & 3.095 \mathrm{E}-16 & 2.685 \mathrm{E}-13 & 2.920 \mathrm{E}-02 & 1.036 \mathrm{E}+02 & 0.000 \mathrm{E}+00\end{array}$ $0.000 \mathrm{E}+00 \quad 1.157 \mathrm{E}-27 \quad 1.349 \mathrm{E}-21 \quad 2.474 \mathrm{E}-20 \quad 1.218 \mathrm{E}-16 \quad 2.913 \mathrm{E}-05 \quad 1.205 \mathrm{E}+00 \quad 0.000 \mathrm{E}+00$

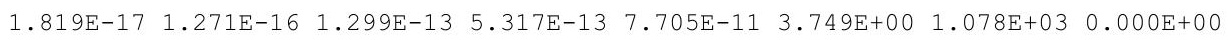

$4.328 \mathrm{E}-16 \quad 4.380 \mathrm{E}-16 \quad 7.860 \mathrm{E}-16 \quad 1.427 \mathrm{E}-15 \quad 1.689 \mathrm{E}-13 \quad 4.580 \mathrm{E}-02 \quad 3.739 \mathrm{E}+00 \quad 0.000 \mathrm{E}+00$

$2.209 \mathrm{E}-22 \quad 6.699 \mathrm{E}-22 \quad 4.126 \mathrm{E}-20 \quad 1.522 \mathrm{E}-19 \quad 1.055 \mathrm{E}-16 \quad 2.402 \mathrm{E}-08 \quad 1.729 \mathrm{E}-04 \quad 0.000 \mathrm{E}+00$ $\begin{array}{lllllllll}8.081 \mathrm{E}-14 & 8.182 \mathrm{E}-14 & 1.499 \mathrm{E}-13 & 2.779 \mathrm{E}-13 & 3.888 \mathrm{E}-11 & 4.243 \mathrm{E}-03 & 3.547 \mathrm{E}+00 & 0.000 \mathrm{E}+00\end{array}$ $\begin{array}{llllllll}8.081 \mathrm{E}-14 & 8.182 \mathrm{E}-14 & 1.499 \mathrm{E}-13 & 2.779 \mathrm{E}-13 & 3.888 \mathrm{E}-11 & 4.243 \mathrm{E}-03 & 3.548 \mathrm{E}+00 & 0.000 \mathrm{E}+00\end{array}$ 
RESRAD, Version 6.5

Summary : RESRAD Parameters for Resident Farmer U-Landfill Forward Run 100,000 Years

File : C: \RESRAD_FAMILY \RESRAD \USERFILES \QCJULY2011 ONSITERF_FORWARD-100000-JULY11.RAD

Individual Nuclide Dose Summed Over All Pathways

Parent Nuclide and Branch Fraction Indicated

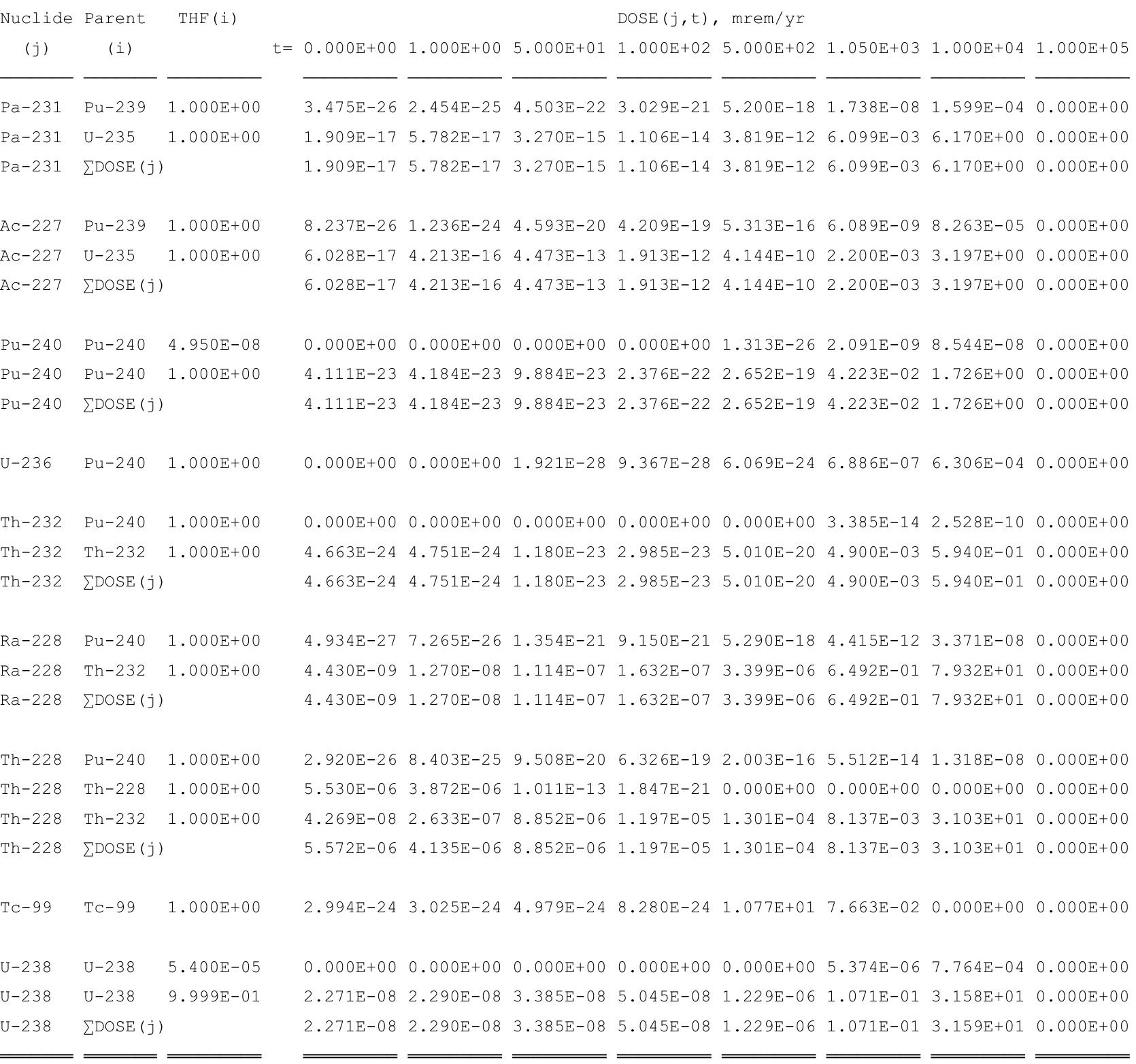

THF (i) is the thread fraction of the parent nuclide. 
Summary : RESRAD Parameters for U-Landfill Resident Gardener Forward Run

File : C: \RESRAD_FAMILY \RESRAD \USERFILES \QCJULY2011 \ULANDFILL-RG_FORWARD-1050YR.RAD

Dose Conversion Factor (and Related) Parameter Summary

Dose Library: ICRP 60 \& ICRP 72 (Adult)

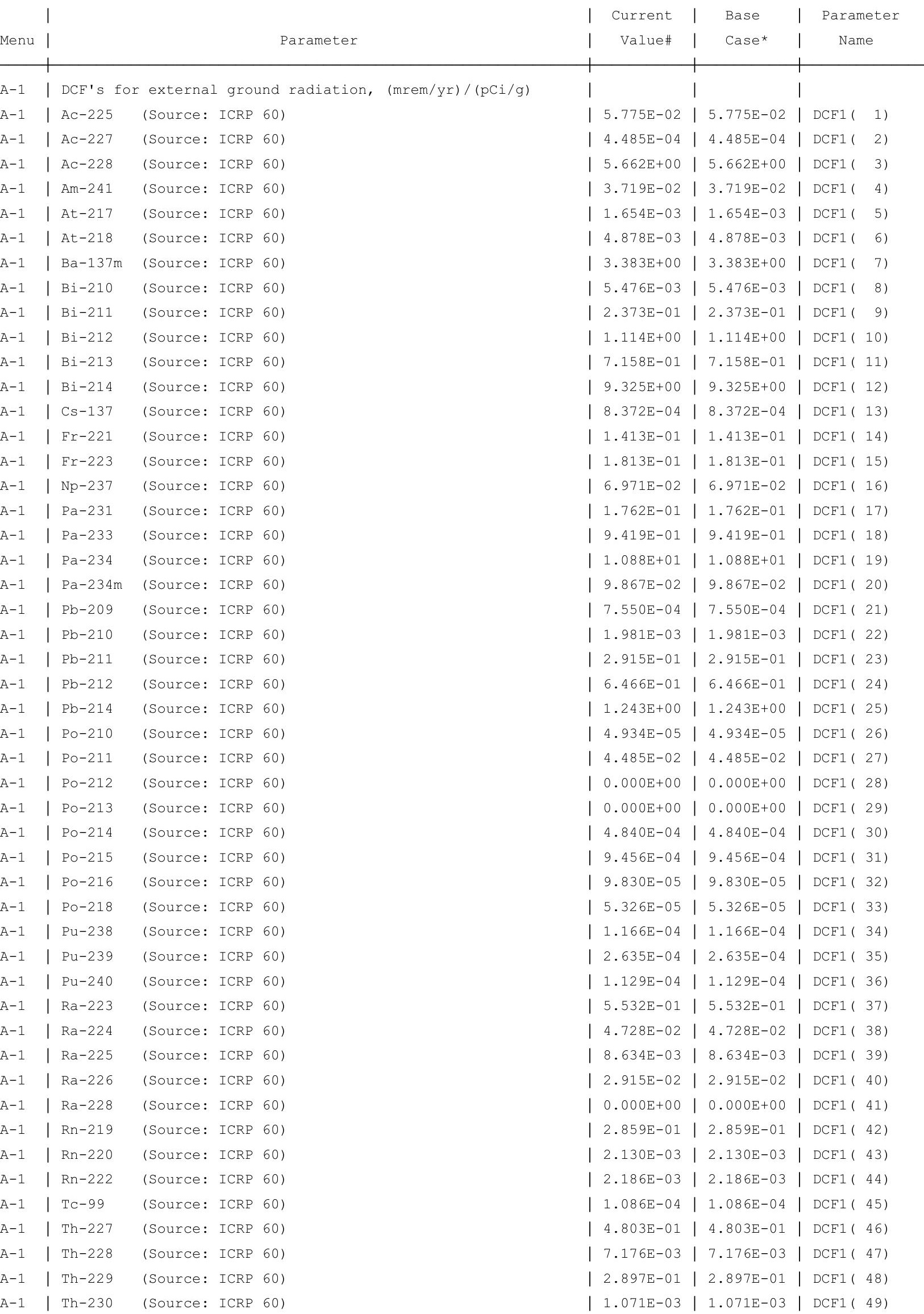


RESRAD, Version $6.5 \quad T^{13 / 2}$ Limit $=180$ days $\quad 07 / 20 / 2011 \quad 14: 38$ Page

Summary : RESRAD Parameters for U-Landfill Resident Gardener Forward Run

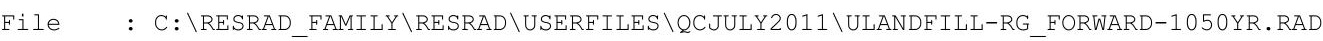

Dose Conversion Factor (and Related) Parameter Summary (continued) Dose Library: ICRP 60 \& ICRP 72 (Adult)

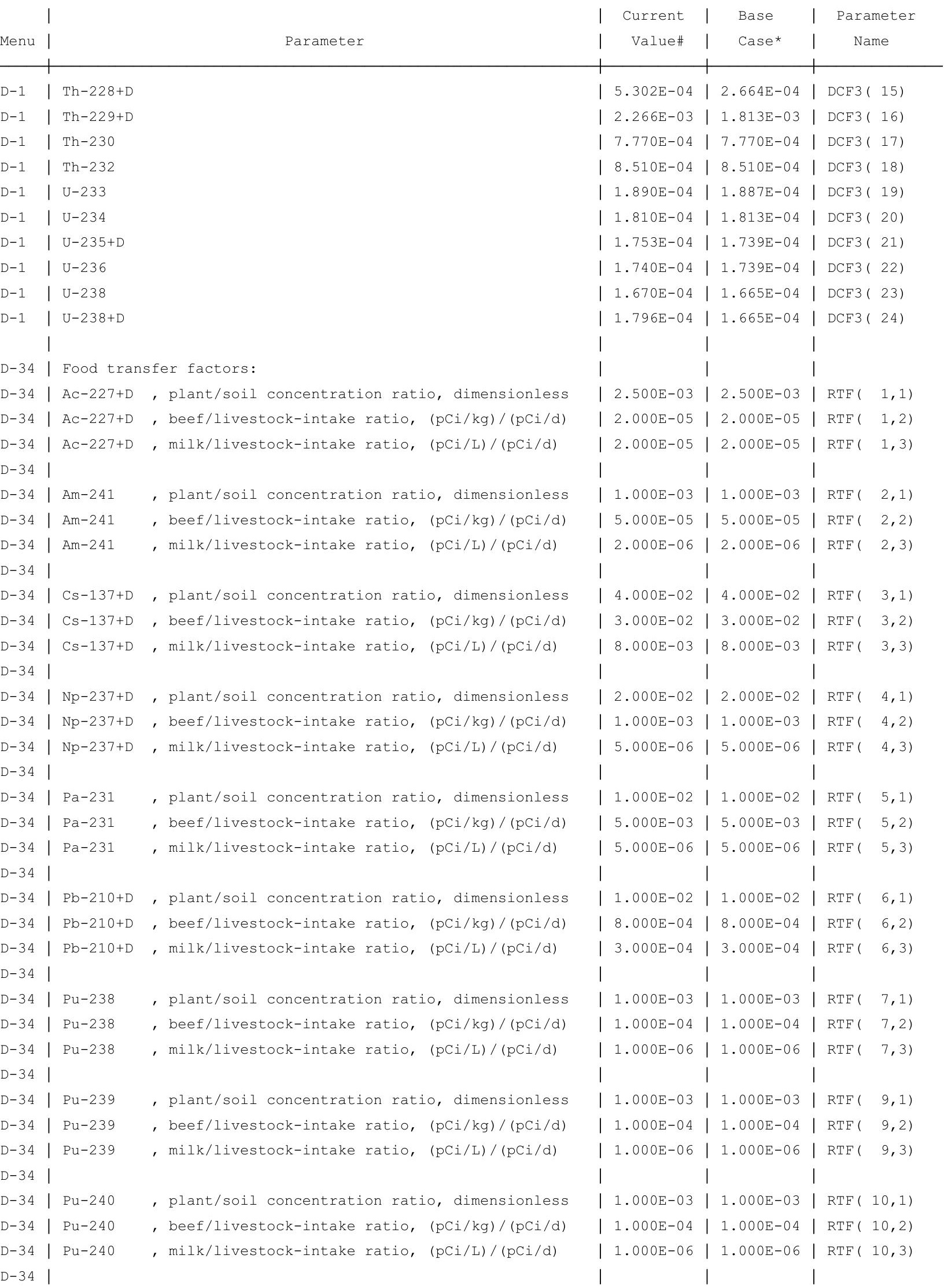


RESRAD, Version $6.5 \quad$ T1/2 Limit $=180$ days $\quad$ 07/20/2011 14:38 Page

Summary : RESRAD Parameters for U-Landfill Resident Gardener Forward Run

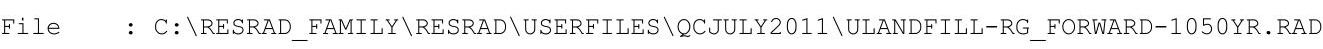

Dose Conversion Factor (and Related) Parameter Summary (continued)

Dose Library: ICRP 60 \& ICRP 72 (Adult)

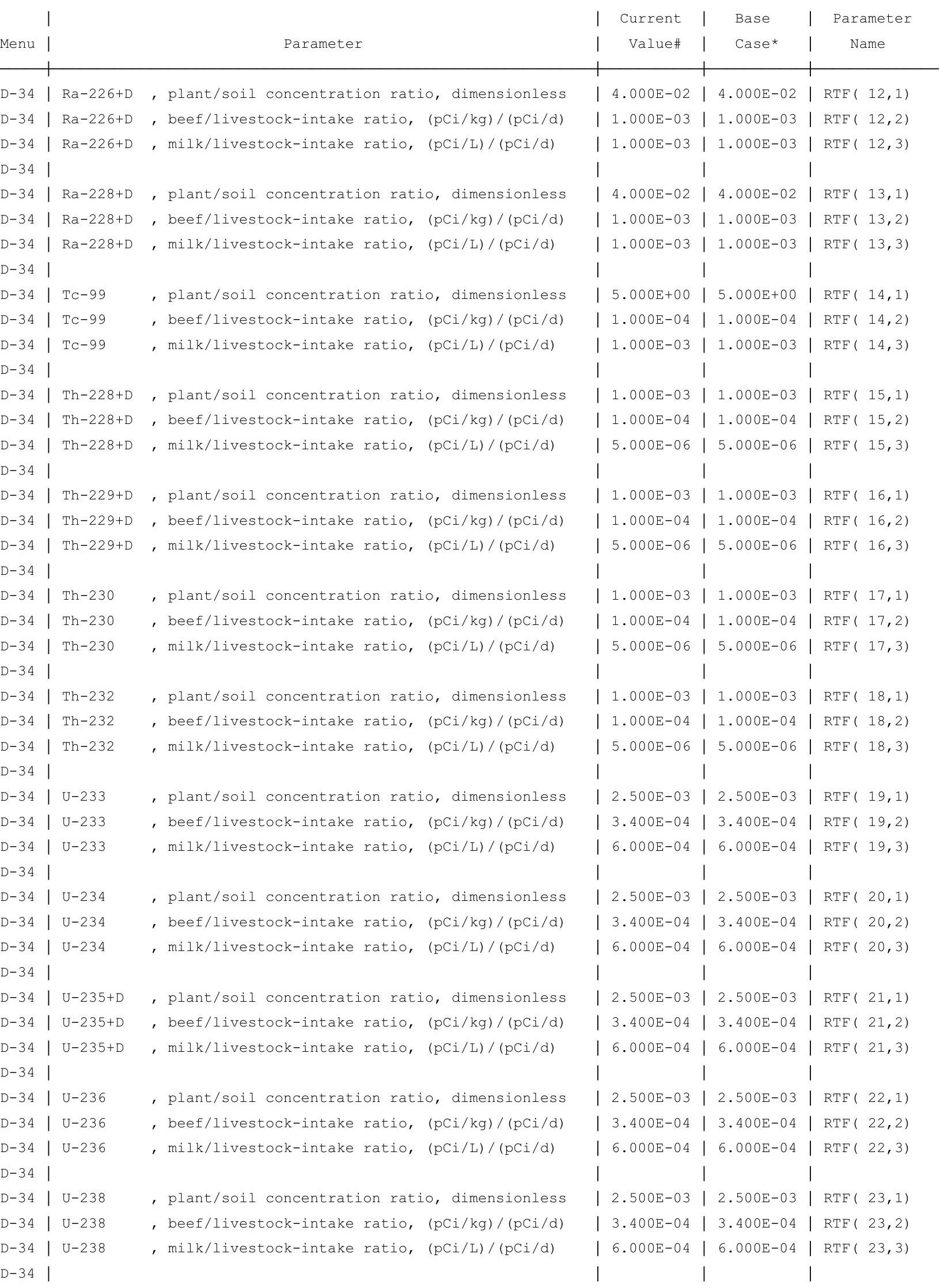


RESRAD, Version $6.5 \quad T^{11 / 2}$ Limit $=180$ days

Summary : RESRAD Parameters for U-Landfill Resident Gardener Forward Run

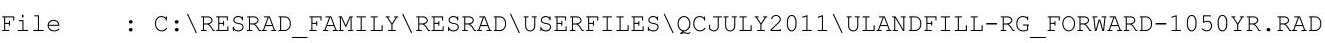

Dose Conversion Factor (and Related) Parameter Summary (continued)

Dose Library: ICRP 60 \& ICRP 72 (Adult)

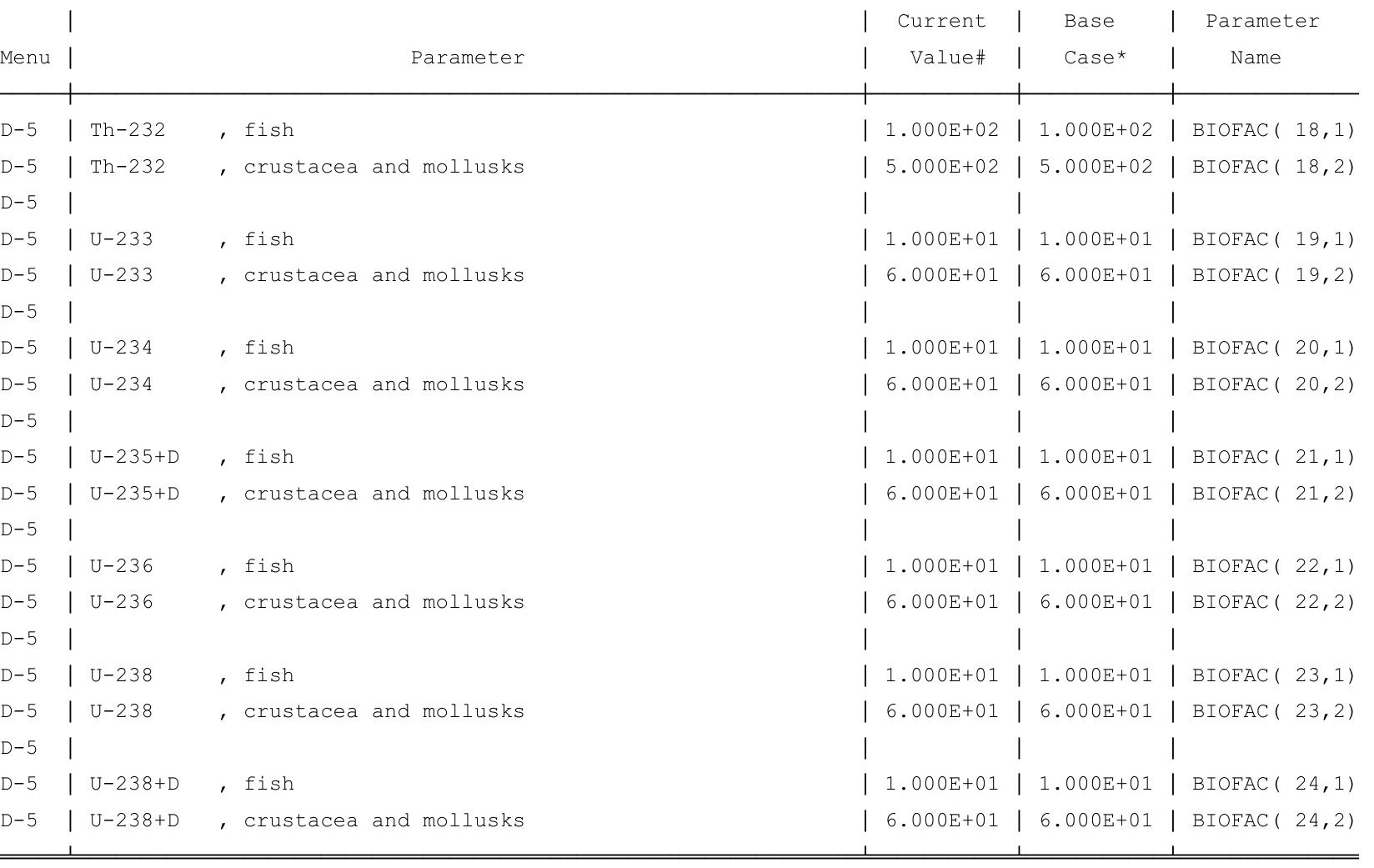

\#For DCFl(xxx) only, factors are for infinite depth \& area. See ETFG table in Ground Pathway of Detailed Report. *Base Case means Default.Lib w/o Associate Nuclide contributions. 
RESRAD, Version 6.5 $\quad T^{1 / 2}$ Limit $=180$ days $\quad 07 / 20 / 2011 \quad 14: 38$ Page

Summary : RESRAD Parameters for U-Landfill Resident Gardener Forward Run

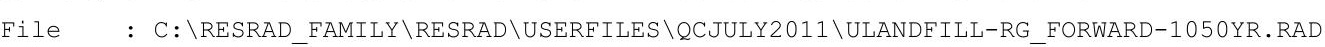

Site-Specific Parameter Summary (continued)

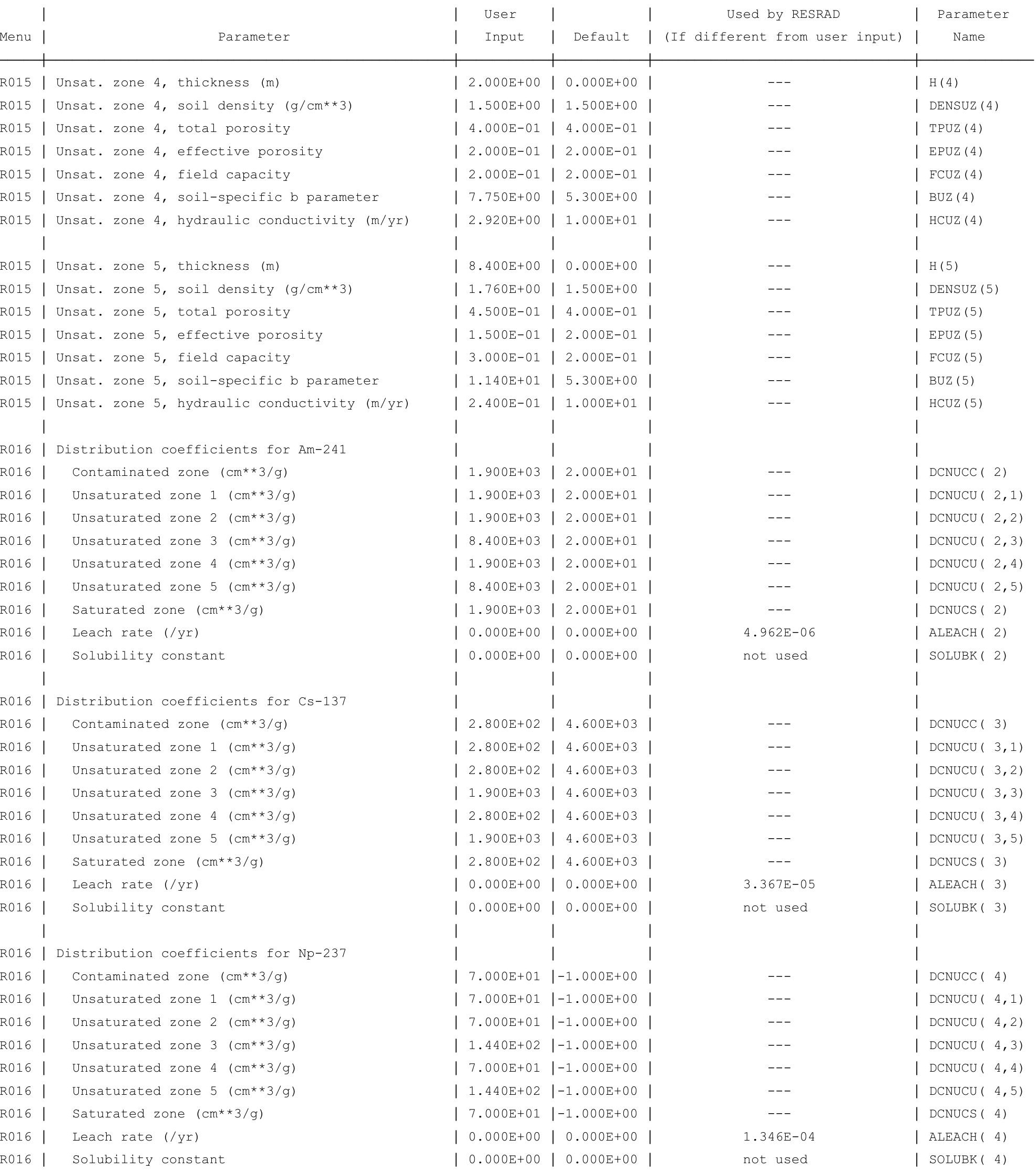


RESRAD, Version $6.5 \quad$ T1/2 Limit $=180$ days $\quad 07 / 20 / 2011 \quad 14: 38$ Page

Summary : RESRAD Parameters for U-Landfill Resident Gardener Forward Run

File : C: \RESRAD_FAMILY \RESRAD \USERFILES $\backslash$ QCJULY2011 \ULANDFILL-RG_FORWARD-1050YR.RAD

Site-Specific Parameter Summary (continued)

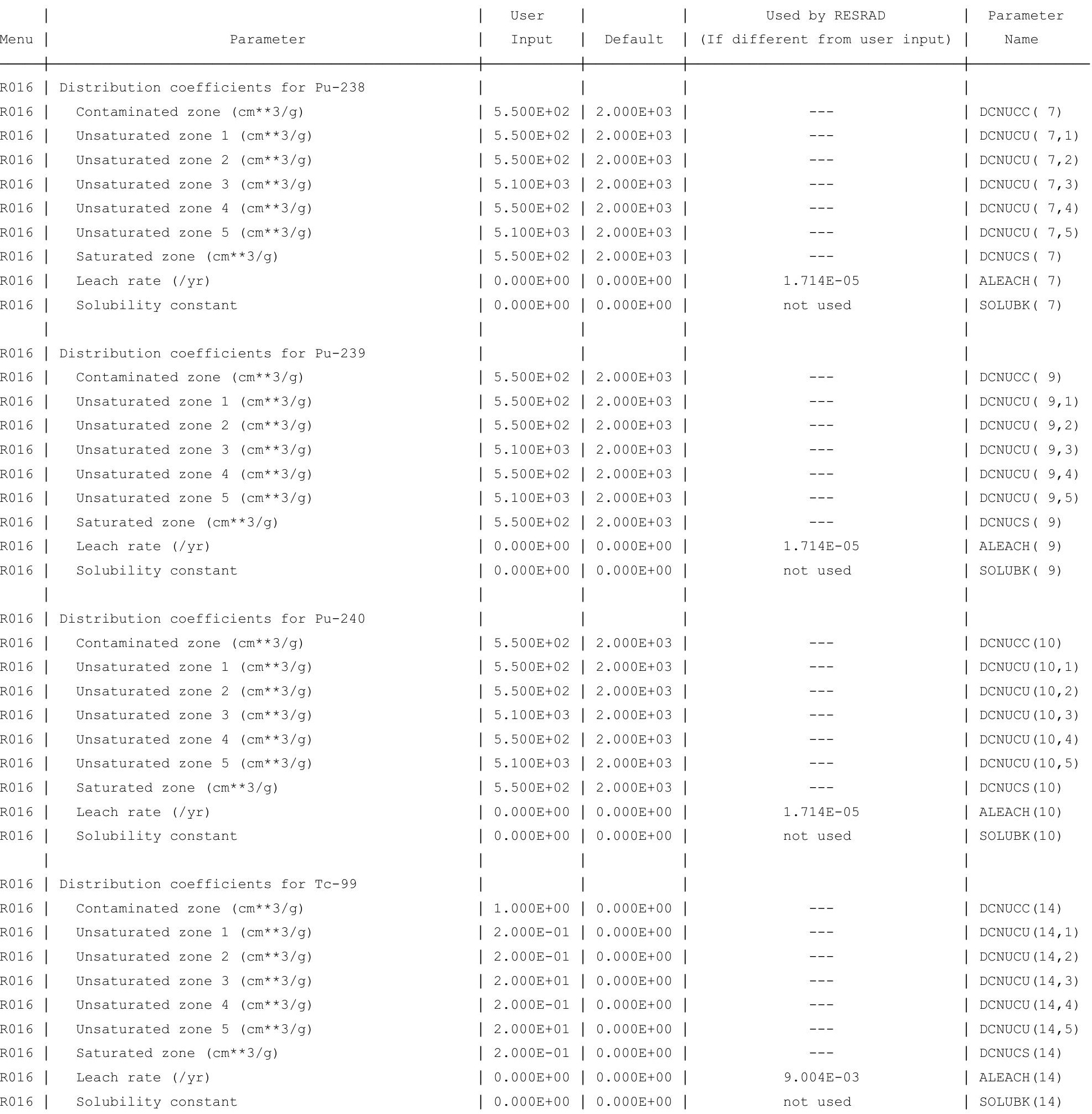


RESRAD, Version 6.5 $\quad T^{1 / 2}$ Limit $=180$ days $\quad 07 / 20 / 2011 \quad 14: 38$ Page

Summary : RESRAD Parameters for U-Landfill Resident Gardener Forward Run

File : C: \RESRAD_FAMILY \RESRAD \USERFILES $\backslash$ QCJULY2011 \ULANDFILL-RG_FORWARD-1050YR.RAD

Site-Specific Parameter Summary (continued)

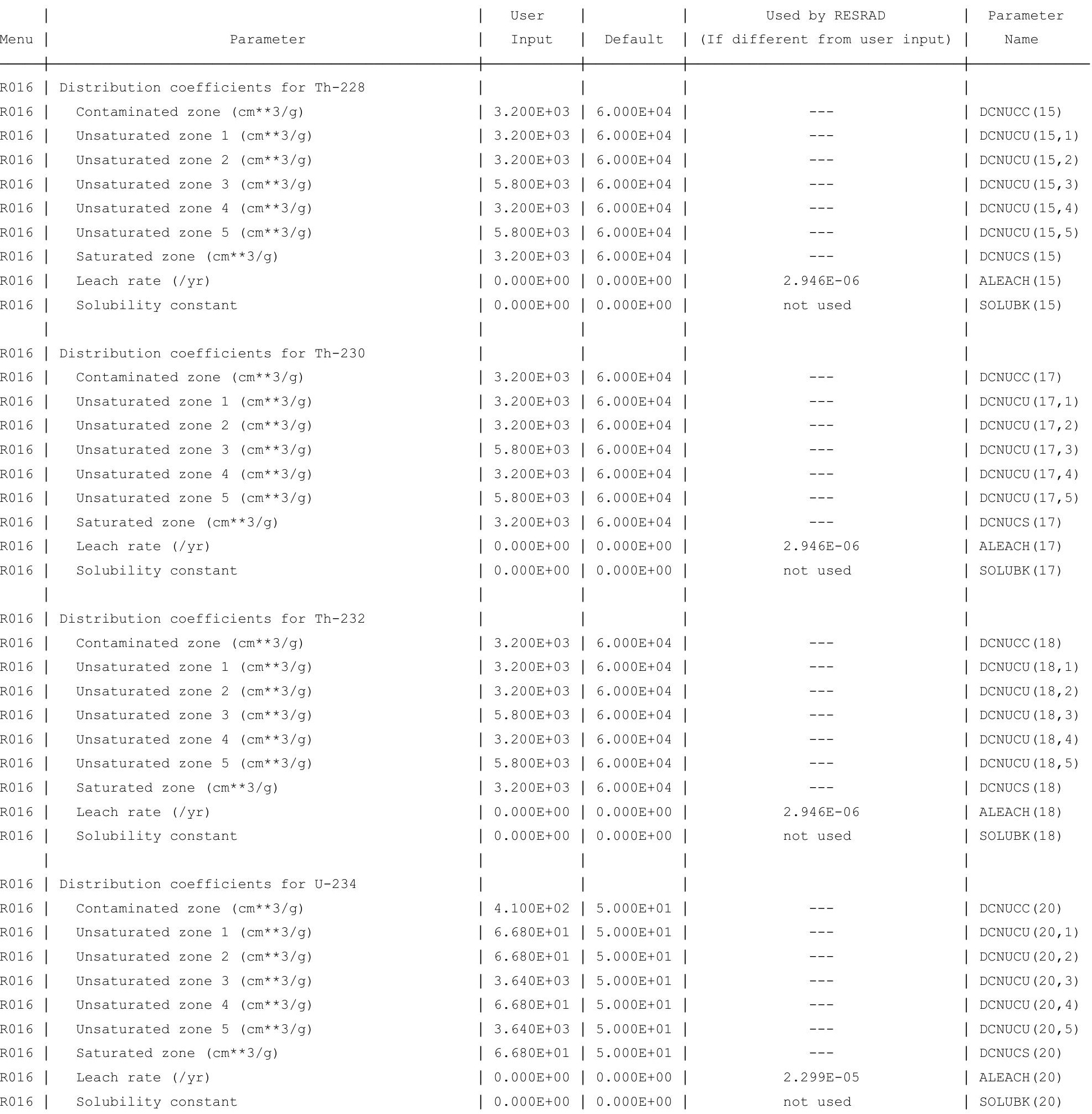


RESRAD, Version 6.5 $\quad T^{1 / 2}$ Limit $=180$ days $\quad 07 / 20 / 2011$ 14:38 Page

Summary : RESRAD Parameters for U-Landfill Resident Gardener Forward Run

File : C: \RESRAD_FAMILY \RESRAD \USERFILES $\backslash$ QCJULY2011 \ULANDFILL-RG_FORWARD-1050YR.RAD

Site-Specific Parameter Summary (continued)

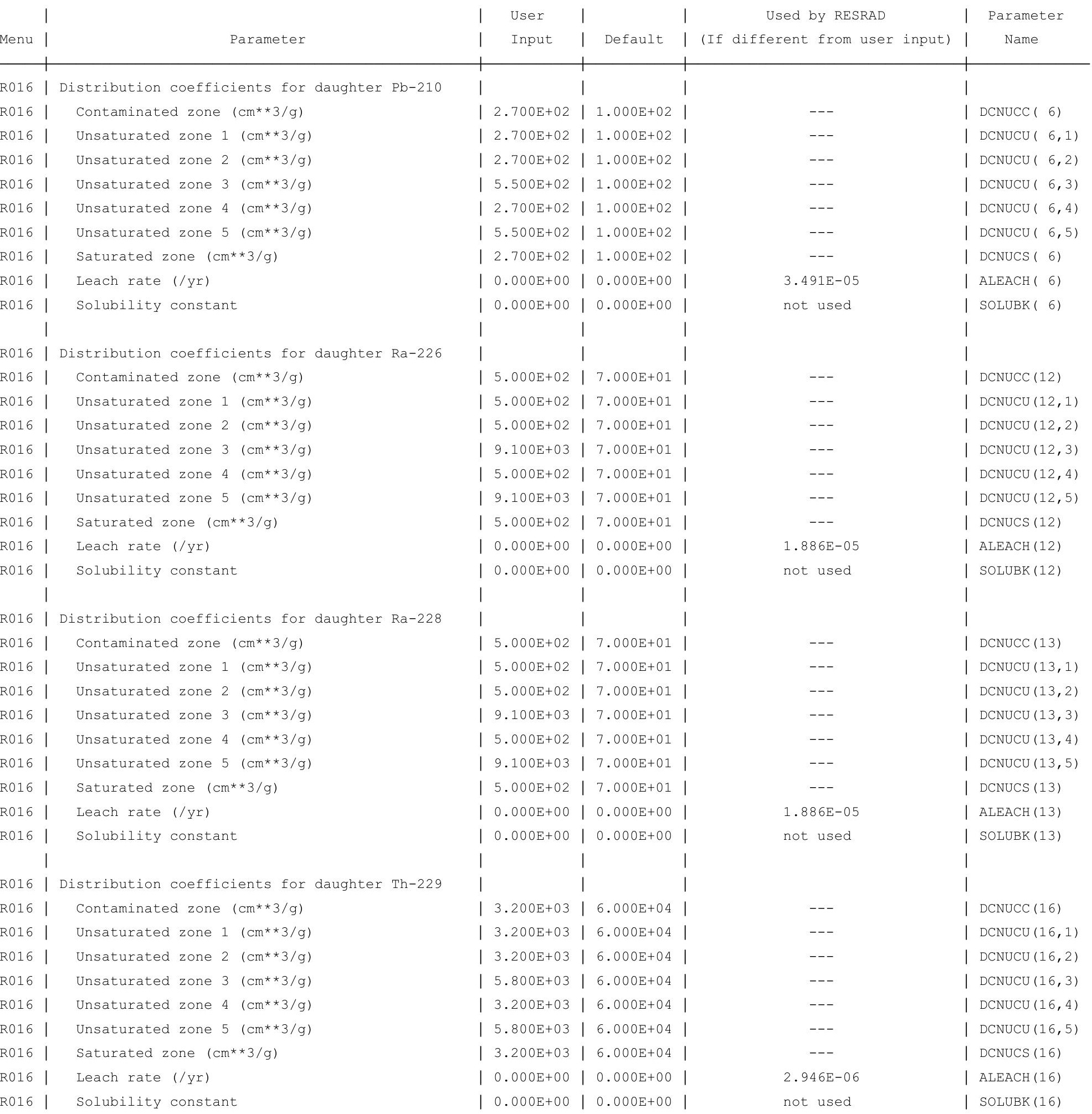


ummary : RESRAD Parameters for U-Landfill Resident Gardener Forward Run

File : C: $\backslash$ RESRAD FAMILY \RESRAD \USERFILES $\backslash Q C J U L Y 2011 \backslash U L A N D F I L L-R G ~ F O R W A R D-1050 Y R$. RAD

Site-Specific Parameter Summary (continued)

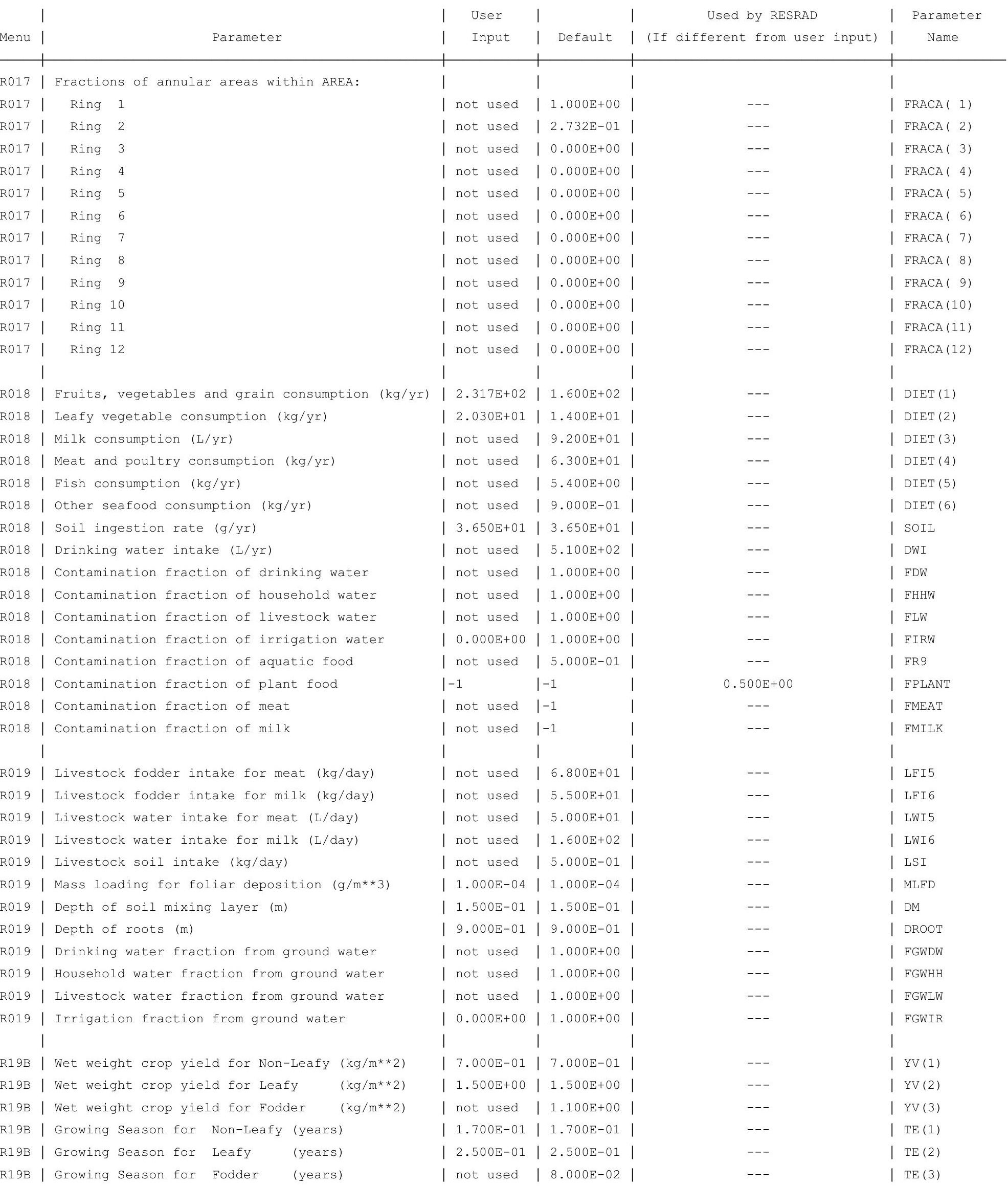


RESRAD, Version $6.5 \quad \mathrm{~T}^{1 / 2}$ Limit $=180$ days

Summary : RESRAD Parameters for U-Landfill Resident Gardener Forward Run

File : C: \RESRAD_FAMILY \RESRAD \USERFILES $\backslash$ QCJULY2011 \ULANDFILL-RG_FORWARD-1050YR.RAD

Site-Specific Parameter Summary (continued)

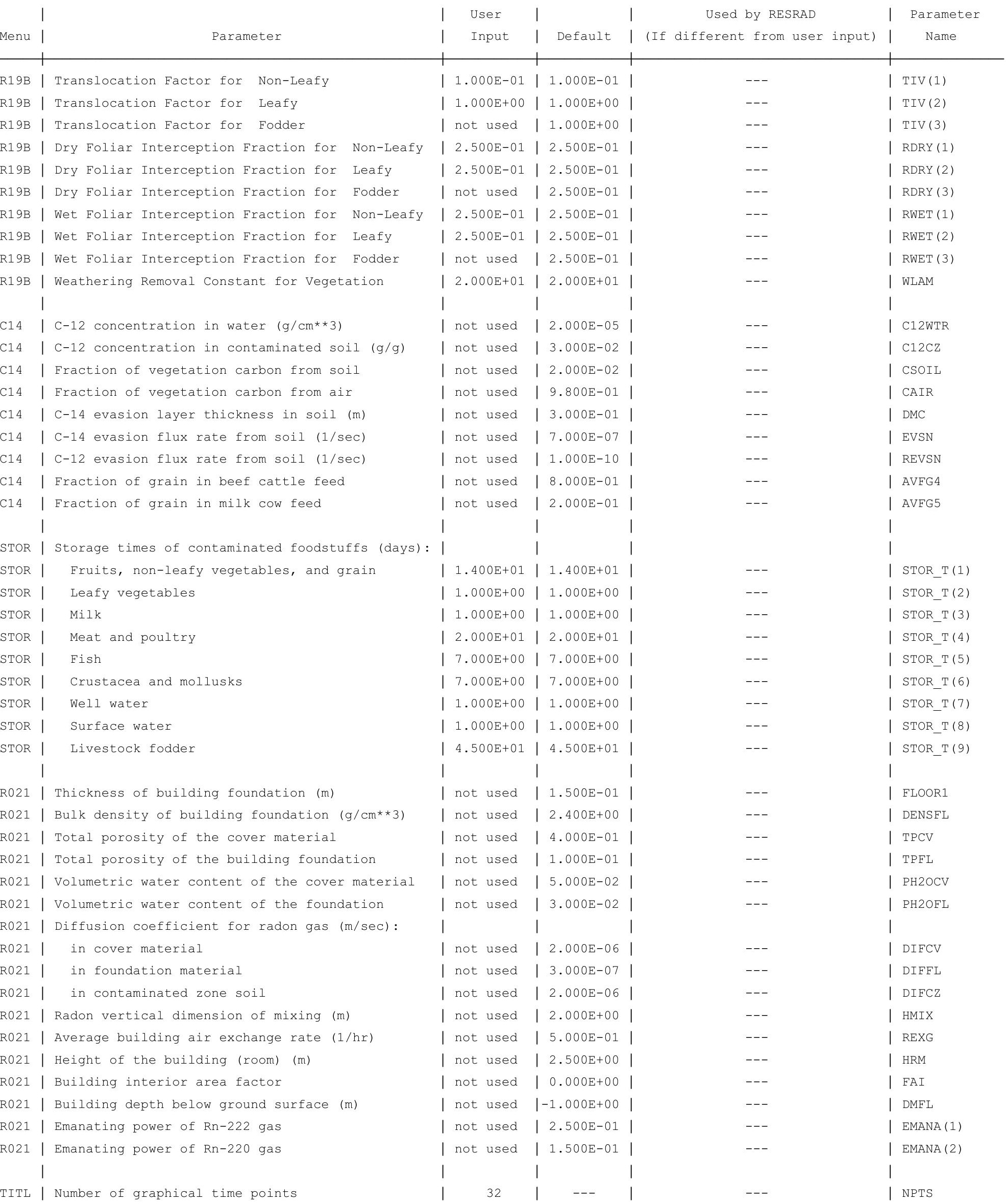

TITL | Number of graphical time points 
RESRAD, Version 6.5

ummary : RESRAD Parameters for U-Landfill Resident Gardener Forward Run

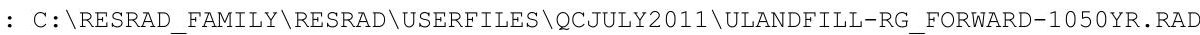

Total Dose Contributions TDOSE (i,p,t) for Individual Radionuclides (i) and Pathways (p) As mrem/yr and Fraction of Total Dose At $t=0.000 \mathrm{E}+00$ years

Water Independent Pathways (Inhalation excludes radon)

\begin{tabular}{|c|c|c|c|c|c|c|c|c|c|c|c|c|c|c|}
\hline & \multicolumn{2}{|c|}{ Ground } & \multicolumn{2}{|c|}{ Inhalation } & \multicolumn{2}{|c|}{ Radon } & \multicolumn{2}{|c|}{ Plant } & \multicolumn{2}{|c|}{ Meat } & \multicolumn{2}{|c|}{ Milk } & \multicolumn{2}{|c|}{ Soil } \\
\hline ide & mrem/yr & fract. & mrem/yr & fract. & mrem/yr & fract. & mrem/yr & fract. & mrem/yr & fract. & mrem/yr & fract. & mrem/yr & fract. \\
\hline-241 & $5.412 \mathrm{E}-18$ & 0.0000 & $0.000 \mathrm{E}+00$ & 0.0000 & $0.000 \mathrm{E}+00$ & 0.0000 & $0.000 \mathrm{E}+00$ & 0.0000 & $0.000 \mathrm{E}+00$ & 0.0000 & $0.000 \mathrm{E}+00$ & 0.0000 & $0.000 \mathrm{E}+00$ & 0.0000 \\
\hline-137 & $2.397 E-08$ & 0.0043 & $0.000 \mathrm{E}+00$ & 0.0000 & $0.000 \mathrm{E}+00$ & 0.0000 & $0.000 \mathrm{E}+00$ & 0.0000 & $0.000 \mathrm{E}+00$ & 0.0000 & $0.000 \mathrm{E}+00$ & 0.0000 & $0.000 \mathrm{E}+00$ & 0.0000 \\
\hline-237 & $5.245 E-12$ & 0.0000 & $0.000 \mathrm{E}+00$ & 0.0000 & $0.000 \mathrm{E}+00$ & 0.0000 & $0.000 \mathrm{E}+00$ & 0.0000 & $0.000 \mathrm{E}+00$ & 0.0000 & $0.000 \mathrm{E}+00$ & 0.0000 & $0.000 \mathrm{E}+00$ & 0.0000 \\
\hline 238 & $3.174 \mathrm{E}-21$ & 0.0000 & $0.000 \mathrm{E}+00$ & 0.0000 & $0.000 \mathrm{E}+00$ & 0.0000 & $0.000 \mathrm{E}+00$ & 0.0000 & $0.000 \mathrm{E}+00$ & 0.0000 & $0.000 \mathrm{E}+00$ & 0.0000 & $0.000 \mathrm{E}+00$ & 0.0000 \\
\hline 239 & $4.328 E-16$ & 0.0000 & $0.000 \mathrm{E}+00$ & 0.0000 & $0.000 \mathrm{E}+00$ & 0.0000 & $0.000 \mathrm{E}+00$ & 0.0000 & $0.000 \mathrm{E}+00$ & 0.0000 & $0.000 \mathrm{E}+00$ & 0.0000 & $0.000 \mathrm{E}+00$ & 0.0000 \\
\hline 240 & $4.115 E-23$ & 0.0000 & $0.000 \mathrm{E}+00$ & 0.0000 & $0.000 \mathrm{E}+00$ & 0.0000 & $0.000 \mathrm{E}+00$ & 0.0000 & $0.000 \mathrm{E}+00$ & 0.0000 & $0.000 \mathrm{E}+00$ & 0.0000 & $0.000 \mathrm{E}+00$ & 0.0000 \\
\hline 99 & $2.994 \mathrm{E}-24$ & 0.0000 & $0.000 \mathrm{E}+00$ & 0.0000 & $0.000 \mathrm{E}+00$ & 0.0000 & $0.000 \mathrm{E}+00$ & 0.0000 & $0.000 \mathrm{E}+00$ & 0.0000 & $0.000 \mathrm{E}+00$ & 0.0000 & $0.000 \mathrm{E}+00$ & 0.0000 \\
\hline 228 & $5.530 \mathrm{E}-06$ & 0.9827 & $0.000 \mathrm{E}+00$ & 0.0000 & $0.000 \mathrm{E}+00$ & 0.0000 & $0.000 \mathrm{E}+00$ & 0.0000 & $0.000 \mathrm{E}+00$ & 0.0000 & $0.000 \mathrm{E}+00$ & 0.0000 & $0.000 \mathrm{E}+00$ & 0.0000 \\
\hline 230 & $3.774 \mathrm{E}-09$ & 0.0007 & $0.000 \mathrm{E}+00$ & 0.0000 & $0.000 \mathrm{E}+00$ & 0.0000 & $0.000 \mathrm{E}+00$ & 0.0000 & $0.000 \mathrm{E}+00$ & 0.0000 & $0.000 \mathrm{E}+00$ & 0.0000 & $0.000 \mathrm{E}+00$ & 0.0000 \\
\hline-232 & $4.712 \mathrm{E}-08$ & 0.0084 & $0.000 \mathrm{E}+00$ & 0.0000 & $0.000 \mathrm{E}+00$ & 0.0000 & $0.000 \mathrm{E}+00$ & 0.0000 & $0.000 \mathrm{E}+00$ & 0.0000 & $0.000 \mathrm{E}+00$ & 0.0000 & $0.000 \mathrm{E}+00$ & 0.0000 \\
\hline 34 & $1.813 \mathrm{E}-14$ & 0.0000 & $0.000 \mathrm{E}+00$ & 0.0000 & $0.000 \mathrm{E}+00$ & 0.0000 & $0.000 \mathrm{E}+00$ & 0.0000 & $0.000 \mathrm{E}+00$ & 0.0000 & $0.000 \mathrm{E}+00$ & 0.0000 & $0.000 \mathrm{E}+00$ & 0.0000 \\
\hline 35 & $8.089 E-14$ & 0.0000 & $0.000 \mathrm{E}+00$ & 0.0000 & $0.000 \mathrm{E}+00$ & 0.0000 & $0.000 \mathrm{E}+00$ & 0.0000 & $0.000 \mathrm{E}+00$ & 0.0000 & $0.000 \mathrm{E}+00$ & 0.0000 & $0.000 \mathrm{E}+00$ & 0.0000 \\
\hline 38 & $2.271 E-08$ & 0.0040 & $0.000 \mathrm{E}+00$ & 0.0000 & $0.000 \mathrm{E}+00$ & 0.0000 & $0.000 \mathrm{E}+00$ & 0.0000 & $0.000 \mathrm{E}+00$ & 0.0000 & $0.000 \mathrm{E}+00$ & 0.0000 & $0.000 \mathrm{E}+00$ & 0.0000 \\
\hline & $5.627 \mathrm{E}-06$ & 1.0000 & $0.000 \mathrm{E}+00$ & 0.0000 & $0.000 \mathrm{E}+00$ & 0.0000 & $0.000 \mathrm{E}+00$ & 0.0000 & $0.000 \mathrm{E}+00$ & 0.0000 & $0.000 \mathrm{E}+00$ & 0.0000 & $.000 \mathrm{E}+00$ & 0.0000 \\
\hline
\end{tabular}

Total Dose Contributions TDOSE(i,p,t) for Individual Radionuclides (i) and Pathways (p) As mrem/yr and Fraction of Total Dose At $t=0.000 \mathrm{E}+00$ years

Water Dependent Pathways

\begin{tabular}{|c|c|c|c|c|c|c|c|c|c|c|c|c|c|c|}
\hline \multirow{2}{*}{$\begin{array}{l}\text { Radio- } \\
\text { Nuclide }\end{array}$} & \multicolumn{2}{|c|}{ Water } & \multicolumn{2}{|c|}{ Fish } & \multicolumn{2}{|c|}{ Radon } & \multicolumn{2}{|c|}{ Plant } & \multicolumn{2}{|c|}{ Meat } & \multicolumn{2}{|c|}{ Milk } & \multicolumn{2}{|c|}{ All Pathways* } \\
\hline & mrem/yr & fract. & mrem/yr & fract. & mrem/yr & fract. & mrem/yr & fract. & mrem/yr & fract. & mrem/yr & fract. & mrem/yr & fract. \\
\hline 241 & $0.000 \mathrm{E}+00$ & 0.0000 & $0.000 \mathrm{E}+00$ & 0.0000 & $0.000 \mathrm{E}+00$ & 0.0000 & $0.000 \mathrm{E}+00$ & 0.0000 & $0.000 \mathrm{E}+00$ & 0.0000 & $0.000 \mathrm{E}+00$ & 0.0000 & $5.412 \mathrm{E}-18$ & 0.0000 \\
\hline-137 & $0.000 \mathrm{E}+00$ & 0.0000 & $0.000 \mathrm{E}+00$ & 0.0000 & $0.000 \mathrm{E}+00$ & 0.0000 & $0.000 \mathrm{E}+00$ & 0.0000 & $0.000 \mathrm{E}+00$ & 0.0000 & $0.000 \mathrm{E}+00$ & 0.0000 & $2.397 \mathrm{E}-08$ & 0.0043 \\
\hline-237 & $0.000 \mathrm{E}+00$ & 0.0000 & $0.000 \mathrm{E}+00$ & 0.0000 & $0.000 \mathrm{E}+00$ & 0.0000 & $0.000 \mathrm{E}+00$ & 0.0000 & $0.000 \mathrm{E}+00$ & 0.0000 & $0.000 \mathrm{E}+00$ & 0.0000 & $5.245 E-12$ & 0.0000 \\
\hline-238 & $0.000 \mathrm{E}+00$ & 0.0000 & $0.000 \mathrm{E}+00$ & 0.0000 & $0.000 \mathrm{E}+00$ & 0.0000 & $0.000 \mathrm{E}+00$ & 0.0000 & $0.000 \mathrm{E}+00$ & 0.0000 & $0.000 \mathrm{E}+00$ & 0.0000 & $3.174 \mathrm{E}-21$ & 0.0000 \\
\hline-239 & $0.000 \mathrm{E}+00$ & 0.0000 & $0.000 \mathrm{E}+00$ & 0.0000 & $0.000 \mathrm{E}+00$ & 0.0000 & $0.000 \mathrm{E}+00$ & 0.0000 & $0.000 \mathrm{E}+00$ & 0.0000 & $0.000 E+00$ & 0.0000 & $4.328 E-16$ & 0.0000 \\
\hline-240 & $0.000 \mathrm{E}+00$ & 0.0000 & $0.000 \mathrm{E}+00$ & 0.0000 & $0.000 \mathrm{E}+00$ & 0.0000 & $0.000 \mathrm{E}+00$ & 0.0000 & $0.000 \mathrm{E}+00$ & 0.0000 & $0.000 E+00$ & 0.0000 & $4.115 \mathrm{E}-23$ & 0.0000 \\
\hline-99 & $0.000 \mathrm{E}+00$ & 0.0000 & $0.000 \mathrm{E}+00$ & 0.0000 & $0.000 \mathrm{E}+00$ & 0.0000 & $0.000 \mathrm{E}+00$ & 0.0000 & $0.000 \mathrm{E}+00$ & 0.0000 & $0.000 \mathrm{E}+00$ & 0.0000 & $2.994 \mathrm{E}-24$ & 0.0000 \\
\hline-228 & $0.000 \mathrm{E}+00$ & 0.0000 & $0.000 \mathrm{E}+00$ & 0.0000 & $0.000 \mathrm{E}+00$ & 0.0000 & $0.000 \mathrm{E}+00$ & 0.0000 & $0.000 \mathrm{E}+00$ & 0.0000 & $0.000 \mathrm{E}+00$ & 0.0000 & $5.530 \mathrm{E}-06$ & 0.9827 \\
\hline-230 & $0.000 \mathrm{E}+00$ & 0.0000 & $0.000 \mathrm{E}+00$ & 0.0000 & $0.000 \mathrm{E}+00$ & 0.0000 & $0.000 \mathrm{E}+00$ & 0.0000 & $0.000 \mathrm{E}+00$ & 0.0000 & $0.000 E+00$ & 0.0000 & $3.774 \mathrm{E}-09$ & 0.0007 \\
\hline 232 & $0.000 \mathrm{E}+00$ & 0.0000 & $0.000 \mathrm{E}+00$ & 0.0000 & $0.000 \mathrm{E}+00$ & 0.0000 & $0.000 \mathrm{E}+00$ & 0.0000 & $0.000 \mathrm{E}+00$ & 0.0000 & $0.000 \mathrm{E}+00$ & 0.0000 & $4.712 \mathrm{E}-08$ & 0.0084 \\
\hline 34 & $0.000 \mathrm{E}+00$ & 0.0000 & $0.000 \mathrm{E}+00$ & 0.0000 & $0.000 \mathrm{E}+00$ & 0.0000 & $0.000 \mathrm{E}+00$ & 0.0000 & $0.000 \mathrm{E}+00$ & 0.0000 & $0.000 \mathrm{E}+00$ & 0.0000 & $1.813 \mathrm{E}-14$ & 0.0000 \\
\hline 35 & $0.000 \mathrm{E}+00$ & 0.0000 & $0.000 \mathrm{E}+00$ & 0.0000 & $0.000 \mathrm{E}+00$ & 0.0000 & $0.000 \mathrm{E}+00$ & 0.0000 & $0.000 \mathrm{E}+00$ & 0.0000 & $0.000 \mathrm{E}+00$ & 0.0000 & $8.089 \mathrm{E}-14$ & 0.0000 \\
\hline 38 & $0.000 \mathrm{E}+00$ & 0.0000 & $0.000 \mathrm{E}+00$ & 0.0000 & $0.000 \mathrm{E}+00$ & 0.0000 & $0.000 \mathrm{E}+00$ & 0.0000 & $0.000 \mathrm{E}+00$ & 0.0000 & $0.000 \mathrm{E}+00$ & 0.0000 & $2.271 E-08$ & 0.0040 \\
\hline & $0.000 \mathrm{E}+00$ & 0.0000 & $0.000 \mathrm{E}+00$ & 0.0000 & $0.000 \mathrm{E}+00$ & 0.0000 & $0.000 \mathrm{E}+00$ & 0.0000 & $0.000 \mathrm{E}+00$ & 0.0000 & $0.000 \mathrm{E}+00$ & 0.0000 & $7 E-06$ & 1. \\
\hline
\end{tabular}

* Sum of all water independent and dependent pathways. 
RESRAD, Version 6.5

ummary : RESRAD Parameters for U-Landfill Resident Gardener Forward Run

: C: \RESRAD_FAMILY \RESRAD \USERFILES \QCJULY2011 \ULANDFILL-RG_FORWARD-1050YR.RAD

Total Dose Contributions TDOSE (i,p,t) for Individual Radionuclides (i) and Pathways (p) As mrem/yr and Fraction of Total Dose At $t=1.000 \mathrm{E}+00$ years

Water Independent Pathways (Inhalation excludes radon)

\begin{tabular}{|c|c|c|c|c|c|c|c|c|c|c|c|c|c|c|}
\hline & \multicolumn{2}{|c|}{ Ground } & \multicolumn{2}{|c|}{ Inhalation } & \multicolumn{2}{|c|}{ Radon } & \multicolumn{2}{|c|}{ Plant } & \multicolumn{2}{|c|}{ Meat } & \multicolumn{2}{|c|}{ Milk } & \multicolumn{2}{|c|}{ Soil } \\
\hline clide & mrem/yr & fract. & mrem/yr & fract. & mrem/yr & fract. & mrem/yr & fract. & mrem/yr & fract. & mrem/yr & fract. & mrem/yr & fract. \\
\hline 241 & $1.638 \mathrm{E}-17$ & 0.0000 & $0.000 \mathrm{E}+00$ & 0.0000 & $0.000 \mathrm{E}+00$ & 0.0000 & $0.000 \mathrm{E}+00$ & 0.0000 & $0.000 \mathrm{E}+00$ & 0.0000 & $0.000 \mathrm{E}+00$ & 0.0000 & $0.000 \mathrm{E}+00$ & 0.0000 \\
\hline-137 & $2.362 E-08$ & 0.0056 & $0.000 \mathrm{E}+00$ & 0.0000 & $0.000 \mathrm{E}+00$ & 0.0000 & $0.000 \mathrm{E}+00$ & 0.0000 & $0.000 \mathrm{E}+00$ & 0.0000 & $0.000 \mathrm{E}+00$ & 0.0000 & $0.000 \mathrm{E}+00$ & 0.0000 \\
\hline-237 & $5.301 E-12$ & 0.0000 & $0.000 \mathrm{E}+00$ & 0.0000 & $0.000 \mathrm{E}+00$ & 0.0000 & $0.000 \mathrm{E}+00$ & 0.0000 & $0.000 \mathrm{E}+00$ & 0.0000 & $0.000 \mathrm{E}+00$ & 0.0000 & $0.000 \mathrm{E}+00$ & 0.0000 \\
\hline-238 & $4.717 \mathrm{E}-20$ & 0.0000 & $0.000 \mathrm{E}+00$ & 0.0000 & $0.000 \mathrm{E}+00$ & 0.0000 & $0.000 \mathrm{E}+00$ & 0.0000 & $0.000 \mathrm{E}+00$ & 0.0000 & $0.000 \mathrm{E}+00$ & 0.0000 & $0.000 \mathrm{E}+00$ & 0.0000 \\
\hline-239 & 4. $380 \mathrm{E}-16$ & 0.0000 & $0.000 \mathrm{E}+00$ & 0.0000 & $0.000 \mathrm{E}+00$ & 0.0000 & $0.000 \mathrm{E}+00$ & 0.0000 & $0.000 \mathrm{E}+00$ & 0.0000 & $0.000 \mathrm{E}+00$ & 0.0000 & $0.000 \mathrm{E}+00$ & 0.0000 \\
\hline-240 & $4.275 E-23$ & 0.0000 & $0.000 \mathrm{E}+00$ & 0.0000 & $0.000 \mathrm{E}+00$ & 0.0000 & $0.000 \mathrm{E}+00$ & 0.0000 & $0.000 \mathrm{E}+00$ & 0.0000 & $0.000 \mathrm{E}+00$ & 0.0000 & $0.000 \mathrm{E}+00$ & 0.0000 \\
\hline 99 & $3.025 E-24$ & 0.0000 & $0.000 \mathrm{E}+00$ & 0.0000 & $0.000 \mathrm{E}+00$ & 0.0000 & $0.000 \mathrm{E}+00$ & 0.0000 & $0.000 \mathrm{E}+00$ & 0.0000 & $0.000 \mathrm{E}+00$ & 0.0000 & $0.000 \mathrm{E}+00$ & 0.0000 \\
\hline-228 & $3.872 E-06$ & 0.9206 & $0.000 \mathrm{E}+00$ & 0.0000 & $0.000 \mathrm{E}+00$ & 0.0000 & $0.000 \mathrm{E}+00$ & 0.0000 & $0.000 \mathrm{E}+00$ & 0.0000 & $0.000 \mathrm{E}+00$ & 0.0000 & $0.000 \mathrm{E}+00$ & 0.0000 \\
\hline-230 & $1.139 \mathrm{E}-08$ & 0.0027 & $0.000 \mathrm{E}+00$ & 0.0000 & $0.000 \mathrm{E}+00$ & 0.0000 & $0.000 \mathrm{E}+00$ & 0.0000 & $0.000 \mathrm{E}+00$ & 0.0000 & $0.000 \mathrm{E}+00$ & 0.0000 & $0.000 \mathrm{E}+00$ & 0.0000 \\
\hline 232 & $2.759 \mathrm{E}-07$ & 0.0656 & $0.000 \mathrm{E}+00$ & 0.0000 & $0.000 \mathrm{E}+00$ & 0.0000 & $0.000 \mathrm{E}+00$ & 0.0000 & $0.000 \mathrm{E}+00$ & 0.0000 & $0.000 \mathrm{E}+00$ & 0.0000 & $0.000 \mathrm{E}+00$ & 0.0000 \\
\hline 234 & $1.277 \mathrm{E}-13$ & 0.0000 & $0.000 \mathrm{E}+00$ & 0.0000 & $0.000 \mathrm{E}+00$ & 0.0000 & $0.000 \mathrm{E}+00$ & 0.0000 & $0.000 \mathrm{E}+00$ & 0.0000 & $0.000 \mathrm{E}+00$ & 0.0000 & $0.000 \mathrm{E}+00$ & 0.0000 \\
\hline 235 & $8.230 \mathrm{E}-14$ & 0.0000 & $0.000 \mathrm{E}+00$ & 0.0000 & $0.000 \mathrm{E}+00$ & 0.0000 & $0.000 \mathrm{E}+00$ & 0.0000 & $0.000 \mathrm{E}+00$ & 0.0000 & $0.000 \mathrm{E}+00$ & 0.0000 & $0.000 \mathrm{E}+00$ & 0.0000 \\
\hline 38 & $2.290 \mathrm{E}-08$ & 0.0054 & $0.000 \mathrm{E}+00$ & 0.0000 & $0.000 \mathrm{E}+00$ & 0.0000 & $0.000 \mathrm{E}+00$ & 0.0000 & $0.000 \mathrm{E}+00$ & 0.0000 & $0.000 \mathrm{E}+00$ & 0.0000 & $0.000 \mathrm{E}+00$ & 0.0000 \\
\hline & $4.206 E-06$ & 1.0000 & $0.000 \mathrm{E}+00$ & 0.0000 & $0.000 \mathrm{E}+00$ & 0.0000 & $0.000 \mathrm{E}+00$ & 0.0000 & $0.000 \mathrm{E}+00$ & 0.0000 & $0.000 \mathrm{E}+00$ & 0.0000 & $0.000 \mathrm{E}+00$ & 0.0000 \\
\hline
\end{tabular}

Total Dose Contributions TDOSE(i,p,t) for Individual Radionuclides (i) and Pathways (p) As mrem/yr and Fraction of Total Dose At $t=1.000 \mathrm{E}+00$ years

Water Dependent Pathways

\begin{tabular}{|c|c|c|c|c|c|c|c|c|c|c|c|c|c|c|}
\hline \multirow{2}{*}{$\begin{array}{l}\text { Radio- } \\
\text { Nuclide }\end{array}$} & \multicolumn{2}{|c|}{ Water } & \multicolumn{2}{|c|}{ Fish } & \multicolumn{2}{|c|}{ Radon } & \multicolumn{2}{|c|}{ Plant } & \multicolumn{2}{|c|}{ Meat } & \multicolumn{2}{|c|}{ Milk } & \multicolumn{2}{|c|}{ All Pathways* } \\
\hline & mrem/yr & fract. & mrem/yr & fract. & mrem/yr & fract. & mrem/yr & fract. & mrem/yr & fract. & mrem/yr & fract. & mrem/yr & fract. \\
\hline 241 & $0.000 \mathrm{E}+00$ & 0.0000 & $0.000 \mathrm{E}+00$ & 0.0000 & $0.000 \mathrm{E}+00$ & 0.0000 & $0.000 \mathrm{E}+00$ & 0.0000 & $0.000 \mathrm{E}+00$ & 0.0000 & $0.000 \mathrm{E}+00$ & 0.0000 & $1.638 \mathrm{E}-17$ & 0.0000 \\
\hline-137 & $0.000 \mathrm{E}+00$ & 0.0000 & $0.000 \mathrm{E}+00$ & 0.0000 & $0.000 \mathrm{E}+00$ & 0.0000 & $0.000 \mathrm{E}+00$ & 0.0000 & $0.000 \mathrm{E}+00$ & 0.0000 & $0.000 \mathrm{E}+00$ & 0.0000 & $2.362 \mathrm{E}-08$ & 0.0056 \\
\hline-237 & $0.000 \mathrm{E}+00$ & 0.0000 & $0.000 \mathrm{E}+00$ & 0.0000 & $0.000 \mathrm{E}+00$ & 0.0000 & $0.000 \mathrm{E}+00$ & 0.0000 & $0.000 \mathrm{E}+00$ & 0.0000 & $0.000 \mathrm{E}+00$ & 0.0000 & $5.301 \mathrm{E}-12$ & 0.0000 \\
\hline-238 & $0.000 \mathrm{E}+00$ & 0.0000 & $0.000 \mathrm{E}+00$ & 0.0000 & $0.000 \mathrm{E}+00$ & 0.0000 & $0.000 \mathrm{E}+00$ & 0.0000 & $0.000 \mathrm{E}+00$ & 0.0000 & $0.000 \mathrm{E}+00$ & 0.0000 & $4.717 \mathrm{E}-20$ & 0.0000 \\
\hline-239 & $0.000 \mathrm{E}+00$ & 0.0000 & $0.000 \mathrm{E}+00$ & 0.0000 & $0.000 \mathrm{E}+00$ & 0.0000 & $0.000 \mathrm{E}+00$ & 0.0000 & $0.000 \mathrm{E}+00$ & 0.0000 & $0.000 E+00$ & 0.0000 & $4.380 \mathrm{E}-16$ & 0.0000 \\
\hline-240 & $0.000 \mathrm{E}+00$ & 0.0000 & $0.000 \mathrm{E}+00$ & 0.0000 & $0.000 \mathrm{E}+00$ & 0.0000 & $0.000 \mathrm{E}+00$ & 0.0000 & $0.000 \mathrm{E}+00$ & 0.0000 & $0.000 E+00$ & 0.0000 & $4.275 E-23$ & 0.0000 \\
\hline-99 & $0.000 \mathrm{E}+00$ & 0.0000 & $0.000 \mathrm{E}+00$ & 0.0000 & $0.000 \mathrm{E}+00$ & 0.0000 & $0.000 \mathrm{E}+00$ & 0.0000 & $0.000 \mathrm{E}+00$ & 0.0000 & $0.000 \mathrm{E}+00$ & 0.0000 & $3.025 \mathrm{E}-24$ & 0.0000 \\
\hline-228 & $0.000 \mathrm{E}+00$ & 0.0000 & $0.000 \mathrm{E}+00$ & 0.0000 & $0.000 \mathrm{E}+00$ & 0.0000 & $0.000 \mathrm{E}+00$ & 0.0000 & $0.000 \mathrm{E}+00$ & 0.0000 & $0.000 \mathrm{E}+00$ & 0.0000 & $3.872 \mathrm{E}-06$ & 0.9206 \\
\hline-230 & $0.000 \mathrm{E}+00$ & 0.0000 & $0.000 \mathrm{E}+00$ & 0.0000 & $0.000 \mathrm{E}+00$ & 0.0000 & $0.000 \mathrm{E}+00$ & 0.0000 & $0.000 \mathrm{E}+00$ & 0.0000 & $0.000 E+00$ & 0.0000 & $1.139 \mathrm{E}-08$ & 0.0027 \\
\hline-232 & $0.000 \mathrm{E}+00$ & 0.0000 & $0.000 \mathrm{E}+00$ & 0.0000 & $0.000 \mathrm{E}+00$ & 0.0000 & $0.000 \mathrm{E}+00$ & 0.0000 & $0.000 \mathrm{E}+00$ & 0.0000 & $0.000 \mathrm{E}+00$ & 0.0000 & $2.759 \mathrm{E}-07$ & 0.0656 \\
\hline 234 & $0.000 \mathrm{E}+00$ & 0.0000 & $0.000 \mathrm{E}+00$ & 0.0000 & $0.000 \mathrm{E}+00$ & 0.0000 & $0.000 \mathrm{E}+00$ & 0.0000 & $0.000 \mathrm{E}+00$ & 0.0000 & $0.000 \mathrm{E}+00$ & 0.0000 & $1.277 \mathrm{E}-13$ & 0.0000 \\
\hline 35 & $0.000 \mathrm{E}+00$ & 0.0000 & $0.000 \mathrm{E}+00$ & 0.0000 & $0.000 \mathrm{E}+00$ & 0.0000 & $0.000 \mathrm{E}+00$ & 0.0000 & $0.000 \mathrm{E}+00$ & 0.0000 & $0.000 \mathrm{E}+00$ & 0.0000 & $8.230 \mathrm{E}-14$ & 0.0000 \\
\hline 38 & $0.000 \mathrm{E}+00$ & 0.0000 & $0.000 \mathrm{E}+00$ & 0.0000 & $0.000 \mathrm{E}+00$ & 0.0000 & $0.000 \mathrm{E}+00$ & 0.0000 & $0.000 \mathrm{E}+00$ & 0.0000 & $0.000 \mathrm{E}+00$ & 0.0000 & $2.290 \mathrm{E}-08$ & 0.0054 \\
\hline & $0.000 \mathrm{E}+00$ & 0.0000 & $0.000 \mathrm{E}+00$ & 0.0000 & $0.000 \mathrm{E}+00$ & 0.0000 & $0.000 \mathrm{E}+00$ & 0.0000 & $0.000 \mathrm{E}+00$ & 0.0000 & $0.000 \mathrm{E}+00$ & 0.0000 & $6 E-06$ & 1. \\
\hline
\end{tabular}

* Sum of all water independent and dependent pathways. 
RESRAD, Version 6.5

ummary : RESRAD Parameters for U-Landfill Resident Gardener Forward Run

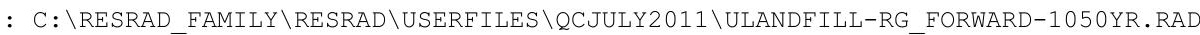

Total Dose Contributions TDOSE (i,p,t) for Individual Radionuclides (i) and Pathways (p) As mrem/yr and Fraction of Total Dose At $t=5.000 \mathrm{E}+01$ years

Water Independent Pathways (Inhalation excludes radon)

\begin{tabular}{|c|c|c|c|c|c|c|c|c|c|c|c|c|c|c|}
\hline \multirow{2}{*}{ Nuclide } & \multicolumn{2}{|c|}{ Ground } & \multicolumn{2}{|c|}{ Inhalation } & \multicolumn{2}{|c|}{ Radon } & \multicolumn{2}{|c|}{ Plant } & \multicolumn{2}{|c|}{ Meat } & \multicolumn{2}{|c|}{ Milk } & \multicolumn{2}{|c|}{ Soil } \\
\hline & mrem/yr & fract. & mrem/yr & fract. & mrem/yr & fract. & mrem/yr & fract. & mrem/yr & fract. & mrem/yr & fract. & mrem/yr & fract. \\
\hline-241 & $8.973 E-16$ & 0.0000 & $0.000 \mathrm{E}+00$ & 0.0000 & $0.000 \mathrm{E}+00$ & 0.0000 & $0.000 \mathrm{E}+00$ & 0.0000 & $0.000 \mathrm{E}+00$ & 0.0000 & $0.000 \mathrm{E}+00$ & 0.0000 & $0.000 \mathrm{E}+00$ & 0.0000 \\
\hline-137 & $1.149 \mathrm{E}-08$ & 0.0012 & $0.000 \mathrm{E}+00$ & 0.0000 & $0.000 \mathrm{E}+00$ & 0.0000 & $0.000 \mathrm{E}+00$ & 0.0000 & $0.000 \mathrm{E}+00$ & 0.0000 & $0.000 \mathrm{E}+00$ & 0.0000 & $0.000 \mathrm{E}+00$ & 0.0000 \\
\hline-237 & $8.957 \mathrm{E}-12$ & 0.0000 & $0.000 \mathrm{E}+00$ & 0.0000 & $0.000 \mathrm{E}+00$ & 0.0000 & $0.000 \mathrm{E}+00$ & 0.0000 & $0.000 \mathrm{E}+00$ & 0.0000 & $0.000 \mathrm{E}+00$ & 0.0000 & $0.000 \mathrm{E}+00$ & 0.0000 \\
\hline-238 & $2.054 \mathrm{E}-15$ & 0.0000 & $0.000 \mathrm{E}+00$ & 0.0000 & $0.000 \mathrm{E}+00$ & 0.0000 & $0.000 \mathrm{E}+00$ & 0.0000 & $0.000 \mathrm{E}+00$ & 0.0000 & $0.000 \mathrm{E}+00$ & 0.0000 & $0.000 \mathrm{E}+00$ & 0.0000 \\
\hline-239 & $7.861 \mathrm{E}-16$ & 0.0000 & $0.000 \mathrm{E}+00$ & 0.0000 & $0.000 \mathrm{E}+00$ & 0.0000 & $0.000 \mathrm{E}+00$ & 0.0000 & $0.000 \mathrm{E}+00$ & 0.0000 & $0.000 \mathrm{E}+00$ & 0.0000 & $0.000 \mathrm{E}+00$ & 0.0000 \\
\hline-240 & $9.653 \mathrm{E}-20$ & 0.0000 & $0.000 \mathrm{E}+00$ & 0.0000 & $0.000 \mathrm{E}+00$ & 0.0000 & $0.000 \mathrm{E}+00$ & 0.0000 & $0.000 \mathrm{E}+00$ & 0.0000 & $0.000 \mathrm{E}+00$ & 0.0000 & $0.000 \mathrm{E}+00$ & 0.0000 \\
\hline 99 & $4.979 E-24$ & 0.0000 & $0.000 \mathrm{E}+00$ & 0.0000 & $0.000 \mathrm{E}+00$ & 0.0000 & $0.000 \mathrm{E}+00$ & 0.0000 & $0.000 \mathrm{E}+00$ & 0.0000 & $0.000 \mathrm{E}+00$ & 0.0000 & $0.000 \mathrm{E}+00$ & 0.0000 \\
\hline-228 & 1.011E-13 & 0.0000 & $0.000 \mathrm{E}+00$ & 0.0000 & $0.000 \mathrm{E}+00$ & 0.0000 & $0.000 \mathrm{E}+00$ & 0.0000 & $0.000 \mathrm{E}+00$ & 0.0000 & $0.000 \mathrm{E}+00$ & 0.0000 & $0.000 \mathrm{E}+00$ & 0.0000 \\
\hline 230 & $5.320 \mathrm{E}-07$ & 0.0558 & $0.000 \mathrm{E}+00$ & 0.0000 & $0.000 \mathrm{E}+00$ & 0.0000 & $0.000 \mathrm{E}+00$ & 0.0000 & $0.000 \mathrm{E}+00$ & 0.0000 & $0.000 \mathrm{E}+00$ & 0.0000 & $0.000 \mathrm{E}+00$ & 0.0000 \\
\hline-232 & $8.963 E-06$ & 0.9395 & $0.000 \mathrm{E}+00$ & 0.0000 & $0.000 \mathrm{E}+00$ & 0.0000 & $0.000 \mathrm{E}+00$ & 0.0000 & $0.000 \mathrm{E}+00$ & 0.0000 & $0.000 \mathrm{E}+00$ & 0.0000 & $0.000 \mathrm{E}+00$ & 0.0000 \\
\hline 234 & 1. $941 \mathrm{E}-10$ & 0.0000 & $0.000 \mathrm{E}+00$ & 0.0000 & $0.000 \mathrm{E}+00$ & 0.0000 & $0.000 \mathrm{E}+00$ & 0.0000 & $0.000 \mathrm{E}+00$ & 0.0000 & $0.000 \mathrm{E}+00$ & 0.0000 & $0.000 \mathrm{E}+00$ & 0.0000 \\
\hline 35 & $6.005 E-13$ & 0.0000 & $0.000 \mathrm{E}+00$ & 0.0000 & $0.000 \mathrm{E}+00$ & 0.0000 & $0.000 \mathrm{E}+00$ & 0.0000 & $0.000 \mathrm{E}+00$ & 0.0000 & $0.000 \mathrm{E}+00$ & 0.0000 & $0.000 \mathrm{E}+00$ & 0.0000 \\
\hline 38 & $3.385 E-08$ & 0.0035 & $0.000 \mathrm{E}+00$ & 0.0000 & $0.000 \mathrm{E}+00$ & 0.0000 & $0.000 \mathrm{E}+00$ & 0.0000 & $0.000 \mathrm{E}+00$ & 0.0000 & $0.000 \mathrm{E}+00$ & 0.0000 & $0.000 \mathrm{E}+00$ & 0.0000 \\
\hline & $9.541 \mathrm{E}-06$ & 1.0000 & $0.000 \mathrm{E}+00$ & 0.0000 & $0.000 \mathrm{E}+00$ & 0.0000 & $0.000 \mathrm{E}+00$ & 0.0000 & $0.000 \mathrm{E}+00$ & 0.0000 & $0.000 \mathrm{E}+00$ & 0.0000 & $.000 \mathrm{E}+00$ & 0.0000 \\
\hline
\end{tabular}

Total Dose Contributions TDOSE(i,p,t) for Individual Radionuclides (i) and Pathways (p) As mrem/yr and Fraction of Total Dose At $t=5.000 \mathrm{E}+01$ years

Water Dependent Pathways

\begin{tabular}{|c|c|c|c|c|c|c|c|c|c|c|c|c|c|c|}
\hline \multirow{2}{*}{ Nuclide } & \multicolumn{2}{|c|}{ Water } & \multicolumn{2}{|c|}{ Fish } & \multicolumn{2}{|c|}{ Radon } & \multicolumn{2}{|c|}{ Plant } & \multicolumn{2}{|c|}{ Meat } & \multicolumn{2}{|c|}{ Milk } & \multicolumn{2}{|c|}{ All Pathways* } \\
\hline & mrem/yr & fract. & mrem/yr & fract. & mrem/yr & fract. & mrem/yr & fract. & mrem/yr & fract. & mrem/yr & fract. & mrem/yr & fract. \\
\hline-241 & $0.000 \mathrm{E}+00$ & 0.0000 & $0.000 \mathrm{E}+00$ & 0.0000 & $0.000 \mathrm{E}+00$ & 0.0000 & $0.000 \mathrm{E}+00$ & 0.0000 & $0.000 \mathrm{E}+00$ & 0.0000 & $0.000 \mathrm{E}+00$ & 0.0000 & $8.973 E-16$ & 0.0000 \\
\hline-137 & $0.000 \mathrm{E}+00$ & 0.0000 & $0.000 \mathrm{E}+00$ & 0.0000 & $0.000 \mathrm{E}+00$ & 0.0000 & $0.000 \mathrm{E}+00$ & 0.0000 & $0.000 \mathrm{E}+00$ & 0.0000 & $0.000 \mathrm{E}+00$ & 0.0000 & $1.149 \mathrm{E}-08$ & 0.0012 \\
\hline-237 & $0.000 \mathrm{E}+00$ & 0.0000 & $0.000 \mathrm{E}+00$ & 0.0000 & $0.000 \mathrm{E}+00$ & 0.0000 & $0.000 \mathrm{E}+00$ & 0.0000 & $0.000 \mathrm{E}+00$ & 0.0000 & $0.000 \mathrm{E}+00$ & 0.0000 & $8.957 \mathrm{E}-12$ & 0.0000 \\
\hline-238 & $0.000 \mathrm{E}+00$ & 0.0000 & $0.000 \mathrm{E}+00$ & 0.0000 & $0.000 \mathrm{E}+00$ & 0.0000 & $0.000 \mathrm{E}+00$ & 0.0000 & $0.000 \mathrm{E}+00$ & 0.0000 & $0.000 \mathrm{E}+00$ & 0.0000 & $2.054 \mathrm{E}-15$ & 0.0000 \\
\hline 239 & $0.000 \mathrm{E}+00$ & 0.0000 & $0.000 \mathrm{E}+00$ & 0.0000 & $0.000 \mathrm{E}+00$ & 0.0000 & $0.000 \mathrm{E}+00$ & 0.0000 & $0.000 \mathrm{E}+00$ & 0.0000 & $0.000 \mathrm{E}+00$ & 0.0000 & $7.861 \mathrm{E}-16$ & 0.0000 \\
\hline-240 & $0.000 \mathrm{E}+00$ & 0.0000 & $0.000 \mathrm{E}+00$ & 0.0000 & $0.000 \mathrm{E}+00$ & 0.0000 & $0.000 \mathrm{E}+00$ & 0.0000 & $0.000 \mathrm{E}+00$ & 0.0000 & $0.000 \mathrm{E}+00$ & 0.0000 & $9.653 \mathrm{E}-20$ & 0.0000 \\
\hline 99 & $0.000 \mathrm{E}+00$ & 0.0000 & $0.000 \mathrm{E}+00$ & 0.0000 & $0.000 \mathrm{E}+00$ & 0.0000 & $0.000 \mathrm{E}+00$ & 0.0000 & $0.000 \mathrm{E}+00$ & 0.0000 & $0.000 \mathrm{E}+00$ & 0.0000 & $4.979 E-24$ & 0.0000 \\
\hline-228 & $0.000 \mathrm{E}+00$ & 0.0000 & $0.000 \mathrm{E}+00$ & 0.0000 & $0.000 \mathrm{E}+00$ & 0.0000 & $0.000 \mathrm{E}+00$ & 0.0000 & $0.000 \mathrm{E}+00$ & 0.0000 & $0.000 \mathrm{E}+00$ & 0.0000 & $1.011 \mathrm{E}-13$ & 0.0000 \\
\hline-230 & $0.000 \mathrm{E}+00$ & 0.0000 & $0.000 \mathrm{E}+00$ & 0.0000 & $0.000 \mathrm{E}+00$ & 0.0000 & $0.000 \mathrm{E}+00$ & 0.0000 & $0.000 \mathrm{E}+00$ & 0.0000 & $0.000 \mathrm{E}+00$ & 0.0000 & $5.320 \mathrm{E}-07$ & 0.0558 \\
\hline-232 & $0.000 \mathrm{E}+00$ & 0.0000 & $0.000 \mathrm{E}+00$ & 0.0000 & $0.000 \mathrm{E}+00$ & 0.0000 & $0.000 \mathrm{E}+00$ & 0.0000 & $0.000 \mathrm{E}+00$ & 0.0000 & $0.000 \mathrm{E}+00$ & 0.0000 & $8.963 E-06$ & 0.9395 \\
\hline 234 & $0.000 \mathrm{E}+00$ & 0.0000 & $0.000 \mathrm{E}+00$ & 0.0000 & $0.000 \mathrm{E}+00$ & 0.0000 & $0.000 \mathrm{E}+00$ & 0.0000 & $0.000 \mathrm{E}+00$ & 0.0000 & $0.000 \mathrm{E}+00$ & 0.0000 & $1.941 \mathrm{E}-10$ & 0.0000 \\
\hline 35 & $0.000 \mathrm{E}+00$ & 0.0000 & $0.000 \mathrm{E}+00$ & 0.0000 & $0.000 \mathrm{E}+00$ & 0.0000 & $0.000 \mathrm{E}+00$ & 0.0000 & $0.000 \mathrm{E}+00$ & 0.0000 & $0.000 \mathrm{E}+00$ & 0.0000 & $6.005 E-13$ & 0.0000 \\
\hline 38 & $0.000 \mathrm{E}+00$ & 0.0000 & $0.000 \mathrm{E}+00$ & 0.0000 & $0.000 \mathrm{E}+00$ & 0.0000 & $0.000 \mathrm{E}+00$ & 0.0000 & $0.000 \mathrm{E}+00$ & 0.0000 & $0.000 \mathrm{E}+00$ & 0.0000 & $3.385 \mathrm{E}-08$ & 0.0035 \\
\hline & $0.000 \mathrm{E}+00$ & 0.0000 & $0.000 \mathrm{E}+00$ & 0.0000 & $0.000 \mathrm{E}+00$ & 0.0000 & $0.000 \mathrm{E}+00$ & 0.0000 & $0.000 \mathrm{E}+00$ & 0.0000 & $0.000 \mathrm{E}+00$ & 0.0000 & $9.541 \mathrm{E}-06$ & 1.0000 \\
\hline
\end{tabular}

* Sum of all water independent and dependent pathways. 
RESRAD, Version 6.5

ummary : RESRAD Parameters for U-Landfill Resident Gardener Forward Run

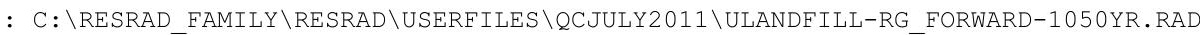

Total Dose Contributions TDOSE (i,p,t) for Individual Radionuclides (i) and Pathways (p) As mrem/yr and Fraction of Total Dose At $t=1.000 \mathrm{E}+02$ years

Water Independent Pathways (Inhalation excludes radon)

\begin{tabular}{|c|c|c|c|c|c|c|c|c|c|c|c|c|c|c|}
\hline & \multicolumn{2}{|c|}{ Ground } & \multicolumn{2}{|c|}{ Inhalation } & \multicolumn{2}{|c|}{ Radon } & \multicolumn{2}{|c|}{ Plant } & \multicolumn{2}{|c|}{ Meat } & \multicolumn{2}{|c|}{ Milk } & \multicolumn{2}{|c|}{ Soil } \\
\hline ide & mrem/yr & fract. & mrem/yr & fract. & mrem/yr & fract. & mrem/yr & fract. & mrem/yr & fract. & mrem/yr & fract. & mrem/yr & fract. \\
\hline-241 & $2.940 \mathrm{E}-15$ & 0.0000 & $0.000 \mathrm{E}+00$ & 0.0000 & $0.000 \mathrm{E}+00$ & 0.0000 & $0.000 \mathrm{E}+00$ & 0.0000 & $0.000 \mathrm{E}+00$ & 0.0000 & $0.000 \mathrm{E}+00$ & 0.0000 & $0.000 \mathrm{E}+00$ & 0.0000 \\
\hline-137 & $5.512 \mathrm{E}-09$ & 0.0004 & $0.000 \mathrm{E}+00$ & 0.0000 & $0.000 \mathrm{E}+00$ & 0.0000 & $0.000 \mathrm{E}+00$ & 0.0000 & $0.000 \mathrm{E}+00$ & 0.0000 & $0.000 \mathrm{E}+00$ & 0.0000 & $0.000 \mathrm{E}+00$ & 0.0000 \\
\hline-237 & $1.534 \mathrm{E}-11$ & 0.0000 & $0.000 \mathrm{E}+00$ & 0.0000 & $0.000 \mathrm{E}+00$ & 0.0000 & $0.000 \mathrm{E}+00$ & 0.0000 & $0.000 \mathrm{E}+00$ & 0.0000 & $0.000 \mathrm{E}+00$ & 0.0000 & $0.000 \mathrm{E}+00$ & 0.0000 \\
\hline 238 & $2.076 \mathrm{E}-14$ & 0.0000 & $0.000 \mathrm{E}+00$ & 0.0000 & $0.000 \mathrm{E}+00$ & 0.0000 & $0.000 \mathrm{E}+00$ & 0.0000 & $0.000 \mathrm{E}+00$ & 0.0000 & $0.000 \mathrm{E}+00$ & 0.0000 & $0.000 \mathrm{E}+00$ & 0.0000 \\
\hline 239 & $1.428 E-15$ & 0.0000 & $0.000 \mathrm{E}+00$ & 0.0000 & $0.000 \mathrm{E}+00$ & 0.0000 & $0.000 \mathrm{E}+00$ & 0.0000 & $0.000 \mathrm{E}+00$ & 0.0000 & $0.000 \mathrm{E}+00$ & 0.0000 & $0.000 \mathrm{E}+00$ & 0.0000 \\
\hline 240 & $6.420 \mathrm{E}-19$ & 0.0000 & $0.000 \mathrm{E}+00$ & 0.0000 & $0.000 \mathrm{E}+00$ & 0.0000 & $0.000 \mathrm{E}+00$ & 0.0000 & $0.000 \mathrm{E}+00$ & 0.0000 & $0.000 \mathrm{E}+00$ & 0.0000 & $0.000 \mathrm{E}+00$ & 0.0000 \\
\hline 99 & $8.280 E-24$ & 0.0000 & $0.000 \mathrm{E}+00$ & 0.0000 & $0.000 \mathrm{E}+00$ & 0.0000 & $0.000 \mathrm{E}+00$ & 0.0000 & $0.000 \mathrm{E}+00$ & 0.0000 & $0.000 \mathrm{E}+00$ & 0.0000 & $0.000 \mathrm{E}+00$ & 0.0000 \\
\hline 228 & $1.847 \mathrm{E}-21$ & 0.0000 & $0.000 \mathrm{E}+00$ & 0.0000 & $0.000 \mathrm{E}+00$ & 0.0000 & $0.000 \mathrm{E}+00$ & 0.0000 & $0.000 \mathrm{E}+00$ & 0.0000 & $0.000 \mathrm{E}+00$ & 0.0000 & $0.000 \mathrm{E}+00$ & 0.0000 \\
\hline 230 & $1.479 \mathrm{E}-06$ & 0.1082 & $0.000 \mathrm{E}+00$ & 0.0000 & $0.000 \mathrm{E}+00$ & 0.0000 & $0.000 \mathrm{E}+00$ & 0.0000 & $0.000 \mathrm{E}+00$ & 0.0000 & $0.000 \mathrm{E}+00$ & 0.0000 & $0.000 \mathrm{E}+00$ & 0.0000 \\
\hline 232 & $1.213 E-05$ & 0.8876 & $0.000 \mathrm{E}+00$ & 0.0000 & $0.000 \mathrm{E}+00$ & 0.0000 & $0.000 \mathrm{E}+00$ & 0.0000 & $0.000 \mathrm{E}+00$ & 0.0000 & $0.000 \mathrm{E}+00$ & 0.0000 & $0.000 \mathrm{E}+00$ & 0.0000 \\
\hline 34 & $1.078 \mathrm{E}-09$ & 0.0001 & $0.000 \mathrm{E}+00$ & 0.0000 & $0.000 \mathrm{E}+00$ & 0.0000 & $0.000 \mathrm{E}+00$ & 0.0000 & $0.000 \mathrm{E}+00$ & 0.0000 & $0.000 \mathrm{E}+00$ & 0.0000 & $0.000 \mathrm{E}+00$ & 0.0000 \\
\hline 35 & $2.202 E-12$ & 0.0000 & $0.000 \mathrm{E}+00$ & 0.0000 & $0.000 \mathrm{E}+00$ & 0.0000 & $0.000 \mathrm{E}+00$ & 0.0000 & $0.000 \mathrm{E}+00$ & 0.0000 & $0.000 \mathrm{E}+00$ & 0.0000 & $0.000 \mathrm{E}+00$ & 0.0000 \\
\hline 38 & $5.045 E-08$ & 0.0037 & $0.000 \mathrm{E}+00$ & 0.0000 & $0.000 \mathrm{E}+00$ & 0.0000 & $0.000 \mathrm{E}+00$ & 0.0000 & $0.000 \mathrm{E}+00$ & 0.0000 & $0.000 \mathrm{E}+00$ & 0.0000 & $0.000 \mathrm{E}+00$ & 0.0000 \\
\hline & $1.367 \mathrm{E}-05$ & 1.0000 & $0.000 \mathrm{E}+00$ & 0.0000 & $0.000 \mathrm{E}+00$ & 0.0000 & $0.000 \mathrm{E}+00$ & 0.0000 & $0.000 \mathrm{E}+00$ & 0.0000 & $0.000 \mathrm{E}+00$ & 0.0000 & $.000 \mathrm{E}+00$ & 0.0000 \\
\hline
\end{tabular}

Total Dose Contributions TDOSE(i,p,t) for Individual Radionuclides (i) and Pathways (p) As mrem/yr and Fraction of Total Dose At $t=1.000 \mathrm{E}+02$ years

Water Dependent Pathways

\begin{tabular}{|c|c|c|c|c|c|c|c|c|c|c|c|c|c|c|}
\hline \multirow{2}{*}{$\begin{array}{l}\text { Radio- } \\
\text { Nuclide }\end{array}$} & \multicolumn{2}{|c|}{ Water } & \multicolumn{2}{|c|}{ Fish } & \multicolumn{2}{|c|}{ Radon } & \multicolumn{2}{|c|}{ Plant } & \multicolumn{2}{|c|}{ Meat } & \multicolumn{2}{|c|}{ Milk } & \multicolumn{2}{|c|}{ All Pathways* } \\
\hline & mrem/yr & fract. & mrem/yr & fract. & mrem/yr & fract. & mrem/yr & fract. & mrem/yr & fract. & mrem/yr & fract. & mrem/yr & fract. \\
\hline 241 & $0.000 \mathrm{E}+00$ & 0.0000 & $0.000 \mathrm{E}+00$ & 0.0000 & $0.000 \mathrm{E}+00$ & 0.0000 & $0.000 \mathrm{E}+00$ & 0.0000 & $0.000 \mathrm{E}+00$ & 0.0000 & $0.000 \mathrm{E}+00$ & 0.0000 & $2.940 \mathrm{E}-15$ & 0.0000 \\
\hline-137 & $0.000 \mathrm{E}+00$ & 0.0000 & $0.000 \mathrm{E}+00$ & 0.0000 & $0.000 \mathrm{E}+00$ & 0.0000 & $0.000 \mathrm{E}+00$ & 0.0000 & $0.000 \mathrm{E}+00$ & 0.0000 & $0.000 \mathrm{E}+00$ & 0.0000 & $5.512 \mathrm{E}-09$ & 0.0004 \\
\hline-237 & $0.000 \mathrm{E}+00$ & 0.0000 & $0.000 \mathrm{E}+00$ & 0.0000 & $0.000 \mathrm{E}+00$ & 0.0000 & $0.000 \mathrm{E}+00$ & 0.0000 & $0.000 \mathrm{E}+00$ & 0.0000 & $0.000 \mathrm{E}+00$ & 0.0000 & $1.534 \mathrm{E}-11$ & 0.0000 \\
\hline-238 & $0.000 \mathrm{E}+00$ & 0.0000 & $0.000 \mathrm{E}+00$ & 0.0000 & $0.000 \mathrm{E}+00$ & 0.0000 & $0.000 \mathrm{E}+00$ & 0.0000 & $0.000 \mathrm{E}+00$ & 0.0000 & $0.000 \mathrm{E}+00$ & 0.0000 & $2.076 \mathrm{E}-14$ & 0.0000 \\
\hline-239 & $0.000 \mathrm{E}+00$ & 0.0000 & $0.000 \mathrm{E}+00$ & 0.0000 & $0.000 \mathrm{E}+00$ & 0.0000 & $0.000 \mathrm{E}+00$ & 0.0000 & $0.000 \mathrm{E}+00$ & 0.0000 & $0.000 E+00$ & 0.0000 & 1. $428 \mathrm{E}-15$ & 0.0000 \\
\hline-240 & $0.000 \mathrm{E}+00$ & 0.0000 & $0.000 \mathrm{E}+00$ & 0.0000 & $0.000 \mathrm{E}+00$ & 0.0000 & $0.000 \mathrm{E}+00$ & 0.0000 & $0.000 \mathrm{E}+00$ & 0.0000 & $0.000 E+00$ & 0.0000 & $6.420 \mathrm{E}-19$ & 0.0000 \\
\hline-99 & $0.000 \mathrm{E}+00$ & 0.0000 & $0.000 \mathrm{E}+00$ & 0.0000 & $0.000 \mathrm{E}+00$ & 0.0000 & $0.000 \mathrm{E}+00$ & 0.0000 & $0.000 \mathrm{E}+00$ & 0.0000 & $0.000 \mathrm{E}+00$ & 0.0000 & $8.280 \mathrm{E}-24$ & 0.0000 \\
\hline-228 & $0.000 \mathrm{E}+00$ & 0.0000 & $0.000 \mathrm{E}+00$ & 0.0000 & $0.000 \mathrm{E}+00$ & 0.0000 & $0.000 \mathrm{E}+00$ & 0.0000 & $0.000 \mathrm{E}+00$ & 0.0000 & $0.000 \mathrm{E}+00$ & 0.0000 & $1.847 \mathrm{E}-21$ & 0.0000 \\
\hline-230 & $0.000 \mathrm{E}+00$ & 0.0000 & $0.000 \mathrm{E}+00$ & 0.0000 & $0.000 \mathrm{E}+00$ & 0.0000 & $0.000 \mathrm{E}+00$ & 0.0000 & $0.000 \mathrm{E}+00$ & 0.0000 & $0.000 E+00$ & 0.0000 & $1.479 \mathrm{E}-06$ & 0.1082 \\
\hline 232 & $0.000 \mathrm{E}+00$ & 0.0000 & $0.000 \mathrm{E}+00$ & 0.0000 & $0.000 \mathrm{E}+00$ & 0.0000 & $0.000 \mathrm{E}+00$ & 0.0000 & $0.000 \mathrm{E}+00$ & 0.0000 & $0.000 \mathrm{E}+00$ & 0.0000 & $1.213 E-05$ & 0.8876 \\
\hline 34 & $0.000 \mathrm{E}+00$ & 0.0000 & $0.000 \mathrm{E}+00$ & 0.0000 & $0.000 \mathrm{E}+00$ & 0.0000 & $0.000 \mathrm{E}+00$ & 0.0000 & $0.000 \mathrm{E}+00$ & 0.0000 & $0.000 \mathrm{E}+00$ & 0.0000 & $1.078 \mathrm{E}-09$ & 0.0001 \\
\hline 35 & $0.000 \mathrm{E}+00$ & 0.0000 & $0.000 \mathrm{E}+00$ & 0.0000 & $0.000 \mathrm{E}+00$ & 0.0000 & $0.000 \mathrm{E}+00$ & 0.0000 & $0.000 \mathrm{E}+00$ & 0.0000 & $0.000 \mathrm{E}+00$ & 0.0000 & 2. $202 \mathrm{E}-12$ & 0.0000 \\
\hline 38 & $0.000 \mathrm{E}+00$ & 0.0000 & $0.000 \mathrm{E}+00$ & 0.0000 & $0.000 \mathrm{E}+00$ & 0.0000 & $0.000 \mathrm{E}+00$ & 0.0000 & $0.000 \mathrm{E}+00$ & 0.0000 & $0.000 \mathrm{E}+00$ & 0.0000 & $5.045 E-08$ & 0.0037 \\
\hline & $0.000 \mathrm{E}+00$ & 0.0000 & $0.000 \mathrm{E}+00$ & 0.0000 & $0.000 \mathrm{E}+00$ & 0.0000 & $0.000 \mathrm{E}+00$ & 0.0000 & $0.000 \mathrm{E}+00$ & 0.0000 & $0.000 \mathrm{E}+00$ & 0.0000 & $7 E-05$ & 1.0000 \\
\hline
\end{tabular}

* Sum of all water independent and dependent pathways. 
RESRAD, Version 6.5

$\mathrm{T}^{1 / 2}$ Limit $=180$ days

07/20/2011 14:38 Page

24

ummary : RESRAD Parameters for U-Landfill Resident Gardener Forward Run

: C: \RESRAD_FAMILY \RESRAD \USERFILES \QCJULY2011 \ULANDFILL-RG_FORWARD-1050YR.RAD

Total Dose Contributions TDOSE (i,p,t) for Individual Radionuclides (i) and Pathways (p) As mrem/yr and Fraction of Total Dose At $t=5.000 \mathrm{E}+02$ years

Water Independent Pathways (Inhalation excludes radon)

\begin{tabular}{|c|c|c|c|c|c|c|c|c|c|c|c|c|c|c|}
\hline & \multicolumn{2}{|c|}{ Ground } & \multicolumn{2}{|c|}{ Inhalation } & \multicolumn{2}{|c|}{ Radon } & \multicolumn{2}{|c|}{ Plant } & \multicolumn{2}{|c|}{ Meat } & \multicolumn{2}{|c|}{ Milk } & \multicolumn{2}{|c|}{ Soil } \\
\hline Iide & mrem/yr & fract. & mrem/yr & fract. & mrem/yr & fract. & mrem/yr & fract. & mrem/yr & fract. & mrem/yr & fract. & mrem/yr & fract. \\
\hline-241 & $8.032 \mathrm{E}-13$ & 0.0000 & $0.000 \mathrm{E}+00$ & 0.0000 & $0.000 \mathrm{E}+00$ & 0.0000 & $0.000 \mathrm{E}+00$ & 0.0000 & $0.000 \mathrm{E}+00$ & 0.0000 & $0.000 \mathrm{E}+00$ & 0.0000 & $0.000 \mathrm{E}+00$ & 0.0000 \\
\hline-137 & $1.540 \mathrm{E}-11$ & 0.0000 & $0.000 \mathrm{E}+00$ & 0.0000 & $0.000 \mathrm{E}+00$ & 0.0000 & $0.000 \mathrm{E}+00$ & 0.0000 & $0.000 \mathrm{E}+00$ & 0.0000 & $0.000 \mathrm{E}+00$ & 0.0000 & $0.000 \mathrm{E}+00$ & 0.0000 \\
\hline-237 & $1.124 \mathrm{E}-09$ & 0.0000 & $0.000 \mathrm{E}+00$ & 0.0000 & $0.000 \mathrm{E}+00$ & 0.0000 & $0.000 \mathrm{E}+00$ & 0.0000 & $0.000 \mathrm{E}+00$ & 0.0000 & $0.000 \mathrm{E}+00$ & 0.0000 & $0.000 \mathrm{E}+00$ & 0.0000 \\
\hline 238 & $2.187 \mathrm{E}-11$ & 0.0000 & $0.000 \mathrm{E}+00$ & 0.0000 & $0.000 \mathrm{E}+00$ & 0.0000 & $0.000 \mathrm{E}+00$ & 0.0000 & $0.000 \mathrm{E}+00$ & 0.0000 & $0.000 \mathrm{E}+00$ & 0.0000 & $0.000 \mathrm{E}+00$ & 0.0000 \\
\hline 239 & $1.695 \mathrm{E}-13$ & 0.0000 & $0.000 \mathrm{E}+00$ & 0.0000 & $0.000 \mathrm{E}+00$ & 0.0000 & $0.000 \mathrm{E}+00$ & 0.0000 & $0.000 \mathrm{E}+00$ & 0.0000 & $0.000 \mathrm{E}+00$ & 0.0000 & $0.000 \mathrm{E}+00$ & 0.0000 \\
\hline 240 & $2.059 \mathrm{E}-16$ & 0.0000 & $0.000 \mathrm{E}+00$ & 0.0000 & $0.000 \mathrm{E}+00$ & 0.0000 & $0.000 \mathrm{E}+00$ & 0.0000 & $0.000 \mathrm{E}+00$ & 0.0000 & $0.000 \mathrm{E}+00$ & 0.0000 & $0.000 \mathrm{E}+00$ & 0.0000 \\
\hline 99 & $4.841 E-22$ & 0.0000 & $0.000 \mathrm{E}+00$ & 0.0000 & $0.000 \mathrm{E}+00$ & 0.0000 & $0.000 \mathrm{E}+00$ & 0.0000 & $0.000 \mathrm{E}+00$ & 0.0000 & $0.000 \mathrm{E}+00$ & 0.0000 & $0.000 \mathrm{E}+00$ & 0.0000 \\
\hline 228 & $0.000 \mathrm{E}+00$ & 0.0000 & $0.000 \mathrm{E}+00$ & 0.0000 & $0.000 \mathrm{E}+00$ & 0.0000 & $0.000 \mathrm{E}+00$ & 0.0000 & $0.000 \mathrm{E}+00$ & 0.0000 & $0.000 \mathrm{E}+00$ & 0.0000 & $0.000 \mathrm{E}+00$ & 0.0000 \\
\hline 230 & $1.071 \mathrm{E}-04$ & 0.4421 & $0.000 \mathrm{E}+00$ & 0.0000 & $0.000 \mathrm{E}+00$ & 0.0000 & $0.000 \mathrm{E}+00$ & 0.0000 & $0.000 \mathrm{E}+00$ & 0.0000 & $0.000 \mathrm{E}+00$ & 0.0000 & $0.000 \mathrm{E}+00$ & 0.0000 \\
\hline 232 & $1.335 E-04$ & 0.5512 & $0.000 \mathrm{E}+00$ & 0.0000 & $0.000 \mathrm{E}+00$ & 0.0000 & $0.000 \mathrm{E}+00$ & 0.0000 & $0.000 \mathrm{E}+00$ & 0.0000 & $0.000 \mathrm{E}+00$ & 0.0000 & $0.000 \mathrm{E}+00$ & 0.0000 \\
\hline 34 & $3.993 E-07$ & 0.0016 & $0.000 \mathrm{E}+00$ & 0.0000 & $0.000 \mathrm{E}+00$ & 0.0000 & $0.000 \mathrm{E}+00$ & 0.0000 & $0.000 \mathrm{E}+00$ & 0.0000 & $0.000 \mathrm{E}+00$ & 0.0000 & $0.000 \mathrm{E}+00$ & 0.0000 \\
\hline 35 & $4.571 E-10$ & 0.0000 & $0.000 \mathrm{E}+00$ & 0.0000 & $0.000 \mathrm{E}+00$ & 0.0000 & $0.000 \mathrm{E}+00$ & 0.0000 & $0.000 \mathrm{E}+00$ & 0.0000 & $0.000 \mathrm{E}+00$ & 0.0000 & $0.000 \mathrm{E}+00$ & 0.0000 \\
\hline 38 & $1.229 \mathrm{E}-06$ & 0.0051 & $0.000 \mathrm{E}+00$ & 0.0000 & $0.000 \mathrm{E}+00$ & 0.0000 & $0.000 \mathrm{E}+00$ & 0.0000 & $0.000 \mathrm{E}+00$ & 0.0000 & $0.000 \mathrm{E}+00$ & 0.0000 & $0.000 \mathrm{E}+00$ & 0.0000 \\
\hline & $2.423 E-04$ & 1.0000 & $0.000 \mathrm{E}+00$ & 0.0000 & $0.000 \mathrm{E}+00$ & 0.0000 & $0.000 \mathrm{E}+00$ & 0.0000 & $0.000 \mathrm{E}+00$ & 0.0000 & $0.000 \mathrm{E}+00$ & 0.0000 & $.000 \mathrm{E}+00$ & 0.0000 \\
\hline
\end{tabular}

Total Dose Contributions TDOSE(i,p,t) for Individual Radionuclides (i) and Pathways (p) As mrem/yr and Fraction of Total Dose At $t=5.000 \mathrm{E}+02$ years

Water Dependent Pathways

\begin{tabular}{|c|c|c|c|c|c|c|c|c|c|c|c|c|c|c|}
\hline & \multicolumn{2}{|c|}{ Water } & \multicolumn{2}{|c|}{ Fish } & \multicolumn{2}{|c|}{ Radon } & \multicolumn{2}{|c|}{ Plant } & \multicolumn{2}{|c|}{ Meat } & \multicolumn{2}{|c|}{ Milk } & \multicolumn{2}{|c|}{ All Pathways* } \\
\hline clide & mrem/yr & fract. & mrem/yr & fract. & mrem/yr & fract. & mrem/yr & fract. & mrem/yr & fract. & mrem/yr & fract. & mrem/yr & fract. \\
\hline-241 & $0.000 \mathrm{E}+00$ & 0.0000 & $0.000 \mathrm{E}+00$ & 0.0000 & $0.000 \mathrm{E}+00$ & 0.0000 & $0.000 \mathrm{E}+00$ & 0.0000 & $0.000 \mathrm{E}+00$ & 0.0000 & $0.000 \mathrm{E}+00$ & 0.0000 & $8.032 \mathrm{E}-13$ & 0.0000 \\
\hline-137 & $0.000 \mathrm{E}+00$ & 0.0000 & $0.000 \mathrm{E}+00$ & 0.0000 & $0.000 \mathrm{E}+00$ & 0.0000 & $0.000 \mathrm{E}+00$ & 0.0000 & $0.000 \mathrm{E}+00$ & 0.0000 & $0.000 \mathrm{E}+00$ & 0.0000 & $1.540 \mathrm{E}-11$ & 0.0000 \\
\hline-237 & $0.000 \mathrm{E}+00$ & 0.0000 & $0.000 \mathrm{E}+00$ & 0.0000 & $0.000 \mathrm{E}+00$ & 0.0000 & $0.000 \mathrm{E}+00$ & 0.0000 & $0.000 \mathrm{E}+00$ & 0.0000 & $0.000 \mathrm{E}+00$ & 0.0000 & $1.124 \mathrm{E}-09$ & 0.0000 \\
\hline 238 & $0.000 \mathrm{E}+00$ & 0.0000 & $0.000 \mathrm{E}+00$ & 0.0000 & $0.000 \mathrm{E}+00$ & 0.0000 & $0.000 \mathrm{E}+00$ & 0.0000 & $0.000 \mathrm{E}+00$ & 0.0000 & $0.000 \mathrm{E}+00$ & 0.0000 & $2.187 \mathrm{E}-11$ & 0.0000 \\
\hline 239 & $0.000 \mathrm{E}+00$ & 0.0000 & $0.000 \mathrm{E}+00$ & 0.0000 & $0.000 \mathrm{E}+00$ & 0.0000 & $0.000 \mathrm{E}+00$ & 0.0000 & $0.000 \mathrm{E}+00$ & 0.0000 & $0.000 \mathrm{E}+00$ & 0.0000 & $1.695 \mathrm{E}-13$ & 0.0000 \\
\hline 240 & $0.000 \mathrm{E}+00$ & 0.0000 & $0.000 \mathrm{E}+00$ & 0.0000 & $0.000 \mathrm{E}+00$ & 0.0000 & $0.000 \mathrm{E}+00$ & 0.0000 & $0.000 \mathrm{E}+00$ & 0.0000 & $0.000 \mathrm{E}+00$ & 0.0000 & $2.059 \mathrm{E}-16$ & 0.0000 \\
\hline 99 & $0.000 \mathrm{E}+00$ & 0.0000 & $0.000 \mathrm{E}+00$ & 0.0000 & $0.000 \mathrm{E}+00$ & 0.0000 & $0.000 \mathrm{E}+00$ & 0.0000 & $0.000 \mathrm{E}+00$ & 0.0000 & $0.000 \mathrm{E}+00$ & 0.0000 & $4.841 \mathrm{E}-22$ & 0.0000 \\
\hline 228 & $0.000 \mathrm{E}+00$ & 0.0000 & $0.000 \mathrm{E}+00$ & 0.0000 & $0.000 \mathrm{E}+00$ & 0.0000 & $0.000 \mathrm{E}+00$ & 0.0000 & $0.000 \mathrm{E}+00$ & 0.0000 & $0.000 \mathrm{E}+00$ & 0.0000 & $0.000 \mathrm{E}+00$ & 0.0000 \\
\hline 230 & $0.000 \mathrm{E}+00$ & 0.0000 & $0.000 \mathrm{E}+00$ & 0.0000 & $0.000 \mathrm{E}+00$ & 0.0000 & $0.000 \mathrm{E}+00$ & 0.0000 & $0.000 \mathrm{E}+00$ & 0.0000 & $0.000 \mathrm{E}+00$ & 0.0000 & $1.071 \mathrm{E}-04$ & 0.4421 \\
\hline 232 & $0.000 \mathrm{E}+00$ & 0.0000 & $0.000 \mathrm{E}+00$ & 0.0000 & $0.000 \mathrm{E}+00$ & 0.0000 & $0.000 \mathrm{E}+00$ & 0.0000 & $0.000 \mathrm{E}+00$ & 0.0000 & $0.000 \mathrm{E}+00$ & 0.0000 & $1.335 \mathrm{E}-04$ & 0.5512 \\
\hline & $0.000 \mathrm{E}+00$ & 0.0000 & $0.000 \mathrm{E}+00$ & 0.0000 & $0.000 \mathrm{E}+00$ & 0.0000 & $0.000 \mathrm{E}+00$ & 0.0000 & $0.000 \mathrm{E}+00$ & 0.0000 & $0.000 \mathrm{E}+00$ & 0.0000 & $3.993 E-07$ & 0.0016 \\
\hline 35 & $0.000 \mathrm{E}+00$ & 0.0000 & $0.000 \mathrm{E}+00$ & 0.0000 & $0.000 \mathrm{E}+00$ & 0.0000 & $0.000 \mathrm{E}+00$ & 0.0000 & $0.000 \mathrm{E}+00$ & 0.0000 & $0.000 \mathrm{E}+00$ & 0.0000 & $4.571 \mathrm{E}-10$ & 0.0000 \\
\hline 38 & $0.000 \mathrm{E}+00$ & 0.0000 & $0.000 \mathrm{E}+00$ & 0.0000 & $0.000 \mathrm{E}+00$ & 0.0000 & $0.000 \mathrm{E}+00$ & 0.0000 & $0.000 \mathrm{E}+00$ & 0.0000 & $0.000 \mathrm{E}+00$ & 0.0000 & $1.229 \mathrm{E}-06$ & 0.0051 \\
\hline & $0.000 \mathrm{E}+00$ & 0.0000 & $0.000 \mathrm{E}+00$ & 0.0000 & $0.000 \mathrm{E}+00$ & 0.0000 & $0.000 \mathrm{E}+00$ & 0.0000 & $0.000 \mathrm{E}+00$ & 0.0000 & $0.000 E+00$ & 000 & -04 & 1.0000 \\
\hline
\end{tabular}

* Sum of all water independent and dependent pathways. 
RESRAD, Version 6.5

$\mathrm{T}^{1 / 2}$ Limit $=180$ days

07/20/2011 14:38 Page

25

ummary : RESRAD Parameters for U-Landfill Resident Gardener Forward Run

: C: \RESRAD_FAMILY \RESRAD \USERFILES \QCJULY2011 \ULANDFILL-RG_FORWARD-1050YR.RAD

Total Dose Contributions TDOSE (i,p,t) for Individual Radionuclides (i) and Pathways (p) As mrem/yr and Fraction of Total Dose At $t=1.050 \mathrm{E}+03$ years

Water Independent Pathways (Inhalation excludes radon)

\begin{tabular}{|c|c|c|c|c|c|c|c|c|c|c|c|c|c|c|}
\hline \multirow[b]{2}{*}{ Nuclide } & \multicolumn{2}{|c|}{ Ground } & \multicolumn{2}{|c|}{ Inhalation } & \multicolumn{2}{|c|}{ Radon } & \multicolumn{2}{|c|}{ Plant } & \multicolumn{2}{|c|}{ Meat } & \multicolumn{2}{|c|}{ Milk } & \multicolumn{2}{|c|}{ Soil } \\
\hline & mrem/yr & fract. & mrem/yr & fract. & mrem/yr & fract. & mrem/yr & fract. & mrem/yr & fract. & mrem/yr & fract. & mrem/yr & fract. \\
\hline-241 & $4.257 E-10$ & 0.0000 & $0.000 \mathrm{E}+00$ & 0.0000 & $0.000 \mathrm{E}+00$ & 0.0000 & $6.939 E-03$ & 0.0010 & $0.000 \mathrm{E}+00$ & 0.0000 & $0.000 \mathrm{E}+00$ & 0.0000 & $0.000 \mathrm{E}+00$ & 0.0000 \\
\hline-137 & $4.741 E-15$ & 0.0000 & $0.000 \mathrm{E}+00$ & 0.0000 & $0.000 \mathrm{E}+00$ & 0.0000 & 1. $461 \mathrm{E}-12$ & 0.0000 & $0.000 \mathrm{E}+00$ & 0.0000 & $0.000 \mathrm{E}+00$ & 0.0000 & $0.000 \mathrm{E}+00$ & 0.0000 \\
\hline-237 & $3.910 E-07$ & 0.0000 & $0.000 \mathrm{E}+00$ & 0.0000 & $0.000 \mathrm{E}+00$ & 0.0000 & $5.637 \mathrm{E}-02$ & 0.0083 & $0.000 \mathrm{E}+00$ & 0.0000 & $0.000 \mathrm{E}+00$ & 0.0000 & $0.000 \mathrm{E}+00$ & 0.0000 \\
\hline-238 & $5.077 \mathrm{E}-09$ & 0.0000 & $0.000 \mathrm{E}+00$ & 0.0000 & $0.000 \mathrm{E}+00$ & 0.0000 & $2.382 E-05$ & 0.0000 & $0.000 \mathrm{E}+00$ & 0.0000 & $0.000 \mathrm{E}+00$ & 0.0000 & $0.000 \mathrm{E}+00$ & 0.0000 \\
\hline-239 & 1. $202 \mathrm{E}-10$ & 0.0000 & $0.000 \mathrm{E}+00$ & 0.0000 & $0.000 \mathrm{E}+00$ & 0.0000 & $4.566 \mathrm{E}-02$ & 0.0067 & $0.000 \mathrm{E}+00$ & 0.0000 & $0.000 \mathrm{E}+00$ & 0.0000 & $0.000 \mathrm{E}+00$ & 0.0000 \\
\hline-240 & $2.914 \mathrm{E}-14$ & 0.0000 & $0.000 \mathrm{E}+00$ & 0.0000 & $0.000 \mathrm{E}+00$ & 0.0000 & $4.210 \mathrm{E}-02$ & 0.0062 & $0.000 \mathrm{E}+00$ & 0.0000 & $0.000 \mathrm{E}+00$ & 0.0000 & $0.000 \mathrm{E}+00$ & 0.0000 \\
\hline 99 & 1. 302E-19 & 0.0000 & $0.000 \mathrm{E}+00$ & 0.0000 & $0.000 \mathrm{E}+00$ & 0.0000 & $6.892 \mathrm{E}-05$ & 0.0000 & $0.000 \mathrm{E}+00$ & 0.0000 & $0.000 \mathrm{E}+00$ & 0.0000 & $0.000 \mathrm{E}+00$ & 0.0000 \\
\hline-228 & $0.000 \mathrm{E}+00$ & 0.0000 & $0.000 \mathrm{E}+00$ & 0.0000 & $0.000 \mathrm{E}+00$ & 0.0000 & $0.000 \mathrm{E}+00$ & 0.0000 & $0.000 \mathrm{E}+00$ & 0.0000 & $0.000 \mathrm{E}+00$ & 0.0000 & $0.000 \mathrm{E}+00$ & 0.0000 \\
\hline 230 & $8.967 \mathrm{E}-03$ & 0.0013 & $0.000 \mathrm{E}+00$ & 0.0000 & $0.000 \mathrm{E}+00$ & 0.0000 & $5.809 \mathrm{E}+00$ & 0.8509 & $0.000 \mathrm{E}+00$ & 0.0000 & $0.000 \mathrm{E}+00$ & 0.0000 & $0.000 \mathrm{E}+00$ & 0.0000 \\
\hline-232 & $3.698 E-03$ & 0.0005 & $0.000 \mathrm{E}+00$ & 0.0000 & $0.000 \mathrm{E}+00$ & 0.0000 & $5.926 \mathrm{E}-01$ & 0.0868 & $0.000 \mathrm{E}+00$ & 0.0000 & $0.000 \mathrm{E}+00$ & 0.0000 & $0.000 \mathrm{E}+00$ & 0.0000 \\
\hline 4 & $7.268 E-05$ & 0.0000 & $0.000 \mathrm{E}+00$ & 0.0000 & $0.000 \mathrm{E}+00$ & 0.0000 & $1.483 \mathrm{E}-01$ & 0.0217 & $0.000 \mathrm{E}+00$ & 0.0000 & $0.000 \mathrm{E}+00$ & 0.0000 & $0.000 \mathrm{E}+00$ & 0.0000 \\
\hline 35 & $1.527 \mathrm{E}-07$ & 0.0000 & $0.000 \mathrm{E}+00$ & 0.0000 & $0.000 \mathrm{E}+00$ & 0.0000 & $1.149 \mathrm{E}-02$ & 0.0017 & $0.000 \mathrm{E}+00$ & 0.0000 & $0.000 \mathrm{E}+00$ & 0.0000 & $0.000 \mathrm{E}+00$ & 0.0000 \\
\hline 38 & $9.919 \mathrm{E}-05$ & 0.0000 & $0.000 \mathrm{E}+00$ & 0.0000 & $0.000 \mathrm{E}+00$ & 0.0000 & $1.013 \mathrm{E}-01$ & 0.0148 & $0.000 \mathrm{E}+00$ & 0.0000 & $0.000 \mathrm{E}+00$ & 0.0000 & $0.000 \mathrm{E}+00$ & 0.0000 \\
\hline & $4 E-02$ & 019 & $.000 \mathrm{E}+00$ & 0.0 & $0.000 \mathrm{E}+00$ & 0 . & $6.814 \mathrm{E}+00$ & 81 & +00 & 0 & +00 & 0 & tud & \\
\hline
\end{tabular}

Total Dose Contributions TDOSE(i,p,t) for Individual Radionuclides (i) and Pathways (p) As mrem/yr and Fraction of Total Dose At $t=1.050 \mathrm{E}+03$ years

Water Dependent Pathways

\begin{tabular}{|c|c|c|c|c|c|c|c|c|c|c|c|c|c|c|}
\hline & \multicolumn{2}{|c|}{ Water } & \multicolumn{2}{|c|}{ Fish } & \multicolumn{2}{|c|}{ Radon } & \multicolumn{2}{|c|}{ Plant } & \multicolumn{2}{|c|}{ Meat } & \multicolumn{2}{|c|}{ Milk } & \multicolumn{2}{|c|}{ All Pathways* } \\
\hline clide & mrem/yr & fract. & mrem/yr & fract. & mrem/yr & fract. & mrem/yr & fract. & mrem/yr & fract. & mrem/yr & fract. & mrem/yr & fract. \\
\hline-241 & $0.000 \mathrm{E}+00$ & 0.0000 & $0.000 \mathrm{E}+00$ & 0.0000 & $0.000 \mathrm{E}+00$ & 0.0000 & $0.000 \mathrm{E}+00$ & 0.0000 & $0.000 \mathrm{E}+00$ & 0.0000 & $0.000 \mathrm{E}+00$ & 0.0000 & $6.939 E-03$ & 0.0010 \\
\hline-137 & $0.000 \mathrm{E}+00$ & 0.0000 & $0.000 \mathrm{E}+00$ & 0.0000 & $0.000 \mathrm{E}+00$ & 0.0000 & $0.000 \mathrm{E}+00$ & 0.0000 & $0.000 \mathrm{E}+00$ & 0.0000 & $0.000 \mathrm{E}+00$ & 0.0000 & $1.465 \mathrm{E}-12$ & 0.0000 \\
\hline-237 & $0.000 \mathrm{E}+00$ & 0.0000 & $0.000 \mathrm{E}+00$ & 0.0000 & $0.000 \mathrm{E}+00$ & 0.0000 & $0.000 \mathrm{E}+00$ & 0.0000 & $0.000 \mathrm{E}+00$ & 0.0000 & $0.000 \mathrm{E}+00$ & 0.0000 & $5.637 \mathrm{E}-02$ & 0.0083 \\
\hline 238 & $0.000 \mathrm{E}+00$ & 0.0000 & $0.000 \mathrm{E}+00$ & 0.0000 & $0.000 \mathrm{E}+00$ & 0.0000 & $0.000 \mathrm{E}+00$ & 0.0000 & $0.000 \mathrm{E}+00$ & 0.0000 & $0.000 \mathrm{E}+00$ & 0.0000 & $2.383 E-05$ & 0.0000 \\
\hline 239 & $0.000 \mathrm{E}+00$ & 0.0000 & $0.000 \mathrm{E}+00$ & 0.0000 & $0.000 \mathrm{E}+00$ & 0.0000 & $0.000 \mathrm{E}+00$ & 0.0000 & $0.000 \mathrm{E}+00$ & 0.0000 & $0.000 \mathrm{E}+00$ & 0.0000 & $4.566 \mathrm{E}-02$ & 0.0067 \\
\hline 240 & $0.000 \mathrm{E}+00$ & 0.0000 & $0.000 \mathrm{E}+00$ & 0.0000 & $0.000 \mathrm{E}+00$ & 0.0000 & $0.000 \mathrm{E}+00$ & 0.0000 & $0.000 \mathrm{E}+00$ & 0.0000 & $0.000 \mathrm{E}+00$ & 0.0000 & $4.210 \mathrm{E}-02$ & 0.0062 \\
\hline 99 & $0.000 \mathrm{E}+00$ & 0.0000 & $0.000 \mathrm{E}+00$ & 0.0000 & $0.000 \mathrm{E}+00$ & 0.0000 & $0.000 \mathrm{E}+00$ & 0.0000 & $0.000 \mathrm{E}+00$ & 0.0000 & $0.000 \mathrm{E}+00$ & 0.0000 & $6.892 \mathrm{E}-05$ & 0.0000 \\
\hline 228 & $0.000 \mathrm{E}+00$ & 0.0000 & $0.000 \mathrm{E}+00$ & 0.0000 & $0.000 \mathrm{E}+00$ & 0.0000 & $0.000 \mathrm{E}+00$ & 0.0000 & $0.000 \mathrm{E}+00$ & 0.0000 & $0.000 \mathrm{E}+00$ & 0.0000 & $0.000 \mathrm{E}+00$ & 0.0000 \\
\hline 230 & $0.000 \mathrm{E}+00$ & 0.0000 & $0.000 \mathrm{E}+00$ & 0.0000 & $0.000 \mathrm{E}+00$ & 0.0000 & $0.000 \mathrm{E}+00$ & 0.0000 & $0.000 \mathrm{E}+00$ & 0.0000 & $0.000 \mathrm{E}+00$ & 0.0000 & $5.818 \mathrm{E}+00$ & 0.8522 \\
\hline 232 & $0.000 \mathrm{E}+00$ & 0.0000 & $0.000 \mathrm{E}+00$ & 0.0000 & $0.000 \mathrm{E}+00$ & 0.0000 & $0.000 \mathrm{E}+00$ & 0.0000 & $0.000 \mathrm{E}+00$ & 0.0000 & $0.000 \mathrm{E}+00$ & 0.0000 & $5.963 \mathrm{E}-01$ & 0.0873 \\
\hline & $0.000 \mathrm{E}+00$ & 0.0000 & $0.000 \mathrm{E}+00$ & 0.0000 & $0.000 \mathrm{E}+00$ & 0.0000 & $0.000 \mathrm{E}+00$ & 0.0000 & $0.000 \mathrm{E}+00$ & 0.0000 & $0.000 \mathrm{E}+00$ & 0.0000 & $1.484 \mathrm{E}-01$ & 0.0217 \\
\hline 35 & $0.000 \mathrm{E}+00$ & 0.0000 & $0.000 \mathrm{E}+00$ & 0.0000 & $0.000 \mathrm{E}+00$ & 0.0000 & $0.000 \mathrm{E}+00$ & 0.0000 & $0.000 \mathrm{E}+00$ & 0.0000 & $0.000 \mathrm{E}+00$ & 0.0000 & $1.149 \mathrm{E}-02$ & 0.0017 \\
\hline 38 & $0.000 \mathrm{E}+00$ & 0.0000 & $0.000 \mathrm{E}+00$ & 0.0000 & $0.000 \mathrm{E}+00$ & 0.0000 & $0.000 \mathrm{E}+00$ & 0.0000 & $0.000 \mathrm{E}+00$ & 0.0000 & $0.000 \mathrm{E}+00$ & 0.0000 & $1.014 \mathrm{E}-01$ & 0.0148 \\
\hline & $0.000 \mathrm{E}+00$ & 0.0000 & $0.000 \mathrm{E}+00$ & 0.0000 & $0.000 \mathrm{E}+00$ & 0.0000 & $0.000 \mathrm{E}+00$ & 0.0000 & $0.000 \mathrm{E}+00$ & 0.0000 & $0.000 E+00$ & 000 & +00 & 1.0000 \\
\hline
\end{tabular}

* Sum of all water independent and dependent pathways. 
RESRAD, Version 6.5

Summary : RESRAD Parameters for U-Landfill Resident Gardener Forward Run

File : C: \RESRAD FAMILY \RESRAD \USERFILES \QCJULY2011 \ULANDFILL-RG FORWARD-1050YR.RAD

Dose/Source Ratios Summed Over All Pathways

Parent and Progeny Principal Radionuclide Contributions Indicated

Parent Product Thread DSR $(j, t)$ At Time in Years (mrem/yr)/(pCi/g)

(i)

(j) Fraction

$0.000 \mathrm{E}+00 \quad 1.000 \mathrm{E}+00 \quad 5.000 \mathrm{E}+01 \quad 1.000 \mathrm{E}+02 \quad 5.000 \mathrm{E}+02 \quad 1.050 \mathrm{E}+03$

Am-241

$\overline{A m-241} \quad \overline{1.000 E+00}$

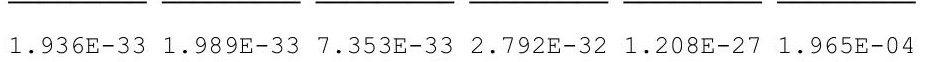

$\begin{array}{lllllllll}\mathrm{Np}-237+\mathrm{D} & 1.000 \mathrm{E}+00 & 1.546 \mathrm{E}-19 & 4.680 \mathrm{E}-19 & 2.562 \mathrm{E}-17 & 8.382 \mathrm{E}-17 & 2.263 \mathrm{E}-14 & 1.773 \mathrm{E}-06\end{array}$

$\begin{array}{lllllllll}\mathrm{U}-233 & 1.000 \mathrm{E}+00 & 3.506 \mathrm{E}-30 & 2.479 \mathrm{E}-29 & 4.863 \mathrm{E}-26 & 3.503 \mathrm{E}-25 & 1.053 \mathrm{E}-21 & 3.056 \mathrm{E}-10\end{array}$

$\begin{array}{llllllll}\mathrm{Th}-229+\mathrm{D} & 1.000 \mathrm{E}+00 & 2.399 \mathrm{E}-26 & 3.618 \mathrm{E}-25 & 1.710 \mathrm{E}-20 & 1.868 \mathrm{E}-19 & 3.195 \mathrm{E}-16 & 5.403 \mathrm{E}-11\end{array}$

$\sum \operatorname{DSR}(j)$

$\begin{array}{lllllll}1.546 \mathrm{E}-19 & 4.680 \mathrm{E}-19 & 2.564 \mathrm{E}-17 & 8.401 \mathrm{E}-17 & 2.295 \mathrm{E}-14 & 1.983 \mathrm{E}-04\end{array}$

$\mathrm{Cs}-137+\mathrm{D} \quad 1.000 \mathrm{E}+00 \quad 1.262 \mathrm{E}-09 \quad 1.243 \mathrm{E}-09 \quad 6.050 \mathrm{E}-10 \quad 2.901 \mathrm{E}-10 \quad 8.104 \mathrm{E}-13 \quad 7.713 \mathrm{E}-14$

$\begin{array}{lllllllll}\mathrm{Np}-237+\mathrm{D} & 1.000 \mathrm{E}+00 & 9.536 \mathrm{E}-13 & 9.638 \mathrm{E}-13 & 1.625 \mathrm{E}-12 & 2.770 \mathrm{E}-12 & 1.974 \mathrm{E}-10 & 1.025 \mathrm{E}-02\end{array}$

$\begin{array}{lllllllll}\mathrm{U}-233 & 1.000 \mathrm{E}+00 & 3.245 \mathrm{E}-23 & 9.844 \mathrm{E}-23 & 6.100 \mathrm{E}-21 & 2.264 \mathrm{E}-20 & 1.650 \mathrm{E}-17 & 2.871 \mathrm{E}-06\end{array}$

$\begin{array}{llllllll}\mathrm{Th}-229+\mathrm{D} & 1.000 \mathrm{E}+00 & 2.962 \mathrm{E}-19 & 2.086 \mathrm{E}-18 & 3.196 \mathrm{E}-15 & 1.788 \mathrm{E}-14 & 7.080 \mathrm{E}-12 & 6.801 \mathrm{E}-07\end{array}$

$\sum \operatorname{DSR}(j)$

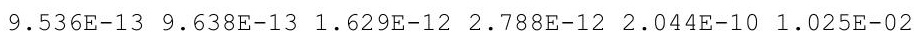

$\mathrm{Pu}-238$

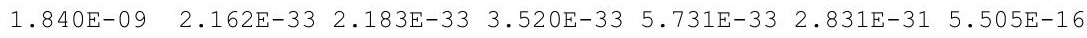

$\begin{array}{lllllllll}\mathrm{Pu}-238 & 1.000 \mathrm{E}+00 & 1.175 \mathrm{E}-24 & 1.186 \mathrm{E}-24 & 1.913 \mathrm{E}-24 & 3.115 \mathrm{E}-24 & 1.539 \mathrm{E}-22 & 2.992 \mathrm{E}-07\end{array}$

$\begin{array}{llllllll}\mathrm{U}-234 & 1.000 \mathrm{E}+00 & 9.778 \mathrm{E}-30 & 2.969 \mathrm{E}-29 & 1.973 \mathrm{E}-27 & 7.960 \mathrm{E}-27 & 1.690 \mathrm{E}-23 & 2.276 \mathrm{E}-07\end{array}$

$\begin{array}{lllllllll}\mathrm{Th}-230 & 1.000 \mathrm{E}+00 & 1.028 \mathrm{E}-33 & 7.286 \mathrm{E}-33 & 1.599 \mathrm{E}-29 & 1.302 \mathrm{E}-28 & 1.306 \mathrm{E}-24 & 3.273 \mathrm{E}-09\end{array}$

$\mathrm{Ra}-226+\mathrm{D} \quad 1.000 \mathrm{E}+00 \quad 8.021 \mathrm{E}-23 \quad 1.208 \mathrm{E}-21 \quad 5.266 \mathrm{E}-17 \quad 5.323 \mathrm{E}-16 \quad 5.607 \mathrm{E}-13 \quad 3.143 \mathrm{E}-08$

$\mathrm{Pb}-210+\mathrm{D} \quad 1.000 \mathrm{E}+00 \quad 2.326 \mathrm{E}-31 \quad 7.210 \mathrm{E}-30 \quad 7.772 \mathrm{E}-24 \quad 1.314 \mathrm{E}-22 \quad 3.671 \mathrm{E}-19 \quad 4.946 \mathrm{E}-08$

$\operatorname{LDSR}(j) \quad 8.139 \mathrm{E}-23 \quad 1.209 \mathrm{E}-21 \quad 5.266 \mathrm{E}-17 \quad 5.323 \mathrm{E}-16 \quad 5.607 \mathrm{E}-13 \quad 6.110 \mathrm{E}-07$

$\begin{array}{llllllll}\mathrm{Pu}-239 & 1.000 \mathrm{E}+00 & 1.202 \mathrm{E}-17 & 1.217 \mathrm{E}-17 & 2.183 \mathrm{E}-17 & 3.965 \mathrm{E}-17 & 4.690 \mathrm{E}-15 & 1.268 \mathrm{E}-03\end{array}$

$\mathrm{U}-235+\mathrm{D} \quad 1.000 \mathrm{E}+00 \quad 6.135 \mathrm{E}-24 \quad 1.861 \mathrm{E}-23 \quad 1.146 \mathrm{E}-21 \quad 4.227 \mathrm{E}-21 \quad 2.931 \mathrm{E}-18 \quad 6.291 \mathrm{E}-10$

$\begin{array}{llllllll}\mathrm{Pa}-231 & 1.000 \mathrm{E}+00 & 9.652 \mathrm{E}-28 & 6.818 \mathrm{E}-27 & 1.251 \mathrm{E}-23 & 8.414 \mathrm{E}-23 & 1.444 \mathrm{E}-19 & 4.191 \mathrm{E}-10\end{array}$

$\mathrm{AC}-227+\mathrm{D} \quad 1.000 \mathrm{E}+00 \quad 2.288 \mathrm{E}-27 \quad 3.434 \mathrm{E}-26 \quad 1.276 \mathrm{E}-21 \quad 1.169 \mathrm{E}-20 \quad 1.476 \mathrm{E}-17 \quad 1.686 \mathrm{E}-10$

$\operatorname{EDSR}(j) \quad 1.202 \mathrm{E}-17 \quad 1.217 \mathrm{E}-17 \quad 2.183 \mathrm{E}-17 \quad 3.966 \mathrm{E}-17 \quad 4.708 \mathrm{E}-15 \quad 1.268 \mathrm{E}-03$

$\begin{array}{llllllll}\mathrm{Pu}-240 \quad 4.950 \mathrm{E}-08 & 5.653 \mathrm{E}-32 & 5.753 \mathrm{E}-32 & 1.359 \mathrm{E}-31 & 3.267 \mathrm{E}-31 & 3.647 \mathrm{E}-28 & 5.789 \mathrm{E}-11\end{array}$

$\begin{array}{lllllllll}\mathrm{Pu}-240 & 1.000 \mathrm{E}+00 & 1.142 \mathrm{E}-24 & 1.162 \mathrm{E}-24 & 2.746 \mathrm{E}-24 & 6.601 \mathrm{E}-24 & 7.367 \mathrm{E}-21 & 1.170 \mathrm{E}-03\end{array}$

$\begin{array}{lllllllll}\mathrm{U}-236 & 1.000 \mathrm{E}+00 & 2.162 \mathrm{E}-32 & 6.590 \mathrm{E}-32 & 5.335 \mathrm{E}-30 & 2.602 \mathrm{E}-29 & 1.686 \mathrm{E}-25 & 1.804 \mathrm{E}-08\end{array}$

$\begin{array}{llllllll}\mathrm{Th}-232 & 1.000 \mathrm{E}+00 & 2.845 \mathrm{E}-43 & 2.028 \mathrm{E}-42 & 5.480 \mathrm{E}-39 & 5.478 \mathrm{E}-38 & 2.238 \mathrm{E}-33 & 9.371 \mathrm{E}-16\end{array}$

$\mathrm{Ra}-228+\mathrm{D} \quad 1.000 \mathrm{E}+00 \quad 1.371 \mathrm{E}-28 \quad 2.018 \mathrm{E}-27 \quad 3.762 \mathrm{E}-23 \quad 2.542 \mathrm{E}-22 \quad 1.470 \mathrm{E}-19 \quad 1.102 \mathrm{E}-13$

$\begin{array}{lllllllll}\mathrm{Th}-228+\mathrm{D} & 1.000 \mathrm{E}+00 & 8.111 \mathrm{E}-28 & 2.334 \mathrm{E}-26 & 2.641 \mathrm{E}-21 & 1.757 \mathrm{E}-20 & 5.564 \mathrm{E}-18 & 1.510 \mathrm{E}-15\end{array}$

$\operatorname{LDSR}(j) \quad 1.143 \mathrm{E}-24 \quad 1.188 \mathrm{E}-24 \quad 2.681 \mathrm{E}-21 \quad 1.783 \mathrm{E}-20 \quad 5.719 \mathrm{E}-18 \quad 1.170 \mathrm{E}-03$

$\begin{array}{llllllll}\text { TC-99 } 1.000 \mathrm{E}+00 & 5.758 \mathrm{E}-26 & 5.817 \mathrm{E}-26 & 9.575 \mathrm{E}-26 & 1.592 \mathrm{E}-25 & 9.310 \mathrm{E}-24 & 1.325 \mathrm{E}-06\end{array}$

$\mathrm{Th}-228+\mathrm{D} \quad 1.000 \mathrm{E}+00 \quad 1.382 \mathrm{E}-06 \quad 9.680 \mathrm{E}-07 \quad 2.527 \mathrm{E}-14 \quad 4.618 \mathrm{E}-22 \quad 0.000 \mathrm{E}+00 \quad 0.000 \mathrm{E}+00$

$\begin{array}{llllllll}\mathrm{Th}-230 & 1.000 \mathrm{E}+00 & 2.412 \mathrm{E}-22 & 2.453 \mathrm{E}-22 & 5.590 \mathrm{E}-22 & 1.295 \mathrm{E}-21 & 1.078 \mathrm{E}-18 & 1.104 \mathrm{E}-03\end{array}$

$\mathrm{Ra}-226+\mathrm{D} \quad 1.000 \mathrm{E}+00 \quad 3.774 \mathrm{E}-11 \quad 1.139 \mathrm{E}-10 \quad 5.320 \mathrm{E}-09 \quad 1.479 \mathrm{E}-08 \quad 1.071 \mathrm{E}-06 \quad 2.165 \mathrm{E}-02$

$\mathrm{Pb}-210+\mathrm{D} \quad 1.000 \mathrm{E}+00 \quad 1.819 \mathrm{E}-19 \quad 1.271 \mathrm{E}-18 \quad 1.299 \mathrm{E}-15 \quad 5.314 \mathrm{E}-15 \quad 7.678 \mathrm{E}-13 \quad 3.543 \mathrm{E}-02$

$\operatorname{EDSR}(j) \quad 3.774 \mathrm{E}-11 \quad 1.139 \mathrm{E}-10 \quad 5.320 \mathrm{E}-09 \quad 1.479 \mathrm{E}-08 \quad 1.071 \mathrm{E}-06 \quad 5.818 \mathrm{E}-02$ 
RESRAD, Version $6.5 \quad T^{1 / 2}$ Limit $=180$ days

Summary : RESRAD Parameters for U-Landfill Resident Gardener Forward Run

File : C: $\backslash$ RESRAD_FAMILY \RESRAD \USERFILES \QCJULY2011 \ULANDFILL-RG_FORWARD-1050YR.RAD

Dose/Source Ratios Summed Over All Pathways

Parent and Progeny Principal Radionuclide Contributions Indicated

\begin{tabular}{|c|c|c|c|c|c|c|c|c|}
\hline $\begin{array}{l}\text { Parent } \\
\text { (i) }\end{array}$ & $\begin{array}{l}\text { Product } \\
\text { (j) }\end{array}$ & $\begin{array}{l}\text { Thread } \\
\text { Fraction }\end{array}$ & $\begin{array}{r}\text { DSR } \\
0.000 \mathrm{E}+00\end{array}$ & $\begin{array}{l}(j, t) \text { At } T \\
1.000 E+00\end{array}$ & $\begin{array}{l}\text { Ime in Year } \\
5.000 \mathrm{E}+01\end{array}$ & $\begin{array}{l}\text { Es (mrem/ } \\
1.000 \mathrm{E}+02\end{array}$ & $\begin{array}{l}/ \mathrm{yr}) /(\mathrm{pCi} / \mathrm{g} \\
5.000 \mathrm{E}+02\end{array}$ & $1.050 \mathrm{E}+03$ \\
\hline 232 & $\mathrm{Th}-232$ & $1.000 \mathrm{E}+00$ & $1.166 \mathrm{E}-24$ & $1.188 \mathrm{E}-24$ & $2.949 E-24$ & $7.462 \mathrm{E}-24$ & 1. $252 \mathrm{E}-20$ & $1.221 \mathrm{E}-03$ \\
\hline 232 & $\mathrm{Ra}-228+\mathrm{D}$ & $1.000 \mathrm{E}+00$ & $1.107 \mathrm{E}-09$ & $3.174 \mathrm{E}-09$ & $2.784 \mathrm{E}-08$ & $4.079 \mathrm{E}-08$ & $8.497 \mathrm{E}-07$ & $1.458 \mathrm{E}-01$ \\
\hline-232 & $\mathrm{Th}-228+\mathrm{D}$ & $1.000 \mathrm{E}+00$ & $1.067 \mathrm{E}-08$ & $6.581 \mathrm{E}-08$ & $2.213 E-06$ & $2.992 \mathrm{E}-06$ & $3.253 E-05$ & $2.007 E-03$ \\
\hline-232 & $\sum \operatorname{DSR}(j)$ & & $1.178 \mathrm{E}-08$ & $6.899 \mathrm{E}-08$ & $2.241 \mathrm{E}-06$ & $3.033 E-06$ & $3.338 E-05$ & $1.491 \mathrm{E}-01$ \\
\hline-234 & $\mathrm{U}-234$ & $1.000 \mathrm{E}+00$ & $6.896 \mathrm{E}-24$ & $7.019 \mathrm{E}-24$ & $1.670 \mathrm{E}-23$ & $4.047 \mathrm{E}-23$ & $4.798 E-20$ & $6.337 \mathrm{E}-04$ \\
\hline-234 & $T h-230$ & $1.000 \mathrm{E}+00$ & $1.089 \mathrm{E}-27$ & $3.315 E-27$ & $2.540 \mathrm{E}-25$ & $1.171 \mathrm{E}-24$ & $4.838 E-21$ & $1.037 \mathrm{E}-05$ \\
\hline 234 & $\mathrm{Ra}-226+\mathrm{D}$ & $1.000 \mathrm{E}+00$ & $1.133 \mathrm{E}-16$ & $7.978 E-16$ & $1.213 E-12$ & $6.737 E-12$ & $2.496 E-09$ & $1.097 \mathrm{E}-04$ \\
\hline 234 & $\mathrm{~Pb}-210+\mathrm{D}$ & $1.000 \mathrm{E}+00$ & $4.102 E-25$ & $6.153 E-24$ & $2.201 \mathrm{E}-19$ & 1. $935 \mathrm{E}-18$ & $1.678 \mathrm{E}-15$ & $1.738 \mathrm{E}-04$ \\
\hline 234 & $\sum \operatorname{DSR}(j)$ & & $1.133 \mathrm{E}-16$ & 7. $978 \mathrm{E}-16$ & $1.213 \mathrm{E}-12$ & $6.737 \mathrm{E}-12$ & $2.496 \mathrm{E}-09$ & $9.276 \mathrm{E}-04$ \\
\hline$-235+D$ & $\mathrm{U}-235+\mathrm{D}$ & $1.000 \mathrm{E}+00$ & 1. $243 \mathrm{E}-14$ & $1.259 \mathrm{E}-14$ & $2.306 \mathrm{E}-14$ & $4.276 \mathrm{E}-14$ & $5.981 \mathrm{E}-12$ & $6.155 \mathrm{E}-04$ \\
\hline$-235+D$ & $\mathrm{~Pa}-231$ & $1.000 \mathrm{E}+00$ & $2.937 \mathrm{E}-18$ & $8.896 \mathrm{E}-18$ & $5.031 \mathrm{E}-16$ & $1.701 \mathrm{E}-15$ & $5.876 \mathrm{E}-13$ & $8.145 \mathrm{E}-04$ \\
\hline$-235+D$ & $A C-227+D$ & $1.000 \mathrm{E}+00$ & $9.274 \mathrm{E}-18$ & $6.481 \mathrm{E}-17$ & $6.882 \mathrm{E}-14$ & $2.943 E-13$ & $6.376 \mathrm{E}-11$ & $3.373 E-04$ \\
\hline$-235+D$ & $\sum \operatorname{DSR}(j)$ & & $1.245 \mathrm{E}-14$ & $1.266 \mathrm{E}-14$ & $9.238 \mathrm{E}-14$ & $3.388 \mathrm{E}-13$ & $7.033 E-11$ & $1.767 \mathrm{E}-03$ \\
\hline-238 & $U-238$ & $5.400 \mathrm{E}-05$ & $0.000 \mathrm{E}+00$ & $0.000 \mathrm{E}+00$ & $0.000 \mathrm{E}+00$ & $0.000 \mathrm{E}+00$ & $0.000 \mathrm{E}+00$ & $3.167 \mathrm{E}-08$ \\
\hline$-238+D$ & $\mathrm{U}-238+\mathrm{D}$ & $9.999 \mathrm{E}-01$ & $1.420 \mathrm{E}-10$ & $1.431 \mathrm{E}-10$ & $2.116 \mathrm{E}-10$ & $3.153 \mathrm{E}-10$ & $7.678 \mathrm{E}-09$ & $6.313 E-04$ \\
\hline $238+D$ & $\mathrm{U}-234$ & $9.999 \mathrm{E}-01$ & $9.803 E-30$ & $2.988 E-29$ & $2.392 E-27$ & $1.153 E-26$ & $6.812 \mathrm{E}-23$ & $1.890 \mathrm{E}-06$ \\
\hline$-238+D$ & $T h-230$ & $9.999 \mathrm{E}-01$ & $1.030 E-33$ & $7.316 E-33$ & $1.818 \mathrm{E}-29$ & $1.668 E-28$ & $3.430 E-24$ & $1.541 \mathrm{E}-08$ \\
\hline$-238+D$ & $\mathrm{Ra}-226+\mathrm{D}$ & $9.999 \mathrm{E}-01$ & $8.034 \mathrm{E}-23$ & 1. $212 \mathrm{E}-21$ & $5.801 \mathrm{E}-17$ & $6.420 \mathrm{E}-16$ & $1.201 \mathrm{E}-12$ & $1.127 \mathrm{E}-07$ \\
\hline$-238+D$ & $\mathrm{~Pb}-210+\mathrm{D}$ & $9.999 \mathrm{E}-01$ & $2.329 E-31$ & $7.229 E-30$ & $8.430 \mathrm{E}-24$ & $1.546 \mathrm{E}-22$ & $7.612 E-19$ & $1.734 \mathrm{E}-07$ \\
\hline$-238+D$ & $\sum \operatorname{DSR}(j)$ & & $1.420 \mathrm{E}-10$ & $1.431 \mathrm{E}-10$ & $2.116 \mathrm{E}-10$ & $3.153 \mathrm{E}-10$ & $7.680 \mathrm{E}-09$ & $6.335 \mathrm{E}-04$ \\
\hline
\end{tabular}

The DSR includes contributions from associated (half-life $\leq 180$ days) daughters. 
RESRAD, Version $6.5 \quad$ T1/2 Limit $=180$ days $\quad 07 / 20 / 2011 \quad 14: 38$ Page

Summary : RESRAD Parameters for U-Landfill Resident Gardener Forward Run

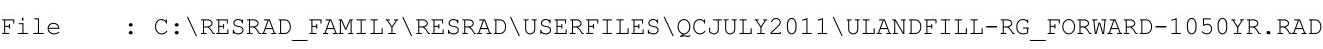

Single Radionuclide Soil Guidelines $G(i, t)$ in pCi/g

Basic Radiation Dose Limit $=1.000 \mathrm{E}+02 \mathrm{mrem} / \mathrm{yr}$

Nuclide

\begin{tabular}{|c|c|c|c|c|c|c|}
\hline (i) & $t=0.000 \mathrm{E}+00$ & $1.000 \mathrm{E}+00$ & $5.000 E+01$ & $1.000 \mathrm{E}+02$ & $5.000 \mathrm{E}+02$ & $1.050 \mathrm{E}+03$ \\
\hline-241 & $\star 3.431 \mathrm{E}+12$ & $\star 3.431 \mathrm{E}+12$ & $\star 3.431 \mathrm{E}+12$ & $\star 3.431 \mathrm{E}+12$ & $\star 3.431 \mathrm{E}+12$ & $5.044 \mathrm{E}+05$ \\
\hline-137 & 7. $925 E+10$ & $8.043 E+10$ & $1.653 E+11$ & $3.447 E+11$ & $\star 8.704 \mathrm{E}+13$ & $\star 8.704 \mathrm{E}+13$ \\
\hline-237 & $\star 7.047 \mathrm{E}+08$ & $\star 7.047 \mathrm{E}+08$ & $\star 7.047 \mathrm{E}+08$ & $\star 7.047 \mathrm{E}+08$ & $\star 7.047 \mathrm{E}+08$ & $9.756 \mathrm{E}+03$ \\
\hline-238 & $\star 1.712 \mathrm{E}+13$ & $\star 1.712 \mathrm{E}+13$ & $\star 1.712 \mathrm{E}+13$ & $\star 1.712 \mathrm{E}+13$ & $\star 1.712 \mathrm{E}+13$ & $1.637 \mathrm{E}+08$ \\
\hline$x-239$ & $* 6.214 \mathrm{E}+10$ & $* 6.214 \mathrm{E}+10$ & $* 6.214 \mathrm{E}+10$ & $\star 6.214 \mathrm{E}+10$ & $* 6.214 \mathrm{E}+10$ & $7.884 \mathrm{E}+04$ \\
\hline-240 & $\star 2.278 \mathrm{E}+11$ & $\star 2.278 \mathrm{E}+11$ & $\star 2.278 \mathrm{E}+11$ & $\star 2.278 \mathrm{E}+11$ & $\star 2.278 \mathrm{E}+11$ & $8.550 \mathrm{E}+04$ \\
\hline$=-99$ & $\star 1.697 \mathrm{E}+10$ & $\star 1.697 \mathrm{E}+10$ & $\star 1.697 \mathrm{E}+10$ & $\star 1.697 \mathrm{E}+10$ & $\star 1.697 \mathrm{E}+10$ & $7.545 \mathrm{E}+07$ \\
\hline-228 & $7.234 \mathrm{E}+07$ & $1.033 \mathrm{E}+08$ & $\star 8.195 \mathrm{E}+14$ & $\star 8.195 E+14$ & $* 8.195 \mathrm{E}+14$ & $\star 8.195 \mathrm{E}+14$ \\
\hline $1-230$ & $\star 2.018 \mathrm{E}+10$ & $\star 2.018 \mathrm{E}+10$ & 1. $880 \mathrm{E}+10$ & $6.761 \mathrm{E}+09$ & $9.336 \mathrm{E}+07$ & $1.719 \mathrm{E}+03$ \\
\hline$h-232$ & $\star 1.097 \mathrm{E}+05$ & $\star 1.097 \mathrm{E}+05$ & $\star 1.097 \mathrm{E}+05$ & $\star 1.097 \mathrm{E}+05$ & $\star 1.097 \mathrm{E}+05$ & $6.708 E+02$ \\
\hline-234 & $* 6.247 \mathrm{E}+09$ & $\star 6.247 \mathrm{E}+09$ & $* 6.247 \mathrm{E}+09$ & $\star 6.247 \mathrm{E}+09$ & $* 6.247 \mathrm{E}+09$ & $1.078 \mathrm{E}+05$ \\
\hline-235 & $\star 2.161 \mathrm{E}+06$ & $\star 2.161 \mathrm{E}+06$ & $\star 2.161 \mathrm{E}+06$ & $\star 2.161 \mathrm{E}+06$ & $\star 2.161 \mathrm{E}+06$ & $5.658 \mathrm{E}+04$ \\
\hline 250 & $\star 3.361 \mathrm{E}+05$ & $\star 3.361 \mathrm{E}+05$ & $\star 3.361 \mathrm{E}+05$ & $\star 3.361 \mathrm{E}+05$ & $\star 3.361 \mathrm{E}+05$ & $1.578 \mathrm{E}+05$ \\
\hline
\end{tabular}

*At specific activity limit

Summed Dose/Source Ratios DSR(i,t) in (mrem/yr)/(pCi/g)

and Single Radionuclide Soil Guidelines G(i,t) in pCi/g

at tmin = time of minimum single radionuclide soil guideline and at $\operatorname{tmax}=$ time of maximum total dose $=1.050 \mathrm{E}+03$ years

\begin{tabular}{|c|c|c|c|c|c|c|}
\hline $\begin{array}{l}\text { uclide } \\
\text { (i) }\end{array}$ & $\begin{array}{l}\text { Initial } \\
(\mathrm{pCi} / \mathrm{g})\end{array}$ & $\begin{array}{c}\text { tmin } \\
\text { (years) }\end{array}$ & $\operatorname{DSR}(i, \operatorname{tmin})$ & $\begin{array}{c}\mathrm{G}(\mathrm{i}, \mathrm{tmin}) \\
(\mathrm{pCi} / \mathrm{g})\end{array}$ & $\operatorname{DSR}(i, t \max )$ & $\begin{array}{c}G(i, \text { tmax }) \\
(p C i / g)\end{array}$ \\
\hline $1-241$ & $3.500 \mathrm{E}+01$ & $1.050 \mathrm{E}+03$ & $1.983 \mathrm{E}-04$ & $5.044 \mathrm{E}+05$ & $1.983 \mathrm{E}-04$ & $5.044 \mathrm{E}+05$ \\
\hline-137 & $1.900 \mathrm{E}+01$ & $0.000 \mathrm{E}+00$ & $1.262 E-09$ & 7. $925 \mathrm{E}+10$ & $7.713 E-14$ & $\star 8.704 \mathrm{E}+13$ \\
\hline-237 & $5.500 \mathrm{E}+00$ & $1.050 \mathrm{E}+03$ & $1.025 \mathrm{E}-02$ & $9.756 \mathrm{E}+03$ & $1.025 E-02$ & $9.756 \mathrm{E}+03$ \\
\hline-238 & $3.900 \mathrm{E}+01$ & $1.050 \mathrm{E}+03$ & $6.110 \mathrm{E}-07$ & $1.637 \mathrm{E}+08$ & $6.110 E-07$ & $1.637 \mathrm{E}+08$ \\
\hline-239 & $3.600 E+01$ & $1.050 \mathrm{E}+03$ & $1.268 \mathrm{E}-03$ & $7.884 \mathrm{E}+04$ & $1.268 \mathrm{E}-03$ & $7.884 \mathrm{E}+04$ \\
\hline-240 & $3.600 \mathrm{E}+01$ & $1.050 \mathrm{E}+03$ & $1.170 \mathrm{E}-03$ & $8.550 \mathrm{E}+04$ & $1.170 \mathrm{E}-03$ & $8.550 \mathrm{E}+04$ \\
\hline-99 & $5.200 \mathrm{E}+01$ & $1.050 \mathrm{E}+03$ & $1.325 \mathrm{E}-06$ & $7.545 \mathrm{E}+07$ & $1.325 \mathrm{E}-06$ & $7.545 \mathrm{E}+07$ \\
\hline-228 & $4.000 \mathrm{E}+00$ & $0.000 \mathrm{E}+00$ & $1.382 \mathrm{E}-06$ & $7.234 \mathrm{E}+07$ & $0.000 \mathrm{E}+00$ & $\star 8.195 \mathrm{E}+14$ \\
\hline-230 & $1.000 \mathrm{E}+02$ & $1.050 \mathrm{E}+03$ & $5.818 \mathrm{E}-02$ & $1.719 \mathrm{E}+03$ & $5.818 \mathrm{E}-02$ & $1.719 \mathrm{E}+03$ \\
\hline-232 & $4.000 E+00$ & $1.050 \mathrm{E}+03$ & $1.491 \mathrm{E}-01$ & $6.708 E+02$ & $1.491 \mathrm{E}-01$ & $6.708 \mathrm{E}+02$ \\
\hline 234 & $1.600 \mathrm{E}+02$ & $1.050 \mathrm{E}+03$ & $9.276 \mathrm{E}-04$ & $1.078 \mathrm{E}+05$ & $9.276 \mathrm{E}-04$ & $1.078 \mathrm{E}+05$ \\
\hline 35 & $6.500 \mathrm{E}+00$ & $1.050 \mathrm{E}+03$ & $1.767 \mathrm{E}-03$ & $5.658 \mathrm{E}+04$ & $1.767 \mathrm{E}-03$ & $5.658 \mathrm{E}+04$ \\
\hline 238 & $1.600 \mathrm{E}+02$ & $1.050 E+03$ & $6.335 E-04$ & $1.578 \mathrm{E}+05$ & $6.335 E-04$ & $1.578 \mathrm{E}+05$ \\
\hline
\end{tabular}

*At specific activity limit 
RESRAD, Version 6.5

Summary : RESRAD Parameters for U-Landfill Resident Gardener Forward Run

File : C: $\backslash$ RESRAD_FAMILY \RESRAD \USERFILES \QCJULY2011 \ULANDFILL-RG_FORWARD-1050YR.RAD

Individual Nuclide Dose Summed Over All Pathways

Parent Nuclide and Branch Fraction Indicated

Nuclide Parent THF(i) DOSE $(j, t), \mathrm{mrem} / \mathrm{yr}$

\begin{tabular}{|c|c|c|}
\hline (j) & (i) & \\
\hline$n-241$ & $A m-241$ & $1.000 \mathrm{E}+00$ \\
\hline-237 & $A m-241$ & $1.000 \mathrm{E}+00$ \\
\hline$p-237$ & $\mathrm{~Np}-237$ & $1.000 \mathrm{E}+00$ \\
\hline $\mathrm{Np}-237$ & $\sum \operatorname{DOSE}(j$ & \\
\hline
\end{tabular}

$\mathrm{U}-233 \quad \mathrm{Am}-241 \quad 1.000 \mathrm{E}+00$

$\mathrm{U}-233 \quad \mathrm{~Np}-237 \quad 1.000 \mathrm{E}+00$

U-233 $\sum \operatorname{DOSE}(j)$

Th-229 Am-241 1.000E+00

Th-229 Np-237 1.000E+00

Th-229 $\sum \operatorname{DOSE}(j)$

Cs-137 Cs-137 1.000E+00

$\mathrm{Pu}-238 \mathrm{Pu}-238 \quad 1.840 \mathrm{E}-09$

$\mathrm{Pu}-238 \mathrm{Pu}-238 \quad 1.000 \mathrm{E}+00$

$\mathrm{Pu}-238 \quad \sum \operatorname{DOSE}(j)$

$\mathrm{U}-234$

$\mathrm{U}-234$

$\mathrm{U}-234$

$\mathrm{U}-234$

Th-230

Th-230

Th -230

Th-230

$\mathrm{Th}-230$

$\mathrm{Ra}-226$

$\mathrm{Ra}-226$

$\mathrm{Ra}-226$

$\mathrm{Ra}-226$

Ra-226

$\mathrm{Pb}-210$

$\mathrm{Pb}-210$

$\mathrm{Pb}-210$

$\mathrm{Pb}-210$

$\mathrm{Pb}-210$

$\mathrm{Pu}-239$

$\mathrm{Pu}-238 \quad 1.000 \mathrm{E}+00$

$\mathrm{U}-234 \quad 1.000 \mathrm{E}+00$

$\mathrm{U}-238 \quad 9.999 \mathrm{E}-01$

$\operatorname{DDOSE}(j)$

$\begin{array}{ll}\mathrm{Pu}-238 & 1.000 \mathrm{E}+00 \\ \mathrm{Th}-230 & 1.000 \mathrm{E}+00 \\ \mathrm{U}-234 & 1.000 \mathrm{E}+00 \\ \mathrm{U}-238 & 9.999 \mathrm{E}-01 \\ \sum \operatorname{DOSE}(j)\end{array}$

$\mathrm{Pu}-238 \quad 1.000 \mathrm{E}+00$

Th-230 1.000E+00

$\mathrm{U}-234 \quad 1.000 \mathrm{E}+00$

$\mathrm{U}-238 \quad 9.999 \mathrm{E}-01$

$\sum \operatorname{DOSE}(j)$

Pu-238 1.000E+00

$\mathrm{Th}-230 \quad 1.000 \mathrm{E}+00$

$\mathrm{U}-234 \quad 1.000 \mathrm{E}+00$

U-238 $9.999 \mathrm{E}-01$

$\operatorname{DOSE}(j)$

$\mathrm{Pu}-239 \quad 1.000 \mathrm{E}+00$

$\mathrm{Pu}-239 \quad 1.000 \mathrm{E}+00$

U-235 1.000E+00

¿DOSE (j) $\mathrm{t}=0.000 \mathrm{E}+00 \quad 1.000 \mathrm{E}+00 \quad 5.000 \mathrm{E}+01 \quad 1.000 \mathrm{E}+02 \quad 5.000 \mathrm{E}+02 \quad 1.050 \mathrm{E}+03$

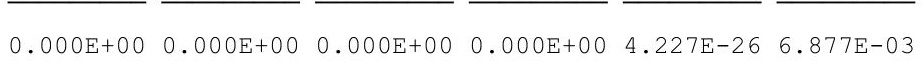

$\begin{array}{llllll}5.412 \mathrm{E}-18 & 1.638 \mathrm{E}-17 & 8.967 \mathrm{E}-16 & 2.934 \mathrm{E}-15 & 7.921 \mathrm{E}-13 & 6.206 \mathrm{E}-05\end{array}$

$\begin{array}{llllll}5.245 \mathrm{E}-12 & 5.301 \mathrm{E}-12 & 8.939 \mathrm{E}-12 & 1.524 \mathrm{E}-11 & 1.085 \mathrm{E}-09 & 5.635 \mathrm{E}-02\end{array}$

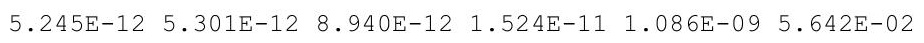

$\begin{array}{llllll}1.227 \mathrm{E}-28 & 8.678 \mathrm{E}-28 & 1.702 \mathrm{E}-24 & 1.226 \mathrm{E}-23 & 3.685 \mathrm{E}-20 & 1.069 \mathrm{E}-08\end{array}$

$\begin{array}{llllll}1.785 \mathrm{E}-22 & 5.414 \mathrm{E}-22 & 3.355 \mathrm{E}-20 & 1.245 \mathrm{E}-19 & 9.076 \mathrm{E}-17 & 1.579 \mathrm{E}-05\end{array}$

$\begin{array}{llllll}1.785 \mathrm{E}-22 & 5.414 \mathrm{E}-22 & 3.355 \mathrm{E}-20 & 1.245 \mathrm{E}-19 & 9.079 \mathrm{E}-17 & 1.580 \mathrm{E}-05\end{array}$

$\begin{array}{llllll}8.395 \mathrm{E}-25 & 1.266 \mathrm{E}-23 & 5.984 \mathrm{E}-19 & 6.539 \mathrm{E}-18 & 1.118 \mathrm{E}-14 & 1.891 \mathrm{E}-09\end{array}$

$\begin{array}{lllllll}1.629 \mathrm{E}-18 & 1.147 \mathrm{E}-17 & 1.758 \mathrm{E}-14 & 9.834 \mathrm{E}-14 & 3.894 \mathrm{E}-11 & 3.741 \mathrm{E}-06\end{array}$

$\begin{array}{llllll}1.629 \mathrm{E}-18 & 1.147 \mathrm{E}-17 & 1.758 \mathrm{E}-14 & 9.835 \mathrm{E}-14 & 3.895 \mathrm{E}-11 & 3.743 \mathrm{E}-06\end{array}$

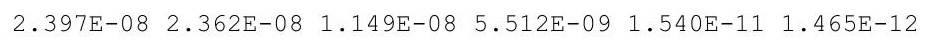

$\begin{array}{llllll}0.000 \mathrm{E}+00 & 0.000 \mathrm{E}+00 & 0.000 \mathrm{E}+00 & 0.000 \mathrm{E}+00 & 0.000 \mathrm{E}+00 & 2.147 \mathrm{E}-14\end{array}$

$\begin{array}{lllllll}4.582 \mathrm{E}-23 & 4.627 \mathrm{E}-23 & 7.461 \mathrm{E}-23 & 1.215 \mathrm{E}-22 & 6.001 \mathrm{E}-21 & 1.167 \mathrm{E}-05\end{array}$

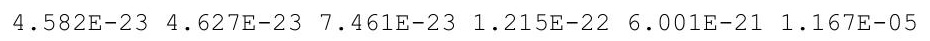

$\begin{array}{llllll}3.813 \mathrm{E}-28 & 1.158 \mathrm{E}-27 & 7.693 \mathrm{E}-26 & 3.104 \mathrm{E}-25 & 6.593 \mathrm{E}-22 & 8.877 \mathrm{E}-06\end{array}$

$\begin{array}{llllll}1.103 \mathrm{E}-21 & 1.123 \mathrm{E}-21 & 2.673 \mathrm{E}-21 & 6.475 \mathrm{E}-21 & 7.677 \mathrm{E}-18 & 1.014 \mathrm{E}-01\end{array}$

$\begin{array}{llllll}1.569 \mathrm{E}-27 & 4.780 \mathrm{E}-27 & 3.827 \mathrm{E}-25 & 1.845 \mathrm{E}-24 & 1.090 \mathrm{E}-20 & 3.024 \mathrm{E}-04\end{array}$

$\begin{array}{llllll}1.103 \mathrm{E}-21 & 1.123 \mathrm{E}-21 & 2.673 \mathrm{E}-21 & 6.477 \mathrm{E}-21 & 7.688 \mathrm{E}-18 & 1.017 \mathrm{E}-01\end{array}$

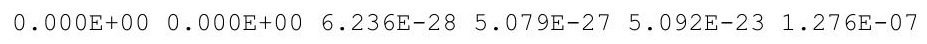

$2.412 \mathrm{E}-20 \quad 2.453 \mathrm{E}-20 \quad 5.590 \mathrm{E}-20 \quad 1.295 \mathrm{E}-19 \quad 1.078 \mathrm{E}-16 \quad 1.104 \mathrm{E}-01$

$\begin{array}{llllll}1.742 \mathrm{E}-25 & 5.304 \mathrm{E}-25 & 4.065 \mathrm{E}-23 & 1.874 \mathrm{E}-22 & 7.741 \mathrm{E}-19 & 1.659 \mathrm{E}-03\end{array}$

$\begin{array}{llllll}0.000 \mathrm{E}+00 & 0.000 \mathrm{E}+00 & 2.909 \mathrm{E}-27 & 2.669 \mathrm{E}-26 & 5.488 \mathrm{E}-22 & 2.466 \mathrm{E}-06\end{array}$

$2.412 \mathrm{E}-20 \quad 2.453 \mathrm{E}-20 \quad 5.594 \mathrm{E}-20 \quad 1.297 \mathrm{E}-19 \quad 1.085 \mathrm{E}-16 \quad 1.121 \mathrm{E}-01$

$\begin{array}{llllll}3.128 \mathrm{E}-21 & 4.712 \mathrm{E}-20 & 2.054 \mathrm{E}-15 & 2.076 \mathrm{E}-14 & 2.187 \mathrm{E}-11 & 1.226 \mathrm{E}-06\end{array}$ $\begin{array}{llllll}3.774 \mathrm{E}-09 & 1.139 \mathrm{E}-08 & 5.320 \mathrm{E}-07 & 1.479 \mathrm{E}-06 & 1.071 \mathrm{E}-04 & 2.165 \mathrm{E}+00\end{array}$ $\begin{array}{lllllll}1.813 \mathrm{E}-14 & 1.277 \mathrm{E}-13 & 1.941 \mathrm{E}-10 & 1.078 \mathrm{E}-09 & 3.993 \mathrm{E}-07 & 1.755 \mathrm{E}-02\end{array}$ $\begin{array}{llllll}1.285 \mathrm{E}-20 & 1.939 \mathrm{E}-19 & 9.281 \mathrm{E}-15 & 1.027 \mathrm{E}-13 & 1.921 \mathrm{E}-10 & 1.804 \mathrm{E}-05\end{array}$

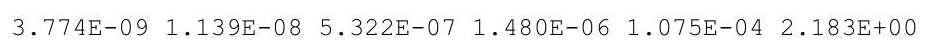

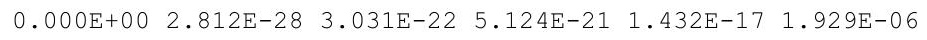
$\begin{array}{llllll}1.819 \mathrm{E}-17 & 1.271 \mathrm{E}-16 & 1.299 \mathrm{E}-13 & 5.314 \mathrm{E}-13 & 7.678 \mathrm{E}-11 & 3.543 \mathrm{E}+00\end{array}$ $\begin{array}{llllll}6.563 \mathrm{E}-23 & 9.844 \mathrm{E}-22 & 3.522 \mathrm{E}-17 & 3.095 \mathrm{E}-16 & 2.685 \mathrm{E}-13 & 2.781 \mathrm{E}-02\end{array}$ $\begin{array}{llllll}0.000 \mathrm{E}+00 & 1.157 \mathrm{E}-27 & 1.349 \mathrm{E}-21 & 2.474 \mathrm{E}-20 & 1.218 \mathrm{E}-16 & 2.774 \mathrm{E}-05\end{array}$ $\begin{array}{llllll}1.819 \mathrm{E}-17 & 1.271 \mathrm{E}-16 & 1.299 \mathrm{E}-13 & 5.317 \mathrm{E}-13 & 7.705 \mathrm{E}-11 & 3.571 \mathrm{E}+00\end{array}$

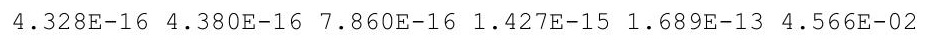

$2.209 \mathrm{E}-22 \quad 6.699 \mathrm{E}-22 \quad 4.126 \mathrm{E}-20 \quad 1.522 \mathrm{E}-19 \quad 1.055 \mathrm{E}-16 \quad 2.265 \mathrm{E}-08$ $\begin{array}{lllllll}8.081 \mathrm{E}-14 & 8.182 \mathrm{E}-14 & 1.499 \mathrm{E}-13 & 2.779 \mathrm{E}-13 & 3.888 \mathrm{E}-11 & 4.001 \mathrm{E}-03\end{array}$ $\begin{array}{llllll}8.081 \mathrm{E}-14 & 8.182 \mathrm{E}-14 & 1.499 \mathrm{E}-13 & 2.779 \mathrm{E}-13 & 3.888 \mathrm{E}-11 & 4.001 \mathrm{E}-03\end{array}$ 
RESRAD, Version $6.5 \quad T^{1 / 2}$ Limit $=180$ days

Summary : RESRAD Parameters for U-Landfill Resident Gardener Forward Run

File : C: $\backslash$ RESRAD_FAMILY \RESRAD \USERFILES \QCJULY2011 \ULANDFILL-RG_FORWARD-1050YR.RAD

Individual Nuclide Dose Summed Over All Pathways

Parent Nuclide and Branch Fraction Indicated

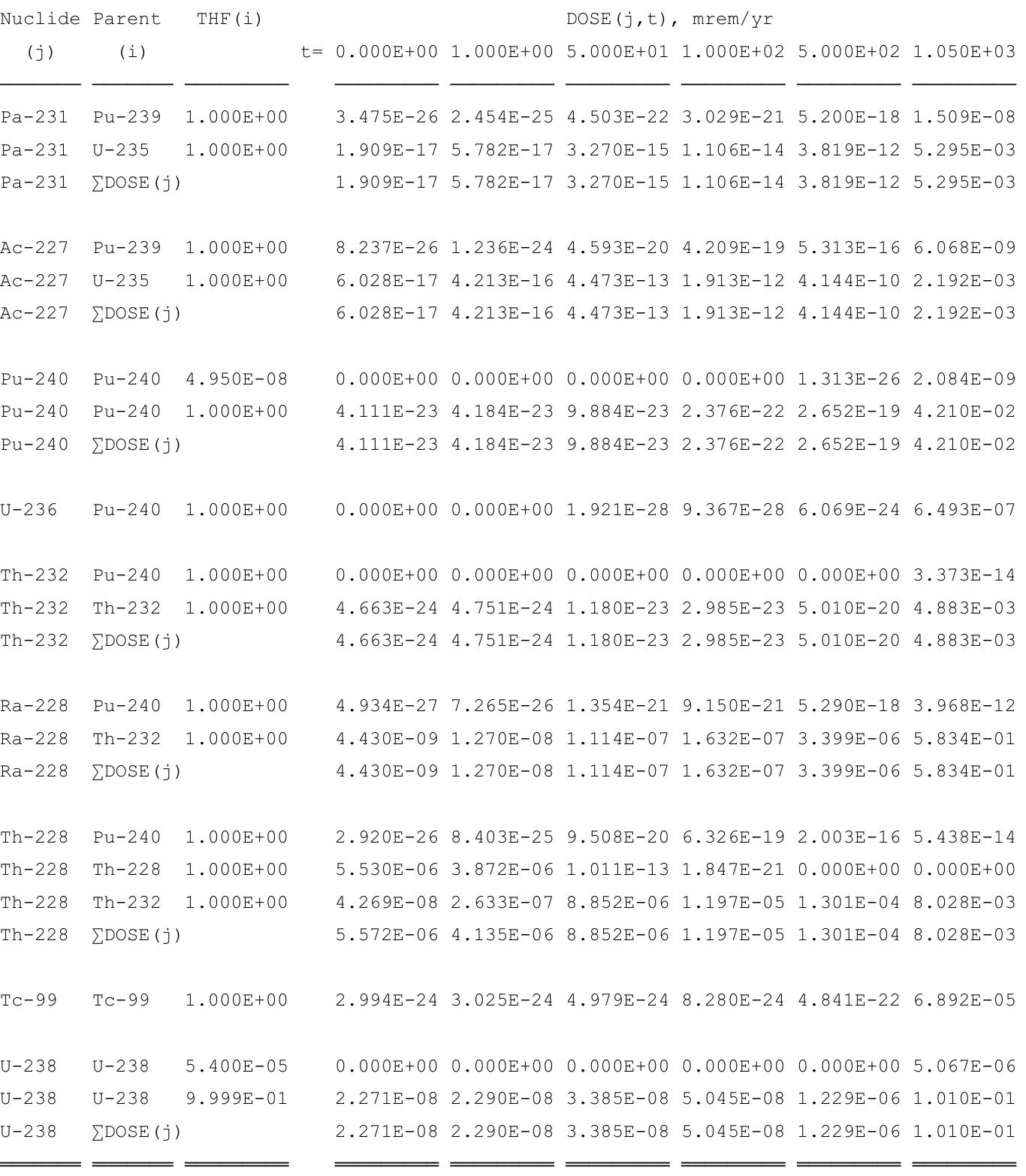

THF (i) is the thread fraction of the parent nuclide. 
RESRAD, Version $6.5 \quad T^{1 / 2}$ Limit $=180$ days

Summary : RESRAD Parameters for U-Landfill Resident Gardener Forward Run

File : C: $\backslash$ RESRAD_FAMILY \RESRAD \USERFILES \QCJULY2011 \ULANDFILL-RG_FORWARD-1050YR.RAD

Individual Nuclide Soil Concentration

Parent Nuclide and Branch Fraction Indicated

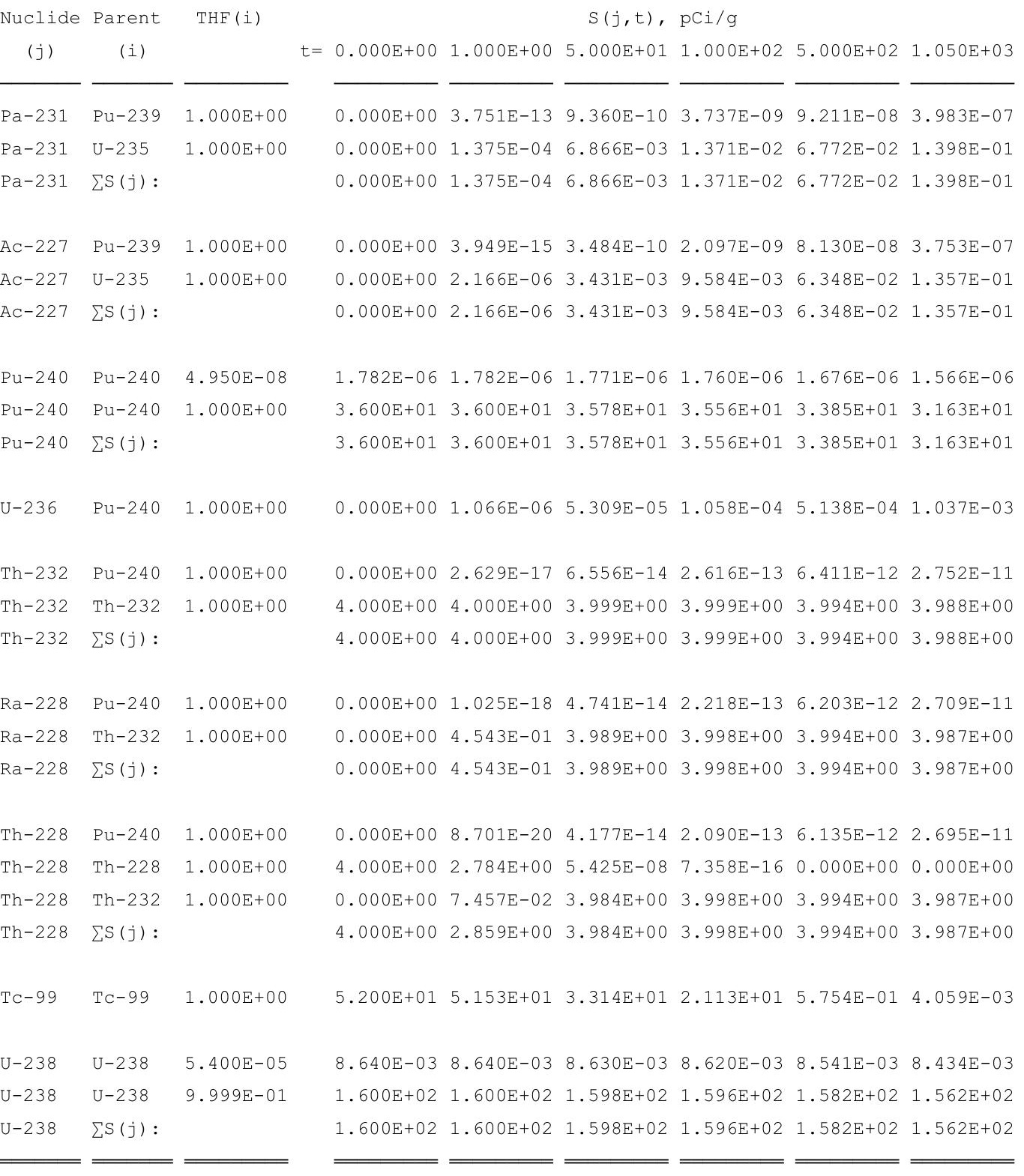

THF (i) is the thread fraction of the parent nuclide.

RESCALC.EXE execution time $=5.38$ seconds 
RESRAD, Version $6.5 \quad \mathrm{~T}^{1 / 2}$ Limit $=180$ days

07/20/2011 14:43 Page

Summary : RESRAD Parameters for U-Landfill Resident Gardener Forward Run at ALs

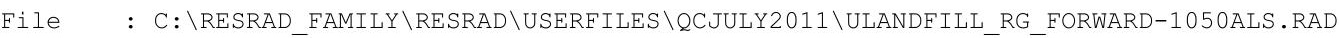

Table of Contents

Part I: Mixture Sums and Single Radionuclide Guidelines

Dose Conversion Factor (and Related) Parameter Summary ... 2

Site-Specific Parameter Summary ............... 8

Summary of Pathway Selections .................... 18

Contaminated Zone and Total Dose Summary ............. 19

Total Dose Components

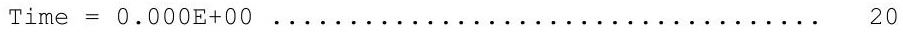

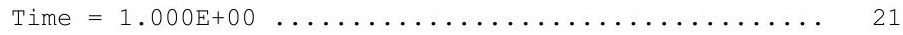

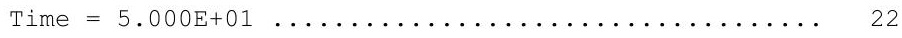

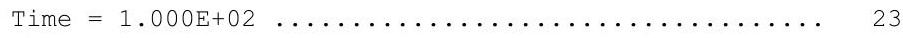

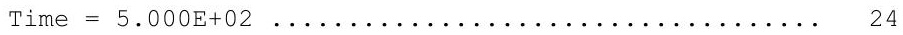

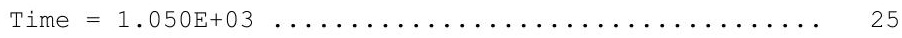

Dose/Source Ratios Summed Over All Pathways .......... 26

Single Radionuclide Soil Guidelines ............... 28

Dose Per Nuclide Summed Over All Pathways ............ 29

Soil Concentration Per Nuclide ................ 31 
Summary : RESRAD Parameters for U-Landfill Resident Gardener Forward Run at ALs

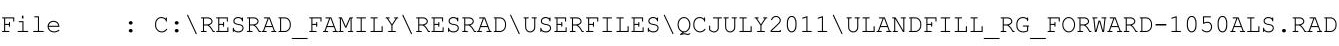

Dose Conversion Factor (and Related) Parameter Summary

Dose Library: ICRP 60 \& ICRP 72 (Adult)

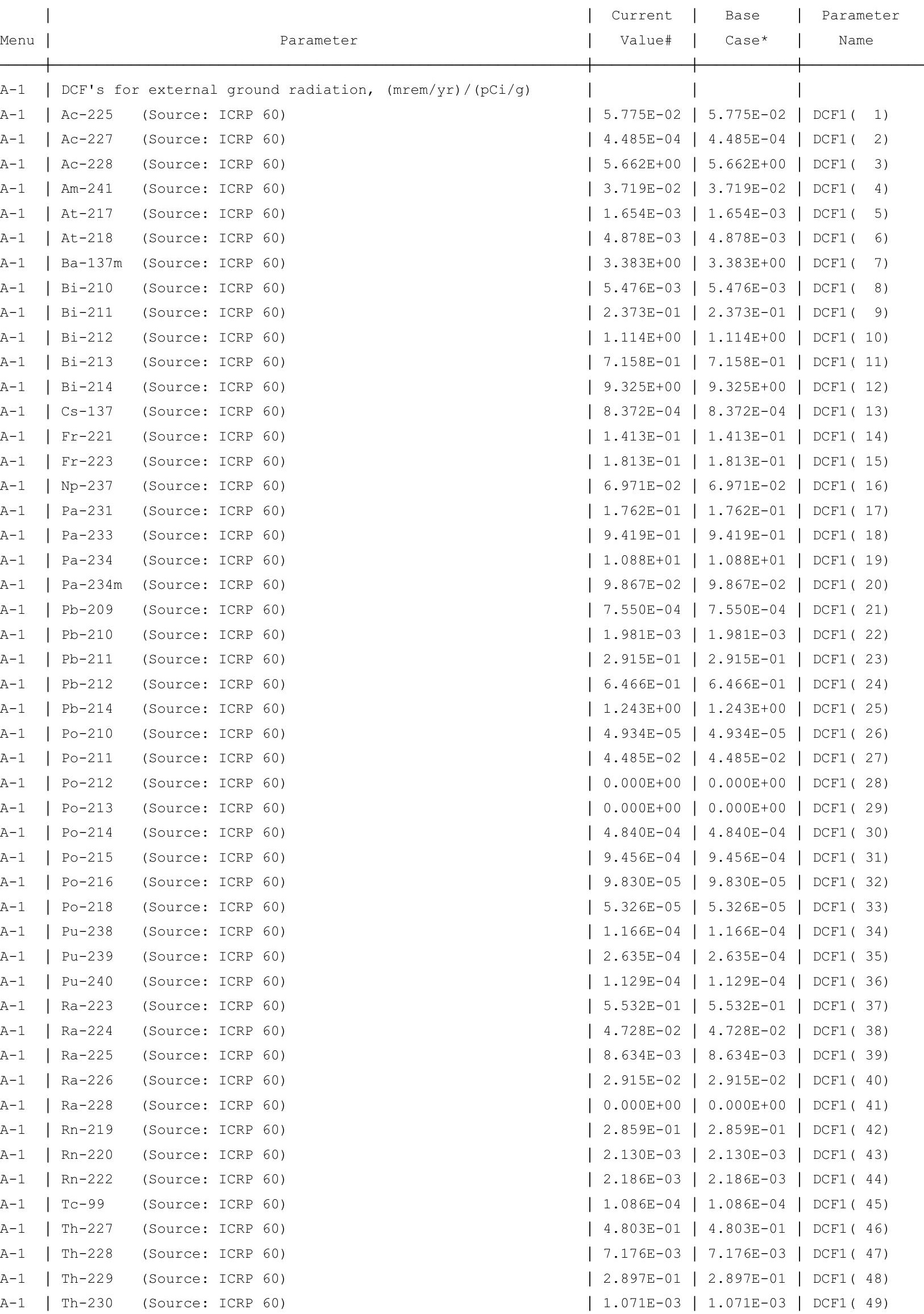


Summary : RESRAD Parameters for U-Landfill Resident Gardener Forward Run at ALs

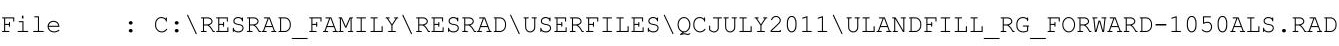

Dose Conversion Factor (and Related) Parameter Summary (continued)

Dose Library: ICRP 60 \& ICRP 72 (Adult)

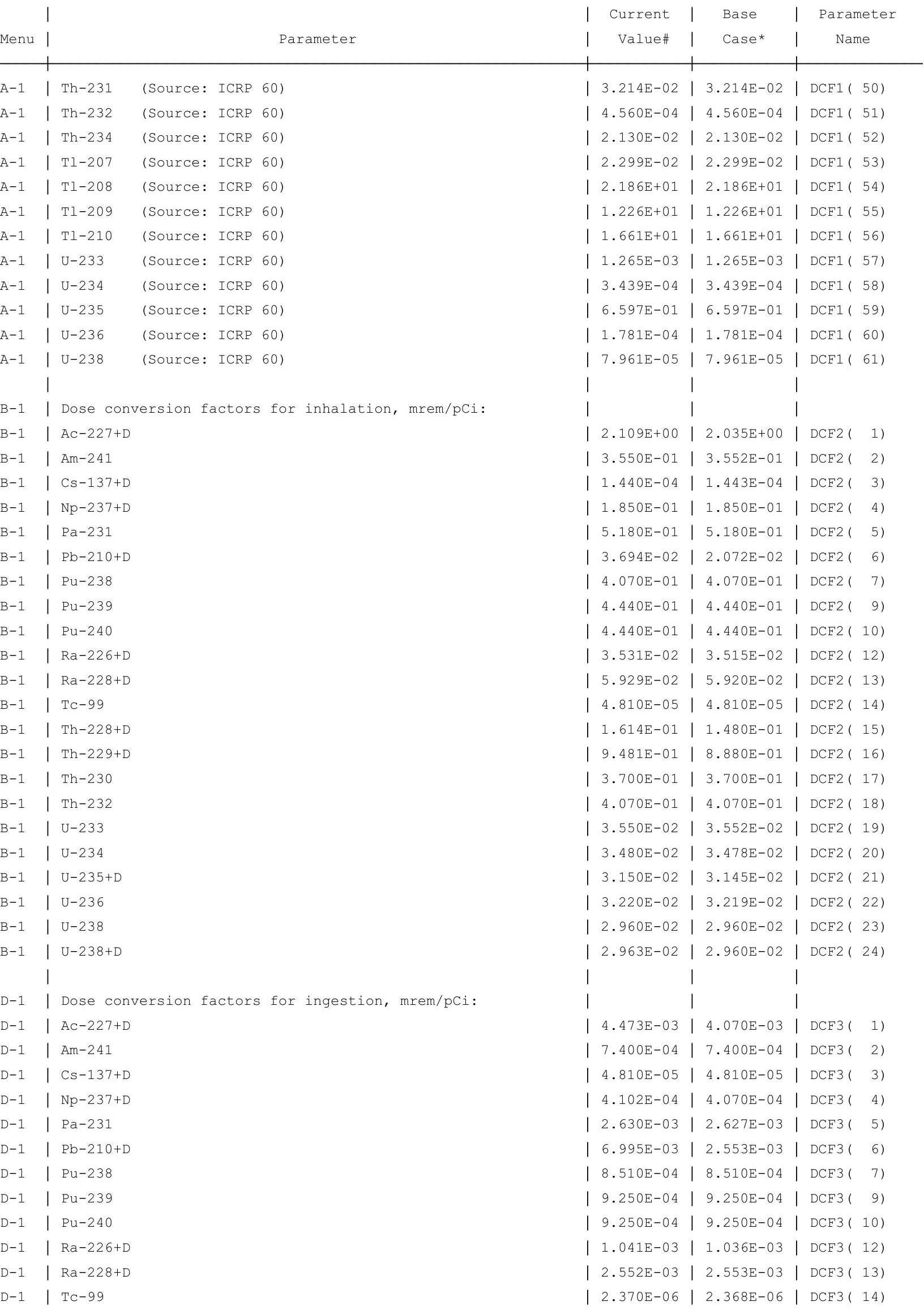


RESRAD, Version $6.5 \quad$ T1/2 Limit $=180$ days $\quad$ 07/20/2011 $14: 43$ Page 4

Summary : RESRAD Parameters for U-Landfill Resident Gardener Forward Run at ALs

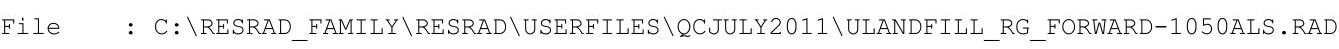

Dose Conversion Factor (and Related) Parameter Summary (continued)

Dose Library: ICRP 60 \& ICRP 72 (Adult)

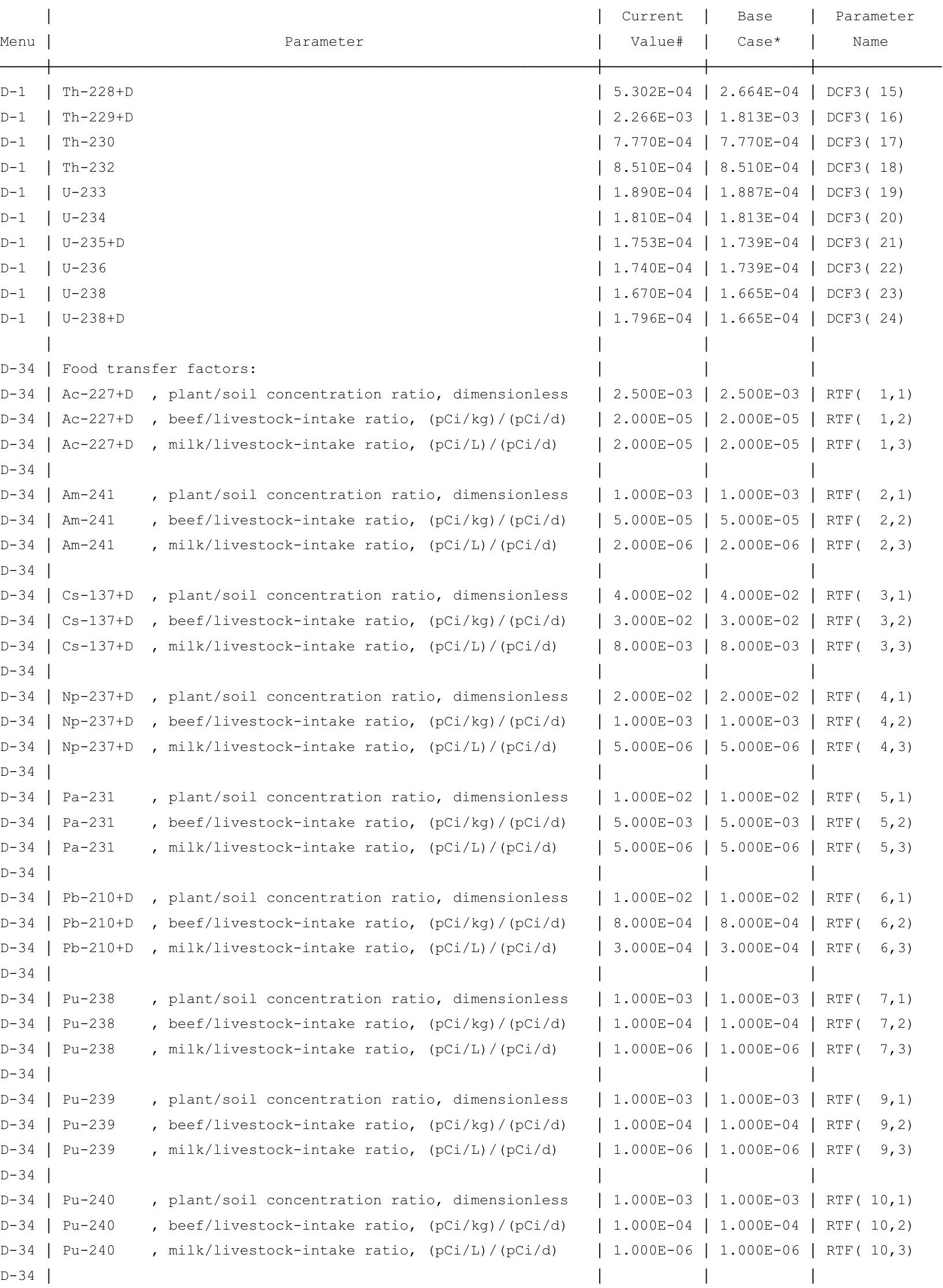

, plant/soil concentration ratio, dimensionless
, beef/livestock-intake ratio, (pCi/kg)/(pCi/d)
, milk/livestock-intake ratio, (pCi/L)/(pCi/d)

, plant/soil concentration ratio, dimensionless , beef/livestock-intake ratio, (pCi/kg)/(pCi/d) , plant/soil concentration ratio, dimensionless beef/livestock-intake ratio, $(\mathrm{pCi} / \mathrm{kg}) /(\mathrm{pCi} / \mathrm{d})$ , plant/soil concentration ratio, dimensionless , beef/livestock-intake ratio, (pCi/kg)/(pCi/d) , plant/soil concentration ratio, dimensionless , beef/livestock-intake ratio, (pCi/kg)/(pCi/d)

plant/soil concentration ratio, dimensionles , beef/livestock-intake ratio, $(\mathrm{pCi} / \mathrm{kg}) /(\mathrm{pCi} / \mathrm{d})$ , plant/soil concentration ratio, dimensionless , beef/livestock-intake ratio, (pCi/kg)/(pCi/d) , milk/livestock-intake ratio, (pCi/L)/(pCi/d)

, plant/soil concentration ratio, dimensionless , beef/livestock-intake ratio, $(\mathrm{pCi} / \mathrm{kg}) /(\mathrm{pCi} / \mathrm{d})$ milk/livestock-intake ratio, $(\mathrm{pCi} / \mathrm{L}) /(\mathrm{pCi} / \mathrm{d})$

, plant/soil concentration ratio, dimensionless \begin{tabular}{|l|l|l|}
\hline $5.302 \mathrm{E}-04$ & $2.664 \mathrm{E}-04$ & $\mathrm{DCF} 3(15)$
\end{tabular}

\begin{tabular}{|l|l|l}
$\mid 8.510 \mathrm{E}-04$ & $8.510 \mathrm{E}-04$ & $\mathrm{DCF} 3(18)$
\end{tabular}

\begin{tabular}{|l|l|l|}
$1.890 \mathrm{E}-04$ & $1.887 \mathrm{E}-04$ & $\mathrm{DCF} 3(19$
\end{tabular}

\begin{tabular}{|l|l|l}
$\mid 1.740 \mathrm{E}-04$ & $1.739 \mathrm{E}-04$ & $\operatorname{DCF} 3(22)$
\end{tabular}

\begin{tabular}{|l|l|l|}
$\mid 1.670 \mathrm{E}-04$ & $1.665 \mathrm{E}-04$ & $\mathrm{DCF} 3(23$
\end{tabular}

\begin{tabular}{l|l|l|l|}
$1.796 \mathrm{E}-04$ & $1.665 \mathrm{E}-04$ & $\operatorname{DCF} 3(24)$
\end{tabular}

\begin{tabular}{|l|l|l|}
$2.500 \mathrm{E}-03$ & $2.500 \mathrm{E}-03$ & $\operatorname{RTF}(1,1)$
\end{tabular}

\begin{tabular}{l|l|l}
$2.000 \mathrm{E}-05$ & $2.000 \mathrm{E}-05$ & $\operatorname{RTF}(1,2)$
\end{tabular}

$1 \quad 1 \quad$ |

\begin{tabular}{l|l|l|}
$1.000 \mathrm{E}-03$ & $1.000 \mathrm{E}-03$ & $\operatorname{RTE}(2,1)$
\end{tabular}

\begin{tabular}{l|l|l|}
$5.000 \mathrm{E}-05$ & $5.000 \mathrm{E}-05$ & $\operatorname{RTF}(2,2)$
\end{tabular}

\begin{tabular}{l|l|l|}
$2.000 \mathrm{E}-06$ & $2.000 \mathrm{E}-06$ & $\operatorname{RTF}(2,3)$
\end{tabular}

\begin{tabular}{|l|l|l|}
$4.000 \mathrm{E}-02$ & $4.000 \mathrm{E}-02$ & $\operatorname{RTF}(3,1)$
\end{tabular}

\begin{tabular}{l|l|l}
$3.000 \mathrm{E}-02$ & $3.000 \mathrm{E}-02$ & $\operatorname{RTF}(3,2)$
\end{tabular}

\begin{tabular}{l|l|l|}
$8.000 \mathrm{E}-03$ & $8.000 \mathrm{E}-03$ & $\operatorname{RTF}(3,3)$
\end{tabular}

\begin{tabular}{l|l|l|}
$2.000 \mathrm{E}-02$ & $2.000 \mathrm{E}-02$ & $\operatorname{RTF}(4,1)$
\end{tabular}

1.000E-03 | 1.000E-03 | RTF(4,2)

\begin{tabular}{l|l|l|}
$5.000 \mathrm{E}-06$ & $5.000 \mathrm{E}-06$ & $\operatorname{RTF}(4,3)$
\end{tabular}

\begin{tabular}{|l|l|l|}
$1.000 \mathrm{E}-02$ & $1.000 \mathrm{E}-02$ & $\operatorname{RTF}(5,1)$
\end{tabular}

\begin{tabular}{|l|l|l|}
$5.000 \mathrm{E}-03$ & $5.000 \mathrm{E}-03$ & $\operatorname{RTF}(5,2)$
\end{tabular}

\begin{tabular}{l|l|l|}
$5.000 \mathrm{E}-06$ & $5.000 \mathrm{E}-06$ & $\operatorname{RTF}(5,3)$
\end{tabular}

\begin{tabular}{|l|l|l|}
$1.000 \mathrm{E}-02$ & $1.000 \mathrm{E}-02$ & $\operatorname{RTF}(6,1)$
\end{tabular}

\begin{tabular}{|l|l|l|}
$8.000 \mathrm{E}-04$ & $8.000 \mathrm{E}-04$ & $\operatorname{RTF}(6,2)$
\end{tabular}

\begin{tabular}{|l|l|l|}
$3.000 \mathrm{E}-04$ & $3.000 \mathrm{E}-04$ & $\operatorname{RTF}(6,3)$
\end{tabular}

1.000E-03 | 1.000E-03 | $\operatorname{RTF}(7,1)$

\begin{tabular}{l|l|l|}
$1.000 \mathrm{E}-04$ & $1.000 \mathrm{E}-04$ & $\operatorname{RTF}(7,2)$
\end{tabular}

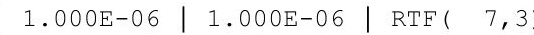

1.000E-03 | 1.000E-03 | $\operatorname{RTF}(9,1)$

\begin{tabular}{|l|l|l|}
$1.000 \mathrm{E}-04$ & $1.000 \mathrm{E}-04$ & $\operatorname{RTF}(9,2)$
\end{tabular}

\begin{tabular}{|l|l|l|}
$1.000 \mathrm{E}-06$ & $1.000 \mathrm{E}-06$ & $\operatorname{RTF}(9,3)$
\end{tabular}

$1.000 \mathrm{E}-03|1.000 \mathrm{E}-03| \operatorname{RTF}(10,1)$

\begin{tabular}{|l|l|l|}
$1.000 \mathrm{E}-04$ & $1.000 \mathrm{E}-04$ & $\operatorname{RTF}(10,2)$
\end{tabular}

| 1.000E-06 | 1.000E-06 | $\operatorname{RTE}(10,3)$ 
RESRAD, Version $6.5 \quad$ T1/2 Limit $=180$ days $\quad$ 07/20/2011 $14: 43$ Page

Summary : RESRAD Parameters for U-Landfill Resident Gardener Forward Run at ALs

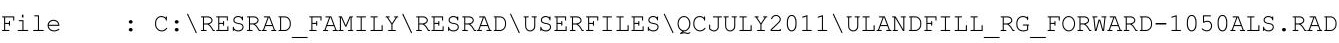

Dose Conversion Factor (and Related) Parameter Summary (continued)

Dose Library: ICRP 60 \& ICRP 72 (Adult)

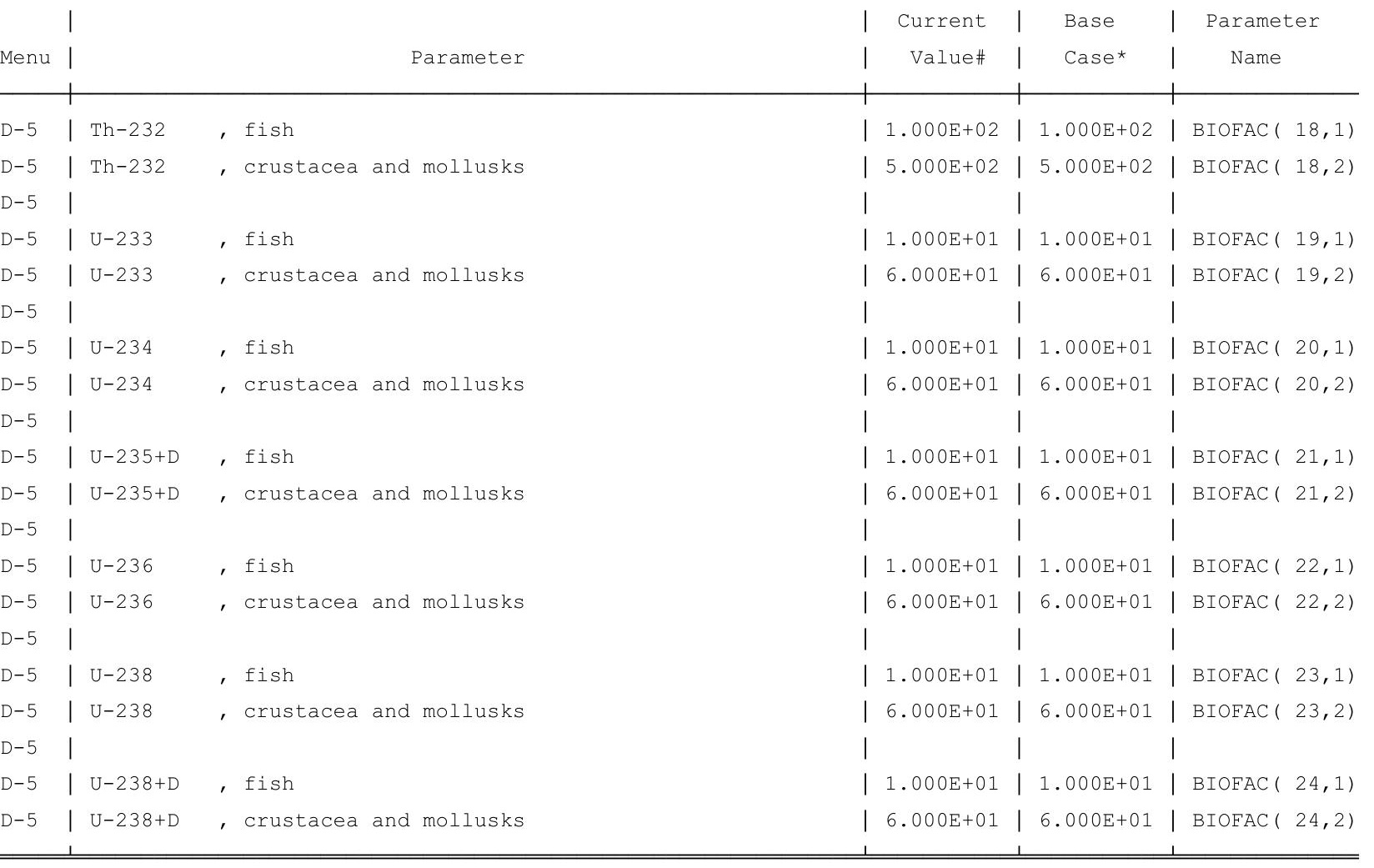

\#For DCF1(xxx) only, factors are for infinite depth \& area. See ETFG table in Ground Pathway of Detailed Report. *Base Case means Default.Lib w/o Associate Nuclide contributions. 
RESRAD, Version $6.5 \quad$ T1/2 Limit $=180$ days $\quad$ 07/20/2011 $14: 43$ Page 10

Summary : RESRAD Parameters for U-Landfill Resident Gardener Forward Run at ALs

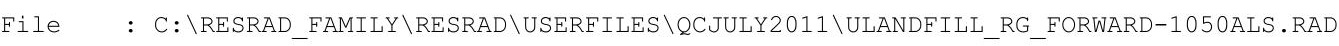

Site-Specific Parameter Summary (continued)

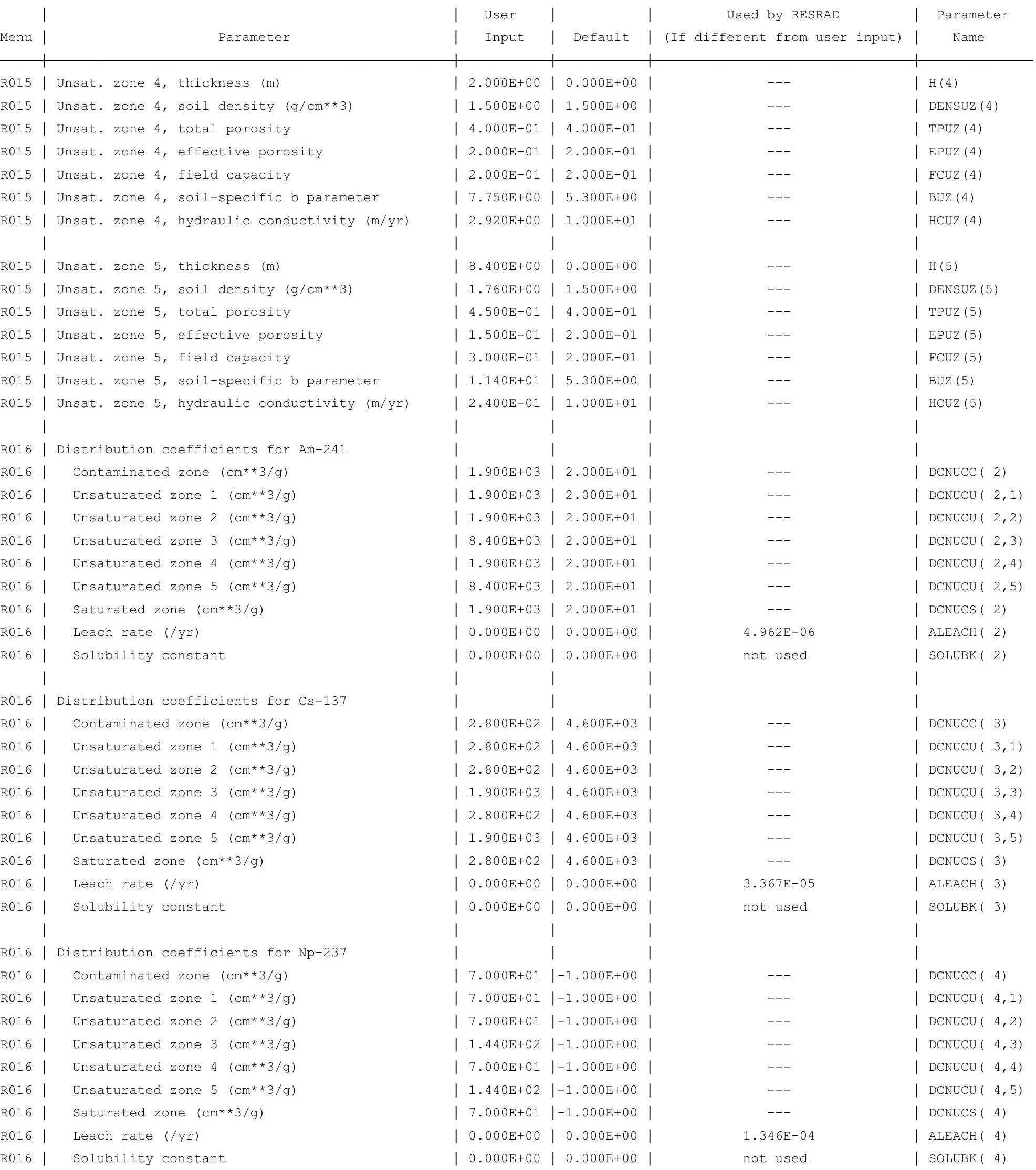

R016 | Solubility constant

\begin{tabular}{|l|l|l|l|l|l}
$0.000 \mathrm{E}+00$ & $0.000 \mathrm{E}+00$ \\
$0.000 \mathrm{E}+00$ & $0.000 \mathrm{E}+00$
\end{tabular}

| SOLUBK( 4) 
RESRAD, Version $6.5 \quad T^{1 / 2}$ Limit $=180$ days $\quad 07 / 20 / 2011 \quad 14: 43$ Page 11

Summary : RESRAD Parameters for U-Landfill Resident Gardener Forward Run at ALs

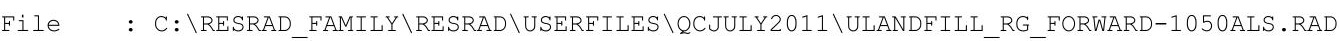

Site-Specific Parameter Summary (continued)

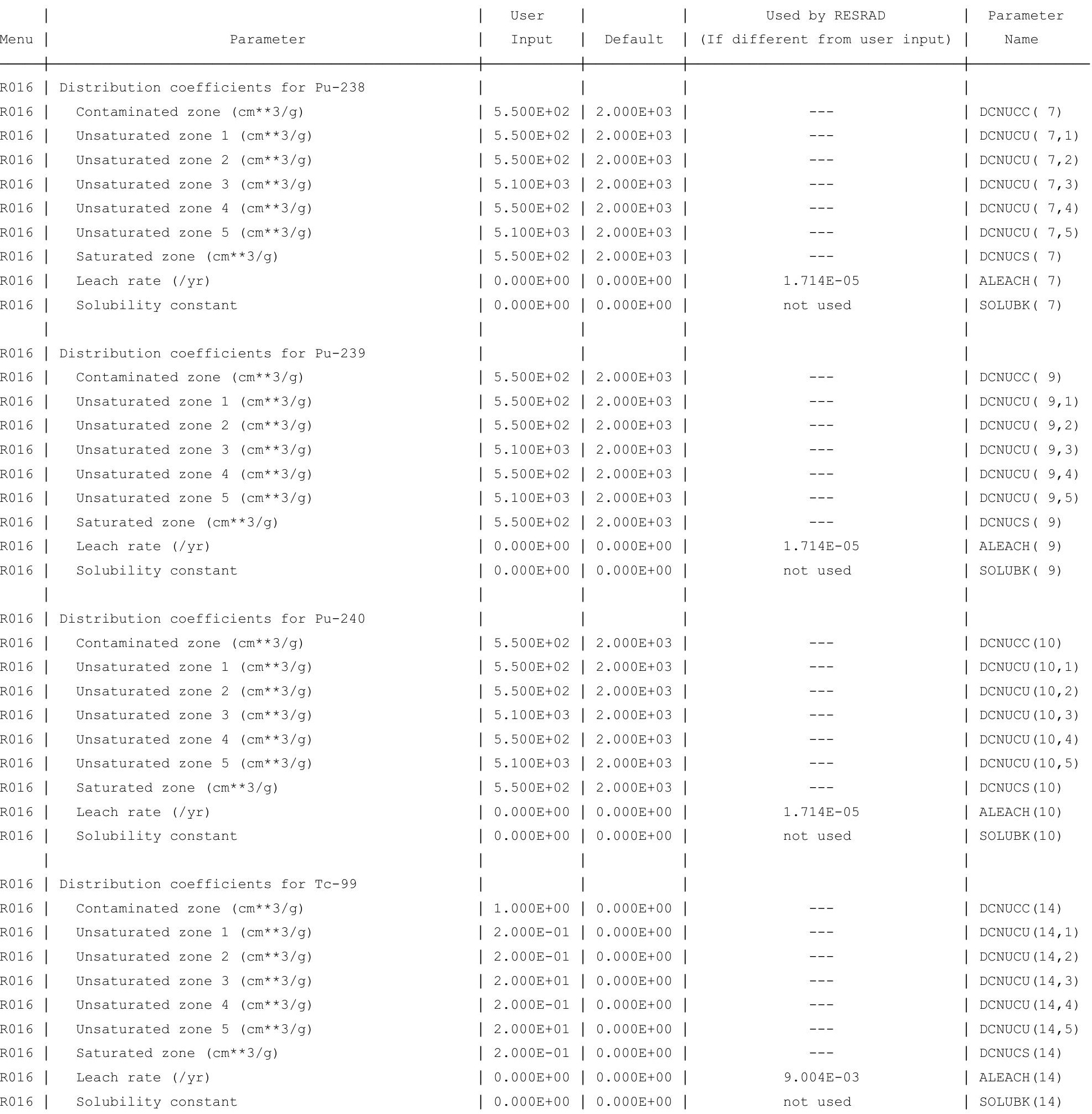


RESRAD, Version $6.5 \quad T^{1 / 2}$ Limit $=180$ days $\quad 07 / 20 / 2011 \quad 14: 43$ Page 14

Summary : RESRAD Parameters for U-Landfill Resident Gardener Forward Run at ALs

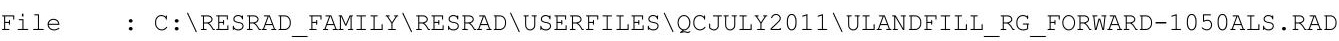

Site-Specific Parameter Summary (continued)

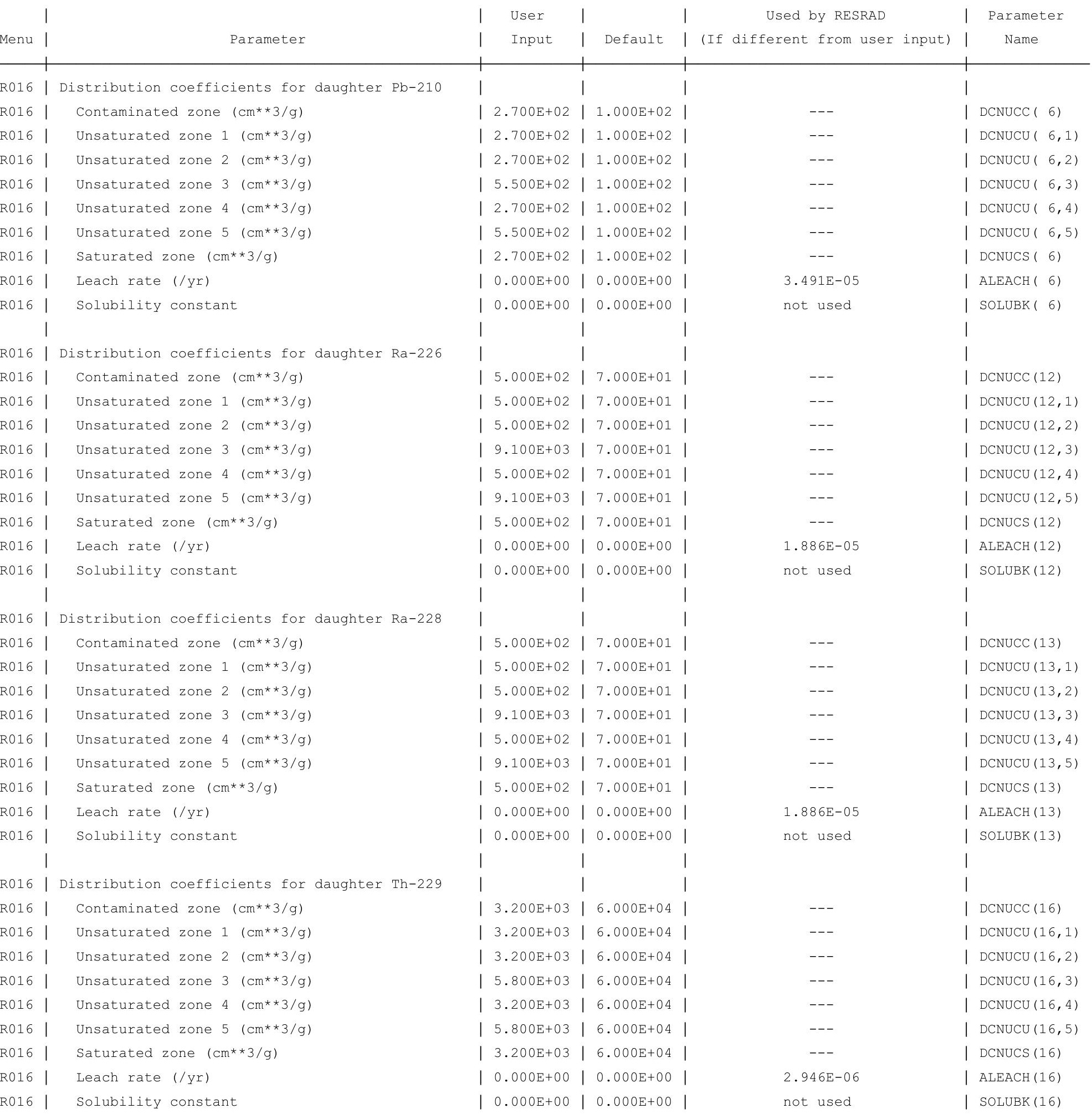


Summary : RESRAD Parameters for U-Landfill Resident Gardener Forward Run at ALs

File : C: $\backslash$ RESRAD FAMILY \RESRAD \USERFILES \QCJULY2011 \ULANDFILL RG FORWARD-1050ALS.RAD

Site-Specific Parameter Summary (continued)

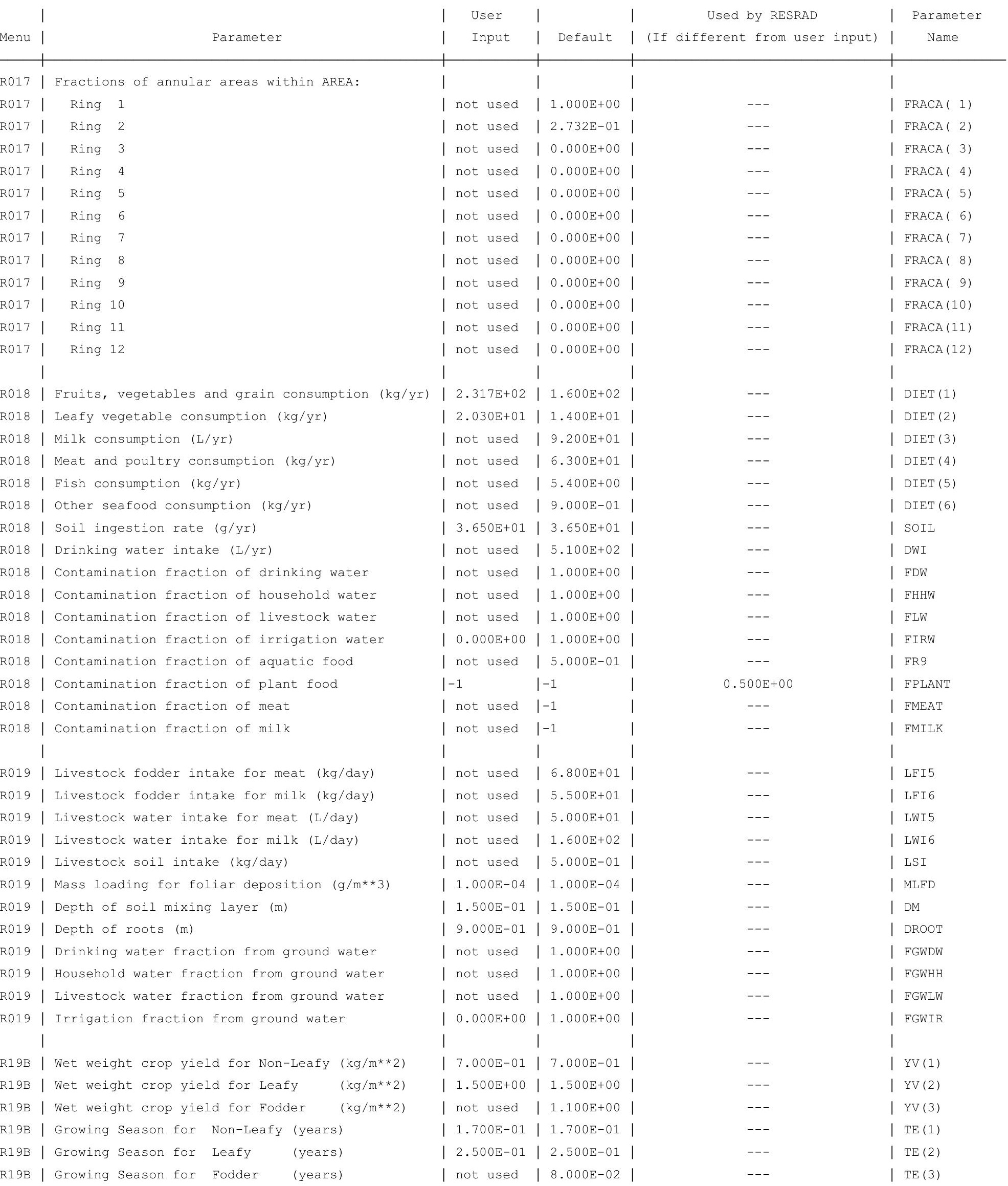


RESRAD, Version $6.5 \quad$ T1/2 Limit $=180$ days $\quad$ 07/20/2011 $14: 43$ Page 19

Summary : RESRAD Parameters for U-Landfill Resident Gardener Forward Run at ALs

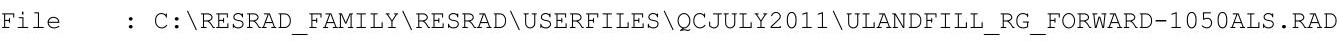

Contaminated Zone Dimensions

Area: 89436.00 square meters

Thickness:

Cover Depth:

\begin{abstract}
13.40 meters
1.52 meters
\end{abstract}

Initial Soil Concentrations, pCi/g

$\begin{array}{ll}\mathrm{Am}-241 & 7.000 \mathrm{E}+01 \\ \mathrm{Cs}-137 & 3.800 \mathrm{E}+01 \\ \mathrm{~Np}-237 & 1.100 \mathrm{E}+01 \\ \mathrm{Pu}-238 & 7.800 \mathrm{E}+01 \\ \mathrm{Pu}-239 & 7.200 \mathrm{E}+01 \\ \mathrm{Pu}-240 & 7.200 \mathrm{E}+01 \\ \mathrm{Tc}-99 & 1.040 \mathrm{E}+02 \\ \mathrm{Th}-228 & 8.000 \mathrm{E}+00 \\ \mathrm{Th}-230 & 2.000 \mathrm{E}+02 \\ \mathrm{Th}-232 & 8.000 \mathrm{E}+00 \\ \mathrm{U}-234 & 3.200 \mathrm{E}+02 \\ \mathrm{U}-235 & 1.300 \mathrm{E}+01 \\ \mathrm{U}-238 & 3.200 \mathrm{E}+02\end{array}$

Total Dose TDOSE(t), mrem/yr

Basic Radiation Dose Limit $=1.000 \mathrm{E}+02 \mathrm{mrem} / \mathrm{yr}$

Total Mixture Sum $\mathrm{M}(\mathrm{t})$ = Fraction of Basic Dose Limit Received at Time (t)

$\begin{array}{rllllll}t \text { (years) }: & 0.000 \mathrm{E}+00 & 1.000 \mathrm{E}+00 & 5.000 \mathrm{E}+01 & 1.000 \mathrm{E}+02 & 5.000 \mathrm{E}+02 & 1.050 \mathrm{E}+03 \\ \mathrm{TDOSE}(\mathrm{t}): & 1.125 \mathrm{E}-05 & 8.412 \mathrm{E}-06 & 1.908 \mathrm{E}-05 & 2.733 \mathrm{E}-05 & 4.845 \mathrm{E}-04 & 1.365 \mathrm{E}+01 \\ \mathrm{M}(\mathrm{t}): & 1.125 \mathrm{E}-07 & 8.412 \mathrm{E}-08 & 1.908 \mathrm{E}-07 & 2.733 \mathrm{E}-07 & 4.845 \mathrm{E}-06 & 1.365 \mathrm{E}-01\end{array}$

Maximum TDOSE(t): $1.365 \mathrm{E}+01 \mathrm{mrem} / \mathrm{yr}$ at $t=1.050 \mathrm{E}+03$ years 
RESRAD, Version $6.5 \quad$ T1/2 Limit $=180$ days $\quad$ 07/20/2011 14:43 Page 20

ummary : RESRAD Parameters for U-Landfill Resident Gardener Forward Run at ALs

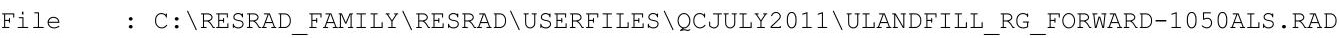

Total Dose Contributions TDOSE (i,p,t) for Individual Radionuclides (i) and Pathways (p) As mrem/yr and Fraction of Total Dose At $t=0.000 \mathrm{E}+00$ years

Water Independent Pathways (Inhalation excludes radon)

\begin{tabular}{|c|c|c|c|c|c|c|c|c|c|c|c|c|c|c|}
\hline \multirow{2}{*}{ Nuclide } & \multicolumn{2}{|c|}{ Ground } & \multicolumn{2}{|c|}{ Inhalation } & \multicolumn{2}{|c|}{ Radon } & \multicolumn{2}{|c|}{ Plant } & \multicolumn{2}{|c|}{ Meat } & \multicolumn{2}{|c|}{ Milk } & \multicolumn{2}{|c|}{ Soil } \\
\hline & mrem/yr & fract. & mrem/yr & fract. & mrem/yr & fract. & mrem/yr & fract. & mrem/yr & fract. & mrem/yr & fract. & mrem/yr & fract. \\
\hline-241 & $1.082 \mathrm{E}-17$ & 0.0000 & $0.000 \mathrm{E}+00$ & 0.0000 & $0.000 \mathrm{E}+00$ & 0.0000 & $0.000 \mathrm{E}+00$ & 0.0000 & $0.000 \mathrm{E}+00$ & 0.0000 & $0.000 \mathrm{E}+00$ & 0.0000 & $0.000 \mathrm{E}+00$ & 0.0000 \\
\hline-137 & $4.795 E-08$ & 0.0043 & $0.000 \mathrm{E}+00$ & 0.0000 & $0.000 \mathrm{E}+00$ & 0.0000 & $0.000 \mathrm{E}+00$ & 0.0000 & $0.000 \mathrm{E}+00$ & 0.0000 & $0.000 \mathrm{E}+00$ & 0.0000 & $0.000 \mathrm{E}+00$ & 0.0000 \\
\hline-237 & $1.049 \mathrm{E}-11$ & 0.0000 & $0.000 \mathrm{E}+00$ & 0.0000 & $0.000 \mathrm{E}+00$ & 0.0000 & $0.000 \mathrm{E}+00$ & 0.0000 & $0.000 \mathrm{E}+00$ & 0.0000 & $0.000 \mathrm{E}+00$ & 0.0000 & $0.000 \mathrm{E}+00$ & 0.0000 \\
\hline-238 & $6.348 E-21$ & 0.0000 & $0.000 \mathrm{E}+00$ & 0.0000 & $0.000 \mathrm{E}+00$ & 0.0000 & $0.000 \mathrm{E}+00$ & 0.0000 & $0.000 \mathrm{E}+00$ & 0.0000 & $0.000 \mathrm{E}+00$ & 0.0000 & $0.000 \mathrm{E}+00$ & 0.0000 \\
\hline-239 & $8.656 \mathrm{E}-16$ & 0.0000 & $0.000 \mathrm{E}+00$ & 0.0000 & $0.000 \mathrm{E}+00$ & 0.0000 & $0.000 \mathrm{E}+00$ & 0.0000 & $0.000 \mathrm{E}+00$ & 0.0000 & $0.000 \mathrm{E}+00$ & 0.0000 & $0.000 \mathrm{E}+00$ & 0.0000 \\
\hline-240 & $8.230 \mathrm{E}-23$ & 0.0000 & $0.000 \mathrm{E}+00$ & 0.0000 & $0.000 \mathrm{E}+00$ & 0.0000 & $0.000 \mathrm{E}+00$ & 0.0000 & $0.000 \mathrm{E}+00$ & 0.0000 & $0.000 \mathrm{E}+00$ & 0.0000 & $0.000 \mathrm{E}+00$ & 0.0000 \\
\hline 99 & $5.988 E-24$ & 0.0000 & $0.000 \mathrm{E}+00$ & 0.0000 & $0.000 \mathrm{E}+00$ & 0.0000 & $0.000 \mathrm{E}+00$ & 0.0000 & $0.000 \mathrm{E}+00$ & 0.0000 & $0.000 \mathrm{E}+00$ & 0.0000 & $0.000 \mathrm{E}+00$ & 0.0000 \\
\hline-228 & $1.106 \mathrm{E}-05$ & 0.9827 & $0.000 \mathrm{E}+00$ & 0.0000 & $0.000 \mathrm{E}+00$ & 0.0000 & $0.000 \mathrm{E}+00$ & 0.0000 & $0.000 \mathrm{E}+00$ & 0.0000 & $0.000 \mathrm{E}+00$ & 0.0000 & $0.000 \mathrm{E}+00$ & 0.0000 \\
\hline-230 & $7.548 \mathrm{E}-09$ & 0.0007 & $0.000 \mathrm{E}+00$ & 0.0000 & $0.000 \mathrm{E}+00$ & 0.0000 & $0.000 \mathrm{E}+00$ & 0.0000 & $0.000 \mathrm{E}+00$ & 0.0000 & $0.000 \mathrm{E}+00$ & 0.0000 & $0.000 \mathrm{E}+00$ & 0.0000 \\
\hline-232 & $9.424 \mathrm{E}-08$ & 0.0084 & $0.000 \mathrm{E}+00$ & 0.0000 & $0.000 \mathrm{E}+00$ & 0.0000 & $0.000 \mathrm{E}+00$ & 0.0000 & $0.000 \mathrm{E}+00$ & 0.0000 & $0.000 \mathrm{E}+00$ & 0.0000 & $0.000 \mathrm{E}+00$ & 0.0000 \\
\hline 34 & $3.626 \mathrm{E}-14$ & 0.0000 & $0.000 \mathrm{E}+00$ & 0.0000 & $0.000 \mathrm{E}+00$ & 0.0000 & $0.000 \mathrm{E}+00$ & 0.0000 & $0.000 \mathrm{E}+00$ & 0.0000 & $0.000 \mathrm{E}+00$ & 0.0000 & $0.000 \mathrm{E}+00$ & 0.0000 \\
\hline 35 & 1. $618 \mathrm{E}-13$ & 0.0000 & $0.000 \mathrm{E}+00$ & 0.0000 & $0.000 \mathrm{E}+00$ & 0.0000 & $0.000 \mathrm{E}+00$ & 0.0000 & $0.000 \mathrm{E}+00$ & 0.0000 & $0.000 \mathrm{E}+00$ & 0.0000 & $0.000 \mathrm{E}+00$ & 0.0000 \\
\hline 38 & $4.543 E-08$ & 0.0040 & $0.000 \mathrm{E}+00$ & 0.0000 & $0.000 \mathrm{E}+00$ & 0.0000 & $0.000 \mathrm{E}+00$ & 0.0000 & $0.000 \mathrm{E}+00$ & 0.0000 & $0.000 \mathrm{E}+00$ & 0.0000 & $0.000 \mathrm{E}+00$ & 0.0000 \\
\hline & $1.125 E-05$ & 1.0000 & $0.000 \mathrm{E}+00$ & 0.0000 & $0.000 \mathrm{E}+00$ & 0.0000 & $0.000 \mathrm{E}+00$ & 0.0000 & $0.000 \mathrm{E}+00$ & 0.0000 & $0.000 \mathrm{E}+00$ & 0.0000 & $.000 \mathrm{E}+00$ & 0.0000 \\
\hline
\end{tabular}

Total Dose Contributions TDOSE(i,p,t) for Individual Radionuclides (i) and Pathways (p) As mrem/yr and Fraction of Total Dose At $t=0.000 \mathrm{E}+00$ years

Water Dependent Pathways

\begin{tabular}{|c|c|c|c|c|c|c|c|c|c|c|c|c|c|c|}
\hline & \multicolumn{2}{|c|}{ Water } & \multicolumn{2}{|c|}{ Fish } & \multicolumn{2}{|c|}{ Radon } & \multicolumn{2}{|c|}{ Plant } & \multicolumn{2}{|c|}{ Meat } & \multicolumn{2}{|c|}{ Milk } & \multicolumn{2}{|c|}{ All Pathways* } \\
\hline clide & mrem/yr & fract. & mrem/yr & fract. & mrem/yr & fract. & mrem/yr & fract. & mrem/yr & fract. & mrem/yr & fract. & mrem/yr & fract. \\
\hline-241 & $0.000 \mathrm{E}+00$ & 0.0000 & $0.000 \mathrm{E}+00$ & 0.0000 & $0.000 \mathrm{E}+00$ & 0.0000 & $0.000 \mathrm{E}+00$ & 0.0000 & $0.000 \mathrm{E}+00$ & 0.0000 & $0.000 \mathrm{E}+00$ & 0.0000 & $1.082 \mathrm{E}-17$ & 0.0000 \\
\hline-137 & $0.000 \mathrm{E}+00$ & 0.0000 & $0.000 \mathrm{E}+00$ & 0.0000 & $0.000 \mathrm{E}+00$ & 0.0000 & $0.000 \mathrm{E}+00$ & 0.0000 & $0.000 \mathrm{E}+00$ & 0.0000 & $0.000 \mathrm{E}+00$ & 0.0000 & $4.795 E-08$ & 0.0043 \\
\hline-237 & $0.000 \mathrm{E}+00$ & 0.0000 & $0.000 \mathrm{E}+00$ & 0.0000 & $0.000 \mathrm{E}+00$ & 0.0000 & $0.000 \mathrm{E}+00$ & 0.0000 & $0.000 \mathrm{E}+00$ & 0.0000 & $0.000 \mathrm{E}+00$ & 0.0000 & $1.049 \mathrm{E}-11$ & 0.0000 \\
\hline 238 & $0.000 \mathrm{E}+00$ & 0.0000 & $0.000 \mathrm{E}+00$ & 0.0000 & $0.000 \mathrm{E}+00$ & 0.0000 & $0.000 \mathrm{E}+00$ & 0.0000 & $0.000 \mathrm{E}+00$ & 0.0000 & $0.000 \mathrm{E}+00$ & 0.0000 & $6.348 E-21$ & 0.0000 \\
\hline 239 & $0.000 \mathrm{E}+00$ & 0.0000 & $0.000 \mathrm{E}+00$ & 0.0000 & $0.000 \mathrm{E}+00$ & 0.0000 & $0.000 \mathrm{E}+00$ & 0.0000 & $0.000 \mathrm{E}+00$ & 0.0000 & $0.000 \mathrm{E}+00$ & 0.0000 & $8.656 \mathrm{E}-16$ & 0.0000 \\
\hline 240 & $0.000 \mathrm{E}+00$ & 0.0000 & $0.000 \mathrm{E}+00$ & 0.0000 & $0.000 \mathrm{E}+00$ & 0.0000 & $0.000 \mathrm{E}+00$ & 0.0000 & $0.000 \mathrm{E}+00$ & 0.0000 & $0.000 \mathrm{E}+00$ & 0.0000 & $8.230 \mathrm{E}-23$ & 0.0000 \\
\hline 99 & $0.000 \mathrm{E}+00$ & 0.0000 & $0.000 \mathrm{E}+00$ & 0.0000 & $0.000 \mathrm{E}+00$ & 0.0000 & $0.000 \mathrm{E}+00$ & 0.0000 & $0.000 \mathrm{E}+00$ & 0.0000 & $0.000 \mathrm{E}+00$ & 0.0000 & $5.988 E-24$ & 0.0000 \\
\hline 228 & $0.000 \mathrm{E}+00$ & 0.0000 & $0.000 \mathrm{E}+00$ & 0.0000 & $0.000 \mathrm{E}+00$ & 0.0000 & $0.000 \mathrm{E}+00$ & 0.0000 & $0.000 \mathrm{E}+00$ & 0.0000 & $0.000 \mathrm{E}+00$ & 0.0000 & $1.106 \mathrm{E}-05$ & 0.9827 \\
\hline 230 & $0.000 \mathrm{E}+00$ & 0.0000 & $0.000 \mathrm{E}+00$ & 0.0000 & $0.000 \mathrm{E}+00$ & 0.0000 & $0.000 \mathrm{E}+00$ & 0.0000 & $0.000 \mathrm{E}+00$ & 0.0000 & $0.000 \mathrm{E}+00$ & 0.0000 & $7.548 \mathrm{E}-09$ & 0.0007 \\
\hline 232 & $0.000 \mathrm{E}+00$ & 0.0000 & $0.000 \mathrm{E}+00$ & 0.0000 & $0.000 \mathrm{E}+00$ & 0.0000 & $0.000 \mathrm{E}+00$ & 0.0000 & $0.000 \mathrm{E}+00$ & 0.0000 & $0.000 \mathrm{E}+00$ & 0.0000 & $9.424 \mathrm{E}-08$ & 0.0084 \\
\hline 34 & $0.000 \mathrm{E}+00$ & 0.0000 & $0.000 \mathrm{E}+00$ & 0.0000 & $0.000 \mathrm{E}+00$ & 0.0000 & $0.000 \mathrm{E}+00$ & 0.0000 & $0.000 \mathrm{E}+00$ & 0.0000 & $0.000 \mathrm{E}+00$ & 0.0000 & $3.626 \mathrm{E}-14$ & 0.0000 \\
\hline 35 & $0.000 \mathrm{E}+00$ & 0.0000 & $0.000 \mathrm{E}+00$ & 0.0000 & $0.000 \mathrm{E}+00$ & 0.0000 & $0.000 \mathrm{E}+00$ & 0.0000 & $0.000 \mathrm{E}+00$ & 0.0000 & $0.000 \mathrm{E}+00$ & 0.0000 & $1.618 \mathrm{E}-13$ & 0.0000 \\
\hline 38 & $0.000 \mathrm{E}+00$ & 0.0000 & $0.000 \mathrm{E}+00$ & 0.0000 & $0.000 \mathrm{E}+00$ & 0.0000 & $0.000 \mathrm{E}+00$ & 0.0000 & $0.000 \mathrm{E}+00$ & 0.0000 & $0.000 \mathrm{E}+00$ & 0.0000 & $4.543 E-08$ & 0.0040 \\
\hline & $0.000 \mathrm{E}+00$ & 0.0000 & $0.000 \mathrm{E}+00$ & 0.0000 & $0.000 \mathrm{E}+00$ & 0.0000 & $0.000 \mathrm{E}+00$ & 0.0000 & $0.000 \mathrm{E}+00$ & 0.0000 & $0.000 \mathrm{E}+00$ & 000 & -05 & 1.0000 \\
\hline
\end{tabular}

* Sum of all water independent and dependent pathways. 
RESRAD, Version $6.5 \quad T^{1 / 2}$ Limit $=180$ days $\quad$ 07/20/2011 14:43 Page 21

Summary : RESRAD Parameters for U-Landfill Resident Gardener Forward Run at ALs

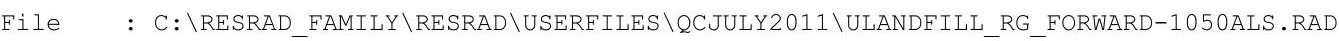

Total Dose Contributions TDOSE (i,p,t) for Individual Radionuclides (i) and Pathways (p) As mrem/yr and Fraction of Total Dose At $t=1.000 \mathrm{E}+00$ years

Water Independent Pathways (Inhalation excludes radon)

\begin{tabular}{|c|c|c|c|c|c|c|c|c|c|c|c|c|c|c|}
\hline & \multicolumn{2}{|c|}{ Ground } & \multicolumn{2}{|c|}{ Inhalation } & \multicolumn{2}{|c|}{ Radon } & \multicolumn{2}{|c|}{ Plant } & \multicolumn{2}{|c|}{ Meat } & \multicolumn{2}{|c|}{ Milk } & \multicolumn{2}{|c|}{ Soil } \\
\hline clide & mrem/yr & fract. & mrem/yr & fract. & mrem/yr & fract. & mrem/yr & fract. & mrem/yr & fract. & mrem/yr & fract. & mrem/yr & fract. \\
\hline 241 & $3.276 \mathrm{E}-17$ & 0.0000 & $0.000 \mathrm{E}+00$ & 0.0000 & $0.000 \mathrm{E}+00$ & 0.0000 & $0.000 \mathrm{E}+00$ & 0.0000 & $0.000 \mathrm{E}+00$ & 0.0000 & $0.000 \mathrm{E}+00$ & 0.0000 & $0.000 \mathrm{E}+00$ & 0.0000 \\
\hline-137 & $4.725 E-08$ & 0.0056 & $0.000 \mathrm{E}+00$ & 0.0000 & $0.000 \mathrm{E}+00$ & 0.0000 & $0.000 \mathrm{E}+00$ & 0.0000 & $0.000 \mathrm{E}+00$ & 0.0000 & $0.000 \mathrm{E}+00$ & 0.0000 & $0.000 \mathrm{E}+00$ & 0.0000 \\
\hline-237 & $1.060 \mathrm{E}-11$ & 0.0000 & $0.000 \mathrm{E}+00$ & 0.0000 & $0.000 \mathrm{E}+00$ & 0.0000 & $0.000 \mathrm{E}+00$ & 0.0000 & $0.000 \mathrm{E}+00$ & 0.0000 & $0.000 \mathrm{E}+00$ & 0.0000 & $0.000 \mathrm{E}+00$ & 0.0000 \\
\hline-238 & $9.433 E-20$ & 0.0000 & $0.000 \mathrm{E}+00$ & 0.0000 & $0.000 \mathrm{E}+00$ & 0.0000 & $0.000 \mathrm{E}+00$ & 0.0000 & $0.000 \mathrm{E}+00$ & 0.0000 & $0.000 \mathrm{E}+00$ & 0.0000 & $0.000 \mathrm{E}+00$ & 0.0000 \\
\hline-239 & $8.760 \mathrm{E}-16$ & 0.0000 & $0.000 \mathrm{E}+00$ & 0.0000 & $0.000 \mathrm{E}+00$ & 0.0000 & $0.000 \mathrm{E}+00$ & 0.0000 & $0.000 \mathrm{E}+00$ & 0.0000 & $0.000 \mathrm{E}+00$ & 0.0000 & $0.000 \mathrm{E}+00$ & 0.0000 \\
\hline-240 & $8.551 E-23$ & 0.0000 & $0.000 \mathrm{E}+00$ & 0.0000 & $0.000 \mathrm{E}+00$ & 0.0000 & $0.000 \mathrm{E}+00$ & 0.0000 & $0.000 \mathrm{E}+00$ & 0.0000 & $0.000 \mathrm{E}+00$ & 0.0000 & $0.000 \mathrm{E}+00$ & 0.0000 \\
\hline 99 & $6.050 \mathrm{E}-24$ & 0.0000 & $0.000 \mathrm{E}+00$ & 0.0000 & $0.000 \mathrm{E}+00$ & 0.0000 & $0.000 \mathrm{E}+00$ & 0.0000 & $0.000 \mathrm{E}+00$ & 0.0000 & $0.000 \mathrm{E}+00$ & 0.0000 & $0.000 \mathrm{E}+00$ & 0.0000 \\
\hline-228 & $7.744 \mathrm{E}-06$ & 0.9206 & $0.000 \mathrm{E}+00$ & 0.0000 & $0.000 \mathrm{E}+00$ & 0.0000 & $0.000 \mathrm{E}+00$ & 0.0000 & $0.000 \mathrm{E}+00$ & 0.0000 & $0.000 \mathrm{E}+00$ & 0.0000 & $0.000 \mathrm{E}+00$ & 0.0000 \\
\hline-230 & $2.278 \mathrm{E}-08$ & 0.0027 & $0.000 \mathrm{E}+00$ & 0.0000 & $0.000 \mathrm{E}+00$ & 0.0000 & $0.000 \mathrm{E}+00$ & 0.0000 & $0.000 \mathrm{E}+00$ & 0.0000 & $0.000 \mathrm{E}+00$ & 0.0000 & $0.000 \mathrm{E}+00$ & 0.0000 \\
\hline 232 & $5.519 \mathrm{E}-07$ & 0.0656 & $0.000 \mathrm{E}+00$ & 0.0000 & $0.000 \mathrm{E}+00$ & 0.0000 & $0.000 \mathrm{E}+00$ & 0.0000 & $0.000 \mathrm{E}+00$ & 0.0000 & $0.000 \mathrm{E}+00$ & 0.0000 & $0.000 \mathrm{E}+00$ & 0.0000 \\
\hline 234 & $2.553 E-13$ & 0.0000 & $0.000 \mathrm{E}+00$ & 0.0000 & $0.000 \mathrm{E}+00$ & 0.0000 & $0.000 \mathrm{E}+00$ & 0.0000 & $0.000 \mathrm{E}+00$ & 0.0000 & $0.000 \mathrm{E}+00$ & 0.0000 & $0.000 \mathrm{E}+00$ & 0.0000 \\
\hline 235 & $1.646 \mathrm{E}-13$ & 0.0000 & $0.000 \mathrm{E}+00$ & 0.0000 & $0.000 \mathrm{E}+00$ & 0.0000 & $0.000 \mathrm{E}+00$ & 0.0000 & $0.000 \mathrm{E}+00$ & 0.0000 & $0.000 \mathrm{E}+00$ & 0.0000 & $0.000 \mathrm{E}+00$ & 0.0000 \\
\hline 38 & $4.579 E-08$ & 0.0054 & $0.000 \mathrm{E}+00$ & 0.0000 & $0.000 \mathrm{E}+00$ & 0.0000 & $0.000 \mathrm{E}+00$ & 0.0000 & $0.000 \mathrm{E}+00$ & 0.0000 & $0.000 \mathrm{E}+00$ & 0.0000 & $0.000 \mathrm{E}+00$ & 0.0000 \\
\hline & $8.412 \mathrm{E}-06$ & 1.0000 & $0.000 \mathrm{E}+00$ & 0.0000 & $0.000 \mathrm{E}+00$ & 0.0000 & $0.000 \mathrm{E}+00$ & 0.0000 & $0.000 \mathrm{E}+00$ & 0.0000 & $0.000 \mathrm{E}+00$ & 0.0000 & $0.000 \mathrm{E}+00$ & 0.0000 \\
\hline
\end{tabular}

Total Dose Contributions TDOSE(i,p,t) for Individual Radionuclides (i) and Pathways (p) As mrem/yr and Fraction of Total Dose At $t=1.000 \mathrm{E}+00$ years

Water Dependent Pathways

\begin{tabular}{|c|c|c|c|c|c|c|c|c|c|c|c|c|c|c|}
\hline \multirow{2}{*}{$\begin{array}{l}\text { Radio- } \\
\text { Nuclide }\end{array}$} & \multicolumn{2}{|c|}{ Water } & \multicolumn{2}{|c|}{ Fish } & \multicolumn{2}{|c|}{ Radon } & \multicolumn{2}{|c|}{ Plant } & \multicolumn{2}{|c|}{ Meat } & \multicolumn{2}{|c|}{ Milk } & \multicolumn{2}{|c|}{ All Pathways* } \\
\hline & mrem/yr & fract. & mrem/yr & fract. & mrem/yr & fract. & mrem/yr & fract. & mrem/yr & fract. & mrem/yr & fract. & mrem/yr & fract. \\
\hline 241 & $0.000 \mathrm{E}+00$ & 0.0000 & $0.000 \mathrm{E}+00$ & 0.0000 & $0.000 \mathrm{E}+00$ & 0.0000 & $0.000 \mathrm{E}+00$ & 0.0000 & $0.000 \mathrm{E}+00$ & 0.0000 & $0.000 \mathrm{E}+00$ & 0.0000 & $3.276 \mathrm{E}-17$ & 0.0000 \\
\hline-137 & $0.000 \mathrm{E}+00$ & 0.0000 & $0.000 \mathrm{E}+00$ & 0.0000 & $0.000 \mathrm{E}+00$ & 0.0000 & $0.000 \mathrm{E}+00$ & 0.0000 & $0.000 \mathrm{E}+00$ & 0.0000 & $0.000 \mathrm{E}+00$ & 0.0000 & $4.725 \mathrm{E}-08$ & 0.0056 \\
\hline-237 & $0.000 \mathrm{E}+00$ & 0.0000 & $0.000 \mathrm{E}+00$ & 0.0000 & $0.000 \mathrm{E}+00$ & 0.0000 & $0.000 \mathrm{E}+00$ & 0.0000 & $0.000 \mathrm{E}+00$ & 0.0000 & $0.000 \mathrm{E}+00$ & 0.0000 & $1.060 \mathrm{E}-11$ & 0.0000 \\
\hline-238 & $0.000 \mathrm{E}+00$ & 0.0000 & $0.000 \mathrm{E}+00$ & 0.0000 & $0.000 \mathrm{E}+00$ & 0.0000 & $0.000 \mathrm{E}+00$ & 0.0000 & $0.000 \mathrm{E}+00$ & 0.0000 & $0.000 \mathrm{E}+00$ & 0.0000 & $9.433 \mathrm{E}-20$ & 0.0000 \\
\hline-239 & $0.000 \mathrm{E}+00$ & 0.0000 & $0.000 \mathrm{E}+00$ & 0.0000 & $0.000 \mathrm{E}+00$ & 0.0000 & $0.000 \mathrm{E}+00$ & 0.0000 & $0.000 \mathrm{E}+00$ & 0.0000 & $0.000 E+00$ & 0.0000 & $8.760 \mathrm{E}-16$ & 0.0000 \\
\hline-240 & $0.000 \mathrm{E}+00$ & 0.0000 & $0.000 \mathrm{E}+00$ & 0.0000 & $0.000 \mathrm{E}+00$ & 0.0000 & $0.000 \mathrm{E}+00$ & 0.0000 & $0.000 \mathrm{E}+00$ & 0.0000 & $0.000 E+00$ & 0.0000 & $8.551 E-23$ & 0.0000 \\
\hline-99 & $0.000 \mathrm{E}+00$ & 0.0000 & $0.000 \mathrm{E}+00$ & 0.0000 & $0.000 \mathrm{E}+00$ & 0.0000 & $0.000 \mathrm{E}+00$ & 0.0000 & $0.000 \mathrm{E}+00$ & 0.0000 & $0.000 \mathrm{E}+00$ & 0.0000 & $6.050 \mathrm{E}-24$ & 0.0000 \\
\hline-228 & $0.000 \mathrm{E}+00$ & 0.0000 & $0.000 \mathrm{E}+00$ & 0.0000 & $0.000 \mathrm{E}+00$ & 0.0000 & $0.000 \mathrm{E}+00$ & 0.0000 & $0.000 \mathrm{E}+00$ & 0.0000 & $0.000 \mathrm{E}+00$ & 0.0000 & $7.744 \mathrm{E}-06$ & 0.9206 \\
\hline-230 & $0.000 \mathrm{E}+00$ & 0.0000 & $0.000 \mathrm{E}+00$ & 0.0000 & $0.000 \mathrm{E}+00$ & 0.0000 & $0.000 \mathrm{E}+00$ & 0.0000 & $0.000 \mathrm{E}+00$ & 0.0000 & $0.000 E+00$ & 0.0000 & $2.278 E-08$ & 0.0027 \\
\hline 232 & $0.000 \mathrm{E}+00$ & 0.0000 & $0.000 \mathrm{E}+00$ & 0.0000 & $0.000 \mathrm{E}+00$ & 0.0000 & $0.000 \mathrm{E}+00$ & 0.0000 & $0.000 \mathrm{E}+00$ & 0.0000 & $0.000 \mathrm{E}+00$ & 0.0000 & $5.519 \mathrm{E}-07$ & 0.0656 \\
\hline 34 & $0.000 \mathrm{E}+00$ & 0.0000 & $0.000 \mathrm{E}+00$ & 0.0000 & $0.000 \mathrm{E}+00$ & 0.0000 & $0.000 \mathrm{E}+00$ & 0.0000 & $0.000 \mathrm{E}+00$ & 0.0000 & $0.000 \mathrm{E}+00$ & 0.0000 & $2.553 E-13$ & 0.0000 \\
\hline 35 & $0.000 \mathrm{E}+00$ & 0.0000 & $0.000 \mathrm{E}+00$ & 0.0000 & $0.000 \mathrm{E}+00$ & 0.0000 & $0.000 \mathrm{E}+00$ & 0.0000 & $0.000 \mathrm{E}+00$ & 0.0000 & $0.000 \mathrm{E}+00$ & 0.0000 & $1.646 \mathrm{E}-13$ & 0.0000 \\
\hline 38 & $0.000 \mathrm{E}+00$ & 0.0000 & $0.000 \mathrm{E}+00$ & 0.0000 & $0.000 \mathrm{E}+00$ & 0.0000 & $0.000 \mathrm{E}+00$ & 0.0000 & $0.000 \mathrm{E}+00$ & 0.0000 & $0.000 \mathrm{E}+00$ & 0.0000 & $4.579 \mathrm{E}-08$ & 0.0054 \\
\hline & $0.000 \mathrm{E}+00$ & 0.0000 & $0.000 \mathrm{E}+00$ & 0.0000 & $0.000 \mathrm{E}+00$ & 0.0000 & $0.000 \mathrm{E}+00$ & 0.0000 & $0.000 \mathrm{E}+00$ & 0.0000 & $0.000 \mathrm{E}+00$ & 0.0000 & $2 E-06$ & 1.0000 \\
\hline
\end{tabular}

* Sum of all water independent and dependent pathways. 
RESRAD, Version $6.5 \quad T^{1} \frac{1}{2}$ Limit $=180$ days $\quad 07 / 20 / 2011 \quad 14: 43$ Page 22

Summary : RESRAD Parameters for U-Landfill Resident Gardener Forward Run at ALs

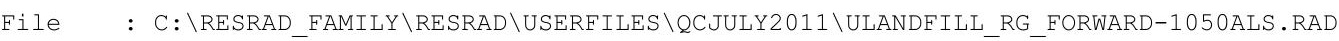

Total Dose Contributions TDOSE (i,p,t) for Individual Radionuclides (i) and Pathways (p) As mrem/yr and Fraction of Total Dose At $t=5.000 \mathrm{E}+01$ years

Water Independent Pathways (Inhalation excludes radon)

\begin{tabular}{|c|c|c|c|c|c|c|c|c|c|c|c|c|c|c|}
\hline \multirow{2}{*}{ Nuclide } & \multicolumn{2}{|c|}{ Ground } & \multicolumn{2}{|c|}{ Inhalation } & \multicolumn{2}{|c|}{ Radon } & \multicolumn{2}{|c|}{ Plant } & \multicolumn{2}{|c|}{ Meat } & \multicolumn{2}{|c|}{ Milk } & \multicolumn{2}{|c|}{ Soil } \\
\hline & mrem/yr & fract. & mrem/yr & fract. & mrem/yr & fract. & mrem/yr & fract. & mrem/yr & fract. & mrem/yr & fract. & mrem/yr & fract. \\
\hline-241 & $1.795 E-15$ & 0.0000 & $0.000 \mathrm{E}+00$ & 0.0000 & $0.000 \mathrm{E}+00$ & 0.0000 & $0.000 \mathrm{E}+00$ & 0.0000 & $0.000 \mathrm{E}+00$ & 0.0000 & $0.000 \mathrm{E}+00$ & 0.0000 & $0.000 \mathrm{E}+00$ & 0.0000 \\
\hline-137 & $2.299 E-08$ & 0.0012 & $0.000 \mathrm{E}+00$ & 0.0000 & $0.000 \mathrm{E}+00$ & 0.0000 & $0.000 \mathrm{E}+00$ & 0.0000 & $0.000 \mathrm{E}+00$ & 0.0000 & $0.000 \mathrm{E}+00$ & 0.0000 & $0.000 \mathrm{E}+00$ & 0.0000 \\
\hline-237 & $1.791 \mathrm{E}-11$ & 0.0000 & $0.000 \mathrm{E}+00$ & 0.0000 & $0.000 \mathrm{E}+00$ & 0.0000 & $0.000 \mathrm{E}+00$ & 0.0000 & $0.000 \mathrm{E}+00$ & 0.0000 & $0.000 \mathrm{E}+00$ & 0.0000 & $0.000 \mathrm{E}+00$ & 0.0000 \\
\hline-238 & $4.107 \mathrm{E}-15$ & 0.0000 & $0.000 \mathrm{E}+00$ & 0.0000 & $0.000 \mathrm{E}+00$ & 0.0000 & $0.000 \mathrm{E}+00$ & 0.0000 & $0.000 \mathrm{E}+00$ & 0.0000 & $0.000 \mathrm{E}+00$ & 0.0000 & $0.000 \mathrm{E}+00$ & 0.0000 \\
\hline-239 & $1.572 \mathrm{E}-15$ & 0.0000 & $0.000 \mathrm{E}+00$ & 0.0000 & $0.000 \mathrm{E}+00$ & 0.0000 & $0.000 \mathrm{E}+00$ & 0.0000 & $0.000 \mathrm{E}+00$ & 0.0000 & $0.000 \mathrm{E}+00$ & 0.0000 & $0.000 \mathrm{E}+00$ & 0.0000 \\
\hline-240 & $1.931 \mathrm{E}-19$ & 0.0000 & $0.000 \mathrm{E}+00$ & 0.0000 & $0.000 \mathrm{E}+00$ & 0.0000 & $0.000 \mathrm{E}+00$ & 0.0000 & $0.000 \mathrm{E}+00$ & 0.0000 & $0.000 \mathrm{E}+00$ & 0.0000 & $0.000 \mathrm{E}+00$ & 0.0000 \\
\hline 99 & $9.958 E-24$ & 0.0000 & $0.000 \mathrm{E}+00$ & 0.0000 & $0.000 \mathrm{E}+00$ & 0.0000 & $0.000 \mathrm{E}+00$ & 0.0000 & $0.000 \mathrm{E}+00$ & 0.0000 & $0.000 \mathrm{E}+00$ & 0.0000 & $0.000 \mathrm{E}+00$ & 0.0000 \\
\hline-228 & $2.021 \mathrm{E}-13$ & 0.0000 & $0.000 \mathrm{E}+00$ & 0.0000 & $0.000 \mathrm{E}+00$ & 0.0000 & $0.000 \mathrm{E}+00$ & 0.0000 & $0.000 \mathrm{E}+00$ & 0.0000 & $0.000 \mathrm{E}+00$ & 0.0000 & $0.000 \mathrm{E}+00$ & 0.0000 \\
\hline-230 & $1.064 \mathrm{E}-06$ & 0.0558 & $0.000 \mathrm{E}+00$ & 0.0000 & $0.000 \mathrm{E}+00$ & 0.0000 & $0.000 \mathrm{E}+00$ & 0.0000 & $0.000 \mathrm{E}+00$ & 0.0000 & $0.000 \mathrm{E}+00$ & 0.0000 & $0.000 \mathrm{E}+00$ & 0.0000 \\
\hline-232 & $1.793 E-05$ & 0.9395 & $0.000 \mathrm{E}+00$ & 0.0000 & $0.000 \mathrm{E}+00$ & 0.0000 & $0.000 \mathrm{E}+00$ & 0.0000 & $0.000 \mathrm{E}+00$ & 0.0000 & $0.000 \mathrm{E}+00$ & 0.0000 & $0.000 \mathrm{E}+00$ & 0.0000 \\
\hline 234 & $3.883 E-10$ & 0.0000 & $0.000 \mathrm{E}+00$ & 0.0000 & $0.000 \mathrm{E}+00$ & 0.0000 & $0.000 \mathrm{E}+00$ & 0.0000 & $0.000 \mathrm{E}+00$ & 0.0000 & $0.000 \mathrm{E}+00$ & 0.0000 & $0.000 \mathrm{E}+00$ & 0.0000 \\
\hline 35 & $1.201 E-12$ & 0.0000 & $0.000 \mathrm{E}+00$ & 0.0000 & $0.000 \mathrm{E}+00$ & 0.0000 & $0.000 \mathrm{E}+00$ & 0.0000 & $0.000 \mathrm{E}+00$ & 0.0000 & $0.000 \mathrm{E}+00$ & 0.0000 & $0.000 \mathrm{E}+00$ & 0.0000 \\
\hline 38 & $6.770 \mathrm{E}-08$ & 0.0035 & $0.000 \mathrm{E}+00$ & 0.0000 & $0.000 \mathrm{E}+00$ & 0.0000 & $0.000 \mathrm{E}+00$ & 0.0000 & $0.000 \mathrm{E}+00$ & 0.0000 & $0.000 \mathrm{E}+00$ & 0.0000 & $0.000 \mathrm{E}+00$ & 0.0000 \\
\hline & $1.908 E-05$ & 1.0000 & $0.000 \mathrm{E}+00$ & 0.0000 & $0.000 \mathrm{E}+00$ & 0.0000 & $0.000 \mathrm{E}+00$ & 0.0000 & $0.000 \mathrm{E}+00$ & 0.0000 & $0.000 \mathrm{E}+00$ & 0.0000 & $0.000 \mathrm{E}+00$ & 0.0000 \\
\hline
\end{tabular}

Total Dose Contributions TDOSE(i,p,t) for Individual Radionuclides (i) and Pathways (p) As mrem/yr and Fraction of Total Dose At $t=5.000 \mathrm{E}+01$ years

Water Dependent Pathways

\begin{tabular}{|c|c|c|c|c|c|c|c|c|c|c|c|c|c|c|}
\hline \multirow{2}{*}{ Nuclide } & \multicolumn{2}{|c|}{ Water } & \multicolumn{2}{|c|}{ Fish } & \multicolumn{2}{|c|}{ Radon } & \multicolumn{2}{|c|}{ Plant } & \multicolumn{2}{|c|}{ Meat } & \multicolumn{2}{|c|}{ Milk } & \multicolumn{2}{|c|}{ All Pathways* } \\
\hline & mrem/yr & fract. & mrem/yr & fract. & mrem/yr & fract. & mrem/yr & fract. & mrem/yr & fract. & mrem/yr & fract. & mrem/yr & fract. \\
\hline-241 & $0.000 \mathrm{E}+00$ & 0.0000 & $0.000 \mathrm{E}+00$ & 0.0000 & $0.000 \mathrm{E}+00$ & 0.0000 & $0.000 \mathrm{E}+00$ & 0.0000 & $0.000 \mathrm{E}+00$ & 0.0000 & $0.000 \mathrm{E}+00$ & 0.0000 & $1.795 \mathrm{E}-15$ & 0.0000 \\
\hline-137 & $0.000 \mathrm{E}+00$ & 0.0000 & $0.000 \mathrm{E}+00$ & 0.0000 & $0.000 \mathrm{E}+00$ & 0.0000 & $0.000 \mathrm{E}+00$ & 0.0000 & $0.000 \mathrm{E}+00$ & 0.0000 & $0.000 \mathrm{E}+00$ & 0.0000 & $2.299 \mathrm{E}-08$ & 0.0012 \\
\hline-237 & $0.000 \mathrm{E}+00$ & 0.0000 & $0.000 \mathrm{E}+00$ & 0.0000 & $0.000 \mathrm{E}+00$ & 0.0000 & $0.000 \mathrm{E}+00$ & 0.0000 & $0.000 \mathrm{E}+00$ & 0.0000 & $0.000 \mathrm{E}+00$ & 0.0000 & $1.791 \mathrm{E}-11$ & 0.0000 \\
\hline-238 & $0.000 \mathrm{E}+00$ & 0.0000 & $0.000 \mathrm{E}+00$ & 0.0000 & $0.000 \mathrm{E}+00$ & 0.0000 & $0.000 \mathrm{E}+00$ & 0.0000 & $0.000 \mathrm{E}+00$ & 0.0000 & $0.000 \mathrm{E}+00$ & 0.0000 & $4.107 \mathrm{E}-15$ & 0.0000 \\
\hline 239 & $0.000 \mathrm{E}+00$ & 0.0000 & $0.000 \mathrm{E}+00$ & 0.0000 & $0.000 \mathrm{E}+00$ & 0.0000 & $0.000 \mathrm{E}+00$ & 0.0000 & $0.000 \mathrm{E}+00$ & 0.0000 & $0.000 \mathrm{E}+00$ & 0.0000 & $1.572 \mathrm{E}-15$ & 0.0000 \\
\hline-240 & $0.000 \mathrm{E}+00$ & 0.0000 & $0.000 \mathrm{E}+00$ & 0.0000 & $0.000 \mathrm{E}+00$ & 0.0000 & $0.000 \mathrm{E}+00$ & 0.0000 & $0.000 \mathrm{E}+00$ & 0.0000 & $0.000 \mathrm{E}+00$ & 0.0000 & $1.931 \mathrm{E}-19$ & 0.0000 \\
\hline 99 & $0.000 \mathrm{E}+00$ & 0.0000 & $0.000 \mathrm{E}+00$ & 0.0000 & $0.000 \mathrm{E}+00$ & 0.0000 & $0.000 \mathrm{E}+00$ & 0.0000 & $0.000 \mathrm{E}+00$ & 0.0000 & $0.000 \mathrm{E}+00$ & 0.0000 & $9.958 \mathrm{E}-24$ & 0.0000 \\
\hline-228 & $0.000 \mathrm{E}+00$ & 0.0000 & $0.000 \mathrm{E}+00$ & 0.0000 & $0.000 \mathrm{E}+00$ & 0.0000 & $0.000 \mathrm{E}+00$ & 0.0000 & $0.000 \mathrm{E}+00$ & 0.0000 & $0.000 \mathrm{E}+00$ & 0.0000 & $2.021 \mathrm{E}-13$ & 0.0000 \\
\hline-230 & $0.000 \mathrm{E}+00$ & 0.0000 & $0.000 \mathrm{E}+00$ & 0.0000 & $0.000 \mathrm{E}+00$ & 0.0000 & $0.000 \mathrm{E}+00$ & 0.0000 & $0.000 \mathrm{E}+00$ & 0.0000 & $0.000 \mathrm{E}+00$ & 0.0000 & $1.064 \mathrm{E}-06$ & 0.0558 \\
\hline-232 & $0.000 \mathrm{E}+00$ & 0.0000 & $0.000 \mathrm{E}+00$ & 0.0000 & $0.000 \mathrm{E}+00$ & 0.0000 & $0.000 \mathrm{E}+00$ & 0.0000 & $0.000 \mathrm{E}+00$ & 0.0000 & $0.000 \mathrm{E}+00$ & 0.0000 & $1.793 E-05$ & 0.9395 \\
\hline 234 & $0.000 \mathrm{E}+00$ & 0.0000 & $0.000 \mathrm{E}+00$ & 0.0000 & $0.000 \mathrm{E}+00$ & 0.0000 & $0.000 \mathrm{E}+00$ & 0.0000 & $0.000 \mathrm{E}+00$ & 0.0000 & $0.000 \mathrm{E}+00$ & 0.0000 & $3.883 \mathrm{E}-10$ & 0.0000 \\
\hline 35 & $0.000 \mathrm{E}+00$ & 0.0000 & $0.000 \mathrm{E}+00$ & 0.0000 & $0.000 \mathrm{E}+00$ & 0.0000 & $0.000 \mathrm{E}+00$ & 0.0000 & $0.000 \mathrm{E}+00$ & 0.0000 & $0.000 \mathrm{E}+00$ & 0.0000 & $1.201 \mathrm{E}-12$ & 0.0000 \\
\hline 38 & $0.000 \mathrm{E}+00$ & 0.0000 & $0.000 \mathrm{E}+00$ & 0.0000 & $0.000 \mathrm{E}+00$ & 0.0000 & $0.000 \mathrm{E}+00$ & 0.0000 & $0.000 \mathrm{E}+00$ & 0.0000 & $0.000 \mathrm{E}+00$ & 0.0000 & $6.770 \mathrm{E}-08$ & 0.0035 \\
\hline & $0.000 \mathrm{E}+00$ & 0.0000 & $0.000 \mathrm{E}+00$ & 0.0000 & $0.000 \mathrm{E}+00$ & 0.0000 & $0.000 \mathrm{E}+00$ & 0.0000 & $0.000 \mathrm{E}+00$ & 0.0000 & $0.000 \mathrm{E}+00$ & 0.0000 & 1. $908 \mathrm{E}-05$ & 1.0000 \\
\hline
\end{tabular}

* Sum of all water independent and dependent pathways. 
RESRAD, Version $6.5 \quad T^{1 / 2}$ Limit $=180$ days $\quad 07 / 20 / 2011$ 14:43 Page 23

Summary : RESRAD Parameters for U-Landfill Resident Gardener Forward Run at ALs

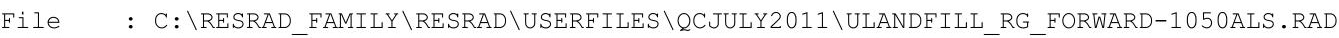

Total Dose Contributions TDOSE (i,p,t) for Individual Radionuclides (i) and Pathways (p) As mrem/yr and Fraction of Total Dose At $t=1.000 \mathrm{E}+02$ years

Water Independent Pathways (Inhalation excludes radon)

\begin{tabular}{|c|c|c|c|c|c|c|c|c|c|c|c|c|c|c|}
\hline \multirow{2}{*}{ Nuclide } & \multicolumn{2}{|c|}{ Ground } & \multicolumn{2}{|c|}{ Inhalation } & \multicolumn{2}{|c|}{ Radon } & \multicolumn{2}{|c|}{ Plant } & \multicolumn{2}{|c|}{ Meat } & \multicolumn{2}{|c|}{ Milk } & \multicolumn{2}{|c|}{ Soil } \\
\hline & mrem/yr & fract. & mrem/yr & fract. & mrem/yr & fract. & mrem/yr & fract. & mrem/yr & fract. & mrem/yr & fract. & mrem/yr & fract. \\
\hline-241 & $5.880 \mathrm{E}-15$ & 0.0000 & $0.000 \mathrm{E}+00$ & 0.0000 & $0.000 \mathrm{E}+00$ & 0.0000 & $0.000 \mathrm{E}+00$ & 0.0000 & $0.000 \mathrm{E}+00$ & 0.0000 & $0.000 \mathrm{E}+00$ & 0.0000 & $0.000 \mathrm{E}+00$ & 0.0000 \\
\hline-137 & $1.102 \mathrm{E}-08$ & 0.0004 & $0.000 \mathrm{E}+00$ & 0.0000 & $0.000 \mathrm{E}+00$ & 0.0000 & $0.000 \mathrm{E}+00$ & 0.0000 & $0.000 \mathrm{E}+00$ & 0.0000 & $0.000 \mathrm{E}+00$ & 0.0000 & $0.000 \mathrm{E}+00$ & 0.0000 \\
\hline-237 & $3.067 \mathrm{E}-11$ & 0.0000 & $0.000 \mathrm{E}+00$ & 0.0000 & $0.000 \mathrm{E}+00$ & 0.0000 & $0.000 \mathrm{E}+00$ & 0.0000 & $0.000 \mathrm{E}+00$ & 0.0000 & $0.000 \mathrm{E}+00$ & 0.0000 & $0.000 \mathrm{E}+00$ & 0.0000 \\
\hline-238 & $4.152 \mathrm{E}-14$ & 0.0000 & $0.000 \mathrm{E}+00$ & 0.0000 & $0.000 \mathrm{E}+00$ & 0.0000 & $0.000 \mathrm{E}+00$ & 0.0000 & $0.000 \mathrm{E}+00$ & 0.0000 & $0.000 \mathrm{E}+00$ & 0.0000 & $0.000 \mathrm{E}+00$ & 0.0000 \\
\hline-239 & $2.856 \mathrm{E}-15$ & 0.0000 & $0.000 \mathrm{E}+00$ & 0.0000 & $0.000 \mathrm{E}+00$ & 0.0000 & $0.000 \mathrm{E}+00$ & 0.0000 & $0.000 \mathrm{E}+00$ & 0.0000 & $0.000 \mathrm{E}+00$ & 0.0000 & $0.000 \mathrm{E}+00$ & 0.0000 \\
\hline-240 & $1.284 \mathrm{E}-18$ & 0.0000 & $0.000 \mathrm{E}+00$ & 0.0000 & $0.000 \mathrm{E}+00$ & 0.0000 & $0.000 \mathrm{E}+00$ & 0.0000 & $0.000 \mathrm{E}+00$ & 0.0000 & $0.000 \mathrm{E}+00$ & 0.0000 & $0.000 \mathrm{E}+00$ & 0.0000 \\
\hline 99 & $1.656 \mathrm{E}-23$ & 0.0000 & $0.000 \mathrm{E}+00$ & 0.0000 & $0.000 \mathrm{E}+00$ & 0.0000 & $0.000 \mathrm{E}+00$ & 0.0000 & $0.000 \mathrm{E}+00$ & 0.0000 & $0.000 \mathrm{E}+00$ & 0.0000 & $0.000 \mathrm{E}+00$ & 0.0000 \\
\hline-228 & $3.694 \mathrm{E}-21$ & 0.0000 & $0.000 \mathrm{E}+00$ & 0.0000 & $0.000 \mathrm{E}+00$ & 0.0000 & $0.000 \mathrm{E}+00$ & 0.0000 & $0.000 \mathrm{E}+00$ & 0.0000 & $0.000 \mathrm{E}+00$ & 0.0000 & $0.000 \mathrm{E}+00$ & 0.0000 \\
\hline-230 & $2.958 \mathrm{E}-06$ & 0.1082 & $0.000 \mathrm{E}+00$ & 0.0000 & $0.000 \mathrm{E}+00$ & 0.0000 & $0.000 \mathrm{E}+00$ & 0.0000 & $0.000 \mathrm{E}+00$ & 0.0000 & $0.000 \mathrm{E}+00$ & 0.0000 & $0.000 \mathrm{E}+00$ & 0.0000 \\
\hline-232 & $2.426 \mathrm{E}-05$ & 0.8876 & $0.000 \mathrm{E}+00$ & 0.0000 & $0.000 \mathrm{E}+00$ & 0.0000 & $0.000 \mathrm{E}+00$ & 0.0000 & $0.000 \mathrm{E}+00$ & 0.0000 & $0.000 \mathrm{E}+00$ & 0.0000 & $0.000 \mathrm{E}+00$ & 0.0000 \\
\hline 34 & $2.156 \mathrm{E}-09$ & 0.0001 & $0.000 \mathrm{E}+00$ & 0.0000 & $0.000 \mathrm{E}+00$ & 0.0000 & $0.000 \mathrm{E}+00$ & 0.0000 & $0.000 \mathrm{E}+00$ & 0.0000 & $0.000 \mathrm{E}+00$ & 0.0000 & $0.000 \mathrm{E}+00$ & 0.0000 \\
\hline 235 & $4.404 \mathrm{E}-12$ & 0.0000 & $0.000 \mathrm{E}+00$ & 0.0000 & $0.000 \mathrm{E}+00$ & 0.0000 & $0.000 \mathrm{E}+00$ & 0.0000 & $0.000 \mathrm{E}+00$ & 0.0000 & $0.000 \mathrm{E}+00$ & 0.0000 & $0.000 \mathrm{E}+00$ & 0.0000 \\
\hline 38 & $1.009 \mathrm{E}-07$ & 0.0037 & $0.000 \mathrm{E}+00$ & 0.0000 & $0.000 \mathrm{E}+00$ & 0.0000 & $0.000 \mathrm{E}+00$ & 0.0000 & $0.000 \mathrm{E}+00$ & 0.0000 & $0.000 \mathrm{E}+00$ & 0.0000 & $0.000 \mathrm{E}+00$ & 0.0000 \\
\hline & $2.733 E-05$ & 1.0000 & $0.000 \mathrm{E}+00$ & 0.0000 & $0.000 \mathrm{E}+00$ & 0.0000 & $0.000 \mathrm{E}+00$ & 0.0000 & $0.000 \mathrm{E}+00$ & 0.0000 & $0.000 \mathrm{E}+00$ & 0.0000 & $0.000 \mathrm{E}+00$ & 0.0000 \\
\hline
\end{tabular}

Total Dose Contributions TDOSE(i,p,t) for Individual Radionuclides (i) and Pathways (p) As mrem/yr and Fraction of Total Dose At $t=1.000 \mathrm{E}+02$ years

Water Dependent Pathways

\begin{tabular}{|c|c|c|c|c|c|c|c|c|c|c|c|c|c|c|}
\hline \multirow{2}{*}{$\begin{array}{l}\text { Radio- } \\
\text { Nuclide }\end{array}$} & \multicolumn{2}{|c|}{ Water } & \multicolumn{2}{|c|}{ Fish } & \multicolumn{2}{|c|}{ Radon } & \multicolumn{2}{|c|}{ Plant } & \multicolumn{2}{|c|}{ Meat } & \multicolumn{2}{|c|}{ Milk } & \multicolumn{2}{|c|}{ All Pathways* } \\
\hline & mrem/yr & fract. & mrem/yr & fract. & mrem/yr & fract. & mrem/yr & fract. & mrem/yr & fract. & mrem/yr & fract. & mrem/yr & fract. \\
\hline 241 & $0.000 \mathrm{E}+00$ & 0.0000 & $0.000 \mathrm{E}+00$ & 0.0000 & $0.000 \mathrm{E}+00$ & 0.0000 & $0.000 \mathrm{E}+00$ & 0.0000 & $0.000 \mathrm{E}+00$ & 0.0000 & $0.000 \mathrm{E}+00$ & 0.0000 & $5.880 \mathrm{E}-15$ & 0.0000 \\
\hline-137 & $0.000 \mathrm{E}+00$ & 0.0000 & $0.000 \mathrm{E}+00$ & 0.0000 & $0.000 \mathrm{E}+00$ & 0.0000 & $0.000 \mathrm{E}+00$ & 0.0000 & $0.000 \mathrm{E}+00$ & 0.0000 & $0.000 \mathrm{E}+00$ & 0.0000 & $1.102 \mathrm{E}-08$ & 0.0004 \\
\hline-237 & $0.000 \mathrm{E}+00$ & 0.0000 & $0.000 \mathrm{E}+00$ & 0.0000 & $0.000 \mathrm{E}+00$ & 0.0000 & $0.000 \mathrm{E}+00$ & 0.0000 & $0.000 \mathrm{E}+00$ & 0.0000 & $0.000 \mathrm{E}+00$ & 0.0000 & $3.067 \mathrm{E}-11$ & 0.0000 \\
\hline-238 & $0.000 \mathrm{E}+00$ & 0.0000 & $0.000 \mathrm{E}+00$ & 0.0000 & $0.000 \mathrm{E}+00$ & 0.0000 & $0.000 \mathrm{E}+00$ & 0.0000 & $0.000 \mathrm{E}+00$ & 0.0000 & $0.000 \mathrm{E}+00$ & 0.0000 & $4.152 \mathrm{E}-14$ & 0.0000 \\
\hline-239 & $0.000 \mathrm{E}+00$ & 0.0000 & $0.000 \mathrm{E}+00$ & 0.0000 & $0.000 \mathrm{E}+00$ & 0.0000 & $0.000 \mathrm{E}+00$ & 0.0000 & $0.000 \mathrm{E}+00$ & 0.0000 & $0.000 E+00$ & 0.0000 & $2.856 \mathrm{E}-15$ & 0.0000 \\
\hline-240 & $0.000 \mathrm{E}+00$ & 0.0000 & $0.000 \mathrm{E}+00$ & 0.0000 & $0.000 \mathrm{E}+00$ & 0.0000 & $0.000 \mathrm{E}+00$ & 0.0000 & $0.000 \mathrm{E}+00$ & 0.0000 & $0.000 E+00$ & 0.0000 & 1. $284 \mathrm{E}-18$ & 0.0000 \\
\hline-99 & $0.000 \mathrm{E}+00$ & 0.0000 & $0.000 \mathrm{E}+00$ & 0.0000 & $0.000 \mathrm{E}+00$ & 0.0000 & $0.000 \mathrm{E}+00$ & 0.0000 & $0.000 \mathrm{E}+00$ & 0.0000 & $0.000 \mathrm{E}+00$ & 0.0000 & $1.656 \mathrm{E}-23$ & 0.0000 \\
\hline-228 & $0.000 \mathrm{E}+00$ & 0.0000 & $0.000 \mathrm{E}+00$ & 0.0000 & $0.000 \mathrm{E}+00$ & 0.0000 & $0.000 \mathrm{E}+00$ & 0.0000 & $0.000 \mathrm{E}+00$ & 0.0000 & $0.000 \mathrm{E}+00$ & 0.0000 & $3.694 \mathrm{E}-21$ & 0.0000 \\
\hline-230 & $0.000 \mathrm{E}+00$ & 0.0000 & $0.000 \mathrm{E}+00$ & 0.0000 & $0.000 \mathrm{E}+00$ & 0.0000 & $0.000 \mathrm{E}+00$ & 0.0000 & $0.000 \mathrm{E}+00$ & 0.0000 & $0.000 E+00$ & 0.0000 & $2.958 E-06$ & 0.1082 \\
\hline 232 & $0.000 \mathrm{E}+00$ & 0.0000 & $0.000 \mathrm{E}+00$ & 0.0000 & $0.000 \mathrm{E}+00$ & 0.0000 & $0.000 \mathrm{E}+00$ & 0.0000 & $0.000 \mathrm{E}+00$ & 0.0000 & $0.000 \mathrm{E}+00$ & 0.0000 & $2.426 \mathrm{E}-05$ & 0.8876 \\
\hline 34 & $0.000 \mathrm{E}+00$ & 0.0000 & $0.000 \mathrm{E}+00$ & 0.0000 & $0.000 \mathrm{E}+00$ & 0.0000 & $0.000 \mathrm{E}+00$ & 0.0000 & $0.000 \mathrm{E}+00$ & 0.0000 & $0.000 \mathrm{E}+00$ & 0.0000 & $2.156 \mathrm{E}-09$ & 0.0001 \\
\hline 35 & $0.000 \mathrm{E}+00$ & 0.0000 & $0.000 \mathrm{E}+00$ & 0.0000 & $0.000 \mathrm{E}+00$ & 0.0000 & $0.000 \mathrm{E}+00$ & 0.0000 & $0.000 \mathrm{E}+00$ & 0.0000 & $0.000 \mathrm{E}+00$ & 0.0000 & $4.404 \mathrm{E}-12$ & 0.0000 \\
\hline 38 & $0.000 \mathrm{E}+00$ & 0.0000 & $0.000 \mathrm{E}+00$ & 0.0000 & $0.000 \mathrm{E}+00$ & 0.0000 & $0.000 \mathrm{E}+00$ & 0.0000 & $0.000 \mathrm{E}+00$ & 0.0000 & $0.000 \mathrm{E}+00$ & 0.0000 & $1.009 \mathrm{E}-07$ & 0.0037 \\
\hline & $0.000 \mathrm{E}+00$ & 0.0000 & $0.000 \mathrm{E}+00$ & 0.0000 & $0.000 \mathrm{E}+00$ & 0.0000 & $0.000 \mathrm{E}+00$ & 0.0000 & $0.000 \mathrm{E}+00$ & 0.0000 & $0.000 \mathrm{E}+00$ & 0.0000 & $3 E-05$ & 1.0000 \\
\hline
\end{tabular}

* Sum of all water independent and dependent pathways. 
RESRAD, Version $6.5 \quad$ T1/2 Limit $=180$ days $\quad$ 07/20/2011 14:43 Page 24

ummary : RESRAD Parameters for U-Landfill Resident Gardener Forward Run at ALs

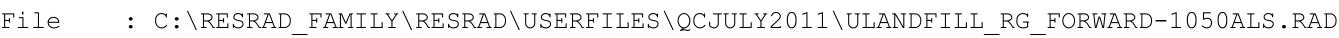

Total Dose Contributions TDOSE (i,p,t) for Individual Radionuclides (i) and Pathways (p) As mrem/yr and Fraction of Total Dose At $t=5.000 \mathrm{E}+02$ years

Water Independent Pathways (Inhalation excludes radon)

\begin{tabular}{|c|c|c|c|c|c|c|c|c|c|c|c|c|c|c|}
\hline & \multicolumn{2}{|c|}{ Ground } & \multicolumn{2}{|c|}{ Inhalation } & \multicolumn{2}{|c|}{ Radon } & \multicolumn{2}{|c|}{ Plant } & \multicolumn{2}{|c|}{ Meat } & \multicolumn{2}{|c|}{ Milk } & \multicolumn{2}{|c|}{ Soil } \\
\hline clide & mrem/yr & fract. & mrem/yr & fract. & mrem/yr & fract. & mrem/yr & fract. & mrem/yr & fract. & mrem/yr & fract. & mrem/yr & fract. \\
\hline 241 & $1.606 \mathrm{E}-12$ & 0.0000 & $0.000 \mathrm{E}+00$ & 0.0000 & $0.000 \mathrm{E}+00$ & 0.0000 & $0.000 \mathrm{E}+00$ & 0.0000 & $0.000 \mathrm{E}+00$ & 0.0000 & $0.000 \mathrm{E}+00$ & 0.0000 & $0.000 \mathrm{E}+00$ & 0.0000 \\
\hline-137 & $3.079 E-11$ & 0.0000 & $0.000 \mathrm{E}+00$ & 0.0000 & $0.000 \mathrm{E}+00$ & 0.0000 & $0.000 \mathrm{E}+00$ & 0.0000 & $0.000 \mathrm{E}+00$ & 0.0000 & $0.000 \mathrm{E}+00$ & 0.0000 & $0.000 \mathrm{E}+00$ & 0.0000 \\
\hline-237 & $2.249 E-09$ & 0.0000 & $0.000 \mathrm{E}+00$ & 0.0000 & $0.000 \mathrm{E}+00$ & 0.0000 & $0.000 \mathrm{E}+00$ & 0.0000 & $0.000 \mathrm{E}+00$ & 0.0000 & $0.000 \mathrm{E}+00$ & 0.0000 & $0.000 \mathrm{E}+00$ & 0.0000 \\
\hline-238 & $4.373 E-11$ & 0.0000 & $0.000 \mathrm{E}+00$ & 0.0000 & $0.000 \mathrm{E}+00$ & 0.0000 & $0.000 \mathrm{E}+00$ & 0.0000 & $0.000 \mathrm{E}+00$ & 0.0000 & $0.000 \mathrm{E}+00$ & 0.0000 & $0.000 \mathrm{E}+00$ & 0.0000 \\
\hline-239 & $3.390 \mathrm{E}-13$ & 0.0000 & $0.000 \mathrm{E}+00$ & 0.0000 & $0.000 \mathrm{E}+00$ & 0.0000 & $0.000 \mathrm{E}+00$ & 0.0000 & $0.000 \mathrm{E}+00$ & 0.0000 & $0.000 \mathrm{E}+00$ & 0.0000 & $0.000 \mathrm{E}+00$ & 0.0000 \\
\hline-240 & $4.117 \mathrm{E}-16$ & 0.0000 & $0.000 \mathrm{E}+00$ & 0.0000 & $0.000 \mathrm{E}+00$ & 0.0000 & $0.000 \mathrm{E}+00$ & 0.0000 & $0.000 \mathrm{E}+00$ & 0.0000 & $0.000 \mathrm{E}+00$ & 0.0000 & $0.000 \mathrm{E}+00$ & 0.0000 \\
\hline-99 & $9.682 \mathrm{E}-22$ & 0.0000 & $0.000 \mathrm{E}+00$ & 0.0000 & $0.000 \mathrm{E}+00$ & 0.0000 & $0.000 \mathrm{E}+00$ & 0.0000 & $0.000 \mathrm{E}+00$ & 0.0000 & $0.000 \mathrm{E}+00$ & 0.0000 & $0.000 \mathrm{E}+00$ & 0.0000 \\
\hline-228 & $0.000 \mathrm{E}+00$ & 0.0000 & $0.000 \mathrm{E}+00$ & 0.0000 & $0.000 \mathrm{E}+00$ & 0.0000 & $0.000 \mathrm{E}+00$ & 0.0000 & $0.000 \mathrm{E}+00$ & 0.0000 & $0.000 \mathrm{E}+00$ & 0.0000 & $0.000 \mathrm{E}+00$ & 0.0000 \\
\hline-230 & $2.142 \mathrm{E}-04$ & 0.4421 & $0.000 \mathrm{E}+00$ & 0.0000 & $0.000 \mathrm{E}+00$ & 0.0000 & $0.000 \mathrm{E}+00$ & 0.0000 & $0.000 \mathrm{E}+00$ & 0.0000 & $0.000 \mathrm{E}+00$ & 0.0000 & $0.000 \mathrm{E}+00$ & 0.0000 \\
\hline-232 & $2.671 E-04$ & 0.5512 & $0.000 \mathrm{E}+00$ & 0.0000 & $0.000 \mathrm{E}+00$ & 0.0000 & $0.000 \mathrm{E}+00$ & 0.0000 & $0.000 \mathrm{E}+00$ & 0.0000 & $0.000 \mathrm{E}+00$ & 0.0000 & $0.000 \mathrm{E}+00$ & 0.0000 \\
\hline 234 & $7.986 \mathrm{E}-07$ & 0.0016 & $0.000 \mathrm{E}+00$ & 0.0000 & $0.000 \mathrm{E}+00$ & 0.0000 & $0.000 \mathrm{E}+00$ & 0.0000 & $0.000 \mathrm{E}+00$ & 0.0000 & $0.000 \mathrm{E}+00$ & 0.0000 & $0.000 \mathrm{E}+00$ & 0.0000 \\
\hline 235 & $9.142 \mathrm{E}-10$ & 0.0000 & $0.000 \mathrm{E}+00$ & 0.0000 & $0.000 \mathrm{E}+00$ & 0.0000 & $0.000 \mathrm{E}+00$ & 0.0000 & $0.000 \mathrm{E}+00$ & 0.0000 & $0.000 \mathrm{E}+00$ & 0.0000 & $0.000 \mathrm{E}+00$ & 0.0000 \\
\hline 38 & $2.457 \mathrm{E}-06$ & 0.0051 & $0.000 \mathrm{E}+00$ & 0.0000 & $0.000 \mathrm{E}+00$ & 0.0000 & $0.000 \mathrm{E}+00$ & 0.0000 & $0.000 \mathrm{E}+00$ & 0.0000 & $0.000 \mathrm{E}+00$ & 0.0000 & $0.000 \mathrm{E}+00$ & 0.0000 \\
\hline & $4.845 E-04$ & 1.0000 & $0.000 \mathrm{E}+00$ & 0.0000 & $0.000 \mathrm{E}+00$ & 0.0000 & $0.000 \mathrm{E}+00$ & 0.0000 & $0.000 \mathrm{E}+00$ & 0.0000 & $0.000 \mathrm{E}+00$ & 0.0000 & $0.000 \mathrm{E}+00$ & 0.0000 \\
\hline
\end{tabular}

Total Dose Contributions TDOSE(i,p,t) for Individual Radionuclides (i) and Pathways (p) As mrem/yr and Fraction of Total Dose At $t=5.000 \mathrm{E}+02$ years

Water Dependent Pathways

\begin{tabular}{|c|c|c|c|c|c|c|c|c|c|c|c|c|c|c|}
\hline \multirow{2}{*}{$\begin{array}{l}\text { Radio- } \\
\text { Nuclide }\end{array}$} & \multicolumn{2}{|c|}{ Water } & \multicolumn{2}{|c|}{ Fish } & \multicolumn{2}{|c|}{ Radon } & \multicolumn{2}{|c|}{ Plant } & \multicolumn{2}{|c|}{ Meat } & \multicolumn{2}{|c|}{ Milk } & \multicolumn{2}{|c|}{ All Pathways* } \\
\hline & mrem/yr & fract. & mrem/yr & fract. & mrem/yr & fract. & mrem/yr & fract. & mrem/yr & fract. & mrem/yr & fract. & mrem/yr & fract. \\
\hline 241 & $0.000 \mathrm{E}+00$ & 0.0000 & $0.000 \mathrm{E}+00$ & 0.0000 & $0.000 \mathrm{E}+00$ & 0.0000 & $0.000 \mathrm{E}+00$ & 0.0000 & $0.000 \mathrm{E}+00$ & 0.0000 & $0.000 \mathrm{E}+00$ & 0.0000 & $1.606 \mathrm{E}-12$ & 0.0000 \\
\hline-137 & $0.000 \mathrm{E}+00$ & 0.0000 & $0.000 \mathrm{E}+00$ & 0.0000 & $0.000 \mathrm{E}+00$ & 0.0000 & $0.000 \mathrm{E}+00$ & 0.0000 & $0.000 \mathrm{E}+00$ & 0.0000 & $0.000 \mathrm{E}+00$ & 0.0000 & $3.079 \mathrm{E}-11$ & 0.0000 \\
\hline-237 & $0.000 \mathrm{E}+00$ & 0.0000 & $0.000 \mathrm{E}+00$ & 0.0000 & $0.000 \mathrm{E}+00$ & 0.0000 & $0.000 \mathrm{E}+00$ & 0.0000 & $0.000 \mathrm{E}+00$ & 0.0000 & $0.000 \mathrm{E}+00$ & 0.0000 & $2.249 E-09$ & 0.0000 \\
\hline-238 & $0.000 \mathrm{E}+00$ & 0.0000 & $0.000 \mathrm{E}+00$ & 0.0000 & $0.000 \mathrm{E}+00$ & 0.0000 & $0.000 \mathrm{E}+00$ & 0.0000 & $0.000 \mathrm{E}+00$ & 0.0000 & $0.000 \mathrm{E}+00$ & 0.0000 & $4.373 E-11$ & 0.0000 \\
\hline-239 & $0.000 \mathrm{E}+00$ & 0.0000 & $0.000 \mathrm{E}+00$ & 0.0000 & $0.000 \mathrm{E}+00$ & 0.0000 & $0.000 \mathrm{E}+00$ & 0.0000 & $0.000 \mathrm{E}+00$ & 0.0000 & $0.000 E+00$ & 0.0000 & $3.390 \mathrm{E}-13$ & 0.0000 \\
\hline-240 & $0.000 \mathrm{E}+00$ & 0.0000 & $0.000 \mathrm{E}+00$ & 0.0000 & $0.000 \mathrm{E}+00$ & 0.0000 & $0.000 \mathrm{E}+00$ & 0.0000 & $0.000 \mathrm{E}+00$ & 0.0000 & $0.000 E+00$ & 0.0000 & $4.117 \mathrm{E}-16$ & 0.0000 \\
\hline-99 & $0.000 \mathrm{E}+00$ & 0.0000 & $0.000 \mathrm{E}+00$ & 0.0000 & $0.000 \mathrm{E}+00$ & 0.0000 & $0.000 \mathrm{E}+00$ & 0.0000 & $0.000 \mathrm{E}+00$ & 0.0000 & $0.000 \mathrm{E}+00$ & 0.0000 & $9.682 \mathrm{E}-22$ & 0.0000 \\
\hline-228 & $0.000 \mathrm{E}+00$ & 0.0000 & $0.000 \mathrm{E}+00$ & 0.0000 & $0.000 \mathrm{E}+00$ & 0.0000 & $0.000 \mathrm{E}+00$ & 0.0000 & $0.000 \mathrm{E}+00$ & 0.0000 & $0.000 \mathrm{E}+00$ & 0.0000 & $0.000 \mathrm{E}+00$ & 0.0000 \\
\hline-230 & $0.000 \mathrm{E}+00$ & 0.0000 & $0.000 \mathrm{E}+00$ & 0.0000 & $0.000 \mathrm{E}+00$ & 0.0000 & $0.000 \mathrm{E}+00$ & 0.0000 & $0.000 \mathrm{E}+00$ & 0.0000 & $0.000 E+00$ & 0.0000 & $2.142 \mathrm{E}-04$ & 0.4421 \\
\hline 232 & $0.000 \mathrm{E}+00$ & 0.0000 & $0.000 \mathrm{E}+00$ & 0.0000 & $0.000 \mathrm{E}+00$ & 0.0000 & $0.000 \mathrm{E}+00$ & 0.0000 & $0.000 \mathrm{E}+00$ & 0.0000 & $0.000 \mathrm{E}+00$ & 0.0000 & $2.671 E-04$ & 0.5512 \\
\hline 34 & $0.000 \mathrm{E}+00$ & 0.0000 & $0.000 \mathrm{E}+00$ & 0.0000 & $0.000 \mathrm{E}+00$ & 0.0000 & $0.000 \mathrm{E}+00$ & 0.0000 & $0.000 \mathrm{E}+00$ & 0.0000 & $0.000 \mathrm{E}+00$ & 0.0000 & $7.986 \mathrm{E}-07$ & 0.0016 \\
\hline 35 & $0.000 \mathrm{E}+00$ & 0.0000 & $0.000 \mathrm{E}+00$ & 0.0000 & $0.000 \mathrm{E}+00$ & 0.0000 & $0.000 \mathrm{E}+00$ & 0.0000 & $0.000 \mathrm{E}+00$ & 0.0000 & $0.000 \mathrm{E}+00$ & 0.0000 & $9.142 \mathrm{E}-10$ & 0.0000 \\
\hline 38 & $0.000 \mathrm{E}+00$ & 0.0000 & $0.000 \mathrm{E}+00$ & 0.0000 & $0.000 \mathrm{E}+00$ & 0.0000 & $0.000 \mathrm{E}+00$ & 0.0000 & $0.000 \mathrm{E}+00$ & 0.0000 & $0.000 \mathrm{E}+00$ & 0.0000 & $2.457 \mathrm{E}-06$ & 0.0051 \\
\hline & $0.000 \mathrm{E}+00$ & 0.0000 & $0.000 \mathrm{E}+00$ & 0.0000 & $0.000 \mathrm{E}+00$ & 0.0000 & $0.000 \mathrm{E}+00$ & 0.0000 & $0.000 \mathrm{E}+00$ & 0.0000 & $0.000 \mathrm{E}+00$ & 0.0000 & $45 E-04$ & 1. \\
\hline
\end{tabular}

* Sum of all water independent and dependent pathways. 
RESRAD, Version $6.5 \quad T^{1 / 2}$ Limit $=180$ days $\quad 07 / 20 / 2011 \quad 14: 43$ Page 25

Summary : RESRAD Parameters for U-Landfill Resident Gardener Forward Run at ALs

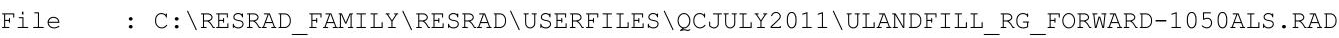

Total Dose Contributions TDOSE (i,p,t) for Individual Radionuclides (i) and Pathways (p) As mrem/yr and Fraction of Total Dose At $t=1.050 \mathrm{E}+03$ years

Water Independent Pathways (Inhalation excludes radon)

\begin{tabular}{|c|c|c|c|c|c|c|c|c|c|c|c|c|c|c|}
\hline & \multicolumn{2}{|c|}{ Ground } & \multicolumn{2}{|c|}{ Inhalation } & \multicolumn{2}{|c|}{ Radon } & \multicolumn{2}{|c|}{ Plant } & \multicolumn{2}{|c|}{ Meat } & \multicolumn{2}{|c|}{ Milk } & \multicolumn{2}{|c|}{ Soil } \\
\hline clide & mrem/yr & fract. & mrem/yr & fract. & mrem/yr & fract. & mrem/yr & fract. & mrem/yr & fract. & mrem/yr & fract. & mrem/yr & fract. \\
\hline 241 & $8.514 \mathrm{E}-10$ & 0.0000 & $0.000 \mathrm{E}+00$ & 0.0000 & $0.000 \mathrm{E}+00$ & 0.0000 & $1.388 \mathrm{E}-02$ & 0.0010 & $0.000 \mathrm{E}+00$ & 0.0000 & $0.000 \mathrm{E}+00$ & 0.0000 & $0.000 \mathrm{E}+00$ & 0.0000 \\
\hline-137 & $9.483 E-15$ & 0.0000 & $0.000 \mathrm{E}+00$ & 0.0000 & $0.000 \mathrm{E}+00$ & 0.0000 & $2.921 \mathrm{E}-12$ & 0.0000 & $0.000 \mathrm{E}+00$ & 0.0000 & $0.000 \mathrm{E}+00$ & 0.0000 & $0.000 \mathrm{E}+00$ & 0.0000 \\
\hline-237 & $7.819 E-07$ & 0.0000 & $0.000 \mathrm{E}+00$ & 0.0000 & $0.000 \mathrm{E}+00$ & 0.0000 & $1.127 \mathrm{E}-01$ & 0.0083 & $0.000 \mathrm{E}+00$ & 0.0000 & $0.000 \mathrm{E}+00$ & 0.0000 & $0.000 \mathrm{E}+00$ & 0.0000 \\
\hline-238 & $1.015 \mathrm{E}-08$ & 0.0000 & $0.000 \mathrm{E}+00$ & 0.0000 & $0.000 \mathrm{E}+00$ & 0.0000 & $4.765 E-05$ & 0.0000 & $0.000 \mathrm{E}+00$ & 0.0000 & $0.000 \mathrm{E}+00$ & 0.0000 & $0.000 \mathrm{E}+00$ & 0.0000 \\
\hline-239 & $2.403 E-10$ & 0.0000 & $0.000 \mathrm{E}+00$ & 0.0000 & $0.000 \mathrm{E}+00$ & 0.0000 & $9.132 \mathrm{E}-02$ & 0.0067 & $0.000 \mathrm{E}+00$ & 0.0000 & $0.000 \mathrm{E}+00$ & 0.0000 & $0.000 \mathrm{E}+00$ & 0.0000 \\
\hline-240 & $5.828 E-14$ & 0.0000 & $0.000 \mathrm{E}+00$ & 0.0000 & $0.000 \mathrm{E}+00$ & 0.0000 & $8.421 E-02$ & 0.0062 & $0.000 \mathrm{E}+00$ & 0.0000 & $0.000 \mathrm{E}+00$ & 0.0000 & $0.000 \mathrm{E}+00$ & 0.0000 \\
\hline-99 & $2.603 E-19$ & 0.0000 & $0.000 \mathrm{E}+00$ & 0.0000 & $0.000 \mathrm{E}+00$ & 0.0000 & $1.378 E-04$ & 0.0000 & $0.000 \mathrm{E}+00$ & 0.0000 & $0.000 \mathrm{E}+00$ & 0.0000 & $0.000 \mathrm{E}+00$ & 0.0000 \\
\hline-228 & $0.000 \mathrm{E}+00$ & 0.0000 & $0.000 \mathrm{E}+00$ & 0.0000 & $0.000 \mathrm{E}+00$ & 0.0000 & $0.000 \mathrm{E}+00$ & 0.0000 & $0.000 \mathrm{E}+00$ & 0.0000 & $0.000 \mathrm{E}+00$ & 0.0000 & $0.000 \mathrm{E}+00$ & 0.0000 \\
\hline-230 & 1.793E-02 & 0.0013 & $0.000 \mathrm{E}+00$ & 0.0000 & $0.000 \mathrm{E}+00$ & 0.0000 & $1.162 \mathrm{E}+01$ & 0.8509 & $0.000 \mathrm{E}+00$ & 0.0000 & $0.000 \mathrm{E}+00$ & 0.0000 & $0.000 \mathrm{E}+00$ & 0.0000 \\
\hline-232 & 7. $395 E-03$ & 0.0005 & $0.000 \mathrm{E}+00$ & 0.0000 & $0.000 \mathrm{E}+00$ & 0.0000 & $1.185 \mathrm{E}+00$ & 0.0868 & $0.000 \mathrm{E}+00$ & 0.0000 & $0.000 \mathrm{E}+00$ & 0.0000 & $0.000 \mathrm{E}+00$ & 0.0000 \\
\hline 234 & $1.454 \mathrm{E}-04$ & 0.0000 & $0.000 \mathrm{E}+00$ & 0.0000 & $0.000 \mathrm{E}+00$ & 0.0000 & $2.967 \mathrm{E}-01$ & 0.0217 & $0.000 \mathrm{E}+00$ & 0.0000 & $0.000 \mathrm{E}+00$ & 0.0000 & $0.000 \mathrm{E}+00$ & 0.0000 \\
\hline 35 & $3.053 \mathrm{E}-07$ & 0.0000 & $0.000 \mathrm{E}+00$ & 0.0000 & $0.000 \mathrm{E}+00$ & 0.0000 & $2.297 \mathrm{E}-02$ & 0.0017 & $0.000 \mathrm{E}+00$ & 0.0000 & $0.000 \mathrm{E}+00$ & 0.0000 & $0.000 \mathrm{E}+00$ & 0.0000 \\
\hline 38 & $1.984 \mathrm{E}-04$ & 0.0000 & $0.000 \mathrm{E}+00$ & 0.0000 & $0.000 \mathrm{E}+00$ & 0.0000 & $2.025 E-01$ & 0.0148 & $0.000 \mathrm{E}+00$ & 0.0000 & $0.000 \mathrm{E}+00$ & 0.0000 & $0.000 \mathrm{E}+00$ & 0.0000 \\
\hline & $2.567 \mathrm{E}-02$ & 0.0019 & $0.000 \mathrm{E}+00$ & 0.0000 & $0.000 \mathrm{E}+00$ & 0.0000 & $1.363 \mathrm{E}+01$ & 0.9981 & $0.000 \mathrm{E}+00$ & 0.0000 & $0.000 \mathrm{E}+00$ & 0.0000 & $0.000 \mathrm{E}+00$ & 0.0000 \\
\hline
\end{tabular}

Total Dose Contributions TDOSE(i,p,t) for Individual Radionuclides (i) and Pathways (p) As mrem/yr and Fraction of Total Dose At $t=1.050 \mathrm{E}+03$ years

Water Dependent Pathways

\begin{tabular}{|c|c|c|c|c|c|c|c|c|c|c|c|c|c|c|}
\hline \multirow{2}{*}{$\begin{array}{l}\text { Radio- } \\
\text { Nuclide }\end{array}$} & \multicolumn{2}{|c|}{ Water } & \multicolumn{2}{|c|}{ Fish } & \multicolumn{2}{|c|}{ Radon } & \multicolumn{2}{|c|}{ Plant } & \multicolumn{2}{|c|}{ Meat } & \multicolumn{2}{|c|}{ Milk } & \multicolumn{2}{|c|}{ All Pathways* } \\
\hline & mrem/yr & fract. & mrem/yr & fract. & mrem/yr & fract. & mrem/yr & fract. & mrem/yr & fract. & mrem/yr & fract. & mrem/yr & fract. \\
\hline 241 & $0.000 \mathrm{E}+00$ & 0.0000 & $0.000 \mathrm{E}+00$ & 0.0000 & $0.000 \mathrm{E}+00$ & 0.0000 & $0.000 \mathrm{E}+00$ & 0.0000 & $0.000 \mathrm{E}+00$ & 0.0000 & $0.000 \mathrm{E}+00$ & 0.0000 & $1.388 \mathrm{E}-02$ & 0.0010 \\
\hline-137 & $0.000 \mathrm{E}+00$ & 0.0000 & $0.000 \mathrm{E}+00$ & 0.0000 & $0.000 \mathrm{E}+00$ & 0.0000 & $0.000 \mathrm{E}+00$ & 0.0000 & $0.000 \mathrm{E}+00$ & 0.0000 & $0.000 \mathrm{E}+00$ & 0.0000 & $2.931 \mathrm{E}-12$ & 0.0000 \\
\hline-237 & $0.000 \mathrm{E}+00$ & 0.0000 & $0.000 \mathrm{E}+00$ & 0.0000 & $0.000 \mathrm{E}+00$ & 0.0000 & $0.000 \mathrm{E}+00$ & 0.0000 & $0.000 \mathrm{E}+00$ & 0.0000 & $0.000 \mathrm{E}+00$ & 0.0000 & $1.127 \mathrm{E}-01$ & 0.0083 \\
\hline-238 & $0.000 \mathrm{E}+00$ & 0.0000 & $0.000 \mathrm{E}+00$ & 0.0000 & $0.000 \mathrm{E}+00$ & 0.0000 & $0.000 \mathrm{E}+00$ & 0.0000 & $0.000 \mathrm{E}+00$ & 0.0000 & $0.000 \mathrm{E}+00$ & 0.0000 & $4.766 \mathrm{E}-05$ & 0.0000 \\
\hline-239 & $0.000 \mathrm{E}+00$ & 0.0000 & $0.000 \mathrm{E}+00$ & 0.0000 & $0.000 \mathrm{E}+00$ & 0.0000 & $0.000 \mathrm{E}+00$ & 0.0000 & $0.000 \mathrm{E}+00$ & 0.0000 & $0.000 E+00$ & 0.0000 & $9.132 \mathrm{E}-02$ & 0.0067 \\
\hline-240 & $0.000 \mathrm{E}+00$ & 0.0000 & $0.000 \mathrm{E}+00$ & 0.0000 & $0.000 \mathrm{E}+00$ & 0.0000 & $0.000 \mathrm{E}+00$ & 0.0000 & $0.000 \mathrm{E}+00$ & 0.0000 & $0.000 E+00$ & 0.0000 & $8.421 E-02$ & 0.0062 \\
\hline-99 & $0.000 \mathrm{E}+00$ & 0.0000 & $0.000 \mathrm{E}+00$ & 0.0000 & $0.000 \mathrm{E}+00$ & 0.0000 & $0.000 \mathrm{E}+00$ & 0.0000 & $0.000 \mathrm{E}+00$ & 0.0000 & $0.000 \mathrm{E}+00$ & 0.0000 & $1.378 \mathrm{E}-04$ & 0.0000 \\
\hline-228 & $0.000 \mathrm{E}+00$ & 0.0000 & $0.000 \mathrm{E}+00$ & 0.0000 & $0.000 \mathrm{E}+00$ & 0.0000 & $0.000 \mathrm{E}+00$ & 0.0000 & $0.000 \mathrm{E}+00$ & 0.0000 & $0.000 \mathrm{E}+00$ & 0.0000 & $0.000 \mathrm{E}+00$ & 0.0000 \\
\hline-230 & $0.000 \mathrm{E}+00$ & 0.0000 & $0.000 \mathrm{E}+00$ & 0.0000 & $0.000 \mathrm{E}+00$ & 0.0000 & $0.000 \mathrm{E}+00$ & 0.0000 & $0.000 \mathrm{E}+00$ & 0.0000 & $0.000 E+00$ & 0.0000 & $1.164 \mathrm{E}+01$ & 0.8522 \\
\hline 232 & $0.000 \mathrm{E}+00$ & 0.0000 & $0.000 \mathrm{E}+00$ & 0.0000 & $0.000 \mathrm{E}+00$ & 0.0000 & $0.000 \mathrm{E}+00$ & 0.0000 & $0.000 \mathrm{E}+00$ & 0.0000 & $0.000 \mathrm{E}+00$ & 0.0000 & $1.193 \mathrm{E}+00$ & 0.0873 \\
\hline 34 & $0.000 \mathrm{E}+00$ & 0.0000 & $0.000 \mathrm{E}+00$ & 0.0000 & $0.000 \mathrm{E}+00$ & 0.0000 & $0.000 \mathrm{E}+00$ & 0.0000 & $0.000 \mathrm{E}+00$ & 0.0000 & $0.000 \mathrm{E}+00$ & 0.0000 & $2.968 \mathrm{E}-01$ & 0.0217 \\
\hline 35 & $0.000 \mathrm{E}+00$ & 0.0000 & $0.000 \mathrm{E}+00$ & 0.0000 & $0.000 \mathrm{E}+00$ & 0.0000 & $0.000 \mathrm{E}+00$ & 0.0000 & $0.000 \mathrm{E}+00$ & 0.0000 & $0.000 \mathrm{E}+00$ & 0.0000 & $2.297 \mathrm{E}-02$ & 0.0017 \\
\hline 38 & $0.000 \mathrm{E}+00$ & 0.0000 & $0.000 \mathrm{E}+00$ & 0.0000 & $0.000 \mathrm{E}+00$ & 0.0000 & $0.000 \mathrm{E}+00$ & 0.0000 & $0.000 \mathrm{E}+00$ & 0.0000 & $0.000 \mathrm{E}+00$ & 0.0000 & $2.027 \mathrm{E}-01$ & 0.0148 \\
\hline & $0.000 \mathrm{E}+00$ & 0.0000 & $0.000 \mathrm{E}+00$ & 0.0000 & $0.000 \mathrm{E}+00$ & 0.0000 & $0.000 \mathrm{E}+00$ & 0.0000 & $0.000 \mathrm{E}+00$ & 0.0000 & $0.000 \mathrm{E}+00$ & 0.0000 & $5 E+01$ & 1. \\
\hline
\end{tabular}

* Sum of all water independent and dependent pathways. 
RESRAD, Version $6.5 \quad$ T1/2 Limit $=180$ days $\quad$ 07/20/2011 14:43 Page 26

Summary : RESRAD Parameters for U-Landfill Resident Gardener Forward Run at ALs

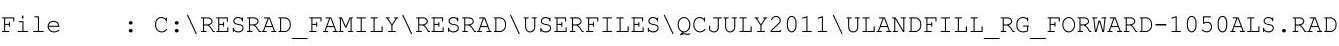

Dose/Source Ratios Summed Over All Pathways

Parent and Progeny Principal Radionuclide Contributions Indicated

Parent Product Thread DSR $(j, t)$ At Time in Years (mrem/yr)/(pCi/g)

(i)

(j) Fraction

$\overline{A m-241} \overline{1.000 \mathrm{E}+00}$

$\mathrm{Np}-237+\mathrm{D} \quad 1.000 \mathrm{E}+00$

$\mathrm{U}-233$

$1.000 \mathrm{E}+00$

Th-229+D 1.000E+00

$\sum \operatorname{DSR}(j)$

Cs $-137+D$

1. $000 \mathrm{E}+0$

$\mathrm{Np}-237+\mathrm{D}$

$\mathrm{U}-233$

1. $000 \mathrm{E}+00$

Th $-229+\mathrm{D}$

1. $000 \mathrm{E}+00$

$\sum \operatorname{DSR}(j)$

$\mathrm{Pu}-238$

\section{$\mathrm{Pu}-238$}

U-234

Th-230

Ra-226+D

$\mathrm{Pb}-210+\mathrm{D}$

$\sum \operatorname{DSR}(j)$

Pu-239

$\mathrm{U}-235+\mathrm{D}$

$\mathrm{Pa}-231$

$\mathrm{AC}-227+\mathrm{D}$

$\sum \operatorname{DSR}(j)$

$\mathrm{Pu}-240$

$\mathrm{Pu}-240$

U-236

Th-232

$\mathrm{Ra}-228+\mathrm{D}$

Th-228+D

$\sum \mathrm{DSR}(j)$

TC-99

Th-228+D

1. $000 \mathrm{E}+00$

Th-230

1. $000 \mathrm{E}+00$

$\mathrm{Ra}-226+\mathrm{D}$

$1.000 \mathrm{E}+00$

$\mathrm{Pb}-210+\mathrm{D}$

$\sum \operatorname{DSR}(j)$

$0.000 \mathrm{E}+00 \quad 1.000 \mathrm{E}+00 \quad 5.000 \mathrm{E}+01 \quad 1.000 \mathrm{E}+02 \quad 5.000 \mathrm{E}+02 \quad 1.050 \mathrm{E}+03$

$\begin{array}{lllllll}1.936 \mathrm{E}-33 & 1.989 \mathrm{E}-33 & 7.353 \mathrm{E}-33 & 2.792 \mathrm{E}-32 & 1.208 \mathrm{E}-27 & 1.965 \mathrm{E}-04\end{array}$

$\begin{array}{lllllllll}1.546 \mathrm{E}-19 & 4.680 \mathrm{E}-19 & 2.562 \mathrm{E}-17 & 8.382 \mathrm{E}-17 & 2.263 \mathrm{E}-14 & 1.773 \mathrm{E}-06\end{array}$

$3.506 \mathrm{E}-30 \quad 2.479 \mathrm{E}-29 \quad 4.863 \mathrm{E}-26 \quad 3.503 \mathrm{E}-25 \quad 1.053 \mathrm{E}-21 \quad 3.056 \mathrm{E}-10$

$2.399 \mathrm{E}-26 \quad 3.618 \mathrm{E}-25 \quad 1.710 \mathrm{E}-20 \quad 1.868 \mathrm{E}-19 \quad 3.195 \mathrm{E}-16 \quad 5.403 \mathrm{E}-11$

$\begin{array}{lllllll}1.546 \mathrm{E}-19 & 4.680 \mathrm{E}-19 & 2.564 \mathrm{E}-17 & 8.401 \mathrm{E}-17 & 2.295 \mathrm{E}-14 & 1.983 \mathrm{E}-04\end{array}$

$\begin{array}{llllll}.262 \mathrm{E}-09 & 1.243 \mathrm{E}-09 & 6.050 \mathrm{E}-10 & 2.901 \mathrm{E}-10 & 8.104 \mathrm{E}-13 & 7.713 \mathrm{E}-14\end{array}$

$9.536 \mathrm{E}-13 \quad 9.638 \mathrm{E}-13 \quad 1.625 \mathrm{E}-12 \quad 2.770 \mathrm{E}-12 \quad 1.974 \mathrm{E}-10 \quad 1.025 \mathrm{E}-02$

$\begin{array}{lllllll}.245 \mathrm{E}-23 & 9.844 \mathrm{E}-23 & 6.100 \mathrm{E}-21 & 2.264 \mathrm{E}-20 & 1.650 \mathrm{E}-17 & 2.871 \mathrm{E}-06\end{array}$

$2.962 \mathrm{E}-19 \quad 2.086 \mathrm{E}-18 \quad 3.196 \mathrm{E}-15 \quad 1.788 \mathrm{E}-14 \quad 7.080 \mathrm{E}-12 \quad 6.801 \mathrm{E}-07$

$9.536 \mathrm{E}-13 \quad 9.638 \mathrm{E}-13 \quad 1.629 \mathrm{E}-12 \quad 2.788 \mathrm{E}-12 \quad 2.044 \mathrm{E}-10 \quad 1.025 \mathrm{E}-02$

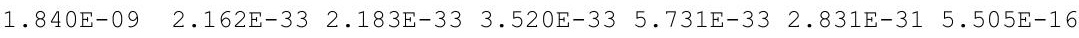

$\begin{array}{lllllllll}1.000 \mathrm{E}+00 & 1.175 \mathrm{E}-24 & 1.186 \mathrm{E}-24 & 1.913 \mathrm{E}-24 & 3.115 \mathrm{E}-24 & 1.539 \mathrm{E}-22 & 2.992 \mathrm{E}-07\end{array}$

$\begin{array}{lllllll}1.000 \mathrm{E}+00 & 9.778 \mathrm{E}-30 & 2.969 \mathrm{E}-29 & 1.973 \mathrm{E}-27 & 7.960 \mathrm{E}-27 & 1.690 \mathrm{E}-23 & 2.276 \mathrm{E}-07\end{array}$

$\begin{array}{lllllll}1.000 \mathrm{E}+00 & 1.028 \mathrm{E}-33 & 7.286 \mathrm{E}-33 & 1.599 \mathrm{E}-29 & 1.302 \mathrm{E}-28 & 1.306 \mathrm{E}-24 & 3.273 \mathrm{E}-09\end{array}$

$\begin{array}{lllllll}1.000 \mathrm{E}+00 & 8.021 \mathrm{E}-23 & 1.208 \mathrm{E}-21 & 5.266 \mathrm{E}-17 & 5.323 \mathrm{E}-16 & 5.607 \mathrm{E}-13 & 3.143 \mathrm{E}-08\end{array}$

$\begin{array}{llllllll}1.000 \mathrm{E}+00 & 2.326 \mathrm{E}-31 & 7.210 \mathrm{E}-30 & 7.772 \mathrm{E}-24 & 1.314 \mathrm{E}-22 & 3.671 \mathrm{E}-19 & 4.946 \mathrm{E}-08\end{array}$

$\begin{array}{llllll}8.139 \mathrm{E}-23 & 1.209 \mathrm{E}-21 & 5.266 \mathrm{E}-17 & 5.323 \mathrm{E}-16 & 5.607 \mathrm{E}-13 & 6.110 \mathrm{E}-07\end{array}$

$\begin{array}{lllllllll}1.000 \mathrm{E}+00 & 1.202 \mathrm{E}-17 & 1.217 \mathrm{E}-17 & 2.183 \mathrm{E}-17 & 3.965 \mathrm{E}-17 & 4.690 \mathrm{E}-15 & 1.268 \mathrm{E}-03\end{array}$

$\begin{array}{lllllll}1.000 \mathrm{E}+00 & 6.135 \mathrm{E}-24 & 1.861 \mathrm{E}-23 & 1.146 \mathrm{E}-21 & 4.227 \mathrm{E}-21 & 2.931 \mathrm{E}-18 & 6.291 \mathrm{E}-10\end{array}$

$\begin{array}{lllllll}1.000 \mathrm{E}+00 & 9.652 \mathrm{E}-28 & 6.818 \mathrm{E}-27 & 1.251 \mathrm{E}-23 & 8.414 \mathrm{E}-23 & 1.444 \mathrm{E}-19 & 4.191 \mathrm{E}-10\end{array}$

$\begin{array}{llllllll}1.000 \mathrm{E}+00 & 2.288 \mathrm{E}-27 & 3.434 \mathrm{E}-26 & 1.276 \mathrm{E}-21 & 1.169 \mathrm{E}-20 & 1.476 \mathrm{E}-17 & 1.686 \mathrm{E}-10\end{array}$

$\begin{array}{llllll}1.202 \mathrm{E}-17 & 1.217 \mathrm{E}-17 & 2.183 \mathrm{E}-17 & 3.966 \mathrm{E}-17 & 4.708 \mathrm{E}-15 & 1.268 \mathrm{E}-03\end{array}$

$\begin{array}{lllllll}4.950 E-08 & 5.653 E-32 & 5.753 E-32 & 1.359 E-31 & 3.267 E-31 & 3.647 E-28 & 5.789 E-11\end{array}$

$\begin{array}{llllllll}1.000 \mathrm{E}+00 & 1.142 \mathrm{E}-24 & 1.162 \mathrm{E}-24 & 2.746 \mathrm{E}-24 & 6.601 \mathrm{E}-24 & 7.367 \mathrm{E}-21 & 1.170 \mathrm{E}-03\end{array}$

$\begin{array}{lllllll}1.000 \mathrm{E}+00 & 2.162 \mathrm{E}-32 & 6.590 \mathrm{E}-32 & 5.335 \mathrm{E}-30 & 2.602 \mathrm{E}-29 & 1.686 \mathrm{E}-25 & 1.804 \mathrm{E}-08\end{array}$

$\begin{array}{lllllll}1.000 \mathrm{E}+00 \quad 2.845 \mathrm{E}-43 & 2.028 \mathrm{E}-42 & 5.480 \mathrm{E}-39 & 5.478 \mathrm{E}-38 & 2.238 \mathrm{E}-33 & 9.371 \mathrm{E}-16\end{array}$

$\begin{array}{llllllll}1.000 \mathrm{E}+00 & 1.371 \mathrm{E}-28 & 2.018 \mathrm{E}-27 & 3.762 \mathrm{E}-23 & 2.542 \mathrm{E}-22 & 1.470 \mathrm{E}-19 & 1.102 \mathrm{E}-13\end{array}$

$\begin{array}{llllllll}1.000 \mathrm{E}+00 & 8.111 \mathrm{E}-28 & 2.334 \mathrm{E}-26 & 2.641 \mathrm{E}-21 & 1.757 \mathrm{E}-20 & 5.564 \mathrm{E}-18 & 1.510 \mathrm{E}-15\end{array}$

$\begin{array}{llllll}1.143 \mathrm{E}-24 & 1.188 \mathrm{E}-24 & 2.681 \mathrm{E}-21 & 1.783 \mathrm{E}-20 & 5.719 \mathrm{E}-18 & 1.170 \mathrm{E}-03\end{array}$

$1.000 \mathrm{E}+00 \quad 5.758 \mathrm{E}-26 \quad 5.817 \mathrm{E}-26 \quad 9.575 \mathrm{E}-26 \quad 1.592 \mathrm{E}-25 \quad 9.310 \mathrm{E}-24 \quad 1.325 \mathrm{E}-06$

$\begin{array}{llllll}.382 \mathrm{E}-06 & 9.680 \mathrm{E}-07 & 2.527 \mathrm{E}-14 & 4.618 \mathrm{E}-22 & 0.000 \mathrm{E}+00 & 0.000 \mathrm{E}+00\end{array}$

.412E-22 2.453E-22 5.590E-22 $1.295 \mathrm{E}-21 \quad 1.078 \mathrm{E}-18 \quad 1.104 \mathrm{E}-03$

$\begin{array}{llllll}3.774 \mathrm{E}-11 & 1.139 \mathrm{E}-10 & 5.320 \mathrm{E}-09 & 1.479 \mathrm{E}-08 & 1.071 \mathrm{E}-06 & 2.165 \mathrm{E}-02\end{array}$

$\begin{array}{llllll}1.819 \mathrm{E}-19 & 1.271 \mathrm{E}-18 & 1.299 \mathrm{E}-15 & 5.314 \mathrm{E}-15 & 7.678 \mathrm{E}-13 & 3.543 \mathrm{E}-02\end{array}$

$\begin{array}{llllll}3.774 \mathrm{E}-11 & 1.139 \mathrm{E}-10 & 5.320 \mathrm{E}-09 & 1.479 \mathrm{E}-08 & 1.071 \mathrm{E}-06 & 5.818 \mathrm{E}-02\end{array}$ 
RESRAD, Version $6.5 \quad$ T1/2 Limit $=180$ days $\quad 07 / 20 / 2011 \quad 14: 43$ Page 27

Summary : RESRAD Parameters for U-Landfill Resident Gardener Forward Run at ALs

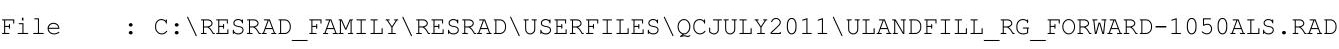

Dose/Source Ratios Summed Over All Pathways

Parent and Progeny Principal Radionuclide Contributions Indicated

\begin{tabular}{|c|c|c|c|c|c|c|c|c|}
\hline Parent & Product & Thread & DSR & $(j, t)$ At & ime in Yea & (mrem, & $(\mathrm{yr}) /(\mathrm{pCi} / \mathrm{q}$ & \\
\hline (i) & (j) & Fraction & $0.000 \mathrm{E}+00$ & $1.000 \mathrm{E}+00$ & $5.000 \mathrm{E}+01$ & $1.000 \mathrm{E}+02$ & $5.000 \mathrm{E}+02$ & $1.050 \mathrm{E}+03$ \\
\hline-232 & Th-232 & $1.000 \mathrm{E}+00$ & $1.166 \mathrm{E}-24$ & $1.188 \mathrm{E}-24$ & $2.949 \mathrm{E}-24$ & 7. $462 \mathrm{E}-24$ & $1.252 \mathrm{E}-20$ & $1.221 \mathrm{E}-03$ \\
\hline-232 & $\mathrm{Ra}-228+\mathrm{D}$ & $1.000 \mathrm{E}+00$ & $1.107 \mathrm{E}-09$ & $3.174 \mathrm{E}-09$ & $2.784 \mathrm{E}-08$ & $4.079 \mathrm{E}-08$ & $8.497 \mathrm{E}-07$ & 1. $458 \mathrm{E}-01$ \\
\hline-232 & $\mathrm{Th}-228+\mathrm{D}$ & $1.000 \mathrm{E}+00$ & $1.067 \mathrm{E}-08$ & $6.581 \mathrm{E}-08$ & $2.213 \mathrm{E}-06$ & $2.992 \mathrm{E}-06$ & $3.253 E-05$ & $2.007 \mathrm{E}-03$ \\
\hline-232 & $\sum \operatorname{DSR}(j)$ & & $1.178 \mathrm{E}-08$ & $6.899 \mathrm{E}-08$ & $2.241 \mathrm{E}-06$ & $3.033 \mathrm{E}-06$ & $3.338 E-05$ & $1.491 \mathrm{E}-01$ \\
\hline 234 & $U-234$ & $1.000 \mathrm{E}+00$ & $6.896 \mathrm{E}-24$ & $7.019 \mathrm{E}-24$ & $1.670 \mathrm{E}-23$ & $4.047 \mathrm{E}-23$ & 4. $798 E-20$ & $6.337 \mathrm{E}-04$ \\
\hline-234 & Th-230 & $1.000 \mathrm{E}+00$ & $1.089 \mathrm{E}-27$ & $3.315 E-27$ & $2.540 \mathrm{E}-25$ & $1.171 \mathrm{E}-24$ & $4.838 E-21$ & $1.037 \mathrm{E}-05$ \\
\hline-234 & $\mathrm{Ra}-226+\mathrm{D}$ & $1.000 \mathrm{E}+00$ & $1.133 \mathrm{E}-16$ & $7.978 \mathrm{E}-16$ & 1. $213 \mathrm{E}-12$ & $6.737 \mathrm{E}-12$ & $2.496 \mathrm{E}-09$ & $1.097 \mathrm{E}-04$ \\
\hline-234 & $\mathrm{~Pb}-210+\mathrm{D}$ & $1.000 \mathrm{E}+00$ & $4.102 E-25$ & $6.153 E-24$ & $2.201 \mathrm{E}-19$ & $1.935 \mathrm{E}-18$ & $1.678 \mathrm{E}-15$ & $1.738 \mathrm{E}-04$ \\
\hline 234 & $\sum \operatorname{DSR}(j)$ & & $1.133 E-16$ & $7.978 E-16$ & 1. $213 \mathrm{E}-12$ & $6.737 \mathrm{E}-12$ & $2.496 \mathrm{E}-09$ & $9.276 \mathrm{E}-04$ \\
\hline$-235+D$ & $\mathrm{U}-235+\mathrm{D}$ & $1.000 \mathrm{E}+00$ & 1. $243 \mathrm{E}-14$ & 1. $259 \mathrm{E}-14$ & $2.306 \mathrm{E}-14$ & $4.276 \mathrm{E}-14$ & $5.981 \mathrm{E}-12$ & $6.155 \mathrm{E}-04$ \\
\hline$-235+D$ & $\mathrm{~Pa}-231$ & $1.000 \mathrm{E}+00$ & $2.937 \mathrm{E}-18$ & $8.896 \mathrm{E}-18$ & $5.031 \mathrm{E}-16$ & $1.701 \mathrm{E}-15$ & $5.876 \mathrm{E}-13$ & $8.145 \mathrm{E}-04$ \\
\hline$-235+D$ & $A C-227+D$ & $1.000 \mathrm{E}+00$ & $9.274 \mathrm{E}-18$ & $6.481 \mathrm{E}-17$ & $6.882 \mathrm{E}-14$ & $2.943 \mathrm{E}-13$ & $6.376 \mathrm{E}-11$ & $3.373 E-04$ \\
\hline$-235+D$ & $\sum \operatorname{DSR}(j)$ & & 1. $245 \mathrm{E}-14$ & $1.266 \mathrm{E}-14$ & $9.238 \mathrm{E}-14$ & $3.388 \mathrm{E}-13$ & $7.033 E-11$ & $1.767 \mathrm{E}-03$ \\
\hline-238 & $\mathrm{U}-238$ & $5.400 \mathrm{E}-05$ & $0.000 \mathrm{E}+00$ & $0.000 \mathrm{E}+00$ & $0.000 \mathrm{E}+00$ & $0.000 \mathrm{E}+00$ & $0.000 \mathrm{E}+00$ & $3.167 \mathrm{E}-08$ \\
\hline$-238+D$ & $\mathrm{U}-238+\mathrm{D}$ & $9.999 \mathrm{E}-01$ & 1. $420 \mathrm{E}-10$ & $1.431 \mathrm{E}-10$ & $2.116 \mathrm{E}-10$ & $3.153 E-10$ & $7.678 E-09$ & $6.313 E-04$ \\
\hline$-238+D$ & $\mathrm{U}-234$ & $9.999 \mathrm{E}-01$ & $9.803 E-30$ & $2.988 \mathrm{E}-29$ & $2.392 \mathrm{E}-27$ & $1.153 \mathrm{E}-26$ & $6.812 \mathrm{E}-23$ & $1.890 \mathrm{E}-06$ \\
\hline$-238+D$ & $\mathrm{Th}-230$ & $9.999 \mathrm{E}-01$ & $1.030 \mathrm{E}-33$ & 7. $316 \mathrm{E}-33$ & $1.818 \mathrm{E}-29$ & $1.668 \mathrm{E}-28$ & $3.430 E-24$ & $1.541 \mathrm{E}-08$ \\
\hline$-238+D$ & $\mathrm{Ra}-226+\mathrm{D}$ & $9.999 \mathrm{E}-01$ & $8.034 E-23$ & 1. $212 \mathrm{E}-21$ & $5.801 \mathrm{E}-17$ & $6.420 \mathrm{E}-16$ & 1. $201 \mathrm{E}-12$ & $1.127 \mathrm{E}-07$ \\
\hline$-238+D$ & $\mathrm{~Pb}-210+\mathrm{D}$ & $9.999 \mathrm{E}-01$ & $2.329 E-31$ & 7. $229 \mathrm{E}-30$ & $8.430 \mathrm{E}-24$ & $1.546 \mathrm{E}-22$ & 7. $612 \mathrm{E}-19$ & $1.734 \mathrm{E}-07$ \\
\hline$-238+D$ & $\sum \operatorname{DSR}(j)$ & & $1.420 \mathrm{E}-10$ & $1.431 \mathrm{E}-10$ & $2.116 \mathrm{E}-10$ & $3.153 \mathrm{E}-10$ & $7.680 \mathrm{E}-09$ & $6.335 E-04$ \\
\hline
\end{tabular}

The DSR includes contributions from associated (half-life $\leq 180$ days) daughters. 
RESRAD, Version $6.5 \quad T^{1 / 2}$ Limit $=180$ days $\quad 07 / 20 / 2011 \quad 14: 43$ Page 28

Summary : RESRAD Parameters for U-Landfill Resident Gardener Forward Run at ALs

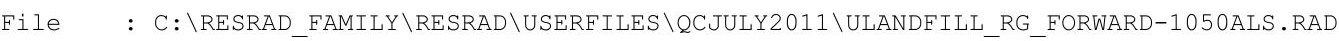

Single Radionuclide Soil Guidelines $G(i, t)$ in $\mathrm{pCi} / \mathrm{g}$

Basic Radiation Dose Limit $=1.000 \mathrm{E}+02 \mathrm{mrem} / \mathrm{yr}$

Nuclide

\begin{tabular}{|c|c|c|c|c|c|c|}
\hline (i) & $t=0.000 E+00$ & $1.000 \mathrm{E}+00$ & $5.000 \mathrm{E}+01$ & $1.000 \mathrm{E}+02$ & $5.000 \mathrm{E}+02$ & $1.050 \mathrm{E}+03$ \\
\hline $1-241$ & $\star 3.431 \mathrm{E}+12$ & $\star 3.431 \mathrm{E}+12$ & $\star 3.431 \mathrm{E}+12$ & $\star 3.431 \mathrm{E}+12$ & $\star 3.431 \mathrm{E}+12$ & $5.044 \mathrm{E}+05$ \\
\hline$s-137$ & $7.925 E+10$ & $8.043 E+10$ & $1.653 \mathrm{E}+11$ & $3.447 \mathrm{E}+11$ & $\star 8.704 \mathrm{E}+13$ & $\star 8.704 \mathrm{E}+13$ \\
\hline$p-237$ & $\star 7.047 \mathrm{E}+08$ & $\star 7.047 \mathrm{E}+08$ & $\star 7.047 \mathrm{E}+08$ & $\star 7.047 \mathrm{E}+08$ & $\star 7.047 \mathrm{E}+08$ & $9.756 \mathrm{E}+03$ \\
\hline$u-238$ & $\star 1.712 \mathrm{E}+13$ & $\star 1.712 \mathrm{E}+13$ & $\star 1.712 \mathrm{E}+13$ & $\star 1.712 \mathrm{E}+13$ & $\star 1.712 \mathrm{E}+13$ & $1.637 \mathrm{E}+08$ \\
\hline $\mathrm{Pu}-239$ & $\star 6.214 \mathrm{E}+10$ & $\star 6.214 \mathrm{E}+10$ & $* 6.214 \mathrm{E}+10$ & $\star 6.214 \mathrm{E}+10$ & $\star 6.214 \mathrm{E}+10$ & $7.884 \mathrm{E}+04$ \\
\hline $\mathrm{Pu}-240$ & $\star 2.278 E+11$ & $\star 2.278 \mathrm{E}+11$ & $\star 2.278 \mathrm{E}+11$ & $\star 2.278 \mathrm{E}+11$ & $\star 2.278 \mathrm{E}+11$ & $8.550 \mathrm{E}+04$ \\
\hline TC-99 & $* 1.697 \mathrm{E}+10$ & $* 1.697 \mathrm{E}+10$ & $\star 1.697 \mathrm{E}+10$ & $* 1.697 \mathrm{E}+10$ & $\star 1.697 \mathrm{E}+10$ & $7.545 \mathrm{E}+07$ \\
\hline Th-228 & $7.234 \mathrm{E}+07$ & $1.033 \mathrm{E}+08$ & $\star 8.195 \mathrm{E}+14$ & $\star 8.195 \mathrm{E}+14$ & $\star 8.195 \mathrm{E}+14$ & $\star 8.195 \mathrm{E}+14$ \\
\hline Th-230 & $\star 2.018 \mathrm{E}+10$ & $\star 2.018 \mathrm{E}+10$ & $1.880 \mathrm{E}+10$ & $6.761 \mathrm{E}+09$ & $9.336 \mathrm{E}+07$ & $1.719 \mathrm{E}+03$ \\
\hline Th-232 & $\star 1.097 \mathrm{E}+05$ & $* 1.097 \mathrm{E}+05$ & $* 1.097 \mathrm{E}+05$ & $\star 1.097 \mathrm{E}+05$ & $\star 1.097 \mathrm{E}+05$ & $6.708 \mathrm{E}+02$ \\
\hline $\mathrm{U}-234$ & $\star 6.247 \mathrm{E}+09$ & $\star 6.247 \mathrm{E}+09$ & $\star 6.247 \mathrm{E}+09$ & $* 6.247 \mathrm{E}+09$ & $\star 6.247 \mathrm{E}+09$ & $1.078 \mathrm{E}+05$ \\
\hline 35 & $\star 2.161 \mathrm{E}+06$ & $\star 2.161 \mathrm{E}+06$ & $\star 2.161 \mathrm{E}+06$ & $\star 2.161 \mathrm{E}+06$ & $\star 2.161 \mathrm{E}+06$ & $5.658 \mathrm{E}+04$ \\
\hline 238 & $\star 3.361 \mathrm{E}+05$ & $\star 3.361 \mathrm{E}+05$ & $\star 3.361 \mathrm{E}+05$ & $\star 3.361 \mathrm{E}+05$ & $\star 3.361 \mathrm{E}+05$ & $1.578 \mathrm{E}+05$ \\
\hline
\end{tabular}

*At specific activity limit

Summed Dose/Source Ratios DSR (i,t) in (mrem/yr)/(pCi/g)

and Single Radionuclide Soil Guidelines G(i,t) in pCi/g

at $\operatorname{tmin}=$ time of minimum single radionuclide soil guideline

and at $\operatorname{tmax}=$ time of maximum total dose $=1.050 \mathrm{E}+03$ years

\begin{tabular}{|c|c|c|c|c|c|c|}
\hline $\begin{array}{l}\text { uclide } \\
\text { (i) }\end{array}$ & $\begin{array}{l}\text { Initial } \\
(\mathrm{pCi} / \mathrm{g})\end{array}$ & $\begin{array}{c}\text { tmin } \\
\text { (years) }\end{array}$ & $\operatorname{DSR}(i, \operatorname{tmin})$ & $\begin{array}{c}G(i, \text { tmin }) \\
(p C i / g)\end{array}$ & $\operatorname{DSR}(i, t \max )$ & $\begin{array}{c}G(i, t \max ) \\
(\mathrm{pCi} / \mathrm{g})\end{array}$ \\
\hline $1-241$ & $7.000 \mathrm{E}+01$ & $1.050 \mathrm{E}+03$ & 1. $983 E-04$ & $5.044 E+05$ & $1.983 E-04$ & $5.044 \mathrm{E}+05$ \\
\hline-137 & $3.800 \mathrm{E}+01$ & $0.000 \mathrm{E}+00$ & $1.262 E-09$ & $7.925 E+10$ & $7.713 E-14$ & $\star 8.704 \mathrm{E}+13$ \\
\hline-237 & $1.100 \mathrm{E}+01$ & $1.050 \mathrm{E}+03$ & $1.025 \mathrm{E}-02$ & $9.756 \mathrm{E}+03$ & $1.025 \mathrm{E}-02$ & $9.756 \mathrm{E}+03$ \\
\hline$x-238$ & $7.800 \mathrm{E}+01$ & $1.050 \mathrm{E}+03$ & $6.110 E-07$ & $1.637 \mathrm{E}+08$ & $6.110 E-07$ & $1.637 \mathrm{E}+08$ \\
\hline-239 & $7.200 \mathrm{E}+01$ & $1.050 \mathrm{E}+03$ & $1.268 E-03$ & $7.884 \mathrm{E}+04$ & $1.268 E-03$ & $7.884 \mathrm{E}+04$ \\
\hline-240 & $7.200 \mathrm{E}+01$ & $1.050 \mathrm{E}+03$ & $1.170 \mathrm{E}-03$ & $8.550 \mathrm{E}+04$ & $1.170 \mathrm{E}-03$ & $8.550 \mathrm{E}+04$ \\
\hline-99 & $1.040 \mathrm{E}+02$ & $1.050 \mathrm{E}+03$ & 1. $325 \mathrm{E}-06$ & $7.545 \mathrm{E}+07$ & 1. $325 \mathrm{E}-06$ & $7.545 \mathrm{E}+07$ \\
\hline-228 & $8.000 \mathrm{E}+00$ & $0.000 \mathrm{E}+00$ & $1.382 E-06$ & $7.234 \mathrm{E}+07$ & $0.000 \mathrm{E}+00$ & $\star 8.195 \mathrm{E}+14$ \\
\hline-230 & $2.000 \mathrm{E}+02$ & $1.050 \mathrm{E}+03$ & $5.818 \mathrm{E}-02$ & $1.719 \mathrm{E}+03$ & $5.818 \mathrm{E}-02$ & $1.719 \mathrm{E}+03$ \\
\hline-232 & $8.000 \mathrm{E}+00$ & $1.050 \mathrm{E}+03$ & $1.491 \mathrm{E}-01$ & $6.708 E+02$ & $1.491 \mathrm{E}-01$ & $6.708 \mathrm{E}+02$ \\
\hline 234 & $3.200 \mathrm{E}+02$ & $1.050 \mathrm{E}+03$ & $9.276 \mathrm{E}-04$ & $1.078 E+05$ & $9.276 \mathrm{E}-04$ & $1.078 \mathrm{E}+05$ \\
\hline-235 & $1.300 \mathrm{E}+01$ & $1.050 \mathrm{E}+03$ & $1.767 \mathrm{E}-03$ & $5.658 \mathrm{E}+04$ & $1.767 \mathrm{E}-03$ & $5.658 \mathrm{E}+04$ \\
\hline 238 & $3.200 \mathrm{E}+02$ & $1.050 \mathrm{E}+03$ & $6.335 E-04$ & $1.578 \mathrm{E}+05$ & $6.335 E-04$ & $1.578 \mathrm{E}+05$ \\
\hline
\end{tabular}

*At specific activity limit 
RESRAD, Version $6.5 \quad T^{1 / 2}$ Limit $=180$ days $\quad 07 / 20 / 2011 \quad 14: 43$ Page 29

Summary : RESRAD Parameters for U-Landfill Resident Gardener Forward Run at ALs

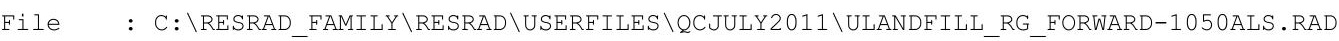

Individual Nuclide Dose Summed Over All Pathways

Parent Nuclide and Branch Fraction Indicated

Nuclide Parent THF(i) DOSE $(j, t)$, mrem/yr

\begin{tabular}{|c|c|c|}
\hline$(j)$ & (i) & \\
\hline$n-241$ & $A m-241$ & $1.000 \mathrm{E}+00$ \\
\hline-237 & $A m-241$ & $1.000 \mathrm{E}+00$ \\
\hline $\mathrm{Np}-237$ & $\mathrm{~Np}-237$ & $1.000 \mathrm{E}+00$ \\
\hline $\mathrm{Np}-237$ & $\sum \operatorname{DOSE}(j$ & \\
\hline
\end{tabular}

$\mathrm{U}-233 \quad \mathrm{Am}-241 \quad 1.000 \mathrm{E}+00$

U-233 Np-237 $1.000 \mathrm{E}+00$

U-233 $\sum \operatorname{DOSE}(j)$

Th-229 Am-241 $1.000 \mathrm{E}+00$

Th-229 Np-237 1.000E+00

Th-229 $\sum \operatorname{DOSE}(j)$

Cs-137 Cs-137 1.000E+00

Pu-238 $\mathrm{Pu}-238 \quad 1.840 \mathrm{E}-09$

$\mathrm{Pu}-238 \mathrm{Pu}-238 \quad 1.000 \mathrm{E}+00$

$\mathrm{Pu}-238 \quad \sum \operatorname{DOSE}(j)$

$\mathrm{U}-234$

$\mathrm{U}-234$

$\mathrm{U}-234$

$\mathrm{U}-234$

Th-230

Th-230

Th -230

Th-230

Th-230

$\mathrm{Ra}-226$

$\mathrm{Ra}-226$

Ra-226

$\mathrm{Ra}-226$

$\mathrm{Ra}-226$

$\mathrm{Pb}-210$

$\mathrm{Pb}-210$

$\mathrm{Pb}-210$

$\mathrm{Pb}-210$

$\mathrm{Pb}-210$

$\mathrm{Pu}-239$

$\mathrm{Pu}-238 \quad 1.000 \mathrm{E}+00$

$\mathrm{U}-234 \quad 1.000 \mathrm{E}+00$

$\mathrm{U}-238 \quad 9.999 \mathrm{E}-01$

$\sum \operatorname{DOSE}(j)$

$\begin{array}{ll}\mathrm{Pu}-238 & 1.000 \mathrm{E}+00 \\ \mathrm{Th}-230 & 1.000 \mathrm{E}+00 \\ \mathrm{U}-234 & 1.000 \mathrm{E}+00 \\ \mathrm{U}-238 & 9.999 \mathrm{E}-01 \\ \sum \operatorname{DOSE}(j)\end{array}$

$\mathrm{Pu}-238 \quad 1.000 \mathrm{E}+00$

Th-230 1.000E+00

$\mathrm{U}-234 \quad 1.000 \mathrm{E}+00$

$\mathrm{U}-238 \quad 9.999 \mathrm{E}-01$

$\sum \operatorname{DOSE}(j)$

Pu-238 1.000E+00

$\mathrm{Th}-230 \quad 1.000 \mathrm{E}+00$

U-234 $1.000 \mathrm{E}+00$

U-238 $9.999 \mathrm{E}-01$

$\operatorname{DOSE}(j)$

$\mathrm{Pu}-239 \quad 1.000 \mathrm{E}+00$

$\mathrm{Pu}-239 \quad 1.000 \mathrm{E}+00$

U-235 1.000E+00

¿DOSE (j) $t=0.000 \mathrm{E}+00 \quad 1.000 \mathrm{E}+00 \quad 5.000 \mathrm{E}+01 \quad 1.000 \mathrm{E}+02 \quad 5.000 \mathrm{E}+02 \quad 1.050 \mathrm{E}+03$

$\begin{array}{llllll}0.000 \mathrm{E}+00 & 0.000 \mathrm{E}+00 & 0.000 \mathrm{E}+00 & 0.000 \mathrm{E}+00 & 8.455 \mathrm{E}-26 & 1.375 \mathrm{E}-02\end{array}$

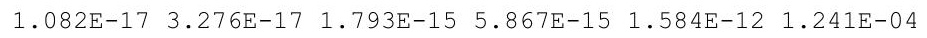

$\begin{array}{llllll}1.049 \mathrm{E}-11 & 1.060 \mathrm{E}-11 & 1.788 \mathrm{E}-11 & 3.047 \mathrm{E}-11 & 2.171 \mathrm{E}-09 & 1.127 \mathrm{E}-01\end{array}$

$\begin{array}{llllll}1.049 \mathrm{E}-11 & 1.060 \mathrm{E}-11 & 1.788 \mathrm{E}-11 & 3.048 \mathrm{E}-11 & 2.172 \mathrm{E}-09 & 1.128 \mathrm{E}-01\end{array}$

$2.454 \mathrm{E}-28 \quad 1.736 \mathrm{E}-27 \quad 3.404 \mathrm{E}-24 \quad 2.452 \mathrm{E}-23 \quad 7.371 \mathrm{E}-20 \quad 2.139 \mathrm{E}-08$

$\begin{array}{llllll}3.570 \mathrm{E}-22 & 1.083 \mathrm{E}-21 & 6.710 \mathrm{E}-20 & 2.490 \mathrm{E}-19 & 1.815 \mathrm{E}-16 & 3.158 \mathrm{E}-05\end{array}$

$\begin{array}{llllll}3.570 \mathrm{E}-22 & 1.083 \mathrm{E}-21 & 6.710 \mathrm{E}-20 & 2.491 \mathrm{E}-19 & 1.816 \mathrm{E}-16 & 3.160 \mathrm{E}-05\end{array}$

$\begin{array}{llllll}1.679 \mathrm{E}-24 & 2.533 \mathrm{E}-23 & 1.197 \mathrm{E}-18 & 1.308 \mathrm{E}-17 & 2.237 \mathrm{E}-14 & 3.782 \mathrm{E}-09\end{array}$

$\begin{array}{llllll}3.258 \mathrm{E}-18 & 2.294 \mathrm{E}-17 & 3.515 \mathrm{E}-14 & 1.967 \mathrm{E}-13 & 7.788 \mathrm{E}-11 & 7.481 \mathrm{E}-06\end{array}$

$\begin{array}{lllllll}3.258 \mathrm{E}-18 & 2.294 \mathrm{E}-17 & 3.516 \mathrm{E}-14 & 1.967 \mathrm{E}-13 & 7.790 \mathrm{E}-11 & 7.485 \mathrm{E}-06\end{array}$

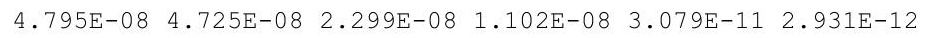

$\begin{array}{llllll}0.000 \mathrm{E}+00 & 0.000 \mathrm{E}+00 & 0.000 \mathrm{E}+00 & 0.000 \mathrm{E}+00 & 0.000 \mathrm{E}+00 & 4.294 \mathrm{E}-14\end{array}$

$\begin{array}{lllllll}9.164 \mathrm{E}-23 & 9.254 \mathrm{E}-23 & 1.492 \mathrm{E}-22 & 2.430 \mathrm{E}-22 & 1.200 \mathrm{E}-20 & 2.334 \mathrm{E}-05\end{array}$

$\begin{array}{llllll}9.164 \mathrm{E}-23 & 9.254 \mathrm{E}-23 & 1.492 \mathrm{E}-22 & 2.430 \mathrm{E}-22 & 1.200 \mathrm{E}-20 & 2.334 \mathrm{E}-05\end{array}$

$\begin{array}{llllll}7.627 \mathrm{E}-28 & 2.316 \mathrm{E}-27 & 1.539 \mathrm{E}-25 & 6.209 \mathrm{E}-25 & 1.319 \mathrm{E}-21 & 1.775 \mathrm{E}-05\end{array}$

$\begin{array}{llllll}2.207 \mathrm{E}-21 & 2.246 \mathrm{E}-21 & 5.346 \mathrm{E}-21 & 1.295 \mathrm{E}-20 & 1.535 \mathrm{E}-17 & 2.028 \mathrm{E}-01\end{array}$

$\begin{array}{lllllll}3.137 \mathrm{E}-27 & 9.560 \mathrm{E}-27 & 7.653 \mathrm{E}-25 & 3.690 \mathrm{E}-24 & 2.180 \mathrm{E}-20 & 6.048 \mathrm{E}-04\end{array}$

$\begin{array}{llllll}2.207 \mathrm{E}-21 & 2.246 \mathrm{E}-21 & 5.346 \mathrm{E}-21 & 1.295 \mathrm{E}-20 & 1.538 \mathrm{E}-17 & 2.034 \mathrm{E}-01\end{array}$

$\begin{array}{llllll}0.000 \mathrm{E}+00 & 0.000 \mathrm{E}+00 & 1.247 \mathrm{E}-27 & 1.016 \mathrm{E}-26 & 1.018 \mathrm{E}-22 & 2.553 \mathrm{E}-07\end{array}$ $\begin{array}{llllll}4.824 \mathrm{E}-20 & 4.906 \mathrm{E}-20 & 1.118 \mathrm{E}-19 & 2.591 \mathrm{E}-19 & 2.155 \mathrm{E}-16 & 2.208 \mathrm{E}-01\end{array}$ $\begin{array}{llllll}3.484 \mathrm{E}-25 & 1.061 \mathrm{E}-24 & 8.129 \mathrm{E}-23 & 3.748 \mathrm{E}-22 & 1.548 \mathrm{E}-18 & 3.317 \mathrm{E}-03\end{array}$ $\begin{array}{llllll}0.000 \mathrm{E}+00 & 0.000 \mathrm{E}+00 & 5.819 \mathrm{E}-27 & 5.338 \mathrm{E}-26 & 1.098 \mathrm{E}-21 & 4.933 \mathrm{E}-06\end{array}$ $\begin{array}{llllll}4.824 \mathrm{E}-20 & 4.906 \mathrm{E}-20 & 1.119 \mathrm{E}-19 & 2.595 \mathrm{E}-19 & 2.171 \mathrm{E}-16 & 2.242 \mathrm{E}-01\end{array}$

$\begin{array}{lllllll}6.257 \mathrm{E}-21 & 9.424 \mathrm{E}-20 & 4.107 \mathrm{E}-15 & 4.152 \mathrm{E}-14 & 4.373 \mathrm{E}-11 & 2.451 \mathrm{E}-06\end{array}$ $\begin{array}{llllll}7.548 \mathrm{E}-09 & 2.278 \mathrm{E}-08 & 1.064 \mathrm{E}-06 & 2.958 \mathrm{E}-06 & 2.142 \mathrm{E}-04 & 4.330 \mathrm{E}+00\end{array}$ $\begin{array}{lllllll}3.626 \mathrm{E}-14 & 2.553 \mathrm{E}-13 & 3.883 \mathrm{E}-10 & 2.156 \mathrm{E}-09 & 7.986 \mathrm{E}-07 & 3.509 \mathrm{E}-02\end{array}$ $\begin{array}{lllllll}2.571 \mathrm{E}-20 & 3.879 \mathrm{E}-19 & 1.856 \mathrm{E}-14 & 2.055 \mathrm{E}-13 & 3.842 \mathrm{E}-10 & 3.607 \mathrm{E}-05\end{array}$ $\begin{array}{llllll}7.548 \mathrm{E}-09 & 2.278 \mathrm{E}-08 & 1.064 \mathrm{E}-06 & 2.960 \mathrm{E}-06 & 2.150 \mathrm{E}-04 & 4.365 \mathrm{E}+00\end{array}$

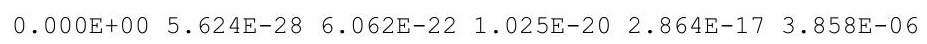
$\begin{array}{llllll}3.638 \mathrm{E}-17 & 2.541 \mathrm{E}-16 & 2.598 \mathrm{E}-13 & 1.063 \mathrm{E}-12 & 1.536 \mathrm{E}-10 & 7.086 \mathrm{E}+00\end{array}$ $\begin{array}{llllll}1.313 \mathrm{E}-22 & 1.969 \mathrm{E}-21 & 7.044 \mathrm{E}-17 & 6.191 \mathrm{E}-16 & 5.370 \mathrm{E}-13 & 5.562 \mathrm{E}-02\end{array}$ $\begin{array}{llllll}0.000 \mathrm{E}+00 & 2.313 \mathrm{E}-27 & 2.698 \mathrm{E}-21 & 4.947 \mathrm{E}-20 & 2.436 \mathrm{E}-16 & 5.548 \mathrm{E}-05\end{array}$ $\begin{array}{llllll}3.638 \mathrm{E}-17 & 2.541 \mathrm{E}-16 & 2.598 \mathrm{E}-13 & 1.063 \mathrm{E}-12 & 1.541 \mathrm{E}-10 & 7.142 \mathrm{E}+00\end{array}$

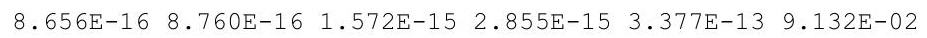

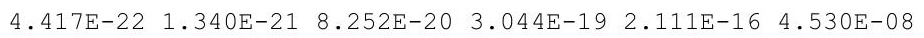
$\begin{array}{lllllll}1.616 \mathrm{E}-13 & 1.636 \mathrm{E}-13 & 2.997 \mathrm{E}-13 & 5.558 \mathrm{E}-13 & 7.775 \mathrm{E}-11 & 8.001 \mathrm{E}-03\end{array}$ $\begin{array}{llllll}1.616 \mathrm{E}-13 & 1.636 \mathrm{E}-13 & 2.997 \mathrm{E}-13 & 5.558 \mathrm{E}-13 & 7.775 \mathrm{E}-11 & 8.001 \mathrm{E}-03\end{array}$ 
RESRAD, Version $6.5 \quad$ T1/2 Limit $=180$ days $\quad 07 / 20 / 2011 \quad 14: 43$ Page 30

Summary : RESRAD Parameters for U-Landfill Resident Gardener Forward Run at ALs

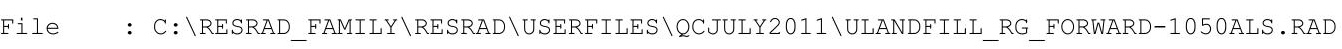

Individual Nuclide Dose Summed Over All Pathways

Parent Nuclide and Branch Fraction Indicated

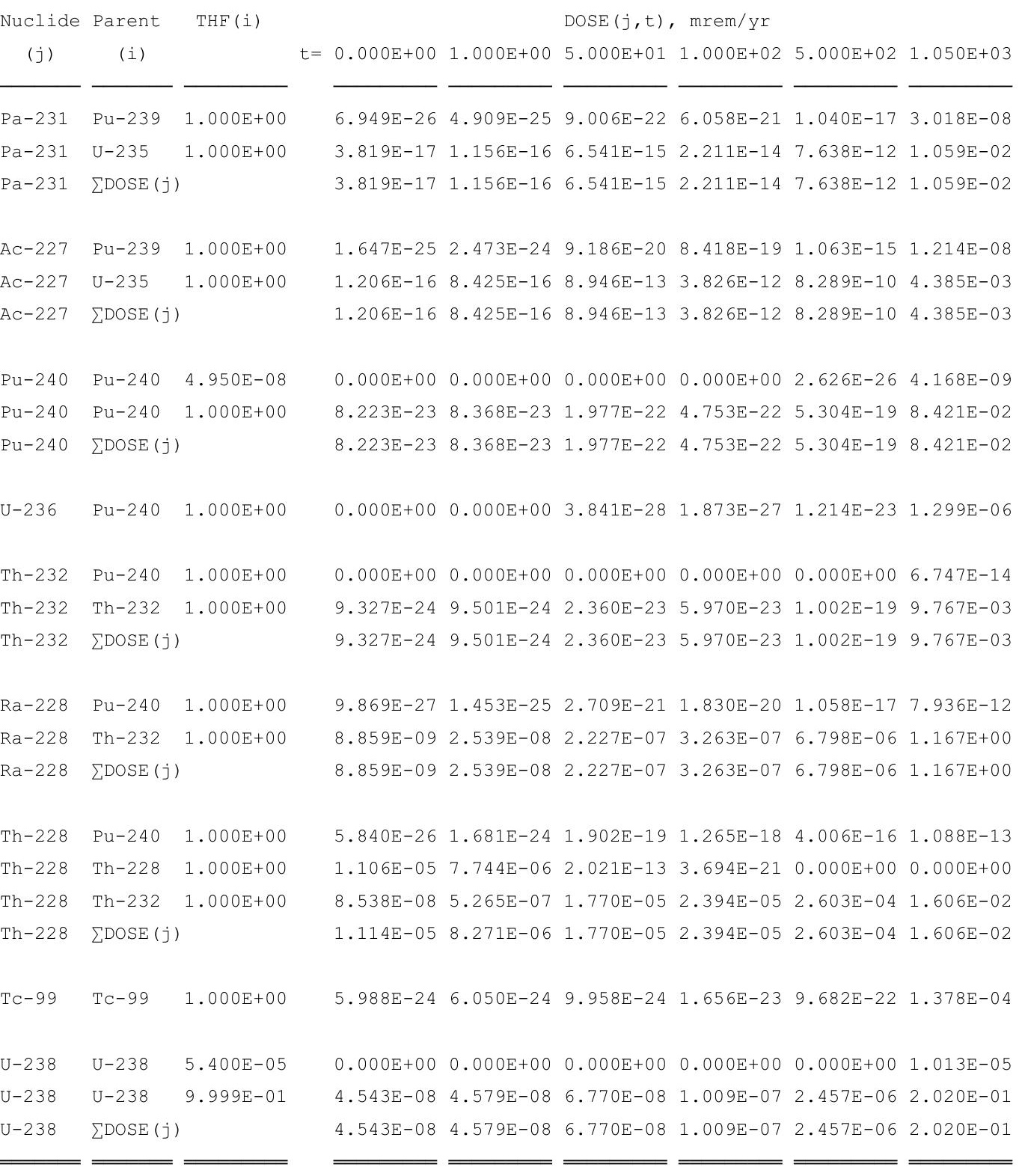

THF (i) is the thread fraction of the parent nuclide. 
RESRAD, Version $6.5 \quad$ T1/2 Limit $=180$ days $\quad 07 / 20 / 2011 \quad 14: 43$ Page 32

Summary : RESRAD Parameters for U-Landfill Resident Gardener Forward Run at ALs

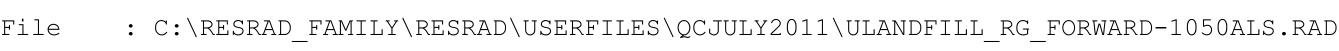

Individual Nuclide Soil Concentration

Parent Nuclide and Branch Fraction Indicated

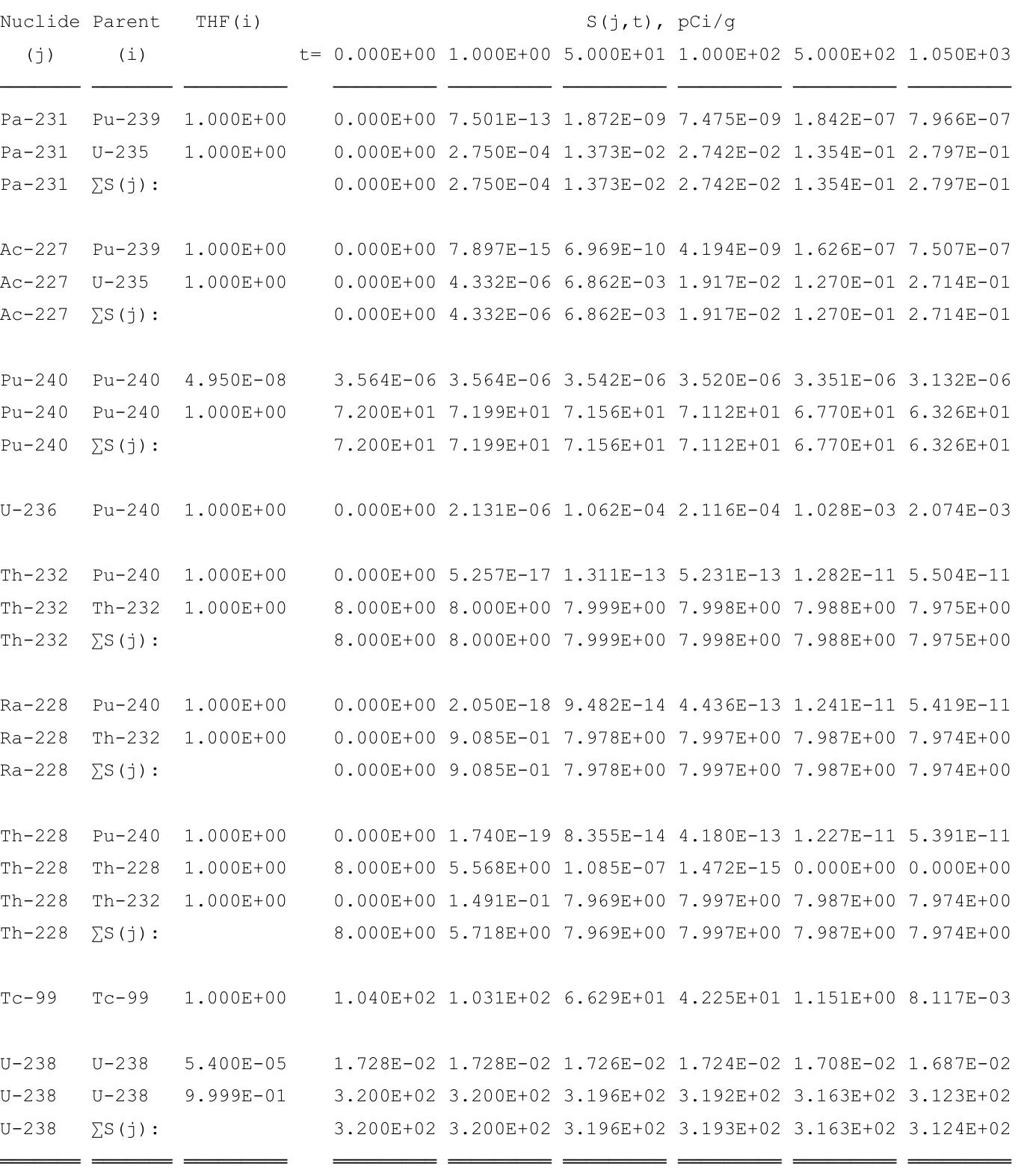

THF (i) is the thread fraction of the parent nuclide.

RESCALC.EXE execution time = 6.02 seconds 
RESRAD, Version $6.5 \quad T^{13 / 2}$ Limit $=180$ days

07/21/2011 $12: 27 \quad$ Page

Summary : RESRAD Parameters for U-Landfill Resident Gardener Forward Run 10,000 years

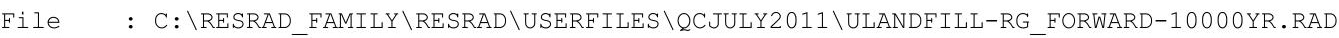

Table of Contents

Part I: Mixture Sums and Single Radionuclide Guidelines

Dose Conversion Factor (and Related) Parameter Summary ... 2

Site-Specific Parameter Summary ................. 8

Summary of Pathway Selections .................... 18

Contaminated Zone and Total Dose Summary ............. 19

Total Dose Components

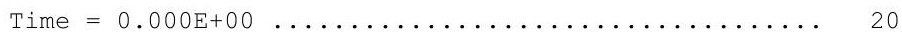

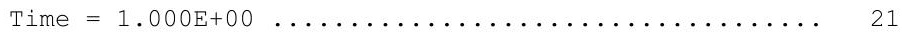

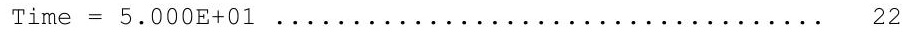

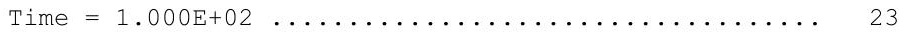

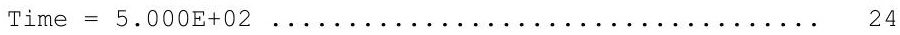

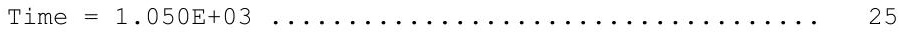

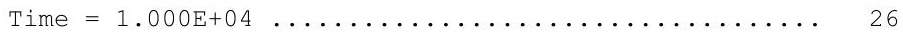

Dose/Source Ratios Summed Over All Pathways .......... 27

Single Radionuclide Soil Guidelines ............... 29

Dose Per Nuclide Summed Over All Pathways ............ 30

Soil Concentration Per Nuclide ............... 32 
Summary : RESRAD Parameters for U-Landfill Resident Gardener Forward Run 10,000 years

File : C: \RESRAD_FAMILY \RESRAD \USERFILES \QCJULY2011 \ULANDFILL-RG_FORWARD-10000YR.RAD

Dose Conversion Factor (and Related) Parameter Summary

Dose Library: ICRP 60 \& ICRP 72 (Adult)

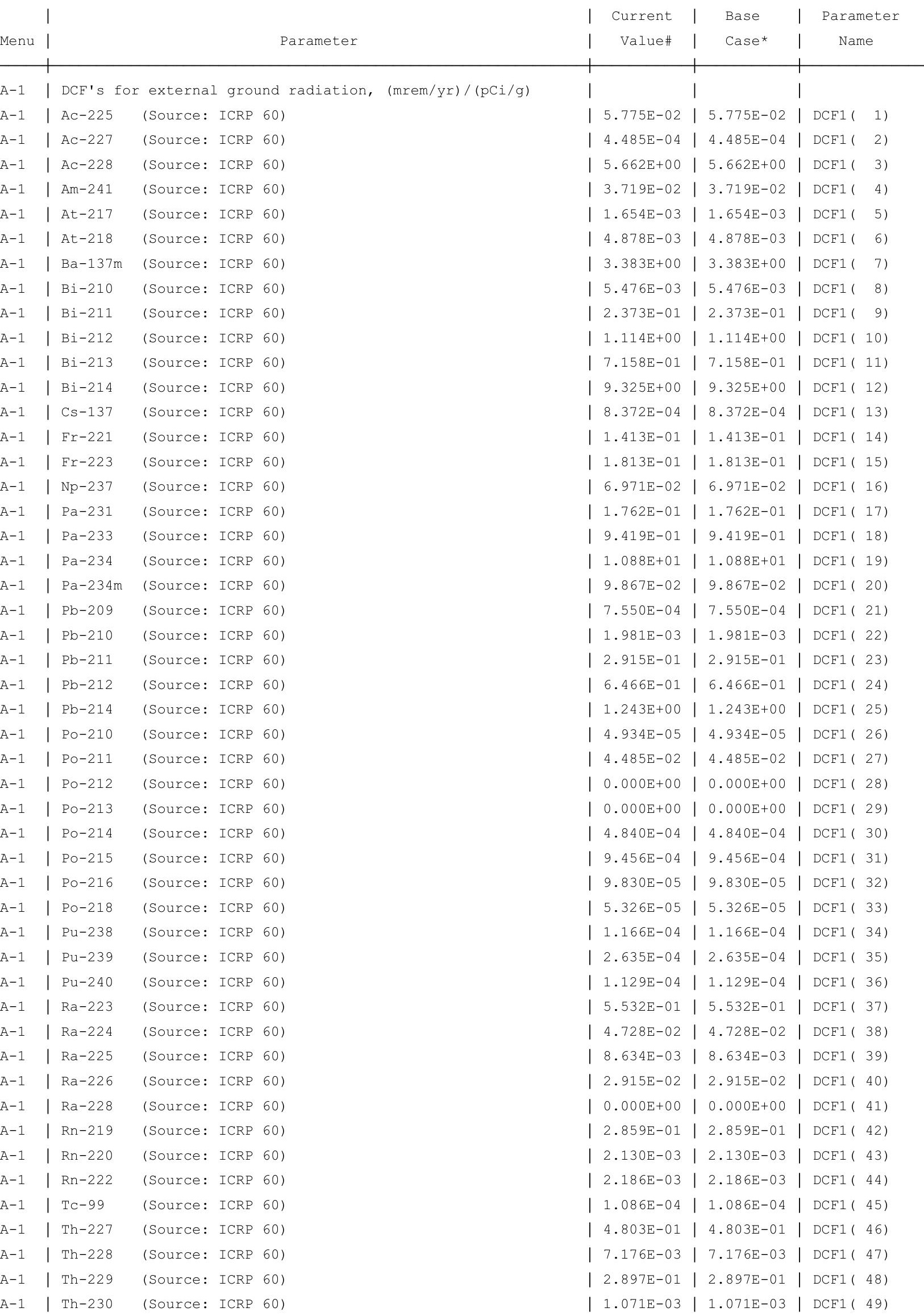




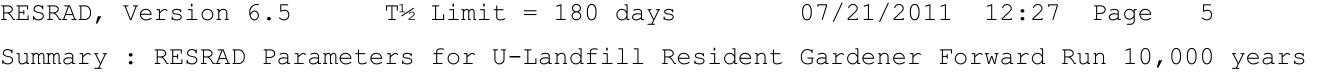

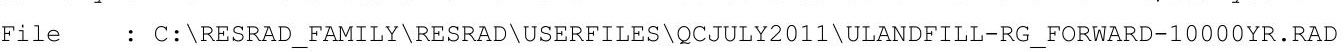

Dose Conversion Factor (and Related) Parameter Summary (continued) Dose Library: ICRP 60 \& ICRP 72 (Adult)

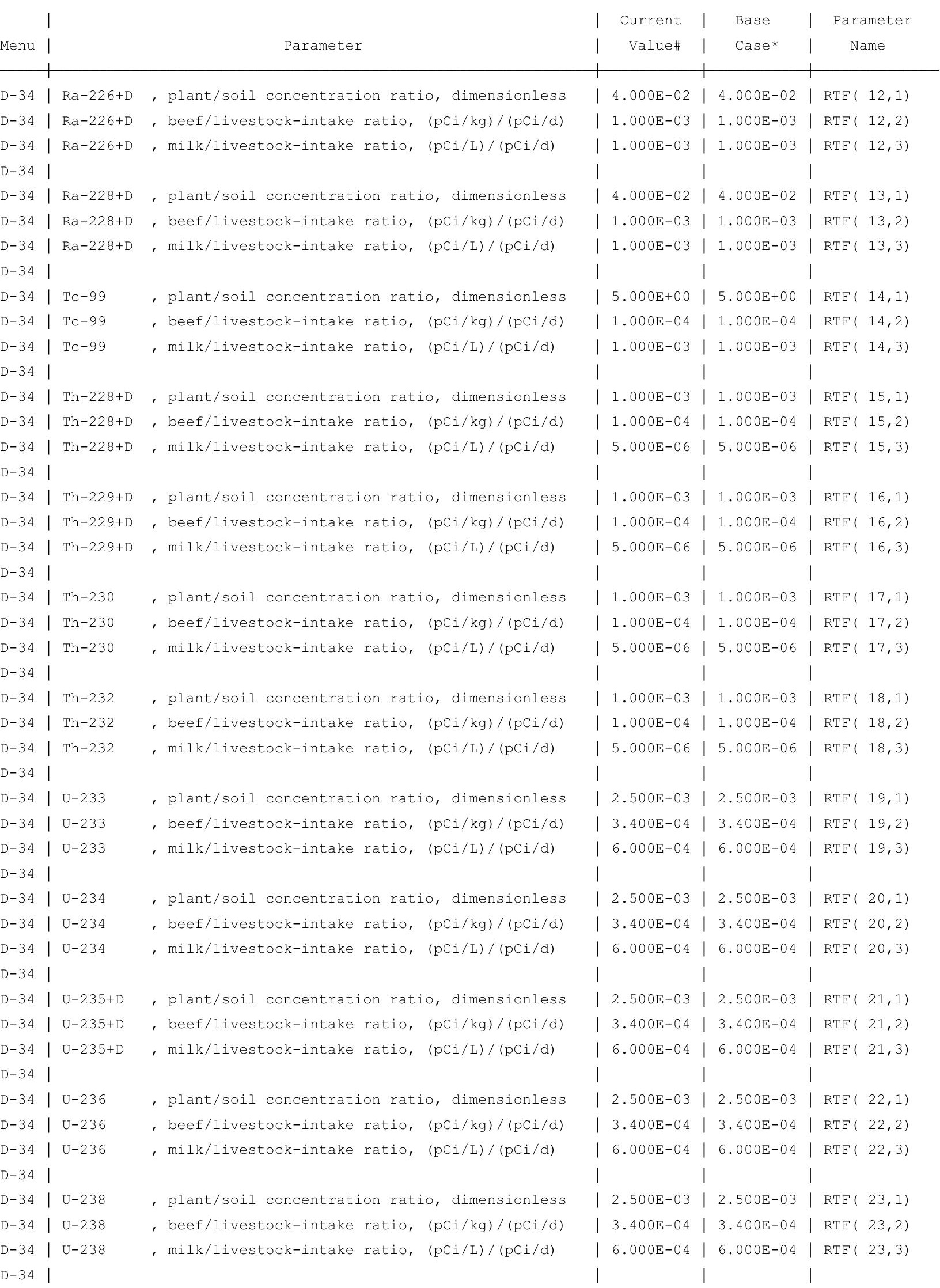


Summary : RESRAD Parameters for U-Landfill Resident Gardener Forward Run 10,000 years

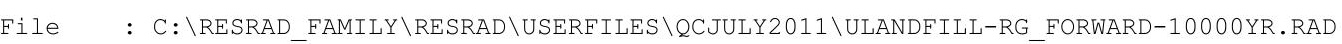

Site-Specific Parameter Summary (continued)

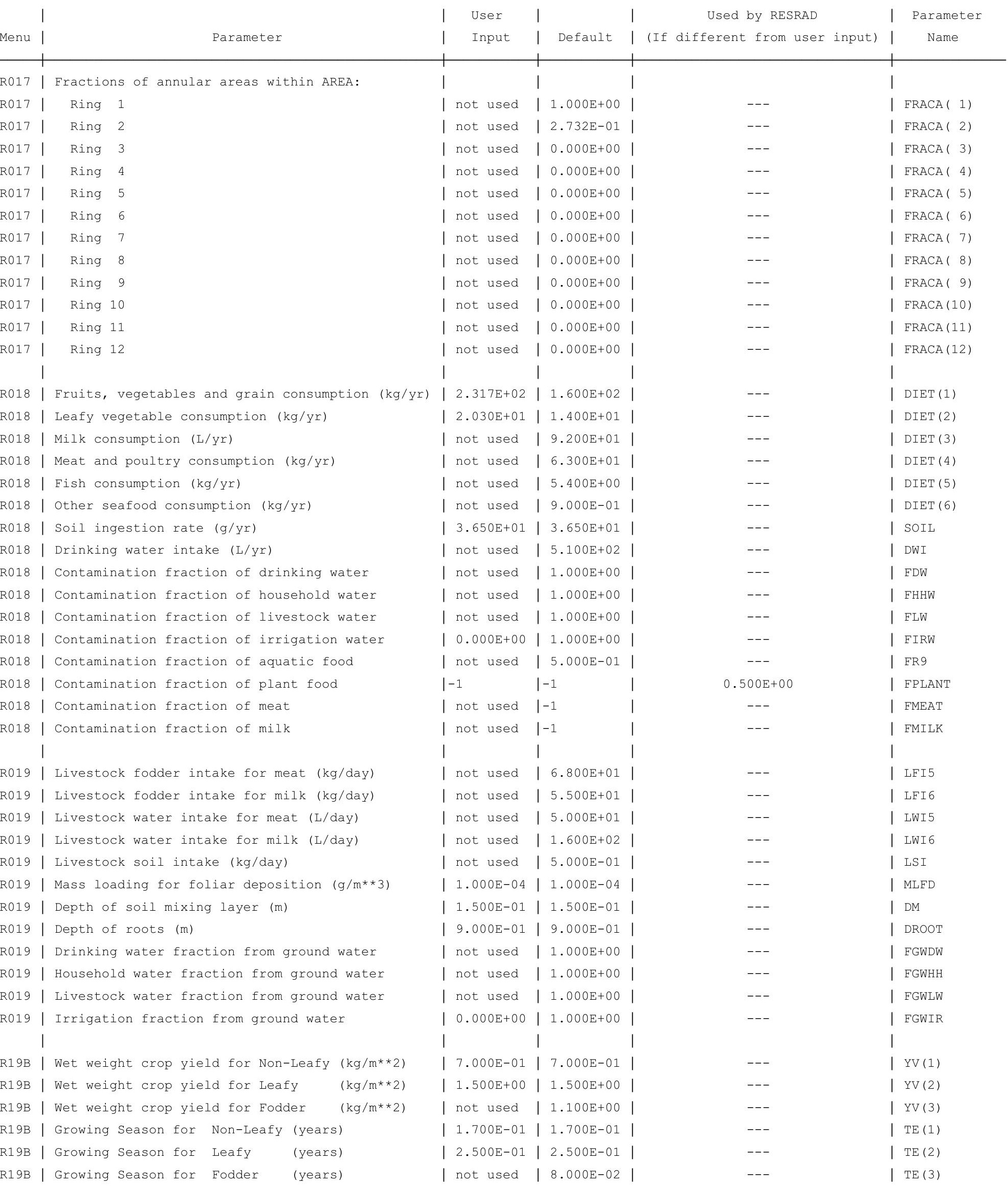


RESRAD, Version $6.5 \quad T^{13 / 2}$ Limit $=180$ days

Summary : RESRAD Parameters for U-Landfill Resident Gardener Forward Run 10,000 years

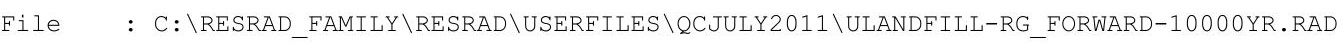

Contaminated Zone Dimensions

Area: 89436.00 square meters

Thickness:

Cover Depth:

\begin{abstract}
13.40 meters
1.52 meters
\end{abstract}

Initial Soil Concentrations, pci/g

$\begin{array}{ll}\text { Am-241 } & 3.500 \mathrm{E}+01 \\ \mathrm{Cs}-137 & 1.900 \mathrm{E}+01 \\ \mathrm{~Np}-237 & 5.500 \mathrm{E}+00 \\ \mathrm{Pu}-238 & 3.900 \mathrm{E}+01 \\ \mathrm{Pu}-239 & 3.600 \mathrm{E}+01 \\ \mathrm{Pu}-240 & 3.600 \mathrm{E}+01 \\ \mathrm{Tc}-99 & 5.200 \mathrm{E}+01 \\ \mathrm{Th}-228 & 4.000 \mathrm{E}+00 \\ \text { Th-230 } & 1.000 \mathrm{E}+02 \\ \text { Th-232 } & 4.000 \mathrm{E}+00 \\ \mathrm{U}-234 & 1.600 \mathrm{E}+02 \\ \mathrm{U}-235 & 6.500 \mathrm{E}+00 \\ \mathrm{U}-238 & 1.600 \mathrm{E}+02\end{array}$

Total Dose TDOSE(t), mrem/yr

Basic Radiation Dose Limit $=1.000 \mathrm{E}+02 \mathrm{mrem} / \mathrm{yr}$

Total Mixture Sum $M(t)$ = Fraction of Basic Dose Limit Received at Time (t)

$\begin{array}{rllllllll}t \text { (years) }: & 0.000 \mathrm{E}+00 & 1.000 \mathrm{E}+00 & 5.000 \mathrm{E}+01 & 1.000 \mathrm{E}+02 & 5.000 \mathrm{E}+02 & 1.050 \mathrm{E}+03 & 1.000 \mathrm{E}+04 \\ \mathrm{TDOSE}(\mathrm{t}): & 5.627 \mathrm{E}-06 & 4.206 \mathrm{E}-06 & 9.541 \mathrm{E}-06 & 1.367 \mathrm{E}-05 & 2.423 \mathrm{E}-04 & 6.827 \mathrm{E}+00 & 2.359 \mathrm{E}+03 \\ \mathrm{M}(\mathrm{t}): & 5.627 \mathrm{E}-08 & 4.206 \mathrm{E}-08 & 9.541 \mathrm{E}-08 & 1.367 \mathrm{E}-07 & 2.423 \mathrm{E}-06 & 6.827 \mathrm{E}-02 & 2.359 \mathrm{E}+01\end{array}$

Maximum TDOSE $(t): 2.359 \mathrm{E}+03 \mathrm{mrem} / \mathrm{yr}$ at $t=1.000 \mathrm{E}+04$ years 
RESRAD, Version $6.5 \quad T^{3 / 2}$ Limit $=180$ days $\quad 07 / 21 / 2011 \quad 12: 27$ Page 21
Summary : RESRAD Parameters for U-Landfill Resident Gardener Forward Run 10,000 years

File : C: $\backslash$ RESRAD_FAMILY \RESRAD \USERFILES \QCJULY2011 \ULANDFILL-RG_FORWARD-10000YR.RAD

Total Dose Contributions TDOSE (i,p,t) for Individual Radionuclides (i) and Pathways (p) As mrem/yr and Fraction of Total Dose At $t=1.000 \mathrm{E}+00$ years

Water Independent Pathways (Inhalation excludes radon)

\begin{tabular}{|c|c|c|c|c|c|c|c|c|c|c|c|c|c|c|}
\hline \multirow[b]{2}{*}{ clide } & \multicolumn{2}{|c|}{ Ground } & \multicolumn{2}{|c|}{ Inhalation } & \multicolumn{2}{|c|}{ Radon } & \multicolumn{2}{|c|}{ Plant } & \multicolumn{2}{|c|}{ Meat } & \multicolumn{2}{|c|}{ Milk } & \multicolumn{2}{|c|}{ Soil } \\
\hline & mrem/yr & fract. & mrem/yr & fract. & mrem/yr & fract. & mrem/yr & fract. & mrem/yr & fract. & mrem/yr & fract. & nrem/yr & fract. \\
\hline-241 & $1.638 \mathrm{E}-17$ & 0.0000 & $0.000 \mathrm{E}+00$ & 0.0000 & $0.000 \mathrm{E}+00$ & 0.0000 & $0.000 \mathrm{E}+00$ & 0.0000 & $0.000 \mathrm{E}+00$ & 0.0000 & $0.000 \mathrm{E}+00$ & 0.0000 & $0.000 \mathrm{E}+00$ & 0000 \\
\hline 137 & $2.362 \mathrm{E}-08$ & 0.0056 & $0.000 \mathrm{E}+00$ & 0.0000 & $0.000 \mathrm{E}+00$ & 0.0000 & $0.000 \mathrm{E}+00$ & 0.0000 & $0.000 \mathrm{E}+00$ & 0.0000 & $0.000 \mathrm{E}+00$ & 0.0000 & $0.000 \mathrm{E}+00$ & 0.0000 \\
\hline 237 & $5.301 \mathrm{E}-12$ & 0.0000 & $0.000 \mathrm{E}+00$ & 0.0000 & $0.000 \mathrm{E}+00$ & 0.0000 & $0.000 \mathrm{E}+00$ & 0.0000 & $0.000 \mathrm{E}+00$ & 0.0000 & $0.000 \mathrm{E}+00$ & 0.0000 & $0.000 \mathrm{E}+00$ & 0.0000 \\
\hline 238 & $4.717 E-20$ & 0.0000 & $0.000 \mathrm{E}+00$ & 0.0000 & $0.000 \mathrm{E}+00$ & 0.0000 & $0.000 \mathrm{E}+00$ & 0.0000 & $0.000 \mathrm{E}+00$ & 0.0000 & $0.000 \mathrm{E}+00$ & 0.0000 & $0.000 \mathrm{E}+00$ & 0.0000 \\
\hline 239 & $4.380 \mathrm{E}-16$ & 0.0000 & $0.000 \mathrm{E}+00$ & 0.0000 & $0.000 \mathrm{E}+00$ & 0.0000 & $0.000 \mathrm{E}+00$ & 0.0000 & $0.000 \mathrm{E}+00$ & 0.0000 & $0.000 \mathrm{E}+00$ & 0.0000 & $0.000 \mathrm{E}+00$ & 0.0000 \\
\hline 240 & $4.275 \mathrm{E}-23$ & 0.0000 & $0.000 \mathrm{E}+00$ & 0.0000 & $0.000 \mathrm{E}+00$ & 0.0000 & $0.000 \mathrm{E}+00$ & 0.0000 & $0.000 \mathrm{E}+00$ & 0.0000 & $0.000 \mathrm{E}+00$ & 0.0000 & $0.000 \mathrm{E}+00$ & 0.0000 \\
\hline & $3.025 E-24$ & 0.000 & $0.000 \mathrm{E}$ & 0 & $0.000 \mathrm{E}+00$ & 0 & $0.000 \mathrm{E}+00$ & 0 & 0 & 00 & $0.000 \mathrm{E}+00$ & 0.0 & $0.000 \mathrm{E}+00$ & 0.0000 \\
\hline 228 & $3.872 \mathrm{E}-06$ & 0.9206 & $0.000 \mathrm{E}+00$ & 0.0000 & $0.000 \mathrm{E}+00$ & 0.0000 & $0.000 \mathrm{E}+00$ & 0.0000 & $0.000 \mathrm{E}+00$ & 0.0000 & $0.000 \mathrm{E}+00$ & 0.0000 & $0.000 \mathrm{E}+00$ & 0.0000 \\
\hline 30 & $1.139 \mathrm{E}-08$ & 0.0027 & $0.000 \mathrm{E}+00$ & 0.0000 & $0.000 \mathrm{E}+00$ & 0.0000 & $0.000 \mathrm{E}+00$ & 0.0000 & $0.000 \mathrm{E}+00$ & 0.0000 & $0.000 \mathrm{E}+00$ & 0.0000 & $0.000 \mathrm{E}+00$ & 0.0000 \\
\hline 2 & $2.759 \mathrm{E}-07$ & 0.0656 & $0.000 \mathrm{E}+00$ & 0.0000 & $0.000 \mathrm{E}+00$ & 0.0000 & $0.000 \mathrm{E}+00$ & 0.0000 & $0.000 \mathrm{E}+00$ & 0.0000 & $0.000 \mathrm{E}+00$ & 0.0000 & $0.000 \mathrm{E}+00$ & 0.0000 \\
\hline & $1.277 \mathrm{E}-13$ & 0.0000 & $0.000 \mathrm{E}+00$ & 0.0000 & $0.000 \mathrm{E}+00$ & 0.0000 & $0.000 \mathrm{E}+00$ & 0.0000 & $0.000 \mathrm{E}+00$ & 0.0000 & $0.000 \mathrm{E}+00$ & 0.0000 & $0.000 \mathrm{E}+00$ & 0.0000 \\
\hline & $8.230 \mathrm{E}-14$ & 0.0000 & $0.000 \mathrm{E}+00$ & 0.0000 & $0.000 \mathrm{E}+00$ & 0.0000 & $0.000 \mathrm{E}+00$ & 0.0000 & $0.000 \mathrm{E}+00$ & 0.0000 & $0.000 \mathrm{E}+00$ & 0.0000 & $0.000 \mathrm{E}+00$ & 0.0000 \\
\hline & $2.290 \mathrm{E}-08$ & 0.0054 & $0.000 \mathrm{E}+00$ & 0.0000 & $0.000 \mathrm{E}+00$ & 0.0000 & $0.000 \mathrm{E}+00$ & 0.0000 & $0.000 \mathrm{E}+00$ & 0.0000 & $0.000 \mathrm{E}+00$ & 0.0000 & $0.000 \mathrm{E}+00$ & 0.0000 \\
\hline & 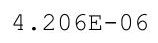 & & $00 \mathrm{E}+00$ & 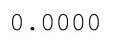 & +00 & ( & $00 \mathrm{E}+00$ & 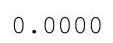 & $0.000 \mathrm{E}+00$ & & . & & $\mathrm{E}+00$ & \\
\hline
\end{tabular}

Total Dose Contributions TDOSE (i,p,t) for Individual Radionuclides (i) and Pathways (p) As mrem/yr and Fraction of Total Dose At $t=1.000 \mathrm{E}+00$ years

Water Dependent Pathways

\begin{tabular}{|c|c|c|c|c|c|c|c|c|c|c|c|c|c|c|}
\hline \multirow[b]{2}{*}{ clide } & \multicolumn{2}{|c|}{ Water } & \multicolumn{2}{|c|}{ Fish } & \multicolumn{2}{|c|}{ Radon } & \multicolumn{2}{|c|}{ Plant } & \multicolumn{2}{|c|}{ Meat } & \multicolumn{2}{|c|}{ Milk } & \multicolumn{2}{|c|}{ All Pathways* } \\
\hline & mrem/yr & fract. & mrem/yr & fract. & mrem/yr & fract. & mrem/yr & fract. & mrem/yr & fract. & mrem/yr & fract. & mrem/yr & fract. \\
\hline \pm & $0.000 \mathrm{E}+00$ & 0.0000 & $0.000 \mathrm{E}+00$ & 0.0000 & $0.000 \mathrm{E}+00$ & 0.0000 & $0.000 \mathrm{E}+00$ & 0.0000 & $0.000 \mathrm{E}+00$ & 0.0000 & $0.000 \mathrm{E}+00$ & 0.0000 & $1.638 \mathrm{E}-17$ & 0.0000 \\
\hline & $0.000 \mathrm{E}+00$ & 0.0000 & $0.000 \mathrm{E}+00$ & 0.0000 & $0.000 \mathrm{E}+00$ & 0.0000 & $0.000 E+00$ & 0.0000 & $0.000 \mathrm{E}+00$ & 0.0000 & $0.000 \mathrm{E}+00$ & 0.0000 & $2.362 \mathrm{E}-08$ & 0.0056 \\
\hline 237 & $0.000 \mathrm{E}+00$ & 0.0000 & $0.000 \mathrm{E}+00$ & 0.0000 & $0.000 \mathrm{E}+00$ & 0.0000 & $0.000 \mathrm{E}+00$ & 0.0000 & $0.000 \mathrm{E}+00$ & 0.0000 & $0.000 \mathrm{E}+00$ & 0.0000 & $5.301 \mathrm{E}-12$ & 0.0000 \\
\hline 8 & $0.000 \mathrm{E}+00$ & 0.0000 & $0.000 \mathrm{E}+00$ & 0.0000 & $0.000 \mathrm{E}+00$ & 0.0000 & $0.000 \mathrm{E}+00$ & 0.0000 & $0.000 \mathrm{E}+00$ & 0.0000 & $0.000 \mathrm{E}+00$ & 0.0000 & $717 E-20$ & 000 \\
\hline & $0.000 \mathrm{E}+00$ & 0 & 0 . & 0 & $0.000 \mathrm{E}+00$ & & & 0 & & & $000 \mathrm{E}+00$ & & 16 & 00 \\
\hline & $0.000 \mathrm{E}+00$ & 0. & $0.000 \mathrm{E}+00$ & 0 & $0.000 \mathrm{E}+00$ & 0.0000 & $0.000 \mathrm{E}+00$ & 0.0 & $0.000 \mathrm{E}+00$ & 0 & $0.000 \mathrm{E}+00$ & 00 & 23 & 000 \\
\hline & $0.000 \mathrm{E}+00$ & 0.0000 & $0.000 \mathrm{E}+00$ & 0.0000 & $0.000 \mathrm{E}+00$ & 0.0000 & $0.000 \mathrm{E}+00$ & 0.0000 & $0.000 \mathrm{E}+00$ & 0.0000 & $0.000 \mathrm{E}+00$ & 0.0000 & $3.025 \mathrm{E}-24$ & 0.0000 \\
\hline 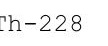 & $0.000 \mathrm{E}+00$ & 0.0000 & $0.000 \mathrm{E}+00$ & 0.0000 & $0.000 \mathrm{E}+00$ & 0.0000 & $0.000 \mathrm{E}+00$ & 0.0000 & $0.000 \mathrm{E}+00$ & 0.0000 & $0.000 \mathrm{E}+00$ & 0.0000 & $3.872 \mathrm{E}-06$ & 0.9206 \\
\hline & $0.000 \mathrm{E}+00$ & 0.0000 & $0.000 \mathrm{E}+00$ & 0.0000 & $0.000 \mathrm{E}+00$ & 0.0000 & $0.000 \mathrm{E}+00$ & 0.0000 & $0.000 \mathrm{E}+00$ & 0.0000 & $0.000 \mathrm{E}+00$ & 0.0000 & $1.139 \mathrm{E}-08$ & 0.0027 \\
\hline & $0.000 \mathrm{E}+00$ & 0.0000 & $0.000 \mathrm{E}+00$ & 0.0000 & $0.000 \mathrm{E}+00$ & 0.0000 & $0.000 \mathrm{E}+00$ & 0.0000 & $0.000 \mathrm{E}+00$ & 0.0000 & $0.000 \mathrm{E}+00$ & 0.0000 & $2.759 \mathrm{E}-07$ & 0.0656 \\
\hline & $0.000 \mathrm{E}+00$ & 0.0000 & $0.000 \mathrm{E}+00$ & 0.0000 & $0.000 \mathrm{E}+00$ & 0.0000 & $0.000 E+00$ & 0.0000 & $0.000 \mathrm{E}+00$ & 0.0000 & $0.000 \mathrm{E}+00$ & 0.0000 & $1.277 \mathrm{E}-13$ & 0.0000 \\
\hline & $0.000 \mathrm{E}+00$ & 0.0000 & $0.000 \mathrm{E}+00$ & 0.0000 & $0.000 \mathrm{E}+00$ & 0.0000 & $0.000 \mathrm{E}+00$ & 0.0000 & $0.000 \mathrm{E}+00$ & 0.0000 & $0.000 \mathrm{E}+00$ & 0.0000 & $8.230 \mathrm{E}-14$ & 0.0000 \\
\hline & $0.000 \mathrm{E}+00$ & 0.0000 & $0.000 \mathrm{E}+00$ & 0.0000 & $0.000 \mathrm{E}+00$ & 0.0000 & $0.000 \mathrm{E}+00$ & 0.0000 & $0.000 \mathrm{E}+00$ & 0.0000 & $0.000 \mathrm{E}+00$ & 0.0000 & $2.290 \mathrm{E}-08$ & 0.0054 \\
\hline & & 00 & $.000 \mathrm{E}+00$ & 0.0000 & $0.000 \mathrm{E}+00$ & 0.0000 & $0.000 \mathrm{E}+00$ & 0.0000 & $0.000 \mathrm{E}+00$ & & +00 & & .06 & \\
\hline
\end{tabular}

*Sum of all water independent and dependent pathways. 
RESRAD, Version $6.5 \quad T^{3 / 2}$ Limit $=180$ days $\quad 07 / 21 / 2011 \quad 12: 27$ Page 22
Summary : RESRAD Parameters for U-Landfill Resident Gardener Forward Run 10,000 years

File : C: $\backslash$ RESRAD_FAMILY \RESRAD \USERFILES \QCJULY2011 \ULANDFILL-RG_FORWARD-10000YR.RAD

Total Dose Contributions TDOSE (i,p,t) for Individual Radionuclides (i) and Pathways (p) As mrem/yr and Fraction of Total Dose At $t=5.000 \mathrm{E}+01$ years

Water Independent Pathways (Inhalation excludes radon)

\begin{tabular}{|c|c|c|c|c|c|c|c|c|c|c|c|c|c|c|}
\hline \multirow[b]{2}{*}{ clide } & \multicolumn{2}{|c|}{ Ground } & \multicolumn{2}{|c|}{ Inhalation } & \multicolumn{2}{|c|}{ Radon } & \multicolumn{2}{|c|}{ Plant } & \multicolumn{2}{|c|}{ Meat } & \multicolumn{2}{|c|}{ Milk } & \multicolumn{2}{|l|}{ Soil } \\
\hline & mrem/yr & fract. & mrem/yr & fract. & mrem/yr & fract. & mrem/yr & fract. & mrem/yr & fract. & mrem/yr & fract. & mrem/yr & fract. \\
\hline-241 & $8.973 E-16$ & 0.0000 & $0.000 \mathrm{E}+00$ & 0.0000 & $0.000 \mathrm{E}+00$ & 0.0000 & $0.000 \mathrm{E}+00$ & 0.0000 & $0.000 \mathrm{E}+00$ & 0.0000 & $0.000 \mathrm{E}+00$ & 0.0000 & $0.000 \mathrm{E}+00$ & 0000 \\
\hline 137 & $1.149 \mathrm{E}-08$ & 0.0012 & $0.000 \mathrm{E}+00$ & 0.0000 & $0.000 \mathrm{E}+00$ & 0.0000 & $0.000 \mathrm{E}+00$ & 0.0000 & $0.000 \mathrm{E}+00$ & 0.0000 & $0.000 \mathrm{E}+00$ & 0.0000 & $0.000 \mathrm{E}+00$ & 0.0000 \\
\hline 237 & $8.957 E-12$ & 0.0000 & $0.000 \mathrm{E}+00$ & 0.0000 & $0.000 \mathrm{E}+00$ & 0.0000 & $0.000 \mathrm{E}+00$ & 0.0000 & $0.000 \mathrm{E}+00$ & 0.0000 & $0.000 \mathrm{E}+00$ & 0.0000 & $0.000 \mathrm{E}+00$ & 0.0000 \\
\hline 238 & $2.054 \mathrm{E}-15$ & 0.0000 & $0.000 \mathrm{E}+00$ & 0.0000 & $0.000 \mathrm{E}+00$ & 0.0000 & $0.000 \mathrm{E}+00$ & 0.0000 & $0.000 \mathrm{E}+00$ & 0.0000 & $0.000 \mathrm{E}+00$ & 0.0000 & $0.000 \mathrm{E}+00$ & 0.0000 \\
\hline 239 & $7.861 \mathrm{E}-16$ & 0.0000 & $0.000 \mathrm{E}+00$ & 0.0000 & $0.000 \mathrm{E}+00$ & 0.0000 & $0.000 \mathrm{E}+00$ & 0.0000 & $0.000 \mathrm{E}+00$ & 0.0000 & $0.000 \mathrm{E}+00$ & 0.0000 & $0.000 \mathrm{E}+00$ & 0.0000 \\
\hline 240 & $9.653 \mathrm{E}-20$ & 0.0000 & $0.000 \mathrm{E}+00$ & 0.0000 & $0.000 \mathrm{E}+00$ & 0.0000 & $0.000 \mathrm{E}+00$ & 0.0000 & $0.000 \mathrm{E}+00$ & 0.0000 & $0.000 \mathrm{E}+00$ & 0.0000 & $0.000 \mathrm{E}+00$ & 0.0000 \\
\hline & $4.979 \mathrm{E}-24$ & 0.00 & $0.000 \mathrm{E}$ & 0 & $0.000 \mathrm{E}+00$ & 0 & $0.000 \mathrm{E}+00$ & 0 & 0 & 00 & $0.000 \mathrm{E}+00$ & 0.0 & $0.000 \mathrm{E}+00$ & 0.0000 \\
\hline 228 & $1.011 \mathrm{E}-13$ & 0.0000 & $0.000 \mathrm{E}+00$ & 0.0000 & $0.000 \mathrm{E}+00$ & 0.0000 & $0.000 \mathrm{E}+00$ & 0.0000 & $0.000 \mathrm{E}+00$ & 0.0000 & $0.000 \mathrm{E}+00$ & 0.0000 & $0.000 \mathrm{E}+00$ & 0.0000 \\
\hline 30 & $5.320 \mathrm{E}-07$ & 0.0558 & $0.000 \mathrm{E}+00$ & 0.0000 & $0.000 \mathrm{E}+00$ & 0.0000 & $0.000 \mathrm{E}+00$ & 0.0000 & $0.000 \mathrm{E}+00$ & 0.0000 & $0.000 \mathrm{E}+00$ & 0.0000 & $0.000 \mathrm{E}+00$ & 0.0000 \\
\hline 2 & $8.963 \mathrm{E}-06$ & 0.9395 & $0.000 \mathrm{E}+00$ & 0.0000 & $0.000 \mathrm{E}+00$ & 0.0000 & $0.000 \mathrm{E}+00$ & 0.0000 & $0.000 \mathrm{E}+00$ & 0.0000 & $0.000 \mathrm{E}+00$ & 0.0000 & $0.000 \mathrm{E}+00$ & 0.0000 \\
\hline & $1.941 \mathrm{E}-10$ & 0.0000 & $0.000 \mathrm{E}+00$ & 0.0000 & $0.000 \mathrm{E}+00$ & 0.0000 & $0.000 \mathrm{E}+00$ & 0.0000 & $0.000 \mathrm{E}+00$ & 0.0000 & $0.000 \mathrm{E}+00$ & 0.0000 & $0.000 \mathrm{E}+00$ & 0.0000 \\
\hline & $6.005 \mathrm{E}-13$ & 0.0000 & $0.000 \mathrm{E}+00$ & 0.0000 & $0.000 \mathrm{E}+00$ & 0.0000 & $0.000 \mathrm{E}+00$ & 0.0000 & $0.000 \mathrm{E}+00$ & 0.0000 & $0.000 \mathrm{E}+00$ & 0.0000 & $0.000 \mathrm{E}+00$ & 0.0000 \\
\hline & $3.385 \mathrm{E}-08$ & 0.0035 & $0.000 \mathrm{E}+00$ & 0.0000 & $0.000 \mathrm{E}+00$ & 0.0000 & $0.000 \mathrm{E}+00$ & 0.0000 & $0.000 \mathrm{E}+00$ & 0.0000 & $0.000 \mathrm{E}+00$ & 0.0000 & $0.000 \mathrm{E}+00$ & 0.0000 \\
\hline & 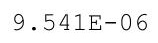 & & $.000 \mathrm{E}+00$ & 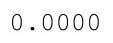 & +00 & 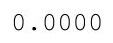 & $000 \mathrm{E}+00$ & 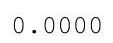 & $.000 \mathrm{E}+00$ & & . & & $\mathrm{E}+00$ & \\
\hline
\end{tabular}

Total Dose Contributions TDOSE (i,p,t) for Individual Radionuclides (i) and Pathways (p) As mrem/yr and Fraction of Total Dose At $t=5.000 \mathrm{E}+01$ years

Water Dependent Pathways

\begin{tabular}{|c|c|c|c|c|c|c|c|c|c|c|c|c|c|c|}
\hline \multirow[b]{2}{*}{ clide } & \multicolumn{2}{|c|}{ Water } & \multicolumn{2}{|c|}{ Fish } & \multicolumn{2}{|c|}{ Radon } & \multicolumn{2}{|c|}{ Plant } & \multicolumn{2}{|c|}{ Meat } & \multicolumn{2}{|c|}{ Milk } & \multicolumn{2}{|c|}{ All Pathways* } \\
\hline & mrem/yr & fract. & mrem/yr & fract. & mrem/yr & fract. & mrem/yr & fract. & mrem/yr & fract. & mrem/yr & fract. & mrem/yr & fract. \\
\hline \pm & $0.000 \mathrm{E}+00$ & 0.0000 & $0.000 \mathrm{E}+00$ & 0.0000 & $0.000 \mathrm{E}+00$ & 0.0000 & $0.000 \mathrm{E}+00$ & 0.0000 & $0.000 \mathrm{E}+00$ & 0.0000 & $0.000 \mathrm{E}+00$ & 0.0000 & $8.973 E-16$ & 0.0000 \\
\hline & $0.000 \mathrm{E}+00$ & 0.0000 & $0.000 \mathrm{E}+00$ & 0.0000 & $0.000 \mathrm{E}+00$ & 0.0000 & $0.000 E+00$ & 0.0000 & $0.000 \mathrm{E}+00$ & 0.0000 & $0.000 \mathrm{E}+00$ & 0.0000 & $1.149 \mathrm{E}-08$ & 0.0012 \\
\hline 237 & $0.000 \mathrm{E}+00$ & 0.0000 & $0.000 \mathrm{E}+00$ & 0.0000 & $0.000 \mathrm{E}+00$ & 0.0000 & $0.000 \mathrm{E}+00$ & 0.0000 & $0.000 \mathrm{E}+00$ & 0.0000 & $0.000 \mathrm{E}+00$ & 0.0000 & $8.957 \mathrm{E}-12$ & 0.0000 \\
\hline 8 & $0.000 \mathrm{E}+00$ & 0.0000 & $0.000 \mathrm{E}+00$ & 0.0000 & $0.000 \mathrm{E}+00$ & 0.0000 & $0.000 \mathrm{E}+00$ & 0.0000 & $0.000 \mathrm{E}+00$ & 0.0000 & $0.000 \mathrm{E}+00$ & 0.0000 & -15 & 000 \\
\hline & $0.000 \mathrm{E}+00$ & 0 & 0 . & 0 & $0.000 \mathrm{E}+00$ & & & 0 & & & $000 \mathrm{E}+00$ & & 16 & 00 \\
\hline & $0.000 \mathrm{E}+00$ & 0. & $0.000 \mathrm{E}+00$ & 0 & $0.000 \mathrm{E}+00$ & 0.0000 & $0.000 \mathrm{E}+00$ & 0.0 & $0.000 \mathrm{E}+00$ & 0 & $0.000 \mathrm{E}+00$ & 00 & 20 & 000 \\
\hline & $0.000 \mathrm{E}+00$ & 0.0000 & $0.000 \mathrm{E}+00$ & 0.0000 & $0.000 \mathrm{E}+00$ & 0.0000 & $0.000 \mathrm{E}+00$ & 0.0000 & $0.000 \mathrm{E}+00$ & 0.0000 & $0.000 \mathrm{E}+00$ & 0.0000 & $4.979 \mathrm{E}-24$ & 0.0000 \\
\hline 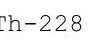 & $0.000 \mathrm{E}+00$ & 0.0000 & $0.000 \mathrm{E}+00$ & 0.0000 & $0.000 \mathrm{E}+00$ & 0.0000 & $0.000 \mathrm{E}+00$ & 0.0000 & $0.000 \mathrm{E}+00$ & 0.0000 & $0.000 \mathrm{E}+00$ & 0.0000 & $1.011 \mathrm{E}-13$ & 0.0000 \\
\hline & $0.000 \mathrm{E}+00$ & 0.0000 & $0.000 \mathrm{E}+00$ & 0.0000 & $0.000 \mathrm{E}+00$ & 0.0000 & $0.000 \mathrm{E}+00$ & 0.0000 & $0.000 \mathrm{E}+00$ & 0.0000 & $0.000 \mathrm{E}+00$ & 0.0000 & $5.320 \mathrm{E}-07$ & 0.0558 \\
\hline & $0.000 \mathrm{E}+00$ & 0.0000 & $0.000 \mathrm{E}+00$ & 0.0000 & $0.000 \mathrm{E}+00$ & 0.0000 & $0.000 \mathrm{E}+00$ & 0.0000 & $0.000 \mathrm{E}+00$ & 0.0000 & $0.000 \mathrm{E}+00$ & 0.0000 & $8.963 E-06$ & 0.9395 \\
\hline & $0.000 \mathrm{E}+00$ & 0.0000 & $0.000 \mathrm{E}+00$ & 0.0000 & $0.000 \mathrm{E}+00$ & 0.0000 & $0.000 E+00$ & 0.0000 & $0.000 \mathrm{E}+00$ & 0.0000 & $0.000 \mathrm{E}+00$ & 0.0000 & $1.941 \mathrm{E}-10$ & 0.0000 \\
\hline & $0.000 \mathrm{E}+00$ & 0.0000 & $0.000 \mathrm{E}+00$ & 0.0000 & $0.000 \mathrm{E}+00$ & 0.0000 & $0.000 \mathrm{E}+00$ & 0.0000 & $0.000 \mathrm{E}+00$ & 0.0000 & $0.000 \mathrm{E}+00$ & 0.0000 & $6.005 \mathrm{E}-13$ & 0.0000 \\
\hline & $0.000 \mathrm{E}+00$ & 0.0000 & $0.000 \mathrm{E}+00$ & 0.0000 & $0.000 \mathrm{E}+00$ & 0.0000 & $0.000 \mathrm{E}+00$ & 0.0000 & $0.000 \mathrm{E}+00$ & 0.0000 & $0.000 \mathrm{E}+00$ & 0.0000 & $3.385 \mathrm{E}-08$ & 0.0035 \\
\hline & & 00 & $.000 \mathrm{E}+00$ & 0.0000 & $0.000 \mathrm{E}+00$ & 0.0000 & $0.000 \mathrm{E}+00$ & 0.0000 & $0.000 \mathrm{E}+00$ & & +00 & & .06 & \\
\hline
\end{tabular}

*Sum of all water independent and dependent pathways. 
RESRAD, Version $6.5 \quad T^{3 / 2}$ Limit $=180$ days $\quad 07 / 21 / 2011 \quad 12: 27$ Page 23
Summary : RESRAD Parameters for U-Landfill Resident Gardener Forward Run 10,000 years

File : C: $\backslash$ RESRAD_FAMILY \RESRAD \USERFILES \QCJULY2011 \ULANDFILL-RG_FORWARD-10000YR.RAD

Total Dose Contributions TDOSE (i,p,t) for Individual Radionuclides (i) and Pathways (p) As mrem/yr and Fraction of Total Dose At $t=1.000 \mathrm{E}+02$ years

Water Independent Pathways (Inhalation excludes radon)

\begin{tabular}{|c|c|c|c|c|c|c|c|c|c|c|c|c|c|c|}
\hline \multirow[b]{2}{*}{ clide } & \multicolumn{2}{|c|}{ Ground } & \multicolumn{2}{|c|}{ Inhalation } & \multicolumn{2}{|c|}{ Radon } & \multicolumn{2}{|c|}{ Plant } & \multicolumn{2}{|c|}{ Meat } & \multicolumn{2}{|c|}{ Milk } & \multicolumn{2}{|c|}{ Soil } \\
\hline & mrem/yr & fract. & mrem/yr & fract. & mrem/yr & fract. & mrem/yr & fract. & mrem/yr & fract. & mrem/yr & fract. & mrem/yr & fract. \\
\hline 241 & $2.940 \mathrm{E}-15$ & 0.0000 & $0.000 \mathrm{E}+00$ & 0.0000 & $0.000 \mathrm{E}+00$ & 0.0000 & $0.000 \mathrm{E}+00$ & 0.0000 & $0.000 \mathrm{E}+00$ & 0.0000 & $0.000 \mathrm{E}+00$ & 0.0000 & $0.000 \mathrm{E}+00$ & 0000 \\
\hline 137 & $5.512 \mathrm{E}-09$ & 0.0004 & $0.000 \mathrm{E}+00$ & 0.0000 & $0.000 \mathrm{E}+00$ & 0.0000 & $0.000 \mathrm{E}+00$ & 0.0000 & $0.000 \mathrm{E}+00$ & 0.0000 & $0.000 \mathrm{E}+00$ & 0.0000 & $0.000 \mathrm{E}+00$ & .0000 \\
\hline 37 & $1.534 \mathrm{E}-11$ & 0.0000 & $0.000 \mathrm{E}+00$ & 0.0000 & $0.000 \mathrm{E}+00$ & 0.0000 & $0.000 \mathrm{E}+00$ & 0.0000 & $0.000 \mathrm{E}+00$ & 0.0000 & $0.000 \mathrm{E}+00$ & 0.0000 & $0.000 \mathrm{E}+00$ & 0.0000 \\
\hline 238 & $2.076 \mathrm{E}-14$ & 0.0000 & $0.000 \mathrm{E}+00$ & 0.0000 & $0.000 \mathrm{E}+00$ & 0.0000 & $0.000 \mathrm{E}+00$ & 0.0000 & $0.000 \mathrm{E}+00$ & 0.0000 & $0.000 \mathrm{E}+00$ & 0.0000 & $0.000 \mathrm{E}+00$ & 0.0000 \\
\hline 239 & $1.428 \mathrm{E}-15$ & 0.0000 & $0.000 \mathrm{E}+00$ & 0.0000 & $0.000 \mathrm{E}+00$ & 0.0000 & $0.000 \mathrm{E}+00$ & 0.0000 & $0.000 \mathrm{E}+00$ & 0.0000 & $0.000 \mathrm{E}+00$ & 0.0000 & $0.000 \mathrm{E}+00$ & 0.0000 \\
\hline 240 & $6.420 \mathrm{E}-19$ & 0.0000 & $0.000 \mathrm{E}+00$ & 0.0000 & $0.000 \mathrm{E}+00$ & 0.0000 & $0.000 \mathrm{E}+00$ & 0.0000 & $0.000 \mathrm{E}+00$ & 0.0000 & $0.000 \mathrm{E}+00$ & 0.0000 & $0.000 \mathrm{E}+00$ & 0.0000 \\
\hline & $8.280 \mathrm{E}-24$ & 0.0000 & $0.000 \mathrm{E}+00$ & 0.0000 & $0.000 \mathrm{E}+00$ & 0.0000 & $0.000 \mathrm{E}+00$ & 0.00 & $0.000 \mathrm{E}+00$ & 00 & $0.000 \mathrm{E}+00$ & 0.0000 & $0.000 \mathrm{E}+00$ & 0.0000 \\
\hline 8 & $1.847 \mathrm{E}-21$ & 0.0000 & $0.000 \mathrm{E}+00$ & 0.0000 & $0.000 \mathrm{E}+00$ & 0.0000 & $0.000 \mathrm{E}+00$ & 0.00 & $0.000 \mathrm{E}+00$ & 0.0000 & $0.000 \mathrm{E}+00$ & 0.0000 & $0.000 \mathrm{E}+00$ & 0.0000 \\
\hline 30 & $1.479 \mathrm{E}-06$ & 0.1082 & $0.000 \mathrm{E}+00$ & 0.0000 & $0.000 \mathrm{E}+00$ & 0.0000 & $0.000 \mathrm{E}+00$ & 0.0000 & $0.000 \mathrm{E}+00$ & 0.0000 & $0.000 \mathrm{E}+00$ & 0.0000 & $0.000 \mathrm{E}+00$ & 0.0000 \\
\hline 2 & $1.213 \mathrm{E}-05$ & 0.8876 & $0.000 \mathrm{E}+00$ & 0.0000 & $0.000 \mathrm{E}+00$ & 0.0000 & $0.000 \mathrm{E}+00$ & 0.0000 & $0.000 \mathrm{E}+00$ & 0.0000 & $0.000 \mathrm{E}+00$ & 0.0000 & $0.000 \mathrm{E}+00$ & 0.0000 \\
\hline & $1.078 \mathrm{E}-09$ & 0.0001 & $0.000 \mathrm{E}+00$ & 0.0000 & $0.000 \mathrm{E}+00$ & 0.0000 & $0.000 \mathrm{E}+00$ & 0.0000 & $0.000 \mathrm{E}+00$ & 0.0000 & $0.000 \mathrm{E}+00$ & 0.0000 & $0.000 \mathrm{E}+00$ & 0.0000 \\
\hline & $2.202 \mathrm{E}-12$ & 0.0000 & $0.000 \mathrm{E}+00$ & 0.0000 & $0.000 \mathrm{E}+00$ & 0.0000 & $0.000 \mathrm{E}+00$ & 0.0000 & $0.000 \mathrm{E}+00$ & 0.0000 & $0.000 \mathrm{E}+00$ & 0.0000 & $0.000 \mathrm{E}+00$ & 0.0000 \\
\hline & $5.045 \mathrm{E}-08$ & 0.0037 & $0.000 \mathrm{E}+00$ & 0.0000 & $0.000 \mathrm{E}+00$ & 0.0000 & $0.000 \mathrm{E}+00$ & 0.0000 & $0.000 \mathrm{E}+00$ & 0.0000 & $0.000 \mathrm{E}+00$ & 0.0000 & $0.000 \mathrm{E}+00$ & 0.0000 \\
\hline & - & - & $.000 \mathrm{E}+00$ & . 000 & $.000 E+00$ & 0.0000 & $.000 \mathrm{E}+00$ & 0.0000 & $0.000 \mathrm{E}+00$ & 0.0000 & . & 0.0000 & $0.000 \mathrm{E}+00$ & \\
\hline
\end{tabular}

Total Dose Contributions TDOSE (i,p,t) for Individual Radionuclides (i) and Pathways (p) As mrem/yr and Fraction of Total Dose At $t=1.000 \mathrm{E}+02$ years

Water Dependent Pathways

\begin{tabular}{|c|c|c|c|c|c|c|c|c|c|c|c|c|c|c|}
\hline \multirow[b]{2}{*}{ clide } & \multicolumn{2}{|c|}{ Water } & \multicolumn{2}{|c|}{ Fish } & \multicolumn{2}{|c|}{ Radon } & \multicolumn{2}{|c|}{ Plant } & \multicolumn{2}{|c|}{ Meat } & \multicolumn{2}{|c|}{ Milk } & \multicolumn{2}{|c|}{ All Pathways* } \\
\hline & mrem/yr & fract. & mrem/yr & fract. & $\mathrm{mrem} / \mathrm{yr}$ & fract. & mrem/yr & fract. & mrem/yr & fract. & mrem/yr & fract. & mrem/yr & fract. \\
\hline 1 & $0.000 \mathrm{E}+00$ & 0.0000 & $0.000 \mathrm{E}+00$ & 0.0000 & $0.000 \mathrm{E}+00$ & 0.0000 & $0.000 \mathrm{E}+00$ & 0.0000 & $0.000 \mathrm{E}+00$ & 0.0000 & $0.000 \mathrm{E}+00$ & 0.0000 & $2.940 \mathrm{E}-15$ & 0.0000 \\
\hline 37 & $0.000 \mathrm{E}+00$ & 0.0000 & $0.000 \mathrm{E}+00$ & 0.0000 & $0.000 \mathrm{E}+00$ & 0.0000 & $0.000 \mathrm{E}+00$ & 0.0000 & $0.000 \mathrm{E}+00$ & 0.0000 & $0.000 \mathrm{E}+00$ & 0.0000 & $5.512 \mathrm{E}-09$ & 0.0004 \\
\hline 37 & $0.000 \mathrm{E}+00$ & 0.0000 & $0.000 \mathrm{E}+00$ & 0.0000 & $0.000 \mathrm{E}+00$ & 0.0000 & $0.000 \mathrm{E}+00$ & 0.0000 & $0.000 \mathrm{E}+00$ & 0.0000 & $0.000 \mathrm{E}+00$ & 0.0000 & $1.534 \mathrm{E}-11$ & 0.0000 \\
\hline 238 & $0.000 \mathrm{E}+00$ & 0.0000 & $0.000 \mathrm{E}+00$ & 0.0000 & $0.000 \mathrm{E}+00$ & 0.0000 & $0.000 \mathrm{E}+00$ & 0.0000 & $0.000 \mathrm{E}+00$ & 0.0000 & $0.000 \mathrm{E}+00$ & 0.0000 & $2.076 \mathrm{E}-14$ & 0.0000 \\
\hline 239 & $0.000 \mathrm{E}+00$ & 0.0000 & $0.000 \mathrm{E}+00$ & 0.0000 & $0.000 \mathrm{E}+00$ & 0.0000 & $0.000 \mathrm{E}+00$ & 0.0000 & $0.000 \mathrm{E}+00$ & 0.0000 & $0.000 \mathrm{E}+00$ & 0.0000 & $1.428 \mathrm{E}-15$ & 0.0000 \\
\hline 240 & $0.000 \mathrm{E}+00$ & 0.0 & 0.00 & 0 & $0.000 \mathrm{E}+00$ & 0 & $0.000 \mathrm{E}+00$ & 0 & 0 & 0 & $0.000 \mathrm{E}+00$ & 0 & -19 & 000 \\
\hline & $0.000 \mathrm{E}+00$ & 0. & $0.000 \mathrm{E}+00$ & 0.0000 & $0.000 \mathrm{E}+00$ & 0.0000 & $0.000 \mathrm{E}+00$ & 0.00 & $0.000 \mathrm{E}+00$ & 0.0000 & $0.000 \mathrm{E}+00$ & 0.0 & $8.280 \mathrm{E}-24$ & 0.0000 \\
\hline 228 & $0.000 \mathrm{E}+00$ & 0.0000 & $0.000 \mathrm{E}+00$ & 0.0000 & $0.000 \mathrm{E}+00$ & 0.0000 & $0.000 \mathrm{E}+00$ & 0.0000 & $0.000 \mathrm{E}+00$ & 0.0000 & $0.000 \mathrm{E}+00$ & 0.0000 & $1.847 \mathrm{E}-21$ & 0.0000 \\
\hline & $0.000 \mathrm{E}+00$ & 0.0000 & $0.000 \mathrm{E}+00$ & 0.0000 & $0.000 \mathrm{E}+00$ & 0.0000 & $0.000 \mathrm{E}+00$ & 0.0000 & $0.000 \mathrm{E}+00$ & 0.0000 & $0.000 \mathrm{E}+00$ & 0.0000 & $1.479 \mathrm{E}-06$ & 0.1082 \\
\hline & $0.000 \mathrm{E}+00$ & 0.0000 & $0.000 \mathrm{E}+00$ & 0.0000 & $0.000 \mathrm{E}+00$ & 0.0000 & $0.000 \mathrm{E}+00$ & 0.0000 & $0.000 \mathrm{E}+00$ & 0.0000 & $0.000 \mathrm{E}+00$ & 0.0000 & $1.213 \mathrm{E}-05$ & 0.8876 \\
\hline & $0.000 \mathrm{E}+00$ & 0.0000 & $0.000 \mathrm{E}+00$ & 0.0000 & $0.000 \mathrm{E}+00$ & 0.0000 & $0.000 \mathrm{E}+00$ & 0.0000 & $0.000 \mathrm{E}+00$ & 0.0000 & $0.000 \mathrm{E}+00$ & 0.0000 & $1.078 \mathrm{E}-09$ & 0.0001 \\
\hline & $0.000 \mathrm{E}+00$ & 0.0000 & $0.000 \mathrm{E}+00$ & 0.0000 & $0.000 \mathrm{E}+00$ & 0.0000 & $0.000 \mathrm{E}+00$ & 0.0000 & $0.000 \mathrm{E}+00$ & 0.0000 & $0.000 \mathrm{E}+00$ & 0.0000 & $2.202 \mathrm{E}-12$ & 0.0000 \\
\hline & $0.000 \mathrm{E}+00$ & 0.0000 & $0.000 \mathrm{E}+00$ & 0.0000 & $0.000 \mathrm{E}+00$ & 0.0000 & $0.000 \mathrm{E}+00$ & 0.0000 & $0.000 \mathrm{E}+00$ & 0.0000 & $0.000 \mathrm{E}+00$ & 0.0000 & $5.045 \mathrm{E}-08$ & 0.0037 \\
\hline & & 00 & $0.000 \mathrm{E}+00$ & 0.0000 & $.000 \mathrm{E}+00$ & 0.0000 & $0.000 \mathrm{E}+00$ & .0000 & $0.000 \mathrm{E}+00$ & 0.0000 & +0 & & & - \\
\hline
\end{tabular}

*Sum of all water independent and dependent pathways. 
RESRAD, Version $6.5 \quad T^{3 / 2}$ Limit $=180$ days $\quad 07 / 21 / 2011 \quad 12: 27$ Page 24
Summary : RESRAD Parameters for U-Landfill Resident Gardener Forward Run 10,000 years

File : C: $\backslash$ RESRAD_FAMILY \RESRAD \USERFILES \QCJULY2011 \ULANDFILL-RG_FORWARD-10000YR.RAD

Total Dose Contributions TDOSE (i,p,t) for Individual Radionuclides (i) and Pathways (p) As mrem/yr and Fraction of Total Dose At $t=5.000 \mathrm{E}+02$ years

Water Independent Pathways (Inhalation excludes radon)

\begin{tabular}{|c|c|c|c|c|c|c|c|c|c|c|c|c|c|c|}
\hline \multirow[b]{2}{*}{ clide } & \multicolumn{2}{|c|}{ Ground } & \multicolumn{2}{|c|}{ Inhalation } & \multicolumn{2}{|c|}{ Radon } & \multicolumn{2}{|c|}{ Plant } & \multicolumn{2}{|c|}{ Meat } & \multicolumn{2}{|c|}{ Milk } & \multicolumn{2}{|l|}{ Soil } \\
\hline & mrem/yr & fract. & mrem/yr & fract. & mrem/yr & fract. & mrem/yr & fract. & mrem/yr & fract. & mrem/yr & fract. & mrem/yr & fract. \\
\hline-241 & $8.032 E-13$ & 0.0000 & $0.000 \mathrm{E}+00$ & 0.0000 & $0.000 \mathrm{E}+00$ & 0.0000 & $0.000 \mathrm{E}+00$ & 0.0000 & $0.000 \mathrm{E}+00$ & 0.0000 & $0.000 \mathrm{E}+00$ & 0.0000 & $0.000 \mathrm{E}+00$ & 0000 \\
\hline 137 & $1.540 \mathrm{E}-11$ & 0.0000 & $0.000 \mathrm{E}+00$ & 0.0000 & $0.000 \mathrm{E}+00$ & 0.0000 & $0.000 \mathrm{E}+00$ & 0.0000 & $0.000 \mathrm{E}+00$ & 0.0000 & $0.000 \mathrm{E}+00$ & 0.0000 & $0.000 \mathrm{E}+00$ & 0.0000 \\
\hline 237 & $1.124 \mathrm{E}-09$ & 0.0000 & $0.000 \mathrm{E}+00$ & 0.0000 & $0.000 \mathrm{E}+00$ & 0.0000 & $0.000 \mathrm{E}+00$ & 0.0000 & $0.000 \mathrm{E}+00$ & 0.0000 & $0.000 \mathrm{E}+00$ & 0.0000 & $0.000 \mathrm{E}+00$ & 0.0000 \\
\hline 238 & $2.187 E-11$ & 0.0000 & $0.000 \mathrm{E}+00$ & 0.0000 & $0.000 \mathrm{E}+00$ & 0.0000 & $0.000 \mathrm{E}+00$ & 0.0000 & $0.000 \mathrm{E}+00$ & 0.0000 & $0.000 \mathrm{E}+00$ & 0.0000 & $0.000 \mathrm{E}+00$ & 0.0000 \\
\hline 239 & $1.695 \mathrm{E}-13$ & 0.0000 & $0.000 \mathrm{E}+00$ & 0.0000 & $0.000 \mathrm{E}+00$ & 0.0000 & $0.000 \mathrm{E}+00$ & 0.0000 & $0.000 \mathrm{E}+00$ & 0.0000 & $0.000 \mathrm{E}+00$ & 0.0000 & $0.000 \mathrm{E}+00$ & 0.0000 \\
\hline 240 & $2.059 \mathrm{E}-16$ & 0.0000 & $0.000 \mathrm{E}+00$ & 0.0000 & $0.000 \mathrm{E}+00$ & 0.0000 & $0.000 \mathrm{E}+00$ & 0.0000 & $0.000 \mathrm{E}+00$ & 0.0000 & $0.000 \mathrm{E}+00$ & 0.0000 & $0.000 \mathrm{E}+00$ & 0.0000 \\
\hline & $4.841 \mathrm{E}-22$ & 0.000 & $0.000 \mathrm{E}$ & 0 & $0.000 \mathrm{E}+00$ & 0 & $0.000 \mathrm{E}+00$ & 0 & $0.000 \mathrm{E}$ & 00 & $0.000 \mathrm{E}+00$ & 0.0 & $0.000 \mathrm{E}+00$ & 0.0000 \\
\hline 228 & $0.000 \mathrm{E}+00$ & 0.0000 & $0.000 \mathrm{E}+00$ & 0.0000 & $0.000 \mathrm{E}+00$ & 0.0000 & $0.000 \mathrm{E}+00$ & 0.0000 & $0.000 \mathrm{E}+00$ & 0.0000 & $0.000 \mathrm{E}+00$ & 0.0000 & $0.000 \mathrm{E}+00$ & 0.0000 \\
\hline 30 & $1.071 \mathrm{E}-04$ & 0.4421 & $0.000 \mathrm{E}+00$ & 0.0000 & $0.000 \mathrm{E}+00$ & 0.0000 & $0.000 \mathrm{E}+00$ & 0.0000 & $0.000 \mathrm{E}+00$ & 0.0000 & $0.000 \mathrm{E}+00$ & 0.0000 & $0.000 \mathrm{E}+00$ & 0.0000 \\
\hline 2 & $1.335 \mathrm{E}-04$ & 0.5512 & $0.000 \mathrm{E}+00$ & 0.0000 & $0.000 \mathrm{E}+00$ & 0.0000 & $0.000 \mathrm{E}+00$ & 0.0000 & $0.000 \mathrm{E}+00$ & 0.0000 & $0.000 \mathrm{E}+00$ & 0.0000 & $0.000 \mathrm{E}+00$ & 0.0000 \\
\hline & $3.993 \mathrm{E}-07$ & 0.0016 & $0.000 \mathrm{E}+00$ & 0.0000 & $0.000 \mathrm{E}+00$ & 0.0000 & $0.000 \mathrm{E}+00$ & 0.0000 & $0.000 \mathrm{E}+00$ & 0.0000 & $0.000 \mathrm{E}+00$ & 0.0000 & $0.000 \mathrm{E}+00$ & 0.0000 \\
\hline & $4.571 \mathrm{E}-10$ & 0.0000 & $0.000 \mathrm{E}+00$ & 0.0000 & $0.000 \mathrm{E}+00$ & 0.0000 & $0.000 \mathrm{E}+00$ & 0.0000 & $0.000 \mathrm{E}+00$ & 0.0000 & $0.000 \mathrm{E}+00$ & 0.0000 & $0.000 \mathrm{E}+00$ & 0.0000 \\
\hline & $1.229 \mathrm{E}-06$ & 0.0051 & $0.000 \mathrm{E}+00$ & 0.0000 & $0.000 \mathrm{E}+00$ & 0.0000 & $0.000 \mathrm{E}+00$ & 0.0000 & $0.000 \mathrm{E}+00$ & 0.0000 & $0.000 \mathrm{E}+00$ & 0.0000 & $0.000 \mathrm{E}+00$ & 0.0000 \\
\hline & . & & $.000 \mathrm{E}+00$ & 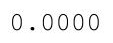 & +00 & ( & $000 \mathrm{E}+00$ & 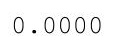 & $.000 \mathrm{E}+00$ & & . & & $\mathrm{E}+00$ & \\
\hline
\end{tabular}

Total Dose Contributions TDOSE (i,p,t) for Individual Radionuclides (i) and Pathways (p) As mrem/yr and Fraction of Total Dose At $t=5.000 \mathrm{E}+02$ years

Water Dependent Pathways

\begin{tabular}{|c|c|c|c|c|c|c|c|c|c|c|c|c|c|c|}
\hline \multirow[b]{2}{*}{ clide } & \multicolumn{2}{|c|}{ Water } & \multicolumn{2}{|c|}{ Fish } & \multicolumn{2}{|c|}{ Radon } & \multicolumn{2}{|c|}{ Plant } & \multicolumn{2}{|c|}{ Meat } & \multicolumn{2}{|c|}{ Milk } & \multicolumn{2}{|c|}{ All Pathways* } \\
\hline & mrem/yr & fract. & mrem/yr & fract. & mrem/yr & fract. & mrem/yr & fract. & mrem/yr & fract. & mrem/yr & fract. & mrem/yr & fract. \\
\hline \pm & $0.000 \mathrm{E}+00$ & 0.0000 & $0.000 \mathrm{E}+00$ & 0.0000 & $0.000 \mathrm{E}+00$ & 0.0000 & $0.000 \mathrm{E}+00$ & 0.0000 & $0.000 \mathrm{E}+00$ & 0.0000 & $0.000 \mathrm{E}+00$ & 0.0000 & $8.032 E-13$ & 0.0000 \\
\hline & $0.000 \mathrm{E}+00$ & 0.0000 & $0.000 \mathrm{E}+00$ & 0.0000 & $0.000 \mathrm{E}+00$ & 0.0000 & $0.000 E+00$ & 0.0000 & $0.000 \mathrm{E}+00$ & 0.0000 & $0.000 \mathrm{E}+00$ & 0.0000 & $1.540 \mathrm{E}-11$ & 0.0000 \\
\hline 237 & $0.000 \mathrm{E}+00$ & 0.0000 & $0.000 \mathrm{E}+00$ & 0.0000 & $0.000 \mathrm{E}+00$ & 0.0000 & $0.000 \mathrm{E}+00$ & 0.0000 & $0.000 \mathrm{E}+00$ & 0.0000 & $0.000 \mathrm{E}+00$ & 0.0000 & $1.124 \mathrm{E}-09$ & 0.0000 \\
\hline 8 & $0.000 \mathrm{E}+00$ & 0.0000 & $0.000 \mathrm{E}+00$ & 0.0000 & $0.000 \mathrm{E}+00$ & 0.0000 & $0.000 \mathrm{E}+00$ & 0.0000 & $0.000 \mathrm{E}+00$ & 0.0000 & $0.000 \mathrm{E}+00$ & 0.0000 & $87 E-11$ & 000 \\
\hline & $0.000 \mathrm{E}+00$ & 0 & 0 . & 0 & $0.000 \mathrm{E}+00$ & & & & & & $000 \mathrm{E}+00$ & & 13 & 00 \\
\hline 40 & $0.000 \mathrm{E}+00$ & 0. & $0.000 \mathrm{E}+00$ & 0 & $0.000 \mathrm{E}+00$ & 0.0000 & $0.000 \mathrm{E}+00$ & 0.0 & $0.000 \mathrm{E}+00$ & 0 & $0.000 \mathrm{E}+00$ & 00 & 2.059 & 000 \\
\hline & $0.000 \mathrm{E}+00$ & 0.0000 & $0.000 \mathrm{E}+00$ & 0.0000 & $0.000 \mathrm{E}+00$ & 0.0000 & $0.000 \mathrm{E}+00$ & 0.0000 & $0.000 \mathrm{E}+00$ & 0.0000 & $0.000 \mathrm{E}+00$ & 0.0000 & $4.841 \mathrm{E}-22$ & 0.0000 \\
\hline 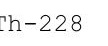 & $0.000 \mathrm{E}+00$ & 0.0000 & $0.000 \mathrm{E}+00$ & 0.0000 & $0.000 \mathrm{E}+00$ & 0.0000 & $0.000 \mathrm{E}+00$ & 0.0000 & $0.000 \mathrm{E}+00$ & 0.0000 & $0.000 \mathrm{E}+00$ & 0.0000 & $0.000 \mathrm{E}+00$ & 0.0000 \\
\hline & $0.000 \mathrm{E}+00$ & 0.0000 & $0.000 \mathrm{E}+00$ & 0.0000 & $0.000 \mathrm{E}+00$ & 0.0000 & $0.000 \mathrm{E}+00$ & 0.0000 & $0.000 \mathrm{E}+00$ & 0.0000 & $0.000 \mathrm{E}+00$ & 0.0000 & $1.071 \mathrm{E}-04$ & 0.4421 \\
\hline & $0.000 \mathrm{E}+00$ & 0.0000 & $0.000 \mathrm{E}+00$ & 0.0000 & $0.000 \mathrm{E}+00$ & 0.0000 & $0.000 \mathrm{E}+00$ & 0.0000 & $0.000 \mathrm{E}+00$ & 0.0000 & $0.000 \mathrm{E}+00$ & 0.0000 & $1.335 \mathrm{E}-04$ & 0.5512 \\
\hline & $0.000 \mathrm{E}+00$ & 0.0000 & $0.000 \mathrm{E}+00$ & 0.0000 & $0.000 \mathrm{E}+00$ & 0.0000 & $0.000 E+00$ & 0.0000 & $0.000 \mathrm{E}+00$ & 0.0000 & $0.000 \mathrm{E}+00$ & 0.0000 & $3.993 \mathrm{E}-07$ & 0.0016 \\
\hline & $0.000 \mathrm{E}+00$ & 0.0000 & $0.000 \mathrm{E}+00$ & 0.0000 & $0.000 \mathrm{E}+00$ & 0.0000 & $0.000 \mathrm{E}+00$ & 0.0000 & $0.000 \mathrm{E}+00$ & 0.0000 & $0.000 \mathrm{E}+00$ & 0.0000 & $4.571 \mathrm{E}-10$ & 0.0000 \\
\hline & $0.000 \mathrm{E}+00$ & 0.0000 & $0.000 \mathrm{E}+00$ & 0.0000 & $0.000 \mathrm{E}+00$ & 0.0000 & $0.000 \mathrm{E}+00$ & 0.0000 & $0.000 \mathrm{E}+00$ & 0.0000 & $0.000 \mathrm{E}+00$ & 0.0000 & $1.229 \mathrm{E}-06$ & 0.0051 \\
\hline & & 00 & $.000 \mathrm{E}+00$ & 0.0000 & $0.000 \mathrm{E}+00$ & 0.0000 & $0.000 \mathrm{E}+00$ & 0.0000 & $0.000 \mathrm{E}+00$ & & +00 & & 04 & \\
\hline
\end{tabular}

*Sum of all water independent and dependent pathways. 
RESRAD, Version $6.5 \quad T^{3 / 2}$ Limit $=180$ days
Summary : RESRAD Parameters for U-Landfill Resident Gardener Forward Run 10,000 years

File : C: $\backslash$ RESRAD_FAMILY \RESRAD \USERFILES \QCJULY2011 \ULANDFILL-RG_FORWARD-10000YR.RAD

Total Dose Contributions TDOSE (i,p,t) for Individual Radionuclides (i) and Pathways (p) As mrem/yr and Fraction of Total Dose At $t=1.000 \mathrm{E}+04$ years

Water Independent Pathways (Inhalation excludes radon)

\begin{tabular}{|c|c|c|c|c|c|c|c|c|c|c|c|c|c|c|}
\hline \multirow[b]{2}{*}{ clide } & \multicolumn{2}{|c|}{ Ground } & \multicolumn{2}{|c|}{ Inhalation } & \multicolumn{2}{|c|}{ Radon } & \multicolumn{2}{|c|}{ Plant } & \multicolumn{2}{|c|}{ Meat } & \multicolumn{2}{|c|}{ Milk } & \multicolumn{2}{|l|}{ Soil } \\
\hline & mrem/yr & fract. & mrem/yr & fract. & mrem/yr & fract. & mrem/yr & fract. & mrem/yr & fract. & mrem/yr & fract. & nrem/yr & fract. \\
\hline-241 & $1.724 \mathrm{E}-03$ & 0.0000 & $1.816 \mathrm{E}-07$ & 0.0000 & $0.000 \mathrm{E}+00$ & 0.0000 & $2.088 \mathrm{E}-03$ & 0.0000 & $0.000 \mathrm{E}+00$ & 0.0000 & $0.000 \mathrm{E}+00$ & 0.0000 & $3.432 \mathrm{E}-05$ & 0000 \\
\hline 7 & $0.000 \mathrm{E}+00$ & 0.0000 & $0.000 \mathrm{E}+00$ & 0.0000 & $0.000 \mathrm{E}+00$ & 0.0000 & $0.000 \mathrm{E}+00$ & 0.0000 & $0.000 \mathrm{E}+00$ & 0.0000 & $0.000 \mathrm{E}+00$ & 0.0000 & $0.000 \mathrm{E}+00$ & 0.0000 \\
\hline 1 & $1.242 \mathrm{E}+00$ & 0.0005 & $1.326 \mathrm{E}-04$ & 0.0000 & $0.000 \mathrm{E}+00$ & 0.0000 & $1.496 \mathrm{E}+00$ & 0.0006 & $0.000 \mathrm{E}+00$ & 0.0000 & $0.000 \mathrm{E}+00$ & 0.0000 & $2.514 \mathrm{E}-02$ & 0.0000 \\
\hline 238 & $6.839 \mathrm{E}-03$ & 0.0000 & $3.439 \mathrm{E}-07$ & 0.0000 & $0.000 \mathrm{E}+00$ & 0.0000 & $1.186 \mathrm{E}-02$ & 0.0000 & $0.000 \mathrm{E}+00$ & 0.0000 & $0.000 \mathrm{E}+00$ & 0.0000 & $3.191 \mathrm{E}-04$ & 0.0000 \\
\hline 239 & $5.108 \mathrm{E}-03$ & 0.0000 & $4.259 \mathrm{E}-03$ & 0.0000 & $0.000 \mathrm{E}+00$ & 0.0000 & $2.652 \mathrm{E}+00$ & 0.0011 & $0.000 \mathrm{E}+00$ & 0.0000 & $0.000 \mathrm{E}+00$ & 0.0000 & $7.370 \mathrm{E}-01$ & 0.0003 \\
\hline 240 & $9.845 \mathrm{E}-04$ & 0.0000 & $1.967 \mathrm{E}-03$ & 0.0000 & $0.000 \mathrm{E}+00$ & 0.0000 & $1.225 \mathrm{E}+00$ & 0.0005 & $0.000 \mathrm{E}+00$ & 0.0000 & $0.000 \mathrm{E}+00$ & 0.0000 & $3.405 \mathrm{E}-01$ & 0.0001 \\
\hline & $0.000 \mathrm{E}+00$ & 0.0000 & $0.000 \mathrm{E}+00$ & 0.0000 & $0.000 \mathrm{E}+00$ & 0.0000 & $0.000 \mathrm{E}+00$ & 0.00 & $0.000 \mathrm{E}+00$ & 00 & $0.000 \mathrm{E}+00$ & 0.0000 & $0.000 \mathrm{E}+00$ & 0.0000 \\
\hline 8 & $0.000 \mathrm{E}+00$ & 0.0000 & $0.000 \mathrm{E}+00$ & 0.0000 & $0.000 \mathrm{E}+00$ & 0.0000 & $0.000 \mathrm{E}+00$ & 0.00 & $0.000 \mathrm{E}+00$ & 0.0000 & $0.000 \mathrm{E}+00$ & 0.0000 & $0.000 \mathrm{E}+00$ & 0.0000 \\
\hline 0 & $7.436 \mathrm{E}+02$ & 0.3152 & $1.648 \mathrm{E}-02$ & 0.0000 & $0.000 \mathrm{E}+00$ & 0.0000 & $1.224 \mathrm{E}+03$ & 0.5187 & $0.000 \mathrm{E}+00$ & 0.0000 & $0.000 \mathrm{E}+00$ & 0.0000 & $2.669 \mathrm{E}+01$ & 0.0113 \\
\hline 232 & $4.839 \mathrm{E}+01$ & 0.0205 & $1.028 \mathrm{E}-03$ & 0.0000 & $0.000 \mathrm{E}+00$ & 0.0000 & $5.054 \mathrm{E}+01$ & 0.0214 & $0.000 \mathrm{E}+00$ & 0.0000 & $0.000 \mathrm{E}+00$ & 0.0000 & $5.352 \mathrm{E}-01$ & 0.0002 \\
\hline & $7.945 \mathrm{E}+01$ & 0.0337 & $3.957 \mathrm{E}-03$ & 0.0000 & $0.000 \mathrm{E}+00$ & 0.0000 & $1.377 \mathrm{E}+02$ & 0.0584 & $0.000 \mathrm{E}+00$ & 0.0000 & $0.000 \mathrm{E}+00$ & 0.0000 & $3.693 \mathrm{E}+00$ & 0.0016 \\
\hline & $4.626 \mathrm{E}+00$ & 0.0020 & $1.189 \mathrm{E}-03$ & 0.0000 & $0.000 \mathrm{E}+00$ & 0.0000 & $5.072 \mathrm{E}+00$ & 0.0022 & $0.000 \mathrm{E}+00$ & 0.0000 & $0.000 \mathrm{E}+00$ & 0.0000 & $2.835 \mathrm{E}-01$ & 0.0001 \\
\hline & $1.706 \mathrm{E}+01$ & 0.0072 & $1.671 \mathrm{E}-03$ & 0.0000 & $0.000 \mathrm{E}+00$ & 0.0000 & $8.921 \mathrm{E}+00$ & 0.0038 & $0.000 \mathrm{E}+00$ & 0.0000 & $0.000 \mathrm{E}+00$ & 0.0000 & $8.572 \mathrm{E}-01$ & 0.0004 \\
\hline & 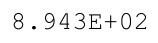 & 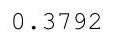 & $3.068 \mathrm{E}-02$ & 0.000 & $.000 \mathrm{E}+00$ & 0.0000 & 年 & 0.0000 & $0.000 \mathrm{E}+00$ & 0.0000 & . & . & (1) & 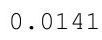 \\
\hline
\end{tabular}

Total Dose Contributions TDOSE (i,p,t) for Individual Radionuclides (i) and Pathways (p) As mrem/yr and Fraction of Total Dose At $t=1.000 \mathrm{E}+04$ years

Water Dependent Pathways

\begin{tabular}{|c|c|c|c|c|c|c|c|c|c|c|c|c|c|c|}
\hline \multirow[b]{2}{*}{ clide } & \multicolumn{2}{|c|}{ Water } & \multicolumn{2}{|c|}{ Fish } & \multicolumn{2}{|c|}{ Radon } & \multicolumn{2}{|c|}{ Plant } & \multicolumn{2}{|c|}{ Meat } & \multicolumn{2}{|c|}{ Milk } & \multicolumn{2}{|c|}{ All Pathways* } \\
\hline & mrem/yr & fract. & mrem/yr & fract. & $\mathrm{mrem} / \mathrm{yr}$ & fract. & mrem/yr & fract. & mrem/yr & fract. & mrem/yr & fract. & mrem/yr & fract. \\
\hline 1 & $0.000 \mathrm{E}+00$ & 0.0000 & $0.000 \mathrm{E}+00$ & 0.0000 & $0.000 \mathrm{E}+00$ & 0.0000 & $0.000 \mathrm{E}+00$ & 0.0000 & $0.000 \mathrm{E}+00$ & 0.0000 & $0.000 \mathrm{E}+00$ & 0.0000 & $3.847 \mathrm{E}-03$ & 0.0000 \\
\hline 37 & $0.000 \mathrm{E}+00$ & 0.0000 & $0.000 \mathrm{E}+00$ & 0.0000 & $0.000 \mathrm{E}+00$ & 0.0000 & $0.000 \mathrm{E}+00$ & 0.0000 & $0.000 \mathrm{E}+00$ & 0.0000 & $0.000 \mathrm{E}+00$ & 0.0000 & $0.000 \mathrm{E}+00$ & 0.0000 \\
\hline 37 & $0.000 \mathrm{E}+00$ & 0.0000 & $0.000 \mathrm{E}+00$ & 0.0000 & $0.000 \mathrm{E}+00$ & 0.0000 & $0.000 \mathrm{E}+00$ & 0.0000 & $0.000 \mathrm{E}+00$ & 0.0000 & $0.000 \mathrm{E}+00$ & 0.0000 & $2.763 \mathrm{E}+00$ & 0.0012 \\
\hline 238 & $0.000 \mathrm{E}+00$ & 0.0000 & $0.000 \mathrm{E}+00$ & 0.0000 & $0.000 \mathrm{E}+00$ & 0.0000 & $0.000 \mathrm{E}+00$ & 0.0000 & $0.000 \mathrm{E}+00$ & 0.0000 & $0.000 \mathrm{E}+00$ & 0.0000 & $1.902 \mathrm{E}-02$ & 0.0000 \\
\hline 239 & $0.000 \mathrm{E}+00$ & 0.0000 & $0.000 \mathrm{E}+00$ & 0.0000 & $0.000 \mathrm{E}+00$ & 0.0000 & $0.000 \mathrm{E}+00$ & 0.0000 & $0.000 \mathrm{E}+00$ & 0.0000 & $0.000 \mathrm{E}+00$ & 0.0000 & $3.398 \mathrm{E}+00$ & 0.0014 \\
\hline 240 & $0.000 \mathrm{E}+00$ & 0.0 & 0.00 & 0 & $0.000 \mathrm{E}+00$ & 0 & $0.000 \mathrm{E}+00$ & 0 & 0 & 0 & $0.000 \mathrm{E}+00$ & 0 & $1.569 \mathrm{E}+00$ & 007 \\
\hline & $0.000 \mathrm{E}+00$ & 0. & $0.000 \mathrm{E}+00$ & 0.0000 & $0.000 \mathrm{E}+00$ & 0.0000 & $0.000 \mathrm{E}+00$ & 0.00 & $0.000 \mathrm{E}+00$ & 0.0000 & $0.000 \mathrm{E}+00$ & 0 . & $0.000 \mathrm{E}+00$ & 0.0000 \\
\hline 228 & $0.000 \mathrm{E}+00$ & 0.0000 & $0.000 \mathrm{E}+00$ & 0.0000 & $0.000 \mathrm{E}+00$ & 0.0000 & $0.000 \mathrm{E}+00$ & 0.0000 & $0.000 \mathrm{E}+00$ & 0.0000 & $0.000 \mathrm{E}+00$ & 0.0000 & $0.000 \mathrm{E}+00$ & 0.0000 \\
\hline & $0.000 \mathrm{E}+00$ & 0.0000 & $0.000 \mathrm{E}+00$ & 0.0000 & $0.000 \mathrm{E}+00$ & 0.0000 & $0.000 \mathrm{E}+00$ & 0.0000 & $0.000 \mathrm{E}+00$ & 0.0000 & $0.000 \mathrm{E}+00$ & 0.0000 & $1.994 \mathrm{E}+03$ & 0.8453 \\
\hline & $0.000 \mathrm{E}+00$ & 0.0000 & $0.000 \mathrm{E}+00$ & 0.0000 & $0.000 \mathrm{E}+00$ & 0.0000 & $0.000 \mathrm{E}+00$ & 0.0000 & $0.000 \mathrm{E}+00$ & 0.0000 & $0.000 \mathrm{E}+00$ & 0.0000 & $9.947 \mathrm{E}+01$ & 0.0422 \\
\hline & $0.000 \mathrm{E}+00$ & 0.0000 & $0.000 \mathrm{E}+00$ & 0.0000 & $0.000 \mathrm{E}+00$ & 0.0000 & $0.000 \mathrm{E}+00$ & 0.0000 & $0.000 \mathrm{E}+00$ & 0.0000 & $0.000 \mathrm{E}+00$ & 0.0000 & $2.208 \mathrm{E}+02$ & 0.0936 \\
\hline & $0.000 \mathrm{E}+00$ & 0.0000 & $0.000 \mathrm{E}+00$ & 0.0000 & $0.000 \mathrm{E}+00$ & 0.0000 & $0.000 \mathrm{E}+00$ & 0.0000 & $0.000 \mathrm{E}+00$ & 0.0000 & $0.000 \mathrm{E}+00$ & 0.0000 & $9.983 \mathrm{E}+00$ & 0.0042 \\
\hline & $0.000 \mathrm{E}+00$ & 0.0000 & $0.000 \mathrm{E}+00$ & 0.0000 & $0.000 \mathrm{E}+00$ & 0.0000 & $0.000 \mathrm{E}+00$ & 0.0000 & $0.000 \mathrm{E}+00$ & 0.0000 & $0.000 \mathrm{E}+00$ & 0.0000 & $2.684 \mathrm{E}+01$ & 0.0114 \\
\hline & & 00 & $0.000 \mathrm{E}+00$ & 0.0000 & $.000 \mathrm{E}+00$ & 0.0000 & $0.000 \mathrm{E}+00$ & 0.0000 & $0.000 \mathrm{E}+00$ & 0.0000 & $8+0$ & & . & 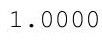 \\
\hline
\end{tabular}

*Sum of all water independent and dependent pathways. 
RESRAD, Version 6.5

Summary : RESRAD Parameters for U-Landfill Resident Gardener Forward Run 10,000 years

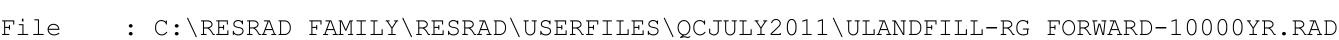

Dose/Source Ratios Summed Over All Pathways

Parent and Progeny Principal Radionuclide Contributions Indicated

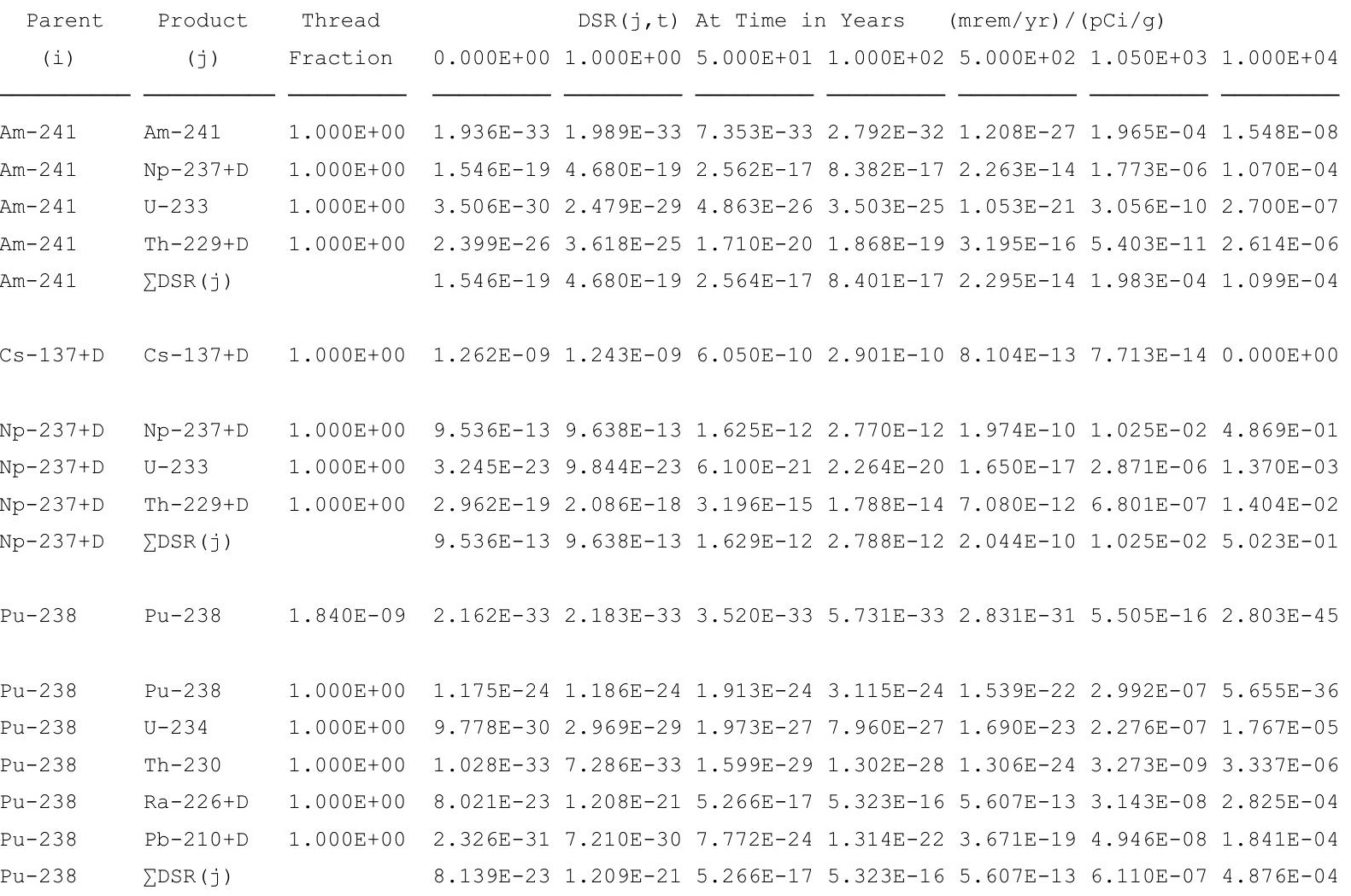

$\begin{array}{lllllllll}\mathrm{Pu}-239 & 1.000 \mathrm{E}+00 & 1.202 \mathrm{E}-17 & 1.217 \mathrm{E}-17 & 2.183 \mathrm{E}-17 & 3.965 \mathrm{E}-17 & 4.690 \mathrm{E}-15 & 1.268 \mathrm{E}-03 & 9.439 \mathrm{E}-02\end{array}$

$\begin{array}{lllllllll}\mathrm{U}-235+\mathrm{D} & 1.000 \mathrm{E}+00 & 6.135 \mathrm{E}-24 & 1.861 \mathrm{E}-23 & 1.146 \mathrm{E}-21 & 4.227 \mathrm{E}-21 & 2.931 \mathrm{E}-18 & 6.291 \mathrm{E}-10 & 4.403 \mathrm{E}-06\end{array}$

$\begin{array}{lllllllll}\mathrm{Pa}-231 & 1.000 \mathrm{E}+00 & 9.652 \mathrm{E}-28 & 6.818 \mathrm{E}-27 & 1.251 \mathrm{E}-23 & 8.414 \mathrm{E}-23 & 1.444 \mathrm{E}-19 & 4.191 \mathrm{E}-10 & 2.591 \mathrm{E}-06\end{array}$

$\mathrm{AC}-227+\mathrm{D} \quad 1.000 \mathrm{E}+00 \quad 2.288 \mathrm{E}-27 \quad 3.434 \mathrm{E}-26 \quad 1.276 \mathrm{E}-21 \quad 1.169 \mathrm{E}-20 \quad 1.476 \mathrm{E}-17 \quad 1.686 \mathrm{E}-10 \quad 2.250 \mathrm{E}-06$

$\operatorname{\sum DSR}(j) \quad 1.202 \mathrm{E}-17 \quad 1.217 \mathrm{E}-17 \quad 2.183 \mathrm{E}-17 \quad 3.966 \mathrm{E}-17 \quad 4.708 \mathrm{E}-15 \quad 1.268 \mathrm{E}-03 \quad 9.440 \mathrm{E}-02$

Pu-240 4.950E-08 5.653E-32 5.753E-32 $1.359 \mathrm{E}-31 \quad 3.267 \mathrm{E}-31 \quad 3.647 \mathrm{E}-28 \quad 5.789 \mathrm{E}-11 \quad 2.157 \mathrm{E}-09$

Pu-240 1.000E+00 1.142E-24 $1.162 \mathrm{E}-24 \quad 2.746 \mathrm{E}-24 \quad 6.601 \mathrm{E}-24 \quad 7.367 \mathrm{E}-21 \quad 1.170 \mathrm{E}-03 \quad 4.357 \mathrm{E}-02$

$\begin{array}{lllllllll}\mathrm{U}-236 & 1.000 \mathrm{E}+00 & 2.162 \mathrm{E}-32 & 6.590 \mathrm{E}-32 & 5.335 \mathrm{E}-30 & 2.602 \mathrm{E}-29 & 1.686 \mathrm{E}-25 & 1.804 \mathrm{E}-08 & 9.074 \mathrm{E}-06\end{array}$

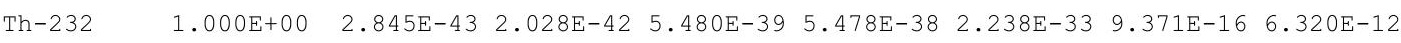

$\mathrm{Ra}-228+\mathrm{D} \quad 1.000 \mathrm{E}+00 \quad 1.371 \mathrm{E}-28 \quad 2.018 \mathrm{E}-27 \quad 3.762 \mathrm{E}-23 \quad 2.542 \mathrm{E}-22 \quad 1.470 \mathrm{E}-19 \quad 1.102 \mathrm{E}-13 \quad 8.021 \mathrm{E}-10$

Th-228+D 1.000E+00 8.111E-28 $2.334 \mathrm{E}-26 \quad 2.641 \mathrm{E}-21 \quad 1.757 \mathrm{E}-20 \quad 5.564 \mathrm{E}-18 \quad 1.510 \mathrm{E}-15 \quad 3.655 \mathrm{E}-10$

$\operatorname{LDSR}(j) \quad 1.143 \mathrm{E}-24 \quad 1.188 \mathrm{E}-24 \quad 2.681 \mathrm{E}-21 \quad 1.783 \mathrm{E}-20 \quad 5.719 \mathrm{E}-18 \quad 1.170 \mathrm{E}-03 \quad 4.358 \mathrm{E}-02$

TC-99 1.000E+00 5.758E-26 5.817E-26 $\quad 9.575 \mathrm{E}-26 \quad 1.592 \mathrm{E}-25 \quad 9.310 \mathrm{E}-24 \quad 1.325 \mathrm{E}-06 \quad 1.128 \mathrm{E}-39$

$\mathrm{Th}-228+\mathrm{D} \quad 1.000 \mathrm{E}+00 \quad 1.382 \mathrm{E}-06 \quad 9.680 \mathrm{E}-07 \quad 2.527 \mathrm{E}-14 \quad 4.618 \mathrm{E}-22 \quad 0.000 \mathrm{E}+00 \quad 0.000 \mathrm{E}+00 \quad 0.000 \mathrm{E}+00$

Th-230 1.000E+00 2.412E-22 2.453E-22 5.590E-22 $1.295 \mathrm{E}-21 \quad 1.078 \mathrm{E}-18 \quad 1.104 \mathrm{E}-03 \quad 1.120 \mathrm{E}-01$ $\mathrm{Ra}-226+\mathrm{D} \quad 1.000 \mathrm{E}+00 \quad 3.774 \mathrm{E}-11 \quad 1.139 \mathrm{E}-10 \quad 5.320 \mathrm{E}-09 \quad 1.479 \mathrm{E}-08 \quad 1.071 \mathrm{E}-06 \quad 2.165 \mathrm{E}-02 \quad 1.199 \mathrm{E}+01$ $\mathrm{Pb}-210+\mathrm{D} \quad 1.000 \mathrm{E}+00 \quad 1.819 \mathrm{E}-19 \quad 1.271 \mathrm{E}-18 \quad 1.299 \mathrm{E}-15 \quad 5.314 \mathrm{E}-15 \quad 7.678 \mathrm{E}-13 \quad 3.543 \mathrm{E}-02 \quad 7.839 \mathrm{E}+00$ $\operatorname{EDSR}(j) \quad 3.774 \mathrm{E}-11 \quad 1.139 \mathrm{E}-10 \quad 5.320 \mathrm{E}-09 \quad 1.479 \mathrm{E}-08 \quad 1.071 \mathrm{E}-06 \quad 5.818 \mathrm{E}-02 \quad 1.994 \mathrm{E}+01$ 
RESRAD, Version $6.5 \quad T^{1 / 2}$ Limit $=180$ days

Summary : RESRAD Parameters for U-Landfill Resident Gardener Forward Run 10,000 years

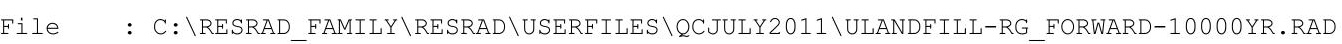

Dose/Source Ratios Summed Over All Pathways

Parent and Progeny Principal Radionuclide Contributions Indicated

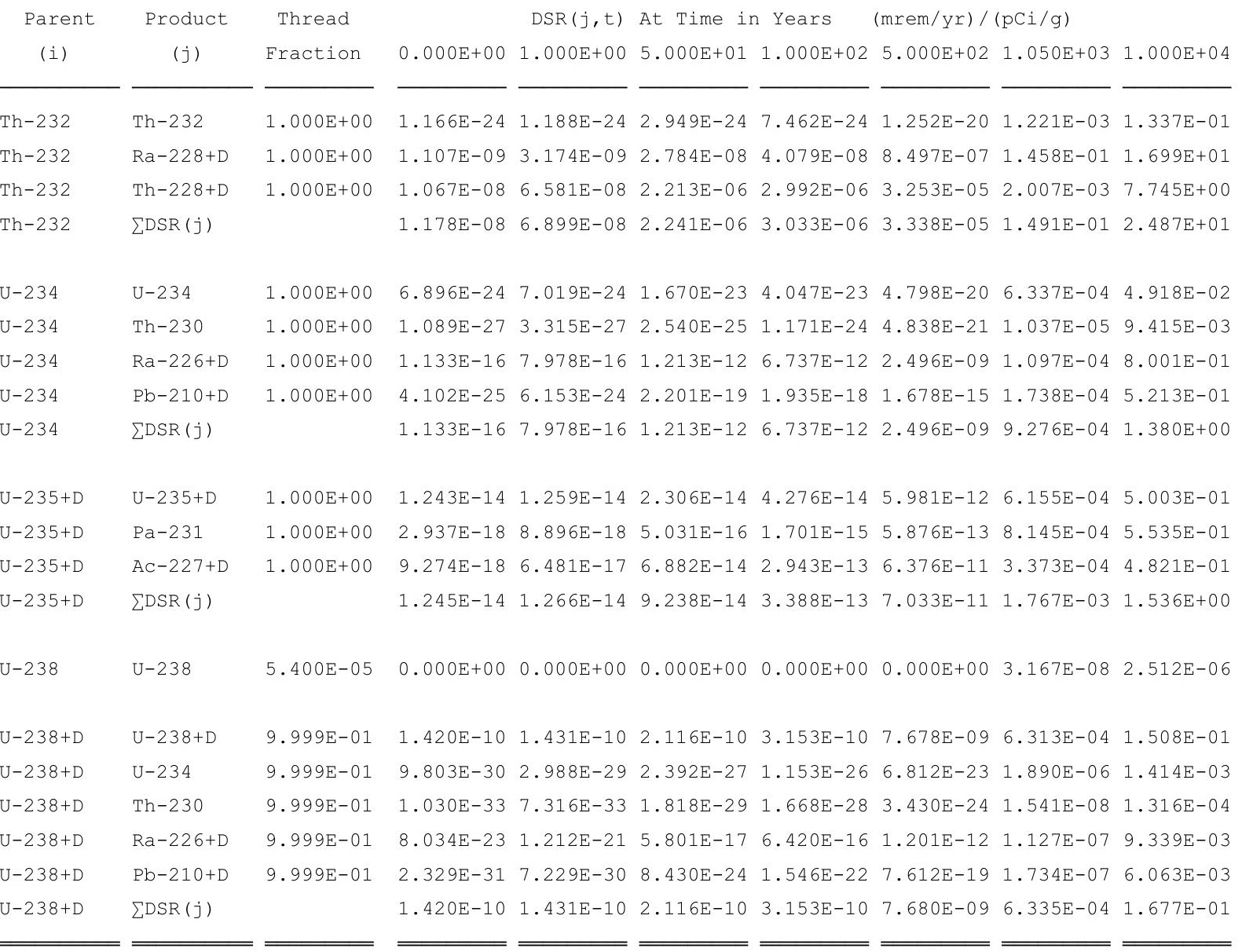

The DSR includes contributions from associated (half-life $\leq 180$ days) daughters. 
RESRAD, Version $6.5 \quad \mathrm{~T}^{1 / 2}$ Limit $=180$ days

Summary : RESRAD Parameters for U-Landfill Resident Gardener Forward Run 10,000 years

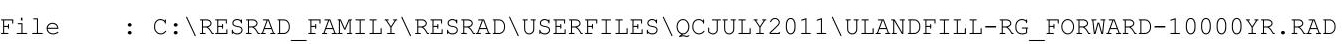

Single Radionuclide Soil Guidelines G(i,t) in pCi/g

Basic Radiation Dose Limit $=1.000 \mathrm{E}+02 \mathrm{mrem} / \mathrm{yr}$

Nuclide

\begin{tabular}{|c|c|c|c|c|c|c|c|}
\hline (i) & $t=0.000 E+00$ & $1.000 \mathrm{E}+00$ & $5.000 E+01$ & $1.000 \mathrm{E}+02$ & $5.000 \mathrm{E}+02$ & $1.050 \mathrm{E}+03$ & $0 \mathrm{E}+04$ \\
\hline$m-241$ & $\star 3.431 \mathrm{E}+12$ & $\star 3.431 \mathrm{E}+12$ & $\star 3.431 \mathrm{E}+12$ & $\star 3.431 \mathrm{E}+12$ & $\star 3.431 \mathrm{E}+12$ & $5.044 \mathrm{E}+05$ & $9.099 \mathrm{E}+05$ \\
\hline-137 & $7.925 \mathrm{E}+10$ & $8.043 E+10$ & $1.653 \mathrm{E}+11$ & $3.447 \mathrm{E}+11$ & $\star 8.704 \mathrm{E}+13$ & $\star 8.704 \mathrm{E}+13$ & $\star 8.704 \mathrm{E}+13$ \\
\hline-237 & $\star 7.047 \mathrm{E}+08$ & $\star 7.047 \mathrm{E}+08$ & $\star 7.047 \mathrm{E}+08$ & $\star 7.047 \mathrm{E}+08$ & $\star 7.047 \mathrm{E}+08$ & $9.756 \mathrm{E}+03$ & $1.991 \mathrm{E}+02$ \\
\hline$u-238$ & $\star 1.712 \mathrm{E}+13$ & $\star 1.712 \mathrm{E}+13$ & $\star 1.712 \mathrm{E}+13$ & $\star 1.712 \mathrm{E}+13$ & $\star 1.712 \mathrm{E}+13$ & $1.637 \mathrm{E}+08$ & $2.051 E+05$ \\
\hline $\mathrm{Pu}-239$ & $\star 6.214 \mathrm{E}+10$ & $* 6.214 \mathrm{E}+10$ & $* 6.214 \mathrm{E}+10$ & $* 6.214 \mathrm{E}+10$ & $* 6.214 \mathrm{E}+10$ & $7.884 \mathrm{E}+04$ & $1.059 \mathrm{E}+0$ \\
\hline $\mathrm{Pu}-240$ & $\star 2.278 \mathrm{E}+11$ & $\star 2.278 \mathrm{E}+11$ & $\star 2.278 \mathrm{E}+11$ & $\star 2.278 \mathrm{E}+11$ & $\star 2.278 \mathrm{E}+11$ & $8.550 \mathrm{E}+04$ & $2.295 \mathrm{E}+0$ \\
\hline Tc-99 & $* 1.697 \mathrm{E}+10$ & $\star 1.697 \mathrm{E}+10$ & $\star 1.697 \mathrm{E}+10$ & $\star 1.697 \mathrm{E}+10$ & $* 1.697 \mathrm{E}+10$ & $7.545 \mathrm{E}+07$ & $* 1.697 \mathrm{E}+10$ \\
\hline Th-228 & $7.234 \mathrm{E}+07$ & $1.033 \mathrm{E}+08$ & $* 8.195 \mathrm{E}+14$ & $\star 8.195 \mathrm{E}+14$ & $\star 8.195 \mathrm{E}+14$ & $\star 8.195 \mathrm{E}+14$ & $\star 8.195 \mathrm{E}+14$ \\
\hline$T h-230$ & $\star 2.018 \mathrm{E}+10$ & $\star 2.018 \mathrm{E}+10$ & $1.880 \mathrm{E}+10$ & $6.761 \mathrm{E}+09$ & $9.336 \mathrm{E}+07$ & $1.719 \mathrm{E}+03$ & $5.016 \mathrm{E}+00$ \\
\hline Th-232 & $* 1.097 \mathrm{E}+05$ & $* 1.097 \mathrm{E}+05$ & $* 1.097 \mathrm{E}+05$ & $\star 1.097 \mathrm{E}+05$ & $\star 1.097 \mathrm{E}+05$ & $6.708 \mathrm{E}+02$ & $4.021 \mathrm{E}+00$ \\
\hline 34 & $\star 6.247 \mathrm{E}+09$ & $\star 6.247 \mathrm{E}+09$ & $* 6.247 \mathrm{E}+09$ & $* 6.247 \mathrm{E}+09$ & $* 6.247 \mathrm{E}+09$ & $1.078 \mathrm{E}+05$ & $7.246 \mathrm{E}+01$ \\
\hline 35 & $\star 2.161 \mathrm{E}+06$ & $\star 2.161 \mathrm{E}+06$ & $\star 2.161 \mathrm{E}+06$ & $\star 2.161 \mathrm{E}+06$ & $\star 2.161 \mathrm{E}+06$ & $5.658 \mathrm{E}+04$ & $6.511 \mathrm{E}+01$ \\
\hline 238 & $\star 3.361 E+05$ & $\star 3.361 \mathrm{E}+05$ & $\star 3.361 \mathrm{E}+05$ & $\star 3.361 \mathrm{E}+05$ & $\star 3.361 \mathrm{E}+05$ & $1.578 \mathrm{E}+05$ & $5.961 E+02$ \\
\hline
\end{tabular}

*At specific activity limit

Summed Dose/Source Ratios DSR(i,t) in (mrem/yr)/(pCi/g) and Single Radionuclide Soil Guidelines $\mathrm{G}(i, \mathrm{t})$ in $\mathrm{pCi} / \mathrm{g}$

at tmin = time of minimum single radionuclide soil guideline and at tmax $=$ time of maximum total dose $=1.000 \mathrm{E}+04$ years

\begin{tabular}{|c|c|c|c|c|c|c|}
\hline $\begin{array}{l}\text { Tuclide } \\
\text { (i) }\end{array}$ & $\begin{array}{l}\text { Initial } \\
(\mathrm{pCi} / \mathrm{g})\end{array}$ & $\begin{array}{c}\text { tmin } \\
\text { (years) }\end{array}$ & $\operatorname{DSR}(i, \operatorname{tmin})$ & $\begin{array}{c}\mathrm{G}(\mathrm{i}, \mathrm{tmin}) \\
\quad(\mathrm{pCi} / \mathrm{g})\end{array}$ & $\operatorname{DSR}(i, \operatorname{tmax})$ & $\begin{array}{c}\text { G }(i, \text { tmax }) \\
(\mathrm{pCi} / \mathrm{g})\end{array}$ \\
\hline-241 & $3.500 \mathrm{E}+01$ & $2536 \pm 5$ & $2.825 \mathrm{E}-03$ & $3.540 \mathrm{E}+04$ & $1.099 \mathrm{E}-04$ & $9.099 \mathrm{E}+05$ \\
\hline 137 & $1.900 \mathrm{E}+01$ & $0.000 \mathrm{E}+00$ & $1.262 \mathrm{E}-09$ & $7.925 \mathrm{E}+10$ & $0.000 \mathrm{E}+00$ & $\star 8.704 \mathrm{E}+13$ \\
\hline 237 & $5.500 \mathrm{E}+00$ & $2533 \pm 5$ & $1.336 \mathrm{E}+00$ & $7.488 \mathrm{E}+01$ & $5.023 \mathrm{E}-01$ & $1.991 \mathrm{E}+02$ \\
\hline-238 & $3.900 \mathrm{E}+01$ & $1.000 \mathrm{E}+04$ & $4.876 \mathrm{E}-04$ & $2.051 E+05$ & $4.876 \mathrm{E}-04$ & $2.051 \mathrm{E}+05$ \\
\hline $\mathrm{Pu}-239$ & $3.600 \mathrm{E}+01$ & $2533 \pm 5$ & $1.330 \mathrm{E}-01$ & $7.518 \mathrm{E}+02$ & $9.440 \mathrm{E}-02$ & $1.059 \mathrm{E}+03$ \\
\hline$u-240$ & $3.600 \mathrm{E}+01$ & $2533 \pm 5$ & $1.093 \mathrm{E}-01$ & $9.150 \mathrm{E}+02$ & $4.358 \mathrm{E}-02$ & $2.295 \mathrm{E}+03$ \\
\hline TC-99 & $5.200 \mathrm{E}+01$ & $1144 \pm 2$ & $3.687 \mathrm{E}-06$ & $2.712 \mathrm{E}+07$ & $0.000 \mathrm{E}+00$ & $* 1.697 \mathrm{E}+10$ \\
\hline$T h-228$ & $4.000 \mathrm{E}+00$ & $0.000 \mathrm{E}+00$ & $1.382 \mathrm{E}-06$ & $7.234 \mathrm{E}+07$ & $0.000 \mathrm{E}+00$ & $\star 8.195 \mathrm{E}+14$ \\
\hline$T h-230$ & $1.000 \mathrm{E}+02$ & $8251 \pm *$ & $2.007 E+01$ & $4.984 \mathrm{E}+00$ & $1.994 \mathrm{E}+01$ & $5.016 \mathrm{E}+00$ \\
\hline 232 & $4.000 \mathrm{E}+00$ & $2536 \pm 5$ & $2.542 \mathrm{E}+01$ & $3.934 \mathrm{E}+00$ & $2.487 \mathrm{E}+01$ & $4.021 E+00$ \\
\hline 34 & $1.600 \mathrm{E}+02$ & $1.000 \mathrm{E}+04$ & $1.380 \mathrm{E}+00$ & $7.246 \mathrm{E}+01$ & $1.380 \mathrm{E}+00$ & $7.246 E+01$ \\
\hline 35 & $6.500 \mathrm{E}+00$ & $1.000 \mathrm{E}+04$ & $1.536 \mathrm{E}+00$ & $6.511 \mathrm{E}+01$ & $1.536 \mathrm{E}+00$ & $6.511 E+01$ \\
\hline 238 & $1.600 \mathrm{E}+02$ & $2536 \pm 5$ & $1.800 \mathrm{E}-01$ & $5.556 \mathrm{E}+02$ & $1.677 \mathrm{E}-01$ & $5.961 E+02$ \\
\hline
\end{tabular}

*At specific activity limit 
RESRAD, Version 6.5

Summary : RESRAD Parameters for U-Landfill Resident Gardener Forward Run 10,000 years

File : C: $\backslash$ RESRAD FAMILY \RESRAD \USERFILES $\backslash Q C J U L Y 2011 \backslash U L A N D F I L L-R G$ FORWARD-10000YR.RAD

Individual Nuclide Dose Summed Over All Pathways

Parent Nuclide and Branch Fraction Indicated

Nuclide Parent THF(i) DOSE $(j, t), \mathrm{mrem} / \mathrm{yr}$

\begin{tabular}{|c|c|c|}
\hline$(j)$ & (i) & \\
\hline$m-241$ & $A m-241$ & $1.000 \mathrm{E}+00$ \\
\hline$p-237$ & Am-241 & $1.000 \mathrm{E}+00$ \\
\hline-237 & $N p-237$ & $1.000 \mathrm{E}+00$ \\
\hline 237 & $\sum \mathrm{DOSE}$ & \\
\hline
\end{tabular}

$\mathrm{U}-233 \quad \mathrm{Am}-241 \quad 1.000 \mathrm{E}+00$

$\mathrm{U}-233 \mathrm{~Np}-237 \quad 1.000 \mathrm{E}+00$

U-233 $\quad$ DDOSE $(j)$

Th-229 Am-241 1.000E+00

$\mathrm{Th}-229 \quad \mathrm{~Np}-237 \quad 1.000 \mathrm{E}+00$

Th-229 $\sum \mathrm{DOSE}(j)$

Cs-137 Cs $-137 \quad 1.000 \mathrm{E}+00$

$\mathrm{Pu}-238$

$\mathrm{Pu}-238$

$\mathrm{Pu}-238$

$\mathrm{U}-234$

$\mathrm{U}-234$

$\mathrm{U}-234$

$\mathrm{U}-234$

Th -230

$\mathrm{Th}-230$

$\mathrm{Th}-230$

$\mathrm{Th}-230$

$\mathrm{Th}-230$

$\mathrm{Ra}-226$

$\mathrm{Ra}-226$

$\mathrm{Ra}-226$

$\mathrm{Ra}-226$

$\mathrm{Ra}-226$

$\mathrm{Pb}-210$

$\mathrm{Pb}-210$

$\mathrm{Pb}-210$

$\mathrm{Pb}-210$

$\mathrm{Pb}-210$

$P u-239$

Pu-238 1.840E-09 $\mathrm{Pu}-238 \quad 1.000 \mathrm{E}+00$ $\sum \operatorname{DOSE}(j)$

$\mathrm{Pu}-238 \quad 1.000 \mathrm{E}+00$ $\mathrm{U}-234 \quad 1.000 \mathrm{E}+00$ U-238 9.999E-01 $\sum \operatorname{DOSE}(j)$

$\mathrm{Pu}-238 \quad 1.000 \mathrm{E}+00$ Th-230 1.000E+00 $\mathrm{U}-234 \quad 1.000 \mathrm{E}+00$ U-238 9.999E-01 $\sum \operatorname{DOSE}(j)$

$\mathrm{Pu}-238 \quad 1.000 \mathrm{E}+00$ $\mathrm{Th}-230 \quad 1.000 \mathrm{E}+00$ $\mathrm{U}-234 \quad 1.000 \mathrm{E}+00$ U-238 9.999E-01 $\sum \operatorname{DOSE}(j)$

$\mathrm{Pu}-238 \quad 1.000 \mathrm{E}+00$ Th-230 1.000E+00 $\mathrm{U}-234 \quad 1.000 \mathrm{E}+00$ U-238 9.999E-01 $\sum \operatorname{DOSE}(j)$

$\mathrm{Pu}-239 \quad 1.000 \mathrm{E}+00$

$\mathrm{Pu}-239 \quad 1.000 \mathrm{E}+00$ U-235 1.000E+00 $\sum \operatorname{DOSE}(j)$ $t=0.000 \mathrm{E}+00 \quad 1.000 \mathrm{E}+00 \quad 5.000 \mathrm{E}+01.1 .000 \mathrm{E}+02 \quad 5.000 \mathrm{E}+02 \quad 1.050 \mathrm{E}+03 \quad 1.000 \mathrm{E}+04$
5.412E-18 1.638E-17 8.967E-16 2.934E-15 $\quad 7.921 \mathrm{E}-13 \quad 6.206 \mathrm{E}-05 \quad 3.745 \mathrm{E}-03$ 5.245E-12 5.301E-12 8.939E-12 $1.524 \mathrm{E}-11 \quad 1.085 \mathrm{E}-09 \quad 5.635 \mathrm{E}-02 \quad 2.678 \mathrm{E}+00$ $5.245 \mathrm{E}-12 \quad 5.301 \mathrm{E}-12 \quad 8.940 \mathrm{E}-12 \quad 1.524 \mathrm{E}-11 \quad 1.086 \mathrm{E}-09 \quad 5.642 \mathrm{E}-02 \quad 2.682 \mathrm{E}+00$

$\begin{array}{lllllll}1.227 \mathrm{E}-28 & 8.678 \mathrm{E}-28 & 1.702 \mathrm{E}-24 & 1.226 \mathrm{E}-23 & 3.685 \mathrm{E}-20 & 1.069 \mathrm{E}-08 & 9.450 \mathrm{E}-06\end{array}$ $\begin{array}{lllllll}1.785 \mathrm{E}-22 & 5.414 \mathrm{E}-22 & 3.355 \mathrm{E}-20 & 1.245 \mathrm{E}-19 & 9.076 \mathrm{E}-17 & 1.579 \mathrm{E}-05 & 7.534 \mathrm{E}-03\end{array}$ $\begin{array}{lllllll}1.785 \mathrm{E}-22 & 5.414 \mathrm{E}-22 & 3.355 \mathrm{E}-20 & 1.245 \mathrm{E}-19 & 9.079 \mathrm{E}-17 & 1.580 \mathrm{E}-05 & 7.544 \mathrm{E}-03\end{array}$

8.395E-25 1.266E-23 5.984E-19 $\quad 6.539 \mathrm{E}-18 \quad 1.118 \mathrm{E}-14 \quad 1.891 \mathrm{E}-09 \quad 9.148 \mathrm{E}-05$ $\begin{array}{llllllll}1.629 \mathrm{E}-18 & 1.147 \mathrm{E}-17 & 1.758 \mathrm{E}-14 & 9.834 \mathrm{E}-14 & 3.894 \mathrm{E}-11 & 3.741 \mathrm{E}-06 & 7.722 \mathrm{E}-02\end{array}$ $\begin{array}{lllllll}1.629 \mathrm{E}-18 & 1.147 \mathrm{E}-17 & 1.758 \mathrm{E}-14 & 9.835 \mathrm{E}-14 & 3.895 \mathrm{E}-11 & 3.743 \mathrm{E}-06 & 7.731 \mathrm{E}-02\end{array}$ $2.397 \mathrm{E}-08 \quad 2.362 \mathrm{E}-08 \quad 1.149 \mathrm{E}-08 \quad 5.512 \mathrm{E}-09 \quad 1.540 \mathrm{E}-11 \quad 1.465 \mathrm{E}-12 \quad 0.000 \mathrm{E}+00$ $\begin{array}{lllllll}0.000 \mathrm{E}+00 & 0.000 \mathrm{E}+00 & 0.000 \mathrm{E}+00 & 0.000 \mathrm{E}+00 & 0.000 \mathrm{E}+00 & 2.147 \mathrm{E}-14 & 0.000 \mathrm{E}+00\end{array}$

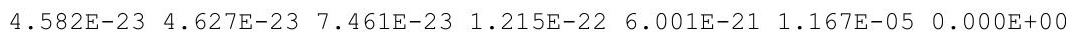
$4.582 \mathrm{E}-23 \quad 4.627 \mathrm{E}-23 \quad 7.461 \mathrm{E}-23 \quad 1.215 \mathrm{E}-22 \quad 6.001 \mathrm{E}-21 \quad 1.167 \mathrm{E}-05 \quad 0.000 \mathrm{E}+00$ $3.813 \mathrm{E}-28 \quad 1.158 \mathrm{E}-27 \quad 7.693 \mathrm{E}-26 \quad 3.104 \mathrm{E}-25 \quad 6.593 \mathrm{E}-22 \quad 8.877 \mathrm{E}-06 \quad 6.890 \mathrm{E}-04$ $\begin{array}{lllllllll}1.103 \mathrm{E}-21 & 1.123 \mathrm{E}-21 & 2.673 \mathrm{E}-21 & 6.475 \mathrm{E}-21 & 7.677 \mathrm{E}-18 & 1.014 \mathrm{E}-01 & 7.868 \mathrm{E}+00\end{array}$ $\begin{array}{lllllll}1.569 \mathrm{E}-27 & 4.780 \mathrm{E}-27 & 3.827 \mathrm{E}-25 & 1.845 \mathrm{E}-24 & 1.090 \mathrm{E}-20 & 3.024 \mathrm{E}-04 & 2.263 \mathrm{E}-01\end{array}$ $\begin{array}{lllllll}1.103 \mathrm{E}-21 & 1.123 \mathrm{E}-21 & 2.673 \mathrm{E}-21 & 6.477 \mathrm{E}-21 & 7.688 \mathrm{E}-18 & 1.017 \mathrm{E}-01 & 8.095 \mathrm{E}+00\end{array}$

$\begin{array}{lllllll}0.000 \mathrm{E}+00 & 0.000 \mathrm{E}+00 & 6.236 \mathrm{E}-28 & 5.079 \mathrm{E}-27 & 5.092 \mathrm{E}-23 & 1.276 \mathrm{E}-07 & 1.301 \mathrm{E}-04\end{array}$ $2.412 \mathrm{E}-20 \quad 2.453 \mathrm{E}-20 \quad 5.590 \mathrm{E}-20 \quad 1.295 \mathrm{E}-19 \quad 1.078 \mathrm{E}-16 \quad 1.104 \mathrm{E}-01 \quad 1.120 \mathrm{E}+01$ $\begin{array}{lllllll}1.742 \mathrm{E}-25 & 5.304 \mathrm{E}-25 & 4.065 \mathrm{E}-23 & 1.874 \mathrm{E}-22 & 7.741 \mathrm{E}-19 & 1.659 \mathrm{E}-03 & 1.506 \mathrm{E}+00\end{array}$ $\begin{array}{lllllll}0.000 \mathrm{E}+00 & 0.000 \mathrm{E}+00 & 2.909 \mathrm{E}-27 & 2.669 \mathrm{E}-26 & 5.488 \mathrm{E}-22 & 2.466 \mathrm{E}-06 & 2.106 \mathrm{E}-02\end{array}$ $2.412 \mathrm{E}-20 \quad 2.453 \mathrm{E}-20 \quad 5.594 \mathrm{E}-20 \quad 1.297 \mathrm{E}-19 \quad 1.085 \mathrm{E}-16 \quad 1.121 \mathrm{E}-01 \quad 1.273 \mathrm{E}+01$

$\begin{array}{lllllll}3.128 \mathrm{E}-21 & 4.712 \mathrm{E}-20 & 2.054 \mathrm{E}-15 & 2.076 \mathrm{E}-14 & 2.187 \mathrm{E}-11 & 1.226 \mathrm{E}-06 & 1.102 \mathrm{E}-02\end{array}$ $\begin{array}{llllllll}3.774 \mathrm{E}-09 & 1.139 \mathrm{E}-08 & 5.320 \mathrm{E}-07 & 1.479 \mathrm{E}-06 & 1.071 \mathrm{E}-04 & 2.165 \mathrm{E}+00 & 1.199 \mathrm{E}+03\end{array}$ $\begin{array}{llllllll}1.813 \mathrm{E}-14 & 1.277 \mathrm{E}-13 & 1.941 \mathrm{E}-10 & 1.078 \mathrm{E}-09 & 3.993 \mathrm{E}-07 & 1.755 \mathrm{E}-02 & 1.280 \mathrm{E}+02\end{array}$ $\begin{array}{lllllll}1.285 \mathrm{E}-20 & 1.939 \mathrm{E}-19 & 9.281 \mathrm{E}-15 & 1.027 \mathrm{E}-13 & 1.921 \mathrm{E}-10 & 1.804 \mathrm{E}-05 & 1.494 \mathrm{E}+00\end{array}$ $\begin{array}{lllllll}3.774 \mathrm{E}-09 & 1.139 \mathrm{E}-08 & 5.322 \mathrm{E}-07 & 1.480 \mathrm{E}-06 & 1.075 \mathrm{E}-04 & 2.183 \mathrm{E}+00 & 1.328 \mathrm{E}+03\end{array}$

$\begin{array}{lllllll}0.000 \mathrm{E}+00 & 2.812 \mathrm{E}-28 & 3.031 \mathrm{E}-22 & 5.124 \mathrm{E}-21 & 1.432 \mathrm{E}-17 & 1.929 \mathrm{E}-06 & 7.179 \mathrm{E}-03\end{array}$ $\begin{array}{lllllll}1.819 \mathrm{E}-17 & 1.271 \mathrm{E}-16 & 1.299 \mathrm{E}-13 & 5.314 \mathrm{E}-13 & 7.678 \mathrm{E}-11 & 3.543 \mathrm{E}+00 & 7.839 \mathrm{E}+02\end{array}$ $\begin{array}{llllllll}6.563 \mathrm{E}-23 & 9.844 \mathrm{E}-22 & 3.522 \mathrm{E}-17 & 3.095 \mathrm{E}-16 & 2.685 \mathrm{E}-13 & 2.781 \mathrm{E}-02 & 8.341 \mathrm{E}+01\end{array}$ $\begin{array}{llllllll}0.000 \mathrm{E}+00 & 1.157 \mathrm{E}-27 & 1.349 \mathrm{E}-21 & 2.474 \mathrm{E}-20 & 1.218 \mathrm{E}-16 & 2.774 \mathrm{E}-05 & 9.701 \mathrm{E}-01\end{array}$ $\begin{array}{lllllll}1.819 \mathrm{E}-17 & 1.271 \mathrm{E}-16 & 1.299 \mathrm{E}-13 & 5.317 \mathrm{E}-13 & 7.705 \mathrm{E}-11 & 3.571 \mathrm{E}+00 & 8.683 \mathrm{E}+02\end{array}$ $4.328 \mathrm{E}-16 \quad 4.380 \mathrm{E}-16 \quad 7.860 \mathrm{E}-16 \quad 1.427 \mathrm{E}-15 \quad 1.689 \mathrm{E}-13 \quad 4.566 \mathrm{E}-02 \quad 3.398 \mathrm{E}+00$ $2.209 \mathrm{E}-22 \quad 6.699 \mathrm{E}-22 \quad 4.126 \mathrm{E}-20 \quad 1.522 \mathrm{E}-19 \quad 1.055 \mathrm{E}-16 \quad 2.265 \mathrm{E}-08 \quad 1.585 \mathrm{E}-04$ $\begin{array}{lllllll}8.081 \mathrm{E}-14 & 8.182 \mathrm{E}-14 & 1.499 \mathrm{E}-13 & 2.779 \mathrm{E}-13 & 3.888 \mathrm{E}-11 & 4.001 \mathrm{E}-03 & 3.252 \mathrm{E}+00\end{array}$ $\begin{array}{llllllll}8.081 \mathrm{E}-14 & 8.182 \mathrm{E}-14 & 1.499 \mathrm{E}-13 & 2.779 \mathrm{E}-13 & 3.888 \mathrm{E}-11 & 4.001 \mathrm{E}-03 & 3.252 \mathrm{E}+00\end{array}$ 
RESRAD, Version 6.5

Summary : RESRAD Parameters for U-Landfill Resident Gardener Forward Run 10,000 years

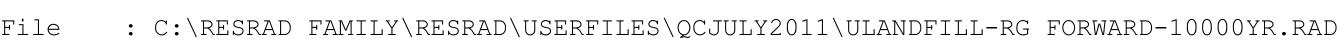

Individual Nuclide Soil Concentration

Parent Nuclide and Branch Fraction Indicated

Nuclide Parent THF(

(j) (i)

Am-241 Am-241 1.000E+00

Np-237 Am-241 1.000E+00

$\mathrm{Np}-237 \quad \mathrm{~Np}-237 \quad 1.000 \mathrm{E}+00$

Np-237 $\sum S(j):$

$\mathrm{U}-233 \quad \mathrm{Am}-241 \quad 1.000 \mathrm{E}+00$

$\mathrm{U}-233 \quad \mathrm{~Np}-237 \quad 1.000 \mathrm{E}+00$

U-233 $\sum S(j):$

Th-229 Am-241 1.000E+00

Th-229 Np-237 1.000E+00

Th-229 $\sum \mathrm{S}(j):$

Cs-137 Cs-137 1.000E+00

$\mathrm{Pu}-238$

$\mathrm{Pu}-238$

Pu-238

$\mathrm{U}-234$

$\mathrm{U}-234$

$\mathrm{U}-234$

$\mathrm{U}-234$

Th-230

Th -230

Th-230

Th-230

$\mathrm{Th}-230$

$\mathrm{Ra}-226$

$\mathrm{Ra}-226$

$\mathrm{Ra}-226$

$\mathrm{Ra}-226$

$\mathrm{Ra}-226$

$\mathrm{Pb}-210$

$\mathrm{Pb}-210$

$\mathrm{Pb}-210$

$\mathrm{Pb}-210$

$\mathrm{Pb}-210$

$\mathrm{Pu}-239$

Pu-238 $1.840 \mathrm{E}-09$

$\mathrm{Pu}-238 \quad 1.000 \mathrm{E}+00$

$\sum S(j):$

$\mathrm{Pu}-238 \quad 1.000 \mathrm{E}+00$

U-234 $1.000 \mathrm{E}+00$

U-238 $9.999 \mathrm{E}-01$

$\sum S(j):$

Pu-238 1.000E+00

Th-230 1.000E+00

$\mathrm{U}-234 \quad 1.000 \mathrm{E}+00$

$\mathrm{U}-238 \quad 9.999 \mathrm{E}-01$

$\sum S(j):$

Pu-238 1.000E+00

Th-230 1.000E+00

$\mathrm{U}-234 \quad 1.000 \mathrm{E}+00$

$\mathrm{U}-238 \quad 9.999 \mathrm{E}-01$

$\sum S(j):$

$\mathrm{Pu}-238 \quad 1.000 \mathrm{E}+00$

Th-230 1.000E+00

$\mathrm{U}-2341.000 \mathrm{E}+00$

$\mathrm{U}-238 \quad 9.999 \mathrm{E}-01$

$\sum S(j):$

Pu-239 1.000E+00

$\mathrm{Pu}-239 \quad 1.000 \mathrm{E}+00$

$\mathrm{U}-2351.000 \mathrm{E}+00$

$\sum S(j):$
$\mathrm{S}(j, \mathrm{t}), \mathrm{pCi} / \mathrm{g}$

$t=0.000 \mathrm{E}+00 \quad 1.000 \mathrm{E}+00 \quad 5.000 \mathrm{E}+01 \quad 1.000 \mathrm{E}+02 \quad 5.000 \mathrm{E}+02 \quad 1.050 \mathrm{E}+03 \quad 1.000 \mathrm{E}+04$

$\begin{array}{llllllll}3.500 \mathrm{E}+01 & 3.494 \mathrm{E}+01 & 3.229 \mathrm{E}+01 & 2.980 \mathrm{E}+01 & 1.566 \mathrm{E}+01 & 6.464 \mathrm{E}+00 & 3.610 \mathrm{E}-06\end{array}$

$0.000 \mathrm{E}+00 \quad 1.133 \mathrm{E}-05 \quad 5.428 \mathrm{E}-04 \quad 1.040 \mathrm{E}-03 \quad 3.749 \mathrm{E}-03 \quad 5.255 \mathrm{E}-03 \quad 1.996 \mathrm{E}-03$

$\begin{array}{lllllll}5.500 \mathrm{E}+00 & 5.499 \mathrm{E}+00 & 5.463 \mathrm{E}+00 & 5.426 \mathrm{E}+00 & 5.141 \mathrm{E}+00 & 4.773 \mathrm{E}+00 & 1.427 \mathrm{E}+00\end{array}$

$\begin{array}{lllllll}5.500 \mathrm{E}+00 & 5.499 \mathrm{E}+00 & 5.464 \mathrm{E}+00 & 5.427 \mathrm{E}+00 & 5.145 \mathrm{E}+00 & 4.779 \mathrm{E}+00 & 1.429 \mathrm{E}+00\end{array}$

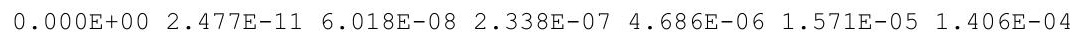

$\begin{array}{lllllll}0.000 \mathrm{E}+00 & 2.405 \mathrm{E}-05 & 1.198 \mathrm{E}-03 & 2.386 \mathrm{E}-03 & 1.155 \mathrm{E}-02 & 2.320 \mathrm{E}-02 & 1.121 \mathrm{E}-01\end{array}$

$\begin{array}{lllllll}0.000 \mathrm{E}+00 & 2.405 \mathrm{E}-05 & 1.198 \mathrm{E}-03 & 2.386 \mathrm{E}-03 & 1.155 \mathrm{E}-02 & 2.322 \mathrm{E}-02 & 1.122 \mathrm{E}-01\end{array}$

$0.000 \mathrm{E}+00 \quad 7.799 \mathrm{E}-16 \quad 9.529 \mathrm{E}-11 \quad 7.450 \mathrm{E}-10 \quad 7.803 \mathrm{E}-08 \quad 5.780 \mathrm{E}-07 \quad 5.806 \mathrm{E}-05$

$0.000 \mathrm{E}+00 \quad 1.136 \mathrm{E}-09 \quad 2.827 \mathrm{E}-06 \quad 1.126 \mathrm{E}-05 \quad 2.719 \mathrm{E}-04 \quad 1.144 \mathrm{E}-03 \quad 4.901 \mathrm{E}-02$

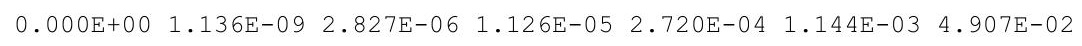

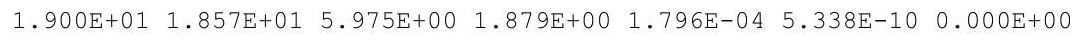

$\begin{array}{lllllll}7.176 \mathrm{E}-08 & 7.119 \mathrm{E}-08 & 4.830 \mathrm{E}-08 & 3.251 \mathrm{E}-08 & 1.370 \mathrm{E}-09 & 1.760 \mathrm{E}-11 & 2.951 \mathrm{E}-42\end{array}$

$\begin{array}{llllllll}3.900 \mathrm{E}+01 & 3.869 \mathrm{E}+01 & 2.625 \mathrm{E}+01 & 1.767 \mathrm{E}+01 & 7.445 \mathrm{E}-01 & 9.567 \mathrm{E}-03 & 1.612 \mathrm{E}-33\end{array}$

$\begin{array}{lllllllll}3.900 \mathrm{E}+01 & 3.869 \mathrm{E}+01 & 2.625 \mathrm{E}+01 & 1.767 \mathrm{E}+01 & 7.445 \mathrm{E}-01 & 9.567 \mathrm{E}-03 & 1.612 \mathrm{E}-33\end{array}$

$0.000 \mathrm{E}+00 \quad 1.101 \mathrm{E}-04 \quad 4.562 \mathrm{E}-03 \quad 7.627 \mathrm{E}-03 \quad 1.356 \mathrm{E}-02 \quad 1.363 \mathrm{E}-02 \quad 1.082 \mathrm{E}-02$

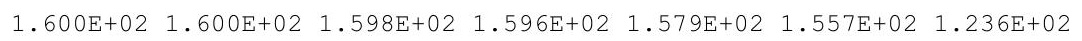

$\begin{array}{llllllll}0.000 \mathrm{E}+00 & 4.536 \mathrm{E}-04 & 2.265 \mathrm{E}-02 & 4.525 \mathrm{E}-02 & 2.240 \mathrm{E}-01 & 4.642 \mathrm{E}-01 & 3.553 \mathrm{E}+00\end{array}$

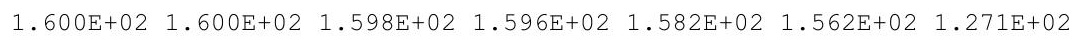

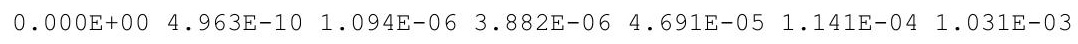
$\begin{array}{lllllllll}1.000 \mathrm{E}+02 & 1.000 \mathrm{E}+02 & 9.994 \mathrm{E}+01 & 9.988 \mathrm{E}+01 & 9.940 \mathrm{E}+01 & 9.875 \mathrm{E}+01 & 8.874 \mathrm{E}+01\end{array}$ $0.000 \mathrm{E}+00 \quad 1.440 \mathrm{E}-03 \quad 7.195 \mathrm{E}-02 \quad 1.438 \mathrm{E}-01 \quad 7.134 \mathrm{E}-01 \quad 1.483 \mathrm{E}+00 \quad 1.193 \mathrm{E}+01$ $\begin{array}{lllllll}0.000 \mathrm{E}+00 & 2.041 \mathrm{E}-09 & 5.099 \mathrm{E}-06 & 2.037 \mathrm{E}-05 & 5.052 \mathrm{E}-04 & 2.203 \mathrm{E}-03 & 1.668 \mathrm{E}-01\end{array}$

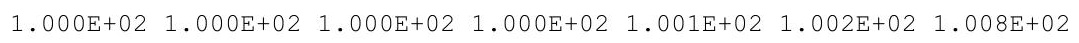

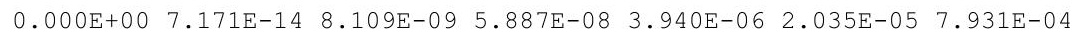
$\begin{array}{llllllll}0.000 \mathrm{E}+00 & 4.331 \mathrm{E}-02 & 2.141 \mathrm{E}+00 & 4.233 \mathrm{E}+00 & 1.933 \mathrm{E}+01 & 3.597 \mathrm{E}+01 & 8.627 \mathrm{E}+01\end{array}$ $\begin{array}{lllllll}0.000 \mathrm{E}+00 & 3.119 \mathrm{E}-07 & 7.736 \mathrm{E}-04 & 3.069 \mathrm{E}-03 & 7.197 \mathrm{E}-02 & 2.914 \mathrm{E}-01 & 9.214 \mathrm{E}+00\end{array}$ $\begin{array}{llllllll}0.000 \mathrm{E}+00 & 2.948 \mathrm{E}-13 & 3.662 \mathrm{E}-0 & 2.911 \mathrm{E}-07 & 3.459 \mathrm{E}-05 & 2.994 \mathrm{E}-04 & 1.075 \mathrm{E}-01\end{array}$ $\begin{array}{lllllll}0.000 \mathrm{E}+00 & 4.331 \mathrm{E}-02 & 2.142 \mathrm{E}+00 & 4.236 \mathrm{E}+00 & 1.940 \mathrm{E}+01 & 3.626 \mathrm{E}+01 & 9.560 \mathrm{E}+01\end{array}$

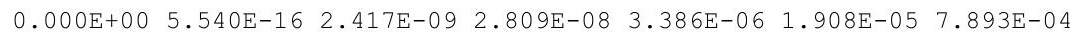
$\begin{array}{llllllll}0.000 \mathrm{E}+00 & 6.662 \mathrm{E}-04 & 1.057 \mathrm{E}+00 & 2.944 \mathrm{E}+00 & 1.819 \mathrm{E}+01 & 3.507 \mathrm{E}+01 & 8.620 \mathrm{E}+01\end{array}$ $\begin{array}{lllllll}0.000 \mathrm{E}+00 & 3.207 \mathrm{E}-09 & 2.836 \mathrm{E}-04 & 1.705 \mathrm{E}-03 & 6.353 \mathrm{E}-02 & 2.751 \mathrm{E}-01 & 9.171 \mathrm{E}+00\end{array}$ $\begin{array}{lllllll}0.000 \mathrm{E}+00 & 2.276 \mathrm{E}-15 & 1.075 \mathrm{E}-08 & 1.355 \mathrm{E}-07 & 2.879 \mathrm{E}-05 & 2.742 \mathrm{E}-04 & 1.066 \mathrm{E}-01\end{array}$ $\begin{array}{lllllll}0.000 \mathrm{E}+00 & 6.663 \mathrm{E}-04 & 1.058 \mathrm{E}+00 & 2.945 \mathrm{E}+00 & 1.825 \mathrm{E}+01 & 3.534 \mathrm{E}+01 & 9.547 \mathrm{E}+01\end{array}$ $\begin{array}{lllllll}3.600 \mathrm{E}+01 & 3.600 \mathrm{E}+01 & 3.592 \mathrm{E}+01 & 3.583 \mathrm{E}+01 & 3.518 \mathrm{E}+01 & 3.430 \mathrm{E}+01 & 2.274 \mathrm{E}+01\end{array}$ $0.000 \mathrm{E}+00 \quad 3.545 \mathrm{E}-08 \quad 1.770 \mathrm{E}-06 \quad 3.533 \mathrm{E}-06 \quad 1.742 \mathrm{E}-05 \quad 3.591 \mathrm{E}-05 \quad 2.517 \mathrm{E}-04$ $\begin{array}{lllllll}6.500 \mathrm{E}+00 & 6.500 \mathrm{E}+00 & 6.493 \mathrm{E}+00 & 6.485 \mathrm{E}+00 & 6.426 \mathrm{E}+00 & 6.345 \mathrm{E}+00 & 5.165 \mathrm{E}+00\end{array}$

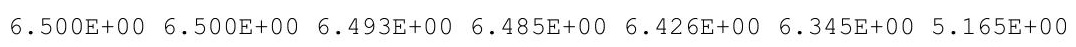


RESRAD, Version $6.5 \quad T^{1 / 2}$ Limit $=180$ days

Summary : RESRAD Parameters for U-Landfill Resident Gardener Forward Run 10,000 years

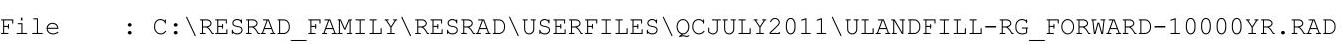

Individual Nuclide Soil Concentration

Parent Nuclide and Branch Fraction Indicated

\begin{tabular}{|c|c|c|c|c|c|c|c|c|c|}
\hline $\begin{array}{l}\text { uclide } \\
(j)\end{array}$ & $\begin{array}{c}\text { Parent } \\
\text { (i) }\end{array}$ & THF (i) & $t=0.000 \mathrm{E}+00$ & $1.000 \mathrm{E}+00$ & $\begin{array}{r}S(j \\
5.000 E+01\end{array}$ & $\begin{array}{l}j, t), \quad p C i / g \\
1.000 \mathrm{E}+02\end{array}$ & $5.000 \mathrm{E}+02$ & $1.050 \mathrm{E}+03$ & $1.000 \mathrm{E}+04$ \\
\hline-231 & $\mathrm{Pu}-239$ & $1.000 \mathrm{E}+00$ & $0.000 \mathrm{E}+00$ & $3.751 \mathrm{E}-13$ & $9.360 \mathrm{E}-10$ & $3.737 \mathrm{E}-09$ & $9.211 \mathrm{E}-08$ & $3.983 E-07$ & $2.627 \mathrm{E}-05$ \\
\hline$a-231$ & $\mathrm{U}-235$ & $1.000 \mathrm{E}+00$ & $0.000 \mathrm{E}+00$ & $1.375 E-04$ & $6.866 E-03$ & $1.371 E-02$ & $6.772 E-02$ & 1.398E-01 & $1.013 \mathrm{E}+00$ \\
\hline$a-231$ & $\sum S(j):$ & & $0.000 \mathrm{E}+00$ & $1.375 E-04$ & $6.866 \mathrm{E}-03$ & $1.371 E-02$ & $6.772 \mathrm{E}-02$ & 1. $398 \mathrm{E}-01$ & $1.013 \mathrm{E}+00$ \\
\hline-227 & $\mathrm{Pu}-239$ & $1.000 \mathrm{E}+00$ & $0.000 \mathrm{E}+00$ & $3.949 \mathrm{E}-15$ & $3.484 \mathrm{E}-10$ & $2.097 \mathrm{E}-09$ & $8.130 \mathrm{E}-08$ & $3.753 \mathrm{E}-07$ & $2.611 \mathrm{E}-05$ \\
\hline$c-227$ & $\mathrm{U}-235$ & $1.000 \mathrm{E}+00$ & $0.000 \mathrm{E}+00$ & $2.166 \mathrm{E}-06$ & $3.431 E-03$ & $9.584 \mathrm{E}-03$ & $6.348 \mathrm{E}-02$ & $1.357 \mathrm{E}-01$ & $1.010 \mathrm{E}+00$ \\
\hline$c-227$ & $\sum S(j):$ & & $0.000 \mathrm{E}+00$ & $2.166 E-06$ & $3.431 E-03$ & $9.584 \mathrm{E}-03$ & $6.348 E-02$ & $1.357 \mathrm{E}-01$ & $1.010 \mathrm{E}+00$ \\
\hline$x-240$ & $\mathrm{Pu}-240$ & $4.950 \mathrm{E}-08$ & $1.782 \mathrm{E}-06$ & $1.782 \mathrm{E}-06$ & $1.771 \mathrm{E}-06$ & $1.760 \mathrm{E}-06$ & $1.676 \mathrm{E}-06$ & $1.566 \mathrm{E}-06$ & $5.200 \mathrm{E}-07$ \\
\hline$x-240$ & $\mathrm{Pu}-240$ & $1.000 \mathrm{E}+00$ & $3.600 \mathrm{E}+01$ & $3.600 \mathrm{E}+01$ & $3.578 \mathrm{E}+01$ & $3.556 \mathrm{E}+01$ & $3.385 \mathrm{E}+01$ & $3.163 \mathrm{E}+01$ & $1.050 \mathrm{E}+01$ \\
\hline$x-240$ & $\sum S(j):$ & & $3.600 \mathrm{E}+01$ & $3.600 \mathrm{E}+01$ & $3.578 \mathrm{E}+01$ & $3.556 \mathrm{E}+01$ & $3.385 E+01$ & $3.163 \mathrm{E}+01$ & $1.050 \mathrm{E}+01$ \\
\hline 236 & $\mathrm{Pu}-240$ & $1.000 \mathrm{E}+00$ & $0.000 \mathrm{E}+00$ & $1.066 \mathrm{E}-06$ & $5.309 E-05$ & $1.058 E-04$ & $5.138 \mathrm{E}-04$ & $1.037 \mathrm{E}-03$ & $5.348 E-03$ \\
\hline-232 & $\mathrm{Pu}-240$ & $1.000 \mathrm{E}+00$ & $0.000 \mathrm{E}+00$ & $2.629 \mathrm{E}-17$ & $6.556 \mathrm{E}-14$ & $2.616 E-13$ & $6.411 \mathrm{E}-12$ & $2.752 \mathrm{E}-11$ & $1.653 \mathrm{E}-09$ \\
\hline-232 & $\mathrm{Th}-232$ & $1.000 \mathrm{E}+00$ & $4.000 \mathrm{E}+00$ & $4.000 \mathrm{E}+00$ & $3.999 \mathrm{E}+00$ & $3.999 \mathrm{E}+00$ & $3.994 \mathrm{E}+00$ & $3.988 \mathrm{E}+00$ & $3.884 \mathrm{E}+00$ \\
\hline-232 & $\sum S(j):$ & & $4.000 \mathrm{E}+00$ & $4.000 \mathrm{E}+00$ & $3.999 \mathrm{E}+00$ & $3.999 \mathrm{E}+00$ & $3.994 \mathrm{E}+00$ & $3.988 \mathrm{E}+00$ & $3.884 \mathrm{E}+00$ \\
\hline-228 & $\mathrm{Pu}-240$ & $1.000 \mathrm{E}+00$ & $0.000 \mathrm{E}+00$ & $1.025 \mathrm{E}-18$ & $4.741 \mathrm{E}-14$ & $2.218 E-13$ & $6.203 E-12$ & $2.709 \mathrm{E}-11$ & $1.650 \mathrm{E}-09$ \\
\hline$a-228$ & $\mathrm{Th}-232$ & $1.000 \mathrm{E}+00$ & $0.000 \mathrm{E}+00$ & $4.543 E-01$ & $3.989 \mathrm{E}+00$ & $3.998 \mathrm{E}+00$ & $3.994 \mathrm{E}+00$ & $3.987 \mathrm{E}+00$ & $3.883 \mathrm{E}+00$ \\
\hline$a-228$ & $\sum S(j):$ & & $0.000 \mathrm{E}+00$ & $4.543 E-01$ & $3.989 \mathrm{E}+00$ & $3.998 \mathrm{E}+00$ & $3.994 \mathrm{E}+00$ & $3.987 \mathrm{E}+00$ & $3.883 \mathrm{E}+00$ \\
\hline-228 & $\mathrm{Pu}-240$ & $1.000 \mathrm{E}+00$ & $0.000 \mathrm{E}+00$ & $8.701 \mathrm{E}-20$ & $4.177 \mathrm{E}-14$ & $2.090 E-13$ & $6.135 E-12$ & $2.695 E-11$ & $1.649 \mathrm{E}-09$ \\
\hline 228 & $T h-228$ & $1.000 \mathrm{E}+00$ & $4.000 \mathrm{E}+00$ & $2.784 \mathrm{E}+00$ & $5.425 E-08$ & 7. $358 E-16$ & $0.000 \mathrm{E}+00$ & $0.000 \mathrm{E}+00$ & $0.000 \mathrm{E}+00$ \\
\hline$h-228$ & $\mathrm{Th}-232$ & $1.000 \mathrm{E}+00$ & $0.000 \mathrm{E}+00$ & $7.457 \mathrm{E}-02$ & $3.984 \mathrm{E}+00$ & $3.998 E+00$ & $3.994 \mathrm{E}+00$ & $3.987 \mathrm{E}+00$ & $3.883 E+00$ \\
\hline$h-228$ & $\sum S(j):$ & & $4.000 \mathrm{E}+00$ & $2.859 \mathrm{E}+00$ & $3.984 \mathrm{E}+00$ & $3.998 \mathrm{E}+00$ & $3.994 \mathrm{E}+00$ & $3.987 \mathrm{E}+00$ & $3.883 E+00$ \\
\hline-99 & TC-99 & $1.000 \mathrm{E}+00$ & $5.200 \mathrm{E}+01$ & $5.153 \mathrm{E}+01$ & $3.314 \mathrm{E}+01$ & $2.113 E+01$ & $5.754 \mathrm{E}-01$ & $4.059 \mathrm{E}-03$ & $3.943 E-38$ \\
\hline 38 & $\mathrm{U}-238$ & $5.400 \mathrm{E}-05$ & $8.640 \mathrm{E}-03$ & $8.640 \mathrm{E}-03$ & $8.630 \mathrm{E}-03$ & $8.620 \mathrm{E}-03$ & $8.541 \mathrm{E}-03$ & $8.434 \mathrm{E}-03$ & $6.865 E-03$ \\
\hline 238 & $\mathrm{U}-238$ & $9.999 \mathrm{E}-01$ & $1.600 \mathrm{E}+02$ & $1.600 \mathrm{E}+02$ & $1.598 \mathrm{E}+02$ & $1.596 \mathrm{E}+02$ & $1.582 \mathrm{E}+02$ & $1.562 \mathrm{E}+02$ & $1.271 \mathrm{E}+02$ \\
\hline 238 & $\sum S(j):$ & & $1.600 \mathrm{E}+02$ & $1.600 \mathrm{E}+02$ & $1.598 \mathrm{E}+02$ & $1.596 \mathrm{E}+02$ & 1. $582 \mathrm{E}+02$ & $1.562 \mathrm{E}+02$ & $1.271 \mathrm{E}+02$ \\
\hline
\end{tabular}

THF (i) is the thread fraction of the parent nuclide.

RESCALC.EXE execution time $=4.83$ seconds 
RESRAD, Version $6.5 \quad T^{13 / 2}$ Limit $=180$ days

07/21/2011 $12: 29$ Page

Summary : RESRAD Parameters for U-Landfill Resident Gardener Forward Run 100,000 years

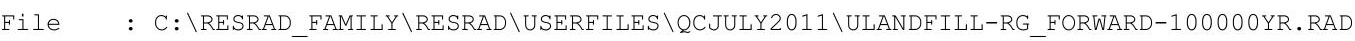

Table of Contents

Part I: Mixture Sums and Single Radionuclide Guidelines

Dose Conversion Factor (and Related) Parameter Summary ... 2

Site-Specific Parameter Summary ................ 8

Summary of Pathway Selections ................... 18

Contaminated Zone and Total Dose Summary ............. 19

Total Dose Components

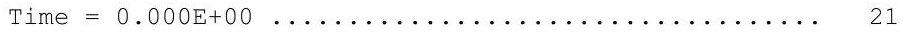

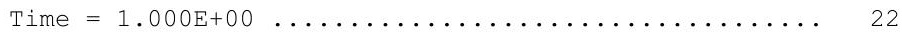

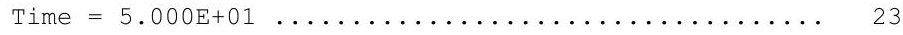

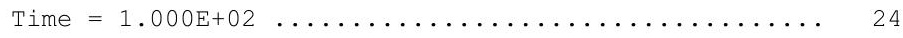

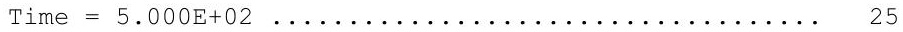

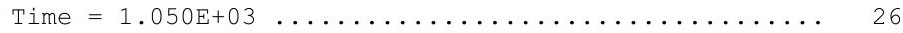

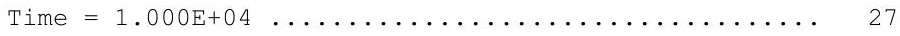

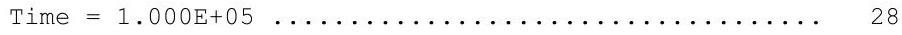

Dose/Source Ratios Summed Over All Pathways ........... 29

Single Radionuclide Soil Guidelines ............... 31

Dose Per Nuclide Summed Over All Pathways ............ 32

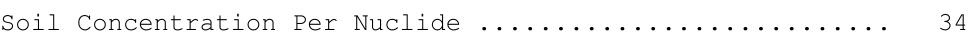


Summary : RESRAD Parameters for U-Landfill Resident Gardener Forward Run 100,000 years

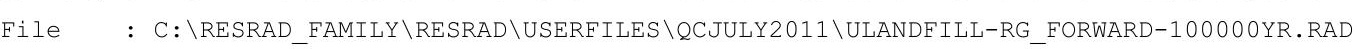

Dose Conversion Factor (and Related) Parameter Summary

Dose Library: ICRP 60 \& ICRP 72 (Adult)

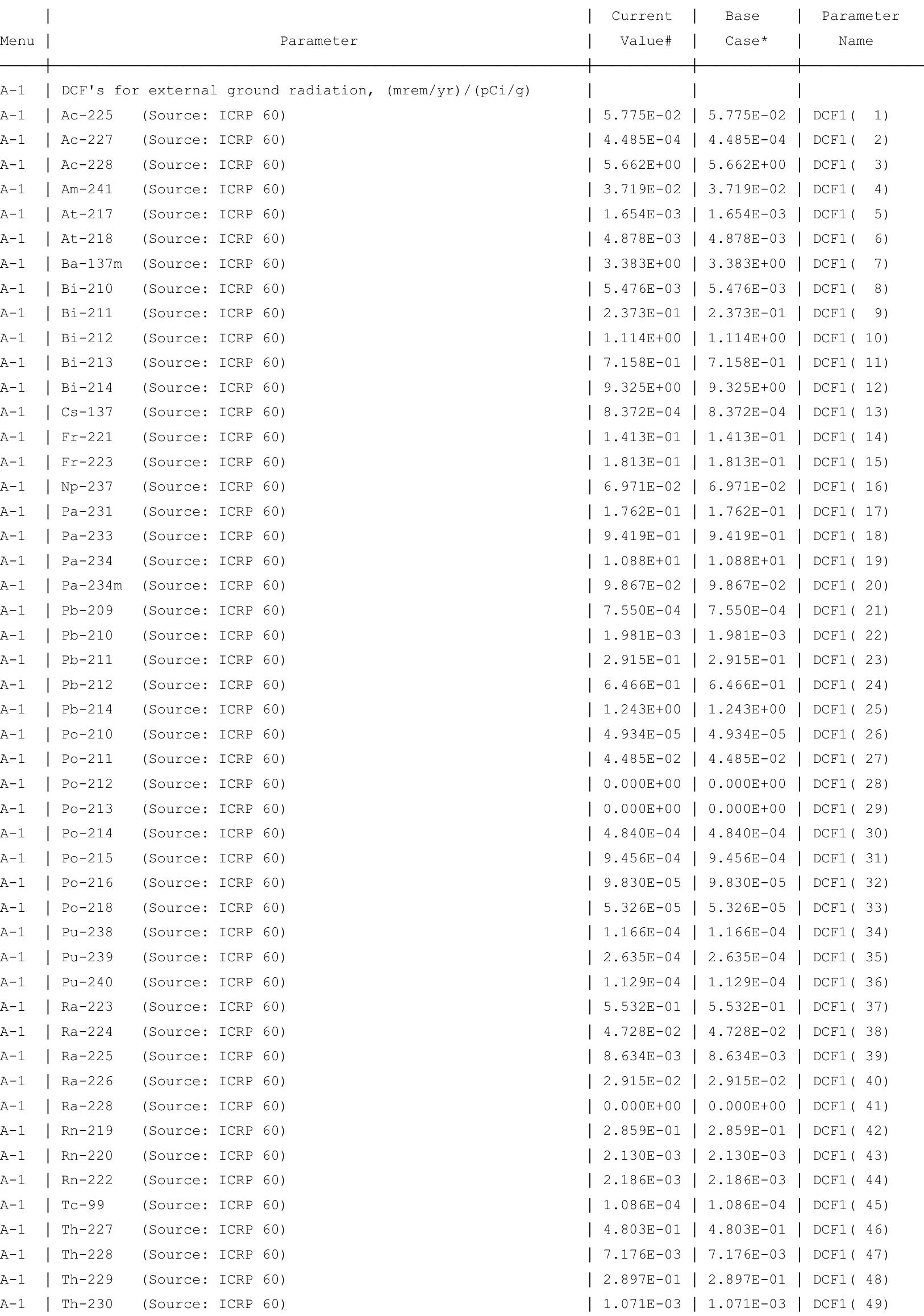


Summary : RESRAD Parameters for U-Landfill Resident Gardener Forward Run 100,000 years

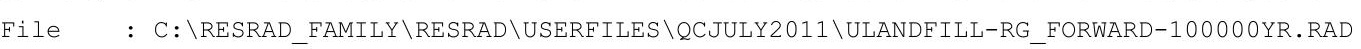

Dose Conversion Factor (and Related) Parameter Summary (continued)

Dose Library: ICRP 60 \& ICRP 72 (Adult)

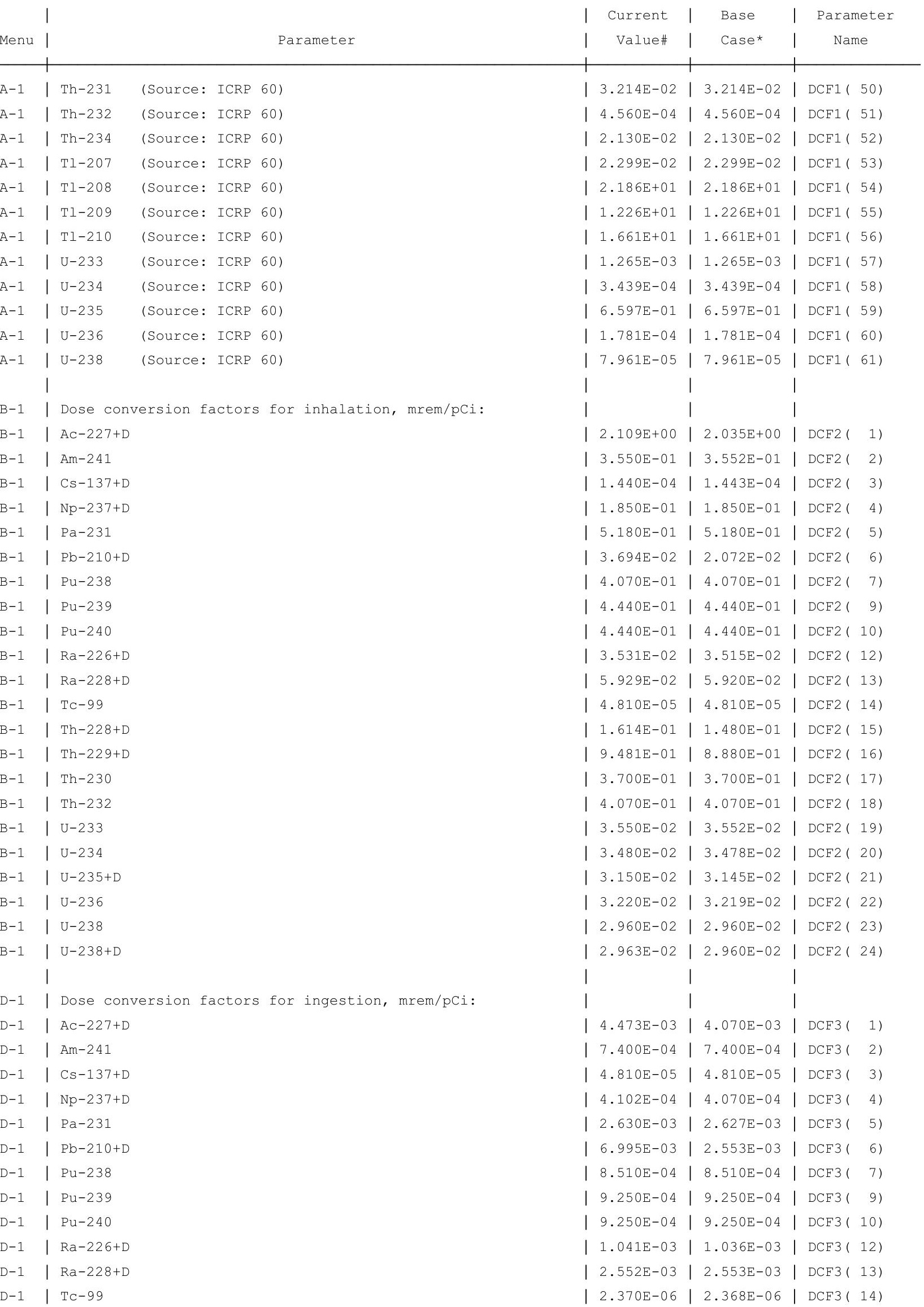


RESRAD, Version $6.5 \quad$ T1/2 Limit $=180$ days
Summary : RESRAD Parameters for U-Landfill Resident Gardener Forward Run 100,000 years

File : C: \RESRAD_FAMILY \RESRAD \USERFILES \QCJULY2011 \ULANDFILL-RG_FORWARD-100000YR.RAD

Dose Conversion Factor (and Related) Parameter Summary (continued)

Dose Library: ICRP 60 \& ICRP 72 (Adult)

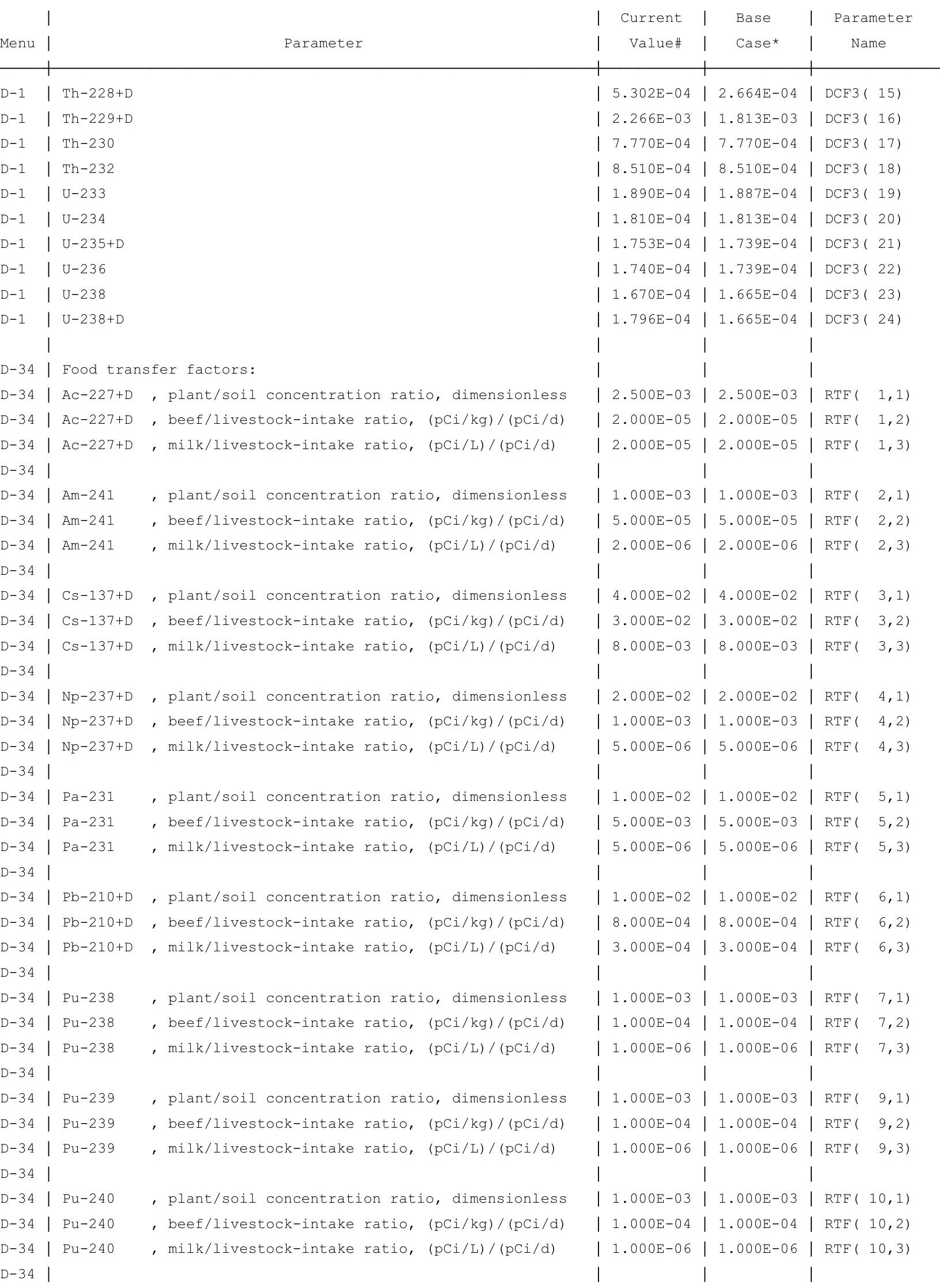




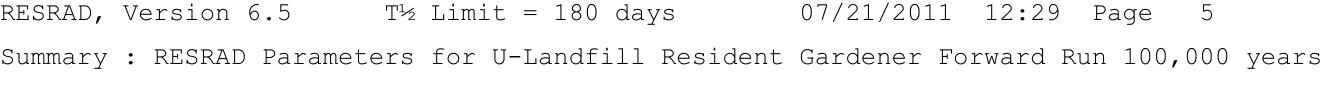

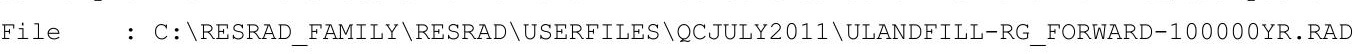

Dose Conversion Factor (and Related) Parameter Summary (continued)

Dose Library: ICRP 60 \& ICRP 72 (Adult)

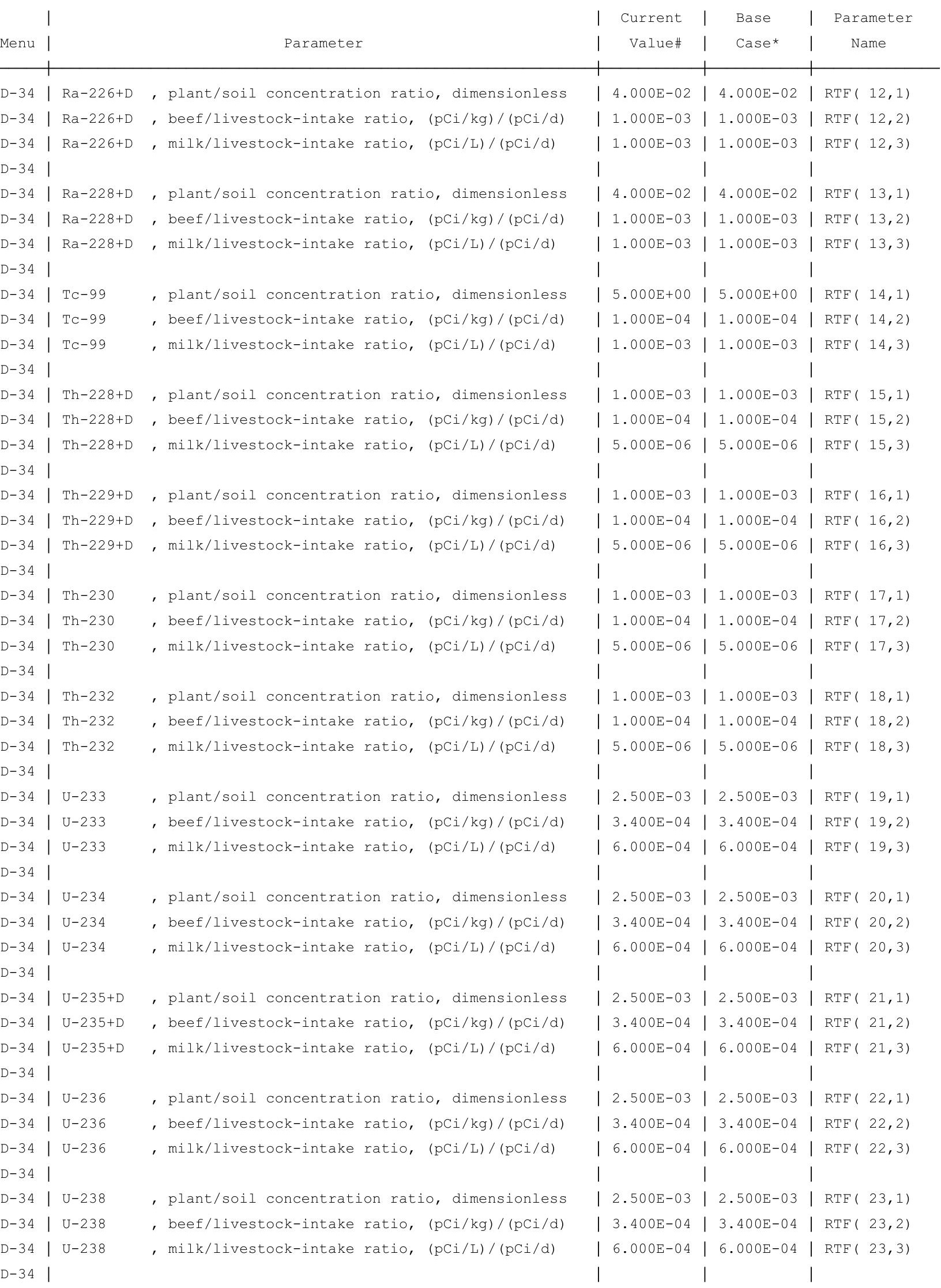


Summary : RESRAD Parameters for U-Landfill Resident Gardener Forward Run 100,000 years

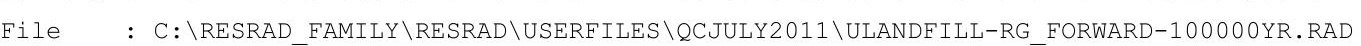

Site-Specific Parameter Summary (continued)

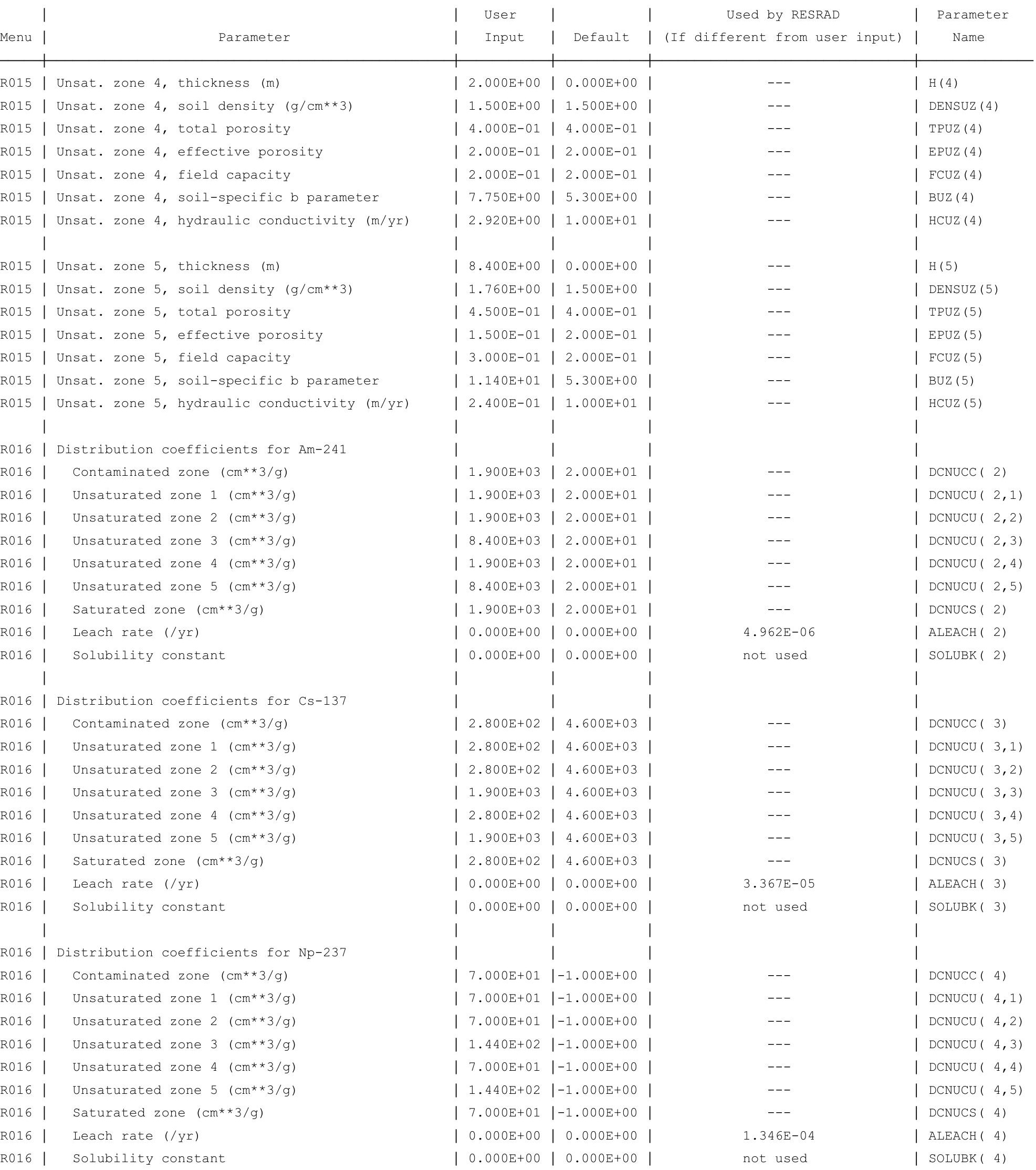


Summary : RESRAD Parameters for U-Landfill Resident Gardener Forward Run 100,000 years

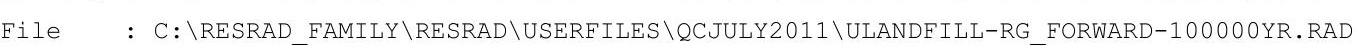

Site-Specific Parameter Summary (continued)

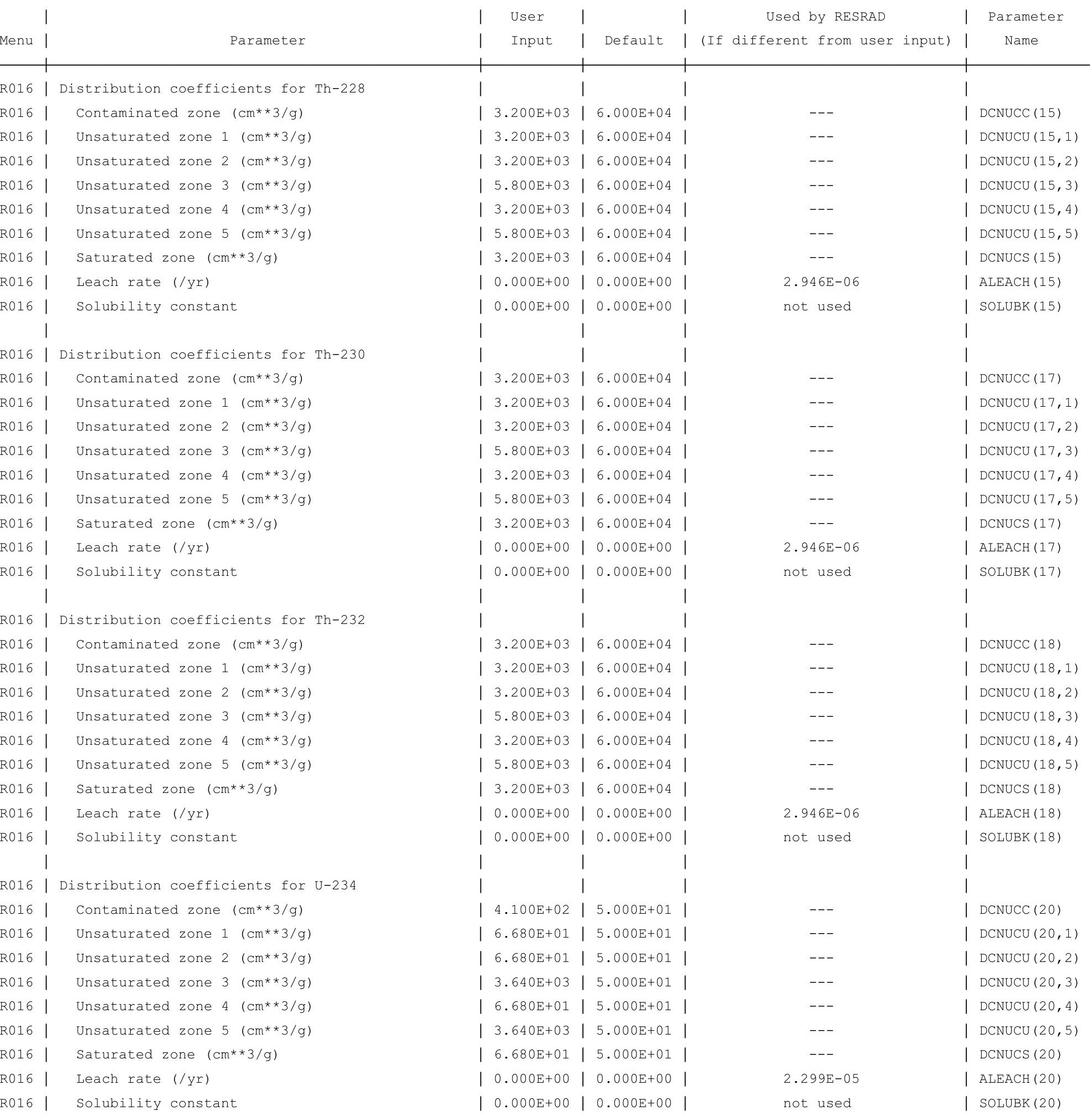


Summary : RESRAD Parameters for U-Landfill Resident Gardener Forward Run 100,000 years

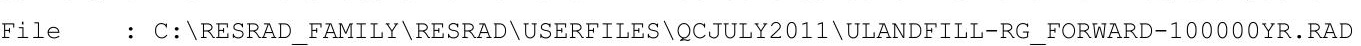

Site-Specific Parameter Summary (continued)

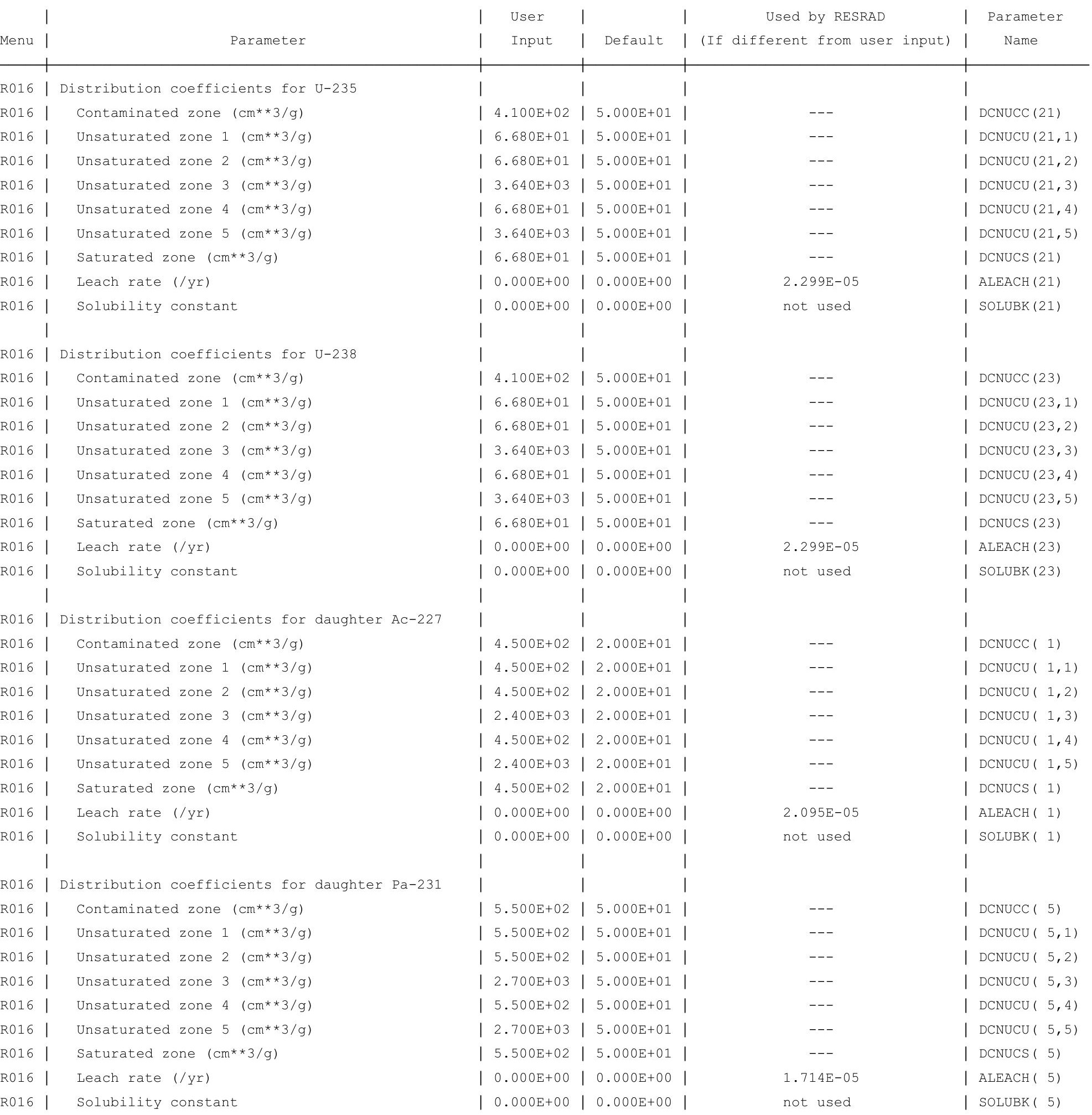




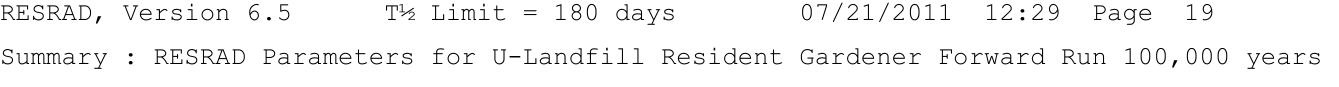

File : C: $\backslash$ RESRAD_FAMILY \RESRAD \USERFILES \QCJULY2011 \ULANDFILL-RG_FORWARD-100000YR.RAD

Contaminated Zone Dimensions

Area: 89436.00 square meters

Thickness:

Cover Depth:

\begin{abstract}
13.40 meters
\end{abstract}
1.52 meters
Initial Soil Concentrations, pCi/g

$\begin{array}{ll}\mathrm{Am}-241 & 3.500 \mathrm{E}+01 \\ \mathrm{Cs}-137 & 1.900 \mathrm{E}+01 \\ \mathrm{~Np}-237 & 5.500 \mathrm{E}+00 \\ \mathrm{Pu}-238 & 3.900 \mathrm{E}+01 \\ \mathrm{Pu}-239 & 3.600 \mathrm{E}+01 \\ \mathrm{Pu}-240 & 3.600 \mathrm{E}+01 \\ \mathrm{TC}-99 & 5.200 \mathrm{E}+01 \\ \mathrm{Th}-228 & 4.000 \mathrm{E}+00 \\ \mathrm{Th}-230 & 1.000 \mathrm{E}+02 \\ \mathrm{Th}-232 & 4.000 \mathrm{E}+00 \\ \mathrm{U}-234 & 1.600 \mathrm{E}+02 \\ \mathrm{U}-235 & 6.500 \mathrm{E}+00 \\ \mathrm{U}-238 & 1.600 \mathrm{E}+02\end{array}$

Total Dose TDOSE(t), mrem/yr

Basic Radiation Dose Limit $=1.000 \mathrm{E}+02 \mathrm{mrem} / \mathrm{yr}$

Total Mixture Sum $M(t)$ = Fraction of Basic Dose Limit Received at Time (t)

$\begin{array}{rlllllllll}t \text { (years) }: & 0.000 \mathrm{E}+00 & 1.000 \mathrm{E}+00 & 5.000 \mathrm{E}+01 & 1.000 \mathrm{E}+02 & 5.000 \mathrm{E}+02 & 1.050 \mathrm{E}+03 & 1.000 \mathrm{E}+04 & 1.000 \mathrm{E}+05 \\ \mathrm{TDOSE}(\mathrm{t}): & 5.627 \mathrm{E}-06 & 4.206 \mathrm{E}-06 & 9.541 \mathrm{E}-06 & 1.367 \mathrm{E}-05 & 2.423 \mathrm{E}-04 & 6.827 \mathrm{E}+00 & 2.359 \mathrm{E}+03 & 0.000 \mathrm{E}+00 \\ \mathrm{M}(\mathrm{t}): & 5.627 \mathrm{E}-08 & 4.206 \mathrm{E}-08 & 9.541 \mathrm{E}-08 & 1.367 \mathrm{E}-07 & 2.423 \mathrm{E}-06 & 6.827 \mathrm{E}-02 & 2.359 \mathrm{E}+01 & 0.000 \mathrm{E}+00\end{array}$

Maximum TDOSE (t): $2.370 \mathrm{E}+03 \mathrm{mrem} / \mathrm{yr}$ at $t=12931 \pm$ * years

Total Dose Contributions TDOSE(i,p,t) for Individual Radionuclides (i) and Pathways (p) As mrem/yr and Fraction of Total Dose At $t=1.293 \mathrm{E}+04$ years

Water Independent Pathways (Inhalation excludes radon)

\begin{tabular}{|c|c|c|c|c|c|c|c|c|c|c|c|c|c|c|}
\hline & \multicolumn{2}{|c|}{ Ground } & \multicolumn{2}{|c|}{ Inhalation } & \multicolumn{2}{|c|}{ Radon } & \multicolumn{2}{|c|}{ Plant } & \multicolumn{2}{|c|}{ Meat } & \multicolumn{2}{|c|}{ Milk } & \multicolumn{2}{|c|}{ Soil } \\
\hline clide & mrem/yr & fract. & mrem/yr & fract. & mrem/yr & fract. & mrem/yr & fract. & mrem/yr & fract. & mrem/yr & fract. & mrem/yr & fract. \\
\hline 241 & $1.209 E-03$ & 0.0000 & $1.387 \mathrm{E}-07$ & 0.0000 & $0.000 \mathrm{E}+00$ & 0.0000 & $1.420 \mathrm{E}-03$ & 0.0000 & $0.000 \mathrm{E}+00$ & 0.0000 & $0.000 \mathrm{E}+00$ & 0.0000 & $2.657 \mathrm{E}-05$ & 0.0000 \\
\hline-137 & $0.000 \mathrm{E}+00$ & 0.0000 & $0.000 \mathrm{E}+00$ & 0.0000 & $0.000 \mathrm{E}+00$ & 0.0000 & $0.000 \mathrm{E}+00$ & 0.0000 & $0.000 \mathrm{E}+00$ & 0.0000 & $0.000 \mathrm{E}+00$ & 0.0000 & $0.000 \mathrm{E}+00$ & 0.0000 \\
\hline-237 & $8.744 E-01$ & 0.0004 & $1.026 \mathrm{E}-04$ & 0.0000 & $0.000 \mathrm{E}+00$ & 0.0000 & $1.019 \mathrm{E}+00$ & 0.0004 & $0.000 \mathrm{E}+00$ & 0.0000 & $0.000 \mathrm{E}+00$ & 0.0000 & $1.973 E-02$ & 0.0000 \\
\hline-238 & $8.950 E-03$ & 0.0000 & $3.764 \mathrm{E}-07$ & 0.0000 & $0.000 \mathrm{E}+00$ & 0.0000 & $1.529 \mathrm{E}-02$ & 0.0000 & $0.000 \mathrm{E}+00$ & 0.0000 & $0.000 \mathrm{E}+00$ & 0.0000 & $3.895 \mathrm{E}-04$ & 0.0000 \\
\hline-239 & $4.534 \mathrm{E}-03$ & 0.0000 & $3.722 \mathrm{E}-03$ & 0.0000 & $0.000 \mathrm{E}+00$ & 0.0000 & $2.318 \mathrm{E}+00$ & 0.0010 & $0.000 \mathrm{E}+00$ & 0.0000 & $0.000 \mathrm{E}+00$ & 0.0000 & $6.441 \mathrm{E}-01$ & 0.0003 \\
\hline 240 & $6.864 \mathrm{E}-04$ & 0.0000 & $1.371 \mathrm{E}-03$ & 0.0000 & $0.000 \mathrm{E}+00$ & 0.0000 & $8.540 \mathrm{E}-01$ & 0.0004 & $0.000 \mathrm{E}+00$ & 0.0000 & $0.000 \mathrm{E}+00$ & 0.0000 & $2.373 E-01$ & 0.0001 \\
\hline 99 & $0.000 \mathrm{E}+00$ & 0.0000 & $0.000 \mathrm{E}+00$ & 0.0000 & $0.000 \mathrm{E}+00$ & 0.0000 & $0.000 \mathrm{E}+00$ & 0.0000 & $0.000 \mathrm{E}+00$ & 0.0000 & $0.000 \mathrm{E}+00$ & 0.0000 & $0.000 \mathrm{E}+00$ & 0.0000 \\
\hline-228 & $0.000 \mathrm{E}+00$ & 0.0000 & $0.000 \mathrm{E}+00$ & 0.0000 & $0.000 \mathrm{E}+00$ & 0.0000 & $0.000 \mathrm{E}+00$ & 0.0000 & $0.000 \mathrm{E}+00$ & 0.0000 & $0.000 \mathrm{E}+00$ & 0.0000 & $0.000 \mathrm{E}+00$ & 0.0000 \\
\hline 230 & $7.244 \mathrm{E}+02$ & 0.3057 & $1.594 \mathrm{E}-02$ & 0.0000 & $0.000 \mathrm{E}+00$ & 0.0000 & $1.192 \mathrm{E}+03$ & 0.5030 & $0.000 \mathrm{E}+00$ & 0.0000 & $0.000 E+00$ & 0.0000 & $2.598 E+01$ & 0.0110 \\
\hline-232 & $4.798 E+01$ & 0.0202 & $1.020 \mathrm{E}-03$ & 0.0000 & $0.000 \mathrm{E}+00$ & 0.0000 & $5.010 \mathrm{E}+01$ & 0.0211 & $0.000 \mathrm{E}+00$ & 0.0000 & $0.000 \mathrm{E}+00$ & 0.0000 & $5.306 \mathrm{E}-01$ & 0.0002 \\
\hline 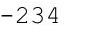 & $1.035 E+02$ & 0.0437 & $4.328 E-03$ & 0.0000 & $0.000 \mathrm{E}+00$ & 0.0000 & $1.768 \mathrm{E}+02$ & 0.0746 & $0.000 \mathrm{E}+00$ & 0.0000 & $0.000 \mathrm{E}+00$ & 0.0000 & $4.495 E+00$ & 0.0019 \\
\hline 35 & $4.746 \mathrm{E}+00$ & 0.0020 & $1.390 \mathrm{E}-03$ & 0.0000 & $0.000 \mathrm{E}+00$ & 0.0000 & $5.930 \mathrm{E}+00$ & 0.0025 & $0.000 \mathrm{E}+00$ & 0.0000 & $0.000 \mathrm{E}+00$ & 0.0000 & $3.275 E-01$ & 0.0001 \\
\hline 38 & $1.669 \mathrm{E}+01$ & 0.0070 & $1.595 \mathrm{E}-03$ & 0.0000 & $0.000 \mathrm{E}+00$ & 0.0000 & $9.607 \mathrm{E}+00$ & 0.0041 & $0.000 \mathrm{E}+00$ & 0.0000 & $0.000 \mathrm{E}+00$ & 0.0000 & $8.344 \mathrm{E}-01$ & 0.0004 \\
\hline & $8.982 \mathrm{E}+02$ & 0.3790 & $2.946 \mathrm{E}-02$ & 0.0000 & $0.000 \mathrm{E}+00$ & 0.0000 & $1.439 \mathrm{E}+03$ & 0.6070 & $0.000 \mathrm{E}+00$ & 0.0000 & $0.000 \mathrm{E}+00$ & & $7 E+01$ & 0.0140 \\
\hline
\end{tabular}


RESRAD, Version $6.5 \quad \mathrm{~T}^{1 / 2}$ Limit $=180$ days

Summary : RESRAD Parameters for U-Landfill Resident Gardener Forward Run 100,000 years

File : C: \RESRAD_FAMILY \RESRAD \USERFILES \QCJULY2011 \ULANDFILL-RG_FORWARD-100000YR.RAD

Total Dose Contributions TDOSE (i,p,t) for Individual Radionuclides (i) and Pathways (p)

As mrem/yr and Fraction of Total Dose At $t=1.293 \mathrm{E}+04$ years

Water Dependent Pathways

\begin{tabular}{|c|c|c|c|c|c|c|c|c|c|c|c|c|c|c|}
\hline & \multicolumn{2}{|c|}{ Water } & \multicolumn{2}{|c|}{ Fish } & \multicolumn{2}{|c|}{ Radon } & \multicolumn{2}{|c|}{ Plant } & \multicolumn{2}{|c|}{ Meat } & \multicolumn{2}{|c|}{ Milk } & \multicolumn{2}{|c|}{ All Pathways* } \\
\hline ide & mrem/yr & fract. & mrem/yr & fract. & mrem/yr & fract. & mrem/yr & fract. & mrem/yr & fract. & mrem/yr & fract. & mrem/yr & fract. \\
\hline-241 & $0.000 \mathrm{E}+00$ & 0.0000 & $0.000 \mathrm{E}+00$ & 0.0000 & $0.000 \mathrm{E}+00$ & 0.0000 & $0.000 \mathrm{E}+00$ & 0.0000 & $0.000 \mathrm{E}+00$ & 0.0000 & $0.000 \mathrm{E}+00$ & 0.0000 & $2.656 \mathrm{E}-03$ & 0.0000 \\
\hline-137 & $0.000 \mathrm{E}+00$ & 0.0000 & $0.000 \mathrm{E}+00$ & 0.0000 & $0.000 \mathrm{E}+00$ & 0.0000 & $0.000 \mathrm{E}+00$ & 0.0000 & $0.000 \mathrm{E}+00$ & 0.0000 & $0.000 \mathrm{E}+00$ & 0.0000 & $0.000 \mathrm{E}+00$ & 0.0000 \\
\hline 237 & $0.000 \mathrm{E}+00$ & 0.0000 & $0.000 \mathrm{E}+00$ & 0.0000 & $0.000 \mathrm{E}+00$ & 0.0000 & $0.000 \mathrm{E}+00$ & 0.0000 & $0.000 \mathrm{E}+00$ & 0.0000 & $0.000 \mathrm{E}+00$ & 0.0000 & $1.913 \mathrm{E}+00$ & 0.0008 \\
\hline 238 & $0.000 \mathrm{E}+00$ & 0.0000 & $0.000 \mathrm{E}+00$ & 0.0000 & $0.000 \mathrm{E}+00$ & 0.0000 & $0.000 \mathrm{E}+00$ & 0.0000 & $0.000 \mathrm{E}+00$ & 0.0000 & $0.000 \mathrm{E}+00$ & 0.0000 & $2.463 E-02$ & 0.0000 \\
\hline-239 & $0.000 \mathrm{E}+00$ & 0.0000 & $0.000 \mathrm{E}+00$ & 0.0000 & $0.000 \mathrm{E}+00$ & 0.0000 & $0.000 \mathrm{E}+00$ & 0.0000 & $0.000 \mathrm{E}+00$ & 0.0000 & $0.000 \mathrm{E}+00$ & 0.0000 & $2.970 \mathrm{E}+00$ & 0.0013 \\
\hline 240 & $0.000 \mathrm{E}+00$ & 0.0000 & $0.000 \mathrm{E}+00$ & 0.0000 & $0.000 \mathrm{E}+00$ & 0.0000 & $0.000 \mathrm{E}+00$ & 0.0000 & $0.000 \mathrm{E}+00$ & 0.0000 & $0.000 \mathrm{E}+00$ & 0.0000 & $1.093 \mathrm{E}+00$ & 0.0005 \\
\hline 99 & $0.000 \mathrm{E}+00$ & 0.0000 & $0.000 \mathrm{E}+00$ & 0.0000 & $0.000 \mathrm{E}+00$ & 0.0000 & $0.000 \mathrm{E}+00$ & 0.0000 & $0.000 \mathrm{E}+00$ & 0.0000 & $0.000 \mathrm{E}+00$ & 0.0000 & $0.000 \mathrm{E}+00$ & 0.0000 \\
\hline 228 & $0.000 \mathrm{E}+00$ & 0.0000 & $0.000 \mathrm{E}+00$ & 0.0000 & $0.000 \mathrm{E}+00$ & 0.0000 & $0.000 \mathrm{E}+00$ & 0.0000 & $0.000 \mathrm{E}+00$ & 0.0000 & $0.000 \mathrm{E}+00$ & 0.0000 & $0.000 \mathrm{E}+00$ & 0.0000 \\
\hline 230 & $0.000 \mathrm{E}+00$ & 0.0000 & $0.000 \mathrm{E}+00$ & 0.0000 & $0.000 \mathrm{E}+00$ & 0.0000 & $0.000 \mathrm{E}+00$ & 0.0000 & $0.000 \mathrm{E}+00$ & 0.0000 & $0.000 \mathrm{E}+00$ & 0.0000 & $1.943 \mathrm{E}+03$ & 0.8196 \\
\hline 232 & $0.000 \mathrm{E}+00$ & 0.0000 & $0.000 \mathrm{E}+00$ & 0.0000 & $0.000 \mathrm{E}+00$ & 0.0000 & $0.000 \mathrm{E}+00$ & 0.0000 & $0.000 \mathrm{E}+00$ & 0.0000 & $0.000 \mathrm{E}+00$ & 0.0000 & $9.861 \mathrm{E}+01$ & 0.0416 \\
\hline & $0.000 \mathrm{E}+00$ & 0.0000 & $0.000 \mathrm{E}+00$ & 0.0000 & $0.000 \mathrm{E}+00$ & 0.0000 & $0.000 \mathrm{E}+00$ & 0.0000 & $0.000 \mathrm{E}+00$ & 0.0000 & $0.000 \mathrm{E}+00$ & 0.0000 & $2.848 E+02$ & 0.1202 \\
\hline 35 & $0.000 \mathrm{E}+00$ & 0.0000 & $0.000 \mathrm{E}+00$ & 0.0000 & $0.000 \mathrm{E}+00$ & 0.0000 & $0.000 \mathrm{E}+00$ & 0.0000 & $0.000 \mathrm{E}+00$ & 0.0000 & $0.000 \mathrm{E}+00$ & 0.0000 & $1.100 \mathrm{E}+01$ & 0.0046 \\
\hline 38 & $0.000 \mathrm{E}+00$ & 0.0000 & $0.000 \mathrm{E}+00$ & 0.0000 & $0.000 \mathrm{E}+00$ & 0.0000 & $0.000 \mathrm{E}+00$ & 0.0000 & $0.000 \mathrm{E}+00$ & 0.0000 & $0.000 \mathrm{E}+00$ & 0.0000 & $2.713 E+01$ & 0.0114 \\
\hline & $0.000 \mathrm{E}+00$ & 0.0000 & $.000 \mathrm{E}+00$ & 0.0000 & $0.000 \mathrm{E}+00$ & 0.0000 & $0.000 \mathrm{E}+00$ & 0.0000 & $0.000 \mathrm{E}+00$ & 0.0000 & $0.000 \mathrm{E}+00$ & 0.0000 & +03 & 000 \\
\hline
\end{tabular}

*Sum of all water independent and dependent pathways. 
$\begin{array}{llll}\text { RESRAD, Version } 6.5 & T^{1 / 2} \text { Limit }=180 \text { days } & 07 / 21 / 2011 & 12: 29 \text { Page } 21 \\ \text { Summary : RESRAD Parameters for U-Landfill Resident Gardener Forward Run 100,000 years }\end{array}$

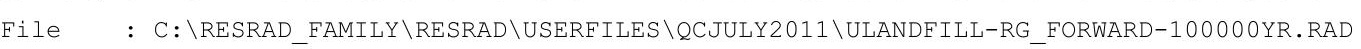

Total Dose Contributions TDOSE (i,p,t) for Individual Radionuclides (i) and Pathways (p) As mrem/yr and Fraction of Total Dose At $t=0.000 \mathrm{E}+00$ years

Water Independent Pathways (Inhalation excludes radon)

\begin{tabular}{|c|c|c|c|c|c|c|c|c|c|c|c|c|c|c|}
\hline \multirow{2}{*}{ ide } & \multicolumn{2}{|c|}{ Ground } & \multicolumn{2}{|c|}{ Inhalation } & \multicolumn{2}{|c|}{ Radon } & \multicolumn{2}{|c|}{ Plant } & \multicolumn{2}{|c|}{ Meat } & \multicolumn{2}{|c|}{ Milk } & \multicolumn{2}{|c|}{ Soil } \\
\hline & $\mathrm{mrem} / \mathrm{yr}$ & fract. & $\mathrm{mrem} / \mathrm{yr}$ & fract. & $\mathrm{mrem} / \mathrm{yr}$ & fract. & mrem/yr & fract. & $\mathrm{mrem} / \mathrm{yr}$ & fract. & $\mathrm{mrem} / \mathrm{yr}$ & fract. & mrem/yr & fract. \\
\hline \pm 1 & $5.412 \mathrm{E}-18$ & 0.0000 & $0.000 \mathrm{E}+00$ & 0.0000 & $0.000 \mathrm{E}+00$ & 0.0000 & $0.000 \mathrm{E}+00$ & 0.0000 & $0.000 \mathrm{E}+00$ & 0.0000 & $0.000 \mathrm{E}+00$ & 0.0000 & $0.000 \mathrm{E}+00$ & 0.0000 \\
\hline 137 & $2.397 E-08$ & 0.0043 & $0.000 \mathrm{E}+00$ & 0.0000 & $0.000 \mathrm{E}+00$ & 0.0000 & $0.000 \mathrm{E}+00$ & 0.0000 & $0.000 \mathrm{E}+00$ & 0.0000 & $0.000 \mathrm{E}+00$ & 0.0000 & $0.000 \mathrm{E}+00$ & 0.0000 \\
\hline 37 & $5.245 \mathrm{E}-12$ & 0.0000 & $0.000 \mathrm{E}+00$ & 0.0000 & $0.000 \mathrm{E}+00$ & 0.0000 & $0.000 \mathrm{E}+00$ & 0.0000 & $0.000 \mathrm{E}+00$ & 0.0000 & $0.000 \mathrm{E}+00$ & 0.0000 & $0.000 \mathrm{E}+00$ & 0.0000 \\
\hline 8 & $3.174 \mathrm{E}-21$ & 0.0000 & $0.000 \mathrm{E}+00$ & 0.0000 & $0.000 \mathrm{E}+00$ & 0.0000 & $0.000 \mathrm{E}+00$ & 0.0000 & $0.000 \mathrm{E}+00$ & 0.0000 & $0.000 \mathrm{E}+00$ & 0.0000 & $0.000 \mathrm{E}+00$ & 0.0000 \\
\hline 9 & $4.328 E-16$ & 0.0000 & $0.000 \mathrm{E}+00$ & 0.0000 & $0.000 \mathrm{E}+00$ & 0.0000 & $0.000 \mathrm{E}+00$ & 0.0000 & $0.000 \mathrm{E}+00$ & 0.0000 & $0.000 \mathrm{E}+00$ & 0.0000 & $0.000 \mathrm{E}+00$ & 0.0000 \\
\hline 240 & $4.115 E-23$ & 0.0000 & $0.000 \mathrm{E}+00$ & 0.0000 & $0.000 \mathrm{E}+00$ & 0.0000 & $0.000 \mathrm{E}+00$ & 0.0000 & $0.000 \mathrm{E}+00$ & 0.0000 & $0.000 \mathrm{E}+00$ & 0.0000 & $0.000 \mathrm{E}+00$ & 0.0000 \\
\hline & $2.994 \mathrm{E}-24$ & 0.0000 & $0.000 \mathrm{E}+00$ & 0.0000 & $0.000 \mathrm{E}+00$ & 0.0000 & $0.000 \mathrm{E}+00$ & 0.0000 & $0.000 \mathrm{E}+00$ & 0.0000 & $0.000 \mathrm{E}+00$ & 0.0000 & $0.000 \mathrm{E}+00$ & 0.0000 \\
\hline 228 & $5.530 \mathrm{E}-06$ & 0.9827 & $0.000 \mathrm{E}+00$ & 0.0000 & $0.000 \mathrm{E}+00$ & 0.0000 & $0.000 \mathrm{E}+00$ & 0.0000 & $0.000 \mathrm{E}+00$ & 0.0 & $0.000 \mathrm{E}+00$ & 0.0000 & $0.000 \mathrm{E}+00$ & 0.0000 \\
\hline & $3.774 \mathrm{E}-09$ & 0.0007 & $0.000 \mathrm{E}+00$ & 0.0000 & $0.000 \mathrm{E}+00$ & 0.0000 & $0.000 \mathrm{E}+00$ & 0.0000 & $0.000 \mathrm{E}+00$ & 0.0000 & $0.000 \mathrm{E}+00$ & 0.0000 & $0.000 \mathrm{E}+00$ & 0.0000 \\
\hline 2 & $4.712 \mathrm{E}-08$ & 0.0084 & $0.000 \mathrm{E}+00$ & 0.0000 & $0.000 \mathrm{E}+00$ & 0.0000 & $0.000 \mathrm{E}+00$ & 0.0000 & $0.000 \mathrm{E}+00$ & 0.0000 & $0.000 \mathrm{E}+00$ & 0.0000 & $0.000 \mathrm{E}+00$ & 0.0000 \\
\hline & $1.813 \mathrm{E}-14$ & 0.0000 & $0.000 \mathrm{E}+00$ & 0.0000 & $0.000 \mathrm{E}+00$ & 0.0000 & $0.000 \mathrm{E}+00$ & 0.0000 & $0.000 \mathrm{E}+00$ & 0.0000 & $0.000 \mathrm{E}+00$ & 0.0000 & $0.000 \mathrm{E}+00$ & 0.0000 \\
\hline & $8.089 \mathrm{E}-14$ & 0.0000 & $0.000 \mathrm{E}+00$ & 0.0000 & $0.000 \mathrm{E}+00$ & 0.0000 & $0.000 \mathrm{E}+00$ & 0.0000 & $0.000 \mathrm{E}+00$ & 0.0000 & $0.000 \mathrm{E}+00$ & 0.0000 & $0.000 \mathrm{E}+00$ & 0.0000 \\
\hline & $2.271 \mathrm{E}-08$ & 0.0040 & $0.000 \mathrm{E}+00$ & 0.0000 & $0.000 \mathrm{E}+00$ & 0.0000 & $0.000 \mathrm{E}+00$ & 0.0000 & $0.000 \mathrm{E}+00$ & 0.0000 & $0.000 \mathrm{E}+00$ & 0.0000 & $0.000 \mathrm{E}+00$ & 0.0000 \\
\hline & . & .0000 & $0.000 \mathrm{E}+00$ & 0.0000 & +00 & 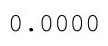 & $0.000 \mathrm{E}+00$ & 0.0000 & $0.000 \mathrm{E}+00$ & 0.0000 & $0.000 \mathrm{E}+00$ & 0.0000 & $0.000 \mathrm{E}+00$ & 0.0000 \\
\hline
\end{tabular}

Total Dose Contributions TDOSE (i,p,t) for Individual Radionuclides (i) and Pathways (p) As mrem/yr and Fraction of Total Dose At $t=0.000 \mathrm{E}+00$ years

Water Dependent Pathways

\begin{tabular}{|c|c|c|c|c|c|c|c|c|c|c|c|c|c|c|}
\hline \multirow[b]{2}{*}{ clide } & \multicolumn{2}{|c|}{ Water } & \multicolumn{2}{|c|}{ Fish } & \multicolumn{2}{|c|}{ Radon } & \multicolumn{2}{|c|}{ Plant } & \multicolumn{2}{|c|}{ Meat } & \multicolumn{2}{|c|}{ Milk } & \multicolumn{2}{|c|}{ All Pathways* } \\
\hline & mrem/yr & fract. & mrem/yr & fract. & $\mathrm{mrem} / \mathrm{yr}$ & fract. & mrem/yr & fract. & mrem/yr & fract. & mrem/yr & fract. & mrem/yr & fract. \\
\hline 1 & $0.000 \mathrm{E}+00$ & 0.0000 & $0.000 \mathrm{E}+00$ & 0.0000 & $0.000 \mathrm{E}+00$ & 0.0000 & $0.000 \mathrm{E}+00$ & 0.0000 & $0.000 \mathrm{E}+00$ & 0.0000 & $0.000 \mathrm{E}+00$ & 0.0000 & $5.412 \mathrm{E}-18$ & 0.0000 \\
\hline 37 & $0.000 \mathrm{E}+00$ & 0.0000 & $0.000 \mathrm{E}+00$ & 0.0000 & $0.000 \mathrm{E}+00$ & 0.0000 & $0.000 \mathrm{E}+00$ & 0.0000 & $0.000 \mathrm{E}+00$ & 0.0000 & $0.000 \mathrm{E}+00$ & 0.0000 & $2.397 \mathrm{E}-08$ & 0.0043 \\
\hline 37 & $0.000 \mathrm{E}+00$ & 0.0000 & $0.000 \mathrm{E}+00$ & 0.0000 & $0.000 \mathrm{E}+00$ & 0.0000 & $0.000 \mathrm{E}+00$ & 0.0000 & $0.000 \mathrm{E}+00$ & 0.0000 & $0.000 \mathrm{E}+00$ & 0.0000 & $5.245 \mathrm{E}-12$ & 0.0000 \\
\hline 238 & $0.000 \mathrm{E}+00$ & 0.0000 & $0.000 \mathrm{E}+00$ & 0.0000 & $0.000 \mathrm{E}+00$ & 0.0000 & $0.000 \mathrm{E}+00$ & 0.0000 & $0.000 \mathrm{E}+00$ & 0.0000 & $0.000 \mathrm{E}+00$ & 0.0000 & $3.174 \mathrm{E}-21$ & 0.0000 \\
\hline 239 & $0.000 \mathrm{E}+00$ & 0.0000 & $0.000 \mathrm{E}+00$ & 0.0000 & $0.000 \mathrm{E}+00$ & 0.0000 & $0.000 \mathrm{E}+00$ & 0.0000 & $0.000 \mathrm{E}+00$ & 0.0000 & $0.000 \mathrm{E}+00$ & 0.0000 & $4.328 \mathrm{E}-16$ & 0.0000 \\
\hline 24 & $0.000 \mathrm{E}+00$ & 0.0 & 0.00 & 0 & $0.000 \mathrm{E}+00$ & 0 & $0.000 \mathrm{E}+00$ & 0 & 0 & 0 & $0.000 \mathrm{E}+00$ & 0 & -23 & 000 \\
\hline & $0.000 \mathrm{E}+00$ & 0. & $0.000 \mathrm{E}+00$ & 0.0000 & $0.000 \mathrm{E}+00$ & 0.0000 & $0.000 \mathrm{E}+00$ & 0.00 & $0.000 \mathrm{E}+00$ & 0.0000 & $0.000 \mathrm{E}+00$ & 0. & $2.994 \mathrm{E}-24$ & 0000 \\
\hline 228 & $0.000 \mathrm{E}+00$ & 0.0000 & $0.000 \mathrm{E}+00$ & 0.0000 & $0.000 \mathrm{E}+00$ & 0.0000 & $0.000 \mathrm{E}+00$ & 0.0000 & $0.000 \mathrm{E}+00$ & 0.0000 & $0.000 \mathrm{E}+00$ & 0.0000 & $5.530 \mathrm{E}-06$ & 0.9827 \\
\hline & $0.000 \mathrm{E}+00$ & 0.0000 & $0.000 \mathrm{E}+00$ & 0.0000 & $0.000 \mathrm{E}+00$ & 0.0000 & $0.000 \mathrm{E}+00$ & 0.0000 & $0.000 \mathrm{E}+00$ & 0.0000 & $0.000 \mathrm{E}+00$ & 0.0000 & $3.774 \mathrm{E}-09$ & 0.0007 \\
\hline & $0.000 \mathrm{E}+00$ & 0.0000 & $0.000 \mathrm{E}+00$ & 0.0000 & $0.000 \mathrm{E}+00$ & 0.0000 & $0.000 \mathrm{E}+00$ & 0.0000 & $0.000 \mathrm{E}+00$ & 0.0000 & $0.000 \mathrm{E}+00$ & 0.0000 & $4.712 \mathrm{E}-08$ & 0.0084 \\
\hline & $0.000 \mathrm{E}+00$ & 0.0000 & $0.000 \mathrm{E}+00$ & 0.0000 & $0.000 \mathrm{E}+00$ & 0.0000 & $0.000 \mathrm{E}+00$ & 0.0000 & $0.000 \mathrm{E}+00$ & 0.0000 & $0.000 \mathrm{E}+00$ & 0.0000 & $1.813 \mathrm{E}-14$ & 0.0000 \\
\hline & $0.000 \mathrm{E}+00$ & 0.0000 & $0.000 \mathrm{E}+00$ & 0.0000 & $0.000 \mathrm{E}+00$ & 0.0000 & $0.000 \mathrm{E}+00$ & 0.0000 & $0.000 \mathrm{E}+00$ & 0.0000 & $0.000 \mathrm{E}+00$ & 0.0000 & $8.089 \mathrm{E}-14$ & 0.0000 \\
\hline & $0.000 \mathrm{E}+00$ & 0.0000 & $0.000 \mathrm{E}+00$ & 0.0000 & $0.000 \mathrm{E}+00$ & 0.0000 & $0.000 \mathrm{E}+00$ & 0.0000 & $0.000 \mathrm{E}+00$ & 0.0000 & $0.000 \mathrm{E}+00$ & 0.0000 & $2.271 \mathrm{E}-08$ & 0.0040 \\
\hline & & 00 & $0.000 \mathrm{E}+00$ & 0.0000 & $.000 \mathrm{E}+00$ & 0.0000 & $0.000 \mathrm{E}+00$ & 0.0000 & $0.000 \mathrm{E}+00$ & 0.0000 & +0 & & $.02 / 400$ & $x^{2}+2$ \\
\hline
\end{tabular}


$\begin{array}{lll}\text { RESRAD, Version } 6.5 & T^{1 / 2} \text { Limit }=180 \text { days } & 07 / 21 / 2011 \quad 12: 29 \text { Page } 22 \\ \text { Summary : RESRAD Parameters for U-Landfill Resident Gardener Forward Run 100,000 years }\end{array}$

File $\quad$ C $: \backslash$ RESRAD_FAMILY \RESRAD \USERFILES \QCJULY2011 \ULANDFILL-RG_FORWARD-100000YR.RAD

Total Dose Contributions TDOSE (i,p,t) for Individual Radionuclides (i) and Pathways (p) As mrem/yr and Fraction of Total Dose At $t=1.000 \mathrm{E}+00$ years

Water Independent Pathways (Inhalation excludes radon)

\begin{tabular}{|c|c|c|c|c|c|c|c|c|c|c|c|c|c|c|}
\hline \multirow[b]{2}{*}{ clide } & \multicolumn{2}{|c|}{ Ground } & \multicolumn{2}{|c|}{ Inhalation } & \multicolumn{2}{|c|}{ Radon } & \multicolumn{2}{|c|}{ Plant } & \multicolumn{2}{|c|}{ Meat } & \multicolumn{2}{|c|}{ Milk } & \multicolumn{2}{|c|}{ Soil } \\
\hline & mrem/yr & fract. & mrem/yr & fract. & mrem/yr & fract. & mrem/yr & fract. & mrem/yr & fract. & mrem/yr & fract. & nrem/yr & fract. \\
\hline-241 & $1.638 \mathrm{E}-17$ & 0.0000 & $0.000 \mathrm{E}+00$ & 0.0000 & $0.000 \mathrm{E}+00$ & 0.0000 & $0.000 \mathrm{E}+00$ & 0.0000 & $0.000 \mathrm{E}+00$ & 0.0000 & $0.000 \mathrm{E}+00$ & 0.0000 & $0.000 \mathrm{E}+00$ & 0000 \\
\hline 137 & $2.362 \mathrm{E}-08$ & 0.0056 & $0.000 \mathrm{E}+00$ & 0.0000 & $0.000 \mathrm{E}+00$ & 0.0000 & $0.000 \mathrm{E}+00$ & 0.0000 & $0.000 \mathrm{E}+00$ & 0.0000 & $0.000 \mathrm{E}+00$ & 0.0000 & $0.000 \mathrm{E}+00$ & 0.0000 \\
\hline 237 & $5.301 \mathrm{E}-12$ & 0.0000 & $0.000 \mathrm{E}+00$ & 0.0000 & $0.000 \mathrm{E}+00$ & 0.0000 & $0.000 \mathrm{E}+00$ & 0.0000 & $0.000 \mathrm{E}+00$ & 0.0000 & $0.000 \mathrm{E}+00$ & 0.0000 & $0.000 \mathrm{E}+00$ & 0.0000 \\
\hline 238 & $4.717 E-20$ & 0.0000 & $0.000 \mathrm{E}+00$ & 0.0000 & $0.000 \mathrm{E}+00$ & 0.0000 & $0.000 \mathrm{E}+00$ & 0.0000 & $0.000 \mathrm{E}+00$ & 0.0000 & $0.000 \mathrm{E}+00$ & 0.0000 & $0.000 \mathrm{E}+00$ & 0.0000 \\
\hline 239 & $4.380 \mathrm{E}-16$ & 0.0000 & $0.000 \mathrm{E}+00$ & 0.0000 & $0.000 \mathrm{E}+00$ & 0.0000 & $0.000 \mathrm{E}+00$ & 0.0000 & $0.000 \mathrm{E}+00$ & 0.0000 & $0.000 \mathrm{E}+00$ & 0.0000 & $0.000 \mathrm{E}+00$ & 0.0000 \\
\hline 240 & $4.275 \mathrm{E}-23$ & 0.0000 & $0.000 \mathrm{E}+00$ & 0.0000 & $0.000 \mathrm{E}+00$ & 0.0000 & $0.000 \mathrm{E}+00$ & 0.0000 & $0.000 \mathrm{E}+00$ & 0.0000 & $0.000 \mathrm{E}+00$ & 0.0000 & $0.000 \mathrm{E}+00$ & 0.0000 \\
\hline & $3.025 E-24$ & 0.000 & $0.000 \mathrm{E}$ & 0 & $0.000 \mathrm{E}+00$ & 0 & $0.000 \mathrm{E}+00$ & 0 & 0 & 00 & $0.000 \mathrm{E}+00$ & 0.0 & $0.000 \mathrm{E}+00$ & 0.0000 \\
\hline 228 & $3.872 \mathrm{E}-06$ & 0.9206 & $0.000 \mathrm{E}+00$ & 0.0000 & $0.000 \mathrm{E}+00$ & 0.0000 & $0.000 \mathrm{E}+00$ & 0.0000 & $0.000 \mathrm{E}+00$ & 0.0000 & $0.000 \mathrm{E}+00$ & 0.0000 & $0.000 \mathrm{E}+00$ & 0.0000 \\
\hline 30 & $1.139 \mathrm{E}-08$ & 0.0027 & $0.000 \mathrm{E}+00$ & 0.0000 & $0.000 \mathrm{E}+00$ & 0.0000 & $0.000 \mathrm{E}+00$ & 0.0000 & $0.000 \mathrm{E}+00$ & 0.0000 & $0.000 \mathrm{E}+00$ & 0.0000 & $0.000 \mathrm{E}+00$ & 0.0000 \\
\hline 2 & $2.759 \mathrm{E}-07$ & 0.0656 & $0.000 \mathrm{E}+00$ & 0.0000 & $0.000 \mathrm{E}+00$ & 0.0000 & $0.000 \mathrm{E}+00$ & 0.0000 & $0.000 \mathrm{E}+00$ & 0.0000 & $0.000 \mathrm{E}+00$ & 0.0000 & $0.000 \mathrm{E}+00$ & 0.0000 \\
\hline & $1.277 \mathrm{E}-13$ & 0.0000 & $0.000 \mathrm{E}+00$ & 0.0000 & $0.000 \mathrm{E}+00$ & 0.0000 & $0.000 \mathrm{E}+00$ & 0.0000 & $0.000 \mathrm{E}+00$ & 0.0000 & $0.000 \mathrm{E}+00$ & 0.0000 & $0.000 \mathrm{E}+00$ & 0.0000 \\
\hline & $8.230 \mathrm{E}-14$ & 0.0000 & $0.000 \mathrm{E}+00$ & 0.0000 & $0.000 \mathrm{E}+00$ & 0.0000 & $0.000 \mathrm{E}+00$ & 0.0000 & $0.000 \mathrm{E}+00$ & 0.0000 & $0.000 \mathrm{E}+00$ & 0.0000 & $0.000 \mathrm{E}+00$ & 0.0000 \\
\hline & $2.290 \mathrm{E}-08$ & 0.0054 & $0.000 \mathrm{E}+00$ & 0.0000 & $0.000 \mathrm{E}+00$ & 0.0000 & $0.000 \mathrm{E}+00$ & 0.0000 & $0.000 \mathrm{E}+00$ & 0.0000 & $0.000 \mathrm{E}+00$ & 0.0000 & $0.000 \mathrm{E}+00$ & 0.0000 \\
\hline & 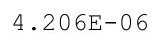 & & $00 \mathrm{E}+00$ & 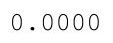 & +00 & ( & $00 \mathrm{E}+00$ & 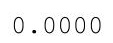 & $0.000 \mathrm{E}+00$ & & . & & $\mathrm{E}+00$ & \\
\hline
\end{tabular}

Total Dose Contributions TDOSE (i,p,t) for Individual Radionuclides (i) and Pathways (p) As mrem/yr and Fraction of Total Dose At $t=1.000 \mathrm{E}+00$ years

Water Dependent Pathways

\begin{tabular}{|c|c|c|c|c|c|c|c|c|c|c|c|c|c|c|}
\hline \multirow[b]{2}{*}{ clide } & \multicolumn{2}{|c|}{ Water } & \multicolumn{2}{|c|}{ Fish } & \multicolumn{2}{|c|}{ Radon } & \multicolumn{2}{|c|}{ Plant } & \multicolumn{2}{|c|}{ Meat } & \multicolumn{2}{|c|}{ Milk } & \multicolumn{2}{|c|}{ All Pathways* } \\
\hline & mrem/yr & fract. & mrem/yr & fract. & mrem/yr & fract. & mrem/yr & fract. & mrem/yr & fract. & mrem/yr & fract. & mrem/yr & fract. \\
\hline \pm & $0.000 \mathrm{E}+00$ & 0.0000 & $0.000 \mathrm{E}+00$ & 0.0000 & $0.000 \mathrm{E}+00$ & 0.0000 & $0.000 \mathrm{E}+00$ & 0.0000 & $0.000 \mathrm{E}+00$ & 0.0000 & $0.000 \mathrm{E}+00$ & 0.0000 & $1.638 \mathrm{E}-17$ & 0.0000 \\
\hline & $0.000 \mathrm{E}+00$ & 0.0000 & $0.000 \mathrm{E}+00$ & 0.0000 & $0.000 \mathrm{E}+00$ & 0.0000 & $0.000 E+00$ & 0.0000 & $0.000 \mathrm{E}+00$ & 0.0000 & $0.000 \mathrm{E}+00$ & 0.0000 & $2.362 \mathrm{E}-08$ & 0.0056 \\
\hline 237 & $0.000 \mathrm{E}+00$ & 0.0000 & $0.000 \mathrm{E}+00$ & 0.0000 & $0.000 \mathrm{E}+00$ & 0.0000 & $0.000 \mathrm{E}+00$ & 0.0000 & $0.000 \mathrm{E}+00$ & 0.0000 & $0.000 \mathrm{E}+00$ & 0.0000 & $5.301 \mathrm{E}-12$ & 0.0000 \\
\hline 8 & $0.000 \mathrm{E}+00$ & 0.0000 & $0.000 \mathrm{E}+00$ & 0.0000 & $0.000 \mathrm{E}+00$ & 0.0000 & $0.000 \mathrm{E}+00$ & 0.0000 & $0.000 \mathrm{E}+00$ & 0.0000 & $0.000 \mathrm{E}+00$ & 0.0000 & $717 E-20$ & 000 \\
\hline & $0.000 \mathrm{E}+00$ & 0 & 0 . & 0 & $0.000 \mathrm{E}+00$ & & & 0 & & & $000 \mathrm{E}+00$ & & 16 & 00 \\
\hline & $0.000 \mathrm{E}+00$ & 0. & $0.000 \mathrm{E}+00$ & 0 & $0.000 \mathrm{E}+00$ & 0.0000 & $0.000 \mathrm{E}+00$ & 0.0 & $0.000 \mathrm{E}+00$ & 0 & $0.000 \mathrm{E}+00$ & 00 & 23 & 000 \\
\hline & $0.000 \mathrm{E}+00$ & 0.0000 & $0.000 \mathrm{E}+00$ & 0.0000 & $0.000 \mathrm{E}+00$ & 0.0000 & $0.000 \mathrm{E}+00$ & 0.0000 & $0.000 \mathrm{E}+00$ & 0.0000 & $0.000 \mathrm{E}+00$ & 0.0000 & $3.025 \mathrm{E}-24$ & 0.0000 \\
\hline 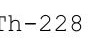 & $0.000 \mathrm{E}+00$ & 0.0000 & $0.000 \mathrm{E}+00$ & 0.0000 & $0.000 \mathrm{E}+00$ & 0.0000 & $0.000 \mathrm{E}+00$ & 0.0000 & $0.000 \mathrm{E}+00$ & 0.0000 & $0.000 \mathrm{E}+00$ & 0.0000 & $3.872 \mathrm{E}-06$ & 0.9206 \\
\hline & $0.000 \mathrm{E}+00$ & 0.0000 & $0.000 \mathrm{E}+00$ & 0.0000 & $0.000 \mathrm{E}+00$ & 0.0000 & $0.000 \mathrm{E}+00$ & 0.0000 & $0.000 \mathrm{E}+00$ & 0.0000 & $0.000 \mathrm{E}+00$ & 0.0000 & $1.139 \mathrm{E}-08$ & 0.0027 \\
\hline & $0.000 \mathrm{E}+00$ & 0.0000 & $0.000 \mathrm{E}+00$ & 0.0000 & $0.000 \mathrm{E}+00$ & 0.0000 & $0.000 \mathrm{E}+00$ & 0.0000 & $0.000 \mathrm{E}+00$ & 0.0000 & $0.000 \mathrm{E}+00$ & 0.0000 & $2.759 \mathrm{E}-07$ & 0.0656 \\
\hline & $0.000 \mathrm{E}+00$ & 0.0000 & $0.000 \mathrm{E}+00$ & 0.0000 & $0.000 \mathrm{E}+00$ & 0.0000 & $0.000 E+00$ & 0.0000 & $0.000 \mathrm{E}+00$ & 0.0000 & $0.000 \mathrm{E}+00$ & 0.0000 & $1.277 \mathrm{E}-13$ & 0.0000 \\
\hline & $0.000 \mathrm{E}+00$ & 0.0000 & $0.000 \mathrm{E}+00$ & 0.0000 & $0.000 \mathrm{E}+00$ & 0.0000 & $0.000 \mathrm{E}+00$ & 0.0000 & $0.000 \mathrm{E}+00$ & 0.0000 & $0.000 \mathrm{E}+00$ & 0.0000 & $8.230 \mathrm{E}-14$ & 0.0000 \\
\hline & $0.000 \mathrm{E}+00$ & 0.0000 & $0.000 \mathrm{E}+00$ & 0.0000 & $0.000 \mathrm{E}+00$ & 0.0000 & $0.000 \mathrm{E}+00$ & 0.0000 & $0.000 \mathrm{E}+00$ & 0.0000 & $0.000 \mathrm{E}+00$ & 0.0000 & $2.290 \mathrm{E}-08$ & 0.0054 \\
\hline & & 00 & $.000 \mathrm{E}+00$ & 0.0000 & $0.000 \mathrm{E}+00$ & 0.0000 & $0.000 \mathrm{E}+00$ & 0.0000 & $0.000 \mathrm{E}+00$ & & +00 & & .06 & \\
\hline
\end{tabular}

*Sum of all water independent and dependent pathways. 
$\begin{array}{lll}\text { RESRAD, Version } 6.5 & T^{1 / 2} \text { Limit }=180 \text { days } & 07 / 21 / 2011 \quad 12: 29 \text { Page } 23 \\ \text { Summary : RESRAD Parameters for U-Landfill Resident Gardener Forward Run 100,000 years }\end{array}$

File $\quad$ C $: \backslash$ RESRAD_FAMILY \RESRAD \USERFILES \QCJULY2011 \ULANDFILL-RG_FORWARD-100000YR.RAD

Total Dose Contributions TDOSE (i,p,t) for Individual Radionuclides (i) and Pathways (p) As mrem/yr and Fraction of Total Dose At $t=5.000 \mathrm{E}+01$ years

Water Independent Pathways (Inhalation excludes radon)

\begin{tabular}{|c|c|c|c|c|c|c|c|c|c|c|c|c|c|c|}
\hline \multirow[b]{2}{*}{ clide } & \multicolumn{2}{|c|}{ Ground } & \multicolumn{2}{|c|}{ Inhalation } & \multicolumn{2}{|c|}{ Radon } & \multicolumn{2}{|c|}{ Plant } & \multicolumn{2}{|c|}{ Meat } & \multicolumn{2}{|c|}{ Milk } & \multicolumn{2}{|l|}{ Soil } \\
\hline & mrem/yr & fract. & mrem/yr & fract. & mrem/yr & fract. & mrem/yr & fract. & mrem/yr & fract. & mrem/yr & fract. & mrem/yr & fract. \\
\hline-241 & $8.973 E-16$ & 0.0000 & $0.000 \mathrm{E}+00$ & 0.0000 & $0.000 \mathrm{E}+00$ & 0.0000 & $0.000 \mathrm{E}+00$ & 0.0000 & $0.000 \mathrm{E}+00$ & 0.0000 & $0.000 \mathrm{E}+00$ & 0.0000 & $0.000 \mathrm{E}+00$ & 0000 \\
\hline 137 & $1.149 \mathrm{E}-08$ & 0.0012 & $0.000 \mathrm{E}+00$ & 0.0000 & $0.000 \mathrm{E}+00$ & 0.0000 & $0.000 \mathrm{E}+00$ & 0.0000 & $0.000 \mathrm{E}+00$ & 0.0000 & $0.000 \mathrm{E}+00$ & 0.0000 & $0.000 \mathrm{E}+00$ & 0.0000 \\
\hline 237 & $8.957 E-12$ & 0.0000 & $0.000 \mathrm{E}+00$ & 0.0000 & $0.000 \mathrm{E}+00$ & 0.0000 & $0.000 \mathrm{E}+00$ & 0.0000 & $0.000 \mathrm{E}+00$ & 0.0000 & $0.000 \mathrm{E}+00$ & 0.0000 & $0.000 \mathrm{E}+00$ & 0.0000 \\
\hline 238 & $2.054 \mathrm{E}-15$ & 0.0000 & $0.000 \mathrm{E}+00$ & 0.0000 & $0.000 \mathrm{E}+00$ & 0.0000 & $0.000 \mathrm{E}+00$ & 0.0000 & $0.000 \mathrm{E}+00$ & 0.0000 & $0.000 \mathrm{E}+00$ & 0.0000 & $0.000 \mathrm{E}+00$ & 0.0000 \\
\hline 239 & $7.861 \mathrm{E}-16$ & 0.0000 & $0.000 \mathrm{E}+00$ & 0.0000 & $0.000 \mathrm{E}+00$ & 0.0000 & $0.000 \mathrm{E}+00$ & 0.0000 & $0.000 \mathrm{E}+00$ & 0.0000 & $0.000 \mathrm{E}+00$ & 0.0000 & $0.000 \mathrm{E}+00$ & 0.0000 \\
\hline 240 & $9.653 \mathrm{E}-20$ & 0.0000 & $0.000 \mathrm{E}+00$ & 0.0000 & $0.000 \mathrm{E}+00$ & 0.0000 & $0.000 \mathrm{E}+00$ & 0.0000 & $0.000 \mathrm{E}+00$ & 0.0000 & $0.000 \mathrm{E}+00$ & 0.0000 & $0.000 \mathrm{E}+00$ & 0.0000 \\
\hline & $4.979 \mathrm{E}-24$ & 0.00 & $0.000 \mathrm{E}$ & 0 & $0.000 \mathrm{E}+00$ & 0 & $0.000 \mathrm{E}+00$ & 0 & 0 & 00 & $0.000 \mathrm{E}+00$ & 0.0 & $0.000 \mathrm{E}+00$ & 0.0000 \\
\hline 228 & $1.011 \mathrm{E}-13$ & 0.0000 & $0.000 \mathrm{E}+00$ & 0.0000 & $0.000 \mathrm{E}+00$ & 0.0000 & $0.000 \mathrm{E}+00$ & 0.0000 & $0.000 \mathrm{E}+00$ & 0.0000 & $0.000 \mathrm{E}+00$ & 0.0000 & $0.000 \mathrm{E}+00$ & 0.0000 \\
\hline 30 & $5.320 \mathrm{E}-07$ & 0.0558 & $0.000 \mathrm{E}+00$ & 0.0000 & $0.000 \mathrm{E}+00$ & 0.0000 & $0.000 \mathrm{E}+00$ & 0.0000 & $0.000 \mathrm{E}+00$ & 0.0000 & $0.000 \mathrm{E}+00$ & 0.0000 & $0.000 \mathrm{E}+00$ & 0.0000 \\
\hline 2 & $8.963 \mathrm{E}-06$ & 0.9395 & $0.000 \mathrm{E}+00$ & 0.0000 & $0.000 \mathrm{E}+00$ & 0.0000 & $0.000 \mathrm{E}+00$ & 0.0000 & $0.000 \mathrm{E}+00$ & 0.0000 & $0.000 \mathrm{E}+00$ & 0.0000 & $0.000 \mathrm{E}+00$ & 0.0000 \\
\hline & $1.941 \mathrm{E}-10$ & 0.0000 & $0.000 \mathrm{E}+00$ & 0.0000 & $0.000 \mathrm{E}+00$ & 0.0000 & $0.000 \mathrm{E}+00$ & 0.0000 & $0.000 \mathrm{E}+00$ & 0.0000 & $0.000 \mathrm{E}+00$ & 0.0000 & $0.000 \mathrm{E}+00$ & 0.0000 \\
\hline & $6.005 \mathrm{E}-13$ & 0.0000 & $0.000 \mathrm{E}+00$ & 0.0000 & $0.000 \mathrm{E}+00$ & 0.0000 & $0.000 \mathrm{E}+00$ & 0.0000 & $0.000 \mathrm{E}+00$ & 0.0000 & $0.000 \mathrm{E}+00$ & 0.0000 & $0.000 \mathrm{E}+00$ & 0.0000 \\
\hline & $3.385 \mathrm{E}-08$ & 0.0035 & $0.000 \mathrm{E}+00$ & 0.0000 & $0.000 \mathrm{E}+00$ & 0.0000 & $0.000 \mathrm{E}+00$ & 0.0000 & $0.000 \mathrm{E}+00$ & 0.0000 & $0.000 \mathrm{E}+00$ & 0.0000 & $0.000 \mathrm{E}+00$ & 0.0000 \\
\hline & 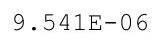 & & $.000 \mathrm{E}+00$ & 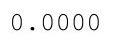 & +00 & 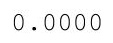 & $000 \mathrm{E}+00$ & 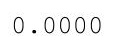 & $.000 \mathrm{E}+00$ & & . & & $\mathrm{E}+00$ & \\
\hline
\end{tabular}

Total Dose Contributions TDOSE (i,p,t) for Individual Radionuclides (i) and Pathways (p) As mrem/yr and Fraction of Total Dose At $t=5.000 \mathrm{E}+01$ years

Water Dependent Pathways

\begin{tabular}{|c|c|c|c|c|c|c|c|c|c|c|c|c|c|c|}
\hline \multirow[b]{2}{*}{ clide } & \multicolumn{2}{|c|}{ Water } & \multicolumn{2}{|c|}{ Fish } & \multicolumn{2}{|c|}{ Radon } & \multicolumn{2}{|c|}{ Plant } & \multicolumn{2}{|c|}{ Meat } & \multicolumn{2}{|c|}{ Milk } & \multicolumn{2}{|c|}{ All Pathways* } \\
\hline & mrem/yr & fract. & mrem/yr & fract. & mrem/yr & fract. & mrem/yr & fract. & mrem/yr & fract. & mrem/yr & fract. & mrem/yr & fract. \\
\hline \pm & $0.000 \mathrm{E}+00$ & 0.0000 & $0.000 \mathrm{E}+00$ & 0.0000 & $0.000 \mathrm{E}+00$ & 0.0000 & $0.000 \mathrm{E}+00$ & 0.0000 & $0.000 \mathrm{E}+00$ & 0.0000 & $0.000 \mathrm{E}+00$ & 0.0000 & $8.973 E-16$ & 0.0000 \\
\hline & $0.000 \mathrm{E}+00$ & 0.0000 & $0.000 \mathrm{E}+00$ & 0.0000 & $0.000 \mathrm{E}+00$ & 0.0000 & $0.000 E+00$ & 0.0000 & $0.000 \mathrm{E}+00$ & 0.0000 & $0.000 \mathrm{E}+00$ & 0.0000 & $1.149 \mathrm{E}-08$ & 0.0012 \\
\hline 237 & $0.000 \mathrm{E}+00$ & 0.0000 & $0.000 \mathrm{E}+00$ & 0.0000 & $0.000 \mathrm{E}+00$ & 0.0000 & $0.000 \mathrm{E}+00$ & 0.0000 & $0.000 \mathrm{E}+00$ & 0.0000 & $0.000 \mathrm{E}+00$ & 0.0000 & $8.957 \mathrm{E}-12$ & 0.0000 \\
\hline 8 & $0.000 \mathrm{E}+00$ & 0.0000 & $0.000 \mathrm{E}+00$ & 0.0000 & $0.000 \mathrm{E}+00$ & 0.0000 & $0.000 \mathrm{E}+00$ & 0.0000 & $0.000 \mathrm{E}+00$ & 0.0000 & $0.000 \mathrm{E}+00$ & 0.0000 & -15 & 000 \\
\hline & $0.000 \mathrm{E}+00$ & 0 & 0 . & 0 & $0.000 \mathrm{E}+00$ & & & 0 & & & $000 \mathrm{E}+00$ & & 16 & 00 \\
\hline & $0.000 \mathrm{E}+00$ & 0. & $0.000 \mathrm{E}+00$ & 0 & $0.000 \mathrm{E}+00$ & 0.0000 & $0.000 \mathrm{E}+00$ & 0.0 & $0.000 \mathrm{E}+00$ & 0 & $0.000 \mathrm{E}+00$ & 00 & 20 & 000 \\
\hline & $0.000 \mathrm{E}+00$ & 0.0000 & $0.000 \mathrm{E}+00$ & 0.0000 & $0.000 \mathrm{E}+00$ & 0.0000 & $0.000 \mathrm{E}+00$ & 0.0000 & $0.000 \mathrm{E}+00$ & 0.0000 & $0.000 \mathrm{E}+00$ & 0.0000 & $4.979 \mathrm{E}-24$ & 0.0000 \\
\hline 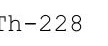 & $0.000 \mathrm{E}+00$ & 0.0000 & $0.000 \mathrm{E}+00$ & 0.0000 & $0.000 \mathrm{E}+00$ & 0.0000 & $0.000 \mathrm{E}+00$ & 0.0000 & $0.000 \mathrm{E}+00$ & 0.0000 & $0.000 \mathrm{E}+00$ & 0.0000 & $1.011 \mathrm{E}-13$ & 0.0000 \\
\hline & $0.000 \mathrm{E}+00$ & 0.0000 & $0.000 \mathrm{E}+00$ & 0.0000 & $0.000 \mathrm{E}+00$ & 0.0000 & $0.000 \mathrm{E}+00$ & 0.0000 & $0.000 \mathrm{E}+00$ & 0.0000 & $0.000 \mathrm{E}+00$ & 0.0000 & $5.320 \mathrm{E}-07$ & 0.0558 \\
\hline & $0.000 \mathrm{E}+00$ & 0.0000 & $0.000 \mathrm{E}+00$ & 0.0000 & $0.000 \mathrm{E}+00$ & 0.0000 & $0.000 \mathrm{E}+00$ & 0.0000 & $0.000 \mathrm{E}+00$ & 0.0000 & $0.000 \mathrm{E}+00$ & 0.0000 & $8.963 E-06$ & 0.9395 \\
\hline & $0.000 \mathrm{E}+00$ & 0.0000 & $0.000 \mathrm{E}+00$ & 0.0000 & $0.000 \mathrm{E}+00$ & 0.0000 & $0.000 E+00$ & 0.0000 & $0.000 \mathrm{E}+00$ & 0.0000 & $0.000 \mathrm{E}+00$ & 0.0000 & $1.941 \mathrm{E}-10$ & 0.0000 \\
\hline & $0.000 \mathrm{E}+00$ & 0.0000 & $0.000 \mathrm{E}+00$ & 0.0000 & $0.000 \mathrm{E}+00$ & 0.0000 & $0.000 \mathrm{E}+00$ & 0.0000 & $0.000 \mathrm{E}+00$ & 0.0000 & $0.000 \mathrm{E}+00$ & 0.0000 & $6.005 \mathrm{E}-13$ & 0.0000 \\
\hline & $0.000 \mathrm{E}+00$ & 0.0000 & $0.000 \mathrm{E}+00$ & 0.0000 & $0.000 \mathrm{E}+00$ & 0.0000 & $0.000 \mathrm{E}+00$ & 0.0000 & $0.000 \mathrm{E}+00$ & 0.0000 & $0.000 \mathrm{E}+00$ & 0.0000 & $3.385 \mathrm{E}-08$ & 0.0035 \\
\hline & & 00 & $.000 \mathrm{E}+00$ & 0.0000 & $0.000 \mathrm{E}+00$ & 0.0000 & $0.000 \mathrm{E}+00$ & 0.0000 & $0.000 \mathrm{E}+00$ & & +00 & & .06 & \\
\hline
\end{tabular}

* Sum of all water independent and dependent pathways. 
RESRAD, Version $6.5 \quad T^{1 / 2}$ Limit $=180$ days

Summary : RESRAD Parameters for U-Landfill Resident Gardener Forward Run 100,000 years

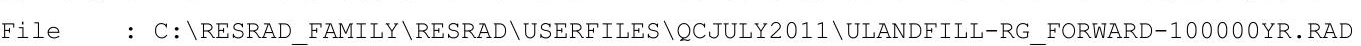

Dose/Source Ratios Summed Over All Pathways

Parent and Progeny Principal Radionuclide Contributions Indicated

\begin{tabular}{|c|c|c|c|c|c|c|c|c|c|c|}
\hline Parent & Product & Thread & & DSR & $(j, t)$ At & ime in Yea & (mrem) & $/ \mathrm{yr}) /(\mathrm{pCi} / \mathrm{g}$ & & \\
\hline (i) & (j) & Fraction & $0.000 \mathrm{E}+00$ & $1.000 \mathrm{E}+00$ & $5.000 \mathrm{E}+01$ & $1.000 \mathrm{E}+02$ & $5.000 \mathrm{E}+02$ & $1.050 \mathrm{E}+03$ & $1.000 \mathrm{E}+04$ & $1.000 \mathrm{E}+05$ \\
\hline-232 & $\mathrm{Th}-232$ & $1.000 \mathrm{E}+00$ & $1.166 \mathrm{E}-24$ & 1. $188 \mathrm{E}-24$ & $2.949 \mathrm{E}-24$ & $7.462 \mathrm{E}-24$ & $1.252 \mathrm{E}-20$ & $1.221 \mathrm{E}-03$ & $1.337 \mathrm{E}-01$ & $0.000 \mathrm{E}+00$ \\
\hline-232 & $\mathrm{Ra}-228+\mathrm{D}$ & $1.000 \mathrm{E}+00$ & $1.107 \mathrm{E}-09$ & $3.174 \mathrm{E}-09$ & $2.784 \mathrm{E}-08$ & $4.079 \mathrm{E}-08$ & $8.497 \mathrm{E}-07$ & $1.458 \mathrm{E}-01$ & $1.699 \mathrm{E}+01$ & $0.000 \mathrm{E}+00$ \\
\hline $1-232$ & $\mathrm{Th}-228+\mathrm{D}$ & $1.000 \mathrm{E}+00$ & $1.067 \mathrm{E}-08$ & $6.581 \mathrm{E}-08$ & $2.213 E-06$ & $2.992 E-06$ & $3.253 E-05$ & $2.007 E-03$ & $7.745 \mathrm{E}+00$ & $0.000 \mathrm{E}+00$ \\
\hline$h-232$ & $\sum \operatorname{DSR}(j)$ & & $1.178 \mathrm{E}-08$ & $6.899 \mathrm{E}-08$ & $2.241 \mathrm{E}-06$ & $3.033 E-06$ & $3.338 E-05$ & 1. $491 \mathrm{E}-01$ & $2.487 \mathrm{E}+01$ & $0.000 \mathrm{E}+00$ \\
\hline-234 & $\mathrm{U}-234$ & $1.000 \mathrm{E}+00$ & $6.896 \mathrm{E}-24$ & $7.019 \mathrm{E}-24$ & $1.670 \mathrm{E}-23$ & $4.047 \mathrm{E}-23$ & $4.798 \mathrm{E}-20$ & $6.337 \mathrm{E}-04$ & $4.918 \mathrm{E}-02$ & $0.000 \mathrm{E}+00$ \\
\hline-234 & Th-230 & $1.000 \mathrm{E}+00$ & $1.089 E-27$ & $3.315 E-27$ & $2.540 \mathrm{E}-25$ & $1.171 \mathrm{E}-24$ & $4.838 E-21$ & $1.037 E-05$ & $9.415 E-03$ & $0.000 \mathrm{E}+00$ \\
\hline-234 & $\mathrm{Ra}-226+\mathrm{D}$ & $1.000 \mathrm{E}+00$ & $1.133 \mathrm{E}-16$ & $7.978 \mathrm{E}-16$ & 1. $213 \mathrm{E}-12$ & $6.737 \mathrm{E}-12$ & $2.496 \mathrm{E}-09$ & $1.097 \mathrm{E}-04$ & $8.001 \mathrm{E}-01$ & $0.000 \mathrm{E}+00$ \\
\hline-234 & $\mathrm{~Pb}-210+\mathrm{D}$ & $1.000 \mathrm{E}+00$ & $4.102 E-25$ & $6.153 \mathrm{E}-24$ & $2.201 \mathrm{E}-19$ & $1.935 \mathrm{E}-18$ & $1.678 \mathrm{E}-15$ & $1.738 \mathrm{E}-04$ & $5.213 \mathrm{E}-01$ & $0.000 \mathrm{E}+00$ \\
\hline-234 & $\sum \operatorname{DSR}(j)$ & & $1.133 E-16$ & $7.978 \mathrm{E}-16$ & $1.213 E-12$ & $6.737 E-12$ & $2.496 \mathrm{E}-09$ & $9.276 E-04$ & $1.380 \mathrm{E}+00$ & $0.000 \mathrm{E}+00$ \\
\hline$-235+D$ & $\mathrm{U}-235+\mathrm{D}$ & $1.000 \mathrm{E}+00$ & 1. $243 \mathrm{E}-14$ & 1. $259 \mathrm{E}-14$ & $2.306 \mathrm{E}-14$ & $4.276 \mathrm{E}-14$ & $5.981 \mathrm{E}-12$ & $6.155 E-04$ & $5.003 E-01$ & $0.000 \mathrm{E}+00$ \\
\hline$-235+D$ & $\mathrm{~Pa}-231$ & $1.000 \mathrm{E}+00$ & $2.937 \mathrm{E}-18$ & $8.896 \mathrm{E}-18$ & $5.031 E-16$ & $1.701 \mathrm{E}-15$ & $5.876 \mathrm{E}-13$ & $8.145 E-04$ & $5.535 E-01$ & $0.000 \mathrm{E}+00$ \\
\hline$-235+D$ & $A C-227+D$ & $1.000 \mathrm{E}+00$ & $9.274 \mathrm{E}-18$ & $6.481 \mathrm{E}-17$ & $6.882 \mathrm{E}-14$ & $2.943 E-13$ & $6.376 \mathrm{E}-11$ & $3.373 E-04$ & $4.821 \mathrm{E}-01$ & $0.000 \mathrm{E}+00$ \\
\hline$-235+D$ & $\sum \operatorname{DSR}(j)$ & & $1.245 \mathrm{E}-14$ & $1.266 \mathrm{E}-14$ & $9.238 \mathrm{E}-14$ & $3.388 \mathrm{E}-13$ & 7.033E-11 & $1.767 \mathrm{E}-03$ & $1.536 \mathrm{E}+00$ & $0.000 \mathrm{E}+00$ \\
\hline-238 & $\mathrm{U}-238$ & $5.400 \mathrm{E}-05$ & $0.000 \mathrm{E}+00$ & $0.000 \mathrm{E}+00$ & $0.000 \mathrm{E}+00$ & $0.000 \mathrm{E}+00$ & $0.000 \mathrm{E}+00$ & $3.167 \mathrm{E}-08$ & $2.512 \mathrm{E}-06$ & $0.000 \mathrm{E}+00$ \\
\hline$-238+D$ & $\mathrm{U}-238+\mathrm{D}$ & $9.999 \mathrm{E}-01$ & $1.420 \mathrm{E}-10$ & 1. $431 \mathrm{E}-10$ & $2.116 \mathrm{E}-10$ & $3.153 \mathrm{E}-10$ & $7.678 E-09$ & $6.313 E-04$ & $1.508 \mathrm{E}-01$ & $0.000 \mathrm{E}+00$ \\
\hline$-238+D$ & $\mathrm{U}-234$ & $9.999 \mathrm{E}-01$ & $9.803 E-30$ & $2.988 E-29$ & $2.392 \mathrm{E}-27$ & $1.153 \mathrm{E}-26$ & $6.812 \mathrm{E}-23$ & $1.890 \mathrm{E}-06$ & $1.414 \mathrm{E}-03$ & $0.000 \mathrm{E}+00$ \\
\hline$-238+D$ & Th-230 & $9.999 E-01$ & $1.030 \mathrm{E}-33$ & $7.316 \mathrm{E}-33$ & $1.818 \mathrm{E}-29$ & $1.668 \mathrm{E}-28$ & $3.430 \mathrm{E}-24$ & $1.541 \mathrm{E}-08$ & $1.316 \mathrm{E}-04$ & $0.000 \mathrm{E}+00$ \\
\hline$-238+D$ & $\mathrm{Ra}-226+\mathrm{D}$ & $9.999 \mathrm{E}-01$ & $8.034 E-23$ & 1. $212 \mathrm{E}-21$ & $5.801 \mathrm{E}-17$ & $6.420 \mathrm{E}-16$ & 1. $201 \mathrm{E}-12$ & $1.127 \mathrm{E}-07$ & $9.339 E-03$ & $0.000 \mathrm{E}+00$ \\
\hline$-238+D$ & $\mathrm{~Pb}-210+\mathrm{D}$ & $9.999 \mathrm{E}-01$ & $2.329 E-31$ & $7.229 \mathrm{E}-30$ & $8.430 \mathrm{E}-24$ & $1.546 \mathrm{E}-22$ & 7. $612 \mathrm{E}-19$ & $1.734 \mathrm{E}-07$ & $6.063 E-03$ & $0.000 \mathrm{E}+00$ \\
\hline$-238+D$ & $\sum \operatorname{DSR}(j)$ & & $1.420 \mathrm{E}-10$ & $1.431 \mathrm{E}-10$ & $2.116 \mathrm{E}-10$ & $3.153 \mathrm{E}-10$ & $7.680 \mathrm{E}-09$ & $6.335 E-04$ & $1.677 \mathrm{E}-01$ & $0.000 \mathrm{E}+00$ \\
\hline
\end{tabular}

The DSR includes contributions from associated (half-life $\leq 180$ days) daughters. 
RESRAD, Version $6.5 \quad \mathrm{~T}^{1 / 2}$ Limit $=180$ days

Summary : RESRAD Parameters for U-Landfill Resident Gardener Forward Run 100,000 years

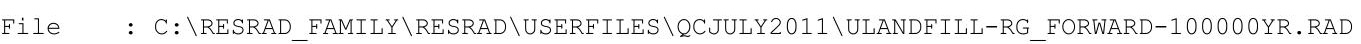

Single Radionuclide Soil Guidelines $G(i, t)$ in $\mathrm{pCi} / \mathrm{g}$

Basic Radiation Dose Limit $=1.000 \mathrm{E}+02 \mathrm{mrem} / \mathrm{yr}$

Nuclide

\begin{tabular}{|c|c|c|c|c|c|c|c|c|}
\hline (i) & $=0.000 \mathrm{E}+00$ & $1.000 \mathrm{E}+00$ & $5.000 E+01$ & $1.000 \mathrm{E}+02$ & $5.000 \mathrm{E}+02$ & $1.050 \mathrm{E}+03$ & $1.000 \mathrm{E}+04$ & $1.000 \mathrm{E}+05$ \\
\hline-241 & $\star 3.431 \mathrm{E}+12$ & $\star 3.431 \mathrm{E}+12$ & $\star 3.431 \mathrm{E}+12$ & $\star 3.431 \mathrm{E}+12$ & $\star 3.431 \mathrm{E}+12$ & $5.044 \mathrm{E}+05$ & $9.099 \mathrm{E}+05$ & $* 3.431 \mathrm{E}+12$ \\
\hline$s-137$ & $7.925 \mathrm{E}+10$ & $8.043 E+10$ & $1.653 \mathrm{E}+11$ & $3.447 \mathrm{E}+11$ & $\star 8.704 \mathrm{E}+13$ & $\star 8.704 \mathrm{E}+13$ & $\star 8.704 \mathrm{E}+13$ & $\star 8.704 \mathrm{E}+13$ \\
\hline-237 & $\star 7.047 \mathrm{E}+08$ & $\star 7.047 \mathrm{E}+08$ & $\star 7.047 \mathrm{E}+08$ & $\star 7.047 \mathrm{E}+08$ & $\star 7.047 \mathrm{E}+08$ & $9.756 \mathrm{E}+03$ & $1.991 \mathrm{E}+02$ & $* 7.047 \mathrm{E}+08$ \\
\hline$u-238$ & $\star 1.712 \mathrm{E}+13$ & $\star 1.712 \mathrm{E}+13$ & $\star 1.712 \mathrm{E}+13$ & $\star 1.712 \mathrm{E}+13$ & $\star 1.712 \mathrm{E}+13$ & $1.637 \mathrm{E}+08$ & $2.051 E+05$ & $* 1.712 \mathrm{E}+13$ \\
\hline$u-239$ & $\star 6.214 \mathrm{E}+10$ & $* 6.214 \mathrm{E}+10$ & $* 6.214 \mathrm{E}+10$ & $* 6.214 \mathrm{E}+10$ & $* 6.214 \mathrm{E}+10$ & $7.884 \mathrm{E}+04$ & $1.059 \mathrm{E}+03$ & $* 6.214 \mathrm{E}+10$ \\
\hline $\mathrm{Pu}-240$ & $\star 2.278 \mathrm{E}+11$ & $\star 2.278 \mathrm{E}+11$ & $\star 2.278 \mathrm{E}+11$ & $\star 2.278 \mathrm{E}+11$ & $\star 2.278 \mathrm{E}+11$ & $8.550 \mathrm{E}+04$ & $2.295 \mathrm{E}+03$ & $\star 2.278 \mathrm{E}+11$ \\
\hline Tc-99 & $\star 1.697 \mathrm{E}+10$ & $\star 1.697 \mathrm{E}+10$ & $* 1.697 \mathrm{E}+10$ & $\star 1.697 \mathrm{E}+10$ & $* 1.697 \mathrm{E}+10$ & $7.545 \mathrm{E}+07$ & $\star 1.697 \mathrm{E}+10$ & $* 1.697 \mathrm{E}+10$ \\
\hline Th-228 & $7.234 \mathrm{E}+07$ & $1.033 \mathrm{E}+08$ & $* 8.195 \mathrm{E}+14$ & $* 8.195 \mathrm{E}+14$ & $* 8.195 \mathrm{E}+14$ & $* 8.195 \mathrm{E}+14$ & $\star 8.195 \mathrm{E}+14$ & $* 8.195 \mathrm{E}+14$ \\
\hline Th-230 & $\star 2.018 \mathrm{E}+10$ & $\star 2.018 \mathrm{E}+10$ & $1.880 \mathrm{E}+10$ & $6.761 E+09$ & $9.336 \mathrm{E}+07$ & $1.719 \mathrm{E}+03$ & $5.016 \mathrm{E}+00$ & $* 2.018 \mathrm{E}+10$ \\
\hline Th-232 & $* 1.097 \mathrm{E}+05$ & $* 1.097 \mathrm{E}+05$ & $* 1.097 \mathrm{E}+05$ & $\star 1.097 \mathrm{E}+05$ & $\star 1.097 \mathrm{E}+05$ & $6.708 \mathrm{E}+02$ & $4.021 \mathrm{E}+00$ & $\star 1.097 \mathrm{E}+05$ \\
\hline $\mathrm{U}-234$ & $* 6.247 \mathrm{E}+09$ & $\star 6.247 \mathrm{E}+09$ & $* 6.247 \mathrm{E}+09$ & $* 6.247 \mathrm{E}+09$ & $* 6.247 \mathrm{E}+09$ & $1.078 \mathrm{E}+05$ & $7.246 \mathrm{E}+01$ & $* 6.247 \mathrm{E}+09$ \\
\hline 35 & $\star 2.161 \mathrm{E}+06$ & $\star 2.161 \mathrm{E}+06$ & $\star 2.161 \mathrm{E}+06$ & $\star 2.161 \mathrm{E}+06$ & $\star 2.161 \mathrm{E}+06$ & $5.658 \mathrm{E}+04$ & $6.511 \mathrm{E}+01$ & $\star 2.161 \mathrm{E}+06$ \\
\hline 238 & $\star 3.361 \mathrm{E}+05$ & $\star 3.361 \mathrm{E}+05$ & $\star 3.361 \mathrm{E}+05$ & $\star 3.361 \mathrm{E}+05$ & $* 3.361 \mathrm{E}+05$ & $1.578 \mathrm{E}+05$ & $5.961 \mathrm{E}+02$ & $\star 3.361 \mathrm{E}+05$ \\
\hline
\end{tabular}

*At specific activity limit

Summed Dose/Source Ratios DSR(i,t) in (mrem/yr)/(pCi/g)

and Single Radionuclide Soil Guidelines $\mathrm{G}(i, \mathrm{t})$ in $\mathrm{pCi} / \mathrm{g}$

at tmin = time of minimum single radionuclide soil guideline and at $\operatorname{tmax}=$ time of maximum total dose $=12931 \pm *$ years

\begin{tabular}{|c|c|c|c|c|c|c|}
\hline $\begin{array}{l}\text { uclide } \\
\text { (i) }\end{array}$ & $\begin{array}{l}\text { Initial } \\
(\mathrm{pCi} / \mathrm{g})\end{array}$ & $\begin{array}{c}\text { tmin } \\
\text { (years) }\end{array}$ & $\operatorname{DSR}(i, \operatorname{tmin})$ & $\begin{array}{l}\mathrm{G}(\mathrm{i}, \mathrm{tmin}) \\
\quad(\mathrm{pCi} / \mathrm{g})\end{array}$ & $\operatorname{DSR}(i, \operatorname{tmax})$ & $\begin{array}{c}G(i, t \max ) \\
(\mathrm{pCi} / \mathrm{g})\end{array}$ \\
\hline-241 & $3.500 \mathrm{E}+01$ & $1670 \pm 3$ & $2.766 \mathrm{E}-03$ & $3.615 E+04$ & $7.589 \mathrm{E}-05$ & $1.318 \mathrm{E}+06$ \\
\hline 137 & $1.900 \mathrm{E}+01$ & $0.000 \mathrm{E}+00$ & $1.262 \mathrm{E}-09$ & $7.925 E+10$ & $0.000 \mathrm{E}+00$ & $\star 8.704 \mathrm{E}+13$ \\
\hline 237 & $5.500 \mathrm{E}+00$ & $2534 \pm 5$ & $1.335 \mathrm{E}+00$ & $7.488 \mathrm{E}+01$ & $3.478 \mathrm{E}-01$ & $2.875 E+02$ \\
\hline 238 & $3.900 \mathrm{E}+01$ & $23363 \pm *$ & $1.021 \mathrm{E}-03$ & $9.790 \mathrm{E}+04$ & $6.315 \mathrm{E}-04$ & $1.584 \mathrm{E}+05$ \\
\hline-239 & $3.600 \mathrm{E}+01$ & $2537 \pm 5$ & $1.330 \mathrm{E}-01$ & $7.519 \mathrm{E}+02$ & $8.251 \mathrm{E}-02$ & $1.212 \mathrm{E}+03$ \\
\hline-240 & $3.600 \mathrm{E}+01$ & $2535 \pm 5$ & $1.093 \mathrm{E}-01$ & $9.151 \mathrm{E}+02$ & $3.037 \mathrm{E}-02$ & $3.293 E+03$ \\
\hline-99 & $5.200 \mathrm{E}+01$ & $1144 \pm 2$ & $3.687 \mathrm{E}-06$ & $2.712 \mathrm{E}+07$ & $0.000 \mathrm{E}+00$ & $\star 1.697 \mathrm{E}+10$ \\
\hline$h-228$ & $4.000 \mathrm{E}+00$ & $0.000 \mathrm{E}+00$ & $1.382 \mathrm{E}-06$ & $7.234 \mathrm{E}+07$ & $0.000 \mathrm{E}+00$ & $\star 8.195 \mathrm{E}+14$ \\
\hline-230 & $1.000 \mathrm{E}+02$ & $8258 \pm *$ & $2.007 \mathrm{E}+01$ & $4.984 \mathrm{E}+00$ & $1.943 \mathrm{E}+01$ & $5.148 \mathrm{E}+00$ \\
\hline-232 & $4.000 \mathrm{E}+00$ & $2534 \pm 5$ & $2.542 \mathrm{E}+01$ & $3.934 \mathrm{E}+00$ & $2.465 E+01$ & $4.056 \mathrm{E}+00$ \\
\hline 34 & $1.600 \mathrm{E}+02$ & $23360 \pm *$ & $2.863 \mathrm{E}+00$ & $3.493 \mathrm{E}+01$ & $1.780 \mathrm{E}+00$ & $5.618 \mathrm{E}+01$ \\
\hline & $6.500 \mathrm{E}+00$ & $23350 \pm *$ & $1.982 \mathrm{E}+00$ & $5.044 \mathrm{E}+01$ & $1.693 \mathrm{E}+00$ & $5.907 \mathrm{E}+01$ \\
\hline 238 & $1.600 \mathrm{E}+02$ & $2534 \pm 5$ & $1.800 \mathrm{E}-01$ & $5.556 \mathrm{E}+02$ & $1.696 \mathrm{E}-01$ & $5.898 \mathrm{E}+02$ \\
\hline
\end{tabular}

*At specific activity limit 
RESRAD, Version 6.5

Summary : RESRAD Parameters for U-Landfill Resident Gardener Forward Run 100,000 years

File : C:\RESRAD_FAMILY \RESRAD \USERFILES \QCJULY2011 \ULANDFILL-RG_FORWARD-100000YR.RAD

Individual Nuclide Dose Summed Over All Pathways

Parent Nuclide and Branch Fraction Indicated

Nuclide Parent THF(i) DOSE $(j, t), \mathrm{mrem} / \mathrm{yr}$

\begin{tabular}{|c|c|c|}
\hline$(j)$ & (i) & \\
\hline-241 & $A m-241$ & $1.000 \mathrm{E}+00$ \\
\hline$p-237$ & $A m-241$ & $1.000 \mathrm{E}+00$ \\
\hline $\mathrm{Np}-237$ & $\mathrm{~Np}-237$ & $1.000 \mathrm{E}+00$ \\
\hline Np-237 & $\sum \operatorname{DOSE}(j$ & \\
\hline
\end{tabular}

$\mathrm{U}-233 \quad \mathrm{Am}-241 \quad 1.000 \mathrm{E}+00$

$\mathrm{U}-233 \quad \mathrm{NP}-237 \quad 1.000 \mathrm{E}+00$

U-233 $\sum \operatorname{DOSE}(j)$

Th-229 Am-241 $1.000 \mathrm{E}+00$

Th-229 Np-237 1.000E+00

Th-229 $\sum \operatorname{DOSE}(j)$

Cs $-137 \quad$ Cs $-137 \quad 1.000 E+00$

Pu-238 $\mathrm{Pu}-238 \quad 1.840 \mathrm{E}-09$

$\mathrm{Pu}-238 \mathrm{Pu}-238 \quad 1.000 \mathrm{E}+00$

$\mathrm{Pu}-238 \quad \sum \operatorname{DOSE}(j)$

$\mathrm{U}-234$

$\mathrm{U}-234$

$\mathrm{U}-234$

$\mathrm{U}-234$

Th-230

Th-230

Th -230

Th-230

$\mathrm{Th}-230$

$\mathrm{Ra}-226$

$\mathrm{Ra}-226$

$\mathrm{Ra}-226$

$\mathrm{Ra}-226$

$\operatorname{Ra}-226$

$\mathrm{Pb}-210$

$\mathrm{Pb}-210$

$\mathrm{Pb}-210$

$\mathrm{Pb}-210$

$\mathrm{Pb}-210$

$\mathrm{Pu}-239$

$\mathrm{Pu}-238 \quad 1.000 \mathrm{E}+00$ $\mathrm{U}-234 \quad 1.000 \mathrm{E}+00$ $\mathrm{U}-238 \quad 9.999 \mathrm{E}-01$ $\operatorname{LDOSE}(j)$

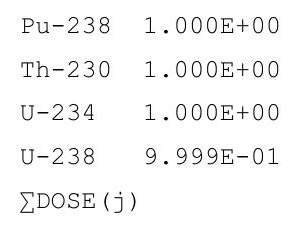

$\mathrm{Pu}-238 \quad 1.000 \mathrm{E}+00$ Th-230 $1.000 \mathrm{E}+00$ $\mathrm{U}-234 \quad 1.000 \mathrm{E}+00$ $\mathrm{U}-238 \quad 9.999 \mathrm{E}-01$ $\operatorname{LDOSE}(j)$

$\mathrm{Pu}-238 \quad 1.000 \mathrm{E}+00$ Th-230 1.000E+00 $\mathrm{U}-234 \quad 1.000 \mathrm{E}+00$ U-238 $9.999 \mathrm{E}-01$ $\operatorname{LOSE}(j)$

$\mathrm{Pu}-239 \quad 1.000 \mathrm{E}+00$

$\mathrm{Pu}-239 \quad 1.000 \mathrm{E}+00$ $\mathrm{U}-2351.000 \mathrm{E}+00$ $\sum \operatorname{DOSE}(j)$ $\mathrm{t}=0.000 \mathrm{E}+00 \quad 1.000 \mathrm{E}+00 \quad 5.000 \mathrm{E}+01 \quad 1.000 \mathrm{E}+02 \quad 5.000 \mathrm{E}+02 \quad 1.050 \mathrm{E}+03 \quad 1.000 \mathrm{E}+04 \quad 1.000 \mathrm{E}+05$

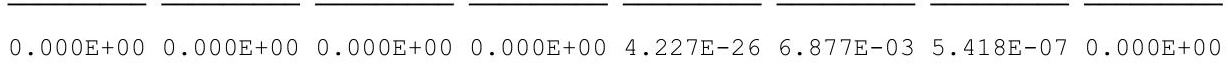

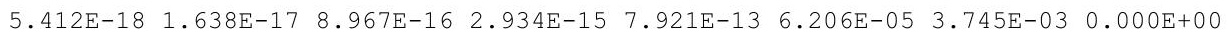
$\begin{array}{llllllll}5.245 \mathrm{E}-12 & 5.301 \mathrm{E}-12 & 8.939 \mathrm{E}-12 & 1.524 \mathrm{E}-11 & 1.085 \mathrm{E}-09 & 5.635 \mathrm{E}-02 & 2.678 \mathrm{E}+00 & 0.000 \mathrm{E}+00\end{array}$

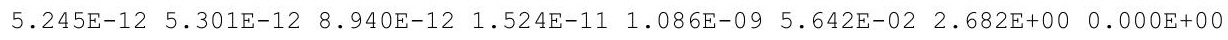

$\begin{array}{llllllll}1.227 \mathrm{E}-28 & 8.678 \mathrm{E}-28 & 1.702 \mathrm{E}-24 & 1.226 \mathrm{E}-23 & 3.685 \mathrm{E}-20 & 1.069 \mathrm{E}-08 & 9.450 \mathrm{E}-06 & 0.000 \mathrm{E}+00\end{array}$ $\begin{array}{llllllll}1.785 \mathrm{E}-22 & 5.414 \mathrm{E}-22 & 3.355 \mathrm{E}-20 & 1.245 \mathrm{E}-19 & 9.076 \mathrm{E}-17 & 1.579 \mathrm{E}-05 & 7.534 \mathrm{E}-03 & 0.000 \mathrm{E}+00\end{array}$

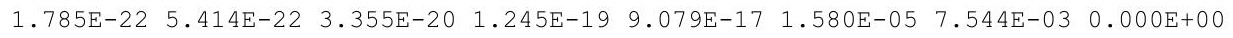

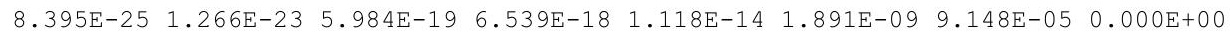
$\begin{array}{llllllll}1.629 \mathrm{E}-18 & 1.147 \mathrm{E}-17 & 1.758 \mathrm{E}-14 & 9.834 \mathrm{E}-14 & 3.894 \mathrm{E}-11 & 3.741 \mathrm{E}-06 & 7.722 \mathrm{E}-02 & 0.000 \mathrm{E}+00\end{array}$ $\begin{array}{lllllllll}1.629 \mathrm{E}-18 & 1.147 \mathrm{E}-17 & 1.758 \mathrm{E}-14 & 9.835 \mathrm{E}-14 & 3.895 \mathrm{E}-11 & 3.743 \mathrm{E}-06 & 7.731 \mathrm{E}-02 & 0.000 \mathrm{E}+00\end{array}$

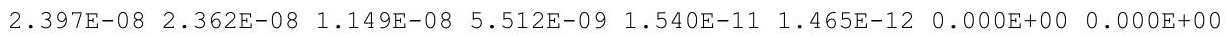

$\begin{array}{lllllllll}0.000 \mathrm{E}+00 & 0.000 \mathrm{E}+00 & 0.000 \mathrm{E}+00 & 0.000 \mathrm{E}+00 & 0.000 \mathrm{E}+00 & 2.147 \mathrm{E}-14 & 0.000 \mathrm{E}+00 & 0.000 \mathrm{E}+00\end{array}$ $\begin{array}{llllllll}4.582 \mathrm{E}-23 & 4.627 \mathrm{E}-23 & 7.461 \mathrm{E}-23 & 1.215 \mathrm{E}-22 & 6.001 \mathrm{E}-21 & 1.167 \mathrm{E}-05 & 0.000 \mathrm{E}+00 & 0.000 \mathrm{E}+00\end{array}$

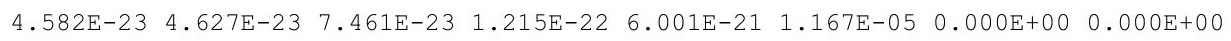

$\begin{array}{llllllll}3.813 \mathrm{E}-28 & 1.158 \mathrm{E}-27 & 7.693 \mathrm{E}-26 & 3.104 \mathrm{E}-25 & 6.593 \mathrm{E}-22 & 8.877 \mathrm{E}-06 & 6.890 \mathrm{E}-04 & 0.000 \mathrm{E}+00\end{array}$ $\begin{array}{lllllllll}1.103 \mathrm{E}-21 & 1.123 \mathrm{E}-21 & 2.673 \mathrm{E}-21 & 6.475 \mathrm{E}-21 & 7.677 \mathrm{E}-18 & 1.014 \mathrm{E}-01 & 7.868 \mathrm{E}+00 & 0.000 \mathrm{E}+00\end{array}$ $\begin{array}{lllllllll}1.569 \mathrm{E}-27 & 4.780 \mathrm{E}-27 & 3.827 \mathrm{E}-25 & 1.845 \mathrm{E}-24 & 1.090 \mathrm{E}-20 & 3.024 \mathrm{E}-04 & 2.263 \mathrm{E}-01 & 0.000 \mathrm{E}+00\end{array}$ $\begin{array}{lllllllll}1.103 \mathrm{E}-21 & 1.123 \mathrm{E}-21 & 2.673 \mathrm{E}-21 & 6.477 \mathrm{E}-21 & 7.688 \mathrm{E}-18 & 1.017 \mathrm{E}-01 & 8.095 \mathrm{E}+00 & 0.000 \mathrm{E}+00\end{array}$

$\begin{array}{llllllll}0.000 \mathrm{E}+00 & 0.000 \mathrm{E}+00 & 6.236 \mathrm{E}-28 & 5.079 \mathrm{E}-27 & 5.092 \mathrm{E}-23 & 1.276 \mathrm{E}-07 & 1.301 \mathrm{E}-04 & 0.000 \mathrm{E}+00\end{array}$ $2.412 \mathrm{E}-20 \quad 2.453 \mathrm{E}-20 \quad 5.590 \mathrm{E}-20 \quad 1.295 \mathrm{E}-19 \quad 1.078 \mathrm{E}-16 \quad 1.104 \mathrm{E}-01 \quad 1.120 \mathrm{E}+01 \quad 0.000 \mathrm{E}+00$ $\begin{array}{llllllll}1.742 \mathrm{E}-25 & 5.304 \mathrm{E}-25 & 4.065 \mathrm{E}-23 & 1.874 \mathrm{E}-22 & 7.741 \mathrm{E}-19 & 1.659 \mathrm{E}-03 & 1.506 \mathrm{E}+00 & 0.000 \mathrm{E}+00\end{array}$ $\begin{array}{llllllll}0.000 \mathrm{E}+00 & 0.000 \mathrm{E}+00 & 2.909 \mathrm{E}-27 & 2.669 \mathrm{E}-26 & 5.488 \mathrm{E}-22 & 2.466 \mathrm{E}-06 & 2.106 \mathrm{E}-02 & 0.000 \mathrm{E}+00\end{array}$

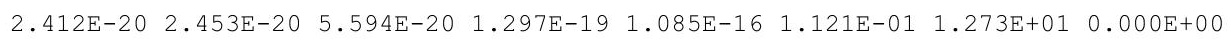

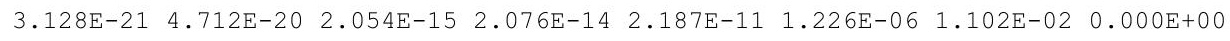
$\begin{array}{llllllll}3.774 \mathrm{E}-09 & 1.139 \mathrm{E}-08 & 5.320 \mathrm{E}-07 & 1.479 \mathrm{E}-06 & 1.071 \mathrm{E}-04 & 2.165 \mathrm{E}+00 & 1.199 \mathrm{E}+03 & 0.000 \mathrm{E}+00\end{array}$ $\begin{array}{llllllll}1.813 \mathrm{E}-14 & 1.277 \mathrm{E}-13 & 1.941 \mathrm{E}-10 & 1.078 \mathrm{E}-09 & 3.993 \mathrm{E}-07 & 1.755 \mathrm{E}-02 & 1.280 \mathrm{E}+02 & 0.000 \mathrm{E}+00\end{array}$

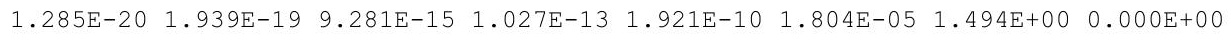

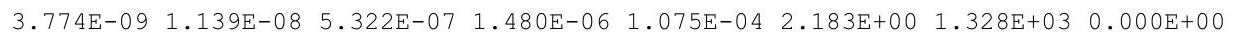

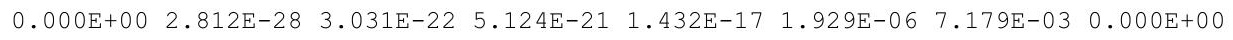
$\begin{array}{lllllllll}1.819 \mathrm{E}-17 & 1.271 \mathrm{E}-16 & 1.299 \mathrm{E}-13 & 5.314 \mathrm{E}-13 & 7.678 \mathrm{E}-11 & 3.543 \mathrm{E}+00 & 7.839 \mathrm{E}+02 & 0.000 \mathrm{E}+00\end{array}$ $\begin{array}{lllllllll}6.563 \mathrm{E}-23 & 9.844 \mathrm{E}-22 & 3.522 \mathrm{E}-17 & 3.095 \mathrm{E}-16 & 2.685 \mathrm{E}-13 & 2.781 \mathrm{E}-02 & 8.341 \mathrm{E}+01 & 0.000 \mathrm{E}+00\end{array}$ $\begin{array}{llllllllll}0.000 \mathrm{E}+00 & 1.157 \mathrm{E}-27 & 1.349 \mathrm{E}-21 & 2.474 \mathrm{E}-20 & 1.218 \mathrm{E}-16 & 2.774 \mathrm{E}-05 & 9.701 \mathrm{E}-01 & 0.000 \mathrm{E}+00\end{array}$ $\begin{array}{llllllll}1.819 \mathrm{E}-17 & 1.271 \mathrm{E}-16 & 1.299 \mathrm{E}-13 & 5.317 \mathrm{E}-13 & 7.705 \mathrm{E}-11 & 3.571 \mathrm{E}+00 & 8.683 \mathrm{E}+02 & 0.000 \mathrm{E}+00\end{array}$

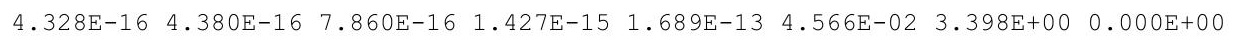

$2.209 \mathrm{E}-22 \quad 6.699 \mathrm{E}-22 \quad 4.126 \mathrm{E}-20 \quad 1.522 \mathrm{E}-19 \quad 1.055 \mathrm{E}-16 \quad 2.265 \mathrm{E}-08 \quad 1.585 \mathrm{E}-04 \quad 0.000 \mathrm{E}+00$ $\begin{array}{lllllllll}8.081 \mathrm{E}-14 & 8.182 \mathrm{E}-14 & 1.499 \mathrm{E}-13 & 2.779 \mathrm{E}-13 & 3.888 \mathrm{E}-11 & 4.001 \mathrm{E}-03 & 3.252 \mathrm{E}+00 & 0.000 \mathrm{E}+00\end{array}$ $\begin{array}{lllllllll}8.081 \mathrm{E}-14 & 8.182 \mathrm{E}-14 & 1.499 \mathrm{E}-13 & 2.779 \mathrm{E}-13 & 3.888 \mathrm{E}-11 & 4.001 \mathrm{E}-03 & 3.252 \mathrm{E}+00 & 0.000 \mathrm{E}+00\end{array}$ 
RESRAD, Version 6.5

Summary : RESRAD Parameters for U-Landfill Resident Gardener Forward Run 100,000 years

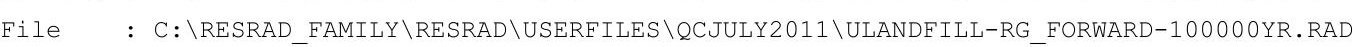

Individual Nuclide Dose Summed Over All Pathways

Parent Nuclide and Branch Fraction Indicated

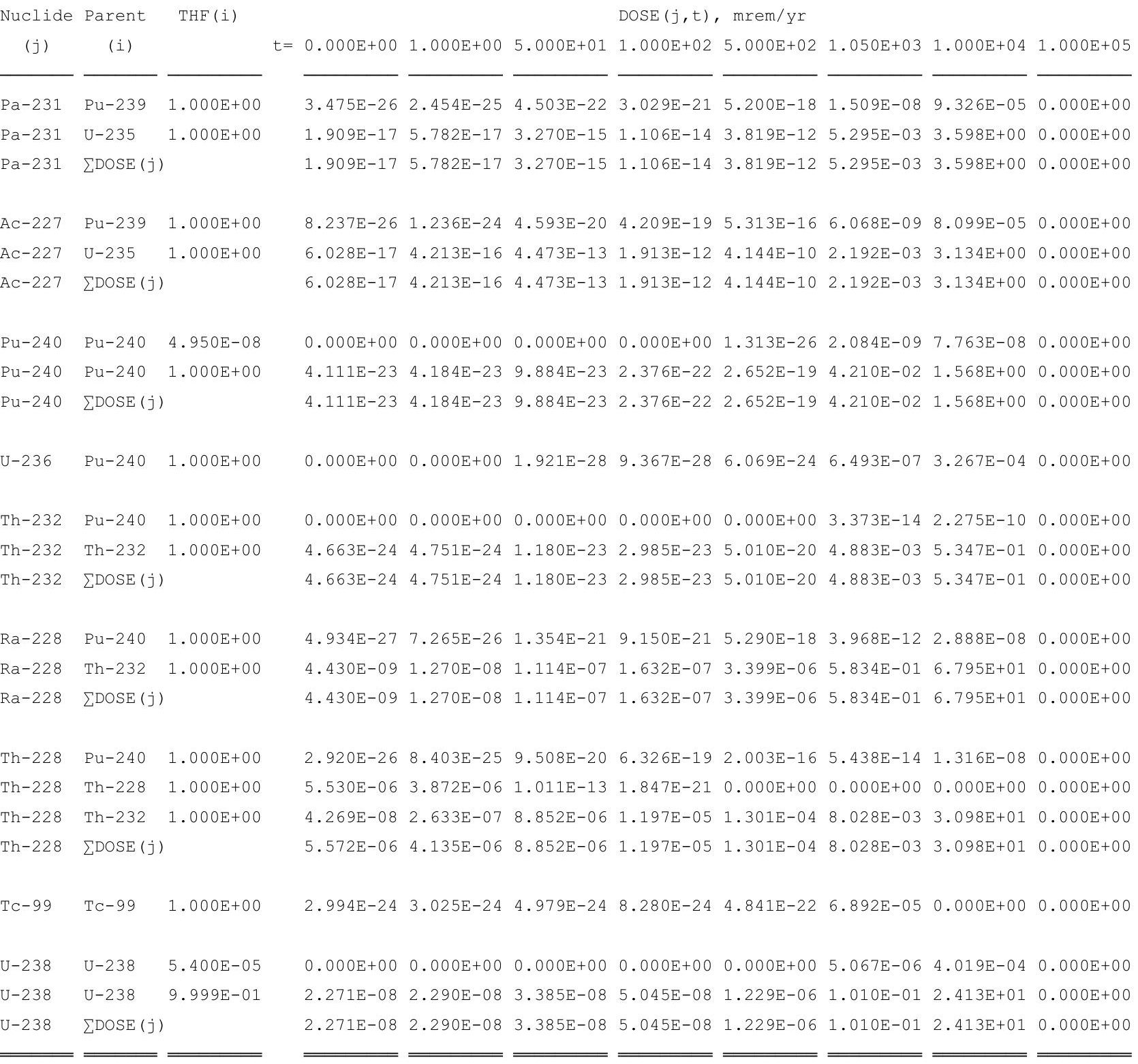

THF (i) is the thread fraction of the parent nuclide. 


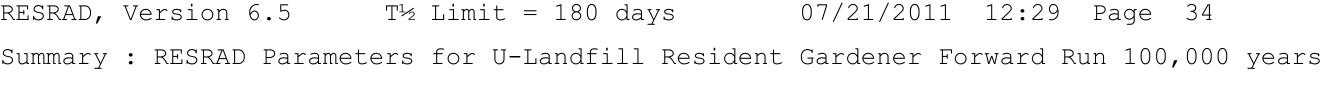

File : C: \RESRAD_FAMILY \RESRAD \USERFILES \QCJULY2011 \ULANDFILL-RG_FORWARD-100000YR.RAD

Individual Nuclide Soil Concentration

Parent Nuclide and Branch Fraction Indicated

Nuclide Parent THF(

(j)

$A m-241$

(i)

$\overline{A m-241} \overline{1.000 \mathrm{E}+00}$

Np-237 Am-241 1.000E+00

$\mathrm{Np}-237 \quad \mathrm{~Np}-237 \quad 1.000 \mathrm{E}+00$

Np-237 $\sum S(j):$

$\mathrm{U}-233 \quad \mathrm{Am}-241 \quad 1.000 \mathrm{E}+00$

$\mathrm{U}-233 \quad \mathrm{~Np}-237 \quad 1.000 \mathrm{E}+00$

U-233 $\sum S(j):$

Th-229 Am-241 1.000E+00

Th-229 Np-237 1.000E+00

Th-229 $\sum S(j):$

Cs-137 Cs-137 1.000E+00

$\mathrm{Pu}-238 \quad \mathrm{Pu}-238 \quad 1.840 \mathrm{E}-09$

$\mathrm{Pu}-238 \mathrm{Pu}-238 \quad 1.000 \mathrm{E}+00$

$\mathrm{Pu}-238 \quad \sum \mathrm{S}(j):$

$\mathrm{U}-234$

$\mathrm{U}-234$

$\mathrm{U}-234$

$\mathrm{U}-234$

Th-230

Th-230

Th -230

Th-230

Th -230

$\mathrm{Ra}-226$

$\mathrm{Ra}-226$

$\mathrm{Ra}-226$

Ra-226

$\mathrm{Ra}-226$

$\mathrm{Pb}-210$

$\mathrm{Pb}-210$

$\mathrm{Pb}-210$

$\mathrm{Pb}-210$

$\mathrm{Pb}-210$

$\mathrm{Pu}-239$

$\mathrm{Pu}-238 \quad 1.000 \mathrm{E}+00$

$\mathrm{U}-234 \quad 1.000 \mathrm{E}+00$

$\mathrm{U}-238 \quad 9.999 \mathrm{E}-01$

$\sum S(j):$

Pu-238 1.000E+00

Th-230 1.000E+00

$\mathrm{U}-234 \quad 1.000 \mathrm{E}+00$

U-238 $9.999 \mathrm{E}-01$

$\sum S(j):$

$\mathrm{Pu}-238 \quad 1.000 \mathrm{E}+00$

$\mathrm{Th}-230 \quad 1.000 \mathrm{E}+00$

$\mathrm{U}-234 \quad 1.000 \mathrm{E}+00$

$\mathrm{U}-238 \quad 9.999 \mathrm{E}-01$

$\sum S(j):$

$\mathrm{Pu}-238 \quad 1.000 \mathrm{E}+00$

Th-230 1.000E+00

U-234 $1.000 \mathrm{E}+00$

U-238 $9.999 \mathrm{E}-01$

$\sum S(j):$

Pu-239 $1.000 \mathrm{E}+00$

Pu-239 1.000E+00

$\mathrm{U}-2351.000 \mathrm{E}+00$

$\sum S(j):$
$S(j, t), p C i / g$

$t=0.000 \mathrm{E}+00 \quad 1.000 \mathrm{E}+00 \quad 5.000 \mathrm{E}+01 \quad 1.000 \mathrm{E}+02 \quad 5.000 \mathrm{E}+02 \quad 1.050 \mathrm{E}+03 \quad 1.000 \mathrm{E}+04 \quad 1.000 \mathrm{E}+05$

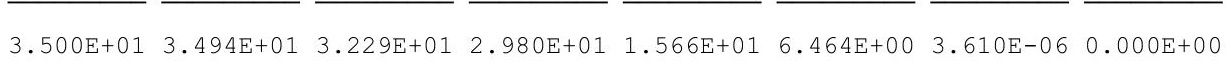

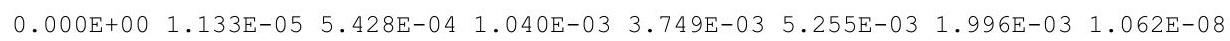

$\begin{array}{llllllll}5.500 \mathrm{E}+00 & 5.499 \mathrm{E}+00 & 5.463 \mathrm{E}+00 & 5.426 \mathrm{E}+00 & 5.141 \mathrm{E}+00 & 4.773 \mathrm{E}+00 & 1.427 \mathrm{E}+00 & 7.597 \mathrm{E}-06\end{array}$

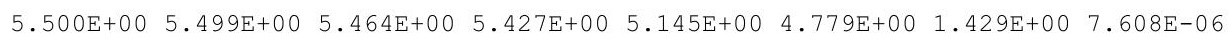

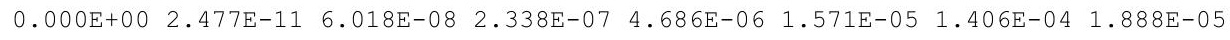

$\begin{array}{llllllll}0.000 \mathrm{E}+00 & 2.405 \mathrm{E}-05 & 1.198 \mathrm{E}-03 & 2.386 \mathrm{E}-03 & 1.155 \mathrm{E}-02 & 2.320 \mathrm{E}-02 & 1.121 \mathrm{E}-01 & 1.449 \mathrm{E}-02\end{array}$

$\begin{array}{llllllll}0.000 \mathrm{E}+00 & 2.405 \mathrm{E}-05 & 1.198 \mathrm{E}-03 & 2.386 \mathrm{E}-03 & 1.155 \mathrm{E}-02 & 2.322 \mathrm{E}-02 & 1.122 \mathrm{E}-01 & 1.451 \mathrm{E}-02\end{array}$

$\begin{array}{llllllll}0.000 \mathrm{E}+00 & 7.799 \mathrm{E}-16 & 9.529 \mathrm{E}-11 & 7.450 \mathrm{E}-10 & 7.803 \mathrm{E}-08 & 5.780 \mathrm{E}-07 & 5.806 \mathrm{E}-05 & 2.540 \mathrm{E}-05\end{array}$

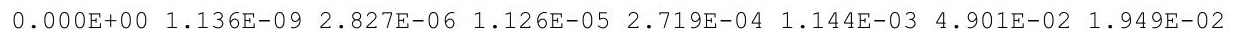

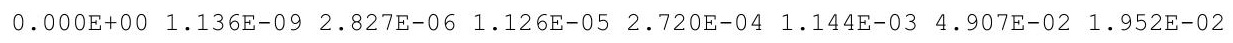

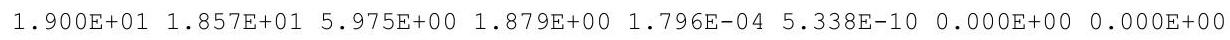

$\begin{array}{llllllll}7.176 \mathrm{E}-08 & 7.119 \mathrm{E}-08 & 4.830 \mathrm{E}-08 & 3.251 \mathrm{E}-08 & 1.370 \mathrm{E}-09 & 1.760 \mathrm{E}-11 & 2.951 \mathrm{E}-42 & 0.000 \mathrm{E}+00\end{array}$

$\begin{array}{llllllllll}3.900 \mathrm{E}+01 & 3.869 \mathrm{E}+01 & 2.625 \mathrm{E}+01 & 1.767 \mathrm{E}+01 & 7.445 \mathrm{E}-01 & 9.567 \mathrm{E}-03 & 1.612 \mathrm{E}-33 & 0.000 \mathrm{E}+00\end{array}$

$\begin{array}{llllllllll}3.900 \mathrm{E}+01 & 3.869 \mathrm{E}+01 & 2.625 \mathrm{E}+01 & 1.767 \mathrm{E}+01 & 7.445 \mathrm{E}-01 & 9.567 \mathrm{E}-03 & 1.612 \mathrm{E}-33 & 0.000 \mathrm{E}+00\end{array}$

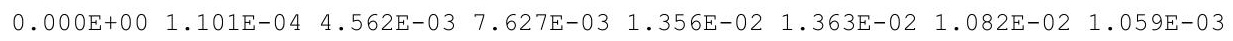

$\begin{array}{llllllll}1.600 \mathrm{E}+02 & 1.600 \mathrm{E}+02 & 1.598 \mathrm{E}+02 & 1.596 \mathrm{E}+02 & 1.579 \mathrm{E}+02 & 1.557 \mathrm{E}+02 & 1.236 \mathrm{E}+02 & 1.209 \mathrm{E}+01\end{array}$

$\begin{array}{lllllllll}0.000 \mathrm{E}+00 & 4.536 \mathrm{E}-04 & 2.265 \mathrm{E}-02 & 4.525 \mathrm{E}-02 & 2.240 \mathrm{E}-01 & 4.642 \mathrm{E}-01 & 3.553 \mathrm{E}+00 & 3.962 \mathrm{E}+00\end{array}$

$\begin{array}{llllllll}1.600 \mathrm{E}+02 & 1.600 \mathrm{E}+02 & 1.598 \mathrm{E}+02 & 1.596 \mathrm{E}+02 & 1.582 \mathrm{E}+02 & 1.562 \mathrm{E}+02 & 1.271 \mathrm{E}+02 & 1.605 \mathrm{E}+01\end{array}$

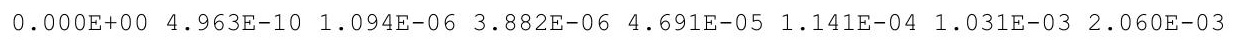
$\begin{array}{llllllllllll}1.000 \mathrm{E}+02 & 1.000 \mathrm{E}+02 & 9.994 \mathrm{E}+01 & 9.988 \mathrm{E}+01 & 9.940 \mathrm{E}+01 & 9.875 \mathrm{E}+01 & 8.874 \mathrm{E}+01 & 3.028 \mathrm{E}+01\end{array}$ $\begin{array}{lllllllllll}0.000 \mathrm{E}+00 & 1.440 \mathrm{E}-03 & 7.195 \mathrm{E}-02 & 1.438 \mathrm{E}-01 & 7.134 \mathrm{E}-01 & 1.483 \mathrm{E}+00 & 1.193 \mathrm{E}+01 & 2.358 \mathrm{E}+01\end{array}$ $\begin{array}{lllllllll}0.000 \mathrm{E}+00 & 2.041 \mathrm{E}-09 & 5.099 \mathrm{E}-06 & 2.037 \mathrm{E}-05 & 5.052 \mathrm{E}-04 & 2.203 \mathrm{E}-03 & 1.668 \mathrm{E}-01 & 2.822 \mathrm{E}+00\end{array}$

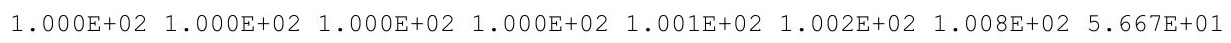

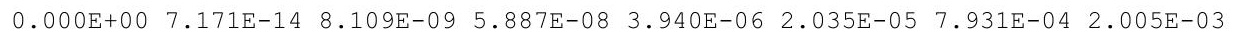
$\begin{array}{llllllllll}0.000 \mathrm{E}+00 & 4.331 \mathrm{E}-02 & 2.141 \mathrm{E}+00 & 4.233 \mathrm{E}+00 & 1.933 \mathrm{E}+01 & 3.597 \mathrm{E}+01 & 8.627 \mathrm{E}+01 & 2.980 \mathrm{E}+01\end{array}$ $\begin{array}{llllllll}0.000 \mathrm{E}+00 & 3.119 \mathrm{E}-07 & 7.736 \mathrm{E}-04 & 3.069 \mathrm{E}-03 & 7.197 \mathrm{E}-02 & 2.914 \mathrm{E}-01 & 9.214 \mathrm{E}+00 & 2.295 \mathrm{E}+01\end{array}$ $\begin{array}{llllllllll}0.000 \mathrm{E}+00 & 2.948 \mathrm{E}-13 & 3.662 \mathrm{E}-08 & 2.911 \mathrm{E}-07 & 3.459 \mathrm{E}-05 & 2.994 \mathrm{E}-04 & 1.075 \mathrm{E}-01 & 2.697 \mathrm{E}+00\end{array}$ $\begin{array}{lllllllll}0.000 \mathrm{E}+00 & 4.331 \mathrm{E}-02 & 2.142 \mathrm{E}+00 & 4.236 \mathrm{E}+00 & 1.940 \mathrm{E}+01 & 3.626 \mathrm{E}+01 & 9.560 \mathrm{E}+01 & 5.545 \mathrm{E}+01\end{array}$

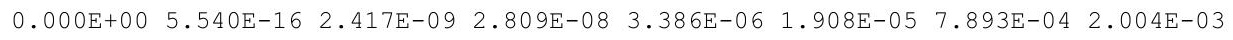
$\begin{array}{llllllllll}0.000 \mathrm{E}+00 & 6.662 \mathrm{E}-04 & 1.057 \mathrm{E}+00 & 2.944 \mathrm{E}+00 & 1.819 \mathrm{E}+01 & 3.507 \mathrm{E}+01 & 8.620 \mathrm{E}+01 & 2.978 \mathrm{E}+01\end{array}$ $\begin{array}{lllllllll}0.000 \mathrm{E}+00 & 3.207 \mathrm{E}-09 & 2.836 \mathrm{E}-04 & 1.705 \mathrm{E}-03 & 6.353 \mathrm{E}-02 & 2.751 \mathrm{E}-01 & 9.171 \mathrm{E}+00 & 2.293 \mathrm{E}+01\end{array}$ $\begin{array}{llllllllll}0.000 \mathrm{E}+00 & 2.276 \mathrm{E}-15 & 1.075 \mathrm{E}-08 & 1.355 \mathrm{E}-07 & 2.879 \mathrm{E}-05 & 2.742 \mathrm{E}-04 & 1.066 \mathrm{E}-01 & 2.694 \mathrm{E}+00\end{array}$ $\begin{array}{lllllllllll}0.000 \mathrm{E}+00 & 6.663 \mathrm{E}-04 & 1.058 \mathrm{E}+00 & 2.945 \mathrm{E}+00 & 1.825 \mathrm{E}+01 & 3.534 \mathrm{E}+01 & 9.547 \mathrm{E}+01 & 5.541 \mathrm{E}+01\end{array}$

$\begin{array}{lllllllllll}3.600 \mathrm{E}+01 & 3.600 \mathrm{E}+01 & 3.592 \mathrm{E}+01 & 3.583 \mathrm{E}+01 & 3.518 \mathrm{E}+01 & 3.430 \mathrm{E}+01 & 2.274 \mathrm{E}+01 & 3.639 \mathrm{E}-01\end{array}$

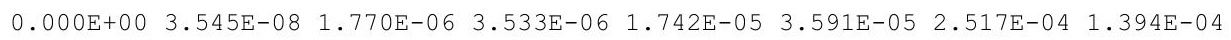
$\begin{array}{llllllll}6.500 \mathrm{E}+00 & 6.500 \mathrm{E}+00 & 6.493 \mathrm{E}+00 & 6.485 \mathrm{E}+00 & 6.426 \mathrm{E}+00 & 6.345 \mathrm{E}+00 & 5.165 \mathrm{E}+00 & 6.520 \mathrm{E}-01\end{array}$

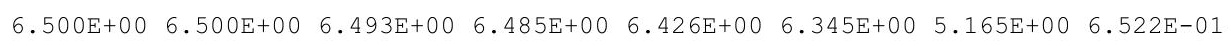


RESRAD, Version 6.5

Summary : RESRAD Parameters for U-Landfill Resident Gardener Forward Run 100,000 years

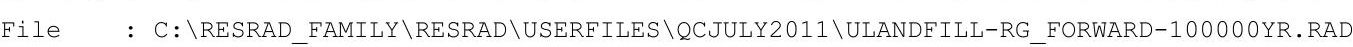

Individual Nuclide Soil Concentration

Parent Nuclide and Branch Fraction Indicated

\begin{tabular}{|c|c|c|c|c|c|c|c|c|c|c|}
\hline $\begin{array}{l}\text { aclide } \\
\text { (j) }\end{array}$ & $\begin{array}{c}\text { Parent } \\
\text { (i) }\end{array}$ & THF (i) & $t=0.000 \mathrm{E}+00$ & $1.000 \mathrm{E}+00$ & $5.000 \mathrm{E}+01$ & $\begin{array}{r}S(j, t), \\
1.000 E+02\end{array}$ & $\begin{array}{l}\mathrm{pCi} / \mathrm{g} \\
5.000 \mathrm{E}+02\end{array}$ & $1.050 \mathrm{E}+03$ & $1.000 \mathrm{E}+04$ & $1.000 \mathrm{E}+05$ \\
\hline-231 & $\mathrm{Pu}-239$ & $1.000 \mathrm{E}+00$ & $0.000 \mathrm{E}+00$ & $3.751 \mathrm{E}-13$ & $9.360 \mathrm{E}-10$ & $3.737 E-09$ & $9.211 \mathrm{E}-08$ & $3.983 \mathrm{E}-07$ & $2.627 E-05$ & $1.183 \mathrm{E}-04$ \\
\hline-231 & $\mathrm{U}-235$ & $1.000 \mathrm{E}+00$ & $0.000 \mathrm{E}+00$ & $1.375 \mathrm{E}-04$ & $6.866 \mathrm{E}-03$ & $1.371 \mathrm{E}-02$ & $6.772 \mathrm{E}-02$ & $1.398 \mathrm{E}-01$ & $1.013 \mathrm{E}+00$ & $7.063 \mathrm{E}-01$ \\
\hline-231 & $\sum S(j):$ & & $0.000 \mathrm{E}+00$ & $1.375 \mathrm{E}-04$ & $6.866 \mathrm{E}-03$ & $1.371 \mathrm{E}-02$ & $6.772 \mathrm{E}-02$ & $1.398 \mathrm{E}-01$ & $1.013 \mathrm{E}+00$ & $7.064 \mathrm{E}-01$ \\
\hline 7 & Pu-239 & $1.000 \mathrm{E}+00$ & $0.000 \mathrm{E}+00$ & $3.949 \mathrm{E}-15$ & $3.484 \mathrm{E}-10$ & $2.097 \mathrm{E}-09$ & $8.130 \mathrm{E}-08$ & $3.753 \mathrm{E}-07$ & $2.611 \mathrm{E}-05$ & $1.182 \mathrm{E}-04$ \\
\hline-227 & $\mathrm{U}-235$ & $1.000 \mathrm{E}+00$ & $0.000 \mathrm{E}+00$ & $2.166 \mathrm{E}-06$ & $3.431 \mathrm{E}-03$ & $9.584 \mathrm{E}-03$ & $6.348 \mathrm{E}-02$ & $1.357 \mathrm{E}-01$ & $1.010 \mathrm{E}+00$ & $7.063 \mathrm{E}-01$ \\
\hline 227 & $\sum S(j):$ & & $0.000 \mathrm{E}+00$ & $2.166 \mathrm{E}-06$ & $3.431 \mathrm{E}-03$ & $9.584 \mathrm{E}-03$ & $6.348 \mathrm{E}-02$ & $1.357 \mathrm{E}-01$ & $1.010 \mathrm{E}+00$ & $7.064 \mathrm{E}-01$ \\
\hline 0 & $\mathrm{Pu}-240$ & $4.950 \mathrm{E}-08$ & $1.782 \mathrm{E}-06$ & $1.782 \mathrm{E}-06$ & $1.771 \mathrm{E}-06$ & $1.760 \mathrm{E}-06$ & $1.676 \mathrm{E}-06$ & $1.566 \mathrm{E}-06$ & $5.200 \mathrm{E}-07$ & $7.970 \mathrm{E}-12$ \\
\hline 240 & $\mathrm{Pu}-240$ & $1.000 \mathrm{E}+00$ & $3.600 \mathrm{E}+01$ & $3.600 \mathrm{E}+01$ & $3.578 \mathrm{E}+01$ & $3.556 \mathrm{E}+01$ & $3.385 \mathrm{E}+01$ & $3.163 \mathrm{E}+01$ & $1.050 \mathrm{E}+01$ & $1.610 \mathrm{E}-04$ \\
\hline 240 & $\sum S(j):$ & & $3.600 \mathrm{E}+01$ & $3.600 \mathrm{E}+01$ & $3.578 \mathrm{E}+01$ & $3.556 \mathrm{E}+01$ & $3.385 \mathrm{E}+01$ & $3.163 \mathrm{E}+01$ & $1.050 \mathrm{E}+01$ & $1.610 \mathrm{E}-04$ \\
\hline 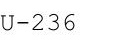 & $\mathrm{Pu}-240$ & $1.000 \mathrm{E}+00$ & $0.000 \mathrm{E}+00$ & $1.066 \mathrm{E}-06$ & $5.309 \mathrm{E}-05$ & $1.058 \mathrm{E}-04$ & $5.138 \mathrm{E}-04$ & $1.037 \mathrm{E}-03$ & $5.348 \mathrm{E}-03$ & $1.064 \mathrm{E}-03$ \\
\hline-232 & $\mathrm{Pu}-240$ & $1.000 \mathrm{E}+00$ & $0.000 \mathrm{E}+00$ & $2.629 \mathrm{E}-17$ & $6.556 \mathrm{E}-14$ & $2.616 \mathrm{E}-13$ & $6.411 \mathrm{E}-12$ & $2.752 \mathrm{E}-11$ & $1.653 \mathrm{E}-09$ & $1.361 \mathrm{E}-08$ \\
\hline-232 & Th-232 & $1.000 \mathrm{E}+00$ & $4.000 \mathrm{E}+00$ & $4.000 \mathrm{E}+00$ & $3.999 \mathrm{E}+00$ & $3.999 \mathrm{E}+00$ & $3.994 \mathrm{E}+00$ & $3.988 \mathrm{E}+00$ & $3.884 \mathrm{E}+00$ & $2.979 \mathrm{E}+00$ \\
\hline-232 & $\sum S(j):$ & & $4.000 \mathrm{E}+00$ & $4.000 \mathrm{E}+00$ & $3.999 \mathrm{E}+00$ & $3.999 \mathrm{E}+00$ & $3.994 \mathrm{E}+00$ & $3.988 \mathrm{E}+00$ & $3.884 \mathrm{E}+00$ & $2.979 \mathrm{E}+00$ \\
\hline 228 & $\mathrm{Pu}-240$ & $1.000 \mathrm{E}+00$ & $0.000 \mathrm{E}+00$ & $1.025 \mathrm{E}-18$ & $4.741 \mathrm{E}-14$ & $2.218 \mathrm{E}-13$ & $6.203 \mathrm{E}-12$ & $2.709 \mathrm{E}-11$ & $1.650 \mathrm{E}-09$ & $1.360 \mathrm{E}-08$ \\
\hline-228 & Th-232 & $1.000 \mathrm{E}+00$ & $0.000 \mathrm{E}+00$ & $4.543 \mathrm{E}-01$ & $3.989 \mathrm{E}+00$ & $3.998 \mathrm{E}+00$ & $3.994 \mathrm{E}+00$ & $3.987 \mathrm{E}+00$ & $3.883 E+00$ & $2.979 \mathrm{E}+00$ \\
\hline-228 & $\sum S(j):$ & & $0.000 \mathrm{E}+00$ & $4.543 \mathrm{E}-01$ & $3.989 \mathrm{E}+00$ & $3.998 \mathrm{E}+00$ & $3.994 \mathrm{E}+00$ & $3.987 \mathrm{E}+00$ & $3.883 \mathrm{E}+00$ & $2.979 \mathrm{E}+00$ \\
\hline $2<0$ & $\mathrm{Pu}-240$ & $1.000 \mathrm{E}+00$ & $0.000 \mathrm{E}+00$ & $8.701 \mathrm{E}-20$ & $4.177 \mathrm{E}-14$ & $2.090 \mathrm{E}-13$ & $6.135 \mathrm{E}-12$ & $2.695 \mathrm{E}-11$ & $1.649 \mathrm{E}-09$ & $1.360 \mathrm{E}-08$ \\
\hline 8 & Th-228 & $1.000 \mathrm{E}+00$ & $4.000 \mathrm{E}+00$ & $2.784 \mathrm{E}+00$ & $5.425 \mathrm{E}-08$ & $7.358 \mathrm{E}-16$ & $0.000 \mathrm{E}+00$ & $0.000 \mathrm{E}+00$ & $0.000 \mathrm{E}+00$ & $0.000 \mathrm{E}+00$ \\
\hline 28 & Th-232 & $1.000 \mathrm{E}+00$ & $0.000 \mathrm{E}+00$ & $7.457 \mathrm{E}-02$ & $3.984 \mathrm{E}+00$ & $3.998 \mathrm{E}+00$ & $3.994 \mathrm{E}+00$ & $3.987 \mathrm{E}+00$ & $3.883 \mathrm{E}+00$ & $2.979 E+00$ \\
\hline 228 & $\sum S(j):$ & & $4.000 \mathrm{E}+00$ & $2.859 \mathrm{E}+00$ & $3.984 \mathrm{E}+00$ & $3.998 \mathrm{E}+00$ & $3.994 \mathrm{E}+00$ & $3.987 \mathrm{E}+00$ & $3.883 \mathrm{E}+00$ & $2.979 \mathrm{E}+00$ \\
\hline & TC-99 & $1.000 \mathrm{E}+00$ & $5.200 \mathrm{E}+01$ & $5.153 \mathrm{E}+01$ & $3.314 \mathrm{E}+01$ & $2.113 E+01$ & $5.754 \mathrm{E}-01$ & $4.059 \mathrm{E}-03$ & $3.943 E-38$ & $0.000 \mathrm{E}+00$ \\
\hline & $\mathrm{U}-238$ & $5.400 \mathrm{E}-05$ & $8.640 \mathrm{E}-03$ & $8.640 \mathrm{E}-03$ & $8.630 \mathrm{E}-03$ & $8.620 \mathrm{E}-03$ & $8.541 \mathrm{E}-03$ & $8.434 \mathrm{E}-03$ & $6.865 \mathrm{E}-03$ & $8.668 \mathrm{E}-04$ \\
\hline & $\mathrm{U}-238$ & $9.999 \mathrm{E}-01$ & $1.600 \mathrm{E}+02$ & $1.600 \mathrm{E}+02$ & $1.598 \mathrm{E}+02$ & $1.596 \mathrm{E}+02$ & $1.582 \mathrm{E}+02$ & $1.562 \mathrm{E}+02$ & $1.271 \mathrm{E}+02$ & $1.605 \mathrm{E}+01$ \\
\hline & $\sum S(j):$ & & $1.600 \mathrm{E}+02$ & $1.600 \mathrm{E}+02$ & $1.598 \mathrm{E}+02$ & $1.596 \mathrm{E}+02$ & $1.582 \mathrm{E}+02$ & $1.562 \mathrm{E}+02$ & $1.271 \mathrm{E}+02$ & $1.605 \mathrm{E}+01$ \\
\hline
\end{tabular}

THF (i) is the thread fraction of the parent nuclide.

RESCALC.EXE execution time $=4.16$ seconds 
RESRAD-OFFSITE, Version 2.5

Title : RESRAD-OFFSITE Drinking Water, Plant, Milk, and Meat Pathways for Offsite Reside File : PBA-1_TC99-DOE-5.ROF

Table of Contents

Part V: Uncertainty Analysis

RESRAD Uncertainty Analysis Results

Probabilistic Inputs ......................... 2

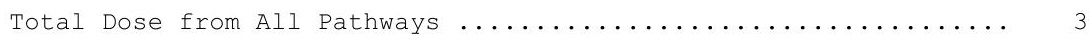

Total Risk from All Pathways ...................... 4

Ground External (water release) Pathway Dose ............. 5

Fish Ingestion (water release) Pathway Dose .............. 6

Radon Inhalation (water release) Pathway Dose ............. 7

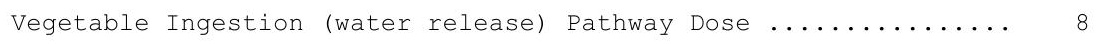

Meat Ingestion (water release) Pathway Dose ............... 9

Milk Ingestion (water release) Pathway Dose ............... 10

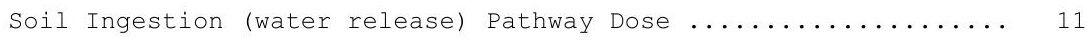

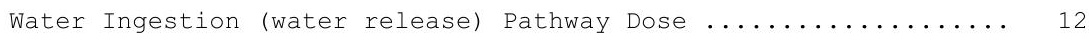

Ground External (direct \& air release) Pathway Dose ......... 13

Inhalation (w/o Radon) (direct \& air) Pathway Dose .......... 14

Radon Inhalation (direct \& air release) Pathway Dose ......... 15

Vegetable Ingestion (direct \& air release) Pathway Dose ....... 16

Meat Ingestion (direct \& air release) Pathway Dose .......... 17

Milk Ingestion (direct \& air release) Pathway Dose .......... 18

Soil Ingestion (direct \& air release) Pathway Dose .......... 19

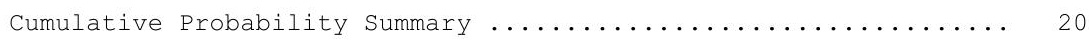

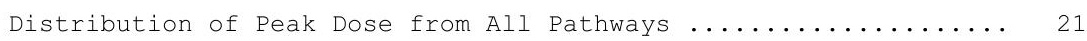

Distribution of Peak Dose from External Ground(Wreleas) ...... 22

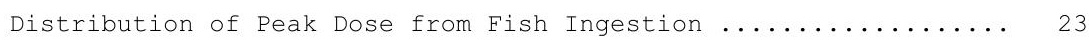

Distribution of Peak Dose from Radon (Waterrelease) ......... 24

Distribution of Peak Dose from Plant (Waterrelease) ........ 25

Distribution of Peak Dose from Meat (Waterrelease) ......... 26

Distribution of Peak Dose from Milk (Waterrelease) ......... 27

Distribution of Peak Dose from Soil Ingestion(Wrelease) ....... 28

Distribution of Peak Dose from Water Ingestion ............ 29

Distribution of Peak Dose from External Ground(CZ\&Air) ....... 30

Distribution of Peak Dose from Inhalation ExcludingRn ........ 31

Distribution of Peak Dose from Radon (CZandAir) ........... 32

Distribution of Peak Dose from Plant (CzandAir) ........... 33

Distribution of Peak Dose from Meat (CZandAir) ............ 34

Distribution of Peak Dose from Milk (CzandAir) ............ 35

Distribution of Peak Dose from Soil Ingestion(CZandAir) ....... 36

Distribution of Peak Risk from All Pathways ............. 37

Distribution of Peak Risk from External Ground(Wreleas) ....... 38

Distribution of Peak Risk from Fish Ingestion ............. 39

Distribution of Peak Risk from Radon (Waterrelease) ......... 40

Distribution of Peak Risk from Plant (Waterrelease) ......... 41

Distribution of Peak Risk from Meat (Waterrelease) ......... 42

Distribution of Peak Risk from Milk (Waterrelease) ......... 43

Distribution of Peak Risk from Soil Ingestion(Wrelease) ....... 44

Distribution of Peak Risk from Water Ingestion ............ 45

Distribution of Peak Risk from External Ground(CZ\&Air) ....... 46

Distribution of Peak Risk from Inhalation ExcludingRn ........ 47

Distribution of Peak Risk from Radon (CZandAir) ............ 48

Distribution of Peak Risk from Plant (CzandAir) ........... 49

Distribution of Peak Risk from Meat (CZandAir) ............ 50

Distribution of Peak Risk from Milk (CzandAir) ........... 51

Distribution of Peak Risk from Soil Ingestion(CZandAir) ....... 52 
Peak of the mean dose at graphical times $\ldots \ldots \ldots \ldots \ldots \ldots \ldots \ldots 188$ 

RESRAD-OFFSITE, Version 2.5

Probabilistic Dose and Risk Report

Title : RESRAD-OFFSITE Drinking Water, Plant, Milk, and Meat Pathways for Offsite Reside File : PBA-1_TC99-DOE-5.ROF

Probabilistic Total Dose Summary

\begin{tabular}{|c|c|c|c|c|c|c|c|c|c|}
\hline Nuclide & Peak & Peak & & & & $\operatorname{DOSE}(j, t)$, & mrem/yr & & \\
\hline$(j)$ & Time & Dose & $t=$ & $0.00 \mathrm{E}+00$ & $1.00 \mathrm{E}+00$ & $5.00 \mathrm{E}+01$ & $1.00 \mathrm{E}+02$ & $5.00 \mathrm{E}+02$ & $1.03 E+03$ \\
\hline \multicolumn{10}{|l|}{$\mathrm{TC}-99$} \\
\hline Min & $5.83 E+02$ & $1.06 \mathrm{E}-01$ & & $0.00 \mathrm{E}+00$ & $0.00 \mathrm{E}+00$ & $0.00 \mathrm{E}+00$ & $0.00 \mathrm{E}+00$ & $3.92 \mathrm{E}-04$ & $9.66 \mathrm{E}-02$ \\
\hline Max & $1.05 E+03$ & $5.70 \mathrm{E}+00$ & & $0.00 \mathrm{E}+00$ & $0.00 \mathrm{E}+00$ & $0.00 \mathrm{E}+00$ & $0.00 \mathrm{E}+00$ & $4.68 E+00$ & $3.43 E+00$ \\
\hline Avg & $1.03 E+03$ & $1.00 \mathrm{E}+00$ & & $0.00 \mathrm{E}+00$ & $0.00 \mathrm{E}+00$ & $0.00 \mathrm{E}+00$ & $0.00 \mathrm{E}+00$ & $1.56 \mathrm{E}-01$ & $9.55 \mathrm{E}-01$ \\
\hline Std & $6.09 \mathrm{E}+01$ & $5.96 \mathrm{E}-01$ & & $0.00 \mathrm{E}+00$ & $0.00 \mathrm{E}+00$ & $0.00 \mathrm{E}+00$ & $0.00 \mathrm{E}+00$ & $3.07 \mathrm{E}-01$ & $5.44 \mathrm{E}-01$ \\
\hline \multicolumn{10}{|l|}{$\sum \mathrm{ALL}$} \\
\hline Min & $5.83 \mathrm{E}+02$ & $1.06 \mathrm{E}-01$ & & $0.00 \mathrm{E}+00$ & $0.00 \mathrm{E}+00$ & $0.00 \mathrm{E}+00$ & $0.00 \mathrm{E}+00$ & $3.92 \mathrm{E}-04$ & $9.66 \mathrm{E}-02$ \\
\hline $\operatorname{Max}$ & $1.05 E+03$ & $5.70 \mathrm{E}+00$ & & $0.00 \mathrm{E}+00$ & $0.00 \mathrm{E}+00$ & $0.00 \mathrm{E}+00$ & $0.00 \mathrm{E}+00$ & 4. $68 \mathrm{E}+00$ & $3.43 E+00$ \\
\hline Avg & 1.03E+03 & 1. $00 \mathrm{E}+00$ & & $0.00 \mathrm{E}+00$ & $0.00 \mathrm{E}+00$ & $0.00 \mathrm{E}+00$ & $0.00 \mathrm{E}+00$ & $1.56 \mathrm{E}-01$ & $9.55 \mathrm{E}-01$ \\
\hline Std & $6.09 \mathrm{E}+01$ & $5.96 \mathrm{E}-01$ & & $0.00 \mathrm{E}+00$ & $0.00 \mathrm{E}+00$ & $0.00 \mathrm{E}+00$ & $0.00 \mathrm{E}+00$ & $3.07 \mathrm{E}-01$ & $5.44 \mathrm{E}-01$ \\
\hline
\end{tabular}

MALL is total dose summed for all nuclides. 
RESRAD-OFFSITE, Version 2.5

Probabilistic Dose and Risk Report

Title : RESRAD-OFFSITE Drinking Water, Plant, Milk, and Meat Pathways for Offsite Reside File : PBA-1_TC99-DOE-5.ROF

Probabilistic Total Risk Summary

\begin{tabular}{|c|c|c|c|c|c|c|c|}
\hline \multirow{2}{*}{$\begin{array}{l}\text { Nuclide } \\
\text { (j) }\end{array}$} & \multicolumn{7}{|c|}{$\operatorname{RISK}(j, t)$} \\
\hline & $t=$ & $0.00 \mathrm{E}+00$ & $1.00 \mathrm{E}+00$ & $5.00 \mathrm{E}+01$ & $1.00 \mathrm{E}+02$ & $5.00 \mathrm{E}+02$ & $1.03 E+03$ \\
\hline \multicolumn{8}{|l|}{$\mathrm{Tc}-99$} \\
\hline Min & & $0.00 E+00$ & $0.00 \mathrm{E}+00$ & $0.00 \mathrm{E}+00$ & $0.00 \mathrm{E}+00$ & 1. $69 \mathrm{E}-08$ & $3.23 E-06$ \\
\hline Max & & $0.00 \mathrm{E}+00$ & $0.00 \mathrm{E}+00$ & $0.00 \mathrm{E}+00$ & 1.21E-13 & $1.55 \mathrm{E}-04$ & $1.08 E-04$ \\
\hline Avg & & $0.00 \mathrm{E}+00$ & $0.00 \mathrm{E}+00$ & $0.00 \mathrm{E}+00$ & $3.23 \mathrm{E}-17$ & $5.48 \mathrm{E}-06$ & $3.08 \mathrm{E}-05$ \\
\hline Std & & $0.00 \mathrm{E}+00$ & $0.00 \mathrm{E}+00$ & $0.00 \mathrm{E}+00$ & $1.67 \mathrm{E}-15$ & $1.04 \mathrm{E}-05$ & 1. $72 \mathrm{E}-05$ \\
\hline \multicolumn{8}{|l|}{$\sum \mathrm{ALL}$} \\
\hline Min & & $0.00 \mathrm{E}+00$ & $0.00 \mathrm{E}+00$ & $0.00 \mathrm{E}+00$ & $0.00 \mathrm{E}+00$ & $1.69 \mathrm{E}-08$ & $3.23 E-06$ \\
\hline $\operatorname{Max}$ & & $0.00 \mathrm{E}+00$ & $0.00 \mathrm{E}+00$ & $0.00 \mathrm{E}+00$ & 1. $21 \mathrm{E}-13$ & $1.55 \mathrm{E}-04$ & $1.08 \mathrm{E}-04$ \\
\hline Avg & & $0.00 \mathrm{E}+00$ & $0.00 \mathrm{E}+00$ & $0.00 \mathrm{E}+00$ & $3.23 \mathrm{E}-17$ & $5.48 \mathrm{E}-06$ & $3.08 E-05$ \\
\hline Std & & $0.00 \mathrm{E}+00$ & $0.00 \mathrm{E}+00$ & $0.00 \mathrm{E}+00$ & $1.67 \mathrm{E}-15$ & $1.04 \mathrm{E}-05$ & 1. $72 \mathrm{E}-05$ \\
\hline
\end{tabular}

MALL is total risk summed for all nuclides. 
RESRAD-OFFSITE, Version 2.5

Probabilistic Dose and Risk Report

Title : RESRAD-OFFSITE Drinking Water, Plant, Milk, and Meat Pathways for Offsite Reside

File : PBA-1_TC99-DOE-5.ROF

Probabilistic Dose vs Pathway(i): Ground External (water release)

Nuclide $\quad \operatorname{DOSE}(i, j, t), \mathrm{mrem} / \mathrm{yr}$

(j) $t=0.00 \mathrm{E}+00 \quad 1.00 \mathrm{E}+00 \quad 5.00 \mathrm{E}+01 \quad 1.00 \mathrm{E}+02 \quad 5.00 \mathrm{E}+02 \quad 1.03 \mathrm{E}+03$

TC-99

$\begin{array}{lllllll}\text { Min } & 0.00 \mathrm{E}+00 & 0.00 \mathrm{E}+00 & 0.00 \mathrm{E}+00 & 0.00 \mathrm{E}+00 & 0.00 \mathrm{E}+00 & 0.00 \mathrm{E}+00\end{array}$

$\begin{array}{lllllll}\operatorname{Max} & 0.00 \mathrm{E}+00 & 0.00 \mathrm{E}+00 & 0.00 \mathrm{E}+00 & 0.00 \mathrm{E}+00 & 0.00 \mathrm{E}+00 & 0.00 \mathrm{E}+00\end{array}$

$\begin{array}{lllllll}A v g & 0.00 \mathrm{E}+00 & 0.00 \mathrm{E}+00 & 0.00 \mathrm{E}+00 & 0.00 \mathrm{E}+00 & 0.00 \mathrm{E}+00 & 0.00 \mathrm{E}+00\end{array}$

$\begin{array}{lllllll}\text { Std } & 0.00 \mathrm{E}+00 & 0.00 \mathrm{E}+00 & 0.00 \mathrm{E}+00 & 0.00 \mathrm{E}+00 & 0.00 \mathrm{E}+00 & 0.00 \mathrm{E}+00\end{array}$ $\sum A L L$

$\begin{array}{lllllll}\text { Min } & 0.00 \mathrm{E}+00 & 0.00 \mathrm{E}+00 & 0.00 \mathrm{E}+00 & 0.00 \mathrm{E}+00 & 0.00 \mathrm{E}+00 & 0.00 \mathrm{E}+00\end{array}$

$\begin{array}{lllllll}\operatorname{Max} & 0.00 \mathrm{E}+00 & 0.00 \mathrm{E}+00 & 0.00 \mathrm{E}+00 & 0.00 \mathrm{E}+00 & 0.00 \mathrm{E}+00 & 0.00 \mathrm{E}+00\end{array}$

$\begin{array}{lllllll}\text { Avg } & 0.00 \mathrm{E}+00 & 0.00 \mathrm{E}+00 & 0.00 \mathrm{E}+00 & 0.00 \mathrm{E}+00 & 0.00 \mathrm{E}+00 & 0.00 \mathrm{E}+00\end{array}$

$\begin{array}{lllllll}\text { Std } & 0.00 \mathrm{E}+00 & 0.00 \mathrm{E}+00 & 0.00 \mathrm{E}+00 & 0.00 \mathrm{E}+00 & 0.00 \mathrm{E}+00 & 0.00 \mathrm{E}+00\end{array}$

MALL is total pathway dose summed for all nuclides. 
RESRAD-OFFSITE, Version 2.5

Probabilistic Dose and Risk Report

Title : RESRAD-OFFSITE Drinking Water, Plant, Milk, and Meat Pathways for Offsite Reside

File : PBA-1_TC99-DOE-5.ROF

Probabilistic Dose vs Pathway(i): Fish Ingestion (water release)

Nuclide $\quad \operatorname{DOSE}(i, j, t), \mathrm{mrem} / \mathrm{yr}$

(j) $t=0.00 \mathrm{E}+00 \quad 1.00 \mathrm{E}+00 \quad 5.00 \mathrm{E}+01 \quad 1.00 \mathrm{E}+02 \quad 5.00 \mathrm{E}+02 \quad 1.03 \mathrm{E}+03$

TC-99

$\begin{array}{lllllll}\text { Min } & 0.00 \mathrm{E}+00 & 0.00 \mathrm{E}+00 & 0.00 \mathrm{E}+00 & 0.00 \mathrm{E}+00 & 0.00 \mathrm{E}+00 & 0.00 \mathrm{E}+00\end{array}$

$\begin{array}{lllllll}\operatorname{Max} & 0.00 \mathrm{E}+00 & 0.00 \mathrm{E}+00 & 0.00 \mathrm{E}+00 & 0.00 \mathrm{E}+00 & 0.00 \mathrm{E}+00 & 0.00 \mathrm{E}+00\end{array}$

$\begin{array}{lllllll}A v g & 0.00 \mathrm{E}+00 & 0.00 \mathrm{E}+00 & 0.00 \mathrm{E}+00 & 0.00 \mathrm{E}+00 & 0.00 \mathrm{E}+00 & 0.00 \mathrm{E}+00\end{array}$

$\begin{array}{lllllll}\text { Std } & 0.00 \mathrm{E}+00 & 0.00 \mathrm{E}+00 & 0.00 \mathrm{E}+00 & 0.00 \mathrm{E}+00 & 0.00 \mathrm{E}+00 & 0.00 \mathrm{E}+00\end{array}$ $\sum A L L$

$\begin{array}{lllllll}\text { Min } & 0.00 \mathrm{E}+00 & 0.00 \mathrm{E}+00 & 0.00 \mathrm{E}+00 & 0.00 \mathrm{E}+00 & 0.00 \mathrm{E}+00 & 0.00 \mathrm{E}+00\end{array}$

$\begin{array}{lllllll}\operatorname{Max} & 0.00 \mathrm{E}+00 & 0.00 \mathrm{E}+00 & 0.00 \mathrm{E}+00 & 0.00 \mathrm{E}+00 & 0.00 \mathrm{E}+00 & 0.00 \mathrm{E}+00\end{array}$

$\begin{array}{lllllll}\text { Avg } & 0.00 \mathrm{E}+00 & 0.00 \mathrm{E}+00 & 0.00 \mathrm{E}+00 & 0.00 \mathrm{E}+00 & 0.00 \mathrm{E}+00 & 0.00 \mathrm{E}+00\end{array}$

$\begin{array}{lllllll}\text { Std } & 0.00 \mathrm{E}+00 & 0.00 \mathrm{E}+00 & 0.00 \mathrm{E}+00 & 0.00 \mathrm{E}+00 & 0.00 \mathrm{E}+00 & 0.00 \mathrm{E}+00\end{array}$

MALL is total pathway dose summed for all nuclides. 
RESRAD-OFFSITE, Version 2.5

Probabilistic Dose and Risk Report

Title : RESRAD-OFFSITE Drinking Water, Plant, Milk, and Meat Pathways for Offsite Reside

File : PBA-1_TC99-DOE-5.ROF

Probabilistic Dose vs Pathway(i): Radon Inhalation (water release)

Nuclide $\quad \operatorname{DOSE}(i, j, t), \mathrm{mrem} / \mathrm{yr}$

(j) $t=0.00 \mathrm{E}+00 \quad 1.00 \mathrm{E}+00 \quad 5.00 \mathrm{E}+01 \quad 1.00 \mathrm{E}+02 \quad 5.00 \mathrm{E}+02 \quad 1.03 \mathrm{E}+03$

TC-99

$\begin{array}{lllllll}\text { Min } & 0.00 \mathrm{E}+00 & 0.00 \mathrm{E}+00 & 0.00 \mathrm{E}+00 & 0.00 \mathrm{E}+00 & 0.00 \mathrm{E}+00 & 0.00 \mathrm{E}+00\end{array}$

$\begin{array}{lllllll}\operatorname{Max} & 0.00 \mathrm{E}+00 & 0.00 \mathrm{E}+00 & 0.00 \mathrm{E}+00 & 0.00 \mathrm{E}+00 & 0.00 \mathrm{E}+00 & 0.00 \mathrm{E}+00\end{array}$

$\begin{array}{lllllll}A v g & 0.00 \mathrm{E}+00 & 0.00 \mathrm{E}+00 & 0.00 \mathrm{E}+00 & 0.00 \mathrm{E}+00 & 0.00 \mathrm{E}+00 & 0.00 \mathrm{E}+00\end{array}$

$\begin{array}{lllllll}\text { Std } & 0.00 \mathrm{E}+00 & 0.00 \mathrm{E}+00 & 0.00 \mathrm{E}+00 & 0.00 \mathrm{E}+00 & 0.00 \mathrm{E}+00 & 0.00 \mathrm{E}+00\end{array}$ $\sum A L L$

$\begin{array}{lllllll}\text { Min } & 0.00 \mathrm{E}+00 & 0.00 \mathrm{E}+00 & 0.00 \mathrm{E}+00 & 0.00 \mathrm{E}+00 & 0.00 \mathrm{E}+00 & 0.00 \mathrm{E}+00\end{array}$

$\begin{array}{lllllll}\operatorname{Max} & 0.00 \mathrm{E}+00 & 0.00 \mathrm{E}+00 & 0.00 \mathrm{E}+00 & 0.00 \mathrm{E}+00 & 0.00 \mathrm{E}+00 & 0.00 \mathrm{E}+00\end{array}$

$\begin{array}{lllllll}\text { Avg } & 0.00 \mathrm{E}+00 & 0.00 \mathrm{E}+00 & 0.00 \mathrm{E}+00 & 0.00 \mathrm{E}+00 & 0.00 \mathrm{E}+00 & 0.00 \mathrm{E}+00\end{array}$

$\begin{array}{lllllll}\text { Std } & 0.00 \mathrm{E}+00 & 0.00 \mathrm{E}+00 & 0.00 \mathrm{E}+00 & 0.00 \mathrm{E}+00 & 0.00 \mathrm{E}+00 & 0.00 \mathrm{E}+00\end{array}$

MALL is total pathway dose summed for all nuclides. 
RESRAD-OFFSITE, Version 2.5

Probabilistic Dose and Risk Report

Title : RESRAD-OFFSITE Drinking Water, Plant, Milk, and Meat Pathways for Offsite Reside

File : PBA-1_TC99-DOE-5.ROF

Probabilistic Dose vs Pathway(i): Meat Ingestion (water release)

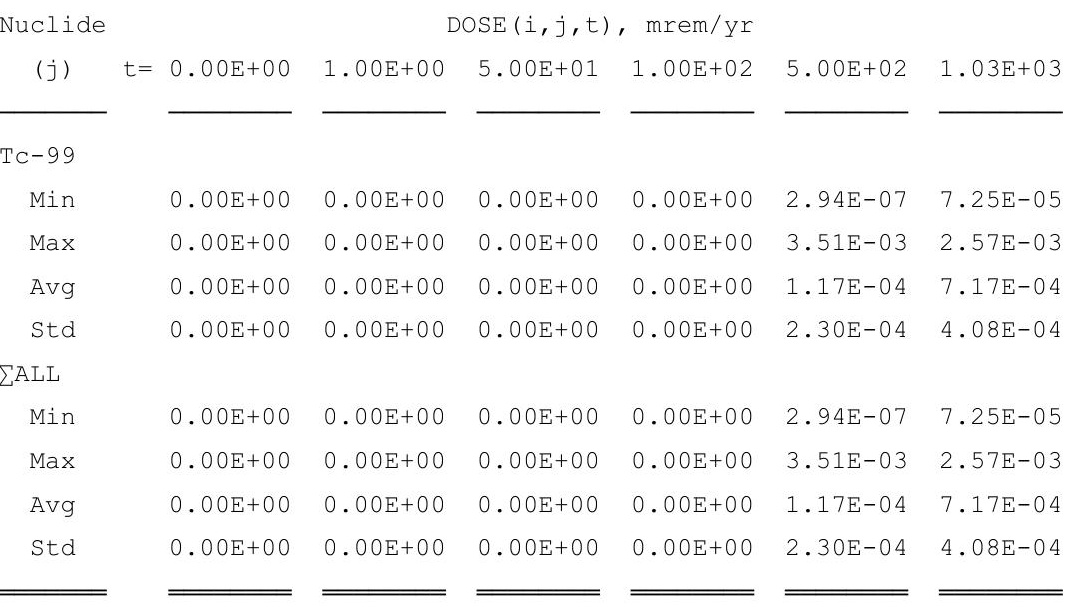

¿ALL is total pathway dose summed for all nuclides. 
RESRAD-OFFSITE, Version 2.5

Probabilistic Dose and Risk Report

Title : RESRAD-OFFSITE Drinking Water, Plant, Milk, and Meat Pathways for Offsite Reside

File : PBA-1_TC99-DOE-5.ROF

Probabilistic Dose vs Pathway(i): Milk Ingestion (water release)

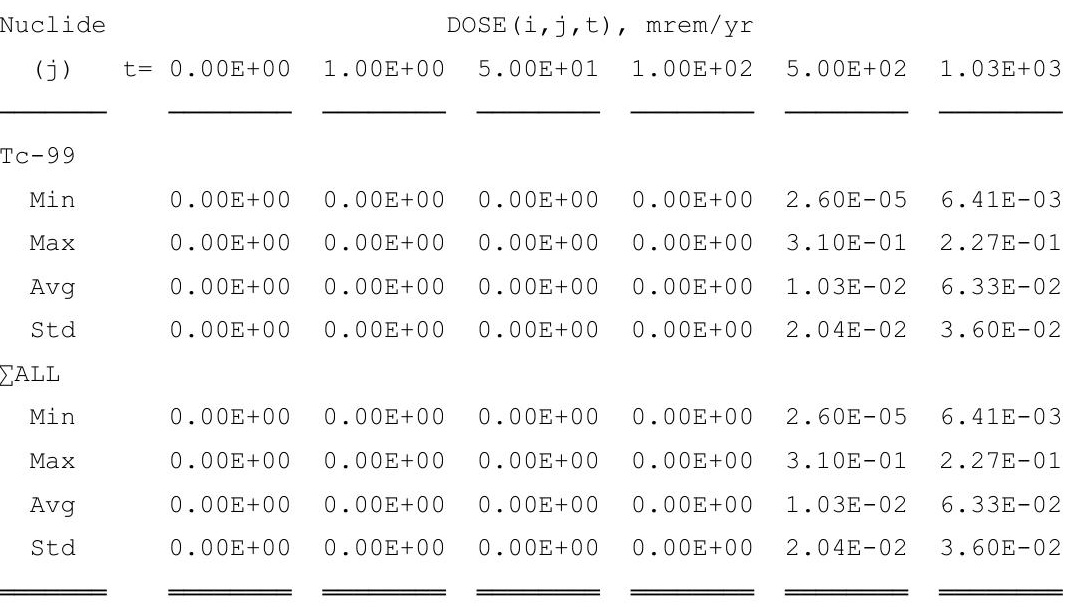

¿ALL is total pathway dose summed for all nuclides. 
RESRAD-OFFSITE, Version 2.5

Probabilistic Dose and Risk Report

Title : RESRAD-OFFSITE Drinking Water, Plant, Milk, and Meat Pathways for Offsite Reside

File : PBA-1_TC99-DOE-5.ROF

Probabilistic Dose vs Pathway(i): Soil Ingestion (water release)

Nuclide $\quad \operatorname{DOSE}(i, j, t), \mathrm{mrem} / \mathrm{yr}$

(j) $t=0.00 \mathrm{E}+00 \quad 1.00 \mathrm{E}+00 \quad 5.00 \mathrm{E}+01 \quad 1.00 \mathrm{E}+02 \quad 5.00 \mathrm{E}+02 \quad 1.03 \mathrm{E}+03$

TC-99

$\begin{array}{lllllll}\text { Min } & 0.00 \mathrm{E}+00 & 0.00 \mathrm{E}+00 & 0.00 \mathrm{E}+00 & 0.00 \mathrm{E}+00 & 0.00 \mathrm{E}+00 & 0.00 \mathrm{E}+00\end{array}$

$\begin{array}{lllllll}\operatorname{Max} & 0.00 \mathrm{E}+00 & 0.00 \mathrm{E}+00 & 0.00 \mathrm{E}+00 & 0.00 \mathrm{E}+00 & 0.00 \mathrm{E}+00 & 0.00 \mathrm{E}+00\end{array}$

$\begin{array}{lllllll}A v g & 0.00 \mathrm{E}+00 & 0.00 \mathrm{E}+00 & 0.00 \mathrm{E}+00 & 0.00 \mathrm{E}+00 & 0.00 \mathrm{E}+00 & 0.00 \mathrm{E}+00\end{array}$

$\begin{array}{lllllll}\text { Std } & 0.00 \mathrm{E}+00 & 0.00 \mathrm{E}+00 & 0.00 \mathrm{E}+00 & 0.00 \mathrm{E}+00 & 0.00 \mathrm{E}+00 & 0.00 \mathrm{E}+00\end{array}$ $\sum A L L$

$\begin{array}{lllllll}\text { Min } & 0.00 \mathrm{E}+00 & 0.00 \mathrm{E}+00 & 0.00 \mathrm{E}+00 & 0.00 \mathrm{E}+00 & 0.00 \mathrm{E}+00 & 0.00 \mathrm{E}+00\end{array}$

$\begin{array}{lllllll}\operatorname{Max} & 0.00 \mathrm{E}+00 & 0.00 \mathrm{E}+00 & 0.00 \mathrm{E}+00 & 0.00 \mathrm{E}+00 & 0.00 \mathrm{E}+00 & 0.00 \mathrm{E}+00\end{array}$

$\begin{array}{lllllll}\text { Avg } & 0.00 \mathrm{E}+00 & 0.00 \mathrm{E}+00 & 0.00 \mathrm{E}+00 & 0.00 \mathrm{E}+00 & 0.00 \mathrm{E}+00 & 0.00 \mathrm{E}+00\end{array}$

$\begin{array}{lllllll}\text { Std } & 0.00 \mathrm{E}+00 & 0.00 \mathrm{E}+00 & 0.00 \mathrm{E}+00 & 0.00 \mathrm{E}+00 & 0.00 \mathrm{E}+00 & 0.00 \mathrm{E}+00\end{array}$

MALL is total pathway dose summed for all nuclides. 
RESRAD-OFFSITE, Version 2.5

Probabilistic Dose and Risk Report

Title : RESRAD-OFFSITE Drinking Water, Plant, Milk, and Meat Pathways for Offsite Reside

File : PBA-1_TC99-DOE-5.ROF

Probabilistic Dose vs Pathway(i): Water Ingestion (water release)

Nuclide $\quad \operatorname{DOSE}(i, j, t), \mathrm{mrem} / \mathrm{yr}$

(j) $t=0.00 \mathrm{E}+00 \quad 1.00 \mathrm{E}+00 \quad 5.00 \mathrm{E}+01 \quad 1.00 \mathrm{E}+02 \quad 5.00 \mathrm{E}+02 \quad 1.03 \mathrm{E}+03$

TC-99

$\begin{array}{lllllll}\text { Min } & 0.00 \mathrm{E}+00 & 0.00 \mathrm{E}+00 & 0.00 \mathrm{E}+00 & 0.00 \mathrm{E}+00 & 2.68 \mathrm{E}-04 & 6.59 \mathrm{E}-02\end{array}$

$\begin{array}{lllllll}\operatorname{Max} & 0.00 \mathrm{E}+00 & 0.00 \mathrm{E}+00 & 0.00 \mathrm{E}+00 & 0.00 \mathrm{E}+00 & 3.19 \mathrm{E}+00 & 2.34 \mathrm{E}+00\end{array}$

$\begin{array}{lllllll}A v g & 0.00 \mathrm{E}+00 & 0.00 \mathrm{E}+00 & 0.00 \mathrm{E}+00 & 0.00 \mathrm{E}+00 & 1.06 \mathrm{E}-01 & 6.52 \mathrm{E}-01\end{array}$

$\begin{array}{lllllll}\text { Std } & 0.00 \mathrm{E}+00 & 0.00 \mathrm{E}+00 & 0.00 \mathrm{E}+00 & 0.00 \mathrm{E}+00 & 2.10 \mathrm{E}-01 & 3.71 \mathrm{E}-01\end{array}$ $\sum A L L$

$\begin{array}{lllllll}\text { Min } & 0.00 \mathrm{E}+00 & 0.00 \mathrm{E}+00 & 0.00 \mathrm{E}+00 & 0.00 \mathrm{E}+00 & 2.68 \mathrm{E}-04 & 6.59 \mathrm{E}-02\end{array}$

$\begin{array}{lllllll}\operatorname{Max} & 0.00 \mathrm{E}+00 & 0.00 \mathrm{E}+00 & 0.00 \mathrm{E}+00 & 0.00 \mathrm{E}+00 & 3.19 \mathrm{E}+00 & 2.34 \mathrm{E}+00\end{array}$

$\begin{array}{lllllll}\text { Avg } & 0.00 \mathrm{E}+00 & 0.00 \mathrm{E}+00 & 0.00 \mathrm{E}+00 & 0.00 \mathrm{E}+00 & 1.06 \mathrm{E}-01 & 6.52 \mathrm{E}-01\end{array}$

$\begin{array}{lllllll}\text { Std } & 0.00 \mathrm{E}+00 & 0.00 \mathrm{E}+00 & 0.00 \mathrm{E}+00 & 0.00 \mathrm{E}+00 & 2.10 \mathrm{E}-01 & 3.71 \mathrm{E}-01\end{array}$

MALL is total pathway dose summed for all nuclides. 
RESRAD-OFFSITE, Version 2.5

Probabilistic Dose and Risk Report

Title : RESRAD-OFFSITE Drinking Water, Plant, Milk, and Meat Pathways for Offsite Reside

File : PBA-1_TC99-DOE-5.ROF

Probabilistic Dose vs Pathway(i): Ground External (direct \& air release)

Nuclide $\quad \operatorname{DOSE}(i, j, t), \mathrm{mrem} / \mathrm{yr}$

(j) $t=0.00 \mathrm{E}+00 \quad 1.00 \mathrm{E}+00 \quad 5.00 \mathrm{E}+01 \quad 1.00 \mathrm{E}+02 \quad 5.00 \mathrm{E}+02 \quad 1.03 \mathrm{E}+03$

TC-99

$\begin{array}{lllllll}\text { Min } & 0.00 \mathrm{E}+00 & 0.00 \mathrm{E}+00 & 0.00 \mathrm{E}+00 & 0.00 \mathrm{E}+00 & 0.00 \mathrm{E}+00 & 0.00 \mathrm{E}+00\end{array}$

$\begin{array}{lllllll}\operatorname{Max} & 0.00 \mathrm{E}+00 & 0.00 \mathrm{E}+00 & 0.00 \mathrm{E}+00 & 0.00 \mathrm{E}+00 & 0.00 \mathrm{E}+00 & 0.00 \mathrm{E}+00\end{array}$

$\begin{array}{lllllll}A v g & 0.00 \mathrm{E}+00 & 0.00 \mathrm{E}+00 & 0.00 \mathrm{E}+00 & 0.00 \mathrm{E}+00 & 0.00 \mathrm{E}+00 & 0.00 \mathrm{E}+00\end{array}$

$\begin{array}{lllllll}\text { Std } & 0.00 \mathrm{E}+00 & 0.00 \mathrm{E}+00 & 0.00 \mathrm{E}+00 & 0.00 \mathrm{E}+00 & 0.00 \mathrm{E}+00 & 0.00 \mathrm{E}+00\end{array}$ $\sum A L L$

$\begin{array}{lllllll}\text { Min } & 0.00 \mathrm{E}+00 & 0.00 \mathrm{E}+00 & 0.00 \mathrm{E}+00 & 0.00 \mathrm{E}+00 & 0.00 \mathrm{E}+00 & 0.00 \mathrm{E}+00\end{array}$

$\begin{array}{lllllll}\operatorname{Max} & 0.00 \mathrm{E}+00 & 0.00 \mathrm{E}+00 & 0.00 \mathrm{E}+00 & 0.00 \mathrm{E}+00 & 0.00 \mathrm{E}+00 & 0.00 \mathrm{E}+00\end{array}$

$\begin{array}{lllllll}\text { Avg } & 0.00 \mathrm{E}+00 & 0.00 \mathrm{E}+00 & 0.00 \mathrm{E}+00 & 0.00 \mathrm{E}+00 & 0.00 \mathrm{E}+00 & 0.00 \mathrm{E}+00\end{array}$

$\begin{array}{lllllll}\text { Std } & 0.00 \mathrm{E}+00 & 0.00 \mathrm{E}+00 & 0.00 \mathrm{E}+00 & 0.00 \mathrm{E}+00 & 0.00 \mathrm{E}+00 & 0.00 \mathrm{E}+00\end{array}$

MALL is total pathway dose summed for all nuclides. 
RESRAD-OFFSITE, Version 2.5

Probabilistic Dose and Risk Report

Title : RESRAD-OFFSITE Drinking Water, Plant, Milk, and Meat Pathways for Offsite Reside

File : PBA-1_TC99-DOE-5.ROF

Probabilistic Dose vs Pathway(i): Inhalation (w/o Radon) (direct \& air)

Nuclide $\quad \operatorname{DOSE}(i, j, t), \mathrm{mrem} / \mathrm{yr}$

(j) $t=0.00 \mathrm{E}+00 \quad 1.00 \mathrm{E}+00 \quad 5.00 \mathrm{E}+01 \quad 1.00 \mathrm{E}+02 \quad 5.00 \mathrm{E}+02 \quad 1.03 \mathrm{E}+03$

TC-99

$\begin{array}{lllllll}\text { Min } & 0.00 \mathrm{E}+00 & 0.00 \mathrm{E}+00 & 0.00 \mathrm{E}+00 & 0.00 \mathrm{E}+00 & 0.00 \mathrm{E}+00 & 0.00 \mathrm{E}+00\end{array}$

$\begin{array}{lllllll}\operatorname{Max} & 0.00 \mathrm{E}+00 & 0.00 \mathrm{E}+00 & 0.00 \mathrm{E}+00 & 0.00 \mathrm{E}+00 & 0.00 \mathrm{E}+00 & 0.00 \mathrm{E}+00\end{array}$

$\begin{array}{lllllll}A v g & 0.00 \mathrm{E}+00 & 0.00 \mathrm{E}+00 & 0.00 \mathrm{E}+00 & 0.00 \mathrm{E}+00 & 0.00 \mathrm{E}+00 & 0.00 \mathrm{E}+00\end{array}$

$\begin{array}{lllllll}\text { Std } & 0.00 \mathrm{E}+00 & 0.00 \mathrm{E}+00 & 0.00 \mathrm{E}+00 & 0.00 \mathrm{E}+00 & 0.00 \mathrm{E}+00 & 0.00 \mathrm{E}+00\end{array}$ $\sum A L L$

Min $\quad \begin{array}{llllll}0.00 \mathrm{E}+00 & 0.00 \mathrm{E}+00 & 0.00 \mathrm{E}+00 & 0.00 \mathrm{E}+00 & 0.00 \mathrm{E}+00 & 0.00 \mathrm{E}+00\end{array}$

$\begin{array}{lllllll}\operatorname{Max} & 0.00 \mathrm{E}+00 & 0.00 \mathrm{E}+00 & 0.00 \mathrm{E}+00 & 0.00 \mathrm{E}+00 & 0.00 \mathrm{E}+00 & 0.00 \mathrm{E}+00\end{array}$

$\begin{array}{lllllll}\text { Avg } & 0.00 \mathrm{E}+00 & 0.00 \mathrm{E}+00 & 0.00 \mathrm{E}+00 & 0.00 \mathrm{E}+00 & 0.00 \mathrm{E}+00 & 0.00 \mathrm{E}+00\end{array}$

$\begin{array}{lllllll}\text { Std } & 0.00 \mathrm{E}+00 & 0.00 \mathrm{E}+00 & 0.00 \mathrm{E}+00 & 0.00 \mathrm{E}+00 & 0.00 \mathrm{E}+00 & 0.00 \mathrm{E}+00\end{array}$

¿ALL is total pathway dose summed for all nuclides. 
RESRAD-OFFSITE, Version 2.5

Probabilistic Dose and Risk Report

Title : RESRAD-OFFSITE Drinking Water, Plant, Milk, and Meat Pathways for Offsite Reside

File : PBA-1_TC99-DOE-5.ROF

Probabilistic Dose vs Pathway(i): Radon Inhalation (direct \& air release)

Nuclide $\quad \operatorname{DOSE}(i, j, t), \mathrm{mrem} / \mathrm{yr}$

(j) $t=0.00 \mathrm{E}+00 \quad 1.00 \mathrm{E}+00 \quad 5.00 \mathrm{E}+01 \quad 1.00 \mathrm{E}+02 \quad 5.00 \mathrm{E}+02 \quad 1.03 \mathrm{E}+03$

TC-99

$\begin{array}{lllllll}\text { Min } & 0.00 \mathrm{E}+00 & 0.00 \mathrm{E}+00 & 0.00 \mathrm{E}+00 & 0.00 \mathrm{E}+00 & 0.00 \mathrm{E}+00 & 0.00 \mathrm{E}+00\end{array}$

$\begin{array}{lllllll}\operatorname{Max} & 0.00 \mathrm{E}+00 & 0.00 \mathrm{E}+00 & 0.00 \mathrm{E}+00 & 0.00 \mathrm{E}+00 & 0.00 \mathrm{E}+00 & 0.00 \mathrm{E}+00\end{array}$

$\begin{array}{lllllll}A v g & 0.00 \mathrm{E}+00 & 0.00 \mathrm{E}+00 & 0.00 \mathrm{E}+00 & 0.00 \mathrm{E}+00 & 0.00 \mathrm{E}+00 & 0.00 \mathrm{E}+00\end{array}$

$\begin{array}{lllllll}\text { Std } & 0.00 \mathrm{E}+00 & 0.00 \mathrm{E}+00 & 0.00 \mathrm{E}+00 & 0.00 \mathrm{E}+00 & 0.00 \mathrm{E}+00 & 0.00 \mathrm{E}+00\end{array}$ $\sum A L L$

$\begin{array}{lllllll}\text { Min } & 0.00 \mathrm{E}+00 & 0.00 \mathrm{E}+00 & 0.00 \mathrm{E}+00 & 0.00 \mathrm{E}+00 & 0.00 \mathrm{E}+00 & 0.00 \mathrm{E}+00\end{array}$

$\begin{array}{lllllll}\operatorname{Max} & 0.00 \mathrm{E}+00 & 0.00 \mathrm{E}+00 & 0.00 \mathrm{E}+00 & 0.00 \mathrm{E}+00 & 0.00 \mathrm{E}+00 & 0.00 \mathrm{E}+00\end{array}$

$\begin{array}{lllllll}\text { Avg } & 0.00 \mathrm{E}+00 & 0.00 \mathrm{E}+00 & 0.00 \mathrm{E}+00 & 0.00 \mathrm{E}+00 & 0.00 \mathrm{E}+00 & 0.00 \mathrm{E}+00\end{array}$

$\begin{array}{lllllll}\text { Std } & 0.00 \mathrm{E}+00 & 0.00 \mathrm{E}+00 & 0.00 \mathrm{E}+00 & 0.00 \mathrm{E}+00 & 0.00 \mathrm{E}+00 & 0.00 \mathrm{E}+00\end{array}$

MALL is total pathway dose summed for all nuclides. 
RESRAD-OFFSITE, Version 2.5

Probabilistic Dose and Risk Report

Title : RESRAD-OFFSITE Drinking Water, Plant, Milk, and Meat Pathways for Offsite Reside

File : PBA-1_TC99-DOE-5.ROF

Probabilistic Dose vs Pathway(i): Vegetable Ingestion (direct \& air release)

Nuclide $\quad \operatorname{DOSE}(i, j, t), \mathrm{mrem} / \mathrm{yr}$

(j) $t=0.00 \mathrm{E}+00 \quad 1.00 \mathrm{E}+00 \quad 5.00 \mathrm{E}+01 \quad 1.00 \mathrm{E}+02 \quad 5.00 \mathrm{E}+02 \quad 1.03 \mathrm{E}+03$

TC-99

$\begin{array}{lllllll}\text { Min } & 0.00 \mathrm{E}+00 & 0.00 \mathrm{E}+00 & 0.00 \mathrm{E}+00 & 0.00 \mathrm{E}+00 & 0.00 \mathrm{E}+00 & 0.00 \mathrm{E}+00\end{array}$

$\begin{array}{lllllll}\operatorname{Max} & 0.00 \mathrm{E}+00 & 0.00 \mathrm{E}+00 & 0.00 \mathrm{E}+00 & 0.00 \mathrm{E}+00 & 0.00 \mathrm{E}+00 & 0.00 \mathrm{E}+00\end{array}$

$\begin{array}{lllllll}A v g & 0.00 \mathrm{E}+00 & 0.00 \mathrm{E}+00 & 0.00 \mathrm{E}+00 & 0.00 \mathrm{E}+00 & 0.00 \mathrm{E}+00 & 0.00 \mathrm{E}+00\end{array}$

$\begin{array}{lllllll}\text { Std } & 0.00 \mathrm{E}+00 & 0.00 \mathrm{E}+00 & 0.00 \mathrm{E}+00 & 0.00 \mathrm{E}+00 & 0.00 \mathrm{E}+00 & 0.00 \mathrm{E}+00\end{array}$ $\sum A L L$

$\begin{array}{lllllll}\text { Min } & 0.00 \mathrm{E}+00 & 0.00 \mathrm{E}+00 & 0.00 \mathrm{E}+00 & 0.00 \mathrm{E}+00 & 0.00 \mathrm{E}+00 & 0.00 \mathrm{E}+00\end{array}$

$\begin{array}{lllllll}\operatorname{Max} & 0.00 \mathrm{E}+00 & 0.00 \mathrm{E}+00 & 0.00 \mathrm{E}+00 & 0.00 \mathrm{E}+00 & 0.00 \mathrm{E}+00 & 0.00 \mathrm{E}+00\end{array}$

$\begin{array}{lllllll}\text { Avg } & 0.00 \mathrm{E}+00 & 0.00 \mathrm{E}+00 & 0.00 \mathrm{E}+00 & 0.00 \mathrm{E}+00 & 0.00 \mathrm{E}+00 & 0.00 \mathrm{E}+00\end{array}$

$\begin{array}{lllllll}\text { Std } & 0.00 \mathrm{E}+00 & 0.00 \mathrm{E}+00 & 0.00 \mathrm{E}+00 & 0.00 \mathrm{E}+00 & 0.00 \mathrm{E}+00 & 0.00 \mathrm{E}+00\end{array}$

MALL is total pathway dose summed for all nuclides. 
RESRAD-OFFSITE, Version 2.5

Probabilistic Dose and Risk Report

Title : RESRAD-OFFSITE Drinking Water, Plant, Milk, and Meat Pathways for Offsite Reside

File : PBA-1_TC99-DOE-5.ROF

Probabilistic Dose vs Pathway(i): Meat Ingestion (direct \& air release)

Nuclide $\quad \operatorname{DOSE}(i, j, t), \mathrm{mrem} / \mathrm{yr}$

(j) $t=0.00 \mathrm{E}+00 \quad 1.00 \mathrm{E}+00 \quad 5.00 \mathrm{E}+01 \quad 1.00 \mathrm{E}+02 \quad 5.00 \mathrm{E}+02 \quad 1.03 \mathrm{E}+03$

TC-99

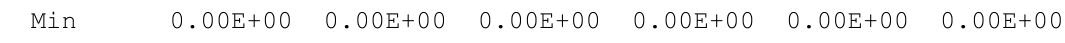

$\begin{array}{lllllll}\operatorname{Max} & 0.00 \mathrm{E}+00 & 0.00 \mathrm{E}+00 & 0.00 \mathrm{E}+00 & 0.00 \mathrm{E}+00 & 0.00 \mathrm{E}+00 & 0.00 \mathrm{E}+00\end{array}$

$\begin{array}{lllllll}A v g & 0.00 \mathrm{E}+00 & 0.00 \mathrm{E}+00 & 0.00 \mathrm{E}+00 & 0.00 \mathrm{E}+00 & 0.00 \mathrm{E}+00 & 0.00 \mathrm{E}+00\end{array}$

$\begin{array}{lllllll}\text { Std } & 0.00 \mathrm{E}+00 & 0.00 \mathrm{E}+00 & 0.00 \mathrm{E}+00 & 0.00 \mathrm{E}+00 & 0.00 \mathrm{E}+00 & 0.00 \mathrm{E}+00\end{array}$ $\sum A L L$

$\begin{array}{lllllll}\text { Min } & 0.00 \mathrm{E}+00 & 0.00 \mathrm{E}+00 & 0.00 \mathrm{E}+00 & 0.00 \mathrm{E}+00 & 0.00 \mathrm{E}+00 & 0.00 \mathrm{E}+00\end{array}$

$\begin{array}{lllllll}\operatorname{Max} & 0.00 \mathrm{E}+00 & 0.00 \mathrm{E}+00 & 0.00 \mathrm{E}+00 & 0.00 \mathrm{E}+00 & 0.00 \mathrm{E}+00 & 0.00 \mathrm{E}+00\end{array}$

$\begin{array}{lllllll}\text { Avg } & 0.00 \mathrm{E}+00 & 0.00 \mathrm{E}+00 & 0.00 \mathrm{E}+00 & 0.00 \mathrm{E}+00 & 0.00 \mathrm{E}+00 & 0.00 \mathrm{E}+00\end{array}$

$\begin{array}{lllllll}\text { Std } & 0.00 \mathrm{E}+00 & 0.00 \mathrm{E}+00 & 0.00 \mathrm{E}+00 & 0.00 \mathrm{E}+00 & 0.00 \mathrm{E}+00 & 0.00 \mathrm{E}+00\end{array}$

MALL is total pathway dose summed for all nuclides. 
RESRAD-OFFSITE, Version 2.5

Probabilistic Dose and Risk Report

Title : RESRAD-OFFSITE Drinking Water, Plant, Milk, and Meat Pathways for Offsite Reside

File : PBA-1_TC99-DOE-5.ROF

Probabilistic Dose vs Pathway(i): Milk Ingestion (direct \& air release)

Nuclide $\quad \operatorname{DOSE}(i, j, t), \mathrm{mrem} / \mathrm{yr}$

(j) $t=0.00 \mathrm{E}+00 \quad 1.00 \mathrm{E}+00 \quad 5.00 \mathrm{E}+01 \quad 1.00 \mathrm{E}+02 \quad 5.00 \mathrm{E}+02 \quad 1.03 \mathrm{E}+03$

TC-99

$\begin{array}{lllllll}\text { Min } & 0.00 \mathrm{E}+00 & 0.00 \mathrm{E}+00 & 0.00 \mathrm{E}+00 & 0.00 \mathrm{E}+00 & 0.00 \mathrm{E}+00 & 0.00 \mathrm{E}+00\end{array}$

$\begin{array}{lllllll}\operatorname{Max} & 0.00 \mathrm{E}+00 & 0.00 \mathrm{E}+00 & 0.00 \mathrm{E}+00 & 0.00 \mathrm{E}+00 & 0.00 \mathrm{E}+00 & 0.00 \mathrm{E}+00\end{array}$

$\begin{array}{lllllll}A v g & 0.00 \mathrm{E}+00 & 0.00 \mathrm{E}+00 & 0.00 \mathrm{E}+00 & 0.00 \mathrm{E}+00 & 0.00 \mathrm{E}+00 & 0.00 \mathrm{E}+00\end{array}$

$\begin{array}{lllllll}\text { Std } & 0.00 \mathrm{E}+00 & 0.00 \mathrm{E}+00 & 0.00 \mathrm{E}+00 & 0.00 \mathrm{E}+00 & 0.00 \mathrm{E}+00 & 0.00 \mathrm{E}+00\end{array}$ $\sum A L L$

$\begin{array}{lllllll}\text { Min } & 0.00 \mathrm{E}+00 & 0.00 \mathrm{E}+00 & 0.00 \mathrm{E}+00 & 0.00 \mathrm{E}+00 & 0.00 \mathrm{E}+00 & 0.00 \mathrm{E}+00\end{array}$

$\begin{array}{lllllll}\operatorname{Max} & 0.00 \mathrm{E}+00 & 0.00 \mathrm{E}+00 & 0.00 \mathrm{E}+00 & 0.00 \mathrm{E}+00 & 0.00 \mathrm{E}+00 & 0.00 \mathrm{E}+00\end{array}$

$\begin{array}{lllllll}\text { Avg } & 0.00 \mathrm{E}+00 & 0.00 \mathrm{E}+00 & 0.00 \mathrm{E}+00 & 0.00 \mathrm{E}+00 & 0.00 \mathrm{E}+00 & 0.00 \mathrm{E}+00\end{array}$

$\begin{array}{lllllll}\text { Std } & 0.00 \mathrm{E}+00 & 0.00 \mathrm{E}+00 & 0.00 \mathrm{E}+00 & 0.00 \mathrm{E}+00 & 0.00 \mathrm{E}+00 & 0.00 \mathrm{E}+00\end{array}$

MALL is total pathway dose summed for all nuclides. 
RESRAD-OFFSITE, Version 2.5

Probabilistic Dose and Risk Report

Title : RESRAD-OFFSITE Drinking Water, Plant, Milk, and Meat Pathways for Offsite Reside

File : PBA-1_TC99-DOE-5.ROF

Probabilistic Dose vs Pathway(i): Soil Ingestion (direct \& air release)

Nuclide $\quad \operatorname{DOSE}(i, j, t), \mathrm{mrem} / \mathrm{yr}$

(j) $t=0.00 \mathrm{E}+00 \quad 1.00 \mathrm{E}+00 \quad 5.00 \mathrm{E}+01 \quad 1.00 \mathrm{E}+02 \quad 5.00 \mathrm{E}+02 \quad 1.03 \mathrm{E}+03$

TC-99

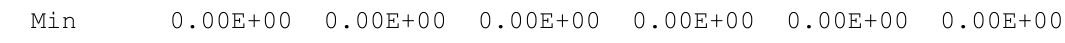

$\begin{array}{lllllll}\operatorname{Max} & 0.00 \mathrm{E}+00 & 0.00 \mathrm{E}+00 & 0.00 \mathrm{E}+00 & 0.00 \mathrm{E}+00 & 0.00 \mathrm{E}+00 & 0.00 \mathrm{E}+00\end{array}$

$\begin{array}{lllllll}A v g & 0.00 \mathrm{E}+00 & 0.00 \mathrm{E}+00 & 0.00 \mathrm{E}+00 & 0.00 \mathrm{E}+00 & 0.00 \mathrm{E}+00 & 0.00 \mathrm{E}+00\end{array}$

$\begin{array}{lllllll}\text { Std } & 0.00 \mathrm{E}+00 & 0.00 \mathrm{E}+00 & 0.00 \mathrm{E}+00 & 0.00 \mathrm{E}+00 & 0.00 \mathrm{E}+00 & 0.00 \mathrm{E}+00\end{array}$ $\sum A L L$

$\begin{array}{lllllll}\text { Min } & 0.00 \mathrm{E}+00 & 0.00 \mathrm{E}+00 & 0.00 \mathrm{E}+00 & 0.00 \mathrm{E}+00 & 0.00 \mathrm{E}+00 & 0.00 \mathrm{E}+00\end{array}$

$\begin{array}{lllllll}\operatorname{Max} & 0.00 \mathrm{E}+00 & 0.00 \mathrm{E}+00 & 0.00 \mathrm{E}+00 & 0.00 \mathrm{E}+00 & 0.00 \mathrm{E}+00 & 0.00 \mathrm{E}+00\end{array}$

$\begin{array}{lllllll}\text { Avg } & 0.00 \mathrm{E}+00 & 0.00 \mathrm{E}+00 & 0.00 \mathrm{E}+00 & 0.00 \mathrm{E}+00 & 0.00 \mathrm{E}+00 & 0.00 \mathrm{E}+00\end{array}$

$\begin{array}{lllllll}\text { Std } & 0.00 \mathrm{E}+00 & 0.00 \mathrm{E}+00 & 0.00 \mathrm{E}+00 & 0.00 \mathrm{E}+00 & 0.00 \mathrm{E}+00 & 0.00 \mathrm{E}+00\end{array}$

MALL is total pathway dose summed for all nuclides. 
RESRAD-OFFSITE, Version 2.5

$\mathrm{T}^{1 / 2}$ Limit $=180$ days

robabilistic Dose and Risk Report

Title : RESRAD-OFFSITE Drinking Water, Plant, Milk, and Meat Pathways for Offsite Reside File : PBA-1_TC99-DOE-5.ROF

Cumulative Probability Summary for: Total Dose Over all Pathways

\begin{tabular}{|c|c|c|c|c|c|c|c|}
\hline \multicolumn{3}{|l|}{ Cumulative } & \multicolumn{5}{|c|}{ Dose $(t), \mathrm{mrem} / \mathrm{yr}$} \\
\hline Probability & $t=$ & $0.00 \mathrm{E}+00$ & $1.00 \mathrm{E}+00$ & $5.00 \mathrm{E}+01$ & $1.00 \mathrm{E}+02$ & $5.00 \mathrm{E}+02$ & $1.03 E+03$ \\
\hline 0.025 & & $0.00 \mathrm{E}+00$ & $0.00 \mathrm{E}+00$ & $0.00 \mathrm{E}+00$ & $0.00 \mathrm{E}+00$ & $1.74 \mathrm{E}-03$ & $2.13 E-01$ \\
\hline 0.050 & & $0.00 \mathrm{E}+00$ & $0.00 \mathrm{E}+00$ & $0.00 \mathrm{E}+00$ & $0.00 \mathrm{E}+00$ & $2.79 \mathrm{E}-03$ & $2.67 \mathrm{E}-01$ \\
\hline 0.075 & & $0.00 \mathrm{E}+00$ & $0.00 \mathrm{E}+00$ & $0.00 \mathrm{E}+00$ & $0.00 \mathrm{E}+00$ & $3.76 \mathrm{E}-03$ & $3.08 \mathrm{E}-01$ \\
\hline 0.100 & & $0.00 \mathrm{E}+00$ & $0.00 \mathrm{E}+00$ & $0.00 \mathrm{E}+00$ & $0.00 \mathrm{E}+00$ & $4.76 \mathrm{E}-03$ & $3.41 \mathrm{E}-01$ \\
\hline 0.125 & & $0.00 \mathrm{E}+00$ & $0.00 \mathrm{E}+00$ & $0.00 \mathrm{E}+00$ & $0.00 \mathrm{E}+00$ & $6.05 E-03$ & $3.76 \mathrm{E}-01$ \\
\hline 0.150 & & $0.00 \mathrm{E}+00$ & $0.00 \mathrm{E}+00$ & $0.00 \mathrm{E}+00$ & $0.00 \mathrm{E}+00$ & $7.45 \mathrm{E}-03$ & $4.07 \mathrm{E}-01$ \\
\hline 0.175 & & $0.00 \mathrm{E}+00$ & $0.00 \mathrm{E}+00$ & $0.00 \mathrm{E}+00$ & $0.00 \mathrm{E}+00$ & $8.87 \mathrm{E}-03$ & $4.40 \mathrm{E}-01$ \\
\hline 0.200 & & $0.00 \mathrm{E}+00$ & $0.00 \mathrm{E}+00$ & $0.00 \mathrm{E}+00$ & $0.00 \mathrm{E}+00$ & $1.04 \mathrm{E}-02$ & $4.69 \mathrm{E}-01$ \\
\hline 0.225 & & $0.00 \mathrm{E}+00$ & $0.00 \mathrm{E}+00$ & $0.00 \mathrm{E}+00$ & $0.00 E+00$ & $1.22 \mathrm{E}-02$ & $5.00 \mathrm{E}-01$ \\
\hline 0.250 & & $0.00 \mathrm{E}+00$ & $0.00 \mathrm{E}+00$ & $0.00 \mathrm{E}+00$ & $0.00 \mathrm{E}+00$ & $1.41 \mathrm{E}-02$ & $5.31 \mathrm{E}-01$ \\
\hline 0.275 & & $0.00 \mathrm{E}+00$ & $0.00 \mathrm{E}+00$ & $0.00 \mathrm{E}+00$ & $0.00 \mathrm{E}+00$ & $1.61 \mathrm{E}-02$ & $5.64 \mathrm{E}-01$ \\
\hline 0.300 & & $0.00 \mathrm{E}+00$ & $0.00 \mathrm{E}+00$ & $0.00 \mathrm{E}+00$ & $0.00 \mathrm{E}+00$ & $1.86 \mathrm{E}-02$ & $5.92 \mathrm{E}-01$ \\
\hline 0.325 & & $0.00 \mathrm{E}+00$ & $0.00 \mathrm{E}+00$ & $0.00 \mathrm{E}+00$ & $0.00 \mathrm{E}+00$ & $2.10 \mathrm{E}-02$ & $6.20 \mathrm{E}-01$ \\
\hline 0.350 & & $0.00 \mathrm{E}+00$ & $0.00 \mathrm{E}+00$ & $0.00 \mathrm{E}+00$ & $0.00 \mathrm{E}+00$ & $2.41 \mathrm{E}-02$ & $6.47 \mathrm{E}-01$ \\
\hline 0.375 & & $0.00 \mathrm{E}+00$ & $0.00 \mathrm{E}+00$ & $0.00 \mathrm{E}+00$ & $0.00 \mathrm{E}+00$ & $2.70 \mathrm{E}-02$ & $6.74 \mathrm{E}-01$ \\
\hline 0.400 & & $0.00 \mathrm{E}+00$ & $0.00 \mathrm{E}+00$ & $0.00 \mathrm{E}+00$ & $0.00 \mathrm{E}+00$ & $3.06 \mathrm{E}-02$ & $7.04 \mathrm{E}-01$ \\
\hline 0.425 & & $0.00 \mathrm{E}+00$ & $0.00 \mathrm{E}+00$ & $0.00 \mathrm{E}+00$ & $0.00 \mathrm{E}+00$ & $3.40 \mathrm{E}-02$ & $7.40 \mathrm{E}-01$ \\
\hline 0.450 & & $0.00 \mathrm{E}+00$ & $0.00 \mathrm{E}+00$ & $0.00 \mathrm{E}+00$ & $0.00 \mathrm{E}+00$ & $3.83 \mathrm{E}-02$ & $7.76 \mathrm{E}-01$ \\
\hline 0.475 & & $0.00 \mathrm{E}+00$ & $0.00 \mathrm{E}+00$ & $0.00 \mathrm{E}+00$ & $0.00 \mathrm{E}+00$ & $4.22 \mathrm{E}-02$ & $8.14 \mathrm{E}-01$ \\
\hline 0.500 & & $0.00 \mathrm{E}+00$ & $0.00 \mathrm{E}+00$ & $0.00 \mathrm{E}+00$ & $0.00 \mathrm{E}+00$ & $4.68 \mathrm{E}-02$ & $8.53 \mathrm{E}-01$ \\
\hline .525 & & $0.00 \mathrm{E}+00$ & $0.00 \mathrm{E}+00$ & $0.00 \mathrm{E}+00$ & $0.00 \mathrm{E}+00$ & $5.27 \mathrm{E}-02$ & $8.88 \mathrm{E}-01$ \\
\hline 0.550 & & $0.00 \mathrm{E}+00$ & $0.00 \mathrm{E}+00$ & $0.00 \mathrm{E}+00$ & $0.00 \mathrm{E}+00$ & $5.89 \mathrm{E}-02$ & $9.24 \mathrm{E}-01$ \\
\hline 0.575 & & $0.00 \mathrm{E}+00$ & $0.00 \mathrm{E}+00$ & $0.00 \mathrm{E}+00$ & $0.00 \mathrm{E}+00$ & $6.49 \mathrm{E}-02$ & $9.58 \mathrm{E}-01$ \\
\hline 0.600 & & $0.00 \mathrm{E}+00$ & $0.00 \mathrm{E}+00$ & $0.00 \mathrm{E}+00$ & $0.00 \mathrm{E}+00$ & $7.25 \mathrm{E}-02$ & $9.97 \mathrm{E}-01$ \\
\hline 0.625 & & $0.00 \mathrm{E}+00$ & $0.00 \mathrm{E}+00$ & $0.00 \mathrm{E}+00$ & $0.00 \mathrm{E}+00$ & $8.05 E-02$ & $1.04 \mathrm{E}+00$ \\
\hline 0.650 & & $0.00 \mathrm{E}+00$ & $0.00 \mathrm{E}+00$ & $0.00 \mathrm{E}+00$ & $0.00 \mathrm{E}+00$ & $9.17 \mathrm{E}-02$ & $1.09 \mathrm{E}+00$ \\
\hline 0.675 & & $0.00 \mathrm{E}+00$ & $0.00 \mathrm{E}+00$ & $0.00 \mathrm{E}+00$ & $0.00 \mathrm{E}+00$ & $1.04 \mathrm{E}-01$ & $1.13 \mathrm{E}+00$ \\
\hline 0.700 & & $0.00 \mathrm{E}+00$ & $0.00 \mathrm{E}+00$ & $0.00 \mathrm{E}+00$ & $0.00 \mathrm{E}+00$ & $1.17 \mathrm{E}-01$ & $1.19 \mathrm{E}+00$ \\
\hline 0.725 & & $0.00 \mathrm{E}+00$ & $0.00 \mathrm{E}+00$ & $0.00 \mathrm{E}+00$ & $0.00 \mathrm{E}+00$ & $1.34 \mathrm{E}-01$ & $1.24 \mathrm{E}+00$ \\
\hline 0.750 & & $0.00 \mathrm{E}+00$ & $0.00 \mathrm{E}+00$ & $0.00 \mathrm{E}+00$ & $0.00 \mathrm{E}+00$ & $1.52 \mathrm{E}-01$ & $1.29 \mathrm{E}+00$ \\
\hline 0.775 & & $0.00 \mathrm{E}+00$ & $0.00 \mathrm{E}+00$ & $0.00 \mathrm{E}+00$ & $0.00 \mathrm{E}+00$ & $1.77 \mathrm{E}-01$ & $1.35 \mathrm{E}+00$ \\
\hline 0.800 & & $0.00 \mathrm{E}+00$ & $0.00 \mathrm{E}+00$ & $0.00 \mathrm{E}+00$ & $0.00 \mathrm{E}+00$ & $2.05 \mathrm{E}-01$ & $1.41 \mathrm{E}+00$ \\
\hline 0.825 & & $0.00 \mathrm{E}+00$ & $0.00 \mathrm{E}+00$ & $0.00 \mathrm{E}+00$ & $0.00 \mathrm{E}+00$ & $2.41 \mathrm{E}-01$ & $1.47 \mathrm{E}+00$ \\
\hline 0.850 & & $0.00 \mathrm{E}+00$ & $0.00 \mathrm{E}+00$ & $0.00 \mathrm{E}+00$ & $0.00 \mathrm{E}+00$ & $2.87 \mathrm{E}-01$ & $1.55 \mathrm{E}+00$ \\
\hline 0.875 & & $0.00 \mathrm{E}+00$ & $0.00 \mathrm{E}+00$ & $0.00 \mathrm{E}+00$ & $0.00 \mathrm{E}+00$ & $3.40 \mathrm{E}-01$ & $1.65 \mathrm{E}+00$ \\
\hline 0.900 & & $0.00 \mathrm{E}+00$ & $0.00 \mathrm{E}+00$ & $0.00 \mathrm{E}+00$ & $0.00 \mathrm{E}+00$ & $4.16 \mathrm{E}-01$ & $1.74 \mathrm{E}+00$ \\
\hline 0.925 & & $0.00 \mathrm{E}+00$ & $0.00 \mathrm{E}+00$ & $0.00 \mathrm{E}+00$ & $0.00 \mathrm{E}+00$ & $5.28 \mathrm{E}-01$ & $1.85 \mathrm{E}+00$ \\
\hline 0.950 & & $0.00 \mathrm{E}+00$ & $0.00 \mathrm{E}+00$ & $0.00 \mathrm{E}+00$ & $0.00 \mathrm{E}+00$ & $6.76 \mathrm{E}-01$ & $2.01 \mathrm{E}+00$ \\
\hline 0.975 & & $0.00 \mathrm{E}+00$ & $0.00 \mathrm{E}+00$ & $0.00 \mathrm{E}+00$ & $0.00 \mathrm{E}+00$ & $1.02 \mathrm{E}+00$ & $2.23 \mathrm{E}+00$ \\
\hline 1.000 & & $0.00 \mathrm{E}+00$ & $0.00 \mathrm{E}+00$ & $0.00 \mathrm{E}+00$ & $0.00 \mathrm{E}+00$ & $4.68 \mathrm{E}+00$ & $3.43 E+00$ \\
\hline
\end{tabular}


RESRAD-OFFSITE, Version 2.5

Probabilistic Dose and Risk Report

Title : RESRAD-OFFSITE Drinking Water, Plant, Milk, and Meat Pathways for Offsite Reside File : PBA-1_TC99-DOE-5.ROF

Statistics and Cumulative distribution function of Peak Dose from All Pathways in mrem/yr

$\begin{array}{ccccc}\text { Repetition }= & 1 & 2 & 3 \\ \text { Mean } & 1.00 \mathrm{E}+00 & 1.00 \mathrm{E}+00 & 1.00 \mathrm{E}+00 \\ \text { Std. Dev. } & 5.99 \mathrm{E}-01 & 5.99 \mathrm{E}-01 & 5.99 \mathrm{E}-01 \\ \text { Minimum } & 1.21 \mathrm{E}-01 & 1.21 \mathrm{E}-01 & 1.21 \mathrm{E}-01 \\ \text { Maximum } & 5.70 \mathrm{E}+00 & 5.70 \mathrm{E}+00 & 5.70 \mathrm{E}+00\end{array}$

Percentile

$0.010 \quad 1.74 \mathrm{E}-01 \quad 1.74 \mathrm{E}-01 \quad 1.74 \mathrm{E}-01$

$\begin{array}{llll}0.025 & 2.26 \mathrm{E}-01 & 2.26 \mathrm{E}-01 & 2.26 \mathrm{E}-01\end{array}$

$\begin{array}{llll}0.050 & 2.77 \mathrm{E}-01 & 2.77 \mathrm{E}-01 & 2.77 \mathrm{E}-01\end{array}$

$0.075 \quad 3.28 \mathrm{E}-01 \quad 3.28 \mathrm{E}-01 \quad 3.28 \mathrm{E}-01$

$0.100 \quad 3.64 \mathrm{E}-01 \quad 3.64 \mathrm{E}-01 \quad 3.64 \mathrm{E}-01$

$0.125 \quad 4.01 \mathrm{E}-01 \quad 4.01 \mathrm{E}-01 \quad 4.01 \mathrm{E}-01$

$0.150 \quad 4.33 \mathrm{E}-01 \quad 4.33 \mathrm{E}-01 \quad 4.33 \mathrm{E}-01$

$0.175 \quad 4.70 \mathrm{E}-01 \quad 4.70 \mathrm{E}-01 \quad 4.70 \mathrm{E}-01$

$0.200 \quad 4.98 \mathrm{E}-01 \quad 4.98 \mathrm{E}-01 \quad 4.98 \mathrm{E}-01$

$0.225 \quad 5.33 \mathrm{E}-01 \quad 5.32 \mathrm{E}-01 \quad 5.32 \mathrm{E}-01$

$0.250 \quad 5.66 \mathrm{E}-01 \quad 5.66 \mathrm{E}-01 \quad 5.66 \mathrm{E}-01$

$0.275 \quad 5.99 \mathrm{E}-01 \quad 5.99 \mathrm{E}-01 \quad 5.99 \mathrm{E}-01$

$\begin{array}{llll}0.300 & 6.32 \mathrm{E}-01 & 6.31 \mathrm{E}-01 & 6.31 \mathrm{E}-01\end{array}$

$0.325 \quad 6.56 \mathrm{E}-01 \quad 6.56 \mathrm{E}-01 \quad 6.56 \mathrm{E}-01$

$\begin{array}{llll}0.350 & 6.82 \mathrm{E}-01 & 6.82 \mathrm{E}-01 & 6.82 \mathrm{E}-01\end{array}$

$0.375 \quad 7.12 \mathrm{E}-01 \quad 7.11 \mathrm{E}-01 \quad 7.12 \mathrm{E}-01$

$0.400 \quad 7.44 \mathrm{E}-01 \quad 7.43 \mathrm{E}-01 \quad 7.44 \mathrm{E}-01$

$0.425 \quad 7.73 \mathrm{E}-01 \quad 7.72 \mathrm{E}-01 \quad 7.73 \mathrm{E}-01$

$0.450 \quad 8.01 \mathrm{E}-01 \quad 8.00 \mathrm{E}-01 \quad 8.01 \mathrm{E}-01$

$0.475 \quad 8.40 \mathrm{E}-01 \quad 8.38 \mathrm{E}-01 \quad 8.38 \mathrm{E}-01$

$0.500 \quad 8.79 \mathrm{E}-01 \quad 8.75 \mathrm{E}-01 \quad 8.77 \mathrm{E}-01$

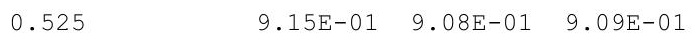

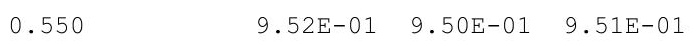

$\begin{array}{llll}0.575 & 9.88 \mathrm{E}-01 & 9.85 \mathrm{E}-01 & 9.86 \mathrm{E}-01\end{array}$

$\begin{array}{llll}0.600 & 1.02 \mathrm{E}+00 & 1.02 \mathrm{E}+00 & 1.02 \mathrm{E}+00\end{array}$

$0.625 \quad 1.06 \mathrm{E}+00 \quad 1.06 \mathrm{E}+00 \quad 1.06 \mathrm{E}+00$

$\begin{array}{llll}0.650 & 1.11 \mathrm{E}+00 & 1.10 \mathrm{E}+00 & 1.10 \mathrm{E}+00\end{array}$

$\begin{array}{llll}0.675 & 1.15 \mathrm{E}+00 & 1.15 \mathrm{E}+00 & 1.15 \mathrm{E}+00\end{array}$

$\begin{array}{llll}0.700 & 1.20 \mathrm{E}+00 & 1.20 \mathrm{E}+00 & 1.20 \mathrm{E}+00\end{array}$

$\begin{array}{llll}0.725 & 1.25 \mathrm{E}+00 & 1.25 \mathrm{E}+00 & 1.25 \mathrm{E}+00\end{array}$

$\begin{array}{llll}0.750 & 1.33 \mathrm{E}+00 & 1.32 \mathrm{E}+00 & 1.33 \mathrm{E}+00\end{array}$

$\begin{array}{llll}0.775 & 1.39 \mathrm{E}+00 & 1.39 \mathrm{E}+00 & 1.39 \mathrm{E}+00\end{array}$

$\begin{array}{llll}0.800 & 1.46 \mathrm{E}+00 & 1.46 \mathrm{E}+00 & 1.46 \mathrm{E}+00\end{array}$

$\begin{array}{llll}0.825 & 1.52 \mathrm{E}+00 & 1.52 \mathrm{E}+00 & 1.52 \mathrm{E}+00\end{array}$

$\begin{array}{llll}0.850 & 1.61 \mathrm{E}+00 & 1.61 \mathrm{E}+00 & 1.61 \mathrm{E}+00\end{array}$

$\begin{array}{llll}0.875 & 1.72 \mathrm{E}+00 & 1.72 \mathrm{E}+00 & 1.72 \mathrm{E}+00\end{array}$

$\begin{array}{llll}0.900 & 1.82 \mathrm{E}+00 & 1.82 \mathrm{E}+00 & 1.82 \mathrm{E}+00\end{array}$

$\begin{array}{llll}0.925 & 1.97 \mathrm{E}+00 & 1.96 \mathrm{E}+00 & 1.97 \mathrm{E}+00\end{array}$

$\begin{array}{llll}0.950 \quad 2.14 \mathrm{E}+00 \quad 2.14 \mathrm{E}+00 \quad 2.14 \mathrm{E}+00 & 0\end{array}$

$\begin{array}{llll}0.975 & 2.42 \mathrm{E}+00 \quad 2.42 \mathrm{E}+00 \quad 2.42 \mathrm{E}+00\end{array}$

$\begin{array}{llll}0.990 & 3.02 \mathrm{E}+00 \quad 3.02 \mathrm{E}+00 \quad 3.02 \mathrm{E}+00\end{array}$ 
RESRAD-OFFSITE, Version 2.5

Probabilistic Dose and Risk Report

Title : RESRAD-OFFSITE Drinking Water, Plant, Milk, and Meat Pathways for Offsite Reside

File : PBA-1_TC99-DOE-5.ROF

Statistics and Cumulative distribution function of Peak Dose from External Ground(Wreleas) in mrem/yr

\begin{tabular}{|c|c|c|c|}
\hline Repetition = & 1 & 2 & 3 \\
\hline Mean & $0.00 \mathrm{E}+00$ & $0.00 \mathrm{E}+00$ & $0.00 \mathrm{E}+00$ \\
\hline Std. Dev. & $0.00 \mathrm{E}+00$ & $0.00 \mathrm{E}+00$ & $0.00 \mathrm{E}+00$ \\
\hline Minimum & $0.00 \mathrm{E}+00$ & $0.00 \mathrm{E}+00$ & $0.00 \mathrm{E}+00$ \\
\hline Maximum & $0.00 \mathrm{E}+00$ & $0.00 \mathrm{E}+00$ & $0.00 \mathrm{E}+00$ \\
\hline
\end{tabular}

Percentile

$\begin{array}{llll}0.010 & 0.00 \mathrm{E}+00 \quad 0.00 \mathrm{E}+00 & 0.00 \mathrm{E}+00\end{array}$

$\begin{array}{llll}0.025 & 0.00 \mathrm{E}+00 \quad 0.00 \mathrm{E}+00 & 0.00 \mathrm{E}+00\end{array}$

$\begin{array}{llll}0.050 & 0.00 \mathrm{E}+00 & 0.00 \mathrm{E}+00 & 0.00 \mathrm{E}+00\end{array}$

$\begin{array}{llll}0.075 & 0.00 \mathrm{E}+00 & 0.00 \mathrm{E}+00 & 0.00 \mathrm{E}+00\end{array}$

$\begin{array}{llll}0.100 & 0.00 \mathrm{E}+00 & 0.00 \mathrm{E}+00 & 0.00 \mathrm{E}+00\end{array}$

$\begin{array}{llll}0.125 & 0.00 \mathrm{E}+00 & 0.00 \mathrm{E}+00 & 0.00 \mathrm{E}+00\end{array}$

$\begin{array}{llll}0.150 & 0.00 \mathrm{E}+00 & 0.00 \mathrm{E}+00 & 0.00 \mathrm{E}+00\end{array}$

$\begin{array}{llll}0.175 & 0.00 \mathrm{E}+00 & 0.00 \mathrm{E}+00 & 0.00 \mathrm{E}+00\end{array}$

$\begin{array}{llll}0.200 & 0.00 \mathrm{E}+00 & 0.00 \mathrm{E}+00 & 0.00 \mathrm{E}+00\end{array}$

$\begin{array}{lllll}0.225 & 0.00 \mathrm{E}+00 & 0.00 \mathrm{E}+00 & 0.00 \mathrm{E}+00\end{array}$

$\begin{array}{lllll}0.250 & 0.00 \mathrm{E}+00 & 0.00 \mathrm{E}+00 & 0.00 \mathrm{E}+00\end{array}$

$\begin{array}{lllll}0.275 & 0.00 \mathrm{E}+00 & 0.00 \mathrm{E}+00 & 0.00 \mathrm{E}+00\end{array}$

$\begin{array}{lllll}0.300 & 0.00 \mathrm{E}+00 & 0.00 \mathrm{E}+00 & 0.00 \mathrm{E}+00\end{array}$

$\begin{array}{lllll}0.325 & 0.00 \mathrm{E}+00 & 0.00 \mathrm{E}+00 & 0.00 \mathrm{E}+00\end{array}$

$\begin{array}{lllll}0.350 & 0.00 \mathrm{E}+00 & 0.00 \mathrm{E}+00 & 0.00 \mathrm{E}+00\end{array}$

$\begin{array}{lllll}0.375 & 0.00 \mathrm{E}+00 & 0.00 \mathrm{E}+00 & 0.00 \mathrm{E}+00\end{array}$

$\begin{array}{lllll}0.400 & 0.00 \mathrm{E}+00 & 0.00 \mathrm{E}+00 & 0.00 \mathrm{E}+00\end{array}$

$\begin{array}{lllll}0.425 & 0.00 \mathrm{E}+00 & 0.00 \mathrm{E}+00 & 0.00 \mathrm{E}+00\end{array}$

$\begin{array}{lllll}0.450 & 0.00 \mathrm{E}+00 & 0.00 \mathrm{E}+00 & 0.00 \mathrm{E}+00\end{array}$

$\begin{array}{lllll}0.475 & 0.00 \mathrm{E}+00 & 0.00 \mathrm{E}+00 & 0.00 \mathrm{E}+00\end{array}$

$\begin{array}{lllll}0.500 & 0.00 \mathrm{E}+00 & 0.00 \mathrm{E}+00 & 0.00 \mathrm{E}+00\end{array}$

$\begin{array}{lllll}0.525 & 0.00 \mathrm{E}+00 & 0.00 \mathrm{E}+00 & 0.00 \mathrm{E}+00\end{array}$

$\begin{array}{lllll}0.550 & 0.00 \mathrm{E}+00 & 0.00 \mathrm{E}+00 & 0.00 \mathrm{E}+00\end{array}$

$\begin{array}{lllll}0.575 & 0.00 \mathrm{E}+00 & 0.00 \mathrm{E}+00 & 0.00 \mathrm{E}+00\end{array}$

$\begin{array}{lllll}0.600 & 0.00 \mathrm{E}+00 & 0.00 \mathrm{E}+00 & 0.00 \mathrm{E}+00\end{array}$

$\begin{array}{lllll}0.625 & 0.00 \mathrm{E}+00 & 0.00 \mathrm{E}+00 & 0.00 \mathrm{E}+00\end{array}$

$\begin{array}{lllll}0.650 & 0.00 \mathrm{E}+00 & 0.00 \mathrm{E}+00 & 0.00 \mathrm{E}+00\end{array}$

$\begin{array}{lllll}0.675 & 0.00 \mathrm{E}+00 & 0.00 \mathrm{E}+00 & 0.00 \mathrm{E}+00\end{array}$

$\begin{array}{llll}0.700 & 0.00 \mathrm{E}+00 & 0.00 \mathrm{E}+00 & 0.00 \mathrm{E}+00\end{array}$

$\begin{array}{lllll}0.725 & 0.00 \mathrm{E}+00 & 0.00 \mathrm{E}+00 & 0.00 \mathrm{E}+00\end{array}$

$\begin{array}{lllll}0.750 & 0.00 \mathrm{E}+00 & 0.00 \mathrm{E}+00 & 0.00 \mathrm{E}+00\end{array}$

$\begin{array}{llll}0.775 & 0.00 \mathrm{E}+00 & 0.00 \mathrm{E}+00 & 0.00 \mathrm{E}+00\end{array}$

$\begin{array}{lllll}0.800 & 0.00 \mathrm{E}+00 & 0.00 \mathrm{E}+00 & 0.00 \mathrm{E}+00\end{array}$

$\begin{array}{lllll}0.825 & 0.00 \mathrm{E}+00 & 0.00 \mathrm{E}+00 & 0.00 \mathrm{E}+00\end{array}$

$\begin{array}{lllll}0.850 & 0.00 \mathrm{E}+00 & 0.00 \mathrm{E}+00 & 0.00 \mathrm{E}+00\end{array}$

$\begin{array}{lllll}0.875 & 0.00 \mathrm{E}+00 & 0.00 \mathrm{E}+00 & 0.00 \mathrm{E}+00\end{array}$

$\begin{array}{lllll}0.900 & 0.00 \mathrm{E}+00 & 0.00 \mathrm{E}+00 & 0.00 \mathrm{E}+00\end{array}$

$\begin{array}{lllll}0.925 & 0.00 \mathrm{E}+00 & 0.00 \mathrm{E}+00 & 0.00 \mathrm{E}+00\end{array}$

$\begin{array}{llll}0.950 & 0.00 \mathrm{E}+00 & 0.00 \mathrm{E}+00 & 0.00 \mathrm{E}+00\end{array}$

$\begin{array}{lllll}0.975 & 0.00 \mathrm{E}+00 & 0.00 \mathrm{E}+00 & 0.00 \mathrm{E}+00\end{array}$

$\begin{array}{lllll}0.990 & 0.00 \mathrm{E}+00 & 0.00 \mathrm{E}+00 & 0.00 \mathrm{E}+00\end{array}$ 
RESRAD-OFFSITE, Version 2.5

Probabilistic Dose and Risk Report

Title : RESRAD-OFFSITE Drinking Water, Plant, Milk, and Meat Pathways for Offsite Reside

File : PBA-1_TC99-DOE-5.ROF

Statistics and Cumulative distribution function of Peak Dose from Fish Ingestion in mrem/yr

\begin{tabular}{|c|c|c|c|}
\hline Repetition = & 1 & 2 & 3 \\
\hline Mean & $0.00 \mathrm{E}+00$ & $0.00 \mathrm{E}+00$ & $0.00 \mathrm{E}+00$ \\
\hline Std. Dev. & $0.00 \mathrm{E}+00$ & $0.00 \mathrm{E}+00$ & $0.00 \mathrm{E}+00$ \\
\hline Minimum & $0.00 \mathrm{E}+00$ & $0.00 \mathrm{E}+00$ & $0.00 \mathrm{E}+00$ \\
\hline Maximum & $0.00 \mathrm{E}+00$ & $0.00 \mathrm{E}+00$ & $0.00 \mathrm{E}+00$ \\
\hline
\end{tabular}

Percentile

$\begin{array}{llll}0.010 & 0.00 \mathrm{E}+00 \quad 0.00 \mathrm{E}+00 & 0.00 \mathrm{E}+00\end{array}$

$\begin{array}{llll}0.025 & 0.00 \mathrm{E}+00 & 0.00 \mathrm{E}+00 & 0.00 \mathrm{E}+00\end{array}$

$\begin{array}{llll}0.050 & 0.00 \mathrm{E}+00 & 0.00 \mathrm{E}+00 & 0.00 \mathrm{E}+00\end{array}$

$\begin{array}{llll}0.075 & 0.00 \mathrm{E}+00 & 0.00 \mathrm{E}+00 & 0.00 \mathrm{E}+00\end{array}$

$\begin{array}{llll}0.100 & 0.00 \mathrm{E}+00 & 0.00 \mathrm{E}+00 & 0.00 \mathrm{E}+00\end{array}$

$\begin{array}{llll}0.125 & 0.00 \mathrm{E}+00 & 0.00 \mathrm{E}+00 & 0.00 \mathrm{E}+00\end{array}$

$\begin{array}{llll}0.150 & 0.00 \mathrm{E}+00 & 0.00 \mathrm{E}+00 & 0.00 \mathrm{E}+00\end{array}$

$\begin{array}{lllll}0.175 & 0.00 \mathrm{E}+00 & 0.00 \mathrm{E}+00 & 0.00 \mathrm{E}+00\end{array}$

$\begin{array}{llll}0.200 & 0.00 \mathrm{E}+00 & 0.00 \mathrm{E}+00 & 0.00 \mathrm{E}+00\end{array}$

$\begin{array}{lllll}0.225 & 0.00 \mathrm{E}+00 & 0.00 \mathrm{E}+00 & 0.00 \mathrm{E}+00\end{array}$

$\begin{array}{lllll}0.250 & 0.00 \mathrm{E}+00 & 0.00 \mathrm{E}+00 & 0.00 \mathrm{E}+00\end{array}$

$\begin{array}{lllll}0.275 & 0.00 \mathrm{E}+00 & 0.00 \mathrm{E}+00 & 0.00 \mathrm{E}+00\end{array}$

$\begin{array}{lllll}0.300 & 0.00 \mathrm{E}+00 & 0.00 \mathrm{E}+00 & 0.00 \mathrm{E}+00\end{array}$

$\begin{array}{lllll}0.325 & 0.00 \mathrm{E}+00 & 0.00 \mathrm{E}+00 & 0.00 \mathrm{E}+00\end{array}$

$\begin{array}{lllll}0.350 & 0.00 \mathrm{E}+00 & 0.00 \mathrm{E}+00 & 0.00 \mathrm{E}+00\end{array}$

$\begin{array}{lllll}0.375 & 0.00 \mathrm{E}+00 & 0.00 \mathrm{E}+00 & 0.00 \mathrm{E}+00\end{array}$

$\begin{array}{lllll}0.400 & 0.00 \mathrm{E}+00 & 0.00 \mathrm{E}+00 & 0.00 \mathrm{E}+00\end{array}$

$\begin{array}{lllll}0.425 & 0.00 \mathrm{E}+00 & 0.00 \mathrm{E}+00 & 0.00 \mathrm{E}+00\end{array}$

$\begin{array}{lllll}0.450 & 0.00 \mathrm{E}+00 & 0.00 \mathrm{E}+00 & 0.00 \mathrm{E}+00\end{array}$

$\begin{array}{lllll}0.475 & 0.00 \mathrm{E}+00 & 0.00 \mathrm{E}+00 & 0.00 \mathrm{E}+00\end{array}$

$\begin{array}{lllll}0.500 & 0.00 \mathrm{E}+00 & 0.00 \mathrm{E}+00 & 0.00 \mathrm{E}+00\end{array}$

$\begin{array}{lllll}0.525 & 0.00 \mathrm{E}+00 & 0.00 \mathrm{E}+00 & 0.00 \mathrm{E}+00\end{array}$

$\begin{array}{lllll}0.550 & 0.00 \mathrm{E}+00 & 0.00 \mathrm{E}+00 & 0.00 \mathrm{E}+00\end{array}$

$\begin{array}{lllll}0.575 & 0.00 \mathrm{E}+00 & 0.00 \mathrm{E}+00 & 0.00 \mathrm{E}+00\end{array}$

$\begin{array}{lllll}0.600 & 0.00 \mathrm{E}+00 & 0.00 \mathrm{E}+00 & 0.00 \mathrm{E}+00\end{array}$

$\begin{array}{lllll}0.625 & 0.00 \mathrm{E}+00 & 0.00 \mathrm{E}+00 & 0.00 \mathrm{E}+00\end{array}$

$\begin{array}{lllll}0.650 & 0.00 \mathrm{E}+00 & 0.00 \mathrm{E}+00 & 0.00 \mathrm{E}+00\end{array}$

$\begin{array}{lllll}0.675 & 0.00 \mathrm{E}+00 & 0.00 \mathrm{E}+00 & 0.00 \mathrm{E}+00\end{array}$

$\begin{array}{llll}0.700 & 0.00 \mathrm{E}+00 & 0.00 \mathrm{E}+00 & 0.00 \mathrm{E}+00\end{array}$

$\begin{array}{lllll}0.725 & 0.00 \mathrm{E}+00 & 0.00 \mathrm{E}+00 & 0.00 \mathrm{E}+00\end{array}$

$\begin{array}{lllll}0.750 & 0.00 \mathrm{E}+00 & 0.00 \mathrm{E}+00 & 0.00 \mathrm{E}+00\end{array}$

$\begin{array}{lllll}0.775 & 0.00 \mathrm{E}+00 & 0.00 \mathrm{E}+00 & 0.00 \mathrm{E}+00\end{array}$

$\begin{array}{lllll}0.800 & 0.00 \mathrm{E}+00 & 0.00 \mathrm{E}+00 & 0.00 \mathrm{E}+00\end{array}$

$\begin{array}{lllll}0.825 & 0.00 \mathrm{E}+00 & 0.00 \mathrm{E}+00 & 0.00 \mathrm{E}+00\end{array}$

$\begin{array}{lllll}0.850 & 0.00 \mathrm{E}+00 & 0.00 \mathrm{E}+00 & 0.00 \mathrm{E}+00\end{array}$

$\begin{array}{lllll}0.875 & 0.00 \mathrm{E}+00 & 0.00 \mathrm{E}+00 & 0.00 \mathrm{E}+00\end{array}$

$\begin{array}{lllll}0.900 & 0.00 \mathrm{E}+00 & 0.00 \mathrm{E}+00 & 0.00 \mathrm{E}+00\end{array}$

$\begin{array}{lllll}0.925 & 0.00 \mathrm{E}+00 & 0.00 \mathrm{E}+00 & 0.00 \mathrm{E}+00\end{array}$

$\begin{array}{llll}0.950 & 0.00 \mathrm{E}+00 & 0.00 \mathrm{E}+00 & 0.00 \mathrm{E}+00\end{array}$

$\begin{array}{lllll}0.975 & 0.00 \mathrm{E}+00 & 0.00 \mathrm{E}+00 & 0.00 \mathrm{E}+00\end{array}$

$\begin{array}{lllll}0.990 & 0.00 \mathrm{E}+00 & 0.00 \mathrm{E}+00 & 0.00 \mathrm{E}+00\end{array}$ 
RESRAD-OFFSITE, Version 2.5

Probabilistic Dose and Risk Report

Title : RESRAD-OFFSITE Drinking Water, Plant, Milk, and Meat Pathways for Offsite Reside

File : PBA-1_TC99-DOE-5.ROF

Statistics and Cumulative distribution function of Peak Dose from Radon (Waterrelease) in mrem/yr

$\begin{array}{ccccc}\text { Repetition }= & 1 & 2 & 3 \\ \text { Mean } & 0.00 \mathrm{E}+00 & 0.00 \mathrm{E}+00 & 0.00 \mathrm{E}+00 \\ \text { Std. Dev. } & 0.00 \mathrm{E}+00 & 0.00 \mathrm{E}+00 & 0.00 \mathrm{E}+00 \\ \text { Minimum } & 0.00 \mathrm{E}+00 & 0.00 \mathrm{E}+00 & 0.00 \mathrm{E}+00 \\ \text { Maximum } & 0.00 \mathrm{E}+00 & 0.00 \mathrm{E}+00 & 0.00 \mathrm{E}+00\end{array}$

Percentile

$\begin{array}{llll}0.010 & 0.00 \mathrm{E}+00 \quad 0.00 \mathrm{E}+00 & 0.00 \mathrm{E}+00\end{array}$

$\begin{array}{llll}0.025 & 0.00 \mathrm{E}+00 & 0.00 \mathrm{E}+00 & 0.00 \mathrm{E}+00\end{array}$

$\begin{array}{llll}0.050 & 0.00 \mathrm{E}+00 & 0.00 \mathrm{E}+00 & 0.00 \mathrm{E}+00\end{array}$

$\begin{array}{llll}0.075 & 0.00 \mathrm{E}+00 & 0.00 \mathrm{E}+00 & 0.00 \mathrm{E}+00\end{array}$

$\begin{array}{llll}0.100 & 0.00 \mathrm{E}+00 & 0.00 \mathrm{E}+00 & 0.00 \mathrm{E}+00\end{array}$

$\begin{array}{llll}0.125 & 0.00 \mathrm{E}+00 & 0.00 \mathrm{E}+00 & 0.00 \mathrm{E}+00\end{array}$

$\begin{array}{lllll}0.150 & 0.00 \mathrm{E}+00 & 0.00 \mathrm{E}+00 & 0.00 \mathrm{E}+00\end{array}$

$\begin{array}{lllll}0.175 & 0.00 \mathrm{E}+00 & 0.00 \mathrm{E}+00 & 0.00 \mathrm{E}+00\end{array}$

$\begin{array}{lllll}0.200 & 0.00 \mathrm{E}+00 & 0.00 \mathrm{E}+00 & 0.00 \mathrm{E}+00\end{array}$

$\begin{array}{lllll}0.225 & 0.00 \mathrm{E}+00 & 0.00 \mathrm{E}+00 & 0.00 \mathrm{E}+00\end{array}$

$\begin{array}{lllll}0.250 & 0.00 \mathrm{E}+00 & 0.00 \mathrm{E}+00 & 0.00 \mathrm{E}+00\end{array}$

$\begin{array}{llll}0.275 & 0.00 \mathrm{E}+00 & 0.00 \mathrm{E}+00 & 0.00 \mathrm{E}+00\end{array}$

$\begin{array}{lllll}0.300 & 0.00 \mathrm{E}+00 & 0.00 \mathrm{E}+00 & 0.00 \mathrm{E}+00\end{array}$

$\begin{array}{lllll}0.325 & 0.00 \mathrm{E}+00 & 0.00 \mathrm{E}+00 & 0.00 \mathrm{E}+00\end{array}$

$\begin{array}{lllll}0.350 & 0.00 \mathrm{E}+00 & 0.00 \mathrm{E}+00 & 0.00 \mathrm{E}+00\end{array}$

$\begin{array}{lllll}0.375 & 0.00 \mathrm{E}+00 & 0.00 \mathrm{E}+00 & 0.00 \mathrm{E}+00\end{array}$

$\begin{array}{lllll}0.400 & 0.00 \mathrm{E}+00 & 0.00 \mathrm{E}+00 & 0.00 \mathrm{E}+00\end{array}$

$\begin{array}{lllll}0.425 & 0.00 \mathrm{E}+00 & 0.00 \mathrm{E}+00 & 0.00 \mathrm{E}+00\end{array}$

$\begin{array}{lllll}0.450 & 0.00 \mathrm{E}+00 & 0.00 \mathrm{E}+00 & 0.00 \mathrm{E}+00\end{array}$

$\begin{array}{lllll}0.475 & 0.00 \mathrm{E}+00 & 0.00 \mathrm{E}+00 & 0.00 \mathrm{E}+00\end{array}$

$\begin{array}{lllll}0.500 & 0.00 \mathrm{E}+00 & 0.00 \mathrm{E}+00 & 0.00 \mathrm{E}+00\end{array}$

$\begin{array}{lllll}0.525 & 0.00 \mathrm{E}+00 & 0.00 \mathrm{E}+00 & 0.00 \mathrm{E}+00\end{array}$

$\begin{array}{lllll}0.550 & 0.00 \mathrm{E}+00 & 0.00 \mathrm{E}+00 & 0.00 \mathrm{E}+00\end{array}$

$\begin{array}{lllll}0.575 & 0.00 \mathrm{E}+00 & 0.00 \mathrm{E}+00 & 0.00 \mathrm{E}+00\end{array}$

$\begin{array}{lllll}0.600 & 0.00 \mathrm{E}+00 & 0.00 \mathrm{E}+00 & 0.00 \mathrm{E}+00\end{array}$

$\begin{array}{lllll}0.625 & 0.00 \mathrm{E}+00 & 0.00 \mathrm{E}+00 & 0.00 \mathrm{E}+00\end{array}$

$\begin{array}{lllll}0.650 & 0.00 \mathrm{E}+00 & 0.00 \mathrm{E}+00 & 0.00 \mathrm{E}+00\end{array}$

$\begin{array}{lllll}0.675 & 0.00 \mathrm{E}+00 & 0.00 \mathrm{E}+00 & 0.00 \mathrm{E}+00\end{array}$

$\begin{array}{lllll}0.700 & 0.00 \mathrm{E}+00 & 0.00 \mathrm{E}+00 & 0.00 \mathrm{E}+00\end{array}$

$\begin{array}{lllll}0.725 & 0.00 \mathrm{E}+00 & 0.00 \mathrm{E}+00 & 0.00 \mathrm{E}+00\end{array}$

$\begin{array}{lllll}0.750 & 0.00 \mathrm{E}+00 & 0.00 \mathrm{E}+00 & 0.00 \mathrm{E}+00\end{array}$

$\begin{array}{lllll}0.775 & 0.00 \mathrm{E}+00 & 0.00 \mathrm{E}+00 & 0.00 \mathrm{E}+00\end{array}$

$\begin{array}{lllll}0.800 & 0.00 \mathrm{E}+00 & 0.00 \mathrm{E}+00 & 0.00 \mathrm{E}+00\end{array}$

$\begin{array}{lllll}0.825 & 0.00 \mathrm{E}+00 & 0.00 \mathrm{E}+00 & 0.00 \mathrm{E}+00\end{array}$

$\begin{array}{lllll}0.850 & 0.00 \mathrm{E}+00 & 0.00 \mathrm{E}+00 & 0.00 \mathrm{E}+00\end{array}$

$\begin{array}{lllll}0.875 & 0.00 \mathrm{E}+00 & 0.00 \mathrm{E}+00 & 0.00 \mathrm{E}+00\end{array}$

$\begin{array}{lllll}0.900 & 0.00 \mathrm{E}+00 & 0.00 \mathrm{E}+00 & 0.00 \mathrm{E}+00\end{array}$

$\begin{array}{lllll}0.925 & 0.00 \mathrm{E}+00 & 0.00 \mathrm{E}+00 & 0.00 \mathrm{E}+00\end{array}$

$\begin{array}{lllll}0.950 & 0.00 \mathrm{E}+00 & 0.00 \mathrm{E}+00 & 0.00 \mathrm{E}+00\end{array}$

$\begin{array}{lllll}0.975 & 0.00 \mathrm{E}+00 & 0.00 \mathrm{E}+00 & 0.00 \mathrm{E}+00\end{array}$

$\begin{array}{lllll}0.990 & 0.00 \mathrm{E}+00 & 0.00 \mathrm{E}+00 & 0.00 \mathrm{E}+00\end{array}$ 
RESRAD-OFFSITE, Version 2.5

Probabilistic Dose and Risk Report

Title : RESRAD-OFFSITE Drinking Water, Plant, Milk, and Meat Pathways for Offsite Reside

File : PBA-1_TC99-DOE-5.ROF

Statistics and Cumulative distribution function of Peak Dose from Plant (Waterrelease) in mrem/yr

$\begin{array}{rcccc}\text { Repetition }= & 1 & 2 & 3 \\ \text { Mean } & 2.52 \mathrm{E}-01 & 2.51 \mathrm{E}-01 & 2.52 \mathrm{E}-01 \\ \text { Std. Dev. } & 1.50 \mathrm{E}-01 & 1.50 \mathrm{E}-01 & 1.50 \mathrm{E}-01 \\ \text { Minimum } & 3.03 \mathrm{E}-02 & 3.03 \mathrm{E}-02 & 3.03 \mathrm{E}-02 \\ \text { Maximum } & 1.43 \mathrm{E}+00 & 1.43 \mathrm{E}+00 & 1.43 \mathrm{E}+00\end{array}$

Percentile

$0.0104 .35 \mathrm{E}-02 \quad 4.35 \mathrm{E}-02 \quad 4.35 \mathrm{E}-02$

$0.025 \quad 5.66 \mathrm{E}-02 \quad 5.66 \mathrm{E}-02 \quad 5.66 \mathrm{E}-02$

$0.0506 .95 \mathrm{E}-02 \quad 6.95 \mathrm{E}-02 \quad 6.95 \mathrm{E}-02$

$0.075 \quad 8.21 \mathrm{E}-02 \quad 8.21 \mathrm{E}-02 \quad 8.21 \mathrm{E}-02$

$0.1009 .11 \mathrm{E}-02 \quad 9.11 \mathrm{E}-02 \quad 9.11 \mathrm{E}-02$

$0.125 \quad 1.00 \mathrm{E}-01 \quad 1.00 \mathrm{E}-01 \quad 1.00 \mathrm{E}-01$

$0.150 \quad 1.08 \mathrm{E}-01 \quad 1.08 \mathrm{E}-01 \quad 1.08 \mathrm{E}-01$

$0.175 \quad 1.18 \mathrm{E}-01 \quad 1.18 \mathrm{E}-01 \quad 1.18 \mathrm{E}-01$

$0.200 \quad 1.25 \mathrm{E}-01 \quad 1.25 \mathrm{E}-01 \quad 1.25 \mathrm{E}-01$

$0.225 \quad 1.33 \mathrm{E}-01 \quad 1.33 \mathrm{E}-01 \quad 1.33 \mathrm{E}-01$

$0.250 \quad 1.42 \mathrm{E}-01 \quad 1.42 \mathrm{E}-01 \quad 1.42 \mathrm{E}-01$

$0.275 \quad 1.50 \mathrm{E}-01 \quad 1.50 \mathrm{E}-01 \quad 1.50 \mathrm{E}-01$

$0.300 \quad 1.58 \mathrm{E}-01 \quad 1.58 \mathrm{E}-01 \quad 1.58 \mathrm{E}-01$

$0.325 \quad 1.64 \mathrm{E}-01 \quad 1.64 \mathrm{E}-01 \quad 1.64 \mathrm{E}-01$

$0.350 \quad 1.71 \mathrm{E}-01 \quad 1.71 \mathrm{E}-01 \quad 1.71 \mathrm{E}-01$

$\begin{array}{llll}0.375 & 1.78 \mathrm{E}-01 & 1.78 \mathrm{E}-01 & 1.78 \mathrm{E}-01\end{array}$

$\begin{array}{llll}0.400 & 1.86 \mathrm{E}-01 & 1.86 \mathrm{E}-01 & 1.86 \mathrm{E}-01\end{array}$

$0.425 \quad 1.93 \mathrm{E}-01 \quad 1.93 \mathrm{E}-01 \quad 1.93 \mathrm{E}-01$

$\begin{array}{llll}0.450 \quad 2.01 \mathrm{E}-01 \quad 2.00 \mathrm{E}-01 & 2.01 \mathrm{E}-01\end{array}$

$0.475 \quad 2.10 \mathrm{E}-01 \quad 2.10 \mathrm{E}-01 \quad 2.10 \mathrm{E}-01$

$\begin{array}{llll}0.500 \quad 2.20 \mathrm{E}-01 & 2.19 \mathrm{E}-01 & 2.20 \mathrm{E}-01\end{array}$

$\begin{array}{llll}0.525 & 2.29 \mathrm{E}-01 & 2.27 \mathrm{E}-01 & 2.28 \mathrm{E}-01\end{array}$

$\begin{array}{llll}0.550 & 2.38 \mathrm{E}-01 & 2.38 \mathrm{E}-01 & 2.38 \mathrm{E}-01\end{array}$

$\begin{array}{llll}0.575 & 2.48 \mathrm{E}-01 & 2.47 \mathrm{E}-01 & 2.47 \mathrm{E}-01\end{array}$

$\begin{array}{llll}0.600 & 2.56 \mathrm{E}-01 & 2.56 \mathrm{E}-01 & 2.56 \mathrm{E}-01\end{array}$

$\begin{array}{llll}0.625 & 2.67 \mathrm{E}-01 & 2.66 \mathrm{E}-01 & 2.66 \mathrm{E}-01\end{array}$

$\begin{array}{llll}0.650 & 2.77 \mathrm{E}-01 & 2.77 \mathrm{E}-01 & 2.77 \mathrm{E}-01\end{array}$

$\begin{array}{llll}0.675 & 2.89 \mathrm{E}-01 & 2.88 \mathrm{E}-01 & 2.88 \mathrm{E}-01\end{array}$

$0.700 \quad 3.02 \mathrm{E}-01 \quad 3.01 \mathrm{E}-01 \quad 3.01 \mathrm{E}-01$

$0.725 \quad 3.14 \mathrm{E}-01 \quad 3.14 \mathrm{E}-01 \quad 3.14 \mathrm{E}-01$

$\begin{array}{llll}0.750 & 3.32 \mathrm{E}-01 & 3.32 \mathrm{E}-01 & 3.32 \mathrm{E}-01\end{array}$

$\begin{array}{llll}0.775 & 3.48 \mathrm{E}-01 & 3.48 \mathrm{E}-01 & 3.48 \mathrm{E}-01\end{array}$

$0.800 \quad 3.66 \mathrm{E}-01 \quad 3.66 \mathrm{E}-01 \quad 3.66 \mathrm{E}-01$

$\begin{array}{llll}0.825 & 3.81 \mathrm{E}-01 & 3.81 \mathrm{E}-01 & 3.81 \mathrm{E}-01\end{array}$

$0.850 \quad 4.03 \mathrm{E}-01 \quad 4.03 \mathrm{E}-01 \quad 4.03 \mathrm{E}-01$

$0.875 \quad 4.31 \mathrm{E}-01 \quad 4.31 \mathrm{E}-01 \quad 4.31 \mathrm{E}-01$

$0.900 \quad 4.55 \mathrm{E}-01 \quad 4.55 \mathrm{E}-01 \quad 4.55 \mathrm{E}-01$

$0.925 \quad 4.92 \mathrm{E}-01 \quad 4.91 \mathrm{E}-01 \quad 4.92 \mathrm{E}-01$

$0.950 \quad 5.35 \mathrm{E}-01 \quad 5.35 \mathrm{E}-01 \quad 5.35 \mathrm{E}-01$

$0.9756 .05 \mathrm{E}-01 \quad 6.05 \mathrm{E}-01 \quad 6.05 \mathrm{E}-01$

$0.990 \quad 7.55 \mathrm{E}-01 \quad 7.55 \mathrm{E}-01 \quad 7.55 \mathrm{E}-01$ 
RESRAD-OFFSITE, Version 2.5

Probabilistic Dose and Risk Report

Title : RESRAD-OFFSITE Drinking Water, Plant, Milk, and Meat Pathways for Offsite Reside

File : PBA-1_TC99-DOE-5.ROF

Statistics and Cumulative distribution function of Peak Dose from Meat (Waterrelease) in mrem/yr

$\begin{array}{ccccc}\text { Repetition }= & 1 & 2 & 3 \\ \text { Mean } & 7.54 \mathrm{E}-04 & 7.54 \mathrm{E}-04 & 7.54 \mathrm{E}-04 \\ \text { Std. Dev. } & 4.50 \mathrm{E}-04 & 4.50 \mathrm{E}-04 & 4.50 \mathrm{E}-04 \\ \text { Minimum } & 9.08 \mathrm{E}-05 & 9.08 \mathrm{E}-05 & 9.08 \mathrm{E}-05 \\ \text { Maximum } & 4.28 \mathrm{E}-03 & 4.28 \mathrm{E}-03 & 4.28 \mathrm{E}-03\end{array}$

Percentile

$0.010 \quad 1.31 \mathrm{E}-04 \quad 1.31 \mathrm{E}-04 \quad 1.31 \mathrm{E}-04$

$0.025 \quad 1.70 \mathrm{E}-04 \quad 1.70 \mathrm{E}-04 \quad 1.70 \mathrm{E}-04$

$\begin{array}{llll}0.050 \quad 2.08 \mathrm{E}-04 & 2.08 \mathrm{E}-04 & 2.08 \mathrm{E}-04\end{array}$

$\begin{array}{llll}0.075 & 2.46 \mathrm{E}-04 & 2.46 \mathrm{E}-04 & 2.46 \mathrm{E}-04\end{array}$

$\begin{array}{llll}0.100 \quad 2.73 E-04 & 2.73 E-04 & 2.73 E-04\end{array}$

$0.125 \quad 3.01 \mathrm{E}-04 \quad 3.01 \mathrm{E}-04 \quad 3.01 \mathrm{E}-04$

$0.150 \quad 3.25 \mathrm{E}-04 \quad 3.25 \mathrm{E}-04 \quad 3.25 \mathrm{E}-04$

$\begin{array}{llll}0.175 & 3.52 \mathrm{E}-04 & 3.52 \mathrm{E}-04 & 3.52 \mathrm{E}-04\end{array}$

$0.200 \quad 3.74 \mathrm{E}-04 \quad 3.74 \mathrm{E}-04 \quad 3.74 \mathrm{E}-04$

$\begin{array}{llll}0.225 & 4.00 \mathrm{E}-04 & 3.99 \mathrm{E}-04 & 3.99 \mathrm{E}-04\end{array}$

$0.250 \quad 4.25 \mathrm{E}-04 \quad 4.25 \mathrm{E}-04 \quad 4.25 \mathrm{E}-04$

$0.275 \quad 4.50 \mathrm{E}-04 \quad 4.50 \mathrm{E}-04 \quad 4.50 \mathrm{E}-04$

$0.300 \quad 4.74 \mathrm{E}-04 \quad 4.74 \mathrm{E}-04 \quad 4.74 \mathrm{E}-04$

$0.325 \quad 4.93 \mathrm{E}-04 \quad 4.92 \mathrm{E}-04 \quad 4.93 \mathrm{E}-04$

$0.350 \quad 5.12 \mathrm{E}-04 \quad 5.12 \mathrm{E}-04 \quad 5.12 \mathrm{E}-04$

$0.375 \quad 5.35 \mathrm{E}-04 \quad 5.34 \mathrm{E}-04 \quad 5.35 \mathrm{E}-04$

$0.400 \quad 5.58 \mathrm{E}-04 \quad 5.58 \mathrm{E}-04 \quad 5.58 \mathrm{E}-04$

$0.425 \quad 5.80 \mathrm{E}-04 \quad 5.79 \mathrm{E}-04 \quad 5.80 \mathrm{E}-04$

$0.450 \quad 6.01 \mathrm{E}-04 \quad 6.01 \mathrm{E}-04 \quad 6.01 \mathrm{E}-04$

$\begin{array}{lllll}0.475 & 6.30 \mathrm{E}-04 & 6.29 \mathrm{E}-04 & 6.29 \mathrm{E}-04\end{array}$

$\begin{array}{lllll}0.500 & 6.60 \mathrm{E}-04 & 6.57 \mathrm{E}-04 & 6.58 \mathrm{E}-04\end{array}$

$\begin{array}{lllll}0.525 & 6.87 \mathrm{E}-04 & 6.82 \mathrm{E}-04 & 6.82 \mathrm{E}-04\end{array}$

$0.550 \quad 7.15 \mathrm{E}-04 \quad 7.13 \mathrm{E}-04 \quad 7.14 \mathrm{E}-04$

$\begin{array}{llll}0.575 & 7.42 \mathrm{E}-04 & 7.39 \mathrm{E}-04 & 7.40 \mathrm{E}-04\end{array}$

$0.600 \quad 7.68 \mathrm{E}-04 \quad 7.68 \mathrm{E}-04 \quad 7.68 \mathrm{E}-04$

$0.625 \quad 7.99 \mathrm{E}-04 \quad 7.98 \mathrm{E}-04 \quad 7.98 \mathrm{E}-04$

$\begin{array}{llll}0.650 & 8.30 \mathrm{E}-04 & 8.29 \mathrm{E}-04 & 8.29 \mathrm{E}-04\end{array}$

$\begin{array}{llll}0.675 & 8.65 \mathrm{E}-04 & 8.64 \mathrm{E}-04 & 8.64 \mathrm{E}-04\end{array}$

$0.700 \quad 9.04 \mathrm{E}-04 \quad 9.02 \mathrm{E}-04 \quad 9.02 \mathrm{E}-04$

$\begin{array}{llll}0.725 & 9.41 \mathrm{E}-04 & 9.41 \mathrm{E}-04 & 9.41 \mathrm{E}-04\end{array}$

\begin{tabular}{l}
$0.750 \quad 9.95 \mathrm{E}-04 \quad 9.94 \mathrm{E}-04 \quad 9.95 \mathrm{E}-04$ \\
\hline
\end{tabular}

$0.775 \quad 1.04 \mathrm{E}-03 \quad 1.04 \mathrm{E}-03 \quad 1.04 \mathrm{E}-03$

$0.800 \quad 1.10 \mathrm{E}-03 \quad 1.10 \mathrm{E}-03 \quad 1.10 \mathrm{E}-03$

$0.825 \quad 1.14 \mathrm{E}-03 \quad 1.14 \mathrm{E}-03 \quad 1.14 \mathrm{E}-03$

$0.850 \quad 1.21 \mathrm{E}-03 \quad 1.21 \mathrm{E}-03 \quad 1.21 \mathrm{E}-03$

$\begin{array}{llll}0.875 & 1.29 \mathrm{E}-03 & 1.29 \mathrm{E}-03 & 1.29 \mathrm{E}-03\end{array}$

$\begin{array}{llll}0.900 \quad 1.36 \mathrm{E}-03 & 1.36 \mathrm{E}-03 & 1.36 \mathrm{E}-03\end{array}$

$0.925 \quad 1.48 \mathrm{E}-03 \quad 1.47 \mathrm{E}-03 \quad 1.48 \mathrm{E}-03$

$0.950 \quad 1.60 \mathrm{E}-03 \quad 1.60 \mathrm{E}-03 \quad 1.60 \mathrm{E}-03$

$0.975 \quad 1.81 \mathrm{E}-03 \quad 1.81 \mathrm{E}-03 \quad 1.81 \mathrm{E}-03$

$0.990 \quad 2.26 \mathrm{E}-03 \quad 2.26 \mathrm{E}-03 \quad 2.26 \mathrm{E}-03$ 
RESRAD-OFFSITE, Version 2.5

Probabilistic Dose and Risk Report

Title : RESRAD-OFFSITE Drinking Water, Plant, Milk, and Meat Pathways for Offsite Reside

File : PBA-1_TC99-DOE-5.ROF

Statistics and Cumulative distribution function of Peak Dose from Milk (Waterrelease) in mrem/yr

$\begin{array}{ccccc}\text { Repetition }= & 1 & 2 & 3 \\ \text { Mean } & 6.66 \mathrm{E}-02 & 6.66 \mathrm{E}-02 & 6.66 \mathrm{E}-02 \\ \text { Std. Dev. } & 3.97 \mathrm{E}-02 & 3.97 \mathrm{E}-02 & 3.97 \mathrm{E}-02 \\ \text { Minimum } & 8.02 \mathrm{E}-03 & 8.02 \mathrm{E}-03 & 8.02 \mathrm{E}-03 \\ \text { Maximum } & 3.78 \mathrm{E}-01 & 3.78 \mathrm{E}-01 & 3.78 \mathrm{E}-01\end{array}$

Percentile

$0.010 \quad 1.15 \mathrm{E}-02 \quad 1.15 \mathrm{E}-02 \quad 1.15 \mathrm{E}-02$

$0.025 \quad 1.50 \mathrm{E}-02 \quad 1.50 \mathrm{E}-02 \quad 1.50 \mathrm{E}-02$

$0.050 \quad 1.84 \mathrm{E}-02 \quad 1.84 \mathrm{E}-02 \quad 1.84 \mathrm{E}-02$

$0.075 \quad 2.17 \mathrm{E}-02 \quad 2.17 \mathrm{E}-02 \quad 2.17 \mathrm{E}-02$

$0.100 \quad 2.41 \mathrm{E}-02 \quad 2.41 \mathrm{E}-02 \quad 2.41 \mathrm{E}-02$

$0.125 \quad 2.66 \mathrm{E}-02 \quad 2.66 \mathrm{E}-02 \quad 2.66 \mathrm{E}-02$

$0.150 \quad 2.87 \mathrm{E}-02 \quad 2.87 \mathrm{E}-02 \quad 2.87 \mathrm{E}-02$

$0.175 \quad 3.11 \mathrm{E}-02 \quad 3.11 \mathrm{E}-02 \quad 3.11 \mathrm{E}-02$

$0.200 \quad 3.30 \mathrm{E}-02 \quad 3.30 \mathrm{E}-02 \quad 3.30 \mathrm{E}-02$

$0.225 \quad 3.53 \mathrm{E}-02 \quad 3.53 \mathrm{E}-02 \quad 3.53 \mathrm{E}-02$

$0.250 \quad 3.76 \mathrm{E}-02 \quad 3.75 \mathrm{E}-02 \quad 3.75 \mathrm{E}-02$

$0.275 \quad 3.97 \mathrm{E}-02 \quad 3.97 \mathrm{E}-02 \quad 3.97 \mathrm{E}-02$

$0.300 \quad 4.19 \mathrm{E}-02 \quad 4.18 \mathrm{E}-02 \quad 4.18 \mathrm{E}-02$

$0.325 \quad 4.35 \mathrm{E}-02 \quad 4.35 \mathrm{E}-02 \quad 4.35 \mathrm{E}-02$

$0.350 \quad 4.52 \mathrm{E}-02 \quad 4.52 \mathrm{E}-02 \quad 4.52 \mathrm{E}-02$

$0.375 \quad 4.72 \mathrm{E}-02 \quad 4.71 \mathrm{E}-02 \quad 4.72 \mathrm{E}-02$

$0.400 \quad 4.93 \mathrm{E}-02 \quad 4.93 \mathrm{E}-02 \quad 4.93 \mathrm{E}-02$

$0.425 \quad 5.12 \mathrm{E}-02 \quad 5.12 \mathrm{E}-02 \quad 5.12 \mathrm{E}-02$

$0.450 \quad 5.31 \mathrm{E}-02 \quad 5.31 \mathrm{E}-02 \quad 5.31 \mathrm{E}-02$

$0.475 \quad 5.57 \mathrm{E}-02 \quad 5.55 \mathrm{E}-02 \quad 5.56 \mathrm{E}-02$

$0.500 \quad 5.83 \mathrm{E}-02 \quad 5.80 \mathrm{E}-02 \quad 5.81 \mathrm{E}-02$

$0.525 \quad 6.07 \mathrm{E}-02 \quad 6.02 \mathrm{E}-02 \quad 6.03 \mathrm{E}-02$

$0.550 \quad 6.31 \mathrm{E}-02 \quad 6.30 \mathrm{E}-02 \quad 6.31 \mathrm{E}-02$

$0.575 \quad 6.55 \mathrm{E}-02 \quad 6.53 \mathrm{E}-02 \quad 6.53 \mathrm{E}-02$

$0.600 \quad 6.79 \mathrm{E}-02 \quad 6.78 \mathrm{E}-02 \quad 6.78 \mathrm{E}-02$

$0.625 \quad 7.05 \mathrm{E}-02 \quad 7.05 \mathrm{E}-02 \quad 7.05 \mathrm{E}-02$

$0.650 \quad 7.33 \mathrm{E}-02 \quad 7.32 \mathrm{E}-02 \quad 7.32 \mathrm{E}-02$

$0.675 \quad 7.64 \mathrm{E}-02 \quad 7.63 \mathrm{E}-02 \quad 7.63 \mathrm{E}-02$

$0.700 \quad 7.98 \mathrm{E}-02 \quad 7.97 \mathrm{E}-02 \quad 7.97 \mathrm{E}-02$

$0.725 \quad 8.31 \mathrm{E}-02 \quad 8.31 \mathrm{E}-02 \quad 8.31 \mathrm{E}-02$

$0.750 \quad 8.79 \mathrm{E}-02 \quad 8.77 \mathrm{E}-02 \quad 8.79 \mathrm{E}-02$

$0.7759 .21 \mathrm{E}-02 \quad 9.20 \mathrm{E}-02 \quad 9.21 \mathrm{E}-02$

$0.800 \quad 9.68 \mathrm{E}-02 \quad 9.67 \mathrm{E}-02 \quad 9.68 \mathrm{E}-02$

$\begin{array}{llll}0.825 & 1.01 \mathrm{E}-01 & 1.01 \mathrm{E}-01 & 1.01 \mathrm{E}-01\end{array}$

$0.850 \quad 1.07 \mathrm{E}-01 \quad 1.07 \mathrm{E}-01 \quad 1.07 \mathrm{E}-01$

$\begin{array}{llll}0.875 & 1.14 \mathrm{E}-01 & 1.14 \mathrm{E}-01 & 1.14 \mathrm{E}-01\end{array}$

$0.900 \quad 1.20 \mathrm{E}-01 \quad 1.20 \mathrm{E}-01 \quad 1.20 \mathrm{E}-01$

$\begin{array}{llll}0.925 & 1.30 \mathrm{E}-01 & 1.30 \mathrm{E}-01 & 1.30 \mathrm{E}-01\end{array}$

$0.950 \quad 1.42 \mathrm{E}-01 \quad 1.42 \mathrm{E}-01 \quad 1.42 \mathrm{E}-01$

$\begin{array}{llll}0.975 & 1.60 \mathrm{E}-01 & 1.60 \mathrm{E}-01 & 1.60 \mathrm{E}-01\end{array}$

$0.990 \quad 2.00 \mathrm{E}-01 \quad 2.00 \mathrm{E}-01 \quad 2.00 \mathrm{E}-01$ 
RESRAD-OFFSITE, Version 2.5

Probabilistic Dose and Risk Report

Title : RESRAD-OFFSITE Drinking Water, Plant, Milk, and Meat Pathways for Offsite Reside

File : PBA-1_TC99-DOE-5.ROF

Statistics and Cumulative distribution function of Peak Dose from Soil Ingestion(Wrelease) in mrem/yr

\begin{tabular}{|c|c|c|c|}
\hline Repetition = & 1 & 2 & 3 \\
\hline Mean & $0.00 \mathrm{E}+00$ & $0.00 \mathrm{E}+00$ & $0.00 \mathrm{E}+00$ \\
\hline Std. Dev. & $0.00 \mathrm{E}+00$ & $0.00 \mathrm{E}+00$ & $0.00 \mathrm{E}+00$ \\
\hline Minimum & $0.00 \mathrm{E}+00$ & $0.00 \mathrm{E}+00$ & $0.00 \mathrm{E}+00$ \\
\hline Maximum & $0.00 \mathrm{E}+00$ & $0.00 \mathrm{E}+00$ & $0.00 \mathrm{E}+00$ \\
\hline
\end{tabular}

Percentile

$\begin{array}{llll}0.010 & 0.00 \mathrm{E}+00 \quad 0.00 \mathrm{E}+00 & 0.00 \mathrm{E}+00\end{array}$

$\begin{array}{llll}0.025 & 0.00 \mathrm{E}+00 \quad 0.00 \mathrm{E}+00 & 0.00 \mathrm{E}+00\end{array}$

$\begin{array}{llll}0.050 & 0.00 \mathrm{E}+00 & 0.00 \mathrm{E}+00 & 0.00 \mathrm{E}+00\end{array}$

$\begin{array}{llll}0.075 & 0.00 \mathrm{E}+00 & 0.00 \mathrm{E}+00 & 0.00 \mathrm{E}+00\end{array}$

$\begin{array}{llll}0.100 & 0.00 \mathrm{E}+00 & 0.00 \mathrm{E}+00 & 0.00 \mathrm{E}+00\end{array}$

$\begin{array}{llll}0.125 & 0.00 \mathrm{E}+00 & 0.00 \mathrm{E}+00 & 0.00 \mathrm{E}+00\end{array}$

$\begin{array}{llll}0.150 & 0.00 \mathrm{E}+00 & 0.00 \mathrm{E}+00 & 0.00 \mathrm{E}+00\end{array}$

$\begin{array}{lllll}0.175 & 0.00 \mathrm{E}+00 & 0.00 \mathrm{E}+00 & 0.00 \mathrm{E}+00\end{array}$

$\begin{array}{llll}0.200 & 0.00 \mathrm{E}+00 & 0.00 \mathrm{E}+00 & 0.00 \mathrm{E}+00\end{array}$

$\begin{array}{lllll}0.225 & 0.00 \mathrm{E}+00 & 0.00 \mathrm{E}+00 & 0.00 \mathrm{E}+00\end{array}$

$\begin{array}{llll}0.250 & 0.00 \mathrm{E}+00 & 0.00 \mathrm{E}+00 & 0.00 \mathrm{E}+00\end{array}$

$\begin{array}{llll}0.275 & 0.00 \mathrm{E}+00 & 0.00 \mathrm{E}+00 & 0.00 \mathrm{E}+00\end{array}$

$\begin{array}{lllll}0.300 & 0.00 \mathrm{E}+00 & 0.00 \mathrm{E}+00 & 0.00 \mathrm{E}+00\end{array}$

$\begin{array}{llll}0.325 & 0.00 \mathrm{E}+00 & 0.00 \mathrm{E}+00 & 0.00 \mathrm{E}+00\end{array}$

$\begin{array}{lllll}0.350 & 0.00 \mathrm{E}+00 & 0.00 \mathrm{E}+00 & 0.00 \mathrm{E}+00\end{array}$

$\begin{array}{lllll}0.375 & 0.00 \mathrm{E}+00 & 0.00 \mathrm{E}+00 & 0.00 \mathrm{E}+00\end{array}$

$\begin{array}{lllll}0.400 & 0.00 \mathrm{E}+00 & 0.00 \mathrm{E}+00 & 0.00 \mathrm{E}+00\end{array}$

$\begin{array}{lllll}0.425 & 0.00 \mathrm{E}+00 & 0.00 \mathrm{E}+00 & 0.00 \mathrm{E}+00\end{array}$

$\begin{array}{lllll}0.450 & 0.00 \mathrm{E}+00 & 0.00 \mathrm{E}+00 & 0.00 \mathrm{E}+00\end{array}$

$\begin{array}{lllll}0.475 & 0.00 \mathrm{E}+00 & 0.00 \mathrm{E}+00 & 0.00 \mathrm{E}+00\end{array}$

$\begin{array}{lllll}0.500 & 0.00 \mathrm{E}+00 & 0.00 \mathrm{E}+00 & 0.00 \mathrm{E}+00\end{array}$

$\begin{array}{lllll}0.525 & 0.00 \mathrm{E}+00 & 0.00 \mathrm{E}+00 & 0.00 \mathrm{E}+00\end{array}$

$\begin{array}{lllll}0.550 & 0.00 \mathrm{E}+00 & 0.00 \mathrm{E}+00 & 0.00 \mathrm{E}+00\end{array}$

$\begin{array}{lllll}0.575 & 0.00 \mathrm{E}+00 & 0.00 \mathrm{E}+00 & 0.00 \mathrm{E}+00\end{array}$

$\begin{array}{lllll}0.600 & 0.00 \mathrm{E}+00 & 0.00 \mathrm{E}+00 & 0.00 \mathrm{E}+00\end{array}$

$\begin{array}{lllll}0.625 & 0.00 \mathrm{E}+00 & 0.00 \mathrm{E}+00 & 0.00 \mathrm{E}+00\end{array}$

$\begin{array}{lllll}0.650 & 0.00 \mathrm{E}+00 & 0.00 \mathrm{E}+00 & 0.00 \mathrm{E}+00\end{array}$

$\begin{array}{lllll}0.675 & 0.00 \mathrm{E}+00 & 0.00 \mathrm{E}+00 & 0.00 \mathrm{E}+00\end{array}$

$\begin{array}{llll}0.700 & 0.00 \mathrm{E}+00 & 0.00 \mathrm{E}+00 & 0.00 \mathrm{E}+00\end{array}$

$\begin{array}{lllll}0.725 & 0.00 \mathrm{E}+00 & 0.00 \mathrm{E}+00 & 0.00 \mathrm{E}+00\end{array}$

$\begin{array}{lllll}0.750 & 0.00 \mathrm{E}+00 & 0.00 \mathrm{E}+00 & 0.00 \mathrm{E}+00\end{array}$

$\begin{array}{llll}0.775 & 0.00 \mathrm{E}+00 & 0.00 \mathrm{E}+00 & 0.00 \mathrm{E}+00\end{array}$

$\begin{array}{lllll}0.800 & 0.00 \mathrm{E}+00 & 0.00 \mathrm{E}+00 & 0.00 \mathrm{E}+00\end{array}$

$\begin{array}{lllll}0.825 & 0.00 \mathrm{E}+00 & 0.00 \mathrm{E}+00 & 0.00 \mathrm{E}+00\end{array}$

$\begin{array}{lllll}0.850 & 0.00 \mathrm{E}+00 & 0.00 \mathrm{E}+00 & 0.00 \mathrm{E}+00\end{array}$

$\begin{array}{lllll}0.875 & 0.00 \mathrm{E}+00 & 0.00 \mathrm{E}+00 & 0.00 \mathrm{E}+00\end{array}$

$\begin{array}{llll}0.900 & 0.00 \mathrm{E}+00 & 0.00 \mathrm{E}+00 & 0.00 \mathrm{E}+00\end{array}$

$\begin{array}{lllll}0.925 & 0.00 \mathrm{E}+00 & 0.00 \mathrm{E}+00 & 0.00 \mathrm{E}+00\end{array}$

$\begin{array}{llll}0.950 & 0.00 \mathrm{E}+00 & 0.00 \mathrm{E}+00 & 0.00 \mathrm{E}+00\end{array}$

$\begin{array}{lllll}0.975 & 0.00 \mathrm{E}+00 & 0.00 \mathrm{E}+00 & 0.00 \mathrm{E}+00\end{array}$

$\begin{array}{lllll}0.990 & 0.00 \mathrm{E}+00 & 0.00 \mathrm{E}+00 & 0.00 \mathrm{E}+00\end{array}$ 
RESRAD-OFFSITE, Version 2.5

Probabilistic Dose and Risk Report

Title : RESRAD-OFFSITE Drinking Water, Plant, Milk, and Meat Pathways for Offsite Reside

File : PBA-1_TC99-DOE-5.ROF

Statistics and Cumulative distribution function of Peak Dose from Water Ingestion in mrem/yr

\begin{tabular}{|c|c|c|c|}
\hline Repetition $=$ & 1 & 2 & 3 \\
\hline Mean & $6.86 \mathrm{E}-01$ & $6.85 E-01$ & $6.86 \mathrm{E}-01$ \\
\hline Std. Dev. & $4.09 E-01$ & 4.09E-01 & $4.09 \mathrm{E}-01$ \\
\hline Minimum & $8.26 \mathrm{E}-02$ & $8.26 \mathrm{E}-02$ & $8.26 \mathrm{E}-02$ \\
\hline Maximum & $3.89 \mathrm{E}+00$ & $3.89 \mathrm{E}+00$ & $3.89 \mathrm{E}+00$ \\
\hline
\end{tabular}

Percentile

$0.010 \quad 1.19 \mathrm{E}-01 \quad 1.19 \mathrm{E}-01 \quad 1.19 \mathrm{E}-01$

$0.025 \quad 1.54 \mathrm{E}-01 \quad 1.54 \mathrm{E}-01 \quad 1.54 \mathrm{E}-01$

$0.050 \quad 1.89 \mathrm{E}-01 \quad 1.89 \mathrm{E}-01 \quad 1.89 \mathrm{E}-01$

$\begin{array}{llll}0.075 & 2.24 \mathrm{E}-01 & 2.24 \mathrm{E}-01 & 2.24 \mathrm{E}-01\end{array}$

$\begin{array}{llll}0.100 & 2.48 \mathrm{E}-01 & 2.48 \mathrm{E}-01 & 2.48 \mathrm{E}-01\end{array}$

$\begin{array}{llll}0.125 & 2.73 \mathrm{E}-01 & 2.73 \mathrm{E}-01 & 2.73 \mathrm{E}-01\end{array}$

$0.150 \quad 2.95 \mathrm{E}-01 \quad 2.95 \mathrm{E}-01 \quad 2.95 \mathrm{E}-01$

$0.175 \quad 3.20 \mathrm{E}-01 \quad 3.20 \mathrm{E}-01 \quad 3.20 \mathrm{E}-01$

$0.200 \quad 3.40 \mathrm{E}-01 \quad 3.40 \mathrm{E}-01 \quad 3.40 \mathrm{E}-01$

$0.225 \quad 3.64 \mathrm{E}-01 \quad 3.63 \mathrm{E}-01 \quad 3.63 \mathrm{E}-01$

$\begin{array}{llll}0.250 & 3.87 \mathrm{E}-01 & 3.86 \mathrm{E}-01 & 3.86 \mathrm{E}-01\end{array}$

$0.275 \quad 4.09 \mathrm{E}-01 \quad 4.09 \mathrm{E}-01 \quad 4.09 \mathrm{E}-01$

$0.300 \quad 4.31 \mathrm{E}-01 \quad 4.31 \mathrm{E}-01 \quad 4.31 \mathrm{E}-01$

$0.325 \quad 4.48 \mathrm{E}-01 \quad 4.48 \mathrm{E}-01 \quad 4.48 \mathrm{E}-01$

$0.350 \quad 4.66 \mathrm{E}-01 \quad 4.66 \mathrm{E}-01 \quad 4.66 \mathrm{E}-01$

$0.375 \quad 4.86 \mathrm{E}-01 \quad 4.85 \mathrm{E}-01 \quad 4.86 \mathrm{E}-01$

$0.400 \quad 5.08 \mathrm{E}-01 \quad 5.07 \mathrm{E}-01 \quad 5.08 \mathrm{E}-01$

$0.425 \quad 5.27 \mathrm{E}-01 \quad 5.27 \mathrm{E}-01 \quad 5.27 \mathrm{E}-01$

$0.450 \quad 5.47 \mathrm{E}-01 \quad 5.46 \mathrm{E}-01 \quad 5.47 \mathrm{E}-01$

$0.475 \quad 5.73 \mathrm{E}-01 \quad 5.72 \mathrm{E}-01 \quad 5.72 \mathrm{E}-01$

$0.500 \quad 6.00 \mathrm{E}-01 \quad 5.97 \mathrm{E}-01 \quad 5.98 \mathrm{E}-01$

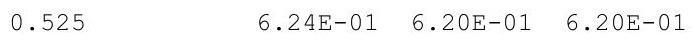

$0.550 \quad 6.50 \mathrm{E}-01 \quad 6.49 \mathrm{E}-01 \quad 6.49 \mathrm{E}-01$

$0.575 \quad 6.74 \mathrm{E}-01 \quad 6.72 \mathrm{E}-01 \quad 6.73 \mathrm{E}-01$

$0.600 \quad 6.99 \mathrm{E}-01 \quad 6.98 \mathrm{E}-01 \quad 6.98 \mathrm{E}-01$

$\begin{array}{llll}0.625 & 7.26 \mathrm{E}-01 & 7.25 \mathrm{E}-01 & 7.25 \mathrm{E}-01\end{array}$

$0.650 \quad 7.55 \mathrm{E}-01 \quad 7.54 \mathrm{E}-01 \quad 7.54 \mathrm{E}-01$

$\begin{array}{llll}0.675 & 7.86 \mathrm{E}-01 & 7.86 \mathrm{E}-01 & 7.86 \mathrm{E}-01\end{array}$

$\begin{array}{llll}0.700 & 8.22 \mathrm{E}-01 & 8.20 \mathrm{E}-01 & 8.20 \mathrm{E}-01\end{array}$

$\begin{array}{llll}0.725 & 8.56 \mathrm{E}-01 & 8.55 \mathrm{E}-01 & 8.55 \mathrm{E}-01\end{array}$

$0.750 \quad 9.04 \mathrm{E}-01 \quad 9.03 \mathrm{E}-01 \quad 9.04 \mathrm{E}-01$

$\begin{array}{llll}0.775 & 9.49 \mathrm{E}-01 & 9.47 \mathrm{E}-01 & 9.49 \mathrm{E}-01\end{array}$

$\begin{array}{llll}0.800 \quad 9.96 \mathrm{E}-01 & 9.96 \mathrm{E}-01 & 9.96 \mathrm{E}-01\end{array}$

$\begin{array}{llll}0.825 & 1.04 \mathrm{E}+00 & 1.04 \mathrm{E}+00 & 1.04 \mathrm{E}+00\end{array}$

$\begin{array}{llll}0.850 & 1.10 \mathrm{E}+00 & 1.10 \mathrm{E}+00 & 1.10 \mathrm{E}+00\end{array}$

$\begin{array}{llll}0.875 & 1.18 \mathrm{E}+00 & 1.17 \mathrm{E}+00 & 1.18 \mathrm{E}+00\end{array}$

$\begin{array}{llll}0.900 & 1.24 \mathrm{E}+00 & 1.24 \mathrm{E}+00 & 1.24 \mathrm{E}+00\end{array}$

$\begin{array}{llll}0.925 & 1.34 \mathrm{E}+00 & 1.34 \mathrm{E}+00 & 1.34 \mathrm{E}+00\end{array}$

$0.950 \quad 1.46 \mathrm{E}+00 \quad 1.46 \mathrm{E}+00 \quad 1.46 \mathrm{E}+00$

$\begin{array}{llll}0.975 & 1.65 \mathrm{E}+00 & 1.65 \mathrm{E}+00 & 1.65 \mathrm{E}+00\end{array}$

$0.990 \quad 2.06 \mathrm{E}+00 \quad 2.06 \mathrm{E}+00 \quad 2.06 \mathrm{E}+00$ 
RESRAD-OFFSITE, Version 2.5

Probabilistic Dose and Risk Report

Title : RESRAD-OFFSITE Drinking Water, Plant, Milk, and Meat Pathways for Offsite Reside

File : PBA-1_TC99-DOE-5.ROF

Statistics and Cumulative distribution function of Peak Dose from External Ground(Cz\&Air) in mrem/yr

$\begin{array}{ccccc}\text { Repetition }= & 1 & 2 & 3 \\ \text { Mean } & 0.00 \mathrm{E}+00 & 0.00 \mathrm{E}+00 & 0.00 \mathrm{E}+00 \\ \text { Std. Dev. } & 0.00 \mathrm{E}+00 & 0.00 \mathrm{E}+00 & 0.00 \mathrm{E}+00 \\ \text { Minimum } & 0.00 \mathrm{E}+00 & 0.00 \mathrm{E}+00 & 0.00 \mathrm{E}+00 \\ \text { Maximum } & 0.00 \mathrm{E}+00 & 0.00 \mathrm{E}+00 & 0.00 \mathrm{E}+00\end{array}$

Percentile

$\begin{array}{llll}0.010 & 0.00 \mathrm{E}+00 \quad 0.00 \mathrm{E}+00 & 0.00 \mathrm{E}+00\end{array}$

$\begin{array}{llll}0.025 & 0.00 \mathrm{E}+00 \quad 0.00 \mathrm{E}+00 & 0.00 \mathrm{E}+00\end{array}$

$\begin{array}{llll}0.050 & 0.00 \mathrm{E}+00 & 0.00 \mathrm{E}+00 & 0.00 \mathrm{E}+00\end{array}$

$\begin{array}{llll}0.075 & 0.00 \mathrm{E}+00 & 0.00 \mathrm{E}+00 & 0.00 \mathrm{E}+00\end{array}$

$\begin{array}{llll}0.100 & 0.00 \mathrm{E}+00 & 0.00 \mathrm{E}+00 & 0.00 \mathrm{E}+00\end{array}$

$\begin{array}{llll}0.125 & 0.00 \mathrm{E}+00 & 0.00 \mathrm{E}+00 & 0.00 \mathrm{E}+00\end{array}$

$\begin{array}{llll}0.150 & 0.00 \mathrm{E}+00 & 0.00 \mathrm{E}+00 & 0.00 \mathrm{E}+00\end{array}$

$\begin{array}{lllll}0.175 & 0.00 \mathrm{E}+00 & 0.00 \mathrm{E}+00 & 0.00 \mathrm{E}+00\end{array}$

$\begin{array}{lllll}0.200 & 0.00 \mathrm{E}+00 & 0.00 \mathrm{E}+00 & 0.00 \mathrm{E}+00\end{array}$

$\begin{array}{lllll}0.225 & 0.00 \mathrm{E}+00 & 0.00 \mathrm{E}+00 & 0.00 \mathrm{E}+00\end{array}$

$\begin{array}{lllll}0.250 & 0.00 \mathrm{E}+00 & 0.00 \mathrm{E}+00 & 0.00 \mathrm{E}+00\end{array}$

$\begin{array}{lllll}0.275 & 0.00 \mathrm{E}+00 & 0.00 \mathrm{E}+00 & 0.00 \mathrm{E}+00\end{array}$

$\begin{array}{lllll}0.300 & 0.00 \mathrm{E}+00 & 0.00 \mathrm{E}+00 & 0.00 \mathrm{E}+00\end{array}$

$\begin{array}{lllll}0.325 & 0.00 \mathrm{E}+00 & 0.00 \mathrm{E}+00 & 0.00 \mathrm{E}+00\end{array}$

$\begin{array}{lllll}0.350 & 0.00 \mathrm{E}+00 & 0.00 \mathrm{E}+00 & 0.00 \mathrm{E}+00\end{array}$

$\begin{array}{lllll}0.375 & 0.00 \mathrm{E}+00 & 0.00 \mathrm{E}+00 & 0.00 \mathrm{E}+00\end{array}$

$\begin{array}{lllll}0.400 & 0.00 \mathrm{E}+00 & 0.00 \mathrm{E}+00 & 0.00 \mathrm{E}+00\end{array}$

$\begin{array}{lllll}0.425 & 0.00 \mathrm{E}+00 & 0.00 \mathrm{E}+00 & 0.00 \mathrm{E}+00\end{array}$

$\begin{array}{lllll}0.450 & 0.00 \mathrm{E}+00 & 0.00 \mathrm{E}+00 & 0.00 \mathrm{E}+00\end{array}$

$\begin{array}{lllll}0.475 & 0.00 \mathrm{E}+00 & 0.00 \mathrm{E}+00 & 0.00 \mathrm{E}+00\end{array}$

$\begin{array}{lllll}0.500 & 0.00 \mathrm{E}+00 & 0.00 \mathrm{E}+00 & 0.00 \mathrm{E}+00\end{array}$

$\begin{array}{lllll}0.525 & 0.00 \mathrm{E}+00 & 0.00 \mathrm{E}+00 & 0.00 \mathrm{E}+00\end{array}$

$\begin{array}{lllll}0.550 & 0.00 \mathrm{E}+00 & 0.00 \mathrm{E}+00 & 0.00 \mathrm{E}+00\end{array}$

$\begin{array}{lllll}0.575 & 0.00 \mathrm{E}+00 & 0.00 \mathrm{E}+00 & 0.00 \mathrm{E}+00\end{array}$

$\begin{array}{lllll}0.600 & 0.00 \mathrm{E}+00 & 0.00 \mathrm{E}+00 & 0.00 \mathrm{E}+00\end{array}$

$\begin{array}{lllll}0.625 & 0.00 \mathrm{E}+00 & 0.00 \mathrm{E}+00 & 0.00 \mathrm{E}+00\end{array}$

$\begin{array}{lllll}0.650 & 0.00 \mathrm{E}+00 & 0.00 \mathrm{E}+00 & 0.00 \mathrm{E}+00\end{array}$

$\begin{array}{lllll}0.675 & 0.00 \mathrm{E}+00 & 0.00 \mathrm{E}+00 & 0.00 \mathrm{E}+00\end{array}$

$\begin{array}{llll}0.700 & 0.00 \mathrm{E}+00 & 0.00 \mathrm{E}+00 & 0.00 \mathrm{E}+00\end{array}$

$\begin{array}{lllll}0.725 & 0.00 \mathrm{E}+00 & 0.00 \mathrm{E}+00 & 0.00 \mathrm{E}+00\end{array}$

$\begin{array}{lllll}0.750 & 0.00 \mathrm{E}+00 & 0.00 \mathrm{E}+00 & 0.00 \mathrm{E}+00\end{array}$

$\begin{array}{lllll}0.775 & 0.00 \mathrm{E}+00 & 0.00 \mathrm{E}+00 & 0.00 \mathrm{E}+00\end{array}$

$\begin{array}{lllll}0.800 & 0.00 \mathrm{E}+00 & 0.00 \mathrm{E}+00 & 0.00 \mathrm{E}+00\end{array}$

$\begin{array}{lllll}0.825 & 0.00 \mathrm{E}+00 & 0.00 \mathrm{E}+00 & 0.00 \mathrm{E}+00\end{array}$

$\begin{array}{lllll}0.850 & 0.00 \mathrm{E}+00 & 0.00 \mathrm{E}+00 & 0.00 \mathrm{E}+00\end{array}$

$\begin{array}{lllll}0.875 & 0.00 \mathrm{E}+00 & 0.00 \mathrm{E}+00 & 0.00 \mathrm{E}+00\end{array}$

$\begin{array}{lllll}0.900 & 0.00 \mathrm{E}+00 & 0.00 \mathrm{E}+00 & 0.00 \mathrm{E}+00\end{array}$

$\begin{array}{lllll}0.925 & 0.00 \mathrm{E}+00 & 0.00 \mathrm{E}+00 & 0.00 \mathrm{E}+00\end{array}$

$\begin{array}{llll}0.950 & 0.00 \mathrm{E}+00 & 0.00 \mathrm{E}+00 & 0.00 \mathrm{E}+00\end{array}$

$\begin{array}{lllll}0.975 & 0.00 \mathrm{E}+00 & 0.00 \mathrm{E}+00 & 0.00 \mathrm{E}+00\end{array}$

$\begin{array}{lllll}0.990 & 0.00 \mathrm{E}+00 & 0.00 \mathrm{E}+00 & 0.00 \mathrm{E}+00\end{array}$ 
RESRAD-OFFSITE, Version 2.5

Probabilistic Dose and Risk Report

Title : RESRAD-OFFSITE Drinking Water, Plant, Milk, and Meat Pathways for Offsite Reside

File : PBA-1_TC99-DOE-5.ROF

Statistics and Cumulative distribution function of Peak Dose from Inhalation ExcludingRn in mrem/yr

$\begin{array}{ccccc}\text { Repetition }= & 1 & 2 & 3 \\ \text { Mean } & 0.00 \mathrm{E}+00 & 0.00 \mathrm{E}+00 & 0.00 \mathrm{E}+00 \\ \text { Std. Dev. } & 0.00 \mathrm{E}+00 & 0.00 \mathrm{E}+00 & 0.00 \mathrm{E}+00 \\ \text { Minimum } & 0.00 \mathrm{E}+00 & 0.00 \mathrm{E}+00 & 0.00 \mathrm{E}+00 \\ \text { Maximum } & 0.00 \mathrm{E}+00 & 0.00 \mathrm{E}+00 & 0.00 \mathrm{E}+00\end{array}$

Percentile

$\begin{array}{llll}0.010 & 0.00 \mathrm{E}+00 \quad 0.00 \mathrm{E}+00 & 0.00 \mathrm{E}+00\end{array}$

$\begin{array}{llll}0.025 & 0.00 \mathrm{E}+00 \quad 0.00 \mathrm{E}+00 & 0.00 \mathrm{E}+00\end{array}$

$\begin{array}{llll}0.050 & 0.00 \mathrm{E}+00 & 0.00 \mathrm{E}+00 & 0.00 \mathrm{E}+00\end{array}$

$\begin{array}{llll}0.075 & 0.00 \mathrm{E}+00 & 0.00 \mathrm{E}+00 & 0.00 \mathrm{E}+00\end{array}$

$\begin{array}{llll}0.100 & 0.00 \mathrm{E}+00 & 0.00 \mathrm{E}+00 & 0.00 \mathrm{E}+00\end{array}$

$\begin{array}{llll}0.125 & 0.00 \mathrm{E}+00 & 0.00 \mathrm{E}+00 & 0.00 \mathrm{E}+00\end{array}$

$\begin{array}{lllll}0.150 & 0.00 \mathrm{E}+00 & 0.00 \mathrm{E}+00 & 0.00 \mathrm{E}+00\end{array}$

$\begin{array}{lllll}0.175 & 0.00 \mathrm{E}+00 & 0.00 \mathrm{E}+00 & 0.00 \mathrm{E}+00\end{array}$

$\begin{array}{lllll}0.200 & 0.00 \mathrm{E}+00 & 0.00 \mathrm{E}+00 & 0.00 \mathrm{E}+00\end{array}$

$\begin{array}{lllll}0.225 & 0.00 \mathrm{E}+00 & 0.00 \mathrm{E}+00 & 0.00 \mathrm{E}+00\end{array}$

$\begin{array}{lllll}0.250 & 0.00 \mathrm{E}+00 & 0.00 \mathrm{E}+00 & 0.00 \mathrm{E}+00\end{array}$

$\begin{array}{lllll}0.275 & 0.00 \mathrm{E}+00 & 0.00 \mathrm{E}+00 & 0.00 \mathrm{E}+00\end{array}$

$\begin{array}{lllll}0.300 & 0.00 \mathrm{E}+00 & 0.00 \mathrm{E}+00 & 0.00 \mathrm{E}+00\end{array}$

$\begin{array}{lllll}0.325 & 0.00 \mathrm{E}+00 & 0.00 \mathrm{E}+00 & 0.00 \mathrm{E}+00\end{array}$

$\begin{array}{lllll}0.350 & 0.00 \mathrm{E}+00 & 0.00 \mathrm{E}+00 & 0.00 \mathrm{E}+00\end{array}$

$\begin{array}{lllll}0.375 & 0.00 \mathrm{E}+00 & 0.00 \mathrm{E}+00 & 0.00 \mathrm{E}+00\end{array}$

$\begin{array}{lllll}0.400 & 0.00 \mathrm{E}+00 & 0.00 \mathrm{E}+00 & 0.00 \mathrm{E}+00\end{array}$

$\begin{array}{lllll}0.425 & 0.00 \mathrm{E}+00 & 0.00 \mathrm{E}+00 & 0.00 \mathrm{E}+00\end{array}$

$\begin{array}{lllll}0.450 & 0.00 \mathrm{E}+00 & 0.00 \mathrm{E}+00 & 0.00 \mathrm{E}+00\end{array}$

$\begin{array}{lllll}0.475 & 0.00 \mathrm{E}+00 & 0.00 \mathrm{E}+00 & 0.00 \mathrm{E}+00\end{array}$

$\begin{array}{lllll}0.500 & 0.00 \mathrm{E}+00 & 0.00 \mathrm{E}+00 & 0.00 \mathrm{E}+00\end{array}$

$\begin{array}{lllll}0.525 & 0.00 \mathrm{E}+00 & 0.00 \mathrm{E}+00 & 0.00 \mathrm{E}+00\end{array}$

$\begin{array}{lllll}0.550 & 0.00 \mathrm{E}+00 & 0.00 \mathrm{E}+00 & 0.00 \mathrm{E}+00\end{array}$

$\begin{array}{lllll}0.575 & 0.00 \mathrm{E}+00 & 0.00 \mathrm{E}+00 & 0.00 \mathrm{E}+00\end{array}$

$\begin{array}{lllll}0.600 & 0.00 \mathrm{E}+00 & 0.00 \mathrm{E}+00 & 0.00 \mathrm{E}+00\end{array}$

$\begin{array}{lllll}0.625 & 0.00 \mathrm{E}+00 & 0.00 \mathrm{E}+00 & 0.00 \mathrm{E}+00\end{array}$

$\begin{array}{lllll}0.650 & 0.00 \mathrm{E}+00 & 0.00 \mathrm{E}+00 & 0.00 \mathrm{E}+00\end{array}$

$\begin{array}{lllll}0.675 & 0.00 \mathrm{E}+00 & 0.00 \mathrm{E}+00 & 0.00 \mathrm{E}+00\end{array}$

$\begin{array}{llll}0.700 & 0.00 \mathrm{E}+00 & 0.00 \mathrm{E}+00 & 0.00 \mathrm{E}+00\end{array}$

$\begin{array}{lllll}0.725 & 0.00 \mathrm{E}+00 & 0.00 \mathrm{E}+00 & 0.00 \mathrm{E}+00\end{array}$

$\begin{array}{lllll}0.750 & 0.00 \mathrm{E}+00 & 0.00 \mathrm{E}+00 & 0.00 \mathrm{E}+00\end{array}$

$\begin{array}{lllll}0.775 & 0.00 \mathrm{E}+00 & 0.00 \mathrm{E}+00 & 0.00 \mathrm{E}+00\end{array}$

$\begin{array}{lllll}0.800 & 0.00 \mathrm{E}+00 & 0.00 \mathrm{E}+00 & 0.00 \mathrm{E}+00\end{array}$

$\begin{array}{lllll}0.825 & 0.00 \mathrm{E}+00 & 0.00 \mathrm{E}+00 & 0.00 \mathrm{E}+00\end{array}$

$\begin{array}{lllll}0.850 & 0.00 \mathrm{E}+00 & 0.00 \mathrm{E}+00 & 0.00 \mathrm{E}+00\end{array}$

$\begin{array}{lllll}0.875 & 0.00 \mathrm{E}+00 & 0.00 \mathrm{E}+00 & 0.00 \mathrm{E}+00\end{array}$

$\begin{array}{lllll}0.900 & 0.00 \mathrm{E}+00 & 0.00 \mathrm{E}+00 & 0.00 \mathrm{E}+00\end{array}$

$\begin{array}{lllll}0.925 & 0.00 \mathrm{E}+00 & 0.00 \mathrm{E}+00 & 0.00 \mathrm{E}+00\end{array}$

$\begin{array}{llll}0.950 & 0.00 \mathrm{E}+00 & 0.00 \mathrm{E}+00 & 0.00 \mathrm{E}+00\end{array}$

$\begin{array}{lllll}0.975 & 0.00 \mathrm{E}+00 & 0.00 \mathrm{E}+00 & 0.00 \mathrm{E}+00\end{array}$

$\begin{array}{lllll}0.990 & 0.00 \mathrm{E}+00 & 0.00 \mathrm{E}+00 & 0.00 \mathrm{E}+00\end{array}$ 
RESRAD-OFFSITE, Version 2.5

Probabilistic Dose and Risk Report

Title : RESRAD-OFFSITE Drinking Water, Plant, Milk, and Meat Pathways for Offsite Reside

File : PBA-1_TC99-DOE-5.ROF

Statistics and Cumulative distribution function of Peak Dose from Radon (CZandAir) in mrem/yr

$\begin{array}{ccccc}\text { Repetition }= & 1 & 2 & 3 \\ \text { Mean } & 0.00 \mathrm{E}+00 & 0.00 \mathrm{E}+00 & 0.00 \mathrm{E}+00 \\ \text { Std. Dev. } & 0.00 \mathrm{E}+00 & 0.00 \mathrm{E}+00 & 0.00 \mathrm{E}+00 \\ \text { Minimum } & 0.00 \mathrm{E}+00 & 0.00 \mathrm{E}+00 & 0.00 \mathrm{E}+00 \\ \text { Maximum } & 0.00 \mathrm{E}+00 & 0.00 \mathrm{E}+00 & 0.00 \mathrm{E}+00\end{array}$

Percentile

$\begin{array}{llll}0.010 & 0.00 \mathrm{E}+00 \quad 0.00 \mathrm{E}+00 & 0.00 \mathrm{E}+00\end{array}$

$\begin{array}{llll}0.025 & 0.00 \mathrm{E}+00 \quad 0.00 \mathrm{E}+00 & 0.00 \mathrm{E}+00\end{array}$

$\begin{array}{llll}0.050 & 0.00 \mathrm{E}+00 & 0.00 \mathrm{E}+00 & 0.00 \mathrm{E}+00\end{array}$

$\begin{array}{llll}0.075 & 0.00 \mathrm{E}+00 & 0.00 \mathrm{E}+00 & 0.00 \mathrm{E}+00\end{array}$

$\begin{array}{llll}0.100 & 0.00 \mathrm{E}+00 & 0.00 \mathrm{E}+00 & 0.00 \mathrm{E}+00\end{array}$

$\begin{array}{llll}0.125 & 0.00 \mathrm{E}+00 & 0.00 \mathrm{E}+00 & 0.00 \mathrm{E}+00\end{array}$

$\begin{array}{llll}0.150 & 0.00 \mathrm{E}+00 & 0.00 \mathrm{E}+00 & 0.00 \mathrm{E}+00\end{array}$

$\begin{array}{lllll}0.175 & 0.00 \mathrm{E}+00 & 0.00 \mathrm{E}+00 & 0.00 \mathrm{E}+00\end{array}$

$\begin{array}{lllll}0.200 & 0.00 \mathrm{E}+00 & 0.00 \mathrm{E}+00 & 0.00 \mathrm{E}+00\end{array}$

$\begin{array}{lllll}0.225 & 0.00 \mathrm{E}+00 & 0.00 \mathrm{E}+00 & 0.00 \mathrm{E}+00\end{array}$

$\begin{array}{lllll}0.250 & 0.00 \mathrm{E}+00 & 0.00 \mathrm{E}+00 & 0.00 \mathrm{E}+00\end{array}$

$\begin{array}{lllll}0.275 & 0.00 \mathrm{E}+00 & 0.00 \mathrm{E}+00 & 0.00 \mathrm{E}+00\end{array}$

$\begin{array}{lllll}0.300 & 0.00 \mathrm{E}+00 & 0.00 \mathrm{E}+00 & 0.00 \mathrm{E}+00\end{array}$

$\begin{array}{lllll}0.325 & 0.00 \mathrm{E}+00 & 0.00 \mathrm{E}+00 & 0.00 \mathrm{E}+00\end{array}$

$\begin{array}{lllll}0.350 & 0.00 \mathrm{E}+00 & 0.00 \mathrm{E}+00 & 0.00 \mathrm{E}+00\end{array}$

$\begin{array}{lllll}0.375 & 0.00 \mathrm{E}+00 & 0.00 \mathrm{E}+00 & 0.00 \mathrm{E}+00\end{array}$

$\begin{array}{lllll}0.400 & 0.00 \mathrm{E}+00 & 0.00 \mathrm{E}+00 & 0.00 \mathrm{E}+00\end{array}$

$\begin{array}{lllll}0.425 & 0.00 \mathrm{E}+00 & 0.00 \mathrm{E}+00 & 0.00 \mathrm{E}+00\end{array}$

$\begin{array}{lllll}0.450 & 0.00 \mathrm{E}+00 & 0.00 \mathrm{E}+00 & 0.00 \mathrm{E}+00\end{array}$

$\begin{array}{lllll}0.475 & 0.00 \mathrm{E}+00 & 0.00 \mathrm{E}+00 & 0.00 \mathrm{E}+00\end{array}$

$\begin{array}{lllll}0.500 & 0.00 \mathrm{E}+00 & 0.00 \mathrm{E}+00 & 0.00 \mathrm{E}+00\end{array}$

$\begin{array}{lllll}0.525 & 0.00 \mathrm{E}+00 & 0.00 \mathrm{E}+00 & 0.00 \mathrm{E}+00\end{array}$

$\begin{array}{lllll}0.550 & 0.00 \mathrm{E}+00 & 0.00 \mathrm{E}+00 & 0.00 \mathrm{E}+00\end{array}$

$\begin{array}{lllll}0.575 & 0.00 \mathrm{E}+00 & 0.00 \mathrm{E}+00 & 0.00 \mathrm{E}+00\end{array}$

$\begin{array}{lllll}0.600 & 0.00 \mathrm{E}+00 & 0.00 \mathrm{E}+00 & 0.00 \mathrm{E}+00\end{array}$

$\begin{array}{lllll}0.625 & 0.00 \mathrm{E}+00 & 0.00 \mathrm{E}+00 & 0.00 \mathrm{E}+00\end{array}$

$\begin{array}{lllll}0.650 & 0.00 \mathrm{E}+00 & 0.00 \mathrm{E}+00 & 0.00 \mathrm{E}+00\end{array}$

$\begin{array}{lllll}0.675 & 0.00 \mathrm{E}+00 & 0.00 \mathrm{E}+00 & 0.00 \mathrm{E}+00\end{array}$

$\begin{array}{llll}0.700 & 0.00 \mathrm{E}+00 & 0.00 \mathrm{E}+00 & 0.00 \mathrm{E}+00\end{array}$

$\begin{array}{lllll}0.725 & 0.00 \mathrm{E}+00 & 0.00 \mathrm{E}+00 & 0.00 \mathrm{E}+00\end{array}$

$\begin{array}{lllll}0.750 & 0.00 \mathrm{E}+00 & 0.00 \mathrm{E}+00 & 0.00 \mathrm{E}+00\end{array}$

$\begin{array}{lllll}0.775 & 0.00 \mathrm{E}+00 & 0.00 \mathrm{E}+00 & 0.00 \mathrm{E}+00\end{array}$

$\begin{array}{lllll}0.800 & 0.00 \mathrm{E}+00 & 0.00 \mathrm{E}+00 & 0.00 \mathrm{E}+00\end{array}$

$\begin{array}{lllll}0.825 & 0.00 \mathrm{E}+00 & 0.00 \mathrm{E}+00 & 0.00 \mathrm{E}+00\end{array}$

$\begin{array}{lllll}0.850 & 0.00 \mathrm{E}+00 & 0.00 \mathrm{E}+00 & 0.00 \mathrm{E}+00\end{array}$

$\begin{array}{lllll}0.875 & 0.00 \mathrm{E}+00 & 0.00 \mathrm{E}+00 & 0.00 \mathrm{E}+00\end{array}$

$\begin{array}{lllll}0.900 & 0.00 \mathrm{E}+00 & 0.00 \mathrm{E}+00 & 0.00 \mathrm{E}+00\end{array}$

$\begin{array}{lllll}0.925 & 0.00 \mathrm{E}+00 & 0.00 \mathrm{E}+00 & 0.00 \mathrm{E}+00\end{array}$

$\begin{array}{llll}0.950 & 0.00 \mathrm{E}+00 & 0.00 \mathrm{E}+00 & 0.00 \mathrm{E}+00\end{array}$

$\begin{array}{lllll}0.975 & 0.00 \mathrm{E}+00 & 0.00 \mathrm{E}+00 & 0.00 \mathrm{E}+00\end{array}$

$\begin{array}{lllll}0.990 & 0.00 \mathrm{E}+00 & 0.00 \mathrm{E}+00 & 0.00 \mathrm{E}+00\end{array}$ 
RESRAD-OFFSITE, Version 2.5

Probabilistic Dose and Risk Report

Title : RESRAD-OFFSITE Drinking Water, Plant, Milk, and Meat Pathways for Offsite Reside

File : PBA-1_TC99-DOE-5.ROF

Statistics and Cumulative distribution function of Peak Dose from Plant (CzandAir) in mrem/yr

$\begin{array}{ccccc}\text { Repetition }= & 1 & 2 & 3 \\ \text { Mean } & 0.00 \mathrm{E}+00 & 0.00 \mathrm{E}+00 & 0.00 \mathrm{E}+00 \\ \text { Std. Dev. } & 0.00 \mathrm{E}+00 & 0.00 \mathrm{E}+00 & 0.00 \mathrm{E}+00 \\ \text { Minimum } & 0.00 \mathrm{E}+00 & 0.00 \mathrm{E}+00 & 0.00 \mathrm{E}+00 \\ \text { Maximum } & 0.00 \mathrm{E}+00 & 0.00 \mathrm{E}+00 & 0.00 \mathrm{E}+00\end{array}$

Percentile

$\begin{array}{llll}0.010 & 0.00 \mathrm{E}+00 \quad 0.00 \mathrm{E}+00 & 0.00 \mathrm{E}+00\end{array}$

$\begin{array}{llll}0.025 & 0.00 \mathrm{E}+00 & 0.00 \mathrm{E}+00 & 0.00 \mathrm{E}+00\end{array}$

$\begin{array}{llll}0.050 & 0.00 \mathrm{E}+00 & 0.00 \mathrm{E}+00 & 0.00 \mathrm{E}+00\end{array}$

$\begin{array}{lllll}0.075 & 0.00 \mathrm{E}+00 & 0.00 \mathrm{E}+00 & 0.00 \mathrm{E}+00\end{array}$

$\begin{array}{llll}0.100 & 0.00 \mathrm{E}+00 & 0.00 \mathrm{E}+00 & 0.00 \mathrm{E}+00\end{array}$

$\begin{array}{llll}0.125 & 0.00 \mathrm{E}+00 & 0.00 \mathrm{E}+00 & 0.00 \mathrm{E}+00\end{array}$

$\begin{array}{llll}0.150 & 0.00 \mathrm{E}+00 & 0.00 \mathrm{E}+00 & 0.00 \mathrm{E}+00\end{array}$

$\begin{array}{lllll}0.175 & 0.00 \mathrm{E}+00 & 0.00 \mathrm{E}+00 & 0.00 \mathrm{E}+00\end{array}$

$\begin{array}{lllll}0.200 & 0.00 \mathrm{E}+00 & 0.00 \mathrm{E}+00 & 0.00 \mathrm{E}+00\end{array}$

$\begin{array}{lllll}0.225 & 0.00 \mathrm{E}+00 & 0.00 \mathrm{E}+00 & 0.00 \mathrm{E}+00\end{array}$

$\begin{array}{lllll}0.250 & 0.00 \mathrm{E}+00 & 0.00 \mathrm{E}+00 & 0.00 \mathrm{E}+00\end{array}$

$\begin{array}{llll}0.275 & 0.00 \mathrm{E}+00 & 0.00 \mathrm{E}+00 & 0.00 \mathrm{E}+00\end{array}$

$\begin{array}{lllll}0.300 & 0.00 \mathrm{E}+00 & 0.00 \mathrm{E}+00 & 0.00 \mathrm{E}+00\end{array}$

$\begin{array}{lllll}0.325 & 0.00 \mathrm{E}+00 & 0.00 \mathrm{E}+00 & 0.00 \mathrm{E}+00\end{array}$

$\begin{array}{lllll}0.350 & 0.00 \mathrm{E}+00 & 0.00 \mathrm{E}+00 & 0.00 \mathrm{E}+00\end{array}$

$\begin{array}{lllll}0.375 & 0.00 \mathrm{E}+00 & 0.00 \mathrm{E}+00 & 0.00 \mathrm{E}+00\end{array}$

$\begin{array}{lllll}0.400 & 0.00 \mathrm{E}+00 & 0.00 \mathrm{E}+00 & 0.00 \mathrm{E}+00\end{array}$

$\begin{array}{lllll}0.425 & 0.00 \mathrm{E}+00 & 0.00 \mathrm{E}+00 & 0.00 \mathrm{E}+00\end{array}$

$\begin{array}{lllll}0.450 & 0.00 \mathrm{E}+00 & 0.00 \mathrm{E}+00 & 0.00 \mathrm{E}+00\end{array}$

$\begin{array}{lllll}0.475 & 0.00 \mathrm{E}+00 & 0.00 \mathrm{E}+00 & 0.00 \mathrm{E}+00\end{array}$

$\begin{array}{lllll}0.500 & 0.00 \mathrm{E}+00 & 0.00 \mathrm{E}+00 & 0.00 \mathrm{E}+00\end{array}$

$\begin{array}{lllll}0.525 & 0.00 \mathrm{E}+00 & 0.00 \mathrm{E}+00 & 0.00 \mathrm{E}+00\end{array}$

$\begin{array}{lllll}0.550 & 0.00 \mathrm{E}+00 & 0.00 \mathrm{E}+00 & 0.00 \mathrm{E}+00\end{array}$

$\begin{array}{lllll}0.575 & 0.00 \mathrm{E}+00 & 0.00 \mathrm{E}+00 & 0.00 \mathrm{E}+00\end{array}$

$\begin{array}{lllll}0.600 & 0.00 \mathrm{E}+00 & 0.00 \mathrm{E}+00 & 0.00 \mathrm{E}+00\end{array}$

$\begin{array}{lllll}0.625 & 0.00 \mathrm{E}+00 & 0.00 \mathrm{E}+00 & 0.00 \mathrm{E}+00\end{array}$

$\begin{array}{lllll}0.650 & 0.00 \mathrm{E}+00 & 0.00 \mathrm{E}+00 & 0.00 \mathrm{E}+00\end{array}$

$\begin{array}{lllll}0.675 & 0.00 \mathrm{E}+00 & 0.00 \mathrm{E}+00 & 0.00 \mathrm{E}+00\end{array}$

$\begin{array}{lllll}0.700 & 0.00 \mathrm{E}+00 & 0.00 \mathrm{E}+00 & 0.00 \mathrm{E}+00\end{array}$

$\begin{array}{lllll}0.725 & 0.00 \mathrm{E}+00 & 0.00 \mathrm{E}+00 & 0.00 \mathrm{E}+00\end{array}$

$\begin{array}{lllll}0.750 & 0.00 \mathrm{E}+00 & 0.00 \mathrm{E}+00 & 0.00 \mathrm{E}+00\end{array}$

$\begin{array}{lllll}0.775 & 0.00 \mathrm{E}+00 & 0.00 \mathrm{E}+00 & 0.00 \mathrm{E}+00\end{array}$

$\begin{array}{lllll}0.800 & 0.00 \mathrm{E}+00 & 0.00 \mathrm{E}+00 & 0.00 \mathrm{E}+00\end{array}$

$\begin{array}{lllll}0.825 & 0.00 \mathrm{E}+00 & 0.00 \mathrm{E}+00 & 0.00 \mathrm{E}+00\end{array}$

$\begin{array}{lllll}0.850 & 0.00 \mathrm{E}+00 & 0.00 \mathrm{E}+00 & 0.00 \mathrm{E}+00\end{array}$

$\begin{array}{lllll}0.875 & 0.00 \mathrm{E}+00 & 0.00 \mathrm{E}+00 & 0.00 \mathrm{E}+00\end{array}$

$\begin{array}{lllll}0.900 & 0.00 \mathrm{E}+00 & 0.00 \mathrm{E}+00 & 0.00 \mathrm{E}+00\end{array}$

$\begin{array}{lllll}0.925 & 0.00 \mathrm{E}+00 & 0.00 \mathrm{E}+00 & 0.00 \mathrm{E}+00\end{array}$

$\begin{array}{llll}0.950 & 0.00 \mathrm{E}+00 & 0.00 \mathrm{E}+00 & 0.00 \mathrm{E}+00\end{array}$

$\begin{array}{lllll}0.975 & 0.00 \mathrm{E}+00 & 0.00 \mathrm{E}+00 & 0.00 \mathrm{E}+00\end{array}$

$\begin{array}{lllll}0.990 & 0.00 \mathrm{E}+00 & 0.00 \mathrm{E}+00 & 0.00 \mathrm{E}+00\end{array}$ 
RESRAD-OFFSITE, Version 2.5

Probabilistic Dose and Risk Report

Title : RESRAD-OFFSITE Drinking Water, Plant, Milk, and Meat Pathways for Offsite Reside

File : PBA-1_TC99-DOE-5.ROF

Statistics and Cumulative distribution function of Peak Dose from Meat (CZandAir) in mrem/yr

\begin{tabular}{ccccc} 
Repetition $=$ & 1 & 2 & 3 \\
\cline { 5 - 5 } Mean & $0.00 \mathrm{E}+00$ & $0.00 \mathrm{E}+00$ & $0.00 \mathrm{E}+00$ \\
Std. Dev. & $0.00 \mathrm{E}+00$ & $0.00 \mathrm{E}+00$ & $0.00 \mathrm{E}+00$ \\
Minimum & $0.00 \mathrm{E}+00$ & $0.00 \mathrm{E}+00$ & $0.00 \mathrm{E}+00$ \\
Maximum & $0.00 \mathrm{E}+00$ & $0.00 \mathrm{E}+00$ & $0.00 \mathrm{E}+00$
\end{tabular}

Percentile

$\begin{array}{llll}0.010 & 0.00 \mathrm{E}+00 \quad 0.00 \mathrm{E}+00 & 0.00 \mathrm{E}+00\end{array}$

$\begin{array}{llll}0.025 & 0.00 \mathrm{E}+00 & 0.00 \mathrm{E}+00 & 0.00 \mathrm{E}+00\end{array}$

$\begin{array}{llll}0.050 & 0.00 \mathrm{E}+00 & 0.00 \mathrm{E}+00 & 0.00 \mathrm{E}+00\end{array}$

$\begin{array}{llll}0.075 & 0.00 \mathrm{E}+00 & 0.00 \mathrm{E}+00 & 0.00 \mathrm{E}+00\end{array}$

$\begin{array}{llll}0.100 & 0.00 \mathrm{E}+00 & 0.00 \mathrm{E}+00 & 0.00 \mathrm{E}+00\end{array}$

$\begin{array}{llll}0.125 & 0.00 \mathrm{E}+00 & 0.00 \mathrm{E}+00 & 0.00 \mathrm{E}+00\end{array}$

$\begin{array}{lllll}0.150 & 0.00 \mathrm{E}+00 & 0.00 \mathrm{E}+00 & 0.00 \mathrm{E}+00\end{array}$

$\begin{array}{lllll}0.175 & 0.00 \mathrm{E}+00 & 0.00 \mathrm{E}+00 & 0.00 \mathrm{E}+00\end{array}$

$\begin{array}{lllll}0.200 & 0.00 \mathrm{E}+00 & 0.00 \mathrm{E}+00 & 0.00 \mathrm{E}+00\end{array}$

$\begin{array}{lllll}0.225 & 0.00 \mathrm{E}+00 & 0.00 \mathrm{E}+00 & 0.00 \mathrm{E}+00\end{array}$

$\begin{array}{lllll}0.250 & 0.00 \mathrm{E}+00 & 0.00 \mathrm{E}+00 & 0.00 \mathrm{E}+00\end{array}$

$\begin{array}{lllll}0.275 & 0.00 \mathrm{E}+00 & 0.00 \mathrm{E}+00 & 0.00 \mathrm{E}+00\end{array}$

$\begin{array}{lllll}0.300 & 0.00 \mathrm{E}+00 & 0.00 \mathrm{E}+00 & 0.00 \mathrm{E}+00\end{array}$

$\begin{array}{lllll}0.325 & 0.00 \mathrm{E}+00 & 0.00 \mathrm{E}+00 & 0.00 \mathrm{E}+00\end{array}$

$\begin{array}{lllll}0.350 & 0.00 \mathrm{E}+00 & 0.00 \mathrm{E}+00 & 0.00 \mathrm{E}+00\end{array}$

$\begin{array}{lllll}0.375 & 0.00 \mathrm{E}+00 & 0.00 \mathrm{E}+00 & 0.00 \mathrm{E}+00\end{array}$

$\begin{array}{lllll}0.400 & 0.00 \mathrm{E}+00 & 0.00 \mathrm{E}+00 & 0.00 \mathrm{E}+00\end{array}$

$\begin{array}{lllll}0.425 & 0.00 \mathrm{E}+00 & 0.00 \mathrm{E}+00 & 0.00 \mathrm{E}+00\end{array}$

$\begin{array}{lllll}0.450 & 0.00 \mathrm{E}+00 & 0.00 \mathrm{E}+00 & 0.00 \mathrm{E}+00\end{array}$

$\begin{array}{lllll}0.475 & 0.00 \mathrm{E}+00 & 0.00 \mathrm{E}+00 & 0.00 \mathrm{E}+00\end{array}$

$\begin{array}{lllll}0.500 & 0.00 \mathrm{E}+00 & 0.00 \mathrm{E}+00 & 0.00 \mathrm{E}+00\end{array}$

$\begin{array}{lllll}0.525 & 0.00 \mathrm{E}+00 & 0.00 \mathrm{E}+00 & 0.00 \mathrm{E}+00\end{array}$

$\begin{array}{lllll}0.550 & 0.00 \mathrm{E}+00 & 0.00 \mathrm{E}+00 & 0.00 \mathrm{E}+00\end{array}$

$\begin{array}{lllll}0.575 & 0.00 \mathrm{E}+00 & 0.00 \mathrm{E}+00 & 0.00 \mathrm{E}+00\end{array}$

$\begin{array}{lllll}0.600 & 0.00 \mathrm{E}+00 & 0.00 \mathrm{E}+00 & 0.00 \mathrm{E}+00\end{array}$

$\begin{array}{lllll}0.625 & 0.00 \mathrm{E}+00 & 0.00 \mathrm{E}+00 & 0.00 \mathrm{E}+00\end{array}$

$\begin{array}{lllll}0.650 & 0.00 \mathrm{E}+00 & 0.00 \mathrm{E}+00 & 0.00 \mathrm{E}+00\end{array}$

$\begin{array}{lllll}0.675 & 0.00 \mathrm{E}+00 & 0.00 \mathrm{E}+00 & 0.00 \mathrm{E}+00\end{array}$

$\begin{array}{llll}0.700 & 0.00 \mathrm{E}+00 & 0.00 \mathrm{E}+00 & 0.00 \mathrm{E}+00\end{array}$

$\begin{array}{lllll}0.725 & 0.00 \mathrm{E}+00 & 0.00 \mathrm{E}+00 & 0.00 \mathrm{E}+00\end{array}$

$\begin{array}{lllll}0.750 & 0.00 \mathrm{E}+00 & 0.00 \mathrm{E}+00 & 0.00 \mathrm{E}+00\end{array}$

$\begin{array}{lllll}0.775 & 0.00 \mathrm{E}+00 & 0.00 \mathrm{E}+00 & 0.00 \mathrm{E}+00\end{array}$

$\begin{array}{lllll}0.800 & 0.00 \mathrm{E}+00 & 0.00 \mathrm{E}+00 & 0.00 \mathrm{E}+00\end{array}$

$\begin{array}{lllll}0.825 & 0.00 \mathrm{E}+00 & 0.00 \mathrm{E}+00 & 0.00 \mathrm{E}+00\end{array}$

$\begin{array}{lllll}0.850 & 0.00 \mathrm{E}+00 & 0.00 \mathrm{E}+00 & 0.00 \mathrm{E}+00\end{array}$

$\begin{array}{lllll}0.875 & 0.00 \mathrm{E}+00 & 0.00 \mathrm{E}+00 & 0.00 \mathrm{E}+00\end{array}$

$\begin{array}{lllll}0.900 & 0.00 \mathrm{E}+00 & 0.00 \mathrm{E}+00 & 0.00 \mathrm{E}+00\end{array}$

$\begin{array}{lllll}0.925 & 0.00 \mathrm{E}+00 & 0.00 \mathrm{E}+00 & 0.00 \mathrm{E}+00\end{array}$

$\begin{array}{llll}0.950 & 0.00 \mathrm{E}+00 & 0.00 \mathrm{E}+00 & 0.00 \mathrm{E}+00\end{array}$

$\begin{array}{lllll}0.975 & 0.00 \mathrm{E}+00 & 0.00 \mathrm{E}+00 & 0.00 \mathrm{E}+00\end{array}$

$\begin{array}{lllll}0.990 & 0.00 \mathrm{E}+00 & 0.00 \mathrm{E}+00 & 0.00 \mathrm{E}+00\end{array}$ 
RESRAD-OFFSITE, Version 2.5

Probabilistic Dose and Risk Report

Title : RESRAD-OFFSITE Drinking Water, Plant, Milk, and Meat Pathways for Offsite Reside

File : PBA-1_TC99-DOE-5.ROF

Statistics and Cumulative distribution function of Peak Dose from Milk (CzandAir) in mrem/yr

$\begin{array}{ccccc}\text { Repetition }= & 1 & 2 & 3 \\ \text { Mean } & 0.00 \mathrm{E}+00 & 0.00 \mathrm{E}+00 & 0.00 \mathrm{E}+00 \\ \text { Std. Dev. } & 0.00 \mathrm{E}+00 & 0.00 \mathrm{E}+00 & 0.00 \mathrm{E}+00 \\ \text { Minimum } & 0.00 \mathrm{E}+00 & 0.00 \mathrm{E}+00 & 0.00 \mathrm{E}+00 \\ \text { Maximum } & 0.00 \mathrm{E}+00 & 0.00 \mathrm{E}+00 & 0.00 \mathrm{E}+00\end{array}$

Percentile

$\begin{array}{llll}0.010 & 0.00 \mathrm{E}+00 \quad 0.00 \mathrm{E}+00 & 0.00 \mathrm{E}+00\end{array}$

$\begin{array}{llll}0.025 & 0.00 \mathrm{E}+00 & 0.00 \mathrm{E}+00 & 0.00 \mathrm{E}+00\end{array}$

$\begin{array}{llll}0.050 & 0.00 \mathrm{E}+00 & 0.00 \mathrm{E}+00 & 0.00 \mathrm{E}+00\end{array}$

$\begin{array}{llll}0.075 & 0.00 \mathrm{E}+00 & 0.00 \mathrm{E}+00 & 0.00 \mathrm{E}+00\end{array}$

$\begin{array}{llll}0.100 & 0.00 \mathrm{E}+00 & 0.00 \mathrm{E}+00 & 0.00 \mathrm{E}+00\end{array}$

$\begin{array}{llll}0.125 & 0.00 \mathrm{E}+00 & 0.00 \mathrm{E}+00 & 0.00 \mathrm{E}+00\end{array}$

$\begin{array}{llll}0.150 & 0.00 \mathrm{E}+00 & 0.00 \mathrm{E}+00 & 0.00 \mathrm{E}+00\end{array}$

$\begin{array}{lllll}0.175 & 0.00 \mathrm{E}+00 & 0.00 \mathrm{E}+00 & 0.00 \mathrm{E}+00\end{array}$

$\begin{array}{lllll}0.200 & 0.00 \mathrm{E}+00 & 0.00 \mathrm{E}+00 & 0.00 \mathrm{E}+00\end{array}$

$\begin{array}{lllll}0.225 & 0.00 \mathrm{E}+00 & 0.00 \mathrm{E}+00 & 0.00 \mathrm{E}+00\end{array}$

$\begin{array}{lllll}0.250 & 0.00 \mathrm{E}+00 & 0.00 \mathrm{E}+00 & 0.00 \mathrm{E}+00\end{array}$

$\begin{array}{lllll}0.275 & 0.00 \mathrm{E}+00 & 0.00 \mathrm{E}+00 & 0.00 \mathrm{E}+00\end{array}$

$\begin{array}{lllll}0.300 & 0.00 \mathrm{E}+00 & 0.00 \mathrm{E}+00 & 0.00 \mathrm{E}+00\end{array}$

$\begin{array}{lllll}0.325 & 0.00 \mathrm{E}+00 & 0.00 \mathrm{E}+00 & 0.00 \mathrm{E}+00\end{array}$

$\begin{array}{lllll}0.350 & 0.00 \mathrm{E}+00 & 0.00 \mathrm{E}+00 & 0.00 \mathrm{E}+00\end{array}$

$\begin{array}{lllll}0.375 & 0.00 \mathrm{E}+00 & 0.00 \mathrm{E}+00 & 0.00 \mathrm{E}+00\end{array}$

$\begin{array}{lllll}0.400 & 0.00 \mathrm{E}+00 & 0.00 \mathrm{E}+00 & 0.00 \mathrm{E}+00\end{array}$

$\begin{array}{lllll}0.425 & 0.00 \mathrm{E}+00 & 0.00 \mathrm{E}+00 & 0.00 \mathrm{E}+00\end{array}$

$\begin{array}{lllll}0.450 & 0.00 \mathrm{E}+00 & 0.00 \mathrm{E}+00 & 0.00 \mathrm{E}+00\end{array}$

$\begin{array}{lllll}0.475 & 0.00 \mathrm{E}+00 & 0.00 \mathrm{E}+00 & 0.00 \mathrm{E}+00\end{array}$

$\begin{array}{lllll}0.500 & 0.00 \mathrm{E}+00 & 0.00 \mathrm{E}+00 & 0.00 \mathrm{E}+00\end{array}$

$\begin{array}{lllll}0.525 & 0.00 \mathrm{E}+00 & 0.00 \mathrm{E}+00 & 0.00 \mathrm{E}+00\end{array}$

$\begin{array}{lllll}0.550 & 0.00 \mathrm{E}+00 & 0.00 \mathrm{E}+00 & 0.00 \mathrm{E}+00\end{array}$

$\begin{array}{lllll}0.575 & 0.00 \mathrm{E}+00 & 0.00 \mathrm{E}+00 & 0.00 \mathrm{E}+00\end{array}$

$\begin{array}{lllll}0.600 & 0.00 \mathrm{E}+00 & 0.00 \mathrm{E}+00 & 0.00 \mathrm{E}+00\end{array}$

$\begin{array}{lllll}0.625 & 0.00 \mathrm{E}+00 & 0.00 \mathrm{E}+00 & 0.00 \mathrm{E}+00\end{array}$

$\begin{array}{lllll}0.650 & 0.00 \mathrm{E}+00 & 0.00 \mathrm{E}+00 & 0.00 \mathrm{E}+00\end{array}$

$\begin{array}{lllll}0.675 & 0.00 \mathrm{E}+00 & 0.00 \mathrm{E}+00 & 0.00 \mathrm{E}+00\end{array}$

$\begin{array}{llll}0.700 & 0.00 \mathrm{E}+00 & 0.00 \mathrm{E}+00 & 0.00 \mathrm{E}+00\end{array}$

$\begin{array}{lllll}0.725 & 0.00 \mathrm{E}+00 & 0.00 \mathrm{E}+00 & 0.00 \mathrm{E}+00\end{array}$

$\begin{array}{lllll}0.750 & 0.00 \mathrm{E}+00 & 0.00 \mathrm{E}+00 & 0.00 \mathrm{E}+00\end{array}$

$\begin{array}{lllll}0.775 & 0.00 \mathrm{E}+00 & 0.00 \mathrm{E}+00 & 0.00 \mathrm{E}+00\end{array}$

$\begin{array}{lllll}0.800 & 0.00 \mathrm{E}+00 & 0.00 \mathrm{E}+00 & 0.00 \mathrm{E}+00\end{array}$

$\begin{array}{lllll}0.825 & 0.00 \mathrm{E}+00 & 0.00 \mathrm{E}+00 & 0.00 \mathrm{E}+00\end{array}$

$\begin{array}{lllll}0.850 & 0.00 \mathrm{E}+00 & 0.00 \mathrm{E}+00 & 0.00 \mathrm{E}+00\end{array}$

$\begin{array}{lllll}0.875 & 0.00 \mathrm{E}+00 & 0.00 \mathrm{E}+00 & 0.00 \mathrm{E}+00\end{array}$

$\begin{array}{lllll}0.900 & 0.00 \mathrm{E}+00 & 0.00 \mathrm{E}+00 & 0.00 \mathrm{E}+00\end{array}$

$\begin{array}{lllll}0.925 & 0.00 \mathrm{E}+00 & 0.00 \mathrm{E}+00 & 0.00 \mathrm{E}+00\end{array}$

$\begin{array}{llll}0.950 & 0.00 \mathrm{E}+00 & 0.00 \mathrm{E}+00 & 0.00 \mathrm{E}+00\end{array}$

$\begin{array}{lllll}0.975 & 0.00 \mathrm{E}+00 & 0.00 \mathrm{E}+00 & 0.00 \mathrm{E}+00\end{array}$

$\begin{array}{lllll}0.990 & 0.00 \mathrm{E}+00 & 0.00 \mathrm{E}+00 & 0.00 \mathrm{E}+00\end{array}$ 
RESRAD-OFFSITE, Version 2.5

Probabilistic Dose and Risk Report

Title : RESRAD-OFFSITE Drinking Water, Plant, Milk, and Meat Pathways for Offsite Reside

File : PBA-1_TC99-DOE-5.ROF

Statistics and Cumulative distribution function of Peak Dose from Soil Ingestion(CZandAir) in mrem/yr

$\begin{array}{rcccc}\text { Repetition }= & 1 & 2 & 3 \\ \text { Mean } & & 0.00 \mathrm{E}+00 & 0.00 \mathrm{E}+00 & 0.00 \mathrm{E}+00 \\ \text { Std. Dev. } & 0.00 \mathrm{E}+00 & 0.00 \mathrm{E}+00 & 0.00 \mathrm{E}+00 \\ \text { Minimum } & 0.00 \mathrm{E}+00 & 0.00 \mathrm{E}+00 & 0.00 \mathrm{E}+00 \\ \text { Maximum } & 0.00 \mathrm{E}+00 & 0.00 \mathrm{E}+00 & 0.00 \mathrm{E}+00\end{array}$

Percentile

$0.010 \quad 0.00 \mathrm{E}+00 \quad 0.00 \mathrm{E}+00 \quad 0.00 \mathrm{E}+00$

$\begin{array}{llll}0.025 & 0.00 \mathrm{E}+00 \quad 0.00 \mathrm{E}+00 & 0.00 \mathrm{E}+00\end{array}$

$\begin{array}{llll}0.050 & 0.00 \mathrm{E}+00 & 0.00 \mathrm{E}+00 & 0.00 \mathrm{E}+00\end{array}$

$\begin{array}{llll}0.075 & 0.00 \mathrm{E}+00 & 0.00 \mathrm{E}+00 & 0.00 \mathrm{E}+00\end{array}$

$\begin{array}{llll}0.100 & 0.00 \mathrm{E}+00 & 0.00 \mathrm{E}+00 & 0.00 \mathrm{E}+00\end{array}$

$\begin{array}{llll}0.125 & 0.00 \mathrm{E}+00 & 0.00 \mathrm{E}+00 & 0.00 \mathrm{E}+00\end{array}$

$\begin{array}{llll}0.150 & 0.00 \mathrm{E}+00 & 0.00 \mathrm{E}+00 & 0.00 \mathrm{E}+00\end{array}$

$\begin{array}{lllll}0.175 & 0.00 \mathrm{E}+00 & 0.00 \mathrm{E}+00 & 0.00 \mathrm{E}+00\end{array}$

$\begin{array}{lllll}0.200 & 0.00 \mathrm{E}+00 & 0.00 \mathrm{E}+00 & 0.00 \mathrm{E}+00\end{array}$

$\begin{array}{lllll}0.225 & 0.00 \mathrm{E}+00 & 0.00 \mathrm{E}+00 & 0.00 \mathrm{E}+00\end{array}$

$\begin{array}{lllll}0.250 & 0.00 \mathrm{E}+00 & 0.00 \mathrm{E}+00 & 0.00 \mathrm{E}+00\end{array}$

$\begin{array}{lllll}0.275 & 0.00 \mathrm{E}+00 & 0.00 \mathrm{E}+00 & 0.00 \mathrm{E}+00\end{array}$

$\begin{array}{lllll}0.300 & 0.00 \mathrm{E}+00 & 0.00 \mathrm{E}+00 & 0.00 \mathrm{E}+00\end{array}$

$\begin{array}{lllll}0.325 & 0.00 \mathrm{E}+00 & 0.00 \mathrm{E}+00 & 0.00 \mathrm{E}+00\end{array}$

$\begin{array}{lllll}0.350 & 0.00 \mathrm{E}+00 & 0.00 \mathrm{E}+00 & 0.00 \mathrm{E}+00\end{array}$

$\begin{array}{lllll}0.375 & 0.00 \mathrm{E}+00 & 0.00 \mathrm{E}+00 & 0.00 \mathrm{E}+00\end{array}$

$\begin{array}{lllll}0.400 & 0.00 \mathrm{E}+00 & 0.00 \mathrm{E}+00 & 0.00 \mathrm{E}+00\end{array}$

$\begin{array}{lllll}0.425 & 0.00 \mathrm{E}+00 & 0.00 \mathrm{E}+00 & 0.00 \mathrm{E}+00\end{array}$

$\begin{array}{lllll}0.450 & 0.00 \mathrm{E}+00 & 0.00 \mathrm{E}+00 & 0.00 \mathrm{E}+00\end{array}$

$\begin{array}{lllll}0.475 & 0.00 \mathrm{E}+00 & 0.00 \mathrm{E}+00 & 0.00 \mathrm{E}+00\end{array}$

$\begin{array}{lllll}0.500 & 0.00 \mathrm{E}+00 & 0.00 \mathrm{E}+00 & 0.00 \mathrm{E}+00\end{array}$

$\begin{array}{lllll}0.525 & 0.00 \mathrm{E}+00 & 0.00 \mathrm{E}+00 & 0.00 \mathrm{E}+00\end{array}$

$\begin{array}{lllll}0.550 & 0.00 \mathrm{E}+00 & 0.00 \mathrm{E}+00 & 0.00 \mathrm{E}+00\end{array}$

$\begin{array}{lllll}0.575 & 0.00 \mathrm{E}+00 & 0.00 \mathrm{E}+00 & 0.00 \mathrm{E}+00\end{array}$

$\begin{array}{lllll}0.600 & 0.00 \mathrm{E}+00 & 0.00 \mathrm{E}+00 & 0.00 \mathrm{E}+00\end{array}$

$\begin{array}{lllll}0.625 & 0.00 \mathrm{E}+00 & 0.00 \mathrm{E}+00 & 0.00 \mathrm{E}+00\end{array}$

$\begin{array}{lllll}0.650 & 0.00 \mathrm{E}+00 & 0.00 \mathrm{E}+00 & 0.00 \mathrm{E}+00\end{array}$

$\begin{array}{lllll}0.675 & 0.00 \mathrm{E}+00 & 0.00 \mathrm{E}+00 & 0.00 \mathrm{E}+00\end{array}$

$\begin{array}{llll}0.700 & 0.00 \mathrm{E}+00 & 0.00 \mathrm{E}+00 & 0.00 \mathrm{E}+00\end{array}$

$\begin{array}{lllll}0.725 & 0.00 \mathrm{E}+00 & 0.00 \mathrm{E}+00 & 0.00 \mathrm{E}+00\end{array}$

$\begin{array}{lllll}0.750 & 0.00 \mathrm{E}+00 & 0.00 \mathrm{E}+00 & 0.00 \mathrm{E}+00\end{array}$

$\begin{array}{llll}0.775 & 0.00 \mathrm{E}+00 & 0.00 \mathrm{E}+00 & 0.00 \mathrm{E}+00\end{array}$

$\begin{array}{lllll}0.800 & 0.00 \mathrm{E}+00 & 0.00 \mathrm{E}+00 & 0.00 \mathrm{E}+00\end{array}$

$\begin{array}{lllll}0.825 & 0.00 \mathrm{E}+00 & 0.00 \mathrm{E}+00 & 0.00 \mathrm{E}+00\end{array}$

$\begin{array}{lllll}0.850 & 0.00 \mathrm{E}+00 & 0.00 \mathrm{E}+00 & 0.00 \mathrm{E}+00\end{array}$

$\begin{array}{lllll}0.875 & 0.00 \mathrm{E}+00 & 0.00 \mathrm{E}+00 & 0.00 \mathrm{E}+00\end{array}$

$\begin{array}{lllll}0.900 & 0.00 \mathrm{E}+00 & 0.00 \mathrm{E}+00 & 0.00 \mathrm{E}+00\end{array}$

$\begin{array}{lllll}0.925 & 0.00 \mathrm{E}+00 & 0.00 \mathrm{E}+00 & 0.00 \mathrm{E}+00\end{array}$

$\begin{array}{llll}0.950 & 0.00 \mathrm{E}+00 & 0.00 \mathrm{E}+00 & 0.00 \mathrm{E}+00\end{array}$

$\begin{array}{lllll}0.975 & 0.00 \mathrm{E}+00 & 0.00 \mathrm{E}+00 & 0.00 \mathrm{E}+00\end{array}$

$\begin{array}{lllll}0.990 & 0.00 \mathrm{E}+00 & 0.00 \mathrm{E}+00 & 0.00 \mathrm{E}+00\end{array}$ 
RESRAD-OFFSITE, Version 2.5

Probabilistic Dose and Risk Report

Title : RESRAD-OFFSITE Drinking Water, Plant, Milk, and Meat Pathways for Offsite Reside File : PBA-1_TC99-DOE-5.ROF

Statistics and Cumulative distribution function of Peak Risk from All Pathways

\begin{tabular}{|c|c|c|c|}
\hline Repetition $=$ & 1 & 2 & 3 \\
\hline Mean & $3.21 \mathrm{E}-05$ & $3.20 \mathrm{E}-05$ & $3.20 \mathrm{E}-05$ \\
\hline Std. Dev. & $1.91 \mathrm{E}-05$ & $1.91 \mathrm{E}-05$ & $1.91 \mathrm{E}-05$ \\
\hline Minimum & $3.86 \mathrm{E}-06$ & $3.86 \mathrm{E}-06$ & $3.86 \mathrm{E}-06$ \\
\hline Maximum & $1.82 \mathrm{E}-04$ & $1.82 \mathrm{E}-04$ & $1.82 \mathrm{E}-04$ \\
\hline
\end{tabular}

Percentile

$0.010 \quad 5.54 \mathrm{E}-06 \quad 5.54 \mathrm{E}-06 \quad 5.54 \mathrm{E}-06$

$0.025 \quad 7.21 \mathrm{E}-06 \quad 7.21 \mathrm{E}-06 \quad 7.21 \mathrm{E}-06$

$0.050 \quad 8.85 \mathrm{E}-06 \quad 8.85 \mathrm{E}-06 \quad 8.85 \mathrm{E}-06$

$0.075 \quad 1.05 \mathrm{E}-05 \quad 1.05 \mathrm{E}-05 \quad 1.05 \mathrm{E}-05$

$0.100 \quad 1.16 \mathrm{E}-05 \quad 1.16 \mathrm{E}-05 \quad 1.16 \mathrm{E}-05$

$\begin{array}{llll}0.125 & 1.28 \mathrm{E}-05 & 1.28 \mathrm{E}-05 & 1.28 \mathrm{E}-05\end{array}$

$0.150 \quad 1.38 \mathrm{E}-05 \quad 1.38 \mathrm{E}-05 \quad 1.38 \mathrm{E}-05$

$0.175 \quad 1.50 \mathrm{E}-05 \quad 1.50 \mathrm{E}-05 \quad 1.50 \mathrm{E}-05$

$\begin{array}{llll}0.200 & 1.59 \mathrm{E}-05 & 1.59 \mathrm{E}-05 & 1.59 \mathrm{E}-05\end{array}$

$0.225 \quad 1.70 \mathrm{E}-05 \quad 1.70 \mathrm{E}-05 \quad 1.70 \mathrm{E}-05$

$0.250 \quad 1.81 \mathrm{E}-05 \quad 1.80 \mathrm{E}-05 \quad 1.80 \mathrm{E}-05$

$\begin{array}{llll}0.275 & 1.91 \mathrm{E}-05 & 1.91 \mathrm{E}-05 & 1.91 \mathrm{E}-05\end{array}$

$\begin{array}{llll}0.300 & 2.01 \mathrm{E}-05 & 2.01 \mathrm{E}-05 & 2.01 \mathrm{E}-05\end{array}$

$\begin{array}{llll}0.325 & 2.09 \mathrm{E}-05 & 2.09 \mathrm{E}-05 & 2.09 \mathrm{E}-05\end{array}$

$0.350 \quad 2.18 \mathrm{E}-05 \quad 2.18 \mathrm{E}-05 \quad 2.18 \mathrm{E}-05$

$\begin{array}{llll}0.375 & 2.27 \mathrm{E}-05 & 2.27 \mathrm{E}-05 & 2.27 \mathrm{E}-05\end{array}$

$\begin{array}{llll}0.400 & 2.37 \mathrm{E}-05 & 2.37 \mathrm{E}-05 & 2.37 \mathrm{E}-05\end{array}$

$\begin{array}{llll}0.425 & 2.46 \mathrm{E}-05 & 2.46 \mathrm{E}-05 & 2.46 \mathrm{E}-05\end{array}$

$\begin{array}{llll}0.450 & 2.56 \mathrm{E}-05 & 2.55 \mathrm{E}-05 & 2.56 \mathrm{E}-05\end{array}$

$\begin{array}{llll}0.475 & 2.68 \mathrm{E}-05 & 2.67 \mathrm{E}-05 & 2.67 \mathrm{E}-05\end{array}$

$\begin{array}{llll}0.500 & 2.80 \mathrm{E}-05 & 2.79 \mathrm{E}-05 & 2.80 \mathrm{E}-05\end{array}$

$\begin{array}{llll}0.525 & 2.92 \mathrm{E}-05 & 2.90 \mathrm{E}-05 & 2.90 \mathrm{E}-05\end{array}$

$0.550 \quad 3.04 \mathrm{E}-05 \quad 3.03 \mathrm{E}-05 \quad 3.03 \mathrm{E}-05$

$0.575 \quad 3.15 \mathrm{E}-05 \quad 3.14 \mathrm{E}-05 \quad 3.14 \mathrm{E}-05$

$\begin{array}{llll}0.600 & 3.26 \mathrm{E}-05 & 3.26 \mathrm{E}-05 & 3.26 \mathrm{E}-05\end{array}$

$\begin{array}{llll}0.625 & 3.39 \mathrm{E}-05 & 3.39 \mathrm{E}-05 & 3.39 \mathrm{E}-05\end{array}$

$0.650 \quad 3.53 \mathrm{E}-05 \quad 3.52 \mathrm{E}-05 \quad 3.52 \mathrm{E}-05$

$0.675 \quad 3.67 \mathrm{E}-05 \quad 3.67 \mathrm{E}-05 \quad 3.67 \mathrm{E}-05$

$0.700 \quad 3.84 \mathrm{E}-05 \quad 3.83 \mathrm{E}-05 \quad 3.83 \mathrm{E}-05$

$0.725 \quad 4.00 \mathrm{E}-05 \quad 4.00 \mathrm{E}-05 \quad 4.00 \mathrm{E}-05$

$0.750 \quad 4.23 \mathrm{E}-05 \quad 4.22 \mathrm{E}-05 \quad 4.23 \mathrm{E}-05$

$0.775 \quad 4.43 \mathrm{E}-05 \quad 4.43 \mathrm{E}-05 \quad 4.43 \mathrm{E}-05$

$0.800 \quad 4.66 \mathrm{E}-05 \quad 4.65 \mathrm{E}-05 \quad 4.66 \mathrm{E}-05$

$0.825 \quad 4.85 \mathrm{E}-05 \quad 4.85 \mathrm{E}-05 \quad 4.85 \mathrm{E}-05$

$0.850 \quad 5.13 \mathrm{E}-05 \quad 5.13 \mathrm{E}-05 \quad 5.13 \mathrm{E}-05$

$\begin{array}{llll}0.875 & 5.49 \mathrm{E}-05 & 5.48 \mathrm{E}-05 & 5.49 \mathrm{E}-05\end{array}$

$\begin{array}{llll}0.900 & 5.79 \mathrm{E}-05 & 5.79 \mathrm{E}-05 & 5.79 \mathrm{E}-05\end{array}$

$\begin{array}{llll}0.925 & 6.27 \mathrm{E}-05 & 6.26 \mathrm{E}-05 & 6.27 \mathrm{E}-05\end{array}$

$\begin{array}{llll}0.950 & 6.81 \mathrm{E}-05 & 6.81 \mathrm{E}-05 & 6.81 \mathrm{E}-05\end{array}$

$\begin{array}{llll}0.975 & 7.70 \mathrm{E}-05 & 7.70 \mathrm{E}-05 & 7.70 \mathrm{E}-05\end{array}$

$0.990 \quad 9.61 \mathrm{E}-05 \quad 9.61 \mathrm{E}-05 \quad 9.61 \mathrm{E}-05$

$\overline{\overline{9.61 \mathrm{E}-05}} \overline{\overline{ }}$ 
RESRAD-OFFSITE, Version 2.5

Probabilistic Dose and Risk Report

Title : RESRAD-OFFSITE Drinking Water, Plant, Milk, and Meat Pathways for Offsite Reside

File : PBA-1_TC99-DOE-5.ROF

Statistics and Cumulative distribution function of Peak Risk from External Ground(Wreleas)

$\begin{array}{ccccc}\text { Repetition }= & 1 & 2 & 3 \\ \begin{array}{c}\text { Mean } \\ \text { Std. Dev. }\end{array} & 0.00 \mathrm{E}+00 & 0.00 \mathrm{E}+00 & 0.00 \mathrm{E}+00 \\ \text { Minimum } & 0.00 \mathrm{E}+00 & 0.00 \mathrm{E}+00 & 0.00 \mathrm{E}+00 \\ \text { Maximum } & 0.00 \mathrm{E}+00 & 0.00 \mathrm{E}+00 & 0.00 \mathrm{E}+00 \\ & 0.00 \mathrm{E}+00 & 0.00 \mathrm{E}+00 & 0.00 \mathrm{E}+00\end{array}$

Percentile

$\begin{array}{llll}0.010 & 0.00 \mathrm{E}+00 \quad 0.00 \mathrm{E}+00 & 0.00 \mathrm{E}+00\end{array}$

$\begin{array}{llll}0.025 & 0.00 \mathrm{E}+00 & 0.00 \mathrm{E}+00 & 0.00 \mathrm{E}+00\end{array}$

$\begin{array}{llll}0.050 & 0.00 \mathrm{E}+00 & 0.00 \mathrm{E}+00 & 0.00 \mathrm{E}+00\end{array}$

$\begin{array}{llll}0.075 & 0.00 \mathrm{E}+00 & 0.00 \mathrm{E}+00 & 0.00 \mathrm{E}+00\end{array}$

$\begin{array}{llll}0.100 & 0.00 \mathrm{E}+00 & 0.00 \mathrm{E}+00 & 0.00 \mathrm{E}+00\end{array}$

$\begin{array}{llll}0.125 & 0.00 \mathrm{E}+00 & 0.00 \mathrm{E}+00 & 0.00 \mathrm{E}+00\end{array}$

$\begin{array}{llll}0.150 & 0.00 \mathrm{E}+00 & 0.00 \mathrm{E}+00 & 0.00 \mathrm{E}+00\end{array}$

$\begin{array}{lllll}0.175 & 0.00 \mathrm{E}+00 & 0.00 \mathrm{E}+00 & 0.00 \mathrm{E}+00\end{array}$

$\begin{array}{lllll}0.200 & 0.00 \mathrm{E}+00 & 0.00 \mathrm{E}+00 & 0.00 \mathrm{E}+00\end{array}$

$\begin{array}{lllll}0.225 & 0.00 \mathrm{E}+00 & 0.00 \mathrm{E}+00 & 0.00 \mathrm{E}+00\end{array}$

$\begin{array}{lllll}0.250 & 0.00 \mathrm{E}+00 & 0.00 \mathrm{E}+00 & 0.00 \mathrm{E}+00\end{array}$

$\begin{array}{lllll}0.275 & 0.00 \mathrm{E}+00 & 0.00 \mathrm{E}+00 & 0.00 \mathrm{E}+00\end{array}$

$\begin{array}{lllll}0.300 & 0.00 \mathrm{E}+00 & 0.00 \mathrm{E}+00 & 0.00 \mathrm{E}+00\end{array}$

$\begin{array}{lllll}0.325 & 0.00 \mathrm{E}+00 & 0.00 \mathrm{E}+00 & 0.00 \mathrm{E}+00\end{array}$

$\begin{array}{lllll}0.350 & 0.00 \mathrm{E}+00 & 0.00 \mathrm{E}+00 & 0.00 \mathrm{E}+00\end{array}$

$\begin{array}{lllll}0.375 & 0.00 \mathrm{E}+00 & 0.00 \mathrm{E}+00 & 0.00 \mathrm{E}+00\end{array}$

$\begin{array}{lllll}0.400 & 0.00 \mathrm{E}+00 & 0.00 \mathrm{E}+00 & 0.00 \mathrm{E}+00\end{array}$

$\begin{array}{lllll}0.425 & 0.00 \mathrm{E}+00 & 0.00 \mathrm{E}+00 & 0.00 \mathrm{E}+00\end{array}$

$\begin{array}{lllll}0.450 & 0.00 \mathrm{E}+00 & 0.00 \mathrm{E}+00 & 0.00 \mathrm{E}+00\end{array}$

$\begin{array}{lllll}0.475 & 0.00 \mathrm{E}+00 & 0.00 \mathrm{E}+00 & 0.00 \mathrm{E}+00\end{array}$

$\begin{array}{lllll}0.500 & 0.00 \mathrm{E}+00 & 0.00 \mathrm{E}+00 & 0.00 \mathrm{E}+00\end{array}$

$\begin{array}{lllll}0.525 & 0.00 \mathrm{E}+00 & 0.00 \mathrm{E}+00 & 0.00 \mathrm{E}+00\end{array}$

$\begin{array}{lllll}0.550 & 0.00 \mathrm{E}+00 & 0.00 \mathrm{E}+00 & 0.00 \mathrm{E}+00\end{array}$

$\begin{array}{lllll}0.575 & 0.00 \mathrm{E}+00 & 0.00 \mathrm{E}+00 & 0.00 \mathrm{E}+00\end{array}$

$\begin{array}{lllll}0.600 & 0.00 \mathrm{E}+00 & 0.00 \mathrm{E}+00 & 0.00 \mathrm{E}+00\end{array}$

$\begin{array}{lllll}0.625 & 0.00 \mathrm{E}+00 & 0.00 \mathrm{E}+00 & 0.00 \mathrm{E}+00\end{array}$

$\begin{array}{lllll}0.650 & 0.00 \mathrm{E}+00 & 0.00 \mathrm{E}+00 & 0.00 \mathrm{E}+00\end{array}$

$\begin{array}{lllll}0.675 & 0.00 \mathrm{E}+00 & 0.00 \mathrm{E}+00 & 0.00 \mathrm{E}+00\end{array}$

$\begin{array}{lllll}0.700 & 0.00 \mathrm{E}+00 & 0.00 \mathrm{E}+00 & 0.00 \mathrm{E}+00\end{array}$

$\begin{array}{lllll}0.725 & 0.00 \mathrm{E}+00 & 0.00 \mathrm{E}+00 & 0.00 \mathrm{E}+00\end{array}$

$\begin{array}{lllll}0.750 & 0.00 \mathrm{E}+00 & 0.00 \mathrm{E}+00 & 0.00 \mathrm{E}+00\end{array}$

$\begin{array}{llll}0.775 & 0.00 \mathrm{E}+00 & 0.00 \mathrm{E}+00 & 0.00 \mathrm{E}+00\end{array}$

$\begin{array}{lllll}0.800 & 0.00 \mathrm{E}+00 & 0.00 \mathrm{E}+00 & 0.00 \mathrm{E}+00\end{array}$

$\begin{array}{lllll}0.825 & 0.00 \mathrm{E}+00 & 0.00 \mathrm{E}+00 & 0.00 \mathrm{E}+00\end{array}$

$\begin{array}{lllll}0.850 & 0.00 \mathrm{E}+00 & 0.00 \mathrm{E}+00 & 0.00 \mathrm{E}+00\end{array}$

$\begin{array}{lllll}0.875 & 0.00 \mathrm{E}+00 & 0.00 \mathrm{E}+00 & 0.00 \mathrm{E}+00\end{array}$

$\begin{array}{lllll}0.900 & 0.00 \mathrm{E}+00 & 0.00 \mathrm{E}+00 & 0.00 \mathrm{E}+00\end{array}$

$\begin{array}{lllll}0.925 & 0.00 \mathrm{E}+00 & 0.00 \mathrm{E}+00 & 0.00 \mathrm{E}+00\end{array}$

$\begin{array}{llll}0.950 & 0.00 \mathrm{E}+00 & 0.00 \mathrm{E}+00 & 0.00 \mathrm{E}+00\end{array}$

$\begin{array}{lllll}0.975 & 0.00 \mathrm{E}+00 & 0.00 \mathrm{E}+00 & 0.00 \mathrm{E}+00\end{array}$

$\begin{array}{lllll}0.990 & 0.00 \mathrm{E}+00 & 0.00 \mathrm{E}+00 & 0.00 \mathrm{E}+00\end{array}$ 
RESRAD-OFFSITE, Version 2.5

Probabilistic Dose and Risk Report

Title : RESRAD-OFFSITE Drinking Water, Plant, Milk, and Meat Pathways for Offsite Reside

File : PBA-1_TC99-DOE-5.ROF

Statistics and Cumulative distribution function of Peak Risk from Fish Ingestion

$\begin{array}{ccccc}\text { Repetition }= & 1 & 2 & 3 \\ \text { Mean } & 0.00 \mathrm{E}+00 & 0.00 \mathrm{E}+00 & 0.00 \mathrm{E}+00 \\ \text { Std. Dev. } & 0.00 \mathrm{E}+00 & 0.00 \mathrm{E}+00 & 0.00 \mathrm{E}+00 \\ \text { Minimum } & 0.00 \mathrm{E}+00 & 0.00 \mathrm{E}+00 & 0.00 \mathrm{E}+00 \\ \text { Maximum } & 0.00 \mathrm{E}+00 & 0.00 \mathrm{E}+00 & 0.00 \mathrm{E}+00\end{array}$

Percentile

$\begin{array}{llll}0.010 & 0.00 \mathrm{E}+00 \quad 0.00 \mathrm{E}+00 & 0.00 \mathrm{E}+00\end{array}$

$\begin{array}{llll}0.025 & 0.00 \mathrm{E}+00 & 0.00 \mathrm{E}+00 & 0.00 \mathrm{E}+00\end{array}$

$\begin{array}{llll}0.050 & 0.00 \mathrm{E}+00 & 0.00 \mathrm{E}+00 & 0.00 \mathrm{E}+00\end{array}$

$\begin{array}{llll}0.075 & 0.00 \mathrm{E}+00 & 0.00 \mathrm{E}+00 & 0.00 \mathrm{E}+00\end{array}$

$\begin{array}{llll}0.100 & 0.00 \mathrm{E}+00 & 0.00 \mathrm{E}+00 & 0.00 \mathrm{E}+00\end{array}$

$\begin{array}{llll}0.125 & 0.00 \mathrm{E}+00 & 0.00 \mathrm{E}+00 & 0.00 \mathrm{E}+00\end{array}$

$\begin{array}{llll}0.150 & 0.00 \mathrm{E}+00 & 0.00 \mathrm{E}+00 & 0.00 \mathrm{E}+00\end{array}$

$\begin{array}{lllll}0.175 & 0.00 \mathrm{E}+00 & 0.00 \mathrm{E}+00 & 0.00 \mathrm{E}+00\end{array}$

$\begin{array}{lllll}0.200 & 0.00 \mathrm{E}+00 & 0.00 \mathrm{E}+00 & 0.00 \mathrm{E}+00\end{array}$

$\begin{array}{lllll}0.225 & 0.00 \mathrm{E}+00 & 0.00 \mathrm{E}+00 & 0.00 \mathrm{E}+00\end{array}$

$\begin{array}{lllll}0.250 & 0.00 \mathrm{E}+00 & 0.00 \mathrm{E}+00 & 0.00 \mathrm{E}+00\end{array}$

$\begin{array}{lllll}0.275 & 0.00 \mathrm{E}+00 & 0.00 \mathrm{E}+00 & 0.00 \mathrm{E}+00\end{array}$

$\begin{array}{lllll}0.300 & 0.00 \mathrm{E}+00 & 0.00 \mathrm{E}+00 & 0.00 \mathrm{E}+00\end{array}$

$\begin{array}{lllll}0.325 & 0.00 \mathrm{E}+00 & 0.00 \mathrm{E}+00 & 0.00 \mathrm{E}+00\end{array}$

$\begin{array}{lllll}0.350 & 0.00 \mathrm{E}+00 & 0.00 \mathrm{E}+00 & 0.00 \mathrm{E}+00\end{array}$

$\begin{array}{lllll}0.375 & 0.00 \mathrm{E}+00 & 0.00 \mathrm{E}+00 & 0.00 \mathrm{E}+00\end{array}$

$\begin{array}{lllll}0.400 & 0.00 \mathrm{E}+00 & 0.00 \mathrm{E}+00 & 0.00 \mathrm{E}+00\end{array}$

$\begin{array}{lllll}0.425 & 0.00 \mathrm{E}+00 & 0.00 \mathrm{E}+00 & 0.00 \mathrm{E}+00\end{array}$

$\begin{array}{lllll}0.450 & 0.00 \mathrm{E}+00 & 0.00 \mathrm{E}+00 & 0.00 \mathrm{E}+00\end{array}$

$\begin{array}{lllll}0.475 & 0.00 \mathrm{E}+00 & 0.00 \mathrm{E}+00 & 0.00 \mathrm{E}+00\end{array}$

$\begin{array}{lllll}0.500 & 0.00 \mathrm{E}+00 & 0.00 \mathrm{E}+00 & 0.00 \mathrm{E}+00\end{array}$

$\begin{array}{lllll}0.525 & 0.00 \mathrm{E}+00 & 0.00 \mathrm{E}+00 & 0.00 \mathrm{E}+00\end{array}$

$\begin{array}{lllll}0.550 & 0.00 \mathrm{E}+00 & 0.00 \mathrm{E}+00 & 0.00 \mathrm{E}+00\end{array}$

$\begin{array}{lllll}0.575 & 0.00 \mathrm{E}+00 & 0.00 \mathrm{E}+00 & 0.00 \mathrm{E}+00\end{array}$

$\begin{array}{lllll}0.600 & 0.00 \mathrm{E}+00 & 0.00 \mathrm{E}+00 & 0.00 \mathrm{E}+00\end{array}$

$\begin{array}{lllll}0.625 & 0.00 \mathrm{E}+00 & 0.00 \mathrm{E}+00 & 0.00 \mathrm{E}+00\end{array}$

$\begin{array}{lllll}0.650 & 0.00 \mathrm{E}+00 & 0.00 \mathrm{E}+00 & 0.00 \mathrm{E}+00\end{array}$

$\begin{array}{lllll}0.675 & 0.00 \mathrm{E}+00 & 0.00 \mathrm{E}+00 & 0.00 \mathrm{E}+00\end{array}$

$\begin{array}{llll}0.700 & 0.00 \mathrm{E}+00 & 0.00 \mathrm{E}+00 & 0.00 \mathrm{E}+00\end{array}$

$\begin{array}{lllll}0.725 & 0.00 \mathrm{E}+00 & 0.00 \mathrm{E}+00 & 0.00 \mathrm{E}+00\end{array}$

$\begin{array}{lllll}0.750 & 0.00 \mathrm{E}+00 & 0.00 \mathrm{E}+00 & 0.00 \mathrm{E}+00\end{array}$

$\begin{array}{lllll}0.775 & 0.00 \mathrm{E}+00 & 0.00 \mathrm{E}+00 & 0.00 \mathrm{E}+00\end{array}$

$\begin{array}{lllll}0.800 & 0.00 \mathrm{E}+00 & 0.00 \mathrm{E}+00 & 0.00 \mathrm{E}+00\end{array}$

$\begin{array}{lllll}0.825 & 0.00 \mathrm{E}+00 & 0.00 \mathrm{E}+00 & 0.00 \mathrm{E}+00\end{array}$

$\begin{array}{lllll}0.850 & 0.00 \mathrm{E}+00 & 0.00 \mathrm{E}+00 & 0.00 \mathrm{E}+00\end{array}$

$\begin{array}{lllll}0.875 & 0.00 \mathrm{E}+00 & 0.00 \mathrm{E}+00 & 0.00 \mathrm{E}+00\end{array}$

$\begin{array}{lllll}0.900 & 0.00 \mathrm{E}+00 & 0.00 \mathrm{E}+00 & 0.00 \mathrm{E}+00\end{array}$

$\begin{array}{lllll}0.925 & 0.00 \mathrm{E}+00 & 0.00 \mathrm{E}+00 & 0.00 \mathrm{E}+00\end{array}$

$\begin{array}{llll}0.950 & 0.00 \mathrm{E}+00 & 0.00 \mathrm{E}+00 & 0.00 \mathrm{E}+00\end{array}$

$\begin{array}{lllll}0.975 & 0.00 \mathrm{E}+00 & 0.00 \mathrm{E}+00 & 0.00 \mathrm{E}+00\end{array}$

$\begin{array}{lllll}0.990 & 0.00 \mathrm{E}+00 & 0.00 \mathrm{E}+00 & 0.00 \mathrm{E}+00\end{array}$ 
RESRAD-OFFSITE, Version 2.5

Probabilistic Dose and Risk Report

Title : RESRAD-OFFSITE Drinking Water, Plant, Milk, and Meat Pathways for Offsite Reside

File : PBA-1_TC99-DOE-5.ROF

Statistics and Cumulative distribution function of Peak Risk from Radon (Waterrelease)

$\begin{array}{ccccc}\text { Repetition }= & 1 & 2 & 3 \\ \text { Mean } & 0.00 \mathrm{E}+00 & 0.00 \mathrm{E}+00 & 0.00 \mathrm{E}+00 \\ \text { Std. Dev. } & 0.00 \mathrm{E}+00 & 0.00 \mathrm{E}+00 & 0.00 \mathrm{E}+00 \\ \text { Minimum } & 0.00 \mathrm{E}+00 & 0.00 \mathrm{E}+00 & 0.00 \mathrm{E}+00 \\ \text { Maximum } & 0.00 \mathrm{E}+00 & 0.00 \mathrm{E}+00 & 0.00 \mathrm{E}+00\end{array}$

Percentile

$\begin{array}{llll}0.010 & 0.00 \mathrm{E}+00 \quad 0.00 \mathrm{E}+00 & 0.00 \mathrm{E}+00\end{array}$

$\begin{array}{llll}0.025 & 0.00 \mathrm{E}+00 & 0.00 \mathrm{E}+00 & 0.00 \mathrm{E}+00\end{array}$

$\begin{array}{llll}0.050 & 0.00 \mathrm{E}+00 & 0.00 \mathrm{E}+00 & 0.00 \mathrm{E}+00\end{array}$

$\begin{array}{llll}0.075 & 0.00 \mathrm{E}+00 & 0.00 \mathrm{E}+00 & 0.00 \mathrm{E}+00\end{array}$

$\begin{array}{llll}0.100 & 0.00 \mathrm{E}+00 & 0.00 \mathrm{E}+00 & 0.00 \mathrm{E}+00\end{array}$

$\begin{array}{llll}0.125 & 0.00 \mathrm{E}+00 & 0.00 \mathrm{E}+00 & 0.00 \mathrm{E}+00\end{array}$

$\begin{array}{llll}0.150 & 0.00 \mathrm{E}+00 & 0.00 \mathrm{E}+00 & 0.00 \mathrm{E}+00\end{array}$

$\begin{array}{lllll}0.175 & 0.00 \mathrm{E}+00 & 0.00 \mathrm{E}+00 & 0.00 \mathrm{E}+00\end{array}$

$\begin{array}{lllll}0.200 & 0.00 \mathrm{E}+00 & 0.00 \mathrm{E}+00 & 0.00 \mathrm{E}+00\end{array}$

$\begin{array}{lllll}0.225 & 0.00 \mathrm{E}+00 & 0.00 \mathrm{E}+00 & 0.00 \mathrm{E}+00\end{array}$

$\begin{array}{lllll}0.250 & 0.00 \mathrm{E}+00 & 0.00 \mathrm{E}+00 & 0.00 \mathrm{E}+00\end{array}$

$\begin{array}{lllll}0.275 & 0.00 \mathrm{E}+00 & 0.00 \mathrm{E}+00 & 0.00 \mathrm{E}+00\end{array}$

$\begin{array}{lllll}0.300 & 0.00 \mathrm{E}+00 & 0.00 \mathrm{E}+00 & 0.00 \mathrm{E}+00\end{array}$

$\begin{array}{lllll}0.325 & 0.00 \mathrm{E}+00 & 0.00 \mathrm{E}+00 & 0.00 \mathrm{E}+00\end{array}$

$\begin{array}{lllll}0.350 & 0.00 \mathrm{E}+00 & 0.00 \mathrm{E}+00 & 0.00 \mathrm{E}+00\end{array}$

$\begin{array}{lllll}0.375 & 0.00 \mathrm{E}+00 & 0.00 \mathrm{E}+00 & 0.00 \mathrm{E}+00\end{array}$

$\begin{array}{lllll}0.400 & 0.00 \mathrm{E}+00 & 0.00 \mathrm{E}+00 & 0.00 \mathrm{E}+00\end{array}$

$\begin{array}{lllll}0.425 & 0.00 \mathrm{E}+00 & 0.00 \mathrm{E}+00 & 0.00 \mathrm{E}+00\end{array}$

$\begin{array}{lllll}0.450 & 0.00 \mathrm{E}+00 & 0.00 \mathrm{E}+00 & 0.00 \mathrm{E}+00\end{array}$

$\begin{array}{lllll}0.475 & 0.00 \mathrm{E}+00 & 0.00 \mathrm{E}+00 & 0.00 \mathrm{E}+00\end{array}$

$\begin{array}{lllll}0.500 & 0.00 \mathrm{E}+00 & 0.00 \mathrm{E}+00 & 0.00 \mathrm{E}+00\end{array}$

$\begin{array}{lllll}0.525 & 0.00 \mathrm{E}+00 & 0.00 \mathrm{E}+00 & 0.00 \mathrm{E}+00\end{array}$

$\begin{array}{lllll}0.550 & 0.00 \mathrm{E}+00 & 0.00 \mathrm{E}+00 & 0.00 \mathrm{E}+00\end{array}$

$\begin{array}{lllll}0.575 & 0.00 \mathrm{E}+00 & 0.00 \mathrm{E}+00 & 0.00 \mathrm{E}+00\end{array}$

$\begin{array}{lllll}0.600 & 0.00 \mathrm{E}+00 & 0.00 \mathrm{E}+00 & 0.00 \mathrm{E}+00\end{array}$

$\begin{array}{lllll}0.625 & 0.00 \mathrm{E}+00 & 0.00 \mathrm{E}+00 & 0.00 \mathrm{E}+00\end{array}$

$\begin{array}{lllll}0.650 & 0.00 \mathrm{E}+00 & 0.00 \mathrm{E}+00 & 0.00 \mathrm{E}+00\end{array}$

$\begin{array}{lllll}0.675 & 0.00 \mathrm{E}+00 & 0.00 \mathrm{E}+00 & 0.00 \mathrm{E}+00\end{array}$

$\begin{array}{lllll}0.700 & 0.00 \mathrm{E}+00 & 0.00 \mathrm{E}+00 & 0.00 \mathrm{E}+00\end{array}$

$\begin{array}{lllll}0.725 & 0.00 \mathrm{E}+00 & 0.00 \mathrm{E}+00 & 0.00 \mathrm{E}+00\end{array}$

$\begin{array}{lllll}0.750 & 0.00 \mathrm{E}+00 & 0.00 \mathrm{E}+00 & 0.00 \mathrm{E}+00\end{array}$

$\begin{array}{lllll}0.775 & 0.00 \mathrm{E}+00 & 0.00 \mathrm{E}+00 & 0.00 \mathrm{E}+00\end{array}$

$\begin{array}{lllll}0.800 & 0.00 \mathrm{E}+00 & 0.00 \mathrm{E}+00 & 0.00 \mathrm{E}+00\end{array}$

$\begin{array}{lllll}0.825 & 0.00 \mathrm{E}+00 & 0.00 \mathrm{E}+00 & 0.00 \mathrm{E}+00\end{array}$

$\begin{array}{lllll}0.850 & 0.00 \mathrm{E}+00 & 0.00 \mathrm{E}+00 & 0.00 \mathrm{E}+00\end{array}$

$\begin{array}{lllll}0.875 & 0.00 \mathrm{E}+00 & 0.00 \mathrm{E}+00 & 0.00 \mathrm{E}+00\end{array}$

$\begin{array}{lllll}0.900 & 0.00 \mathrm{E}+00 & 0.00 \mathrm{E}+00 & 0.00 \mathrm{E}+00\end{array}$

$\begin{array}{lllll}0.925 & 0.00 \mathrm{E}+00 & 0.00 \mathrm{E}+00 & 0.00 \mathrm{E}+00\end{array}$

$\begin{array}{llll}0.950 & 0.00 \mathrm{E}+00 & 0.00 \mathrm{E}+00 & 0.00 \mathrm{E}+00\end{array}$

$\begin{array}{lllll}0.975 & 0.00 \mathrm{E}+00 & 0.00 \mathrm{E}+00 & 0.00 \mathrm{E}+00\end{array}$

$\begin{array}{lllll}0.990 & 0.00 \mathrm{E}+00 & 0.00 \mathrm{E}+00 & 0.00 \mathrm{E}+00\end{array}$ 
RESRAD-OFFSITE, Version 2.5

Probabilistic Dose and Risk Report

Title : RESRAD-OFFSITE Drinking Water, Plant, Milk, and Meat Pathways for Offsite Reside

File : PBA-1_TC99-DOE-5.ROF

Statistics and Cumulative distribution function of Peak Risk from Plant (Waterrelease)

$\begin{array}{ccccc}\text { Repetition }= & 1 & 2 & 3 \\ \text { Mean } & 1.02 \mathrm{E}-05 & 1.02 \mathrm{E}-05 & 1.02 \mathrm{E}-05 \\ \text { Std. Dev. } & 6.09 \mathrm{E}-06 & 6.08 \mathrm{E}-06 & 6.09 \mathrm{E}-06 \\ \text { Minimum } & 1.23 \mathrm{E}-06 & 1.23 \mathrm{E}-06 & 1.23 \mathrm{E}-06 \\ \text { Maximum } & 5.79 \mathrm{E}-05 & 5.79 \mathrm{E}-05 & 5.79 \mathrm{E}-05\end{array}$

Percentile

$\begin{array}{llll}0.010 & 1.76 \mathrm{E}-06 & 1.76 \mathrm{E}-06 & 1.76 \mathrm{E}-06\end{array}$

$0.025 \quad 2.30 \mathrm{E}-06 \quad 2.30 \mathrm{E}-06 \quad 2.30 \mathrm{E}-06$

$\begin{array}{llll}0.050 \quad 2.82 \mathrm{E}-06 & 2.82 \mathrm{E}-06 & 2.82 \mathrm{E}-06\end{array}$

$0.075 \quad 3.33 \mathrm{E}-06 \quad 3.33 \mathrm{E}-06 \quad 3.33 \mathrm{E}-06$

$0.100 \quad 3.69 \mathrm{E}-06 \quad 3.69 \mathrm{E}-06 \quad 3.69 \mathrm{E}-06$

$0.125 \quad 4.07 \mathrm{E}-06 \quad 4.07 \mathrm{E}-06 \quad 4.07 \mathrm{E}-06$

$0.150 \quad 4.39 \mathrm{E}-06 \quad 4.39 \mathrm{E}-06 \quad 4.39 \mathrm{E}-06$

$0.175 \quad 4.77 \mathrm{E}-06 \quad 4.77 \mathrm{E}-06 \quad 4.77 \mathrm{E}-06$

$0.200 \quad 5.06 \mathrm{E}-06 \quad 5.06 \mathrm{E}-06 \quad 5.06 \mathrm{E}-06$

$0.225 \quad 5.41 \mathrm{E}-06 \quad 5.40 \mathrm{E}-06 \quad 5.40 \mathrm{E}-06$

$0.250 \quad 5.75 \mathrm{E}-06 \quad 5.74 \mathrm{E}-06 \quad 5.74 \mathrm{E}-06$

$\begin{array}{llll}0.275 & 6.09 \mathrm{E}-06 & 6.09 \mathrm{E}-06 & 6.09 \mathrm{E}-06\end{array}$

$0.300 \quad 6.41 \mathrm{E}-06 \quad 6.41 \mathrm{E}-06 \quad 6.41 \mathrm{E}-06$

$0.325 \quad 6.66 \mathrm{E}-06 \quad 6.66 \mathrm{E}-06 \quad 6.66 \mathrm{E}-06$

$0.350 \quad 6.93 \mathrm{E}-06 \quad 6.93 \mathrm{E}-06 \quad 6.93 \mathrm{E}-06$

$\begin{array}{llll}0.375 & 7.23 \mathrm{E}-06 \quad 7.22 \mathrm{E}-06 \quad 7.23 \mathrm{E}-06\end{array}$

$0.400 \quad 7.55 \mathrm{E}-06 \quad 7.55 \mathrm{E}-06 \quad 7.55 \mathrm{E}-06$

$0.425 \quad 7.84 \mathrm{E}-06 \quad 7.84 \mathrm{E}-06 \quad 7.84 \mathrm{E}-06$

$0.450 \quad 8.13 \mathrm{E}-06 \quad 8.13 \mathrm{E}-06 \quad 8.13 \mathrm{E}-06$

$0.475 \quad 8.53 \mathrm{E}-06 \quad 8.51 \mathrm{E}-06 \quad 8.51 \mathrm{E}-06$

$0.500 \quad 8.93 \mathrm{E}-06 \quad 8.88 \mathrm{E}-06 \quad 8.90 \mathrm{E}-06$

$0.5259 .29 \mathrm{E}-06 \quad 9.22 \mathrm{E}-06 \quad 9.23 \mathrm{E}-06$
0.550

$0.550 \quad 9.67 \mathrm{E}-06 \quad 9.65 \mathrm{E}-06 \quad 9.66 \mathrm{E}-06$

$0.575 \quad 1.00 \mathrm{E}-05 \quad 1.00 \mathrm{E}-05 \quad 1.00 \mathrm{E}-05$

$0.600 \quad 1.04 \mathrm{E}-05 \quad 1.04 \mathrm{E}-05 \quad 1.04 \mathrm{E}-05$

$0.625 \quad 1.08 \mathrm{E}-05 \quad 1.08 \mathrm{E}-05 \quad 1.08 \mathrm{E}-05$

$0.650 \quad 1.12 \mathrm{E}-05 \quad 1.12 \mathrm{E}-05 \quad 1.12 \mathrm{E}-05$

$0.675 \quad 1.17 \mathrm{E}-05 \quad 1.17 \mathrm{E}-05 \quad 1.17 \mathrm{E}-05$

$0.700 \quad 1.22 \mathrm{E}-05 \quad 1.22 \mathrm{E}-05 \quad 1.22 \mathrm{E}-05$

$0.725 \quad 1.27 \mathrm{E}-05 \quad 1.27 \mathrm{E}-05 \quad 1.27 \mathrm{E}-05$

$0.750 \quad 1.35 \mathrm{E}-05 \quad 1.34 \mathrm{E}-05 \quad 1.35 \mathrm{E}-05$

$0.775 \quad 1.41 \mathrm{E}-05 \quad 1.41 \mathrm{E}-05 \quad 1.41 \mathrm{E}-05$

$0.800 \quad 1.48 \mathrm{E}-05 \quad 1.48 \mathrm{E}-05 \quad 1.48 \mathrm{E}-05$

$0.825 \quad 1.55 \mathrm{E}-05 \quad 1.54 \mathrm{E}-05 \quad 1.55 \mathrm{E}-05$

$0.850 \quad 1.63 \mathrm{E}-05 \quad 1.63 \mathrm{E}-05 \quad 1.63 \mathrm{E}-05$

$\begin{array}{llll}0.875 & 1.75 \mathrm{E}-05 & 1.75 \mathrm{E}-05 & 1.75 \mathrm{E}-05\end{array}$

$0.900 \quad 1.84 \mathrm{E}-05 \quad 1.84 \mathrm{E}-05 \quad 1.84 \mathrm{E}-05$

$0.925 \quad 2.00 \mathrm{E}-05 \quad 1.99 \mathrm{E}-05 \quad 2.00 \mathrm{E}-05$

$0.950 \quad 2.17 \mathrm{E}-05 \quad 2.17 \mathrm{E}-05 \quad 2.17 \mathrm{E}-05$

$0.975 \quad 2.45 \mathrm{E}-05 \quad 2.45 \mathrm{E}-05 \quad 2.45 \mathrm{E}-05$

$0.990 \quad 3.06 \mathrm{E}-05 \quad 3.06 \mathrm{E}-05 \quad 3.06 \mathrm{E}-05$ 
RESRAD-OFFSITE, Version 2.5

Probabilistic Dose and Risk Report

Title : RESRAD-OFFSITE Drinking Water, Plant, Milk, and Meat Pathways for Offsite Reside

File : PBA-1_TC99-DOE-5.ROF

Statistics and Cumulative distribution function of Peak Risk from Meat (Waterrelease)

$\begin{array}{rcccc}\text { Repetition }= & 1 & 2 & 3 \\ \text { Mean } & & 3.06 \mathrm{E}-08 & 3.05 \mathrm{E}-08 & 3.06 \mathrm{E}-08 \\ \text { Std. Dev. } & 1.82 \mathrm{E}-08 & 1.82 \mathrm{E}-08 & 1.82 \mathrm{E}-08 \\ \text { Minimum } & 3.68 \mathrm{E}-09 & 3.68 \mathrm{E}-09 & 3.68 \mathrm{E}-09 \\ \text { Maximum } & 1.73 \mathrm{E}-07 & 1.73 \mathrm{E}-07 & 1.73 \mathrm{E}-07\end{array}$

Percentile

$0.010 \quad 5.29 \mathrm{E}-09 \quad 5.29 \mathrm{E}-09 \quad 5.29 \mathrm{E}-09$

$0.025 \quad 6.88 \mathrm{E}-09 \quad 6.88 \mathrm{E}-09 \quad 6.88 \mathrm{E}-09$

$\begin{array}{llll}0.050 \quad 8.44 \mathrm{E}-09 \quad 8.44 \mathrm{E}-09 \quad 8.44 \mathrm{E}-09 & 9.98\end{array}$

$0.0759 .98 \mathrm{E}-09 \quad 9.98 \mathrm{E}-09 \quad 9.98 \mathrm{E}-09$

$0.100 \quad 1.11 \mathrm{E}-08 \quad 1.11 \mathrm{E}-08 \quad 1.11 \mathrm{E}-08$

$\begin{array}{llll}0.125 & 1.22 \mathrm{E}-08 & 1.22 \mathrm{E}-08 & 1.22 \mathrm{E}-08\end{array}$

$\begin{array}{llll}0.150 & 1.32 \mathrm{E}-08 & 1.32 \mathrm{E}-08 & 1.32 \mathrm{E}-08\end{array}$

$0.175 \quad 1.43 \mathrm{E}-08 \quad 1.43 \mathrm{E}-08 \quad 1.43 \mathrm{E}-08$

$0.200 \quad 1.52 \mathrm{E}-08 \quad 1.52 \mathrm{E}-08 \quad 1.52 \mathrm{E}-08$

$\begin{array}{llll}0.225 & 1.62 \mathrm{E}-08 & 1.62 \mathrm{E}-08 & 1.62 \mathrm{E}-08\end{array}$

$\begin{array}{llll}0.250 & 1.72 \mathrm{E}-08 & 1.72 \mathrm{E}-08 & 1.72 \mathrm{E}-08\end{array}$

$\begin{array}{llll}0.275 & 1.82 \mathrm{E}-08 & 1.82 \mathrm{E}-08 & 1.82 \mathrm{E}-08\end{array}$

$0.300 \quad 1.92 \mathrm{E}-08 \quad 1.92 \mathrm{E}-08 \quad 1.92 \mathrm{E}-08$

$\begin{array}{llll}0.325 & 2.00 \mathrm{E}-08 \quad 2.00 \mathrm{E}-08 \quad 2.00 \mathrm{E}-08\end{array}$

$\begin{array}{llll}0.350 \quad 2.08 \mathrm{E}-08 \quad 2.08 \mathrm{E}-08 \quad 2.08 \mathrm{E}-08 & \end{array}$

$\begin{array}{llll}0.375 & 2.17 \mathrm{E}-08 \quad 2.16 \mathrm{E}-08 \quad 2.17 \mathrm{E}-08\end{array}$

$\begin{array}{llll}0.400 \quad 2.26 \mathrm{E}-08 & 2.26 \mathrm{E}-08 \quad 2.26 \mathrm{E}-08\end{array}$

$\begin{array}{llll}0.425 & 2.35 \mathrm{E}-08 & 2.35 \mathrm{E}-08 & 2.35 \mathrm{E}-08\end{array}$

$\begin{array}{llll}0.450 \quad 2.44 \mathrm{E}-08 & 2.44 \mathrm{E}-08 \quad 2.44 \mathrm{E}-08\end{array}$

$\begin{array}{llll}0.475 & 2.56 \mathrm{E}-08 & 2.55 \mathrm{E}-08 & 2.55 \mathrm{E}-08\end{array}$

$0.500 \quad 2.68 \mathrm{E}-08 \quad 2.66 \mathrm{E}-08 \quad 2.67 \mathrm{E}-08$

$\begin{array}{llll}0.5252 .78 \mathrm{E}-08 & 2.76 \mathrm{E}-08 \quad 2.77 \mathrm{E}-08\end{array}$

$\begin{array}{llll}0.550 \quad 2.90 \mathrm{E}-08 & 2.89 \mathrm{E}-08 \quad 2.89 \mathrm{E}-08\end{array}$

$0.575 \quad 3.01 \mathrm{E}-08 \quad 3.00 \mathrm{E}-08 \quad 3.00 \mathrm{E}-08$

$0.600 \quad 3.12 \mathrm{E}-08 \quad 3.11 \mathrm{E}-08 \quad 3.11 \mathrm{E}-08$

$\begin{array}{llll}0.625 & 3.24 \mathrm{E}-08 \quad 3.23 \mathrm{E}-08 \quad 3.23 \mathrm{E}-08\end{array}$

$\begin{array}{llll}0.650 & 3.37 \mathrm{E}-08 & 3.36 \mathrm{E}-08 & 3.36 \mathrm{E}-08\end{array}$

$\begin{array}{lll}0.675 & 3.51 \mathrm{E}-08 \quad 3.50 \mathrm{E}-08 \quad 3.50 \mathrm{E}-08\end{array}$

$0.700 \quad 3.66 \mathrm{E}-08 \quad 3.66 \mathrm{E}-08 \quad 3.66 \mathrm{E}-08$

$0.725 \quad 3.82 \mathrm{E}-08 \quad 3.81 \mathrm{E}-08 \quad 3.81 \mathrm{E}-08$

$0.750 \quad 4.03 \mathrm{E}-08 \quad 4.03 \mathrm{E}-08 \quad 4.03 \mathrm{E}-08$

$0.775 \quad 4.23 \mathrm{E}-08 \quad 4.22 \mathrm{E}-08 \quad 4.23 \mathrm{E}-08$

$0.800 \quad 4.44 \mathrm{E}-08 \quad 4.44 \mathrm{E}-08 \quad 4.44 \mathrm{E}-08$

$0.825 \quad 4.63 \mathrm{E}-08 \quad 4.63 \mathrm{E}-08 \quad 4.63 \mathrm{E}-08$

$0.850 \quad 4.89 \mathrm{E}-08 \quad 4.89 \mathrm{E}-08 \quad 4.89 \mathrm{E}-08$

$\begin{array}{llll}0.875 & 5.24 \mathrm{E}-08 \quad 5.23 \mathrm{E}-08 \quad 5.24 \mathrm{E}-08\end{array}$

$0.900 \quad 5.53 \mathrm{E}-08 \quad 5.52 \mathrm{E}-08 \quad 5.53 \mathrm{E}-08$

$0.925 \quad 5.98 \mathrm{E}-08 \quad 5.97 \mathrm{E}-08 \quad 5.98 \mathrm{E}-08$

$0.950 \quad 6.50 \mathrm{E}-08 \quad 6.50 \mathrm{E}-08 \quad 6.50 \mathrm{E}-08$

$\begin{array}{llll}0.975 & 7.35 \mathrm{E}-08 \quad 7.35 \mathrm{E}-08 \quad 7.35 \mathrm{E}-08\end{array}$

$0.990 \quad 9.17 \mathrm{E}-08 \quad 9.17 \mathrm{E}-08 \quad 9.17 \mathrm{E}-08$

$\overline{\overline{ }} \overline{\underline{ }}$ 
RESRAD-OFFSITE, Version 2.5

Probabilistic Dose and Risk Report

Title : RESRAD-OFFSITE Drinking Water, Plant, Milk, and Meat Pathways for Offsite Reside

File : PBA-1_TC99-DOE-5.ROF

Statistics and Cumulative distribution function of Peak Risk from Milk (Waterrelease)

$\begin{array}{rcccc}\text { Repetition }= & 1 & 2 & 3 \\ \text { Mean } & & 2.70 \mathrm{E}-06 & 2.70 \mathrm{E}-06 & 2.70 \mathrm{E}-06 \\ \text { Std. Dev. } & 1.61 \mathrm{E}-06 & 1.61 \mathrm{E}-06 & 1.61 \mathrm{E}-06 \\ \text { Minimum } & 3.25 \mathrm{E}-07 & 3.25 \mathrm{E}-07 & 3.25 \mathrm{E}-07 \\ \text { Maximum } & 1.53 \mathrm{E}-05 & 1.53 \mathrm{E}-05 & 1.53 \mathrm{E}-05\end{array}$

Percentile

$0.010 \quad 4.67 \mathrm{E}-07 \quad 4.67 \mathrm{E}-07 \quad 4.67 \mathrm{E}-07$

$0.025 \quad 6.08 \mathrm{E}-07 \quad 6.08 \mathrm{E}-07 \quad 6.08 \mathrm{E}-07$

$0.050 \quad 7.46 \mathrm{E}-07 \quad 7.46 \mathrm{E}-07 \quad 7.46 \mathrm{E}-07$

$\begin{array}{llll}0.075 & 8.82 \mathrm{E}-07 \quad 8.82 \mathrm{E}-07 \quad 8.82 \mathrm{E}-07\end{array}$

$0.100 \quad 9.78 \mathrm{E}-07 \quad 9.78 \mathrm{E}-07 \quad 9.78 \mathrm{E}-07$

$0.125 \quad 1.08 \mathrm{E}-06 \quad 1.08 \mathrm{E}-06 \quad 1.08 \mathrm{E}-06$

$0.150 \quad 1.16 \mathrm{E}-06 \quad 1.16 \mathrm{E}-06 \quad 1.16 \mathrm{E}-06$

$\begin{array}{lllll}0.175 & 1.26 \mathrm{E}-06 & 1.26 \mathrm{E}-06 & 1.26 \mathrm{E}-06\end{array}$

$\begin{array}{lllll}0.200 \quad 1.34 \mathrm{E}-06 & 1.34 \mathrm{E}-06 & 1.34 \mathrm{E}-06\end{array}$

$0.225 \quad 1.43 \mathrm{E}-06 \quad 1.43 \mathrm{E}-06 \quad 1.43 \mathrm{E}-06$

$\begin{array}{lllll}0.250 & 1.52 \mathrm{E}-06 & 1.52 \mathrm{E}-06 & 1.52 \mathrm{E}-06\end{array}$

$\begin{array}{llll}0.275 & 1.61 \mathrm{E}-06 & 1.61 \mathrm{E}-06 & 1.61 \mathrm{E}-06\end{array}$

$0.300 \quad 1.70 \mathrm{E}-06 \quad 1.70 \mathrm{E}-06 \quad 1.70 \mathrm{E}-06$

$\begin{array}{lllll}0.325 & 1.76 \mathrm{E}-06 & 1.76 \mathrm{E}-06 & 1.76 \mathrm{E}-06\end{array}$

$0.350 \quad 1.83 \mathrm{E}-06 \quad 1.83 \mathrm{E}-06 \quad 1.83 \mathrm{E}-06$

$0.375 \quad 1.91 \mathrm{E}-06 \quad 1.91 \mathrm{E}-06 \quad 1.91 \mathrm{E}-06$

$0.400 \quad 2.00 \mathrm{E}-06 \quad 2.00 \mathrm{E}-06 \quad 2.00 \mathrm{E}-06$

$\begin{array}{llll}0.425 & 2.08 \mathrm{E}-06 & 2.07 \mathrm{E}-06 & 2.08 \mathrm{E}-06\end{array}$

$0.450 \quad 2.15 \mathrm{E}-06 \quad 2.15 \mathrm{E}-06 \quad 2.15 \mathrm{E}-06$

$\begin{array}{llll}0.475 & 2.26 \mathrm{E}-06 & 2.25 \mathrm{E}-06 & 2.25 \mathrm{E}-06\end{array}$

$0.500 \quad 2.36 \mathrm{E}-06 \quad 2.35 \mathrm{E}-06 \quad 2.36 \mathrm{E}-06$

$\begin{array}{llll}0.525 & 2.46 \mathrm{E}-06 & 2.44 \mathrm{E}-06 & 2.44 \mathrm{E}-06\end{array}$

$0.550 \quad 2.56 \mathrm{E}-06 \quad 2.55 \mathrm{E}-06 \quad 2.56 \mathrm{E}-06$

$\begin{array}{llll}0.575 & 2.66 \mathrm{E}-06 & 2.65 \mathrm{E}-06 & 2.65 \mathrm{E}-06\end{array}$

$\begin{array}{llll}0.600 & 2.75 \mathrm{E}-06 & 2.75 \mathrm{E}-06 & 2.75 \mathrm{E}-06\end{array}$

$\begin{array}{llll}0.625 & 2.86 \mathrm{E}-06 & 2.86 \mathrm{E}-06 & 2.86 \mathrm{E}-06\end{array}$

$\begin{array}{llll}0.650 & 2.97 \mathrm{E}-06 & 2.97 \mathrm{E}-06 & 2.97 \mathrm{E}-06\end{array}$

$0.675 \quad 3.10 \mathrm{E}-06 \quad 3.09 \mathrm{E}-06 \quad 3.09 \mathrm{E}-06$

$\begin{array}{lllll}0.700 & 3.24 \mathrm{E}-06 & 3.23 \mathrm{E}-06 & 3.23 \mathrm{E}-06\end{array}$

$\begin{array}{llll}0.725 & 3.37 \mathrm{E}-06 & 3.37 \mathrm{E}-06 & 3.37 \mathrm{E}-06\end{array}$

$\begin{array}{llll}0.750 & 3.56 \mathrm{E}-06 & 3.56 \mathrm{E}-06 & 3.56 \mathrm{E}-06\end{array}$

$\begin{array}{llll}0.775 & 3.74 \mathrm{E}-06 & 3.73 \mathrm{E}-06 & 3.74 \mathrm{E}-06\end{array}$

$0.800 \quad 3.92 \mathrm{E}-06 \quad 3.92 \mathrm{E}-06 \quad 3.92 \mathrm{E}-06$

$0.825 \quad 4.09 \mathrm{E}-06 \quad 4.09 \mathrm{E}-06 \quad 4.09 \mathrm{E}-06$

$0.850 \quad 4.32 \mathrm{E}-06 \quad 4.32 \mathrm{E}-06 \quad 4.32 \mathrm{E}-06$

$0.875 \quad 4.63 \mathrm{E}-06 \quad 4.62 \mathrm{E}-06 \quad 4.63 \mathrm{E}-06$

$0.900 \quad 4.88 \mathrm{E}-06 \quad 4.88 \mathrm{E}-06 \quad 4.88 \mathrm{E}-06$

$0.925 \quad 5.28 \mathrm{E}-06 \quad 5.27 \mathrm{E}-06 \quad 5.28 \mathrm{E}-06$

$0.950 \quad 5.74 \mathrm{E}-06 \quad 5.74 \mathrm{E}-06 \quad 5.74 \mathrm{E}-06$

$\begin{array}{lllll}0.975 & 6.49 \mathrm{E}-06 & 6.49 \mathrm{E}-06 & 6.49 \mathrm{E}-06\end{array}$

$0.990 \quad 8.10 \mathrm{E}-06 \quad 8.10 \mathrm{E}-06 \quad 8.10 \mathrm{E}-06$ 
RESRAD-OFFSITE, Version 2.5

Probabilistic Dose and Risk Report

Title : RESRAD-OFFSITE Drinking Water, Plant, Milk, and Meat Pathways for Offsite Reside

File : PBA-1_TC99-DOE-5.ROF

Statistics and Cumulative distribution function of Peak Risk from Soil Ingestion(Wrelease)

$\begin{array}{ccccc}\text { Repetition }= & 1 & 2 & 3 \\ \text { Mean } & 0.00 \mathrm{E}+00 & 0.00 \mathrm{E}+00 & 0.00 \mathrm{E}+00 \\ \text { Std. Dev. } & 0.00 \mathrm{E}+00 & 0.00 \mathrm{E}+00 & 0.00 \mathrm{E}+00 \\ \text { Minimum } & 0.00 \mathrm{E}+00 & 0.00 \mathrm{E}+00 & 0.00 \mathrm{E}+00 \\ \text { Maximum } & 0.00 \mathrm{E}+00 & 0.00 \mathrm{E}+00 & 0.00 \mathrm{E}+00\end{array}$

Percentile

$\begin{array}{llll}0.010 & 0.00 \mathrm{E}+00 \quad 0.00 \mathrm{E}+00 & 0.00 \mathrm{E}+00\end{array}$

$\begin{array}{llll}0.025 & 0.00 \mathrm{E}+00 \quad 0.00 \mathrm{E}+00 & 0.00 \mathrm{E}+00\end{array}$

$\begin{array}{llll}0.050 & 0.00 \mathrm{E}+00 & 0.00 \mathrm{E}+00 & 0.00 \mathrm{E}+00\end{array}$

$\begin{array}{llll}0.075 & 0.00 \mathrm{E}+00 & 0.00 \mathrm{E}+00 & 0.00 \mathrm{E}+00\end{array}$

$\begin{array}{llll}0.100 & 0.00 \mathrm{E}+00 & 0.00 \mathrm{E}+00 & 0.00 \mathrm{E}+00\end{array}$

$\begin{array}{llll}0.125 & 0.00 \mathrm{E}+00 & 0.00 \mathrm{E}+00 & 0.00 \mathrm{E}+00\end{array}$

$\begin{array}{llll}0.150 & 0.00 \mathrm{E}+00 & 0.00 \mathrm{E}+00 & 0.00 \mathrm{E}+00\end{array}$

$\begin{array}{lllll}0.175 & 0.00 \mathrm{E}+00 & 0.00 \mathrm{E}+00 & 0.00 \mathrm{E}+00\end{array}$

$\begin{array}{lllll}0.200 & 0.00 \mathrm{E}+00 & 0.00 \mathrm{E}+00 & 0.00 \mathrm{E}+00\end{array}$

$\begin{array}{lllll}0.225 & 0.00 \mathrm{E}+00 & 0.00 \mathrm{E}+00 & 0.00 \mathrm{E}+00\end{array}$

$\begin{array}{lllll}0.250 & 0.00 \mathrm{E}+00 & 0.00 \mathrm{E}+00 & 0.00 \mathrm{E}+00\end{array}$

$\begin{array}{lllll}0.275 & 0.00 \mathrm{E}+00 & 0.00 \mathrm{E}+00 & 0.00 \mathrm{E}+00\end{array}$

$\begin{array}{lllll}0.300 & 0.00 \mathrm{E}+00 & 0.00 \mathrm{E}+00 & 0.00 \mathrm{E}+00\end{array}$

$\begin{array}{lllll}0.325 & 0.00 \mathrm{E}+00 & 0.00 \mathrm{E}+00 & 0.00 \mathrm{E}+00\end{array}$

$\begin{array}{lllll}0.350 & 0.00 \mathrm{E}+00 & 0.00 \mathrm{E}+00 & 0.00 \mathrm{E}+00\end{array}$

$\begin{array}{lllll}0.375 & 0.00 \mathrm{E}+00 & 0.00 \mathrm{E}+00 & 0.00 \mathrm{E}+00\end{array}$

$\begin{array}{lllll}0.400 & 0.00 \mathrm{E}+00 & 0.00 \mathrm{E}+00 & 0.00 \mathrm{E}+00\end{array}$

$\begin{array}{lllll}0.425 & 0.00 \mathrm{E}+00 & 0.00 \mathrm{E}+00 & 0.00 \mathrm{E}+00\end{array}$

$\begin{array}{lllll}0.450 & 0.00 \mathrm{E}+00 & 0.00 \mathrm{E}+00 & 0.00 \mathrm{E}+00\end{array}$

$\begin{array}{lllll}0.475 & 0.00 \mathrm{E}+00 & 0.00 \mathrm{E}+00 & 0.00 \mathrm{E}+00\end{array}$

$\begin{array}{lllll}0.500 & 0.00 \mathrm{E}+00 & 0.00 \mathrm{E}+00 & 0.00 \mathrm{E}+00\end{array}$

$\begin{array}{lllll}0.525 & 0.00 \mathrm{E}+00 & 0.00 \mathrm{E}+00 & 0.00 \mathrm{E}+00\end{array}$

$\begin{array}{lllll}0.550 & 0.00 \mathrm{E}+00 & 0.00 \mathrm{E}+00 & 0.00 \mathrm{E}+00\end{array}$

$\begin{array}{lllll}0.575 & 0.00 \mathrm{E}+00 & 0.00 \mathrm{E}+00 & 0.00 \mathrm{E}+00\end{array}$

$\begin{array}{lllll}0.600 & 0.00 \mathrm{E}+00 & 0.00 \mathrm{E}+00 & 0.00 \mathrm{E}+00\end{array}$

$\begin{array}{lllll}0.625 & 0.00 \mathrm{E}+00 & 0.00 \mathrm{E}+00 & 0.00 \mathrm{E}+00\end{array}$

$\begin{array}{lllll}0.650 & 0.00 \mathrm{E}+00 & 0.00 \mathrm{E}+00 & 0.00 \mathrm{E}+00\end{array}$

$\begin{array}{lllll}0.675 & 0.00 \mathrm{E}+00 & 0.00 \mathrm{E}+00 & 0.00 \mathrm{E}+00\end{array}$

$\begin{array}{llll}0.700 & 0.00 \mathrm{E}+00 & 0.00 \mathrm{E}+00 & 0.00 \mathrm{E}+00\end{array}$

$\begin{array}{lllll}0.725 & 0.00 \mathrm{E}+00 & 0.00 \mathrm{E}+00 & 0.00 \mathrm{E}+00\end{array}$

$\begin{array}{lllll}0.750 & 0.00 \mathrm{E}+00 & 0.00 \mathrm{E}+00 & 0.00 \mathrm{E}+00\end{array}$

$\begin{array}{lllll}0.775 & 0.00 \mathrm{E}+00 & 0.00 \mathrm{E}+00 & 0.00 \mathrm{E}+00\end{array}$

$\begin{array}{lllll}0.800 & 0.00 \mathrm{E}+00 & 0.00 \mathrm{E}+00 & 0.00 \mathrm{E}+00\end{array}$

$\begin{array}{lllll}0.825 & 0.00 \mathrm{E}+00 & 0.00 \mathrm{E}+00 & 0.00 \mathrm{E}+00\end{array}$

$\begin{array}{lllll}0.850 & 0.00 \mathrm{E}+00 & 0.00 \mathrm{E}+00 & 0.00 \mathrm{E}+00\end{array}$

$\begin{array}{lllll}0.875 & 0.00 \mathrm{E}+00 & 0.00 \mathrm{E}+00 & 0.00 \mathrm{E}+00\end{array}$

$\begin{array}{lllll}0.900 & 0.00 \mathrm{E}+00 & 0.00 \mathrm{E}+00 & 0.00 \mathrm{E}+00\end{array}$

$\begin{array}{lllll}0.925 & 0.00 \mathrm{E}+00 & 0.00 \mathrm{E}+00 & 0.00 \mathrm{E}+00\end{array}$

$\begin{array}{llll}0.950 & 0.00 \mathrm{E}+00 & 0.00 \mathrm{E}+00 & 0.00 \mathrm{E}+00\end{array}$

$\begin{array}{lllll}0.975 & 0.00 \mathrm{E}+00 & 0.00 \mathrm{E}+00 & 0.00 \mathrm{E}+00\end{array}$

$\begin{array}{lllll}0.990 & 0.00 \mathrm{E}+00 & 0.00 \mathrm{E}+00 & 0.00 \mathrm{E}+00\end{array}$ 
RESRAD-OFFSITE, Version 2.5

Probabilistic Dose and Risk Report

Title : RESRAD-OFFSITE Drinking Water, Plant, Milk, and Meat Pathways for Offsite Reside

File : PBA-1_TC99-DOE-5.ROF

Statistics and Cumulative distribution function of Peak Risk from Water Ingestion

$\begin{array}{ccccc}\text { Repetition }= & 1 & 2 & 3 \\ \text { Mean } & 1.91 \mathrm{E}-05 & 1.91 \mathrm{E}-05 & 1.91 \mathrm{E}-05 \\ \text { Std. Dev. } & 1.14 \mathrm{E}-05 & 1.14 \mathrm{E}-05 & 1.14 \mathrm{E}-05 \\ \text { Minimum } & 2.30 \mathrm{E}-06 & 2.30 \mathrm{E}-06 & 2.30 \mathrm{E}-06 \\ \text { Maximum } & 1.08 \mathrm{E}-04 & 1.08 \mathrm{E}-04 & 1.08 \mathrm{E}-04\end{array}$

Percentile

$0.010 \quad 3.31 \mathrm{E}-06 \quad 3.31 \mathrm{E}-06 \quad 3.31 \mathrm{E}-06$

$0.025 \quad 4.30 \mathrm{E}-06 \quad 4.30 \mathrm{E}-06 \quad 4.30 \mathrm{E}-06$

$0.050 \quad 5.28 \mathrm{E}-06 \quad 5.28 \mathrm{E}-06 \quad 5.28 \mathrm{E}-06$

$0.075 \quad 6.24 \mathrm{E}-06 \quad 6.24 \mathrm{E}-06 \quad 6.24 \mathrm{E}-06$

$0.100 \quad 6.92 \mathrm{E}-06 \quad 6.92 \mathrm{E}-06 \quad 6.92 \mathrm{E}-06$

$\begin{array}{lllll}0.125 & 7.62 \mathrm{E}-06 \quad 7.62 \mathrm{E}-06 & 7.62 \mathrm{E}-06\end{array}$

$0.150 \quad 8.23 \mathrm{E}-06 \quad 8.23 \mathrm{E}-06 \quad 8.23 \mathrm{E}-06$

$0.175 \quad 8.93 \mathrm{E}-06 \quad 8.93 \mathrm{E}-06 \quad 8.93 \mathrm{E}-06$

$0.200 \quad 9.48 \mathrm{E}-06 \quad 9.48 \mathrm{E}-06 \quad 9.48 \mathrm{E}-06$

$0.225 \quad 1.01 \mathrm{E}-05 \quad 1.01 \mathrm{E}-05 \quad 1.01 \mathrm{E}-05$

$0.250 \quad 1.08 \mathrm{E}-05 \quad 1.08 \mathrm{E}-05 \quad 1.08 \mathrm{E}-05$

$0.275 \quad 1.14 \mathrm{E}-05 \quad 1.14 \mathrm{E}-05 \quad 1.14 \mathrm{E}-05$

$0.300 \quad 1.20 \mathrm{E}-05 \quad 1.20 \mathrm{E}-05 \quad 1.20 \mathrm{E}-05$

$0.325 \quad 1.25 \mathrm{E}-05 \quad 1.25 \mathrm{E}-05 \quad 1.25 \mathrm{E}-05$

$0.350 \quad 1.30 \mathrm{E}-05 \quad 1.30 \mathrm{E}-05 \quad 1.30 \mathrm{E}-05$

$0.375 \quad 1.35 \mathrm{E}-05 \quad 1.35 \mathrm{E}-05 \quad 1.35 \mathrm{E}-05$

$0.400 \quad 1.41 \mathrm{E}-05 \quad 1.41 \mathrm{E}-05 \quad 1.41 \mathrm{E}-05$

$0.425 \quad 1.47 \mathrm{E}-05 \quad 1.47 \mathrm{E}-05 \quad 1.47 \mathrm{E}-05$

$0.450 \quad 1.52 \mathrm{E}-05 \quad 1.52 \mathrm{E}-05 \quad 1.52 \mathrm{E}-05$

$0.475 \quad 1.60 \mathrm{E}-05 \quad 1.59 \mathrm{E}-05 \quad 1.59 \mathrm{E}-05$

$0.500 \quad 1.67 \mathrm{E}-05 \quad 1.66 \mathrm{E}-05 \quad 1.67 \mathrm{E}-05$

$0.525 \quad 1.74 \mathrm{E}-05 \quad 1.73 \mathrm{E}-05 \quad 1.73 \mathrm{E}-05$

$0.550 \quad 1.81 \mathrm{E}-05 \quad 1.81 \mathrm{E}-05 \quad 1.81 \mathrm{E}-05$

$0.575 \quad 1.88 \mathrm{E}-05 \quad 1.87 \mathrm{E}-05 \quad 1.87 \mathrm{E}-05$

$0.600 \quad 1.95 \mathrm{E}-05 \quad 1.95 \mathrm{E}-05 \quad 1.95 \mathrm{E}-05$

$0.625 \quad 2.02 \mathrm{E}-05 \quad 2.02 \mathrm{E}-05 \quad 2.02 \mathrm{E}-05$

$0.650 \quad 2.10 \mathrm{E}-05 \quad 2.10 \mathrm{E}-05 \quad 2.10 \mathrm{E}-05$

$0.675 \quad 2.19 \mathrm{E}-05 \quad 2.19 \mathrm{E}-05 \quad 2.19 \mathrm{E}-05$

$\begin{array}{llll}0.700 & 2.29 \mathrm{E}-05 & 2.29 \mathrm{E}-05 & 2.29 \mathrm{E}-05\end{array}$

$\begin{array}{llll}0.725 & 2.38 \mathrm{E}-05 & 2.38 \mathrm{E}-05 & 2.38 \mathrm{E}-05\end{array}$

$\begin{array}{llll}0.750 & 2.52 \mathrm{E}-05 & 2.52 \mathrm{E}-05 & 2.52 \mathrm{E}-05\end{array}$

$\begin{array}{llll}0.775 & 2.64 \mathrm{E}-05 & 2.64 \mathrm{E}-05 & 2.64 \mathrm{E}-05\end{array}$

$\begin{array}{llll}0.800 \quad 2.78 \mathrm{E}-05 & 2.78 \mathrm{E}-05 \quad 2.78 \mathrm{E}-05\end{array}$

$\begin{array}{llll}0.825 & 2.89 \mathrm{E}-05 & 2.89 \mathrm{E}-05 & 2.89 \mathrm{E}-05\end{array}$

$0.850 \quad 3.06 \mathrm{E}-05 \quad 3.06 \mathrm{E}-05 \quad 3.06 \mathrm{E}-05$

$0.875 \quad 3.28 \mathrm{E}-05 \quad 3.27 \mathrm{E}-05 \quad 3.28 \mathrm{E}-05$

$0.900 \quad 3.45 \mathrm{E}-05 \quad 3.45 \mathrm{E}-05 \quad 3.45 \mathrm{E}-05$

$0.925 \quad 3.74 \mathrm{E}-05 \quad 3.73 \mathrm{E}-05 \quad 3.74 \mathrm{E}-05$

$0.950 \quad 4.06 \mathrm{E}-05 \quad 4.06 \mathrm{E}-05 \quad 4.06 \mathrm{E}-05$

$0.975 \quad 4.59 \mathrm{E}-05 \quad 4.59 \mathrm{E}-05 \quad 4.59 \mathrm{E}-05$

$0.990 \quad 5.73 E-05 \quad 5.73 E-05 \quad 5.73 E-05$ 
RESRAD-OFFSITE, Version 2.5

Probabilistic Dose and Risk Report

Title : RESRAD-OFFSITE Drinking Water, Plant, Milk, and Meat Pathways for Offsite Reside

File : PBA-1_TC99-DOE-5.ROF

Statistics and Cumulative distribution function of Peak Risk from External Ground(Cz\&Air)

$\begin{array}{ccccc}\text { Repetition }= & 1 & 2 & 3 \\ \text { Mean } & 0.00 \mathrm{E}+00 & 0.00 \mathrm{E}+00 & 0.00 \mathrm{E}+00 \\ \text { Std. Dev. } & 0.00 \mathrm{E}+00 & 0.00 \mathrm{E}+00 & 0.00 \mathrm{E}+00 \\ \text { Minimum } & 0.00 \mathrm{E}+00 & 0.00 \mathrm{E}+00 & 0.00 \mathrm{E}+00 \\ \text { Maximum } & 0.00 \mathrm{E}+00 & 0.00 \mathrm{E}+00 & 0.00 \mathrm{E}+00\end{array}$

Percentile

$\begin{array}{llll}0.010 & 0.00 \mathrm{E}+00 \quad 0.00 \mathrm{E}+00 & 0.00 \mathrm{E}+00\end{array}$

$\begin{array}{llll}0.025 & 0.00 \mathrm{E}+00 & 0.00 \mathrm{E}+00 & 0.00 \mathrm{E}+00\end{array}$

$\begin{array}{llll}0.050 & 0.00 \mathrm{E}+00 & 0.00 \mathrm{E}+00 & 0.00 \mathrm{E}+00\end{array}$

$\begin{array}{llll}0.075 & 0.00 \mathrm{E}+00 & 0.00 \mathrm{E}+00 & 0.00 \mathrm{E}+00\end{array}$

$\begin{array}{llll}0.100 & 0.00 \mathrm{E}+00 & 0.00 \mathrm{E}+00 & 0.00 \mathrm{E}+00\end{array}$

$\begin{array}{llll}0.125 & 0.00 \mathrm{E}+00 & 0.00 \mathrm{E}+00 & 0.00 \mathrm{E}+00\end{array}$

$\begin{array}{llll}0.150 & 0.00 \mathrm{E}+00 & 0.00 \mathrm{E}+00 & 0.00 \mathrm{E}+00\end{array}$

$\begin{array}{lllll}0.175 & 0.00 \mathrm{E}+00 & 0.00 \mathrm{E}+00 & 0.00 \mathrm{E}+00\end{array}$

$\begin{array}{lllll}0.200 & 0.00 \mathrm{E}+00 & 0.00 \mathrm{E}+00 & 0.00 \mathrm{E}+00\end{array}$

$\begin{array}{lllll}0.225 & 0.00 \mathrm{E}+00 & 0.00 \mathrm{E}+00 & 0.00 \mathrm{E}+00\end{array}$

$\begin{array}{lllll}0.250 & 0.00 \mathrm{E}+00 & 0.00 \mathrm{E}+00 & 0.00 \mathrm{E}+00\end{array}$

$\begin{array}{lllll}0.275 & 0.00 \mathrm{E}+00 & 0.00 \mathrm{E}+00 & 0.00 \mathrm{E}+00\end{array}$

$\begin{array}{lllll}0.300 & 0.00 \mathrm{E}+00 & 0.00 \mathrm{E}+00 & 0.00 \mathrm{E}+00\end{array}$

$\begin{array}{lllll}0.325 & 0.00 \mathrm{E}+00 & 0.00 \mathrm{E}+00 & 0.00 \mathrm{E}+00\end{array}$

$\begin{array}{lllll}0.350 & 0.00 \mathrm{E}+00 & 0.00 \mathrm{E}+00 & 0.00 \mathrm{E}+00\end{array}$

$\begin{array}{lllll}0.375 & 0.00 \mathrm{E}+00 & 0.00 \mathrm{E}+00 & 0.00 \mathrm{E}+00\end{array}$

$\begin{array}{lllll}0.400 & 0.00 \mathrm{E}+00 & 0.00 \mathrm{E}+00 & 0.00 \mathrm{E}+00\end{array}$

$\begin{array}{lllll}0.425 & 0.00 \mathrm{E}+00 & 0.00 \mathrm{E}+00 & 0.00 \mathrm{E}+00\end{array}$

$\begin{array}{lllll}0.450 & 0.00 \mathrm{E}+00 & 0.00 \mathrm{E}+00 & 0.00 \mathrm{E}+00\end{array}$

$\begin{array}{lllll}0.475 & 0.00 \mathrm{E}+00 & 0.00 \mathrm{E}+00 & 0.00 \mathrm{E}+00\end{array}$

$\begin{array}{lllll}0.500 & 0.00 \mathrm{E}+00 & 0.00 \mathrm{E}+00 & 0.00 \mathrm{E}+00\end{array}$

$\begin{array}{lllll}0.525 & 0.00 \mathrm{E}+00 & 0.00 \mathrm{E}+00 & 0.00 \mathrm{E}+00\end{array}$

$\begin{array}{lllll}0.550 & 0.00 \mathrm{E}+00 & 0.00 \mathrm{E}+00 & 0.00 \mathrm{E}+00\end{array}$

$\begin{array}{lllll}0.575 & 0.00 \mathrm{E}+00 & 0.00 \mathrm{E}+00 & 0.00 \mathrm{E}+00\end{array}$

$\begin{array}{lllll}0.600 & 0.00 \mathrm{E}+00 & 0.00 \mathrm{E}+00 & 0.00 \mathrm{E}+00\end{array}$

$\begin{array}{lllll}0.625 & 0.00 \mathrm{E}+00 & 0.00 \mathrm{E}+00 & 0.00 \mathrm{E}+00\end{array}$

$\begin{array}{lllll}0.650 & 0.00 \mathrm{E}+00 & 0.00 \mathrm{E}+00 & 0.00 \mathrm{E}+00\end{array}$

$\begin{array}{lllll}0.675 & 0.00 \mathrm{E}+00 & 0.00 \mathrm{E}+00 & 0.00 \mathrm{E}+00\end{array}$

$\begin{array}{lllll}0.700 & 0.00 \mathrm{E}+00 & 0.00 \mathrm{E}+00 & 0.00 \mathrm{E}+00\end{array}$

$\begin{array}{lllll}0.725 & 0.00 \mathrm{E}+00 & 0.00 \mathrm{E}+00 & 0.00 \mathrm{E}+00\end{array}$

$\begin{array}{lllll}0.750 & 0.00 \mathrm{E}+00 & 0.00 \mathrm{E}+00 & 0.00 \mathrm{E}+00\end{array}$

$\begin{array}{llll}0.775 & 0.00 \mathrm{E}+00 & 0.00 \mathrm{E}+00 & 0.00 \mathrm{E}+00\end{array}$

$\begin{array}{lllll}0.800 & 0.00 \mathrm{E}+00 & 0.00 \mathrm{E}+00 & 0.00 \mathrm{E}+00\end{array}$

$\begin{array}{lllll}0.825 & 0.00 \mathrm{E}+00 & 0.00 \mathrm{E}+00 & 0.00 \mathrm{E}+00\end{array}$

$\begin{array}{lllll}0.850 & 0.00 \mathrm{E}+00 & 0.00 \mathrm{E}+00 & 0.00 \mathrm{E}+00\end{array}$

$\begin{array}{lllll}0.875 & 0.00 \mathrm{E}+00 & 0.00 \mathrm{E}+00 & 0.00 \mathrm{E}+00\end{array}$

$\begin{array}{lllll}0.900 & 0.00 \mathrm{E}+00 & 0.00 \mathrm{E}+00 & 0.00 \mathrm{E}+00\end{array}$

$\begin{array}{lllll}0.925 & 0.00 \mathrm{E}+00 & 0.00 \mathrm{E}+00 & 0.00 \mathrm{E}+00\end{array}$

$\begin{array}{llll}0.950 & 0.00 \mathrm{E}+00 & 0.00 \mathrm{E}+00 & 0.00 \mathrm{E}+00\end{array}$

$\begin{array}{lllll}0.975 & 0.00 \mathrm{E}+00 & 0.00 \mathrm{E}+00 & 0.00 \mathrm{E}+00\end{array}$

$\begin{array}{lllll}0.990 & 0.00 \mathrm{E}+00 & 0.00 \mathrm{E}+00 & 0.00 \mathrm{E}+00\end{array}$ 
RESRAD-OFFSITE, Version 2.5

Probabilistic Dose and Risk Report

Title : RESRAD-OFFSITE Drinking Water, Plant, Milk, and Meat Pathways for Offsite Reside

File : PBA-1_TC99-DOE-5.ROF

Statistics and Cumulative distribution function of Peak Risk from Inhalation ExcludingRn

\begin{tabular}{ccccc} 
Repetition $=$ & 1 & 2 & 3 \\
\cline { 5 - 5 } Mean & $0.00 \mathrm{E}+00$ & $0.00 \mathrm{E}+00$ & $0.00 \mathrm{E}+00$ \\
Std. Dev. & $0.00 \mathrm{E}+00$ & $0.00 \mathrm{E}+00$ & $0.00 \mathrm{E}+00$ \\
Minimum & $0.00 \mathrm{E}+00$ & $0.00 \mathrm{E}+00$ & $0.00 \mathrm{E}+00$ \\
Maximum & $0.00 \mathrm{E}+00$ & $0.00 \mathrm{E}+00$ & $0.00 \mathrm{E}+00$
\end{tabular}

Percentile

$\begin{array}{llll}0.010 & 0.00 \mathrm{E}+00 \quad 0.00 \mathrm{E}+00 & 0.00 \mathrm{E}+00\end{array}$

$\begin{array}{llll}0.025 & 0.00 \mathrm{E}+00 \quad 0.00 \mathrm{E}+00 & 0.00 \mathrm{E}+00\end{array}$

$\begin{array}{llll}0.050 & 0.00 \mathrm{E}+00 & 0.00 \mathrm{E}+00 & 0.00 \mathrm{E}+00\end{array}$

$\begin{array}{llll}0.075 & 0.00 \mathrm{E}+00 & 0.00 \mathrm{E}+00 & 0.00 \mathrm{E}+00\end{array}$

$\begin{array}{llll}0.100 & 0.00 \mathrm{E}+00 & 0.00 \mathrm{E}+00 & 0.00 \mathrm{E}+00\end{array}$

$\begin{array}{llll}0.125 & 0.00 \mathrm{E}+00 & 0.00 \mathrm{E}+00 & 0.00 \mathrm{E}+00\end{array}$

$\begin{array}{llll}0.150 & 0.00 \mathrm{E}+00 & 0.00 \mathrm{E}+00 & 0.00 \mathrm{E}+00\end{array}$

$\begin{array}{lllll}0.175 & 0.00 \mathrm{E}+00 & 0.00 \mathrm{E}+00 & 0.00 \mathrm{E}+00\end{array}$

$\begin{array}{lllll}0.200 & 0.00 \mathrm{E}+00 & 0.00 \mathrm{E}+00 & 0.00 \mathrm{E}+00\end{array}$

$\begin{array}{lllll}0.225 & 0.00 \mathrm{E}+00 & 0.00 \mathrm{E}+00 & 0.00 \mathrm{E}+00\end{array}$

$\begin{array}{lllll}0.250 & 0.00 \mathrm{E}+00 & 0.00 \mathrm{E}+00 & 0.00 \mathrm{E}+00\end{array}$

$\begin{array}{lllll}0.275 & 0.00 \mathrm{E}+00 & 0.00 \mathrm{E}+00 & 0.00 \mathrm{E}+00\end{array}$

$\begin{array}{lllll}0.300 & 0.00 \mathrm{E}+00 & 0.00 \mathrm{E}+00 & 0.00 \mathrm{E}+00\end{array}$

$\begin{array}{lllll}0.325 & 0.00 \mathrm{E}+00 & 0.00 \mathrm{E}+00 & 0.00 \mathrm{E}+00\end{array}$

$\begin{array}{lllll}0.350 & 0.00 \mathrm{E}+00 & 0.00 \mathrm{E}+00 & 0.00 \mathrm{E}+00\end{array}$

$\begin{array}{lllll}0.375 & 0.00 \mathrm{E}+00 & 0.00 \mathrm{E}+00 & 0.00 \mathrm{E}+00\end{array}$

$\begin{array}{lllll}0.400 & 0.00 \mathrm{E}+00 & 0.00 \mathrm{E}+00 & 0.00 \mathrm{E}+00\end{array}$

$\begin{array}{lllll}0.425 & 0.00 \mathrm{E}+00 & 0.00 \mathrm{E}+00 & 0.00 \mathrm{E}+00\end{array}$

$\begin{array}{lllll}0.450 & 0.00 \mathrm{E}+00 & 0.00 \mathrm{E}+00 & 0.00 \mathrm{E}+00\end{array}$

$\begin{array}{lllll}0.475 & 0.00 \mathrm{E}+00 & 0.00 \mathrm{E}+00 & 0.00 \mathrm{E}+00\end{array}$

$\begin{array}{lllll}0.500 & 0.00 \mathrm{E}+00 & 0.00 \mathrm{E}+00 & 0.00 \mathrm{E}+00\end{array}$

$\begin{array}{lllll}0.525 & 0.00 \mathrm{E}+00 & 0.00 \mathrm{E}+00 & 0.00 \mathrm{E}+00\end{array}$

$\begin{array}{lllll}0.550 & 0.00 \mathrm{E}+00 & 0.00 \mathrm{E}+00 & 0.00 \mathrm{E}+00\end{array}$

$\begin{array}{lllll}0.575 & 0.00 \mathrm{E}+00 & 0.00 \mathrm{E}+00 & 0.00 \mathrm{E}+00\end{array}$

$\begin{array}{lllll}0.600 & 0.00 \mathrm{E}+00 & 0.00 \mathrm{E}+00 & 0.00 \mathrm{E}+00\end{array}$

$\begin{array}{lllll}0.625 & 0.00 \mathrm{E}+00 & 0.00 \mathrm{E}+00 & 0.00 \mathrm{E}+00\end{array}$

$\begin{array}{lllll}0.650 & 0.00 \mathrm{E}+00 & 0.00 \mathrm{E}+00 & 0.00 \mathrm{E}+00\end{array}$

$\begin{array}{lllll}0.675 & 0.00 \mathrm{E}+00 & 0.00 \mathrm{E}+00 & 0.00 \mathrm{E}+00\end{array}$

$\begin{array}{llll}0.700 & 0.00 \mathrm{E}+00 & 0.00 \mathrm{E}+00 & 0.00 \mathrm{E}+00\end{array}$

$\begin{array}{lllll}0.725 & 0.00 \mathrm{E}+00 & 0.00 \mathrm{E}+00 & 0.00 \mathrm{E}+00\end{array}$

$\begin{array}{lllll}0.750 & 0.00 \mathrm{E}+00 & 0.00 \mathrm{E}+00 & 0.00 \mathrm{E}+00\end{array}$

$\begin{array}{lllll}0.775 & 0.00 \mathrm{E}+00 & 0.00 \mathrm{E}+00 & 0.00 \mathrm{E}+00\end{array}$

$\begin{array}{lllll}0.800 & 0.00 \mathrm{E}+00 & 0.00 \mathrm{E}+00 & 0.00 \mathrm{E}+00\end{array}$

$\begin{array}{lllll}0.825 & 0.00 \mathrm{E}+00 & 0.00 \mathrm{E}+00 & 0.00 \mathrm{E}+00\end{array}$

$\begin{array}{lllll}0.850 & 0.00 \mathrm{E}+00 & 0.00 \mathrm{E}+00 & 0.00 \mathrm{E}+00\end{array}$

$\begin{array}{lllll}0.875 & 0.00 \mathrm{E}+00 & 0.00 \mathrm{E}+00 & 0.00 \mathrm{E}+00\end{array}$

$\begin{array}{lllll}0.900 & 0.00 \mathrm{E}+00 & 0.00 \mathrm{E}+00 & 0.00 \mathrm{E}+00\end{array}$

$\begin{array}{lllll}0.925 & 0.00 \mathrm{E}+00 & 0.00 \mathrm{E}+00 & 0.00 \mathrm{E}+00\end{array}$

$\begin{array}{llll}0.950 & 0.00 \mathrm{E}+00 & 0.00 \mathrm{E}+00 & 0.00 \mathrm{E}+00\end{array}$

$\begin{array}{lllll}0.975 & 0.00 \mathrm{E}+00 & 0.00 \mathrm{E}+00 & 0.00 \mathrm{E}+00\end{array}$

$\begin{array}{lllll}0.990 & 0.00 \mathrm{E}+00 & 0.00 \mathrm{E}+00 & 0.00 \mathrm{E}+00\end{array}$ 
RESRAD-OFFSITE, Version 2.5

Probabilistic Dose and Risk Report

Title : RESRAD-OFFSITE Drinking Water, Plant, Milk, and Meat Pathways for Offsite Reside

File : PBA-1_TC99-DOE-5.ROF

Statistics and Cumulative distribution function of Peak Risk from Radon (CZandAir)

$\begin{array}{ccccc}\text { Repetition }= & 1 & 2 & 3 \\ \text { Mean } & 0.00 \mathrm{E}+00 & 0.00 \mathrm{E}+00 & 0.00 \mathrm{E}+00 \\ \text { Std. Dev. } & 0.00 \mathrm{E}+00 & 0.00 \mathrm{E}+00 & 0.00 \mathrm{E}+00 \\ \text { Minimum } & 0.00 \mathrm{E}+00 & 0.00 \mathrm{E}+00 & 0.00 \mathrm{E}+00 \\ \text { Maximum } & 0.00 \mathrm{E}+00 & 0.00 \mathrm{E}+00 & 0.00 \mathrm{E}+00\end{array}$

Percentile

$\begin{array}{llll}0.010 & 0.00 \mathrm{E}+00 \quad 0.00 \mathrm{E}+00 & 0.00 \mathrm{E}+00\end{array}$

$\begin{array}{llll}0.025 & 0.00 \mathrm{E}+00 & 0.00 \mathrm{E}+00 & 0.00 \mathrm{E}+00\end{array}$

$\begin{array}{llll}0.050 & 0.00 \mathrm{E}+00 & 0.00 \mathrm{E}+00 & 0.00 \mathrm{E}+00\end{array}$

$\begin{array}{llll}0.075 & 0.00 \mathrm{E}+00 & 0.00 \mathrm{E}+00 & 0.00 \mathrm{E}+00\end{array}$

$\begin{array}{llll}0.100 & 0.00 \mathrm{E}+00 & 0.00 \mathrm{E}+00 & 0.00 \mathrm{E}+00\end{array}$

$\begin{array}{llll}0.125 & 0.00 \mathrm{E}+00 & 0.00 \mathrm{E}+00 & 0.00 \mathrm{E}+00\end{array}$

$\begin{array}{llll}0.150 & 0.00 \mathrm{E}+00 & 0.00 \mathrm{E}+00 & 0.00 \mathrm{E}+00\end{array}$

$\begin{array}{lllll}0.175 & 0.00 \mathrm{E}+00 & 0.00 \mathrm{E}+00 & 0.00 \mathrm{E}+00\end{array}$

$\begin{array}{lllll}0.200 & 0.00 \mathrm{E}+00 & 0.00 \mathrm{E}+00 & 0.00 \mathrm{E}+00\end{array}$

$\begin{array}{lllll}0.225 & 0.00 \mathrm{E}+00 & 0.00 \mathrm{E}+00 & 0.00 \mathrm{E}+00\end{array}$

$\begin{array}{lllll}0.250 & 0.00 \mathrm{E}+00 & 0.00 \mathrm{E}+00 & 0.00 \mathrm{E}+00\end{array}$

$\begin{array}{lllll}0.275 & 0.00 \mathrm{E}+00 & 0.00 \mathrm{E}+00 & 0.00 \mathrm{E}+00\end{array}$

$\begin{array}{lllll}0.300 & 0.00 \mathrm{E}+00 & 0.00 \mathrm{E}+00 & 0.00 \mathrm{E}+00\end{array}$

$\begin{array}{lllll}0.325 & 0.00 \mathrm{E}+00 & 0.00 \mathrm{E}+00 & 0.00 \mathrm{E}+00\end{array}$

$\begin{array}{lllll}0.350 & 0.00 \mathrm{E}+00 & 0.00 \mathrm{E}+00 & 0.00 \mathrm{E}+00\end{array}$

$\begin{array}{lllll}0.375 & 0.00 \mathrm{E}+00 & 0.00 \mathrm{E}+00 & 0.00 \mathrm{E}+00\end{array}$

$\begin{array}{lllll}0.400 & 0.00 \mathrm{E}+00 & 0.00 \mathrm{E}+00 & 0.00 \mathrm{E}+00\end{array}$

$\begin{array}{lllll}0.425 & 0.00 \mathrm{E}+00 & 0.00 \mathrm{E}+00 & 0.00 \mathrm{E}+00\end{array}$

$\begin{array}{lllll}0.450 & 0.00 \mathrm{E}+00 & 0.00 \mathrm{E}+00 & 0.00 \mathrm{E}+00\end{array}$

$\begin{array}{lllll}0.475 & 0.00 \mathrm{E}+00 & 0.00 \mathrm{E}+00 & 0.00 \mathrm{E}+00\end{array}$

$\begin{array}{lllll}0.500 & 0.00 \mathrm{E}+00 & 0.00 \mathrm{E}+00 & 0.00 \mathrm{E}+00\end{array}$

$\begin{array}{lllll}0.525 & 0.00 \mathrm{E}+00 & 0.00 \mathrm{E}+00 & 0.00 \mathrm{E}+00\end{array}$

$\begin{array}{lllll}0.550 & 0.00 \mathrm{E}+00 & 0.00 \mathrm{E}+00 & 0.00 \mathrm{E}+00\end{array}$

$\begin{array}{lllll}0.575 & 0.00 \mathrm{E}+00 & 0.00 \mathrm{E}+00 & 0.00 \mathrm{E}+00\end{array}$

$\begin{array}{lllll}0.600 & 0.00 \mathrm{E}+00 & 0.00 \mathrm{E}+00 & 0.00 \mathrm{E}+00\end{array}$

$\begin{array}{lllll}0.625 & 0.00 \mathrm{E}+00 & 0.00 \mathrm{E}+00 & 0.00 \mathrm{E}+00\end{array}$

$\begin{array}{lllll}0.650 & 0.00 \mathrm{E}+00 & 0.00 \mathrm{E}+00 & 0.00 \mathrm{E}+00\end{array}$

$\begin{array}{lllll}0.675 & 0.00 \mathrm{E}+00 & 0.00 \mathrm{E}+00 & 0.00 \mathrm{E}+00\end{array}$

$\begin{array}{lllll}0.700 & 0.00 \mathrm{E}+00 & 0.00 \mathrm{E}+00 & 0.00 \mathrm{E}+00\end{array}$

$\begin{array}{lllll}0.725 & 0.00 \mathrm{E}+00 & 0.00 \mathrm{E}+00 & 0.00 \mathrm{E}+00\end{array}$

$\begin{array}{lllll}0.750 & 0.00 \mathrm{E}+00 & 0.00 \mathrm{E}+00 & 0.00 \mathrm{E}+00\end{array}$

$\begin{array}{llll}0.775 & 0.00 \mathrm{E}+00 & 0.00 \mathrm{E}+00 & 0.00 \mathrm{E}+00\end{array}$

$\begin{array}{lllll}0.800 & 0.00 \mathrm{E}+00 & 0.00 \mathrm{E}+00 & 0.00 \mathrm{E}+00\end{array}$

$\begin{array}{lllll}0.825 & 0.00 \mathrm{E}+00 & 0.00 \mathrm{E}+00 & 0.00 \mathrm{E}+00\end{array}$

$\begin{array}{lllll}0.850 & 0.00 \mathrm{E}+00 & 0.00 \mathrm{E}+00 & 0.00 \mathrm{E}+00\end{array}$

$\begin{array}{lllll}0.875 & 0.00 \mathrm{E}+00 & 0.00 \mathrm{E}+00 & 0.00 \mathrm{E}+00\end{array}$

$\begin{array}{lllll}0.900 & 0.00 \mathrm{E}+00 & 0.00 \mathrm{E}+00 & 0.00 \mathrm{E}+00\end{array}$

$\begin{array}{lllll}0.925 & 0.00 \mathrm{E}+00 & 0.00 \mathrm{E}+00 & 0.00 \mathrm{E}+00\end{array}$

$\begin{array}{llll}0.950 & 0.00 \mathrm{E}+00 & 0.00 \mathrm{E}+00 & 0.00 \mathrm{E}+00\end{array}$

$\begin{array}{lllll}0.975 & 0.00 \mathrm{E}+00 & 0.00 \mathrm{E}+00 & 0.00 \mathrm{E}+00\end{array}$

$\begin{array}{lllll}0.990 & 0.00 \mathrm{E}+00 & 0.00 \mathrm{E}+00 & 0.00 \mathrm{E}+00\end{array}$ 
RESRAD-OFFSITE, Version 2.5

Probabilistic Dose and Risk Report

Title : RESRAD-OFFSITE Drinking Water, Plant, Milk, and Meat Pathways for Offsite Reside

File : PBA-1_TC99-DOE-5.ROF

Statistics and Cumulative distribution function of Peak Risk from Plant (CzandAir)

$\begin{array}{ccccc}\text { Repetition }= & 1 & 2 & 3 \\ \text { Mean } & 0.00 \mathrm{E}+00 & 0.00 \mathrm{E}+00 & 0.00 \mathrm{E}+00 \\ \text { Std. Dev. } & 0.00 \mathrm{E}+00 & 0.00 \mathrm{E}+00 & 0.00 \mathrm{E}+00 \\ \text { Minimum } & 0.00 \mathrm{E}+00 & 0.00 \mathrm{E}+00 & 0.00 \mathrm{E}+00 \\ \text { Maximum } & 0.00 \mathrm{E}+00 & 0.00 \mathrm{E}+00 & 0.00 \mathrm{E}+00\end{array}$

Percentile

$\begin{array}{llll}0.010 & 0.00 \mathrm{E}+00 \quad 0.00 \mathrm{E}+00 & 0.00 \mathrm{E}+00\end{array}$

$\begin{array}{llll}0.025 & 0.00 \mathrm{E}+00 & 0.00 \mathrm{E}+00 & 0.00 \mathrm{E}+00\end{array}$

$\begin{array}{llll}0.050 & 0.00 \mathrm{E}+00 & 0.00 \mathrm{E}+00 & 0.00 \mathrm{E}+00\end{array}$

$\begin{array}{lllll}0.075 & 0.00 \mathrm{E}+00 & 0.00 \mathrm{E}+00 & 0.00 \mathrm{E}+00\end{array}$

$\begin{array}{llll}0.100 & 0.00 \mathrm{E}+00 & 0.00 \mathrm{E}+00 & 0.00 \mathrm{E}+00\end{array}$

$\begin{array}{llll}0.125 & 0.00 \mathrm{E}+00 & 0.00 \mathrm{E}+00 & 0.00 \mathrm{E}+00\end{array}$

$\begin{array}{llll}0.150 & 0.00 \mathrm{E}+00 & 0.00 \mathrm{E}+00 & 0.00 \mathrm{E}+00\end{array}$

$\begin{array}{lllll}0.175 & 0.00 \mathrm{E}+00 & 0.00 \mathrm{E}+00 & 0.00 \mathrm{E}+00\end{array}$

$\begin{array}{lllll}0.200 & 0.00 \mathrm{E}+00 & 0.00 \mathrm{E}+00 & 0.00 \mathrm{E}+00\end{array}$

$\begin{array}{lllll}0.225 & 0.00 \mathrm{E}+00 & 0.00 \mathrm{E}+00 & 0.00 \mathrm{E}+00\end{array}$

$\begin{array}{lllll}0.250 & 0.00 \mathrm{E}+00 & 0.00 \mathrm{E}+00 & 0.00 \mathrm{E}+00\end{array}$

$\begin{array}{llll}0.275 & 0.00 \mathrm{E}+00 & 0.00 \mathrm{E}+00 & 0.00 \mathrm{E}+00\end{array}$

$\begin{array}{lllll}0.300 & 0.00 \mathrm{E}+00 & 0.00 \mathrm{E}+00 & 0.00 \mathrm{E}+00\end{array}$

$\begin{array}{lllll}0.325 & 0.00 \mathrm{E}+00 & 0.00 \mathrm{E}+00 & 0.00 \mathrm{E}+00\end{array}$

$\begin{array}{lllll}0.350 & 0.00 \mathrm{E}+00 & 0.00 \mathrm{E}+00 & 0.00 \mathrm{E}+00\end{array}$

$\begin{array}{lllll}0.375 & 0.00 \mathrm{E}+00 & 0.00 \mathrm{E}+00 & 0.00 \mathrm{E}+00\end{array}$

$\begin{array}{lllll}0.400 & 0.00 \mathrm{E}+00 & 0.00 \mathrm{E}+00 & 0.00 \mathrm{E}+00\end{array}$

$\begin{array}{lllll}0.425 & 0.00 \mathrm{E}+00 & 0.00 \mathrm{E}+00 & 0.00 \mathrm{E}+00\end{array}$

$\begin{array}{lllll}0.450 & 0.00 \mathrm{E}+00 & 0.00 \mathrm{E}+00 & 0.00 \mathrm{E}+00\end{array}$

$\begin{array}{lllll}0.475 & 0.00 \mathrm{E}+00 & 0.00 \mathrm{E}+00 & 0.00 \mathrm{E}+00\end{array}$

$\begin{array}{lllll}0.500 & 0.00 \mathrm{E}+00 & 0.00 \mathrm{E}+00 & 0.00 \mathrm{E}+00\end{array}$

$\begin{array}{lllll}0.525 & 0.00 \mathrm{E}+00 & 0.00 \mathrm{E}+00 & 0.00 \mathrm{E}+00\end{array}$

$\begin{array}{lllll}0.550 & 0.00 \mathrm{E}+00 & 0.00 \mathrm{E}+00 & 0.00 \mathrm{E}+00\end{array}$

$\begin{array}{lllll}0.575 & 0.00 \mathrm{E}+00 & 0.00 \mathrm{E}+00 & 0.00 \mathrm{E}+00\end{array}$

$\begin{array}{lllll}0.600 & 0.00 \mathrm{E}+00 & 0.00 \mathrm{E}+00 & 0.00 \mathrm{E}+00\end{array}$

$\begin{array}{lllll}0.625 & 0.00 \mathrm{E}+00 & 0.00 \mathrm{E}+00 & 0.00 \mathrm{E}+00\end{array}$

$\begin{array}{lllll}0.650 & 0.00 \mathrm{E}+00 & 0.00 \mathrm{E}+00 & 0.00 \mathrm{E}+00\end{array}$

$\begin{array}{lllll}0.675 & 0.00 \mathrm{E}+00 & 0.00 \mathrm{E}+00 & 0.00 \mathrm{E}+00\end{array}$

$\begin{array}{llll}0.700 & 0.00 \mathrm{E}+00 & 0.00 \mathrm{E}+00 & 0.00 \mathrm{E}+00\end{array}$

$\begin{array}{lllll}0.725 & 0.00 \mathrm{E}+00 & 0.00 \mathrm{E}+00 & 0.00 \mathrm{E}+00\end{array}$

$\begin{array}{lllll}0.750 & 0.00 \mathrm{E}+00 & 0.00 \mathrm{E}+00 & 0.00 \mathrm{E}+00\end{array}$

$\begin{array}{lllll}0.775 & 0.00 \mathrm{E}+00 & 0.00 \mathrm{E}+00 & 0.00 \mathrm{E}+00\end{array}$

$\begin{array}{lllll}0.800 & 0.00 \mathrm{E}+00 & 0.00 \mathrm{E}+00 & 0.00 \mathrm{E}+00\end{array}$

$\begin{array}{lllll}0.825 & 0.00 \mathrm{E}+00 & 0.00 \mathrm{E}+00 & 0.00 \mathrm{E}+00\end{array}$

$\begin{array}{lllll}0.850 & 0.00 \mathrm{E}+00 & 0.00 \mathrm{E}+00 & 0.00 \mathrm{E}+00\end{array}$

$\begin{array}{lllll}0.875 & 0.00 \mathrm{E}+00 & 0.00 \mathrm{E}+00 & 0.00 \mathrm{E}+00\end{array}$

$\begin{array}{lllll}0.900 & 0.00 \mathrm{E}+00 & 0.00 \mathrm{E}+00 & 0.00 \mathrm{E}+00\end{array}$

$\begin{array}{lllll}0.925 & 0.00 \mathrm{E}+00 & 0.00 \mathrm{E}+00 & 0.00 \mathrm{E}+00\end{array}$

$\begin{array}{llll}0.950 & 0.00 \mathrm{E}+00 & 0.00 \mathrm{E}+00 & 0.00 \mathrm{E}+00\end{array}$

$\begin{array}{lllll}0.975 & 0.00 \mathrm{E}+00 & 0.00 \mathrm{E}+00 & 0.00 \mathrm{E}+00\end{array}$

$\begin{array}{lllll}0.990 & 0.00 \mathrm{E}+00 & 0.00 \mathrm{E}+00 & 0.00 \mathrm{E}+00\end{array}$ 
RESRAD-OFFSITE, Version 2.5

Probabilistic Dose and Risk Report

Title : RESRAD-OFFSITE Drinking Water, Plant, Milk, and Meat Pathways for Offsite Reside

File : PBA-1_TC99-DOE-5.ROF

Statistics and Cumulative distribution function of Peak Risk from Meat (CZandAir)

$\begin{array}{ccccc}\text { Repetition }= & 1 & 2 & 3 \\ \text { Mean } & 0.00 \mathrm{E}+00 & 0.00 \mathrm{E}+00 & 0.00 \mathrm{E}+00 \\ \text { Std. Dev. } & 0.00 \mathrm{E}+00 & 0.00 \mathrm{E}+00 & 0.00 \mathrm{E}+00 \\ \text { Minimum } & 0.00 \mathrm{E}+00 & 0.00 \mathrm{E}+00 & 0.00 \mathrm{E}+00 \\ \text { Maximum } & 0.00 \mathrm{E}+00 & 0.00 \mathrm{E}+00 & 0.00 \mathrm{E}+00\end{array}$

Percentile

$\begin{array}{llll}0.010 & 0.00 \mathrm{E}+00 \quad 0.00 \mathrm{E}+00 & 0.00 \mathrm{E}+00\end{array}$

$\begin{array}{llll}0.025 & 0.00 \mathrm{E}+00 & 0.00 \mathrm{E}+00 & 0.00 \mathrm{E}+00\end{array}$

$\begin{array}{llll}0.050 & 0.00 \mathrm{E}+00 & 0.00 \mathrm{E}+00 & 0.00 \mathrm{E}+00\end{array}$

$\begin{array}{lllll}0.075 & 0.00 \mathrm{E}+00 & 0.00 \mathrm{E}+00 & 0.00 \mathrm{E}+00\end{array}$

$\begin{array}{llll}0.100 & 0.00 \mathrm{E}+00 & 0.00 \mathrm{E}+00 & 0.00 \mathrm{E}+00\end{array}$

$\begin{array}{llll}0.125 & 0.00 \mathrm{E}+00 & 0.00 \mathrm{E}+00 & 0.00 \mathrm{E}+00\end{array}$

$\begin{array}{lllll}0.150 & 0.00 \mathrm{E}+00 & 0.00 \mathrm{E}+00 & 0.00 \mathrm{E}+00\end{array}$

$\begin{array}{lllll}0.175 & 0.00 \mathrm{E}+00 & 0.00 \mathrm{E}+00 & 0.00 \mathrm{E}+00\end{array}$

$\begin{array}{lllll}0.200 & 0.00 \mathrm{E}+00 & 0.00 \mathrm{E}+00 & 0.00 \mathrm{E}+00\end{array}$

$\begin{array}{lllll}0.225 & 0.00 \mathrm{E}+00 & 0.00 \mathrm{E}+00 & 0.00 \mathrm{E}+00\end{array}$

$\begin{array}{lllll}0.250 & 0.00 \mathrm{E}+00 & 0.00 \mathrm{E}+00 & 0.00 \mathrm{E}+00\end{array}$

$\begin{array}{llll}0.275 & 0.00 \mathrm{E}+00 & 0.00 \mathrm{E}+00 & 0.00 \mathrm{E}+00\end{array}$

$\begin{array}{lllll}0.300 & 0.00 \mathrm{E}+00 & 0.00 \mathrm{E}+00 & 0.00 \mathrm{E}+00\end{array}$

$\begin{array}{lllll}0.325 & 0.00 \mathrm{E}+00 & 0.00 \mathrm{E}+00 & 0.00 \mathrm{E}+00\end{array}$

$\begin{array}{lllll}0.350 & 0.00 \mathrm{E}+00 & 0.00 \mathrm{E}+00 & 0.00 \mathrm{E}+00\end{array}$

$\begin{array}{lllll}0.375 & 0.00 \mathrm{E}+00 & 0.00 \mathrm{E}+00 & 0.00 \mathrm{E}+00\end{array}$

$\begin{array}{lllll}0.400 & 0.00 \mathrm{E}+00 & 0.00 \mathrm{E}+00 & 0.00 \mathrm{E}+00\end{array}$

$\begin{array}{lllll}0.425 & 0.00 \mathrm{E}+00 & 0.00 \mathrm{E}+00 & 0.00 \mathrm{E}+00\end{array}$

$\begin{array}{lllll}0.450 & 0.00 \mathrm{E}+00 & 0.00 \mathrm{E}+00 & 0.00 \mathrm{E}+00\end{array}$

$\begin{array}{lllll}0.475 & 0.00 \mathrm{E}+00 & 0.00 \mathrm{E}+00 & 0.00 \mathrm{E}+00\end{array}$

$\begin{array}{lllll}0.500 & 0.00 \mathrm{E}+00 & 0.00 \mathrm{E}+00 & 0.00 \mathrm{E}+00\end{array}$

$\begin{array}{lllll}0.525 & 0.00 \mathrm{E}+00 & 0.00 \mathrm{E}+00 & 0.00 \mathrm{E}+00\end{array}$

$\begin{array}{lllll}0.550 & 0.00 \mathrm{E}+00 & 0.00 \mathrm{E}+00 & 0.00 \mathrm{E}+00\end{array}$

$\begin{array}{lllll}0.575 & 0.00 \mathrm{E}+00 & 0.00 \mathrm{E}+00 & 0.00 \mathrm{E}+00\end{array}$

$\begin{array}{lllll}0.600 & 0.00 \mathrm{E}+00 & 0.00 \mathrm{E}+00 & 0.00 \mathrm{E}+00\end{array}$

$\begin{array}{lllll}0.625 & 0.00 \mathrm{E}+00 & 0.00 \mathrm{E}+00 & 0.00 \mathrm{E}+00\end{array}$

$\begin{array}{lllll}0.650 & 0.00 \mathrm{E}+00 & 0.00 \mathrm{E}+00 & 0.00 \mathrm{E}+00\end{array}$

$\begin{array}{lllll}0.675 & 0.00 \mathrm{E}+00 & 0.00 \mathrm{E}+00 & 0.00 \mathrm{E}+00\end{array}$

$\begin{array}{llll}0.700 & 0.00 \mathrm{E}+00 & 0.00 \mathrm{E}+00 & 0.00 \mathrm{E}+00\end{array}$

$\begin{array}{lllll}0.725 & 0.00 \mathrm{E}+00 & 0.00 \mathrm{E}+00 & 0.00 \mathrm{E}+00\end{array}$

$\begin{array}{lllll}0.750 & 0.00 \mathrm{E}+00 & 0.00 \mathrm{E}+00 & 0.00 \mathrm{E}+00\end{array}$

$\begin{array}{lllll}0.775 & 0.00 \mathrm{E}+00 & 0.00 \mathrm{E}+00 & 0.00 \mathrm{E}+00\end{array}$

$\begin{array}{lllll}0.800 & 0.00 \mathrm{E}+00 & 0.00 \mathrm{E}+00 & 0.00 \mathrm{E}+00\end{array}$

$\begin{array}{lllll}0.825 & 0.00 \mathrm{E}+00 & 0.00 \mathrm{E}+00 & 0.00 \mathrm{E}+00\end{array}$

$\begin{array}{lllll}0.850 & 0.00 \mathrm{E}+00 & 0.00 \mathrm{E}+00 & 0.00 \mathrm{E}+00\end{array}$

$\begin{array}{lllll}0.875 & 0.00 \mathrm{E}+00 & 0.00 \mathrm{E}+00 & 0.00 \mathrm{E}+00\end{array}$

$\begin{array}{lllll}0.900 & 0.00 \mathrm{E}+00 & 0.00 \mathrm{E}+00 & 0.00 \mathrm{E}+00\end{array}$

$\begin{array}{lllll}0.925 & 0.00 \mathrm{E}+00 & 0.00 \mathrm{E}+00 & 0.00 \mathrm{E}+00\end{array}$

$\begin{array}{llll}0.950 & 0.00 \mathrm{E}+00 & 0.00 \mathrm{E}+00 & 0.00 \mathrm{E}+00\end{array}$

$\begin{array}{lllll}0.975 & 0.00 \mathrm{E}+00 & 0.00 \mathrm{E}+00 & 0.00 \mathrm{E}+00\end{array}$

$\begin{array}{lllll}0.990 & 0.00 \mathrm{E}+00 & 0.00 \mathrm{E}+00 & 0.00 \mathrm{E}+00\end{array}$ 
RESRAD-OFFSITE, Version 2.5

Probabilistic Dose and Risk Report

Title : RESRAD-OFFSITE Drinking Water, Plant, Milk, and Meat Pathways for Offsite Reside

File : PBA-1_TC99-DOE-5.ROF

Statistics and Cumulative distribution function of Peak Risk from Milk (CzandAir)

$\begin{array}{ccccc}\text { Repetition }= & 1 & 2 & 3 \\ \text { Mean } & 0.00 \mathrm{E}+00 & 0.00 \mathrm{E}+00 & 0.00 \mathrm{E}+00 \\ \text { Std. Dev. } & 0.00 \mathrm{E}+00 & 0.00 \mathrm{E}+00 & 0.00 \mathrm{E}+00 \\ \text { Minimum } & 0.00 \mathrm{E}+00 & 0.00 \mathrm{E}+00 & 0.00 \mathrm{E}+00 \\ \text { Maximum } & 0.00 \mathrm{E}+00 & 0.00 \mathrm{E}+00 & 0.00 \mathrm{E}+00\end{array}$

Percentile

$\begin{array}{llll}0.010 & 0.00 \mathrm{E}+00 \quad 0.00 \mathrm{E}+00 & 0.00 \mathrm{E}+00\end{array}$

$\begin{array}{llll}0.025 & 0.00 \mathrm{E}+00 & 0.00 \mathrm{E}+00 & 0.00 \mathrm{E}+00\end{array}$

$\begin{array}{llll}0.050 & 0.00 \mathrm{E}+00 & 0.00 \mathrm{E}+00 & 0.00 \mathrm{E}+00\end{array}$

$\begin{array}{lllll}0.075 & 0.00 \mathrm{E}+00 & 0.00 \mathrm{E}+00 & 0.00 \mathrm{E}+00\end{array}$

$\begin{array}{llll}0.100 & 0.00 \mathrm{E}+00 & 0.00 \mathrm{E}+00 & 0.00 \mathrm{E}+00\end{array}$

$\begin{array}{llll}0.125 & 0.00 \mathrm{E}+00 & 0.00 \mathrm{E}+00 & 0.00 \mathrm{E}+00\end{array}$

$\begin{array}{llll}0.150 & 0.00 \mathrm{E}+00 & 0.00 \mathrm{E}+00 & 0.00 \mathrm{E}+00\end{array}$

$\begin{array}{lllll}0.175 & 0.00 \mathrm{E}+00 & 0.00 \mathrm{E}+00 & 0.00 \mathrm{E}+00\end{array}$

$\begin{array}{lllll}0.200 & 0.00 \mathrm{E}+00 & 0.00 \mathrm{E}+00 & 0.00 \mathrm{E}+00\end{array}$

$\begin{array}{lllll}0.225 & 0.00 \mathrm{E}+00 & 0.00 \mathrm{E}+00 & 0.00 \mathrm{E}+00\end{array}$

$\begin{array}{lllll}0.250 & 0.00 \mathrm{E}+00 & 0.00 \mathrm{E}+00 & 0.00 \mathrm{E}+00\end{array}$

$\begin{array}{llll}0.275 & 0.00 \mathrm{E}+00 & 0.00 \mathrm{E}+00 & 0.00 \mathrm{E}+00\end{array}$

$\begin{array}{lllll}0.300 & 0.00 \mathrm{E}+00 & 0.00 \mathrm{E}+00 & 0.00 \mathrm{E}+00\end{array}$

$\begin{array}{lllll}0.325 & 0.00 \mathrm{E}+00 & 0.00 \mathrm{E}+00 & 0.00 \mathrm{E}+00\end{array}$

$\begin{array}{lllll}0.350 & 0.00 \mathrm{E}+00 & 0.00 \mathrm{E}+00 & 0.00 \mathrm{E}+00\end{array}$

$\begin{array}{lllll}0.375 & 0.00 \mathrm{E}+00 & 0.00 \mathrm{E}+00 & 0.00 \mathrm{E}+00\end{array}$

$\begin{array}{lllll}0.400 & 0.00 \mathrm{E}+00 & 0.00 \mathrm{E}+00 & 0.00 \mathrm{E}+00\end{array}$

$\begin{array}{lllll}0.425 & 0.00 \mathrm{E}+00 & 0.00 \mathrm{E}+00 & 0.00 \mathrm{E}+00\end{array}$

$\begin{array}{lllll}0.450 & 0.00 \mathrm{E}+00 & 0.00 \mathrm{E}+00 & 0.00 \mathrm{E}+00\end{array}$

$\begin{array}{lllll}0.475 & 0.00 \mathrm{E}+00 & 0.00 \mathrm{E}+00 & 0.00 \mathrm{E}+00\end{array}$

$\begin{array}{lllll}0.500 & 0.00 \mathrm{E}+00 & 0.00 \mathrm{E}+00 & 0.00 \mathrm{E}+00\end{array}$

$\begin{array}{lllll}0.525 & 0.00 \mathrm{E}+00 & 0.00 \mathrm{E}+00 & 0.00 \mathrm{E}+00\end{array}$

$\begin{array}{lllll}0.550 & 0.00 \mathrm{E}+00 & 0.00 \mathrm{E}+00 & 0.00 \mathrm{E}+00\end{array}$

$\begin{array}{lllll}0.575 & 0.00 \mathrm{E}+00 & 0.00 \mathrm{E}+00 & 0.00 \mathrm{E}+00\end{array}$

$\begin{array}{lllll}0.600 & 0.00 \mathrm{E}+00 & 0.00 \mathrm{E}+00 & 0.00 \mathrm{E}+00\end{array}$

$\begin{array}{lllll}0.625 & 0.00 \mathrm{E}+00 & 0.00 \mathrm{E}+00 & 0.00 \mathrm{E}+00\end{array}$

$\begin{array}{lllll}0.650 & 0.00 \mathrm{E}+00 & 0.00 \mathrm{E}+00 & 0.00 \mathrm{E}+00\end{array}$

$\begin{array}{lllll}0.675 & 0.00 \mathrm{E}+00 & 0.00 \mathrm{E}+00 & 0.00 \mathrm{E}+00\end{array}$

$\begin{array}{llll}0.700 & 0.00 \mathrm{E}+00 & 0.00 \mathrm{E}+00 & 0.00 \mathrm{E}+00\end{array}$

$\begin{array}{lllll}0.725 & 0.00 \mathrm{E}+00 & 0.00 \mathrm{E}+00 & 0.00 \mathrm{E}+00\end{array}$

$\begin{array}{lllll}0.750 & 0.00 \mathrm{E}+00 & 0.00 \mathrm{E}+00 & 0.00 \mathrm{E}+00\end{array}$

$\begin{array}{lllll}0.775 & 0.00 \mathrm{E}+00 & 0.00 \mathrm{E}+00 & 0.00 \mathrm{E}+00\end{array}$

$\begin{array}{lllll}0.800 & 0.00 \mathrm{E}+00 & 0.00 \mathrm{E}+00 & 0.00 \mathrm{E}+00\end{array}$

$\begin{array}{lllll}0.825 & 0.00 \mathrm{E}+00 & 0.00 \mathrm{E}+00 & 0.00 \mathrm{E}+00\end{array}$

$\begin{array}{lllll}0.850 & 0.00 \mathrm{E}+00 & 0.00 \mathrm{E}+00 & 0.00 \mathrm{E}+00\end{array}$

$\begin{array}{lllll}0.875 & 0.00 \mathrm{E}+00 & 0.00 \mathrm{E}+00 & 0.00 \mathrm{E}+00\end{array}$

$\begin{array}{lllll}0.900 & 0.00 \mathrm{E}+00 & 0.00 \mathrm{E}+00 & 0.00 \mathrm{E}+00\end{array}$

$\begin{array}{lllll}0.925 & 0.00 \mathrm{E}+00 & 0.00 \mathrm{E}+00 & 0.00 \mathrm{E}+00\end{array}$

$\begin{array}{llll}0.950 & 0.00 \mathrm{E}+00 & 0.00 \mathrm{E}+00 & 0.00 \mathrm{E}+00\end{array}$

$\begin{array}{lllll}0.975 & 0.00 \mathrm{E}+00 & 0.00 \mathrm{E}+00 & 0.00 \mathrm{E}+00\end{array}$

$\begin{array}{lllll}0.990 & 0.00 \mathrm{E}+00 & 0.00 \mathrm{E}+00 & 0.00 \mathrm{E}+00\end{array}$ 
RESRAD-OFFSITE, Version 2.5

Probabilistic Dose and Risk Report

Title : RESRAD-OFFSITE Drinking Water, Plant, Milk, and Meat Pathways for Offsite Reside

File : PBA-1_TC99-DOE-5.ROF

Statistics and Cumulative distribution function of Peak Risk from Soil Ingestion(CZandAir)

$\begin{array}{ccccc}\text { Repetition }= & 1 & 2 & 3 \\ \text { Mean } & 0.00 \mathrm{E}+00 & 0.00 \mathrm{E}+00 & 0.00 \mathrm{E}+00 \\ \text { Std. Dev. } & 0.00 \mathrm{E}+00 & 0.00 \mathrm{E}+00 & 0.00 \mathrm{E}+00 \\ \text { Minimum } & 0.00 \mathrm{E}+00 & 0.00 \mathrm{E}+00 & 0.00 \mathrm{E}+00 \\ \text { Maximum } & 0.00 \mathrm{E}+00 & 0.00 \mathrm{E}+00 & 0.00 \mathrm{E}+00\end{array}$

Percentile

$\begin{array}{llll}0.010 & 0.00 \mathrm{E}+00 \quad 0.00 \mathrm{E}+00 & 0.00 \mathrm{E}+00\end{array}$

$\begin{array}{llll}0.025 & 0.00 \mathrm{E}+00 \quad 0.00 \mathrm{E}+00 & 0.00 \mathrm{E}+00\end{array}$

$\begin{array}{llll}0.050 & 0.00 \mathrm{E}+00 & 0.00 \mathrm{E}+00 & 0.00 \mathrm{E}+00\end{array}$

$\begin{array}{llll}0.075 & 0.00 \mathrm{E}+00 & 0.00 \mathrm{E}+00 & 0.00 \mathrm{E}+00\end{array}$

$\begin{array}{llll}0.100 & 0.00 \mathrm{E}+00 & 0.00 \mathrm{E}+00 & 0.00 \mathrm{E}+00\end{array}$

$\begin{array}{llll}0.125 & 0.00 \mathrm{E}+00 & 0.00 \mathrm{E}+00 & 0.00 \mathrm{E}+00\end{array}$

$\begin{array}{llll}0.150 & 0.00 \mathrm{E}+00 & 0.00 \mathrm{E}+00 & 0.00 \mathrm{E}+00\end{array}$

$\begin{array}{lllll}0.175 & 0.00 \mathrm{E}+00 & 0.00 \mathrm{E}+00 & 0.00 \mathrm{E}+00\end{array}$

$\begin{array}{lllll}0.200 & 0.00 \mathrm{E}+00 & 0.00 \mathrm{E}+00 & 0.00 \mathrm{E}+00\end{array}$

$\begin{array}{lllll}0.225 & 0.00 \mathrm{E}+00 & 0.00 \mathrm{E}+00 & 0.00 \mathrm{E}+00\end{array}$

$\begin{array}{lllll}0.250 & 0.00 \mathrm{E}+00 & 0.00 \mathrm{E}+00 & 0.00 \mathrm{E}+00\end{array}$

$\begin{array}{lllll}0.275 & 0.00 \mathrm{E}+00 & 0.00 \mathrm{E}+00 & 0.00 \mathrm{E}+00\end{array}$

$\begin{array}{lllll}0.300 & 0.00 \mathrm{E}+00 & 0.00 \mathrm{E}+00 & 0.00 \mathrm{E}+00\end{array}$

$\begin{array}{lllll}0.325 & 0.00 \mathrm{E}+00 & 0.00 \mathrm{E}+00 & 0.00 \mathrm{E}+00\end{array}$

$\begin{array}{lllll}0.350 & 0.00 \mathrm{E}+00 & 0.00 \mathrm{E}+00 & 0.00 \mathrm{E}+00\end{array}$

$\begin{array}{lllll}0.375 & 0.00 \mathrm{E}+00 & 0.00 \mathrm{E}+00 & 0.00 \mathrm{E}+00\end{array}$

$\begin{array}{lllll}0.400 & 0.00 \mathrm{E}+00 & 0.00 \mathrm{E}+00 & 0.00 \mathrm{E}+00\end{array}$

$\begin{array}{lllll}0.425 & 0.00 \mathrm{E}+00 & 0.00 \mathrm{E}+00 & 0.00 \mathrm{E}+00\end{array}$

$\begin{array}{lllll}0.450 & 0.00 \mathrm{E}+00 & 0.00 \mathrm{E}+00 & 0.00 \mathrm{E}+00\end{array}$

$\begin{array}{lllll}0.475 & 0.00 \mathrm{E}+00 & 0.00 \mathrm{E}+00 & 0.00 \mathrm{E}+00\end{array}$

$\begin{array}{lllll}0.500 & 0.00 \mathrm{E}+00 & 0.00 \mathrm{E}+00 & 0.00 \mathrm{E}+00\end{array}$

$\begin{array}{lllll}0.525 & 0.00 \mathrm{E}+00 & 0.00 \mathrm{E}+00 & 0.00 \mathrm{E}+00\end{array}$

$\begin{array}{lllll}0.550 & 0.00 \mathrm{E}+00 & 0.00 \mathrm{E}+00 & 0.00 \mathrm{E}+00\end{array}$

$\begin{array}{lllll}0.575 & 0.00 \mathrm{E}+00 & 0.00 \mathrm{E}+00 & 0.00 \mathrm{E}+00\end{array}$

$\begin{array}{lllll}0.600 & 0.00 \mathrm{E}+00 & 0.00 \mathrm{E}+00 & 0.00 \mathrm{E}+00\end{array}$

$\begin{array}{lllll}0.625 & 0.00 \mathrm{E}+00 & 0.00 \mathrm{E}+00 & 0.00 \mathrm{E}+00\end{array}$

$\begin{array}{lllll}0.650 & 0.00 \mathrm{E}+00 & 0.00 \mathrm{E}+00 & 0.00 \mathrm{E}+00\end{array}$

$\begin{array}{lllll}0.675 & 0.00 \mathrm{E}+00 & 0.00 \mathrm{E}+00 & 0.00 \mathrm{E}+00\end{array}$

$\begin{array}{lllll}0.700 & 0.00 \mathrm{E}+00 & 0.00 \mathrm{E}+00 & 0.00 \mathrm{E}+00\end{array}$

$\begin{array}{lllll}0.725 & 0.00 \mathrm{E}+00 & 0.00 \mathrm{E}+00 & 0.00 \mathrm{E}+00\end{array}$

$\begin{array}{lllll}0.750 & 0.00 \mathrm{E}+00 & 0.00 \mathrm{E}+00 & 0.00 \mathrm{E}+00\end{array}$

$\begin{array}{lllll}0.775 & 0.00 \mathrm{E}+00 & 0.00 \mathrm{E}+00 & 0.00 \mathrm{E}+00\end{array}$

$\begin{array}{lllll}0.800 & 0.00 \mathrm{E}+00 & 0.00 \mathrm{E}+00 & 0.00 \mathrm{E}+00\end{array}$

$\begin{array}{lllll}0.825 & 0.00 \mathrm{E}+00 & 0.00 \mathrm{E}+00 & 0.00 \mathrm{E}+00\end{array}$

$\begin{array}{lllll}0.850 & 0.00 \mathrm{E}+00 & 0.00 \mathrm{E}+00 & 0.00 \mathrm{E}+00\end{array}$

$\begin{array}{lllll}0.875 & 0.00 \mathrm{E}+00 & 0.00 \mathrm{E}+00 & 0.00 \mathrm{E}+00\end{array}$

$\begin{array}{lllll}0.900 & 0.00 \mathrm{E}+00 & 0.00 \mathrm{E}+00 & 0.00 \mathrm{E}+00\end{array}$

$\begin{array}{lllll}0.925 & 0.00 \mathrm{E}+00 & 0.00 \mathrm{E}+00 & 0.00 \mathrm{E}+00\end{array}$

$\begin{array}{llll}0.950 & 0.00 \mathrm{E}+00 & 0.00 \mathrm{E}+00 & 0.00 \mathrm{E}+00\end{array}$

$\begin{array}{lllll}0.975 & 0.00 \mathrm{E}+00 & 0.00 \mathrm{E}+00 & 0.00 \mathrm{E}+00\end{array}$

$\begin{array}{lllll}0.990 & 0.00 \mathrm{E}+00 & 0.00 \mathrm{E}+00 & 0.00 \mathrm{E}+00\end{array}$ 
RESRAD-OFFSITE, Version 2.5

robabilistic Dose and Risk Report

Title : RESRAD-OFFSITE Drinking Water, Plant, Milk, and Meat Pathways for offsite Reside File : PBA-1_TC99-DOE-5.ROF

Time

Years

$0.00 \mathrm{E}+00$

$5.13 \mathrm{E}-01$

$1.03 \mathrm{E}+00$

$1.54 \mathrm{E}+00$

$2.05 \mathrm{E}+00$

$2.56 \mathrm{E}+00$

$3.08 \mathrm{E}+00$

$3.59 \mathrm{E}+00$

$4.10 \mathrm{E}+00$

$4.61 \mathrm{E}+00$

$5.13 \mathrm{E}+00$

$5.64 \mathrm{E}+00$

$6.15 \mathrm{E}+00$

$6.67 \mathrm{E}+00$

$7.18 \mathrm{E}+00$

$7.69 \mathrm{E}+00$

$8.20 \mathrm{E}+00$

$8.72 \mathrm{E}+00$

$9.23 \mathrm{E}+00$

$9.74 \mathrm{E}+00$

$1.03 \mathrm{E}+01$

$1.08 \mathrm{E}+01$

$1.13 \mathrm{E}+01$

$1.18 \mathrm{E}+01$

$1.23 \mathrm{E}+01$

$1.28 \mathrm{E}+01$

$1.33 \mathrm{E}+01$

$1.38 \mathrm{E}+01$

$1.44 \mathrm{E}+01$

$1.49 \mathrm{E}+01$

$1.54 \mathrm{E}+01$

$1.59 \mathrm{E}+01$

$1.64 \mathrm{E}+01$

$1.69 \mathrm{E}+01$

$1.74 \mathrm{E}+01$

$1.79 \mathrm{E}+01$

$1.85 \mathrm{E}+01$

1. $90 \mathrm{E}+01$

1. $95 \mathrm{E}+01$

$2.00 \mathrm{E}+01$

$2.05 \mathrm{E}+01$

$2.10 \mathrm{E}+01$

$2.15 \mathrm{E}+01$

2. $20 \mathrm{E}+01$

$2.26 \mathrm{E}+01$

$2.31 \mathrm{E}+01$
Summary of dose at graphical times, reptition 1

Dose statistics at graphical times, mrem/yr

\begin{tabular}{|c|c|c|c|c|c|c|c|}
\hline Inimum & laximum & Mean & Median & $90 \%$ & $95 \%$ & $97.5 \%$ & $\%$ \\
\hline 0 & $.00 \mathrm{E}+00$ & $0 \mathrm{E}+00$ & $0.00 \mathrm{E}+00$ & $00 E+00$ & $0 \mathrm{E}+00$ & $00 E+00$ & $\mathrm{~F}+0 \mathrm{CS}-\mathrm{se}$ \\
\hline$E+00$ & 00 & $\mathrm{OE}+$ & 00 & 00 & $0.00 \mathrm{E}+00$ & 00 & $\mathrm{OE}+\mathrm{OC}$ \\
\hline$E+00$ & $\mathrm{E}+00$ & $\mathrm{E}+00$ & 0 & 00 & $0 \mathrm{E}+00$ & 00 & $0 \mathrm{E}+0 \mathrm{C}$ \\
\hline 00 & $E+00$ & 0 & 00 & 00 & $0 \mathrm{E}+00$ & -00 & +00 \\
\hline+00 & $E+00$ & $E+00$ & $E+00$ & $\mathrm{OE}+$ & 00 & 00 & $0 \mathrm{E}+00$ \\
\hline$E+00$ & 0 & 0 & 0 & 0 & 00 & $E+00$ & $00 \mathrm{E}+00$ \\
\hline $.00 \mathrm{E}+00$ & $0.00 \mathrm{E}+00$ & $.00 \mathrm{E}+00$ & $0 \mathrm{E}+00$ & $0 \mathrm{E}+00$ & $.00 \mathrm{E}+00$ & $E+00$ & $E+00$ \\
\hline $.00 \mathrm{E}+00$ & $0.00 \mathrm{E}+00$ & $.00 \mathrm{E}+00$ & $0.00 \mathrm{E}+00$ & $0.00 \mathrm{E}+00$ & $.00 \mathrm{E}+00$ & $.00 \mathrm{E}+00$ & $.00 \mathrm{E}+00$ \\
\hline $.00 \mathrm{E}+00$ & $0.00 \mathrm{E}+00$ & $.00 \mathrm{E}+00$ & $0.00 \mathrm{E}+00$ & $0.00 \mathrm{E}+00$ & $0.00 \mathrm{E}+00$ & $.00 \mathrm{E}+00$ & $00 \mathrm{E}+00$ \\
\hline$E+00$ & -00 & $E+00$ & +00 & $0 \mathrm{E}+00$ & $0 \mathrm{E}+00$ & +00 & $\mathrm{E}+00$ \\
\hline $.00 \mathrm{E}+00$ & $0.00 \mathrm{E}+00$ & $0.00 \mathrm{E}+00$ & $0 \mathrm{E}+00$ & $0.00 \mathrm{E}+00$ & $0.00 \mathrm{E}+00$ & $00 \mathrm{E}+00$ & $00 E+00$ \\
\hline 100 & 0 & 0 & $E+00$ & 0 & 0 & 00 & $E+00$ \\
\hline $.00 \mathrm{E}+00$ & $.0 U E+U 0$ & $\mathrm{E}+00$ & $E+00$ & 00 & $0 \mathrm{E}+00$ & +00 & $E+00$ \\
\hline $.00 \mathrm{E}+00$ & 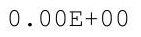 & $0.00 \mathrm{E}+00$ & $0.00 \mathrm{E}+00$ & $0.00 E+00$ & . & $.00 \mathrm{E}+00$ & $.00 \mathrm{E}+00$ \\
\hline $\mathrm{E}+00$ & $0.00 \mathrm{E}+00$ & $0 \mathrm{E}+00$ & $0.00 \mathrm{E}+00$ & $0.00 \mathrm{E}+00$ & $00 \mathrm{E}+00$ & $0 E+00$ & $0 \mathrm{E}+00$ \\
\hline$E+00$ & 00 & o & -00 & $0 \mathrm{E}+00$ & $0 \mathrm{E}+00$ & $E+00$ & $0 \mathrm{E}+00$ \\
\hline $.00 \mathrm{E}+00$ & $0.00 \mathrm{E}+00$ & & & & $0.00 \mathrm{E}+00$ & $.00 \mathrm{E}+00$ & $.00 \mathrm{E}+00$ \\
\hline $\mathrm{E}+00$ & $E+00$ & $0 \mathrm{E}+00$ & $0 \mathrm{E}+00$ & $\mathrm{E}+00$ & $E+00$ & +00 & $0 \mathrm{E}+00$ \\
\hline $.00 \mathrm{E}+00$ & $00 \mathrm{E}+00$ & $.00 \mathrm{E}+00$ & $00 \mathrm{E}+00$ & $0 \mathrm{E}+00$ & $0 \mathrm{E}+00$ & $0 \mathrm{E}+00$ & $\mathrm{OE}+\mathrm{OC}$ \\
\hline $0 \mathrm{E}+00$ & $0.00 \mathrm{E}+00$ & $0 \mathrm{E}+00$ & $\mathrm{DE}+00$ & 00 & $0 \mathrm{E}+00$ & $E+00$ & $0 \mathrm{E}+00$ \\
\hline $.00 \mathrm{E}+00$ & $0.00 \mathrm{E}+00$ & $.00 \mathrm{E}+00$ & $0.00 \mathrm{E}+00$ & & $0 \mathrm{E}+00$ & $0 \mathrm{E}+00$ & $0 \mathrm{E}+00$ \\
\hline $.00 E+00$ & $0.00 \mathrm{E}+00$ & $0.00 \mathrm{E}+00$ & $0.00 \mathrm{E}+00$ & $0.00 \mathrm{E}+00$ & $0.00 \mathrm{E}+00$ & $00 \mathrm{E}+00$ & +00 \\
\hline מח & $.00 E+00$ & & $00 E+00$ & $0 \mathrm{E}+00$ & (2) & $0 \mathrm{E}+00$ & $0 \mathrm{E}+00$ \\
\hline $.00 \mathrm{E}+00$ & $0.00 \mathrm{E}+00$ & $.00 \mathrm{E}+00$ & $0 \mathrm{E}+00$ & $0 \mathrm{E}+$ & $00 \mathrm{E}+00$ & $0 \mathrm{E}+00$ & $00 \mathrm{E}+00$ \\
\hline $.00 \mathrm{E}+00$ & $0.00 \mathrm{E}+00$ & $0.00 \mathrm{E}+00$ & $0.00 \mathrm{E}+00$ & $0 \mathrm{E}+00$ & $\mathrm{DE}+00$ & $E+00$ & $00 \mathrm{E}+00$ \\
\hline+00 & $E+00$ & $\mathrm{E}+00$ & 00 & 00 & 00 & +00 & $0 E+00$ \\
\hline$E+00$ & +00 & $\mathrm{E}+00$ & $0 \mathrm{E}+00$ & $0 \mathrm{E}+00$ & $0 E+00$ & $0 \mathrm{E}+00$ & $0 \mathrm{E}+00$ \\
\hline $.00 \mathrm{E}+00$ & $0.00 \mathrm{E}+00$ & $0.00 \mathrm{E}+00$ & $0.00 \mathrm{E}+00$ & $0.00 \mathrm{E}+00$ & $0.00 \mathrm{E}+00$ & $.00 \mathrm{E}+00$ & $.00 \mathrm{E}+00$ \\
\hline $.00 \mathrm{E}+00$ & $0.00 \mathrm{E}+00$ & $0.00 \mathrm{E}+00$ & $0.00 \mathrm{E}+00$ & $0.00 \mathrm{E}+00$ & $0.00 \mathrm{E}+00$ & $.00 \mathrm{E}+00$ & $.00 \mathrm{E}+00$ \\
\hline 然 & 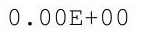 & 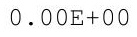 & $0.00 \mathrm{E}+00$ & $0 E+00$ & (1) & $0 \mathrm{E}+00$ & $0.00 \mathrm{E}+0 \mathrm{C}$ \\
\hline 0 & & & & & & $E+00$ & $00 \mathrm{E}+0 \mathrm{C}$ \\
\hline$\Xi+00$ & $E+00$ & $0 \mathrm{E}+00$ & $\mathrm{E}+00$ & $0 \mathrm{E}+00$ & $\mathrm{OE}+00$ & $E+00$ & $\mathrm{OE}+\mathrm{OC}$ \\
\hline+00 & +00 & $E+00$ & $E+00$ & 0 & 0 & & $0 \mathrm{E}+00$ \\
\hline .00 ET+ & $0.00 \mathrm{E}+00$ & $0.00 \mathrm{E}+00$ & $0.00 \mathrm{E}+00$ & $0.00 \mathrm{E}+00$ & $00 \mathrm{E}+00$ & $.00 \mathrm{E}+00$ & $.00 E+00$ \\
\hline . & & $0.00 \mathrm{E}+00$ & & $0.00 \mathrm{E}+00$ & . U ता U & $.00 \mathrm{E}+00$ & $.00 E+00$ \\
\hline & & & & & & & \\
\hline مค & ( & 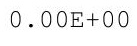 & 0 & 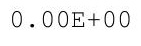 & 0 & 0 & $0 \Omega$ \\
\hline 0 & 0 & 0 & $\mathrm{E}+00$ & 0 & 0 & 0 & 00 \\
\hline & & & & 0 & $\mathrm{E}+00$ & +00 & $0 \mathrm{E}+00$ \\
\hline$E+00$ & +00 & E+ & 00 & 0 & 0 & & $0 \mathrm{E}+00$ \\
\hline 0 & & & $00 E+00$ & 然 & 0 & & $.00 E+00$ \\
\hline 0 & 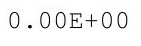 & 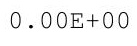 & & & 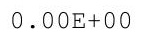 & 0 & DT \\
\hline 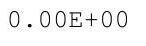 & 0 & 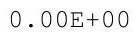 & 0 & .000 & 0 & $0 E+00$ & $.00 \mathrm{E}+00$ \\
\hline 0 & 0 & 0 & 0 & 00 & 0 & 0 & 00 \\
\hline+00 & $E+00$ & . & 0 . & 00 & 0 & +00 & $0 \mathrm{E}+00$ \\
\hline $.00 \mathrm{E}+00$ & $.00 \mathrm{E}+00$ & $.00 \mathrm{E}+00$ & $.00 \mathrm{E}+00$ & $0.00 \mathrm{E}+00$ & $0.00 \mathrm{E}+00$ & $0.00 \mathrm{E}+00$ & $0.00 \mathrm{E}+00$ \\
\hline
\end{tabular}


RESRAD-OFFSITE, Version 2.5

Probabilistic Dose and Risk Report

Title : RESRAD-OFFSITE Drinking Water, Plant, Milk, and Meat Pathways for Offsite Reside File : PBA-1 TC99-DOE-5.ROF

Summary of dose at graphical times, reptition 1 (continued)

Time

Years

2. $36 \mathrm{E}+01$

2. $41 \mathrm{E}+01$

$2.46 \mathrm{E}+01$

$2.51 \mathrm{E}+01$

$2.56 \mathrm{E}+01$

2. $61 \mathrm{E}+01$

$2.67 \mathrm{E}+01$

$2.72 \mathrm{E}+01$

2. $77 \mathrm{E}+01$

2. $82 \mathrm{E}+01$

$2.87 \mathrm{E}+01$

2. $92 \mathrm{E}+01$

2. $97 \mathrm{E}+01$

3. $02 \mathrm{E}+01$

$3.08 \mathrm{E}+01$

3. $13 \mathrm{E}+01$

3. $18 \mathrm{E}+01$

3. $23 \mathrm{E}+01$

3. $28 \mathrm{E}+01$

3. $33 \mathrm{E}+01$

3. $38 \mathrm{E}+01$

3. $44 \mathrm{E}+01$

3. $49 \mathrm{E}+01$

3. $54 \mathrm{E}+01$

3. $59 \mathrm{E}+01$

3. $64 \mathrm{E}+01$

3. $69 \mathrm{E}+01$

$3.74 \mathrm{E}+01$

3. $79 \mathrm{E}+01$

$3.85 \mathrm{E}+01$

3. $90 \mathrm{E}+01$

$3.95 \mathrm{E}+01$

$4.00 \mathrm{E}+01$

$4.05 \mathrm{E}+01$

$4.10 \mathrm{E}+01$

4. $15 \mathrm{E}+01$

4. $20 \mathrm{E}+01$

$4.26 \mathrm{E}+01$

$4.31 \mathrm{E}+01$

$4.36 \mathrm{E}+01$

4. $41 \mathrm{E}+01$

$4.46 \mathrm{E}+01$

4. $51 \mathrm{E}+01$

$4.56 \mathrm{E}+01$

4. $61 \mathrm{E}+01$

$4.67 \mathrm{E}+01$
Dose statistics at graphical times, mrem/yr

\begin{tabular}{|c|c|c|c|c|c|c|c|}
\hline m & num & ean & n & & & $\%$ & \\
\hline 00 & 00 & $E+00$ & $\mathrm{E}+00$ & +00 & +00 & +00 & +00 \\
\hline $.00 \mathrm{E}+00$ & $.00 \mathrm{E}+00$ & $.00 \mathrm{E}+00$ & $0.00 \mathrm{E}+00$ & $0.00 \mathrm{E}+00$ & $0.00 \mathrm{E}+00$ & $.00 \mathrm{E}+00$ & $.00 \mathrm{E}+00$ \\
\hline $00 F+00$ & $00 F+00$ & $00 E+00$ & $.00 E+00$ & $00 \mathrm{E}+00$ & $00 F+00$ & $00 \mathrm{E}+00$ & $00 F+00$ \\
\hline 00 & & & & & & & 00 \\
\hline+00 & +00 & & & & 00 & & +00 \\
\hline $.00 \mathrm{E}+00$ & $E+00$ & $0 \mathrm{E}+00$ & $0 E+00$ & $0 E+00$ & $0 \mathrm{E}+00$ & 00 & +00 \\
\hline $.00 \mathrm{E}+00$ & +00 & $E+00$ & $\mathrm{E}+00$ & +00 & +00 & +00 & $\mathrm{E}+00$ \\
\hline $.00 E+00$ & $0.00 \mathrm{E}+00$ & $0 \mathrm{E}+00$ & $0 \mathrm{E}+00$ & $00 E+00$ & $.00 \mathrm{E}+00$ & $.00 \mathrm{E}+00$ & $00 E+00$ \\
\hline $00 E+00$ & $00 \mathrm{E}+00$ & $.00 E+00$ & $.00 E+00$ & $0 \mathrm{E}+00$ & $0 \mathrm{E}+00$ & $E+00$ & $\exists+00$ \\
\hline $00 \mathrm{E}+00$ & $O P F+6-5-5$ & $00 E+00$ & $0 E+00$ & 0 & +0 & $00 E+00$ & +00 \\
\hline$E+00$ & $\mathrm{~F}+00$ & $E+00$ & & & & & +00 \\
\hline $.00 \mathrm{E}+00$ & $0.00 \mathrm{E}+00$ & $.00 \mathrm{E}+00$ & $0.00 \mathrm{E}+00$ & $0.00 \mathrm{E}+00$ & $0.00 \mathrm{E}+00$ & $.00 \mathrm{E}+00$ & $.00 E+00$ \\
\hline $.00 E+00$ & $0.00 \mathrm{E}+00$ & $0.00 \mathrm{E}+00$ & $0.00 \mathrm{E}+00$ & $0.00 \mathrm{E}+00$ & $0.00 \mathrm{E}+00$ & $.00 \mathrm{E}+00$ & $.00 \mathrm{E}+00$ \\
\hline $.00 E+00$ & $0=0$ & $00 E+00$ & $0 \mathrm{E}+00$ & $E+00$ & $\mathrm{E}+00$ & +00 & $\mathrm{E}+00$ \\
\hline $\mathrm{OE}+$ & $.00 \mathrm{E}+\mathrm{C}$ & $.00 E+00$ & $.00 E+00$ & $0 E+00$ & 0 & 0 & 00 \\
\hline 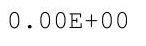 & ק & 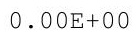 & 0 & & ( & 0 & +00 \\
\hline$O \cap F+O \Omega$ & $00 F+00$ & $0 \mathrm{E}+00$ & $E+00$ & $E+00$ & +00 & 0 & +00 \\
\hline $.00 E+00$ & $0 \cap F+00$ & $0 \mathrm{E}+00$ & $0 E+00$ & $\mathrm{E}+00$ & $0 E+00$ & $O E+00$ & $0 E+00$ \\
\hline $.00 \mathrm{E}+00$ & $.00 \mathrm{E}+00$ & $0.00 \mathrm{E}+00$ & $0.00 \mathrm{E}+00$ & $.00 \mathrm{E}+00$ & $0.00 \mathrm{E}+00$ & $.00 \mathrm{E}+00$ & $0 \mathrm{E}+00$ \\
\hline $.00 E+00$ & $0 \cap F+\cap 0$ & $.00 \mathrm{E}+00$ & $.00 E+00$ & $0 \mathrm{E}+00$ & $00 E+00$ & $E+00$ & $0 \mathrm{E}+00$ \\
\hline & & & & & & & +00 \\
\hline & & & & & & & $0 E+00$ \\
\hline$=0$ & & & & & $\mathrm{E}+00$ & 0 & 00 \\
\hline $.00 \mathrm{E}+00$ & $.00 \mathrm{E}+00$ & $.00 \mathrm{E}+00$ & $.00 \mathrm{E}+00$ & $00 \mathrm{E}+00$ & $00 \mathrm{E}+00$ & $.00 E+00$ & $00 E+00$ \\
\hline $.00 \mathrm{E}+00$ & $.00 \mathrm{E}+00$ & $0.00 \mathrm{E}+00$ & $0.00 \mathrm{E}+00$ & $0.00 \mathrm{E}+00$ & $00 \mathrm{E}+00$ & $.00 \mathrm{E}+00$ & $00 \mathrm{E}+0 \mathrm{C}$ \\
\hline $\mathrm{F}+00$ & $.00 E+00$ & $.00 \mathrm{E}+00$ & $0.00 E+00$ & $0 \mathrm{E}+00$ & $00 \mathrm{E}+00$ & $00 \mathrm{E}+00$ & $00 E+00$ \\
\hline & & & & & & & $00 E+00$ \\
\hline & & & & & & & $00 \mathrm{E}+00$ \\
\hline תחת & & & & & 0 & & 00 \\
\hline $.00 \mathrm{E}+00$ & $0.00 \mathrm{E}+00$ & $0.00 \mathrm{E}+00$ & $0.00 \mathrm{E}+00$ & $0.00 \mathrm{E}+00$ & $0.00 \mathrm{E}+00$ & $.00 \mathrm{E}+00$ & $.00 \mathrm{E}+00$ \\
\hline $00 \mathrm{E}+$ & $.00 \mathrm{E}+0$ & $.00 \mathrm{E}+0 \mathrm{C}$ & $0.00 \mathrm{E}+00$ & $.00 E+00$ & $.00 \mathrm{E}+00$ & $.00 \mathrm{E}+00$ & $.00 \mathrm{E}+0 \mathrm{C}$ \\
\hline חم +Fחم & $.00 \mathrm{E}+00$ & $0.00 \mathrm{E}+00$ & $0.00 \mathrm{E}+00$ & $0 \mathrm{E}+00$ & $00 \mathrm{E}+00$ & $.00 E+00$ & $00 \mathrm{E}+00$ \\
\hline 00 & & & & & & & $0 \mathrm{E}+00$ \\
\hline & & & & & & & $00 \mathrm{E}+00$ \\
\hline $.00 \mathrm{E}+00$ & $0.00 \mathrm{E}+00$ & $0.00 \mathrm{E}+00$ & $0.00 \mathrm{E}+00$ & $0.00 \mathrm{E}+00$ & $0.00 \mathrm{E}+00$ & $.00 \mathrm{E}+00$ & $.00 \mathrm{E}+00$ \\
\hline 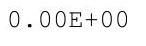 & . & •. & $0.00 \mathrm{E}+00$ & & & $.00 E+00$ & $.00 \mathrm{E}+0 \mathrm{C}$ \\
\hline & . & & & & & & . V LT \\
\hline $00 \mathrm{E}+0$ & $0.00 \mathrm{E}+0$ & $0.00 \mathrm{E}+00$ & $0.00 \mathrm{E}+00$ & $.00 E+00$ & $.00 E+00$ & $.00 \mathrm{E}+00$ & $.00 E+00$ \\
\hline $\mathrm{E}+$ & & & $.00 E+00$ & $\mathrm{E}+00$ & $\mathrm{E}+00$ & $0 E+00$ & $00 \mathrm{E}+00$ \\
\hline $0 E+00$ & & & $0.00 E+00$ & $0.00 E+00$ & $00 E+00$ & +00 & $.00 \mathrm{E}+00$ \\
\hline $.00 \mathrm{E}+00$ & $0.00 \mathrm{E}+00$ & $.00 \mathrm{E}+00$ & $0.00 \mathrm{E}+00$ & $0 E+00$ & $00 \mathrm{E}+00$ & 0 & $.00 \mathrm{E}+00$ \\
\hline $.00 \mathrm{E}+00$ & 0 & OOE+ & & & 00 & $0 E+00$ & $.00 \mathrm{E}+0 \mathrm{C}$ \\
\hline $.00 \mathrm{E}+00$ & $0.00 \mathrm{E}+00$ & $0.00 \mathrm{E}+00$ & $.00 E+00$ & $0.00 E+00$ & $0.00 \mathrm{E}+00$ & $0.00 \mathrm{E}+00$ & $0.00 \mathrm{E}+00$ \\
\hline $.00 \mathrm{E}+00$ & $0.00 \mathrm{E}+00$ & $0.00 \mathrm{E}+00$ & $0.00 \mathrm{E}+00$ & $0.00 \mathrm{E}+00$ & $0.00 \mathrm{E}+00$ & $0.00 \mathrm{E}+00$ & $0.00 \mathrm{E}+00$ \\
\hline $00 E+00$ & & & & $0.00 \mathrm{E}+00$ & $0.00 \mathrm{E}+00$ & $.00 \mathrm{E}+00$ & $0.00 \mathrm{E}+00$ \\
\hline+00 & $.00 \mathrm{E}+00$ & $.00 \mathrm{E}+00$ & $.00 E+00$ & $.00 E+00$ & $0.00 \mathrm{E}+00$ & $.00 \mathrm{E}+00$ & $.00 \mathrm{E}+00$ \\
\hline
\end{tabular}


RESRAD-OFFSITE, Version 2.5

robabilistic Dose and Risk Report

Title : RESRAD-OFFSITE Drinking Water, Plant, Milk, and Meat Pathways for Offsite Reside File : PBA-1_TC99-DOE-5.ROF

Summary of dose at graphical times, reptition 1 (continued)

Time

Years

$4.72 \mathrm{E}+01$

$4.77 \mathrm{E}+01$

$4.82 \mathrm{E}+01$

$4.87 \mathrm{E}+01$

4. $92 \mathrm{E}+01$

$4.97 \mathrm{E}+01$

$5.02 \mathrm{E}+01$

$5.08 \mathrm{E}+01$

$5.13 \mathrm{E}+01$

$5.18 \mathrm{E}+01$

$5.23 \mathrm{E}+01$

$5.28 \mathrm{E}+01$

$5.33 \mathrm{E}+01$

$5.38 \mathrm{E}+01$

$5.43 \mathrm{E}+01$

$5.49 \mathrm{E}+01$

$5.54 \mathrm{E}+01$

$5.59 \mathrm{E}+01$

$5.64 \mathrm{E}+01$

$5.69 \mathrm{E}+01$

$5.74 \mathrm{E}+01$

$5.79 \mathrm{E}+01$

$5.84 \mathrm{E}+01$

$5.90 \mathrm{E}+01$

$5.95 \mathrm{E}+01$

$6.00 \mathrm{E}+01$

$6.05 \mathrm{E}+01$

$6.10 \mathrm{E}+01$

$6.15 \mathrm{E}+01$

$6.20 \mathrm{E}+01$

$6.25 \mathrm{E}+01$

$6.31 \mathrm{E}+01$

$6.36 \mathrm{E}+01$

$6.41 \mathrm{E}+01$

$6.46 \mathrm{E}+01$

$6.51 \mathrm{E}+01$

$6.56 \mathrm{E}+01$

$6.61 \mathrm{E}+01$

$6.67 \mathrm{E}+01$

$6.72 \mathrm{E}+01$

$6.77 \mathrm{E}+01$

$6.82 \mathrm{E}+01$

$6.87 \mathrm{E}+01$

$6.92 \mathrm{E}+01$

$6.97 \mathrm{E}+01$

$7.02 \mathrm{E}+01$
Dose statistics at graphical times, mrem/yr

\begin{tabular}{|c|c|c|c|c|c|c|c|}
\hline m & num & ean & n & & & $\%$ & \\
\hline 00 & 00 & $E+00$ & $\mathrm{E}+00$ & +00 & +00 & +00 & +00 \\
\hline $.00 \mathrm{E}+00$ & $.00 \mathrm{E}+00$ & $.00 \mathrm{E}+00$ & $0.00 \mathrm{E}+00$ & $0.00 \mathrm{E}+00$ & $0.00 \mathrm{E}+00$ & $.00 \mathrm{E}+00$ & $.00 \mathrm{E}+00$ \\
\hline $00 F+00$ & $00 F+00$ & $00 E+00$ & $.00 E+00$ & $00 \mathrm{E}+00$ & $00 F+00$ & $00 \mathrm{E}+00$ & $00 F+00$ \\
\hline 00 & & & & & & & 00 \\
\hline+00 & +00 & & & & 00 & & +00 \\
\hline $.00 \mathrm{E}+00$ & $E+00$ & $0 \mathrm{E}+00$ & $0 E+00$ & $0 E+00$ & $0 \mathrm{E}+00$ & 00 & +00 \\
\hline $.00 \mathrm{E}+00$ & +00 & $E+00$ & $\mathrm{E}+00$ & +00 & +00 & +00 & $\mathrm{E}+00$ \\
\hline $.00 E+00$ & $0.00 \mathrm{E}+00$ & $0 \mathrm{E}+00$ & $0 \mathrm{E}+00$ & $00 E+00$ & $.00 \mathrm{E}+00$ & $.00 \mathrm{E}+00$ & $00 E+00$ \\
\hline $00 E+00$ & $00 \mathrm{E}+00$ & $.00 E+00$ & $.00 E+00$ & $0 \mathrm{E}+00$ & $0 \mathrm{E}+00$ & $E+00$ & $\exists+00$ \\
\hline $00 \mathrm{E}+00$ & $O P F+6-5-5$ & $00 E+00$ & $0 E+00$ & 0 & +0 & $00 E+00$ & +00 \\
\hline$E+00$ & $\mathrm{~F}+00$ & $E+00$ & & & & & +00 \\
\hline $.00 \mathrm{E}+00$ & $0.00 \mathrm{E}+00$ & $.00 \mathrm{E}+00$ & $0.00 \mathrm{E}+00$ & $0.00 \mathrm{E}+00$ & $0.00 \mathrm{E}+00$ & $.00 \mathrm{E}+00$ & $.00 E+00$ \\
\hline $.00 E+00$ & $0.00 \mathrm{E}+00$ & $0.00 \mathrm{E}+00$ & $0.00 \mathrm{E}+00$ & $0.00 \mathrm{E}+00$ & $0.00 \mathrm{E}+00$ & $.00 \mathrm{E}+00$ & $.00 \mathrm{E}+00$ \\
\hline $.00 E+00$ & $0=0$ & $00 E+00$ & $0 \mathrm{E}+00$ & $E+00$ & $\mathrm{E}+00$ & +00 & $\mathrm{E}+00$ \\
\hline $\mathrm{OE}+$ & $.00 \mathrm{E}+\mathrm{C}$ & $.00 E+00$ & $.00 E+00$ & $0 E+00$ & 0 & 0 & 00 \\
\hline 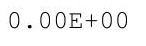 & ק & 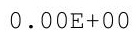 & 0 & & ( & 0 & +00 \\
\hline$O \cap F+O \Omega$ & $00 F+00$ & $0 \mathrm{E}+00$ & $E+00$ & $E+00$ & +00 & 0 & +00 \\
\hline $.00 E+00$ & $0 \cap F+00$ & $0 \mathrm{E}+00$ & $0 E+00$ & $\mathrm{E}+00$ & $0 E+00$ & $O E+00$ & $0 E+00$ \\
\hline $.00 \mathrm{E}+00$ & $.00 \mathrm{E}+00$ & $0.00 \mathrm{E}+00$ & $0.00 \mathrm{E}+00$ & $.00 \mathrm{E}+00$ & $0.00 \mathrm{E}+00$ & $.00 \mathrm{E}+00$ & $0 \mathrm{E}+00$ \\
\hline $.00 E+00$ & $0 \cap F+\cap 0$ & $.00 \mathrm{E}+00$ & $.00 E+00$ & $0 \mathrm{E}+00$ & $00 E+00$ & $E+00$ & $0 \mathrm{E}+00$ \\
\hline & & & & & & & +00 \\
\hline & & & & & & & $0 E+00$ \\
\hline$=0$ & & & & & $\mathrm{E}+00$ & 0 & 00 \\
\hline $.00 \mathrm{E}+00$ & $.00 \mathrm{E}+00$ & $.00 \mathrm{E}+00$ & $.00 \mathrm{E}+00$ & $00 \mathrm{E}+00$ & $00 \mathrm{E}+00$ & $.00 E+00$ & $00 E+00$ \\
\hline $.00 \mathrm{E}+00$ & $.00 \mathrm{E}+00$ & $0.00 \mathrm{E}+00$ & $0.00 \mathrm{E}+00$ & $0.00 \mathrm{E}+00$ & $00 \mathrm{E}+00$ & $.00 \mathrm{E}+00$ & $00 \mathrm{E}+0 \mathrm{C}$ \\
\hline $\mathrm{F}+00$ & $.00 E+00$ & $.00 \mathrm{E}+00$ & $0.00 E+00$ & $0 \mathrm{E}+00$ & $00 \mathrm{E}+00$ & $00 \mathrm{E}+00$ & $00 E+00$ \\
\hline & & & & & & & $00 E+00$ \\
\hline & & & & & & & $00 \mathrm{E}+00$ \\
\hline תחת & & & & & 0 & & 00 \\
\hline $.00 \mathrm{E}+00$ & $0.00 \mathrm{E}+00$ & $0.00 \mathrm{E}+00$ & $0.00 \mathrm{E}+00$ & $0.00 \mathrm{E}+00$ & $0.00 \mathrm{E}+00$ & $.00 \mathrm{E}+00$ & $.00 \mathrm{E}+00$ \\
\hline $00 \mathrm{E}+$ & $.00 \mathrm{E}+0$ & $.00 \mathrm{E}+0 \mathrm{C}$ & $0.00 \mathrm{E}+00$ & $.00 E+00$ & $.00 \mathrm{E}+00$ & $.00 \mathrm{E}+00$ & $.00 \mathrm{E}+0 \mathrm{C}$ \\
\hline חم +Fחم & $.00 \mathrm{E}+00$ & $0.00 \mathrm{E}+00$ & $0.00 \mathrm{E}+00$ & $0 \mathrm{E}+00$ & $00 \mathrm{E}+00$ & $.00 E+00$ & $00 \mathrm{E}+00$ \\
\hline 00 & & & & & & & $0 \mathrm{E}+00$ \\
\hline & & & & & & & $00 \mathrm{E}+00$ \\
\hline $.00 \mathrm{E}+00$ & $0.00 \mathrm{E}+00$ & $0.00 \mathrm{E}+00$ & $0.00 \mathrm{E}+00$ & $0.00 \mathrm{E}+00$ & $0.00 \mathrm{E}+00$ & $.00 \mathrm{E}+00$ & $.00 \mathrm{E}+00$ \\
\hline 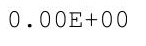 & . & •. & $0.00 \mathrm{E}+00$ & & & $.00 E+00$ & $.00 \mathrm{E}+0 \mathrm{C}$ \\
\hline & . & & & & & & . V LT \\
\hline $00 \mathrm{E}+0$ & $0.00 \mathrm{E}+0$ & $0.00 \mathrm{E}+00$ & $0.00 \mathrm{E}+00$ & $.00 E+00$ & $.00 E+00$ & $.00 \mathrm{E}+00$ & $.00 E+00$ \\
\hline $\mathrm{E}+$ & & & $.00 E+00$ & $\mathrm{E}+00$ & $\mathrm{E}+00$ & $0 E+00$ & $00 \mathrm{E}+00$ \\
\hline $0 E+00$ & & & $0.00 E+00$ & $0.00 E+00$ & $00 E+00$ & +00 & $.00 \mathrm{E}+00$ \\
\hline $.00 \mathrm{E}+00$ & $0.00 \mathrm{E}+00$ & $.00 \mathrm{E}+00$ & $0.00 \mathrm{E}+00$ & $0 E+00$ & $00 \mathrm{E}+00$ & 0 & $.00 \mathrm{E}+00$ \\
\hline $.00 \mathrm{E}+00$ & 0 & OOE+ & & & 00 & $0 E+00$ & $.00 \mathrm{E}+0 \mathrm{C}$ \\
\hline $.00 \mathrm{E}+00$ & $0.00 \mathrm{E}+00$ & $0.00 \mathrm{E}+00$ & $.00 E+00$ & $0.00 E+00$ & $0.00 \mathrm{E}+00$ & $0.00 \mathrm{E}+00$ & $0.00 \mathrm{E}+00$ \\
\hline $.00 \mathrm{E}+00$ & $0.00 \mathrm{E}+00$ & $0.00 \mathrm{E}+00$ & $0.00 \mathrm{E}+00$ & $0.00 \mathrm{E}+00$ & $0.00 \mathrm{E}+00$ & $0.00 \mathrm{E}+00$ & $0.00 \mathrm{E}+00$ \\
\hline $00 E+00$ & & & & $0.00 \mathrm{E}+00$ & $0.00 \mathrm{E}+00$ & $.00 \mathrm{E}+00$ & $0.00 \mathrm{E}+00$ \\
\hline+00 & $.00 \mathrm{E}+00$ & $.00 \mathrm{E}+00$ & $.00 E+00$ & $.00 E+00$ & $0.00 \mathrm{E}+00$ & $.00 \mathrm{E}+00$ & $.00 \mathrm{E}+00$ \\
\hline
\end{tabular}


RESRAD-OFFSITE, Version 2.5 
RESRAD-OFFSITE, Version 2.5 
RESRAD-OFFSITE, Version 2.5

robabilistic Dose and Risk Report

Title : RESRAD-OFFSITE Drinking Water, Plant, Milk, and Meat Pathways for Offsite Reside File : PBA-1_TC99-DOE-5.ROF

Summary of dose at graphical times, reptition 1 (continued)

Time

Years

$1.18 \mathrm{E}+02$

$1.18 \mathrm{E}+02$

1. $19 \mathrm{E}+02$

1. $19 \mathrm{E}+02$

1. $20 \mathrm{E}+02$

1. $20 \mathrm{E}+02$

1. $21 \mathrm{E}+02$

1. $22 \mathrm{E}+02$

1. $22 \mathrm{E}+02$

1. $23 \mathrm{E}+02$

1. $23 \mathrm{E}+02$

1. $24 \mathrm{E}+02$

1. $24 \mathrm{E}+02$

1. $25 \mathrm{E}+02$

1. $25 \mathrm{E}+02$

1. $26 \mathrm{E}+02$

1. $26 \mathrm{E}+02$

$1.27 \mathrm{E}+02$

1. $27 \mathrm{E}+02$

1. $28 \mathrm{E}+02$

1. $28 \mathrm{E}+02$

1. $29 \mathrm{E}+02$

1. $29 \mathrm{E}+02$

1. $30 \mathrm{E}+02$

1. $30 \mathrm{E}+02$

1. $31 \mathrm{E}+02$

1. $31 \mathrm{E}+02$

1. $32 \mathrm{E}+02$

1. $32 \mathrm{E}+02$

1. $33 \mathrm{E}+02$

1. $33 \mathrm{E}+02$

1. $34 \mathrm{E}+02$

1. $34 \mathrm{E}+02$

1. $35 \mathrm{E}+02$

1. $35 \mathrm{E}+02$

1. $36 \mathrm{E}+02$

1. $36 \mathrm{E}+02$

1. $37 \mathrm{E}+02$

1. $37 \mathrm{E}+02$

1. $38 \mathrm{E}+02$

1. $38 \mathrm{E}+02$

1. $39 \mathrm{E}+02$

1. $39 \mathrm{E}+02$

$1.40 \mathrm{E}+02$

1. $40 \mathrm{E}+02$

1. $41 \mathrm{E}+02$

Dose statistics at graphical times, mrem/yr

\begin{tabular}{|c|c|c|c|c|c|c|c|}
\hline inimum & aximum & Mean & ledian & $0 \%$ & $5 \%$ & $97.5 \%$ & $\%$ \\
\hline+00 & $5.33 E-12$ & $34 E-15$ & $0.00 \mathrm{E}+00$ & $0 \mathrm{E}+00$ & $0.00 \mathrm{E}+00$ & $.00 \mathrm{E}+00$ & $\mathrm{OE}+\mathrm{OC}$ \\
\hline $\mathrm{E}+00$ & -11 & 15 & $\mathrm{E}+00$ & $\mathrm{OE}+$ & $0 E+00$ & 00 & 100 \\
\hline+00 & -11 & $6 E-14$ & 00 & $\mathrm{DE}+00$ & 00 & -00 & +00 \\
\hline+00 & 11 & & & 0 & & 00 & +00 \\
\hline+00 & -10 & 3 & 0 & 00 & 00 & $E+00$ & $\mathrm{E}+00$ \\
\hline $.00 \mathrm{E}+00$ & -10 & $0 E-13$ & $\mathrm{E}+00$ & $0.00 \mathrm{E}+00$ & $0.00 \mathrm{E}+00$ & $0 E+00$ & $00 \mathrm{E}+00$ \\
\hline+00 & 10 & $5.03 E-13$ & 0 & $\mathrm{E}+00$ & 00 & +00 & $\mathrm{i}+0 \mathrm{c}$ \\
\hline $.00 E+00$ & $1.47 \mathrm{E}-09$ & • & & $0.00 \mathrm{E}+00$ & & $.00 \mathrm{E}+00$ & $00 \mathrm{E}+0 \mathrm{C}$ \\
\hline+00 & -09 & $E-12$ & +00 & $0 E+00$ & $00 \mathrm{E}+00$ & +00 & +00 \\
\hline $.00 \mathrm{E}+00$ & $2 E-09$ & $3 E-12$ & $\mathrm{OE}+00$ & $0 \mathrm{E}+00$ & $00 \mathrm{E}+00$ & $E+00$ & $E+00$ \\
\hline+00 & $E-09$ & $E-12$ & & & & 00 & +00 \\
\hline$E+00$ & -08 & $6 \mathrm{E}-12$ & $\mathrm{E}+00$ & & & +00 & $O E+0 C$ \\
\hline $.00 \mathrm{E}+00$ & $1.79 \mathrm{E}-08$ & $3 E-11$ & $\mathrm{E}+00$ & $E+00$ & $+2+00$ & $E+00$ & +00 \\
\hline$E+00$ & -08 & $E-11$ & $0.00 \mathrm{E}+00$ & $0.00 \mathrm{E}+00$ & +00 & $0 E+00$ & $00 \mathrm{E}+00$ \\
\hline$E+00$ & 08 & 11 & $\mathrm{E}+00$ & $0.00 \mathrm{E}+00$ & 00 & $E+00$ & +00 \\
\hline $.00 \mathrm{E}+00$ & $5.79 \mathrm{E}-08$ & -11 & $0.00 \mathrm{E}+00$ & $0.00 \mathrm{E}+00$ & $00 \mathrm{E}+00$ & $0 \mathrm{E}+00$ & $0 \mathrm{E}+00$ \\
\hline $.00 \mathrm{E}+00$ & $D E-08$ & $3 E-11$ & $0 E+00$ & $00 \mathrm{E}+00$ & $00 \mathrm{E}+00$ & $0 E+00$ & $00 \mathrm{E}+00$ \\
\hline $.00 E+00$ & $4 E-07$ & $0 E-10$ & $0 E+00$ & $0 \mathrm{E}+00$ & $00 \mathrm{E}+00$ & $\mathrm{OE}+00$ & $00 \mathrm{E}+0 \mathrm{C}$ \\
\hline$E+00$ & -07 & -10 & 00 & 00 & 00 & +00 & $-2<$ \\
\hline $.00 \mathrm{E}+00$ & -07 & -10 & $0.00 \mathrm{E}+00$ & $0 \mathrm{E}+00$ & +00 & $E+00$ & -25 \\
\hline $.00 \mathrm{E}+00$ & $2.01+01$ & 10 & & & & 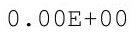 & -23 \\
\hline $.00 \mathrm{E}+00$ & $3.70 \mathrm{E}-07$ & $E-10$ & $0.00 \mathrm{E}+00$ & & $0.00 \mathrm{E}+00$ & $E+00$ & -21 \\
\hline $00 E+00$ & 7 & 0 & $.00 \mathrm{E}+00$ & $0 \mathrm{E}+00$ & $0 \mathrm{E}+0$ & $.00 \mathrm{E}+00$ & $.18 \mathrm{E}-19$ \\
\hline $.00 \mathrm{E}+00$ & $.16 \mathrm{E}-07$ & 7. $29 \mathrm{E}-10$ & $0.00 \mathrm{E}+00$ & $0 \mathrm{E}+00$ & $00 \mathrm{E}+00$ & $0 \mathrm{E}+00$ & $43 E-18$ \\
\hline+00 & $82 \mathrm{E}-07$ & $54 \mathrm{E}-10$ & & & & +00 & $E-17$ \\
\hline+00 & $E-07$ & $E-09$ & $E+00$ & 0 & 0 & +00 & -16 \\
\hline $.00 \mathrm{E}+00$ & $1.22 \mathrm{E}-06$ & -09 & $\mathrm{OE}+00$ & 00 & 00 & +00 & -15 \\
\hline $.00 E+00$ & $1.51 \mathrm{E}-06$ & $2.01 E-09$ & $0.00 \mathrm{E}+00$ & $0.00 \mathrm{E}+00$ & $.0 \mathrm{CLT}$ & $.00 \mathrm{E}+00$ & $72 E-14$ \\
\hline $0 E+00$ & 6 & - & $00 E+00$ & $00 \mathrm{E}+$ & $00 \mathrm{E}+$ & $0 E+00$ & $5 E-14$ \\
\hline 0 & - & -5 & & $\mathrm{E}+$ & & $E+C$ & 13 \\
\hline $\mathrm{E}+00$ & $.71 E-06$ & $93 F-09$ & $\mathrm{E}+00$ & $0 \mathrm{E}+00$ & $0 E+00$ & $\mathrm{DE}+00$ & $E-12$ \\
\hline+00 & 06 & $E-09$ & & & & & -12 \\
\hline & 06 & & & & & & \\
\hline $.00 \mathrm{E}+00$ & $4.56 \mathrm{E}-06$ & $7.17 \mathrm{E}-09$ & $0.00 \mathrm{E}+00$ & $0.00 \mathrm{E}+00$ & $.00 \mathrm{E}+00$ & $.00 \mathrm{E}+00$ & $74 \mathrm{E}-11$ \\
\hline . & $5.45 E-06$ & $0.035-49$ & & . О СТ & & $.00 \mathrm{E}+00$ & $.15 E-11$ \\
\hline 0 & & & & & & & $07 E-10$ \\
\hline 0 & 6 & 8 & & 0 & & 0 & 10 \\
\hline 0 & & & & & & & 10 \\
\hline$E+00$ & & & & & $\mathrm{E}+00$ & $\mathrm{E}+00$ & -09 \\
\hline $.00 \mathrm{E}+00$ & $1.29 \mathrm{E}-05$ & $2.05 E-08$ & 0 . & 0 & 0 & & -09 \\
\hline$E+00$ & 5 & $2.40 \mathrm{E}-08$ & & $\mathrm{OE}+$ & & & -09 \\
\hline$E+00$ & $\perp \cdot$ & 08 & $00 \mathrm{E}+00$ & $00 E+00$ & . & $95 E-27$ & $145-09$ \\
\hline 政 & $2 \cdot U \perp E$ & . & $0.00 \mathrm{E}+\mathrm{C}$ & $00 \mathrm{E}-$ & & $41 E-24$ & 0 \\
\hline $0.00 \mathrm{E}+00$ & $+\infty$ & & $0.00 \mathrm{E}$ & 0 & 0 & 2 & 08 \\
\hline $.00 \mathrm{E}+00$ & $5-05$ & $4.34 \mathrm{E}-08$ & $0.00 \mathrm{E}+00$ & $0.00 \mathrm{E}+00$ & $0.00 \mathrm{E}+00$ & $E-21$ & $.86 \mathrm{E}-08$ \\
\hline $.00 E+00$ & $3.02 E-05$ & $4.98 E-08$ & $.00 \mathrm{E}+00$ & $.00 E+00$ & $0.00 \mathrm{E}+00$ & 2. $96 \mathrm{E}-19$ & $2.76 E-08$ \\
\hline
\end{tabular}


RESRAD-OFFSITE, Version 2.5

robabilistic Dose and Risk Report

Title : RESRAD-OFFSITE Drinking Water, Plant, Milk, and Meat Pathways for offsite Reside File : PBA-1 TC99-DOE-5.ROF

Summary of dose at graphical times, reptition 1 (continued)

Time

Years

1. $42 \mathrm{E}+02$

1. $42 \mathrm{E}+02$

$1.43 \mathrm{E}+02$

1. $43 \mathrm{E}+02$

1. $44 \mathrm{E}+02$

1. $44 \mathrm{E}+02$

1. $45 \mathrm{E}+02$

1. $45 \mathrm{E}+02$

1. $46 \mathrm{E}+02$

1. $46 \mathrm{E}+02$

1. $47 \mathrm{E}+02$

1. $47 \mathrm{E}+02$

1. $48 \mathrm{E}+02$

1. $48 \mathrm{E}+02$

1. $49 \mathrm{E}+02$

1. $49 \mathrm{E}+02$

1. $50 \mathrm{E}+02$

1. $50 \mathrm{E}+02$

1. $51 \mathrm{E}+02$

1. $51 \mathrm{E}+02$

1. $52 \mathrm{E}+02$

1. $52 \mathrm{E}+02$

1. $53 \mathrm{E}+02$

$1.53 \mathrm{E}+02$

$1.54 \mathrm{E}+02$

1. $54 \mathrm{E}+02$

1. $55 \mathrm{E}+02$

1. $55 \mathrm{E}+02$

1. $56 \mathrm{E}+02$

1. $56 \mathrm{E}+02$

1. $57 \mathrm{E}+02$

1. $57 \mathrm{E}+02$

1. $58 \mathrm{E}+02$

1. $58 \mathrm{E}+02$

1. $59 \mathrm{E}+02$

1. $59 \mathrm{E}+02$

1. $60 \mathrm{E}+02$

1. $60 \mathrm{E}+02$

1. $61 \mathrm{E}+02$

1. $61 \mathrm{E}+02$

1. $62 \mathrm{E}+02$

1. $63 \mathrm{E}+02$

1. $63 \mathrm{E}+02$

1. $64 \mathrm{E}+02$

1. $64 \mathrm{E}+02$

1. $65 \mathrm{E}+02$

Dose statistics at graphical times, mrem/yr

\begin{tabular}{|c|c|c|c|c|c|c|c|}
\hline $\mathrm{m}$ & $m$ & Mean & ledian & & & $\%$ & \\
\hline $00 \mathrm{E}+00$ & 05 & -08 & $0.00 \mathrm{E}+00$ & $0.00 \mathrm{E}+00$ & $0.00 \mathrm{E}+00$ & -18 & -08 \\
\hline $.00 \mathrm{E}+00$ & -05 & $.53 E-08$ & & $0.00 \mathrm{E}+00$ & $0.00 \mathrm{E}+00$ & -17 & $73 E-08$ \\
\hline $.00 \mathrm{E}+00$ & $4.36 \mathrm{E}-05$ & $4 E-08$ & $0.00 \mathrm{E}+00$ & $0.00 \mathrm{E}+00$ & $0.00 \mathrm{E}+00$ & -16 & $.08 \mathrm{E}-08$ \\
\hline $.00 \mathrm{E}+00$ & $0 F-05$ & $5 E-08$ & $.00 \mathrm{E}+00$ & $.00 \mathrm{E}+00$ & $00 \mathrm{E}+00$ & $06 \mathrm{E}-15$ & $12 \mathrm{E}-07$ \\
\hline $0 E+00$ & $8 \mathrm{~F}_{-1}-\mathrm{C}^{-1}$ & $7 \mathrm{~F}-08$ & $.00 E+00$ & OF & $00 E+00$ & 4 & $54 \mathrm{~F}-07$ \\
\hline 00 & 5 & 7 & & & & & 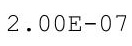 \\
\hline-00 & $E-05$ & $E-07$ & & & & & -07 \\
\hline $.00 \mathrm{E}+00$ & 30 & -07 & & & & & -07 \\
\hline $.00 \mathrm{E}+00$ & -05 & $E-07$ & +00 & +00 & +00 & -12 & -07 \\
\hline $00 \mathrm{E}+00$ & & $2 E-07$ & & & $0 \mathrm{E}+00$ & -11 & -07 \\
\hline $0 E+00$ & $01=0$ & $035-0$ & $0 \mathrm{E}+00$ & $0 E+00$ & $.00 \mathrm{E}+00$ & 1 & $.73 E-07$ \\
\hline+00 & $1 E-04$ & 7 & & -00 & 00 & 11 & -07 \\
\hline $2+00$ & $22 F-04$ & $E-07$ & $E+00$ & & 00 & -10 & -06 \\
\hline $.00 \mathrm{E}+00$ & $1.34 \mathrm{E}-04$ & $2.66 \mathrm{E}-07$ & $0.00 \mathrm{E}+00$ & $0.00 \mathrm{E}+00$ & $0.00 \mathrm{E}+00$ & $4.53 \mathrm{E}-10$ & $.62 E-06$ \\
\hline $.00 E+00$ & $1.46 \mathrm{E}-04$ & $2.94 \mathrm{E}-07$ & $0.00 \mathrm{E}+00$ & $0.00 \mathrm{E}+00$ & $0.00 \mathrm{E}+00$ & -10 & $E-06$ \\
\hline 00 & 04 & $26 \mathrm{E}-07$ & & & & -09 & -06 \\
\hline ק קחمص & 7 & 1 & 0 & & 0 & & -06 \\
\hline $\mathrm{E}+00$ & ק & $t$ & & & $00 \mathrm{E}+00$ & & 6 \\
\hline$\cap \cap F+\cap 0$ & $203 F-04$ & $8 E-07$ & & $0 E+00$ & $0 E+00$ & $E-09$ & $60 E-06$ \\
\hline $.00 E+00$ & $2.19 E-04$ & $4.82 \mathrm{E}-07$ & $0.00 \mathrm{E}+00$ & $0.00 \mathrm{E}+00$ & $.00 \mathrm{E}+00$ & $.27 E-08$ & $.53 E-06$ \\
\hline $.00 E+00$ & $2.37 E-04$ & $.29 E-07$ & $0.00 \mathrm{E}+00$ & $00 \mathrm{E}+00$ & $00 \mathrm{E}+00$ & $8 E-08$ & -06 \\
\hline & & & & & & & \\
\hline & & $5 E-07$ & & & -25 & 08 & -06 \\
\hline $.00 E+00$ & $.95 \mathrm{E}-$ & 07 & & & -23 & 8 & 05 \\
\hline $00 E+00$ & (1) & 7 & & & 1 & 8 & 05 \\
\hline مिOF+ & , & $3.27 \mathrm{E}-07$ & $0.00 \mathrm{E}+00$ & $.00 \mathrm{E}+00$ & $41 E-19$ & $1 E-07$ & $48 \mathrm{~F}-0$ \\
\hline $.00 \mathrm{E}+00$ & $3.64 \mathrm{E}-04$ & $.01 \mathrm{E}-07$ & & & $.25 E-18$ & $.35 E-07$ & $.70 \mathrm{E}-05$ \\
\hline & & & & & & & -05 \\
\hline & & $7 E-06$ & & & & & 05 \\
\hline $.00 \mathrm{E}+00$ & $4 \cdot 4$ & 06 & & $0.00 \mathrm{E}+00$ & & & -05 \\
\hline 政 & 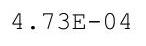 & $1.25 \mathrm{E}-06$ & $0.00 \mathrm{E}+00$ & $0.00 \mathrm{E}+00$ & $Z \cdot 4 \perp E-14$ & $4.16 \mathrm{E}-07$ & $.82 \mathrm{E}-05$ \\
\hline $.00 \mathrm{E}+00$ & 然 & $1.36 \mathrm{E}-06$ & & & 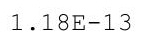 & 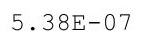 & 0 \\
\hline $.00 \mathrm{E}+0$ & $E-C$ & $1.47 \mathrm{E}-0$ & & & & & \\
\hline & & & & & & & .05 \\
\hline & $.04 E-04$ & $1 E-06$ & $0 E+00$ & $0 \mathrm{E}+00$ & $79 E-12$ & & -05 \\
\hline $.00 \mathrm{E}+00$ & $6.40 \mathrm{E}-04$ & $5 E-06$ & $0.00 \mathrm{E}+00$ & .00 & 11 & 06 & $8 \mathrm{E}-05$ \\
\hline . OULTण & $0.19 \mathrm{E}-\mathrm{U}$ & -06 & $0.00 \mathrm{E}+00$ & $0.00 \mathrm{E}+00$ & $21 E-11$ & 06 & $85 E-05$ \\
\hline (6) & & & & & & & $20+80$ \\
\hline - & 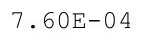 & - & & & & & 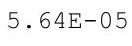 \\
\hline מ & & & & & & & 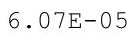 \\
\hline קתחת & & & & & $4 \mathrm{E}-10$ & 6 & 05 \\
\hline$E+00$ & $8.96 \mathrm{E}-04$ & $2.86 E-06$ & & & $05 E-09$ & $5 E-06$ & $.22 \mathrm{E}-05$ \\
\hline & 4 & 06 & & & & & \\
\hline & & & & & & & (0) \\
\hline $00 E+00$ & & 06 & & & & & • \\
\hline $00 E+00$ & $10 E-03$ & $5 E-06$ & $0 E+00$ & $0 \mathrm{E}+00$ & 09 & -06 & -04 \\
\hline
\end{tabular}


RESRAD-OFFSITE, Version 2.5

$\mathrm{T}^{1 / 2}$ Limit $=180$ days

Title : RESRAD-OFFSITE Drinking Water, Plant, Milk, and Meat Pathways for Offsite Reside File : PBA-1_TC99-DOE-5.ROF

Summary of dose at graphical times, reptition 1 (continued)

Time

Years

1. $65 \mathrm{E}+02$

$1.66 \mathrm{E}+02$

$1.66 \mathrm{E}+02$

$1.67 \mathrm{E}+02$

1. $67 \mathrm{E}+02$

1. $68 \mathrm{E}+02$

1. $68 \mathrm{E}+02$

1. $69 \mathrm{E}+02$

1. $69 \mathrm{E}+02$

1. $70 \mathrm{E}+02$

1. $70 \mathrm{E}+02$

1. $71 \mathrm{E}+02$

1. $71 \mathrm{E}+02$

1. $72 \mathrm{E}+02$

1. $72 \mathrm{E}+02$

1. $73 \mathrm{E}+02$

1. $73 \mathrm{E}+02$

1. $74 \mathrm{E}+02$

1. $74 \mathrm{E}+02$

1. $75 \mathrm{E}+02$

$1.75 \mathrm{E}+02$

$1.76 \mathrm{E}+02$

$1.76 \mathrm{E}+02$

$1.77 \mathrm{E}+02$

1. $77 \mathrm{E}+02$

1. $78 \mathrm{E}+02$

1. $78 \mathrm{E}+02$

$1.79 \mathrm{E}+02$

$1.79 \mathrm{E}+02$

$1.80 \mathrm{E}+02$

1. $80 \mathrm{E}+02$

$1.81 \mathrm{E}+02$

$1.81 \mathrm{E}+02$

1. $82 \mathrm{E}+02$

$1.83 \mathrm{E}+02$

$1.83 \mathrm{E}+02$

$1.84 \mathrm{E}+02$

$1.84 \mathrm{E}+02$

1. $85 \mathrm{E}+02$

$1.85 \mathrm{E}+02$

$1.86 \mathrm{E}+02$

$1.86 \mathrm{E}+02$

$1.87 \mathrm{E}+02$

$1.87 \mathrm{E}+02$

$1.88 \mathrm{E}+02$

$1.88 \mathrm{E}+02$

Dose statistics at graphical times, mrem/yr

\begin{tabular}{|c|c|c|c|c|c|c|c|}
\hline Inimum & laximum & Mean & Median & $90 \%$ & $95 \%$ & $97.5 \%$ & \\
\hline 0 & 03 & -06 & $0.00 E+00$ & $00 E+00$ & 8 & 66 & -0 \\
\hline $0 E+00$ & 1.22E-03 & $8 E-06$ & $0.00 \mathrm{E}+00$ & $0.00 \mathrm{E}+00$ & $1.73 E-08$ & 06 & $.29 \mathrm{E}-04$ \\
\hline$E+00$ & $8 E-03$ & $7 E-06$ & $E+00$ & bo & $51 E-08$ & 06 & $42 E-04$ \\
\hline+00 & $E-03$ & $7 E-06$ & $\mathrm{E}+00$ & 00 & $1 E-08$ & 05 & $5 E-04$ \\
\hline $.00 \mathrm{E}+00$ & 03 & -06 & $\mathrm{DE}+00$ & $0 \mathrm{E}+00$ & 08 & 05 & $68 E-04$ \\
\hline$E+00$ & $E-03$ & $E-06$ & & 0 & 8 & -05 & $81 E-04$ \\
\hline $.00 E+00$ & 1. $55 \mathrm{E}-03$ & $8 \mathrm{E}-06$ & $0 E+00$ & $E+00$ & $0 E-08$ & 05 & $E-04$ \\
\hline $.00 E+00$ & $1.63 E-03$ & $5 E-06$ & $0.00 \mathrm{E}+00$ & $0.00 \mathrm{E}+00$ & $.38 E-07$ & -05 & $08 E-04$ \\
\hline$E+00$ & -03 & $E-06$ & 00 & 00 & $90 \mathrm{E}-07$ & 05 & $21 \mathrm{E}-04$ \\
\hline+00 & -03 & $E-06$ & +00 & +00 & 7 & -05 & $33 E-04$ \\
\hline $.00 \mathrm{E}+00$ & $1.87 \mathrm{E}-03$ & $3 E-06$ & & & $49 \mathrm{E}-07$ & $28 E-05$ & $.47 E-04$ \\
\hline+00 & $E-03$ & -06 & +00 & $\mathrm{~s}+00$ & 7 & 05 & $\exists-04$ \\
\hline $.00 \mathrm{E}+00$ & $2.04 \mathrm{E}-03$ & $E-06$ & $0 \mathrm{E}+00$ & $E-28$ & oE-U & & $76 \mathrm{E}-04$ \\
\hline $.00 \mathrm{E}+00$ & $2 \cdot 13 \mathrm{E}-03$ & $1 \mathrm{E}-06$ & $0.00 \mathrm{E}+00$ & $4.48 E-25$ & पडE- & 05 & $96 E-04$ \\
\hline $\mathrm{DE}+00$ & 更 & $E-06$ & $0 E+00$ & $5.83 E-23$ & 07 & & $21 E-04$ \\
\hline $.00 \mathrm{E}+00$ & 03 & $8 \mathrm{E}-06$ & -00 & 21 & 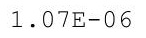 & 05 & $43 E-04$ \\
\hline $.00 E+00$ & $2.42 E-03$ & $.06 E-05$ & & $1.18 \mathrm{E}-19$ & $1.28 E-06$ & $8 E-05$ & $62 E-04$ \\
\hline$\Xi+00$ & $2.52 E-03$ & $E-05$ & $0 E+00$ & $3 E-18$ & $2 E-06$ & -05 & $81 E-04$ \\
\hline $.00 \mathrm{E}+00$ & $2.63 E-03$ & $1.18 \mathrm{E}-05$ & $0.00 \mathrm{E}+00$ & $4 \mathrm{E}-17$ & 6 & -05 & -04 \\
\hline $.00 \mathrm{E}+00$ & $2.74 \mathrm{E}-03$ & $E-05$ & +00 & -16 & 6 & 05 & $22 E-04$ \\
\hline . & $2.85 E-03$ & $1 E-05$ & & -15 & & & $43 E-04$ \\
\hline $.00 \mathrm{E}+00$ & $2.97 \mathrm{E}-03$ & $1.38 E-05$ & $0.00 \mathrm{E}+00$ & $1.79 \mathrm{E}-14$ & & -05 & $66 \mathrm{E}-04$ \\
\hline $00 \mathrm{E}+00$ & 20 ח תמת & $6 E-05$ & $0 \mathrm{E}+00$ & $6 \mathrm{E}-14$ & 1 & -05 & $E-04$ \\
\hline $.00 E+00$ & $3.21 E-03$ & $3 E-05$ & 0 & -13 & 06 & 05 & $13 E-04$ \\
\hline $\mathrm{E}+00$ & $E-03$ & $.62 E-05$ & & -12 & -06 & -05 & $E-04$ \\
\hline $\mathrm{E}+00$ & $E-03$ & $E-05$ & 00 & $5 E-12$ & 6 & 05 & $E-04$ \\
\hline$D E+00$ & $E-03$ & $9 \mathrm{E}-05$ & $0 \mathrm{E}+00$ & 11 & 6 & & \\
\hline $.00 \mathrm{E}+00$ & $3.75 \mathrm{E}-03$ & $1.88 E-05$ & $0.00 \mathrm{E}+00$ & $2.85 \mathrm{E}-11$ & $6.93 E-06$ & $.08 E-04$ & $.19 \mathrm{E}-04$ \\
\hline . & ك & $1.98 \mathrm{E}-05$ & $0.00 \mathrm{E}+00$ & $6.82 \mathrm{E}-11$ & $1.00 \mathrm{D}-00$ & $16 \mathrm{E}-04$ & $.47 \mathrm{E}-04$ \\
\hline (2) & $4.045-03$ & $7 E-05$ & $0.00 \mathrm{E}+00$ & 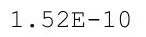 & 更 & -04 & $77 E-04$ \\
\hline 0 & 3 & 5 & $E+00$ & 10 & 6 & 04 & -04 \\
\hline$E+00$ & $E-03$ & $3 E-05$ & $E+00$ & $2 E-10$ & 5 & 04 & -04 \\
\hline $.00 \mathrm{E}+00$ & $4.51 \mathrm{E}-03$ & $2.40 \mathrm{E}-05$ & $0.00 \mathrm{E}+00$ & $0 E-09$ & $7 E-05$ & $56 E-04$ & $73 E-04$ \\
\hline $.00 \mathrm{E}+00$ & $4.68 \mathrm{E}-03$ & $2.51 \mathrm{E}-05$ & $0.00 \mathrm{E}+00$ & $1.72 \mathrm{E}-09$ & $1.43 \mathrm{E}-05$ & $.69 \mathrm{E}-04$ & $.07 E-04$ \\
\hline 年 & $4.85 E-03$ & & & & & $.81 E-04$ & $42 E-04$ \\
\hline+ & 5 & & & & & & \\
\hline & & & & & & 4 & \\
\hline 0 & 3 & 5 & 0 & 8 & 5 & 4 & -04 \\
\hline $\mathrm{E}+00$ & $5.58 E-03$ & $6 E-05$ & 0 . & 08 & $3 E-05$ & -04 & $4 E-04$ \\
\hline $.00 E+00$ & $5.77 \mathrm{E}$ & 5 & . & & 5 & & -03 \\
\hline 0 & & $5 E-05$ & & & 5 & & -03 \\
\hline $\mathrm{NE}+\mathrm{U}$ & 6. & & 0 & 8 & 5 & 04 & $12 \mathrm{E}-\mathrm{US}$ \\
\hline & 6 & $3.77 \mathrm{E}-05$ & 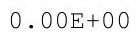 & 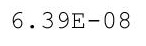 & & & -03 \\
\hline $0.00 \mathrm{E}+00$ & & 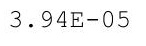 & 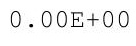 & 0 & 5 & 4 & 03 \\
\hline+00 & 6.8 & $E-05$ & $\mathrm{E}+00$ & $1.22 \mathrm{~F}$ & 4. & 04 & -03 \\
\hline $.00 E+00$ & $7.05 E-03$ & $4.29 E-05$ & $.00 \mathrm{E}+00$ & $1.68 \mathrm{E}-07$ & $4.34 \mathrm{E}-05$ & $3.44 \mathrm{E}-04$ & $1.33 E-03$ \\
\hline
\end{tabular}


RESRAD-OFFSITE, Version 2.5

$\mathrm{T}^{1 / 2}$ Limit $=180$ days

Title : RESRAD-OFFSITE Drinking Water, Plant, Milk, and Meat Pathways for Offsite Reside File : PBA-1_TC99-DOE-5.ROF

Summary of dose at graphical times, reptition 1 (continued)

Time

Years

$1.89 \mathrm{E}+02$

1. $89 \mathrm{E}+02$

1. $90 \mathrm{E}+02$

1. $90 \mathrm{E}+02$

1. $91 \mathrm{E}+02$

1. $91 \mathrm{E}+02$

1. $92 \mathrm{E}+02$

1. $92 \mathrm{E}+02$

1. $93 \mathrm{E}+02$

1. $93 \mathrm{E}+02$

1. $94 \mathrm{E}+02$

1. $94 \mathrm{E}+02$

1. $95 \mathrm{E}+02$

1. $95 \mathrm{E}+02$

1. $96 \mathrm{E}+02$

1. $96 \mathrm{E}+02$

1. $97 \mathrm{E}+02$

1. $97 \mathrm{E}+02$

1. $98 \mathrm{E}+02$

1. $98 \mathrm{E}+02$

1. $99 \mathrm{E}+02$

1. $99 \mathrm{E}+02$

$2.00 \mathrm{E}+02$

$2.00 \mathrm{E}+02$

$2.01 \mathrm{E}+02$

$2.01 \mathrm{E}+02$

$2.02 \mathrm{E}+02$

$2.03 \mathrm{E}+02$

$2.03 E+02$

$2.04 \mathrm{E}+02$

$2.04 \mathrm{E}+02$

$2.05 \mathrm{E}+02$

$2.05 \mathrm{E}+02$

$2.06 \mathrm{E}+02$

$2.06 \mathrm{E}+02$

$2.07 \mathrm{E}+02$

$2.07 \mathrm{E}+02$

$2.08 \mathrm{E}+02$

$2.08 \mathrm{E}+02$

2. $09 \mathrm{E}+02$

$2.09 \mathrm{E}+02$

$2.10 \mathrm{E}+02$

$2.10 \mathrm{E}+02$

$2.11 \mathrm{E}+02$

$2.11 E+02$

$2.12 \mathrm{E}+02$
Dose statistics at graphical times, mrem/yr

\begin{tabular}{|c|c|c|c|c|c|c|c|}
\hline inimum & aximum & Mean & ledian & $90 \%$ & $95 \%$ & $97.5 \%$ & $\%$ \\
\hline $0 \mathrm{E}+00$ & $7.28 \mathrm{E}-03$ & $4.47 \mathrm{E}-05$ & $0.00 \mathrm{E}+00$ & $.29 \mathrm{E}-07$ & $4.69 \mathrm{E}-05$ & $3.62 E-04$ & $1.39 \mathrm{E}-03$ \\
\hline$E+00$ & $E-03$ & $6 \mathrm{E}-$ & $0 E+00$ & $97 E-07$ & $05 E-$ & -04 & $.45 E-03$ \\
\hline$E+00$ & $7.77 E-03$ & $36 E-05$ & 00 & $74 E-07$ & $7 \mathrm{E}$ & -04 & $52 E-03$ \\
\hline$E+00$ & $E-03$ & & & & & 04 & 03 \\
\hline 00 & -03 & & & 7 & & -04 & $66 E-03$ \\
\hline $00 \mathrm{E}+00$ & $4 E-03$ & $.49 E-05$ & $.00 E+00$ & -07 & 5 & -04 & 03 \\
\hline $0 E+00$ & $1 E-03$ & $.71 \mathrm{E}-05$ & $.00 \mathrm{E}+00$ & $58 \mathrm{E}-07$ & 5 & -04 & 0. \\
\hline $.00 E+00$ & $9.08 E-03$ & 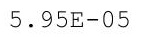 & $.00 E+00$ & $04 E-06$ & . & $.08 E-04$ & $.88 E-03$ \\
\hline$E+00$ & $E-03$ & 5 & 00 & 6 & 5 & -04 & $96 E-03$ \\
\hline $00 \mathrm{E}+00$ & $9.65 \mathrm{E}-03$ & 5 & & $53 E-06$ & 5 & -04 & $5 E-03$ \\
\hline $00 \mathrm{E}+00$ & $9.95 E-03$ & $.69 E-05$ & & $79 \mathrm{E}-06$ & & $82 E-04$ & $14 \mathrm{E}-03$ \\
\hline $0 E+00$ & -02 & & $\mathrm{E}+00$ & 6 & & -04 & -03 \\
\hline $.00 \mathrm{E}+00$ & $1.06 \mathrm{E}-02$ & $7.22 \mathrm{E}-05$ & $.00 \mathrm{E}+00$ & $.5 \perp E-U 6$ & $.08 \mathrm{E}-04$ & $E-04$ & $E-03$ \\
\hline $00 \mathrm{E}+00$ & $1.09 \mathrm{E}-02$ & $.50 E-05$ & $.00 \mathrm{E}+00$ & 06 & 然 & -04 & 03 \\
\hline $0 \mathrm{E}+00$ & $1.12 \mathrm{E}-02$ & 5 & $\mathrm{E}+00$ & 6 & $2-2+3$ & -04 & 03 \\
\hline $.00 \mathrm{E}+00$ & $1.15 \mathrm{E}-02$ & $.09 \mathrm{E}-05$ & & $.25 E-06$ & . & -04 & -03 \\
\hline $.00 \mathrm{E}+00$ & $1.19 \mathrm{E}-02$ & $.39 E-05$ & $.00 E+00$ & $.01 E-06$ & $.36 \mathrm{E}-$ & $.53 E-04$ & $.70 \mathrm{E}-03$ \\
\hline$E+00$ & $2 E-02$ & $1 E-05$ & $\mathrm{E}+00$ & $7 E-06$ & 4 & $E-04$ & $30 E-03$ \\
\hline$E+00$ & $E-02$ & $E-05$ & $E+00$ & 6 & 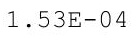 & -04 & -03 \\
\hline $.00 \mathrm{E}+00$ & $1.29 \mathrm{E}-02$ & $.37 E-05$ & $.00 E+00$ & $56 \pm-06$ & $0<\mathrm{E}-04$ & -04 & -03 \\
\hline $0 \mathrm{E}+00$ & $1.33 E-02$ & $.71 \mathrm{E}-05$ & & 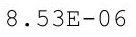 & (1) & -04 & -03 \\
\hline $.00 \mathrm{E}+00$ & $1.37 \mathrm{E}-02$ & $\cdot .01 \mathrm{~L}-U 4$ & $.00 \mathrm{E}+00$ & 年 & . & -04 & -03 \\
\hline $0 \mathrm{E}+00$ & $.40 E-02$ & $.04 \mathrm{E}-04$ & $00 \mathrm{E}+00$ & ( & ل ه & $E-04$ & $34 E-03$ \\
\hline$E+00$ & $44 \mathrm{E}-02$ & $08 E-04$ & $\mathrm{E}+00$ & $21 \mathrm{E}-$ & تحم0 & $E-04$ & -03 \\
\hline+00 & $E-02$ & $.12 \mathrm{E}-04$ & $\mathrm{E}+00$ & 5 & F & $E-03$ & $8 E-03$ \\
\hline $\mathrm{E}+00$ & $E-02$ & 4 & 0 & 5 & & 03 & $0 E-03$ \\
\hline $0 \mathrm{E}+00$ & $1.57 \mathrm{E}-02$ & $.20 \mathrm{E}-04$ & $0 E+00$ & 等 & & -03 & $33 E-03$ \\
\hline $.00 \mathrm{E}+00$ & 1. $61 \mathrm{E}-02$ & $1.24 \mathrm{E}-04$ & $0.00 \mathrm{E}+00$ & $87 E-05$ & $.41 E-04$ & $.13 E-03$ & $.96 E-03$ \\
\hline $.00 \mathrm{E}+00$ & $.65 E-02$ & $.28 E-04$ & $00 E+00$ & $14 E-05$ & $.54 \mathrm{E}-04$ & $.17 E-03$ & $.07 E-03$ \\
\hline $.00 \mathrm{E}+00$ & $1.70 \mathrm{E}-02$ & I. & & ل & 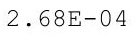 & -03 & $.20 \mathrm{E}-03$ \\
\hline & 2 & 4 & & & ( & -03 & 03 \\
\hline$E+00$ & $E-02$ & $.42 E-04$ & $E+00$ & 5 & $7 \mathrm{~F}$ & $E-03$ & $4 E-03$ \\
\hline $0 \mathrm{E}+00$ & $.83 E-02$ & $.47 \mathrm{E}-04$ & $.00 \mathrm{E}+00$ & 5 & LE- & -03 & $7 E-03$ \\
\hline $.00 \mathrm{E}+00$ & $.88 E-02$ & $1.52 E-04$ & $.00 E+00$ & $35 E-05$ & $.200^{-1}$ & $E-03$ & $.70 E-03$ \\
\hline DET U & $93 E-02$ & $.57 E-04$ & & & $\cdot .4+5-04$ & $.47 E-03$ & $.84 E-03$ \\
\hline & & & & & & & \\
\hline & & & & & & 3 & \\
\hline 0 & 2 & 4 & $\Xi+00$ & 5 & 4 & 3 & 03 \\
\hline+00 & & & & 05 & & & \\
\hline $00 \mathrm{E}+00$ & $2.19 \mathrm{E}-02$ & $.84 \mathrm{E}-04$ & 0 & 5 & & 03 & $5 E-03$ \\
\hline$E+00$ & 2.210 & 4 & & & & & 03 \\
\hline $\mathrm{E}+00$ & $2.30 E-02$ & $.96 E-04$ & $00 E+00$ & $55 E-05$ & $.55 E-04$ & $.87 E-03$ & -03 \\
\hline $.00 E+00$ & 2 & 4 & & & 4 & 3 & 3 \\
\hline $0.00 \mathrm{E}+00$ & $2.41 E-02$ & & 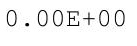 & 5 & 4 & 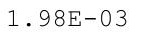 & 3 \\
\hline$E+00$ & $E-02$ & 2 & $E+00$ & 55 & 4 & 03 & -03 \\
\hline $00 \mathrm{E}+00$ & $53 E-02$ & $22 \mathrm{E}-04$ & $00 \mathrm{E}+00$ & $52 E-05$ & $5.40 \mathrm{E}-04$ & $.10 \mathrm{E}-03$ & $6.52 \mathrm{E}-03$ \\
\hline
\end{tabular}


RESRAD-OFFSITE, Version 2.5

$\mathrm{T}^{1 / 2}$ Limit $=180$ days

Title : RESRAD-OFFSITE Drinking Water, Plant, Milk, and Meat Pathways for Offsite Reside File : PBA-1_TC99-DOE-5.ROF

Summary of dose at graphical times, reptition 1 (continued)

Time

Years

$2.12 \mathrm{E}+02$

$2.13 \mathrm{E}+02$

$2.13 \mathrm{E}+02$

$2.14 \mathrm{E}+02$

$2.14 \mathrm{E}+02$

$2.15 \mathrm{E}+02$

$2.15 \mathrm{E}+02$

$2.16 \mathrm{E}+02$

$2.16 \mathrm{E}+02$

$2.17 \mathrm{E}+02$

$2.17 \mathrm{E}+02$

$2.18 \mathrm{E}+02$

$2.18 \mathrm{E}+02$

$2.19 \mathrm{E}+02$

$2.19 \mathrm{E}+02$

$2.20 \mathrm{E}+02$

$2.20 \mathrm{E}+02$

$2.21 \mathrm{E}+02$

$2.21 \mathrm{E}+02$

$2.22 \mathrm{E}+02$

$2.23 \mathrm{E}+02$

$2.23 \mathrm{E}+02$

$2.24 \mathrm{E}+02$

$2.24 \mathrm{E}+02$

$2.25 \mathrm{E}+02$

$2.25 \mathrm{E}+02$

$2.26 \mathrm{E}+02$

$2.26 \mathrm{E}+02$

$2.27 \mathrm{E}+02$

$2.27 \mathrm{E}+02$

$2.28 \mathrm{E}+02$

$2.28 \mathrm{E}+02$

$2.29 \mathrm{E}+02$

$2.29 \mathrm{E}+02$

$2.30 \mathrm{E}+02$

2. $30 \mathrm{E}+02$

2. $31 \mathrm{E}+02$

$2.31 \mathrm{E}+02$

2. $32 \mathrm{E}+02$

2. $32 \mathrm{E}+02$

$2.33 \mathrm{E}+02$

2. $33 \mathrm{E}+02$

$2.34 \mathrm{E}+02$

2. $34 \mathrm{E}+02$

2. $35 \mathrm{E}+02$

$2.35 \mathrm{E}+02$
Dose statistics at graphical times, mrem/yr

\begin{tabular}{|c|c|c|c|c|c|c|c|}
\hline inimum & Iaximum & Mean & ledian & $90 \%$ & $95 \%$ & $97.5 \%$ & $9 \%$ \\
\hline $0 \mathrm{E}+00$ & $2.59 \mathrm{E}-02$ & $2.29 E-04$ & $0.00 \mathrm{E}+00$ & $07 E-05$ & $5.59 \mathrm{E}-04$ & $.16 \mathrm{E}-03$ & $72 E-03$ \\
\hline$E+00$ & $E-02$ & $36 E-04$ & $0 E+00$ & $61 E-05$ & $79 E-04$ & $.22 E-03$ & $91 E-03$ \\
\hline$E+00$ & $2.71 E-02$ & $2.43 E-04$ & 00 & $02 E-04$ & $1 E-04$ & $.28 \mathrm{E}-03$ & $11 E-03$ \\
\hline$E+00$ & $2.78 E-02$ & -04 & 0 & & 4 & 3 & -03 \\
\hline 00 & -02 & $3 E-04$ & & 4 & 4 & 03 & $52 E-03$ \\
\hline $00 E+00$ & $2.91 \mathrm{E}-02$ & $2.66 \mathrm{E}-04$ & $.00 E+00$ & 4 & -04 & 03 & 03 \\
\hline $0 \mathrm{E}+00$ & $E-02$ & $2.74 \mathrm{E}-04$ & $.00 \mathrm{E}+00$ & $31 E-04$ & -04 & - & 0. \\
\hline $.00 E+00$ & $3.04 E-02$ & $2.82 E-04$ & $.00 E+00$ & $.41 \mathrm{E}-04$ & . 20 क & -03 & $18 E-03$ \\
\hline$E+00$ & $E-02$ & $E-04$ & 00 & 4 & $1 E-04$ & -03 & $41 E-03$ \\
\hline $00 E+00$ & $3.18 \mathrm{E}-02$ & $2.99 E-04$ & & $.61 \mathrm{E}$ & $E-04$ & -03 & $64 E-03$ \\
\hline $00 E+00$ & $3.25 E-02$ & $3.08 \mathrm{E}-04$ & & $.70 \mathrm{E}-04$ & $37 E-04$ & $.89 E-03$ & $87 E-03$ \\
\hline$E+00$ & -02 & -04 & $\mathrm{E}+00$ & 4 & & 3 & 03 \\
\hline $.00 E+00$ & $3.40 \mathrm{E}-02$ & $3.26 \mathrm{E}-04$ & $.00 \mathrm{E}+00$ & $.88 E-04$ & $-1 \mathrm{E}-04$ & -03 & $36 \mathrm{E}-03$ \\
\hline $00 \mathrm{E}+00$ & $3.48 \mathrm{E}-02$ & $3.35 \mathrm{E}-04$ & $.00 \mathrm{E}+00$ & 4 & 4 & S & 03 \\
\hline $0 \mathrm{E}+00$ & $E-02$ & $3.44 \mathrm{E}-04$ & $\mathrm{E}+00$ & 4 & 1 & S & 03 \\
\hline $.00 \mathrm{E}+00$ & $3.63 \mathrm{E}-02$ & $3.54 \mathrm{E}-04$ & & $.19 \mathrm{E}-04$ & $03 \mathrm{~F}-03$ & -03 & -02 \\
\hline $.00 \mathrm{E}+00$ & $3.71 E-02$ & $3.64 E-04$ & $.00 E+00$ & $.30 E-04$ & $.07 E-03$ & $46 E-03$ & $04 E-02$ \\
\hline $\mathrm{E}+00$ & $E-02$ & $E-04$ & $\mathrm{E}+00$ & 4 & 3 & -03 & $7 E-02$ \\
\hline $.00 \mathrm{E}+00$ & $3.87 \mathrm{E}-02$ & $3.85 E-04$ & $.00 \mathrm{E}+00$ & $7 E-04$ & 20 ת תמת & -05 & $0 \mathrm{E}-02$ \\
\hline $.00 \mathrm{E}+00$ & $3.95 E-02$ & $3.95 \mathrm{E}-04$ & $.00 E+00$ & 04 & 3 & -03 & $12 \mathrm{E}-02$ \\
\hline $0 \mathrm{E}+00$ & $E-02$ & $.06 E-04$ & & OTL & 20 & כ & $15 E-02$ \\
\hline $.00 \mathrm{E}+00$ & $4.12 \mathrm{E}-02$ & $4.17 \mathrm{E}-04$ & $.00 \mathrm{E}+00$ & • & 5 & ( & -02 \\
\hline $0 \mathrm{E}+00$ & $.20 \mathrm{E}-02$ & $29 E-04$ & $00 E+00$ & $14 E-04$ & ג & $F_{0} 0$ & $21 E-02$ \\
\hline$E+00$ & $9 \mathrm{E}-02$ & $40 E-04$ & $\mathrm{E}+00$ & $.27 \mathrm{E}-$ & $55_{-1}$ & 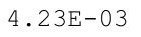 & $24 \mathrm{E}-02$ \\
\hline+00 & $E-02$ & $52 E-04$ & $\mathrm{E}+00$ & 4 & $39 E-03$ & 3 & $27 E-02$ \\
\hline $\mathrm{DE}+00$ & $E-02$ & -04 & $E+00$ & 4 & & & $1 E-02$ \\
\hline $0 \mathrm{E}+00$ & $E-02$ & $6 \mathrm{E}-04$ & $0 \mathrm{E}+00$ & 然 & 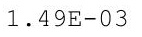 & & $.34 \mathrm{E}-02$ \\
\hline $.00 \mathrm{E}+00$ & 4. $65 \mathrm{E}-02$ & $4.89 E-04$ & $.00 \mathrm{E}+00$ & $82 E-04$ & $54 \mathrm{E}-03$ & $.70 \mathrm{E}-03$ & $.37 E-02$ \\
\hline $.00 E+00$ & $4.75 \mathrm{E}-02$ & $5.02 E-04$ & $00 E+00$ & $.97 E-04$ & 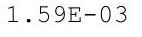 & $.83 E-03$ & $.40 \mathrm{E}-02$ \\
\hline $00 \mathrm{E}+00$ & $4.84 \mathrm{E}-02$ & . & & 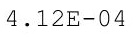 & & J & $.44 \mathrm{E}-02$ \\
\hline & 2 & 4 & $\mathrm{E}+00$ & 4 & & 3 & -02 \\
\hline$E+00$ & $E-02$ & $.42 E-04$ & $E+00$ & 4 & 3 & 3 & $1 E-02$ \\
\hline $.00 \mathrm{E}+00$ & $5.13 E-02$ & $5.56 \mathrm{E}-04$ & $0.00 \mathrm{E}+00$ & $4.66 \mathrm{E}-04$ & $82 E-03$ & $E-03$ & $.54 \mathrm{E}-02$ \\
\hline $.00 \mathrm{E}+00$ & $5.24 \mathrm{E}-02$ & $5.70 \mathrm{E}-04$ & $0.00 \mathrm{E}+00$ & $4.88 E-04$ & $.88 E-03$ & $.55 E-03$ & $.58 \mathrm{E}-02$ \\
\hline $0 E+00$ & $35 E-02$ & $.85 E-04$ & & & & & $.62 \mathrm{E}-02$ \\
\hline & & & & & & & -02 \\
\hline & & & & & & & \\
\hline 0 & 2 & 4 & +00 & 4 & 3 & 3 & 02 \\
\hline 00 & 2 & 4 & & & 3 & 03 & 02 \\
\hline $00 E+00$ & $.92 \mathrm{E}-02$ & $1 E-04$ & & 4 & 3 & & $81 E-02$ \\
\hline$E+00$ & 2 & 4 & & & & & -02 \\
\hline$E+00$ & $.17 E-02$ & $.94 \mathrm{E}-04$ & $00 E+00$ & $69 \mathrm{E}-0$ & $.40 \mathrm{E}-\mathrm{C}$ & & 02 \\
\hline $.00 E+00$ & 2 & & & & & & 2 \\
\hline $0.00 \mathrm{E}+00$ & & 04 & P & 4 & S & 3 & 02 \\
\hline $\mathrm{E}+00$ & 6.5 & 7.4 & $E+00$ & 4 & 3 & 3 & 2.03 \\
\hline $.00 E+00$ & $.70 \mathrm{E}-02$ & $7.64 \mathrm{E}-04$ & $.00 \mathrm{E}+00$ & $7.76 E-04$ & $.67 E-03$ & $7.48 \mathrm{E}-03$ & $2.07 E-02$ \\
\hline
\end{tabular}


RESRAD-OFFSITE, Version 2.5

$\mathrm{T}^{1 / 2}$ Limit $=180$ days

Title : RESRAD-OFFSITE Drinking Water, Plant, Milk, and Meat Pathways for Offsite Reside File : PBA-1_TC99-DOE-5.ROF

Summary of dose at graphical times, reptition 1 (continued)

Time

Years

$2.36 \mathrm{E}+02$

$2.36 \mathrm{E}+02$

$2.37 \mathrm{E}+02$

$2.37 \mathrm{E}+02$

$2.38 \mathrm{E}+02$

$2.38 \mathrm{E}+02$

$2.39 \mathrm{E}+02$

$2.39 \mathrm{E}+02$

$2.40 \mathrm{E}+02$

$2.40 \mathrm{E}+02$

$2.41 \mathrm{E}+02$

$2.41 \mathrm{E}+02$

$2.42 \mathrm{E}+02$

$2.43 \mathrm{E}+02$

$2.43 \mathrm{E}+02$

$2.44 \mathrm{E}+02$

$2.44 \mathrm{E}+02$

$2.45 \mathrm{E}+02$

$2.45 \mathrm{E}+02$

$2.46 \mathrm{E}+02$

$2.46 \mathrm{E}+02$

$2.47 \mathrm{E}+02$

$2.47 \mathrm{E}+02$

$2.48 \mathrm{E}+02$

$2.48 \mathrm{E}+02$

$2.49 \mathrm{E}+02$

$2.49 \mathrm{E}+02$

$2.50 \mathrm{E}+02$

$2.50 \mathrm{E}+02$

$2.51 \mathrm{E}+02$

$2.51 \mathrm{E}+02$

$2.52 \mathrm{E}+02$

$2.52 \mathrm{E}+02$

$2.53 \mathrm{E}+02$

$2.53 \mathrm{E}+02$

$2.54 \mathrm{E}+02$

$2.54 \mathrm{E}+02$

$2.55 \mathrm{E}+02$

$2.55 \mathrm{E}+02$

$2.56 \mathrm{E}+02$

$2.56 \mathrm{E}+02$

$2.57 \mathrm{E}+02$

$2.57 \mathrm{E}+02$

$2.58 \mathrm{E}+02$

$2.58 \mathrm{E}+02$

$2.59 \mathrm{E}+02$
Dose statistics at graphical times, mrem/yr

\begin{tabular}{|c|c|c|c|c|c|c|c|}
\hline inimum & aximum & Mean & ledian & $0 \%$ & $5 \%$ & $97.5 \%$ & \\
\hline-00 & $36 E-02$ & $2 E-04$ & $0.00 \mathrm{E}+00$ & $5 E-04$ & $4 E-03$ & $7.66 \mathrm{E}-03$ & $E-02$ \\
\hline+00 & 02 & -04 & $E+00$ & 4 & 3 & 3 & 政 \\
\hline-00 & -02 & -04 & & $2 E-04$ & 03 & 03 & -02 \\
\hline+00 & 02 & & & & & & -02 \\
\hline $\mathrm{E}+00$ & 02 & -04 & & & & 03 & $31 E-02$ \\
\hline $\mathrm{E}+00$ & -02 & -04 & $E+00$ & $8 E-04$ & -03 & -03 & $6 E-02$ \\
\hline 00 & -02 & $3 F-0$ & $0 \mathrm{E}+00$ & $E-04$ & 3 & -03 & . \\
\hline $.00 E+00$ & $8.04 \mathrm{E}-02$ & 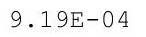 & & $1.02 E-03$ & & -03 & $46 E-02$ \\
\hline-00 & -02 & $E-04$ & 00 & $5 E-03$ & 03 & -03 & -02 \\
\hline $.00 \mathrm{E}+00$ & $10 \mathrm{E}-02$ & $2 E-04$ & & -03 & 03 & -03 & $56 \mathrm{E}-02$ \\
\hline+00 & $E-02$ & $E-04$ & & & & & $E-02$ \\
\hline$E+00$ & -02 & כ & +00 & & & $E-03$ & $E-02$ \\
\hline $.00 \mathrm{E}+00$ & $6 \mathrm{E}-02$ & • & $\mathrm{E}+00$ & -03 & 3 & -03 & $-0<$ \\
\hline$E+00$ & -02 & $E-03$ & -00 & $1.2 \pm$ & & -02 & $78 E-02$ \\
\hline$E+00$ & 02 & 03 & -00 & 03 & & -02 & -02 \\
\hline $.00 \mathrm{E}+00$ & $9.56 \mathrm{E}-02$ & -03 & & 03 & 03 & -02 & -02 \\
\hline $.00 \mathrm{E}+00$ & $5 E-02$ & $2 E-03$ & $\mathrm{E}+00$ & $1.32 \mathrm{E}-03$ & $3 E-03$ & $E-02$ & $93 E-02$ \\
\hline $0 E+00$ & $7 E-02$ & $5 E-03$ & $0 E+00$ & $37 E-03$ & $5 E-03$ & $10 E-02$ & $98 \mathrm{E}-02$ \\
\hline$E+00$ & -01 & $7 E-03$ & 00 & 3 & & 2 & $-0<$ \\
\hline+00 & 01 & -03 & -00 & 3 & & -02 & -02 \\
\hline $.00 \mathrm{E}+00$ & $1.06 \mathrm{E}-01$ & J & & & & -02 & -02 \\
\hline $.00 \mathrm{E}+00$ & $1.08 \mathrm{E}-01$ & $.25 E-03$ & $0.00 \mathrm{E}+00$ & $1.56 \mathrm{E}-$ & & -02 & -02 \\
\hline $00 E+00$ & $10 \mathrm{E}-01$ & $28 E-$ & $0.00 \mathrm{E}+00$ & 3 & 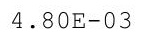 & -02 & $27 \mathrm{E}-02$ \\
\hline $.00 \mathrm{E}+00$ & $1.13 \mathrm{E}-01$ & $1.30 \mathrm{E}-03$ & $0 \mathrm{E}+00$ & $1.66 \mathrm{E}-03$ & $94 \mathrm{E}-03$ & $.26 \mathrm{E}-02$ & $34 E-02$ \\
\hline+00 & $1.15 \mathrm{E}-01$ & $.33 E-03$ & & & 03 & $F-02$ & $40 \mathrm{E}-02$ \\
\hline-00 & & & & & & & -02 \\
\hline $.00 \mathrm{E}+00$ & -01 & -03 & $0.00 \mathrm{E}+00$ & 3 & & -02 & -02 \\
\hline $.00 E+00$ & $1.22 \mathrm{E}-01$ & $42 E-03$ & $0.00 \mathrm{E}+00$ & $.87 E-03$ & $45-20$ & $.37 E-02$ & $59 E-02$ \\
\hline $0 E+00$ & 1 & 3 & $00 E+00$ & - & 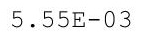 & -02 & $65 E-02$ \\
\hline 0 & -1 & - & $4 E-27$ & - & & - & -5 \\
\hline$F+0 \Omega$ & $E-01$ & $0 F-03$ & $3 E-25$ & $2 E-03$ & & 2 & $9 E-02$ \\
\hline+00 & $E-01$ & $E-03$ & & & & 2 & 02 \\
\hline & & $7 E-03$ & & & & 2 & 02 \\
\hline $.00 E+00$ & $1.37 \mathrm{E}-01$ & $.60 E-03$ & $1 E-19$ & $2.22 \mathrm{E}-03$ & $1 E-03$ & $.55 \mathrm{E}-02$ & $99 E-02$ \\
\hline . & 1. $40 \mathrm{E}-01$ & $1.63 E-03$ & $4 E-18$ & $205-03$ & & & $7 E-02$ \\
\hline 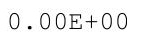 & & & & & & & \\
\hline 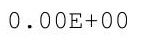 & 1 & 3 & & & & & 02 \\
\hline $.00 \mathrm{E}+00$ & & & 5 & & & & 02 \\
\hline$E+00$ & -01 & & & & 03 & 02 & 02 \\
\hline $.00 \mathrm{E}+00$ & $1.54 \mathrm{E}-01$ & $.80 E-03$ & $7 E-14$ & 3 & 3 & & $43 E-02$ \\
\hline$E+00$ & 1.5 & & & 3 & & 2 & -02 \\
\hline $\mathrm{JE}+00$ & $1.59 \mathrm{E}$ & $+\cdot 010$ & 12 & 3 & & 02 & $395-02$ \\
\hline 0 & 1. & 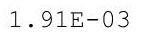 & $04 E-12$ & 2. & - & . & 1.00 \\
\hline . VUT & 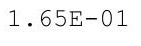 & - & & & & & 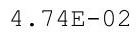 \\
\hline $\mathrm{E}+00$ & 1.6 & $1.98 E-03$ & $E-11$ & $2.94 E-03$ & $7.90 \mathrm{E}-03$ & $1.92 \mathrm{E}-02$ & $4.82 E-02$ \\
\hline $.00 E+00$ & $1.71 \mathrm{E}-01$ & $2.02 E-03$ & $.73 E-11$ & $3.01 E-03$ & $8.08 E-03$ & $1.96 \mathrm{E}-02$ & $4.90 E-02$ \\
\hline
\end{tabular}


RESRAD-OFFSITE, Version 2.5

$\mathrm{T}^{1 / 2}$ Limit $=180$ days

Title : RESRAD-OFFSITE Drinking Water, Plant, Milk, and Meat Pathways for Offsite Reside File : PBA-1_TC99-DOE-5.ROF

Summary of dose at graphical times, reptition 1 (continued)

Time

Years

$2.59 \mathrm{E}+02$

$2.60 \mathrm{E}+02$

$2.60 \mathrm{E}+02$

$2.61 \mathrm{E}+02$

$2.61 \mathrm{E}+02$

2. $62 \mathrm{E}+02$

$2.63 \mathrm{E}+02$

2. $63 \mathrm{E}+02$

$2.64 \mathrm{E}+02$

$2.64 \mathrm{E}+02$

. $65 \mathrm{E}+02$

$2.65 \mathrm{E}+02$

$2.66 \mathrm{E}+02$

$2.66 \mathrm{E}+02$

$2.67 \mathrm{E}+02$

$2.67 \mathrm{E}+02$

2. $68 \mathrm{E}+02$

2. $68 \mathrm{E}+02$

$2.69 \mathrm{E}+02$

$2.69 \mathrm{E}+02$

$2.70 \mathrm{E}+02$

$2.70 \mathrm{E}+02$

$2.71 \mathrm{E}+02$

$2.71 \mathrm{E}+02$

2. $72 \mathrm{E}+02$

$2.72 \mathrm{E}+02$

$2.73 E+02$

$2.73 \mathrm{E}+02$

$2.74 \mathrm{E}+02$

$2.74 \mathrm{E}+02$

$2.75 \mathrm{E}+02$

$2.75 \mathrm{E}+02$

$2.76 \mathrm{E}+02$

$2.76 \mathrm{E}+02$

$2.77 \mathrm{E}+02$

$2.77 \mathrm{E}+02$

$2.78 \mathrm{E}+02$

$2.78 \mathrm{E}+02$

$2.79 \mathrm{E}+02$

$2.79 \mathrm{E}+02$

$2.80 \mathrm{E}+02$

$2.80 \mathrm{E}+02$

$2.81 \mathrm{E}+02$

$2.81 E+02$

$2.82 \mathrm{E}+02$

$2.82 \mathrm{E}+02$
Dose statistics at graphical times, mrem/yr

\begin{tabular}{|c|c|c|c|c|c|c|c|}
\hline inimum & aximum & Mean & ledian & $90 \%$ & $5 \%$ & $97.5 \%$ & $3 \%$ \\
\hline+00 & $1.74 E-01$ & $6 E-03$ & 1. 19E-10 & $8 E-03$ & $8.26 \mathrm{E}-03$ & $.99 \mathrm{E}-02$ & $4.99 \mathrm{E}-02$ \\
\hline$\Xi+00$ & $E-01$ & $E-03$ & $E-10$ & 3 & 03 & 02 & -02 \\
\hline-00 & $1 E-01$ & $4 E-03$ & $E-10$ & $1 E-03$ & 03 & 02 & -02 \\
\hline $\mathrm{z}+00$ & $4 E-01$ & $8 E-03$ & $E-10$ & -03 & & 02 & -02 \\
\hline+00 & -01 & -03 & -09 & 3 & & 02 & $32 E-02$ \\
\hline $\mathrm{DE}+00$ & -01 & -03 & -09 & 03 & 3 & 02 & 02 \\
\hline $0 E+00$ & -01 & J & -09 & J & J & -02 & 0 \\
\hline $.00 E+00$ & $1.97 \mathrm{E}-01$ & $2.07+0$ & $E-09$ & 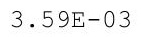 & & -02 & $59 E-02$ \\
\hline-00 & 01 & 03 & 09 & $7 E-03$ & 03 & -02 & -02 \\
\hline $.00 \mathrm{E}+00$ & 01 & 3 & 88 & 03 & 02 & -02 & -02 \\
\hline+00 & $E-01$ & $E-03$ & -08 & 3 & & -02 & $E-02$ \\
\hline$E+00$ & & & & & & -02 & -02 \\
\hline $.00 \mathrm{E}+00$ & $2.14 \mathrm{E}-01$ & $2.56 \mathrm{E}-03$ & $E-08$ & $0 E-03$ & -02 & $E-02$ & $-0<$ \\
\hline$E+00$ & -01 & E-03 & -08 & $8 E-03$ & 02 & -02 & -02 \\
\hline$E+00$ & 01 & 03 & 08 & 3 & 02 & -02 & -02 \\
\hline $.00 \mathrm{E}+00$ & $2.25 \mathrm{E}-01$ & -03 & -07 & 03 & 02 & -02 & -02 \\
\hline $.00 \mathrm{E}+00$ & $9 \mathrm{E}-01$ & $5 E-03$ & $0 E-07$ & $7 E-03$ & -02 & $E-02$ & $43 E-02$ \\
\hline $0 E+00$ & $2.33 E-01$ & $80 E-03$ & $3 E-07$ & $7 E-03$ & $19 E-02$ & -02 & $E-02$ \\
\hline $\mathrm{E}+00$ & 01 & -03 & 07 & 3 & 2 & -02 & -02 \\
\hline $\mathrm{E}+00$ & -01 & -03 & -07 & -03 & 02 & -02 & $73 E-02$ \\
\hline$E+00$ & -01 & -03 & 07 & $E-03$ & 02 & -02 & -02 \\
\hline $.00 \mathrm{E}+00$ & $2.48 \mathrm{E}-01$ & -03 & 07 & & 02 & -02 & -02 \\
\hline $.00 \mathrm{E}+00$ & $2.52 \mathrm{E}-01$ & $3.05 E-03$ & $6.04 \mathrm{E}-07$ & $5.01 \mathrm{E}-03$ & 1. $32 \mathrm{E}-02$ & $2 E-02$ & $.04 \mathrm{E}-02$ \\
\hline $.00 \mathrm{E}+00$ & $2.56 \mathrm{E}-01$ & $3.11 \mathrm{E}-03$ & $2 E-07$ & $2 E-03$ & $34 \mathrm{E}-02$ & $7 E-02$ & $-4 \mathrm{E}-02$ \\
\hline+00 & $E-01$ & $E-03$ & 07 & 03 & 02 & -02 & $E-02$ \\
\hline$E+00$ & 01 & -03 & 06 & & & 02 & -02 \\
\hline $\mathrm{E}+00$ & $2.68 \mathrm{E}-01$ & $E-03$ & -06 & $7 E-03$ & & -02 & $47 E-02$ \\
\hline $.00 \mathrm{E}+00$ & $2.73 E-01$ & $3.32 E-03$ & $1.65 E-06$ & $5.58 \mathrm{E}-03$ & $1.43 \mathrm{E}-02$ & $.15 \mathrm{E}-02$ & $.58 \mathrm{E}-02$ \\
\hline $.00 \mathrm{E}+00$ & $2.77 E-01$ & $3.38 E-03$ & $1.90 E-06$ & $5.68 E-03$ & $.46 \mathrm{E}-02$ & -02 & $.69 E-02$ \\
\hline $.00 \mathrm{E}+00$ & $2.81 E-01$ & . $17+10$ & $2+00$ & 年 & 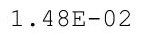 & 等 & $80 \mathrm{E}-02$ \\
\hline$\exists+00$ & $E-01$ & $E-03$ & $E-06$ & 3 & 2 & 02 & -02 \\
\hline$E+00$ & E-01 & $E-03$ & $E-06$ & 3 & 02 & 02 & -02 \\
\hline $.00 \mathrm{E}+00$ & $2.94 \mathrm{E}-01$ & $3.61 E-03$ & $3.31 E-06$ & $3 E-03$ & $1.56 \mathrm{E}-02$ & $0 \mathrm{E}-02$ & $14 \mathrm{E}-02$ \\
\hline $.00 \mathrm{E}+00$ & $2.99 \mathrm{E}-01$ & $3.67 \mathrm{E}-03$ & $3.77 \mathrm{E}-06$ & $6.24 \mathrm{E}-03$ & $1.59 \mathrm{E}-02$ & $45-02$ & $26 E-02$ \\
\hline . Uूस & $3.03 E-01$ & $3.73 E-03$ & & & & & $.40 \mathrm{E}-02$ \\
\hline 者 & & & & & & & \\
\hline مिم+ & & & & & & & \\
\hline 0 & 1 & 3 & 6 & 3 & 2 & 2 & 02 \\
\hline & & & & & 2 & & 02 \\
\hline $00 \mathrm{E}+00$ & 3.2 & 3 & 06 & 3 & 2 & & -02 \\
\hline $\mathrm{E}+00$ & 1 & 3 & & & & & -02 \\
\hline $.00 E+00$ & & $.17 E-03$ & & $.25 E-03$ & & & -02 \\
\hline .00 Et 00 & 3 & & 3 & P & $87 E-02$ & 2 & ser \\
\hline . OLT & & $4.31 E-03$ & & 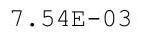 & 2 & 02 & 2 \\
\hline+00 & 3.5 & 4.3 & 05 & 03 & 1 . & 02 & -02 \\
\hline $.00 E+00$ & $3.55 E-01$ & $4.45 E-03$ & $.34 E-05$ & $7.87 E-03$ & $1.98 \mathrm{E}-02$ & $4.09 \mathrm{E}-02$ & $9.99 \mathrm{E}-02$ \\
\hline
\end{tabular}


RESRAD-OFFSITE, Version 2.5

$\mathrm{T}^{1 / 2}$ Limit $=180$ days

Title : RESRAD-OFFSITE Drinking Water, Plant, Milk, and Meat Pathways for Offsite Reside File : PBA-1_TC99-DOE-5.ROF

Summary of dose at graphical times, reptition 1 (continued)

Time

Years

$2.83 \mathrm{E}+02$

$2.84 \mathrm{E}+02$

$2.84 \mathrm{E}+02$

$2.85 \mathrm{E}+02$

$2.85 \mathrm{E}+02$

$2.86 \mathrm{E}+02$

$2.86 \mathrm{E}+02$

$2.87 \mathrm{E}+02$

$2.87 \mathrm{E}+02$

$2.88 \mathrm{E}+02$

$2.88 \mathrm{E}+02$

$2.89 \mathrm{E}+02$

$2.89 \mathrm{E}+02$

$2.90 \mathrm{E}+02$

$2.90 \mathrm{E}+02$

2. $91 \mathrm{E}+02$

$2.91 \mathrm{E}+02$

$2.92 \mathrm{E}+02$

$2.92 \mathrm{E}+02$

2. $93 \mathrm{E}+02$

$2.93 \mathrm{E}+02$

$2.94 \mathrm{E}+02$

$2.94 \mathrm{E}+02$

$2.95 \mathrm{E}+02$

$2.95 \mathrm{E}+02$

$2.96 \mathrm{E}+02$

$2.96 \mathrm{E}+02$

$2.97 \mathrm{E}+02$

$2.97 \mathrm{E}+02$

$2.98 \mathrm{E}+02$

$2.98 \mathrm{E}+02$

2. $99 \mathrm{E}+02$

$2.99 \mathrm{E}+02$

$3.00 \mathrm{E}+02$

$3.00 \mathrm{E}+02$

$3.01 \mathrm{E}+02$

3. $01 \mathrm{E}+02$

$3.02 \mathrm{E}+02$

$3.02 \mathrm{E}+02$

3. $03 \mathrm{E}+02$

3. $04 \mathrm{E}+02$

$3.04 \mathrm{E}+02$

$3.05 \mathrm{E}+02$

$3.05 \mathrm{E}+02$

$3.06 \mathrm{E}+02$

$3.06 \mathrm{E}+02$
Dose statistics at graphical times, mrem/yr

\begin{tabular}{|c|c|c|c|c|c|c|c|}
\hline inimum & aximum & Mean & ledian & $90 \%$ & $5 \%$ & $97.5 \%$ & $\%$ \\
\hline+00 & $3.60 E-01$ & $4.51 E-03$ & $1.47 E-05$ & $4 E-03$ & $2.01 E-02$ & $4.15 \mathrm{E}-02$ & 要 \\
\hline+00 & $E-01$ & $9 E-03$ & $9 E-05$ & 3 & 02 & 02 & - \\
\hline-00 & $E-01$ & $E-03$ & $E-05$ & $7 E-03$ & 02 & 02 & -01 \\
\hline $\mathrm{z}+00$ & $5 E-01$ & $E-03$ & & 3 & 2 & 02 & -01 \\
\hline+00 & 01 & 3 & & & 2 & 02 & $8 \mathrm{E}-01$ \\
\hline $.00 E+00$ & -01 & $E-03$ & -05 & 03 & 02 & 02 & 01 \\
\hline $0 E+00$ & -01 & $5 E-03$ & -05 & J & 2 & -02 & -01 \\
\hline $.00 E+00$ & $3.97 E-01$ & $.0 \angle 2$ US & $2.63 E-05$ & $9.16 \mathrm{E}-03$ & $2.28 \mathrm{E}-02$ & -02 & $.13 E-01$ \\
\hline-00 & -01 & 03 & 05 & 03 & 02 & -02 & -01 \\
\hline $.00 \mathrm{E}+00$ & -01 & 3 & 05 & 03 & 02 & -02 & $E-01$ \\
\hline+00 & -01 & 3 & 5 & 3 & & -02 & $E-01$ \\
\hline$E+00$ & & & & & & & -01 \\
\hline $.00 \mathrm{E}+00$ & $4.24 \mathrm{E}-01$ & $5.41 E-03$ & $3.71 E-05$ & $1.01 \mathrm{E}-02$ & $2.48 \mathrm{E}-02$ & -02 & $21 E-01$ \\
\hline$E+00$ & -01 & -03 & -05 & $1.03 E-02$ & 02 & -02 & $.22 E-01$ \\
\hline$E+00$ & 01 & 03 & 05 & 02 & 02 & 02 & -01 \\
\hline $.00 \mathrm{E}+00$ & -01 & -03 & -05 & -02 & 02 & -02 & -01 \\
\hline $.00 \mathrm{E}+00$ & $E-01$ & $E-03$ & $E-05$ & $1.08 \mathrm{E}-02$ & $65 E-02$ & $E-02$ & $.27 E-01$ \\
\hline $\mathrm{DE}+00$ & $3 E-01$ & $3 E-03$ & $0 E-05$ & $E-02$ & $69 E-02$ & -02 & $29 \mathrm{E}-01$ \\
\hline $.00 \mathrm{E}+00$ & $9 E-01$ & $1 E-03$ & $E-05$ & $E-02$ & & 02 & -01 \\
\hline $\mathrm{E}+00$ & -01 & -03 & -05 & 02 & -02 & -02 & $.32 E-01$ \\
\hline$E+00$ & -01 & -03 & -05 & -02 & & -02 & -01 \\
\hline $.00 \mathrm{E}+00$ & $4.77 \mathrm{E}-01$ & -03 & -05 & 02 & & -02 & -01 \\
\hline $.00 \mathrm{E}+00$ & $4.83 E-01$ & $6.26 \mathrm{E}-03$ & $6.69 \mathrm{E}-05$ & $1.19 \mathrm{E}-02$ & $2.92 \square-02$ & $.75 E-02$ & $.37 E-01$ \\
\hline $.00 \mathrm{E}+00$ & $9 \mathrm{E}-01$ & $5 E-03$ & $0 E-05$ & $1.21 \mathrm{E}-02$ & $97 \mathrm{E}-02$ & $E-02$ & $39 E-01$ \\
\hline+00 & $5 E-01$ & $4 E-03$ & -05 & 02 & 02 & -02 & -01 \\
\hline$E+00$ & 01 & $E-03$ & -05 & 02 & & 02 & -01 \\
\hline $\mathrm{E}+00$ & $E-01$ & $E-03$ & -05 & 1. $28 \mathrm{E}-02$ & -02 & -02 & $45 E-01$ \\
\hline $.00 \mathrm{E}+00$ & $5.13 E-01$ & $6.72 E-03$ & $8.66 \mathrm{E}-05$ & $1.30 \mathrm{E}-02$ & $3.16 \mathrm{E}-02$ & $.18 \mathrm{E}-02$ & $.46 \mathrm{E}-01$ \\
\hline $.00 \mathrm{E}+00$ & $5.20 \mathrm{E}-01$ & $6.81 E-03$ & $9.08 E-05$ & 1. $32 \mathrm{E}-02$ & $3 . \angle \perp E-0 Z$ & -02 & $.48 \mathrm{E}-01$ \\
\hline $.00 \mathrm{E}+00$ & $5.26 \mathrm{E}-01$ & 政 & - & 1.078 & & 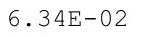 & $.50 \mathrm{E}-01$ \\
\hline 00 & $E-01$ & $E-03$ & $3 E-05$ & 2 & 2 & 02 & $E-01$ \\
\hline$E+00$ & $E-01$ & $E-03$ & $E-04$ & $9 \mathrm{E}-02$ & 02 & & -01 \\
\hline $.00 \mathrm{E}+00$ & $6 \mathrm{E}-01$ & $E-03$ & $9 E-04$ & 02 & 2 & -02 & $56 \mathrm{E}-01$ \\
\hline $.00 \mathrm{E}+00$ & $5.52 \mathrm{E}-01$ & $7.30 \mathrm{E}-03$ & $1.14 \mathrm{E}-04$ & $1.43 \mathrm{E}-02$ & $3.45 \mathrm{E}-02$ & $7 E-02$ & $.58 E-01$ \\
\hline 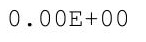 & $5.59 \mathrm{E}-01$ & $7.40 E-03$ & $.19 E-04$ & & & & $.60 E-01$ \\
\hline 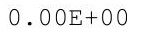 & & & & & & & \\
\hline مिم+ & & & t & & & & 01 \\
\hline 0 & 1 & F & 4 & 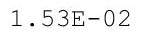 & 2 & 2 & \\
\hline & & & & & & 02 & 01 \\
\hline $.00 \mathrm{E}+00$ & 1 & $1 \mathrm{E}-$ & $5 E-04$ & 2 & 2 & & $69 E-01$ \\
\hline $\mathrm{E}+00$ & & 3 & 04 & 2 & & & -01 \\
\hline $.00 E+00$ & & $.12 \mathrm{E}-03$ & & $1.63 E-02$ & & & $.73 E-01$ \\
\hline $.00 \mathrm{E}+00$ & & $8.23 E-03$ & 4 &.+ & 2 & 2 & $1.76 \mathrm{E}-01$ \\
\hline . OLT & $6.20 \mathrm{E}-01$ & & & 2 & 2 & 02 & 1 \\
\hline$E+00$ & 6.2 & $8.45 \mathrm{E}$ & -04 & 1. & 4 & 02 & -01 \\
\hline $.00 E+00$ & $6.34 E-01$ & $8.56 E-03$ & $.85 E-04$ & $.74 E-02$ & $4.09 \mathrm{E}-02$ & $7.70 \mathrm{E}-02$ & 1. $82 \mathrm{E}-01$ \\
\hline
\end{tabular}


RESRAD-OFFSITE, Version 2.5

$\mathrm{T}^{1 / 2}$ Limit $=180$ days

Title : RESRAD-OFFSITE Drinking Water, Plant, Milk, and Meat Pathways for Offsite Reside File : PBA-1_TC99-DOE-5.ROF

Summary of dose at graphical times, reptition 1 (continued)

Time

Years

$3.07 \mathrm{E}+02$

$3.07 \mathrm{E}+02$

$3.08 \mathrm{E}+02$

$3.08 \mathrm{E}+02$

$3.09 \mathrm{E}+02$

$3.09 \mathrm{E}+02$

$3.10 \mathrm{E}+02$

$3.10 \mathrm{E}+02$

$3.11 \mathrm{E}+02$

$3.11 \mathrm{E}+02$

$3.12 \mathrm{E}+02$

$3.12 \mathrm{E}+02$

$3.13 E+02$

$3.13 \mathrm{E}+02$

$3.14 \mathrm{E}+02$

$3.14 \mathrm{E}+02$

$3.15 \mathrm{E}+02$

$3.15 \mathrm{E}+02$

$3.16 \mathrm{E}+02$

$3.16 \mathrm{E}+02$

$3.17 \mathrm{E}+02$

$3.17 \mathrm{E}+02$

$3.18 \mathrm{E}+02$

$3.18 \mathrm{E}+02$

$3.19 \mathrm{E}+02$

$3.19 \mathrm{E}+02$

$3.20 \mathrm{E}+02$

$3.20 \mathrm{E}+02$

$3.21 \mathrm{E}+02$

$3.21 \mathrm{E}+02$

$3.22 \mathrm{E}+02$

$3.22 \mathrm{E}+02$

$3.23 \mathrm{E}+02$

$3.24 \mathrm{E}+02$

$3.24 \mathrm{E}+02$

$3.25 \mathrm{E}+02$

$3.25 \mathrm{E}+02$

$3.26 \mathrm{E}+02$

$3.26 \mathrm{E}+02$

$3.27 \mathrm{E}+02$

$3.27 \mathrm{E}+02$

3. $28 \mathrm{E}+02$

$3.28 \mathrm{E}+02$

$3.29 \mathrm{E}+02$

$3.29 \mathrm{E}+02$

$3.30 \mathrm{E}+02$
Dose statistics at graphical times, mrem/yr

\begin{tabular}{|c|c|c|c|c|c|c|c|}
\hline inimum & Maximum & Mean & Median & $90 \%$ & $95 \frac{\circ}{\circ}$ & $7.5 \%$ & $9 \frac{\circ}{0}$ \\
\hline $.00 \mathrm{E}+00$ & $6.41 \mathrm{E}-01$ & $8.67 \mathrm{E}-03$ & $1.92 \mathrm{E}-04$ & $1.77 \mathrm{E}-02$ & $4.15 \mathrm{E}-02$ & $7.79 \mathrm{E}-02$ & $1.84 \mathrm{E}-01$ \\
\hline $0.00 \mathrm{E}+00$ & $6.49 \mathrm{E}-01$ & $8.79 \mathrm{E}-03$ & $2.00 \mathrm{E}-04$ & $1.80 \mathrm{E}-02$ & $4.21 \mathrm{E}-02$ & $7.88 \mathrm{E}-02$ & $1.86 \mathrm{E}-01$ \\
\hline $0.00 \mathrm{E}+00$ & $6.56 \mathrm{E}-01$ & $8.90 \mathrm{E}-03$ & $2.08 \mathrm{E}-04$ & $1.83 \mathrm{E}-02$ & $4.27 \mathrm{E}-02$ & $7.97 \mathrm{E}-02$ & $1.88 \mathrm{E}-01$ \\
\hline $0.00 \mathrm{E}+00$ & $6.63 \mathrm{E}-01$ & $9.02 E-03$ & $2.17 \mathrm{E}-04$ & $1.85 \mathrm{E}-02$ & $4.33 E-02$ & $8.06 \mathrm{E}-02$ & $1.90 \mathrm{E}-01$ \\
\hline $0.00 \mathrm{E}+00$ & $6.70 \mathrm{E}-01$ & $9.13 \mathrm{E}-03$ & $2.26 \mathrm{E}-04$ & $1.88 \mathrm{E}-02$ & $40 \mathrm{E}-02$ & $8.16 \mathrm{E}-02$ & $.92 \mathrm{E}-01$ \\
\hline $0.00 \mathrm{E}+00$ & $6.78 \mathrm{E}-01$ & $9.25 \mathrm{E}-03$ & $2.34 \mathrm{E}-04$ & $1.91 \mathrm{E}-02$ & $.46 \mathrm{E}-02$ & $8.24 \mathrm{E}-02$ & $1.95 \mathrm{E}-01$ \\
\hline $00 \mathrm{E}+00$ & $6.85 \mathrm{E}-01$ & $9.37 \mathrm{E}-03$ & $2.41 \mathrm{E}-04$ & $1.94 \mathrm{E}-02$ & $.52 \mathrm{E}-02$ & $8.33 E-02$ & $1.97 \mathrm{E}-01$ \\
\hline $.00 \mathrm{E}+00$ & $6.93 \mathrm{E}-01$ & $9.49 \mathrm{E}-03$ & $2.49 \mathrm{E}-04$ & $1.97 \mathrm{E}-02$ & $4.57 \mathrm{E}-02$ & $8.42 \mathrm{E}-02$ & $1.99 \mathrm{E}-01$ \\
\hline $.00 \mathrm{E}+00$ & $7.00 \mathrm{E}-01$ & $9.61 \mathrm{E}-03$ & $2.57 \mathrm{E}-04$ & $2.00 \mathrm{E}-02$ & $4.63 \mathrm{E}-02$ & $8.50 \mathrm{E}-02$ & $2.01 \mathrm{E}-01$ \\
\hline $.00 \mathrm{E}+00$ & $7.08 \mathrm{E}-01$ & $9.73 \mathrm{E}-03$ & $2.65 \mathrm{E}-04$ & $2.04 \mathrm{E}-02$ & $4.69 \mathrm{E}-02$ & $8.59 \mathrm{E}-02$ & $2.03 \mathrm{E}-01$ \\
\hline $0.00 \mathrm{E}+00$ & $7.15 \mathrm{E}-01$ & $9.86 \mathrm{E}-03$ & $2.73 \mathrm{E}-04$ & $2.07 \mathrm{E}-02$ & $4.75 \mathrm{E}-02$ & $8.68 \mathrm{E}-02$ & $2.06 \mathrm{E}-01$ \\
\hline $0.00 \mathrm{E}+00$ & $7.23 \mathrm{E}-01$ & $9.98 \mathrm{E}-03$ & $2.81 \mathrm{E}-04$ & $2.10 \mathrm{E}-02$ & $4.80 \mathrm{E}-02$ & $8.77 \mathrm{E}-02$ & $2.08 \mathrm{E}-01$ \\
\hline $0.00 \mathrm{E}+00$ & $7.31 \mathrm{E}-01$ & $1.01 \mathrm{E}-02$ & $2.91 \mathrm{E}-04$ & $2.13 \mathrm{E}-02$ & $4.86 \mathrm{E}-02$ & $8.86 \mathrm{E}-02$ & $2.10 \mathrm{E}-01$ \\
\hline $0.00 \mathrm{E}+00$ & $7.38 \mathrm{E}-01$ & $1.02 \mathrm{E}-02$ & $3.01 \mathrm{E}-04$ & $2.16 \mathrm{E}-02$ & $4.92 \mathrm{E}-02$ & $8.95 \mathrm{E}-02$ & $2.13 \mathrm{E}-01$ \\
\hline $0.00 \mathrm{E}+00$ & $7.46 \mathrm{E}-01$ & $1.04 \mathrm{E}-02$ & $3.10 \mathrm{E}-04$ & $2.20 \mathrm{E}-02$ & $4.98 \mathrm{E}-02$ & $9.04 \mathrm{E}-02$ & $2.15 \mathrm{E}-01$ \\
\hline $0.00 \mathrm{E}+00$ & $7.54 \mathrm{E}-01$ & $1.05 \mathrm{E}-02$ & $3.19 \mathrm{E}-04$ & $2.23 \mathrm{E}-02$ & $5.04 \mathrm{E}-02$ & $9.13 \mathrm{E}-02$ & $2.17 \mathrm{E}-01$ \\
\hline $0.00 \mathrm{E}+00$ & 7. $62 \mathrm{E}-01$ & $1.06 \mathrm{E}-02$ & $3.30 \mathrm{E}-04$ & $2.25 \mathrm{E}-02$ & $5.10 \mathrm{E}-02$ & $9.22 \mathrm{E}-02$ & $2.20 \mathrm{E}-01$ \\
\hline $0.00 \mathrm{E}+00$ & $7.70 \mathrm{E}-01$ & $1.07 \mathrm{E}-02$ & $3.39 \mathrm{E}-04$ & $2.28 \mathrm{E}-02$ & $5.16 \mathrm{E}-02$ & $9.31 \mathrm{E}-02$ & $2.22 \mathrm{E}-01$ \\
\hline $0.00 \mathrm{E}+00$ & $7.78 \mathrm{E}-01$ & $1.09 \mathrm{E}-02$ & $3.47 \mathrm{E}-04$ & $2.31 \mathrm{E}-02$ & $5.22 \mathrm{E}-02$ & $9.41 \mathrm{E}-02$ & $2.24 \mathrm{E}-01$ \\
\hline $0.00 \mathrm{E}+00$ & $7.86 \mathrm{E}-01$ & $1.10 \mathrm{E}-02$ & $3.60 \mathrm{E}-04$ & $2.34 \mathrm{E}-02$ & $5.28 \mathrm{E}-02$ & $9.52 \mathrm{E}-02$ & $.27 \mathrm{E}-01$ \\
\hline $0.00 \mathrm{E}+00$ & 7 & 1 & & & & 2 & \\
\hline $0.00 \mathrm{E}+00$ & 8 & 1 & 3 & 2 & 2 & 2 & 01 \\
\hline $0.00 \mathrm{E}+00$ & $8.10 \mathrm{E}-01$ & $1.14 \mathrm{E}-02$ & $3.96 \mathrm{E}-04$ & $2.44 \mathrm{E}-02$ & $5.47 \mathrm{E}-02$ & $9.87 \mathrm{E}-02$ & -01 \\
\hline $0.00 \mathrm{E}+00$ & $8.18 \mathrm{E}-01$ & $1.16 \mathrm{E}-02$ & $4.06 \mathrm{E}-04$ & $2.47 \mathrm{E}-02$ & $5.53 \mathrm{E}-02$ & $9.98 \mathrm{E}-02$ & $2.36 \mathrm{E}-01$ \\
\hline $0.00 \mathrm{E}+00$ & $8.27 \mathrm{E}-01$ & $1.17 \mathrm{E}-02$ & $4.16 \mathrm{E}-04$ & $2.50 \mathrm{E}-02$ & $5.60 \mathrm{E}-02$ & $1.01 \mathrm{E}-01$ & $2.39 \mathrm{E}-01$ \\
\hline $0.00 \mathrm{E}+00$ & $8.35 \mathrm{E}-01$ & $1.18 \mathrm{E}-02$ & $4.29 \mathrm{E}-04$ & $2.53 \mathrm{E}-02$ & $5.67 \mathrm{E}-02$ & $1.02 \mathrm{E}-01$ & $2.41 \mathrm{E}-01$ \\
\hline $0.00 \mathrm{E}+00$ & $8.43 \mathrm{E}-01$ & $1.20 \mathrm{E}-02$ & $4.42 \mathrm{E}-04$ & $2.56 \mathrm{E}-02$ & $5.74 \mathrm{E}-02$ & $1.03 \mathrm{E}-01$ & $2.44 \mathrm{E}-01$ \\
\hline $0.00 \mathrm{E}+00$ & $8.51 \mathrm{E}-01$ & $1.21 \mathrm{E}-02$ & $4.54 \mathrm{E}-04$ & $2.60 \mathrm{E}-02$ & $5.80 \mathrm{E}-02$ & $1.05 \mathrm{E}-01$ & $2.46 \mathrm{E}-01$ \\
\hline $0.00 \mathrm{E}+00$ & $8.60 \mathrm{E}-01$ & $1.23 \mathrm{E}-02$ & $4.66 \mathrm{E}-04$ & $2.64 \mathrm{E}-02$ & $5.86 \mathrm{E}-02$ & $1.06 \mathrm{E}-01$ & $2.49 \mathrm{E}-01$ \\
\hline $0.00 \mathrm{E}+00$ & $8.68 \mathrm{E}-01$ & 1.2 & 4. & $2.67 \mathrm{E}-02$ & 5.93 & $1.07 \mathrm{E}-01$ & $2.52 \mathrm{E}-01$ \\
\hline $00 E+00$ & 8. & 1 . & 4 & 2 & 2 & $1.08 \mathrm{E}-01$ & $2.54 \mathrm{E}-01$ \\
\hline $0.00 \mathrm{E}+00$ & $8.85 \mathrm{E}-01$ & $1.27 \mathrm{E}-02$ & $5.09 \mathrm{E}-04$ & $2.75 \mathrm{E}-02$ & $6.06 \mathrm{E}-02$ & $1.09 \mathrm{E}-01$ & $2.57 \mathrm{E}-01$ \\
\hline $0.00 \mathrm{E}+00$ & $8.94 \mathrm{E}-01$ & $1.28 \mathrm{E}-02$ & $5.21 \mathrm{E}-04$ & $2.79 \mathrm{E}-02$ & $6.12 \mathrm{E}-02$ & $1.10 \mathrm{E}-01$ & $2.59 \mathrm{E}-01$ \\
\hline $0.00 \mathrm{E}+00$ & $9.02 \mathrm{E}-01$ & $1.30 \mathrm{E}-02$ & $5.33 \mathrm{E}-04$ & $2.82 \mathrm{E}-02$ & $6.19 \mathrm{E}-02$ & $1.11 \mathrm{E}-01$ & $2.62 \mathrm{E}-01$ \\
\hline $0.00 \mathrm{E}+00$ & $9.11 \mathrm{E}-01$ & $1.31 \mathrm{E}-02$ & $5.45 \mathrm{E}-04$ & $2.86 \mathrm{E}-02$ & $6.26 \mathrm{E}-02$ & $1.13 \mathrm{E}-01$ & $2.64 \mathrm{E}-01$ \\
\hline $0.00 \mathrm{E}+00$ & $9.20 \mathrm{E}-01$ & $1.33 \mathrm{E}-02$ & $5.58 \mathrm{E}-04$ & $2.90 \mathrm{E}-02$ & $6.33 \mathrm{E}-02$ & $1.14 \mathrm{E}-01$ & $2.67 \mathrm{E}-01$ \\
\hline $0.00 \mathrm{E}+00$ & $9.29 \mathrm{E}-01$ & $1.35 \mathrm{E}-02$ & $5.73 \mathrm{E}-04$ & $2.94 \mathrm{E}-02$ & $6.40 \mathrm{E}-02$ & $1.15 \mathrm{E}-01$ & $2.69 \mathrm{E}-01$ \\
\hline $0.00 \mathrm{E}+00$ & $9.37 \mathrm{E}-01$ & $1.36 \mathrm{E}-02$ & $5.89 \mathrm{E}-04$ & $2.98 \mathrm{E}-02$ & $6.47 \mathrm{E}-02$ & $1.16 \mathrm{E}-01$ & $2.72 \mathrm{E}-01$ \\
\hline $0.00 \mathrm{E}+00$ & $9.46 \mathrm{E}-01$ & $1.38 \mathrm{E}-02$ & $6.03 E-04$ & $3.02 \mathrm{E}-02$ & $6.55 \mathrm{E}-02$ & $1.17 \mathrm{E}-01$ & $2.74 \mathrm{E}-01$ \\
\hline $0.00 \mathrm{E}+00$ & $9.55 \mathrm{E}-01$ & $1.39 \mathrm{E}-02$ & $6.16 \mathrm{E}-04$ & $3.06 \mathrm{E}-02$ & $6.62 \mathrm{E}-02$ & $1.18 \mathrm{E}-01$ & $2.77 \mathrm{E}-01$ \\
\hline $0.00 \mathrm{E}+00$ & $9.64 \mathrm{E}-01$ & $1.41 \mathrm{E}-02$ & $6.32 \mathrm{E}-04$ & $3.09 \mathrm{E}-02$ & $6.69 \mathrm{E}-02$ & $1.20 \mathrm{E}-01$ & $2.79 \mathrm{E}-01$ \\
\hline $0.00 \mathrm{E}+00$ & $9.73 \mathrm{E}-01$ & $1.42 \mathrm{E}-02$ & $6.48 \mathrm{E}-04$ & $3.13 \mathrm{E}-02$ & $6.76 \mathrm{E}-02$ & $1.21 \mathrm{E}-01$ & $2.81 \mathrm{E}-01$ \\
\hline $0.00 \mathrm{E}+00$ & $9.82 \mathrm{E}-01$ & $1.44 \mathrm{E}-02$ & $6.63 \mathrm{E}-04$ & $3.17 \mathrm{E}-02$ & $6.83 \mathrm{E}-02$ & $1.22 \mathrm{E}-01$ & $2.83 \mathrm{E}-01$ \\
\hline $0.00 \mathrm{E}+00$ & $9.91 \mathrm{E}-01$ & $1.46 \mathrm{E}-02$ & $6.77 \mathrm{E}-04$ & $3.20 \mathrm{E}-02$ & $6.91 \mathrm{E}-02$ & $1.24 \mathrm{E}-01$ & $2.86 \mathrm{E}-01$ \\
\hline $0.00 \mathrm{E}+00$ & $1.00 \mathrm{E}+00$ & $1.47 \mathrm{E}-02$ & $6.94 \mathrm{E}-04$ & $3.24 \mathrm{E}-02$ & $6.98 \mathrm{E}-02$ & $1.25 \mathrm{E}-01$ & $2.88 \mathrm{E}-01$ \\
\hline $00 \mathrm{E}+00$ & $1.01 \mathrm{E}+00$ & $1.49 \mathrm{E}-02$ & $7.13 \mathrm{E}-04$ & $3.28 \mathrm{E}-02$ & 7.05 & 1.26 & 2 . \\
\hline
\end{tabular}


RESRAD-OFFSITE, Version 2.5

$\mathrm{T}^{1 / 2}$ Limit $=180$ days

Title : RESRAD-OFFSITE Drinking Water, Plant, Milk, and Meat Pathways for Offsite Reside File : PBA-1_TC99-DOE-5.ROF

Summary of dose at graphical times, reptition 1 (continued)

Time

Years

$3.30 \mathrm{E}+02$

$3.31 \mathrm{E}+02$

$3.31 \mathrm{E}+02$

$3.32 \mathrm{E}+02$

3. $32 \mathrm{E}+02$

$3.33 \mathrm{E}+02$

$3.33 \mathrm{E}+02$

$3.34 \mathrm{E}+02$

$3.34 \mathrm{E}+02$

$3.35 \mathrm{E}+02$

$3.35 \mathrm{E}+02$

$3.36 \mathrm{E}+02$

$3.36 \mathrm{E}+02$

$3.37 \mathrm{E}+02$

$3.37 \mathrm{E}+02$

$3.38 \mathrm{E}+02$

$3.38 \mathrm{E}+02$

$3.39 \mathrm{E}+02$

$3.39 \mathrm{E}+02$

3. $40 \mathrm{E}+02$

$3.40 \mathrm{E}+02$

$3.41 \mathrm{E}+02$

$3.41 \mathrm{E}+02$

$3.42 \mathrm{E}+02$

$3.42 \mathrm{E}+02$

$3.43 \mathrm{E}+02$

$3.44 \mathrm{E}+02$

$3.44 \mathrm{E}+02$

$3.45 \mathrm{E}+02$

$3.45 \mathrm{E}+02$

$3.46 \mathrm{E}+02$

$3.46 \mathrm{E}+02$

$3.47 \mathrm{E}+02$

$3.47 \mathrm{E}+02$

$3.48 \mathrm{E}+02$

$3.48 \mathrm{E}+02$

3. $49 \mathrm{E}+02$

3. $49 \mathrm{E}+02$

$3.50 \mathrm{E}+02$

$3.50 \mathrm{E}+02$

3. $51 \mathrm{E}+02$

3. $51 \mathrm{E}+02$

3. $52 \mathrm{E}+02$

3. $52 \mathrm{E}+02$

$3.53 \mathrm{E}+02$

$3.53 \mathrm{E}+02$
Dose statistics at graphical times, mrem/yr

\begin{tabular}{|c|c|c|c|c|c|c|c|}
\hline m & num & ean & ed & & & & \\
\hline 0 & 0 & 2 & 4 & 2 & 02 & 1 & -01 \\
\hline$E+00$ & $3 E+00$ & $2 E-02$ & $5 E-04$ & $3.36 \mathrm{E}-02$ & $7.21 \mathrm{E}-02$ & $1.29 \mathrm{E}-01$ & $95 E-01$ \\
\hline $0 \cap F+00$ & $04 E+00$ & $54 \mathrm{E}-02$ & $70 F-04$ & $40 F-02$ & $28 \mathrm{E}-02$ & $30 E-01$ & $97 \mathrm{~F}-01$ \\
\hline $\mathrm{E}+00$ & & $56 E-02$ & 04 & & & & 01 \\
\hline & & 02 & 04 & 2 & 2 & & -01 \\
\hline $.00 E+00$ & 00 & -02 & 04 & 02 & -02 & & -01 \\
\hline $\mathrm{E}+00$ & 0 & 2 & 04 & 02 & 02 & & $06 E-01$ \\
\hline+00 & $E+00$ & $E-02$ & $E-04$ & -02 & $5 E-02$ & $\mathrm{~g}-01$ & $E-01$ \\
\hline $\mathrm{E}+00$ & $09 E+00$ & $64 E-02$ & $5 E-04$ & -02 & -02 & 1 & $E-01$ \\
\hline $0 \mathrm{E}+00$ & $10 F+00$ & $6 E-02$ & $2 E-04$ & & & & 01 \\
\hline & & & & & & & -01 \\
\hline+00 & $2 \mathrm{E}+00$ & $E-02$ & $E-04$ & $8 E-02$ & -02 & 1 & $E-01$ \\
\hline $.00 E+00$ & $1.13 \mathrm{E}+00$ & $1.71 \mathrm{E}-02$ & $.73 E-04$ & $3 E-02$ & $7 E-02$ & & $.20 \mathrm{E}-01$ \\
\hline+00 & 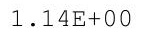 & $E-02$ & $E-04$ & 02 & 2 & & -01 \\
\hline & $5 \mathrm{~F}+$ & $75 E-02$ & & 2 & & & -01 \\
\hline 0 & $165+0$ & $.77 E-02$ & & & & 1 & -01 \\
\hline 0 & 1 & בק & 3 & 2 & 2 & 1 & -01 \\
\hline$E+00$ & $118 \mathrm{~F}+00$ & $.81 E-02$ & $8 E-03$ & & 02 & 1 & -01 \\
\hline $.00 \mathrm{E}+00$ & $1.19 \mathrm{E}+00$ & $1.83 \mathrm{E}-02$ & $.11 \mathrm{E}-03$ & $4.12 \mathrm{E}-02$ & $.59 \mathrm{E}-02$ & $.52 E-01$ & $.34 E-01$ \\
\hline $.00 E+00$ & $1.20 \mathrm{E}+00$ & $1.84 \mathrm{E}-02$ & $1.13 E-03$ & $7 E-02$ & $9 E-02$ & -01 & $36 E-01$ \\
\hline & & & & & & & \\
\hline & & & & & & 1 & -01 \\
\hline $.00 E+00$ & $1.23 \mathrm{E}+00$ & & & & & & 01 \\
\hline $\mathrm{Ft}$ & $4 \mathrm{E}+0$ & 2 & 3 & 2 & 2 & 1 & -01 \\
\hline $\mathrm{F}+08 \mathrm{~g}-5$ & $1.25 \mathrm{E}+00$ & $1.94 E-02$ & $1.26 \mathrm{E}-03$ & $4 E-02$ & $0 E-02$ & $.63 E-01$ & $48 E-01$ \\
\hline مח & $1.26 \mathrm{E}+00$ & $1.96 \mathrm{E}-02$ & $1.29 E-03$ & $4.49 \mathrm{E}-02$ & $31 E-02$ & $64 F-01$ & $50 F-01$ \\
\hline $7+00$ & $1.27 \mathrm{E}+00$ & $1.98 \mathrm{E}-02$ & & $55-02$ & & & -01 \\
\hline & & & & & & & -01 \\
\hline & & & & & 02 & & -01 \\
\hline $.00 \mathrm{E}+00$ & $1.30 \mathrm{E}+00$ & $2.04 \mathrm{E}-02$ & $1.40 \mathrm{E}-03$ & $4.71 E-02$ & $79 E-02$ & $\perp \cdot T \perp \mathrm{L}$ & $60 E-01$ \\
\hline e & 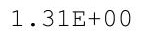 & $2.06 \mathrm{E}-02$ & $.43 E-03$ & $4.76 \mathrm{E}-02$ & $9.91 \mathrm{E}-02$ & te & $62 E-01$ \\
\hline & 1. $32 \mathrm{E}+$ & & & & & & 01 \\
\hline & & & & & & & 01 \\
\hline & $1.34 \mathrm{E}+00$ & & $1 E-03$ & $E-02$ & $E-01$ & 1 & -01 \\
\hline$E+00$ & $1.35 \mathrm{E}+00$ & $15 E-02$ & 03 & 02 & 1 & 1 & $2 E-01$ \\
\hline 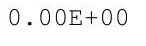 & म. & $2.17 \mathrm{E}-02$ & $1.57 \mathrm{E}-03$ & $5.05 \mathrm{E}-02$ & $.05 E-01$ & $1.81 \mathrm{E}-01$ & $.75 E-01$ \\
\hline 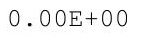 & te & $.19 \mathrm{E}-02$ & & & & & s \\
\hline - & I. & & & & & & trat \\
\hline 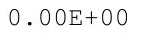 & $1.39 \mathrm{E}+0$ & $.23 \mathrm{E}$ & 3 & 2 & -01 & 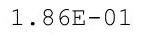 & 01 \\
\hline + & & 2 & 03 & 02 & 1 & 1 & -01 \\
\hline & $1.41 \mathrm{E}+00$ & $.28 \mathrm{E}-02$ & $1.71 E-03$ & $3 E-02$ & $E-01$ & $E-01$ & -01 \\
\hline+00 & $1.43 E+00$ & $0 \mathrm{E}-02$ & $E-03$ & -02 & 1 & 01 & -01 \\
\hline & 土. & & & & & & \\
\hline 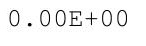 & te tos & & & & & & (e) \\
\hline $\mathrm{E}+00$ & म. & $2.37 \mathrm{E}-02$ & & & & & ( \\
\hline 00 & $\mathrm{E}+00$ & $E-02$ & $E-03$ & $E-02$ & -01 & -01 & -01 \\
\hline
\end{tabular}


RESRAD-OFFSITE, Version 2.5

$\mathrm{T}^{1 / 2}$ Limit $=180$ days

Title : RESRAD-OFFSITE Drinking Water, Plant, Milk, and Meat Pathways for Offsite Reside File : PBA-1_TC99-DOE-5.ROF

Summary of dose at graphical times, reptition 1 (continued)

Time

Years

$3.54 \mathrm{E}+02$

$3.54 \mathrm{E}+02$

$3.55 \mathrm{E}+02$

$3.55 \mathrm{E}+02$

$3.56 \mathrm{E}+02$

$3.56 \mathrm{E}+02$

$3.57 \mathrm{E}+02$

$3.57 \mathrm{E}+02$

$3.58 \mathrm{E}+02$

$3.58 \mathrm{E}+02$

$3.59 \mathrm{E}+02$

$3.59 \mathrm{E}+02$

$3.60 \mathrm{E}+02$

$3.60 \mathrm{E}+02$

$3.61 \mathrm{E}+02$

$3.61 \mathrm{E}+02$

$3.62 \mathrm{E}+02$

$3.62 \mathrm{E}+02$

$3.63 \mathrm{E}+02$

3. $64 \mathrm{E}+02$

$3.64 \mathrm{E}+02$

$3.65 \mathrm{E}+02$

$3.65 \mathrm{E}+02$

$3.66 \mathrm{E}+02$

$3.66 \mathrm{E}+02$

$3.67 \mathrm{E}+02$

$3.67 \mathrm{E}+02$

$3.68 \mathrm{E}+02$

$3.68 \mathrm{E}+02$

$3.69 \mathrm{E}+02$

$3.69 \mathrm{E}+02$

$3.70 \mathrm{E}+02$

$3.70 \mathrm{E}+02$

$3.71 \mathrm{E}+02$

$3.71 \mathrm{E}+02$

3. $72 \mathrm{E}+02$

$3.72 \mathrm{E}+02$

$3.73 \mathrm{E}+02$

$3.73 E+02$

$3.74 \mathrm{E}+02$

$3.74 \mathrm{E}+02$

$3.75 \mathrm{E}+02$

$3.75 \mathrm{E}+02$

$3.76 \mathrm{E}+02$

$3.76 \mathrm{E}+02$

$3.77 \mathrm{E}+02$
Dose statistics at graphical times, mrem/yr

\begin{tabular}{|c|c|c|c|c|c|c|c|}
\hline $\mathrm{m}$ & um & Mean & ledian & & & & \\
\hline $.00 \mathrm{E}+00$ & $1.48 \mathrm{E}+00$ & -02 & 03 & -02 & -01 & -01 & -0 \\
\hline+00 & +00 & $3 E-02$ & 03 & 02 & 01 & -01 & -01 \\
\hline+00 & $50 \mathrm{E}+00$ & $6 E-02$ & 03 & $E-02$ & 01 & 01 & -01 \\
\hline $.00 \mathrm{E}+00$ & $.51 \mathrm{E}+00$ & $48 \mathrm{~F}-02$ & $03 F-03$ & $83 \mathrm{~F}-02$ & $18 F-01$ & -01 & $17 \mathrm{~F}-01-1-1$ \\
\hline $00 E+00$ & $.52 \mathrm{E}+00$ & 2 & 3 & 2 & 1 & 1 & -01 \\
\hline $.00 \mathrm{E}+00$ & 00 & 2 & & & & & -01 \\
\hline $.00 \mathrm{E}+00$ & & & & & & & -01 \\
\hline $.00 \mathrm{E}+00$ & +00 & -02 & 03 & -02 & -01 & -01 & -01 \\
\hline $.00 \mathrm{E}+00$ & +00 & $0 E-02$ & -03 & -02 & -01 & -01 & -01 \\
\hline $\mathrm{E}+00$ & $58 E+00$ & $62 \mathrm{E}-02$ & $.27 E-03$ & $1 E-02$ & $.24 \mathrm{E}-01$ & 1 & -01 \\
\hline+00 & 0 & $2.65 \mathrm{E}-02$ & 3 & 2 & 1 & 1 & -01 \\
\hline+00 & $1.60 \mathrm{E}$ & $7 E-02$ & 3 & 2 & 1 & -01 & -01 \\
\hline $.00 \mathrm{E}+00$ & $1.61 \mathrm{E}+00$ & $2.70 \mathrm{E}-02$ & & & & $2.24 \mathrm{E}-01$ & -01 \\
\hline $.00 \mathrm{E}+00$ & $1.62 \mathrm{E}+00$ & $2.72 \mathrm{E}-02$ & $2.43 E-03$ & $6.48 \mathrm{E}-02$ & $1.29 \mathrm{E}-01$ & $2.26 \mathrm{E}-01$ & $49 E-01$ \\
\hline+00 & $1.63 \mathrm{E}+00$ & $5 E-02$ & $8 E-03$ & $5 E-02$ & -01 & -01 & -01 \\
\hline+00 & $1.64 \mathrm{E}+\mathrm{C}$ & $.77 \mathrm{E}-02$ & & 2 & & 01 & 01 \\
\hline 0 & & 2 & & & 1 & 1 & 01 \\
\hline$E+00$ & $67 F+00$ & $82 \mathrm{E}-02$ & 3 & & & 1 & 01 \\
\hline$E+00$ & $1.68 \mathrm{E}+00$ & $85 E-02$ & $4 E-03$ & $3 E-02$ & $36 E-01$ & $7 E-01$ & -01 \\
\hline $.00 E+00$ & $1.69 \mathrm{E}+00$ & $.87 \mathrm{E}-02$ & $2.68 \mathrm{E}-03$ & $6.90 \mathrm{E}-02$ & $1.37 \mathrm{E}-01$ & $2.39 \mathrm{E}-01$ & $3 E-01$ \\
\hline+00 & $E+00$ & $90 E-02$ & $72 E-03$ & & & -01 & -01 \\
\hline & & & & & & & -01 \\
\hline$E+00$ & $1.72 \mathrm{E}+\mathrm{C}$ & & & & & & -01 \\
\hline$E+00$ & $1.73 \mathrm{E}+00$ & $8 \mathrm{E}-$ & 3 & & 1 & 01 & -01 \\
\hline $\mathrm{E}+00$ & $.75 \mathrm{E}+00$ & $.00 \mathrm{E}-$ & $.90 \mathrm{E}-$ & $2 \mathrm{E}-$ & $.44 \mathrm{E}-01$ & $99-01$ & -01 \\
\hline $.00 \mathrm{E}+00$ & $1.76 \mathrm{E}+00$ & $.03 E-02$ & $2.95 E-03$ & $29 E-02$ & $1.46 \mathrm{E}-01$ & $.52 \mathrm{E}-01$ & $9 E-01$ \\
\hline+00 & $1.77 \mathrm{E}+00$ & $.06 E-02$ & $.00 \mathrm{E}-03$ & & & $.54 \mathrm{E}-01$ & $3 E-01$ \\
\hline & & & & & & -01 & -01 \\
\hline & & & $9 E-03$ & & & & -01 \\
\hline $.00 \mathrm{E}+00$ & $1.80 \mathrm{E}+00$ & $3.14 \mathrm{E}-02$ & -03 & $7.60 \mathrm{E}-02$ & $1.51 \mathrm{E}-01$ & $2.61 \mathrm{E}-01$ & $E-01$ \\
\hline $.00 \mathrm{E}+00$ & $1.81 \mathrm{E}+00$ & $.17 \mathrm{E}-02$ & $.19 \mathrm{E}-03$ & $7.68 \mathrm{E}-02$ & 1. 53E-01 & $2.64 \mathrm{E}-01$ & $08 E-01$ \\
\hline $.00 \mathrm{E}+00$ & 土. & $3.19 \mathrm{E}-02$ & & & & $66 \mathrm{E}-01$ & -0 \\
\hline & & & & & & & 01 \\
\hline$E+00$ & & & & & $7 E-01$ & -01 & 01 \\
\hline$E+00$ & & $28 E-02$ & $38 E-03$ & $00 E-02$ & -01 & -01 & -01 \\
\hline $00 E+00$ & $.87 E+00$ & & & & $1.59 \mathrm{E}-01$ & -01 & \\
\hline $.00 E+00$ & $1.88 \mathrm{E}+00$ & $.33 E-02$ & 03 & $5 E$ & - On & 01 & -01 \\
\hline $00 \mathrm{E}+00$ & $1.90 \mathrm{E}+00$ & & & & & & . \\
\hline 0 & 1.91E+ & . & 3 & 2 & 1 & 1 & 01 \\
\hline & $1.92 \mathrm{E}+00$ & & & & & & 01 \\
\hline $0 E+00$ & $1.93 \mathrm{E}+00$ & & $3.69 \mathrm{E}-03$ & & $1.66 \mathrm{E}-01$ & $2.88 \mathrm{E}-01$ & -01 \\
\hline & $1.94 \mathrm{E}+00$ & $48 E-02$ & $74 E-03$ & $53 E-02$ & $1.67 \mathrm{E}-01$ & $2.91 \mathrm{E}-01$ & $3 E-01$ \\
\hline & $1 \cdot 9$ & & & & & & \\
\hline $.00 \mathrm{E}+00$ & Р.9ILTU & $.53 E-02$ & & 2 & & & • \\
\hline $.00 \mathrm{E}+00$ & $1.98 \mathrm{E}+00$ & $3.00 \mathrm{~L}-\mathrm{CZ}$ & & & & $8 E-01$ & 1 \\
\hline 0 & $.99 \mathrm{E}+00$ & $E-02$ & $E-03$ & -02 & -01 & $E-01$ & -01 \\
\hline
\end{tabular}


RESRAD-OFFSITE, Version 2.5

$\mathrm{T}^{1 / 2}$ Limit $=180$ days

Title : RESRAD-OFFSITE Drinking Water, Plant, Milk, and Meat Pathways for Offsite Reside File : PBA-1_TC99-DOE-5.ROF

Summary of dose at graphical times, reptition 1 (continued)

Time

Years

$3.77 \mathrm{E}+02$

$3.78 \mathrm{E}+02$

$3.78 \mathrm{E}+02$

$3.79 \mathrm{E}+02$

$3.79 \mathrm{E}+02$

$3.80 \mathrm{E}+02$

$3.80 \mathrm{E}+02$

$3.81 \mathrm{E}+02$

$3.81 \mathrm{E}+02$

$3.82 \mathrm{E}+02$

$3.82 \mathrm{E}+02$

$3.83 \mathrm{E}+02$

$3.83 E+02$

$3.84 \mathrm{E}+02$

$3.85 \mathrm{E}+02$

$3.85 \mathrm{E}+02$

$3.86 \mathrm{E}+02$

$3.86 \mathrm{E}+02$

$3.87 \mathrm{E}+02$

$3.87 \mathrm{E}+02$

$3.88 \mathrm{E}+02$

$3.88 \mathrm{E}+02$

$3.89 \mathrm{E}+02$

$3.89 \mathrm{E}+02$

$3.90 \mathrm{E}+02$

$3.90 \mathrm{E}+02$

$3.91 \mathrm{E}+02$

3. $91 \mathrm{E}+02$

3. $92 \mathrm{E}+02$

3. $92 \mathrm{E}+02$

3. $93 \mathrm{E}+02$

3. $93 \mathrm{E}+02$

$3.94 \mathrm{E}+02$

$3.94 \mathrm{E}+02$

$3.95 \mathrm{E}+02$

$3.95 \mathrm{E}+02$

$3.96 \mathrm{E}+02$

$3.96 \mathrm{E}+02$

3. $97 \mathrm{E}+02$

3. $97 \mathrm{E}+02$

$3.98 \mathrm{E}+02$

3. $98 \mathrm{E}+02$

$3.99 \mathrm{E}+02$

3. $99 \mathrm{E}+02$

$4.00 \mathrm{E}+02$

$4.00 \mathrm{E}+02$
Dose statistics at graphical times, mrem/yr

\begin{tabular}{|c|c|c|c|c|c|c|c|}
\hline inimum & aximum & Mean & ledian & $90 \%$ & $5 \%$ & $97.5 \%$ & \\
\hline-00 & $\mathrm{E}+00$ & $3.62 E-02$ & $4.03 E-03$ & $0 E-02$ & $1.74 \mathrm{E}-01$ & $2 E-01$ & s \\
\hline+00 & -00 & $E-02$ & 3 & 2 & 1 & 01 & . \\
\hline-00 & +00 & -02 & 03 & $6 E-02$ & 01 & 01 & -01 \\
\hline+00 & $E+00$ & 02 & & 2 & & & -01 \\
\hline $\mathrm{E}+00$ & -00 & 2 & 3 & 2 & & -01 & $90 \mathrm{E}-01$ \\
\hline $\mathrm{DE}+00$ & $E+00$ & $\Xi-02$ & -03 & $E-02$ & $2 E-01$ & 01 & $E-01$ \\
\hline-00 & +00 & $F$ & $E-03$ & 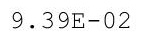 & \pm & 1 & 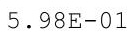 \\
\hline $.00 E+00$ & $2.08 E+00$ & $\begin{array}{l}.040 \\
\end{array}$ & & & $1.85 \mathrm{E}-01$ & -01 & $02 E-01$ \\
\hline-00 & +00 & 02 & 03 & 02 & 01 & -01 & -01 \\
\hline $.00 \mathrm{E}+00$ & $2.11 \mathrm{E}+00$ & $E-02$ & -03 & -02 & -01 & -01 & -01 \\
\hline+00 & +00 & $E-02$ & -03 & 2 & 1 & -01 & $E-01$ \\
\hline$E+00$ & +00 & $E-02$ & & & & & -01 \\
\hline $.00 \mathrm{E}+00$ & $2.14 \mathrm{E}+00$ & $9 E-02$ & -03 & -02 & $\perp$ & -01 & -0 \\
\hline$E+00$ & +00 & E-02 & -03 & $00 E-01$ & $.93 E-01$ & -01 & $26 E-01$ \\
\hline$E+00$ & -00 & 02 & 03 & 01 & 01 & 01 & -01 \\
\hline $.00 \mathrm{E}+00$ & $2.18 \mathrm{E}+00$ & -02 & -03 & 01 & 01 & -01 & -01 \\
\hline $.00 \mathrm{E}+00$ & $2.19 \mathrm{E}+00$ & $2 \mathrm{E}-02$ & $9 E-03$ & $1.03 \mathrm{E}-01$ & $1.97 \mathrm{E}-01$ & $E-01$ & $38 E-01$ \\
\hline $0 E+00$ & $.20 \mathrm{E}+00$ & $6 E-02$ & $6 E-03$ & $E-01$ & $99 E-01$ & $\mathrm{E}-01$ & $E-01$ \\
\hline $\mathrm{E}+00$ & $2 \mathrm{E}+00$ & $9 E-02$ & 03 & 1 & 1 & -01 & -0 \\
\hline$E+00$ & $2.23 E+00$ & $E-02$ & 03 & 01 & 01 & -01 & $\Xi-01$ \\
\hline $\mathrm{E}+00$ & 2.2 & $E-02$ & -03 & & & -01 & -01 \\
\hline $.00 \mathrm{E}+00$ & $2.25 \mathrm{E}+00$ & $.29 \mathrm{E}-02$ & 03 & 01 & & -01 & -01 \\
\hline $.00 E+00$ & $2.26 \mathrm{E}+00$ & 4.32E-02 & $53 E-03$ & $09 \mathrm{E}-01$ & $07 E-01$ & $6 \mathrm{E}-01$ & $51 E-01$ \\
\hline $.00 \mathrm{E}+00$ & $2.28 \mathrm{E}+00$ & $35 E-02$ & $1 E-03$ & $1.09 \mathrm{E}-01$ & $09 \mathrm{E}-01$ & $9 E-01$ & $65 E-01$ \\
\hline$E-27$ & $2.29 \mathrm{E}+00$ & $39 E-02$ & $E-03$ & $10 E-01$ & $1 \mathrm{E}-01$ & -01 & $E-01$ \\
\hline-25 & $E+00$ & $2 E-02$ & $E-03$ & $1 E-01$ & 1 & -01 & -01 \\
\hline $78 \mathrm{E}-23$ & $2.31 \mathrm{E}+00$ & -02 & 03 & 1 & 1 & 01 & -01 \\
\hline $68 E-21$ & $2.33 E+00$ & $49 E-02$ & $5.92 \mathrm{E}-03$ & $1.13 \mathrm{E}-01$ & $2.16 \mathrm{E}-01$ & $70 E-01$ & $80 E-01$ \\
\hline 20 & $34 \mathrm{E}+00$ & $52 E-02$ & $0 E-03$ & 1 & - & $5-01$ & -01 \\
\hline 年 & -5 & $56 \mathrm{E}-02$ & 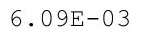 & 1 & - & 政- $\perp$ & $87 E-01$ \\
\hline-18 & & $9 E-02$ & $.17 \mathrm{E}-03$ & $5 E-01$ & & $\mathrm{~F}-01$ & $E-01$ \\
\hline-17 & $2.37 \mathrm{E}+00$ & $3 E-02$ & $5-03$ & $6 E-01$ & $3 F-01$ & $E-01$ & $E-01$ \\
\hline & & & & & & & \\
\hline $.46 \mathrm{E}-15$ & $2.40 \mathrm{E}+00$ & $.70 \mathrm{E}-02$ & $6.41 E-03$ & $1.18 \mathrm{E}-01$ & $2.26 \mathrm{E}-01$ & $6 E-01$ & $.01 E-01$ \\
\hline $09 E-14$ & $2.4 \perp \Gamma T U$ & $4.73 E-02$ & $6.50 E-03$ & 1.19E-01 & & $88 E-01$ & $.04 E-01$ \\
\hline & & & & & & & \\
\hline $180=-12$ & & & & & & 1 & 01 \\
\hline 3 & 2.45 & & & & & & 01 \\
\hline & & & & & & & 01 \\
\hline $.86 \mathrm{E}-12$ & $2.47 E+00$ & $1 \mathrm{E}-02$ & $E-03$ & $1 . \angle J \amalg$ & 1 & 01 & $22 \mathrm{E}-01$ \\
\hline $64 \mathrm{E}-12$ & $8 \mathrm{E}+00$ & 02 & & 1 & 1 & & -01 \\
\hline 1 & $2.50 \mathrm{E}+00$ & $4.98 E-02$ & 3 & $1.20 \mathrm{~T}$ & & 01 & $295-01$ \\
\hline$\perp$ & $2.51 E+00$ & 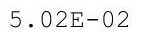 & $\cdot \cos$ & $+\cdot 201$ & $\pm S E-U \perp$ & $08 E-01$ & 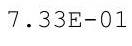 \\
\hline $3.11 \mathrm{D}-11$ & - & & $+\infty$ & 土. 210 & $2 \cdot 100$ & tita & - \\
\hline$E-10$ & $2.53 E+00$ & $E-02$ & 7. & 1.2 & 2.4 & 01 & -01 \\
\hline $88 E-10$ & $2.54 \mathrm{E}+00$ & $.13 E-02$ & $.47 E-03$ & 1.29E-01 & $2.49 \mathrm{E}-01$ & $4.16 \mathrm{E}-01$ & 7. $44 \mathrm{E}-01$ \\
\hline
\end{tabular}


RESRAD-OFFSITE, Version 2.5

$\mathrm{T}^{1 / 2}$ Limit $=180$ days

Title : RESRAD-OFFSITE Drinking Water, Plant, Milk, and Meat Pathways for Offsite Reside File : PBA-1_TC99-DOE-5.ROF

Summary of dose at graphical times, reptition 1 (continued)

Time

Years

$4.01 E+02$

$4.01 \mathrm{E}+02$

$4.02 \mathrm{E}+02$

$4.02 \mathrm{E}+02$

$4.03 \mathrm{E}+02$

$4.03 \mathrm{E}+02$

$4.04 \mathrm{E}+02$

$4.05 \mathrm{E}+02$

$4.05 \mathrm{E}+02$

$4.06 \mathrm{E}+02$

$4.06 \mathrm{E}+02$

$4.07 \mathrm{E}+02$

$4.07 \mathrm{E}+02$

$4.08 \mathrm{E}+02$

$4.08 \mathrm{E}+02$

$4.09 \mathrm{E}+02$

$4.09 \mathrm{E}+02$

$4.10 \mathrm{E}+02$

$4.10 \mathrm{E}+02$

$4.11 \mathrm{E}+02$

$4.11 \mathrm{E}+02$

$4.12 \mathrm{E}+02$

$4.12 \mathrm{E}+02$

$4.13 \mathrm{E}+02$

$4.13 \mathrm{E}+02$

$4.14 \mathrm{E}+02$

$4.14 \mathrm{E}+02$

$4.15 \mathrm{E}+02$

$4.15 \mathrm{E}+02$

$4.16 \mathrm{E}+02$

$4.16 \mathrm{E}+02$

$4.17 \mathrm{E}+02$

$4.17 \mathrm{E}+02$

$4.18 \mathrm{E}+02$

$4.18 \mathrm{E}+02$

4. $19 \mathrm{E}+02$

$4.19 \mathrm{E}+02$

$4.20 \mathrm{E}+02$

$4.20 \mathrm{E}+02$

$4.21 \mathrm{E}+02$

$4.21 \mathrm{E}+02$

$4.22 \mathrm{E}+02$

$4.22 \mathrm{E}+02$

$4.23 E+02$

$4.23 E+02$

$4.24 \mathrm{E}+02$
Dose statistics at graphical times, mrem/yr

\begin{tabular}{|c|c|c|c|c|c|c|c|}
\hline inimum & aximum & Mean & ledian & $90 \%$ & $5 \%$ & $97.5 \%$ & \\
\hline 10 & $56 \mathrm{E}+00$ & $5.17 \mathrm{E}-02$ & $7.56 \mathrm{E}-03$ & $1.30 \mathrm{E}-01$ & $2.51 \mathrm{E}-01$ & $.19 \mathrm{E}-01$ & $E-0$ \\
\hline 10 & +00 & 02 & 3 & 1 & 1 & 01 & 01 \\
\hline$E-10$ & $E+00$ & $E-02$ & 03 & $2 E-01$ & 01 & -01 & -01 \\
\hline$E-09$ & $E+00$ & 02 & & 1 & 1 & 01 & -01 \\
\hline-09 & -00 & 2 & & 01 & & 01 & $62 E-01$ \\
\hline $5 E-09$ & $2 \mathrm{E}+00$ & -02 & 03 & $+0^{\circ}$ & 1 & 01 & 01 \\
\hline 09 & +00 & 5 工 & -03 & (- & 1 & -01 & 0 \\
\hline $.39 E-09$ & $2.64 \mathrm{E}+00$ & 政 & $6 E-03$ & 1. $38 \mathrm{E}-01$ & & -01 & $.73 E-01$ \\
\hline 09 & +00 & 02 & 03 & 01 & 1 & -01 & -01 \\
\hline $25 E-08$ & $2.67 \mathrm{E}+00$ & $1 E-02$ & -03 & $40 E-01$ & -01 & -01 & $80 \mathrm{E}-01$ \\
\hline-08 & $E+00$ & 2 & 3 & 1 & & -01 & $E-01$ \\
\hline & +00 & -02 & & & & & -01 \\
\hline $.03 E-08$ & $2.70 \mathrm{E}+00$ & $E-U 2$ & $9 E-03$ & $1.43 \mathrm{E}-01$ & $-U \perp$ & -01 & -0 \\
\hline $.98 \mathrm{E}-08$ & $2.72 \mathrm{E}+00$ & $E-02$ & -03 & 01 & & -01 & -01 \\
\hline$E-08$ & -00 & 02 & 03 & 01 & 01 & 01 & -01 \\
\hline $.60 \mathrm{E}-08$ & $2.74 \mathrm{E}+00$ & -02 & -03 & 01 & 01 & -01 & -01 \\
\hline $.37 E-08$ & $2.75 \mathrm{E}+00$ & $9 \mathrm{E}-02$ & $E-03$ & $1.47 \mathrm{E}-01$ & $76 \mathrm{E}-01$ & $E-01$ & $06 \mathrm{E}-01$ \\
\hline$E-07$ & $.77 E+00$ & $33 E-02$ & $9 E-03$ & $8 E-01$ & $78 E-01$ & $E-01$ & $E-01$ \\
\hline 07 & $8 E+00$ & -02 & 03 & $\perp$ & & -01 & -01 \\
\hline$E-07$ & +00 & -02 & -03 & 01 & -01 & -01 & $18 \mathrm{E}-01$ \\
\hline $.97 \mathrm{E}-07$ & & -02 & & & & -01 & -01 \\
\hline $.39 E-07$ & $2.81 \mathrm{E}+00$ & $.99 \mathrm{E}-02$ & 03 & $1.53 \mathrm{~F}$ & & -01 & -01 \\
\hline $.88 E-07$ & $2.83 E+00$ & $6.03 E-02$ & $5 E-03$ & $1.54 \mathrm{E}-01$ & $87 E-01$ & $81 E-01$ & $29 E-01$ \\
\hline$E-07$ & $2.84 \mathrm{E}+00$ & $.07 \mathrm{E}-02$ & $7 E-03$ & $1.55 \mathrm{E}-01$ & $89 \mathrm{E}-01$ & $84 \mathrm{E}-01$ & $33 E-01$ \\
\hline 07 & $2.85 \mathrm{E}+00$ & $11 \mathrm{E}-02$ & -02 & & & -01 & -01 \\
\hline 07 & 00 & -02 & 02 & 01 & & & -01 \\
\hline $.68 E-07$ & $2.88 E+00$ & $E-02$ & -02 & 1.00 & & 01 & -01 \\
\hline $.63 E-07$ & $2.89 \mathrm{E}+00$ & $6.24 \mathrm{E}-02$ & $1.05 E-02$ & $1.59 \mathrm{E}-01$ & $2.96 \mathrm{E}-01$ & $.93 E-01$ & $49 \mathrm{E}-01$ \\
\hline 07 & $.90 E+00$ & 2 & $06 E-02$ & 1 & • & $.905-U 1$ & -01 \\
\hline 7 & -5 & $32 E-02$ & 2 & 1 & 1 & 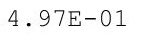 & 01 \\
\hline$F-06$ & $2.92 E+00$ & $6 \mathrm{~F}-02$ & $2 F-0 ?$ & $2 E-01$ & & $E-01$ & $E-01$ \\
\hline$E-06$ & $2.94 \mathrm{E}+00$ & $E-02$ & $E-02$ & $3 E-01$ & -01 & -01 & -01 \\
\hline $.33 E-06$ & $2.95 \mathrm{E}+00$ & $E-02$ & -02 & 01 & 1 & -01 & $68 \mathrm{E}-01$ \\
\hline $.51 \mathrm{E}-06$ & $2.96 \mathrm{E}+00$ & $.49 \mathrm{E}-02$ & $.13 \mathrm{E}-02$ & $1.65 \mathrm{E}-01$ & $3.07 \mathrm{E}-01$ & $.06 \mathrm{E}-01$ & $.72 \mathrm{E}-01$ \\
\hline $.71 E-06$ & & $6.54 E-02$ & & & & OL-U1 & $.76 \mathrm{E}-01$ \\
\hline 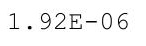 & & & & & & & \\
\hline $.15 E-06$ & 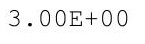 & & & & & 1 & 01 \\
\hline 6 & 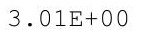 & & & & & & 01 \\
\hline 6 & & & & & & & \\
\hline $.96 E-06$ & $3.03 E+00$ & $5 E-02$ & $0 E-02$ & 1 & 1 & 01 & $5 E-01$ \\
\hline $3 E-06$ & 0 & & & 1 & & & $9 E-01$ \\
\hline 6 & $005+00$ & $84 \mathrm{E}-02$ & & 1 & & 01 & $3 E-U \perp$ \\
\hline 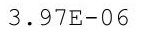 & $.07 \mathrm{E}+0$ & 2 & $\perp \cdot 2 U \amalg-2$ & 1 & 1 & 01 & . \\
\hline $4.36 \mathrm{E}-06$ & 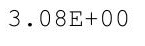 & & 20 & . & 1 & 1 & 1 \\
\hline 06 & $3.10 \mathrm{E}+00$ & $E-02$ & -02 & 1. & 01 & 01 & -01 \\
\hline $20 E-06$ & $3.11 \mathrm{E}+00$ & $.02 E-02$ & 1. $28 E-02$ & $1.79 E-01$ & $3.31 E-01$ & $5.35 E-01$ & $9.19 \mathrm{E}-01$ \\
\hline
\end{tabular}


RESRAD-OFFSITE, Version 2.5 
RESRAD-OFFSITE, Version 2.5 
RESRAD-OFFSITE, Version 2.5 
RESRAD-OFFSITE, Version 2.5 
RESRAD-OFFSITE, Version 2.5

$\mathrm{T}^{1 / 2}$ Limit $=180$ days

Title : RESRAD-OFFSITE Drinking Water, Plant, Milk, and Meat Pathways for Offsite Reside File : PBA-1_TC99-DOE-5.ROF

Summary of dose at graphical times, reptition 1 (continued)

Time

Years

$5.19 \mathrm{E}+02$

$5.19 \mathrm{E}+02$

$5.20 \mathrm{E}+02$

$5.20 \mathrm{E}+02$

$5.21 \mathrm{E}+02$

$5.21 \mathrm{E}+02$

$5.22 \mathrm{E}+02$

$5.22 \mathrm{E}+02$

$5.23 \mathrm{E}+02$

$5.23 \mathrm{E}+02$

$5.24 \mathrm{E}+02$

$5.24 \mathrm{E}+02$

$5.25 \mathrm{E}+02$

$5.26 \mathrm{E}+02$

$5.26 \mathrm{E}+02$

$5.27 \mathrm{E}+02$

$5.27 \mathrm{E}+02$

$5.28 \mathrm{E}+02$

$5.28 \mathrm{E}+02$

$5.29 \mathrm{E}+02$

$5.29 \mathrm{E}+02$

$5.30 \mathrm{E}+02$

$5.30 \mathrm{E}+02$

$5.31 \mathrm{E}+02$

$5.31 \mathrm{E}+02$

$5.32 \mathrm{E}+02$

$5.32 \mathrm{E}+02$

$5.33 \mathrm{E}+02$

$5.33 \mathrm{E}+02$

$5.34 \mathrm{E}+02$

$5.34 \mathrm{E}+02$

$5.35 \mathrm{E}+02$

$5.35 \mathrm{E}+02$

$5.36 \mathrm{E}+02$

$5.36 \mathrm{E}+02$

$5.37 \mathrm{E}+02$

$5.37 \mathrm{E}+02$

$5.38 \mathrm{E}+02$

$5.38 \mathrm{E}+02$

$5.39 \mathrm{E}+02$

$5.39 \mathrm{E}+02$

$5.40 \mathrm{E}+02$

$5.40 \mathrm{E}+02$

$5.41 \mathrm{E}+02$

$5.41 \mathrm{E}+02$

$5.42 \mathrm{E}+02$
Dose statistics at graphical times, mrem/yr

\begin{tabular}{|c|c|c|c|c|c|c|c|}
\hline inimum & aximum & Mean & ledian & $90 \%$ & $\%$ & $97.5 \%$ & $3 \%$ \\
\hline-04 & $97 E+00$ & $1.80 \mathrm{E}-01$ & $3 E-02$ & $4.64 E-01$ & $7.66 \mathrm{E}-01$ & $.13 E+00$ & $.70 \mathrm{E}+0$ \\
\hline-04 & +00 & 1 & $E-02$ & $6 \mathrm{E}-$ & 1 & -00 & $70 \mathrm{E}+00$ \\
\hline$E-04$ & $E+00$ & $2 E-01$ & $E-02$ & $3 E-01$ & 01 & +00 & +00 \\
\hline-04 & $E+00$ & 01 & 02 & 1 & 1 & 00 & +00 \\
\hline $.30 E-04$ & 00 & 1 & 02 & & 01 & $15 E+00$ & $71 E+00$ \\
\hline-04 & +00 & -01 & 02 & 01 & $E-01$ & $E+00$ & $.72 \mathrm{E}+00$ \\
\hline-04 & +00 & $.85 E-01$ & -02 & 4. $75 \mathrm{E}-01$ & 01 & +00 & $72 \mathrm{E}+00$ \\
\hline $.57 E-04$ & $5.02 E+00$ & (c) & $2 E-02$ & $4.77 E-01$ & $7.83 E-01$ & +00 & $.73 E+00$ \\
\hline-04 & 00 & 1 & -02 & $9 E-01$ & 01 & +00 & +00 \\
\hline $.75 E-04$ & $3 E+00$ & $3 E-01$ & $E-02$ & $E-01$ & -01 & $16 \mathrm{E}+00$ & $.73 E+00$ \\
\hline-04 & -00 & 1 & -02 & 1 & & 00 & $74 \mathrm{E}+00$ \\
\hline-04 & +00 & & & & & +00 & +00 \\
\hline $.02 E-04$ & $5.05 \mathrm{E}+00$ & $1.89 \mathrm{E}-01$ & $E-02$ & $4.87 E-01$ & 97-U1 & $E+00$ & . $13 \mathrm{E}+\mathrm{U}$ \\
\hline-04 & -00 & 工 & -02 & $9 E-01$ & 01 & +00 & $.75 E+00$ \\
\hline 04 & -00 & 1 & 02 & 01 & 01 & +00 & +00 \\
\hline $.31 E-04$ & $5.07 \mathrm{E}+00$ & 1 & -02 & 01 & 01 & $18 \mathrm{E}+00$ & $.76 \mathrm{E}+00$ \\
\hline $.40 E-04$ & $5.08 \mathrm{E}+00$ & $1.92 \mathrm{E}-01$ & $1 E-02$ & $6 \mathrm{E}-01$ & $08 E-01$ & $18 \mathrm{E}+00$ & $.76 \mathrm{E}+00$ \\
\hline-04 & $09 E+00$ & $.93 E-01$ & $5 E-02$ & $3 E-01$ & $E-01$ & $19 E+00$ & $76 E+00$ \\
\hline$D E-04$ & $5.09 \mathrm{E}+00$ & $1.94 \mathrm{E}-01$ & $E-02$ & $0 E-01$ & E-01 & $E+00$ & $7 E+00$ \\
\hline$E-04$ & -00 & -01 & -02 & $2 E-01$ & -01 & +00 & $.77 \mathrm{E}+0 \mathrm{C}$ \\
\hline $9 E-04$ & & & & & & 100 & +00 \\
\hline $.89 E-04$ & $5.11 \mathrm{E}+00$ & $1.96 \mathrm{E}-01$ & 02 & 1 & & $.20 \mathrm{E}+00$ & $.78 \mathrm{E}+00$ \\
\hline $.99 E-04$ & $5.12 \mathrm{E}+00$ & $1.97 \mathrm{E}-01$ & $6 E-02$ & $8 E-01$ & $8.24 \mathrm{E}-01$ & $.21 E+00$ & $.79 E+00$ \\
\hline$D E-04$ & $.13 E+00$ & $1.97 \mathrm{E}-01$ & $1 E-02$ & $0 E-01$ & $27 E-01$ & $.21 E+00$ & $.79 \mathrm{E}+0 \mathrm{C}$ \\
\hline-04 & $3 E+00$ & 1. $98 \mathrm{E}-01$ & $E-02$ & -01 & -01 & 00 & 100 \\
\hline 04 & -00 & 1 & 02 & 1 & & & +00 \\
\hline $1 E-04$ & $5.15 E+U 0$ & & -02 & 1 & & $\cdot \angle \angle E+U U$ & $81 \mathrm{E}+00$ \\
\hline $.51 \mathrm{E}-04$ & . IJETU & $2.01 E-01$ & 7. $28 E-02$ & $5.19 E-01$ & $8.38 \mathrm{E}-01$ & $22 \mathrm{E}+00$ & $.81 \mathrm{E}+00$ \\
\hline 04 & ל על & -2 & 年 & 1 & $\begin{array}{ll}4 \\
\end{array}$ & $.23 E+00$ & $82 \mathrm{E}+0 \mathrm{C}$ \\
\hline 1 & 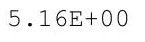 & 然 & -0 & 1 & 1 & $23 E+00$ & $82 \mathrm{E}+$ \\
\hline 04 & $17 \mathrm{~F}+0$ & $.03 E-01$ & $2 E-02$ & $5 E-01$ & & $3 E+00$ & $83 E+00$ \\
\hline 04 & $\mathrm{E}+00$ & $4 E-01$ & $E-02$ & & 1 & 0 & $83 E+00$ \\
\hline $\mathrm{E}-03$ & $5.18 \mathrm{E}+00$ & $E-01$ & -02 & $9 E-01$ & 1 & 00 & $.84 \mathrm{E}+00$ \\
\hline $.02 \mathrm{E}-03$ & $3.19 E+00$ & $2.05 E-01$ & $6 E-02$ & $32 E-01$ & $55 E-01$ & $.24 \mathrm{E}+00$ & $.84 \mathrm{E}+00$ \\
\hline $03 E-03$ & & & & & & $.24 \mathrm{E}+00$ & $.85 E+00$ \\
\hline 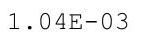 & & & & & & & $.85 E+00$ \\
\hline 3 & $5.21 \mathrm{E}+00$ & & & 1 & & 0 & 0 \\
\hline 3 & & & & 1 & & & \\
\hline$E-03$ & & & & & & & $.86 \mathrm{E}+00$ \\
\hline $8 E-03$ & $E+00$ & 2. & 02 & 1 & 1 & & $87 \mathrm{E}+0 \mathrm{C}$ \\
\hline 03 & & 2. & & 1 & & & $.87 \mathrm{E}+0 \mathrm{C}$ \\
\hline 3 & $3.24 \mathrm{E}+00$ & $2 \cdot+ \pm$ & & 1 & & $.26 \mathrm{E}+00$ & $1.00 \mathrm{E}+00$ \\
\hline & $5.24 \mathrm{E}+00$ & 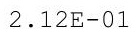 & 2 & 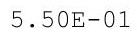 & $\perp$ & $.27 \mathrm{E}+00$ & $88 E+00$ \\
\hline $13 F-03$ & 0 & & . & 0.02 & $0.19 \mathrm{E}$ & 0 & $88 \mathrm{E}$ \\
\hline 03 & $5.25 E+00$ & 2 . & 8 & 5 & 01 & $1.27 \mathrm{E}+00$ & $1.89 \mathrm{E}+00$ \\
\hline $.15 E-03$ & $5.26 \mathrm{E}+00$ & $.14 \mathrm{E}-01$ & $8.12 E-02$ & $.56 \mathrm{E}-01$ & $8.83 E-01$ & 1. $28 \mathrm{E}+00$ & $1.89 \mathrm{E}+00$ \\
\hline
\end{tabular}


RESRAD-OFFSITE, Version 2.5 
RESRAD-OFFSITE, Version 2.5

$\mathrm{T}^{1 / 2}$ Limit $=180$ days

Title : RESRAD-OFFSITE Drinking Water, Plant, Milk, and Meat Pathways for Offsite Reside File : PBA-1_TC99-DOE-5.ROF

Summary of dose at graphical times, reptition 1 (continued)

Time

Years

$5.66 \mathrm{E}+02$

$5.67 \mathrm{E}+02$

$5.67 \mathrm{E}+02$

$5.68 \mathrm{E}+02$

$5.68 \mathrm{E}+02$

$5.69 \mathrm{E}+02$

$5.69 \mathrm{E}+02$

$5.70 \mathrm{E}+02$

$5.70 \mathrm{E}+02$

$5.71 \mathrm{E}+02$

$5.71 \mathrm{E}+02$

$5.72 \mathrm{E}+02$

$5.72 \mathrm{E}+02$

$5.73 \mathrm{E}+02$

$5.73 E+02$

$5.74 \mathrm{E}+02$

$5.74 \mathrm{E}+02$

$5.75 \mathrm{E}+02$

$5.75 \mathrm{E}+02$

$5.76 \mathrm{E}+02$

$5.76 \mathrm{E}+02$

$5.77 \mathrm{E}+02$

$5.77 \mathrm{E}+02$

$5.78 \mathrm{E}+02$

$5.78 \mathrm{E}+02$

$5.79 \mathrm{E}+02$

$5.79 \mathrm{E}+02$

$5.80 \mathrm{E}+02$

$5.80 \mathrm{E}+02$

$5.81 \mathrm{E}+02$

$5.81 \mathrm{E}+02$

$5.82 \mathrm{E}+02$

$5.82 \mathrm{E}+02$

$5.83 \mathrm{E}+02$

$5.83 \mathrm{E}+02$

$5.84 \mathrm{E}+02$

$5.84 \mathrm{E}+02$

$5.85 \mathrm{E}+02$

$5.85 \mathrm{E}+02$

$5.86 \mathrm{E}+02$

$5.87 \mathrm{E}+02$

$5.87 \mathrm{E}+02$

$5.88 \mathrm{E}+02$

$5.88 \mathrm{E}+02$

$5.89 \mathrm{E}+02$

$5.89 \mathrm{E}+02$
Dose statistics at graphical times, mrem/yr

\begin{tabular}{|c|c|c|c|c|c|c|c|}
\hline $\mathrm{m}$ & um & ean & ed & & & & \\
\hline 3 & 0 & 1 & 1 & 1 & 00 & 0 & +00 \\
\hline $.86 E-03$ & $48 E+00$ & $2.53 \mathrm{E}-01$ & $.06 \mathrm{E}-01$ & $6.42 \mathrm{E}-01$ & $1.02 \mathrm{E}+00$ & $1.41 \mathrm{E}+00$ & $08 \mathrm{E}+0 \mathrm{C}$ \\
\hline$F-03$ & $\mathrm{~F}+00$ & $4 E-01$ & $07 \mathrm{~F}-01$ & $44 \mathrm{E}-01$ & $02 \mathrm{~F}+00$ & $.41 E+00$ & $8 F+00$ \\
\hline$E-03$ & $49 E+00$ & $.55 \mathrm{E}-01$ & 01 & & & & 100 \\
\hline 03 & & 1 & 1 & & & & +00 \\
\hline $93 E-03$ & 00 & 01 & 01 & 1 & & 00 & $\mathrm{E}+\mathrm{OC}$ \\
\hline 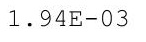 & & 1 & & & 0 & $.42 E+00$ & $E+00$ \\
\hline $.96 E-03$ & - & $E-01$ & $E-01$ & $E-01$ & $E+00$ & $E+00$ & $\mathrm{E}+00$ \\
\hline $98 E-03$ & $E+$ & $E-01$ & $E-01$ & -01 & $\Xi+00$ & $E+00$ & $\mathrm{E}+\mathrm{OC}$ \\
\hline$F-03$ & & & $11 \mathrm{E}-01$ & & & $.43 E+00$ & $10 F+0 R$ \\
\hline$E-03$ & & & & & & & +00 \\
\hline$E-03$ & $E+00$ & $2 E-01$ & $2 E-01$ & 1 & $5 E+00$ & $.44 \mathrm{E}+00$ & $\mathrm{E}+00$ \\
\hline $.05 E-03$ & $5.52 \mathrm{E}+00$ & $2.63 E-01$ & $1.13 E-01$ & $6.66 \mathrm{E}-01$ & $1.05 \mathrm{E}+00$ & $1.44 \mathrm{E}+00$ & $11 E+00$ \\
\hline-03 & & $E-01$ & -01 & & & & $\mathrm{E}+\mathrm{OC}$ \\
\hline 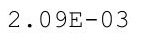 & & & & & & & +00 \\
\hline 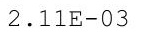 & & $65 F-0$ & & 1 & 0 & $.45 \mathrm{E}+$ & $12 \pi$ \\
\hline $.13 E-03$ & $5.54 \mathrm{E}+00$ & 5 & 1 & 1 & 0 & 0 & 00 \\
\hline$F-03$ & $4 \mathrm{~F}+0 \Omega$ & $57 E-01$ & $E-01$ & & +00 & $.45 \mathrm{E}+00$ & $12 \mathrm{E}+00$ \\
\hline $.17 \mathrm{E}-03$ & $.54 \mathrm{E}+00$ & $2.68 \mathrm{E}-01$ & $1.16 \mathrm{E}-01$ & $79 E-01$ & $1.06 \mathrm{E}+00$ & $1.46 \mathrm{E}+00$ & $.12 \mathrm{E}+00$ \\
\hline $19 E-03$ & $.55 E+00$ & $.69 \mathrm{E}-01$ & $1.17 \mathrm{E}-01$ & $6.80 \mathrm{E}-01$ & $1.07 \mathrm{E}+00$ & $1.46 \mathrm{E}+00$ & $.12 \mathrm{E}+0 \mathrm{C}$ \\
\hline & & & & & & & \\
\hline & & & & & & $.46 \mathrm{E}+$ & $13 E+00$ \\
\hline${ }^{2}$ & & & & & & L $47 \mathrm{E}+$ & $13 E+00$ \\
\hline 3 & $6 \mathrm{E}+$ & 1 & 1 & 1 & $8 \mathrm{E}+00$ & $E+$ & $13 E+00$ \\
\hline $\mathrm{F}-\ell \cdot(-2)$ & $.56 \mathrm{E}+0$ & $.73 E-01$ & $1.20 E-01$ & $1 E-01$ & $1.08 \mathrm{E}+00$ & $.47 E+0$ & $.14 \mathrm{E}+00$ \\
\hline $5-0$ & $.57 E+00$ & $2.74 \mathrm{E}-01$ & $1.20 E-01$ & $4 E-01$ & $1.08 \mathrm{E}+00$ & $.47 E+00$ & $14 E+00$ \\
\hline$F-03$ & $57 F+00$ & $2.74 \mathrm{E}-01$ & $1.21 \mathrm{E}-01$ & & & & \\
\hline & & & & & & & $14 \mathrm{E}+0 \mathrm{C}$ \\
\hline & & & & & & 0 & \\
\hline $.39 E-03$ & $5.58 \mathrm{E}+00$ & $2.77 E-01$ & $1.22 \mathrm{E}-01$ & $7.01 \mathrm{E}-01$ & $1.09 \mathrm{E}+00$ & $1.49 \mathrm{E}+00$ & $.15 E+00$ \\
\hline - & (2) & $.78 \mathrm{E}-01$ & $.23 E-01$ & $.03 E-01$ & $1.10 \mathrm{E}+00$ & $1.49 \mathrm{E}+00$ & $.15 \mathrm{E}+0$ \\
\hline 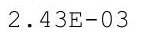 & & & 1 & & & & $.15 E+0$ \\
\hline 0 & $.59 \mathrm{E}+0$ & & & & & & \\
\hline & & & & & & & \\
\hline 3 & 0 & 1 & $E-01$ & & $E+00$ & 1.5 & \\
\hline $.51 E-03$ & $5.59 \mathrm{E}+00$ & $2.82 \mathrm{E}-01$ & $1.26 \mathrm{E}-01$ & $7.15 \mathrm{E}-01$ & $1.11 \mathrm{E}+$ & ton & $2.16 \mathrm{E}+0 \mathrm{C}$ \\
\hline 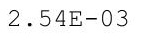 & & •.ООD-UD & 01 & $\perp$ & & & ट. +1 मा \\
\hline 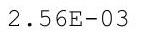 & ( & & $1.27 \mathrm{E}-01$ & & - -1 & & $17 \mathrm{E}+0$ \\
\hline $58 \mathrm{~F}-03$ & $5.60 \mathrm{E}+0$ & $2.85 \mathrm{E}-$ & 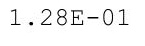 & 1 & & $1.51 \mathrm{E}+00$ & $.18 \mathrm{E}+0 \mathrm{C}$ \\
\hline $2.60 \mathrm{E}-03$ & 0 & 1 & & 1 & $1.12 \mathrm{E}+00$ & & \\
\hline $2 E-03$ & $5.61 \mathrm{E}+00$ & $2.87 \mathrm{E}-01$ & $1.29 \mathrm{E}-01$ & $8 E-01$ & $1.12 \mathrm{E}+00$ & 1 . & $18 \mathrm{E}+00$ \\
\hline $5-03$ & $E+00$ & $7 E-01$ & $1.29 \mathrm{E}-01$ & $0 \mathrm{E}-01$ & 1. & & +00 \\
\hline & & & & & & & $2.19 \pm 10$ \\
\hline 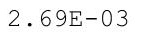 & 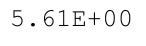 & $\perp$ & 01 & & $\perp \cdot \perp$ LTU & $1.52 \mathrm{E}+00$ & $2.19 \mathrm{E}+00$ \\
\hline 皮 & & . & & & & & $2.20 \mathrm{E}+00$ \\
\hline 03 & $E+00$ & $E-01$ & E-01 & $E-01$ & $.14 \mathrm{E}+00$ & $.53 E+00$ & $.20 E+00$ \\
\hline
\end{tabular}


RESRAD-OFFSITE, Version 2.5 
RESRAD-OFFSITE, Version 2.5 
RESRAD-OFFSITE, Version 2.5

robabilistic Dose and Risk Report

Title : RESRAD-OFFSITE Drinking Water, Plant, Milk, and Meat Pathways for Offsite Reside File : PBA-1_TC99-DOE-5.ROF

Summary of dose at graphical times, reptition 1 (continued)

Time

Years

$6.37 \mathrm{E}+02$

$6.37 \mathrm{E}+02$

$6.38 \mathrm{E}+02$

$6.38 \mathrm{E}+02$

$6.39 \mathrm{E}+02$

$6.39 \mathrm{E}+02$

$6.40 \mathrm{E}+02$

$6.40 \mathrm{E}+02$

$6.41 \mathrm{E}+02$

$6.41 \mathrm{E}+02$

$6.42 \mathrm{E}+02$

$6.42 \mathrm{E}+02$

$6.43 \mathrm{E}+02$

$6.43 \mathrm{E}+02$

$6.44 \mathrm{E}+02$

$6.44 \mathrm{E}+02$

$6.45 \mathrm{E}+02$

$6.45 \mathrm{E}+02$

$6.46 \mathrm{E}+02$

$6.47 \mathrm{E}+02$

$6.47 \mathrm{E}+02$

$6.48 \mathrm{E}+02$

$6.48 \mathrm{E}+02$

$6.49 \mathrm{E}+02$

$6.49 \mathrm{E}+02$

$6.50 \mathrm{E}+02$

$6.50 \mathrm{E}+02$

$6.51 \mathrm{E}+02$

$6.51 \mathrm{E}+02$

$6.52 \mathrm{E}+02$

$6.52 \mathrm{E}+02$

$6.53 \mathrm{E}+02$

$6.53 \mathrm{E}+02$

$6.54 \mathrm{E}+02$

$6.54 \mathrm{E}+02$

$6.55 \mathrm{E}+02$

$6.55 \mathrm{E}+02$

$6.56 \mathrm{E}+02$

$6.56 \mathrm{E}+02$

$6.57 \mathrm{E}+02$

$6.57 \mathrm{E}+02$

$6.58 \mathrm{E}+02$

$6.58 \mathrm{E}+02$

$6.59 \mathrm{E}+02$

$6.59 \mathrm{E}+02$

$6.60 \mathrm{E}+02$
Dose statistics at graphical times, mrem/yr

\begin{tabular}{|c|c|c|c|c|c|c|c|}
\hline $\mathrm{m}$ & um & ean & 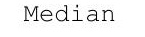 & & & & \\
\hline 3 & 0 & 1 & 1 & 1 & 00 & 0 & +00 \\
\hline $.60 E-03$ & $69 E+00$ & $5 E-01$ & 1.95E-01 & $9.40 \mathrm{E}-01$ & $1.37 \mathrm{E}+00$ & $1.79 \mathrm{E}+00$ & $2.46 \mathrm{E}+0 \mathrm{C}$ \\
\hline-03 & $69 F+00$ & $6 E-01$ & $96 \mathrm{~F}-01$ & $42 E-01$ & $37 E+00$ & $.79 E+00$ & $46 F+00$ \\
\hline$E-03$ & $.69 \mathrm{E}+00$ & $.77 \mathrm{E}-01$ & 01 & & & & 100 \\
\hline 03 & & 1 & 1 & 1 & & & +00 \\
\hline $76 E-03$ & 00 & 1 & -01 & 1 & & $.80 \mathrm{E}+00$ & $46 \mathrm{E}+00$ \\
\hline 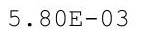 & & 01 & & 01 & 0 & $.81 E+00$ & $46 E+00$ \\
\hline 政 & $5+6$ & E-01 & $E-01$ & $3 E-01$ & $E+00$ & $E+00$ & $47 \mathrm{E}+00$ \\
\hline-2 & $9 \mathrm{E}+$ & $2 E-01$ & $E-01$ & -01 & $\mathrm{E}+00$ & $.81 E+00$ & $E+00$ \\
\hline $2 F-03$ & $69 F+00$ & $35-8$ & & & $39 \mathrm{E}+00$ & $.81 E+00$ & $47 \mathrm{~F}+00$ \\
\hline$E-03$ & & & & & & & +00 \\
\hline$E-03$ & $5.69 \mathrm{E}+00$ & $5 E-01$ & $3 E-01$ & 01 & $.40 \mathrm{E}+00$ & $1.81 \mathrm{E}+00$ & $47 E+00$ \\
\hline $.04 E-03$ & $5.69 \mathrm{E}+00$ & $.86 \mathrm{E}-01$ & $3 E-01$ & $63 E-01$ & $1.40 \mathrm{E}+00$ & $1.81 \mathrm{E}+00$ & $.48 E+00$ \\
\hline$E-03$ & & $E-01$ & -01 & & & & $\mathrm{E}+00$ \\
\hline & & & & & & & +00 \\
\hline & & & & & & $.82 E+00$ & $48 \mathrm{E}+0 \mathrm{C}$ \\
\hline $.20 E-03$ & 0 & 1 & 1 & 1 & 0 & 0 & +00 \\
\hline$F-03$ & $68 \mathrm{~F}+00$ & $0 E-01$ & -01 & 01 & $1.41 \mathrm{E}+00$ & $.82 E+00$ & $48 \mathrm{E}+00$ \\
\hline $29 E-03$ & $.68 \mathrm{E}+00$ & $91 \mathrm{E}-01$ & $2.08 E-01$ & $.75 E-01$ & $1.41 \mathrm{E}+00$ & $1.82 \mathrm{E}+00$ & $.49 \mathrm{E}+00$ \\
\hline$E-03$ & $.68 E+00$ & $.92 \mathrm{E}-01$ & $2.09 E-01$ & $7 E-01$ & $1.42 \mathrm{E}+00$ & $1.82 \mathrm{E}+00$ & $.49 \mathrm{E}+0 \mathrm{C}$ \\
\hline & & & & & & & 00 \\
\hline & & & & & & 0 & $49 E+00$ \\
\hline & & & & & & 1. $83 \mathrm{E}+$ & $49 \mathrm{E}+0 \mathrm{C}$ \\
\hline 3 & $8 \mathrm{E}+$ & 1 & 1 & 1 & $2 E+00$ & L. $84 \mathrm{E}+$ & $49 \mathrm{E}+00$ \\
\hline-0 & $.67 E+0$ & $.97 E-01$ & $2.14 \mathrm{E}-01$ & $6 \mathrm{E}-01$ & $1.43 E+00$ & $1.84 \mathrm{E}+00$ & $.50 \mathrm{E}+00$ \\
\hline 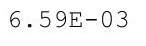 & $.67 E+00$ & $.98 \mathrm{E}-01$ & $2.14 \mathrm{E}-01$ & $8 E-01$ & $1.43 E+00$ & L. $84 \mathrm{E}+00$ & $.50 E+0 C$ \\
\hline$F-03$ & $67 F+00$ & $9 E-01$ & $5 E-01$ & & & & $50 \mathrm{E}+00$ \\
\hline & & & & & & & \\
\hline & & & & & & - & \\
\hline $.76 \mathrm{E}-03$ & $5.67 \mathrm{E}+00$ & 4.01E-01 & $2.17 \mathrm{E}-01$ & $9.95 \mathrm{E}-01$ & $1.44 \mathrm{E}+00$ & $1.85 \mathrm{E}+00$ & $.50 E+00$ \\
\hline . & - & $.02 E-01$ & $2.18 \mathrm{E}-01$ & $.96 \mathrm{E}-01$ & $1.44 \mathrm{E}+00$ & $1.85 \mathrm{E}+00$ & $.51 \mathrm{E}+0$ \\
\hline 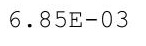 & & & & & & & $51 E+0$ \\
\hline & & & & & & & $51 \mathrm{E}+00$ \\
\hline$E-03$ & & & & & & & \\
\hline & & & & $1.00 \mathrm{E}$ & & & \\
\hline $.03 E-03$ & $5.66 \mathrm{E}+00$ & $.07 \mathrm{E}-01$ & $2.22 \mathrm{E}-01$ & $1.01 \mathrm{E}+00$ & $1.45 \mathrm{E}+00$ & $1.87 \mathrm{E}+00$ & $2.51 E+00$ \\
\hline 更 & 年 & $O L-U \perp$ & & & & 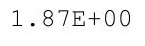 & Z.JILTU \\
\hline - & (- & & 1 & 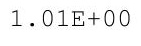 & - & & $.52 \mathrm{E}+0 \mathrm{C}$ \\
\hline $.17 \mathrm{E}-03$ & $5.66 \mathrm{E}+0$ & 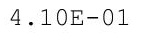 & 1 & 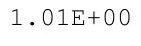 & $1.45 \mathrm{E}+00$ & & $2.52 \mathrm{E}+0 \mathrm{C}$ \\
\hline $7.22 \mathrm{E}-03$ & & & & 0 & $1.45 \mathrm{E}+00$ & & $2 \mathrm{E}+00$ \\
\hline$E-03$ & & $.12 \mathrm{E}-01$ & $2.26 \mathrm{E}-01$ & $2 \mathrm{E}+00$ & $6 \mathrm{E}+00$ & & $2 \mathrm{E}+00$ \\
\hline$E-03$ & $5.65 \mathrm{E}+00$ & $12 \mathrm{E}-01$ & $2.26 \mathrm{E}-01$ & & & & $2 \mathrm{E}+0 \mathrm{C}$ \\
\hline & & & & & & & $2.52 \mathrm{E}+0$ \\
\hline 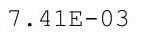 & . & & 01 & $1.02 \mathrm{E}+00$ & $1.40 \mathrm{LT} 0$ & $1.88 \mathrm{E}+00$ & $2.53 E+00$ \\
\hline & & & & & & & $2.53 E+00$ \\
\hline-03 & $E+00$ & $E-01$ & E-01 & $3 E+00$ & $6 \mathrm{E}+00$ & $1.89 \mathrm{E}+00$ & $.53 E+00$ \\
\hline
\end{tabular}


RESRAD-OFFSITE, Version 2.5

$\mathrm{T}^{1 / 2}$ Limit $=180$ days

Title : RESRAD-OFFSITE Drinking Water, Plant, Milk, and Meat Pathways for Offsite Reside File : PBA-1_TC99-DOE-5.ROF

Summary of dose at graphical times, reptition 1 (continued)

Time

Years

$6.60 \mathrm{E}+02$

$6.61 \mathrm{E}+02$

$6.61 \mathrm{E}+02$

$6.62 \mathrm{E}+02$

$6.62 \mathrm{E}+02$

$6.63 \mathrm{E}+02$

$6.63 \mathrm{E}+02$

$6.64 \mathrm{E}+02$

$6.64 \mathrm{E}+02$

$6.65 \mathrm{E}+02$

$6.65 \mathrm{E}+02$

$6.66 \mathrm{E}+02$

$6.67 \mathrm{E}+02$

$6.67 \mathrm{E}+02$

$6.68 \mathrm{E}+02$

$6.68 \mathrm{E}+02$

$6.69 \mathrm{E}+02$

$6.69 \mathrm{E}+02$

$6.70 \mathrm{E}+02$

$6.70 \mathrm{E}+02$

$6.71 \mathrm{E}+02$

$6.71 \mathrm{E}+02$

$6.72 \mathrm{E}+02$

$6.72 \mathrm{E}+02$

$6.73 \mathrm{E}+02$

$6.73 E+02$

$6.74 \mathrm{E}+02$

$6.74 \mathrm{E}+02$

$6.75 \mathrm{E}+02$

$6.75 \mathrm{E}+02$

$6.76 \mathrm{E}+02$

$6.76 \mathrm{E}+02$

$6.77 \mathrm{E}+02$

$6.77 \mathrm{E}+02$

$6.78 \mathrm{E}+02$

$6.78 \mathrm{E}+02$

$6.79 \mathrm{E}+02$

$6.79 \mathrm{E}+02$

$6.80 \mathrm{E}+02$

$6.80 \mathrm{E}+02$

$6.81 \mathrm{E}+02$

$6.81 \mathrm{E}+02$

$6.82 \mathrm{E}+02$

$6.82 \mathrm{E}+02$

$6.83 \mathrm{E}+02$

$6.83 \mathrm{E}+02$
Dose statistics at graphical times, mrem/yr

\begin{tabular}{|c|c|c|c|c|c|c|c|}
\hline inimum & aximum & Mean & ledian & $0 \%$ & $5 \%$ & $97.5 \%$ & $3 \%$ \\
\hline 3 & +00 & $E-01$ & $E-01$ & $3 E+00$ & +00 & +00 & +08 \\
\hline 03 & +00 & 1 & 1 & $3 \mathrm{E}+$ & $47 E+00$ & +00 & $3 E+00$ \\
\hline$E-03$ & +00 & $E-01$ & $E-01$ & $3 E+00$ & 00 & +00 & +00 \\
\hline$E-03$ & $E+00$ & 1 & 1 & 0 & & 00 & +00 \\
\hline-03 & 00 & 1 & & & 00 & $E+00$ & $54 \mathrm{E}+00$ \\
\hline $\mathrm{s}-03$ & +00 & $2 E-01$ & -01 & $1.04 \mathrm{E}+00$ & $.47 E+00$ & $\mathrm{OE}+00$ & $E+00$ \\
\hline J & +00 & $E-01$ & -01 & 00 & 00 & +00 & +00 \\
\hline $.89 E-03$ & $5.63 E+00$ & . & $2.36 \mathrm{E}-01$ & 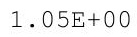 & $1.48 \mathrm{E}+00$ & $\mathrm{E}+00$ & $55 \mathrm{E}+0 \mathrm{C}$ \\
\hline 03 & 00 & 1 & 01 & 00 & 00 & +00 & +00 \\
\hline $.99 E-03$ & $5.63 \mathrm{E}+00$ & $6 \mathrm{E}-01$ & $E-01$ & $.05 E+00$ & $1.48 \mathrm{E}+00$ & $91 \mathrm{E}+00$ & $E+00$ \\
\hline-03 & -00 & $E-01$ & 1 & & & 00 & $E+00$ \\
\hline & -00 & & & & & +00 & +00 \\
\hline $.14 \mathrm{E}-03$ & $5.62 \mathrm{E}+00$ & $4 \cdot 28 \mathrm{E}-01$ & $E-01$ & $1.00 \mathrm{E}+00$ & $1 \cdot 491$ & $.91 E+00$ & $56 \mathrm{E}+0 \mathrm{C}$ \\
\hline 03 & +00 & $E-01$ & -01 & -00 & 00 & +00 & +00 \\
\hline 03 & -00 & 1 & 01 & 00 & 00 & +00 & +00 \\
\hline $.29 E-03$ & $5.61 \mathrm{E}+00$ & 1 & -01 & & $1.50 \mathrm{E}+00$ & $.92 \mathrm{E}+00$ & $7 \mathrm{E}+00$ \\
\hline $34 \mathrm{E}-03$ & $5.61 \mathrm{E}+00$ & $2 E-01$ & $3 E-01$ & $1.06 \mathrm{E}+00$ & $1.50 \mathrm{E}+00$ & $.92 E+00$ & $57 E+00$ \\
\hline-03 & $61 E+00$ & $3 E-01$ & $4 E-01$ & $7 \mathrm{E}+00$ & $50 \mathrm{E}+00$ & $93 E+00$ & $7 \mathrm{E}+00$ \\
\hline $.45 E-03$ & $5.61 \mathrm{E}+00$ & $4 E-01$ & $5 E-01$ & $7 \mathrm{E}+00$ & $1.51 \mathrm{E}+00$ & $E+00$ & $58 \mathrm{E}+00$ \\
\hline$E-03$ & +00 & -01 & -01 & & 00 & +00 & +00 \\
\hline$E-03$ & . 0 & & -01 & & & 100 & +00 \\
\hline $.60 E-03$ & $5.60 \mathrm{E}+00$ & 1 & 01 & $1.07 \mathrm{E}+00$ & & $.93 E+00$ & $8 \mathrm{E}+00$ \\
\hline $665-03$ & $56 \cap 5+00$ & $4.38 \mathrm{E}-01$ & $2.48 E-01$ & $1.07 \mathrm{E}+00$ & $151=+00$ & $94 \mathrm{E}+00$ & $59 \mathrm{E}+00$ \\
\hline $.71 E-03$ & $.60 \mathrm{E}+00$ & $.39 \mathrm{E}-01$ & $2.49 \mathrm{E}-01$ & $1.08 \mathrm{E}+00$ & $1.52 \mathrm{E}+00$ & $94 \mathrm{E}+00$ & $59 \mathrm{E}+0 \mathrm{C}$ \\
\hline 03 & $\mathrm{E}+00$ & $10 E-01$ & -01 & & & $E+00$ & +00 \\
\hline 03 & 00 & $8-01$ & -01 & & & & +00 \\
\hline $87 E-03$ & $3.39 \mathrm{E}+00$ & $E-01$ & -01 & $1.00 \mathrm{~s}$ & 1.025 & +00 & $59 \mathrm{E}+00$ \\
\hline $92 E-03$ & $5.59 \mathrm{E}+00$ & 4. $42 \mathrm{E}-01$ & $2.52 E-01$ & $1.08 \mathrm{E}+00$ & $1.52 \mathrm{E}+00$ & $.94 \mathrm{E}+00$ & $.60 \mathrm{E}+00$ \\
\hline 03 & 政 & - & 年 & 0 & $53 E+00$ & $95 E+00$ & $.60 \mathrm{E}+0 \mathrm{C}$ \\
\hline $.03 E-03$ & ( & $4.44 \mathrm{E}-01$ & $2.54 \mathrm{E}-01$ & $-x_{0}-1$ & & $5 E+00$ & $60 \mathrm{E}+0$ \\
\hline 03 & $3 \mathrm{~F}+0$ & & $4 E-01$ & $9 \mathrm{E}+00$ & $.53 E+00$ & $5 \mathrm{~F}+00$ & $61 \mathrm{E}+00$ \\
\hline 03 & $\mathrm{E}+00$ & $5 E-01$ & $5 E-01$ & 0 & & & \\
\hline$E-03$ & $5.58 \mathrm{E}+00$ & $E-01$ & $E-01$ & 00 & $1.35 E$ & $5 E+00$ & +00 \\
\hline $25 E-03$ & $3.31 \mathrm{E}+00$ & $8 E-01$ & $2.57 E-01$ & $1.09 \mathrm{E}+00$ & $1.54 \mathrm{E}+00$ & $.96 E+00$ & $.62 \mathrm{E}+00$ \\
\hline $015-43$ & & $4.49 E-01$ & $2.57 E-01$ & & & . & $.62 \mathrm{E}+0 \mathrm{C}$ \\
\hline $.36 E-03$ & & & & & & & $.62 \mathrm{E}+00$ \\
\hline $.42 E-03$ & ( & & 1 & 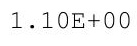 & & 0 & ה \\
\hline 3 & & & & & 0 & & \\
\hline$E-03$ & $5 E+00$ & $3 E-01$ & $E-01$ & 1 . & 1.5 & 00 & $63 E+00$ \\
\hline $9 E-03$ & $6 \mathrm{E}+00$ & $E-01$ & 2 . & 1 . & 0 & & +00 \\
\hline 3 & $56 \mathrm{E}+00$ & - & & & & & $.64 \mathrm{E}+0 \mathrm{C}$ \\
\hline & 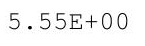 & ent & & & $1.35 \mathrm{E}+00$ & $97 E+00$ & $.64 \mathrm{E}+00$ \\
\hline & 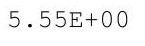 & & 1 & & & $.97 \mathrm{E}+$ & $.64 \mathrm{E}+00$ \\
\hline $82 F-03$ & $5.55 \mathrm{E}+00$ & + & 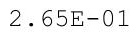 & 1 & 0 & 0 & $64 \mathrm{E}+00$ \\
\hline 03 & $5.55 \mathrm{E}+00$ & 4. & 2 . & $1.11 \mathrm{E}+00$ & $1.56 \mathrm{E}+00$ & $1.97 \mathrm{E}+00$ & $2.64 \mathrm{E}+00$ \\
\hline $.93 E-03$ & $5.54 \mathrm{E}+00$ & $.59 \mathrm{E}-01$ & $.66 E-01$ & $1.11 \mathrm{E}+00$ & $1.56 \mathrm{E}+00$ & $.97 E+00$ & $.65 E+00$ \\
\hline
\end{tabular}


RESRAD-OFFSITE, Version 2.5

Title : RESRAD-OFFSITE Drinking Water, Plant, Milk, and Meat Pathways for Offsite Reside File : PBA-1_TC99-DOE-5.ROF

Summary of dose at graphical times, reptition 1 (continued)

Time

Years

$6.84 \mathrm{E}+02$

$6.84 \mathrm{E}+02$

$6.85 \mathrm{E}+02$

$6.85 \mathrm{E}+02$

$6.86 \mathrm{E}+02$

$6.86 \mathrm{E}+02$

$6.87 \mathrm{E}+02$

$6.88 \mathrm{E}+02$

$6.88 \mathrm{E}+02$

$6.89 \mathrm{E}+02$

$6.89 \mathrm{E}+02$

$6.90 \mathrm{E}+02$

$6.90 \mathrm{E}+02$

$6.91 \mathrm{E}+02$

$6.91 \mathrm{E}+02$

$6.92 \mathrm{E}+02$

$6.92 \mathrm{E}+02$

$6.93 \mathrm{E}+02$

$6.93 \mathrm{E}+02$

$6.94 \mathrm{E}+02$

$6.94 \mathrm{E}+02$

$6.95 \mathrm{E}+02$

$6.95 \mathrm{E}+02$

$6.96 \mathrm{E}+02$

$6.96 \mathrm{E}+02$

$6.97 \mathrm{E}+02$

$6.97 \mathrm{E}+02$

$6.98 \mathrm{E}+02$

$6.98 \mathrm{E}+02$

$6.99 \mathrm{E}+02$

$6.99 \mathrm{E}+02$

$7.00 \mathrm{E}+02$

$7.00 \mathrm{E}+02$

$7.01 \mathrm{E}+02$

$7.01 \mathrm{E}+02$

$7.02 \mathrm{E}+02$

7. $02 \mathrm{E}+02$

$7.03 \mathrm{E}+02$

7.03E+02

7. $04 \mathrm{E}+02$

$7.04 \mathrm{E}+02$

$7.05 \mathrm{E}+02$

7. $05 \mathrm{E}+02$

$7.06 \mathrm{E}+02$

$7.06 \mathrm{E}+02$

$7.07 \mathrm{E}+02$
Dose statistics at graphical times, mrem/yr

\begin{tabular}{|c|c|c|c|c|c|c|c|}
\hline inimum & aximum & Mean & ledian & $0 \%$ & $5 \%$ & $97.5 \%$ & $3 \%$ \\
\hline 3 & +00 & $E-01$ & -01 & 00 & 00 & +00 & +00 \\
\hline 02 & +00 & 1 & 1 & $12 \mathrm{E}+$ & $56 \mathrm{E}+00$ & 00 & 100 \\
\hline 02 & -00 & $E-01$ & $E-01$ & $E+00$ & 00 & -00 & +00 \\
\hline$E-02$ & $E+00$ & 1 & 1 & 0 & & 00 & +00 \\
\hline $.02 E-02$ & -00 & & 01 & 00 & 00 & $8 E+00$ & $65 E+00$ \\
\hline $.03 E-02$ & +00 & $E-01$ & $E-01$ & $1.12 \mathrm{E}+00$ & $.57 E+00$ & $\mathrm{E}+00$ & $66 \mathrm{E}+00$ \\
\hline-02 & +00 & 然 & $2.72 \mathrm{E}-01$ & 1.12E & 00 & +00 & $\mathrm{E}+0 \mathrm{C}$ \\
\hline $.04 E-02$ & $5.52 \mathrm{E}+00$ & 年 & $2.73 E-01$ & $1.13 E+00$ & & $E+00$ & $.66 \mathrm{E}+00$ \\
\hline 02 & +00 & F- & 01 & $13 E+00$ & 00 & +00 & +00 \\
\hline $.05 E-02$ & $5.52 \mathrm{E}+00$ & $9 E-01$ & $4 E-01$ & $1.13 \mathrm{E}+00$ & $58 \mathrm{E}+00$ & $9 \mathrm{E}+00$ & $6 \mathrm{E}+00$ \\
\hline-02 & -00 & $E-01$ & -01 & & & 00 & $E+00$ \\
\hline-02 & -00 & & & & & +00 & $E+00$ \\
\hline $.07 E-02$ & $5.51 \mathrm{E}+00$ & $4 \cdot 71 E-01$ & $2.77 \mathrm{E}-01$ & $1.13 \mathrm{E}+00$ & $1.58 \mathrm{E}+00$ & $E+00$ & $\mathrm{E}+0 \mathrm{C}$ \\
\hline$E-02$ & +00 & $2 E-01$ & -01 & 00 & 00 & +00 & +00 \\
\hline 02 & $E+00$ & 1 & 01 & 00 & 00 & +00 & +00 \\
\hline $.09 E-02$ & $5.50 \mathrm{E}+00$ & 1 & -01 & $1.14 \mathrm{E}+00$ & $1.59 \mathrm{E}+00$ & $\mathrm{OE}+00$ & $66 \mathrm{E}+00$ \\
\hline $\mathrm{E}-02$ & $E+00$ & $5 E-01$ & $2 E-01$ & $1.14 \mathrm{E}+00$ & $.59 \mathrm{E}+00$ & $0 \mathrm{E}+00$ & $.66 \mathrm{E}+00$ \\
\hline-02 & $9 \mathrm{E}+00$ & $6 E-01$ & $2 E-01$ & $14 \mathrm{E}+00$ & $9 E+00$ & $00 \mathrm{E}+00$ & $66 \mathrm{E}+00$ \\
\hline $.11 \mathrm{E}-02$ & $5.49 \mathrm{E}+00$ & $7 E-01$ & $3 E-01$ & $4 \mathrm{E}+00$ & & $\mathrm{E}+00$ & $66 \mathrm{E}+00$ \\
\hline $1 E-02$ & +00 & -01 & -01 & $1 \cdot 141$ & 00 & +00 & +00 \\
\hline $2 E-02$ & 政 & & -01 & 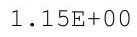 & & 100 & +00 \\
\hline $.13 E-02$ & $5.48 \mathrm{E}+00$ & $.80 \mathrm{E}-01$ & 01 & $1.15 \mathrm{E}+00$ & $1.60 \mathrm{E}+0 \mathrm{C}$ & $1 E+00$ & $56 \mathrm{E}+00$ \\
\hline $.13 E-02$ & $5.48 \mathrm{E}+00$ & $4.81 \mathrm{E}-01$ & $2.86 E-01$ & $1.15 \mathrm{E}+00$ & $1.60 \mathrm{E}+00$ & $1 E+00$ & $66 \mathrm{E}+00$ \\
\hline$E-02$ & $5.48 \mathrm{E}+00$ & $.82 \mathrm{E}-01$ & $2.87 \mathrm{E}-01$ & $1.15 \mathrm{E}+00$ & $1.60 \mathrm{E}+00$ & $02 E+00$ & $.66 \mathrm{E}+00$ \\
\hline 02 & +00 & $83 E-01$ & $8 E-01$ & & & 00 & $6 \mathrm{E}+00$ \\
\hline 02 & 00 & 1 & 01 & & & & +00 \\
\hline $16 \mathrm{E}-02$ & $7 \mathrm{E}+00$ & & -01 & I. & & +00 & $.66 \mathrm{E}+00$ \\
\hline $.17 \mathrm{E}-02$ & . $.40 \mathrm{DT} U$ & $4.85 E-01$ & $2.91 E-01$ & $15 E+00$ & 1. OLLTU & $.02 E+00$ & $.66 \mathrm{E}+00$ \\
\hline 02 & 然 & 然 & 年 & te & $61 \mathrm{E}+00$ & $.03 E+00$ & $.66 \mathrm{E}+0 \mathrm{C}$ \\
\hline $.18 \mathrm{E}-02$ & 年 & $4.87 \mathrm{E}-01$ & $2 E-01$ & $1.16 \mathrm{E}+$ & & $3 E+00$ & $.66 \mathrm{E}+0$ \\
\hline 02 & $F+00$ & & $3 E-01$ & $1.16 \mathrm{E}+00$ & $52 \mathrm{E}+00$ & $3 F+00$ & $66 \mathrm{E}+00$ \\
\hline$E-02$ & $\mathrm{E}+00$ & $9 E-01$ & $4 E-01$ & $E+00$ & & & \\
\hline $20 \mathrm{E}-02$ & $5 E+00$ & $E-01$ & $5 E-01$ & $1.16 \mathrm{E}$ & 0 & $\mathrm{E}+00$ & +00 \\
\hline $.20 \mathrm{E}-02$ & $3.44 \mathrm{E}+00$ & $.91 \mathrm{E}-01$ & $2.96 E-01$ & $1.16 \mathrm{E}+00$ & $1.0 \angle E+U 0$ & $.04 \mathrm{E}+00$ & $.66 \mathrm{E}+00$ \\
\hline $21 E-02$ & & $4.92 E-01$ & $2.97 E-01$ & & & & $.66 \mathrm{E}+0 \mathrm{C}$ \\
\hline 2 & & & & & & & \\
\hline 2 & ( & & & 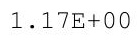 & & 0 & $6 \mathrm{E}+00$ \\
\hline 2 & & & & & & & \\
\hline 02 & & & -01 & & & & \\
\hline $.25 E-02$ & $5.42 E+00$ & $.97 \mathrm{E}-01$ & $1 E-01$ & $1.17 \mathrm{E}$ & & & $6 \mathrm{E}+00$ \\
\hline 2 & & $.98 \mathrm{E}-01$ & $.02 \mathrm{E}-01$ & $1.17 \mathrm{E}+00$ & & & $.66 \mathrm{E}+0 \mathrm{C}$ \\
\hline 2 & $4 \angle E+O 0$ & 1 & & $1.18 \mathrm{E}+00$ & $1.04 E+00$ & $.05 E+00$ & $.00 E+00$ \\
\hline & +00 & $\perp$ & 1 & & & $.06 \mathrm{E}+$ & $.66 \mathrm{E}+0 \mathrm{C}$ \\
\hline $275-02$ & ( & E & & 0 & 0 & 0 & $66 \mathrm{E}-$ \\
\hline$E-02$ & $5.41 E+00$ & -01 & $E-01$ & $1.18 \mathrm{E}+00$ & $1.64 \mathrm{E}+00$ & $2.06 \mathrm{E}+00$ & $2.66 \mathrm{E}+00$ \\
\hline $29 E-02$ & $5.40 \mathrm{E}+00$ & $.02 E-01$ & $.06 E-01$ & $1.18 \mathrm{E}+00$ & $1.65 \mathrm{E}+00$ & $2.06 \mathrm{E}+00$ & $.66 \mathrm{E}+00$ \\
\hline
\end{tabular}


RESRAD-OFFSITE, Version 2.5

$\mathrm{T}^{1 / 2}$ Limit $=180$ days

Title : RESRAD-OFFSITE Drinking Water, Plant, Milk, and Meat Pathways for Offsite Reside File : PBA-1_TC99-DOE-5.ROF

Summary of dose at graphical times, reptition 1 (continued)

Time

Years

$7.08 \mathrm{E}+02$

$7.08 \mathrm{E}+02$

$7.09 \mathrm{E}+02$

$7.09 \mathrm{E}+02$

$7.10 \mathrm{E}+02$

$7.10 \mathrm{E}+02$

7. $11 \mathrm{E}+02$

7. $11 \mathrm{E}+02$

$7.12 \mathrm{E}+02$

$7.12 \mathrm{E}+02$

7. $13 \mathrm{E}+02$

7. $13 \mathrm{E}+02$

$7.14 \mathrm{E}+02$

$7.14 \mathrm{E}+02$

7. $15 \mathrm{E}+02$

7. $15 \mathrm{E}+02$

$7.16 \mathrm{E}+02$

7. $16 \mathrm{E}+02$

$7.17 \mathrm{E}+02$

7. $17 \mathrm{E}+02$

$7.18 \mathrm{E}+02$

$7.18 \mathrm{E}+02$

7. $19 \mathrm{E}+02$

7. $19 \mathrm{E}+02$

$7.20 \mathrm{E}+02$

$7.20 \mathrm{E}+02$

$7.21 \mathrm{E}+02$

$7.21 \mathrm{E}+02$

7. $22 \mathrm{E}+02$

$7.22 \mathrm{E}+02$

7. $23 \mathrm{E}+02$

7. $23 \mathrm{E}+02$

$7.24 \mathrm{E}+02$

7. $24 \mathrm{E}+02$

$7.25 \mathrm{E}+02$

7. $25 \mathrm{E}+02$

$7.26 \mathrm{E}+02$

$7.26 \mathrm{E}+02$

$7.27 \mathrm{E}+02$

$7.28 \mathrm{E}+02$

$7.28 \mathrm{E}+02$

$7.29 \mathrm{E}+02$

$7.29 \mathrm{E}+02$

7. $30 \mathrm{E}+02$

$7.30 \mathrm{E}+02$

$7.31 \mathrm{E}+02$
Dose statistics at graphical times, mrem/yr

\begin{tabular}{|c|c|c|c|c|c|c|c|}
\hline inimum & aximum & Mean & ledian & $0 \%$ & $5 \%$ & $97.5 \%$ & \\
\hline-02 & $\mathrm{E}+00$ & $5.03 E-01$ & $3.07 E-01$ & $1.19 \mathrm{E}+00$ & $1.65 \mathrm{E}+00$ & $.06 \mathrm{E}+00$ & $56 \mathrm{E}+0$ \\
\hline 02 & +00 & 01 & $3 E-01$ & $19 \mathrm{E}+$ & $5 E+00$ & $E+00$ & $E+00$ \\
\hline 02 & -00 & 01 & -01 & 00 & 00 & -00 & +00 \\
\hline 02 & 00 & 1 & 1 & 0 & & 00 & +00 \\
\hline $32 E-02$ & -00 & 1 & & 00 & 00 & $\mathrm{E}+00$ & $E+00$ \\
\hline $33 E-02$ & $8 \mathrm{E}+00$ & -01 & $E-01$ & $1.19 \mathrm{E}+00$ & $.65 E+00$ & $\mathrm{E}+00$ & $67 \mathrm{E}+00$ \\
\hline 02 & +00 & -0 & 1 & 0 & 0 & $E+00$ & $E+0 C$ \\
\hline $.34 E-02$ & $5.37 \mathrm{E}+00$ & • IUL UL & $3.13 E-01$ & $1.20 \mathrm{E}+00$ & $1.65 \mathrm{E}+00$ & $\mathrm{E}+00$ & $.67 E+00$ \\
\hline 02 & +00 & 1 & 01 & +00 & 00 & +00 & +00 \\
\hline $.36 \mathrm{E}-02$ & $7 \mathrm{E}+00$ & $2 E-01$ & $E-01$ & $1.20 \mathrm{E}+00$ & $1.66 \mathrm{E}+00$ & $7 E+00$ & $67 \mathrm{E}+00$ \\
\hline-02 & +00 & 1 & 1 & & & 00 & $E+00$ \\
\hline$E-02$ & +00 & & & & & +00 & $E+00$ \\
\hline-02 & $E+00$ & $\begin{array}{lll}0 \\
0\end{array}$ & $E-01$ & $1.21 \mathrm{E}+00$ & +00 & $E+00$ & +0 \\
\hline $\mathrm{E}-02$ & +00 & 1 & -01 & 00 & 00 & +00 & +00 \\
\hline 02 & $5 \mathrm{E}+00$ & $\perp$ & 01 & 00 & -0.0 & $\mathrm{E}+00$ & +00 \\
\hline $.40 \mathrm{E}-02$ & $5.35 \mathrm{E}+00$ & 1 & -01 & $1.22 \mathrm{E}+00$ & $1.67 \mathrm{E}+00$ & $7 E+00$ & $.68 \mathrm{E}+00$ \\
\hline $.41 \mathrm{E}-02$ & $5.34 \mathrm{E}+00$ & $8 \mathrm{E}-01$ & $2 E-01$ & 1.22E+00 & $.67 E+00$ & $7 E+00$ & $.68 \mathrm{E}+00$ \\
\hline$E-02$ & $4 E+00$ & $9 E-01$ & $3 E-01$ & $1.22 \mathrm{E}+00$ & $1.67 \mathrm{E}+00$ & $.07 E+00$ & $68 \mathrm{E}+00$ \\
\hline 02 & $E+00$ & 1 & -01 & 1.2 & & +00 & +00 \\
\hline-02 & +00 & $-U \perp$ & -01 & $1.2 J \pm$ & 00 & +00 & $\mathrm{i}+0 \mathrm{c}$ \\
\hline $.44 \mathrm{E}-02$ & & & -01 & 1.201 & & (10 & +00 \\
\hline $.45 E-02$ & $5.32 \mathrm{E}+00$ & $E-01$ & $E-01$ & $1.23 \mathrm{E}+00$ & & $7 E+00$ & $68 E+00$ \\
\hline 02 & : $32 \mathrm{~F}+00$ & 1 & 1 & $1.23 E+00$ & $.68 \mathrm{E}+00$ & $.07 \mathrm{E}+00$ & $.69 \mathrm{E}+00$ \\
\hline $.46 \mathrm{E}-02$ & $.31 E+00$ & $.25 \mathrm{E}-01$ & $9 E-01$ & $1.24 \mathrm{E}+00$ & $1.68 \mathrm{E}+00$ & $7 E+00$ & $.69 \mathrm{E}+00$ \\
\hline 02 & $E+00$ & $25 E-01$ & $E-01$ & & & $7 E+00$ & $9 E+00$ \\
\hline 02 & & & & & & +00 & +00 \\
\hline $48 \mathrm{E}-02$ & $3.30 \mathrm{E}+00$ & -01 & -01 & $\perp \cdot 2 I+$ & & $5+00$ & +00 \\
\hline $49 \mathrm{E}-02$ & . & $\cdot 200$ & $32 E-01$ & $1.25 \mathrm{E}+00$ & 1. OIDTU & $.07 E+00$ & $.70 E+00$ \\
\hline 02 & $30 \mathrm{E}+$ & 1 & 1 & $.25 \mathrm{E}+00$ & $1.69 \mathrm{E}+00$ & $.07 E+00$ & $.70 \mathrm{E}+0 \mathrm{C}$ \\
\hline 2 & 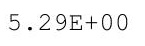 & - & 1 & $25 E+C$ & & $.06 \mathrm{E}+0$ & $70 \mathrm{E}+0$ \\
\hline 02 & $=0$ & $1 F-01$ & $5 E-01$ & $1.25 \mathrm{E}+00$ & $69 E+00$ & $06 E+00$ & $11 \mathrm{E}+00$ \\
\hline 02 & & & & & & & \\
\hline & & & & & & & \\
\hline $.54 \mathrm{E}-02$ & $5.28 \mathrm{E}+00$ & $.34 \mathrm{E}-01$ & $3.38 E-01$ & $1.25 \mathrm{E}+00$ & $1.70 E+00$ & $.07 \mathrm{E}+00$ & $71 \mathrm{E}+00$ \\
\hline $55 E-02$ & & . & $3.39 E-01$ & & & . VILTU & . TIDTU \\
\hline 2 & & & & & & & $.72 \mathrm{E}+00$ \\
\hline 2 & ( & & & & & 0 & $2 \mathrm{E}+00$ \\
\hline 2 & & & & & & & \\
\hline $3 E-02$ & & 1 & & & $1 \mathrm{E}+00$ & $7 E+00$ & \\
\hline $.58 E-02$ & $5.25 E+00$ & $.39 E-01$ & $3 E-01$ & $1.26 \mathrm{E}+$ & & $E+00$ & $B E+00$ \\
\hline 02 & $\mathrm{E}+00$ & $0 \mathrm{E}-01$ & 01 & $1.26 \mathrm{E}+$ & & & $\mathrm{E}+\mathrm{OC}$ \\
\hline 02 & $3.24 \mathrm{E}+00$ & 1 & 01 & $1.27 \mathrm{E}+00$ & $\perp \cdot I \perp E+U 0$ & $.08 \mathrm{E}+00$ & . $135+00$ \\
\hline 2 & $24 E+0$ & . & & 土.21 & & $08 E+00$ & $.73 E+0$ \\
\hline 2 & 5 & & & 0 & 0 & 0 & $.74 E+00$ \\
\hline $3 E-02$ & $5.23 E+00$ & $5.44 \mathrm{E}-01$ & $3.48 \mathrm{E}-01$ & $1.27 \mathrm{E}+00$ & $1.72 \mathrm{E}+00$ & $2.08 E+00$ & $.74 \mathrm{E}+00$ \\
\hline $.63 E-02$ & $5.23 E+00$ & $45 E-01$ & $.49 E-01$ & $1.27 \mathrm{E}+00$ & $1.72 E+00$ & $.08 \mathrm{E}+00$ & $.74 \mathrm{E}+00$ \\
\hline
\end{tabular}


RESRAD-OFFSITE, Version 2.5 
RESRAD-OFFSITE, Version 2.5

$\mathrm{T}^{1 / 2}$ Limit $=180$ days

Title : RESRAD-OFFSITE Drinking Water, Plant, Milk, and Meat Pathways for Offsite Reside File : PBA-1_TC99-DOE-5.ROF

Summary of dose at graphical times, reptition 1 (continued)

Time

Years

$7.55 E+02$

$7.55 \mathrm{E}+02$

$7.56 \mathrm{E}+02$

$7.56 \mathrm{E}+02$

$7.57 \mathrm{E}+02$

$7.57 \mathrm{E}+02$

$7.58 \mathrm{E}+02$

$7.58 \mathrm{E}+02$

$7.59 \mathrm{E}+02$

$7.59 \mathrm{E}+02$

$7.60 \mathrm{E}+02$

$7.60 \mathrm{E}+02$

$7.61 \mathrm{E}+02$

$7.61 \mathrm{E}+02$

$7.62 \mathrm{E}+02$

7. $62 \mathrm{E}+02$

$7.63 \mathrm{E}+02$

$7.63 \mathrm{E}+02$

$7.64 \mathrm{E}+02$

$7.64 \mathrm{E}+02$

$7.65 \mathrm{E}+02$

$7.65 \mathrm{E}+02$

$7.66 \mathrm{E}+02$

$7.66 \mathrm{E}+02$

$7.67 \mathrm{E}+02$

$7.68 \mathrm{E}+02$

$7.68 \mathrm{E}+02$

$7.69 \mathrm{E}+02$

$7.69 \mathrm{E}+02$

$7.70 \mathrm{E}+02$

$7.70 \mathrm{E}+02$

$7.71 \mathrm{E}+02$

$7.71 \mathrm{E}+02$

7. $72 \mathrm{E}+02$

$7.72 \mathrm{E}+02$

$7.73 E+02$

7. $73 \mathrm{E}+02$

$7.74 \mathrm{E}+02$

$7.74 \mathrm{E}+02$

$7.75 \mathrm{E}+02$

$7.75 \mathrm{E}+02$

$7.76 \mathrm{E}+02$

$7.76 \mathrm{E}+02$

$7.77 \mathrm{E}+02$

$7.77 \mathrm{E}+02$

$7.78 \mathrm{E}+02$
Dose statistics at graphical times, mrem/yr

\begin{tabular}{|c|c|c|c|c|c|c|c|}
\hline inimum & aximum & Mean & ledian & $0 \%$ & $5 \%$ & $97.5 \%$ & \\
\hline 02 & +00 & $5.88 E-01$ & $3.88 \mathrm{E}-01$ & $1.36 \mathrm{E}+00$ & $1.77 \mathrm{E}+00$ & $2.15 \mathrm{E}+00$ & $9 \mathrm{E}+0$ \\
\hline 2 & +00 & 1 & 1 & 0 & 00 & 00 & 00 \\
\hline 02 & -00 & 01 & 1 & 0 & & 00 & +00 \\
\hline 02 & 00 & 1 & & & & 00 & +00 \\
\hline-02 & -00 & & & 00 & 00 & $E+00$ & $79 \mathrm{E}+00$ \\
\hline $.09 E-02$ & $E+00$ & -01 & -01 & $36 \mathrm{E}+00$ & $78 E+00$ & $\mathrm{E}+00$ & $79 E+00$ \\
\hline 02 & -00 & 01 & -01 & 0 & 0 & $E+00$ & $\mathrm{E}+\mathrm{OC}$ \\
\hline 02 & $99 E+00$ & & & & & +00 & $79 \mathrm{E}+0 \mathrm{C}$ \\
\hline 02 & +00 & $\perp$ & 01 & 00 & 00 & +00 & +00 \\
\hline $.13 E-02$ & $98 \mathrm{E}+00$ & $6 E-01$ & $E-01$ & $.37 E+00$ & $.79 \mathrm{E}+00$ & $6 \mathrm{E}+00$ & $E+00$ \\
\hline $.14 \mathrm{E}-02$ & $97 \mathrm{E}+00$ & $7 E-01$ & $E-01$ & & & & $78 \mathrm{E}+00$ \\
\hline-02 & +00 & $E-01$ & -01 & & 00 & +00 & $E+O C$ \\
\hline-02 & $4.97 \mathrm{E}+00$ & -01 & $E-01$ & $7 \mathrm{E}+00$ & 0 & $E+00$ & +0 \\
\hline 2 & 0 & $9 \mathrm{E}-01$ & 1 & 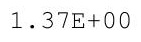 & 0 & +00 & 0 \\
\hline 02 & +00 & & & 00 & -0.0 & $\mathrm{E}+00$ & +00 \\
\hline 02 & -00 & 1 & 1 & & 0 & $\mathrm{E}+00$ & +00 \\
\hline $20 E-02$ & $4.95 \mathrm{E}+00$ & $6.02 \mathrm{E}-01$ & 4.01E-01 & 1. $37 \mathrm{E}+00$ & $1.80 \mathrm{E}+00$ & $2.17 \mathrm{E}+00$ & $.78 \mathrm{E}+00$ \\
\hline-02 & $4 E+00$ & $3 E-01$ & $2 E-01$ & $8 E+00$ & $81 E+00$ & $7 E+00$ & $78 E+00$ \\
\hline 02 & & & & & & $E+00$ & +00 \\
\hline 02 & +00 & 1 & 01 & .00 & & +00 & +0 \\
\hline 2 & & & 1 & 0 & & 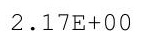 & 0 \\
\hline 02 & & 1 & 1 & 0 & 0 & $\mathrm{~F}+00$ & $E+00$ \\
\hline$E-02$ & $92 \mathrm{E}+00$ & $08 \mathrm{E}-$ & $08 \mathrm{E}-$ & $.39 E+00$ & $.81 E+00$ & $.17 \mathrm{E}+00$ & $8 \mathrm{E}+00$ \\
\hline$E-02$ & $.91 \mathrm{E}+00$ & $08 E-01$ & $9 E-01$ & $9 \mathrm{E}+00$ & $.81 \mathrm{E}+00$ & $.17 \mathrm{E}+00$ & $78 \mathrm{E}+0 \mathrm{C}$ \\
\hline$E-02$ & $4.91 \mathrm{E}+00$ & $9 E-01$ & $0 \mathrm{E}-01$ & & & $7 F+00$ & $78 \mathrm{E}+00$ \\
\hline & & & & & & & \\
\hline & & & & & & & \\
\hline $31 E-02$ & $4.89 E+00$ & $.12 \mathrm{E}-01$ & $4.13 E-01$ & $1.39 \mathrm{E}+00$ & $1.82 \mathrm{E}+00$ & $.17 \mathrm{E}+00$ & $.79 E+00$ \\
\hline 02 & $4.89 \mathrm{E}+00$ & 1 & $4 E-01$ & $39 E+00$ & $.82 \mathrm{E}+00$ & $2.17 \mathrm{E}+00$ & $79 \mathrm{E}+0 \mathrm{C}$ \\
\hline 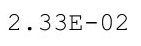 & - & -5 & $15 E-01$ & $0 \mathrm{E}+0$ & $.82 \mathrm{E}+\mathrm{C}$ & $7 \mathrm{E}+0$ & $.79 \mathrm{E}+0$ \\
\hline $\mathrm{F}-02$ & $4.88 E+00$ & & $6 E-01$ & & $.82 \mathrm{E}+00$ & $7 \mathrm{E}+00$ & $79 \mathrm{E}+00$ \\
\hline 02 & & & & & & & \\
\hline & & & $8 E-01$ & & & & $9 \mathrm{E}+0 \mathrm{C}$ \\
\hline $.37 E-02$ & $4.86 \mathrm{E}+00$ & $.17 \mathrm{E}-01$ & $4.19 \mathrm{E}-01$ & $1.40 \mathrm{E}+00$ & $1.82 \mathrm{E}+00$ & $6 \mathrm{E}+00$ & $.79 E+0 c$ \\
\hline $38 E-02$ & . . OOLTU & & $4.20 E-01$ & & I.OZLTU & Z. IILTU & $2.79 \mathrm{E}+0$ \\
\hline 2 & & & & & & & \\
\hline 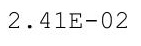 & 4 & & & & & 0 & 00 \\
\hline & & & & & 0 & & $9 F+00$ \\
\hline 02 & & 1 & $24 E-01$ & & $1.82 \mathrm{E}+00$ & $7 E+00$ & $.79 E+00$ \\
\hline $.44 \mathrm{E}-02$ & $4.83 E+00$ & $23 E-01$ & $4.25 E-01$ & 1. $41 \mathrm{E}+$ & 0 & 00 & $9 \mathrm{E}+0 \mathrm{C}$ \\
\hline 02 & & & 01 & & $.83 \mathrm{E}+$ & & $2.79 \mathrm{E}+00$ \\
\hline & $4.02 \mathrm{E}+00$ & $\perp$ & & 1. $41 \mathrm{E}+00$ & $1.03 E+00$ & $2.18 \mathrm{E}+00$ & $2.19 \pm+00$ \\
\hline 2 & $4.82 E+00$ & ( & $8 E-01$ & $1.41 \mathrm{E}+$ & $1.83 \mathrm{E}+00$ & $2.18 \mathrm{E}+00$ & $2.79 \mathrm{E}+0$ \\
\hline 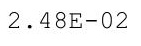 & - & & & 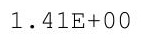 & $1.83 \mathrm{E}$ & $2.18 \mathrm{E}+00$ & $2.79 \mathrm{E}+00$ \\
\hline $9 E-02$ & $4.81 E+00$ & $E-01$ & -01 & $1.41 \mathrm{E}$ & $1.83 \mathrm{E}+00$ & $2.18 \mathrm{E}+00$ & $2.79 \mathrm{E}+00$ \\
\hline $.50 E-02$ & $4.80 \mathrm{E}+00$ & $28 E-01$ & $.32 E-01$ & 1. $41 \mathrm{E}+00$ & $1.84 \mathrm{E}+00$ & $2.19 \mathrm{E}+00$ & $2.79 \mathrm{E}+00$ \\
\hline
\end{tabular}


RESRAD-OFFSITE, Version 2.5

$\mathrm{T}^{1 / 2}$ Limit $=180$ days

Title : RESRAD-OFFSITE Drinking Water, Plant, Milk, and Meat Pathways for Offsite Reside File : PBA-1_TC99-DOE-5.ROF

Summary of dose at graphical times, reptition 1 (continued)

Time

Years

$7.78 \mathrm{E}+02$

$7.79 \mathrm{E}+02$

$7.79 \mathrm{E}+02$

$7.80 \mathrm{E}+02$

$7.80 \mathrm{E}+02$

$7.81 \mathrm{E}+02$

$7.81 \mathrm{E}+02$

$7.82 \mathrm{E}+02$

$7.82 \mathrm{E}+02$

$7.83 \mathrm{E}+02$

$7.83 \mathrm{E}+02$

$7.84 \mathrm{E}+02$

$7.84 \mathrm{E}+02$

$7.85 \mathrm{E}+02$

$7.85 \mathrm{E}+02$

$7.86 \mathrm{E}+02$

$7.86 \mathrm{E}+02$

$7.87 \mathrm{E}+02$

$7.88 \mathrm{E}+02$

$7.88 \mathrm{E}+02$

$7.89 \mathrm{E}+02$

$7.89 \mathrm{E}+02$

$7.90 \mathrm{E}+02$

$7.90 \mathrm{E}+02$

$7.91 \mathrm{E}+02$

$7.91 \mathrm{E}+02$

$7.92 \mathrm{E}+02$

7. $92 \mathrm{E}+02$

7. $93 \mathrm{E}+02$

$7.93 \mathrm{E}+02$

7. $94 \mathrm{E}+02$

$7.94 \mathrm{E}+02$

7. $95 \mathrm{E}+02$

7. $95 \mathrm{E}+02$

$7.96 \mathrm{E}+02$

7. $96 \mathrm{E}+02$

$7.97 \mathrm{E}+02$

7. $97 \mathrm{E}+02$

7. $98 \mathrm{E}+02$

7. $98 \mathrm{E}+02$

$7.99 \mathrm{E}+02$

7. $99 \mathrm{E}+02$

$8.00 \mathrm{E}+02$

$8.00 \mathrm{E}+02$

$8.01 \mathrm{E}+02$

$8.01 \mathrm{E}+02$
Dose statistics at graphical times, mrem/yr

\begin{tabular}{|c|c|c|c|c|c|c|c|}
\hline $\mathrm{m}$ & um & ean & 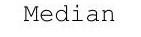 & & & & \\
\hline 2 & 0 & 1 & 1 & 00 & 00 & 0 & +00 \\
\hline $.52 \mathrm{E}-02$ & $0 \mathrm{E}+00$ & $.30 E-01$ & $4.34 \mathrm{E}-01$ & $1.41 \mathrm{E}+00$ & $1.84 \mathrm{E}+00$ & $19 \mathrm{E}+00$ & $79 \mathrm{E}+0 \mathrm{C}$ \\
\hline $\mathrm{E}-02$ & $9 F+00$ & $31 E-01$ & $35 E-01$ & $42 F+00$ & $84 \mathrm{~F}+00$ & $19 \mathrm{E}+00$ & $78 F+00$ \\
\hline$E-02$ & $4.79 E+00$ & $.31 E-01$ & $4.36 \mathrm{E}$ & $1.42 \mathrm{E}+$ & & 00 & $8 \mathrm{E}+0 \mathrm{C}$ \\
\hline 02 & 00 & 01 & -01 & & & & +00 \\
\hline $.57 E-02$ & 00 & -01 & -01 & 0 & & $20 E+00$ & $78 \mathrm{E}+0 \mathrm{C}$ \\
\hline $3 E-02$ & & -01 & & +00 & 0 & $2.20 \mathrm{E}+00$ & $78 E+00$ \\
\hline $.59 E-02$ & $6 \mathrm{E}+00$ & $5 E-01$ & $E-01$ & 1. $42 \mathrm{E}+00$ & $85 E+00$ & +00 & $.78 E+00$ \\
\hline $.60 E-02$ & $6 \mathrm{E}+00$ & $6 E-01$ & $41 E-01$ & $.42 \mathrm{E}+00$ & $5 \mathrm{E}+00$ & $.21 \mathrm{E}+$ & $\mathrm{E}+\mathrm{OC}$ \\
\hline $61 E-02$ & $5 F+00$ & & & 0 & $5 \mathrm{~F}+8 \cdot 3-3$ & $21 \mathrm{~F}+$ & $78 \mathrm{~F}+00$ \\
\hline 2 & & & & & & & +00 \\
\hline$E-02$ & $E+00$ & $E-01$ & $2 E-01$ & $43 E+00$ & +00 & +00 & $E+00$ \\
\hline $.64 E-02$ & & $9 \mathrm{E}-01$ & $4.43 E-01$ & $1.43 E+00$ & $1.86 \mathrm{E}+00$ & $2.21 \mathrm{E}+00$ & $77 E+00$ \\
\hline $65 E-02$ & $4.73 E+00$ & $6.40 E-01$ & $4.44 \mathrm{E}-01$ & & & $2.22 \mathrm{E}+00$ & $.77 \mathrm{E}+00$ \\
\hline $67 E-02$ & & & & & & & +00 \\
\hline (60 & & & & & & & 00 \\
\hline 2 & ג & & $7 E-01$ & 0 & 0 & $225+$ & +00 \\
\hline $70 F-02$ & 4. $71 \mathrm{~F}+0$ م & $4 E-01$ & $8 E-01$ & $1.43 E+00$ & $86 \mathrm{E}+00$ & $22 E+00$ & $77 E+00$ \\
\hline $.71 \mathrm{E}-02$ & $4.71 \mathrm{E}+00$ & $.45 \mathrm{E}-01$ & $4.49 \mathrm{E}-01$ & $1.44 \mathrm{E}+00$ & $1.86 \mathrm{E}+00$ & $2.23 E+00$ & $.77 \mathrm{E}+00$ \\
\hline $72 \mathrm{E}-02$ & $4.70 \mathrm{E}+00$ & $6.45 E-01$ & $4.50 \mathrm{E}-01$ & $44 \mathrm{E}+00$ & $86 \mathrm{E}+00$ & $23 E+00$ & $.77 E+0 C$ \\
\hline & & & & & & & \\
\hline & & & & & & & $78 \mathrm{E}+00$ \\
\hline 2 & & & $4.53 \mathrm{E}-$ & $1.44 \mathrm{E}+\mathrm{C}$ & & $.23 E+$ & $78 \mathrm{E}+00$ \\
\hline 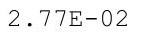 & $68 E+00$ & 1 & 1 & 1. $44 \mathrm{E}+00$ & $7 E+00$ & 0 & $78 E+00$ \\
\hline $3 F-0$ & $.68 E+00$ & $.50 E-01$ & $56 \mathrm{E}-01$ & $1.44 \mathrm{E}+00$ & $1.87 \mathrm{E}+00$ & $2.24 E+00$ & $.78 E+00$ \\
\hline $.79 E-02$ & $4.67 E+00$ & $.51 E-01$ & $4.57 E-01$ & $1.44 \mathrm{E}+00$ & $.87 E+00$ & $2.24 \mathrm{E}+00$ & $.78 \mathrm{E}+00$ \\
\hline & & & $E-01$ & & & & \\
\hline & & & & & & & $78 E+00$ \\
\hline & & & & $5 E+00$ & & & \\
\hline $.84 E-02$ & $4.65 \mathrm{E}+00$ & $54 E-01$ & $4.60 \mathrm{E}-01$ & $1.45 \mathrm{E}+00$ & $1.87 \mathrm{E}+00$ & $2.24 \mathrm{E}+00$ & $78 E+00$ \\
\hline - & t. & $.55 E-01$ & 4. $61 \mathrm{E}-01$ & $1.45 \mathrm{E}+00$ & $1.87 \mathrm{E}+00$ & $2.24 \mathrm{E}+00$ & $.78 \mathrm{E}+0$ \\
\hline 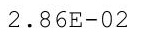 & 1.0 & & $4.62 E-01$ & & & & $78 \mathrm{E}+0$ \\
\hline 8 & & & & & & & $79 E+00$ \\
\hline 2 & & & & & & & \\
\hline & & & & $1.45 \mathrm{E}$ & $7 \mathrm{E}+00$ & & \\
\hline $.91 E-02$ & $4.62 E+00$ & $.59 \mathrm{E}-01$ & 4. $66 \mathrm{E}-01$ & $1.46 \mathrm{E}+00$ & $1.87 \mathrm{E}+00$ & $2.25 \mathrm{E}+00$ & $2.79 \mathrm{E}+0 \mathrm{C}$ \\
\hline - & & & $4.67 \mathrm{E}-01$ & & & & 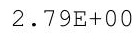 \\
\hline $93 E-02$ & & 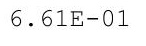 & $68 E-01$ & - & & & $.79 E+00$ \\
\hline $94 \mathrm{~F}-02$ & $4.61 \mathrm{E}+0$ & 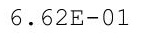 & 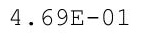 & $1.46 \mathrm{E}+00$ & & & $.79 E+00$ \\
\hline $.95 E-02$ & $0 \mathrm{E}+00$ & & 01 & $46 \mathrm{E}+00$ & $1.88 \mathrm{E}+00$ & $E+00$ & $9 \mathrm{E}+00$ \\
\hline $97 E-02$ & & & $4.71 \mathrm{E}-01$ & $1.46 \mathrm{E}+00$ & $8 E+00$ & & $2.79 \mathrm{E}+00$ \\
\hline $3 E-02$ & $E+00$ & $64 \mathrm{E}-01$ & $4.72 \mathrm{E}-01$ & $1.46 \mathrm{E}+00$ & & & +00 \\
\hline & & & & & & & $2.19 \pm 10$ \\
\hline L & 1. & 1 & & $1.47 \mathrm{E}+00$ & I. OOLTU & $2.25 \mathrm{E}+00$ & 2. \\
\hline & the & & & & & & $2.79 \mathrm{E}+00$ \\
\hline-02 & +00 & E-01 & $E-01$ & $E+00$ & $.88 E+00$ & $2.25 \mathrm{E}+00$ & $.80 E+00$ \\
\hline
\end{tabular}


RESRAD-OFFSITE, Version 2.5 
RESRAD-OFFSITE, Version 2.5

robabilistic Dose and Risk Report

Title : RESRAD-OFFSITE Drinking Water, Plant, Milk, and Meat Pathways for Offsite Reside File : PBA-1_TC99-DOE-5.ROF

Summary of dose at graphical times, reptition 1 (continued)

Time

Years

$8.25 \mathrm{E}+02$

$8.26 \mathrm{E}+02$

$8.26 \mathrm{E}+02$

$8.27 \mathrm{E}+02$

$8.27 \mathrm{E}+02$

$8.28 \mathrm{E}+02$

$8.29 \mathrm{E}+02$

$8.29 \mathrm{E}+02$

$8.30 \mathrm{E}+02$

$8.30 \mathrm{E}+02$

$8.31 \mathrm{E}+02$

$8.31 \mathrm{E}+02$

$8.32 \mathrm{E}+02$

$8.32 \mathrm{E}+02$

$8.33 E+02$

$8.33 \mathrm{E}+02$

$8.34 \mathrm{E}+02$

$8.34 \mathrm{E}+02$

$8.35 \mathrm{E}+02$

$8.35 \mathrm{E}+02$

$8.36 \mathrm{E}+02$

$8.36 \mathrm{E}+02$

$8.37 \mathrm{E}+02$

$8.37 \mathrm{E}+02$

$8.38 \mathrm{E}+02$

$8.38 \mathrm{E}+02$

$8.39 \mathrm{E}+02$

$8.39 \mathrm{E}+02$

$8.40 \mathrm{E}+02$

$8.40 \mathrm{E}+02$

$8.41 \mathrm{E}+02$

8. $41 \mathrm{E}+02$

$8.42 \mathrm{E}+02$

$8.42 \mathrm{E}+02$

$8.43 \mathrm{E}+02$

$8.43 \mathrm{E}+02$

$8.44 \mathrm{E}+02$

$8.44 \mathrm{E}+02$

$8.45 \mathrm{E}+02$

$8.45 \mathrm{E}+02$

$8.46 \mathrm{E}+02$

$8.46 \mathrm{E}+02$

$8.47 \mathrm{E}+02$

$8.47 \mathrm{E}+02$

$8.48 \mathrm{E}+02$

$8.49 \mathrm{E}+02$
Dose statistics at graphical times, mrem/yr

\begin{tabular}{|c|c|c|c|c|c|c|c|}
\hline & num & 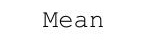 & 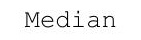 & & & & \\
\hline $63 \mathrm{E}-02$ & $.32 \mathrm{E}+00$ & $7.07 \mathrm{E}-01$ & $5.18 \mathrm{E}-01$ & $1.52 \mathrm{E}+00$ & $1.93 \mathrm{E}+00$ & $2.25 \mathrm{E}+00$ & $2.80 \mathrm{E}+00$ \\
\hline $.64 \mathrm{E}-02$ & $.32 \mathrm{E}+00$ & $7.08 \mathrm{E}-01$ & $5.19 \mathrm{E}-01$ & $1.52 \mathrm{E}+00$ & $1.93 \mathrm{E}+00$ & $2.25 \mathrm{E}+00$ & $2.80 \mathrm{E}+00$ \\
\hline $3.65 E-02$ & $31 \mathrm{E}+00$ & $7.09 \mathrm{E}-01$ & $5.20 \mathrm{E}-01$ & $1.52 \mathrm{E}+00$ & $1.93 \mathrm{E}+00$ & $2.25 \mathrm{E}+00$ & $2.80 \mathrm{E}+00$ \\
\hline $3.67 \mathrm{E}-02$ & $4.31 \mathrm{E}+00$ & $7.09 \mathrm{E}-01$ & $5.21 \mathrm{E}-01$ & $1.52 \mathrm{E}+00$ & $1.93 \mathrm{E}+00$ & $2.25 \mathrm{E}+00$ & $2.80 \mathrm{E}+00$ \\
\hline $3.68 \mathrm{E}-02$ & $4.30 \mathrm{E}+00$ & $7.10 \mathrm{E}-01$ & $5.22 \mathrm{E}-01$ & $1.53 \mathrm{E}+00$ & $1.93 \mathrm{E}+00$ & $2.25 \mathrm{E}+00$ & $2.80 \mathrm{E}+00$ \\
\hline $3.69 \mathrm{E}-02$ & $4.29 \mathrm{E}+00$ & $7.11 \mathrm{E}-01$ & $5.22 \mathrm{E}-01$ & $1.53 \mathrm{E}+00$ & $1.93 \mathrm{E}+00$ & $2.25 \mathrm{E}+00$ & $2.79 \mathrm{E}+00$ \\
\hline $3.71 E-02$ & $4.29 \mathrm{E}+00$ & $7.12 \mathrm{E}-01$ & $5.23 \mathrm{E}-01$ & $1.53 \mathrm{E}+00$ & $1.94 \mathrm{E}+00$ & $2.25 \mathrm{E}+00$ & $2.79 \mathrm{E}+00$ \\
\hline $3.72 E-02$ & $4.28 \mathrm{E}+00$ & $7.13 \mathrm{E}-01$ & $5.24 \mathrm{E}-01$ & $1.53 \mathrm{E}+00$ & $1.94 \mathrm{E}+00$ & $2.25 \mathrm{E}+00$ & $2.79 \mathrm{E}+00$ \\
\hline $3.74 \mathrm{E}-02$ & $4.28 \mathrm{E}+00$ & $7.13 \mathrm{E}-01$ & $5.25 \mathrm{E}-01$ & $1.53 \mathrm{E}+00$ & $1.94 \mathrm{E}+00$ & $2.25 \mathrm{E}+00$ & $2.79 \mathrm{E}+00$ \\
\hline $3.75 E-02$ & $4.27 \mathrm{E}+00$ & $7.14 \mathrm{E}-$ & $5.26 \mathrm{E}-$ & $1.53 \mathrm{E}+00$ & $1.94 \mathrm{E}+00$ & $2.26 \mathrm{E}+00$ & $2.79 \mathrm{E}+00$ \\
\hline $76 \mathrm{E}-02$ & $4.27 \mathrm{E}+00$ & $7.15 \mathrm{E}-01$ & $5.27 \mathrm{E}-01$ & $1.53 \mathrm{E}+00$ & $1.94 \mathrm{E}+00$ & $2.26 \mathrm{E}+00$ & $2.79 \mathrm{E}+00$ \\
\hline $.78 \mathrm{E}-02$ & $4.26 \mathrm{E}+00$ & $7.16 \mathrm{E}-01$ & $5.28 \mathrm{E}-01$ & $1.53 \mathrm{E}+00$ & $1.94 \mathrm{E}+00$ & $2.26 \mathrm{E}+00$ & $2.78 \mathrm{E}+00$ \\
\hline $.79 \mathrm{E}-02$ & $4.26 \mathrm{E}+00$ & $7.17 \mathrm{E}-01$ & $5.29 \mathrm{E}-01$ & $1.53 \mathrm{E}+00$ & $1.94 \mathrm{E}+00$ & $2.26 \mathrm{E}+00$ & $2.78 \mathrm{E}+00$ \\
\hline $.80 \mathrm{E}-02$ & $4.25 \mathrm{E}+00$ & $7.18 \mathrm{E}-01$ & $5.30 \mathrm{E}-01$ & $1.53 \mathrm{E}+00$ & $1.94 \mathrm{E}+00$ & $2.26 \mathrm{E}+00$ & $.78 \mathrm{E}+00$ \\
\hline $3.82 E-02$ & $4.25 \mathrm{E}+00$ & $7.18 \mathrm{E}-01$ & $5.31 \mathrm{E}-01$ & $1.53 \mathrm{E}+00$ & $95 E+00$ & $2.26 \mathrm{E}+00$ & $.78 E+00$ \\
\hline $3.83 \mathrm{E}-02$ & $4.24 \mathrm{E}+00$ & $7.19 \mathrm{E}-01$ & $5.32 \mathrm{E}-01$ & $1.54 \mathrm{E}+00$ & $1.95 \mathrm{E}+00$ & $2.26 \mathrm{E}+00$ & $2.78 \mathrm{E}+00$ \\
\hline $3.85 E-02$ & $4.24 \mathrm{E}+00$ & $7.20 \mathrm{E}-01$ & $5.32 \mathrm{E}-01$ & $1.54 \mathrm{E}+00$ & $1.95 \mathrm{E}+00$ & $2.26 \mathrm{E}+00$ & $2.78 \mathrm{E}+00$ \\
\hline $3.86 \mathrm{E}-02$ & $4.23 \mathrm{E}+00$ & $7.21 \mathrm{E}-01$ & $5.33 \mathrm{E}-01$ & $1.54 \mathrm{E}+00$ & $1.95 \mathrm{E}+00$ & $2.26 \mathrm{E}+00$ & $2.77 \mathrm{E}+00$ \\
\hline $3.87 \mathrm{E}-02$ & $4.23 E+00$ & $7.22 \mathrm{E}-01$ & $5.34 \mathrm{E}-01$ & $1.54 \mathrm{E}+00$ & $1.95 \mathrm{E}+00$ & $2.26 \mathrm{E}+00$ & $2.77 \mathrm{E}+00$ \\
\hline $3.89 \mathrm{E}-02$ & $4.22 \mathrm{E}+00$ & $7.22 \mathrm{E}-01$ & $5.35 \mathrm{E}-01$ & $1.54 \mathrm{E}+00$ & $1.95 \mathrm{E}+00$ & $2.26 \mathrm{E}+00$ & $2.77 \mathrm{E}+00$ \\
\hline $3.90 \mathrm{E}-02$ & $4.21 \mathrm{E}+00$ & $7.23 \mathrm{E}-01$ & $5.36 \mathrm{E}-01$ & $1.54 \mathrm{E}+00$ & $1.95 \mathrm{E}+00$ & $2.26 \mathrm{E}+00$ & $2.77 \mathrm{E}+00$ \\
\hline $3.92 \mathrm{E}-02$ & $4.21 \mathrm{E}+00$ & $7.24 \mathrm{E}-01$ & $5.37 \mathrm{E}-01$ & $1.54 \mathrm{E}+00$ & $1.95 \mathrm{E}+00$ & $2.26 \mathrm{E}+00$ & $2.77 \mathrm{E}+00$ \\
\hline $93 \mathrm{E}-02$ & $4.20 \mathrm{E}+00$ & 7 & 1 & $1.54 \mathrm{E}+00$ & $1.95 \mathrm{E}+00$ & $2.26 \mathrm{E}+00$ & $2.76 \mathrm{E}+00$ \\
\hline 2 & $4.20 \mathrm{E}+00$ & r & 1 & 0 & $1.95 \mathrm{E}+00$ & $2.26 \mathrm{E}+00$ & $2.76 \mathrm{E}+00$ \\
\hline $3.96 \mathrm{E}-02$ & $4.19 \mathrm{E}+00$ & & & $1.55 \mathrm{E}-$ & $1.95 \mathrm{E}+00$ & $2.26 \mathrm{E}+00$ & $2.76 \mathrm{E}+00$ \\
\hline $3.97 \mathrm{E}-02$ & $4.19 \mathrm{E}+00$ & $7.27 \mathrm{E}-01$ & $5.41 \mathrm{E}-01$ & $1.55 \mathrm{E}+00$ & $1.95 \mathrm{E}+00$ & $2.26 \mathrm{E}+00$ & $2.76 \mathrm{E}+00$ \\
\hline $3.99 \mathrm{E}-02$ & $4.18 \mathrm{E}+00$ & $7.28 \mathrm{E}-01$ & $5.42 \mathrm{E}-01$ & $1.55 \mathrm{E}+00$ & $1.96 \mathrm{E}+00$ & $2.26 \mathrm{E}+00$ & $2.76 \mathrm{E}+00$ \\
\hline $4.00 \mathrm{E}-02$ & $4.18 \mathrm{E}+00$ & $7.29 \mathrm{E}-01$ & $5.44 \mathrm{E}-01$ & $1.55 \mathrm{E}+00$ & $1.96 \mathrm{E}+00$ & $2.26 \mathrm{E}+00$ & $2.76 \mathrm{E}+00$ \\
\hline $4.02 \mathrm{E}-02$ & $4.17 \mathrm{E}+00$ & $7.30 \mathrm{E}-01$ & $5.44 \mathrm{E}-01$ & $1.55 \mathrm{E}+00$ & $1.96 \mathrm{E}+00$ & $2.26 \mathrm{E}+00$ & $2.75 \mathrm{E}+00$ \\
\hline $4.03 E-02$ & $4.17 \mathrm{E}+00$ & $7.30 \mathrm{E}-01$ & $5.45 \mathrm{E}-01$ & $1.55 \mathrm{E}+00$ & $1.96 \mathrm{E}+00$ & $2.26 \mathrm{E}+00$ & $2.75 \mathrm{E}+00$ \\
\hline $4.04 \mathrm{E}-02$ & $4.16 \mathrm{E}+00$ & $7.31 \mathrm{E}-01$ & $5.46 \mathrm{E}-01$ & $1.56 \mathrm{E}+00$ & $1.96 \mathrm{E}+00$ & $2.26 \mathrm{E}+00$ & $2.75 \mathrm{E}+00$ \\
\hline $4.06 \mathrm{E}-02$ & $4.16 \mathrm{E}+00$ & $7.32 \mathrm{E}-01$ & $5.47 \mathrm{E}-01$ & $1.56 \mathrm{E}+00$ & $1.96 \mathrm{E}+00$ & $2.26 \mathrm{E}+00$ & $2.75 \mathrm{E}+00$ \\
\hline $4.07 \mathrm{E}-02$ & $4.15 \mathrm{E}+00$ & $7.33 \mathrm{E}-01$ & $5.48 \mathrm{E}-01$ & $1.56 \mathrm{E}+00$ & $1.96 \mathrm{E}+00$ & $2.26 \mathrm{E}+00$ & $2.75 \mathrm{E}+00$ \\
\hline $4.09 \mathrm{E}-02$ & $4.14 \mathrm{E}+00$ & $7.33 \mathrm{E}-01$ & $5.48 \mathrm{E}-01$ & $1.56 \mathrm{E}+00$ & $1.96 \mathrm{E}+00$ & $2.26 \mathrm{E}+00$ & $2.74 \mathrm{E}+00$ \\
\hline $4.10 \mathrm{E}-02$ & $4.14 \mathrm{E}+00$ & $7.34 \mathrm{E}-01$ & $5.49 \mathrm{E}-01$ & $1.56 \mathrm{E}+00$ & $1.96 \mathrm{E}+00$ & $2.26 \mathrm{E}+00$ & $2.74 \mathrm{E}+00$ \\
\hline $4.12 \mathrm{E}-02$ & $4.13 \mathrm{E}+00$ & $7.35 \mathrm{E}-01$ & $5.50 \mathrm{E}-01$ & $1.56 \mathrm{E}+00$ & $1.96 \mathrm{E}+00$ & $2.26 \mathrm{E}+00$ & $2.74 \mathrm{E}+00$ \\
\hline $4.13 E-02$ & $4.13 E+00$ & $7.36 \mathrm{E}-01$ & $5.50 \mathrm{E}-01$ & $1.56 \mathrm{E}+00$ & $1.96 \mathrm{E}+00$ & $2.26 \mathrm{E}+00$ & $2.74 \mathrm{E}+00$ \\
\hline $4.15 E-02$ & $4.12 \mathrm{E}+00$ & $7.37 \mathrm{E}-01$ & $5.51 \mathrm{E}-01$ & $1.57 \mathrm{E}+00$ & $1.96 \mathrm{E}+00$ & $2.26 \mathrm{E}+00$ & $2.74 \mathrm{E}+00$ \\
\hline $4.16 \mathrm{E}-02$ & $4.12 \mathrm{E}+00$ & $7.37 \mathrm{E}-01$ & $5.52 \mathrm{E}-01$ & $1.57 \mathrm{E}+00$ & $1.96 \mathrm{E}+00$ & $2.26 \mathrm{E}+00$ & $2.73 \mathrm{E}+00$ \\
\hline $4.17 \mathrm{E}-02$ & $4.11 \mathrm{E}+00$ & $7.38 \mathrm{E}-01$ & $5.53 \mathrm{E}-01$ & $1.57 \mathrm{E}+00$ & $1.96 \mathrm{E}+00$ & $2.26 \mathrm{E}+00$ & $2.73 \mathrm{E}+00$ \\
\hline $4.19 \mathrm{E}-02$ & $4.11 \mathrm{E}+00$ & $7.39 \mathrm{E}-01$ & $5.54 \mathrm{E}-01$ & $1.57 \mathrm{E}+00$ & $1.96 \mathrm{E}+00$ & $2.26 \mathrm{E}+00$ & $2.73 \mathrm{E}+00$ \\
\hline $4.20 \mathrm{E}-02$ & $4.10 \mathrm{E}+00$ & $7.40 \mathrm{E}-01$ & $5.55 \mathrm{E}-01$ & $1.57 \mathrm{E}+00$ & $1.96 \mathrm{E}+00$ & $2.26 \mathrm{E}+00$ & $2.73 \mathrm{E}+00$ \\
\hline $4.22 \mathrm{E}-02$ & $4.10 \mathrm{E}+00$ & $7.41 \mathrm{E}-01$ & $5.56 \mathrm{E}-01$ & $1.57 \mathrm{E}+00$ & $1.96 \mathrm{E}+00$ & $2.26 \mathrm{E}+00$ & $2.73 \mathrm{E}+00$ \\
\hline $4.23 \mathrm{E}-02$ & $4.09 \mathrm{E}+00$ & $7.41 \mathrm{E}-01$ & $5.57 \mathrm{E}-01$ & $1.57 \mathrm{E}+00$ & $1.96 \mathrm{E}+00$ & $2.26 \mathrm{E}+00$ & $2.73 \mathrm{E}+00$ \\
\hline $4.25 E-02$ & $4.09 \mathrm{E}+00$ & $7.42 \mathrm{E}-01$ & $5.58 \mathrm{E}-01$ & $1.58 \mathrm{E}+00$ & $1.97 \mathrm{E}+00$ & $2.27 \mathrm{E}+00$ & $2.72 \mathrm{E}+00$ \\
\hline $4.26 \mathrm{E}-02$ & $4.08 \mathrm{E}+00$ & $7.43 \mathrm{E}-01$ & $5.59 \mathrm{E}-01$ & $1.58 \mathrm{E}+00$ & $1.97 \mathrm{E}+00$ & $2.27 \mathrm{E}+00$ & $2.72 \mathrm{E}+00$ \\
\hline
\end{tabular}


RESRAD-OFFSITE, Version 2.5 
RESRAD-OFFSITE, Version 2.5 
RESRAD-OFFSITE, Version 2.5 
RESRAD-OFFSITE, Version 2.5

Title : RESRAD-OFFSITE Drinking Water, Plant, Milk, and Meat Pathways for Offsite Reside File : PBA-1_TC99-DOE-5.ROF

Summary of dose at graphical times, reptition 1 (continued)

Time

Years

$9.20 \mathrm{E}+02$

$9.20 \mathrm{E}+02$

$9.21 \mathrm{E}+02$

$9.21 \mathrm{E}+02$

$9.22 \mathrm{E}+02$

$9.22 \mathrm{E}+02$

$9.23 \mathrm{E}+02$

$9.23 \mathrm{E}+02$

$9.24 \mathrm{E}+02$

$9.24 \mathrm{E}+02$

$9.25 \mathrm{E}+02$

$9.25 \mathrm{E}+02$

$9.26 \mathrm{E}+02$

$9.26 \mathrm{E}+02$

$9.27 \mathrm{E}+02$

$9.27 \mathrm{E}+02$

$9.28 \mathrm{E}+02$

$9.28 \mathrm{E}+02$

$9.29 \mathrm{E}+02$

9. $30 \mathrm{E}+02$

9. $30 \mathrm{E}+02$

9. $31 \mathrm{E}+02$

$9.31 \mathrm{E}+02$

9. $32 \mathrm{E}+02$

9. $32 \mathrm{E}+02$

$9.33 \mathrm{E}+02$

9. $33 \mathrm{E}+02$

$9.34 \mathrm{E}+02$

9. $34 \mathrm{E}+02$

$9.35 \mathrm{E}+02$

9. $35 \mathrm{E}+02$

9. $36 \mathrm{E}+02$

9. $36 \mathrm{E}+02$

9. $37 \mathrm{E}+02$

9. $37 \mathrm{E}+02$

$9.38 \mathrm{E}+02$

$9.38 \mathrm{E}+02$

$9.39 \mathrm{E}+02$

9. $39 \mathrm{E}+02$

$9.40 \mathrm{E}+02$

$9.40 \mathrm{E}+02$

9. $41 \mathrm{E}+02$

9. $41 \mathrm{E}+02$

9. $42 \mathrm{E}+02$

$9.42 \mathrm{E}+02$

$9.43 \mathrm{E}+02$
Dose statistics at graphical times, mrem/yr

\begin{tabular}{|c|c|c|c|c|c|c|c|}
\hline & mum & 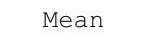 & 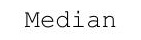 & & & & \\
\hline $60 \mathrm{E}-02$ & $.79 \mathrm{E}+00$ & $8.43 \mathrm{E}-01$ & $6.86 \mathrm{E}-01$ & $1.69 \mathrm{E}+00$ & $2.02 \mathrm{E}+00$ & $2.28 \mathrm{E}+00$ & $2.64 \mathrm{E}+00$ \\
\hline $.62 \mathrm{E}-02$ & $.79 \mathrm{E}+00$ & $8.44 \mathrm{E}-01$ & $6.87 \mathrm{E}-01$ & $1.69 \mathrm{E}+00$ & $2.02 \mathrm{E}+00$ & $2.28 \mathrm{E}+00$ & $2.64 \mathrm{E}+00$ \\
\hline $.64 \mathrm{E}-02$ & $3.79 \mathrm{E}+00$ & $8.44 \mathrm{E}-01$ & $6.88 \mathrm{E}-01$ & $1.69 \mathrm{E}+00$ & $2.02 \mathrm{E}+00$ & $2.28 \mathrm{E}+00$ & $2.64 \mathrm{E}+00$ \\
\hline $6.65 \mathrm{E}-02$ & $3.79 \mathrm{E}+00$ & $8.45 E-01$ & $6.88 \mathrm{E}-01$ & $1.69 \mathrm{E}+00$ & $2.02 \mathrm{E}+00$ & $2.28 \mathrm{E}+00$ & $2.64 \mathrm{E}+00$ \\
\hline $6.67 \mathrm{E}-02$ & $3.79 \mathrm{E}+00$ & $8.46 \mathrm{E}-01$ & $6.89 \mathrm{E}-01$ & $1.69 \mathrm{E}+00$ & $2.02 \mathrm{E}+00$ & $2.28 \mathrm{E}+00$ & $2.64 \mathrm{E}+00$ \\
\hline $6.69 \mathrm{E}-02$ & $3.78 \mathrm{E}+00$ & $8.46 \mathrm{E}-01$ & $6.90 \mathrm{E}-01$ & $1.69 \mathrm{E}+00$ & $2.02 \mathrm{E}+00$ & $2.28 \mathrm{E}+00$ & $2.64 \mathrm{E}+00$ \\
\hline $6.71 \mathrm{E}-02$ & $3.78 \mathrm{E}+00$ & $8.47 \mathrm{E}-01$ & $6.91 \mathrm{E}-01$ & $1.69 \mathrm{E}+00$ & $2.02 \mathrm{E}+00$ & $2.28 \mathrm{E}+00$ & $2.64 \mathrm{E}+00$ \\
\hline $6.73 \mathrm{E}-02$ & $3.78 \mathrm{E}+00$ & $8.47 \mathrm{E}-01$ & $6.92 \mathrm{E}-01$ & $1.69 \mathrm{E}+00$ & $2.02 \mathrm{E}+00$ & $2.28 \mathrm{E}+00$ & $2.63 \mathrm{E}+00$ \\
\hline $6.75 \mathrm{E}-02$ & $3.78 \mathrm{E}+00$ & $8.48 \mathrm{E}-01$ & $6.93 \mathrm{E}-01$ & $1.69 \mathrm{E}+00$ & $2.02 \mathrm{E}+00$ & $2.28 \mathrm{E}+00$ & $2.63 \mathrm{E}+00$ \\
\hline $6.77 \mathrm{E}-02$ & $3.78 \mathrm{E}+00$ & $8.49 \mathrm{E}-01$ & $6.94 \mathrm{E}-01$ & $1.69 \mathrm{E}+00$ & $2.02 \mathrm{E}+00$ & $2.28 \mathrm{E}+00$ & $2.63 \mathrm{E}+00$ \\
\hline $6.79 \mathrm{E}-02$ & $3.78 \mathrm{E}+00$ & $8.49 \mathrm{E}-01$ & $6.95 \mathrm{E}-01$ & $1.69 \mathrm{E}+00$ & $2.02 E+00$ & $2.29 \mathrm{E}$ & $2.63 \mathrm{E}+00$ \\
\hline $6.81 \mathrm{E}-02$ & $3.78 \mathrm{E}+00$ & $8.50 \mathrm{E}-01$ & $6.96 \mathrm{E}-01$ & $1.69 \mathrm{E}+00$ & $2.02 \mathrm{E}+00$ & $2.29 \mathrm{E}+00$ & $2.63 \mathrm{E}+00$ \\
\hline $.82 \mathrm{E}-02$ & $3.78 \mathrm{E}+00$ & $8.51 \mathrm{E}-01$ & $6.97 \mathrm{E}-01$ & $1.69 \mathrm{E}+00$ & $2.02 \mathrm{E}+00$ & $2.29 \mathrm{E}+00$ & $2.63 \mathrm{E}+00$ \\
\hline $.84 \mathrm{E}-02$ & $3.77 \mathrm{E}+00$ & $8.51 \mathrm{E}-01$ & $6.98 \mathrm{E}-01$ & $1.69 \mathrm{E}+00$ & $2.02 \mathrm{E}+00$ & $2.29 \mathrm{E}+00$ & $2.62 \mathrm{E}+00$ \\
\hline $6.86 \mathrm{E}-02$ & $3.77 \mathrm{E}+00$ & $8.52 \mathrm{E}-01$ & $6.99 \mathrm{E}-01$ & $1.69 \mathrm{E}+00$ & $2.02 E+00$ & $2.29 \mathrm{E}+00$ & $2.62 \mathrm{E}+00$ \\
\hline $6.88 \mathrm{E}-02$ & $3.77 \mathrm{E}+00$ & $8.53 \mathrm{E}-01$ & $7.00 \mathrm{E}-01$ & $1.69 \mathrm{E}+00$ & $2.02 \mathrm{E}+00$ & $2.29 \mathrm{E}+00$ & $2.62 \mathrm{E}+00$ \\
\hline $6.90 \mathrm{E}-02$ & $3.77 \mathrm{E}+00$ & $8.53 \mathrm{E}-01$ & $7.00 \mathrm{E}-01$ & $1.69 \mathrm{E}+00$ & $2.02 \mathrm{E}+00$ & $2.29 \mathrm{E}+00$ & $2.62 \mathrm{E}+00$ \\
\hline $6.92 \mathrm{E}-02$ & $3.77 \mathrm{E}+00$ & $8.54 \mathrm{E}-01$ & $7.01 \mathrm{E}-01$ & $1.69 \mathrm{E}+00$ & $2.02 \mathrm{E}+00$ & $2.29 \mathrm{E}+00$ & $2.62 \mathrm{E}+00$ \\
\hline $6.94 \mathrm{E}-02$ & $3.77 \mathrm{E}+00$ & $8.55 \mathrm{E}-01$ & $7.02 \mathrm{E}-01$ & $1.69 \mathrm{E}+00$ & $2.02 \mathrm{E}+00$ & $2.29 \mathrm{E}+00$ & $2.62 \mathrm{E}+00$ \\
\hline $6.96 \mathrm{E}-02$ & $3.77 \mathrm{E}+00$ & $8.55 \mathrm{E}-01$ & $7.03 \mathrm{E}-01$ & $1.69 \mathrm{E}+00$ & $2.02 \mathrm{E}+00$ & $2.29 \mathrm{E}+00$ & $2.62 \mathrm{E}+00$ \\
\hline $6.98 \mathrm{E}-02$ & $3.77 \mathrm{E}+00$ & $8.56 \mathrm{E}-01$ & $7.03 \mathrm{E}-01$ & $1.69 \mathrm{E}+00$ & $2.01 \mathrm{E}+00$ & $2.29 \mathrm{E}+00$ & $2.61 \mathrm{E}+00$ \\
\hline $00 \mathrm{E}-02$ & $3.76 \mathrm{E}+00$ & $8.56 \mathrm{E}-01$ & $7.04 \mathrm{E}-01$ & $1.69 \mathrm{E}+00$ & $2.01 \mathrm{E}+00$ & $2.29 \mathrm{E}+00$ & $2.61 \mathrm{E}+00$ \\
\hline $02 E-02$ & $3.76 \mathrm{E}+00$ & $8.57 \mathrm{E}-$ & 7 & $1.69 \mathrm{E}+00$ & $2.01 \mathrm{E}+00$ & $2.29 \mathrm{E}+00$ & $2.61 \mathrm{E}+00$ \\
\hline $7.04 \mathrm{E}-02$ & $3.76 \mathrm{E}+00$ & 0 & 1 & 0 & $2.01 \mathrm{E}+00$ & $2.29 \mathrm{E}+$ & $2.61 \mathrm{E}+00$ \\
\hline $7.06 \mathrm{E}-02$ & $3.76 \mathrm{E}+00$ & $8.58 \mathrm{E}-01$ & $7.06 \mathrm{E}-01$ & $1.70 \mathrm{E}+00$ & $2.01 \mathrm{E}+00$ & $2.29 \mathrm{E}+00$ & $2.61 \mathrm{E}+00$ \\
\hline $7.07 \mathrm{E}-02$ & $3.76 \mathrm{E}+00$ & $8.59 \mathrm{E}-01$ & $7.07 \mathrm{E}-01$ & $1.70 \mathrm{E}+00$ & $2.01 \mathrm{E}+00$ & $2.29 \mathrm{E}+00$ & $2.61 \mathrm{E}+00$ \\
\hline $7.09 \mathrm{E}-02$ & $3.76 \mathrm{E}+00$ & $8.60 \mathrm{E}-01$ & $7.07 \mathrm{E}-01$ & $1.70 \mathrm{E}+00$ & $2.01 \mathrm{E}+00$ & $2.29 \mathrm{E}+00$ & $2.61 \mathrm{E}+00$ \\
\hline $7.11 \mathrm{E}-02$ & $3.76 \mathrm{E}+00$ & $8.60 \mathrm{E}-01$ & $7.08 \mathrm{E}-01$ & $1.70 \mathrm{E}+00$ & $2.01 \mathrm{E}+00$ & $2.29 \mathrm{E}+00$ & $2.61 \mathrm{E}+00$ \\
\hline $7.13 \mathrm{E}-02$ & $3.76 \mathrm{E}+00$ & $8.61 \mathrm{E}-01$ & $7.09 \mathrm{E}-01$ & $1.70 \mathrm{E}+00$ & $2.01 \mathrm{E}+00$ & $2.29 \mathrm{E}+00$ & $2.61 \mathrm{E}+00$ \\
\hline $7.15 \mathrm{E}-02$ & $3.75 \mathrm{E}+00$ & $8.61 \mathrm{E}-01$ & $7.10 \mathrm{E}-01$ & $1.70 \mathrm{E}+00$ & $2.01 \mathrm{E}+00$ & $2.29 \mathrm{E}+00$ & $2.61 \mathrm{E}+00$ \\
\hline $7.17 \mathrm{E}-02$ & $3.75 \mathrm{E}+00$ & $8.62 \mathrm{E}-01$ & $7.11 \mathrm{E}-01$ & $1.70 \mathrm{E}+00$ & $2.01 \mathrm{E}+00$ & $2.29 \mathrm{E}+00$ & $2.61 \mathrm{E}+00$ \\
\hline $7.19 \mathrm{E}-02$ & $3.75 \mathrm{E}+00$ & $8.63 \mathrm{E}-01$ & $7.12 \mathrm{E}-01$ & $1.70 \mathrm{E}+00$ & $2.01 \mathrm{E}+00$ & $2.29 \mathrm{E}+00$ & $2.60 \mathrm{E}+00$ \\
\hline $7.21 \mathrm{E}-02$ & $3.75 \mathrm{E}+00$ & $8.63 \mathrm{E}-01$ & $7.13 \mathrm{E}-01$ & $1.70 \mathrm{E}+00$ & $2.01 \mathrm{E}+00$ & $2.29 \mathrm{E}+00$ & $2.60 \mathrm{E}+00$ \\
\hline $7.23 \mathrm{E}-02$ & $3.75 \mathrm{E}+00$ & $8.64 \mathrm{E}-01$ & $7.14 \mathrm{E}-01$ & $1.70 \mathrm{E}+00$ & $2.01 \mathrm{E}+00$ & $2.29 \mathrm{E}+00$ & $2.60 \mathrm{E}+00$ \\
\hline $25 \mathrm{E}-02$ & $3.75 \mathrm{E}+00$ & $8.65 \mathrm{E}-01$ & $7.15 \mathrm{E}-01$ & $1.70 \mathrm{E}+00$ & $2.01 \mathrm{E}+00$ & $2.29 \mathrm{E}+00$ & $2.60 \mathrm{E}+00$ \\
\hline $7.27 \mathrm{E}-02$ & $3.75 \mathrm{E}+00$ & $8.65 \mathrm{E}-01$ & $7.15 \mathrm{E}-01$ & $1.70 \mathrm{E}+00$ & $2.01 \mathrm{E}+00$ & $2.29 \mathrm{E}+00$ & $2.60 \mathrm{E}+00$ \\
\hline $7.29 \mathrm{E}-02$ & $3.74 \mathrm{E}+00$ & $8.66 \mathrm{E}-01$ & $7.16 \mathrm{E}-01$ & $1.71 \mathrm{E}+00$ & $2.01 \mathrm{E}+00$ & $2.29 \mathrm{E}+00$ & $2.60 \mathrm{E}+00$ \\
\hline $7.31 \mathrm{E}-02$ & $3.74 \mathrm{E}+00$ & $8.66 \mathrm{E}-01$ & $7.17 \mathrm{E}-01$ & $1.71 \mathrm{E}+00$ & $2.01 \mathrm{E}+00$ & $2.29 \mathrm{E}+00$ & $2.60 \mathrm{E}+00$ \\
\hline $7.33 \mathrm{E}-02$ & $3.74 \mathrm{E}+00$ & $8.67 \mathrm{E}-01$ & $7.17 \mathrm{E}-01$ & $1.71 \mathrm{E}+00$ & $2.01 \mathrm{E}+00$ & $2.29 \mathrm{E}+00$ & $2.60 \mathrm{E}+00$ \\
\hline $7.35 \mathrm{E}-02$ & $3.74 \mathrm{E}+00$ & $8.68 \mathrm{E}-01$ & $7.18 \mathrm{E}-01$ & $1.71 \mathrm{E}+00$ & $2.01 \mathrm{E}+00$ & $2.28 \mathrm{E}+00$ & $2.60 \mathrm{E}+00$ \\
\hline $7.37 \mathrm{E}-02$ & $3.74 \mathrm{E}+00$ & $8.68 \mathrm{E}-01$ & $7.19 \mathrm{E}-01$ & $1.71 \mathrm{E}+00$ & $2.02 E+00$ & $2.28 \mathrm{E}+00$ & $2.59 \mathrm{E}+00$ \\
\hline $7.39 \mathrm{E}-02$ & $3.74 \mathrm{E}+00$ & $8.69 \mathrm{E}-01$ & $7.20 \mathrm{E}-01$ & $1.71 \mathrm{E}+00$ & $2.02 \mathrm{E}+00$ & $2.28 \mathrm{E}+00$ & $2.59 \mathrm{E}+00$ \\
\hline $7.41 \mathrm{E}-02$ & $3.74 \mathrm{E}+00$ & $8.70 \mathrm{E}-01$ & $7.21 \mathrm{E}-01$ & $1.71 \mathrm{E}+00$ & $2.02 E+00$ & $2.28 \mathrm{E}+00$ & $2.59 \mathrm{E}+00$ \\
\hline $7.43 \mathrm{E}-02$ & $3.73 \mathrm{E}+00$ & $8.70 \mathrm{E}-01$ & $7.22 \mathrm{E}-01$ & $1.71 \mathrm{E}+00$ & $2.02 \mathrm{E}+00$ & $2.28 \mathrm{E}+00$ & $2.59 \mathrm{E}+00$ \\
\hline $7.45 \mathrm{E}-02$ & $3.73 \mathrm{E}+00$ & $8.71 \mathrm{E}-01$ & $7.23 \mathrm{E}-01$ & $1.71 \mathrm{E}+00$ & $2.02 E+00$ & $2.28 \mathrm{E}+00$ & $2.59 \mathrm{E}+00$ \\
\hline $7.47 \mathrm{E}-02$ & $3.73 \mathrm{E}+00$ & $8.71 \mathrm{E}-01$ & $7.23 \mathrm{E}-01$ & $1.71 \mathrm{E}+00$ & $2.02 E+00$ & $2.28 \mathrm{E}+00$ & $2.59 \mathrm{E}+00$ \\
\hline
\end{tabular}


RESRAD-OFFSITE, Version 2.5

Title : RESRAD-OFFSITE Drinking Water, Plant, Milk, and Meat Pathways for Offsite Reside File : PBA-1_TC99-DOE-5.ROF

Summary of dose at graphical times, reptition 1 (continued)

Time

Years

9. $43 \mathrm{E}+02$

9. $44 \mathrm{E}+02$

$9.44 \mathrm{E}+02$

9. $45 \mathrm{E}+02$

9. $45 \mathrm{E}+02$

$9.46 \mathrm{E}+02$

$9.46 \mathrm{E}+02$

$9.47 \mathrm{E}+02$

9. $47 \mathrm{E}+02$

9. $48 \mathrm{E}+02$

9. $48 \mathrm{E}+02$

9. $49 \mathrm{E}+02$

$9.50 \mathrm{E}+02$

9. $50 \mathrm{E}+02$

9. $51 \mathrm{E}+02$

9. $51 \mathrm{E}+02$

$9.52 \mathrm{E}+02$

9. $52 \mathrm{E}+02$

$9.53 \mathrm{E}+02$

$9.53 \mathrm{E}+02$

$9.54 \mathrm{E}+02$

$9.54 \mathrm{E}+02$

9. $55 \mathrm{E}+02$

9. $55 \mathrm{E}+02$

9. $56 \mathrm{E}+02$

9. $56 \mathrm{E}+02$

9. $57 \mathrm{E}+02$

9. $57 \mathrm{E}+02$

9. $58 \mathrm{E}+02$

$9.58 \mathrm{E}+02$

$9.59 \mathrm{E}+02$

$9.59 \mathrm{E}+02$

$9.60 \mathrm{E}+02$

$9.60 \mathrm{E}+02$

$9.61 \mathrm{E}+02$

9. $61 \mathrm{E}+02$

$9.62 \mathrm{E}+02$

$9.62 \mathrm{E}+02$

$9.63 \mathrm{E}+02$

$9.63 \mathrm{E}+02$

$9.64 \mathrm{E}+02$

$9.64 \mathrm{E}+02$

$9.65 \mathrm{E}+02$

$9.65 \mathrm{E}+02$

$9.66 \mathrm{E}+02$

$9.66 \mathrm{E}+02$
Dose statistics at graphical times, mrem/yr

\begin{tabular}{|c|c|c|c|c|c|c|c|}
\hline inimum & aximum & Mean & ledian & $0 \%$ & $5 \%$ & $97.5 \%$ & $3 \%$ \\
\hline-02 & $3.73 E+00$ & $8.72 E-01$ & 7. $24 \mathrm{E}-01$ & $1.71 \mathrm{E}+00$ & $02 E+00$ & $.28 E+00$ & $.59 E+0$ \\
\hline 02 & +00 & $B E$ & 1 & $.71 \mathrm{E}+$ & 00 & 00 & +00 \\
\hline-02 & +00 & $3 E-01$ & $E-01$ & 00 & 00 & +00 & +00 \\
\hline$E-02$ & $E+00$ & 1 & 1 & 0 & 0 & +00 & +00 \\
\hline-02 & -00 & 1 & -01 & 0 & 00 & $29 E+00$ & $58 E+00$ \\
\hline-02 & $2 E+00$ & $5 E-01$ & 01 & $1.71 \mathrm{E}+00$ & $2.02 \mathrm{E}+$ & $E+00$ & $8 \mathrm{E}+00$ \\
\hline 02 & +00 & $6 \mathrm{E}-01$ & -01 & $.71 \mathrm{E}$ & 00 & +00 & $\mathrm{E}+00$ \\
\hline $.63 E-02$ & $3.72 E+00$ & 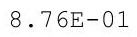 & 7. $30 \mathrm{E}-01$ & 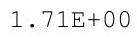 & $.02 E+00$ & $.29 E+00$ & $58 \mathrm{E}+00$ \\
\hline 02 & +00 & F- & 01 & $1.71 \mathrm{E}$ & 00 & +00 & +00 \\
\hline $.67 E-02$ & $2 \mathrm{E}+00$ & -01 & -01 & 1. $71 \mathrm{E}+00$ & $02 E+00$ & $.29 \mathrm{E}+00$ & $57 \mathrm{E}+00$ \\
\hline-02 & +00 & $E-01$ & $E-01$ & 0 & & +00 & $E+00$ \\
\hline-02 & +00 & & & & & +00 & +00 \\
\hline $.73 E-02$ & $3.71 \mathrm{E}+00$ & $8.19 E-01$ & 7. $33 E-01$ & 1.98700 & $2 \cdot 0=\mathrm{E}$ & $.29 E+00$ & $56 \mathrm{E}+0 \mathrm{C}$ \\
\hline $.75 E-02$ & +00 & -01 & 01 & $1.72 \mathrm{E}+00$ & 00 & +00 & +00 \\
\hline$E-02$ & -00 & 01 & 01 & 土. & 00 & $\mathrm{E}+00$ & +00 \\
\hline $.79 \mathrm{E}-02$ & $3.71 \mathrm{E}+00$ & 1 & -01 & 1. $72 \mathrm{E}+00$ & & $.29 \mathrm{E}+00$ & $6 \mathrm{E}+00$ \\
\hline $.81 E-02$ & $3.71 \mathrm{E}+00$ & $2 E-01$ & $7 E-01$ & $1.72 \mathrm{E}+00$ & $02 \mathrm{E}+00$ & $.29 \mathrm{E}+00$ & $56 \mathrm{E}+00$ \\
\hline-02 & $70 E+00$ & $2 E-01$ & $8 E-01$ & $72 E+00$ & $02 E+00$ & $29 E+00$ & $5 E+0 C$ \\
\hline $.85 E-02$ & $3.70 \mathrm{E}+00$ & $3 E-01$ & $E-01$ & $1.72 \mathrm{E}$ & & $E+00$ & $E+00$ \\
\hline $.87 \mathrm{E}-02$ & +00 & -01 & -01 & $1.72 \mathrm{E}+00$ & & $E+00$ & +00 \\
\hline $.89 \mathrm{E}-02$ & +00 & 1 & -01 & $1.92 \mathrm{D}-1$ & & كا كات & +00 \\
\hline $.91 \mathrm{E}-02$ & $3.70 \mathrm{E}+00$ & (6) & 01 & $1.72 \mathrm{E}+00$ & 010 & $.28 \mathrm{E}+00$ & $E+00$ \\
\hline $.93 E-02$ & $3.70 \mathrm{E}+00$ & $8.85 \mathrm{E}-01$ & 7. $42 \mathrm{E}-01$ & $1.72 \mathrm{E}+00$ & $2.01 E+00$ & $.28 E+00$ & $55 \mathrm{E}+00$ \\
\hline $.95 E-02$ & $3.69 \mathrm{E}+00$ & $6 \mathrm{E}-01$ & $3 E-01$ & $1.72 \mathrm{E}+00$ & $01 \mathrm{E}+00$ & $.28 \mathrm{E}+00$ & $5 \mathrm{E}+0 \mathrm{C}$ \\
\hline 02 & $69 \mathrm{E}+00$ & $6 E-01$ & $E-01$ & 0 & & $E+00$ & $\mathrm{E}+00$ \\
\hline$E-02$ & +00 & 01 & 01 & 00 & & +00 & +00 \\
\hline $.01 E-02$ & $E+00$ & $E-01$ & -01 & $1.7 \angle 4$ & & $.28 \mathrm{E}+00$ & $E+00$ \\
\hline $.03 E-02$ & $3.69 \mathrm{E}+00$ & $8.88 E-01$ & $7.47 \mathrm{E}-01$ & $1.72 \mathrm{E}+00$ & $.02 E+00$ & $.28 \mathrm{E}+00$ & $.55 E+00$ \\
\hline 2 & ل & 然 & - & 年 & • & . & $5 E+00$ \\
\hline $.08 E-02$ & 年 & $8.89 \mathrm{E}-01$ & $8 E-01$ & -1 & & 政 & $5 \mathrm{E}+0$ \\
\hline 2 & $68 E+00$ & $E-01$ & $9 E-01$ & $72 \mathrm{E}+00$ & $02 \mathrm{E}+00$ & $28 E+00$ & $\mathrm{E}+00$ \\
\hline-02 & $\mathrm{E}+00$ & $0 E-01$ & $D E-01$ & $E+00$ & $E+00$ & 0 & $\mathrm{E}+00$ \\
\hline $.14 \mathrm{E}-02$ & $3.68 \mathrm{E}+00$ & $E-01$ & $E-01$ & $1.73 E+00$ & 00 & $.28 E+00$ & $5 E+00$ \\
\hline $.16 \mathrm{E}-02$ & $3.68 \mathrm{E}+00$ & $8.91 E-01$ & $.52 \mathrm{E}-01$ & $1.73 E+00$ & $.0 \angle E+U 0$ & $.28 E+00$ & $5 E+00$ \\
\hline $18 E-02$ & & $.92 E-01$ & $.53 E-01$ & 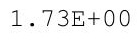 & & & $.55 E+0 C$ \\
\hline & & & & & & & \\
\hline $.22 \mathrm{E}-02$ & ( & & & 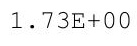 & & 0 & 0 \\
\hline 2 & 0 & 1 & 1 & 0 & & & \\
\hline 2 & & & 1 & & & 00 & $5 E+00$ \\
\hline$E-02$ & $3.67 E+00$ & $5 E-01$ & $57 E-01$ & 0 & 0 & 0 & +00 \\
\hline 02 & & $.95 E-01$ & & $73 E+00$ & & & $.56 E+0 c$ \\
\hline & $.67 E+00$ & $.96 \mathrm{E}-01$ & $7.59 E-01$ & $1.73 E+00$ & $2.02 \mathrm{E}+00$ & $2.27 E+00$ & $.56 \mathrm{E}+00$ \\
\hline & 3 & 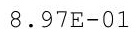 & 1 & 0 & $02 \mathrm{E}$ & - & 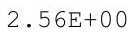 \\
\hline $0.3 / E-U Z$ & 3 & 1 & & 0 & 0 & 0 & 00 \\
\hline 2 & $E+00$ & $E-01$ & 7. & $1.73 \mathrm{E}$ & $2.02 \mathrm{E}+00$ & $E+00$ & $2.56 \mathrm{E}+00$ \\
\hline $41 E-02$ & $3.66 \mathrm{E}+00$ & $.98 E-01$ & 7. $62 \mathrm{E}-01$ & $1.73 E+00$ & $2.02 E+00$ & $2.26 \mathrm{E}+00$ & $.56 \mathrm{E}+00$ \\
\hline
\end{tabular}


RESRAD-OFFSITE, Version 2.5 
RESRAD-OFFSITE, Version 2.5

Title : RESRAD-OFFSITE Drinking Water, Plant, Milk, and Meat Pathways for Offsite Reside File : PBA-1_TC99-DOE-5.ROF

Summary of dose at graphical times, reptition 1 (continued)

Time

Years

$9.91 \mathrm{E}+02$

9. $91 \mathrm{E}+02$

9. $92 \mathrm{E}+02$

9. $92 \mathrm{E}+02$

9. $93 \mathrm{E}+02$

9. $93 \mathrm{E}+02$

9. $94 \mathrm{E}+02$

$9.94 \mathrm{E}+02$

9. $95 \mathrm{E}+02$

9. $95 \mathrm{E}+02$

9. $96 \mathrm{E}+02$

9. $96 \mathrm{E}+02$

$9.97 \mathrm{E}+02$

9. $97 \mathrm{E}+02$

$9.98 \mathrm{E}+02$

$9.98 \mathrm{E}+02$

$9.99 \mathrm{E}+02$

$9.99 \mathrm{E}+02$

$1.00 \mathrm{E}+03$

$1.00 \mathrm{E}+03$

$1.00 \mathrm{E}+03$

$1.00 \mathrm{E}+03$

$1.00 \mathrm{E}+03$

$1.00 \mathrm{E}+03$

$1.00 \mathrm{E}+03$

$1.00 \mathrm{E}+03$

$1.00 \mathrm{E}+03$

$1.00 \mathrm{E}+03$

$1.00 \mathrm{E}+03$

$1.01 \mathrm{E}+03$

$1.01 \mathrm{E}+03$

$1.01 \mathrm{E}+03$

$1.01 \mathrm{E}+03$

$1.01 \mathrm{E}+03$

$1.01 \mathrm{E}+03$

$1.01 \mathrm{E}+03$

$1.01 E+03$

$1.01 \mathrm{E}+03$

$1.01 \mathrm{E}+03$

$1.01 \mathrm{E}+03$

$1.01 \mathrm{E}+03$

$1.01 \mathrm{E}+03$

$1.01 \mathrm{E}+03$

$1.01 \mathrm{E}+03$

$1.01 \mathrm{E}+03$

$1.01 \mathrm{E}+03$
Dose statistics at graphical times, mrem/yr

\begin{tabular}{|c|c|c|c|c|c|c|c|}
\hline inimum & aximum & Mean & ledian & $0 \%$ & $5 \%$ & $97.5 \%$ & $3 \%$ \\
\hline 02 & $3.57 E+00$ & $9.24 \mathrm{E}-01$ & $5 E-01$ & $4 E+00$ & $0 E+00$ & $.23 E+00$ & $.56 \mathrm{E}+0$ \\
\hline 02 & $\mathrm{E}+00$ & 1 & 1 & 0 & $0 \mathrm{E}+00$ & +00 & $6 \mathrm{E}+00$ \\
\hline$E-02$ & +00 & $E-01$ & $E-01$ & 00 & 00 & +00 & +00 \\
\hline-02 & 00 & 1 & 1 & 0 & 0 & 00 & +00 \\
\hline 2 & 0 & 1 & 1 & 0 & 0 & +00 & $\exists+00$ \\
\hline-02 & $6 \mathrm{E}+00$ & $E-01$ & -01 & $1.74 \mathrm{E}+00$ & $\mathrm{E}+00$ & $23 E+00$ & $\mathrm{E}+00$ \\
\hline 02 & -00 & $7 E-01$ & -01 & 0 & 00 & +00 & +00 \\
\hline $.58 E-02$ & $3.56 \mathrm{E}+00$ & t & $8.02 E-01$ & $1.74 \mathrm{E}+00$ & 00 & +00 & +00 \\
\hline 02 & +00 & -6 & 01 & +00 & 00 & +00 & +00 \\
\hline $.62 E-02$ & $5 E+00$ & $8 E-01$ & -01 & $1.74 \mathrm{E}+00$ & $00 \mathrm{E}+00$ & $.23 E+00$ & $E+00$ \\
\hline-02 & +00 & 1 & 1 & & & 00 & $\Xi+00$ \\
\hline-02 & -00 & 1 & & & & +00 & +00 \\
\hline $.69 E-02$ & $3.55 \mathrm{E}+00$ & $9.30 \mathrm{E}-01$ & $E-01$ & $1.14 E+00$ & 00 & +00 & +00 \\
\hline 02 & +00 & -01 & -01 & $\pm .11+8$ & 00 & +00 & +00 \\
\hline 02 & +00 & -01 & 01 & & S & $E+00$ & +00 \\
\hline $.76 \mathrm{E}-02$ & $3.54 \mathrm{E}+00$ & 1 & -01 & & $01 \mathrm{E}+00$ & $.22 E+00$ & $4 \mathrm{E}+00$ \\
\hline $.78 \mathrm{E}-02$ & $4 \mathrm{E}+00$ & $2 E-01$ & $1 E-01$ & $1.74 \mathrm{E}+00$ & $01 \mathrm{E}+00$ & $.22 \mathrm{E}+00$ & $4 \mathrm{E}+00$ \\
\hline$D E-02$ & $4 E+00$ & $2 E-01$ & $1 E-01$ & (70 & $01 \mathrm{E}+00$ & $.22 E+00$ & $4 \mathrm{E}+00$ \\
\hline $2 E-02$ & $3.54 \mathrm{E}+00$ & $3 E-01$ & $2 E-01$ & 0 & & $E+00$ & +00 \\
\hline$E-02$ & +00 & $E-01$ & -01 & & & +00 & +00 \\
\hline $.87 \mathrm{E}-02$ & $3.53 \mathrm{E}+00$ & 1 & 01 & & & 100 & +00 \\
\hline $.89 \mathrm{E}-02$ & $3.53 \mathrm{E}+00$ & $E-01$ & $5 E-01$ & $1.74 \mathrm{E}+00$ & & $.22 \mathrm{E}+00$ & $3 E+00$ \\
\hline $.91 E-02$ & $3 E+00$ & $E-01$ & $E-01$ & & $01 E+00$ & $22 E+00$ & $3 E+00$ \\
\hline $.94 \mathrm{E}-02$ & $3.53 \mathrm{E}+00$ & $9.35 E-01$ & $8.16 \mathrm{E}-01$ & $1.74 \mathrm{E}+00$ & $2.01 \mathrm{E}+00$ & $.22 \mathrm{E}+00$ & $53 E+0 c$ \\
\hline 02 & +00 & 01 & 01 & & & -00 & +00 \\
\hline 02 & +ou & & & & & +00 & +00 \\
\hline $.00 \mathrm{E}-01$ & $3.52 \mathrm{E}+00$ & $9.37 E-01$ & $8 E-01$ & & & $\cdot . \angle 2 E+U U$ & $3 E+00$ \\
\hline $.00 \mathrm{E}-01$ & $3.52 \mathrm{E}+00$ & $9.37 \mathrm{E}-01$ & $8.19 E-01$ & $1.74 \mathrm{E}+00$ & $2.01 \mathrm{E}+00$ & $.22 \mathrm{E}+00$ & $.53 E+00$ \\
\hline 01 & 3 & 1 & 1 & $74 \mathrm{E}-$ & $.01 \mathrm{E}+$ & $.22 \mathrm{E}+00$ & $53 E+00$ \\
\hline $.01 E-01$ & 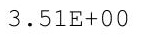 & $3 E-01$ & -01 & & & $.22 E+00$ & $3 E+0$ \\
\hline$E-01$ & $3.51 \mathrm{E}+00$ & $9 E-01$ & $1 E-01$ & $4 E+00$ & $1 E+00$ & $.22 E+00$ & $3 E+00$ \\
\hline$E-01$ & $E+00$ & $F-$ & 01 & 00 & & & \\
\hline $1 E-01$ & $3.51 \mathrm{E}+00$ & $E-01$ & $2 E-01$ & 1 . & & $.22 \mathrm{E}+00$ & $2 \mathrm{E}+00$ \\
\hline $.02 \mathrm{E}-01$ & $3.51 \mathrm{E}+00$ & $.40 \mathrm{E}-01$ & $8.23 E-01$ & $1.74 \mathrm{E}+00$ & $2.01 E+00$ & $.22 E+00$ & $52 E+00$ \\
\hline $.02 \mathrm{E}-01$ & & & & & & $.22 \mathrm{E}+00$ & $52 \mathrm{E}+0 \mathrm{C}$ \\
\hline 1 & & & & & & & \\
\hline 1 & re & 1 & & & & קר? & $2 \mathrm{E}+0 \mathrm{C}$ \\
\hline 1 & & & 01 & & 0 & +00 & +00 \\
\hline $3 E-01$ & $\mathrm{E}+00$ & $2 E-01$ & $E-01$ & 00 & 00 & 00 & +00 \\
\hline 01 & $3.49 \mathrm{E}+$ & 1 & 01 & 0 & & 0 & +00 \\
\hline & & & & $74 \mathrm{E}+00$ & & & $.51 \mathrm{E}+0 \mathrm{C}$ \\
\hline & $3.49 \mathrm{E}+00$ & & & & & & $\cdot 3 \perp \mathrm{E}+U 0$ \\
\hline & 3.4 & & & & & & $51 E+00$ \\
\hline $0 \wedge=0-1$ & 3. & te & 工 & 1 & 0 & 0 & $0 \mathrm{E}+00$ \\
\hline $4 E-01$ & $3.48 E+00$ & 9. & 8 . & $1.74 \mathrm{E}+00$ & $2.01 \mathrm{E}+00$ & $2.22 \mathrm{E}+00$ & $2.50 \mathrm{E}+00$ \\
\hline $.04 E-01$ & $3.48 \mathrm{E}+00$ & $.46 \mathrm{E}-01$ & $33 E-01$ & $1.74 \mathrm{E}+00$ & $2.01 E+00$ & $.22 E+00$ & $.50 E+00$ \\
\hline
\end{tabular}


RESRAD-OFFSITE, Version 2.5

$\mathrm{T}^{1 / 2}$ Limit $=180$ days

Title : RESRAD-OFFSITE Drinking Water, Plant, Milk, and Meat Pathways for Offsite Reside File : PBA-1_TC99-DOE-5.ROF

Summary of dose at graphical times, reptition 1 (continued)

Time

Years

$1.01 \mathrm{E}+03$

$1.01 \mathrm{E}+03$

$1.02 \mathrm{E}+03$

$1.02 \mathrm{E}+03$

$1.02 \mathrm{E}+03$

1. $02 \mathrm{E}+03$

$1.02 \mathrm{E}+03$

1. $02 \mathrm{E}+03$

$1.02 \mathrm{E}+03$

1. $02 \mathrm{E}+03$

$1.02 \mathrm{E}+03$

$1.02 \mathrm{E}+03$

$1.02 \mathrm{E}+03$

$1.02 \mathrm{E}+03$

$1.02 \mathrm{E}+03$

$1.02 \mathrm{E}+03$

$1.02 \mathrm{E}+03$

$1.02 \mathrm{E}+03$

$1.02 \mathrm{E}+03$

$1.02 \mathrm{E}+03$

$1.02 \mathrm{E}+03$

$1.02 \mathrm{E}+03$

$1.03 \mathrm{E}+03$

1. $03 \mathrm{E}+03$

$1.03 E+03$

$1.03 \mathrm{E}+03$

$1.03 E+03$

$1.03 \mathrm{E}+03$

$1.03 E+03$

$1.03 \mathrm{E}+03$

$1.03 E+03$

$1.03 \mathrm{E}+03$

$1.03 \mathrm{E}+03$

$1.03 \mathrm{E}+03$

$1.03 \mathrm{E}+03$

$1.03 \mathrm{E}+03$

$1.03 \mathrm{E}+03$

$1.03 \mathrm{E}+03$

$1.03 \mathrm{E}+03$

$1.03 \mathrm{E}+03$

$1.03 \mathrm{E}+03$

$1.04 \mathrm{E}+03$

$1.04 \mathrm{E}+03$

$1.04 \mathrm{E}+03$

$1.04 \mathrm{E}+03$

$1.04 \mathrm{E}+03$
Dose statistics at graphical times, mrem/yr

\begin{tabular}{|c|c|c|c|c|c|c|c|}
\hline inimum & aximum & Mean & ledian & $0 \%$ & $5 \%$ & $97.5 \%$ & $3 \%$ \\
\hline 1 & +00 & $E-01$ & -01 & +00 & 00 & +00 & +08 \\
\hline 01 & $E+00$ & 1 & $5 E-$ & $4 \mathrm{E}+$ & 00 & $E+00$ & $50 \mathrm{E}+00$ \\
\hline 01 & +00 & $E-01$ & -01 & 00 & 00 & +00 & +00 \\
\hline$E-01$ & $E+00$ & 1 & 1 & 0 & 0 & +00 & +00 \\
\hline-01 & 00 & & & & 00 & $21 E+00$ & $E+00$ \\
\hline $.06 \mathrm{E}-01$ & $7 \mathrm{E}+00$ & $E-01$ & $E-01$ & $1.74 \mathrm{E}+00$ & $E+00$ & $.21 E+00$ & $0 \mathrm{E}+00$ \\
\hline $.06 \mathrm{E}-01$ & $7 \mathrm{E}+00$ & $9 \mathrm{E}-01$ & $E-01$ & 00 & 00 & +00 & +00 \\
\hline $.06 E-01$ & $3.46 \mathrm{E}+00$ & & $0 E-01$ & $1.74 \mathrm{E}+00$ & & +00 & $50 \mathrm{E}+0 \mathrm{C}$ \\
\hline 01 & +00 & 1 & 01 & 00 & 00 & +00 & +00 \\
\hline $.07 E-01$ & $3.46 \mathrm{E}+00$ & $D E-01$ & $E-01$ & $.74 \mathrm{E}+00$ & $.01 E+00$ & $.20 \mathrm{E}+00$ & $0 \mathrm{E}+00$ \\
\hline-01 & +00 & 1 & -01 & & & 00 & $E+00$ \\
\hline-01 & -00 & & & & & +00 & +00 \\
\hline $.07 E-01$ & $3.45 \mathrm{E}+00$ & $9.3 \angle E-01$ & $8.42 E-01$ & $1.74 \mathrm{E}+00$ & 00 & $.20 \mathrm{E}+00$ & $E+0 C$ \\
\hline $3 E-01$ & +00 & 工 & -01 & $1.74 \mathrm{E}+00$ & 00 & +00 & +00 \\
\hline $3 E-01$ & +00 & 01 & 01 & 00 & 00 & +00 & +00 \\
\hline $.08 \mathrm{E}-01$ & +00 & 1 & -01 & & $01 \mathrm{E}+00$ & $.20 \mathrm{E}+00$ & $49 \mathrm{E}+00$ \\
\hline $.08 \mathrm{E}-01$ & $4 \mathrm{E}+00$ & $4 E-01$ & $E-01$ & $1.74 \mathrm{E}+00$ & $01 \mathrm{E}+00$ & $.20 \mathrm{E}+00$ & $.49 \mathrm{E}+00$ \\
\hline-01 & $4 E+00$ & $E-01$ & $5 E-01$ & $74 \mathrm{E}+00$ & $01 \mathrm{E}+00$ & $20 E+00$ & $49 E+00$ \\
\hline $.09 \mathrm{E}-01$ & $3.44 \mathrm{E}+00$ & $5 E-01$ & $E-01$ & $4 \mathrm{E}+00$ & & $E+00$ & $49 \mathrm{E}+00$ \\
\hline $9 E-01$ & +00 & $E-01$ & -01 & 00 & & +00 & +00 \\
\hline $9 E-01$ & 3.4 & 1 & -01 & & & 100 & +00 \\
\hline $.09 \mathrm{E}-01$ & $3.43 \mathrm{E}+00$ & $.56 \mathrm{E}-01$ & 01 & $1.74 \mathrm{E}+00$ & & $.20 \mathrm{E}+00$ & $48 \mathrm{E}+00$ \\
\hline $.10 E-01$ & $3.43 E+00$ & $9.56 \mathrm{E}-01$ & $0 E-01$ & & $2.01 \mathrm{E}+00$ & $.20 \mathrm{E}+00$ & $48 E+00$ \\
\hline$E-01$ & $3.43 E+00$ & $7 E-01$ & $0 E-01$ & $1.74 \mathrm{E}+00$ & $2.01 \mathrm{E}+00$ & $.20 \mathrm{E}+00$ & $48 \mathrm{E}+00$ \\
\hline-01 & +00 & $E-01$ & 01 & & & 00 & $8 \mathrm{E}+00$ \\
\hline 01 & 00 & 1 & & & & & +00 \\
\hline $11 \mathrm{E}-01$ & $3.42 \mathrm{E}+00$ & $9.58 \mathrm{E}-01$ & -01 & & & • $\angle U E+U O$ & $48 \mathrm{E}+00$ \\
\hline $.11 \mathrm{E}-01$ & $3.4 \angle L T U U$ & (. & $8.51 E-01$ & $1.74 \mathrm{E}+00$ & Z. UILTU & $20 \mathrm{E}+00$ & $.48 \mathrm{E}+00$ \\
\hline 1 & 1 & 然 & 1 & - & $.01 \mathrm{E}+00$ & $.20 \mathrm{E}+00$ & $.48 \mathrm{E}+0 \mathrm{C}$ \\
\hline $.11 \mathrm{E}-01$ & . & $.59 \mathrm{E}-01$ & $8.52 \mathrm{E}-01$ & & & $.20 \mathrm{E}+00$ & $48 \mathrm{E}+0$ \\
\hline 01 & $3.41 \mathrm{E}+00$ & & $3 E-01$ & $4 \mathrm{E}+00$ & $01 \mathrm{E}+00$ & $.20 E+00$ & $97 \mathrm{E}+00$ \\
\hline$E-01$ & $\mathrm{E}+00$ & $E-01$ & $E-01$ & 0 & 0 & 0 & 00 \\
\hline $2 E-01$ & $3.41 \mathrm{E}+00$ & $E-01$ & $5 E-01$ & 00 & & $.20 \mathrm{E}+00$ & $7 E+00$ \\
\hline $.12 \mathrm{E}-01$ & $3.41 \mathrm{E}+00$ & $9.61 \mathrm{E}-01$ & $5 E-01$ & $1.74 \mathrm{E}+00$ & $2.01 E+00$ & $.20 \mathrm{E}+00$ & $.47 E+00$ \\
\hline $.13 E-01$ & $3.4 U \mathrm{LTOU}$ & $9.62 E-01$ & $8.56 E-01$ & & & $.20 E+00$ & $.4 / D T U$ \\
\hline $.13 \mathrm{E}-01$ & & & & & & & \\
\hline $135-01$ & re & & & & & 0 & 00 \\
\hline 1 & & & & & & & \\
\hline 1 & & 1 & & & & $.20 E+00$ & $47 E+00$ \\
\hline$E-01$ & $3.39 E+00$ & $4 E-01$ & $0 E-01$ & 0 & & 0 & $7 \mathrm{E}+00$ \\
\hline 1 & & & & 0 & & & $47 \mathrm{E}+0 \mathrm{C}$ \\
\hline & 39E+U0 & 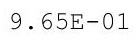 & 1 & $74 \mathrm{E}+00$ & & $20 E+00$ & $472+00$ \\
\hline & & $\perp$ & & $1+$ & > & $20 \mathrm{E}+$ & $47 E+0$ \\
\hline $15 \mathrm{~F}-01$ & 0 & 1 & & 1 & 0 & 0 & 00 \\
\hline 01 & $3.38 \mathrm{E}+00$ & $E-01$ & 8. & $1.74 \mathrm{E}+00$ & $2.00 \mathrm{E}+00$ & $2.20 \mathrm{E}+00$ & $2.46 \mathrm{E}+00$ \\
\hline $.15 \mathrm{E}-$ & $3.38 \mathrm{E}+00$ & $.66 \mathrm{E}-01$ & $.64 E-01$ & $1.74 \mathrm{E}+00$ & $2.00 \mathrm{E}+00$ & $2.20 \mathrm{E}+00$ & $.46 \mathrm{E}+00$ \\
\hline
\end{tabular}


RESRAD-OFFSITE, Version 2.5

$T^{1 / 2}$ Limit $=180$ days

robabilistic Dose and Risk Report

Title : RESRAD-OFFSITE Drinking Water, Plant, Milk, and Meat Pathways for Offsite Reside

File : PBA-1_TC99-DOE-5.ROF

Time

Years

1. $04 \mathrm{E}+03$

1. $04 \mathrm{E}+03$

$1.04 \mathrm{E}+03$

$1.04 \mathrm{E}+03$

1. $04 \mathrm{E}+03$

1. $04 \mathrm{E}+03$

1. $04 \mathrm{E}+03$

1. $04 \mathrm{E}+03$

1. $04 \mathrm{E}+03$

1. $04 \mathrm{E}+03$

1. $04 \mathrm{E}+03$

1. $04 \mathrm{E}+03$

1. $04 \mathrm{E}+03$

1. $04 \mathrm{E}+03$

1. $04 \mathrm{E}+03$

1. $05 \mathrm{E}+03$

1. $05 \mathrm{E}+03$

1. $05 \mathrm{E}+03$

1. $05 \mathrm{E}+03$

1. $05 \mathrm{E}+03$

1. $05 \mathrm{E}+03$

1. $05 \mathrm{E}+03$

1. $05 \mathrm{E}+03$

$1.05 \mathrm{E}+03$

$1.05 \mathrm{E}+03$
Summary of dose at graphical times, reptition 1 (continued)

Dose statistics at graphical times, mrem/yr

\begin{tabular}{|c|c|c|c|c|c|c|c|}
\hline Minimum & Maximum & Mean & Median & $90 \%$ & $95 \%$ & $97.5 \%$ & $3 \%$ \\
\hline 1 & $8 \mathrm{E}+00$ & 1 & $8.65 E-01$ & $1.74 \mathrm{E}+00$ & $2.00 \mathrm{Et}$ & $2.20 \mathrm{E}+$ & $.46 \mathrm{E}+00$ \\
\hline+ & 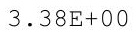 & 1 & 1 & 0 & 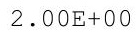 & 0 & 00 \\
\hline 01 & 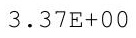 & $3 E-01$ & 01 & 0 & 00 & 00 & 00 \\
\hline 01 & 0 & $E-01$ & 1 & 0 & 0 & 0 & 100 \\
\hline $.16 \mathrm{E}-0$ & ח & $8 E-01$ & $67 E-01$ & & $2.00 \mathrm{E}+00$ & & $45 E+00$ \\
\hline $.17 \mathrm{E}-01$ & & 1 & 8 & & 6 & 0 & $E+00$ \\
\hline $.17 \mathrm{E}-01$ & $3.36 \mathrm{E}+00$ & 1 & $\perp$ & & ( & & 00 \\
\hline 5 & (1) & 4 & $\partial-01$ & & & to & +00 \\
\hline 我 & . & H & 1 & 0 & 0 & 0 & 00 \\
\hline+ & 3. & O & 1 & 0 & & 0 & +00 \\
\hline $1.18 \mathrm{E}-01$ & 3 & $9.71 \mathrm{E}-01$ & & & & & 00 \\
\hline $.18 E-01$ & 50 & 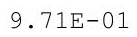 & 15 & & 0 & 00 & $45 E+00$ \\
\hline $.18 \mathrm{E}-0$ & $3.35 \mathrm{E}+0$ & $2 E-$ & 8 & 1. & קתمמم & ג קم & $5 E+0 c$ \\
\hline 7. 01 & 3.3 & $2 E-01$ & $2 E-01$ & & $E+00$ & $E+00$ & $\mathrm{E}+00$ \\
\hline-01 & -00 & $F-$ & $2 E-01$ & 0 & 0 & +00 & +00 \\
\hline$E-01$ & 3 & $E-$ & 8 & & $O E$ & 00 & +00 \\
\hline $.19 \mathrm{E}-01$ & $3.34 \mathrm{E}+00$ & $9.73 \mathrm{E}-01$ & $8.73 E-01$ & $1.74 \mathrm{E}+00$ & $2.00 \mathrm{E}+00$ & $2.18 \mathrm{E}+00$ & $2.44 \mathrm{E}+00$ \\
\hline $.20 \mathrm{E}-01$ & $3.34 \mathrm{E}+00$ & $4 E-01$ & $8.74 \mathrm{E}-01$ & & $2.00 \mathrm{E}+00$ & +00 & $2.44 \mathrm{E}+00$ \\
\hline 1. $20 \mathrm{E}-01$ & & & 1 & & & & of \\
\hline 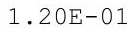 & $3.33 E+00$ & 50 & $5 E-01$ & $1705+6$ & ק קم: & 0 & (2) \\
\hline $.20 E-01$ & $3.33 E+00$ & $9.75 \mathrm{E}-01$ & 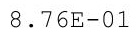 & $1.74 \mathrm{E}+00$ & $0 \mathrm{E}+00$ & $E+00$ & $2.44 \mathrm{E}+00$ \\
\hline $.20 \mathrm{E}-01$ & $3.33 \mathrm{E}+00$ & $9.75 \mathrm{E}-01$ & $8.76 \mathrm{E}-01$ & $1.75 \mathrm{E}+00$ & $2.00 \mathrm{E}+00$ & $2.18 \mathrm{E}+00$ & $2.44 \mathrm{E}+00$ \\
\hline $.21 E-01$ & $3.33 \mathrm{E}+00$ & $9.76 \mathrm{E}-01$ & $8.77 \mathrm{E}-01$ & $1.75 \mathrm{E}+00$ & $2.00 \mathrm{E}+00$ & $2.18 \mathrm{E}+00$ & $2.43 E+00$ \\
\hline .2 & & -01 & $E-01$ & & 2. & & +00 \\
\hline $.21 E-01$ & $.32 \mathrm{E}+00$ & $.76 \mathrm{E}-01$ & $.77 E-01$ & 1. $75 \mathrm{E}+00$ & $2.00 \mathrm{E}+00$ & $2.18 \mathrm{E}+00$ & $2.43 E+00$ \\
\hline
\end{tabular}


RESRAD-OFFSITE, Version 2.5

robabilistic Dose and Risk Report

Title : RESRAD-OFFSITE Drinking Water, Plant, Milk, and Meat Pathways for offsite Reside File : PBA-1_TC99-DOE-5.ROF

Time

Years

$0.00 \mathrm{E}+00$

$5.13 \mathrm{E}-01$

$1.03 \mathrm{E}+00$

$1.54 \mathrm{E}+00$

$2.05 \mathrm{E}+00$

$2.56 \mathrm{E}+00$

$3.08 \mathrm{E}+00$

$3.59 \mathrm{E}+00$

$4.10 \mathrm{E}+00$

$4.61 \mathrm{E}+00$

$5.13 \mathrm{E}+00$

$5.64 \mathrm{E}+00$

$6.15 \mathrm{E}+00$

$6.67 \mathrm{E}+00$

$7.18 \mathrm{E}+00$

$7.69 \mathrm{E}+00$

$8.20 \mathrm{E}+00$

$8.72 \mathrm{E}+00$

$9.23 \mathrm{E}+00$

$9.74 \mathrm{E}+00$

$1.03 \mathrm{E}+01$

$1.08 \mathrm{E}+01$

$1.13 \mathrm{E}+01$

$1.18 \mathrm{E}+01$

$1.23 \mathrm{E}+01$

$1.28 \mathrm{E}+01$

$1.33 \mathrm{E}+01$

$1.38 \mathrm{E}+01$

$1.44 \mathrm{E}+01$

$1.49 \mathrm{E}+01$

$1.54 \mathrm{E}+01$

$1.59 \mathrm{E}+01$

$1.64 \mathrm{E}+01$

$1.69 \mathrm{E}+01$

$1.74 \mathrm{E}+01$

$1.79 \mathrm{E}+01$

$1.85 \mathrm{E}+01$

1. $90 \mathrm{E}+01$

1. $95 \mathrm{E}+01$

$2.00 \mathrm{E}+01$

$2.05 \mathrm{E}+01$

$2.10 \mathrm{E}+01$

$2.15 \mathrm{E}+01$

2. $20 \mathrm{E}+01$

2. $26 \mathrm{E}+01$

$2.31 \mathrm{E}+01$
Summary of dose at graphical times, reptition 2

Dose statistics at graphical times, mrem/yr

\begin{tabular}{|c|c|c|c|c|c|c|c|}
\hline Inimum & laximum & Mean & Median & $90 \%$ & $95 \%$ & $97.5 \%$ & $\%$ \\
\hline 0 & $.00 \mathrm{E}+00$ & $0 \mathrm{E}+00$ & $0.00 \mathrm{E}+00$ & $00 E+00$ & $0 \mathrm{E}+00$ & $00 E+00$ & $\mathrm{~F}+0 \mathrm{CS}-\mathrm{se}$ \\
\hline$E+00$ & 00 & $\mathrm{OE}+$ & 00 & 00 & $0.00 \mathrm{E}+00$ & 00 & $\mathrm{OE}+\mathrm{OC}$ \\
\hline$E+00$ & $\mathrm{E}+00$ & $\mathrm{E}+00$ & 0 & 00 & $0 \mathrm{E}+00$ & 00 & $0 \mathrm{E}+0 \mathrm{C}$ \\
\hline 00 & $E+00$ & 0 & 00 & 00 & $0 \mathrm{E}+00$ & -00 & +00 \\
\hline+00 & $E+00$ & $E+00$ & $E+00$ & $\mathrm{OE}+$ & 00 & 00 & $0 \mathrm{E}+00$ \\
\hline$E+00$ & 0 & 0 & 0 & 0 & 00 & $E+00$ & $00 \mathrm{E}+00$ \\
\hline $.00 \mathrm{E}+00$ & $0.00 \mathrm{E}+00$ & $.00 \mathrm{E}+00$ & $0 \mathrm{E}+00$ & $0 \mathrm{E}+00$ & $.00 \mathrm{E}+00$ & $E+00$ & $E+00$ \\
\hline $.00 \mathrm{E}+00$ & $0.00 \mathrm{E}+00$ & $.00 \mathrm{E}+00$ & $0.00 \mathrm{E}+00$ & $0.00 \mathrm{E}+00$ & $.00 \mathrm{E}+00$ & $.00 \mathrm{E}+00$ & $.00 \mathrm{E}+00$ \\
\hline $.00 \mathrm{E}+00$ & $0.00 \mathrm{E}+00$ & $.00 \mathrm{E}+00$ & $0.00 \mathrm{E}+00$ & $0.00 \mathrm{E}+00$ & $0.00 \mathrm{E}+00$ & $.00 \mathrm{E}+00$ & $00 \mathrm{E}+00$ \\
\hline$E+00$ & -00 & $E+00$ & +00 & $0 \mathrm{E}+00$ & $0 \mathrm{E}+00$ & +00 & $\mathrm{E}+00$ \\
\hline $.00 \mathrm{E}+00$ & $0.00 \mathrm{E}+00$ & $0.00 \mathrm{E}+00$ & $0 \mathrm{E}+00$ & $0.00 \mathrm{E}+00$ & $0.00 \mathrm{E}+00$ & $00 \mathrm{E}+00$ & $00 E+00$ \\
\hline 100 & 0 & 0 & $E+00$ & 0 & 0 & 00 & $E+00$ \\
\hline $.00 \mathrm{E}+00$ & $.0 U E+U 0$ & $\mathrm{E}+00$ & $E+00$ & 00 & $0 \mathrm{E}+00$ & +00 & $E+00$ \\
\hline $.00 \mathrm{E}+00$ & 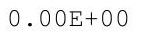 & $0.00 \mathrm{E}+00$ & $0.00 \mathrm{E}+00$ & $0.00 E+00$ & . & $.00 \mathrm{E}+00$ & $.00 \mathrm{E}+00$ \\
\hline $\mathrm{E}+00$ & $0.00 \mathrm{E}+00$ & $0 \mathrm{E}+00$ & $0.00 \mathrm{E}+00$ & $0.00 \mathrm{E}+00$ & $00 \mathrm{E}+00$ & $0 E+00$ & $0 \mathrm{E}+00$ \\
\hline$E+00$ & 00 & o & -00 & $0 \mathrm{E}+00$ & $0 \mathrm{E}+00$ & $E+00$ & $0 \mathrm{E}+00$ \\
\hline $.00 \mathrm{E}+00$ & $0.00 \mathrm{E}+00$ & & & & $0.00 \mathrm{E}+00$ & $.00 \mathrm{E}+00$ & $.00 \mathrm{E}+00$ \\
\hline $\mathrm{E}+00$ & $E+00$ & $0 \mathrm{E}+00$ & $0 \mathrm{E}+00$ & $\mathrm{E}+00$ & $E+00$ & +00 & $0 \mathrm{E}+00$ \\
\hline $.00 \mathrm{E}+00$ & $00 \mathrm{E}+00$ & $.00 \mathrm{E}+00$ & $00 \mathrm{E}+00$ & $0 \mathrm{E}+00$ & $0 \mathrm{E}+00$ & $0 \mathrm{E}+00$ & $\mathrm{OE}+\mathrm{OC}$ \\
\hline $0 \mathrm{E}+00$ & $0.00 \mathrm{E}+00$ & $0 \mathrm{E}+00$ & $\mathrm{DE}+00$ & 00 & $0 \mathrm{E}+00$ & $E+00$ & $0 \mathrm{E}+00$ \\
\hline $.00 \mathrm{E}+00$ & $0.00 \mathrm{E}+00$ & $.00 \mathrm{E}+00$ & $0.00 \mathrm{E}+00$ & & $0 \mathrm{E}+00$ & $0 \mathrm{E}+00$ & $0 \mathrm{E}+00$ \\
\hline $.00 E+00$ & $0.00 \mathrm{E}+00$ & $0.00 \mathrm{E}+00$ & $0.00 \mathrm{E}+00$ & $0.00 \mathrm{E}+00$ & $0.00 \mathrm{E}+00$ & $00 \mathrm{E}+00$ & +00 \\
\hline מח & $.00 E+00$ & & $00 E+00$ & $0 \mathrm{E}+00$ & (2) & $0 \mathrm{E}+00$ & $0 \mathrm{E}+00$ \\
\hline $.00 \mathrm{E}+00$ & $0.00 \mathrm{E}+00$ & $.00 \mathrm{E}+00$ & $0 \mathrm{E}+00$ & $0 \mathrm{E}+$ & $00 \mathrm{E}+00$ & $0 \mathrm{E}+00$ & $00 \mathrm{E}+00$ \\
\hline $.00 \mathrm{E}+00$ & $0.00 \mathrm{E}+00$ & $0.00 \mathrm{E}+00$ & $0.00 \mathrm{E}+00$ & $0 \mathrm{E}+00$ & $\mathrm{DE}+00$ & $E+00$ & $00 \mathrm{E}+00$ \\
\hline+00 & $E+00$ & $\mathrm{E}+00$ & 00 & 00 & 00 & +00 & $0 E+00$ \\
\hline$E+00$ & +00 & $\mathrm{E}+00$ & $0 \mathrm{E}+00$ & $0 \mathrm{E}+00$ & $0 E+00$ & $0 \mathrm{E}+00$ & $0 \mathrm{E}+00$ \\
\hline $.00 \mathrm{E}+00$ & $0.00 \mathrm{E}+00$ & $0.00 \mathrm{E}+00$ & $0.00 \mathrm{E}+00$ & $0.00 \mathrm{E}+00$ & $0.00 \mathrm{E}+00$ & $.00 \mathrm{E}+00$ & $.00 \mathrm{E}+00$ \\
\hline $.00 \mathrm{E}+00$ & $0.00 \mathrm{E}+00$ & $0.00 \mathrm{E}+00$ & $0.00 \mathrm{E}+00$ & $0.00 \mathrm{E}+00$ & $0.00 \mathrm{E}+00$ & $.00 \mathrm{E}+00$ & $.00 \mathrm{E}+00$ \\
\hline 然 & 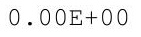 & 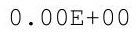 & $0.00 \mathrm{E}+00$ & $0 E+00$ & (1) & $0 \mathrm{E}+00$ & $0.00 \mathrm{E}+0 \mathrm{C}$ \\
\hline 0 & & & & & & $E+00$ & $00 \mathrm{E}+0 \mathrm{C}$ \\
\hline$\Xi+00$ & $E+00$ & $0 \mathrm{E}+00$ & $\mathrm{E}+00$ & $0 \mathrm{E}+00$ & $\mathrm{OE}+00$ & $E+00$ & $\mathrm{OE}+\mathrm{OC}$ \\
\hline+00 & +00 & $E+00$ & $E+00$ & 0 & 0 & & $0 \mathrm{E}+00$ \\
\hline .00 ET+ & $0.00 \mathrm{E}+00$ & $0.00 \mathrm{E}+00$ & $0.00 \mathrm{E}+00$ & $0.00 \mathrm{E}+00$ & $00 \mathrm{E}+00$ & $.00 \mathrm{E}+00$ & $.00 E+00$ \\
\hline . & & $0.00 \mathrm{E}+00$ & & $0.00 \mathrm{E}+00$ & . U ता U & $.00 \mathrm{E}+00$ & $.00 E+00$ \\
\hline & & & & & & & \\
\hline مค & ( & 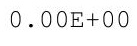 & 0 & 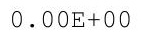 & 0 & 0 & $0 \Omega$ \\
\hline 0 & 0 & 0 & $\mathrm{E}+00$ & 0 & 0 & 0 & 00 \\
\hline & & & & 0 & $\mathrm{E}+00$ & +00 & $0 \mathrm{E}+00$ \\
\hline$E+00$ & +00 & E+ & 00 & 0 & 0 & & $0 \mathrm{E}+00$ \\
\hline 0 & & & $00 E+00$ & 然 & 0 & & $.00 E+00$ \\
\hline 0 & 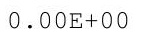 & 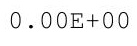 & & & 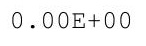 & 0 & DT \\
\hline 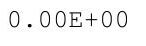 & 0 & 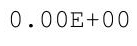 & 0 & .000 & 0 & $0 E+00$ & $.00 \mathrm{E}+00$ \\
\hline 0 & 0 & 0 & 0 & 00 & 0 & 0 & 00 \\
\hline+00 & $E+00$ & . & 0 . & 00 & 0 & +00 & $0 \mathrm{E}+00$ \\
\hline $.00 \mathrm{E}+00$ & $.00 \mathrm{E}+00$ & $.00 \mathrm{E}+00$ & $.00 \mathrm{E}+00$ & $0.00 \mathrm{E}+00$ & $0.00 \mathrm{E}+00$ & $0.00 \mathrm{E}+00$ & $0.00 \mathrm{E}+00$ \\
\hline
\end{tabular}


RESRAD-OFFSITE, Version 2.5

robabilistic Dose and Risk Report

Title : RESRAD-OFFSITE Drinking Water, Plant, Milk, and Meat Pathways for Offsite Reside File : PBA-1_TC99-DOE-5.ROF

Summary of dose at graphical times, reptition 2 (continued)

Time

Years

2. $36 \mathrm{E}+01$

$2.41 \mathrm{E}+01$

$2.46 \mathrm{E}+01$

$2.51 \mathrm{E}+01$

$2.56 \mathrm{E}+01$

$2.61 \mathrm{E}+01$

$2.67 \mathrm{E}+01$

$2.72 \mathrm{E}+01$

2. $77 \mathrm{E}+01$

2. $82 \mathrm{E}+01$

$2.87 \mathrm{E}+01$

2. $92 \mathrm{E}+01$

2. $97 \mathrm{E}+01$

3. $02 \mathrm{E}+01$

$3.08 \mathrm{E}+01$

3. $13 \mathrm{E}+01$

3. $18 \mathrm{E}+01$

3. $23 \mathrm{E}+01$

3. $28 \mathrm{E}+01$

3. $33 \mathrm{E}+01$

3. $38 \mathrm{E}+01$

3. $44 \mathrm{E}+01$

3. $49 \mathrm{E}+01$

3. $54 \mathrm{E}+01$

3. $59 \mathrm{E}+01$

3. $64 \mathrm{E}+01$

3. $69 \mathrm{E}+01$

$3.74 \mathrm{E}+01$

3. $79 \mathrm{E}+01$

$3.85 \mathrm{E}+01$

3. $90 \mathrm{E}+01$

$3.95 \mathrm{E}+01$

$4.00 \mathrm{E}+01$

$4.05 \mathrm{E}+01$

$4.10 \mathrm{E}+01$

4. $15 \mathrm{E}+01$

4. $20 \mathrm{E}+01$

$4.26 \mathrm{E}+01$

$4.31 \mathrm{E}+01$

$4.36 \mathrm{E}+01$

4. $41 \mathrm{E}+01$

$4.46 \mathrm{E}+01$

4. $51 \mathrm{E}+01$

$4.56 \mathrm{E}+01$

4. $61 \mathrm{E}+01$

$4.67 \mathrm{E}+01$
Dose statistics at graphical times, mrem/yr

\begin{tabular}{|c|c|c|c|c|c|c|c|}
\hline m & num & ean & n & & & $\%$ & \\
\hline 00 & 00 & $E+00$ & $\mathrm{E}+00$ & +00 & +00 & +00 & +00 \\
\hline $.00 \mathrm{E}+00$ & $.00 \mathrm{E}+00$ & $.00 \mathrm{E}+00$ & $0.00 \mathrm{E}+00$ & $0.00 \mathrm{E}+00$ & $0.00 \mathrm{E}+00$ & $.00 \mathrm{E}+00$ & $.00 \mathrm{E}+00$ \\
\hline $00 F+00$ & $00 F+00$ & $00 E+00$ & $.00 E+00$ & $00 \mathrm{E}+00$ & $00 F+00$ & $00 \mathrm{E}+00$ & $00 F+00$ \\
\hline 00 & & & & & & & 00 \\
\hline+00 & +00 & & & & 00 & & +00 \\
\hline $.00 \mathrm{E}+00$ & $E+00$ & $0 \mathrm{E}+00$ & $0 E+00$ & $0 E+00$ & $0 \mathrm{E}+00$ & 00 & +00 \\
\hline $.00 \mathrm{E}+00$ & +00 & $E+00$ & $\mathrm{E}+00$ & +00 & +00 & +00 & $\mathrm{E}+00$ \\
\hline $.00 E+00$ & $0.00 \mathrm{E}+00$ & $0 \mathrm{E}+00$ & $0 \mathrm{E}+00$ & $00 E+00$ & $.00 \mathrm{E}+00$ & $.00 \mathrm{E}+00$ & $00 E+00$ \\
\hline $00 E+00$ & $00 \mathrm{E}+00$ & $.00 E+00$ & $.00 E+00$ & $0 \mathrm{E}+00$ & $0 \mathrm{E}+00$ & $E+00$ & $\exists+00$ \\
\hline $00 \mathrm{E}+00$ & $O P F+6-5-5$ & $00 E+00$ & $0 E+00$ & 0 & +0 & $00 E+00$ & +00 \\
\hline$E+00$ & $\mathrm{~F}+00$ & $E+00$ & & & & & +00 \\
\hline $.00 \mathrm{E}+00$ & $0.00 \mathrm{E}+00$ & $.00 \mathrm{E}+00$ & $0.00 \mathrm{E}+00$ & $0.00 \mathrm{E}+00$ & $0.00 \mathrm{E}+00$ & $.00 \mathrm{E}+00$ & $.00 E+00$ \\
\hline $.00 E+00$ & $0.00 \mathrm{E}+00$ & $0.00 \mathrm{E}+00$ & $0.00 \mathrm{E}+00$ & $0.00 \mathrm{E}+00$ & $0.00 \mathrm{E}+00$ & $.00 \mathrm{E}+00$ & $.00 \mathrm{E}+00$ \\
\hline $.00 E+00$ & $0=0$ & $00 E+00$ & $0 \mathrm{E}+00$ & $E+00$ & $\mathrm{E}+00$ & +00 & $\mathrm{E}+00$ \\
\hline $\mathrm{OE}+$ & $.00 \mathrm{E}+\mathrm{C}$ & $.00 E+00$ & $.00 E+00$ & $0 E+00$ & 0 & 0 & 00 \\
\hline 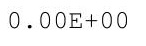 & ק & 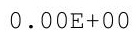 & 0 & & ( & 0 & +00 \\
\hline$O \cap F+O \Omega$ & $00 F+00$ & $0 \mathrm{E}+00$ & $E+00$ & $E+00$ & +00 & 0 & +00 \\
\hline $.00 E+00$ & $0 \cap F+00$ & $0 \mathrm{E}+00$ & $0 E+00$ & $\mathrm{E}+00$ & $0 E+00$ & $O E+00$ & $0 E+00$ \\
\hline $.00 \mathrm{E}+00$ & $.00 \mathrm{E}+00$ & $0.00 \mathrm{E}+00$ & $0.00 \mathrm{E}+00$ & $.00 \mathrm{E}+00$ & $0.00 \mathrm{E}+00$ & $.00 \mathrm{E}+00$ & $0 \mathrm{E}+00$ \\
\hline $.00 E+00$ & $0 \cap F+\cap 0$ & $.00 \mathrm{E}+00$ & $.00 E+00$ & $0 \mathrm{E}+00$ & $00 E+00$ & $E+00$ & $0 \mathrm{E}+00$ \\
\hline & & & & & & & +00 \\
\hline & & & & & & & $0 E+00$ \\
\hline$=0$ & & & & & $\mathrm{E}+00$ & 0 & 00 \\
\hline $.00 \mathrm{E}+00$ & $.00 \mathrm{E}+00$ & $.00 \mathrm{E}+00$ & $.00 \mathrm{E}+00$ & $00 \mathrm{E}+00$ & $00 \mathrm{E}+00$ & $.00 E+00$ & $00 E+00$ \\
\hline $.00 \mathrm{E}+00$ & $.00 \mathrm{E}+00$ & $0.00 \mathrm{E}+00$ & $0.00 \mathrm{E}+00$ & $0.00 \mathrm{E}+00$ & $00 \mathrm{E}+00$ & $.00 \mathrm{E}+00$ & $00 \mathrm{E}+0 \mathrm{C}$ \\
\hline $\mathrm{F}+00$ & $.00 E+00$ & $.00 \mathrm{E}+00$ & $0.00 E+00$ & $0 \mathrm{E}+00$ & $00 \mathrm{E}+00$ & $00 \mathrm{E}+00$ & $00 E+00$ \\
\hline & & & & & & & $00 E+00$ \\
\hline & & & & & & & $00 \mathrm{E}+00$ \\
\hline תחת & & & & & 0 & & 00 \\
\hline $.00 \mathrm{E}+00$ & $0.00 \mathrm{E}+00$ & $0.00 \mathrm{E}+00$ & $0.00 \mathrm{E}+00$ & $0.00 \mathrm{E}+00$ & $0.00 \mathrm{E}+00$ & $.00 \mathrm{E}+00$ & $.00 \mathrm{E}+00$ \\
\hline $00 \mathrm{E}+$ & $.00 \mathrm{E}+0$ & $.00 \mathrm{E}+0 \mathrm{C}$ & $0.00 \mathrm{E}+00$ & $.00 E+00$ & $.00 \mathrm{E}+00$ & $.00 \mathrm{E}+00$ & $.00 \mathrm{E}+0 \mathrm{C}$ \\
\hline חم +Fחم & $.00 \mathrm{E}+00$ & $0.00 \mathrm{E}+00$ & $0.00 \mathrm{E}+00$ & $0 \mathrm{E}+00$ & $00 \mathrm{E}+00$ & $.00 E+00$ & $00 \mathrm{E}+00$ \\
\hline 00 & & & & & & & $0 \mathrm{E}+00$ \\
\hline & & & & & & & $00 \mathrm{E}+00$ \\
\hline $.00 \mathrm{E}+00$ & $0.00 \mathrm{E}+00$ & $0.00 \mathrm{E}+00$ & $0.00 \mathrm{E}+00$ & $0.00 \mathrm{E}+00$ & $0.00 \mathrm{E}+00$ & $.00 \mathrm{E}+00$ & $.00 \mathrm{E}+00$ \\
\hline 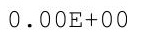 & . & •. & $0.00 \mathrm{E}+00$ & & & $.00 E+00$ & $.00 \mathrm{E}+0 \mathrm{C}$ \\
\hline & . & & & & & & . V LT \\
\hline $00 \mathrm{E}+0$ & $0.00 \mathrm{E}+0$ & $0.00 \mathrm{E}+00$ & $0.00 \mathrm{E}+00$ & $.00 E+00$ & $.00 E+00$ & $.00 \mathrm{E}+00$ & $.00 E+00$ \\
\hline $\mathrm{E}+$ & & & $.00 E+00$ & $\mathrm{E}+00$ & $\mathrm{E}+00$ & $0 E+00$ & $00 \mathrm{E}+00$ \\
\hline $0 E+00$ & & & $0.00 E+00$ & $0.00 E+00$ & $00 E+00$ & +00 & $.00 \mathrm{E}+00$ \\
\hline $.00 \mathrm{E}+00$ & $0.00 \mathrm{E}+00$ & $.00 \mathrm{E}+00$ & $0.00 \mathrm{E}+00$ & $0 E+00$ & $00 \mathrm{E}+00$ & 0 & $.00 \mathrm{E}+00$ \\
\hline $.00 \mathrm{E}+00$ & 0 & OOE+ & & & 00 & $0 E+00$ & $.00 \mathrm{E}+0 \mathrm{C}$ \\
\hline $.00 \mathrm{E}+00$ & $0.00 \mathrm{E}+00$ & $0.00 \mathrm{E}+00$ & $.00 E+00$ & $0.00 E+00$ & $0.00 \mathrm{E}+00$ & $0.00 \mathrm{E}+00$ & $0.00 \mathrm{E}+00$ \\
\hline $.00 \mathrm{E}+00$ & $0.00 \mathrm{E}+00$ & $0.00 \mathrm{E}+00$ & $0.00 \mathrm{E}+00$ & $0.00 \mathrm{E}+00$ & $0.00 \mathrm{E}+00$ & $0.00 \mathrm{E}+00$ & $0.00 \mathrm{E}+00$ \\
\hline $00 E+00$ & & & & $0.00 \mathrm{E}+00$ & $0.00 \mathrm{E}+00$ & $.00 \mathrm{E}+00$ & $0.00 \mathrm{E}+00$ \\
\hline+00 & $.00 \mathrm{E}+00$ & $.00 \mathrm{E}+00$ & $.00 E+00$ & $.00 E+00$ & $0.00 \mathrm{E}+00$ & $.00 \mathrm{E}+00$ & $.00 \mathrm{E}+00$ \\
\hline
\end{tabular}


RESRAD-OFFSITE, Version 2.5

Title : RESRAD-OFFSITE Drinking Water, Plant, Milk, and Meat Pathways for offsite Reside File : PBA-1_TC99-DOE-5.ROF

Summary of dose at graphical times, reptition 2 (continued)

Time

Years

$4.72 \mathrm{E}+01$

$4.77 \mathrm{E}+01$

$4.82 \mathrm{E}+01$

$4.87 \mathrm{E}+01$

4. $92 \mathrm{E}+01$

$4.97 \mathrm{E}+01$

$5.02 \mathrm{E}+01$

$5.08 \mathrm{E}+01$

$5.13 \mathrm{E}+01$

$5.18 \mathrm{E}+01$

$5.23 \mathrm{E}+01$

$5.28 \mathrm{E}+01$

$5.33 \mathrm{E}+01$

$5.38 \mathrm{E}+01$

$5.43 \mathrm{E}+01$

$5.49 \mathrm{E}+01$

$5.54 \mathrm{E}+01$

$5.59 \mathrm{E}+01$

$5.64 \mathrm{E}+01$

$5.69 \mathrm{E}+01$

$5.74 \mathrm{E}+01$

$5.79 \mathrm{E}+01$

$5.84 \mathrm{E}+01$

$5.90 \mathrm{E}+01$

$5.95 \mathrm{E}+01$

$6.00 \mathrm{E}+01$

$6.05 \mathrm{E}+01$

$6.10 \mathrm{E}+01$

$6.15 \mathrm{E}+01$

$6.20 \mathrm{E}+01$

$6.25 \mathrm{E}+01$

$6.31 \mathrm{E}+01$

$6.36 \mathrm{E}+01$

$6.41 \mathrm{E}+01$

$6.46 \mathrm{E}+01$

$6.51 \mathrm{E}+01$

$6.56 \mathrm{E}+01$

$6.61 \mathrm{E}+01$

$6.67 \mathrm{E}+01$

$6.72 \mathrm{E}+01$

$6.77 \mathrm{E}+01$

$6.82 \mathrm{E}+01$

$6.87 \mathrm{E}+01$

$6.92 \mathrm{E}+01$

$6.97 \mathrm{E}+01$

$7.02 \mathrm{E}+01$
Dose statistics at graphical times, mrem/yr

\begin{tabular}{|c|c|c|c|c|c|c|c|}
\hline m & num & ean & n & & & $\%$ & \\
\hline 00 & 00 & $E+00$ & $\mathrm{E}+00$ & +00 & +00 & +00 & +00 \\
\hline $.00 \mathrm{E}+00$ & $.00 \mathrm{E}+00$ & $.00 \mathrm{E}+00$ & $0.00 \mathrm{E}+00$ & $0.00 \mathrm{E}+00$ & $0.00 \mathrm{E}+00$ & $.00 \mathrm{E}+00$ & $.00 \mathrm{E}+00$ \\
\hline $00 F+00$ & $00 F+00$ & $00 E+00$ & $.00 E+00$ & $00 \mathrm{E}+00$ & $00 F+00$ & $00 \mathrm{E}+00$ & $00 F+00$ \\
\hline 00 & & & & & & & 00 \\
\hline+00 & +00 & & & & 00 & & +00 \\
\hline $.00 \mathrm{E}+00$ & $E+00$ & $0 \mathrm{E}+00$ & $0 E+00$ & $0 E+00$ & $0 \mathrm{E}+00$ & 00 & +00 \\
\hline $.00 \mathrm{E}+00$ & +00 & $E+00$ & $\mathrm{E}+00$ & +00 & +00 & +00 & $\mathrm{E}+00$ \\
\hline $.00 E+00$ & $0.00 \mathrm{E}+00$ & $0 \mathrm{E}+00$ & $0 \mathrm{E}+00$ & $00 E+00$ & $.00 \mathrm{E}+00$ & $.00 \mathrm{E}+00$ & $00 E+00$ \\
\hline $00 E+00$ & $00 \mathrm{E}+00$ & $.00 E+00$ & $.00 E+00$ & $0 \mathrm{E}+00$ & $0 \mathrm{E}+00$ & $E+00$ & $\exists+00$ \\
\hline $00 \mathrm{E}+00$ & $O P F+6-5-5$ & $00 E+00$ & $0 E+00$ & 0 & +0 & $00 E+00$ & +00 \\
\hline$E+00$ & $\mathrm{~F}+00$ & $E+00$ & & & & & +00 \\
\hline $.00 \mathrm{E}+00$ & $0.00 \mathrm{E}+00$ & $.00 \mathrm{E}+00$ & $0.00 \mathrm{E}+00$ & $0.00 \mathrm{E}+00$ & $0.00 \mathrm{E}+00$ & $.00 \mathrm{E}+00$ & $.00 E+00$ \\
\hline $.00 E+00$ & $0.00 \mathrm{E}+00$ & $0.00 \mathrm{E}+00$ & $0.00 \mathrm{E}+00$ & $0.00 \mathrm{E}+00$ & $0.00 \mathrm{E}+00$ & $.00 \mathrm{E}+00$ & $.00 \mathrm{E}+00$ \\
\hline $.00 E+00$ & $0=0$ & $00 E+00$ & $0 \mathrm{E}+00$ & $E+00$ & $\mathrm{E}+00$ & +00 & $\mathrm{E}+00$ \\
\hline $\mathrm{OE}+$ & $.00 \mathrm{E}+\mathrm{C}$ & $.00 E+00$ & $.00 E+00$ & $0 E+00$ & 0 & 0 & 00 \\
\hline 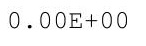 & ק & 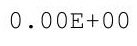 & 0 & & ( & 0 & +00 \\
\hline$O \cap F+O \Omega$ & $00 F+00$ & $0 \mathrm{E}+00$ & $E+00$ & $E+00$ & +00 & 0 & +00 \\
\hline $.00 E+00$ & $0 \cap F+00$ & $0 \mathrm{E}+00$ & $0 E+00$ & $\mathrm{E}+00$ & $0 E+00$ & $O E+00$ & $0 E+00$ \\
\hline $.00 \mathrm{E}+00$ & $.00 \mathrm{E}+00$ & $0.00 \mathrm{E}+00$ & $0.00 \mathrm{E}+00$ & $.00 \mathrm{E}+00$ & $0.00 \mathrm{E}+00$ & $.00 \mathrm{E}+00$ & $0 \mathrm{E}+00$ \\
\hline $.00 E+00$ & $0 \cap F+\cap 0$ & $.00 \mathrm{E}+00$ & $.00 E+00$ & $0 \mathrm{E}+00$ & $00 E+00$ & $E+00$ & $0 \mathrm{E}+00$ \\
\hline & & & & & & & +00 \\
\hline & & & & & & & $0 E+00$ \\
\hline$=0$ & & & & & $\mathrm{E}+00$ & 0 & 00 \\
\hline $.00 \mathrm{E}+00$ & $.00 \mathrm{E}+00$ & $.00 \mathrm{E}+00$ & $.00 \mathrm{E}+00$ & $00 \mathrm{E}+00$ & $00 \mathrm{E}+00$ & $.00 E+00$ & $00 E+00$ \\
\hline $.00 \mathrm{E}+00$ & $.00 \mathrm{E}+00$ & $0.00 \mathrm{E}+00$ & $0.00 \mathrm{E}+00$ & $0.00 \mathrm{E}+00$ & $00 \mathrm{E}+00$ & $.00 \mathrm{E}+00$ & $00 \mathrm{E}+0 \mathrm{C}$ \\
\hline $\mathrm{F}+00$ & $.00 E+00$ & $.00 \mathrm{E}+00$ & $0.00 E+00$ & $0 \mathrm{E}+00$ & $00 \mathrm{E}+00$ & $00 \mathrm{E}+00$ & $00 E+00$ \\
\hline & & & & & & & $00 E+00$ \\
\hline & & & & & & & $00 \mathrm{E}+00$ \\
\hline תחת & & & & & 0 & & 00 \\
\hline $.00 \mathrm{E}+00$ & $0.00 \mathrm{E}+00$ & $0.00 \mathrm{E}+00$ & $0.00 \mathrm{E}+00$ & $0.00 \mathrm{E}+00$ & $0.00 \mathrm{E}+00$ & $.00 \mathrm{E}+00$ & $.00 \mathrm{E}+00$ \\
\hline $00 \mathrm{E}+$ & $.00 \mathrm{E}+0$ & $.00 \mathrm{E}+0 \mathrm{C}$ & $0.00 \mathrm{E}+00$ & $.00 E+00$ & $.00 \mathrm{E}+00$ & $.00 \mathrm{E}+00$ & $.00 \mathrm{E}+0 \mathrm{C}$ \\
\hline חم +Fחم & $.00 \mathrm{E}+00$ & $0.00 \mathrm{E}+00$ & $0.00 \mathrm{E}+00$ & $0 \mathrm{E}+00$ & $00 \mathrm{E}+00$ & $.00 E+00$ & $00 \mathrm{E}+00$ \\
\hline 00 & & & & & & & $0 \mathrm{E}+00$ \\
\hline & & & & & & & $00 \mathrm{E}+00$ \\
\hline $.00 \mathrm{E}+00$ & $0.00 \mathrm{E}+00$ & $0.00 \mathrm{E}+00$ & $0.00 \mathrm{E}+00$ & $0.00 \mathrm{E}+00$ & $0.00 \mathrm{E}+00$ & $.00 \mathrm{E}+00$ & $.00 \mathrm{E}+00$ \\
\hline 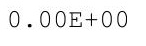 & . & •. & $0.00 \mathrm{E}+00$ & & & $.00 E+00$ & $.00 \mathrm{E}+0 \mathrm{C}$ \\
\hline & . & & & & & & . V LT \\
\hline $00 \mathrm{E}+0$ & $0.00 \mathrm{E}+0$ & $0.00 \mathrm{E}+00$ & $0.00 \mathrm{E}+00$ & $.00 E+00$ & $.00 E+00$ & $.00 \mathrm{E}+00$ & $.00 E+00$ \\
\hline $\mathrm{E}+$ & & & $.00 E+00$ & $\mathrm{E}+00$ & $\mathrm{E}+00$ & $0 E+00$ & $00 \mathrm{E}+00$ \\
\hline $0 E+00$ & & & $0.00 E+00$ & $0.00 E+00$ & $00 E+00$ & +00 & $.00 \mathrm{E}+00$ \\
\hline $.00 \mathrm{E}+00$ & $0.00 \mathrm{E}+00$ & $.00 \mathrm{E}+00$ & $0.00 \mathrm{E}+00$ & $0 E+00$ & $00 \mathrm{E}+00$ & 0 & $.00 \mathrm{E}+00$ \\
\hline $.00 \mathrm{E}+00$ & 0 & OOE+ & & & 00 & $0 E+00$ & $.00 \mathrm{E}+0 \mathrm{C}$ \\
\hline $.00 \mathrm{E}+00$ & $0.00 \mathrm{E}+00$ & $0.00 \mathrm{E}+00$ & $.00 E+00$ & $0.00 E+00$ & $0.00 \mathrm{E}+00$ & $0.00 \mathrm{E}+00$ & $0.00 \mathrm{E}+00$ \\
\hline $.00 \mathrm{E}+00$ & $0.00 \mathrm{E}+00$ & $0.00 \mathrm{E}+00$ & $0.00 \mathrm{E}+00$ & $0.00 \mathrm{E}+00$ & $0.00 \mathrm{E}+00$ & $0.00 \mathrm{E}+00$ & $0.00 \mathrm{E}+00$ \\
\hline $00 E+00$ & & & & $0.00 \mathrm{E}+00$ & $0.00 \mathrm{E}+00$ & $.00 \mathrm{E}+00$ & $0.00 \mathrm{E}+00$ \\
\hline+00 & $.00 \mathrm{E}+00$ & $.00 \mathrm{E}+00$ & $.00 E+00$ & $.00 E+00$ & $0.00 \mathrm{E}+00$ & $.00 \mathrm{E}+00$ & $.00 \mathrm{E}+00$ \\
\hline
\end{tabular}


RESRAD-OFFSITE, Version 2.5

Title : RESRAD-OFFSITE Drinking Water, Plant, Milk, and Meat Pathways for Offsite Reside File : PBA-1_TC99-DOE-5.ROF

Summary of dose at graphical times, reptition 2 (continued)

Time

Years

7. $08 \mathrm{E}+01$

7. $13 \mathrm{E}+01$

$7.18 \mathrm{E}+01$

$7.23 E+01$

7. $28 \mathrm{E}+01$

7. $33 \mathrm{E}+01$

7. $38 \mathrm{E}+01$

7. $43 \mathrm{E}+01$

7. $49 \mathrm{E}+01$

7. $54 \mathrm{E}+01$

7. $59 \mathrm{E}+01$

7. $64 \mathrm{E}+01$

7. $69 \mathrm{E}+01$

7. $74 \mathrm{E}+01$

7. $79 \mathrm{E}+01$

7. $84 \mathrm{E}+01$

7. $90 \mathrm{E}+01$

7. $95 \mathrm{E}+01$

8. $00 \mathrm{E}+01$

$8.05 \mathrm{E}+01$

$8.10 \mathrm{E}+01$

$8.15 \mathrm{E}+01$

8. $20 \mathrm{E}+01$

$8.25 \mathrm{E}+01$

8. $31 \mathrm{E}+01$

8. $36 \mathrm{E}+01$

8. $41 \mathrm{E}+01$

8. $46 \mathrm{E}+01$

8. $51 \mathrm{E}+01$

8. $56 \mathrm{E}+01$

8. $61 \mathrm{E}+01$

8. $66 \mathrm{E}+01$

$8.72 \mathrm{E}+01$

$8.77 \mathrm{E}+01$

8. $82 \mathrm{E}+01$

$8.87 \mathrm{E}+01$

8. $92 \mathrm{E}+01$

$8.97 \mathrm{E}+01$

9. $02 \mathrm{E}+01$

$9.07 \mathrm{E}+01$

$9.13 \mathrm{E}+01$

$9.18 \mathrm{E}+01$

$9.23 \mathrm{E}+01$

$9.28 \mathrm{E}+01$

9. $33 \mathrm{E}+01$

9. $38 \mathrm{E}+01$
Dose statistics at graphical times, mrem/yr

\begin{tabular}{|c|c|c|c|c|c|c|c|}
\hline m & num & ean & n & & & $\%$ & \\
\hline 00 & 00 & $E+00$ & $\mathrm{E}+00$ & +00 & +00 & +00 & +00 \\
\hline $.00 \mathrm{E}+00$ & $.00 \mathrm{E}+00$ & $.00 \mathrm{E}+00$ & $0.00 \mathrm{E}+00$ & $0.00 \mathrm{E}+00$ & $0.00 \mathrm{E}+00$ & $.00 \mathrm{E}+00$ & $.00 \mathrm{E}+00$ \\
\hline $00 F+00$ & $00 F+00$ & $00 E+00$ & $.00 E+00$ & $00 \mathrm{E}+00$ & $00 F+00$ & $00 \mathrm{E}+00$ & $00 F+00$ \\
\hline 00 & & & & & & & 00 \\
\hline+00 & +00 & & & & 00 & & +00 \\
\hline $.00 \mathrm{E}+00$ & $E+00$ & $0 \mathrm{E}+00$ & $0 E+00$ & $0 E+00$ & $0 \mathrm{E}+00$ & 00 & +00 \\
\hline $.00 \mathrm{E}+00$ & +00 & $E+00$ & $\mathrm{E}+00$ & +00 & +00 & +00 & $\mathrm{E}+00$ \\
\hline $.00 E+00$ & $0.00 \mathrm{E}+00$ & $0 \mathrm{E}+00$ & $0 \mathrm{E}+00$ & $00 E+00$ & $.00 \mathrm{E}+00$ & $.00 \mathrm{E}+00$ & $00 E+00$ \\
\hline $00 E+00$ & $00 \mathrm{E}+00$ & $.00 E+00$ & $.00 E+00$ & $0 \mathrm{E}+00$ & $0 \mathrm{E}+00$ & $E+00$ & $\exists+00$ \\
\hline $00 \mathrm{E}+00$ & $O P F+6-5-5$ & $00 E+00$ & $0 E+00$ & 0 & +0 & $00 E+00$ & +00 \\
\hline$E+00$ & $\mathrm{~F}+00$ & $E+00$ & & & & & +00 \\
\hline $.00 \mathrm{E}+00$ & $0.00 \mathrm{E}+00$ & $.00 \mathrm{E}+00$ & $0.00 \mathrm{E}+00$ & $0.00 \mathrm{E}+00$ & $0.00 \mathrm{E}+00$ & $.00 \mathrm{E}+00$ & $.00 E+00$ \\
\hline $.00 E+00$ & $0.00 \mathrm{E}+00$ & $0.00 \mathrm{E}+00$ & $0.00 \mathrm{E}+00$ & $0.00 \mathrm{E}+00$ & $0.00 \mathrm{E}+00$ & $.00 \mathrm{E}+00$ & $.00 \mathrm{E}+00$ \\
\hline $.00 E+00$ & $0=0$ & $00 E+00$ & $0 \mathrm{E}+00$ & $E+00$ & $\mathrm{E}+00$ & +00 & $\mathrm{E}+00$ \\
\hline $\mathrm{OE}+$ & $.00 \mathrm{E}+\mathrm{C}$ & $.00 E+00$ & $.00 E+00$ & $0 E+00$ & 0 & 0 & 00 \\
\hline 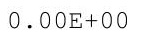 & ק & 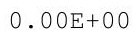 & 0 & & ( & 0 & +00 \\
\hline$O \cap F+O \Omega$ & $00 F+00$ & $0 \mathrm{E}+00$ & $E+00$ & $E+00$ & +00 & 0 & +00 \\
\hline $.00 E+00$ & $0 \cap F+00$ & $0 \mathrm{E}+00$ & $0 E+00$ & $\mathrm{E}+00$ & $0 E+00$ & $O E+00$ & $0 E+00$ \\
\hline $.00 \mathrm{E}+00$ & $.00 \mathrm{E}+00$ & $0.00 \mathrm{E}+00$ & $0.00 \mathrm{E}+00$ & $.00 \mathrm{E}+00$ & $0.00 \mathrm{E}+00$ & $.00 \mathrm{E}+00$ & $0 \mathrm{E}+00$ \\
\hline $.00 E+00$ & $0 \cap F+\cap 0$ & $.00 \mathrm{E}+00$ & $.00 E+00$ & $0 \mathrm{E}+00$ & $00 E+00$ & $E+00$ & $0 \mathrm{E}+00$ \\
\hline & & & & & & & +00 \\
\hline & & & & & & & $0 E+00$ \\
\hline$=0$ & & & & & $\mathrm{E}+00$ & 0 & 00 \\
\hline $.00 \mathrm{E}+00$ & $.00 \mathrm{E}+00$ & $.00 \mathrm{E}+00$ & $.00 \mathrm{E}+00$ & $00 \mathrm{E}+00$ & $00 \mathrm{E}+00$ & $.00 E+00$ & $00 E+00$ \\
\hline $.00 \mathrm{E}+00$ & $.00 \mathrm{E}+00$ & $0.00 \mathrm{E}+00$ & $0.00 \mathrm{E}+00$ & $0.00 \mathrm{E}+00$ & $00 \mathrm{E}+00$ & $.00 \mathrm{E}+00$ & $00 \mathrm{E}+0 \mathrm{C}$ \\
\hline $\mathrm{F}+00$ & $.00 E+00$ & $.00 \mathrm{E}+00$ & $0.00 E+00$ & $0 \mathrm{E}+00$ & $00 \mathrm{E}+00$ & $00 \mathrm{E}+00$ & $00 E+00$ \\
\hline & & & & & & & $00 E+00$ \\
\hline & & & & & & & $00 \mathrm{E}+00$ \\
\hline תחת & & & & & 0 & & 00 \\
\hline $.00 \mathrm{E}+00$ & $0.00 \mathrm{E}+00$ & $0.00 \mathrm{E}+00$ & $0.00 \mathrm{E}+00$ & $0.00 \mathrm{E}+00$ & $0.00 \mathrm{E}+00$ & $.00 \mathrm{E}+00$ & $.00 \mathrm{E}+00$ \\
\hline $00 \mathrm{E}+$ & $.00 \mathrm{E}+0$ & $.00 \mathrm{E}+0 \mathrm{C}$ & $0.00 \mathrm{E}+00$ & $.00 E+00$ & $.00 \mathrm{E}+00$ & $.00 \mathrm{E}+00$ & $.00 \mathrm{E}+0 \mathrm{C}$ \\
\hline חم +Fחم & $.00 \mathrm{E}+00$ & $0.00 \mathrm{E}+00$ & $0.00 \mathrm{E}+00$ & $0 \mathrm{E}+00$ & $00 \mathrm{E}+00$ & $.00 E+00$ & $00 \mathrm{E}+00$ \\
\hline 00 & & & & & & & $0 \mathrm{E}+00$ \\
\hline & & & & & & & $00 \mathrm{E}+00$ \\
\hline $.00 \mathrm{E}+00$ & $0.00 \mathrm{E}+00$ & $0.00 \mathrm{E}+00$ & $0.00 \mathrm{E}+00$ & $0.00 \mathrm{E}+00$ & $0.00 \mathrm{E}+00$ & $.00 \mathrm{E}+00$ & $.00 \mathrm{E}+00$ \\
\hline 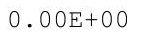 & . & •. & $0.00 \mathrm{E}+00$ & & & $.00 E+00$ & $.00 \mathrm{E}+0 \mathrm{C}$ \\
\hline & . & & & & & & . V LT \\
\hline $00 \mathrm{E}+0$ & $0.00 \mathrm{E}+0$ & $0.00 \mathrm{E}+00$ & $0.00 \mathrm{E}+00$ & $.00 E+00$ & $.00 E+00$ & $.00 \mathrm{E}+00$ & $.00 E+00$ \\
\hline $\mathrm{E}+$ & & & $.00 E+00$ & $\mathrm{E}+00$ & $\mathrm{E}+00$ & $0 E+00$ & $00 \mathrm{E}+00$ \\
\hline $0 E+00$ & & & $0.00 E+00$ & $0.00 E+00$ & $00 E+00$ & +00 & $.00 \mathrm{E}+00$ \\
\hline $.00 \mathrm{E}+00$ & $0.00 \mathrm{E}+00$ & $.00 \mathrm{E}+00$ & $0.00 \mathrm{E}+00$ & $0 E+00$ & $00 \mathrm{E}+00$ & 0 & $.00 \mathrm{E}+00$ \\
\hline $.00 \mathrm{E}+00$ & 0 & OOE+ & & & 00 & $0 E+00$ & $.00 \mathrm{E}+0 \mathrm{C}$ \\
\hline $.00 \mathrm{E}+00$ & $0.00 \mathrm{E}+00$ & $0.00 \mathrm{E}+00$ & $.00 E+00$ & $0.00 E+00$ & $0.00 \mathrm{E}+00$ & $0.00 \mathrm{E}+00$ & $0.00 \mathrm{E}+00$ \\
\hline $.00 \mathrm{E}+00$ & $0.00 \mathrm{E}+00$ & $0.00 \mathrm{E}+00$ & $0.00 \mathrm{E}+00$ & $0.00 \mathrm{E}+00$ & $0.00 \mathrm{E}+00$ & $0.00 \mathrm{E}+00$ & $0.00 \mathrm{E}+00$ \\
\hline $00 E+00$ & & & & $0.00 \mathrm{E}+00$ & $0.00 \mathrm{E}+00$ & $.00 \mathrm{E}+00$ & $0.00 \mathrm{E}+00$ \\
\hline+00 & $.00 \mathrm{E}+00$ & $.00 \mathrm{E}+00$ & $.00 E+00$ & $.00 E+00$ & $0.00 \mathrm{E}+00$ & $.00 \mathrm{E}+00$ & $.00 \mathrm{E}+00$ \\
\hline
\end{tabular}


RESRAD-OFFSITE, Version 2.5

robabilistic Dose and Risk Report

Title : RESRAD-OFFSITE Drinking Water, Plant, Milk, and Meat Pathways for Offsite Reside File : PBA-1_TC99-DOE-5.ROF

Summary of dose at graphical times, reptition 2 (continued)

Time

Years

9. $43 \mathrm{E}+01$

9. $48 \mathrm{E}+01$

9. $54 \mathrm{E}+01$

$9.59 \mathrm{E}+01$

9. $64 \mathrm{E}+01$

$9.69 \mathrm{E}+01$

$9.74 \mathrm{E}+01$

$9.79 \mathrm{E}+01$

9. $84 \mathrm{E}+01$

9. $90 \mathrm{E}+01$

9. $95 \mathrm{E}+01$

$1.00 \mathrm{E}+02$

1. $00 \mathrm{E}+02$

$1.01 \mathrm{E}+02$

1. $02 \mathrm{E}+02$

1. $02 \mathrm{E}+02$

$1.03 \mathrm{E}+02$

$1.03 \mathrm{E}+02$

$1.04 \mathrm{E}+02$

$1.04 \mathrm{E}+02$

$1.05 \mathrm{E}+02$

$1.05 \mathrm{E}+02$

$1.06 \mathrm{E}+02$

$1.06 \mathrm{E}+02$

$1.07 \mathrm{E}+02$

$1.07 \mathrm{E}+02$

$1.08 \mathrm{E}+02$

$1.08 \mathrm{E}+02$

1. $09 \mathrm{E}+02$

1. $09 \mathrm{E}+02$

1. $10 \mathrm{E}+02$

1. $10 \mathrm{E}+02$

1. $11 \mathrm{E}+02$

1. $11 \mathrm{E}+02$

1. $12 \mathrm{E}+02$

1. $12 \mathrm{E}+02$

1. $13 \mathrm{E}+02$

1. $13 \mathrm{E}+02$

1. $14 \mathrm{E}+02$

1. $14 \mathrm{E}+02$

1. $15 \mathrm{E}+02$

$1.15 \mathrm{E}+02$

$1.16 \mathrm{E}+02$

$1.16 \mathrm{E}+02$

$1.17 \mathrm{E}+02$

1. $17 \mathrm{E}+02$

Dose statistics at graphical times, mrem/yr

\begin{tabular}{|c|c|c|c|c|c|c|c|}
\hline Inimum & laximum & Mean & Median & $90 \%$ & $95 \%$ & $97.5 \%$ & $9 \%$ \\
\hline 0 & $00 \mathrm{E}+00$ & $0.00 \mathrm{E}+00$ & $0.00 E+00$ & $0.00 E+00$ & $00 E+00$ & $.00 \mathrm{E}+00$ & $E+00$ \\
\hline $0 E+00$ & $0 \mathrm{E}+00$ & $0 \mathrm{E}+00$ & $0.00 \mathrm{E}+00$ & $0.00 \mathrm{E}+00$ & $.00 \mathrm{E}+00$ & -00 & $0 \mathrm{E}+0 \mathrm{C}$ \\
\hline$E+00$ & $0 E+00$ & $E+00$ & $E+00$ & 0 & $0 \mathrm{E}+00$ & +00 & $0 \mathrm{E}+00$ \\
\hline $\mathrm{s}+00$ & $E+00$ & $E+00$ & $\mathrm{E}+00$ & $0 \mathrm{E}+00$ & $0 \mathrm{E}+00$ & +00 & $0 \mathrm{E}+00$ \\
\hline $.00 \mathrm{E}+00$ & +00 & $\mathrm{E}+00$ & $0 \mathrm{E}+00$ & $00 \mathrm{E}+00$ & $00 \mathrm{E}+00$ & $0 E+00$ & $00 \mathrm{E}+00$ \\
\hline $\mathrm{DE}+00$ & +00 & 0 & 0 & 0 & +00 & $E+00$ & $00 \mathrm{E}+00$ \\
\hline $.00 E+00$ & $0.00 \mathrm{E}+00$ & $0 \mathrm{E}+00$ & $0 E+00$ & $\mathrm{E}+00$ & $0 E+00$ & $\mathrm{E}+00$ & $E+00$ \\
\hline $.00 E+00$ & $0.00 \mathrm{E}+00$ & 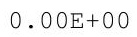 & $0.00 \mathrm{E}+00$ & $0.00 \mathrm{E}+00$ & $.00 \mathrm{E}+00$ & $.00 \mathrm{E}+00$ & $.00 \mathrm{E}+00$ \\
\hline $.00 \mathrm{E}+00$ & $0.00 \mathrm{E}+00$ & $0.00 \mathrm{E}+00$ & $0.00 \mathrm{E}+00$ & $0.00 \mathrm{E}+00$ & $00 \mathrm{E}+00$ & $.00 \mathrm{E}+00$ & $0 \mathrm{E}+00$ \\
\hline$E+00$ & +00 & $E+00$ & +00 & $0 \mathrm{E}+00$ & +00 & $0 \mathrm{E}+00$ & $E+00$ \\
\hline $.00 \mathrm{E}+00$ & $0.00 \mathrm{E}+00$ & $0.00 \mathrm{E}+00$ & $00 \mathrm{E}+00$ & & & $.00 \mathrm{E}+00$ & $00 \mathrm{E}+00$ \\
\hline$E+00$ & $E+00$ & $\mathrm{E}+00$ & $\mathrm{E}+00$ & $E+00$ & 00 & 00 & $E+00$ \\
\hline $.00 E+00$ & $.00 E+00$ & $0.00 \mathrm{E}+00$ & $\mathrm{E}+00$ & $\mathrm{E}+0 \mathrm{U}$ & $\mathrm{OE}+00$ & $E+00$ & $E+00$ \\
\hline $.00 \mathrm{E}+00$ & . OUET & $0.00 \mathrm{E}+00$ & $0.00 \mathrm{E}+00$ & $0.00 \mathrm{E}+00$ & 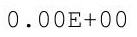 & $E+00$ & $\mathrm{E}+00$ \\
\hline $\mathrm{DE}+00$ & $0.00 \mathrm{E}+00$ & $0 \mathrm{E}+00$ & $0 \mathrm{E}+00$ & $0.00 \mathrm{E}+00$ & $00 \mathrm{E}+00$ & $0 E+00$ & $0 \mathrm{E}+00$ \\
\hline $.00 \mathrm{E}+00$ & +00 & . & $0 \mathrm{E}+00$ & 00 & $0 \mathrm{E}+00$ & $E+00$ & +00 \\
\hline $.00 E+00$ & $0.00 \mathrm{E}+00$ & $0.00 \mathrm{E}+00$ & $0.00 \mathrm{E}+00$ & $0.00 \mathrm{E}+00$ & $00 E+00$ & $00 \mathrm{E}+00$ & $.00 \mathrm{E}+00$ \\
\hline$E+00$ & $0.00 \mathrm{E}+00$ & $0 E+00$ & $0 E+00$ & $0 E+00$ & $\mathrm{E}+00$ & +00 & $\mathrm{E}+00$ \\
\hline $\mathrm{E}+00$ & $0.00 \mathrm{E}+00$ & $\mathrm{E}+00$ & $E+00$ & 00 & $\mathrm{E}+00$ & +00 & $\Xi+00$ \\
\hline $.00 E+00$ & $0.00 \mathrm{E}+00$ & $0.00 \mathrm{E}+00$ & $0.00 \mathrm{E}+00$ & $0 \mathrm{E}+00$ & $0 \mathrm{E}+00$ & $0 E+00$ & $0 \mathrm{E}+00$ \\
\hline $.00 E+00$ & . VUETU & $.00 \mathrm{E}+00$ & $0.00 \mathrm{E}+00$ & & $0 E+00$ & $E+00$ & $E+00$ \\
\hline $.00 \mathrm{E}+00$ & $0.00 \mathrm{E}+00$ & $0.00 \mathrm{E}+00$ & $0.00 \mathrm{E}+00$ & $0.00 \mathrm{E}+00$ & $00 \mathrm{E}+00$ & +00 & +00 \\
\hline 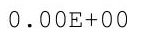 & $0.00 \mathrm{E}+00$ & . & $0.00 \mathrm{E}+00$ & $0.00 \mathrm{E}+00$ & 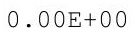 & $.00 \mathrm{E}+00$ & $.00 \mathrm{E}+00$ \\
\hline $.00 E+00$ & $0.00 \mathrm{E}+00$ & $0.00 \mathrm{E}+00$ & $0 \mathrm{E}+00$ & $0 \mathrm{E}+00$ & $00 \mathrm{E}+00$ & $E+00$ & $0 \mathrm{E}+00$ \\
\hline$E+00$ & $0.00 \mathrm{E}+00$ & $\mathrm{OE}+00$ & $\mathrm{E}+00$ & & 00 & +00 & $E+00$ \\
\hline$E+00$ & $0.00 \mathrm{E}+00$ & $E+00$ & $0 E+00$ & 00 & $0 \mathrm{E}+00$ & $0 E+00$ & $0 \mathrm{E}+00$ \\
\hline $0 \mathrm{E}+00$ & $0.00 \mathrm{E}+00$ & $0 \mathrm{E}+00$ & $0 \mathrm{E}+00$ & $0 \mathrm{E}+00$ & $0 \mathrm{E}+00$ & $0 \mathrm{E}+00$ & $0 \mathrm{E}+00$ \\
\hline $.00 \mathrm{E}+00$ & $0.00 \mathrm{E}+00$ & $0.00 \mathrm{E}+00$ & $0.00 \mathrm{E}+00$ & $0.00 \mathrm{E}+00$ & $.00 E+00$ & $.00 \mathrm{E}+00$ & $.00 \mathrm{E}+00$ \\
\hline $.00 \mathrm{E}+00$ & $0.00 \mathrm{E}+00$ & $0.00 \mathrm{E}+00$ & $0.00 \mathrm{E}+00$ & $0.00 \mathrm{E}+00$ & $.00 \mathrm{E}+00$ & $0.00 \mathrm{E}+00$ & $.00 \mathrm{E}+00$ \\
\hline (4) & $0.00 \mathrm{E}+00$ & 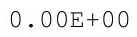 & $0.00 \mathrm{E}+00$ & 0 & 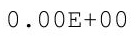 & $0 E+00$ & $0.00 \mathrm{E}+0$ \\
\hline$E+00$ & $00 \mathrm{E}+00$ & $00 \mathrm{E}+00$ & $\mathrm{E}+00$ & $\mathrm{E}+00$ & $0 \mathrm{E}+00$ & $\mathrm{E}+00$ & $0 E+00$ \\
\hline $\mathrm{DE}+00$ & $0.00 \mathrm{E}+00$ & $E+00$ & $0 E+00$ & $0 \mathrm{E}+00$ & $0 E+00$ & $0 \mathrm{E}+00$ & $0 E+00$ \\
\hline $.00 \mathrm{E}+00$ & $1.82 \mathrm{E}-25$ & $9.10 \mathrm{E}-29$ & $0.00 \mathrm{E}+00$ & $0.00 \mathrm{E}+00$ & $00 \mathrm{E}+00$ & $0.00 \mathrm{E}+00$ & $.00 \mathrm{E}+00$ \\
\hline $.00 \mathrm{E}+00$ & $8.03 E-23$ & $4.01 \mathrm{E}-26$ & $0.00 \mathrm{E}+00$ & $0.00 \mathrm{E}+00$ & $.00 \mathrm{E}+00$ & $.00 \mathrm{E}+00$ & $.00 \mathrm{E}+00$ \\
\hline . & 7. $31 E-21$ & $3.66 \mathrm{E}-24$ & & & DET & & $.00 \mathrm{E}+00$ \\
\hline $00 \mathrm{E}+00$ & & & & & & & $0.00 \mathrm{E}+00$ \\
\hline ה & & & & & 0 & 0 & 00 \\
\hline 0 & 6 & -20 & $E+00$ & $\mathrm{E}+00$ & $0 \mathrm{E}+00$ & +00 & $E+00$ \\
\hline $\mathrm{E}+00$ & $E-15$ & $0 E-19$ & $0 E+00$ & 00 & 00 & 00 & $0 E+00$ \\
\hline $.00 E+00$ & 8 & 4 & & & 0 & & +00 \\
\hline 0 & $8 E-14$ & 0 & & & 0 & & $00 \mathrm{E}+00$ \\
\hline $\mathrm{NE}+\mathrm{U}$ & 2 & 6 & 0 & $0.00 \mathrm{E}+00$ & $.00 \mathrm{E}+00$ & $0.00 \mathrm{E}+00$ & $0.00 \mathrm{E}+00$ \\
\hline & 1 & $6.16 \mathrm{E}-16$ & 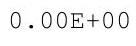 & 0 & 0 & 0 & 0 \\
\hline ( & & & 0 & 0 & 0 & 0 & +00 \\
\hline$E+00$ & -11 & 7 & $0.00 \mathrm{E}+00$ & $0.00 \mathrm{E}+00$ & $.00 \mathrm{E}+00$ & $00 \mathrm{E}+00$ & $0.00 \mathrm{E}+00$ \\
\hline $.00 E+00$ & $4.25 E-11$ & $.15 \mathrm{E}-14$ & $.00 \mathrm{E}+00$ & $0.00 \mathrm{E}+00$ & $0.00 \mathrm{E}+00$ & $0.00 \mathrm{E}+00$ & $0.00 \mathrm{E}+00$ \\
\hline
\end{tabular}


RESRAD-OFFSITE, Version 2.5

Title : RESRAD-OFFSITE Drinking Water, Plant, Milk, and Meat Pathways for Offsite Reside File : PBA-1_TC99-DOE-5.ROF

Summary of dose at graphical times, reptition 2 (continued)

Time

Years

1. $18 \mathrm{E}+02$

$1.18 \mathrm{E}+02$

1. $19 \mathrm{E}+02$

1. $19 \mathrm{E}+02$

1. $20 \mathrm{E}+02$

1. $20 \mathrm{E}+02$

1. $21 \mathrm{E}+02$

1. $22 \mathrm{E}+02$

1. $22 \mathrm{E}+02$

1. $23 \mathrm{E}+02$

1. $23 \mathrm{E}+02$

1. $24 \mathrm{E}+02$

1. $24 \mathrm{E}+02$

1. $25 \mathrm{E}+02$

1. $25 \mathrm{E}+02$

1. $26 \mathrm{E}+02$

1. $26 \mathrm{E}+02$

$1.27 \mathrm{E}+02$

$1.27 \mathrm{E}+02$

1. $28 \mathrm{E}+02$

1. $28 \mathrm{E}+02$

1. $29 \mathrm{E}+02$

1. $29 \mathrm{E}+02$

1. $30 \mathrm{E}+02$

1. $30 \mathrm{E}+02$

1. $31 \mathrm{E}+02$

1. $31 \mathrm{E}+02$

1. $32 \mathrm{E}+02$

1. $32 \mathrm{E}+02$

1. $33 \mathrm{E}+02$

1. $33 \mathrm{E}+02$

1. $34 \mathrm{E}+02$

1. $34 \mathrm{E}+02$

1. $35 \mathrm{E}+02$

1. $35 \mathrm{E}+02$

1. $36 \mathrm{E}+02$

1. $36 \mathrm{E}+02$

1. $37 \mathrm{E}+02$

1. $37 \mathrm{E}+02$

1. $38 \mathrm{E}+02$

1. $38 \mathrm{E}+02$

1. $39 \mathrm{E}+02$

1. $39 \mathrm{E}+02$

$1.40 \mathrm{E}+02$

1. $40 \mathrm{E}+02$

1. $41 \mathrm{E}+02$

Dose statistics at graphical times, mrem/yr

\begin{tabular}{|c|c|c|c|c|c|c|c|}
\hline inimum & aximum & Mean & ledian & $0 \%$ & $5 \%$ & $97.5 \%$ & $3 \%$ \\
\hline+00 & -10 & $5.66 \mathrm{E}-14$ & $0.00 \mathrm{E}+00$ & $0.00 \mathrm{E}+00$ & $0.00 \mathrm{E}+00$ & $.00 \mathrm{E}+00$ & $0 \mathrm{E}+0$ \\
\hline$E+00$ & $E-10$ & 3 & $0 E+00$ & $0 \mathrm{E}+00$ & $0 E+00$ & -00 & $00 \mathrm{E}+00$ \\
\hline+00 & $5.97 \mathrm{E}-10$ & $7 E-13$ & 00 & $\mathrm{E}+00$ & 00 & +00 & +00 \\
\hline+00 & 09 & & 0 & 0 & & 00 & +00 \\
\hline+00 & -09 & 2 & 0 & 0 & 00 & $E+00$ & $\mathrm{E}+00$ \\
\hline $.00 E+00$ & $E-09$ & -12 & $\mathrm{E}+00$ & $00 \mathrm{E}+00$ & 00 & $0 E+00$ & $00 \mathrm{E}+00$ \\
\hline $\mathrm{E}+00$ & $4 E-09$ & $E-12$ & $0 \mathrm{E}+00$ & $\mathrm{E}+00$ & +00 & +00 & $E+0 C$ \\
\hline $.00 E+00$ & 1. $42 E-08$ & $.51 \mathrm{E}-12$ & $0.00 \mathrm{E}+00$ & $0.00 \mathrm{E}+00$ & $.00 E+00$ & $.00 \mathrm{E}+00$ & $00 \mathrm{E}+0 \mathrm{C}$ \\
\hline+00 & -08 & $E-11$ & +00 & $0 E+00$ & $00 \mathrm{E}+00$ & +00 & +00 \\
\hline $.00 \mathrm{E}+00$ & $E-08$ & $4 E-11$ & $0 \mathrm{E}+00$ & $0 \mathrm{E}+00$ & $00 \mathrm{E}+00$ & $E+00$ & $E+00$ \\
\hline+00 & $E-08$ & $E-11$ & +00 & & & 00 & $E+00$ \\
\hline$E+00$ & -08 & -11 & +00 & & & +00 & +00 \\
\hline $.00 E+00$ & $1.35 E-07$ & $7.37 E-11$ & $0.00 \mathrm{E}+00$ & $0.00 \mathrm{E}+00$ & $.005+00$ & $.00 \mathrm{E}+00$ & $\mathrm{E}+\mathrm{OC}$ \\
\hline$E+00$ & -07 & $.08 \mathrm{E}-10$ & $0.00 \mathrm{E}+00$ & $0.00 \mathrm{E}+00$ & +00 & $0 E+00$ & $.00 \mathrm{E}+00$ \\
\hline$E+00$ & 07 & $E-10$ & $\mathrm{E}+00$ & $0.00 \mathrm{E}+00$ & 00 & $0 E+00$ & +00 \\
\hline $.00 \mathrm{E}+00$ & -07 & -10 & $0.00 \mathrm{E}+00$ & $0.00 \mathrm{E}+00$ & $00 \mathrm{E}+00$ & $0 \mathrm{E}+00$ & $0 \mathrm{E}+00$ \\
\hline $.00 \mathrm{E}+00$ & $2 E-07$ & $6 \mathrm{E}-10$ & $0 \mathrm{E}+00$ & $0 \mathrm{E}+00$ & $00 \mathrm{E}+00$ & $0 \mathrm{E}+00$ & $00 \mathrm{E}+00$ \\
\hline $.00 \mathrm{E}+00$ & $6 E-07$ & $8 E-10$ & $0 \mathrm{E}+00$ & $0 \mathrm{E}+00$ & $00 \mathrm{E}+00$ & $\mathrm{OE}+00$ & $0 E+00$ \\
\hline $.00 \mathrm{E}+00$ & $9.86 \mathrm{E}-07$ & $5 E-10$ & $0 \mathrm{E}+00$ & $\mathrm{OE}+00$ & $E+00$ & $\mathrm{DE}+00$ & $E+00$ \\
\hline $\mathrm{E}+00$ & -06 & $E-10$ & $0 E+00$ & $0 \mathrm{E}+00$ & +00 & $E+00$ & $33 E-25$ \\
\hline $.00 \mathrm{E}+00$ & -06 & -10 & & & & +00 & -23 \\
\hline $.00 \mathrm{E}+00$ & $9 E-06$ & 1. $29 \mathrm{E}-09$ & & & & $0 F+0$ & $E-21$ \\
\hline $.00 E+00$ & $0 E-06$ & $6 E-09$ & $0 \mathrm{E}+00$ & $0 \mathrm{E}+00$ & $00 \mathrm{E}+00$ & $0 \mathrm{E}+00$ & $56 E-19$ \\
\hline $.00 \mathrm{E}+00$ & $3.53 E-06$ & $2.12 \mathrm{E}-09$ & $0.00 \mathrm{E}+00$ & $0 \mathrm{E}+00$ & $00 \mathrm{E}+00$ & $0 \mathrm{E}+00$ & $24 E-18$ \\
\hline+00 & -06 & 09 & 00 & & & 00 & -17 \\
\hline$E+00$ & -06 & 09 & 00 & 00 & 00 & +00 & -16 \\
\hline $.00 \mathrm{E}+00$ & $6.73 E-06$ & $E-09$ & $0.00 \mathrm{E}+00$ & $00 \mathrm{E}+00$ & 00 & $0 E+00$ & $.20 \mathrm{E}-15$ \\
\hline $.00 \mathrm{E}+00$ & $8.21 E-06$ & $5.14 \mathrm{E}-09$ & $0.00 \mathrm{E}+00$ & $0.00 \mathrm{E}+00$ & $00 \mathrm{E}+00$ & $.00 \mathrm{E}+00$ & $.89 E-14$ \\
\hline $.00 \mathrm{E}+00$ & $9.93 E-06$ & $6.30 \mathrm{E}-09$ & $0.00 \mathrm{E}+00$ & $0.00 \mathrm{E}+00$ & $00 E+00$ & $00 E+00$ & $18 E-14$ \\
\hline $.00 \mathrm{E}+00$ & $1.19 \mathrm{E}-05$ & $5 E-09$ & & 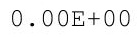 & & $0 \mathrm{E}+00$ & $77 \mathrm{E}-13$ \\
\hline$E+00$ & $2 E-05$ & $.27 E-09$ & $D E+00$ & $0 E+00$ & $0 \mathrm{E}+00$ & $0 E+00$ & $E-12$ \\
\hline $\mathrm{E}+00$ & $1.69 \mathrm{E}-05$ & $1 E-08$ & $E+00$ & & & & $9 E-12$ \\
\hline $.00 \mathrm{E}+00$ & $1.99 E-05$ & $3 E-08$ & $0.00 \mathrm{E}+00$ & $0 \mathrm{E}+00$ & $0 E+00$ & $0 \mathrm{E}+00$ & $13 E-11$ \\
\hline $.00 \mathrm{E}+00$ & $2.33 E-05$ & $1.58 \mathrm{E}-08$ & $0.00 \mathrm{E}+00$ & $0.00 \mathrm{E}+00$ & $00 \mathrm{E}+00$ & $.00 \mathrm{E}+00$ & $73 E-11$ \\
\hline 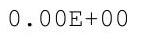 & $2.72 E-05$ & $1.88 E-08$ & & . Uूt & & $.00 \mathrm{E}+00$ & $.14 \mathrm{E}-11$ \\
\hline $.00 \mathrm{E}+00$ & & & & & & & $E-10$ \\
\hline 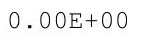 & 5 & 8 & 邽 & 0 & & 0 & 10 \\
\hline 0 & & & & 0 & +00 & $E+00$ & -10 \\
\hline $\mathrm{E}+00$ & $4.80 E-05$ & $3.52 \mathrm{E}-08$ & $\mathrm{DE}+00$ & 00 & 00 & +00 & $E-09$ \\
\hline $00 E+00$ & $5.47 E-05$ & $E-08$ & . & 0 & & 0 & -09 \\
\hline $0 E+00$ & & & & $.00 \mathrm{E}+00$ & & & $23 E-09$ \\
\hline Et+o & 15 & 8 & $.00 \mathrm{E}+00$ & $00 \mathrm{E}+00$ & $00 \mathrm{E}+00$ & & $475-09$ \\
\hline & 7. & 8 & & $00 \mathrm{E}+\mathrm{C}$ & & & s. \\
\hline 00 & & 8 & 0 . & 0 & 0 & 4 & -08 \\
\hline $\mathrm{E}+00$ & $9.95 E-05$ & 8. & $0.00 \mathrm{E}+00$ & $0.00 \mathrm{E}+00$ & $.00 \mathrm{E}+00$ & $3.66 \mathrm{E}-22$ & $2.22 E-08$ \\
\hline $.00 E+00$ & $1.11 E-04$ & $9.17 \mathrm{E}-08$ & $.00 E+00$ & $0.00 \mathrm{E}+00$ & $.00 E+00$ & 1. $60 \mathrm{E}-20$ & $3.35 \mathrm{E}-08$ \\
\hline
\end{tabular}


RESRAD-OFFSITE, Version 2.5

Title : RESRAD-OFFSITE Drinking Water, Plant, Milk, and Meat Pathways for Offsite Reside File : PBA-1_TC99-DOE-5.ROF

Summary of dose at graphical times, reptition 2 (continued)

Time

Years

1. $42 \mathrm{E}+02$

1. $42 \mathrm{E}+02$

1. $43 \mathrm{E}+02$

1. $43 \mathrm{E}+02$

1. $44 \mathrm{E}+02$

1. $44 \mathrm{E}+02$

1. $45 \mathrm{E}+02$

1. $45 \mathrm{E}+02$

1. $46 \mathrm{E}+02$

1. $46 \mathrm{E}+02$

1. $47 \mathrm{E}+02$

1. $47 \mathrm{E}+02$

1. $48 \mathrm{E}+02$

1. $48 \mathrm{E}+02$

1. $49 \mathrm{E}+02$

1. $49 \mathrm{E}+02$

1. $50 \mathrm{E}+02$

1. $50 \mathrm{E}+02$

1. $51 \mathrm{E}+02$

1. $51 \mathrm{E}+02$

1. $52 \mathrm{E}+02$

1. $52 \mathrm{E}+02$

1. $53 \mathrm{E}+02$

1. $53 \mathrm{E}+02$

1. $54 \mathrm{E}+02$

1. $54 \mathrm{E}+02$

1. $55 \mathrm{E}+02$

1. $55 \mathrm{E}+02$

1. $56 \mathrm{E}+02$

1. $56 \mathrm{E}+02$

1. $57 \mathrm{E}+02$

1. $57 \mathrm{E}+02$

$1.58 \mathrm{E}+02$

1. $58 \mathrm{E}+02$

1. $59 \mathrm{E}+02$

1. $59 \mathrm{E}+02$

1. $60 \mathrm{E}+02$

$1.60 \mathrm{E}+02$

1. $61 \mathrm{E}+02$

1. $61 \mathrm{E}+02$

$1.62 \mathrm{E}+02$

1. $63 \mathrm{E}+02$

$1.63 \mathrm{E}+02$

$1.64 \mathrm{E}+02$

1. $64 \mathrm{E}+02$

1. $65 \mathrm{E}+02$

Dose statistics at graphical times, mrem/yr

\begin{tabular}{|c|c|c|c|c|c|c|c|}
\hline Inimum & laximum & Mean & Median & $90 \%$ & $95 \%$ & $97.5 \%$ & $\%$ \\
\hline 00 & -04 & $4 E-07$ & $0.00 E+00$ & $00 E+00$ & $00 E+00$ & 9 & -08 \\
\hline $0 E+00$ & $1.37 \mathrm{E}-04$ & $7 E-07$ & $0.00 \mathrm{E}+00$ & $0.00 \mathrm{E}+00$ & $0.00 \mathrm{E}+00$ & 18 & -08 \\
\hline$E+00$ & $2 E-04$ & $2 E-07$ & $E+00$ & 0 & $0 E+00$ & 17 & $08 E-07$ \\
\hline$\Xi+00$ & $8 E-04$ & $E-07$ & $\mathrm{E}+00$ & $0 \mathrm{E}+00$ & $0 \mathrm{E}+00$ & 16 & $0 E-07$ \\
\hline $.00 \mathrm{E}+00$ & $E-04$ & -07 & $0 \mathrm{E}+00$ & $0 \mathrm{E}+00$ & $00 \mathrm{E}+00$ & 15 & $07 E-07$ \\
\hline 100 & $3 E-04$ & $6 \mathrm{E}-07$ & 0 & 0 & +00 & -14 & $E-07$ \\
\hline $0 E+00$ & $2.22 E-04$ & $3 E-07$ & $0 E+00$ & $\mathrm{E}+00$ & $0 \mathrm{E}+00$ & -14 & $5 E-07$ \\
\hline $.00 E+00$ & $2.43 E-04$ & • & $0.00 \mathrm{E}+00$ & . & $00 \mathrm{E}+00$ & -13 & $.75 E-07$ \\
\hline $.00 \mathrm{E}+00$ & $2.66 \mathrm{E}-04$ & Ler & $0.00 \mathrm{E}+00$ & 00 & $00 \mathrm{E}+00$ & -12 & $10 E-07$ \\
\hline$E+00$ & -04 & $E-07$ & +00 & +00 & 00 & 12 & -07 \\
\hline $.00 \mathrm{E}+00$ & $3.15 \mathrm{E}-04$ & $6 \mathrm{E}-07$ & & & & $.03 E-11$ & $.46 E-07$ \\
\hline+00 & -04 & -6 & $\mathrm{E}+00$ & $\mathrm{E}+00$ & 0 & -11 & -06 \\
\hline $.00 E+00$ & $3.71 E-04$ & L & $0 \mathrm{E}+00$ & 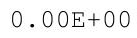 & $0 \mathrm{E}+00$ & -11 & $42 E-06$ \\
\hline $.00 \mathrm{E}+00$ & $4.01 E-04$ & $4.245-01$ & $0.00 \mathrm{E}+00$ & $0.00 \mathrm{E}+00$ & 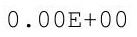 & -10 & $71 E-06$ \\
\hline $.00 E+00$ & $4.33 E-04$ & 1 & $0 E+00$ & 00 & $0 E+00$ & 10 & $08 E-06$ \\
\hline $.00 \mathrm{E}+00$ & -04 & r & -00 & 00 & $0 E+00$ & 10 & -06 \\
\hline $.00 E+00$ & $5.03 E-04$ & $E-07$ & $0.00 \mathrm{E}+00$ & $00 E+00$ & $00 \mathrm{E}+00$ & -09 & $10 E-06$ \\
\hline$\exists+00$ & $2 E-04$ & $E-07$ & $0 \mathrm{E}+00$ & 0 & $\mathrm{E}+00$ & -09 & $70 E-06$ \\
\hline $.00 \mathrm{E}+00$ & $5.82 \mathrm{E}-04$ & $0 \mathrm{E}-07$ & $0.00 \mathrm{E}+00$ & & $0 \mathrm{E}+00$ & 9 & -06 \\
\hline $.00 E+00$ & $6.24 \mathrm{E}-04$ & $.31 E-07$ & $0.00 \mathrm{E}+00$ & -00 & $0 \mathrm{E}+00$ & 09 & $E-06$ \\
\hline $.00 E+00$ & $6.69 E-04$ & T & $0 E+00$ & & $0 \mathrm{E}+00$ & 09 & $30 E-06$ \\
\hline $.00 \mathrm{E}+00$ & $7.16 \mathrm{E}-04$ & 1 & $0.00 \mathrm{E}+00$ & $0.00 \mathrm{E}+00$ & -28 & -08 & $68 \mathrm{E}-06$ \\
\hline 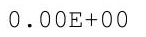 & 7. $65 \mathrm{E}-04$ & . & $0.00 \mathrm{E}+00$ & $0.00 \mathrm{E}+00$ & $.01 \mathrm{E}-2 \mathrm{~J}$ & & $.64 E-06$ \\
\hline $.00 E+00$ & $8.17 \mathrm{E}-04$ & $.02 E-06$ & $0 \mathrm{E}+00$ & 00 & $7 E-23$ & .08 & $77 E-06$ \\
\hline $.00 \mathrm{E}+00$ & $8.71 \mathrm{E}-04$ & $1.11 \mathrm{E}-06$ & $0.00 \mathrm{E}+00$ & & $3 E-21$ & -08 & $1 E-05$ \\
\hline$E+00$ & $E-04$ & $E-06$ & $0 E+00$ & 00 & 19 & 08 & $E-05$ \\
\hline$D E+00$ & $9.88 E-04$ & $0 \mathrm{E}-06$ & $0 \mathrm{E}+00$ & 00 & 18 & & $33 E-05$ \\
\hline 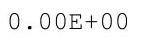 & 年 & 1.90 & $0.00 \mathrm{E}+00$ & 1. & $E-17$ & $.52 E-07$ & $51 E-05$ \\
\hline . & $1.12 \mathrm{E}-03$ & I. & $0.00 \mathrm{E}+00$ & $0.00 \mathrm{E}+00$ & $65 \pm-16$ & $08 E-07$ & $.71 \mathrm{E}-05$ \\
\hline (2) & $1.18 \mathrm{E}-03$ & 年 & & & $7 E-15$ & -07 & $3 E-0$ \\
\hline 00 & 03 & $E-06$ & $\mathrm{E}+00$ & $0 \mathrm{E}+00$ & 4 & 7 & -05 \\
\hline$E+00$ & $E-03$ & $E-06$ & $0 \mathrm{E}+00$ & $0 \mathrm{E}+00$ & $1 E-14$ & 07 & $E-05$ \\
\hline $.00 \mathrm{E}+00$ & $1.41 \mathrm{E}-03$ & $2.03 E-06$ & $0.00 \mathrm{E}+00$ & $0.00 \mathrm{E}+00$ & $4 E-13$ & -07 & $72 E-05$ \\
\hline $.00 \mathrm{E}+00$ & $1.49 \mathrm{E}-03$ & $2.18 \mathrm{E}-06$ & $0.00 \mathrm{E}+00$ & $0.00 \mathrm{E}+00$ & $40 E-12$ & $4 \mathrm{E}-07$ & $03 E-05$ \\
\hline • & $1.58 \mathrm{E}-03$ & & & & & & $.32 E-05$ \\
\hline 1 & $1.66 \mathrm{E}$ & & & & & & \\
\hline 00 & 3 & & 0 & 0 & 1 & & 0 \\
\hline+00 & 03 & $E-06$ & 00 & 00 & 1 & 6 & $9 E-05$ \\
\hline $\mathrm{E}+00$ & 1. $95 \mathrm{E}-03$ & $3.08 E-06$ & $0 \mathrm{E}+00$ & 00 & $4 E-10$ & -06 & $6 E-05$ \\
\hline $.00 E+00$ & $2.06 \mathrm{E}-03$ & 6 & & & 0 & & -05 \\
\hline 0 & $2.16 \mathrm{E}-03$ & & & & 0 & & -05 \\
\hline $.00 \mathrm{E}+00$ & $2.28 E-03$ & $3.75 \mathrm{E}-06$ & $0.00 \mathrm{E}+00$ & $0.00 \mathrm{E}+00$ & $1.27 \mathrm{E}-09$ & & $.90 \mathrm{E}-05$ \\
\hline & 2 & $3.99 \mathrm{E}-06$ & 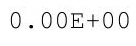 & ) & & & $6.37 \mathrm{E}-05$ \\
\hline & & 06 & 0 & 0 & 9 & 6 & -0 \\
\hline+00 & 2 . & 4. & $0.00 \mathrm{E}+00$ & 0. & 9 & 06 & $7.36 \mathrm{E}-05$ \\
\hline $.00 E+00$ & $77 E-03$ & $82 E-06$ & $.00 E+00$ & $0.00 \mathrm{E}+00$ & $8.66 \mathrm{E}-09$ & $6.30 \mathrm{E}-06$ & $7.91 \mathrm{E}-05$ \\
\hline
\end{tabular}


RESRAD-OFFSITE, Version 2.5

Title : RESRAD-OFFSITE Drinking Water, Plant, Milk, and Meat Pathways for Offsite Reside File : PBA-1_TC99-DOE-5.ROF

Summary of dose at graphical times, reptition 2 (continued)

Time

Years

1. $65 \mathrm{E}+02$

$1.66 \mathrm{E}+02$

$1.66 \mathrm{E}+02$

$1.67 \mathrm{E}+02$

1. $67 \mathrm{E}+02$

1. $68 \mathrm{E}+02$

1. $68 \mathrm{E}+02$

1. $69 \mathrm{E}+02$

1. $69 \mathrm{E}+02$

1. $70 \mathrm{E}+02$

1. $70 \mathrm{E}+02$

1. $71 \mathrm{E}+02$

1. $71 \mathrm{E}+02$

1. $72 \mathrm{E}+02$

1. $72 \mathrm{E}+02$

1. $73 \mathrm{E}+02$

1. $73 \mathrm{E}+02$

1. $74 \mathrm{E}+02$

1. $74 \mathrm{E}+02$

1. $75 \mathrm{E}+02$

$1.75 \mathrm{E}+02$

1. $76 \mathrm{E}+02$

$1.76 \mathrm{E}+02$

$1.77 \mathrm{E}+02$

1. $77 \mathrm{E}+02$

1. $78 \mathrm{E}+02$

1. $78 \mathrm{E}+02$

$1.79 \mathrm{E}+02$

$1.79 \mathrm{E}+02$

$1.80 \mathrm{E}+02$

1. $80 \mathrm{E}+02$

$1.81 \mathrm{E}+02$

$1.81 \mathrm{E}+02$

1. $82 \mathrm{E}+02$

$1.83 \mathrm{E}+02$

$1.83 \mathrm{E}+02$

$1.84 \mathrm{E}+02$

$1.84 \mathrm{E}+02$

1. $85 \mathrm{E}+02$

$1.85 \mathrm{E}+02$

$1.86 \mathrm{E}+02$

$1.86 \mathrm{E}+02$

$1.87 \mathrm{E}+02$

$1.87 \mathrm{E}+02$

$1.88 \mathrm{E}+02$

$1.88 \mathrm{E}+02$

Dose statistics at graphical times, mrem/yr

\begin{tabular}{|c|c|c|c|c|c|c|c|}
\hline m & aximum & ean & ed & & & & \\
\hline 0 & 3 & 6 & +00 & 00 & 08 & 06 & -05 \\
\hline $\mathrm{DE}+00$ & $.05 E-03$ & $5 E-06$ & $0 \mathrm{E}+00$ & $0 \mathrm{E}+00$ & $5 E-08$ & $8.85 E-06$ & $10 \mathrm{E}-05$ \\
\hline $0 \cap F+00$ & $9 F-03$ & $9 F-06$ & $00 F+00$ & $00 F+00$ & $85 E-08$ & $01 F-05$ & $74 \mathrm{E}-05$ \\
\hline & & $.15 E-06$ & & & & & 0 \\
\hline & 03 & 06 & & & & & -04 \\
\hline$E+00$ & 3 & 06 & & & & & -04 \\
\hline ( & 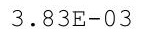 & 6 & 0 & 00 & 7 & & -04 \\
\hline+00 & $E-03$ & $E-06$ & $E+00$ & $\mathrm{E}+00$ & $9 \mathrm{E}-07$ & -05 & $E-04$ \\
\hline $\mathrm{E}+00$ & $3 E-03$ & $2 E-06$ & $0 \mathrm{E}+00$ & $E+00$ & -07 & 05 & $E-04$ \\
\hline $0 \mathrm{E}+00$ & $6 E-03$ & 6 & & & & 5 & 04 \\
\hline & & & & & & & -04 \\
\hline $\mathrm{E}+00$ & $4.75 \mathrm{E}-03$ & $.72 \mathrm{E}-06$ & $0 \mathrm{E}+00$ & & & 05 & $E-04$ \\
\hline $.00 E+00$ & $4.95 E-03$ & $.03 E-05$ & $0.00 \mathrm{E}+00$ & -27 & & & $.88 E-04$ \\
\hline+00 & 03 & $E-05$ & & -24 & & & -04 \\
\hline & & & & 2 & & & -04 \\
\hline 0 & & $21 E-05$ & & 1 & 6 & 5 & 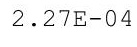 \\
\hline 0 & $5.83 E-03$ & F & & 9 & 6 & 5 & 04 \\
\hline$E+00$ & $507 F-03$ & $E-05$ & & & 6 & 05 & -04 \\
\hline $.00 \mathrm{E}+00$ & $6.31 \mathrm{E}-03$ & $1.41 \mathrm{E}-05$ & $0.00 \mathrm{E}+00$ & $5.67 \mathrm{E}-17$ & $1.92 \mathrm{E}-06$ & $.53 E-05$ & $.83 E-04$ \\
\hline $00 E+00$ & $7 F-03$ & $1.49 \mathrm{E}-05$ & $0.00 \mathrm{E}+00$ & $7 E-16$ & $3 E-06$ & -05 & $99 E-04$ \\
\hline & & & & & & & \\
\hline & & & & & & & -04 \\
\hline$E+00$ & & & & & & & 04 \\
\hline$F+0 \Omega$ & 3 & 5 & & 3 & & 5 & -04 \\
\hline$\cap \cap F+\cap C$ & $95 \mathrm{~F}-0$ & $1.91 E-05$ & $0.00 \mathrm{E}+00$ & $8 E-12$ & $37 F-06$ & $5 E-05$ & $91 F-04$ \\
\hline $00 F+00$ & $25 \mathrm{~F}-03$ & $2.01 E-05$ & $0.00 \mathrm{E}+00$ & $89 E-12$ & $75 E-06$ & $E-05$ & $E-04$ \\
\hline+00 & $E-03$ & & & & & & 04 \\
\hline & & & & & & & -04 \\
\hline$E+00$ & . & & & -11 & & & -04 \\
\hline 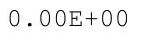 & . & $2.43 E-05$ & $0.00 \mathrm{E}+00$ & 1. $22 \mathrm{E}-10$ & $9.54 \mathrm{E}-06$ & $1.35 \mathrm{E}-04$ & $02 E-04$ \\
\hline ter & . & $.54 \mathrm{E}-05$ & $0.00 \mathrm{E}+00$ & $2.61 \mathrm{E}-10$ & $1.07 \mathrm{E}-05$ & $1.46 \mathrm{E}-04$ & $E-0$ \\
\hline & $1.02 \mathrm{E}-$ & & & & & & 04 \\
\hline & & & & & & & 04 \\
\hline & 02 & $2 E-05$ & & & & & 04 \\
\hline $\mathrm{E}+00$ & 1 . & $E-05$ & $0.00 \mathrm{E}+00$ & 09 & 5 & 4 & -04 \\
\hline 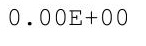 & $\perp \cdot 10 \mathrm{O}-0<$ & $3.19 \mathrm{E}-05$ & $0.00 \mathrm{E}+00$ & $4.15 E-09$ & $39 E-05$ & 04 & 7. $55 E-04$ \\
\hline 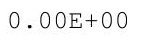 & $\pm \cdot 2<+\quad 0<$ & $3.34 \mathrm{E}-05$ & & & & & $1.90 \mathrm{~L}-\mathrm{C}$ \\
\hline - & - & 5 & & 9 & & & 04 \\
\hline 0 & & . & & & ( & 4 & 04 \\
\hline $\mathrm{E}+00$ & 02 & 05 & $\mathrm{OE}+00$ & 8 & 5 & 4 & -04 \\
\hline $0 E+00$ & $1.39 \mathrm{E}-02$ & $7 E-05$ & & -08 & $6 E-05$ & $5 E-04$ & $E-04$ \\
\hline+00 & $4 \mathrm{E}-02$ & $E-05$ & & -08 & & & -04 \\
\hline & & & & & & & . \\
\hline 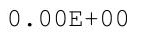 & - & & & & & . 20 & - \\
\hline $\mathrm{E}+00$ & & & & & & & - \\
\hline+00 & $E-02$ & $E-05$ & $.00 E+00$ & $E-07$ & -05 & $3-04$ & -03 \\
\hline
\end{tabular}


RESRAD-OFFSITE, Version 2.5

Title : RESRAD-OFFSITE Drinking Water, Plant, Milk, and Meat Pathways for Offsite Reside File : PBA-1_TC99-DOE-5.ROF

Summary of dose at graphical times, reptition 2 (continued)

Time

Years

$1.89 \mathrm{E}+02$

$1.89 \mathrm{E}+02$

$1.90 \mathrm{E}+02$

$1.90 \mathrm{E}+02$

$1.91 \mathrm{E}+02$

1. $91 \mathrm{E}+02$

$1.92 \mathrm{E}+02$

1. $92 \mathrm{E}+02$

$1.93 \mathrm{E}+02$

$1.93 \mathrm{E}+02$

$1.94 \mathrm{E}+02$

$1.94 \mathrm{E}+02$

$1.95 \mathrm{E}+02$

$1.95 \mathrm{E}+02$

$1.96 \mathrm{E}+02$

$1.96 \mathrm{E}+02$

$1.97 \mathrm{E}+02$

$1.97 \mathrm{E}+02$

1. $98 \mathrm{E}+02$

$1.98 \mathrm{E}+02$

$1.99 \mathrm{E}+02$

$1.99 \mathrm{E}+02$

$2.00 \mathrm{E}+02$

$2.00 \mathrm{E}+02$

$2.01 \mathrm{E}+02$

$2.01 \mathrm{E}+02$

$2.02 \mathrm{E}+02$

$2.03 \mathrm{E}+02$

$2.03 E+02$

$2.04 \mathrm{E}+02$

$2.04 \mathrm{E}+02$

$2.05 \mathrm{E}+02$

$2.05 \mathrm{E}+02$

$2.06 \mathrm{E}+02$

$2.06 \mathrm{E}+02$

$2.07 \mathrm{E}+02$

$2.07 \mathrm{E}+02$

$2.08 \mathrm{E}+02$

$2.08 \mathrm{E}+02$

2. $09 \mathrm{E}+02$

$2.09 \mathrm{E}+02$

$2.10 \mathrm{E}+02$

$2.10 \mathrm{E}+02$

$2.11 \mathrm{E}+02$

$2.11 E+02$

$2.12 \mathrm{E}+02$
Dose statistics at graphical times, mrem/yr

\begin{tabular}{|c|c|c|c|c|c|c|c|}
\hline inimum & aximum & Mean & ledian & $90 \%$ & $5 \%$ & $97.5 \%$ & $\%$ \\
\hline $0 \mathrm{E}+00$ & $1.68 \mathrm{E}-02$ & $5.11 \mathrm{E}-05$ & $0.00 \mathrm{E}+00$ & $91 E-07$ & $5.18 \mathrm{E}-05$ & $3.76 E-04$ & $1.22 \mathrm{E}-03$ \\
\hline$E+00$ & 02 & $2 E-05$ & $\mathrm{OE}+00$ & $45 \mathrm{E}-$ & $65 \mathrm{E}-$ & -04 & $.28 E-03$ \\
\hline$E+00$ & $1.79 E-02$ & $4 E-05$ & 00 & $4 E-07$ & $1 \mathrm{E}$ & -04 & $.33 E-03$ \\
\hline$E+00$ & L $85 E-02$ & 5 & & & 5 & 04 & -03 \\
\hline 00 & -02 & & & 7 & & -04 & $44 E-03$ \\
\hline $00 \mathrm{E}+00$ & $.96 \mathrm{E}-02$ & 5 & $.00 E+00$ & 07 & 5 & -04 & $.50 \mathrm{E}$ \\
\hline $0 E+00$ & $2.02 E-02$ & $8 E-05$ & $.00 \mathrm{E}+00$ & $94 \mathrm{E}-07$ & 5 & -04 & 0. \\
\hline $.00 E+00$ & $2.08 E-02$ & $\begin{array}{l}0 \\
\end{array}$ & $.00 E+00$ & $69 E-07$ & 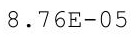 & -04 & $.64 \mathrm{E}-03$ \\
\hline$E+00$ & -02 & 5 & 00 & 6 & 5 & -04 & $.71 E-03$ \\
\hline $00 \mathrm{E}+00$ & -02 & -05 & & $41 E-06$ & $99 \mathrm{E}-$ & -04 & $.79 E-03$ \\
\hline $00 \mathrm{E}+00$ & $2.27 E-02$ & $7.56 \mathrm{E}-05$ & & $68 \mathrm{E}-06$ & $.06 \mathrm{E}-04$ & $87 E-04$ & $.87 \mathrm{E}-03$ \\
\hline+00 & -02 & 5 & $E+00$ & & 1 & -04 & 03 \\
\hline $.00 \mathrm{E}+00$ & $2.41 \mathrm{E}-02$ & $.15 E-05$ & $.00 \mathrm{E}+00$ & . $35 \mathrm{E}-00$ & - $2 \angle \mathrm{E}-04$ & $E-04$ & -03 \\
\hline $.00 E+00$ & $2.48 E-02$ & $.46 E-05$ & $.00 E+00$ & $75 E-06$ & 然 & -04 & $.13 E-03$ \\
\hline $0 \mathrm{E}+00$ & $2.55 E-02$ & $.77 E-05$ & $\mathrm{OE}+00$ & 6 & 40 & -04 & 03 \\
\hline $.00 \mathrm{E}+00$ & $2.62 \mathrm{E}-02$ & $.10 \mathrm{E}-05$ & $.00 \mathrm{E}+00$ & $.77 E-06$ & 管 & -04 & $.32 \mathrm{E}-03$ \\
\hline $.00 \mathrm{E}+00$ & $2.70 \mathrm{E}-02$ & $.44 \mathrm{E}-05$ & $.00 E+00$ & $32 E-06$ & $.56 \mathrm{E}-\mathrm{C}$ & $.50 E-04$ & $.41 E-03$ \\
\hline$E+00$ & $.77 E-02$ & $3 E-05$ & $\mathrm{E}+00$ & 06 & 4 & -04 & $.50 E-03$ \\
\hline$E+00$ & $E-02$ & $E-04$ & $E+00$ & OE- & D & -04 & $59 E-03$ \\
\hline $.00 \mathrm{E}+00$ & $2.93 E-02$ & $.05 E-04$ & $.00 E+00$ & $35 E-06$ & 年 & -04 & $9 E-03$ \\
\hline $0 \mathrm{E}+00$ & $E-02$ & $.09 E-04$ & $\mathrm{E}+00$ & $\angle 2+-00$ & & -04 & $9 E-03$ \\
\hline $.00 \mathrm{E}+00$ & $3.09 \mathrm{E}-02$ & $1.13 \mathrm{E}-04$ & $.00 \mathrm{E}+00$ & 06 & •l. & -04 & -03 \\
\hline $00 \mathrm{E}+00$ & $.18 E-02$ & $.17 E-04$ & $00 \mathrm{E}+00$ & $37 E-06$ & ( & $E-04$ & 03 \\
\hline$E+00$ & $3.26 \mathrm{E}-02$ & $.21 \mathrm{E}-04$ & $\mathrm{E}+00$ & ( 50 & $35 \mathrm{~F}$ & $E-03$ & -03 \\
\hline+00 & $E-02$ & $.25 E-04$ & $\mathrm{E}+00$ & 5 & 6 & $E-03$ & $1 E-03$ \\
\hline $\mathrm{E}+00$ & -02 & $E-04$ & 0 & $3 \mathrm{~F}$ & 4 & 03 & $3 E-03$ \\
\hline $0 \mathrm{E}+00$ & $E-02$ & $.34 \mathrm{E}-04$ & $0 E+00$ & $48 \mathrm{E}-$ & - & -03 & $45 E-03$ \\
\hline $.00 \mathrm{E}+00$ & $3.62 \mathrm{E}-02$ & $1.38 E-04$ & $.00 \mathrm{E}+00$ & $65 E-05$ & $.84 \mathrm{E}-04$ & $20 \mathrm{E}-03$ & $.57 E-03$ \\
\hline $0 E+00$ & $2 \mathrm{E}-02$ & 4 & $00 \mathrm{E}+00$ & 5 & 年 & $.25 \mathrm{E}-03$ & $.69 \mathrm{E}-03$ \\
\hline $.00 \mathrm{E}+00$ & $3.81 E-02$ & $1.401-04$ & & 年 & 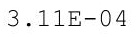 & -03 & $81 E-03$ \\
\hline & 2 & 4 & $E+00$ & 5 & & -03 & 03 \\
\hline+00 & -02 & $E-04$ & $\mathrm{E}+00$ & 5 & 4 & -03 & $8 E-03$ \\
\hline $.00 \mathrm{E}+00$ & $E-02$ & $.63 E-04$ & $0 \mathrm{E}+00$ & $4 \mathrm{E}$ & $5 E-$ & -03 & $1 E-03$ \\
\hline $.00 \mathrm{E}+00$ & $.22 \mathrm{E}-02$ & $1.69 E-04$ & $.00 E+00$ & $99 E-05$ & $3.1 \angle \mathrm{E}-$ & $3 E-03$ & $.35 E-03$ \\
\hline 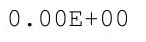 & $.32 E-02$ & $.74 \mathrm{E}-04$ & & & & $.59 E-03$ & $.50 E-03$ \\
\hline & & & & & & & \\
\hline & 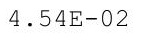 & & & & & -03 & 3 \\
\hline 0 & 2 & $1.91 \mathrm{E}-04$ & D & 5 & 4 & 3 & 03 \\
\hline & & 4 & & 05 & & & 03 \\
\hline $00 E+00$ & $4.88 E-02$ & $2.04 E-04$ & $E+00$ & 5 & 4 & 03 & $8 E-03$ \\
\hline$E+00$ & & 4 & & & & & -03 \\
\hline $\mathrm{E}+00$ & $11 \mathrm{E}-02$ & $.17 E-04$ & $00 E+00$ & $54 E-05$ & $25 E-04$ & & -03 \\
\hline $.00 E+00$ & 2 & 4 & 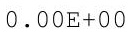 & 5 & 4 & & 5 \\
\hline $0.00 \mathrm{E}+00$ & $5.36 \mathrm{E}-02$ & & 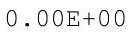 & 70 & 4 & 3 & . \\
\hline$E+00$ & $E-02$ & 2 & $E+00$ & 55 & 5. & 03 & 6.10 \\
\hline $00 \mathrm{E}+00$ & $61 E-02$ & $45 \mathrm{E}-04$ & $00 \mathrm{E}+00$ & $50 E-05$ & $17 E-04$ & $2.38 E-03$ & $6.27 E-03$ \\
\hline
\end{tabular}


RESRAD-OFFSITE, Version 2.5

$\mathrm{T}^{1 / 2}$ Limit $=180$ days

Title : RESRAD-OFFSITE Drinking Water, Plant, Milk, and Meat Pathways for Offsite Reside File : PBA-1_TC99-DOE-5.ROF

Summary of dose at graphical times, reptition 2 (continued)

Time

Years

$2.12 \mathrm{E}+02$

$2.13 \mathrm{E}+02$

$2.13 E+02$

$2.14 \mathrm{E}+02$

$2.14 \mathrm{E}+02$

$2.15 \mathrm{E}+02$

$2.15 \mathrm{E}+02$

$2.16 \mathrm{E}+02$

$2.16 \mathrm{E}+02$

$2.17 \mathrm{E}+02$

$2.17 \mathrm{E}+02$

$2.18 \mathrm{E}+02$

$2.18 \mathrm{E}+02$

$2.19 \mathrm{E}+02$

$2.19 \mathrm{E}+02$

$2.20 \mathrm{E}+02$

$2.20 \mathrm{E}+02$

$2.21 \mathrm{E}+02$

$2.21 \mathrm{E}+02$

$2.22 \mathrm{E}+02$

$2.23 \mathrm{E}+02$

2. $23 E+02$

$2.24 \mathrm{E}+02$

$2.24 \mathrm{E}+02$

$2.25 \mathrm{E}+02$

$2.25 \mathrm{E}+02$

$2.26 \mathrm{E}+02$

$2.26 \mathrm{E}+02$

$2.27 \mathrm{E}+02$

$2.27 \mathrm{E}+02$

2. $28 \mathrm{E}+02$

$2.28 \mathrm{E}+02$

$2.29 \mathrm{E}+02$

$2.29 \mathrm{E}+02$

$2.30 \mathrm{E}+02$

2. $30 \mathrm{E}+02$

$2.31 E+02$

$2.31 E+02$

2. $32 \mathrm{E}+02$

2. $32 E+02$

$2.33 E+02$

2. $33 \mathrm{E}+02$

$2.34 \mathrm{E}+02$

2. $34 \mathrm{E}+02$

$2.35 \mathrm{E}+02$

$2.35 E+02$
Dose statistics at graphical times, mrem/yr

\begin{tabular}{|c|c|c|c|c|c|c|c|}
\hline Minimum & aximum & Mean & ledian & $90 \%$ & $95 \%$ & $97.5 \%$ & $\%$ \\
\hline $0 \mathrm{E}+00$ & $5.74 \mathrm{E}-02$ & $2.52 \mathrm{E}-04$ & $.00 \mathrm{E}+00$ & $04 E-05$ & $6.46 \mathrm{E}-04$ & $47 E-03$ & $5 \mathrm{E}-03$ \\
\hline$E+00$ & $7 E-02$ & $0 E-04$ & $0 \mathrm{E}+00$ & $62 \mathrm{E}$ & $75 E-04$ & $56 E-03$ & $63 E-03$ \\
\hline$E+00$ & $6.01 E-02$ & $2.67 E-04$ & 00 & $25 E-05$ & $05 E-04$ & -03 & $32 E-03$ \\
\hline$E+00$ & $E-02$ & -04 & & & 4 & 3 & -03 \\
\hline 00 & -02 & -04 & & 4 & 4 & 03 & $21 E-03$ \\
\hline $00 \mathrm{E}+00$ & $.42 \mathrm{E}-02$ & $E-04$ & $.00 E+00$ & 4 & -04 & -03 & 03 \\
\hline $0 E+00$ & $7 \mathrm{E}-02$ & $3.00 \mathrm{E}-04$ & $.00 \mathrm{E}+00$ & $20 \mathrm{E}-04$ & -04 & (0) & 0. \\
\hline $.00 E+00$ & $6.71 E-02$ & . & $.00 E+00$ & $.28 \mathrm{E}-04$ & 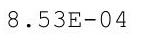 & -03 & $.89 E-03$ \\
\hline$E+00$ & $E-02$ & $E-04$ & 00 & 4 & 4 & 03 & $13 E-03$ \\
\hline $00 \mathrm{E}+00$ & -02 & $.27 E-04$ & & $45 \mathrm{E}-$ & $15 E-04$ & -03 & $.37 E-03$ \\
\hline $00 \mathrm{E}+00$ & $7.16 \mathrm{E}-02$ & $.36 \mathrm{E}-04$ & & $.54 \mathrm{E}-04$ & $46 E-04$ & $E-03$ & $60 E-03$ \\
\hline$E+00$ & -02 & -04 & $E+00$ & 4 & & 3 & 03 \\
\hline $.00 \mathrm{E}+00$ & $7.47 \mathrm{E}-02$ & $3.56 \mathrm{E}-04$ & $.00 \mathrm{E}+00$ & $.74 \mathrm{E}-04$ & S & S & -03 \\
\hline $00 \mathrm{E}+00$ & 7. $63 \mathrm{E}-02$ & $3.66 \mathrm{E}-04$ & $.00 \mathrm{E}+00$ & . & st & J & -03 \\
\hline $0 \mathrm{E}+00$ & $E-02$ & $.76 \mathrm{E}-04$ & $\mathrm{E}+00$ & 4 & 皮 & ك & 03 \\
\hline $.00 \mathrm{E}+00$ & $7.96 \mathrm{E}-02$ & $3.86 \mathrm{E}-04$ & $.00 \mathrm{E}+00$ & $.08 E-04$ & -5 & -03 & -03 \\
\hline $.00 \mathrm{E}+00$ & $8.12 E-02$ & $3.97 E-04$ & $.00 E+00$ & $.20 E-04$ & $.15 E-03$ & $9 E-03$ & $01 E-02$ \\
\hline$E+00$ & $E-02$ & $3 E-04$ & $\mathrm{E}+00$ & 4 & 3 & $=03$ & $04 E-02$ \\
\hline$E+00$ & -02 & $E-04$ & +00 & 4 & מ ת חתרת & -03 & $7 E-02$ \\
\hline $.00 \mathrm{E}+00$ & $8.64 \mathrm{E}-02$ & $4.30 \mathrm{E}-04$ & $.00 E+00$ & 04 & $20 E-03$ & -03 & $9 E-02$ \\
\hline $0 \mathrm{E}+00$ & $E-02$ & $.42 E-04$ & $\mathrm{E}+00$ & ل & & J & $12 \mathrm{E}-02$ \\
\hline $00 \mathrm{E}+00$ & $.99 \mathrm{E}-02$ & $4.53 E-04$ & $.00 \mathrm{E}+00$ & 政 & (5) & 0 & -02 \\
\hline $0 \mathrm{E}+00$ & $.17 E-02$ & $56 E-04$ & $00 \mathrm{E}+00$ & $02 E-04$ & ( & $\Gamma=0$ & $18 E-02$ \\
\hline $00 \mathrm{E}+00$ & $E-02$ & $78 E-04$ & $\mathrm{E}+00$ & $17 \mathrm{E}-$ & ק & 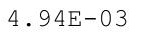 & $21 E-02$ \\
\hline+00 & $E-02$ & $90 E-04$ & $\mathrm{E}+00$ & 4 & $6 \mathrm{~F}$ & 3 & $24 E-02$ \\
\hline $\mathrm{E}+00$ & $E-02$ & 04 & 0 & 4 & P & 3 & $7 \mathrm{E}-02$ \\
\hline $0 \mathrm{E}+00$ & $2 E-02$ & $6 \mathrm{E}-04$ & $0 \mathrm{E}+00$ & 4 & 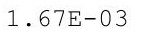 & -03 & $.31 E-02$ \\
\hline $.00 \mathrm{E}+00$ & $1.01 \mathrm{E}-01$ & $5.30 E-04$ & $0.00 \mathrm{E}+00$ & $75 E-04$ & $72 E-03$ & $.39 E-03$ & $.34 E-02$ \\
\hline $00 \mathrm{E}+00$ & $03 E-01$ & 4 & $00 \mathrm{E}+$ & $.91 E-04$ & 每 & . & $.37 \mathrm{E}-02$ \\
\hline $.00 \mathrm{E}+00$ & $1.05 E-01$ & 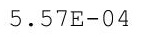 & & $x_{-1}+5$ & $x_{-1}-5$ & 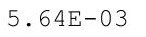 & $.40 \mathrm{E}-02$ \\
\hline & 1 & 4 & & & 3 & & 02 \\
\hline $\mathrm{E}+00$ & $E-01$ & $E-04$ & $E+00$ & 4 & 3 & 3 & $7 \mathrm{E}-02$ \\
\hline $0 \mathrm{E}+00$ & $.11 \mathrm{E}-01$ & $1 E-04$ & $00 E+00$ & 4 & 3 & 3 & $50 \mathrm{E}-02$ \\
\hline $.00 \mathrm{E}+00$ & $.13 \mathrm{E}-01$ & $6.16 E-04$ & $.00 E+00$ & 60" & $.03 E-43$ & $8 E-03$ & $.54 \mathrm{E}-02$ \\
\hline $0 E+00$ & $.15 E-01$ & $.31 E-04$ & & & & & $.57 \mathrm{E}-02$ \\
\hline & $\perp \cdot 10 \mathrm{O}-U \perp$ & & & & & & 02 \\
\hline & & & & & & & \\
\hline 0 & 1 & 4 & $\Xi+00$ & 4 & 3 & 3 & 02 \\
\hline+00 & & 4 & & & & 3 & \\
\hline $00 \mathrm{E}+00$ & $27 \mathrm{E}-01$ & $12 \mathrm{E}-04$ & & 4 & 3 & & $.75 E-02$ \\
\hline$E+00$ & 1 & 4 & & & & & -02 \\
\hline $\mathrm{E}+00$ & $.31 E-01$ & $.47 E-04$ & $00 E+00$ & & & & $.83 E-02$ \\
\hline $.00 E+00$ & $\perp$ & 4 & & 4 & & & 02 \\
\hline $0.00 \mathrm{E}+00$ & & 04 & P & It & S & 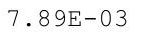 & 02 \\
\hline$E+00$ & 1.3 & 4 & +00 & 4 & 3 & 3 & 1.951 \\
\hline $00 \mathrm{E}+00$ & $41 E-01$ & $E-04$ & $00 E+00$ & $30 \mathrm{E}$ & $78 E-03$ & $.22 \mathrm{E}-03$ & $1.99 \mathrm{E}-02$ \\
\hline
\end{tabular}


RESRAD-OFFSITE, Version 2.5

Title : RESRAD-OFFSITE Drinking Water, Plant, Milk, and Meat Pathways for Offsite Reside File : PBA-1_TC99-DOE-5.ROF

Summary of dose at graphical times, reptition 2 (continued)

Time

Years

$2.36 \mathrm{E}+02$

$2.36 \mathrm{E}+02$

$2.37 \mathrm{E}+02$

$2.37 \mathrm{E}+02$

$2.38 \mathrm{E}+02$

$2.38 \mathrm{E}+02$

$2.39 \mathrm{E}+02$

$2.39 \mathrm{E}+02$

$2.40 \mathrm{E}+02$

$2.40 \mathrm{E}+02$

$2.41 \mathrm{E}+02$

$2.41 \mathrm{E}+02$

$2.42 \mathrm{E}+02$

$2.43 \mathrm{E}+02$

$2.43 \mathrm{E}+02$

$2.44 \mathrm{E}+02$

$2.44 \mathrm{E}+02$

$2.45 \mathrm{E}+02$

$2.45 \mathrm{E}+02$

$2.46 \mathrm{E}+02$

$2.46 \mathrm{E}+02$

$2.47 \mathrm{E}+02$

$2.47 \mathrm{E}+02$

$2.48 \mathrm{E}+02$

$2.48 \mathrm{E}+02$

$2.49 \mathrm{E}+02$

$2.49 \mathrm{E}+02$

$2.50 \mathrm{E}+02$

$2.50 \mathrm{E}+02$

$2.51 \mathrm{E}+02$

$2.51 \mathrm{E}+02$

$2.52 \mathrm{E}+02$

$2.52 \mathrm{E}+02$

$2.53 \mathrm{E}+02$

$2.53 \mathrm{E}+02$

$2.54 \mathrm{E}+02$

$2.54 \mathrm{E}+02$

$2.55 \mathrm{E}+02$

$2.55 \mathrm{E}+02$

$2.56 \mathrm{E}+02$

$2.56 \mathrm{E}+02$

$2.57 \mathrm{E}+02$

$2.57 \mathrm{E}+02$

$2.58 \mathrm{E}+02$

$2.58 \mathrm{E}+02$

$2.59 \mathrm{E}+02$
Dose statistics at graphical times, mrem/yr

\begin{tabular}{|c|c|c|c|c|c|c|c|}
\hline inimum & aximum & Mean & ledian & $90 \%$ & $5 \%$ & $97.5 \%$ & \\
\hline 0 & 01 & $E-04$ & $E+00$ & 04 & 03 & 03 & ? \\
\hline+00 & -01 & $9 E-04$ & $\mathrm{OE}+00$ & 4 & 03 & 03 & $8 E-02$ \\
\hline+00 & $3 E-01$ & $E-04$ & 0 & $9 E-04$ & 03 & 03 & -02 \\
\hline$E+00$ & 01 & 04 & & 4 & & & -02 \\
\hline$E+00$ & -01 & 4 & & 4 & & 03 & $21 E-02$ \\
\hline $.00 \mathrm{E}+00$ & $1.56 \mathrm{E}-01$ & $E-04$ & $E+00$ & $E-04$ & ك & 03 & -02 \\
\hline $\mathrm{EE}+00$ & -01 & $3 E-04$ & $0 E+00$ & 4 & J & -03 & -02 \\
\hline $.00 E+00$ & 1. $61 \mathrm{E}-01$ & •. & & $9.29 \mathrm{E}-04$ & & -03 & $.35 E-02$ \\
\hline-00 & 01 & 03 & 00 & $5 E-04$ & 03 & -02 & -02 \\
\hline $.00 \mathrm{E}+00$ & $1.67 \mathrm{E}$ & -03 & & 04 & 03 & -02 & $44 E-02$ \\
\hline+00 & $E-01$ & $E-03$ & & & & 02 & $9 E-02$ \\
\hline$E+00$ & & -03 & & & & & -02 \\
\hline $.00 \mathrm{E}+00$ & $1.75 \mathrm{E}-01$ & $\cdot 10 E-U 3$ & $0.00 \mathrm{E}+00$ & $1.07 \mathrm{E}-03$ & -03 & -02 & $09 \pm-02$ \\
\hline$E+00$ & -01 & $2 E-03$ & +00 & 03 & 03 & -02 & $65 E-02$ \\
\hline$E+00$ & 01 & 03 & $\mathrm{E}+00$ & 3 & & 02 & -02 \\
\hline $.00 \mathrm{E}+00$ & $1.83 \mathrm{E}-01$ & -03 & & 03 & 03 & -02 & -02 \\
\hline $.00 \mathrm{E}+00$ & $1.86 \mathrm{E}-01$ & $0 \mathrm{E}-03$ & $0 \mathrm{E}+00$ & 1.22E-03 & $3 E-03$ & $E-02$ & $82 E-02$ \\
\hline $0 \mathrm{E}+00$ & $1.89 E-01$ & $2 E-03$ & $0 E+00$ & $5 E-03$ & $7 E-03$ & $E-02$ & $88 E-02$ \\
\hline $\mathrm{E}+00$ & 01 & -03 & 00 & 3 & & -02 & -02 \\
\hline$E+00$ & -01 & $E-03$ & $\mathrm{OE}+00$ & $1.33 E-03$ & 03 & -02 & $0 E-02$ \\
\hline$E+00$ & -01 & J & & & & -02 & -02 \\
\hline $.00 \mathrm{E}+00$ & -01 & $.33 E-03$ & $0.00 \mathrm{E}+00$ & $1.41 \mathrm{E}$ & & -02 & -02 \\
\hline $.00 \mathrm{E}+00$ & $2.05 E-01$ & $1.36 E-03$ & $0.00 \mathrm{E}+00$ & $1.46 \mathrm{E}-03$ & $7 E-03$ & $36 E-02$ & $20 E-02$ \\
\hline $.00 \mathrm{E}+00$ & $2.08 \mathrm{E}-01$ & $1.39 \mathrm{E}-03$ & $0.00 \mathrm{E}+00$ & $1.50 \mathrm{E}-03$ & $88 E-03$ & $39 \mathrm{E}-02$ & $26 E-02$ \\
\hline+00 & $2.11 \mathrm{E}-01$ & $42 E-03$ & & & 03 & -02 & $3 E-02$ \\
\hline$E+00$ & $E-01$ & $E-03$ & 00 & & & & -02 \\
\hline $.00 \mathrm{E}+00$ & $2.17 \mathrm{E}-01$ & $1.48 E-03$ & $0.00 \mathrm{E}+00$ & 1.00 & & -02 & -02 \\
\hline $.00 E+00$ & $2.21 E-01$ & $51 E-03$ & $0.00 \mathrm{E}+00$ & $67 E-03$ & $8 / 2-03$ & $1 E-02$ & $53 E-02$ \\
\hline $00 E+00$ & $.24 \mathrm{E}-01$ & 3 & $.00 \mathrm{E}+00$ & 3 & 年 & $5 E-02$ & $61 E-02$ \\
\hline 0 & 1 & - & 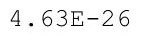 & - & $61 E-03$ & - & - \\
\hline$F+00$ & $2.30 E-01$ & $0 F-03$ & $8 E-23$ & $1 E-03$ & 3 & $E-02$ & $5 E-02$ \\
\hline+00 & $2.34 E-01$ & $3 E-03$ & $9 E-21$ & 3 & 03 & -02 & -02 \\
\hline $.00 \mathrm{E}+00$ & $2.37 \mathrm{E}-01$ & $6 E-03$ & -20 & 03 & 03 & 02 & $0 E-02$ \\
\hline $.00 E+00$ & $2.41 E-01$ & $1.70 E-03$ & $9.46 \mathrm{E}-19$ & $1.96 \mathrm{E}-03$ & $7 E-03$ & $71 E-02$ & $98 E-02$ \\
\hline (2) & $2.44 E-01$ & $1.73 E-03$ & $1.32 E-17$ & $2.0<5-03$ & & & $.06 \mathrm{E}-02$ \\
\hline 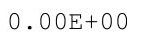 & & & & & & & \\
\hline 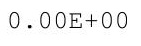 & 1 & 3 & & $2.12 E-03$ & & & 02 \\
\hline 0 & 1 & 3 & & & & & 02 \\
\hline & & & & 3 & 03 & 02 & 02 \\
\hline $.00 E+00$ & $2.62 E-01$ & $1.91 E-03$ & $7 E-13$ & 3 & 3 & & $8 E-02$ \\
\hline$E+00$ & 1 & $E-03$ & 13 & 3 & & & -02 \\
\hline$E+00$ & 2.69 & $1.98 E-03$ & 12 & 3 & & 02 & $65 E-02$ \\
\hline 0 & se & $2+-03$ & $27 E-12$ & 20 & (1) & 2 & -02 \\
\hline U. ULT & t & 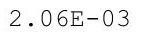 & & & & & - \\
\hline $\mathrm{E}+00$ & $2.80 E-01$ & -03 & $E-11$ & $2.57 E-03$ & $7.80 \mathrm{E}-03$ & $E-02$ & $4.90 \mathrm{E}-02$ \\
\hline $.00 E+00$ & $2.84 E-01$ & $2.14 E-03$ & $.61 E-11$ & $2.64 E-03$ & $7.96 \mathrm{E}-03$ & $2.12 \mathrm{E}-02$ & $4.98 \mathrm{E}-02$ \\
\hline
\end{tabular}


RESRAD-OFFSITE, Version 2.5

$\mathrm{T}^{1 / 2}$ Limit $=180$ days

Title : RESRAD-OFFSITE Drinking Water, Plant, Milk, and Meat Pathways for Offsite Reside File : PBA-1_TC99-DOE-5.ROF

Summary of dose at graphical times, reptition 2 (continued)

Time

Years

$2.59 \mathrm{E}+02$

$2.60 \mathrm{E}+02$

$2.60 \mathrm{E}+02$

$2.61 E+02$

$2.61 \mathrm{E}+02$

2. $62 \mathrm{E}+02$

2. $63 \mathrm{E}+02$

$2.63 \mathrm{E}+02$

$2.64 \mathrm{E}+02$

$2.64 \mathrm{E}+02$

$2.65 \mathrm{E}+02$

2. $65 \mathrm{E}+02$

$2.66 \mathrm{E}+02$

2. $66 \mathrm{E}+02$

$2.67 \mathrm{E}+02$

$2.67 \mathrm{E}+02$

$2.68 \mathrm{E}+02$

$2.68 \mathrm{E}+02$

$2.69 \mathrm{E}+02$

$2.69 \mathrm{E}+02$

$2.70 \mathrm{E}+02$

$2.70 \mathrm{E}+02$

$2.71 \mathrm{E}+02$

$2.71 \mathrm{E}+02$

$2.72 \mathrm{E}+02$

$2.72 \mathrm{E}+02$

$2.73 E+02$

$2.73 \mathrm{E}+02$

$2.74 \mathrm{E}+02$

$2.74 \mathrm{E}+02$

$2.75 \mathrm{E}+02$

$2.75 \mathrm{E}+02$

$2.76 \mathrm{E}+02$

$2.76 \mathrm{E}+02$

$2.77 \mathrm{E}+02$

$2.77 \mathrm{E}+02$

$2.78 \mathrm{E}+02$

$2.78 \mathrm{E}+02$

$2.79 \mathrm{E}+02$

$2.79 \mathrm{E}+02$

$2.80 \mathrm{E}+02$

$2.80 \mathrm{E}+02$

$2.81 \mathrm{E}+02$

$2.81 E+02$

$2.82 \mathrm{E}+02$

$2.82 \mathrm{E}+02$
Dose statistics at graphical times, mrem/yr

\begin{tabular}{|c|c|c|c|c|c|c|c|}
\hline inimum & Maximum & Mean & Median & $90 \%$ & $95 \frac{\circ}{\circ}$ & $7.5 \%$ & $9 \frac{\circ}{0}$ \\
\hline $.00 \mathrm{E}+00$ & $2.88 \mathrm{E}-01$ & $2.18 \mathrm{E}-03$ & $1.15 \mathrm{E}-10$ & $2.70 \mathrm{E}-03$ & $8.12 \mathrm{E}-03$ & $2.16 \mathrm{E}-02$ & $5.06 \mathrm{E}-02$ \\
\hline $0.00 \mathrm{E}+00$ & $2.92 \mathrm{E}-01$ & $2.22 \mathrm{E}-03$ & $2.19 \mathrm{E}-10$ & $2.77 \mathrm{E}-03$ & $8.29 E-03$ & $2.20 \mathrm{E}-02$ & $5.14 \mathrm{E}-02$ \\
\hline $0.00 \mathrm{E}+00$ & $2.96 \mathrm{E}-01$ & $2.26 \mathrm{E}-03$ & $4.02 \mathrm{E}-10$ & $2.85 \mathrm{E}-03$ & $8.49 \mathrm{E}-03$ & $2.24 \mathrm{E}-02$ & $5.23 \mathrm{E}-02$ \\
\hline $0.00 \mathrm{E}+00$ & $3.00 \mathrm{E}-01$ & $2.30 \mathrm{E}-03$ & $7.14 \mathrm{E}-10$ & $2.93 \mathrm{E}-03$ & $8.67 E-03$ & $2.27 \mathrm{E}-02$ & $5.32 \mathrm{E}-02$ \\
\hline $0.00 \mathrm{E}+00$ & $3.04 \mathrm{E}-01$ & $2.34 \mathrm{E}-03$ & $1.22 \mathrm{E}-09$ & $3.01 \mathrm{E}-03$ & $8.86 \mathrm{E}-03$ & $2.31 \mathrm{E}-02$ & $5.40 \mathrm{E}-02$ \\
\hline $0.00 \mathrm{E}+00$ & $3.08 \mathrm{E}-01$ & $2.38 \mathrm{E}-03$ & $2.01 \mathrm{E}-09$ & $3.10 \mathrm{E}-03$ & $9.06 \mathrm{E}-03$ & $2.35 \mathrm{E}-02$ & $5.49 \mathrm{E}-02$ \\
\hline $00 \mathrm{E}+00$ & $3.12 \mathrm{E}-01$ & $2.43 \mathrm{E}-03$ & $3.21 \mathrm{E}-09$ & $3.18 \mathrm{E}-03$ & $26 \mathrm{E}-03$ & $2.39 \mathrm{E}-02$ & $58 \mathrm{E}-02$ \\
\hline $.00 \mathrm{E}+00$ & $3.16 \mathrm{E}-01$ & $2.47 \mathrm{E}-03$ & $4.98 \mathrm{E}-09$ & $3.25 \mathrm{E}-03$ & $47 E-03$ & $2.43 \mathrm{E}-02$ & $67 \mathrm{E}-02$ \\
\hline $0.00 \mathrm{E}+00$ & $3.20 \mathrm{E}-01$ & $2.52 \mathrm{E}-03$ & $7.58 \mathrm{E}-09$ & $3.32 \mathrm{E}-03$ & $9.67 \mathrm{E}-03$ & $2.48 \mathrm{E}-02$ & $5.76 \mathrm{E}-02$ \\
\hline $.00 \mathrm{E}+00$ & $3.24 \mathrm{E}-01$ & $2.56 \mathrm{E}-03$ & $1.15 \mathrm{E}-08$ & $3.40 \mathrm{E}-03$ & $9.88 E-03$ & $2.52 \mathrm{E}-02$ & $5.85 \mathrm{E}-02$ \\
\hline $0.00 \mathrm{E}+00$ & $3.28 \mathrm{E}-01$ & $2.61 \mathrm{E}-03$ & $1.68 \mathrm{E}-08$ & $3.49 \mathrm{E}-03$ & $1.01 \mathrm{E}-02$ & $2.56 \mathrm{E}-02$ & $5.95 \mathrm{E}-02$ \\
\hline $0.00 \mathrm{E}+00$ & $3.32 \mathrm{E}-01$ & $2.66 \mathrm{E}-03$ & $2.39 \mathrm{E}-08$ & $3.58 \mathrm{E}-03$ & $1.03 \mathrm{E}-02$ & $2.60 \mathrm{E}-02$ & $6.04 \mathrm{E}-02$ \\
\hline $0.00 \mathrm{E}+00$ & $3.37 \mathrm{E}-01$ & $2.70 \mathrm{E}-03$ & $3.35 \mathrm{E}-08$ & $3.67 \mathrm{E}-03$ & $1.05 E-02$ & $2.65 \mathrm{E}-02$ & $6.14 \mathrm{E}-02$ \\
\hline $0.00 \mathrm{E}+00$ & $3.41 \mathrm{E}-01$ & $2.75 \mathrm{E}-03$ & $4.59 \mathrm{E}-08$ & $3.76 \mathrm{E}-03$ & $1.08 \mathrm{E}-02$ & $2.69 \mathrm{E}-02$ & $6.23 \mathrm{E}-02$ \\
\hline $0.00 \mathrm{E}+00$ & $3.45 \mathrm{E}-01$ & $2.80 \mathrm{E}-03$ & $6.18 \mathrm{E}-08$ & $3.86 \mathrm{E}-03$ & $1.10 \mathrm{E}-02$ & $2.74 \mathrm{E}-02$ & $6.33 \mathrm{E}-02$ \\
\hline $0.00 \mathrm{E}+00$ & $3.49 \mathrm{E}-01$ & $2.85 \mathrm{E}-03$ & $8.26 \mathrm{E}-08$ & $3.96 \mathrm{E}-03$ & $1.12 \mathrm{E}-02$ & $2.78 \mathrm{E}-02$ & $6.43 \mathrm{E}-02$ \\
\hline $0.00 \mathrm{E}+00$ & $3.54 \mathrm{E}-01$ & $2.90 \mathrm{E}-03$ & $1.09 \mathrm{E}-07$ & $4.06 \mathrm{E}-03$ & $1.15 \mathrm{E}-02$ & $2.83 \mathrm{E}-02$ & $6.53 \mathrm{E}-02$ \\
\hline $0.00 \mathrm{E}+00$ & $3.58 \mathrm{E}-01$ & $2.95 \mathrm{E}-03$ & $1.41 \mathrm{E}-07$ & $4.17 \mathrm{E}-03$ & $1.17 \mathrm{E}-02$ & $2.87 \mathrm{E}-02$ & $6.63 \mathrm{E}-02$ \\
\hline $0.00 \mathrm{E}+00$ & $3.62 \mathrm{E}-01$ & $3.00 \mathrm{E}-03$ & $1.80 \mathrm{E}-07$ & $4.27 \mathrm{E}-03$ & $1.19 \mathrm{E}-02$ & $2.92 \mathrm{E}-02$ & $6.73 \mathrm{E}-02$ \\
\hline $0.00 \mathrm{E}+00$ & $3.67 \mathrm{E}-01$ & $3.05 \mathrm{E}-03$ & $2.27 \mathrm{E}-07$ & $4.37 \mathrm{E}-03$ & $1.22 \mathrm{E}-02$ & $2.96 \mathrm{E}-02$ & $.83 E-02$ \\
\hline $0.00 \mathrm{E}+00$ & 3 & & & & & 2 & 02 \\
\hline $.00 \mathrm{E}+00$ & 3 & 3 & 3 & 3 & 2 & 2 & 02 \\
\hline $0.00 \mathrm{E}+00$ & $3.80 \mathrm{E}-01$ & $3.21 \mathrm{E}-03$ & $4.38 \mathrm{E}-07$ & $4.68 \mathrm{E}-03$ & $1.29 \mathrm{E}-02$ & $3.10 \mathrm{E}-02$ & $15 \mathrm{E}-02$ \\
\hline $0.00 \mathrm{E}+00$ & $3.85 \mathrm{E}-01$ & $3.27 \mathrm{E}-03$ & $5.46 \mathrm{E}-07$ & $4.79 \mathrm{E}-03$ & $1.32 \mathrm{E}-02$ & $3.15 \mathrm{E}-02$ & $7.25 \mathrm{E}-02$ \\
\hline $0.00 \mathrm{E}+00$ & $3.89 \mathrm{E}-01$ & $3.32 \mathrm{E}-03$ & $6.80 \mathrm{E}-07$ & $4.90 \mathrm{E}-03$ & $1.34 \mathrm{E}-02$ & $3.20 \mathrm{E}-02$ & $7.36 \mathrm{E}-02$ \\
\hline $0.00 \mathrm{E}+00$ & $3.94 \mathrm{E}-01$ & $3.38 \mathrm{E}-03$ & $8.38 \mathrm{E}-07$ & $5.02 \mathrm{E}-03$ & $1.37 \mathrm{E}-02$ & $3.25 \mathrm{E}-02$ & $7.47 \mathrm{E}-02$ \\
\hline $0.00 \mathrm{E}+00$ & $3.99 \mathrm{E}-01$ & $3.43 \mathrm{E}-03$ & $1.02 \mathrm{E}-06$ & $5.13 \mathrm{E}-03$ & $1.39 \mathrm{E}-02$ & $3.30 \mathrm{E}-02$ & $7.58 \mathrm{E}-02$ \\
\hline $0.00 \mathrm{E}+00$ & $4.03 \mathrm{E}-01$ & $3.49 \mathrm{E}-03$ & $1.22 \mathrm{E}-06$ & $5.24 \mathrm{E}-03$ & $1.42 \mathrm{E}-02$ & $3.35 \mathrm{E}-02$ & $7.69 \mathrm{E}-02$ \\
\hline $0.00 \mathrm{E}+00$ & $4.08 \mathrm{E}-01$ & $3.55 \mathrm{E}-03$ & $1.45 \mathrm{E}-06$ & $5.35 \mathrm{E}-03$ & $1.45 \mathrm{E}-02$ & $3.40 \mathrm{E}-02$ & $7.80 \mathrm{E}-02$ \\
\hline $0.00 \mathrm{E}+00$ & $4.13 \mathrm{E}-01$ & $3.61 \mathrm{E}-03$ & 1. & 3 & 1.48 & -02 & -02 \\
\hline $0.00 \mathrm{E}+00$ & 4 & 3 & 2 & 3 & 2 & 02 & -02 \\
\hline $0.00 \mathrm{E}+00$ & $4.22 \mathrm{E}-01$ & $3.73 E-03$ & $2.33 \mathrm{E}-06$ & $5.71 \mathrm{E}-03$ & $1.54 \mathrm{E}-02$ & $3.56 \mathrm{E}-02$ & -02 \\
\hline $0.00 \mathrm{E}+00$ & $4.27 \mathrm{E}-01$ & $3.79 \mathrm{E}-03$ & $2.71 \mathrm{E}-06$ & $5.84 \mathrm{E}-03$ & $1.57 \mathrm{E}-02$ & $3.61 \mathrm{E}-02$ & $8.26 \mathrm{E}-02$ \\
\hline $0.00 \mathrm{E}+00$ & $4.32 \mathrm{E}-01$ & $3.85 \mathrm{E}-03$ & $3.22 \mathrm{E}-06$ & $5.97 \mathrm{E}-03$ & $1.60 \mathrm{E}-02$ & $3.67 \mathrm{E}-02$ & $8.38 \mathrm{E}-02$ \\
\hline $0.00 \mathrm{E}+00$ & $4.37 \mathrm{E}-01$ & $3.91 \mathrm{E}-03$ & $3.80 \mathrm{E}-06$ & $6.08 \mathrm{E}-03$ & $1.63 \mathrm{E}-02$ & $3.72 \mathrm{E}-02$ & $8.50 \mathrm{E}-02$ \\
\hline $0.00 \mathrm{E}+00$ & $4.42 \mathrm{E}-01$ & $3.98 \mathrm{E}-03$ & $4.35 \mathrm{E}-06$ & $6.21 \mathrm{E}-03$ & $1.66 \mathrm{E}-02$ & $3.77 \mathrm{E}-02$ & $8.62 \mathrm{E}-02$ \\
\hline $0.00 \mathrm{E}+00$ & $4.46 \mathrm{E}-01$ & $4.04 \mathrm{E}-03$ & $4.90 \mathrm{E}-06$ & $6.35 \mathrm{E}-03$ & $1.70 \mathrm{E}-02$ & $3.83 \mathrm{E}-02$ & $8.74 \mathrm{E}-02$ \\
\hline $0.00 \mathrm{E}+00$ & $4.51 \mathrm{E}-01$ & $4.10 \mathrm{E}-03$ & $5.60 \mathrm{E}-06$ & $6.49 \mathrm{E}-03$ & $1.73 \mathrm{E}-02$ & $3.89 \mathrm{E}-02$ & $8.86 \mathrm{E}-02$ \\
\hline $0.00 \mathrm{E}+00$ & $4.56 \mathrm{E}-01$ & $4.17 \mathrm{E}-03$ & $6.30 \mathrm{E}-06$ & $6.63 \mathrm{E}-03$ & $1.75 \mathrm{E}-02$ & $3.95 \mathrm{E}-02$ & $8.98 \mathrm{E}-02$ \\
\hline $0.00 \mathrm{E}+00$ & $4.61 \mathrm{E}-01$ & $4.24 \mathrm{E}-03$ & $7.07 \mathrm{E}-06$ & $6.78 \mathrm{E}-03$ & $1.78 \mathrm{E}-02$ & $4.01 \mathrm{E}-02$ & $9.11 \mathrm{E}-02$ \\
\hline $0.00 \mathrm{E}+00$ & $4.66 \mathrm{E}-01$ & $4.30 \mathrm{E}-03$ & $7.97 \mathrm{E}-06$ & $6.92 \mathrm{E}-03$ & $1.81 E-02$ & $4.08 \mathrm{E}-02$ & $9.23 \mathrm{E}-02$ \\
\hline $0.00 \mathrm{E}+00$ & $4.71 \mathrm{E}-01$ & $4.37 \mathrm{E}-03$ & $8.76 \mathrm{E}-06$ & $7.08 \mathrm{E}-03$ & $1.84 \mathrm{E}-02$ & $4.14 \mathrm{E}-02$ & $9.36 \mathrm{E}-02$ \\
\hline $0.00 \mathrm{E}+00$ & $4.77 \mathrm{E}-01$ & $4.44 \mathrm{E}-03$ & $9.80 \mathrm{E}-06$ & $7.23 \mathrm{E}-03$ & $1.87 \mathrm{E}-02$ & $4.20 \mathrm{E}-02$ & $9.48 \mathrm{E}-02$ \\
\hline $0.00 \mathrm{E}+00$ & $4.82 \mathrm{E}-01$ & $4.51 \mathrm{E}-03$ & $1.08 \mathrm{E}-05$ & $7.38 \mathrm{E}-03$ & $1.90 \mathrm{E}-02$ & $4.26 \mathrm{E}-02$ & $9.60 \mathrm{E}-02$ \\
\hline $0.00 \mathrm{E}+00$ & $4.87 \mathrm{E}-01$ & $4.58 \mathrm{E}-03$ & $1.21 \mathrm{E}-05$ & $7.54 \mathrm{E}-03$ & $1.93 \mathrm{E}-02$ & $4.33 \mathrm{E}-02$ & $9.72 \mathrm{E}-02$ \\
\hline $.00 \mathrm{E}+00$ & $4.92 \mathrm{E}-01$ & $4.65 E-03$ & $1.33 \mathrm{E}-05$ & $7.70 \mathrm{E}-03$ & $1.96 \mathrm{E}-02$ & $4.40 \mathrm{E}-02$ & $9.84 \mathrm{E}-02$ \\
\hline
\end{tabular}


RESRAD-OFFSITE, Version 2.5

$\mathrm{T}^{1 / 2}$ Limit $=180$ days

Title : RESRAD-OFFSITE Drinking Water, Plant, Milk, and Meat Pathways for Offsite Reside File : PBA-1_TC99-DOE-5.ROF

Summary of dose at graphical times, reptition 2 (continued)

Time

Years

$2.83 \mathrm{E}+02$

$2.84 \mathrm{E}+02$

$2.84 \mathrm{E}+02$

$2.85 \mathrm{E}+02$

$2.85 \mathrm{E}+02$

$2.86 \mathrm{E}+02$

$2.86 \mathrm{E}+02$

$2.87 \mathrm{E}+02$

$2.87 \mathrm{E}+02$

$2.88 \mathrm{E}+02$

$2.88 \mathrm{E}+02$

$2.89 \mathrm{E}+02$

$2.89 \mathrm{E}+02$

$2.90 \mathrm{E}+02$

$2.90 \mathrm{E}+02$

2. $91 \mathrm{E}+02$

$2.91 \mathrm{E}+02$

$2.92 \mathrm{E}+02$

$2.92 \mathrm{E}+02$

2. $93 \mathrm{E}+02$

$2.93 \mathrm{E}+02$

$2.94 \mathrm{E}+02$

$2.94 \mathrm{E}+02$

$2.95 \mathrm{E}+02$

$2.95 \mathrm{E}+02$

$2.96 \mathrm{E}+02$

$2.96 \mathrm{E}+02$

$2.97 \mathrm{E}+02$

$2.97 \mathrm{E}+02$

$2.98 \mathrm{E}+02$

$2.98 \mathrm{E}+02$

2. $99 \mathrm{E}+02$

$2.99 \mathrm{E}+02$

$3.00 \mathrm{E}+02$

$3.00 \mathrm{E}+02$

$3.01 \mathrm{E}+02$

$3.01 \mathrm{E}+02$

$3.02 \mathrm{E}+02$

$3.02 \mathrm{E}+02$

$3.03 \mathrm{E}+02$

3. $04 \mathrm{E}+02$

$3.04 \mathrm{E}+02$

$3.05 \mathrm{E}+02$

$3.05 \mathrm{E}+02$

$3.06 \mathrm{E}+02$

$3.06 \mathrm{E}+02$
Dose statistics at graphical times, mrem/yr

\begin{tabular}{|c|c|c|c|c|c|c|c|}
\hline inimum & aximum & Mean & ledian & $90 \%$ & $5 \%$ & $97.5 \%$ & $\%$ \\
\hline+00 & $4.97 E-01$ & $4.72 E-03$ & $1.46 \mathrm{E}-05$ & $7.87 E-03$ & $1.99 \mathrm{E}-02$ & $4.47 E-02$ & $96 \mathrm{E}-02$ \\
\hline+00 & $2 E-01$ & $0 E-03$ & $8 E-05$ & 3 & 02 & 02 & 01 \\
\hline-00 & $8 \mathrm{E}-01$ & $37 E-03$ & $E-05$ & $2 E-03$ & 02 & -02 & -01 \\
\hline $\mathrm{z}+00$ & $E-01$ & $4 \mathrm{E}-03$ & $3 E-05$ & 3 & 02 & 02 & -01 \\
\hline+00 & -01 & 3 & & 3 & 2 & 02 & $05 E-01$ \\
\hline $\mathrm{DE}+00$ & -01 & -03 & 05 & 03 & 02 & -02 & 01 \\
\hline $.00 \mathrm{E}+00$ & -01 & 年 & -05 & כ & 02 & -02 & -01 \\
\hline $.00 E+00$ & $5.34 E-01$ & . & $2.57 E-05$ & $9.15 \mathrm{E}-03$ & 02 & -02 & $E-01$ \\
\hline 00 & 01 & 03 & 05 & 03 & 02 & -02 & -01 \\
\hline $.00 \mathrm{E}+00$ & -01 & 3 & 5 & 03 & 02 & -02 & -01 \\
\hline+00 & -01 & $E-03$ & 5 & 3 & & -02 & $E-01$ \\
\hline$E+00$ & & & & & & & -01 \\
\hline $.00 \mathrm{E}+00$ & $5.62 \mathrm{E}-01$ & $5.05 \mathrm{E}-03$ & $9 E-05$ & $1.00 \mathrm{E}-02$ & $-0<$ & $E-02$ & -0 \\
\hline$E+00$ & -01 & $3 E-03$ & -05 & $1.02 \mathrm{E}-02$ & 02 & -02 & $.16 \mathrm{E}-01$ \\
\hline $.00 \mathrm{E}+00$ & 01 & 03 & 05 & 02 & 02 & 02 & -01 \\
\hline $.00 \mathrm{E}+00$ & $5.79 \mathrm{E}-01$ & -03 & -05 & 02 & 02 & -02 & -01 \\
\hline $.00 \mathrm{E}+00$ & $E-01$ & -03 & -05 & $8 E-02$ & $56 \mathrm{E}-02$ & -02 & $.20 \mathrm{E}-01$ \\
\hline $\mathrm{DE}+00$ & $0 E-01$ & $7 E-03$ & $5 E-05$ & -02 & -02 & -02 & $E-01$ \\
\hline $.00 \mathrm{E}+00$ & $5.96 \mathrm{E}-01$ & $6 E-03$ & -05 & -02 & & 02 & -01 \\
\hline $.00 E+00$ & -01 & $E-03$ & -05 & 02 & -02 & -02 & $.25 E-01$ \\
\hline $\mathrm{E}+00$ & -01 & -03 & -05 & -02 & -02 & -02 & $E-01$ \\
\hline $.00 \mathrm{E}+00$ & $6.13 \mathrm{E}-01$ & $3 E-03$ & 05 & 02 & 02 & -02 & -01 \\
\hline $.00 \mathrm{E}+00$ & $6.19 \mathrm{E}-01$ & $6.52 \mathrm{E}-03$ & $6.52 \mathrm{E}-05$ & $1.19 \mathrm{E}-02$ & $2.12 \pm-02$ & $.25 E-02$ & $.29 \mathrm{E}-01$ \\
\hline $.00 \mathrm{E}+00$ & $6.24 \mathrm{E}-01$ & $6.61 \mathrm{E}-03$ & $9 E-05$ & $1.21 \mathrm{E}-02$ & $83 E-02$ & $E-02$ & $E-01$ \\
\hline $\mathrm{E}+00$ & $D E-01$ & $1 E-03$ & -05 & 02 & 02 & -02 & -01 \\
\hline$E+00$ & 01 & $E-03$ & 05 & 02 & & 02 & -01 \\
\hline $\mathrm{E}+00$ & $E-01$ & $E-03$ & -05 & 1. $28 \mathrm{E}-02$ & & -02 & $.35 \mathrm{E}-01$ \\
\hline $.00 \mathrm{E}+00$ & $6.48 \mathrm{E}-01$ & $6.99 E-03$ & $8.55 E-05$ & $1.30 \mathrm{E}-02$ & $3.00 \mathrm{E}-02$ & $71 \mathrm{E}-02$ & $.36 \mathrm{E}-01$ \\
\hline $.00 \mathrm{E}+00$ & $6.54 \mathrm{E}-01$ & $7.09 \mathrm{E}-03$ & $9.02 E-05$ & 1. $32 \mathrm{E}-02$ & . & $0 E-02$ & $.38 E-01$ \\
\hline $.00 \mathrm{E}+00$ & $6.60 \mathrm{E}-01$ & 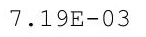 & $2+40$ & 1.078 & & 等 & $.40 \mathrm{E}-01$ \\
\hline-00 & 01 & $3 E-03$ & $E-04$ & 02 & 2 & 02 & -01 \\
\hline$\exists+00$ & $E-01$ & $E-03$ & -04 & $9 \mathrm{E}-02$ & 2 & 02 & -01 \\
\hline $.00 \mathrm{E}+00$ & $6.78 \mathrm{E}-01$ & $7.48 E-03$ & $1 E-04$ & $1.41 \mathrm{E}-02$ & 2 & $0 E-02$ & $.44 \mathrm{E}-01$ \\
\hline $.00 \mathrm{E}+00$ & $6.84 \mathrm{E}-01$ & $7.59 \mathrm{E}-03$ & $1.15 E-04$ & $1.43 \mathrm{E}-02$ & $3.27 \mathrm{E}-02$ & $.30 \mathrm{E}-02$ & $.46 E-01$ \\
\hline . Uूस & $6.90 \mathrm{E}-01$ & $7.69 \mathrm{E}-03$ & $1.21 \mathrm{E}-04$ & $1.40 \mathrm{~L}-02$ & & & $.48 \mathrm{E}-01$ \\
\hline 者 & & & & & & & \\
\hline مिم+ & & & & & & & 01 \\
\hline 0 & 1 & 3 & 4 & 2 & 2 & 2 & 01 \\
\hline & & & & & 02 & 02 & 01 \\
\hline $.00 \mathrm{E}+00$ & 1 & 3 & -04 & 2 & 2 & 02 & $.56 \mathrm{E}-01$ \\
\hline $\mathrm{E}+00$ & & & 04 & 2 & & & -01 \\
\hline $0 E+00$ & & & $.65 E-04$ & $1.63 E-02$ & & & $.59 \mathrm{E}-$ \\
\hline $.00 \mathrm{E}+00$ & & $8.55 E-03$ & 4 & \pm & 2 & 2 & . \\
\hline . OLT & & & & & 2 & 2 & \\
\hline+00 & 7.5 & 3 & 04 & 02 & 02 & 02 & 1.6 \\
\hline $.00 E+00$ & $7.58 \mathrm{E}-01$ & $8.89 E-03$ & 1.93E-04 & $1.73 E-02$ & $3.84 \mathrm{E}-02$ & $8.44 \mathrm{E}-02$ & $1.66 \mathrm{E}-01$ \\
\hline
\end{tabular}


RESRAD-OFFSITE, Version 2.5

$\mathrm{T}^{1 / 2}$ Limit $=180$ days

Title : RESRAD-OFFSITE Drinking Water, Plant, Milk, and Meat Pathways for Offsite Reside File : PBA-1_TC99-DOE-5.ROF

Summary of dose at graphical times, reptition 2 (continued)

Time

Years

$3.07 \mathrm{E}+02$

$3.07 \mathrm{E}+02$

$3.08 \mathrm{E}+02$

$3.08 \mathrm{E}+02$

$3.09 \mathrm{E}+02$

$3.09 \mathrm{E}+02$

$3.10 \mathrm{E}+02$

$3.10 \mathrm{E}+02$

$3.11 \mathrm{E}+02$

$3.11 E+02$

$3.12 \mathrm{E}+02$

$3.12 \mathrm{E}+02$

$3.13 \mathrm{E}+02$

$3.13 \mathrm{E}+02$

$3.14 \mathrm{E}+02$

$3.14 \mathrm{E}+02$

$3.15 \mathrm{E}+02$

$3.15 \mathrm{E}+02$

$3.16 \mathrm{E}+02$

$3.16 \mathrm{E}+02$

$3.17 \mathrm{E}+02$

$3.17 \mathrm{E}+02$

$3.18 \mathrm{E}+02$

$3.18 \mathrm{E}+02$

$3.19 \mathrm{E}+02$

$3.19 \mathrm{E}+02$

$3.20 \mathrm{E}+02$

$3.20 \mathrm{E}+02$

$3.21 \mathrm{E}+02$

$3.21 \mathrm{E}+02$

$3.22 \mathrm{E}+02$

$3.22 \mathrm{E}+02$

$3.23 \mathrm{E}+02$

$3.24 \mathrm{E}+02$

$3.24 \mathrm{E}+02$

$3.25 \mathrm{E}+02$

$3.25 \mathrm{E}+02$

$3.26 \mathrm{E}+02$

$3.26 \mathrm{E}+02$

$3.27 \mathrm{E}+02$

$3.27 \mathrm{E}+02$

3. $28 \mathrm{E}+02$

$3.28 \mathrm{E}+02$

$3.29 \mathrm{E}+02$

$3.29 \mathrm{E}+02$

$3.30 \mathrm{E}+02$
Dose statistics at graphical times, mrem/yr

\begin{tabular}{|c|c|c|c|c|c|c|c|}
\hline inimum & Maximum & Mean & Median & $90 \%$ & $95 \frac{\circ}{\circ}$ & $7.5 \%$ & $9 \frac{\circ}{0}$ \\
\hline $.00 \mathrm{E}+00$ & $7.65 \mathrm{E}-01$ & $9.00 \mathrm{E}-03$ & $2.00 \mathrm{E}-04$ & $1.76 \mathrm{E}-02$ & $3.89 \mathrm{E}-02$ & $8.55 \mathrm{E}-02$ & $1.68 \mathrm{E}-01$ \\
\hline $0.00 \mathrm{E}+00$ & $7.71 \mathrm{E}-01$ & $9.12 \mathrm{E}-03$ & $2.07 \mathrm{E}-04$ & $1.79 \mathrm{E}-02$ & $3.95 \mathrm{E}-02$ & $8.65 \mathrm{E}-02$ & $1.69 \mathrm{E}-01$ \\
\hline $0.00 \mathrm{E}+00$ & $7.78 \mathrm{E}-01$ & $9.24 \mathrm{E}-03$ & $2.13 \mathrm{E}-04$ & $1.82 \mathrm{E}-02$ & $4.00 \mathrm{E}-02$ & $8.76 \mathrm{E}-02$ & $1.71 \mathrm{E}-01$ \\
\hline $0.00 \mathrm{E}+00$ & $7.84 \mathrm{E}-01$ & $9.35 E-03$ & $2.20 \mathrm{E}-04$ & $1.85 \mathrm{E}-02$ & $4.05 \mathrm{E}-02$ & $8.86 \mathrm{E}-02$ & $1.73 \mathrm{E}-01$ \\
\hline $0.00 \mathrm{E}+00$ & $7.90 \mathrm{E}-01$ & $9.47 \mathrm{E}-03$ & $2.29 \mathrm{E}-04$ & $1.88 \mathrm{E}-02$ & $4.11 \mathrm{E}$ & $8.96 \mathrm{E}-02$ & $.75 \mathrm{E}-01$ \\
\hline $0.00 \mathrm{E}+00$ & $7.97 \mathrm{E}-01$ & $9.59 \mathrm{E}-03$ & $2.38 \mathrm{E}-04$ & $1.90 \mathrm{E}-02$ & $.16 \mathrm{E}-02$ & $9.07 \mathrm{E}-02$ & $1.76 \mathrm{E}-01$ \\
\hline $00 \mathrm{E}+00$ & $8.03 \mathrm{E}-01$ & $9.71 \mathrm{E}-03$ & $2.44 \mathrm{E}-04$ & $1.94 \mathrm{E}-02$ & $22 \mathrm{E}-02$ & $9.17 \mathrm{E}-02$ & $1.78 \mathrm{E}-01$ \\
\hline $.00 \mathrm{E}+00$ & $8.10 \mathrm{E}-01$ & $9.84 \mathrm{E}-03$ & $2.51 \mathrm{E}-04$ & $1.97 \mathrm{E}-02$ & $.28 \mathrm{E}-02$ & $9.28 \mathrm{E}-02$ & $1.80 \mathrm{E}-01$ \\
\hline $.00 \mathrm{E}+00$ & $8.16 \mathrm{E}-01$ & $9.96 \mathrm{E}-03$ & $2.60 \mathrm{E}-04$ & $2.00 \mathrm{E}-02$ & $4.33 \mathrm{E}-02$ & $9.38 \mathrm{E}-02$ & $1.82 \mathrm{E}-01$ \\
\hline $.00 \mathrm{E}+00$ & $8.23 E-01$ & $1.01 \mathrm{E}-02$ & $2.70 \mathrm{E}-04$ & $2.03 \mathrm{E}-02$ & $4.39 \mathrm{E}-02$ & $9.49 \mathrm{E}-02$ & $1.84 \mathrm{E}-01$ \\
\hline $0.00 \mathrm{E}+00$ & $8.30 \mathrm{E}-01$ & $1.02 \mathrm{E}-02$ & $2.78 \mathrm{E}-04$ & $2.06 \mathrm{E}-02$ & $4.45 \mathrm{E}-02$ & $9.60 \mathrm{E}-02$ & $1.85 \mathrm{E}-01$ \\
\hline $0.00 \mathrm{E}+00$ & $8.36 \mathrm{E}-01$ & $1.03 \mathrm{E}-02$ & $2.89 \mathrm{E}-04$ & $2.08 \mathrm{E}-02$ & $4.52 \mathrm{E}-02$ & $9.71 \mathrm{E}-02$ & $1.87 \mathrm{E}-01$ \\
\hline $0.00 \mathrm{E}+00$ & $8.43 \mathrm{E}-01$ & $1.05 \mathrm{E}-02$ & $2.98 \mathrm{E}-04$ & $2.11 \mathrm{E}-02$ & $4.57 \mathrm{E}-02$ & $9.82 \mathrm{E}-02$ & $1.89 \mathrm{E}-01$ \\
\hline $0.00 \mathrm{E}+00$ & $8.49 \mathrm{E}-01$ & $1.06 \mathrm{E}-02$ & $3.08 \mathrm{E}-04$ & $2.14 \mathrm{E}-02$ & $4.63 \mathrm{E}-02$ & $9.93 E-02$ & $1.91 \mathrm{E}-01$ \\
\hline $0.00 \mathrm{E}+00$ & $8.56 \mathrm{E}-01$ & $1.07 \mathrm{E}-02$ & $3.18 \mathrm{E}-04$ & $2.17 \mathrm{E}-02$ & $4.69 \mathrm{E}-02$ & $1.00 \mathrm{E}-01$ & $1.93 \mathrm{E}-01$ \\
\hline $0.00 \mathrm{E}+00$ & $8.63 \mathrm{E}-01$ & $1.09 \mathrm{E}-02$ & $3.28 \mathrm{E}-04$ & $2.20 \mathrm{E}-02$ & $4.76 \mathrm{E}-02$ & $1.02 \mathrm{E}-01$ & $1.95 \mathrm{E}-01$ \\
\hline $0.00 \mathrm{E}+00$ & $8.69 \mathrm{E}-01$ & $1.10 \mathrm{E}-02$ & $3.39 \mathrm{E}-04$ & $2.23 \mathrm{E}-02$ & $4.82 \mathrm{E}-02$ & $1.03 \mathrm{E}-01$ & $1.97 \mathrm{E}-01$ \\
\hline $0.00 \mathrm{E}+00$ & $8.76 \mathrm{E}-01$ & $1.11 \mathrm{E}-02$ & $3.48 \mathrm{E}-04$ & $2.26 \mathrm{E}-02$ & $4.88 \mathrm{E}-02$ & $1.04 \mathrm{E}-01$ & $1.99 \mathrm{E}-01$ \\
\hline $0.00 \mathrm{E}+00$ & $8.83 E-01$ & $1.13 \mathrm{E}-02$ & $3.58 \mathrm{E}-04$ & $2.30 \mathrm{E}-02$ & $4.94 \mathrm{E}-02$ & $1.05 \mathrm{E}-01$ & $2.00 \mathrm{E}-01$ \\
\hline $0.00 \mathrm{E}+00$ & $8.89 \mathrm{E}-01$ & $1.14 \mathrm{E}-02$ & $3.68 \mathrm{E}-04$ & $2.33 \mathrm{E}-02$ & $5.00 \mathrm{E}-02$ & $1.06 \mathrm{E}-01$ & $02 E-01$ \\
\hline $0.00 \mathrm{E}+00$ & 8 & 1 & & & & 1 & \\
\hline $.00 \mathrm{E}+00$ & 9 & 1 & 3 & 2 & 2 & 1 & 01 \\
\hline $0.00 \mathrm{E}+00$ & $9.10 \mathrm{E}-01$ & $1.18 \mathrm{E}-02$ & $4.02 \mathrm{E}-04$ & $2.44 \mathrm{E}-02$ & $5.20 \mathrm{E}-02$ & 1.1 & -01 \\
\hline $0.00 \mathrm{E}+00$ & $9.17 \mathrm{E}-01$ & $1.20 \mathrm{E}-02$ & $4.14 \mathrm{E}-04$ & $2.48 \mathrm{E}-02$ & $5.26 \mathrm{E}-02$ & $1.11 \mathrm{E}-01$ & $2.10 \mathrm{E}-01$ \\
\hline $0.00 \mathrm{E}+00$ & $9.23 \mathrm{E}-01$ & $1.21 \mathrm{E}-02$ & $4.27 \mathrm{E}-04$ & $2.52 \mathrm{E}-02$ & $5.33 \mathrm{E}-02$ & $1.12 \mathrm{E}-01$ & $2.12 \mathrm{E}-01$ \\
\hline $0.00 \mathrm{E}+00$ & $9.30 \mathrm{E}-01$ & $1.22 \mathrm{E}-02$ & $4.40 \mathrm{E}-04$ & $2.55 \mathrm{E}-02$ & $5.39 \mathrm{E}-02$ & $1.13 \mathrm{E}-01$ & $2.14 \mathrm{E}-01$ \\
\hline $0.00 \mathrm{E}+00$ & $9.37 \mathrm{E}-01$ & $1.24 \mathrm{E}-02$ & $4.54 \mathrm{E}-04$ & $2.59 \mathrm{E}-02$ & $5.46 \mathrm{E}-02$ & $1.15 \mathrm{E}-01$ & $2.16 \mathrm{E}-01$ \\
\hline $0.00 \mathrm{E}+00$ & $9.44 \mathrm{E}-01$ & $1.25 \mathrm{E}-02$ & $4.68 \mathrm{E}-04$ & $2.62 \mathrm{E}-02$ & $5.53 \mathrm{E}-02$ & $1.16 \mathrm{E}-01$ & $2.18 \mathrm{E}-01$ \\
\hline $0.00 \mathrm{E}+00$ & $9.51 \mathrm{E}-01$ & $1.27 \mathrm{E}-02$ & $4.80 \mathrm{E}-04$ & $2.66 \mathrm{E}-02$ & $5.60 \mathrm{E}-02$ & $1.17 \mathrm{E}-01$ & $2.20 \mathrm{E}-01$ \\
\hline $0.00 \mathrm{E}+00$ & $9.58 \mathrm{E}-01$ & 1.28 & 4. & 2.70 & 5.68 & $1.1 \varepsilon$ & $2.22 \mathrm{E}-01$ \\
\hline $0.00 \mathrm{E}+00$ & 9. & 1. & 4 & 2 & 2 & 01 & -01 \\
\hline $0.00 \mathrm{E}+00$ & $9.72 \mathrm{E}-01$ & $1.31 \mathrm{E}-02$ & $5.20 \mathrm{E}-04$ & $2.77 \mathrm{E}-02$ & $5.84 \mathrm{E}-02$ & $1.21 \mathrm{E}-01$ & $2.26 \mathrm{E}-01$ \\
\hline $0.00 \mathrm{E}+00$ & $9.79 \mathrm{E}-01$ & $1.33 \mathrm{E}-02$ & $5.38 \mathrm{E}-04$ & $2.80 \mathrm{E}-02$ & $5.91 \mathrm{E}-02$ & $1.22 \mathrm{E}-01$ & $2.28 \mathrm{E}-01$ \\
\hline $0.00 \mathrm{E}+00$ & $9.86 \mathrm{E}-01$ & $1.34 \mathrm{E}-02$ & $5.53 \mathrm{E}-04$ & $2.83 \mathrm{E}-02$ & $5.99 \mathrm{E}-02$ & $1.24 \mathrm{E}-01$ & $2.30 \mathrm{E}-01$ \\
\hline $0.00 \mathrm{E}+00$ & $9.93 \mathrm{E}-01$ & $1.36 \mathrm{E}-02$ & $5.67 \mathrm{E}-04$ & $2.87 \mathrm{E}-02$ & $6.06 \mathrm{E}-02$ & $1.25 \mathrm{E}-01$ & $2.32 \mathrm{E}-01$ \\
\hline $0.00 \mathrm{E}+00$ & $1.00 \mathrm{E}+00$ & $1.37 \mathrm{E}-02$ & $5.80 \mathrm{E}-04$ & $2.91 \mathrm{E}-02$ & $6.13 \mathrm{E}-02$ & $1.27 \mathrm{E}-01$ & $2.35 \mathrm{E}-01$ \\
\hline $0.00 \mathrm{E}+00$ & $1.01 \mathrm{E}+00$ & $1.39 \mathrm{E}-02$ & $5.95 \mathrm{E}-04$ & $2.95 \mathrm{E}-02$ & $6.20 \mathrm{E}-02$ & $1.28 \mathrm{E}-01$ & $2.37 \mathrm{E}-01$ \\
\hline $0.00 \mathrm{E}+00$ & $1.01 \mathrm{E}+00$ & $1.40 \mathrm{E}-02$ & $6.11 \mathrm{E}-04$ & $2.99 \mathrm{E}-02$ & $6.27 \mathrm{E}-02$ & $1.29 \mathrm{E}-01$ & $2.39 \mathrm{E}-01$ \\
\hline $0.00 \mathrm{E}+00$ & $1.02 \mathrm{E}+00$ & $1.42 \mathrm{E}-02$ & $6.28 \mathrm{E}-04$ & $3.04 \mathrm{E}-02$ & $6.34 \mathrm{E}-02$ & $1.31 \mathrm{E}-01$ & $2.41 \mathrm{E}-01$ \\
\hline $0.00 \mathrm{E}+00$ & $1.03 \mathrm{E}+00$ & $1.44 \mathrm{E}-02$ & $6.43 \mathrm{E}-04$ & $3.07 \mathrm{E}-02$ & $6.41 \mathrm{E}-02$ & 1. $32 \mathrm{E}-01$ & $2.43 \mathrm{E}-01$ \\
\hline $0.00 \mathrm{E}+00$ & $1.03 E+00$ & $1.45 \mathrm{E}-02$ & $6.57 \mathrm{E}-04$ & $3.11 \mathrm{E}-02$ & $6.47 \mathrm{E}-02$ & $1.33 \mathrm{E}-01$ & $2.45 \mathrm{E}-01$ \\
\hline $0.00 \mathrm{E}+00$ & $1.04 \mathrm{E}+00$ & $1.47 \mathrm{E}-02$ & $6.71 \mathrm{E}-04$ & $3.15 \mathrm{E}-02$ & $6.54 \mathrm{E}-02$ & $1.35 \mathrm{E}-01$ & $2.47 \mathrm{E}-01$ \\
\hline $0.00 \mathrm{E}+00$ & $1.05 \mathrm{E}+00$ & $1.49 \mathrm{E}-02$ & $6.86 \mathrm{E}-04$ & $3.19 \mathrm{E}-02$ & $6.61 \mathrm{E}-02$ & $1.36 \mathrm{E}-01$ & $2.49 \mathrm{E}-01$ \\
\hline $0.00 \mathrm{E}+00$ & $1.06 \mathrm{E}+00$ & $1.50 \mathrm{E}-02$ & $7.04 \mathrm{E}-04$ & $3.22 \mathrm{E}-02$ & $6.68 \mathrm{E}-02$ & $1.38 \mathrm{E}-01$ & $2.51 \mathrm{E}-01$ \\
\hline $0.00 \mathrm{E}+00$ & $1.06 \mathrm{E}+00$ & $1.52 \mathrm{E}-02$ & $7.22 \mathrm{E}-04$ & $3.26 \mathrm{E}-02$ & $6.75 \mathrm{E}-02$ & $1.39 \mathrm{E}-01$ & $2.54 \mathrm{E}-01$ \\
\hline $00 \mathrm{E}+00$ & $1.07 \mathrm{E}+00$ & $1.54 \mathrm{E}-02$ & $7.38 \mathrm{E}-04$ & 3.30 & 6.82 & 1.4 & 2.56 \\
\hline
\end{tabular}


RESRAD-OFFSITE, Version 2.5

$\mathrm{T}^{1 / 2}$ Limit $=180$ days

Title : RESRAD-OFFSITE Drinking Water, Plant, Milk, and Meat Pathways for Offsite Reside File : PBA-1_TC99-DOE-5.ROF

Summary of dose at graphical times, reptition 2 (continued)

Time

Years

$3.30 \mathrm{E}+02$

$3.31 \mathrm{E}+02$

$3.31 \mathrm{E}+02$

$3.32 \mathrm{E}+02$

3. $32 \mathrm{E}+02$

$3.33 \mathrm{E}+02$

$3.33 \mathrm{E}+02$

$3.34 \mathrm{E}+02$

$3.34 \mathrm{E}+02$

$3.35 \mathrm{E}+02$

$3.35 \mathrm{E}+02$

$3.36 \mathrm{E}+02$

$3.36 \mathrm{E}+02$

$3.37 \mathrm{E}+02$

$3.37 \mathrm{E}+02$

$3.38 \mathrm{E}+02$

$3.38 \mathrm{E}+02$

$3.39 \mathrm{E}+02$

$3.39 \mathrm{E}+02$

3. $40 \mathrm{E}+02$

$3.40 \mathrm{E}+02$

$3.41 \mathrm{E}+02$

$3.41 \mathrm{E}+02$

$3.42 \mathrm{E}+02$

$3.42 \mathrm{E}+02$

$3.43 \mathrm{E}+02$

$3.44 \mathrm{E}+02$

$3.44 \mathrm{E}+02$

$3.45 \mathrm{E}+02$

$3.45 \mathrm{E}+02$

3. $46 \mathrm{E}+02$

$3.46 \mathrm{E}+02$

$3.47 \mathrm{E}+02$

$3.47 \mathrm{E}+02$

$3.48 \mathrm{E}+02$

$3.48 \mathrm{E}+02$

3. $49 \mathrm{E}+02$

3. $49 \mathrm{E}+02$

$3.50 \mathrm{E}+02$

$3.50 \mathrm{E}+02$

3. $51 \mathrm{E}+02$

3. $51 \mathrm{E}+02$

3. $52 \mathrm{E}+02$

3. $52 \mathrm{E}+02$

$3.53 \mathrm{E}+02$

$3.53 \mathrm{E}+02$
Dose statistics at graphical times, mrem/yr

\begin{tabular}{|c|c|c|c|c|c|c|c|}
\hline m & num & ean & eq & & & & \\
\hline 0 & 0 & 2 & 4 & 2 & 02 & 1 & -01 \\
\hline$E+00$ & $08 E+00$ & $7 E-02$ & $7.73 E-04$ & $9 E-02$ & $97 E-02$ & $1.44 \mathrm{E}-01$ & $50 E-01$ \\
\hline $0 \cap F+00$ & $09 E+00$ & $59 F-02$ & $91 \mathrm{~F}-04$ & $44 F-02$ & $04 E-02$ & $.45 E-01$ & $52 F-01$ \\
\hline $\mathrm{E}+00$ & 1. $10 \mathrm{E}+00$ & $60 \mathrm{E}-02$ & 04 & & & & 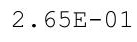 \\
\hline & & 02 & 04 & 2 & 2 & 1 & $E-01$ \\
\hline $.00 E+00$ & 00 & -02 & 04 & 02 & 2 & 1 & -01 \\
\hline $\mathrm{E}+00$ & 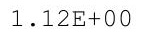 & -02 & & 02 & 02 & & $71 \mathrm{E}-01$ \\
\hline+00 & $E+00$ & $E-02$ & $E-04$ & $5 E-02$ & $2 E-02$ & -01 & $E-01$ \\
\hline $00 \mathrm{E}+00$ & $14 \mathrm{E}+00$ & $69 E-02$ & $0 E-04$ & -02 & $0 E-02$ & 01 & $76 E-01$ \\
\hline $0 \mathrm{E}+00$ & $14 F+00$ & $1 \mathrm{E}-02$ & $9 E-04$ & & & 1 & 01 \\
\hline & 1 & & & & & & -01 \\
\hline+00 & $E+00$ & $5 E-02$ & $E-04$ & -02 & -02 & 1 & $E-01$ \\
\hline $.00 E+00$ & $1.16 \mathrm{E}+00$ & $1.77 \mathrm{E}-02$ & $0 E-04$ & $39 E-02$ & $7.82 \mathrm{E}-02$ & & $85 E-01$ \\
\hline+00 & +0 & $E-02$ & $E-03$ & & 02 & & $E-01$ \\
\hline & $8 \mathrm{~B}+1$ & -02 & & 2 & & & -01 \\
\hline 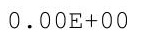 & $5=0$ & $2 E-02$ & & 2 & & 1 & -01 \\
\hline 0 & 1 & 2 & 3 & 2 & 2 & 1 & -01 \\
\hline$E+00$ & $12 \cap F+00$ & $6 E-02$ & 03 & & 02 & 1 & $E-01$ \\
\hline $.00 \mathrm{E}+00$ & $1.21 \mathrm{E}+00$ & $1.88 \mathrm{E}-02$ & $.12 \mathrm{E}-03$ & $4.17 \mathrm{E}-02$ & $30 \mathrm{E}-02$ & $.69 \mathrm{E}-01$ & $99 \mathrm{E}-01$ \\
\hline $.00 E+00$ & $1.22 \mathrm{E}+00$ & $1.90 \mathrm{E}-02$ & $1.14 \mathrm{E}-03$ & $22 E-02$ & $7 E-02$ & $.71 E-01$ & $E-01$ \\
\hline & & & & & & & \\
\hline & & & & & & 1 & -01 \\
\hline 0 & 1.24E+ & & & & & 1 & 01 \\
\hline$F+00$ & $1.25 \mathrm{E}+0$ & $8 \mathrm{E}-$ & 3 & 2 & 2 & 1 & -01 \\
\hline $\mathrm{F}+08 \mathrm{~g}-5$ & $1.25 \mathrm{E}+00$ & $2.00 E-02$ & $1.26 \mathrm{E}-03$ & $9 E-02$ & $9 \mathrm{E}-02$ & $.78 \mathrm{E}-01$ & $3 E-01$ \\
\hline$\cap \cap F+\cap 0$ & $1.26 \mathrm{E}+00$ & $2.02 E-02$ & $1.28 E-03$ & $4.55 E-02$ & $37 E-02$ & $80 F-01$ & $15 E-01$ \\
\hline ro & $1.27 \mathrm{E}+00$ & & & & & & 01 \\
\hline & & & & & & & 01 \\
\hline & & & & & & & \\
\hline $.00 \mathrm{E}+00$ & $1.29 \mathrm{E}+00$ & $2.10 \mathrm{E}-02$ & $1.39 E-03$ & $4.77 E-02$ & $2 E-02$ & $1.86 \mathrm{E}-01$ & $26 \mathrm{E}-01$ \\
\hline e & $1.30 \mathrm{E}+00$ & $2.12 \mathrm{E}-02$ & $1.42 \mathrm{E}-03$ & $4.82 E-02$ & $.31 \mathrm{E}-02$ & te & $.29 \mathrm{E}-01$ \\
\hline & 1.30E+ & & & & & & 11 \\
\hline & 1. $31 \mathrm{E}+$ & & & & & & 01 \\
\hline & $1.32 \mathrm{E}+00$ & & $E-03$ & $E-02$ & 2 & & -01 \\
\hline$E+00$ & $1.33 E+00$ & $1 E-02$ & 03 & 02 & 02 & 1 & -01 \\
\hline 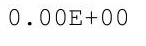 & म. & $2.23 E-02$ & $1.58 \mathrm{E}-03$ & $12 E-02$ & $31 E-02$ & $1.95 \mathrm{E}-01$ & $4 \mathrm{E}-01$ \\
\hline 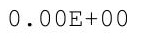 & te & $.25 E-02$ & & & & & s. \\
\hline (6) & 1. & & & & & & ( \\
\hline & $1.36 \mathrm{E}+0$ & $.29 \mathrm{E}$ & & 2 & 1 & 1 & 01 \\
\hline + & $1.36 \mathrm{E}+00$ & 2 & 03 & 02 & 1 & 1 & -01 \\
\hline $0 \mathrm{E}+00$ & $1.37 \mathrm{E}+00$ & $2.34 \mathrm{E}-02$ & $1.73 E-03$ & $5 E-02$ & $3 E-01$ & 01 & $E-01$ \\
\hline+00 & $1.38 \mathrm{E}+$ & $36 \mathrm{E}-02$ & $E-03$ & $E-02$ & 1 & 01 & -01 \\
\hline & 土. & & & & & & $3.03 E-U \perp$ \\
\hline 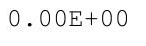 & 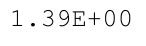 & $.41 E-02$ & & 02 & & & - 00 \\
\hline $0 E+00$ & 土. & $E-02$ & & & & & + \\
\hline+00 & $E+00$ & $E-02$ & $E-03$ & $E-02$ & $E-01$ & -01 & -01 \\
\hline
\end{tabular}


RESRAD-OFFSITE, Version 2.5

Title : RESRAD-OFFSITE Drinking Water, Plant, Milk, and Meat Pathways for Offsite Reside File : PBA-1_TC99-DOE-5.ROF

Summary of dose at graphical times, reptition 2 (continued)

Time

Years

$3.54 \mathrm{E}+02$

$3.54 \mathrm{E}+02$

$3.55 \mathrm{E}+02$

$3.55 \mathrm{E}+02$

$3.56 \mathrm{E}+02$

$3.56 \mathrm{E}+02$

$3.57 \mathrm{E}+02$

$3.57 \mathrm{E}+02$

$3.58 \mathrm{E}+02$

$3.58 \mathrm{E}+02$

$3.59 \mathrm{E}+02$

$3.59 \mathrm{E}+02$

$3.60 \mathrm{E}+02$

$3.60 \mathrm{E}+02$

$3.61 \mathrm{E}+02$

3. $61 \mathrm{E}+02$

$3.62 \mathrm{E}+02$

3. $62 \mathrm{E}+02$

$3.63 \mathrm{E}+02$

3. $64 \mathrm{E}+02$

$3.64 \mathrm{E}+02$

$3.65 \mathrm{E}+02$

$3.65 \mathrm{E}+02$

$3.66 \mathrm{E}+02$

$3.66 \mathrm{E}+02$

$3.67 \mathrm{E}+02$

$3.67 \mathrm{E}+02$

$3.68 \mathrm{E}+02$

$3.68 \mathrm{E}+02$

$3.69 \mathrm{E}+02$

$3.69 \mathrm{E}+02$

$3.70 \mathrm{E}+02$

$3.70 \mathrm{E}+02$

3. $71 \mathrm{E}+02$

$3.71 \mathrm{E}+02$

$3.72 \mathrm{E}+02$

$3.72 \mathrm{E}+02$

$3.73 E+02$

$3.73 E+02$

$3.74 \mathrm{E}+02$

$3.74 \mathrm{E}+02$

$3.75 \mathrm{E}+02$

$3.75 \mathrm{E}+02$

$3.76 \mathrm{E}+02$

$3.76 \mathrm{E}+02$

$3.77 \mathrm{E}+02$
Dose statistics at graphical times, mrem/yr

\begin{tabular}{|c|c|c|c|c|c|c|c|}
\hline m & num & ean & ed & & & & \\
\hline $\mathrm{E}+00$ & 0 & 02 & 3 & 2 & 01 & 1 & -01 \\
\hline$E+00$ & $42 E+00$ & $0 E-02$ & $1.96 \mathrm{E}-03$ & $4 \mathrm{E}-02$ & $1.11 \mathrm{E}-01$ & $14 \mathrm{E}-01$ & $30 E-01$ \\
\hline $00 F+00$ & $43 E+00$ & $52 F-02$ & $00 F-03$ & $1 F-02$ & $12 \mathrm{~F}-01$ & $16 \mathrm{E}-01$ & $E-01-2$ \\
\hline $0 E+00$ & $.44 \mathrm{E}+00$ & $5 E-02$ & & & & & 01 \\
\hline & & 02 & 03 & 2 & & & -01 \\
\hline $.00 E+00$ & 00 & -02 & 03 & 02 & 1 & & -01 \\
\hline $\mathrm{E}+00$ & -00 & -02 & & 02 & 01 & & $6 \mathrm{E}-01$ \\
\hline+00 & $E+00$ & $E-02$ & $7 E-03$ & $6 E-02$ & $7 \mathrm{E}-01$ & -01 & $E-01$ \\
\hline $\mathrm{E}+00$ & $48 E+00$ & $67 E-02$ & $1 E-03$ & -02 & 1 & -01 & $E-01$ \\
\hline $0 \mathrm{E}+00$ & $49 F+00$ & $69 \mathrm{E}-02$ & $4 E-03$ & & 1 & & 01 \\
\hline $.00 \mathrm{E}+00$ & & & & & & & -01 \\
\hline$E+00$ & $1.50 \mathrm{E}+00$ & $4 E-02$ & $2.32 \mathrm{E}-03$ & $2 E-02$ & $1.22 \mathrm{E}-01$ & 01 & $E-01$ \\
\hline $.00 E+00$ & $1.51 \mathrm{E}+00$ & $2.77 E-02$ & $2.36 E-03$ & & $1.23 \mathrm{E}-01$ & & $15 E-01$ \\
\hline+00 & $E+00$ & $9 E-02$ & $E-03$ & 02 & & & $E-01$ \\
\hline & $F_{1}$ & $82 E-02$ & & 2 & & & -01 \\
\hline 0 & $1.53 \mathrm{E}+0$ & $.84 \mathrm{E}-02$ & 3 & 2 & 1 & & $E-01$ \\
\hline 0 & 0 & 2 & 3 & 2 & 1 & 1 & 01 \\
\hline$E+00$ & $155 \mathrm{~F}+00$ & $9 E-02$ & $2.56 \mathrm{E}-03$ & & $129 \mathrm{~F}$ & 1 & $E-01$ \\
\hline $.00 \mathrm{E}+00$ & $1.55 \mathrm{E}+00$ & $2.92 \mathrm{E}-02$ & $2.60 \mathrm{E}-03$ & $7.07 \mathrm{E}-02$ & 1. $30 \mathrm{E}-01$ & $2.45 \mathrm{E}-01$ & $36 E-01$ \\
\hline $.00 E+00$ & $1.56 \mathrm{E}+00$ & $.94 \mathrm{E}-02$ & $2.64 \mathrm{E}-03$ & $4 \mathrm{E}-02$ & $31 E-01$ & $2.47 \mathrm{E}-01$ & $39 E-01$ \\
\hline & & & & & & & \\
\hline & & & & & & & -01 \\
\hline $.00 E+00$ & $1.58 \mathrm{E}+00$ & & & & & & 01 \\
\hline $5+$ & $9 \mathrm{E}+\mathrm{C}$ & 2 & 3 & 2 & 1 & 1 & -01 \\
\hline$F+0$ & $1.60 \mathrm{E}+00$ & $.08 E-02$ & $2.85 E-03$ & $3 E-02$ & $.38 \mathrm{E}-01$ & $7 E-01$ & $7 E-01$ \\
\hline مח & $1.61 \mathrm{E}+00$ & $.10 \mathrm{E}-02$ & $2.89 E-03$ & $0 E-02$ & $1.39 \mathrm{E}-01$ & $9 E-01$ & $60 F-01$ \\
\hline $\mathrm{G}+00$ & $.61 E+00$ & $.13 \mathrm{E}-02$ & $3 E-03$ & $3 E-02$ & & & $E-01$ \\
\hline & & & & & & & -01 \\
\hline & & & & & & & -01 \\
\hline $.00 \mathrm{E}+00$ & $1.64 \mathrm{E}+00$ & $3.21 \mathrm{E}-02$ & $3.08 \mathrm{E}-03$ & $7.92 \mathrm{E}-02$ & $1.44 \mathrm{E}-01$ & $2.67 \mathrm{E}-01$ & $75 E-01$ \\
\hline e & te & $.24 \mathrm{E}-02$ & $.12 \mathrm{E}-03$ & $8.01 \mathrm{E}-02$ & $1.45 \mathrm{E}-01$ & 2.0001 & $78 \mathrm{E}-01$ \\
\hline & $1.65 \mathrm{E}+$ & & & & & & 11 \\
\hline & & & & & & & 01 \\
\hline & $1.67 \mathrm{E}+00$ & & $E-03$ & 02 & & & -01 \\
\hline $\mathrm{E}+00$ & $1.67 \mathrm{E}+00$ & $5 E-02$ & 03 & & 1 & 1 & $E-01$ \\
\hline 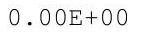 & म. & $3.38 \mathrm{E}-02$ & $3.37 \mathrm{E}-03$ & $8.42 \mathrm{E}-02$ & $1.3 \angle E-U \perp$ & $2.78 \mathrm{E}-01$ & $97 E-01$ \\
\hline . & 土. & $3.41 E-02$ & & & 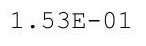 & & . \\
\hline (6) & t. & $4 \mathrm{E}-02$ & & 2 & - & & $04 \mathrm{E}-0$ \\
\hline 0 & 1. $71 \mathrm{E}+0$ & 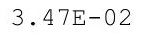 & & 2 & (6) & 1 & 0 \\
\hline 0 & $E+00$ & 2 & 03 & 02 & 1 & 1 & -01 \\
\hline $0 E+00$ & $1.72 \mathrm{E}+00$ & $3 E-02$ & $E-03$ & $5 E-02$ & $9 E-01$ & 01 & $E-01$ \\
\hline+00 & $1.73 \mathrm{E}+$ & $E-02$ & $E-03$ & $E-02$ & 1 . & 01 & -01 \\
\hline & 土. & & & & & & $.2 S E-01$ \\
\hline 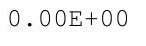 & 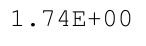 & 02 & & & & & $\perp$ \\
\hline $\mathrm{E}+00$ & (1) & & & & & & 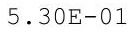 \\
\hline 00 & $E+00$ & $E-02$ & $E-03$ & $E-02$ & $E-01$ & -01 & -01 \\
\hline
\end{tabular}


RESRAD-OFFSITE, Version 2.5

Title : RESRAD-OFFSITE Drinking Water, Plant, Milk, and Meat Pathways for Offsite Reside File : PBA-1_TC99-DOE-5.ROF

Summary of dose at graphical times, reptition 2 (continued)

Time

Years

$3.77 \mathrm{E}+02$

$3.78 \mathrm{E}+02$

$3.78 \mathrm{E}+02$

$3.79 \mathrm{E}+02$

$3.79 \mathrm{E}+02$

$3.80 \mathrm{E}+02$

$3.80 \mathrm{E}+02$

$3.81 \mathrm{E}+02$

$3.81 \mathrm{E}+02$

$3.82 \mathrm{E}+02$

$3.82 \mathrm{E}+02$

$3.83 \mathrm{E}+02$

$3.83 E+02$

$3.84 \mathrm{E}+02$

$3.85 \mathrm{E}+02$

$3.85 \mathrm{E}+02$

$3.86 \mathrm{E}+02$

3. $86 \mathrm{E}+02$

$3.87 \mathrm{E}+02$

$3.87 \mathrm{E}+02$

$3.88 \mathrm{E}+02$

$3.88 \mathrm{E}+02$

3. $89 \mathrm{E}+02$

3. $89 \mathrm{E}+02$

3. $90 \mathrm{E}+02$

$3.90 \mathrm{E}+02$

3. $91 \mathrm{E}+02$

3. $91 \mathrm{E}+02$

3. $92 \mathrm{E}+02$

3. $92 \mathrm{E}+02$

3. $93 \mathrm{E}+02$

3. $93 \mathrm{E}+02$

$3.94 \mathrm{E}+02$

$3.94 \mathrm{E}+02$

$3.95 \mathrm{E}+02$

$3.95 \mathrm{E}+02$

3. $96 \mathrm{E}+02$

$3.96 \mathrm{E}+02$

3. $97 \mathrm{E}+02$

3. $97 \mathrm{E}+02$

$3.98 \mathrm{E}+02$

3. $98 \mathrm{E}+02$

$3.99 \mathrm{E}+02$

3. $99 \mathrm{E}+02$

$4.00 \mathrm{E}+02$

$4.00 \mathrm{E}+02$
Dose statistics at graphical times, mrem/yr

\begin{tabular}{|c|c|c|c|c|c|c|c|}
\hline inimum & aximum & Mean & ledian & $90 \%$ & $5 \%$ & $97.5 \%$ & \\
\hline 00 & $77 E+00$ & $3.71 E-02$ & $3.95 E-03$ & $0 E-02$ & $1.68 \mathrm{E}-01$ & $0 E-01$ & $E-0$ \\
\hline+00 & $E+00$ & 02 & $E-03$ & 2 & 1 & 1 & 01 \\
\hline-00 & $\mathrm{E}+00$ & $E-02$ & $E-03$ & $6 E-02$ & 01 & 01 & -01 \\
\hline $\mathrm{z}+00$ & $E+00$ & 02 & & 2 & & 01 & -01 \\
\hline+00 & 00 & 2 & 3 & & 1 & 01 & $51 E-01$ \\
\hline+00 & $\mathrm{E}+00$ & $E-02$ & -03 & 02 & $E-01$ & 01 & 01 \\
\hline$E+00$ & $1.81 \mathrm{E}+00$ & $9 E-02$ & -03 & 02 & 1 & 01 & -01 \\
\hline $.00 E+00$ & $1.82 \mathrm{E}+00$ & • & $4.35 E-03$ & $9.85 E-02$ & 01 & -01 & $E-01$ \\
\hline-00 & 00 & 02 & 03 & $3 E-02$ & 01 & -01 & -01 \\
\hline $.00 \mathrm{E}+00$ & $33 E+00$ & -02 & -03 & -01 & $80 E-01$ & -01 & $E-01$ \\
\hline+00 & +00 & $\mathrm{E}-02$ & -03 & 1 & 1 & -01 & $2 E-01$ \\
\hline$E+00$ & $5 E+00$ & 02 & & & & & -01 \\
\hline $.00 \mathrm{E}+00$ & $1.86 \mathrm{E}+00$ & $8 E-02$ & $E-03$ & $1.03 \mathrm{E}-01$ & $1.83 \mathrm{E}-01$ & $E-01$ & $E-01$ \\
\hline$E+00$ & +00 & -02 & -03 & 01 & 01 & -01 & $82 E-01$ \\
\hline$E+00$ & -00 & 02 & 03 & 01 & 01 & 01 & -01 \\
\hline $.00 \mathrm{E}+00$ & $1.88 \mathrm{E}+00$ & -02 & -03 & 01 & 01 & -01 & -01 \\
\hline $.00 \mathrm{E}+00$ & $1.89 \mathrm{E}+00$ & $1 E-02$ & $4 E-03$ & $7 E-01$ & $1.88 \mathrm{E}-01$ & $E-01$ & $93 E-01$ \\
\hline $0 E+00$ & $1.89 \mathrm{E}+00$ & $4 E-02$ & $0 E-03$ & $8 E-01$ & $89 E-01$ & -01 & $E-01$ \\
\hline $.00 \mathrm{E}+00$ & $1.90 \mathrm{E}+00$ & $8 \mathrm{E}-02$ & $E-03$ & -01 & & -01 & -01 \\
\hline $\mathrm{E}+00$ & +00 & -02 & -03 & 01 & -01 & -01 & $E-01$ \\
\hline$E+00$ & $+{ }^{\prime}$ & -02 & -03 & & & -01 & -01 \\
\hline $.00 \mathrm{E}+00$ & $1.92 \mathrm{E}+00$ & $8 E-02$ & 03 & & 01 & 1 & -01 \\
\hline $.00 \mathrm{E}+00$ & $1.93 \mathrm{E}+00$ & $4.41 E-02$ & $5.35 \mathrm{E}-03$ & $1.12 \mathrm{E}-01$ & $1.95 \mathrm{E}-01$ & $55 E-01$ & $14 \mathrm{E}-01$ \\
\hline $.00 \mathrm{E}+00$ & $1.94 \mathrm{E}+00$ & $5 E-02$ & $1 E-03$ & $1.13 \mathrm{E}-01$ & $1.97 \mathrm{E}-01$ & $7 E-01$ & $18 \mathrm{E}-01$ \\
\hline+00 & $4 \mathrm{E}+00$ & $8 E-02$ & 03 & & & -01 & $E-01$ \\
\hline$E+00$ & 00 & -02 & 03 & 01 & 01 & & -01 \\
\hline $.29 \mathrm{E}-25$ & $1.90 \mathrm{E}+00$ & $E-02$ & -03 & & & -01 & $29 \mathrm{E}-01$ \\
\hline $.77 E-23$ & $1.97 \mathrm{E}+00$ & $4.58 E-02$ & $5.71 E-03$ & $1.17 \mathrm{E}-01$ & $2.02 \mathrm{E}-01$ & $68 \mathrm{E}-01$ & $32 E-01$ \\
\hline 21 & $1.97 \mathrm{E}+$ & 2 & 3 & 1 & . & 1 & -01 \\
\hline $.51 E-20$ & 土. & $5 E-02$ & L & $1.19 \mathrm{E}-01$ & 年 & 1 & $39 E-01$ \\
\hline-18 & $1.99 \mathrm{E}+00$ & $9 E-02$ & $7 E-03$ & $0 E-01$ & $07 E-01$ & $E-01$ & $E-01$ \\
\hline$E-17$ & $\mathrm{E}+00$ & $2 E-02$ & $5-03$ & & & 01 & -01 \\
\hline$E-16$ & $2.00 \mathrm{E}+00$ & $E-02$ & -03 & 01 & 1 & 01 & $50 E-01$ \\
\hline $.60 \mathrm{E}-15$ & $2.01 \mathrm{E}+00$ & $4.79 E-02$ & $6.20 \mathrm{E}-03$ & 1. $23 \mathrm{E}-01$ & $2.12 \mathrm{E}-01$ & $83 E-01$ & $.54 \mathrm{E}-01$ \\
\hline $45-10$ & Z. OZLTU & $4.83 E-02$ & $5.28 E-03$ & & & कOL-U & $.58 E-01$ \\
\hline & 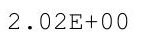 & & & & & & \\
\hline $875-12$ & 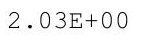 & & & & & & 01 \\
\hline $.59 E-13$ & & & & & & 01 & 01 \\
\hline & & & & & & -01 & 01 \\
\hline $69 \mathrm{E}-12$ & $2.05 \mathrm{E}+00$ & -02 & 03 & 1 & 1 & & $7 E-01$ \\
\hline$E-11$ & 2.0 & 2 & & 1 & & & -01 \\
\hline 1 & $2.07 \mathrm{E}+00$ & 2 & & 1 & & 01 & $25-2+$ \\
\hline 1. $250-11$ & 2. & 2 & s & 1.020 & 2.210 & 01 & 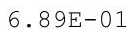 \\
\hline 17F-10 & . & $5.16 \mathrm{E}-02$ & & (5) & $29 \mathrm{E}-01$ & $+2+$ & . \\
\hline $1 E-10$ & $2.09 \mathrm{E}+00$ & $E-02$ & -03 & 1 & 2.3 & 01 & $96 E-01$ \\
\hline $.14 \mathrm{E}-10$ & $2.10 \mathrm{E}+00$ & $23 E-02$ & $.19 E-03$ & 1. $35 \mathrm{E}-01$ & $2.33 E-01$ & $4.17 \mathrm{E}-01$ & $7.00 \mathrm{E}-01$ \\
\hline
\end{tabular}


RESRAD-OFFSITE, Version 2.5

$\mathrm{T}^{1 / 2}$ Limit $=180$ days

Title : RESRAD-OFFSITE Drinking Water, Plant, Milk, and Meat Pathways for Offsite Reside File : PBA-1_TC99-DOE-5.ROF

Summary of dose at graphical times, reptition 2 (continued)

Time

Years

$4.01 \mathrm{E}+02$

$4.01 \mathrm{E}+02$

$4.02 \mathrm{E}+02$

$4.02 \mathrm{E}+02$

$4.03 E+02$

$4.03 \mathrm{E}+02$

$4.04 \mathrm{E}+02$

$4.05 \mathrm{E}+02$

$4.05 \mathrm{E}+02$

$4.06 \mathrm{E}+02$

$4.06 \mathrm{E}+02$

$4.07 \mathrm{E}+02$

$4.07 \mathrm{E}+02$

$4.08 \mathrm{E}+02$

$4.08 \mathrm{E}+02$

$4.09 \mathrm{E}+02$

$4.09 \mathrm{E}+02$

4. $10 \mathrm{E}+02$

$4.10 \mathrm{E}+02$

$4.11 \mathrm{E}+02$

$4.11 \mathrm{E}+02$

$4.12 \mathrm{E}+02$

$4.12 \mathrm{E}+02$

$4.13 \mathrm{E}+02$

$4.13 \mathrm{E}+02$

$4.14 \mathrm{E}+02$

$4.14 \mathrm{E}+02$

$4.15 \mathrm{E}+02$

$4.15 \mathrm{E}+02$

$4.16 \mathrm{E}+02$

$4.16 \mathrm{E}+02$

$4.17 \mathrm{E}+02$

$4.17 \mathrm{E}+02$

$4.18 \mathrm{E}+02$

$4.18 \mathrm{E}+02$

4. $19 \mathrm{E}+02$

$4.19 \mathrm{E}+02$

$4.20 \mathrm{E}+02$

$4.20 \mathrm{E}+02$

$4.21 E+02$

$4.21 \mathrm{E}+02$

4. $22 \mathrm{E}+02$

$4.22 \mathrm{E}+02$

$4.23 \mathrm{E}+02$

$4.23 E+02$

$4.24 \mathrm{E}+02$
Dose statistics at graphical times, mrem/yr

\begin{tabular}{|c|c|c|c|c|c|c|c|}
\hline m & um & Mean & ledian & & & & \\
\hline 10 & +00 & -02 & 03 & -01 & $2.35 E-01$ & -01 & -0 \\
\hline $.51 E-09$ & +00 & $1 E-02$ & 03 & 01 & 01 & -01 & $08 E-01$ \\
\hline $.46 \mathrm{E}-09$ & $.12 \mathrm{E}+00$ & $35 E-02$ & $7.47 \mathrm{E}-03$ & 1. $38 \mathrm{E}-01$ & $2.38 \mathrm{E}-01$ & -01 & -01 \\
\hline$F-09$ & $13 F+00$ & $38 \mathrm{~F}-02$ & $56 F-03$ & $.39 \mathrm{E}-01$ & $40 \mathrm{E}-01$ & -01 & $-0-1+3-1+3$ \\
\hline 09 & -00 & & 3 & 1 & 01 & 1 & $-01+2 \cdot-x$ \\
\hline 09 & & & & & & & -01 \\
\hline $30 E-08$ & & & & & & & -01 \\
\hline $.87 E-08$ & +00 & -02 & 03 & 01 & -01 & -01 & -01 \\
\hline $62 E-08$ & $16 \mathrm{E}+00$ & $58 E-02$ & -03 & $45 E-01$ & 01 & -01 & $E-01$ \\
\hline $62 E-08$ & $.17 \mathrm{E}+00$ & $62 E-02$ & $6 E-03$ & 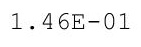 & & 01 & 01 \\
\hline$E-08$ & $18 F+00$ & & & 1 & 1 & 1 & -01 \\
\hline $57 \mathrm{E}-08$ & 00 & $0 \mathrm{E}-02$ & $7 E-03$ & 1 & 01 & -01 & -01 \\
\hline $.66 \mathrm{E}-08$ & $2.19 \mathrm{E}+00$ & $.74 E-02$ & $8.47 E-03$ & $1.49 \mathrm{E}-01$ & & -01 & -01 \\
\hline $.13 E-07$ & $2.20 \mathrm{E}+00$ & $.78 \mathrm{E}-02$ & $8.56 \mathrm{E}-03$ & $1.50 \mathrm{E}-01$ & $2.59 \mathrm{E}-01$ & $.57 \mathrm{E}-01$ & $57 E-01$ \\
\hline-07 & $0 \mathrm{E}+00$ & $2 E-02$ & $E-03$ & & & -01 & -01 \\
\hline 7 & م & 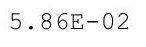 & & - & & 01 & 01 \\
\hline $2 \mathrm{E}-07$ & & & & & & 1 & 01 \\
\hline $89 \mathrm{E}-07$ & $22 F+00$ & ת ת & & & & 1 & 01 \\
\hline $57 \mathrm{E}-07$ & $23 \mathrm{~F}+00$ & $98 E-02$ & $6 E-03$ & $5 E-01$ & $8 E-01$ & $E-01$ & $79 E-01$ \\
\hline $36 E-07$ & $.24 \mathrm{E}+00$ & $6.02 \mathrm{E}-02$ & $.17 \mathrm{E}-03$ & $1.56 \mathrm{E}-01$ & $.70 \mathrm{E}-01$ & $E-01$ & $83 \mathrm{E}-01$ \\
\hline 07 & $25 E+00$ & $6 \mathrm{E}-02$ & 03 & 1 & & -01 & -01 \\
\hline 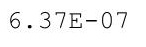 & & & & & & & 01 \\
\hline & & & & & & & -01 \\
\hline $.02 E-07$ & $27 E+00$ & $18 \mathrm{E}-$ & 3 & 1 & & 1 & -01 \\
\hline 6 & $.27 E+00$ & $22 \mathrm{E}-$ & 3 & 1 & 1 & $E-01$ & 01 \\
\hline $24 \mathrm{E}-06$ & $.28 E+00$ & $5.27 \mathrm{E}-02$ & $.82 E-03$ & 1. $63 \mathrm{E}-01$ & $31 E-01$ & $90 \mathrm{E}-01$ & $10 E-01$ \\
\hline$E-06$ & $2.29 \mathrm{E}+00$ & $5.31 \mathrm{E}-02$ & $4 E-03$ & & & $3 E-01$ & $E-01$ \\
\hline & & & & & & $E-01$ & -01 \\
\hline 6 & & & & 01 & & & 01 \\
\hline $21 E-06$ & $2.31 E+00$ & $6.44 \mathrm{E}-02$ & $.03 E-02$ & 1. $68 \mathrm{E}-01$ & $9 E-01$ & $3 E-01$ & $E-01$ \\
\hline $52 E-06$ & $2.31 \mathrm{E}+00$ & $.48 E-02$ & $.04 E-02$ & 1. $69 \mathrm{E}-01$ & $2.91 \mathrm{E}-01$ & $6 \mathrm{E}-01$ & $32 \mathrm{E}-0$ \\
\hline 6 & 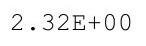 & $0.0 \angle D-$ U & & 工象 & & 1 & 01 \\
\hline 6 & & $56 \mathrm{E}-0$ & & & & & 01 \\
\hline & & & & & & -01 & 01 \\
\hline & & $6.65 \mathrm{E}-02$ & $1.09 E-02$ & & & -01 & \\
\hline & & & & & 01 & -01 & 01 \\
\hline $.08 E-06$ & $2.35 \mathrm{E}+00$ & $.74 E-02$ & 02 & $.76 E-01$ & 1 & 01 & -01 \\
\hline $63 E-06$ & 2.00 - 100 & & & & & & . \\
\hline & $2.37 \mathrm{E}+$ & 2 & & 1 & & 1 & 01 \\
\hline & & & & & & & 01 \\
\hline $5 E-06$ & & & & & & -01 & \\
\hline-06 & $2.39 E+00$ & $.96 \mathrm{E}-02$ & $1.18 \mathrm{E}-02$ & $1.83 \mathrm{E}-01$ & $09 E-01$ & $36 \mathrm{E}-01$ & -01 \\
\hline & 0 & & & & & & 01 \\
\hline & $2.405 T$ T & $7.05 E-02$ & & 1 & & $43 \mathrm{E}-01$ & . 1 \\
\hline 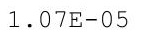 & $2.41 E+00$ & 25-02 & $1.22 \mathrm{E}-02$ & $1.88 \mathrm{E}-01$ & & $.46 E-01$ & . \\
\hline 5 & $E+00$ & -02 & $23 E-02$ & $.89 E-01$ & $E-01$ & -01 & $E-01$ \\
\hline
\end{tabular}


RESRAD-OFFSITE, Version 2.5

Title : RESRAD-OFFSITE Drinking Water, Plant, Milk, and Meat Pathways for Offsite Reside File : PBA-1_TC99-DOE-5.ROF

Summary of dose at graphical times, reptition 2 (continued)

Time

Years

$4.25 \mathrm{E}+02$

$4.25 \mathrm{E}+02$

$4.26 \mathrm{E}+02$

$4.26 \mathrm{E}+02$

$4.27 \mathrm{E}+02$

$4.27 \mathrm{E}+02$

$4.28 \mathrm{E}+02$

$4.28 \mathrm{E}+02$

$4.29 \mathrm{E}+02$

$4.29 \mathrm{E}+02$

$4.30 \mathrm{E}+02$

$4.30 \mathrm{E}+02$

$4.31 \mathrm{E}+02$

$4.31 \mathrm{E}+02$

4. $32 \mathrm{E}+02$

4. $32 \mathrm{E}+02$

$4.33 E+02$

$4.33 \mathrm{E}+02$

$4.34 \mathrm{E}+02$

4. $34 \mathrm{E}+02$

$4.35 \mathrm{E}+02$

4. $35 \mathrm{E}+02$

$4.36 \mathrm{E}+02$

$4.36 \mathrm{E}+02$

$4.37 \mathrm{E}+02$

$4.37 \mathrm{E}+02$

$4.38 \mathrm{E}+02$

$4.38 \mathrm{E}+02$

$4.39 \mathrm{E}+02$

$4.39 \mathrm{E}+02$

$4.40 \mathrm{E}+02$

$4.40 \mathrm{E}+02$

$4.41 \mathrm{E}+02$

4. $41 \mathrm{E}+02$

$4.42 \mathrm{E}+02$

$4.42 \mathrm{E}+02$

$4.43 \mathrm{E}+02$

$4.43 \mathrm{E}+02$

$4.44 \mathrm{E}+02$

$4.45 \mathrm{E}+02$

4. $45 \mathrm{E}+02$

4. $46 \mathrm{E}+02$

$4.46 \mathrm{E}+02$

$4.47 \mathrm{E}+02$

$4.47 \mathrm{E}+02$

$4.48 \mathrm{E}+02$
Dose statistics at graphical times, mrem/yr

\begin{tabular}{|c|c|c|c|c|c|c|c|}
\hline inimum & aximum & Mean & ledian & $0 \%$ & $5 \%$ & $97.5 \%$ & \\
\hline 5 & +00 & $E-02$ & -02 & 01 & 1 & 1 & $9.04 \mathrm{E}-01$ \\
\hline 05 & $E+00$ & 02 & $E-02$ & $1.92 \mathrm{E}$ & 1 & 01 & . \\
\hline$E-05$ & $\mathrm{E}+00$ & $E-02$ & $E-02$ & $3 E-01$ & 01 & 01 & -01 \\
\hline $3 E-05$ & $E+00$ & $E-02$ & 2 & & 1 & 01 & $18 \mathrm{E}-01$ \\
\hline-05 & +00 & -02 & -02 & 01 & 01 & -01 & $23 E-01$ \\
\hline $.82 E-05$ & $2.45 \mathrm{E}+00$ & $1 E-02$ & -02 & 01 & 01 & -01 & -01 \\
\hline a & +00 & L & -02 & 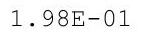 & 01 & -01 & -01 \\
\hline $.08 E-05$ & $2.46 \mathrm{E}+00$ & $.51 E-02$ & -02 & & 01 & -01 & $36 E-01$ \\
\hline 05 & +00 & 02 & 02 & 01 & 01 & -01 & -01 \\
\hline $.36 E-05$ & $2.48 \mathrm{E}+00$ & -02 & $7 E-02$ & $E-01$ & 01 & -01 & $E-01$ \\
\hline$E-05$ & $E+00$ & $E-02$ & -02 & 1 & 01 & -01 & $E-01$ \\
\hline-05 & +00 & -02 & -02 & & 1 & -01 & $E-01$ \\
\hline $.83 \mathrm{E}-05$ & $2.50 \mathrm{E}+00$ & $7.74 \mathrm{E}-02$ & 1. $41 E-02$ & $2.08 \mathrm{E}-01$ & $3.38 \mathrm{E}-01$ & $E-01$ & -0 \\
\hline 05 & -00 & $9 E-02$ & -02 & $9 \mathrm{E}-01$ & 01 & -01 & -01 \\
\hline 05 & -00 & 02 & 02 & 01 & 01 & 01 & -01 \\
\hline $.35 E-05$ & $2.52 \mathrm{E}+00$ & -02 & -02 & 01 & 01 & -01 & -01 \\
\hline $.53 E-05$ & $2.52 \mathrm{E}+00$ & $3 E-02$ & $7 E-02$ & $2.13 \mathrm{E}-01$ & $46 \mathrm{E}-01$ & $E-01$ & $78 \mathrm{E}-01$ \\
\hline-05 & $53 E+00$ & $8 E-02$ & $9 \mathrm{E}-02$ & $5 E-01$ & $E-01$ & $\mathrm{E}-01$ & $E-01$ \\
\hline 05 & $\mathrm{E}+00$ & -02 & -02 & $\perp$ & 1 & -01 & -0 \\
\hline $2 E-05$ & $2.54 \mathrm{E}+00$ & -02 & -02 & 1 & 01 & -01 & -01 \\
\hline $.33 E-05$ & $5+00$ & -02 & -02 & $E-01$ & & -01 & -01 \\
\hline $.54 \mathrm{E}-05$ & $2.55 \mathrm{E}+00$ & $E-02$ & $1.55 \mathrm{E}-02$ & 01 & 1 & -01 & $00 \mathrm{E}+00$ \\
\hline $725-05$ & $2.56 \mathrm{E}+00$ & $8.22 E-02$ & $1.56 \mathrm{E}-02$ & $2.22 \mathrm{E}-01$ & $58 E-01$ & $E-01$ & $01 E+00$ \\
\hline $.88 \mathrm{E}-05$ & $2.56 \mathrm{E}+00$ & $.27 \mathrm{E}-02$ & $1.58 \mathrm{E}-02$ & $23 E-01$ & $59 \mathrm{E}-01$ & $5 E-01$ & $.01 E+00$ \\
\hline 05 & $.57 \mathrm{E}+00$ & $32 E-02$ & $9 E-02$ & $24 \mathrm{E}-01$ & -01 & $E-01$ & $02 \mathrm{E}+00$ \\
\hline 05 & $E+00$ & -02 & 02 & 01 & & & +00 \\
\hline $.36 \mathrm{E}-05$ & $2.58 \mathrm{E}+00$ & $8.42 E-02$ & 1. $63 \mathrm{E}-02$ & $2.27 \mathrm{E}-01$ & 1 & $E-01$ & $02 E+00$ \\
\hline $.53 E-05$ & $2.59 \mathrm{E}+00$ & $47 E-02$ & $1.64 \mathrm{E}-02$ & $2.28 E-01$ & $67 E-01$ & $38-01$ & $.03 E+00$ \\
\hline 05 & $2.60 \mathrm{E}+00$ & 2 & $66 \mathrm{E}-02$ & $2.29 \mathrm{E}-01$ & . & $2 \pm-01$ & $.03 E+00$ \\
\hline 5 & - & $57 E-02$ & $68 E-02$ & 1 & - & - & $2-5$ \\
\hline 5 & $2.61 \mathrm{E}+00$ & $2 E-02$ & $9 E-02$ & $2 E-01$ & & 1 & $04 \mathrm{E}+00$ \\
\hline$E-05$ & $2.61 E+00$ & $7 E-02$ & $1 E-02$ & $3 E-01$ & $E-01$ & -01 & $5 \mathrm{E}+00$ \\
\hline & & & & & & 01 & \\
\hline $.59 E-05$ & $2.63 E+00$ & $8.77 \mathrm{E}-02$ & $1.74 \mathrm{E}-02$ & $2.36 \mathrm{E}-01$ & $79 E-01$ & $7 E-01$ & $.06 \mathrm{E}+00$ \\
\hline $.10 \mathrm{x}-\mathrm{U}$ & Z.ОЛЕТ О & $8.82 E-02$ & & $2.37 E-01$ & & OL-U1 & . V OLTU \\
\hline & 2.075100 & & & & & & \\
\hline & & & & & & 1 & 00 \\
\hline 5 & $2.65 \mathrm{E}+\mathrm{C}$ & 2 & & & & & \\
\hline & & & & & & & \\
\hline$\cdot 14 \mathrm{E}^{-}$ & $2.66 \mathrm{E}+00$ & $8 E-02$ & $1.84 \mathrm{E}-02$ & 1 & 1 & & $09 E+00$ \\
\hline כ & $4+00$ & & & 1 & & & $9 \mathrm{E}+0 \mathrm{C}$ \\
\hline & $2.6 / E+00$ & 02 & 02 & 1 & 1 & 01 & $.10 \mathrm{E}+00$ \\
\hline $.31 E-05$ & $3 E+00$ & -4D- 02 & +001 & 2. & 1 & 01 & $\cdot 1 U E+U 0$ \\
\hline $0 . J \perp E-U U$ & 急 & & $+\infty$ & 1 & $+\infty$ & 01 & I t \\
\hline 5 & $2.69 \mathrm{E}+00$ & $E-02$ & 02 & 01 & 01 & 01 & $.11 E+00$ \\
\hline $90 E-05$ & $2.69 E+00$ & $.40 \mathrm{E}-02$ & 1. $95 E-02$ & $2.53 E-01$ & $4.06 \mathrm{E}-01$ & $6.94 \mathrm{E}-01$ & L. $11 E+00$ \\
\hline
\end{tabular}


RESRAD-OFFSITE, Version 2.5

Title : RESRAD-OFFSITE Drinking Water, Plant, Milk, and Meat Pathways for Offsite Reside File : PBA-1_TC99-DOE-5.ROF

Summary of dose at graphical times, reptition 2 (continued)

Time

Years

$4.48 \mathrm{E}+02$

$4.49 \mathrm{E}+02$

$4.49 \mathrm{E}+02$

$4.50 \mathrm{E}+02$

$4.50 \mathrm{E}+02$

$4.51 \mathrm{E}+02$

$4.51 \mathrm{E}+02$

4. $52 \mathrm{E}+02$

4. $52 \mathrm{E}+02$

4. $53 \mathrm{E}+02$

4. $53 \mathrm{E}+02$

4. $54 \mathrm{E}+02$

$4.54 \mathrm{E}+02$

4. $55 \mathrm{E}+02$

$4.55 \mathrm{E}+02$

4. $56 \mathrm{E}+02$

4. $56 \mathrm{E}+02$

4. $57 \mathrm{E}+02$

$4.57 \mathrm{E}+02$

$4.58 \mathrm{E}+02$

$4.58 \mathrm{E}+02$

$4.59 \mathrm{E}+02$

$4.59 \mathrm{E}+02$

$4.60 \mathrm{E}+02$

$4.60 \mathrm{E}+02$

$4.61 \mathrm{E}+02$

4. $61 \mathrm{E}+02$

$4.62 \mathrm{E}+02$

4. $62 \mathrm{E}+02$

$4.63 \mathrm{E}+02$

$4.63 \mathrm{E}+02$

$4.64 \mathrm{E}+02$

$4.65 \mathrm{E}+02$

$4.65 \mathrm{E}+02$

$4.66 \mathrm{E}+02$

$4.66 \mathrm{E}+02$

$4.67 \mathrm{E}+02$

$4.67 \mathrm{E}+02$

$4.68 \mathrm{E}+02$

$4.68 \mathrm{E}+02$

$4.69 \mathrm{E}+02$

$4.69 \mathrm{E}+02$

$4.70 \mathrm{E}+02$

$4.70 \mathrm{E}+02$

$4.71 \mathrm{E}+02$

$4.71 E+02$
Dose statistics at graphical times, mrem/yr

\begin{tabular}{|c|c|c|c|c|c|c|c|}
\hline inimum & aximum & Mean & ledian & $0 \%$ & $5 \%$ & $97.5 \%$ & \\
\hline 5 & +00 & $E-02$ & $E-02$ & 01 & 1 & 1 & +00 \\
\hline 05 & +00 & 2 & 2 & 1 & 1 & 01 & +00 \\
\hline 05 & +00 & -02 & $E-02$ & $6 E-01$ & 01 & 01 & +00 \\
\hline$E-05$ & $E+00$ & 2 & 2 & 1 & 1 & & +00 \\
\hline $4 E-05$ & -00 & 2 & 02 & 01 & & -01 & $14 \mathrm{E}+00$ \\
\hline $.02 E-04$ & $\mathrm{E}+00$ & -02 & -02 & $E-$ & 01 & $3 E-01$ & $E+00$ \\
\hline $.04 E-04$ & $3 E+00$ & $7 E-02$ & -02 & 01 & 1 & 01 & +00 \\
\hline $.06 E-04$ & $2.74 E+00$ & $.82 E-02$ & $0 E-02$ & $2.64 \mathrm{E}-01$ & 01 & -01 & $.15 \mathrm{E}+0 \mathrm{C}$ \\
\hline 04 & +00 & -02 & -02 & 01 & 01 & -01 & +00 \\
\hline $.11 \mathrm{E}-04$ & $2.75 \mathrm{E}+00$ & $3 E-02$ & $3 E-02$ & $3 E-01$ & $27 E-01$ & -01 & $.16 \mathrm{E}+00$ \\
\hline-04 & +00 & 2 & -02 & 1 & 1 & -01 & $7 \mathrm{E}+00$ \\
\hline-04 & +00 & -01 & & & & & +00 \\
\hline $.18 \mathrm{E}-04$ & $2.77 \mathrm{E}+00$ & $.01 \mathrm{E}-01$ & $2.19 \mathrm{E}-02$ & $2.74 \mathrm{E}-01$ & $32 E-01$ & -01 & $18 \mathrm{E}+0$ \\
\hline-04 & +00 & -01 & -02 & $75 E-01$ & 01 & -01 & $.18 \mathrm{E}+00$ \\
\hline 04 & -00 & 01 & 02 & 01 & 01 & 01 & $.19 \mathrm{E}+00$ \\
\hline $.25 E-04$ & $2.78 \mathrm{E}+00$ & -01 & -02 & 01 & 01 & -01 & $.19 \mathrm{E}+00$ \\
\hline $.27 E-04$ & $2.79 \mathrm{E}+00$ & $3 E-01$ & $7 E-02$ & $31 E-01$ & $40 E-01$ & $E-01$ & $.20 \mathrm{E}+00$ \\
\hline-04 & $.79 E+00$ & $04 E-01$ & $9 E-02$ & $2 E-01$ & $42 E-01$ & $E-01$ & $20 E+00$ \\
\hline 04 & $\mathrm{E}+00$ & $4 E-01$ & -02 & -01 & & -01 & $.20 \mathrm{E}+0 \mathrm{C}$ \\
\hline $5-04$ & +00 & -01 & -02 & $35 E-01$ & -01 & -01 & $.21 \mathrm{E}+00$ \\
\hline $8 E-04$ & 2.0 & -01 & -02 & & & 01 & +00 \\
\hline $.40 E-04$ & $2.82 \mathrm{E}+00$ & $.06 \mathrm{E}-01$ & -02 & & & -01 & $.22 \mathrm{E}+00$ \\
\hline $.43 E-04$ & $2.82 \mathrm{E}+00$ & $1.07 \mathrm{E}-01$ & $2.39 E-02$ & $89 E-01$ & $54 E-01$ & $68 E-01$ & $.22 \mathrm{E}+00$ \\
\hline$E-04$ & $.83 E+00$ & $1.07 \mathrm{E}-01$ & 2. $41 \mathrm{E}-02$ & $91 \mathrm{E}-01$ & $57 \mathrm{E}-01$ & $72 E-01$ & $.23 E+00$ \\
\hline 04 & $.83 E+00$ & $08 \mathrm{E}-01$ & 02 & 01 & & -01 & +00 \\
\hline 04 & 00 & 01 & 02 & & & & +00 \\
\hline $.54 \mathrm{E}-04$ & $2.04 \mathrm{E}+00$ & -01 & -02 & & & 01 & $.24 \mathrm{E}+00$ \\
\hline $.57 E-04$ & $2.0 J E T U$ & 1.09E-01 & $2.50 E-02$ & $2.98 E-01$ & $67 E-01$ & $.86 E-01$ & $.24 \mathrm{E}+00$ \\
\hline 04 & $2.85 \mathrm{E}+00$ & . & $52 E-02$ & 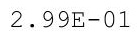 & $69 E-01$ & 然 & $25 E+0 c$ \\
\hline 4 & - & $.11 \mathrm{E}-01$ & - & 1 & - & - & $25 \mathrm{E}+$ \\
\hline 4 & $86 \mathrm{~F}+00$ & $1 E-01$ & $6 E-02$ & $3 E-01$ & & 1 & $25 E+00$ \\
\hline$E-04$ & $.87 \mathrm{E}+00$ & $2 E-01$ & $E-02$ & 1 & -01 & 01 & $26 \mathrm{E}+00$ \\
\hline $1 E-04$ & $2.87 \mathrm{E}+00$ & $2 E-01$ & 02 & 01 & 1 & -01 & $26 \mathrm{E}+00$ \\
\hline $.74 \mathrm{E}-04$ & $2.88 \mathrm{E}+00$ & $.13 \mathrm{E}-01$ & $2.63 E-02$ & $8 E-01$ & $.82 \mathrm{E}-01$ & $7 E-01$ & $.27 E+00$ \\
\hline $.78 E-04$ & $2.00 \mathrm{TTU}$ & $1.13 E-01$ & & & & $10 \mathrm{E}-01$ & - CILTU \\
\hline 7 & & & & & & & \\
\hline 4 & $2.89 \mathrm{E}+00$ & & & 1 & & & ho \\
\hline 4 & 2.9 & & & & & & \\
\hline & & & & & & & \\
\hline $3 E-04$ & $2.91 E+00$ & $6 E-01$ & $5 E-02$ & 1 & 1 & & $.29 E+00$ \\
\hline$E-04$ & $2.92 E+00$ & 1 & & & & & $.29 \mathrm{E}+00$ \\
\hline 04 & $2.95 \mathrm{E}+00$ & $.18 \mathrm{E}-01$ & & & & 01 & 1. SUETU \\
\hline 4 & $2.95 \mathrm{E}$ & 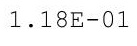 & 2 & - & 1 & 01 & $1.30 \mathrm{E}$ \\
\hline 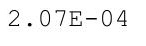 & 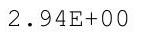 & set & & 200 & 西 & 1 & 00 \\
\hline 04 & $2.95 E+00$ & 1 & $2.88 E-02$ & 3. & 01 & 01 & $1.31 \mathrm{E}+00$ \\
\hline $.14 \mathrm{E}-04$ & $2.96 \mathrm{E}+00$ & $1.20 \mathrm{E}-01$ & $.90 E-02$ & $3.30 E-01$ & $5.08 E-01$ & $8.50 \mathrm{E}-01$ & $1.31 \mathrm{E}+00$ \\
\hline
\end{tabular}


RESRAD-OFFSITE, Version 2.5

Title : RESRAD-OFFSITE Drinking Water, Plant, Milk, and Meat Pathways for Offsite Reside File : PBA-1_TC99-DOE-5.ROF

Summary of dose at graphical times, reptition 2 (continued)

Time

Years

$4.72 \mathrm{E}+02$

$4.72 \mathrm{E}+02$

$4.73 \mathrm{E}+02$

$4.73 \mathrm{E}+02$

$4.74 \mathrm{E}+02$

$4.74 \mathrm{E}+02$

$4.75 E+02$

$4.75 \mathrm{E}+02$

$4.76 \mathrm{E}+02$

$4.76 \mathrm{E}+02$

$4.77 \mathrm{E}+02$

$4.77 \mathrm{E}+02$

$4.78 \mathrm{E}+02$

$4.78 \mathrm{E}+02$

$4.79 \mathrm{E}+02$

$4.79 \mathrm{E}+02$

$4.80 \mathrm{E}+02$

$4.80 \mathrm{E}+02$

$4.81 \mathrm{E}+02$

$4.81 \mathrm{E}+02$

$4.82 \mathrm{E}+02$

$4.82 \mathrm{E}+02$

$4.83 \mathrm{E}+02$

$4.83 \mathrm{E}+02$

$4.84 \mathrm{E}+02$

$4.84 \mathrm{E}+02$

$4.85 \mathrm{E}+02$

$4.86 \mathrm{E}+02$

$4.86 \mathrm{E}+02$

$4.87 \mathrm{E}+02$

$4.87 \mathrm{E}+02$

$4.88 \mathrm{E}+02$

$4.88 \mathrm{E}+02$

$4.89 \mathrm{E}+02$

$4.89 \mathrm{E}+02$

$4.90 \mathrm{E}+02$

$4.90 E+02$

$4.91 \mathrm{E}+02$

4. $91 \mathrm{E}+02$

$4.92 \mathrm{E}+02$

4. $92 \mathrm{E}+02$

$4.93 E+02$

4. $93 \mathrm{E}+02$

$4.94 \mathrm{E}+02$

4. $94 \mathrm{E}+02$

$4.95 E+02$
Dose statistics at graphical times, mrem/yr

\begin{tabular}{|c|c|c|c|c|c|c|c|}
\hline inimum & aximum & Mean & ledian & $0 \%$ & $5 \%$ & $97.5 \%$ & \\
\hline 4 & +00 & -01 & -02 & 01 & 1 & 1 & 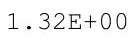 \\
\hline-04 & $E+00$ & 1 & $E-02$ & 1 & 1 & 01 & $.32 E+00$ \\
\hline-04 & $\mathrm{E}+00$ & $2 E-01$ & $E-02$ & $5 E-01$ & -01 & -01 & +00 \\
\hline-04 & -00 & 01 & 02 & 1 & 1 & 01 & $3 \mathrm{E}+00$ \\
\hline $2 E-04$ & -00 & -01 & 02 & 1 & 01 & -01 & $33 E+00$ \\
\hline $35 E-04$ & $E+00$ & -01 & -02 & $10 E-01$ & $E-01$ & -01 & $33 E+00$ \\
\hline 04 & -00 & 01 & -02 & -01 & 1 & -01 & $.34 \mathrm{E}+00$ \\
\hline$E-04$ & $3.01 E+00$ & . 20401 & $E-02$ & $3.43 E-01$ & 01 & -01 & $.34 \mathrm{E}+0 \mathrm{C}$ \\
\hline 04 & +00 & 1 & 02 & 01 & 01 & -01 & +00 \\
\hline $.50 E-04$ & $3.03 E+00$ & $1.26 \mathrm{E}-01$ & -02 & $E-01$ & $28 \mathrm{E}-01$ & -01 & $.35 E+00$ \\
\hline-04 & +00 & $7 E-01$ & -02 & 1 & & -01 & $E+00$ \\
\hline-04 & +00 & -01 & -02 & & -01 & -01 & $\mathrm{E}+\mathrm{OC}$ \\
\hline $62 \mathrm{E}-04$ & $.05 E+00$ & $.28 E-01$ & -02 & 1 & 1 & -01 & $\mathrm{E}+0 \mathrm{c}$ \\
\hline-04 & -00 & . & -02 & $3 E-01$ & 01 & -01 & $.36 \mathrm{E}+00$ \\
\hline 04 & +00 & 1.201 & 02 & 1 & 01 & -01 & +00 \\
\hline $.74 \mathrm{E}-04$ & $3.07 \mathrm{E}+00$ & 1.30 & -02 & 01 & 01 & -01 & $.37 E+00$ \\
\hline $.79 \mathrm{E}-04$ & $3.08 \mathrm{E}+00$ & $.30 \mathrm{E}-01$ & $4 \mathrm{E}-02$ & $58 E-01$ & $44 \mathrm{E}-01$ & $E-01$ & $.38 \mathrm{E}+00$ \\
\hline $3 E-04$ & $.08 E+00$ & $.31 E-01$ & $7 E-02$ & $0 E-01$ & $47 E-01$ & -01 & $38 \mathrm{E}+00$ \\
\hline 04 & 00 & 1 & 02 & 1 & 1 & -01 & +00 \\
\hline 04 & -00 & -01 & -02 & 01 & 1 & -01 & +00 \\
\hline 4 & 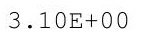 & 1 & 2 & & & 1 & 00 \\
\hline-04 & $3.11 \mathrm{E}+00$ & 1 & 2 & 1 & 1 & -01 & $40 \mathrm{E}+00$ \\
\hline$E-04$ & $.12 \mathrm{E}+00$ & $.34 \mathrm{E}-$ & $E-02$ & 1 & 1 & 1 & $40 E+00$ \\
\hline E-04 & $3.12 \mathrm{E}+00$ & $1.35 \mathrm{E}-01$ & $4 E-02$ & $2 \mathrm{E}-01$ & $64 \mathrm{E}-01$ & $8 E-01$ & $.41 E+00$ \\
\hline$E-04$ & $.13 \mathrm{E}+00$ & $.36 \mathrm{E}-01$ & $7 E-02$ & $4 E-01$ & -01 & $E-01$ & $41 E+00$ \\
\hline & & & & & & 01 & +00 \\
\hline & & $\pm \cdot$ & & & 01 & -01 & +00 \\
\hline $.27 E-04$ & . & $.37 \mathrm{E}-01$ & $56 E-02$ & $8 E-01$ & $73 E-01$ & $2 E-01$ & $.42 E+00$ \\
\hline 04 & $+0+\frac{1}{10}$ & 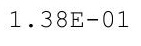 & $9 E-02$ & 1 & 1 & $E-01$ & $43 E+00$ \\
\hline 4 & - & $.39 E-01$ & 2 & 1 & 1 & 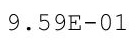 & $.43 E+0$ \\
\hline$=04$ & م & & $5 E-02$ & $E-01$ & & $E-01$ & $44 \mathrm{E}+00$ \\
\hline 04 & & & & & & 01 & $44 \mathrm{E}+00$ \\
\hline 04 & & & & & 1 & -01 & $.45 E+00$ \\
\hline $.56 \mathrm{E}-04$ & $3.19 \mathrm{E}+00$ & $1.41 \mathrm{E}-01$ & $3.83 E-02$ & $8 E-01$ & $87 E-01$ & $5 E-01$ & $.45 \mathrm{E}+00$ \\
\hline $61 E-04$ &.$\angle U E T U O$ & $1.42 \mathrm{E}-01$ & $3.86 E-02$ & & & $79 E-01$ & $.46 E+0 c$ \\
\hline 4 & & & & & & & $.46 \mathrm{E}+00$ \\
\hline 4 & $3.21 E+00$ & - & & 1 & & 1 & $47 E+00$ \\
\hline 4 & & & & 1 & & & $47 E+00$ \\
\hline 04 & & & & -01 & 1 & -01 & $.48 E+00$ \\
\hline $86 \mathrm{E}-04$ & $3.23 E+00$ & 1. $45 \mathrm{E}-01$ & $E-02$ & 01 & 1 & 1 & 1. $48 \mathrm{E}+0 \mathrm{C}$ \\
\hline 04 & & $.46 E-01$ & & 1 & & & $.49 \mathrm{E}+00$ \\
\hline$E-04$ & $3.24 \mathrm{E}+00$ & $1.47 \mathrm{E}-01$ & 2 & 1 & & $.01 E+00$ & $1.49 \mathrm{E}+00$ \\
\hline Di- 4 & $3.25 \mathrm{E}+00$ & $1.47 \mathrm{E}-01$ & $-\angle E-U \angle 2$ & $25-01$ & $07 E-01$ & $.01 E+00$ & $.50 \mathrm{E}+0$ \\
\hline 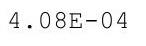 & . & te & & $4.07 \mathrm{E}-01$ & $.10 \mathrm{E}-01$ & $02 \mathrm{E}+$ & $50 E+00$ \\
\hline $3 E-04$ & $3.26 \mathrm{E}+00$ & $1.49 \mathrm{E}-01$ & $E-02$ & 4.09 & 01 & $1.02 \mathrm{E}+00$ & $1.51 \mathrm{E}+00$ \\
\hline $.19 \mathrm{E}-04$ & $3.27 E+00$ & 1. $49 \mathrm{E}-01$ & $4.22 E-02$ & $4.10 \mathrm{E}-01$ & $5.15 E-01$ & $1.02 \mathrm{E}+00$ & 1. $51 \mathrm{E}+00$ \\
\hline
\end{tabular}


RESRAD-OFFSITE, Version 2.5

Title : RESRAD-OFFSITE Drinking Water, Plant, Milk, and Meat Pathways for Offsite Reside File : PBA-1_TC99-DOE-5.ROF

Summary of dose at graphical times, reptition 2 (continued)

Time

Years

$4.95 \mathrm{E}+02$

$4.96 \mathrm{E}+02$

$4.96 \mathrm{E}+02$

$4.97 \mathrm{E}+02$

$4.97 \mathrm{E}+02$

4. $98 \mathrm{E}+02$

4. $98 \mathrm{E}+02$

$4.99 \mathrm{E}+02$

$4.99 \mathrm{E}+02$

$5.00 \mathrm{E}+02$

$5.00 \mathrm{E}+02$

$5.01 \mathrm{E}+02$

$5.01 \mathrm{E}+02$

$5.02 \mathrm{E}+02$

$5.02 \mathrm{E}+02$

$5.03 \mathrm{E}+02$

$5.03 \mathrm{E}+02$

$5.04 \mathrm{E}+02$

$5.04 \mathrm{E}+02$

$5.05 \mathrm{E}+02$

$5.06 \mathrm{E}+02$

$5.06 \mathrm{E}+02$

$5.07 \mathrm{E}+02$

$5.07 \mathrm{E}+02$

$5.08 \mathrm{E}+02$

$5.08 \mathrm{E}+02$

$5.09 \mathrm{E}+02$

$5.09 \mathrm{E}+02$

$5.10 \mathrm{E}+02$

$5.10 \mathrm{E}+02$

$5.11 \mathrm{E}+02$

$5.11 E+02$

$5.12 \mathrm{E}+02$

$5.12 \mathrm{E}+02$

$5.13 \mathrm{E}+02$

$5.13 \mathrm{E}+02$

$5.14 \mathrm{E}+02$

$5.14 \mathrm{E}+02$

$5.15 \mathrm{E}+02$

$5.15 \mathrm{E}+02$

$5.16 \mathrm{E}+02$

$5.16 \mathrm{E}+02$

$5.17 \mathrm{E}+02$

$5.17 \mathrm{E}+02$

$5.18 \mathrm{E}+02$

$5.18 \mathrm{E}+02$
Dose statistics at graphical times, mrem/yr

\begin{tabular}{|c|c|c|c|c|c|c|c|}
\hline inimum & Maximum & Mean & Median & $90 \%$ & $95 \%$ & $7.5 \%$ & $9 \%$ \\
\hline $.24 \mathrm{E}-04$ & $.27 \mathrm{E}+00$ & $1.50 \mathrm{E}-01$ & $4.25 \mathrm{E}-02$ & $4.12 \mathrm{E}-01$ & $6.18 \mathrm{E}-01$ & $1.03 \mathrm{E}+00$ & $1.52 \mathrm{E}+00$ \\
\hline $4.30 \mathrm{E}-04$ & $3.28 \mathrm{E}+00$ & $1.51 \mathrm{E}-01$ & $4.28 \mathrm{E}-02$ & $4.13 \mathrm{E}-01$ & $6.20 \mathrm{E}-01$ & $1.03 \mathrm{E}+00$ & $1.52 \mathrm{E}+00$ \\
\hline $4.35 \mathrm{E}-04$ & $3.28 \mathrm{E}+00$ & $1.51 \mathrm{E}-01$ & $4.32 \mathrm{E}-02$ & $4.15 \mathrm{E}-01$ & $6.23 \mathrm{E}-01$ & $1.04 \mathrm{E}+00$ & $1.53 \mathrm{E}+00$ \\
\hline $4.41 \mathrm{E}-04$ & $3.29 \mathrm{E}+00$ & $1.52 \mathrm{E}-01$ & $4.35 \mathrm{E}-02$ & $4.17 \mathrm{E}-01$ & $6.26 \mathrm{E}-01$ & $1.04 \mathrm{E}+00$ & $.53 E+00$ \\
\hline $4.47 \mathrm{E}-04$ & $3.30 \mathrm{E}+00$ & $1.53 \mathrm{E}-01$ & $4.38 \mathrm{E}-02$ & $4.19 \mathrm{E}-01$ & $6.29 \mathrm{E}-01$ & $1.04 \mathrm{E}+00$ & $1.53 \mathrm{E}+00$ \\
\hline $4.53 \mathrm{E}-04$ & $3.30 \mathrm{E}+00$ & $1.53 \mathrm{E}-01$ & $4.42 \mathrm{E}-02$ & $4.21 \mathrm{E}-01$ & $6.31 \mathrm{E}-01$ & $1.05 \mathrm{E}+00$ & $1.54 \mathrm{E}+00$ \\
\hline $4.59 \mathrm{E}-04$ & $.31 E+00$ & $1.54 \mathrm{E}-01$ & $4.45 \mathrm{E}-02$ & $4.23 \mathrm{E}-01$ & $6.34 \mathrm{E}-01$ & $1.05 \mathrm{E}+00$ & $1.54 \mathrm{E}+00$ \\
\hline $.65 \mathrm{E}-04$ & $3.31 E+00$ & $1.55 \mathrm{E}-01$ & $4.48 \mathrm{E}-02$ & $4.24 \mathrm{E}-01$ & $6.36 \mathrm{E}-01$ & $1.06 \mathrm{E}+00$ & $1.55 \mathrm{E}+00$ \\
\hline $4.71 \mathrm{E}-04$ & $3.32 \mathrm{E}+00$ & $1.55 \mathrm{E}-01$ & $4.52 \mathrm{E}-02$ & $4.26 \mathrm{E}-01$ & $6.39 \mathrm{E}-01$ & $1.06 \mathrm{E}+00$ & $1.55 \mathrm{E}+00$ \\
\hline $4.77 \mathrm{E}-04$ & $3.33 E+00$ & $1.56 \mathrm{E}-01$ & $4.55 \mathrm{E}-02$ & $4.28 \mathrm{E}-01$ & $6.42 \mathrm{E}-01$ & $1.06 \mathrm{E}+00$ & $1.56 \mathrm{E}+00$ \\
\hline $4.83 E-04$ & $3.33 E+00$ & $1.57 \mathrm{E}-01$ & $4.58 \mathrm{E}-02$ & $4.30 \mathrm{E}-01$ & $6.44 \mathrm{E}-01$ & $1.07 \mathrm{E}+00$ & $1.56 \mathrm{E}+00$ \\
\hline $4.89 \mathrm{E}-04$ & $3.34 \mathrm{E}+00$ & $1.57 \mathrm{E}-01$ & 4. $62 \mathrm{E}-02$ & $4.32 \mathrm{E}-01$ & $6.47 \mathrm{E}-01$ & $1.07 \mathrm{E}+00$ & $1.57 \mathrm{E}+00$ \\
\hline $4.95 \mathrm{E}-04$ & $3.34 \mathrm{E}+00$ & $1.58 \mathrm{E}-01$ & $4.65 \mathrm{E}-02$ & $4.34 \mathrm{E}-01$ & $6.49 \mathrm{E}-01$ & $1.07 \mathrm{E}+00$ & $1.57 \mathrm{E}+00$ \\
\hline $5.01 \mathrm{E}-04$ & $3.35 \mathrm{E}+00$ & $1.59 \mathrm{E}-01$ & $4.69 \mathrm{E}-02$ & $4.36 \mathrm{E}-01$ & $6.52 \mathrm{E}-01$ & $1.08 \mathrm{E}+00$ & $1.57 \mathrm{E}+00$ \\
\hline $5.08 \mathrm{E}-04$ & $3.36 \mathrm{E}+00$ & $1.59 \mathrm{E}-01$ & $4.72 \mathrm{E}-02$ & $4.39 \mathrm{E}-01$ & $6.54 \mathrm{E}-01$ & $1.08 \mathrm{E}+00$ & $1.58 \mathrm{E}+00$ \\
\hline $5.14 \mathrm{E}-04$ & $3.36 \mathrm{E}+00$ & $1.60 \mathrm{E}-01$ & $4.76 \mathrm{E}-02$ & $4.40 \mathrm{E}-01$ & $6.57 \mathrm{E}-01$ & $1.09 \mathrm{E}+00$ & $1.58 \mathrm{E}+00$ \\
\hline $5.21 \mathrm{E}-04$ & $3.37 \mathrm{E}+00$ & $1.61 \mathrm{E}-01$ & $4.79 \mathrm{E}-02$ & $4.42 \mathrm{E}-01$ & $6.59 \mathrm{E}-01$ & $1.09 \mathrm{E}+00$ & $1.59 \mathrm{E}+00$ \\
\hline $5.27 \mathrm{E}-04$ & $3.37 \mathrm{E}+00$ & $1.62 \mathrm{E}-01$ & $4.82 \mathrm{E}-02$ & $4.44 \mathrm{E}-01$ & $6.62 \mathrm{E}-01$ & $1.09 \mathrm{E}+00$ & $1.59 \mathrm{E}+00$ \\
\hline $34 \mathrm{E}-04$ & $3.38 \mathrm{E}+00$ & $1.62 \mathrm{E}-01$ & $4.86 \mathrm{E}-02$ & $4.45 \mathrm{E}-01$ & $6.65 \mathrm{E}-01$ & $1.10 \mathrm{E}+00$ & $1.59 \mathrm{E}+00$ \\
\hline $.40 \mathrm{E}-04$ & $3.38 \mathrm{E}+00$ & $1.63 \mathrm{E}-01$ & $4.89 \mathrm{E}-02$ & $4.47 \mathrm{E}-01$ & $6.67 \mathrm{E}-01$ & $1.10 \mathrm{E}+00$ & $1.60 \mathrm{E}+00$ \\
\hline 4 & $3.39 \mathrm{E}+00$ & 1 & & & & $1.11 \mathrm{E}+00$ & $1.60 \mathrm{E}+00$ \\
\hline 年 & $3.40 \mathrm{E}+00$ & 1.6 & 2 & 1 & 6 & $1.11 \mathrm{E}+00$ & $1.60 \mathrm{E}+00$ \\
\hline $5.60 \mathrm{E}-04$ & $3.40 \mathrm{E}+00$ & $1.65 \mathrm{E}-01$ & $0 \mathrm{E}-02$ & 1 & 01 & $1.11 \mathrm{E}+00$ & $1.61 \mathrm{E}+00$ \\
\hline $5.67 \mathrm{E}-04$ & $3.41 \mathrm{E}+00$ & $1.66 \mathrm{E}-01$ & $5.03 \mathrm{E}-02$ & $4.53 \mathrm{E}-01$ & $6.78 \mathrm{E}-01$ & $1.11 \mathrm{E}+00$ & $1.61 \mathrm{E}+00$ \\
\hline $5.74 \mathrm{E}-04$ & $3.41 \mathrm{E}+00$ & $1.66 \mathrm{E}-01$ & $5.07 \mathrm{E}-02$ & $4.55 \mathrm{E}-01$ & $6.81 \mathrm{E}-01$ & $1.12 \mathrm{E}+00$ & $1.62 \mathrm{E}+00$ \\
\hline $5.81 \mathrm{E}-04$ & $3.42 \mathrm{E}+00$ & $1.67 \mathrm{E}-01$ & $5.10 \mathrm{E}-02$ & $4.57 \mathrm{E}-01$ & $6.83 \mathrm{E}-01$ & $1.12 \mathrm{E}+00$ & $1.62 \mathrm{E}+00$ \\
\hline $5.88 \mathrm{E}-04$ & $3.42 \mathrm{E}+00$ & $1.68 \mathrm{E}-01$ & $5.15 \mathrm{E}-02$ & $4.58 \mathrm{E}-01$ & $6.86 \mathrm{E}-01$ & $1.12 \mathrm{E}+00$ & $1.62 \mathrm{E}+00$ \\
\hline $5.95 \mathrm{E}-04$ & $3.43 E+00$ & $1.69 \mathrm{E}-01$ & $5.18 \mathrm{E}-02$ & $4.60 \mathrm{E}-01$ & $6.89 \mathrm{E}-01$ & $1.13 \mathrm{E}+00$ & $1.63 \mathrm{E}+00$ \\
\hline $6.03 \mathrm{E}-04$ & $3.43 \mathrm{E}+00$ & $1.69 \mathrm{E}-01$ & $5.21 \mathrm{E}-02$ & $4.62 \mathrm{E}-01$ & $6.91 \mathrm{E}-01$ & $1.13 \mathrm{E}+00$ & $1.63 \mathrm{E}+00$ \\
\hline $6.10 \mathrm{E}-04$ & $3.44 \mathrm{E}+00$ & $1.70 \mathrm{E}-01$ & $5.25 \mathrm{E}$ & $4.63 \mathrm{E}-01$ & $6.94 \mathrm{E}-01$ & $1.13 \mathrm{E}+00$ & $1.64 \mathrm{E}+00$ \\
\hline $6.17 \mathrm{E}-04$ & $3.45 \mathrm{E}+00$ & $1.71 \mathrm{E}$ & 2 & $4.65 \mathrm{E}-01$ & $97 E-01$ & $1.14 \mathrm{E}+00$ & $1.64 \mathrm{E}+00$ \\
\hline $6.24 \mathrm{E}-04$ & $3.45 \mathrm{E}+00$ & $1.71 \mathrm{E}-01$ & $5.33 \mathrm{E}-02$ & $4.67 \mathrm{E}-01$ & $6.99 \mathrm{E}-01$ & $1.14 \mathrm{E}+00$ & $1.65 \mathrm{E}+00$ \\
\hline $6.32 \mathrm{E}-04$ & $3.46 \mathrm{E}+00$ & $1.72 \mathrm{E}-01$ & $5.37 \mathrm{E}-02$ & $4.69 \mathrm{E}-01$ & $7.01 \mathrm{E}-01$ & $1.14 \mathrm{E}+00$ & $1.65 \mathrm{E}+00$ \\
\hline $6.39 \mathrm{E}-04$ & $3.46 \mathrm{E}+00$ & $1.73 \mathrm{E}-01$ & $5.41 \mathrm{E}-02$ & $4.71 \mathrm{E}-01$ & $7.03 \mathrm{E}-01$ & $1.15 \mathrm{E}+00$ & $1.66 \mathrm{E}+00$ \\
\hline $6.47 \mathrm{E}-04$ & $3.47 \mathrm{E}+00$ & $1.74 \mathrm{E}-01$ & $5.45 \mathrm{E}-02$ & $4.73 \mathrm{E}-01$ & $7.06 \mathrm{E}-01$ & $1.15 \mathrm{E}+00$ & $1.66 \mathrm{E}+00$ \\
\hline $6.55 \mathrm{E}-04$ & $3.47 \mathrm{E}+00$ & $1.74 \mathrm{E}-01$ & $5.49 \mathrm{E}-02$ & $4.75 \mathrm{E}-01$ & $7.08 \mathrm{E}-01$ & $1.15 \mathrm{E}+00$ & $1.66 \mathrm{E}+00$ \\
\hline $6.62 \mathrm{E}-04$ & $3.48 \mathrm{E}+00$ & $1.75 \mathrm{E}-01$ & $5.53 \mathrm{E}-02$ & $4.77 \mathrm{E}-01$ & $7.10 \mathrm{E}-01$ & $1.16 \mathrm{E}+00$ & $1.67 \mathrm{E}+00$ \\
\hline $6.70 \mathrm{E}-04$ & $3.48 \mathrm{E}+00$ & $1.76 \mathrm{E}-01$ & $5.57 \mathrm{E}-02$ & $4.79 \mathrm{E}-01$ & $7.12 \mathrm{E}-01$ & $1.16 \mathrm{E}+00$ & $1.67 \mathrm{E}+00$ \\
\hline $6.78 \mathrm{E}-04$ & $3.49 \mathrm{E}+00$ & $1.76 \mathrm{E}-01$ & $5.61 \mathrm{E}-02$ & $4.81 \mathrm{E}-01$ & $7.14 \mathrm{E}-01$ & $1.16 \mathrm{E}+00$ & $1.68 \mathrm{E}+00$ \\
\hline $6.86 \mathrm{E}-04$ & $3.49 \mathrm{E}+00$ & $1.77 \mathrm{E}-01$ & $5.65 \mathrm{E}-02$ & $4.83 \mathrm{E}-01$ & $7.17 \mathrm{E}-01$ & $1.17 \mathrm{E}+00$ & $1.68 \mathrm{E}+00$ \\
\hline $6.94 \mathrm{E}-04$ & $3.50 \mathrm{E}+00$ & $1.78 \mathrm{E}-01$ & $5.68 \mathrm{E}-02$ & $4.85 \mathrm{E}-01$ & $7.19 \mathrm{E}-01$ & $1.17 \mathrm{E}+00$ & $1.69 \mathrm{E}+00$ \\
\hline $7.02 \mathrm{E}-04$ & $3.50 \mathrm{E}+00$ & $1.79 \mathrm{E}-01$ & $5.72 \mathrm{E}-02$ & $4.87 \mathrm{E}-01$ & $7.21 \mathrm{E}-01$ & $1.17 \mathrm{E}+00$ & $1.69 \mathrm{E}+00$ \\
\hline $7.10 \mathrm{E}-04$ & $3.51 \mathrm{E}+00$ & $1.79 \mathrm{E}-01$ & $5.75 \mathrm{E}-02$ & $4.89 \mathrm{E}-01$ & $7.23 \mathrm{E}-01$ & $1.18 \mathrm{E}+00$ & $1.70 \mathrm{E}+00$ \\
\hline $7.18 \mathrm{E}-04$ & $3.51 \mathrm{E}+00$ & $1.80 \mathrm{E}-01$ & $5.79 \mathrm{E}-02$ & $4.91 \mathrm{E}-01$ & $7.25 \mathrm{E}-01$ & $1.18 \mathrm{E}+00$ & $1.70 \mathrm{E}+00$ \\
\hline $7.26 \mathrm{E}-04$ & $3.52 \mathrm{E}+00$ & $1.81 \mathrm{E}-01$ & $5.82 \mathrm{E}-02$ & $4.94 \mathrm{E}-01$ & $7.28 \mathrm{E}-01$ & $1.18 \mathrm{E}+00$ & $1.71 \mathrm{E}+00$ \\
\hline $34 \mathrm{E}-04$ & $3.52 \mathrm{E}+00$ & $1.82 \mathrm{E}-01$ & $5.86 \mathrm{E}-02$ & $4.96 \mathrm{E}-01$ & 7.30 & $1.18 \mathrm{E}+00$ & $1.71 \mathrm{E}+00$ \\
\hline
\end{tabular}


RESRAD-OFFSITE, Version 2.5

Title : RESRAD-OFFSITE Drinking Water, Plant, Milk, and Meat Pathways for Offsite Reside File : PBA-1_TC99-DOE-5.ROF

Summary of dose at graphical times, reptition 2 (continued)

Time

Years

$5.19 \mathrm{E}+02$

$5.19 \mathrm{E}+02$

$5.20 \mathrm{E}+02$

$5.20 \mathrm{E}+02$

$5.21 \mathrm{E}+02$

$5.21 \mathrm{E}+02$

$5.22 \mathrm{E}+02$

$5.22 \mathrm{E}+02$

$5.23 \mathrm{E}+02$

$5.23 E+02$

$5.24 \mathrm{E}+02$

$5.24 \mathrm{E}+02$

$5.25 \mathrm{E}+02$

$5.26 \mathrm{E}+02$

$5.26 \mathrm{E}+02$

$5.27 \mathrm{E}+02$

$5.27 \mathrm{E}+02$

$5.28 \mathrm{E}+02$

$5.28 \mathrm{E}+02$

$5.29 \mathrm{E}+02$

$5.29 \mathrm{E}+02$

$5.30 \mathrm{E}+02$

$5.30 \mathrm{E}+02$

$5.31 \mathrm{E}+02$

$5.31 \mathrm{E}+02$

$5.32 \mathrm{E}+02$

$5.32 \mathrm{E}+02$

$5.33 \mathrm{E}+02$

$5.33 \mathrm{E}+02$

$5.34 \mathrm{E}+02$

$5.34 \mathrm{E}+02$

$5.35 \mathrm{E}+02$

$5.35 \mathrm{E}+02$

$5 \cdot 36 \mathrm{E}+02$

$5 \cdot 36 \mathrm{E}+02$

$5.37 \mathrm{E}+02$

$5.37 \mathrm{E}+02$

$5.38 \mathrm{E}+02$

$5.38 \mathrm{E}+02$

$5.39 \mathrm{E}+02$

$5.39 \mathrm{E}+02$

$5.40 \mathrm{E}+02$

$5.40 \mathrm{E}+02$

$5.41 \mathrm{E}+02$

$5.41 \mathrm{E}+02$

$5.42 \mathrm{E}+02$
Dose statistics at graphical times, mrem/yr

\begin{tabular}{|c|c|c|c|c|c|c|c|}
\hline inimum & Maximum & Mean & Median & $90 \%$ & $95 \%$ & $7.5 \%$ & $9 \%$ \\
\hline $7.43 \mathrm{E}-04$ & $.53 \mathrm{E}+00$ & $1.82 \mathrm{E}-01$ & $5.90 \mathrm{E}-02$ & $4.99 \mathrm{E}-01$ & $7.32 \mathrm{E}-01$ & $1.19 \mathrm{E}+00$ & $1.71 \mathrm{E}+00$ \\
\hline $7.51 \mathrm{E}-04$ & $3.53 \mathrm{E}+00$ & $1.83 \mathrm{E}-01$ & $5.94 \mathrm{E}-02$ & $5.01 \mathrm{E}-01$ & $7.34 \mathrm{E}-01$ & $1.19 \mathrm{E}+00$ & $1.72 \mathrm{E}+00$ \\
\hline $7.60 \mathrm{E}-04$ & $3.54 \mathrm{E}+00$ & $1.84 \mathrm{E}-01$ & $5.98 \mathrm{E}-02$ & $5.04 \mathrm{E}-01$ & $7.36 \mathrm{E}-01$ & $1.19 \mathrm{E}+00$ & $1.72 \mathrm{E}+00$ \\
\hline $7.68 \mathrm{E}-04$ & $3.54 \mathrm{E}+00$ & $1.85 \mathrm{E}-01$ & $6.01 \mathrm{E}-02$ & $5.06 \mathrm{E}-01$ & $7.39 \mathrm{E}-01$ & $1.19 \mathrm{E}+00$ & $.73 E+00$ \\
\hline $7.77 \mathrm{E}-04$ & $3.55 \mathrm{E}+00$ & $1.85 \mathrm{E}-01$ & $6.05 \mathrm{E}-02$ & $5.08 \mathrm{E}-01$ & $7.41 \mathrm{E}-01$ & $1.20 \mathrm{E}+00$ & $1.73 \mathrm{E}+00$ \\
\hline $7.86 \mathrm{E}-04$ & $3.55 \mathrm{E}+00$ & $1.86 \mathrm{E}-01$ & $6.09 \mathrm{E}-02$ & $5.09 \mathrm{E}-01$ & $7.43 \mathrm{E}-01$ & $1.20 \mathrm{E}+00$ & $1.74 \mathrm{E}+00$ \\
\hline $7.94 \mathrm{E}-04$ & $.56 \mathrm{E}+00$ & $1.87 \mathrm{E}-01$ & $6.13 \mathrm{E}-02$ & $5.11 \mathrm{E}-01$ & $.45 \mathrm{E}-01$ & $1.20 \mathrm{E}+00$ & $1.74 \mathrm{E}+00$ \\
\hline $.03 E-04$ & $.56 \mathrm{E}+00$ & $1.87 \mathrm{E}-01$ & $6.16 \mathrm{E}-02$ & $5.13 \mathrm{E}-01$ & $.47 \mathrm{E}-01$ & $1.20 \mathrm{E}+00$ & $1.75 \mathrm{E}+00$ \\
\hline $8.12 \mathrm{E}-04$ & $3.57 \mathrm{E}+00$ & $1.88 \mathrm{E}-01$ & $6.20 \mathrm{E}-02$ & $5.14 \mathrm{E}-01$ & $7.50 \mathrm{E}-01$ & $1.20 \mathrm{E}+00$ & $1.75 \mathrm{E}+00$ \\
\hline $8.21 \mathrm{E}-04$ & $3.57 \mathrm{E}+00$ & $1.89 \mathrm{E}-01$ & $6.23 \mathrm{E}-02$ & $5.16 \mathrm{E}-01$ & $7.52 \mathrm{E}-01$ & $1.21 \mathrm{E}+00$ & $1.76 \mathrm{E}+00$ \\
\hline $8.30 \mathrm{E}-04$ & $3.58 \mathrm{E}+00$ & $1.90 \mathrm{E}-01$ & $6.27 \mathrm{E}-02$ & $5.18 \mathrm{E}-01$ & $7.55 \mathrm{E}-01$ & $1.21 \mathrm{E}+00$ & $1.76 \mathrm{E}+00$ \\
\hline $8.39 \mathrm{E}-04$ & $3.58 \mathrm{E}+00$ & $1.90 \mathrm{E}-01$ & $6.31 \mathrm{E}-02$ & $5.20 \mathrm{E}-01$ & $7.58 \mathrm{E}-01$ & $1.21 \mathrm{E}+00$ & $.76 \mathrm{E}+00$ \\
\hline $8.49 \mathrm{E}-04$ & $3.59 \mathrm{E}+00$ & $1.91 \mathrm{E}-01$ & $6.35 \mathrm{E}-02$ & $5.22 \mathrm{E}-01$ & $7.61 \mathrm{E}-01$ & $1.21 \mathrm{E}+00$ & $.77 \mathrm{E}+00$ \\
\hline $8.58 \mathrm{E}-04$ & $3.59 \mathrm{E}+00$ & $1.92 \mathrm{E}-01$ & $6.39 \mathrm{E}-02$ & $5.24 \mathrm{E}-01$ & $7.64 \mathrm{E}-01$ & $1.22 \mathrm{E}+00$ & $1.77 \mathrm{E}+00$ \\
\hline $8.67 E-04$ & $3.60 \mathrm{E}+00$ & $1.93 \mathrm{E}-01$ & $6.43 \mathrm{E}-02$ & $5.26 \mathrm{E}-01$ & $7.67 \mathrm{E}-01$ & $1.22 \mathrm{E}+00$ & $1.78 \mathrm{E}+00$ \\
\hline $8.77 \mathrm{E}-04$ & $3.60 \mathrm{E}+00$ & $1.93 \mathrm{E}-01$ & $6.48 \mathrm{E}-02$ & $5.28 \mathrm{E}-01$ & $7.70 \mathrm{E}-01$ & $1.22 \mathrm{E}+00$ & $1.78 \mathrm{E}+00$ \\
\hline $8.86 \mathrm{E}-04$ & $3.60 \mathrm{E}+00$ & $1.94 \mathrm{E}-01$ & $6.52 \mathrm{E}-02$ & $5.30 \mathrm{E}-01$ & $7.74 \mathrm{E}-01$ & $1.23 \mathrm{E}+00$ & $1.78 \mathrm{E}+00$ \\
\hline $8.96 \mathrm{E}-04$ & $3.61 \mathrm{E}+00$ & $1.95 \mathrm{E}-01$ & $6.56 \mathrm{E}-02$ & $5.32 \mathrm{E}-01$ & $7.77 \mathrm{E}-01$ & $1.23 \mathrm{E}+00$ & $1.79 \mathrm{E}+00$ \\
\hline $9.05 \mathrm{E}-04$ & $3.61 E+00$ & $1.96 \mathrm{E}-01$ & $6.60 \mathrm{E}-02$ & $5.35 \mathrm{E}-01$ & $7.80 \mathrm{E}-01$ & $1.23 \mathrm{E}+00$ & $1.79 \mathrm{E}+00$ \\
\hline $.15 \mathrm{E}-04$ & $3.62 \mathrm{E}+00$ & $1.96 \mathrm{E}-01$ & $6.65 \mathrm{E}-02$ & $5.37 \mathrm{E}-01$ & $83 E-01$ & $1.23 \mathrm{E}+00$ & $1.80 \mathrm{E}+00$ \\
\hline 9.2 & $3.62 \mathrm{E}+00$ & & & & & $1.24 \mathrm{E}+00$ & $1.80 \mathrm{E}+00$ \\
\hline $9.35 \mathrm{E}-$ & $3.63 \mathrm{E}+00$ & 1 & 6 & 1 & 1 & $1.24 \mathrm{E}+00$ & $1.81 \mathrm{E}+00$ \\
\hline $9.45 \mathrm{E}-04$ & $3.63 \mathrm{E}+00$ & $1.99 \mathrm{E}-01$ & $6.78 \mathrm{E}-02$ & 01 & 01 & $1.24 \mathrm{E}+00$ & $1.81 \mathrm{E}+00$ \\
\hline $9.55 \mathrm{E}-04$ & $3.64 \mathrm{E}+00$ & $2.00 \mathrm{E}-01$ & $6.82 \mathrm{E}-02$ & $5.45 \mathrm{E}-01$ & $7.95 \mathrm{E}-01$ & $1.24 \mathrm{E}+00$ & $1.82 \mathrm{E}+00$ \\
\hline $9.65 \mathrm{E}-04$ & $3.64 \mathrm{E}+00$ & $2.00 \mathrm{E}-01$ & $6.87 \mathrm{E}-02$ & $5.48 \mathrm{E}-01$ & $7.98 \mathrm{E}-01$ & $1.25 \mathrm{E}+00$ & $1.82 \mathrm{E}+00$ \\
\hline $9.75 \mathrm{E}-04$ & $3.64 \mathrm{E}+00$ & $2.01 \mathrm{E}-01$ & $6.91 \mathrm{E}-02$ & $5.50 \mathrm{E}-01$ & $8.01 \mathrm{E}-01$ & $1.25 \mathrm{E}+00$ & $1.82 \mathrm{E}+00$ \\
\hline $9.86 \mathrm{E}-04$ & $3.65 \mathrm{E}+00$ & $2.02 \mathrm{E}-01$ & $6.96 \mathrm{E}-02$ & $5.52 \mathrm{E}-01$ & $8.04 \mathrm{E}-01$ & $1.25 \mathrm{E}+00$ & $1.83 \mathrm{E}+00$ \\
\hline $9.96 \mathrm{E}-04$ & $3.65 E+00$ & $2.03 E-01$ & $7.01 \mathrm{E}-02$ & $5.54 \mathrm{E}-01$ & $8.07 \mathrm{E}-01$ & $1.26 \mathrm{E}+00$ & $1.83 \mathrm{E}+00$ \\
\hline $1.01 \mathrm{E}-03$ & $3.66 \mathrm{E}+00$ & $2.03 E-01$ & $7.06 \mathrm{E}-02$ & $5.56 \mathrm{E}-01$ & $8.10 \mathrm{E}-01$ & $1.26 \mathrm{E}+00$ & $1.84 \mathrm{E}+00$ \\
\hline $1.02 \mathrm{E}-03$ & $3.66 \mathrm{E}+00$ & $2.04 \mathrm{E}-01$ & $7.10 \mathrm{E}$ & $5.58 \mathrm{E}$ & $8.13 \mathrm{E}-01$ & $1.26 \mathrm{E}+00$ & $1.84 \mathrm{E}+00$ \\
\hline $1.03 \mathrm{E}-03$ & $3.67 \mathrm{E}+00$ & $2.05 \mathrm{E}$ & 7 & 1 & 8.10 & $1.26 \mathrm{E}+00$ & $1.85 \mathrm{E}+00$ \\
\hline $1.04 \mathrm{E}-03$ & $3.67 \mathrm{E}+00$ & $2.06 \mathrm{E}-01$ & $7.19 \mathrm{E}-02$ & $5.63 \mathrm{E}-01$ & $8.20 \mathrm{E}-01$ & $1.26 \mathrm{E}+00$ & $1.85 \mathrm{E}+00$ \\
\hline $1.05 \mathrm{E}-03$ & $3.67 \mathrm{E}+00$ & $2.06 \mathrm{E}-01$ & $7.23 \mathrm{E}-02$ & $5.65 \mathrm{E}-01$ & $8.23 \mathrm{E}-01$ & $1.27 \mathrm{E}+00$ & $1.85 \mathrm{E}+00$ \\
\hline $1.06 \mathrm{E}-03$ & $3.68 \mathrm{E}+00$ & $2.07 \mathrm{E}-01$ & $7.28 \mathrm{E}-02$ & $5.67 \mathrm{E}-01$ & $8.26 \mathrm{E}-01$ & $1.27 \mathrm{E}+00$ & $1.86 \mathrm{E}+00$ \\
\hline $1.07 \mathrm{E}-03$ & $3.68 \mathrm{E}+00$ & $2.08 \mathrm{E}-01$ & $7.32 \mathrm{E}-02$ & $5.69 \mathrm{E}-01$ & $8.29 \mathrm{E}-01$ & $1.27 \mathrm{E}+00$ & $1.86 \mathrm{E}+00$ \\
\hline $1.08 \mathrm{E}-03$ & $3.69 \mathrm{E}+00$ & $2.09 \mathrm{E}-01$ & $7.37 \mathrm{E}-02$ & $5.72 \mathrm{E}-01$ & $8.32 \mathrm{E}-01$ & $1.27 \mathrm{E}+00$ & $1.87 \mathrm{E}+00$ \\
\hline $1.09 \mathrm{E}-03$ & $3.69 \mathrm{E}+00$ & $2.10 \mathrm{E}-01$ & $7.41 \mathrm{E}-02$ & $5.74 \mathrm{E}-01$ & $8.35 \mathrm{E}-01$ & $1.28 \mathrm{E}+00$ & $1.87 \mathrm{E}+00$ \\
\hline $1.10 \mathrm{E}-03$ & $3.69 \mathrm{E}+00$ & $2.10 \mathrm{E}-01$ & $7.46 \mathrm{E}-02$ & $5.76 \mathrm{E}-01$ & $8.37 \mathrm{E}-01$ & $1.28 \mathrm{E}+00$ & $1.88 \mathrm{E}+00$ \\
\hline $1.12 \mathrm{E}-03$ & $3.70 \mathrm{E}+00$ & $2.11 \mathrm{E}-01$ & $7.51 \mathrm{E}-02$ & $5.78 \mathrm{E}-01$ & $8.40 \mathrm{E}-01$ & $1.28 \mathrm{E}+00$ & $1.88 \mathrm{E}+00$ \\
\hline $1.13 \mathrm{E}-03$ & $3.70 \mathrm{E}+00$ & $2.12 \mathrm{E}-01$ & $7.56 \mathrm{E}-02$ & $5.80 \mathrm{E}-01$ & $8.42 \mathrm{E}-01$ & $1.28 \mathrm{E}+00$ & $1.88 \mathrm{E}+00$ \\
\hline $1.14 \mathrm{E}-03$ & $3.71 \mathrm{E}+00$ & $2.13 \mathrm{E}-01$ & $7.60 \mathrm{E}-02$ & $5.83 \mathrm{E}-01$ & $8.45 \mathrm{E}-01$ & $1.29 \mathrm{E}+00$ & $1.89 \mathrm{E}+00$ \\
\hline $1.15 \mathrm{E}-03$ & $3.71 E+00$ & $2.13 \mathrm{E}-01$ & $7.65 \mathrm{E}-02$ & $5.85 \mathrm{E}-01$ & $8.47 \mathrm{E}-01$ & $1.29 \mathrm{E}+00$ & $1.89 \mathrm{E}+00$ \\
\hline $1.16 \mathrm{E}-03$ & $3.71 \mathrm{E}+00$ & $2.14 \mathrm{E}-01$ & $7.70 \mathrm{E}-02$ & $5.87 \mathrm{E}-01$ & $8.49 \mathrm{E}-01$ & $1.29 \mathrm{E}+00$ & $1.90 \mathrm{E}+00$ \\
\hline $1.17 \mathrm{E}-03$ & $3.72 \mathrm{E}+00$ & $2.15 \mathrm{E}-01$ & $7.74 \mathrm{E}-02$ & $5.89 \mathrm{E}-01$ & $8.52 \mathrm{E}-01$ & $1.29 \mathrm{E}+00$ & $1.90 \mathrm{E}+00$ \\
\hline $1.19 \mathrm{E}-03$ & $3.72 \mathrm{E}+00$ & $2.16 \mathrm{E}-01$ & $7.79 \mathrm{E}-02$ & $5.91 \mathrm{E}-01$ & $8.54 \mathrm{E}-01$ & $1.29 \mathrm{E}+00$ & $1.91 \mathrm{E}+00$ \\
\hline $20 \mathrm{E}-03$ & $3.72 \mathrm{E}+00$ & $2.17 \mathrm{E}-01$ & $7.83 \mathrm{E}-02$ & 5.94 & 8.56 & $1.30 \mathrm{E}+00$ & $1.91 \mathrm{E}+00$ \\
\hline
\end{tabular}


RESRAD-OFFSITE, Version 2.5

Title : RESRAD-OFFSITE Drinking Water, Plant, Milk, and Meat Pathways for Offsite Reside File : PBA-1_TC99-DOE-5.ROF

Summary of dose at graphical times, reptition 2 (continued)

Time

Years

$5.42 \mathrm{E}+02$

$5.43 \mathrm{E}+02$

$5.43 E+02$

$5.44 \mathrm{E}+02$

$5.44 \mathrm{E}+02$

$5.45 \mathrm{E}+02$

$5.46 \mathrm{E}+02$

$5.46 \mathrm{E}+02$

$5.47 \mathrm{E}+02$

$5.47 \mathrm{E}+02$

$5.48 \mathrm{E}+02$

$5.48 \mathrm{E}+02$

$5.49 \mathrm{E}+02$

$5.49 \mathrm{E}+02$

$5.50 \mathrm{E}+02$

$5.50 \mathrm{E}+02$

$5.51 \mathrm{E}+02$

$5.51 \mathrm{E}+02$

$5.52 \mathrm{E}+02$

$5.52 \mathrm{E}+02$

$5.53 \mathrm{E}+02$

$5.53 \mathrm{E}+02$

$5.54 \mathrm{E}+02$

$5.54 \mathrm{E}+02$

$5.55 \mathrm{E}+02$

$5.55 \mathrm{E}+02$

$5.56 \mathrm{E}+02$

$5.56 \mathrm{E}+02$

$5.57 \mathrm{E}+02$

$5.57 \mathrm{E}+02$

$5.58 \mathrm{E}+02$

$5.58 \mathrm{E}+02$

$5.59 \mathrm{E}+02$

$5.59 \mathrm{E}+02$

$5.60 \mathrm{E}+02$

$5.60 \mathrm{E}+02$

$5.61 \mathrm{E}+02$

$5.61 \mathrm{E}+02$

$5.62 \mathrm{E}+02$

$5.62 \mathrm{E}+02$

$5.63 \mathrm{E}+02$

$5.63 \mathrm{E}+02$

$5.64 \mathrm{E}+02$

$5.64 \mathrm{E}+02$

$5.65 \mathrm{E}+02$

$5.66 \mathrm{E}+02$
Dose statistics at graphical times, mrem/yr

\begin{tabular}{|c|c|c|c|c|c|c|c|}
\hline inimum & aximum & Mean & ledian & $0 \%$ & $\%$ & $97.5 \%$ & \\
\hline 03 & $3.73 E+00$ & $2.17 \mathrm{E}-01$ & $7.88 \mathrm{E}-02$ & $5.96 \mathrm{E}-01$ & $8.59 \mathrm{E}-01$ & $.30 E+00$ & $\mathrm{E}+\mathrm{OC}$ \\
\hline 03 & +00 & 1 & 2 & $8 \mathrm{E}$ & 1 & +00 & +00 \\
\hline 03 & +00 & $E-01$ & $E-02$ & $0 E-01$ & -01 & -00 & +00 \\
\hline 03 & 00 & 1 & 2 & 1 & & 00 & +00 \\
\hline $26 E-03$ & -00 & 1 & & 01 & 01 & $31 E+00$ & $93 E+00$ \\
\hline $.27 E-03$ & $E+00$ & $1 E-01$ & -02 & $E-01$ & $2 E-01$ & $.31 E+00$ & $\mathrm{E}+00$ \\
\hline $.28 E-03$ & $5 \mathrm{E}+00$ & $.22 \mathrm{E}-01$ & -02 & 01 & 01 & +00 & $E+0 C$ \\
\hline $.30 E-03$ & $3.75 \mathrm{E}+00$ & $\begin{array}{ll}-2 \\
\end{array}$ & -02 & $6.11 E-01$ & $8.77 \mathrm{E}-01$ & +00 & $.94 \mathrm{E}+0 \mathrm{C}$ \\
\hline 03 & +00 & 1 & 02 & 01 & 01 & +00 & +00 \\
\hline $.32 E-03$ & $.76 \mathrm{E}+00$ & 2. $25 \mathrm{E}-01$ & $1 E-02$ & $E-01$ & -01 & $.32 E+00$ & $5 E+00$ \\
\hline$E-03$ & +00 & 1 & -02 & 1 & 1 & 00 & $E+00$ \\
\hline-03 & +00 & -01 & & & & +00 & +00 \\
\hline$E-03$ & $3.77 \mathrm{E}+00$ & 更 & -02 & 1 & 1 & +00 & +0 \\
\hline $.37 E-03$ & +00 & 工 & -02 & 01 & 01 & +00 & $97 E+00$ \\
\hline 03 & $E+00$ & 1 & 02 & 01 & 01 & $.33 E+00$ & +00 \\
\hline $.40 E-03$ & $3.78 \mathrm{E}+00$ & 1 & -02 & 1 & 01 & $.33 E+00$ & $.98 \mathrm{E}+00$ \\
\hline $.41 E-03$ & $3.78 \mathrm{E}+00$ & $2.30 \mathrm{E}-01$ & $9 E-02$ & $3 E-01$ & $0 E-01$ & $.33 E+00$ & $.98 \mathrm{E}+00$ \\
\hline$E-03$ & $79 E+00$ & $1 E-01$ & $4 E-02$ & $5 E-01$ & $E-01$ & $34 E+00$ & $99 \mathrm{E}+0 \mathrm{C}$ \\
\hline 03 & $\mathrm{E}+00$ & 1 & -02 & 1 & 1 & +00 & +00 \\
\hline 03 & -00 & 1 & -02 & 01 & 01 & +00 & $E+00$ \\
\hline $.47 E-03$ & & $E-01$ & -02 & & & 政 & +00 \\
\hline $.48 E-03$ & $3.80 \mathrm{E}+00$ & 01 & -02 & 01 & & $.35 E+00$ & $0 \mathrm{E}+00$ \\
\hline 3 & $.80 \mathrm{E}+00$ & 1 & 2 & 1 & 1 & $5 E+00$ & $01 \mathrm{E}+00$ \\
\hline $.51 E-03$ & $3.81 \mathrm{E}+00$ & $2.36 \mathrm{E}-01$ & $6 E-02$ & $48 \mathrm{E}-01$ & $16 \mathrm{E}-01$ & $5 \mathrm{E}+00$ & $01 \mathrm{E}+0 \mathrm{C}$ \\
\hline 03 & $E+00$ & $37 \mathrm{E}-01$ & $E-02$ & $E-01$ & 01 & 00 & $E+00$ \\
\hline 03 & & 1 & & & & 0 & +00 \\
\hline $55 E-03$ & $3.0 \angle E+00$ & $E-01$ & -02 & & & $E+U 0$ & +00 \\
\hline 年 & $3.0 \angle \mathrm{T} U \mathrm{O}$ & $2 \cdot 0,1$ & $25 E-02$ & $56 E-01$ & $26 E-01$ & $.36 E+00$ & $.03 E+00$ \\
\hline 03 & 0 & $2 \cdot 700$ & 2 & 1 & 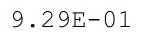 & $.36 \mathrm{E}+00$ & $.03 E+0 C$ \\
\hline ( & 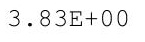 & - & 2 & 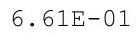 & 1 & $36 \mathrm{E}+00$ & $04 \mathrm{E}+0$ \\
\hline 03 & $83 F+00$ & $.42 E-01$ & $E-02$ & $4 E-01$ & & $6 \mathrm{E}+00$ & $04 \mathrm{E}+00$ \\
\hline$E-03$ & $E+00$ & $E-01$ & & & 1 & +00 & +00 \\
\hline $.64 \mathrm{E}-03$ & $3.83 \mathrm{E}+00$ & $E-01$ & -02 & $9 E-01$ & 01 & $.37 E+00$ & $5 \mathrm{E}+00$ \\
\hline $.66 \mathrm{E}-03$ & $3.84 \mathrm{E}+00$ & $2.44 \mathrm{E}-01$ & $7 E-02$ & $72 E-01$ & $41 E-01$ & $.37 E+00$ & $05 E+00$ \\
\hline $.67 E-03$ & & & & & & $.37 E+00$ & $.06 E+00$ \\
\hline 3 & & & & & & & $.06 E+00$ \\
\hline 3 & $3.85 \mathrm{E}+00$ & & & 1 & & 0 & 00 \\
\hline 3 & & & & & & & \\
\hline$E-03$ & & & & 6 & 1 & $.38 \mathrm{E}+00$ & \\
\hline $.75 E-03$ & $3.85 \mathrm{E}+00$ & $9 E-01$ & 02 & 1 & 1 & & +00 \\
\hline 03 & $3.86 \mathrm{E}+00$ & $.50 \mathrm{E}-$ & & 1 & & & $E+00$ \\
\hline 5 & $3.00 \mathrm{E}+00$ & 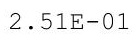 & 02 & 1 & & $.39 E+00$ & $.08 \mathrm{E}+00$ \\
\hline & ( & 2. & 1 & ( & 1 & $1.39 \mathrm{E}+00$ & $.08 \mathrm{E}+0$ \\
\hline P & 3 & & & 0.91 & .0 & $39 \mathrm{E}+$ & $08 \mathrm{E}$ \\
\hline $83 E-03$ & $3.87 \mathrm{E}+00$ & $2.53 E-01$ & $1.02 \mathrm{E}-01$ & 6 & 01 & $1.39 \mathrm{E}+00$ & $2.09 \mathrm{E}+00$ \\
\hline $.85 E-03$ & $3.87 \mathrm{E}+00$ & $.54 \mathrm{E}-01$ & $.02 E-01$ & $5.97 E-01$ & $9.75 \mathrm{E}-01$ & $40 E+00$ & $.09 \mathrm{E}+00$ \\
\hline
\end{tabular}


RESRAD-OFFSITE, Version 2.5

$\mathrm{T}^{1 / 2}$ Limit $=180$ days

Title : RESRAD-OFFSITE Drinking Water, Plant, Milk, and Meat Pathways for Offsite Reside File : PBA-1_TC99-DOE-5.ROF

Summary of dose at graphical times, reptition 2 (continued)

Time

Years

$5.66 \mathrm{E}+02$

$5.67 \mathrm{E}+02$

$5.67 \mathrm{E}+02$

$5.68 \mathrm{E}+02$

$5.68 \mathrm{E}+02$

$5.69 \mathrm{E}+02$

$5.69 \mathrm{E}+02$

$5.70 \mathrm{E}+02$

$5.70 \mathrm{E}+02$

$5.71 E+02$

$5.71 \mathrm{E}+02$

$5.72 \mathrm{E}+02$

$5.72 \mathrm{E}+02$

$5.73 \mathrm{E}+02$

$5.73 \mathrm{E}+02$

$5.74 \mathrm{E}+02$

$5.74 \mathrm{E}+02$

$5.75 \mathrm{E}+02$

$5.75 \mathrm{E}+02$

$5.76 \mathrm{E}+02$

$5.76 \mathrm{E}+02$

$5.77 \mathrm{E}+02$

$5.77 \mathrm{E}+02$

$5.78 \mathrm{E}+02$

$5.78 \mathrm{E}+02$

$5.79 \mathrm{E}+02$

$5.79 \mathrm{E}+02$

$5.80 \mathrm{E}+02$

$5.80 \mathrm{E}+02$

$5.81 \mathrm{E}+02$

$5.81 \mathrm{E}+02$

$5.82 \mathrm{E}+02$

$5.82 \mathrm{E}+02$

$5.83 \mathrm{E}+02$

$5.83 \mathrm{E}+02$

$5.84 \mathrm{E}+02$

$5.84 \mathrm{E}+02$

$5.85 \mathrm{E}+02$

$5.85 \mathrm{E}+02$

$5.86 \mathrm{E}+02$

$5.87 \mathrm{E}+02$

$5.87 \mathrm{E}+02$

$5.88 \mathrm{E}+02$

$5.88 \mathrm{E}+02$

$5.89 \mathrm{E}+02$

$5.89 \mathrm{E}+02$
Dose statistics at graphical times, mrem/yr

\begin{tabular}{|c|c|c|c|c|c|c|c|}
\hline inimum & aximum & Mean & ledian & $0 \%$ & $5 \%$ & $97.5 \%$ & \\
\hline 03 & $3.87 E+00$ & $2.55 E-01$ & 1.03E-01 & 1 & 1 & 00 & + \\
\hline 03 & +00 & 1 & 1 & 1 & 1 & 00 & +00 \\
\hline 03 & +00 & -01 & 01 & $5 E-01$ & $83 E-01$ & 00 & +00 \\
\hline 03 & 00 & 1 & & & & 00 & +00 \\
\hline $3 E-03$ & -00 & & & 01 & 01 & +00 & $10 \mathrm{E}+00$ \\
\hline $.95 E-03$ & +00 & $E-01$ & $E-01$ & 1 & $2 E-$ & $.41 E+00$ & $11 E+00$ \\
\hline $.97 E-03$ & +00 & 要 & -01 & . & 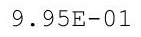 & +00 & +00 \\
\hline $.98 E-03$ & $3.89 \mathrm{E}+00$ & t & & $7.17 \mathrm{E}-01$ & 年 & +00 & +00 \\
\hline 03 & +00 & 1 & 01 & 01 & 00 & +00 & +00 \\
\hline $.02 E-03$ & $9 \mathrm{E}+00$ & $.62 E-01$ & -01 & $E-01$ & $00 \mathrm{E}+00$ & $.42 \mathrm{E}+00$ & $12 \mathrm{E}+00$ \\
\hline-03 & -00 & 1 & -01 & 1 & & 00 & $12 \mathrm{E}+00$ \\
\hline-03 & +00 & $\perp$ & & & & +00 & +00 \\
\hline $.07 \mathrm{E}-03$ & $\mathrm{E}+00$ & 型 & -01 & 1 & 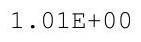 & +00 & +0 \\
\hline 03 & -00 & H & 01 & 01 & 00 & +00 & $13 E+00$ \\
\hline 03 & -00 & 1 & 01 & 01 & 00 & +00 & +00 \\
\hline $.13 E-03$ & $3.91 \mathrm{E}+00$ & 1 & -01 & 1 & $1.02 \mathrm{E}+00$ & $.43 E+00$ & $14 \mathrm{E}+00$ \\
\hline $.14 \mathrm{E}-03$ & $3.91 \mathrm{E}+00$ & $2.68 \mathrm{E}-01$ & $1 E-01$ & $36 E-01$ & $.02 \mathrm{E}+00$ & $.44 \mathrm{E}+00$ & $.14 \mathrm{E}+00$ \\
\hline$E-03$ & $91 E+00$ & $.69 E-01$ & $2 E-01$ & $9 E-01$ & $02 E+00$ & $44 E+00$ & $14 \mathrm{E}+0 \mathrm{C}$ \\
\hline 03 & $E+00$ & 1 & 01 & 1 & & +00 & $E+U$ \\
\hline $20 E-03$ & $3.92 E+00$ & $2.71 E-01$ & 01 & 1 & & +00 & $15 E+0 c$ \\
\hline $.22 \mathrm{E}-03$ & & & -01 & & & +00 & +00 \\
\hline$E-03$ & $3.92 \mathrm{E}+00$ & -01 & 01 & 1 & $1.03 \mathrm{E}+00$ & $.45 E+00$ & $15 \mathrm{E}+00$ \\
\hline 03 & & 1 & 1 & 1 & $.03 E+00$ & $.45 E+00$ & $.15 E+00$ \\
\hline $3 E-03$ & $.92 \mathrm{E}+00$ & $2.74 \mathrm{E}-01$ & 1. 15E-01 & $55 E-01$ & $1.04 \mathrm{E}+00$ & $.45 \mathrm{E}+00$ & $16 \mathrm{E}+0 \mathrm{C}$ \\
\hline 03 & $93 E+00$ & $.75 \mathrm{E}-01$ & $6 \mathrm{E}-01$ & $8 E-01$ & & $46 E+00$ & $16 \mathrm{E}+0 \mathrm{c}$ \\
\hline 3 & 0 & & & & & 00 & 100 \\
\hline $.33 E-03$ & $3 E+00$ & -01 & -01 & 1 & 1.01 & $E+U 0$ & +00 \\
\hline $35 E-03$ & . . & $2.78 E-01$ & $.18 \mathrm{E}-01$ & $66 E-01$ & 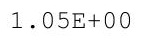 & $.46 \mathrm{E}+00$ & $.17 \mathrm{E}+00$ \\
\hline 03 & י עل & 年 & $19 E-01$ & 1 & $.05 E+00$ & $.46 \mathrm{E}+00$ & $.17 \mathrm{E}+0 \mathrm{C}$ \\
\hline- & 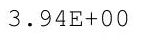 & $79 E-01$ & -0 & 1 & & $47 E+00$ & $17 \mathrm{E}+$ \\
\hline$F-03$ & Q & & $E-01$ & $2 E-01$ & $05 E+00$ & $\mathrm{E}+00$ & $18 \mathrm{E}+00$ \\
\hline$E-03$ & $\mathrm{E}+00$ & & & & & & \\
\hline 03 & & & & -01 & & 0 & \\
\hline $.48 E-03$ & $3.94 \mathrm{E}+00$ & $2.83 E-01$ & 1.22E-01 & $79 E-01$ & $1.06 E+00$ & $.48 E+00$ & $.18 \mathrm{E}+0 \mathrm{c}$ \\
\hline $30-40$ & & $2.84 E-01$ & $.22 E-01$ & $7.81 E-01$ & 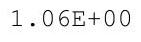 & $.48 \mathrm{E}+00$ & $.19 E+0$ \\
\hline & & & & & & & \\
\hline $.54 \mathrm{E}-03$ & $3.95 \mathrm{E}+00$ & & 1 & & 0 & & ד \\
\hline 3 & & & & & & & \\
\hline$E-03$ & & & -01 & 01 & $7 E+00$ & $.49 \mathrm{E}+00$ & $.20 \mathrm{E}+00$ \\
\hline $0 E-03$ & $3.95 \mathrm{E}+00$ & $2.88 E-01$ & -01 & 1 & 0 & 0 & $0 \mathrm{E}+00$ \\
\hline $2 E-03$ & $\mathrm{E}+$ & 1 & 01 & 1 & $.07 \mathrm{E}+$ & & $.20 \mathrm{E}+0 \mathrm{C}$ \\
\hline 03 & $3.90 \pm+00$ & $2 \cdot 201$ & 01 & 1 & $1.08 \mathrm{E}+00$ & $.50 \mathrm{E}+00$ & $.20 E+00$ \\
\hline 3 & $3.96 \mathrm{E}+0$ & + & $1.27 E-01$ & - & $1.08 \mathrm{E}+$ & $.50 \mathrm{E}+00$ & $.21 E+0$ \\
\hline P & $3.96 \mathrm{E}+00$ & . & & ( & 0 & 0 & $21 E-$ \\
\hline$E-03$ & $5 \mathrm{E}+00$ & $2.92 E-01$ & $8 E-01$ & 01 & $1.08 \mathrm{E}+00$ & $.51 \mathrm{E}+00$ & $2.21 \mathrm{E}+00$ \\
\hline $.73 E-03$ & $3.96 \mathrm{E}+00$ & $.93 E-01$ & 1. $29 \mathrm{E}-01$ & 8.03E-01 & $1.09 \mathrm{E}+00$ & 1. $51 \mathrm{E}+00$ & $.21 E+00$ \\
\hline
\end{tabular}


RESRAD-OFFSITE, Version 2.5

Title : RESRAD-OFFSITE Drinking Water, Plant, Milk, and Meat Pathways for Offsite Reside File : PBA-1_TC99-DOE-5.ROF

Summary of dose at graphical times, reptition 2 (continued)

Time

Years

$5.90 \mathrm{E}+02$

$5.90 \mathrm{E}+02$

$5.91 \mathrm{E}+02$

$5.91 \mathrm{E}+02$

$5.92 \mathrm{E}+02$

$5.92 \mathrm{E}+02$

$5.93 \mathrm{E}+02$

$5.93 \mathrm{E}+02$

$5.94 \mathrm{E}+02$

$5.94 \mathrm{E}+02$

$5.95 \mathrm{E}+02$

$5.95 \mathrm{E}+02$

$5.96 \mathrm{E}+02$

$5.96 \mathrm{E}+02$

$5.97 \mathrm{E}+02$

$5.97 \mathrm{E}+02$

$5.98 \mathrm{E}+02$

$5.98 \mathrm{E}+02$

$5.99 \mathrm{E}+02$

$5.99 \mathrm{E}+02$

$6.00 \mathrm{E}+02$

$6.00 \mathrm{E}+02$

$6.01 \mathrm{E}+02$

$6.01 \mathrm{E}+02$

$6.02 \mathrm{E}+02$

$6.02 \mathrm{E}+02$

$6.03 E+02$

$6.03 \mathrm{E}+02$

$6.04 \mathrm{E}+02$

$6.04 \mathrm{E}+02$

$6.05 \mathrm{E}+02$

$6.05 \mathrm{E}+02$

$6.06 \mathrm{E}+02$

$6.07 \mathrm{E}+02$

$6.07 \mathrm{E}+02$

$6.08 \mathrm{E}+02$

$6.08 \mathrm{E}+02$

$6.09 \mathrm{E}+02$

$6.09 \mathrm{E}+02$

$6.10 \mathrm{E}+02$

$6.10 \mathrm{E}+02$

$6.11 \mathrm{E}+02$

$6.11 \mathrm{E}+02$

$6.12 \mathrm{E}+02$

$6.12 \mathrm{E}+02$

$6.13 \mathrm{E}+02$
Dose statistics at graphical times, mrem/yr

\begin{tabular}{|c|c|c|c|c|c|c|c|}
\hline inimum & aximum & Mean & ledian & $0 \%$ & $\%$ & $97.5 \%$ & \\
\hline 3 & +00 & 01 & 01 & 1 & 00 & -00 & +0 \\
\hline 03 & $E+00$ & 1 & 1 & 1 & 00 & 00 & 100 \\
\hline-03 & +00 & 01 & 1 & $9 E-01$ & 00 & 00 & +00 \\
\hline 03 & 00 & 1 & & & & 00 & +00 \\
\hline-03 & 00 & & & & 00 & $E+00$ & $22 E+00$ \\
\hline $.86 E-03$ & $E+00$ & $E-01$ & -01 & 01 & $.10 \mathrm{E}+00$ & $E+00$ & $.23 E+00$ \\
\hline 03 & -00 & -01 & -01 & 1 & ח & $3 E+00$ & $23 E+0$ \\
\hline 03 & $3.97 \mathrm{E}+00$ & 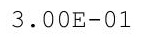 & & & $1 . \pm 1$ & +00 & $.23 E+0$ \\
\hline 03 & +00 & 1 & 01 & 01 & 00 & +00 & +00 \\
\hline $.96 \mathrm{E}-03$ & $97 \mathrm{E}+00$ & $2 E-01$ & $5 E-01$ & $E-01$ & & $E+00$ & $23 E+00$ \\
\hline-03 & +00 & 1 & -01 & 1 & & 00 & $\mathrm{E}+00$ \\
\hline & +00 & & & & & -00 & $\mathrm{E}+\mathrm{OC}$ \\
\hline-03 & $E+00$ & 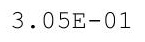 & -01 & 1 & $1 \cdot x_{2}$ & $E+00$ & +0 \\
\hline 03 & -00 & $\perp$ & 01 & 01 & 00 & +00 & $.24 \mathrm{E}+0$ \\
\hline 03 & $3.98 \mathrm{E}+00$ & - & & 1 & 00 & +00 & $E+00$ \\
\hline-03 & $3.98 \mathrm{E}+00$ & - & -01 & 1 & & $E+00$ & $.25 E+00$ \\
\hline $.12 \mathrm{E}-03$ & $8 \mathrm{E}+00$ & $8 \mathrm{E}-01$ & $9 E-01$ & $8.33 E-01$ & $1.14 \mathrm{E}+00$ & $7 \mathrm{E}+00$ & $.25 \mathrm{E}+00$ \\
\hline-03 & $8 E+00$ & $9 E-01$ & $0 \mathrm{E}-01$ & $5 E-01$ & $1.14 \mathrm{E}+00$ & $7 E+00$ & $26 E+00$ \\
\hline 03 & +00 & & 01 & 1 & 0 & +00 & +0 \\
\hline 03 & -00 & $\perp$ & 01 & 01 & 0 & +00 & +0 \\
\hline $.22 E-03$ & & & -01 & & & (1) & +00 \\
\hline 03 & $E+00$ & 1 & 1 & & $115 \mathrm{~F}$ & $8 F+0$ & $26 E+00$ \\
\hline 3 & $99 E+00$ & 1 & $3 E-01$ & 1 & $1.16 \mathrm{E}+00$ & $.59 E+00$ & $27 E+00$ \\
\hline$E-03$ & $.99 \mathrm{E}+00$ & $3.14 \mathrm{E}-01$ & $4 \mathrm{E}-01$ & $48 \mathrm{E}-01$ & $1.16 \mathrm{E}+00$ & $.59 \mathrm{E}+00$ & $.27 E+00$ \\
\hline 03 & $\mathrm{E}+00$ & $5 E-01$ & $E-01$ & $0 E-01$ & & $\mathrm{~F}+00$ & $27 E+0 c$ \\
\hline & & & & & & & +00 \\
\hline $37 E-03$ & $E+00$ & -01 & 01 & 1 & 1.1 & $1.60 E+00$ & $28 E+00$ \\
\hline $.40 E-03$ & . . & $.18 \mathrm{E}-01$ & $1.47 \mathrm{E}-01$ & $8.57 E-01$ & $\perp \cdot \perp / \mathrm{LT} U$ & $.60 \mathrm{E}+00$ & $.28 E+00$ \\
\hline 03 & ע על & 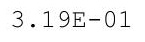 & $47 E-01$ & 1 & $1.17 \mathrm{E}+00$ & $.61 E+00$ & $.28 E+00$ \\
\hline 3 & 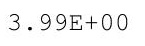 & - & 1 & 1 & $.18 \mathrm{E}+$ & $.61 \mathrm{E}+0$ & $.28 \mathrm{E}+0$ \\
\hline-03 & مaF+ag & $1 F-01$ & & $6 E-01$ & $1.18 \mathrm{E}+00$ & $F+00$ & $.29 E+00$ \\
\hline & & & & & & & \\
\hline & & & & & & & $.29 E+00$ \\
\hline $.56 E-03$ & $4.00 \mathrm{E}+00$ & $3.23 E-01$ & 1. $51 \mathrm{E}-01$ & $74 \mathrm{E}-01$ & $1 \cdot 19 E+00$ & $1.62 \mathrm{E}+00$ & $2.29 \mathrm{E}+0 \mathrm{C}$ \\
\hline $205-43$ & & & $1.52 \mathrm{E}-01$ & $8.77 E-01$ & & 1. OJETU & $2.30 \mathrm{E}+0$ \\
\hline 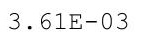 & & & & & & & $.30 \mathrm{E}+0 \mathrm{C}$ \\
\hline & $4.00 \mathrm{E}+00$ & & & 1 & & 0 & קת \\
\hline 3 & & & & 1 & & & \\
\hline 3 & & 1 & $5 E-01$ & 1 & $1.20 \mathrm{E}+00$ & & $2.31 E+00$ \\
\hline $2 E-03$ & $4.00 \mathrm{E}+00$ & $E-01$ & 01 & 1 & 1.20 & & $2.31 \mathrm{E}+00$ \\
\hline 3 & & & & & & & $2.31 \mathrm{E}+0$ \\
\hline & $4.00 \mathrm{E}+00$ & $\perp$ & 1 & 1 & $\perp \cdot \angle \perp E+U 0$ & $1.65 \mathrm{E}+00$ & $2.325+00$ \\
\hline 3 & $00 E+00$ & + & $1.57 \mathrm{E}-01$ & . & $\begin{array}{ll}2 \\
0\end{array}$ & $1.65 \mathrm{E}+00$ & $2.32 \mathrm{E}+0$ \\
\hline $3.83 E-03$ & & & & 1 & $22 \mathrm{E}$ & $66 \mathrm{E}+$ & 2. $32 E+00$ \\
\hline-03 & $4.00 \mathrm{E}+00$ & $3 E-01$ & $8 E-01$ & 01 & $1.22 \mathrm{E}+00$ & $1.66 \mathrm{E}+00$ & $2.32 \mathrm{E}+00$ \\
\hline $.89 E-03$ & $4.00 \mathrm{E}+00$ & $.34 \mathrm{E}-01$ & $1.59 \mathrm{E}-01$ & $9.04 \mathrm{E}-01$ & $1.22 \mathrm{E}+00$ & $1.66 \mathrm{E}+00$ & $2.33 E+00$ \\
\hline
\end{tabular}


RESRAD-OFFSITE, Version 2.5

Title : RESRAD-OFFSITE Drinking Water, Plant, Milk, and Meat Pathways for Offsite Reside File : PBA-1_TC99-DOE-5.ROF

Summary of dose at graphical times, reptition 2 (continued)

Time

Years

$6.13 \mathrm{E}+02$

$6.14 \mathrm{E}+02$

$6.14 \mathrm{E}+02$

$6.15 \mathrm{E}+02$

$6.15 \mathrm{E}+02$

$6.16 \mathrm{E}+02$

$6.16 \mathrm{E}+02$

$6.17 \mathrm{E}+02$

$6.17 \mathrm{E}+02$

$6.18 \mathrm{E}+02$

$6.18 \mathrm{E}+02$

$6.19 \mathrm{E}+02$

$6.19 \mathrm{E}+02$

$6.20 \mathrm{E}+02$

$6.20 \mathrm{E}+02$

$6.21 \mathrm{E}+02$

$6.21 \mathrm{E}+02$

$6.22 \mathrm{E}+02$

$6.22 \mathrm{E}+02$

$6.23 \mathrm{E}+02$

$6.23 \mathrm{E}+02$

$6.24 \mathrm{E}+02$

$6.24 \mathrm{E}+02$

$6.25 \mathrm{E}+02$

$6.25 \mathrm{E}+02$

$6.26 \mathrm{E}+02$

$6.27 \mathrm{E}+02$

$6.27 \mathrm{E}+02$

$6.28 \mathrm{E}+02$

$6.28 \mathrm{E}+02$

$6.29 \mathrm{E}+02$

$6.29 \mathrm{E}+02$

$6.30 \mathrm{E}+02$

$6.30 \mathrm{E}+02$

$6.31 \mathrm{E}+02$

$6.31 \mathrm{E}+02$

$6.32 \mathrm{E}+02$

$6.32 \mathrm{E}+02$

$6.33 \mathrm{E}+02$

$6.33 \mathrm{E}+02$

$6.34 \mathrm{E}+02$

$6.34 \mathrm{E}+02$

$6.35 \mathrm{E}+02$

$6.35 \mathrm{E}+02$

$6.36 \mathrm{E}+02$

$6.36 \mathrm{E}+02$
Dose statistics at graphical times, mrem/yr

\begin{tabular}{|c|c|c|c|c|c|c|c|}
\hline inimum & aximum & Mean & ledian & $0 \%$ & $5 \%$ & $97.5 \%$ & \\
\hline 3 & +00 & 1 & -01 & 01 & 00 & -00 & +00 \\
\hline 03 & +00 & 1 & 1 & $9 \mathrm{E}-$ & $22 E+00$ & 00 & $33 E+00$ \\
\hline 03 & +00 & 1 & 01 & 1 & 00 & 00 & +00 \\
\hline-03 & $E+00$ & 1 & & & & +00 & +00 \\
\hline-03 & 00 & & & 01 & 00 & $\mathrm{E}+00$ & $34 \mathrm{E}+00$ \\
\hline $6 E-03$ & $E+00$ & -01 & -01 & .17 & $1.24 \mathrm{E}+$ & $.68 E+00$ & $34 \mathrm{E}+00$ \\
\hline-03 & +00 & $E-01$ & -01 & $E-01$ & 00 & +00 & $5 E+00$ \\
\hline $2 E-03$ & $4.00 \mathrm{E}+00$ & & & $9.20 \mathrm{E}-01$ & 00 & +00 & $35 \mathrm{E}+0 \mathrm{C}$ \\
\hline 03 & -00 & 1 & 01 & $22 E-01$ & 00 & +00 & +00 \\
\hline $.18 \mathrm{E}-03$ & $4.00 \mathrm{E}+00$ & $3 E-01$ & $6 E-01$ & $23 E-01$ & 1. $25 E+00$ & $.70 \mathrm{E}+00$ & $E+00$ \\
\hline-03 & +00 & 1 & 1 & 1 & & 00 & $E+00$ \\
\hline & +00 & 1 & & & 00 & +00 & $E+00$ \\
\hline$E-03$ & $E+00$ & 更 & $E-01$ & -01 & $-25 E+00$ & +00 & +00 \\
\hline 03 & -00 & I & -01 & $30 E-01$ & 00 & +00 & +00 \\
\hline 03 & -00 & 1 & 01 & 01 & - & $\mathrm{E}+00$ & +00 \\
\hline $.36 \mathrm{E}-03$ & $4.01 \mathrm{E}+00$ & $\Gamma$ & -01 & 1 & $1.26 \mathrm{E}+00$ & $.71 E+00$ & $37 \mathrm{E}+00$ \\
\hline $.40 E-03$ & $1 E+00$ & $E-01$ & $1 E-01$ & $36 \mathrm{E}-01$ & $1.27 \mathrm{E}+00$ & $.71 \mathrm{E}+00$ & $.37 E+00$ \\
\hline-03 & $01 E+00$ & $E-01$ & $2 E-01$ & $8 E-01$ & $1.27 \mathrm{E}+00$ & $.71 E+00$ & $37 E+00$ \\
\hline 03 & $1 \mathrm{E}+00$ & 1 & 01 & 1 & 0 & +00 & +00 \\
\hline 03 & 00 & -01 & -01 & 01 & 0 & +00 & +00 \\
\hline $.52 E-03$ & & & -01 & & 1.0 & 更 & +00 \\
\hline $.55 E-03$ & $4.01 \mathrm{E}+00$ & -01 & -01 & & $1.28 \mathrm{E}+00$ & $.72 \mathrm{E}+0$ & $38 \mathrm{E}+00$ \\
\hline 3 & 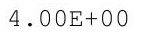 & 1 & $5 E-01$ & 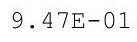 & $1.28 \mathrm{E}+00$ & $.72 E+00$ & $.39 E+00$ \\
\hline $2 E-03$ & $.00 \mathrm{E}+00$ & $6 \mathrm{E}-01$ & $6 E-01$ & $49 \mathrm{E}-01$ & $1.28 \mathrm{E}+00$ & $.73 E+00$ & $.39 \mathrm{E}+0 \mathrm{C}$ \\
\hline 03 & $.00 \mathrm{E}+00$ & $7 E-01$ & $7 E-01$ & $1 E-01$ & & $.73 E+00$ & $9 E+0 c$ \\
\hline 03 & & & 01 & 1 & & 00 & 100 \\
\hline $2+-03$ & $00 \mathrm{E}+00$ & & -01 & & 要 & $.13 E+U 0$ & +00 \\
\hline 有 & . OULTOU & 象 & $9 E-01$ & $56 E-01$ & Р. . & $.73 E+00$ & $.40 \mathrm{E}+00$ \\
\hline 03 & $00 \mathrm{E}+00$ & 更 & 1 & 1 & $1.29 \mathrm{E}+00$ & $.74 \mathrm{E}+00$ & $.40 \mathrm{E}+0$ \\
\hline 3 & - & - & - & 1 & & $.74 \mathrm{E}+0$ & $40 \mathrm{E}+0$ \\
\hline-03 & $\cap \cap F+\cap \cap$ & & $1 E-01$ & $1 E-01$ & $1.30 \mathrm{E}+00$ & $74 \mathrm{~F}+00$ & $41 E+00$ \\
\hline 3 & & & & 1 & & & +00 \\
\hline$E-03$ & $4.00 \mathrm{E}+00$ & 1 & 01 & 01 & 1.50 & $.74 \mathrm{E}+00$ & $41 E+00$ \\
\hline $.95 E-03$ & $4.005+00$ & $.65 E-01$ & $1.83 E-01$ & $8 E-01$ & $1.315+00$ & $.75 E+00$ & $.41 E+00$ \\
\hline $805-43$ & . VULTU & & $1.84 E-01$ & & & $.75 E+00$ & $.42 E+0$ \\
\hline 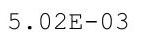 & & & & & & & \\
\hline 3 & $4.00 \mathrm{E}+00$ & & & & & 0 & $42 \mathrm{E}+0 \mathrm{C}$ \\
\hline 3 & & & & 1 & & $\mathrm{E}+00$ & \\
\hline 03 & & & & -01 & $1.32 \mathrm{E}+00$ & $76 E+00$ & \\
\hline $6 E-03$ & $4.00 \mathrm{E}+00$ & $E-01$ & 1 . & 1 & 1.32 & 0 & +00 \\
\hline 3 & $4.00 \mathrm{E}+00$ & 1 & & 1 & & $.76 \mathrm{E}+00$ & $.43 E+0 C$ \\
\hline & $4.00 \mathrm{E}+00$ & 1 & & 1 & $1.33 \mathrm{E}+00$ & $.76 \mathrm{E}+00$ & $.43 E+00$ \\
\hline 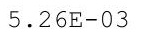 & $4.00 \mathrm{E}+00$ & 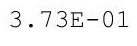 & . & ( & 1.33E+ & $.76 \mathrm{E}+00$ & $.44 \mathrm{E}+0 \mathrm{C}$ \\
\hline P & 4.00 & - & $\perp \cdot 915$ & 1 & $33 E$ & 0 & $44 \mathrm{E}+00$ \\
\hline$E-03$ & $4.00 \mathrm{E}+00$ & $E-01$ & 1 & 01 & $1.33 E+00$ & $1.77 \mathrm{E}+00$ & $2.44 \mathrm{E}+00$ \\
\hline $.37 E-03$ & $4.00 \mathrm{E}+00$ & $.76 E-01$ & 1. $92 \mathrm{E}-01$ & $9.92 E-01$ & $1.34 \mathrm{E}+00$ & $1.77 \mathrm{E}+00$ & $2.45 \mathrm{E}+00$ \\
\hline
\end{tabular}


RESRAD-OFFSITE, Version 2.5

Title : RESRAD-OFFSITE Drinking Water, Plant, Milk, and Meat Pathways for Offsite Reside File : PBA-1_TC99-DOE-5.ROF

Summary of dose at graphical times, reptition 2 (continued)

Time

Years

$6.37 \mathrm{E}+02$

$6.37 \mathrm{E}+02$

$6.38 \mathrm{E}+02$

$6.38 \mathrm{E}+02$

$6.39 \mathrm{E}+02$

$6.39 \mathrm{E}+02$

$6.40 \mathrm{E}+02$

$6.40 \mathrm{E}+02$

$6.41 \mathrm{E}+02$

$6.41 \mathrm{E}+02$

$6.42 \mathrm{E}+02$

$6.42 \mathrm{E}+02$

$6.43 \mathrm{E}+02$

$6.43 \mathrm{E}+02$

$6.44 \mathrm{E}+02$

$6.44 \mathrm{E}+02$

$6.45 \mathrm{E}+02$

$6.45 \mathrm{E}+02$

$6.46 \mathrm{E}+02$

$6.47 \mathrm{E}+02$

$6.47 \mathrm{E}+02$

$6.48 \mathrm{E}+02$

$6.48 \mathrm{E}+02$

$6.49 \mathrm{E}+02$

$6.49 \mathrm{E}+02$

$6.50 \mathrm{E}+02$

$6.50 \mathrm{E}+02$

$6.51 \mathrm{E}+02$

$6.51 \mathrm{E}+02$

$6.52 \mathrm{E}+02$

$6.52 \mathrm{E}+02$

$6.53 \mathrm{E}+02$

$6.53 \mathrm{E}+02$

$6.54 \mathrm{E}+02$

$6.54 \mathrm{E}+02$

$6.55 \mathrm{E}+02$

$6.55 \mathrm{E}+02$

$6.56 \mathrm{E}+02$

$6.56 \mathrm{E}+02$

$6.57 \mathrm{E}+02$

$6.57 \mathrm{E}+02$

$6.58 \mathrm{E}+02$

$6.58 \mathrm{E}+02$

$6.59 \mathrm{E}+02$

$6.59 \mathrm{E}+02$

$6.60 \mathrm{E}+02$
Dose statistics at graphical times, mrem/yr

\begin{tabular}{|c|c|c|c|c|c|c|c|}
\hline inimum & aximum & Mean & ledian & $0 \%$ & $5 \%$ & $97.5 \%$ & $3 \%$ \\
\hline 3 & +00 & $E-01$ & $E-01$ & 01 & 00 & +00 & +00 \\
\hline 03 & -00 & 1 & 1 & $5 E-$ & 00 & -00 & +00 \\
\hline 03 & +00 & -01 & $E-01$ & 1 & 00 & 00 & +00 \\
\hline 03 & 00 & 1 & & & & 00 & +00 \\
\hline-03 & 00 & & & 0 & 00 & $E+00$ & $46 E+00$ \\
\hline-03 & +00 & -01 & $E-01$ & $1.00 \mathrm{E}+00$ & $E+00$ & $.78 E+00$ & $.46 \mathrm{E}+00$ \\
\hline-03 & $9 \mathrm{E}+00$ & $E-01$ & $8 E-01$ & 00 & 00 & +00 & $47 \mathrm{E}+0 \mathrm{C}$ \\
\hline $6 E-03$ & $3.99 \mathrm{E}+00$ & & $1.99 \mathrm{E}-01$ & & & $.78 E+00$ & $.47 \mathrm{E}+0 \mathrm{C}$ \\
\hline 03 & +00 & 1 & 01 & 00 & 00 & +00 & +00 \\
\hline $4 E-03$ & $3.99 \mathrm{E}+00$ & $E-01$ & $0 E-01$ & $01 E+00$ & $1.36 \mathrm{E}+00$ & $.79 E+00$ & $.47 E+00$ \\
\hline-03 & +00 & 1 & -01 & & & 00 & $E+00$ \\
\hline & -00 & & & & & +00 & +00 \\
\hline $.85 \mathrm{E}-03$ & $3.99 \mathrm{E}+00$ & 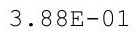 & $2.02 E-01$ & $1 . U \perp E+U 0$ & 1.37E+U0 & $.79 \mathrm{E}+00$ & $.48 \mathrm{E}+0 \mathrm{C}$ \\
\hline 03 & $3.99 \mathrm{E}+00$ & 工 & -01 & $1.02 \mathrm{E}+00$ & & +00 & $.48 E+00$ \\
\hline 03 & $9 \mathrm{E}+00$ & 1 & 01 & 00 & 00 & +00 & +00 \\
\hline $.97 E-03$ & $3.99 \mathrm{E}+00$ & 1 & -01 & $1.02 \mathrm{E}+00$ & & $.80 \mathrm{E}+00$ & $.49 \mathrm{E}+00$ \\
\hline $.00 \mathrm{E}-03$ & $3.99 \mathrm{E}+00$ & $2 E-01$ & $5 E-01$ & $1.02 \mathrm{E}+00$ & $.38 \mathrm{E}+00$ & $.80 \mathrm{E}+00$ & $.49 \mathrm{E}+00$ \\
\hline-03 & $98 E+00$ & $3 E-01$ & $6 E-01$ & $2 \mathrm{E}+00$ & $38 E+00$ & $80 E+00$ & $49 \mathrm{E}+00$ \\
\hline $8 E-03$ & $3.98 \mathrm{E}+00$ & $4 \mathrm{E}-01$ & $E-01$ & $2 \mathrm{E}+00$ & & $E+00$ & $0 \mathrm{E}+0 \mathrm{C}$ \\
\hline-03 & $E+00$ & -01 & -01 & 00 & & +00 & +00 \\
\hline$E-03$ & ט ט & & -01 & & & 100 & +00 \\
\hline $.20 E-03$ & $3.98 \mathrm{E}+00$ & $E-01$ & 01 & $1.03 E+00$ & $1.39 \mathrm{E}+00$ & $.81 E+00$ & $50 \mathrm{E}+00$ \\
\hline $1 F-03$ & $3.98 \mathrm{E}+00$ & $3.97 \mathrm{E}-01$ & $2.10 E-01$ & $1.03 E+00$ & $1.39 \mathrm{E}+00$ & $.81 E+00$ & $51 E+00$ \\
\hline $3 E-03$ & $.98 \mathrm{E}+00$ & $.98 E-01$ & $2.11 \mathrm{E}-01$ & $1.03 \mathrm{E}+00$ & $1.40 \mathrm{E}+00$ & $.82 E+00$ & $.51 \mathrm{E}+0 \mathrm{C}$ \\
\hline 03 & $98 E+00$ & $9 \mathrm{E}-01$ & $2 E-01$ & & & 00 & +00 \\
\hline 03 & 00 & 01 & $E-01$ & & & 0 & 100 \\
\hline$E-03$ & $5+00$ & -01 & -01 & & & $5+00$ & +00 \\
\hline $.44 \mathrm{E}-03$ & $3.90 \mathrm{THO}$ & $02 E-01$ & $2.14 \mathrm{E}-01$ & $1.04 \mathrm{E}+00$ & $\perp \cdot 4 \perp \mathrm{LT} U$ & $.83 E+00$ & $.52 \mathrm{E}+00$ \\
\hline 03 & 政 & 年 & 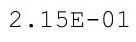 & טע & • & $.83 E+00$ & $.52 \mathrm{E}+0 \mathrm{C}$ \\
\hline 3 & 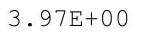 & - & 1 & 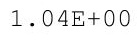 & 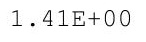 & $83 E+00$ & $52 \mathrm{E}+$ \\
\hline 03 & $97 F+0$ & $5 E-01$ & $6 E-01$ & $4 \mathrm{E}+00$ & $.42 \mathrm{E}+00$ & $83 E+00$ & $53 E+00$ \\
\hline 03 & $E+00$ & $5 E-01$ & $7 E-01$ & 0 & & & \\
\hline & & & & & & 0 & $53 E+00$ \\
\hline $.69 E-03$ & $3.97 \mathrm{E}+00$ & $.08 E-01$ & $2.19 E-01$ & $1.03 E+U 0$ & $1.43 E+00$ & $.84 \mathrm{E}+00$ & $.53 E+0 c$ \\
\hline $145-03$ & & & $2.20 E-01$ & $1.00 \mathrm{ET}$ & & $.84 \mathrm{E}+00$ & . J4ГTU \\
\hline $.78 E-03$ & & & & & & & \\
\hline $.82 E-03$ & $3.97 \mathrm{E}+00$ & & & 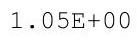 & & & 00 \\
\hline 3 & & & & & & & \\
\hline & & & -01 & & $1.44 \mathrm{E}+00$ & $.85 E+00$ & \\
\hline $5 E-03$ & $3.96 \mathrm{E}+00$ & -01 & -01 & 0 & 0 & 0 & +00 \\
\hline & $\mathrm{E}+$ & 1 & & 0 & & & $54 \mathrm{E}+0 \mathrm{C}$ \\
\hline & $3.90 \pm+00$ & -0 & 01 & $06 \mathrm{E}+00$ & $1.45 E+00$ & $.85 E+00$ & $.55 E+00$ \\
\hline & $3.96 \mathrm{E}+00$ & 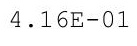 & ( & $1.00 \mathrm{~L}$ & $45 \mathrm{E}+$ & $.86 E+00$ & $.55 E+0$ \\
\hline P & 3 & & 2.टाम & 0 & $45 E$ & 0 & $55 \mathrm{E}-$ \\
\hline 03 & $3.96 \mathrm{E}+00$ & 4 & 2. & $1.06 \mathrm{E}+00$ & $1.45 \mathrm{E}+00$ & $.86 \mathrm{E}+00$ & $2.55 \mathrm{E}+00$ \\
\hline $.21 E-03$ & $3.95 \mathrm{E}+00$ & $.19 \mathrm{E}-01$ & $.28 E-01$ & $1.07 \mathrm{E}+00$ & $1.45 \mathrm{E}+00$ & $1.86 \mathrm{E}+00$ & $.55 E+00$ \\
\hline
\end{tabular}


RESRAD-OFFSITE, Version 2.5

Title : RESRAD-OFFSITE Drinking Water, Plant, Milk, and Meat Pathways for Offsite Reside File : PBA-1_TC99-DOE-5.ROF

Summary of dose at graphical times, reptition 2 (continued)

Time

Years

$6.60 \mathrm{E}+02$

$6.61 \mathrm{E}+02$

$6.61 \mathrm{E}+02$

$6.62 \mathrm{E}+02$

$6.62 \mathrm{E}+02$

$6.63 \mathrm{E}+02$

$6.63 \mathrm{E}+02$

$6.64 \mathrm{E}+02$

$6.64 \mathrm{E}+02$

$6.65 \mathrm{E}+02$

$6.65 \mathrm{E}+02$

$6.66 \mathrm{E}+02$

$6.67 \mathrm{E}+02$

$6.67 \mathrm{E}+02$

$6.68 \mathrm{E}+02$

$6.68 \mathrm{E}+02$

$6.69 \mathrm{E}+02$

$6.69 \mathrm{E}+02$

$6.70 \mathrm{E}+02$

$6.70 \mathrm{E}+02$

$6.71 \mathrm{E}+02$

$6.71 \mathrm{E}+02$

$6.72 \mathrm{E}+02$

$6.72 \mathrm{E}+02$

$6.73 \mathrm{E}+02$

$6.73 \mathrm{E}+02$

$6.74 \mathrm{E}+02$

$6.74 \mathrm{E}+02$

$6.75 \mathrm{E}+02$

$6.75 \mathrm{E}+02$

$6.76 \mathrm{E}+02$

$6.76 \mathrm{E}+02$

$6.77 \mathrm{E}+02$

$6.77 \mathrm{E}+02$

$6.78 \mathrm{E}+02$

$6.78 \mathrm{E}+02$

$6.79 \mathrm{E}+02$

$6.79 \mathrm{E}+02$

$6.80 \mathrm{E}+02$

$6.80 \mathrm{E}+02$

$6.81 \mathrm{E}+02$

$6.81 \mathrm{E}+02$

$6.82 \mathrm{E}+02$

$6.82 \mathrm{E}+02$

$6.83 \mathrm{E}+02$

$6.83 \mathrm{E}+02$
Dose statistics at graphical times, mrem/yr

\begin{tabular}{|c|c|c|c|c|c|c|c|}
\hline inimum & aximum & Mean & ledian & $0 \%$ & $5 \%$ & $97.5 \%$ & $3 \%$ \\
\hline-03 & $.95 E+00$ & 4. 20E-01 & 2. $29 \mathrm{E}-01$ & $1.07 \mathrm{E}+00$ & $1.46 \mathrm{E}+00$ & $.86 E+00$ & $55 \mathrm{E}+0$ \\
\hline 03 & $E+00$ & 1 & 1 & $7 \mathrm{E}+$ & 00 & $E+00$ & 100 \\
\hline-03 & +00 & $2 E-01$ & -01 & $7 \mathrm{E}+00$ & 00 & -00 & +00 \\
\hline-03 & $E+00$ & 1 & 1 & 0 & & 00 & +00 \\
\hline $4 E-03$ & -00 & & & 0 & 00 & $87 E+00$ & $56 \mathrm{E}+00$ \\
\hline $48 E-03$ & +00 & -01 & -01 & $1.08 \mathrm{E}+00$ & $.47 \mathrm{E}+$ & $E+00$ & $E+00$ \\
\hline-03 & +00 & $25 E-01$ & -01 & 0 & $1.47 \mathrm{E}$ & +00 & $\mathrm{E}+0 \mathrm{C}$ \\
\hline $.57 E-03$ & $3.94 \mathrm{E}+00$ & . 20 r & -01 & $1.08 \mathrm{E}+00$ & $1.48 \mathrm{E}+00$ & $\mathrm{E}+00$ & $56 \mathrm{E}+0 \mathrm{C}$ \\
\hline 03 & +00 & 1 & 01 & +00 & 00 & +00 & +00 \\
\hline $.66 \mathrm{E}-03$ & $94 \mathrm{E}+00$ & $28 E-01$ & $E-01$ & $.08 E+00$ & $1.48 \mathrm{E}+00$ & $.89 \mathrm{E}+00$ & $6 \mathrm{E}+00$ \\
\hline-03 & -00 & $E-01$ & 1 & & & 00 & $E+00$ \\
\hline-03 & +00 & & & & & +00 & +00 \\
\hline $.80 \mathrm{E}-03$ & $3.94 \mathrm{E}+00$ & $.31 \mathrm{E}-01$ & $2.38 \mathrm{E}-01$ & ט & $1.49 \mathrm{E}+00$ & $E+00$ & $E+0 C$ \\
\hline$E-03$ & +00 & + & -01 & 00 & 00 & +00 & +00 \\
\hline 03 & -00 & 1 & 01 & 00 & 00 & +00 & +00 \\
\hline $.94 \mathrm{E}-03$ & $3.93 \mathrm{E}+00$ & 1 & -01 & & $1.50 \mathrm{E}+00$ & $.91 E+00$ & $7 \mathrm{E}+00$ \\
\hline E-03 & $3.93 \mathrm{E}+00$ & $5 E-01$ & $1 E-01$ & $1.09 \mathrm{E}+00$ & $1.50 \mathrm{E}+00$ & $.91 E+00$ & $7 \mathrm{E}+00$ \\
\hline-03 & $33 E+00$ & $6 E-01$ & $2 E-01$ & $09 \mathrm{E}+00$ & $50 \mathrm{E}+00$ & $91 E+00$ & $7 \mathrm{E}+0 \mathrm{C}$ \\
\hline 03 & $E+00$ & $7 E-01$ & $3 E-01$ & $\perp$ & 0 & $4+\infty$ & $\mathrm{E}+00$ \\
\hline$E-03$ & $3.92 \mathrm{E}+00$ & $E-01$ & -01 & 00 & 00 & +00 & +00 \\
\hline $3 E-03$ & & & -01 & & & 100 & +00 \\
\hline$E-03$ & $.92 E+00$ & $E-01$ & -01 & $1.10 \mathrm{E}+00$ & & $.92 \mathrm{E}+00$ & $8 \mathrm{E}+00$ \\
\hline $3 F-03$ & $3.92 \mathrm{E}+00$ & $4.40 \mathrm{E}-01$ & $2.46 E-01$ & $1.10 \mathrm{E}+00$ & $1.51 \mathrm{E}+00$ & $93 E+00$ & $58 \mathrm{E}+00$ \\
\hline$E-03$ & $.92 \mathrm{E}+00$ & $.41 \mathrm{E}-01$ & $2.47 \mathrm{E}-01$ & 1.10E +00 & $1.52 \mathrm{E}+00$ & $.93 E+00$ & $58 \mathrm{E}+00$ \\
\hline 03 & $92 \mathrm{E}+00$ & $42 E-01$ & $3 E-01$ & & 00 & $E+00$ & $E+00$ \\
\hline 03 & -00 & 1 & & & & +00 & +00 \\
\hline $48 E-03$ & $3.91 E+00$ & & $E-01$ & $I \cdot+{ }_{1}$ & $1.0<1$ & +00 & $59 \mathrm{E}+00$ \\
\hline 年 & . . ILTU & 4. $45 E-01$ & $2.50 E-01$ & 1.11E+00 & 1.JगएTU & $.94 E+00$ & $.59 \mathrm{E}+00$ \\
\hline 03 & 年 & - & 年 & 20 & $53 E+00$ & $94 \mathrm{E}+00$ & $.59 E+0 c$ \\
\hline $63 E-03$ & 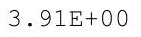 & $4.47 \mathrm{E}-01$ & $2.52 \mathrm{E}-01$ & $1.11 \mathrm{E}+$ & & $4 \mathrm{E}+00$ & $59 \mathrm{E}+0$ \\
\hline-03 & $915+0$ & & $3 E-01$ & $1.11 \mathrm{E}+00$ & $.53 E+00$ & $95 \mathrm{~F}+00$ & $9 \mathrm{E}+00$ \\
\hline & & & & & & & \\
\hline $3 E-03$ & $3.90 \mathrm{E}+00$ & $E-01$ & $E-01$ & $1.12 \mathrm{E}$ & $1.35 E$ & $5 E+00$ & $0 \mathrm{E}+00$ \\
\hline $.83 E-03$ & $3.90 E+00$ & $.51 \mathrm{E}-01$ & $2.55 E-01$ & $1.12 \mathrm{E}+00$ & $1.53 \mathrm{E}+00$ & $.95 E+00$ & $0 \mathrm{E}+00$ \\
\hline O०-U & & & $2.56 E-01$ & $\perp \cdot \perp \angle \mathrm{L} T U$ & & . & $.60 E+00$ \\
\hline $.93 E-03$ & & & & & & & $.60 \mathrm{E}+00$ \\
\hline $.98 E-03$ & $3.89 \mathrm{E}+00$ & & 1 & 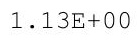 & & 0 & $0 E+0 C$ \\
\hline 3 & & & & & 0 & & \\
\hline 3 & & 1 & & & 00 & & \\
\hline$E-03$ & $3.89 \mathrm{E}+00$ & -01 & -01 & $1.13 \mathrm{E}$ & 0 & & +00 \\
\hline 3 & & $.57 E-01$ & & & & & $.61 E+0 c$ \\
\hline 3 & OE+U0 & & & & $1.35 \mathrm{E}+00$ & $.96 \mathrm{E}+00$ & $.61 \mathrm{E}+00$ \\
\hline & 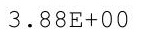 & 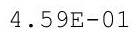 & 1 & $\perp$ & & $.97 E+00$ & $61 E+00$ \\
\hline $9.30 \mathrm{E}-\mathrm{C}$ & 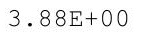 & 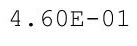 & ( & 0 & 0 & 0 & $61 E+00$ \\
\hline 03 & $3.88 \mathrm{E}+00$ & 4.6 & 2 . & $1.14 \mathrm{E}+00$ & $1.55 \mathrm{E}+00$ & $1.97 \mathrm{E}+00$ & $2.61 \mathrm{E}+00$ \\
\hline $46 E-03$ & $3.88 \mathrm{E}+00$ & $.62 \mathrm{E}-01$ & $.65 E-01$ & $1.14 \mathrm{E}+00$ & $1.56 \mathrm{E}+00$ & $.97 E+00$ & 2. $62 \mathrm{E}+00$ \\
\hline
\end{tabular}


RESRAD-OFFSITE, Version 2.5

robabilistic Dose and Risk Report

Title : RESRAD-OFFSITE Drinking Water, Plant, Milk, and Meat Pathways for Offsite Reside File : PBA-1_TC99-DOE-5.ROF

Summary of dose at graphical times, reptition 2 (continued)

Time

Years

$6.84 \mathrm{E}+02$

$6.84 \mathrm{E}+02$

$6.85 \mathrm{E}+02$

$6.85 \mathrm{E}+02$

$6.86 \mathrm{E}+02$

$6.86 \mathrm{E}+02$

$6.87 \mathrm{E}+02$

$6.88 \mathrm{E}+02$

$6.88 \mathrm{E}+02$

$6.89 \mathrm{E}+02$

$6.89 \mathrm{E}+02$

$6.90 \mathrm{E}+02$

$6.90 \mathrm{E}+02$

$6.91 E+02$

$6.91 \mathrm{E}+02$

$6.92 \mathrm{E}+02$

$6.92 \mathrm{E}+02$

$6.93 \mathrm{E}+02$

$6.93 \mathrm{E}+02$

$6.94 \mathrm{E}+02$

$6.94 \mathrm{E}+02$

$6.95 \mathrm{E}+02$

$6.95 \mathrm{E}+02$

$6.96 \mathrm{E}+02$

$6.96 \mathrm{E}+02$

$6.97 \mathrm{E}+02$

$6.97 \mathrm{E}+02$

$6.98 \mathrm{E}+02$

$6.98 \mathrm{E}+02$

$6.99 \mathrm{E}+02$

$6.99 \mathrm{E}+02$

$7.00 \mathrm{E}+02$

$7.00 \mathrm{E}+02$

$7.01 \mathrm{E}+02$

$7.01 \mathrm{E}+02$

$7.02 \mathrm{E}+02$

$7.02 \mathrm{E}+02$

$7.03 \mathrm{E}+02$

$7.03 E+02$

$7.04 \mathrm{E}+02$

$7.04 \mathrm{E}+02$

$7.05 \mathrm{E}+02$

$7.05 \mathrm{E}+02$

$7.06 \mathrm{E}+02$

$7.06 \mathrm{E}+02$

$7.07 \mathrm{E}+02$
Dose statistics at graphical times, mrem/yr

\begin{tabular}{|c|c|c|c|c|c|c|c|}
\hline inimum & aximum & Mean & ledian & $0 \%$ & $\%$ & $97.5 \%$ & \\
\hline 3 & 0 & 01 & 1 & 00 & 00 & 00 & +0 \\
\hline 03 & +00 & 1 & 1 & 0 & 00 & 00 & +00 \\
\hline 03 & -00 & 01 & 1 & 00 & 00 & 00 & +00 \\
\hline 03 & 00 & & & & & 00 & +00 \\
\hline $3 E-03$ & -00 & & & 00 & 00 & $\mathrm{E}+00$ & $62 \mathrm{E}+00$ \\
\hline $.78 E-03$ & $6 \mathrm{E}+00$ & $E-01$ & -01 & $1.15 \mathrm{E}+00$ & $.57 E+00$ & $E+00$ & $63 E+00$ \\
\hline 03 & -00 & $.68 \mathrm{E}-01$ & 1 & 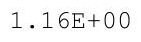 & 0 & +00 & $\Xi+00$ \\
\hline $9 E-03$ & $3.86 \mathrm{E}+00$ & & $2.72 \mathrm{E}-01$ & & & +00 & $63 E+00$ \\
\hline 03 & +00 & $\perp$ & 01 & 00 & 00 & +00 & +00 \\
\hline$E-02$ & $6 \mathrm{E}+00$ & $1 E-01$ & $3 E-01$ & $1.16 \mathrm{E}+00$ & $57 \mathrm{E}+00$ & $3 E+00$ & $3 E+00$ \\
\hline $.01 \mathrm{E}-02$ & $3.85 \mathrm{E}+00$ & $.72 E-01$ & $E-01$ & & & $.98 \mathrm{E}+00$ & $63 E+00$ \\
\hline-02 & +00 & $E-01$ & $\mathrm{E}-01$ & +00 & & +00 & $E+00$ \\
\hline$E-02$ & $E+00$ & $4 \mathrm{E}-\mathrm{U}$ & -01 & $7 \mathrm{E}+00$ & +00 & $E+00$ & +0 \\
\hline 02 & 00 & $.75 \mathrm{E}-01$ & 1 & 0 & 0 & +00 & +00 \\
\hline 02 & -00 & $\perp$ & 01 & 00 & & $\mathrm{E}+00$ & +00 \\
\hline$E-02$ & $F+00$ & L & 1 & $17 \mathrm{E}+00$ & 0 & $E+00$ & +00 \\
\hline $.04 \mathrm{E}-02$ & $3.84 \mathrm{E}+00$ & $8 \mathrm{E}-01$ & $9 E-01$ & $1.18 \mathrm{E}+00$ & $.59 \mathrm{E}+00$ & $9 \mathrm{E}+00$ & $.64 \mathrm{E}+00$ \\
\hline$E-02$ & $34 E+00$ & $9 E-01$ & $0 E-01$ & $1.18 \mathrm{E}+00$ & $9 E+00$ & $9 E+00$ & $64 \mathrm{E}+00$ \\
\hline 02 & +00 & & -01 & 0 & & +00 & +00 \\
\hline 02 & +00 & $\perp$ & -01 & 00 & 0 & +00 & +0 \\
\hline 2 & & & 1 & 0 & & (10 & +00 \\
\hline 02 & $3 F+00$ & 1 & 1 & $118=+$ & (2) & $\mathrm{E}+00$ & $E+00$ \\
\hline$E-02$ & $3 \mathrm{E}+00$ & 1 & 1 & $1.19 \mathrm{E}+00$ & $.60 \mathrm{E}+00$ & $0 \mathrm{E}+00$ & $.65 E+00$ \\
\hline $.08 \mathrm{E}-02$ & $3.83 \mathrm{E}+00$ & $.84 \mathrm{E}-01$ & $5 E-01$ & $1.19 \mathrm{E}+00$ & $1.60 \mathrm{E}+00$ & $\mathrm{OE}+00$ & $.66 \mathrm{E}+00$ \\
\hline 02 & $.82 \mathrm{E}+00$ & $85 \mathrm{E}-01$ & $6 E-01$ & & & $0 F+00$ & $66 \mathrm{E}+00$ \\
\hline & & & & & & & +00 \\
\hline & & & & & & & +00 \\
\hline$\cdot 10 \mathrm{~L}-\mathrm{Z}$ & $3.82 \mathrm{E}+00$ & $88 E-01$ & $2.89 E-01$ & $1.20 \mathrm{E}+00$ & I.OILTU & $.00 \mathrm{E}+00$ & $.67 \mathrm{E}+00$ \\
\hline 02 & 0 & 1 & $E-01$ & $20 \mathrm{E}+00$ & $62 E+00$ & $.00 E+00$ & $.67 E+00$ \\
\hline 2 & 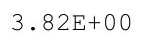 & - & 1 & $1.20 \mathrm{E}+0$ & & $.01 \mathrm{E}+0$ & $.67 \mathrm{E}+0$ \\
\hline $\mathrm{F}-02$ & $81=+80$ & & $E-01$ & $1.20 \mathrm{E}+00$ & $2 E+00$ & $1 \mathrm{E}+00$ & $67 E+00$ \\
\hline 02 & & & & & & & \\
\hline & & & 01 & & & & \\
\hline $.14 \mathrm{E}-02$ & $3.81 \mathrm{E}+00$ & $.94 \mathrm{E}-01$ & $4 E-01$ & $1.20 \mathrm{E}+00$ & $1.62 \mathrm{E}+00$ & $2.01 E+00$ & $2.68 \mathrm{E}+00$ \\
\hline $15 E-02$ & & & $2.95 E-01$ & $\perp \cdot \angle \perp \perp T U 0$ & & Z. UZLTU & Z. . OOLTU \\
\hline 2 & & & & & & & $2.69 \mathrm{E}+00$ \\
\hline 2 & $3.81 E+00$ & & & $1.21 \mathrm{E}+00$ & & 0 & $69 \mathrm{E}+00$ \\
\hline 2 & & & & & & & \\
\hline 02 & & 1 & & $121 \mathrm{~F}$ & $3 E+00$ & $2 E+00$ & $59 \mathrm{E}+00$ \\
\hline $3 E-02$ & $3.80 \mathrm{E}+00$ & $99 E-01$ & 01 & 1.21E+ & & & +00 \\
\hline 2 & & & & 1.21E+ & & & $\mathrm{E}+0 \mathrm{C}$ \\
\hline & $3.00 E+00$ & 1 & & 1. $22 \mathrm{E}+00$ & $1.04 E+00$ & $2.03 E+00$ & $2.105+00$ \\
\hline & $80 \mathrm{E}+0$ & . & & $1.2 \angle \amalg$ & & $2.03 E+00$ & $2.70 \mathrm{E}+0$ \\
\hline 2 & 0 & & & 1 . & $1.64 \mathrm{E}$ & $.03 E+$ & $2.71 \mathrm{E}+00$ \\
\hline-02 & $3.80 \mathrm{E}+00$ & $5.04 \mathrm{E}-01$ & -01 & $1.22 \mathrm{E}+00$ & $1.65 \mathrm{E}+00$ & $2.03 E+00$ & $2.71 \mathrm{E}+00$ \\
\hline $.21 E-02$ & $3.80 \mathrm{E}+00$ & $.05 E-01$ & $.05 E-01$ & $1.22 \mathrm{E}+00$ & $1.65 \mathrm{E}+00$ & $2.03 E+00$ & $2.71 E+00$ \\
\hline
\end{tabular}


RESRAD-OFFSITE, Version 2.5

Title : RESRAD-OFFSITE Drinking Water, Plant, Milk, and Meat Pathways for Offsite Reside File : PBA-1_TC99-DOE-5.ROF

Summary of dose at graphical times, reptition 2 (continued)

Time

Years

$7.08 \mathrm{E}+02$

$7.08 \mathrm{E}+02$

$7.09 \mathrm{E}+02$

$7.09 \mathrm{E}+02$

$7.10 \mathrm{E}+02$

$7.10 \mathrm{E}+02$

$7.11 \mathrm{E}+02$

$7.11 \mathrm{E}+02$

$7.12 \mathrm{E}+02$

$7.12 \mathrm{E}+02$

$7.13 \mathrm{E}+02$

7. $13 \mathrm{E}+02$

$7.14 \mathrm{E}+02$

$7.14 \mathrm{E}+02$

7. $15 \mathrm{E}+02$

7. $15 \mathrm{E}+02$

$7.16 \mathrm{E}+02$

7. $16 \mathrm{E}+02$

$7.17 \mathrm{E}+02$

$7.17 \mathrm{E}+02$

$7.18 \mathrm{E}+02$

$7.18 \mathrm{E}+02$

$7.19 \mathrm{E}+02$

$7.19 \mathrm{E}+02$

$7.20 \mathrm{E}+02$

$7.20 \mathrm{E}+02$

$7.21 \mathrm{E}+02$

$7.21 \mathrm{E}+02$

7. $22 \mathrm{E}+02$

$7.22 \mathrm{E}+02$

7. $23 \mathrm{E}+02$

7. $23 \mathrm{E}+02$

$7.24 \mathrm{E}+02$

7. $24 \mathrm{E}+02$

$7.25 \mathrm{E}+02$

7. $25 \mathrm{E}+02$

$7.26 \mathrm{E}+02$

$7.26 \mathrm{E}+02$

$7.27 \mathrm{E}+02$

$7.28 \mathrm{E}+02$

$7.28 \mathrm{E}+02$

$7.29 \mathrm{E}+02$

$7.29 \mathrm{E}+02$

$7.30 \mathrm{E}+02$

$7.30 \mathrm{E}+02$

$7.31 \mathrm{E}+02$
Dose statistics at graphical times, mrem/yr

\begin{tabular}{|c|c|c|c|c|c|c|c|}
\hline inimum & Maximum & Mean & Median & $90 \%$ & $95 \%$ & $.5 \%$ & $9 \%$ \\
\hline $1.22 \mathrm{E}-02$ & $3.80 \mathrm{E}+00$ & $5.06 \mathrm{E}-01$ & $3.05 \mathrm{E}-01$ & $1.22 \mathrm{E}+00$ & $1.65 \mathrm{E}+00$ & $2.03 E+00$ & $2.71 \mathrm{E}+00$ \\
\hline $1.23 \mathrm{E}-02$ & $3.80 \mathrm{E}+00$ & $5.07 \mathrm{E}-01$ & $3.06 \mathrm{E}-01$ & $1.23 \mathrm{E}+00$ & $1.65 \mathrm{E}+00$ & $2.03 \mathrm{E}+00$ & $2.72 \mathrm{E}+00$ \\
\hline $1.23 \mathrm{E}-02$ & $3.79 \mathrm{E}+00$ & $5.08 \mathrm{E}-01$ & $3.07 \mathrm{E}-01$ & $1.23 \mathrm{E}+00$ & $1.65 \mathrm{E}+00$ & $2.04 \mathrm{E}+00$ & $2.72 \mathrm{E}+00$ \\
\hline $1.24 \mathrm{E}-02$ & $3.79 \mathrm{E}+00$ & $5.09 \mathrm{E}-01$ & $3.08 \mathrm{E}-01$ & $1.23 \mathrm{E}+00$ & $66 \mathrm{E}+00$ & $2.04 \mathrm{E}+00$ & $.72 \mathrm{E}+00$ \\
\hline $1.25 \mathrm{E}-02$ & $3.79 \mathrm{E}+00$ & $5.10 \mathrm{E}-01$ & $3.09 \mathrm{E}-01$ & $1.23 \mathrm{E}+00$ & $.66 E+00$ & $2.04 \mathrm{E}+00$ & $2.72 \mathrm{E}+00$ \\
\hline $1.25 \mathrm{E}-02$ & $3.79 \mathrm{E}+00$ & $5.10 \mathrm{E}-01$ & $3.10 \mathrm{E}-01$ & $1.23 \mathrm{E}+00$ & $1.66 \mathrm{E}+00$ & $2.04 \mathrm{E}+00$ & $2.73 \mathrm{E}+00$ \\
\hline $1.26 \mathrm{E}-02$ & $.79 \mathrm{E}+00$ & $5.11 \mathrm{E}-01$ & $3.11 \mathrm{E}-01$ & $1.23 \mathrm{E}+00$ & $.66 \mathrm{E}+00$ & $2.04 \mathrm{E}+00$ & $2.73 \mathrm{E}+00$ \\
\hline $27 \mathrm{E}-02$ & $3.79 \mathrm{E}+00$ & $5.12 \mathrm{E}-01$ & $3.12 \mathrm{E}-01$ & $1.24 \mathrm{E}+00$ & $1.67 \mathrm{E}+00$ & $2.05 \mathrm{E}+00$ & $2.73 \mathrm{E}+00$ \\
\hline $.27 \mathrm{E}-02$ & $3.79 \mathrm{E}+00$ & $5.13 \mathrm{E}-01$ & $3.12 \mathrm{E}-01$ & $1.24 \mathrm{E}+00$ & $1.67 \mathrm{E}+00$ & $2.05 \mathrm{E}+00$ & $2.73 E+00$ \\
\hline $1.28 \mathrm{E}-02$ & $3.78 \mathrm{E}+00$ & $5.14 \mathrm{E}-01$ & $3.13 \mathrm{E}-01$ & $1.24 \mathrm{E}+00$ & $1.67 \mathrm{E}+00$ & $2.05 \mathrm{E}+00$ & $2.73 \mathrm{E}+00$ \\
\hline $1.29 \mathrm{E}-02$ & $3.78 \mathrm{E}+00$ & $5.15 \mathrm{E}-01$ & $3.14 \mathrm{E}-01$ & $1.24 \mathrm{E}+00$ & $1.67 \mathrm{E}+00$ & $2.05 \mathrm{E}+00$ & $2.74 \mathrm{E}+00$ \\
\hline $1.29 \mathrm{E}-02$ & $3.78 \mathrm{E}+00$ & $5.16 \mathrm{E}-01$ & $3.15 \mathrm{E}-01$ & $1.24 \mathrm{E}+00$ & $1.68 \mathrm{E}+00$ & $2.06 \mathrm{E}+00$ & $2.74 \mathrm{E}+00$ \\
\hline $1.30 \mathrm{E}-02$ & $3.78 \mathrm{E}+00$ & $5.17 \mathrm{E}-01$ & $3.16 \mathrm{E}-01$ & $1.25 \mathrm{E}+00$ & $1.68 \mathrm{E}+00$ & $2.06 \mathrm{E}+00$ & $2.74 \mathrm{E}+00$ \\
\hline $1.31 \mathrm{E}-02$ & $3.78 \mathrm{E}+00$ & $5.18 \mathrm{E}-01$ & $3.17 \mathrm{E}-01$ & $1.25 \mathrm{E}+00$ & $1.68 \mathrm{E}+00$ & $2.06 \mathrm{E}+00$ & $2.74 \mathrm{E}+00$ \\
\hline $1.31 \mathrm{E}-02$ & $3.78 \mathrm{E}+00$ & $5.19 \mathrm{E}-01$ & $3.18 \mathrm{E}-01$ & $1.25 \mathrm{E}+00$ & $1.68 \mathrm{E}+00$ & $2.06 \mathrm{E}+00$ & $2.75 \mathrm{E}+00$ \\
\hline $1.32 \mathrm{E}-02$ & $3.78 \mathrm{E}+00$ & $5.20 \mathrm{E}-01$ & $3.19 \mathrm{E}-01$ & $1.25 \mathrm{E}+00$ & $1.69 \mathrm{E}+00$ & $2.06 \mathrm{E}+00$ & $2.75 \mathrm{E}+00$ \\
\hline $1.33 \mathrm{E}-02$ & $3.78 \mathrm{E}+00$ & $5.21 \mathrm{E}-01$ & $3.20 \mathrm{E}-01$ & $1.25 \mathrm{E}+00$ & $1.69 \mathrm{E}+00$ & $2.07 \mathrm{E}+00$ & $2.75 \mathrm{E}+00$ \\
\hline $1.33 \mathrm{E}-02$ & $3.77 \mathrm{E}+00$ & $5.22 \mathrm{E}-01$ & $3.21 \mathrm{E}-01$ & $1.26 \mathrm{E}+00$ & $1.69 \mathrm{E}+00$ & $2.07 \mathrm{E}+00$ & $2.75 \mathrm{E}+00$ \\
\hline $1.34 \mathrm{E}-02$ & $3.77 \mathrm{E}+00$ & $5.23 \mathrm{E}-01$ & $3.22 \mathrm{E}-01$ & $1.26 \mathrm{E}+00$ & $1.70 \mathrm{E}+00$ & $2.07 \mathrm{E}+00$ & $2.75 \mathrm{E}+00$ \\
\hline $35 E-02$ & $3.77 \mathrm{E}+00$ & $5.23 \mathrm{E}-01$ & $3.23 \mathrm{E}-01$ & $1.26 \mathrm{E}+00$ & $1.70 \mathrm{E}+00$ & $2.07 E+00$ & $2.76 \mathrm{E}+00$ \\
\hline 1.3 & $3.77 \mathrm{E}+00$ & & & $1.26 \mathrm{E}+00$ & $1.70 \mathrm{E}+00$ & $2.07 \mathrm{E}+00$ & $.76 \mathrm{E}+00$ \\
\hline $1.36 \mathrm{E}-02$ & $3.77 \mathrm{E}+00$ & 5 & 3 & $1.26 \mathrm{E}+00$ & $1.70 \mathrm{E}+00$ & $2.08 \mathrm{E}+00$ & $.76 \mathrm{E}+00$ \\
\hline $1.37 \mathrm{E}-02$ & $3.77 \mathrm{E}+00$ & $5.26 \mathrm{E}-01$ & $3.26 \mathrm{E}-01$ & $1.26 \mathrm{E}+00$ & $1.71 \mathrm{E}+00$ & $2.08 \mathrm{E}+00$ & $2.76 \mathrm{E}+00$ \\
\hline $1.37 \mathrm{E}-02$ & $3.76 \mathrm{E}+00$ & $5.27 \mathrm{E}-01$ & $3.27 \mathrm{E}-01$ & $1.26 \mathrm{E}+00$ & $1.71 \mathrm{E}+00$ & $2.08 \mathrm{E}+00$ & $2.77 \mathrm{E}+00$ \\
\hline $1.38 \mathrm{E}-02$ & $3.76 \mathrm{E}+00$ & $5.28 \mathrm{E}-01$ & $3.28 \mathrm{E}-01$ & $1.27 \mathrm{E}+00$ & $1.71 \mathrm{E}+00$ & $2.08 \mathrm{E}+00$ & $2.77 \mathrm{E}+00$ \\
\hline $1.39 \mathrm{E}-02$ & $3.76 \mathrm{E}+00$ & $5.29 \mathrm{E}-01$ & $3.29 \mathrm{E}-01$ & $1.27 \mathrm{E}+00$ & $1.71 \mathrm{E}+00$ & $2.08 \mathrm{E}+00$ & $2.77 \mathrm{E}+00$ \\
\hline $1.39 \mathrm{E}-02$ & $3.76 \mathrm{E}+00$ & $5.30 \mathrm{E}-01$ & $3.30 \mathrm{E}-01$ & $1.27 \mathrm{E}+00$ & $1.71 \mathrm{E}+00$ & $2.09 \mathrm{E}+00$ & $2.77 \mathrm{E}+00$ \\
\hline $1.40 \mathrm{E}-02$ & $3.76 \mathrm{E}+00$ & $5.31 \mathrm{E}-01$ & $3.31 \mathrm{E}-01$ & $1.27 \mathrm{E}+00$ & $1.71 \mathrm{E}+00$ & $2.09 \mathrm{E}+00$ & $2.77 \mathrm{E}+00$ \\
\hline $1.41 \mathrm{E}-02$ & $3.76 \mathrm{E}+00$ & $5.32 \mathrm{E}-01$ & $3.32 \mathrm{E}-01$ & $1.27 \mathrm{E}+00$ & $1.72 \mathrm{E}+00$ & $2.09 \mathrm{E}+00$ & $2.77 \mathrm{E}+00$ \\
\hline $1.41 \mathrm{E}-02$ & $3.76 \mathrm{E}+00$ & 5.3 & 3.3 & $1.27 \mathrm{E}+00$ & $1.72 \mathrm{E}+00$ & $2.09 \mathrm{E}+00$ & $2.77 \mathrm{E}+00$ \\
\hline $1.42 \mathrm{E}-02$ & $3.75 E+00$ & 5. & 3 & $1.27 \mathrm{E}+00$ & $1.72 \mathrm{E}+00$ & $2.09 \mathrm{E}+00$ & $2.78 \mathrm{E}+00$ \\
\hline $1.43 \mathrm{E}-02$ & $3.75 \mathrm{E}+00$ & $5.35 \mathrm{E}-01$ & $3.35 \mathrm{E}-01$ & $1.28 \mathrm{E}+00$ & $1.72 \mathrm{E}+00$ & $2.09 \mathrm{E}+00$ & $2.78 \mathrm{E}+00$ \\
\hline $1.44 \mathrm{E}-02$ & $3.75 \mathrm{E}+00$ & $5.35 \mathrm{E}-01$ & $3.36 \mathrm{E}-01$ & $1.28 \mathrm{E}+00$ & $1.72 \mathrm{E}+00$ & $2.09 \mathrm{E}+00$ & $2.78 \mathrm{E}+00$ \\
\hline $1.44 \mathrm{E}-02$ & $3.75 \mathrm{E}+00$ & $5.36 \mathrm{E}-01$ & $3.37 \mathrm{E}-01$ & $1.28 \mathrm{E}+00$ & $1.72 \mathrm{E}+00$ & $2.09 \mathrm{E}+00$ & $2.78 \mathrm{E}+00$ \\
\hline $1.45 \mathrm{E}-02$ & $3.75 E+00$ & $5.37 \mathrm{E}-01$ & $3.38 \mathrm{E}-01$ & $1.28 \mathrm{E}+00$ & $1.72 \mathrm{E}+00$ & $2.09 \mathrm{E}+00$ & $2.78 \mathrm{E}+00$ \\
\hline $1.46 \mathrm{E}-02$ & $3.75 E+00$ & $5.38 \mathrm{E}-01$ & $3.38 \mathrm{E}-01$ & $1.28 \mathrm{E}+00$ & $1.73 \mathrm{E}+00$ & $2.09 \mathrm{E}+00$ & $2.78 \mathrm{E}+00$ \\
\hline $1.46 \mathrm{E}-02$ & $3.74 \mathrm{E}+00$ & $5.39 \mathrm{E}-01$ & $3.39 \mathrm{E}-01$ & $1.29 \mathrm{E}+00$ & $1.73 \mathrm{E}+00$ & $2.09 \mathrm{E}+00$ & $2.78 \mathrm{E}+00$ \\
\hline $1.47 \mathrm{E}-02$ & $3.74 \mathrm{E}+00$ & $5.40 \mathrm{E}-01$ & $3.40 \mathrm{E}-01$ & $1.29 \mathrm{E}+00$ & $1.73 \mathrm{E}+00$ & $2.10 \mathrm{E}+00$ & $2.78 \mathrm{E}+00$ \\
\hline $1.48 \mathrm{E}-02$ & $3.74 \mathrm{E}+00$ & $5.41 \mathrm{E}-01$ & $3.41 \mathrm{E}-01$ & $1.29 \mathrm{E}+00$ & $1.73 \mathrm{E}+00$ & $2.10 \mathrm{E}+00$ & $2.78 \mathrm{E}+00$ \\
\hline $1.49 \mathrm{E}-02$ & $3.74 \mathrm{E}+00$ & $5.42 \mathrm{E}-01$ & $3.42 \mathrm{E}-01$ & $1.29 \mathrm{E}+00$ & $1.73 \mathrm{E}+00$ & $2.10 \mathrm{E}+00$ & $2.78 \mathrm{E}+00$ \\
\hline $1.49 \mathrm{E}-02$ & $3.74 \mathrm{E}+00$ & $5.43 \mathrm{E}-01$ & $3.43 \mathrm{E}-01$ & $1.29 \mathrm{E}+00$ & $1.74 \mathrm{E}+00$ & $2.10 \mathrm{E}+00$ & $2.79 \mathrm{E}+00$ \\
\hline $1.50 \mathrm{E}-02$ & $3.74 \mathrm{E}+00$ & $5.44 \mathrm{E}-01$ & $3.44 \mathrm{E}-01$ & $1.29 \mathrm{E}+00$ & $1.74 \mathrm{E}+00$ & $2.10 \mathrm{E}+00$ & $2.79 \mathrm{E}+00$ \\
\hline $1.51 \mathrm{E}-02$ & $3.73 E+00$ & $5.45 \mathrm{E}-01$ & $3.45 \mathrm{E}-01$ & $1.29 \mathrm{E}+00$ & $1.74 \mathrm{E}+00$ & $2.11 \mathrm{E}+00$ & $2.79 \mathrm{E}+00$ \\
\hline $1.52 \mathrm{E}-02$ & $3.73 \mathrm{E}+00$ & $5.46 \mathrm{E}-01$ & $3.46 \mathrm{E}-01$ & $1.30 \mathrm{E}+00$ & $1.74 \mathrm{E}+00$ & $2.11 \mathrm{E}+00$ & $2.79 \mathrm{E}+00$ \\
\hline $1.52 \mathrm{E}-02$ & $3.73 E+00$ & $5.47 \mathrm{E}-01$ & $3.47 \mathrm{E}-01$ & $1.30 \mathrm{E}+00$ & $1.74 \mathrm{E}+00$ & $2.11 \mathrm{E}+00$ & $2.79 \mathrm{E}+00$ \\
\hline $1.53 \mathrm{E}-02$ & $3.73 E+00$ & $5.47 \mathrm{E}-01$ & $3.48 \mathrm{E}-01$ & $1.30 \mathrm{E}+00$ & $1.74 \mathrm{E}+00$ & $2.11 \mathrm{E}+00$ & $2.79 \mathrm{E}+00$ \\
\hline
\end{tabular}


RESRAD-OFFSITE, Version 2.5

Title : RESRAD-OFFSITE Drinking Water, Plant, Milk, and Meat Pathways for Offsite Reside File : PBA-1_TC99-DOE-5.ROF

Summary of dose at graphical times, reptition 2 (continued)

Time

Years

$7.31 \mathrm{E}+02$

$7.32 \mathrm{E}+02$

$7.32 \mathrm{E}+02$

7. $33 \mathrm{E}+02$

$7.33 \mathrm{E}+02$

7. $34 \mathrm{E}+02$

7. $34 \mathrm{E}+02$

7. $35 \mathrm{E}+02$

7. $35 \mathrm{E}+02$

7. $36 \mathrm{E}+02$

$7.36 \mathrm{E}+02$

7. $37 \mathrm{E}+02$

7. $37 \mathrm{E}+02$

7. $38 \mathrm{E}+02$

7. $38 \mathrm{E}+02$

7. $39 \mathrm{E}+02$

$7.39 \mathrm{E}+02$

$7.40 \mathrm{E}+02$

$7.40 \mathrm{E}+02$

$7.41 \mathrm{E}+02$

7. $41 \mathrm{E}+02$

7. $42 \mathrm{E}+02$

$7.42 \mathrm{E}+02$

$7.43 \mathrm{E}+02$

7. $43 \mathrm{E}+02$

$7.44 \mathrm{E}+02$

$7.44 \mathrm{E}+02$

$7.45 \mathrm{E}+02$

7. $45 \mathrm{E}+02$

$7.46 \mathrm{E}+02$

$7.46 \mathrm{E}+02$

$7.47 \mathrm{E}+02$

$7.48 \mathrm{E}+02$

$7.48 \mathrm{E}+02$

7. $49 \mathrm{E}+02$

$7.49 \mathrm{E}+02$

7. $50 \mathrm{E}+02$

$7.50 \mathrm{E}+02$

$7.51 \mathrm{E}+02$

$7.51 \mathrm{E}+02$

$7.52 \mathrm{E}+02$

7. $52 \mathrm{E}+02$

$7.53 \mathrm{E}+02$

$7.53 \mathrm{E}+02$

7. $54 \mathrm{E}+02$

$7.54 \mathrm{E}+02$
Dose statistics at graphical times, mrem/yr

\begin{tabular}{|c|c|c|c|c|c|c|c|}
\hline inimum & Maximum & Mean & Median & $90 \%$ & $95 \%$ & $7.5 \%$ & $9 \%$ \\
\hline 1. $54 \mathrm{E}-02$ & $3.73 \mathrm{E}+00$ & $5.48 \mathrm{E}-01$ & $3.49 \mathrm{E}-01$ & $1.30 \mathrm{E}+00$ & $1.75 \mathrm{E}+00$ & $2.11 \mathrm{E}+00$ & $2.79 \mathrm{E}+00$ \\
\hline $1.54 \mathrm{E}-02$ & $3.73 E+00$ & $5.49 \mathrm{E}-01$ & $3.50 \mathrm{E}-01$ & $1.31 \mathrm{E}+00$ & $1.75 \mathrm{E}+00$ & $2.11 \mathrm{E}+00$ & $2.79 \mathrm{E}+00$ \\
\hline $1.55 \mathrm{E}-02$ & $3.72 \mathrm{E}+00$ & $5.50 \mathrm{E}-01$ & $3.51 \mathrm{E}-01$ & $1.31 \mathrm{E}+00$ & $1.75 \mathrm{E}+00$ & $2.12 \mathrm{E}+00$ & $2.79 \mathrm{E}+00$ \\
\hline $1.56 \mathrm{E}-02$ & $3.72 \mathrm{E}+00$ & $5.51 \mathrm{E}-01$ & $3.52 E-01$ & $1.31 \mathrm{E}+00$ & $.75 E+00$ & $2.12 \mathrm{E}+00$ & $.79 \mathrm{E}+00$ \\
\hline $1.57 \mathrm{E}-02$ & $3.72 \mathrm{E}+00$ & $5.52 \mathrm{E}-01$ & $3.53 \mathrm{E}-01$ & $1.31 \mathrm{E}+00$ & $1.75 \mathrm{E}+00$ & $2.12 \mathrm{E}+00$ & $2.79 \mathrm{E}+00$ \\
\hline $1.57 \mathrm{E}-02$ & $3.72 \mathrm{E}+00$ & $5.53 \mathrm{E}-01$ & $3.54 \mathrm{E}-01$ & $1.31 \mathrm{E}+00$ & $1.75 \mathrm{E}+00$ & $2.12 \mathrm{E}+00$ & $2.79 \mathrm{E}+00$ \\
\hline $1.58 \mathrm{E}-02$ & $.72 \mathrm{E}+00$ & $5.54 \mathrm{E}-01$ & $3.55 \mathrm{E}-01$ & $1.32 \mathrm{E}+00$ & $.75 \mathrm{E}+00$ & $2.12 \mathrm{E}+00$ & $2.79 \mathrm{E}+00$ \\
\hline $.59 \mathrm{E}-02$ & $3.71 E+00$ & $5.55 \mathrm{E}-01$ & $3.56 \mathrm{E}-01$ & $1.32 \mathrm{E}+00$ & $.75 \mathrm{E}+00$ & $2.13 \mathrm{E}+00$ & $2.79 \mathrm{E}+00$ \\
\hline $.60 \mathrm{E}-02$ & $3.71 \mathrm{E}+00$ & $5.56 \mathrm{E}-01$ & $3.57 \mathrm{E}-01$ & $1.32 \mathrm{E}+00$ & $1.75 \mathrm{E}+00$ & $2.13 E+00$ & $2.79 \mathrm{E}+00$ \\
\hline $1.60 \mathrm{E}-02$ & $3.71 E+00$ & $5.57 \mathrm{E}-01$ & $3.58 \mathrm{E}-01$ & $1.32 \mathrm{E}+00$ & $1.75 \mathrm{E}+00$ & $2.13 \mathrm{E}+00$ & $2.79 \mathrm{E}+00$ \\
\hline $1.61 \mathrm{E}-02$ & $3.71 E+00$ & $5.58 \mathrm{E}-01$ & $3.59 \mathrm{E}-01$ & $1.32 \mathrm{E}+00$ & $1.75 \mathrm{E}+00$ & $2.13 E+00$ & $2.79 \mathrm{E}+00$ \\
\hline $1.62 \mathrm{E}-02$ & $3.71 \mathrm{E}+00$ & $5.58 \mathrm{E}-01$ & $3.60 \mathrm{E}-01$ & $1.33 \mathrm{E}+00$ & $1.75 \mathrm{E}+00$ & $2.13 \mathrm{E}+00$ & $2.79 \mathrm{E}+00$ \\
\hline $1.63 \mathrm{E}-02$ & $3.71 \mathrm{E}+00$ & $5.59 \mathrm{E}-01$ & $3.61 \mathrm{E}-01$ & $1.33 \mathrm{E}+00$ & $1.76 \mathrm{E}+00$ & $2.13 \mathrm{E}+00$ & $2.79 \mathrm{E}+00$ \\
\hline $1.64 \mathrm{E}-02$ & $3.70 \mathrm{E}+00$ & $5.60 \mathrm{E}-01$ & $3.62 \mathrm{E}-01$ & $1.33 \mathrm{E}+00$ & $1.76 \mathrm{E}+00$ & $2.14 \mathrm{E}+00$ & $2.79 \mathrm{E}+00$ \\
\hline $1.64 \mathrm{E}-02$ & $3.70 \mathrm{E}+00$ & $5.61 \mathrm{E}-01$ & $3.63 E-01$ & $1.33 \mathrm{E}+00$ & $1.76 \mathrm{E}+00$ & $2.14 \mathrm{E}+00$ & $2.79 \mathrm{E}+00$ \\
\hline $1.65 \mathrm{E}-02$ & $3.70 \mathrm{E}+00$ & $5.62 \mathrm{E}-01$ & $3.64 \mathrm{E}-01$ & $1.33 \mathrm{E}+00$ & $1.76 \mathrm{E}+00$ & $2.14 \mathrm{E}+00$ & $2.79 \mathrm{E}+00$ \\
\hline $1.66 \mathrm{E}-02$ & $3.70 \mathrm{E}+00$ & $5.63 \mathrm{E}-01$ & $3.65 E-01$ & $1.33 \mathrm{E}+00$ & $1.76 \mathrm{E}+00$ & $2.14 \mathrm{E}+00$ & $2.79 \mathrm{E}+00$ \\
\hline $1.67 \mathrm{E}-02$ & $3.70 \mathrm{E}+00$ & $5.64 \mathrm{E}-01$ & $3.66 \mathrm{E}-01$ & $1.34 \mathrm{E}+00$ & $1.77 \mathrm{E}+00$ & $2.14 \mathrm{E}+00$ & $2.79 \mathrm{E}+00$ \\
\hline $1.67 \mathrm{E}-02$ & $3.69 \mathrm{E}+00$ & $5.65 \mathrm{E}-01$ & $3.67 E-01$ & $1.34 \mathrm{E}+00$ & $1.77 \mathrm{E}+00$ & $2.15 \mathrm{E}+00$ & $2.78 \mathrm{E}+00$ \\
\hline $68 \mathrm{E}-02$ & $3.69 \mathrm{E}+00$ & $5.66 \mathrm{E}-01$ & $3.68 \mathrm{E}-01$ & $1.34 \mathrm{E}+00$ & $1.77 \mathrm{E}+00$ & $2.15 \mathrm{E}+00$ & $2.78 \mathrm{E}+00$ \\
\hline $1.69 \mathrm{E}-$ & $3.69 \mathrm{E}+00$ & 5 & & $1.34 \mathrm{E}+00$ & $1.77 \mathrm{E}+00$ & $2.15 \mathrm{E}+00$ & $2.78 \mathrm{E}+00$ \\
\hline 1.7 & $3.69 \mathrm{E}+00$ & 5 & 1 & $34 \mathrm{E}+00$ & $1.77 \mathrm{E}+00$ & $2.15 \mathrm{E}+00$ & $2.78 \mathrm{E}+00$ \\
\hline $1.71 \mathrm{E}-02$ & $3.69 \mathrm{E}+00$ & $5.69 \mathrm{E}-01$ & $3.71 \mathrm{E}-01$ & $1.34 \mathrm{E}+00$ & $1.77 \mathrm{E}+00$ & $2.15 \mathrm{E}+00$ & $2.78 \mathrm{E}+00$ \\
\hline $1.71 \mathrm{E}-02$ & $3.68 \mathrm{E}+00$ & $5.69 \mathrm{E}-01$ & $3.72 \mathrm{E}-01$ & $1.34 \mathrm{E}+00$ & $1.77 \mathrm{E}+00$ & $2.15 \mathrm{E}+00$ & $2.78 \mathrm{E}+00$ \\
\hline $1.72 \mathrm{E}-02$ & $3.68 \mathrm{E}+00$ & $5.70 \mathrm{E}-01$ & $3.73 \mathrm{E}-01$ & $1.34 \mathrm{E}+00$ & $1.77 \mathrm{E}+00$ & $2.16 \mathrm{E}+00$ & $2.78 \mathrm{E}+00$ \\
\hline $1.73 \mathrm{E}-02$ & $3.68 \mathrm{E}+00$ & $5.71 \mathrm{E}-01$ & $3.73 E-01$ & $1.35 \mathrm{E}+00$ & $1.78 \mathrm{E}+00$ & $2.16 \mathrm{E}+00$ & $2.78 \mathrm{E}+00$ \\
\hline $1.74 \mathrm{E}-02$ & $3.68 \mathrm{E}+00$ & $5.72 \mathrm{E}-01$ & $3.74 \mathrm{E}-01$ & $1.35 \mathrm{E}+00$ & $1.78 \mathrm{E}+00$ & $2.16 \mathrm{E}+00$ & $2.78 \mathrm{E}+00$ \\
\hline $1.75 \mathrm{E}-02$ & $3.68 \mathrm{E}+00$ & $5.73 E-01$ & $3.75 \mathrm{E}-01$ & $1.35 \mathrm{E}+00$ & $1.78 \mathrm{E}+00$ & $2.16 \mathrm{E}+00$ & $2.78 \mathrm{E}+00$ \\
\hline $1.75 \mathrm{E}-02$ & $3.67 \mathrm{E}+00$ & $5.74 \mathrm{E}-01$ & $3.76 \mathrm{E}-01$ & $1.35 \mathrm{E}+00$ & $1.78 \mathrm{E}+00$ & $2.16 \mathrm{E}+00$ & $2.77 \mathrm{E}+00$ \\
\hline $1.76 \mathrm{E}-02$ & $3.67 \mathrm{E}+00$ & $5.75 \mathrm{E}$ & 3.76 & $1.35 \mathrm{E}+00$ & $1.78 \mathrm{E}+00$ & $2.16 \mathrm{E}+00$ & $2.77 \mathrm{E}+00$ \\
\hline $1.77 \mathrm{E}-02$ & $3.67 \mathrm{E}+00$ & 5. & 01 & $1.35 \mathrm{E}+00$ & $1.78 \mathrm{E}+00$ & $.16 \mathrm{E}+00$ & $2.77 \mathrm{E}+00$ \\
\hline $1.78 \mathrm{E}-02$ & $3.67 \mathrm{E}+00$ & $5.77 \mathrm{E}-01$ & $3.78 \mathrm{E}-01$ & $1.36 \mathrm{E}+00$ & $1.79 \mathrm{E}+00$ & $2.17 \mathrm{E}+00$ & $2.77 \mathrm{E}+00$ \\
\hline $1.79 \mathrm{E}-02$ & $3.67 \mathrm{E}+00$ & $5.78 \mathrm{E}-01$ & $3.79 \mathrm{E}-01$ & $1.36 \mathrm{E}+00$ & $1.79 \mathrm{E}+00$ & $2.17 \mathrm{E}+00$ & $2.77 \mathrm{E}+00$ \\
\hline $1.79 \mathrm{E}-02$ & $3.66 \mathrm{E}+00$ & $5.79 \mathrm{E}-01$ & $3.80 \mathrm{E}-01$ & $1.36 \mathrm{E}+00$ & $1.79 \mathrm{E}+00$ & $2.17 \mathrm{E}+00$ & $2.77 \mathrm{E}+00$ \\
\hline $1.80 \mathrm{E}-02$ & $3.66 \mathrm{E}+00$ & $5.79 \mathrm{E}-01$ & $3.81 E-01$ & $1.36 \mathrm{E}+00$ & $1.79 \mathrm{E}+00$ & $2.17 \mathrm{E}+00$ & $2.77 \mathrm{E}+00$ \\
\hline $1.81 \mathrm{E}-02$ & $3.66 \mathrm{E}+00$ & $5.80 \mathrm{E}-01$ & $3.82 \mathrm{E}-01$ & $1.36 \mathrm{E}+00$ & $1.79 \mathrm{E}+00$ & $2.17 \mathrm{E}+00$ & $2.77 \mathrm{E}+00$ \\
\hline $1.82 \mathrm{E}-02$ & $3.66 \mathrm{E}+00$ & $5.81 \mathrm{E}-01$ & $3.83 E-01$ & $1.36 \mathrm{E}+00$ & $1.79 \mathrm{E}+00$ & $2.17 \mathrm{E}+00$ & $2.77 \mathrm{E}+00$ \\
\hline $1.83 \mathrm{E}-02$ & $3.66 \mathrm{E}+00$ & $5.82 \mathrm{E}-01$ & $3.84 \mathrm{E}-01$ & $1.37 \mathrm{E}+00$ & $1.79 \mathrm{E}+00$ & $2.17 \mathrm{E}+00$ & $2.77 \mathrm{E}+00$ \\
\hline $1.84 \mathrm{E}-02$ & $3.65 \mathrm{E}+00$ & $5.83 \mathrm{E}-01$ & $3.85 \mathrm{E}-01$ & $1.37 \mathrm{E}+00$ & $1.80 \mathrm{E}+00$ & $2.17 \mathrm{E}+00$ & $2.77 \mathrm{E}+00$ \\
\hline $1.84 \mathrm{E}-02$ & $3.65 \mathrm{E}+00$ & $5.84 \mathrm{E}-01$ & $3.87 \mathrm{E}-01$ & $1.37 \mathrm{E}+00$ & $1.80 \mathrm{E}+00$ & $2.17 \mathrm{E}+00$ & $2.77 \mathrm{E}+00$ \\
\hline $1.85 \mathrm{E}-02$ & $3.65 \mathrm{E}+00$ & $5.85 \mathrm{E}-01$ & $3.88 E-01$ & $1.37 \mathrm{E}+00$ & $1.80 \mathrm{E}+00$ & $2.17 \mathrm{E}+00$ & $2.77 \mathrm{E}+00$ \\
\hline $1.86 \mathrm{E}-02$ & $3.65 E+00$ & $5.86 \mathrm{E}-01$ & $3.89 \mathrm{E}-01$ & $1.37 \mathrm{E}+00$ & $1.80 \mathrm{E}+00$ & $2.17 \mathrm{E}+00$ & $2.77 \mathrm{E}+00$ \\
\hline $1.87 \mathrm{E}-02$ & $3.64 \mathrm{E}+00$ & $5.87 \mathrm{E}-01$ & $3.90 \mathrm{E}-01$ & $1.38 \mathrm{E}+00$ & $1.80 \mathrm{E}+00$ & $2.17 \mathrm{E}+00$ & $2.77 \mathrm{E}+00$ \\
\hline $1.88 \mathrm{E}-02$ & $3.64 \mathrm{E}+00$ & $5.88 \mathrm{E}-01$ & $3.91 E-01$ & $1.38 \mathrm{E}+00$ & $1.80 \mathrm{E}+00$ & $2.17 \mathrm{E}+00$ & $2.77 \mathrm{E}+00$ \\
\hline $1.89 \mathrm{E}-02$ & $3.64 \mathrm{E}+00$ & $5.88 \mathrm{E}-01$ & $3.92 \mathrm{E}-01$ & $1.38 \mathrm{E}+00$ & $1.80 \mathrm{E}+00$ & $2.17 \mathrm{E}+00$ & $2.77 \mathrm{E}+00$ \\
\hline $1.89 \mathrm{E}-02$ & $3.64 \mathrm{E}+00$ & $5.89 \mathrm{E}-01$ & $3.93 E-01$ & $1.38 \mathrm{E}+00$ & $1.80 \mathrm{E}+00$ & $2.17 \mathrm{E}+00$ & $2.77 \mathrm{E}+00$ \\
\hline
\end{tabular}


RESRAD-OFFSITE, Version 2.5

$\mathrm{T}^{1 / 2}$ Limit $=180$ days

Title : RESRAD-OFFSITE Drinking Water, Plant, Milk, and Meat Pathways for Offsite Reside File : PBA-1_TC99-DOE-5.ROF

Summary of dose at graphical times, reptition 2 (continued)

Time

Years

$7.55 E+02$

$7.55 \mathrm{E}+02$

$7.56 \mathrm{E}+02$

$7.56 \mathrm{E}+02$

$7.57 \mathrm{E}+02$

$7.57 \mathrm{E}+02$

$7.58 \mathrm{E}+02$

$7.58 \mathrm{E}+02$

$7.59 \mathrm{E}+02$

$7.59 \mathrm{E}+02$

$7.60 \mathrm{E}+02$

$7.60 \mathrm{E}+02$

$7.61 \mathrm{E}+02$

$7.61 \mathrm{E}+02$

$7.62 \mathrm{E}+02$

7. $62 \mathrm{E}+02$

$7.63 \mathrm{E}+02$

$7.63 \mathrm{E}+02$

$7.64 \mathrm{E}+02$

$7.64 \mathrm{E}+02$

$7.65 \mathrm{E}+02$

$7.65 \mathrm{E}+02$

$7.66 \mathrm{E}+02$

$7.66 \mathrm{E}+02$

$7.67 \mathrm{E}+02$

$7.68 \mathrm{E}+02$

$7.68 \mathrm{E}+02$

$7.69 \mathrm{E}+02$

7. $69 \mathrm{E}+02$

$7.70 \mathrm{E}+02$

$7.70 \mathrm{E}+02$

$7.71 \mathrm{E}+02$

$7.71 \mathrm{E}+02$

7. $72 \mathrm{E}+02$

$7.72 \mathrm{E}+02$

$7.73 E+02$

$7.73 \mathrm{E}+02$

$7.74 \mathrm{E}+02$

$7.74 \mathrm{E}+02$

$7.75 \mathrm{E}+02$

$7.75 \mathrm{E}+02$

$7.76 \mathrm{E}+02$

$7.76 \mathrm{E}+02$

$7.77 \mathrm{E}+02$

$7.77 \mathrm{E}+02$

$7.78 \mathrm{E}+02$
Dose statistics at graphical times, mrem/yr

\begin{tabular}{|c|c|c|c|c|c|c|c|}
\hline inimum & aximum & Mean & ledian & $90 \%$ & $5 \%$ & $97.5 \%$ & \\
\hline 02 & $3.64 \mathrm{E}+00$ & $5.90 \mathrm{E}-01$ & $3.94 \mathrm{E}-01$ & $1.39 \mathrm{E}+00$ & $1.81 \mathrm{E}+00$ & $7 E+00$ & $7 \mathrm{E}+0$ \\
\hline 02 & +00 & 1 & 1 & $.39 \mathrm{E}+$ & 00 & $E+00$ & $7 \mathrm{E}+00$ \\
\hline-02 & +00 & $E-01$ & 01 & +00 & 00 & +00 & $\mathrm{E}+00$ \\
\hline-02 & 00 & 1 & & 0 & & 00 & $\Xi+00$ \\
\hline-02 & 0 & & & 0 & 00 & $\mathrm{E}+00$ & $77 \mathrm{E}+00$ \\
\hline $.95 E-02$ & $3.63 \mathrm{E}+00$ & $E-01$ & 01 & 1. $40 \mathrm{E}+00$ & $.81 E+00$ & $\mathrm{E}+00$ & $7 \mathrm{E}+00$ \\
\hline 02 & +00 & 0 & -01 & 00 & 00 & +00 & $8 \mathrm{E}+0 \mathrm{C}$ \\
\hline $.96 E-02$ & $3.62 E+00$ & t & $4.01 E-01$ & 1. $40 \mathrm{E}+00$ & $1.82 \mathrm{E}+00$ & $\mathrm{E}+00$ & $78 \mathrm{E}+00$ \\
\hline 02 & +00 & 1 & 01 & 00 & 00 & +00 & $8 \mathrm{E}+00$ \\
\hline $.98 \mathrm{E}-02$ & $3.62 \mathrm{E}+00$ & $E-01$ & $E-01$ & L. $41 E+00$ & $.82 E+00$ & $7 E+00$ & $78 E+00$ \\
\hline-02 & -00 & 1 & -01 & & & 00 & $8 \mathrm{E}+00$ \\
\hline & -00 & & & & & +00 & $\mathrm{E}+\mathrm{OC}$ \\
\hline$E-02$ & $E+00$ & 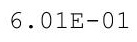 & -01 & 1 & 0 & $E+00$ & $E+0 C$ \\
\hline 02 & +00 & 工 & -01 & 00 & 00 & +00 & $.78 E+00$ \\
\hline 02 & -00 & 01 & 01 & 00 & 00 & +00 & $78 E+00$ \\
\hline $.03 E-02$ & $3.60 \mathrm{E}+00$ & 1 & -01 & & $1.82 \mathrm{E}+00$ & $7 \mathrm{E}+00$ & $77 E+00$ \\
\hline $.04 \mathrm{E}-02$ & $3.60 \mathrm{E}+00$ & $5 E-01$ & $9 E-01$ & 1. $42 \mathrm{E}+00$ & $.82 \mathrm{E}+00$ & $7 \mathrm{E}+00$ & $77 \mathrm{E}+00$ \\
\hline$E-02$ & $60 E+00$ & $6 E-01$ & $0 E-01$ & 1. $42 \mathrm{E}+00$ & $82 E+00$ & $17 E+00$ & $77 \mathrm{E}+00$ \\
\hline 02 & $\mathrm{E}+00$ & $6 E-01$ & -01 & $1 \cdot .20$ & & +00 & $77 \mathrm{E}+0 \mathrm{C}$ \\
\hline$E-02$ & $3.59 \mathrm{E}+00$ & -01 & -01 & 00 & 00 & +00 & $77 \mathrm{E}+0 \mathrm{C}$ \\
\hline $.08 \mathrm{E}-02$ & & & -01 & $1 . T_{1}+4$ & & 100 & +00 \\
\hline $9 \mathrm{E}-02$ & $3.59 \mathrm{E}+00$ & -01 & 01 & $1.43 E+00$ & & $7 \mathrm{E}+00$ & $76 \mathrm{E}+00$ \\
\hline$E-02$ & $59 F+0$ & 1 & 1 & 1. $43 \mathrm{E}+00$ & $83 E+0$ & $7 E+00$ & $76 \mathrm{E}+00$ \\
\hline $11 \mathrm{E}-02$ & $.58 \mathrm{E}+00$ & $.11 \mathrm{E}-01$ & $5 E-01$ & $1.43 \mathrm{E}+00$ & $1.84 \mathrm{E}+00$ & $7 E+00$ & $.76 \mathrm{E}+0 \mathrm{C}$ \\
\hline$E-02$ & $8 \mathrm{E}+00$ & $12 \mathrm{E}-01$ & $5 E-01$ & & & 00 & $76 \mathrm{E}+0 \mathrm{C}$ \\
\hline 02 & $E+O U$ & 1 & & & & & +00 \\
\hline $13 E-02$ & $3.58 \mathrm{E}+00$ & $E-01$ & $E-01$ & $1.43 E+00$ & t. & $E+00$ & $6 \mathrm{E}+00$ \\
\hline $14 \mathrm{E}-02$ & S.JITU & $6.14 \mathrm{E}-01$ & $4.18 E-01$ & $1.43 E+00$ & 1.OSLTU & . DOLTU & $.75 E+00$ \\
\hline 02 & 0 & - & $19 E-01$ & $43 E+00$ & $85 E+00$ & $.18 \mathrm{E}+00$ & $.75 E+0 c$ \\
\hline $.16 \mathrm{E}-02$ & 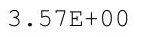 & $5 E-01$ & $E-01$ & 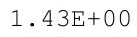 & & $8 \mathrm{E}+00$ & $5 E+0$ \\
\hline$F-02$ & $F+0$ & & $1 E-01$ & 1. $43 \mathrm{E}+00$ & $85 E+00$ & $8 F+00$ & $75 E+00$ \\
\hline 02 & & & $E-01$ & & & & \\
\hline$E-02$ & $3.56 \mathrm{E}+00$ & $E-01$ & 4. & $1 \cdot 4$ & $\perp \cdot 0=1$ & $9 \mathrm{E}+00$ & $5 E+00$ \\
\hline $20 E-02$ & $3.56 E+00$ & $.20 E-01$ & $4.24 E-01$ & 1. $44 \mathrm{E}+00$ & $1.85 E+00$ & $.19 \mathrm{E}+00$ & $.75 E+00$ \\
\hline $21 E-02$ & & $6.21 E-01$ & $4.25 E-01$ & & & 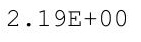 & $.74 \mathrm{E}+0 \mathrm{C}$ \\
\hline 2 & & & & & & & $.75 E+00$ \\
\hline $235-02$ & re & & & & & 0 & 00 \\
\hline 2 & & & & & 0 & & \\
\hline 2 & & & -01 & & $E+00$ & $0 E+00$ & $75 E+00$ \\
\hline $25 E-02$ & $3.55 \mathrm{E}+00$ & $E-01$ & $E-01$ & $1 \cdot 4$ & & & $5 E+00$ \\
\hline $6 E-02$ & & & & $1.45 E+00$ & & & $.75 \mathrm{E}+0 \mathrm{C}$ \\
\hline 02 & $3.34 \mathrm{E}+00$ & 1 & & $1.45 E+00$ & . $12+00$ & $20 E+00$ & $150+00$ \\
\hline 2 & $3.54 \mathrm{E}+$ & 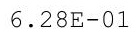 & 1 & $45 E$ & $87 E+$ & $.20 E+00$ & $75 E+0$ \\
\hline 2 & & & & 0 & 0 & 0 & $75 E$ \\
\hline-02 & $3.53 \mathrm{E}+00$ & $6.29 \mathrm{E}-01$ & 4. & $1.46 \mathrm{E}+00$ & $1.88 \mathrm{E}+00$ & $2.21 \mathrm{E}+00$ & $2.75 \mathrm{E}+00$ \\
\hline $31 E-02$ & $3.53 E+00$ & $.30 \mathrm{E}-01$ & 35E-01 & $1.46 \mathrm{E}+00$ & $1.88 \mathrm{E}+00$ & $2.21 E+00$ & $.75 \mathrm{E}+00$ \\
\hline
\end{tabular}


RESRAD-OFFSITE, Version 2.5

$\mathrm{T}^{1 / 2}$ Limit $=180$ days

Title : RESRAD-OFFSITE Drinking Water, Plant, Milk, and Meat Pathways for Offsite Reside File : PBA-1_TC99-DOE-5.ROF

Summary of dose at graphical times, reptition 2 (continued)

Time

Years

$7.78 \mathrm{E}+02$

$7.79 \mathrm{E}+02$

$7.79 \mathrm{E}+02$

$7.80 \mathrm{E}+02$

$7.80 \mathrm{E}+02$

$7.81 \mathrm{E}+02$

$7.81 \mathrm{E}+02$

$7.82 \mathrm{E}+02$

$7.82 \mathrm{E}+02$

$7.83 \mathrm{E}+02$

$7.83 \mathrm{E}+02$

$7.84 \mathrm{E}+02$

$7.84 \mathrm{E}+02$

$7.85 \mathrm{E}+02$

$7.85 \mathrm{E}+02$

$7.86 \mathrm{E}+02$

$7.86 \mathrm{E}+02$

$7.87 \mathrm{E}+02$

$7.88 \mathrm{E}+02$

$7.88 \mathrm{E}+02$

$7.89 \mathrm{E}+02$

$7.89 \mathrm{E}+02$

$7.90 \mathrm{E}+02$

$7.90 \mathrm{E}+02$

$7.91 \mathrm{E}+02$

$7.91 \mathrm{E}+02$

$7.92 \mathrm{E}+02$

7. $92 \mathrm{E}+02$

7. $93 \mathrm{E}+02$

$7.93 \mathrm{E}+02$

7. $94 \mathrm{E}+02$

$7.94 \mathrm{E}+02$

$7.95 \mathrm{E}+02$

7. $95 \mathrm{E}+02$

$7.96 \mathrm{E}+02$

7. $96 \mathrm{E}+02$

$7.97 \mathrm{E}+02$

$7.97 \mathrm{E}+02$

$7.98 \mathrm{E}+02$

$7.98 \mathrm{E}+02$

$7.99 \mathrm{E}+02$

$7.99 \mathrm{E}+02$

$8.00 \mathrm{E}+02$

$8.00 \mathrm{E}+02$

$8.01 \mathrm{E}+02$

$8.01 \mathrm{E}+02$
Dose statistics at graphical times, mrem/yr

\begin{tabular}{|c|c|c|c|c|c|c|c|}
\hline $\mathrm{m}$ & m & ean & 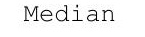 & & & & \\
\hline 2 & 0 & 1 & 1 & 00 & 00 & 0 & +00 \\
\hline $33 E-02$ & $3 E+00$ & $6.32 \mathrm{E}-01$ & 4. 37E-01 & $1.46 \mathrm{E}+00$ & $1.88 \mathrm{E}+00$ & $2.21 E+00$ & $75 E+0 C$ \\
\hline-02 & $\mathrm{~F}+00$ & $33-01$ & $39 E-01$ & $46 F+00$ & $88 F+00$ & $.21 E+00$ & $5 E+00$ \\
\hline & $.52 E+00$ & $4 E-01$ & 01 & & & & 100 \\
\hline 02 & & 1 & 1 & & & & +00 \\
\hline $37 E-02$ & 00 & 01 & 01 & 0 & & 00 & $E+00$ \\
\hline $38 E-02$ & 0 & 01 & & +00 & 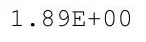 & $2.21 E+00$ & $76 \mathrm{E}+00$ \\
\hline-02 & +00 & E-01 & $1 E-01$ & $47 E+00$ & $E+00$ & $E+00$ & $\mathrm{E}+00$ \\
\hline$E-02$ & $E+$ & $8 E-01$ & $5 E-01$ & $.47 E+00$ & $9 \mathrm{E}+00$ & $.21 \mathrm{E}+00$ & $\mathrm{E}+\mathrm{OC}$ \\
\hline $41 F-02$ & $50 F+00$ & $9 E-01$ & $46 \mathrm{E}-01$ & $47 E+00$ & & $21 E+00$ & $76 \mathrm{~F}+00$ \\
\hline 2 & & & & & & & +00 \\
\hline$E-02$ & $E+00$ & $E-01$ & $9 E-01$ & +00 & $E+00$ & 0 & $E+00$ \\
\hline $.44 E-02$ & $3.50 \mathrm{E}+00$ & $2 E-01$ & $4.50 E-01$ & & $1.89 \mathrm{E}+00$ & $2.22 \mathrm{E}+00$ & $.76 E+00$ \\
\hline$E-02$ & 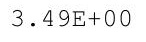 & $E-01$ & $E-01$ & & & & $E+00$ \\
\hline $46 E-02$ & & & & & & & +00 \\
\hline 2 & & & & & & & $E+00$ \\
\hline $\mathrm{F}$ & , & $\mathrm{F}$ & 1 & 0 & 0 & 0 & 00 \\
\hline $9 F-02$ & $3 F+00$ & $E-01$ & -01 & $1.48 \mathrm{E}+00$ & $\mathrm{E}+00$ & $.23 E+00$ & $76 \mathrm{E}+00$ \\
\hline $.50 E-02$ & $.48 \mathrm{E}+00$ & $.47 E-01$ & $4.57 \mathrm{E}-01$ & 1. $48 \mathrm{E}+00$ & 1. $90 \mathrm{E}+00$ & $2.23 E+00$ & $.76 \mathrm{E}+00$ \\
\hline $1 E-02$ & $.48 E+00$ & $5.48 \mathrm{E}-01$ & $4.57 \mathrm{E}-01$ & $48 \mathrm{E}+00$ & $90 \mathrm{E}+00$ & $2.23 \mathrm{E}+00$ & $76 \mathrm{E}+0 \mathrm{C}$ \\
\hline & & & & & & & \\
\hline & & & & & & & $76 \mathrm{E}+0 \mathrm{C}$ \\
\hline 2 & & & 01 & & & $.24 \mathrm{E}+$ & $76 \mathrm{E}+00$ \\
\hline 2 & $7 \mathrm{E}+\mathrm{C}$ & 1 & 1 & 1. $49 \mathrm{E}+00$ & & .2 & +00 \\
\hline 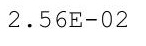 & $.47 E+0$ & $52 E-01$ & $.62 E-01$ & 1. $49 \mathrm{E}+00$ & $91 E+00$ & $.24 E+0$ & $76 E+00$ \\
\hline$F-02$ & $.46 E+00$ & $.53 E-01$ & $4.63 E-01$ & 1. $49 \mathrm{E}+00$ & $.91 E+00$ & $.24 E+00$ & $76 E+00$ \\
\hline$E-02$ & $16 \mathrm{~F}+0$ & & $.64 \mathrm{E}-01$ & & & & $76 \mathrm{E}+0 \mathrm{C}$ \\
\hline & & & & & & & \\
\hline & & & & & & & \\
\hline $.61 E-02$ & $3.45 \mathrm{E}+00$ & $6 E-01$ & $4.67 \mathrm{E}-01$ & $1.50 \mathrm{E}+00$ & म. & $2.25 \mathrm{E}+00$ & $76 \mathrm{E}+0 \mathrm{C}$ \\
\hline 舟 & - & $.57 E-01$ & $4.68 \mathrm{E}-01$ & $1.50 \mathrm{E}+00$ & $1.91 \mathrm{E}+00$ & $2.25 \mathrm{E}+00$ & $.77 \mathrm{E}+0$ \\
\hline 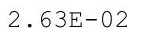 & & & $4.69 E-01$ & & & & $77 E+0$ \\
\hline 0 & & & & & & & $77 E+00$ \\
\hline & & & & & & & \\
\hline 02 & 0 & & $4.71 E-01$ & 0 & $E+00$ & 2.201 & \\
\hline $.67 \mathrm{E}-02$ & $3.45 \mathrm{E}+00$ & $1 \mathrm{E}-01$ & $4.72 \mathrm{E}-01$ & $1.51 \mathrm{E}+00$ & $1.92 \mathrm{E}+00$ & . & $2.76 \mathrm{E}+0 \mathrm{C}$ \\
\hline प & & {$[-U \perp$} & 01 & 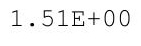 & & & 2. \\
\hline $70 E-02$ & (- & 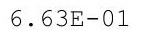 & $73 E-01$ & - & & $2.25 \mathrm{E}$ & $76 \mathrm{E}+0 \mathrm{C}$ \\
\hline 2 & $3.45 E+0$ & 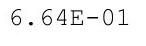 & 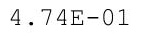 & 1. $51 \mathrm{E}+00$ & $1.92 \mathrm{E}+\mathrm{C}$ & $2.26 \mathrm{E}+$ & $76 \mathrm{E}+0 \mathrm{C}$ \\
\hline 2 & 0 & & 1 & $51 E+00$ & $1.92 \mathrm{E}+00$ & $E+00$ & $\mathrm{E}+00$ \\
\hline $3 E-02$ & $3.46 \mathrm{E}+00$ & & $4.75 E-01$ & & $2 \mathrm{E}+00$ & $2.26 \mathrm{E}$ & $76 \mathrm{E}+00$ \\
\hline $4 E-02$ & $3.46 \mathrm{E}+00$ & $67 E-01$ & $E-01$ & $1.51 \mathrm{E}+00$ & & & +00 \\
\hline & & & & & & & 2.10010 \\
\hline 02 & . & $\perp$ & & $1.52 \mathrm{E}+00$ & $1.9 \angle \mathrm{LT} 0$ & $2.26 \mathrm{E}+00$ & 2. \\
\hline (1) & & & & $1.52 \mathrm{E}+00$ & & & $2.76 \mathrm{E}+00$ \\
\hline-02 & +00 & E-01 & $E-01$ & $E+00$ & $.92 E+00$ & $.26 E+00$ & $76 \mathrm{E}+00$ \\
\hline
\end{tabular}


RESRAD-OFFSITE, Version 2.5

Title : RESRAD-OFFSITE Drinking Water, Plant, Milk, and Meat Pathways for Offsite Reside File : PBA-1_TC99-DOE-5.ROF

Summary of dose at graphical times, reptition 2 (continued)

Time

Years

$8.02 \mathrm{E}+02$

$8.02 \mathrm{E}+02$

$8.03 \mathrm{E}+02$

$8.03 \mathrm{E}+02$

$8.04 \mathrm{E}+02$

$8.04 \mathrm{E}+02$

$8.05 \mathrm{E}+02$

$8.05 \mathrm{E}+02$

$8.06 \mathrm{E}+02$

$8.06 \mathrm{E}+02$

$8.07 \mathrm{E}+02$

$8.07 \mathrm{E}+02$

$8.08 \mathrm{E}+02$

$8.09 \mathrm{E}+02$

$8.09 \mathrm{E}+02$

$8.10 \mathrm{E}+02$

$8.10 \mathrm{E}+02$

$8.11 \mathrm{E}+02$

$8.11 \mathrm{E}+02$

$8.12 \mathrm{E}+02$

$8.12 \mathrm{E}+02$

$8.13 \mathrm{E}+02$

$8.13 \mathrm{E}+02$

$8.14 \mathrm{E}+02$

$8.14 \mathrm{E}+02$

$8.15 \mathrm{E}+02$

$8.15 \mathrm{E}+02$

$8.16 \mathrm{E}+02$

$8.16 \mathrm{E}+02$

$8.17 \mathrm{E}+02$

$8.17 \mathrm{E}+02$

$8.18 \mathrm{E}+02$

$8.18 \mathrm{E}+02$

$8.19 \mathrm{E}+02$

$8.19 \mathrm{E}+02$

$8.20 \mathrm{E}+02$

$8.20 \mathrm{E}+02$

$8.21 \mathrm{E}+02$

$8.21 \mathrm{E}+02$

$8.22 \mathrm{E}+02$

$8.22 \mathrm{E}+02$

$8.23 E+02$

$8.23 \mathrm{E}+02$

$8.24 \mathrm{E}+02$

$8.24 \mathrm{E}+02$

$8.25 \mathrm{E}+02$
Dose statistics at graphical times, mrem/yr

\begin{tabular}{|c|c|c|c|c|c|c|c|}
\hline $\mathrm{m}$ & גm & ean & eq & & & & \\
\hline 2 & 0 & 1 & 1 & 00 & 00 & 0 & +00 \\
\hline $.80 E-02$ & $.46 \mathrm{E}+00$ & $6.72 \mathrm{E}-01$ & 4. $81 E-01$ & $1.52 \mathrm{E}+00$ & 1. $93 \mathrm{E}+00$ & $2.27 \mathrm{E}+00$ & $76 \mathrm{E}+0 \mathrm{C}$ \\
\hline$F-02$ & $46 E+00$ & $73 E-01$ & $82 F-01$ & $53 F+00$ & $93 E+00$ & $27 E+00$ & $76 F+00$ \\
\hline 02 & $.46 \mathrm{E}+00$ & $3 E-01$ & 01 & & & & 100 \\
\hline 02 & & 1 & 1 & & & & +00 \\
\hline $85 E-02$ & 00 & 01 & 01 & 00 & & 00 & $E+00$ \\
\hline $.86 \mathrm{E}-02$ & 0 & 1 & & +00 & 0 & $2.27 \mathrm{E}+00$ & $5 E+00$ \\
\hline-02 & $\Xi+00$ & $E-01$ & $7 E-01$ & $\mathrm{E}+00$ & $\Xi+00$ & $E+00$ & $E+00$ \\
\hline $88 E-02$ & $E+00$ & $8 E-01$ & $8 E-01$ & $E+00$ & $E+00$ & $27 E+00$ & $E+00$ \\
\hline $9 F-02$ & $47 F+00$ & $.78 \mathrm{E}-01$ & $0 E-01$ & & & $.27 E+00$ & $75 \mathrm{~F}+0$ \\
\hline 2 & & & & & & & +00 \\
\hline$E-02$ & $E+00$ & $E-01$ & $2 E-01$ & $4 \mathrm{E}+00$ & +00 & +00 & $\exists+00$ \\
\hline $.92 E-02$ & $3.47 \mathrm{E}+00$ & $E-01$ & 4.93E-01 & & $1.94 \mathrm{E}+00$ & $2.28 \mathrm{E}+00$ & $75 E+00$ \\
\hline$E-02$ & +00 & $2 E-01$ & $E-01$ & & & +00 & $E+00$ \\
\hline $95 E-02$ & & & & & & & +00 \\
\hline 2 & & & & & & & $E+00$ \\
\hline $.97 E-02$ & 0 & 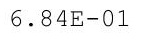 & 1 & 0 & 0 & 0 & 00 \\
\hline $8 F-02$ & $7 F+00$ & $5 \mathrm{~F}$ & 01 & $5 E+00$ & +00 & $28 E+00$ & $E+00$ \\
\hline $99 \mathrm{E}-02$ & $.47 \mathrm{E}+00$ & $.86 \mathrm{E}-01$ & $4.98 E-01$ & 1. $55 \mathrm{E}+00$ & $1.94 \mathrm{E}+00$ & $2.28 \mathrm{E}+00$ & $.75 E+00$ \\
\hline$E-02$ & $.48 E+00$ & $6.87 \mathrm{E}-01$ & $4.99 E-01$ & $1.55 \mathrm{E}+00$ & $1.94 \mathrm{E}+00$ & $2.28 \mathrm{E}+00$ & $.74 \mathrm{E}+0 \mathrm{C}$ \\
\hline & & & & & & & \\
\hline & & & & & & & 00 \\
\hline & & & 01 & & & $.28 \mathrm{E}+$ & $74 \mathrm{E}+0 \mathrm{C}$ \\
\hline 2 & $3 E+C$ & 1 & 1 & $6 \mathrm{E}+00$ & $\mathrm{E}+00$ & 0 & +00 \\
\hline-0 & $.48 E+0$ & $91 E-01$ & $4 E-01$ & $1.56 \mathrm{E}+00$ & $94 \mathrm{E}+00$ & $.28 \mathrm{E}+0$ & $74 E+00$ \\
\hline$F-02$ & $.48 E+00$ & $5.92 \mathrm{E}-01$ & $.05 E-01$ & $1.56 \mathrm{E}+00$ & $.94 \mathrm{E}+00$ & $.28 E+00$ & $.74 \mathrm{E}+0 \mathrm{C}$ \\
\hline$E-02$ & $48 F+00$ & $3 E-01$ & $6 E-01$ & & & & $74 \mathrm{E}+0 \mathrm{C}$ \\
\hline & & & & & & & \\
\hline & & & & & & & $4 \mathrm{E}+0 \mathrm{C}$ \\
\hline 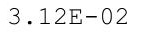 & $3.48 \mathrm{E}+00$ & $6.95 E-01$ & $5.09 \mathrm{E}-01$ & $1.56 \mathrm{E}+00$ & $1.95 \mathrm{E}+00$ & $2.28 \mathrm{E}+00$ & $74 \mathrm{E}+0 \mathrm{C}$ \\
\hline 2 & - & $.96 \mathrm{E}-01$ & $10 \mathrm{E}-01$ & $1.57 \mathrm{E}+00$ & $1.95 \mathrm{E}+00$ & $2.28 \mathrm{E}+00$ & $.74 \mathrm{E}+0$ \\
\hline 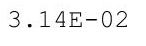 & & & & & & & $74 E+0$ \\
\hline $5 E-02$ & $48 \mathrm{E}+0$ & & & & & & $74 \mathrm{E}+00$ \\
\hline & & & & & & & \\
\hline & & & & 00 & -00 & 0 & $A E+O C$ \\
\hline $.19 E-02$ & $3.48 \mathrm{E}+00$ & $.00 \mathrm{E}-01$ & $.14 \mathrm{E}-01$ & $1.57 \mathrm{E}+00$ & $1.95 \mathrm{E}+00$ & $2.29 \mathrm{E}+00$ & $2.74 \mathrm{E}+0 \mathrm{C}$ \\
\hline 2 & 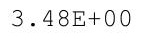 & 01 & 01 & म. & & & . . \\
\hline 2 & (- & 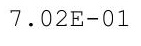 & 1 & 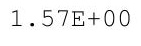 & & $2.29 \mathrm{E}+$ & $74 \mathrm{E}+0 \mathrm{C}$ \\
\hline & & 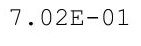 & 1 & $1.57 \mathrm{E}+00$ & 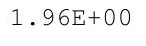 & & $74 \mathrm{E}+0 \mathrm{C}$ \\
\hline $.23 \mathrm{E}-02$ & & & 1 & $E+00$ & $6 \mathrm{E}+00$ & 0 & $\mathrm{E}+00$ \\
\hline 02 & & $.04 \mathrm{E}-01$ & $5.19 \mathrm{E}-01$ & $\mathrm{E}+00$ & 00 & 2 . & $74 \mathrm{E}+00$ \\
\hline$E-02$ & $3.49 \mathrm{E}+00$ & $05 E-01$ & $E-01$ & 1 & & & +00 \\
\hline & & & & & & & 2.14010 \\
\hline L & . & 1 & 01 & $1.57 \mathrm{E}+00$ & . . & $2.29 \mathrm{E}+00$ & 2. \\
\hline & & & & & & & $2.74 \mathrm{E}+00$ \\
\hline 02 & $\mathrm{E}+00$ & E-01 & E-01 & $E+00$ & $.96 \mathrm{E}+00$ & $.29 E+00$ & $.74 \mathrm{E}+00$ \\
\hline
\end{tabular}


RESRAD-OFFSITE, Version 2.5

Title : RESRAD-OFFSITE Drinking Water, Plant, Milk, and Meat Pathways for Offsite Reside File : PBA-1_TC99-DOE-5.ROF

Summary of dose at graphical times, reptition 2 (continued)

Time

Years

$8.25 \mathrm{E}+02$

$8.26 \mathrm{E}+02$

$8.26 \mathrm{E}+02$

$8.27 \mathrm{E}+02$

$8.27 \mathrm{E}+02$

$8.28 \mathrm{E}+02$

$8.29 \mathrm{E}+02$

$8.29 \mathrm{E}+02$

$8.30 \mathrm{E}+02$

$8.30 \mathrm{E}+02$

$8.31 \mathrm{E}+02$

$8.31 \mathrm{E}+02$

$8.32 \mathrm{E}+02$

$8.32 \mathrm{E}+02$

$8.33 \mathrm{E}+02$

8. $33 \mathrm{E}+02$

$8.34 \mathrm{E}+02$

$8.34 \mathrm{E}+02$

$8.35 \mathrm{E}+02$

$8.35 \mathrm{E}+02$

$8.36 \mathrm{E}+02$

$8.36 \mathrm{E}+02$

$8.37 \mathrm{E}+02$

$8.37 \mathrm{E}+02$

$8.38 \mathrm{E}+02$

$8.38 \mathrm{E}+02$

$8.39 \mathrm{E}+02$

$8.39 \mathrm{E}+02$

$8.40 \mathrm{E}+02$

$8.40 \mathrm{E}+02$

$8.41 \mathrm{E}+02$

$8.41 \mathrm{E}+02$

$8.42 \mathrm{E}+02$

$8.42 \mathrm{E}+02$

$8.43 \mathrm{E}+02$

$8.43 E+02$

$8.44 \mathrm{E}+02$

$8.44 \mathrm{E}+02$

$8.45 \mathrm{E}+02$

$8.45 \mathrm{E}+02$

$8.46 \mathrm{E}+02$

$8.46 \mathrm{E}+02$

$8.47 \mathrm{E}+02$

$8.47 \mathrm{E}+02$

$8.48 \mathrm{E}+02$

$8.49 \mathrm{E}+02$
Dose statistics at graphical times, mrem/yr

\begin{tabular}{|c|c|c|c|c|c|c|c|}
\hline inimum & Maximum & Mean & Median & $90 \%$ & $95 \%$ & $5 \%$ & $9 \%$ \\
\hline $3.32 \mathrm{E}-02$ & $3.49 \mathrm{E}+00$ & $7.09 \mathrm{E}-01$ & $5.26 \mathrm{E}-01$ & $1.57 \mathrm{E}+00$ & $1.97 \mathrm{E}+00$ & $2.30 \mathrm{E}+00$ & $2.74 \mathrm{E}+00$ \\
\hline $3.33 \mathrm{E}-02$ & $3.49 \mathrm{E}+00$ & $7.10 \mathrm{E}-01$ & $5.27 \mathrm{E}-01$ & $1.57 \mathrm{E}+00$ & $1.97 \mathrm{E}+00$ & $2.30 \mathrm{E}+00$ & $2.74 \mathrm{E}+00$ \\
\hline $3.34 \mathrm{E}-02$ & $3.49 \mathrm{E}+00$ & $7.11 \mathrm{E}-01$ & $5.28 \mathrm{E}-01$ & $1.57 \mathrm{E}+00$ & $1.97 \mathrm{E}+00$ & $2.30 \mathrm{E}+00$ & $2.74 \mathrm{E}+00$ \\
\hline $3.35 \mathrm{E}-02$ & $3.49 \mathrm{E}+00$ & $7.11 \mathrm{E}-01$ & $5.29 \mathrm{E}-01$ & $1.57 \mathrm{E}+00$ & $.97 \mathrm{E}+00$ & $2.30 \mathrm{E}+00$ & $.74 \mathrm{E}+00$ \\
\hline $3.36 \mathrm{E}-02$ & $3.49 \mathrm{E}+00$ & $7.12 \mathrm{E}-01$ & $5.30 \mathrm{E}-01$ & $1.58 \mathrm{E}+00$ & $1.97 \mathrm{E}+00$ & $2.30 \mathrm{E}+00$ & $2.73 \mathrm{E}+00$ \\
\hline $3.38 \mathrm{E}-02$ & $3.49 \mathrm{E}+00$ & $7.13 \mathrm{E}-01$ & $5.31 \mathrm{E}-01$ & $1.58 \mathrm{E}+00$ & $1.97 \mathrm{E}+00$ & $2.30 \mathrm{E}+00$ & $2.73 \mathrm{E}+00$ \\
\hline $3.39 \mathrm{E}-02$ & $.49 \mathrm{E}+00$ & $7.14 \mathrm{E}-01$ & $5.32 \mathrm{E}-01$ & $1.58 \mathrm{E}+00$ & $.97 \mathrm{E}+00$ & $2.30 \mathrm{E}+00$ & $2.73 \mathrm{E}+00$ \\
\hline $40 \mathrm{E}-02$ & $3.49 \mathrm{E}+00$ & $7.15 \mathrm{E}-01$ & $5.32 \mathrm{E}-01$ & $1.58 \mathrm{E}+00$ & $1.97 \mathrm{E}+00$ & $2.30 \mathrm{E}+00$ & $2.73 \mathrm{E}+00$ \\
\hline $.41 \mathrm{E}-02$ & $3.49 \mathrm{E}+00$ & $7.15 \mathrm{E}-01$ & $5.33 \mathrm{E}-01$ & $1.58 \mathrm{E}+00$ & $1.97 \mathrm{E}+00$ & $2.30 \mathrm{E}+00$ & $2.73 E+00$ \\
\hline $3.42 \mathrm{E}-02$ & $3.49 \mathrm{E}+00$ & $7.16 \mathrm{E}-01$ & $5.34 \mathrm{E}-01$ & $1.58 \mathrm{E}+00$ & $1.97 \mathrm{E}+00$ & $2.30 \mathrm{E}+00$ & $2.73 \mathrm{E}+00$ \\
\hline $3.44 \mathrm{E}-02$ & $3.49 \mathrm{E}+00$ & $7.17 \mathrm{E}-01$ & $5.34 \mathrm{E}-01$ & $1.58 \mathrm{E}+00$ & $1.98 \mathrm{E}+00$ & $2.30 \mathrm{E}+00$ & $2.73 E+00$ \\
\hline $3.45 \mathrm{E}-02$ & $3.49 \mathrm{E}+00$ & $7.18 \mathrm{E}-01$ & $5.35 \mathrm{E}-01$ & $1.58 \mathrm{E}+00$ & $1.98 \mathrm{E}+00$ & $2.30 \mathrm{E}+00$ & $2.72 \mathrm{E}+00$ \\
\hline $3.46 \mathrm{E}-02$ & $3.49 \mathrm{E}+00$ & $7.19 \mathrm{E}-01$ & $5.36 \mathrm{E}-01$ & $1.58 \mathrm{E}+00$ & $1.98 \mathrm{E}+00$ & $2.30 \mathrm{E}+00$ & $2.72 \mathrm{E}+00$ \\
\hline $3.47 \mathrm{E}-02$ & $3.49 \mathrm{E}+00$ & $7.20 \mathrm{E}-01$ & $5.36 \mathrm{E}-01$ & $1.58 \mathrm{E}+00$ & $1.98 \mathrm{E}+00$ & $2.30 \mathrm{E}+00$ & $2.72 \mathrm{E}+00$ \\
\hline $3.48 \mathrm{E}-02$ & $3.49 \mathrm{E}+00$ & $7.20 \mathrm{E}-01$ & $5.37 \mathrm{E}-01$ & $1.58 \mathrm{E}+00$ & $1.98 \mathrm{E}+00$ & $2.30 \mathrm{E}+00$ & $2.72 \mathrm{E}+00$ \\
\hline $3.50 \mathrm{E}-02$ & $3.49 \mathrm{E}+00$ & $7.21 \mathrm{E}-01$ & $5.38 \mathrm{E}-01$ & $1.59 \mathrm{E}+00$ & $1.98 \mathrm{E}+00$ & $2.30 \mathrm{E}+00$ & $2.72 \mathrm{E}+00$ \\
\hline $3.51 \mathrm{E}-02$ & $3.49 \mathrm{E}+00$ & $7.22 \mathrm{E}-01$ & $5.38 \mathrm{E}-01$ & $1.59 \mathrm{E}+00$ & $1.98 \mathrm{E}+00$ & $2.30 \mathrm{E}+00$ & $2.72 \mathrm{E}+00$ \\
\hline $3.52 \mathrm{E}-02$ & $3.49 \mathrm{E}+00$ & $7.23 \mathrm{E}-01$ & $5.39 \mathrm{E}-01$ & $1.59 \mathrm{E}+00$ & $1.98 \mathrm{E}+00$ & $2.30 \mathrm{E}+00$ & $2.71 \mathrm{E}+00$ \\
\hline $3.53 \mathrm{E}-02$ & $3.49 \mathrm{E}+00$ & $7.24 \mathrm{E}-01$ & $5.40 \mathrm{E}-01$ & $1.59 \mathrm{E}+00$ & $1.98 \mathrm{E}+00$ & $2.30 \mathrm{E}+00$ & $2.71 \mathrm{E}+00$ \\
\hline $55 E-02$ & $3.49 \mathrm{E}+00$ & $7.24 \mathrm{E}-01$ & $5.40 \mathrm{E}-01$ & $1.59 \mathrm{E}+00$ & $1.98 \mathrm{E}+00$ & $2.31 \mathrm{E}+00$ & $2.71 \mathrm{E}+00$ \\
\hline 2 & $3.49 \mathrm{E}+00$ & & 1 & $1.59 \mathrm{E}+00$ & $1.98 \mathrm{E}+00$ & $2.31 \mathrm{E}+00$ & $.71 \mathrm{E}+00$ \\
\hline $7 \mathrm{E}-02$ & $3.49 \mathrm{E}+00$ & 7 & 1 & $1.59 \mathrm{E}+00$ & $1.98 \mathrm{E}+00$ & $2.31 \mathrm{E}+00$ & $.71 E+00$ \\
\hline $3.58 \mathrm{E}-02$ & $3.50 \mathrm{E}+00$ & $7.27 \mathrm{E}-01$ & $5.43 \mathrm{E}-01$ & $1.60 \mathrm{E}+00$ & $1.98 \mathrm{E}+00$ & $2.31 \mathrm{E}+00$ & $2.71 \mathrm{E}+00$ \\
\hline $3.60 \mathrm{E}-02$ & $3.50 \mathrm{E}+00$ & $7.27 \mathrm{E}-01$ & $5.44 \mathrm{E}-01$ & $1.60 \mathrm{E}+00$ & $1.98 \mathrm{E}+00$ & $2.31 \mathrm{E}+00$ & $2.71 \mathrm{E}+00$ \\
\hline $3.61 \mathrm{E}-02$ & $3.50 \mathrm{E}+00$ & $7.28 \mathrm{E}-01$ & $5.45 \mathrm{E}-01$ & $1.60 \mathrm{E}+00$ & $1.98 \mathrm{E}+00$ & $2.31 \mathrm{E}+00$ & $2.70 \mathrm{E}+00$ \\
\hline $3.62 \mathrm{E}-02$ & $3.50 \mathrm{E}+00$ & $7.29 \mathrm{E}-01$ & $5.46 \mathrm{E}-01$ & $1.60 \mathrm{E}+00$ & $1.98 \mathrm{E}+00$ & $2.31 \mathrm{E}+00$ & $2.70 \mathrm{E}+00$ \\
\hline $3.63 \mathrm{E}-02$ & $3.50 \mathrm{E}+00$ & $7.30 \mathrm{E}-01$ & $5.47 \mathrm{E}-01$ & $1.60 \mathrm{E}+00$ & $1.98 \mathrm{E}+00$ & $2.31 \mathrm{E}+00$ & $2.70 \mathrm{E}+00$ \\
\hline $3.65 \mathrm{E}-02$ & $3.50 \mathrm{E}+00$ & $7.31 \mathrm{E}-01$ & $5.47 \mathrm{E}-01$ & $1.60 \mathrm{E}+00$ & $1.98 \mathrm{E}+00$ & $2.31 \mathrm{E}+00$ & $2.70 \mathrm{E}+00$ \\
\hline $3.66 \mathrm{E}-02$ & $3.50 \mathrm{E}+00$ & $7.31 \mathrm{E}-01$ & $5.48 \mathrm{E}-01$ & $1.60 \mathrm{E}+00$ & $1.98 \mathrm{E}+00$ & $2.31 \mathrm{E}+00$ & $2.70 \mathrm{E}+00$ \\
\hline $3.67 \mathrm{E}-02$ & $3.50 \mathrm{E}+00$ & 7.3 & $5.49 \mathrm{E}-01$ & $1.60 \mathrm{E}+00$ & $1.98 \mathrm{E}+00$ & $2.31 \mathrm{E}+00$ & $2.69 \mathrm{E}+00$ \\
\hline $9 E-02$ & $3.50 \mathrm{E}+00$ & 7 & 1 & $1.60 \mathrm{E}+00$ & $1.98 \mathrm{E}+00$ & $2.31 \mathrm{E}+00$ & $2.69 \mathrm{E}+00$ \\
\hline $3.70 \mathrm{E}-02$ & $3.50 \mathrm{E}+00$ & $7.34 \mathrm{E}-01$ & $5.51 \mathrm{E}-01$ & $1.60 \mathrm{E}+00$ & $1.98 \mathrm{E}+00$ & $2.31 \mathrm{E}+00$ & $2.69 \mathrm{E}+00$ \\
\hline $3.71 \mathrm{E}-02$ & $3.50 \mathrm{E}+00$ & $7.35 \mathrm{E}-01$ & $5.52 \mathrm{E}-01$ & $1.60 \mathrm{E}+00$ & $1.99 \mathrm{E}+00$ & $2.31 \mathrm{E}+00$ & $2.69 \mathrm{E}+00$ \\
\hline $3.72 \mathrm{E}-02$ & $3.50 \mathrm{E}+00$ & $7.35 \mathrm{E}-01$ & $5.53 \mathrm{E}-01$ & $1.61 \mathrm{E}+00$ & $1.99 \mathrm{E}+00$ & $2.31 \mathrm{E}+00$ & $2.68 \mathrm{E}+00$ \\
\hline $3.74 \mathrm{E}-02$ & $3.50 \mathrm{E}+00$ & $7.36 \mathrm{E}-01$ & $5.53 \mathrm{E}-01$ & $1.61 \mathrm{E}+00$ & $1.99 \mathrm{E}+00$ & $2.31 \mathrm{E}+00$ & $2.68 \mathrm{E}+00$ \\
\hline $3.75 \mathrm{E}-02$ & $3.50 \mathrm{E}+00$ & $7.37 \mathrm{E}-01$ & $5.54 \mathrm{E}-01$ & $1.61 \mathrm{E}+00$ & $1.99 \mathrm{E}+00$ & $2.31 \mathrm{E}+00$ & $2.68 \mathrm{E}+00$ \\
\hline $3.76 \mathrm{E}-02$ & $3.50 \mathrm{E}+00$ & $7.38 \mathrm{E}-01$ & $5.55 \mathrm{E}-01$ & $1.61 \mathrm{E}+00$ & $1.99 \mathrm{E}+00$ & $2.31 \mathrm{E}+00$ & $2.68 \mathrm{E}+00$ \\
\hline $3.77 \mathrm{E}-02$ & $3.50 \mathrm{E}+00$ & $7.39 \mathrm{E}-01$ & $5.56 \mathrm{E}-01$ & $1.61 \mathrm{E}+00$ & $1.99 \mathrm{E}+00$ & $2.31 \mathrm{E}+00$ & $2.68 \mathrm{E}+00$ \\
\hline $3.79 \mathrm{E}-02$ & $3.50 \mathrm{E}+00$ & $7.39 \mathrm{E}-01$ & $5.57 \mathrm{E}-01$ & $1.61 \mathrm{E}+00$ & $1.99 \mathrm{E}+00$ & $2.31 \mathrm{E}+00$ & $2.67 \mathrm{E}+00$ \\
\hline $3.80 \mathrm{E}-02$ & $3.50 \mathrm{E}+00$ & $7.40 \mathrm{E}-01$ & $5.57 \mathrm{E}-01$ & $1.61 \mathrm{E}+00$ & $1.99 \mathrm{E}+00$ & $2.31 \mathrm{E}+00$ & $2.67 \mathrm{E}+00$ \\
\hline $3.81 \mathrm{E}-02$ & $3.50 \mathrm{E}+00$ & $7.41 \mathrm{E}-01$ & $5.58 \mathrm{E}-01$ & $1.62 \mathrm{E}+00$ & $1.99 \mathrm{E}+00$ & $2.32 \mathrm{E}+00$ & $2.67 \mathrm{E}+00$ \\
\hline $3.83 \mathrm{E}-02$ & $3.50 \mathrm{E}+00$ & 7. $42 \mathrm{E}-01$ & $5.58 \mathrm{E}-01$ & $1.62 \mathrm{E}+00$ & $1.99 \mathrm{E}+00$ & $2.32 \mathrm{E}+00$ & $2.67 \mathrm{E}+00$ \\
\hline $3.84 \mathrm{E}-02$ & $3.50 \mathrm{E}+00$ & $7.42 \mathrm{E}-01$ & $5.59 \mathrm{E}-01$ & $1.62 \mathrm{E}+00$ & $1.99 \mathrm{E}+00$ & $2.32 \mathrm{E}+00$ & $2.67 \mathrm{E}+00$ \\
\hline $3.85 \mathrm{E}-02$ & $3.50 \mathrm{E}+00$ & $7.43 \mathrm{E}-01$ & $5.60 \mathrm{E}-01$ & $1.62 \mathrm{E}+00$ & $1.99 \mathrm{E}+00$ & $2.32 \mathrm{E}+00$ & $2.67 \mathrm{E}+00$ \\
\hline $3.87 \mathrm{E}-02$ & $3.50 \mathrm{E}+00$ & $7.44 \mathrm{E}-01$ & $5.61 \mathrm{E}-01$ & $1.62 \mathrm{E}+00$ & $1.99 \mathrm{E}+00$ & $2.32 \mathrm{E}+00$ & $2.67 \mathrm{E}+00$ \\
\hline $8 E-02$ & $3.50 \mathrm{E}+00$ & $7.45 \mathrm{E}-01$ & $5.62 \mathrm{E}-01$ & $1.62 \mathrm{E}+00$ & $1.99 \mathrm{E}+00$ & $2.32 \mathrm{E}+00$ & $2.67 \mathrm{E}+00$ \\
\hline
\end{tabular}


RESRAD-OFFSITE, Version 2.5

Title : RESRAD-OFFSITE Drinking Water, Plant, Milk, and Meat Pathways for Offsite Reside File : PBA-1_TC99-DOE-5.ROF

Summary of dose at graphical times, reptition 2 (continued)

Time

Years

8. $49 \mathrm{E}+02$

$8.50 \mathrm{E}+02$

$8.50 \mathrm{E}+02$

$8.51 \mathrm{E}+02$

$8.51 \mathrm{E}+02$

$8.52 \mathrm{E}+02$

8. $52 \mathrm{E}+02$

8. $53 \mathrm{E}+02$

8. $53 \mathrm{E}+02$

8. $54 \mathrm{E}+02$

$8.54 \mathrm{E}+02$

8. $55 \mathrm{E}+02$

$8.55 \mathrm{E}+02$

8. $56 \mathrm{E}+02$

$8.56 \mathrm{E}+02$

$8.57 \mathrm{E}+02$

$8.57 \mathrm{E}+02$

8. $58 \mathrm{E}+02$

8. $58 \mathrm{E}+02$

8. $59 \mathrm{E}+02$

8. $59 \mathrm{E}+02$

8. $60 \mathrm{E}+02$

$8.60 \mathrm{E}+02$

$8.61 \mathrm{E}+02$

$8.61 \mathrm{E}+02$

$8.62 \mathrm{E}+02$

$8.62 \mathrm{E}+02$

$8.63 \mathrm{E}+02$

$8.63 \mathrm{E}+02$

$8.64 \mathrm{E}+02$

$8.64 \mathrm{E}+02$

$8.65 \mathrm{E}+02$

$8.65 \mathrm{E}+02$

$8.66 \mathrm{E}+02$

$8.66 \mathrm{E}+02$

$8.67 \mathrm{E}+02$

$8.67 \mathrm{E}+02$

$8.68 \mathrm{E}+02$

$8.69 \mathrm{E}+02$

$8.69 \mathrm{E}+02$

$8.70 \mathrm{E}+02$

$8.70 \mathrm{E}+02$

$8.71 \mathrm{E}+02$

$8.71 E+02$

8. $72 \mathrm{E}+02$

$8.72 \mathrm{E}+02$

Dose statistics at graphical times, mrem/yr

\begin{tabular}{|c|c|c|c|c|c|c|c|}
\hline inimum & aximum & Mean & ledian & $0 \%$ & $5 \%$ & $97.5 \%$ & \\
\hline 02 & $3.50 \mathrm{E}+00$ & $6 E-01$ & $3 E-01$ & $1.63 \mathrm{E}+00$ & $1.99 \mathrm{E}+00$ & $.32 E+00$ & $7 \mathrm{E}+0$ \\
\hline 02 & +00 & $E-01$ & 1 & 0 & 00 & +00 & $7 \mathrm{E}+00$ \\
\hline 02 & +00 & -01 & 01 & 00 & 00 & -00 & +00 \\
\hline 02 & 00 & 1 & & 0 & & 00 & $6 E+00$ \\
\hline-02 & -00 & 1 & & 00 & 00 & $E+00$ & $66 \mathrm{E}+00$ \\
\hline $.96 \mathrm{E}-02$ & $0 \mathrm{E}+00$ & $E-01$ & -01 & $1.63 \mathrm{E}+00$ & $E+00$ & $.32 E+00$ & $66 \mathrm{E}+00$ \\
\hline 02 & -00 & $7.50 \mathrm{E}-01$ & 1 & 0 & 0 & +00 & $E+0 C$ \\
\hline $8 E-02$ & $3.50 \mathrm{E}+00$ & 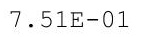 & & $1.63 \mathrm{E}+00$ & & +00 & $.66 \mathrm{E}+00$ \\
\hline 02 & +00 & 01 & 01 & $63 E+00$ & 00 & +00 & +00 \\
\hline $.01 E-02$ & $0 \mathrm{E}+00$ & $2 E-01$ & $3 E-01$ & $1.63 \mathrm{E}+00$ & $00 \mathrm{E}+00$ & $32 E+00$ & $E+00$ \\
\hline-02 & +00 & 1 & -01 & & & 00 & $E+00$ \\
\hline-02 & +00 & & & & 00 & +00 & $\mathrm{E}+\mathrm{OC}$ \\
\hline-02 & $E+00$ & $\begin{array}{lll}4 \\
\end{array}$ & -01 & +00 & 0 & +00 & +00 \\
\hline 02 & +00 & $U_{1}$ & -01 & 00 & 00 & +00 & +00 \\
\hline 02 & +00 & $\perp$ & 01 & 00 & 00 & +00 & +00 \\
\hline $.09 E-02$ & $\mathrm{E}+00$ & $E-01$ & -01 & & $01 E+00$ & $.31 E+00$ & $56 \mathrm{E}+00$ \\
\hline $10 \mathrm{E}-02$ & $3.49 \mathrm{E}+00$ & $8 \mathrm{E}-01$ & $0 E-01$ & $1.64 \mathrm{E}+00$ & $01 \mathrm{E}+00$ & $.31 E+00$ & $.65 E+00$ \\
\hline-02 & $9 \mathrm{E}+00$ & $9 \mathrm{E}-01$ & $1 E-01$ & $1.64 \mathrm{E}+00$ & $01 E+00$ & $31 E+00$ & $5 \mathrm{E}+0 \mathrm{C}$ \\
\hline-02 & $\mathrm{E}+00$ & 1 & -01 & 00 & & +00 & +00 \\
\hline 02 & +00 & $\perp$ & -01 & 00 & & +00 & +00 \\
\hline $.16 \mathrm{E}-02$ & & & -01 & & & 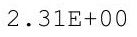 & +00 \\
\hline 02 & $\mathrm{E}+00$ & 1 & 1 & 0 & & $1 E+00$ & $E+00$ \\
\hline 02 & 39 & $E-01$ & 1 & $1.64 \mathrm{E}+00$ & $.02 E+00$ & $.31 E+00$ & $.65 E+00$ \\
\hline$E-02$ & $.49 \mathrm{E}+00$ & $7.63 \mathrm{E}-01$ & $5 E-01$ & $1.64 \mathrm{E}+00$ & $02 \mathrm{E}+00$ & $.31 E+00$ & $.65 E+00$ \\
\hline 02 & $3.49 \mathrm{E}+00$ & $64 \mathrm{E}-01$ & $6 E-01$ & & & $31 E+00$ & $64 \mathrm{E}+00$ \\
\hline & & & & & & & +00 \\
\hline & & & & & & & +00 \\
\hline $.26 \mathrm{E}-02$ & $3.49 \mathrm{E}+00$ & $.66 \mathrm{E}-01$ & $0 E-01$ & $1.64 \mathrm{E}+00$ & $\angle .0 \angle \mathrm{LT} U 0$ & $.31 E+00$ & $.64 \mathrm{E}+00$ \\
\hline 02 & $10+$ & 1 & 1 & $64 \mathrm{E}+00$ & $.02 \mathrm{E}+00$ & $.31 E+00$ & $.64 \mathrm{E}+0 \mathrm{C}$ \\
\hline 2 & - & - & 1 & $65 \mathrm{E}+$ & & $.31 E+00$ & $.64 \mathrm{E}+0$ \\
\hline 02 & $\mathrm{E}+00$ & $68 E-01$ & $3 E-01$ & $5 E+00$ & $2 \mathrm{E}+00$ & $32 E+00$ & $64 \mathrm{E}+00$ \\
\hline 02 & $5+0$ & & & & & & \\
\hline 02 & & & $E-01$ & & & & \\
\hline $34 E-02$ & $3.49 \mathrm{E}+00$ & $.71 E-01$ & $6 E-01$ & $1.65 \mathrm{E}+00$ & $2.03 E+00$ & $.32 E+00$ & $.63 E+00$ \\
\hline $35 E-02$ & & $7.71 E-01$ & $.97 E-01$ & $1.0 \mathrm{DTT}$ & & $.32 E+00$ & . OJLTU \\
\hline 2 & & & & & & & $.63 E+00$ \\
\hline 2 & $3.49 \mathrm{E}+00$ & & & 0 & & 0 & $\mathrm{E}+\mathrm{OC}$ \\
\hline 2 & & & & & & & \\
\hline 02 & & -01 & $1 E-01$ & $1.65 \mathrm{E}+00$ & $3 E+00$ & $2.32 \mathrm{E}+00$ & $.63 E+00$ \\
\hline $.42 \mathrm{E}-02$ & $3.49 \mathrm{E}+00$ & $75 E-01$ & -01 & 1. $65 \mathrm{E}+$ & & 0 & +00 \\
\hline & $\mathrm{E}+00$ & $E-01$ & 01 & 1. $65 \mathrm{E}+$ & & & $\mathrm{E}+\mathrm{OC}$ \\
\hline 02 & $3.49 \mathrm{E}+00$ & $7 \mathrm{E}-01$ & & $1.65 \mathrm{E}+00$ & $2.03 E+00$ & $32 \mathrm{E}+00$ & $.63 E+00$ \\
\hline $40 E-02$ & $3.49 \mathrm{E}+0$ & (1) & $05 E-01$ & $1.65 \mathrm{E}+$ & $2.03 E+$ & $2.33 E+00$ & $.63 E+0$ \\
\hline 2 & 3 & & & 0 & $2.03 \mathrm{E}$ & $.33 E+$ & $.63 E+00$ \\
\hline $9 E-02$ & $3.49 \mathrm{E}+00$ & $E-01$ & -01 & $1.65 \mathrm{E}+00$ & $2.03 E+00$ & $2.33 \mathrm{E}+00$ & $.63 E+00$ \\
\hline $.51 E-02$ & $3.49 \mathrm{E}+00$ & $7.80 \mathrm{E}-01$ & $.09 E-01$ & $1.65 \mathrm{E}+00$ & $2.03 E+00$ & 2. $32 E+00$ & $.63 E+00$ \\
\hline
\end{tabular}


RESRAD-OFFSITE, Version 2.5

Title : RESRAD-OFFSITE Drinking Water, Plant, Milk, and Meat Pathways for Offsite Reside File : PBA-1_TC99-DOE-5.ROF

Summary of dose at graphical times, reptition 2 (continued)

Time

Years

$8.73 \mathrm{E}+02$

$8.73 \mathrm{E}+02$

$8.74 \mathrm{E}+02$

$8.74 \mathrm{E}+02$

$8.75 \mathrm{E}+02$

$8.75 \mathrm{E}+02$

$8.76 \mathrm{E}+02$

$8.76 \mathrm{E}+02$

$8.77 \mathrm{E}+02$

$8.77 \mathrm{E}+02$

$8.78 \mathrm{E}+02$

$8.78 \mathrm{E}+02$

$8.79 \mathrm{E}+02$

$8.79 \mathrm{E}+02$

$8.80 \mathrm{E}+02$

$8.80 \mathrm{E}+02$

$8.81 \mathrm{E}+02$

8. $81 \mathrm{E}+02$

$8.82 \mathrm{E}+02$

$8.82 \mathrm{E}+02$

$8.83 \mathrm{E}+02$

$8.83 \mathrm{E}+02$

$8.84 \mathrm{E}+02$

$8.84 \mathrm{E}+02$

$8.85 \mathrm{E}+02$

$8.85 \mathrm{E}+02$

$8.86 \mathrm{E}+02$

$8.86 \mathrm{E}+02$

$8.87 \mathrm{E}+02$

$8.87 \mathrm{E}+02$

$8.88 \mathrm{E}+02$

$8.89 \mathrm{E}+02$

$8.89 \mathrm{E}+02$

$8.90 \mathrm{E}+02$

$8.90 \mathrm{E}+02$

$8.91 \mathrm{E}+02$

$8.91 \mathrm{E}+02$

8. $92 \mathrm{E}+02$

8. $92 \mathrm{E}+02$

$8.93 \mathrm{E}+02$

8. $93 \mathrm{E}+02$

$8.94 \mathrm{E}+02$

8. $94 \mathrm{E}+02$

8. $95 \mathrm{E}+02$

$8.95 \mathrm{E}+02$

$8.96 \mathrm{E}+02$
Dose statistics at graphical times, mrem/yr

\begin{tabular}{|c|c|c|c|c|c|c|c|}
\hline inimum & aximum & Mean & ledian & $0 \%$ & $\%$ & $97.5 \%$ & \\
\hline 02 & $E+00$ & $7.80 \mathrm{E}-01$ & $E-01$ & $1.66 \mathrm{E}+00$ & $3 E+00$ & $2.32 \mathrm{E}+00$ & $53 E+0$ \\
\hline 02 & +00 & -01 & 1 & $6 \mathrm{E}+$ & 00 & 00 & +00 \\
\hline 02 & +00 & $E-01$ & 1 & 00 & 00 & 00 & +00 \\
\hline 02 & 00 & 1 & & & & 00 & +00 \\
\hline-02 & -00 & 1 & & 00 & 00 & $\mathrm{E}+00$ & $63 E+00$ \\
\hline $9 E-02$ & $3 E+00$ & -01 & -01 & $1.66 \mathrm{E}+00$ & $\mathrm{E}+00$ & $E+00$ & $E+00$ \\
\hline 02 & -00 & $7.85 \mathrm{E}-01$ & 1 & 0 & 0 & +00 & +00 \\
\hline $2 E-02$ & $3.48 \mathrm{E}+00$ & • & & & & +00 & +00 \\
\hline 02 & +00 & $\perp$ & 01 & 00 & 00 & +00 & +00 \\
\hline $65 E-02$ & $3.48 \mathrm{E}+00$ & $37 E-01$ & $3 E-01$ & $.66 \mathrm{E}+00$ & $03 E+00$ & $.31 E+00$ & $\mathrm{E}+00$ \\
\hline $67 \mathrm{E}-02$ & $3.48 \mathrm{E}+00$ & $8 E-01$ & $3 E-01$ & & & $2.31 \mathrm{E}+00$ & $63 E+00$ \\
\hline-02 & -00 & -01 & & & 0 & +00 & +00 \\
\hline-02 & $E+00$ & $+-0 \perp$ & $E-01$ & $1.07 \mathrm{E}+00$ & +00 & $E+00$ & +0 \\
\hline 2 & 0 & $E-01$ & 1 & 0 & 0 & +00 & +00 \\
\hline 02 & +00 & $U_{\perp}$ & & 00 & & $\mathrm{E}+00$ & +00 \\
\hline$E-02$ & $3 F+00$ & $7.91 \mathrm{E}-01$ & 1 & & 0 & +00 & +00 \\
\hline $.75 \mathrm{E}-02$ & $8 \mathrm{E}+00$ & $2 E-01$ & $4 E-01$ & $1.67 \mathrm{E}+00$ & $3 E+00$ & $.31 E+00$ & $.62 \mathrm{E}+00$ \\
\hline-02 & $8 E+00$ & $3 E-01$ & $5 E-01$ & $1.67 \mathrm{E}+00$ & $03 E+00$ & $.31 E+00$ & $62 \mathrm{E}+0 \mathrm{C}$ \\
\hline-02 & +00 & & 01 & 00 & & +00 & +0 \\
\hline 02 & -00 & $\perp$ & -01 & 0 & & +00 & +0 \\
\hline 2 & & & 1 & 0 & & 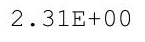 & 00 \\
\hline 02 & $E+00$ & 1 & 1 & 0 & & $31 \mathrm{~F}+0 \cap$ & $\mathrm{E}+00$ \\
\hline$E-02$ & $.47 \mathrm{E}+00$ & $E-01$ & $E-01$ & $1.67 \mathrm{E}+00$ & $03 E+0$ & $.31 E+00$ & $.61 E+00$ \\
\hline$E-02$ & $.47 E+00$ & $7.97 \mathrm{E}-01$ & $1 \mathrm{E}-01$ & $1.67 \mathrm{E}+00$ & $3 E+00$ & $.31 E+00$ & $.61 \mathrm{E}+00$ \\
\hline 02 & $E+00$ & $98 \mathrm{E}-01$ & $2 E-01$ & & & $31 \mathrm{~F}+00$ & $61 \mathrm{E}+00$ \\
\hline & & & & & & & +00 \\
\hline & & & & 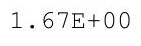 & & & +00 \\
\hline $91 E-02$ & $3.47 \mathrm{E}+00$ & $00 E-01$ & $35 E-01$ & $1.67 \mathrm{E}+00$ & $2.04 \mathrm{ET} 00$ & $2.31 \mathrm{E}+00$ & $.61 \mathrm{E}+00$ \\
\hline 02 & 0 & - & 1 & $67 E+00$ & $.04 \mathrm{E}+00$ & $.31 E+00$ & $.61 E+00$ \\
\hline 2 & - & - & 1 & $68 \mathrm{E}+$ & & $31 E+0$ & $.61 \mathrm{E}+\mathrm{C}$ \\
\hline$E-02$ & $E+00$ & $02 F-01$ & $8 E-01$ & $1.68 \mathrm{E}+00$ & & $31 E+00$ & $60 \mathrm{E}+00$ \\
\hline 02 & 3 & & & & & & \\
\hline 02 & & & & & & & \\
\hline $.00 \mathrm{E}-02$ & $3.47 \mathrm{E}+00$ & $.04 E-01$ & $E-01$ & $1.68 \mathrm{E}+00$ & $4 E+O 0$ & $2.31 \mathrm{E}+00$ & $.60 \mathrm{E}+00$ \\
\hline $.02 E-02$ & $.4 / E T U O$ & & $6.41 E-01$ & & & Z. OILTU & Z. OULT \\
\hline 2 & & & & & & & $.60 \mathrm{E}+00$ \\
\hline 2 & 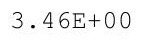 & & & 0 & & 0 & 00 \\
\hline 2 & & & & & & & \\
\hline-02 & & 1 & -01 & & $4 E+00$ & $2.31 E+00$ & $60 \mathrm{E}+00$ \\
\hline$E-02$ & $3.46 \mathrm{E}+00$ & $E-01$ & 01 & 0 & & 0 & +00 \\
\hline 02 & $E+00$ & 1 & 01 & $.68 \mathrm{E}+$ & & & $E+00$ \\
\hline & $3.40 E+00$ & $\perp$ & & $1.68 \mathrm{E}+00$ & & $31 E+00$ & $2.005+00$ \\
\hline & (2. & $\perp$ & 1 & 土. & & $2.31 E+00$ & $2.60 \mathrm{E}+0$ \\
\hline 2 & 0 & & 01 & 1.69 & $2.04 \mathrm{E}$ & $2.31 \mathrm{E}+$ & $.60 E+00$ \\
\hline-02 & $3.46 \mathrm{E}+00$ & $8.12 \mathrm{E}-01$ & -01 & $1.69 \mathrm{E}+00$ & $2.04 \mathrm{E}+00$ & $2.30 \mathrm{E}+00$ & $2.60 \mathrm{E}+00$ \\
\hline $.19 \mathrm{E}-02$ & $.46 \mathrm{E}+00$ & $.12 \mathrm{E}-01$ & $.51 E-01$ & $1.69 \mathrm{E}+00$ & $2.04 \mathrm{E}+00$ & $2.30 \mathrm{E}+00$ & $2.60 \mathrm{E}+00$ \\
\hline
\end{tabular}


RESRAD-OFFSITE, Version 2.5

Title : RESRAD-OFFSITE Drinking Water, Plant, Milk, and Meat Pathways for Offsite Reside File : PBA-1_TC99-DOE-5.ROF

Summary of dose at graphical times, reptition 2 (continued)

Time

Years

$8.96 \mathrm{E}+02$

$8.97 \mathrm{E}+02$

$8.97 \mathrm{E}+02$

$8.98 \mathrm{E}+02$

$8.98 \mathrm{E}+02$

$8.99 \mathrm{E}+02$

$8.99 \mathrm{E}+02$

$9.00 \mathrm{E}+02$

$9.00 \mathrm{E}+02$

$9.01 \mathrm{E}+02$

$9.01 \mathrm{E}+02$

$9.02 \mathrm{E}+02$

$9.02 \mathrm{E}+02$

$9.03 \mathrm{E}+02$

$9.03 E+02$

$9.04 \mathrm{E}+02$

$9.04 \mathrm{E}+02$

$9.05 \mathrm{E}+02$

$9.05 \mathrm{E}+02$

$9.06 \mathrm{E}+02$

$9.06 \mathrm{E}+02$

$9.07 \mathrm{E}+02$

$9.07 \mathrm{E}+02$

$9.08 \mathrm{E}+02$

$9.08 \mathrm{E}+02$

$9.09 \mathrm{E}+02$

$9.10 \mathrm{E}+02$

$9.10 \mathrm{E}+02$

9. $11 \mathrm{E}+02$

9. $11 \mathrm{E}+02$

$9.12 \mathrm{E}+02$

9. $12 \mathrm{E}+02$

$9.13 \mathrm{E}+02$

9. $13 \mathrm{E}+02$

$9.14 \mathrm{E}+02$

9. $14 \mathrm{E}+02$

9. $15 \mathrm{E}+02$

$9.15 \mathrm{E}+02$

9. $16 \mathrm{E}+02$

$9.16 \mathrm{E}+02$

$9.17 \mathrm{E}+02$

$9.17 \mathrm{E}+02$

9. $18 \mathrm{E}+02$

9. $18 \mathrm{E}+02$

$9.19 \mathrm{E}+02$

$9.19 \mathrm{E}+02$
Dose statistics at graphical times, mrem/yr

\begin{tabular}{|c|c|c|c|c|c|c|c|}
\hline inimum & aximum & Mean & ledian & $0 \%$ & $5 \div$ & $97.5 \%$ & \\
\hline 02 & $.46 E+00$ & $3 E-01$ & $6.52 \mathrm{E}-01$ & $1.69 \mathrm{E}+00$ & $5 E+00$ & $2.30 \mathrm{E}+00$ & $\mathrm{E}+\mathrm{OC}$ \\
\hline 02 & $E+00$ & 01 & 01 & $9 \mathrm{E}+$ & $\mathrm{E}+00$ & 00 & 100 \\
\hline 02 & +00 & -01 & 01 & 00 & 00 & 00 & +00 \\
\hline 02 & 00 & 1 & & 0 & & 00 & +00 \\
\hline-02 & -00 & & 1 & 00 & 00 & $E+00$ & $\exists+00$ \\
\hline-02 & +00 & -01 & -01 & $1.69 \mathrm{E}+00$ & $\mathrm{E}+00$ & $E+00$ & $61 E+00$ \\
\hline 02 & -00 & -0 & 1 & 0 & 00 & +00 & +00 \\
\hline$E-02$ & $3.45 \mathrm{E}+00$ & . I L & $8 E-01$ & $1.69 \mathrm{E}+00$ & $2.05 E+00$ & $\mathrm{E}+00$ & +00 \\
\hline 02 & +00 & $\perp$ & 01 & $9 \mathrm{E}+00$ & 00 & +00 & +00 \\
\hline$E-02$ & $3.45 \mathrm{E}+00$ & $9 E-01$ & $E-01$ & $.70 \mathrm{E}+00$ & $5 E+00$ & $0 \mathrm{E}+00$ & $61 \mathrm{E}+00$ \\
\hline-02 & +00 & 1 & -01 & & & 00 & +00 \\
\hline & -00 & & & & & +00 & +00 \\
\hline-02 & $\mathrm{E}+00$ & $1+-0 \perp$ & -01 & +00 & $E+00$ & $E+00$ & +0 \\
\hline 02 & -00 & 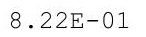 & -01 & 00 & & +00 & +00 \\
\hline 02 & -00 & $\perp$ & 01 & 00 & 00 & +00 & +00 \\
\hline-02 & $\mathrm{E}+00$ & $\perp$ & -01 & & $5 \mathrm{E}+00$ & $30 \mathrm{E}+00$ & $61 \mathrm{E}+00$ \\
\hline $.45 E-02$ & $4 \mathrm{E}+00$ & $.24 \mathrm{E}-01$ & $4 E-01$ & 1. $70 \mathrm{E}+00$ & $5 E+00$ & $30 \mathrm{E}+00$ & $61 E+00$ \\
\hline-02 & $4 E+00$ & $5 E-01$ & $E-01$ & $0 \mathrm{E}+00$ & $5 E+00$ & $30 \mathrm{E}+00$ & $60 \mathrm{E}+00$ \\
\hline 02 & +00 & 1 & -01 & 00 & & +00 & +0 \\
\hline$E-02$ & +00 & $u-U \perp$ & -01 & 00 & & +00 & +00 \\
\hline $.51 \mathrm{E}-02$ & & & -01 & & & (1) & +00 \\
\hline $.53 E-02$ & $3.44 \mathrm{E}+00$ & -01 & -01 & $1.71 \mathrm{E}+00$ & & $\mathrm{OE}+00$ & $60 \mathrm{E}+00$ \\
\hline$E-02$ & $3.44 \mathrm{E}+00$ & $8.28 \mathrm{E}-01$ & $9 E-01$ & & $.05 E+00$ & $30 E+00$ & $.60 \mathrm{E}+00$ \\
\hline$E-02$ & $.44 \mathrm{E}+00$ & $.29 \mathrm{E}-01$ & $0 E-01$ & 1. $71 \mathrm{E}+00$ & $05 \mathrm{E}+00$ & $\mathrm{OE}+00$ & $.60 \mathrm{E}+0 \mathrm{C}$ \\
\hline 02 & $E+00$ & $29 E-01$ & $E-01$ & & & $30 \mathrm{E}+00$ & $60 \mathrm{E}+00$ \\
\hline 02 & & & & & & & +00 \\
\hline$E-02$ & +00 & $\perp$ & -01 & & & +00 & +00 \\
\hline $63 E-02$ & $3.45 \mathrm{ET} 0$ & ( & $4 E-01$ & $1.71 \mathrm{E}+00$ & $2.00 \mathrm{ET} 00$ & $2.31 \mathrm{E}+00$ & $.59 E+00$ \\
\hline 2 & $10+$ & 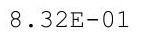 & $5 E-01$ & $71 \mathrm{E}+$ & $05 E+00$ & $.31 E+00$ & $59 \mathrm{E}+0 \mathrm{C}$ \\
\hline 2 & 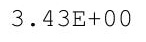 & - & 1 & & & $.31 \mathrm{E}+0$ & $59 \mathrm{E}+$ \\
\hline 02 & $13 F+00$ & $3 F-01$ & $7 E-01$ & $1 E+00$ & $5 \mathrm{E}+00$ & $1 E+00$ & $58 \mathrm{E}+00$ \\
\hline 02 & $F+00$ & $E-01$ & & & & & \\
\hline & & & 01 & & & & \\
\hline $.72 E-02$ & $3.43 E+00$ & $8.35 E-01$ & $30 E-01$ & $1.71 \mathrm{E}+00$ & $3 E+00$ & $2.31 E+00$ & $.58 E+0 C$ \\
\hline $74 E-02$ & S. & & $6.80 E-01$ & I.T工एTU & & & Z. $.0 \mathrm{LT}$ \\
\hline 2 & & & & & & & \\
\hline 2 & - & & & 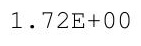 & & 0 & 00 \\
\hline 2 & & & & & & & \\
\hline 02 & & 1 & -01 & & $6 \mathrm{E}+00$ & $2.31 E+00$ & \\
\hline $2 E-02$ & $3.42 \mathrm{E}+00$ & $39 E-01$ & 01 & $72 \mathrm{E}$ & & & +00 \\
\hline 2 & $E+00$ & $E-01$ & 01 & $.72 \mathrm{E}-$ & & & $E+00$ \\
\hline & $4 \angle E+U 0$ & & & $72 \mathrm{E}+00$ & . $65+00$ & $2.31 E+00$ & $2.01 \mathrm{E}+00$ \\
\hline & $E+00$ & $x^{2}$ & 1 & 土. & $06 \mathrm{E}+$ & $2.31 E+00$ & $2.57 \mathrm{E}+0$ \\
\hline 2 & 0 & & 1 & 1 & $2.06 \mathrm{E}$ & $2.31 \mathrm{E}$ & 00 \\
\hline-02 & $3.42 \mathrm{E}+00$ & $8.43 E-01$ & $E-01$ & $1.72 \mathrm{E}+00$ & $2.06 \mathrm{E}+00$ & $2.31 \mathrm{E}+00$ & $2.57 \mathrm{E}+00$ \\
\hline $92 E-02$ & $3.42 \mathrm{E}+00$ & $.43 E-01$ & $.92 E-01$ & $1.72 \mathrm{E}+00$ & $2.06 \mathrm{E}+00$ & $2.31 E+00$ & $2.58 \mathrm{E}+00$ \\
\hline
\end{tabular}


RESRAD-OFFSITE, Version 2.5

Title : RESRAD-OFFSITE Drinking Water, Plant, Milk, and Meat Pathways for Offsite Reside File : PBA-1_TC99-DOE-5.ROF

Summary of dose at graphical times, reptition 2 (continued)

Time

Years

$9.20 \mathrm{E}+02$

$9.20 \mathrm{E}+02$

$9.21 \mathrm{E}+02$

$9.21 \mathrm{E}+02$

$9.22 \mathrm{E}+02$

$9.22 \mathrm{E}+02$

$9.23 \mathrm{E}+02$

$9.23 \mathrm{E}+02$

$9.24 \mathrm{E}+02$

$9.24 \mathrm{E}+02$

$9.25 \mathrm{E}+02$

$9.25 \mathrm{E}+02$

$9.26 \mathrm{E}+02$

$9.26 \mathrm{E}+02$

$9.27 \mathrm{E}+02$

$9.27 \mathrm{E}+02$

$9.28 \mathrm{E}+02$

9. $28 \mathrm{E}+02$

$9.29 \mathrm{E}+02$

9. $30 \mathrm{E}+02$

$9.30 \mathrm{E}+02$

$9.31 \mathrm{E}+02$

$9.31 \mathrm{E}+02$

9. $32 \mathrm{E}+02$

9. $32 \mathrm{E}+02$

$9.33 \mathrm{E}+02$

9. $33 \mathrm{E}+02$

$9.34 \mathrm{E}+02$

9. $34 \mathrm{E}+02$

$9.35 \mathrm{E}+02$

9. $35 \mathrm{E}+02$

9. $36 \mathrm{E}+02$

$9.36 \mathrm{E}+02$

9. $37 \mathrm{E}+02$

9. $37 \mathrm{E}+02$

9. $38 \mathrm{E}+02$

9. $38 \mathrm{E}+02$

$9.39 \mathrm{E}+02$

$9.39 \mathrm{E}+02$

$9.40 \mathrm{E}+02$

$9.40 \mathrm{E}+02$

9. $41 \mathrm{E}+02$

9. $41 \mathrm{E}+02$

9. $42 \mathrm{E}+02$

$9.42 \mathrm{E}+02$

$9.43 \mathrm{E}+02$
Dose statistics at graphical times, mrem/yr

\begin{tabular}{|c|c|c|c|c|c|c|c|}
\hline Minimum & Maximum & Mean & Median & $90 \%$ & $95 \%$ & $5 \%$ & $9 \%$ \\
\hline $.93 \mathrm{E}-02$ & $3.41 \mathrm{E}+00$ & $8.44 \mathrm{E}-01$ & $6.92 \mathrm{E}-01$ & $1.72 \mathrm{E}+00$ & $2.06 \mathrm{E}+00$ & $2.31 \mathrm{E}+00$ & $2.58 \mathrm{E}+00$ \\
\hline $5.95 \mathrm{E}-02$ & $3.41 E+00$ & $8.45 \mathrm{E}-01$ & $6.93 E-01$ & $1.72 \mathrm{E}+00$ & $2.06 \mathrm{E}+00$ & $2.31 \mathrm{E}+00$ & $2.58 \mathrm{E}+00$ \\
\hline $.97 \mathrm{E}-02$ & $3.41 \mathrm{E}+00$ & $8.45 \mathrm{E}-01$ & $6.94 \mathrm{E}-01$ & $1.72 \mathrm{E}+00$ & $2.06 \mathrm{E}+00$ & $2.31 \mathrm{E}+00$ & $2.58 \mathrm{E}+00$ \\
\hline $5.98 \mathrm{E}-02$ & $3.41 \mathrm{E}+00$ & $8.46 \mathrm{E}-01$ & $6.95 \mathrm{E}-01$ & $1.72 \mathrm{E}+00$ & $.06 \mathrm{E}+00$ & $2.31 \mathrm{E}+00$ & $.58 \mathrm{E}+00$ \\
\hline $6.00 \mathrm{E}-02$ & $.41 \mathrm{E}+00$ & $8.47 \mathrm{E}-01$ & $6.96 \mathrm{E}-01$ & $1.72 \mathrm{E}+00$ & $2.06 \mathrm{E}+00$ & $2.31 \mathrm{E}+00$ & $2.58 \mathrm{E}+00$ \\
\hline $6.02 \mathrm{E}-02$ & $3.41 \mathrm{E}+00$ & $8.47 \mathrm{E}-01$ & $6.97 \mathrm{E}-01$ & $1.72 \mathrm{E}+00$ & $2.06 \mathrm{E}+00$ & $2.31 \mathrm{E}+00$ & $2.58 \mathrm{E}+00$ \\
\hline $03 E-02$ & $.41 \mathrm{E}+00$ & $8.48 \mathrm{E}-01$ & $6.98 \mathrm{E}-01$ & $1.72 \mathrm{E}+00$ & $.06 \mathrm{E}+00$ & $2.31 \mathrm{E}+00$ & $2.58 \mathrm{E}+00$ \\
\hline $.05 \mathrm{E}-02$ & $.41 E+00$ & $8.48 \mathrm{E}-01$ & $6.99 \mathrm{E}-01$ & $1.72 \mathrm{E}+00$ & $2.06 \mathrm{E}+00$ & $2.31 \mathrm{E}+00$ & $2.58 \mathrm{E}+00$ \\
\hline $07 \mathrm{E}-02$ & $3.41 \mathrm{E}+00$ & $8.49 \mathrm{E}-01$ & $7.00 \mathrm{E}-01$ & $1.72 \mathrm{E}+00$ & $2.06 \mathrm{E}+00$ & $2.31 \mathrm{E}+00$ & $2.58 \mathrm{E}+00$ \\
\hline $.08 \mathrm{E}-02$ & $3.40 \mathrm{E}+00$ & $8.50 \mathrm{E}-01$ & $7.01 E-01$ & $1.72 \mathrm{E}+00$ & $2.06 \mathrm{E}+00$ & $2.31 \mathrm{E}+00$ & $2.58 \mathrm{E}+00$ \\
\hline $.10 \mathrm{E}-02$ & $3.40 \mathrm{E}+00$ & $8.50 \mathrm{E}-01$ & $7.02 E-01$ & $1.72 \mathrm{E}+00$ & $2.06 \mathrm{E}+00$ & $2.31 \mathrm{E}+00$ & $2.58 \mathrm{E}+00$ \\
\hline $6.12 \mathrm{E}-02$ & $3.40 \mathrm{E}+00$ & $8.51 \mathrm{E}-01$ & $7.03 \mathrm{E}-01$ & $1.73 \mathrm{E}+00$ & $2.06 \mathrm{E}+00$ & $2.31 \mathrm{E}+00$ & $.58 \mathrm{E}+00$ \\
\hline $6.13 \mathrm{E}-02$ & $3.40 \mathrm{E}+00$ & $8.52 \mathrm{E}-01$ & $7.04 \mathrm{E}-01$ & $1.73 \mathrm{E}+00$ & $2.06 \mathrm{E}+00$ & $2.31 \mathrm{E}+00$ & $2.58 \mathrm{E}+00$ \\
\hline $6.15 \mathrm{E}-02$ & $3.40 \mathrm{E}+00$ & $8.52 \mathrm{E}-01$ & $7.04 \mathrm{E}-01$ & $1.73 \mathrm{E}+00$ & $2.06 \mathrm{E}+00$ & $2.31 \mathrm{E}+00$ & $2.58 \mathrm{E}+00$ \\
\hline $6.17 \mathrm{E}-02$ & $3.40 \mathrm{E}+00$ & $8.53 \mathrm{E}-01$ & $7.05 E-01$ & $1.73 \mathrm{E}+00$ & $2.06 \mathrm{E}+00$ & $2.31 \mathrm{E}+00$ & $2.58 \mathrm{E}+00$ \\
\hline $6.18 \mathrm{E}-02$ & $3.40 \mathrm{E}+00$ & $8.54 \mathrm{E}-01$ & $7.06 \mathrm{E}-01$ & $1.73 \mathrm{E}+00$ & $2.06 \mathrm{E}+00$ & $2.31 \mathrm{E}+00$ & $2.58 \mathrm{E}+00$ \\
\hline $6.20 \mathrm{E}-02$ & $3.40 \mathrm{E}+00$ & $8.54 \mathrm{E}-01$ & $7.06 \mathrm{E}-01$ & $1.73 \mathrm{E}+00$ & $2.06 \mathrm{E}+00$ & $2.31 \mathrm{E}+00$ & $2.58 \mathrm{E}+00$ \\
\hline $22 \mathrm{E}-02$ & $3.39 \mathrm{E}+00$ & $8.55 \mathrm{E}-01$ & $7.07 \mathrm{E}-01$ & $1.73 \mathrm{E}+00$ & $2.06 \mathrm{E}+00$ & $2.30 \mathrm{E}+00$ & $2.58 \mathrm{E}+00$ \\
\hline $23 \mathrm{E}-02$ & $3.39 E+00$ & $8.55 \mathrm{E}-01$ & $7.07 E-01$ & $1.72 \mathrm{E}+00$ & $2.06 \mathrm{E}+00$ & $2.30 \mathrm{E}+00$ & $2.58 \mathrm{E}+00$ \\
\hline $25 \mathrm{E}-02$ & $3.39 \mathrm{E}+00$ & $8.56 \mathrm{E}-01$ & $.08 \mathrm{E}-01$ & $1.72 \mathrm{E}+00$ & $2.06 \mathrm{E}+00$ & $2.30 \mathrm{E}+00$ & $2.58 \mathrm{E}+00$ \\
\hline 2 & $3.39 \mathrm{E}+00$ & 8 & & $1.72 \mathrm{E}+00$ & $2.06 \mathrm{E}+00$ & $2.30 \mathrm{E}+00$ & $.58 \mathrm{E}+00$ \\
\hline 2 & $3.39 \mathrm{E}+00$ & 8 & 1 & $72 \mathrm{E}+00$ & $2.06 \mathrm{E}+00$ & $2.30 \mathrm{E}+00$ & $.58 \mathrm{E}+00$ \\
\hline $6.30 \mathrm{E}-02$ & $3.39 \mathrm{E}+00$ & $8.58 \mathrm{E}-01$ & $7.10 \mathrm{E}-01$ & $1.72 \mathrm{E}+00$ & $2.06 \mathrm{E}+00$ & $2.30 \mathrm{E}+00$ & $2.58 \mathrm{E}+00$ \\
\hline $6.32 \mathrm{E}-02$ & $3.39 \mathrm{E}+00$ & $8.59 \mathrm{E}-01$ & 7. $11 \mathrm{E}-01$ & $1.72 \mathrm{E}+00$ & $2.06 \mathrm{E}+00$ & $2.30 \mathrm{E}+00$ & $2.58 \mathrm{E}+00$ \\
\hline $6.33 \mathrm{E}-02$ & $3.39 \mathrm{E}+00$ & $8.59 \mathrm{E}-01$ & $7.11 \mathrm{E}-01$ & $1.72 \mathrm{E}+00$ & $2.06 \mathrm{E}+00$ & $2.30 \mathrm{E}+00$ & $2.58 \mathrm{E}+00$ \\
\hline $6.35 \mathrm{E}-02$ & $3.38 \mathrm{E}+00$ & $8.60 \mathrm{E}-01$ & $7.12 \mathrm{E}-01$ & $1.72 \mathrm{E}+00$ & $2.06 \mathrm{E}+00$ & $2.30 \mathrm{E}+00$ & $2.58 \mathrm{E}+00$ \\
\hline $6.37 \mathrm{E}-02$ & $3.38 \mathrm{E}+00$ & $8.60 \mathrm{E}-01$ & $7.13 \mathrm{E}-01$ & $1.72 \mathrm{E}+00$ & $2.06 \mathrm{E}+00$ & $2.30 \mathrm{E}+00$ & $2.58 \mathrm{E}+00$ \\
\hline $6.38 \mathrm{E}-02$ & $3.38 \mathrm{E}+00$ & $8.61 \mathrm{E}-01$ & $7.13 \mathrm{E}-01$ & $1.72 \mathrm{E}+00$ & $2.06 \mathrm{E}+00$ & $2.30 \mathrm{E}+00$ & $2.58 \mathrm{E}+00$ \\
\hline $6.40 \mathrm{E}-02$ & $3.38 \mathrm{E}+00$ & $8.62 \mathrm{E}-01$ & $7.14 \mathrm{E}-01$ & $1.72 \mathrm{E}+00$ & $2.06 \mathrm{E}+00$ & $2.30 \mathrm{E}+00$ & $2.58 \mathrm{E}+00$ \\
\hline $6.42 \mathrm{E}-02$ & $3.38 \mathrm{E}+00$ & $8.62 \mathrm{E}-01$ & 1 & $1.72 \mathrm{E}+00$ & $2.06 \mathrm{E}+00$ & $2.30 \mathrm{E}+00$ & $2.58 \mathrm{E}+00$ \\
\hline $6.44 \mathrm{E}-02$ & $3.38 \mathrm{E}+00$ & 8. & 1 & $1.72 \mathrm{E}+00$ & $2.06 \mathrm{E}+00$ & $2.30 \mathrm{E}+00$ & $2.58 \mathrm{E}+00$ \\
\hline $6.45 \mathrm{E}-02$ & $3.38 \mathrm{E}+00$ & $8.64 \mathrm{E}-01$ & $7.17 \mathrm{E}-01$ & $1.72 \mathrm{E}+00$ & $2.06 \mathrm{E}+00$ & $2.30 \mathrm{E}+00$ & $2.57 \mathrm{E}+00$ \\
\hline $6.47 \mathrm{E}-02$ & $3.38 \mathrm{E}+00$ & $8.64 \mathrm{E}-01$ & $7.17 \mathrm{E}-01$ & $1.72 \mathrm{E}+00$ & $2.06 \mathrm{E}+00$ & $2.30 \mathrm{E}+00$ & $2.57 \mathrm{E}+00$ \\
\hline $6.49 \mathrm{E}-02$ & $3.37 \mathrm{E}+00$ & $8.65 \mathrm{E}-01$ & $7.18 \mathrm{E}-01$ & $1.72 \mathrm{E}+00$ & $2.06 \mathrm{E}+00$ & $2.30 \mathrm{E}+00$ & $2.57 \mathrm{E}+00$ \\
\hline $6.50 \mathrm{E}-02$ & $3.37 \mathrm{E}+00$ & $8.65 \mathrm{E}-01$ & $7.19 \mathrm{E}-01$ & $1.72 \mathrm{E}+00$ & $2.06 \mathrm{E}+00$ & $2.31 \mathrm{E}+00$ & $2.57 \mathrm{E}+00$ \\
\hline $6.52 \mathrm{E}-02$ & $3.37 \mathrm{E}+00$ & $8.66 \mathrm{E}-01$ & $7.19 \mathrm{E}-01$ & $1.73 \mathrm{E}+00$ & $2.06 \mathrm{E}+00$ & $2.30 \mathrm{E}+00$ & $2.57 \mathrm{E}+00$ \\
\hline $6.54 \mathrm{E}-02$ & $3.37 E+00$ & $8.67 \mathrm{E}-01$ & $7.20 \mathrm{E}-01$ & $1.73 \mathrm{E}+00$ & $2.06 \mathrm{E}+00$ & $2.30 \mathrm{E}+00$ & $2.57 \mathrm{E}+00$ \\
\hline $6.56 \mathrm{E}-02$ & $3.37 \mathrm{E}+00$ & $8.67 \mathrm{E}-01$ & $7.21 \mathrm{E}-01$ & $1.73 \mathrm{E}+00$ & $2.06 \mathrm{E}+00$ & $2.30 \mathrm{E}+00$ & $2.57 \mathrm{E}+00$ \\
\hline $6.57 \mathrm{E}-02$ & $3.37 \mathrm{E}+00$ & $8.68 \mathrm{E}-01$ & $7.22 \mathrm{E}-01$ & $1.73 \mathrm{E}+00$ & $2.06 \mathrm{E}+00$ & $2.30 \mathrm{E}+00$ & $2.57 \mathrm{E}+00$ \\
\hline $6.59 \mathrm{E}-02$ & $3.37 \mathrm{E}+00$ & $8.68 \mathrm{E}-01$ & $7.22 \mathrm{E}-01$ & $1.73 \mathrm{E}+00$ & $2.06 \mathrm{E}+00$ & $2.30 \mathrm{E}+00$ & $2.57 \mathrm{E}+00$ \\
\hline $6.61 \mathrm{E}-02$ & $3.37 \mathrm{E}+00$ & $8.69 \mathrm{E}-01$ & $7.23 E-01$ & $1.73 \mathrm{E}+00$ & $2.06 \mathrm{E}+00$ & $2.30 \mathrm{E}+00$ & $2.57 \mathrm{E}+00$ \\
\hline $6.63 \mathrm{E}-02$ & $3.36 \mathrm{E}+00$ & $8.70 \mathrm{E}-01$ & $7.24 \mathrm{E}-01$ & $1.73 \mathrm{E}+00$ & $2.06 \mathrm{E}+00$ & $2.30 \mathrm{E}+00$ & $2.57 \mathrm{E}+00$ \\
\hline $6.64 \mathrm{E}-02$ & $3.36 \mathrm{E}+00$ & $8.70 \mathrm{E}-01$ & $7.24 \mathrm{E}-01$ & $1.73 \mathrm{E}+00$ & $2.06 \mathrm{E}+00$ & $2.30 \mathrm{E}+00$ & $2.57 \mathrm{E}+00$ \\
\hline $6.66 \mathrm{E}-02$ & $3.36 \mathrm{E}+00$ & $8.71 \mathrm{E}-01$ & $7.25 \mathrm{E}-01$ & $1.73 \mathrm{E}+00$ & $2.06 \mathrm{E}+00$ & $2.30 \mathrm{E}+00$ & $2.57 \mathrm{E}+00$ \\
\hline $6.68 \mathrm{E}-02$ & $3.36 \mathrm{E}+00$ & $8.71 \mathrm{E}-01$ & $7.26 \mathrm{E}-01$ & $1.73 \mathrm{E}+00$ & $2.06 \mathrm{E}+00$ & $2.30 \mathrm{E}+00$ & $2.57 \mathrm{E}+00$ \\
\hline $69 \mathrm{E}-02$ & $3.36 \mathrm{E}+00$ & $8.72 \mathrm{E}-01$ & $7.27 \mathrm{E}-01$ & $1.73 \mathrm{E}+00$ & $2.06 \mathrm{E}+00$ & $2.30 \mathrm{E}+00$ & $2.57 \mathrm{E}+00$ \\
\hline
\end{tabular}


RESRAD-OFFSITE, Version 2.5

Title : RESRAD-OFFSITE Drinking Water, Plant, Milk, and Meat Pathways for Offsite Reside File : PBA-1_TC99-DOE-5.ROF

Summary of dose at graphical times, reptition 2 (continued)

Time

Years

9. $43 \mathrm{E}+02$

9. $44 \mathrm{E}+02$

9. $44 \mathrm{E}+02$

$9.45 \mathrm{E}+02$

9. $45 \mathrm{E}+02$

$9.46 \mathrm{E}+02$

9. $46 \mathrm{E}+02$

$9.47 \mathrm{E}+02$

$9.47 \mathrm{E}+02$

$9.48 \mathrm{E}+02$

9. $48 \mathrm{E}+02$

9. $49 \mathrm{E}+02$

9. $50 \mathrm{E}+02$

$9.50 \mathrm{E}+02$

9. $51 \mathrm{E}+02$

9. $51 \mathrm{E}+02$

9. $52 \mathrm{E}+02$

9. $52 \mathrm{E}+02$

9. $53 \mathrm{E}+02$

9. $53 \mathrm{E}+02$

9. $54 \mathrm{E}+02$

9. $54 \mathrm{E}+02$

9. $55 \mathrm{E}+02$

9. $55 \mathrm{E}+02$

9. $56 \mathrm{E}+02$

9. $56 \mathrm{E}+02$

9. $57 \mathrm{E}+02$

9. $57 \mathrm{E}+02$

9. $58 \mathrm{E}+02$

$9.58 \mathrm{E}+02$

$9.59 \mathrm{E}+02$

$9.59 \mathrm{E}+02$

$9.60 \mathrm{E}+02$

$9.60 \mathrm{E}+02$

$9.61 \mathrm{E}+02$

9. $61 \mathrm{E}+02$

$9.62 \mathrm{E}+02$

$9.62 \mathrm{E}+02$

$9.63 \mathrm{E}+02$

$9.63 \mathrm{E}+02$

$9.64 \mathrm{E}+02$

$9.64 \mathrm{E}+02$

$9.65 \mathrm{E}+02$

$9.65 \mathrm{E}+02$

$9.66 \mathrm{E}+02$

$9.66 \mathrm{E}+02$
Dose statistics at graphical times, mrem/yr

\begin{tabular}{|c|c|c|c|c|c|c|c|}
\hline inimum & aximum & Mean & ledian & $0 \%$ & $5 \%$ & $97.5 \%$ & \\
\hline 02 & $.36 \mathrm{E}+00$ & $3 E-01$ & $7.28 \mathrm{E}-01$ & $1.73 E+00$ & $6 \mathrm{E}+00$ & $2.30 \mathrm{E}+00$ & $7 E+0$ \\
\hline 2 & +00 & 1 & 1 & 0 & 00 & 00 & +00 \\
\hline 02 & -00 & 01 & 1 & 00 & 00 & 00 & +00 \\
\hline 02 & 00 & 1 & & 0 & & 00 & +00 \\
\hline-02 & -00 & 1 & & 00 & 00 & $E+00$ & $58 \mathrm{E}+00$ \\
\hline $.80 E-02$ & $E+00$ & $5 E-01$ & -01 & $E+00$ & $2.06 \mathrm{E}+00$ & $\mathrm{E}+00$ & $8 \mathrm{E}+00$ \\
\hline 02 & -00 & $.76 \mathrm{E}-01$ & 1 & 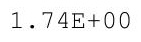 & 0 & +00 & $E+O C$ \\
\hline $3 E-02$ & $3.35 E+00$ & 西 & & 00 & & +00 & $\mathrm{E}+0 \mathrm{C}$ \\
\hline 02 & +00 & $\perp$ & 01 & 00 & 00 & +00 & +00 \\
\hline $.87 E-02$ & $E+00$ & $8 E-01$ & $5 E-01$ & $.74 \mathrm{E}+00$ & $06 \mathrm{E}+00$ & $0 \mathrm{E}+00$ & $7 \mathrm{E}+00$ \\
\hline-02 & +00 & $E-01$ & 1 & & & 00 & $\mathrm{E}+00$ \\
\hline 02 & -00 & & & & 00 & +00 & $7 \mathrm{E}+0 \mathrm{C}$ \\
\hline$\exists-02$ & $E+00$ & $\mathrm{E}-\mathrm{U}$ & $E-01$ & +00 & 0 & $E+00$ & $5+0$ \\
\hline 02 & -00 & $U_{1}$ & 01 & 00 & 00 & +00 & $7 E+00$ \\
\hline 02 & -00 & 1 & 01 & & & $.30 E+00$ & $7 \mathrm{E}+00$ \\
\hline$E-02$ & $.34 \mathrm{E}+00$ & $8.82 \mathrm{E}-01$ & 1 & 0 & $5 \mathrm{E}+00$ & +00 & $57 E+00$ \\
\hline $.99 \mathrm{E}-02$ & $3 E+00$ & $8.82 \mathrm{E}-01$ & $1 E-01$ & 1. $74 \mathrm{E}+00$ & $06 \mathrm{E}+00$ & $30 \mathrm{E}+00$ & $.56 \mathrm{E}+00$ \\
\hline-02 & $3 E+00$ & $3 E-01$ & $2 E-01$ & $75 E+00$ & $06 \mathrm{E}+00$ & $30 \mathrm{E}+00$ & $6 \mathrm{E}+0 \mathrm{C}$ \\
\hline-02 & +00 & 1 & 01 & 00 & & +00 & $E+U$ \\
\hline 02 & +00 & & 01 & 00 & & +00 & $E+00$ \\
\hline $.06 \mathrm{E}-02$ & & & -01 & & & 100 & +00 \\
\hline$E-02$ & $3.33 \mathrm{E}+00$ & $.85 \mathrm{E}-01$ & $E-01$ & $1.75 \mathrm{E}+00$ & & $9 \mathrm{E}+00$ & $6 \mathrm{E}+00$ \\
\hline$E-02$ & $33 E+00$ & 1 & $E-01$ & $75 E+00$ & $05 E+00$ & $29 E+00$ & $6 \mathrm{E}+00$ \\
\hline$E-02$ & $.32 E+00$ & $.86 \mathrm{E}-01$ & $46 E-01$ & $1.75 \mathrm{E}+00$ & $05 E+00$ & $.29 E+00$ & $56 \mathrm{E}+00$ \\
\hline 02 & $32 \mathrm{E}+00$ & $87 E-01$ & $7 E-01$ & & & $29 F+00$ & $\mathrm{E}+00$ \\
\hline 02 & & & & & & & +00 \\
\hline & & & & & & & +00 \\
\hline $.19 \mathrm{E}-02$ & $3.32 \mathrm{E}+00$ & $.89 \mathrm{E}-01$ & $.49 \mathrm{E}-01$ & $1.75 \mathrm{E}+00$ & $2.00 \mathrm{ET} 00$ & $2.29 \mathrm{E}+00$ & $.55 E+00$ \\
\hline 02 & $2 \mathrm{E}+$ & 1 & 1 & $75 \mathrm{E}+00$ & $.05 E+00$ & $2.29 \mathrm{E}+00$ & $55 \mathrm{E}+00$ \\
\hline 2 & - & - & 1 & & & $.29 E+0$ & $5 E+0$ \\
\hline$F-02$ & $31 \mathrm{E}+00$ & $0 F-01$ & $2 E-01$ & $5 E+00$ & $6 E+00$ & $2.29 \mathrm{E}+00$ & $5 E+00$ \\
\hline 02 & (1) & & & & & & \\
\hline 02 & & & 01 & & & & \\
\hline $.30 E-02$ & $3.31 E+00$ & $92 E-01$ & $.54 E-01$ & $1.75 \mathrm{E}+00$ & $2.00 E+00$ & $2.29 \mathrm{E}+00$ & $2.55 \mathrm{E}+0 \mathrm{C}$ \\
\hline $32 E-02$ & & $0.905-U 1$ & $7.55 E-01$ & & & Z. Z शूTU & S.JULTU \\
\hline & & & & & & & \\
\hline 2 & re & & & & & 0 & 00 \\
\hline 2 & & & & 0 & & & \\
\hline$E-02$ & & 1 & $58 E-01$ & & $5 E+00$ & $2.29 \mathrm{E}+00$ & $5 E+00$ \\
\hline $.41 \mathrm{E}-02$ & $3.30 \mathrm{E}+00$ & $95 E-01$ & -01 & 1 . & & & +00 \\
\hline & & 1 & & $.76 \mathrm{E}+$ & & & $E+O C$ \\
\hline & $3.30 \mathrm{E}+00$ & $E-U \perp$ & & $76 \mathrm{E}+00$ & $05 E+00$ & $2.29 \mathrm{E}+00$ & $2.50 \mathrm{E}+00$ \\
\hline & $3.305+$ & 1 & $61 E-01$ & 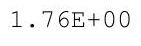 & $05 \mathrm{E}+$ & $2.29 \mathrm{E}+00$ & $2.55 \mathrm{E}+0$ \\
\hline 2 & & & & 0 & $2.05 \mathrm{E}+$ & $2.29 \mathrm{E}+$ & $55 E+00$ \\
\hline-02 & $3.29 \mathrm{E}+00$ & $8.98 E-01$ & 7. $63 \mathrm{E}-01$ & $1.76 \mathrm{E}+00$ & $2.05 E+00$ & $2.29 \mathrm{E}+00$ & $2.55 \mathrm{E}+00$ \\
\hline $.52 \mathrm{E}-02$ & $.29 E+00$ & $.99 E-01$ & $7.64 \mathrm{E}-01$ & $1.76 \mathrm{E}+00$ & $2.05 E+00$ & $2.29 \mathrm{E}+00$ & $2.55 \mathrm{E}+00$ \\
\hline
\end{tabular}


RESRAD-OFFSITE, Version 2.5

Title : RESRAD-OFFSITE Drinking Water, Plant, Milk, and Meat Pathways for Offsite Reside File : PBA-1_TC99-DOE-5.ROF

Summary of dose at graphical times, reptition 2 (continued)

Time

Years

$9.67 \mathrm{E}+02$

$9.67 \mathrm{E}+02$

$9.68 \mathrm{E}+02$

$9.68 \mathrm{E}+02$

$9.69 \mathrm{E}+02$

$9.70 \mathrm{E}+02$

$9.70 \mathrm{E}+02$

$9.71 \mathrm{E}+02$

$9.71 \mathrm{E}+02$

$9.72 \mathrm{E}+02$

$9.72 \mathrm{E}+02$

$9.73 \mathrm{E}+02$

$9.73 E+02$

$9.74 \mathrm{E}+02$

$9.74 \mathrm{E}+02$

$9.75 \mathrm{E}+02$

$9.75 \mathrm{E}+02$

$9.76 \mathrm{E}+02$

$9.76 \mathrm{E}+02$

$9.77 \mathrm{E}+02$

$9.77 \mathrm{E}+02$

$9.78 \mathrm{E}+02$

$9.78 \mathrm{E}+02$

$9.79 \mathrm{E}+02$

$9.79 \mathrm{E}+02$

$9.80 \mathrm{E}+02$

$9.80 \mathrm{E}+02$

$9.81 \mathrm{E}+02$

9. $81 \mathrm{E}+02$

$9.82 \mathrm{E}+02$

$9.82 \mathrm{E}+02$

$9.83 \mathrm{E}+02$

$9.83 \mathrm{E}+02$

$9.84 \mathrm{E}+02$

$9.84 \mathrm{E}+02$

$9.85 \mathrm{E}+02$

$9.85 \mathrm{E}+02$

$9.86 \mathrm{E}+02$

$9.86 \mathrm{E}+02$

$9.87 \mathrm{E}+02$

$9.87 \mathrm{E}+02$

$9.88 \mathrm{E}+02$

$9.88 \mathrm{E}+02$

$9.89 \mathrm{E}+02$

9. $90 \mathrm{E}+02$

9. $90 \mathrm{E}+02$
Dose statistics at graphical times, mrem/yr

\begin{tabular}{|c|c|c|c|c|c|c|c|}
\hline $\mathrm{m}$ & um & ean & e & & & & \\
\hline 2 & 0 & 1 & 1 & 00 & 00 & 0 & +00 \\
\hline $5 E-02$ & $3.29 \mathrm{E}+00$ & $9.00 \mathrm{E}-01$ & $7.65 E-01$ & $1.76 \mathrm{E}+00$ & $5 E+00$ & $2.28 \mathrm{E}+00$ & $55 E+0 C$ \\
\hline $\mathrm{F}-02$ & $9 F+00$ & $0 F-01$ & $66 \mathrm{~F}-01$ & $76 F+00$ & $05 \mathrm{~F}+00$ & $28 E+00$ & $5 F+00$ \\
\hline 2 & & & & & & & 100 \\
\hline 02 & & 1 & 1 & & & & +00 \\
\hline $63 E-02$ & 00 & -01 & 01 & $6 \mathrm{E}+00$ & $5 E+00$ & $.28 E+00$ & $\exists+00$ \\
\hline$E-02$ & 0 & 01 & & +00 & 0 & $2.28 \mathrm{E}+00$ & $\Xi+00$ \\
\hline-02 & +00 & $E-01$ & $E-01$ & $7 \mathrm{E}+00$ & $E+00$ & $E+00$ & $E+00$ \\
\hline $.68 E-02$ & $28 E+00$ & $E-01$ & $1 E-01$ & $E+00$ & $5 \mathrm{E}+00$ & $9 \mathrm{E}+00$ & $\exists+00$ \\
\hline $0 F-02$ & $27 \mathrm{~F}+00$ & PQF- & $2 E-01$ & & & $.29 \mathrm{E}+00$ & $4 \mathrm{E}+00$ \\
\hline 2 & & & & & & & +00 \\
\hline-02 & $3.27 \mathrm{E}+00$ & $E-01$ & $7.74 \mathrm{E}-01$ & $1.77 \mathrm{E}+00$ & $5 E+00$ & $2.28 \mathrm{E}+00$ & $E+00$ \\
\hline $.76 E-02$ & $3.27 \mathrm{E}+00$ & $E-01$ & $7.75 E-01$ & $1.77 \mathrm{E}+00$ & $2.04 \mathrm{E}+00$ & $2.28 \mathrm{E}+00$ & $\mathrm{E}+00$ \\
\hline 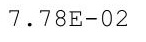 & & $E-01$ & $E-01$ & & & 00 & $\Xi+00$ \\
\hline (6) & & & & & & & +00 \\
\hline 2 & & 1 & 1 & 0 & & 0 & $E+00$ \\
\hline $.83 E-02$ & $3.26 \mathrm{E}+00$ & $8 \mathrm{~F}$ & 1 & 0 & 0 & 0 & 00 \\
\hline$F-02$ & $326 F+00$ & $9 \mathrm{E}-01$ & -01 & & +00 & $28 E+00$ & $\mathrm{E}+00$ \\
\hline $.87 \mathrm{E}-02$ & $.26 \mathrm{E}+00$ & $.09 \mathrm{E}-01$ & $.79 E-01$ & 1. $77 \mathrm{E}+00$ & $2.04 \mathrm{E}+00$ & $2.28 \mathrm{E}+00$ & $.54 \mathrm{E}+00$ \\
\hline $89 E-02$ & $3.26 \mathrm{E}+00$ & $.10 \mathrm{E}-01$ & $80 E-01$ & $1.77 \mathrm{E}+00$ & $2.04 \mathrm{E}+00$ & $2.28 \mathrm{E}+00$ & $.54 \mathrm{E}+0 \mathrm{C}$ \\
\hline & & & & & & & \\
\hline & & & & & & & 00 \\
\hline & & & & & & $.28 \mathrm{E}+$ & $55 E+0 C$ \\
\hline $6 \mathrm{~F}$ & $5 \mathrm{E}+$ & 1 & 1 & $.77 E+00$ & & 0 & $E+00$ \\
\hline$F-0$ & $25 \mathrm{~F}+00$ & $.12 \mathrm{E}-01$ & $34 E-01$ & $1.77 \mathrm{E}+00$ & $04 E+00$ & $2.28 \mathrm{E}+00$ & $55 \mathrm{E}+00$ \\
\hline-02 & $.25 E+00$ & $.13 E-01$ & $7.84 \mathrm{E}-01$ & $1.77 \mathrm{E}+00$ & $.04 E+00$ & $2.28 E+00$ & $55 \mathrm{E}+0 \mathrm{C}$ \\
\hline$E-02$ & $5+2+0$ & $3 E-01$ & $4 E-01$ & & & & \\
\hline & & & & & & & \\
\hline & & & $86 E-01$ & & & & \\
\hline $.08 E-02$ & $3.24 \mathrm{E}+00$ & $9.15 \mathrm{E}-01$ & $7.86 \mathrm{E}-01$ & $1.77 \mathrm{E}+00$ & $2.04 \mathrm{E}+00$ & $2.28 \mathrm{E}+00$ & $55 E+0 c$ \\
\hline 2 & - 20 - & $.15 \mathrm{E}-01$ & $.87 \mathrm{E}-01$ & $1.77 \mathrm{E}+00$ & $2.04 \mathrm{E}+00$ & $2.27 \mathrm{E}+00$ & $.55 E+0$ \\
\hline - & & & & & & & $55 E+0$ \\
\hline $3 E-02$ & & & & & & & $55 \mathrm{E}+00$ \\
\hline 2 & & & & & $4 \mathrm{E}+00$ & & \\
\hline & & & 01 & $1.77 \mathrm{E}+00$ & & $7 E+00$ & \\
\hline $.19 E-02$ & $3.23 \mathrm{E}+00$ & $.18 \mathrm{E}-01$ & $.88 \mathrm{E}-01$ & $1.77 \mathrm{E}+00$ & $2.04 \mathrm{E}+00$ & $2.27 \mathrm{E}+00$ & $2.55 \mathrm{E}+00$ \\
\hline - & & & 01 & & & & 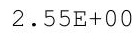 \\
\hline$E-02$ & 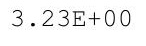 & 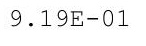 & & 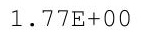 & & & $55 \mathrm{E}+0 \mathrm{C}$ \\
\hline $.25 E-02$ & $.23 E+0$ & 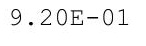 & 1 & & 2. & & $2.55 \mathrm{E}+00$ \\
\hline $.27 E-02$ & & & & $E+00$ & $4 \mathrm{E}+00$ & $7 \mathrm{E}+00$ & $E+00$ \\
\hline$E-02$ & & $21 E-01$ & $7.91 \mathrm{E}-01$ & $1.77 \mathrm{E}+00$ & $E+00$ & $E+00$ & $5 E+00$ \\
\hline$E-02$ & $3.22 \mathrm{E}+00$ & $21 \mathrm{E}-01$ & $1 E-01$ & & & & +00 \\
\hline & & & & & & & 2.00010 \\
\hline 2 & . & 1 & & & $2.04 \mathrm{LT} 0$ & $2.27 \mathrm{E}+00$ & 2.0 \\
\hline & & & & & & & $2.55 \mathrm{E}+00$ \\
\hline-02 & $E+00$ & E-01 & E-01 & $E+00$ & $.04 E+00$ & $.27 E+00$ & $.55 E+00$ \\
\hline
\end{tabular}


RESRAD-OFFSITE, Version 2.5

Title : RESRAD-OFFSITE Drinking Water, Plant, Milk, and Meat Pathways for Offsite Reside File : PBA-1_TC99-DOE-5.ROF

Summary of dose at graphical times, reptition 2 (continued)

Time

Years

$9.91 \mathrm{E}+02$

9. $91 \mathrm{E}+02$

9. $92 \mathrm{E}+02$

9. $92 \mathrm{E}+02$

9. $93 \mathrm{E}+02$

9. $93 \mathrm{E}+02$

9. $94 \mathrm{E}+02$

9. $94 \mathrm{E}+02$

9. $95 \mathrm{E}+02$

$9.95 \mathrm{E}+02$

9. $96 \mathrm{E}+02$

9. $96 \mathrm{E}+02$

9. $97 \mathrm{E}+02$

9. $97 \mathrm{E}+02$

9. $98 \mathrm{E}+02$

9. $98 \mathrm{E}+02$

9. $99 \mathrm{E}+02$

9. $99 \mathrm{E}+02$

$1.00 \mathrm{E}+03$

$1.00 \mathrm{E}+03$

$1.00 \mathrm{E}+03$

$1.00 \mathrm{E}+03$

$1.00 \mathrm{E}+03$

$1.00 \mathrm{E}+03$

$1.00 \mathrm{E}+03$

$1.00 \mathrm{E}+03$

$1.00 \mathrm{E}+03$

$1.00 \mathrm{E}+03$

$1.00 \mathrm{E}+03$

$1.01 \mathrm{E}+03$

$1.01 \mathrm{E}+03$

$1.01 \mathrm{E}+03$

$1.01 \mathrm{E}+03$

$1.01 \mathrm{E}+03$

$1.01 \mathrm{E}+03$

$1.01 \mathrm{E}+03$

$1.01 \mathrm{E}+03$

$1.01 \mathrm{E}+03$

$1.01 \mathrm{E}+03$

$1.01 \mathrm{E}+03$

$1.01 \mathrm{E}+03$

$1.01 \mathrm{E}+03$

$1.01 \mathrm{E}+03$

$1.01 \mathrm{E}+03$

$1.01 \mathrm{E}+03$

$1.01 \mathrm{E}+03$
Dose statistics at graphical times, mrem/yr

\begin{tabular}{|c|c|c|c|c|c|c|c|}
\hline inimum & aximum & Mean & ledian & $0 \%$ & $5 \%$ & $97.5 \%$ & $3 \%$ \\
\hline 02 & +00 & $4 E-01$ & $E-01$ & $1.77 \mathrm{E}+00$ & $4 \mathrm{E}+00$ & $2.28 \mathrm{E}+00$ & $2.55 \mathrm{E}+0$ \\
\hline 02 & +00 & 1 & 1 & $7 \mathrm{E}+$ & 00 & 00 & 100 \\
\hline 02 & +00 & -01 & 1 & $\exists+00$ & 00 & -00 & +00 \\
\hline 02 & 00 & 1 & & 0 & & 00 & +00 \\
\hline-02 & 00 & & & & 00 & $E+00$ & $E+00$ \\
\hline $.50 \mathrm{E}-02$ & $0 E+00$ & $6 E-01$ & -01 & $1.77 \mathrm{E}+00$ & $04 \mathrm{E}+00$ & $\mathrm{E}+00$ & $\mathrm{E}+00$ \\
\hline 02 & -00 & $9.27 \mathrm{E}-01$ & 1 & $7 \mathrm{~F}$ & 0 & +00 & +00 \\
\hline 02 & $3.20 \mathrm{E}+00$ & . & & $1.77 \mathrm{E}+00$ & & +00 & +00 \\
\hline 02 & +00 & 01 & 01 & $.77 E+00$ & 00 & +00 & +00 \\
\hline $.58 E-02$ & $9 \mathrm{E}+00$ & $8 \mathrm{E}-01$ & $1 \mathrm{E}-01$ & $1.77 \mathrm{E}+00$ & & $.27 E+00$ & $E+00$ \\
\hline-02 & -00 & 1 & 1 & & & 00 & $E+00$ \\
\hline & +00 & & & & 00 & +00 & +00 \\
\hline $64 \mathrm{E}-02$ & $\mathrm{E}+00$ & $E-U \perp$ & -01 & $1 \mathrm{t}+00$ & 0 & $E+00$ & +0 \\
\hline 02 & +00 & $U_{1}$ & 01 & 土. & & +00 & +0 \\
\hline 02 & -00 & 1 & 01 & 00 & & $\mathrm{E}+00$ & +00 \\
\hline$E-02$ & $3.18 \mathrm{E}+00$ & $\perp$ & -01 & & $04 \mathrm{E}+00$ & $2.27 \mathrm{E}+00$ & $E+00$ \\
\hline $.71 \mathrm{E}-02$ & $3.18 \mathrm{E}+00$ & $2 E-01$ & $5-01$ & 1. $77 \mathrm{E}+00$ & $04 \mathrm{E}+00$ & $2.27 \mathrm{E}+00$ & $E+00$ \\
\hline-02 & $.18 \mathrm{E}+00$ & $2 E-01$ & $6 E-01$ & $1.77 \mathrm{E}+00$ & $04 \mathrm{E}+00$ & $.27 E+00$ & $4 E+00$ \\
\hline 02 & +00 & 1 & -01 & 0 & & +00 & +00 \\
\hline $.77 E-02$ & +00 & $E-U \perp$ & -01 & $.17 \mathrm{E}+00$ & & +00 & +00 \\
\hline $.79 \mathrm{E}-02$ & 3.1 & & -01 & & & 100 & +00 \\
\hline $1 E-02$ & $3.17 \mathrm{E}+00$ & -01 & $E-01$ & $1.77 \mathrm{E}+00$ & & $2.27 \mathrm{E}+00$ & $E+00$ \\
\hline 02 & $3.17 \mathrm{E}+00$ & 1 & 1 & $77 \mathrm{E}+00$ & $04 \mathrm{E}+0$ & $.27 E+00$ & $3 E+00$ \\
\hline$E-02$ & $3.17 \mathrm{E}+00$ & $.35 \mathrm{E}-01$ & $9 \mathrm{E}-01$ & 1. $77 \mathrm{E}+00$ & $04 \mathrm{E}+00$ & $.27 E+00$ & $53 E+0 c$ \\
\hline-02 & $\mathrm{E}+00$ & $36 E-01$ & $E-01$ & 0 & & $27 F+00$ & +00 \\
\hline & & & & & & & +00 \\
\hline $1 E-02$ & 3.16 & $-U \perp$ & -01 & & & $E+00$ & +00 \\
\hline $93 E-02$ & J. DETU & $37 E-01$ & $2 E-01$ & $1.77 \mathrm{E}+00$ & $2.04 \mathrm{ET} 00$ & $2.27 \mathrm{E}+00$ & $.53 E+00$ \\
\hline 02 & (2) & 1 & 1 & $77 E+00$ & $.04 \mathrm{E}+00$ & $.27 E+00$ & $52 E+00$ \\
\hline-1 & 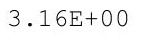 & - & 1 & $77 \mathrm{E}+$ & & $.27 E+0$ & $2 \mathrm{E}+0 \mathrm{C}$ \\
\hline$E-02$ & $3.16 \mathrm{E}+00$ & $8 F-01$ & $3 E-01$ & $77 E+00$ & $04 \mathrm{E}+00$ & $27 \mathrm{~F}+00$ & $2 \mathrm{E}+00$ \\
\hline 02 & $5+0$ & & & & & & \\
\hline 02 & & & & & & 2.2 & \\
\hline $.05 E-02$ & $3.15 \mathrm{E}+00$ & $9.40 \mathrm{E}-01$ & $8.14 \mathrm{E}-01$ & $1.77 \mathrm{E}+00$ & $2.04 E+00$ & $2.27 \mathrm{E}+00$ & $2.52 \mathrm{E}+00$ \\
\hline $07 E-02$ & & & $8.14 \mathrm{E}-01$ & 1.TIГTU & & Z. ZILTU & $\angle . J \perp \triangle T U L$ \\
\hline 2 & & & & & & & $.51 \mathrm{E}+00$ \\
\hline 2 & re & & & & & 0 & 00 \\
\hline 2 & & & & & & & \\
\hline 2 & & 1 & -01 & & $4 E+00$ & $2.26 \mathrm{E}+00$ & \\
\hline E-02 & $3.14 \mathrm{E}+00$ & $E-01$ & 01 & 0 & & 0 & +00 \\
\hline & & & & 0 & & & $E+00$ \\
\hline & $3 . \perp J E+U 0$ & $\perp$ & & $77 \mathrm{E}+00$ & & $2.26 \mathrm{E}+00$ & $2.31 \mathrm{~L}+00$ \\
\hline & - & $\perp$ & 1 & 土. & $2.04 \mathrm{E}+$ & $2.26 \mathrm{E}+00$ & $2.51 \mathrm{E}+0$ \\
\hline 2 & & & & 0 & $2.03 \mathrm{E}$ & 0 & $50 \mathrm{E}-$ \\
\hline-02 & $3.13 \mathrm{E}+00$ & -01 & $3 E-01$ & $1.77 \mathrm{E}+00$ & $2.03 E+00$ & $2.26 \mathrm{E}+00$ & $2.50 \mathrm{E}+00$ \\
\hline $.29 E-02$ & $3.13 E+00$ & $.46 \mathrm{E}-01$ & $.19 \mathrm{E}-01$ & $1.77 \mathrm{E}+00$ & $2.03 E+00$ & $2.26 \mathrm{E}+00$ & $2.50 \mathrm{E}+00$ \\
\hline
\end{tabular}


RESRAD-OFFSITE, Version 2.5

$\mathrm{T}^{1 / 2}$ Limit $=180$ days

Title : RESRAD-OFFSITE Drinking Water, Plant, Milk, and Meat Pathways for Offsite Reside File : PBA-1_TC99-DOE-5.ROF

Summary of dose at graphical times, reptition 2 (continued)

Time

Years

1. $01 \mathrm{E}+03$

1. $01 \mathrm{E}+03$

1. $02 \mathrm{E}+03$

1. $02 \mathrm{E}+03$

$1.02 \mathrm{E}+03$

1. $02 \mathrm{E}+03$

1. $02 \mathrm{E}+03$

1. $02 \mathrm{E}+03$

1. $02 \mathrm{E}+03$

1. $02 \mathrm{E}+03$

1. $02 \mathrm{E}+03$

1. $02 \mathrm{E}+03$

1. $02 \mathrm{E}+03$

1. $02 \mathrm{E}+03$

1. $02 \mathrm{E}+03$

1. $02 \mathrm{E}+03$

1. $02 \mathrm{E}+03$

$1.02 \mathrm{E}+03$

1. $02 \mathrm{E}+03$

$1.02 \mathrm{E}+03$

1. $02 \mathrm{E}+03$

1. $02 \mathrm{E}+03$

1. $03 \mathrm{E}+03$

$1.03 \mathrm{E}+03$

$1.03 \mathrm{E}+03$

$1.03 \mathrm{E}+03$

$1.03 E+03$

$1.03 E+03$

$1.03 \mathrm{E}+03$

$1.03 \mathrm{E}+03$

$1.03 \mathrm{E}+03$

$1.03 \mathrm{E}+03$

$1.03 \mathrm{E}+03$

$1.03 \mathrm{E}+03$

$1.03 \mathrm{E}+03$

$1.03 E+03$

$1.03 E+03$

$1.03 E+03$

$1.03 E+03$

$1.03 E+03$

$1.03 \mathrm{E}+03$

$1.04 \mathrm{E}+03$

1. $04 \mathrm{E}+03$

$1.04 \mathrm{E}+03$

1. $04 \mathrm{E}+03$

$1.04 \mathrm{E}+03$
Dose statistics at graphical times, mrem/yr

\begin{tabular}{|c|c|c|c|c|c|c|c|}
\hline inimum & aximum & Mean & ledian & $0 \%$ & $5 \div$ & $97.5 \%$ & \\
\hline 02 & +00 & $6 \mathrm{E}-01$ & $9 E-01$ & $1.77 \mathrm{E}+00$ & $3 E+00$ & $2.26 \mathrm{E}+00$ & $50 \mathrm{E}+0$ \\
\hline 02 & +00 & 1 & 1 & $7 \mathrm{E}+$ & 00 & $E+00$ & 100 \\
\hline 02 & +00 & 01 & 01 & $\exists+00$ & 00 & 00 & +00 \\
\hline-02 & 00 & 1 & & 0 & & 00 & +00 \\
\hline $\mathrm{E}-02$ & -00 & & & & 00 & $2.26 \mathrm{E}+00$ & $50 \mathrm{E}+00$ \\
\hline-02 & +00 & $E-01$ & -01 & $1.77 \mathrm{E}+00$ & $E+00$ & $\mathrm{E}+00$ & $E+00$ \\
\hline 02 & -00 & $9.49 \mathrm{E}-01$ & 1 & 0 & 0 & +00 & +00 \\
\hline 02 & $3.11 \mathrm{E}+00$ & & -01 & $1.77 \mathrm{E}+00$ & & +00 & $E+0 C$ \\
\hline 02 & +00 & 01 & 01 & 00 & 00 & +00 & +00 \\
\hline $.49 E-02$ & $3.11 \mathrm{E}+00$ & $0 E-01$ & $E-01$ & $.77 E+00$ & $3 E+00$ & $.25 E+00$ & $E+00$ \\
\hline-02 & -00 & 1 & 1 & & & 00 & $\Xi+00$ \\
\hline & +00 & & & & & +00 & $\mathrm{E}+\mathrm{OC}$ \\
\hline $.55 \mathrm{E}-02$ & $3.10 \mathrm{E}+00$ & . & $8.28 E-01$ & $1.17 \pm+U 0$ & & $E+00$ & $\mathrm{e}+\mathrm{U}$ \\
\hline 02 & -00 & 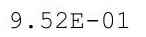 & -01 & 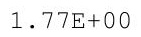 & & +00 & +00 \\
\hline 02 & -00 & $\perp$ & 01 & 00 & 00 & +00 & +00 \\
\hline-02 & $3.09 \mathrm{E}+00$ & $\perp$ & -01 & $1.76 \mathrm{E}+00$ & $3 E+00$ & $.25 E+00$ & $9 \mathrm{E}+00$ \\
\hline $.63 E-02$ & $3.09 \mathrm{E}+00$ & $3 E-01$ & $0 E-01$ & $1.76 \mathrm{E}+00$ & $3 E+00$ & $2.25 \mathrm{E}+00$ & $.49 \mathrm{E}+00$ \\
\hline-02 & $.09 E+00$ & $1 E-01$ & $0 E-01$ & $76 \mathrm{E}+00$ & $03 E+00$ & $.25 E+00$ & $49 E+00$ \\
\hline 02 & $E+00$ & 1 & -01 & 0 & & +00 & +00 \\
\hline$E-02$ & +00 & $E-01$ & -01 & & & +00 & +00 \\
\hline $.71 \mathrm{E}-02$ & & & -01 & & & 100 & +00 \\
\hline $.73 E-02$ & $3.08 \mathrm{E}+00$ & $.55 \mathrm{E}-01$ & $E-01$ & $1.76 \mathrm{E}+00$ & & $E+00$ & $49 \mathrm{E}+00$ \\
\hline $.76 \mathrm{E}-02$ & $3.08 \mathrm{E}+00$ & $9.56 \mathrm{E}-01$ & $4 E-01$ & $1.76 \mathrm{E}+00$ & $03 E+00$ & $.24 \mathrm{E}+00$ & $49 E+00$ \\
\hline$E-02$ & $3.08 \mathrm{E}+00$ & $6 \mathrm{E}-01$ & $4 \mathrm{E}-01$ & $1.76 \mathrm{E}+00$ & $03 E+00$ & $.24 E+00$ & $.49 \mathrm{E}+0 \mathrm{C}$ \\
\hline 02 & $.08 E+00$ & $7 E-01$ & $E-01$ & & & $\mathrm{E}+00$ & $49 \mathrm{E}+0 \mathrm{C}$ \\
\hline 02 & & & & & & 0 & +00 \\
\hline$E-02$ & $3.08 \mathrm{E}+00$ & $\perp$ & -01 & & & +00 & +00 \\
\hline 它 & 3.0 О Т U & 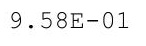 & $35 E-01$ & $1.76 \mathrm{E}+00$ & $\angle .0 \angle \mathrm{LT} U 0$ & $2.24 \mathrm{E}+00$ & $.49 E+00$ \\
\hline 02 & (1) & 1 & 1 & $76 \mathrm{E}+$ & $.02 \mathrm{E}+00$ & $.24 E+00$ & $.48 E+00$ \\
\hline 2 & - & - & 1 & & & $.24 E+0$ & $48 \mathrm{E}+$ \\
\hline 02 & $3.07 E+00$ & $9 F-01$ & $7 E-01$ & $76 E+00$ & $2 E+00$ & $24 F+00$ & $48 E+00$ \\
\hline 02 & $E+00$ & 1 & & & & & \\
\hline 02 & & & & & & 0 & \\
\hline $.98 E-02$ & $3.07 \mathrm{E}+00$ & $1 E-01$ & $8.39 E-01$ & $1.76 \mathrm{E}+00$ & $\angle .0 \angle E+00$ & $2.24 \mathrm{E}+00$ & $2.48 \mathrm{E}+00$ \\
\hline $00 E-01$ & & & $8.39 E-01$ & 1. & & & $2.48 \mathrm{E}+0 \mathrm{C}$ \\
\hline 1 & & & & & & & \\
\hline ( & re & & & & & 0 & 00 \\
\hline 1 & & & & & & & \\
\hline 01 & & 1 & $1 E-01$ & & & $E+00$ & \\
\hline $01 \mathrm{E}-01$ & $3.06 \mathrm{E}+00$ & $3 E-01$ & $2 E-01$ & 0 & & 0 & $7 \mathrm{E}+00$ \\
\hline 1 & & & & 0 & & & $.47 \mathrm{E}+0 \mathrm{C}$ \\
\hline & $3.06 E+00$ & $\perp$ & & $75 \mathrm{E}+00$ & & & $2.47 \mathrm{~L}+00$ \\
\hline & $3.06 \mathrm{E}+$ & $\perp$ & 1 & 0 & $2.02 \mathrm{E}+$ & $2.23 E+$ & $2.47 \mathrm{E}+0$ \\
\hline $1.0 \angle E-01$ & 3 & & & 1.75 & $2.02 \mathrm{E}$ & 0 & 00 \\
\hline 1 & $3.05 E+00$ & -01 & 8. & $1.75 \mathrm{E}+00$ & $2.02 \mathrm{E}+00$ & $2.23 \mathrm{E}+00$ & $2.47 \mathrm{E}+00$ \\
\hline $.02 E-01$ & $3.05 E+00$ & $.66 \mathrm{E}-01$ & $.46 \mathrm{E}-01$ & $1.75 \mathrm{E}+00$ & $2.02 E+00$ & $2.23 E+00$ & $2.47 \mathrm{E}+00$ \\
\hline
\end{tabular}


RESRAD-OFFSITE, Version 2.5

$T^{1 / 2}$ Limit $=180$ days

robabilistic Dose and Risk Report

Title : RESRAD-OFFSITE Drinking Water, Plant, Milk, and Meat Pathways for Offsite Reside

File : PBA-1_TC99-DOE-5.ROF

Time

Years

1. $04 \mathrm{E}+03$

1. $04 \mathrm{E}+03$

$1.04 \mathrm{E}+03$

$1.04 \mathrm{E}+03$

1. $04 \mathrm{E}+03$

1. $04 \mathrm{E}+03$

1. $04 \mathrm{E}+03$

1. $04 \mathrm{E}+03$

1. $04 \mathrm{E}+03$

1. $04 \mathrm{E}+03$

1. $04 \mathrm{E}+03$

1. $04 \mathrm{E}+03$

1. $04 \mathrm{E}+03$

1. $04 \mathrm{E}+03$

1. $04 \mathrm{E}+03$

1. $05 \mathrm{E}+03$

1. $05 \mathrm{E}+03$

1. $05 \mathrm{E}+03$

1. $05 \mathrm{E}+03$

1. $05 \mathrm{E}+03$

1. $05 \mathrm{E}+03$

1. $05 \mathrm{E}+03$

1. $05 \mathrm{E}+03$

$1.05 \mathrm{E}+03$

$1.05 \mathrm{E}+03$
Summary of dose at graphical times, reptition 2 (continued)

Dose statistics at graphical times, mrem/yr

\begin{tabular}{|c|c|c|c|c|c|c|c|}
\hline Minimum & Maximum & Mean & Median & $90 \%$ & $95 \%$ & $97.5 \%$ & $\%$ \\
\hline 1 & $.05 E+00$ & $56 E-01$ & $47 E-01$ & $1.75 E+00$ & $2.02 \mathrm{E}+00$ & $223 F+00$ & $.47 E+00$ \\
\hline 1 & 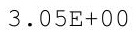 & 1 & 1 & 0 & b & (5) & 00 \\
\hline 01 & $\mathrm{E}+00$ & $7 E-01$ & 01 & 0 & 00 & 00 & 00 \\
\hline 01 & +00 & $E-01$ & 1 & 0 & 0 & 00 & $6 \mathrm{E}+00$ \\
\hline $.03 E-01$ & $3 \quad 5 F+0$ & $8 E-01$ & $9 E-01$ & & $2.02 \mathrm{E}+00$ & & $46 \mathrm{E}+00$ \\
\hline $04 F-01$ & & $\perp$ & 8 & & 0 & 0 & $6 \mathrm{E}+00$ \\
\hline 1 10 & $3.04 \mathrm{E}+00$ & 1 & 1 & & ( & & +00 \\
\hline 14 & ט & $E-01$ & $2 E-01$ & $1.10 \mathrm{E}-1$ & D एका & 00 & +00 \\
\hline L & 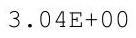 & 然 & 1 & 0 & 0 & 0 & 00 \\
\hline+ & 年 & 政 01 & 1 & 0 & & 0 & $6 \mathrm{E}+00$ \\
\hline $1.05 \mathrm{E}-01$ & 3 & $9.70 \mathrm{E}-01$ & 1 & & & 0 & 00 \\
\hline $.05 E-01$ & +0 & $\Gamma$ & 䧑 & & & 00 & $46 E+00$ \\
\hline $.05 E-0$ & $3.04 \mathrm{E}+0$ & $1 \mathrm{E}-$ & 1 & 1 . & 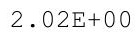 & $.24 \mathrm{E}+$ & $46 \mathrm{E}+0 \mathrm{C}$ \\
\hline-01 & $3.03 E+00$ & $1 E-01$ & $E-01$ & & $2 \mathrm{E}+00$ & $E+00$ & $5 E+00$ \\
\hline$E-01$ & +00 & $F-$ & $E-01$ & 1 & 0 & +00 & $5 E+00$ \\
\hline$E-01$ & $3 E+00$ & $E-$ & $3 E-01$ & & $\mathrm{~F}$ & 00 & +00 \\
\hline $.06 \mathrm{E}-01$ & $3.03 E+00$ & $9.73 \mathrm{E}-01$ & $8.59 E-01$ & $1.75 \mathrm{E}+00$ & $2.01 \mathrm{E}+00$ & $2.23 E+00$ & $.45 E+00$ \\
\hline $.06 \mathrm{E}-01$ & $3.03 \mathrm{E}+00$ & $3 E-01$ & $8.60 \mathrm{E}-01$ & & $2.01 \mathrm{E}+00$ & 2.2 & $2.45 \mathrm{E}+00$ \\
\hline $1.06 \mathrm{E}-01$ & & & 1 & & & 0 & 20 \\
\hline $1.07 \mathrm{E}-01$ & 3 & $9.74 \mathrm{E}-01$ & 1 & 0 & 0 & 0 & 00 \\
\hline $.07 E-01$ & $3.02 \mathrm{E}+00$ & $9.74 \mathrm{E}-01$ & $8.61 E-01$ & $1.75 \mathrm{E}+00$ & $1 E+00$ & +00 & $2.45 \mathrm{E}+00$ \\
\hline $.07 \mathrm{E}-01$ & $3.02 \mathrm{E}+00$ & $9.75 \mathrm{E}-01$ & $8.62 E-01$ & $1.75 \mathrm{E}+00$ & $2.01 \mathrm{E}+00$ & $2.22 \mathrm{E}+00$ & $2.45 \mathrm{E}+00$ \\
\hline $.07 E-01$ & $3.02 \mathrm{E}+00$ & $9.75 \mathrm{E}-01$ & $8.63 E-01$ & $1.74 \mathrm{E}+00$ & $2.01 \mathrm{E}+00$ & $2.22 \mathrm{E}+00$ & $2.45 \mathrm{E}+00$ \\
\hline $.07 \mathrm{E}-01$ & $3.02 \mathrm{E}+00$ & $9.75 \mathrm{E}-01$ & $8.63 E-01$ & & $2.01 \mathrm{E}+00$ & $2.22 \mathrm{E}+00$ & $2.45 \mathrm{E}+00$ \\
\hline $.07 E-01$ & $.02 \mathrm{E}+00$ & $.75 \mathrm{E}-01$ & $.64 \mathrm{E}-01$ & $1.74 \mathrm{E}+00$ & $2.01 \mathrm{E}+00$ & $2.22 \mathrm{E}+00$ & $2.44 \mathrm{E}+00$ \\
\hline
\end{tabular}


RESRAD-OFFSITE, Version 2.5

robabilistic Dose and Risk Report

Title : RESRAD-OFFSITE Drinking Water, Plant, Milk, and Meat Pathways for Offsite Reside File : PBA-1_TC99-DOE-5.ROF

Time

Years

$0.00 \mathrm{E}+00$

$5.13 \mathrm{E}-01$

$1.03 \mathrm{E}+00$

$1.54 \mathrm{E}+00$

$2.05 \mathrm{E}+00$

$2.56 \mathrm{E}+00$

$3.08 \mathrm{E}+00$

$3.59 \mathrm{E}+00$

$4.10 \mathrm{E}+00$

$4.61 \mathrm{E}+00$

$5.13 \mathrm{E}+00$

$5.64 \mathrm{E}+00$

$6.15 \mathrm{E}+00$

$6.67 \mathrm{E}+00$

$7.18 \mathrm{E}+00$

$7.69 \mathrm{E}+00$

$8.20 \mathrm{E}+00$

$8.72 \mathrm{E}+00$

$9.23 \mathrm{E}+00$

$9.74 \mathrm{E}+00$

$1.03 \mathrm{E}+01$

$1.08 \mathrm{E}+01$

$1.13 \mathrm{E}+01$

$1.18 \mathrm{E}+01$

$1.23 \mathrm{E}+01$

$1.28 \mathrm{E}+01$

$1.33 \mathrm{E}+01$

$1.38 \mathrm{E}+01$

$1.44 \mathrm{E}+01$

$1.49 \mathrm{E}+01$

$1.54 \mathrm{E}+01$

$1.59 \mathrm{E}+01$

$1.64 \mathrm{E}+01$

$1.69 \mathrm{E}+01$

$1.74 \mathrm{E}+01$

$1.79 \mathrm{E}+01$

$1.85 \mathrm{E}+01$

1. $90 \mathrm{E}+01$

1. $95 \mathrm{E}+01$

$2.00 \mathrm{E}+01$

$2.05 \mathrm{E}+01$

$2.10 \mathrm{E}+01$

$2.15 \mathrm{E}+01$

2. $20 \mathrm{E}+01$

$2.26 \mathrm{E}+01$

$2.31 \mathrm{E}+01$
Summary of dose at graphical times, reptition 3

Dose statistics at graphical times, mrem/yr

\begin{tabular}{|c|c|c|c|c|c|c|c|}
\hline Inimum & laximum & Mean & Median & $90 \%$ & $95 \%$ & $97.5 \%$ & $\%$ \\
\hline 0 & $.00 \mathrm{E}+00$ & $0 \mathrm{E}+00$ & $0.00 \mathrm{E}+00$ & $00 E+00$ & $0 \mathrm{E}+00$ & $00 E+00$ & $\mathrm{~F}+0 \mathrm{CS}-\mathrm{se}$ \\
\hline$E+00$ & 00 & $\mathrm{OE}+$ & 00 & 00 & $0.00 \mathrm{E}+00$ & 00 & $\mathrm{OE}+\mathrm{OC}$ \\
\hline$E+00$ & $\mathrm{E}+00$ & $\mathrm{E}+00$ & 0 & 00 & $0 \mathrm{E}+00$ & 00 & $0 \mathrm{E}+0 \mathrm{C}$ \\
\hline 00 & $E+00$ & 0 & 00 & 00 & $0 \mathrm{E}+00$ & -00 & +00 \\
\hline+00 & $E+00$ & $E+00$ & $E+00$ & $\mathrm{OE}+$ & 00 & 00 & $0 \mathrm{E}+00$ \\
\hline$E+00$ & 0 & 0 & 0 & 0 & 00 & $E+00$ & $00 \mathrm{E}+00$ \\
\hline $.00 \mathrm{E}+00$ & $0.00 \mathrm{E}+00$ & $.00 \mathrm{E}+00$ & $0 \mathrm{E}+00$ & $0 \mathrm{E}+00$ & $.00 \mathrm{E}+00$ & $E+00$ & $E+00$ \\
\hline $.00 \mathrm{E}+00$ & $0.00 \mathrm{E}+00$ & $.00 \mathrm{E}+00$ & $0.00 \mathrm{E}+00$ & $0.00 \mathrm{E}+00$ & $.00 \mathrm{E}+00$ & $.00 \mathrm{E}+00$ & $.00 \mathrm{E}+00$ \\
\hline $.00 \mathrm{E}+00$ & $0.00 \mathrm{E}+00$ & $.00 \mathrm{E}+00$ & $0.00 \mathrm{E}+00$ & $0.00 \mathrm{E}+00$ & $0.00 \mathrm{E}+00$ & $.00 \mathrm{E}+00$ & $00 \mathrm{E}+00$ \\
\hline$E+00$ & -00 & $E+00$ & +00 & $0 \mathrm{E}+00$ & $0 \mathrm{E}+00$ & +00 & $\mathrm{E}+00$ \\
\hline $.00 \mathrm{E}+00$ & $0.00 \mathrm{E}+00$ & $0.00 \mathrm{E}+00$ & $0 \mathrm{E}+00$ & $0.00 \mathrm{E}+00$ & $0.00 \mathrm{E}+00$ & $00 \mathrm{E}+00$ & $00 E+00$ \\
\hline 100 & 0 & 0 & $E+00$ & 0 & 0 & 00 & $E+00$ \\
\hline $.00 \mathrm{E}+00$ & $.0 U E+U 0$ & $\mathrm{E}+00$ & $E+00$ & 00 & $0 \mathrm{E}+00$ & +00 & $E+00$ \\
\hline $.00 \mathrm{E}+00$ & 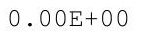 & $0.00 \mathrm{E}+00$ & $0.00 \mathrm{E}+00$ & $0.00 E+00$ & . & $.00 \mathrm{E}+00$ & $.00 \mathrm{E}+00$ \\
\hline $\mathrm{E}+00$ & $0.00 \mathrm{E}+00$ & $0 \mathrm{E}+00$ & $0.00 \mathrm{E}+00$ & $0.00 \mathrm{E}+00$ & $00 \mathrm{E}+00$ & $0 E+00$ & $0 \mathrm{E}+00$ \\
\hline$E+00$ & 00 & o & -00 & $0 \mathrm{E}+00$ & $0 \mathrm{E}+00$ & $E+00$ & $0 \mathrm{E}+00$ \\
\hline $.00 \mathrm{E}+00$ & $0.00 \mathrm{E}+00$ & & & & $0.00 \mathrm{E}+00$ & $.00 \mathrm{E}+00$ & $.00 \mathrm{E}+00$ \\
\hline $\mathrm{E}+00$ & $E+00$ & $0 \mathrm{E}+00$ & $0 \mathrm{E}+00$ & $\mathrm{E}+00$ & $E+00$ & +00 & $0 \mathrm{E}+00$ \\
\hline $.00 \mathrm{E}+00$ & $00 \mathrm{E}+00$ & $.00 \mathrm{E}+00$ & $00 \mathrm{E}+00$ & $0 \mathrm{E}+00$ & $0 \mathrm{E}+00$ & $0 \mathrm{E}+00$ & $\mathrm{OE}+\mathrm{OC}$ \\
\hline $0 \mathrm{E}+00$ & $0.00 \mathrm{E}+00$ & $0 \mathrm{E}+00$ & $\mathrm{DE}+00$ & 00 & $0 \mathrm{E}+00$ & $E+00$ & $0 \mathrm{E}+00$ \\
\hline $.00 \mathrm{E}+00$ & $0.00 \mathrm{E}+00$ & $.00 \mathrm{E}+00$ & $0.00 \mathrm{E}+00$ & & $0 \mathrm{E}+00$ & $0 \mathrm{E}+00$ & $0 \mathrm{E}+00$ \\
\hline $.00 E+00$ & $0.00 \mathrm{E}+00$ & $0.00 \mathrm{E}+00$ & $0.00 \mathrm{E}+00$ & $0.00 \mathrm{E}+00$ & $0.00 \mathrm{E}+00$ & $00 \mathrm{E}+00$ & +00 \\
\hline מח & $.00 E+00$ & & $00 E+00$ & $0 \mathrm{E}+00$ & (2) & $0 \mathrm{E}+00$ & $0 \mathrm{E}+00$ \\
\hline $.00 \mathrm{E}+00$ & $0.00 \mathrm{E}+00$ & $.00 \mathrm{E}+00$ & $0 \mathrm{E}+00$ & $0 \mathrm{E}+$ & $00 \mathrm{E}+00$ & $0 \mathrm{E}+00$ & $00 \mathrm{E}+00$ \\
\hline $.00 \mathrm{E}+00$ & $0.00 \mathrm{E}+00$ & $0.00 \mathrm{E}+00$ & $0.00 \mathrm{E}+00$ & $0 \mathrm{E}+00$ & $\mathrm{DE}+00$ & $E+00$ & $00 \mathrm{E}+00$ \\
\hline+00 & $E+00$ & $\mathrm{E}+00$ & 00 & 00 & 00 & +00 & $0 E+00$ \\
\hline$E+00$ & +00 & $\mathrm{E}+00$ & $0 \mathrm{E}+00$ & $0 \mathrm{E}+00$ & $0 E+00$ & $0 \mathrm{E}+00$ & $0 \mathrm{E}+00$ \\
\hline $.00 \mathrm{E}+00$ & $0.00 \mathrm{E}+00$ & $0.00 \mathrm{E}+00$ & $0.00 \mathrm{E}+00$ & $0.00 \mathrm{E}+00$ & $0.00 \mathrm{E}+00$ & $.00 \mathrm{E}+00$ & $.00 \mathrm{E}+00$ \\
\hline $.00 \mathrm{E}+00$ & $0.00 \mathrm{E}+00$ & $0.00 \mathrm{E}+00$ & $0.00 \mathrm{E}+00$ & $0.00 \mathrm{E}+00$ & $0.00 \mathrm{E}+00$ & $.00 \mathrm{E}+00$ & $.00 \mathrm{E}+00$ \\
\hline 然 & 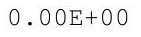 & 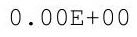 & $0.00 \mathrm{E}+00$ & $0 E+00$ & (1) & $0 \mathrm{E}+00$ & $0.00 \mathrm{E}+0 \mathrm{C}$ \\
\hline 0 & & & & & & $E+00$ & $00 \mathrm{E}+0 \mathrm{C}$ \\
\hline$\Xi+00$ & $E+00$ & $0 \mathrm{E}+00$ & $\mathrm{E}+00$ & $0 \mathrm{E}+00$ & $\mathrm{OE}+00$ & $E+00$ & $\mathrm{OE}+\mathrm{OC}$ \\
\hline+00 & +00 & $E+00$ & $E+00$ & 0 & 0 & & $0 \mathrm{E}+00$ \\
\hline .00 ET+ & $0.00 \mathrm{E}+00$ & $0.00 \mathrm{E}+00$ & $0.00 \mathrm{E}+00$ & $0.00 \mathrm{E}+00$ & $00 \mathrm{E}+00$ & $.00 \mathrm{E}+00$ & $.00 E+00$ \\
\hline . & & $0.00 \mathrm{E}+00$ & & $0.00 \mathrm{E}+00$ & . U ता U & $.00 \mathrm{E}+00$ & $.00 E+00$ \\
\hline & & & & & & & \\
\hline مค & ( & 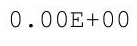 & 0 & 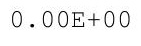 & 0 & 0 & $0 \Omega$ \\
\hline 0 & 0 & 0 & $\mathrm{E}+00$ & 0 & 0 & 0 & 00 \\
\hline & & & & 0 & $\mathrm{E}+00$ & +00 & $0 \mathrm{E}+00$ \\
\hline$E+00$ & +00 & E+ & 00 & 0 & 0 & & $0 \mathrm{E}+00$ \\
\hline 0 & & & $00 E+00$ & 然 & 0 & & $.00 E+00$ \\
\hline 0 & 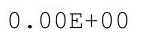 & 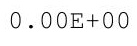 & & & 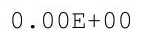 & 0 & DT \\
\hline 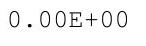 & 0 & 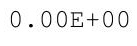 & 0 & .000 & 0 & $0 E+00$ & $.00 \mathrm{E}+00$ \\
\hline 0 & 0 & 0 & 0 & 00 & 0 & 0 & 00 \\
\hline+00 & $E+00$ & . & 0 . & 00 & 0 & +00 & $0 \mathrm{E}+00$ \\
\hline $.00 \mathrm{E}+00$ & $.00 \mathrm{E}+00$ & $.00 \mathrm{E}+00$ & $.00 \mathrm{E}+00$ & $0.00 \mathrm{E}+00$ & $0.00 \mathrm{E}+00$ & $0.00 \mathrm{E}+00$ & $0.00 \mathrm{E}+00$ \\
\hline
\end{tabular}


RESRAD-OFFSITE, Version 2.5

Title : RESRAD-OFFSITE Drinking Water, Plant, Milk, and Meat Pathways for Offsite Reside File : PBA-1_TC99-DOE-5.ROF

Summary of dose at graphical times, reptition 3 (continued)

Time

Years

2. $36 \mathrm{E}+01$

$2.41 \mathrm{E}+01$

$2.46 \mathrm{E}+01$

$2.51 \mathrm{E}+01$

$2.56 \mathrm{E}+01$

2. $61 \mathrm{E}+01$

$2.67 \mathrm{E}+01$

2. $72 \mathrm{E}+01$

2. $77 \mathrm{E}+01$

2. $82 \mathrm{E}+01$

2. $87 \mathrm{E}+01$

2. $92 \mathrm{E}+01$

2. $97 \mathrm{E}+01$

3. $02 \mathrm{E}+01$

$3.08 \mathrm{E}+01$

3. $13 \mathrm{E}+01$

3. $18 \mathrm{E}+01$

3. $23 \mathrm{E}+01$

3. $28 \mathrm{E}+01$

3. $33 \mathrm{E}+01$

3. $38 \mathrm{E}+01$

3. $44 \mathrm{E}+01$

3. $49 \mathrm{E}+01$

3. $54 \mathrm{E}+01$

3. $59 \mathrm{E}+01$

3. $64 \mathrm{E}+01$

3. $69 \mathrm{E}+01$

$3.74 \mathrm{E}+01$

3. $79 \mathrm{E}+01$

$3.85 \mathrm{E}+01$

3. $90 \mathrm{E}+01$

$3.95 \mathrm{E}+01$

$4.00 \mathrm{E}+01$

$4.05 \mathrm{E}+01$

$4.10 \mathrm{E}+01$

4. $15 \mathrm{E}+01$

4. $20 \mathrm{E}+01$

$4.26 \mathrm{E}+01$

$4.31 \mathrm{E}+01$

$4.36 \mathrm{E}+01$

4. $41 \mathrm{E}+01$

$4.46 \mathrm{E}+01$

4. $51 \mathrm{E}+01$

$4.56 \mathrm{E}+01$

4. $61 \mathrm{E}+01$

$4.67 \mathrm{E}+01$
Dose statistics at graphical times, mrem/yr

\begin{tabular}{|c|c|c|c|c|c|c|c|}
\hline m & num & ean & n & & & $\%$ & \\
\hline 00 & 00 & $E+00$ & $\mathrm{E}+00$ & +00 & +00 & +00 & +00 \\
\hline $.00 \mathrm{E}+00$ & $.00 \mathrm{E}+00$ & $.00 \mathrm{E}+00$ & $0.00 \mathrm{E}+00$ & $0.00 \mathrm{E}+00$ & $0.00 \mathrm{E}+00$ & $.00 \mathrm{E}+00$ & $.00 \mathrm{E}+00$ \\
\hline $00 F+00$ & $00 F+00$ & $00 E+00$ & $.00 E+00$ & $00 \mathrm{E}+00$ & $00 F+00$ & $00 \mathrm{E}+00$ & $00 F+00$ \\
\hline 00 & & & & & & & 00 \\
\hline+00 & +00 & & & & 00 & & +00 \\
\hline $.00 \mathrm{E}+00$ & $E+00$ & $0 \mathrm{E}+00$ & $0 E+00$ & $0 E+00$ & $0 \mathrm{E}+00$ & 00 & +00 \\
\hline $.00 \mathrm{E}+00$ & +00 & $E+00$ & $\mathrm{E}+00$ & +00 & +00 & +00 & $\mathrm{E}+00$ \\
\hline $.00 E+00$ & $0.00 \mathrm{E}+00$ & $0 \mathrm{E}+00$ & $0 \mathrm{E}+00$ & $00 E+00$ & $.00 \mathrm{E}+00$ & $.00 \mathrm{E}+00$ & $00 E+00$ \\
\hline $00 E+00$ & $00 \mathrm{E}+00$ & $.00 E+00$ & $.00 E+00$ & $0 \mathrm{E}+00$ & $0 \mathrm{E}+00$ & $E+00$ & $\exists+00$ \\
\hline $00 \mathrm{E}+00$ & $O P F+6-5-5$ & $00 E+00$ & $0 E+00$ & 0 & +0 & $00 E+00$ & +00 \\
\hline$E+00$ & $\mathrm{~F}+00$ & $E+00$ & & & & & +00 \\
\hline $.00 \mathrm{E}+00$ & $0.00 \mathrm{E}+00$ & $.00 \mathrm{E}+00$ & $0.00 \mathrm{E}+00$ & $0.00 \mathrm{E}+00$ & $0.00 \mathrm{E}+00$ & $.00 \mathrm{E}+00$ & $.00 E+00$ \\
\hline $.00 E+00$ & $0.00 \mathrm{E}+00$ & $0.00 \mathrm{E}+00$ & $0.00 \mathrm{E}+00$ & $0.00 \mathrm{E}+00$ & $0.00 \mathrm{E}+00$ & $.00 \mathrm{E}+00$ & $.00 \mathrm{E}+00$ \\
\hline $.00 E+00$ & $0=0$ & $00 E+00$ & $0 \mathrm{E}+00$ & $E+00$ & $\mathrm{E}+00$ & +00 & $\mathrm{E}+00$ \\
\hline $\mathrm{OE}+$ & $.00 \mathrm{E}+\mathrm{C}$ & $.00 E+00$ & $.00 E+00$ & $0 E+00$ & 0 & 0 & 00 \\
\hline 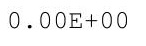 & ק & 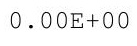 & 0 & & ( & 0 & +00 \\
\hline$O \cap F+O \Omega$ & $00 F+00$ & $0 \mathrm{E}+00$ & $E+00$ & $E+00$ & +00 & 0 & +00 \\
\hline $.00 E+00$ & $0 \cap F+00$ & $0 \mathrm{E}+00$ & $0 E+00$ & $\mathrm{E}+00$ & $0 E+00$ & $O E+00$ & $0 E+00$ \\
\hline $.00 \mathrm{E}+00$ & $.00 \mathrm{E}+00$ & $0.00 \mathrm{E}+00$ & $0.00 \mathrm{E}+00$ & $.00 \mathrm{E}+00$ & $0.00 \mathrm{E}+00$ & $.00 \mathrm{E}+00$ & $0 \mathrm{E}+00$ \\
\hline $.00 E+00$ & $0 \cap F+\cap 0$ & $.00 \mathrm{E}+00$ & $.00 E+00$ & $0 \mathrm{E}+00$ & $00 E+00$ & $E+00$ & $0 \mathrm{E}+00$ \\
\hline & & & & & & & +00 \\
\hline & & & & & & & $0 E+00$ \\
\hline$=0$ & & & & & $\mathrm{E}+00$ & 0 & 00 \\
\hline $.00 \mathrm{E}+00$ & $.00 \mathrm{E}+00$ & $.00 \mathrm{E}+00$ & $.00 \mathrm{E}+00$ & $00 \mathrm{E}+00$ & $00 \mathrm{E}+00$ & $.00 E+00$ & $00 E+00$ \\
\hline $.00 \mathrm{E}+00$ & $.00 \mathrm{E}+00$ & $0.00 \mathrm{E}+00$ & $0.00 \mathrm{E}+00$ & $0.00 \mathrm{E}+00$ & $00 \mathrm{E}+00$ & $.00 \mathrm{E}+00$ & $00 \mathrm{E}+0 \mathrm{C}$ \\
\hline $\mathrm{F}+00$ & $.00 E+00$ & $.00 \mathrm{E}+00$ & $0.00 E+00$ & $0 \mathrm{E}+00$ & $00 \mathrm{E}+00$ & $00 \mathrm{E}+00$ & $00 E+00$ \\
\hline & & & & & & & $00 E+00$ \\
\hline & & & & & & & $00 \mathrm{E}+00$ \\
\hline תחת & & & & & 0 & & 00 \\
\hline $.00 \mathrm{E}+00$ & $0.00 \mathrm{E}+00$ & $0.00 \mathrm{E}+00$ & $0.00 \mathrm{E}+00$ & $0.00 \mathrm{E}+00$ & $0.00 \mathrm{E}+00$ & $.00 \mathrm{E}+00$ & $.00 \mathrm{E}+00$ \\
\hline $00 \mathrm{E}+$ & $.00 \mathrm{E}+0$ & $.00 \mathrm{E}+0 \mathrm{C}$ & $0.00 \mathrm{E}+00$ & $.00 E+00$ & $.00 \mathrm{E}+00$ & $.00 \mathrm{E}+00$ & $.00 \mathrm{E}+0 \mathrm{C}$ \\
\hline חم +Fחم & $.00 \mathrm{E}+00$ & $0.00 \mathrm{E}+00$ & $0.00 \mathrm{E}+00$ & $0 \mathrm{E}+00$ & $00 \mathrm{E}+00$ & $.00 E+00$ & $00 \mathrm{E}+00$ \\
\hline 00 & & & & & & & $0 \mathrm{E}+00$ \\
\hline & & & & & & & $00 \mathrm{E}+00$ \\
\hline $.00 \mathrm{E}+00$ & $0.00 \mathrm{E}+00$ & $0.00 \mathrm{E}+00$ & $0.00 \mathrm{E}+00$ & $0.00 \mathrm{E}+00$ & $0.00 \mathrm{E}+00$ & $.00 \mathrm{E}+00$ & $.00 \mathrm{E}+00$ \\
\hline 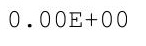 & . & •. & $0.00 \mathrm{E}+00$ & & & $.00 E+00$ & $.00 \mathrm{E}+0 \mathrm{C}$ \\
\hline & . & & & & & & . V LT \\
\hline $00 \mathrm{E}+0$ & $0.00 \mathrm{E}+0$ & $0.00 \mathrm{E}+00$ & $0.00 \mathrm{E}+00$ & $.00 E+00$ & $.00 E+00$ & $.00 \mathrm{E}+00$ & $.00 E+00$ \\
\hline $\mathrm{E}+$ & & & $.00 E+00$ & $\mathrm{E}+00$ & $\mathrm{E}+00$ & $0 E+00$ & $00 \mathrm{E}+00$ \\
\hline $0 E+00$ & & & $0.00 E+00$ & $0.00 E+00$ & $00 E+00$ & +00 & $.00 \mathrm{E}+00$ \\
\hline $.00 \mathrm{E}+00$ & $0.00 \mathrm{E}+00$ & $.00 \mathrm{E}+00$ & $0.00 \mathrm{E}+00$ & $0 E+00$ & $00 \mathrm{E}+00$ & 0 & $.00 \mathrm{E}+00$ \\
\hline $.00 \mathrm{E}+00$ & 0 & OOE+ & & & 00 & $0 E+00$ & $.00 \mathrm{E}+0 \mathrm{C}$ \\
\hline $.00 \mathrm{E}+00$ & $0.00 \mathrm{E}+00$ & $0.00 \mathrm{E}+00$ & $.00 E+00$ & $0.00 E+00$ & $0.00 \mathrm{E}+00$ & $0.00 \mathrm{E}+00$ & $0.00 \mathrm{E}+00$ \\
\hline $.00 \mathrm{E}+00$ & $0.00 \mathrm{E}+00$ & $0.00 \mathrm{E}+00$ & $0.00 \mathrm{E}+00$ & $0.00 \mathrm{E}+00$ & $0.00 \mathrm{E}+00$ & $0.00 \mathrm{E}+00$ & $0.00 \mathrm{E}+00$ \\
\hline $00 E+00$ & & & & $0.00 \mathrm{E}+00$ & $0.00 \mathrm{E}+00$ & $.00 \mathrm{E}+00$ & $0.00 \mathrm{E}+00$ \\
\hline+00 & $.00 \mathrm{E}+00$ & $.00 \mathrm{E}+00$ & $.00 E+00$ & $.00 E+00$ & $0.00 \mathrm{E}+00$ & $.00 \mathrm{E}+00$ & $.00 \mathrm{E}+00$ \\
\hline
\end{tabular}


RESRAD-OFFSITE, Version 2.5

Title : RESRAD-OFFSITE Drinking Water, Plant, Milk, and Meat Pathways for Offsite Reside File : PBA-1_TC99-DOE-5.ROF

Summary of dose at graphical times, reptition 3 (continued)

Time

Years

$4.72 \mathrm{E}+01$

$4.77 \mathrm{E}+01$

$4.82 \mathrm{E}+01$

$4.87 \mathrm{E}+01$

4. $92 \mathrm{E}+01$

$4.97 \mathrm{E}+01$

$5.02 \mathrm{E}+01$

$5.08 \mathrm{E}+01$

$5.13 \mathrm{E}+01$

$5.18 \mathrm{E}+01$

$5.23 \mathrm{E}+01$

$5.28 \mathrm{E}+01$

$5.33 \mathrm{E}+01$

$5.38 \mathrm{E}+01$

$5.43 \mathrm{E}+01$

$5.49 \mathrm{E}+01$

$5.54 \mathrm{E}+01$

$5.59 \mathrm{E}+01$

$5.64 \mathrm{E}+01$

$5.69 \mathrm{E}+01$

$5.74 \mathrm{E}+01$

$5.79 \mathrm{E}+01$

$5.84 \mathrm{E}+01$

$5.90 \mathrm{E}+01$

$5.95 \mathrm{E}+01$

$6.00 \mathrm{E}+01$

$6.05 \mathrm{E}+01$

$6.10 \mathrm{E}+01$

$6.15 \mathrm{E}+01$

$6.20 \mathrm{E}+01$

$6.25 \mathrm{E}+01$

$6.31 \mathrm{E}+01$

$6.36 \mathrm{E}+01$

$6.41 \mathrm{E}+01$

$6.46 \mathrm{E}+01$

$6.51 \mathrm{E}+01$

$6.56 \mathrm{E}+01$

$6.61 \mathrm{E}+01$

$6.67 \mathrm{E}+01$

$6.72 \mathrm{E}+01$

$6.77 \mathrm{E}+01$

$6.82 \mathrm{E}+01$

$6.87 \mathrm{E}+01$

$6.92 \mathrm{E}+01$

$6.97 \mathrm{E}+01$

$7.02 \mathrm{E}+01$
Dose statistics at graphical times, mrem/yr

\begin{tabular}{|c|c|c|c|c|c|c|c|}
\hline m & num & ean & n & & & $\%$ & \\
\hline 00 & 00 & $E+00$ & $\mathrm{E}+00$ & +00 & +00 & +00 & +00 \\
\hline $.00 \mathrm{E}+00$ & $.00 \mathrm{E}+00$ & $.00 \mathrm{E}+00$ & $0.00 \mathrm{E}+00$ & $0.00 \mathrm{E}+00$ & $0.00 \mathrm{E}+00$ & $.00 \mathrm{E}+00$ & $.00 \mathrm{E}+00$ \\
\hline $00 F+00$ & $00 F+00$ & $00 E+00$ & $.00 E+00$ & $00 \mathrm{E}+00$ & $00 F+00$ & $00 \mathrm{E}+00$ & $00 F+00$ \\
\hline 00 & & & & & & & 00 \\
\hline+00 & +00 & & & & 00 & & +00 \\
\hline $.00 \mathrm{E}+00$ & $E+00$ & $0 \mathrm{E}+00$ & $0 E+00$ & $0 E+00$ & $0 \mathrm{E}+00$ & 00 & +00 \\
\hline $.00 \mathrm{E}+00$ & +00 & $E+00$ & $\mathrm{E}+00$ & +00 & +00 & +00 & $\mathrm{E}+00$ \\
\hline $.00 E+00$ & $0.00 \mathrm{E}+00$ & $0 \mathrm{E}+00$ & $0 \mathrm{E}+00$ & $00 E+00$ & $.00 \mathrm{E}+00$ & $.00 \mathrm{E}+00$ & $00 E+00$ \\
\hline $00 E+00$ & $00 \mathrm{E}+00$ & $.00 E+00$ & $.00 E+00$ & $0 \mathrm{E}+00$ & $0 \mathrm{E}+00$ & $E+00$ & $\exists+00$ \\
\hline $00 \mathrm{E}+00$ & $O P F+6-5-5$ & $00 E+00$ & $0 E+00$ & 0 & +0 & $00 E+00$ & +00 \\
\hline$E+00$ & $\mathrm{~F}+00$ & $E+00$ & & & & & +00 \\
\hline $.00 \mathrm{E}+00$ & $0.00 \mathrm{E}+00$ & $.00 \mathrm{E}+00$ & $0.00 \mathrm{E}+00$ & $0.00 \mathrm{E}+00$ & $0.00 \mathrm{E}+00$ & $.00 \mathrm{E}+00$ & $.00 E+00$ \\
\hline $.00 E+00$ & $0.00 \mathrm{E}+00$ & $0.00 \mathrm{E}+00$ & $0.00 \mathrm{E}+00$ & $0.00 \mathrm{E}+00$ & $0.00 \mathrm{E}+00$ & $.00 \mathrm{E}+00$ & $.00 \mathrm{E}+00$ \\
\hline $.00 E+00$ & $0=0$ & $00 E+00$ & $0 \mathrm{E}+00$ & $E+00$ & $\mathrm{E}+00$ & +00 & $\mathrm{E}+00$ \\
\hline $\mathrm{OE}+$ & $.00 \mathrm{E}+\mathrm{C}$ & $.00 E+00$ & $.00 E+00$ & $0 E+00$ & 0 & 0 & 00 \\
\hline 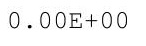 & ק & 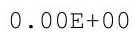 & 0 & & ( & 0 & +00 \\
\hline$O \cap F+O \Omega$ & $00 F+00$ & $0 \mathrm{E}+00$ & $E+00$ & $E+00$ & +00 & 0 & +00 \\
\hline $.00 E+00$ & $0 \cap F+00$ & $0 \mathrm{E}+00$ & $0 E+00$ & $\mathrm{E}+00$ & $0 E+00$ & $O E+00$ & $0 E+00$ \\
\hline $.00 \mathrm{E}+00$ & $.00 \mathrm{E}+00$ & $0.00 \mathrm{E}+00$ & $0.00 \mathrm{E}+00$ & $.00 \mathrm{E}+00$ & $0.00 \mathrm{E}+00$ & $.00 \mathrm{E}+00$ & $0 \mathrm{E}+00$ \\
\hline $.00 E+00$ & $0 \cap F+\cap 0$ & $.00 \mathrm{E}+00$ & $.00 E+00$ & $0 \mathrm{E}+00$ & $00 E+00$ & $E+00$ & $0 \mathrm{E}+00$ \\
\hline & & & & & & & +00 \\
\hline & & & & & & & $0 E+00$ \\
\hline$=0$ & & & & & $\mathrm{E}+00$ & 0 & 00 \\
\hline $.00 \mathrm{E}+00$ & $.00 \mathrm{E}+00$ & $.00 \mathrm{E}+00$ & $.00 \mathrm{E}+00$ & $00 \mathrm{E}+00$ & $00 \mathrm{E}+00$ & $.00 E+00$ & $00 E+00$ \\
\hline $.00 \mathrm{E}+00$ & $.00 \mathrm{E}+00$ & $0.00 \mathrm{E}+00$ & $0.00 \mathrm{E}+00$ & $0.00 \mathrm{E}+00$ & $00 \mathrm{E}+00$ & $.00 \mathrm{E}+00$ & $00 \mathrm{E}+0 \mathrm{C}$ \\
\hline $\mathrm{F}+00$ & $.00 E+00$ & $.00 \mathrm{E}+00$ & $0.00 E+00$ & $0 \mathrm{E}+00$ & $00 \mathrm{E}+00$ & $00 \mathrm{E}+00$ & $00 E+00$ \\
\hline & & & & & & & $00 E+00$ \\
\hline & & & & & & & $00 \mathrm{E}+00$ \\
\hline תחת & & & & & 0 & & 00 \\
\hline $.00 \mathrm{E}+00$ & $0.00 \mathrm{E}+00$ & $0.00 \mathrm{E}+00$ & $0.00 \mathrm{E}+00$ & $0.00 \mathrm{E}+00$ & $0.00 \mathrm{E}+00$ & $.00 \mathrm{E}+00$ & $.00 \mathrm{E}+00$ \\
\hline $00 \mathrm{E}+$ & $.00 \mathrm{E}+0$ & $.00 \mathrm{E}+0 \mathrm{C}$ & $0.00 \mathrm{E}+00$ & $.00 E+00$ & $.00 \mathrm{E}+00$ & $.00 \mathrm{E}+00$ & $.00 \mathrm{E}+0 \mathrm{C}$ \\
\hline חم +Fחم & $.00 \mathrm{E}+00$ & $0.00 \mathrm{E}+00$ & $0.00 \mathrm{E}+00$ & $0 \mathrm{E}+00$ & $00 \mathrm{E}+00$ & $.00 E+00$ & $00 \mathrm{E}+00$ \\
\hline 00 & & & & & & & $0 \mathrm{E}+00$ \\
\hline & & & & & & & $00 \mathrm{E}+00$ \\
\hline $.00 \mathrm{E}+00$ & $0.00 \mathrm{E}+00$ & $0.00 \mathrm{E}+00$ & $0.00 \mathrm{E}+00$ & $0.00 \mathrm{E}+00$ & $0.00 \mathrm{E}+00$ & $.00 \mathrm{E}+00$ & $.00 \mathrm{E}+00$ \\
\hline 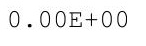 & . & •. & $0.00 \mathrm{E}+00$ & & & $.00 E+00$ & $.00 \mathrm{E}+0 \mathrm{C}$ \\
\hline & . & & & & & & . V LT \\
\hline $00 \mathrm{E}+0$ & $0.00 \mathrm{E}+0$ & $0.00 \mathrm{E}+00$ & $0.00 \mathrm{E}+00$ & $.00 E+00$ & $.00 E+00$ & $.00 \mathrm{E}+00$ & $.00 E+00$ \\
\hline $\mathrm{E}+$ & & & $.00 E+00$ & $\mathrm{E}+00$ & $\mathrm{E}+00$ & $0 E+00$ & $00 \mathrm{E}+00$ \\
\hline $0 E+00$ & & & $0.00 E+00$ & $0.00 E+00$ & $00 E+00$ & +00 & $.00 \mathrm{E}+00$ \\
\hline $.00 \mathrm{E}+00$ & $0.00 \mathrm{E}+00$ & $.00 \mathrm{E}+00$ & $0.00 \mathrm{E}+00$ & $0 E+00$ & $00 \mathrm{E}+00$ & 0 & $.00 \mathrm{E}+00$ \\
\hline $.00 \mathrm{E}+00$ & 0 & OOE+ & & & 00 & $0 E+00$ & $.00 \mathrm{E}+0 \mathrm{C}$ \\
\hline $.00 \mathrm{E}+00$ & $0.00 \mathrm{E}+00$ & $0.00 \mathrm{E}+00$ & $.00 E+00$ & $0.00 E+00$ & $0.00 \mathrm{E}+00$ & $0.00 \mathrm{E}+00$ & $0.00 \mathrm{E}+00$ \\
\hline $.00 \mathrm{E}+00$ & $0.00 \mathrm{E}+00$ & $0.00 \mathrm{E}+00$ & $0.00 \mathrm{E}+00$ & $0.00 \mathrm{E}+00$ & $0.00 \mathrm{E}+00$ & $0.00 \mathrm{E}+00$ & $0.00 \mathrm{E}+00$ \\
\hline $00 E+00$ & & & & $0.00 \mathrm{E}+00$ & $0.00 \mathrm{E}+00$ & $.00 \mathrm{E}+00$ & $0.00 \mathrm{E}+00$ \\
\hline+00 & $.00 \mathrm{E}+00$ & $.00 \mathrm{E}+00$ & $.00 E+00$ & $.00 E+00$ & $0.00 \mathrm{E}+00$ & $.00 \mathrm{E}+00$ & $.00 \mathrm{E}+00$ \\
\hline
\end{tabular}


RESRAD-OFFSITE, Version 2.5

Title : RESRAD-OFFSITE Drinking Water, Plant, Milk, and Meat Pathways for Offsite Reside File : PBA-1_TC99-DOE-5.ROF

Summary of dose at graphical times, reptition 3 (continued)

Time

Years

7. $08 \mathrm{E}+01$

7. $13 \mathrm{E}+01$

7. $18 \mathrm{E}+01$

$7.23 E+01$

7. $28 \mathrm{E}+01$

7. $33 \mathrm{E}+01$

7. $38 \mathrm{E}+01$

7. $43 \mathrm{E}+01$

7. $49 \mathrm{E}+01$

7. $54 \mathrm{E}+01$

7. $59 \mathrm{E}+01$

7. $64 \mathrm{E}+01$

7. $69 \mathrm{E}+01$

7. $74 \mathrm{E}+01$

7. $79 \mathrm{E}+01$

7. $84 \mathrm{E}+01$

7. $90 \mathrm{E}+01$

7. $95 \mathrm{E}+01$

8. $00 \mathrm{E}+01$

$8.05 \mathrm{E}+01$

$8.10 \mathrm{E}+01$

$8.15 \mathrm{E}+01$

8. $20 \mathrm{E}+01$

$8.25 \mathrm{E}+01$

8. $31 \mathrm{E}+01$

8. $36 \mathrm{E}+01$

8. $41 \mathrm{E}+01$

8. $46 \mathrm{E}+01$

8. $51 \mathrm{E}+01$

8. $56 \mathrm{E}+01$

8. $61 \mathrm{E}+01$

8. $66 \mathrm{E}+01$

$8.72 \mathrm{E}+01$

$8.77 \mathrm{E}+01$

8. $82 \mathrm{E}+01$

$8.87 \mathrm{E}+01$

8. $92 \mathrm{E}+01$

$8.97 \mathrm{E}+01$

$9.02 \mathrm{E}+01$

$9.07 \mathrm{E}+01$

$9.13 \mathrm{E}+01$

$9.18 \mathrm{E}+01$

$9.23 \mathrm{E}+01$

$9.28 \mathrm{E}+01$

9. $33 \mathrm{E}+01$

9. $38 \mathrm{E}+01$
Dose statistics at graphical times, mrem/yr

\begin{tabular}{|c|c|c|c|c|c|c|c|}
\hline m & num & ean & n & & & $\%$ & \\
\hline 00 & 00 & $E+00$ & $\mathrm{E}+00$ & +00 & +00 & +00 & +00 \\
\hline $.00 \mathrm{E}+00$ & $.00 \mathrm{E}+00$ & $.00 \mathrm{E}+00$ & $0.00 \mathrm{E}+00$ & $0.00 \mathrm{E}+00$ & $0.00 \mathrm{E}+00$ & $.00 \mathrm{E}+00$ & $.00 \mathrm{E}+00$ \\
\hline $00 F+00$ & $00 F+00$ & $00 E+00$ & $.00 E+00$ & $00 \mathrm{E}+00$ & $00 F+00$ & $00 \mathrm{E}+00$ & $00 F+00$ \\
\hline 00 & & & & & & & 00 \\
\hline+00 & +00 & & & & 00 & & +00 \\
\hline $.00 \mathrm{E}+00$ & $E+00$ & $0 \mathrm{E}+00$ & $0 E+00$ & $0 E+00$ & $0 \mathrm{E}+00$ & 00 & +00 \\
\hline $.00 \mathrm{E}+00$ & +00 & $E+00$ & $\mathrm{E}+00$ & +00 & +00 & +00 & $\mathrm{E}+00$ \\
\hline $.00 E+00$ & $0.00 \mathrm{E}+00$ & $0 \mathrm{E}+00$ & $0 \mathrm{E}+00$ & $00 E+00$ & $.00 \mathrm{E}+00$ & $.00 \mathrm{E}+00$ & $00 E+00$ \\
\hline $00 E+00$ & $00 \mathrm{E}+00$ & $.00 E+00$ & $.00 E+00$ & $0 \mathrm{E}+00$ & $0 \mathrm{E}+00$ & $E+00$ & $\exists+00$ \\
\hline $00 \mathrm{E}+00$ & $O P F+6-5-5$ & $00 E+00$ & $0 E+00$ & 0 & +0 & $00 E+00$ & +00 \\
\hline$E+00$ & $\mathrm{~F}+00$ & $E+00$ & & & & & +00 \\
\hline $.00 \mathrm{E}+00$ & $0.00 \mathrm{E}+00$ & $.00 \mathrm{E}+00$ & $0.00 \mathrm{E}+00$ & $0.00 \mathrm{E}+00$ & $0.00 \mathrm{E}+00$ & $.00 \mathrm{E}+00$ & $.00 E+00$ \\
\hline $.00 E+00$ & $0.00 \mathrm{E}+00$ & $0.00 \mathrm{E}+00$ & $0.00 \mathrm{E}+00$ & $0.00 \mathrm{E}+00$ & $0.00 \mathrm{E}+00$ & $.00 \mathrm{E}+00$ & $.00 \mathrm{E}+00$ \\
\hline $.00 E+00$ & $0=0$ & $00 E+00$ & $0 \mathrm{E}+00$ & $E+00$ & $\mathrm{E}+00$ & +00 & $\mathrm{E}+00$ \\
\hline $\mathrm{OE}+$ & $.00 \mathrm{E}+\mathrm{C}$ & $.00 E+00$ & $.00 E+00$ & $0 E+00$ & 0 & 0 & 00 \\
\hline 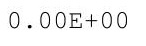 & ק & 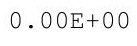 & 0 & & ( & 0 & +00 \\
\hline$O \cap F+O \Omega$ & $00 F+00$ & $0 \mathrm{E}+00$ & $E+00$ & $E+00$ & +00 & 0 & +00 \\
\hline $.00 E+00$ & $0 \cap F+00$ & $0 \mathrm{E}+00$ & $0 E+00$ & $\mathrm{E}+00$ & $0 E+00$ & $O E+00$ & $0 E+00$ \\
\hline $.00 \mathrm{E}+00$ & $.00 \mathrm{E}+00$ & $0.00 \mathrm{E}+00$ & $0.00 \mathrm{E}+00$ & $.00 \mathrm{E}+00$ & $0.00 \mathrm{E}+00$ & $.00 \mathrm{E}+00$ & $0 \mathrm{E}+00$ \\
\hline $.00 E+00$ & $0 \cap F+\cap 0$ & $.00 \mathrm{E}+00$ & $.00 E+00$ & $0 \mathrm{E}+00$ & $00 E+00$ & $E+00$ & $0 \mathrm{E}+00$ \\
\hline & & & & & & & +00 \\
\hline & & & & & & & $0 E+00$ \\
\hline$=0$ & & & & & $\mathrm{E}+00$ & 0 & 00 \\
\hline $.00 \mathrm{E}+00$ & $.00 \mathrm{E}+00$ & $.00 \mathrm{E}+00$ & $.00 \mathrm{E}+00$ & $00 \mathrm{E}+00$ & $00 \mathrm{E}+00$ & $.00 E+00$ & $00 E+00$ \\
\hline $.00 \mathrm{E}+00$ & $.00 \mathrm{E}+00$ & $0.00 \mathrm{E}+00$ & $0.00 \mathrm{E}+00$ & $0.00 \mathrm{E}+00$ & $00 \mathrm{E}+00$ & $.00 \mathrm{E}+00$ & $00 \mathrm{E}+0 \mathrm{C}$ \\
\hline $\mathrm{F}+00$ & $.00 E+00$ & $.00 \mathrm{E}+00$ & $0.00 E+00$ & $0 \mathrm{E}+00$ & $00 \mathrm{E}+00$ & $00 \mathrm{E}+00$ & $00 E+00$ \\
\hline & & & & & & & $00 E+00$ \\
\hline & & & & & & & $00 \mathrm{E}+00$ \\
\hline תחת & & & & & 0 & & 00 \\
\hline $.00 \mathrm{E}+00$ & $0.00 \mathrm{E}+00$ & $0.00 \mathrm{E}+00$ & $0.00 \mathrm{E}+00$ & $0.00 \mathrm{E}+00$ & $0.00 \mathrm{E}+00$ & $.00 \mathrm{E}+00$ & $.00 \mathrm{E}+00$ \\
\hline $00 \mathrm{E}+$ & $.00 \mathrm{E}+0$ & $.00 \mathrm{E}+0 \mathrm{C}$ & $0.00 \mathrm{E}+00$ & $.00 E+00$ & $.00 \mathrm{E}+00$ & $.00 \mathrm{E}+00$ & $.00 \mathrm{E}+0 \mathrm{C}$ \\
\hline חم +Fחم & $.00 \mathrm{E}+00$ & $0.00 \mathrm{E}+00$ & $0.00 \mathrm{E}+00$ & $0 \mathrm{E}+00$ & $00 \mathrm{E}+00$ & $.00 E+00$ & $00 \mathrm{E}+00$ \\
\hline 00 & & & & & & & $0 \mathrm{E}+00$ \\
\hline & & & & & & & $00 \mathrm{E}+00$ \\
\hline $.00 \mathrm{E}+00$ & $0.00 \mathrm{E}+00$ & $0.00 \mathrm{E}+00$ & $0.00 \mathrm{E}+00$ & $0.00 \mathrm{E}+00$ & $0.00 \mathrm{E}+00$ & $.00 \mathrm{E}+00$ & $.00 \mathrm{E}+00$ \\
\hline 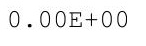 & . & •. & $0.00 \mathrm{E}+00$ & & & $.00 E+00$ & $.00 \mathrm{E}+0 \mathrm{C}$ \\
\hline & . & & & & & & . V LT \\
\hline $00 \mathrm{E}+0$ & $0.00 \mathrm{E}+0$ & $0.00 \mathrm{E}+00$ & $0.00 \mathrm{E}+00$ & $.00 E+00$ & $.00 E+00$ & $.00 \mathrm{E}+00$ & $.00 E+00$ \\
\hline $\mathrm{E}+$ & & & $.00 E+00$ & $\mathrm{E}+00$ & $\mathrm{E}+00$ & $0 E+00$ & $00 \mathrm{E}+00$ \\
\hline $0 E+00$ & & & $0.00 E+00$ & $0.00 E+00$ & $00 E+00$ & +00 & $.00 \mathrm{E}+00$ \\
\hline $.00 \mathrm{E}+00$ & $0.00 \mathrm{E}+00$ & $.00 \mathrm{E}+00$ & $0.00 \mathrm{E}+00$ & $0 E+00$ & $00 \mathrm{E}+00$ & 0 & $.00 \mathrm{E}+00$ \\
\hline $.00 \mathrm{E}+00$ & 0 & OOE+ & & & 00 & $0 E+00$ & $.00 \mathrm{E}+0 \mathrm{C}$ \\
\hline $.00 \mathrm{E}+00$ & $0.00 \mathrm{E}+00$ & $0.00 \mathrm{E}+00$ & $.00 E+00$ & $0.00 E+00$ & $0.00 \mathrm{E}+00$ & $0.00 \mathrm{E}+00$ & $0.00 \mathrm{E}+00$ \\
\hline $.00 \mathrm{E}+00$ & $0.00 \mathrm{E}+00$ & $0.00 \mathrm{E}+00$ & $0.00 \mathrm{E}+00$ & $0.00 \mathrm{E}+00$ & $0.00 \mathrm{E}+00$ & $0.00 \mathrm{E}+00$ & $0.00 \mathrm{E}+00$ \\
\hline $00 E+00$ & & & & $0.00 \mathrm{E}+00$ & $0.00 \mathrm{E}+00$ & $.00 \mathrm{E}+00$ & $0.00 \mathrm{E}+00$ \\
\hline+00 & $.00 \mathrm{E}+00$ & $.00 \mathrm{E}+00$ & $.00 E+00$ & $.00 E+00$ & $0.00 \mathrm{E}+00$ & $.00 \mathrm{E}+00$ & $.00 \mathrm{E}+00$ \\
\hline
\end{tabular}


RESRAD-OFFSITE, Version 2.5

robabilistic Dose and Risk Report

Title : RESRAD-OFFSITE Drinking Water, Plant, Milk, and Meat Pathways for Offsite Reside File : PBA-1_TC99-DOE-5.ROF

Summary of dose at graphical times, reptition 3 (continued)

Time

Years

9. $43 \mathrm{E}+01$

9. $48 \mathrm{E}+01$

9. $54 \mathrm{E}+01$

$9.59 \mathrm{E}+01$

9. $64 \mathrm{E}+01$

$9.69 \mathrm{E}+01$

$9.74 \mathrm{E}+01$

$9.79 \mathrm{E}+01$

9. $84 \mathrm{E}+01$

9. $90 \mathrm{E}+01$

9. $95 \mathrm{E}+01$

$1.00 \mathrm{E}+02$

1. $00 \mathrm{E}+02$

$1.01 \mathrm{E}+02$

1. $02 \mathrm{E}+02$

1. $02 \mathrm{E}+02$

$1.03 \mathrm{E}+02$

$1.03 \mathrm{E}+02$

$1.04 \mathrm{E}+02$

$1.04 \mathrm{E}+02$

$1.05 \mathrm{E}+02$

$1.05 \mathrm{E}+02$

$1.06 \mathrm{E}+02$

$1.06 \mathrm{E}+02$

$1.07 \mathrm{E}+02$

$1.07 \mathrm{E}+02$

$1.08 \mathrm{E}+02$

$1.08 \mathrm{E}+02$

1. $09 \mathrm{E}+02$

1. $09 \mathrm{E}+02$

1. $10 \mathrm{E}+02$

1. $10 \mathrm{E}+02$

1. $11 \mathrm{E}+02$

1. $11 \mathrm{E}+02$

1. $12 \mathrm{E}+02$

1. $12 \mathrm{E}+02$

1. $13 \mathrm{E}+02$

1. $13 \mathrm{E}+02$

1. $14 \mathrm{E}+02$

1. $14 \mathrm{E}+02$

1. $15 \mathrm{E}+02$

$1.15 \mathrm{E}+02$

$1.16 \mathrm{E}+02$

$1.16 \mathrm{E}+02$

$1.17 \mathrm{E}+02$

1. $17 \mathrm{E}+02$

Dose statistics at graphical times, mrem/yr

\begin{tabular}{|c|c|c|c|c|c|c|c|}
\hline num & aximum & ean & ed & & & $\%$ & \\
\hline 00 & 0 & $E+00$ & $E+00$ & +00 & +00 & +00 & +00 \\
\hline $.00 \mathrm{E}+00$ & $.00 \mathrm{E}+00$ & $00 \mathrm{E}+00$ & $00 \mathrm{E}+00$ & $0 \mathrm{E}+00$ & $0.00 \mathrm{E}+00$ & $.00 \mathrm{E}+00$ & $00 \mathrm{E}+00$ \\
\hline$O \cap F+O \Omega$ & $00 F+00$ & $00 F+00$ & $.00 E+00$ & $00 F+00$ & $00 F+00$ & $00 \mathrm{E}+00$ & $00 F+00=$ \\
\hline 0 & & & & & & & +00 \\
\hline $\mathrm{E}+00$ & +00 & $E+00$ & & & 0 & & +00 \\
\hline$E+00$ & $00 \mathrm{E}+00$ & $0 E+00$ & $0 \mathrm{E}+00$ & $\mathrm{E}+00$ & & 00 & +00 \\
\hline$E+00$ & $E+00$ & $\mathrm{E}+00$ & $\mathrm{E}+00$ & 00 & . & 00 & $\Xi+00$ \\
\hline $.00 E+00$ & $E+00$ & $\mathrm{E}+00$ & $\mathrm{E}+00$ & $0 \mathrm{E}+00$ & $00 \mathrm{E}+00$ & $00 \mathrm{E}+00$ & $E+00$ \\
\hline $00 E+00$ & $00 \mathrm{E}+00$ & $.00 E+00$ & $00 \mathrm{E}+00$ & $0 E+00$ & $0 E+00$ & $E+00$ & $\mathrm{E}+\mathrm{OC}$ \\
\hline $0 E+00$ & $F$ & $2+6-3 x$ & $\mathrm{E}+00$ & 0 & 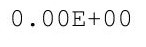 & 0 & 00 \\
\hline$E+00$ & & & & & +00 & 0 & +00 \\
\hline$E+00$ & $E+00$ & $\mathrm{E}+00$ & +00 & $E+00$ & $\mathrm{E}+00$ & 0 & +00 \\
\hline $.00 E+00$ & $0.00 \mathrm{E}+00$ & $.00 \mathrm{E}+00$ & $0.00 \mathrm{E}+00$ & $0.00 \mathrm{E}+00$ & $0.00 \mathrm{E}+00$ & $.00 \mathrm{E}+00$ & $.00 E+00$ \\
\hline$E+00$ & $E+00$ & $\mathrm{E}+00$ & $\mathrm{E}+00$ & $E+00$ & $E+00$ & & $E+00$ \\
\hline $00 E+00$ & 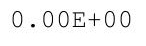 & 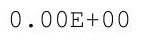 & & & 0 & 0 & +00 \\
\hline $00 E+00$ & $\mathrm{E}+00$ & O & & & & & +00 \\
\hline $\mathrm{F}$ & 0 & $\mathrm{~F}+0 \mathrm{O}$ & 0 & 0 & 0 & 0 & +00 \\
\hline $\mathrm{DE}+00$ & $0 \cap F+00$ & $0.00 \mathrm{E}+00$ & $0 \mathrm{E}+00$ & & $0 E+00$ & $\mathrm{E}+00$ & $\mathrm{E}+00$ \\
\hline $.00 \mathrm{E}+00$ & $0.00 \mathrm{E}+00$ & $0.00 \mathrm{E}+00$ & $0.00 \mathrm{E}+00$ & $0.00 \mathrm{E}+00$ & $0.00 \mathrm{E}+00$ & $.00 \mathrm{E}+00$ & $.00 \mathrm{E}+00$ \\
\hline $.00 E+00$ & $0.00 \mathrm{E}+00$ & $0.00 \mathrm{E}+00$ & $0.00 \mathrm{E}+00$ & $0 E+00$ & $00 E+00$ & $0 E+00$ & $0 \mathrm{E}+00$ \\
\hline 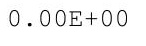 & & & & & & & 00 \\
\hline & & & & & +00 & & +00 \\
\hline $.00 E+00$ & $.00 \mathrm{E}+00$ & $0.00 \mathrm{E}+00$ & & & & & $O E+O C$ \\
\hline 00 & $.00 \mathrm{E}+$ & $.00 \mathrm{E}+00$ & $0.00 \mathrm{E}+00$ & $0 \mathrm{E}+00$ & $\mathrm{E}+00$ & 0 & $E+00$ \\
\hline $.00 \mathrm{E}+00$ & $.00 \mathrm{E}+00$ & $0.00 \mathrm{E}+00$ & $0.00 \mathrm{E}+00$ & $.00 \mathrm{E}+00$ & $00 \mathrm{E}+00$ & $0 E+00$ & $0 \mathrm{E}+00$ \\
\hline $.00 E+00$ & $0.00 \mathrm{E}+00$ & $0.00 \mathrm{E}+00$ & $0.00 \mathrm{E}+00$ & $0.00 \mathrm{E}+00$ & $0.00 \mathrm{E}+00$ & $.00 \mathrm{E}+00$ & $.00 E+00$ \\
\hline$E+00$ & $00 \mathrm{E}+00$ & D & $0.00 \mathrm{E}+00$ & $E+00$ & $\mathrm{E}+00$ & $00 \mathrm{E}+00$ & $0 \mathrm{E}+00$ \\
\hline & & & & & & & 00 \\
\hline & & & & & & & 00 \\
\hline $.00 \mathrm{E}+00$ & $7.19 \mathrm{E}-28$ & $3.59 E-31$ & $0.00 \mathrm{E}+00$ & $0.00 \mathrm{E}+00$ & $0.00 \mathrm{E}+00$ & $.00 \mathrm{E}+00$ & $00 \mathrm{E}+00$ \\
\hline $00 E+00$ & - -5 & $2.60 E-28$ & $0.00 \mathrm{E}+00$ & $0.00 \mathrm{E}+00$ & $0.00 \mathrm{E}+00$ & $.00 \mathrm{E}+00$ & $.00 \mathrm{E}+0 \mathrm{C}$ \\
\hline $00 E+C$ & $.51 E-2$ & 3. $26 \mathrm{E}-2$ & & & & & $.00 E+0 C$ \\
\hline 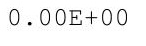 & & & & & & & $00 \mathrm{E}+00$ \\
\hline & $E-19$ & $2 E-23$ & $\mathrm{OE}+00$ & & $0 E+00$ & & $0 E+0 C$ \\
\hline $.00 \mathrm{E}+00$ & $2.04 \mathrm{E}-18$ & $2 E-21$ & $0.00 \mathrm{E}+00$ & $0.00 \mathrm{E}+00$ & $0 E+00$ & $0 E+00$ & $0 \mathrm{E}+00$ \\
\hline 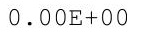 & $2.352-11$ & $.20 E-\angle 0$ & $0.00 \mathrm{E}+00$ & $0.00 \mathrm{E}+00$ & $00 \mathrm{E}+00$ & $.00 \mathrm{E}+00$ & $.00 \mathrm{E}+00$ \\
\hline 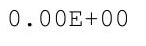 & . & & & & & & . UОЕТ \\
\hline se & - & 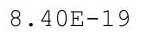 & $.00 \mathrm{E}+00$ & $00 \mathrm{E}+00$ & $00 \mathrm{E}+0$ & $.00 \mathrm{E}+00$ & $.00 E+0 C$ \\
\hline 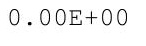 & (2) & ser & $0.00 \mathrm{E}+00$ & $00 \mathrm{E}+00$ & 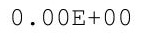 & $.00 \mathrm{E}+00$ & $.00 \mathrm{E}+00$ \\
\hline $.00 \mathrm{E}+00$ & 14 & $1 \mathrm{E}-17$ & $.00 \mathrm{E}+00$ & $0 \mathrm{E}+00$ & $00 \mathrm{E}+00$ & $\mathrm{OE}+00$ & $\mathrm{OE}+00$ \\
\hline $0 E+00$ & $1.88 \mathrm{E}-13$ & $9.40 \mathrm{E}-17$ & $0.00 \mathrm{E}+00$ & 00 & $0 E+00$ & $E+00$ & $0 \mathrm{E}+00$ \\
\hline+00 & $6.66 \mathrm{E}-13$ & $3 E-16$ & & & $\mathrm{E}+00$ & & $E+00$ \\
\hline & & & & & & & $.00 \mathrm{E}+00$ \\
\hline $.00 \mathrm{E}+00$ & 12 & $95 E-15$ & $0.00 \mathrm{E}+00$ & $0.00 \mathrm{E}+00$ & $0.00 \mathrm{E}+00$ & $0.00 \mathrm{E}+00$ & $0.00 \mathrm{E}+00$ \\
\hline $0 \mathrm{E}+00$ & $+x^{2}$ & & & & & $.00 \mathrm{E}+00$ & $.00 \mathrm{E}+00$ \\
\hline$\Xi+00$ & $E-11$ & $E-14$ & $\mathrm{OE}+00$ & $\mathrm{E}+00$ & $0 E+00$ & $.00 \mathrm{E}+00$ & $.00 \mathrm{E}+00$ \\
\hline
\end{tabular}


RESRAD-OFFSITE, Version 2.5

Title : RESRAD-OFFSITE Drinking Water, Plant, Milk, and Meat Pathways for Offsite Reside File : PBA-1_TC99-DOE-5.ROF

Summary of dose at graphical times, reptition 3 (continued)

Time

Years

$1.18 \mathrm{E}+02$

$1.18 \mathrm{E}+02$

1. $19 \mathrm{E}+02$

1. $19 \mathrm{E}+02$

1. $20 \mathrm{E}+02$

1. $20 \mathrm{E}+02$

1. $21 \mathrm{E}+02$

1. $22 \mathrm{E}+02$

1. $22 \mathrm{E}+02$

1. $23 \mathrm{E}+02$

1. $23 \mathrm{E}+02$

1. $24 \mathrm{E}+02$

1. $24 \mathrm{E}+02$

1. $25 \mathrm{E}+02$

1. $25 \mathrm{E}+02$

1. $26 \mathrm{E}+02$

1. $26 \mathrm{E}+02$

$1.27 \mathrm{E}+02$

1. $27 \mathrm{E}+02$

1. $28 \mathrm{E}+02$

1. $28 \mathrm{E}+02$

1. $29 \mathrm{E}+02$

1. $29 \mathrm{E}+02$

1. $30 \mathrm{E}+02$

1. $30 \mathrm{E}+02$

1. $31 \mathrm{E}+02$

1. $31 \mathrm{E}+02$

1. $32 \mathrm{E}+02$

1. $32 \mathrm{E}+02$

1. $33 \mathrm{E}+02$

1. $33 \mathrm{E}+02$

1. $34 \mathrm{E}+02$

1. $34 \mathrm{E}+02$

1. $35 \mathrm{E}+02$

1. $35 \mathrm{E}+02$

1. $36 \mathrm{E}+02$

1. $36 \mathrm{E}+02$

1. $37 \mathrm{E}+02$

1. $37 \mathrm{E}+02$

1. $38 \mathrm{E}+02$

1. $38 \mathrm{E}+02$

1. $39 \mathrm{E}+02$

1. $39 \mathrm{E}+02$

1. $40 \mathrm{E}+02$

1. $40 \mathrm{E}+02$

1. $41 \mathrm{E}+02$

Dose statistics at graphical times, mrem/yr

\begin{tabular}{|c|c|c|c|c|c|c|c|}
\hline inimum & aximum & Mean & ledian & $0 \%$ & $5 \%$ & $97.5 \%$ & $\%$ \\
\hline+00 & 7. $99 \mathrm{E}-11$ & $4.01 E-14$ & $0.00 \mathrm{E}+00$ & $0 \mathrm{E}+00$ & $0.00 \mathrm{E}+00$ & $.00 \mathrm{E}+00$ & $\mathrm{OE}+\mathrm{OC}$ \\
\hline$E+00$ & 10 & 14 & $\mathrm{E}+00$ & $\mathrm{OE}+$ & $0 E+00$ & 00 & +00 \\
\hline+00 & $7 E-10$ & $E-13$ & 00 & $\mathrm{DE}+00$ & 00 & -00 & +00 \\
\hline+00 & 10 & & & & & 00 & +00 \\
\hline+00 & -09 & 3 & 0 & 00 & 00 & $E+00$ & $\mathrm{E}+00$ \\
\hline $.00 \mathrm{E}+00$ & -09 & $9 \mathrm{E}-13$ & $\mathrm{E}+00$ & $0.00 \mathrm{E}+00$ & $0.00 \mathrm{E}+00$ & $0 E+00$ & $00 \mathrm{E}+00$ \\
\hline+00 & in & $F$ & 0 & $E+00$ & 0 & +00 & $\mathrm{i}+0 \mathrm{c}$ \\
\hline $.00 E+00$ & $5.11 \mathrm{E}-09$ & $.71 \mathrm{E}-12$ & $0.00 \mathrm{E}+00$ & $0.00 \mathrm{E}+00$ & $0.00 \mathrm{E}+00$ & $.00 \mathrm{E}+00$ & $00 \mathrm{E}+0 \mathrm{C}$ \\
\hline+00 & -09 & $3 E-12$ & +00 & $0 E+00$ & $00 \mathrm{E}+00$ & +00 & +00 \\
\hline $.00 \mathrm{E}+00$ & -08 & $6 E-12$ & $\mathrm{E}+00$ & $0 \mathrm{E}+00$ & $00 \mathrm{E}+00$ & $E+00$ & $E+00$ \\
\hline+00 & $E-08$ & E-11 & $\mathrm{g}+00$ & & & 00 & $E+00$ \\
\hline$E+00$ & -08 & $\mathrm{~s}-11$ & +00 & & $E+00$ & +00 & $\mathrm{E}+\mathrm{OC}$ \\
\hline $.00 \mathrm{E}+00$ & $9 E-08$ & $8 \mathrm{E}-11$ & $\mathrm{E}+00$ & $E+00$ & $E+U 0$ & $E+00$ & +00 \\
\hline$E+00$ & -08 & E-11 & $0.00 \mathrm{E}+00$ & $0.00 \mathrm{E}+00$ & +00 & $E+00$ & $00 \mathrm{E}+00$ \\
\hline$E+00$ & 08 & 11 & $\mathrm{E}+00$ & $0.00 \mathrm{E}+00$ & 00 & $0 \mathrm{E}+00$ & +00 \\
\hline $.00 \mathrm{E}+00$ & 1.0 & -11 & $0.00 \mathrm{E}+00$ & $0.00 \mathrm{E}+00$ & $00 \mathrm{E}+00$ & $0 E+00$ & $0 \mathrm{E}+00$ \\
\hline $.00 \mathrm{E}+00$ & $1.41 \mathrm{E}-07$ & $8 E-11$ & $0 E+00$ & $00 \mathrm{E}+00$ & $00 \mathrm{E}+00$ & $0 E+00$ & $.00 \mathrm{E}+00$ \\
\hline $.00 E+00$ & $1.87 \mathrm{E}-07$ & $3 E-10$ & $0 E+00$ & $0 \mathrm{E}+00$ & $00 \mathrm{E}+00$ & $0 \mathrm{E}+00$ & $00 \mathrm{E}+0 \mathrm{O}$ \\
\hline$E+00$ & -07 & 10 & 00 & 00 & 00 & +00 & -2 \\
\hline$E+00$ & -07 & -10 & $\mathrm{E}+00$ & 00 & 00 & +00 & -23 \\
\hline $.00 \mathrm{E}+00$ & -07 & $\perp 0$ & & & & 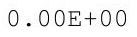 & -21 \\
\hline $.00 \mathrm{E}+00$ & $5.21 \mathrm{E}-07$ & $E-10$ & $0.00 \mathrm{E}+00$ & & & $E+00$ & $E-20$ \\
\hline $.00 \mathrm{E}+00$ & 7 & 0 & $00 E+00$ & $0 \mathrm{E}+00$ & $0 \mathrm{E}+00$ & $.00 \mathrm{E}+00$ & $.84 \mathrm{E}-19$ \\
\hline $.00 \mathrm{E}+00$ & $.19 \mathrm{E}-07$ & $6.94 \mathrm{E}-10$ & $0.00 \mathrm{E}+00$ & $0 \mathrm{E}+00$ & $00 \mathrm{E}+00$ & $0 \mathrm{E}+00$ & $12 \mathrm{E}-17$ \\
\hline+00 & $.01 \mathrm{E}-06$ & $93 E-10$ & & & & +00 & $05 E-16$ \\
\hline+00 & $E-06$ & $E-09$ & 0 & & & +00 & -16 \\
\hline $.00 \mathrm{E}+00$ & $\perp \cdot 3 \perp \mathrm{E}$ & - & $\mathrm{OE}+00$ & 0 & & +00 & -15 \\
\hline $.00 E+00$ & $83 E-06$ & . $01 \mathrm{~L}-\mathrm{U}$ & $0.00 \mathrm{E}+00$ & $0.00 \mathrm{E}+00$ & $.0 \mathrm{CLT}$ & $.00 \mathrm{E}+00$ & $22 E-14$ \\
\hline $0 E+00$ & 6 & $27 E-09$ & $00 E+00$ & $.00 \mathrm{E}+$ & $00 \mathrm{E}+$ & $0 E+00$ & $47 E-14$ \\
\hline 0 & 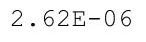 & . & & $\mathrm{E}+$ & & $E+C$ & 13 \\
\hline$F+00$ & $.11 E-06$ & $.47 E-09$ & $\mathrm{E}+00$ & $0 \mathrm{E}+00$ & $0 E+00$ & $\mathrm{DE}+00$ & $8 E-12$ \\
\hline+00 & 06 & $E-09$ & & & 0 & $E+00$ & -12 \\
\hline & 06 & & & & 00 & +00 & 12 \\
\hline $.00 \mathrm{E}+00$ & $5.01 \mathrm{E}-06$ & $6.31 E-09$ & $0.00 \mathrm{E}+00$ & $0.00 \mathrm{E}+00$ & $.00 \mathrm{E}+00$ & $.00 \mathrm{E}+00$ & $54 \mathrm{E}-11$ \\
\hline . & $5.81 E-06$ & $1.0<5-U 9$ & & . О ЕT TU & & $.00 \mathrm{E}+00$ & $.03 E-11$ \\
\hline 0 & & & & & & & $34 \mathrm{E}-10$ \\
\hline 0 & 6 & 8 & & 0 & & 0 & 10 \\
\hline 0 & & & & & & & 10 \\
\hline & 5 & .08 & & & $\mathrm{E}+00$ & $E+00$ & \\
\hline $.00 \mathrm{E}+00$ & $1.15 \mathrm{E}-05$ & $\mathrm{~s}-08$ & 0 . & 0 & 0 & & -09 \\
\hline$E+00$ & $1.30 \mathrm{E}-05$ & $.16 \mathrm{E}-08$ & & $\mathrm{OE}+$ & & & -09 \\
\hline JETU & $\perp \cdot$ & 8 & $00 E+00$ & $00 E+00$ & . & 26 & $35-09$ \\
\hline$E+00$ & $1.13 E$ & 0 & $00 E+0$ & $00 \mathrm{E}+\mathrm{C}$ & & $12 E-23$ & $20-00$ \\
\hline 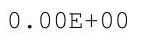 & 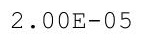 & & $0.00 \mathrm{E}$ & 0 & 0 & 21 & 08 \\
\hline $.00 \mathrm{E}+00$ & $2.32 E-05$ & $4.01 E-08$ & $0.00 \mathrm{E}+00$ & $0.00 \mathrm{E}+00$ & $0.00 \mathrm{E}+00$ & $6 E-20$ & $3.35 E-08$ \\
\hline $.00 E+00$ & $2.67 \mathrm{E}-05$ & $4.64 E-08$ & $.00 \mathrm{E}+00$ & $.00 E+00$ & $0.00 \mathrm{E}+00$ & 1. $39 \mathrm{E}-18$ & $4.94 \mathrm{E}-08$ \\
\hline
\end{tabular}


RESRAD-OFFSITE, Version 2.5

Title : RESRAD-OFFSITE Drinking Water, Plant, Milk, and Meat Pathways for Offsite Reside File : PBA-1_TC99-DOE-5.ROF

Summary of dose at graphical times, reptition 3 (continued)

Time

Years

1. $42 \mathrm{E}+02$

1. $42 \mathrm{E}+02$

1. $43 \mathrm{E}+02$

1. $43 \mathrm{E}+02$

1. $44 \mathrm{E}+02$

1. $44 \mathrm{E}+02$

1. $45 \mathrm{E}+02$

1. $45 \mathrm{E}+02$

1. $46 \mathrm{E}+02$

$1.46 \mathrm{E}+02$

1. $47 \mathrm{E}+02$

1. $47 \mathrm{E}+02$

1. $48 \mathrm{E}+02$

1. $48 \mathrm{E}+02$

1. $49 \mathrm{E}+02$

1. $49 \mathrm{E}+02$

1. $50 \mathrm{E}+02$

1. $50 \mathrm{E}+02$

1. $51 \mathrm{E}+02$

1. $51 \mathrm{E}+02$

1. $52 \mathrm{E}+02$

1. $52 \mathrm{E}+02$

1. $53 \mathrm{E}+02$

1. $53 \mathrm{E}+02$

1. $54 \mathrm{E}+02$

1. $54 \mathrm{E}+02$

1. $55 \mathrm{E}+02$

1. $55 \mathrm{E}+02$

1. $56 \mathrm{E}+02$

1. $56 \mathrm{E}+02$

1. $57 \mathrm{E}+02$

1. $57 \mathrm{E}+02$

$1.58 \mathrm{E}+02$

1. $58 \mathrm{E}+02$

1. $59 \mathrm{E}+02$

1. $59 \mathrm{E}+02$

1. $60 \mathrm{E}+02$

$1.60 \mathrm{E}+02$

1. $61 \mathrm{E}+02$

1. $61 \mathrm{E}+02$

1. $62 \mathrm{E}+02$

1. $63 \mathrm{E}+02$

$1.63 \mathrm{E}+02$

$1.64 \mathrm{E}+02$

1. $64 \mathrm{E}+02$

1. $65 \mathrm{E}+02$

Dose statistics at graphical times, mrem/yr

\begin{tabular}{|c|c|c|c|c|c|c|c|}
\hline Inimum & Maximum & Mean & Median & $90 \%$ & $95 \%$ & $97.5 \%$ & $9 \%$ \\
\hline+00 & 05 & $5.37 E-08$ & $0.00 E+00$ & $00 E+00$ & $00 E+00$ & 7 & -08 \\
\hline $0 \mathrm{E}+00$ & 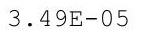 & $8 E-08$ & $0 \mathrm{E}+00$ & $0.00 \mathrm{E}+00$ & $0.00 \mathrm{E}+00$ & 16 & -08 \\
\hline$E+00$ & $97 E-05$ & $E-08$ & $E+00$ & 0 & $0 \mathrm{E}+00$ & 15 & $38 E-07$ \\
\hline$\Xi+00$ & $9 E-05$ & $E-08$ & $\mathrm{E}+00$ & $0 \mathrm{E}+00$ & $0 \mathrm{E}+00$ & 15 & $8 \mathrm{E}-07$ \\
\hline $.00 \mathrm{E}+00$ & $E-05$ & 08 & $0 \mathrm{E}+00$ & $00 \mathrm{E}+00$ & $00 \mathrm{E}+00$ & & $53 E-07$ \\
\hline 0 & $E-05$ & $E-07$ & 0 & 0 & +00 & -13 & $36 \mathrm{E}-07$ \\
\hline $.00 E+00$ & $9 E-05$ & $1 E-07$ & $0 E+00$ & $\mathrm{E}+00$ & $0 \mathrm{E}+00$ & -13 & $E-07$ \\
\hline $.00 E+00$ & $7.14 \mathrm{E}-05$ & 口. & $0.00 \mathrm{E}+00$ & . & $.00 E+00$ & -12 & $.73 E-07$ \\
\hline $.00 \mathrm{E}+00$ & $7.95 \mathrm{E}-05$ & 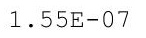 & $0.00 \mathrm{E}+00$ & $0.00 \mathrm{E}+00$ & $00 \mathrm{E}+00$ & -12 & $.35 E-07$ \\
\hline$E+00$ & -05 & $E-07$ & +00 & +00 & $0 E+00$ & $E-11$ & $35 E-07$ \\
\hline $.00 \mathrm{E}+00$ & $9.79 \mathrm{E}-05$ & $1.97 \mathrm{E}-07$ & $0 \mathrm{E}+00$ & & & $.22 \mathrm{E}-11$ & $.18 E-06$ \\
\hline$E+00$ & 4 & $E-07$ & $\mathrm{E}+00$ & $\mathrm{E}+00$ & 0 & -11 & -06 \\
\hline $.00 E+00$ & $1.19 \mathrm{E}-04$ & $9 \mathrm{E}-07$ & $0 E+00$ & $U E+U 0$ & $0 \mathrm{E}+00$ & -10 & $E-06$ \\
\hline $.00 \mathrm{E}+00$ & $\perp \cdot J \perp E-U 4$ & $2.19 \mathrm{E}-01$ & $0.00 \mathrm{E}+00$ & $0.00 \mathrm{E}+00$ & 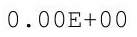 & -10 & $23 E-06$ \\
\hline $.00 E+00$ & $E-04$ & $2 E-07$ & $0 E+00$ & $0.00 \mathrm{E}+00$ & $00 \mathrm{E}+00$ & 10 & $71 E-06$ \\
\hline $.00 \mathrm{E}+00$ & $1.58 \mathrm{E}-04$ & $E-07$ & $0 \mathrm{E}+00$ & 00 & $0 \mathrm{E}+00$ & -10 & -06 \\
\hline $.00 E+00$ & $1.72 \mathrm{E}-04$ & $E-07$ & $0.00 \mathrm{E}+00$ & $0.00 \mathrm{E}+00$ & $00 \mathrm{E}+00$ & $59-09$ & $93 E-06$ \\
\hline$E+00$ & $1.88 \mathrm{E}-04$ & $E-07$ & $0 E+00$ & 0 & $\mathrm{E}+00$ & -09 & $6 E-06$ \\
\hline $.00 \mathrm{E}+00$ & $2.04 \mathrm{E}-04$ & $9 E-07$ & $0 \mathrm{E}+00$ & $0 \mathrm{E}+00$ & $0 \mathrm{E}+00$ & 9 & $8-06$ \\
\hline $.00 E+00$ & $2.22 E-04$ & $1 \mathrm{E}-07$ & $0.00 \mathrm{E}+00$ & -00 & $0 \mathrm{E}+00$ & 09 & $E-06$ \\
\hline $.00 E+00$ & 2.4 & {$[-01$} & $0 \mathrm{E}+00$ & & $0 E+00$ & 08 & $8 E-06$ \\
\hline $.00 \mathrm{E}+00$ & $2.61 \mathrm{E}-04$ & יר & $0.00 \mathrm{E}+00$ & . & $85 E-26$ & -08 & $E-06$ \\
\hline 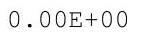 & $2.82 E-04$ & • • • & $0.00 \mathrm{E}+00$ & $0.00 \mathrm{E}+00$ & • & & $.29 E-06$ \\
\hline $.00 E+00$ & $3.04 \mathrm{E}-04$ & $7 E-07$ & $0 \mathrm{E}+00$ & 00 & -22 & .08 & -05 \\
\hline $.00 \mathrm{E}+00$ & $3.28 \mathrm{E}-04$ & $E-07$ & $0 \mathrm{E}+00$ & & $E-20$ & -08 & $22 \mathrm{E}-05$ \\
\hline$E+00$ & $E-04$ & $E-07$ & $0 E+00$ & 00 & 18 & 08 & $9 E-05$ \\
\hline $0 \mathrm{E}+00$ & $9 E-04$ & $E-06$ & $0 \mathrm{E}+00$ & 00 & $3 E-17$ & & $57 E-05$ \\
\hline $.00 \mathrm{E}+00$ & $4.07 E-04$ & $1.14 \mathrm{E}-06$ & $0.00 \mathrm{E}+00$ & . & $E-16$ & $21 \mathrm{E}-07$ & $78 \mathrm{E}-05$ \\
\hline . & $4.37 E-04$ & $1.24 \mathrm{E}-06$ & $0.00 \mathrm{E}+00$ & $0.00 \mathrm{E}+00$ & $99=-15$ & $.61 \mathrm{E}-07$ & $.00 \mathrm{E}-05$ \\
\hline (2) & $4.67 \mathrm{E}-04$ & 西 & $0.00 \mathrm{E}+00$ & & -14 & 7 & $5 E-05$ \\
\hline 00 & 4 & -06 & $\mathrm{E}+00$ & 00 & 4 & 07 & -05 \\
\hline $\mathrm{DE}+00$ & $E-04$ & $E-06$ & $0 \mathrm{E}+00$ & $0 \mathrm{E}+00$ & $E-13$ & 7 & -05 \\
\hline $.00 \mathrm{E}+00$ & $5.70 \mathrm{E}-04$ & $1.74 \mathrm{E}-06$ & $0.00 \mathrm{E}+00$ & $0.00 \mathrm{E}+00$ & $72 E-13$ & 07 & $14 \mathrm{E}-05$ \\
\hline $.00 \mathrm{E}+00$ & $6.07 \mathrm{E}-04$ & $1.89 \mathrm{E}-06$ & $0.00 \mathrm{E}+00$ & $0.00 \mathrm{E}+00$ & $33 E-12$ & $3 E-07$ & $49 E-05$ \\
\hline $.00 \mathrm{E}+00$ & $6.46 \mathrm{E}-04$ & $2.05 E-06$ & & & & & $.86 E-05$ \\
\hline 0 & & & & & & & \\
\hline 00 & trat & 06 & 0 & 0 & 1 & & 0 \\
\hline $.00 \mathrm{E}+00$ & $7.76 \mathrm{E}-04$ & $2.59 \mathrm{E}-06$ & $0.00 \mathrm{E}+00$ & 00 & $5 E-11$ & 06 & -05 \\
\hline $.00 \mathrm{E}+00$ & $8.23 E-04$ & $9 E-06$ & $0.00 \mathrm{E}+00$ & 00 & $9 \mathrm{E}-10$ & -06 & $E-05$ \\
\hline $.00 \mathrm{E}+00$ & $8.72 \mathrm{E}-04$ & $00 \mathrm{E}-06$ & $0.00 \mathrm{E}+00$ & & $9 E-10$ & & $23 E-05$ \\
\hline $.00 E+00$ & $9.23 E-04$ & $3 E-06$ & & & & & $81 E-05$ \\
\hline $5+00$ & 9. & 6 & $0.00 \mathrm{E}+00$ & $0.00 \mathrm{E}+00$ & 9 & 6 & 05 \\
\hline $.00 \mathrm{E}+00$ & 1 & $3.73 E-06$ & 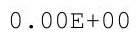 & 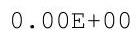 & & 6 & $8.09 \mathrm{E}-05$ \\
\hline 00 & & 6 & 0 & 0 & 9 & 6 & 0 \\
\hline+00 & 1 . & 06 & $0.00 \mathrm{E}+00$ & $0.00 \mathrm{E}$ & 9 & 06 & -05 \\
\hline $.00 E+00$ & $1.21 \mathrm{E}-03$ & $58 E-06$ & $.00 E+00$ & $0.00 \mathrm{E}+00$ & $1.04 \mathrm{E}-08$ & $5.41 \mathrm{E}-06$ & $1.03 E-04$ \\
\hline
\end{tabular}


RESRAD-OFFSITE, Version 2.5

Title : RESRAD-OFFSITE Drinking Water, Plant, Milk, and Meat Pathways for Offsite Reside File : PBA-1_TC99-DOE-5.ROF

Summary of dose at graphical times, reptition 3 (continued)

Time

Years

1. $65 \mathrm{E}+02$

$1.66 \mathrm{E}+02$

1. $66 \mathrm{E}+02$

1. $67 \mathrm{E}+02$

1. $67 \mathrm{E}+02$

1. $68 \mathrm{E}+02$

1. $68 \mathrm{E}+02$

1. $69 \mathrm{E}+02$

1. $69 \mathrm{E}+02$

1. $70 \mathrm{E}+02$

1. $70 \mathrm{E}+02$

1. $71 \mathrm{E}+02$

1. $71 \mathrm{E}+02$

1. $72 \mathrm{E}+02$

1. $72 \mathrm{E}+02$

1. $73 \mathrm{E}+02$

1. $73 \mathrm{E}+02$

1. $74 \mathrm{E}+02$

1. $74 \mathrm{E}+02$

1. $75 \mathrm{E}+02$

1. $75 \mathrm{E}+02$

$1.76 \mathrm{E}+02$

$1.76 \mathrm{E}+02$

$1.77 \mathrm{E}+02$

$1.77 \mathrm{E}+02$

$1.78 \mathrm{E}+02$

$1.78 \mathrm{E}+02$

$1.79 \mathrm{E}+02$

$1.79 \mathrm{E}+02$

1. $80 \mathrm{E}+02$

1. $80 \mathrm{E}+02$

1. $81 \mathrm{E}+02$

1. $81 \mathrm{E}+02$

1. $82 \mathrm{E}+02$

1. $83 \mathrm{E}+02$

1. $83 \mathrm{E}+02$

$1.84 \mathrm{E}+02$

$1.84 \mathrm{E}+02$

1. $85 \mathrm{E}+02$

1. $85 \mathrm{E}+02$

$1.86 \mathrm{E}+02$

$1.86 \mathrm{E}+02$

$1.87 \mathrm{E}+02$

$1.87 \mathrm{E}+02$

$1.88 \mathrm{E}+02$

$1.88 \mathrm{E}+02$
Dose statistics at graphical times, mrem/yr

\begin{tabular}{|c|c|c|c|c|c|c|c|}
\hline $\mathrm{m}$ & $m$ & Mean & ledian & & & & \\
\hline $00 \mathrm{E}+00$ & 03 & -06 & $0.00 \mathrm{E}+00$ & $0.00 \mathrm{E}+00$ & $1.55 \mathrm{E}-08$ & -06 & -04 \\
\hline $.00 \mathrm{E}+00$ & -03 & $E-06$ & & $0.00 \mathrm{E}+00$ & -08 & -06 & -0 \\
\hline $.00 \mathrm{E}+00$ & $1.42 \mathrm{E}-03$ & $9 E-06$ & $0 \mathrm{E}+00$ & $00 \mathrm{E}+00$ & $29 E-08$ & $7.85 \mathrm{E}-06$ & $.30 E-04$ \\
\hline $.00 \mathrm{E}+00$ & $49 \mathrm{E}-03$ & $6 \mathrm{E}-06$ & $.00 \mathrm{E}+00$ & $00 \mathrm{E}+00$ & $74 \mathrm{E}-08$ & -06 & $E-04$ \\
\hline $00 E+00$ & $57 \mathrm{~F}-\mathrm{CH}$ & $6 F-06$ & $\cap \cap F+\cap 0$ & $\cap \cap F+0 \cap$ & $62 \mathrm{~F}-08$ & -06 & -04 \\
\hline 0 & 3 & 06 & & & 8 & 5 & 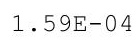 \\
\hline 00 & $E-03$ & -06 & & & 7 & 5 & -04 \\
\hline $.00 \mathrm{E}+00$ & & -06 & & & 7 & & $.78 \mathrm{E}-04$ \\
\hline $.00 E+00$ & -03 & $E-06$ & 00 & +00 & $15 E-07$ & -05 & -04 \\
\hline $0 \mathrm{E}+00$ & $00 E-03$ & $E-06$ & & & 07 & -05 & -04 \\
\hline $0 E+00$ & $E-03$ & $6 E-06$ & & $0 \mathrm{E}+00$ & 7 & & $2.14 \mathrm{E}-04$ \\
\hline+00 & 3 & & & & & & -04 \\
\hline $2+00$ & $F-03$ & $3 E-05$ & & $E+00$ & -07 & -05 & -04 \\
\hline $.00 \mathrm{E}+00$ & $2.40 E-03$ & $.09 E-05$ & $0.00 \mathrm{E}+00$ & $2.22 E-26$ & $.14 \mathrm{E}-07$ & $2.57 \mathrm{E}-05$ & $.60 \mathrm{E}-04$ \\
\hline $.00 E+00$ & $.51 \mathrm{E}-03$ & $.15 E-05$ & $0.00 \mathrm{E}+00$ & 8. $67 \mathrm{E}-24$ & $.75 \mathrm{E}-07$ & $.85 E-05$ & $.77 E-04$ \\
\hline 00 & -03 & $22 \mathrm{E}-05$ & & -22 & & -05 & -04 \\
\hline S & J & 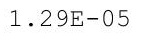 & 0 & 0 & 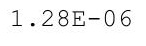 & & -04 \\
\hline $\mathrm{E}+00$ & $2.86 E-03$ & & & & & & 04 \\
\hline $.00 \mathrm{E}+00$ & $99 \mathrm{9}-03$ & $3 E-05$ & & $9 E-17$ & $83 E-06$ & -05 & -04 \\
\hline $.00 E+00$ & $.12 E-03$ & $1.51 \mathrm{E}-05$ & $0.00 \mathrm{E}+00$ & $.18 \mathrm{E}-16$ & $.16 \mathrm{E}-06$ & $E-05$ & $75 E-04$ \\
\hline $.00 E+00$ & $3.25 E-03$ & $1.59 \mathrm{E}-05$ & $0.00 \mathrm{E}+00$ & $07 E-15$ & $54 \mathrm{E}-06$ & $E-05$ & $98 E-04$ \\
\hline & & & & & & & \\
\hline & & & & & 0 & & -04 \\
\hline & 3 & $6 E-05$ & & & & J & -04 \\
\hline $00 \mathrm{E}+00$ & 3 & $.96 E-05$ & & 3 & 0 & 5 & 04 \\
\hline O & $98 \mathrm{~F}-03$ & $2.06 \mathrm{E}-05$ & $0.00 \mathrm{E}+00$ & $2.41 \mathrm{E}-12$ & $06 E-06$ & $3 E-05$ & $21 F-04$ \\
\hline $.00 \mathrm{E}+00$ & $15 \mathrm{~F}-03$ & $.16 E-05$ & & $77 E-12$ & $97 E-06$ & -05 & $9-04+2-2$ \\
\hline & & & & & & -04 & -04 \\
\hline & & & & & & & -04 \\
\hline & & & & 11 & & & -04 \\
\hline $.00 E+00$ & $4.84 \mathrm{E}-03$ & $2.63 E-05$ & $0.00 \mathrm{E}+00$ & $1.90 \mathrm{E}-10$ & $1 \cdot \angle 25-00$ & $1.27 \mathrm{E}-04$ & $.49 E-04$ \\
\hline . & $5.03 E-03$ & $2.75 E-05$ & & $74 \mathrm{E}-10$ & 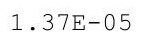 & 1. $35 \mathrm{E}-04$ & $82 \mathrm{E}-0$ \\
\hline $.00 \mathrm{E}+\mathrm{C}$ & $22 \mathrm{E}-0$ & $2.89 E-05$ & $\cap \cap \cap F+\cap 0$ & & & & 4 \\
\hline & & & & & & & 04 \\
\hline & $62 E-03$ & $7 E-05$ & & $E-09$ & $92 E-05$ & $E-04$ & -04 \\
\hline & & 5 & 0 & 09 & 5 & 04 & -04 \\
\hline $.00 E+00$ & $6.04 \mathrm{E}-03$ & $.47 E-05$ & $.00 E+00$ & -09 & $37 E-05$ & $1.91 \mathrm{E}-04$ & $68 E-04$ \\
\hline (.0 & & & & & & & $\begin{array}{ll}* \\
*\end{array}$ \\
\hline ( & 3 & 5 & & & & 4 & ( \\
\hline מ & & & & & & & $-x^{2}+2$ \\
\hline ג תחמת & & & & $99 E-08$ & 05 & -04 & 03 \\
\hline $0 E+00$ & $.21 E-03$ & $4.32 E-05$ & & $4.35 E-08$ & $7 E-05$ & -04 & 1.1 \\
\hline & 03 & & & & & & 2. \\
\hline & & & & & & & $+\cdot 2<$ \\
\hline & & & & 7 & & -04 & $\pm \cdot 21000$ \\
\hline $\mathrm{E}+00$ & $26 E-03$ & $E-05$ & $O E+00$ & $E-07$ & -05 & -04 & 00 \\
\hline
\end{tabular}


RESRAD-OFFSITE, Version 2.5

$\mathrm{T}^{1 / 2}$ Limit $=180$ days

Title : RESRAD-OFFSITE Drinking Water, Plant, Milk, and Meat Pathways for Offsite Reside File : PBA-1_TC99-DOE-5.ROF

Summary of dose at graphical times, reptition 3 (continued)

Time

Years

$1.89 \mathrm{E}+02$

1. $89 \mathrm{E}+02$

1. $90 \mathrm{E}+02$

1. $90 \mathrm{E}+02$

1. $91 \mathrm{E}+02$

1. $91 \mathrm{E}+02$

1. $92 \mathrm{E}+02$

1. $92 \mathrm{E}+02$

1. $93 \mathrm{E}+02$

1. $93 \mathrm{E}+02$

$1.94 \mathrm{E}+02$

1. $94 \mathrm{E}+02$

1. $95 \mathrm{E}+02$

1. $95 \mathrm{E}+02$

1. $96 \mathrm{E}+02$

1. $96 \mathrm{E}+02$

$1.97 \mathrm{E}+02$

1. $97 \mathrm{E}+02$

1. $98 \mathrm{E}+02$

1. $98 \mathrm{E}+02$

1. $99 \mathrm{E}+02$

1. $99 \mathrm{E}+02$

$2.00 \mathrm{E}+02$

$2.00 \mathrm{E}+02$

$2.01 \mathrm{E}+02$

$2.01 \mathrm{E}+02$

$2.02 \mathrm{E}+02$

$2.03 \mathrm{E}+02$

$2.03 E+02$

$2.04 \mathrm{E}+02$

$2.04 \mathrm{E}+02$

$2.05 \mathrm{E}+02$

$2.05 \mathrm{E}+02$

$2.06 \mathrm{E}+02$

$2.06 \mathrm{E}+02$

$2.07 \mathrm{E}+02$

$2.07 \mathrm{E}+02$

$2.08 \mathrm{E}+02$

$2.08 \mathrm{E}+02$

2. $09 \mathrm{E}+02$

$2.09 \mathrm{E}+02$

$2.10 \mathrm{E}+02$

$2.10 \mathrm{E}+02$

$2.11 \mathrm{E}+02$

$2.11 E+02$

$2.12 \mathrm{E}+02$
Dose statistics at graphical times, mrem/yr

\begin{tabular}{|c|c|c|c|c|c|c|c|}
\hline inimum & Iaximum & Mean & ledian & $90 \%$ & $95 \%$ & $97.5 \%$ & $\%$ \\
\hline $0 \mathrm{E}+00$ & $8.54 \mathrm{E}-03$ & $5.34 \mathrm{E}-05$ & $0.00 \mathrm{E}+00$ & $96 \mathrm{E}-07$ & $5.49 E-05$ & $3.48 E-04$ & $1.40 \mathrm{E}-03$ \\
\hline$E+00$ & $E-03$ & $6 E-05$ & $0 E+00$ & $55 E-07$ & $01 E-05$ & $.70 \mathrm{E}-04$ & $.46 E-03$ \\
\hline$E+00$ & $9.13 \mathrm{E}-03$ & $E-05$ & 00 & $27 E-07$ & $57 \mathrm{E}$ & -04 & $53 E-03$ \\
\hline$E+00$ & $E-03$ & & & & 5 & 04 & 03 \\
\hline 00 & -03 & & & 7 & 5 & -04 & $66 E-03$ \\
\hline $00 \mathrm{E}+00$ & $.01 E-02$ & 5 & $.00 E+00$ & 07 & 5 & -04 & 03 \\
\hline $0 E+00$ & $1.04 \mathrm{E}-02$ & $80 \mathrm{E}-05$ & $.00 \mathrm{E}+00$ & $45 E-07$ & 5 & -04 & -03 \\
\hline $.00 E+00$ & $1.07 E-02$ & . & $.00 E+00$ & $01 E-07$ & 年 & -04 & $.87 E-03$ \\
\hline$E+00$ & $E-02$ & 5 & +00 & 6 & 4 & -04 & $9 \mathrm{E}-03$ \\
\hline $00 \mathrm{E}+00$ & $E-02$ & $65 E-05$ & & $38 E-06$ & $11 \mathrm{E}-$ & -04 & $1 E-03$ \\
\hline $00 \mathrm{E}+00$ & $1.18 \mathrm{E}-02$ & $.95 E-05$ & & $.70 \mathrm{E}-06$ & $.18 E-04$ & $E-04$ & $9 \mathrm{E}-03$ \\
\hline$E+00$ & -02 & & $\mathrm{E}+00$ & 6 & 20 & -04 & -03 \\
\hline $.00 \mathrm{E}+00$ & $1.25 \mathrm{E}-02$ & $.57 \mathrm{E}-05$ & $.00 \mathrm{E}+00$ & $.40 E-00$ & $.33 E-04$ & $E-04$ & $E-03$ \\
\hline $.00 E+00$ & $1.29 \mathrm{E}-02$ & $.90 E-05$ & $.00 E+00$ & $80 E-06$ & IL & -04 & $.33 E-03$ \\
\hline $0 \mathrm{E}+00$ & $1.33 E-02$ & 5 & $\mathrm{E}+00$ & 6 & 年 & -04 & 03 \\
\hline $.00 \mathrm{E}+00$ & $1.37 \mathrm{E}-02$ & $.59 \mathrm{E}-05$ & $.00 \mathrm{E}+00$ & $.75 E-06$ & . & -04 & -03 \\
\hline $.00 \mathrm{E}+00$ & $1.41 E-02$ & $.95 E-05$ & $.00 E+00$ & $31 E-06$ & $.66 \mathrm{E}-\mathrm{C}$ & $.90 E-04$ & $.59 E-03$ \\
\hline$E+00$ & $5 E-02$ & $E-04$ & $\mathrm{E}+00$ & 6 & 4 & $E-04$ & $58 \mathrm{E}-03$ \\
\hline $.00 \mathrm{E}+00$ & $1.50 \mathrm{E}-02$ & $.07 E-04$ & $.00 \mathrm{E}+00$ & 的 & OJE- & -04 & $7 E-03$ \\
\hline $.00 \mathrm{E}+00$ & $1.54 \mathrm{E}-02$ & $.11 \mathrm{E}-04$ & $.00 E+00$ & $72 E-06$ & $96 \pm-04$ & -04 & $87 E-03$ \\
\hline $0 E+00$ & $1.58 \mathrm{E}-02$ & $.15 E-04$ & $E+00$ & ( & & -04 & $7 E-03$ \\
\hline $.00 \mathrm{E}+00$ & $1.63 \mathrm{E}-02$ & $.19 \mathrm{E}-04$ & $.00 \mathrm{E}+00$ & tor & E & -03 & -03 \\
\hline $0 \mathrm{E}+00$ & $.68 \mathrm{E}-02$ & $.23 E-04$ & $00 \mathrm{E}+00$ & $35 E-06$ & ( & $E-03$ & $-7 E-03$ \\
\hline$E+00$ & $1.74 \mathrm{E}-02$ & $.28 \mathrm{E}-04$ & $\mathrm{E}+00$ & ( 50 & $38 \mathrm{E}-$ & $E-03$ & $28 E-03$ \\
\hline+00 & $E-02$ & $E-04$ & 00 & 5 & 2 & -03 & $9 E-03$ \\
\hline $\mathrm{DE}+00$ & $E-02$ & $E-04$ & $\mathrm{E}+00$ & $5 \mathrm{E}$ & 4 & 03 & $0 E-03$ \\
\hline $0 \mathrm{E}+00$ & $E-02$ & $.42 \mathrm{E}-04$ & $0 \mathrm{E}+00$ & $53 \mathrm{E}-$ & & $26 \mathrm{E}-03$ & $51 E-03$ \\
\hline $.00 \mathrm{E}+00$ & $1.96 \mathrm{E}-02$ & $1.46 \mathrm{E}-04$ & $.00 \mathrm{E}+00$ & $74 E-05$ & $.95 E-0$ & $.32 E-03$ & $.73 E-03$ \\
\hline $0 \mathrm{E}+00$ & $02 \mathrm{E}-02$ & $2 \mathrm{E}-$ & $\mathrm{E}+$ & $.94 \mathrm{E}-05$ & (2) & $.38 \mathrm{E}-03$ & $.85 E-03$ \\
\hline $.00 \mathrm{E}+00$ & $2.09 E-02$ & 土. & & 至 & 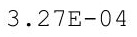 & -03 & $7 E-0$ \\
\hline 00 & 02 & 4 & $E+00$ & 5 & 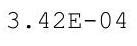 & 03 & -03 \\
\hline $\mathrm{E}+00$ & $E-02$ & $7 E-04$ & $E+00$ & 5 & $8 \mathrm{~F} \cdot \mathrm{r}$ & -03 & $3 E-03$ \\
\hline $.00 \mathrm{E}+00$ & $2.28 \mathrm{E}-02$ & $1.73 E-04$ & $0.00 \mathrm{E}+00$ & $2.79 \mathrm{E}-05$ & $3.16 \mathrm{E}-$ & $E-03$ & $36 E-03$ \\
\hline $.00 \mathrm{E}+00$ & $2.35 E-02$ & $1.79 \mathrm{E}-04$ & $0.00 \mathrm{E}+00$ & $.04 E-05$ & $.98 E-04$ & $.68 \mathrm{E}-03$ & $.50 \mathrm{E}-03$ \\
\hline SETU & $.41 E-02$ & $.85 E-04$ & & 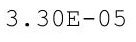 & & $.75 E-03$ & $.64 \mathrm{E}-03$ \\
\hline & 2.104 & & & & & & \\
\hline & 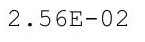 & & & & & -03 & \\
\hline 00 & -05 & 4 & $\Xi+00$ & 5 & 4 & 3 & 03 \\
\hline & & & & 05 & & 03 & 03 \\
\hline $00 \mathrm{E}+00$ & $E-02$ & 4 & & 5 & 4 & 03 & $38 E-03$ \\
\hline $\mathrm{E}+00$ & $2.86 \mathrm{E}-02$ & $23 E-04$ & & & & & $54 E-03$ \\
\hline $\mathrm{E}+00$ & $2.94 E-02$ & $.30 E-04$ & $.00 E+00$ & $96 E-05$ & & & $.70 E-03$ \\
\hline $.00 E+00$ & $3.02 E-02$ & 4 & & & & & 3 \\
\hline $0.00 \mathrm{E}+00$ & $3.10 \mathrm{E}-02$ & 4 & P & 5 & 4 & 3 & 3 \\
\hline$E+00$ & 3.1 & 2 & +00 & 5 & 4 & 03 & 03 \\
\hline $.00 E+00$ & $.27 E-02$ & $.60 E-04$ & $.00 \mathrm{E}+00$ & $.23 E-05$ & $.91 E-04$ & $2.55 E-03$ & $6.39 E-03$ \\
\hline
\end{tabular}


RESRAD-OFFSITE, Version 2.5

Title : RESRAD-OFFSITE Drinking Water, Plant, Milk, and Meat Pathways for Offsite Reside File : PBA-1_TC99-DOE-5.ROF

Summary of dose at graphical times, reptition 3 (continued)

Time

Years

$2.12 \mathrm{E}+02$

$2.13 \mathrm{E}+02$

$2.13 \mathrm{E}+02$

$2.14 \mathrm{E}+02$

$2.14 \mathrm{E}+02$

$2.15 \mathrm{E}+02$

$2.15 \mathrm{E}+02$

$2.16 \mathrm{E}+02$

$2.16 \mathrm{E}+02$

$2.17 \mathrm{E}+02$

$2.17 \mathrm{E}+02$

$2.18 \mathrm{E}+02$

$2.18 \mathrm{E}+02$

$2.19 \mathrm{E}+02$

$2.19 \mathrm{E}+02$

$2.20 \mathrm{E}+02$

$2.20 \mathrm{E}+02$

$2.21 \mathrm{E}+02$

$2.21 \mathrm{E}+02$

2. $22 \mathrm{E}+02$

$2.23 \mathrm{E}+02$

$2.23 \mathrm{E}+02$

$2.24 \mathrm{E}+02$

$2.24 \mathrm{E}+02$

$2.25 \mathrm{E}+02$

$2.25 \mathrm{E}+02$

$2.26 \mathrm{E}+02$

$2.26 \mathrm{E}+02$

$2.27 \mathrm{E}+02$

$2.27 \mathrm{E}+02$

$2.28 \mathrm{E}+02$

$2.28 \mathrm{E}+02$

$2.29 \mathrm{E}+02$

$2.29 \mathrm{E}+02$

$2.30 \mathrm{E}+02$

2. $30 \mathrm{E}+02$

$2.31 E+02$

$2.31 E+02$

2. $32 \mathrm{E}+02$

2. $32 \mathrm{E}+02$

$2.33 \mathrm{E}+02$

2. $33 \mathrm{E}+02$

$2.34 \mathrm{E}+02$

$2.34 \mathrm{E}+02$

2. $35 \mathrm{E}+02$

$2.35 \mathrm{E}+02$
Dose statistics at graphical times, mrem/yr

\begin{tabular}{|c|c|c|c|c|c|c|c|}
\hline inimum & aximum & Mean & ledian & $90 \%$ & $5 \%$ & $97.5 \%$ & $\%$ \\
\hline+00 & $3.36 \mathrm{E}-02$ & $2.68 E-04$ & $0.00 \mathrm{E}+00$ & $7 E-05$ & $7.25 E-04$ & $53 E-03$ & $E-0$ \\
\hline$E+00$ & -02 & 4 & $\mathrm{E}+00$ & 5 & 04 & 33 & -03 \\
\hline-00 & $E-02$ & -04 & 00 & $6 E-05$ & 04 & -03 & -03 \\
\hline+00 & 02 & 4 & & & & & -03 \\
\hline$E+00$ & -02 & 4 & & 4 & 04 & 03 & $33 E-03$ \\
\hline$E+00$ & -02 & $E-04$ & $\mathrm{E}+00$ & $1.17 \mathrm{E}-04$ & $5-4$ & -03 & 03 \\
\hline+00 & -02 & 4 & 0 & $3 F-\delta$ & 4 & -03 & 03 \\
\hline $.00 E+00$ & $4.03 E-02$ & $3.29 \mathrm{E}-04$ & & $1.29 \mathrm{E}-04$ & t & -03 & $95 E-03$ \\
\hline+00 & -02 & $E-04$ & +00 & $.37 E-04$ & 04 & -03 & -03 \\
\hline $.00 \mathrm{E}+00$ & $4 \mathrm{E}-02$ & $8 E-04$ & $\mathrm{E}+00$ & $.46 E-04$ & 03 & -03 & $38 E-03$ \\
\hline+00 & -02 & $E-04$ & & 4 & & 03 & $E-03$ \\
\hline$E+00$ & -02 & $E-04$ & +00 & & & & $E-03$ \\
\hline $.00 \mathrm{E}+00$ & $4.56 \mathrm{E}-02$ & $E-04$ & $\mathrm{E}+00$ & 04 & 3 & -03 & -0 \\
\hline$E+00$ & -02 & $3.89 \mathrm{E}-04$ & $0.00 \mathrm{E}+00$ & $1.85 \mathrm{E}-04$ & S & -03 & $30 E-03$ \\
\hline$E+00$ & 02 & 04 & $E+00$ & 4 & 03 & -03 & -03 \\
\hline $.00 \mathrm{E}+00$ & $4.91 \mathrm{E}-02$ & -04 & $0.00 \mathrm{E}+00$ & 04 & 03 & -03 & -03 \\
\hline $.00 \mathrm{E}+00$ & $3 E-02$ & $3 E-04$ & $\mathrm{OE}+00$ & $2.14 \mathrm{E}-04$ & $30 E-03$ & -03 & $.00 \mathrm{E}-02$ \\
\hline $.00 E+00$ & $5 E-02$ & $4 E-04$ & $0 E+00$ & $3 E-04$ & $35 E-03$ & $E-03$ & $E-02$ \\
\hline $\mathrm{E}+00$ & -02 & -04 & -00 & 04 & & -03 & $-0<2+a-a$ \\
\hline $.00 \mathrm{E}+00$ & -02 & $4.58 E-04$ & $0.00 \mathrm{E}+00$ & 4 & 3 & -03 & $E-02$ \\
\hline $.00 \mathrm{E}+00$ & $5.52 \mathrm{E}-02$ & $E-04$ & & & & J & -02 \\
\hline $.00 \mathrm{E}+00$ & $5.65 \mathrm{E}-02$ & $4.83 E-04$ & $0.00 \mathrm{E}+00$ & $2.69 \mathrm{E}-$ & . & S & -02 \\
\hline $\mathrm{E}+00$ & 2 & 年 & $0.00 \mathrm{E}+00$ & 4 & 然 & $.00 E-03$ & $.16 \mathrm{E}-02$ \\
\hline $.00 \mathrm{E}+00$ & $.92 \mathrm{E}-02$ & $5.09 \mathrm{E}-04$ & $0.00 \mathrm{E}+00$ & $94 \mathrm{E}-04$ & $650-0$ & $4 E-03$ & $19 E-02$ \\
\hline+00 & $6 \mathrm{E}-02$ & $23 E-04$ & & $6 E-04$ & 03 & $E-03$ & -02 \\
\hline+00 & $E-02$ & $E-04$ & 0 & & & & 02 \\
\hline $.00 \mathrm{E}+00$ & -02 & $E-04$ & $\mathrm{OE}+00$ & 4 & 3 & -03 & -02 \\
\hline $.00 E+00$ & $6.48 E-02$ & $.65 E-04$ & $0.00 \mathrm{E}+00$ & $52 E-04$ & \% $2-03$ & $72 E-03$ & $.30 E-02$ \\
\hline $0 E+00$ & 2 & 我 & $00 E+00$ & 4 & te & -03 & -02 \\
\hline 0 & 2 & - & & - & - & 3 & - \\
\hline$F+00$ & $92 E-02$ & $.09 E-04$ & $\mathrm{E}+00$ & $4 E-04$ & & 3 & $39 E-02$ \\
\hline+00 & 2 & $E-04$ & & & & 3 & 02 \\
\hline & -02 & -04 & & & 03 & 03 & -02 \\
\hline $.00 E+00$ & $7.39 E-02$ & $6.56 E-04$ & $0.00 \mathrm{E}+00$ & $4.46 \mathrm{E}-04$ & $2.30 E-03$ & $55 E-03$ & $.48 E-02$ \\
\hline . & $7.55 E-02$ & $6.73 E-04$ & & $4.68 E-04$ & & & . $325-42$ \\
\hline 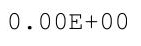 & & & & & & & \\
\hline 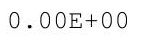 & 2 & & & & & & 02 \\
\hline 0 & & & & & & & 02 \\
\hline$E+00$ & & & & & -03 & -03 & -02 \\
\hline $.00 \mathrm{E}+00$ & $8.39 \mathrm{E}-02$ & $59 E-04$ & 0 & 4 & 3 & 3 & $59 \mathrm{E}-02$ \\
\hline$E+00$ & & $7 E-04$ & $.00 \mathrm{E}+$ & 4 & & & $73 E-02$ \\
\hline$E+00$ & 02 & $E-04$ & $00 \mathrm{E}+00$ & 4 & 3 & & $10 \pm-02$ \\
\hline 政0 & 8 & 4 & $0.00 \mathrm{E}+\mathrm{C}$ & 4 & . & 03 & 02 \\
\hline $0.00 \mathrm{E}+00$ & y & & 我 & 6.60 & 3.0 & 33 & 02 \\
\hline $00 \mathrm{E}+00$ & $9.30 \mathrm{E}-02$ & $4 E-04$ & $0.00 \mathrm{E}+00$ & $6.84 \mathrm{E}$ & 3.1 & $E-03$ & $.88 \mathrm{E}-02$ \\
\hline $.00 E+00$ & $9.48 E-02$ & $8.74 \mathrm{E}-04$ & $0.00 \mathrm{E}+00$ & $7.07 E-04$ & $3.21 E-03$ & $8.74 E-03$ & 1. $92 \mathrm{E}-02$ \\
\hline
\end{tabular}


RESRAD-OFFSITE, Version 2.5

Title : RESRAD-OFFSITE Drinking Water, Plant, Milk, and Meat Pathways for Offsite Reside File : PBA-1_TC99-DOE-5.ROF

Summary of dose at graphical times, reptition 3 (continued)

Time

Years

$2.36 \mathrm{E}+02$

$2.36 \mathrm{E}+02$

$2.37 \mathrm{E}+02$

2. $37 \mathrm{E}+02$

2. $38 \mathrm{E}+02$

$2.38 \mathrm{E}+02$

$2.39 \mathrm{E}+02$

2. $39 \mathrm{E}+02$

2. $40 \mathrm{E}+02$

2. $40 \mathrm{E}+02$

2. $41 \mathrm{E}+02$

2. $41 \mathrm{E}+02$

2. $42 \mathrm{E}+02$

2. $43 \mathrm{E}+02$

$2.43 \mathrm{E}+02$

2. $44 \mathrm{E}+02$

2. $44 \mathrm{E}+02$

$2.45 \mathrm{E}+02$

2. $45 \mathrm{E}+02$

$2.46 \mathrm{E}+02$

$2.46 \mathrm{E}+02$

$2.47 \mathrm{E}+02$

2. $47 \mathrm{E}+02$

$2.48 \mathrm{E}+02$

$2.48 \mathrm{E}+02$

2. $49 \mathrm{E}+02$

2. $49 \mathrm{E}+02$

$2.50 \mathrm{E}+02$

2. $50 \mathrm{E}+02$

$2.51 \mathrm{E}+02$

2. $51 \mathrm{E}+02$

2. $52 \mathrm{E}+02$

$2.52 \mathrm{E}+02$

$2.53 \mathrm{E}+02$

$2.53 \mathrm{E}+02$

2. $54 \mathrm{E}+02$

$2.54 \mathrm{E}+02$

$2.55 \mathrm{E}+02$

$2.55 \mathrm{E}+02$

$2.56 \mathrm{E}+02$

$2.56 \mathrm{E}+02$

$2.57 \mathrm{E}+02$

$2.57 \mathrm{E}+02$

$2.58 \mathrm{E}+02$

$2.58 \mathrm{E}+02$

$2.59 \mathrm{E}+02$
Dose statistics at graphical times, mrem/yr

\begin{tabular}{|c|c|c|c|c|c|c|c|}
\hline Inimum & Maximum & Mean & Median & $90 \%$ & $95 \%$ & $97.5 \%$ & \%응 \\
\hline 00 & $8 E-02$ & $5 E-04$ & $0.00 E+00$ & 04 & 3 & 3 & 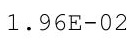 \\
\hline $0 \mathrm{E}+00$ & $87 E-02$ & $5 E-04$ & $0.00 \mathrm{E}+00$ & 04 & $3.39 \mathrm{E}-03$ & 03 & -02 \\
\hline$E+00$ & $1 \mathrm{E}-01$ & $7 E-04$ & $E+00$ & 04 & $9 E-03$ & 03 & $5 E-02$ \\
\hline+00 & $3 E-01$ & $8 E-04$ & $\mathrm{E}+00$ & $3 E-04$ & $0 \mathrm{E}-03$ & 03 & $E-02$ \\
\hline $.00 \mathrm{E}+00$ & 01 & 04 & $0 \mathrm{E}+00$ & 4 & 3 & 03 & $13 E-02$ \\
\hline 0 & $E-01$ & -03 & & -04 & -03 & 03 & $18 \mathrm{E}-02$ \\
\hline $.00 E+00$ & $9 E-01$ & $2 E-03$ & $0 E+00$ & -04 & -03 & -02 & $E-02$ \\
\hline $.00 E+00$ & $1.11 \mathrm{E}-01$ & . & $0.00 \mathrm{E}+00$ & $.21 \mathrm{~L}-4$ & $03 E-03$ & -02 & $.27 E-02$ \\
\hline $.00 \mathrm{E}+00$ & $1.13 E-01$ & $.07 E-03$ & $0.00 \mathrm{E}+00$ & $9.61 \mathrm{E}-04$ & $15 E-03$ & -02 & $31 E-02$ \\
\hline$E+00$ & -01 & $E-03$ & +00 & 04 & $27 E-03$ & 02 & $36 \mathrm{E}-02$ \\
\hline $.00 \mathrm{E}+00$ & $1.17 \mathrm{E}-01$ & $2 E-03$ & & & $39 E-03$ & $.12 \mathrm{E}-02$ & $41 E-02$ \\
\hline$E+00$ & $E-01$ & $\Xi-03$ & $\mathrm{E}+00$ & 3 & 3 & & -02 \\
\hline $.00 E+00$ & $1.22 \mathrm{E}-01$ & $7 E-03$ & $0 E+00$ & -03 & $5 E-03$ & -02 & $50 \mathrm{E}-02$ \\
\hline $.00 \mathrm{E}+00$ & $1.24 \mathrm{E}-01$ & $1.20 \mathrm{~L}-03$ & $0.00 \mathrm{E}+00$ & $1.13 E-03$ & S & -02 & $55 E-02$ \\
\hline $\mathrm{DE}+00$ & $E-01$ & $1.22 \mathrm{E}-03$ & $0 \mathrm{E}+00$ & 03 & 03 & 02 & $60 \mathrm{E}-02$ \\
\hline $.00 \mathrm{E}+00$ & -01 & $5 E-03$ & -00 & 3 & J & 02 & -02 \\
\hline $.00 E+00$ & $1.31 E-01$ & $E-03$ & & $1.24 \mathrm{E}-03$ & $17 E-03$ & $.29 E-02$ & $.70 E-02$ \\
\hline $\mathrm{OE}+00$ & $.34 \mathrm{E}-01$ & $1.30 \mathrm{E}-03$ & $.00 \mathrm{E}+00$ & $8 E-03$ & 03 & -02 & $75 E-02$ \\
\hline $\mathrm{E}+00$ & -01 & -03 & -00 & 03 & 3 & 02 & -02 \\
\hline $.00 E+00$ & 1.39E-01 & $1.36 \mathrm{E}-03$ & $0.00 \mathrm{E}+00$ & $1.36 \mathrm{E}-03$ & 3 & 02 & $E-02$ \\
\hline $.00 E+00$ & $E-01$ & $9 E-03$ & $0.00 \mathrm{E}+00$ & & 正 & 02 & $E-02$ \\
\hline $.00 \mathrm{E}+00$ & $1.44 \mathrm{E}-01$ & 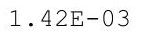 & $0.00 \mathrm{E}+00$ & -03 & 列 & -02 & $97 E-02$ \\
\hline 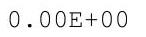 & $1.46 \mathrm{E}-01$ & 土.尹U & & $1.49 \mathrm{E}-03$ & • & $.47 \mathrm{E}-02$ & $.03 E-02$ \\
\hline $.00 E+00$ & 1. $49 \mathrm{E}-01$ & 1. $48 \mathrm{E}-03$ & 0 & $3 E-03$ & 03 & -02 & -02 \\
\hline$E+00$ & 1. $51 \mathrm{E}-01$ & $E-03$ & $\mathrm{OE}+00$ & -03 & 03 & 02 & $E-02$ \\
\hline $\mathrm{E}+00$ & $E-01$ & $E-03$ & -00 & $1 E-03$ & 3 & 02 & $E-02$ \\
\hline$D E+00$ & $1.57 \mathrm{E}-01$ & $E-03$ & $0 \mathrm{E}+00$ & 03 & 3 & & $26 \mathrm{E}-02$ \\
\hline $.00 \mathrm{E}+00$ & $1.59 \mathrm{E}-01$ & $1.60 \mathrm{E}-03$ & $0.00 \mathrm{E}+00$ & $1.70 \mathrm{E}-03$ & $61 E-03$ & $.63 E-02$ & $32 E-02$ \\
\hline . & 1. $62 \mathrm{E}-01$ & 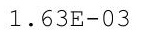 & $0.00 \mathrm{E}+00$ & $1.74 \mathrm{E}-03$ & $10 \mathrm{E}-03$ & $.66 \mathrm{E}-02$ & $.38 \mathrm{E}-02$ \\
\hline (2) & 1. $65 \mathrm{E}-01$ & 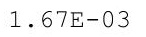 & $1 \mathrm{I}-20$ & 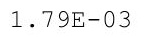 & כ & -02 & $44 E-02$ \\
\hline 00 & 01 & 3 & 24 & 3 & 3 & 2 & -02 \\
\hline$E+00$ & $E-01$ & $E-03$ & $E-22$ & 3 & 3 & 02 & -02 \\
\hline $.00 \mathrm{E}+00$ & $1.74 \mathrm{E}-01$ & $1.77 \mathrm{E}-03$ & $2.52 \mathrm{E}-20$ & $1.93 \mathrm{E}$ & 3 & -02 & $64 \mathrm{E}-02$ \\
\hline $.00 \mathrm{E}+00$ & $1.76 \mathrm{E}-01$ & $1.80 \mathrm{E}-03$ & $5.43 E-19$ & $1.98 \mathrm{E}-03$ & $53 E-03$ & $3 E-02$ & $71 \mathrm{E}-02$ \\
\hline • & $1.79 E-01$ & $1.04 \mathrm{E}-03$ & & & & & $.78 \mathrm{E}-02$ \\
\hline 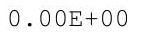 & 1.8 & & & & & & \\
\hline 0 & & & & & & & \\
\hline 0 & 1 & $E-03$ & 15 & 3 & 3 & 2 & -02 \\
\hline $\mathrm{E}+00$ & 1. $91 \mathrm{E}-01$ & $9 E-03$ & $3 E-14$ & $7 E-03$ & 3 & 02 & $8 E-02$ \\
\hline $.00 E+00$ & 1.9 & 3 & 13 & & 3 & & -02 \\
\hline 0 & & & & & 3 & & $24 E-02$ \\
\hline $.00 \mathrm{E}+00$ & $2.01 E-01$ & & $.21 E-12$ & $2.46 E-03$ & $03 E-03$ & & $.32 E-02$ \\
\hline & & & 2 & & & & \\
\hline & & & & S & 3 & 2 & 02 \\
\hline 0 & 2.1 & 2. & 2 & 03 & 3 & 02 & -02 \\
\hline $.00 \mathrm{E}+00$ & $.14 \mathrm{E}-01$ & $2.27 E-03$ & $.74 E-11$ & $.74 E-03$ & $9.83 E-03$ & $2.28 \mathrm{E}-02$ & $4.65 E-02$ \\
\hline
\end{tabular}


RESRAD-OFFSITE, Version 2.5

$\mathrm{T}^{1 / 2}$ Limit $=180$ days

Title : RESRAD-OFFSITE Drinking Water, Plant, Milk, and Meat Pathways for Offsite Reside File : PBA-1_TC99-DOE-5.ROF

Summary of dose at graphical times, reptition 3 (continued)

Time

Years

$2.59 \mathrm{E}+02$

$2.60 \mathrm{E}+02$

$2.60 \mathrm{E}+02$

$2.61 \mathrm{E}+02$

$2.61 \mathrm{E}+02$

$2.62 \mathrm{E}+02$

$2.63 \mathrm{E}+02$

$2.63 \mathrm{E}+02$

$2.64 \mathrm{E}+02$

$2.64 \mathrm{E}+02$

$2.65 \mathrm{E}+02$

$2.65 \mathrm{E}+02$

$2.66 \mathrm{E}+02$

$2.66 \mathrm{E}+02$

$2.67 \mathrm{E}+02$

$2.67 \mathrm{E}+02$

$2.68 \mathrm{E}+02$

$2.68 \mathrm{E}+02$

$2.69 \mathrm{E}+02$

$2.69 \mathrm{E}+02$

$2.70 \mathrm{E}+02$

$2.70 \mathrm{E}+02$

$2.71 \mathrm{E}+02$

$2.71 \mathrm{E}+02$

$2.72 \mathrm{E}+02$

$2.72 \mathrm{E}+02$

$2.73 E+02$

$2.73 \mathrm{E}+02$

$2.74 \mathrm{E}+02$

$2.74 \mathrm{E}+02$

$2.75 \mathrm{E}+02$

$2.75 \mathrm{E}+02$

$2.76 \mathrm{E}+02$

$2.76 \mathrm{E}+02$

$2.77 \mathrm{E}+02$

$2.77 \mathrm{E}+02$

$2.78 \mathrm{E}+02$

$2.78 \mathrm{E}+02$

$2.79 \mathrm{E}+02$

$2.79 \mathrm{E}+02$

$2.80 \mathrm{E}+02$

$2.80 \mathrm{E}+02$

$2.81 \mathrm{E}+02$

$2.81 E+02$

$2.82 \mathrm{E}+02$

$2.82 \mathrm{E}+02$
Dose statistics at graphical times, mrem/yr

\begin{tabular}{|c|c|c|c|c|c|c|c|}
\hline inimum & aximum & Mean & ledian & $90 \%$ & $5 \%$ & $97.5 \%$ & $3 \%$ \\
\hline 0 & 1 & $E-03$ & $E-10$ & 03 & 02 & 02 & r \\
\hline+00 & -01 & $E-03$ & 10 & 3 & 02 & 02 & -02 \\
\hline-00 & $4 E-01$ & $E-03$ & $3 E-10$ & $3 E-03$ & 02 & 02 & -02 \\
\hline$E+00$ & $3 E-01$ & $E-03$ & 0 & & 2 & 02 & -02 \\
\hline+00 & -01 & -03 & 9 & 3 & 2 & -02 & $08 E-02$ \\
\hline $\mathrm{DE}+00$ & -01 & -03 & -09 & 03 & 02 & -02 & 02 \\
\hline $0 \mathrm{E}+00$ & -01 & ك & -09 & J & 02 & -02 & 0 \\
\hline $.00 E+00$ & $2.42 E-01$ & $2.0 \angle \mathrm{U}$ & $8 E-09$ & . & & -02 & $36 E-02$ \\
\hline-00 & 01 & 03 & 09 & $1 E-03$ & 02 & -02 & -02 \\
\hline $.00 \mathrm{E}+00$ & -01 & 3 & 08 & 03 & 02 & -02 & -02 \\
\hline+00 & -01 & $E-03$ & -08 & 3 & 02 & -02 & $E-02$ \\
\hline$E+00$ & & & & & & & -02 \\
\hline $.00 \mathrm{E}+00$ & $2.60 \mathrm{E}-01$ & $2.86 \mathrm{E}-03$ & $E-08$ & $8 \pm-03$ & $-0<$ & $E-02$ & $-0<$ \\
\hline$E+00$ & -01 & -03 & -08 & $7 E-03$ & 02 & -02 & $E-02$ \\
\hline$E+00$ & 01 & 03 & 08 & 3 & 02 & 02 & -02 \\
\hline $.00 \mathrm{E}+00$ & $2.72 \mathrm{E}-01$ & -03 & -08 & 03 & 02 & -02 & -02 \\
\hline $.00 \mathrm{E}+00$ & $6 E-01$ & $E-03$ & $E-07$ & $5 E-03$ & $1.35 \mathrm{E}-02$ & -02 & $26 \mathrm{E}-02$ \\
\hline $0 \mathrm{E}+00$ & $79 E-01$ & $2 E-03$ & $2 E-07$ & $E-03$ & $37 E-02$ & -02 & $E-02$ \\
\hline$E+00$ & 01 & -03 & 07 & & & 02 & -02 \\
\hline$E+00$ & -01 & $E-03$ & -07 & $8 E-03$ & 02 & -02 & $58 E-02$ \\
\hline $\mathrm{E}+00$ & -01 & -03 & 07 & & & & -02 \\
\hline $.00 \mathrm{E}+00$ & $2.96 \mathrm{E}-01$ & 03 & -07 & & 02 & -02 & -02 \\
\hline $.00 \mathrm{E}+00$ & $3.00 \mathrm{E}-01$ & $3.40 E-03$ & $0 E-07$ & $8 E-03$ & $51 E-02$ & $5 E-02$ & $92 E-02$ \\
\hline $.00 \mathrm{E}+00$ & $3.04 \mathrm{E}-01$ & $46 \mathrm{E}-03$ & $5 E-07$ & $8 E-03$ & $3 E-02$ & $E-02$ & $3 E-02$ \\
\hline+00 & $.08 \mathrm{E}-01$ & $E-03$ & 07 & & & 02 & $E-02$ \\
\hline$E+00$ & 01 & $E-03$ & 07 & 3 & & 02 & -02 \\
\hline $\mathrm{EE}+00$ & $E-01$ & $E-03$ & -07 & $0 E-03$ & & -02 & $39 E-02$ \\
\hline $.00 \mathrm{E}+00$ & $3.21 \mathrm{E}-01$ & $3.69 E-03$ & $1.13 E-06$ & $5.42 \mathrm{E}-03$ & $1.64 \mathrm{E}-02$ & $.62 \mathrm{E}-02$ & $.51 \mathrm{E}-02$ \\
\hline $.00 E+00$ & $3.25 E-01$ & $3.75 E-03$ & $1.33 E-06$ & $5.55 \mathrm{E}-03$ & 土. & -02 & $63 E-02$ \\
\hline $.00 \mathrm{E}+00$ & $3.29 \mathrm{E}-01$ & . & 每 & 年 & & 等 & $.75 E-02$ \\
\hline$E+00$ & $E-01$ & $3 E-03$ & $E-06$ & 3 & 2 & $E-02$ & $E-02$ \\
\hline$E+00$ & $E-01$ & $E-03$ & -06 & 3 & 02 & 02 & -02 \\
\hline $.00 \mathrm{E}+00$ & $E-01$ & $E-03$ & $3 E-06$ & 3 & 2 & 02 & $3 E-02$ \\
\hline $.00 \mathrm{E}+00$ & $3.47 \mathrm{E}-01$ & $4.07 E-03$ & $2.99 E-06$ & $6.15 \mathrm{E}-03$ & $1.82 \mathrm{E}-02$ & $98 E-02$ & $26 E-02$ \\
\hline . ООЕТ & $3.52 \mathrm{E}-01$ & $4.13 E-03$ & & & & & $.39 \mathrm{E}-02$ \\
\hline 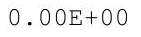 & & & & & & & \\
\hline مिم+ & & & & $6.53 E-03$ & & & 2 \\
\hline 0 & 1 & 3 & 6 & 3 & 2 & 2 & 02 \\
\hline & & & & & & & 02 \\
\hline $00 E+00$ & $3.75 \mathrm{E}$ & $4.47 \mathrm{E}-$ & 06 & 3 & & & $4 E-02$ \\
\hline$E+00$ & & 3 & & & & & -02 \\
\hline $.00 E+00$ & $3.85 E-01$ & $.62 E-03$ & $.57 E-06$ & & & & $29 E-02$ \\
\hline .00 Et 00 & 3 & $4.69 \mathrm{E}-03$ & 0 & 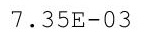 & 2.10 & 2 & 02 \\
\hline . OLT & 3 & & P & & & 02 & 02 \\
\hline+00 & 3.9 & 4.8 & 05 & $7.64 \mathrm{E}$ & 2.17 & 02 & $E-02$ \\
\hline $.00 E+00$ & $4.04 E-01$ & $4.91 E-03$ & $.28 \mathrm{E}-05$ & $7.78 \mathrm{E}-03$ & $2.20 E-02$ & $4.79 \mathrm{E}-02$ & $9.79 \mathrm{E}-02$ \\
\hline
\end{tabular}


RESRAD-OFFSITE, Version 2.5

Title : RESRAD-OFFSITE Drinking Water, Plant, Milk, and Meat Pathways for Offsite Reside File : PBA-1_TC99-DOE-5.ROF

Summary of dose at graphical times, reptition 3 (continued)

Time

Years

$2.83 \mathrm{E}+02$

$2.84 \mathrm{E}+02$

$2.84 \mathrm{E}+02$

$2.85 \mathrm{E}+02$

$2.85 \mathrm{E}+02$

$2.86 \mathrm{E}+02$

$2.86 \mathrm{E}+02$

$2.87 \mathrm{E}+02$

$2.87 \mathrm{E}+02$

$2.88 \mathrm{E}+02$

$2.88 \mathrm{E}+02$

$2.89 \mathrm{E}+02$

$2.89 \mathrm{E}+02$

$2.90 \mathrm{E}+02$

$2.90 \mathrm{E}+02$

$2.91 \mathrm{E}+02$

$2.91 \mathrm{E}+02$

$2.92 \mathrm{E}+02$

$2.92 \mathrm{E}+02$

2. $93 \mathrm{E}+02$

$2.93 \mathrm{E}+02$

$2.94 \mathrm{E}+02$

$2.94 \mathrm{E}+02$

$2.95 \mathrm{E}+02$

$2.95 \mathrm{E}+02$

$2.96 \mathrm{E}+02$

$2.96 \mathrm{E}+02$

$2.97 \mathrm{E}+02$

$2.97 \mathrm{E}+02$

$2.98 \mathrm{E}+02$

$2.98 \mathrm{E}+02$

2. $99 \mathrm{E}+02$

$2.99 \mathrm{E}+02$

$3.00 \mathrm{E}+02$

$3.00 \mathrm{E}+02$

$3.01 \mathrm{E}+02$

3. $01 \mathrm{E}+02$

$3.02 \mathrm{E}+02$

$3.02 \mathrm{E}+02$

3. $03 \mathrm{E}+02$

$3.04 \mathrm{E}+02$

$3.04 \mathrm{E}+02$

$3.05 \mathrm{E}+02$

$3.05 \mathrm{E}+02$

$3.06 \mathrm{E}+02$

$3.06 \mathrm{E}+02$
Dose statistics at graphical times, mrem/yr

\begin{tabular}{|c|c|c|c|c|c|c|c|}
\hline inimum & Maximum & Mean & Median & $90 \%$ & $95 \frac{\circ}{\circ}$ & $7.5 \%$ & $9 \frac{\circ}{0}$ \\
\hline $.00 \mathrm{E}+00$ & $4.09 \mathrm{E}-01$ & $4.98 \mathrm{E}-03$ & $1.43 E-05$ & $7.93 \mathrm{E}-03$ & $2.23 \mathrm{E}-02$ & $4.87 \mathrm{E}-02$ & $9.92 \mathrm{E}-02$ \\
\hline $0.00 \mathrm{E}+00$ & $4.14 \mathrm{E}-01$ & $5.06 \mathrm{E}-03$ & $1.57 E-05$ & $8.08 \mathrm{E}-03$ & $2.27 \mathrm{E}-02$ & $4.95 \mathrm{E}-02$ & $1.00 \mathrm{E}-01$ \\
\hline $0.00 \mathrm{E}+00$ & $4.19 \mathrm{E}-01$ & $5.14 \mathrm{E}-03$ & $1.71 \mathrm{E}-05$ & $8.24 \mathrm{E}-03$ & $2.31 \mathrm{E}-02$ & $5.03 E-02$ & $1.02 \mathrm{E}-01$ \\
\hline $0.00 \mathrm{E}+00$ & $4.24 \mathrm{E}-01$ & $5.21 \mathrm{E}-03$ & $1.87 \mathrm{E}-05$ & $8.39 \mathrm{E}-03$ & $2.35 \mathrm{E}-02$ & $5.11 \mathrm{E}-02$ & $.03 \mathrm{E}-01$ \\
\hline $0.00 \mathrm{E}+00$ & $4.29 \mathrm{E}-01$ & $5.29 \mathrm{E}-03$ & $2.08 E-05$ & $8.55 \mathrm{E}-03$ & $2.38 \mathrm{E}-02$ & $5.19 \mathrm{E}-02$ & $1.04 \mathrm{E}-01$ \\
\hline $0.00 \mathrm{E}+00$ & $4.35 \mathrm{E}-01$ & $5.37 \mathrm{E}-03$ & $2.32 E-05$ & $8.71 \mathrm{E}-03$ & $2.42 \mathrm{E}-02$ & $5.26 \mathrm{E}-02$ & $1.06 \mathrm{E}-01$ \\
\hline $00 \mathrm{E}+00$ & $4.40 \mathrm{E}-01$ & $5.45 \mathrm{E}-03$ & $2.54 \mathrm{E}-05$ & $8.87 \mathrm{E}-03$ & $2.46 \mathrm{E}-02$ & $5.33 E-02$ & $1.07 \mathrm{E}-01$ \\
\hline $.00 \mathrm{E}+00$ & $4.45 \mathrm{E}-01$ & $5.53 \mathrm{E}-03$ & $2.72 E-05$ & $9.04 \mathrm{E}-03$ & $2.50 \mathrm{E}-02$ & $5.40 \mathrm{E}-02$ & $1.08 \mathrm{E}-01$ \\
\hline $.00 \mathrm{E}+00$ & $4.50 \mathrm{E}-01$ & $5.61 \mathrm{E}-03$ & $2.91 E-05$ & $9.21 \mathrm{E}-03$ & $2.54 \mathrm{E}-02$ & $5.47 \mathrm{E}-02$ & $1.10 \mathrm{E}-01$ \\
\hline $.00 \mathrm{E}+00$ & $4.56 \mathrm{E}-01$ & $5.70 \mathrm{E}-03$ & $3.16 \mathrm{E}-05$ & $9.37 \mathrm{E}-03$ & $2.58 \mathrm{E}-02$ & $5.55 \mathrm{E}-02$ & $1.11 \mathrm{E}-01$ \\
\hline $0.00 \mathrm{E}+00$ & $4.61 \mathrm{E}-01$ & $5.78 \mathrm{E}-03$ & $3.38 E-05$ & $9.55 \mathrm{E}-03$ & $2.62 \mathrm{E}-02$ & $5.62 \mathrm{E}-02$ & $1.13 \mathrm{E}-01$ \\
\hline $0.00 \mathrm{E}+00$ & $4.66 \mathrm{E}-01$ & $5.87 \mathrm{E}-03$ & $3.62 \mathrm{E}-05$ & $9.72 \mathrm{E}-03$ & $2.66 \mathrm{E}-02$ & $5.70 \mathrm{E}-02$ & $1.14 \mathrm{E}-01$ \\
\hline $0.00 \mathrm{E}+00$ & $4.72 \mathrm{E}-01$ & $5.95 \mathrm{E}-03$ & $3.86 \mathrm{E}-05$ & $9.90 \mathrm{E}-03$ & $2.70 \mathrm{E}-02$ & $5.78 \mathrm{E}-02$ & $1.16 \mathrm{E}-01$ \\
\hline $0.00 \mathrm{E}+00$ & $4.77 \mathrm{E}-01$ & $6.04 \mathrm{E}-03$ & $4.13 E-05$ & $1.01 \mathrm{E}-02$ & $2.73 \mathrm{E}-02$ & $5.87 \mathrm{E}-02$ & $1.17 \mathrm{E}-01$ \\
\hline $0.00 \mathrm{E}+00$ & $4.83 \mathrm{E}-01$ & $6.13 \mathrm{E}-03$ & $4.46 \mathrm{E}-05$ & $1.03 \mathrm{E}-02$ & $2.77 \mathrm{E}-02$ & $5.95 \mathrm{E}-02$ & $1.19 \mathrm{E}-01$ \\
\hline $0.00 \mathrm{E}+00$ & $4.88 \mathrm{E}-01$ & $6.21 \mathrm{E}-03$ & $4.77 E-05$ & $1.04 \mathrm{E}-02$ & $2.81 \mathrm{E}-02$ & $6.04 \mathrm{E}-02$ & $1.20 \mathrm{E}-01$ \\
\hline $0.00 \mathrm{E}+00$ & $4.94 \mathrm{E}-01$ & $6.30 \mathrm{E}-03$ & $5.05 E-05$ & $1.06 \mathrm{E}-02$ & $2.85 \mathrm{E}-02$ & $6.12 \mathrm{E}-02$ & $1.22 \mathrm{E}-01$ \\
\hline $0.00 \mathrm{E}+00$ & $4.99 \mathrm{E}-01$ & $6.39 \mathrm{E}-03$ & $5.32 \mathrm{E}-05$ & $1.08 \mathrm{E}-02$ & $2.89 \mathrm{E}-02$ & $6.21 \mathrm{E}-02$ & $1.24 \mathrm{E}-01$ \\
\hline $0.00 \mathrm{E}+00$ & $5.05 E-01$ & $6.48 \mathrm{E}-03$ & $5.58 E-05$ & $1.10 \mathrm{E}-02$ & $2.93 \mathrm{E}-02$ & $6.30 \mathrm{E}-02$ & $1.25 \mathrm{E}-01$ \\
\hline $0.00 \mathrm{E}+00$ & $5.11 \mathrm{E}-01$ & $6.58 \mathrm{E}-03$ & $5.95 E-05$ & $1.12 \mathrm{E}-02$ & $2.97 \mathrm{E}-02$ & $6.39 \mathrm{E}-02$ & $1.27 \mathrm{E}-01$ \\
\hline $0.00 \mathrm{E}+00$ & 5 & & & & & 2 & 01 \\
\hline $0.00 \mathrm{E}+00$ & 5 & 6 & 6 & 2 & 2 & 2 & 01 \\
\hline $0.00 \mathrm{E}+00$ & $5.28 \mathrm{E}-01$ & $6.86 \mathrm{E}-03$ & $6.96 \mathrm{E}-05$ & $1.19 \mathrm{E}-02$ & $3.09 \mathrm{E}-02$ & $6.65 \mathrm{E}-02$ & $1.31 \mathrm{E}-01$ \\
\hline $0.00 \mathrm{E}+00$ & $5.34 \mathrm{E}-01$ & $6.95 \mathrm{E}-03$ & 7. $32 \mathrm{E}-05$ & $1.21 \mathrm{E}-02$ & $3.13 \mathrm{E}-02$ & $6.75 \mathrm{E}-02$ & $1.33 \mathrm{E}-01$ \\
\hline $0.00 \mathrm{E}+00$ & $5.39 \mathrm{E}-01$ & $7.05 \mathrm{E}-03$ & $7.72 \mathrm{E}-05$ & $1.23 \mathrm{E}-02$ & $3.17 \mathrm{E}-02$ & $6.84 \mathrm{E}-02$ & $1.34 \mathrm{E}-01$ \\
\hline $0.00 \mathrm{E}+00$ & $5.45 \mathrm{E}-01$ & $7.15 \mathrm{E}-03$ & $8.12 E-05$ & $1.25 \mathrm{E}-02$ & $3.21 \mathrm{E}-02$ & $6.94 \mathrm{E}-02$ & $1.36 \mathrm{E}-01$ \\
\hline $0.00 \mathrm{E}+00$ & $5.51 \mathrm{E}-01$ & $7.25 \mathrm{E}-03$ & $8.51 \mathrm{E}-05$ & $1.27 \mathrm{E}-02$ & $3.25 \mathrm{E}-02$ & $7.04 \mathrm{E}-02$ & $1.37 \mathrm{E}-01$ \\
\hline $0.00 \mathrm{E}+00$ & $5.57 \mathrm{E}-01$ & $7.35 \mathrm{E}-03$ & $9.01 E-05$ & $1.30 \mathrm{E}-02$ & $3.30 \mathrm{E}-02$ & $7.14 \mathrm{E}-02$ & $1.38 \mathrm{E}-01$ \\
\hline $0.00 \mathrm{E}+00$ & $5.63 \mathrm{E}-01$ & $7.45 \mathrm{E}-03$ & $9.42 \mathrm{E}-05$ & $1.32 \mathrm{E}-02$ & $3.34 \mathrm{E}-02$ & $7.24 \mathrm{E}-02$ & $1.40 \mathrm{E}-01$ \\
\hline $0.00 \mathrm{E}+00$ & $5.69 \mathrm{E}-01$ & 7.5 & $9.83 \mathrm{E}$ & 1.34 & 3.3 & 7.3 & $1.42 \mathrm{E}-01$ \\
\hline $0.00 \mathrm{E}+00$ & 5 & 7 & 4 & 1.3 & 2 & 02 & $1.43 \mathrm{E}-01$ \\
\hline $0.00 \mathrm{E}+00$ & $5.81 \mathrm{E}-01$ & $7.76 \mathrm{E}-03$ & $1.07 \mathrm{E}-04$ & $1.38 \mathrm{E}-02$ & $3.47 \mathrm{E}-02$ & $7.53 \mathrm{E}-02$ & $1.45 \mathrm{E}-01$ \\
\hline $0.00 \mathrm{E}+00$ & $5.87 \mathrm{E}-01$ & $7.86 \mathrm{E}-03$ & $1.12 \mathrm{E}-04$ & $1.40 \mathrm{E}-02$ & $3.52 \mathrm{E}-02$ & $7.63 \mathrm{E}-02$ & $1.46 \mathrm{E}-01$ \\
\hline $0.00 \mathrm{E}+00$ & $5.93 \mathrm{E}-01$ & $7.97 \mathrm{E}-03$ & $1.18 \mathrm{E}-04$ & $1.43 \mathrm{E}-02$ & $3.57 \mathrm{E}-02$ & $7.74 \mathrm{E}-02$ & $1.48 \mathrm{E}-01$ \\
\hline $0.00 \mathrm{E}+00$ & $6.00 \mathrm{E}-01$ & $8.07 E-03$ & $1.24 \mathrm{E}-04$ & $1.45 \mathrm{E}-02$ & $3.62 \mathrm{E}-02$ & $7.84 \mathrm{E}-02$ & $1.50 \mathrm{E}-01$ \\
\hline $0.00 \mathrm{E}+00$ & $6.06 \mathrm{E}-01$ & $8.18 \mathrm{E}-03$ & $1.29 \mathrm{E}-04$ & $1.47 \mathrm{E}-02$ & $3.67 \mathrm{E}-02$ & $7.94 \mathrm{E}-02$ & $1.51 \mathrm{E}-01$ \\
\hline $0.00 \mathrm{E}+00$ & $6.12 \mathrm{E}-01$ & $8.29 \mathrm{E}-03$ & $1.34 \mathrm{E}-04$ & $1.49 \mathrm{E}-02$ & $3.72 \mathrm{E}-02$ & $8.04 \mathrm{E}-02$ & $1.53 \mathrm{E}-01$ \\
\hline $0.00 \mathrm{E}+00$ & $6.18 \mathrm{E}-01$ & $8.40 \mathrm{E}-03$ & $1.40 \mathrm{E}-04$ & $1.52 \mathrm{E}-02$ & $3.76 \mathrm{E}-02$ & $8.13 E-02$ & $1.54 \mathrm{E}-01$ \\
\hline $0.00 \mathrm{E}+00$ & $6.25 \mathrm{E}-01$ & $8.51 \mathrm{E}-03$ & $1.45 \mathrm{E}-04$ & $1.54 \mathrm{E}-02$ & $3.82 \mathrm{E}-02$ & $8.23 E-02$ & $1.56 \mathrm{E}-01$ \\
\hline $0.00 \mathrm{E}+00$ & $6.31 \mathrm{E}-01$ & $8.62 \mathrm{E}-03$ & $1.51 \mathrm{E}-04$ & $1.56 \mathrm{E}-02$ & $3.87 \mathrm{E}-02$ & $8.33 E-02$ & $1.58 \mathrm{E}-01$ \\
\hline $0.00 \mathrm{E}+00$ & $6.37 \mathrm{E}-01$ & $8.73 E-03$ & $1.57 \mathrm{E}-04$ & $1.59 \mathrm{E}-02$ & $3.92 \mathrm{E}-02$ & $8.43 \mathrm{E}-02$ & $1.60 \mathrm{E}-01$ \\
\hline $0.00 \mathrm{E}+00$ & $6.44 \mathrm{E}-01$ & $8.85 \mathrm{E}-03$ & $1.64 \mathrm{E}-04$ & $1.61 \mathrm{E}-02$ & $3.97 \mathrm{E}-02$ & $8.53 E-02$ & $1.62 \mathrm{E}-01$ \\
\hline $0.00 \mathrm{E}+00$ & $6.50 \mathrm{E}-01$ & $8.96 \mathrm{E}-03$ & $1.70 \mathrm{E}-04$ & $1.64 \mathrm{E}-02$ & $4.02 \mathrm{E}-02$ & $8.62 \mathrm{E}-02$ & $1.64 \mathrm{E}-01$ \\
\hline $0.00 \mathrm{E}+00$ & $6.57 \mathrm{E}-01$ & $9.08 \mathrm{E}-03$ & $1.76 \mathrm{E}-04$ & $1.67 \mathrm{E}-02$ & $4.07 \mathrm{E}-02$ & $8.71 \mathrm{E}-02$ & $1.66 \mathrm{E}-01$ \\
\hline $0.00 \mathrm{E}+00$ & $6.63 \mathrm{E}-01$ & $9.20 \mathrm{E}-03$ & $1.82 \mathrm{E}-04$ & $1.70 \mathrm{E}-02$ & $4.13 \mathrm{E}-02$ & $8.80 \mathrm{E}-02$ & $1.68 \mathrm{E}-01$ \\
\hline $.00 \mathrm{E}+00$ & $6.70 \mathrm{E}-01$ & $9.31 \mathrm{E}-03$ & $1.87 \mathrm{E}-04$ & $1.73 \mathrm{E}-02$ & $4.18 \mathrm{E}-02$ & $8.89 \mathrm{E}-02$ & $1.70 \mathrm{E}-01$ \\
\hline
\end{tabular}


RESRAD-OFFSITE, Version 2.5

$\mathrm{T}^{1 / 2}$ Limit $=180$ days

Title : RESRAD-OFFSITE Drinking Water, Plant, Milk, and Meat Pathways for Offsite Reside File : PBA-1_TC99-DOE-5.ROF

Summary of dose at graphical times, reptition 3 (continued)

Time

Years

$3.07 \mathrm{E}+02$

$3.07 \mathrm{E}+02$

$3.08 \mathrm{E}+02$

$3.08 \mathrm{E}+02$

$3.09 \mathrm{E}+02$

$3.09 \mathrm{E}+02$

$3.10 \mathrm{E}+02$

$3.10 \mathrm{E}+02$

$3.11 \mathrm{E}+02$

$3.11 E+02$

$3.12 \mathrm{E}+02$

$3.12 \mathrm{E}+02$

$3.13 E+02$

$3.13 \mathrm{E}+02$

$3.14 \mathrm{E}+02$

$3.14 \mathrm{E}+02$

$3.15 \mathrm{E}+02$

$3.15 \mathrm{E}+02$

$3.16 \mathrm{E}+02$

$3.16 \mathrm{E}+02$

$3.17 \mathrm{E}+02$

$3.17 \mathrm{E}+02$

$3.18 \mathrm{E}+02$

$3.18 \mathrm{E}+02$

$3.19 \mathrm{E}+02$

$3.19 \mathrm{E}+02$

$3.20 \mathrm{E}+02$

$3.20 \mathrm{E}+02$

$3.21 \mathrm{E}+02$

$3.21 \mathrm{E}+02$

$3.22 \mathrm{E}+02$

$3.22 \mathrm{E}+02$

$3.23 \mathrm{E}+02$

$3.24 \mathrm{E}+02$

$3.24 \mathrm{E}+02$

$3.25 \mathrm{E}+02$

$3.25 \mathrm{E}+02$

$3.26 \mathrm{E}+02$

$3.26 \mathrm{E}+02$

$3.27 \mathrm{E}+02$

$3.27 \mathrm{E}+02$

3. $28 \mathrm{E}+02$

$3.28 \mathrm{E}+02$

$3.29 \mathrm{E}+02$

$3.29 \mathrm{E}+02$

$3.30 \mathrm{E}+02$
Dose statistics at graphical times, mrem/yr

\begin{tabular}{|c|c|c|c|c|c|c|c|}
\hline um & aximum & thit & 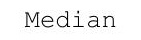 & & & & \\
\hline $00 \mathrm{E}+00$ & $.76 \mathrm{E}-01$ & $9.43 \mathrm{E}-03$ & $1.93 \mathrm{E}-04$ & $1.76 \mathrm{E}-02$ & $4.23 \mathrm{E}-02$ & $8.98 \mathrm{E}-02$ & $1.72 \mathrm{E}-01$ \\
\hline $.00 \mathrm{E}+00$ & $6.83 \mathrm{E}-01$ & $9.55 \mathrm{E}-03$ & $1.99 \mathrm{E}-04$ & $1.78 \mathrm{E}-02$ & $4.29 \mathrm{E}-02$ & $9.07 \mathrm{E}-02$ & $1.74 \mathrm{E}-01$ \\
\hline $.00 \mathrm{E}+00$ & $6.90 \mathrm{E}-01$ & $9.67 \mathrm{E}-03$ & $2.06 \mathrm{E}-04$ & $1.81 \mathrm{E}-02$ & $4.34 \mathrm{E}-02$ & $9.17 \mathrm{E}-02$ & $1.76 \mathrm{E}-01$ \\
\hline $0.00 \mathrm{E}+00$ & $6.96 \mathrm{E}-01$ & $9.80 \mathrm{E}-03$ & $2.13 \mathrm{E}-04$ & $1.84 \mathrm{E}-02$ & $4.40 \mathrm{E}-02$ & $9.26 \mathrm{E}-02$ & $1.78 \mathrm{E}-01$ \\
\hline $0.00 \mathrm{E}+00$ & $7.03 \mathrm{E}-01$ & $9.92 \mathrm{E}-03$ & $2.21 \mathrm{E}-04$ & $1.87 \mathrm{E}-02$ & $4.45 \mathrm{E}-02$ & $9.36 \mathrm{E}-02$ & $1.80 \mathrm{E}-01$ \\
\hline $0.00 \mathrm{E}+00$ & $7.10 \mathrm{E}-01$ & $1.00 \mathrm{E}-02$ & $2.29 \mathrm{E}-04$ & $1.89 \mathrm{E}-02$ & $4.51 \mathrm{E}-02$ & $9.47 \mathrm{E}-02$ & $1.82 \mathrm{E}-01$ \\
\hline $0.00 \mathrm{E}+00$ & $7.16 \mathrm{E}-01$ & $1.02 \mathrm{E}-02$ & $2.39 \mathrm{E}-04$ & $1.92 \mathrm{E}-02$ & $4.57 \mathrm{E}-02$ & $9.59 \mathrm{E}-02$ & $1.84 \mathrm{E}-01$ \\
\hline $0.00 \mathrm{E}+00$ & $7.23 \mathrm{E}-01$ & $1.03 \mathrm{E}-02$ & $2.48 \mathrm{E}-04$ & $1.95 \mathrm{E}-02$ & $4.62 \mathrm{E}-02$ & $9.70 \mathrm{E}-02$ & $1.86 \mathrm{E}-01$ \\
\hline $0.00 \mathrm{E}+00$ & $7.30 \mathrm{E}-01$ & $1.04 \mathrm{E}-02$ & $2.56 \mathrm{E}-04$ & $1.98 \mathrm{E}-02$ & $4.68 \mathrm{E}-02$ & $9.82 \mathrm{E}-02$ & $1.87 \mathrm{E}-01$ \\
\hline $0.00 \mathrm{E}+00$ & $7.37 \mathrm{E}-01$ & $1.06 \mathrm{E}-02$ & $2.64 \mathrm{E}-04$ & $2.01 \mathrm{E}-02$ & $74 \mathrm{E}$ & 9.94 & $89 \mathrm{E}-01$ \\
\hline $.00 \mathrm{E}+00$ & $7.44 \mathrm{E}-01$ & $1.07 \mathrm{E}-02$ & $2.72 \mathrm{E}$ & $2.04 \mathrm{E}-02$ & $4.80 \mathrm{E}$ & 1.01 & -01 \\
\hline $.00 \mathrm{E}+00$ & $7.51 \mathrm{E}-01$ & $1.08 \mathrm{E}-02$ & $2.82 \mathrm{E}-04$ & $2.07 \mathrm{E}-02$ & $4.86 \mathrm{E}-02$ & $1.02 \mathrm{E}-01$ & $1.93 \mathrm{E}-01$ \\
\hline $0.00 \mathrm{E}+00$ & $7.58 \mathrm{E}-01$ & $1.09 \mathrm{E}-02$ & $2.91 \mathrm{E}-04$ & $2.10 \mathrm{E}-02$ & $4.92 \mathrm{E}-02$ & $1.03 \mathrm{E}-01$ & $1.95 \mathrm{E}-01$ \\
\hline $.00 \mathrm{E}+00$ & $7.65 \mathrm{E}-01$ & $1.11 \mathrm{E}-02$ & $3.00 \mathrm{E}-04$ & $2.14 \mathrm{E}-02$ & $4.98 \mathrm{E}-02$ & $1.04 \mathrm{E}-01$ & $98 E-01$ \\
\hline $0.00 \mathrm{E}+00$ & $7.72 \mathrm{E}-01$ & $1.12 \mathrm{E}-02$ & $3.12 \mathrm{E}-04$ & $2.17 \mathrm{E}-02$ & $5.04 \mathrm{E}-02$ & $1.06 \mathrm{E}-01$ & $2.00 \mathrm{E}-01$ \\
\hline $0.00 \mathrm{E}+00$ & $7.79 \mathrm{E}-01$ & $1.14 \mathrm{E}-02$ & $3.22 \mathrm{E}-04$ & $2.20 \mathrm{E}-02$ & $5.10 \mathrm{E}-02$ & $1.07 \mathrm{E}-01$ & $2.02 \mathrm{E}-01$ \\
\hline $0.00 \mathrm{E}+00$ & $7.86 \mathrm{E}-01$ & $1.15 \mathrm{E}-02$ & $3.33 \mathrm{E}-04$ & $2.24 \mathrm{E}-02$ & $5.16 \mathrm{E}-02$ & $1.08 \mathrm{E}-01$ & $2.04 \mathrm{E}-01$ \\
\hline $0.00 \mathrm{E}+00$ & $7.93 \mathrm{E}-01$ & $1.16 \mathrm{E}-02$ & $3.45 \mathrm{E}-04$ & $2.27 \mathrm{E}-02$ & $5.23 \mathrm{E}-02$ & $1.09 \mathrm{E}-01$ & $2.06 \mathrm{E}-01$ \\
\hline $0.00 \mathrm{E}+00$ & $8.00 \mathrm{E}-01$ & $1.18 \mathrm{E}-02$ & $3.56 \mathrm{E}-04$ & $2.31 \mathrm{E}-02$ & $5.30 \mathrm{E}-02$ & $1.11 \mathrm{E}-01$ & $2.09 \mathrm{E}-01$ \\
\hline $0.00 \mathrm{E}+00$ & $8.07 \mathrm{E}-01$ & $1.19 \mathrm{E}-02$ & $3.68 \mathrm{E}-04$ & $2.34 \mathrm{E}-02$ & $5.37 \mathrm{E}-02$ & $1.12 \mathrm{E}-01$ & $2.11 \mathrm{E}-01$ \\
\hline $0.00 \mathrm{E}+00$ & $8.15 \mathrm{E}-01$ & $1.21 \mathrm{E}-02$ & $3.81 \mathrm{E}-04$ & $2.38 \mathrm{E}-02$ & $5.45 \mathrm{E}-02$ & $1.13 \mathrm{E}-01$ & $2.13 \mathrm{E}-01$ \\
\hline $.00 \mathrm{E}+00$ & $8.22 \mathrm{E}-01$ & $1.22 \mathrm{E}-02$ & $3.94 \mathrm{E}-04$ & $2.41 \mathrm{E}-02$ & $5.52 \mathrm{E}-02$ & $1.14 \mathrm{E}-01$ & $2.16 \mathrm{E}-01$ \\
\hline $.00 \mathrm{E}+00$ & $8.29 \mathrm{E}-$ & $1.23 \mathrm{E}-02$ & 4. & 2 & 2 & 1 & -01 \\
\hline $.00 \mathrm{E}+00$ & 8 & 1 & 4 & 2 & & 1 & 01 \\
\hline $0.00 \mathrm{E}+00$ & $8.44 \mathrm{E}-01$ & $1.26 \mathrm{E}-02$ & $4.30 \mathrm{E}-04$ & $2.51 \mathrm{E}-02$ & 22 & $9 E-01$ & \\
\hline $0.00 \mathrm{E}+00$ & $8.51 \mathrm{E}-01$ & $1.28 \mathrm{E}-02$ & $4.42 \mathrm{E}-04$ & $2.55 \mathrm{E}-02$ & $5.81 \mathrm{E}-02$ & $1.20 \mathrm{E}-01$ & $2.25 \mathrm{E}-01$ \\
\hline $0.00 \mathrm{E}+00$ & $8.58 \mathrm{E}-01$ & $1.29 \mathrm{E}-02$ & $4.58 \mathrm{E}-04$ & $2.59 \mathrm{E}-02$ & $5.87 \mathrm{E}-02$ & $1.22 \mathrm{E}-01$ & $2.27 \mathrm{E}-01$ \\
\hline $0.00 \mathrm{E}+00$ & $8.66 \mathrm{E}-01$ & $1.31 \mathrm{E}-02$ & $4.70 \mathrm{E}-04$ & $2.62 \mathrm{E}-02$ & $5.94 \mathrm{E}-02$ & $1.23 \mathrm{E}-01$ & $2.30 \mathrm{E}-01$ \\
\hline $0.00 \mathrm{E}+00$ & $8.73 \mathrm{E}-01$ & $1.32 \mathrm{E}-02$ & $4.82 \mathrm{E}-04$ & $2.66 \mathrm{E}-02$ & $6.01 \mathrm{E}-02$ & $1.25 \mathrm{E}-01$ & $2.32 \mathrm{E}-01$ \\
\hline $0.00 \mathrm{E}+00$ & $8.81 \mathrm{E}-01$ & $1.34 \mathrm{E}-02$ & $4.93 \mathrm{E}-04$ & $2.69 \mathrm{E}-02$ & $6.08 \mathrm{E}-02$ & $1.26 \mathrm{E}-01$ & $2.35 \mathrm{E}-01$ \\
\hline $0.00 \mathrm{E}+00$ & $8.88 \mathrm{E}-01$ & $1.35 \mathrm{E}-02$ & $5.05 \mathrm{E}-04$ & $2.73 \mathrm{E}-02$ & $6.15 \mathrm{E}-02$ & $1.28 \mathrm{E}-01$ & $2.37 \mathrm{E}-01$ \\
\hline $0.00 \mathrm{E}+00$ & $8.96 \mathrm{E}-01$ & $1.37 \mathrm{E}-02$ & $5.21 \mathrm{E}-04$ & $2.77 \mathrm{E}-02$ & $6.22 \mathrm{E}-02$ & $1.29 \mathrm{E}-01$ & $2.40 \mathrm{E}-01$ \\
\hline $.00 E+00$ & $9.03 \mathrm{E}-01$ & $1.38 \mathrm{E}-02$ & $5.36 \mathrm{E}-04$ & $2.80 \mathrm{E}$ & 0.301 & $1.31 \mathrm{E}-01$ & $2.42 \mathrm{E}-01$ \\
\hline $0.00 \mathrm{E}+00$ & $9.11 \mathrm{E}-01$ & $1.40 \mathrm{E}-02$ & $5.51 \mathrm{E}-04$ & $2.84 \mathrm{E}-02$ & $6.37 \mathrm{E}-02$ & $1.32 \mathrm{E}-01$ & $2.44 \mathrm{E}-01$ \\
\hline $00 \mathrm{E}+00$ & $9.19 \mathrm{E}-01$ & $1.42 \mathrm{E}-02$ & $5.66 \mathrm{E}-04$ & $2.87 \mathrm{E}-02$ & $6.44 \mathrm{E}-02$ & $1.33 \mathrm{E}-01$ & $2.47 \mathrm{E}-01$ \\
\hline $00 \mathrm{E}+00$ & $9.26 \mathrm{E}-01$ & $1.43 \mathrm{E}-02$ & $5.82 \mathrm{E}-04$ & $2.91 \mathrm{E}-02$ & $6.52 \mathrm{E}-02$ & $1.35 \mathrm{E}-01$ & 2.49 \\
\hline $0.00 \mathrm{E}+00$ & $9.34 \mathrm{E}-01$ & $1.45 \mathrm{E}-02$ & $5.97 \mathrm{E}-04$ & $2.95 \mathrm{E}-02$ & $E-02$ & $1.36 \mathrm{E}-01$ & $2.52 \mathrm{E}-01$ \\
\hline $0.00 \mathrm{E}+00$ & $9.42 \mathrm{E}-01$ & $1.46 \mathrm{E}-02$ & $6.13 \mathrm{E}-04$ & $2.99 \mathrm{E}-02$ & $6.68 \mathrm{E}-02$ & $1.38 \mathrm{E}-01$ & $2.55 \mathrm{E}-01$ \\
\hline $0.00 \mathrm{E}+00$ & $9.49 \mathrm{E}-01$ & $1.48 \mathrm{E}-02$ & $6.28 \mathrm{E}-04$ & $3.03 E-02$ & $6.76 \mathrm{E}-02$ & $1.39 \mathrm{E}-01$ & $2.57 \mathrm{E}-01$ \\
\hline $0.00 \mathrm{E}+00$ & $9.57 \mathrm{E}-01$ & $1.50 \mathrm{E}-02$ & $6.43 \mathrm{E}-04$ & $3.08 \mathrm{E}-02$ & $6.84 \mathrm{E}-02$ & $1.41 \mathrm{E}-01$ & $2.60 \mathrm{E}-01$ \\
\hline $0.00 \mathrm{E}+00$ & $9.65 \mathrm{E}-01$ & $1.51 \mathrm{E}-02$ & $6.59 \mathrm{E}-04$ & $3.12 \mathrm{E}-02$ & $6.92 \mathrm{E}-02$ & $1.42 \mathrm{E}-01$ & $2.62 \mathrm{E}-01$ \\
\hline $0.00 \mathrm{E}+00$ & $9.73 \mathrm{E}-01$ & $1.53 \mathrm{E}-02$ & $6.76 \mathrm{E}-04$ & $3.17 \mathrm{E}-02$ & $7.01 \mathrm{E}-02$ & $1.44 \mathrm{E}-01$ & $2.65 \mathrm{E}-01$ \\
\hline $0.00 \mathrm{E}+00$ & $9.81 \mathrm{E}-01$ & $1.55 \mathrm{E}-02$ & $6.92 \mathrm{E}-04$ & $3.21 \mathrm{E}-02$ & $7.09 \mathrm{E}-02$ & $1.45 \mathrm{E}-01$ & $2.67 \mathrm{E}-01$ \\
\hline $0.00 \mathrm{E}+00$ & $9.88 \mathrm{E}-01$ & $1.56 \mathrm{E}-02$ & $7.07 \mathrm{E}-04$ & $3.26 \mathrm{E}-02$ & $7.18 \mathrm{E}-02$ & $1.47 \mathrm{E}-01$ & $2.70 \mathrm{E}-01$ \\
\hline $0.00 \mathrm{E}+00$ & $9.96 \mathrm{E}-01$ & $1.58 \mathrm{E}-02$ & $7.23 \mathrm{E}-04$ & $3.30 \mathrm{E}-02$ & $7.27 \mathrm{E}-02$ & $1.48 \mathrm{E}-01$ & $2.73 \mathrm{E}-01$ \\
\hline $0.00 \mathrm{E}+00$ & $1.00 \mathrm{E}+00$ & $1.60 \mathrm{E}-02$ & $7.40 \mathrm{E}-04$ & $3.35 \mathrm{E}-02$ & $7.36 \mathrm{E}-02$ & $1.49 \mathrm{E}-01$ & $2.75 \mathrm{E}-01$ \\
\hline
\end{tabular}


RESRAD-OFFSITE, Version 2.5

Title : RESRAD-OFFSITE Drinking Water, Plant, Milk, and Meat Pathways for Offsite Reside File : PBA-1_TC99-DOE-5.ROF

Summary of dose at graphical times, reptition 3 (continued)

Time

Years

3. $30 \mathrm{E}+02$

3. $31 \mathrm{E}+02$

$3.31 E+02$

3. $32 \mathrm{E}+02$

3. $32 \mathrm{E}+02$

3. $33 \mathrm{E}+02$

3. $33 E+02$

3. $34 \mathrm{E}+02$

3. $34 \mathrm{E}+02$

3. $35 \mathrm{E}+02$

3. $35 \mathrm{E}+02$

3. $36 \mathrm{E}+02$

3. $36 \mathrm{E}+02$

3. $37 \mathrm{E}+02$

3. $37 \mathrm{E}+02$

3. $38 \mathrm{E}+02$

3. $38 \mathrm{E}+02$

3. $39 \mathrm{E}+02$

3. $39 \mathrm{E}+02$

3. $40 \mathrm{E}+02$

$3.40 \mathrm{E}+02$

3. $41 \mathrm{E}+02$

3. $41 \mathrm{E}+02$

3. $42 \mathrm{E}+02$

$3.42 \mathrm{E}+02$

3. $43 \mathrm{E}+02$

3. $44 \mathrm{E}+02$

3. $44 \mathrm{E}+02$

3. $45 \mathrm{E}+02$

$3.45 \mathrm{E}+02$

$3.46 \mathrm{E}+02$

$3.46 \mathrm{E}+02$

$3.47 \mathrm{E}+02$

$3.47 \mathrm{E}+02$

$3.48 \mathrm{E}+02$

$3.48 \mathrm{E}+02$

$3.49 \mathrm{E}+02$

$3.49 \mathrm{E}+02$

$3.50 \mathrm{E}+02$

$3.50 \mathrm{E}+02$

3. $51 \mathrm{E}+02$

$3.51 \mathrm{E}+02$

$3.52 \mathrm{E}+02$

$3.52 \mathrm{E}+02$

$3.53 E+02$

$3.53 E+02$
Dose statistics at graphical times, mrem/yr

\begin{tabular}{|c|c|c|c|c|c|c|c|}
\hline inimum & aximum & Mean & ledian & $0 \%$ & $5 \%$ & $97.5 \%$ & \\
\hline+00 & $01 E+00$ & 1. $62 \mathrm{E}-02$ & $7.59 \mathrm{E}-04$ & $3.39 E-02$ & $5 E-02$ & $.51 E-01$ & 年 \\
\hline+00 & +00 & 02 & 4 & 2 & 2 & 01 & 01 \\
\hline-00 & $E+00$ & $E-02$ & -04 & $7 E-02$ & 02 & 01 & -01 \\
\hline+00 & $E+00$ & 02 & 4 & 2 & 2 & & -01 \\
\hline$E+00$ & -00 & 2 & & 02 & 02 & -01 & $89 E-01$ \\
\hline $.00 \mathrm{E}+00$ & $1.05 \mathrm{E}+00$ & -02 & -04 & -02 & $E-02$ & $8 E-01$ & 01 \\
\hline+00 & +00 & $F=0 ?$ & -04 & $E-02$ & 2 & 1 & 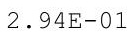 \\
\hline $.00 E+00$ & $1.07 \mathrm{E}+00$ & $\begin{array}{ll}-1 \\
\text { TH }\end{array}$ & -04 & $3.69 E-02$ & 02 & -01 & $E-01$ \\
\hline 00 & +00 & 02 & 04 & $3 E-02$ & 02 & -01 & -01 \\
\hline $.00 \mathrm{E}+00$ & $1.08 \mathrm{E}+00$ & -02 & -04 & -02 & -02 & -01 & $E-01$ \\
\hline+00 & $E+00$ & $E-02$ & -04 & 2 & 2 & -01 & $E-01$ \\
\hline$E+00$ & $0 E+00$ & -02 & & & & & -01 \\
\hline $.00 \mathrm{E}+00$ & $1.11 \mathrm{E}+00$ & $1.83 \mathrm{E}-02$ & $3 E-04$ & $2 E-02$ & $4 / E-U<$ & -01 & -01 \\
\hline $\mathrm{E}+00$ & $1.12 \mathrm{E}+00$ & $E-02$ & -03 & 02 & 02 & -01 & $z-01$ \\
\hline$E+00$ & $1.13 \mathrm{E}+00$ & 02 & 03 & 02 & & 01 & -01 \\
\hline $.00 \mathrm{E}+00$ & $1.13 \mathrm{E}+00$ & -02 & -03 & 02 & 02 & -01 & -01 \\
\hline $.00 \mathrm{E}+00$ & $1.14 \mathrm{E}+00$ & $1 E-02$ & $8 \mathrm{E}-03$ & $0 E-02$ & $82 E-02$ & $E-01$ & $.23 E-01$ \\
\hline $0 E+00$ & $1.15 \mathrm{E}+00$ & $.93 E-02$ & $0 E-03$ & $5 E-02$ & $0 E-02$ & $7 E-01$ & $26 \mathrm{E}-01$ \\
\hline $\mathrm{E}+00$ & $1.16 \mathrm{E}+00$ & -02 & 03 & 2 & & -01 & -01 \\
\hline$E+00$ & $1.17 \mathrm{E}+00$ & -02 & 03 & 02 & 02 & -01 & -01 \\
\hline$E+00$ & +00 & & -03 & & & -01 & -01 \\
\hline $.00 \mathrm{E}+00$ & $1.18 \mathrm{E}+00$ & $.01 \mathrm{E}-02$ & -03 & 02 & -02 & -01 & -01 \\
\hline $.00 \mathrm{E}+00$ & $1.19 \mathrm{E}+00$ & $2.03 E-02$ & $21 E-03$ & $40 E-02$ & $38 E-02$ & $35 E-01$ & $40 E-01$ \\
\hline $.00 \mathrm{E}+00$ & $1.20 \mathrm{E}+00$ & $2.05 E-02$ & $1.24 \mathrm{E}-03$ & $45 E-02$ & $48 \mathrm{E}-02$ & $36 E-01$ & $43 E-01$ \\
\hline$E+00$ & $1.21 \mathrm{E}+00$ & $2.07 \mathrm{E}-02$ & $27 E-03$ & $1 E-02$ & $E-02$ & $8 E-01$ & $E-01$ \\
\hline+00 & $\mathrm{E}+00$ & $9 E-02$ & $E-03$ & & & & -01 \\
\hline $.00 \mathrm{E}+00$ & $1.23 E+00$ & -02 & 03 & 2 & & 01 & -01 \\
\hline $.00 \mathrm{E}+00$ & Р.Z४LTU & $2.13 E-02$ & $1.34 \mathrm{E}-03$ & $4.67 \mathrm{E}-02$ & $9.89 \mathrm{E}-02$ & $.92 E-01$ & $.56 \mathrm{E}-01$ \\
\hline $0 E+00$ & $1.24 \mathrm{E}+00$ & $16 E-02$ & $36 E-03$ & 2 & 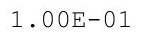 & $E-01$ & -01 \\
\hline 0 & -5 & $18 E-02$ & - & 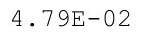 & - & $6 E-01$ & 01 \\
\hline$F+00$ & $26 \mathrm{~F}+00$ & $2.20 \mathrm{E}-02$ & $2 E-03$ & & & $E-01$ & $E-01$ \\
\hline+00 & $1.27 \mathrm{E}+00$ & $.22 E-02$ & $E-03$ & & & 01 & 01 \\
\hline & & & -03 & & & -01 & 01 \\
\hline $.00 E+00$ & $1.29 \mathrm{E}+00$ & $2.26 \mathrm{E}-02$ & $1.51 E-03$ & $0 E-02$ & $.05 \mathrm{E}-01$ & $2 E-01$ & $74 \mathrm{E}-01$ \\
\hline OUTO & P.JULTO & $2.29 \mathrm{E}-02$ & $.53 E-03$ & & & $4 \mathrm{E}-01$ & $77 E-01$ \\
\hline 0 & $1.30 \mathrm{E}+0$ & & & & & & \\
\hline 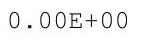 & 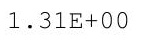 & & & $5.16 \mathrm{E}-02$ & & 1 & 01 \\
\hline $0 \mathrm{E}+00$ & 1 & & & & & & 01 \\
\hline & & & & & & & \\
\hline $.00 E+00$ & $1.34 \mathrm{E}+00$ & $.40 E-02$ & $1.68 E-03$ & 2 & 1 & 01 & $3 E-01$ \\
\hline$E+00$ & $1.35 \mathrm{E}+00$ & $2 E-02$ & 03 & 2 & 1 & & -01 \\
\hline$E+00$ & $1.30 E+U 0$ & $4 \mathrm{E}-02$ & 03 & 2 & & 01 & $995-01$ \\
\hline मा & $1.37 \mathrm{E}+00$ & $7 E-02$ & $1.10 \mathrm{E}-03$ & - & $10 E-U 1$ & $.17 E-01$ & $\angle \angle D-O \perp$ \\
\hline . VUET & + & 2 & & & & $19 \mathrm{E}-01$ & . \\
\hline$E+00$ & $1.38 \mathrm{E}+00$ & $2.51 \mathrm{E}-02$ & -03 & $5.65 E-02$ & 1.1 & 01 & $08 E-01$ \\
\hline $.00 E+00$ & $1.39 \mathrm{E}+00$ & $.54 \mathrm{E}-02$ & $1.87 E-03$ & $.72 E-02$ & $1.19 \mathrm{E}-01$ & $2.22 \mathrm{E}-01$ & $4.11 E-01$ \\
\hline
\end{tabular}


RESRAD-OFFSITE, Version 2.5

$\mathrm{T}^{1 / 2}$ Limit $=180$ days

Title : RESRAD-OFFSITE Drinking Water, Plant, Milk, and Meat Pathways for Offsite Reside File : PBA-1_TC99-DOE-5.ROF

Summary of dose at graphical times, reptition 3 (continued)

Time

Years

$3.54 \mathrm{E}+02$

$3.54 \mathrm{E}+02$

$3.55 \mathrm{E}+02$

$3.55 \mathrm{E}+02$

$3.56 \mathrm{E}+02$

$3.56 \mathrm{E}+02$

$3.57 \mathrm{E}+02$

$3.57 \mathrm{E}+02$

$3.58 \mathrm{E}+02$

$3.58 \mathrm{E}+02$

$3.59 \mathrm{E}+02$

$3.59 \mathrm{E}+02$

$3.60 \mathrm{E}+02$

$3.60 \mathrm{E}+02$

$3.61 \mathrm{E}+02$

3. $61 \mathrm{E}+02$

$3.62 \mathrm{E}+02$

$3.62 \mathrm{E}+02$

$3.63 \mathrm{E}+02$

3. $64 \mathrm{E}+02$

3. $64 \mathrm{E}+02$

$3.65 \mathrm{E}+02$

$3.65 \mathrm{E}+02$

$3.66 \mathrm{E}+02$

$3.66 \mathrm{E}+02$

$3.67 \mathrm{E}+02$

$3.67 \mathrm{E}+02$

$3.68 \mathrm{E}+02$

$3.68 \mathrm{E}+02$

$3.69 \mathrm{E}+02$

$3.69 \mathrm{E}+02$

3. $70 \mathrm{E}+02$

$3.70 \mathrm{E}+02$

$3.71 \mathrm{E}+02$

$3.71 \mathrm{E}+02$

3. $72 \mathrm{E}+02$

$3.72 \mathrm{E}+02$

$3.73 E+02$

$3.73 E+02$

$3.74 \mathrm{E}+02$

$3.74 \mathrm{E}+02$

$3.75 \mathrm{E}+02$

$3.75 \mathrm{E}+02$

$3.76 \mathrm{E}+02$

$3.76 \mathrm{E}+02$

$3.77 \mathrm{E}+02$
Dose statistics at graphical times, mrem/yr

\begin{tabular}{|c|c|c|c|c|c|c|c|}
\hline m & aximum & ean & ed & & & & \\
\hline $\mathrm{E}+00$ & 0 & 02 & 3 & 2 & 01 & 1 & -01 \\
\hline $\mathrm{E}+00$ & $41 E+00$ & $8 \mathrm{E}-02$ & $93 E-03$ & $5 E-02$ & $1.21 \mathrm{E}-01$ & $2.26 \mathrm{E}-01$ & $17 E-01$ \\
\hline $00 F+00$ & $42 F+00$ & $61 E-02$ & $96 \mathrm{E}-03$ & $92 \mathrm{~F}-02$ & $22 F-01$ & $28 E-01$ & $0 F-01$ \\
\hline $0 E+00$ & $.43 E+00$ & $3 E-02$ & 03 & & & 01 & -01 \\
\hline $\mathrm{E}+00$ & & 02 & 03 & 2 & 1 & 1 & -01 \\
\hline $.00 E+00$ & 00 & -02 & 03 & 02 & 1 & 1 & -01 \\
\hline $.00 E+00$ & +00 & -02 & 03 & 02 & 01 & & $33 E-01$ \\
\hline+00 & $\mathrm{E}+00$ & $3 E-02$ & $E-03$ & $5 E-02$ & $8 E-01$ & E-01 & $E-01$ \\
\hline $\mathrm{E}+00$ & $47 E+00$ & $75 E-02$ & $7 E-03$ & -02 & $0 E-01$ & -01 & -01 \\
\hline $0 \mathrm{E}+00$ & $48 F+00$ & $.78 \mathrm{E}-02$ & $1 E-03$ & & 1 & & 01 \\
\hline $.00 \mathrm{E}+00$ & & & & & & & -01 \\
\hline$E+00$ & $1.50 \mathrm{E}+00$ & $E-02$ & $E-03$ & $5 E-02$ & $33 E-01$ & 1 & $E-01$ \\
\hline $.00 E+00$ & $1.51 \mathrm{E}+00$ & $2.86 E-02$ & $2.32 E-03$ & $3 E-02$ & & & $E-01$ \\
\hline$\exists+00$ & $E+00$ & $E-02$ & $E-03$ & -02 & 1 & & -01 \\
\hline & $F$ & & & 2 & & & -01 \\
\hline $\mathrm{E}+00$ & & $.93 E-02$ & 3 & 2 & 1 & 1 & -01 \\
\hline 0 & 0 & 2 & 3 & 2 & 1 & 1 & -01 \\
\hline$E+00$ & $156 F+00$ & $9 E-02$ & $3 E-03$ & -02 & $14 \cap \mathrm{F}$ & 1 & -01 \\
\hline $.00 \mathrm{E}+00$ & $1.56 \mathrm{E}+00$ & $.01 \mathrm{E}-02$ & $2.57 \mathrm{E}-03$ & $7.03 E-02$ & $1.41 \mathrm{E}-01$ & $2.59 \mathrm{E}-01$ & $.75 E-01$ \\
\hline $.00 E+00$ & $1.57 \mathrm{E}+00$ & $3.04 \mathrm{E}-02$ & $2.62 E-03$ & $0 E-02$ & $43 E-01$ & $2.61 \mathrm{E}-01$ & $E-01$ \\
\hline & & & & & & & \\
\hline & & & & & & & -01 \\
\hline $.00 \mathrm{E}+00$ & $1.60 \mathrm{E}+00$ & & & & & & -01 \\
\hline $\mathrm{Ft}$ & $1 \mathrm{E}+0$ & 2 & 3 & 2 & 1 & 1 & -01 \\
\hline $.00 \mathrm{E}+00$ & $1.62 \mathrm{E}+00$ & $.17 \mathrm{E}-02$ & $2.87 \mathrm{E}-03$ & $7 \mathrm{E}-02$ & $.49 E-01$ & $.73 E-01$ & $E-01$ \\
\hline مח & $1.63 \mathrm{E}+00$ & $3.20 \mathrm{E}-02$ & $2.91 E-03$ & $4 E-02$ & $150 F-01$ & $2.75 \mathrm{E}-01$ & $E-01$ \\
\hline $\mathrm{F}+00$ & $64 \mathrm{~F}+00$ & $.23 E-02$ & $6 E-03$ & & & 2775 & 01 \\
\hline & & & & & & & -01 \\
\hline & & & & & & & -01 \\
\hline $.00 \mathrm{E}+00$ & $1.67 \mathrm{E}+00$ & $1 E-02$ & $3.12 \mathrm{E}-03$ & $7.87 \mathrm{E}-02$ & $1.56 \mathrm{E}-01$ & $2.84 \mathrm{E}-01$ & $15 E-01$ \\
\hline $.00 E+00$ & t. & $34 \mathrm{E}-02$ & $.17 E-03$ & $7.96 \mathrm{E}-02$ & $1.57 \mathrm{E}-01$ & $2.86 \mathrm{E}-01$ & $E-01$ \\
\hline & $1.68 \mathrm{E}+$ & & & & & & 11 \\
\hline & $1.69 \mathrm{E}+0$ & & & & & & 01 \\
\hline & $1.70 \mathrm{E}+00$ & & $E-03$ & 02 & & & -01 \\
\hline $\mathrm{E}+00$ & $1.71 \mathrm{E}+00$ & $E-02$ & 03 & 02 & 1 & 1 & -01 \\
\hline 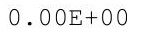 & 土. & $.48 \mathrm{E}-02$ & $3.42 \mathrm{E}-03$ & $8.39 \mathrm{E}-02$ & $1.65 \mathrm{E}-01$ & $2.97 \mathrm{E}-01$ & $38 E-01$ \\
\hline . & 土. & $3.51 \mathrm{E}-02$ & & $0.405-02$ & & & - $1+a^{2}$ \\
\hline (6) & t. & & & 2 & & & -01 \\
\hline 0 & $1.75 \mathrm{E}+0$ & 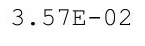 & & 2 & + & 1 & 01 \\
\hline 0 & $5 \mathrm{E}+00$ & 2 & 03 & 02 & 1 & 1 & -01 \\
\hline $0 \mathrm{E}+00$ & $1.77 \mathrm{E}+00$ & $3.63 E-02$ & $E-03$ & $3 E-02$ & $1.73 E-01$ & 01 & $E-01$ \\
\hline+00 & $1.78 \mathrm{E}+00$ & $E-02$ & $E-03$ & -02 & 1 . & 01 & -01 \\
\hline & 土. & & & & & & $.025-01$ \\
\hline 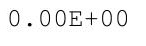 & 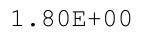 & 02 & & & 1. & & $\perp$ \\
\hline $\mathrm{E}+00$ & म. & & & & & & - 120 प \\
\hline 00 & $\mathrm{E}+00$ & $E-02$ & $E-03$ & $3 E-02$ & $E-01$ & -01 & -01 \\
\hline
\end{tabular}


RESRAD-OFFSITE, Version 2.5

Title : RESRAD-OFFSITE Drinking Water, Plant, Milk, and Meat Pathways for Offsite Reside File : PBA-1_TC99-DOE-5.ROF

Summary of dose at graphical times, reptition 3 (continued)

Time

Years

$3.77 \mathrm{E}+02$

$3.78 \mathrm{E}+02$

$3.78 \mathrm{E}+02$

$3.79 \mathrm{E}+02$

$3.79 \mathrm{E}+02$

$3.80 \mathrm{E}+02$

$3.80 \mathrm{E}+02$

3. $81 E+02$

$3.81 E+02$

3. $82 \mathrm{E}+02$

3. $82 \mathrm{E}+02$

$3.83 E+02$

3. $83 \mathrm{E}+02$

$3.84 \mathrm{E}+02$

$3.85 \mathrm{E}+02$

$3.85 \mathrm{E}+02$

$3.86 \mathrm{E}+02$

$3.86 \mathrm{E}+02$

$3.87 \mathrm{E}+02$

$3.87 \mathrm{E}+02$

$3.88 \mathrm{E}+02$

$3.88 \mathrm{E}+02$

$3.89 \mathrm{E}+02$

$3.89 \mathrm{E}+02$

3. $90 \mathrm{E}+02$

$3.90 \mathrm{E}+02$

3. $91 \mathrm{E}+02$

3. $91 \mathrm{E}+02$

3. $92 \mathrm{E}+02$

$3.92 \mathrm{E}+02$

3. $93 \mathrm{E}+02$

$3.93 \mathrm{E}+02$

$3.94 \mathrm{E}+02$

$3.94 \mathrm{E}+02$

$3.95 \mathrm{E}+02$

$3.95 \mathrm{E}+02$

$3.96 \mathrm{E}+02$

$3.96 \mathrm{E}+02$

$3.97 \mathrm{E}+02$

$3.97 \mathrm{E}+02$

$3.98 \mathrm{E}+02$

$3.98 \mathrm{E}+02$

$3.99 \mathrm{E}+02$

$3.99 \mathrm{E}+02$

$4.00 \mathrm{E}+02$

$4.00 \mathrm{E}+02$
Dose statistics at graphical times, mrem/yr

\begin{tabular}{|c|c|c|c|c|c|c|c|}
\hline inimum & aximum & Mean & ledian & $90 \%$ & $5 \%$ & $97.5 \%$ & \\
\hline 00 & $83 E+00$ & $3.81 E-02$ & $4.05 E-03$ & $9.37 E-02$ & $1.82 \mathrm{E}-01$ & $.20 \mathrm{E}-01$ & s \\
\hline+00 & -00 & 02 & 3 & 2 & 1 & 1 & 01 \\
\hline-00 & +00 & $E-02$ & -03 & $5 E-02$ & 01 & 01 & -01 \\
\hline+00 & $5 \mathrm{E}+00$ & 02 & & 2 & & & -01 \\
\hline+00 & 00 & 2 & 3 & & & -01 & $96 \mathrm{E}-01$ \\
\hline $\mathrm{E}+00$ & $E+00$ & $E-02$ & -03 & 02 & $E-01$ & 01 & 01 \\
\hline $\mathrm{DE}+00$ & $E+00$ & 2 & -03 & 02 & 1 & -01 & 0 \\
\hline $.00 E+00$ & $1.89 \mathrm{E}+00$ & . & $4.47 E-03$ & $1.00 \mathrm{E}-01$ & & -01 & $E-01$ \\
\hline 00 & +00 & 02 & 03 & $1 E-01$ & 01 & -01 & -01 \\
\hline $.00 \mathrm{E}+00$ & $1.91 \mathrm{E}+00$ & -02 & -03 & -01 & -01 & -01 & -01 \\
\hline+00 & $E+00$ & $E-02$ & -03 & 1 & & -01 & $E-01$ \\
\hline$E+00$ & +00 & -02 & & & & & -01 \\
\hline $.00 \mathrm{E}+00$ & $1.94 \mathrm{E}+00$ & $.19 \mathrm{E}-02$ & $4.79 E-03$ & $1.05 \mathrm{E}-01$ & $\Delta-U 1$ & $E-01$ & -0 \\
\hline$E+00$ & $1.95 \mathrm{E}+00$ & $.22 \mathrm{E}-02$ & -03 & 01 & 01 & -01 & $32 E-01$ \\
\hline$E+00$ & -00 & 02 & 03 & 01 & 01 & 01 & -01 \\
\hline $.00 \mathrm{E}+00$ & $1.97 \mathrm{E}+00$ & -02 & -03 & 01 & 01 & -01 & -01 \\
\hline $.00 \mathrm{E}+00$ & $1.98 \mathrm{E}+00$ & $2 E-02$ & $7 E-03$ & $8 E-01$ & $6 \mathrm{E}-01$ & $E-01$ & $4 \mathrm{E}-01$ \\
\hline $0 E+00$ & 1.99E+00 & $5 E-02$ & $4 E-03$ & $9 E-01$ & $08 E-01$ & -01 & $E-01$ \\
\hline $.00 \mathrm{E}+00$ & $2.00 \mathrm{E}+00$ & $9 \mathrm{E}-02$ & $2 E-03$ & -01 & & -01 & -01 \\
\hline$E+00$ & +00 & $E-02$ & -03 & 01 & -01 & -01 & $56 E-01$ \\
\hline$E+00$ & 2.0 & -02 & -03 & & & -01 & -01 \\
\hline $.00 \mathrm{E}+00$ & $2.02 \mathrm{E}+00$ & $.49 \mathrm{E}-02$ & 03 & 01 & & -01 & -01 \\
\hline $.00 \mathrm{E}+00$ & $2.03 E+00$ & 4. $52 \mathrm{E}-02$ & $2 E-03$ & $1.14 \mathrm{E}-01$ & $16 E-01$ & $72 E-01$ & $68 E-01$ \\
\hline $.00 \mathrm{E}+00$ & $2.04 \mathrm{E}+00$ & $6 \mathrm{E}-02$ & $9 E-03$ & $1.14 \mathrm{E}-01$ & $18 \mathrm{E}-01$ & $74 \mathrm{E}-01$ & $72 \mathrm{E}-01$ \\
\hline+00 & $2.05 \mathrm{E}+00$ & $59 E-02$ & $E-03$ & 01 & 01 & -01 & $E-01$ \\
\hline$\exists+00$ & 2.0 & $E-02$ & 03 & 1 & & & -01 \\
\hline $.00 E+00$ & $2.07 E+00$ & $6 \mathrm{E}-02$ & -03 & & 1 & 01 & -01 \\
\hline $.00 \mathrm{E}+00$ & $2.08 \mathrm{E}+00$ & $4.70 E-02$ & $5.91 E-03$ & $1.18 \mathrm{E}-01$ & $2.24 \mathrm{E}-01$ & $83 E-01$ & $88 E-01$ \\
\hline $00 \mathrm{E}+00$ & $2.09 E+00$ & $73 E-02$ & 3 & 1 & . 20001 & 1 & -01 \\
\hline $.54 \mathrm{E}-28$ & 50 & $4.77 \mathrm{E}-02$ & S & 1.20E-01 & S & N & $7 E-0$ \\
\hline-25 & $2.11 E+00$ & $80 F-02$ & $.15 E-03$ & $0 E-01$ & & 1 & $E-01$ \\
\hline-23 & $2.12 \mathrm{E}+00$ & $4 E-02$ & $E-03$ & $1 E-01$ & -01 & -01 & $E-01$ \\
\hline $3 E-21$ & $2.13 \mathrm{E}+00$ & $E-02$ & 03 & $1 . \angle 2 \mathrm{E}$ & 1 & 01 & $9 E-01$ \\
\hline $47 E-19$ & $2.14 \mathrm{E}+00$ & $91 E-02$ & $6.40 E-03$ & 1. $23 \mathrm{E}-01$ & $35 E-01$ & $.97 E-01$ & $.13 \mathrm{E}-01$ \\
\hline $77 E-18$ & $\angle \cdot \perp J \mathrm{~T} T U$ & $4.95 E-02$ & $6.48 E-03$ & $1.24 \mathrm{E}-01$ & & $.02 \mathrm{~L}-U$ & $.17 E-01$ \\
\hline 17 & & & & & & & \\
\hline $155-16$ & $2.17 \mathrm{E}+00$ & & & & & 1 & 01 \\
\hline $.19 \mathrm{E}-15$ & 2.18 & & & & & & 01 \\
\hline$F-14$ & & & & & & & 01 \\
\hline $.55 E-14$ & $2.20 E+00$ & $3 E-02$ & $9 E-03$ & 1 & 1 & 1 & $9 E-01$ \\
\hline$E-13$ & $2.21 \mathrm{E}+$ & 2 & & 1 & & & -01 \\
\hline 13 & $\angle \cdot \angle \perp E+U 0$ & & & $+\cdot 0+$ & & & $4 / 2-U \perp$ \\
\hline$\cdot 1 J \pm-12$ & 0 & 2 & s & 1.020 & 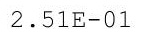 & 01 & $\perp$ \\
\hline $.14 E-12$ & - & 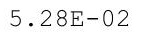 & & 20 & $2.53 E-01$ & $2<4$ & ter \\
\hline $\mathrm{E}-11$ & $2.24 \mathrm{E}+00$ & $E-02$ & 03 & 1.3 & 01 & 01 & $60 E-01$ \\
\hline $15 E-11$ & $2.25 E+00$ & $.35 E-02$ & $.41 E-03$ & 1. $34 \mathrm{E}-01$ & $2.57 \mathrm{E}-01$ & $27 E-01$ & 7. $64 \mathrm{E}-01$ \\
\hline
\end{tabular}


RESRAD-OFFSITE, Version 2.5

$\mathrm{T}^{1 / 2}$ Limit $=180$ days

Title : RESRAD-OFFSITE Drinking Water, Plant, Milk, and Meat Pathways for Offsite Reside File : PBA-1_TC99-DOE-5.ROF

Summary of dose at graphical times, reptition 3 (continued)

Time

Years

$4.01 \mathrm{E}+02$

$4.01 \mathrm{E}+02$

$4.02 \mathrm{E}+02$

$4.02 \mathrm{E}+02$

$4.03 E+02$

$4.03 \mathrm{E}+02$

$4.04 \mathrm{E}+02$

$4.05 \mathrm{E}+02$

$4.05 \mathrm{E}+02$

$4.06 \mathrm{E}+02$

$4.06 \mathrm{E}+02$

$4.07 \mathrm{E}+02$

$4.07 \mathrm{E}+02$

$4.08 \mathrm{E}+02$

$4.08 \mathrm{E}+02$

$4.09 \mathrm{E}+02$

$4.09 \mathrm{E}+02$

$4.10 \mathrm{E}+02$

$4.10 \mathrm{E}+02$

$4.11 \mathrm{E}+02$

$4.11 \mathrm{E}+02$

$4.12 \mathrm{E}+02$

$4.12 \mathrm{E}+02$

$4.13 \mathrm{E}+02$

$4.13 \mathrm{E}+02$

$4.14 \mathrm{E}+02$

$4.14 \mathrm{E}+02$

$4.15 \mathrm{E}+02$

$4.15 \mathrm{E}+02$

$4.16 \mathrm{E}+02$

$4.16 \mathrm{E}+02$

$4.17 \mathrm{E}+02$

$4.17 \mathrm{E}+02$

$4.18 \mathrm{E}+02$

$4.18 \mathrm{E}+02$

4. $19 \mathrm{E}+02$

$4.19 \mathrm{E}+02$

$4.20 \mathrm{E}+02$

$4.20 \mathrm{E}+02$

$4.21 \mathrm{E}+02$

$4.21 \mathrm{E}+02$

4. $22 \mathrm{E}+02$

4. $22 \mathrm{E}+02$

$4.23 \mathrm{E}+02$

$4.23 \mathrm{E}+02$

$4.24 \mathrm{E}+02$
Dose statistics at graphical times, mrem/yr

\begin{tabular}{|c|c|c|c|c|c|c|c|}
\hline m & hum & ean & eq & & & & \\
\hline 11 & 0 & 2 & 3 & 1 & 01 & 1 & -01 \\
\hline $30 \mathrm{E}-10$ & $.27 \mathrm{E}+00$ & $3 E-02$ & $7.60 \mathrm{E}-03$ & $1.36 \mathrm{E}-01$ & $2.60 \mathrm{E}-01$ & $.33 E-01$ & $73 E-01$ \\
\hline $\mathrm{F}-10$ & $28 F+00$ & $7 F-02$ & $0 E-03$ & $.37 E-01$ & $62 E-01$ & 01 & $77 F-01$ \\
\hline 10 & $9 F+00$ & & 3 & & & & 01 \\
\hline 10 & $E+00$ & 02 & 03 & 1 & 1 & 1 & $E-01$ \\
\hline $23 E-09$ & $.31 E+00$ & $8 E-02$ & 03 & 1 & 1 & & -01 \\
\hline $96 E-09$ & $2 \mathrm{E}+00$ & -02 & & & & & $94 E-01$ \\
\hline$E-09$ & $\Xi+00$ & $E-02$ & $E-03$ & $.42 E-01$ & $E-01$ & -01 & $E-01$ \\
\hline $.58 E-09$ & $4 \mathrm{E}+00$ & $E-02$ & -03 & -01 & 01 & 1 & $E-01$ \\
\hline $.75 E-09$ & $35 \mathrm{~F}+00$ & $74 F-02$ & $9 E-03$ & $135-$ & & & 21 \\
\hline 9 & & & & & & & -01 \\
\hline $37 E-08$ & $7 \mathrm{E}+00$ & $2 E-02$ & $E-03$ & $45 E-01$ & $0 E-01$ & 1 & $E-01$ \\
\hline $.91 E-08$ & $2.38 E+00$ & $.86 E-02$ & $8.72 E-03$ & $1.46 E-01$ & $2.82 \mathrm{E}-01$ & $63 E-01$ & $20 E-01$ \\
\hline$E-08$ & $E+00$ & $E-02$ & -03 & & & & $\exists-01$ \\
\hline & & & & & & & -01 \\
\hline & & $.98 \mathrm{E}-02$ & & & & & 01 \\
\hline 8 & & & 03 & 1 & & 1 & -01 \\
\hline $77 F-08$ & $242 F+00$ & $.06 E-02$ & $7 E-03$ & $153 \mathrm{~F}$ & 1 & $77 \mathrm{E}-01$ & -01 \\
\hline$E-08$ & $.43 E+00$ & $10 E-02$ & $8 E-03$ & $54 E-01$ & $4 E-01$ & $30 E-01$ & $46 E-01$ \\
\hline $.25 E-07$ & $.44 \mathrm{E}+00$ & $6.14 \mathrm{E}-02$ & $9.49 \mathrm{E}-03$ & $1.56 \mathrm{E}-01$ & $2.96 \mathrm{E}-01$ & $83 E-01$ & $E-01$ \\
\hline & $15 F+0$ & & & & & & \\
\hline & & & & & & & 01 \\
\hline 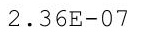 & $2.47 \mathrm{E}+\mathrm{C}$ & & 03 & & & & 01 \\
\hline $6 \mathrm{E}-07$ & $.48 E+0$ & 2 & 3 & 1 & & 1 & -01 \\
\hline$=-0$ & $.49 E+00$ & $.35 E-02$ & $.01 \mathrm{E}-02$ & $.62 E-01$ & $5 E-0$ & $7 E-01$ & $z-01$ \\
\hline $12 \mathrm{~F}-07$ & $.50 \mathrm{E}+00$ & $.39 E-02$ & $1.02 \mathrm{E}-02$ & $1.63 E-01$ & $7 F-01$ & $E-01$ & $77 E-01$ \\
\hline-07 & $.51 E+00$ & $E-02$ & $3 E-02$ & & & & 01 \\
\hline & & & & & & & 01 \\
\hline & & & & & & & \\
\hline 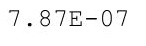 & & 2 & 02 & +0 & - & 1 & 01 \\
\hline $.11 \mathrm{E}-07$ & $2.54 \mathrm{E}+00$ & $.60 E-02$ & $.08 \mathrm{E}-02$ & $1.69 \mathrm{E}-01$ & $3.16 \mathrm{E}-01$ & - & $99 E-01$ \\
\hline - & & & & & & & 11 \\
\hline $2+2$ & & & & & & & 01 \\
\hline & & & & & & & 01 \\
\hline & & & & 1 & & & \\
\hline $.76 \mathrm{E}-06$ & $2.59 \mathrm{E}+00$ & $6.82 \mathrm{E}-02$ & $1.14 \mathrm{E}-02$ & $1.75 \mathrm{E}-01$ & $3.23 E-0 \perp$ & $8 E-01$ & $22 E-01$ \\
\hline 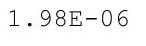 & - & $15-2<$ & 02 & - & & & $0 \perp$ \\
\hline cer & - & & & & & & $31 E-01$ \\
\hline $.48 E-06$ & $2.62 \mathrm{E}+0$ & . & 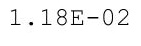 & 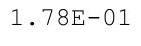 & (5) & $36 E-01$ & 01 \\
\hline $.76 E-06$ & & & & 1 & 1 & 1 & 01 \\
\hline $6 E-06$ & & $.04 E-02$ & 1.20E-02 & $1.80 \mathrm{E}-01$ & $E-01$ & $2 E-01$ & $44 E-01$ \\
\hline$E-06$ & $2.65 \mathrm{E}+00$ & $09 \mathrm{E}-02$ & 1.22E-02 & $1.82 \mathrm{E}-01$ & 01 & 01 & -01 \\
\hline & 2. & & & & & & -01 \\
\hline tron & ट. & 02 & 02 & t. & e. & 1 & . \\
\hline 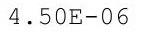 & e & क्रिए & & $1.86 \mathrm{E}-01$ & & $53 E-01$ & गुण \\
\hline-06 & $E+00$ & $E-02$ & $E-02$ & $7 E-01$ & $E-01$ & $E-01$ & -01 \\
\hline
\end{tabular}


RESRAD-OFFSITE, Version 2.5

Title : RESRAD-OFFSITE Drinking Water, Plant, Milk, and Meat Pathways for Offsite Reside File : PBA-1_TC99-DOE-5.ROF

Summary of dose at graphical times, reptition 3 (continued)

Time

Years

$4.25 E+02$

$4.25 \mathrm{E}+02$

$4.26 \mathrm{E}+02$

$4.26 \mathrm{E}+02$

$4.27 \mathrm{E}+02$

$4.27 \mathrm{E}+02$

$4.28 \mathrm{E}+02$

$4.28 \mathrm{E}+02$

$4.29 \mathrm{E}+02$

$4.29 \mathrm{E}+02$

$4.30 \mathrm{E}+02$

4. $30 \mathrm{E}+02$

4. $31 \mathrm{E}+02$

4. $31 \mathrm{E}+02$

4. $32 \mathrm{E}+02$

4. $32 \mathrm{E}+02$

4. $33 \mathrm{E}+02$

4. $33 \mathrm{E}+02$

4. $34 \mathrm{E}+02$

4. $34 \mathrm{E}+02$

4. $35 \mathrm{E}+02$

4. $35 \mathrm{E}+02$

4. $36 \mathrm{E}+02$

$4.36 \mathrm{E}+02$

$4.37 \mathrm{E}+02$

$4.37 \mathrm{E}+02$

$4.38 \mathrm{E}+02$

$4.38 \mathrm{E}+02$

4. $39 \mathrm{E}+02$

$4.39 \mathrm{E}+02$

$4.40 \mathrm{E}+02$

4. $40 \mathrm{E}+02$

$4.41 \mathrm{E}+02$

4. $41 \mathrm{E}+02$

4. $42 \mathrm{E}+02$

4. $42 \mathrm{E}+02$

$4.43 E+02$

$4.43 \mathrm{E}+02$

4. $44 \mathrm{E}+02$

4. $45 \mathrm{E}+02$

4. $45 \mathrm{E}+02$

$4.46 \mathrm{E}+02$

$4.46 \mathrm{E}+02$

$4.47 \mathrm{E}+02$

4. $47 \mathrm{E}+02$

$4.48 \mathrm{E}+02$
Dose statistics at graphical times, mrem/yr

\begin{tabular}{|c|c|c|c|c|c|c|c|}
\hline Inimum & Iaximum & Mean & Median & $90 \%$ & $95 \%$ & $97.5 \%$ & \\
\hline 6 & $9 E+00$ & 02 & $29 E-02$ & 1 & 1 & 01 & 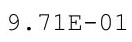 \\
\hline $3 E-06$ & $0 \mathrm{E}+00$ & $6 \mathrm{E}-02$ & 1. $30 \mathrm{E}-02$ & $1.90 \mathrm{E}-01$ & $3.49 \mathrm{E}-01$ & -01 & - \\
\hline $2 E-06$ & $E+00$ & $E-02$ & $2 E-02$ & 1 & 01 & 01 & $80 \mathrm{E}-01$ \\
\hline-06 & $E+00$ & $E-02$ & $3 E-02$ & $3 E-01$ & $3 E-01$ & -01 & $5 E-01$ \\
\hline $.39 E-06$ & $2.73 \mathrm{E}+00$ & -02 & -02 & 1 & 01 & $9 \mathrm{E}-01$ & $89 \mathrm{E}-01$ \\
\hline $7 E-06$ & +00 & -02 & -02 & 1 & 1 & -01 & $E-01$ \\
\hline $7 E-06$ & $5 E+00$ & $9 E-02$ & $1.37 E-02$ & 01 & $0 E-01$ & -01 & $E-01$ \\
\hline $1 E-06$ & $2.76 \mathrm{E}+00$ & $7.64 \mathrm{E}-02$ & 1. 39E-02 & $1.99 \mathrm{E}-01$ & $3.62 \mathrm{E}-01$ & $.77 \mathrm{E}-01$ & $.00 \mathrm{E}+00$ \\
\hline $.87 E-06$ & $2.77 \mathrm{E}+00$ & $1.00 \mathrm{C}$ & 1. $40 \mathrm{E}-02$ & & $3.64 \mathrm{E}-01$ & -01 & $1 \mathrm{E}+00$ \\
\hline$E-05$ & $E+00$ & $E-02$ & -02 & 01 & 01 & -01 & $1 E+00$ \\
\hline $.13 E-05$ & $2.78 \mathrm{E}+00$ & $7.78 \mathrm{E}-02$ & 1. $43 E-02$ & $2.03 \mathrm{E}-$ & $68 \mathrm{E}-01$ & $86 \mathrm{E}-01$ & $.02 \mathrm{E}+00$ \\
\hline$J$ & $E+00$ & -02 & -02 & 1 & & 01 & $2 E+00$ \\
\hline $\begin{array}{ll}\cdot 200 \\
0\end{array}$ & $2.80 \mathrm{E}+00$ & $7 E-02$ & $6 E-02$ & & $2 \mathrm{E}-\mathrm{U} \perp$ & -01 & $03 E+00$ \\
\hline SOE- & Z.OLETU & $1.9 \angle \mathrm{E}-0 \angle$ & 1. $47 \mathrm{E}-02$ & 2.00 & $3.7 \mathrm{E}-0 \perp$ & -01 & $.03 E+00$ \\
\hline$E-05$ & $E+00$ & $E-02$ & 02 & 1 & $77 \mathrm{E}-01$ & 01 & $03 E+00$ \\
\hline ك & $2.83 E+00$ & -02 & 02 & 1 & $79 E-01$ & 01 & $E+00$ \\
\hline $.62 E-05$ & $2.84 \mathrm{E}+00$ & $E-02$ & $1.52 \mathrm{E}-02$ & 2.11 & $82 E-01$ & $3 E-01$ & $.04 \mathrm{E}+00$ \\
\hline$E-05$ & $5 E+00$ & $E-02$ & $4 \mathrm{E}-02$ & 01 & $E-01$ & -01 & $5 E+00$ \\
\hline $.81 E-05$ & $2.85 \mathrm{E}+00$ & $6 \mathrm{E}-02$ & $1.55 \mathrm{E}-02$ & & $6 \mathrm{E}-01$ & 01 & $05 E+00$ \\
\hline $.91 E-05$ & $2.86 \mathrm{E}+00$ & $1 E-02$ & -02 & 01 & $9 E-01$ & 01 & $\mathrm{E}+00$ \\
\hline $25-03$ & 2.8 & $6 E-02$ & $1.59 \mathrm{E}-02$ & & & & $6 \mathrm{E}+00$ \\
\hline $2 E-05$ & $2.88 \mathrm{E}+00$ & $.30 \mathrm{E}-02$ & $1.60 \mathrm{E}-02$ & $2.10 \mathrm{H}$ & $93 \mathrm{E}-01$ & -01 & +00 \\
\hline $.23 E-05$ & $2.89 \mathrm{E}+00$ & $8.35 E-02$ & 1. $62 \mathrm{E}-02$ & $2.20 \mathrm{E}-01$ & $3.95 \mathrm{E}-01$ & $0 E-01$ & $.07 E+00$ \\
\hline$E-05$ & $2.90 \mathrm{E}+00$ & $0 E-02$ & $4 E-02$ & 01 & $97 E-01$ & -01 & $08 \mathrm{E}+00$ \\
\hline 05 & $2.91 \mathrm{E}+00$ & $5 E-02$ & $E-02$ & & $E-01$ & -01 & $8 \mathrm{E}+00$ \\
\hline$E-05$ & 00 & $E-02$ & -02 & 1 & 01 & 01 & $8 E+00$ \\
\hline JE-US & $2.93 E+00$ & $E-02$ & $0 E-02$ & 01 & $4 E-01$ & & $9 \mathrm{E}+00$ \\
\hline $.83 E-05$ & $2.93 \mathrm{E}+00$ & $8.60 \mathrm{E}-02$ & $1.71 \mathrm{E}-02$ & $2.27 \mathrm{E}-01$ & $4.06 \mathrm{E}-01$ & $.35 E-01$ & $.09 \mathrm{E}+00$ \\
\hline $.96 E-05$ & $2.94 \mathrm{E}+00$ & $8.65 E-02$ & $1.73 E-02$ & $2.28 \mathrm{E}-01$ & $4.08 \mathrm{E}-01$ & $37 E-01$ & $.10 \mathrm{E}+00$ \\
\hline . & 2.90 ETU & $8.70 \mathrm{E}-02$ & $1.75 E-02$ & $2.30 \mathrm{E}-01$ & 正 & -01 & • \\
\hline $3 F-05$ & P & $E-02$ & $E-02$ & & 1 & 1 & $11 \mathrm{E}+00$ \\
\hline 05 & $2.97 \mathrm{E}+00$ & $E-02$ & $8 E-02$ & 1 & 1 & 01 & 00 \\
\hline $1 E-05$ & $2.98 \mathrm{E}+00$ & $5 E-02$ & $1.80 \mathrm{E}-02$ & 2 . & 1 & $0 E-01$ & $12 \mathrm{E}+00$ \\
\hline $.65 E-05$ & $2.99 \mathrm{E}+00$ & $8.90 \mathrm{E}-02$ & $1.82 \mathrm{E}-02$ & $2.35 \mathrm{E}-01$ & $4.20 \mathrm{E}-01$ & $3 E-01$ & $.12 \mathrm{E}+00$ \\
\hline 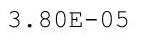 & $3.00 E+00$ & $.95 E-02$ & $1.84 \mathrm{E}-02$ & & & $57 E-01$ & • $\perp S E+U C$ \\
\hline & & & & & & & $13 \mathrm{E}+0 \mathrm{C}$ \\
\hline & & & & & $\perp$ & 1 & 00 \\
\hline $27=0$ & 再 & 2 & 2 & 1 & 1 & 01 & 00 \\
\hline $.43 E-05$ & & & & & & -01 & \\
\hline $0 E-05$ & $4 \mathrm{E}+00$ & $E-02$ & $1.93 E-02$ & & 1 & & $5 E+00$ \\
\hline $5-03$ & ד & $26 E-02$ & 2 & & 1 & & $15 \mathrm{E}+0 \mathrm{C}$ \\
\hline 5 & 0 & 2 & 02 & 1 & 01 & 01 & $1.10 \mathrm{E}+00$ \\
\hline & 3 & 2 & & & $\perp$ & 1 & +0 \\
\hline & 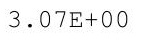 & & 2 & 1 & 1 & 1 & 00 \\
\hline$E-05$ & $E+00$ & $E-02$ & 2. & 01 & 4. & 01 & $1.17 \mathrm{E}+00$ \\
\hline $.66 E-05$ & $3.09 \mathrm{E}+00$ & $.53 E-02$ & $2.04 \mathrm{E}-02$ & $2.53 E-01$ & $4.51 \mathrm{E}-01$ & $6.93 \mathrm{E}-01$ & $1.17 \mathrm{E}+00$ \\
\hline
\end{tabular}


RESRAD-OFFSITE, Version 2.5

Title : RESRAD-OFFSITE Drinking Water, Plant, Milk, and Meat Pathways for Offsite Reside File : PBA-1_TC99-DOE-5.ROF

Summary of dose at graphical times, reptition 3 (continued)

Time

Years

$4.48 \mathrm{E}+02$

$4.49 \mathrm{E}+02$

$4.49 \mathrm{E}+02$

$4.50 \mathrm{E}+02$

$4.50 \mathrm{E}+02$

$4.51 \mathrm{E}+02$

$4.51 \mathrm{E}+02$

4. $52 \mathrm{E}+02$

4. $52 \mathrm{E}+02$

4. $53 \mathrm{E}+02$

4. $53 \mathrm{E}+02$

4. $54 \mathrm{E}+02$

4. $54 \mathrm{E}+02$

4. $55 \mathrm{E}+02$

4. $55 \mathrm{E}+02$

4. $56 \mathrm{E}+02$

4. $56 \mathrm{E}+02$

4. $57 \mathrm{E}+02$

$4.57 \mathrm{E}+02$

$4.58 \mathrm{E}+02$

$4.58 \mathrm{E}+02$

$4.59 \mathrm{E}+02$

$4.59 \mathrm{E}+02$

$4.60 \mathrm{E}+02$

$4.60 \mathrm{E}+02$

$4.61 \mathrm{E}+02$

4. $61 \mathrm{E}+02$

$4.62 \mathrm{E}+02$

4. $62 \mathrm{E}+02$

$4.63 E+02$

$4.63 \mathrm{E}+02$

$4.64 \mathrm{E}+02$

$4.65 \mathrm{E}+02$

$4.65 \mathrm{E}+02$

$4.66 \mathrm{E}+02$

$4.66 \mathrm{E}+02$

$4.67 \mathrm{E}+02$

$4.67 \mathrm{E}+02$

$4.68 \mathrm{E}+02$

$4.68 \mathrm{E}+02$

$4.69 \mathrm{E}+02$

$4.69 \mathrm{E}+02$

$4.70 \mathrm{E}+02$

$4.70 \mathrm{E}+02$

$4.71 \mathrm{E}+02$

$4.71 E+02$
Dose statistics at graphical times, mrem/yr

\begin{tabular}{|c|c|c|c|c|c|c|c|}
\hline inimum & aximum & Mean & ledian & $0 \%$ & $\%$ & $7.5 \%$ & \\
\hline 05 & +00 & $9.58 \mathrm{E}-02$ & $6 E-02$ & $2.55 \mathrm{E}-01$ & $4.54 \mathrm{E}-01$ & $6.96 \mathrm{E}-01$ & $8 \mathrm{E}+0$ \\
\hline 05 & +00 & 2 & 2 & 1 & 1 & 1 & 100 \\
\hline 05 & +00 & -02 & -02 & $\exists-01$ & 01 & 01 & +00 \\
\hline-05 & +00 & 2 & & 1 & & & +00 \\
\hline $65 E-05$ & +00 & 2 & & & 01 & $9 E-01$ & $.19 \mathrm{E}+00$ \\
\hline $.86 E-05$ & +00 & -02 & $E-02$ & $E-C$ & $E-01$ & $E-01$ & $E+00$ \\
\hline-05 & +00 & 2 & -02 & 1 & 1 & 01 & 0 \\
\hline $.28 E-05$ & $3.16 \mathrm{E}+00$ & $5 E-02$ & & $2.65 E-01$ & & -01 & +00 \\
\hline 05 & -00 & 01 & 02 & 01 & 1 & -01 & +00 \\
\hline $2 E-05$ & $.17 \mathrm{E}+00$ & $1 \mathrm{E}-01$ & $5 E-02$ & $8 E-01$ & $76 \mathrm{E}-01$ & $E-01$ & $.22 \mathrm{E}+00$ \\
\hline $.93 E-05$ & $3.18 \mathrm{E}+00$ & $1 E-01$ & $7 E-02$ & $0 \mathrm{E}-01$ & $78 E-01$ & $.29 \mathrm{E}-01$ & $.22 \mathrm{E}+00$ \\
\hline 05 & +00 & $E-01$ & $q-02$ & 1 & 1 & -01 & +00 \\
\hline$E-03$ & $\mathrm{E}+00$ & $.02 \mathrm{E}-01$ & -02 & 1 & $\perp$ & -01 & +0 \\
\hline 5 & 0 & 1 & 2 & 1 & 1 & -01 & +00 \\
\hline 05 & -00 & 01 & 02 & 1 & 1 & -01 & $\Xi+00$ \\
\hline$E-05$ & $3.22 \mathrm{E}+00$ & -01 & -02 & 1 & 01 & -01 & +00 \\
\hline $.13 E-05$ & $3.23 E+00$ & $4 E-01$ & $9 E-02$ & $9 E-01$ & $1 \mathrm{E}-01$ & $49 \mathrm{E}-01$ & 1. $25 \mathrm{E}+00$ \\
\hline 05 & $4 E+00$ & $5 E-01$ & $1 E-02$ & $0 E-01$ & $3 E-01$ & $E-01$ & $25 E+00$ \\
\hline & 0 & & -02 & 1 & & -01 & +0 \\
\hline 05 & -00 & 01 & 02 & 01 & 01 & -01 & +00 \\
\hline 5 & & & & & & 1 & 00 \\
\hline 04 & $F+0$ & 1 & 2 & & & -01 & $E+00$ \\
\hline$E-04$ & $28 \mathrm{E}+00$ & $08 E-01$ & $E-02$ & 1 & 1 & $5 E-01$ & $27 E+00$ \\
\hline $6 \mathrm{E}-04$ & $.29 E+00$ & $1.08 \mathrm{E}-01$ & $5 \mathrm{E}-02$ & $39 E-01$ & $07 E-01$ & $57 E-01$ & $.28 \mathrm{E}+00$ \\
\hline 04 & $0 \mathrm{E}+00$ & $.09 E-01$ & $8 \mathrm{E}-02$ & & -01 & $\mathrm{~F}-01$ & $.28 \mathrm{E}+00$ \\
\hline & & & & & & & \\
\hline & & & & & & -01 & $.29 \mathrm{E}+00$ \\
\hline$\cdot 10 \mathrm{D}-04$ & $3.32 \mathrm{E}+00$ & $.11 \mathrm{E}-01$ & $2.65 E-02$ & $5 E-01$ & $16 \mathrm{E}-01$ & $.77 \mathrm{E}-01$ & 1. $29 \mathrm{E}+00$ \\
\hline 04 & 0 & 1 & $.68 E-02$ & 1 & $\perp$ & $9 E-01$ & $.30 E+0 C$ \\
\hline 4 & . & $.12 \mathrm{E}-01$ & $1 \mathrm{E}-02$ & 1 & & - & . $30 \mathrm{E}+0$ \\
\hline-04 & $3 \triangle F+0$ & $2 E-01$ & & 1 & & $F-01$ & $.31 E+00$ \\
\hline 04 & & & & & & 01 & \\
\hline & & & & & 1 & -01 & \\
\hline $.31 E-04$ & $3.37 \mathrm{E}+00$ & $.14 \mathrm{E}-01$ & $E-02$ & $4 E-01$ & $32 E-01$ & $0 E-01$ & $1.32 \mathrm{E}+0 \mathrm{C}$ \\
\hline $.33 E-04$ & & $1.15 E-01$ & & & & $1.905-U 1$ & Р.SОЕТО \\
\hline 7 & & & & & & & \\
\hline 4 & $3.39 \mathrm{E}+00$ & & & 1 & & 1 & $33 E$ \\
\hline 4 & & & & 1 & & & \\
\hline$E-04$ & & & & 1 & 1 & 01 & $1.34 \mathrm{E}+00$ \\
\hline $.47 E-04$ & $3.41 E+00$ & $8 E-01$ & $E-02$ & 1 & 1 & & $1.35 \mathrm{E}+00$ \\
\hline 4 & & $E-01$ & & & & & 1.35 \\
\hline 4 & $3.45 E+00$ & $1.19 \mathrm{E}-01$ & & 1 & & & $1.30 \mathrm{E}+00$ \\
\hline 4 & $3.44 \mathrm{E}+0$ & $\perp$ & $1 E-02$ & $17 E-01$ & $00 E-U 1$ & $-4 E-U \perp$ & $1.36 \mathrm{E}+0$ \\
\hline \pm & - & $\perp \cdot 2 U D-U \perp$ & & $3.19 \mathrm{E}-01$ & $5.63 \mathrm{E}-01$ & $E-01$ & $1.37 \mathrm{E}+00$ \\
\hline 04 & $3.45 \mathrm{E}+00$ & $1.21 \mathrm{E}-01$ & $E-02$ & 01 & 01 & 01 & $1.37 \mathrm{E}+00$ \\
\hline $.64 E-04$ & $3.46 \mathrm{E}+00$ & 1.21E-01 & $.10 \mathrm{E}-02$ & $3.23 E-01$ & $5.68 \mathrm{E}-01$ & $8.24 \mathrm{E}-01$ & $1.37 \mathrm{E}+00$ \\
\hline
\end{tabular}


RESRAD-OFFSITE, Version 2.5

Title : RESRAD-OFFSITE Drinking Water, Plant, Milk, and Meat Pathways for Offsite Reside File : PBA-1_TC99-DOE-5.ROF

Summary of dose at graphical times, reptition 3 (continued)

Time

Years

$4.72 \mathrm{E}+02$

$4.72 \mathrm{E}+02$

$4.73 \mathrm{E}+02$

$4.73 \mathrm{E}+02$

$4.74 \mathrm{E}+02$

$4.74 \mathrm{E}+02$

$4.75 \mathrm{E}+02$

$4.75 \mathrm{E}+02$

$4.76 \mathrm{E}+02$

$4.76 \mathrm{E}+02$

$4.77 \mathrm{E}+02$

$4.77 \mathrm{E}+02$

$4.78 \mathrm{E}+02$

$4.78 \mathrm{E}+02$

$4.79 \mathrm{E}+02$

$4.79 \mathrm{E}+02$

$4.80 \mathrm{E}+02$

$4.80 \mathrm{E}+02$

$4.81 \mathrm{E}+02$

$4.81 \mathrm{E}+02$

$4.82 \mathrm{E}+02$

$4.82 \mathrm{E}+02$

$4.83 \mathrm{E}+02$

$4.83 \mathrm{E}+02$

$4.84 \mathrm{E}+02$

$4.84 \mathrm{E}+02$

$4.85 \mathrm{E}+02$

$4.86 \mathrm{E}+02$

$4.86 \mathrm{E}+02$

$4.87 \mathrm{E}+02$

$4.87 \mathrm{E}+02$

$4.88 \mathrm{E}+02$

$4.88 \mathrm{E}+02$

$4.89 \mathrm{E}+02$

$4.89 \mathrm{E}+02$

$4.90 \mathrm{E}+02$

$4.90 \mathrm{E}+02$

$4.91 E+02$

$4.91 \mathrm{E}+02$

$4.92 \mathrm{E}+02$

$4.92 \mathrm{E}+02$

$4.93 E+02$

4. $93 \mathrm{E}+02$

$4.94 \mathrm{E}+02$

4. $94 \mathrm{E}+02$

$4.95 \mathrm{E}+02$
Dose statistics at graphical times, mrem/yr

\begin{tabular}{|c|c|c|c|c|c|c|c|}
\hline inimum & aximum & Mean & ledian & $0 \%$ & $5 \%$ & $97.5 \%$ & \\
\hline 4 & +00 & $2 E-01$ & $E-02$ & 01 & 1 & 01 & 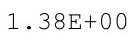 \\
\hline 04 & $\mathrm{E}+00$ & $22 E-01$ & $5 E-02$ & $7 \mathrm{E}-$ & 1 & 01 & $.38 E+00$ \\
\hline-04 & $E+00$ & $23 E-01$ & $E-02$ & $9 \mathrm{E}-01$ & 01 & -01 & +00 \\
\hline 04 & 00 & 1 & 02 & 1 & 1 & 01 & +00 \\
\hline-04 & 00 & 1 & 2 & 1 & 01 & -01 & $E+00$ \\
\hline $.82 E-04$ & $0 \mathrm{E}+00$ & $.25 E-01$ & $E-02$ & $5 E-01$ & $5 E-01$ & $5 E-01$ & $.40 \mathrm{E}+00$ \\
\hline $.85 E-04$ & +00 & . & -02 & $3.37 \mathrm{E}-$ & 01 & -01 & +00 \\
\hline $.89 E-04$ & $3.52 \mathrm{E}+00$ & 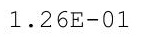 & $3.34 \mathrm{E}-02$ & $3.39 E-01$ & $92 E-01$ & -01 & +00 \\
\hline 04 & +00 & $.27 \mathrm{E}-$ & -02 & 01 & 01 & -01 & +00 \\
\hline $.95 E-04$ & $3.53 \mathrm{E}+00$ & $1.27 E-01$ & -02 & 01 & 01 & -01 & $.42 \mathrm{E}+00$ \\
\hline$E-04$ & -00 & 1 & -02 & 1 & & -01 & +00 \\
\hline-04 & +00 & 1 & & & & & +00 \\
\hline$E-04$ & $E+00$ & 1.29E-U1 & $\exists-02$ & 1 & 1 & -01 & +00 \\
\hline-04 & +00 & $.30 \mathrm{E}-01$ & -02 & $52 \mathrm{E}-01$ & 01 & -01 & +00 \\
\hline 04 & +00 & 01 & 02 & 01 & 01 & -01 & +00 \\
\hline $.16 \mathrm{E}-04$ & $3.58 \mathrm{E}+00$ & $1.31 \mathrm{E}$ & -02 & 01 & 01 & -01 & $.44 \mathrm{E}+00$ \\
\hline $.19 \mathrm{E}-04$ & $9 \mathrm{E}+00$ & 1. $32 \mathrm{E}-01$ & $8 \mathrm{E}-02$ & $58 E-01$ & $20 E-01$ & -01 & $.45 \mathrm{E}+00$ \\
\hline$E-04$ & $9 \mathrm{E}+00$ & $32 E-01$ & $1 \mathrm{E}-02$ & $E-01$ & $E-01$ & -01 & $45 E+00$ \\
\hline $.26 \mathrm{E}-04$ & $3.60 \mathrm{E}+00$ & $1.33 E-01$ & $3 E-02$ & $2 E-01$ & & -01 & $.46 E+00$ \\
\hline$E-04$ & +00 & -01 & -02 & $3 E-01$ & -01 & -01 & +00 \\
\hline $.34 \mathrm{E}-04$ & & 2.01 & -02 & & & -01 & +00 \\
\hline $38 E-04$ & $3.62 \mathrm{E}+00$ & 1. $35 \mathrm{E}-01$ & 02 & & & 01 & $.47 \mathrm{E}+00$ \\
\hline $.41 E-04$ & $3.63 E+00$ & $1.35 E-01$ & $3 E-02$ & $.68 E-01$ & $37 E-01$ & $4 \mathrm{E}-01$ & $.48 \mathrm{E}+00$ \\
\hline $.45 E-04$ & $.63 E+00$ & $1.36 \mathrm{E}-01$ & $6 \mathrm{E}-02$ & $70 \mathrm{E}-01$ & $40 \mathrm{E}-01$ & $8 E-01$ & $.48 \mathrm{E}+00$ \\
\hline-04 & $E+00$ & $7 \mathrm{E}-01$ & 02 & 01 & & -01 & +00 \\
\hline-04 & & -01 & & & & & +00 \\
\hline $.57 E-04$ & $3.00 E+00$ & $1.38 \mathrm{E}-01$ & -02 & & & -01 & $.49 \mathrm{E}+00$ \\
\hline $.61 E-04$ & . . OETU & 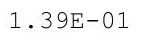 & $3.87 \mathrm{E}-02$ & $3.76 \mathrm{E}-01$ & $51 E-01$ & $21 \mathrm{E}-01$ & $.50 \mathrm{E}+00$ \\
\hline 04 & ל & 年 & 2 & 1 & 1 & $E-01$ & $50 \mathrm{E}+00$ \\
\hline $.69 E-04$ & 年 & 1.7040 & $2 E-02$ & $9 E-01$ & $57 \mathrm{E}-01$ & $8 E-01$ & $.51 \mathrm{E}+0$ \\
\hline $73 E-04$ & $68 F+00$ & & $5 F-0 ?$ & $1 E-01$ & & $E-01$ & $51 E+00$ \\
\hline$E-04$ & 0 & $1 E-01$ & & 1 & 1 & 01 & \\
\hline $.81 E-04$ & $3.70 \mathrm{E}+00$ & $E-01$ & 02 & 01 & 1 & $7 E-01$ & $.52 \mathrm{E}+00$ \\
\hline $.86 E-04$ & $3.10 \mathrm{E}+00$ & $1.42 \mathrm{E}-01$ & $4.03 E-02$ & $86 E-01$ & $68 E-01$ & $1 E-01$ & $.52 \mathrm{E}+00$ \\
\hline $90 E-04$ & & $1.4 J 5-U \perp$ & & $3.87 \mathrm{E}-01$ & & $44 E-01$ & $.53 E+00$ \\
\hline 4 & & & & & & & \\
\hline 4 & $3.72 \mathrm{E}+00$ & & & & & 1 & 00 \\
\hline 4 & & & & & & 01 & \\
\hline 04 & & & & & & -01 & $.55 E+00$ \\
\hline $.12 \mathrm{E}-04$ & $3.74 \mathrm{E}+00$ & $1.46 \mathrm{E}-01$ & 02 & 1 & 1 & 1 & $1.55 \mathrm{E}+00$ \\
\hline $7 E-04$ & $75 E+00$ & $1.47 E-01$ & & 1 & & & $.56 \mathrm{E}+0 \mathrm{C}$ \\
\hline 04 & $105+00$ & $1.48 \mathrm{E}-\mathrm{U} \perp$ & & 1 & & 01 & $1.50 \mathrm{E}+00$ \\
\hline & $3.10 \mathrm{E}$ & $48 \mathrm{E}-$ & $9 \pm-02$ & $\perp$ & 01 & 01 & $1.57 \mathrm{E}+00$ \\
\hline 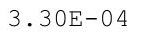 & o & 1 & 02 & 1 & 急 & 1 & $57 E+00$ \\
\hline-04 & $3.78 \mathrm{E}+00$ & $E-01$ & 02 & 01 & 01 & 01 & $1.58 \mathrm{E}+00$ \\
\hline $40 E-04$ & $3.78 \mathrm{E}+00$ & $1.50 \mathrm{E}-01$ & $.38 \mathrm{E}-02$ & $4.03 E-01$ & $6.98 \mathrm{E}-01$ & $9.79 \mathrm{E}-01$ & $1.58 \mathrm{E}+00$ \\
\hline
\end{tabular}


RESRAD-OFFSITE, Version 2.5

Title : RESRAD-OFFSITE Drinking Water, Plant, Milk, and Meat Pathways for Offsite Reside File : PBA-1_TC99-DOE-5.ROF

Summary of dose at graphical times, reptition 3 (continued)

Time

Years

$4.95 \mathrm{E}+02$

$4.96 \mathrm{E}+02$

$4.96 \mathrm{E}+02$

$4.97 \mathrm{E}+02$

$4.97 \mathrm{E}+02$

4. $98 \mathrm{E}+02$

4. $98 \mathrm{E}+02$

$4.99 \mathrm{E}+02$

$4.99 \mathrm{E}+02$

$5.00 \mathrm{E}+02$

$5.00 \mathrm{E}+02$

$5.01 \mathrm{E}+02$

$5.01 \mathrm{E}+02$

$5.02 \mathrm{E}+02$

$5.02 \mathrm{E}+02$

$5.03 \mathrm{E}+02$

$5.03 \mathrm{E}+02$

$5.04 \mathrm{E}+02$

$5.04 \mathrm{E}+02$

$5.05 \mathrm{E}+02$

$5.06 \mathrm{E}+02$

$5.06 \mathrm{E}+02$

$5.07 \mathrm{E}+02$

$5.07 \mathrm{E}+02$

$5.08 \mathrm{E}+02$

$5.08 \mathrm{E}+02$

$5.09 \mathrm{E}+02$

$5.09 \mathrm{E}+02$

$5.10 \mathrm{E}+02$

$5.10 \mathrm{E}+02$

$5.11 \mathrm{E}+02$

$5.11 \mathrm{E}+02$

$5.12 \mathrm{E}+02$

$5.12 \mathrm{E}+02$

$5.13 \mathrm{E}+02$

$5.13 \mathrm{E}+02$

$5.14 \mathrm{E}+02$

$5.14 \mathrm{E}+02$

$5.15 \mathrm{E}+02$

$5.15 \mathrm{E}+02$

$5.16 \mathrm{E}+02$

$5.16 \mathrm{E}+02$

$5.17 \mathrm{E}+02$

$5.17 \mathrm{E}+02$

$5.18 \mathrm{E}+02$

$5.18 \mathrm{E}+02$
Dose statistics at graphical times, mrem/yr

\begin{tabular}{|c|c|c|c|c|c|c|c|}
\hline inimum & aximum & Mean & ledian & $0 \%$ & $5 \%$ & $97.5 \%$ & \\
\hline 4 & $E+00$ & $E-01$ & $E-02$ & -01 & 1 & 1 & 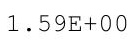 \\
\hline-04 & $E+00$ & $2 E-01$ & $5 E-02$ & $5 \mathrm{E}-$ & 01 & 01 & +00 \\
\hline-04 & +00 & $2 E-01$ & $E-02$ & $7 E-01$ & 01 & -01 & +00 \\
\hline$E-04$ & $E+00$ & $3 E-01$ & $E-02$ & 1 & 1 & 01 & +00 \\
\hline-04 & 00 & 1 & -02 & & & $5 E-01$ & $61 E+00$ \\
\hline-04 & -00 & -01 & -02 & $\perp$ & 1 & 01 & $\mathrm{E}+00$ \\
\hline $5 E-04$ & +00 & $5 E-01$ & -02 & 01 & 01 & -00 & +00 \\
\hline $.80 E-04$ & $3.83 E+00$ & & 4. $65 E-02$ & $4 . \perp / L-01$ & 01 & +00 & +00 \\
\hline 04 & 00 & 1 & -02 & 01 & 01 & +00 & +00 \\
\hline $.90 E-04$ & $5 \mathrm{E}+00$ & $7 E-01$ & $E-02$ & $21 E-01$ & -01 & $01 E+00$ & $.63 E+00$ \\
\hline-04 & +00 & 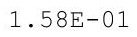 & $E-02$ & 1 & 1 & 00 & $E+00$ \\
\hline & +00 & & & & & & +00 \\
\hline $.06 \mathrm{E}-04$ & $3.86 \mathrm{E}+00$ & $1.39 E-01$ & $E-02$ & $4.27 \mathrm{E}-01$ & $28 E-01$ & $.02 E+00$ & $\mathrm{~s}+00$ \\
\hline$E-04$ & $3.87 \mathrm{E}+00$ & 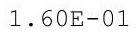 & -02 & 01 & 01 & +00 & +00 \\
\hline 04 & $3.88 \mathrm{E}+00$ & 1 & 02 & 01 & 01 & +00 & +00 \\
\hline $.23 E-04$ & $3.88 \mathrm{E}+00$ & 1 & -02 & 01 & 01 & $3 E+00$ & $.66 \mathrm{E}+00$ \\
\hline $.29 \mathrm{E}-04$ & $3.89 \mathrm{E}+00$ & $52 \mathrm{E}-01$ & $7 E-02$ & $4.35 \mathrm{E}-01$ & $37 E-01$ & $03 E+00$ & $.66 \mathrm{E}+00$ \\
\hline-04 & $0 E+00$ & $52 E-01$ & $1 E-02$ & $E-01$ & $39 E-01$ & $04 \mathrm{E}+00$ & $67 \mathrm{E}+0 \mathrm{C}$ \\
\hline $0 E-04$ & $3.90 \mathrm{E}+00$ & $3 E-01$ & $E-02$ & $9 E-01$ & & $E+00$ & $E+00$ \\
\hline $6 E-04$ & $3.91 \mathrm{E}+00$ & -01 & -02 & $4.42 \mathrm{E}-01$ & -01 & +00 & +00 \\
\hline $2 E-04$ & 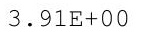 & 2.0 & -02 & 01 & & 0 & +00 \\
\hline $.58 \mathrm{E}-04$ & $3.92 \mathrm{E}+00$ & 01 & 02 & & 01 & $05 E+00$ & $.68 \mathrm{E}+00$ \\
\hline $.63 E-04$ & $3.93 \mathrm{E}+00$ & $1.66 \mathrm{E}-01$ & $5.19 \mathrm{E}-02$ & $4.48 \mathrm{E}-01$ & $.51 \mathrm{E}-01$ & $.05 E+00$ & $.69 \mathrm{E}+00$ \\
\hline$E-04$ & $.93 E+00$ & $1.67 \mathrm{E}-01$ & $2 E-02$ & $50 \mathrm{E}-01$ & $53 E-01$ & $E+00$ & $69 \mathrm{E}+0 \mathrm{C}$ \\
\hline 04 & -00 & $7 E-01$ & 02 & 01 & 01 & 00 & +00 \\
\hline 04 & +00 & 1 & 02 & 1 & 01 & +00 & +00 \\
\hline $.88 \mathrm{E}-04$ & प्र०स+U0 & & -02 & & & -00 & +00 \\
\hline $.94 \mathrm{E}-04$ & $3.95 \mathrm{E}+00$ & $1.69 \mathrm{E}-01$ & $5.38 E-02$ & $4.58 \mathrm{E}-01$ & $7.63 \mathrm{E}-01$ & $.07 E+00$ & $.71 \mathrm{E}+00$ \\
\hline 04 & - & 等 & 年 & 1 & 年 & . & $71 \mathrm{E}+0 \mathrm{C}$ \\
\hline $.07 E-04$ & (2) & $1.71 \mathrm{E}-01$ & -02 & $4.62 \mathrm{E}-01$ & -01 & $E+00$ & $.72 \mathrm{E}+0$ \\
\hline 04 & $97 E+00$ & $2 E-01$ & $E-02$ & $65 E-01$ & 1 & $8 \mathrm{E}+00$ & $2 \mathrm{E}+00$ \\
\hline$E-04$ & 0 & $2 E-01$ & $E-02$ & 1 & & 0 & $72 \mathrm{E}+00$ \\
\hline $6 E-04$ & $3.98 \mathrm{E}+00$ & $E-01$ & $3 E-02$ & 01 & 1 & 00 & $73 \mathrm{E}+00$ \\
\hline $32 \mathrm{E}-04$ & $3.99 E+00$ & $1.74 \mathrm{E}-01$ & $.62 \mathrm{E}-02$ & $4.71 \mathrm{E}-01$ & $76 E-01$ & $9 \mathrm{E}+00$ & $.73 E+00$ \\
\hline $39 E-04$ & & $1.74 E-01$ & & $4.72 E-01$ & & . IULtul & . Я \\
\hline & & & & & & & \\
\hline 4 & $4.00 \mathrm{E}+00$ & & & & & 0 & 00 \\
\hline 4 & & & & & & 0 & \\
\hline & & & & & 1 & $1.11 \mathrm{E}+00$ & $75 \mathrm{E}+00$ \\
\hline $3 E-04$ & $4.02 \mathrm{E}+00$ & $1 \cdot$ & 02 & 1 & & & +00 \\
\hline 04 & & & & 1 & & & +00 \\
\hline & . $55+00$ & & & & & $.11 \mathrm{E}+00$ & • $178+00$ \\
\hline 4 & & & 2 & 1 & 1 & $.12 \mathrm{E}+$ & $.77 \mathrm{E}+$ \\
\hline$\Psi^{4}$ & 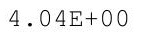 & 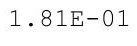 & & $1.00 \mathrm{D}$ & $.90 \mathrm{D}$ & 0 & 0 \\
\hline 4 & $4.05 E+00$ & 1 . & 6 . & 4 & 01 & $1.12 \mathrm{E}+00$ & $1.78 \mathrm{E}+00$ \\
\hline $.16 \mathrm{E}-04$ & $4.05 E+00$ & $1.82 \mathrm{E}-01$ & $.12 E-02$ & $4.93 E-01$ & $8.00 E-01$ & $.12 \mathrm{E}+00$ & $1.78 \mathrm{E}+00$ \\
\hline
\end{tabular}


RESRAD-OFFSITE, Version 2.5

Title : RESRAD-OFFSITE Drinking Water, Plant, Milk, and Meat Pathways for Offsite Reside File : PBA-1_TC99-DOE-5.ROF

Summary of dose at graphical times, reptition 3 (continued)

Time

Years

$5.19 \mathrm{E}+02$

$5.19 \mathrm{E}+02$

$5.20 \mathrm{E}+02$

$5.20 \mathrm{E}+02$

$5.21 \mathrm{E}+02$

$5.21 \mathrm{E}+02$

$5.22 \mathrm{E}+02$

$5.22 \mathrm{E}+02$

$5.23 \mathrm{E}+02$

$5.23 \mathrm{E}+02$

$5.24 \mathrm{E}+02$

$5.24 \mathrm{E}+02$

$5.25 \mathrm{E}+02$

$5.26 \mathrm{E}+02$

$5.26 \mathrm{E}+02$

$5.27 \mathrm{E}+02$

$5.27 \mathrm{E}+02$

$5.28 \mathrm{E}+02$

$5.28 \mathrm{E}+02$

$5.29 \mathrm{E}+02$

$5.29 \mathrm{E}+02$

$5.30 \mathrm{E}+02$

$5.30 \mathrm{E}+02$

$5.31 \mathrm{E}+02$

$5.31 \mathrm{E}+02$

$5.32 \mathrm{E}+02$

$5.32 \mathrm{E}+02$

$5.33 \mathrm{E}+02$

$5.33 \mathrm{E}+02$

$5.34 \mathrm{E}+02$

$5.34 \mathrm{E}+02$

$5.35 \mathrm{E}+02$

$5.35 \mathrm{E}+02$

$5.36 \mathrm{E}+02$

$5.36 \mathrm{E}+02$

$5.37 \mathrm{E}+02$

$5.37 \mathrm{E}+02$

$5.38 \mathrm{E}+02$

$5.38 \mathrm{E}+02$

$5.39 \mathrm{E}+02$

$5.39 \mathrm{E}+02$

$5.40 \mathrm{E}+02$

$5.40 \mathrm{E}+02$

$5.41 \mathrm{E}+02$

$5.41 \mathrm{E}+02$

$5.42 \mathrm{E}+02$
Dose statistics at graphical times, mrem/yr

\begin{tabular}{|c|c|c|c|c|c|c|c|}
\hline inimum & Maximum & Mean & Median & $90 \%$ & $95 \%$ & $7.5 \%$ & $9 \%$ \\
\hline $.23 E-04$ & $4.06 \mathrm{E}+00$ & $1.83 \mathrm{E}-01$ & $6.16 \mathrm{E}-02$ & $4.95 \mathrm{E}-01$ & $8.02 \mathrm{E}-01$ & $1.13 \mathrm{E}+00$ & $1.79 \mathrm{E}+00$ \\
\hline $6.31 \mathrm{E}-04$ & $4.06 \mathrm{E}+00$ & $1.84 \mathrm{E}-01$ & $6.21 \mathrm{E}-02$ & $4.97 \mathrm{E}-01$ & $8.04 \mathrm{E}-01$ & $1.13 \mathrm{E}+00$ & $1.79 \mathrm{E}+00$ \\
\hline $6.38 \mathrm{E}-04$ & $4.07 \mathrm{E}+00$ & $1.85 \mathrm{E}-01$ & $6.25 \mathrm{E}-02$ & $4.99 \mathrm{E}-01$ & $8.06 \mathrm{E}-01$ & $1.13 \mathrm{E}+00$ & $1.80 \mathrm{E}+00$ \\
\hline $6.46 \mathrm{E}-04$ & $4.07 \mathrm{E}+00$ & $1.85 \mathrm{E}-01$ & $6.30 \mathrm{E}-02$ & $5.01 \mathrm{E}-01$ & $8.08 \mathrm{E}-01$ & $1.14 \mathrm{E}+00$ & $.80 \mathrm{E}+00$ \\
\hline $6.53 \mathrm{E}-04$ & $4.08 \mathrm{E}+00$ & $1.86 \mathrm{E}-01$ & $6.34 \mathrm{E}-02$ & $5.03 \mathrm{E}-01$ & $8.10 \mathrm{E}-01$ & $1.14 \mathrm{E}+00$ & $1.80 \mathrm{E}+00$ \\
\hline $6.61 \mathrm{E}-04$ & $4.08 \mathrm{E}+00$ & $1.87 \mathrm{E}-01$ & $6.39 \mathrm{E}-02$ & $5.05 \mathrm{E}-01$ & $8.12 \mathrm{E}-01$ & $1.14 \mathrm{E}+00$ & $1.81 \mathrm{E}+00$ \\
\hline $6.69 \mathrm{E}-04$ & $.09 \mathrm{E}+00$ & $1.87 \mathrm{E}-01$ & $6.43 \mathrm{E}-02$ & $5.07 \mathrm{E}-01$ & $8.14 \mathrm{E}-01$ & $1.15 \mathrm{E}+00$ & $1.81 \mathrm{E}+00$ \\
\hline $.77 \mathrm{E}-04$ & $4.09 \mathrm{E}+00$ & $1.88 \mathrm{E}-01$ & $6.48 \mathrm{E}-02$ & $5.09 \mathrm{E}-01$ & $8.16 \mathrm{E}-01$ & $1.15 \mathrm{E}+00$ & $1.82 \mathrm{E}+00$ \\
\hline $.84 \mathrm{E}-04$ & $4.10 \mathrm{E}+00$ & $1.89 \mathrm{E}-01$ & $6.53 \mathrm{E}-02$ & $5.10 \mathrm{E}-01$ & $8.19 \mathrm{E}-01$ & $1.15 \mathrm{E}+00$ & $1.82 \mathrm{E}+00$ \\
\hline $6.92 \mathrm{E}-04$ & $4.10 \mathrm{E}+00$ & $1.90 \mathrm{E}-01$ & $6.57 \mathrm{E}-02$ & $5.12 \mathrm{E}-01$ & $8.21 \mathrm{E}-01$ & $1.16 \mathrm{E}+00$ & $1.82 \mathrm{E}+00$ \\
\hline $.00 \mathrm{E}-04$ & $4.11 E+00$ & $1.90 \mathrm{E}-01$ & $6.62 \mathrm{E}-02$ & $5.13 \mathrm{E}-01$ & $8.24 \mathrm{E}-01$ & $1.16 \mathrm{E}+00$ & $1.83 \mathrm{E}+00$ \\
\hline $.08 \mathrm{E}-04$ & $4.11 \mathrm{E}+00$ & $1.91 \mathrm{E}-01$ & $6.67 \mathrm{E}-02$ & $5.15 \mathrm{E}-01$ & $8.26 \mathrm{E}-01$ & $1.16 \mathrm{E}+00$ & $1.83 \mathrm{E}+00$ \\
\hline $7.17 \mathrm{E}-04$ & $4.12 \mathrm{E}+00$ & $1.92 \mathrm{E}-01$ & $6.71 \mathrm{E}-02$ & $5.17 \mathrm{E}-01$ & $8.28 \mathrm{E}-01$ & $1.17 \mathrm{E}+00$ & $1.83 \mathrm{E}+00$ \\
\hline $7.25 \mathrm{E}-04$ & $4.12 \mathrm{E}+00$ & $1.93 \mathrm{E}-01$ & $6.76 \mathrm{E}-02$ & $5.18 \mathrm{E}-01$ & $8.31 \mathrm{E}-01$ & $1.17 \mathrm{E}+00$ & $1.84 \mathrm{E}+00$ \\
\hline $7.33 \mathrm{E}-04$ & $4.13 E+00$ & $1.93 \mathrm{E}-01$ & $6.80 \mathrm{E}-02$ & $5.20 \mathrm{E}-01$ & $8.33 \mathrm{E}-01$ & $1.17 \mathrm{E}+00$ & $1.84 \mathrm{E}+00$ \\
\hline $7.41 \mathrm{E}-04$ & $4.13 \mathrm{E}+00$ & $1.94 \mathrm{E}-01$ & $6.85 \mathrm{E}-02$ & $5.21 \mathrm{E}-01$ & $8.36 \mathrm{E}-01$ & $1.18 \mathrm{E}+00$ & $1.84 \mathrm{E}+00$ \\
\hline $7.50 \mathrm{E}-04$ & $4.14 \mathrm{E}+00$ & $1.95 \mathrm{E}-01$ & $6.90 \mathrm{E}-02$ & $5.23 \mathrm{E}-01$ & $8.38 \mathrm{E}-01$ & $1.18 \mathrm{E}+00$ & $1.85 \mathrm{E}+00$ \\
\hline $7.58 \mathrm{E}-04$ & $4.14 \mathrm{E}+00$ & $1.96 \mathrm{E}-01$ & $6.94 \mathrm{E}-02$ & $5.25 \mathrm{E}-01$ & $8.41 \mathrm{E}-01$ & $1.18 \mathrm{E}+00$ & $1.85 \mathrm{E}+00$ \\
\hline $7.67 \mathrm{E}-04$ & $4.15 \mathrm{E}+00$ & $1.96 \mathrm{E}-01$ & $6.99 \mathrm{E}-02$ & $5.27 \mathrm{E}-01$ & $8.44 \mathrm{E}-01$ & $1.19 \mathrm{E}+00$ & $1.85 \mathrm{E}+00$ \\
\hline $76 \mathrm{E}-04$ & $4.15 \mathrm{E}+00$ & $1.97 \mathrm{E}-01$ & $7.04 \mathrm{E}-02$ & $5.29 \mathrm{E}-01$ & $8.46 \mathrm{E}-01$ & $1.19 \mathrm{E}+00$ & $1.86 \mathrm{E}+00$ \\
\hline 4 & $4.16 \mathrm{E}+00$ & & & & 1 & $1.19 \mathrm{E}+00$ & $1.86 \mathrm{E}+00$ \\
\hline $7.93 \mathrm{E}-04$ & $4.16 \mathrm{E}+00$ & 1.9 & 7.1 & 1 & 1 & $1.19 \mathrm{E}+00$ & $1.86 \mathrm{E}+00$ \\
\hline $8.02 \mathrm{E}-04$ & $4.17 \mathrm{E}+00$ & 1.9 & 7. & 01 & 01 & $1.20 \mathrm{E}+00$ & $1.87 \mathrm{E}+00$ \\
\hline $8.11 \mathrm{E}-04$ & $4.17 \mathrm{E}+00$ & $2.00 \mathrm{E}-01$ & $7.22 \mathrm{E}-02$ & $5.38 \mathrm{E}-01$ & $8.56 \mathrm{E}-01$ & $1.20 \mathrm{E}+00$ & $1.87 \mathrm{E}+00$ \\
\hline $8.20 \mathrm{E}-04$ & $4.18 \mathrm{E}+00$ & $2.01 \mathrm{E}-01$ & $7.27 \mathrm{E}-02$ & $5.41 \mathrm{E}-01$ & $8.59 \mathrm{E}-01$ & $1.20 \mathrm{E}+00$ & $1.87 \mathrm{E}+00$ \\
\hline $8.29 \mathrm{E}-04$ & $4.18 \mathrm{E}+00$ & $2.02 \mathrm{E}-01$ & $7.32 \mathrm{E}-02$ & $5.43 \mathrm{E}-01$ & $8.61 \mathrm{E}-01$ & $1.21 \mathrm{E}+00$ & $1.88 \mathrm{E}+00$ \\
\hline $8.38 \mathrm{E}-04$ & $4.19 \mathrm{E}+00$ & $2.02 \mathrm{E}-01$ & $7.36 \mathrm{E}-02$ & $5.45 \mathrm{E}-01$ & $8.64 \mathrm{E}-01$ & $1.21 \mathrm{E}+00$ & $1.88 \mathrm{E}+00$ \\
\hline $8.47 \mathrm{E}-04$ & $4.19 \mathrm{E}+00$ & $2.03 E-01$ & $7.40 \mathrm{E}-02$ & $5.48 \mathrm{E}-01$ & $8.66 \mathrm{E}-01$ & $1.22 \mathrm{E}+00$ & $1.88 \mathrm{E}+00$ \\
\hline $8.56 \mathrm{E}-04$ & $4.20 \mathrm{E}+00$ & $2.04 \mathrm{E}-01$ & $7.45 \mathrm{E}-02$ & $5.50 \mathrm{E}-01$ & $8.68 \mathrm{E}-01$ & $1.22 \mathrm{E}+00$ & $1.89 \mathrm{E}+00$ \\
\hline $8.66 \mathrm{E}-04$ & $4.20 \mathrm{E}+00$ & $2.05 \mathrm{E}-01$ & $7.49 \mathrm{E}-02$ & -01 & $8.71 \mathrm{E}-01$ & $1.22 \mathrm{E}+00$ & $1.89 \mathrm{E}+00$ \\
\hline $5 E-04$ & $4.20 \mathrm{E}+00$ & $2.05 \mathrm{E}-$ & 7.53 & 1 & $8.13 E$ & $1.23 \mathrm{E}+00$ & $1.89 \mathrm{E}+00$ \\
\hline $8.85 \mathrm{E}-04$ & $4.21 \mathrm{E}+00$ & $2.06 \mathrm{E}-01$ & $7.58 \mathrm{E}-02$ & $5.57 \mathrm{E}-01$ & $8.75 \mathrm{E}-01$ & $1.23 \mathrm{E}+00$ & $1.90 \mathrm{E}+00$ \\
\hline $8.94 \mathrm{E}-04$ & $4.21 \mathrm{E}+00$ & $2.07 E-01$ & $7.63 \mathrm{E}-02$ & $5.60 \mathrm{E}-01$ & $8.78 \mathrm{E}-01$ & $1.24 \mathrm{E}+00$ & $1.90 \mathrm{E}+00$ \\
\hline $9.04 \mathrm{E}-04$ & $4.22 \mathrm{E}+00$ & $2.08 \mathrm{E}-01$ & $7.68 \mathrm{E}-02$ & $5.61 \mathrm{E}-01$ & $8.80 \mathrm{E}-01$ & $1.24 \mathrm{E}+00$ & $1.90 \mathrm{E}+00$ \\
\hline $9.14 \mathrm{E}-04$ & $4.22 \mathrm{E}+00$ & $2.08 \mathrm{E}-01$ & $7.73 \mathrm{E}-02$ & $5.63 \mathrm{E}-01$ & $8.82 \mathrm{E}-01$ & $1.25 \mathrm{E}+00$ & $1.91 \mathrm{E}+00$ \\
\hline $9.24 \mathrm{E}-04$ & $4.23 E+00$ & $2.09 \mathrm{E}-01$ & $7.78 \mathrm{E}-02$ & $5.65 \mathrm{E}-01$ & $8.84 \mathrm{E}-01$ & $1.25 \mathrm{E}+00$ & $1.91 \mathrm{E}+00$ \\
\hline $9.33 \mathrm{E}-04$ & $4.23 E+00$ & $2.10 \mathrm{E}-01$ & $7.83 \mathrm{E}-02$ & $5.67 \mathrm{E}-01$ & $8.87 \mathrm{E}-01$ & $1.25 \mathrm{E}+00$ & $1.91 \mathrm{E}+00$ \\
\hline $9.43 \mathrm{E}-04$ & $4.23 \mathrm{E}+00$ & $2.11 \mathrm{E}-01$ & $7.88 \mathrm{E}-02$ & $5.69 \mathrm{E}-01$ & $8.89 \mathrm{E}-01$ & $1.26 \mathrm{E}+00$ & $1.92 \mathrm{E}+00$ \\
\hline $9.53 \mathrm{E}-04$ & $4.24 \mathrm{E}+00$ & $2.12 \mathrm{E}-01$ & $7.93 \mathrm{E}-02$ & $5.71 \mathrm{E}-01$ & $8.91 \mathrm{E}-01$ & $1.26 \mathrm{E}+00$ & $1.92 \mathrm{E}+00$ \\
\hline $9.64 \mathrm{E}-04$ & $4.24 \mathrm{E}+00$ & $2.12 \mathrm{E}-01$ & $7.98 \mathrm{E}-02$ & $5.73 \mathrm{E}-01$ & $8.94 \mathrm{E}-01$ & $1.27 \mathrm{E}+00$ & $1.92 \mathrm{E}+00$ \\
\hline $9.74 \mathrm{E}-04$ & $4.25 \mathrm{E}+00$ & $2.13 \mathrm{E}-01$ & $8.03 E-02$ & $5.75 \mathrm{E}-01$ & $8.97 \mathrm{E}-01$ & $1.27 \mathrm{E}+00$ & $1.93 \mathrm{E}+00$ \\
\hline $9.84 \mathrm{E}-04$ & $4.25 E+00$ & $2.14 \mathrm{E}-01$ & $8.08 \mathrm{E}-02$ & $5.77 \mathrm{E}-01$ & $9.00 \mathrm{E}-01$ & $1.28 \mathrm{E}+00$ & $1.93 \mathrm{E}+00$ \\
\hline $9.94 \mathrm{E}-04$ & $4.26 \mathrm{E}+00$ & $2.15 \mathrm{E}-01$ & $8.14 \mathrm{E}-02$ & $5.79 \mathrm{E}-01$ & $9.02 \mathrm{E}-01$ & $1.28 \mathrm{E}+00$ & $1.93 \mathrm{E}+00$ \\
\hline $1.00 \mathrm{E}-03$ & $4.26 \mathrm{E}+00$ & $2.15 \mathrm{E}-01$ & $8.18 \mathrm{E}-02$ & $5.81 \mathrm{E}-01$ & $9.04 \mathrm{E}-01$ & $1.28 \mathrm{E}+00$ & $1.94 \mathrm{E}+00$ \\
\hline $1.02 \mathrm{E}-03$ & $4.26 \mathrm{E}+00$ & $2.16 \mathrm{E}-01$ & $8.23 \mathrm{E}-02$ & $5.83 \mathrm{E}-01$ & $9.07 \mathrm{E}-01$ & $1.29 \mathrm{E}+00$ & $1.94 \mathrm{E}+00$ \\
\hline $03 E-03$ & $4.27 E+00$ & $2.17 \mathrm{E}-01$ & $8.28 \mathrm{E}-02$ & 5.85 & 9.09 & $1.29 \mathrm{E}+00$ & $1.94 \mathrm{E}$ \\
\hline
\end{tabular}


RESRAD-OFFSITE, Version 2.5

Title : RESRAD-OFFSITE Drinking Water, Plant, Milk, and Meat Pathways for Offsite Reside File : PBA-1_TC99-DOE-5.ROF

Summary of dose at graphical times, reptition 3 (continued)

Time

Years

$5.42 \mathrm{E}+02$

$5.43 \mathrm{E}+02$

$5.43 \mathrm{E}+02$

$5.44 \mathrm{E}+02$

$5.44 \mathrm{E}+02$

$5.45 \mathrm{E}+02$

$5.46 \mathrm{E}+02$

$5.46 \mathrm{E}+02$

$5.47 \mathrm{E}+02$

$5.47 \mathrm{E}+02$

$5.48 \mathrm{E}+02$

$5.48 \mathrm{E}+02$

$5.49 \mathrm{E}+02$

$5.49 \mathrm{E}+02$

$5.50 \mathrm{E}+02$

$5.50 \mathrm{E}+02$

$5.51 \mathrm{E}+02$

$5.51 \mathrm{E}+02$

$5.52 \mathrm{E}+02$

$5.52 \mathrm{E}+02$

$5.53 \mathrm{E}+02$

$5.53 \mathrm{E}+02$

$5.54 \mathrm{E}+02$

$5.54 \mathrm{E}+02$

$5.55 \mathrm{E}+02$

$5.55 \mathrm{E}+02$

$5.56 \mathrm{E}+02$

$5.56 \mathrm{E}+02$

$5.57 \mathrm{E}+02$

$5.57 \mathrm{E}+02$

$5.58 \mathrm{E}+02$

$5.58 \mathrm{E}+02$

$5.59 \mathrm{E}+02$

$5.59 \mathrm{E}+02$

$5.60 \mathrm{E}+02$

$5.60 \mathrm{E}+02$

$5.61 \mathrm{E}+02$

$5.61 \mathrm{E}+02$

$5.62 \mathrm{E}+02$

$5.62 \mathrm{E}+02$

$5.63 \mathrm{E}+02$

$5.63 \mathrm{E}+02$

$5.64 \mathrm{E}+02$

$5.64 \mathrm{E}+02$

$5.65 \mathrm{E}+02$

$5.66 \mathrm{E}+02$
Dose statistics at graphical times, mrem/yr

\begin{tabular}{|c|c|c|c|c|c|c|c|}
\hline inimum & Maximum & Mean & Median & $90 \%$ & $95 \%$ & $7.5 \%$ & $9 \%$ \\
\hline $1.04 \mathrm{E}-03$ & $.27 \mathrm{E}+00$ & $2.18 \mathrm{E}-01$ & $8.33 \mathrm{E}-02$ & $5.87 \mathrm{E}-01$ & $9.12 \mathrm{E}-01$ & $1.29 \mathrm{E}+00$ & $1.94 \mathrm{E}+00$ \\
\hline $1.05 \mathrm{E}-03$ & $4.28 \mathrm{E}+00$ & $2.19 \mathrm{E}-01$ & $8.38 \mathrm{E}-02$ & $5.89 \mathrm{E}-01$ & $9.14 \mathrm{E}-01$ & $1.30 \mathrm{E}+00$ & $1.95 \mathrm{E}+00$ \\
\hline $1.06 \mathrm{E}-03$ & $4.28 \mathrm{E}+00$ & $2.19 \mathrm{E}-01$ & $8.44 \mathrm{E}-02$ & $5.91 \mathrm{E}-01$ & $9.16 \mathrm{E}-01$ & $1.30 \mathrm{E}+00$ & $1.95 \mathrm{E}+00$ \\
\hline $1.07 \mathrm{E}-03$ & $4.28 \mathrm{E}+00$ & $2.20 \mathrm{E}-01$ & $8.49 \mathrm{E}-02$ & $5.92 \mathrm{E}-01$ & $9.19 \mathrm{E}-01$ & $1.30 \mathrm{E}+00$ & $.95 \mathrm{E}+00$ \\
\hline $1.08 \mathrm{E}-03$ & $.29 \mathrm{E}+00$ & $2.21 \mathrm{E}-01$ & $8.54 \mathrm{E}-02$ & $5.94 \mathrm{E}-01$ & $9.22 \mathrm{E}-01$ & $1.31 \mathrm{E}+00$ & $1.96 \mathrm{E}+00$ \\
\hline $1.09 \mathrm{E}-03$ & $4.29 \mathrm{E}+00$ & $2.22 \mathrm{E}-01$ & $8.60 \mathrm{E}-02$ & $5.97 \mathrm{E}-01$ & $9.25 \mathrm{E}-01$ & $1.31 \mathrm{E}+00$ & $1.96 \mathrm{E}+00$ \\
\hline $1.10 \mathrm{E}-03$ & $.30 \mathrm{E}+00$ & $2.22 \mathrm{E}-01$ & $8.65 \mathrm{E}-02$ & $5.99 \mathrm{E}-01$ & $28 \mathrm{E}-01$ & $1.31 \mathrm{E}+00$ & $1.96 \mathrm{E}+00$ \\
\hline $.11 \mathrm{E}-03$ & $4.30 \mathrm{E}+00$ & $2.23 \mathrm{E}-01$ & $8.70 \mathrm{E}-02$ & $6.01 \mathrm{E}-01$ & $9.31 \mathrm{E}-01$ & $1.32 \mathrm{E}+00$ & $1.97 \mathrm{E}+00$ \\
\hline $1.13 \mathrm{E}-03$ & $4.30 \mathrm{E}+00$ & $2.24 \mathrm{E}-01$ & $8.75 \mathrm{E}-02$ & $6.03 \mathrm{E}-01$ & $9.33 \mathrm{E}-01$ & $1.32 \mathrm{E}+00$ & $1.97 \mathrm{E}+00$ \\
\hline $1.14 \mathrm{E}-03$ & $4.31 E+00$ & $2.25 \mathrm{E}-01$ & $8.80 \mathrm{E}-02$ & $6.05 \mathrm{E}-01$ & $9.36 \mathrm{E}-01$ & $1.32 \mathrm{E}+00$ & $1.97 \mathrm{E}+00$ \\
\hline $1.15 \mathrm{E}-03$ & $4.31 E+00$ & $2.26 \mathrm{E}-01$ & $8.85 \mathrm{E}-02$ & $6.08 \mathrm{E}-01$ & $9.39 \mathrm{E}-01$ & $1.33 \mathrm{E}+00$ & $1.97 \mathrm{E}+00$ \\
\hline $1.16 \mathrm{E}-03$ & $4.31 \mathrm{E}+00$ & $2.26 \mathrm{E}-01$ & $8.90 \mathrm{E}-02$ & $6.10 \mathrm{E}-01$ & $9.42 \mathrm{E}-01$ & $1.33 \mathrm{E}+00$ & $1.98 \mathrm{E}+00$ \\
\hline $1.17 \mathrm{E}-03$ & $4.32 \mathrm{E}+00$ & $2.27 \mathrm{E}-01$ & $8.95 \mathrm{E}-02$ & $6.12 \mathrm{E}-01$ & $9.45 \mathrm{E}-01$ & $1.34 \mathrm{E}+00$ & $1.98 \mathrm{E}+00$ \\
\hline $1.18 \mathrm{E}-03$ & $4.32 \mathrm{E}+00$ & $2.28 \mathrm{E}-01$ & $9.00 \mathrm{E}-02$ & $6.14 \mathrm{E}-01$ & $9.48 \mathrm{E}-01$ & $1.34 \mathrm{E}+00$ & $1.98 \mathrm{E}+00$ \\
\hline $1.20 \mathrm{E}-03$ & $4.33 E+00$ & $2.29 \mathrm{E}-01$ & $9.05 \mathrm{E}-02$ & $6.16 \mathrm{E}-01$ & $9.50 \mathrm{E}-01$ & $1.34 \mathrm{E}+00$ & $1.99 \mathrm{E}+00$ \\
\hline $1.21 \mathrm{E}-03$ & $4.33 E+00$ & $2.30 \mathrm{E}-01$ & $9.11 \mathrm{E}-02$ & $6.18 \mathrm{E}-01$ & $9.53 \mathrm{E}-01$ & $1.35 \mathrm{E}+00$ & $1.99 \mathrm{E}+00$ \\
\hline $1.22 \mathrm{E}-03$ & $4.33 E+00$ & $2.30 \mathrm{E}-01$ & $9.16 \mathrm{E}-02$ & $6.21 \mathrm{E}-01$ & $9.56 \mathrm{E}-01$ & $1.35 \mathrm{E}+00$ & $1.99 \mathrm{E}+00$ \\
\hline $1.23 \mathrm{E}-03$ & $4.34 \mathrm{E}+00$ & $2.31 \mathrm{E}-01$ & $9.21 \mathrm{E}-02$ & $6.23 \mathrm{E}-01$ & $9.59 \mathrm{E}-01$ & $1.36 \mathrm{E}+00$ & $1.99 \mathrm{E}+00$ \\
\hline $1.24 \mathrm{E}-03$ & $4.34 \mathrm{E}+00$ & $2.32 \mathrm{E}-01$ & $9.26 \mathrm{E}-02$ & $6.25 \mathrm{E}-01$ & $9.62 \mathrm{E}-01$ & $1.36 \mathrm{E}+00$ & $2.00 \mathrm{E}+00$ \\
\hline $26 \mathrm{E}-03$ & $4.34 \mathrm{E}+00$ & $2.33 \mathrm{E}-01$ & $9.31 \mathrm{E}-02$ & $6.27 \mathrm{E}-01$ & $9.64 \mathrm{E}-01$ & $1.36 \mathrm{E}+00$ & $2.00 \mathrm{E}+00$ \\
\hline 1.2 & $4.35 \mathrm{E}+00$ & & & & & $1.37 \mathrm{E}+00$ & $2.00 \mathrm{E}+00$ \\
\hline $1.28 \mathrm{E}-03$ & $4.35 E+00$ & 2. & 2 & 1 & 1 & $1.37 \mathrm{E}+00$ & $2.01 \mathrm{E}+00$ \\
\hline $1.29 \mathrm{E}-03$ & $4.35 \mathrm{E}+00$ & $2.35 \mathrm{E}-01$ & $9.46 \mathrm{E}-02$ & $6.34 \mathrm{E}-01$ & $9.70 \mathrm{E}-01$ & $1.37 \mathrm{E}+00$ & $2.01 \mathrm{E}+00$ \\
\hline $1.31 \mathrm{E}-03$ & $4.36 \mathrm{E}+00$ & $2.36 \mathrm{E}-01$ & $9.51 \mathrm{E}-02$ & $6.36 \mathrm{E}-01$ & $9.72 \mathrm{E}-01$ & $1.38 \mathrm{E}+00$ & $2.01 \mathrm{E}+00$ \\
\hline $1.32 \mathrm{E}-03$ & $4.36 \mathrm{E}+00$ & $2.37 \mathrm{E}-01$ & $9.56 \mathrm{E}-02$ & $6.39 \mathrm{E}-01$ & $9.74 \mathrm{E}-01$ & $1.38 \mathrm{E}+00$ & $2.01 \mathrm{E}+00$ \\
\hline $1.33 \mathrm{E}-03$ & $4.36 \mathrm{E}+00$ & $2.38 \mathrm{E}-01$ & $9.61 \mathrm{E}-02$ & $6.41 \mathrm{E}-01$ & $9.77 \mathrm{E}-01$ & $1.38 \mathrm{E}+00$ & $2.02 \mathrm{E}+00$ \\
\hline $1.34 \mathrm{E}-03$ & $4.37 \mathrm{E}+00$ & $2.38 \mathrm{E}-01$ & $9.66 \mathrm{E}-02$ & $6.43 \mathrm{E}-01$ & $9.80 \mathrm{E}-01$ & $1.39 \mathrm{E}+00$ & $2.02 \mathrm{E}+00$ \\
\hline $1.36 \mathrm{E}-03$ & $4.37 \mathrm{E}+00$ & $2.39 \mathrm{E}-01$ & $9.71 \mathrm{E}-02$ & $6.46 \mathrm{E}-01$ & $9.83 \mathrm{E}-01$ & $1.39 \mathrm{E}+00$ & $2.02 \mathrm{E}+00$ \\
\hline $1.37 \mathrm{E}-03$ & $4.37 \mathrm{E}+00$ & $2.40 \mathrm{E}-01$ & $9.76 \mathrm{E}-02$ & $6.48 \mathrm{E}-01$ & $9.86 \mathrm{E}$ & $1.39 \mathrm{E}+00$ & $2.02 \mathrm{E}+00$ \\
\hline $1.38 \mathrm{E}-03$ & $4.38 \mathrm{E}+00$ & $2.41 \mathrm{E}-01$ & 9.8 & 6. & 9.891 & $1.40 \mathrm{E}+00$ & $2.03 E+00$ \\
\hline $1.40 \mathrm{E}-03$ & $4.38 \mathrm{E}+00$ & $2.42 \mathrm{E}-$ & 2 & 0.5 & 01 & $1.40 \mathrm{E}+00$ & $2.03 E+00$ \\
\hline $1.41 \mathrm{E}-03$ & $4.38 \mathrm{E}+00$ & $2.42 \mathrm{E}-01$ & $9.91 \mathrm{E}-02$ & $6.55 \mathrm{E}-01$ & $9.93 \mathrm{E}-01$ & $1.40 \mathrm{E}+00$ & $2.03 E+00$ \\
\hline $1.42 \mathrm{E}-03$ & $4.39 E+00$ & $2.43 E-01$ & $9.95 \mathrm{E}-02$ & $6.57 \mathrm{E}-01$ & $9.95 \mathrm{E}-01$ & $1.41 \mathrm{E}+00$ & $2.03 E+00$ \\
\hline $1.44 \mathrm{E}-03$ & $4.39 \mathrm{E}+00$ & $2.44 \mathrm{E}-01$ & $1.00 \mathrm{E}-01$ & $6.59 \mathrm{E}-01$ & $9.97 \mathrm{E}-01$ & $1.41 \mathrm{E}+00$ & $2.04 \mathrm{E}+00$ \\
\hline $1.45 \mathrm{E}-03$ & $4.39 E+00$ & $2.45 \mathrm{E}-01$ & $1.01 \mathrm{E}-01$ & $6.61 \mathrm{E}-01$ & $9.99 \mathrm{E}-01$ & $1.41 \mathrm{E}+00$ & $2.04 \mathrm{E}+00$ \\
\hline $1.47 \mathrm{E}-03$ & $4.40 \mathrm{E}+00$ & $2.46 \mathrm{E}-01$ & $1.01 \mathrm{E}-01$ & $6.63 \mathrm{E}-01$ & $1.00 \mathrm{E}+00$ & $1.42 \mathrm{E}+00$ & $2.04 \mathrm{E}+00$ \\
\hline $1.48 \mathrm{E}-03$ & $4.40 \mathrm{E}+00$ & $2.47 \mathrm{E}-01$ & $1.02 \mathrm{E}-01$ & $6.65 \mathrm{E}-01$ & $1.00 \mathrm{E}+00$ & $1.42 \mathrm{E}+00$ & $2.04 \mathrm{E}+00$ \\
\hline $1.49 \mathrm{E}-03$ & $4.40 \mathrm{E}+00$ & $2.47 \mathrm{E}-01$ & $1.02 \mathrm{E}-01$ & $6.67 \mathrm{E}-01$ & $1.01 \mathrm{E}+00$ & $1.42 \mathrm{E}+00$ & $2.05 \mathrm{E}+00$ \\
\hline $1.51 \mathrm{E}-03$ & $4.41 \mathrm{E}+00$ & $2.48 \mathrm{E}-01$ & $1.03 \mathrm{E}-01$ & $6.69 \mathrm{E}-01$ & $1.01 \mathrm{E}+00$ & $1.42 \mathrm{E}+00$ & $2.05 \mathrm{E}+00$ \\
\hline $1.52 \mathrm{E}-03$ & $4.41 \mathrm{E}+00$ & $2.49 \mathrm{E}-01$ & $1.03 \mathrm{E}-01$ & $6.70 \mathrm{E}-01$ & $1.01 \mathrm{E}+00$ & $1.43 \mathrm{E}+00$ & $2.05 \mathrm{E}+00$ \\
\hline $1.54 \mathrm{E}-03$ & $4.41 \mathrm{E}+00$ & $2.50 \mathrm{E}-01$ & $1.04 \mathrm{E}-01$ & $6.72 \mathrm{E}-01$ & $1.01 \mathrm{E}+00$ & $1.43 \mathrm{E}+00$ & $2.05 \mathrm{E}+00$ \\
\hline $1.55 \mathrm{E}-03$ & $4.42 \mathrm{E}+00$ & $2.51 \mathrm{E}-01$ & $1.05 \mathrm{E}-01$ & $6.74 \mathrm{E}-01$ & $1.01 \mathrm{E}+00$ & $1.43 E+00$ & $2.05 \mathrm{E}+00$ \\
\hline $1.57 \mathrm{E}-03$ & $4.42 \mathrm{E}+00$ & $2.51 \mathrm{E}-01$ & $1.05 \mathrm{E}-01$ & $6.76 \mathrm{E}-01$ & $1.02 \mathrm{E}+00$ & $1.44 \mathrm{E}+00$ & $2.06 \mathrm{E}+00$ \\
\hline $1.58 \mathrm{E}-03$ & $4.42 \mathrm{E}+00$ & $2.52 \mathrm{E}-01$ & $1.06 \mathrm{E}-01$ & $6.78 \mathrm{E}-01$ & $1.02 \mathrm{E}+00$ & $1.44 \mathrm{E}+00$ & $2.06 \mathrm{E}+00$ \\
\hline $1.59 \mathrm{E}-03$ & $4.42 \mathrm{E}+00$ & $2.53 \mathrm{E}-01$ & $1.06 \mathrm{E}-01$ & $6.79 \mathrm{E}-01$ & $1.02 \mathrm{E}+00$ & $1.44 \mathrm{E}+00$ & $2.06 \mathrm{E}+00$ \\
\hline $1.61 \mathrm{E}-03$ & $4.43 E+00$ & $2.54 \mathrm{E}-01$ & $1.07 \mathrm{E}-01$ & $6.81 \mathrm{E}-01$ & $1.02 \mathrm{E}+00$ & $1.45 \mathrm{E}+00$ & $2.06 \mathrm{E}+00$ \\
\hline
\end{tabular}


RESRAD-OFFSITE, Version 2.5

$\mathrm{T}^{1 / 2}$ Limit $=180$ days

Title : RESRAD-OFFSITE Drinking Water, Plant, Milk, and Meat Pathways for Offsite Reside File : PBA-1_TC99-DOE-5.ROF

Summary of dose at graphical times, reptition 3 (continued)

Time

Years

$5.66 \mathrm{E}+02$

$5.67 \mathrm{E}+02$

$5.67 \mathrm{E}+02$

$5.68 \mathrm{E}+02$

$5.68 \mathrm{E}+02$

$5.69 \mathrm{E}+02$

$5.69 \mathrm{E}+02$

$5.70 \mathrm{E}+02$

$5.70 \mathrm{E}+02$

$5.71 \mathrm{E}+02$

$5.71 \mathrm{E}+02$

$5.72 \mathrm{E}+02$

$5.72 \mathrm{E}+02$

$5.73 \mathrm{E}+02$

$5.73 \mathrm{E}+02$

$5.74 \mathrm{E}+02$

$5.74 \mathrm{E}+02$

$5.75 \mathrm{E}+02$

$5.75 \mathrm{E}+02$

$5.76 \mathrm{E}+02$

$5.76 \mathrm{E}+02$

$5.77 \mathrm{E}+02$

$5.77 \mathrm{E}+02$

$5.78 \mathrm{E}+02$

$5.78 \mathrm{E}+02$

$5.79 \mathrm{E}+02$

$5.79 \mathrm{E}+02$

$5.80 \mathrm{E}+02$

$5.80 \mathrm{E}+02$

$5.81 \mathrm{E}+02$

$5.81 \mathrm{E}+02$

$5.82 \mathrm{E}+02$

$5.82 \mathrm{E}+02$

$5.83 \mathrm{E}+02$

$5.83 \mathrm{E}+02$

$5.84 \mathrm{E}+02$

$5.84 \mathrm{E}+02$

$5.85 \mathrm{E}+02$

$5.85 \mathrm{E}+02$

$5.86 \mathrm{E}+02$

$5.87 \mathrm{E}+02$

$5.87 \mathrm{E}+02$

$5.88 \mathrm{E}+02$

$5.88 \mathrm{E}+02$

$5.89 \mathrm{E}+02$

$5.89 \mathrm{E}+02$
Dose statistics at graphical times, mrem/yr

\begin{tabular}{|c|c|c|c|c|c|c|c|}
\hline inimum & aximum & Mean & ledian & $0 \%$ & $5 \%$ & $97.5 \%$ & $3 \%$ \\
\hline 3 & +00 & $E-01$ & $E-01$ & 1 & 00 & +00 & 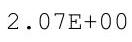 \\
\hline 03 & +00 & 1 & $8 E-01$ & $5 E-$ & $3 E+00$ & -00 & $7 E+00$ \\
\hline$E-03$ & $E+00$ & $E-01$ & $E-01$ & $6 E-01$ & 00 & +00 & $\exists+00$ \\
\hline$E-03$ & $E+00$ & 1 & & 1 & 0 & 00 & +00 \\
\hline-03 & -00 & 1 & & & 00 & $46 E+00$ & $08 E+00$ \\
\hline $.70 E-03$ & $E+00$ & $E-01$ & $E-01$ & $2 E-$ & +00 & $.46 E+00$ & $E+00$ \\
\hline e & $E+00$ & 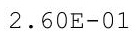 & 1 & 1 & 0 & +00 & $E+0 C$ \\
\hline $.73 E-03$ & $4.45 E+00$ & • & 1. $12 \mathrm{E}-01$ & $96 E-01$ & 00 & +00 & $08 \mathrm{E}+00$ \\
\hline 03 & +00 & 1 & 01 & 01 & 00 & +00 & +00 \\
\hline $.76 \mathrm{E}-03$ & $4.45 \mathrm{E}+00$ & $.62 E-01$ & $3 E-01$ & 01 & L. $05 E+00$ & $.48 E+00$ & $E+00$ \\
\hline$E-03$ & +00 & $E-01$ & -01 & 1 & & -00 & $E+00$ \\
\hline-03 & +00 & 1 & & & 00 & +00 & $9 \mathrm{E}+0 \mathrm{C}$ \\
\hline $.81 \mathrm{E}-03$ & $4.46 \mathrm{E}+00$ & $2.05 E-01$ & $1.15 \mathrm{E}-01$ & $5 E-01$ & 年 & $.48 E+00$ & $E+0 C$ \\
\hline 03 & -00 & ז & -01 & $z-01$ & 00 & +00 & $\mathrm{E}+\mathrm{OC}$ \\
\hline 03 & -00 & 1 & 01 & 01 & 00 & +00 & +00 \\
\hline $.86 \mathrm{E}-03$ & $7 \mathrm{E}+00$ & 1 & -01 & 1 & $1.06 \mathrm{E}+00$ & $.49 \mathrm{E}+00$ & $10 \mathrm{E}+00$ \\
\hline $.88 \mathrm{E}-03$ & $7 \mathrm{E}+00$ & $2.68 \mathrm{E}-01$ & $.7 E-01$ & $3 E-01$ & $1.07 \mathrm{E}+00$ & $.50 \mathrm{E}+00$ & $10 \mathrm{E}+00$ \\
\hline-03 & $7 E+00$ & $.69 E-01$ & $8 E-01$ & $5 E-01$ & $07 E+00$ & $50 E+00$ & $10 \mathrm{E}+00$ \\
\hline 03 & $E+00$ & $E-U 1$ & -01 & -01 & & $4+\infty u$ & $\mathrm{E}+0 \mathrm{C}$ \\
\hline $.93 E-03$ & +00 & -01 & -01 & 01 & & +00 & +00 \\
\hline $.95 E-03$ & 10 & & -01 & & & 100 & +00 \\
\hline $.96 \mathrm{E}-03$ & $4.48 \mathrm{E}+00$ & 01 & 01 & & & $.51 E+0$ & $11 E+00$ \\
\hline 3 & $49 \mathrm{E}+00$ & 1 & 1 & $7.24 \mathrm{E}-01$ & $1.09 \mathrm{E}+00$ & $.51 \mathrm{E}+00$ & $.11 \mathrm{E}+00$ \\
\hline $.00 E-03$ & $49 \mathrm{E}+00$ & $2.74 \mathrm{E}-01$ & 1. $21 \mathrm{E}-01$ & $26 \mathrm{E}-01$ & $1.09 \mathrm{E}+00$ & $52 \mathrm{E}+00$ & $.12 \mathrm{E}+0 \mathrm{C}$ \\
\hline$E-03$ & $\mathrm{E}+00$ & $75 E-01$ & 1. $22 \mathrm{E}-01$ & 01 & & 00 & 100 \\
\hline 03 & 00 & 1 & -01 & 1 & & 00 & +00 \\
\hline $.05 E-03$ & $4.50 E+00$ & $7 E-01$ & 1. $23 E-01$ & 1 & & . $23 \mathrm{E}+00$ & $.12 \mathrm{E}+0 \mathrm{C}$ \\
\hline 3 & . .JUसT & 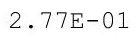 & 1. $23 E-01$ & 每 & I.IULTU & $.53 E+00$ & $13 E+00$ \\
\hline 3 & 然 & (2) & 然 & 1 & $11 \mathrm{E}+00$ & $53 E+00$ & $13 E+0 c$ \\
\hline $.10 \mathrm{E}-03$ & 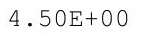 & $2.79 \mathrm{E}-01$ & 1. $24 \mathrm{E}-01$ & $9 E-01$ & & $.54 \mathrm{E}+00$ & $13 E+0$ \\
\hline$F-03$ & $5 \cap F+0 \cap$ & $.80 \mathrm{E}-01$ & $5 E-01$ & $1 E-01$ & $1.11 \mathrm{E}+00$ & $E+00$ & $14 \mathrm{E}+00$ \\
\hline 03 & $E+00$ & $E-01$ & 01 & 1 & & & \\
\hline$E-03$ & $4.51 \mathrm{E}+00$ & $2 E-01$ & 1. & 01 & 0 & $.55 \mathrm{E}+00$ & $14 \mathrm{E}+00$ \\
\hline $.18 \mathrm{E}-03$ & $4.3 \perp E+00$ & $2.83 E-01$ & $1.27 \mathrm{E}-01$ & $6 E-01$ & $1 \cdot 1 \angle \mathrm{E}+U 0$ & $.55 E+00$ & $.15 \mathrm{E}+0 \mathrm{C}$ \\
\hline $205-20$ & 4.UILTU & & $.27 E-01$ & 7. $48 \mathrm{E}-01$ & & $.55 E+00$ & $.15 E+0 c$ \\
\hline $.22 E-03$ & & & & & & & $.15 \mathrm{E}+00$ \\
\hline $235-03$ & 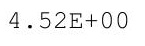 & & 1 & 1 & & 0 & 16 \\
\hline 3 & & & & & & 0 & \\
\hline$E-03$ & $E+00$ & $7 E-01$ & 1. $30 \mathrm{E}-01$ & $5 E-01$ & 1 . & 00 & +00 \\
\hline$E-03$ & $4.52 E+00$ & $E-$ & 1 & 1 & 1.1 & & $7 \mathrm{E}+0 \mathrm{C}$ \\
\hline $1 E-03$ & & $2.88 E-01$ & & & & & $.17 \mathrm{E}+0 \mathrm{C}$ \\
\hline & $4.3 \angle \mathrm{E}+00$ & 年 & & & $1.15 \mathrm{E}+00$ & $.57 \mathrm{E}+00$ & • $\perp I E+U 0$ \\
\hline & (1) & . & . & - & $15 E+$ & $.57 \mathrm{E}+$ & $18 \mathrm{E}+0$ \\
\hline $375-03$ & 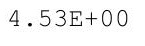 & t. & + & 1.00 & 0 & 0 & $18 \mathrm{E}$ \\
\hline$E-03$ & $4.53 E+00$ & 2. & 1 . & 7. & $1.16 \mathrm{E}+00$ & $.58 E+00$ & $2.18 \mathrm{E}+00$ \\
\hline $.41 E-03$ & $4.53 E+00$ & $.93 E-01$ & 1. $33 \mathrm{E}-01$ & 7. $70 \mathrm{E}-01$ & $1.16 \mathrm{E}+00$ & 1. $58 \mathrm{E}+00$ & $.19 \mathrm{E}+00$ \\
\hline
\end{tabular}


RESRAD-OFFSITE, Version 2.5

Title : RESRAD-OFFSITE Drinking Water, Plant, Milk, and Meat Pathways for Offsite Reside File : PBA-1_TC99-DOE-5.ROF

Summary of dose at graphical times, reptition 3 (continued)

Time

Years

$5.90 \mathrm{E}+02$

$5.90 \mathrm{E}+02$

$5.91 \mathrm{E}+02$

$5.91 \mathrm{E}+02$

$5.92 \mathrm{E}+02$

$5.92 \mathrm{E}+02$

$5.93 \mathrm{E}+02$

$5.93 \mathrm{E}+02$

$5.94 \mathrm{E}+02$

$5.94 \mathrm{E}+02$

$5.95 \mathrm{E}+02$

$5.95 \mathrm{E}+02$

$5.96 \mathrm{E}+02$

$5.96 \mathrm{E}+02$

$5.97 \mathrm{E}+02$

$5.97 \mathrm{E}+02$

$5.98 \mathrm{E}+02$

$5.98 \mathrm{E}+02$

$5.99 \mathrm{E}+02$

$5.99 \mathrm{E}+02$

$6.00 \mathrm{E}+02$

$6.00 \mathrm{E}+02$

$6.01 \mathrm{E}+02$

$6.01 \mathrm{E}+02$

$6.02 \mathrm{E}+02$

$6.02 \mathrm{E}+02$

$6.03 E+02$

$6.03 \mathrm{E}+02$

$6.04 \mathrm{E}+02$

$6.04 \mathrm{E}+02$

$6.05 \mathrm{E}+02$

$6.05 \mathrm{E}+02$

$6.06 \mathrm{E}+02$

$6.07 \mathrm{E}+02$

$6.07 \mathrm{E}+02$

$6.08 \mathrm{E}+02$

$6.08 \mathrm{E}+02$

$6.09 \mathrm{E}+02$

$6.09 \mathrm{E}+02$

$6.10 \mathrm{E}+02$

$6.10 \mathrm{E}+02$

$6.11 \mathrm{E}+02$

$6.11 \mathrm{E}+02$

$6.12 \mathrm{E}+02$

$6.12 \mathrm{E}+02$

$6.13 \mathrm{E}+02$
Dose statistics at graphical times, mrem/yr

\begin{tabular}{|c|c|c|c|c|c|c|c|}
\hline & hum & 1 & Median & & & & \\
\hline $43 E-03$ & $.53 \mathrm{E}+00$ & $2.94 \mathrm{E}-01$ & $1.34 \mathrm{E}-01$ & $7.72 \mathrm{E}-01$ & $1.16 \mathrm{E}+00$ & $1.58 \mathrm{E}+00$ & $2.19 \mathrm{E}+00$ \\
\hline $2.45 E-03$ & $.54 \mathrm{E}+00$ & $2.95 \mathrm{E}-01$ & $1.35 \mathrm{E}-01$ & $7.74 \mathrm{E}-01$ & $1.16 \mathrm{E}+00$ & $1.58 \mathrm{E}+00$ & $2.19 \mathrm{E}+00$ \\
\hline $2.47 \mathrm{E}-03$ & $.54 \mathrm{E}+00$ & $2.95 \mathrm{E}-01$ & $1.35 \mathrm{E}-01$ & $7.76 \mathrm{E}-01$ & $1.17 \mathrm{E}+00$ & $1.59 \mathrm{E}+00$ & $2.19 \mathrm{E}+00$ \\
\hline $2.49 \mathrm{E}-03$ & $4.54 \mathrm{E}+00$ & $2.96 \mathrm{E}-01$ & $1.36 \mathrm{E}-01$ & $7.78 \mathrm{E}-01$ & $1.17 \mathrm{E}+00$ & $1.59 \mathrm{E}+00$ & $2.20 \mathrm{E}+00$ \\
\hline $2.51 E-03$ & $4.54 \mathrm{E}+00$ & $2.97 \mathrm{E}-01$ & $1.37 \mathrm{E}-01$ & $7.80 \mathrm{E}-01$ & $1.17 \mathrm{E}+00$ & $1.59 \mathrm{E}+00$ & $2.20 \mathrm{E}+00$ \\
\hline $2.53 E-03$ & $4.54 \mathrm{E}+00$ & $2.98 \mathrm{E}-01$ & $1.37 \mathrm{E}-01$ & $7.82 \mathrm{E}-01$ & $1.17 \mathrm{E}+00$ & $1.59 \mathrm{E}+00$ & $2.20 \mathrm{E}+00$ \\
\hline $2.55 E-03$ & $4.54 \mathrm{E}+00$ & $2.99 \mathrm{E}-01$ & $1.38 \mathrm{E}-01$ & $7.84 \mathrm{E}-01$ & $1.18 \mathrm{E}+00$ & $1.59 \mathrm{E}+00$ & $2.21 \mathrm{E}+00$ \\
\hline $2.57 \mathrm{E}-03$ & $4.55 \mathrm{E}+00$ & $3.00 \mathrm{E}-01$ & $1.38 \mathrm{E}-01$ & $7.86 \mathrm{E}-01$ & $1.18 \mathrm{E}+00$ & $1.60 \mathrm{E}+00$ & $2.21 \mathrm{E}+00$ \\
\hline $2.60 \mathrm{E}-03$ & $4.55 \mathrm{E}+00$ & $3.01 \mathrm{E}-01$ & $1.39 \mathrm{E}-01$ & $7.88 \mathrm{E}-01$ & $1.18 \mathrm{E}+00$ & $1.60 \mathrm{E}+00$ & $2.21 \mathrm{E}+00$ \\
\hline $2.62 \mathrm{E}-03$ & $4.55 \mathrm{E}+00$ & $3.01 \mathrm{E}-01$ & $1.40 \mathrm{E}-01$ & $7.90 \mathrm{E}-01$ & $1.18 \mathrm{E}+00$ & $1.60 \mathrm{E}+00$ & $2.22 \mathrm{E}+00$ \\
\hline $2.64 \mathrm{E}-03$ & $.55 \mathrm{E}+00$ & $3.02 \mathrm{E}-01$ & $1.40 \mathrm{E}-01$ & $7.92 \mathrm{E}$ & $1.19 \mathrm{E}+00$ & $1.60 \mathrm{E}+00$ & $2.22 \mathrm{E}+00$ \\
\hline $2.66 \mathrm{E}-03$ & $4.55 \mathrm{E}+00$ & $3.03 E-01$ & $1.41 \mathrm{E}-01$ & $7.94 \mathrm{E}-01$ & $1.19 \mathrm{E}+00$ & $1.61 \mathrm{E}+00$ & $2.22 \mathrm{E}+00$ \\
\hline $.68 \mathrm{E}-03$ & $4.55 \mathrm{E}+00$ & $3.04 \mathrm{E}-01$ & $1.42 \mathrm{E}-01$ & $7.96 \mathrm{E}-01$ & $1.19 \mathrm{E}+00$ & $1.61 \mathrm{E}+00$ & $2.23 \mathrm{E}+00$ \\
\hline $.70 \mathrm{E}-03$ & $4.55 \mathrm{E}+00$ & $3.05 \mathrm{E}-01$ & $1.42 \mathrm{E}-01$ & $7.98 \mathrm{E}-01$ & $1.19 \mathrm{E}+00$ & $1.61 \mathrm{E}+00$ & $2.23 \mathrm{E}+00$ \\
\hline $2.73 E-03$ & $4.56 \mathrm{E}+00$ & $3.06 \mathrm{E}-01$ & $1.43 \mathrm{E}-01$ & $8.00 \mathrm{E}-01$ & $1.19 \mathrm{E}+00$ & $1.61 \mathrm{E}+00$ & $.23 E+00$ \\
\hline $2.75 E-03$ & $4.56 \mathrm{E}+00$ & $3.07 \mathrm{E}-01$ & $1.44 \mathrm{E}-01$ & $8.02 \mathrm{E}-01$ & $1.19 \mathrm{E}+00$ & $1.62 \mathrm{E}+00$ & $2.23 \mathrm{E}+00$ \\
\hline $2.77 E-03$ & $4.56 \mathrm{E}+00$ & $3.08 \mathrm{E}-01$ & $1.44 \mathrm{E}-01$ & $8.04 \mathrm{E}-01$ & $1.20 \mathrm{E}+00$ & $1.62 \mathrm{E}+00$ & $2.24 \mathrm{E}+00$ \\
\hline $2.79 \mathrm{E}-03$ & $4.56 \mathrm{E}+00$ & $3.08 \mathrm{E}-01$ & $1.45 \mathrm{E}-01$ & $8.05 \mathrm{E}-01$ & $1.20 \mathrm{E}+00$ & $1.62 \mathrm{E}+00$ & $2.24 \mathrm{E}+00$ \\
\hline $2.81 E-03$ & $4.56 \mathrm{E}+00$ & $3.09 \mathrm{E}-01$ & $1.46 \mathrm{E}-01$ & $8.07 \mathrm{E}-01$ & $1.20 \mathrm{E}+00$ & $1.62 \mathrm{E}+00$ & $2.25 \mathrm{E}+00$ \\
\hline $2.84 \mathrm{E}-03$ & $4.56 \mathrm{E}+00$ & $3.10 \mathrm{E}-01$ & $1.46 \mathrm{E}-01$ & $8.09 \mathrm{E}-01$ & $1.20 \mathrm{E}+00$ & $1.63 \mathrm{E}+00$ & $2.25 \mathrm{E}+00$ \\
\hline $2.86 \mathrm{E}-03$ & $4.56 \mathrm{E}+00$ & $3.11 \mathrm{E}-01$ & $1.47 \mathrm{E}-01$ & $8.11 \mathrm{E}-01$ & $1.21 \mathrm{E}+00$ & $1.63 \mathrm{E}+00$ & $2.25 \mathrm{E}+00$ \\
\hline $2.88 \mathrm{E}-03$ & $4.56 \mathrm{E}+00$ & $3.12 \mathrm{E}-01$ & $1.48 \mathrm{E}-01$ & $8.12 \mathrm{E}-01$ & $1.21 \mathrm{E}+00$ & $1.63 \mathrm{E}+00$ & $2.26 \mathrm{E}+00$ \\
\hline $2.91 E-03$ & $4.57 \mathrm{E}+00$ & $3.13 \mathrm{E}-01$ & $1.48 \mathrm{E}-01$ & $4 \mathrm{E}-01$ & $1.21 \mathrm{E}+00$ & $1.63 \mathrm{E}+00$ & $2.26 \mathrm{E}+00$ \\
\hline 9 & $4.57 \mathrm{E}+00$ & 3 & 1 & 1 & $1.21 \mathrm{E}+00$ & $1.63 \mathrm{E}+00$ & $2.26 \mathrm{E}+00$ \\
\hline $2.95 E-03$ & & & 1. & 1 & $1.22 \mathrm{E}+00$ & & $2.27 \mathrm{E}+00$ \\
\hline $2.98 \mathrm{E}-03$ & $4.57 \mathrm{E}+00$ & $3.15 \mathrm{E}-01$ & $1.50 \mathrm{E}-01$ & $8.19 \mathrm{E}-01$ & $1.22 \mathrm{E}+00$ & $1.64 \mathrm{E}+00$ & $2.27 \mathrm{E}+00$ \\
\hline $3.00 \mathrm{E}-03$ & $4.57 \mathrm{E}+00$ & $3.16 \mathrm{E}-01$ & $1.51 \mathrm{E}-01$ & $8.21 \mathrm{E}-01$ & $1.22 \mathrm{E}+00$ & $1.64 \mathrm{E}+00$ & $2.27 \mathrm{E}+00$ \\
\hline $3.02 \mathrm{E}-03$ & $4.57 \mathrm{E}+00$ & $3.17 \mathrm{E}-01$ & $1.51 \mathrm{E}-01$ & $8.23 \mathrm{E}-01$ & $1.22 \mathrm{E}+00$ & $1.64 \mathrm{E}+00$ & $2.28 \mathrm{E}+00$ \\
\hline $3.05 E-03$ & $4.57 \mathrm{E}+00$ & $3.18 \mathrm{E}-01$ & $1.52 \mathrm{E}-01$ & $8.26 \mathrm{E}-01$ & $1.22 \mathrm{E}+00$ & $1.65 \mathrm{E}+00$ & $2.28 \mathrm{E}+00$ \\
\hline $3.07 E-03$ & $4.57 \mathrm{E}+00$ & $3.19 \mathrm{E}-01$ & $1.52 \mathrm{E}-01$ & $8.28 \mathrm{E}-01$ & $1.22 \mathrm{E}+00$ & $1.65 \mathrm{E}+00$ & $2.28 \mathrm{E}+00$ \\
\hline $3.09 \mathrm{E}-03$ & $4.57 \mathrm{E}+00$ & $3.20 \mathrm{E}-01$ & $1.53 \mathrm{E}-01$ & $8.31 \mathrm{E}-01$ & $1.23 \mathrm{E}+00$ & $1.65 \mathrm{E}+00$ & $2.29 \mathrm{E}+00$ \\
\hline $3.12 \mathrm{E}-03$ & $4.57 \mathrm{E}+00$ & $3.21 \mathrm{E}-01$ & $1.54 \mathrm{E}-01$ & $8.33 \mathrm{E}-01$ & $1.23 \mathrm{E}+00$ & $1.65 \mathrm{E}+00$ & $2.29 \mathrm{E}+00$ \\
\hline $3.14 \mathrm{E}-03$ & $4.58 \mathrm{E}+00$ & $3.22 \mathrm{E}-01$ & $1.54 \mathrm{E}-01$ & $8.36 \mathrm{E}-01$ & $1.23 \mathrm{E}+00$ & $1.66 \mathrm{E}+00$ & $2.30 \mathrm{E}+00$ \\
\hline $3.17 \mathrm{E}-03$ & $4.58 \mathrm{E}+0$ & $3.23 \mathrm{E}-01$ & $1.55 \mathrm{E}-01$ & $8.39 \mathrm{E}-01$ & $1.23 \mathrm{E}+00$ & $1.66 \mathrm{E}+00$ & $2.30 \mathrm{E}+00$ \\
\hline $3.19 \mathrm{E}-03$ & $4.58 \mathrm{E}+00$ & $3.23 \mathrm{E}-01$ & $1.55 \mathrm{E}-01$ & $8.41 \mathrm{E}-01$ & $1.24 \mathrm{E}+00$ & $1.66 \mathrm{E}+00$ & $2.30 \mathrm{E}+00$ \\
\hline$E-03$ & $4.58 \mathrm{E}+00$ & $3.24 \mathrm{E}-01$ & $1.56 \mathrm{E}-01$ & 8.43 & $1.24 \mathrm{E}+00$ & $1.67 \mathrm{E}+00$ & $2.30 \mathrm{E}+00$ \\
\hline $3.24 \mathrm{E}-03$ & $4.58 \mathrm{E}+00$ & $3.25 \mathrm{E}-01$ & $1.56 \mathrm{E}-01$ & $8.45 \mathrm{E}-01$ & $1.24 \mathrm{E}+00$ & $1.67 \mathrm{E}+00$ & $2.31 \mathrm{E}+00$ \\
\hline $3.27 E-03$ & $4.58 \mathrm{E}+00$ & $3.26 \mathrm{E}-01$ & $1.57 \mathrm{E}-01$ & $8.47 \mathrm{E}-01$ & $1.24 \mathrm{E}+00$ & $1.67 \mathrm{E}+00$ & $2.31 \mathrm{E}+00$ \\
\hline $3.29 \mathrm{E}-03$ & $4.58 \mathrm{E}+00$ & $3.27 \mathrm{E}-01$ & $1.57 \mathrm{E}-01$ & $8.48 \mathrm{E}-01$ & $1.24 \mathrm{E}+00$ & $1.68 \mathrm{E}+00$ & $2.31 \mathrm{E}+00$ \\
\hline $3.32 E-03$ & $4.58 \mathrm{E}+00$ & $3.28 \mathrm{E}-01$ & $1.58 \mathrm{E}-01$ & $8.50 \mathrm{E}-01$ & $1.24 \mathrm{E}+00$ & $1.68 \mathrm{E}+00$ & $2.31 \mathrm{E}+00$ \\
\hline $3.34 E-03$ & $4.58 \mathrm{E}+00$ & $3.29 \mathrm{E}-01$ & $1.58 \mathrm{E}-01$ & $8.52 \mathrm{E}-01$ & $1.25 \mathrm{E}+00$ & $1.68 \mathrm{E}+00$ & $2.32 \mathrm{E}+00$ \\
\hline $3.37 \mathrm{E}-03$ & $4.58 \mathrm{E}+00$ & $3.30 \mathrm{E}-01$ & $1.59 \mathrm{E}-01$ & $8.53 \mathrm{E}-01$ & $1.25 \mathrm{E}+00$ & $1.69 \mathrm{E}+00$ & $2.32 \mathrm{E}+00$ \\
\hline $3.39 E-03$ & $4.58 \mathrm{E}+00$ & $3.30 \mathrm{E}-01$ & $1.60 \mathrm{E}-01$ & $8.55 \mathrm{E}-01$ & $1.25 \mathrm{E}+00$ & $1.69 \mathrm{E}+00$ & $2.32 \mathrm{E}+00$ \\
\hline $3.42 \mathrm{E}-03$ & $4.59 \mathrm{E}+00$ & $3.31 \mathrm{E}-01$ & $1.60 \mathrm{E}-01$ & $8.56 \mathrm{E}-01$ & $1.25 \mathrm{E}+00$ & $1.69 \mathrm{E}+00$ & $2.32 \mathrm{E}+00$ \\
\hline $3.45 E-03$ & $4.59 \mathrm{E}+00$ & $3.32 \mathrm{E}-01$ & $1.61 \mathrm{E}-01$ & $8.58 \mathrm{E}-01$ & $1.25 \mathrm{E}+00$ & $1.69 \mathrm{E}+00$ & $2.33 E+00$ \\
\hline $3.47 E-03$ & $4.59 \mathrm{E}+00$ & $3.33 \mathrm{E}-01$ & $1.62 \mathrm{E}-01$ & $8.60 \mathrm{E}-01$ & $1.25 \mathrm{E}+00$ & $1.70 \mathrm{E}+00$ & $2.33 E+00$ \\
\hline
\end{tabular}


RESRAD-OFFSITE, Version 2.5

Title : RESRAD-OFFSITE Drinking Water, Plant, Milk, and Meat Pathways for Offsite Reside File : PBA-1_TC99-DOE-5.ROF

Summary of dose at graphical times, reptition 3 (continued)

Time

Years

$6.13 \mathrm{E}+02$

$6.14 \mathrm{E}+02$

$6.14 \mathrm{E}+02$

$6.15 \mathrm{E}+02$

$6.15 \mathrm{E}+02$

$6.16 \mathrm{E}+02$

$6.16 \mathrm{E}+02$

$6.17 \mathrm{E}+02$

$6.17 \mathrm{E}+02$

$6.18 \mathrm{E}+02$

$6.18 \mathrm{E}+02$

$6.19 \mathrm{E}+02$

$6.19 \mathrm{E}+02$

$6.20 \mathrm{E}+02$

$6.20 \mathrm{E}+02$

$6.21 \mathrm{E}+02$

$6.21 \mathrm{E}+02$

$6.22 \mathrm{E}+02$

$6.22 \mathrm{E}+02$

$6.23 \mathrm{E}+02$

$6.23 \mathrm{E}+02$

$6.24 \mathrm{E}+02$

$6.24 \mathrm{E}+02$

$6.25 \mathrm{E}+02$

$6.25 \mathrm{E}+02$

$6.26 \mathrm{E}+02$

$6.27 \mathrm{E}+02$

$6.27 \mathrm{E}+02$

$6.28 \mathrm{E}+02$

$6.28 \mathrm{E}+02$

$6.29 \mathrm{E}+02$

$6.29 \mathrm{E}+02$

$6.30 \mathrm{E}+02$

$6.30 \mathrm{E}+02$

$6.31 \mathrm{E}+02$

$6.31 \mathrm{E}+02$

$6.32 \mathrm{E}+02$

$6.32 \mathrm{E}+02$

$6.33 \mathrm{E}+02$

$6.33 \mathrm{E}+02$

$6.34 \mathrm{E}+02$

$6.34 \mathrm{E}+02$

$6.35 \mathrm{E}+02$

$6.35 \mathrm{E}+02$

$6.36 \mathrm{E}+02$

$6.36 \mathrm{E}+02$
Dose statistics at graphical times, mrem/yr

\begin{tabular}{|c|c|c|c|c|c|c|c|}
\hline inimum & aximum & Mean & ledian & $0 \%$ & $\%$ & $97.5 \%$ & \\
\hline 03 & $59 E+00$ & $4 \mathrm{E}-01$ & 1. $62 \mathrm{E}-01$ & $2 E-01$ & $1.26 \mathrm{E}+00$ & $1.70 \mathrm{E}+00$ & $2.33 E+0$ \\
\hline 03 & +00 & 1 & 1 & 1 & 00 & 00 & 100 \\
\hline 03 & -00 & 1 & 1 & 1 & 00 & 00 & +00 \\
\hline 03 & 00 & 1 & & 1 & & +00 & +00 \\
\hline 03 & 00 & & & 01 & 00 & $.71 \mathrm{E}+00$ & $34 \mathrm{E}+00$ \\
\hline $3 E-03$ & $E+00$ & -01 & -01 & 01 & $1.27 \mathrm{E}+00$ & $1.72 \mathrm{E}+00$ & $.34 \mathrm{E}+0 \mathrm{C}$ \\
\hline 03 & -00 & 01 & -01 & 1 & ח & +00 & $\mathrm{i}+0 \mathrm{c}$ \\
\hline 03 & -00 & & & 1 & 0 & 00 & 00 \\
\hline 03 & +00 & 1 & 01 & 01 & 00 & -00 & 100 \\
\hline$E-03$ & $4.59 \mathrm{E}+00$ & $2 E-01$ & $59 E-01$ & $81 E-01$ & $1.28 \mathrm{E}+00$ & $.73 E+00$ & $E+00$ \\
\hline $.77 \mathrm{E}-03$ & $E+00$ & $3 E-01$ & $0 E-01$ & $83 E-01$ & & $.74 \mathrm{E}+00$ & $35 E+00$ \\
\hline-03 & +00 & -01 & -01 & 01 & & +00 & $E+00$ \\
\hline S & $E+00$ & $5-0 \perp$ & $1 E-01$ & 1 & $1.29 E+00$ & $E+00$ & +0 \\
\hline 3 & 00 & $E-01$ & 1 & 1 & 0 & +00 & +00 \\
\hline 03 & -00 & $\perp$ & 01 & 1 & 00 & $.75 E+00$ & $\Xi+00$ \\
\hline-03 & $4.59 \mathrm{E}+00$ & $\Gamma$ & -01 & 1 & $1.30 \mathrm{E}+00$ & $E+00$ & +00 \\
\hline $.94 \mathrm{E}-03$ & $E+00$ & $E-01$ & $4 E-01$ & $95 E-01$ & $1.30 \mathrm{E}+00$ & $.76 \mathrm{E}+00$ & $.37 E+00$ \\
\hline-03 & $9 E+00$ & $9 E-01$ & $4 E-01$ & $7 E-01$ & $30 \mathrm{E}+00$ & $.76 \mathrm{E}+00$ & $37 \mathrm{E}+0 \mathrm{C}$ \\
\hline & $\mathrm{E}+00$ & & & 1 & 0 & +00 & +00 \\
\hline 03 & -00 & & 01 & 1 & 0 & +00 & +0 \\
\hline 3 & & & 1 & & & 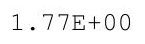 & 00 \\
\hline 03 & $E+00$ & 1 & 1 & 1 & 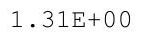 & $78 \mathrm{~F}+00$ & $E+00$ \\
\hline 3 & $60 \mathrm{E}+00$ & 1 & $8 E-01$ & $8 \mathrm{E}-01$ & 1. $32 \mathrm{E}+00$ & $.78 E+00$ & $.38 E+00$ \\
\hline$E-03$ & $.60 \mathrm{E}+00$ & $5 E-01$ & $9 E-01$ & $10 E-01$ & $1.32 \mathrm{E}+00$ & $.78 E+00$ & $.38 \mathrm{E}+00$ \\
\hline 03 & $60 \mathrm{~F}+00$ & $6 \mathrm{E}-01$ & $0 \mathrm{E}-01$ & $12 E-01$ & & $79 F+00$ & $39 E+00$ \\
\hline & & & & & & & \\
\hline & & & & & & 1. & \\
\hline 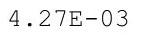 & $4.60 \mathrm{E}+00$ & $.58 E-01$ & $.82 \mathrm{E}-01$ & $18 E-01$ & $1.34 \mathrm{E}+00$ & $1.79 \mathrm{E}+00$ & $.39 E+00$ \\
\hline 03 & $4.60 \mathrm{E}+00$ & 1 & $83 E-01$ & 1 & $1.34 \mathrm{E}+00$ & $.80 \mathrm{E}+00$ & $.39 \mathrm{E}+0$ \\
\hline 3 & - & - & $83 E-01$ & 1 & & $.80 E+0$ & $.40 \mathrm{E}+0$ \\
\hline 03 & $.60 \mathrm{E}+00$ & & $4 E-01$ & $23 E-01$ & $1.35 \mathrm{E}+00$ & $80 F+00$ & $40 \mathrm{E}+00$ \\
\hline & ( & & & & & & \\
\hline & & & $6 E-01$ & 01 & & & \\
\hline $5 E-03$ & $4.60 \mathrm{E}+00$ & $.64 E-01$ & $1.86 \mathrm{E}-01$ & $27 E-01$ & $1.35 \mathrm{E}+00$ & $1.81 \mathrm{E}+00$ & $2.40 \mathrm{E}+0 \mathrm{C}$ \\
\hline $.405-03$ & . OULTU & & $1.87 E-01$ & $9.29 E-01$ & & $1.81 \mathrm{E}+00$ & $2.41 \mathrm{E}+0$ \\
\hline & & & & & & & \\
\hline $.55 E-03$ & 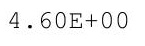 & & & 1 & & 0 & 0 \\
\hline 3 & & & & 1 & & & \\
\hline 03 & & 1 & $0 E-01$ & 1 & $1.37 \mathrm{E}+00$ & $1.82 \mathrm{E}+00$ & $2.42 \mathrm{E}+00$ \\
\hline $4 E-03$ & $4.60 \mathrm{E}+00$ & $69 E-01$ & 01 & 01 & 0 & 0 & +00 \\
\hline 03 & $4.60 \mathrm{E}+00$ & & & 1 & & & $2.42 \mathrm{E}+0 \mathrm{C}$ \\
\hline & $4.00 \mathrm{E}+00$ & $\perp$ & 1 & 1 & $1.37+00$ & $1.83 \mathrm{E}+00$ & $2.42 \mathrm{E}+00$ \\
\hline 10 & $4.60 \mathrm{E}+00$ & 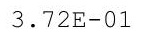 & $2 E-01$ & 1 & 1. $38 \mathrm{E}+$ & $1.83 \mathrm{E}+00$ & $2.43 E+00$ \\
\hline $.78 E-03$ & . & & & $10+$ & $38 \mathrm{E}$ & $.83 \mathrm{E}+$ & $43 E+00$ \\
\hline$E-03$ & $4.59 \mathrm{E}+00$ & $E-01$ & 01 & 9.4 & $1.38 \mathrm{E}+00$ & $1.84 \mathrm{E}+00$ & $2.43 E+00$ \\
\hline $.84 E-03$ & $4.59 \mathrm{E}+00$ & $.75 E-01$ & $1.95 \mathrm{E}-01$ & $.49 E-01$ & $1.38 \mathrm{E}+00$ & $1.84 \mathrm{E}+00$ & $2.44 \mathrm{E}+00$ \\
\hline
\end{tabular}


RESRAD-OFFSITE, Version 2.5

Title : RESRAD-OFFSITE Drinking Water, Plant, Milk, and Meat Pathways for Offsite Reside File : PBA-1_TC99-DOE-5.ROF

Summary of dose at graphical times, reptition 3 (continued)

Time

Years

$6.37 \mathrm{E}+02$

$6.37 \mathrm{E}+02$

$6.38 \mathrm{E}+02$

$6.38 \mathrm{E}+02$

$6.39 \mathrm{E}+02$

$6.39 \mathrm{E}+02$

$6.40 \mathrm{E}+02$

$6.40 \mathrm{E}+02$

$6.41 \mathrm{E}+02$

$6.41 \mathrm{E}+02$

$6.42 \mathrm{E}+02$

$6.42 \mathrm{E}+02$

$6.43 \mathrm{E}+02$

$6.43 \mathrm{E}+02$

$6.44 \mathrm{E}+02$

$6.44 \mathrm{E}+02$

$6.45 \mathrm{E}+02$

$6.45 \mathrm{E}+02$

$6.46 \mathrm{E}+02$

$6.47 \mathrm{E}+02$

$6.47 \mathrm{E}+02$

$6.48 \mathrm{E}+02$

$6.48 \mathrm{E}+02$

$6.49 \mathrm{E}+02$

$6.49 \mathrm{E}+02$

$6.50 \mathrm{E}+02$

$6.50 \mathrm{E}+02$

$6.51 \mathrm{E}+02$

$6.51 \mathrm{E}+02$

$6.52 \mathrm{E}+02$

$6.52 \mathrm{E}+02$

$6.53 \mathrm{E}+02$

$6.53 \mathrm{E}+02$

$6.54 \mathrm{E}+02$

$6.54 \mathrm{E}+02$

$6.55 \mathrm{E}+02$

$6.55 \mathrm{E}+02$

$6.56 \mathrm{E}+02$

$6.56 \mathrm{E}+02$

$6.57 \mathrm{E}+02$

$6.57 \mathrm{E}+02$

$6.58 \mathrm{E}+02$

$6.58 \mathrm{E}+02$

$6.59 \mathrm{E}+02$

$6.59 \mathrm{E}+02$

$6.60 \mathrm{E}+02$

Dose statistics at graphical times, mrem/yr

\begin{tabular}{|c|c|c|c|c|c|c|c|}
\hline inimum & aximum & Mean & ledian & $0 \%$ & $\%$ & $7.5 \%$ & \\
\hline 3 & +00 & 01 & 01 & 1 & 00 & 00 & +0 \\
\hline 03 & +00 & $E-01$ & 1 & 1 & 00 & 00 & 100 \\
\hline-03 & +00 & 01 & 1 & 1 & 00 & 00 & +00 \\
\hline 03 & $E+00$ & 1 & & & & 00 & +00 \\
\hline-03 & 0 & & & 01 & 00 & +00 & $45 E+00$ \\
\hline$E-03$ & +00 & -01 & -01 & 01 & $E+00$ & $E+00$ & $45 E+00$ \\
\hline 03 & +00 & 01 & -01 & $3 E-01$ & ho & +00 & +00 \\
\hline 03 & -00 & I & & 1 & 00 & 00 & 00 \\
\hline 03 & +00 & $\perp$ & 01 & $7 E-01$ & 00 & -00 & +00 \\
\hline $3 E-03$ & $4.59 \mathrm{E}+00$ & $4 E-01$ & $2 E-01$ & $E-01$ & $1.40 \mathrm{E}+00$ & $.86 \mathrm{E}+00$ & $46 \mathrm{E}+00$ \\
\hline $22 \mathrm{E}-03$ & $9 \mathrm{E}+00$ & $5 E-01$ & $2 E-01$ & $1 E-01$ & & $.87 \mathrm{E}+00$ & $47 E+00$ \\
\hline-03 & -00 & -01 & 1 & & 00 & 00 & +00 \\
\hline ك & $\mathrm{E}+00$ & $7 \pm-0 \perp$ & -01 & -01 & 00 & $E+00$ & +0 \\
\hline 3 & 00 & $7 E-01$ & 1 & 1 & & +00 & +00 \\
\hline 03 & $9 \mathrm{E}+00$ & $\perp$ & 01 & 1 & 00 & $\mathrm{E}+00$ & +00 \\
\hline-03 & $4.59 \mathrm{E}+00$ & 1 & -01 & 1 & $1.41 \mathrm{E}+00$ & L. $88 \mathrm{E}+00$ & $.48 \mathrm{E}+00$ \\
\hline $.44 \mathrm{E}-03$ & $4.59 \mathrm{E}+00$ & $3.90 \mathrm{E}-01$ & $2.06 \mathrm{E}-01$ & $.84 E-01$ & $1.41 \mathrm{E}+00$ & $1.88 \mathrm{E}+00$ & $.48 E+00$ \\
\hline-03 & $E+00$ & $1 E-01$ & $7 E-01$ & $6 E-01$ & $1.42 \mathrm{E}+00$ & $88 \mathrm{E}+00$ & $49 E+00$ \\
\hline 03 & +00 & $\perp$ & 01 & 1 & & +00 & +00 \\
\hline 03 & -00 & $\perp$ & 01 & 1 & 0 & +00 & +00 \\
\hline $.58 \mathrm{E}-03$ & & & -01 & & & 年 & +00 \\
\hline 03 & $\mathrm{E}+00$ & 1 & 1 & & (1) & $F+0$ & $E+00$ \\
\hline $5=03$ & $58 \mathrm{E}+00$ & 1 & $E-01$ & 1 & $.43 E+00$ & $.89 E+00$ & $50 \mathrm{E}+00$ \\
\hline$E-03$ & $.58 \mathrm{E}+00$ & $7 E-01$ & $2.11 \mathrm{E}-01$ & $98 \mathrm{E}-01$ & $1.43 \mathrm{E}+00$ & $.90 \mathrm{E}+00$ & $.50 \mathrm{E}+00$ \\
\hline 03 & $58 F+00$ & $8 E-01$ & $2 \mathrm{E}-01$ & & & $\mathrm{~F}+00$ & $50 \mathrm{E}+00$ \\
\hline & & & & & & & 100 \\
\hline $1+-03$ & $8+00$ & & & & & $1.90 E+00$ & +00 \\
\hline . & SOLTU & $00 \mathrm{E}-01$ & $2.14 \mathrm{E}-01$ & $1.01 \mathrm{E}+00$ & $1.4 J 5 T 00$ & $1.91 \mathrm{E}+00$ & $.51 E+00$ \\
\hline 03 & . & - & 1 & - & $1.45 \mathrm{E}+00$ & $.91 E+00$ & $51 E+0$ \\
\hline $.92 E-03$ & - & ( & 1 & 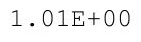 & & $.91 E+0$ & $52 \mathrm{E}+0$ \\
\hline $5-03$ & $4.58 E+00$ & & $7 E-01$ & $1 E+00$ & & $.91 \mathrm{E}+00$ & $52 E+00$ \\
\hline 03 & D & $E-01$ & & & & & \\
\hline & & & & & & & \\
\hline $.08 E-03$ & $4.57 E+00$ & $6 E-01$ & $2.20 \mathrm{E}-01$ & $1.02 \mathrm{E}+00$ & $1.46 \mathrm{E}+00$ & $1.92 \mathrm{E}+00$ & $.53 E+0 c$ \\
\hline $12 \mathrm{~L}-U 3$ & . JTLTU & & & 1.UСЕТО & & $.92 \mathrm{E}+00$ & Z.JULTU \\
\hline $.16 \mathrm{E}-03$ & & & & & & & $.53 E+00$ \\
\hline & $4.57 E+00$ & & & 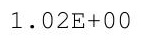 & & 0 & 00 \\
\hline 3 & & & & & & & \\
\hline$E-03$ & & 1 & $2.23 E-01$ & & $1.48 \mathrm{E}+00$ & $1.93 \mathrm{E}+00$ & \\
\hline $2 E-03$ & $4.57 \mathrm{E}+00$ & $E-01$ & 01 & 0 & & & +00 \\
\hline & & & & 0 & & & $E+0$ \\
\hline & $4.3 / E+00$ & & & $03 E+00$ & $1.49 E+00$ & $.94 \mathrm{E}+00$ & $2.50 \mathrm{E}+00$ \\
\hline 3 & 0 & $\perp$ & $27 E-01$ & 土. & $49 \mathrm{E}+$ & $1.95 \mathrm{E}+00$ & $.55 E+00$ \\
\hline $.48 E-03$ & & & & 0 & 0 & 1.95E+ & $2.55 E+00$ \\
\hline 03 & $4.56 \mathrm{E}+00$ & -01 & $2.28 E-01$ & $1.04 \mathrm{E}+00$ & $1.50 \mathrm{E}+00$ & $1.95 \mathrm{E}+00$ & $2.55 \mathrm{E}+00$ \\
\hline $.56 E-03$ & $4.56 \mathrm{E}+00$ & $.17 E-01$ & $.29 E-01$ & $1.04 \mathrm{E}+00$ & $1.50 \mathrm{E}+00$ & $1.96 \mathrm{E}+00$ & $2.55 \mathrm{E}+00$ \\
\hline
\end{tabular}


RESRAD-OFFSITE, Version 2.5

$\mathrm{T}^{1 / 2}$ Limit $=180$ days

Title : RESRAD-OFFSITE Drinking Water, Plant, Milk, and Meat Pathways for Offsite Reside File : PBA-1_TC99-DOE-5.ROF

Summary of dose at graphical times, reptition 3 (continued)

Time

Years

$6.60 \mathrm{E}+02$

$6.61 \mathrm{E}+02$

$6.61 \mathrm{E}+02$

$6.62 \mathrm{E}+02$

$6.62 \mathrm{E}+02$

$6.63 \mathrm{E}+02$

$6.63 \mathrm{E}+02$

$6.64 \mathrm{E}+02$

$6.64 \mathrm{E}+02$

$6.65 \mathrm{E}+02$

$6.65 \mathrm{E}+02$

$6.66 \mathrm{E}+02$

$6.67 \mathrm{E}+02$

$6.67 \mathrm{E}+02$

$6.68 \mathrm{E}+02$

$6.68 \mathrm{E}+02$

$6.69 \mathrm{E}+02$

$6.69 \mathrm{E}+02$

$6.70 \mathrm{E}+02$

$6.70 \mathrm{E}+02$

$6.71 \mathrm{E}+02$

$6.71 \mathrm{E}+02$

$6.72 \mathrm{E}+02$

$6.72 \mathrm{E}+02$

$6.73 \mathrm{E}+02$

$6.73 \mathrm{E}+02$

$6.74 \mathrm{E}+02$

$6.74 \mathrm{E}+02$

$6.75 \mathrm{E}+02$

$6.75 \mathrm{E}+02$

$6.76 \mathrm{E}+02$

$6.76 \mathrm{E}+02$

$6.77 \mathrm{E}+02$

$6.77 \mathrm{E}+02$

$6.78 \mathrm{E}+02$

$6.78 \mathrm{E}+02$

$6.79 \mathrm{E}+02$

$6.79 \mathrm{E}+02$

$6.80 \mathrm{E}+02$

$6.80 \mathrm{E}+02$

$6.81 \mathrm{E}+02$

$6.81 \mathrm{E}+02$

$6.82 \mathrm{E}+02$

$6.82 \mathrm{E}+02$

$6.83 \mathrm{E}+02$

$6.83 \mathrm{E}+02$
Dose statistics at graphical times, mrem/yr

\begin{tabular}{|c|c|c|c|c|c|c|c|}
\hline$m$ & um & ean & ec & & & & \\
\hline 3 & 0 & 1 & 1 & 00 & 00 & 0 & +00 \\
\hline $.65 E-03$ & $6 \mathrm{E}+00$ & $.19 \mathrm{E}-01$ & 2. $31 E-01$ & $4 \mathrm{E}+00$ & $1.51 \mathrm{E}+00$ & $1.96 \mathrm{E}+00$ & $56 \mathrm{E}+0 \mathrm{C}$ \\
\hline$F F-03$ & $6 E+00$ & $20 E-01$ & $32 E-01$ & $4 E+00$ & $51 E+00$ & $96 \mathrm{E}+00$ & $56 \mathrm{~F}+00$ \\
\hline $73 E-03$ & $56 E+00$ & $.21 E-01$ & $2.33 E-01$ & $1.05 \mathrm{E}+00$ & +00 & $.97 E+00$ & +00 \\
\hline $.77 \mathrm{E}-03$ & & $E-01$ & 1 & & & & +00 \\
\hline $82 E-03$ & 00 & $E-01$ & $5 E-01$ & 00 & 00 & 00 & $\mathrm{E}+\mathrm{OC}$ \\
\hline 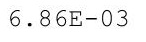 & 0 & $E-01$ & -01 & +00 & उषणि & $1.98 \mathrm{E}+00$ & $56 \mathrm{E}+00$ \\
\hline $90 E-03$ & $5 E+00$ & $4 E-01$ & $2.37 E-01$ & 1. $05 \mathrm{E}+00$ & $.52 \mathrm{E}+00$ & $1.98 \mathrm{E}+00$ & $\mathrm{E}+00$ \\
\hline $.95 E-0$ & $5 E+00$ & $5 E-01$ & $37 E-01$ & $E+00$ & $E+00$ & $98 \mathrm{E}+$ & $E+00$ \\
\hline ac $r a r a t$ & $5 \mathrm{~F}+00$ & & $8 \mathrm{~F}-2 \cdot 3-1$ & 0 & 1 & 0 & $57 \mathrm{~F}+00$ \\
\hline F & & & & & & & +00 \\
\hline$F-03$ & $5 \mathrm{E}+00$ & $8 E-01$ & $0 E-01$ & +00 & +00 & +00 & $57 \mathrm{E}+00$ \\
\hline $.12 \mathrm{E}-03$ & 4. $55 \mathrm{E}+00$ & $9 E-01$ & $2.41 E-01$ & $1.06 \mathrm{E}+00$ & $1.53 \mathrm{E}+00$ & $1.99 \mathrm{E}+00$ & $57 E+00$ \\
\hline $.16 E-03$ & & $4.30 \mathrm{E}-01$ & $2.41 E-01$ & & & $1.99 \mathrm{E}+00$ & $57 E+00$ \\
\hline - & & & & & & & +00 \\
\hline $.25 E-03$ & & & & & & & 00 \\
\hline 3 & (1) & $3 \mathrm{~F}-\mathrm{r}-\mathrm{r}$ & 1 & 0 & 0 & 0 & +00 \\
\hline $34 F-03$ & $4 F+00$ & $3 E-01$ & $5 E-01$ & & $4 \mathrm{E}+00$ & $\mathrm{E}+00$ & $7 \mathrm{E}+00$ \\
\hline $.39 E-03$ & $4.54 \mathrm{E}+00$ & $.34 \mathrm{E}-01$ & $2.45 E-01$ & $1.07 \mathrm{E}+00$ & $1.54 \mathrm{E}+00$ & $2.00 \mathrm{E}+00$ & $.58 \mathrm{E}+00$ \\
\hline$E-03$ & $4.54 \mathrm{E}+00$ & $35 E-01$ & $46 E-01$ & $7 \mathrm{E}+00$ & $4 \mathrm{E}+00$ & $E+00$ & $58 \mathrm{E}+00$ \\
\hline & & & & & & & \\
\hline & & & & & & & $\mathrm{E}+00$ \\
\hline & & & & & & & $8 E+00$ \\
\hline 625 & $.53 E+C$ & $39 E-$ & 1 & $8 \mathrm{E}+00$ & $5 E+00$ & $\mathrm{E}+00$ & $B E+00$ \\
\hline $66 \mathrm{~F}-0$ & $.53 E+00$ & $.40 E-01$ & $2.50 E-01$ & $1.08 \mathrm{E}+00$ & $1.55 \mathrm{E}+00$ & $2.02 E+00$ & $.58 E+00$ \\
\hline $71 \mathrm{~F}-03$ & $4.53 E+00$ & $4.41 \mathrm{E}-01$ & $2.51 E-01$ & $1.08 \mathrm{E}+00$ & $1.55 \mathrm{E}+00$ & $2.02 E+00$ & $.58 \mathrm{E}+0 \mathrm{C}$ \\
\hline 03 & & & $2 E-01$ & & & & \\
\hline & & & & & & & \\
\hline & & & & & & & $59 E+00$ \\
\hline $.90 \mathrm{E}-03$ & $4.52 \mathrm{E}+00$ & $4.45 E-01$ & $2.54 \mathrm{E}-01$ & $1.09 \mathrm{E}+00$ & $1.56 \mathrm{E}+00$ & $2.03 E+00$ & $59 \mathrm{E}+0 \mathrm{C}$ \\
\hline (- & $4.52 \mathrm{E}+00$ & $.45 \mathrm{E}-01$ & $2.55 E-01$ & $1.09 \mathrm{E}+00$ & $1.57 \mathrm{E}+00$ & $2.03 E+00$ & $.59 \mathrm{E}+0$ \\
\hline - & $4.52 \mathrm{E}+$ & & & & & & $9 \mathrm{E}+0$ \\
\hline & & & & & & & $59 \mathrm{E}+00$ \\
\hline$E-03$ & & & & & & & \\
\hline & & & & & $E+00$ & & \\
\hline 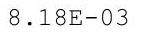 & $4.51 \mathrm{E}+00$ & $.50 E-01$ & $2.59 \mathrm{E}-01$ & $1.10 \mathrm{E}+00$ & $1.58 \mathrm{E}+00$ & $2.04 \mathrm{E}+00$ & $2.59 \mathrm{E}+0 \mathrm{C}$ \\
\hline (2) & & $.51 E-01$ & & & & & 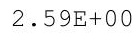 \\
\hline (- & tostr & & 1 & - & & $2.05 \mathrm{E}+00$ & $59 E+0 C$ \\
\hline $.33 E-03$ & 4. $51 \mathrm{E}+0$ & 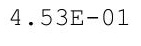 & $2.62 \mathrm{E}-$ & & . & & $60 \mathrm{E}+0 \mathrm{C}$ \\
\hline $.38 E-03$ & 4. $50 \mathrm{E}+\mathrm{C}$ & & 1 & & $9 \mathrm{E}+00$ & & $\mathrm{E}+00$ \\
\hline $3 F-03$ & & $.55 \mathrm{E}-01$ & $2.63 E-01$ & & $1.59 \mathrm{E}+00$ & & $\mathrm{OE}+\mathrm{OC}$ \\
\hline $48 E-03$ & $4.50 E+00$ & $56 \mathrm{E}-01$ & $2.64 \mathrm{E}-01$ & $1.11 \mathrm{E}+00$ & & & $\mathrm{E}+\mathrm{OC}$ \\
\hline & & & & & & & 2.00010 \\
\hline 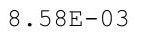 & 1. & & & $1.12 \mathrm{E}+00$ & $1.60 \mathrm{E}+00$ & $2.06 \mathrm{E}+00$ & $2.60 \mathrm{E}+00$ \\
\hline & & & & & & & $2.60 \mathrm{E}+00$ \\
\hline 03 & $9 \mathrm{E}+00$ & E-01 & $E-01$ & $2 E+00$ & $.60 E+00$ & $2.07 \mathrm{E}+00$ & $.60 E+00$ \\
\hline
\end{tabular}


RESRAD-OFFSITE, Version 2.5

Title : RESRAD-OFFSITE Drinking Water, Plant, Milk, and Meat Pathways for Offsite Reside File : PBA-1_TC99-DOE-5.ROF

Summary of dose at graphical times, reptition 3 (continued)

Time

Years

$6.84 \mathrm{E}+02$

$6.84 \mathrm{E}+02$

$6.85 \mathrm{E}+02$

$6.85 \mathrm{E}+02$

$6.86 \mathrm{E}+02$

$6.86 \mathrm{E}+02$

$6.87 \mathrm{E}+02$

$6.88 \mathrm{E}+02$

$6.88 \mathrm{E}+02$

$6.89 \mathrm{E}+02$

$6.89 \mathrm{E}+02$

$6.90 \mathrm{E}+02$

$6.90 \mathrm{E}+02$

$6.91 \mathrm{E}+02$

$6.91 \mathrm{E}+02$

$6.92 \mathrm{E}+02$

$6.92 \mathrm{E}+02$

$6.93 \mathrm{E}+02$

$6.93 \mathrm{E}+02$

$6.94 \mathrm{E}+02$

$6.94 \mathrm{E}+02$

$6.95 \mathrm{E}+02$

$6.95 \mathrm{E}+02$

$6.96 \mathrm{E}+02$

$6.96 \mathrm{E}+02$

$6.97 \mathrm{E}+02$

$6.97 \mathrm{E}+02$

$6.98 \mathrm{E}+02$

$6.98 \mathrm{E}+02$

$6.99 \mathrm{E}+02$

$6.99 \mathrm{E}+02$

$7.00 \mathrm{E}+02$

$7.00 \mathrm{E}+02$

$7.01 \mathrm{E}+02$

$7.01 \mathrm{E}+02$

$7.02 \mathrm{E}+02$

7. $02 \mathrm{E}+02$

$7.03 \mathrm{E}+02$

7. $03 \mathrm{E}+02$

7. $04 \mathrm{E}+02$

$7.04 \mathrm{E}+02$

$7.05 \mathrm{E}+02$

7. $05 \mathrm{E}+02$

$7.06 \mathrm{E}+02$

$7.06 \mathrm{E}+02$

$7.07 \mathrm{E}+02$
Dose statistics at graphical times, mrem/yr

\begin{tabular}{|c|c|c|c|c|c|c|c|}
\hline inimum & aximum & Mean & ledian & $0 \%$ & $5 \%$ & $97.5 \%$ & $3 \%$ \\
\hline 03 & $49 E+00$ & $4.60 E-01$ & $9 E-01$ & $1.12 \mathrm{E}+00$ & $1.60 \mathrm{E}+00$ & $.07 E+00$ & $0 \mathrm{E}+0$ \\
\hline 03 & +00 & 01 & 1 & 0 & $60 \mathrm{E}+00$ & $E+00$ & +00 \\
\hline 03 & $E+00$ & $2 E-01$ & 01 & $3 E+00$ & 00 & -00 & +00 \\
\hline-03 & $E+00$ & 1 & 1 & 0 & & 00 & +00 \\
\hline-03 & -00 & & & 00 & 00 & $8 E+00$ & $61 E+00$ \\
\hline-03 & $\mathrm{E}+00$ & $E-01$ & -01 & $1.13 \mathrm{E}+00$ & $1.61 \mathrm{E}+00$ & $E+00$ & $61 E+00$ \\
\hline 03 & +00 & -01 & -01 & 00 & 00 & +00 & +00 \\
\hline-03 & $4.48 E+00$ & & & & 00 & +00 & +00 \\
\hline 03 & +00 & $\perp$ & 01 & 00 & 00 & +00 & +00 \\
\hline $.20 E-03$ & $4.47 \mathrm{E}+00$ & $59 E-01$ & $6 \mathrm{E}-01$ & $1.14 \mathrm{E}+00$ & $1.62 \mathrm{E}+00$ & $9 E+00$ & $61 \mathrm{E}+00$ \\
\hline-03 & +00 & $E-01$ & -01 & & & 00 & $E+00$ \\
\hline & -00 & & & & & +00 & +00 \\
\hline $.36 E-03$ & $4.47 \mathrm{E}+00$ & $4.7 \perp E-U \perp$ & $2.78 E-01$ & $1.15 \mathrm{E}+U \mathrm{U}$ & 4.01 & $E+00$ & +0 \\
\hline 03 & -00 & 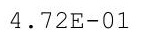 & -01 & 00 & 00 & +00 & +00 \\
\hline 03 & -00 & $\perp$ & 01 & 00 & 00 & +00 & +00 \\
\hline-03 & $4.46 \mathrm{E}+00$ & $\perp$ & -01 & $1.15 \mathrm{E}+00$ & $1.63 \mathrm{E}+00$ & $\mathrm{OE}+00$ & $62 E+00$ \\
\hline $.57 E-03$ & $4.46 \mathrm{E}+00$ & $5 E-01$ & $2 E-01$ & $1.15 \mathrm{E}+00$ & $.63 E+00$ & $10 \mathrm{E}+00$ & $.62 \mathrm{E}+00$ \\
\hline-03 & $6 E+00$ & $6 E-01$ & $3 E-01$ & $15 E+00$ & $63 E+00$ & $10 \mathrm{E}+00$ & $62 \mathrm{E}+0 \mathrm{C}$ \\
\hline $3 E-03$ & $4.45 \mathrm{E}+00$ & $7 E-01$ & $E-01$ & $1.15 \mathrm{E}+00$ & & $E+00$ & $62 \mathrm{E}+0 \mathrm{C}$ \\
\hline $3 E-03$ & $\mathrm{E}+00$ & -01 & -01 & 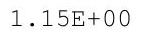 & 00 & +00 & +00 \\
\hline $.79 \mathrm{E}-03$ & 4.4 & & -01 & & & 100 & +00 \\
\hline$E-03$ & $4.45 \mathrm{E}+00$ & $.80 \mathrm{E}-01$ & $5 E-01$ & $1.16 \mathrm{E}+00$ & & $11 \mathrm{E}+00$ & $53 \mathrm{E}+00$ \\
\hline $\mathrm{T}=03$ & $45 \mathrm{E}+00$ & 1 & 1 & $1.16 \mathrm{E}+00$ & $1.64 \mathrm{E}+00$ & $.11 E+00$ & $.63 E+00$ \\
\hline$E-03$ & $44 \mathrm{E}+00$ & $.82 \mathrm{E}-01$ & $2.89 \mathrm{E}-01$ & $1.16 \mathrm{E}+00$ & $1.64 \mathrm{E}+00$ & $11 \mathrm{E}+00$ & $.63 E+00$ \\
\hline 02 & $E+00$ & & 01 & & & 00 & +00 \\
\hline 02 & 00 & 1 & & & & & +00 \\
\hline $01 \mathrm{E}-02$ & & & -01 & $1 .+0$ & 1.00 & +00 & +00 \\
\hline . & . . 4 & $4.85 E-01$ & $2.92 \mathrm{E}-01$ & $.17 \mathrm{E}+00$ & 1. OJETU & $10 \mathrm{E}+00$ & $.64 \mathrm{E}+00$ \\
\hline 02 & $43 E+00$ & 1 & 1 & $17 \mathrm{E}+00$ & $1.65 \mathrm{E}+00$ & $.10 \mathrm{E}+00$ & $.64 \mathrm{E}+0 \mathrm{C}$ \\
\hline $.03 E-02$ & 4. & . & -01 & $1.17 \mathrm{E}+$ & & $.10 \mathrm{E}+00$ & $.64 \mathrm{E}+0$ \\
\hline $2-03$ & $4.43 E+00$ & & $5 E-01$ & $1.17 \mathrm{E}+00$ & $66 \mathrm{E}+00$ & $1 \cap F+0 \cap$ & $64 \mathrm{E}+00$ \\
\hline$E-02$ & $4.43 E+00$ & $9 E-01$ & 01 & & & & \\
\hline$E-02$ & $2 \mathrm{E}+00$ & 1 & 01 & $1.18 \mathrm{E}$ & 1.00 & +00 & $5 E+00$ \\
\hline $.05 E-02$ & $4.4 \angle E+O U$ & $91 E-01$ & $2.98 E-01$ & $1.18 \mathrm{E}+00$ & $1.66 \mathrm{E}+00$ & $.11 E+00$ & $.65 E+00$ \\
\hline $00 \overline{-2}$ & . . $2 \angle D T U O$ & & & & & & $.65 E+0 c$ \\
\hline 2 & 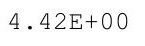 & & & & & & $.65 \mathrm{E}+00$ \\
\hline ( $07=0 ?$ & 4 & & & 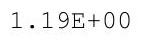 & & ת1. & $5 F+00$ \\
\hline 0 & 2 & & & & 0 & & \\
\hline & & 1 & -01 & & & & $65 \mathrm{E}+00$ \\
\hline$E-02$ & $4.41 E+00$ & $.96 \mathrm{E}-01$ & $3 E-01$ & $1.19 \mathrm{E}$ & & & $E+00$ \\
\hline & & $.97 E-01$ & & $1.20 \mathrm{E}+00$ & & & $.65 E+0 C$ \\
\hline & $4.40 \mathrm{E}+00$ & & & 1. $20 \mathrm{E}+00$ & & & $.0 J E+U 0$ \\
\hline & & $\perp$ & & & & & $.65 E+0$ \\
\hline $11 \mathrm{~F}-0 ?$ & 0 & & 1 & 1 & 0 & $11 \mathrm{E}+$ & $65 E+00$ \\
\hline$E-02$ & $4.40 \mathrm{E}+00$ & $E-01$ & 01 & $1.20 \mathrm{E}+00$ & $1.68 \mathrm{E}+00$ & $2.11 \mathrm{E}+00$ & $.65 \mathrm{E}+00$ \\
\hline $.12 E-02$ & $4.39 E+00$ & $.02 E-01$ & $.07 E-01$ & $1.20 \mathrm{E}+00$ & $1.68 \mathrm{E}+00$ & $.11 \mathrm{E}+00$ & $.65 E+00$ \\
\hline
\end{tabular}


RESRAD-OFFSITE, Version 2.5

Title : RESRAD-OFFSITE Drinking Water, Plant, Milk, and Meat Pathways for Offsite Reside File : PBA-1_TC99-DOE-5.ROF

Summary of dose at graphical times, reptition 3 (continued)

Time

Years

$7.08 \mathrm{E}+02$

$7.08 \mathrm{E}+02$

$7.09 \mathrm{E}+02$

$7.09 \mathrm{E}+02$

$7.10 \mathrm{E}+02$

$7.10 \mathrm{E}+02$

$7.11 \mathrm{E}+02$

7. $11 \mathrm{E}+02$

$7.12 \mathrm{E}+02$

$7.12 \mathrm{E}+02$

$7.13 \mathrm{E}+02$

$7.13 \mathrm{E}+02$

$7.14 \mathrm{E}+02$

$7.14 \mathrm{E}+02$

7. $15 \mathrm{E}+02$

7. $15 \mathrm{E}+02$

$7.16 \mathrm{E}+02$

7. $16 \mathrm{E}+02$

$7.17 \mathrm{E}+02$

$7.17 \mathrm{E}+02$

$7.18 \mathrm{E}+02$

$7.18 \mathrm{E}+02$

$7.19 \mathrm{E}+02$

$7.19 \mathrm{E}+02$

7. $20 \mathrm{E}+02$

$7.20 \mathrm{E}+02$

$7.21 \mathrm{E}+02$

$7.21 \mathrm{E}+02$

7. $22 \mathrm{E}+02$

$7.22 \mathrm{E}+02$

7. $23 \mathrm{E}+02$

7. $23 \mathrm{E}+02$

$7.24 \mathrm{E}+02$

7. $24 \mathrm{E}+02$

$7.25 \mathrm{E}+02$

7. $25 \mathrm{E}+02$

$7.26 \mathrm{E}+02$

$7.26 \mathrm{E}+02$

$7.27 \mathrm{E}+02$

$7.28 \mathrm{E}+02$

$7.28 \mathrm{E}+02$

$7.29 \mathrm{E}+02$

$7.29 \mathrm{E}+02$

$7.30 \mathrm{E}+02$

$7.30 \mathrm{E}+02$

$7.31 \mathrm{E}+02$
Dose statistics at graphical times, mrem/yr

\begin{tabular}{|c|c|c|c|c|c|c|c|}
\hline Minimum & aximum & Mean & ledian & $90 \%$ & $95 \%$ & $97.5 \%$ & $\%$ \\
\hline 2 & $9 E+00$ & $03 E-01$ & $F-01$ & $21 E+00$ & $69 E+00$ & +00 & +00 \\
\hline 2 & $9 E+00$ & $04 \mathrm{E}-01$ & $8 E-01$ & $21 E+00$ & $69 \mathrm{E}+00$ & -00 & $65 E+00$ \\
\hline $4 E-02$ & $9 \mathrm{E}+00$ & $05 E-01$ & $E-01$ & $21 E+00$ & 00 & 00 & +00 \\
\hline $5 E-02$ & $3 E+00$ & -01 & & & & & +00 \\
\hline 2 & -00 & $\perp$ & & $21 E-$ & $59 E+00$ & $1 E+00$ & $65 E+00$ \\
\hline L & $3 E+00$ & 1 & $\perp$ & $.22 E+00$ & $.70 E+00$ & 00 & +00 \\
\hline • & $38 \mathrm{E}+00$ & $N_{1}$ & ${ }^{2}$ & $.22 \mathrm{E}+00$ & $.70 E+00$ & +00 & +00 \\
\hline $.17 E-02$ & $37 E+00$ & • & & $.22 E+00$ & 1. $70 \mathrm{E}+00$ & $2.12 \mathrm{E}+00$ & $2.65 \mathrm{E}+00$ \\
\hline 02 & $E+00$ & 01 & 01 & $.22 E+00$ & +00 & 00 & -00 \\
\hline $.18 \mathrm{E}-02$ & $37 \mathrm{E}+00$ & 1 & 1 & $.22 E+00$ & $.71 E+00$ & & $65 \mathrm{E}+00$ \\
\hline-02 & +00 & 1 & & $22 E$ & & & +00 \\
\hline & +00 & & & $23 E+00$ & & & +00 \\
\hline • $\angle U D-0$ & $36 \mathrm{E}+00$ & $\cdot .4 \mathrm{E}-\mathrm{U} \perp$ & $.18 \mathrm{E}-U 1$ & $-23 E+00$ & $1.71 \mathrm{E}+00$ & $.13 E+00$ & 2. $65 E+00$ \\
\hline $.21 E-02$ & $36 E+00$ & 等 & $\perp$ & $1.23 \mathrm{E}+00$ & 1. $71 \mathrm{E}+00$ & +00 & +00 \\
\hline 02 & $5 \mathrm{E}+00$ & $.16 \mathrm{E}-01$ & 01 & $.23 E+00$ & +00 & 00 & +00 \\
\hline $.22 \mathrm{E}-02$ & $35 E+00$ & $.17 \mathrm{E}-01$ & -01 & $.24 \mathrm{E}+00$ & $.72 \mathrm{E}+00$ & +00 & $.65 \mathrm{E}+00$ \\
\hline $.23 E-02$ & $35 E+00$ & -01 & -01 & $.24 \mathrm{E}+00$ & $.72 \mathrm{E}+00$ & $4 \mathrm{E}+00$ & $2.65 \mathrm{E}+00$ \\
\hline-02 & $\mathrm{E}+00$ & $E-01$ & $E-01$ & 00 & 0 & $5 E+00$ & +00 \\
\hline $.24 \mathrm{E}-02$ & $E+00$ & $-U \perp$ & $\perp$ & $24 E+U 0$ & +00 & 00 & +00 \\
\hline $.25 E-02$ & +00 & -01 & $\perp$ & 00 & +00 & 00 & +00 \\
\hline $.25 \mathrm{E}-02$ & $34 \mathrm{E}+00$ & -01 & $\mathrm{E}-01$ & $.25 \mathrm{E}+00$ & 100 & & +00 \\
\hline $\begin{array}{l}.200 \\
\end{array}$ & $34 \mathrm{E}+U 0$ & $.22 E-01$ & . $\begin{array}{lll} & \end{array}$ & $.25 \mathrm{E}$ & 0 & & \pm+00 \\
\hline $.27 E-02$ & $33 E+00$ & 1 & 1 & $.25 E+00$ & $.73 E+00$ & $6 \mathrm{E}+00$ & $65 E+00$ \\
\hline $.27 E-02$ & $33 E+00$ & $24 \mathrm{E}-01$ & $29 \mathrm{E}-01$ & $.25 \mathrm{E}+00$ & $73 E+00$ & 0 & $65 E+00$ \\
\hline 02 & $E+00$ & $25 E-01$ & 01 & 00 & 00 & & $E+00$ \\
\hline$E-02$ & +00 & 01 & 01 & $E+00$ & 00 & & +00 \\
\hline $.29 E-02$ & $2 E+00$ & $E-01$ & $E-01$ & $.25 E+00$ & 0 & & +00 \\
\hline $.30 \mathrm{E}-02$ & $32 \mathrm{E}+00$ & $.28 E-01$ & $3.33 E-01$ & L. $25 E+00$ & $.74 \mathrm{E}+00$ & $.17 \mathrm{E}+00$ & $.65 E+00$ \\
\hline $.31 E-02$ & $.32 E+00$ & $.29 \mathrm{E}-01$ & $3.34 \mathrm{E}-01$ & 1. $26 \mathrm{E}+00$ & $1.74 \mathrm{E}+00$ & $.17 \mathrm{E}+00$ & $.65 E+00$ \\
\hline $.31 E-02$ & (2) & . & 年 & . ट्या & & & 2.040 \\
\hline 2 & $E+00$ & 1 & & 00 & $5 E+00$ & & $5 \mathrm{E}+00$ \\
\hline $\mathrm{E}-02$ & $E+00$ & $E-01$ & $E-01$ & $26 E+00$ & 00 & & $5 E+00$ \\
\hline $.33 E-02$ & $E+00$ & $.32 \mathrm{E}-01$ & $E-01$ & $1.26 \mathrm{E}+00$ & $5 \mathrm{E}+00$ & 00 & $5 E+00$ \\
\hline $.34 \mathrm{E}-02$ & $.30 \mathrm{E}+00$ & $.33 E-01$ & $3.38 E-01$ & $.26 \mathrm{E}+00$ & $1.75 E+00$ & $2.17 \mathrm{E}+00$ & $2.65 \mathrm{E}+00$ \\
\hline $35 E-02$ & SUTण & $.345-01$ & & • ZILTU & & & $2.65 E+00$ \\
\hline 2 & & & & & & & $.65 E+00$ \\
\hline & & & & 0 & & & 00 \\
\hline 2 & חم & $.37 E-01$ & 1 & 0 & 0 & 0 & 00 \\
\hline $38 E-02$ & $.29 \mathrm{E}+00$ & $3 E-01$ & $E-01$ & $1.27 \mathrm{E}$ & 0 & 00 & $5 E+00$ \\
\hline L. $38 \mathrm{E}-02$ & $29 E+00$ & $.39 E-01$ & 01 & $.28 \mathrm{E}$ & 0 & 0 & $5 E+00$ \\
\hline 2 & & & & & & & $5 E+00$ \\
\hline $.40 \mathrm{E}-02$ & $.28 E+00$ & & & $1.28 \mathrm{E}+00$ & $1.76 \mathrm{E}+00$ & $2.18 \mathrm{E}+00$ & $2.65 \mathrm{E}+00$ \\
\hline 2 & $4.28 E+00$ & \pm & $\perp$ & 1. $28 \mathrm{E}+00$ & & 0 & 年 \\
\hline$=$ & & & & $1.29 \mathrm{E}+00$ & 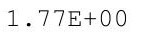 & & ( \\
\hline 02 & $E+00$ & 01 & 01 & 1.29 & 1 . & 00 & $2.65 E+00$ \\
\hline L $42 \mathrm{E}-02$ & $27 E+00$ & $.44 \mathrm{E}-01$ & $3.49 \mathrm{E}-01$ & $1.29 \mathrm{E}+00$ & $1.77 \mathrm{E}+00$ & $2.18 \mathrm{E}+00$ & $2.65 E+00$ \\
\hline
\end{tabular}


RESRAD-OFFSITE, Version 2.5

Title : RESRAD-OFFSITE Drinking Water, Plant, Milk, and Meat Pathways for Offsite Reside File : PBA-1_TC99-DOE-5.ROF

Summary of dose at graphical times, reptition 3 (continued)

Time

Years

$7.31 \mathrm{E}+02$

$7.32 \mathrm{E}+02$

$7.32 \mathrm{E}+02$

$7.33 \mathrm{E}+02$

$7.33 \mathrm{E}+02$

7. $34 \mathrm{E}+02$

7. $34 \mathrm{E}+02$

7. $35 \mathrm{E}+02$

7. $35 \mathrm{E}+02$

7. $36 \mathrm{E}+02$

7. $36 \mathrm{E}+02$

7. $37 \mathrm{E}+02$

7. $37 \mathrm{E}+02$

7. $38 \mathrm{E}+02$

7. $38 \mathrm{E}+02$

7. $39 \mathrm{E}+02$

$7.39 \mathrm{E}+02$

$7.40 \mathrm{E}+02$

$7.40 \mathrm{E}+02$

$7.41 \mathrm{E}+02$

7. $41 \mathrm{E}+02$

7. $42 \mathrm{E}+02$

$7.42 \mathrm{E}+02$

$7.43 \mathrm{E}+02$

7. $43 \mathrm{E}+02$

$7.44 \mathrm{E}+02$

7. $44 \mathrm{E}+02$

$7.45 \mathrm{E}+02$

7. $45 \mathrm{E}+02$

$7.46 \mathrm{E}+02$

$7.46 \mathrm{E}+02$

$7.47 \mathrm{E}+02$

$7.48 \mathrm{E}+02$

$7.48 \mathrm{E}+02$

7. $49 \mathrm{E}+02$

$7.49 \mathrm{E}+02$

7. $50 \mathrm{E}+02$

$7.50 \mathrm{E}+02$

$7.51 \mathrm{E}+02$

$7.51 \mathrm{E}+02$

$7.52 \mathrm{E}+02$

7. $52 \mathrm{E}+02$

$7.53 \mathrm{E}+02$

$7.53 \mathrm{E}+02$

7. $54 \mathrm{E}+02$

$7.54 \mathrm{E}+02$
Dose statistics at graphical times, mrem/yr

\begin{tabular}{|c|c|c|c|c|c|c|c|}
\hline inimum & Maximum & Mean & Median & $90 \%$ & $95 \%$ & $5 \%$ & $9 \%$ \\
\hline $1.43 \mathrm{E}-02$ & $.27 \mathrm{E}+00$ & $5.45 \mathrm{E}-01$ & $3.50 \mathrm{E}-01$ & $1.29 \mathrm{E}+00$ & $1.77 \mathrm{E}+00$ & $2.18 \mathrm{E}+00$ & $2.65 \mathrm{E}+00$ \\
\hline $1.44 \mathrm{E}-02$ & $4.26 \mathrm{E}+00$ & $5.46 \mathrm{E}-01$ & $3.51 \mathrm{E}-01$ & $1.29 \mathrm{E}+00$ & $1.77 \mathrm{E}+00$ & $2.19 \mathrm{E}+00$ & $2.65 \mathrm{E}+00$ \\
\hline $1.45 \mathrm{E}-02$ & $4.26 \mathrm{E}+00$ & $5.47 \mathrm{E}-01$ & $3.52 \mathrm{E}-01$ & $1.30 \mathrm{E}+00$ & $.78 \mathrm{E}+00$ & $2.19 \mathrm{E}+00$ & $2.65 \mathrm{E}+00$ \\
\hline $1.45 \mathrm{E}-02$ & $4.26 \mathrm{E}+00$ & $5.48 \mathrm{E}-01$ & $3.53 \mathrm{E}-01$ & $1.30 \mathrm{E}+00$ & $.78 \mathrm{E}+00$ & $2.19 \mathrm{E}+00$ & $.65 \mathrm{E}+00$ \\
\hline $1.46 \mathrm{E}-02$ & $4.25 \mathrm{E}+00$ & $5.49 \mathrm{E}-01$ & $3.54 \mathrm{E}-01$ & $1.30 \mathrm{E}+00$ & $1.78 \mathrm{E}+00$ & $2.19 \mathrm{E}+00$ & $2.65 \mathrm{E}+00$ \\
\hline $1.47 \mathrm{E}-02$ & $4.25 \mathrm{E}+00$ & $5.50 \mathrm{E}-01$ & $3.55 \mathrm{E}-01$ & $1.30 \mathrm{E}+00$ & $1.78 \mathrm{E}+00$ & $2.19 \mathrm{E}+00$ & $2.65 \mathrm{E}+00$ \\
\hline $1.47 \mathrm{E}-02$ & $.25 \mathrm{E}+00$ & $5.50 \mathrm{E}-01$ & $3.56 \mathrm{E}-01$ & $1.30 \mathrm{E}+00$ & $.78 \mathrm{E}+00$ & $2.20 \mathrm{E}+00$ & $2.65 \mathrm{E}+00$ \\
\hline $.48 \mathrm{E}-02$ & $4.24 \mathrm{E}+00$ & $5.51 \mathrm{E}-01$ & $3.57 \mathrm{E}-01$ & $1.30 \mathrm{E}+00$ & $1.79 \mathrm{E}+00$ & $2.20 \mathrm{E}+00$ & $2.65 \mathrm{E}+00$ \\
\hline $1.49 \mathrm{E}-02$ & $4.24 \mathrm{E}+00$ & $5.52 \mathrm{E}-01$ & $3.58 \mathrm{E}-01$ & $1.31 \mathrm{E}+00$ & $1.79 \mathrm{E}+00$ & $2.20 \mathrm{E}+00$ & $2.65 \mathrm{E}+00$ \\
\hline $1.50 \mathrm{E}-02$ & $4.24 \mathrm{E}+00$ & $5.53 \mathrm{E}-01$ & $3.59 \mathrm{E}-01$ & $1.31 \mathrm{E}+00$ & $1.79 \mathrm{E}+00$ & $2.20 \mathrm{E}+00$ & $2.65 \mathrm{E}+00$ \\
\hline $1.50 \mathrm{E}-02$ & $4.24 \mathrm{E}+00$ & $5.54 \mathrm{E}-01$ & $3.60 \mathrm{E}-01$ & $1.31 \mathrm{E}+00$ & $1.79 \mathrm{E}+00$ & $2.20 \mathrm{E}+00$ & $2.65 \mathrm{E}+00$ \\
\hline $1.51 \mathrm{E}-02$ & $4.23 \mathrm{E}+00$ & $5.55 \mathrm{E}-01$ & $3.61 \mathrm{E}-01$ & $1.31 \mathrm{E}+00$ & $1.79 \mathrm{E}+00$ & $2.20 \mathrm{E}+00$ & $2.65 \mathrm{E}+00$ \\
\hline $1.52 \mathrm{E}-02$ & $4.23 E+00$ & $5.56 \mathrm{E}-01$ & $3.62 \mathrm{E}-01$ & $1.31 \mathrm{E}+00$ & $1.80 \mathrm{E}+00$ & $2.21 \mathrm{E}+00$ & $2.65 \mathrm{E}+00$ \\
\hline $1.53 \mathrm{E}-02$ & $4.23 \mathrm{E}+00$ & $5.57 \mathrm{E}-01$ & $3.63 \mathrm{E}-01$ & $1.31 \mathrm{E}+00$ & $1.80 \mathrm{E}+00$ & $2.21 \mathrm{E}+00$ & $2.65 \mathrm{E}+00$ \\
\hline $1.53 \mathrm{E}-02$ & $4.22 \mathrm{E}+00$ & $5.58 \mathrm{E}-01$ & $3.64 \mathrm{E}-01$ & $1.32 \mathrm{E}+00$ & $1.80 \mathrm{E}+00$ & $2.21 \mathrm{E}+00$ & $2.65 \mathrm{E}+00$ \\
\hline $1.54 \mathrm{E}-02$ & $4.22 \mathrm{E}+00$ & $5.59 \mathrm{E}-01$ & $3.65 \mathrm{E}-01$ & $1.32 \mathrm{E}+00$ & $1.80 \mathrm{E}+00$ & $2.21 \mathrm{E}+00$ & $2.65 \mathrm{E}+00$ \\
\hline $1.55 \mathrm{E}-02$ & $4.22 \mathrm{E}+00$ & $5.60 \mathrm{E}-01$ & $3.66 \mathrm{E}-01$ & $1.32 \mathrm{E}+00$ & $1.80 \mathrm{E}+00$ & $2.21 \mathrm{E}+00$ & $2.66 \mathrm{E}+00$ \\
\hline $1.56 \mathrm{E}-02$ & $4.21 \mathrm{E}+00$ & $5.60 \mathrm{E}-01$ & $3.67 \mathrm{E}-01$ & $1.32 \mathrm{E}+00$ & $1.81 \mathrm{E}+00$ & $2.22 \mathrm{E}+00$ & $2.66 \mathrm{E}+00$ \\
\hline $1.56 \mathrm{E}-02$ & $4.21 E+00$ & $5.61 \mathrm{E}-01$ & $3.68 \mathrm{E}-01$ & $1.32 \mathrm{E}+00$ & $1.81 \mathrm{E}+00$ & $2.22 \mathrm{E}+00$ & $2.66 \mathrm{E}+00$ \\
\hline $57 E-02$ & $4.21 \mathrm{E}+00$ & $5.62 \mathrm{E}-01$ & $3.69 \mathrm{E}-01$ & $1.32 \mathrm{E}+00$ & $1.81 \mathrm{E}+00$ & $2.22 \mathrm{E}+00$ & $2.66 \mathrm{E}+00$ \\
\hline 1 & $4.20 \mathrm{E}+00$ & 5 & & $1.32 \mathrm{E}+00$ & $1.81 \mathrm{E}+00$ & $2.22 \mathrm{E}+00$ & $2.66 \mathrm{E}+00$ \\
\hline $1.59 \mathrm{E}-02$ & $4.20 \mathrm{E}+00$ & 5. & 3 & $1.32 \mathrm{E}+00$ & $1.82 \mathrm{E}+00$ & $2.22 \mathrm{E}+00$ & $2.66 \mathrm{E}+00$ \\
\hline $1.59 \mathrm{E}-02$ & $4.20 \mathrm{E}+00$ & $5.65 \mathrm{E}-01$ & $3.73 \mathrm{E}-01$ & $1.32 \mathrm{E}+00$ & $1.82 \mathrm{E}+00$ & $2.22 \mathrm{E}+00$ & $2.66 \mathrm{E}+00$ \\
\hline $1.60 \mathrm{E}-02$ & $4.19 \mathrm{E}+00$ & $5.66 \mathrm{E}-01$ & $3.74 \mathrm{E}-01$ & $1.32 \mathrm{E}+00$ & $1.82 \mathrm{E}+00$ & $2.23 E+00$ & $2.66 \mathrm{E}+00$ \\
\hline $1.61 \mathrm{E}-02$ & $4.19 \mathrm{E}+00$ & $5.67 \mathrm{E}-01$ & $3.75 \mathrm{E}-01$ & $1.32 \mathrm{E}+00$ & $1.82 \mathrm{E}+00$ & $2.23 E+00$ & $2.66 \mathrm{E}+00$ \\
\hline $1.62 \mathrm{E}-02$ & $4.19 \mathrm{E}+00$ & $5.68 \mathrm{E}-01$ & $3.76 \mathrm{E}-01$ & $1.33 \mathrm{E}+00$ & $1.82 \mathrm{E}+00$ & $2.23 E+00$ & $2.66 \mathrm{E}+00$ \\
\hline $1.62 \mathrm{E}-02$ & $4.19 \mathrm{E}+00$ & $5.69 \mathrm{E}-01$ & $3.77 \mathrm{E}-01$ & $1.33 \mathrm{E}+00$ & $1.82 \mathrm{E}+00$ & $2.23 \mathrm{E}+00$ & $2.66 \mathrm{E}+00$ \\
\hline $1.63 \mathrm{E}-02$ & $4.18 \mathrm{E}+00$ & $5.69 \mathrm{E}-01$ & $3.77 \mathrm{E}-01$ & $1.33 \mathrm{E}+00$ & $1.83 \mathrm{E}+00$ & $2.23 E+00$ & $2.66 \mathrm{E}+00$ \\
\hline $1.64 \mathrm{E}-02$ & $4.18 \mathrm{E}+00$ & $5.70 \mathrm{E}-01$ & $3.78 \mathrm{E}-01$ & $1.33 \mathrm{E}+00$ & $1.83 \mathrm{E}+00$ & $2.23 E+00$ & $2.66 \mathrm{E}+00$ \\
\hline $1.65 \mathrm{E}-02$ & $4.18 \mathrm{E}+00$ & $5.71 \mathrm{H}$ & 3.79 & $1.33 \mathrm{E}+00$ & $1.83 \mathrm{E}+00$ & $2.24 \mathrm{E}+00$ & $2.67 \mathrm{E}+00$ \\
\hline $1.66 \mathrm{E}-02$ & $4.17 \mathrm{E}+00$ & 5. & 3 & $1.33 \mathrm{E}+00$ & $1.83 \mathrm{E}+00$ & $2.24 \mathrm{E}+00$ & $2.67 \mathrm{E}+00$ \\
\hline $1.66 \mathrm{E}-02$ & $4.17 \mathrm{E}+00$ & $5.73 \mathrm{E}-01$ & $3.81 \mathrm{E}-01$ & $1.33 \mathrm{E}+00$ & $1.83 \mathrm{E}+00$ & $2.24 \mathrm{E}+00$ & $2.67 \mathrm{E}+00$ \\
\hline $1.67 \mathrm{E}-02$ & $4.17 \mathrm{E}+00$ & $5.74 \mathrm{E}-01$ & $3.82 \mathrm{E}-01$ & $1.33 \mathrm{E}+00$ & $1.84 \mathrm{E}+00$ & $2.24 \mathrm{E}+00$ & $2.67 \mathrm{E}+00$ \\
\hline $1.68 \mathrm{E}-02$ & $4.16 \mathrm{E}+00$ & $5.75 \mathrm{E}-01$ & $3.83 \mathrm{E}-01$ & $1.33 \mathrm{E}+00$ & $1.84 \mathrm{E}+00$ & $2.24 \mathrm{E}+00$ & $2.67 \mathrm{E}+00$ \\
\hline $1.69 \mathrm{E}-02$ & $4.16 \mathrm{E}+00$ & $5.76 \mathrm{E}-01$ & $3.84 \mathrm{E}-01$ & $1.33 \mathrm{E}+00$ & $1.84 \mathrm{E}+00$ & $2.24 \mathrm{E}+00$ & $2.67 \mathrm{E}+00$ \\
\hline $1.70 \mathrm{E}-02$ & $4.16 \mathrm{E}+00$ & $5.77 \mathrm{E}-01$ & $3.84 \mathrm{E}-01$ & $1.33 \mathrm{E}+00$ & $1.84 \mathrm{E}+00$ & $2.24 \mathrm{E}+00$ & $2.67 \mathrm{E}+00$ \\
\hline $1.70 \mathrm{E}-02$ & $4.15 \mathrm{E}+00$ & $5.78 \mathrm{E}-01$ & $3.85 \mathrm{E}-01$ & $1.34 \mathrm{E}+00$ & $1.84 \mathrm{E}+00$ & $2.25 \mathrm{E}+00$ & $2.67 \mathrm{E}+00$ \\
\hline $1.71 \mathrm{E}-02$ & $4.15 \mathrm{E}+00$ & $5.78 \mathrm{E}-01$ & $3.86 \mathrm{E}-01$ & $1.34 \mathrm{E}+00$ & $1.84 \mathrm{E}+00$ & $2.25 \mathrm{E}+00$ & $2.68 \mathrm{E}+00$ \\
\hline $1.72 \mathrm{E}-02$ & $4.15 \mathrm{E}+00$ & $5.79 \mathrm{E}-01$ & $3.87 \mathrm{E}-01$ & $1.34 \mathrm{E}+00$ & $1.84 \mathrm{E}+00$ & $2.25 \mathrm{E}+00$ & $2.68 \mathrm{E}+00$ \\
\hline $1.73 \mathrm{E}-02$ & $4.14 \mathrm{E}+00$ & $5.80 \mathrm{E}-01$ & $3.88 \mathrm{E}-01$ & $1.34 \mathrm{E}+00$ & $1.85 \mathrm{E}+00$ & $2.25 \mathrm{E}+00$ & $2.68 \mathrm{E}+00$ \\
\hline $1.74 \mathrm{E}-02$ & $4.14 \mathrm{E}+00$ & $5.81 \mathrm{E}-01$ & $3.89 \mathrm{E}-01$ & $1.34 \mathrm{E}+00$ & $1.85 \mathrm{E}+00$ & $2.25 \mathrm{E}+00$ & $2.68 \mathrm{E}+00$ \\
\hline $1.74 \mathrm{E}-02$ & $4.14 \mathrm{E}+00$ & $5.82 \mathrm{E}-01$ & $3.90 \mathrm{E}-01$ & $1.34 \mathrm{E}+00$ & $1.85 \mathrm{E}+00$ & $2.25 \mathrm{E}+00$ & $2.68 \mathrm{E}+00$ \\
\hline $1.75 \mathrm{E}-02$ & $4.13 E+00$ & $5.83 \mathrm{E}-01$ & $3.91 \mathrm{E}-01$ & $1.34 \mathrm{E}+00$ & $1.85 \mathrm{E}+00$ & $2.26 \mathrm{E}+00$ & $2.68 \mathrm{E}+00$ \\
\hline $1.76 \mathrm{E}-02$ & $4.13 \mathrm{E}+00$ & $5.84 \mathrm{E}-01$ & $3.92 \mathrm{E}-01$ & $1.34 \mathrm{E}+00$ & $1.85 \mathrm{E}+00$ & $2.26 \mathrm{E}+00$ & $2.68 \mathrm{E}+00$ \\
\hline $1.77 \mathrm{E}-02$ & $4.13 E+00$ & $5.85 \mathrm{E}-01$ & $3.92 \mathrm{E}-01$ & $1.35 \mathrm{E}+00$ & $1.85 \mathrm{E}+00$ & $2.26 \mathrm{E}+00$ & $2.69 \mathrm{E}+00$ \\
\hline $1.78 \mathrm{E}-02$ & $4.12 \mathrm{E}+00$ & $5.86 \mathrm{E}-01$ & $3.93 \mathrm{E}-01$ & $1.35 \mathrm{E}+00$ & $1.85 \mathrm{E}+00$ & $2.26 \mathrm{E}+00$ & $2.69 \mathrm{E}+00$ \\
\hline
\end{tabular}


RESRAD-OFFSITE, Version 2.5

Title : RESRAD-OFFSITE Drinking Water, Plant, Milk, and Meat Pathways for Offsite Reside File : PBA-1_TC99-DOE-5.ROF

Summary of dose at graphical times, reptition 3 (continued)

Time

Years

$7.55 E+02$

$7.55 \mathrm{E}+02$

$7.56 \mathrm{E}+02$

$7.56 \mathrm{E}+02$

$7.57 \mathrm{E}+02$

$7.57 \mathrm{E}+02$

$7.58 \mathrm{E}+02$

$7.58 \mathrm{E}+02$

$7.59 \mathrm{E}+02$

$7.59 \mathrm{E}+02$

$7.60 \mathrm{E}+02$

$7.60 \mathrm{E}+02$

$7.61 \mathrm{E}+02$

$7.61 \mathrm{E}+02$

$7.62 \mathrm{E}+02$

7. $62 \mathrm{E}+02$

$7.63 \mathrm{E}+02$

$7.63 \mathrm{E}+02$

$7.64 \mathrm{E}+02$

$7.64 \mathrm{E}+02$

$7.65 \mathrm{E}+02$

$7.65 \mathrm{E}+02$

$7.66 \mathrm{E}+02$

$7.66 \mathrm{E}+02$

$7.67 \mathrm{E}+02$

$7.68 \mathrm{E}+02$

$7.68 \mathrm{E}+02$

$7.69 \mathrm{E}+02$

7. $69 \mathrm{E}+02$

$7.70 \mathrm{E}+02$

$7.70 \mathrm{E}+02$

$7.71 \mathrm{E}+02$

$7.71 \mathrm{E}+02$

$7.72 \mathrm{E}+02$

$7.72 \mathrm{E}+02$

$7.73 \mathrm{E}+02$

$7.73 \mathrm{E}+02$

$7.74 \mathrm{E}+02$

$7.74 \mathrm{E}+02$

$7.75 \mathrm{E}+02$

$7.75 \mathrm{E}+02$

$7.76 \mathrm{E}+02$

$7.76 \mathrm{E}+02$

$7.77 \mathrm{E}+02$

$7.77 \mathrm{E}+02$

$7.78 \mathrm{E}+02$
Dose statistics at graphical times, mrem/yr

\begin{tabular}{|c|c|c|c|c|c|c|c|}
\hline m & um & ean & e & & & & \\
\hline 2 & 0 & 1 & 1 & 00 & 00 & 0 & +00 \\
\hline $.79 E-02$ & $2 \mathrm{E}+00$ & $.87 \mathrm{E}-01$ & $3.95 E-01$ & $1.35 \mathrm{E}+00$ & $1.86 \mathrm{E}+00$ & $2.26 \mathrm{E}+00$ & $2.69 \mathrm{E}+0 \mathrm{C}$ \\
\hline $.80 E-02$ & $1 E+00$ & $88 E-01$ & $96 E-01$ & $1.35 E+00$ & $.86 \mathrm{E}+00$ & $.26 \mathrm{E}+00$ & $69 \mathrm{E}+0 \mathrm{C}$ \\
\hline & & $.89 \mathrm{E}-01$ & & & & & 100 \\
\hline 02 & & 1 & 1 & & & & +00 \\
\hline $83 E-02$ & 00 & -01 & -01 & 00 & & $26 E+00$ & $E+00$ \\
\hline $83 E-02$ & & -01 & & +00 & 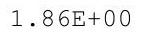 & $2.26 \mathrm{E}+00$ & $69 E+00$ \\
\hline $.84 \mathrm{E}-02$ & 0 & E-01 & $E-01$ & $\Xi+00$ & $E+00$ & $E+00$ & $\mathrm{E}+00$ \\
\hline $85 E-02$ & $9 \mathrm{E}+00$ & $E-01$ & -01 & +00 & $6 \mathrm{E}+00$ & $26 E+00$ & $E+00$ \\
\hline $36 F-02$ & $09 F+00$ & $95 E-01$ & $2 E-01$ & $36 \mathrm{E}+00$ & $.86 \mathrm{E}+00$ & $.26 \mathrm{E}+00$ & $70 \mathrm{~F}+00$ \\
\hline 2 & & & & & & & +00 \\
\hline$E-02$ & $\mathrm{E}+00$ & $6 \mathrm{E}-01$ & -01 & $.37 E+00$ & $6 \mathrm{E}+00$ & $E+00$ & $E+00$ \\
\hline $.88 E-02$ & & $.97 \mathrm{E}-01$ & $5 E-01$ & $1.37 E+00$ & $1.86 \mathrm{E}+00$ & $2.26 \mathrm{E}+00$ & $.70 \mathrm{E}+00$ \\
\hline$E-02$ & ( & $E-01$ & $E-01$ & & & +00 & $E+00$ \\
\hline t & & & & & & & +00 \\
\hline 2 & & & & & & & $70 \mathrm{E}+0 \mathrm{C}$ \\
\hline 2 & & & 01 & 0 & 0 & 0 & +00 \\
\hline $93 F-02$ & $4.6 F+00$ & $02 E-01$ & $0 E-01$ & $1.37 \mathrm{E}+00$ & $37 E+00$ & $27 E+00$ & $71 \mathrm{E}+00$ \\
\hline $94 \mathrm{E}-02$ & $4.06 \mathrm{E}+00$ & $.03 E-01$ & $4.10 \mathrm{E}-01$ & $1.37 \mathrm{E}+00$ & $1.87 \mathrm{E}+00$ & $2.28 \mathrm{E}+00$ & $.71 \mathrm{E}+00$ \\
\hline $95 E-02$ & $4.05 E+00$ & $5.03 E-01$ & $4.11 E-01$ & $1.38 \mathrm{E}+00$ & $1.87 \mathrm{E}+00$ & $2.28 \mathrm{E}+00$ & $.71 E+00$ \\
\hline & & & & & & & \\
\hline & & & & & & & 00 \\
\hline & & & & & & $.28 \mathrm{E}+$ & $71 \mathrm{E}+00$ \\
\hline 2 & $4.04 \mathrm{E}+0$ & 1 & 1 & $8 E+00$ & & $295+$ & $71 \mathrm{E}+00$ \\
\hline 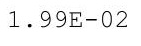 & $4.04 \mathrm{E}+00$ & $08 \mathrm{E}-01$ & $15 E-01$ & $1.38 \mathrm{E}+00$ & $.87 E+00$ & $.29 E+00$ & $71 E+00$ \\
\hline$F-02$ & $4.03 E+00$ & $.09 E-01$ & $4.16 E-01$ & $1.38 \mathrm{E}+00$ & $1.87 \mathrm{E}+00$ & $2.29 \mathrm{E}+00$ & $.71 E+00$ \\
\hline$E-02$ & $4.03 E+00$ & & & $38 E+00$ & $37 E+00$ & & $.71 E+00$ \\
\hline & & & & & & & \\
\hline & & & & & & & $.71 E+00$ \\
\hline $.03 E-02$ & $4.02 \mathrm{E}+00$ & $6.12 \mathrm{E}-01$ & $4.20 \mathrm{E}-01$ & $1.39 \mathrm{E}+00$ & $1.87 \mathrm{E}+00$ & $2.30 \mathrm{E}+00$ & $.71 E+00$ \\
\hline the & . & $.13 E-01$ & $4.21 E-01$ & $1.39 \mathrm{E}+00$ & $1.88 \mathrm{E}+00$ & $2.30 \mathrm{E}+00$ & $.71 \mathrm{E}+0$ \\
\hline 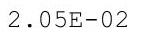 & 1.0工力 & & & & & & $71 E+0$ \\
\hline$F-0$ & $4.01 \mathrm{E}+0$ & & & & & & $71 \mathrm{E}+00$ \\
\hline & & & & & & & \\
\hline & & & & $9 \mathrm{E}+00$ & & $2.30 \mathrm{E}$ & $\mathrm{E}+\mathrm{OC}$ \\
\hline $.09 E-02$ & $4.00 \mathrm{E}+00$ & $7 E-01$ & $4.26 \mathrm{E}-01$ & 1. $40 \mathrm{E}+00$ & $1.88 \mathrm{E}+00$ & $2.30 \mathrm{E}+00$ & $2.70 \mathrm{E}+0 \mathrm{C}$ \\
\hline 2 & e & $\perp$ & 01 & & & & 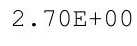 \\
\hline 2 & enter & & $4.29 \mathrm{E}-01$ & 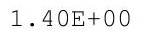 & & 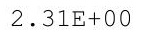 & $.69 \mathrm{E}+0$ \\
\hline $12 \mathrm{~F}-02$ & $3.99 \mathrm{E}+0$ & 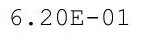 & 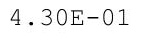 & 1. $40 \mathrm{E}+00$ & & $2.31 \mathrm{E}+$ & $.69 \mathrm{E}+00$ \\
\hline $.12 \mathrm{E}-02$ & & & & & $1.88 \mathrm{E}+00$ & $E+00$ & $69 \mathrm{E}+00$ \\
\hline $3 E-02$ & & $.22 \mathrm{E}-01$ & $4.32 \mathrm{E}-01$ & & $3 E+00$ & $2.31 \mathrm{E}$ & $69 E+00$ \\
\hline-02 & $3.98 E+00$ & $23 E-01$ & $4.33 E-01$ & 1. $40 \mathrm{E}+00$ & & & $9 \mathrm{E}+0 \mathrm{C}$ \\
\hline & & & & & & & $2.09 \pm 10$ \\
\hline L & 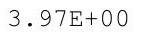 & $\perp$ & 01 & 1. $40 \mathrm{E}+00$ & 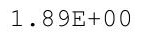 & $2.32 \mathrm{E}+00$ & $2.69 E+00$ \\
\hline ( & & & & & & & $2.69 \mathrm{E}+00$ \\
\hline-02 & $E+00$ & E-01 & $E-01$ & $E+00$ & $.89 \mathrm{E}+00$ & $.32 E+00$ & $69 E+00$ \\
\hline
\end{tabular}


RESRAD-OFFSITE, Version 2.5

Title : RESRAD-OFFSITE Drinking Water, Plant, Milk, and Meat Pathways for Offsite Reside File : PBA-1_TC99-DOE-5.ROF

Summary of dose at graphical times, reptition 3 (continued)

Time

Years

$7.78 \mathrm{E}+02$

$7.79 \mathrm{E}+02$

$7.79 \mathrm{E}+02$

$7.80 \mathrm{E}+02$

$7.80 \mathrm{E}+02$

$7.81 \mathrm{E}+02$

$7.81 \mathrm{E}+02$

$7.82 \mathrm{E}+02$

$7.82 \mathrm{E}+02$

$7.83 \mathrm{E}+02$

$7.83 \mathrm{E}+02$

$7.84 \mathrm{E}+02$

$7.84 \mathrm{E}+02$

$7.85 \mathrm{E}+02$

$7.85 \mathrm{E}+02$

$7.86 \mathrm{E}+02$

$7.86 \mathrm{E}+02$

$7.87 \mathrm{E}+02$

$7.88 \mathrm{E}+02$

$7.88 \mathrm{E}+02$

$7.89 \mathrm{E}+02$

$7.89 \mathrm{E}+02$

$7.90 \mathrm{E}+02$

$7.90 \mathrm{E}+02$

$7.91 \mathrm{E}+02$

$7.91 \mathrm{E}+02$

$7.92 \mathrm{E}+02$

$7.92 \mathrm{E}+02$

7. $93 \mathrm{E}+02$

$7.93 \mathrm{E}+02$

7. $94 \mathrm{E}+02$

$7.94 \mathrm{E}+02$

$7.95 \mathrm{E}+02$

7. $95 \mathrm{E}+02$

$7.96 \mathrm{E}+02$

7. $96 \mathrm{E}+02$

$7.97 \mathrm{E}+02$

$7.97 \mathrm{E}+02$

$7.98 \mathrm{E}+02$

$7.98 \mathrm{E}+02$

$7.99 \mathrm{E}+02$

$7.99 \mathrm{E}+02$

$8.00 \mathrm{E}+02$

$8.00 \mathrm{E}+02$

$8.01 \mathrm{E}+02$

$8.01 \mathrm{E}+02$
Dose statistics at graphical times, mrem/yr

\begin{tabular}{|c|c|c|c|c|c|c|c|}
\hline inimum & aximum & Mean & ledian & $90 \%$ & $5 \%$ & $97.5 \%$ & \\
\hline 2 & +00 & 01 & 01 & 00 & 00 & 00 & +0 \\
\hline 02 & +00 & 01 & 1 & 0 & 00 & 00 & 100 \\
\hline 02 & -00 & -01 & -01 & 00 & 00 & 00 & +00 \\
\hline 02 & 00 & 1 & & 0 & & 00 & +00 \\
\hline $.23 E-02$ & -00 & 1 & 1 & 00 & 00 & $32 \mathrm{E}+00$ & $69 \mathrm{E}+00$ \\
\hline $.24 \mathrm{E}-02$ & +00 & -01 & -01 & $1.41 \mathrm{E}+00$ & $\mathrm{E}+00$ & $E+00$ & $68 E+00$ \\
\hline 02 & -00 & 01 & -01 & 0 & 0 & +00 & $68 \mathrm{E}+0 \mathrm{C}$ \\
\hline $.26 E-02$ & $3.93 E+00$ & & & 00 & & +00 & $68 \mathrm{E}+00$ \\
\hline 02 & +00 & 1 & 01 & 00 & 00 & +00 & +00 \\
\hline $.27 E-02$ & $3.92 \mathrm{E}+00$ & $5 E-01$ & $3 E-01$ & $1.41 \mathrm{E}+00$ & $91 \mathrm{E}+00$ & $32 E+00$ & $8 \mathrm{E}+00$ \\
\hline-02 & +00 & $E-01$ & $E-01$ & & & 00 & $E+00$ \\
\hline-02 & -00 & -01 & $E-01$ & 00 & & +00 & $58 E+00$ \\
\hline$E-02$ & $E+00$ & D- 1 & $E-01$ & 1. $42 \mathrm{E}+00$ & & +00 & +0 \\
\hline 02 & 00 & $3 E-01$ & 1 & 0 & 0 & +00 & +00 \\
\hline 02 & $3.91 \mathrm{E}+00$ & & & 00 & & +00 & +00 \\
\hline$E-02$ & -00 & 1 & 1 & 1. $42 \mathrm{E}+00$ & 0 & $\mathrm{E}+00$ & +00 \\
\hline $.34 \mathrm{E}-02$ & $3.90 \mathrm{E}+00$ & $E-01$ & $4.53 \mathrm{E}-01$ & $1.43 E+00$ & $1.91 \mathrm{E}+00$ & $33 E+00$ & $.68 \mathrm{E}+00$ \\
\hline$E-02$ & $90 \mathrm{E}+00$ & $2 E-01$ & $4 E-01$ & 1. $43 \mathrm{E}+00$ & $91 E+00$ & $3 E+00$ & $68 E+00$ \\
\hline 02 & 00 & & 1 & 0 & & +00 & +00 \\
\hline 02 & +00 & $\perp$ & 01 & 0 & 0 & +00 & +0 \\
\hline 2 & & & 1 & 0 & & 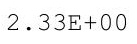 & 00 \\
\hline 02 & $8 \mathrm{E}+00$ & 1 & 1 & 1. $43 \mathrm{E}+$ & & $E+00$ & $E+00$ \\
\hline $40 E-02$ & $88 \mathrm{E}+00$ & $46 \mathrm{E}-$ & $9 \mathrm{E}-$ & $1.43 E+00$ & $.92 \mathrm{E}+00$ & $.33 E+00$ & $.67 E+00$ \\
\hline $1 E-02$ & $3.87 \mathrm{E}+00$ & $5.47 \mathrm{E}-01$ & $59 E-01$ & 1. $44 \mathrm{E}+00$ & $1.92 \mathrm{E}+00$ & $\mathrm{E}+00$ & $.67 E+00$ \\
\hline$E-02$ & $3.87 \mathrm{E}+00$ & $48 E-01$ & $0 E-01$ & & & $4 \mathrm{E}+00$ & $67 E+00$ \\
\hline & & & & & & & +00 \\
\hline & & & & 1. $44 \mathrm{E}+$ & & 00 & +00 \\
\hline $.45 \mathrm{E}-02$ & $3.86 \mathrm{E}+00$ & $.50 \mathrm{E}-01$ & $4.63 E-01$ & $1.44 \mathrm{E}+00$ & 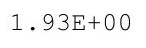 & $.34 E+00$ & $.67 \mathrm{E}+00$ \\
\hline 02 & $85 E+00$ & 1 & $4 E-01$ & $44 \mathrm{E}+00$ & $93 E+00$ & $.34 E+00$ & $.67 \mathrm{E}+0 \mathrm{C}$ \\
\hline 2 & - & - & $65 E-01$ & $44 \mathrm{E}+$ & & $34 \mathrm{E}+00$ & $.67 \mathrm{E}+0$ \\
\hline $\mathrm{F}-02$ & $385 \mathrm{~F}+00$ & $3 E-01$ & $6 E-01$ & $1.45 \mathrm{E}+00$ & & $4 \mathrm{E}+00$ & $67 E+00$ \\
\hline 02 & & & & & & & \\
\hline 02 & & & & & & & $6 \mathrm{E}+00$ \\
\hline $.51 E-02$ & $3.83 \mathrm{E}+00$ & $.55 E-01$ & $4.68 \mathrm{E}-01$ & 1. $45 \mathrm{E}+00$ & $1 \cdot 94 \mathrm{E}+00$ & $34 \mathrm{E}+00$ & $.66 \mathrm{E}+00$ \\
\hline $52 E-02$ & & $0.30 \mathrm{~L}-\mathrm{U}$ & $4.68 E-01$ & $1.435 T 00$ & & $.34 E+00$ & . OOLTU \\
\hline 2 & & & & & & & \\
\hline 2 & re & & & 0 & & & 00 \\
\hline 2 & & & & 0 & & & \\
\hline$\Xi-02$ & & & $1 \mathrm{E}-01$ & & $1.94 \mathrm{E}+00$ & & $.66 \mathrm{E}+00$ \\
\hline E-02 & $3.81 \mathrm{E}+00$ & $61 E-01$ & $72 E-01$ & 1. $45 \mathrm{E}+$ & 0 & 0 & $56 \mathrm{E}+00$ \\
\hline$E-02$ & $3.81 \mathrm{E}+00$ & $1 \mathrm{E}-01$ & 01 & 1. $45 \mathrm{E}+$ & & & $66 \mathrm{E}+00$ \\
\hline 02 & $3.00 \mathrm{E}+00$ & 1 & 01 & 1. $45 \mathrm{E}+00$ & $1.94 \mathrm{E}+00$ & $.34 \mathrm{E}+00$ & $.66 \mathrm{E}+00$ \\
\hline 2 & $3.80 \mathrm{E}+$ & $\perp$ & $6 E-01$ & $1.46 \mathrm{E}$ & $1.94 \mathrm{E}+$ & $2.34 \mathrm{E}+00$ & $.66 \mathrm{E}+0 \mathrm{C}$ \\
\hline 2 & 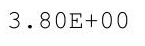 & & & 0 & 0 & $.35 \mathrm{E}+$ & $.66 \mathrm{E}+00$ \\
\hline$E-02$ & $3.79 \mathrm{E}+00$ & $6.65 E-01$ & $4.78 E-01$ & $1.46 \mathrm{E}+00$ & $1.94 \mathrm{E}+00$ & $2.35 \mathrm{E}+00$ & $67 E+00$ \\
\hline $.64 E-02$ & $3.79 \mathrm{E}+00$ & $.66 \mathrm{E}-01$ & $.79 E-01$ & $1.46 \mathrm{E}+00$ & $1.94 \mathrm{E}+00$ & $2.35 E+00$ & $.67 E+00$ \\
\hline
\end{tabular}


RESRAD-OFFSITE, Version 2.5

Title : RESRAD-OFFSITE Drinking Water, Plant, Milk, and Meat Pathways for Offsite Reside File : PBA-1_TC99-DOE-5.ROF

Summary of dose at graphical times, reptition 3 (continued)

Time

Years

$8.02 \mathrm{E}+02$

$8.02 \mathrm{E}+02$

$8.03 \mathrm{E}+02$

$8.03 \mathrm{E}+02$

$8.04 \mathrm{E}+02$

$8.04 \mathrm{E}+02$

$8.05 \mathrm{E}+02$

$8.05 \mathrm{E}+02$

$8.06 \mathrm{E}+02$

$8.06 \mathrm{E}+02$

$8.07 \mathrm{E}+02$

$8.07 \mathrm{E}+02$

$8.08 \mathrm{E}+02$

$8.09 \mathrm{E}+02$

$8.09 \mathrm{E}+02$

$8.10 \mathrm{E}+02$

$8.10 \mathrm{E}+02$

$8.11 \mathrm{E}+02$

$8.11 \mathrm{E}+02$

$8.12 \mathrm{E}+02$

$8.12 \mathrm{E}+02$

$8.13 E+02$

$8.13 \mathrm{E}+02$

$8.14 \mathrm{E}+02$

$8.14 \mathrm{E}+02$

$8.15 \mathrm{E}+02$

$8.15 \mathrm{E}+02$

$8.16 \mathrm{E}+02$

$8.16 \mathrm{E}+02$

$8.17 \mathrm{E}+02$

$8.17 \mathrm{E}+02$

$8.18 \mathrm{E}+02$

$8.18 \mathrm{E}+02$

$8.19 \mathrm{E}+02$

$8.19 \mathrm{E}+02$

$8.20 \mathrm{E}+02$

$8.20 \mathrm{E}+02$

$8.21 \mathrm{E}+02$

$8.21 \mathrm{E}+02$

$8.22 \mathrm{E}+02$

$8.22 \mathrm{E}+02$

$8.23 E+02$

$8.23 \mathrm{E}+02$

$8.24 \mathrm{E}+02$

$8.24 \mathrm{E}+02$

$8.25 \mathrm{E}+02$
Dose statistics at graphical times, mrem/yr

\begin{tabular}{|c|c|c|c|c|c|c|c|}
\hline $\mathrm{m}$ & um & ean & ec & & & & \\
\hline 2 & 0 & 1 & 1 & 00 & 00 & 0 & +00 \\
\hline $66 \mathrm{E}-02$ & $8 \mathrm{E}+00$ & $7 \mathrm{E}-01$ & 4. $81 E-01$ & 1. $46 \mathrm{E}+00$ & 1. $94 \mathrm{E}+00$ & $35 E+00$ & $67 \mathrm{E}+00$ \\
\hline $67 F-02$ & $8 F+00$ & $68 F-01$ & $82 F-01$ & $46 E+00$ & $94 \mathrm{~F}+00$ & $35 E+00$ & $67 \mathrm{~F}+00$ \\
\hline $8 E-02$ & $.77 \mathrm{E}+00$ & $9 \mathrm{E}-01$ & $4.83 \mathrm{E}$ & & & & 100 \\
\hline 02 & 00 & 01 & 1 & & & & +00 \\
\hline $.70 E-02$ & $7 \mathrm{E}+00$ & -01 & -01 & 00 & & $35 E+00$ & $67 \mathrm{E}+0 \mathrm{C}$ \\
\hline $.71 E-02$ & +00 & 1 & 01 & +00 & 0 & $E+00$ & $68 \mathrm{E}+00$ \\
\hline $.72 \mathrm{E}-02$ & $E+00$ & $E-01$ & $6 E-01$ & $E+00$ & $\mathrm{E}+00$ & $E+00$ & $68 \mathrm{E}+00$ \\
\hline $73 E-02$ & $E+00$ & $73 E-01$ & $6 E-01$ & $E+00$ & $5 \mathrm{E}+00$ & $36 \mathrm{E}+$ & $68 \mathrm{E}+00$ \\
\hline $4 E-02$ & $5+0$ & & & 0 & $5 \mathrm{5}+8$ & $36 \mathrm{E}+00$ & $68 \mathrm{~F}+00$ \\
\hline 2 & & & & & & & +00 \\
\hline $7 E-02$ & $E+00$ & $6 E-01$ & $E-01$ & $47 E+00$ & +00 & +00 & $E+00$ \\
\hline $.78 E-02$ & $3.74 \mathrm{E}+00$ & $7 E-01$ & 4. $91 E-01$ & $1.47 E+00$ & $1.95 \mathrm{E}+00$ & $2.36 \mathrm{E}+00$ & $68 E+00$ \\
\hline$E-02$ & $\Xi+00$ & $E-01$ & $1 \mathrm{E}-01$ & & & 00 & $E+00$ \\
\hline 02 & & & & & & & +00 \\
\hline & & & & & & & $69 \mathrm{E}+0 \mathrm{C}$ \\
\hline $2.82 E-02$ & $\mathrm{Ft}$ & 1 & 1 & 0 & 0 & 0 & $8 E+00$ \\
\hline $83 F-02$ & $372 \mathrm{~F}+00$ & $81 E-01$ & -01 & $1.48 \mathrm{E}+00$ & $E+00$ & $37 E+00$ & $68 \mathrm{E}+00$ \\
\hline $84 \mathrm{E}-02$ & $.71 \mathrm{E}+00$ & $.82 \mathrm{E}-01$ & $4.96 \mathrm{E}-01$ & 1. $49 \mathrm{E}+00$ & $1.95 \mathrm{E}+00$ & $2.37 \mathrm{E}+00$ & $.68 \mathrm{E}+00$ \\
\hline $85 E-02$ & $.71 \mathrm{E}+00$ & $6.82 \mathrm{E}-01$ & $4.97 \mathrm{E}-01$ & $49 \mathrm{E}+00$ & $5 E+00$ & $2.37 \mathrm{E}+00$ & $68 E+00$ \\
\hline & & & & & & & \\
\hline & & & & & & & $7 \mathrm{E}+00$ \\
\hline 2 & & & & $1.49 \mathrm{E}+$ & & & $67 \mathrm{E}+00$ \\
\hline F & $9 \mathrm{E}+$ & 1 & 1 & 1. $49 \mathrm{E}+00$ & & 0 & $E+00$ \\
\hline $5-0$ & $.69 \mathrm{E}+00$ & $.87 \mathrm{E}-01$ & $1 E-01$ & 1. $49 \mathrm{E}+00$ & $96 E+00$ & $2.37 E+00$ & $.67 \mathrm{E}+00$ \\
\hline $92 E-02$ & $.69 E+00$ & $5.87 \mathrm{E}-01$ & $5.02 E-01$ & 1. $49 \mathrm{E}+00$ & $.96 E+00$ & $2.37 E+00$ & $.67 E+00$ \\
\hline 02 & & $E-01$ & $3 E-01$ & & & & $66 \mathrm{E}+00$ \\
\hline & & & & & & & \\
\hline & & & & & & & \\
\hline $.97 E-02$ & $3.67 \mathrm{E}+00$ & $6.91 \mathrm{E}-01$ & $.06 \mathrm{E}-01$ & 1. $49 \mathrm{E}+00$ & $1.96 \mathrm{E}+00$ & $2.37 \mathrm{E}+00$ & $.66 E+00$ \\
\hline (- & (- -2 & $.91 \mathrm{E}-01$ & $.07 E-01$ & 1. $49 \mathrm{E}+00$ & $1.96 \mathrm{E}+00$ & $2.37 \mathrm{E}+00$ & $.66 \mathrm{E}+0$ \\
\hline 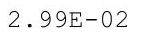 & & & & & & & $.66 \mathrm{E}+0$ \\
\hline-0 & $3.66 \mathrm{E}+0$ & & & & & & $66 \mathrm{E}+00$ \\
\hline 2 & & & & & & & $56 \mathrm{E}+0 \mathrm{C}$ \\
\hline $2 E-02$ & $3.65 \mathrm{E}+00$ & $5 E-01$ & 01 & $1.50 \mathrm{E}+$ & $1.96 \mathrm{E}+00$ & 2 . & $56 \mathrm{E}+0 \mathrm{C}$ \\
\hline $.03 E-02$ & . & $.96 \mathrm{E}-01$ & $.12 \mathrm{E}-01$ & $1.50 \mathrm{E}+00$ & $1.96 \mathrm{E}+00$ & $2.37 \mathrm{E}+00$ & $.66 \mathrm{E}+00$ \\
\hline 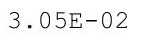 & . & & $5.13 E-01$ & 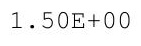 & & & 2.00010 \\
\hline 2 & (- & 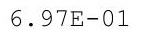 & 1 & - & 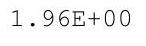 & & $.66 \mathrm{E}+00$ \\
\hline $07 F-02$ & & 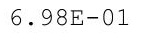 & 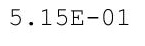 & $1.50 \mathrm{E}+00$ & $1.96 \mathrm{E}+\mathrm{C}$ & & $66 \mathrm{E}+0 \mathrm{C}$ \\
\hline $.08 \mathrm{E}-02$ & & 1 & 01 & $1.51 \mathrm{E}+00$ & $6 \mathrm{E}+00$ & 0 & $\mathrm{E}+00$ \\
\hline-02 & & $.00 \mathrm{E}-01$ & $5.17 \mathrm{E}-01$ & $1.51 \mathrm{E}+00$ & 00 & & $6 \mathrm{E}+00$ \\
\hline-02 & $3.62 \mathrm{E}+00$ & $E-01$ & $8 E-01$ & $1.51 \mathrm{E}+00$ & & & $\mathrm{E}+\mathrm{OC}$ \\
\hline & & & & & & & $2.00 \pm 10$ \\
\hline 2 & . & 1 & 01 & $1.51 \mathrm{E}+00$ & . . & $2.36 \mathrm{E}+00$ & $2.66 \mathrm{E}+00$ \\
\hline & & & & & & & $2.66 \mathrm{E}+00$ \\
\hline 02 & +00 & $E-01$ & E-01 & $E+00$ & $.97 E+00$ & $.36 E+00$ & $66 \mathrm{E}+00$ \\
\hline
\end{tabular}


RESRAD-OFFSITE, Version 2.5

Title : RESRAD-OFFSITE Drinking Water, Plant, Milk, and Meat Pathways for Offsite Reside File : PBA-1_TC99-DOE-5.ROF

Summary of dose at graphical times, reptition 3 (continued)

Time

Years

$8.25 \mathrm{E}+02$

$8.26 \mathrm{E}+02$

$8.26 \mathrm{E}+02$

$8.27 \mathrm{E}+02$

$8.27 \mathrm{E}+02$

$8.28 \mathrm{E}+02$

$8.29 \mathrm{E}+02$

$8.29 \mathrm{E}+02$

$8.30 \mathrm{E}+02$

$8.30 \mathrm{E}+02$

$8.31 \mathrm{E}+02$

$8.31 \mathrm{E}+02$

$8.32 \mathrm{E}+02$

$8.32 \mathrm{E}+02$

$8.33 \mathrm{E}+02$

8. $33 \mathrm{E}+02$

$8.34 \mathrm{E}+02$

$8.34 \mathrm{E}+02$

$8.35 \mathrm{E}+02$

$8.35 \mathrm{E}+02$

$8.36 \mathrm{E}+02$

$8.36 \mathrm{E}+02$

$8.37 \mathrm{E}+02$

$8.37 \mathrm{E}+02$

$8.38 \mathrm{E}+02$

$8.38 \mathrm{E}+02$

$8.39 \mathrm{E}+02$

$8.39 \mathrm{E}+02$

$8.40 \mathrm{E}+02$

$8.40 \mathrm{E}+02$

$8.41 \mathrm{E}+02$

$8.41 \mathrm{E}+02$

$8.42 \mathrm{E}+02$

$8.42 \mathrm{E}+02$

$8.43 \mathrm{E}+02$

$8.43 E+02$

$8.44 \mathrm{E}+02$

$8.44 \mathrm{E}+02$

$8.45 \mathrm{E}+02$

$8.45 \mathrm{E}+02$

$8.46 \mathrm{E}+02$

$8.46 \mathrm{E}+02$

$8.47 \mathrm{E}+02$

$8.47 \mathrm{E}+02$

$8.48 \mathrm{E}+02$

$8.49 \mathrm{E}+02$
Dose statistics at graphical times, mrem/yr

\begin{tabular}{|c|c|c|c|c|c|c|c|}
\hline inimum & Maximum & Mean & Median & $90 \%$ & $95 \%$ & $7.5 \%$ & $9 \%$ \\
\hline $3.16 \mathrm{E}-02$ & $3.60 \mathrm{E}+00$ & $7.04 \mathrm{E}-01$ & $5.23 \mathrm{E}-01$ & $1.51 \mathrm{E}+00$ & $1.97 \mathrm{E}+00$ & $2.36 \mathrm{E}+00$ & $2.66 \mathrm{E}+00$ \\
\hline $3.17 \mathrm{E}-02$ & $3.60 \mathrm{E}+00$ & $7.05 \mathrm{E}-01$ & $5.24 \mathrm{E}-01$ & $1.52 \mathrm{E}+00$ & $1.97 \mathrm{E}+00$ & $2.36 \mathrm{E}+00$ & $2.66 \mathrm{E}+00$ \\
\hline $3.18 \mathrm{E}-02$ & $3.60 \mathrm{E}+00$ & $7.06 \mathrm{E}-01$ & $5.25 \mathrm{E}-01$ & $1.52 \mathrm{E}+00$ & $1.97 \mathrm{E}+00$ & $2.36 \mathrm{E}+00$ & $2.66 \mathrm{E}+00$ \\
\hline $3.20 \mathrm{E}-02$ & $3.59 \mathrm{E}+00$ & $7.07 \mathrm{E}-01$ & $5.27 \mathrm{E}-01$ & $1.52 \mathrm{E}+00$ & $.97 \mathrm{E}+00$ & $2.36 \mathrm{E}+00$ & $.66 \mathrm{E}+00$ \\
\hline $3.21 \mathrm{E}-02$ & $3.59 \mathrm{E}+00$ & $7.08 \mathrm{E}-01$ & $5.27 \mathrm{E}-01$ & $1.52 \mathrm{E}+00$ & $1.97 \mathrm{E}+00$ & $2.36 \mathrm{E}+00$ & $2.66 \mathrm{E}+00$ \\
\hline $3.22 \mathrm{E}-02$ & $3.58 \mathrm{E}+00$ & $7.09 \mathrm{E}-01$ & $5.28 \mathrm{E}-01$ & $1.52 \mathrm{E}+00$ & $1.97 \mathrm{E}+00$ & $2.36 \mathrm{E}+00$ & $2.66 \mathrm{E}+00$ \\
\hline $3.23 \mathrm{E}-02$ & $.58 \mathrm{E}+00$ & $7.09 \mathrm{E}-01$ & $5.29 \mathrm{E}-01$ & $1.52 \mathrm{E}+00$ & $.97 \mathrm{E}+00$ & $2.36 \mathrm{E}+00$ & $2.66 \mathrm{E}+00$ \\
\hline $24 \mathrm{E}-02$ & $.58 \mathrm{E}+00$ & $7.10 \mathrm{E}-01$ & $5.30 \mathrm{E}-01$ & $1.52 \mathrm{E}+00$ & $1.97 \mathrm{E}+00$ & $2.36 \mathrm{E}+00$ & $2.66 \mathrm{E}+00$ \\
\hline $26 \mathrm{E}-02$ & $3.57 \mathrm{E}+00$ & $7.11 \mathrm{E}-01$ & $5.31 \mathrm{E}-01$ & $1.53 \mathrm{E}+00$ & $1.98 \mathrm{E}+00$ & $2.36 \mathrm{E}+00$ & $2.66 \mathrm{E}+00$ \\
\hline $3.27 \mathrm{E}-02$ & $3.57 \mathrm{E}+00$ & $7.12 \mathrm{E}-01$ & $5.32 \mathrm{E}-01$ & $1.53 \mathrm{E}+00$ & $1.98 \mathrm{E}+00$ & $2.37 \mathrm{E}+00$ & $2.66 \mathrm{E}+00$ \\
\hline $3.28 \mathrm{E}-02$ & $3.56 \mathrm{E}+00$ & $7.13 \mathrm{E}-01$ & $5.32 \mathrm{E}-01$ & $1.53 \mathrm{E}+00$ & $1.98 \mathrm{E}+00$ & $2.37 \mathrm{E}+00$ & $2.66 \mathrm{E}+00$ \\
\hline $3.29 \mathrm{E}-02$ & $3.56 \mathrm{E}+00$ & $7.13 \mathrm{E}-01$ & $5.33 \mathrm{E}-01$ & $1.53 \mathrm{E}+00$ & $1.98 \mathrm{E}+00$ & $2.37 \mathrm{E}+00$ & $2.67 \mathrm{E}+00$ \\
\hline $3.30 \mathrm{E}-02$ & $3.55 \mathrm{E}+00$ & $7.14 \mathrm{E}-01$ & $5.34 \mathrm{E}-01$ & $1.53 \mathrm{E}+00$ & $1.98 \mathrm{E}+00$ & $2.37 \mathrm{E}+00$ & $2.67 \mathrm{E}+00$ \\
\hline $3.32 \mathrm{E}-02$ & $3.55 \mathrm{E}+00$ & $7.15 \mathrm{E}-01$ & $5.35 \mathrm{E}-01$ & $1.53 \mathrm{E}+00$ & $1.98 \mathrm{E}+00$ & $2.37 \mathrm{E}+00$ & $2.67 \mathrm{E}+00$ \\
\hline $3.33 E-02$ & $3.55 \mathrm{E}+00$ & $7.16 \mathrm{E}-01$ & $5.36 \mathrm{E}-01$ & $1.53 \mathrm{E}+00$ & $1.98 \mathrm{E}+00$ & $2.37 \mathrm{E}+00$ & $2.67 \mathrm{E}+00$ \\
\hline $3.34 \mathrm{E}-02$ & $3.54 \mathrm{E}+00$ & $7.17 \mathrm{E}-01$ & $5.37 \mathrm{E}-01$ & $1.53 \mathrm{E}+00$ & $1.98 \mathrm{E}+00$ & $2.37 E+00$ & $2.67 \mathrm{E}+00$ \\
\hline $3.35 \mathrm{E}-02$ & $3.54 \mathrm{E}+00$ & $7.17 \mathrm{E}-01$ & $5.37 \mathrm{E}-01$ & $1.54 \mathrm{E}+00$ & $1.98 \mathrm{E}+00$ & $2.37 \mathrm{E}+00$ & $2.67 \mathrm{E}+00$ \\
\hline $3.37 \mathrm{E}-02$ & $3.53 \mathrm{E}+00$ & $7.18 \mathrm{E}-01$ & $5.38 \mathrm{E}-01$ & $1.54 \mathrm{E}+00$ & $1.98 \mathrm{E}+00$ & $2.37 \mathrm{E}+00$ & $2.67 \mathrm{E}+00$ \\
\hline $3.38 \mathrm{E}-02$ & $3.53 \mathrm{E}+00$ & $7.19 \mathrm{E}-01$ & $5.39 \mathrm{E}-01$ & $1.54 \mathrm{E}+00$ & $1.99 \mathrm{E}+00$ & $2.37 \mathrm{E}+00$ & $2.67 \mathrm{E}+00$ \\
\hline $39 \mathrm{E}-02$ & $3.53 \mathrm{E}+00$ & $7.20 \mathrm{E}-01$ & $5.40 \mathrm{E}-01$ & $1.54 \mathrm{E}+00$ & $1.99 \mathrm{E}+00$ & $2.37 E+00$ & $2.67 \mathrm{E}+00$ \\
\hline 2 & $3.52 \mathrm{E}+00$ & 7 & 1 & $1.54 \mathrm{E}+00$ & $1.99 \mathrm{E}+00$ & $2.37 \mathrm{E}+00$ & $.67 \mathrm{E}+00$ \\
\hline $41 \mathrm{E}-02$ & $3.52 \mathrm{E}+00$ & 7 & 5 & $1.54 \mathrm{E}+00$ & $1.99 \mathrm{E}+00$ & $2.37 E+00$ & $.67 \mathrm{E}+00$ \\
\hline $3.43 \mathrm{E}-02$ & $3.52 \mathrm{E}+00$ & $7.22 \mathrm{E}-01$ & 5. & $1.54 \mathrm{E}$ & $1.99 \mathrm{E}+00$ & $2.37 \mathrm{E}+00$ & $2.67 \mathrm{E}+00$ \\
\hline $3.44 \mathrm{E}-02$ & $3.52 \mathrm{E}+00$ & $7.23 \mathrm{E}-01$ & $5.44 \mathrm{E}-01$ & $1.54 \mathrm{E}+00$ & $1.99 \mathrm{E}+00$ & $2.37 \mathrm{E}+00$ & $2.67 \mathrm{E}+00$ \\
\hline $3.45 \mathrm{E}-02$ & $3.52 \mathrm{E}+00$ & $7.24 \mathrm{E}-01$ & $5.45 \mathrm{E}-01$ & $1.54 \mathrm{E}+00$ & $1.99 \mathrm{E}+00$ & $2.37 \mathrm{E}+00$ & $2.67 \mathrm{E}+00$ \\
\hline $3.46 \mathrm{E}-02$ & $3.52 \mathrm{E}+00$ & $7.24 \mathrm{E}-01$ & $5.46 \mathrm{E}-01$ & $1.54 \mathrm{E}+00$ & $1.99 \mathrm{E}+00$ & $2.37 \mathrm{E}+00$ & $2.67 \mathrm{E}+00$ \\
\hline $3.48 \mathrm{E}-02$ & $3.52 \mathrm{E}+00$ & $7.25 \mathrm{E}-01$ & $5.47 \mathrm{E}-01$ & $1.55 \mathrm{E}+00$ & $1.99 \mathrm{E}+00$ & $2.37 \mathrm{E}+00$ & $2.67 \mathrm{E}+00$ \\
\hline $3.49 \mathrm{E}-02$ & $3.51 \mathrm{E}+00$ & $7.26 \mathrm{E}-01$ & $5.47 \mathrm{E}-01$ & $1.55 \mathrm{E}+00$ & $2.00 \mathrm{E}+00$ & $2.37 \mathrm{E}+00$ & $2.67 \mathrm{E}+00$ \\
\hline $3.50 \mathrm{E}-02$ & $3.51 \mathrm{E}+00$ & $7.27 \mathrm{E}-01$ & $5.48 \mathrm{E}-01$ & $1.55 \mathrm{E}+00$ & $2.00 \mathrm{E}+00$ & $2.37 \mathrm{E}+00$ & $2.67 \mathrm{E}+00$ \\
\hline $3.51 \mathrm{E}-02$ & $3.51 \mathrm{E}+00$ & 7. & $5.49 \mathrm{E}-01$ & $1.55 \mathrm{E}+00$ & $2.00 \mathrm{E}+00$ & $2.37 \mathrm{E}+00$ & $2.67 \mathrm{E}+00$ \\
\hline $3.53 \mathrm{E}-02$ & $3.51 \mathrm{E}+00$ & 7 & 01 & $1.55 \mathrm{E}+00$ & $2.00 \mathrm{E}+00$ & $2.37 E+00$ & $2.67 \mathrm{E}+00$ \\
\hline $3.54 \mathrm{E}-02$ & $3.51 \mathrm{E}+00$ & $7.29 \mathrm{E}-01$ & $5.51 \mathrm{E}-01$ & $1.55 \mathrm{E}+00$ & $2.00 \mathrm{E}+00$ & $2.37 \mathrm{E}+00$ & $2.67 \mathrm{E}+00$ \\
\hline $3.55 \mathrm{E}-02$ & $3.51 \mathrm{E}+00$ & $7.30 \mathrm{E}-01$ & $5.51 \mathrm{E}-01$ & $1.56 \mathrm{E}+00$ & $2.00 \mathrm{E}+00$ & $2.37 \mathrm{E}+00$ & $2.67 \mathrm{E}+00$ \\
\hline $3.56 \mathrm{E}-02$ & $3.51 \mathrm{E}+00$ & $7.31 \mathrm{E}-01$ & $5.52 \mathrm{E}-01$ & $1.56 \mathrm{E}+00$ & $2.00 \mathrm{E}+00$ & $2.37 \mathrm{E}+00$ & $2.68 \mathrm{E}+00$ \\
\hline $3.58 \mathrm{E}-02$ & $3.51 \mathrm{E}+00$ & 7. $32 \mathrm{E}-01$ & $5.53 \mathrm{E}-01$ & $1.56 \mathrm{E}+00$ & $2.00 \mathrm{E}+00$ & $2.37 \mathrm{E}+00$ & $2.68 \mathrm{E}+00$ \\
\hline $3.59 \mathrm{E}-02$ & $3.50 \mathrm{E}+00$ & $7.32 \mathrm{E}-01$ & $5.54 \mathrm{E}-01$ & $1.56 \mathrm{E}+00$ & $2.00 \mathrm{E}+00$ & $2.37 \mathrm{E}+00$ & $2.68 \mathrm{E}+00$ \\
\hline $3.60 \mathrm{E}-02$ & $3.50 \mathrm{E}+00$ & $7.33 \mathrm{E}-01$ & $5.55 \mathrm{E}-01$ & $1.56 \mathrm{E}+00$ & $2.00 \mathrm{E}+00$ & $2.37 \mathrm{E}+00$ & $2.68 \mathrm{E}+00$ \\
\hline $3.61 \mathrm{E}-02$ & $3.50 \mathrm{E}+00$ & $7.34 \mathrm{E}-01$ & $5.56 \mathrm{E}-01$ & $1.56 \mathrm{E}+00$ & $2.00 \mathrm{E}+00$ & $2.37 \mathrm{E}+00$ & $2.68 \mathrm{E}+00$ \\
\hline $3.63 \mathrm{E}-02$ & $3.50 \mathrm{E}+00$ & $7.35 \mathrm{E}-01$ & $5.57 \mathrm{E}-01$ & $1.57 \mathrm{E}+00$ & $2.00 \mathrm{E}+00$ & $2.37 \mathrm{E}+00$ & $2.68 \mathrm{E}+00$ \\
\hline $3.64 \mathrm{E}-02$ & $3.50 \mathrm{E}+00$ & $7.35 \mathrm{E}-01$ & $5.58 \mathrm{E}-01$ & $1.57 \mathrm{E}+00$ & $2.00 \mathrm{E}+00$ & $2.37 \mathrm{E}+00$ & $2.68 \mathrm{E}+00$ \\
\hline $3.65 \mathrm{E}-02$ & $3.50 \mathrm{E}+00$ & $7.36 \mathrm{E}-01$ & $5.59 \mathrm{E}-01$ & $1.57 \mathrm{E}+00$ & $2.00 \mathrm{E}+00$ & $2.37 \mathrm{E}+00$ & $2.69 \mathrm{E}+00$ \\
\hline $3.67 \mathrm{E}-02$ & $3.50 \mathrm{E}+00$ & $7.37 \mathrm{E}-01$ & $5.60 \mathrm{E}-01$ & $1.57 \mathrm{E}+00$ & $2.00 \mathrm{E}+00$ & $2.37 E+00$ & $2.69 \mathrm{E}+00$ \\
\hline $3.68 \mathrm{E}-02$ & $3.50 \mathrm{E}+00$ & $7.38 \mathrm{E}-01$ & $5.61 \mathrm{E}-01$ & $1.57 \mathrm{E}+00$ & $2.00 \mathrm{E}+00$ & $2.37 \mathrm{E}+00$ & $2.69 \mathrm{E}+00$ \\
\hline $3.69 \mathrm{E}-02$ & $3.49 \mathrm{E}+00$ & $7.39 \mathrm{E}-01$ & $5.62 \mathrm{E}-01$ & $1.57 \mathrm{E}+00$ & $2.00 \mathrm{E}+00$ & $2.37 \mathrm{E}+00$ & $2.69 \mathrm{E}+00$ \\
\hline $3.70 \mathrm{E}-02$ & $3.49 E+00$ & $7.39 \mathrm{E}-01$ & $5.63 \mathrm{E}-01$ & $1.57 \mathrm{E}+00$ & $2.00 \mathrm{E}+00$ & $2.37 \mathrm{E}+00$ & $2.69 \mathrm{E}+00$ \\
\hline $72 E-02$ & $3.49 \mathrm{E}+00$ & $7.40 \mathrm{E}-01$ & $5.64 \mathrm{E}-01$ & $1.57 \mathrm{E}+00$ & $2.01 \mathrm{E}+00$ & $2.38 \mathrm{E}+00$ & $2.69 \mathrm{E}+00$ \\
\hline
\end{tabular}


RESRAD-OFFSITE, Version 2.5

Title : RESRAD-OFFSITE Drinking Water, Plant, Milk, and Meat Pathways for Offsite Reside File : PBA-1_TC99-DOE-5.ROF

Summary of dose at graphical times, reptition 3 (continued)

Time

Years

$8.49 \mathrm{E}+02$

$8.50 \mathrm{E}+02$

$8.50 \mathrm{E}+02$

$8.51 \mathrm{E}+02$

$8.51 \mathrm{E}+02$

$8.52 \mathrm{E}+02$

$8.52 \mathrm{E}+02$

$8.53 \mathrm{E}+02$

$8.53 \mathrm{E}+02$

$8.54 \mathrm{E}+02$

$8.54 \mathrm{E}+02$

$8.55 \mathrm{E}+02$

$8.55 \mathrm{E}+02$

$8.56 \mathrm{E}+02$

$8.56 \mathrm{E}+02$

$8.57 \mathrm{E}+02$

$8.57 \mathrm{E}+02$

$8.58 \mathrm{E}+02$

$8.58 \mathrm{E}+02$

$8.59 \mathrm{E}+02$

$8.59 \mathrm{E}+02$

$8.60 \mathrm{E}+02$

$8.60 \mathrm{E}+02$

$8.61 \mathrm{E}+02$

$8.61 \mathrm{E}+02$

$8.62 \mathrm{E}+02$

$8.62 \mathrm{E}+02$

$8.63 \mathrm{E}+02$

$8.63 \mathrm{E}+02$

$8.64 \mathrm{E}+02$

$8.64 \mathrm{E}+02$

$8.65 \mathrm{E}+02$

$8.65 \mathrm{E}+02$

$8.66 \mathrm{E}+02$

$8.66 \mathrm{E}+02$

$8.67 \mathrm{E}+02$

$8.67 \mathrm{E}+02$

$8.68 \mathrm{E}+02$

$8.69 \mathrm{E}+02$

$8.69 \mathrm{E}+02$

$8.70 \mathrm{E}+02$

$8.70 \mathrm{E}+02$

$8.71 \mathrm{E}+02$

$8.71 E+02$

$8.72 \mathrm{E}+02$

$8.72 \mathrm{E}+02$
Dose statistics at graphical times, mrem/yr

\begin{tabular}{|c|c|c|c|c|c|c|c|}
\hline inimum & aximum & Mean & ledian & $0 \%$ & $5 \%$ & $97.5 \%$ & \\
\hline 02 & $3.49 \mathrm{E}+00$ & $7.41 \mathrm{E}-01$ & $5.65 \mathrm{E}-01$ & $1.57 \mathrm{E}+00$ & $1 \mathrm{E}+00$ & $.38 E+00$ & $5 \mathrm{E}+0$ \\
\hline 02 & $E+00$ & $E-01$ & 1 & $57 \mathrm{E}+$ & $E+00$ & $E+00$ & +00 \\
\hline 02 & +00 & $E-01$ & -01 & 00 & 00 & -00 & +00 \\
\hline 02 & 00 & 1 & & 0 & & 00 & +00 \\
\hline-02 & 00 & & & 00 & 00 & $E+00$ & $70 E+00$ \\
\hline-02 & $E+00$ & $E-01$ & -01 & $1.58 \mathrm{E}+00$ & $\mathrm{E}+00$ & $E+00$ & $0 E+00$ \\
\hline 02 & +00 & S & -01 & 00 & 00 & +00 & $\mathrm{E}+00$ \\
\hline 02 & $3.48 \mathrm{E}+00$ & & $5.72 E-01$ & $1.58 \mathrm{E}+00$ & & +00 & $70 \mathrm{E}+00$ \\
\hline 02 & +00 & 1 & 01 & 00 & 00 & +00 & +00 \\
\hline$E-02$ & $3.48 \mathrm{E}+00$ & $8 E-01$ & $E-01$ & 1. $58 \mathrm{E}+00$ & $01 \mathrm{E}+00$ & $37 E+00$ & $70 \mathrm{E}+00$ \\
\hline-02 & +00 & $E-01$ & -01 & & & 00 & $E+00$ \\
\hline & +00 & & & & & +00 & +00 \\
\hline E-02 & $3.47 \mathrm{E}+00$ & . & $5.77 E-01$ & $1.58 \mathrm{E}+00$ & & $E+00$ & $71 \mathrm{E}+0 \mathrm{C}$ \\
\hline 02 & -00 & 1 & -01 & 00 & 00 & +00 & +00 \\
\hline 02 & -00 & $\perp$ & 01 & 00 & & $\mathrm{E}+00$ & $E+00$ \\
\hline $.93 E-02$ & $3.47 \mathrm{E}+00$ & $\perp$ & -01 & & $01 \mathrm{E}+00$ & $.37 E+00$ & $.71 E+00$ \\
\hline$E-02$ & $7 E+00$ & $3 E-01$ & $0 \mathrm{E}-01$ & $1.58 \mathrm{E}+00$ & $01 \mathrm{E}+00$ & $6 \mathrm{E}+00$ & $.70 \mathrm{E}+00$ \\
\hline-02 & $7 E+00$ & $4 \mathrm{E}-01$ & $1 \mathrm{E}-01$ & $9 \mathrm{E}+00$ & $01 E+00$ & $36 E+00$ & $70 \mathrm{E}+0 \mathrm{C}$ \\
\hline 02 & $E+00$ & 1 & -01 & 0 & & +00 & +00 \\
\hline $3 E-02$ & $E+00$ & -01 & -01 & & & +00 & +00 \\
\hline $.99 \mathrm{E}-02$ & & & -01 & & & 100 & +00 \\
\hline $1 E-02$ & $3.46 \mathrm{E}+00$ & $7 E-01$ & $5 E-01$ & $1.59 \mathrm{E}+00$ & & $7 \mathrm{E}+00$ & $70 \mathrm{E}+00$ \\
\hline$E-02$ & $3.46 \mathrm{E}+00$ & $E-01$ & $E-01$ & $9 E+00$ & $01 E+00$ & $.37 E+00$ & $.70 \mathrm{E}+00$ \\
\hline $\mathrm{E}-02$ & $.46 \mathrm{E}+00$ & $7.58 \mathrm{E}-01$ & $7 E-01$ & $1.59 \mathrm{E}+00$ & $2.01 \mathrm{E}+00$ & $37 E+00$ & $.70 E+00$ \\
\hline-02 & $E+00$ & $59 E-01$ & $E-01$ & $9 \mathrm{E}+00$ & & $\mathrm{E}+00$ & +00 \\
\hline 02 & & & & & & $4+00$ & 100 \\
\hline $8 E-02$ & $3.46 \mathrm{E}+00$ & $-U 1$ & -01 & L & & $7 \mathrm{E}+00$ & $.70 \mathrm{E}+00$ \\
\hline $9 E-02$ & 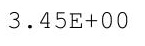 & . & $.91 E-01$ & $1.59 \mathrm{E}+00$ & $2.0 \perp E T U$ & $.37 E+00$ & $69 E+00$ \\
\hline 2 & I & 1 & 1 & $60 \mathrm{E}+00$ & $.01 \mathrm{E}+00$ & $.37 \mathrm{E}+00$ & $.69 \mathrm{E}+0 \mathrm{C}$ \\
\hline 2 & 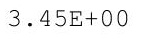 & $2-5$ & 1 & OE+ & & $37 E+0$ & $69 E+0$ \\
\hline$F-02$ & $3.45 E+00$ & & $4 E-01$ & $0 E+00$ & $01 E+00$ & 7F+00 & $69 E+00$ \\
\hline 02 & $E+00$ & & & & & & +00 \\
\hline$E-02$ & $3.45 E+00$ & $E-01$ & -01 & 00 & & $.37 E+00$ & $.69 E+00$ \\
\hline $.17 \mathrm{E}-02$ & $3.45 \mathrm{E}+00$ & $.66 \mathrm{E}-01$ & $98 E-01$ & $1.60 \mathrm{E}+00$ & $2.01 E+00$ & $.36 E+00$ & $.69 E+00$ \\
\hline $19 \mathrm{E}-02$ & $3.44 \mathrm{TT} U$ & $1.01 \mathrm{~L}-U \perp$ & $.99 \mathrm{E}-01$ & 1.00 다이 & & .20 काष & $.69 \mathrm{E}+0 \mathrm{C}$ \\
\hline 2 & & & & & & & \\
\hline 2 & 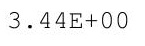 & & & 0 & & 0 & $69 \mathrm{E}+00$ \\
\hline 2 & & & & 0 & & & \\
\hline-02 & & $0 E-01$ & -01 & $1.60 \mathrm{E}+00$ & $2.01 E+00$ & $6 \mathrm{E}+00$ & $69 E+00$ \\
\hline $6 \mathrm{E}-02$ & $3.44 \mathrm{E}+00$ & $70 E-01$ & -01 & 1 . & & & +00 \\
\hline & & $E-01$ & 01 & 1. $60 \mathrm{E}+$ & & & $.68 \mathrm{E}+0 \mathrm{C}$ \\
\hline & $3.45 E+00$ & 1 & & $1.60 \mathrm{E}+00$ & & $36 \mathrm{E}+00$ & $.00 \mathrm{E}+00$ \\
\hline 2 & $43 E+00$ & 1 & . & $1.60 \mathrm{E}+\mathrm{C}$ & & $36 E+00$ & $.68 E+00$ \\
\hline 2 & & & & 1 . & $2.01 \mathrm{E}$ & 0 & $68 E+00$ \\
\hline$E-02$ & $3.43 E+00$ & $7.74 \mathrm{E}-01$ & $E-01$ & $1.60 \mathrm{E}+00$ & $2.01 \mathrm{E}+00$ & $2.35 E+00$ & $2.68 \mathrm{E}+00$ \\
\hline $.34 E-02$ & $3.43 E+00$ & $7.75 E-01$ & $.08 E-01$ & $1.60 \mathrm{E}+00$ & $2.00 \mathrm{E}+00$ & $.35 E+00$ & $.68 \mathrm{E}+00$ \\
\hline
\end{tabular}


RESRAD-OFFSITE, Version 2.5

Title : RESRAD-OFFSITE Drinking Water, Plant, Milk, and Meat Pathways for Offsite Reside File : PBA-1_TC99-DOE-5.ROF

Summary of dose at graphical times, reptition 3 (continued)

Time

Years

$8.73 \mathrm{E}+02$

$8.73 \mathrm{E}+02$

$8.74 \mathrm{E}+02$

$8.74 \mathrm{E}+02$

$8.75 \mathrm{E}+02$

$8.75 \mathrm{E}+02$

$8.76 \mathrm{E}+02$

$8.76 \mathrm{E}+02$

$8.77 \mathrm{E}+02$

$8.77 \mathrm{E}+02$

$8.78 \mathrm{E}+02$

$8.78 \mathrm{E}+02$

$8.79 \mathrm{E}+02$

$8.79 \mathrm{E}+02$

$8.80 \mathrm{E}+02$

$8.80 \mathrm{E}+02$

$8.81 \mathrm{E}+02$

$8.81 \mathrm{E}+02$

$8.82 \mathrm{E}+02$

$8.82 \mathrm{E}+02$

$8.83 \mathrm{E}+02$

$8.83 \mathrm{E}+02$

$8.84 \mathrm{E}+02$

$8.84 \mathrm{E}+02$

$8.85 \mathrm{E}+02$

$8.85 \mathrm{E}+02$

$8.86 \mathrm{E}+02$

$8.86 \mathrm{E}+02$

$8.87 \mathrm{E}+02$

$8.87 \mathrm{E}+02$

$8.88 \mathrm{E}+02$

$8.89 \mathrm{E}+02$

$8.89 \mathrm{E}+02$

8. $90 \mathrm{E}+02$

$8.90 \mathrm{E}+02$

$8.91 \mathrm{E}+02$

$8.91 \mathrm{E}+02$

8. $92 \mathrm{E}+02$

$8.92 \mathrm{E}+02$

$8.93 \mathrm{E}+02$

$8.93 \mathrm{E}+02$

8. $94 \mathrm{E}+02$

$8.94 \mathrm{E}+02$

8. $95 \mathrm{E}+02$

$8.95 \mathrm{E}+02$

$8.96 \mathrm{E}+02$
Dose statistics at graphical times, mrem/yr

\begin{tabular}{|c|c|c|c|c|c|c|c|}
\hline inimum & aximum & Mean & ledian & $90 \%$ & $5 \%$ & $97.5 \%$ & \\
\hline 02 & +00 & $7.76 \mathrm{E}-01$ & $E-01$ & $1.60 \mathrm{E}+00$ & $0 \mathrm{E}+00$ & $2.35 \mathrm{E}+00$ & $58 \mathrm{E}+0$ \\
\hline 02 & +00 & $E-01$ & 1 & 0 & $0 \mathrm{E}+00$ & 00 & $E+00$ \\
\hline-02 & -00 & 01 & -01 & 00 & 00 & 00 & +00 \\
\hline 02 & 00 & 1 & & & & 00 & +00 \\
\hline 02 & 00 & 1 & & 00 & 00 & $E+00$ & $67 E+00$ \\
\hline $.43 E-02$ & $E+00$ & -01 & -01 & $1.61 \mathrm{E}+00$ & $E+00$ & $\Xi+00$ & $7 \mathrm{E}+00$ \\
\hline 02 & -00 & 01 & 1 & $1 \mathrm{~F}$ & ח & +00 & $\Xi+00$ \\
\hline 02 & 00 & 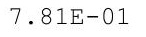 & & 00 & & 00 & 00 \\
\hline 02 & +00 & $\perp$ & 01 & +00 & 00 & +00 & +00 \\
\hline $48 E-02$ & $3.42 \mathrm{E}+00$ & $82 \mathrm{E}-01$ & $7 E-01$ & $1.61 \mathrm{E}+00$ & $01 \mathrm{E}+00$ & $E+00$ & $67 \mathrm{E}+00$ \\
\hline $50 \mathrm{E}-02$ & $3.42 \mathrm{E}+00$ & $3 E-01$ & $8 E-01$ & & & $E+00$ & $67 E+00$ \\
\hline 02 & -00 & 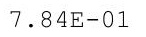 & & & 0 & +00 & $E+00$ \\
\hline-02 & $\mathrm{E}+00$ & $\begin{array}{lll}0 \\
0\end{array}$ & -01 & +00 & 0 & $E+00$ & $4+0$ \\
\hline 2 & 0 & $5 E-01$ & 1 & 0 & 0 & +00 & +00 \\
\hline 02 & -00 & $\perp$ & 01 & & & $\mathrm{E}+00$ & +00 \\
\hline $.57 E-02$ & $3.42 \mathrm{E}+00$ & $\Gamma$ & 01 & & $01 E+00$ & $E+00$ & $66 \mathrm{E}+00$ \\
\hline $.58 \mathrm{E}-02$ & $3.42 \mathrm{E}+00$ & $7 E-01$ & $4 E-01$ & 1. $61 \mathrm{E}+00$ & $01 E+00$ & $5 \mathrm{E}+00$ & $.66 \mathrm{E}+00$ \\
\hline-02 & $2 E+00$ & $8 E-01$ & $5 E-01$ & $1.61 \mathrm{E}+00$ & $01 E+00$ & $4 E+00$ & $66 \mathrm{E}+00$ \\
\hline 02 & +00 & & 01 & 0 & & +00 & +0 \\
\hline 02 & -00 & $\perp$ & -01 & 0 & & +00 & +0 \\
\hline 2 & & & 1 & 0 & & 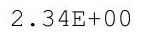 & 00 \\
\hline 02 & $1 E+00$ & L & 1 & קГרת & & $E+00$ & $E+00$ \\
\hline$E-02$ & $.41 \mathrm{E}+00$ & $E-01$ & $E-01$ & 1. $62 \mathrm{E}+00$ & $01 \mathrm{E}+0$ & $4 \mathrm{E}+00$ & $.66 \mathrm{E}+00$ \\
\hline$E-02$ & $.41 E+00$ & $.92 \mathrm{E}-01$ & $0 E-01$ & 1. $62 \mathrm{E}+00$ & $01 \mathrm{E}+00$ & $E+00$ & $65 E+00$ \\
\hline 02 & $.41 \mathrm{E}+00$ & $93 E-01$ & $31 E-01$ & & & $F+00$ & $5 E+00$ \\
\hline & & & & & & & +00 \\
\hline & & & & $1.62 \mathrm{E}$ & & 00 & +00 \\
\hline $.75 \mathrm{E}-02$ & $3.41 E+00$ & $.95 E-01$ & $34 E-01$ & $1.62 \mathrm{E}+00$ & $2.0 \perp E T U$ & $2.34 \mathrm{E}+00$ & $.65 E+00$ \\
\hline 2 & $41 \mathrm{E}+$ & ser & 1 & $.62 E+00$ & $.01 E+00$ & $.34 E+00$ & $.65 E+00$ \\
\hline 2 & $41 \mathrm{E}+$ & - & 1 & $62 \mathrm{E}+$ & & $34 \mathrm{E}+0$ & $.65 \mathrm{E}+0$ \\
\hline$E-02$ & $41 F+0$ & & $6 E-01$ & $1.62 \mathrm{E}+00$ & & $\mathrm{E}+00$ & $65 E+00$ \\
\hline 02 & & & & & & & \\
\hline & & & $8 E-01$ & & & & \\
\hline $.84 E-02$ & $3.41 \mathrm{E}+00$ & $.99 \mathrm{E}-01$ & $E-01$ & $1.63 \mathrm{E}+00$ & $\angle \cdot U \perp E+U 0$ & $4 \mathrm{E}+00$ & $2.64 \mathrm{E}+0 \mathrm{C}$ \\
\hline $85 E-02$ & $3.4 \perp \Gamma T U$ & & $6.41 E-01$ & 1. ООБТ & & 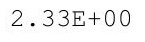 & Z. О4ЕТО \\
\hline 2 & & & & & & & $.64 \mathrm{E}+00$ \\
\hline 2 & $3.41 E+00$ & & & 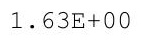 & & 0 & 00 \\
\hline 2 & & & & & & & \\
\hline 02 & & 1 & $5 E-01$ & 1 . & 00 & $3 E+00$ & \\
\hline $.93 E-02$ & $3.41 \mathrm{E}+00$ & $\mathrm{~s}-01$ & 01 & $1.63 \mathrm{E}+$ & & & +00 \\
\hline 02 & & & & 0 & & & $64 \mathrm{E}+0 \mathrm{C}$ \\
\hline & $405+00$ & 1 & & $1.63 \mathrm{E}+00$ & & $.33 E+00$ & $2.64 \mathrm{E}+00$ \\
\hline & $40 \mathrm{E}+$ & 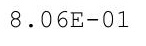 & 1 & 土. & . & $2.33 E+00$ & $2.64 \mathrm{E}+0 \mathrm{C}$ \\
\hline 2 & & & & 0 & $2.01 \mathrm{E}$ & $.33 E+$ & $2.64 \mathrm{E}+00$ \\
\hline $.00 \mathrm{E}-02$ & $3.40 \mathrm{E}+00$ & $7 E-01$ & $6.50 \mathrm{E}-01$ & $1.63 \mathrm{E}+00$ & $2.01 \mathrm{E}+00$ & $2.33 \mathrm{E}+00$ & $2.64 \mathrm{E}+00$ \\
\hline $.02 E-02$ & $3.40 \mathrm{E}+00$ & $.08 E-01$ & $.50 E-01$ & $1.63 \mathrm{E}+00$ & $2.01 E+00$ & $2.33 E+00$ & $2.64 \mathrm{E}+00$ \\
\hline
\end{tabular}


RESRAD-OFFSITE, Version 2.5

Title : RESRAD-OFFSITE Drinking Water, Plant, Milk, and Meat Pathways for Offsite Reside File : PBA-1_TC99-DOE-5.ROF

Summary of dose at graphical times, reptition 3 (continued)

Time

Years

$8.96 \mathrm{E}+02$

$8.97 \mathrm{E}+02$

$8.97 \mathrm{E}+02$

$8.98 \mathrm{E}+02$

$8.98 \mathrm{E}+02$

8. $99 \mathrm{E}+02$

$8.99 \mathrm{E}+02$

$9.00 \mathrm{E}+02$

$9.00 \mathrm{E}+02$

$9.01 \mathrm{E}+02$

$9.01 \mathrm{E}+02$

$9.02 \mathrm{E}+02$

$9.02 \mathrm{E}+02$

$9.03 \mathrm{E}+02$

$9.03 \mathrm{E}+02$

$9.04 \mathrm{E}+02$

$9.04 \mathrm{E}+02$

$9.05 \mathrm{E}+02$

$9.05 \mathrm{E}+02$

$9.06 \mathrm{E}+02$

$9.06 \mathrm{E}+02$

$9.07 \mathrm{E}+02$

$9.07 \mathrm{E}+02$

$9.08 \mathrm{E}+02$

$9.08 \mathrm{E}+02$

$9.09 \mathrm{E}+02$

$9.10 \mathrm{E}+02$

$9.10 \mathrm{E}+02$

9. $11 \mathrm{E}+02$

9. $11 \mathrm{E}+02$

$9.12 \mathrm{E}+02$

9. $12 \mathrm{E}+02$

$9.13 \mathrm{E}+02$

9. $13 \mathrm{E}+02$

$9.14 \mathrm{E}+02$

9. $14 \mathrm{E}+02$

9. $15 \mathrm{E}+02$

$9.15 \mathrm{E}+02$

9. $16 \mathrm{E}+02$

$9.16 \mathrm{E}+02$

$9.17 \mathrm{E}+02$

$9.17 \mathrm{E}+02$

$9.18 \mathrm{E}+02$

9. $18 \mathrm{E}+02$

$9.19 \mathrm{E}+02$

$9.19 \mathrm{E}+02$
Dose statistics at graphical times, mrem/yr

\begin{tabular}{|c|c|c|c|c|c|c|c|}
\hline inimum & aximum & Mean & ledian & $0 \%$ & $5 \%$ & $97.5 \%$ & \\
\hline 02 & $\mathrm{E}+00$ & $E-01$ & $1 E-01$ & $1.63 \mathrm{E}+00$ & $1 \mathrm{E}+00$ & $2.33 E+00$ & $3 E+0$ \\
\hline 02 & -00 & 01 & 1 & 0 & $E+00$ & 00 & 100 \\
\hline 02 & +00 & 01 & 01 & 00 & 00 & 00 & +00 \\
\hline-02 & 00 & 1 & & & & 00 & +00 \\
\hline-02 & 00 & & & & 00 & $E+00$ & $63 E+00$ \\
\hline-02 & +00 & -01 & -01 & $4 E+00$ & $E+00$ & $E+00$ & $\mathrm{E}+00$ \\
\hline 02 & -00 & -0 & -01 & 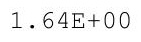 & 0 & +00 & $\mathrm{i}+0 \mathrm{c}$ \\
\hline 02 & $3.40 \mathrm{E}+00$ & . & $8 E-01$ & 00 & & +00 & +00 \\
\hline 02 & +00 & 1 & 01 & 00 & 00 & +00 & +00 \\
\hline $.17 E-02$ & $3.40 \mathrm{E}+00$ & $5 E-01$ & $E-01$ & $.64 \mathrm{E}+00$ & $02 \mathrm{E}+00$ & $3 E+00$ & $E+00$ \\
\hline $.19 \mathrm{E}-02$ & $3.40 \mathrm{E}+00$ & $5 E-01$ & $1 E-01$ & & & $.33 E+00$ & $62 \mathrm{E}+00$ \\
\hline & -00 & & & & & +00 & $2 E+00$ \\
\hline-02 & $E+00$ & $7 \pm-0 \perp$ & -01 & +00 & 0 & $E+00$ & +0 \\
\hline 02 & +00 & 1 & -01 & 00 & 00 & +00 & +00 \\
\hline 02 & $9 \mathrm{E}+00$ & $\perp$ & 01 & 00 & 00 & $E+00$ & +00 \\
\hline $.27 E-02$ & $3.39 \mathrm{E}+00$ & $\perp$ & -01 & & $02 \mathrm{E}+00$ & $3 E+00$ & $61 \mathrm{E}+00$ \\
\hline $28 \mathrm{E}-02$ & $9 \mathrm{E}+00$ & $9 \mathrm{E}-01$ & $5 E-01$ & $1.64 \mathrm{E}+00$ & $02 E+00$ & $3 E+00$ & $61 E+00$ \\
\hline 02 & $9 \mathrm{E}+00$ & $0 \mathrm{E}-01$ & $6 E-01$ & $1.64 \mathrm{E}+00$ & $02 E+00$ & $3 E+00$ & $61 E+00$ \\
\hline 02 & $E+00$ & 1 & -01 & 00 & & +00 & +00 \\
\hline $3 E-02$ & $3.39 \mathrm{E}+00$ & $-U \perp$ & 01 & {$[\cdot 01+$} & & +00 & +00 \\
\hline $.34 \mathrm{E}-02$ & & & -01 & & & 100 & +00 \\
\hline$E-02$ & $3.39 \mathrm{E}+00$ & -01 & $E-01$ & $1.65 \mathrm{E}+00$ & & $E+00$ & $60 \mathrm{E}+00$ \\
\hline $3 E-02$ & $3.39 \mathrm{E}+00$ & $8.23 \mathrm{E}-01$ & $1 E-01$ & $1.65 \mathrm{E}+00$ & $.02 \mathrm{E}+00$ & $.34 \mathrm{E}+00$ & $.60 \mathrm{E}+00$ \\
\hline $\mathrm{E}-02$ & $.39 E+00$ & $.24 \mathrm{E}-01$ & $1 E-01$ & $1.65 \mathrm{E}+00$ & $02 \mathrm{E}+00$ & $1 E+00$ & $.60 \mathrm{E}+0 \mathrm{C}$ \\
\hline 02 & $E+00$ & $25 E-01$ & $2 E-01$ & & & $F+00$ & $0 E+00$ \\
\hline 02 & & & & & & & $60 E+00$ \\
\hline 2 & & & & $\pm \cdot 00$ & & $1 \mathrm{E}+00$ & +00 \\
\hline $6 E-02$ & $3.30 \mathrm{~T}$ & $.27 \mathrm{E}-01$ & $5 E-01$ & $1.65 \mathrm{E}+00$ & $2.03 \mathrm{LT}$ & $2.34 \mathrm{E}+00$ & $.60 E+00$ \\
\hline 02 & 0 & (le & $6 E-01$ & $65 \mathrm{E}+$ & $.03 E+00$ & $.34 E+00$ & $.59 E+0 C$ \\
\hline 2 & 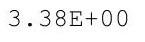 & - & 1 & $5 \mathrm{E}+$ & & $4 \mathrm{E}+0$ & $59 \mathrm{E}+0$ \\
\hline 02 & $38 F+00$ & $295-01$ & $8 E-01$ & $5 E+00$ & $03 E+00$ & $4 \mathrm{E}+00$ & $59 \mathrm{E}+00$ \\
\hline 02 & $5+0$ & 1 & & & & & \\
\hline & & & & & & & \\
\hline $.55 E-02$ & $3.38 \mathrm{E}+00$ & $31 E-01$ & $1 E-01$ & $1.65 \mathrm{E}+00$ & $2.03 E+00$ & $2.34 \mathrm{E}+00$ & $.59 \mathrm{E}+0 \mathrm{c}$ \\
\hline $57 E-02$ & & $0 . J \perp L-U \perp$ & $6.82 E-01$ & & & Z. J4LTU & Z. ОЛЕТО \\
\hline 2 & & & & & & & $.59 \mathrm{E}+00$ \\
\hline 2 & re & & & 0 & & 0 & 00 \\
\hline 2 & & & & & & & \\
\hline 02 & & 1 & -01 & $1.66 \mathrm{E}$ & $3 E+00$ & $4 \mathrm{E}+00$ & $59 \mathrm{E}+00$ \\
\hline $5 E-02$ & $3.37 \mathrm{E}+00$ & $35 E-01$ & -01 & 0 & & & +00 \\
\hline 02 & $7 \mathrm{E}+00$ & 1 & 01 & $6 \mathrm{E}+$ & & & +0 \\
\hline & $3.3 / E+00$ & 1 & 1 & $1.66 \mathrm{E}+00$ & $2.05 E+00$ & $2.34 \mathrm{E}+00$ & $2.395+00$ \\
\hline & $3.37 \mathrm{E}+$ & 車 & 01 & $1.00 \mathrm{~L}$ & $03 \mathrm{E}+$ & $2.34 \mathrm{E}+00$ & $2.59 \mathrm{E}+0$ \\
\hline 2 & 3. & & 1 & $1.66 \mathrm{E}$ & $2.03 \mathrm{E}$ & $2.34 \mathrm{E}+$ & $.59 E+00$ \\
\hline$E-02$ & $E+00$ & $8.38 E-01$ & 01 & $1.66 \mathrm{E}+00$ & $2.03 E+00$ & $2.34 \mathrm{E}+00$ & $2.59 \mathrm{E}+00$ \\
\hline $.75 E-02$ & $37 E+00$ & $.39 E-01$ & $.91 E-01$ & $1.66 \mathrm{E}+00$ & $2.03 E+00$ & $2.34 \mathrm{E}+00$ & $2.59 \mathrm{E}+00$ \\
\hline
\end{tabular}


RESRAD-OFFSITE, Version 2.5

Title : RESRAD-OFFSITE Drinking Water, Plant, Milk, and Meat Pathways for Offsite Reside File : PBA-1_TC99-DOE-5.ROF

Summary of dose at graphical times, reptition 3 (continued)

Time

Years

$9.20 \mathrm{E}+02$

$9.20 \mathrm{E}+02$

$9.21 \mathrm{E}+02$

$9.21 \mathrm{E}+02$

$9.22 \mathrm{E}+02$

$9.22 \mathrm{E}+02$

$9.23 \mathrm{E}+02$

$9.23 \mathrm{E}+02$

$9.24 \mathrm{E}+02$

$9.24 \mathrm{E}+02$

$9.25 \mathrm{E}+02$

$9.25 \mathrm{E}+02$

$9.26 \mathrm{E}+02$

$9.26 \mathrm{E}+02$

$9.27 \mathrm{E}+02$

$9.27 \mathrm{E}+02$

$9.28 \mathrm{E}+02$

$9.28 \mathrm{E}+02$

$9.29 \mathrm{E}+02$

9. $30 \mathrm{E}+02$

$9.30 \mathrm{E}+02$

$9.31 \mathrm{E}+02$

$9.31 \mathrm{E}+02$

9. $32 \mathrm{E}+02$

9. $32 \mathrm{E}+02$

$9.33 \mathrm{E}+02$

9. $33 \mathrm{E}+02$

$9.34 \mathrm{E}+02$

9. $34 \mathrm{E}+02$

9. $35 \mathrm{E}+02$

9. $35 \mathrm{E}+02$

9. $36 \mathrm{E}+02$

9. $36 \mathrm{E}+02$

9. $37 \mathrm{E}+02$

9. $37 \mathrm{E}+02$

$9.38 \mathrm{E}+02$

9. $38 \mathrm{E}+02$

$9.39 \mathrm{E}+02$

$9.39 \mathrm{E}+02$

$9.40 \mathrm{E}+02$

9. $40 \mathrm{E}+02$

9. $41 \mathrm{E}+02$

9. $41 \mathrm{E}+02$

9. $42 \mathrm{E}+02$

$9.42 \mathrm{E}+02$

$9.43 \mathrm{E}+02$
Dose statistics at graphical times, mrem/yr

\begin{tabular}{|c|c|c|c|c|c|c|c|}
\hline inimum & aximum & Mean & ledian & $0 \%$ & $5 \%$ & $97.5 \%$ & $3 \%$ \\
\hline-02 & $3.37 E+00$ & $9 \mathrm{E}-01$ & $2 E-01$ & $1.66 \mathrm{E}+00$ & $3 E+00$ & $.34 E+00$ & $.59 \mathrm{E}+0$ \\
\hline 02 & $E+00$ & 01 & 1 & $66 \mathrm{E}+$ & $E+00$ & $E+00$ & +00 \\
\hline 02 & +00 & $E-01$ & -01 & 00 & 00 & 00 & +00 \\
\hline-02 & 00 & 1 & 1 & 0 & & 00 & +00 \\
\hline-02 & 00 & 1 & 01 & 0 & 00 & $E+00$ & $\mathrm{E}+00$ \\
\hline-02 & +00 & -01 & -01 & $1.66 \mathrm{E}+00$ & $E+00$ & $E+00$ & $8 \mathrm{E}+00$ \\
\hline 02 & $6 \mathrm{E}+00$ & 岸 & -01 & $1.66 \mathrm{E}$ & 00 & +00 & $\mathrm{E}+00$ \\
\hline $.88 E-02$ & $3.36 \mathrm{E}+00$ & 4 & $9 E-01$ & $1.66 \mathrm{E}+00$ & $2.03 E+00$ & $.33 E+00$ & $58 \mathrm{E}+0 \mathrm{C}$ \\
\hline 02 & +00 & 1 & 01 & +00 & 00 & +00 & +00 \\
\hline $.91 E-02$ & $6 \mathrm{E}+00$ & $5 E-01$ & $1 E-01$ & $1.66 \mathrm{E}+00$ & $03 E+00$ & $B E+00$ & $E+00$ \\
\hline-02 & +00 & $E-01$ & $E-01$ & & & 00 & $E+00$ \\
\hline & -00 & & & & & +00 & +00 \\
\hline $.96 \mathrm{E}-02$ & $3.36 \mathrm{E}+00$ & $.47 \mathrm{E}-\mathrm{U}$ & $E-01$ & $1.07 \mathrm{E}+00$ & 00 & $E+00$ & $\mathrm{E}+0 \mathrm{C}$ \\
\hline 02 & -00 & -01 & -01 & $1.67 \mathrm{E}+00$ & 00 & +00 & +00 \\
\hline 02 & $5 \mathrm{E}+00$ & $\perp$ & 01 & 00 & 00 & $.33 E+00$ & +00 \\
\hline $.01 E-02$ & $3.35 \mathrm{E}+00$ & 1 & -01 & $1.67 \mathrm{E}+00$ & $02 \mathrm{E}+00$ & $.33 E+00$ & $7 \mathrm{E}+00$ \\
\hline $3 E-02$ & $5 E+00$ & $0 \mathrm{E}-01$ & $8 E-01$ & $1.67 \mathrm{E}+00$ & $02 \mathrm{E}+00$ & $33 E+00$ & $57 E+00$ \\
\hline-02 & $5 \mathrm{E}+00$ & $0 E-01$ & $9 E-01$ & $1.67 \mathrm{E}+00$ & $02 E+00$ & $3 E+00$ & $7 E+00$ \\
\hline 02 & $E+00$ & $1 \mathrm{E}-01$ & $E-01$ & $1.67 \mathrm{E}+00$ & & \pm+00 & $\mathrm{E}+00$ \\
\hline$E-02$ & $E+00$ & -01 & -01 & 1.015 & & +00 & +00 \\
\hline$E-02$ & & (2) & -01 & 土. & & 100 & +00 \\
\hline$E-02$ & $3.35 \mathrm{E}+00$ & $.53 E-01$ & 01 & $1.67 \mathrm{E}+00$ & & $E+00$ & $57 E+00$ \\
\hline $3 E-02$ & $3.35 \mathrm{E}+00$ & $8.53 \mathrm{E}-01$ & $3 E-01$ & $1.67 \mathrm{E}+00$ & $01 E+00$ & $3 \mathrm{E}+00$ & $57 E+00$ \\
\hline $\mathrm{E}-02$ & $.35 E+00$ & $.54 \mathrm{E}-01$ & $3 E-01$ & $1.67 \mathrm{E}+00$ & $2.01 \mathrm{E}+00$ & $3 E+00$ & $57 \mathrm{E}+0 \mathrm{C}$ \\
\hline-02 & $\mathrm{E}+00$ & $5 E-01$ & -01 & & & 00 & $E+00$ \\
\hline 02 & 00 & 1 & -01 & & & .00 & +00 \\
\hline $20 \mathrm{E}-02$ & $3.34 \mathrm{E}+00$ & $8.36 \pm-U 1$ & $E-01$ & $1.67 \mathrm{E}+00$ & & +00 & $57 E+00$ \\
\hline 2 & . . & (1) & $7.17 E-01$ & $1.67 \mathrm{E}+00$ & $\angle . U \perp \perp T U U$ & $34 E+00$ & $.57 E+00$ \\
\hline 2 & - & 1 & te & $.07 \mathrm{E}+00$ & $.01 E+00$ & $.33 E+00$ & $.57 \mathrm{E}+0 \mathrm{C}$ \\
\hline $.25 E-02$ & 年 & 年 & $E-01$ & $1.67 \mathrm{E}+$ & & $3 E+00$ & $7 \mathrm{E}+0$ \\
\hline 02 & $34 \mathrm{~F}+0 \Omega$ & $8 \mathrm{E}-01$ & $E-01$ & $1.67 \mathrm{E}+00$ & $1 \mathrm{E}+00$ & AF+ & $7 \mathrm{E}+00$ \\
\hline 02 & 0 & & & & & & \\
\hline $\mathrm{E}-02$ & $3.34 \mathrm{E}+00$ & $E-01$ & -01 & $1.0 / \mathrm{E}$ & 00 & +00 & $57 E+00$ \\
\hline $.32 \mathrm{E}-02$ & $3.34 \mathrm{E}+00$ & $8.60 E-01$ & $.22 E-01$ & $1.67 \mathrm{E}+00$ & $2.00 \pm+00$ & $.34 \mathrm{E}+00$ & $57 E+00$ \\
\hline $34 E-02$ & & $0.0 \perp \Gamma-U \perp$ & 7. $23 E-01$ & & & •. गटन TU & •JILTU \\
\hline 2 & & & & & & & $57 \mathrm{E}+00$ \\
\hline $375-0 ?$ & re & & & 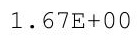 & & 0 & 00 \\
\hline 2 & & & & 0 & & & \\
\hline 02 & & 1 & & 1. & $0 E+00$ & $3 E+00$ & $7 \mathrm{E}+00$ \\
\hline $2 E-02$ & $3.33 E+00$ & -01 & $E-01$ & $1.07 \mathrm{E}$ & & & +00 \\
\hline 2 & & & & $.67 \mathrm{E}+$ & & & $\mathrm{E}+\mathrm{OC}$ \\
\hline & $3.35 \mathrm{E}+00$ & $5 E-U \perp$ & & $1.67 \mathrm{E}+00$ & & $33 E+00$ & . $210+00$ \\
\hline & (1) & $\perp$ & - & 10 & & $33 E+$ & $.56 E+00$ \\
\hline 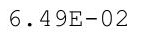 & & & 7 & 1. & 0 & 0 & 00 \\
\hline$E-02$ & $3.32 \mathrm{E}+00$ & $E-01$ & 7. & $1.68 \mathrm{E}+00$ & $2.01 \mathrm{E}+00$ & $2.33 E+00$ & $56 \mathrm{E}+00$ \\
\hline $.53 E-02$ & $3.32 E+00$ & $.68 \mathrm{E}-01$ & 7. $33 \mathrm{E}-01$ & $1.68 \mathrm{E}+00$ & $2.01 E+00$ & $.33 E+00$ & $.56 \mathrm{E}+00$ \\
\hline
\end{tabular}


RESRAD-OFFSITE, Version 2.5

Title : RESRAD-OFFSITE Drinking Water, Plant, Milk, and Meat Pathways for Offsite Reside File : PBA-1_TC99-DOE-5.ROF

Summary of dose at graphical times, reptition 3 (continued)

Time

Years

$9.43 \mathrm{E}+02$

$9.44 \mathrm{E}+02$

$9.44 \mathrm{E}+02$

$9.45 \mathrm{E}+02$

$9.45 \mathrm{E}+02$

$9.46 \mathrm{E}+02$

$9.46 \mathrm{E}+02$

9. $47 \mathrm{E}+02$

$9.47 \mathrm{E}+02$

$9.48 \mathrm{E}+02$

$9.48 \mathrm{E}+02$

$9.49 \mathrm{E}+02$

$9.50 \mathrm{E}+02$

$9.50 \mathrm{E}+02$

$9.51 \mathrm{E}+02$

$9.51 \mathrm{E}+02$

$9.52 \mathrm{E}+02$

9. $52 \mathrm{E}+02$

$9.53 \mathrm{E}+02$

$9.53 \mathrm{E}+02$

$9.54 \mathrm{E}+02$

$9.54 \mathrm{E}+02$

$9.55 \mathrm{E}+02$

$9.55 \mathrm{E}+02$

$9.56 \mathrm{E}+02$

$9.56 \mathrm{E}+02$

$9.57 \mathrm{E}+02$

$9.57 \mathrm{E}+02$

$9.58 \mathrm{E}+02$

$9.58 \mathrm{E}+02$

$9.59 \mathrm{E}+02$

$9.59 \mathrm{E}+02$

$9.60 \mathrm{E}+02$

$9.60 \mathrm{E}+02$

9. $61 \mathrm{E}+02$

9. $61 \mathrm{E}+02$

$9.62 \mathrm{E}+02$

$9.62 \mathrm{E}+02$

9. $63 \mathrm{E}+02$

$9.63 \mathrm{E}+02$

$9.64 \mathrm{E}+02$

$9.64 \mathrm{E}+02$

$9.65 \mathrm{E}+02$

$9.65 \mathrm{E}+02$

$9.66 \mathrm{E}+02$

$9.66 \mathrm{E}+02$
Dose statistics at graphical times, mrem/yr

\begin{tabular}{|c|c|c|c|c|c|c|c|}
\hline inimum & aximum & Mean & ledian & $0 \%$ & $5 \%$ & $97.5 \%$ & \\
\hline 02 & +00 & $3 E-01$ & -01 & $1.68 \mathrm{E}+00$ & $1 \mathrm{E}+00$ & $2.33 E+00$ & $2.56 \mathrm{E}+0$ \\
\hline 2 & -00 & 1 & 1 & 0 & 00 & 00 & 100 \\
\hline 02 & -00 & 01 & -01 & 00 & 00 & 00 & +00 \\
\hline 02 & 00 & & & 0 & & 00 & +00 \\
\hline-02 & -00 & & & 00 & 00 & $E+00$ & $E+00$ \\
\hline $63 E-02$ & $E+00$ & $1 E-01$ & $E-01$ & $1.68 \mathrm{E}+00$ & $E+00$ & $E+00$ & $E+00$ \\
\hline 02 & -00 & $8.72 E-01$ & 1 & 0 & 0 & +00 & +00 \\
\hline$E-02$ & $3.32 E+00$ & $\begin{array}{ll}.1 \\
\end{array}$ & & $1.68 \mathrm{E}+00$ & & +00 & +00 \\
\hline 02 & +00 & 1 & 01 & $8 E+00$ & 00 & +00 & +00 \\
\hline $.71 E-02$ & $3.31 \mathrm{E}+00$ & $4 E-01$ & $E-01$ & $.68 \mathrm{E}+00$ & $00 \mathrm{E}+00$ & $.32 E+00$ & $E+00$ \\
\hline-02 & $E+00$ & 1 & -01 & & & 00 & +00 \\
\hline & +00 & & & & & +00 & +00 \\
\hline $.76 \mathrm{E}-02$ & $3.31 \mathrm{E}+00$ & $\cdot$ & $E-01$ & $1.09 \mathrm{E}+00$ & & $2.32 E+00$ & +0 \\
\hline 02 & -00 & $U_{\perp}$ & 01 & 00 & & +00 & +00 \\
\hline 02 & -00 & $\perp$ & 01 & 00 & & $.32 E+00$ & +00 \\
\hline $.81 E-02$ & $3.31 \mathrm{E}+00$ & 1 & -01 & & $00 \mathrm{E}+00$ & $.32 E+00$ & $\mathrm{E}+00$ \\
\hline $.83 E-02$ & $3.31 \mathrm{E}+00$ & $8 \mathrm{E}-01$ & $8 E-01$ & $1.68 \mathrm{E}+00$ & $00 \mathrm{E}+00$ & $.32 E+00$ & $5 E+00$ \\
\hline-02 & $31 E+00$ & $8 E-01$ & $9 E-01$ & $8 \mathrm{E}+00$ & $00 \mathrm{E}+00$ & $32 E+00$ & $5 \mathrm{E}+\mathrm{OC}$ \\
\hline 02 & $\mathrm{E}+00$ & 1 & 01 & 00 & & +00 & +00 \\
\hline$E-02$ & $3.31 \mathrm{E}+00$ & $9 E-01$ & -01 & 00 & & +00 & +00 \\
\hline $.90 \mathrm{E}-02$ & & & -01 & 0 & & (10 & +00 \\
\hline $.92 \mathrm{E}-02$ & $3.31 \mathrm{E}+00$ & $1 E-01$ & $2 E-01$ & $1.69 \mathrm{E}+00$ & & $.32 E+00$ & $\mathrm{E}+00$ \\
\hline $.94 \mathrm{E}-02$ & $3.31 \mathrm{E}+00$ & $8.81 \mathrm{E}-01$ & $3 E-01$ & $1.69 \mathrm{E}+00$ & $.00 \mathrm{E}+00$ & $32 \mathrm{E}+00$ & $5 \mathrm{E}+00$ \\
\hline $6 \mathrm{E}-02$ & $.30 \mathrm{E}+00$ & $.82 \mathrm{E}-01$ & $4 E-01$ & $1.68 \mathrm{E}+00$ & $00 \mathrm{E}+00$ & $.32 E+00$ & $5 E+0 c$ \\
\hline$E-02$ & $0 \mathrm{E}+00$ & $82 \mathrm{E}-01$ & $5 E-01$ & & & $32 F+00$ & +00 \\
\hline-02 & & & & & & & +00 \\
\hline$E-02$ & $3.30 \mathrm{E}+00$ & & 01 & 土. & & $E+00$ & +00 \\
\hline $.03 E-02$ & . & 8 & $.59 \mathrm{E}-01$ & $1.69 \mathrm{E}+00$ & $2.0 \perp E T U$ & $2.32 \mathrm{E}+00$ & $55 E+00$ \\
\hline 02 & $\mathrm{OE}+$ & 1 & 1 & $69 \mathrm{E}+$ & $.01 E+00$ & $.32 E+00$ & $54 \mathrm{E}+0 \mathrm{C}$ \\
\hline 2 & - & - & 1 & $9 \mathrm{E}+$ & & $.32 \mathrm{E}+0$ & $E+0$ \\
\hline$F-0 ?$ & $3 \cap F+0$ & $86 \mathrm{~F}-01$ & $2 E-01$ & $9 E+00$ & & $2 E+00$ & $\mathrm{E}+00$ \\
\hline-02 & $5+0$ & $E-01$ & & & & & \\
\hline & & & & & & & \\
\hline $.14 \mathrm{E}-02$ & $3.30 \mathrm{E}+00$ & $8.88 E-01$ & $4 E-01$ & $1.69 \mathrm{E}+00$ & $1 E+00$ & $2.31 E+00$ & $2.54 \mathrm{E}+0 \mathrm{C}$ \\
\hline $16 \mathrm{E}-02$ & & $0.00 \mathrm{~L}-U 1$ & $7.65 E-01$ & 1. О्याँ & & Z. OILTU & $2.34 \mathrm{LT}$ \\
\hline & & & & & & & \\
\hline 2 & re & & & 0 & & 0 & 00 \\
\hline 2 & & & & & & & \\
\hline $3 E-02$ & & 1 & -01 & 0 & $1 E+00$ & $2.31 E+00$ & \\
\hline $5 E-02$ & $3.29 \mathrm{E}+00$ & $91 E-01$ & -01 & 0 & & & +00 \\
\hline & & $2 E-01$ & & $.70 \mathrm{E}+$ & & & +0 \\
\hline 2 & $295+00$ & $2 \pm-U \perp$ & 1 & $0 \mathrm{E}+00$ & & $2.31 \mathrm{E}+00$ & $2.35 \mathrm{E}+00$ \\
\hline & (2) & + & 1 & 土. & $00 \mathrm{E}+$ & $2.31 E+00$ & $2.53 \mathrm{E}+0$ \\
\hline 2 & & & - & 0 & $2.00 \mathrm{E}$ & $.30 \mathrm{E}+$ & $53 E$ \\
\hline $34 E-02$ & $3.29 \mathrm{E}+00$ & -01 & -01 & $1.70 \mathrm{E}+00$ & $2.00 \mathrm{E}+00$ & $2.30 \mathrm{E}+00$ & $2.53 E+00$ \\
\hline $.36 E-02$ & $.29 E+00$ & $.94 \mathrm{E}-01$ & $7.74 \mathrm{E}-01$ & $1.70 \mathrm{E}+00$ & $2.00 \mathrm{E}+00$ & $2.30 \mathrm{E}+00$ & $2.53 E+00$ \\
\hline
\end{tabular}


RESRAD-OFFSITE, Version 2.5

Title : RESRAD-OFFSITE Drinking Water, Plant, Milk, and Meat Pathways for Offsite Reside File : PBA-1_TC99-DOE-5.ROF

Summary of dose at graphical times, reptition 3 (continued)

Time

Years

$9.67 \mathrm{E}+02$

$9.67 \mathrm{E}+02$

$9.68 \mathrm{E}+02$

$9.68 \mathrm{E}+02$

$9.69 \mathrm{E}+02$

$9.70 \mathrm{E}+02$

$9.70 \mathrm{E}+02$

$9.71 \mathrm{E}+02$

$9.71 \mathrm{E}+02$

$9.72 \mathrm{E}+02$

$9.72 \mathrm{E}+02$

$9.73 \mathrm{E}+02$

$9.73 \mathrm{E}+02$

$9.74 \mathrm{E}+02$

$9.74 \mathrm{E}+02$

$9.75 \mathrm{E}+02$

$9.75 \mathrm{E}+02$

$9.76 \mathrm{E}+02$

$9.76 \mathrm{E}+02$

$9.77 \mathrm{E}+02$

$9.77 \mathrm{E}+02$

$9.78 \mathrm{E}+02$

$9.78 \mathrm{E}+02$

$9.79 \mathrm{E}+02$

$9.79 \mathrm{E}+02$

$9.80 \mathrm{E}+02$

$9.80 \mathrm{E}+02$

$9.81 \mathrm{E}+02$

9. $81 \mathrm{E}+02$

$9.82 \mathrm{E}+02$

$9.82 \mathrm{E}+02$

$9.83 \mathrm{E}+02$

$9.83 \mathrm{E}+02$

$9.84 \mathrm{E}+02$

$9.84 \mathrm{E}+02$

$9.85 \mathrm{E}+02$

$9.85 \mathrm{E}+02$

$9.86 \mathrm{E}+02$

$9.86 \mathrm{E}+02$

$9.87 \mathrm{E}+02$

$9.87 \mathrm{E}+02$

$9.88 \mathrm{E}+02$

$9.88 \mathrm{E}+02$

$9.89 \mathrm{E}+02$

$9.90 \mathrm{E}+02$

$9.90 \mathrm{E}+02$
Dose statistics at graphical times, mrem/yr

\begin{tabular}{|c|c|c|c|c|c|c|c|}
\hline inimum & aximum & Mean & ledian & $0 \%$ & $5 \%$ & $97.5 \%$ & $3 \%$ \\
\hline 02 & $3.29 \mathrm{E}+00$ & $8.95 E-01$ & $5 E-01$ & $1.70 \mathrm{E}+00$ & $0 \mathrm{E}+00$ & $.30 E+00$ & $53 E+0$ \\
\hline 02 & $\mathrm{E}+00$ & 01 & 1 & $\mathrm{OE}+$ & 00 & 00 & 100 \\
\hline 02 & +00 & -01 & -01 & 00 & 00 & -00 & +00 \\
\hline-02 & 00 & 1 & 1 & 0 & 0 & 00 & +00 \\
\hline $.45 E-02$ & +00 & 01 & 01 & $0 \mathrm{E}+00$ & 00 & $30 \mathrm{E}+00$ & $52 \mathrm{E}+00$ \\
\hline $47 E-02$ & $3 E+00$ & $E-01$ & $E-01$ & $1.70 \mathrm{E}+00$ & $00 \mathrm{E}+00$ & $E+00$ & $52 E+00$ \\
\hline 02 & +00 & $F$ & 1 & $\mathrm{~F}$ & 0 & +00 & $\Xi+00$ \\
\hline $51 E-02$ & $3.28 \mathrm{E}+00$ & 1. & $7.81 \mathrm{E}-01$ & $1.70 \mathrm{E}+00$ & 00 & $.29 \mathrm{E}+00$ & $52 E+0 C$ \\
\hline 02 & +00 & 1 & 01 & $0 E+00$ & 00 & +00 & +00 \\
\hline $.55 E-02$ & $8 \mathrm{E}+00$ & $E-01$ & -01 & $.70 \mathrm{E}+00$ & $01 E+00$ & $29 \mathrm{E}+00$ & $2 \mathrm{E}+00$ \\
\hline-02 & +00 & 1 & -01 & & & 00 & $E+00$ \\
\hline $3 E-02$ & +00 & & & & & +00 & $2 E+0 C$ \\
\hline $.60 \mathrm{E}-02$ & $3.28 \mathrm{E}+00$ & $9.0 \angle \mathrm{E}-01$ & $5-01$ & $1.70 \mathrm{E}+00$ & $2.00 E+00$ & $.29 \mathrm{E}+00$ & $\mathrm{E}+0 \mathrm{C}$ \\
\hline 02 & +00 & $E-01$ & -01 & $1.70 \mathrm{E}+00$ & 00 & +00 & $E+00$ \\
\hline 02 & -00 & $\perp$ & 01 & 00 & 00 & +00 & +00 \\
\hline $.66 \mathrm{E}-02$ & $3.27 \mathrm{E}+00$ & 1 & -01 & $1.70 \mathrm{E}+00$ & $00 \mathrm{E}+00$ & $.29 E+00$ & $1 \mathrm{E}+00$ \\
\hline $.68 \mathrm{E}-02$ & $3.27 \mathrm{E}+00$ & $4 \mathrm{E}-01$ & $E-01$ & 1. $70 \mathrm{E}+00$ & $00 \mathrm{E}+00$ & $.29 \mathrm{E}+00$ & $.51 E+00$ \\
\hline-02 & $7 E+00$ & $4 \mathrm{E}-01$ & $0 E-01$ & $70 E+00$ & $00 \mathrm{E}+00$ & $28 E+00$ & $51 E+00$ \\
\hline 02 & $E+00$ & $E-U 1$ & -01 & 00 & & +00 & +00 \\
\hline $.74 \mathrm{E}-02$ & $3.27 \mathrm{E}+00$ & E-01 & 01 & $.70 \mathrm{E}+00$ & & +00 & $E+O C$ \\
\hline $.76 \mathrm{E}-02$ & .2 & . & -01 & & & 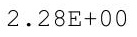 & +00 \\
\hline $.77 \mathrm{E}-02$ & $3.27 \mathrm{E}+00$ & E-01 & 01 & $1.70 \mathrm{E}+00$ & $2.00 \mathrm{E}+00$ & $.28 \mathrm{E}+00$ & $1 \mathrm{E}+00$ \\
\hline $.79 E-02$ & $3.27 \mathrm{E}+00$ & $9.07 \mathrm{E}-01$ & $4 E-01$ & $1.70 \mathrm{E}+00$ & $.00 \mathrm{E}+00$ & $28 \mathrm{E}+00$ & $51 E+00$ \\
\hline $.81 \mathrm{E}-02$ & $3.26 \mathrm{E}+00$ & $.08 \mathrm{E}-01$ & $4 E-01$ & 1. $70 \mathrm{E}+00$ & $00 \mathrm{E}+00$ & $.28 \mathrm{E}+00$ & $50 \mathrm{E}+0 \mathrm{C}$ \\
\hline-02 & $6 \mathrm{E}+00$ & $8 E-01$ & $5 E-01$ & & & $28 \mathrm{E}+00$ & $E+00$ \\
\hline 02 & +00 & 1 & & & & & +00 \\
\hline & & & & & & & +00 \\
\hline $.89 E-02$ & $3.26 \mathrm{E}+00$ & $10 \mathrm{E}-01$ & $.97 \mathrm{E}-01$ & $1.70 \mathrm{E}+00$ & $2.00 \mathrm{ET} 00$ & $.28 \mathrm{E}+00$ & $50 E+00$ \\
\hline 02 & 0 & 1 & 1 & $0 \mathrm{E}+$ & $.00 E+00$ & $.28 E+00$ & $50 \mathrm{E}+0 \mathrm{C}$ \\
\hline 2 & 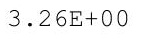 & 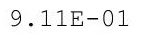 & 1 & OE+ & & $.27 E+00$ & $50 \mathrm{E}+$ \\
\hline$E-02$ & $3.26 \mathrm{E}+00$ & $1 \mathrm{~F}-01$ & $E-01$ & $0 E+00$ & $0 E+00$ & $7 E+00$ & $50 \mathrm{E}+00$ \\
\hline$E-02$ & $\mathrm{~F}+00$ & $2 E-01$ & $E-01$ & $0 \mathrm{E}+00$ & & & \\
\hline 02 & & & & & & 0 & \\
\hline $.00 E-02$ & $3.25 E+00$ & $9.13 \mathrm{E}-01$ & $8.02 \mathrm{E}-01$ & $1.70 \mathrm{E}+00$ & $2.00 \mathrm{E}+00$ & $.27 E+00$ & $.49 \mathrm{E}+00$ \\
\hline $02 E-02$ & & $\cdot 13 D-U \perp$ & $8.02 E-01$ & $1.70 \mathrm{E}+00$ & & $.27 E+00$ & $.495 T U$ \\
\hline 2 & & & & & & & $.49 \mathrm{E}+00$ \\
\hline $.06 \mathrm{E}-02$ & re & & & & & & 00 \\
\hline 2 & & & & & & & \\
\hline 02 & & 1 & -01 & & & $.27 E+00$ & \\
\hline $2 E-02$ & $3.25 \mathrm{E}+00$ & $6 E-01$ & -01 & $71 \mathrm{E}$ & & 00 & $9 \mathrm{E}+00$ \\
\hline$E-02$ & $E+00$ & $E-01$ & 01 & $.71 \mathrm{E}+$ & & & $49 \mathrm{E}+0 \mathrm{C}$ \\
\hline & $3.25 \mathrm{E}+00$ & $E-U 1$ & 01 & 1. $71 \mathrm{E}+00$ & $2.00 \mathrm{E}+00$ & $27 E+00$ & $.49 E+00$ \\
\hline & $3.24 \mathrm{E}$ & $\perp$ & 01 & $\perp \cdot 1 \mathrm{~L}$ & $2.00 \mathrm{E}+$ & $.27 E+00$ & $.49 \mathrm{E}+0$ \\
\hline 2 & 3 & & & 0 & $2.00 \mathrm{E}+00$ & 00 & $49 E+00$ \\
\hline 02 & $3.24 \mathrm{E}+00$ & $E-01$ & 01 & $1.71 \mathrm{E}$ & $2.00 \mathrm{E}+00$ & $2.27 \mathrm{E}+00$ & $2.49 \mathrm{E}+00$ \\
\hline $.24 \mathrm{E}-02$ & $3.24 \mathrm{E}+00$ & $.19 \mathrm{E}-01$ & $.12 \mathrm{E}-01$ & $1.71 \mathrm{E}+00$ & $2.00 \mathrm{E}+00$ & $2.27 \mathrm{E}+00$ & $.48 E+00$ \\
\hline
\end{tabular}


RESRAD-OFFSITE, Version 2.5

Title : RESRAD-OFFSITE Drinking Water, Plant, Milk, and Meat Pathways for Offsite Reside File : PBA-1_TC99-DOE-5.ROF

Summary of dose at graphical times, reptition 3 (continued)

Time

Years

$9.91 \mathrm{E}+02$

$9.91 \mathrm{E}+02$

9. $92 \mathrm{E}+02$

9. $92 \mathrm{E}+02$

$9.93 \mathrm{E}+02$

9. $93 \mathrm{E}+02$

9. $94 \mathrm{E}+02$

9. $94 \mathrm{E}+02$

9. $95 \mathrm{E}+02$

9. $95 \mathrm{E}+02$

9. $96 \mathrm{E}+02$

9. $96 \mathrm{E}+02$

$9.97 \mathrm{E}+02$

9. $97 \mathrm{E}+02$

9. $98 \mathrm{E}+02$

9. $98 \mathrm{E}+02$

9. $99 \mathrm{E}+02$

$9.99 \mathrm{E}+02$

$1.00 \mathrm{E}+03$

$1.00 \mathrm{E}+03$

$1.00 \mathrm{E}+03$

$1.00 \mathrm{E}+03$

$1.00 \mathrm{E}+03$

$1.00 \mathrm{E}+03$

$1.00 \mathrm{E}+03$

$1.00 \mathrm{E}+03$

$1.00 \mathrm{E}+03$

$1.00 \mathrm{E}+03$

$1.00 \mathrm{E}+03$

$1.01 \mathrm{E}+03$

$1.01 \mathrm{E}+03$

$1.01 \mathrm{E}+03$

$1.01 \mathrm{E}+03$

$1.01 \mathrm{E}+03$

$1.01 \mathrm{E}+03$

$1.01 \mathrm{E}+03$

$1.01 E+03$

$1.01 \mathrm{E}+03$

$1.01 \mathrm{E}+03$

$1.01 \mathrm{E}+03$

$1.01 \mathrm{E}+03$

$1.01 \mathrm{E}+03$

$1.01 \mathrm{E}+03$

$1.01 \mathrm{E}+03$

$1.01 \mathrm{E}+03$

$1.01 \mathrm{E}+03$
Dose statistics at graphical times, mrem/yr

\begin{tabular}{|c|c|c|c|c|c|c|c|}
\hline inimum & aximum & Mean & ledian & $90 \%$ & $5 \%$ & $97.5 \%$ & \\
\hline 02 & +00 & $0 E-01$ & $3 E-01$ & $1.71 \mathrm{E}+00$ & $0 E+00$ & $2.27 \mathrm{E}+00$ & $8 \mathrm{E}+0$ \\
\hline 02 & +00 & 01 & 1 & 0 & 00 & $E+00$ & 100 \\
\hline 02 & -00 & 01 & -01 & 00 & 00 & 00 & +00 \\
\hline 02 & 00 & 1 & & 0 & & +00 & +00 \\
\hline-02 & -00 & & & 00 & 00 & $\mathrm{E}+00$ & $48 E+00$ \\
\hline $5 E-02$ & +00 & $2 E-01$ & $E-01$ & $1.71 \mathrm{E}+00$ & $0 \mathrm{E}+00$ & $2.27 \mathrm{E}+00$ & $48 E+00$ \\
\hline 02 & -00 & $9.23 E-01$ & 1 & $1 \mathrm{~F}$ & 0 & +00 & +00 \\
\hline-02 & $3.23 E+00$ & . & & $1.71 \mathrm{E}+00$ & & +00 & +00 \\
\hline 02 & +00 & 01 & 01 & $71 E+00$ & 00 & +00 & +00 \\
\hline $.43 E-02$ & $3.23 E+00$ & $4 E-01$ & $E-01$ & $1.71 \mathrm{E}+00$ & $99 \mathrm{E}+00$ & $.27 E+00$ & $48 \mathrm{E}+00$ \\
\hline-02 & +00 & 1 & -01 & & & 00 & $\Xi+00$ \\
\hline$E-02$ & +00 & $E-01$ & & & & +00 & $\Xi+00$ \\
\hline-02 & $\mathrm{E}+00$ & +01 & $E-01$ & $1 \perp E+U 0$ & 00 & $E+00$ & +0 \\
\hline 02 & +00 & $U_{1}$ & -01 & 00 & 00 & +00 & +0 \\
\hline 02 & -00 & $\perp$ & & 00 & & +00 & +00 \\
\hline $.55 E-02$ & $3.22 \mathrm{E}+00$ & $\perp$ & -01 & $1.71 \mathrm{E}+00$ & $E+00$ & $.27 E+00$ & $.48 \mathrm{E}+00$ \\
\hline$E-02$ & $3.22 \mathrm{E}+00$ & $8 \mathrm{E}-01$ & $5 E-01$ & 1. $71 \mathrm{E}+00$ & $9 E+00$ & $2.27 \mathrm{E}+00$ & $.48 \mathrm{E}+00$ \\
\hline-02 & $22 E+00$ & $8 E-01$ & $5 E-01$ & L. $71 E+00$ & $99 \mathrm{E}+00$ & $.27 E+00$ & $48 E+00$ \\
\hline-02 & +00 & & -01 & 0 & & +00 & +00 \\
\hline 02 & +00 & $\perp$ & 01 & 00 & 00 & +00 & +00 \\
\hline 2 & 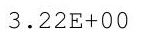 & & 1 & 0 & & 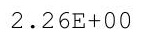 & 00 \\
\hline-02 & $22 \mathrm{~F}+0$ & L & 1 & 17 & 0 & 0 & $E+00$ \\
\hline 02 & $.21 \mathrm{E}+00$ & 1 & $E-01$ & $.72 E+00$ & $.99 E+00$ & $.26 E+00$ & $48 E+00$ \\
\hline$E-02$ & $3.21 \mathrm{E}+00$ & $.31 \mathrm{E}-01$ & $30 E-01$ & 1. $72 \mathrm{E}+00$ & $99 \mathrm{E}+00$ & $.26 E+00$ & $.48 \mathrm{E}+0 \mathrm{C}$ \\
\hline$E-02$ & $.21 \mathrm{E}+00$ & $32 E-01$ & $1 E-01$ & 0 & & $26 F+00$ & $48 E+00$ \\
\hline & & & & & & & \\
\hline & & & & $1.72 \mathrm{E}$ & & $6 \mathrm{E}+00$ & +00 \\
\hline $.79 E-02$ & $3.21 \mathrm{E}+00$ & $33 E-01$ & $33 E-01$ & $1.72 \mathrm{E}+00$ & 1. . & $2.26 \mathrm{E}+00$ & $.48 \mathrm{E}+00$ \\
\hline 02 & $21 \mathrm{E}+$ & 1 & $34 E-01$ & $72 \mathrm{E}+00$ & $.00 \mathrm{E}+00$ & $.26 E+00$ & $.48 \mathrm{E}+0 \mathrm{C}$ \\
\hline 2 & - & - & 1 & $72 \mathrm{E}+$ & & $.26 \mathrm{E}+0$ & $48 \mathrm{E}+$ \\
\hline-02 & $3.20 \mathrm{E}+00$ & $5 F-01$ & $6 E-01$ & $72 \mathrm{E}+00$ & $0 \mathrm{E}+00$ & $26 \mathrm{~F}+00$ & $48 E+00$ \\
\hline 02 & & & & & & & \\
\hline-02 & & & 01 & & & 2.2 & \\
\hline $.92 E-02$ & $3.20 \mathrm{E}+00$ & $.36 \mathrm{E}-01$ & $8.38 E-01$ & $1.72 \mathrm{E}+00$ & $2.00 E+00$ & $2.26 \mathrm{E}+00$ & $2.48 E+00$ \\
\hline $94 \mathrm{E}-02$ & & & $8.38 E-01$ & 1.TСЕТО & & & $2.48 E+0$ \\
\hline 2 & & & & & & & \\
\hline 2 & $3.20 \mathrm{E}+00$ & & & 0 & & 0 & ק תمי \\
\hline 2 & & & & & & & \\
\hline 02 & & 1 & $41 E-01$ & $172 \mathrm{~F}$ & $0 E+00$ & $2.26 \mathrm{E}+00$ & $.48 E+00$ \\
\hline$E-02$ & $3.19 \mathrm{E}+00$ & $39 E-01$ & 01 & 0 & & 0 & +00 \\
\hline 02 & & 1 & & 0 & & & $2.47 \mathrm{E}+00$ \\
\hline & $3 .+9 E+U 0$ & $\perp$ & & $72 \mathrm{E}+00$ & & $2.26 \mathrm{E}+00$ & $2.47 \mathrm{E}+00$ \\
\hline 2 & ter & $\perp$ & 1 & 土. & $00 \mathrm{E}+$ & $2.25 \mathrm{E}+00$ & $2.47 \mathrm{E}+0$ \\
\hline 2 & 3 & & & 0 & $2.00 \mathrm{E}+$ & $2.25 E+$ & $2.47 \mathrm{E}+00$ \\
\hline 02 & $3.19 \mathrm{E}+00$ & -01 & $E-01$ & $1.72 \mathrm{E}$ & $2.00 \mathrm{E}+00$ & $2.25 \mathrm{E}+00$ & $2.47 \mathrm{E}+00$ \\
\hline $.16 \mathrm{E}-02$ & $3.19 E+00$ & $.42 \mathrm{E}-01$ & $.47 E-01$ & $1.72 \mathrm{E}+00$ & $2.00 \mathrm{E}+00$ & $2.25 \mathrm{E}+00$ & $2.47 \mathrm{E}+00$ \\
\hline
\end{tabular}


RESRAD-OFFSITE, Version 2.5

Title : RESRAD-OFFSITE Drinking Water, Plant, Milk, and Meat Pathways for Offsite Reside File : PBA-1_TC99-DOE-5.ROF

Summary of dose at graphical times, reptition 3 (continued)

Time

Years

$1.01 \mathrm{E}+03$

1. $01 \mathrm{E}+03$

$1.02 \mathrm{E}+03$

1. $02 \mathrm{E}+03$

1. $02 \mathrm{E}+03$

1. $02 \mathrm{E}+03$

1. $02 \mathrm{E}+03$

1. $02 \mathrm{E}+03$

1. $02 \mathrm{E}+03$

1. $02 \mathrm{E}+03$

1. $02 \mathrm{E}+03$

1. $02 \mathrm{E}+03$

1. $02 \mathrm{E}+03$

1. $02 \mathrm{E}+03$

1. $02 \mathrm{E}+03$

1. $02 \mathrm{E}+03$

1. $02 \mathrm{E}+03$

$1.02 \mathrm{E}+03$

1. $02 \mathrm{E}+03$

$1.02 \mathrm{E}+03$

1. $02 \mathrm{E}+03$

1. $02 \mathrm{E}+03$

1. $03 \mathrm{E}+03$

$1.03 \mathrm{E}+03$

$1.03 \mathrm{E}+03$

$1.03 \mathrm{E}+03$

$1.03 E+03$

$1.03 E+03$

$1.03 \mathrm{E}+03$

$1.03 \mathrm{E}+03$

$1.03 \mathrm{E}+03$

$1.03 \mathrm{E}+03$

$1.03 \mathrm{E}+03$

$1.03 \mathrm{E}+03$

$1.03 \mathrm{E}+03$

$1.03 \mathrm{E}+03$

$1.03 E+03$

$1.03 E+03$

$1.03 E+03$

$1.03 E+03$

$1.03 \mathrm{E}+03$

$1.04 \mathrm{E}+03$

1. $04 \mathrm{E}+03$

$1.04 \mathrm{E}+03$

1. $04 \mathrm{E}+03$

$1.04 \mathrm{E}+03$
Dose statistics at graphical times, mrem/yr

\begin{tabular}{|c|c|c|c|c|c|c|c|}
\hline inimum & aximum & Mean & ledian & $0 \%$ & $5 \%$ & $97.5 \%$ & $3 \%$ \\
\hline-02 & $E+00$ & $2 \mathrm{E}-01$ & $8.47 E-01$ & $1.72 \mathrm{E}+00$ & $2.00 \mathrm{E}+00$ & $.25 E+00$ & $.47 E+0$ \\
\hline 02 & +00 & 1 & $3 E-01$ & $72 \mathrm{E}+$ & $0 E+00$ & +00 & $47 E+00$ \\
\hline 02 & +00 & -01 & $E-01$ & $2 E+00$ & 00 & +00 & $\mathrm{E}+00$ \\
\hline 02 & 00 & 1 & 1 & 0 & 0 & +00 & +00 \\
\hline-02 & 00 & & 01 & 0 & 00 & +00 & $47 E+00$ \\
\hline-02 & +00 & -01 & $E-01$ & $1.72 \mathrm{E}+00$ & $0 \mathrm{E}+00$ & $E+00$ & $.47 \mathrm{E}+00$ \\
\hline 02 & +00 & $E-01$ & $2 E-01$ & $.72 \mathrm{E}$ & 00 & +00 & $7 \mathrm{E}+0 \mathrm{C}$ \\
\hline $2 E-02$ & $3.17 \mathrm{E}+00$ & & $8.53 E-01$ & $1.72 \mathrm{E}+00$ & $2.00 \mathrm{E}+00$ & +00 & $.47 \mathrm{E}+0 \mathrm{C}$ \\
\hline 02 & +00 & 1 & 01 & $72 E+00$ & 00 & +00 & $E+00$ \\
\hline $.37 E-02$ & $3.17 \mathrm{E}+00$ & $6 E-01$ & $E-01$ & L. $72 \mathrm{E}+00$ & $00 \mathrm{E}+00$ & $24 \mathrm{E}+00$ & $47 E+00$ \\
\hline-02 & +00 & 1 & -01 & 0 & & 00 & $\mathrm{E}+00$ \\
\hline & -00 & & & & & +00 & $\mathrm{E}+\mathrm{OC}$ \\
\hline $3 E-02$ & $3.17 \mathrm{E}+00$ & $9.48 \mathrm{E}-01$ & $E-01$ & 1. $72 \mathrm{E}+00$ & 00 & +00 & $\mathrm{E}+0 \mathrm{C}$ \\
\hline-02 & +00 & 至 & -01 & $1.73 E+00$ & 00 & +00 & $.47 E+00$ \\
\hline 02 & $E+00$ & 01 & 01 & 00 & 00 & +00 & $\mathrm{E}+00$ \\
\hline$E-02$ & $3.16 \mathrm{E}+00$ & 1 & -01 & $1.73 \mathrm{E}+00$ & $00 \mathrm{E}+00$ & $.24 \mathrm{E}+00$ & $.47 \mathrm{E}+00$ \\
\hline $.51 \mathrm{E}-02$ & $3.16 \mathrm{E}+00$ & $E-01$ & $9 E-01$ & $1.73 \mathrm{E}+00$ & $00 \mathrm{E}+00$ & $.24 \mathrm{E}+00$ & $.47 \mathrm{E}+00$ \\
\hline-02 & $.16 \mathrm{E}+00$ & $0 E-01$ & $0 E-01$ & $73 E+00$ & $00 \mathrm{E}+00$ & $.24 E+00$ & $47 E+00$ \\
\hline$E-02$ & $3.16 \mathrm{E}+00$ & $0 E-01$ & $E-01$ & $73 E+00$ & & $E+00$ & $47 \mathrm{E}+00$ \\
\hline$E-02$ & +00 & -01 & -01 & $1.70 \mathrm{C}$ & & +00 & $46 E+00$ \\
\hline $9 E-02$ & 年 & $1 E-01$ & -01 & & & 100 & +00 \\
\hline$E-02$ & $3.15 \mathrm{E}+00$ & $2 E-01$ & $E-01$ & $1.73 E+00$ & & $.24 \mathrm{E}+00$ & $46 \mathrm{E}+00$ \\
\hline $64 \mathrm{E}-02$ & $3.15 \mathrm{E}+00$ & $9.52 \mathrm{E}-01$ & $8.63 E-01$ & $1.73 E+00$ & $00 \mathrm{E}+00$ & $.24 \mathrm{E}+00$ & $.46 \mathrm{E}+00$ \\
\hline$E-02$ & $3.15 \mathrm{E}+00$ & $.53 E-01$ & $53 E-01$ & $1.73 \mathrm{E}+00$ & $00 \mathrm{E}+00$ & $.24 \mathrm{E}+00$ & $.46 \mathrm{E}+0 \mathrm{C}$ \\
\hline 02 & $E+00$ & $3 E-01$ & 01 & & & $E+00$ & $\mathrm{E}+\mathrm{OC}$ \\
\hline$E-02$ & & 01 & & & & & +00 \\
\hline $72 \mathrm{E}-02$ & $3.15 \mathrm{E}+00$ & $9.54 \mathrm{E}-01$ & -01 & $1.13 E+00$ & & +00 & $.46 \mathrm{E}+00$ \\
\hline $.74 \mathrm{E}-02$ & $3.15 \mathrm{E}+00$ & $9.54 \mathrm{E}-01$ & $8.65 E-01$ & $1.73 E+00$ & $2.00 \mathrm{E}+00$ & $.24 \mathrm{E}+00$ & $.46 \mathrm{E}+00$ \\
\hline 02 & 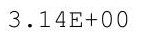 & 1 & 年 & $73 \mathrm{E}+$ & $.00 \mathrm{E}+00$ & $.24 \mathrm{E}+00$ & $46 E+0 c$ \\
\hline $.78 \mathrm{E}-02$ & . & $.55 E-01$ & $8.67 \mathrm{E}-01$ & $73 \mathrm{E}+$ & & $.24 \mathrm{E}+00$ & $.46 \mathrm{E}+0$ \\
\hline 02 & $3.14 \mathrm{E}+00$ & $5 E-01$ & $7 E-01$ & $73 E+00$ & $0 \mathrm{E}+00$ & $.24 E+00$ & $46 E+00$ \\
\hline 02 & $\mathrm{E}+00$ & $E-01$ & & & & & $\mathrm{E}+00$ \\
\hline$E-02$ & $3.14 \mathrm{E}+00$ & $E-01$ & $E-01$ & $3 E+00$ & 00 & $E+00$ & $.46 \mathrm{E}+00$ \\
\hline $.87 \mathrm{E}-02$ & $3.14 \mathrm{E}+00$ & $7 E-01$ & $9 E-01$ & $1.73 E+00$ & $2.00 \pm+00$ & $.23 E+00$ & $.46 E+00$ \\
\hline $89 E-02$ & 3.14 ЕT U & $.57 E-01$ & $8.70 E-01$ & I. IOETU & & & $.46 E+0 c$ \\
\hline 2 & & & & & & & \\
\hline $035-0 ?$ & re & & 1 & 0 & & 0 & 65 \\
\hline 2 & & & & & & & \\
\hline 2 & & 1 & & & & $.23 E+00$ & $46 E+00$ \\
\hline $9 E-02$ & $3.13 \mathrm{E}+00$ & $E-01$ & -01 & 0 & & 0 & $.46 \mathrm{E}+00$ \\
\hline 1 & & $.60 \mathrm{E}-01$ & & $1.73 E+00$ & & & $.46 \mathrm{E}+0 \mathrm{C}$ \\
\hline & $3.13 E+00$ & 1 & & $73 E+00$ & & $23 E+00$ & $.45 E+U 0$ \\
\hline & $3.12 \mathrm{E}+00$ & 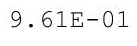 & 01 & $1.73 \mathrm{E}$ & OOE+ & $2.23 \mathrm{E}+$ & $.45 E+0 c$ \\
\hline$\perp$ & 3 & & 1 & 1 & $2.00 \mathrm{E}$ & $23 E+$ & 00 \\
\hline 01 & $3.12 \mathrm{E}+00$ & -01 & 8 & $1.73 E+00$ & $2.00 \mathrm{E}+00$ & $2.23 \mathrm{E}+00$ & $2.45 \mathrm{E}+00$ \\
\hline $.01 E-01$ & $3.12 \mathrm{E}+00$ & $.62 E-01$ & $.78 E-01$ & $1.73 E+00$ & $2.00 \mathrm{E}+00$ & $2.22 E+00$ & $2.45 \mathrm{E}+00$ \\
\hline
\end{tabular}


RESRAD-OFFSITE, Version 2.5

$T^{1 / 2}$ Limit $=180$ days

robabilistic Dose and Risk Report

Title : RESRAD-OFFSITE Drinking Water, Plant, Milk, and Meat Pathways for Offsite Reside

File : PBA-1_TC99-DOE-5.ROF

Time

Years

1. $04 \mathrm{E}+03$

1. $04 \mathrm{E}+03$

$1.04 \mathrm{E}+03$

$1.04 \mathrm{E}+03$

1. $04 \mathrm{E}+03$

1. $04 \mathrm{E}+03$

1. $04 \mathrm{E}+03$

1. $04 \mathrm{E}+03$

1. $04 \mathrm{E}+03$

1. $04 \mathrm{E}+03$

1. $04 \mathrm{E}+03$

1. $04 \mathrm{E}+03$

1. $04 \mathrm{E}+03$

1. $04 \mathrm{E}+03$

1. $04 \mathrm{E}+03$

1. $05 \mathrm{E}+03$

1. $05 \mathrm{E}+03$

1. $05 \mathrm{E}+03$

1. $05 \mathrm{E}+03$

1. $05 \mathrm{E}+03$

1. $05 \mathrm{E}+03$

1. $05 \mathrm{E}+03$

1. $05 \mathrm{E}+03$

$1.05 \mathrm{E}+03$

$1.05 \mathrm{E}+03$
Summary of dose at graphical times, reptition 3 (continued)

Dose statistics at graphical times, mrem/yr

\begin{tabular}{|c|c|c|c|c|c|c|c|}
\hline m & num & ean & ed & & & & $9 \%$ \\
\hline 01 & +00 & $3 E-01$ & $8.78 E-01$ & 1. $73 \mathrm{E}+00$ & $2.00 \mathrm{E}+00$ & $.22 \mathrm{E}+00$ & $.45 E+00$ \\
\hline $.02 E-01$ & $E+00$ & $3 E-01$ & $8.79 E-01$ & $1.73 \mathrm{E}+00$ & $2.00 \mathrm{E}+00$ & $2.22 \mathrm{E}+00$ & $45 E+00$ \\
\hline OF & $12 \mathrm{~F}+00$ & $E-01$ & $805-$ & $73 E+00$ & $0 \cap F+00$ & $.22 \mathrm{E}+00$ & $5 E+0 C$ \\
\hline & $3.11 \mathrm{E}+00$ & & & & & 00 & +00 \\
\hline $.02 E-01$ & $E+00$ & $E-01$ & 1 & $2 \mathrm{E}+00$ & 0 & & +00 \\
\hline$E-01$ & & $E-01$ & -01 & $.72 E+00$ & 0 & 0 & +00 \\
\hline $.03 E-01$ & 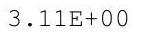 & $9.65 E-01$ & $8.83 E-01$ & 1. $72 \mathrm{E}+00$ & $2.00 \mathrm{E}+00$ & $.21 E+00$ & $.45 E+00$ \\
\hline 01 & $.11 E+00$ & $5 E-01$ & $3 E-01$ & $1.72 \mathrm{E}+00$ & $00 \mathrm{E}+00$ & $21 E+00$ & $5 E+00$ \\
\hline 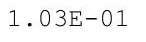 & & 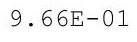 & & 0 & & 0 & +00 \\
\hline$\perp$ & & & 1 & ter & 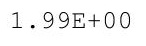 & 0 & +00 \\
\hline C & & & & & & 0 & 00 \\
\hline$F_{-}$ & $.10 \mathrm{E}+0$ & 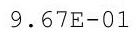 & 1 & $1.72 \mathrm{E}+00$ & & $.21 E+00$ & $5 E+00$ \\
\hline $5=0$ & $.10 \mathrm{E}+0$ & $.67 E-01$ & $.88 E-01$ & $1.72 \mathrm{E}+00$ & $1.99 \mathrm{E}+00$ & $.21 \mathrm{E}+00$ & $.45 E+00$ \\
\hline $.04 \mathrm{E}-01$ & $3.10 \mathrm{E}+00$ & $.68 \mathrm{E}-01$ & $8.88 E-01$ & $1.72 \mathrm{E}+00$ & $1.99 \mathrm{E}+00$ & $.21 E+00$ & $.45 E+00$ \\
\hline $5-01-1-1-1$ & $3.10 \mathrm{E}+00$ & $8 E-01$ & & $1.72 \mathrm{E}+00$ & & $.21 E+00$ & $45 E+00$ \\
\hline 1 & & & & & & & \\
\hline & & & & & & & \\
\hline $.05 E-01$ & $3.09 E+00$ & $9.70 \mathrm{E}-01$ & $8.91 E-01$ & 1. $72 \mathrm{E}+00$ & $1.99 \mathrm{E}+00$ & $2.20 \mathrm{E}+00$ & $.45 E+00$ \\
\hline . & $3.09 E+00$ & . & $8.91 E-01$ & $1.72 E+00$ & $1.99 \mathrm{E}+00$ & $2.20 E+00$ & $.45 E+00$ \\
\hline .0 & $3.09 \mathrm{E}+00$ & • $1 U L U 1$ & & 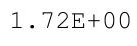 & $1.99 \mathrm{E}+00$ & $2.20 \mathrm{E}+00$ & $.45 E+00$ \\
\hline 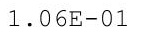 & $3.09 \mathrm{E}+0$ & - & 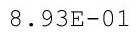 & $72 \mathrm{E}+00$ & $1.99 \mathrm{E}+00$ & $2.20 \mathrm{E}+00$ & $.45 E+00$ \\
\hline ( & $3.09 \mathrm{E}+\mathrm{C}$ & & & & & $2.20 \mathrm{E}+00$ & $2.45 \mathrm{E}+00$ \\
\hline $06 \mathrm{E}-01$ & $3.08 \mathrm{E}+00$ & & $8.95 E-01$ & $1.72 \mathrm{E}+00$ & $1.99 \mathrm{E}+00$ & $2.20 \mathrm{E}+00$ & $2.45 \mathrm{E}+00$ \\
\hline $.06 \mathrm{E}-01$ & $3.08 \mathrm{E}+00$ & $.72 E-01$ & $8.95 E-01$ & $1.72 \mathrm{E}+00$ & $1.99 \mathrm{E}+00$ & $2.20 E+00$ & $2.45 \mathrm{E}+00$ \\
\hline $06 \mathrm{E}-01$ & $3.08 \mathrm{E}+00$ & $9.72 E-01$ & $5 E-01$ & $.72 \mathrm{E}+00$ & +00 & $2.20 \mathrm{E}+00$ & $2.45 \mathrm{E}+00$ \\
\hline
\end{tabular}


$\mathrm{T}^{1 / 2}$ Limit $=180$ days $\quad 07 / 17 / 2011 \quad 20: 19 \quad$ Page 188

Probabilistic Dose and Risk Report

Title : RESRAD-OFFSITE Drinking Water, Plant, Milk, and Meat Pathways for Offsite Reside File : PBA-1_TC99-DOE-5.ROF

Repetition

1

2

3

$\begin{array}{cc}\begin{array}{c}\text { Peak of the mean dose } \\ \text { Time of peak mean dose } \\ \text { Years }\end{array} & \begin{array}{c}\text { Peak mean dose } \\ \text { mrem/yr }\end{array} \\ 1.050 \mathrm{E}+03 & 9.762 \mathrm{E}-01 \\ 1.050 \mathrm{E}+03 & 9.754 \mathrm{E}-01 \\ 1.050 \mathrm{E}+03 & 9.719 \mathrm{E}-01\end{array}$


RESRAD-OFFSITE Regression and Correlation output 07/18/11 00:37 Page: Coef 1
Title : RESRAD-OFFSITE Drinking Water, Plant, Milk, and Meat Pathways for Offsite Reside

File : PBA-1_TC99-DOE-5.ROF

Coefficients for peak All Pathways Dose

Coefficient $=$
Repetition $=$

Description of Probabilistic Variable

\footnotetext{
-R-SQUARE varies between 0 and 1 and is called the coefficient of determination; it provides a measure of the variation in the dependent variable (Dose) explained by regression on the independent variables.

-Sig is set to zero if the dose or risk is zero or the correlation matrix is singular.
}

Sig Coeff Sig Coeff Sig Coeff Sig Coeff Sig Co

Kd of Tc-99 in Contaminated Zone

$2-0.86$

Total porosity of saturated zone

$5-0.02$

$2-0.87$

$2-0.86$

$2-0.61$

50.02

60.01

$5-0.02$

$6 \quad 0.02$

$6-0.02$

$5-0.02$

60.01

Hydraulic Conductivity of saturated zone

$3-0.67$

$3-0.66$

$3-0.66$

$3-0.33$

40.24

40.25

40.26

40.09

Effective Porosity of Unsaturated zone 5

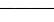

$1-0.88$

$1-0.87$

$1-0.61$

0.87

0.88

0.87

0.87 
RESRAD-OFFSITE, Version 2.5

$\mathrm{T}^{1 / 2}$ Limit $=180$ days

Probabilistic Dose and Risk Report

Title : RESRAD-OFFSITE External Gamma, Inhalation, and Soil Ingestion for Offsite Reside File : PBA-1_TC99-DOE-5-1.ROF

Table of Contents

Part V: Uncertainty Analysis

RESRAD Uncertainty Analysis Results

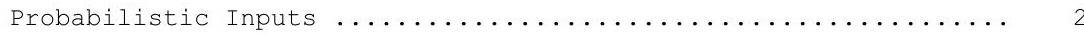

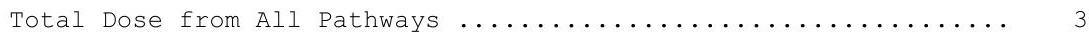

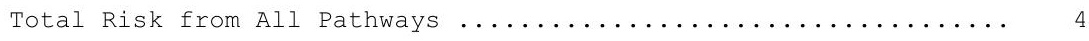

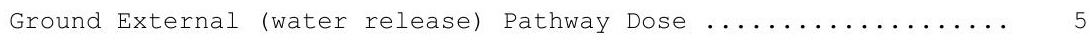

Fish Ingestion (water release) Pathway Dose $\ldots \ldots \ldots \ldots \ldots \ldots \ldots .6$

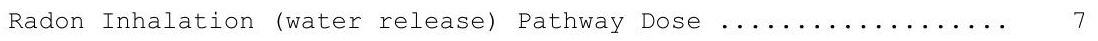

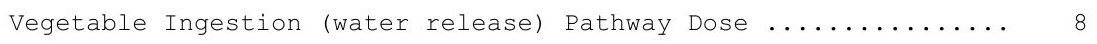

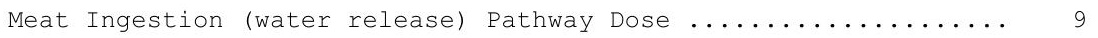

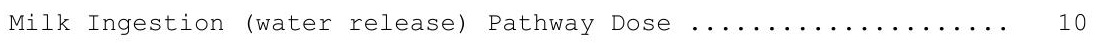

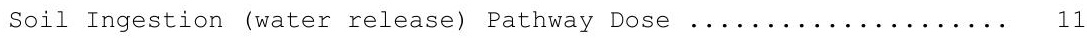

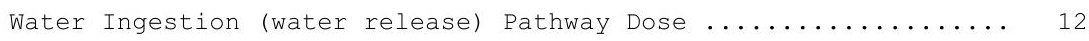

Ground External (direct \& air release) Pathway Dose ........... 13

Inhalation (w/o Radon) (direct \& air) Pathway Dose ............ 14

Radon Inhalation (direct \& air release) Pathway Dose .................. 15

Vegetable Ingestion (direct \& air release) Pathway Dose ........... 16

Meat Ingestion (direct \& air release) Pathway Dose .................... 17

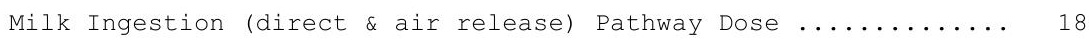

Soil Ingestion (direct \& air release) Pathway Dose ............ 19

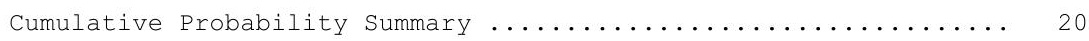

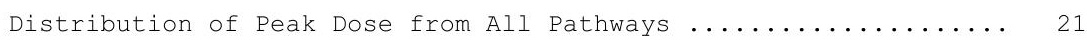

Distribution of Peak Dose from External Ground(Wreleas) ....... 22

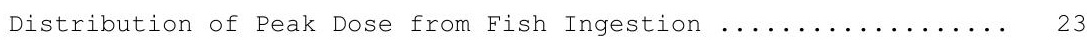

Distribution of Peak Dose from Radon (Waterrelease) ......... 24

Distribution of Peak Dose from Plant (Waterrelease) .......... 25

Distribution of Peak Dose from Meat (Waterrelease) .......... 26

Distribution of Peak Dose from Milk (Waterrelease) .......... 27

Distribution of Peak Dose from Soil Ingestion(Wrelease) ....... 28

Distribution of Peak Dose from Water Ingestion ............. 29

Distribution of Peak Dose from External Ground(CZ\&Air) ........ 30

Distribution of Peak Dose from Inhalation ExcludingRn ......... 31

Distribution of Peak Dose from Radon (CZandAir) ............ 32

Distribution of Peak Dose from Plant (CzandAir) ............. 33

Distribution of Peak Dose from Meat (CZandAir) ............. 34

Distribution of Peak Dose from Milk (CzandAir) $\ldots \ldots \ldots \ldots \ldots \ldots . . \ldots \ldots$

Distribution of Peak Dose from Soil Ingestion(CZandAir) ....... 36

Distribution of Peak Risk from All Pathways ................. 37

Distribution of Peak Risk from External Ground(Wreleas) ....... 38

Distribution of Peak Risk from Fish Ingestion ............. 39

Distribution of Peak Risk from Radon (Waterrelease) ......... 40

Distribution of Peak Risk from Plant (Waterrelease) .......... 41

Distribution of Peak Risk from Meat (Waterrelease) .......... 42

Distribution of Peak Risk from Milk (Waterrelease) ........... 43

Distribution of Peak Risk from Soil Ingestion(Wrelease) ....... 44

Distribution of Peak Risk from water Ingestion ............. 45

Distribution of Peak Risk from External Ground(CZ\&Air) . ...... 46

Distribution of Peak Risk from Inhalation ExcludingRn ........ 47

Distribution of Peak Risk from Radon (CZandAir) ............. 48

Distribution of Peak Risk from Plant (CzandAir) .............. 49

Distribution of Peak Risk from Meat (CZandAir) ............. 50

Distribution of Peak Risk from Milk (CzandAir) ............. 51

Distribution of Peak Risk from Soil Ingestion(CZandAir) ........ 52 
Peak of the mean dose at graphical times $\ldots \ldots \ldots \ldots \ldots \ldots \ldots \ldots 188$ 

RESRAD-OFFSITE, Version 2.5

Probabilistic Dose and Risk Report

Title : RESRAD-OFFSITE External Gamma, Inhalation, and Soil Ingestion for offsite Reside File : PBA-1_TC99-DOE-5-1.ROF

Probabilistic Inputs

Number of Sample Runs: 6000

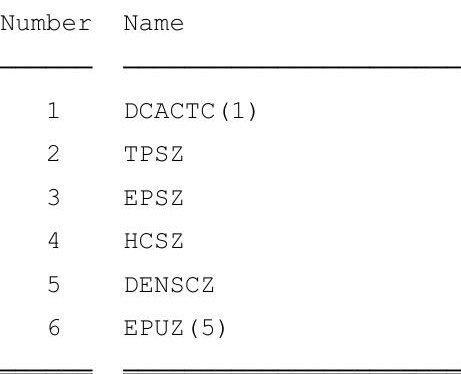

\begin{tabular}{lllll} 
Distribution & & \multicolumn{3}{l}{ Parameters } \\
\cline { 1 - 1 } TRIANGULAR & & .1 & 1 & 10 \\
TRIANGULAR & .27 & .39 & .54 \\
TRIANGULAR & .22 & .3 & .35 \\
TRIANGULAR & 27034 & 38938 & 67642 \\
TRIANGULAR & 1.5 & 1.85 & 2.5 \\
TRIANGULAR & .1 & .25 & .4 \\
\hline \hline
\end{tabular}


RESRAD-OFFSITE, Version 2.5

Probabilistic Dose and Risk Report

Title : RESRAD-OFFSITE External Gamma, Inhalation, and Soil Ingestion for offsite Reside File : PBA-1_TC99-DOE-5-1.ROF

\begin{tabular}{|c|c|c|c|c|c|c|c|c|c|}
\hline Nuclide & Peak & Peak & & & & $\operatorname{DOSE}(j, t)$, & mrem/yr & & \\
\hline (j) & Time & Dose & $t=$ & $0.00 \mathrm{E}+00$ & $1.00 \mathrm{E}+00$ & $5.00 \mathrm{E}+01$ & $1.00 \mathrm{E}+02$ & $5.00 E+02$ & $1.03 E+03$ \\
\hline \multicolumn{10}{|l|}{ TC-99 } \\
\hline Min & $5.83 E+02$ & $1.79 \mathrm{E}-07$ & & 1. $45 E-32$ & 1. $42 E-32$ & $4.91 E-33$ & $1.66 \mathrm{E}-33$ & $6.54 \mathrm{E}-10$ & $1.63 \mathrm{E}-07$ \\
\hline Max & $1.05 E+03$ & $9.61 \mathrm{E}-06$ & & 1. $48 E-32$ & 1. $51 \mathrm{E}-32$ & $3.50 \mathrm{E}-32$ & $8.27 E-32$ & $7.88 \mathrm{E}-06$ & $5.78 \mathrm{E}-06$ \\
\hline Avg & $1.03 E+03$ & $1.69 \mathrm{E}-06$ & & 1. $48 E-32$ & $1.50 E-32$ & $3.19 \mathrm{E}-32$ & $6.96 E-32$ & $2.62 E-07$ & $1.61 \mathrm{E}-06$ \\
\hline Std & $6.08 \mathrm{E}+01$ & $1.01 \mathrm{E}-06$ & & $0.00 \mathrm{E}+00$ & $0.00 \mathrm{E}+00$ & $0.00 \mathrm{E}+00$ & $0.00 \mathrm{E}+00$ & $5.17 \mathrm{E}-07$ & $9.17 \mathrm{E}-07$ \\
\hline \multicolumn{10}{|l|}{$\sum A L L$} \\
\hline Min & $5.83 E+02$ & $1.79 \mathrm{E}-07$ & & $1.45 E-32$ & 1. $42 \mathrm{E}-32$ & $4.91 E-33$ & $1.66 \mathrm{E}-33$ & $6.54 \mathrm{E}-10$ & $1.63 E-07$ \\
\hline $\operatorname{Max}$ & $1.05 \mathrm{E}+03$ & $9.61 E-06$ & & 1. $48 E-32$ & $1.51 E-32$ & $3.50 \mathrm{E}-32$ & $8.27 E-32$ & $7.88 E-06$ & $5.78 \mathrm{E}-06$ \\
\hline Avg & $1.03 E+03$ & $1.69 \mathrm{E}-06$ & & $1.48 E-32$ & $1.50 \mathrm{E}-32$ & $3.19 \mathrm{E}-32$ & $6.96 \mathrm{E}-32$ & $2.62 \mathrm{E}-07$ & $1.61 \mathrm{E}-06$ \\
\hline Std & $6.08 \mathrm{E}+01$ & $1.01 E-06$ & & $0.00 \mathrm{E}+00$ & $0.00 \mathrm{E}+00$ & $0.00 \mathrm{E}+00$ & $0.00 \mathrm{E}+00$ & $5.17 \mathrm{E}-07$ & $9.17 \mathrm{E}-07$ \\
\hline
\end{tabular}

¿ALL is total dose summed for all nuclides. 
RESRAD-OFFSITE, Version 2.5

Probabilistic Dose and Risk Report

Title : RESRAD-OFFSITE External Gamma, Inhalation, and Soil Ingestion for offsite Reside File : PBA-1_TC99-DOE-5-1.ROF

Probabilistic Total Risk Summary

\begin{tabular}{|c|c|c|c|c|c|c|c|}
\hline \multirow{2}{*}{$\begin{array}{l}\text { Nuclide } \\
\text { (j) }\end{array}$} & \multicolumn{7}{|c|}{$\operatorname{RISK}(j, t)$} \\
\hline & $t=$ & $0.00 \mathrm{E}+00$ & $1.00 \mathrm{E}+00$ & $5.00 \mathrm{E}+01$ & $1.00 \mathrm{E}+02$ & $5.00 \mathrm{E}+02$ & $1.03 E+03$ \\
\hline \multicolumn{8}{|l|}{ TC-99 } \\
\hline Min & & $2.06 \mathrm{E}-37$ & $2.02 \mathrm{E}-37$ & $6.95 E-38$ & $2.35 E-38$ & $2.50 \mathrm{E}-14$ & 4. $83 E-12$ \\
\hline $\operatorname{Max}$ & & $3.27 E-37$ & $3.33 E-37$ & $7.73 E-37$ & 1. $40 \mathrm{E}-19$ & $2.32 E-10$ & $1.61 \mathrm{E}-10$ \\
\hline Avg & & $3.19 \mathrm{E}-37$ & $3.24 \mathrm{E}-37$ & $6.91 E-37$ & $3.71 \mathrm{E}-23$ & $8.17 \mathrm{E}-12$ & 4. $61 \mathrm{E}-11$ \\
\hline Std & & $0.00 \mathrm{E}+00$ & $0.00 \mathrm{E}+00$ & $0.00 \mathrm{E}+00$ & 1. $92 \mathrm{E}-21$ & $1.55 \mathrm{E}-11$ & $2.57 \mathrm{E}-11$ \\
\hline \multicolumn{8}{|l|}{$\sum A L L$} \\
\hline Min & & $2.06 \mathrm{E}-37$ & $2.02 E-37$ & $6.95 E-38$ & $2.35 E-38$ & $2.50 E-14$ & $4.83 E-12$ \\
\hline $\operatorname{Max}$ & & $3.27 E-37$ & $3.33 E-37$ & $7.73 E-37$ & 1. $40 \mathrm{E}-19$ & $2.32 E-10$ & $1.61 \mathrm{E}-10$ \\
\hline Avg & & $3.19 \mathrm{E}-37$ & $3.24 \mathrm{E}-37$ & $6.91 \mathrm{E}-37$ & $3.71 \mathrm{E}-23$ & $8.17 \mathrm{E}-12$ & 4. $61 \mathrm{E}-11$ \\
\hline Std & & $0.00 \mathrm{E}+00$ & $0.00 \mathrm{E}+00$ & $0.00 \mathrm{E}+00$ & 1. $92 \mathrm{E}-21$ & $1.55 E-11$ & $2.57 \mathrm{E}-11$ \\
\hline
\end{tabular}

MALL is total risk summed for all nuclides. 
RESRAD-OFFSITE, Version 2.5

Probabilistic Dose and Risk Report

Title : RESRAD-OFFSITE External Gamma, Inhalation, and Soil Ingestion for offsite Reside

File : PBA-1_TC99-DOE-5-1.ROF

Probabilistic Dose vs Pathway(i): Ground External (water release)

Nuclide $\quad \operatorname{DOSE}(i, j, t), \mathrm{mrem} / \mathrm{yr}$

(j) $t=0.00 \mathrm{E}+00 \quad 1.00 \mathrm{E}+00 \quad 5.00 \mathrm{E}+01 \quad 1.00 \mathrm{E}+02 \quad 5.00 \mathrm{E}+02 \quad 1.03 \mathrm{E}+03$

TC-99

$\begin{array}{lllllll}\text { Min } & 0.00 \mathrm{E}+00 & 0.00 \mathrm{E}+00 & 0.00 \mathrm{E}+00 & 0.00 \mathrm{E}+00 & 3.55 \mathrm{E}-10 & 8.82 \mathrm{E}-08\end{array}$

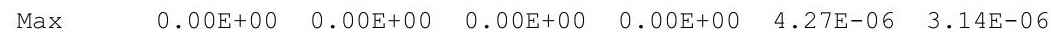

$\begin{array}{lllllll}A v g & 0.00 \mathrm{E}+00 & 0.00 \mathrm{E}+00 & 0.00 \mathrm{E}+00 & 0.00 \mathrm{E}+00 & 1.42 \mathrm{E}-07 & 8.73 \mathrm{E}-07\end{array}$

$\begin{array}{lllllll}\text { Std } & 0.00 \mathrm{E}+00 & 0.00 \mathrm{E}+00 & 0.00 \mathrm{E}+00 & 0.00 \mathrm{E}+00 & 2.80 \mathrm{E}-07 & 4.97 \mathrm{E}-07\end{array}$ $\sum A L L$

$\begin{array}{lllllll}\text { Min } & 0.00 \mathrm{E}+00 & 0.00 \mathrm{E}+00 & 0.00 \mathrm{E}+00 & 0.00 \mathrm{E}+00 & 3.55 \mathrm{E}-10 & 8.82 \mathrm{E}-08\end{array}$

$\begin{array}{lllllll}\operatorname{Max} & 0.00 \mathrm{E}+00 & 0.00 \mathrm{E}+00 & 0.00 \mathrm{E}+00 & 0.00 \mathrm{E}+00 & 4.27 \mathrm{E}-06 & 3.14 \mathrm{E}-06\end{array}$

$\begin{array}{lllllll}\text { Avg } & 0.00 \mathrm{E}+00 & 0.00 \mathrm{E}+00 & 0.00 \mathrm{E}+00 & 0.00 \mathrm{E}+00 & 1.42 \mathrm{E}-07 & 8.73 \mathrm{E}-07\end{array}$

$\begin{array}{lllllll}\text { Std } & 0.00 \mathrm{E}+00 & 0.00 \mathrm{E}+00 & 0.00 \mathrm{E}+00 & 0.00 \mathrm{E}+00 & 2.80 \mathrm{E}-07 & 4.97 \mathrm{E}-07\end{array}$

MALL is total pathway dose summed for all nuclides. 
RESRAD-OFFSITE, Version 2.5

Probabilistic Dose and Risk Report

Title : RESRAD-OFFSITE External Gamma, Inhalation, and Soil Ingestion for offsite Reside

File : PBA-1_TC99-DOE-5-1.ROF

Probabilistic Dose vs Pathway(i): Fish Ingestion (water release)

Nuclide $\quad \operatorname{DOSE}(i, j, t), \mathrm{mrem} / \mathrm{yr}$

(j) $t=0.00 \mathrm{E}+00 \quad 1.00 \mathrm{E}+00 \quad 5.00 \mathrm{E}+01 \quad 1.00 \mathrm{E}+02 \quad 5.00 \mathrm{E}+02 \quad 1.03 \mathrm{E}+03$

TC-99

$\begin{array}{lllllll}\text { Min } & 0.00 \mathrm{E}+00 & 0.00 \mathrm{E}+00 & 0.00 \mathrm{E}+00 & 0.00 \mathrm{E}+00 & 0.00 \mathrm{E}+00 & 0.00 \mathrm{E}+00\end{array}$

$\begin{array}{lllllll}\operatorname{Max} & 0.00 \mathrm{E}+00 & 0.00 \mathrm{E}+00 & 0.00 \mathrm{E}+00 & 0.00 \mathrm{E}+00 & 0.00 \mathrm{E}+00 & 0.00 \mathrm{E}+00\end{array}$

$\begin{array}{lllllll}A v g & 0.00 \mathrm{E}+00 & 0.00 \mathrm{E}+00 & 0.00 \mathrm{E}+00 & 0.00 \mathrm{E}+00 & 0.00 \mathrm{E}+00 & 0.00 \mathrm{E}+00\end{array}$

$\begin{array}{lllllll}\text { Std } & 0.00 \mathrm{E}+00 & 0.00 \mathrm{E}+00 & 0.00 \mathrm{E}+00 & 0.00 \mathrm{E}+00 & 0.00 \mathrm{E}+00 & 0.00 \mathrm{E}+00\end{array}$ $\sum A L L$

$\begin{array}{lllllll}\text { Min } & 0.00 \mathrm{E}+00 & 0.00 \mathrm{E}+00 & 0.00 \mathrm{E}+00 & 0.00 \mathrm{E}+00 & 0.00 \mathrm{E}+00 & 0.00 \mathrm{E}+00\end{array}$

$\begin{array}{lllllll}\operatorname{Max} & 0.00 \mathrm{E}+00 & 0.00 \mathrm{E}+00 & 0.00 \mathrm{E}+00 & 0.00 \mathrm{E}+00 & 0.00 \mathrm{E}+00 & 0.00 \mathrm{E}+00\end{array}$

$\begin{array}{lllllll}\text { Avg } & 0.00 \mathrm{E}+00 & 0.00 \mathrm{E}+00 & 0.00 \mathrm{E}+00 & 0.00 \mathrm{E}+00 & 0.00 \mathrm{E}+00 & 0.00 \mathrm{E}+00\end{array}$

$\begin{array}{lllllll}\text { Std } & 0.00 \mathrm{E}+00 & 0.00 \mathrm{E}+00 & 0.00 \mathrm{E}+00 & 0.00 \mathrm{E}+00 & 0.00 \mathrm{E}+00 & 0.00 \mathrm{E}+00\end{array}$

MALL is total pathway dose summed for all nuclides. 
RESRAD-OFFSITE, Version 2.5

Probabilistic Dose and Risk Report

Title : RESRAD-OFFSITE External Gamma, Inhalation, and Soil Ingestion for offsite Reside

File : PBA-1_TC99-DOE-5-1.ROF

Probabilistic Dose vs Pathway(i): Radon Inhalation (water release)

Nuclide $\quad \operatorname{DOSE}(i, j, t), \mathrm{mrem} / \mathrm{yr}$

(j) $t=0.00 \mathrm{E}+00 \quad 1.00 \mathrm{E}+00 \quad 5.00 \mathrm{E}+01 \quad 1.00 \mathrm{E}+02 \quad 5.00 \mathrm{E}+02 \quad 1.03 \mathrm{E}+03$

TC-99

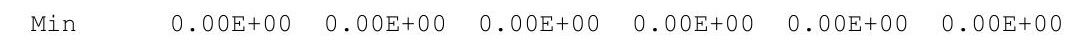

$\begin{array}{lllllll}\operatorname{Max} & 0.00 \mathrm{E}+00 & 0.00 \mathrm{E}+00 & 0.00 \mathrm{E}+00 & 0.00 \mathrm{E}+00 & 0.00 \mathrm{E}+00 & 0.00 \mathrm{E}+00\end{array}$

$\begin{array}{lllllll}A v g & 0.00 \mathrm{E}+00 & 0.00 \mathrm{E}+00 & 0.00 \mathrm{E}+00 & 0.00 \mathrm{E}+00 & 0.00 \mathrm{E}+00 & 0.00 \mathrm{E}+00\end{array}$

$\begin{array}{lllllll}\text { Std } & 0.00 \mathrm{E}+00 & 0.00 \mathrm{E}+00 & 0.00 \mathrm{E}+00 & 0.00 \mathrm{E}+00 & 0.00 \mathrm{E}+00 & 0.00 \mathrm{E}+00\end{array}$ $\sum A L L$

$\begin{array}{lllllll}\text { Min } & 0.00 \mathrm{E}+00 & 0.00 \mathrm{E}+00 & 0.00 \mathrm{E}+00 & 0.00 \mathrm{E}+00 & 0.00 \mathrm{E}+00 & 0.00 \mathrm{E}+00\end{array}$

$\begin{array}{lllllll}\operatorname{Max} & 0.00 \mathrm{E}+00 & 0.00 \mathrm{E}+00 & 0.00 \mathrm{E}+00 & 0.00 \mathrm{E}+00 & 0.00 \mathrm{E}+00 & 0.00 \mathrm{E}+00\end{array}$

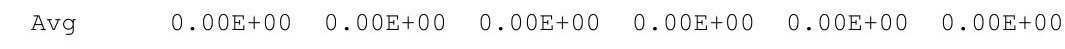

$\begin{array}{lllllll}\text { Std } & 0.00 \mathrm{E}+00 & 0.00 \mathrm{E}+00 & 0.00 \mathrm{E}+00 & 0.00 \mathrm{E}+00 & 0.00 \mathrm{E}+00 & 0.00 \mathrm{E}+00\end{array}$

¿ALL is total pathway dose summed for all nuclides. 
RESRAD-OFFSITE, Version 2.5

Probabilistic Dose and Risk Report

Title : RESRAD-OFFSITE External Gamma, Inhalation, and Soil Ingestion for offsite Reside

File : PBA-1_TC99-DOE-5-1.ROF

Probabilistic Dose vs Pathway(i): Vegetable Ingestion (water release)

Nuclide $\quad \operatorname{DOSE}(i, j, t), \mathrm{mrem} / \mathrm{yr}$

(j) $\quad \mathrm{t}=0.00 \mathrm{E}+00 \quad 1.00 \mathrm{E}+00 \quad 5.00 \mathrm{E}+01 \quad 1.00 \mathrm{E}+02 \quad 5.00 \mathrm{E}+02 \quad 1.03 \mathrm{E}+03$

TC-99

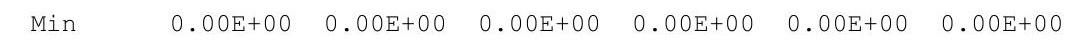

$\begin{array}{lllllll}\operatorname{Max} & 0.00 \mathrm{E}+00 & 0.00 \mathrm{E}+00 & 0.00 \mathrm{E}+00 & 0.00 \mathrm{E}+00 & 0.00 \mathrm{E}+00 & 0.00 \mathrm{E}+00\end{array}$

$\begin{array}{lllllll}A v g & 0.00 \mathrm{E}+00 & 0.00 \mathrm{E}+00 & 0.00 \mathrm{E}+00 & 0.00 \mathrm{E}+00 & 0.00 \mathrm{E}+00 & 0.00 \mathrm{E}+00\end{array}$

$\begin{array}{lllllll}\text { Std } & 0.00 \mathrm{E}+00 & 0.00 \mathrm{E}+00 & 0.00 \mathrm{E}+00 & 0.00 \mathrm{E}+00 & 0.00 \mathrm{E}+00 & 0.00 \mathrm{E}+00\end{array}$ $\sum A L L$

Min $\quad \begin{array}{llllll}0.00 \mathrm{E}+00 & 0.00 \mathrm{E}+00 & 0.00 \mathrm{E}+00 & 0.00 \mathrm{E}+00 & 0.00 \mathrm{E}+00 & 0.00 \mathrm{E}+00\end{array}$

$\begin{array}{lllllll}\operatorname{Max} & 0.00 \mathrm{E}+00 & 0.00 \mathrm{E}+00 & 0.00 \mathrm{E}+00 & 0.00 \mathrm{E}+00 & 0.00 \mathrm{E}+00 & 0.00 \mathrm{E}+00\end{array}$

$\begin{array}{lllllll}\text { Avg } & 0.00 \mathrm{E}+00 & 0.00 \mathrm{E}+00 & 0.00 \mathrm{E}+00 & 0.00 \mathrm{E}+00 & 0.00 \mathrm{E}+00 & 0.00 \mathrm{E}+00\end{array}$

$\begin{array}{lllllll}\text { Std } & 0.00 \mathrm{E}+00 & 0.00 \mathrm{E}+00 & 0.00 \mathrm{E}+00 & 0.00 \mathrm{E}+00 & 0.00 \mathrm{E}+00 & 0.00 \mathrm{E}+00\end{array}$

¿ALL is total pathway dose summed for all nuclides. 
RESRAD-OFFSITE, Version 2.5

Probabilistic Dose and Risk Report

Title : RESRAD-OFFSITE External Gamma, Inhalation, and Soil Ingestion for offsite Reside

File : PBA-1_TC99-DOE-5-1.ROF

Probabilistic Dose vs Pathway(i): Meat Ingestion (water release)

Nuclide $\quad \operatorname{DOSE}(i, j, t), \mathrm{mrem} / \mathrm{yr}$

(j) $t=0.00 \mathrm{E}+00 \quad 1.00 \mathrm{E}+00 \quad 5.00 \mathrm{E}+01 \quad 1.00 \mathrm{E}+02 \quad 5.00 \mathrm{E}+02 \quad 1.03 \mathrm{E}+03$

TC-99

$\begin{array}{lllllll}\text { Min } & 0.00 \mathrm{E}+00 & 0.00 \mathrm{E}+00 & 0.00 \mathrm{E}+00 & 0.00 \mathrm{E}+00 & 0.00 \mathrm{E}+00 & 0.00 \mathrm{E}+00\end{array}$

$\begin{array}{lllllll}\operatorname{Max} & 0.00 \mathrm{E}+00 & 0.00 \mathrm{E}+00 & 0.00 \mathrm{E}+00 & 0.00 \mathrm{E}+00 & 0.00 \mathrm{E}+00 & 0.00 \mathrm{E}+00\end{array}$

$\begin{array}{lllllll}A v g & 0.00 \mathrm{E}+00 & 0.00 \mathrm{E}+00 & 0.00 \mathrm{E}+00 & 0.00 \mathrm{E}+00 & 0.00 \mathrm{E}+00 & 0.00 \mathrm{E}+00\end{array}$

$\begin{array}{lllllll}\text { Std } & 0.00 \mathrm{E}+00 & 0.00 \mathrm{E}+00 & 0.00 \mathrm{E}+00 & 0.00 \mathrm{E}+00 & 0.00 \mathrm{E}+00 & 0.00 \mathrm{E}+00\end{array}$ $\sum A L L$

$\begin{array}{lllllll}\text { Min } & 0.00 \mathrm{E}+00 & 0.00 \mathrm{E}+00 & 0.00 \mathrm{E}+00 & 0.00 \mathrm{E}+00 & 0.00 \mathrm{E}+00 & 0.00 \mathrm{E}+00\end{array}$

$\begin{array}{lllllll}\operatorname{Max} & 0.00 \mathrm{E}+00 & 0.00 \mathrm{E}+00 & 0.00 \mathrm{E}+00 & 0.00 \mathrm{E}+00 & 0.00 \mathrm{E}+00 & 0.00 \mathrm{E}+00\end{array}$

$\begin{array}{lllllll}\text { Avg } & 0.00 \mathrm{E}+00 & 0.00 \mathrm{E}+00 & 0.00 \mathrm{E}+00 & 0.00 \mathrm{E}+00 & 0.00 \mathrm{E}+00 & 0.00 \mathrm{E}+00\end{array}$

$\begin{array}{lllllll}\text { Std } & 0.00 \mathrm{E}+00 & 0.00 \mathrm{E}+00 & 0.00 \mathrm{E}+00 & 0.00 \mathrm{E}+00 & 0.00 \mathrm{E}+00 & 0.00 \mathrm{E}+00\end{array}$

MALL is total pathway dose summed for all nuclides. 
RESRAD-OFFSITE, Version 2.5

Probabilistic Dose and Risk Report

Title : RESRAD-OFFSITE External Gamma, Inhalation, and Soil Ingestion for offsite Reside

File : PBA-1_TC99-DOE-5-1.ROF

Probabilistic Dose vs Pathway(i): Milk Ingestion (water release)

Nuclide $\quad \operatorname{DOSE}(i, j, t), \mathrm{mrem} / \mathrm{yr}$

(j) $t=0.00 \mathrm{E}+00 \quad 1.00 \mathrm{E}+00 \quad 5.00 \mathrm{E}+01 \quad 1.00 \mathrm{E}+02 \quad 5.00 \mathrm{E}+02 \quad 1.03 \mathrm{E}+03$

TC-99

$\begin{array}{lllllll}\text { Min } & 0.00 \mathrm{E}+00 & 0.00 \mathrm{E}+00 & 0.00 \mathrm{E}+00 & 0.00 \mathrm{E}+00 & 0.00 \mathrm{E}+00 & 0.00 \mathrm{E}+00\end{array}$

$\begin{array}{lllllll}\operatorname{Max} & 0.00 \mathrm{E}+00 & 0.00 \mathrm{E}+00 & 0.00 \mathrm{E}+00 & 0.00 \mathrm{E}+00 & 0.00 \mathrm{E}+00 & 0.00 \mathrm{E}+00\end{array}$

$\begin{array}{lllllll}A v g & 0.00 \mathrm{E}+00 & 0.00 \mathrm{E}+00 & 0.00 \mathrm{E}+00 & 0.00 \mathrm{E}+00 & 0.00 \mathrm{E}+00 & 0.00 \mathrm{E}+00\end{array}$

$\begin{array}{lllllll}\text { Std } & 0.00 \mathrm{E}+00 & 0.00 \mathrm{E}+00 & 0.00 \mathrm{E}+00 & 0.00 \mathrm{E}+00 & 0.00 \mathrm{E}+00 & 0.00 \mathrm{E}+00\end{array}$ $\sum A L L$

$\begin{array}{lllllll}\text { Min } & 0.00 \mathrm{E}+00 & 0.00 \mathrm{E}+00 & 0.00 \mathrm{E}+00 & 0.00 \mathrm{E}+00 & 0.00 \mathrm{E}+00 & 0.00 \mathrm{E}+00\end{array}$

$\begin{array}{lllllll}\operatorname{Max} & 0.00 \mathrm{E}+00 & 0.00 \mathrm{E}+00 & 0.00 \mathrm{E}+00 & 0.00 \mathrm{E}+00 & 0.00 \mathrm{E}+00 & 0.00 \mathrm{E}+00\end{array}$

$\begin{array}{lllllll}\text { Avg } & 0.00 \mathrm{E}+00 & 0.00 \mathrm{E}+00 & 0.00 \mathrm{E}+00 & 0.00 \mathrm{E}+00 & 0.00 \mathrm{E}+00 & 0.00 \mathrm{E}+00\end{array}$

$\begin{array}{lllllll}\text { Std } & 0.00 \mathrm{E}+00 & 0.00 \mathrm{E}+00 & 0.00 \mathrm{E}+00 & 0.00 \mathrm{E}+00 & 0.00 \mathrm{E}+00 & 0.00 \mathrm{E}+00\end{array}$

MALL is total pathway dose summed for all nuclides. 


\section{RESRAD-OFFSITE, Version 2.5}

Probabilistic Dose and Risk Report

Title : RESRAD-OFFSITE External Gamma, Inhalation, and Soil Ingestion for offsite Reside

File : PBA-1_TC99-DOE-5-1.ROF

Probabilistic Dose vs Pathway(i): Soil Ingestion (water release)

Nuclide $\quad \operatorname{DOSE}(i, j, t), \mathrm{mrem} / \mathrm{yr}$

(j) $t=0.00 \mathrm{E}+00 \quad 1.00 \mathrm{E}+00 \quad 5.00 \mathrm{E}+01 \quad 1.00 \mathrm{E}+02 \quad 5.00 \mathrm{E}+02 \quad 1.03 \mathrm{E}+03$

TC-99

$\begin{array}{lllllll}\text { Min } & 0.00 \mathrm{E}+00 & 0.00 \mathrm{E}+00 & 0.00 \mathrm{E}+00 & 0.00 \mathrm{E}+00 & 2.99 \mathrm{E}-10 & 7.45 \mathrm{E}-08\end{array}$

$\begin{array}{lllllll}\operatorname{Max} & 0.00 \mathrm{E}+00 & 0.00 \mathrm{E}+00 & 0.00 \mathrm{E}+00 & 0.00 \mathrm{E}+00 & 3.61 \mathrm{E}-06 & 2.65 \mathrm{E}-06\end{array}$

$\begin{array}{lllllll}\text { Avg } & 0.00 \mathrm{E}+00 & 0.00 \mathrm{E}+00 & 0.00 \mathrm{E}+00 & 0.00 \mathrm{E}+00 & 1.20 \mathrm{E}-07 & 7.37 \mathrm{E}-07\end{array}$

$\begin{array}{lllllll}\text { Std } & 0.00 \mathrm{E}+00 & 0.00 \mathrm{E}+00 & 0.00 \mathrm{E}+00 & 0.00 \mathrm{E}+00 & 2.37 \mathrm{E}-07 & 4.20 \mathrm{E}-07\end{array}$ $\sum A L L$

$\begin{array}{lllllll}\text { Min } & 0.00 \mathrm{E}+00 & 0.00 \mathrm{E}+00 & 0.00 \mathrm{E}+00 & 0.00 \mathrm{E}+00 & 2.99 \mathrm{E}-10 & 7.45 \mathrm{E}-08\end{array}$

$\begin{array}{lllllll}\operatorname{Max} & 0.00 \mathrm{E}+00 & 0.00 \mathrm{E}+00 & 0.00 \mathrm{E}+00 & 0.00 \mathrm{E}+00 & 3.61 \mathrm{E}-06 & 2.65 \mathrm{E}-06\end{array}$

$\begin{array}{lllllll}\text { Avg } & 0.00 \mathrm{E}+00 & 0.00 \mathrm{E}+00 & 0.00 \mathrm{E}+00 & 0.00 \mathrm{E}+00 & 1.20 \mathrm{E}-07 & 7.37 \mathrm{E}-07\end{array}$

$\begin{array}{lllllll}\text { Std } & 0.00 \mathrm{E}+00 & 0.00 \mathrm{E}+00 & 0.00 \mathrm{E}+00 & 0.00 \mathrm{E}+00 & 2.37 \mathrm{E}-07 & 4.20 \mathrm{E}-07\end{array}$

¿ALL is total pathway dose summed for all nuclides. 
RESRAD-OFFSITE, Version 2.5

Probabilistic Dose and Risk Report

Title : RESRAD-OFFSITE External Gamma, Inhalation, and Soil Ingestion for offsite Reside

File : PBA-1_TC99-DOE-5-1.ROF

Probabilistic Dose vs Pathway(i): Water Ingestion (water release)

Nuclide $\quad \operatorname{DOSE}(i, j, t), \mathrm{mrem} / \mathrm{yr}$

(j) $t=0.00 \mathrm{E}+00 \quad 1.00 \mathrm{E}+00 \quad 5.00 \mathrm{E}+01 \quad 1.00 \mathrm{E}+02 \quad 5.00 \mathrm{E}+02 \quad 1.03 \mathrm{E}+03$

TC-99

$\begin{array}{lllllll}\text { Min } & 0.00 \mathrm{E}+00 & 0.00 \mathrm{E}+00 & 0.00 \mathrm{E}+00 & 0.00 \mathrm{E}+00 & 0.00 \mathrm{E}+00 & 0.00 \mathrm{E}+00\end{array}$

$\begin{array}{lllllll}\operatorname{Max} & 0.00 \mathrm{E}+00 & 0.00 \mathrm{E}+00 & 0.00 \mathrm{E}+00 & 0.00 \mathrm{E}+00 & 0.00 \mathrm{E}+00 & 0.00 \mathrm{E}+00\end{array}$

$\begin{array}{lllllll}A v g & 0.00 \mathrm{E}+00 & 0.00 \mathrm{E}+00 & 0.00 \mathrm{E}+00 & 0.00 \mathrm{E}+00 & 0.00 \mathrm{E}+00 & 0.00 \mathrm{E}+00\end{array}$

$\begin{array}{lllllll}\text { Std } & 0.00 \mathrm{E}+00 & 0.00 \mathrm{E}+00 & 0.00 \mathrm{E}+00 & 0.00 \mathrm{E}+00 & 0.00 \mathrm{E}+00 & 0.00 \mathrm{E}+00\end{array}$ $\sum A L L$

$\begin{array}{lllllll}\text { Min } & 0.00 \mathrm{E}+00 & 0.00 \mathrm{E}+00 & 0.00 \mathrm{E}+00 & 0.00 \mathrm{E}+00 & 0.00 \mathrm{E}+00 & 0.00 \mathrm{E}+00\end{array}$

$\begin{array}{lllllll}\operatorname{Max} & 0.00 \mathrm{E}+00 & 0.00 \mathrm{E}+00 & 0.00 \mathrm{E}+00 & 0.00 \mathrm{E}+00 & 0.00 \mathrm{E}+00 & 0.00 \mathrm{E}+00\end{array}$

$\begin{array}{lllllll}\text { Avg } & 0.00 \mathrm{E}+00 & 0.00 \mathrm{E}+00 & 0.00 \mathrm{E}+00 & 0.00 \mathrm{E}+00 & 0.00 \mathrm{E}+00 & 0.00 \mathrm{E}+00\end{array}$

$\begin{array}{lllllll}\text { Std } & 0.00 \mathrm{E}+00 & 0.00 \mathrm{E}+00 & 0.00 \mathrm{E}+00 & 0.00 \mathrm{E}+00 & 0.00 \mathrm{E}+00 & 0.00 \mathrm{E}+00\end{array}$

MALL is total pathway dose summed for all nuclides. 


\section{RESRAD-OFFSITE, Version 2.5}

Probabilistic Dose and Risk Report

Title : RESRAD-OFFSITE External Gamma, Inhalation, and Soil Ingestion for offsite Reside

File : PBA-1_TC99-DOE-5-1.ROF

Probabilistic Dose vs Pathway(i): Ground External (direct \& air release)

Nuclide $\quad \operatorname{DOSE}(i, j, t), \mathrm{mrem} / \mathrm{yr}$

(j) $t=0.00 \mathrm{E}+00 \quad 1.00 \mathrm{E}+00 \quad 5.00 \mathrm{E}+01 \quad 1.00 \mathrm{E}+02 \quad 5.00 \mathrm{E}+02 \quad 1.03 \mathrm{E}+03$

TC-99

Min $\quad 1.45 \mathrm{E}-32 \quad 1.42 \mathrm{E}-32 \quad 4.91 \mathrm{E}-33 \quad 1.66 \mathrm{E}-33 \quad 2.80 \mathrm{E}-37 \quad 3.07 \mathrm{E}-42$

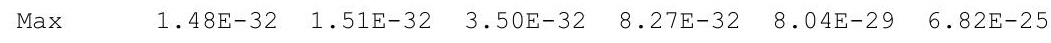

Avg $\quad \begin{array}{llllll}1.48 \mathrm{E}-32 & 1.50 \mathrm{E}-32 & 3.19 \mathrm{E}-32 & 6.96 \mathrm{E}-32 & 4.22 \mathrm{E}-29 & 2.35 \mathrm{E}-25\end{array}$

$\begin{array}{lllllll}\text { Std } & 0.00 \mathrm{E}+00 & 0.00 \mathrm{E}+00 & 0.00 \mathrm{E}+00 & 0.00 \mathrm{E}+00 & 0.00 \mathrm{E}+00 & 0.00 \mathrm{E}+00\end{array}$ $\sum A L L$

Min $\quad \begin{array}{llllll}1.45 \mathrm{E}-32 & 1.42 \mathrm{E}-32 & 4.91 \mathrm{E}-33 & 1.66 \mathrm{E}-33 & 2.80 \mathrm{E}-37 & 3.07 \mathrm{E}-42\end{array}$

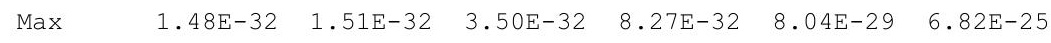

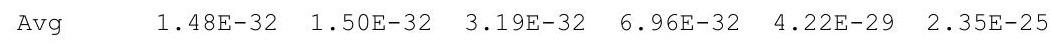

$\begin{array}{lllllll}\text { Std } & 0.00 \mathrm{E}+00 & 0.00 \mathrm{E}+00 & 0.00 \mathrm{E}+00 & 0.00 \mathrm{E}+00 & 0.00 \mathrm{E}+00 & 0.00 \mathrm{E}+00\end{array}$

MALL is total pathway dose summed for all nuclides. 
RESRAD-OFFSITE, Version 2.5

Probabilistic Dose and Risk Report

Title : RESRAD-OFFSITE External Gamma, Inhalation, and Soil Ingestion for offsite Reside

File : PBA-1_TC99-DOE-5-1.ROF

Probabilistic Dose vs Pathway(i): Inhalation (w/o Radon) (direct \& air)

Nuclide $\quad \operatorname{DOSE}(i, j, t), \mathrm{mrem} / \mathrm{yr}$

(j) $\quad t=0.00 \mathrm{E}+00 \quad 1.00 \mathrm{E}+00 \quad 5.00 \mathrm{E}+01 \quad 1.00 \mathrm{E}+02 \quad 5.00 \mathrm{E}+02 \quad 1.03 \mathrm{E}+03$

TC-99

$\begin{array}{lllllll}\text { Min } & 0.00 \mathrm{E}+00 & 0.00 \mathrm{E}+00 & 0.00 \mathrm{E}+00 & 0.00 \mathrm{E}+00 & 0.00 \mathrm{E}+00 & 0.00 \mathrm{E}+00\end{array}$

$\begin{array}{lllllll}\operatorname{Max} & 0.00 \mathrm{E}+00 & 0.00 \mathrm{E}+00 & 0.00 \mathrm{E}+00 & 0.00 \mathrm{E}+00 & 0.00 \mathrm{E}+00 & 0.00 \mathrm{E}+00\end{array}$

$\begin{array}{lllllll}A v g & 0.00 \mathrm{E}+00 & 0.00 \mathrm{E}+00 & 0.00 \mathrm{E}+00 & 0.00 \mathrm{E}+00 & 0.00 \mathrm{E}+00 & 0.00 \mathrm{E}+00\end{array}$

$\begin{array}{lllllll}\text { Std } & 0.00 \mathrm{E}+00 & 0.00 \mathrm{E}+00 & 0.00 \mathrm{E}+00 & 0.00 \mathrm{E}+00 & 0.00 \mathrm{E}+00 & 0.00 \mathrm{E}+00\end{array}$ $\sum A L L$

Min $\quad \begin{array}{llllll}0.00 \mathrm{E}+00 & 0.00 \mathrm{E}+00 & 0.00 \mathrm{E}+00 & 0.00 \mathrm{E}+00 & 0.00 \mathrm{E}+00 & 0.00 \mathrm{E}+00\end{array}$

$\begin{array}{lllllll}\operatorname{Max} & 0.00 \mathrm{E}+00 & 0.00 \mathrm{E}+00 & 0.00 \mathrm{E}+00 & 0.00 \mathrm{E}+00 & 0.00 \mathrm{E}+00 & 0.00 \mathrm{E}+00\end{array}$

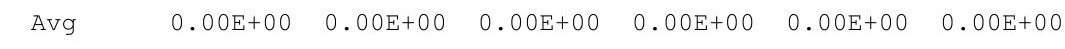

$\begin{array}{lllllll}\text { Std } & 0.00 \mathrm{E}+00 & 0.00 \mathrm{E}+00 & 0.00 \mathrm{E}+00 & 0.00 \mathrm{E}+00 & 0.00 \mathrm{E}+00 & 0.00 \mathrm{E}+00\end{array}$

MALL is total pathway dose summed for all nuclides. 
RESRAD-OFFSITE, Version 2.5

Probabilistic Dose and Risk Report

Title : RESRAD-OFFSITE External Gamma, Inhalation, and Soil Ingestion for offsite Reside

File : PBA-1_TC99-DOE-5-1.ROF

Probabilistic Dose vs Pathway(i): Radon Inhalation (direct \& air release)

Nuclide $\quad \operatorname{DOSE}(i, j, t), \mathrm{mrem} / \mathrm{yr}$

(j) $t=0.00 \mathrm{E}+00 \quad 1.00 \mathrm{E}+00 \quad 5.00 \mathrm{E}+01 \quad 1.00 \mathrm{E}+02 \quad 5.00 \mathrm{E}+02 \quad 1.03 \mathrm{E}+03$

TC-99

$\begin{array}{lllllll}\text { Min } & 0.00 \mathrm{E}+00 & 0.00 \mathrm{E}+00 & 0.00 \mathrm{E}+00 & 0.00 \mathrm{E}+00 & 0.00 \mathrm{E}+00 & 0.00 \mathrm{E}+00\end{array}$

$\begin{array}{lllllll}\operatorname{Max} & 0.00 \mathrm{E}+00 & 0.00 \mathrm{E}+00 & 0.00 \mathrm{E}+00 & 0.00 \mathrm{E}+00 & 0.00 \mathrm{E}+00 & 0.00 \mathrm{E}+00\end{array}$

$\begin{array}{lllllll}A v g & 0.00 \mathrm{E}+00 & 0.00 \mathrm{E}+00 & 0.00 \mathrm{E}+00 & 0.00 \mathrm{E}+00 & 0.00 \mathrm{E}+00 & 0.00 \mathrm{E}+00\end{array}$

$\begin{array}{lllllll}\text { Std } & 0.00 \mathrm{E}+00 & 0.00 \mathrm{E}+00 & 0.00 \mathrm{E}+00 & 0.00 \mathrm{E}+00 & 0.00 \mathrm{E}+00 & 0.00 \mathrm{E}+00\end{array}$ $\sum A L L$

$\begin{array}{lllllll}\text { Min } & 0.00 \mathrm{E}+00 & 0.00 \mathrm{E}+00 & 0.00 \mathrm{E}+00 & 0.00 \mathrm{E}+00 & 0.00 \mathrm{E}+00 & 0.00 \mathrm{E}+00\end{array}$

$\begin{array}{lllllll}\operatorname{Max} & 0.00 \mathrm{E}+00 & 0.00 \mathrm{E}+00 & 0.00 \mathrm{E}+00 & 0.00 \mathrm{E}+00 & 0.00 \mathrm{E}+00 & 0.00 \mathrm{E}+00\end{array}$

$\begin{array}{lllllll}\text { Avg } & 0.00 \mathrm{E}+00 & 0.00 \mathrm{E}+00 & 0.00 \mathrm{E}+00 & 0.00 \mathrm{E}+00 & 0.00 \mathrm{E}+00 & 0.00 \mathrm{E}+00\end{array}$

$\begin{array}{lllllll}\text { Std } & 0.00 \mathrm{E}+00 & 0.00 \mathrm{E}+00 & 0.00 \mathrm{E}+00 & 0.00 \mathrm{E}+00 & 0.00 \mathrm{E}+00 & 0.00 \mathrm{E}+00\end{array}$

MALL is total pathway dose summed for all nuclides. 
RESRAD-OFFSITE, Version 2.5

Probabilistic Dose and Risk Report

Title : RESRAD-OFFSITE External Gamma, Inhalation, and Soil Ingestion for offsite Reside

File : PBA-1_TC99-DOE-5-1.ROF

Probabilistic Dose vs Pathway(i): Vegetable Ingestion (direct \& air release)

Nuclide $\quad \operatorname{DOSE}(i, j, t), \mathrm{mrem} / \mathrm{yr}$

(j) $t=0.00 \mathrm{E}+00 \quad 1.00 \mathrm{E}+00 \quad 5.00 \mathrm{E}+01 \quad 1.00 \mathrm{E}+02 \quad 5.00 \mathrm{E}+02 \quad 1.03 \mathrm{E}+03$

TC-99

$\begin{array}{lllllll}\text { Min } & 0.00 \mathrm{E}+00 & 0.00 \mathrm{E}+00 & 0.00 \mathrm{E}+00 & 0.00 \mathrm{E}+00 & 0.00 \mathrm{E}+00 & 0.00 \mathrm{E}+00\end{array}$

$\begin{array}{lllllll}\operatorname{Max} & 0.00 \mathrm{E}+00 & 0.00 \mathrm{E}+00 & 0.00 \mathrm{E}+00 & 0.00 \mathrm{E}+00 & 0.00 \mathrm{E}+00 & 0.00 \mathrm{E}+00\end{array}$

$\begin{array}{lllllll}A v g & 0.00 \mathrm{E}+00 & 0.00 \mathrm{E}+00 & 0.00 \mathrm{E}+00 & 0.00 \mathrm{E}+00 & 0.00 \mathrm{E}+00 & 0.00 \mathrm{E}+00\end{array}$

$\begin{array}{lllllll}\text { Std } & 0.00 \mathrm{E}+00 & 0.00 \mathrm{E}+00 & 0.00 \mathrm{E}+00 & 0.00 \mathrm{E}+00 & 0.00 \mathrm{E}+00 & 0.00 \mathrm{E}+00\end{array}$ $\sum A L L$

$\begin{array}{lllllll}\text { Min } & 0.00 \mathrm{E}+00 & 0.00 \mathrm{E}+00 & 0.00 \mathrm{E}+00 & 0.00 \mathrm{E}+00 & 0.00 \mathrm{E}+00 & 0.00 \mathrm{E}+00\end{array}$

$\begin{array}{lllllll}\operatorname{Max} & 0.00 \mathrm{E}+00 & 0.00 \mathrm{E}+00 & 0.00 \mathrm{E}+00 & 0.00 \mathrm{E}+00 & 0.00 \mathrm{E}+00 & 0.00 \mathrm{E}+00\end{array}$

$\begin{array}{lllllll}\text { Avg } & 0.00 \mathrm{E}+00 & 0.00 \mathrm{E}+00 & 0.00 \mathrm{E}+00 & 0.00 \mathrm{E}+00 & 0.00 \mathrm{E}+00 & 0.00 \mathrm{E}+00\end{array}$

$\begin{array}{lllllll}\text { Std } & 0.00 \mathrm{E}+00 & 0.00 \mathrm{E}+00 & 0.00 \mathrm{E}+00 & 0.00 \mathrm{E}+00 & 0.00 \mathrm{E}+00 & 0.00 \mathrm{E}+00\end{array}$

MALL is total pathway dose summed for all nuclides. 
RESRAD-OFFSITE, Version 2.5

Probabilistic Dose and Risk Report

Title : RESRAD-OFFSITE External Gamma, Inhalation, and Soil Ingestion for offsite Reside

File : PBA-1_TC99-DOE-5-1.ROF

Probabilistic Dose vs Pathway(i): Meat Ingestion (direct \& air release)

Nuclide $\quad \operatorname{DOSE}(i, j, t), \mathrm{mrem} / \mathrm{yr}$

(j) $t=0.00 \mathrm{E}+00 \quad 1.00 \mathrm{E}+00 \quad 5.00 \mathrm{E}+01 \quad 1.00 \mathrm{E}+02 \quad 5.00 \mathrm{E}+02 \quad 1.03 \mathrm{E}+03$

TC-99

$\begin{array}{lllllll}\text { Min } & 0.00 \mathrm{E}+00 & 0.00 \mathrm{E}+00 & 0.00 \mathrm{E}+00 & 0.00 \mathrm{E}+00 & 0.00 \mathrm{E}+00 & 0.00 \mathrm{E}+00\end{array}$

$\begin{array}{lllllll}\operatorname{Max} & 0.00 \mathrm{E}+00 & 0.00 \mathrm{E}+00 & 0.00 \mathrm{E}+00 & 0.00 \mathrm{E}+00 & 0.00 \mathrm{E}+00 & 0.00 \mathrm{E}+00\end{array}$

$\begin{array}{lllllll}A v g & 0.00 \mathrm{E}+00 & 0.00 \mathrm{E}+00 & 0.00 \mathrm{E}+00 & 0.00 \mathrm{E}+00 & 0.00 \mathrm{E}+00 & 0.00 \mathrm{E}+00\end{array}$

$\begin{array}{lllllll}\text { Std } & 0.00 \mathrm{E}+00 & 0.00 \mathrm{E}+00 & 0.00 \mathrm{E}+00 & 0.00 \mathrm{E}+00 & 0.00 \mathrm{E}+00 & 0.00 \mathrm{E}+00\end{array}$ $\sum A L L$

Min $\quad \begin{array}{llllll}0.00 \mathrm{E}+00 & 0.00 \mathrm{E}+00 & 0.00 \mathrm{E}+00 & 0.00 \mathrm{E}+00 & 0.00 \mathrm{E}+00 & 0.00 \mathrm{E}+00\end{array}$

$\begin{array}{lllllll}\operatorname{Max} & 0.00 \mathrm{E}+00 & 0.00 \mathrm{E}+00 & 0.00 \mathrm{E}+00 & 0.00 \mathrm{E}+00 & 0.00 \mathrm{E}+00 & 0.00 \mathrm{E}+00\end{array}$

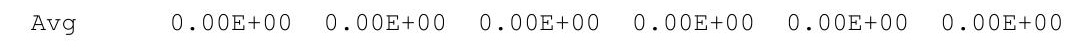

$\begin{array}{lllllll}\text { Std } & 0.00 \mathrm{E}+00 & 0.00 \mathrm{E}+00 & 0.00 \mathrm{E}+00 & 0.00 \mathrm{E}+00 & 0.00 \mathrm{E}+00 & 0.00 \mathrm{E}+00\end{array}$

MALL is total pathway dose summed for all nuclides. 
RESRAD-OFFSITE, Version 2.5

Probabilistic Dose and Risk Report

Title : RESRAD-OFFSITE External Gamma, Inhalation, and Soil Ingestion for offsite Reside

File : PBA-1_TC99-DOE-5-1.ROF

Probabilistic Dose vs Pathway(i): Milk Ingestion (direct \& air release)

Nuclide $\quad \operatorname{DOSE}(i, j, t), \mathrm{mrem} / \mathrm{yr}$

(j) $t=0.00 \mathrm{E}+00 \quad 1.00 \mathrm{E}+00 \quad 5.00 \mathrm{E}+01 \quad 1.00 \mathrm{E}+02 \quad 5.00 \mathrm{E}+02 \quad 1.03 \mathrm{E}+03$

TC-99

$\begin{array}{lllllll}\text { Min } & 0.00 \mathrm{E}+00 & 0.00 \mathrm{E}+00 & 0.00 \mathrm{E}+00 & 0.00 \mathrm{E}+00 & 0.00 \mathrm{E}+00 & 0.00 \mathrm{E}+00\end{array}$

$\begin{array}{lllllll}\operatorname{Max} & 0.00 \mathrm{E}+00 & 0.00 \mathrm{E}+00 & 0.00 \mathrm{E}+00 & 0.00 \mathrm{E}+00 & 0.00 \mathrm{E}+00 & 0.00 \mathrm{E}+00\end{array}$

$\begin{array}{lllllll}A v g & 0.00 \mathrm{E}+00 & 0.00 \mathrm{E}+00 & 0.00 \mathrm{E}+00 & 0.00 \mathrm{E}+00 & 0.00 \mathrm{E}+00 & 0.00 \mathrm{E}+00\end{array}$

$\begin{array}{lllllll}\text { Std } & 0.00 \mathrm{E}+00 & 0.00 \mathrm{E}+00 & 0.00 \mathrm{E}+00 & 0.00 \mathrm{E}+00 & 0.00 \mathrm{E}+00 & 0.00 \mathrm{E}+00\end{array}$ $\sum A L L$

Min $\quad \begin{array}{llllll}0.00 \mathrm{E}+00 & 0.00 \mathrm{E}+00 & 0.00 \mathrm{E}+00 & 0.00 \mathrm{E}+00 & 0.00 \mathrm{E}+00 & 0.00 \mathrm{E}+00\end{array}$

$\begin{array}{lllllll}\operatorname{Max} & 0.00 \mathrm{E}+00 & 0.00 \mathrm{E}+00 & 0.00 \mathrm{E}+00 & 0.00 \mathrm{E}+00 & 0.00 \mathrm{E}+00 & 0.00 \mathrm{E}+00\end{array}$

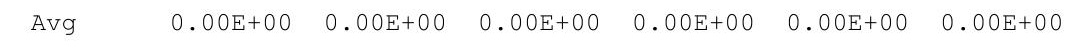

$\begin{array}{lllllll}\text { Std } & 0.00 \mathrm{E}+00 & 0.00 \mathrm{E}+00 & 0.00 \mathrm{E}+00 & 0.00 \mathrm{E}+00 & 0.00 \mathrm{E}+00 & 0.00 \mathrm{E}+00\end{array}$

MALL is total pathway dose summed for all nuclides. 
RESRAD-OFFSITE, Version 2.5

Probabilistic Dose and Risk Report

Title : RESRAD-OFFSITE External Gamma, Inhalation, and Soil Ingestion for offsite Reside

File : PBA-1_TC99-DOE-5-1.ROF

Probabilistic Dose vs Pathway(i): Soil Ingestion (direct \& air release)

Nuclide $\quad \operatorname{DOSE}(i, j, t), \mathrm{mrem} / \mathrm{yr}$

(j) $t=0.00 \mathrm{E}+00 \quad 1.00 \mathrm{E}+00 \quad 5.00 \mathrm{E}+01 \quad 1.00 \mathrm{E}+02 \quad 5.00 \mathrm{E}+02 \quad 1.03 \mathrm{E}+03$

TC-99

$\begin{array}{lllllll}\text { Min } & 0.00 \mathrm{E}+00 & 0.00 \mathrm{E}+00 & 0.00 \mathrm{E}+00 & 0.00 \mathrm{E}+00 & 0.00 \mathrm{E}+00 & 0.00 \mathrm{E}+00\end{array}$

$\begin{array}{lllllll}\operatorname{Max} & 0.00 \mathrm{E}+00 & 0.00 \mathrm{E}+00 & 0.00 \mathrm{E}+00 & 0.00 \mathrm{E}+00 & 0.00 \mathrm{E}+00 & 0.00 \mathrm{E}+00\end{array}$

$\begin{array}{lllllll}A v g & 0.00 \mathrm{E}+00 & 0.00 \mathrm{E}+00 & 0.00 \mathrm{E}+00 & 0.00 \mathrm{E}+00 & 0.00 \mathrm{E}+00 & 0.00 \mathrm{E}+00\end{array}$

$\begin{array}{lllllll}\text { Std } & 0.00 \mathrm{E}+00 & 0.00 \mathrm{E}+00 & 0.00 \mathrm{E}+00 & 0.00 \mathrm{E}+00 & 0.00 \mathrm{E}+00 & 0.00 \mathrm{E}+00\end{array}$ $\sum A L L$

Min $\quad \begin{array}{llllll}0.00 \mathrm{E}+00 & 0.00 \mathrm{E}+00 & 0.00 \mathrm{E}+00 & 0.00 \mathrm{E}+00 & 0.00 \mathrm{E}+00 & 0.00 \mathrm{E}+00\end{array}$

$\begin{array}{lllllll}\operatorname{Max} & 0.00 \mathrm{E}+00 & 0.00 \mathrm{E}+00 & 0.00 \mathrm{E}+00 & 0.00 \mathrm{E}+00 & 0.00 \mathrm{E}+00 & 0.00 \mathrm{E}+00\end{array}$

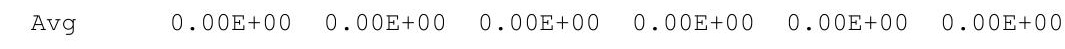

$\begin{array}{lllllll}\text { Std } & 0.00 \mathrm{E}+00 & 0.00 \mathrm{E}+00 & 0.00 \mathrm{E}+00 & 0.00 \mathrm{E}+00 & 0.00 \mathrm{E}+00 & 0.00 \mathrm{E}+00\end{array}$

¿ALL is total pathway dose summed for all nuclides. 
RESRAD-OFFSITE, Version 2.5

$\mathrm{T}^{1 / 2}$ Limit $=180$ days

robabilistic Dose and Risk Report

Title : RESRAD-OFFSITE External Gamma, Inhalation, and Soil Ingestion for offsite Reside File : PBA-1_TC99-DOE-5-1.ROF

Cumulative Probability Summary for: Total Dose Over all Pathways

\begin{tabular}{|c|c|c|c|c|c|c|}
\hline \multicolumn{3}{|l|}{ Cumulative } & \multicolumn{3}{|c|}{ Dose $(t), \mathrm{mrem} / \mathrm{yr}$} & \multirow[b]{2}{*}{$1.03 E+03$} \\
\hline Probability & $t=0.00 \mathrm{E}+00$ & 1.00E+00 & $5.00 \mathrm{E}+01$ & 1. $00 \mathrm{E}+02$ & $5.00 \mathrm{E}+02$ & \\
\hline 0.025 & 1. $48 \mathrm{E}-32$ & $1.49 \mathrm{E}-32$ & $2.30 E-32$ & $3.59 \mathrm{E}-32$ & $2.91 E-09$ & $3.59 \mathrm{E}-07$ \\
\hline 0.050 & 1. $48 \mathrm{E}-32$ & 1. $49 \mathrm{E}-32$ & $2.56 \mathrm{E}-32$ & $4.44 \mathrm{E}-32$ & 4. 66E-09 & $4.49 \mathrm{E}-07$ \\
\hline 0.075 & 1. $48 \mathrm{E}-32$ & $1.50 \mathrm{E}-32$ & $2.69 \mathrm{E}-32$ & $4.90 \mathrm{E}-32$ & $6.29 \mathrm{E}-09$ & $5.19 \mathrm{E}-07$ \\
\hline 0.100 & $1.48 \mathrm{E}-32$ & $1.50 \mathrm{E}-32$ & $2.79 E-32$ & $5.25 E-32$ & $7.97 \mathrm{E}-09$ & $5.75 \mathrm{E}-07$ \\
\hline 0.125 & $1.48 \mathrm{E}-32$ & $1.50 \mathrm{E}-32$ & $2.87 E-32$ & $5.55 E-32$ & $1.01 \mathrm{E}-08$ & $6.33 \mathrm{E}-07$ \\
\hline 0.150 & 1. $48 \mathrm{E}-32$ & $1.50 \mathrm{E}-32$ & $2.93 E-32$ & $5.79 \mathrm{E}-32$ & $1.25 \mathrm{E}-08$ & $6.86 \mathrm{E}-07$ \\
\hline 0.175 & $1.48 \mathrm{E}-32$ & $1.50 E-32$ & $2.98 E-32$ & $5.99 E-32$ & $1.49 E-08$ & $7.42 \mathrm{E}-07$ \\
\hline 0.200 & $1.48 E-32$ & $1.50 E-32$ & $3.03 E-32$ & $6.19 E-32$ & $1.75 E-08$ & $7.90 \mathrm{E}-07$ \\
\hline 0.225 & 1. $48 \mathrm{E}-32$ & $1.50 \mathrm{E}-32$ & $3.07 E-32$ & $6.35 E-32$ & $2.05 E-08$ & $8.42 \mathrm{E}-07$ \\
\hline 0.250 & $1.48 \mathrm{E}-32$ & $1.50 E-32$ & $3.10 E-32$ & $6.48 E-32$ & $2.36 E-08$ & $8.96 \mathrm{E}-07$ \\
\hline 0.275 & $1.48 E-32$ & $1.50 E-32$ & $3.13 E-32$ & $6.61 E-32$ & $2.71 E-08$ & $9.50 \mathrm{E}-07$ \\
\hline 0.300 & $1.48 \mathrm{E}-32$ & $1.50 \mathrm{E}-32$ & $3.16 \mathrm{E}-32$ & $6.74 \mathrm{E}-32$ & $3.12 \mathrm{E}-08$ & $9.98 \mathrm{E}-07$ \\
\hline 0.325 & $1.48 \mathrm{E}-32$ & $1.50 \mathrm{E}-32$ & $3.18 E-32$ & $6.85 E-32$ & $3.52 \mathrm{E}-08$ & $1.05 \mathrm{E}-06$ \\
\hline 0.350 & $1.48 \mathrm{E}-32$ & $1.50 \mathrm{E}-32$ & $3.21 \mathrm{E}-32$ & $6.94 \mathrm{E}-32$ & $4.05 E-08$ & $1.09 \mathrm{E}-06$ \\
\hline 0.375 & $1.48 \mathrm{E}-32$ & $1.50 \mathrm{E}-32$ & $3.23 E-32$ & $7.03 E-32$ & $4.52 E-08$ & $1.14 \mathrm{E}-06$ \\
\hline 0.400 & $1.48 \mathrm{E}-32$ & $1.50 E-32$ & $3.25 E-32$ & $7.12 \mathrm{E}-32$ & $5.13 E-08$ & $1.19 \mathrm{E}-06$ \\
\hline 0.425 & $1.48 \mathrm{E}-32$ & $1.50 \mathrm{E}-32$ & $3.26 \mathrm{E}-32$ & $7.18 \mathrm{E}-32$ & $5.70 E-08$ & $1.25 \mathrm{E}-06$ \\
\hline 0.450 & $1.48 \mathrm{E}-32$ & $1.50 \mathrm{E}-32$ & $3.28 \mathrm{E}-32$ & $7.25 E-32$ & $6.42 E-08$ & $1.31 \mathrm{E}-06$ \\
\hline 0.475 & $1.48 E-32$ & $1.50 E-32$ & $3.29 E-32$ & $7.31 E-32$ & $7.08 E-08$ & $1.37 \mathrm{E}-06$ \\
\hline 0.500 & $1.48 \mathrm{E}-32$ & $1.50 \mathrm{E}-32$ & $3.31 \mathrm{E}-32$ & $7.38 \mathrm{E}-32$ & $7.86 \mathrm{E}-08$ & $1.44 \mathrm{E}-06$ \\
\hline 0.525 & $1.48 \mathrm{E}-32$ & $1.51 \mathrm{E}-32$ & $3.32 E-32$ & $7.44 E-32$ & $8.84 \mathrm{E}-08$ & $1.50 \mathrm{E}-06$ \\
\hline 0.550 & $1.48 E-32$ & $1.51 \mathrm{E}-32$ & $3.33 E-32$ & $7.49 E-32$ & $9.88 E-08$ & $1.56 \mathrm{E}-06$ \\
\hline 0.575 & $1.48 \mathrm{E}-32$ & $1.51 \mathrm{E}-32$ & $3.34 \mathrm{E}-32$ & $7.54 \mathrm{E}-32$ & $1.09 \mathrm{E}-07$ & $1.62 \mathrm{E}-06$ \\
\hline 0.600 & $1.48 \mathrm{E}-32$ & $1.51 \mathrm{E}-32$ & $3.35 E-32$ & $7.60 E-32$ & $1.22 \mathrm{E}-07$ & $1.68 \mathrm{E}-06$ \\
\hline 0.625 & $1.48 E-32$ & $1.51 E-32$ & $3.36 E-32$ & $7.64 E-32$ & $1.35 E-07$ & $1.76 \mathrm{E}-06$ \\
\hline 0.650 & $1.48 \mathrm{E}-32$ & $1.51 \mathrm{E}-32$ & $3.37 E-32$ & $7.68 \mathrm{E}-32$ & $1.54 \mathrm{E}-07$ & $1.83 \mathrm{E}-06$ \\
\hline 0.675 & $1.48 E-32$ & $1.51 E-32$ & $3.38 E-32$ & $7.72 E-32$ & $1.74 \mathrm{E}-07$ & 1.91E-06 \\
\hline 0.700 & $1.48 \mathrm{E}-32$ & $1.51 \mathrm{E}-32$ & $3.39 \mathrm{E}-32$ & 7. $76 \mathrm{E}-32$ & $1.96 \mathrm{E}-07$ & $2.00 \mathrm{E}-06$ \\
\hline 0.725 & $1.48 E-32$ & $1.51 E-32$ & $3.40 E-32$ & $7.80 E-32$ & $2.24 E-07$ & $2.09 E-06$ \\
\hline 0.750 & $1.48 \mathrm{E}-32$ & $1.51 \mathrm{E}-32$ & $3.41 \mathrm{E}-32$ & $7.83 E-32$ & $2.55 E-07$ & $2.17 \mathrm{E}-06$ \\
\hline 0.775 & $1.48 E-32$ & $1.51 \mathrm{E}-32$ & $3.41 E-32$ & $7.87 E-32$ & $2.97 \mathrm{E}-07$ & $2.27 E-06$ \\
\hline 0.800 & $1.48 \mathrm{E}-32$ & $1.51 E-32$ & $3.42 E-32$ & $7.90 E-32$ & $3.44 \mathrm{E}-07$ & $2.37 \mathrm{E}-06$ \\
\hline 0.825 & $1.48 E-32$ & $1.51 E-32$ & $3.43 E-32$ & $7.93 E-32$ & $4.04 E-07$ & $2.48 E-06$ \\
\hline 0.850 & 1. $48 E-32$ & $1.51 E-32$ & $3.44 E-32$ & $7.97 E-32$ & $4.82 E-07$ & $2.61 E-06$ \\
\hline 0.875 & $1.48 E-32$ & $1.51 E-32$ & $3.44 \mathrm{E}-32$ & $8.00 E-32$ & $5.72 \mathrm{E}-07$ & $2.78 E-06$ \\
\hline 0.900 & $1.48 E-32$ & $1.51 E-32$ & $3.45 E-32$ & $8.03 E-32$ & $7.00 \mathrm{E}-07$ & $2.93 E-06$ \\
\hline 0.925 & $1.48 E-32$ & $1.51 E-32$ & $3.46 \mathrm{E}-32$ & $8.06 E-32$ & $8.87 E-07$ & $3.12 \mathrm{E}-06$ \\
\hline 0.950 & $1.48 \mathrm{E}-32$ & $1.51 \mathrm{E}-32$ & $3.47 E-32$ & $8.11 \mathrm{E}-32$ & $1.14 \mathrm{E}-06$ & $3.39 \mathrm{E}-06$ \\
\hline 0.975 & $1.48 \mathrm{E}-32$ & $1.51 \mathrm{E}-32$ & $3.48 E-32$ & $8.16 \mathrm{E}-32$ & $1.71 \mathrm{E}-06$ & $3.76 \mathrm{E}-06$ \\
\hline 1.000 & $1.48 \mathrm{E}-32$ & $1.51 \mathrm{E}-32$ & $3.50 E-32$ & $8.27 E-32$ & $7.88 \mathrm{E}-06$ & $5.78 \mathrm{E}-06$ \\
\hline
\end{tabular}


RESRAD-OFFSITE, Version 2.5

Probabilistic Dose and Risk Report

Title : RESRAD-OFFSITE External Gamma, Inhalation, and Soil Ingestion for Offsite Reside

File : PBA-1_TC99-DOE-5-1.ROF

Statistics and Cumulative distribution function of Peak Dose from All Pathways in mrem/yr

$\begin{array}{ccccc}\text { Repetition }= & 1 & 2 & 3 \\ \text { Mean } & 1.69 \mathrm{E}-06 & 1.69 \mathrm{E}-06 & 1.69 \mathrm{E}-06 \\ \text { Std. Dev. } & 1.01 \mathrm{E}-06 & 1.01 \mathrm{E}-06 & 1.01 \mathrm{E}-06 \\ \text { Minimum } & 2.04 \mathrm{E}-07 & 2.04 \mathrm{E}-07 & 2.04 \mathrm{E}-07 \\ \text { Maximum } & 9.61 \mathrm{E}-06 & 9.61 \mathrm{E}-06 & 9.61 \mathrm{E}-06\end{array}$

Percentile

$\begin{array}{llll}0.010 \quad 2.93 \mathrm{E}-07 \quad 2.93 \mathrm{E}-07 \quad 2.93 \mathrm{E}-07 & 07\end{array}$

$0.025 \quad 3.81 \mathrm{E}-07 \quad 3.81 \mathrm{E}-07 \quad 3.81 \mathrm{E}-07$

$0.050 \quad 4.67 \mathrm{E}-07 \quad 4.67 \mathrm{E}-07 \quad 4.67 \mathrm{E}-07$

$0.075 \quad 5.53 \mathrm{E}-07 \quad 5.53 \mathrm{E}-07 \quad 5.53 \mathrm{E}-07$

$0.100 \quad 6.13 \mathrm{E}-07 \quad 6.13 \mathrm{E}-07 \quad 6.13 \mathrm{E}-07$

$0.125 \quad 6.75 \mathrm{E}-07 \quad 6.75 \mathrm{E}-07 \quad 6.75 \mathrm{E}-07$

$0.150 \quad 7.29 \mathrm{E}-07 \quad 7.29 \mathrm{E}-07 \quad 7.29 \mathrm{E}-07$

$0.175 \quad 7.91 \mathrm{E}-07 \quad 7.91 \mathrm{E}-07 \quad 7.91 \mathrm{E}-07$

$0.200 \quad 8.40 \mathrm{E}-07 \quad 8.40 \mathrm{E}-07 \quad 8.40 \mathrm{E}-07$

$0.225 \quad 8.98 \mathrm{E}-07 \quad 8.96 \mathrm{E}-07 \quad 8.96 \mathrm{E}-07$
0.2507

$\begin{array}{llll}0.250 \quad 9.54 \mathrm{E}-07 & 9.53 \mathrm{E}-07 & 9.53 \mathrm{E}-07\end{array}$

$0.275 \quad 1.01 \mathrm{E}-06 \quad 1.01 \mathrm{E}-06 \quad 1.01 \mathrm{E}-06$

$0.300 \quad 1.06 \mathrm{E}-06 \quad 1.06 \mathrm{E}-06 \quad 1.06 \mathrm{E}-06$

$0.325 \quad 1.11 \mathrm{E}-06 \quad 1.11 \mathrm{E}-06 \quad 1.11 \mathrm{E}-06$

$0.350 \quad 1.15 \mathrm{E}-06 \quad 1.15 \mathrm{E}-06 \quad 1.15 \mathrm{E}-06$

$\begin{array}{lllll}0.375 & 1.20 \mathrm{E}-06 & 1.20 \mathrm{E}-06 & 1.20 \mathrm{E}-06\end{array}$

$0.400 \quad 1.25 \mathrm{E}-06 \quad 1.25 \mathrm{E}-06 \quad 1.25 \mathrm{E}-06$

$0.425 \quad 1.30 \mathrm{E}-06 \quad 1.30 \mathrm{E}-06 \quad 1.30 \mathrm{E}-06$

$0.450 \quad 1.35 \mathrm{E}-06 \quad 1.35 \mathrm{E}-06 \quad 1.35 \mathrm{E}-06$

$0.475 \quad 1.42 \mathrm{E}-06 \quad 1.41 \mathrm{E}-06 \quad 1.41 \mathrm{E}-06$

$0.500 \quad 1.48 \mathrm{E}-06 \quad 1.47 \mathrm{E}-06 \quad 1.48 \mathrm{E}-06$

$0.525 \quad 1.54 \mathrm{E}-06 \quad 1.53 \mathrm{E}-06 \quad 1.53 \mathrm{E}-06$

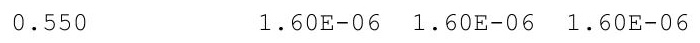

$\begin{array}{llll}0.575 & 1.67 \mathrm{E}-06 & 1.66 \mathrm{E}-06 & 1.66 \mathrm{E}-06\end{array}$

$0.600 \quad 1.73 \mathrm{E}-06 \quad 1.72 \mathrm{E}-06 \quad 1.72 \mathrm{E}-06$

$\begin{array}{lllll}0.625 & 1.79 \mathrm{E}-06 & 1.79 \mathrm{E}-06 & 1.79 \mathrm{E}-06\end{array}$

$0.650 \quad 1.86 \mathrm{E}-06 \quad 1.86 \mathrm{E}-06 \quad 1.86 \mathrm{E}-06$

$\begin{array}{llll}0.675 & 1.94 \mathrm{E}-06 & 1.94 \mathrm{E}-06 & 1.94 \mathrm{E}-06\end{array}$

$0.700 \quad 2.03 E-06 \quad 2.03 E-06 \quad 2.03 E-06$

$\begin{array}{llll}0.725 & 2.11 \mathrm{E}-06 \quad 2.11 \mathrm{E}-06 & 2.11 \mathrm{E}-06\end{array}$

$\begin{array}{llll}0.750 & 2.23 \mathrm{E}-06 & 2.23 \mathrm{E}-06 & 2.23 \mathrm{E}-06\end{array}$

$\begin{array}{llll}0.775 & 2.34 \mathrm{E}-06 & 2.34 \mathrm{E}-06 & 2.34 \mathrm{E}-06\end{array}$

$\begin{array}{llll}0.800 \quad 2.46 \mathrm{E}-06 & 2.46 \mathrm{E}-06 & 2.46 \mathrm{E}-06\end{array}$

$\begin{array}{llll}0.825 & 2.57 \mathrm{E}-06 & 2.57 \mathrm{E}-06 & 2.57 \mathrm{E}-06\end{array}$

$\begin{array}{llll}0.850 \quad 2.71 E-06 & 2.71 \mathrm{E}-06 & 2.71 \mathrm{E}-06\end{array}$

$\begin{array}{llll}0.875 & 2.90 \mathrm{E}-06 & 2.90 \mathrm{E}-06 & 2.90 \mathrm{E}-06\end{array}$

$0.900 \quad 3.06 \mathrm{E}-06 \quad 3.06 \mathrm{E}-06 \quad 3.06 \mathrm{E}-06$

$0.925 \quad 3.31 \mathrm{E}-06 \quad 3.31 \mathrm{E}-06 \quad 3.31 \mathrm{E}-06$

$0.950 \quad 3.60 \mathrm{E}-06 \quad 3.60 \mathrm{E}-06 \quad 3.60 \mathrm{E}-06$

$0.975 \quad 4.07 \mathrm{E}-06 \quad 4.07 \mathrm{E}-06 \quad 4.07 \mathrm{E}-06$

$0.990 \quad 5.08 \mathrm{E}-06 \quad 5.08 \mathrm{E}-06 \quad 5.08 \mathrm{E}-06$ 
RESRAD-OFFSITE, Version 2.5

Probabilistic Dose and Risk Report

Title : RESRAD-OFFSITE External Gamma, Inhalation, and Soil Ingestion for Offsite Reside

File : PBA-1_TC99-DOE-5-1.ROF

Statistics and Cumulative distribution function of Peak Dose from External Ground(Wreleas) in mrem/yr

\begin{tabular}{|c|c|c|c|}
\hline Repetition $=$ & 1 & 2 & 3 \\
\hline Mean & $9.19 \mathrm{E}-07$ & $9.18 \mathrm{E}-07$ & $9.18 \mathrm{E}-07$ \\
\hline Std. Dev. & $5.48 \mathrm{E}-07$ & $5.48 \mathrm{E}-07$ & $5.48 \mathrm{E}-07$ \\
\hline Minimum & $1.10 \mathrm{E}-07$ & $1.10 \mathrm{E}-07$ & $1.10 \mathrm{E}-07$ \\
\hline Maximum & $5.21 \mathrm{E}-06$ & $5.21 \mathrm{E}-06$ & $5.21 \mathrm{E}-06$ \\
\hline
\end{tabular}

Percentile

$\begin{array}{llll}0.010 & 1.59 \mathrm{E}-07 \quad 1.59 \mathrm{E}-07 \quad 1.59 \mathrm{E}-07\end{array}$

$\begin{array}{llll}0.025 & 2.07 \mathrm{E}-07 \quad 2.07 \mathrm{E}-07 & 2.07 \mathrm{E}-07\end{array}$

$\begin{array}{llll}0.050 & 2.53 \mathrm{E}-07 & 2.53 \mathrm{E}-07 & 2.53 \mathrm{E}-07\end{array}$

$0.0753 .00 \mathrm{E}-07 \quad 3.00 \mathrm{E}-07 \quad 3.00 \mathrm{E}-07$

$\begin{array}{llll}0.100 & 3.32 \mathrm{E}-07 & 3.32 \mathrm{E}-07 & 3.32 \mathrm{E}-07\end{array}$

$\begin{array}{llll}0.125 & 3.66 \mathrm{E}-07 & 3.66 \mathrm{E}-07 & 3.66 \mathrm{E}-07\end{array}$

$0.150 \quad 3.95 \mathrm{E}-07 \quad 3.95 \mathrm{E}-07 \quad 3.95 \mathrm{E}-07$

$0.175 \quad 4.29 \mathrm{E}-07 \quad 4.29 \mathrm{E}-07 \quad 4.29 \mathrm{E}-07$

$0.200 \quad 4.55 \mathrm{E}-07 \quad 4.55 \mathrm{E}-07 \quad 4.55 \mathrm{E}-07$

$0.225 \quad 4.87 \mathrm{E}-07 \quad 4.86 \mathrm{E}-07 \quad 4.86 \mathrm{E}-07$

$\begin{array}{llll}0.250 \quad 5.17 \mathrm{E}-07 & 5.17 \mathrm{E}-07 & 5.17 \mathrm{E}-07\end{array}$

$\begin{array}{llll}0.275 & 5.48 \mathrm{E}-07 & 5.48 \mathrm{E}-07 & 5.48 \mathrm{E}-07\end{array}$

$\begin{array}{llll}0.300 & 5.77 \mathrm{E}-07 & 5.77 \mathrm{E}-07 & 5.77 \mathrm{E}-07\end{array}$

$\begin{array}{llll}0.325 & 6.00 \mathrm{E}-07 & 5.99 \mathrm{E}-07 & 6.00 \mathrm{E}-07\end{array}$

$\begin{array}{llll}0.350 & 6.24 \mathrm{E}-07 & 6.23 \mathrm{E}-07 & 6.24 \mathrm{E}-07\end{array}$

$\begin{array}{llll}0.375 & 6.51 \mathrm{E}-07 & 6.50 \mathrm{E}-07 & 6.51 \mathrm{E}-07\end{array}$

$\begin{array}{llll}0.400 & 6.79 \mathrm{E}-07 & 6.79 \mathrm{E}-07 & 6.79 \mathrm{E}-07\end{array}$

$\begin{array}{llll}0.425 & 7.06 \mathrm{E}-07 & 7.05 \mathrm{E}-07 & 7.06 \mathrm{E}-07\end{array}$

$\begin{array}{llll}0.450 & 7.32 \mathrm{E}-07 & 7.31 \mathrm{E}-07 & 7.32 \mathrm{E}-07\end{array}$

$\begin{array}{llll}0.475 & 7.67 \mathrm{E}-07 & 7.66 \mathrm{E}-07 & 7.66 \mathrm{E}-07\end{array}$

$0.500 \quad 8.04 \mathrm{E}-07 \quad 7.99 \mathrm{E}-07 \quad 8.01 \mathrm{E}-07$
0.525

$0.5258 .36 \mathrm{E}-07 \quad 8.30 \mathrm{E}-07 \quad 8.30 \mathrm{E}-07$
0.550

$\begin{array}{llll}0.550 & 8.70 \mathrm{E}-07 & 8.69 \mathrm{E}-07 & 8.69 \mathrm{E}-07\end{array}$

$0.5759 .03 \mathrm{E}-07 \quad 9.00 \mathrm{E}-07 \quad 9.01 \mathrm{E}-07$
0.600

$\begin{array}{llll}0.600 & 9.36 \mathrm{E}-07 & 9.35 \mathrm{E}-07 & 9.35 \mathrm{E}-07\end{array}$

$\begin{array}{llll}0.625 & 9.73 \mathrm{E}-07 & 9.72 \mathrm{E}-07 & 9.72 \mathrm{E}-07\end{array}$

$\begin{array}{llll}0.650 & 1.01 \mathrm{E}-06 & 1.01 \mathrm{E}-06 & 1.01 \mathrm{E}-06\end{array}$

$0.675 \quad 1.05 \mathrm{E}-06 \quad 1.05 \mathrm{E}-06 \quad 1.05 \mathrm{E}-06$

$0.700 \quad 1.10 \mathrm{E}-06 \quad 1.10 \mathrm{E}-06 \quad 1.10 \mathrm{E}-06$

$0.725 \quad 1.15 \mathrm{E}-06 \quad 1.15 \mathrm{E}-06 \quad 1.15 \mathrm{E}-06$

$\begin{array}{llll}0.750 & 1.21 \mathrm{E}-06 & 1.21 \mathrm{E}-06 & 1.21 \mathrm{E}-06\end{array}$

$\begin{array}{llll}0.775 & 1.27 \mathrm{E}-06 & 1.27 \mathrm{E}-06 & 1.27 \mathrm{E}-06\end{array}$

$0.800 \quad 1.33 \mathrm{E}-06 \quad 1.33 \mathrm{E}-06 \quad 1.33 \mathrm{E}-06$

$\begin{array}{llll}0.825 & 1.39 \mathrm{E}-06 & 1.39 \mathrm{E}-06 & 1.39 \mathrm{E}-06\end{array}$

$\begin{array}{llll}0.850 & 1.47 \mathrm{E}-06 & 1.47 \mathrm{E}-06 & 1.47 \mathrm{E}-06\end{array}$

$\begin{array}{llll}0.875 & 1.57 \mathrm{E}-06 & 1.57 \mathrm{E}-06 & 1.57 \mathrm{E}-06\end{array}$

$\begin{array}{llll}0.900 & 1.66 \mathrm{E}-06 & 1.66 \mathrm{E}-06 & 1.66 \mathrm{E}-06\end{array}$

$\begin{array}{llll}0.925 & 1.80 \mathrm{E}-06 & 1.79 \mathrm{E}-06 & 1.80 \mathrm{E}-06\end{array}$

$\begin{array}{llll}0.950 & 1.95 \mathrm{E}-06 & 1.95 \mathrm{E}-06 & 1.95 \mathrm{E}-06\end{array}$

$\begin{array}{llll}0.975 & 2.21 \mathrm{E}-06 & 2.21 \mathrm{E}-06 & 2.21 \mathrm{E}-06\end{array}$

$\begin{array}{llll}0.990 & 2.76 \mathrm{E}-06 & 2.76 \mathrm{E}-06 & 2.76 \mathrm{E}-06\end{array}$ 
RESRAD-OFFSITE, Version 2.5

Probabilistic Dose and Risk Report

Title : RESRAD-OFFSITE External Gamma, Inhalation, and Soil Ingestion for offsite Reside

File : PBA-1_TC99-DOE-5-1.ROF

Statistics and Cumulative distribution function of Peak Dose from Fish Ingestion in mrem/yr

$\begin{array}{rcccc}\text { Repetition }= & 1 & 2 & 3 \\ \text { Mean } & & 0.00 \mathrm{E}+00 & 0.00 \mathrm{E}+00 & 0.00 \mathrm{E}+00 \\ \text { Std. Dev. } & 0.00 \mathrm{E}+00 & 0.00 \mathrm{E}+00 & 0.00 \mathrm{E}+00 \\ \text { Minimum } & 0.00 \mathrm{E}+00 & 0.00 \mathrm{E}+00 & 0.00 \mathrm{E}+00 \\ \text { Maximum } & 0.00 \mathrm{E}+00 & 0.00 \mathrm{E}+00 & 0.00 \mathrm{E}+00\end{array}$

Percentile

$\begin{array}{llll}0.010 & 0.00 \mathrm{E}+00 \quad 0.00 \mathrm{E}+00 & 0.00 \mathrm{E}+00\end{array}$

$\begin{array}{llll}0.025 & 0.00 \mathrm{E}+00 \quad 0.00 \mathrm{E}+00 & 0.00 \mathrm{E}+00\end{array}$

$\begin{array}{llll}0.050 & 0.00 \mathrm{E}+00 & 0.00 \mathrm{E}+00 & 0.00 \mathrm{E}+00\end{array}$

$\begin{array}{llll}0.075 & 0.00 \mathrm{E}+00 & 0.00 \mathrm{E}+00 & 0.00 \mathrm{E}+00\end{array}$

$\begin{array}{llll}0.100 & 0.00 \mathrm{E}+00 & 0.00 \mathrm{E}+00 & 0.00 \mathrm{E}+00\end{array}$

$\begin{array}{llll}0.125 & 0.00 \mathrm{E}+00 & 0.00 \mathrm{E}+00 & 0.00 \mathrm{E}+00\end{array}$

$\begin{array}{lllll}0.150 & 0.00 \mathrm{E}+00 & 0.00 \mathrm{E}+00 & 0.00 \mathrm{E}+00\end{array}$

$\begin{array}{lllll}0.175 & 0.00 \mathrm{E}+00 & 0.00 \mathrm{E}+00 & 0.00 \mathrm{E}+00\end{array}$

$\begin{array}{lllll}0.200 & 0.00 \mathrm{E}+00 & 0.00 \mathrm{E}+00 & 0.00 \mathrm{E}+00\end{array}$

$\begin{array}{lllll}0.225 & 0.00 \mathrm{E}+00 & 0.00 \mathrm{E}+00 & 0.00 \mathrm{E}+00\end{array}$

$\begin{array}{lllll}0.250 & 0.00 \mathrm{E}+00 & 0.00 \mathrm{E}+00 & 0.00 \mathrm{E}+00\end{array}$

$\begin{array}{lllll}0.275 & 0.00 \mathrm{E}+00 & 0.00 \mathrm{E}+00 & 0.00 \mathrm{E}+00\end{array}$

$\begin{array}{lllll}0.300 & 0.00 \mathrm{E}+00 & 0.00 \mathrm{E}+00 & 0.00 \mathrm{E}+00\end{array}$

$\begin{array}{lllll}0.325 & 0.00 \mathrm{E}+00 & 0.00 \mathrm{E}+00 & 0.00 \mathrm{E}+00\end{array}$

$\begin{array}{lllll}0.350 & 0.00 \mathrm{E}+00 & 0.00 \mathrm{E}+00 & 0.00 \mathrm{E}+00\end{array}$

$\begin{array}{lllll}0.375 & 0.00 \mathrm{E}+00 & 0.00 \mathrm{E}+00 & 0.00 \mathrm{E}+00\end{array}$

$\begin{array}{lllll}0.400 & 0.00 \mathrm{E}+00 & 0.00 \mathrm{E}+00 & 0.00 \mathrm{E}+00\end{array}$

$\begin{array}{lllll}0.425 & 0.00 \mathrm{E}+00 & 0.00 \mathrm{E}+00 & 0.00 \mathrm{E}+00\end{array}$

$\begin{array}{lllll}0.450 & 0.00 \mathrm{E}+00 & 0.00 \mathrm{E}+00 & 0.00 \mathrm{E}+00\end{array}$

$\begin{array}{lllll}0.475 & 0.00 \mathrm{E}+00 & 0.00 \mathrm{E}+00 & 0.00 \mathrm{E}+00\end{array}$

$\begin{array}{lllll}0.500 & 0.00 \mathrm{E}+00 & 0.00 \mathrm{E}+00 & 0.00 \mathrm{E}+00\end{array}$

$\begin{array}{lllll}0.525 & 0.00 \mathrm{E}+00 & 0.00 \mathrm{E}+00 & 0.00 \mathrm{E}+00\end{array}$

$\begin{array}{lllll}0.550 & 0.00 \mathrm{E}+00 & 0.00 \mathrm{E}+00 & 0.00 \mathrm{E}+00\end{array}$

$\begin{array}{lllll}0.575 & 0.00 \mathrm{E}+00 & 0.00 \mathrm{E}+00 & 0.00 \mathrm{E}+00\end{array}$

$\begin{array}{lllll}0.600 & 0.00 \mathrm{E}+00 & 0.00 \mathrm{E}+00 & 0.00 \mathrm{E}+00\end{array}$

$\begin{array}{lllll}0.625 & 0.00 \mathrm{E}+00 & 0.00 \mathrm{E}+00 & 0.00 \mathrm{E}+00\end{array}$

$\begin{array}{lllll}0.650 & 0.00 \mathrm{E}+00 & 0.00 \mathrm{E}+00 & 0.00 \mathrm{E}+00\end{array}$

$\begin{array}{lllll}0.675 & 0.00 \mathrm{E}+00 & 0.00 \mathrm{E}+00 & 0.00 \mathrm{E}+00\end{array}$

$\begin{array}{lllll}0.700 & 0.00 \mathrm{E}+00 & 0.00 \mathrm{E}+00 & 0.00 \mathrm{E}+00\end{array}$

$\begin{array}{lllll}0.725 & 0.00 \mathrm{E}+00 & 0.00 \mathrm{E}+00 & 0.00 \mathrm{E}+00\end{array}$

$\begin{array}{lllll}0.750 & 0.00 \mathrm{E}+00 & 0.00 \mathrm{E}+00 & 0.00 \mathrm{E}+00\end{array}$

$\begin{array}{lllll}0.775 & 0.00 \mathrm{E}+00 & 0.00 \mathrm{E}+00 & 0.00 \mathrm{E}+00\end{array}$

$\begin{array}{lllll}0.800 & 0.00 \mathrm{E}+00 & 0.00 \mathrm{E}+00 & 0.00 \mathrm{E}+00\end{array}$

$\begin{array}{lllll}0.825 & 0.00 \mathrm{E}+00 & 0.00 \mathrm{E}+00 & 0.00 \mathrm{E}+00\end{array}$

$\begin{array}{lllll}0.850 & 0.00 \mathrm{E}+00 & 0.00 \mathrm{E}+00 & 0.00 \mathrm{E}+00\end{array}$

$\begin{array}{lllll}0.875 & 0.00 \mathrm{E}+00 & 0.00 \mathrm{E}+00 & 0.00 \mathrm{E}+00\end{array}$

$\begin{array}{lllll}0.900 & 0.00 \mathrm{E}+00 & 0.00 \mathrm{E}+00 & 0.00 \mathrm{E}+00\end{array}$

$\begin{array}{lllll}0.925 & 0.00 \mathrm{E}+00 & 0.00 \mathrm{E}+00 & 0.00 \mathrm{E}+00\end{array}$

$\begin{array}{llll}0.950 & 0.00 \mathrm{E}+00 & 0.00 \mathrm{E}+00 & 0.00 \mathrm{E}+00\end{array}$

$\begin{array}{lllll}0.975 & 0.00 \mathrm{E}+00 & 0.00 \mathrm{E}+00 & 0.00 \mathrm{E}+00\end{array}$

$\begin{array}{llll}0.990 & 0.00 \mathrm{E}+00 & 0.00 \mathrm{E}+00 & 0.00 \mathrm{E}+00\end{array}$ 
RESRAD-OFFSITE, Version 2.5

Probabilistic Dose and Risk Report

Title : RESRAD-OFFSITE External Gamma, Inhalation, and Soil Ingestion for offsite Reside

File : PBA-1_TC99-DOE-5-1.ROF

Statistics and Cumulative distribution function of Peak Dose from Radon (Waterrelease) in mrem/yr

$\begin{array}{rcccc}\text { Repetition }= & 1 & 2 & 3 \\ \text { Mean } & & 0.00 \mathrm{E}+00 & 0.00 \mathrm{E}+00 & 0.00 \mathrm{E}+00 \\ \text { Std. Dev. } & 0.00 \mathrm{E}+00 & 0.00 \mathrm{E}+00 & 0.00 \mathrm{E}+00 \\ \text { Minimum } & 0.00 \mathrm{E}+00 & 0.00 \mathrm{E}+00 & 0.00 \mathrm{E}+00 \\ \text { Maximum } & 0.00 \mathrm{E}+00 & 0.00 \mathrm{E}+00 & 0.00 \mathrm{E}+00\end{array}$

Percentile

$\begin{array}{llll}0.010 & 0.00 \mathrm{E}+00 \quad 0.00 \mathrm{E}+00 & 0.00 \mathrm{E}+00\end{array}$

$\begin{array}{llll}0.025 & 0.00 \mathrm{E}+00 & 0.00 \mathrm{E}+00 & 0.00 \mathrm{E}+00\end{array}$

$\begin{array}{lllll}0.050 & 0.00 \mathrm{E}+00 & 0.00 \mathrm{E}+00 & 0.00 \mathrm{E}+00\end{array}$

$\begin{array}{lllll}0.075 & 0.00 \mathrm{E}+00 & 0.00 \mathrm{E}+00 & 0.00 \mathrm{E}+00\end{array}$

$\begin{array}{llll}0.100 & 0.00 \mathrm{E}+00 & 0.00 \mathrm{E}+00 & 0.00 \mathrm{E}+00\end{array}$

$\begin{array}{lllll}0.125 & 0.00 \mathrm{E}+00 & 0.00 \mathrm{E}+00 & 0.00 \mathrm{E}+00\end{array}$

$\begin{array}{lllll}0.150 & 0.00 \mathrm{E}+00 & 0.00 \mathrm{E}+00 & 0.00 \mathrm{E}+00\end{array}$

$\begin{array}{lllll}0.175 & 0.00 \mathrm{E}+00 & 0.00 \mathrm{E}+00 & 0.00 \mathrm{E}+00\end{array}$

$\begin{array}{lllll}0.200 & 0.00 \mathrm{E}+00 & 0.00 \mathrm{E}+00 & 0.00 \mathrm{E}+00\end{array}$

$\begin{array}{lllll}0.225 & 0.00 \mathrm{E}+00 & 0.00 \mathrm{E}+00 & 0.00 \mathrm{E}+00\end{array}$

$\begin{array}{lllll}0.250 & 0.00 \mathrm{E}+00 & 0.00 \mathrm{E}+00 & 0.00 \mathrm{E}+00\end{array}$

$\begin{array}{lllll}0.275 & 0.00 \mathrm{E}+00 & 0.00 \mathrm{E}+00 & 0.00 \mathrm{E}+00\end{array}$

$\begin{array}{lllll}0.300 & 0.00 \mathrm{E}+00 & 0.00 \mathrm{E}+00 & 0.00 \mathrm{E}+00\end{array}$

$\begin{array}{lllll}0.325 & 0.00 \mathrm{E}+00 & 0.00 \mathrm{E}+00 & 0.00 \mathrm{E}+00\end{array}$

$\begin{array}{lllll}0.350 & 0.00 \mathrm{E}+00 & 0.00 \mathrm{E}+00 & 0.00 \mathrm{E}+00\end{array}$

$\begin{array}{lllll}0.375 & 0.00 \mathrm{E}+00 & 0.00 \mathrm{E}+00 & 0.00 \mathrm{E}+00\end{array}$

$\begin{array}{lllll}0.400 & 0.00 \mathrm{E}+00 & 0.00 \mathrm{E}+00 & 0.00 \mathrm{E}+00\end{array}$

$\begin{array}{lllll}0.425 & 0.00 \mathrm{E}+00 & 0.00 \mathrm{E}+00 & 0.00 \mathrm{E}+00\end{array}$

$\begin{array}{lllll}0.450 & 0.00 \mathrm{E}+00 & 0.00 \mathrm{E}+00 & 0.00 \mathrm{E}+00\end{array}$

$\begin{array}{lllll}0.475 & 0.00 \mathrm{E}+00 & 0.00 \mathrm{E}+00 & 0.00 \mathrm{E}+00\end{array}$

$\begin{array}{lllll}0.500 & 0.00 \mathrm{E}+00 & 0.00 \mathrm{E}+00 & 0.00 \mathrm{E}+00\end{array}$

$\begin{array}{lllll}0.525 & 0.00 \mathrm{E}+00 & 0.00 \mathrm{E}+00 & 0.00 \mathrm{E}+00\end{array}$

$\begin{array}{lllll}0.550 & 0.00 \mathrm{E}+00 & 0.00 \mathrm{E}+00 & 0.00 \mathrm{E}+00\end{array}$

$\begin{array}{lllll}0.575 & 0.00 \mathrm{E}+00 & 0.00 \mathrm{E}+00 & 0.00 \mathrm{E}+00\end{array}$

$\begin{array}{lllll}0.600 & 0.00 \mathrm{E}+00 & 0.00 \mathrm{E}+00 & 0.00 \mathrm{E}+00\end{array}$

$\begin{array}{lllll}0.625 & 0.00 \mathrm{E}+00 & 0.00 \mathrm{E}+00 & 0.00 \mathrm{E}+00\end{array}$

$\begin{array}{lllll}0.650 & 0.00 \mathrm{E}+00 & 0.00 \mathrm{E}+00 & 0.00 \mathrm{E}+00\end{array}$

$\begin{array}{lllll}0.675 & 0.00 \mathrm{E}+00 & 0.00 \mathrm{E}+00 & 0.00 \mathrm{E}+00\end{array}$

$\begin{array}{lllll}0.700 & 0.00 \mathrm{E}+00 & 0.00 \mathrm{E}+00 & 0.00 \mathrm{E}+00\end{array}$

$\begin{array}{lllll}0.725 & 0.00 \mathrm{E}+00 & 0.00 \mathrm{E}+00 & 0.00 \mathrm{E}+00\end{array}$

$\begin{array}{lllll}0.750 & 0.00 \mathrm{E}+00 & 0.00 \mathrm{E}+00 & 0.00 \mathrm{E}+00\end{array}$

$\begin{array}{lllll}0.775 & 0.00 \mathrm{E}+00 & 0.00 \mathrm{E}+00 & 0.00 \mathrm{E}+00\end{array}$

$\begin{array}{lllll}0.800 & 0.00 \mathrm{E}+00 & 0.00 \mathrm{E}+00 & 0.00 \mathrm{E}+00\end{array}$

$\begin{array}{lllll}0.825 & 0.00 \mathrm{E}+00 & 0.00 \mathrm{E}+00 & 0.00 \mathrm{E}+00\end{array}$

$\begin{array}{lllll}0.850 & 0.00 \mathrm{E}+00 & 0.00 \mathrm{E}+00 & 0.00 \mathrm{E}+00\end{array}$

$\begin{array}{lllll}0.875 & 0.00 \mathrm{E}+00 & 0.00 \mathrm{E}+00 & 0.00 \mathrm{E}+00\end{array}$

$\begin{array}{lllll}0.900 & 0.00 \mathrm{E}+00 & 0.00 \mathrm{E}+00 & 0.00 \mathrm{E}+00\end{array}$

$\begin{array}{lllll}0.925 & 0.00 \mathrm{E}+00 & 0.00 \mathrm{E}+00 & 0.00 \mathrm{E}+00\end{array}$

$\begin{array}{lllll}0.950 & 0.00 \mathrm{E}+00 & 0.00 \mathrm{E}+00 & 0.00 \mathrm{E}+00\end{array}$

$\begin{array}{lllll}0.975 & 0.00 \mathrm{E}+00 & 0.00 \mathrm{E}+00 & 0.00 \mathrm{E}+00\end{array}$

$\begin{array}{llll}0.990 & 0.00 \mathrm{E}+00 & 0.00 \mathrm{E}+00 & 0.00 \mathrm{E}+00\end{array}$ 
RESRAD-OFFSITE, Version 2.5

Probabilistic Dose and Risk Report

Title : RESRAD-OFFSITE External Gamma, Inhalation, and Soil Ingestion for offsite Reside

File : PBA-1_TC99-DOE-5-1.ROF

Statistics and Cumulative distribution function of Peak Dose from Plant (Waterrelease) in mrem/yr

$\begin{array}{rcccc}\text { Repetition }= & 1 & 2 & 3 \\ \text { Mean } & & 0.00 \mathrm{E}+00 & 0.00 \mathrm{E}+00 & 0.00 \mathrm{E}+00 \\ \text { Std. Dev. } & 0.00 \mathrm{E}+00 & 0.00 \mathrm{E}+00 & 0.00 \mathrm{E}+00 \\ \text { Minimum } & 0.00 \mathrm{E}+00 & 0.00 \mathrm{E}+00 & 0.00 \mathrm{E}+00 \\ \text { Maximum } & 0.00 \mathrm{E}+00 & 0.00 \mathrm{E}+00 & 0.00 \mathrm{E}+00\end{array}$

Percentile

$\begin{array}{llll}0.010 & 0.00 \mathrm{E}+00 \quad 0.00 \mathrm{E}+00 & 0.00 \mathrm{E}+00\end{array}$

$\begin{array}{llll}0.025 & 0.00 \mathrm{E}+00 & 0.00 \mathrm{E}+00 & 0.00 \mathrm{E}+00\end{array}$

$\begin{array}{lllll}0.050 & 0.00 \mathrm{E}+00 & 0.00 \mathrm{E}+00 & 0.00 \mathrm{E}+00\end{array}$

$\begin{array}{lllll}0.075 & 0.00 \mathrm{E}+00 & 0.00 \mathrm{E}+00 & 0.00 \mathrm{E}+00\end{array}$

$\begin{array}{llll}0.100 & 0.00 \mathrm{E}+00 & 0.00 \mathrm{E}+00 & 0.00 \mathrm{E}+00\end{array}$

$\begin{array}{lllll}0.125 & 0.00 \mathrm{E}+00 & 0.00 \mathrm{E}+00 & 0.00 \mathrm{E}+00\end{array}$

$\begin{array}{lllll}0.150 & 0.00 \mathrm{E}+00 & 0.00 \mathrm{E}+00 & 0.00 \mathrm{E}+00\end{array}$

$\begin{array}{lllll}0.175 & 0.00 \mathrm{E}+00 & 0.00 \mathrm{E}+00 & 0.00 \mathrm{E}+00\end{array}$

$\begin{array}{lllll}0.200 & 0.00 \mathrm{E}+00 & 0.00 \mathrm{E}+00 & 0.00 \mathrm{E}+00\end{array}$

$\begin{array}{lllll}0.225 & 0.00 \mathrm{E}+00 & 0.00 \mathrm{E}+00 & 0.00 \mathrm{E}+00\end{array}$

$\begin{array}{lllll}0.250 & 0.00 \mathrm{E}+00 & 0.00 \mathrm{E}+00 & 0.00 \mathrm{E}+00\end{array}$

$\begin{array}{lllll}0.275 & 0.00 \mathrm{E}+00 & 0.00 \mathrm{E}+00 & 0.00 \mathrm{E}+00\end{array}$

$\begin{array}{lllll}0.300 & 0.00 \mathrm{E}+00 & 0.00 \mathrm{E}+00 & 0.00 \mathrm{E}+00\end{array}$

$\begin{array}{lllll}0.325 & 0.00 \mathrm{E}+00 & 0.00 \mathrm{E}+00 & 0.00 \mathrm{E}+00\end{array}$

$\begin{array}{lllll}0.350 & 0.00 \mathrm{E}+00 & 0.00 \mathrm{E}+00 & 0.00 \mathrm{E}+00\end{array}$

$\begin{array}{lllll}0.375 & 0.00 \mathrm{E}+00 & 0.00 \mathrm{E}+00 & 0.00 \mathrm{E}+00\end{array}$

$\begin{array}{lllll}0.400 & 0.00 \mathrm{E}+00 & 0.00 \mathrm{E}+00 & 0.00 \mathrm{E}+00\end{array}$

$\begin{array}{lllll}0.425 & 0.00 \mathrm{E}+00 & 0.00 \mathrm{E}+00 & 0.00 \mathrm{E}+00\end{array}$

$\begin{array}{lllll}0.450 & 0.00 \mathrm{E}+00 & 0.00 \mathrm{E}+00 & 0.00 \mathrm{E}+00\end{array}$

$\begin{array}{lllll}0.475 & 0.00 \mathrm{E}+00 & 0.00 \mathrm{E}+00 & 0.00 \mathrm{E}+00\end{array}$

$\begin{array}{lllll}0.500 & 0.00 \mathrm{E}+00 & 0.00 \mathrm{E}+00 & 0.00 \mathrm{E}+00\end{array}$

$\begin{array}{lllll}0.525 & 0.00 \mathrm{E}+00 & 0.00 \mathrm{E}+00 & 0.00 \mathrm{E}+00\end{array}$

$\begin{array}{lllll}0.550 & 0.00 \mathrm{E}+00 & 0.00 \mathrm{E}+00 & 0.00 \mathrm{E}+00\end{array}$

$\begin{array}{lllll}0.575 & 0.00 \mathrm{E}+00 & 0.00 \mathrm{E}+00 & 0.00 \mathrm{E}+00\end{array}$

$\begin{array}{lllll}0.600 & 0.00 \mathrm{E}+00 & 0.00 \mathrm{E}+00 & 0.00 \mathrm{E}+00\end{array}$

$\begin{array}{lllll}0.625 & 0.00 \mathrm{E}+00 & 0.00 \mathrm{E}+00 & 0.00 \mathrm{E}+00\end{array}$

$\begin{array}{lllll}0.650 & 0.00 \mathrm{E}+00 & 0.00 \mathrm{E}+00 & 0.00 \mathrm{E}+00\end{array}$

$\begin{array}{lllll}0.675 & 0.00 \mathrm{E}+00 & 0.00 \mathrm{E}+00 & 0.00 \mathrm{E}+00\end{array}$

$\begin{array}{lllll}0.700 & 0.00 \mathrm{E}+00 & 0.00 \mathrm{E}+00 & 0.00 \mathrm{E}+00\end{array}$

$\begin{array}{lllll}0.725 & 0.00 \mathrm{E}+00 & 0.00 \mathrm{E}+00 & 0.00 \mathrm{E}+00\end{array}$

$\begin{array}{lllll}0.750 & 0.00 \mathrm{E}+00 & 0.00 \mathrm{E}+00 & 0.00 \mathrm{E}+00\end{array}$

$\begin{array}{lllll}0.775 & 0.00 \mathrm{E}+00 & 0.00 \mathrm{E}+00 & 0.00 \mathrm{E}+00\end{array}$

$\begin{array}{lllll}0.800 & 0.00 \mathrm{E}+00 & 0.00 \mathrm{E}+00 & 0.00 \mathrm{E}+00\end{array}$

$\begin{array}{lllll}0.825 & 0.00 \mathrm{E}+00 & 0.00 \mathrm{E}+00 & 0.00 \mathrm{E}+00\end{array}$

$\begin{array}{lllll}0.850 & 0.00 \mathrm{E}+00 & 0.00 \mathrm{E}+00 & 0.00 \mathrm{E}+00\end{array}$

$\begin{array}{lllll}0.875 & 0.00 \mathrm{E}+00 & 0.00 \mathrm{E}+00 & 0.00 \mathrm{E}+00\end{array}$

$\begin{array}{lllll}0.900 & 0.00 \mathrm{E}+00 & 0.00 \mathrm{E}+00 & 0.00 \mathrm{E}+00\end{array}$

$\begin{array}{lllll}0.925 & 0.00 \mathrm{E}+00 & 0.00 \mathrm{E}+00 & 0.00 \mathrm{E}+00\end{array}$

$\begin{array}{lllll}0.950 & 0.00 \mathrm{E}+00 & 0.00 \mathrm{E}+00 & 0.00 \mathrm{E}+00\end{array}$

$\begin{array}{lllll}0.975 & 0.00 \mathrm{E}+00 & 0.00 \mathrm{E}+00 & 0.00 \mathrm{E}+00\end{array}$

$\begin{array}{llll}0.990 & 0.00 \mathrm{E}+00 & 0.00 \mathrm{E}+00 & 0.00 \mathrm{E}+00\end{array}$ 
RESRAD-OFFSITE, Version 2.5

Probabilistic Dose and Risk Report

Title : RESRAD-OFFSITE External Gamma, Inhalation, and Soil Ingestion for offsite Reside

File : PBA-1_TC99-DOE-5-1.ROF

Statistics and Cumulative distribution function of Peak Dose from Meat (Waterrelease) in mrem/yr

$\begin{array}{ccccc}\text { Repetition }= & 1 & 2 & 3 \\ \begin{array}{c}\text { Mean } \\ \text { Std. Dev. }\end{array} & 0.00 \mathrm{E}+00 & 0.00 \mathrm{E}+00 & 0.00 \mathrm{E}+00 \\ \text { Minimum } & 0.00 \mathrm{E}+00 & 0.00 \mathrm{E}+00 & 0.00 \mathrm{E}+00 \\ \text { Maximum } & 0.00 \mathrm{E}+00 & 0.00 \mathrm{E}+00 & 0.00 \mathrm{E}+00 \\ & 0.00 \mathrm{E}+00 & 0.00 \mathrm{E}+00 & 0.00 \mathrm{E}+00\end{array}$

Percentile

$\begin{array}{llll}0.010 & 0.00 \mathrm{E}+00 \quad 0.00 \mathrm{E}+00 & 0.00 \mathrm{E}+00\end{array}$

$\begin{array}{llll}0.025 & 0.00 \mathrm{E}+00 & 0.00 \mathrm{E}+00 & 0.00 \mathrm{E}+00\end{array}$

$\begin{array}{lllll}0.050 & 0.00 \mathrm{E}+00 & 0.00 \mathrm{E}+00 & 0.00 \mathrm{E}+00\end{array}$

$\begin{array}{lllll}0.075 & 0.00 \mathrm{E}+00 & 0.00 \mathrm{E}+00 & 0.00 \mathrm{E}+00\end{array}$

$\begin{array}{llll}0.100 & 0.00 \mathrm{E}+00 & 0.00 \mathrm{E}+00 & 0.00 \mathrm{E}+00\end{array}$

$\begin{array}{lllll}0.125 & 0.00 \mathrm{E}+00 & 0.00 \mathrm{E}+00 & 0.00 \mathrm{E}+00\end{array}$

$\begin{array}{lllll}0.150 & 0.00 \mathrm{E}+00 & 0.00 \mathrm{E}+00 & 0.00 \mathrm{E}+00\end{array}$

$\begin{array}{lllll}0.175 & 0.00 \mathrm{E}+00 & 0.00 \mathrm{E}+00 & 0.00 \mathrm{E}+00\end{array}$

$\begin{array}{lllll}0.200 & 0.00 \mathrm{E}+00 & 0.00 \mathrm{E}+00 & 0.00 \mathrm{E}+00\end{array}$

$\begin{array}{lllll}0.225 & 0.00 \mathrm{E}+00 & 0.00 \mathrm{E}+00 & 0.00 \mathrm{E}+00\end{array}$

$\begin{array}{lllll}0.250 & 0.00 \mathrm{E}+00 & 0.00 \mathrm{E}+00 & 0.00 \mathrm{E}+00\end{array}$

$\begin{array}{lllll}0.275 & 0.00 \mathrm{E}+00 & 0.00 \mathrm{E}+00 & 0.00 \mathrm{E}+00\end{array}$

$\begin{array}{lllll}0.300 & 0.00 \mathrm{E}+00 & 0.00 \mathrm{E}+00 & 0.00 \mathrm{E}+00\end{array}$

$\begin{array}{lllll}0.325 & 0.00 \mathrm{E}+00 & 0.00 \mathrm{E}+00 & 0.00 \mathrm{E}+00\end{array}$

$\begin{array}{lllll}0.350 & 0.00 \mathrm{E}+00 & 0.00 \mathrm{E}+00 & 0.00 \mathrm{E}+00\end{array}$

$\begin{array}{lllll}0.375 & 0.00 \mathrm{E}+00 & 0.00 \mathrm{E}+00 & 0.00 \mathrm{E}+00\end{array}$

$\begin{array}{lllll}0.400 & 0.00 \mathrm{E}+00 & 0.00 \mathrm{E}+00 & 0.00 \mathrm{E}+00\end{array}$

$\begin{array}{lllll}0.425 & 0.00 \mathrm{E}+00 & 0.00 \mathrm{E}+00 & 0.00 \mathrm{E}+00\end{array}$

$\begin{array}{lllll}0.450 & 0.00 \mathrm{E}+00 & 0.00 \mathrm{E}+00 & 0.00 \mathrm{E}+00\end{array}$

$\begin{array}{lllll}0.475 & 0.00 \mathrm{E}+00 & 0.00 \mathrm{E}+00 & 0.00 \mathrm{E}+00\end{array}$

$\begin{array}{lllll}0.500 & 0.00 \mathrm{E}+00 & 0.00 \mathrm{E}+00 & 0.00 \mathrm{E}+00\end{array}$

$\begin{array}{lllll}0.525 & 0.00 \mathrm{E}+00 & 0.00 \mathrm{E}+00 & 0.00 \mathrm{E}+00\end{array}$

$\begin{array}{lllll}0.550 & 0.00 \mathrm{E}+00 & 0.00 \mathrm{E}+00 & 0.00 \mathrm{E}+00\end{array}$

$\begin{array}{lllll}0.575 & 0.00 \mathrm{E}+00 & 0.00 \mathrm{E}+00 & 0.00 \mathrm{E}+00\end{array}$

$\begin{array}{lllll}0.600 & 0.00 \mathrm{E}+00 & 0.00 \mathrm{E}+00 & 0.00 \mathrm{E}+00\end{array}$

$\begin{array}{lllll}0.625 & 0.00 \mathrm{E}+00 & 0.00 \mathrm{E}+00 & 0.00 \mathrm{E}+00\end{array}$

$\begin{array}{lllll}0.650 & 0.00 \mathrm{E}+00 & 0.00 \mathrm{E}+00 & 0.00 \mathrm{E}+00\end{array}$

$\begin{array}{lllll}0.675 & 0.00 \mathrm{E}+00 & 0.00 \mathrm{E}+00 & 0.00 \mathrm{E}+00\end{array}$

$\begin{array}{lllll}0.700 & 0.00 \mathrm{E}+00 & 0.00 \mathrm{E}+00 & 0.00 \mathrm{E}+00\end{array}$

$\begin{array}{lllll}0.725 & 0.00 \mathrm{E}+00 & 0.00 \mathrm{E}+00 & 0.00 \mathrm{E}+00\end{array}$

$\begin{array}{lllll}0.750 & 0.00 \mathrm{E}+00 & 0.00 \mathrm{E}+00 & 0.00 \mathrm{E}+00\end{array}$

$\begin{array}{lllll}0.775 & 0.00 \mathrm{E}+00 & 0.00 \mathrm{E}+00 & 0.00 \mathrm{E}+00\end{array}$

$\begin{array}{lllll}0.800 & 0.00 \mathrm{E}+00 & 0.00 \mathrm{E}+00 & 0.00 \mathrm{E}+00\end{array}$

$\begin{array}{lllll}0.825 & 0.00 \mathrm{E}+00 & 0.00 \mathrm{E}+00 & 0.00 \mathrm{E}+00\end{array}$

$\begin{array}{lllll}0.850 & 0.00 \mathrm{E}+00 & 0.00 \mathrm{E}+00 & 0.00 \mathrm{E}+00\end{array}$

$\begin{array}{lllll}0.875 & 0.00 \mathrm{E}+00 & 0.00 \mathrm{E}+00 & 0.00 \mathrm{E}+00\end{array}$

$\begin{array}{lllll}0.900 & 0.00 \mathrm{E}+00 & 0.00 \mathrm{E}+00 & 0.00 \mathrm{E}+00\end{array}$

$\begin{array}{lllll}0.925 & 0.00 \mathrm{E}+00 & 0.00 \mathrm{E}+00 & 0.00 \mathrm{E}+00\end{array}$

$\begin{array}{lllll}0.950 & 0.00 \mathrm{E}+00 & 0.00 \mathrm{E}+00 & 0.00 \mathrm{E}+00\end{array}$

$\begin{array}{lllll}0.975 & 0.00 \mathrm{E}+00 & 0.00 \mathrm{E}+00 & 0.00 \mathrm{E}+00\end{array}$

$\begin{array}{lllll}0.990 & 0.00 \mathrm{E}+00 & 0.00 \mathrm{E}+00 & 0.00 \mathrm{E}+00\end{array}$ 
RESRAD-OFFSITE, Version 2.5

Probabilistic Dose and Risk Report

Title : RESRAD-OFFSITE External Gamma, Inhalation, and Soil Ingestion for offsite Reside

File : PBA-1_TC99-DOE-5-1.ROF

Statistics and Cumulative distribution function of Peak Dose from Milk (Waterrelease) in mrem/yr

$\begin{array}{ccccc}\text { Repetition }= & 1 & 2 & 3 \\ \begin{array}{c}\text { Mean } \\ \text { Std. Dev. }\end{array} & 0.00 \mathrm{E}+00 & 0.00 \mathrm{E}+00 & 0.00 \mathrm{E}+00 \\ \text { Minimum } & 0.00 \mathrm{E}+00 & 0.00 \mathrm{E}+00 & 0.00 \mathrm{E}+00 \\ \text { Maximum } & 0.00 \mathrm{E}+00 & 0.00 \mathrm{E}+00 & 0.00 \mathrm{E}+00 \\ & 0.00 \mathrm{E}+00 & 0.00 \mathrm{E}+00 & 0.00 \mathrm{E}+00\end{array}$

Percentile

$\begin{array}{llll}0.010 & 0.00 \mathrm{E}+00 \quad 0.00 \mathrm{E}+00 & 0.00 \mathrm{E}+00\end{array}$

$\begin{array}{llll}0.025 & 0.00 \mathrm{E}+00 & 0.00 \mathrm{E}+00 & 0.00 \mathrm{E}+00\end{array}$

$\begin{array}{lllll}0.050 & 0.00 \mathrm{E}+00 & 0.00 \mathrm{E}+00 & 0.00 \mathrm{E}+00\end{array}$

$\begin{array}{lllll}0.075 & 0.00 \mathrm{E}+00 & 0.00 \mathrm{E}+00 & 0.00 \mathrm{E}+00\end{array}$

$\begin{array}{llll}0.100 & 0.00 \mathrm{E}+00 & 0.00 \mathrm{E}+00 & 0.00 \mathrm{E}+00\end{array}$

$\begin{array}{lllll}0.125 & 0.00 \mathrm{E}+00 & 0.00 \mathrm{E}+00 & 0.00 \mathrm{E}+00\end{array}$

$\begin{array}{lllll}0.150 & 0.00 \mathrm{E}+00 & 0.00 \mathrm{E}+00 & 0.00 \mathrm{E}+00\end{array}$

$\begin{array}{lllll}0.175 & 0.00 \mathrm{E}+00 & 0.00 \mathrm{E}+00 & 0.00 \mathrm{E}+00\end{array}$

$\begin{array}{lllll}0.200 & 0.00 \mathrm{E}+00 & 0.00 \mathrm{E}+00 & 0.00 \mathrm{E}+00\end{array}$

$\begin{array}{lllll}0.225 & 0.00 \mathrm{E}+00 & 0.00 \mathrm{E}+00 & 0.00 \mathrm{E}+00\end{array}$

$\begin{array}{lllll}0.250 & 0.00 \mathrm{E}+00 & 0.00 \mathrm{E}+00 & 0.00 \mathrm{E}+00\end{array}$

$\begin{array}{lllll}0.275 & 0.00 \mathrm{E}+00 & 0.00 \mathrm{E}+00 & 0.00 \mathrm{E}+00\end{array}$

$\begin{array}{lllll}0.300 & 0.00 \mathrm{E}+00 & 0.00 \mathrm{E}+00 & 0.00 \mathrm{E}+00\end{array}$

$\begin{array}{lllll}0.325 & 0.00 \mathrm{E}+00 & 0.00 \mathrm{E}+00 & 0.00 \mathrm{E}+00\end{array}$

$\begin{array}{lllll}0.350 & 0.00 \mathrm{E}+00 & 0.00 \mathrm{E}+00 & 0.00 \mathrm{E}+00\end{array}$

$\begin{array}{lllll}0.375 & 0.00 \mathrm{E}+00 & 0.00 \mathrm{E}+00 & 0.00 \mathrm{E}+00\end{array}$

$\begin{array}{lllll}0.400 & 0.00 \mathrm{E}+00 & 0.00 \mathrm{E}+00 & 0.00 \mathrm{E}+00\end{array}$

$\begin{array}{lllll}0.425 & 0.00 \mathrm{E}+00 & 0.00 \mathrm{E}+00 & 0.00 \mathrm{E}+00\end{array}$

$\begin{array}{lllll}0.450 & 0.00 \mathrm{E}+00 & 0.00 \mathrm{E}+00 & 0.00 \mathrm{E}+00\end{array}$

$\begin{array}{lllll}0.475 & 0.00 \mathrm{E}+00 & 0.00 \mathrm{E}+00 & 0.00 \mathrm{E}+00\end{array}$

$\begin{array}{lllll}0.500 & 0.00 \mathrm{E}+00 & 0.00 \mathrm{E}+00 & 0.00 \mathrm{E}+00\end{array}$

$\begin{array}{lllll}0.525 & 0.00 \mathrm{E}+00 & 0.00 \mathrm{E}+00 & 0.00 \mathrm{E}+00\end{array}$

$\begin{array}{lllll}0.550 & 0.00 \mathrm{E}+00 & 0.00 \mathrm{E}+00 & 0.00 \mathrm{E}+00\end{array}$

$\begin{array}{lllll}0.575 & 0.00 \mathrm{E}+00 & 0.00 \mathrm{E}+00 & 0.00 \mathrm{E}+00\end{array}$

$\begin{array}{lllll}0.600 & 0.00 \mathrm{E}+00 & 0.00 \mathrm{E}+00 & 0.00 \mathrm{E}+00\end{array}$

$\begin{array}{lllll}0.625 & 0.00 \mathrm{E}+00 & 0.00 \mathrm{E}+00 & 0.00 \mathrm{E}+00\end{array}$

$\begin{array}{lllll}0.650 & 0.00 \mathrm{E}+00 & 0.00 \mathrm{E}+00 & 0.00 \mathrm{E}+00\end{array}$

$\begin{array}{lllll}0.675 & 0.00 \mathrm{E}+00 & 0.00 \mathrm{E}+00 & 0.00 \mathrm{E}+00\end{array}$

$\begin{array}{lllll}0.700 & 0.00 \mathrm{E}+00 & 0.00 \mathrm{E}+00 & 0.00 \mathrm{E}+00\end{array}$

$\begin{array}{lllll}0.725 & 0.00 \mathrm{E}+00 & 0.00 \mathrm{E}+00 & 0.00 \mathrm{E}+00\end{array}$

$\begin{array}{lllll}0.750 & 0.00 \mathrm{E}+00 & 0.00 \mathrm{E}+00 & 0.00 \mathrm{E}+00\end{array}$

$\begin{array}{lllll}0.775 & 0.00 \mathrm{E}+00 & 0.00 \mathrm{E}+00 & 0.00 \mathrm{E}+00\end{array}$

$\begin{array}{lllll}0.800 & 0.00 \mathrm{E}+00 & 0.00 \mathrm{E}+00 & 0.00 \mathrm{E}+00\end{array}$

$\begin{array}{lllll}0.825 & 0.00 \mathrm{E}+00 & 0.00 \mathrm{E}+00 & 0.00 \mathrm{E}+00\end{array}$

$\begin{array}{lllll}0.850 & 0.00 \mathrm{E}+00 & 0.00 \mathrm{E}+00 & 0.00 \mathrm{E}+00\end{array}$

$\begin{array}{lllll}0.875 & 0.00 \mathrm{E}+00 & 0.00 \mathrm{E}+00 & 0.00 \mathrm{E}+00\end{array}$

$\begin{array}{lllll}0.900 & 0.00 \mathrm{E}+00 & 0.00 \mathrm{E}+00 & 0.00 \mathrm{E}+00\end{array}$

$\begin{array}{lllll}0.925 & 0.00 \mathrm{E}+00 & 0.00 \mathrm{E}+00 & 0.00 \mathrm{E}+00\end{array}$

$\begin{array}{lllll}0.950 & 0.00 \mathrm{E}+00 & 0.00 \mathrm{E}+00 & 0.00 \mathrm{E}+00\end{array}$

$\begin{array}{lllll}0.975 & 0.00 \mathrm{E}+00 & 0.00 \mathrm{E}+00 & 0.00 \mathrm{E}+00\end{array}$

$\begin{array}{lllll}0.990 & 0.00 \mathrm{E}+00 & 0.00 \mathrm{E}+00 & 0.00 \mathrm{E}+00\end{array}$ 
RESRAD-OFFSITE, Version 2.5

Probabilistic Dose and Risk Report

Title : RESRAD-OFFSITE External Gamma, Inhalation, and Soil Ingestion for Offsite Reside

File : PBA-1_TC99-DOE-5-1.ROF

Statistics and Cumulative distribution function of Peak Dose from Soil Ingestion(Wrelease) in mrem/yr

$\begin{array}{rcrlc}\text { Repetition }= & 1 & 2 & 3 \\ \text { Mean } & & 7.75 \mathrm{E}-07 & 7.75 \mathrm{E}-07 & 7.75 \mathrm{E}-07 \\ \text { Std. Dev. } & & 4.63 \mathrm{E}-07 & 4.62 \mathrm{E}-07 & 4.63 \mathrm{E}-07 \\ \text { Minimum } & 9.32 \mathrm{E}-08 & 9.32 \mathrm{E}-08 & 9.32 \mathrm{E}-08 \\ \text { Maximum } & & 4.40 \mathrm{E}-06 & 4.40 \mathrm{E}-06 & 4.40 \mathrm{E}-06\end{array}$

Percentile

$0.010 \quad 1.34 \mathrm{E}-07 \quad 1.34 \mathrm{E}-07 \quad 1.34 \mathrm{E}-07$

$0.025 \quad 1.74 \mathrm{E}-07 \quad 1.74 \mathrm{E}-07 \quad 1.74 \mathrm{E}-07$

$\begin{array}{llll}0.050 & 2.14 \mathrm{E}-07 & 2.14 \mathrm{E}-07 & 2.14 \mathrm{E}-07\end{array}$

$\begin{array}{llll}0.075 & 2.53 \mathrm{E}-07 & 2.53 \mathrm{E}-07 & 2.53 \mathrm{E}-07\end{array}$

$\begin{array}{llll}0.100 & 2.81 \mathrm{E}-07 & 2.81 \mathrm{E}-07 & 2.81 \mathrm{E}-07\end{array}$

$\begin{array}{llll}0.125 & 3.09 \mathrm{E}-07 & 3.09 \mathrm{E}-07 & 3.09 \mathrm{E}-07\end{array}$

$\begin{array}{lllll}0.150 & 3.34 \mathrm{E}-07 & 3.34 \mathrm{E}-07 & 3.34 \mathrm{E}-07\end{array}$

$\begin{array}{llll}0.175 & 3.62 \mathrm{E}-07 & 3.62 \mathrm{E}-07 & 3.62 \mathrm{E}-07\end{array}$

$0.200 \quad 3.84 \mathrm{E}-07 \quad 3.84 \mathrm{E}-07 \quad 3.84 \mathrm{E}-07$

$0.225 \quad 4.11 \mathrm{E}-07 \quad 4.10 \mathrm{E}-07 \quad 4.10 \mathrm{E}-07$

$0.250 \quad 4.37 \mathrm{E}-07 \quad 4.36 \mathrm{E}-07 \quad 4.36 \mathrm{E}-07$

$0.275 \quad 4.62 \mathrm{E}-07 \quad 4.62 \mathrm{E}-07 \quad 4.62 \mathrm{E}-07$

$0.300 \quad 4.87 \mathrm{E}-07 \quad 4.87 \mathrm{E}-07 \quad 4.87 \mathrm{E}-07$

$\begin{array}{llll}0.325 & 5.06 \mathrm{E}-07 & 5.06 \mathrm{E}-07 & 5.06 \mathrm{E}-07\end{array}$

$\begin{array}{llll}0.350 & 5.26 \mathrm{E}-07 & 5.26 \mathrm{E}-07 & 5.26 \mathrm{E}-07\end{array}$

$0.375 \quad 5.49 \mathrm{E}-07 \quad 5.48 \mathrm{E}-07 \quad 5.49 \mathrm{E}-07$

$\begin{array}{llll}0.400 \quad 5.74 \mathrm{E}-07 & 5.73 \mathrm{E}-07 & 5.74 \mathrm{E}-07\end{array}$

$\begin{array}{llll}0.425 & 5.96 \mathrm{E}-07 & 5.96 \mathrm{E}-07 & 5.96 \mathrm{E}-07\end{array}$

$\begin{array}{llll}0.450 & 6.18 \mathrm{E}-07 & 6.17 \mathrm{E}-07 & 6.18 \mathrm{E}-07\end{array}$

$\begin{array}{llll}0.475 & 6.48 \mathrm{E}-07 & 6.47 \mathrm{E}-07 & 6.47 \mathrm{E}-07\end{array}$

$\begin{array}{llll}0.500 & 6.79 \mathrm{E}-07 & 6.75 \mathrm{E}-07 & 6.76 \mathrm{E}-07\end{array}$

$\begin{array}{lllll}0.525 & 7.06 \mathrm{E}-07 & 7.01 \mathrm{E}-07 & 7.01 \mathrm{E}-07\end{array}$

$\begin{array}{llll}0.550 & 7.34 \mathrm{E}-07 & 7.33 \mathrm{E}-07 & 7.34 \mathrm{E}-07\end{array}$

$\begin{array}{llll}0.575 & 7.63 \mathrm{E}-07 \quad 7.60 \mathrm{E}-07 \quad 7.61 \mathrm{E}-07\end{array}$

$\begin{array}{llll}0.600 & 7.90 \mathrm{E}-07 & 7.90 \mathrm{E}-07 & 7.90 \mathrm{E}-07\end{array}$

$0.6258 .21 \mathrm{E}-07 \quad 8.20 \mathrm{E}-07 \quad 8.20 \mathrm{E}-07$
0.650

$\begin{array}{llll}0.650 & 8.54 \mathrm{E}-07 & 8.52 \mathrm{E}-07 & 8.52 \mathrm{E}-07\end{array}$

$\begin{array}{llll}0.675 & 8.89 \mathrm{E}-07 \quad 8.88 \mathrm{E}-07 \quad 8.88 \mathrm{E}-07\end{array}$

$\begin{array}{llll}0.700 & 9.29 \mathrm{E}-07 & 9.27 \mathrm{E}-07 & 9.27 \mathrm{E}-07\end{array}$

$\begin{array}{llll}0.725 & 9.68 \mathrm{E}-07 & 9.67 \mathrm{E}-07 & 9.67 \mathrm{E}-07\end{array}$

$\begin{array}{llll}0.750 & 1.02 \mathrm{E}-06 & 1.02 \mathrm{E}-06 & 1.02 \mathrm{E}-06\end{array}$

$\begin{array}{llll}0.775 & 1.07 \mathrm{E}-06 & 1.07 \mathrm{E}-06 & 1.07 \mathrm{E}-06\end{array}$

$0.800 \quad 1.13 \mathrm{E}-06 \quad 1.13 \mathrm{E}-06 \quad 1.13 \mathrm{E}-06$

$\begin{array}{llll}0.825 & 1.17 \mathrm{E}-06 & 1.17 \mathrm{E}-06 & 1.17 \mathrm{E}-06\end{array}$

$\begin{array}{llll}0.850 & 1.24 \mathrm{E}-06 & 1.24 \mathrm{E}-06 & 1.24 \mathrm{E}-06\end{array}$

$0.8751 .33 \mathrm{E}-06 \quad 1.33 \mathrm{E}-06 \quad 1.33 \mathrm{E}-06$

$0.9001 .40 \mathrm{E}-06 \quad 1.40 \mathrm{E}-06 \quad 1.40 \mathrm{E}-06$

$\begin{array}{llll}0.925 & 1.52 \mathrm{E}-06 & 1.51 \mathrm{E}-06 & 1.52 \mathrm{E}-06\end{array}$

$\begin{array}{llll}0.950 & 1.65 \mathrm{E}-06 & 1.65 \mathrm{E}-06 & 1.65 \mathrm{E}-06\end{array}$

$\begin{array}{llll}0.975 & 1.86 \mathrm{E}-06 & 1.86 \mathrm{E}-06 & 1.86 \mathrm{E}-06\end{array}$

$0.990 \quad 2.33 \mathrm{E}-06 \quad 2.33 \mathrm{E}-06 \quad 2.33 \mathrm{E}-06$ 
RESRAD-OFFSITE, Version 2.5

Probabilistic Dose and Risk Report

Title : RESRAD-OFFSITE External Gamma, Inhalation, and Soil Ingestion for offsite Reside

File : PBA-1_TC99-DOE-5-1.ROF

Statistics and Cumulative distribution function of Peak Dose from Water Ingestion in mrem/yr

\begin{tabular}{ccccc} 
Repetition $=$ & 1 & 2 & 3 \\
\cline { 5 - 5 } Mean & $0.00 \mathrm{E}+00$ & $0.00 \mathrm{E}+00$ & $0.00 \mathrm{E}+00$ \\
Std. Dev. & $0.00 \mathrm{E}+00$ & $0.00 \mathrm{E}+00$ & $0.00 \mathrm{E}+00$ \\
Minimum & $0.00 \mathrm{E}+00$ & $0.00 \mathrm{E}+00$ & $0.00 \mathrm{E}+00$ \\
Maximum & $0.00 \mathrm{E}+00$ & $0.00 \mathrm{E}+00$ & $0.00 \mathrm{E}+00$
\end{tabular}

Percentile

$\begin{array}{llll}0.010 & 0.00 \mathrm{E}+00 \quad 0.00 \mathrm{E}+00 & 0.00 \mathrm{E}+00\end{array}$

$\begin{array}{llll}0.025 & 0.00 \mathrm{E}+00 & 0.00 \mathrm{E}+00 & 0.00 \mathrm{E}+00\end{array}$

$\begin{array}{lllll}0.050 & 0.00 \mathrm{E}+00 & 0.00 \mathrm{E}+00 & 0.00 \mathrm{E}+00\end{array}$

$\begin{array}{lllll}0.075 & 0.00 \mathrm{E}+00 & 0.00 \mathrm{E}+00 & 0.00 \mathrm{E}+00\end{array}$

$\begin{array}{lllll}0.100 & 0.00 \mathrm{E}+00 & 0.00 \mathrm{E}+00 & 0.00 \mathrm{E}+00\end{array}$

$\begin{array}{lllll}0.125 & 0.00 \mathrm{E}+00 & 0.00 \mathrm{E}+00 & 0.00 \mathrm{E}+00\end{array}$

$\begin{array}{lllll}0.150 & 0.00 \mathrm{E}+00 & 0.00 \mathrm{E}+00 & 0.00 \mathrm{E}+00\end{array}$

$\begin{array}{lllll}0.175 & 0.00 \mathrm{E}+00 & 0.00 \mathrm{E}+00 & 0.00 \mathrm{E}+00\end{array}$

$\begin{array}{lllll}0.200 & 0.00 \mathrm{E}+00 & 0.00 \mathrm{E}+00 & 0.00 \mathrm{E}+00\end{array}$

$\begin{array}{lllll}0.225 & 0.00 \mathrm{E}+00 & 0.00 \mathrm{E}+00 & 0.00 \mathrm{E}+00\end{array}$

$\begin{array}{lllll}0.250 & 0.00 \mathrm{E}+00 & 0.00 \mathrm{E}+00 & 0.00 \mathrm{E}+00\end{array}$

$\begin{array}{lllll}0.275 & 0.00 \mathrm{E}+00 & 0.00 \mathrm{E}+00 & 0.00 \mathrm{E}+00\end{array}$

$\begin{array}{lllll}0.300 & 0.00 \mathrm{E}+00 & 0.00 \mathrm{E}+00 & 0.00 \mathrm{E}+00\end{array}$

$\begin{array}{lllll}0.325 & 0.00 \mathrm{E}+00 & 0.00 \mathrm{E}+00 & 0.00 \mathrm{E}+00\end{array}$

$\begin{array}{lllll}0.350 & 0.00 \mathrm{E}+00 & 0.00 \mathrm{E}+00 & 0.00 \mathrm{E}+00\end{array}$

$\begin{array}{lllll}0.375 & 0.00 \mathrm{E}+00 & 0.00 \mathrm{E}+00 & 0.00 \mathrm{E}+00\end{array}$

$\begin{array}{lllll}0.400 & 0.00 \mathrm{E}+00 & 0.00 \mathrm{E}+00 & 0.00 \mathrm{E}+00\end{array}$

$\begin{array}{lllll}0.425 & 0.00 \mathrm{E}+00 & 0.00 \mathrm{E}+00 & 0.00 \mathrm{E}+00\end{array}$

$\begin{array}{lllll}0.450 & 0.00 \mathrm{E}+00 & 0.00 \mathrm{E}+00 & 0.00 \mathrm{E}+00\end{array}$

$\begin{array}{lllll}0.475 & 0.00 \mathrm{E}+00 & 0.00 \mathrm{E}+00 & 0.00 \mathrm{E}+00\end{array}$

$\begin{array}{lllll}0.500 & 0.00 \mathrm{E}+00 & 0.00 \mathrm{E}+00 & 0.00 \mathrm{E}+00\end{array}$

$\begin{array}{lllll}0.525 & 0.00 \mathrm{E}+00 & 0.00 \mathrm{E}+00 & 0.00 \mathrm{E}+00\end{array}$

$\begin{array}{lllll}0.550 & 0.00 \mathrm{E}+00 & 0.00 \mathrm{E}+00 & 0.00 \mathrm{E}+00\end{array}$

$\begin{array}{lllll}0.575 & 0.00 \mathrm{E}+00 & 0.00 \mathrm{E}+00 & 0.00 \mathrm{E}+00\end{array}$

$\begin{array}{lllll}0.600 & 0.00 \mathrm{E}+00 & 0.00 \mathrm{E}+00 & 0.00 \mathrm{E}+00\end{array}$

$\begin{array}{lllll}0.625 & 0.00 \mathrm{E}+00 & 0.00 \mathrm{E}+00 & 0.00 \mathrm{E}+00\end{array}$

$\begin{array}{lllll}0.650 & 0.00 \mathrm{E}+00 & 0.00 \mathrm{E}+00 & 0.00 \mathrm{E}+00\end{array}$

$\begin{array}{lllll}0.675 & 0.00 \mathrm{E}+00 & 0.00 \mathrm{E}+00 & 0.00 \mathrm{E}+00\end{array}$

$\begin{array}{lllll}0.700 & 0.00 \mathrm{E}+00 & 0.00 \mathrm{E}+00 & 0.00 \mathrm{E}+00\end{array}$

$\begin{array}{lllll}0.725 & 0.00 \mathrm{E}+00 & 0.00 \mathrm{E}+00 & 0.00 \mathrm{E}+00\end{array}$

$\begin{array}{lllll}0.750 & 0.00 \mathrm{E}+00 & 0.00 \mathrm{E}+00 & 0.00 \mathrm{E}+00\end{array}$

$\begin{array}{lllll}0.775 & 0.00 \mathrm{E}+00 & 0.00 \mathrm{E}+00 & 0.00 \mathrm{E}+00\end{array}$

$\begin{array}{lllll}0.800 & 0.00 \mathrm{E}+00 & 0.00 \mathrm{E}+00 & 0.00 \mathrm{E}+00\end{array}$

$\begin{array}{lllll}0.825 & 0.00 \mathrm{E}+00 & 0.00 \mathrm{E}+00 & 0.00 \mathrm{E}+00\end{array}$

$\begin{array}{lllll}0.850 & 0.00 \mathrm{E}+00 & 0.00 \mathrm{E}+00 & 0.00 \mathrm{E}+00\end{array}$

$\begin{array}{lllll}0.875 & 0.00 \mathrm{E}+00 & 0.00 \mathrm{E}+00 & 0.00 \mathrm{E}+00\end{array}$

$\begin{array}{lllll}0.900 & 0.00 \mathrm{E}+00 & 0.00 \mathrm{E}+00 & 0.00 \mathrm{E}+00\end{array}$

$\begin{array}{lllll}0.925 & 0.00 \mathrm{E}+00 & 0.00 \mathrm{E}+00 & 0.00 \mathrm{E}+00\end{array}$

$\begin{array}{lllll}0.950 & 0.00 \mathrm{E}+00 & 0.00 \mathrm{E}+00 & 0.00 \mathrm{E}+00\end{array}$

$\begin{array}{lllll}0.975 & 0.00 \mathrm{E}+00 & 0.00 \mathrm{E}+00 & 0.00 \mathrm{E}+00\end{array}$

$\begin{array}{lllll}0.990 & 0.00 \mathrm{E}+00 & 0.00 \mathrm{E}+00 & 0.00 \mathrm{E}+00\end{array}$ 
RESRAD-OFFSITE, Version 2.5

Probabilistic Dose and Risk Report

Title : RESRAD-OFFSITE External Gamma, Inhalation, and Soil Ingestion for Offsite Reside

File : PBA-1_TC99-DOE-5-1.ROF

Statistics and Cumulative distribution function of Peak Dose from External Ground(Cz\&Air) in mrem/yr

\begin{tabular}{|c|c|c|c|}
\hline Repetition $=$ & 1 & 2 & 3 \\
\hline Mean & $3.47 \mathrm{E}-25$ & $3.47 \mathrm{E}-25$ & $3.47 \mathrm{E}-25$ \\
\hline Std. Dev. & $0.00 \mathrm{E}+00$ & $0.00 \mathrm{E}+00$ & $0.00 \mathrm{E}+00$ \\
\hline Minimum & $1.46 \mathrm{E}-32$ & $1.46 \mathrm{E}-32$ & $1.46 \mathrm{E}-32$ \\
\hline Maximum & $1.02 \mathrm{E}-24$ & $1.02 \mathrm{E}-24$ & $1.02 \mathrm{E}-24$ \\
\hline
\end{tabular}

Percentile

$0.010 \quad 5.13 \mathrm{E}-30 \quad 5.13 \mathrm{E}-30 \quad 5.13 \mathrm{E}-30$

$\begin{array}{llll}0.025 & 1.56 \mathrm{E}-28 & 1.56 \mathrm{E}-28 & 1.29 \mathrm{E}-28\end{array}$

$\begin{array}{llll}0.050 & 1.69 \mathrm{E}-27 & 1.69 \mathrm{E}-27 & 1.68 \mathrm{E}-27\end{array}$

$\begin{array}{llll}0.075 & 4.08 \mathrm{E}-27 & 4.25 \mathrm{E}-27 & 4.08 \mathrm{E}-27\end{array}$

$\begin{array}{llll}0.100 & 8.23 \mathrm{E}-27 & 8.48 \mathrm{E}-27 & 8.39 \mathrm{E}-27\end{array}$

$\begin{array}{llll}0.125 & 1.59 \mathrm{E}-26 & 1.65 \mathrm{E}-26 & 1.62 \mathrm{E}-26\end{array}$

$\begin{array}{llll}0.150 & 2.52 \mathrm{E}-26 & 2.55 \mathrm{E}-26 & 2.54 \mathrm{E}-26\end{array}$

$\begin{array}{llll}0.175 & 3.66 \mathrm{E}-26 & 3.70 \mathrm{E}-26 & 3.68 \mathrm{E}-26\end{array}$

$\begin{array}{llll}0.200 \quad 5.14 \mathrm{E}-26 & 5.19 \mathrm{E}-26 & 5.19 \mathrm{E}-26\end{array}$

$\begin{array}{llll}0.225 & 6.71 \mathrm{E}-26 & 6.76 \mathrm{E}-26 & 6.76 \mathrm{E}-26\end{array}$

$\begin{array}{llll}0.250 & 8.18 \mathrm{E}-26 & 8.34 \mathrm{E}-26 & 8.34 \mathrm{E}-26\end{array}$

$\begin{array}{llll}0.275 & 9.94 \mathrm{E}-26 & 1.01 \mathrm{E}-25 & 1.01 \mathrm{E}-25\end{array}$

$\begin{array}{llll}0.300 & 1.21 \mathrm{E}-25 & 1.22 \mathrm{E}-25 & 1.22 \mathrm{E}-25\end{array}$

$\begin{array}{llll}0.325 & 1.41 \mathrm{E}-25 & 1.42 \mathrm{E}-25 & 1.42 \mathrm{E}-25\end{array}$

$\begin{array}{llll}0.350 & 1.63 \mathrm{E}-25 & 1.64 \mathrm{E}-25 & 1.64 \mathrm{E}-25\end{array}$

$0.375 \quad 1.86 \mathrm{E}-25 \quad 1.86 \mathrm{E}-25 \quad 1.86 \mathrm{E}-25$

$\begin{array}{llll}0.400 & 2.14 \mathrm{E}-25 & 2.15 \mathrm{E}-25 & 2.15 \mathrm{E}-25\end{array}$

$\begin{array}{llll}0.425 & 2.33 \mathrm{E}-25 & 2.34 \mathrm{E}-25 & 2.34 \mathrm{E}-25\end{array}$

$\begin{array}{llll}0.450 & 2.54 \mathrm{E}-25 & 2.54 \mathrm{E}-25 & 2.54 \mathrm{E}-25\end{array}$

$\begin{array}{llll}0.475 & 2.80 \mathrm{E}-25 & 2.81 \mathrm{E}-25 & 2.80 \mathrm{E}-25\end{array}$

$0.500 \quad 3.11 \mathrm{E}-25 \quad 3.12 \mathrm{E}-25 \quad 3.12 \mathrm{E}-25$

$0.525 \quad 3.41 \mathrm{E}-25 \quad 3.42 \mathrm{E}-25 \quad 3.41 \mathrm{E}-25$

$\begin{array}{llll}0.550 & 3.62 \mathrm{E}-25 & 3.62 \mathrm{E}-25 & 3.62 \mathrm{E}-25\end{array}$

$0.575 \quad 3.87 \mathrm{E}-25 \quad 3.89 \mathrm{E}-25 \quad 3.88 \mathrm{E}-25$

$0.600 \quad 4.17 \mathrm{E}-25 \quad 4.18 \mathrm{E}-25 \quad 4.17 \mathrm{E}-25$

$0.625 \quad 4.43 \mathrm{E}-25 \quad 4.43 \mathrm{E}-25 \quad 4.43 \mathrm{E}-25$

$0.650 \quad 4.61 \mathrm{E}-25 \quad 4.62 \mathrm{E}-25 \quad 4.62 \mathrm{E}-25$

$0.675 \quad 4.91 \mathrm{E}-25 \quad 4.92 \mathrm{E}-25 \quad 4.92 \mathrm{E}-25$

$0.700 \quad 5.17 \mathrm{E}-25 \quad 5.19 \mathrm{E}-25 \quad 5.19 \mathrm{E}-25$

$\begin{array}{llll}0.725 & 5.47 \mathrm{E}-25 & 5.48 \mathrm{E}-25 & 5.48 \mathrm{E}-25\end{array}$

$\begin{array}{llll}0.750 & 5.74 \mathrm{E}-25 & 5.75 \mathrm{E}-25 & 5.76 \mathrm{E}-25\end{array}$

$\begin{array}{llll}0.775 & 6.02 \mathrm{E}-25 & 6.02 \mathrm{E}-25 & 6.03 \mathrm{E}-25\end{array}$

$\begin{array}{llll}0.800 & 6.29 \mathrm{E}-25 & 6.29 \mathrm{E}-25 & 6.29 \mathrm{E}-25\end{array}$

$\begin{array}{llll}0.825 & 6.63 \mathrm{E}-25 & 6.64 \mathrm{E}-25 & 6.64 \mathrm{E}-25\end{array}$

$\begin{array}{llll}0.850 & 6.89 \mathrm{E}-25 & 6.89 \mathrm{E}-25 & 6.89 \mathrm{E}-25\end{array}$

$\begin{array}{llll}0.875 & 7.20 \mathrm{E}-25 & 7.20 \mathrm{E}-25 & 7.21 \mathrm{E}-25\end{array}$

$\begin{array}{llll}0.900 & 7.55 \mathrm{E}-25 & 7.55 \mathrm{E}-25 & 7.56 \mathrm{E}-25\end{array}$

$\begin{array}{llll}0.925 & 7.83 \mathrm{E}-25 & 7.83 \mathrm{E}-25 & 7.84 \mathrm{E}-25\end{array}$

$\begin{array}{llll}0.950 & 8.26 \mathrm{E}-25 & 8.26 \mathrm{E}-25 & 8.26 \mathrm{E}-25\end{array}$

$\begin{array}{llll}0.975 & 8.81 \mathrm{E}-25 & 8.81 \mathrm{E}-25 & 8.81 \mathrm{E}-25\end{array}$

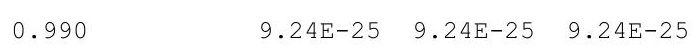


RESRAD-OFFSITE, Version 2.5

Probabilistic Dose and Risk Report

Title : RESRAD-OFFSITE External Gamma, Inhalation, and Soil Ingestion for offsite Reside

File : PBA-1_TC99-DOE-5-1.ROF

Statistics and Cumulative distribution function of Peak Dose from Inhalation ExcludingRn in mrem/yr

\begin{tabular}{ccccc} 
Repetition $=$ & 1 & 2 & 3 \\
\cline { 5 - 5 } Mean & $0.00 \mathrm{E}+00$ & $0.00 \mathrm{E}+00$ & $0.00 \mathrm{E}+00$ \\
Std. Dev. & $0.00 \mathrm{E}+00$ & $0.00 \mathrm{E}+00$ & $0.00 \mathrm{E}+00$ \\
Minimum & $0.00 \mathrm{E}+00$ & $0.00 \mathrm{E}+00$ & $0.00 \mathrm{E}+00$ \\
Maximum & $0.00 \mathrm{E}+00$ & $0.00 \mathrm{E}+00$ & $0.00 \mathrm{E}+00$
\end{tabular}

Percentile

$\begin{array}{llll}0.010 & 0.00 \mathrm{E}+00 \quad 0.00 \mathrm{E}+00 & 0.00 \mathrm{E}+00\end{array}$

$\begin{array}{llll}0.025 & 0.00 \mathrm{E}+00 & 0.00 \mathrm{E}+00 & 0.00 \mathrm{E}+00\end{array}$

$\begin{array}{lllll}0.050 & 0.00 \mathrm{E}+00 & 0.00 \mathrm{E}+00 & 0.00 \mathrm{E}+00\end{array}$

$\begin{array}{lllll}0.075 & 0.00 \mathrm{E}+00 & 0.00 \mathrm{E}+00 & 0.00 \mathrm{E}+00\end{array}$

$\begin{array}{llll}0.100 & 0.00 \mathrm{E}+00 & 0.00 \mathrm{E}+00 & 0.00 \mathrm{E}+00\end{array}$

$\begin{array}{lllll}0.125 & 0.00 \mathrm{E}+00 & 0.00 \mathrm{E}+00 & 0.00 \mathrm{E}+00\end{array}$

$\begin{array}{lllll}0.150 & 0.00 \mathrm{E}+00 & 0.00 \mathrm{E}+00 & 0.00 \mathrm{E}+00\end{array}$

$\begin{array}{lllll}0.175 & 0.00 \mathrm{E}+00 & 0.00 \mathrm{E}+00 & 0.00 \mathrm{E}+00\end{array}$

$\begin{array}{lllll}0.200 & 0.00 \mathrm{E}+00 & 0.00 \mathrm{E}+00 & 0.00 \mathrm{E}+00\end{array}$

$\begin{array}{lllll}0.225 & 0.00 \mathrm{E}+00 & 0.00 \mathrm{E}+00 & 0.00 \mathrm{E}+00\end{array}$

$\begin{array}{lllll}0.250 & 0.00 \mathrm{E}+00 & 0.00 \mathrm{E}+00 & 0.00 \mathrm{E}+00\end{array}$

$\begin{array}{lllll}0.275 & 0.00 \mathrm{E}+00 & 0.00 \mathrm{E}+00 & 0.00 \mathrm{E}+00\end{array}$

$\begin{array}{lllll}0.300 & 0.00 \mathrm{E}+00 & 0.00 \mathrm{E}+00 & 0.00 \mathrm{E}+00\end{array}$

$\begin{array}{lllll}0.325 & 0.00 \mathrm{E}+00 & 0.00 \mathrm{E}+00 & 0.00 \mathrm{E}+00\end{array}$

$\begin{array}{lllll}0.350 & 0.00 \mathrm{E}+00 & 0.00 \mathrm{E}+00 & 0.00 \mathrm{E}+00\end{array}$

$\begin{array}{lllll}0.375 & 0.00 \mathrm{E}+00 & 0.00 \mathrm{E}+00 & 0.00 \mathrm{E}+00\end{array}$

$\begin{array}{lllll}0.400 & 0.00 \mathrm{E}+00 & 0.00 \mathrm{E}+00 & 0.00 \mathrm{E}+00\end{array}$

$\begin{array}{lllll}0.425 & 0.00 \mathrm{E}+00 & 0.00 \mathrm{E}+00 & 0.00 \mathrm{E}+00\end{array}$

$\begin{array}{lllll}0.450 & 0.00 \mathrm{E}+00 & 0.00 \mathrm{E}+00 & 0.00 \mathrm{E}+00\end{array}$

$\begin{array}{lllll}0.475 & 0.00 \mathrm{E}+00 & 0.00 \mathrm{E}+00 & 0.00 \mathrm{E}+00\end{array}$

$\begin{array}{lllll}0.500 & 0.00 \mathrm{E}+00 & 0.00 \mathrm{E}+00 & 0.00 \mathrm{E}+00\end{array}$

$\begin{array}{lllll}0.525 & 0.00 \mathrm{E}+00 & 0.00 \mathrm{E}+00 & 0.00 \mathrm{E}+00\end{array}$

$\begin{array}{lllll}0.550 & 0.00 \mathrm{E}+00 & 0.00 \mathrm{E}+00 & 0.00 \mathrm{E}+00\end{array}$

$\begin{array}{lllll}0.575 & 0.00 \mathrm{E}+00 & 0.00 \mathrm{E}+00 & 0.00 \mathrm{E}+00\end{array}$

$\begin{array}{lllll}0.600 & 0.00 \mathrm{E}+00 & 0.00 \mathrm{E}+00 & 0.00 \mathrm{E}+00\end{array}$

$\begin{array}{lllll}0.625 & 0.00 \mathrm{E}+00 & 0.00 \mathrm{E}+00 & 0.00 \mathrm{E}+00\end{array}$

$\begin{array}{lllll}0.650 & 0.00 \mathrm{E}+00 & 0.00 \mathrm{E}+00 & 0.00 \mathrm{E}+00\end{array}$

$\begin{array}{lllll}0.675 & 0.00 \mathrm{E}+00 & 0.00 \mathrm{E}+00 & 0.00 \mathrm{E}+00\end{array}$

$\begin{array}{lllll}0.700 & 0.00 \mathrm{E}+00 & 0.00 \mathrm{E}+00 & 0.00 \mathrm{E}+00\end{array}$

$\begin{array}{lllll}0.725 & 0.00 \mathrm{E}+00 & 0.00 \mathrm{E}+00 & 0.00 \mathrm{E}+00\end{array}$

$\begin{array}{lllll}0.750 & 0.00 \mathrm{E}+00 & 0.00 \mathrm{E}+00 & 0.00 \mathrm{E}+00\end{array}$

$\begin{array}{lllll}0.775 & 0.00 \mathrm{E}+00 & 0.00 \mathrm{E}+00 & 0.00 \mathrm{E}+00\end{array}$

$\begin{array}{lllll}0.800 & 0.00 \mathrm{E}+00 & 0.00 \mathrm{E}+00 & 0.00 \mathrm{E}+00\end{array}$

$\begin{array}{lllll}0.825 & 0.00 \mathrm{E}+00 & 0.00 \mathrm{E}+00 & 0.00 \mathrm{E}+00\end{array}$

$\begin{array}{lllll}0.850 & 0.00 \mathrm{E}+00 & 0.00 \mathrm{E}+00 & 0.00 \mathrm{E}+00\end{array}$

$\begin{array}{lllll}0.875 & 0.00 \mathrm{E}+00 & 0.00 \mathrm{E}+00 & 0.00 \mathrm{E}+00\end{array}$

$\begin{array}{lllll}0.900 & 0.00 \mathrm{E}+00 & 0.00 \mathrm{E}+00 & 0.00 \mathrm{E}+00\end{array}$

$\begin{array}{lllll}0.925 & 0.00 \mathrm{E}+00 & 0.00 \mathrm{E}+00 & 0.00 \mathrm{E}+00\end{array}$

$\begin{array}{lllll}0.950 & 0.00 \mathrm{E}+00 & 0.00 \mathrm{E}+00 & 0.00 \mathrm{E}+00\end{array}$

$\begin{array}{lllll}0.975 & 0.00 \mathrm{E}+00 & 0.00 \mathrm{E}+00 & 0.00 \mathrm{E}+00\end{array}$

$\begin{array}{lllll}0.990 & 0.00 \mathrm{E}+00 & 0.00 \mathrm{E}+00 & 0.00 \mathrm{E}+00\end{array}$ 
RESRAD-OFFSITE, Version 2.5

Probabilistic Dose and Risk Report

Title : RESRAD-OFFSITE External Gamma, Inhalation, and Soil Ingestion for offsite Reside

File : PBA-1_TC99-DOE-5-1.ROF

Statistics and Cumulative distribution function of Peak Dose from Radon (CZandAir) in mrem/yr

$\begin{array}{ccccc}\text { Repetition }= & 1 & 2 & 3 \\ \text { Mean } & 0.00 \mathrm{E}+00 & 0.00 \mathrm{E}+00 & 0.00 \mathrm{E}+00 \\ \text { Std. Dev. } & 0.00 \mathrm{E}+00 & 0.00 \mathrm{E}+00 & 0.00 \mathrm{E}+00 \\ \text { Minimum } & 0.00 \mathrm{E}+00 & 0.00 \mathrm{E}+00 & 0.00 \mathrm{E}+00 \\ \text { Maximum } & 0.00 \mathrm{E}+00 & 0.00 \mathrm{E}+00 & 0.00 \mathrm{E}+00\end{array}$

Percentile

$\begin{array}{llll}0.010 & 0.00 \mathrm{E}+00 \quad 0.00 \mathrm{E}+00 & 0.00 \mathrm{E}+00\end{array}$

$\begin{array}{llll}0.025 & 0.00 \mathrm{E}+00 \quad 0.00 \mathrm{E}+00 & 0.00 \mathrm{E}+00\end{array}$

$\begin{array}{llll}0.050 & 0.00 \mathrm{E}+00 & 0.00 \mathrm{E}+00 & 0.00 \mathrm{E}+00\end{array}$

$\begin{array}{llll}0.075 & 0.00 \mathrm{E}+00 & 0.00 \mathrm{E}+00 & 0.00 \mathrm{E}+00\end{array}$

$\begin{array}{llll}0.100 & 0.00 \mathrm{E}+00 & 0.00 \mathrm{E}+00 & 0.00 \mathrm{E}+00\end{array}$

$\begin{array}{lllll}0.125 & 0.00 \mathrm{E}+00 & 0.00 \mathrm{E}+00 & 0.00 \mathrm{E}+00\end{array}$

$\begin{array}{lllll}0.150 & 0.00 \mathrm{E}+00 & 0.00 \mathrm{E}+00 & 0.00 \mathrm{E}+00\end{array}$

$\begin{array}{lllll}0.175 & 0.00 \mathrm{E}+00 & 0.00 \mathrm{E}+00 & 0.00 \mathrm{E}+00\end{array}$

$\begin{array}{lllll}0.200 & 0.00 \mathrm{E}+00 & 0.00 \mathrm{E}+00 & 0.00 \mathrm{E}+00\end{array}$

$\begin{array}{lllll}0.225 & 0.00 \mathrm{E}+00 & 0.00 \mathrm{E}+00 & 0.00 \mathrm{E}+00\end{array}$

$\begin{array}{lllll}0.250 & 0.00 \mathrm{E}+00 & 0.00 \mathrm{E}+00 & 0.00 \mathrm{E}+00\end{array}$

$\begin{array}{lllll}0.275 & 0.00 \mathrm{E}+00 & 0.00 \mathrm{E}+00 & 0.00 \mathrm{E}+00\end{array}$

$\begin{array}{lllll}0.300 & 0.00 \mathrm{E}+00 & 0.00 \mathrm{E}+00 & 0.00 \mathrm{E}+00\end{array}$

$\begin{array}{lllll}0.325 & 0.00 \mathrm{E}+00 & 0.00 \mathrm{E}+00 & 0.00 \mathrm{E}+00\end{array}$

$\begin{array}{lllll}0.350 & 0.00 \mathrm{E}+00 & 0.00 \mathrm{E}+00 & 0.00 \mathrm{E}+00\end{array}$

$\begin{array}{lllll}0.375 & 0.00 \mathrm{E}+00 & 0.00 \mathrm{E}+00 & 0.00 \mathrm{E}+00\end{array}$

$\begin{array}{lllll}0.400 & 0.00 \mathrm{E}+00 & 0.00 \mathrm{E}+00 & 0.00 \mathrm{E}+00\end{array}$

$\begin{array}{lllll}0.425 & 0.00 \mathrm{E}+00 & 0.00 \mathrm{E}+00 & 0.00 \mathrm{E}+00\end{array}$

$\begin{array}{lllll}0.450 & 0.00 \mathrm{E}+00 & 0.00 \mathrm{E}+00 & 0.00 \mathrm{E}+00\end{array}$

$\begin{array}{lllll}0.475 & 0.00 \mathrm{E}+00 & 0.00 \mathrm{E}+00 & 0.00 \mathrm{E}+00\end{array}$

$\begin{array}{lllll}0.500 & 0.00 \mathrm{E}+00 & 0.00 \mathrm{E}+00 & 0.00 \mathrm{E}+00\end{array}$

$\begin{array}{lllll}0.525 & 0.00 \mathrm{E}+00 & 0.00 \mathrm{E}+00 & 0.00 \mathrm{E}+00\end{array}$

$\begin{array}{lllll}0.550 & 0.00 \mathrm{E}+00 & 0.00 \mathrm{E}+00 & 0.00 \mathrm{E}+00\end{array}$

$\begin{array}{lllll}0.575 & 0.00 \mathrm{E}+00 & 0.00 \mathrm{E}+00 & 0.00 \mathrm{E}+00\end{array}$

$\begin{array}{lllll}0.600 & 0.00 \mathrm{E}+00 & 0.00 \mathrm{E}+00 & 0.00 \mathrm{E}+00\end{array}$

$\begin{array}{lllll}0.625 & 0.00 \mathrm{E}+00 & 0.00 \mathrm{E}+00 & 0.00 \mathrm{E}+00\end{array}$

$\begin{array}{lllll}0.650 & 0.00 \mathrm{E}+00 & 0.00 \mathrm{E}+00 & 0.00 \mathrm{E}+00\end{array}$

$\begin{array}{lllll}0.675 & 0.00 \mathrm{E}+00 & 0.00 \mathrm{E}+00 & 0.00 \mathrm{E}+00\end{array}$

$\begin{array}{lllll}0.700 & 0.00 \mathrm{E}+00 & 0.00 \mathrm{E}+00 & 0.00 \mathrm{E}+00\end{array}$

$\begin{array}{lllll}0.725 & 0.00 \mathrm{E}+00 & 0.00 \mathrm{E}+00 & 0.00 \mathrm{E}+00\end{array}$

$\begin{array}{lllll}0.750 & 0.00 \mathrm{E}+00 & 0.00 \mathrm{E}+00 & 0.00 \mathrm{E}+00\end{array}$

$\begin{array}{lllll}0.775 & 0.00 \mathrm{E}+00 & 0.00 \mathrm{E}+00 & 0.00 \mathrm{E}+00\end{array}$

$\begin{array}{lllll}0.800 & 0.00 \mathrm{E}+00 & 0.00 \mathrm{E}+00 & 0.00 \mathrm{E}+00\end{array}$

$\begin{array}{lllll}0.825 & 0.00 \mathrm{E}+00 & 0.00 \mathrm{E}+00 & 0.00 \mathrm{E}+00\end{array}$

$\begin{array}{lllll}0.850 & 0.00 \mathrm{E}+00 & 0.00 \mathrm{E}+00 & 0.00 \mathrm{E}+00\end{array}$

$\begin{array}{lllll}0.875 & 0.00 \mathrm{E}+00 & 0.00 \mathrm{E}+00 & 0.00 \mathrm{E}+00\end{array}$

$\begin{array}{lllll}0.900 & 0.00 \mathrm{E}+00 & 0.00 \mathrm{E}+00 & 0.00 \mathrm{E}+00\end{array}$

$\begin{array}{lllll}0.925 & 0.00 \mathrm{E}+00 & 0.00 \mathrm{E}+00 & 0.00 \mathrm{E}+00\end{array}$

$\begin{array}{llll}0.950 & 0.00 \mathrm{E}+00 & 0.00 \mathrm{E}+00 & 0.00 \mathrm{E}+00\end{array}$

$\begin{array}{lllll}0.975 & 0.00 \mathrm{E}+00 & 0.00 \mathrm{E}+00 & 0.00 \mathrm{E}+00\end{array}$

$\begin{array}{lllll}0.990 & 0.00 \mathrm{E}+00 & 0.00 \mathrm{E}+00 & 0.00 \mathrm{E}+00\end{array}$ 
RESRAD-OFFSITE, Version 2.5

Probabilistic Dose and Risk Report

Title : RESRAD-OFFSITE External Gamma, Inhalation, and Soil Ingestion for offsite Reside

File : PBA-1_TC99-DOE-5-1.ROF

Statistics and Cumulative distribution function of Peak Dose from Plant (CzandAir) in mrem/yr

$\begin{array}{rcccc}\text { Repetition }= & 1 & 2 & 3 \\ \text { Mean } & & 0.00 \mathrm{E}+00 & 0.00 \mathrm{E}+00 & 0.00 \mathrm{E}+00 \\ \text { Std. Dev. } & 0.00 \mathrm{E}+00 & 0.00 \mathrm{E}+00 & 0.00 \mathrm{E}+00 \\ \text { Minimum } & 0.00 \mathrm{E}+00 & 0.00 \mathrm{E}+00 & 0.00 \mathrm{E}+00 \\ \text { Maximum } & 0.00 \mathrm{E}+00 & 0.00 \mathrm{E}+00 & 0.00 \mathrm{E}+00\end{array}$

Percentile

$\begin{array}{llll}0.010 & 0.00 \mathrm{E}+00 \quad 0.00 \mathrm{E}+00 & 0.00 \mathrm{E}+00\end{array}$

$\begin{array}{llll}0.025 & 0.00 \mathrm{E}+00 \quad 0.00 \mathrm{E}+00 & 0.00 \mathrm{E}+00\end{array}$

$\begin{array}{llll}0.050 & 0.00 \mathrm{E}+00 & 0.00 \mathrm{E}+00 & 0.00 \mathrm{E}+00\end{array}$

$\begin{array}{llll}0.075 & 0.00 \mathrm{E}+00 & 0.00 \mathrm{E}+00 & 0.00 \mathrm{E}+00\end{array}$

$\begin{array}{llll}0.100 & 0.00 \mathrm{E}+00 & 0.00 \mathrm{E}+00 & 0.00 \mathrm{E}+00\end{array}$

$\begin{array}{lllll}0.125 & 0.00 \mathrm{E}+00 & 0.00 \mathrm{E}+00 & 0.00 \mathrm{E}+00\end{array}$

$\begin{array}{lllll}0.150 & 0.00 \mathrm{E}+00 & 0.00 \mathrm{E}+00 & 0.00 \mathrm{E}+00\end{array}$

$\begin{array}{lllll}0.175 & 0.00 \mathrm{E}+00 & 0.00 \mathrm{E}+00 & 0.00 \mathrm{E}+00\end{array}$

$\begin{array}{lllll}0.200 & 0.00 \mathrm{E}+00 & 0.00 \mathrm{E}+00 & 0.00 \mathrm{E}+00\end{array}$

$\begin{array}{lllll}0.225 & 0.00 \mathrm{E}+00 & 0.00 \mathrm{E}+00 & 0.00 \mathrm{E}+00\end{array}$

$\begin{array}{lllll}0.250 & 0.00 \mathrm{E}+00 & 0.00 \mathrm{E}+00 & 0.00 \mathrm{E}+00\end{array}$

$\begin{array}{lllll}0.275 & 0.00 \mathrm{E}+00 & 0.00 \mathrm{E}+00 & 0.00 \mathrm{E}+00\end{array}$

$\begin{array}{lllll}0.300 & 0.00 \mathrm{E}+00 & 0.00 \mathrm{E}+00 & 0.00 \mathrm{E}+00\end{array}$

$\begin{array}{lllll}0.325 & 0.00 \mathrm{E}+00 & 0.00 \mathrm{E}+00 & 0.00 \mathrm{E}+00\end{array}$

$\begin{array}{lllll}0.350 & 0.00 \mathrm{E}+00 & 0.00 \mathrm{E}+00 & 0.00 \mathrm{E}+00\end{array}$

$\begin{array}{lllll}0.375 & 0.00 \mathrm{E}+00 & 0.00 \mathrm{E}+00 & 0.00 \mathrm{E}+00\end{array}$

$\begin{array}{lllll}0.400 & 0.00 \mathrm{E}+00 & 0.00 \mathrm{E}+00 & 0.00 \mathrm{E}+00\end{array}$

$\begin{array}{lllll}0.425 & 0.00 \mathrm{E}+00 & 0.00 \mathrm{E}+00 & 0.00 \mathrm{E}+00\end{array}$

$\begin{array}{lllll}0.450 & 0.00 \mathrm{E}+00 & 0.00 \mathrm{E}+00 & 0.00 \mathrm{E}+00\end{array}$

$\begin{array}{lllll}0.475 & 0.00 \mathrm{E}+00 & 0.00 \mathrm{E}+00 & 0.00 \mathrm{E}+00\end{array}$

$\begin{array}{lllll}0.500 & 0.00 \mathrm{E}+00 & 0.00 \mathrm{E}+00 & 0.00 \mathrm{E}+00\end{array}$

$\begin{array}{lllll}0.525 & 0.00 \mathrm{E}+00 & 0.00 \mathrm{E}+00 & 0.00 \mathrm{E}+00\end{array}$

$\begin{array}{lllll}0.550 & 0.00 \mathrm{E}+00 & 0.00 \mathrm{E}+00 & 0.00 \mathrm{E}+00\end{array}$

$\begin{array}{lllll}0.575 & 0.00 \mathrm{E}+00 & 0.00 \mathrm{E}+00 & 0.00 \mathrm{E}+00\end{array}$

$\begin{array}{lllll}0.600 & 0.00 \mathrm{E}+00 & 0.00 \mathrm{E}+00 & 0.00 \mathrm{E}+00\end{array}$

$\begin{array}{lllll}0.625 & 0.00 \mathrm{E}+00 & 0.00 \mathrm{E}+00 & 0.00 \mathrm{E}+00\end{array}$

$\begin{array}{lllll}0.650 & 0.00 \mathrm{E}+00 & 0.00 \mathrm{E}+00 & 0.00 \mathrm{E}+00\end{array}$

$\begin{array}{lllll}0.675 & 0.00 \mathrm{E}+00 & 0.00 \mathrm{E}+00 & 0.00 \mathrm{E}+00\end{array}$

$\begin{array}{lllll}0.700 & 0.00 \mathrm{E}+00 & 0.00 \mathrm{E}+00 & 0.00 \mathrm{E}+00\end{array}$

$\begin{array}{lllll}0.725 & 0.00 \mathrm{E}+00 & 0.00 \mathrm{E}+00 & 0.00 \mathrm{E}+00\end{array}$

$\begin{array}{lllll}0.750 & 0.00 \mathrm{E}+00 & 0.00 \mathrm{E}+00 & 0.00 \mathrm{E}+00\end{array}$

$\begin{array}{lllll}0.775 & 0.00 \mathrm{E}+00 & 0.00 \mathrm{E}+00 & 0.00 \mathrm{E}+00\end{array}$

$\begin{array}{lllll}0.800 & 0.00 \mathrm{E}+00 & 0.00 \mathrm{E}+00 & 0.00 \mathrm{E}+00\end{array}$

$\begin{array}{lllll}0.825 & 0.00 \mathrm{E}+00 & 0.00 \mathrm{E}+00 & 0.00 \mathrm{E}+00\end{array}$

$\begin{array}{lllll}0.850 & 0.00 \mathrm{E}+00 & 0.00 \mathrm{E}+00 & 0.00 \mathrm{E}+00\end{array}$

$\begin{array}{lllll}0.875 & 0.00 \mathrm{E}+00 & 0.00 \mathrm{E}+00 & 0.00 \mathrm{E}+00\end{array}$

$\begin{array}{lllll}0.900 & 0.00 \mathrm{E}+00 & 0.00 \mathrm{E}+00 & 0.00 \mathrm{E}+00\end{array}$

$\begin{array}{lllll}0.925 & 0.00 \mathrm{E}+00 & 0.00 \mathrm{E}+00 & 0.00 \mathrm{E}+00\end{array}$

$\begin{array}{llll}0.950 & 0.00 \mathrm{E}+00 & 0.00 \mathrm{E}+00 & 0.00 \mathrm{E}+00\end{array}$

$\begin{array}{lllll}0.975 & 0.00 \mathrm{E}+00 & 0.00 \mathrm{E}+00 & 0.00 \mathrm{E}+00\end{array}$

$\begin{array}{llll}0.990 & 0.00 \mathrm{E}+00 & 0.00 \mathrm{E}+00 & 0.00 \mathrm{E}+00\end{array}$ 
RESRAD-OFFSITE, Version 2.5

Probabilistic Dose and Risk Report

Title : RESRAD-OFFSITE External Gamma, Inhalation, and Soil Ingestion for offsite Reside

File : PBA-1_TC99-DOE-5-1.ROF

Statistics and Cumulative distribution function of Peak Dose from Meat (CZandAir) in mrem/yr

$\begin{array}{ccccc}\text { Repetition }= & 1 & 2 & 3 \\ \begin{array}{c}\text { Mean } \\ \text { Std. Dev. }\end{array} & 0.00 \mathrm{E}+00 & 0.00 \mathrm{E}+00 & 0.00 \mathrm{E}+00 \\ \text { Minimum } & 0.00 \mathrm{E}+00 & 0.00 \mathrm{E}+00 & 0.00 \mathrm{E}+00 \\ \text { Maximum } & 0.00 \mathrm{E}+00 & 0.00 \mathrm{E}+00 & 0.00 \mathrm{E}+00 \\ & 0.00 \mathrm{E}+00 & 0.00 \mathrm{E}+00 & 0.00 \mathrm{E}+00\end{array}$

Percentile

$\begin{array}{llll}0.010 & 0.00 \mathrm{E}+00 \quad 0.00 \mathrm{E}+00 & 0.00 \mathrm{E}+00\end{array}$

$\begin{array}{llll}0.025 & 0.00 \mathrm{E}+00 & 0.00 \mathrm{E}+00 & 0.00 \mathrm{E}+00\end{array}$

$\begin{array}{lllll}0.050 & 0.00 \mathrm{E}+00 & 0.00 \mathrm{E}+00 & 0.00 \mathrm{E}+00\end{array}$

$\begin{array}{lllll}0.075 & 0.00 \mathrm{E}+00 & 0.00 \mathrm{E}+00 & 0.00 \mathrm{E}+00\end{array}$

$\begin{array}{llll}0.100 & 0.00 \mathrm{E}+00 & 0.00 \mathrm{E}+00 & 0.00 \mathrm{E}+00\end{array}$

$\begin{array}{lllll}0.125 & 0.00 \mathrm{E}+00 & 0.00 \mathrm{E}+00 & 0.00 \mathrm{E}+00\end{array}$

$\begin{array}{lllll}0.150 & 0.00 \mathrm{E}+00 & 0.00 \mathrm{E}+00 & 0.00 \mathrm{E}+00\end{array}$

$\begin{array}{lllll}0.175 & 0.00 \mathrm{E}+00 & 0.00 \mathrm{E}+00 & 0.00 \mathrm{E}+00\end{array}$

$\begin{array}{lllll}0.200 & 0.00 \mathrm{E}+00 & 0.00 \mathrm{E}+00 & 0.00 \mathrm{E}+00\end{array}$

$\begin{array}{lllll}0.225 & 0.00 \mathrm{E}+00 & 0.00 \mathrm{E}+00 & 0.00 \mathrm{E}+00\end{array}$

$\begin{array}{lllll}0.250 & 0.00 \mathrm{E}+00 & 0.00 \mathrm{E}+00 & 0.00 \mathrm{E}+00\end{array}$

$\begin{array}{lllll}0.275 & 0.00 \mathrm{E}+00 & 0.00 \mathrm{E}+00 & 0.00 \mathrm{E}+00\end{array}$

$\begin{array}{lllll}0.300 & 0.00 \mathrm{E}+00 & 0.00 \mathrm{E}+00 & 0.00 \mathrm{E}+00\end{array}$

$\begin{array}{lllll}0.325 & 0.00 \mathrm{E}+00 & 0.00 \mathrm{E}+00 & 0.00 \mathrm{E}+00\end{array}$

$\begin{array}{lllll}0.350 & 0.00 \mathrm{E}+00 & 0.00 \mathrm{E}+00 & 0.00 \mathrm{E}+00\end{array}$

$\begin{array}{lllll}0.375 & 0.00 \mathrm{E}+00 & 0.00 \mathrm{E}+00 & 0.00 \mathrm{E}+00\end{array}$

$\begin{array}{lllll}0.400 & 0.00 \mathrm{E}+00 & 0.00 \mathrm{E}+00 & 0.00 \mathrm{E}+00\end{array}$

$\begin{array}{lllll}0.425 & 0.00 \mathrm{E}+00 & 0.00 \mathrm{E}+00 & 0.00 \mathrm{E}+00\end{array}$

$\begin{array}{lllll}0.450 & 0.00 \mathrm{E}+00 & 0.00 \mathrm{E}+00 & 0.00 \mathrm{E}+00\end{array}$

$\begin{array}{lllll}0.475 & 0.00 \mathrm{E}+00 & 0.00 \mathrm{E}+00 & 0.00 \mathrm{E}+00\end{array}$

$\begin{array}{lllll}0.500 & 0.00 \mathrm{E}+00 & 0.00 \mathrm{E}+00 & 0.00 \mathrm{E}+00\end{array}$

$\begin{array}{lllll}0.525 & 0.00 \mathrm{E}+00 & 0.00 \mathrm{E}+00 & 0.00 \mathrm{E}+00\end{array}$

$\begin{array}{lllll}0.550 & 0.00 \mathrm{E}+00 & 0.00 \mathrm{E}+00 & 0.00 \mathrm{E}+00\end{array}$

$\begin{array}{lllll}0.575 & 0.00 \mathrm{E}+00 & 0.00 \mathrm{E}+00 & 0.00 \mathrm{E}+00\end{array}$

$\begin{array}{lllll}0.600 & 0.00 \mathrm{E}+00 & 0.00 \mathrm{E}+00 & 0.00 \mathrm{E}+00\end{array}$

$\begin{array}{lllll}0.625 & 0.00 \mathrm{E}+00 & 0.00 \mathrm{E}+00 & 0.00 \mathrm{E}+00\end{array}$

$\begin{array}{lllll}0.650 & 0.00 \mathrm{E}+00 & 0.00 \mathrm{E}+00 & 0.00 \mathrm{E}+00\end{array}$

$\begin{array}{lllll}0.675 & 0.00 \mathrm{E}+00 & 0.00 \mathrm{E}+00 & 0.00 \mathrm{E}+00\end{array}$

$\begin{array}{lllll}0.700 & 0.00 \mathrm{E}+00 & 0.00 \mathrm{E}+00 & 0.00 \mathrm{E}+00\end{array}$

$\begin{array}{lllll}0.725 & 0.00 \mathrm{E}+00 & 0.00 \mathrm{E}+00 & 0.00 \mathrm{E}+00\end{array}$

$\begin{array}{lllll}0.750 & 0.00 \mathrm{E}+00 & 0.00 \mathrm{E}+00 & 0.00 \mathrm{E}+00\end{array}$

$\begin{array}{lllll}0.775 & 0.00 \mathrm{E}+00 & 0.00 \mathrm{E}+00 & 0.00 \mathrm{E}+00\end{array}$

$\begin{array}{lllll}0.800 & 0.00 \mathrm{E}+00 & 0.00 \mathrm{E}+00 & 0.00 \mathrm{E}+00\end{array}$

$\begin{array}{lllll}0.825 & 0.00 \mathrm{E}+00 & 0.00 \mathrm{E}+00 & 0.00 \mathrm{E}+00\end{array}$

$\begin{array}{lllll}0.850 & 0.00 \mathrm{E}+00 & 0.00 \mathrm{E}+00 & 0.00 \mathrm{E}+00\end{array}$

$\begin{array}{lllll}0.875 & 0.00 \mathrm{E}+00 & 0.00 \mathrm{E}+00 & 0.00 \mathrm{E}+00\end{array}$

$\begin{array}{lllll}0.900 & 0.00 \mathrm{E}+00 & 0.00 \mathrm{E}+00 & 0.00 \mathrm{E}+00\end{array}$

$\begin{array}{lllll}0.925 & 0.00 \mathrm{E}+00 & 0.00 \mathrm{E}+00 & 0.00 \mathrm{E}+00\end{array}$

$\begin{array}{lllll}0.950 & 0.00 \mathrm{E}+00 & 0.00 \mathrm{E}+00 & 0.00 \mathrm{E}+00\end{array}$

$\begin{array}{lllll}0.975 & 0.00 \mathrm{E}+00 & 0.00 \mathrm{E}+00 & 0.00 \mathrm{E}+00\end{array}$

$\begin{array}{lllll}0.990 & 0.00 \mathrm{E}+00 & 0.00 \mathrm{E}+00 & 0.00 \mathrm{E}+00\end{array}$ 
RESRAD-OFFSITE, Version 2.5

Probabilistic Dose and Risk Report

Title : RESRAD-OFFSITE External Gamma, Inhalation, and Soil Ingestion for offsite Reside

File : PBA-1_TC99-DOE-5-1.ROF

Statistics and Cumulative distribution function of Peak Dose from Milk (CzandAir) in mrem/yr

$\begin{array}{ccccc}\text { Repetition }= & 1 & 2 & 3 \\ \begin{array}{c}\text { Mean } \\ \text { Std. Dev. }\end{array} & 0.00 \mathrm{E}+00 & 0.00 \mathrm{E}+00 & 0.00 \mathrm{E}+00 \\ \text { Minimum } & 0.00 \mathrm{E}+00 & 0.00 \mathrm{E}+00 & 0.00 \mathrm{E}+00 \\ \text { Maximum } & 0.00 \mathrm{E}+00 & 0.00 \mathrm{E}+00 & 0.00 \mathrm{E}+00 \\ & 0.00 \mathrm{E}+00 & 0.00 \mathrm{E}+00 & 0.00 \mathrm{E}+00\end{array}$

Percentile

$\begin{array}{llll}0.010 & 0.00 \mathrm{E}+00 \quad 0.00 \mathrm{E}+00 & 0.00 \mathrm{E}+00\end{array}$

$\begin{array}{llll}0.025 & 0.00 \mathrm{E}+00 & 0.00 \mathrm{E}+00 & 0.00 \mathrm{E}+00\end{array}$

$\begin{array}{lllll}0.050 & 0.00 \mathrm{E}+00 & 0.00 \mathrm{E}+00 & 0.00 \mathrm{E}+00\end{array}$

$\begin{array}{lllll}0.075 & 0.00 \mathrm{E}+00 & 0.00 \mathrm{E}+00 & 0.00 \mathrm{E}+00\end{array}$

$\begin{array}{llll}0.100 & 0.00 \mathrm{E}+00 & 0.00 \mathrm{E}+00 & 0.00 \mathrm{E}+00\end{array}$

$\begin{array}{lllll}0.125 & 0.00 \mathrm{E}+00 & 0.00 \mathrm{E}+00 & 0.00 \mathrm{E}+00\end{array}$

$\begin{array}{lllll}0.150 & 0.00 \mathrm{E}+00 & 0.00 \mathrm{E}+00 & 0.00 \mathrm{E}+00\end{array}$

$\begin{array}{lllll}0.175 & 0.00 \mathrm{E}+00 & 0.00 \mathrm{E}+00 & 0.00 \mathrm{E}+00\end{array}$

$\begin{array}{lllll}0.200 & 0.00 \mathrm{E}+00 & 0.00 \mathrm{E}+00 & 0.00 \mathrm{E}+00\end{array}$

$\begin{array}{lllll}0.225 & 0.00 \mathrm{E}+00 & 0.00 \mathrm{E}+00 & 0.00 \mathrm{E}+00\end{array}$

$\begin{array}{lllll}0.250 & 0.00 \mathrm{E}+00 & 0.00 \mathrm{E}+00 & 0.00 \mathrm{E}+00\end{array}$

$\begin{array}{lllll}0.275 & 0.00 \mathrm{E}+00 & 0.00 \mathrm{E}+00 & 0.00 \mathrm{E}+00\end{array}$

$\begin{array}{lllll}0.300 & 0.00 \mathrm{E}+00 & 0.00 \mathrm{E}+00 & 0.00 \mathrm{E}+00\end{array}$

$\begin{array}{lllll}0.325 & 0.00 \mathrm{E}+00 & 0.00 \mathrm{E}+00 & 0.00 \mathrm{E}+00\end{array}$

$\begin{array}{lllll}0.350 & 0.00 \mathrm{E}+00 & 0.00 \mathrm{E}+00 & 0.00 \mathrm{E}+00\end{array}$

$\begin{array}{lllll}0.375 & 0.00 \mathrm{E}+00 & 0.00 \mathrm{E}+00 & 0.00 \mathrm{E}+00\end{array}$

$\begin{array}{lllll}0.400 & 0.00 \mathrm{E}+00 & 0.00 \mathrm{E}+00 & 0.00 \mathrm{E}+00\end{array}$

$\begin{array}{lllll}0.425 & 0.00 \mathrm{E}+00 & 0.00 \mathrm{E}+00 & 0.00 \mathrm{E}+00\end{array}$

$\begin{array}{lllll}0.450 & 0.00 \mathrm{E}+00 & 0.00 \mathrm{E}+00 & 0.00 \mathrm{E}+00\end{array}$

$\begin{array}{lllll}0.475 & 0.00 \mathrm{E}+00 & 0.00 \mathrm{E}+00 & 0.00 \mathrm{E}+00\end{array}$

$\begin{array}{lllll}0.500 & 0.00 \mathrm{E}+00 & 0.00 \mathrm{E}+00 & 0.00 \mathrm{E}+00\end{array}$

$\begin{array}{lllll}0.525 & 0.00 \mathrm{E}+00 & 0.00 \mathrm{E}+00 & 0.00 \mathrm{E}+00\end{array}$

$\begin{array}{lllll}0.550 & 0.00 \mathrm{E}+00 & 0.00 \mathrm{E}+00 & 0.00 \mathrm{E}+00\end{array}$

$\begin{array}{lllll}0.575 & 0.00 \mathrm{E}+00 & 0.00 \mathrm{E}+00 & 0.00 \mathrm{E}+00\end{array}$

$\begin{array}{lllll}0.600 & 0.00 \mathrm{E}+00 & 0.00 \mathrm{E}+00 & 0.00 \mathrm{E}+00\end{array}$

$\begin{array}{lllll}0.625 & 0.00 \mathrm{E}+00 & 0.00 \mathrm{E}+00 & 0.00 \mathrm{E}+00\end{array}$

$\begin{array}{lllll}0.650 & 0.00 \mathrm{E}+00 & 0.00 \mathrm{E}+00 & 0.00 \mathrm{E}+00\end{array}$

$\begin{array}{lllll}0.675 & 0.00 \mathrm{E}+00 & 0.00 \mathrm{E}+00 & 0.00 \mathrm{E}+00\end{array}$

$\begin{array}{lllll}0.700 & 0.00 \mathrm{E}+00 & 0.00 \mathrm{E}+00 & 0.00 \mathrm{E}+00\end{array}$

$\begin{array}{lllll}0.725 & 0.00 \mathrm{E}+00 & 0.00 \mathrm{E}+00 & 0.00 \mathrm{E}+00\end{array}$

$\begin{array}{lllll}0.750 & 0.00 \mathrm{E}+00 & 0.00 \mathrm{E}+00 & 0.00 \mathrm{E}+00\end{array}$

$\begin{array}{lllll}0.775 & 0.00 \mathrm{E}+00 & 0.00 \mathrm{E}+00 & 0.00 \mathrm{E}+00\end{array}$

$\begin{array}{lllll}0.800 & 0.00 \mathrm{E}+00 & 0.00 \mathrm{E}+00 & 0.00 \mathrm{E}+00\end{array}$

$\begin{array}{lllll}0.825 & 0.00 \mathrm{E}+00 & 0.00 \mathrm{E}+00 & 0.00 \mathrm{E}+00\end{array}$

$\begin{array}{lllll}0.850 & 0.00 \mathrm{E}+00 & 0.00 \mathrm{E}+00 & 0.00 \mathrm{E}+00\end{array}$

$\begin{array}{lllll}0.875 & 0.00 \mathrm{E}+00 & 0.00 \mathrm{E}+00 & 0.00 \mathrm{E}+00\end{array}$

$\begin{array}{lllll}0.900 & 0.00 \mathrm{E}+00 & 0.00 \mathrm{E}+00 & 0.00 \mathrm{E}+00\end{array}$

$\begin{array}{lllll}0.925 & 0.00 \mathrm{E}+00 & 0.00 \mathrm{E}+00 & 0.00 \mathrm{E}+00\end{array}$

$\begin{array}{lllll}0.950 & 0.00 \mathrm{E}+00 & 0.00 \mathrm{E}+00 & 0.00 \mathrm{E}+00\end{array}$

$\begin{array}{lllll}0.975 & 0.00 \mathrm{E}+00 & 0.00 \mathrm{E}+00 & 0.00 \mathrm{E}+00\end{array}$

$\begin{array}{lllll}0.990 & 0.00 \mathrm{E}+00 & 0.00 \mathrm{E}+00 & 0.00 \mathrm{E}+00\end{array}$ 
RESRAD-OFFSITE, Version 2.5

Probabilistic Dose and Risk Report

Title : RESRAD-OFFSITE External Gamma, Inhalation, and Soil Ingestion for offsite Reside

File : PBA-1_TC99-DOE-5-1.ROF

Statistics and Cumulative distribution function of Peak Dose from Soil Ingestion(CZandAir) in mrem/yr

$\begin{array}{rcccc}\text { Repetition }= & 1 & 2 & 3 \\ \text { Mean } & 0.00 \mathrm{E}+00 & 0.00 \mathrm{E}+00 & 0.00 \mathrm{E}+00 \\ \text { Std. Dev. } & 0.00 \mathrm{E}+00 & 0.00 \mathrm{E}+00 & 0.00 \mathrm{E}+00 \\ \text { Minimum } & 0.00 \mathrm{E}+00 & 0.00 \mathrm{E}+00 & 0.00 \mathrm{E}+00 \\ \text { Maximum } & 0.00 \mathrm{E}+00 & 0.00 \mathrm{E}+00 & 0.00 \mathrm{E}+00\end{array}$

Percentile

$\begin{array}{llll}0.010 & 0.00 \mathrm{E}+00 \quad 0.00 \mathrm{E}+00 & 0.00 \mathrm{E}+00\end{array}$

$\begin{array}{llll}0.025 & 0.00 \mathrm{E}+00 \quad 0.00 \mathrm{E}+00 & 0.00 \mathrm{E}+00\end{array}$

$\begin{array}{llll}0.050 & 0.00 \mathrm{E}+00 & 0.00 \mathrm{E}+00 & 0.00 \mathrm{E}+00\end{array}$

$\begin{array}{llll}0.075 & 0.00 \mathrm{E}+00 & 0.00 \mathrm{E}+00 & 0.00 \mathrm{E}+00\end{array}$

$\begin{array}{llll}0.100 & 0.00 \mathrm{E}+00 & 0.00 \mathrm{E}+00 & 0.00 \mathrm{E}+00\end{array}$

$\begin{array}{llll}0.125 & 0.00 \mathrm{E}+00 & 0.00 \mathrm{E}+00 & 0.00 \mathrm{E}+00\end{array}$

$\begin{array}{lllll}0.150 & 0.00 \mathrm{E}+00 & 0.00 \mathrm{E}+00 & 0.00 \mathrm{E}+00\end{array}$

$\begin{array}{lllll}0.175 & 0.00 \mathrm{E}+00 & 0.00 \mathrm{E}+00 & 0.00 \mathrm{E}+00\end{array}$

$\begin{array}{lllll}0.200 & 0.00 \mathrm{E}+00 & 0.00 \mathrm{E}+00 & 0.00 \mathrm{E}+00\end{array}$

$\begin{array}{lllll}0.225 & 0.00 \mathrm{E}+00 & 0.00 \mathrm{E}+00 & 0.00 \mathrm{E}+00\end{array}$

$\begin{array}{lllll}0.250 & 0.00 \mathrm{E}+00 & 0.00 \mathrm{E}+00 & 0.00 \mathrm{E}+00\end{array}$

$\begin{array}{lllll}0.275 & 0.00 \mathrm{E}+00 & 0.00 \mathrm{E}+00 & 0.00 \mathrm{E}+00\end{array}$

$\begin{array}{lllll}0.300 & 0.00 \mathrm{E}+00 & 0.00 \mathrm{E}+00 & 0.00 \mathrm{E}+00\end{array}$

$\begin{array}{lllll}0.325 & 0.00 \mathrm{E}+00 & 0.00 \mathrm{E}+00 & 0.00 \mathrm{E}+00\end{array}$

$\begin{array}{lllll}0.350 & 0.00 \mathrm{E}+00 & 0.00 \mathrm{E}+00 & 0.00 \mathrm{E}+00\end{array}$

$\begin{array}{lllll}0.375 & 0.00 \mathrm{E}+00 & 0.00 \mathrm{E}+00 & 0.00 \mathrm{E}+00\end{array}$

$\begin{array}{lllll}0.400 & 0.00 \mathrm{E}+00 & 0.00 \mathrm{E}+00 & 0.00 \mathrm{E}+00\end{array}$

$\begin{array}{lllll}0.425 & 0.00 \mathrm{E}+00 & 0.00 \mathrm{E}+00 & 0.00 \mathrm{E}+00\end{array}$

$\begin{array}{lllll}0.450 & 0.00 \mathrm{E}+00 & 0.00 \mathrm{E}+00 & 0.00 \mathrm{E}+00\end{array}$

$\begin{array}{lllll}0.475 & 0.00 \mathrm{E}+00 & 0.00 \mathrm{E}+00 & 0.00 \mathrm{E}+00\end{array}$

$\begin{array}{lllll}0.500 & 0.00 \mathrm{E}+00 & 0.00 \mathrm{E}+00 & 0.00 \mathrm{E}+00\end{array}$

$\begin{array}{lllll}0.525 & 0.00 \mathrm{E}+00 & 0.00 \mathrm{E}+00 & 0.00 \mathrm{E}+00\end{array}$

$\begin{array}{lllll}0.550 & 0.00 \mathrm{E}+00 & 0.00 \mathrm{E}+00 & 0.00 \mathrm{E}+00\end{array}$

$\begin{array}{lllll}0.575 & 0.00 \mathrm{E}+00 & 0.00 \mathrm{E}+00 & 0.00 \mathrm{E}+00\end{array}$

$\begin{array}{lllll}0.600 & 0.00 \mathrm{E}+00 & 0.00 \mathrm{E}+00 & 0.00 \mathrm{E}+00\end{array}$

$\begin{array}{lllll}0.625 & 0.00 \mathrm{E}+00 & 0.00 \mathrm{E}+00 & 0.00 \mathrm{E}+00\end{array}$

$\begin{array}{lllll}0.650 & 0.00 \mathrm{E}+00 & 0.00 \mathrm{E}+00 & 0.00 \mathrm{E}+00\end{array}$

$\begin{array}{lllll}0.675 & 0.00 \mathrm{E}+00 & 0.00 \mathrm{E}+00 & 0.00 \mathrm{E}+00\end{array}$

$\begin{array}{lllll}0.700 & 0.00 \mathrm{E}+00 & 0.00 \mathrm{E}+00 & 0.00 \mathrm{E}+00\end{array}$

$\begin{array}{lllll}0.725 & 0.00 \mathrm{E}+00 & 0.00 \mathrm{E}+00 & 0.00 \mathrm{E}+00\end{array}$

$\begin{array}{lllll}0.750 & 0.00 \mathrm{E}+00 & 0.00 \mathrm{E}+00 & 0.00 \mathrm{E}+00\end{array}$

$\begin{array}{lllll}0.775 & 0.00 \mathrm{E}+00 & 0.00 \mathrm{E}+00 & 0.00 \mathrm{E}+00\end{array}$

$\begin{array}{lllll}0.800 & 0.00 \mathrm{E}+00 & 0.00 \mathrm{E}+00 & 0.00 \mathrm{E}+00\end{array}$

$\begin{array}{lllll}0.825 & 0.00 \mathrm{E}+00 & 0.00 \mathrm{E}+00 & 0.00 \mathrm{E}+00\end{array}$

$\begin{array}{lllll}0.850 & 0.00 \mathrm{E}+00 & 0.00 \mathrm{E}+00 & 0.00 \mathrm{E}+00\end{array}$

$\begin{array}{lllll}0.875 & 0.00 \mathrm{E}+00 & 0.00 \mathrm{E}+00 & 0.00 \mathrm{E}+00\end{array}$

$\begin{array}{lllll}0.900 & 0.00 \mathrm{E}+00 & 0.00 \mathrm{E}+00 & 0.00 \mathrm{E}+00\end{array}$

$\begin{array}{lllll}0.925 & 0.00 \mathrm{E}+00 & 0.00 \mathrm{E}+00 & 0.00 \mathrm{E}+00\end{array}$

$\begin{array}{llll}0.950 & 0.00 \mathrm{E}+00 & 0.00 \mathrm{E}+00 & 0.00 \mathrm{E}+00\end{array}$

$\begin{array}{lllll}0.975 & 0.00 \mathrm{E}+00 & 0.00 \mathrm{E}+00 & 0.00 \mathrm{E}+00\end{array}$

$\begin{array}{llll}0.990 & 0.00 \mathrm{E}+00 & 0.00 \mathrm{E}+00 & 0.00 \mathrm{E}+00\end{array}$ 
RESRAD-OFFSITE, Version 2.5

Probabilistic Dose and Risk Report

Title : RESRAD-OFFSITE External Gamma, Inhalation, and Soil Ingestion for Offsite Reside File : PBA-1_TC99-DOE-5-1.ROF

Statistics and Cumulative distribution function of Peak Risk from All Pathways

$\begin{array}{rcccc}\text { Repetition }= & 1 & 2 & 3 \\ \text { Mean } & & 4.80 \mathrm{E}-11 & 4.79 \mathrm{E}-11 & 4.79 \mathrm{E}-11 \\ \text { Std. Dev. } & & 2.86 \mathrm{E}-11 & 2.86 \mathrm{E}-11 & 2.86 \mathrm{E}-11 \\ \text { Minimum } & 5.77 \mathrm{E}-12 & 5.77 \mathrm{E}-12 & 5.77 \mathrm{E}-12 \\ \text { Maximum } & & 2.72 \mathrm{E}-10 & 2.72 \mathrm{E}-10 & 2.72 \mathrm{E}-10\end{array}$

Percentile

0.010

8.29E-12 8.29E-12 8.29E-12

0.025

$1.08 \mathrm{E}-11 \quad 1.08 \mathrm{E}-11 \quad 1.08 \mathrm{E}-11$

0.050

1.32E-11 1.32E-11 1.32E-11

0.075

$1.56 \mathrm{E}-11 \quad 1.56 \mathrm{E}-11 \quad 1.56 \mathrm{E}-11$

0.100

$1.74 \mathrm{E}-11 \quad 1.74 \mathrm{E}-11 \quad 1.74 \mathrm{E}-11$

0.125

$1.91 \mathrm{E}-11 \quad 1.91 \mathrm{E}-11 \quad 1.91 \mathrm{E}-11$

0.150

$2.06 \mathrm{E}-11 \quad 2.06 \mathrm{E}-11 \quad 2.06 \mathrm{E}-11$

0.175

$2.24 \mathrm{E}-11 \quad 2.24 \mathrm{E}-11 \quad 2.24 \mathrm{E}-11$

0.200

2.38E-11 2.38E-11 2.38E-11

0.225

$2.54 \mathrm{E}-11 \quad 2.54 \mathrm{E}-11 \quad 2.54 \mathrm{E}-11$

0.250

$2.70 \mathrm{E}-11 \quad 2.70 \mathrm{E}-11 \quad 2.70 \mathrm{E}-11$

0.275

0.300

$2.86 \mathrm{E}-11 \quad 2.86 \mathrm{E}-11 \quad 2.86 \mathrm{E}-11$

0.325

3.01E-11 3.01E-11 3.01E-11

0.350

3.13E-11 3.13E-11 3.13E-11

0.375

3. $26 \mathrm{E}-113.25 \mathrm{E}-11 \quad 3.26 \mathrm{E}-11$

3. $40 \mathrm{E}-113.39 \mathrm{E}-113.40 \mathrm{E}-11$

0.400

0.425

$3.55 \mathrm{E}-113.55 \mathrm{E}-11 \quad 3.55 \mathrm{E}-11$

$3.69 \mathrm{E}-11 \quad 3.68 \mathrm{E}-11 \quad 3.69 \mathrm{E}-11$

0.450

3. $82 \mathrm{E}-11 \quad 3.82 \mathrm{E}-11 \quad 3.82 \mathrm{E}-11$

4.01E-11 4.00E-11 4.00E-11

4.20E-11 4.17E-11 4.18E-11

4.37E-11 4.33E-11 4.34E-11

4.54E-11 4.53E-11 4.54E-11

4.72E-11 4.70E-11 4.71E-11

$4.89 \mathrm{E}-11 \quad 4.88 \mathrm{E}-11 \quad 4.88 \mathrm{E}-11$

$5.08 \mathrm{E}-11 \quad 5.07 \mathrm{E}-11 \quad 5.07 \mathrm{E}-11$

$5.28 \mathrm{E}-11 \quad 5.27 \mathrm{E}-11 \quad 5.27 \mathrm{E}-11$

$5.50 \mathrm{E}-11 \quad 5.49 \mathrm{E}-11 \quad 5.49 \mathrm{E}-11$

$5.74 \mathrm{E}-11 \quad 5.74 \mathrm{E}-11 \quad 5.74 \mathrm{E}-11$

$5.98 \mathrm{E}-11 \quad 5.98 \mathrm{E}-11 \quad 5.98 \mathrm{E}-11$

6.32E-11 6.32E-11 6.32E-11

$6.63 \mathrm{E}-11 \quad 6.62 \mathrm{E}-11 \quad 6.63 \mathrm{E}-11$

$6.97 \mathrm{E}-11 \quad 6.97 \mathrm{E}-11 \quad 6.97 \mathrm{E}-11$

$7.26 \mathrm{E}-11 \quad 7.26 \mathrm{E}-11 \quad 7.26 \mathrm{E}-11$

$7.68 \mathrm{E}-11 \quad 7.67 \mathrm{E}-11 \quad 7.68 \mathrm{E}-11$

8.22E-11 8.21E-11 8.22E-11

8.67E-11 8.67E-11 8.67E-11

$9.38 \mathrm{E}-11 \quad 9.36 \mathrm{E}-11 \quad 9.38 \mathrm{E}-11$

$1.02 \mathrm{E}-10 \quad 1.02 \mathrm{E}-10 \quad 1.02 \mathrm{E}-10$

$1.15 \mathrm{E}-10 \quad 1.15 \mathrm{E}-10 \quad 1.15 \mathrm{E}-10$

$1.44 \mathrm{E}-10 \quad 1.44 \mathrm{E}-10 \quad 1.44 \mathrm{E}-10$ 
RESRAD-OFFSITE, Version 2.5

Probabilistic Dose and Risk Report

Title : RESRAD-OFFSITE External Gamma, Inhalation, and Soil Ingestion for Offsite Reside File : PBA-1_TC99-DOE-5-1.ROF

Statistics and Cumulative distribution function of Peak Risk from External Ground(Wreleas)

$\begin{array}{rcccc}\text { Repetition }= & 1 & 2 & 3 \\ \text { Mean } & & 1.65 \mathrm{E}-11 & 1.65 \mathrm{E}-11 & 1.65 \mathrm{E}-11 \\ \text { Std. Dev. } & & 9.86 \mathrm{E}-12 & 9.85 \mathrm{E}-12 & 9.86 \mathrm{E}-12 \\ \text { Minimum } & & 1.99 \mathrm{E}-12 & 1.99 \mathrm{E}-12 & 1.99 \mathrm{E}-12 \\ \text { Maximum } & 9.37 \mathrm{E}-11 & 9.37 \mathrm{E}-11 & 9.37 \mathrm{E}-11\end{array}$

Percentile

$0.010 \quad 2.86 \mathrm{E}-12 \quad 2.86 \mathrm{E}-12 \quad 2.86 \mathrm{E}-12$

$0.025 \quad 3.72 \mathrm{E}-12 \quad 3.72 \mathrm{E}-12 \quad 3.72 \mathrm{E}-12$

$0.050 \quad 4.56 \mathrm{E}-12 \quad 4.56 \mathrm{E}-12 \quad 4.56 \mathrm{E}-12$

$0.075 \quad 5.39 \mathrm{E}-12 \quad 5.39 \mathrm{E}-12 \quad 5.39 \mathrm{E}-12$

$0.100 \quad 5.98 \mathrm{E}-12 \quad 5.98 \mathrm{E}-12 \quad 5.98 \mathrm{E}-12$

$0.125 \quad 6.58 \mathrm{E}-12 \quad 6.58 \mathrm{E}-12 \quad 6.58 \mathrm{E}-12$

$0.150 \quad 7.11 \mathrm{E}-12 \quad 7.11 \mathrm{E}-12 \quad 7.11 \mathrm{E}-12$

$0.175 \quad 7.72 \mathrm{E}-12 \quad 7.72 \mathrm{E}-12 \quad 7.72 \mathrm{E}-12$

$0.200 \quad 8.19 \mathrm{E}-12 \quad 8.19 \mathrm{E}-12 \quad 8.19 \mathrm{E}-12$

$0.225 \quad 8.76 \mathrm{E}-12 \quad 8.74 \mathrm{E}-12 \quad 8.74 \mathrm{E}-12$

$0.250 \quad 9.31 \mathrm{E}-12 \quad 9.30 \mathrm{E}-12 \quad 9.30 \mathrm{E}-12$

$0.2759 .85 \mathrm{E}-12 \quad 9.85 \mathrm{E}-12 \quad 9.85 \mathrm{E}-12$

$0.300 \quad 1.04 \mathrm{E}-11 \quad 1.04 \mathrm{E}-11 \quad 1.04 \mathrm{E}-11$

$0.325 \quad 1.08 \mathrm{E}-11 \quad 1.08 \mathrm{E}-11 \quad 1.08 \mathrm{E}-11$

$0.350 \quad 1.12 \mathrm{E}-11 \quad 1.12 \mathrm{E}-11 \quad 1.12 \mathrm{E}-11$

$0.375 \quad 1.17 \mathrm{E}-11 \quad 1.17 \mathrm{E}-11 \quad 1.17 \mathrm{E}-11$

$0.400 \quad 1.22 \mathrm{E}-11 \quad 1.22 \mathrm{E}-11 \quad 1.22 \mathrm{E}-11$

$\begin{array}{llll}0.425 & 1.27 \mathrm{E}-11 & 1.27 \mathrm{E}-11 & 1.27 \mathrm{E}-11\end{array}$

$\begin{array}{llll}0.450 & 1.32 \mathrm{E}-11 & 1.32 \mathrm{E}-11 & 1.32 \mathrm{E}-11\end{array}$

$\begin{array}{llll}0.475 & 1.38 \mathrm{E}-11 & 1.38 \mathrm{E}-11 & 1.38 \mathrm{E}-11\end{array}$

$0.500 \quad 1.45 \mathrm{E}-11 \quad 1.44 \mathrm{E}-11 \quad 1.44 \mathrm{E}-11$

$\begin{array}{llll}0.525 & 1.50 \mathrm{E}-11 & 1.49 \mathrm{E}-11 & 1.49 \mathrm{E}-11\end{array}$

$0.550 \quad 1.57 \mathrm{E}-11 \quad 1.56 \mathrm{E}-11 \quad 1.56 \mathrm{E}-11$

$0.575 \quad 1.62 \mathrm{E}-11 \quad 1.62 \mathrm{E}-11 \quad 1.62 \mathrm{E}-11$

$0.600 \quad 1.68 \mathrm{E}-11 \quad 1.68 \mathrm{E}-11 \quad 1.68 \mathrm{E}-11$

$\begin{array}{llll}0.625 & 1.75 \mathrm{E}-11 & 1.75 \mathrm{E}-11 & 1.75 \mathrm{E}-11\end{array}$

$\begin{array}{llll}0.650 & 1.82 \mathrm{E}-11 & 1.82 \mathrm{E}-11 & 1.82 \mathrm{E}-11\end{array}$

$\begin{array}{llll}0.675 & 1.89 \mathrm{E}-11 & 1.89 \mathrm{E}-11 & 1.89 \mathrm{E}-11\end{array}$

$0.700 \quad 1.98 \mathrm{E}-11 \quad 1.98 \mathrm{E}-11 \quad 1.98 \mathrm{E}-11$

$0.725 \quad 2.06 \mathrm{E}-11 \quad 2.06 \mathrm{E}-11 \quad 2.06 \mathrm{E}-11$

$\begin{array}{llll}0.750 & 2.18 \mathrm{E}-11 & 2.18 \mathrm{E}-11 & 2.18 \mathrm{E}-11\end{array}$

$\begin{array}{llll}0.775 & 2.29 \mathrm{E}-11 & 2.28 \mathrm{E}-11 & 2.29 \mathrm{E}-11\end{array}$

$\begin{array}{llll}0.800 \quad 2.40 \mathrm{E}-11 & 2.40 \mathrm{E}-11 & 2.40 \mathrm{E}-11\end{array}$

$\begin{array}{llll}0.825 & 2.50 \mathrm{E}-11 & 2.50 \mathrm{E}-11 & 2.50 \mathrm{E}-11\end{array}$

$\begin{array}{llll}0.850 & 2.64 \mathrm{E}-11 & 2.64 \mathrm{E}-11 & 2.64 \mathrm{E}-11\end{array}$

$\begin{array}{llll}0.875 & 2.83 \mathrm{E}-11 & 2.83 \mathrm{E}-11 & 2.83 \mathrm{E}-11\end{array}$

$\begin{array}{llll}0.900 \quad 2.99 \mathrm{E}-11 & 2.99 \mathrm{E}-11 \quad 2.99 \mathrm{E}-11\end{array}$

$\begin{array}{llll}0.925 & 3.23 E-11 & 3.23 E-11 & 3.23 E-11\end{array}$

$0.950 \quad 3.51 \mathrm{E}-11 \quad 3.51 \mathrm{E}-11 \quad 3.51 \mathrm{E}-11$

$0.975 \quad 3.97 \mathrm{E}-11 \quad 3.97 \mathrm{E}-11 \quad 3.97 \mathrm{E}-11$

$0.990 \quad 4.96 \mathrm{E}-11 \quad 4.96 \mathrm{E}-11 \quad 4.96 \mathrm{E}-11$ 
RESRAD-OFFSITE, Version 2.5

Probabilistic Dose and Risk Report

Title : RESRAD-OFFSITE External Gamma, Inhalation, and Soil Ingestion for offsite Reside

File : PBA-1_TC99-DOE-5-1.ROF

Statistics and Cumulative distribution function of Peak Risk from Fish Ingestion

\begin{tabular}{ccccc} 
Repetition $=$ & 1 & 2 & 3 \\
\cline { 5 - 5 } Mean & $0.00 \mathrm{E}+00$ & $0.00 \mathrm{E}+00$ & $0.00 \mathrm{E}+00$ \\
Std. Dev. & $0.00 \mathrm{E}+00$ & $0.00 \mathrm{E}+00$ & $0.00 \mathrm{E}+00$ \\
Minimum & $0.00 \mathrm{E}+00$ & $0.00 \mathrm{E}+00$ & $0.00 \mathrm{E}+00$ \\
Maximum & $0.00 \mathrm{E}+00$ & $0.00 \mathrm{E}+00$ & $0.00 \mathrm{E}+00$
\end{tabular}

Percentile

$\begin{array}{llll}0.010 & 0.00 \mathrm{E}+00 \quad 0.00 \mathrm{E}+00 & 0.00 \mathrm{E}+00\end{array}$

$\begin{array}{llll}0.025 & 0.00 \mathrm{E}+00 & 0.00 \mathrm{E}+00 & 0.00 \mathrm{E}+00\end{array}$

$\begin{array}{lllll}0.050 & 0.00 \mathrm{E}+00 & 0.00 \mathrm{E}+00 & 0.00 \mathrm{E}+00\end{array}$

$\begin{array}{lllll}0.075 & 0.00 \mathrm{E}+00 & 0.00 \mathrm{E}+00 & 0.00 \mathrm{E}+00\end{array}$

$\begin{array}{llll}0.100 & 0.00 \mathrm{E}+00 & 0.00 \mathrm{E}+00 & 0.00 \mathrm{E}+00\end{array}$

$\begin{array}{lllll}0.125 & 0.00 \mathrm{E}+00 & 0.00 \mathrm{E}+00 & 0.00 \mathrm{E}+00\end{array}$

$\begin{array}{lllll}0.150 & 0.00 \mathrm{E}+00 & 0.00 \mathrm{E}+00 & 0.00 \mathrm{E}+00\end{array}$

$\begin{array}{lllll}0.175 & 0.00 \mathrm{E}+00 & 0.00 \mathrm{E}+00 & 0.00 \mathrm{E}+00\end{array}$

$\begin{array}{lllll}0.200 & 0.00 \mathrm{E}+00 & 0.00 \mathrm{E}+00 & 0.00 \mathrm{E}+00\end{array}$

$\begin{array}{lllll}0.225 & 0.00 \mathrm{E}+00 & 0.00 \mathrm{E}+00 & 0.00 \mathrm{E}+00\end{array}$

$\begin{array}{lllll}0.250 & 0.00 \mathrm{E}+00 & 0.00 \mathrm{E}+00 & 0.00 \mathrm{E}+00\end{array}$

$\begin{array}{lllll}0.275 & 0.00 \mathrm{E}+00 & 0.00 \mathrm{E}+00 & 0.00 \mathrm{E}+00\end{array}$

$\begin{array}{lllll}0.300 & 0.00 \mathrm{E}+00 & 0.00 \mathrm{E}+00 & 0.00 \mathrm{E}+00\end{array}$

$\begin{array}{lllll}0.325 & 0.00 \mathrm{E}+00 & 0.00 \mathrm{E}+00 & 0.00 \mathrm{E}+00\end{array}$

$\begin{array}{lllll}0.350 & 0.00 \mathrm{E}+00 & 0.00 \mathrm{E}+00 & 0.00 \mathrm{E}+00\end{array}$

$\begin{array}{lllll}0.375 & 0.00 \mathrm{E}+00 & 0.00 \mathrm{E}+00 & 0.00 \mathrm{E}+00\end{array}$

$\begin{array}{lllll}0.400 & 0.00 \mathrm{E}+00 & 0.00 \mathrm{E}+00 & 0.00 \mathrm{E}+00\end{array}$

$\begin{array}{lllll}0.425 & 0.00 \mathrm{E}+00 & 0.00 \mathrm{E}+00 & 0.00 \mathrm{E}+00\end{array}$

$\begin{array}{lllll}0.450 & 0.00 \mathrm{E}+00 & 0.00 \mathrm{E}+00 & 0.00 \mathrm{E}+00\end{array}$

$\begin{array}{lllll}0.475 & 0.00 \mathrm{E}+00 & 0.00 \mathrm{E}+00 & 0.00 \mathrm{E}+00\end{array}$

$\begin{array}{lllll}0.500 & 0.00 \mathrm{E}+00 & 0.00 \mathrm{E}+00 & 0.00 \mathrm{E}+00\end{array}$

$\begin{array}{lllll}0.525 & 0.00 \mathrm{E}+00 & 0.00 \mathrm{E}+00 & 0.00 \mathrm{E}+00\end{array}$

$\begin{array}{lllll}0.550 & 0.00 \mathrm{E}+00 & 0.00 \mathrm{E}+00 & 0.00 \mathrm{E}+00\end{array}$

$\begin{array}{lllll}0.575 & 0.00 \mathrm{E}+00 & 0.00 \mathrm{E}+00 & 0.00 \mathrm{E}+00\end{array}$

$\begin{array}{lllll}0.600 & 0.00 \mathrm{E}+00 & 0.00 \mathrm{E}+00 & 0.00 \mathrm{E}+00\end{array}$

$\begin{array}{lllll}0.625 & 0.00 \mathrm{E}+00 & 0.00 \mathrm{E}+00 & 0.00 \mathrm{E}+00\end{array}$

$\begin{array}{lllll}0.650 & 0.00 \mathrm{E}+00 & 0.00 \mathrm{E}+00 & 0.00 \mathrm{E}+00\end{array}$

$\begin{array}{lllll}0.675 & 0.00 \mathrm{E}+00 & 0.00 \mathrm{E}+00 & 0.00 \mathrm{E}+00\end{array}$

$\begin{array}{lllll}0.700 & 0.00 \mathrm{E}+00 & 0.00 \mathrm{E}+00 & 0.00 \mathrm{E}+00\end{array}$

$\begin{array}{lllll}0.725 & 0.00 \mathrm{E}+00 & 0.00 \mathrm{E}+00 & 0.00 \mathrm{E}+00\end{array}$

$\begin{array}{lllll}0.750 & 0.00 \mathrm{E}+00 & 0.00 \mathrm{E}+00 & 0.00 \mathrm{E}+00\end{array}$

$\begin{array}{lllll}0.775 & 0.00 \mathrm{E}+00 & 0.00 \mathrm{E}+00 & 0.00 \mathrm{E}+00\end{array}$

$\begin{array}{lllll}0.800 & 0.00 \mathrm{E}+00 & 0.00 \mathrm{E}+00 & 0.00 \mathrm{E}+00\end{array}$

$\begin{array}{lllll}0.825 & 0.00 \mathrm{E}+00 & 0.00 \mathrm{E}+00 & 0.00 \mathrm{E}+00\end{array}$

$\begin{array}{lllll}0.850 & 0.00 \mathrm{E}+00 & 0.00 \mathrm{E}+00 & 0.00 \mathrm{E}+00\end{array}$

$\begin{array}{lllll}0.875 & 0.00 \mathrm{E}+00 & 0.00 \mathrm{E}+00 & 0.00 \mathrm{E}+00\end{array}$

$\begin{array}{lllll}0.900 & 0.00 \mathrm{E}+00 & 0.00 \mathrm{E}+00 & 0.00 \mathrm{E}+00\end{array}$

$\begin{array}{lllll}0.925 & 0.00 \mathrm{E}+00 & 0.00 \mathrm{E}+00 & 0.00 \mathrm{E}+00\end{array}$

$\begin{array}{lllll}0.950 & 0.00 \mathrm{E}+00 & 0.00 \mathrm{E}+00 & 0.00 \mathrm{E}+00\end{array}$

$\begin{array}{lllll}0.975 & 0.00 \mathrm{E}+00 & 0.00 \mathrm{E}+00 & 0.00 \mathrm{E}+00\end{array}$

$\begin{array}{lllll}0.990 & 0.00 \mathrm{E}+00 & 0.00 \mathrm{E}+00 & 0.00 \mathrm{E}+00\end{array}$ 
RESRAD-OFFSITE, Version 2.5

Probabilistic Dose and Risk Report

Title : RESRAD-OFFSITE External Gamma, Inhalation, and Soil Ingestion for offsite Reside

File : PBA-1_TC99-DOE-5-1.ROF

Statistics and Cumulative distribution function of Peak Risk from Radon (Waterrelease)

$\begin{array}{ccccc}\text { Repetition }= & 1 & 2 & 3 \\ \begin{array}{c}\text { Mean } \\ \text { Std. Dev. }\end{array} & 0.00 \mathrm{E}+00 & 0.00 \mathrm{E}+00 & 0.00 \mathrm{E}+00 \\ \text { Minimum } & 0.00 \mathrm{E}+00 & 0.00 \mathrm{E}+00 & 0.00 \mathrm{E}+00 \\ \text { Maximum } & 0.00 \mathrm{E}+00 & 0.00 \mathrm{E}+00 & 0.00 \mathrm{E}+00 \\ & 0.00 \mathrm{E}+00 & 0.00 \mathrm{E}+00 & 0.00 \mathrm{E}+00\end{array}$

Percentile

$\begin{array}{llll}0.010 & 0.00 \mathrm{E}+00 \quad 0.00 \mathrm{E}+00 & 0.00 \mathrm{E}+00\end{array}$

$\begin{array}{llll}0.025 & 0.00 \mathrm{E}+00 & 0.00 \mathrm{E}+00 & 0.00 \mathrm{E}+00\end{array}$

$\begin{array}{lllll}0.050 & 0.00 \mathrm{E}+00 & 0.00 \mathrm{E}+00 & 0.00 \mathrm{E}+00\end{array}$

$\begin{array}{lllll}0.075 & 0.00 \mathrm{E}+00 & 0.00 \mathrm{E}+00 & 0.00 \mathrm{E}+00\end{array}$

$\begin{array}{llll}0.100 & 0.00 \mathrm{E}+00 & 0.00 \mathrm{E}+00 & 0.00 \mathrm{E}+00\end{array}$

$\begin{array}{lllll}0.125 & 0.00 \mathrm{E}+00 & 0.00 \mathrm{E}+00 & 0.00 \mathrm{E}+00\end{array}$

$\begin{array}{lllll}0.150 & 0.00 \mathrm{E}+00 & 0.00 \mathrm{E}+00 & 0.00 \mathrm{E}+00\end{array}$

$\begin{array}{lllll}0.175 & 0.00 \mathrm{E}+00 & 0.00 \mathrm{E}+00 & 0.00 \mathrm{E}+00\end{array}$

$\begin{array}{lllll}0.200 & 0.00 \mathrm{E}+00 & 0.00 \mathrm{E}+00 & 0.00 \mathrm{E}+00\end{array}$

$\begin{array}{lllll}0.225 & 0.00 \mathrm{E}+00 & 0.00 \mathrm{E}+00 & 0.00 \mathrm{E}+00\end{array}$

$\begin{array}{lllll}0.250 & 0.00 \mathrm{E}+00 & 0.00 \mathrm{E}+00 & 0.00 \mathrm{E}+00\end{array}$

$\begin{array}{lllll}0.275 & 0.00 \mathrm{E}+00 & 0.00 \mathrm{E}+00 & 0.00 \mathrm{E}+00\end{array}$

$\begin{array}{lllll}0.300 & 0.00 \mathrm{E}+00 & 0.00 \mathrm{E}+00 & 0.00 \mathrm{E}+00\end{array}$

$\begin{array}{lllll}0.325 & 0.00 \mathrm{E}+00 & 0.00 \mathrm{E}+00 & 0.00 \mathrm{E}+00\end{array}$

$\begin{array}{lllll}0.350 & 0.00 \mathrm{E}+00 & 0.00 \mathrm{E}+00 & 0.00 \mathrm{E}+00\end{array}$

$\begin{array}{lllll}0.375 & 0.00 \mathrm{E}+00 & 0.00 \mathrm{E}+00 & 0.00 \mathrm{E}+00\end{array}$

$\begin{array}{lllll}0.400 & 0.00 \mathrm{E}+00 & 0.00 \mathrm{E}+00 & 0.00 \mathrm{E}+00\end{array}$

$\begin{array}{lllll}0.425 & 0.00 \mathrm{E}+00 & 0.00 \mathrm{E}+00 & 0.00 \mathrm{E}+00\end{array}$

$\begin{array}{lllll}0.450 & 0.00 \mathrm{E}+00 & 0.00 \mathrm{E}+00 & 0.00 \mathrm{E}+00\end{array}$

$\begin{array}{lllll}0.475 & 0.00 \mathrm{E}+00 & 0.00 \mathrm{E}+00 & 0.00 \mathrm{E}+00\end{array}$

$\begin{array}{lllll}0.500 & 0.00 \mathrm{E}+00 & 0.00 \mathrm{E}+00 & 0.00 \mathrm{E}+00\end{array}$

$\begin{array}{lllll}0.525 & 0.00 \mathrm{E}+00 & 0.00 \mathrm{E}+00 & 0.00 \mathrm{E}+00\end{array}$

$\begin{array}{lllll}0.550 & 0.00 \mathrm{E}+00 & 0.00 \mathrm{E}+00 & 0.00 \mathrm{E}+00\end{array}$

$\begin{array}{lllll}0.575 & 0.00 \mathrm{E}+00 & 0.00 \mathrm{E}+00 & 0.00 \mathrm{E}+00\end{array}$

$\begin{array}{lllll}0.600 & 0.00 \mathrm{E}+00 & 0.00 \mathrm{E}+00 & 0.00 \mathrm{E}+00\end{array}$

$\begin{array}{lllll}0.625 & 0.00 \mathrm{E}+00 & 0.00 \mathrm{E}+00 & 0.00 \mathrm{E}+00\end{array}$

$\begin{array}{lllll}0.650 & 0.00 \mathrm{E}+00 & 0.00 \mathrm{E}+00 & 0.00 \mathrm{E}+00\end{array}$

$\begin{array}{lllll}0.675 & 0.00 \mathrm{E}+00 & 0.00 \mathrm{E}+00 & 0.00 \mathrm{E}+00\end{array}$

$\begin{array}{llll}0.700 & 0.00 \mathrm{E}+00 & 0.00 \mathrm{E}+00 & 0.00 \mathrm{E}+00\end{array}$

$\begin{array}{lllll}0.725 & 0.00 \mathrm{E}+00 & 0.00 \mathrm{E}+00 & 0.00 \mathrm{E}+00\end{array}$

$\begin{array}{lllll}0.750 & 0.00 \mathrm{E}+00 & 0.00 \mathrm{E}+00 & 0.00 \mathrm{E}+00\end{array}$

$\begin{array}{lllll}0.775 & 0.00 \mathrm{E}+00 & 0.00 \mathrm{E}+00 & 0.00 \mathrm{E}+00\end{array}$

$\begin{array}{lllll}0.800 & 0.00 \mathrm{E}+00 & 0.00 \mathrm{E}+00 & 0.00 \mathrm{E}+00\end{array}$

$\begin{array}{lllll}0.825 & 0.00 \mathrm{E}+00 & 0.00 \mathrm{E}+00 & 0.00 \mathrm{E}+00\end{array}$

$\begin{array}{lllll}0.850 & 0.00 \mathrm{E}+00 & 0.00 \mathrm{E}+00 & 0.00 \mathrm{E}+00\end{array}$

$\begin{array}{lllll}0.875 & 0.00 \mathrm{E}+00 & 0.00 \mathrm{E}+00 & 0.00 \mathrm{E}+00\end{array}$

$\begin{array}{lllll}0.900 & 0.00 \mathrm{E}+00 & 0.00 \mathrm{E}+00 & 0.00 \mathrm{E}+00\end{array}$

$\begin{array}{lllll}0.925 & 0.00 \mathrm{E}+00 & 0.00 \mathrm{E}+00 & 0.00 \mathrm{E}+00\end{array}$

$\begin{array}{llll}0.950 & 0.00 \mathrm{E}+00 & 0.00 \mathrm{E}+00 & 0.00 \mathrm{E}+00\end{array}$

$\begin{array}{lllll}0.975 & 0.00 \mathrm{E}+00 & 0.00 \mathrm{E}+00 & 0.00 \mathrm{E}+00\end{array}$

$\begin{array}{lllll}0.990 & 0.00 \mathrm{E}+00 & 0.00 \mathrm{E}+00 & 0.00 \mathrm{E}+00\end{array}$ 
RESRAD-OFFSITE, Version 2.5

Probabilistic Dose and Risk Report

Title : RESRAD-OFFSITE External Gamma, Inhalation, and Soil Ingestion for offsite Reside

File : PBA-1_TC99-DOE-5-1.ROF

Statistics and Cumulative distribution function of Peak Risk from Plant (Waterrelease)

$\begin{array}{ccccc}\text { Repetition }= & 1 & 2 & 3 \\ \begin{array}{c}\text { Mean } \\ \text { Std. Dev. }\end{array} & 0.00 \mathrm{E}+00 & 0.00 \mathrm{E}+00 & 0.00 \mathrm{E}+00 \\ \text { Minimum } & 0.00 \mathrm{E}+00 & 0.00 \mathrm{E}+00 & 0.00 \mathrm{E}+00 \\ \text { Maximum } & 0.00 \mathrm{E}+00 & 0.00 \mathrm{E}+00 & 0.00 \mathrm{E}+00 \\ & 0.00 \mathrm{E}+00 & 0.00 \mathrm{E}+00 & 0.00 \mathrm{E}+00\end{array}$

Percentile

$\begin{array}{llll}0.010 & 0.00 \mathrm{E}+00 \quad 0.00 \mathrm{E}+00 & 0.00 \mathrm{E}+00\end{array}$

$\begin{array}{lllll}0.025 & 0.00 \mathrm{E}+00 & 0.00 \mathrm{E}+00 & 0.00 \mathrm{E}+00\end{array}$

$\begin{array}{lllll}0.050 & 0.00 \mathrm{E}+00 & 0.00 \mathrm{E}+00 & 0.00 \mathrm{E}+00\end{array}$

$\begin{array}{lllll}0.075 & 0.00 \mathrm{E}+00 & 0.00 \mathrm{E}+00 & 0.00 \mathrm{E}+00\end{array}$

$\begin{array}{llll}0.100 & 0.00 \mathrm{E}+00 & 0.00 \mathrm{E}+00 & 0.00 \mathrm{E}+00\end{array}$

$\begin{array}{lllll}0.125 & 0.00 \mathrm{E}+00 & 0.00 \mathrm{E}+00 & 0.00 \mathrm{E}+00\end{array}$

$\begin{array}{lllll}0.150 & 0.00 \mathrm{E}+00 & 0.00 \mathrm{E}+00 & 0.00 \mathrm{E}+00\end{array}$

$\begin{array}{lllll}0.175 & 0.00 \mathrm{E}+00 & 0.00 \mathrm{E}+00 & 0.00 \mathrm{E}+00\end{array}$

$\begin{array}{lllll}0.200 & 0.00 \mathrm{E}+00 & 0.00 \mathrm{E}+00 & 0.00 \mathrm{E}+00\end{array}$

$\begin{array}{lllll}0.225 & 0.00 \mathrm{E}+00 & 0.00 \mathrm{E}+00 & 0.00 \mathrm{E}+00\end{array}$

$\begin{array}{lllll}0.250 & 0.00 \mathrm{E}+00 & 0.00 \mathrm{E}+00 & 0.00 \mathrm{E}+00\end{array}$

$\begin{array}{lllll}0.275 & 0.00 \mathrm{E}+00 & 0.00 \mathrm{E}+00 & 0.00 \mathrm{E}+00\end{array}$

$\begin{array}{lllll}0.300 & 0.00 \mathrm{E}+00 & 0.00 \mathrm{E}+00 & 0.00 \mathrm{E}+00\end{array}$

$\begin{array}{lllll}0.325 & 0.00 \mathrm{E}+00 & 0.00 \mathrm{E}+00 & 0.00 \mathrm{E}+00\end{array}$

$\begin{array}{lllll}0.350 & 0.00 \mathrm{E}+00 & 0.00 \mathrm{E}+00 & 0.00 \mathrm{E}+00\end{array}$

$\begin{array}{lllll}0.375 & 0.00 \mathrm{E}+00 & 0.00 \mathrm{E}+00 & 0.00 \mathrm{E}+00\end{array}$

$\begin{array}{lllll}0.400 & 0.00 \mathrm{E}+00 & 0.00 \mathrm{E}+00 & 0.00 \mathrm{E}+00\end{array}$

$\begin{array}{lllll}0.425 & 0.00 \mathrm{E}+00 & 0.00 \mathrm{E}+00 & 0.00 \mathrm{E}+00\end{array}$

$\begin{array}{lllll}0.450 & 0.00 \mathrm{E}+00 & 0.00 \mathrm{E}+00 & 0.00 \mathrm{E}+00\end{array}$

$\begin{array}{lllll}0.475 & 0.00 \mathrm{E}+00 & 0.00 \mathrm{E}+00 & 0.00 \mathrm{E}+00\end{array}$

$\begin{array}{lllll}0.500 & 0.00 \mathrm{E}+00 & 0.00 \mathrm{E}+00 & 0.00 \mathrm{E}+00\end{array}$

$\begin{array}{lllll}0.525 & 0.00 \mathrm{E}+00 & 0.00 \mathrm{E}+00 & 0.00 \mathrm{E}+00\end{array}$

$\begin{array}{lllll}0.550 & 0.00 \mathrm{E}+00 & 0.00 \mathrm{E}+00 & 0.00 \mathrm{E}+00\end{array}$

$\begin{array}{lllll}0.575 & 0.00 \mathrm{E}+00 & 0.00 \mathrm{E}+00 & 0.00 \mathrm{E}+00\end{array}$

$\begin{array}{lllll}0.600 & 0.00 \mathrm{E}+00 & 0.00 \mathrm{E}+00 & 0.00 \mathrm{E}+00\end{array}$

$\begin{array}{lllll}0.625 & 0.00 \mathrm{E}+00 & 0.00 \mathrm{E}+00 & 0.00 \mathrm{E}+00\end{array}$

$\begin{array}{lllll}0.650 & 0.00 \mathrm{E}+00 & 0.00 \mathrm{E}+00 & 0.00 \mathrm{E}+00\end{array}$

$\begin{array}{lllll}0.675 & 0.00 \mathrm{E}+00 & 0.00 \mathrm{E}+00 & 0.00 \mathrm{E}+00\end{array}$

$\begin{array}{llll}0.700 & 0.00 \mathrm{E}+00 & 0.00 \mathrm{E}+00 & 0.00 \mathrm{E}+00\end{array}$

$\begin{array}{lllll}0.725 & 0.00 \mathrm{E}+00 & 0.00 \mathrm{E}+00 & 0.00 \mathrm{E}+00\end{array}$

$\begin{array}{lllll}0.750 & 0.00 \mathrm{E}+00 & 0.00 \mathrm{E}+00 & 0.00 \mathrm{E}+00\end{array}$

$\begin{array}{lllll}0.775 & 0.00 \mathrm{E}+00 & 0.00 \mathrm{E}+00 & 0.00 \mathrm{E}+00\end{array}$

$\begin{array}{lllll}0.800 & 0.00 \mathrm{E}+00 & 0.00 \mathrm{E}+00 & 0.00 \mathrm{E}+00\end{array}$

$\begin{array}{lllll}0.825 & 0.00 \mathrm{E}+00 & 0.00 \mathrm{E}+00 & 0.00 \mathrm{E}+00\end{array}$

$\begin{array}{lllll}0.850 & 0.00 \mathrm{E}+00 & 0.00 \mathrm{E}+00 & 0.00 \mathrm{E}+00\end{array}$

$\begin{array}{lllll}0.875 & 0.00 \mathrm{E}+00 & 0.00 \mathrm{E}+00 & 0.00 \mathrm{E}+00\end{array}$

$\begin{array}{lllll}0.900 & 0.00 \mathrm{E}+00 & 0.00 \mathrm{E}+00 & 0.00 \mathrm{E}+00\end{array}$

$\begin{array}{lllll}0.925 & 0.00 \mathrm{E}+00 & 0.00 \mathrm{E}+00 & 0.00 \mathrm{E}+00\end{array}$

$\begin{array}{llll}0.950 & 0.00 \mathrm{E}+00 & 0.00 \mathrm{E}+00 & 0.00 \mathrm{E}+00\end{array}$

$\begin{array}{lllll}0.975 & 0.00 \mathrm{E}+00 & 0.00 \mathrm{E}+00 & 0.00 \mathrm{E}+00\end{array}$

$\begin{array}{lllll}0.990 & 0.00 \mathrm{E}+00 & 0.00 \mathrm{E}+00 & 0.00 \mathrm{E}+00\end{array}$ 
RESRAD-OFFSITE, Version 2.5

Probabilistic Dose and Risk Report

Title : RESRAD-OFFSITE External Gamma, Inhalation, and Soil Ingestion for offsite Reside

File : PBA-1_TC99-DOE-5-1.ROF

Statistics and Cumulative distribution function of Peak Risk from Meat (Waterrelease)

$\begin{array}{ccccc}\text { Repetition }= & 1 & 2 & 3 \\ \begin{array}{c}\text { Mean } \\ \text { Std. Dev. }\end{array} & 0.00 \mathrm{E}+00 & 0.00 \mathrm{E}+00 & 0.00 \mathrm{E}+00 \\ \text { Minimum } & 0.00 \mathrm{E}+00 & 0.00 \mathrm{E}+00 & 0.00 \mathrm{E}+00 \\ \text { Maximum } & 0.00 \mathrm{E}+00 & 0.00 \mathrm{E}+00 & 0.00 \mathrm{E}+00 \\ & 0.00 \mathrm{E}+00 & 0.00 \mathrm{E}+00 & 0.00 \mathrm{E}+00\end{array}$

Percentile

$\begin{array}{llll}0.010 & 0.00 \mathrm{E}+00 \quad 0.00 \mathrm{E}+00 & 0.00 \mathrm{E}+00\end{array}$

$\begin{array}{llll}0.025 & 0.00 \mathrm{E}+00 \quad 0.00 \mathrm{E}+00 & 0.00 \mathrm{E}+00\end{array}$

$\begin{array}{llll}0.050 & 0.00 \mathrm{E}+00 & 0.00 \mathrm{E}+00 & 0.00 \mathrm{E}+00\end{array}$

$\begin{array}{llll}0.075 & 0.00 \mathrm{E}+00 & 0.00 \mathrm{E}+00 & 0.00 \mathrm{E}+00\end{array}$

$\begin{array}{llll}0.100 & 0.00 \mathrm{E}+00 & 0.00 \mathrm{E}+00 & 0.00 \mathrm{E}+00\end{array}$

$\begin{array}{lllll}0.125 & 0.00 \mathrm{E}+00 & 0.00 \mathrm{E}+00 & 0.00 \mathrm{E}+00\end{array}$

$\begin{array}{lllll}0.150 & 0.00 \mathrm{E}+00 & 0.00 \mathrm{E}+00 & 0.00 \mathrm{E}+00\end{array}$

$\begin{array}{lllll}0.175 & 0.00 \mathrm{E}+00 & 0.00 \mathrm{E}+00 & 0.00 \mathrm{E}+00\end{array}$

$\begin{array}{lllll}0.200 & 0.00 \mathrm{E}+00 & 0.00 \mathrm{E}+00 & 0.00 \mathrm{E}+00\end{array}$

$\begin{array}{lllll}0.225 & 0.00 \mathrm{E}+00 & 0.00 \mathrm{E}+00 & 0.00 \mathrm{E}+00\end{array}$

$\begin{array}{lllll}0.250 & 0.00 \mathrm{E}+00 & 0.00 \mathrm{E}+00 & 0.00 \mathrm{E}+00\end{array}$

$\begin{array}{lllll}0.275 & 0.00 \mathrm{E}+00 & 0.00 \mathrm{E}+00 & 0.00 \mathrm{E}+00\end{array}$

$\begin{array}{lllll}0.300 & 0.00 \mathrm{E}+00 & 0.00 \mathrm{E}+00 & 0.00 \mathrm{E}+00\end{array}$

$\begin{array}{lllll}0.325 & 0.00 \mathrm{E}+00 & 0.00 \mathrm{E}+00 & 0.00 \mathrm{E}+00\end{array}$

$\begin{array}{lllll}0.350 & 0.00 \mathrm{E}+00 & 0.00 \mathrm{E}+00 & 0.00 \mathrm{E}+00\end{array}$

$\begin{array}{lllll}0.375 & 0.00 \mathrm{E}+00 & 0.00 \mathrm{E}+00 & 0.00 \mathrm{E}+00\end{array}$

$\begin{array}{lllll}0.400 & 0.00 \mathrm{E}+00 & 0.00 \mathrm{E}+00 & 0.00 \mathrm{E}+00\end{array}$

$\begin{array}{lllll}0.425 & 0.00 \mathrm{E}+00 & 0.00 \mathrm{E}+00 & 0.00 \mathrm{E}+00\end{array}$

$\begin{array}{lllll}0.450 & 0.00 \mathrm{E}+00 & 0.00 \mathrm{E}+00 & 0.00 \mathrm{E}+00\end{array}$

$\begin{array}{lllll}0.475 & 0.00 \mathrm{E}+00 & 0.00 \mathrm{E}+00 & 0.00 \mathrm{E}+00\end{array}$

$\begin{array}{lllll}0.500 & 0.00 \mathrm{E}+00 & 0.00 \mathrm{E}+00 & 0.00 \mathrm{E}+00\end{array}$

$\begin{array}{lllll}0.525 & 0.00 \mathrm{E}+00 & 0.00 \mathrm{E}+00 & 0.00 \mathrm{E}+00\end{array}$

$\begin{array}{lllll}0.550 & 0.00 \mathrm{E}+00 & 0.00 \mathrm{E}+00 & 0.00 \mathrm{E}+00\end{array}$

$\begin{array}{lllll}0.575 & 0.00 \mathrm{E}+00 & 0.00 \mathrm{E}+00 & 0.00 \mathrm{E}+00\end{array}$

$\begin{array}{lllll}0.600 & 0.00 \mathrm{E}+00 & 0.00 \mathrm{E}+00 & 0.00 \mathrm{E}+00\end{array}$

$\begin{array}{lllll}0.625 & 0.00 \mathrm{E}+00 & 0.00 \mathrm{E}+00 & 0.00 \mathrm{E}+00\end{array}$

$\begin{array}{lllll}0.650 & 0.00 \mathrm{E}+00 & 0.00 \mathrm{E}+00 & 0.00 \mathrm{E}+00\end{array}$

$\begin{array}{lllll}0.675 & 0.00 \mathrm{E}+00 & 0.00 \mathrm{E}+00 & 0.00 \mathrm{E}+00\end{array}$

$\begin{array}{llll}0.700 & 0.00 \mathrm{E}+00 & 0.00 \mathrm{E}+00 & 0.00 \mathrm{E}+00\end{array}$

$\begin{array}{lllll}0.725 & 0.00 \mathrm{E}+00 & 0.00 \mathrm{E}+00 & 0.00 \mathrm{E}+00\end{array}$

$\begin{array}{lllll}0.750 & 0.00 \mathrm{E}+00 & 0.00 \mathrm{E}+00 & 0.00 \mathrm{E}+00\end{array}$

$\begin{array}{lllll}0.775 & 0.00 \mathrm{E}+00 & 0.00 \mathrm{E}+00 & 0.00 \mathrm{E}+00\end{array}$

$\begin{array}{lllll}0.800 & 0.00 \mathrm{E}+00 & 0.00 \mathrm{E}+00 & 0.00 \mathrm{E}+00\end{array}$

$\begin{array}{lllll}0.825 & 0.00 \mathrm{E}+00 & 0.00 \mathrm{E}+00 & 0.00 \mathrm{E}+00\end{array}$

$\begin{array}{lllll}0.850 & 0.00 \mathrm{E}+00 & 0.00 \mathrm{E}+00 & 0.00 \mathrm{E}+00\end{array}$

$\begin{array}{lllll}0.875 & 0.00 \mathrm{E}+00 & 0.00 \mathrm{E}+00 & 0.00 \mathrm{E}+00\end{array}$

$\begin{array}{lllll}0.900 & 0.00 \mathrm{E}+00 & 0.00 \mathrm{E}+00 & 0.00 \mathrm{E}+00\end{array}$

$\begin{array}{lllll}0.925 & 0.00 \mathrm{E}+00 & 0.00 \mathrm{E}+00 & 0.00 \mathrm{E}+00\end{array}$

$\begin{array}{llll}0.950 & 0.00 \mathrm{E}+00 & 0.00 \mathrm{E}+00 & 0.00 \mathrm{E}+00\end{array}$

$\begin{array}{lllll}0.975 & 0.00 \mathrm{E}+00 & 0.00 \mathrm{E}+00 & 0.00 \mathrm{E}+00\end{array}$

$\begin{array}{lllll}0.990 & 0.00 \mathrm{E}+00 & 0.00 \mathrm{E}+00 & 0.00 \mathrm{E}+00\end{array}$ 
RESRAD-OFFSITE, Version 2.5

Probabilistic Dose and Risk Report

Title : RESRAD-OFFSITE External Gamma, Inhalation, and Soil Ingestion for offsite Reside

File : PBA-1_TC99-DOE-5-1.ROF

Statistics and Cumulative distribution function of Peak Risk from Milk (Waterrelease)

$\begin{array}{ccccc}\text { Repetition }= & 1 & 2 & 3 \\ \begin{array}{c}\text { Mean } \\ \text { Std. Dev. }\end{array} & 0.00 \mathrm{E}+00 & 0.00 \mathrm{E}+00 & 0.00 \mathrm{E}+00 \\ \text { Minimum } & 0.00 \mathrm{E}+00 & 0.00 \mathrm{E}+00 & 0.00 \mathrm{E}+00 \\ \text { Maximum } & 0.00 \mathrm{E}+00 & 0.00 \mathrm{E}+00 & 0.00 \mathrm{E}+00 \\ & 0.00 \mathrm{E}+00 & 0.00 \mathrm{E}+00 & 0.00 \mathrm{E}+00\end{array}$

Percentile

$\begin{array}{llll}0.010 & 0.00 \mathrm{E}+00 \quad 0.00 \mathrm{E}+00 & 0.00 \mathrm{E}+00\end{array}$

$\begin{array}{llll}0.025 & 0.00 \mathrm{E}+00 \quad 0.00 \mathrm{E}+00 & 0.00 \mathrm{E}+00\end{array}$

$\begin{array}{llll}0.050 & 0.00 \mathrm{E}+00 & 0.00 \mathrm{E}+00 & 0.00 \mathrm{E}+00\end{array}$

$\begin{array}{llll}0.075 & 0.00 \mathrm{E}+00 & 0.00 \mathrm{E}+00 & 0.00 \mathrm{E}+00\end{array}$

$\begin{array}{llll}0.100 & 0.00 \mathrm{E}+00 & 0.00 \mathrm{E}+00 & 0.00 \mathrm{E}+00\end{array}$

$\begin{array}{lllll}0.125 & 0.00 \mathrm{E}+00 & 0.00 \mathrm{E}+00 & 0.00 \mathrm{E}+00\end{array}$

$\begin{array}{lllll}0.150 & 0.00 \mathrm{E}+00 & 0.00 \mathrm{E}+00 & 0.00 \mathrm{E}+00\end{array}$

$\begin{array}{lllll}0.175 & 0.00 \mathrm{E}+00 & 0.00 \mathrm{E}+00 & 0.00 \mathrm{E}+00\end{array}$

$\begin{array}{lllll}0.200 & 0.00 \mathrm{E}+00 & 0.00 \mathrm{E}+00 & 0.00 \mathrm{E}+00\end{array}$

$\begin{array}{lllll}0.225 & 0.00 \mathrm{E}+00 & 0.00 \mathrm{E}+00 & 0.00 \mathrm{E}+00\end{array}$

$\begin{array}{lllll}0.250 & 0.00 \mathrm{E}+00 & 0.00 \mathrm{E}+00 & 0.00 \mathrm{E}+00\end{array}$

$\begin{array}{lllll}0.275 & 0.00 \mathrm{E}+00 & 0.00 \mathrm{E}+00 & 0.00 \mathrm{E}+00\end{array}$

$\begin{array}{lllll}0.300 & 0.00 \mathrm{E}+00 & 0.00 \mathrm{E}+00 & 0.00 \mathrm{E}+00\end{array}$

$\begin{array}{lllll}0.325 & 0.00 \mathrm{E}+00 & 0.00 \mathrm{E}+00 & 0.00 \mathrm{E}+00\end{array}$

$\begin{array}{lllll}0.350 & 0.00 \mathrm{E}+00 & 0.00 \mathrm{E}+00 & 0.00 \mathrm{E}+00\end{array}$

$\begin{array}{lllll}0.375 & 0.00 \mathrm{E}+00 & 0.00 \mathrm{E}+00 & 0.00 \mathrm{E}+00\end{array}$

$\begin{array}{lllll}0.400 & 0.00 \mathrm{E}+00 & 0.00 \mathrm{E}+00 & 0.00 \mathrm{E}+00\end{array}$

$\begin{array}{lllll}0.425 & 0.00 \mathrm{E}+00 & 0.00 \mathrm{E}+00 & 0.00 \mathrm{E}+00\end{array}$

$\begin{array}{lllll}0.450 & 0.00 \mathrm{E}+00 & 0.00 \mathrm{E}+00 & 0.00 \mathrm{E}+00\end{array}$

$\begin{array}{lllll}0.475 & 0.00 \mathrm{E}+00 & 0.00 \mathrm{E}+00 & 0.00 \mathrm{E}+00\end{array}$

$\begin{array}{lllll}0.500 & 0.00 \mathrm{E}+00 & 0.00 \mathrm{E}+00 & 0.00 \mathrm{E}+00\end{array}$

$\begin{array}{lllll}0.525 & 0.00 \mathrm{E}+00 & 0.00 \mathrm{E}+00 & 0.00 \mathrm{E}+00\end{array}$

$\begin{array}{lllll}0.550 & 0.00 \mathrm{E}+00 & 0.00 \mathrm{E}+00 & 0.00 \mathrm{E}+00\end{array}$

$\begin{array}{lllll}0.575 & 0.00 \mathrm{E}+00 & 0.00 \mathrm{E}+00 & 0.00 \mathrm{E}+00\end{array}$

$\begin{array}{lllll}0.600 & 0.00 \mathrm{E}+00 & 0.00 \mathrm{E}+00 & 0.00 \mathrm{E}+00\end{array}$

$\begin{array}{lllll}0.625 & 0.00 \mathrm{E}+00 & 0.00 \mathrm{E}+00 & 0.00 \mathrm{E}+00\end{array}$

$\begin{array}{lllll}0.650 & 0.00 \mathrm{E}+00 & 0.00 \mathrm{E}+00 & 0.00 \mathrm{E}+00\end{array}$

$\begin{array}{lllll}0.675 & 0.00 \mathrm{E}+00 & 0.00 \mathrm{E}+00 & 0.00 \mathrm{E}+00\end{array}$

$\begin{array}{llll}0.700 & 0.00 \mathrm{E}+00 & 0.00 \mathrm{E}+00 & 0.00 \mathrm{E}+00\end{array}$

$\begin{array}{lllll}0.725 & 0.00 \mathrm{E}+00 & 0.00 \mathrm{E}+00 & 0.00 \mathrm{E}+00\end{array}$

$\begin{array}{lllll}0.750 & 0.00 \mathrm{E}+00 & 0.00 \mathrm{E}+00 & 0.00 \mathrm{E}+00\end{array}$

$\begin{array}{lllll}0.775 & 0.00 \mathrm{E}+00 & 0.00 \mathrm{E}+00 & 0.00 \mathrm{E}+00\end{array}$

$\begin{array}{lllll}0.800 & 0.00 \mathrm{E}+00 & 0.00 \mathrm{E}+00 & 0.00 \mathrm{E}+00\end{array}$

$\begin{array}{lllll}0.825 & 0.00 \mathrm{E}+00 & 0.00 \mathrm{E}+00 & 0.00 \mathrm{E}+00\end{array}$

$\begin{array}{lllll}0.850 & 0.00 \mathrm{E}+00 & 0.00 \mathrm{E}+00 & 0.00 \mathrm{E}+00\end{array}$

$\begin{array}{lllll}0.875 & 0.00 \mathrm{E}+00 & 0.00 \mathrm{E}+00 & 0.00 \mathrm{E}+00\end{array}$

$\begin{array}{lllll}0.900 & 0.00 \mathrm{E}+00 & 0.00 \mathrm{E}+00 & 0.00 \mathrm{E}+00\end{array}$

$\begin{array}{lllll}0.925 & 0.00 \mathrm{E}+00 & 0.00 \mathrm{E}+00 & 0.00 \mathrm{E}+00\end{array}$

$\begin{array}{llll}0.950 & 0.00 \mathrm{E}+00 & 0.00 \mathrm{E}+00 & 0.00 \mathrm{E}+00\end{array}$

$\begin{array}{lllll}0.975 & 0.00 \mathrm{E}+00 & 0.00 \mathrm{E}+00 & 0.00 \mathrm{E}+00\end{array}$

$\begin{array}{llll}0.990 & 0.00 \mathrm{E}+00 & 0.00 \mathrm{E}+00 & 0.00 \mathrm{E}+00\end{array}$ 
RESRAD-OFFSITE, Version 2.5

Probabilistic Dose and Risk Report

Title : RESRAD-OFFSITE External Gamma, Inhalation, and Soil Ingestion for Offsite Reside

File : PBA-1_TC99-DOE-5-1.ROF

Statistics and Cumulative distribution function of Peak Risk from Soil Ingestion(Wrelease)

\begin{tabular}{|c|c|c|c|}
\hline Repetition = & 1 & 2 & 3 \\
\hline Mean & $3.14 \mathrm{E}-11$ & $3.14 \mathrm{E}-11$ & $3.14 \mathrm{E}-11$ \\
\hline Std. Dev. & $1.88 \mathrm{E}-11$ & $1.87 \mathrm{E}-11$ & $1.88 \mathrm{E}-11$ \\
\hline Minimum & $3.78 \mathrm{E}-12$ & $3.78 \mathrm{E}-12$ & $3.78 E-12$ \\
\hline Maximum & $1.78 \mathrm{E}-10$ & $1.78 \mathrm{E}-10$ & $1.78 \mathrm{E}-10$ \\
\hline
\end{tabular}

Percentile

$0.010 \quad 5.43 \mathrm{E}-12 \quad 5.43 \mathrm{E}-12 \quad 5.43 \mathrm{E}-12$

$\begin{array}{llll}0.025 & 7.07 \mathrm{E}-12 & 7.07 \mathrm{E}-12 & 7.07 \mathrm{E}-12\end{array}$

$0.050 \quad 8.67 \mathrm{E}-12 \quad 8.67 \mathrm{E}-12 \quad 8.67 \mathrm{E}-12$

$0.0751 .03 \mathrm{E}-11 \quad 1.03 \mathrm{E}-11 \quad 1.03 \mathrm{E}-11$

$0.100 \quad 1.14 \mathrm{E}-11 \quad 1.14 \mathrm{E}-11 \quad 1.14 \mathrm{E}-11$

$\begin{array}{llll}0.125 & 1.25 \mathrm{E}-11 & 1.25 \mathrm{E}-11 & 1.25 \mathrm{E}-11\end{array}$

$\begin{array}{llll}0.150 & 1.35 \mathrm{E}-11 & 1.35 \mathrm{E}-11 & 1.35 \mathrm{E}-11\end{array}$

$\begin{array}{llll}0.175 & 1.47 \mathrm{E}-11 & 1.47 \mathrm{E}-11 & 1.47 \mathrm{E}-11\end{array}$

$0.2001 .56 \mathrm{E}-11 \quad 1.56 \mathrm{E}-11 \quad 1.56 \mathrm{E}-11$

$\begin{array}{llll}0.225 & 1.67 \mathrm{E}-11 & 1.66 \mathrm{E}-11 & 1.66 \mathrm{E}-11\end{array}$

$\begin{array}{llll}0.250 & 1.77 \mathrm{E}-11 & 1.77 \mathrm{E}-11 & 1.77 \mathrm{E}-11\end{array}$

$\begin{array}{llll}0.275 & 1.87 \mathrm{E}-11 & 1.87 \mathrm{E}-11 & 1.87 \mathrm{E}-11\end{array}$

$\begin{array}{llll}0.300 & 1.98 \mathrm{E}-11 & 1.97 \mathrm{E}-11 & 1.97 \mathrm{E}-11\end{array}$

$\begin{array}{llll}0.325 & 2.05 \mathrm{E}-11 & 2.05 \mathrm{E}-11 & 2.05 \mathrm{E}-11\end{array}$

$\begin{array}{llll}0.350 & 2.13 \mathrm{E}-11 & 2.13 \mathrm{E}-11 & 2.13 \mathrm{E}-11\end{array}$

$\begin{array}{llll}0.375 & 2.23 \mathrm{E}-11 & 2.22 \mathrm{E}-11 & 2.23 \mathrm{E}-11\end{array}$

$\begin{array}{llll}0.400 & 2.33 \mathrm{E}-11 & 2.32 \mathrm{E}-11 & 2.33 \mathrm{E}-11\end{array}$

$\begin{array}{llll}0.425 & 2.42 \mathrm{E}-11 & 2.41 \mathrm{E}-11 & 2.42 \mathrm{E}-11\end{array}$

$\begin{array}{llll}0.450 & 2.51 \mathrm{E}-11 & 2.50 \mathrm{E}-11 & 2.51 \mathrm{E}-11\end{array}$

$\begin{array}{llll}0.475 & 2.63 \mathrm{E}-11 & 2.62 \mathrm{E}-11 & 2.62 \mathrm{E}-11\end{array}$

$\begin{array}{llll}0.500 & 2.75 \mathrm{E}-11 & 2.74 \mathrm{E}-11 & 2.74 \mathrm{E}-11\end{array}$

$\begin{array}{llll}0.525 & 2.86 \mathrm{E}-11 & 2.84 \mathrm{E}-11 & 2.84 \mathrm{E}-11\end{array}$

$\begin{array}{llll}0.550 & 2.98 \mathrm{E}-11 & 2.97 \mathrm{E}-11 & 2.97 \mathrm{E}-11\end{array}$

$0.5753 .09 \mathrm{E}-11 \quad 3.08 \mathrm{E}-11 \quad 3.08 \mathrm{E}-11$

$\begin{array}{llll}0.600 & 3.20 \mathrm{E}-11 & 3.20 \mathrm{E}-11 & 3.20 \mathrm{E}-11\end{array}$

$\begin{array}{llll}0.625 & 3.33 \mathrm{E}-11 & 3.32 \mathrm{E}-11 & 3.32 \mathrm{E}-11\end{array}$

$0.650 \quad 3.46 \mathrm{E}-11 \quad 3.45 \mathrm{E}-11 \quad 3.45 \mathrm{E}-11$

$0.675 \quad 3.60 \mathrm{E}-11 \quad 3.60 \mathrm{E}-11 \quad 3.60 \mathrm{E}-11$

$\begin{array}{llll}0.700 & 3.77 \mathrm{E}-11 & 3.76 \mathrm{E}-11 & 3.76 \mathrm{E}-11\end{array}$

$0.725 \quad 3.92 \mathrm{E}-11 \quad 3.92 \mathrm{E}-11 \quad 3.92 \mathrm{E}-11$

$0.750 \quad 4.15 \mathrm{E}-11 \quad 4.14 \mathrm{E}-11 \quad 4.15 \mathrm{E}-11$

$0.775 \quad 4.35 \mathrm{E}-11 \quad 4.34 \mathrm{E}-11 \quad 4.35 \mathrm{E}-11$

$0.800 \quad 4.57 \mathrm{E}-11 \quad 4.57 \mathrm{E}-11 \quad 4.57 \mathrm{E}-11$

$\begin{array}{llll}0.825 & 4.76 \mathrm{E}-11 & 4.76 \mathrm{E}-11 & 4.76 \mathrm{E}-11\end{array}$

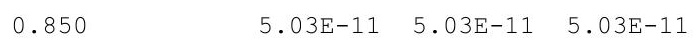

$\begin{array}{llll}0.875 & 5.39 \mathrm{E}-11 & 5.38 \mathrm{E}-11 & 5.39 \mathrm{E}-11\end{array}$

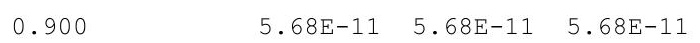

$\begin{array}{llll}0.925 & 6.15 \mathrm{E}-11 & 6.14 \mathrm{E}-11 & 6.15 \mathrm{E}-11\end{array}$

$\begin{array}{llll}0.950 & 6.68 \mathrm{E}-11 & 6.68 \mathrm{E}-11 & 6.68 \mathrm{E}-11\end{array}$

$0.975 \quad 7.56 \mathrm{E}-11 \quad 7.56 \mathrm{E}-11 \quad 7.56 \mathrm{E}-11$

\begin{tabular}{l}
$0.990 \quad 9.43 \mathrm{E}-11 \quad 9.43 \mathrm{E}-11 \quad 9.43 \mathrm{E}-11$ \\
\hline
\end{tabular}

$\overline{\underline{ }} \overline{=} \overline{=}$ 
RESRAD-OFFSITE, Version 2.5

Probabilistic Dose and Risk Report

Title : RESRAD-OFFSITE External Gamma, Inhalation, and Soil Ingestion for offsite Reside

File : PBA-1_TC99-DOE-5-1.ROF

Statistics and Cumulative distribution function of Peak Risk from Water Ingestion

\begin{tabular}{ccccc} 
Repetition $=$ & 1 & 2 & 3 \\
\cline { 5 - 5 } Mean & $0.00 \mathrm{E}+00$ & $0.00 \mathrm{E}+00$ & $0.00 \mathrm{E}+00$ \\
Std. Dev. & $0.00 \mathrm{E}+00$ & $0.00 \mathrm{E}+00$ & $0.00 \mathrm{E}+00$ \\
Minimum & $0.00 \mathrm{E}+00$ & $0.00 \mathrm{E}+00$ & $0.00 \mathrm{E}+00$ \\
Maximum & $0.00 \mathrm{E}+00$ & $0.00 \mathrm{E}+00$ & $0.00 \mathrm{E}+00$
\end{tabular}

Percentile

$\begin{array}{llll}0.010 & 0.00 \mathrm{E}+00 \quad 0.00 \mathrm{E}+00 & 0.00 \mathrm{E}+00\end{array}$

$\begin{array}{llll}0.025 & 0.00 \mathrm{E}+00 \quad 0.00 \mathrm{E}+00 & 0.00 \mathrm{E}+00\end{array}$

$\begin{array}{lllll}0.050 & 0.00 \mathrm{E}+00 & 0.00 \mathrm{E}+00 & 0.00 \mathrm{E}+00\end{array}$

$\begin{array}{lllll}0.075 & 0.00 \mathrm{E}+00 & 0.00 \mathrm{E}+00 & 0.00 \mathrm{E}+00\end{array}$

$\begin{array}{lllll}0.100 & 0.00 \mathrm{E}+00 & 0.00 \mathrm{E}+00 & 0.00 \mathrm{E}+00\end{array}$

$\begin{array}{lllll}0.125 & 0.00 \mathrm{E}+00 & 0.00 \mathrm{E}+00 & 0.00 \mathrm{E}+00\end{array}$

$\begin{array}{lllll}0.150 & 0.00 \mathrm{E}+00 & 0.00 \mathrm{E}+00 & 0.00 \mathrm{E}+00\end{array}$

$\begin{array}{lllll}0.175 & 0.00 \mathrm{E}+00 & 0.00 \mathrm{E}+00 & 0.00 \mathrm{E}+00\end{array}$

$\begin{array}{lllll}0.200 & 0.00 \mathrm{E}+00 & 0.00 \mathrm{E}+00 & 0.00 \mathrm{E}+00\end{array}$

$\begin{array}{lllll}0.225 & 0.00 \mathrm{E}+00 & 0.00 \mathrm{E}+00 & 0.00 \mathrm{E}+00\end{array}$

$\begin{array}{lllll}0.250 & 0.00 \mathrm{E}+00 & 0.00 \mathrm{E}+00 & 0.00 \mathrm{E}+00\end{array}$

$\begin{array}{lllll}0.275 & 0.00 \mathrm{E}+00 & 0.00 \mathrm{E}+00 & 0.00 \mathrm{E}+00\end{array}$

$\begin{array}{lllll}0.300 & 0.00 \mathrm{E}+00 & 0.00 \mathrm{E}+00 & 0.00 \mathrm{E}+00\end{array}$

$\begin{array}{lllll}0.325 & 0.00 \mathrm{E}+00 & 0.00 \mathrm{E}+00 & 0.00 \mathrm{E}+00\end{array}$

$\begin{array}{lllll}0.350 & 0.00 \mathrm{E}+00 & 0.00 \mathrm{E}+00 & 0.00 \mathrm{E}+00\end{array}$

$\begin{array}{lllll}0.375 & 0.00 \mathrm{E}+00 & 0.00 \mathrm{E}+00 & 0.00 \mathrm{E}+00\end{array}$

$\begin{array}{lllll}0.400 & 0.00 \mathrm{E}+00 & 0.00 \mathrm{E}+00 & 0.00 \mathrm{E}+00\end{array}$

$\begin{array}{lllll}0.425 & 0.00 \mathrm{E}+00 & 0.00 \mathrm{E}+00 & 0.00 \mathrm{E}+00\end{array}$

$\begin{array}{lllll}0.450 & 0.00 \mathrm{E}+00 & 0.00 \mathrm{E}+00 & 0.00 \mathrm{E}+00\end{array}$

$\begin{array}{lllll}0.475 & 0.00 \mathrm{E}+00 & 0.00 \mathrm{E}+00 & 0.00 \mathrm{E}+00\end{array}$

$\begin{array}{lllll}0.500 & 0.00 \mathrm{E}+00 & 0.00 \mathrm{E}+00 & 0.00 \mathrm{E}+00\end{array}$

$\begin{array}{lllll}0.525 & 0.00 \mathrm{E}+00 & 0.00 \mathrm{E}+00 & 0.00 \mathrm{E}+00\end{array}$

$\begin{array}{lllll}0.550 & 0.00 \mathrm{E}+00 & 0.00 \mathrm{E}+00 & 0.00 \mathrm{E}+00\end{array}$

$\begin{array}{lllll}0.575 & 0.00 \mathrm{E}+00 & 0.00 \mathrm{E}+00 & 0.00 \mathrm{E}+00\end{array}$

$\begin{array}{lllll}0.600 & 0.00 \mathrm{E}+00 & 0.00 \mathrm{E}+00 & 0.00 \mathrm{E}+00\end{array}$

$\begin{array}{lllll}0.625 & 0.00 \mathrm{E}+00 & 0.00 \mathrm{E}+00 & 0.00 \mathrm{E}+00\end{array}$

$\begin{array}{lllll}0.650 & 0.00 \mathrm{E}+00 & 0.00 \mathrm{E}+00 & 0.00 \mathrm{E}+00\end{array}$

$\begin{array}{lllll}0.675 & 0.00 \mathrm{E}+00 & 0.00 \mathrm{E}+00 & 0.00 \mathrm{E}+00\end{array}$

$\begin{array}{lllll}0.700 & 0.00 \mathrm{E}+00 & 0.00 \mathrm{E}+00 & 0.00 \mathrm{E}+00\end{array}$

$\begin{array}{lllll}0.725 & 0.00 \mathrm{E}+00 & 0.00 \mathrm{E}+00 & 0.00 \mathrm{E}+00\end{array}$

$\begin{array}{lllll}0.750 & 0.00 \mathrm{E}+00 & 0.00 \mathrm{E}+00 & 0.00 \mathrm{E}+00\end{array}$

$\begin{array}{lllll}0.775 & 0.00 \mathrm{E}+00 & 0.00 \mathrm{E}+00 & 0.00 \mathrm{E}+00\end{array}$

$\begin{array}{lllll}0.800 & 0.00 \mathrm{E}+00 & 0.00 \mathrm{E}+00 & 0.00 \mathrm{E}+00\end{array}$

$\begin{array}{lllll}0.825 & 0.00 \mathrm{E}+00 & 0.00 \mathrm{E}+00 & 0.00 \mathrm{E}+00\end{array}$

$\begin{array}{lllll}0.850 & 0.00 \mathrm{E}+00 & 0.00 \mathrm{E}+00 & 0.00 \mathrm{E}+00\end{array}$

$\begin{array}{lllll}0.875 & 0.00 \mathrm{E}+00 & 0.00 \mathrm{E}+00 & 0.00 \mathrm{E}+00\end{array}$

$\begin{array}{lllll}0.900 & 0.00 \mathrm{E}+00 & 0.00 \mathrm{E}+00 & 0.00 \mathrm{E}+00\end{array}$

$\begin{array}{lllll}0.925 & 0.00 \mathrm{E}+00 & 0.00 \mathrm{E}+00 & 0.00 \mathrm{E}+00\end{array}$

$\begin{array}{lllll}0.950 & 0.00 \mathrm{E}+00 & 0.00 \mathrm{E}+00 & 0.00 \mathrm{E}+00\end{array}$

$\begin{array}{lllll}0.975 & 0.00 \mathrm{E}+00 & 0.00 \mathrm{E}+00 & 0.00 \mathrm{E}+00\end{array}$

$\begin{array}{lllll}0.990 & 0.00 \mathrm{E}+00 & 0.00 \mathrm{E}+00 & 0.00 \mathrm{E}+00\end{array}$ 
RESRAD-OFFSITE, Version 2.5

Probabilistic Dose and Risk Report

Title : RESRAD-OFFSITE External Gamma, Inhalation, and Soil Ingestion for Offsite Reside File : PBA-1_TC99-DOE-5-1.ROF

Statistics and Cumulative distribution function of Peak Risk from External Ground(Cz\&Air)

\begin{tabular}{|c|c|c|c|}
\hline Repetition = & 1 & 2 & 3 \\
\hline Mean & $6.24 \mathrm{E}-30$ & $6.25 E-30$ & $6.25 \mathrm{E}-30$ \\
\hline Std. Dev. & $0.00 \mathrm{E}+00$ & $0.00 \mathrm{E}+00$ & $0.00 \mathrm{E}+00$ \\
\hline Minimum & $2.38 \mathrm{E}-37$ & $2.38 E-37$ & $2.38 \mathrm{E}-37$ \\
\hline Maximum & $1.84 \mathrm{E}-29$ & $1.84 \mathrm{E}-29$ & $1.84 \mathrm{E}-29$ \\
\hline
\end{tabular}

Percentile

$0.010 \quad 9.23 \mathrm{E}-35 \quad 9.23 \mathrm{E}-35 \quad 9.23 \mathrm{E}-35$

$0.025 \quad 2.80 \mathrm{E}-33 \quad 2.80 \mathrm{E}-33 \quad 2.32 \mathrm{E}-33$

$0.050 \quad 3.03 E-32 \quad 3.03 E-32 \quad 3.02 E-32$

$0.075 \quad 7.34 \mathrm{E}-32 \quad 7.64 \mathrm{E}-32 \quad 7.34 \mathrm{E}-32$

$0.100 \quad 1.48 \mathrm{E}-31 \quad 1.52 \mathrm{E}-31 \quad 1.51 \mathrm{E}-31$

$\begin{array}{llll}0.125 & 2.86 \mathrm{E}-31 & 2.96 \mathrm{E}-31 & 2.92 \mathrm{E}-31\end{array}$

$0.150 \quad 4.54 \mathrm{E}-31 \quad 4.59 \mathrm{E}-31 \quad 4.57 \mathrm{E}-31$

$0.175 \quad 6.59 \mathrm{E}-31 \quad 6.66 \mathrm{E}-31 \quad 6.62 \mathrm{E}-31$

$0.200 \quad 9.24 \mathrm{E}-31 \quad 9.34 \mathrm{E}-31 \quad 9.34 \mathrm{E}-31$

$0.225 \quad 1.21 \mathrm{E}-30 \quad 1.22 \mathrm{E}-30 \quad 1.22 \mathrm{E}-30$

$0.250 \quad 1.47 \mathrm{E}-30 \quad 1.50 \mathrm{E}-30 \quad 1.50 \mathrm{E}-30$

$0.275 \quad 1.79 \mathrm{E}-30 \quad 1.81 \mathrm{E}-30 \quad 1.81 \mathrm{E}-30$

$0.300 \quad 2.18 \mathrm{E}-30 \quad 2.20 \mathrm{E}-30 \quad 2.19 \mathrm{E}-30$

$\begin{array}{lll}0.325 & 2.54 \mathrm{E}-30 \quad 2.55 \mathrm{E}-30 \quad 2.55 \mathrm{E}-30\end{array}$

$0.350 \quad 2.93 E-30 \quad 2.95 E-30 \quad 2.94 E-30$

$\begin{array}{lll}0.375 & 3.34 \mathrm{E}-30 \quad 3.35 \mathrm{E}-30 \quad 3.34 \mathrm{E}-30\end{array}$

$0.400 \quad 3.85 \mathrm{E}-30 \quad 3.87 \mathrm{E}-30 \quad 3.86 \mathrm{E}-30$

$0.425 \quad 4.20 \mathrm{E}-30 \quad 4.22 \mathrm{E}-30 \quad 4.20 \mathrm{E}-30$

$0.450 \quad 4.56 \mathrm{E}-30 \quad 4.57 \mathrm{E}-30 \quad 4.56 \mathrm{E}-30$

$0.475 \quad 5.04 \mathrm{E}-30 \quad 5.05 \mathrm{E}-30 \quad 5.05 \mathrm{E}-30$

$0.500 \quad 5.60 \mathrm{E}-30 \quad 5.62 \mathrm{E}-30 \quad 5.61 \mathrm{E}-30$

$0.5256 .13 \mathrm{E}-30 \quad 6.15 \mathrm{E}-30 \quad 6.14 \mathrm{E}-30$

$0.550 \quad 6.51 \mathrm{E}-30 \quad 6.51 \mathrm{E}-30 \quad 6.51 \mathrm{E}-30$

$0.575 \quad 6.96 \mathrm{E}-30 \quad 7.00 \mathrm{E}-30 \quad 6.98 \mathrm{E}-30$

$0.600 \quad 7.49 \mathrm{E}-30 \quad 7.51 \mathrm{E}-30 \quad 7.51 \mathrm{E}-30$

$0.625 \quad 7.96 \mathrm{E}-30 \quad 7.97 \mathrm{E}-30 \quad 7.96 \mathrm{E}-30$

$0.650 \quad 8.30 \mathrm{E}-30 \quad 8.31 \mathrm{E}-30 \quad 8.31 \mathrm{E}-30$

$0.675 \quad 8.83 \mathrm{E}-30 \quad 8.85 \mathrm{E}-30 \quad 8.85 \mathrm{E}-30$

$0.700 \quad 9.30 \mathrm{E}-30 \quad 9.34 \mathrm{E}-30 \quad 9.34 \mathrm{E}-30$

$0.725 \quad 9.85 \mathrm{E}-30 \quad 9.85 \mathrm{E}-30 \quad 9.85 \mathrm{E}-30$

$\begin{array}{llll}0.750 & 1.03 \mathrm{E}-29 & 1.03 \mathrm{E}-29 & 1.04 \mathrm{E}-29\end{array}$

$0.775 \quad 1.08 \mathrm{E}-29 \quad 1.08 \mathrm{E}-29 \quad 1.08 \mathrm{E}-29$

$\begin{array}{llll}0.800 \quad 1.13 \mathrm{E}-29 & 1.13 \mathrm{E}-29 & 1.13 \mathrm{E}-29\end{array}$

$\begin{array}{llll}0.825 & 1.19 \mathrm{E}-29 & 1.19 \mathrm{E}-29 & 1.19 \mathrm{E}-29\end{array}$

$\begin{array}{llll}0.850 & 1.24 \mathrm{E}-29 & 1.24 \mathrm{E}-29 & 1.24 \mathrm{E}-29\end{array}$

$\begin{array}{llll}0.875 & 1.30 \mathrm{E}-29 & 1.30 \mathrm{E}-29 & 1.30 \mathrm{E}-29\end{array}$

$0.900 \quad 1.36 \mathrm{E}-29 \quad 1.36 \mathrm{E}-29 \quad 1.36 \mathrm{E}-29$

$0.925 \quad 1.41 \mathrm{E}-29 \quad 1.41 \mathrm{E}-29 \quad 1.41 \mathrm{E}-29$

$0.950 \quad 1.49 \mathrm{E}-29 \quad 1.49 \mathrm{E}-29 \quad 1.49 \mathrm{E}-29$

$0.975 \quad 1.58 \mathrm{E}-29 \quad 1.58 \mathrm{E}-29 \quad 1.58 \mathrm{E}-29$

$0.990 \quad 1.66 \mathrm{E}-29 \quad 1.66 \mathrm{E}-29 \quad 1.66 \mathrm{E}-29$ 
RESRAD-OFFSITE, Version 2.5

Probabilistic Dose and Risk Report

Title : RESRAD-OFFSITE External Gamma, Inhalation, and Soil Ingestion for offsite Reside

File : PBA-1_TC99-DOE-5-1.ROF

Statistics and Cumulative distribution function of Peak Risk from Inhalation ExcludingRn

\begin{tabular}{ccccc} 
Repetition $=$ & 1 & 2 & 3 \\
\cline { 5 - 5 } Mean & $0.00 \mathrm{E}+00$ & $0.00 \mathrm{E}+00$ & $0.00 \mathrm{E}+00$ \\
Std. Dev. & $0.00 \mathrm{E}+00$ & $0.00 \mathrm{E}+00$ & $0.00 \mathrm{E}+00$ \\
Minimum & $0.00 \mathrm{E}+00$ & $0.00 \mathrm{E}+00$ & $0.00 \mathrm{E}+00$ \\
Maximum & $0.00 \mathrm{E}+00$ & $0.00 \mathrm{E}+00$ & $0.00 \mathrm{E}+00$
\end{tabular}

Percentile

$\begin{array}{llll}0.010 & 0.00 \mathrm{E}+00 \quad 0.00 \mathrm{E}+00 & 0.00 \mathrm{E}+00\end{array}$

$\begin{array}{llll}0.025 & 0.00 \mathrm{E}+00 \quad 0.00 \mathrm{E}+00 & 0.00 \mathrm{E}+00\end{array}$

$\begin{array}{lllll}0.050 & 0.00 \mathrm{E}+00 & 0.00 \mathrm{E}+00 & 0.00 \mathrm{E}+00\end{array}$

$\begin{array}{lllll}0.075 & 0.00 \mathrm{E}+00 & 0.00 \mathrm{E}+00 & 0.00 \mathrm{E}+00\end{array}$

$\begin{array}{lllll}0.100 & 0.00 \mathrm{E}+00 & 0.00 \mathrm{E}+00 & 0.00 \mathrm{E}+00\end{array}$

$\begin{array}{lllll}0.125 & 0.00 \mathrm{E}+00 & 0.00 \mathrm{E}+00 & 0.00 \mathrm{E}+00\end{array}$

$\begin{array}{lllll}0.150 & 0.00 \mathrm{E}+00 & 0.00 \mathrm{E}+00 & 0.00 \mathrm{E}+00\end{array}$

$\begin{array}{lllll}0.175 & 0.00 \mathrm{E}+00 & 0.00 \mathrm{E}+00 & 0.00 \mathrm{E}+00\end{array}$

$\begin{array}{lllll}0.200 & 0.00 \mathrm{E}+00 & 0.00 \mathrm{E}+00 & 0.00 \mathrm{E}+00\end{array}$

$\begin{array}{lllll}0.225 & 0.00 \mathrm{E}+00 & 0.00 \mathrm{E}+00 & 0.00 \mathrm{E}+00\end{array}$

$\begin{array}{lllll}0.250 & 0.00 \mathrm{E}+00 & 0.00 \mathrm{E}+00 & 0.00 \mathrm{E}+00\end{array}$

$\begin{array}{lllll}0.275 & 0.00 \mathrm{E}+00 & 0.00 \mathrm{E}+00 & 0.00 \mathrm{E}+00\end{array}$

$\begin{array}{lllll}0.300 & 0.00 \mathrm{E}+00 & 0.00 \mathrm{E}+00 & 0.00 \mathrm{E}+00\end{array}$

$\begin{array}{lllll}0.325 & 0.00 \mathrm{E}+00 & 0.00 \mathrm{E}+00 & 0.00 \mathrm{E}+00\end{array}$

$\begin{array}{lllll}0.350 & 0.00 \mathrm{E}+00 & 0.00 \mathrm{E}+00 & 0.00 \mathrm{E}+00\end{array}$

$\begin{array}{lllll}0.375 & 0.00 \mathrm{E}+00 & 0.00 \mathrm{E}+00 & 0.00 \mathrm{E}+00\end{array}$

$\begin{array}{lllll}0.400 & 0.00 \mathrm{E}+00 & 0.00 \mathrm{E}+00 & 0.00 \mathrm{E}+00\end{array}$

$\begin{array}{lllll}0.425 & 0.00 \mathrm{E}+00 & 0.00 \mathrm{E}+00 & 0.00 \mathrm{E}+00\end{array}$

$\begin{array}{lllll}0.450 & 0.00 \mathrm{E}+00 & 0.00 \mathrm{E}+00 & 0.00 \mathrm{E}+00\end{array}$

$\begin{array}{lllll}0.475 & 0.00 \mathrm{E}+00 & 0.00 \mathrm{E}+00 & 0.00 \mathrm{E}+00\end{array}$

$\begin{array}{lllll}0.500 & 0.00 \mathrm{E}+00 & 0.00 \mathrm{E}+00 & 0.00 \mathrm{E}+00\end{array}$

$\begin{array}{lllll}0.525 & 0.00 \mathrm{E}+00 & 0.00 \mathrm{E}+00 & 0.00 \mathrm{E}+00\end{array}$

$\begin{array}{lllll}0.550 & 0.00 \mathrm{E}+00 & 0.00 \mathrm{E}+00 & 0.00 \mathrm{E}+00\end{array}$

$\begin{array}{lllll}0.575 & 0.00 \mathrm{E}+00 & 0.00 \mathrm{E}+00 & 0.00 \mathrm{E}+00\end{array}$

$\begin{array}{lllll}0.600 & 0.00 \mathrm{E}+00 & 0.00 \mathrm{E}+00 & 0.00 \mathrm{E}+00\end{array}$

$\begin{array}{lllll}0.625 & 0.00 \mathrm{E}+00 & 0.00 \mathrm{E}+00 & 0.00 \mathrm{E}+00\end{array}$

$\begin{array}{lllll}0.650 & 0.00 \mathrm{E}+00 & 0.00 \mathrm{E}+00 & 0.00 \mathrm{E}+00\end{array}$

$\begin{array}{lllll}0.675 & 0.00 \mathrm{E}+00 & 0.00 \mathrm{E}+00 & 0.00 \mathrm{E}+00\end{array}$

$\begin{array}{lllll}0.700 & 0.00 \mathrm{E}+00 & 0.00 \mathrm{E}+00 & 0.00 \mathrm{E}+00\end{array}$

$\begin{array}{lllll}0.725 & 0.00 \mathrm{E}+00 & 0.00 \mathrm{E}+00 & 0.00 \mathrm{E}+00\end{array}$

$\begin{array}{lllll}0.750 & 0.00 \mathrm{E}+00 & 0.00 \mathrm{E}+00 & 0.00 \mathrm{E}+00\end{array}$

$\begin{array}{lllll}0.775 & 0.00 \mathrm{E}+00 & 0.00 \mathrm{E}+00 & 0.00 \mathrm{E}+00\end{array}$

$\begin{array}{lllll}0.800 & 0.00 \mathrm{E}+00 & 0.00 \mathrm{E}+00 & 0.00 \mathrm{E}+00\end{array}$

$\begin{array}{lllll}0.825 & 0.00 \mathrm{E}+00 & 0.00 \mathrm{E}+00 & 0.00 \mathrm{E}+00\end{array}$

$\begin{array}{lllll}0.850 & 0.00 \mathrm{E}+00 & 0.00 \mathrm{E}+00 & 0.00 \mathrm{E}+00\end{array}$

$\begin{array}{lllll}0.875 & 0.00 \mathrm{E}+00 & 0.00 \mathrm{E}+00 & 0.00 \mathrm{E}+00\end{array}$

$\begin{array}{lllll}0.900 & 0.00 \mathrm{E}+00 & 0.00 \mathrm{E}+00 & 0.00 \mathrm{E}+00\end{array}$

$\begin{array}{lllll}0.925 & 0.00 \mathrm{E}+00 & 0.00 \mathrm{E}+00 & 0.00 \mathrm{E}+00\end{array}$

$\begin{array}{lllll}0.950 & 0.00 \mathrm{E}+00 & 0.00 \mathrm{E}+00 & 0.00 \mathrm{E}+00\end{array}$

$\begin{array}{lllll}0.975 & 0.00 \mathrm{E}+00 & 0.00 \mathrm{E}+00 & 0.00 \mathrm{E}+00\end{array}$

$\begin{array}{llll}0.990 & 0.00 \mathrm{E}+00 & 0.00 \mathrm{E}+00 & 0.00 \mathrm{E}+00\end{array}$ 
RESRAD-OFFSITE, Version 2.5

Probabilistic Dose and Risk Report

Title : RESRAD-OFFSITE External Gamma, Inhalation, and Soil Ingestion for offsite Reside

File : PBA-1_TC99-DOE-5-1.ROF

Statistics and Cumulative distribution function of Peak Risk from Radon (CZandAir)

\begin{tabular}{ccccc} 
Repetition $=$ & 1 & 2 & 3 \\
\cline { 5 - 5 } Mean & $0.00 \mathrm{E}+00$ & $0.00 \mathrm{E}+00$ & $0.00 \mathrm{E}+00$ \\
Std. Dev. & $0.00 \mathrm{E}+00$ & $0.00 \mathrm{E}+00$ & $0.00 \mathrm{E}+00$ \\
Minimum & $0.00 \mathrm{E}+00$ & $0.00 \mathrm{E}+00$ & $0.00 \mathrm{E}+00$ \\
Maximum & $0.00 \mathrm{E}+00$ & $0.00 \mathrm{E}+00$ & $0.00 \mathrm{E}+00$
\end{tabular}

Percentile

$\begin{array}{llll}0.010 & 0.00 \mathrm{E}+00 \quad 0.00 \mathrm{E}+00 & 0.00 \mathrm{E}+00\end{array}$

$\begin{array}{llll}0.025 & 0.00 \mathrm{E}+00 & 0.00 \mathrm{E}+00 & 0.00 \mathrm{E}+00\end{array}$

$\begin{array}{llll}0.050 & 0.00 \mathrm{E}+00 & 0.00 \mathrm{E}+00 & 0.00 \mathrm{E}+00\end{array}$

$\begin{array}{lllll}0.075 & 0.00 \mathrm{E}+00 & 0.00 \mathrm{E}+00 & 0.00 \mathrm{E}+00\end{array}$

$\begin{array}{llll}0.100 & 0.00 \mathrm{E}+00 & 0.00 \mathrm{E}+00 & 0.00 \mathrm{E}+00\end{array}$

$\begin{array}{lllll}0.125 & 0.00 \mathrm{E}+00 & 0.00 \mathrm{E}+00 & 0.00 \mathrm{E}+00\end{array}$

$\begin{array}{lllll}0.150 & 0.00 \mathrm{E}+00 & 0.00 \mathrm{E}+00 & 0.00 \mathrm{E}+00\end{array}$

$\begin{array}{lllll}0.175 & 0.00 \mathrm{E}+00 & 0.00 \mathrm{E}+00 & 0.00 \mathrm{E}+00\end{array}$

$\begin{array}{lllll}0.200 & 0.00 \mathrm{E}+00 & 0.00 \mathrm{E}+00 & 0.00 \mathrm{E}+00\end{array}$

$\begin{array}{lllll}0.225 & 0.00 \mathrm{E}+00 & 0.00 \mathrm{E}+00 & 0.00 \mathrm{E}+00\end{array}$

$\begin{array}{lllll}0.250 & 0.00 \mathrm{E}+00 & 0.00 \mathrm{E}+00 & 0.00 \mathrm{E}+00\end{array}$

$\begin{array}{llll}0.275 & 0.00 \mathrm{E}+00 & 0.00 \mathrm{E}+00 & 0.00 \mathrm{E}+00\end{array}$

$\begin{array}{lllll}0.300 & 0.00 \mathrm{E}+00 & 0.00 \mathrm{E}+00 & 0.00 \mathrm{E}+00\end{array}$

$\begin{array}{lllll}0.325 & 0.00 \mathrm{E}+00 & 0.00 \mathrm{E}+00 & 0.00 \mathrm{E}+00\end{array}$

$\begin{array}{lllll}0.350 & 0.00 \mathrm{E}+00 & 0.00 \mathrm{E}+00 & 0.00 \mathrm{E}+00\end{array}$

$\begin{array}{lllll}0.375 & 0.00 \mathrm{E}+00 & 0.00 \mathrm{E}+00 & 0.00 \mathrm{E}+00\end{array}$

$\begin{array}{lllll}0.400 & 0.00 \mathrm{E}+00 & 0.00 \mathrm{E}+00 & 0.00 \mathrm{E}+00\end{array}$

$\begin{array}{lllll}0.425 & 0.00 \mathrm{E}+00 & 0.00 \mathrm{E}+00 & 0.00 \mathrm{E}+00\end{array}$

$\begin{array}{lllll}0.450 & 0.00 \mathrm{E}+00 & 0.00 \mathrm{E}+00 & 0.00 \mathrm{E}+00\end{array}$

$\begin{array}{lllll}0.475 & 0.00 \mathrm{E}+00 & 0.00 \mathrm{E}+00 & 0.00 \mathrm{E}+00\end{array}$

$\begin{array}{lllll}0.500 & 0.00 \mathrm{E}+00 & 0.00 \mathrm{E}+00 & 0.00 \mathrm{E}+00\end{array}$

$\begin{array}{lllll}0.525 & 0.00 \mathrm{E}+00 & 0.00 \mathrm{E}+00 & 0.00 \mathrm{E}+00\end{array}$

$\begin{array}{lllll}0.550 & 0.00 \mathrm{E}+00 & 0.00 \mathrm{E}+00 & 0.00 \mathrm{E}+00\end{array}$

$\begin{array}{lllll}0.575 & 0.00 \mathrm{E}+00 & 0.00 \mathrm{E}+00 & 0.00 \mathrm{E}+00\end{array}$

$\begin{array}{lllll}0.600 & 0.00 \mathrm{E}+00 & 0.00 \mathrm{E}+00 & 0.00 \mathrm{E}+00\end{array}$

$\begin{array}{lllll}0.625 & 0.00 \mathrm{E}+00 & 0.00 \mathrm{E}+00 & 0.00 \mathrm{E}+00\end{array}$

$\begin{array}{lllll}0.650 & 0.00 \mathrm{E}+00 & 0.00 \mathrm{E}+00 & 0.00 \mathrm{E}+00\end{array}$

$\begin{array}{lllll}0.675 & 0.00 \mathrm{E}+00 & 0.00 \mathrm{E}+00 & 0.00 \mathrm{E}+00\end{array}$

$\begin{array}{lllll}0.700 & 0.00 \mathrm{E}+00 & 0.00 \mathrm{E}+00 & 0.00 \mathrm{E}+00\end{array}$

$\begin{array}{lllll}0.725 & 0.00 \mathrm{E}+00 & 0.00 \mathrm{E}+00 & 0.00 \mathrm{E}+00\end{array}$

$\begin{array}{lllll}0.750 & 0.00 \mathrm{E}+00 & 0.00 \mathrm{E}+00 & 0.00 \mathrm{E}+00\end{array}$

$\begin{array}{lllll}0.775 & 0.00 \mathrm{E}+00 & 0.00 \mathrm{E}+00 & 0.00 \mathrm{E}+00\end{array}$

$\begin{array}{lllll}0.800 & 0.00 \mathrm{E}+00 & 0.00 \mathrm{E}+00 & 0.00 \mathrm{E}+00\end{array}$

$\begin{array}{lllll}0.825 & 0.00 \mathrm{E}+00 & 0.00 \mathrm{E}+00 & 0.00 \mathrm{E}+00\end{array}$

$\begin{array}{lllll}0.850 & 0.00 \mathrm{E}+00 & 0.00 \mathrm{E}+00 & 0.00 \mathrm{E}+00\end{array}$

$\begin{array}{lllll}0.875 & 0.00 \mathrm{E}+00 & 0.00 \mathrm{E}+00 & 0.00 \mathrm{E}+00\end{array}$

$\begin{array}{lllll}0.900 & 0.00 \mathrm{E}+00 & 0.00 \mathrm{E}+00 & 0.00 \mathrm{E}+00\end{array}$

$\begin{array}{lllll}0.925 & 0.00 \mathrm{E}+00 & 0.00 \mathrm{E}+00 & 0.00 \mathrm{E}+00\end{array}$

$\begin{array}{llll}0.950 & 0.00 \mathrm{E}+00 & 0.00 \mathrm{E}+00 & 0.00 \mathrm{E}+00\end{array}$

$\begin{array}{lllll}0.975 & 0.00 \mathrm{E}+00 & 0.00 \mathrm{E}+00 & 0.00 \mathrm{E}+00\end{array}$

$\begin{array}{llll}0.990 & 0.00 \mathrm{E}+00 & 0.00 \mathrm{E}+00 & 0.00 \mathrm{E}+00\end{array}$ 
RESRAD-OFFSITE, Version 2.5

Probabilistic Dose and Risk Report

Title : RESRAD-OFFSITE External Gamma, Inhalation, and Soil Ingestion for offsite Reside

File : PBA-1_TC99-DOE-5-1.ROF

Statistics and Cumulative distribution function of Peak Risk from Plant (CzandAir)

\begin{tabular}{ccccc} 
Repetition $=$ & 1 & 2 & 3 \\
\cline { 5 - 5 } Mean & $0.00 \mathrm{E}+00$ & $0.00 \mathrm{E}+00$ & $0.00 \mathrm{E}+00$ \\
Std. Dev. & $0.00 \mathrm{E}+00$ & $0.00 \mathrm{E}+00$ & $0.00 \mathrm{E}+00$ \\
Minimum & $0.00 \mathrm{E}+00$ & $0.00 \mathrm{E}+00$ & $0.00 \mathrm{E}+00$ \\
Maximum & $0.00 \mathrm{E}+00$ & $0.00 \mathrm{E}+00$ & $0.00 \mathrm{E}+00$
\end{tabular}

Percentile

$\begin{array}{llll}0.010 & 0.00 \mathrm{E}+00 \quad 0.00 \mathrm{E}+00 & 0.00 \mathrm{E}+00\end{array}$

$\begin{array}{llll}0.025 & 0.00 \mathrm{E}+00 \quad 0.00 \mathrm{E}+00 & 0.00 \mathrm{E}+00\end{array}$

$\begin{array}{lllll}0.050 & 0.00 \mathrm{E}+00 & 0.00 \mathrm{E}+00 & 0.00 \mathrm{E}+00\end{array}$

$\begin{array}{lllll}0.075 & 0.00 \mathrm{E}+00 & 0.00 \mathrm{E}+00 & 0.00 \mathrm{E}+00\end{array}$

$\begin{array}{llll}0.100 & 0.00 \mathrm{E}+00 & 0.00 \mathrm{E}+00 & 0.00 \mathrm{E}+00\end{array}$

$\begin{array}{lllll}0.125 & 0.00 \mathrm{E}+00 & 0.00 \mathrm{E}+00 & 0.00 \mathrm{E}+00\end{array}$

$\begin{array}{lllll}0.150 & 0.00 \mathrm{E}+00 & 0.00 \mathrm{E}+00 & 0.00 \mathrm{E}+00\end{array}$

$\begin{array}{lllll}0.175 & 0.00 \mathrm{E}+00 & 0.00 \mathrm{E}+00 & 0.00 \mathrm{E}+00\end{array}$

$\begin{array}{lllll}0.200 & 0.00 \mathrm{E}+00 & 0.00 \mathrm{E}+00 & 0.00 \mathrm{E}+00\end{array}$

$\begin{array}{lllll}0.225 & 0.00 \mathrm{E}+00 & 0.00 \mathrm{E}+00 & 0.00 \mathrm{E}+00\end{array}$

$\begin{array}{lllll}0.250 & 0.00 \mathrm{E}+00 & 0.00 \mathrm{E}+00 & 0.00 \mathrm{E}+00\end{array}$

$\begin{array}{llll}0.275 & 0.00 \mathrm{E}+00 & 0.00 \mathrm{E}+00 & 0.00 \mathrm{E}+00\end{array}$

$\begin{array}{lllll}0.300 & 0.00 \mathrm{E}+00 & 0.00 \mathrm{E}+00 & 0.00 \mathrm{E}+00\end{array}$

$\begin{array}{lllll}0.325 & 0.00 \mathrm{E}+00 & 0.00 \mathrm{E}+00 & 0.00 \mathrm{E}+00\end{array}$

$\begin{array}{lllll}0.350 & 0.00 \mathrm{E}+00 & 0.00 \mathrm{E}+00 & 0.00 \mathrm{E}+00\end{array}$

$\begin{array}{lllll}0.375 & 0.00 \mathrm{E}+00 & 0.00 \mathrm{E}+00 & 0.00 \mathrm{E}+00\end{array}$

$\begin{array}{lllll}0.400 & 0.00 \mathrm{E}+00 & 0.00 \mathrm{E}+00 & 0.00 \mathrm{E}+00\end{array}$

$\begin{array}{lllll}0.425 & 0.00 \mathrm{E}+00 & 0.00 \mathrm{E}+00 & 0.00 \mathrm{E}+00\end{array}$

$\begin{array}{lllll}0.450 & 0.00 \mathrm{E}+00 & 0.00 \mathrm{E}+00 & 0.00 \mathrm{E}+00\end{array}$

$\begin{array}{lllll}0.475 & 0.00 \mathrm{E}+00 & 0.00 \mathrm{E}+00 & 0.00 \mathrm{E}+00\end{array}$

$\begin{array}{lllll}0.500 & 0.00 \mathrm{E}+00 & 0.00 \mathrm{E}+00 & 0.00 \mathrm{E}+00\end{array}$

$\begin{array}{lllll}0.525 & 0.00 \mathrm{E}+00 & 0.00 \mathrm{E}+00 & 0.00 \mathrm{E}+00\end{array}$

$\begin{array}{lllll}0.550 & 0.00 \mathrm{E}+00 & 0.00 \mathrm{E}+00 & 0.00 \mathrm{E}+00\end{array}$

$\begin{array}{lllll}0.575 & 0.00 \mathrm{E}+00 & 0.00 \mathrm{E}+00 & 0.00 \mathrm{E}+00\end{array}$

$\begin{array}{lllll}0.600 & 0.00 \mathrm{E}+00 & 0.00 \mathrm{E}+00 & 0.00 \mathrm{E}+00\end{array}$

$\begin{array}{lllll}0.625 & 0.00 \mathrm{E}+00 & 0.00 \mathrm{E}+00 & 0.00 \mathrm{E}+00\end{array}$

$\begin{array}{lllll}0.650 & 0.00 \mathrm{E}+00 & 0.00 \mathrm{E}+00 & 0.00 \mathrm{E}+00\end{array}$

$\begin{array}{lllll}0.675 & 0.00 \mathrm{E}+00 & 0.00 \mathrm{E}+00 & 0.00 \mathrm{E}+00\end{array}$

$\begin{array}{lllll}0.700 & 0.00 \mathrm{E}+00 & 0.00 \mathrm{E}+00 & 0.00 \mathrm{E}+00\end{array}$

$\begin{array}{lllll}0.725 & 0.00 \mathrm{E}+00 & 0.00 \mathrm{E}+00 & 0.00 \mathrm{E}+00\end{array}$

$\begin{array}{lllll}0.750 & 0.00 \mathrm{E}+00 & 0.00 \mathrm{E}+00 & 0.00 \mathrm{E}+00\end{array}$

$\begin{array}{lllll}0.775 & 0.00 \mathrm{E}+00 & 0.00 \mathrm{E}+00 & 0.00 \mathrm{E}+00\end{array}$

$\begin{array}{lllll}0.800 & 0.00 \mathrm{E}+00 & 0.00 \mathrm{E}+00 & 0.00 \mathrm{E}+00\end{array}$

$\begin{array}{lllll}0.825 & 0.00 \mathrm{E}+00 & 0.00 \mathrm{E}+00 & 0.00 \mathrm{E}+00\end{array}$

$\begin{array}{lllll}0.850 & 0.00 \mathrm{E}+00 & 0.00 \mathrm{E}+00 & 0.00 \mathrm{E}+00\end{array}$

$\begin{array}{lllll}0.875 & 0.00 \mathrm{E}+00 & 0.00 \mathrm{E}+00 & 0.00 \mathrm{E}+00\end{array}$

$\begin{array}{lllll}0.900 & 0.00 \mathrm{E}+00 & 0.00 \mathrm{E}+00 & 0.00 \mathrm{E}+00\end{array}$

$\begin{array}{lllll}0.925 & 0.00 \mathrm{E}+00 & 0.00 \mathrm{E}+00 & 0.00 \mathrm{E}+00\end{array}$

$\begin{array}{lllll}0.950 & 0.00 \mathrm{E}+00 & 0.00 \mathrm{E}+00 & 0.00 \mathrm{E}+00\end{array}$

$\begin{array}{lllll}0.975 & 0.00 \mathrm{E}+00 & 0.00 \mathrm{E}+00 & 0.00 \mathrm{E}+00\end{array}$

$\begin{array}{lllll}0.990 & 0.00 \mathrm{E}+00 & 0.00 \mathrm{E}+00 & 0.00 \mathrm{E}+00\end{array}$ 
RESRAD-OFFSITE, Version 2.5

Probabilistic Dose and Risk Report

Title : RESRAD-OFFSITE External Gamma, Inhalation, and Soil Ingestion for offsite Reside

File : PBA-1_TC99-DOE-5-1.ROF

Statistics and Cumulative distribution function of Peak Risk from Meat (CZandAir)

\begin{tabular}{ccccc} 
Repetition $=$ & 1 & 2 & 3 \\
\cline { 5 - 5 } Mean & $0.00 \mathrm{E}+00$ & $0.00 \mathrm{E}+00$ & $0.00 \mathrm{E}+00$ \\
Std. Dev. & $0.00 \mathrm{E}+00$ & $0.00 \mathrm{E}+00$ & $0.00 \mathrm{E}+00$ \\
Minimum & $0.00 \mathrm{E}+00$ & $0.00 \mathrm{E}+00$ & $0.00 \mathrm{E}+00$ \\
Maximum & $0.00 \mathrm{E}+00$ & $0.00 \mathrm{E}+00$ & $0.00 \mathrm{E}+00$
\end{tabular}

Percentile

$\begin{array}{llll}0.010 & 0.00 \mathrm{E}+00 \quad 0.00 \mathrm{E}+00 & 0.00 \mathrm{E}+00\end{array}$

$\begin{array}{llll}0.025 & 0.00 \mathrm{E}+00 & 0.00 \mathrm{E}+00 & 0.00 \mathrm{E}+00\end{array}$

$\begin{array}{lllll}0.050 & 0.00 \mathrm{E}+00 & 0.00 \mathrm{E}+00 & 0.00 \mathrm{E}+00\end{array}$

$\begin{array}{lllll}0.075 & 0.00 \mathrm{E}+00 & 0.00 \mathrm{E}+00 & 0.00 \mathrm{E}+00\end{array}$

$\begin{array}{llll}0.100 & 0.00 \mathrm{E}+00 & 0.00 \mathrm{E}+00 & 0.00 \mathrm{E}+00\end{array}$

$\begin{array}{lllll}0.125 & 0.00 \mathrm{E}+00 & 0.00 \mathrm{E}+00 & 0.00 \mathrm{E}+00\end{array}$

$\begin{array}{lllll}0.150 & 0.00 \mathrm{E}+00 & 0.00 \mathrm{E}+00 & 0.00 \mathrm{E}+00\end{array}$

$\begin{array}{lllll}0.175 & 0.00 \mathrm{E}+00 & 0.00 \mathrm{E}+00 & 0.00 \mathrm{E}+00\end{array}$

$\begin{array}{lllll}0.200 & 0.00 \mathrm{E}+00 & 0.00 \mathrm{E}+00 & 0.00 \mathrm{E}+00\end{array}$

$\begin{array}{lllll}0.225 & 0.00 \mathrm{E}+00 & 0.00 \mathrm{E}+00 & 0.00 \mathrm{E}+00\end{array}$

$\begin{array}{lllll}0.250 & 0.00 \mathrm{E}+00 & 0.00 \mathrm{E}+00 & 0.00 \mathrm{E}+00\end{array}$

$\begin{array}{lllll}0.275 & 0.00 \mathrm{E}+00 & 0.00 \mathrm{E}+00 & 0.00 \mathrm{E}+00\end{array}$

$\begin{array}{lllll}0.300 & 0.00 \mathrm{E}+00 & 0.00 \mathrm{E}+00 & 0.00 \mathrm{E}+00\end{array}$

$\begin{array}{lllll}0.325 & 0.00 \mathrm{E}+00 & 0.00 \mathrm{E}+00 & 0.00 \mathrm{E}+00\end{array}$

$\begin{array}{lllll}0.350 & 0.00 \mathrm{E}+00 & 0.00 \mathrm{E}+00 & 0.00 \mathrm{E}+00\end{array}$

$\begin{array}{lllll}0.375 & 0.00 \mathrm{E}+00 & 0.00 \mathrm{E}+00 & 0.00 \mathrm{E}+00\end{array}$

$\begin{array}{lllll}0.400 & 0.00 \mathrm{E}+00 & 0.00 \mathrm{E}+00 & 0.00 \mathrm{E}+00\end{array}$

$\begin{array}{lllll}0.425 & 0.00 \mathrm{E}+00 & 0.00 \mathrm{E}+00 & 0.00 \mathrm{E}+00\end{array}$

$\begin{array}{lllll}0.450 & 0.00 \mathrm{E}+00 & 0.00 \mathrm{E}+00 & 0.00 \mathrm{E}+00\end{array}$

$\begin{array}{lllll}0.475 & 0.00 \mathrm{E}+00 & 0.00 \mathrm{E}+00 & 0.00 \mathrm{E}+00\end{array}$

$\begin{array}{lllll}0.500 & 0.00 \mathrm{E}+00 & 0.00 \mathrm{E}+00 & 0.00 \mathrm{E}+00\end{array}$

$\begin{array}{lllll}0.525 & 0.00 \mathrm{E}+00 & 0.00 \mathrm{E}+00 & 0.00 \mathrm{E}+00\end{array}$

$\begin{array}{lllll}0.550 & 0.00 \mathrm{E}+00 & 0.00 \mathrm{E}+00 & 0.00 \mathrm{E}+00\end{array}$

$\begin{array}{lllll}0.575 & 0.00 \mathrm{E}+00 & 0.00 \mathrm{E}+00 & 0.00 \mathrm{E}+00\end{array}$

$\begin{array}{lllll}0.600 & 0.00 \mathrm{E}+00 & 0.00 \mathrm{E}+00 & 0.00 \mathrm{E}+00\end{array}$

$\begin{array}{lllll}0.625 & 0.00 \mathrm{E}+00 & 0.00 \mathrm{E}+00 & 0.00 \mathrm{E}+00\end{array}$

$\begin{array}{lllll}0.650 & 0.00 \mathrm{E}+00 & 0.00 \mathrm{E}+00 & 0.00 \mathrm{E}+00\end{array}$

$\begin{array}{lllll}0.675 & 0.00 \mathrm{E}+00 & 0.00 \mathrm{E}+00 & 0.00 \mathrm{E}+00\end{array}$

$\begin{array}{lllll}0.700 & 0.00 \mathrm{E}+00 & 0.00 \mathrm{E}+00 & 0.00 \mathrm{E}+00\end{array}$

$\begin{array}{lllll}0.725 & 0.00 \mathrm{E}+00 & 0.00 \mathrm{E}+00 & 0.00 \mathrm{E}+00\end{array}$

$\begin{array}{lllll}0.750 & 0.00 \mathrm{E}+00 & 0.00 \mathrm{E}+00 & 0.00 \mathrm{E}+00\end{array}$

$\begin{array}{lllll}0.775 & 0.00 \mathrm{E}+00 & 0.00 \mathrm{E}+00 & 0.00 \mathrm{E}+00\end{array}$

$\begin{array}{lllll}0.800 & 0.00 \mathrm{E}+00 & 0.00 \mathrm{E}+00 & 0.00 \mathrm{E}+00\end{array}$

$\begin{array}{lllll}0.825 & 0.00 \mathrm{E}+00 & 0.00 \mathrm{E}+00 & 0.00 \mathrm{E}+00\end{array}$

$\begin{array}{lllll}0.850 & 0.00 \mathrm{E}+00 & 0.00 \mathrm{E}+00 & 0.00 \mathrm{E}+00\end{array}$

$\begin{array}{lllll}0.875 & 0.00 \mathrm{E}+00 & 0.00 \mathrm{E}+00 & 0.00 \mathrm{E}+00\end{array}$

$\begin{array}{lllll}0.900 & 0.00 \mathrm{E}+00 & 0.00 \mathrm{E}+00 & 0.00 \mathrm{E}+00\end{array}$

$\begin{array}{lllll}0.925 & 0.00 \mathrm{E}+00 & 0.00 \mathrm{E}+00 & 0.00 \mathrm{E}+00\end{array}$

$\begin{array}{lllll}0.950 & 0.00 \mathrm{E}+00 & 0.00 \mathrm{E}+00 & 0.00 \mathrm{E}+00\end{array}$

$\begin{array}{lllll}0.975 & 0.00 \mathrm{E}+00 & 0.00 \mathrm{E}+00 & 0.00 \mathrm{E}+00\end{array}$

$\begin{array}{lllll}0.990 & 0.00 \mathrm{E}+00 & 0.00 \mathrm{E}+00 & 0.00 \mathrm{E}+00\end{array}$ 
RESRAD-OFFSITE, Version 2.5

Probabilistic Dose and Risk Report

Title : RESRAD-OFFSITE External Gamma, Inhalation, and Soil Ingestion for offsite Reside

File : PBA-1_TC99-DOE-5-1.ROF

Statistics and Cumulative distribution function of Peak Risk from Milk (CzandAir)

\begin{tabular}{ccccc} 
Repetition $=$ & 1 & 2 & 3 \\
\cline { 5 - 5 } Mean & $0.00 \mathrm{E}+00$ & $0.00 \mathrm{E}+00$ & $0.00 \mathrm{E}+00$ \\
Std. Dev. & $0.00 \mathrm{E}+00$ & $0.00 \mathrm{E}+00$ & $0.00 \mathrm{E}+00$ \\
Minimum & $0.00 \mathrm{E}+00$ & $0.00 \mathrm{E}+00$ & $0.00 \mathrm{E}+00$ \\
Maximum & $0.00 \mathrm{E}+00$ & $0.00 \mathrm{E}+00$ & $0.00 \mathrm{E}+00$
\end{tabular}

Percentile

$\begin{array}{llll}0.010 & 0.00 \mathrm{E}+00 \quad 0.00 \mathrm{E}+00 & 0.00 \mathrm{E}+00\end{array}$

$\begin{array}{llll}0.025 & 0.00 \mathrm{E}+00 & 0.00 \mathrm{E}+00 & 0.00 \mathrm{E}+00\end{array}$

$\begin{array}{lllll}0.050 & 0.00 \mathrm{E}+00 & 0.00 \mathrm{E}+00 & 0.00 \mathrm{E}+00\end{array}$

$\begin{array}{lllll}0.075 & 0.00 \mathrm{E}+00 & 0.00 \mathrm{E}+00 & 0.00 \mathrm{E}+00\end{array}$

$\begin{array}{llll}0.100 & 0.00 \mathrm{E}+00 & 0.00 \mathrm{E}+00 & 0.00 \mathrm{E}+00\end{array}$

$\begin{array}{lllll}0.125 & 0.00 \mathrm{E}+00 & 0.00 \mathrm{E}+00 & 0.00 \mathrm{E}+00\end{array}$

$\begin{array}{lllll}0.150 & 0.00 \mathrm{E}+00 & 0.00 \mathrm{E}+00 & 0.00 \mathrm{E}+00\end{array}$

$\begin{array}{lllll}0.175 & 0.00 \mathrm{E}+00 & 0.00 \mathrm{E}+00 & 0.00 \mathrm{E}+00\end{array}$

$\begin{array}{lllll}0.200 & 0.00 \mathrm{E}+00 & 0.00 \mathrm{E}+00 & 0.00 \mathrm{E}+00\end{array}$

$\begin{array}{lllll}0.225 & 0.00 \mathrm{E}+00 & 0.00 \mathrm{E}+00 & 0.00 \mathrm{E}+00\end{array}$

$\begin{array}{lllll}0.250 & 0.00 \mathrm{E}+00 & 0.00 \mathrm{E}+00 & 0.00 \mathrm{E}+00\end{array}$

$\begin{array}{lllll}0.275 & 0.00 \mathrm{E}+00 & 0.00 \mathrm{E}+00 & 0.00 \mathrm{E}+00\end{array}$

$\begin{array}{lllll}0.300 & 0.00 \mathrm{E}+00 & 0.00 \mathrm{E}+00 & 0.00 \mathrm{E}+00\end{array}$

$\begin{array}{lllll}0.325 & 0.00 \mathrm{E}+00 & 0.00 \mathrm{E}+00 & 0.00 \mathrm{E}+00\end{array}$

$\begin{array}{lllll}0.350 & 0.00 \mathrm{E}+00 & 0.00 \mathrm{E}+00 & 0.00 \mathrm{E}+00\end{array}$

$\begin{array}{lllll}0.375 & 0.00 \mathrm{E}+00 & 0.00 \mathrm{E}+00 & 0.00 \mathrm{E}+00\end{array}$

$\begin{array}{lllll}0.400 & 0.00 \mathrm{E}+00 & 0.00 \mathrm{E}+00 & 0.00 \mathrm{E}+00\end{array}$

$\begin{array}{lllll}0.425 & 0.00 \mathrm{E}+00 & 0.00 \mathrm{E}+00 & 0.00 \mathrm{E}+00\end{array}$

$\begin{array}{lllll}0.450 & 0.00 \mathrm{E}+00 & 0.00 \mathrm{E}+00 & 0.00 \mathrm{E}+00\end{array}$

$\begin{array}{lllll}0.475 & 0.00 \mathrm{E}+00 & 0.00 \mathrm{E}+00 & 0.00 \mathrm{E}+00\end{array}$

$\begin{array}{lllll}0.500 & 0.00 \mathrm{E}+00 & 0.00 \mathrm{E}+00 & 0.00 \mathrm{E}+00\end{array}$

$\begin{array}{lllll}0.525 & 0.00 \mathrm{E}+00 & 0.00 \mathrm{E}+00 & 0.00 \mathrm{E}+00\end{array}$

$\begin{array}{lllll}0.550 & 0.00 \mathrm{E}+00 & 0.00 \mathrm{E}+00 & 0.00 \mathrm{E}+00\end{array}$

$\begin{array}{lllll}0.575 & 0.00 \mathrm{E}+00 & 0.00 \mathrm{E}+00 & 0.00 \mathrm{E}+00\end{array}$

$\begin{array}{lllll}0.600 & 0.00 \mathrm{E}+00 & 0.00 \mathrm{E}+00 & 0.00 \mathrm{E}+00\end{array}$

$\begin{array}{lllll}0.625 & 0.00 \mathrm{E}+00 & 0.00 \mathrm{E}+00 & 0.00 \mathrm{E}+00\end{array}$

$\begin{array}{lllll}0.650 & 0.00 \mathrm{E}+00 & 0.00 \mathrm{E}+00 & 0.00 \mathrm{E}+00\end{array}$

$\begin{array}{lllll}0.675 & 0.00 \mathrm{E}+00 & 0.00 \mathrm{E}+00 & 0.00 \mathrm{E}+00\end{array}$

$\begin{array}{lllll}0.700 & 0.00 \mathrm{E}+00 & 0.00 \mathrm{E}+00 & 0.00 \mathrm{E}+00\end{array}$

$\begin{array}{lllll}0.725 & 0.00 \mathrm{E}+00 & 0.00 \mathrm{E}+00 & 0.00 \mathrm{E}+00\end{array}$

$\begin{array}{lllll}0.750 & 0.00 \mathrm{E}+00 & 0.00 \mathrm{E}+00 & 0.00 \mathrm{E}+00\end{array}$

$\begin{array}{lllll}0.775 & 0.00 \mathrm{E}+00 & 0.00 \mathrm{E}+00 & 0.00 \mathrm{E}+00\end{array}$

$\begin{array}{lllll}0.800 & 0.00 \mathrm{E}+00 & 0.00 \mathrm{E}+00 & 0.00 \mathrm{E}+00\end{array}$

$\begin{array}{lllll}0.825 & 0.00 \mathrm{E}+00 & 0.00 \mathrm{E}+00 & 0.00 \mathrm{E}+00\end{array}$

$\begin{array}{lllll}0.850 & 0.00 \mathrm{E}+00 & 0.00 \mathrm{E}+00 & 0.00 \mathrm{E}+00\end{array}$

$\begin{array}{lllll}0.875 & 0.00 \mathrm{E}+00 & 0.00 \mathrm{E}+00 & 0.00 \mathrm{E}+00\end{array}$

$\begin{array}{lllll}0.900 & 0.00 \mathrm{E}+00 & 0.00 \mathrm{E}+00 & 0.00 \mathrm{E}+00\end{array}$

$\begin{array}{lllll}0.925 & 0.00 \mathrm{E}+00 & 0.00 \mathrm{E}+00 & 0.00 \mathrm{E}+00\end{array}$

$\begin{array}{lllll}0.950 & 0.00 \mathrm{E}+00 & 0.00 \mathrm{E}+00 & 0.00 \mathrm{E}+00\end{array}$

$\begin{array}{lllll}0.975 & 0.00 \mathrm{E}+00 & 0.00 \mathrm{E}+00 & 0.00 \mathrm{E}+00\end{array}$

$\begin{array}{lllll}0.990 & 0.00 \mathrm{E}+00 & 0.00 \mathrm{E}+00 & 0.00 \mathrm{E}+00\end{array}$ 
RESRAD-OFFSITE, Version 2.5

Probabilistic Dose and Risk Report

Title : RESRAD-OFFSITE External Gamma, Inhalation, and Soil Ingestion for offsite Reside

File : PBA-1_TC99-DOE-5-1.ROF

Statistics and Cumulative distribution function of Peak Risk from Soil Ingestion(CZandAir)

\begin{tabular}{ccccc} 
Repetition $=$ & 1 & 2 & 3 \\
\cline { 5 - 5 } Mean & $0.00 \mathrm{E}+00$ & $0.00 \mathrm{E}+00$ & $0.00 \mathrm{E}+00$ \\
Std. Dev. & $0.00 \mathrm{E}+00$ & $0.00 \mathrm{E}+00$ & $0.00 \mathrm{E}+00$ \\
Minimum & $0.00 \mathrm{E}+00$ & $0.00 \mathrm{E}+00$ & $0.00 \mathrm{E}+00$ \\
Maximum & $0.00 \mathrm{E}+00$ & $0.00 \mathrm{E}+00$ & $0.00 \mathrm{E}+00$
\end{tabular}

Percentile

$\begin{array}{llll}0.010 & 0.00 \mathrm{E}+00 \quad 0.00 \mathrm{E}+00 & 0.00 \mathrm{E}+00\end{array}$

$\begin{array}{llll}0.025 & 0.00 \mathrm{E}+00 \quad 0.00 \mathrm{E}+00 & 0.00 \mathrm{E}+00\end{array}$

$\begin{array}{llll}0.050 & 0.00 \mathrm{E}+00 & 0.00 \mathrm{E}+00 & 0.00 \mathrm{E}+00\end{array}$

$\begin{array}{llll}0.075 & 0.00 \mathrm{E}+00 & 0.00 \mathrm{E}+00 & 0.00 \mathrm{E}+00\end{array}$

$\begin{array}{lllll}0.100 & 0.00 \mathrm{E}+00 & 0.00 \mathrm{E}+00 & 0.00 \mathrm{E}+00\end{array}$

$\begin{array}{lllll}0.125 & 0.00 \mathrm{E}+00 & 0.00 \mathrm{E}+00 & 0.00 \mathrm{E}+00\end{array}$

$\begin{array}{lllll}0.150 & 0.00 \mathrm{E}+00 & 0.00 \mathrm{E}+00 & 0.00 \mathrm{E}+00\end{array}$

$\begin{array}{lllll}0.175 & 0.00 \mathrm{E}+00 & 0.00 \mathrm{E}+00 & 0.00 \mathrm{E}+00\end{array}$

$\begin{array}{lllll}0.200 & 0.00 \mathrm{E}+00 & 0.00 \mathrm{E}+00 & 0.00 \mathrm{E}+00\end{array}$

$\begin{array}{lllll}0.225 & 0.00 \mathrm{E}+00 & 0.00 \mathrm{E}+00 & 0.00 \mathrm{E}+00\end{array}$

$\begin{array}{lllll}0.250 & 0.00 \mathrm{E}+00 & 0.00 \mathrm{E}+00 & 0.00 \mathrm{E}+00\end{array}$

$\begin{array}{lllll}0.275 & 0.00 \mathrm{E}+00 & 0.00 \mathrm{E}+00 & 0.00 \mathrm{E}+00\end{array}$

$\begin{array}{lllll}0.300 & 0.00 \mathrm{E}+00 & 0.00 \mathrm{E}+00 & 0.00 \mathrm{E}+00\end{array}$

$\begin{array}{lllll}0.325 & 0.00 \mathrm{E}+00 & 0.00 \mathrm{E}+00 & 0.00 \mathrm{E}+00\end{array}$

$\begin{array}{lllll}0.350 & 0.00 \mathrm{E}+00 & 0.00 \mathrm{E}+00 & 0.00 \mathrm{E}+00\end{array}$

$\begin{array}{lllll}0.375 & 0.00 \mathrm{E}+00 & 0.00 \mathrm{E}+00 & 0.00 \mathrm{E}+00\end{array}$

$\begin{array}{lllll}0.400 & 0.00 \mathrm{E}+00 & 0.00 \mathrm{E}+00 & 0.00 \mathrm{E}+00\end{array}$

$\begin{array}{lllll}0.425 & 0.00 \mathrm{E}+00 & 0.00 \mathrm{E}+00 & 0.00 \mathrm{E}+00\end{array}$

$\begin{array}{lllll}0.450 & 0.00 \mathrm{E}+00 & 0.00 \mathrm{E}+00 & 0.00 \mathrm{E}+00\end{array}$

$\begin{array}{lllll}0.475 & 0.00 \mathrm{E}+00 & 0.00 \mathrm{E}+00 & 0.00 \mathrm{E}+00\end{array}$

$\begin{array}{lllll}0.500 & 0.00 \mathrm{E}+00 & 0.00 \mathrm{E}+00 & 0.00 \mathrm{E}+00\end{array}$

$\begin{array}{lllll}0.525 & 0.00 \mathrm{E}+00 & 0.00 \mathrm{E}+00 & 0.00 \mathrm{E}+00\end{array}$

$\begin{array}{lllll}0.550 & 0.00 \mathrm{E}+00 & 0.00 \mathrm{E}+00 & 0.00 \mathrm{E}+00\end{array}$

$\begin{array}{lllll}0.575 & 0.00 \mathrm{E}+00 & 0.00 \mathrm{E}+00 & 0.00 \mathrm{E}+00\end{array}$

$\begin{array}{lllll}0.600 & 0.00 \mathrm{E}+00 & 0.00 \mathrm{E}+00 & 0.00 \mathrm{E}+00\end{array}$

$\begin{array}{lllll}0.625 & 0.00 \mathrm{E}+00 & 0.00 \mathrm{E}+00 & 0.00 \mathrm{E}+00\end{array}$

$\begin{array}{lllll}0.650 & 0.00 \mathrm{E}+00 & 0.00 \mathrm{E}+00 & 0.00 \mathrm{E}+00\end{array}$

$\begin{array}{lllll}0.675 & 0.00 \mathrm{E}+00 & 0.00 \mathrm{E}+00 & 0.00 \mathrm{E}+00\end{array}$

$\begin{array}{lllll}0.700 & 0.00 \mathrm{E}+00 & 0.00 \mathrm{E}+00 & 0.00 \mathrm{E}+00\end{array}$

$\begin{array}{lllll}0.725 & 0.00 \mathrm{E}+00 & 0.00 \mathrm{E}+00 & 0.00 \mathrm{E}+00\end{array}$

$\begin{array}{lllll}0.750 & 0.00 \mathrm{E}+00 & 0.00 \mathrm{E}+00 & 0.00 \mathrm{E}+00\end{array}$

$\begin{array}{lllll}0.775 & 0.00 \mathrm{E}+00 & 0.00 \mathrm{E}+00 & 0.00 \mathrm{E}+00\end{array}$

$\begin{array}{lllll}0.800 & 0.00 \mathrm{E}+00 & 0.00 \mathrm{E}+00 & 0.00 \mathrm{E}+00\end{array}$

$\begin{array}{lllll}0.825 & 0.00 \mathrm{E}+00 & 0.00 \mathrm{E}+00 & 0.00 \mathrm{E}+00\end{array}$

$\begin{array}{lllll}0.850 & 0.00 \mathrm{E}+00 & 0.00 \mathrm{E}+00 & 0.00 \mathrm{E}+00\end{array}$

$\begin{array}{lllll}0.875 & 0.00 \mathrm{E}+00 & 0.00 \mathrm{E}+00 & 0.00 \mathrm{E}+00\end{array}$

$\begin{array}{lllll}0.900 & 0.00 \mathrm{E}+00 & 0.00 \mathrm{E}+00 & 0.00 \mathrm{E}+00\end{array}$

$\begin{array}{lllll}0.925 & 0.00 \mathrm{E}+00 & 0.00 \mathrm{E}+00 & 0.00 \mathrm{E}+00\end{array}$

$\begin{array}{llll}0.950 & 0.00 \mathrm{E}+00 & 0.00 \mathrm{E}+00 & 0.00 \mathrm{E}+00\end{array}$

$\begin{array}{lllll}0.975 & 0.00 \mathrm{E}+00 & 0.00 \mathrm{E}+00 & 0.00 \mathrm{E}+00\end{array}$

$\begin{array}{lllll}0.990 & 0.00 \mathrm{E}+00 & 0.00 \mathrm{E}+00 & 0.00 \mathrm{E}+00\end{array}$ 
RESRAD-OFFSITE, Version 2.5

$\mathrm{T}^{1 / 2}$ Limit $=180$ days

Title : RESRAD-OFFSITE External Gamma, Inhalation, and Soil Ingestion for Offsite Reside File : PBA-1_TC99-DOE-5-1.ROF

Time

Years

$0.00 \mathrm{E}+00$

$5.13 \mathrm{E}-01$

$1.03 \mathrm{E}+00$

1. $54 \mathrm{E}+00$

$2.05 \mathrm{E}+00$

$2.56 \mathrm{E}+00$

$3.08 \mathrm{E}+00$

$3.59 \mathrm{E}+00$

$4.10 \mathrm{E}+00$

4. $61 \mathrm{E}+00$

$5.13 \mathrm{E}+00$

$5.64 \mathrm{E}+00$

$6.15 \mathrm{E}+00$

$6.67 \mathrm{E}+00$

$7.18 \mathrm{E}+00$

$7.69 \mathrm{E}+00$

$8.20 \mathrm{E}+00$

$8.72 \mathrm{E}+00$

$9.23 \mathrm{E}+00$

$9.74 \mathrm{E}+00$

$1.03 \mathrm{E}+01$

$1.08 \mathrm{E}+01$

$1.13 \mathrm{E}+01$

$1.18 \mathrm{E}+01$

$1.23 \mathrm{E}+01$

$1.28 \mathrm{E}+01$

1. $33 \mathrm{E}+01$

1. $38 \mathrm{E}+01$

$1.44 \mathrm{E}+01$

1. $49 \mathrm{E}+01$

$1.54 \mathrm{E}+01$

$1.59 \mathrm{E}+01$

1. $64 \mathrm{E}+01$

$1.69 \mathrm{E}+01$

1. $74 \mathrm{E}+01$

$1.79 \mathrm{E}+01$

$1.85 \mathrm{E}+01$

1. $90 \mathrm{E}+01$

1. $95 \mathrm{E}+01$

$2.00 \mathrm{E}+01$

2. $05 \mathrm{E}+01$

2. $10 \mathrm{E}+01$

$2.15 \mathrm{E}+01$

$2.20 \mathrm{E}+01$

$2.26 \mathrm{E}+01$

$2.31 \mathrm{E}+01$
Summary of dose at graphical times, reptition 1

Dose statistics at graphical times, mrem/yr

\begin{tabular}{|c|c|c|c|c|c|c|c|}
\hline $\mathrm{m}$ & aximum & lean & eal & & & & \\
\hline 2 & 2 & 32 & 2 & 32 & 32 & 2 & -22 \\
\hline $46 E-32$ & $49 E-32$ & $9 E-32$ & $.49 E-32$ & 1. $49 \mathrm{E}-32$ & $1.49 E-32$ & 1. $49 \mathrm{E}-32$ & $.49 E-32$ \\
\hline $55-32$ & 32 & $=-32$ & 32 & $51 \mathrm{~F}$ & $51 \mathrm{~F}$ & 32 & $51 F-32=$ \\
\hline 2 & & 32 & & & 32 & 32 & $52 \mathrm{E}-32$ \\
\hline 32 & 32 & $E-32$ & 32 & 32 & 32 & 32 & -32 \\
\hline $43 E-32$ & 32 & -32 & & 32 & -32 & & -32 \\
\hline $42 E-32$ & & & & & 32 & -32 & $.56 \mathrm{E}-32$ \\
\hline 32 & -32 & -32 & -32 & 32 & 32 & -32 & $.58 E-32$ \\
\hline $41 E-32$ & -32 & -32 & -32 & 2 & 2 & 32 & $E-32$ \\
\hline$E-32$ & 2 & 2 & 2 & 2 & 2 & 2 & $.60 E-32$ \\
\hline 2 & & & & & & & -32 \\
\hline $39 E-32$ & $1.63 E-32$ & $E-32$ & $52 E-32$ & 32 & $63 E-32$ & -32 & $E-32$ \\
\hline $39 E-32$ & 1. $65 \mathrm{E}-32$ & $3 E-32$ & 1. $63 E-32$ & $1.64 \mathrm{E}-32$ & $1.64 \mathrm{E}-32$ & 1. $65 \mathrm{E}-32$ & $.65 E-32$ \\
\hline 32 & 2 & 32 & & & 32 & 32 & $E-32$ \\
\hline 32 & 32 & $2-28$ & 32 & 2 & 2 & 32 & $5-2$ \\
\hline 2 & 2 & 2 & 2 & 2 & 2 & 32 & 3 \\
\hline $.36 E-32$ & $1.71 \mathrm{E}-32$ & & & & & & -32 \\
\hline $35 E-32$ & $1.72 \mathrm{E}-32$ & & & $72 E-32$ & 32 & -32 & $72 E-32$ \\
\hline $35 E-32$ & $1.74 \mathrm{E}-32$ & $1.70 \mathrm{E}-32$ & 1. $72 \mathrm{E}-32$ & $1.73 E-32$ & $1.73 E-32$ & $.73 E-32$ & $.73 E-32$ \\
\hline $34 \mathrm{E}-32$ & $1.75 E-32$ & $1.72 \mathrm{E}-32$ & $3 E-32$ & -32 & $1.75 \mathrm{E}-32$ & -32 & $.75 E-32$ \\
\hline & 32 & & & & & 32 & $E-32$ \\
\hline & & & & & & & 32 \\
\hline 6D-32 & $\perp \cdot c$ & & & 2 & & 2 & -32 \\
\hline 2 & 2 & 32 & & 2 & 2 & 2 & -32 \\
\hline$=-32$ & $835-32$ & $1.79 \mathrm{E}-32$ & $1.80 \mathrm{E}-32$ & $2 E-32$ & $33 F-32$ & $E-32$ & $83 F-32$ \\
\hline $31 E-32$ & $1.85 \mathrm{E}-32$ & $1.80 \mathrm{E}-32$ & 1. $82 \mathrm{E}-32$ & & $845-32$ & $E-32$ & $84 E-32$ \\
\hline 32 & $186 \mathrm{~F}-32$ & $.82 E-32$ & $3 E-32$ & & & $E-32$ & $6 E-32$ \\
\hline & & & & & & & -32 \\
\hline $29 E-32$ & $1.90 \mathrm{E}-32$ & $1.84 \mathrm{E}-32$ & $1.86 \mathrm{E}-32$ & $1.89 \mathrm{E}-32$ & $1.89 \mathrm{E}-32$ & $E-32$ & $.89 E-32$ \\
\hline . $200-32$ & 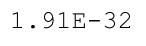 & $86 E-32$ & $.88 E-32$ & $.90 E-32$ & $1 \cdot 915-52$ & -32 & $91 E-32$ \\
\hline 年 & 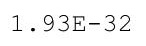 & 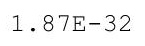 & $1.90 \mathrm{E}-32$ & - & 1.024 & -22 & $.93 E-32$ \\
\hline . & $.95 E-3$ & & & & & -32 & $94 \mathrm{E}-32$ \\
\hline-32 & 18 & $0 E-32$ & & & & & 32 \\
\hline $.26 E-32$ & & & & & & & 32 \\
\hline $25 E-32$ & $2.00 E-32$ & $1.93 E-32$ & $1.96 \mathrm{E}-32$ & $1.99 \mathrm{~d}$ & $1.99 \mathrm{E}-32$ & 32 & $00 E-32$ \\
\hline . $5275-22$ & $2.0<\mathrm{E}$ & & & & $2.01+$ & & $1 \pm-32$ \\
\hline $24+32$ & & & & & & & $.03 E-3$ \\
\hline 0 & 2 & 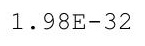 & & & 2 & 2 & 32 \\
\hline $.23 E-32$ & & & & & & & 32 \\
\hline-32 & & & & & -32 & -32 & 32 \\
\hline $22 \mathrm{E}-32$ & 2.1 & $.03 E-32$ & & & 2 & & $0 E-32$ \\
\hline 2 & $2 \cdot$ & & & & & & 32 \\
\hline 2 & $2 \cdot 13 \pm-32$ & $2.06 \mathrm{E}-32$ & & & 2 & & $14 \mathrm{E}-32$ \\
\hline $20 E-32$ & $2.16 \mathrm{E}-32$ & $2.07 E-32$ & & & & & $\cdot 16 \pm-32$ \\
\hline 2 & $2 \cdot 10 \mathrm{O}$ & 2.07 & & 170 & $2.17 \mathrm{E}-32$ & $E-32$ & 32 \\
\hline-32 & $E-32$ & $11 E-32$ & $.15 E-32$ & $.19 E-32$ & $2.19 \mathrm{E}-32$ & $E-32$ & $.20 E-32$ \\
\hline
\end{tabular}


RESRAD-OFFSITE, Version 2.5

$\mathrm{T}^{1 / 2}$ Limit $=180$ days

Title : RESRAD-OFFSITE External Gamma, Inhalation, and Soil Ingestion for offsite Reside File : PBA-1_TC99-DOE-5-1.ROF

Summary of dose at graphical times, reptition 1 (continued)

Time

Years

2. $36 \mathrm{E}+01$

2. $41 \mathrm{E}+01$

2. $46 \mathrm{E}+01$

$2.51 E+01$

2. $56 \mathrm{E}+01$

2. $61 \mathrm{E}+01$

$2.67 \mathrm{E}+01$

2. $72 \mathrm{E}+01$

2. $77 \mathrm{E}+01$

$2.82 \mathrm{E}+01$

$2.87 \mathrm{E}+01$

2. $92 \mathrm{E}+01$

2. $97 \mathrm{E}+01$

3. $02 \mathrm{E}+01$

$3.08 \mathrm{E}+01$

$3.13 \mathrm{E}+01$

$3.18 \mathrm{E}+01$

3. $23 E+01$

3. $28 \mathrm{E}+01$

3. $33 E+01$

3. $38 \mathrm{E}+01$

3. $44 \mathrm{E}+01$

$3.49 \mathrm{E}+01$

3. $54 \mathrm{E}+01$

3. $59 \mathrm{E}+01$

3. $64 \mathrm{E}+01$

$3.69 \mathrm{E}+01$

$3.74 \mathrm{E}+01$

3. $79 \mathrm{E}+01$

$3.85 \mathrm{E}+01$

$3.90 \mathrm{E}+01$

$3.95 \mathrm{E}+01$

$4.00 \mathrm{E}+01$

4. $05 \mathrm{E}+01$

4. $10 \mathrm{E}+01$

4. $15 \mathrm{E}+01$

4. $20 \mathrm{E}+01$

$4.26 \mathrm{E}+01$

4. $31 \mathrm{E}+01$

$4.36 \mathrm{E}+01$

4. $41 \mathrm{E}+01$

$4.46 \mathrm{E}+01$

$4.51 \mathrm{E}+01$

$4.56 \mathrm{E}+01$

4. $61 \mathrm{E}+01$

$4.67 \mathrm{E}+01$
Dose statistics at graphical times, mrem/yr

\begin{tabular}{|c|c|c|c|c|c|c|c|}
\hline m & um & Mean & ledian & & & & \\
\hline-32 & -32 & $2.12 \mathrm{E}-32$ & 32 & 32 & 32 & -32 & $4-32$ \\
\hline $3 E-32$ & $2.24 \mathrm{E}-32$ & $2.14 \mathrm{E}-32$ & -32 & -32 & 32 & -32 & $24 E-32$ \\
\hline $3 E-32$ & $.26 \mathrm{E}-32$ & $.16 \mathrm{E}-32$ & $2.20 \mathrm{E}-32$ & $2.25 E-32$ & $2.25 E-32$ & -32 & $E-32$ \\
\hline-32 & -32 & $18 F-32$ & $22 F-32$ & $27 F-32$ & $275-32$ & -32 & $285-32=$ \\
\hline 32 & 32 & 32 & 32 & 32 & 32 & -32 & -32 \\
\hline 32 & 32 & & & & & & -32 \\
\hline-32 & 32 & 32 & & 32 & & 32 & -32 \\
\hline-32 & -32 & $5 E-32$ & & 32 & 32 & -32 & -32 \\
\hline-32 & -32 & $26 E-32$ & -32 & $2.37 E-32$ & -32 & -32 & -32 \\
\hline 32 & -32 & $28 \mathrm{~F}-32$ & ק ת2 & 2 & & 2 & -3 \\
\hline 2 & 2 & 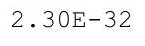 & 2 & $E-32$ & & 2 & -3 \\
\hline 32 & 24 & 2 & 32 & 2 & 2 & -32 & -32 \\
\hline $.13 E-32$ & $2.47 \mathrm{E}-32$ & $2.34 \mathrm{E}-32$ & & & & & $E-32$ \\
\hline $12 \mathrm{E}-32$ & $2.49 \mathrm{E}-32$ & $2.35 E-32$ & $2.41 E-32$ & $2.47 \mathrm{E}-32$ & $.48 E-32$ & -32 & $E-32$ \\
\hline-32 & $51 E-32$ & $37 \mathrm{E}-32$ & & & & -32 & -32 \\
\hline-32 & $54 \mathrm{E}-32$ & $39 \mathrm{E}-32$ & & 2 & 2 & 2 & -2 \\
\hline 32 & 2 & & & & & & 32 \\
\hline 2 & 2 & 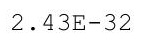 & & & & 2 & 32 \\
\hline $10 \mathrm{E}-32$ & $2.61 E-32$ & $2.45 E-32$ & $2.51 E-32$ & $2.58 E-32$ & $2.59 \mathrm{E}-32$ & $2.59 E-32$ & $.60 E-32$ \\
\hline-32 & $.63 E-32$ & $2.47 \mathrm{E}-32$ & $2.53 E-32$ & $2.60 \mathrm{E}-32$ & & $62 E-32$ & $62 E-32$ \\
\hline $.09 E-32$ & $2.65 E-32$ & $49 \mathrm{E}-32$ & & & & 2 & -32 \\
\hline & & & & & & 32 & -32 \\
\hline & & & & & & & -32 \\
\hline$E-32$ & $72 \mathrm{E}$ & 2 & 2 & 2 & & 32 & -32 \\
\hline te & - & ( & 2 & 2 & 2 & 2 & $74 E-32$ \\
\hline $6 \mathrm{E}-32$ & $.77 E-32$ & $59 E-32$ & $2.66 \mathrm{E}-32$ & $4 E-32$ & $5 \pi^{2}-3$ & $76 \mathrm{E}-32$ & $76 E-32$ \\
\hline-32 & $80 F-32$ & $.61 E-32$ & & & & $E-32$ & -32 \\
\hline & & & & & & & -32 \\
\hline & & & & & & & \\
\hline $.04 E-32$ & & & & & & -32 & 32 \\
\hline $04 \mathrm{E}-32$ & $2.90 \mathrm{E}-32$ & $2.69 E-32$ & $2.77 E-32$ & $2.86 \mathrm{E}-32$ & .0ta 32 & $.88 E-32$ & $88 E-32$ \\
\hline 年 & (2.0 & $2 \cdot 1+\mathrm{L} 2 \mathrm{z}$ & & & & 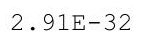 & $91 \mathrm{E}-32$ \\
\hline 3 & & & & & & & -32 \\
\hline & & & & & & & \\
\hline & & & & & & 32 & \\
\hline $.02 E-32$ & $3.03 E-32$ & $2.80 E-32$ & $2.89 E-32$ & $2 \cdot 37 \pm$ & 32 & 32 & $3.01 \mathrm{E}-32$ \\
\hline . U IL-32 & $3.035-32$ & $2.8< \pm-3<$ & & 32 & 2 & & -32 \\
\hline 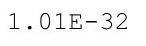 & & & & & & & $E-32$ \\
\hline 2 & 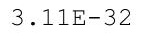 & 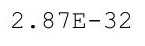 & & c & & 2 & 32 \\
\hline & & & & & & & 32 \\
\hline-33 & & & & & & 32 & 32 \\
\hline$E-33$ & $3.19 E-32$ & $2.94 \mathrm{E}-32$ & $3 E-32$ & $15 E-32$ & $6 E-32$ & 32 & -32 \\
\hline & & & & & & & -32 \\
\hline & & $.99 E-32$ & & 32 & & & 28 \\
\hline & & & & & & 32 & 22 \\
\hline-33 & $E-32$ & $E-32$ & $E-32$ & -32 & -32 & 32 & -32 \\
\hline
\end{tabular}


RESRAD-OFFSITE, Version 2.5

$\mathrm{T}^{1 / 2}$ Limit $=180$ days

Title : RESRAD-OFFSITE External Gamma, Inhalation, and Soil Ingestion for Offsite Reside

File : PBA-1_TC99-DOE-5-1.ROF

Summary of dose at graphical times, reptition 1 (continued)

Time

Years

$4.72 \mathrm{E}+01$

$4.77 \mathrm{E}+01$

$4.82 \mathrm{E}+01$

$4.87 \mathrm{E}+01$

4. $92 \mathrm{E}+01$

$4.97 \mathrm{E}+01$

$5.02 \mathrm{E}+01$

$5.08 \mathrm{E}+01$

$5.13 \mathrm{E}+01$

$5.18 \mathrm{E}+01$

$5.23 \mathrm{E}+01$

$5.28 \mathrm{E}+01$

$5.33 \mathrm{E}+01$

$5.38 \mathrm{E}+01$

$5.43 \mathrm{E}+01$

$5.49 \mathrm{E}+01$

$5.54 \mathrm{E}+01$

$5.59 \mathrm{E}+01$

$5.64 \mathrm{E}+01$

$5.69 \mathrm{E}+01$

$5.74 \mathrm{E}+01$

$5.79 \mathrm{E}+01$

$5.84 \mathrm{E}+01$

$5.90 \mathrm{E}+01$

$5.95 \mathrm{E}+01$

$6.00 \mathrm{E}+01$

$6.05 \mathrm{E}+01$

$6.10 \mathrm{E}+01$

$6.15 \mathrm{E}+01$

$6.20 \mathrm{E}+01$

$6.25 \mathrm{E}+01$

$6.31 \mathrm{E}+01$

$6.36 \mathrm{E}+01$

$6.41 \mathrm{E}+01$

$6.46 \mathrm{E}+01$

$6.51 \mathrm{E}+01$

$6.56 \mathrm{E}+01$

$6.61 \mathrm{E}+01$

$6.67 \mathrm{E}+01$

$6.72 \mathrm{E}+01$

$6.77 \mathrm{E}+01$

$6.82 \mathrm{E}+01$

$6.87 \mathrm{E}+01$

$6.92 \mathrm{E}+01$

$6.97 \mathrm{E}+01$

$7.02 \mathrm{E}+01$
Dose statistics at graphical times, mrem/yr

\begin{tabular}{|c|c|c|c|c|c|c|c|}
\hline inimum & aximum & Mean & ledian & $90 \%$ & $5 \%$ & $97.5 \%$ & \\
\hline 33 & -32 & $6 E-32$ & $3.16 \mathrm{E}-32$ & $3.29 E-32$ & $3.30 E-32$ & $31 E-32$ & $E-32$ \\
\hline 33 & 32 & 2 & 2 & 2 & 32 & 32 & -32 \\
\hline-33 & -32 & $E-32$ & -32 & 32 & 32 & -32 & -32 \\
\hline$E-33$ & $E-32$ & 32 & 2 & & & 32 & -32 \\
\hline-33 & 32 & & & & & 32 & $44 E-32$ \\
\hline $5 E-33$ & -32 & -32 & -32 & -32 & 32 & $6 E-32$ & -32 \\
\hline 3 & 32 & $3.21 E-32$ & 2 & 2 & 2 & 32 & -32 \\
\hline $36 E-33$ & $3.55 E-32$ & $3.23 E-32$ & & & -32 & -32 & $53 E-32$ \\
\hline 33 & 32 & 32 & 32 & 32 & 32 & -32 & -32 \\
\hline $.28 E-33$ & $61 E-32$ & $8 E-32$ & $0 \mathrm{E}-32$ & $56 E-32$ & -32 & -32 & $E-32$ \\
\hline-33 & 32 & & & & & -32 & $E-32$ \\
\hline & & & & & & & -32 \\
\hline$\cdot 15 \mathrm{E}-33$ & $1 \mathrm{E}-32$ & $6 \pm-32$ & $9 E-32$ & $3.05 \mathrm{E}-32$ & $1 \mathrm{E}-32$ & -32 & $\mathrm{e}-3 \mathrm{~s}^{2}+x$ \\
\hline $.11 E-33$ & $3.74 \mathrm{E}-32$ & $E-32$ & -32 & & & -32 & $72 E-32$ \\
\hline$E-33$ & -32 & -32 & -32 & 32 & 32 & -32 & -32 \\
\hline $.03 E-33$ & -32 & -32 & -32 & 32 & 32 & -32 & -32 \\
\hline $.99 E-33$ & $3.84 E-32$ & $E-32$ & $E-32$ & $78 E-32$ & $80 E-32$ & -32 & $82 E-32$ \\
\hline-33 & $7 E-32$ & $0 E-32$ & $E-32$ & 32 & & -32 & $E-32$ \\
\hline-33 & -32 & -32 & 32 & 2 & & -32 & -32 \\
\hline $.87 E-33$ & $3.94 E-32$ & $E-32$ & -32 & 32 & 32 & -32 & -32 \\
\hline $.83 E-33$ & 300 & & & & & -32 & $E-32$ \\
\hline $.79 E-33$ & $4.01 \mathrm{E}-32$ & -32 & 32 & & & -32 & -32 \\
\hline $.75 E-33$ & 4.05E-32 & $3.64 \mathrm{E}-32$ & $9 E-32$ & $98 E-32$ & $00 E-32$ & $1 E-32$ & $03 E-32$ \\
\hline $.71 E-33$ & $08 E-32$ & $.67 E-32$ & $2 E-32$ & $02 E-32$ & $04 \mathrm{E}-32$ & $5 E-32$ & $06 E-32$ \\
\hline 33 & $12 E-32$ & $70 E-32$ & $5 E-32$ & & $7 E-32$ & -32 & $10 E-32$ \\
\hline 33 & $E-32$ & -32 & -32 & & & 32 & -32 \\
\hline $.59 E-33$ & -32 & $E-32$ & 2 & & & 32 & $E-32$ \\
\hline 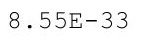 & $4.23 E-32$ & $9 E-32$ & $5 E-32$ & $4.16 E-32$ & $10 \mathrm{~L}-32$ & $9 E-32$ & $21 E-32$ \\
\hline 33 & 2 & 2 & 2 & 2 & 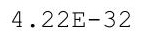 & $23 E-32$ & $.24 \mathrm{E}-32$ \\
\hline 我 & - & 然 & 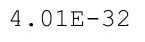 & -5 & & $27 E-32$ & $28 E-32$ \\
\hline 33 & $F-32$ & $8 F-32$ & & & & -32 & $32 E-32$ \\
\hline-33 & $8 E-32$ & $1 F-32$ & $8 E-32$ & $30 E-32$ & $3 E-32$ & -32 & $E-32$ \\
\hline $36 E-33$ & $E-32$ & $E-32$ & -32 & 32 & 32 & 32 & $9 E-32$ \\
\hline $33 E-33$ & $4.46 E-32$ & $3.98 E-32$ & $4.15 E-32$ & $4.38 E-32$ & $40 E-32$ & $2 E-32$ & $43 E-32$ \\
\hline $525-20$ & $4.50 E-32$ & $4.01 E-32$ & & & & $46 E-32$ & $.47 E-32$ \\
\hline & & & & & & & $51 \mathrm{E}-32$ \\
\hline $.21 E-33$ & 2 & & & & & 2 & 32 \\
\hline 3 & & & & 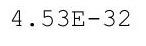 & & & 32 \\
\hline 3 & & & & & & -32 & 32 \\
\hline $10 \mathrm{E}-33$ & $4.70 E-32$ & $7 E-32$ & $6 E-32$ & 2 & 2 & 32 & $7 E-32$ \\
\hline 3 & & & & & & & -32 \\
\hline & 32 & & & 2 & $2<$ & $74 E-32$ & $16 \pm-32$ \\
\hline 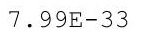 & 2 & 2 & 2 & 2 & 2 & 32 & -32 \\
\hline $1.90 \mathrm{x}-30$ & - & 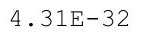 & 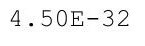 & - & & & 32 \\
\hline-33 & $4.92 E-32$ & $4.34 \mathrm{E}-32$ & $E-32$ & $4.82 E-32$ & $5 E-32$ & 32 & $.88 E-32$ \\
\hline $.89 \mathrm{E}-3$ & $4.96 E-32$ & $.37 E-32$ & $.58 E-32$ & $4.86 E-32$ & $4.89 E-32$ & $4.91 E-32$ & $4.93 E-32$ \\
\hline
\end{tabular}


RESRAD-OFFSITE, Version 2.5

$\mathrm{T}^{1 / 2}$ Limit $=180$ days

Title : RESRAD-OFFSITE External Gamma, Inhalation, and Soil Ingestion for Offsite Reside File : PBA-1_TC99-DOE-5-1.ROF

Summary of dose at graphical times, reptition 1 (continued)

Time

Years

$7.08 \mathrm{E}+01$

$7.13 \mathrm{E}+01$

7. $18 \mathrm{E}+01$

7. $23 \mathrm{E}+01$

7. $28 \mathrm{E}+01$

7. $33 \mathrm{E}+01$

7. $38 \mathrm{E}+01$

7. $43 \mathrm{E}+01$

$7.49 \mathrm{E}+01$

$7.54 \mathrm{E}+01$

$7.59 \mathrm{E}+01$

7. $64 \mathrm{E}+01$

$7.69 \mathrm{E}+01$

$7.74 \mathrm{E}+01$

$7.79 \mathrm{E}+01$

$7.84 \mathrm{E}+01$

7. $90 \mathrm{E}+01$

7. $95 \mathrm{E}+01$

$8.00 \mathrm{E}+01$

$8.05 \mathrm{E}+01$

8. $10 \mathrm{E}+01$

$8.15 \mathrm{E}+01$

$8.20 \mathrm{E}+01$

$8.25 \mathrm{E}+01$

$8.31 \mathrm{E}+01$

$8.36 \mathrm{E}+01$

$8.41 \mathrm{E}+01$

$8.46 \mathrm{E}+01$

$8.51 \mathrm{E}+01$

$8.56 \mathrm{E}+01$

8. $61 \mathrm{E}+01$

$8.66 \mathrm{E}+01$

$8.72 \mathrm{E}+01$

$8.77 \mathrm{E}+01$

$8.82 \mathrm{E}+01$

8. $87 \mathrm{E}+01$

$8.92 \mathrm{E}+01$

$8.97 \mathrm{E}+01$

9. $02 \mathrm{E}+01$

$9.07 \mathrm{E}+01$

$9.13 \mathrm{E}+01$

9. $18 \mathrm{E}+01$

9. $23 \mathrm{E}+01$

$9.28 \mathrm{E}+01$

$9.33 \mathrm{E}+01$

$9.38 \mathrm{E}+01$
Dose statistics at graphical times, mrem/yr

\begin{tabular}{|c|c|c|c|c|c|c|c|}
\hline Minimum & Maximum & Mean & Median & $90 \%$ & $95 \%$ & $7.5 \%$ & $9 \%$ \\
\hline $7.85 \mathrm{E}-33$ & $5.00 \mathrm{E}-32$ & $4.41 \mathrm{E}-32$ & $4.61 E-32$ & $4.90 \mathrm{E}-32$ & $4.93 E-32$ & $4.95 \mathrm{E}-32$ & $4.97 \mathrm{E}-32$ \\
\hline $7.82 E-33$ & $5.05 E-32$ & $4.45 E-32$ & $4.65 E-32$ & $4.94 \mathrm{E}-32$ & $4.97 E-32$ & $5.00 \mathrm{E}-32$ & $5.01 \mathrm{E}-32$ \\
\hline $7.78 \mathrm{E}-33$ & $5.09 \mathrm{E}-32$ & $4.48 \mathrm{E}-32$ & $4.69 \mathrm{E}-32$ & $4.99 \mathrm{E}-32$ & $5.02 \mathrm{E}-32$ & $5.04 \mathrm{E}-32$ & $5.06 \mathrm{E}-32$ \\
\hline $7.75 \mathrm{E}-33$ & $5.14 \mathrm{E}-32$ & $4.52 \mathrm{E}-32$ & $4.73 E-32$ & $5.03 E-32$ & $5.06 \mathrm{E}-32$ & $5.08 \mathrm{E}-32$ & $.10 \mathrm{E}-32$ \\
\hline $7.71 \mathrm{E}-33$ & $5.18 \mathrm{E}-32$ & $4.55 \mathrm{E}-32$ & $4.77 E-32$ & $5.07 \mathrm{E}-32$ & $5.11 \mathrm{E}-32$ & $5.13 E-32$ & $.15 E-32$ \\
\hline $7.68 \mathrm{E}-33$ & $5.23 E-32$ & $4.59 \mathrm{E}-32$ & $4.81 E-32$ & $5.12 \mathrm{E}-32$ & $5.15 \mathrm{E}-32$ & $5.17 \mathrm{E}-32$ & $5.19 \mathrm{E}-32$ \\
\hline $7.64 \mathrm{E}-33$ & $5.27 \mathrm{E}-32$ & $4.63 \mathrm{E}-32$ & $4.85 E-32$ & $5.16 \mathrm{E}-32$ & $20 \mathrm{E}-32$ & $5.22 \mathrm{E}-32$ & $24 E-32$ \\
\hline $61 \mathrm{E}-33$ & $5.32 \mathrm{E}-32$ & $4.66 \mathrm{E}-32$ & $4.89 \mathrm{E}-32$ & $5.21 \mathrm{E}-32$ & $24 \mathrm{E}-32$ & $5.26 \mathrm{E}-32$ & $28 \mathrm{E}-32$ \\
\hline $7.57 \mathrm{E}-33$ & $5.37 E-32$ & $4.70 \mathrm{E}-32$ & $4.93 E-32$ & $5.25 \mathrm{E}-32$ & $5.29 \mathrm{E}-32$ & $5.31 \mathrm{E}-32$ & $5.33 \mathrm{E}-32$ \\
\hline $7.54 \mathrm{E}-33$ & $5.42 \mathrm{E}-32$ & $4.74 \mathrm{E}-32$ & $4.97 E-32$ & $5.30 \mathrm{E}-32$ & $5.33 E-32$ & $5.36 \mathrm{E}-32$ & $5.38 \mathrm{E}-32$ \\
\hline $7.51 \mathrm{E}-33$ & $5.46 \mathrm{E}-32$ & $4.78 \mathrm{E}-32$ & $5.01 E-32$ & $5.34 \mathrm{E}-32$ & $5.38 \mathrm{E}-32$ & $5.40 \mathrm{E}-32$ & $5.42 \mathrm{E}-32$ \\
\hline $7.47 \mathrm{E}-33$ & $5.51 \mathrm{E}-32$ & $4.81 \mathrm{E}-32$ & $5.05 E-32$ & $5.39 \mathrm{E}-32$ & $5.43 E-32$ & $5.45 \mathrm{E}-32$ & $.47 \mathrm{E}-32$ \\
\hline $7.44 \mathrm{E}-33$ & $5.56 \mathrm{E}-32$ & $4.85 \mathrm{E}-32$ & $5.09 \mathrm{E}-32$ & $5.44 \mathrm{E}-32$ & $5.47 \mathrm{E}-32$ & $5.50 \mathrm{E}-32$ & $5.52 \mathrm{E}-32$ \\
\hline $7.41 \mathrm{E}-33$ & $5.61 \mathrm{E}-32$ & $4.89 \mathrm{E}-32$ & $5.14 \mathrm{E}-32$ & $5.49 \mathrm{E}-32$ & $5.52 \mathrm{E}-32$ & $5.55 \mathrm{E}-32$ & $5.57 \mathrm{E}-32$ \\
\hline $7.37 E-33$ & $5.66 \mathrm{E}-32$ & $4.93 E-32$ & $5.18 E-32$ & $5.53 \mathrm{E}-32$ & $5.57 \mathrm{E}-32$ & $5.60 \mathrm{E}-32$ & $5.62 \mathrm{E}-32$ \\
\hline $7.34 \mathrm{E}-33$ & $5.71 \mathrm{E}-32$ & $4.97 \mathrm{E}-32$ & $5.22 \mathrm{E}-32$ & $5.58 \mathrm{E}-32$ & $5.62 \mathrm{E}-32$ & $5.65 \mathrm{E}-32$ & $5.67 \mathrm{E}-32$ \\
\hline $7.31 \mathrm{E}-33$ & $5.76 \mathrm{E}-32$ & $5.01 \mathrm{E}-32$ & $5.26 \mathrm{E}-32$ & $5.63 \mathrm{E}-32$ & $5.67 \mathrm{E}-32$ & $5.70 \mathrm{E}-32$ & $5.72 \mathrm{E}-32$ \\
\hline $7.27 \mathrm{E}-33$ & $5.81 E-32$ & $5.05 E-32$ & $5.31 E-32$ & $5.68 \mathrm{E}-32$ & $5.72 \mathrm{E}-32$ & $5.75 \mathrm{E}-32$ & $5.77 \mathrm{E}-32$ \\
\hline $7.24 \mathrm{E}-33$ & $5.86 \mathrm{E}-32$ & $5.09 \mathrm{E}-32$ & $5.35 E-32$ & $5.73 E-32$ & $5.77 \mathrm{E}-32$ & $5.80 \mathrm{E}-32$ & $5.82 \mathrm{E}-32$ \\
\hline $21 E-33$ & $5.91 \mathrm{E}-32$ & $5.13 E-32$ & $5.40 \mathrm{E}-32$ & $5.78 \mathrm{E}$ & 32 & $5.85 \mathrm{E}-32$ & $87 E-32$ \\
\hline .1 & & 2 & & 2 & & & \\
\hline $7.14 \mathrm{E}-33$ & $6.02 \mathrm{E}-$ & 5. & 2 & 2 & 32 & 32 & -32 \\
\hline $7.11 \mathrm{E}-33$ & $6.07 \mathrm{E}-32$ & $5.26 \mathrm{E}-32$ & $5.53 E-32$ & $5.93 \mathrm{E}-32$ & $5.97 \mathrm{E}-32$ & $6.00 \mathrm{E}-32$ & $6.03 E-32$ \\
\hline $7.08 \mathrm{E}-33$ & $6.13 \mathrm{E}-32$ & $5.30 \mathrm{E}-32$ & $5.58 \mathrm{E}-32$ & $5.98 \mathrm{E}-32$ & $6.02 \mathrm{E}-32$ & $6.06 \mathrm{E}-32$ & $6.08 \mathrm{E}-32$ \\
\hline $7.05 \mathrm{E}-33$ & $6.18 \mathrm{E}-32$ & $5.34 \mathrm{E}-32$ & $5.62 \mathrm{E}-32$ & $6.03 E-32$ & $6.08 \mathrm{E}-32$ & $6.11 \mathrm{E}-32$ & $6.13 \mathrm{E}-32$ \\
\hline $7.02 \mathrm{E}-33$ & $6.24 \mathrm{E}-32$ & $5.39 \mathrm{E}-32$ & $5.67 E-32$ & $6.09 \mathrm{E}-32$ & $6.13 \mathrm{E}-32$ & $6.16 \mathrm{E}-32$ & $6.19 \mathrm{E}-32$ \\
\hline $6.98 \mathrm{E}-33$ & $6.29 \mathrm{E}-32$ & $5.43 \mathrm{E}-32$ & $5.72 \mathrm{E}-32$ & $6.14 \mathrm{E}-32$ & $6.18 \mathrm{E}-32$ & $6.22 \mathrm{E}-32$ & $6.24 \mathrm{E}-32$ \\
\hline $6.95 \mathrm{E}-33$ & $6.35 E-32$ & $5.47 \mathrm{E}-32$ & $5.76 \mathrm{E}-32$ & $6.19 \mathrm{E}-32$ & $6.24 \mathrm{E}-32$ & $6.27 E-32$ & $6.30 \mathrm{E}-32$ \\
\hline $6.92 \mathrm{E}-33$ & $6.40 \mathrm{E}-32$ & $5.52 \mathrm{E}-32$ & $5.81 E-32$ & $6.25 \mathrm{E}-32$ & $6.29 \mathrm{E}-32$ & $6.33 E-32$ & $6.35 \mathrm{E}-32$ \\
\hline $6.89 \mathrm{E}-33$ & $6.46 \mathrm{E}$ & 5.561 & $5.86 \mathrm{E}$ & 32 & 6.35 & 6.38 & $6.41 \mathrm{E}-32$ \\
\hline $6.86 \mathrm{E}-33$ & 6. & 5.6 & $E-32$ & 2 & 2 & 32 & $6.46 \mathrm{E}-32$ \\
\hline $6.83 \mathrm{E}-33$ & $6.57 \mathrm{E}-32$ & $5.65 \mathrm{E}-32$ & $5.96 \mathrm{E}-32$ & $6.41 \mathrm{E}-32$ & $6.46 \mathrm{E}-32$ & $6.49 \mathrm{E}-32$ & $6.52 \mathrm{E}-32$ \\
\hline $6.80 \mathrm{E}-33$ & $6.63 \mathrm{E}-32$ & $5.70 \mathrm{E}-32$ & $6.01 E-32$ & $6.47 \mathrm{E}-32$ & $6.52 \mathrm{E}-32$ & $6.55 \mathrm{E}-32$ & $6.58 \mathrm{E}-32$ \\
\hline $6.77 \mathrm{E}-33$ & $6.69 \mathrm{E}-32$ & $5.74 \mathrm{E}-32$ & $6.06 \mathrm{E}-32$ & $6.52 \mathrm{E}-32$ & $6.57 E-32$ & $6.61 \mathrm{E}-32$ & $6.64 \mathrm{E}-32$ \\
\hline $6.74 \mathrm{E}-33$ & $6.75 E-32$ & $5.79 \mathrm{E}-32$ & $6.11 E-32$ & $6.58 \mathrm{E}-32$ & $6.63 \mathrm{E}-32$ & $6.67 \mathrm{E}-32$ & $6.69 \mathrm{E}-32$ \\
\hline $6.71 \mathrm{E}-33$ & $6.81 \mathrm{E}-32$ & $5.83 E-32$ & $6.16 \mathrm{E}-32$ & $6.64 \mathrm{E}-32$ & $6.69 \mathrm{E}-32$ & $6.73 E-32$ & $6.75 \mathrm{E}-32$ \\
\hline $6.68 \mathrm{E}-33$ & $6.87 \mathrm{E}-32$ & $5.88 \mathrm{E}-32$ & $6.21 E-32$ & $6.70 \mathrm{E}-32$ & $6.75 E-32$ & $6.78 \mathrm{E}-32$ & $6.81 \mathrm{E}-32$ \\
\hline $6.65 \mathrm{E}-33$ & $6.93 \mathrm{E}-32$ & $5.93 E-32$ & $6.26 \mathrm{E}-32$ & $6.75 \mathrm{E}-32$ & $6.81 \mathrm{E}-32$ & $6.84 \mathrm{E}-32$ & $6.87 \mathrm{E}-32$ \\
\hline $6.62 \mathrm{E}-33$ & $6.99 \mathrm{E}-32$ & $5.98 \mathrm{E}-32$ & $6.31 E-32$ & $6.81 \mathrm{E}-32$ & $6.87 E-32$ & $6.90 \mathrm{E}-32$ & $6.93 \mathrm{E}-32$ \\
\hline $6.59 \mathrm{E}-33$ & $7.06 \mathrm{E}-32$ & $6.02 \mathrm{E}-32$ & $6.36 \mathrm{E}-32$ & $6.87 \mathrm{E}-32$ & $6.93 \mathrm{E}-32$ & $6.97 \mathrm{E}-32$ & $6.99 \mathrm{E}-32$ \\
\hline $6.56 \mathrm{E}-33$ & $7.12 \mathrm{E}-32$ & $6.07 \mathrm{E}-32$ & $6.42 E-32$ & $6.93 \mathrm{E}-32$ & $6.99 \mathrm{E}-32$ & $7.03 E-32$ & $7.06 \mathrm{E}-32$ \\
\hline $6.53 \mathrm{E}-33$ & $7.18 \mathrm{E}-32$ & $6.12 \mathrm{E}-32$ & $6.47 E-32$ & $6.99 \mathrm{E}-32$ & $7.05 \mathrm{E}-32$ & $7.09 \mathrm{E}-32$ & $7.12 \mathrm{E}-32$ \\
\hline $6.50 \mathrm{E}-33$ & $7.24 \mathrm{E}-32$ & $6.17 \mathrm{E}-32$ & $6.52 \mathrm{E}-32$ & $7.05 E-32$ & $7.11 \mathrm{E}-32$ & $7.15 \mathrm{E}-32$ & $7.18 \mathrm{E}-32$ \\
\hline $6.47 \mathrm{E}-33$ & 7. $31 \mathrm{E}-32$ & $6.22 \mathrm{E}-32$ & $6.58 \mathrm{E}-32$ & $7.12 \mathrm{E}-32$ & $7.17 \mathrm{E}-32$ & $7.21 \mathrm{E}-32$ & $7.24 \mathrm{E}-32$ \\
\hline $6.44 \mathrm{E}-33$ & $7.37 \mathrm{E}-32$ & $6.27 \mathrm{E}-32$ & $6.63 E-32$ & $7.18 \mathrm{E}-32$ & $7.23 E-32$ & $7.28 \mathrm{E}-32$ & $7.31 \mathrm{E}-32$ \\
\hline $.41 E-33$ & $7.44 \mathrm{E}-32$ & $6.32 \mathrm{E}-32$ & $6.69 E-32$ & $7.24 \mathrm{E}-32$ & $7.30 \mathrm{E}-32$ & $7.34 \mathrm{E}-32$ & $7.37 \mathrm{E}-32$ \\
\hline
\end{tabular}


RESRAD-OFFSITE, Version 2.5

$\mathrm{T}^{1 / 2}$ Limit $=180$ days

Title : RESRAD-OFFSITE External Gamma, Inhalation, and Soil Ingestion for Offsite Reside File : PBA-1_TC99-DOE-5-1.ROF

Summary of dose at graphical times, reptition 1 (continued)

Time

Years

9. $43 \mathrm{E}+01$

9. $48 \mathrm{E}+01$

9. $54 \mathrm{E}+01$

$9.59 \mathrm{E}+01$

9. $64 \mathrm{E}+01$

$9.69 \mathrm{E}+01$

$9.74 \mathrm{E}+01$

$9.79 \mathrm{E}+01$

$9.84 \mathrm{E}+01$

9. $90 \mathrm{E}+01$

$9.95 \mathrm{E}+01$

$1.00 \mathrm{E}+02$

$1.00 \mathrm{E}+02$

$1.01 \mathrm{E}+02$

$1.02 \mathrm{E}+02$

$1.02 \mathrm{E}+02$

$1.03 \mathrm{E}+02$

$1.03 \mathrm{E}+02$

$1.04 \mathrm{E}+02$

$1.04 \mathrm{E}+02$

$1.05 \mathrm{E}+02$

$1.05 \mathrm{E}+02$

$1.06 \mathrm{E}+02$

$1.06 \mathrm{E}+02$

$1.07 \mathrm{E}+02$

$1.07 \mathrm{E}+02$

$1.08 \mathrm{E}+02$

$1.08 \mathrm{E}+02$

$1.09 \mathrm{E}+02$

$1.09 \mathrm{E}+02$

1. $10 \mathrm{E}+02$

1. $10 \mathrm{E}+02$

$1.11 \mathrm{E}+02$

1. $11 \mathrm{E}+02$

$1.12 \mathrm{E}+02$

1. $12 \mathrm{E}+02$

1. $13 \mathrm{E}+02$

1. $13 \mathrm{E}+02$

1. $14 \mathrm{E}+02$

1. $14 \mathrm{E}+02$

$1.15 \mathrm{E}+02$

1. $15 \mathrm{E}+02$

$1.16 \mathrm{E}+02$

$1.16 \mathrm{E}+02$

$1.17 \mathrm{E}+02$

$1.17 \mathrm{E}+02$
Dose statistics at graphical times, mrem/yr

\begin{tabular}{|c|c|c|c|c|c|c|c|}
\hline $\mathrm{m}$ & um & Mean & ledian & & & & \\
\hline-33 & -32 & -32 & 32 & 32 & $7.36 \mathrm{E}-32$ & -32 & $4-32$ \\
\hline $35 E-33$ & $7.57 \mathrm{E}-32$ & $2 E-32$ & $0 E-32$ & $7 E-32$ & $3 E-32$ & -32 & $50 E-32$ \\
\hline $32 E-33$ & $.64 \mathrm{E}-32$ & $.48 \mathrm{E}-32$ & $5 E-32$ & $3 E-32$ & $7.49 \mathrm{E}-32$ & -32 & -32 \\
\hline-33 & -32 & $53 F-32$ & $1 F-32$ & -32 & 2 & 32 & $-32+x+2$ \\
\hline 33 & 32 & 32 & 32 & 32 & 32 & 32 & -32 \\
\hline 33 & & & & & & & -32 \\
\hline $21 \mathrm{E}-33$ & 32 & & & & & & -32 \\
\hline $18 \mathrm{E}-33$ & -32 & -32 & & 32 & 32 & -32 & -32 \\
\hline-33 & -32 & $9 E-32$ & & & $9 E-32$ & -32 & -32 \\
\hline 33 & 32 & $85 F-32$ & $6 E-32$ & & & 2 & -3 \\
\hline 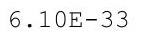 & 2 & 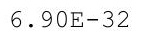 & 2 & $E-32$ & $8.03 E-32$ & 2 & 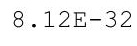 \\
\hline .33 & 32 & 32 & 32 & 2 & 2 & 32 & -32 \\
\hline $.05 E-33$ & $8.34 E-32$ & $.02 E-32$ & & & $8.17 \mathrm{E}-32$ & -32 & -32 \\
\hline $.02 E-33$ & $8.42 \mathrm{E}-32$ & $.07 E-32$ & $7.50 \mathrm{E}-32$ & -32 & -32 & -32 & -32 \\
\hline-33 & -32 & -32 & & & 32 & -32 & -32 \\
\hline P & $57 E-32$ & $9 E-32$ & & & & 2 & -32 \\
\hline s & 2 & 2 & & & & 2 & 32 \\
\hline 33 & 2 & 2 & 2 & & & 2 & 32 \\
\hline $88 F-3=$ & $80 E-32$ & $36 E-32$ & $2 E-32$ & $4 E-32$ & $1 E-32$ & -32 & -32 \\
\hline-33 & $87 E-32$ & $42 \mathrm{E}-32$ & $7.88 E-32$ & $1 E-32$ & $9 E-32$ & -32 & $79 E-32$ \\
\hline-33 & 32 & $E-32$ & & & & -32 & -32 \\
\hline & & & & & & 32 & -32 \\
\hline 20 20 & & & & & & 32 & 2 \\
\hline-33 & 2 & 2 & 2 & & 2 & 32 & -32 \\
\hline בנ- & 2 & 2 & 2 & 2 & 2 & 2 & -32 \\
\hline $5-33+2 \cdot 1$ & $36 E-32$ & $7.79 \mathrm{E}-32$ & $8 E-32$ & $7 E-32$ & $5=3$ & $E-32$ & $26 \mathrm{~F}-32 \mathrm{2}$ \\
\hline-33 & $44 F-32$ & $.85 E-32$ & & & & -32 & -32 \\
\hline & & & & & & & -32 \\
\hline & & & & & & & 32 \\
\hline $.60 E-33$ & & & & 32 & -32 & -32 & -32 \\
\hline 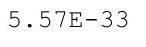 & $9.10 \mathrm{E}-32$ & $.11 E-32$ & $.63 E-32$ & $9.47 E-32$ & $56 E-32$ & -32 & $67 E-32$ \\
\hline 然 & 然 & $0 . \perp T D$ JZ & $8.70 E-32$ & $.55 E-32$ & & $\cdot 1+4-32$ & $76 E-32$ \\
\hline$F-3$ & 0055 & & & & & -32 & -32 \\
\hline & & & & & & & 32 \\
\hline-33 & & $8.38 E-32$ & & & & 32 & -31 \\
\hline & & & & & & & 31 \\
\hline . $402-30$ & $3.94 \mathrm{~L}-21$ & $.06 \mathrm{E}-30$ & -32 & 32 & $.01 E-31$ & 31 & -31 \\
\hline 年 & & $7.21 \mathrm{E}-29$ & & & & & $.03 E-3$ \\
\hline $38 F-33$ & 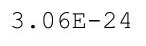 & (2) & 2 & 1 & 1 & 1 & 31 \\
\hline & & & & & & & 31 \\
\hline-33 & $.41 E-22$ & & & & & 31 & -31 \\
\hline$E-33$ & $3.42 \mathrm{E}-21$ & $1.72 \mathrm{E}-24$ & $45 E-32$ & $04 E-31$ & $5 E-31$ & $E-31$ & $E-31$ \\
\hline 3 & 0 & 3 & & & & & 31 \\
\hline & & & & 1 & $1.0 / \mathrm{E}-31$ & $08 E-31$ & 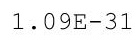 \\
\hline & & & & 1 & OL- 21 & & 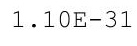 \\
\hline 3 & $E-18$ & $E-22$ & $E-32$ & $E-31$ & -31 & $E-31$ & -31 \\
\hline
\end{tabular}


RESRAD-OFFSITE, Version 2.5

$\mathrm{T}^{1 / 2}$ Limit $=180$ days

Title : RESRAD-OFFSITE External Gamma, Inhalation, and Soil Ingestion for Offsite Reside File : PBA-1_TC99-DOE-5-1.ROF

Summary of dose at graphical times, reptition 1 (continued)

Time

Years

$1.18 \mathrm{E}+02$

$1.18 \mathrm{E}+02$

$1.19 \mathrm{E}+02$

$1.19 \mathrm{E}+02$

$1.20 \mathrm{E}+02$

1. $20 \mathrm{E}+02$

1. $21 \mathrm{E}+02$

1. $22 \mathrm{E}+02$

1. $22 \mathrm{E}+02$

1. $23 \mathrm{E}+02$

1. $23 \mathrm{E}+02$

$1.24 \mathrm{E}+02$

$1.24 \mathrm{E}+02$

$1.25 \mathrm{E}+02$

$1.25 \mathrm{E}+02$

$1.26 \mathrm{E}+02$

1. $26 \mathrm{E}+02$

$1.27 \mathrm{E}+02$

$1.27 \mathrm{E}+02$

1. $28 \mathrm{E}+02$

$1.28 \mathrm{E}+02$

1. $29 \mathrm{E}+02$

$1.29 \mathrm{E}+02$

1. $30 \mathrm{E}+02$

1. $30 \mathrm{E}+02$

1. $31 \mathrm{E}+02$

1. $31 \mathrm{E}+02$

1. $32 \mathrm{E}+02$

1. $32 \mathrm{E}+02$

1. $33 \mathrm{E}+02$

1. $33 \mathrm{E}+02$

1. $34 \mathrm{E}+02$

1. $34 \mathrm{E}+02$

1. $35 \mathrm{E}+02$

1. $35 \mathrm{E}+02$

1. $36 \mathrm{E}+02$

1. $36 \mathrm{E}+02$

1. $37 \mathrm{E}+02$

1. $37 \mathrm{E}+02$

1. $38 \mathrm{E}+02$

1. $38 \mathrm{E}+02$

1. $39 \mathrm{E}+02$

1. $39 \mathrm{E}+02$

1. $40 \mathrm{E}+02$

1. $40 \mathrm{E}+02$

1. $41 \mathrm{E}+02$
Dose statistics at graphical times, mrem/yr

\begin{tabular}{|c|c|c|c|c|c|c|c|}
\hline $\mathrm{m}$ & גm & Mean & ledian & & & & \\
\hline-33 & 18 & -21 & -32 & 31 & -31 & -31 & -2 \\
\hline-33 & -17 & $E-21$ & 32 & 31 & 31 & -31 & -31 \\
\hline-33 & $.19 \mathrm{E}-17$ & $33 E-20$ & $.00 \mathrm{E}-31$ & $1.11 \mathrm{E}-31$ & $1.12 \mathrm{E}-31$ & -31 & -31 \\
\hline-33 & 16 & $77 \mathrm{~F}-20$ & $01 E-31$ & $.12 \mathrm{E}-31$ & -31 & 1 & $-31+x-1$ \\
\hline 33 & 6 & 9 & 31 & 31 & & 31 & -31 \\
\hline 33 & 16 & & & & & & -31 \\
\hline $.05 E-33$ & $.47 E-16$ & & & $1.15 \mathrm{E}-31$ & & & $E-31$ \\
\hline-33 & 15 & -18 & & 31 & 31 & -31 & -31 \\
\hline$E-33$ & -15 & $5 E-18$ & 31 & 31 & 31 & -31 & -31 \\
\hline 33 & 15 & 18 & 1 & 1 & \pm & 1 & 31 \\
\hline $5 E-33$ & 15 & -18 & $E-31$ & - & 1 & 1 & $31-1 \cdot r \cdot 1$ \\
\hline-33 & $50 F-14$ & -17 & 31 & 1 & 1 & -31 & -31 \\
\hline $.91 \mathrm{E}-33$ & $2.35 E-14$ & $1.84 \mathrm{E}-17$ & & 1.2 & 1 & & -31 \\
\hline $.89 E-33$ & $.59 \mathrm{E}-14$ & $.92 \mathrm{E}-17$ & $1.10 \mathrm{E}-31$ & $1.22 \mathrm{E}-31$ & & $E-31$ & $E-31$ \\
\hline-33 & -14 & $4 \mathrm{E}-17$ & & 1 & & -31 & -31 \\
\hline 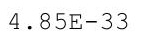 & 14 & $89 E-17$ & & & & 31 & 31 \\
\hline $3 E-33$ & & & & 1 & \pm & & 31 \\
\hline 3 & 3 & 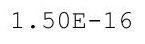 & 1 & 1 & 1 & 1 & 31 \\
\hline $35-33+25$ & $.18 \mathrm{E}-13$ & $4 E-16$ & $E-31$ & $27 \mathrm{~F}-$ & $29 E-31$ & $30 E-31$ & -31 \\
\hline $.76 E-33$ & $.97 E-13$ & $.02 E-16$ & $.15 \mathrm{E}-31$ & $1.28 \mathrm{E}-$ & $1.30 \mathrm{E}-31$ & $E-31$ & $3 E-31$ \\
\hline-33 & 13 & $4.19 \mathrm{E}-16$ & & & & -31 & -29 \\
\hline$-33 \cdot \operatorname{ra}-x$ & & & & & & 31 & -27 \\
\hline ( & is & $75 \mathrm{E}$ & & & & 31 & -2 \\
\hline+ & 3 & 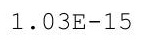 & 1 & 1 & $\perp$ & 31 & -24 \\
\hline 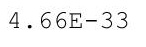 & 12 & 5 & 1 & 1 & 1 & -31 & -23 \\
\hline $5-3$ & $.43 E-12$ & 1. $77 \mathrm{E}-15$ & $1.21 E-31$ & $1.35 \mathrm{E}-$ & $1.37 \mathrm{E}-$ & $8 E-31$ & $E-22$ \\
\hline $15-33$ & $80 F-12$ & $229 F-15$ & $22 E-31$ & & & -31 & $E-21$ \\
\hline & & & & & & & 20 \\
\hline & & & & & & & \\
\hline 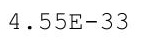 & & 5 & 31 & 1.74 & 1.12 & -31 & -19 \\
\hline eda & $4.05 \mathrm{E}-12$ & $.78 E-15$ & $.27 E-31$ & $1.41 \mathrm{E}-31$ & & $45 E-31$ & -18 \\
\hline 年 & $4.87 \mathrm{E}-12$ & $7.14 \mathrm{E}-15$ & $1.28 \mathrm{E}-31$ & 50 & & $1.46 \mathrm{E}-31$ & $85 E-18$ \\
\hline ? & & $.76 \mathrm{E}-15$ & & & & -31 & $E-17$ \\
\hline & & & & & & & \\
\hline$=3$ & & $1.29 \mathrm{E}-14$ & & & & $.51 E-31$ & \\
\hline & & & & & & -31 & \\
\hline $.41 E-33$ & $1 \cdot 18 \mathrm{E}-11$ & $.86 E-14$ & -31 & 1.75 & +5 & -31 & -16 \\
\hline & & $2.22 \mathrm{E}-14$ & & & & & • \\
\hline 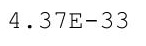 & I & 4 & & 1 & & 1 & 15 \\
\hline & & & & & & 1 & \\
\hline $3 F-33$ & & & & & & -31 & -15 \\
\hline$E-33$ & $2.67 \mathrm{E}-11$ & $4.26 \mathrm{E}-14$ & $1.39 E-31$ & $1.56 \mathrm{E}-31$ & $1.58 \mathrm{E}-31$ & 31 & $3 E-15$ \\
\hline & & & & & & & 1. $05 \mathrm{E}-14$ \\
\hline & & & & & $\perp \cdot 0 \perp \mathrm{L}$ & $1.69 \mathrm{E}-28$ & $03-14$ \\
\hline & & & & +.0 & & $E-27$ & $\cdot 4 / 2-14$ \\
\hline 3 & $E-11$ & $E-14$ & $E-31$ & -31 & -31 & $E-25$ & $E-14$ \\
\hline
\end{tabular}


RESRAD-OFFSITE, Version 2.5

$\mathrm{T}^{1 / 2}$ Limit $=180$ days

Title : RESRAD-OFFSITE External Gamma, Inhalation, and Soil Ingestion for Offsite Reside

File : PBA-1_TC99-DOE-5-1.ROF

Summary of dose at graphical times, reptition 1 (continued)

Time

Years

$1.42 \mathrm{E}+02$

$1.42 \mathrm{E}+02$

$1.43 \mathrm{E}+02$

$1.43 \mathrm{E}+02$

$1.44 \mathrm{E}+02$

1. $44 \mathrm{E}+02$

1. $45 \mathrm{E}+02$

$1.45 \mathrm{E}+02$

$1.46 \mathrm{E}+02$

$1.46 \mathrm{E}+02$

$1.47 \mathrm{E}+02$

$1.47 \mathrm{E}+02$

1. $48 \mathrm{E}+02$

$1.48 \mathrm{E}+02$

$1.49 \mathrm{E}+02$

$1.49 \mathrm{E}+02$

$1.50 \mathrm{E}+02$

$1.50 \mathrm{E}+02$

$1.51 \mathrm{E}+02$

$1.51 \mathrm{E}+02$

$1.52 \mathrm{E}+02$

$1.52 \mathrm{E}+02$

$1.53 \mathrm{E}+02$

1. $53 \mathrm{E}+02$

$1.54 \mathrm{E}+02$

$1.54 \mathrm{E}+02$

$1.55 \mathrm{E}+02$

$1.55 \mathrm{E}+02$

$1.56 \mathrm{E}+02$

$1.56 \mathrm{E}+02$

$1.57 \mathrm{E}+02$

$1.57 \mathrm{E}+02$

$1.58 \mathrm{E}+02$

$1.58 \mathrm{E}+02$

$1.59 \mathrm{E}+02$

$1.59 \mathrm{E}+02$

1. $60 \mathrm{E}+02$

$1.60 \mathrm{E}+02$

1. $61 \mathrm{E}+02$

1. $61 \mathrm{E}+02$

$1.62 \mathrm{E}+02$

$1.63 \mathrm{E}+02$

$1.63 \mathrm{E}+02$

1. $64 \mathrm{E}+02$

1. $64 \mathrm{E}+02$

$1.65 \mathrm{E}+02$
Dose statistics at graphical times, mrem/yr

\begin{tabular}{|c|c|c|c|c|c|c|c|}
\hline inimum & aximum & Mean & ledian & $0 \%$ & $5 \%$ & $97.5 \%$ & $3 \%$ \\
\hline 3 & -11 & $E-14$ & $E-31$ & 31 & 31 & 24 & $5.41 \mathrm{E}-14$ \\
\hline-33 & $2 E-11$ & $E-13$ & $5 E-31$ & 1 & 1 & -23 & -14 \\
\hline$E-33$ & $6.80 \mathrm{E}-11$ & $E-13$ & $E-31$ & $6 E-31$ & $9 E-31$ & -22 & -13 \\
\hline$E-33$ & $5 E-11$ & $E-13$ & -31 & 31 & 31 & -21 & 13 \\
\hline 33 & 11 & & & 31 & & -20 & -13 \\
\hline 33 & 11 & 13 & 31 & 31 & 1 & -19 & 13 \\
\hline . & 10 & 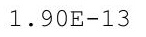 & -31 & 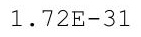 & 31 & -19 & -13 \\
\hline $.08 E-33$ & 1.19E-10 & 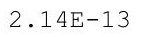 & & $1.73 E-31$ & $1.77 \mathrm{E}-31$ & -18 & $84 E-13$ \\
\hline 33 & 10 & 13 & 31 & 31 & 31 & -18 & -13 \\
\hline $05 E-33$ & $6 \mathrm{E}-10$ & $E-13$ & 1 & 31 & -31 & -17 & $36 E-13$ \\
\hline-33 & -10 & 13 & & 1 & 1 & -17 & $10 \mathrm{E}-12$ \\
\hline & & & & & & & 12 \\
\hline $.99 E-33$ & $1.94 \mathrm{E}-10$ & $5 E-13$ & $E-31$ & & . & -16 & -12 \\
\hline $.98 E-33$ & -10 & +4 & -31 & $1.00+\frac{1}{4}$ & & -16 & -12 \\
\hline 33 & 10 & 13 & 31 & 1.00 & 31 & -15 & -12 \\
\hline-33 & -10 & 10 & -31 & 31 & 31 & -15 & -12 \\
\hline $.92 E-33$ & $E-10$ & $E-13$ & $6 E-31$ & 31 & -31 & -15 & $59 E-12$ \\
\hline 33 & $9 E-10$ & -13 & 1 & & 31 & -15 & $E-12$ \\
\hline $9 E-33$ & $4 \mathrm{E}-10$ & $2 E-13$ & $9 E-31$ & 1 & & -14 & 12 \\
\hline $7 E-33$ & $1 \mathrm{E}-10$ & -13 & $0 E-31$ & & -31 & -14 & -12 \\
\hline $5 E-33$ & -10 & 13 & -31 & 31 & 31 & 14 & -12 \\
\hline 33 & 10 & 13 & 1 & 1 & & 4 & 11 \\
\hline $825-33$ & $4.41 \mathrm{E}-10$ & $1.01 \mathrm{E}-12$ & $1.75 E-31$ & $1.99 \mathrm{E}-31$ & $64 E-31$ & $30 E-14$ & $40 E-11$ \\
\hline $.80 \mathrm{E}-33$ & $4.74 \mathrm{E}-10$ & $10 \mathrm{E}-12$ & $5 E-31$ & 1 & $62 \mathrm{E}-29$ & $47 E-14$ & -11 \\
\hline 33 & $E-10$ & 12 & & & & -13 & -11 \\
\hline$E-33$ & 10 & $E-12$ & -31 & 1 & 5 & -13 & $E-11$ \\
\hline $5 E-33$ & $6 E-10$ & $3 E-12$ & -31 & 1 & $8 E-24$ & -13 & $61 \mathrm{E}-11$ \\
\hline $.73 E-33$ & $6.27 \mathrm{E}-10$ & $1.56 \mathrm{E}-12$ & $1.82 \mathrm{E}-31$ & $2.08 E-31$ & $.24 E-23$ & $.54 \mathrm{E}-13$ & $02 E-11$ \\
\hline 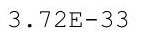 & . & $1.70 \mathrm{E}-12$ & $1.84 \mathrm{E}-31$ & 31 & $2 z$ & $0 E-13$ & $46 E-11$ \\
\hline $.70 \mathrm{E}-33$ & $7.16 \mathrm{E}-10$ & $E-12$ & $5 E-31$ & 1 & $2 \perp$ & -13 & $6 E-11$ \\
\hline 33 & $E-10$ & $E-12$ & 1 & 1 & 0 & -13 & $E-11$ \\
\hline$E-33$ & $E-10$ & $E-12$ & $3 E-31$ & 1 & 9 & -13 & $2 E-11$ \\
\hline $.65 E-33$ & $8.66 \mathrm{E}-10$ & $2.35 E-12$ & $0 E-31$ & 2 . & -19 & -13 & $45 E-11$ \\
\hline $.63 E-33$ & $9.20 \mathrm{E}-10$ & $2.54 \mathrm{E}-12$ & $1.92 \mathrm{E}-31$ & $2.20 \mathrm{E}-31$ & $1.60 \mathrm{E}-18$ & $26 E-12$ & $02 \mathrm{E}-11$ \\
\hline . $02 \mathrm{E}-\mathrm{S}$ & $9.10 \mathrm{E}-10$ & & & & & $8 E-12$ & $61 \mathrm{E}-11$ \\
\hline 要 & & & & & & & -11 \\
\hline 83 & 09 & 12 & 1 & 1 & 7 & 2 & 11 \\
\hline-33 & $E-09$ & $E-12$ & $E-31$ & 31 & 7 & 2 & -11 \\
\hline$E-33$ & 1.23E-09 & $E-12$ & -31 & 2 . & 6 & $E-12$ & $E-11$ \\
\hline 33 & $1.30 E-09$ & $E-12$ & & 31 & & & $E-11$ \\
\hline 3 & & & & 1 & & & \\
\hline & & & & $2.37 E-31$ & & & $.15 \mathrm{E}-10$ \\
\hline & & & & 1 & & & \\
\hline כ & (2) & 12 & 31 & 1 & 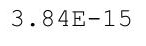 & 2 & 10 \\
\hline 33 & 1 . & 12 & 2 & 31 & 5 & 12 & $52 \mathrm{E}-10$ \\
\hline$E-$ & $.80 E-09$ & $05 E-12$ & $.12 E-31$ & $.46 E-31$ & $9.95 \mathrm{E}-15$ & $.03 E-11$ & 1. $68 \mathrm{E}-10$ \\
\hline
\end{tabular}


RESRAD-OFFSITE, Version 2.5

$\mathrm{T}^{1 / 2}$ Limit $=180$ days

Title : RESRAD-OFFSITE External Gamma, Inhalation, and Soil Ingestion for offsite Reside File : PBA-1_TC99-DOE-5-1.ROF

Summary of dose at graphical times, reptition 1 (continued)

Time

Years

$1.65 \mathrm{E}+02$

1. $66 \mathrm{E}+02$

1. $66 \mathrm{E}+02$

$1.67 \mathrm{E}+02$

$1.67 \mathrm{E}+02$

1. $68 \mathrm{E}+02$

1. $68 \mathrm{E}+02$

1. $69 \mathrm{E}+02$

$1.69 \mathrm{E}+02$

1. $70 \mathrm{E}+02$

1. $70 \mathrm{E}+02$

1. $71 \mathrm{E}+02$

$1.71 \mathrm{E}+02$

1. $72 \mathrm{E}+02$

$1.72 \mathrm{E}+02$

1. $73 \mathrm{E}+02$

1. $73 \mathrm{E}+02$

$1.74 \mathrm{E}+02$

$1.74 \mathrm{E}+02$

$1.75 \mathrm{E}+02$

$1.75 \mathrm{E}+02$

1. $76 \mathrm{E}+02$

$1.76 \mathrm{E}+02$

$1.77 \mathrm{E}+02$

$1.77 \mathrm{E}+02$

$1.78 \mathrm{E}+02$

$1.78 \mathrm{E}+02$

$1.79 \mathrm{E}+02$

$1.79 \mathrm{E}+02$

$1.80 \mathrm{E}+02$

1. $80 \mathrm{E}+02$

1. $81 \mathrm{E}+02$

1. $81 \mathrm{E}+02$

1. $82 \mathrm{E}+02$

1. $83 \mathrm{E}+02$

1. $83 \mathrm{E}+02$

$1.84 \mathrm{E}+02$

$1.84 \mathrm{E}+02$

$1.85 \mathrm{E}+02$

$1.85 \mathrm{E}+02$

$1.86 \mathrm{E}+02$

1. $86 \mathrm{E}+02$

$1.87 \mathrm{E}+02$

$1.87 \mathrm{E}+02$

1. $88 \mathrm{E}+02$

$1.88 \mathrm{E}+02$
Dose statistics at graphical times, mrem/yr

\begin{tabular}{|c|c|c|c|c|c|c|c|}
\hline Inimum & laximum & Mean & Median & $90 \%$ & $95 \%$ & $97.5 \%$ & $\%$ \\
\hline 3 & 09 & 2 & 2 . & 31 & 14 & 1 & 10 \\
\hline $1 E-33$ & $39 E-09$ & 12 & $2.16 \mathrm{E}-31$ & $2.50 \mathrm{E}-31$ & 14 & 11 & -10 \\
\hline-33 & -09 & $7 \mathrm{E}-$ & 1 & 31 & 14 & 11 & -10 \\
\hline-33 & $E-09$ & $7 E-12$ & $E-31$ & 31 & $9 \mathrm{E}-14$ & 11 & $E-10$ \\
\hline $37 E-33$ & -09 & $E-12$ & -31 & -31 & -14 & -11 & $9 E-10$ \\
\hline$E-33$ & $2 E-09$ & $E-12$ & -31 & 31 & -14 & -11 & $E-10$ \\
\hline $.33 E-33$ & $2.54 \mathrm{E}-09$ & $1 E-12$ & $6 E-31$ & & -13 & -11 & $E-10$ \\
\hline 年 & $6 E-09$ & $1 \mathrm{E}-11$ & 2. $28 E-31$ & & -13 & -11 & -10 \\
\hline $.30 E-33$ & $2.78 E-09$ & $1.07 \mathrm{E}-11$ & $2.30 \mathrm{E}-31$ & 2.004 & -13 & -11 & $58 E-10$ \\
\hline$E-33$ & -09 & $E-11$ & 31 & 31 & 13 & -11 & $79 \mathrm{E}-10$ \\
\hline $28 E-33$ & $3.05 E-09$ & $1.21 \mathrm{E}-11$ & $2.34 \mathrm{E}-31$ & & $1 E-13$ & $61 E-11$ & $01 \mathrm{E}-10$ \\
\hline & 09 & $E-11$ & 1 & 1 & -13 & 1 & -10 \\
\hline . & $E-09$ & $6 \mathrm{E}-11$ & $3 E-31$ & & $4-13$ & -11 & -10 \\
\hline • & $3.48 E-09$ & 1. $45 \mathrm{E}-11$ & $2.40 E-31$ & . & $.0 J 5-12$ & $E-11$ & $74 E-10$ \\
\hline كנ-5 & -09 & $3 E-11$ & $2 E-31$ & (- & $0 E-12$ & -11 & $13 E-10$ \\
\hline$E-33$ & -09 & 11 & 31 & (1) & 12 & $\perp \perp$ & -10 \\
\hline $.19 \mathrm{E}-33$ & $3.96 \mathrm{E}-09$ & 1. $71 \mathrm{E}-11$ & $2.46 \mathrm{E}-31$ & $1.08 E-25$ & 1. $92 \mathrm{E}-12$ & $4 \mathrm{E}-11$ & $88 E-10$ \\
\hline$E-33$ & $E-09$ & $1 E-11$ & $3 E-31$ & 4 & $9 E-12$ & -11 & $E-10$ \\
\hline $.16 \mathrm{E}-33$ & $4.31 E-09$ & $.91 \mathrm{E}-11$ & $1 E-31$ & $3.55 \mathrm{E}-23$ & $2 E-12$ & -11 & $E-10$ \\
\hline $.5 E-33$ & $4.49 \mathrm{E}-09$ & $2.02 \mathrm{E}-11$ & -31 & 22 & -12 & 11 & -10 \\
\hline ك & $4.68 E-09$ & $3 E-11$ & $5 E-31$ & $00 \mathrm{D}-2 \perp$ & $6 E-12$ & $3 E-11$ & $23 E-10$ \\
\hline • & $4.87 \mathrm{E}-09$ & 2. $25 \mathrm{E}-11$ & $2.57 E-31$ & $1.65 \mathrm{E}-20$ & -12 & 10 & -10 \\
\hline 20 20 & $.07 E-09$ & $7 E-11$ & $9 E-31$ & (18 & $8 E-12$ & & $8 E-10$ \\
\hline $.09 E-33$ & $5.28 E-09$ & $0 E-11$ & -31 & 9 & 12 & -10 & -10 \\
\hline 33 & -09 & $3 E-11$ & 31 & & 12 & 0 & -10 \\
\hline 33 & 09 & 11 & -31 & 18 & -12 & 0 & -10 \\
\hline $8 \pm-33$ & $3 E-09$ & $E-11$ & -31 & -1 & 12 & & $E-10$ \\
\hline $.03 E-33$ & $6.16 \mathrm{E}-09$ & $3.06 \mathrm{E}-11$ & $2.71 \mathrm{E}-31$ & $3.08 \mathrm{E}-17$ & $1.07 \mathrm{E}-11$ & $.73 E-10$ & $.01 E-09$ \\
\hline 33 & $6.40 \mathrm{E}-09$ & $3.22 \mathrm{E}-11$ & $2.73 E-31$ & $7.55 \mathrm{E}-17$ & $1.22 \mathrm{E}-11$ & $.87 E-10$ & $.06 \mathrm{E}-09$ \\
\hline 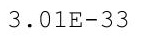 & $6.64 \mathrm{E}-09$ & $3.38 \mathrm{E}-11$ & $2.76 E-31$ & $\pm \cdot 12+10$ & 等 $\perp \perp$ & -10 & 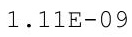 \\
\hline $95-33$ & 09 & $E-11$ & 31 & 6 & 1 & 0 & 09 \\
\hline $5-33 x-2 x$ & $E-09$ & $E-11$ & $E-31$ & $E-16$ & -11 & 0 & 09 \\
\hline $7 E-33$ & $7.42 \mathrm{E}-09$ & $3.91 \mathrm{E}-11$ & $2.84 \mathrm{E}-31$ & $3 E-15$ & $1.98 \mathrm{E}-11$ & $0 E-10$ & -09 \\
\hline $.95 E-33$ & $7.70 \mathrm{E}-09$ & $4.10 \mathrm{E}-11$ & $2.86 \mathrm{E}-31$ & $2.15 \mathrm{E}-15$ & $2.23 \mathrm{E}-11$ & $.70 E-10$ & $.32 E-09$ \\
\hline ك ע & $1.90 \mathrm{E}-09$ & 4. 30E-11 & & & & & $.30 \mathrm{E}-09$ \\
\hline & & & & & & & $44 \mathrm{E}-09$ \\
\hline & & & & & & & \\
\hline $90 F-33$ & $\varepsilon$ & 1 & 1 & 4 & 1 & 10 & -09 \\
\hline$E-33$ & $E-09$ & $E-11$ & $E-31$ & $5 E-14$ & 1 & 10 & -09 \\
\hline $7 E-33$ & $9.51 \mathrm{E}-09$ & $41 E-11$ & & 4 & & & $1.70 \mathrm{E}-09$ \\
\hline 泟 & $84 \mathrm{E}-09$ & 1 & & & & & $1 / 1-09$ \\
\hline $85 E-33$ & $.02 E-08$ & $.91 E-11$ & $.07 E-31$ & 4 & 1 & & -09 \\
\hline & 1 & $\perp$ & & & & & \\
\hline $2.82 E-33$ & & & & 3 & $\perp$ & 0 & 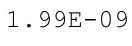 \\
\hline 3 & 1.1 & $E-11$ & 3. & 13 & 1 & 10 & -09 \\
\hline $.80 E-33$ & $1.16 \mathrm{E}-08$ & $7.02 \mathrm{E}-11$ & $3.19 E-31$ & $2.33 E-13$ & $6.95 E-11$ & $5.58 \mathrm{E}-10$ & $2.17 \mathrm{E}-09$ \\
\hline
\end{tabular}


RESRAD-OFFSITE, Version 2.5

$\mathrm{T}^{1 / 2}$ Limit $=180$ days

Title : RESRAD-OFFSITE External Gamma, Inhalation, and Soil Ingestion for offsite Reside File : PBA-1_TC99-DOE-5-1.ROF

Summary of dose at graphical times, reptition 1 (continued)

Time

Years

1. $89 \mathrm{E}+02$

1. $89 \mathrm{E}+02$

1. $90 \mathrm{E}+02$

1. $90 \mathrm{E}+02$

1. $91 \mathrm{E}+02$

$.91 E+02$

1. $92 \mathrm{E}+02$

$.92 \mathrm{E}+02$

1. $93 \mathrm{E}+02$

1. $93 \mathrm{E}+02$

. $94 \mathrm{E}+02$

1. $94 \mathrm{E}+02$

1. $95 \mathrm{E}+02$

1. $95 \mathrm{E}+02$

1. $96 \mathrm{E}+02$

1. $96 \mathrm{E}+02$

$1.97 \mathrm{E}+02$

$1.97 \mathrm{E}+02$

1. $98 \mathrm{E}+02$

1. $98 \mathrm{E}+02$

$1.99 \mathrm{E}+02$

1. $99 \mathrm{E}+02$

$2.00 \mathrm{E}+02$

$2.00 \mathrm{E}+02$

$2.01 \mathrm{E}+02$

$2.01 \mathrm{E}+02$

$2.02 E+02$

$2.03 E+02$

$2.03 E+02$

$2.04 \mathrm{E}+02$

$2.04 \mathrm{E}+02$

$2.05 \mathrm{E}+02$

$2.05 \mathrm{E}+02$

$2.06 \mathrm{E}+02$

$2.06 \mathrm{E}+02$

$2.07 \mathrm{E}+02$

$2.07 \mathrm{E}+02$

$2.08 \mathrm{E}+02$

$2.08 \mathrm{E}+02$

$2.09 \mathrm{E}+02$

2. $09 \mathrm{E}+02$

$2.10 \mathrm{E}+02$

$2.10 \mathrm{E}+02$

$2.11 E+02$

$2.11 \mathrm{E}+02$

$2.12 \mathrm{E}+02$
Dose statistics at graphical times, mrem/yr

\begin{tabular}{|c|c|c|c|c|c|c|c|}
\hline inimum & aximum & Mean & ledian & $90 \%$ & $5 \%$ & $97.5 \%$ & $\%$ \\
\hline 3 & -08 & 1 & 31 & 13 & 1 & 0 & nge \\
\hline$E-33$ & -08 & 1 & 1 & 3 & 1 & 10 & -09 \\
\hline$E-33$ & $E-08$ & $E-11$ & $E-31$ & $5 E-13$ & 11 & 10 & $8 E-09$ \\
\hline$E-33$ & $2 E-08$ & 11 & $E-31$ & & & & -09 \\
\hline $.73 E-33$ & -08 & & & 13 & & -10 & $71 E-09$ \\
\hline $.72 E-33$ & -08 & -11 & -31 & -12 & 10 & -10 & -09 \\
\hline 7 & 8 & $9.38 E-11$ & 1 & 2 & 0 & 0 & 09 \\
\hline $.70 E-33$ & $1.50 E-08$ & • $10 \pm 1$ & & $1.55 \mathrm{E}-12$ & $\perp \cdot 20+10$ & -10 & $08 \mathrm{E}-0$ \\
\hline 33 & 08 & 0 & 1 & $38 E-12$ & 10 & 10 & 09 \\
\hline $.67 E-33$ & -08 & $6 \mathrm{E}-10$ & 31 & $E-12$ & $46 \mathrm{E}-10$ & -10 & -09 \\
\hline-33 & -08 & 0 & & 12 & 10 & & $E-09$ \\
\hline-33 & & & & & & & $6 \mathrm{E}-09$ \\
\hline $.04 \mathrm{E}-33$ & $1.74 \mathrm{E}-08$ & • & $9 E-31$ & $3.77 \mathrm{E}-12$ & $1.15 \mathrm{E}-10$ & -09 & $E-09$ \\
\hline-33 & -08 & 地 & -31 & $4.50 \mathrm{E}-12$ & 10 & 09 & -09 \\
\hline 33 & 08 & 10 & -31 & $5.35 E-12$ & 10 & 09 & -09 \\
\hline $.60 \mathrm{E}-33$ & -08 & -10 & -31 & -12 & -10 & -09 & -09 \\
\hline $.59 \mathrm{E}-33$ & $1.96 \mathrm{E}-08$ & $8 E-10$ & $3 E-31$ & 7. $63 \mathrm{E}-12$ & $21 \mathrm{E}-10$ & $E-09$ & $43 E-09$ \\
\hline-33 & $2.02 E-08$ & $3 E-10$ & $E-31$ & $7 E-12$ & $34 E-10$ & $E-09$ & $60 \mathrm{E}-09$ \\
\hline-33 & -08 & 10 & -31 & $E-11$ & 10 & 9 & -09 \\
\hline 33 & -08 & -10 & 31 & -11 & -10 & & -09 \\
\hline $.54 \mathrm{E}-33$ & 2.20 & & & & & & -09 \\
\hline $.53 E-33$ & $2.26 \mathrm{E}-08$ & $1.66 \mathrm{E}-10$ & -31 & 50 & 10 & -09 & -09 \\
\hline $525-33$ & $2.32 E-08$ & 1. $72 \mathrm{E}-10$ & $3.94 E-31$ & $1.69 \mathrm{E}-11$ & $09 \mathrm{E}-10$ & $6 E-09$ & $50 E-09$ \\
\hline $.51 E-33$ & $2.39 E-08$ & 1. $78 \mathrm{E}-10$ & $97 E-31$ & $1.89 \mathrm{E}-11$ & $25 E-10$ & $1 E-09$ & $69 E-09$ \\
\hline$E-33$ & $2.46 \mathrm{E}-08$ & $1.84 \mathrm{E}-10$ & $E-31$ & $2 E-11$ & $E-10$ & $E-09$ & $E-09$ \\
\hline 33 & -08 & 10 & & -11 & & & 09 \\
\hline $48 E-33$ & $2.59 E-08$ & 1. $98 \mathrm{E}-10$ & $8 E-31$ & 2.020 & & 9 & 09 \\
\hline$\cdot 4 / 2-35$ & $2.66 \mathrm{E}-08$ & $2.05 E-10$ & $4.12 E-31$ & $2.90 \mathrm{E}-11$ & $3.945-10$ & $.86 E-09$ & $.53 E-09$ \\
\hline 3 & 8 & test & $15 E-31$ & 1 & • & $.93 E-09$ & $73 E-09$ \\
\hline 20 & $81 E-08$ & - & $19 E-31$ & - & 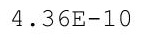 & - & 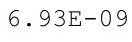 \\
\hline 3 & $2.88 E-08$ & $7 E-10$ & & & $60 E-10$ & $E-09$ & $E-09$ \\
\hline-33 & $2.96 \mathrm{E}-08$ & $.34 \mathrm{E}-10$ & $7 E-31$ & $7 E-11$ & $36 E-10$ & 9 & $E-09$ \\
\hline 33 & & & & & & -09 & -09 \\
\hline $.40 E-33$ & $3.12 \mathrm{E}-08$ & $2.50 \mathrm{E}-10$ & $4.35 E-31$ & $5.29 \mathrm{E}-11$ & $33 E-10$ & $32 E-09$ & $.78 E-09$ \\
\hline . $2 x^{2}-22$ & $3.20 E-08$ & $2.59 E-10$ & $39 E-31$ & $5.84 E-11$ & & & $.00 E-09$ \\
\hline 政 & & & & & & & \\
\hline $.37 E-33$ & 8 & 0 & & & & & 09 \\
\hline 3 & & & & & & & 09 \\
\hline 3 & & & 31 & & & 09 & \\
\hline $.34 \mathrm{E}-33$ & $3.63 E-08$ & $3.04 \mathrm{E}-10$ & $9 E-31$ & $6 E-11$ & 0 & & $9 E-09$ \\
\hline 3 & $3.72 \mathrm{E}-08$ & $E-10$ & 31 & 10 & & & -09 \\
\hline 3 & 08 & $24 \mathrm{E}-10$ & $4.68 E-31$ & 10 & & & $105-09$ \\
\hline 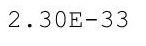 & 3 & 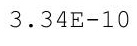 & 1 & 0 & -0 & & 0 \\
\hline $2395-33$ & & 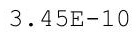 & & 0 & 0 & 9 & 08 \\
\hline $3 E-33$ & $E-08$ & $3.56 \mathrm{E}-10$ & $4.81 E-31$ & 1.3 & 8.5 & -09 & $.05 E-08$ \\
\hline $.27 E-33$ & $4.20 E-08$ & $3.67 \mathrm{E}-10$ & 1. $86 E-31$ & 1. $38 \mathrm{E}-10$ & $8.88 \mathrm{E}-10$ & $3.47 \mathrm{E}-09$ & $1.08 \mathrm{E}-08$ \\
\hline
\end{tabular}


RESRAD-OFFSITE, Version 2.5

$\mathrm{T}^{1 / 2}$ Limit $=180$ days

Title : RESRAD-OFFSITE External Gamma, Inhalation, and Soil Ingestion for Offsite Reside File : PBA-1_TC99-DOE-5-1.ROF

Summary of dose at graphical times, reptition 1 (continued)

Time

Years

$2.12 \mathrm{E}+02$

$2.13 \mathrm{E}+02$

$2.13 \mathrm{E}+02$

$2.14 \mathrm{E}+02$

$2.14 \mathrm{E}+02$

$2.15 \mathrm{E}+02$

$2.15 \mathrm{E}+02$

$2.16 \mathrm{E}+02$

$2.16 \mathrm{E}+02$

$2.17 \mathrm{E}+02$

$2.17 \mathrm{E}+02$

$2.18 \mathrm{E}+02$

$2.18 \mathrm{E}+02$

$2.19 \mathrm{E}+02$

$2.19 \mathrm{E}+02$

$2.20 \mathrm{E}+02$

$2.20 \mathrm{E}+02$

$2.21 \mathrm{E}+02$

$2.21 \mathrm{E}+02$

$2.22 \mathrm{E}+02$

$2.23 \mathrm{E}+02$

$2.23 \mathrm{E}+02$

$2.24 \mathrm{E}+02$

$2.24 \mathrm{E}+02$

$2.25 \mathrm{E}+02$

$2.25 \mathrm{E}+02$

$2.26 \mathrm{E}+02$

$2.26 \mathrm{E}+02$

$2.27 \mathrm{E}+02$

$2.27 \mathrm{E}+02$

$2.28 \mathrm{E}+02$

$2.28 \mathrm{E}+02$

$2.29 \mathrm{E}+02$

$2.29 \mathrm{E}+02$

$2.30 \mathrm{E}+02$

2. $30 \mathrm{E}+02$

$2.31 E+02$

$2.31 \mathrm{E}+02$

2. $32 \mathrm{E}+02$

2. $32 \mathrm{E}+02$

2. $33 \mathrm{E}+02$

2. $33 \mathrm{E}+02$

$2.34 \mathrm{E}+02$

2. $34 \mathrm{E}+02$

$2.35 \mathrm{E}+02$

$2.35 \mathrm{E}+02$
Dose statistics at graphical times, mrem/yr

\begin{tabular}{|c|c|c|c|c|c|c|c|}
\hline m & um & ea & ledian & & & & \\
\hline 33 & 08 & 10 & 31 & 10 & 10 & 09 & - \\
\hline $25 E-33$ & $10 E-08$ & $90 E-10$ & 31 & $1.56 \mathrm{E}-10$ & $4 E-10$ & -09 & $14 E-08$ \\
\hline-33 & $50 \mathrm{E}-08$ & $02 E-10$ & $5.01 \mathrm{E}-31$ & $1.65 \mathrm{E}-10$ & $9.88 \mathrm{E}-10$ & -09 & -08 \\
\hline $3 F-33$ & -08 & $14 \mathrm{~F}-10$ & $06 E-31$ & $76 \mathrm{~F}-10$ & -09 & 09 & $-08+5-3 x$ \\
\hline-33 & 08 & 10 & 31 & 10 & & 09 & -08 \\
\hline 33 & 08 & 0 & & & & & -08 \\
\hline $20 E-33$ & -08 & 10 & & 10 & & & -08 \\
\hline-33 & -08 & -10 & & -10 & 9 & -09 & -08 \\
\hline $.18 \mathrm{E}-33$ & -08 & $0 \mathrm{E}-10$ & -31 & $43 E-10$ & $25 E-09$ & -09 & -08 \\
\hline$E-33$ & -08 & $04=-10$ & 1 & -10 & 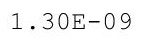 & 9 & 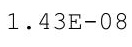 \\
\hline 33 & 8 & 0 & 1 & 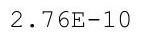 & $1.37 \mathrm{E}-$ & 9 & $E-08$ \\
\hline$E-33$ & $2 E-08$ & $E-10$ & 1 & -10 & 9 & 99 & -08 \\
\hline $.14 \mathrm{E}-33$ & $5.65 E-08$ & $5.39 \mathrm{E}-10$ & $5.52 \mathrm{E}-31$ & $3.06 \mathrm{E}-10$ & & & -08 \\
\hline $.13 E-33$ & $5.77 \mathrm{E}-08$ & $5.54 \mathrm{E}-10$ & $5.57 \mathrm{E}-31$ & $3.24 \mathrm{E}-10$ & $1.56 \mathrm{E}-09$ & $22 E-09$ & $z-08$ \\
\hline $12 \mathrm{E}-33$ & $E-08$ & -10 & & -10 & & -09 & -08 \\
\hline 33 & $3 E-08$ & 0 & 1 & 0 & & 9 & 08 \\
\hline 20 & 00 & & $\perp$ & & & & 8 \\
\hline 33 & 8 & $6.19 \mathrm{E}-10$ & 1 & 0 & & 9 & 08 \\
\hline $.09 E-33$ & $6.43 E-08$ & $6.37 E-10$ & $5.86 \mathrm{E}-31$ & $4.17 E-10$ & $1.88 \mathrm{E}-09$ & $08 E-09$ & $.81 E-08$ \\
\hline $08 E-33$ & $.57 \mathrm{E}-08$ & $6.54 \mathrm{E}-10$ & $91 E-31$ & $4.43 E-10$ & $.95 E-09$ & $E-09$ & $86 E-08$ \\
\hline-33 & $.70 \mathrm{E}-08$ & $.72 \mathrm{E}-10$ & 1 & $4.67 \mathrm{E}-10$ & & -09 & -08 \\
\hline-33 & -08 & $91 E-10$ & & & & & -08 \\
\hline 20 & 08 & 10 & & & & & \\
\hline$E-33$ & 8 & 20 & 1 & 0 & 9 & 09 & 08 \\
\hline . & 8 & 0 & 1 & 0 & 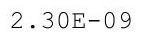 & $E-09$ & $0 \varepsilon$ \\
\hline $02 E-3$ & $.43 E-08$ & $.69 \mathrm{E}-10$ & $6.29 E-31$ & $9 E-10$ & $37 E-09$ & $9 E-09$ & $6 \mathrm{~F}-08 \mathrm{~g}$ \\
\hline $01 F-33$ & $7.58 \mathrm{E}-08$ & $.89 \mathrm{E}-10$ & $6.35 E-31$ & $3 E-10$ & & $E-09$ & $25 F-08$ \\
\hline 3 & & & & & & & \\
\hline & & & & & & & \\
\hline 3 & & & 31 & & -09 & -09 & 8 \\
\hline 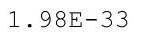 & $8.21 \mathrm{E}-08$ & $.75 E-10$ & $6.62 E-31$ & $.04 \mathrm{E}-10$ & $6.005-03$ & -09 & -08 \\
\hline 皮 & $0.30 \mathrm{~L}$ & $8.98 \mathrm{E}-10$ & $6.68 \mathrm{E}-31$ & $7.31 \mathrm{E}-10$ & & $8 E-09$ & . \\
\hline 3 & & & & & & & -08 \\
\hline$E-33$ & & & & & & & \\
\hline-33 & 08 & & & & & .09 & \\
\hline 0 & & & & & & 09 & 08 \\
\hline $92 E-33$ & $9.21 \pm-08$ & $.02 E-09$ & $3 E-31$ & $11 E-10$ & 09 & 09 & -08 \\
\hline 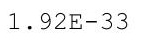 & & & & & & & •.0OH \\
\hline $.91 E-33$ & . & - & 1 & 0 & & 8 & 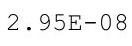 \\
\hline & & & & & & & \\
\hline $9 F-33$ & & & & & 9 & 08 & \\
\hline $88 E-33$ & $1.03 E-07$ & $1.15 \mathrm{E}-09$ & $7.39 E-31$ & $10 E-09$ & $6 E-09$ & $3 E-08$ & -08 \\
\hline 3 & 07 & & & & & & \\
\hline & & $1.21 \mathrm{E}-09$ & 31 & $1 .+10$ & & $18 \mathrm{E}-08$ & $\cdot 30 \pm-08$ \\
\hline 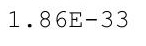 & & 政 & $.63 E-31$ & $1.23 E-09$ & $4.295-09$ & & . \\
\hline 3 & $E-07$ & $E-09$ & $2 E-31$ & $.28 E-09$ & $.41 E-09$ & $.24 E-08$ & $.44 E-08$ \\
\hline
\end{tabular}


RESRAD-OFFSITE, Version 2.5

$\mathrm{T}^{1 / 2}$ Limit $=180$ days

Title : RESRAD-OFFSITE External Gamma, Inhalation, and Soil Ingestion for offsite Reside File : PBA-1_TC99-DOE-5-1.ROF

Summary of dose at graphical times, reptition 1 (continued)

Time

Years

$2.36 E+02$

$2.36 \mathrm{E}+02$

$2.37 \mathrm{E}+02$

$2.37 \mathrm{E}+02$

2. $38 \mathrm{E}+02$

2. $38 \mathrm{E}+02$

$2.39 \mathrm{E}+02$

2. $39 \mathrm{E}+02$

$2.40 \mathrm{E}+02$

$2.40 \mathrm{E}+02$

$2.41 \mathrm{E}+02$

$2.41 \mathrm{E}+02$

2. $42 \mathrm{E}+02$

2. $43 \mathrm{E}+02$

$2.43 \mathrm{E}+02$

$2.44 \mathrm{E}+02$

$2.44 \mathrm{E}+02$

$2.45 \mathrm{E}+02$

$2.45 \mathrm{E}+02$

$2.46 \mathrm{E}+02$

$2.46 \mathrm{E}+02$

$2.47 \mathrm{E}+02$

$2.47 \mathrm{E}+02$

$2.48 \mathrm{E}+02$

$2.48 \mathrm{E}+02$

$2.49 \mathrm{E}+02$

$2.49 \mathrm{E}+02$

$2.50 \mathrm{E}+02$

$2.50 \mathrm{E}+02$

$2.51 \mathrm{E}+02$

$2.51 \mathrm{E}+02$

$2.52 \mathrm{E}+02$

$2.52 \mathrm{E}+02$

$2.53 \mathrm{E}+02$

$2.53 \mathrm{E}+02$

2. $54 \mathrm{E}+02$

$2.54 \mathrm{E}+02$

$2.55 \mathrm{E}+02$

$2.55 \mathrm{E}+02$

$2.56 \mathrm{E}+02$

$2.56 \mathrm{E}+02$

$2.57 \mathrm{E}+02$

$2.57 \mathrm{E}+02$

$2.58 \mathrm{E}+02$

$2.58 \mathrm{E}+02$

$2.59 \mathrm{E}+02$
Dose statistics at graphical times, mrem/yr

\begin{tabular}{|c|c|c|c|c|c|c|c|}
\hline inimum & aximum & Mean & ledian & $0 \%$ & $5 \%$ & $97.5 \%$ & $\%$ \\
\hline 3 & -07 & $E-09$ & $E-31$ & $2 E-09$ & 09 & 08 & 08 \\
\hline-33 & -07 & $E-09$ & $E-31$ & $.37 \mathrm{E}-$ & 09 & 08 & -08 \\
\hline-33 & $E-07$ & $E-09$ & $E-31$ & $2 E-09$ & 09 & 08 & $8 E-08$ \\
\hline $1 E-33$ & $E-07$ & $E-09$ & 1 & 9 & & & $6 E-08$ \\
\hline $.81 E-33$ & -07 & 9 & & 9 & & 08 & $84 E-08$ \\
\hline $.80 E-33$ & -07 & $6 E-09$ & 31 & 09 & 09 & 08 & -08 \\
\hline 更 & $\perp \cdot D_{\perp}$ & ك & $9 \mathrm{E}-31$ & $1.61 \mathrm{E}-09$ & 09 & -08 & -08 \\
\hline $.78 E-33$ & $1.33 E-07$ & $1.53 E-09$ & $8.38 E-31$ & $1.67 \mathrm{E}-09$ & & -08 & $09 E-08$ \\
\hline 33 & 07 & 09 & 31 & 09 & 9 & -08 & -08 \\
\hline $.77 E-33$ & -07 & $0 E-09$ & 1 & 09 & 09 & -08 & $E-08$ \\
\hline-33 & -07 & -09 & & & & 08 & $E-08$ \\
\hline & -07 & & & & & & -08 \\
\hline$\cdot .74 \mathrm{E}-33$ & $1.49 \mathrm{E}-07$ & $1.71 \mathrm{E}-09$ & $5 E-31$ & $1.95 \mathrm{E}-09$ & -09 & $E-08$ & $E-08$ \\
\hline $.73 E-33$ & $1.52 \mathrm{E}-07$ & $1.75 \mathrm{E}-09$ & -31 & $2.00 \mathrm{E}-09$ & כ & -08 & $E-08$ \\
\hline $.73 E-33$ & $1.55 E-07$ & $3 E-09$ & -31 & 09 & 9 & 08 & $72 E-08$ \\
\hline $.72 E-33$ & -07 & -09 & -31 & 09 & 09 & -08 & -08 \\
\hline $.71 E-33$ & $2 E-07$ & $6 E-09$ & $E-31$ & $2.18 \mathrm{E}-09$ & $57 E-09$ & $E-08$ & $38 \mathrm{E}-08$ \\
\hline-33 & $1.66 \mathrm{E}-07$ & $91 E-09$ & $E-31$ & $5 E-09$ & $6 E-09$ & -08 & $E-08$ \\
\hline 33 & -07 & 09 & 31 & 9 & & 8 & -08 \\
\hline $.69 E-33$ & $1.73 E-07$ & -09 & -31 & 9 & 9 & 08 & -08 \\
\hline $.68 \mathrm{E}-33$ & -07 & -09 & & 09 & & -08 & -08 \\
\hline $.67 E-33$ & $1.80 \mathrm{E}-07$ & -09 & -31 & 09 & 09 & -08 & -08 \\
\hline $.67 E-33$ & $1.84 \mathrm{E}-07$ & $2.12 \mathrm{E}-09$ & $91 \mathrm{E}-31$ & $2.66 \mathrm{E}-09$ & $.94 \mathrm{E}-09$ & $.04 \mathrm{E}-08$ & $45 E-08$ \\
\hline $.66 \mathrm{E}-33$ & $1.87 \mathrm{E}-07$ & $2.17 \mathrm{E}-09$ & $O E-30$ & $74 \mathrm{E}-09$ & $17 E-09$ & $9 E-08$ & $5 E-08$ \\
\hline 33 & $E-07$ & $2.21 E-09$ & 30 & 09 & & -08 & -08 \\
\hline 33 & -07 & 09 & -30 & 9 & & & \\
\hline $.62 E-33$ & $1.99 \mathrm{E}-07$ & $E-09$ & -30 & $99 E-09$ & & -08 & $E-08$ \\
\hline $.61 E-33$ & $2.03 E-07$ & $2.35 E-09$ & $1.06 \mathrm{E}-30$ & $3.09 \mathrm{E}-09$ & $01 E-09$ & $.27 \mathrm{E}-08$ & $98 E-08$ \\
\hline . & 2.010 T & $2.40 \mathrm{E}-09$ & $1.08 E-30$ & $3.18 \mathrm{E}-09$ & $22 E-09$ & -08 & $9 E-08$ \\
\hline $.60 \mathrm{E}-33$ & $2.11 \mathrm{E}-07$ & $2.45 \mathrm{E}-09$ & טل & . & $43 E-09$ & • & 年 \\
\hline 3 & $E-07$ & $E-09$ & 30 & $5 E-09$ & 9 & -08 & $E-08$ \\
\hline$E-33$ & $E-07$ & $E-09$ & $E-28$ & 9 & 09 & 08 & 08 \\
\hline $.57 E-33$ & $2.24 \mathrm{E}-07$ & $2.61 E-09$ & $7.25 \mathrm{E}-27$ & $3.56 \mathrm{E}-09$ & 8 & $.52 E-08$ & $54 \mathrm{E}-08$ \\
\hline $.56 \mathrm{E}-33$ & $2.28 \mathrm{E}-07$ & $2.66 \mathrm{E}-09$ & $2.55 E-25$ & $3.67 \mathrm{E}-09$ & $.03 E-08$ & $.57 \mathrm{E}-08$ & $66 \mathrm{E}-08$ \\
\hline . & $2.33 E-07$ & $2.71 \mathrm{E}-09$ & & $1 \mathrm{~L}-0$ & & & $.77 E-08$ \\
\hline & $2.31 \pm-01$ & & & & & & \\
\hline & 7 & & & & & & 08 \\
\hline 3 & $2.46 \mathrm{E}-$ & $8 E-09$ & 1 & 9 & 8 & 08 & 08 \\
\hline & & & & & & -08 & 08 \\
\hline$E-33$ & $2.56 \mathrm{E}-07$ & $2.99 E-09$ & $3 E-20$ & 9 & 8 & & $9 E-08$ \\
\hline 3 & 07 & & & y & & & -08 \\
\hline$E-33$ & $2.65 E-07$ & $.11 E-09$ & & $.52 E-09$ & $.23 E-08$ & & $64 E-08$ \\
\hline 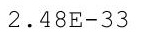 & 2 . & $3.17 \mathrm{E}-09$ & & $4.63 E-09$ & & 8 & 7. $77 \mathrm{E}-08$ \\
\hline $247 F-33$ & 2 & & & $75 \mathrm{E}$ & 8 & 0 & 0 \\
\hline-33 & 2.8 & 3.3 & 17 & 4. & 131 & 08 & -08 \\
\hline $.45 E-33$ & $2.85 E-07$ & $3.36 \mathrm{E}-09$ & $.51 E-17$ & $5.00 E-09$ & 1. $34 \mathrm{E}-08$ & $3.25 E-08$ & $8.17 \mathrm{E}-08$ \\
\hline
\end{tabular}


RESRAD-OFFSITE, Version 2.5

$\mathrm{T}^{1 / 2}$ Limit $=180$ days

Title : RESRAD-OFFSITE External Gamma, Inhalation, and Soil Ingestion for offsite Reside File : PBA-1_TC99-DOE-5-1.ROF

Summary of dose at graphical times, reptition 1 (continued)

Time

Years

$2.59 \mathrm{E}+02$

$2.60 \mathrm{E}+02$

$2.60 \mathrm{E}+02$

$2.61 E+02$

. $61 \mathrm{E}+02$

2. $62 \mathrm{E}+02$

. $63 \mathrm{E}+02$

2. $63 \mathrm{E}+02$

2. $64 \mathrm{E}+02$

2. $64 \mathrm{E}+02$

. $65 \mathrm{E}+02$

. $65 E+02$

. $66 \mathrm{E}+02$

$2.66 \mathrm{E}+02$

$2.67 \mathrm{E}+02$

$2.67 \mathrm{E}+02$

$2.68 \mathrm{E}+02$

2. $68 \mathrm{E}+02$

$2.69 \mathrm{E}+02$

$2.69 \mathrm{E}+02$

$2.70 \mathrm{E}+02$

$2.70 \mathrm{E}+02$

$2.71 \mathrm{E}+02$

$2.71 \mathrm{E}+02$

2. $72 \mathrm{E}+02$

2. $72 \mathrm{E}+02$

$2.73 E+02$

$2.73 \mathrm{E}+02$

$2.74 \mathrm{E}+02$

$2.74 \mathrm{E}+02$

$2.75 \mathrm{E}+02$

$2.75 \mathrm{E}+02$

$2.76 \mathrm{E}+02$

$2.76 \mathrm{E}+02$

$2.77 \mathrm{E}+02$

$2.77 \mathrm{E}+02$

$2.78 \mathrm{E}+02$

$2.78 \mathrm{E}+02$

$2.79 \mathrm{E}+02$

$2.79 \mathrm{E}+02$

$2.80 \mathrm{E}+02$

$2.80 \mathrm{E}+02$

$2.81 \mathrm{E}+02$

$2.81 E+02$

$2.82 \mathrm{E}+02$

$2.82 \mathrm{E}+02$
Dose statistics at graphical times, mrem/yr

\begin{tabular}{|c|c|c|c|c|c|c|c|}
\hline inimum & aximum & Mean & ledian & $90 \%$ & $5 \%$ & $97.5 \%$ & \\
\hline 3 & -07 & -09 & 16 & 09 & 08 & 08 & 08 \\
\hline 33 & -07 & 09 & 6 & 9 & 08 & 08 & -08 \\
\hline $43 E-33$ & -07 & $E-09$ & -16 & $4 E-09$ & 08 & 08 & -08 \\
\hline 33 & 07 & & & & & & -08 \\
\hline-33 & -07 & 9 & & & 08 & 08 & $88 E-08$ \\
\hline $40 E-33$ & -07 & $E-09$ & -15 & $9 E-09$ & -08 & -08 & $E-08$ \\
\hline 33 & -07 & $.83 E-09$ & 15 & $\mathrm{~F}$ & 8 & -08 & $F$ \\
\hline $.38 E-33$ & $3.28 E-07$ & • & $7.40 \mathrm{E}-15$ & $5.95 E-09$ & $1.60 \mathrm{E}-08$ & -08 & $32 E-08$ \\
\hline 33 & 07 & 09 & -14 & 09 & 08 & -08 & 08 \\
\hline $.37 E-33$ & $40 E-07$ & $5 E-09$ & $6 \mathrm{E}-14$ & $3 E-09$ & $.67 E-08$ & -08 & -08 \\
\hline-33 & -07 & -09 & & 9 & & 08 & $E-08$ \\
\hline 32 & -07 & -09 & -14 & & & -08 & $E-08$ \\
\hline $34 \mathrm{E}-32$ & $.5 / E-01$ & $7 E-09$ & -14 & JE-09 & $4-08$ & -08 & -0 \\
\hline $.34 \mathrm{E}-32$ & -07 & $E-09$ & -14 & 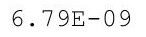 & & -08 & -07 \\
\hline 32 & -07 & 09 & 13 & 09 & & -08 & -07 \\
\hline $.35 E-32$ & -07 & -09 & -13 & 9 & 08 & -08 & -07 \\
\hline $.35 E-32$ & $3.82 E-07$ & $9 E-09$ & $9 E-13$ & $6 E-09$ & $94 E-08$ & $E-08$ & $.07 \mathrm{E}-07$ \\
\hline-32 & $38 E-07$ & $7 E-09$ & $1 E-13$ & $2 E-09$ & $8 E-08$ & $E-08$ & $9 \mathrm{E}-07$ \\
\hline 32 & -07 & 09 & 13 & 9 & & -08 & -07 \\
\hline $35 E-32$ & -07 & -09 & 13 & 9 & 08 & -08 & -07 \\
\hline $.36 \mathrm{E}-32$ & -07 & & -13 & & & -08 & -07 \\
\hline $36 E-32$ & -07 & $5.00 \mathrm{E}-09$ & 13 & & & -08 & $16 \mathrm{E}-07$ \\
\hline $36 E-32$ & $E-07$ & 9 & 3 & 9 & 8 & $37 E-08$ & $.17 \mathrm{E}-07$ \\
\hline $36 \mathrm{E}-32$ & $4.27 E-07$ & $8 E-09$ & $0 \mathrm{E}-12$ & $50 E-09$ & $23 E-08$ & $5 E-08$ & $19 E-07$ \\
\hline-32 & $34 E-07$ & $27 E-09$ & $7 E-12$ & $9 E-09$ & $E-08$ & -08 & -07 \\
\hline 32 & -07 & 09 & 12 & & & & 07 \\
\hline $37 E-32$ & $4.48 E-07$ & $20-09$ & -12 & & 8 & 08 & $25 E-07$ \\
\hline $.37 E-32$ & $5 E-07$ & $54 E-09$ & $8 E-12$ & $28 E-09$ & $325-00$ & $6 E-08$ & $.26 E-07$ \\
\hline 年 & 07 & 9 & 2 & 9 & 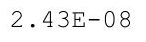 & 8 & $28 E-07$ \\
\hline - & - & - & 2 & - & - & 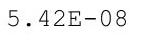 & - \\
\hline $5-32$ & $65-07$ & $83 F-09$ & $3 F-12$ & & & $F-08$ & $32 E-07$ \\
\hline 2 & $E-07$ & $E-09$ & & & & & -07 \\
\hline $38 E-32$ & $4.91 \mathrm{E}-07$ & $E-09$ & $E-12$ & 8 & 8 & 08 & $36 E-07$ \\
\hline $38 \mathrm{E}-32$ & $4.98 E-07$ & $6.12 \mathrm{E}-09$ & $.85 E-12$ & $.04 \mathrm{E}-08$ & $2.65 E-08$ & $5 E-08$ & $.38 E-07$ \\
\hline . $42 ⿰-225$ & $5.06 \mathrm{E}-07$ & $6.22 E-09$ & $6.63 E-12$ & $1.00 \mathrm{D}-00$ & & & $.40 E-07$ \\
\hline 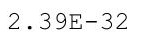 & & & & & & & \\
\hline 2 & 7 & & & & & & 07 \\
\hline 2 & & & & & & & 07 \\
\hline$E-32$ & & & & & -08 & -08 & 07 \\
\hline $40 \mathrm{E}-32$ & $5.45 E-07$ & $5 E-09$ & $6 E-11$ & 8 & 8 & & $.52 \mathrm{E}-07$ \\
\hline 2 & 07 & 9 & & 8 & & & $34 \mathrm{E}-0$ \\
\hline 82 & 01 & $96 \mathrm{E}-09$ & $43 E-11$ & $1.2+5$ & 0 & & $\begin{array}{c}-31 \mathrm{E}-01 \\
\end{array}$ \\
\hline 2 & 年 & . & - & 1.201 & & 8 & 1 \\
\hline the & 7 & set & & & & 08 & 07 \\
\hline $41 E-32$ & $5.85 E-07$ & $7.30 \mathrm{E}-09$ & $1 E-11$ & $1.28 \mathrm{E}-08$ & $3.24 \mathrm{E}-08$ & 08 & -07 \\
\hline $.41 E-32$ & $5.94 E-07$ & $7.42 \mathrm{E}-09$ & $.12 \mathrm{E}-11$ & 1. $31 E-08$ & $3.30 E-08$ & $5.83 E-08$ & 1. $67 E-07$ \\
\hline
\end{tabular}


RESRAD-OFFSITE, Version 2.5

$\mathrm{T}^{1 / 2}$ Limit $=180$ days

Title : RESRAD-OFFSITE External Gamma, Inhalation, and Soil Ingestion for Offsite Reside File : PBA-1_TC99-DOE-5-1.ROF

Summary of dose at graphical times, reptition 1 (continued)

Time

Years

$2.83 \mathrm{E}+02$

$2.84 \mathrm{E}+02$

$2.84 \mathrm{E}+02$

$.85 \mathrm{E}+02$

$2.85 \mathrm{E}+02$

$2.86 \mathrm{E}+02$

$2.86 \mathrm{E}+02$

$2.87 \mathrm{E}+02$

$2.87 \mathrm{E}+02$

2. $88 \mathrm{E}+02$

$2.88 \mathrm{E}+02$

$2.89 \mathrm{E}+02$

$2.89 \mathrm{E}+02$

2. $90 \mathrm{E}+02$

2. $90 \mathrm{E}+02$

2. $91 \mathrm{E}+02$

2. $91 \mathrm{E}+02$

2. $92 \mathrm{E}+02$

2. $92 \mathrm{E}+02$

2. $93 \mathrm{E}+02$

2. $93 \mathrm{E}+02$

2. $94 \mathrm{E}+02$

2. $94 \mathrm{E}+02$

2. $95 \mathrm{E}+02$

2. $95 \mathrm{E}+02$

2. $96 \mathrm{E}+02$

$2.96 \mathrm{E}+02$

2. $97 \mathrm{E}+02$

$2.97 \mathrm{E}+02$

$2.98 \mathrm{E}+02$

$2.98 \mathrm{E}+02$

2. $99 \mathrm{E}+02$

2. $99 \mathrm{E}+02$

$3.00 \mathrm{E}+02$

$3.00 \mathrm{E}+02$

$3.01 \mathrm{E}+02$

$3.01 \mathrm{E}+02$

$3.02 \mathrm{E}+02$

$3.02 \mathrm{E}+02$

$3.03 \mathrm{E}+02$

3. $04 \mathrm{E}+02$

$3.04 \mathrm{E}+02$

$3.05 \mathrm{E}+02$

$3.05 \mathrm{E}+02$

$3.06 \mathrm{E}+02$

$3.06 \mathrm{E}+02$
Dose statistics at graphical times, mrem/yr

\begin{tabular}{|c|c|c|c|c|c|c|c|}
\hline inimum & Iaximum & Mean & ledian & $90 \%$ & $5 \%$ & $97.5 \%$ & \\
\hline 2 & -07 & $E-09$ & 1 & 08 & 08 & 08 & 0 \\
\hline-32 & -07 & 09 & 1 & 8 & 08 & 88 & 07 \\
\hline $42 E-32$ & $E-07$ & $E-09$ & 1 & $9 E-08$ & 08 & 08 & -07 \\
\hline $42 E-32$ & -07 & 09 & & 8 & & 08 & -07 \\
\hline $.42 E-32$ & -07 & 99 & & 8 & 08 & $31 E-08$ & $80 E-07$ \\
\hline $42 E-32$ & -07 & -09 & 11 & $1.47 E-08$ & -08 & -08 & $82 E-07$ \\
\hline 32 & -07 & -09 & 11 & $E-08$ & -08 & -08 & 7 \\
\hline $.43 E-32$ & $6.63 E-07$ & 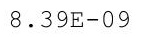 & & $1.53 E-08$ & & -08 & $88 E-07$ \\
\hline 32 & -07 & 09 & 1 & 08 & 8 & 08 & -07 \\
\hline $.43 E-32$ & $81 \mathrm{E}-07$ & $4 \mathrm{E}-09$ & $E-11$ & $1.58 \mathrm{E}-08$ & -08 & -08 & $93 E-07$ \\
\hline $43 E-32$ & $E-07$ & -09 & & & & 08 & $E-07$ \\
\hline 32 & -07 & $s-09$ & & & & -08 & $9 E-07$ \\
\hline $44 \mathrm{E}-32$ & $2 E-07$ & $E-09$ & $E-11$ & -08 & 08 & -08 & $-0 T$ \\
\hline $.44 \mathrm{E}-32$ & -07 & $E-09$ & 11 & 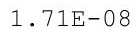 & 0 & -08 & -07 \\
\hline 32 & -07 & 09 & 11 & 8 & 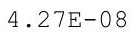 & -08 & -07 \\
\hline $.44 \mathrm{E}-32$ & -07 & -09 & 11 & -08 & 08 & -08 & -07 \\
\hline $45 E-32$ & $7.47 E-07$ & $9 E-09$ & $8 E-11$ & $1.81 \mathrm{E}-08$ & $42 E-08$ & $E-08$ & $12 \mathrm{E}-07$ \\
\hline $45 E-32$ & $57 E-07$ & $3 E-09$ & $3 E-11$ & $3 E-08$ & $49 E-08$ & $E-08$ & $15 E-07$ \\
\hline-32 & -07 & $E-09$ & -11 & 08 & 08 & -08 & -07 \\
\hline $45 E-32$ & $7.77 \mathrm{E}-07$ & -08 & 11 & 08 & 8 & -08 & -07 \\
\hline $46 \mathrm{E}-32$ & $7.87 \mathrm{E}-07$ & $1.02 E-08$ & & & & -08 & -07 \\
\hline $.46 \mathrm{E}-32$ & $7.97 \mathrm{E}-07$ & $1.03 E-08$ & & 1. $95 \mathrm{E}-08$ & 08 & -08 & $27 \mathrm{E}-07$ \\
\hline $46 E-32$ & 07 & $05 E-$ & 0 & $9 E-08$ & $87 \mathrm{E}-$ & $.60 E-08$ & $.30 \mathrm{E}-07$ \\
\hline $46 \mathrm{E}-32$ & $8.17 E-07$ & $1.06 \mathrm{E}-08$ & $5 E-10$ & $2 \mathrm{E}-08$ & $95 E-08$ & $5 E-08$ & $.33 E-07$ \\
\hline $46 \mathrm{E}-32$ & $8.27 E-07$ & $.08 E-08$ & & & $3 E-08$ & $E-08$ & $36 E-07$ \\
\hline 32 & $E-07$ & $09 E-08$ & 0 & & & & -07 \\
\hline$E-32$ & -07 & -08 & & 8 & & 07 & $42 E-07$ \\
\hline $.47 E-32$ & $8.59 E-07$ & $12 E-08$ & $1+\infty$ & $.17 E-08$ & $215-00$ & $03 E-07$ & $.45 E-07$ \\
\hline 3 & 07 & 8 & 20 & $20 E-08$ & 0 & $.05 E-07$ & $.48 E-07$ \\
\hline $48 \mathrm{E}-$ & - & $.15 \mathrm{E}-08$ & - & -5 & 2 & - & - \\
\hline $48 E-32$ & $8.91 E-07$ & $7 E-08$ & & & $52 \mathrm{E}-08$ & $E-07$ & $54 \mathrm{E}-07$ \\
\hline 2 & 7 & & & & 8 & 7 & -07 \\
\hline $48 E-32$ & $E-07$ & $20 E-08$ & $8 E-10$ & 08 & 8 & -07 & $50 E-07$ \\
\hline $.48 E-32$ & $9.23 E-07$ & $1.22 \mathrm{E}-08$ & $1.87 \mathrm{E}-10$ & $2.39 E-08$ & $7 E-08$ & $11 E-07$ & $64 \mathrm{E}-07$ \\
\hline $49 E-32$ & $9.34 \mathrm{E}-07$ & $1.24 E-08$ & & & & $\cdot \cos 201$ & $.67 E-07$ \\
\hline . & & & & & & & \\
\hline 2 & 7 & & & P & & & 07 \\
\hline 2 & & & & & & 07 & 07 \\
\hline$E-32$ & & & & & 08 & -07 & \\
\hline $50 \mathrm{E}-32$ & $9.91 \mathrm{E}-07$ & $E-08$ & 2. & 08 & & & $3 E-07$ \\
\hline 2 & 06 & $.34 \mathrm{E}-08$ & & 8 & & & $1 E-01$ \\
\hline 32 & $1.01 \mathrm{E}-06$ & $.36 \mathrm{E}-08$ & $2.57 \mathrm{E}-10$ & 2. & & $23 E-07$ & $90 \mathrm{E}-07$ \\
\hline 2 & 0 & $38 \mathrm{E}-$ & 然 & - & - & $24 \mathrm{E}-07$ & $94 E-07$ \\
\hline 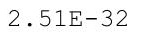 & - & 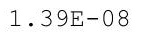 & & 8 & 08 & 7 & 07 \\
\hline $1 E-32$ & $1.05 E-06$ & $1.41 \mathrm{E}-08$ & $2.93 E-10$ & $2.86 \mathrm{E}$ & 08 & 07 & 3.011 \\
\hline $51 E-32$ & $1.06 E-06$ & 1. $43 E-08$ & $3.04 \mathrm{E}-10$ & $2.90 E-08$ & $5.82 E-08$ & 1.29E-07 & $3.04 \mathrm{E}-07$ \\
\hline
\end{tabular}


RESRAD-OFFSITE, Version 2.5

$\mathrm{T}^{1 / 2}$ Limit $=180$ days

Title : RESRAD-OFFSITE External Gamma, Inhalation, and Soil Ingestion for offsite Reside File : PBA-1_TC99-DOE-5-1.ROF

Summary of dose at graphical times, reptition 1 (continued)

Time

Years

$3.07 \mathrm{E}+02$

$3.07 \mathrm{E}+02$

$3.08 \mathrm{E}+02$

$3.08 \mathrm{E}+02$

$3.09 \mathrm{E}+02$

$3.09 \mathrm{E}+02$

$3.10 \mathrm{E}+02$

$3.10 \mathrm{E}+02$

$3.11 \mathrm{E}+02$

$3.11 E+02$

$3.12 \mathrm{E}+02$

3. $12 \mathrm{E}+02$

$3.13 \mathrm{E}+02$

$3.13 \mathrm{E}+02$

$3.14 \mathrm{E}+02$

$3.14 \mathrm{E}+02$

$3.15 \mathrm{E}+02$

$3.15 \mathrm{E}+02$

$3.16 \mathrm{E}+02$

$3.16 \mathrm{E}+02$

$3.17 \mathrm{E}+02$

$3.17 \mathrm{E}+02$

$3.18 \mathrm{E}+02$

$3.18 \mathrm{E}+02$

$3.19 \mathrm{E}+02$

$3.19 \mathrm{E}+02$

$3.20 \mathrm{E}+02$

$3.20 \mathrm{E}+02$

$3.21 \mathrm{E}+02$

$3.21 \mathrm{E}+02$

$3.22 \mathrm{E}+02$

$3.22 \mathrm{E}+02$

$3.23 \mathrm{E}+02$

$3.24 \mathrm{E}+02$

3. $24 \mathrm{E}+02$

$3.25 \mathrm{E}+02$

$3.25 \mathrm{E}+02$

$3.26 \mathrm{E}+02$

$3.26 \mathrm{E}+02$

$3.27 \mathrm{E}+02$

$3.27 \mathrm{E}+02$

3. $28 \mathrm{E}+02$

$3.28 \mathrm{E}+02$

$3.29 \mathrm{E}+02$

$3.29 \mathrm{E}+02$

$3.30 \mathrm{E}+02$
Dose statistics at graphical times, mrem/yr

\begin{tabular}{|c|c|c|c|c|c|c|c|}
\hline inimum & aximum & Mean & ledian & $90 \%$ & $5 \%$ & $97.5 \%$ & \\
\hline 2 & 6 & $E-08$ & 10 & 08 & 8 & 7 & $3.08 \mathrm{E}-07$ \\
\hline 32 & -06 & 8 & 0 & 8 & 8 & 7 & 07 \\
\hline$E-32$ & -06 & -08 & -10 & $5 E-08$ & 08 & -07 & -07 \\
\hline$E-32$ & 06 & 8 & & & & & -07 \\
\hline $2 E-32$ & -06 & 8 & & & 08 & 07 & $22 E-07$ \\
\hline $52 E-32$ & -06 & -08 & -10 & $19 \mathrm{E}-08$ & -08 & -07 & $6 E-07$ \\
\hline 32 & 06 & -08 & -10 & -08 & 8 & -07 & $F-07$ \\
\hline $3 E-32$ & $1.16 \mathrm{E}-06$ & • & -10 & $3.29 \mathrm{E}-08$ & & -07 & $33 E-07$ \\
\hline 32 & 06 & 08 & -10 & 08 & 8 & 07 & -07 \\
\hline $.18 \mathrm{E}-32$ & $1.18 \mathrm{E}-06$ & $53 E-08$ & $8 E-10$ & $E-08$ & -08 & $E-07$ & -07 \\
\hline-32 & -06 & 8 & 10 & & & -07 & $E-07$ \\
\hline & -06 & -08 & -10 & & & & $8 E-07$ \\
\hline-32 & 1. $22 E-06$ & $5-08$ & $E-10$ & -08 & -08 & -07 & -07 \\
\hline $20 \mathrm{E}-32$ & -06 & $\begin{array}{l}1.1 \\
\end{array}$ & -10 & 0 & & -07 & -07 \\
\hline 32 & 06 & $1.73 E-08$ & -10 & 08 & 8 & 1 & -07 \\
\hline $20 E-32$ & 1.26 & $1.75 \mathrm{E}-08$ & -10 & 08 & 08 & -07 & -07 \\
\hline $.21 E-32$ & $1.28 \mathrm{E}-06$ & $1.78 \mathrm{E}-08$ & $4 \mathrm{E}-10$ & $77 E-08$ & $53 E-08$ & $E-07$ & $68 E-07$ \\
\hline 32 & $9 E-06$ & $.80 E-08$ & $2 E-10$ & $2 E-08$ & & $56 \mathrm{E}-07$ & $72 E-07$ \\
\hline-32 & -06 & -08 & -10 & 08 & 8 & 1 & -07 \\
\hline $22 E-32$ & 1. $32 E-06$ & -08 & -10 & 08 & & -01 & -07 \\
\hline $22 \mathrm{E}-32$ & $1.33 E-06$ & -08 & -10 & & & & -07 \\
\hline $23 E-32$ & $1.34 \mathrm{E}-06$ & $1.89 \mathrm{E}-08$ & -10 & $2 E-08$ & 08 & -07 & -07 \\
\hline$E-32$ & $6 E-06$ & 8 & 0 & 8 & 5 & $.65 \mathrm{E}-07$ & $.92 E-07$ \\
\hline$E-32$ & $1.37 E-06$ & 1.93E-08 & $3 E-10$ & $12 E-08$ & $26 E-08$ & $.67 E-07$ & $96 \mathrm{E}-07$ \\
\hline 32 & 1. $38 E-06$ & $1.96 \mathrm{E}-08$ & $9 \mathrm{E}-10$ & $8 E-08$ & $36 E-08$ & & $E-07$ \\
\hline & & & & & & & \\
\hline $25 E-32$ & -06 & -08 & -10 & 8 & & -07 & -07 \\
\hline $25 E-32$ & $1.43 E-06$ & $03 E-08$ & $3 E-10$ & $34 E-08$ & $105-00$ & $.75 E-07$ & $13 E-07$ \\
\hline 2 & 6 & 然 & 0 & - & 年 & • & $.17 \mathrm{E}-07$ \\
\hline 2 & - & 年 & 0 & - & - & 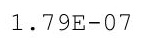 & $=$ \\
\hline 32 & $F-06$ & $0=-08$ & $E-10$ & $3 E-08$ & & & $25 E-07$ \\
\hline & & $E-08$ & & & 7 & 7 & -07 \\
\hline$E-32$ & $1.50 \mathrm{E}-06$ & $2.15 \mathrm{E}-08$ & $E-10$ & 08 & 7 & 7 & $34 \mathrm{E}-07$ \\
\hline $28 E-32$ & $1.51 \mathrm{E}-06$ & $2.17 \mathrm{E}-08$ & $4 E-10$ & $4.72 E-08$ & $.04 \mathrm{E}-07$ & $.87 \mathrm{E}-07$ & $38 E-07$ \\
\hline $28 E-32$ & $1.53 E-06$ & $2.20 E-08$ & & & & & $.43 E-07$ \\
\hline 2 & $1.54 \mathrm{E}-$ & & & & & & 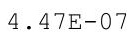 \\
\hline 2 & 1 & 8 & & & & & 07 \\
\hline 2 & & & & & & & 07 \\
\hline 32 & & & & & -07 & -07 & \\
\hline $0 E-32$ & $1.60 \mathrm{E}-06$ & $E-08$ & 09 & 08 & 7 & 7 & $4 E-07$ \\
\hline & 1.6 & 8 & & & & & $8 \mathrm{E}-01$ \\
\hline 32 & $1.63 \mathrm{E}-$ & $.38 E-08$ & & 8 & & $2.02 \mathrm{E}-07$ & $.72 \mathrm{E}-07$ \\
\hline & 1 & & 9 & 8 & the & JE-U & . $130-01$ \\
\hline$=$ & 象 & - & & ter & $1 .+0$ & $7 E-07$ & 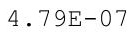 \\
\hline$E-32$ & $3 E-06$ & $2.46 \mathrm{E}-08$ & $1.15 \mathrm{E}-09$ & 08 & 1.1 & $E-07$ & $4.83 E-07$ \\
\hline $33 E-32$ & $1.69 E-06$ & $2.49 E-08$ & $.18 \mathrm{E}-09$ & $.48 E-08$ & $1.18 \mathrm{E}-07$ & $2.11 E-07$ & $4.87 \mathrm{E}-07$ \\
\hline
\end{tabular}


RESRAD-OFFSITE, Version 2.5

$\mathrm{T}^{1 / 2}$ Limit $=180$ days

Title : RESRAD-OFFSITE External Gamma, Inhalation, and Soil Ingestion for Offsite Reside

File : PBA-1_TC99-DOE-5-1.ROF

Summary of dose at graphical times, reptition 1 (continued)

Time

Years

$3.30 \mathrm{E}+02$

$3.31 \mathrm{E}+02$

$3.31 \mathrm{E}+02$

$3.32 \mathrm{E}+02$

3. $32 \mathrm{E}+02$

$3.33 \mathrm{E}+02$

$3.33 \mathrm{E}+02$

$3.34 \mathrm{E}+02$

$3.34 \mathrm{E}+02$

$3.35 E+02$

$3.35 \mathrm{E}+02$

$3.36 \mathrm{E}+02$

$3.36 \mathrm{E}+02$

$3.37 \mathrm{E}+02$

$3.37 \mathrm{E}+02$

$3.38 \mathrm{E}+02$

$3.38 \mathrm{E}+02$

$3.39 \mathrm{E}+02$

$3.39 \mathrm{E}+02$

$3.40 \mathrm{E}+02$

$3.40 \mathrm{E}+02$

$3.41 \mathrm{E}+02$

$3.41 \mathrm{E}+02$

$3.42 \mathrm{E}+02$

$3.42 \mathrm{E}+02$

$3.43 \mathrm{E}+02$

$3.44 \mathrm{E}+02$

$3.44 \mathrm{E}+02$

$3.45 \mathrm{E}+02$

$3.45 \mathrm{E}+02$

$3.46 \mathrm{E}+02$

$3.46 \mathrm{E}+02$

$3.47 \mathrm{E}+02$

$3.47 \mathrm{E}+02$

$3.48 \mathrm{E}+02$

$3.48 \mathrm{E}+02$

$3.49 \mathrm{E}+02$

3. $49 \mathrm{E}+02$

$3.50 \mathrm{E}+02$

$3.50 \mathrm{E}+02$

3. $51 \mathrm{E}+02$

3. $51 \mathrm{E}+02$

3. $52 \mathrm{E}+02$

3. $52 \mathrm{E}+02$

$3.53 \mathrm{E}+02$

$3.53 \mathrm{E}+02$
Dose statistics at graphical times, mrem/yr

\begin{tabular}{|c|c|c|c|c|c|c|c|}
\hline m & um & ea & ledian & & & & \\
\hline $33 E-32$ & -06 & $2.52 E-08$ & -09 & $5 E-08$ & -07 & -07 & $3-0$ \\
\hline $34 E-32$ & $1.72 \mathrm{E}-06$ & $.55 E-08$ & $1.25 E-09$ & -08 & 07 & $6 E-07$ & $4 E-07$ \\
\hline-32 & $1.74 \mathrm{E}-06$ & $.58 \mathrm{E}-08$ & 1. $28 \mathrm{E}-09$ & $8 E-08$ & $22 \mathrm{E}-07$ & -07 & -07 \\
\hline-32 & $75 E-06$ & $6 \cap F-08$ & $31 \mathrm{~F}-09$ & $5 \mathrm{~F}-08$ & $23 F_{-}$ & 07 & -0 \\
\hline 32 & 06 & 8 & 9 & & & 7 & 07 \\
\hline 32 & 06 & & & & & & -07 \\
\hline $11 \mathrm{E}-31$ & $1.80 \mathrm{E}-06$ & & & & $.27 \mathrm{E}-07$ & & -07 \\
\hline-31 & -06 & -08 & -09 & 8 & 7 & -07 & -07 \\
\hline-31 & $E-06$ & $5 E-08$ & -09 & -08 & $29 \mathrm{E}-$ & -07 & -07 \\
\hline-31 & $5 E-06$ & $78 E-08$ & $52 E-09$ & & & 7 & 7 \\
\hline 31 & 06 & $2.81 E-08$ & 9 & 8 & -07 & & 0 \\
\hline-31 & 06 & $84 E-08$ & 9 & 8 & 7 & 7 & -07 \\
\hline $16 \mathrm{E}-31$ & $1.90 \mathrm{E}-06$ & $2.87 \mathrm{E}-08$ & & & & -07 & -07 \\
\hline $17 \mathrm{E}-31$ & $1.91 \mathrm{E}-06$ & $2.90 \mathrm{E}-08$ & $1.65 \mathrm{E}-09$ & $6.48 \mathrm{E}-08$ & $1.37 \mathrm{E}-07$ & $2.43 E-07$ & $40 \mathrm{E}-07$ \\
\hline-31 & $3 E-06$ & $3 E-08$ & -09 & $\Xi-08$ & & -07 & -07 \\
\hline 1 & $94 \mathrm{E}-06$ & $96 \mathrm{E}-08$ & & & & & 07 \\
\hline - 2 & & & & & & & 7 \\
\hline 1 & 6 & 8 & 9 & & & 7 & 07 \\
\hline $22 E-31$ & $1.99 \mathrm{E}-06$ & $3.06 \mathrm{E}-08$ & $1.84 \mathrm{E}-09$ & $6.89 E-08$ & $1.44 \mathrm{E}-07$ & $2.55 E-07$ & $.60 E-07$ \\
\hline $23 E-31$ & $2.01 E-06$ & $.09 \mathrm{E}-08$ & $1.88 \mathrm{E}-09$ & $.97 \mathrm{E}-08$ & $1.45 \mathrm{E}-07$ & $E-07$ & $E-07$ \\
\hline 31 & $2.03 E-06$ & $2 E-08$ & $93 E-09$ & $E-08$ & & 7 & -07 \\
\hline 31 & & & & & & & \\
\hline 31 & 2.06 & & & & & & -07 \\
\hline $26 \mathrm{E}-31$ & 2. & 8 & 9 & 8 & 1 & 7 & -07 \\
\hline 1 & 6 & - & 9 & 8 & 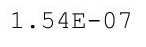 & $E-07$ & 07 \\
\hline $28 \mathrm{~F}-31$ & $.11 E-06$ & $.29 \mathrm{E}-08$ & $2.14 \mathrm{E}-09$ & $1 \mathrm{E}-08$ & $56 \mathrm{E}-0$ & $.75 E-07$ & $88 \mathrm{~F}-07-\mathrm{T}$ \\
\hline $29 F-31$ & $2.13 E-06$ & $32 \mathrm{E}-08$ & $2.18 \mathrm{E}-09$ & & & $78 \mathrm{~F}-07$ & -07 \\
\hline & & & & & & & \\
\hline & & & & & & & -07 \\
\hline $45 E-31$ & $2.18 \mathrm{E}-06$ & $3.42 \mathrm{E}-08$ & $2.32 \mathrm{E}-09$ & $7.88 \mathrm{E}-08$ & $1.64 \mathrm{E}-07$ & $7 E-07$ & $E-07$ \\
\hline $46 \mathrm{E}-31$ & $2.20 \mathrm{E}-06$ & $.46 E-08$ & $2.38 E-09$ & $7.97 \mathrm{E}-08$ & 1.000 t & $2.095-01$ & $00 \mathrm{x}-0$ \\
\hline • & $2.21 \mathrm{E}-06$ & $3.47 \pm 00$ & $2.42 \mathrm{E}-09$ & & & & \\
\hline 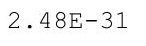 & $23 F-06$ & & & & & & \\
\hline & & & & & & & \\
\hline & & & & & & -07 & \\
\hline $.51 \mathrm{E}-31$ & $2.28 E-06$ & $3.63 E-08$ & $2.61 E-09$ & $8.45 E-08$ & $1.75 \mathrm{E}-07$ & $3 E-07$ & $29 \mathrm{E}-07$ \\
\hline$\cdot 5<E-31$ & $2.30 \mathrm{E}-06$ & $7 E-08$ & $2.67 \mathrm{E}-09$ & 08 & 舟 & & - \\
\hline $402-21$ & $2.32 \mathrm{E}-06$ & & & & & & 車 \\
\hline $54 \mathrm{~F}-31$ & ${ }^{2}$ & 8 & 9 & 8 & & $t$ & 7 \\
\hline $2.55 E-31$ & & & & & 7 & 7 & 07 \\
\hline $71 E-31$ & $2.37 \mathrm{E}$ & & & & $3 E-07$ & -07 & \\
\hline $66 \mathrm{E}-31$ & $2.39 E-06$ & $3.85 E-08$ & $2.91 E-09$ & $02 E-08$ & $4 E-07$ & 07 & -07 \\
\hline & 06 & & & & & & -07 \\
\hline & $2.43 E-06$ & $3.93 E-08$ & & & & 07 & 1 \\
\hline$\perp$ & & 0 & $3.06 \mathrm{E}-09$ & $9.29 \mathrm{E}-08$ & $1.09 \mathrm{E}-1$ & $3.30 \mathrm{E}-07$ & $0.14 \mathrm{~L}-01$ \\
\hline-31 & $E-06$ & $E-08$ & $.12 E-09$ & $8 E-08$ & $1.91 \mathrm{E}-07$ & $3 E-07$ & -07 \\
\hline
\end{tabular}


RESRAD-OFFSITE, Version 2.5

$\mathrm{T}^{1 / 2}$ Limit $=180$ days

Title : RESRAD-OFFSITE External Gamma, Inhalation, and Soil Ingestion for Offsite Reside File : PBA-1_TC99-DOE-5-1.ROF

Summary of dose at graphical times, reptition 1 (continued)

Time

Years

$3.54 \mathrm{E}+02$

$3.54 \mathrm{E}+02$

$3.55 \mathrm{E}+02$

$3.55 \mathrm{E}+02$

$3.56 \mathrm{E}+02$

$3.56 \mathrm{E}+02$

$3.57 \mathrm{E}+02$

$3.57 \mathrm{E}+02$

$3.58 \mathrm{E}+02$

$3.58 \mathrm{E}+02$

$3.59 \mathrm{E}+02$

$3.59 \mathrm{E}+02$

$3.60 \mathrm{E}+02$

$3.60 \mathrm{E}+02$

3. $61 \mathrm{E}+02$

$3.61 \mathrm{E}+02$

3. $62 \mathrm{E}+02$

$3.62 \mathrm{E}+02$

3. $63 \mathrm{E}+02$

$3.64 \mathrm{E}+02$

$3.64 \mathrm{E}+02$

$3.65 \mathrm{E}+02$

3. $65 \mathrm{E}+02$

3. $66 \mathrm{E}+02$

3. $66 \mathrm{E}+02$

3. $67 \mathrm{E}+02$

$3.67 \mathrm{E}+02$

3. $68 \mathrm{E}+02$

3. $68 \mathrm{E}+02$

$3.69 \mathrm{E}+02$

$3.69 \mathrm{E}+02$

$3.70 \mathrm{E}+02$

$3.70 \mathrm{E}+02$

3. $71 \mathrm{E}+02$

$3.71 \mathrm{E}+02$

$3.72 \mathrm{E}+02$

$3.72 \mathrm{E}+02$

$3.73 \mathrm{E}+02$

$3.73 \mathrm{E}+02$

$3.74 \mathrm{E}+02$

$3.74 \mathrm{E}+02$

$3.75 \mathrm{E}+02$

$3.75 \mathrm{E}+02$

$3.76 \mathrm{E}+02$

$3.76 \mathrm{E}+02$

$3.77 \mathrm{E}+02$
Dose statistics at graphical times, mrem/yr

\begin{tabular}{|c|c|c|c|c|c|c|c|}
\hline inimum & aximum & Mean & ledian & $90 \%$ & $5 \%$ & $97.5 \%$ & \\
\hline 1 & 6 & -08 & -09 & 08 & 07 & 7 & 0 \\
\hline 31 & 06 & 08 & 9 & 8 & 07 & 7 & 07 \\
\hline$E-31$ & $2 E-06$ & $E-08$ & -09 & $7 E-08$ & 07 & -07 & -07 \\
\hline 31 & 06 & 8 & & 8 & & 07 & -07 \\
\hline-31 & -06 & 8 & & 8 & & 07 & $5 E-07$ \\
\hline $5-31$ & -06 & -08 & -09 & $7 E-08$ & t & $E-07$ & $E-07$ \\
\hline 31 & -06 & -08 & $E-09$ & 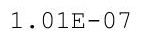 & $2.03 E-07$ & 7 & 7 \\
\hline 31 & 06 & $2 E-08$ & 09 & 07 & (1) & 07 & 07 \\
\hline 30 & -06 & 08 & 09 & $3 E-07$ & 7 & -07 & -07 \\
\hline $.11 \mathrm{E}-30$ & $2.65 \mathrm{E}-06$ & $40 \mathrm{E}-08$ & $7 E-09$ & $04 \mathrm{E}-07$ & $08 E-07$ & -07 & -07 \\
\hline $12 \mathrm{E}-30$ & $2.66 \mathrm{E}-06$ & $4 E-08$ & & $1.05 \mathrm{E}-07$ & & $68 E-07$ & $.37 E-07$ \\
\hline & -06 & $E-08$ & 09 & & & & $2 E-07$ \\
\hline $.13 \mathrm{E}-30$ & $2.70 E-06$ & $2 \mathrm{E}-08$ & $E-09$ & -01 & 7 & -07 & -07 \\
\hline $4 E-30$ & -06 & -08 & 9 & I & & -07 & $53 E-07$ \\
\hline $5-30$ & 06 & 08 & 09 & 07 & & 1 & -07 \\
\hline $.15 \mathrm{E}-30$ & $2.76 \mathrm{E}-06$ & -08 & -09 & 07 & 7 & -07 & -07 \\
\hline $.16 \mathrm{E}-30$ & $2.78 E-06$ & $9 E-08$ & $7 E-09$ & $1.12 \mathrm{E}-07$ & $23 E-07$ & $E-07$ & $69 \mathrm{E}-07$ \\
\hline-30 & $.80 E-06$ & $73 E-08$ & $4 E-09$ & $3 E-07$ & $25 E-07$ & $E-07$ & $75 E-07$ \\
\hline 30 & -06 & -08 & 09 & & & 7 & -07 \\
\hline-30 & -06 & $E-08$ & 09 & 1 & 1 & -07 & $E-07$ \\
\hline $.19 \mathrm{E}-30$ & $2.85 E-06$ & -08 & -09 & & & & -07 \\
\hline $20 E-30$ & $2.87 \mathrm{E}-06$ & $4.90 \mathrm{E}-08$ & -09 & $1.18 \mathrm{E}-$ & & -07 & -07 \\
\hline$F-30$ & $89 \mathrm{E}-06$ & 8 & 9 & $1.19 \mathrm{E}-07$ & $2.37 E-07$ & $1 E-07$ & $.03 E-07$ \\
\hline $.21 \mathrm{E}-30$ & $2.91 \mathrm{E}-06$ & $4.99 \mathrm{E}-08$ & $6 \mathrm{E}-09$ & $1.20 \mathrm{E}-07$ & $39 E-07$ & $4 E-07$ & $09 E-07$ \\
\hline 30 & $2.93 E-06$ & $3 E-08$ & $3 E-09$ & & $E-07$ & $E-07$ & $5 E-07$ \\
\hline 30 & 06 & $E-08$ & & 07 & & & -07 \\
\hline $23 E-30$ & -00 & -08 & 09 & 7 & & -07 & -07 \\
\hline $24 E-30$ & $2.99 E-06$ & $17 \mathrm{E}-08$ & $8 E-09$ & $1.25 \mathrm{E}-07$ & $2.495-01$ & $.30 E-07$ & $.33 E-07$ \\
\hline 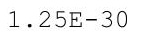 & 6 & 8 & 9 & 7 & 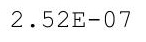 & 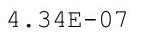 & $39 E-07$ \\
\hline $.26 \mathrm{E}-30$ & - & - & 9 & $-\sigma_{0}$ & - & - & 07 \\
\hline 30 & $05 \mathrm{~F}-06$ & $1 E-08$ & $3 E-09$ & $129 \mathrm{~F}-07$ & & $E-07$ & $2 E-07$ \\
\hline-30 & $E-06$ & $5 E-08$ & $E-09$ & 07 & 7 & $E-07$ & 07 \\
\hline $28 \mathrm{E}-30$ & $3.08 \mathrm{E}-06$ & $E-08$ & $E-09$ & $1.31 \mathrm{E}$ & 7 & 07 & $5 E-07$ \\
\hline • $29 E-30$ & $3.10 \mathrm{E}-06$ & $.45 E-08$ & $.57 E-09$ & $1.33 E-07$ & $2.03 E-01$ & $4 E-07$ & $72 E-07$ \\
\hline $.200-20$ & $3.12 E-06$ & $5.49 E-08$ & & & & & $.79 E-07$ \\
\hline L. $30 E-30$ & & & & & & & \\
\hline $315-30$ & 6 & 8 & & $1.37 \mathrm{E}-07$ & & & 07 \\
\hline $.32 E-30$ & & & & & & 7 & 07 \\
\hline & & & & & 07 & -07 & \\
\hline $.42 \mathrm{E}-30$ & $3.22 \mathrm{E}-06$ & $E-08$ & 09 & 7 & 7 & 7 & $4 E-07$ \\
\hline 30 & & $E-08$ & & 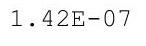 & & & -01 \\
\hline 0 & 6 & $.83 E-08$ & 9 & $+\cdots$ & & & $28 \mathrm{E}-01$ \\
\hline $.44 E-30$ & 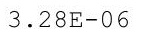 & 0 & . & \pm & & 1 & 年 \\
\hline $45 F-30$ & 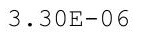 & & 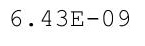 & 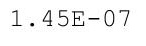 & 2.00 & 7 & 07 \\
\hline $4 E-30$ & $E-06$ & $5.98 E-08$ & $E-09$ & $1.47 \mathrm{E}$ & 2 . & 07 & -07 \\
\hline $.55 E-3$ & $3.34 E-06$ & $.03 E-08$ & $.62 E-09$ & $1.48 E-07$ & $2.90 E-07$ & $5.03 E-07$ & $9.56 \mathrm{E}-07$ \\
\hline
\end{tabular}


RESRAD-OFFSITE, Version 2.5

$\mathrm{T}^{1 / 2}$ Limit $=180$ days

Title : RESRAD-OFFSITE External Gamma, Inhalation, and Soil Ingestion for offsite Reside File : PBA-1_TC99-DOE-5-1.ROF

Summary of dose at graphical times, reptition 1 (continued)

Time

Years

$3.77 \mathrm{E}+02$

$3.78 \mathrm{E}+02$

$3.78 \mathrm{E}+02$

$3.79 \mathrm{E}+02$

$3.79 \mathrm{E}+02$

$3.80 \mathrm{E}+02$

$3.80 \mathrm{E}+02$

3. $81 \mathrm{E}+02$

$3.81 \mathrm{E}+02$

$3.82 \mathrm{E}+02$

$3.82 \mathrm{E}+02$

$3.83 \mathrm{E}+02$

$3.83 \mathrm{E}+02$

$3.84 \mathrm{E}+02$

$3.85 \mathrm{E}+02$

$3.85 \mathrm{E}+02$

$3.86 \mathrm{E}+02$

$3.86 \mathrm{E}+02$

$3.87 \mathrm{E}+02$

$3.87 \mathrm{E}+02$

$3.88 \mathrm{E}+02$

$3.88 \mathrm{E}+02$

3. $89 \mathrm{E}+02$

3. $89 \mathrm{E}+02$

3. $90 \mathrm{E}+02$

$3.90 \mathrm{E}+02$

3. $91 \mathrm{E}+02$

3. $91 \mathrm{E}+02$

3. $92 \mathrm{E}+02$

3. $92 \mathrm{E}+02$

3. $93 \mathrm{E}+02$

3. $93 \mathrm{E}+02$

$3.94 \mathrm{E}+02$

3. $94 \mathrm{E}+02$

$3.95 \mathrm{E}+02$

$3.95 \mathrm{E}+02$

3. $96 \mathrm{E}+02$

$3.96 \mathrm{E}+02$

3. $97 \mathrm{E}+02$

3. $97 \mathrm{E}+02$

$3.98 \mathrm{E}+02$

3. $98 \mathrm{E}+02$

$3.99 \mathrm{E}+02$

3. $99 \mathrm{E}+02$

$4.00 \mathrm{E}+02$

$4.00 \mathrm{E}+02$
Dose statistics at graphical times, mrem/yr

\begin{tabular}{|c|c|c|c|c|c|c|c|}
\hline inimum & aximum & Mean & ledian & $90 \%$ & $5 \%$ & $97.5 \%$ & $3 \%$ \\
\hline 0 & -06 & $E-08$ & $E-09$ & -07 & 7 & 07 & 0 \\
\hline-30 & $3 E-06$ & $E-08$ & $2 E-09$ & $1.51 E-07$ & 07 & 07 & 07 \\
\hline$E-30$ & $E-06$ & $E-08$ & $2 E-09$ & $52 E-07$ & $E-07$ & 07 & -07 \\
\hline$E-30$ & $E-06$ & $E-08$ & 9 & 7 & & 07 & -07 \\
\hline-30 & -06 & 8 & 9 & 7 & & 07 & $90 \mathrm{E}-07$ \\
\hline $62 E-30$ & -06 & -08 & -09 & 07 & 政 & 07 & -07 \\
\hline-30 & -06 & - & -09 & 土. & 1 & -07 & -06 \\
\hline $.65 E-30$ & $3.50 E-06$ & $3 E-08$ & $4 E-09$ & ; & & -07 & $E-06$ \\
\hline 30 & -06 & 08 & 09 & 7 & $r$ & 07 & -06 \\
\hline $.39 E-30$ & -06 & $E-08$ & -09 & 07 & 7 & -07 & -06 \\
\hline-30 & -06 & 8 & 9 & & & & $E-06$ \\
\hline & & & & & & & -06 \\
\hline $.40 E-30$ & $3.60 \mathrm{E}-06$ & $E-08$ & $E-09$ & $1.00 \mathrm{E}-01$ & $3.2 \angle 5-01$ & -07 & -0 \\
\hline $.45 E-30$ & -06 & $6.75 \mathrm{E}-08$ & -09 & 1.000 & & & -06 \\
\hline$E-30$ & 06 & 08 & 09 & 07 & 1 & 07 & -06 \\
\hline $.23 E-30$ & -06 & 然 & -09 & 7 & 7 & -07 & -06 \\
\hline $.29 E-30$ & $8 \mathrm{E}-06$ & $E-08$ & $E-09$ & $1.73 E-07$ & -07 & -07 & $07 E-06$ \\
\hline-30 & $0 E-06$ & $7 E-08$ & $2 E-09$ & 7 & $x^{-1}$ & -07 & $E-06$ \\
\hline-30 & -06 & -08 & -09 & 1 & & 7 & -06 \\
\hline $48 E-30$ & $E-06$ & $\mathrm{E}-08$ & -09 & 7 & 17 & 07 & -06 \\
\hline $.54 \mathrm{E}-30$ & $E-06$ & $E-08$ & -09 & $1.79 \mathrm{E}-07$ & & & $E-06$ \\
\hline $.56 \mathrm{E}-30$ & -06 & -08 & 09 & 07 & & 7 & -06 \\
\hline $.63 E-30$ & $3.80 \mathrm{E}-06$ & $7.25 \mathrm{E}-08$ & $9.24 \mathrm{E}-09$ & $1.82 \mathrm{E}-07$ & t & 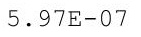 & $11 \mathrm{E}-06$ \\
\hline $.71 \mathrm{E}-30$ & $2 E-06$ & $0 E-08$ & $7 E-09$ & $1.83 \mathrm{E}-$ & 7 & $2 E-07$ & $12 \mathrm{E}-06$ \\
\hline-30 & $E-06$ & -08 & -09 & 07 & & 7 & -06 \\
\hline 29 & 06 & -08 & 09 & 7 & & & -06 \\
\hline$E-29$ & $9 E-06$ & $E-08$ & $E-09$ & $1.80 \mathrm{E}-01$ & -01 & -07 & -06 \\
\hline $.45 E-27$ & $3.91 \mathrm{E}-06$ & $7.53 E-08$ & $9.90 E-09$ & $1.89 \mathrm{E}-07$ & $3.62 \mathrm{E}-07$ & $20 \mathrm{E}-07$ & $.14 \mathrm{E}-06$ \\
\hline $.33 E-26$ & $3.93 E-06$ & $7.59 \mathrm{E}-08$ & $1.00 \mathrm{E}-08$ & $1.90 \mathrm{E}-07$ & 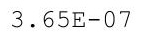 & T & $.15 \mathrm{E}-06$ \\
\hline . & $3.95 E-06$ & 至 & $\begin{array}{l}\cdot 0 \angle-00 \\
\end{array}$ & 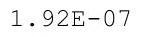 & - & r & 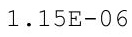 \\
\hline 24 & $E-06$ & $E-08$ & $3 E-08$ & $3 E-07$ & 7 & 7 & -06 \\
\hline-23 & $E-06$ & $E-08$ & $E-08$ & $5 E-07$ & 7 & 7 & -06 \\
\hline $.32 E-22$ & $4.01 \mathrm{E}-06$ & $7.82 \mathrm{E}-08$ & $6 \mathrm{E}-08$ & $1.96 \mathrm{E}-07$ & 每 & 07 & $17 E-06$ \\
\hline $.31 \mathrm{E}-21$ & $4.03 E-06$ & $7.88 E-08$ & $1.07 \mathrm{E}-08$ & $1.98 \mathrm{E}-07$ & $3.79 \mathrm{E}-07$ & $48 \mathrm{E}-07$ & $.18 \mathrm{E}-06$ \\
\hline $.05 E-20$ & $4.05 E-06$ & $7.94 \mathrm{E}-08$ & & & & & $\begin{array}{ll}-10 \mathrm{~L}-00 \\
0\end{array}$ \\
\hline 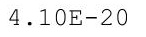 & & & & & & & \\
\hline & & & & & & & \\
\hline 9 & 6 & 8 & 8 & 7 & 7 & 07 & 26 \\
\hline 8 & 4 & 8 & 8 & 7 & -07 & -07 & \\
\hline $.13 E-18$ & $E-06$ & $E-08$ & $6 E-08$ & 7 & 7 & 7 & $1 E-06$ \\
\hline 8 & & & & & & & -00 \\
\hline $65 E-17$ & & $.36 E-08$ & & $10 E-07$ & & & $.23 E-06$ \\
\hline$\cdot 44 \mathrm{E}-17$ & & 0 & & 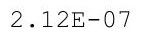 & & & 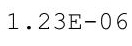 \\
\hline $0.005-11$ & & & & t & 1 & 1 & - \\
\hline$E-16$ & 06 & 8 & 08 & 07 & 7 & 07 & 1.24 \\
\hline $.32 E-16$ & $4.28 E-06$ & $.61 E-08$ & $1.25 E-08$ & $2.16 \mathrm{E}-07$ & $4.17 E-07$ & $6.99 \mathrm{E}-07$ & $1.25 \mathrm{E}-06$ \\
\hline
\end{tabular}


RESRAD-OFFSITE, Version 2.5

$\mathrm{T}^{1 / 2}$ Limit $=180$ days

Title : RESRAD-OFFSITE External Gamma, Inhalation, and Soil Ingestion for offsite Reside File : PBA-1_TC99-DOE-5-1.ROF

Summary of dose at graphical times, reptition 1 (continued)

Time

Years

4. $01 \mathrm{E}+02$

$4.01 \mathrm{E}+02$

$4.02 E+02$

4. $02 \mathrm{E}+02$

$4.03 E+02$

$4.03 \mathrm{E}+02$

4. $04 \mathrm{E}+02$

4. $05 \mathrm{E}+02$

$4.05 \mathrm{E}+02$

4. $06 \mathrm{E}+02$

$4.06 \mathrm{E}+02$

$4.07 \mathrm{E}+02$

$4.07 \mathrm{E}+02$

$4.08 \mathrm{E}+02$

$4.08 \mathrm{E}+02$

$4.09 \mathrm{E}+02$

$4.09 \mathrm{E}+02$

$4.10 \mathrm{E}+02$

$4.10 \mathrm{E}+02$

$4.11 \mathrm{E}+02$

$4.11 \mathrm{E}+02$

$4.12 \mathrm{E}+02$

$4.12 \mathrm{E}+02$

$4.13 \mathrm{E}+02$

$4.13 \mathrm{E}+02$

$4.14 \mathrm{E}+02$

$4.14 \mathrm{E}+02$

$4.15 \mathrm{E}+02$

$4.15 \mathrm{E}+02$

$4.16 \mathrm{E}+02$

$4.16 \mathrm{E}+02$

$4.17 \mathrm{E}+02$

$4.17 \mathrm{E}+02$

$4.18 \mathrm{E}+02$

$4.18 \mathrm{E}+02$

4. $19 \mathrm{E}+02$

$4.19 \mathrm{E}+02$

$4.20 \mathrm{E}+02$

$4.20 \mathrm{E}+02$

$4.21 \mathrm{E}+02$

$4.21 \mathrm{E}+02$

$4.22 \mathrm{E}+02$

$4.22 \mathrm{E}+02$

$4.23 E+02$

$4.23 E+02$

4. $24 \mathrm{E}+02$

Dose statistics at graphical times, mrem/yr

\begin{tabular}{|c|c|c|c|c|c|c|c|}
\hline Minimum & Maximum & Mean & Median & $90 \%$ & $95 \%$ & $97.5 \%$ & $99 \%$ \\
\hline $4.03 E-16$ & $4.30 E-06$ & $8.67 E-08$ & 1. $26 \mathrm{E}-08$ & $2.18 E-07$ & $4.20 E-07$ & $7.04 \mathrm{E}-07$ & $1.26 \mathrm{E}-06$ \\
\hline $6.77 E-16$ & $4.32 \mathrm{E}-06$ & $8.74 \mathrm{E}-08$ & $1.28 \mathrm{E}-08$ & $2.20 \mathrm{E}-07$ & $4.23 E-07$ & $7.08 \mathrm{E}-07$ & $1.26 \mathrm{E}-06$ \\
\hline $1.10 \mathrm{E}-15$ & $4.34 E-06$ & $8.80 E-08$ & 1. $30 \mathrm{E}-08$ & $2.22 \mathrm{E}-07$ & $4.26 \mathrm{E}-07$ & $7.13 \mathrm{E}-07$ & $1.27 \mathrm{E}-06$ \\
\hline $1.75 \mathrm{E}-15$ & $4.36 \mathrm{E}-06$ & $8.86 \mathrm{E}-08$ & $1.31 \mathrm{E}-08$ & $2.24 \mathrm{E}-07$ & $4.29 \mathrm{E}-07$ & $7.18 \mathrm{E}-07$ & $1.27 \mathrm{E}-06$ \\
\hline $2.70 \mathrm{E}-15$ & $4.38 \mathrm{E}-06$ & $8.93 E-08$ & $1.33 E-08$ & $.26 \mathrm{E}-07$ & $.31 \mathrm{E}-07$ & $.23 E-07$ & $.28 E-06$ \\
\hline $4.07 E-15$ & $4.40 \mathrm{E}-06$ & $8.99 \mathrm{E}-08$ & $1.35 \mathrm{E}-08$ & $.28 E-07$ & $34 \mathrm{E}-07$ & $7.28 \mathrm{E}-07$ & $.29 E-06$ \\
\hline $6.01 \mathrm{E}-15$ & $4.42 E-06$ & $9.06 \mathrm{E}-08$ & $1.36 \mathrm{E}-08$ & $2.30 \mathrm{E}-07$ & $4.37 \mathrm{E}-07$ & $7.33 \mathrm{E}-07$ & $1.29 \mathrm{E}-06$ \\
\hline $8.69 \mathrm{E}-15$ & $4.44 \mathrm{E}-06$ & $9.12 \mathrm{E}-08$ & $1.38 \mathrm{E}-08$ & $2.31 \mathrm{E}-07$ & $4.40 \mathrm{E}-07$ & $7.37 \mathrm{E}-07$ & $1.30 \mathrm{E}-06$ \\
\hline $1.23 E-14$ & $4.46 \mathrm{E}-06$ & $9.18 \mathrm{E}-08$ & $1.40 \mathrm{E}-08$ & $2.33 E-07$ & $4.42 \mathrm{E}-07$ & 7. $42 \mathrm{E}-07$ & $1.30 \mathrm{E}-06$ \\
\hline $1.72 \mathrm{E}-14$ & $4.48 E-06$ & $9.25 \mathrm{E}-08$ & $.42 \mathrm{E}-08$ & $.35 E-07$ & $.45 E-07$ & $7.47 \mathrm{E}-07$ & $1.31 \mathrm{E}-06$ \\
\hline $2.37 E-14$ & $4.50 \mathrm{E}-06$ & $9.32 \mathrm{E}-08$ & $1.44 E-08$ & $.37 E-07$ & $.48 E-07$ & $.52 E-07$ & $.32 E-06$ \\
\hline $3.21 \mathrm{E}-14$ & $4.53 \mathrm{E}-06$ & $9.38 \mathrm{E}-08$ & $1.45 E-08$ & $2.38 \mathrm{E}-07$ & $4.51 \mathrm{E}-07$ & $7.57 \mathrm{E}-07$ & $1.32 \mathrm{E}-06$ \\
\hline $4.30 E-14$ & $4.55 E-06$ & $9.45 \mathrm{E}-08$ & $1.47 \mathrm{E}-08$ & $2.40 \mathrm{E}-07$ & $4.53 E-07$ & $7.62 \mathrm{E}-07$ & $1.33 \mathrm{E}-06$ \\
\hline $5.67 \mathrm{E}-14$ & $4.57 \mathrm{E}-06$ & $9.51 \mathrm{E}-08$ & $1.49 \mathrm{E}-08$ & $2.42 \mathrm{E}-07$ & $4.56 \mathrm{E}-07$ & $7.67 \mathrm{E}-07$ & $1.34 \mathrm{E}-06$ \\
\hline 7. $39 \mathrm{E}-14$ & $4.59 \mathrm{E}-06$ & $9.58 \mathrm{E}-08$ & $1.50 \mathrm{E}-08$ & $2.44 \mathrm{E}-07$ & $4.59 \mathrm{E}-07$ & $7.72 \mathrm{E}-07$ & $1.34 \mathrm{E}-06$ \\
\hline $9.53 E-14$ & $4.61 \mathrm{E}-06$ & $9.65 \mathrm{E}-08$ & $1.52 \mathrm{E}-08$ & $.46 \mathrm{E}-07$ & $.61 \mathrm{E}-07$ & $7.77 \mathrm{E}-07$ & $1.35 \mathrm{E}-06$ \\
\hline $1.22 \mathrm{E}-13$ & $4.63 E-06$ & $9.71 \mathrm{E}-08$ & $1.54 \mathrm{E}-08$ & $47 E-07$ & $.64 \mathrm{E}-07$ & $7.82 \mathrm{E}-07$ & $.35 E-06$ \\
\hline 1. $53 \mathrm{E}-13$ & $4.65 \mathrm{E}-06$ & $9.78 \mathrm{E}-08$ & $1.55 E-08$ & $2.49 E-07$ & $4.67 \mathrm{E}-07$ & $7.87 \mathrm{E}-07$ & $1.36 \mathrm{E}-06$ \\
\hline $1.92 \mathrm{E}-13$ & $4.67 \mathrm{E}-06$ & $9.85 \mathrm{E}-08$ & $1.57 \mathrm{E}-08$ & $2.51 E-07$ & $4.70 \mathrm{E}-07$ & $7.92 \mathrm{E}-07$ & $1.37 \mathrm{E}-06$ \\
\hline $2.38 E-13$ & $4.69 \mathrm{E}-06$ & $9.92 \mathrm{E}-08$ & $1.59 \mathrm{E}-08$ & $2.53 \mathrm{E}-07$ & $4.73 E-07$ & $7.97 \mathrm{E}-07$ & $1.37 \mathrm{E}-06$ \\
\hline $2.92 \mathrm{E}-13$ & $4.71 \mathrm{E}-06$ & $9.99 \mathrm{E}-08$ & $1.61 \mathrm{E}-08$ & $.54 \mathrm{E}-07$ & $4.76 \mathrm{E}-07$ & $8.01 \mathrm{E}-07$ & $1.38 \mathrm{E}-06$ \\
\hline $3.56 \mathrm{E}-13$ & $4.73 E-06$ & $1.01 \mathrm{E}-07$ & $63 E-08$ & $56 E-07$ & $4.79 \mathrm{E}-07$ & $8.05 E-07$ & $.39 E-06$ \\
\hline $4 \cdot 31 E-13$ & $4.75 \mathrm{E}-06$ & $1.01 \mathrm{E}-07$ & $1.65 \mathrm{E}-08$ & $2.58 \mathrm{E}-07$ & $4.82 \mathrm{E}-07$ & $8.09 \mathrm{E}-07$ & $.39 E-06$ \\
\hline $5.18 \mathrm{E}-13$ & $4.77 \mathrm{E}-06$ & $1.02 \mathrm{E}-07$ & $1.67 \mathrm{E}-08$ & $2.60 \mathrm{E}-07$ & $4.85 E-07$ & $8.13 \mathrm{E}-07$ & $1.40 \mathrm{E}-06$ \\
\hline $6.18 E-13$ & $4.79 E-06$ & $1.03 E-07$ & $1.69 \mathrm{E}-08$ & $2.62 E-07$ & $4.88 E-07$ & $8.17 \mathrm{E}-07$ & $1.41 \mathrm{E}-06$ \\
\hline 7. $33 E-13$ & $4.81 \mathrm{E}-06$ & $1.03 E-07$ & $1.71 \mathrm{E}-08$ & $2.63 E-07$ & $4.91 \mathrm{E}-07$ & $8.21 \mathrm{E}-07$ & $1.41 \mathrm{E}-06$ \\
\hline $8.64 \mathrm{E}-13$ & $4.84 \mathrm{E}-06$ & $1.04 \mathrm{E}-07$ & $1.73 E-08$ & $2.65 \mathrm{E}-07$ & $4.94 \mathrm{E}-07$ & $8.25 \mathrm{E}-07$ & $1.42 \mathrm{E}-06$ \\
\hline $1.01 \mathrm{E}-12$ & $4.86 \mathrm{E}-06$ & $1.05 \mathrm{E}-07$ & $1.76 \mathrm{E}-08$ & $2.67 \mathrm{E}-07$ & $4.97 \mathrm{E}-07$ & $8.29 E-07$ & $1.43 E-06$ \\
\hline $1.18 \mathrm{E}-12$ & $4.88 E-06$ & $1.05 \mathrm{E}-07$ & $1.78 E-08$ & $.69 \mathrm{E}-07$ & $5.00 \mathrm{E}-07$ & $8.32 \mathrm{E}-07$ & $1.43 E-06$ \\
\hline 1. $36 \mathrm{E}-12$ & $4.90 \mathrm{E}-06$ & $1.06 \mathrm{E}-07$ & $1.80 \mathrm{E}-08$ & $2.70 \mathrm{E}-07$ & $5.03 E-07$ & $8.36 \mathrm{E}-07$ & $1.44 \mathrm{E}-06$ \\
\hline $1.57 \mathrm{E}-12$ & $4.92 E-06$ & $1.07 \mathrm{E}-07$ & $1.82 \mathrm{E}-08$ & $2.72 \mathrm{E}-07$ & $5.06 \mathrm{E}-07$ & $8.40 \mathrm{E}-07$ & $1.45 \mathrm{E}-06$ \\
\hline $1.80 \mathrm{E}-12$ & $4.94 \mathrm{E}-06$ & $1.08 \mathrm{E}-07$ & $1.84 \mathrm{E}-08$ & $2.74 \mathrm{E}-07$ & $5.09 \mathrm{E}-07$ & $8.43 E-07$ & $1.45 \mathrm{E}-06$ \\
\hline $2.06 \mathrm{E}-12$ & $4.96 \mathrm{E}-06$ & $1.08 E-07$ & $1.86 E-08$ & $2.75 E-07$ & $5.12 \mathrm{E}-07$ & $8.47 \mathrm{E}-07$ & $1.46 \mathrm{E}-06$ \\
\hline $2.34 \mathrm{E}-12$ & $4.98 E-06$ & $1.09 \mathrm{E}-07$ & $1.88 \mathrm{E}-08$ & $2.77 \mathrm{E}-07$ & $5.15 \mathrm{E}-07$ & $8.51 E-07$ & $1.47 \mathrm{E}-06$ \\
\hline $2.65 E-12$ & $5.00 \mathrm{E}-06$ & $1.10 \mathrm{E}-07$ & $1.91 E-08$ & $2.79 E-07$ & $5.19 \mathrm{E}-07$ & $8.54 \mathrm{E}-07$ & $1.47 \mathrm{E}-06$ \\
\hline $2.99 E-12$ & $5.02 E-06$ & $1.10 \mathrm{E}-07$ & $1.93 E-08$ & $2.81 E-07$ & $5.23 E-07$ & $8.58 \mathrm{E}-07$ & $1.48 E-06$ \\
\hline $3.36 \mathrm{E}-12$ & $5.04 \mathrm{E}-06$ & $1.11 \mathrm{E}-07$ & $1.95 \mathrm{E}-08$ & $2.82 E-07$ & $5.26 \mathrm{E}-07$ & $8.61 E-07$ & $1.49 \mathrm{E}-06$ \\
\hline $3.76 \mathrm{E}-12$ & $5.06 \mathrm{E}-06$ & $1.12 \mathrm{E}-07$ & $1.97 \mathrm{E}-08$ & $2.84 \mathrm{E}-07$ & $5.29 \mathrm{E}-07$ & $8.64 \mathrm{E}-07$ & $1.49 \mathrm{E}-06$ \\
\hline $4.20 E-12$ & . & $1.13 \mathrm{E}-07$ & $1.99 E-08$ & $2.86 \mathrm{E}-07$ & $5.33 E-07$ & $8.68 \mathrm{E}-07$ & $1.50 \mathrm{E}-06$ \\
\hline $4.66 \mathrm{E}-12$ & $5.10 \mathrm{E}-06$ & $1.13 \mathrm{E}-07$ & $2.01 \mathrm{E}-08$ & $2.88 \mathrm{E}-07$ & $5.36 \mathrm{E}-07$ & $8.71 \mathrm{E}-07$ & $1.51 \mathrm{E}-06$ \\
\hline $5.17 \mathrm{E}-12$ & $5.12 \mathrm{E}-06$ & $1.14 \mathrm{E}-07$ & $2.04 \mathrm{E}-08$ & $2.90 \mathrm{E}-07$ & $5.39 \mathrm{E}-07$ & $8.76 \mathrm{E}-07$ & $1.51 \mathrm{E}-06$ \\
\hline $5.71 \mathrm{E}-12$ & $5.14 \mathrm{E}-06$ & $1.15 \mathrm{E}-07$ & $2.06 E-08$ & $2.92 \mathrm{E}-07$ & $5.43 E-07$ & $8.81 \mathrm{E}-07$ & $1.52 \mathrm{E}-06$ \\
\hline $6.29 \mathrm{E}-12$ & $5.16 \mathrm{E}-06$ & $1.16 \mathrm{E}-07$ & $2.08 \mathrm{E}-08$ & $2.94 \mathrm{E}-07$ & $5.46 \mathrm{E}-07$ & $8.85 \mathrm{E}-07$ & $1.53 \mathrm{E}-06$ \\
\hline $6.91 \mathrm{E}-12$ & $5.18 \mathrm{E}-06$ & $1.16 \mathrm{E}-07$ & $2.11 \mathrm{E}-08$ & $2.96 \mathrm{E}-07$ & $5.49 \mathrm{E}-07$ & $8.90 \mathrm{E}-07$ & $1.53 \mathrm{E}-06$ \\
\hline $7.57 \mathrm{E}-12$ & $5.21 \mathrm{E}-06$ & $1.17 \mathrm{E}-07$ & $2.13 E-08$ & $2.98 E-07$ & $5.53 E-07$ & $8.94 \mathrm{E}-07$ & $1.54 \mathrm{E}-06$ \\
\hline $8.27 E-12$ & $5.23 E-06$ & $1.18 \mathrm{E}-07$ & $2.15 E-08$ & $3.01 \mathrm{E}-07$ & $5.56 \mathrm{E}-07$ & $8.99 \mathrm{E}-07$ & $1.54 \mathrm{E}-06$ \\
\hline
\end{tabular}


RESRAD-OFFSITE, Version 2.5 
RESRAD-OFFSITE, Version 2.5 
RESRAD-OFFSITE, Version 2.5 
RESRAD-OFFSITE, Version 2.5 
RESRAD-OFFSITE, Version 2.5

$\mathrm{T}^{1 / 2}$ Limit $=180$ days

Title : RESRAD-OFFSITE External Gamma, Inhalation, and Soil Ingestion for offsite Reside File : PBA-1_TC99-DOE-5-1.ROF

Summary of dose at graphical times, reptition 1 (continued)

Time

Years

$5.19 \mathrm{E}+02$

$5.19 \mathrm{E}+02$

$5.20 \mathrm{E}+02$

$5.20 \mathrm{E}+02$

$5.21 \mathrm{E}+02$

$5.21 E+02$

$5.22 E+02$

$5.22 \mathrm{E}+02$

$5.23 E+02$

$5.23 E+02$

$5.24 \mathrm{E}+02$

$5.24 \mathrm{E}+02$

$5.25 \mathrm{E}+02$

$5.26 \mathrm{E}+02$

$5.26 \mathrm{E}+02$

$5.27 \mathrm{E}+02$

$5.27 \mathrm{E}+02$

$5.28 \mathrm{E}+02$

$5.28 \mathrm{E}+02$

$5.29 \mathrm{E}+02$

$5.29 \mathrm{E}+02$

$5.30 \mathrm{E}+02$

$5.30 \mathrm{E}+02$

$5.31 \mathrm{E}+02$

$5.31 \mathrm{E}+02$

$5.32 \mathrm{E}+02$

$5.32 \mathrm{E}+02$

$5.33 \mathrm{E}+02$

$5.33 \mathrm{E}+02$

$5.34 \mathrm{E}+02$

$5.34 \mathrm{E}+02$

$5.35 \mathrm{E}+02$

$5.35 \mathrm{E}+02$

$5.36 \mathrm{E}+02$

$5.36 \mathrm{E}+02$

$5.37 \mathrm{E}+02$

$5.37 \mathrm{E}+02$

$5.38 \mathrm{E}+02$

$5.38 \mathrm{E}+02$

$5.39 \mathrm{E}+02$

$5.39 \mathrm{E}+02$

$5.40 \mathrm{E}+02$

$5.40 \mathrm{E}+02$

$5.41 \mathrm{E}+02$

$5.41 \mathrm{E}+02$

$5.42 \mathrm{E}+02$

Dose statistics at graphical times, mrem/yr

\begin{tabular}{|c|c|c|c|c|c|c|c|}
\hline $\mathrm{m}$ & um & Mean & ledian & & & & \\
\hline-09 & -06 & -07 & 07 & 07 & -06 & -06 & -0 \\
\hline $.18 E-09$ & $.38 E-06$ & $4 E-07$ & 07 & 07 & 06 & -06 & -06 \\
\hline-09 & $.40 \mathrm{E}-06$ & $06 \mathrm{E}-07$ & -07 & $7.87 \mathrm{E}-07$ & $30 E-06$ & -06 & $E-06$ \\
\hline$F-09$ & -06 & $07 F-07$ & $05 \mathrm{~F}-07$ & $90 F-07$ & $30 \mathrm{~F}-06$ & -06 & $38 \mathrm{~F}-0$ \\
\hline 09 & 06 & 7 & 7 & 7 & 6 & 06 & -06 \\
\hline 09 & 06 & 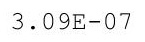 & & & & & -06 \\
\hline $25 E-09$ & 06 & & & & & & -06 \\
\hline $.27 E-09$ & -06 & 7 & 7 & 07 & 6 & -06 & -06 \\
\hline $3 E-09$ & -06 & $3 E-07$ & 7 & $E-07$ & 06 & -06 & -06 \\
\hline 09 & -06 & $3.14 \mathrm{E}-07$ & 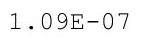 & & $1.33 E-06$ & 06 & $-06 r a r a r$ \\
\hline 9 & 06 & & & & 1. $33 \mathrm{E}-06$ & 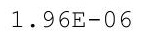 & -0 \\
\hline $33 E-09$ & $50 F-06$ & 7 & 7 & $6 E-07$ & 6 & 06 & -06 \\
\hline $.34 \mathrm{E}-09$ & $8.51 E-06$ & $3.18 \mathrm{E}-07$ & & & & & -06 \\
\hline $36 \mathrm{E}-09$ & $3.53 \mathrm{E}-06$ & $3.19 \mathrm{E}-07$ & $1.12 \mathrm{E}-07$ & $8.23 E-07$ & & $1.97 \mathrm{E}-06$ & $z-06$ \\
\hline-09 & -06 & $1 E-07$ & & $5 E-07$ & & -06 & -06 \\
\hline 09 & 6 & קרת קר & 的 & & 0 & 6 & 06 \\
\hline$E-09$ & & & & & & & $96 \mathrm{E}-06$ \\
\hline 9 & & $3.24 \mathrm{E}-07$ & & & & 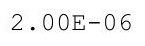 & 0 \\
\hline $.44 \mathrm{E}-09$ & $8.58 E-06$ & $3.26 \mathrm{E}-07$ & $1.16 \mathrm{E}-07$ & $8.40 E-07$ & 1. $37 \mathrm{E}-06$ & $E-06$ & $98 E-06$ \\
\hline $45 E-09$ & $9 E-06$ & $.27 \mathrm{E}-07$ & $1.16 \mathrm{E}-07$ & $.44 \mathrm{E}-07$ & & -06 & $8 E-06$ \\
\hline 09 & 06 & $8 \mathrm{~F}_{-}$ & & & & & -06 \\
\hline & & & & & & & 06 \\
\hline . & & & & & & & \\
\hline-09 & 6 & 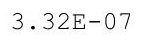 & 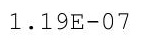 & & 0 & 0 & 0 \\
\hline 9 & 6 & 325 & $O E$ & 7 & $1.40 \mathrm{E}-06$ & 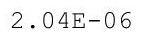 & 0 \\
\hline $5 E-09$ & $.66 E-06$ & $35 E-07$ & 1.21E-07 & $5 E-07$ & $1.40 \mathrm{E}-0$ & $5 E-06$ & $F-06$ \\
\hline-09 & $67 \mathrm{~F}-06$ & & 1 & & & $5 F-06$ & $-06+2 \cdot a+2$ \\
\hline & & & & & & & -0 \\
\hline 9 & & & & & & & \\
\hline $.63 E-09$ & $8.10 \pm-06$ & . & $1 \cdot 245-4$ & $8.79 \mathrm{E}-07$ & 1.124 & $5-06$ & $5-0$ \\
\hline $65 E-09$ & $8.71 \mathrm{E}-06$ & 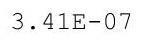 & 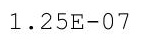 & $.83 E-07$ & 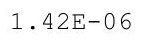 & $2.07 \mathrm{~L}-00$ & 40 \\
\hline 9 & $8.72 \mathrm{E}-06$ & 舟 & 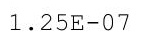 & & & & 年 \\
\hline $7-09$ & $F-06$ & & & & & & \\
\hline & & & & & & & 0 \\
\hline$E-09$ & $8.75 E-06$ & 7 & & & & & -0 \\
\hline $.74 \mathrm{E}-09$ & $8.76 E-06$ & $3.48 \mathrm{E}-07$ & $1.28 \mathrm{E}-07$ & $0 E-07$ & $\perp \cdot 4 J \amalg$ & 66 & -0 \\
\hline $.16 \mathrm{-}-09$ & $8.77 \mathrm{E}-06$ & $3.495-01$ & 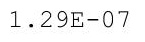 & $9.04 E-01$ & $1.45 \mathrm{~L}-00$ & & $3 . \perp J E-0$ \\
\hline $78 E-09$ & & & & & & & \\
\hline 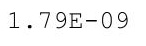 & & - & - & & & & $14 \mathrm{E}-06$ \\
\hline 9 & & 7 & & 7 & 6 & 6 & 06 \\
\hline $3 E-09$ & & & & $3 E-07$ & 1 . & 06 & \\
\hline 09 & $8.82 \mathrm{E}-06$ & $55 E-07$ & $1.33 E-07$ & $2 E-07$ & 1 . & 06 & 06 \\
\hline & & & & & & & \\
\hline & & & & & $\perp \cdot$ & & c \\
\hline & 06 & & & & & & 00 \\
\hline 9 & $E-06$ & -07 & $.36 E-07$ & $5 E-07$ & -06 & -06 & -06 \\
\hline
\end{tabular}


RESRAD-OFFSITE, Version 2.5

$\mathrm{T}^{1 / 2}$ Limit $=180$ days

Title : RESRAD-OFFSITE External Gamma, Inhalation, and Soil Ingestion for offsite Reside File : PBA-1_TC99-DOE-5-1.ROF

Summary of dose at graphical times, reptition 1 (continued)

Time

Years

$5.42 \mathrm{E}+02$

$5.43 \mathrm{E}+02$

$5.43 \mathrm{E}+02$

$5.44 \mathrm{E}+02$

$5.44 \mathrm{E}+02$

$5.45 \mathrm{E}+02$

$5.46 \mathrm{E}+02$

$5.46 \mathrm{E}+02$

$5.47 \mathrm{E}+02$

$5.47 \mathrm{E}+02$

$5.48 \mathrm{E}+02$

$5.48 \mathrm{E}+02$

$5.49 \mathrm{E}+02$

$5.49 \mathrm{E}+02$

$5.50 \mathrm{E}+02$

$5.50 \mathrm{E}+02$

$5.51 \mathrm{E}+02$

$5.51 \mathrm{E}+02$

$5.52 \mathrm{E}+02$

$5.52 \mathrm{E}+02$

$5.53 \mathrm{E}+02$

$5.53 \mathrm{E}+02$

$5.54 \mathrm{E}+02$

$5.54 \mathrm{E}+02$

$5.55 \mathrm{E}+02$

$5.55 \mathrm{E}+02$

$5.56 \mathrm{E}+02$

$5.56 \mathrm{E}+02$

$5.57 \mathrm{E}+02$

$5.57 \mathrm{E}+02$

$5.58 \mathrm{E}+02$

$5.58 \mathrm{E}+02$

$5.59 \mathrm{E}+02$

$5.59 \mathrm{E}+02$

$5.60 \mathrm{E}+02$

$5.60 \mathrm{E}+02$

$5.61 \mathrm{E}+02$

$5.61 \mathrm{E}+02$

$5.62 \mathrm{E}+02$

$5.62 \mathrm{E}+02$

$5.63 \mathrm{E}+02$

$5.63 \mathrm{E}+02$

$5.64 \mathrm{E}+02$

$5.64 \mathrm{E}+02$

$5.65 \mathrm{E}+02$

$5.66 \mathrm{E}+02$
Dose statistics at graphical times, mrem/yr

\begin{tabular}{|c|c|c|c|c|c|c|c|}
\hline inimum & aximum & Mean & ledian & $90 \%$ & $5 \%$ & $97.5 \%$ & $\%$ \\
\hline 09 & -06 & $3.62 E-07$ & $1.37 \mathrm{E}-07$ & $8 E-07$ & $1.49 \mathrm{E}-06$ & $5 E-06$ & $E-0$ \\
\hline 09 & -06 & $E-07$ & 7 & 7 & 6 & 06 & -06 \\
\hline$E-09$ & -06 & -07 & 07 & 07 & 6 & 06 & -06 \\
\hline-09 & 06 & & & & & & -06 \\
\hline $.04 E-09$ & -06 & 7 & & & 06 & -06 & $22 E-06$ \\
\hline $.06 E-09$ & -06 & -07 & -07 & -07 & -06 & -06 & $23 E-06$ \\
\hline 09 & 06 & 7 & 7 & 7 & 6 & -06 & $23 \mathrm{E}-0$ \\
\hline 09 & 06 & ( & & & - & 06 & -06 \\
\hline 09 & 06 & 1 & 7 & 7 & 6 & 06 & 06 \\
\hline $.15 E-09$ & $5 E-06$ & $4 E-07$ & $4 E-07$ & -07 & $52 E-06$ & -06 & $8-06$ \\
\hline-09 & -06 & 7 & & & 6 & 06 & $6 E-06$ \\
\hline-09 & -06 & 7 & 7 & 7 & & -06 & $E-06$ \\
\hline $21 E-09$ & $3 E-06$ & (2) & $E-07$ & -07 & -00 & -06 & -0 \\
\hline 9 & 06 & $3.79 \mathrm{E}-07$ & & 1 & & 6 & 0 \\
\hline 09 & 06 & S & 7 & & & & -06 \\
\hline $3 E-09$ & 6 & $3.82 \mathrm{E}-07$ & 7 & 7 & 6 & 6 & -06 \\
\hline $.30 E-09$ & $1 E-06$ & $3 E-07$ & $1.50 \mathrm{E}-07$ & $4 E-07$ & $1.56 \mathrm{E}-06$ & $3 E-06$ & $.30 E-06$ \\
\hline$E-09$ & $2 E-06$ & $5 E-07$ & 7 & $7 E-07$ & $6 E-06$ & $3 E-06$ & $E-06$ \\
\hline 09 & -06 & 1 & 7 & 06 & & -06 & -06 \\
\hline 09 & 06 & 1 & 1 & 6 & 6 & -06 & -06 \\
\hline $.40 \mathrm{E}-09$ & -06 & 开 & & & & - & -06 \\
\hline 09 & 06 & $3.90 \mathrm{E}-07$ & 7 & 6 & 0 & 6 & 6 \\
\hline $45 E-09$ & -06 & 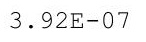 & $5 \mathrm{E}-$ & 6 & $59 \mathrm{E}-$ & -06 & $34 E-06$ \\
\hline $.47 E-09$ & $.07 E-06$ & $.93 E-07$ & $6 \mathrm{E}-07$ & $2 E-06$ & $1.59 \mathrm{E}-06$ & $6 E-06$ & $34 \mathrm{E}-06$ \\
\hline-09 & $8 E-06$ & $94 \mathrm{~F}-07$ & & $2 E-06$ & 06 & $7 F-06$ & $E-06$ \\
\hline 09 & & & & & & & 06 \\
\hline $.54 \mathrm{E}-09$ & -06 & 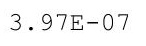 & 7 & & & 0 & -06 \\
\hline $.57 E-09$ & $10 E-06$ & $20 \mathrm{D}-\mathrm{t}$ & $.60 \mathrm{E}-07$ & $3 E-06$ & $1.01 \mathrm{~L}-0$ & $.28 E-06$ & $37 E-06$ \\
\hline 09 & 6 & 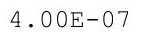 & - & 6 & - & $8 E-06$ & -06 \\
\hline 年 & ter & - & 然 & 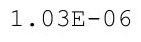 & -5 & . & - \\
\hline$F-09$ & $2 F-06$ & $3 E-07$ & & & & $9 E-06$ & $9 E-06$ \\
\hline$E-09$ & $F-06$ & $5-07$ & $E-07$ & & & 6 & \\
\hline & & & & & & 6 & \\
\hline $.72 E-09$ & $9.15 \mathrm{E}-06$ & $4.07 E-07$ & $1.65 \mathrm{E}-07$ & $1.04 \mathrm{E}-06$ & $1.64 \mathrm{E}-06$ & $1 E-06$ & $41 E-06$ \\
\hline $.75 E-09$ & $9.15 E-06$ & $4.00 \mathrm{D}-\mathrm{t}$ & & & & & $\cdot 4 \perp-4-0$ \\
\hline 年 & & & & & & & \\
\hline a & 6 & & & & 6 & & he \\
\hline & & & & & & & 06 \\
\hline 09 & & & & 06 & -06 & -06 & 06 \\
\hline $.88 E-09$ & $9.19 \mathrm{E}-06$ & $5 E-07$ & $1.71 \mathrm{E}-07$ & 06 & 6 & & $5 E-06$ \\
\hline 9 & 06 & 1 & & & & & -0 \\
\hline 9 & & & & 6 & & $2.35 \mathrm{E}-06$ & $105-06$ \\
\hline 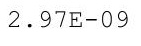 & & & 7 & 土. & ( & $35 E-06$ & c \\
\hline 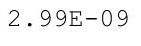 & -4 & - & & te & $1.69 \mathrm{E}-06$ & . 0.0 & the \\
\hline $2 E-09$ & $9.22 \mathrm{E}-06$ & $4.22 E-07$ & $6 E-07$ & 1. & 1 . & -06 & $.48 E-06$ \\
\hline $.05 E-$ & $9.23 E-06$ & $.23 E-07$ & $1.77 \mathrm{E}-07$ & $1.07 \mathrm{E}-06$ & $1.70 \mathrm{E}-06$ & $2.37 \mathrm{E}-06$ & $3.48 E-06$ \\
\hline
\end{tabular}


RESRAD-OFFSITE, Version 2.5

$\mathrm{T}^{1 / 2}$ Limit $=180$ days

Title : RESRAD-OFFSITE External Gamma, Inhalation, and Soil Ingestion for Offsite Reside File : PBA-1_TC99-DOE-5-1.ROF

Summary of dose at graphical times, reptition 1 (continued)

Time

Years

$5.66 \mathrm{E}+02$

$5.67 \mathrm{E}+02$

$5.67 \mathrm{E}+02$

$5.68 \mathrm{E}+02$

$5.68 \mathrm{E}+02$

$5.69 \mathrm{E}+02$

$5.69 \mathrm{E}+02$

$5.70 \mathrm{E}+02$

$5.70 \mathrm{E}+02$

$5.71 \mathrm{E}+02$

$5.71 \mathrm{E}+02$

$5.72 \mathrm{E}+02$

$5.72 \mathrm{E}+02$

$5.73 \mathrm{E}+02$

$5.73 \mathrm{E}+02$

$5.74 \mathrm{E}+02$

$5.74 \mathrm{E}+02$

$5.75 \mathrm{E}+02$

$5.75 \mathrm{E}+02$

$5.76 \mathrm{E}+02$

$5.76 \mathrm{E}+02$

$5.77 \mathrm{E}+02$

$5.77 \mathrm{E}+02$

$5.78 \mathrm{E}+02$

$5.78 \mathrm{E}+02$

$5.79 \mathrm{E}+02$

$5.79 \mathrm{E}+02$

$5.80 \mathrm{E}+02$

$5.80 \mathrm{E}+02$

$5.81 \mathrm{E}+02$

$5.81 \mathrm{E}+02$

$5.82 \mathrm{E}+02$

$5.82 \mathrm{E}+02$

$5.83 \mathrm{E}+02$

$5.83 \mathrm{E}+02$

$5.84 \mathrm{E}+02$

$5.84 \mathrm{E}+02$

$5.85 \mathrm{E}+02$

$5.85 \mathrm{E}+02$

$5.86 \mathrm{E}+02$

$5.87 \mathrm{E}+02$

$5.87 \mathrm{E}+02$

$5.88 \mathrm{E}+02$

$5.88 \mathrm{E}+02$

$5.89 \mathrm{E}+02$

$5.89 \mathrm{E}+02$
Dose statistics at graphical times, mrem/yr

\begin{tabular}{|c|c|c|c|c|c|c|c|}
\hline inimum & aximum & Mean & ledian & $90 \%$ & $5 \%$ & $97.5 \%$ & \\
\hline 9 & 6 & $E-07$ & $E-07$ & 06 & 06 & 6 & 0 \\
\hline 09 & -06 & -07 & 7 & 6 & 6 & 06 & -06 \\
\hline 09 & -06 & $\Xi-07$ & -07 & $E-06$ & 6 & 06 & -06 \\
\hline-09 & 06 & & & & & & -06 \\
\hline-09 & 06 & 7 & & & 6 & 06 & $51 E-06$ \\
\hline-09 & 06 & -07 & -07 & 06 & 06 & -06 & $2 E-06$ \\
\hline 09 & -06 & 4. $33 E-07$ & $1.83 E-07$ & -06 & 6 & -06 & 0 \\
\hline E-09 & $9.28 E-06$ & • & & $1.10 \mathrm{E}-06$ & 20 & -06 & $53 E-06$ \\
\hline 09 & 06 & 1 & 1 & 06 & 6 & 06 & -06 \\
\hline $.35 E-09$ & $E-06$ & $8 E-07$ & $6 \mathrm{E}-07$ & $1.11 \mathrm{E}-06$ & $.75 E-06$ & $41 E-06$ & $4 E-06$ \\
\hline-09 & -06 & 7 & & 6 & 6 & 06 & $5 E-06$ \\
\hline-09 & -06 & 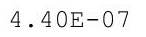 & 7 & & & & -06 \\
\hline $.44 \mathrm{E}-09$ & $9.31 \mathrm{E}-06$ & . $4 \angle \mathrm{L}-01$ & $=01$ & $1.12 \mathrm{E}-06$ & $1.77 \mathrm{E}-06$ & -06 & $E-0$ \\
\hline $.47 E-09$ & $9.32 \mathrm{E}-06$ & 要 & & 06 & & -06 & -06 \\
\hline 09 & 06 & r & 年 & 6 & e.r & r & -06 \\
\hline $.53 E-09$ & -06 & 5 & 1 . & $1.13 \mathrm{E}$ & 06 & -06 & -06 \\
\hline $.57 E-09$ & $E-06$ & $7 \mathrm{E}-07$ & $3 E-07$ & $1.14 \mathrm{E}-06$ & $1.78 \mathrm{E}-06$ & $E-06$ & $.57 E-06$ \\
\hline-09 & $E-06$ & $9 \mathrm{E}-07$ & 7 & $14 E-06$ & $79 E-06$ & $5 E-06$ & $E-06$ \\
\hline 09 & 06 & 1 & 1 & 66 & 10 & 6 & -06 \\
\hline $5 E-09$ & $.35 E-06$ & $E-07$ & & 06 & 6 & -06 & -06 \\
\hline $.70 \mathrm{E}-09$ & $9.36 \mathrm{E}-06$ & 1 & 1 & 06 & & 0 & -06 \\
\hline $.73 E-09$ & $E-06$ & 19 & 1. & $1.15 \mathrm{E}-06$ & $80 \mathrm{~F}$ & -06 & -06 \\
\hline $.76 E-09$ & $9.37 \mathrm{E}-06$ & $565-7$ & 1 & $1.15 E-06$ & $101=010$ & $47 E-06$ & $59 E-06$ \\
\hline $.79 E-09$ & $.37 E-06$ & $8 E-07$ & $0 E-07$ & $1.16 \mathrm{E}-06$ & $1.81 \mathrm{E}-06$ & $47 E-06$ & $59 \mathrm{E}-06$ \\
\hline 09 & $8 E-06$ & $95-07$ & & & & $E-06$ & -06 \\
\hline & -06 & 1 & t & & & & \\
\hline $0 E-09$ & -06 & 4 & 1 & 6 & 6 & 0 & 06 \\
\hline $.93 E-09$ & . & 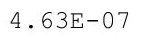 & $45-01$ & $1.17 \mathrm{E}-06$ & $.025-20$ & $49 E-06$ & $1 E-06$ \\
\hline 09 & 6 & 然 & 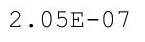 & 6 & $.84 E-06$ & $50 E-06$ & $61 \mathrm{E}-0$ \\
\hline 9 & 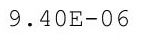 & - & 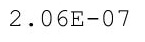 & -5 & $-T_{-1}$ & - & $62 \mathrm{E}-06$ \\
\hline 9 & $F-06$ & & & & & $E-06$ & $E-06$ \\
\hline 09 & $F-06$ & $695-07$ & 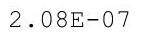 & 6 & 6 & & 06 \\
\hline$E-09$ & $E-06$ & 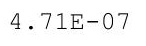 & 7 & 06 & 6 & 6 & $3 E-06$ \\
\hline $.14 \mathrm{E}-09$ & $9.42 E-06$ & $4 \cdot 1 \angle E-01$ & $2 \cdot 10 \pm-01$ & $1.19 \mathrm{E}-06$ & $1.86 \mathrm{E}-06$ & $52 E-06$ & $63 E-06$ \\
\hline $18 E-09$ & $9.42 E-06$ & $4.105-01$ & & & & & $.045-04$ \\
\hline & & & & & & & \\
\hline 9 & 6 & & & 6 & & & 06 \\
\hline & & & & & & & 06 \\
\hline 9 & & & & 06 & -06 & 06 & 06 \\
\hline $.36 E-09$ & $9.45 E-06$ & $4.81 E-07$ & $E-07$ & $1.2 \angle \mathrm{E}$ & 6 & & $7 E-06$ \\
\hline & & 1 & & & & & -0 \\
\hline g & 6 & & & 1.200 & 6 & 6 & $60 \mathrm{E}-06$ \\
\hline 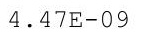 & & 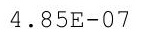 & & + & 6 & 0 & c \\
\hline $.51 E-09$ & y & & & 21 & 6 & 6 & the \\
\hline$E-09$ & $9.47 E-06$ & $4.88 E-07$ & $E-07$ & 66 & 1.91 & 06 & $.70 E-06$ \\
\hline 9 & $9.47 E-06$ & $4.89 E-07$ & $.22 E-07$ & $1.24 \mathrm{E}-06$ & $1.92 \mathrm{E}-06$ & $2.57 \mathrm{E}-06$ & $3.71 E-06$ \\
\hline
\end{tabular}


RESRAD-OFFSITE, Version 2.5

$\mathrm{T}^{1 / 2}$ Limit $=180$ days

Title : RESRAD-OFFSITE External Gamma, Inhalation, and Soil Ingestion for offsite Reside File : PBA-1_TC99-DOE-5-1.ROF

Summary of dose at graphical times, reptition 1 (continued)

Time

Years

$5.90 \mathrm{E}+02$

$5.90 \mathrm{E}+02$

$5.91 \mathrm{E}+02$

$5.91 \mathrm{E}+02$

$5.92 \mathrm{E}+02$

$5.92 \mathrm{E}+02$

$5.93 \mathrm{E}+02$

$5.93 \mathrm{E}+02$

$5.94 \mathrm{E}+02$

$5.94 \mathrm{E}+02$

$5.95 \mathrm{E}+02$

$5.95 \mathrm{E}+02$

$5.96 \mathrm{E}+02$

$5.96 \mathrm{E}+02$

$5.97 \mathrm{E}+02$

$5.97 \mathrm{E}+02$

$5.98 \mathrm{E}+02$

$5.98 \mathrm{E}+02$

$5.99 \mathrm{E}+02$

$5.99 \mathrm{E}+02$

$6.00 \mathrm{E}+02$

$6.00 \mathrm{E}+02$

$6.01 \mathrm{E}+02$

$6.01 \mathrm{E}+02$

$6.02 \mathrm{E}+02$

$6.02 \mathrm{E}+02$

$6.03 E+02$

$6.03 \mathrm{E}+02$

$6.04 \mathrm{E}+02$

$6.04 \mathrm{E}+02$

$6.05 \mathrm{E}+02$

$6.05 \mathrm{E}+02$

$6.06 \mathrm{E}+02$

$6.07 \mathrm{E}+02$

$6.07 \mathrm{E}+02$

$6.08 \mathrm{E}+02$

$6.08 \mathrm{E}+02$

$6.09 \mathrm{E}+02$

$6.09 \mathrm{E}+02$

$6.10 \mathrm{E}+02$

$6.10 \mathrm{E}+02$

$6.11 \mathrm{E}+02$

$6.11 \mathrm{E}+02$

$6.12 \mathrm{E}+02$

$6.12 \mathrm{E}+02$

$6.13 \mathrm{E}+02$
Dose statistics at graphical times, mrem/yr

\begin{tabular}{|c|c|c|c|c|c|c|c|}
\hline inimum & aximum & Mean & ledian & $0 \%$ & $5 \%$ & $97.5 \%$ & $\%$ \\
\hline 9 & -06 & $E-07$ & $E-07$ & 06 & 06 & 06 & 0 \\
\hline$E-09$ & $E-06$ & $2 E-07$ & $E-07$ & $.25 \mathrm{E}-$ & 06 & 06 & -06 \\
\hline$E-09$ & $E-06$ & $4 E-07$ & $5 E-07$ & $26 E-06$ & 06 & 06 & $3 E-06$ \\
\hline-09 & $E-06$ & 7 & 7 & 6 & & 6 & -06 \\
\hline-09 & -06 & -07 & 7 & 6 & 6 & 06 & $74 E-06$ \\
\hline-09 & -06 & $\Xi-07$ & $E-07$ & 06 & 06 & $E-06$ & -06 \\
\hline $.86 \mathrm{E}-09$ & -06 & $0 E-07$ & -07 & -06 & 06 & -06 & -06 \\
\hline $90 E-09$ & $9.50 \mathrm{E}-06$ & . & & $1.28 E-06$ & 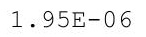 & -06 & $76 E-06$ \\
\hline 09 & 06 & 1 & 7 & 06 & 6 & 06 & -06 \\
\hline $.99 E-09$ & -06 & $4 \mathrm{E}-07$ & $2 \mathrm{E}-07$ & -06 & -06 & -06 & $77 E-06$ \\
\hline-09 & -06 & 7 & & 6 & & 06 & $E-06$ \\
\hline & & & & & & & -06 \\
\hline $.11 \mathrm{E}-09$ & $9.52 \mathrm{E}-06$ & ו & $E-U 1$ & $1.30 \mathrm{E}-06$ & $5-00$ & -06 & $E-0$ \\
\hline $5 E-09$ & $9.52 \mathrm{E}-06$ & i & $2.0+8$ & 06 & 06 & -06 & -06 \\
\hline 09 & 06 & S & 年 & 6 & 6 & 06 & -06 \\
\hline-09 & -06 & - & 2 . & 06 & 06 & -06 & -06 \\
\hline $.28 E-09$ & $E-06$ & $E-07$ & $0 E-07$ & $1.31 \mathrm{E}-06$ & $9 E-06$ & $E-06$ & $81 E-06$ \\
\hline-09 & -06 & $6 \mathrm{E}-07$ & 7 & 6 & 06 & -06 & $E-06$ \\
\hline 09 & -06 & 1 & 1 & 66 & & 6 & -06 \\
\hline $1 E-09$ & -06 & $\mathrm{E}-07$ & 7 & 06 & 6 & -06 & -06 \\
\hline $5 E-09$ & $9.54 \mathrm{E}-06$ & $0^{\circ}$ & 1 & 06 & & 06 & -06 \\
\hline $.50 E-09$ & 06 & . & 20 & 06 & $2.01 E-06$ & 06 & -06 \\
\hline $4 E-09$ & $5-06$ & 5 & 20 & $1.33 E-06$ & D & $67 E-06$ & $84 E-06$ \\
\hline $3 E-09$ & $E-06$ & $5 E-07$ & $8 E-07$ & $1.33 \mathrm{E}-06$ & $2 E-06$ & $8 E-06$ & $85 \mathrm{E}-06$ \\
\hline 09 & 06 & $7 E-07$ & & & & 6 & -06 \\
\hline 09 & 06 & 7 & 7 & 06 & & & 06 \\
\hline $2 E-09$ & $9.56 \mathrm{E}-06$ & $2-01$ & $E-01$ & -06 & & -06 & $E-06$ \\
\hline $.77 E-09$ & $9.56 \mathrm{E}-06$ & $5.31 E-07$ & $2.52 \mathrm{E}-07$ & $1.35 \mathrm{E}-06$ & $2.04 \mathrm{E}-06$ & $.70 \mathrm{E}-06$ & $87 E-06$ \\
\hline $.81 E-09$ & $9.56 \mathrm{E}-06$ & 1 & 2. & $1.35 \mathrm{E}-06$ & $=0$ & 0 & 年 \\
\hline $.86 \mathrm{E}-09$ & $9.56 \mathrm{E}-06$ & ? & 2.014 & 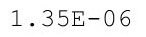 & 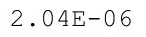 & 0 & $88 \mathrm{E}-0$ \\
\hline 09 & -06 & $6 \mathrm{E}-07$ & 7 & $35 E-06$ & 6 & -06 & $E-06$ \\
\hline 09 & $E-06$ & $E-07$ & $E-07$ & 06 & 6 & 6 & 06 \\
\hline $.00 E-09$ & $9.57 \mathrm{E}-06$ & $5.39 \mathrm{E}-07$ & $2.58 \mathrm{E}-07$ & $1.36 \mathrm{E}-06$ & 2. & $73 E-06$ & $90 \mathrm{E}-06$ \\
\hline $.04 \mathrm{E}-09$ & $9.57 \mathrm{E}-06$ & $5.40 \mathrm{E}-07$ & $2.59 \mathrm{E}-07$ & $1.36 \mathrm{E}-06$ & $2.06 \mathrm{E}-06$ & $.74 \mathrm{E}-06$ & $91 E-06$ \\
\hline $.09 E-09$ & $9.57 \mathrm{E}-06$ & . & & & & & $21 \mathrm{~L}-0$ \\
\hline & & & & & & & \\
\hline & 6 & & & & & & ne \\
\hline 9 & 6 & 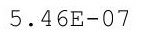 & 䧑 & 6 & 6 & 6 & 06 \\
\hline 9 & & & & & 6 & -06 & 06 \\
\hline $3 E-09$ & $3 E-06$ & $.49 E-07$ & 7 & 6 & & & -06 \\
\hline 9 & & & & & & & ce \\
\hline & $.59 E-06$ & & & $.39 E-06$ & & & $95 E-06$ \\
\hline & & $5.54 \mathrm{E}-07$ & $2.67 \mathrm{E}-07$ & 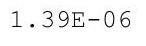 & & & \\
\hline $.53 E-09$ & 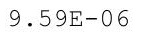 & & . & 0 & 6 & 6 & 0 \\
\hline 09 & 9.5 & 07 & 2 . & 1. & 2 & 06 & 06 \\
\hline $.63 E-$ & $9.59 \mathrm{E}-06$ & $.58 \mathrm{E}-07$ & $.71 E-07$ & $1.40 \mathrm{E}-06$ & $2.11 E-06$ & $2.80 \mathrm{E}-06$ & $3.97 \mathrm{E}-06$ \\
\hline
\end{tabular}


RESRAD-OFFSITE, Version 2.5

itle : RESRAD-OFfSITE External Gamma, Inhalation, and Soil Ingestion for offsite Reside

File: PBA-1_TC99-DOE-5-1.ROF

Summary of dose at graphical times, reptition 1 (continued)

Time

Years

$6.13 \mathrm{E}+02$

$6.14 \mathrm{E}+02$

$6.14 \mathrm{E}+02$

$6.15 \mathrm{E}+02$

$6.15 \mathrm{E}+02$

$6.16 \mathrm{E}+02$

$6.16 \mathrm{E}+02$

$6.17 \mathrm{E}+02$

$6.17 \mathrm{E}+02$

$6.18 \mathrm{E}+02$

$6.18 \mathrm{E}+02$

$6.19 \mathrm{E}+02$

$6.19 \mathrm{E}+02$

$6.20 \mathrm{E}+02$

$6.20 \mathrm{E}+02$

$6.21 \mathrm{E}+02$

$6.21 \mathrm{E}+02$

$6.22 \mathrm{E}+02$

$6.22 \mathrm{E}+02$

$6.23 \mathrm{E}+02$

$6.23 \mathrm{E}+02$

$6.24 \mathrm{E}+02$

$6.24 \mathrm{E}+02$

$6.25 \mathrm{E}+02$

$6.25 \mathrm{E}+02$

$6.26 \mathrm{E}+02$

$6.27 \mathrm{E}+02$

$6.27 \mathrm{E}+02$

$6.28 \mathrm{E}+02$

$6.28 \mathrm{E}+02$

$6.29 \mathrm{E}+02$

$6.29 \mathrm{E}+02$

$6.30 \mathrm{E}+02$

$6.30 \mathrm{E}+02$

$6.31 \mathrm{E}+02$

$6.31 \mathrm{E}+02$

$6.32 \mathrm{E}+02$

$6.32 \mathrm{E}+02$

$6.33 \mathrm{E}+02$

$6.33 \mathrm{E}+02$

$6.34 \mathrm{E}+02$

$6.34 \mathrm{E}+02$

$6.35 \mathrm{E}+02$

$6.35 \mathrm{E}+02$

$6.36 \mathrm{E}+02$

$6.36 \mathrm{E}+02$

Dose statistics at graphical times, mrem/yr

\begin{tabular}{|c|c|c|c|c|c|c|c|}
\hline$m$ & $m$ & Mean & ledian & & & $\%$ & \\
\hline 09 & -06 & $5.60 \mathrm{E}-07$ & 07 & $1.41 \mathrm{E}-06$ & $2.11 \mathrm{E}-06$ & $2.81 \mathrm{E}-06$ & -06 \\
\hline $.73 E-09$ & -06 & $.61 \mathrm{E}-07$ & & $1.41 \mathrm{E}-06$ & -06 & -06 & $98 E-06$ \\
\hline $.78 \mathrm{E}-09$ & $.60 \mathrm{E}-06$ & $3 E-07$ & -07 & $1.41 \mathrm{E}-06$ & $2.12 \mathrm{E}-06$ & $2.82 \mathrm{E}-06$ & $.98 E-06$ \\
\hline $.84 \mathrm{E}-09$ & $.60 \mathrm{E}-06$ & $4 E-07$ & $75 E-07$ & $1.42 \mathrm{E}-06$ & $2.12 \mathrm{E}-06$ & $2.83 E-06$ & $99 \mathrm{E}-06$ \\
\hline $9 E-09$ & $60 E-06$ & $6 \mathrm{~F}$ & 07 & -06 & $E-06$ & $33 E-06$ & 06 \\
\hline 09 & 06 & & & 6 & 6 & & -0 \\
\hline $.99 E-09$ & -06 & 7 & & 1.431 & 06 & 6 & -06 \\
\hline $.04 E-09$ & -06 & 7 & & 1.431 & & $2.85 \mathrm{E}-06$ & $00 E-06$ \\
\hline 09 & -06 & $E-07$ & -07 & -06 & 6 & -06 & -06 \\
\hline E-09 & 06 & $E-07$ & & 06 & 06 & -06 & -06 \\
\hline$E-09$ & $61 E-06$ & $755-0$ & תבת ק & 6 & 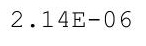 & 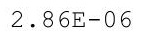 & 0 \\
\hline 9 & & & & 6 & & 6 & $06-2$ \\
\hline$F-09$ & $9.61 \mathrm{E}-06$ & $=0$ & $F_{-}$ & $1.45 \mathrm{I}$ & 06 & -06 & -06 \\
\hline $.37 E-09$ & $9.61 \mathrm{E}-06$ & $5.79 \mathrm{E}-07$ & $2.86 \mathrm{E}-07$ & $1.45 \mathrm{E}-06$ & $2.16 \mathrm{E}-06$ & $2.87 \mathrm{E}-06$ & $.02 \mathrm{E}-06$ \\
\hline $42 \mathrm{E}-09$ & $.61 E-06$ & $5.81 \mathrm{E}-07$ & $2.87 \mathrm{E}-07$ & $1.46 \mathrm{E}-06$ & $2.16 \mathrm{E}-06$ & $.88 E-06$ & -06 \\
\hline 09 & 06 & & & 06 & & -06 & -06 \\
\hline 9 & $1 E-06$ & & & 6 & & 0 & 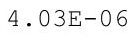 \\
\hline a & 6 & & & 6 & & & 6 \\
\hline $64 E-09$ & $.61 E-06$ & $7 \mathrm{~F}-07$ & & $1.47 E-06$ & 6 & -06 & $z-06$ \\
\hline $.70 E-09$ & $9.61 \mathrm{E}-06$ & $5.89 \mathrm{E}-07$ & $2.94 \mathrm{E}-07$ & $1.47 \mathrm{E}-06$ & $.18 \mathrm{E}-06$ & $.89 E-06$ & $04 \mathrm{E}-06$ \\
\hline $.76 E-09$ & $9.61 \mathrm{E}-06$ & $.90 \mathrm{E}-07$ & 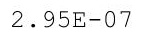 & $1.48 E-06$ & $.19 \mathrm{E}-06$ & $9 E-06$ & $\exists-06$ \\
\hline 09 & & & & & & & -06 \\
\hline & & & & 6 & & 6 & 06 \\
\hline & & & & te.th & & 0 & -06 \\
\hline 9 & $61 \mathrm{E}-$ & $.96 \mathrm{E}-$ & 7 & $50 \mathrm{E}-$ & $20+$ & 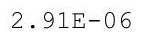 & 06 \\
\hline$F-0$ & $.61 E-06$ & $.98 E-07$ & $1 \mathrm{E}-$ & $1.50 \mathrm{E}-06$ & $.21 E-06$ & $91 E-06$ & $7 E-06$ \\
\hline$F-0$ & $61 E-06$ & $5.99 \mathrm{E}-07$ & $3.02 \mathrm{E}-07$ & $1.50 \mathrm{E}-06$ & $.21 E-06$ & $91 \mathrm{E}-06$ & $F-06-2-25$ \\
\hline-09 & $61 E-06$ & & & $51 E-06$ & & & \\
\hline & & & & & & & -06 \\
\hline & & & & 6 & -06 & 06 & -06 \\
\hline 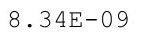 & $9.61 \mathrm{E}-06$ & $.06 E-07$ & $3.012-01$ & $1.52 \mathrm{E}-06$ & $\angle . \angle S E-00$ & $2.93 E-06$ & $08 E-06$ \\
\hline 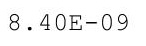 & $9.61 \mathrm{E}-06$ & 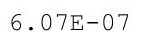 & & $1.52 \mathrm{E}-06$ & 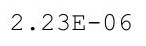 & $2 \cdot 90 \mathrm{~L}-0$ & • U त- \\
\hline 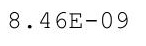 & $61 \mathrm{E}-0$ & & & & & & \\
\hline$F-09$ & & (2) 0. & ( & $3 E-$ & & & 06 \\
\hline 9 & & & & 6 & -06 & -06 & 06 \\
\hline & & & & 1.34 & -06 & -06 & \\
\hline $.70 E-09$ & $9.61 \mathrm{E}-06$ & $5 E-07$ & -01 & 1.04 & 06 & $.96 E-06$ & $10 E-06$ \\
\hline 政 & $.61 E-06$ & & & $1.27 \mathrm{~A}-0$ & & & • $\perp \perp+\Delta$ \\
\hline $.83 E-09$ & & 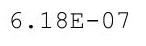 & & +.00 & & & 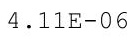 \\
\hline & & & & & & & 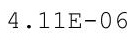 \\
\hline & & & & & & -06 & 06 \\
\hline 09 & $.61 E-06$ & $6.23 E-07$ & $3.21 \mathrm{E}-07$ & $1.56 \mathrm{E}-06$ & 06 & 06 & -06 \\
\hline & 06 & 7 & & & & & \\
\hline & & & & & & & \\
\hline & & & & & & & 0 \\
\hline 09 & $1 E-06$ & $E-07$ & $E-07$ & $3 E-06$ & 06 & -06 & -06 \\
\hline
\end{tabular}


RESRAD-OFFSITE, Version 2.5

robabilistic Dose and Risk Report

Title : RESRAD-OFFSITE External Gamma, Inhalation, and Soil Ingestion for Offsite Reside File : PBA-1_TC99-DOE-5-1.ROF

Summary of dose at graphical times, reptition 1 (continued)

Time

Years

$6.37 \mathrm{E}+02$

$6.37 \mathrm{E}+02$

$6.38 \mathrm{E}+02$

$6.38 \mathrm{E}+02$

$6.39 \mathrm{E}+02$

$6.39 \mathrm{E}+02$

$6.40 \mathrm{E}+02$

$6.40 \mathrm{E}+02$

$6.41 \mathrm{E}+02$

$6.41 \mathrm{E}+02$

$6.42 \mathrm{E}+02$

$6.42 \mathrm{E}+02$

$6.43 \mathrm{E}+02$

$6.43 \mathrm{E}+02$

$6.44 \mathrm{E}+02$

$6.44 \mathrm{E}+02$

$6.45 \mathrm{E}+02$

$6.45 \mathrm{E}+02$

$6.46 \mathrm{E}+02$

$6.47 \mathrm{E}+02$

$6.47 \mathrm{E}+02$

$6.48 \mathrm{E}+02$

$6.48 \mathrm{E}+02$

$6.49 \mathrm{E}+02$

$6.49 \mathrm{E}+02$

$6.50 \mathrm{E}+02$

$6.50 \mathrm{E}+02$

$6.51 \mathrm{E}+02$

$6.51 \mathrm{E}+02$

$6.52 \mathrm{E}+02$

$6.52 \mathrm{E}+02$

$6.53 \mathrm{E}+02$

$6.53 \mathrm{E}+02$

$6.54 \mathrm{E}+02$

$6.54 \mathrm{E}+02$

$6.55 \mathrm{E}+02$

$6.55 \mathrm{E}+02$

$6.56 \mathrm{E}+02$

$6.56 \mathrm{E}+02$

$6.57 \mathrm{E}+02$

$6.57 \mathrm{E}+02$

$6.58 \mathrm{E}+02$

$6.58 \mathrm{E}+02$

$6.59 \mathrm{E}+02$

$6.59 \mathrm{E}+02$

$6.60 \mathrm{E}+02$

Dose statistics at graphical times, mrem/yr

\begin{tabular}{|c|c|c|c|c|c|c|c|}
\hline inimum & aximum & Mean & ledian & $90 \%$ & $5 \%$ & $97.5 \%$ & $\%$ \\
\hline 9 & 6 & $E-07$ & -07 & 06 & 6 & 6 & 0 \\
\hline 09 & -06 & -07 & 7 & 6 & 6 & 06 & -06 \\
\hline-09 & $E-06$ & $E-07$ & $E-07$ & $E-06$ & 6 & 06 & -06 \\
\hline-09 & 06 & & & & & & -06 \\
\hline-09 & 06 & & & & 6 & 06 & $15 E-06$ \\
\hline $.66 E-09$ & -06 & $E-07$ & -07 & -06 & $2 E-06$ & 06 & -06 \\
\hline $3 E-09$ & -06 & (- & r & -06 & 06 & -06 & -0 \\
\hline $.80 E-09$ & $9.60 E-06$ & 政 & & $1.60 \mathrm{E}-06$ & $2 \cdot 400$ & -06 & $16 \mathrm{E}-06$ \\
\hline 09 & 06 & 1 & 7 & 06 & 6 & -06 & -06 \\
\hline $.93 E-09$ & -06 & $4 E-07$ & $8 E-07$ & $.61 E-06$ & $34 \mathrm{E}-06$ & -06 & $8-06$ \\
\hline-08 & -06 & & & 6 & 6 & 06 & $17 E-06$ \\
\hline-08 & 06 & & & & & -06 & -06 \\
\hline $.01 E-08$ & $9.59 \mathrm{E}-06$ & $9 \pm-01$ & $3.4 \angle E-U 1$ & $1.62 \mathrm{E}-06$ & $2.36 \mathrm{E}-06$ & $E-06$ & $E-0$ \\
\hline $.02 E-08$ & $9.59 \mathrm{E}-06$ & ו & , & 06 & 06 & -06 & $17 E-06$ \\
\hline $3 E-08$ & 06 & r & 年 & 06 & 6 & 06 & -06 \\
\hline $.03 E-08$ & $9.59 \mathrm{E}-06$ & -0 & 7 & 06 & 06 & -06 & -06 \\
\hline $.04 \mathrm{E}-08$ & $E-06$ & $5 E-07$ & $8 \mathrm{E}-07$ & $1.63 \mathrm{E}-06$ & $37 E-06$ & $E-06$ & $.18 \mathrm{E}-06$ \\
\hline$E-08$ & $E-06$ & $7 E-07$ & $9 E-07$ & -06 & $8 E-06$ & $E-06$ & $19 \mathrm{E}-06$ \\
\hline 08 & -06 & 1 & 1 & 06 & & 6 & -06 \\
\hline $.06 E-08$ & -06 & -07 & 7 & 06 & 6 & -06 & -06 \\
\hline $7 E-08$ & $9.58 \mathrm{E}-06$ & T & 1 & & & 0 & -06 \\
\hline $.08 E-08$ & $9.58 \mathrm{E}-06$ & (6) & & $1.65 \mathrm{E}-06$ & 00 & -06 & -06 \\
\hline $.08 E-08$ & $9.57 \mathrm{E}-06$ & $6.65 E-07$ & 7 & $1.65 E-06$ & $2.40 \mathrm{E}-06$ & $9 E-06$ & $20 E-06$ \\
\hline $9-08$ & $.57 E-06$ & $6.66 \mathrm{E}-07$ & $8 E-07$ & $1.66 \mathrm{E}-06$ & $40 E-06$ & $9 E-06$ & $20 E-06$ \\
\hline 08 & -06 & $68 E-07$ & & & & -06 & -06 \\
\hline 08 & 06 & 7 & & 06 & 06 & -06 & .06 \\
\hline $1 E-08$ & $7 \pm-06$ & 4 & 1 & $1.67 \mathrm{E}-06$ & & & 06 \\
\hline $.12 \mathrm{E}-08$ & $9.56 \mathrm{E}-06$ & $0.12 \mathrm{x}-01$ & $3.025-21$ & $1.67 \mathrm{E}-06$ & $2.4 \perp \Sigma-00$ & $11 \mathrm{E}-06$ & $21 E-06$ \\
\hline 08 & 6 & (2) -2 & (c) & 6 & $.42 E-06$ & 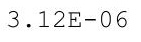 & $22 E-06$ \\
\hline 8 & 6 & 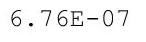 & - & 6 & 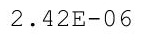 & 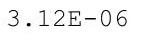 & 2 \\
\hline 28 & $F-06$ & $677=6$ & & & & $E-06$ & $22 \mathrm{E}-06$ \\
\hline$E-08$ & $E-06$ & $.79 \mathrm{E}-07$ & $E-07$ & $8 E-06$ & 6 & 06 & $3 E-06$ \\
\hline $6 E-08$ & $5 E-06$ & $E-07$ & 7 & 06 & 6 & & $23 E-06$ \\
\hline $.17 \mathrm{E}-08$ & $9.55 \mathrm{E}-06$ & $.8 \angle E-U 1$ & $3.10 \pm-01$ & $1.69 \mathrm{E}-06$ & $2.43 E-06$ & $4 E-06$ & $.23 E-06$ \\
\hline $.17 E-08$ & $9.55 E-06$ & $0.035-4$ & & $1.69 \mathrm{E}-06$ & & & . $235-2$ \\
\hline 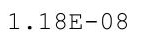 & & & & & & & \\
\hline 8 & 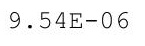 & & & 6 & & & 06 \\
\hline 8 & & & & & 6 & 6 & 06 \\
\hline & & & & & -06 & -06 & 06 \\
\hline $21 \mathrm{E}-08$ & $E-06$ & $E-07$ & -07 & 06 & 6 & & $5 E-06$ \\
\hline 08 & & & & 6 & & & -00 \\
\hline 8 & 0 & ( & & 6 & & & $205-06$ \\
\hline & & 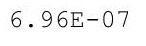 & & 0 & 6 & & 00 \\
\hline $245-0$ & $9.53 E-06$ & 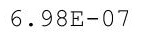 & 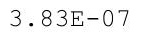 & 6 & 6 & 6 & - \\
\hline$E-08$ & -06 & $E-07$ & 3. & 66 & 2.4 & -06 & $4.26 \mathrm{E}-06$ \\
\hline $.26 E-08$ & $9.52 E-06$ & $.01 E-07$ & $.86 E-07$ & $1.73 E-06$ & $2.47 E-06$ & $3.18 \mathrm{E}-06$ & $4.26 \mathrm{E}-06$ \\
\hline
\end{tabular}


RESRAD-OFFSITE, Version 2.5

$\mathrm{T}^{1 / 2}$ Limit $=180$ days

Title : RESRAD-OFFSITE External Gamma, Inhalation, and Soil Ingestion for Offsite Reside File : PBA-1_TC99-DOE-5-1.ROF

Summary of dose at graphical times, reptition 1 (continued)

Time

Years

$6.60 \mathrm{E}+02$

$6.61 \mathrm{E}+02$

$6.61 \mathrm{E}+02$

$6.62 \mathrm{E}+02$

$6.62 \mathrm{E}+02$

$6.63 \mathrm{E}+02$

$6.63 \mathrm{E}+02$

$6.64 \mathrm{E}+02$

$6.64 \mathrm{E}+02$

$6.65 \mathrm{E}+02$

$6.65 \mathrm{E}+02$

$6.66 \mathrm{E}+02$

$6.67 \mathrm{E}+02$

$6.67 \mathrm{E}+02$

$6.68 \mathrm{E}+02$

$6.68 \mathrm{E}+02$

$6.69 \mathrm{E}+02$

$6.69 \mathrm{E}+02$

$6.70 \mathrm{E}+02$

$6.70 \mathrm{E}+02$

$6.71 \mathrm{E}+02$

$6.71 \mathrm{E}+02$

$6.72 \mathrm{E}+02$

$6.72 \mathrm{E}+02$

$6.73 E+02$

$6.73 \mathrm{E}+02$

$6.74 \mathrm{E}+02$

$6.74 \mathrm{E}+02$

$6.75 \mathrm{E}+02$

$6.75 \mathrm{E}+02$

$6.76 \mathrm{E}+02$

$6.76 \mathrm{E}+02$

$6.77 \mathrm{E}+02$

$6.77 \mathrm{E}+02$

$6.78 \mathrm{E}+02$

$6.78 \mathrm{E}+02$

$6.79 \mathrm{E}+02$

$6.79 \mathrm{E}+02$

$6.80 \mathrm{E}+02$

$6.80 \mathrm{E}+02$

$6.81 \mathrm{E}+02$

$6.81 \mathrm{E}+02$

$6.82 \mathrm{E}+02$

$6.82 \mathrm{E}+02$

$6.83 \mathrm{E}+02$

$6.83 \mathrm{E}+02$
Dose statistics at graphical times, mrem/yr

\begin{tabular}{|c|c|c|c|c|c|c|c|}
\hline inimum & aximum & Mean & ledian & $0 \%$ & $5 \%$ & $97.5 \%$ & \\
\hline 8 & -06 & $E-07$ & $E-07$ & $3 E-06$ & 06 & 6 & net \\
\hline-08 & -06 & $E-07$ & $9 E-07$ & 6 & 06 & 06 & -06 \\
\hline-08 & -06 & $E-07$ & $E-07$ & $4 E-06$ & 06 & 06 & -06 \\
\hline$E-08$ & 06 & 1 & & 6 & 6 & 06 & -06 \\
\hline $30 E-08$ & 06 & & & & 6 & 06 & $28 E-06$ \\
\hline $31 E-08$ & -06 & 政 & 07 & 06 & $E-06$ & 06 & -06 \\
\hline $.32 \mathrm{E}-08$ & -06 & 1 & r & -06 & 06 & -06 & -0 \\
\hline $.32 E-08$ & $9.50 E-06$ & • & ; & $1.76 \mathrm{E}-06$ & 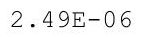 & -06 & $.29 E-06$ \\
\hline 08 & 06 & - & 1 & 06 & 6 & 06 & -06 \\
\hline $.34 \mathrm{E}-08$ & -06 & $6 E-07$ & $0 E-07$ & $77 E-06$ & 06 & -06 & $30 E-06$ \\
\hline-08 & -06 & 7 & 7 & 6 & 6 & & $E-06$ \\
\hline-08 & 06 & & & & & & 06 \\
\hline $.37 E-08$ & $9.48 \mathrm{E}-06$ & $.2 \perp \amalg-01$ & $E-01$ & $1.78 \mathrm{E}-06$ & -06 & -06 & -0 \\
\hline $38 \mathrm{E}-08$ & -06 & i & 1 & 06 & 0 & -06 & $32 E-06$ \\
\hline $38 E-08$ & 06 & 1 & 1 & 6 & 6 & 06 & -06 \\
\hline $.39 \mathrm{E}-08$ & -06 & r & 1 & 06 & 06 & -06 & -06 \\
\hline $.40 \mathrm{E}-08$ & $E-06$ & $7 E-07$ & $9 \mathrm{E}-07$ & $1.79 \mathrm{E}-06$ & $2.53 E-06$ & -06 & $.33 E-06$ \\
\hline-08 & $E-06$ & $9 \mathrm{E}-07$ & $1 \mathrm{E}-07$ & 06 & 06 & -06 & $E-06$ \\
\hline 08 & -06 & 1 & & 06 & & 6 & -06 \\
\hline $43 E-08$ & -06 & 1 & 7 & 06 & 6 & -06 & -06 \\
\hline $.44 \mathrm{E}-08$ & -06 & 7 & & & & 0 & -06 \\
\hline $.44 \mathrm{E}-08$ & -06 & ים & & $1.81 \mathrm{~F}$ & 5 & 6 & -06 \\
\hline $.45 E-08$ & $.45 E-06$ & $727=070$ & 1 $17=0$ & $.81 E-06$ & $55 \Gamma-068$ & $6 E-06$ & $36 E-06$ \\
\hline $.46 \mathrm{E}-08$ & $4 \mathrm{E}-06$ & $39 E-07$ & $8 E-07$ & $1.81 \mathrm{E}-06$ & $55 E-06$ & $7 E-06$ & $36 \mathrm{E}-06$ \\
\hline 08 & $E-06$ & & & $E-06$ & & 6 & -06 \\
\hline 08 & 06 & 7 & 7 & 06 & & & 06 \\
\hline $.49 \mathrm{E}-08$ & $E-06$ & -01 & -01 & $1.82 \mathrm{E}-06$ & 6 & -06 & $37 E-06$ \\
\hline $.50 E-08$ & $9.43 E-06$ & $7.45 E-07$ & $4.24 \mathrm{E}-07$ & $1.82 \mathrm{E}-06$ & $2.57 \mathrm{E}-06$ & $28 E-06$ & $.38 E-06$ \\
\hline 8 & 6 & 然 & 年 & 6 & 年 & 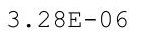 & 06 \\
\hline $.52 E-08$ & $9.42 \mathrm{E}-06$ & 然 & 20. & $1.00 \mathrm{~L}-0$ & - & 政 & . \\
\hline 8 & $E-06$ & $\Gamma$ & 7 & 6 & 6 & $E-06$ & $39 E-06$ \\
\hline 08 & $E-06$ & 7 & 7 & -06 & 6 & 6 & $9 E-06$ \\
\hline $4 E-08$ & $E-06$ & $E-U 1$ & 4 . & 06 & 6 & 6 & $0 E-06$ \\
\hline $.55 E-08$ & $9.40 E-06$ & $.34 \mathrm{E}-01$ & $4.3< \pm-01$ & $1.84 \mathrm{E}-06$ & $2.59 \mathrm{E}-06$ & $30 E-06$ & $41 \mathrm{E}-06$ \\
\hline $56 E-08$ & $9.40 E-06$ & (.) & & $1.84 \mathrm{E}-06$ & & & $\cdot 4 \perp 5-U$ \\
\hline 0 & & & & & & & \\
\hline $.58 E-08$ & 6 & & & & & & he \\
\hline 8 & se & 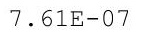 & $37 E-07$ & & & 6 & 26 \\
\hline & & & & & 06 & 6 & \\
\hline $.61 \mathrm{E}-08$ & 06 & $4 E-07$ & $0 E-07$ & 06 & 6 & & $.44 \mathrm{E}-06$ \\
\hline 08 & & tis & & 6 & & & -0 \\
\hline 8 & 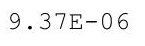 & 年 & & 6 & & & $405-06$ \\
\hline 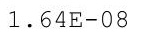 & 9 & 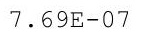 & & 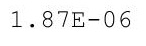 & 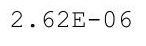 & & to \\
\hline 1. & se & $7.70 \mathrm{E}-07$ & 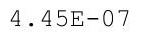 & 6 & 6 & 6 & 0 \\
\hline-08 & -06 & $E-07$ & 4.4 & 66 & 2 . & -06 & -06 \\
\hline $.67 E-08$ & $9.35 E-06$ & $7.73 E-07$ & $.48 E-07$ & $1.88 \mathrm{E}-06$ & $2.63 E-06$ & $.33 E-06$ & $4.46 \mathrm{E}-06$ \\
\hline
\end{tabular}


RESRAD-OFFSITE, Version 2.5

Title : RESRAD-OFFSITE External Gamma, Inhalation, and Soil Ingestion for offsite Reside File : PBA-1_TC99-DOE-5-1.ROF

Summary of dose at graphical times, reptition 1 (continued)

Time

Years

$6.84 \mathrm{E}+02$

$6.84 \mathrm{E}+02$

$6.85 \mathrm{E}+02$

$6.85 \mathrm{E}+02$

$6.86 \mathrm{E}+02$

$6.86 \mathrm{E}+02$

$6.87 \mathrm{E}+02$

$6.88 \mathrm{E}+02$

$6.88 \mathrm{E}+02$

$6.89 \mathrm{E}+02$

$6.89 \mathrm{E}+02$

$6.90 \mathrm{E}+02$

$6.90 \mathrm{E}+02$

$6.91 \mathrm{E}+02$

$6.91 \mathrm{E}+02$

$6.92 \mathrm{E}+02$

$6.92 \mathrm{E}+02$

$6.93 \mathrm{E}+02$

$6.93 \mathrm{E}+02$

$6.94 \mathrm{E}+02$

$6.94 \mathrm{E}+02$

$6.95 \mathrm{E}+02$

$6.95 \mathrm{E}+02$

$6.96 \mathrm{E}+02$

$6.96 \mathrm{E}+02$

$6.97 \mathrm{E}+02$

$6.97 \mathrm{E}+02$

$6.98 \mathrm{E}+02$

$6.98 \mathrm{E}+02$

$6.99 \mathrm{E}+02$

$6.99 \mathrm{E}+02$

$7.00 \mathrm{E}+02$

$7.00 \mathrm{E}+02$

$7.01 \mathrm{E}+02$

$7.01 \mathrm{E}+02$

$7.02 \mathrm{E}+02$

$7.02 \mathrm{E}+02$

$7.03 \mathrm{E}+02$

$7.03 E+02$

$7.04 \mathrm{E}+02$

$7.04 \mathrm{E}+02$

$7.05 \mathrm{E}+02$

$7.05 \mathrm{E}+02$

$7.06 \mathrm{E}+02$

$7.06 \mathrm{E}+02$

$7.07 \mathrm{E}+02$
Dose statistics at graphical times, mrem/yr

\begin{tabular}{|c|c|c|c|c|c|c|c|}
\hline Iinimum & Iaximum & Mean & Median & $90 \%$ & $95 \%$ & $97.5 \%$ & $\%$ \\
\hline 08 & -06 & $.75 E-07$ & $50 E-07$ & $1.88 \mathrm{E}$ & 2 . & 6 & -0 \\
\hline $9 E-08$ & -06 & $6 E-07$ & $1 E-07$ & 06 & $3 E-06$ & -06 & $47 \mathrm{E}-06$ \\
\hline $.70 E-08$ & $4 E-06$ & $3 E-07$ & $52 \mathrm{E}-$ & 06 & 06 & 06 & $47 E-06$ \\
\hline$E-08$ & $3 E-06$ & $E-07$ & $E-07$ & $9 E-06$ & $4 E-06$ & 06 & $7 \mathrm{E}-06$ \\
\hline $.72 E-08$ & -06 & -07 & -07 & -06 & -06 & 06 & $47 E-06$ \\
\hline$E-08$ & $E-06$ & $F-\ell(20)-1$ & $\mathrm{~F}-1$ & -06 & $4 E-06$ & -06 & $48 E-06$ \\
\hline $.74 E-08$ & $2 E-06$ & $4 E-0$ & $8 E-07$ & $89 E-06$ & $5 E-06$ & -06 & $E-06$ \\
\hline $.75 E-08$ & $9.32 \mathrm{E}-06$ & r & 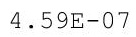 & $1.90 \mathrm{E}-06$ & $2.65 E-06$ & -06 & $.48 E-06$ \\
\hline $.76 \mathrm{E}-08$ & $9.31 E-06$ & ? & 9.0001 & $1.90 \mathrm{E}-06$ & $2.65 \mathrm{E}-06$ & -06 & $49 E-06$ \\
\hline $7 E-08$ & $E-06$ & $E-$ & 4 & 6 & -06 & 06 & $49 E-06$ \\
\hline $.78 E-08$ & $9.30 \mathrm{E}-06$ & $1 E-07$ & $3 E-07$ & & & & $49 E-06$ \\
\hline .08 & -06 & 7 & -07 & -06 & 6 & 6 & $49 E-06$ \\
\hline $.80 E-08$ & $9 E-06$ & 4 & $E-01$ & -06 & $7 E-06$ & -06 & $49 E-06$ \\
\hline $.01 \mathrm{E}-00$ & $9.29 \mathrm{E}-06$ & ? & $4.00 \mathrm{E}-01$ & -06 & 2.01 & -06 & $49 E-06$ \\
\hline $.82 E-08$ & $E-06$ & $E-07$ & $E-07$ & 06 & 06 & 06 & $49 E-06$ \\
\hline $.83 E-08$ & -06 & ? & 1 & 6 & 0 & 06 & $49 E-06$ \\
\hline $.84 E-08$ & $E-06$ & $8.00 \mathrm{E}-07$ & $4 E-07$ & $1.92 \mathrm{E}-06$ & $8 E-06$ & $8 E-06$ & $.49 E-06$ \\
\hline$E-08$ & $E-06$ & $E-07$ & $5 E-07$ & $E-06$ & 06 & -06 & $49 E-06$ \\
\hline $.86 E-08$ & $6 \mathrm{E}-06$ & $3 E-07$ & & & & 6 & -06 \\
\hline $.87 E-08$ & $9.26 \mathrm{E}-06$ & oE-0 1 & $4.18 \mathrm{E}-01$ & $1.93 \mathrm{E}-06$ & 06 & .06 & $49 E-06$ \\
\hline $8 E-08$ & $E-06$ & H & 4. & & & & $49 E-06$ \\
\hline $9 E-08$ & 9.2 & 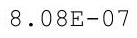 & 70 & $1 \cdot 0^{-1}$ & $2.69 \mathrm{E}-06$ & $.39 E-06$ & -06 \\
\hline • & $9.24 \mathrm{E}-06$ & $8.10 \mathrm{E}-07$ & $4.82 E-07$ & $1.94 \mathrm{E}-06$ & & $9 \mathrm{E}-00$ & $.49 E-06$ \\
\hline $.91 E-08$ & $9.24 \mathrm{E}-06$ & $1 \mathrm{E}-0$ & 4. & -06 & -06 & -06 & $49 E-06$ \\
\hline $3 E-08$ & $E-06$ & $3 E-07$ & 1 & 06 & 06 & 06 & $49 E-06$ \\
\hline$E-08$ & -06 & -07 & -07 & 06 & 6 & 06 & $9 \mathrm{E}-06$ \\
\hline $5 E-08$ & $9.22 \mathrm{E}-06$ & $5-01$ & $8 E-07$ & & & & $49 E-06$ \\
\hline 皮 & 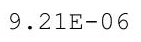 & 要 & ע & 6 & 6 & 6 & -06 \\
\hline ט & $9.21 \mathrm{E}$ & 然 & $4.91 \mathrm{E}-07$ & 06 & $72 E-06$ & -06 & $.49 \mathrm{E}-06$ \\
\hline $.98 E-08$ & $20 E-06$ & 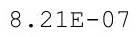 & 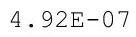 & 1. $95 \mathrm{E}-06$ & 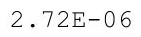 & $.42 E-06$ & -0 \\
\hline 88 & 06 & $E-07$ & 35 & 06 & 6 & 06 & $9 \mathrm{E}-06$ \\
\hline$E-08$ & $E-06$ & $E-07$ & $E-07$ & $5 E-06$ & 6 & 06 & $9 \mathrm{E}-06$ \\
\hline $.01 \mathrm{E}-08$ & $9.19 \mathrm{E}-06$ & $8.25 E-07$ & $4.96 \mathrm{E}-$ & $1.96 \mathrm{E}$ & 6 & & $49 E-06$ \\
\hline $.02 E-08$ & $9.18 \mathrm{E}-06$ & $8.27 \mathrm{E}-07$ & $4.98 \mathrm{E}-07$ & $1.96 \mathrm{E}-06$ & $74 \mathrm{E}-06$ & $3 E-06$ & $.49 \mathrm{E}-06$ \\
\hline . & $9.18 \mathrm{E}-06$ & $0.20 \mathrm{E}-01$ & & & & & $49 \mathrm{E}-06$ \\
\hline م0 050 & 6 & $8.30 \mathrm{E}-07$ & $5.00 \mathrm{E}-07$ & & & & $4.49 \mathrm{E}-06$ \\
\hline 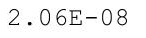 & $E-06$ & בת ת ברת & ד ר & $7 E-06$ & $5 E-06$ & -06 & $9 \mathrm{E}-06$ \\
\hline $7 E-08$ & $E-06$ & $3 E-C$ & 5 & E-06 & 6 & 06 & $9 E-06$ \\
\hline $.08 \mathrm{E}-08$ & $E-06$ & $5 E-07$ & $5 E-07$ & $1.97 \mathrm{E}-06$ & $5 E-06$ & -06 & $49 E-06$ \\
\hline$E-08$ & & & & & & & $49 E-06$ \\
\hline & & & & & & & $49 E-06$ \\
\hline $.11 \mathrm{E}-08$ & $9.14 \mathrm{E}-06$ & $8.39 \mathrm{E}-07$ & $5.09 \mathrm{E}-07$ & $1.98 \mathrm{E}-06$ & $2.76 \mathrm{E}-06$ & $6 \mathrm{E}-06$ & $49 \mathrm{E}-06$ \\
\hline 8 & s & $8.41 \mathrm{E}-07$ & $5.11 \mathrm{E}-07$ & 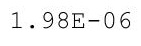 & 5 & 6 & $4.49 \mathrm{E}-06$ \\
\hline $4 E-08$ & $9.13 E-06$ & 政 & 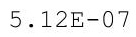 & $1.99 \mathrm{E}$ & $2.7 / E$ & .06 & $4.495-0$ \\
\hline-08 & -06 & 8. & 5 & $E-06$ & $E-06$ & $E-06$ & $4.49 \mathrm{E}-06$ \\
\hline $.16 \mathrm{E}-08$ & $11 E-06$ & $46 \mathrm{E}-07$ & $.15 \mathrm{E}-07$ & $1.99 \mathrm{E}-06$ & $2.77 E-06$ & $3.47 \mathrm{E}-06$ & $4.49 \mathrm{E}-06$ \\
\hline
\end{tabular}


RESRAD-OFFSITE, Version 2.5

$\mathrm{T}^{1 / 2}$ Limit $=180$ days

Title : RESRAD-OFFSITE External Gamma, Inhalation, and Soil Ingestion for Offsite Reside File : PBA-1_TC99-DOE-5-1.ROF

Summary of dose at graphical times, reptition 1 (continued)

Time

Years

$7.08 \mathrm{E}+02$

$7.08 \mathrm{E}+02$

$7.09 \mathrm{E}+02$

$7.09 \mathrm{E}+02$

$7.10 \mathrm{E}+02$

7. $10 \mathrm{E}+02$

7. $11 \mathrm{E}+02$

$7.11 \mathrm{E}+02$

$7.12 \mathrm{E}+02$

$7.12 \mathrm{E}+02$

7. $13 \mathrm{E}+02$

7. $13 \mathrm{E}+02$

$7.14 \mathrm{E}+02$

$7.14 \mathrm{E}+02$

$7.15 \mathrm{E}+02$

7. $15 \mathrm{E}+02$

7. $16 \mathrm{E}+02$

7. $16 \mathrm{E}+02$

$7.17 \mathrm{E}+02$

$7.17 \mathrm{E}+02$

7. $18 \mathrm{E}+02$

$7.18 \mathrm{E}+02$

7. $19 \mathrm{E}+02$

$7.19 \mathrm{E}+02$

$7.20 \mathrm{E}+02$

$7.20 \mathrm{E}+02$

$7.21 \mathrm{E}+02$

$7.21 \mathrm{E}+02$

7. $22 \mathrm{E}+02$

$7.22 \mathrm{E}+02$

7. $23 \mathrm{E}+02$

7. $23 \mathrm{E}+02$

$7.24 \mathrm{E}+02$

$7.24 \mathrm{E}+02$

$7.25 \mathrm{E}+02$

7. $25 \mathrm{E}+02$

$7.26 \mathrm{E}+02$

$7.26 \mathrm{E}+02$

$7.27 \mathrm{E}+02$

$7.28 \mathrm{E}+02$

$7.28 \mathrm{E}+02$

$7.29 \mathrm{E}+02$

$7.29 \mathrm{E}+02$

7. $30 \mathrm{E}+02$

7. $30 \mathrm{E}+02$

$7.31 \mathrm{E}+02$
Dose statistics at graphical times, mrem/yr

\begin{tabular}{|c|c|c|c|c|c|c|c|}
\hline Minimum & Maximum & Mean & Median & $90 \%$ & $95 \%$ & $97.5 \%$ & $99 \%$ \\
\hline $2.17 E-08$ & $9.11 \mathrm{E}-06$ & $8.47 E-07$ & $5.17 \mathrm{E}-07$ & $2.00 E-06$ & $2.78 E-06$ & $3.47 E-06$ & $4.49 \mathrm{E}-06$ \\
\hline $2.18 \mathrm{E}-08$ & $9.10 \mathrm{E}-06$ & $8.49 \mathrm{E}-07$ & $5.18 \mathrm{E}-07$ & $2.00 \mathrm{E}-06$ & $2.78 \mathrm{E}-06$ & $3.48 \mathrm{E}-06$ & $4.49 \mathrm{E}-06$ \\
\hline $2.20 E-08$ & $9.10 \mathrm{E}-06$ & $8.51 \mathrm{E}-07$ & $5.20 \mathrm{E}-07$ & $2.00 \mathrm{E}-06$ & $2.78 \mathrm{E}-06$ & $3.48 \mathrm{E}-06$ & $4.49 \mathrm{E}-06$ \\
\hline $2.21 E-08$ & $9.09 \mathrm{E}-06$ & $8.52 \mathrm{E}-07$ & $5.21 \mathrm{E}-07$ & $2.00 \mathrm{E}-06$ & $2.78 E-06$ & $3.48 \mathrm{E}-06$ & $4.49 \mathrm{E}-06$ \\
\hline $2.22 E-08$ & $9.08 \mathrm{E}-06$ & $8.54 \mathrm{E}-07$ & $23 E-07$ & $2.01 E-06$ & $2.78 E-06$ & $3 E-06$ & $4.49 \mathrm{E}-06$ \\
\hline $2.23 E-08$ & $9.08 E-06$ & $8.55 E-07$ & $5.24 \mathrm{E}-07$ & $2.01 E-06$ & $2.78 \mathrm{E}-06$ & $3.49 \mathrm{E}-06$ & $4.49 \mathrm{E}-06$ \\
\hline $2.24 \mathrm{E}-08$ & $9.07 E-06$ & $8.57 E-07$ & $5.26 \mathrm{E}-07$ & $2.02 E-06$ & $2.79 E-06$ & $3.49 \mathrm{E}-06$ & $4.50 \mathrm{E}-06$ \\
\hline $2.26 \mathrm{E}-08$ & $9.07 E-06$ & $8.58 \mathrm{E}-07$ & $5.27 \mathrm{E}-07$ & $2.02 \mathrm{E}-06$ & $2.79 E-06$ & $3.49 \mathrm{E}-06$ & $4.50 \mathrm{E}-06$ \\
\hline $2.27 E-08$ & $9.06 \mathrm{E}-06$ & $8.60 \mathrm{E}-07$ & $5.29 \mathrm{E}-07$ & $2.02 E-06$ & $2.79 \mathrm{E}-06$ & $3.49 \mathrm{E}-06$ & $4.50 \mathrm{E}-06$ \\
\hline $2.28 \mathrm{E}-08$ & $9.05 E-06$ & $8.61 \mathrm{E}-07$ & $5.30 \mathrm{E}-07$ & $2.03 E-06$ & $2.79 E-06$ & $3.49 \mathrm{E}-06$ & $4.50 \mathrm{E}-06$ \\
\hline $2.29 \mathrm{E}-08$ & -06 & $3 E-07$ & $2 E-07$ & $3 E-06$ & $9 E-06$ & -06 & -06 \\
\hline $2.30 E-08$ & $9.04 E-06$ & $8.65 E-07$ & $5.34 \mathrm{E}-07$ & $2.03 E-06$ & $2.80 \mathrm{E}-06$ & $3.49 E-06$ & $4.51 \mathrm{E}-06$ \\
\hline $2.32 E-08$ & $9.04 E-06$ & $8.66 \mathrm{E}-07$ & $5.35 \mathrm{E}-07$ & $2.04 \mathrm{E}-06$ & $2.80 \mathrm{E}-06$ & $3.49 \mathrm{E}-06$ & $4.51 \mathrm{E}-06$ \\
\hline $2.33 E-08$ & $9.03 E-06$ & $8.68 \mathrm{E}-07$ & $5.37 \mathrm{E}-07$ & $2.04 \mathrm{E}-06$ & $2.80 \mathrm{E}-06$ & $3.49 \mathrm{E}-06$ & $4.51 \mathrm{E}-06$ \\
\hline $2.34 \mathrm{E}-08$ & $9.02 E-06$ & $8.69 E-07$ & $5.38 E-07$ & $2.05 E-06$ & $2.80 \mathrm{E}-06$ & $3.49 \mathrm{E}-06$ & $4.51 \mathrm{E}-06$ \\
\hline $2.35 E-08$ & $9.02 \mathrm{E}-06$ & $8.71 \mathrm{E}-07$ & $5.40 \mathrm{E}-07$ & $2.05 E-06$ & $2.81 \mathrm{E}-06$ & $3.49 \mathrm{E}-06$ & $4.51 \mathrm{E}-06$ \\
\hline $2.37 E-08$ & $9.01 \mathrm{E}-06$ & $2 E-07$ & $\begin{array}{c}0 \\
0\end{array}$ & $2.05 E-06$ & $E-06$ & -06 & $4.51 \mathrm{E}-06$ \\
\hline $2.38 E-08$ & $9.01 E-06$ & $8.74 E-07$ & $3 E-07$ & $2.06 E-06$ & -06 & $E-06$ & $4.52 \mathrm{E}-06$ \\
\hline $2.39 \mathrm{E}-08$ & $9.00 E-06$ & $8.76 E-07$ & $5.45 E-07$ & $2.06 E-06$ & $2.81 \mathrm{E}-06$ & $3.49 E-06$ & $4.52 \mathrm{E}-06$ \\
\hline $2.40 E-08$ & $8.99 E-06$ & $8.77 \mathrm{E}-07$ & $5.47 \mathrm{E}-07$ & $2.07 E-06$ & $2.82 \mathrm{E}-06$ & $3.49 \mathrm{E}-06$ & $4.52 \mathrm{E}-06$ \\
\hline $2.42 E-08$ & $8.99 E-06$ & $8.79 E-07$ & $5.48 E-07$ & $2.07 E-06$ & $2.82 \mathrm{E}-06$ & $3.49 E-06$ & $4.52 \mathrm{E}-06$ \\
\hline $2.43 E-08$ & $8.98 E-06$ & $8.80 \mathrm{E}-07$ & $5.50 \mathrm{E}-07$ & $2.07 E-06$ & $2.82 \mathrm{E}-06$ & $.49 E-06$ & $4.52 \mathrm{E}-06$ \\
\hline $2.44 \mathrm{E}-08$ & $8.97 \mathrm{E}-06$ & $8.82 \mathrm{E}-07$ & $5.51 \mathrm{E}-07$ & $2.08 E-06$ & $2.83 E-06$ & $3.48 \mathrm{E}-06$ & $4.53 E-06$ \\
\hline $2.45 E-08$ & $8.97 \mathrm{E}-06$ & $8.83 E-07$ & $5.53 \mathrm{E}-07$ & $2.08 E-06$ & $2.83 E-06$ & $3.48 \mathrm{E}-06$ & $4.53 E-06$ \\
\hline $2.47 E-08$ & $8.96 \mathrm{E}-06$ & -07 & -07 & -06 & $2.83 E-06$ & -06 & $4.53 E-06$ \\
\hline $2.48 E-08$ & $8.95 E-06$ & $8.87 \mathrm{E}-07$ & $5.56 \mathrm{E}-07$ & $2.09 E-06$ & $2.84 \mathrm{E}-06$ & $3.48 \mathrm{E}-06$ & $4.54 \mathrm{E}-06$ \\
\hline $2.49 E-08$ & $8.95 E-06$ & $8.88 E-07$ & $5.57 \mathrm{E}-07$ & $2.09 E-06$ & $2.84 \mathrm{E}-06$ & $3.48 E-06$ & $4.54 \mathrm{E}-06$ \\
\hline $2.50 E-08$ & $E-06$ & $8.90 \mathrm{E}-07$ & $5.59 \mathrm{E}-07$ & $2.10 \mathrm{E}-$ & $2.84 \mathrm{E}-06$ & $3.48 \mathrm{E}-06$ & $4.55 E-06$ \\
\hline $2.52 E-08$ & $8.93 E-06$ & $8.91 \mathrm{E}-07$ & $5.61 \mathrm{E}-07$ & $2.10 \mathrm{E}-06$ & $2.85 E-06$ & $3.48 \mathrm{E}-06$ & $4.55 \mathrm{E}-06$ \\
\hline $2.53 E-08$ & $8.93 E-06$ & $8.93 E-07$ & $5.62 \mathrm{E}-07$ & $2.10 \mathrm{E}-06$ & $2.85 E-06$ & $3.48 \mathrm{E}-06$ & $4.55 \mathrm{E}-06$ \\
\hline $2.54 \mathrm{E}-08$ & $8.92 E-06$ & $8.94 \mathrm{E}-07$ & $5.64 \mathrm{E}-07$ & $2.11 \mathrm{E}-06$ & $2.85 E-06$ & $3.48 E-06$ & $4.56 \mathrm{E}-06$ \\
\hline $2.56 \mathrm{E}-$ & 8.9 & $8.96 \mathrm{E}-07$ & $5.65 \mathrm{E}-07$ & $2.11 \mathrm{E}-06$ & $2.86 \mathrm{E}-06$ & $3.48 \mathrm{E}-06$ & $4.56 \mathrm{E}-06$ \\
\hline $2.57 E-08$ & $8.91 \mathrm{E}-06$ & $8.97 \mathrm{E}-07$ & $5 \quad 67 \mathrm{~F}-07$ & $2.11 \mathrm{E}-06$ & $2.86 \mathrm{E}-06$ & $3.48 E-06$ & $4.57 \mathrm{E}-06$ \\
\hline $2.58 E-08$ & $8.90 \mathrm{E}-06$ & $8.99 \mathrm{E}-07$ & $5.68 \mathrm{E}-07$ & $2.11 \mathrm{E}-06$ & $2.86 \mathrm{E}-06$ & $3.49 \mathrm{E}-06$ & $4.57 E-06$ \\
\hline $2.60 E-08$ & $8.89 E-06$ & $9.01 \mathrm{E}-07$ & $5.70 \mathrm{E}-07$ & $2.12 \mathrm{E}-06$ & $2.87 \mathrm{E}-06$ & $3.49 \mathrm{E}-06$ & $4.57 \mathrm{E}-06$ \\
\hline $2.61 E-08$ & $8.89 E-06$ & $9.02 \mathrm{E}-07$ & $5.71 \mathrm{E}-07$ & $2.12 E-06$ & $2.87 \mathrm{E}-06$ & $3.49 \mathrm{E}-06$ & $4.58 \mathrm{E}-06$ \\
\hline $2.62 E-08$ & $8.88 E-06$ & $9.04 \mathrm{E}-07$ & $5.73 E-07$ & $2.12 \mathrm{E}-06$ & $2.87 \mathrm{E}-06$ & $3.49 \mathrm{E}-06$ & $4.58 \mathrm{E}-06$ \\
\hline $2.64 \mathrm{E}-08$ & $8.87 \mathrm{E}-06$ & $9.05 \mathrm{E}-07$ & $5.75 \mathrm{E}-07$ & $2.12 \mathrm{E}-06$ & $2.87 \mathrm{E}-06$ & $3.49 \mathrm{E}-06$ & $4.59 \mathrm{E}-06$ \\
\hline 8 & 6 & 9. & . & 6 & $2.88 \mathrm{E}-06$ & $3.50 \mathrm{E}-06$ & $4.59 \mathrm{E}-06$ \\
\hline $2.66 \mathrm{E}-08$ & $8.86 \mathrm{E}-06$ & $9.08 \mathrm{E}-07$ & $5.78 \mathrm{E}-07$ & $2.13 E-06$ & $2.88 \mathrm{E}-06$ & $3.50 \mathrm{E}-06$ & $4.59 \mathrm{E}-06$ \\
\hline $2.68 E-08$ & $8.85 E-06$ & $9.10 \mathrm{E}-07$ & $5.80 \mathrm{E}-07$ & $2.13 E-06$ & $2.88 \mathrm{E}-06$ & $3.50 \mathrm{E}-06$ & $4.60 \mathrm{E}-06$ \\
\hline $2.69 E-08$ & $8.85 E-06$ & $9.12 \mathrm{E}-07$ & $5.81 \mathrm{E}-07$ & $2.13 E-06$ & $2.88 \mathrm{E}-06$ & $3.50 \mathrm{E}-06$ & $4.60 \mathrm{E}-06$ \\
\hline $2.70 E-08$ & $8.84 \mathrm{E}-06$ & $9.13 \mathrm{E}-07$ & $5.82 \mathrm{E}-07$ & $2.14 \mathrm{E}-06$ & $2.89 \mathrm{E}-06$ & $3.50 \mathrm{E}-06$ & $4.61 \mathrm{E}-06$ \\
\hline $2.72 E-08$ & $8.83 E-06$ & $9.15 \mathrm{E}-07$ & $5.84 \mathrm{E}-07$ & $2.14 \mathrm{E}-06$ & $2.89 E-06$ & $3.51 \mathrm{E}-06$ & $4.61 \mathrm{E}-06$ \\
\hline $2.73 E-08$ & $8.83 E-06$ & $9.16 \mathrm{E}-07$ & $5.85 E-07$ & $2.14 E-06$ & $2.89 E-06$ & $3.51 \mathrm{E}-06$ & $4.61 E-06$ \\
\hline $2.74 E-08$ & $8.82 E-06$ & $9.18 \mathrm{E}-07$ & $5.87 \mathrm{E}-07$ & $2.15 E-06$ & $2.89 \mathrm{E}-06$ & $3.51 \mathrm{E}-06$ & $4.62 \mathrm{E}-06$ \\
\hline
\end{tabular}


RESRAD-OFFSITE, Version 2.5

itle : RESRAD-OFFSITE External Gamma, Inhalation, and Soil Ingestion for offsite Reside

File: $:$ PBA-1_TC99-DOE-5-1.ROF

Summary of dose at graphical times, reptition 1 (continued)

Time

Years

7. $31 \mathrm{E}+02$

7. $32 \mathrm{E}+02$

7. $32 \mathrm{E}+02$

7. $33 \mathrm{E}+02$

7. $33 \mathrm{E}+02$

7. $34 \mathrm{E}+02$

7. $34 \mathrm{E}+02$

7. $35 \mathrm{E}+02$

7. $35 \mathrm{E}+02$

7. $36 \mathrm{E}+02$

7. $36 \mathrm{E}+02$

7. $37 \mathrm{E}+02$

7. $37 \mathrm{E}+02$

7. $38 \mathrm{E}+02$

7. $38 \mathrm{E}+02$

7. $39 \mathrm{E}+02$

7. $39 \mathrm{E}+02$

$7.40 \mathrm{E}+02$

$7.40 \mathrm{E}+02$

7. $41 \mathrm{E}+02$

7. $41 \mathrm{E}+02$

7. $42 \mathrm{E}+02$

$7.42 \mathrm{E}+02$

$7.43 \mathrm{E}+02$

$7.43 \mathrm{E}+02$

7. $44 \mathrm{E}+02$

$7.44 \mathrm{E}+02$

$7.45 \mathrm{E}+02$

7. $45 \mathrm{E}+02$

7. $46 \mathrm{E}+02$

7. $46 \mathrm{E}+02$

7. $47 \mathrm{E}+02$

7. $48 \mathrm{E}+02$

7. $48 \mathrm{E}+02$

7. $49 \mathrm{E}+02$

7. $49 \mathrm{E}+02$

$7.50 \mathrm{E}+02$

$7.50 \mathrm{E}+02$

7. $51 \mathrm{E}+02$

$7.51 \mathrm{E}+02$

$7.52 \mathrm{E}+02$

$7.52 \mathrm{E}+02$

$7.53 \mathrm{E}+02$

$7.53 \mathrm{E}+02$

$7.54 \mathrm{E}+02$

$7.54 \mathrm{E}+02$
Dose statistics at graphical times, mrem/yr

\begin{tabular}{|c|c|c|c|c|c|c|c|}
\hline in & $m$ & a & 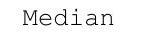 & $0 \%$ & & \% & \% \\
\hline $76 \mathrm{E}-08$ & $.81 E-06$ & $19 \mathrm{E}-07$ & $.88 \mathrm{E}-07$ & $.15 \mathrm{E}-06$ & $2.90 \mathrm{E}-06$ & $3.51 \mathrm{E}-06$ & 4. $.0 \angle E-06$ \\
\hline $.77 E-08$ & $.81 E-06$ & $.21 E-07$ & & $15 E-06$ & $.90 \mathrm{E}-06$ & $.51 E-06$ & $3 E-06$ \\
\hline $.79 E-08$ & $.80 E-06$ & $.22 E-07$ & $.91 E-07$ & $.16 \mathrm{E}-06$ & $2.90 \mathrm{E}-06$ & $3.52 E-06$ & $4.63 E-06$ \\
\hline $.80 \mathrm{E}-08$ & $.79 \mathrm{E}-06$ & $.24 \mathrm{E}-07$ & $.92 \mathrm{E}-07$ & $.16 \mathrm{E}-06$ & $.91 E-06$ & $.52 \mathrm{E}-06$ & 4. $63 \mathrm{E}-06$ \\
\hline $81 \mathrm{~F}-08$ & $78 \mathrm{~F}-06$ & $5 \mathrm{~F}-07$ & $94=07-7-7$ & -06 & -06 & $25-06$ & $64 E-06$ \\
\hline 08 & 06 & & & & 6 & 6 & -06 \\
\hline $84 \mathrm{E}-08$ & $.77 E-06$ & $29 \mathrm{E}-07$ & & 6 & 6 & 6 & -06 \\
\hline $.86 \mathrm{E}-08$ & $76 E-06$ & & & $.17 \mathrm{E}-06$ & $2.92 \mathrm{E}-06$ & $3.53 E-06$ & $65 E-06$ \\
\hline $.87 \mathrm{E}-08$ & $5 E-06$ & $.32 E-07$ & & $.18 \mathrm{E}-06$ & $.92 \mathrm{E}-06$ & -06 & $65 E-06$ \\
\hline $88 E-08$ & $E-06$ & $33 E-07$ & & $18 \mathrm{E}-06$ & 6 & -06 & -06 \\
\hline م०=-08 & $74 E-06$ & $35 E-07$ & קת תח & $19 F-06$ & 6 & 06 & -06 \\
\hline-08 & 6 & & & 6 & 6 & 6 & 6 \\
\hline $3 E-08$ & $3 E-06$ & -07 & & $9 E-06$ & 06 & -06 & $57 E-06$ \\
\hline $.94 \mathrm{E}-08$ & $.72 \mathrm{E}-06$ & $.39 \mathrm{E}-07$ & $.07 E-07$ & $.20 \mathrm{E}-06$ & $.93 E-06$ & $3.54 \mathrm{E}-06$ & $4.67 \mathrm{E}-06$ \\
\hline $.96 \mathrm{E}-08$ & $.71 \mathrm{E}-06$ & $.41 \mathrm{E}-07$ & & $.20 \mathrm{E}-06$ & -06 & -06 & $57 E-06$ \\
\hline $97 \mathrm{E}-08$ & $1 \mathrm{E}-06$ & -07 & & 21 & -06 & -00 & -06 \\
\hline $98 E-08$ & 6 & & & & 6 & 6 & 06 \\
\hline & & & & & 6 & 6 & 6 \\
\hline $.01 E-08$ & $8 E-06$ & -07 & $6.13 \mathrm{E}-07$ & $21 E-06$ & $94 \mathrm{E}-06$ & -06 & $9 E-06$ \\
\hline $03 E-08$ & $E-06$ & $49 E-07$ & $5-07$ & $21 \mathrm{~F}-06$ & $94 E-06$ & -06 & $69 E-06$ \\
\hline $04 \mathrm{E}-08$ & $67 E-06$ & -07 & & $.22 \mathrm{E}-06$ & -06 & -06 & -06 \\
\hline-08 & & & & $225-0$ & 6 & 0 & -06 \\
\hline $07 E-08$ & & & & & & & 06 \\
\hline & & & & & & & 06 \\
\hline $10 E-08$ & 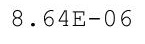 & 1 & $6.21 E-07$ & 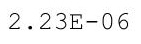 & 6 & $3.56 \mathrm{E}-06$ & 06 \\
\hline $2 E-08$ & $3 E-06$ & $E-07$ & T & $23 E-0$ & $95 E-06$ & r & $70 \mathrm{E}-06$ \\
\hline $3 F-08$ & $3 F-06$ & $=07$ & & $.24 \mathrm{E}-06$ & $.95 E-06$ & -06 & $.70 \mathrm{E}-0$ \\
\hline $5 E-08$ & $E-06$ & -07 & ת & $24 E-06$ & $95 E-06$ & -06 & $70 E-06$ \\
\hline & & & & & & & 06 \\
\hline & & & & & & & -06 \\
\hline $.19 \mathrm{E}-08$ & $.60 E-06$ & $.66 \mathrm{E}-07$ & (1 & $.25 E-06$ & $.95 E-06$ & $4-0$ & $.70 E-06$ \\
\hline $21 E-08$ & $.59 E-06$ & $.012-01$ & & . & $.20 \mathrm{D}-00$ & 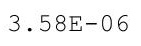 & $.70 \mathrm{E}-0$ \\
\hline $22 E-08$ & $58 \mathrm{~F}-06$ & & & & & -06 & -06 \\
\hline $24 E-08$ & -06 & 0 & ת & $25 E-$ & & & 06 \\
\hline$E-08$ & -06 & 07 & & & 06 & 06 & -06 \\
\hline $27 E-08$ & $.56 E-06$ & $.73 E-07$ & $6.37 E-07$ & $2.26 \mathrm{E}-06$ & $2.96 \mathrm{E}-06$ & $3.59 E-06$ & $4.71 \mathrm{E}-06$ \\
\hline $.28 E-08$ & $.55 E-06$ & $.15 \mathrm{E}-01$ & . & $.26 E-06$ & -06 & -00 & 4. $11 \mathrm{E}-06$ \\
\hline $30 E-00$ & $.54 \mathrm{E}-06$ & & & $\begin{array}{cc}. \\
\text {. }\end{array}$ & & & 4. $11 \mathrm{E}-\mathrm{C}$ \\
\hline $3.31 E-08$ & 6 & 7 & $6.41 \mathrm{E}-07$ & cre & 6 & 6 & 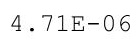 \\
\hline & & & & & & & 06 \\
\hline 08 & 06 & 7 & & & & 06 & -06 \\
\hline $36 E-08$ & $.51 E-06$ & $.82 \mathrm{E}-07$ & $4 E-07$ & $2.28 \mathrm{E}-06$ & 06 & 06 & $E-06$ \\
\hline $38 E-08$ & 6 & & & & & & -06 \\
\hline - & 6 & & & $.28 E-06$ & $2.98 \mathrm{E}-06$ & $3.61 \mathrm{E}-06$ & $4.11 E-06$ \\
\hline & & & & $28 E-06$ & $2.90 \pm-06$ & $3.0 \angle E-00$ & 4. $11 \mathrm{E}-06$ \\
\hline$E-08$ & $E-06$ & $9 E-07$ & $51 E-07$ & $29 E-06$ & $98 E-06$ & $2 E-06$ & -06 \\
\hline
\end{tabular}


RESRAD-OFFSITE, Version 2.5

$\mathrm{T}^{1 / 2}$ Limit $=180$ days

Title : RESRAD-OFFSITE External Gamma, Inhalation, and Soil Ingestion for Offsite Reside File : PBA-1_TC99-DOE-5-1.ROF

Summary of dose at graphical times, reptition 1 (continued)

Time

Years

$7.55 \mathrm{E}+02$

$7.55 \mathrm{E}+02$

$7.56 \mathrm{E}+02$

$7.56 \mathrm{E}+02$

$7.57 \mathrm{E}+02$

$7.57 \mathrm{E}+02$

$7.58 \mathrm{E}+02$

7. $58 \mathrm{E}+02$

7. $59 \mathrm{E}+02$

$7.59 \mathrm{E}+02$

7. $60 \mathrm{E}+02$

7. $60 \mathrm{E}+02$

7. $61 \mathrm{E}+02$

7. $61 \mathrm{E}+02$

$7.62 \mathrm{E}+02$

7. $62 \mathrm{E}+02$

$7.63 \mathrm{E}+02$

$7.63 \mathrm{E}+02$

$7.64 \mathrm{E}+02$

$7.64 \mathrm{E}+02$

$7.65 \mathrm{E}+02$

7. $65 \mathrm{E}+02$

$7.66 \mathrm{E}+02$

$7.66 \mathrm{E}+02$

$7.67 \mathrm{E}+02$

$7.68 \mathrm{E}+02$

$7.68 \mathrm{E}+02$

$7.69 \mathrm{E}+02$

$7.69 \mathrm{E}+02$

$7.70 \mathrm{E}+02$

$7.70 \mathrm{E}+02$

$7.71 \mathrm{E}+02$

$7.71 \mathrm{E}+02$

7. $72 \mathrm{E}+02$

$7.72 \mathrm{E}+02$

$7.73 E+02$

7. $73 \mathrm{E}+02$

$7.74 \mathrm{E}+02$

$7.74 \mathrm{E}+02$

$7.75 \mathrm{E}+02$

$7.75 \mathrm{E}+02$

$7.76 \mathrm{E}+02$

7. $76 \mathrm{E}+02$

$7.77 \mathrm{E}+02$

$7.77 \mathrm{E}+02$

$7.78 \mathrm{E}+02$
Dose statistics at graphical times, mrem/yr

\begin{tabular}{|c|c|c|c|c|c|c|c|}
\hline inimum & aximum & Mean & ledian & $0 \%$ & $5 \%$ & $97.5 \%$ & $\%$ \\
\hline 8 & 6 & 7 & 07 & 66 & 6 & 06 & 0 \\
\hline 08 & $.47 \mathrm{E}-06$ & 07 & 07 & $2.29 \mathrm{E}$ & 06 & 06 & -06 \\
\hline$E-08$ & $E-06$ & 07 & 07 & 06 & 06 & 06 & -06 \\
\hline$E-08$ & $.45 E-06$ & 07 & & & & 6 & -06 \\
\hline $50 E-08$ & 06 & 7 & & 6 & $00 E-06$ & -06 & $71 E-06$ \\
\hline $52 \mathrm{E}-08$ & -06 & -07 & -07 & $.29 E-06$ & 6 & $E-06$ & $E-06$ \\
\hline $.54 \mathrm{E}-08$ & -06 & $9 E-07$ & 年 & 06 & 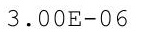 & -06 & , \\
\hline 08 & 06 & 0 & & 列 & 每 & 和 & $4.70 \mathrm{E}-06$ \\
\hline 08 & -06 & 6 & 1 & 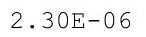 & 6 & 06 & $0 E-06$ \\
\hline $59 \mathrm{E}-08$ & $E-06$ & $.00 \mathrm{E}-06$ & & -06 & & -06 & $.70 E-06$ \\
\hline $60 \mathrm{E}-08$ & $8.39 E-06$ & $.01 \mathrm{E}-06$ & & $.30 \mathrm{E}-06$ & & $=06$ & $.69 \mathrm{E}-06$ \\
\hline 08 & -06 & -06 & & & & -06 & $9 E-06$ \\
\hline $.63 E-08$ & $8.38 \mathrm{E}-06$ & $.01 \mathrm{E}-06$ & ( & C. & (1) & 00 & -06 \\
\hline 08 & 06 & 6 & & $31 E-06$ & . & -06 & 06 \\
\hline 8 & 6 & 6 & & $31 E-06$ & . & -06 & 6 \\
\hline $68 \mathrm{E}-08$ & $8.35 \mathrm{E}-06$ & -06 & r & -06 & 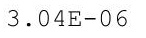 & -06 & -06 \\
\hline $.70 E-08$ & $8.35 E-06$ & $1.01 E-06$ & $.76 E-07$ & $2.32 \mathrm{E}-06$ & $.04 \mathrm{E}-06$ & $.65 E-06$ & $.69 E-06$ \\
\hline$E-08$ & $E-06$ & $.02 E-06$ & & 6 & & $=06$ & $59 E-06$ \\
\hline & 06 & 06 & & 0 & & -06 & -06 \\
\hline & 06 & -06 & & 0 & & -06 & -06 \\
\hline 8 & 6 & & & & & 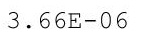 & -06 \\
\hline 8 & 6 & 6 & 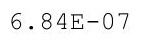 & $2.33 E-06$ & 政 & $3.66 \mathrm{E}-06$ & -06 \\
\hline 08 & 6 & 6 & 7 & & $3.05 \mathrm{E}-06$ & -06 & -06 \\
\hline $2 E-08$ & $29 E-06$ & $1.02 E-06$ & 7 & $34 \mathrm{E}-\mathrm{C}$ & 055 & $66 \mathrm{E}-06$ & $69 E-06$ \\
\hline-08 & $E-06$ & $.03 E-06$ & & & 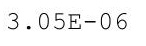 & $6 E-06$ & $59 E-06$ \\
\hline-08 & $\mathrm{E}-06$ & $\mathrm{E}-06$ & & & & & .06 \\
\hline-08 & & & & & & & 06 \\
\hline $89 E-08$ & $8.26 \mathrm{E}-06$ & $.03 E-06$ & (2)- & $5.325-00$ & 更 & $35-20$ & $70 E-06$ \\
\hline 8 & $5 E-06$ & $3 E-06$ & 西 & ( & . & 更 & $70 E-06$ \\
\hline $92 E-08$ & $24 E-06$ & $1.03 E-06$ & (4) & & 年- & ( & $.70 E-06$ \\
\hline$E-08$ & $E-06$ & $E-06$ & & & & $E-06$ & $70 E-06$ \\
\hline$E-08$ & $E-06$ & $E-06$ & 7 & 6 & & & 06 \\
\hline $7 E-08$ & & & & & & & \\
\hline $.99 E-08$ & $8.21 E-06$ & $1.04 \mathrm{E}-06$ & $7.05 E-07$ & $2.36 \mathrm{E}-06$ & $.0 / 2-06$ & $5 E-06$ & $.70 \mathrm{E}-06$ \\
\hline $.01 E-08$ & $.20 E-06$ & $.04 E-06$ & & & & 40 & $.70 E-06$ \\
\hline & $19 E-06$ & & & & & & - \\
\hline 8 & 6 & 6 & & & & 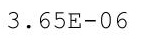 & e \\
\hline & 6 & & $7.11 \mathrm{E}-07$ & & & & 06 \\
\hline $8 E-08$ & 6 & 6 & & & & & 06 \\
\hline $10 \mathrm{E}-08$ & $8.16 \mathrm{E}-06$ & $.05 E-06$ & $.15 \mathrm{E}-07$ & $2.31 \mathrm{E}$ & 6 & -06 & $4.70 \mathrm{E}-06$ \\
\hline $11 \mathrm{E}-08$ & $8.15 E-06$ & $.05 E-06$ & & $38 \mathrm{E}$ & 6 & 06 & $0 E-06$ \\
\hline $3 E-08$ & $\cdot+1+$ & $.05 E-06$ & 10 & 2.000 & 6 & $6 / E-06$ & $4.10 \pm-06$ \\
\hline He & . & एक & 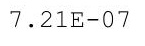 & 2.00 & 6 & $67 E-06$ & $4.71 E-06$ \\
\hline 8 & $2+$ & 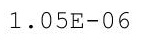 & & 2.000 & & & $4.71 E-06$ \\
\hline $.19 \mathrm{E}-08$ & $8.12 E-06$ & $6 E-06$ & $7.25 E-07$ & $2.38 E-06$ & $3.09 \mathrm{E}-06$ & -06 & $4.70 \mathrm{E}$ \\
\hline $.20 E-08$ & $8.11 E-06$ & $.06 E-06$ & $.26 E-07$ & $2.38 \mathrm{E}-06$ & $3.09 E-06$ & $3.68 \mathrm{E}-06$ & $4.70 E-06$ \\
\hline
\end{tabular}


RESRAD-OFFSITE, Version 2.5

$\mathrm{T}^{1 / 2}$ Limit $=180$ days

Title : RESRAD-OFFSITE External Gamma, Inhalation, and Soil Ingestion for offsite Reside File : PBA-1_TC99-DOE-5-1.ROF

Summary of dose at graphical times, reptition 1 (continued)

Time

Years

$7.78 \mathrm{E}+02$

$7.79 \mathrm{E}+02$

$7.79 \mathrm{E}+02$

$7.80 \mathrm{E}+02$

$7.80 \mathrm{E}+02$

$7.81 \mathrm{E}+02$

$7.81 \mathrm{E}+02$

$7.82 \mathrm{E}+02$

$7.82 \mathrm{E}+02$

$7.83 \mathrm{E}+02$

$7.83 \mathrm{E}+02$

$7.84 \mathrm{E}+02$

$7.84 \mathrm{E}+02$

$7.85 \mathrm{E}+02$

$7.85 \mathrm{E}+02$

$7.86 \mathrm{E}+02$

$7.86 \mathrm{E}+02$

$7.87 \mathrm{E}+02$

$7.88 \mathrm{E}+02$

$7.88 \mathrm{E}+02$

$7.89 \mathrm{E}+02$

$7.89 \mathrm{E}+02$

$7.90 \mathrm{E}+02$

$7.90 \mathrm{E}+02$

7. $91 \mathrm{E}+02$

7. $91 \mathrm{E}+02$

7. $92 \mathrm{E}+02$

7. $92 \mathrm{E}+02$

7. $93 \mathrm{E}+02$

7. $93 \mathrm{E}+02$

$7.94 \mathrm{E}+02$

$7.94 \mathrm{E}+02$

$7.95 \mathrm{E}+02$

7. $95 \mathrm{E}+02$

$7.96 \mathrm{E}+02$

7. $96 \mathrm{E}+02$

$7.97 \mathrm{E}+02$

$7.97 \mathrm{E}+02$

7. $98 \mathrm{E}+02$

$7.98 \mathrm{E}+02$

$7.99 \mathrm{E}+02$

7. $99 \mathrm{E}+02$

$8.00 \mathrm{E}+02$

$8.00 \mathrm{E}+02$

$8.01 \mathrm{E}+02$

$8.01 \mathrm{E}+02$
Dose statistics at graphical times, mrem/yr

\begin{tabular}{|c|c|c|c|c|c|c|c|}
\hline um & aximum & lean & edi & & & & \\
\hline$E-08$ & 6 & 06 & 7 & 6 & 06 & 06 & -06 \\
\hline $.24 \mathrm{E}-08$ & $.09 E-06$ & $6 E-06$ & $7.30 \mathrm{E}-07$ & $2.38 \mathrm{E}-06$ & $3.10 \mathrm{E}-06$ & $3.69 \mathrm{E}-06$ & $70 \mathrm{E}-06$ \\
\hline$F-08$ & $8 F-06$ & $6 F-06$ & $32 E-07$ & $9 E-06$ & $10 F-06$ & 06 & -06 \\
\hline $8 \mathrm{~F}-2 \cdot-$ & 6 & $.06 \mathrm{E}-06$ & & & 06 & & 06 \\
\hline$E-08$ & 06 & -06 & 7 & 06 & 6 & & -06 \\
\hline $31 E-08$ & 06 & -06 & 7 & 66 & 6 & & 06 \\
\hline $3 E-08$ & -06 & -06 & & & 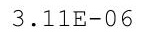 & & -06 \\
\hline$E-08$ & -06 & $E-06$ & -07 & -06 & $12 E-06$ & -06 & -06 \\
\hline $.37 E-08$ & $E-06$ & $E-06$ & $7.42 E-07$ & -06 & $12 E-06$ & -06 & -06 \\
\hline $.39 E-08$ & $02 \mathrm{E}-06$ & $.07 E-06$ & $.43 E-07$ & & $12 F-06$ & -06 & 6 \\
\hline & & & & & & & 06 \\
\hline$E-08$ & $E-06$ & $.08 E-06$ & $5 E-07$ & & $13 E-06$ & 06 & -06 \\
\hline $.44 \mathrm{E}-08$ & $8.00 E-06$ & $.08 E-06$ & $7.46 E-07$ & & $3.13 E-06$ & & $68 E-06$ \\
\hline $5 E-08$ & -06 & $\Xi-06$ & 07 & & 0 & & \\
\hline 08 & 06 & & & & & & \\
\hline 8 & $97 E-06$ & $.08 E-06$ & & & & & 06 \\
\hline 8 & 6 & 6 & 7 & 6 & $3.13 F-06$ & 6 & 06 \\
\hline $4 E-08$ & $E-06$ & $3 E-06$ & $5 E-07$ & & $11 \mathrm{~F}-2-10$ & -06 & 06 \\
\hline $.56 \mathrm{E}-08$ & $.95 E-06$ & $1.09 E-06$ & $7.56 \mathrm{E}-07$ & $2.42 E-06$ & $.14 \mathrm{E}-06$ & -06 & $67 \mathrm{E}-06$ \\
\hline $58 E-08$ & $.94 E-06$ & $1.09 E-06$ & $7.58 \mathrm{E}-07$ & $.42 E-06$ & $E-06$ & -06 & -06 \\
\hline & & & & & & & \\
\hline & & & & & & & -06 \\
\hline & & & & & & & 06 \\
\hline 8 & 06 & $9 E-06$ & 7 & 6 & 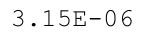 & 06 & -0 \\
\hline $7 F-$ & $.90 \mathrm{E}-06$ & $1.09 \mathrm{E}-06$ & $7.67 \mathrm{E}-07$ & $2.43 E-06$ & $15 \mathrm{~F}-\mathrm{d}$ & $77 \mathrm{E}-06$ & $06-2-2 \cdot-3$ \\
\hline $.69 E-08$ & $.89 E-06$ & $.10 \mathrm{E}-06$ & $69 E-07$ & $.43 E-06$ & $15 E-06$ & -06 & 06 \\
\hline $71 \mathrm{E}-08$ & $.88 E-06$ & $1.10 \mathrm{E}-06$ & $0 E-07$ & -06 & & & -06 \\
\hline & & & & & & & \\
\hline & & & & & & & \\
\hline $.77 \mathrm{E}-08$ & $7.85 \mathrm{E}-06$ & $1.10 \mathrm{E}-06$ & $7.75 \mathrm{E}-07$ & $2.44 \mathrm{E}-06$ & $\begin{array}{ll}. \pm 0 \\
0\end{array}$ & 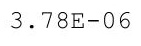 & OD \\
\hline $.79 E-08$ & $7.84 \mathrm{E}-06$ & $.10 \mathrm{E}-06$ & $7.77 E-07$ & $2.44 \mathrm{E}-06$ & 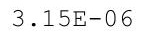 & - & sec- \\
\hline 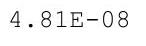 & & & $8 E-07$ & & & 6 & \\
\hline$F-0$ & $83 E-06$ & $1 E-06$ & $E-07$ & & & & 06 \\
\hline & & & & & & & 06 \\
\hline & & & & & & & -06 \\
\hline $.89 E-08$ & $7.80 \mathrm{E}-06$ & $1.11 \mathrm{E}-06$ & $7.85 \mathrm{E}-07$ & $2.45 E-06$ & $3.16 \mathrm{E}-06$ & $79 E-06$ & $705-00$ \\
\hline cita vo & $79 E-06$ & $.11 \mathrm{E}-06$ & 07 & 06 & 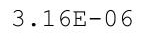 & & - \\
\hline & & $1.11 \mathrm{E}-06$ & $38 E-07$ & & & & 0 \\
\hline $95 F-08$ & & $.11 \mathrm{E}$ & 7 & 6 & & -06 & 06 \\
\hline $4.97 \mathrm{E}-08$ & & & 07 & 06 & 6 & 6 & 06 \\
\hline $9 E-08$ & $.76 \mathrm{E}-06$ & $1.12 \mathrm{E}-06$ & $3 E-07$ & -06 & & & -06 \\
\hline$E-08$ & $E-06$ & $1.12 \mathrm{E}-06$ & $5 E-07$ & -06 & -06 & 06 & -06 \\
\hline & & & & & & & 06 \\
\hline 0 & & 06 & 07 & - 1.5 & (-) & 06 & -00 \\
\hline & & $1.12 \mathrm{E}-06$ & & & & & th \\
\hline $.09 E-08$ & $E-06$ & $2 E-06$ & $2 E-07$ & $7 E-06$ & $17 E-06$ & -06 & -06 \\
\hline
\end{tabular}


RESRAD-OFFSITE, Version 2.5

Title : RESRAD-OFFSITE External Gamma, Inhalation, and Soil Ingestion for offsite Reside File : PBA-1_TC99-DOE-5-1.ROF

Summary of dose at graphical times, reptition 1 (continued)

Time

Years

8. $02 \mathrm{E}+02$

$8.02 \mathrm{E}+02$

$8.03 E+02$

$8.03 \mathrm{E}+02$

$8.04 \mathrm{E}+02$

$8.04 \mathrm{E}+02$

$8.05 E+02$

$8.05 \mathrm{E}+02$

$8.06 \mathrm{E}+02$

$8.06 \mathrm{E}+02$

$8.07 \mathrm{E}+02$

$8.07 \mathrm{E}+02$

$8.08 \mathrm{E}+02$

$8.09 \mathrm{E}+02$

$8.09 \mathrm{E}+02$

$8.10 \mathrm{E}+02$

$8.10 \mathrm{E}+02$

$8.11 \mathrm{E}+02$

$8.11 \mathrm{E}+02$

$8.12 \mathrm{E}+02$

$8.12 \mathrm{E}+02$

$8.13 \mathrm{E}+02$

$8.13 \mathrm{E}+02$

$8.14 \mathrm{E}+02$

$8.14 \mathrm{E}+02$

$8.15 \mathrm{E}+02$

$8.15 \mathrm{E}+02$

$8.16 \mathrm{E}+02$

$8.16 \mathrm{E}+02$

$8.17 \mathrm{E}+02$

$8.17 \mathrm{E}+02$

$8.18 \mathrm{E}+02$

$8.18 \mathrm{E}+02$

$8.19 \mathrm{E}+02$

$8.19 \mathrm{E}+02$

8. $20 \mathrm{E}+02$

$8.20 \mathrm{E}+02$

$8.21 E+02$

$8.21 E+02$

$8.22 \mathrm{E}+02$

$8.22 \mathrm{E}+02$

$8.23 \mathrm{E}+02$

$8.23 E+02$

$8.24 \mathrm{E}+02$

$8.24 \mathrm{E}+02$

$8.25 E+02$

Dose statistics at graphical times, mrem/yr

\begin{tabular}{|c|c|c|c|c|c|c|c|}
\hline m & um & az & ledian & & & & \\
\hline 08 & -06 & $1.13 E-06$ & -07 & -06 & -06 & -06 & -06 \\
\hline $.13 E-08$ & $7.70 \mathrm{E}-06$ & $.13 E-06$ & -07 & $8 E-06$ & $8 E-06$ & -06 & $72 E-06$ \\
\hline$E-08$ & $69 E-06$ & $.13 E-06$ & -07 & $48 E-06$ & $3.18 \mathrm{E}-06$ & $3.79 E-06$ & $\Xi-06$ \\
\hline-08 & -06 & $13 F-06$ & $08 F-07$ & $48 E-06$ & -06 & .06 & -06 \\
\hline 08 & 06 & 06 & 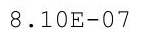 & 06 & 06 & 06 & -06 \\
\hline 08 & 06 & 6 & & & & & -06 \\
\hline $23 E-08$ & 06 & & & & & & $72 E-06$ \\
\hline $25 E-08$ & -06 & -06 & 7 & 06 & 6 & -06 & -06 \\
\hline-08 & -06 & $E-06$ & 7 & $9 E-06$ & -06 & -06 & -06 \\
\hline 08 & 06 & $14 E-06$ & ח & 6 & & 6 & -06 \\
\hline 8 & 6 & 6 & $E-07$ & o & & 6 & -0 \\
\hline$E-08$ & $E-06$ & $4 \mathrm{E}-06$ & $9 E-07$ & 6 & 6 & 06 & -06 \\
\hline $.36 \mathrm{E}-08$ & $7.60 \mathrm{E}-06$ & $1.14 \mathrm{E}-06$ & & & & & $.73 E-06$ \\
\hline-08 & -06 & $E-06$ & 7 & $0 E-06$ & & -06 & $E-06$ \\
\hline-08 & -06 & $5 E-06$ & & $0 E-06$ & & -06 & -06 \\
\hline 08 & 06 & $.15 \mathrm{E}-06$ & & & 0 & 6 & 06 \\
\hline 8 & & & & & & & 06 \\
\hline 8 & 6 & 6 & $8.28 E-07$ & & & 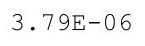 & 0 \\
\hline $.48 \mathrm{E}-08$ & $7.54 \mathrm{E}-06$ & $1.15 \mathrm{E}-06$ & $8.29 E-07$ & $2.51 E-06$ & $.20 E-06$ & $.79 E-06$ & -06 \\
\hline$E-08$ & $4 E-06$ & $1.15 \mathrm{E}-06$ & $8.31 E-07$ & $2.51 \mathrm{E}-06$ & $E-06$ & $E-06$ & $74 \mathrm{E}-06$ \\
\hline 08 & 06 & $.15 E-06$ & & & & 6 & -06 \\
\hline & & & & & & & 06 \\
\hline 8 & & & & & & & 06 \\
\hline 08 & 6 & 6 & 1 & 6 & & 0 & -06 \\
\hline 8 & 6 & $.16 \mathrm{E}-$ & 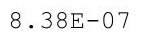 & 6 & $3.22 \mathrm{E}-06$ & 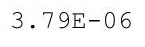 & 0 \\
\hline$E-08$ & $7.48 \mathrm{E}-06$ & $1.16 \mathrm{E}-06$ & $8.39 E-07$ & $2 E-06$ & $22 E-0$ & $9 E-06$ & $74 \mathrm{~F}-06$ \\
\hline-08 & $.47 \mathrm{E}-06$ & $1.16 \mathrm{E}-06$ & & $52 E-06$ & & $E-06$ & $74 \mathrm{~F}-06$ \\
\hline & & & & & & & 06 \\
\hline & & & & & & & 06 \\
\hline & & & & 66 & -00 & $5-06$ & -06 \\
\hline $.74 \mathrm{E}-08$ & $7.44 \mathrm{E}-06$ & $.17 \mathrm{E}-06$ & . 700 vi & $.53 E-06$ & . & - & $10 \mathrm{D}-0$ \\
\hline 8 & $7.43 E-06$ & $1.17 \mathrm{E}-06$ & 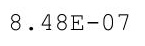 & $2.53 E-06$ & & & 然 \\
\hline-08 & $742 \mathrm{~F}-06$ & & & & & & $F-06-25-5$ \\
\hline & & & & & & & 06 \\
\hline 08 & $7.40 \mathrm{E}$ & & & & -06 & -06 & \\
\hline & & & & & 06 & -06 & 06 \\
\hline $.88 E-08$ & $7.38 \mathrm{E}-06$ & $.18 E-06$ & $25-21$ & 00 & 0 & 06 & ce \\
\hline $90 \mathrm{E}-08$ & & & & & & & • \\
\hline 8 & 6 & $1.18 \mathrm{E}-06$ & $8.58 \mathrm{E}-07$ & 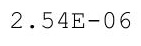 & & & 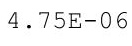 \\
\hline & & & & & & 6 & 66 \\
\hline-08 & 7.3 & & $1 E-07$ & $5 E-06$ & -06 & -06 & 06 \\
\hline$E-08$ & $7.34 \mathrm{E}-06$ & $1.18 \mathrm{E}-06$ & $63 E-07$ & $5 E-06$ & 6 & $E-06$ & -06 \\
\hline 08 & & $1.19 \mathrm{E}-06$ & & & & & \\
\hline & & $1.19 \mathrm{E}-06$ & 1 & 6 & & & -00 \\
\hline & & & . & 2.00 & & & $17+00$ \\
\hline-08 & $E-06$ & $E-06$ & $E-07$ & -06 & $25 E-06$ & $D E-06$ & -06 \\
\hline
\end{tabular}


RESRAD-OFFSITE, Version 2.5

itle : RESRAD-OFfSITE External Gamma, Inhalation, and Soil Ingestion for offsite Reside

File: $:$ PBA-1_TC99-DOE-5-1.ROF

Summary of dose at graphical times, reptition 1 (continued)

Time

Years

$8.25 E+02$

$8.26 \mathrm{E}+02$

$8.26 \mathrm{E}+02$

$8.27 \mathrm{E}+02$

$8.27 \mathrm{E}+02$

$8.28 \mathrm{E}+02$

$8.29 \mathrm{E}+02$

$8.29 \mathrm{E}+02$

$8.30 \mathrm{E}+02$

$8.30 \mathrm{E}+02$

$8.31 \mathrm{E}+02$

8. $31 \mathrm{E}+02$

$8.32 \mathrm{E}+02$

$8.32 \mathrm{E}+02$

$8.33 E+02$

$8.33 \mathrm{E}+02$

$8.34 \mathrm{E}+02$

$8.34 \mathrm{E}+02$

$8.35 \mathrm{E}+02$

$8.35 \mathrm{E}+02$

$8.36 \mathrm{E}+02$

$8.36 \mathrm{E}+02$

$8.37 \mathrm{E}+02$

$8.37 \mathrm{E}+02$

$8.38 \mathrm{E}+02$

$8.38 \mathrm{E}+02$

$8.39 \mathrm{E}+02$

$8.39 \mathrm{E}+02$

$8.40 \mathrm{E}+02$

$8.40 \mathrm{E}+02$

$8.41 \mathrm{E}+02$

$8.41 \mathrm{E}+02$

$8.42 \mathrm{E}+02$

$8.42 \mathrm{E}+02$

$8.43 \mathrm{E}+02$

$8.43 E+02$

$8.44 \mathrm{E}+02$

$8.44 \mathrm{E}+02$

$8.45 \mathrm{E}+02$

$8.45 \mathrm{E}+02$

$8.46 \mathrm{E}+02$

$8.46 \mathrm{E}+02$

$8.47 \mathrm{E}+02$

$8.47 \mathrm{E}+02$

$8.48 \mathrm{E}+02$

$8.49 \mathrm{E}+02$
Dose statistics at graphical times, mrem/yr

\begin{tabular}{|c|c|c|c|c|c|c|c|}
\hline inimum & Maximum & Mean & Median & $90 \%$ & $95 \frac{\circ}{\circ}$ & $7.5 \%$ & $9 \%$ \\
\hline $10 \mathrm{E}-08$ & $7.29 \mathrm{E}-06$ & $1.19 \mathrm{E}-06$ & $8.72 E-07$ & $2.56 \mathrm{E}-06$ & $3.25 \mathrm{E}-06$ & $3.80 \mathrm{E}-06$ & $4.73 \mathrm{E}-06$ \\
\hline $6.12 \mathrm{E}-08$ & $7.28 \mathrm{E}-06$ & $1.19 \mathrm{E}-06$ & $8.74 \mathrm{E}-07$ & $2.56 \mathrm{E}-06$ & $3.25 E-06$ & $3.79 \mathrm{E}-06$ & $4.73 E-06$ \\
\hline $6.15 \mathrm{E}-08$ & $7.28 \mathrm{E}-06$ & $1.19 \mathrm{E}-06$ & $8.76 \mathrm{E}-07$ & $2.57 \mathrm{E}-06$ & $3.25 \mathrm{E}-06$ & $3.79 \mathrm{E}-06$ & $4.72 \mathrm{E}-06$ \\
\hline $6.17 \mathrm{E}-08$ & $7.27 \mathrm{E}-06$ & $1.20 \mathrm{E}-06$ & $8.77 \mathrm{E}-07$ & $2.57 \mathrm{E}-06$ & $3.25 \mathrm{E}-06$ & $3.79 \mathrm{E}-06$ & $.72 \mathrm{E}-06$ \\
\hline $.19 \mathrm{E}-08$ & $7.26 \mathrm{E}-06$ & $1.20 \mathrm{E}-06$ & $8.79 \mathrm{E}-07$ & $2.57 \mathrm{E}$ & $3.26 \mathrm{E}-06$ & $3.79 \mathrm{E}$ & $.72 \mathrm{E}-06$ \\
\hline $6.21 \mathrm{E}-08$ & $7.25 \mathrm{E}-06$ & $1.20 \mathrm{E}-06$ & $8.80 E-07$ & $2.57 \mathrm{E}-06$ & $3.26 \mathrm{E}-06$ & $3.79 \mathrm{E}-06$ & $4.72 \mathrm{E}-06$ \\
\hline $24 \mathrm{E}-08$ & $7.24 \mathrm{E}-06$ & $1.20 \mathrm{E}-06$ & $8.81 \mathrm{E}-07$ & $2.57 \mathrm{E}-06$ & $26 \mathrm{E}-06$ & $3.80 \mathrm{E}-06$ & $71 \mathrm{E}-06$ \\
\hline $26 \mathrm{E}-08$ & $7.23 E-06$ & $1.20 \mathrm{E}-06$ & $8.82 E-07$ & $2.58 \mathrm{E}-06$ & $3.26 \mathrm{E}-06$ & $3.80 \mathrm{E}-06$ & $4.71 \mathrm{E}-06$ \\
\hline $28 \mathrm{E}-08$ & $7.22 \mathrm{E}-06$ & $1.20 \mathrm{E}-06$ & $8.84 E-07$ & $2.58 \mathrm{E}-06$ & $3.27 E-06$ & $3.80 \mathrm{E}-06$ & $4.71 \mathrm{E}-06$ \\
\hline $6.31 \mathrm{E}-08$ & $7.21 \mathrm{E}-06$ & $1.20 \mathrm{E}-06$ & $8.85 E-07$ & $2.58 \mathrm{E}-06$ & $3.27 E-06$ & $3.80 \mathrm{E}-06$ & $4.70 \mathrm{E}-06$ \\
\hline $.33 E-08$ & $7.20 \mathrm{E}-06$ & $1.20 \mathrm{E}-06$ & $8.87 E-07$ & $2.58 \mathrm{E}-06$ & $3.27 E-06$ & $3.80 \mathrm{E}-06$ & $4.70 \mathrm{E}-06$ \\
\hline $6.35 \mathrm{E}-08$ & $7.19 \mathrm{E}-06$ & $1.21 \mathrm{E}-06$ & $8.89 \mathrm{E}-07$ & $2.58 \mathrm{E}-06$ & $3.27 \mathrm{E}-06$ & $3.81 \mathrm{E}-06$ & $4.70 \mathrm{E}-06$ \\
\hline $6.38 \mathrm{E}-08$ & $7.19 \mathrm{E}-06$ & $1.21 \mathrm{E}-06$ & $8.90 \mathrm{E}-07$ & $2.58 \mathrm{E}-06$ & $3.28 \mathrm{E}-06$ & $3.81 \mathrm{E}-06$ & $4.69 \mathrm{E}-06$ \\
\hline $6.40 \mathrm{E}-08$ & $7.18 \mathrm{E}-06$ & $1.21 \mathrm{E}-06$ & $8.92 \mathrm{E}-07$ & $2.58 \mathrm{E}-06$ & $3.28 \mathrm{E}-06$ & $3.81 \mathrm{E}-06$ & $4.69 \mathrm{E}-06$ \\
\hline $6.42 \mathrm{E}-08$ & $7.17 \mathrm{E}-06$ & $1.21 \mathrm{E}-06$ & $8.94 \mathrm{E}-07$ & $2.59 \mathrm{E}-06$ & $3.28 E-06$ & $3.81 \mathrm{E}-06$ & $4.69 \mathrm{E}-06$ \\
\hline $6.45 \mathrm{E}-08$ & $7.16 \mathrm{E}-06$ & $1.21 \mathrm{E}-06$ & $8.95 E-07$ & $2.59 \mathrm{E}-06$ & $3.28 \mathrm{E}-06$ & $3.81 \mathrm{E}-06$ & $4.69 \mathrm{E}-06$ \\
\hline $6.47 E-08$ & $7.15 \mathrm{E}-06$ & $1.21 \mathrm{E}-06$ & $8.97 E-07$ & $2.59 \mathrm{E}-06$ & $3.28 E-06$ & $3.81 \mathrm{E}-06$ & $4.68 \mathrm{E}-06$ \\
\hline $6.49 \mathrm{E}-08$ & $7.14 \mathrm{E}-06$ & $1.21 \mathrm{E}-06$ & $8.98 \mathrm{E}-07$ & $2.59 \mathrm{E}-06$ & $3.28 \mathrm{E}-06$ & $3.81 \mathrm{E}-06$ & $4.68 \mathrm{E}-06$ \\
\hline $6.52 \mathrm{E}-08$ & $7.13 \mathrm{E}-06$ & $1.22 \mathrm{E}-06$ & $9.00 \mathrm{E}-07$ & $2.59 \mathrm{E}-06$ & $3.28 E-06$ & $3.81 \mathrm{E}-06$ & $4.68 \mathrm{E}-06$ \\
\hline $.54 \mathrm{E}-08$ & $7.12 \mathrm{E}-06$ & $1.22 \mathrm{E}-06$ & $9.01 \mathrm{E}-$ & $2.60 \mathrm{E}$ & 6 & $3.81 \mathrm{E}-06$ & $.67 \mathrm{E}-06$ \\
\hline 5 & 7 & 1 & & & & & \\
\hline . & 7 & 1 & 9 & 6 & 6 & 6 & 06 \\
\hline $6.61 \mathrm{E}-08$ & $7.09 \mathrm{E}-06$ & $1.22 \mathrm{E}-06$ & $9.05 \mathrm{E}-07$ & $2.60 \mathrm{E}-06$ & $3.29 \mathrm{E}-06$ & $3.81 \mathrm{E}-06$ & $4.66 \mathrm{E}-06$ \\
\hline $6.64 \mathrm{E}-08$ & $7.09 \mathrm{E}-06$ & $1.22 \mathrm{E}-06$ & $9.07 E-07$ & $2.60 \mathrm{E}-06$ & $3.29 \mathrm{E}-06$ & $3.81 \mathrm{E}-06$ & $4.66 \mathrm{E}-06$ \\
\hline $6.66 \mathrm{E}-08$ & $7.08 \mathrm{E}-06$ & $1.22 \mathrm{E}-06$ & $9.09 \mathrm{E}-07$ & $2.61 \mathrm{E}-06$ & $3.29 \mathrm{E}-06$ & $3.81 \mathrm{E}-06$ & $4.66 \mathrm{E}-06$ \\
\hline $6.68 \mathrm{E}-08$ & $7.07 E-06$ & $1.23 \mathrm{E}-06$ & $9.11 \mathrm{E}-07$ & $2.61 \mathrm{E}-06$ & $3.29 \mathrm{E}-06$ & $3.81 \mathrm{E}-06$ & $4.65 \mathrm{E}-06$ \\
\hline $6.71 \mathrm{E}-08$ & $7.06 \mathrm{E}-06$ & $1.23 \mathrm{E}-06$ & $9.13 \mathrm{E}-07$ & $2.61 \mathrm{E}-06$ & $3.30 \mathrm{E}-06$ & $3.81 \mathrm{E}-06$ & $4.65 \mathrm{E}-06$ \\
\hline $6.73 \mathrm{E}-08$ & $7.05 E-06$ & $1.23 \mathrm{E}-06$ & $9.15 \mathrm{E}-07$ & $2.61 \mathrm{E}-06$ & $3.30 E-06$ & $3.81 \mathrm{E}-06$ & $4.65 \mathrm{E}-06$ \\
\hline $6.76 \mathrm{E}-08$ & $7.04 \mathrm{E}-06$ & $1.23 \mathrm{E}-06$ & $9.17 \mathrm{E}-07$ & $2.62 \mathrm{E}-06$ & $3.30 \mathrm{E}-06$ & $3.81 \mathrm{E}-06$ & $4.65 \mathrm{E}-06$ \\
\hline $6.78 \mathrm{E}-08$ & $7.03 \mathrm{E}-06$ & $1.23 \mathrm{E}-06$ & 9.19 & $2.6 \angle E$ & 3.00 & $3.81 \mathrm{E}-06$ & $4.64 \mathrm{E}-06$ \\
\hline $6.80 \mathrm{E}-08$ & 7 & 1 & 7 & 6 & 6 & 0.0 & $.64 \mathrm{E}-06$ \\
\hline $6.83 \mathrm{E}-08$ & $7.01 \mathrm{E}-06$ & $1.23 \mathrm{E}-06$ & $9.21 \mathrm{E}-07$ & $2.62 \mathrm{E}-06$ & $3.30 \mathrm{E}-06$ & $3.80 \mathrm{E}-06$ & $4.64 \mathrm{E}-06$ \\
\hline $6.85 \mathrm{E}-08$ & $7.00 \mathrm{E}-06$ & $1.23 \mathrm{E}-06$ & $9.22 \mathrm{E}-07$ & $2.63 \mathrm{E}-06$ & $3.30 \mathrm{E}-06$ & $3.80 \mathrm{E}-06$ & $4.63 \mathrm{E}-06$ \\
\hline $6.88 \mathrm{E}-08$ & $7.00 \mathrm{E}-06$ & $1.24 \mathrm{E}-06$ & $9.24 \mathrm{E}-07$ & $2.63 \mathrm{E}-06$ & $3.30 \mathrm{E}-06$ & $3.80 \mathrm{E}-06$ & $4.63 \mathrm{E}-06$ \\
\hline $6.90 \mathrm{E}-08$ & $6.99 \mathrm{E}-06$ & $1.24 \mathrm{E}-06$ & $9.25 \mathrm{E}-07$ & $2.63 \mathrm{E}-06$ & $3.30 \mathrm{E}-06$ & $3.80 \mathrm{E}-06$ & $4.63 \mathrm{E}-06$ \\
\hline $6.92 \mathrm{E}-08$ & $6.98 \mathrm{E}-06$ & $1.24 \mathrm{E}-06$ & $9.26 \mathrm{E}-07$ & $2.63 \mathrm{E}-06$ & $3.30 \mathrm{E}-06$ & $3.81 \mathrm{E}-06$ & $4.62 \mathrm{E}-06$ \\
\hline $6.95 \mathrm{E}-08$ & $6.97 \mathrm{E}-06$ & $1.24 \mathrm{E}-06$ & $9.27 E-07$ & $2.64 \mathrm{E}-06$ & $3.31 E-06$ & $3.81 \mathrm{E}-06$ & $4.62 \mathrm{E}-06$ \\
\hline $6.97 \mathrm{E}-08$ & $6.96 \mathrm{E}-06$ & $1.24 \mathrm{E}-06$ & $9.28 \mathrm{E}-07$ & $2.64 \mathrm{E}-06$ & $3.31 \mathrm{E}-06$ & $3.81 \mathrm{E}-06$ & $4.62 \mathrm{E}-06$ \\
\hline $7.00 \mathrm{E}-08$ & $6.95 \mathrm{E}-06$ & $1.24 \mathrm{E}-06$ & $9.30 \mathrm{E}-07$ & $2.64 \mathrm{E}-06$ & $3.31 \mathrm{E}-06$ & $3.81 \mathrm{E}-06$ & $4.61 \mathrm{E}-06$ \\
\hline $7.02 \mathrm{E}-08$ & $6.94 \mathrm{E}-06$ & $1.24 \mathrm{E}-06$ & $9.31 \mathrm{E}-07$ & $2.64 \mathrm{E}-06$ & $3.31 \mathrm{E}-06$ & $3.81 \mathrm{E}-06$ & $4.61 \mathrm{E}-06$ \\
\hline $7.05 \mathrm{E}-08$ & $6.93 \mathrm{E}-06$ & $1.25 \mathrm{E}-06$ & $9.33 E-07$ & $2.65 \mathrm{E}-06$ & $3.31 E-06$ & $3.81 \mathrm{E}-06$ & $4.61 \mathrm{E}-06$ \\
\hline $7.07 \mathrm{E}-08$ & $6.92 \mathrm{E}-06$ & $1.25 \mathrm{E}-06$ & $9.35 \mathrm{E}-07$ & $2.65 \mathrm{E}-06$ & $3.31 E-06$ & $3.81 \mathrm{E}-06$ & $4.60 \mathrm{E}-06$ \\
\hline $7.10 \mathrm{E}-08$ & $6.91 \mathrm{E}-06$ & $1.25 \mathrm{E}-06$ & $9.36 \mathrm{E}-07$ & $2.65 \mathrm{E}-06$ & $3.31 \mathrm{E}-06$ & $3.81 \mathrm{E}-06$ & $4.60 \mathrm{E}-06$ \\
\hline $7.12 \mathrm{E}-08$ & $6.90 \mathrm{E}-06$ & $1.25 \mathrm{E}-06$ & $9.38 \mathrm{E}-07$ & $2.65 \mathrm{E}-06$ & $3.31 E-06$ & $3.82 \mathrm{E}-06$ & $4.60 \mathrm{E}-06$ \\
\hline $7.15 \mathrm{E}-08$ & $6.90 \mathrm{E}-06$ & $1.25 \mathrm{E}-06$ & $9.40 \mathrm{E}-07$ & $2.66 \mathrm{E}-06$ & $3.31 \mathrm{E}-06$ & $3.82 \mathrm{E}-06$ & $4.59 \mathrm{E}-06$ \\
\hline $.17 \mathrm{E}-08$ & $6.89 \mathrm{E}-06$ & $1.25 \mathrm{E}-06$ & $9.41 E-07$ & $2.66 \mathrm{E}-06$ & $3.31 E-06$ & $3.82 \mathrm{E}-06$ & $4.59 \mathrm{E}-06$ \\
\hline
\end{tabular}


RESRAD-OFFSITE, Version 2.5

itle : RESRAD-OFFSITE External Gamma, Inhalation, and Soil Ingestion for offsite Reside

File: PBA-1_TC99-DOE-5-1.ROF

Summary of dose at graphical times, reptition 1 (continued)

Time

Years

8. $49 \mathrm{E}+02$

$8.50 \mathrm{E}+02$

$8.50 \mathrm{E}+02$

8. $51 \mathrm{E}+02$

8. $51 \mathrm{E}+02$

8. $52 \mathrm{E}+02$

8. $52 \mathrm{E}+02$

8. $53 \mathrm{E}+02$

8. $53 \mathrm{E}+02$

8. $54 \mathrm{E}+02$

$8.54 \mathrm{E}+02$

$8.55 \mathrm{E}+02$

8. $55 \mathrm{E}+02$

$8.56 \mathrm{E}+02$

$8.56 \mathrm{E}+02$

$8.57 \mathrm{E}+02$

8. $57 \mathrm{E}+02$

8. $58 \mathrm{E}+02$

8. $58 \mathrm{E}+02$

8. $59 \mathrm{E}+02$

8. $59 \mathrm{E}+02$

8. $60 \mathrm{E}+02$

$8.60 \mathrm{E}+02$

$8.61 \mathrm{E}+02$

$8.61 \mathrm{E}+02$

$8.62 \mathrm{E}+02$

8. $62 \mathrm{E}+02$

$8.63 \mathrm{E}+02$

$8.63 \mathrm{E}+02$

8. $64 \mathrm{E}+02$

$8.64 \mathrm{E}+02$

$8.65 \mathrm{E}+02$

$8.65 \mathrm{E}+02$

$8.66 \mathrm{E}+02$

$8.66 \mathrm{E}+02$

$8.67 \mathrm{E}+02$

$8.67 \mathrm{E}+02$

$8.68 \mathrm{E}+02$

$8.69 \mathrm{E}+02$

$8.69 \mathrm{E}+02$

$8.70 \mathrm{E}+02$

$8.70 \mathrm{E}+02$

$8.71 \mathrm{E}+02$

$8.71 E+02$

8. $72 \mathrm{E}+02$

$8.72 \mathrm{E}+02$
Dose statistics at graphical times, mrem/yr

\begin{tabular}{|c|c|c|c|c|c|c|c|}
\hline inimum & aximum & Mean & ledian & $90 \%$ & $5 \%$ & $97.5 \%$ & $\%$ \\
\hline 8 & 6 & $5 E-06$ & $E-07$ & 66 & 6 & 06 & 0 \\
\hline 08 & $E-06$ & 06 & $E-07$ & 6 & 06 & 06 & -06 \\
\hline$E-08$ & $6.86 \mathrm{E}-06$ & $E-06$ & $E-07$ & $6 E-06$ & 06 & 06 & -06 \\
\hline$E-08$ & 06 & 06 & & 06 & 6 & 06 & -06 \\
\hline $30 E-08$ & -06 & -06 & 7 & $7 E-06$ & 6 & 06 & $58 E-06$ \\
\hline-08 & -06 & $E-06$ & $E-07$ & $7 E-06$ & $2 E-06$ & -06 & $8 E-06$ \\
\hline $.35 E-08$ & -06 & $.26 \mathrm{E}-06$ & r & $2.67 \mathrm{E}-06$ & 06 & -06 & -06 \\
\hline $.37 E-08$ & $6.81 E-06$ & $1.26 \mathrm{E}-06$ & . & $2.67 E-06$ & 正 & -06 & $58 E-06$ \\
\hline 08 & 06 & 06 & 7 & 06 & 6 & -06 & -06 \\
\hline $.42 E-08$ & -06 & $1.26 \mathrm{E}-06$ & 7 & 06 & 06 & -06 & -06 \\
\hline-08 & -06 & -06 & & 6 & & 06 & $E-06$ \\
\hline-08 & -06 & -06 & & & & & -06 \\
\hline $.50 \mathrm{E}-08$ & $6.77 \mathrm{E}-06$ & $1.27 \mathrm{E}-06$ & $0-01$ & $2.68 \mathrm{E}-06$ & $4 E-06$ & -06 & -0 \\
\hline $.53 E-08$ & -06 & $1.27 \mathrm{E}-06$ & ti & 06 & 0 & -06 & -06 \\
\hline $5-08$ & 06 & 06 & 年 & 6 & 6 & 06 & -06 \\
\hline $.58 \mathrm{E}-08$ & -06 & $1.27 E-06$ & 1 & 06 & 06 & -06 & -06 \\
\hline $.60 \mathrm{E}-08$ & $E-06$ & $27 E-06$ & $E-07$ & $E-06$ & -06 & -06 & $59 E-06$ \\
\hline-08 & $2 E-06$ & $8 E-06$ & 7 & 06 & 06 & -06 & $E-06$ \\
\hline 08 & $E-06$ & -06 & 1 & 06 & & 6 & -06 \\
\hline $.68 E-08$ & -06 & -06 & 1 & 06 & 06 & -06 & -06 \\
\hline $.71 \mathrm{E}-08$ & -06 & $1.28 \mathrm{E}-06$ & & $E-06$ & & 0 & $5 \mathrm{E}-06$ \\
\hline $.73 E-08$ & $6.69 \mathrm{E}-06$ & $1.28 \mathrm{E}-06$ & & 06 & 0 & -06 & -06 \\
\hline $.76 E-08$ & $.68 E-06$ & $1.28 E-06$ & גר & $0 E-06$ & $6 \sigma_{0} 0$ & $3 E-06$ & $9 E-06$ \\
\hline $.78 \mathrm{E}-08$ & $67 E-06$ & $1.28 \mathrm{E}-06$ & 07 & $0 E-06$ & $6 E-06$ & $E-06$ & $9 \mathrm{E}-06$ \\
\hline 08 & $6 E-06$ & $.28 \mathrm{E}-06$ & & 06 & 06 & $E-06$ & -06 \\
\hline 08 & 06 & 06 & 7 & & & & 06 \\
\hline $.86 \mathrm{E}-08$ & -06 & $.29 \mathrm{E}-06$ & -01 & & & -06 & -06 \\
\hline $.89 E-08$ & $6.63 \mathrm{E}-06$ & $1.29 E-06$ & $9.85 E-07$ & $2.71 E-06$ & $3.36 \mathrm{E}-06$ & $83 E-06$ & $.59 \mathrm{E}-06$ \\
\hline $.92 E-08$ & $6.62 \mathrm{E}-06$ & $1.29 \mathrm{E}-06$ & $9.86 \mathrm{E}-07$ & $2.71 E-06$ & $36 E-06$ & $3 E-06$ & $59 E-06$ \\
\hline $.94 \mathrm{E}-08$ & $6.61 \mathrm{E}-06$ & $1.29 \mathrm{E}-06$ & 政 & 足 & - & - & ( \\
\hline 8 & 6 & $1.29 E-06$ & $E-07$ & $2 E-06$ & 6 & 6 & $E-06$ \\
\hline-08 & $E-06$ & $E-06$ & $E-07$ & $E-06$ & 6 & 6 & -06 \\
\hline $.02 \mathrm{E}-08$ & $6.59 \mathrm{E}-06$ & $1.29 \mathrm{E}-06$ & $2 E-07$ & $2.72 \mathrm{E}-06$ & 6 & 06 & $59 \mathrm{E}-06$ \\
\hline $.05 E-08$ & $6.58 \mathrm{E}-06$ & $1.30 \mathrm{E}-06$ & $9.94 \mathrm{E}-07$ & $2.72 \mathrm{E}-06$ & $3.37 \mathrm{E}-06$ & $33 E-06$ & $59 E-06$ \\
\hline $07 E-08$ & $6.57 \mathrm{E}-06$ & $.30 E-06$ & & $2.72 \mathrm{E}-06$ & & & . \\
\hline & & & & & & & \\
\hline $.13 E-08$ & & & & & & & 06 \\
\hline 8 & 6 & 6 & 7 & 6 & 6 & 06 & 06 \\
\hline 8 & & & & & & -06 & 06 \\
\hline $.21 E-08$ & $2 E-06$ & $1.30 \mathrm{E}-06$ & $E-06$ & 06 & 6 & & -06 \\
\hline $4 E-08$ & 06 & $E-06$ & & 6 & & & -00 \\
\hline & $.52 E-06$ & $.31 E-06$ & & $.73 E-06$ & & & $9 E-06$ \\
\hline & 6 & & & 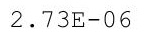 & & & 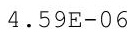 \\
\hline $0.3 \angle E-V O$ & 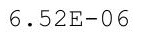 & & & 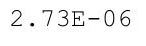 & 6 & 0 & . \\
\hline 08 & 6.5 & -06 & 06 & 06 & 06 & 06 & -06 \\
\hline $.37 E-08$ & $6.52 E-06$ & $1.31 E-06$ & $.01 E-06$ & $2.73 E-06$ & $3.37 E-06$ & $3.81 E-06$ & $4.59 \mathrm{E}-06$ \\
\hline
\end{tabular}


RESRAD-OFFSITE, Version 2.5

Title : RESRAD-OFFSITE External Gamma, Inhalation, and Soil Ingestion for offsite Reside File : PBA-1_TC99-DOE-5-1.ROF

Summary of dose at graphical times, reptition 1 (continued)

Time

Years

$8.73 E+02$

$8.73 \mathrm{E}+02$

$8.74 \mathrm{E}+02$

8. $74 \mathrm{E}+02$

$8.75 \mathrm{E}+02$

$8.75 \mathrm{E}+02$

$8.76 \mathrm{E}+02$

8. $76 \mathrm{E}+02$

$8.77 \mathrm{E}+02$

8. $77 \mathrm{E}+02$

$8.78 \mathrm{E}+02$

$8.78 \mathrm{E}+02$

8. $79 \mathrm{E}+02$

$8.79 \mathrm{E}+02$

$8.80 \mathrm{E}+02$

$8.80 \mathrm{E}+02$

$8.81 \mathrm{E}+02$

$8.81 \mathrm{E}+02$

$8.82 \mathrm{E}+02$

$8.82 \mathrm{E}+02$

$8.83 \mathrm{E}+02$

8. $83 \mathrm{E}+02$

$8.84 \mathrm{E}+02$

$8.84 \mathrm{E}+02$

$8.85 \mathrm{E}+02$

$8.85 \mathrm{E}+02$

$8.86 \mathrm{E}+02$

$8.86 \mathrm{E}+02$

$8.87 \mathrm{E}+02$

$8.87 \mathrm{E}+02$

$8.88 \mathrm{E}+02$

$8.89 \mathrm{E}+02$

$8.89 \mathrm{E}+02$

8. $90 \mathrm{E}+02$

8. $90 \mathrm{E}+02$

8. $91 \mathrm{E}+02$

8. $91 \mathrm{E}+02$

8. $92 \mathrm{E}+02$

8. $92 \mathrm{E}+02$

8. $93 \mathrm{E}+02$

$8.93 E+02$

8. $94 \mathrm{E}+02$

$8.94 \mathrm{E}+02$

$8.95 \mathrm{E}+02$

$8.95 \mathrm{E}+02$

$8.96 \mathrm{E}+02$
Dose statistics at graphical times, mrem/yr

\begin{tabular}{|c|c|c|c|c|c|c|c|}
\hline Inimum & Maximum & Mean & ledian & $90 \%$ & $95 \%$ & $97.5 \%$ & \\
\hline 8 & 6 & 6 & 6 & 6 & 6 & 6 & -0 \\
\hline $3 E-08$ & $6.52 \mathrm{E}-06$ & $.31 \mathrm{E}-06$ & $.02 E-06$ & $2.74 \mathrm{E}-06$ & $3.37 \mathrm{E}-06$ & -06 & $.60 \mathrm{E}-06$ \\
\hline$E-08$ & 06 & 6 & 06 & 6 & $7 E-06$ & 06 & $60 E-06$ \\
\hline$E-08$ & -06 & $E-06$ & 06 & 6 & $7 E-06$ & 06 & $0 E-06$ \\
\hline $.51 E-08$ & -06 & $.32 \mathrm{E}-06$ & -06 & 6 & $E-06$ & 06 & $60 \mathrm{E}-06$ \\
\hline $53 E-08$ & -06 & 6 & 6 & & $E-06$ & -06 & -06 \\
\hline $6 \mathrm{E}-08$ & $1 E-06$ & $32 E-06$ & $2 E-06$ & $4 E-06$ & $E-06$ & -06 & $E-06$ \\
\hline $9 E-08$ & $1 E-06$ & $.32 \mathrm{E}-06$ & $.03 E-06$ & 政 & 皮 & -06 & -0 \\
\hline 08 & 6 & 6 & 0 & $2.75 E-06$ & $3.38 E-06$ & 6 & 06 \\
\hline$E-08$ & $E-06$ & $.32 E-06$ & 06 & 6 & $8 E-06$ & $E-06$ & $60 \mathrm{E}-06$ \\
\hline $.67 E-08$ & $.51 E-06$ & $.32 \mathrm{E}-06$ & & & & $.80 \mathrm{E}-06$ & $.60 \mathrm{E}-06$ \\
\hline $\mathrm{s}-08$ & -06 & -06 & 6 & 6 & 6 & 6 & -06 \\
\hline-08 & $1 E-06$ & $E-06$ & $3 E-06$ & & 急 & $5-00$ & -06 \\
\hline 00 & 06 & 06 & 06 & $2.75 E-06$ & 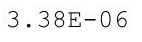 & 0 & -06 \\
\hline 08 & 6 & 6 & & $5 E-06$ & $7 E-06$ & & 06 \\
\hline$E-08$ & $E-06$ & $.33 E-06$ & 06 & ( & 要 & 0 & -06 \\
\hline $.84 \mathrm{E}-08$ & $6.51 \mathrm{E}-06$ & 1. $33 E-06$ & $1.04 \mathrm{E}-06$ & $2.75 E-06$ & $.38 E-06$ & $.80 \mathrm{E}-06$ & $.60 E-06$ \\
\hline $.87 E-08$ & $50 E-06$ & $.33 E-06$ & $.04 \mathrm{E}-06$ & $5 E-06$ & $3 E-06$ & $0 E-06$ & 4. $60 \mathrm{E}-06$ \\
\hline$E-08$ & $0 E-06$ & $.33 E-06$ & $4 E-06$ & 5E-U & - & -00 & -06 \\
\hline$E-08$ & $E-06$ & -06 & -06 & 0 & $38 \pm-06$ & 06 & -06 \\
\hline $5 E-08$ & $D E-06$ & $.34 E-06$ & $5 E-06$ & 年 & & & $60 E-06$ \\
\hline 08 & 6 & 6 & 6 & 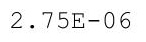 & 的 & -06 & $.60 E-06$ \\
\hline $01 E-08$ & $0 E-06$ & $34 \mathrm{E}-06$ & $5 E-06$ & 0 & 年 & 0 & -06 \\
\hline $04 E-08$ & $50 E-06$ & $.34 \mathrm{E}-06$ & -06 & 6 & $E-06$ & -06 & -06 \\
\hline$E-08$ & $0 \mathrm{E}-06$ & $.34 \mathrm{E}-06$ & $E-06$ & $6 E-06$ & $3 E-06$ & $E-06$ & -06 \\
\hline$E-08$ & $E-06$ & 06 & -06 & & $38 E-06$ & & -06 \\
\hline 08 & -06 & -06 & 06 & ti & & & -06 \\
\hline $35-00$ & $9 E-06$ & $.35 E-06$ & $.06 \mathrm{E}-06$ & $2.10 \pm-00$ & $.39 \pm-00$ & . $195-00$ & $.60 \mathrm{E}-06$ \\
\hline $.18 E-08$ & $.49 E-06$ & $.35 E-06$ & $1.06 \mathrm{E}-06$ & $2.77 \mathrm{E}-06$ & $39 E-06$ & $79 E-06$ & $4.60 E-06$ \\
\hline $1 E-08$ & $495-0$ & $35 E-06$ & $06 E-06$ & 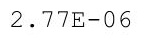 & & E & $60 E-06$ \\
\hline 8 & 6 & 6 & & & & 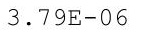 & 06 \\
\hline$E-08$ & $E-06$ & $E-06$ & 6 & 6 & 6 & 6 & $0 E-06$ \\
\hline 08 & 06 & 6 & & & & & 06 \\
\hline $32 E-08$ & $.49 \mathrm{E}-06$ & $.35 E-06$ & $1.07 \mathrm{E}-06$ & $2.78 \mathrm{E}-06$ & $9 E-06$ & $9 E-06$ & $.59 E-06$ \\
\hline $35 E-08$ & $.49 E-06$ & $.35 E-06$ & & & & & $.59 E-06$ \\
\hline & & & & & & & .00 \\
\hline & & & & & & & 66 \\
\hline 8 & 6 & 6 & 6 & 6 & 6 & 6 & 06 \\
\hline $7 E-08$ & $.48 \mathrm{E}-06$ & $.36 \mathrm{E}-06$ & $8 E-06$ & 6 & 6 & 6 & $8 E-06$ \\
\hline $50 E-08$ & $8 E-06$ & 06 & & 6 & & & -06 \\
\hline $3 E-08$ & $8 E-06$ & $36 E-06$ & & & & & $.58 E-06$ \\
\hline $5 E-08$ & $8 E-06$ & 6 & 6 & 2. & 6 & & $.58 \mathrm{E}-06$ \\
\hline & & & & 2 & & & $4.57 \mathrm{E}-06$ \\
\hline & & & & & t & 06 & 06 \\
\hline$E-08$ & $E-06$ & $7 E-06$ & 1. & 6 & 6 & -06 & $4.57 \mathrm{E}$ \\
\hline $67 E-08$ & $.47 E-06$ & $.37 E-06$ & $.09 E-06$ & $2.80 E-06$ & $.39 E-06$ & $3.80 E-06$ & $4.57 \mathrm{E}-06$ \\
\hline
\end{tabular}


RESRAD-OFFSITE, Version 2.5

Title : RESRAD-OFFSITE External Gamma, Inhalation, and Soil Ingestion for offsite Reside File : PBA-1_TC99-DOE-5-1.ROF

Summary of dose at graphical times, reptition 1 (continued)

Time

Years

$8.96 \mathrm{E}+02$

8. $97 \mathrm{E}+02$

8. $97 \mathrm{E}+02$

8. $98 \mathrm{E}+02$

$8.98 \mathrm{E}+02$

$8.99 \mathrm{E}+02$

8. $99 \mathrm{E}+02$

9. $00 \mathrm{E}+02$

9. $00 \mathrm{E}+02$

9. $01 \mathrm{E}+02$

9. $01 \mathrm{E}+02$

$9.02 \mathrm{E}+02$

$9.02 \mathrm{E}+02$

$9.03 \mathrm{E}+02$

$9.03 \mathrm{E}+02$

$9.04 \mathrm{E}+02$

$9.04 \mathrm{E}+02$

$9.05 \mathrm{E}+02$

$9.05 \mathrm{E}+02$

$9.06 \mathrm{E}+02$

$9.06 \mathrm{E}+02$

$9.07 \mathrm{E}+02$

$9.07 \mathrm{E}+02$

$9.08 \mathrm{E}+02$

$9.08 \mathrm{E}+02$

$9.09 \mathrm{E}+02$

9. $10 \mathrm{E}+02$

$9.10 \mathrm{E}+02$

9. $11 \mathrm{E}+02$

$9.11 \mathrm{E}+02$

9. $12 \mathrm{E}+02$

$9.12 \mathrm{E}+02$

$9.13 \mathrm{E}+02$

$9.13 \mathrm{E}+02$

$9.14 \mathrm{E}+02$

9. $14 \mathrm{E}+02$

$9.15 \mathrm{E}+02$

$9.15 \mathrm{E}+02$

$9.16 \mathrm{E}+02$

$9.16 \mathrm{E}+02$

$9.17 \mathrm{E}+02$

$9.17 \mathrm{E}+02$

9. $18 \mathrm{E}+02$

$9.18 \mathrm{E}+02$

$9.19 \mathrm{E}+02$

$9.19 \mathrm{E}+02$
Dose statistics at graphical times, mrem/yr

\begin{tabular}{|c|c|c|c|c|c|c|c|}
\hline Iinimum & aximum & ean & ea & \% & & $97.5 \%$ & $1 \%$ \\
\hline 08 & 6 & $7 E-06$ & $E-06$ & $0 E-06$ & -06 & -06 & -06 \\
\hline $3 E-08$ & $6.47 \mathrm{E}-06$ & $.37 E-06$ & $.09 \mathrm{E}-06$ & $.80 \mathrm{E}-06$ & $.39 \mathrm{E}-06$ & -06 & $6 E-06$ \\
\hline 8 & 6 & 6 & 6 & 6 & 6 & 6 & 06 \\
\hline 08 & 6 & 06 & 06 & $80 E-06$ & 6 & -06 & $6 E-06$ \\
\hline 08 & 06 & 6 & & 6 & & & 06 \\
\hline $85 E-08$ & -06 & $.37 E-06$ & & $.80 \mathrm{E}-06$ & $39 E-06$ & $E-06$ & $E-06$ \\
\hline $88 E-08$ & $5 E-06$ & $.38 E-06$ & $E-06$ & $80 E-06$ & $38 E-06$ & -06 & $55 E-06$ \\
\hline $91 E-08$ & $46 E-06$ & $.38 \mathrm{E}-06$ & $8-06$ & $.81 E-06$ & $3 E-06$ & -06 & $5 E-06$ \\
\hline 8 & 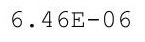 & 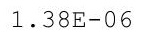 & 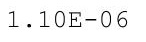 & $2.81 E-06$ & 6 & -06 & 06 \\
\hline $7 E-08$ & 6 & 6 & 06 & $1 E-06$ & 6 & 06 & 06 \\
\hline $00 \mathrm{E}-07$ & $46 E-06$ & $.38 E-06$ & & $1 E-06$ & 6 & 06 & -06 \\
\hline $.00 E-07$ & $.45 E-06$ & $.38 E-06$ & & $.81 E-06$ & $38 E-06$ & $81 E-06$ & $E-06$ \\
\hline-07 & 6 & 6 & & $1 F-$ & 06 & 06 & -06 \\
\hline $01 E-07$ & $45 E-06$ & .3 & & $81 \mathrm{E}-$ & 6 & 0 & -06 \\
\hline $01 E-07$ & 06 & .001 & 0 & $+\infty$ & 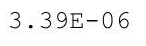 & $2 E-06$ & 0 \\
\hline 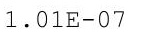 & & & & & 6 & $E-06$ & 6 \\
\hline $02 \mathrm{E}-07$ & $.45 E-06$ & $.39 E-06$ & -06 & $82 E-06$ & $E-06$ & -06 & -06 \\
\hline $.02 \mathrm{E}-07$ & $.44 E-06$ & $.39 E-06$ & $.11 \mathrm{E}-06$ & $.82 \mathrm{E}-06$ & $.39 E-06$ & $2 E-06$ & $53 E-06$ \\
\hline $.02 \mathrm{E}-07$ & $.44 \mathrm{E}-06$ & $.39 E-06$ & $.11 \mathrm{E}-06$ & $.82 E-06$ & $9 E-06$ & $E-06$ & $3 E-06$ \\
\hline $.03 E-07$ & $44 E-06$ & o & & $82 \mathrm{~F}-0 \mathrm{~F}$ & & 0 & $E-06$ \\
\hline $3 E-07$ & & & & & & & 06 \\
\hline & & & & & & & 06 \\
\hline $04 E-07$ & 6 & 0 & 6 & 6 & 6 & $3.82 E-06$ & -06 \\
\hline $04 E-07$ & $.43 E-06$ & $.39 E-06$ & $.12 \mathrm{E}-06$ & $83 E-06$ & $39 E-06$ & 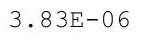 & $51 E-06$ \\
\hline $04 \mathrm{E}-07$ & $43 E-06$ & $40 F-06$ & $12 \mathrm{E}-06$ & $83 E-06$ & $9 E-06$ & $-006 r a r a r$ & $1 \mathrm{~F}-0$ \\
\hline $05 E-07$ & $43 E-06$ & $40 \mathrm{~F}-06$ & $12 E-06$ & $83 E-06$ & $9 E-06$ & -06 & $1 E-06$ \\
\hline $05 E-07$ & & & & & & & 06 \\
\hline ת5 & & & & & & & 06 \\
\hline $.05 E-07$ & $.43 E-06$ & $.40 \mathrm{E}-06$ & $.13 E-06$ & $.83 E-06$ & $39 E-06$ & एक & 30- \\
\hline $.06 \mathrm{E}-07$ & •-4ZL- & 土. & $.13 E-06$ & $83 E-06$ & $39 E-06$ & 00 & $.50 E-0$ \\
\hline $06 \mathrm{E}-0$ & 6 & $.40 \mathrm{E}-$ & $.13 \mathrm{E}-\mathrm{C}$ & $83 E-06$ & $9 \mathrm{E}-$ & - & $50 \mathrm{E}-$ \\
\hline $06 E-07$ & $42 F-06$ & ค10 & $F-06$ & $83 F-06$ & $9 E-06$ & -06 & 0 \\
\hline $07 F-07$ & 6 & 6 & & & 6 & 06 & 06 \\
\hline $07 E-07$ & & & & & & 06 & 06 \\
\hline $.07 E-07$ & $.42 E-06$ & $1.41 \mathrm{E}-06$ & $.14 \mathrm{E}-06$ & $.83 E-06$ & $0 E-06$ & -00 & $.49 E-06$ \\
\hline $.08 E-07$ & $.41 E-06$ & $\perp \cdot 4 \perp+-0$ & & $33 E-06$ & $0 E-06$ & 0 & 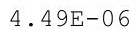 \\
\hline $.08 E-07$ & 6 & 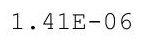 & & & 6 & $3.84 \mathrm{E}-06$ & -06 \\
\hline 7 & 6 & & & & & 6 & 06 \\
\hline & & & & & & & 06 \\
\hline $.09 E-07$ & $.41 E-06$ & $.41 \mathrm{E}-06$ & $.15 E-06$ & $2.84 \mathrm{E}-06$ & $0 E-06$ & 06 & $4.48 E-06$ \\
\hline $09 E-07$ & $.40 E-06$ & $.41 \mathrm{E}$ & 6 & 6 & 6 & & $7 E-06$ \\
\hline $.09 E-07$ & $.40 E-06$ & $.42 E-06$ & & $.84 \mathrm{E}-06$ & $.40 \mathrm{E}-$ & & $4.47 E-06$ \\
\hline - $5-$ t & - & $1 \cdot 4 \angle L-00$ & $35-20$ & $6.045-00$ & $0 E-06$ & $E-06$ & $4.4 / E-06$ \\
\hline $.10 \mathrm{E}-07$ & $.40 E-06$ & $1.42 \mathrm{E}-06$ & $15 E-06$ & $2.84 E-06$ & $3.40 E-06$ & $3.04 \mathrm{E}-00$ & $4.47 E-06$ \\
\hline $.10 \mathrm{E}-07$ & 06 & 1.42 & 06 & $2.84 \mathrm{E}$ & 6 & 06 & 4.47 \\
\hline $.11 \mathrm{E}-07$ & $.39 E-06$ & $.42 \mathrm{E}-06$ & $15 E-06$ & $84 E-06$ & 6 & 66 & 4.4 \\
\hline
\end{tabular}


RESRAD-OFFSITE, Version 2.5

Title : RESRAD-OFFSITE External Gamma, Inhalation, and Soil Ingestion for offsite Reside File : PBA-1_TC99-DOE-5-1.ROF

Summary of dose at graphical times, reptition 1 (continued)

Time

Years

9. $20 \mathrm{E}+02$

9. $20 \mathrm{E}+02$

9. $21 \mathrm{E}+02$

9. $21 \mathrm{E}+02$

9. $22 \mathrm{E}+02$

9. $22 \mathrm{E}+02$

9. $23 \mathrm{E}+02$

9. $23 \mathrm{E}+02$

9. $24 \mathrm{E}+02$

9. $24 \mathrm{E}+02$

9. $25 \mathrm{E}+02$

9. $25 \mathrm{E}+02$

9. $26 \mathrm{E}+02$

$9.26 \mathrm{E}+02$

$9.27 \mathrm{E}+02$

$9.27 \mathrm{E}+02$

$9.28 \mathrm{E}+02$

$9.28 \mathrm{E}+02$

$9.29 \mathrm{E}+02$

$9.30 \mathrm{E}+02$

$9.30 \mathrm{E}+02$

9. $31 \mathrm{E}+02$

9. $31 \mathrm{E}+02$

9. $32 \mathrm{E}+02$

9. $32 \mathrm{E}+02$

9. $33 \mathrm{E}+02$

9. $33 \mathrm{E}+02$

9. $34 \mathrm{E}+02$

9. $34 \mathrm{E}+02$

$9.35 \mathrm{E}+02$

9. $35 \mathrm{E}+02$

9. $36 \mathrm{E}+02$

$9.36 \mathrm{E}+02$

$9.37 \mathrm{E}+02$

$9.37 \mathrm{E}+02$

$9.38 \mathrm{E}+02$

9. $38 \mathrm{E}+02$

$9.39 \mathrm{E}+02$

$9.39 \mathrm{E}+02$

$9.40 \mathrm{E}+02$

9. $40 \mathrm{E}+02$

$9.41 \mathrm{E}+02$

9. $41 \mathrm{E}+02$

$9.42 \mathrm{E}+02$

9. $42 \mathrm{E}+02$

$9.43 \mathrm{E}+02$
Dose statistics at graphical times, mrem/yr

\begin{tabular}{|c|c|c|c|c|c|c|c|}
\hline inimum & aximum & Mean & ledian & $0 \%$ & $\%$ & $7.5 \%$ & $\%$ \\
\hline 07 & $6.39 E-06$ & $.42 \mathrm{E}-06$ & $1.16 \mathrm{E}-06$ & $2.84 \mathrm{E}-06$ & $.40 \mathrm{E}-06$ & $3.85 E-06$ & $5 E-0$ \\
\hline 07 & 06 & $.42 \mathrm{E}$ & 06 & 06 & 06 & 06 & -06 \\
\hline$E-07$ & 06 & 06 & 06 & 6 & 6 & 06 & -06 \\
\hline-07 & 06 & 06 & & & 6 & 6 & -06 \\
\hline $12 \mathrm{E}-07$ & $8 E-06$ & $43 E-06$ & $6 E-06$ & $2.84 E-06$ & $40 E-06$ & $.85 E-06$ & $45 E-06$ \\
\hline $.13 E-07$ & -06 & -06 & -06 & $85 E-06$ & $40 E-06$ & -06 & $.45 E-06$ \\
\hline 07 & 06 & -06 & 6 & 6 & 6 & 06 & -0 \\
\hline 7 & 6 & . & 6 & $2.85 E-06$ & . & -06 & 06 \\
\hline 07 & 06 & 6 & 6 & 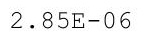 & 6 & 06 & -06 \\
\hline $.14 \mathrm{E}-07$ & $E-06$ & $.43 E-06$ & $7 E-06$ & & $40 \mathrm{E}-$ & -06 & -06 \\
\hline $.14 \mathrm{E}-07$ & $.37 \mathrm{E}-06$ & $.43 E-06$ & & & & $85 E-06$ & $.44 \mathrm{E}-06$ \\
\hline-07 & 06 & -06 & 06 & & & -06 & $E-06$ \\
\hline $.15 E-07$ & $.37 E-06$ & $.43 E-06$ & $1.17 E-06$ & . & 年 & - & -06 \\
\hline 07 & 06 & 6 & & & & -06 & 06 \\
\hline 7 & 6 & 6 & 6 & & $40 F-06$ & -06 & 06 \\
\hline $6=-07$ & 6 & 6 & 6 & 6 & 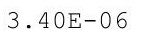 & 06 & 06 \\
\hline $.16 E-07$ & $.36 E-06$ & $1.44 E-06$ & $1.18 \mathrm{E}-06$ & $2.85 E-06$ & $.40 E-06$ & $.86 \mathrm{E}-06$ & $.42 E-06$ \\
\hline $16 \mathrm{E}-07$ & $.36 E-06$ & $.44 \mathrm{E}-06$ & $.18 \mathrm{E}-06$ & & 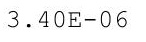 & -06 & $42 E-06$ \\
\hline $.17 \mathrm{E}-07$ & & 06 & & & & 0 & -06 \\
\hline 07 & 06 & & & & & -06 & -06 \\
\hline 7 & & & & & & & 06 \\
\hline $18 \mathrm{E}-07$ & 6 & 6 & 6 & & & $3.86 \mathrm{E}-06$ & 06 \\
\hline $8 E-07$ & 6 & 6 & $E-06$ & $\Gamma^{-1}$ & تص & -06 & -06 \\
\hline $18 \mathrm{E}-07$ & $34 E-06$ & $.45 E-06$ & $.19 \mathrm{E}-06$ & $86 \mathrm{~F}-06$ & ل & $E-06$ & $.40 E-06$ \\
\hline $9 \mathrm{E}-07$ & $E-06$ & $.45 \mathrm{E}-06$ & -06 & & & $E-06$ & $40 \mathrm{E}-06$ \\
\hline$E-07$ & & & & & & & 06 \\
\hline & & & & & & & 06 \\
\hline $.20 E-07$ & $34 E-06$ & $.45 E-06$ & $.19 \mathrm{E}-06$ & O०D- & 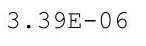 & 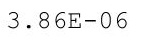 & $.40 E-06$ \\
\hline $20 E-07$ & 6 & $45 E-06$ & $20 E-06$ & 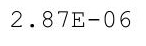 & 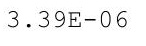 & -06 & $40 E-06$ \\
\hline $20 E-07$ & $33 E-06$ & $.45 E-06$ & $1.20 \mathrm{E}-06$ & & & +2 & $.40 E-06$ \\
\hline $5-07$ & $E-06$ & $.45 E-06$ & & & & $5 E-06$ & $39 E-06$ \\
\hline $1 F-07$ & $E-06$ & $E-06$ & 6 & & & & 06 \\
\hline $.21 E-07$ & & & & & & & 06 \\
\hline $.22 E-07$ & $.32 E-06$ & $.46 E-06$ & $1.20 E-06$ & $2.87 \mathrm{E}-06$ & $405-06$ & $6 E-06$ & $.39 E-06$ \\
\hline $22 E-07$ & $.32 E-06$ & $.46 \mathrm{E}-06$ & $1.20 E-06$ & & 年 & $2 \mathrm{~L}-20$ & 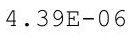 \\
\hline $.22 E-07$ & & & & & & & 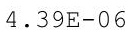 \\
\hline 7 & & 6 & & & & 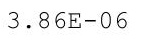 & 06 \\
\hline 7 & & & & & & & 06 \\
\hline $.23 E-07$ & $E-06$ & $.46 \mathrm{E}-06$ & 06 & 6 & 6 & -06 & $8 E-06$ \\
\hline $.24 E-07$ & $31 E-06$ & $.46 E-06$ & $\perp \cdot 2 \perp+$ & 6 & 6 & -06 & $4.38 E-06$ \\
\hline $24 \mathrm{E}-07$ & 6 & $.46 \mathrm{E}$ & 6 & & & 00 & .00 \\
\hline $4 \mathrm{E}-07$ & 0 & $.46 \mathrm{E}-06$ & & 0 & 0 & 06 & 1.0 \\
\hline 年 & 0 & म. & & & - & $85 E-06$ & $4.375-00$ \\
\hline & 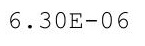 & te the & & & & & $4.37 E-06$ \\
\hline $.25 E-07$ & $.30 E-06$ & $1.47 \mathrm{E}-06$ & $1.22 \mathrm{E}-06$ & $2.88 E-06$ & $.40 \mathrm{E}-06$ & -06 & 4.361 \\
\hline $26 \mathrm{E}-07$ & 06 & $.47 \mathrm{E}-06$ & $.22 E-06$ & -06 & -06 & $5 E-06$ & 4. $36 \mathrm{E}-06$ \\
\hline
\end{tabular}


RESRAD-OFFSITE, Version 2.5

Title : RESRAD-OFFSITE External Gamma, Inhalation, and Soil Ingestion for offsite Reside File : PBA-1 TC99-DOE-5-1.ROF

Summary of dose at graphical times, reptition 1 (continued)

Time

Years

9. $43 \mathrm{E}+02$

9. $44 \mathrm{E}+02$

9. $44 \mathrm{E}+02$

$9.45 \mathrm{E}+02$

9. $45 \mathrm{E}+02$

$9.46 \mathrm{E}+02$

9. $46 \mathrm{E}+02$

$9.47 \mathrm{E}+02$

$9.47 \mathrm{E}+02$

9. $48 \mathrm{E}+02$

9. $48 \mathrm{E}+02$

$9.49 \mathrm{E}+02$

$9.50 \mathrm{E}+02$

$9.50 \mathrm{E}+02$

9. $51 \mathrm{E}+02$

9. $51 \mathrm{E}+02$

9. $52 \mathrm{E}+02$

9. $52 \mathrm{E}+02$

$9.53 \mathrm{E}+02$

9. $53 \mathrm{E}+02$

9. $54 \mathrm{E}+02$

9. $54 \mathrm{E}+02$

9. $55 \mathrm{E}+02$

9. $55 \mathrm{E}+02$

9. $56 \mathrm{E}+02$

9. $56 \mathrm{E}+02$

9. $57 \mathrm{E}+02$

9. $57 \mathrm{E}+02$

9. $58 \mathrm{E}+02$

$9.58 \mathrm{E}+02$

$9.59 \mathrm{E}+02$

$9.59 \mathrm{E}+02$

$9.60 \mathrm{E}+02$

$9.60 \mathrm{E}+02$

$9.61 \mathrm{E}+02$

9. $61 \mathrm{E}+02$

$9.62 \mathrm{E}+02$

$9.62 \mathrm{E}+02$

$9.63 \mathrm{E}+02$

$9.63 \mathrm{E}+02$

$9.64 \mathrm{E}+02$

$9.64 \mathrm{E}+02$

$9.65 \mathrm{E}+02$

$9.65 \mathrm{E}+02$

$9.66 \mathrm{E}+02$

$9.66 \mathrm{E}+02$
Dose statistics at graphical times, mrem/yr

\begin{tabular}{|c|c|c|c|c|c|c|c|}
\hline inimum & aximum & Mean & ledian & $0 \%$ & $\%$ & $7.5 \%$ & $\%$ \\
\hline 07 & $6.29 E-06$ & $.47 \mathrm{E}-06$ & 6 & 6 & 6 & 06 & 0 \\
\hline 07 & 06 & $.47 \mathrm{E}$ & 06 & 06 & 06 & 06 & -06 \\
\hline $7 E-07$ & 06 & 06 & 06 & 6 & 06 & 06 & -06 \\
\hline E-07 & 06 & 06 & & & 6 & 6 & -06 \\
\hline $27 E-07$ & $8 E-06$ & $47 E-06$ & $1.23 E-06$ & $2.88 E-06$ & $40 E-06$ & $E-06$ & $36 E-06$ \\
\hline $.28 E-07$ & $E-06$ & $.47 E-06$ & $.23 E-06$ & $.00 \mathrm{E}-00$ & $40 E-06$ & -06 & $.35 E-06$ \\
\hline 07 & 06 & $48 E-06$ & 06 & 6 & 6 & 0 & $35 F-0$ \\
\hline 7 & 6 & . & 6 & $2.88 E-06$ & 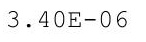 & -06 & $4.35 E-06$ \\
\hline 07 & 06 & 6 & 6 & 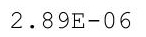 & 6 & 06 & -06 \\
\hline $.29 E-07$ & $27 E-06$ & $.48 E-06$ & $.23 E-06$ & -06 & $40 \mathrm{E}-$ & -06 & -06 \\
\hline $.29 E-07$ & $.27 E-06$ & $.48 E-06$ & $.23 E-06$ & & & $86 E-06$ & $.33 E-06$ \\
\hline-07 & -06 & -06 & -06 & & 6 & -06 & $E-06$ \\
\hline $.30 E-07$ & $.26 \mathrm{E}-06$ & $.48 E-06$ & $1.24 \mathrm{E}-06$ & C.0 & 年 & - & -06 \\
\hline 07 & 06 & 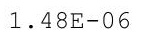 & 6 & & & -06 & 06 \\
\hline 7 & 6 & 6 & 6 & & & -06 & 06 \\
\hline $31 \mathrm{~F}-07$ & 6 & 6 & 6 & $2.90 E-06$ & 0 & 0 & 06 \\
\hline $.31 E-07$ & $6.25 \mathrm{E}-06$ & 1. $49 \mathrm{E}-06$ & $1.24 \mathrm{E}-06$ & $2.90 \mathrm{E}-06$ & $.40 E-06$ & $.86 \mathrm{E}-06$ & $.31 E-06$ \\
\hline $32 E-07$ & $.25 E-06$ & $.49 \mathrm{E}-06$ & $.24 \mathrm{E}-06$ & & ת תח & -06 & $31 E-06$ \\
\hline $32 \mathrm{E}-07$ & 06 & 06 & & & & -06 & -06 \\
\hline 07 & 06 & & & & & -06 & -06 \\
\hline & & & & & & & 06 \\
\hline $33 E-07$ & 6 & 6 & 6 & $2.90 E-06$ & & $3.85 E-06$ & 06 \\
\hline $34 \mathrm{E}$ & 6 & 6 & $E-06$ & 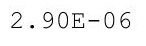 & 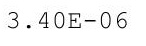 & -06 & -06 \\
\hline $34 \mathrm{E}-07$ & $.23 E-06$ & $.49 E-06$ & $1.25 E-06$ & $91 \mathrm{~F}-06$ & ل & $E-06$ & $.30 E-06$ \\
\hline$E-07$ & -06 & $.49 \mathrm{E}-06$ & -06 & & & $E-06$ & $0 E-06$ \\
\hline $35 E-07$ & 06 & & & & & & 06 \\
\hline & & & & & & & 06 \\
\hline $.35 E-07$ & $.22 \mathrm{E}-06$ & $.50 E-06$ & $.26 E-06$ & $9 \perp-20$ & 40 & UL- & $.30 E-06$ \\
\hline $36 E-07$ & $22 E-06$ & $50 E-06$ & $26 E-06$ & - & ter & -06 & $0 E-06$ \\
\hline 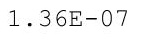 & $22 E-06$ & $1.50 E-06$ & $1.26 \mathrm{E}-06$ & & & -4 & $30 E-06$ \\
\hline $6 E-07$ & $F-06$ & $.50 E-06$ & & & & $E-06$ & $0 E-06$ \\
\hline $7 E-07$ & $E-06$ & $E-06$ & $E-06$ & 6 & & & 06 \\
\hline $.37 E-07$ & & & & & & & \\
\hline $.37 E-07$ & $.20 E-06$ & $.50 E-06$ & $1.27 \mathrm{E}-06$ & $2.91 \mathrm{E}-06$ & $4+E-U 6$ & $4 E-06$ & $.30 E-06$ \\
\hline 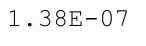 & $.20 E-06$ & $.50 \mathrm{E}-06$ & $1.27 E-06$ & & & $4 \mathrm{~L}-20$ & . \\
\hline $.38 E-07$ & & $.50 E-06$ & & & & & 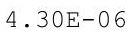 \\
\hline 7 & & 6 & & & & 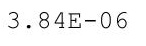 & 06 \\
\hline 7 & & & & & & & 06 \\
\hline $.39 E-07$ & $E-06$ & $.51 \mathrm{E}-06$ & 06 & 6 & 6 & 06 & $1 E-06$ \\
\hline $.39 E-07$ & $.19 \mathrm{E}-06$ & $.51 E-06$ & +.20 & 6 & 6 & -06 & $4.31 E-06$ \\
\hline $40 \mathrm{E}-07$ & 6 & $.51 E-06$ & & & & 00 & . \\
\hline$E-07$ & 0 & 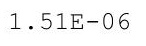 & $\pm \cdot 200$ & & & $2 \pm-06$ & $4.315-06$ \\
\hline 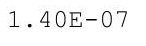 & 0 & PL- & 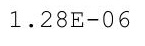 & & $1+2$ & $.82 E-06$ & $4.315-06$ \\
\hline 7 & +0 & $+\cdot 0+5$ & & & & & $4.315-00$ \\
\hline $.41 \mathrm{E}-07$ & $.17 \mathrm{E}-$ & $1.51 \mathrm{E}-06$ & $1.28 \mathrm{E}-06$ & $2.91 E-06$ & $.41 \mathrm{E}-06$ & -06 & 4.31 \\
\hline $42 \mathrm{E}-07$ & 06 & $51 E-06$ & $E-06$ & $91 E-06$ & $41 \mathrm{E}$ & $1 E-06$ & 4. $31 E-06$ \\
\hline
\end{tabular}


RESRAD-OFFSITE, Version 2.5

Title : RESRAD-OFFSITE External Gamma, Inhalation, and Soil Ingestion for offsite Reside File : PBA-1 TC99-DOE-5-1.ROF

Summary of dose at graphical times, reptition 1 (continued)

Time

Years

9. $67 \mathrm{E}+02$

9. $67 \mathrm{E}+02$

$9.68 \mathrm{E}+02$

9. $68 \mathrm{E}+02$

$9.69 \mathrm{E}+02$

$9.70 \mathrm{E}+02$

$9.70 \mathrm{E}+02$

9. $71 \mathrm{E}+02$

9. $71 \mathrm{E}+02$

9. $72 \mathrm{E}+02$

9. $72 \mathrm{E}+02$

$9.73 \mathrm{E}+02$

$9.73 \mathrm{E}+02$

9. $74 \mathrm{E}+02$

9. $74 \mathrm{E}+02$

$9.75 \mathrm{E}+02$

$9.75 \mathrm{E}+02$

$9.76 \mathrm{E}+02$

$9.76 \mathrm{E}+02$

$9.77 \mathrm{E}+02$

$9.77 \mathrm{E}+02$

$9.78 \mathrm{E}+02$

$9.78 \mathrm{E}+02$

$9.79 \mathrm{E}+02$

$9.79 \mathrm{E}+02$

$9.80 \mathrm{E}+02$

$9.80 \mathrm{E}+02$

$9.81 \mathrm{E}+02$

$9.81 \mathrm{E}+02$

$9.82 \mathrm{E}+02$

$9.82 \mathrm{E}+02$

$9.83 \mathrm{E}+02$

$9.83 \mathrm{E}+02$

$9.84 \mathrm{E}+02$

$9.84 \mathrm{E}+02$

$9.85 \mathrm{E}+02$

$9.85 \mathrm{E}+02$

$9.86 \mathrm{E}+02$

$9.86 \mathrm{E}+02$

$9.87 \mathrm{E}+02$

$9.87 \mathrm{E}+02$

$9.88 \mathrm{E}+02$

$9.88 \mathrm{E}+02$

$9.89 \mathrm{E}+02$

9. $90 \mathrm{E}+02$

$9.90 \mathrm{E}+02$
Dose statistics at graphical times, mrem/yr

\begin{tabular}{|c|c|c|c|c|c|c|c|}
\hline Iinimum & laximum & Mean & ledian & $90 \%$ & $95 \%$ & $97.5 \%$ & \\
\hline 7 & 6 & 6 & 6 & 6 & 6 & 66 & -0 \\
\hline • & $7 E-06$ & $.52 \mathrm{E}-06$ & $.29 \mathrm{E}-06$ & $2.91 \mathrm{E}-06$ & $.41 \mathrm{E}-06$ & -06 & $.32 \mathrm{E}-06$ \\
\hline$E-07$ & 6 & $2 E-06$ & 6 & 6 & $40 E-06$ & 06 & $.32 E-06$ \\
\hline$E-07$ & 06 & 06 & 6 & 6 & $O E-$ & 06 & -06 \\
\hline $.43 E-07$ & $E-06$ & $2 E-06$ & $29 E-06$ & & & 06 & $32 E-06$ \\
\hline 07 & 06 & 6 & 6 & 10 & 6 & -06 & -06 \\
\hline $.44 \mathrm{E}-07$ & $5 E-06$ & $.52 E-06$ & $.29 E-06$ & .91 & $0 E-06$ & -06 & $32 E-06$ \\
\hline 1. & $5 E-06$ & $.52 \mathrm{E}-06$ & $29 E-06$ & r & se & -06 & -0 \\
\hline 年 & 6 & 6 & - & $2.91 E-06$ & $3.40 E-06$ & 6 & -06 \\
\hline-07 & 06 & $E-06$ & 06 & ( & 6 & 06 & -06 \\
\hline $.45 E-07$ & $.14 \mathrm{E}-06$ & $.52 \mathrm{E}-06$ & & & & & $.32 E-06$ \\
\hline $.46 E-07$ & -06 & -06 & -06 & 0 & & 06 & -06 \\
\hline-01 & $E-06$ & $E-06$ & $.30 E-06$ & & 年 & -00 & -06 \\
\hline $7 E-07$ & 06 & 06 & 06 & $91 E-06$ & $.40=-00$ & 0 & -06 \\
\hline 年 & 06 & 6 & 6 & & & & -06 \\
\hline 1 & 06 & $3 E-06$ & 06 & $15-06$ & 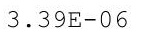 & r & -06 \\
\hline $48 E-07$ & $.12 E-06$ & $.53 E-06$ & $.31 E-06$ & $2.91 E-06$ & $.39 E-06$ & $79 \mathrm{E}-06$ & $.31 E-06$ \\
\hline $.48 E-07$ & $.12 \mathrm{E}-06$ & $.53 E-06$ & $.31 \mathrm{E}-06$ & $2.91 E-06$ & $39 E-06$ & $9 E-06$ & $.31 E-06$ \\
\hline $8 E-07$ & $1 E-06$ & $E-06$ & $1.31 E-06$ & 6 & & & $31 E-06$ \\
\hline E-07 & $1 \mathrm{E}-06$ & $E-06$ & -06 & 0 & $39 E-06$ & 06 & -06 \\
\hline $.495-01$ & $E-06$ & $E-06$ & 06 & & & & -06 \\
\hline . & $.11 \mathrm{E}-06$ & $.53 E-06$ & $1.31 E-06$ & & ( & o & -06 \\
\hline $.50 E-07$ & $10 E-06$ & $54 \mathrm{E}-06$ & $.31 E-06$ & (1) 0 & ل ه & 0 & $.31 E-06$ \\
\hline $.50 E-07$ & $6.10 \mathrm{E}-06$ & $.54 \mathrm{E}-06$ & 1. $32 \mathrm{E}-06$ & $2.91 \mathrm{E}-06$ & $39 E-06$ & $9 \mathrm{E}-06$ & $.31 E-06$ \\
\hline $.51 \mathrm{E}-07$ & $E-06$ & $1 E-06$ & $.32 E-06$ & $92 E-06$ & $9 E-06$ & $E-06$ & -06 \\
\hline$=7=7$ & $E-06$ & -06 & 06 & 6 & & & -06 \\
\hline 1 & 06 & 06 & 6 & 21 & & & -06 \\
\hline $.3 \angle E-41$ & $.09 E-06$ & $.54 E-06$ & $32 E-06$ & $2.92 \pm-00$ & $29-06$ & OE-U & $.31 E-06$ \\
\hline . $28 \mathrm{~L}$ - & $08 E-06$ & $4 E-06$ & $32 E-06$ & 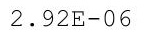 & 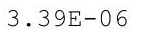 & 0 & -06 \\
\hline (1) & OL- & $54 \mathrm{E}-06$ & 6 & 政 & & 年 & 年 \\
\hline $.53 E-07$ & 6 & & 6 & $.92 E-06$ & & 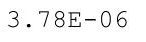 & 06 \\
\hline$=0-7-2-1$ & $F-06$ & -06 & 6 & D & 5 & 6 & $31 E-06$ \\
\hline & & & & & & & -06 \\
\hline $.54 \mathrm{E}-07$ & $.07 \mathrm{E}-06$ & $.55 \mathrm{E}-06$ & $1.33 E-06$ & $2.92 \mathrm{E}-06$ & $39 E-06$ & $1+5-06$ & $.31 \mathrm{E}-06$ \\
\hline . $345-01$ & $.00 E-06$ & $.55 E-06$ & $.33 E-06$ & $2.935-00$ & & & $.31 E-06$ \\
\hline 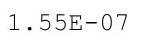 & & & & & & & (1) \\
\hline 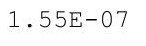 & & & & 6 & & & 06 \\
\hline , & 6 & 6 & 6 & & & & 06 \\
\hline $.56 \mathrm{E}-07$ & $5 E-06$ & $.55 E-06$ & $.34 E-06$ & $2.92 \mathrm{E}$ & 6 & 6 & -06 \\
\hline $.56 \mathrm{E}-07$ & $05 E-06$ & 06 & 6 & 6 & 5 & & -06 \\
\hline $.56 \mathrm{E}-01$ & $5 E-06$ & $5 E-06$ & & ( & & & $.31 E-06$ \\
\hline $7 \pm-01$ & $E-U 6$ & 6 & 6 & 2. & 6 & & -06 \\
\hline & & & & 2 & 5 & & -06 \\
\hline 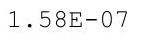 & & & & & & & 06 \\
\hline$E-07$ & $E-06$ & $6 E-06$ & 1.3 & 2. & 6 & 06 & -06 \\
\hline $.58 E-07$ & $.03 E-06$ & $.56 \mathrm{E}-06$ & $.34 E-06$ & $2.93 E-06$ & $.38 E-06$ & $3.76 \mathrm{E}-06$ & $4.31 E-06$ \\
\hline
\end{tabular}


RESRAD-OFFSITE, Version 2.5

Title : RESRAD-OFFSITE External Gamma, Inhalation, and Soil Ingestion for offsite Reside File : PBA-1_TC99-DOE-5-1.ROF

Summary of dose at graphical times, reptition 1 (continued)

Time

Years

$9.91 \mathrm{E}+02$

9. $91 \mathrm{E}+02$

9. $92 \mathrm{E}+02$

9. $92 \mathrm{E}+02$

9. $93 \mathrm{E}+02$

9. $93 \mathrm{E}+02$

9. $94 \mathrm{E}+02$

$9.94 \mathrm{E}+02$

9. $95 \mathrm{E}+02$

9. $95 \mathrm{E}+02$

9. $96 \mathrm{E}+02$

9. $96 \mathrm{E}+02$

$9.97 \mathrm{E}+02$

9. $97 \mathrm{E}+02$

$9.98 \mathrm{E}+02$

9. $98 \mathrm{E}+02$

9. $99 \mathrm{E}+02$

$9.99 \mathrm{E}+02$

$1.00 \mathrm{E}+03$

$1.00 \mathrm{E}+03$

$1.00 \mathrm{E}+03$

$1.00 \mathrm{E}+03$

$1.00 \mathrm{E}+03$

$1.00 \mathrm{E}+03$

$1.00 \mathrm{E}+03$

$1.00 \mathrm{E}+03$

$1.00 \mathrm{E}+03$

$1.00 \mathrm{E}+03$

$1.00 \mathrm{E}+03$

$1.01 \mathrm{E}+03$

$1.01 \mathrm{E}+03$

$1.01 \mathrm{E}+03$

$1.01 \mathrm{E}+03$

$1.01 \mathrm{E}+03$

$1.01 \mathrm{E}+03$

$1.01 \mathrm{E}+03$

$1.01 E+03$

$1.01 \mathrm{E}+03$

$1.01 \mathrm{E}+03$

$1.01 \mathrm{E}+03$

$1.01 \mathrm{E}+03$

1. $01 \mathrm{E}+03$

$1.01 \mathrm{E}+03$

$1.01 \mathrm{E}+03$

$1.01 \mathrm{E}+03$

$1.01 \mathrm{E}+03$
Dose statistics at graphical times, mrem/yr

\begin{tabular}{|c|c|c|c|c|c|c|c|}
\hline num & hum & ean & ed & & & & \\
\hline E-07 & 6 & 6 & 6 & 6 & 6 & 6 & -06 \\
\hline $.59 \mathrm{E}-07$ & $6.02 \mathrm{E}-06$ & $56 \mathrm{E}-06$ & $.34 \mathrm{E}-06$ & $2.94 \mathrm{E}-06$ & $38 E-06$ & $3.76 \mathrm{E}-06$ & $31 \mathrm{E}-06$ \\
\hline $.59 E-07$ & $.02 E-06$ & $6 E-06$ & $.34 E-06$ & $2.94 \mathrm{E}-06$ & $8 E-06$ & 06 & $E-06$ \\
\hline 7 & 6 & $.56 \mathrm{E}-06$ & -06 & & & & -06 \\
\hline 07 & -06 & $E-06$ & 06 & 06 & 6 & & -06 \\
\hline $60 E-07$ & 06 & $6 E-06$ & -06 & -06 & 6 & & -06 \\
\hline 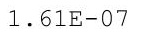 & -06 & -06 & & & & & -06 \\
\hline $61 E-07$ & $E-06$ & $E-06$ & $E-06$ & -06 & -06 & -06 & $E-06$ \\
\hline $.62 E-07$ & $E-06$ & $E-06$ & $E-06$ & -06 & -06 & -06 & -0 \\
\hline $52 \mathrm{~F}-07$ & $.00 \mathrm{E}-06$ & $.56 \mathrm{E}-06$ & $5 E-06$ & & & & $-06-2-3 \cdot$ \\
\hline $\mathrm{F}$ & & & & & & & -06 \\
\hline $63 E-07$ & $E-06$ & $7 E-06$ & -06 & 06 & & & $29 E-06$ \\
\hline $.63 E-07$ & $5.99 E-06$ & $.57 E-06$ & $1.36 \mathrm{E}-06$ & $2.94 E-06$ & & & $.29 E-06$ \\
\hline $64 \mathrm{E}-07$ & -06 & $E-06$ & -06 & & & & -06 \\
\hline 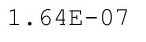 & & & & & & & -0 \\
\hline ק & & $.57 \mathrm{E}-06$ & & & & & -06 \\
\hline 7 & 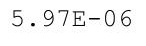 & 6 & 6 & 6 & $3.38 \mathrm{E}-06$ & $3.75 \mathrm{E}-06$ & .06 \\
\hline $65 F-07$ & $E-06$ & $7 E-06$ & $1.37 E-06$ & & 6 & 6 & -06 \\
\hline $65 E-07$ & $.97 E-06$ & $1.57 \mathrm{E}-06$ & $1.37 \mathrm{E}-06$ & $2.93 E-06$ & $.38 E-06$ & -06 & $.28 E-06$ \\
\hline $66 \mathrm{E}-07$ & $.96 E-06$ & $1.57 \mathrm{E}-06$ & $1.37 E-06$ & $.93 E-06$ & -06 & -06 & $\exists-06$ \\
\hline & & & & & & & -06 \\
\hline & & & & & & & 06 \\
\hline $.67 \mathrm{E}-$ & & & 06 & & & & -06 \\
\hline 6 & 06 & 06 & 06 & 6 & . & 66 & -06 \\
\hline $3 F-$ & $E-06$ & $1.58 \mathrm{E}-06$ & $8 E-06$ & $4 E-06$ & $F-06$ & $E-06$ & $26 E-06$ \\
\hline $68 F-0$ & $.94 E-06$ & $1.58 \mathrm{E}-06$ & $1.38 E-06$ & $4 E-06$ & $3 E-06$ & -06 & $E-06$ \\
\hline $68 \mathrm{~F}-07-2-1$ & $94 E-06$ & $1.58 \mathrm{E}-06$ & $.38 E-06$ & & & & -06 \\
\hline & & & & & & & \\
\hline & & & & & & & \\
\hline $.70 E-07$ & $5.93 E-06$ & $1.58 \mathrm{E}-06$ & $1.38 \mathrm{E}-06$ & $2.94 \mathrm{E}-06$ & 正 0 & $0.145-00$ & $26 E-06$ \\
\hline (- & $.93 E-06$ & $1.58 \mathrm{E}-06$ & $1.38 \mathrm{E}-06$ & $2.94 \mathrm{E}-06$ & 年 & t4 & $26 \mathrm{E}-0$ \\
\hline 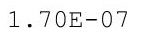 & & & $1.38 E-06$ & & & & 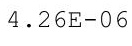 \\
\hline$F_{0}$ & -0 & $58 E-06$ & & & & & 06 \\
\hline $\mathrm{F}$ & & & & & 6 & & 06 \\
\hline & & & & & 6 & 66 & \\
\hline $.72 \mathrm{E}-07$ & $5.91 \mathrm{E}-06$ & $1.59 \mathrm{E}-06$ & $1.39 \mathrm{E}-06$ & $2.94 \mathrm{E}-06$ & $9 E-06$ & $5 E-06$ & $.25 E-06$ \\
\hline - 120 र & $3.90 \mathrm{E}-0$ & $1.59 \mathrm{E}-06$ & 06 & & & & c \\
\hline $73 E-07$ & $5.90 \mathrm{E}-06$ & $1.59 \mathrm{E}-06$ & $1.39 \mathrm{E}-06$ & & & & 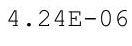 \\
\hline $73 \mathrm{~F}-07$ & & 6 & 6 & 5 & 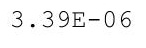 & 6 & 06 \\
\hline $.73 E-07$ & & & 06 & 6 & 6 & 6 & 06 \\
\hline $4 E-07$ & $.89 E-06$ & $1.59 \mathrm{E}-06$ & $1.40 \mathrm{E}-06$ & -06 & 6 & & -06 \\
\hline $4 E-07$ & E-06 & $9 E-06$ & $1.40 \mathrm{E}-06$ & 06 & 6 & 06 & -06 \\
\hline 7 & & & & & & & -00 \\
\hline 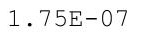 & . & 06 & 06 & 6 & 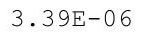 & & - -1 \\
\hline 象 & & o & & & & & che \\
\hline-07 & $E-06$ & $E-06$ & $E-06$ & $E-06$ & $9 E-06$ & -06 & -06 \\
\hline
\end{tabular}


RESRAD-OFFSITE, Version 2.5

$\mathrm{T}^{1 / 2}$ Limit $=180$ days

Title : RESRAD-OFFSITE External Gamma, Inhalation, and Soil Ingestion for offsite Reside File : PBA-1_TC99-DOE-5-1.ROF

Summary of dose at graphical times, reptition 1 (continued)

Time

Years

1. $01 \mathrm{E}+03$

$1.01 \mathrm{E}+03$

1. $02 \mathrm{E}+03$

1. $02 \mathrm{E}+03$

1. $02 \mathrm{E}+03$

1. $02 \mathrm{E}+03$

$1.02 \mathrm{E}+03$

1. $02 \mathrm{E}+03$

1. $02 \mathrm{E}+03$

1. $02 \mathrm{E}+03$

1. $02 \mathrm{E}+03$

1. $02 \mathrm{E}+03$

1. $02 \mathrm{E}+03$

1. $02 \mathrm{E}+03$

1. $02 \mathrm{E}+03$

1. $02 \mathrm{E}+03$

1. $02 \mathrm{E}+03$

1. $02 \mathrm{E}+03$

1. $02 \mathrm{E}+03$

1. $02 \mathrm{E}+03$

1. $02 \mathrm{E}+03$

1. $02 \mathrm{E}+03$

1. $03 \mathrm{E}+03$

$1.03 \mathrm{E}+03$

$1.03 \mathrm{E}+03$

$1.03 \mathrm{E}+03$

$1.03 E+03$

$1.03 E+03$

$1.03 \mathrm{E}+03$

$1.03 \mathrm{E}+03$

$1.03 \mathrm{E}+03$

$1.03 \mathrm{E}+03$

$1.03 \mathrm{E}+03$

$1.03 \mathrm{E}+03$

$1.03 \mathrm{E}+03$

$1.03 \mathrm{E}+03$

$1.03 E+03$

$1.03 E+03$

$1.03 E+03$

$1.03 \mathrm{E}+03$

$1.03 \mathrm{E}+03$

$1.04 \mathrm{E}+03$

1. $04 \mathrm{E}+03$

$1.04 \mathrm{E}+03$

1. $04 \mathrm{E}+03$

$1.04 \mathrm{E}+03$
Dose statistics at graphical times, mrem/yr

\begin{tabular}{|c|c|c|c|c|c|c|c|}
\hline Iinimum & laximum & Mean & Median & $90 \%$ & $95 \%$ & $97.5 \%$ & \\
\hline 7 & 06 & $50 E-06$ & $1.40 \mathrm{E}-06$ & 6 & 6 & 6 & -0 \\
\hline $7 E-07$ & $7 E-06$ & $60 E-06$ & $.41 \mathrm{E}-06$ & $2.94 \mathrm{E}-06$ & $3.39 \mathrm{E}-06$ & -06 & $.22 \mathrm{E}-06$ \\
\hline $.77 E-07$ & $6 E-06$ & $0 E-06$ & $E-06$ & 06 & $8 E-06$ & 06 & $22 E-06$ \\
\hline E-07 & $E-06$ & $E-06$ & $E-06$ & $E-06$ & $8 E-06$ & 06 & $22 E-06$ \\
\hline $.78 \mathrm{E}-07$ & 06 & $E-06$ & $1 E-06$ & -06 & & & $22 E-06$ \\
\hline $.78 E-07$ & -06 & -06 & -06 & 6 & 6 & 06 & $22 E-06$ \\
\hline $.78 E-07$ & $E-06$ & $.60 E-06$ & $41 E-06$ & -06 & -06 & -06 & $22 E-06$ \\
\hline 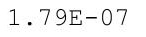 & -06 & $.60 \mathrm{E}-06$ & $.41 E-06$ & -06 & 06 & -06 & -06 \\
\hline 政 & $5.84 \mathrm{E}-06$ & $.60 \mathrm{E}-06$ & $1.42 \mathrm{E}-06$ & $2.94 \mathrm{E}-06$ & 正 & -06 & $.22 E-06$ \\
\hline-07 & 06 & -06 & 06 & 06 & 06 & 06 & $22 E-06$ \\
\hline $.80 E-07$ & $5.83 E-06$ & $1.60 \mathrm{E}-06$ & 1. $42 \mathrm{E}-06$ & & & & $.21 E-06$ \\
\hline $30 \mathrm{E}-07$ & 06 & $0 E-06$ & $2 E-06$ & 6 & 6 & 06 & $E-06$ \\
\hline $.8 \perp \mathrm{E}-\mathrm{U} /$ & $E-06$ & $E-06$ & $42 E-06$ & -06 & $3 E-06$ & -06 & $21 E-06$ \\
\hline $.01 \mathrm{~L}-01$ & $5.82 \mathrm{E}-06$ & $1.61 \mathrm{E}-06$ & $2 E-06$ & 0 & 0 & 6 & 06 \\
\hline 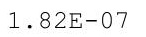 & -06 & 06 & $1.42 E-06$ & 06 & 06 & 06 & $20 E-06$ \\
\hline • & 06 & 06 & 06 & 06 & 0 & 06 & -06 \\
\hline $.82 \mathrm{E}-07$ & $5.81 E-06$ & $1.61 \mathrm{E}-06$ & 1. $42 \mathrm{E}-06$ & $2.93 E-06$ & $3.38 \mathrm{E}-06$ & $71 \mathrm{E}-06$ & $.20 E-06$ \\
\hline $.83 E-07$ & $5.81 \mathrm{E}-06$ & $1.61 \mathrm{E}-06$ & $1.43 E-06$ & $3 E-06$ & $8 E-06$ & $E-06$ & $20 E-06$ \\
\hline 07 & 06 & 06 & 06 & & & & -06 \\
\hline $.84 \mathrm{E}-07$ & $5.80 \mathrm{E}-06$ & $1.61 \mathrm{E}-06$ & -06 & 06 & 6 & 06 & $E-06$ \\
\hline 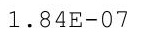 & $E-06$ & $E-06$ & -06 & & & & $19 E-06$ \\
\hline $.84 \mathrm{E}-07$ & $5.79 \mathrm{E}-06$ & $1.61 \mathrm{E}-06$ & -06 & & & - & -06 \\
\hline - & $E-06$ & $1.61 \mathrm{E}-06$ & $43 E-06$ & $3 E-06$ & 品 & -06 & $19 E-06$ \\
\hline $.85 E-07$ & $9 E-06$ & $1.61 E-06$ & $3 E-06$ & 06 & 06 & -06 & $18 E-06$ \\
\hline 07 & $E-06$ & $51 E-06$ & $E-06$ & & & 06 & $3 E-06$ \\
\hline 07 & 06 & 06 & -06 & 06 & & & $E-06$ \\
\hline $5 E-07$ & $E-06$ & $2 E-06$ & 06 & & & & $8 E-06$ \\
\hline $.87 E-07$ & $5.77 \mathrm{E}-06$ & $1.62 \mathrm{E}-06$ & $1.44 \mathrm{E}-06$ & $2.93 E-06$ & $3.38 \mathrm{E}-06$ & $72 \mathrm{E}-06$ & $.18 E-06$ \\
\hline . & $5.1 / \mathrm{E}-00$ & $1.62 \mathrm{E}-06$ & $1.44 \mathrm{E}-06$ & $2.93 \mathrm{E}-06$ & & $72 E-06$ & $.18 \mathrm{E}-06$ \\
\hline . & $5.76 E-06$ & 1. $62 E-06$ & $1.44 \mathrm{E}-06$ & 正 & 工 & -06 & • $\perp$ H \\
\hline 07 & 06 & $E-06$ & -06 & 6 & 6 & 6 & 06 \\
\hline$E-07$ & $E-06$ & $E-06$ & -06 & -06 & 6 & 06 & $E-06$ \\
\hline $.89 E-07$ & $5.75 E-06$ & $1.62 \mathrm{E}-06$ & $E-06$ & 06 & 6 & 66 & $17 E-06$ \\
\hline $.89 \mathrm{E}-07$ & $5.75 \mathrm{E}-06$ & $1.62 \mathrm{E}-06$ & $1.44 \mathrm{E}-06$ & $2.93 E-06$ & $3.38 \mathrm{E}-06$ & $71 E-06$ & $.17 \mathrm{E}-06$ \\
\hline . $90 \mathrm{E}-0 \mathrm{~T}$ & $5.74 E-06$ & 1. $62 E-06$ & & & & & $\cdot 1 / E-06$ \\
\hline ו & & & & & & & \\
\hline & & & & & & & \\
\hline 7 & 6 & 6 & 6 & 6 & 6 & 6 & -06 \\
\hline$E-07$ & $E-06$ & $2 E-06$ & $E-06$ & 66 & 6 & 6 & $6 E-06$ \\
\hline $92 \mathrm{E}-07$ & 06 & $1.62 E-06$ & 06 & & & & $4.16 \mathrm{E}-06$ \\
\hline $2 \pm-01$ & 06 & $63 E-06$ & & & & & -06 \\
\hline $92 E-07$ & $.72 E-06$ & $.63 E-06$ & $1.45 E-06$ & $2.93 E-06$ & & & $16 E-06$ \\
\hline & & & & & & & $4.16 \mathrm{E}-06$ \\
\hline & & & 06 & 0 & 6 & 6 & 0 \\
\hline$E-07$ & $E-06$ & $E-06$ & 06 & 06 & 6 & 6 & -06 \\
\hline $.94 E-07$ & $70 E-06$ & 1. $63 E-06$ & $1.46 E-06$ & $2.93 E-06$ & $3.38 E-06$ & $3.70 \mathrm{E}-06$ & $4.15 E-06$ \\
\hline
\end{tabular}


RESRAD-OFFSITE, Version 2.5

$\mathrm{T}^{1 / 2}$ Limit $=180$ days

robabilistic Dose and Risk Report

Title : RESRAD-OFFSITE External Gamma, Inhalation, and Soil Ingestion for offsite Reside File : PBA-1_TC99-DOE-5-1.ROF

Time

Years

$1.04 \mathrm{E}+03$

$1.04 \mathrm{E}+03$

$1.04 \mathrm{E}+03$

$1.04 \mathrm{E}+03$

$1.04 \mathrm{E}+03$

$1.04 \mathrm{E}+03$

$1.04 \mathrm{E}+03$

$1.04 \mathrm{E}+03$

$1.04 \mathrm{E}+03$

$1.04 \mathrm{E}+03$

$1.04 \mathrm{E}+03$

$1.04 \mathrm{E}+03$

$1.04 \mathrm{E}+03$

$1.04 \mathrm{E}+03$

$1.04 \mathrm{E}+03$

$1.05 \mathrm{E}+03$

$1.05 \mathrm{E}+03$

$1.05 \mathrm{E}+03$

$1.05 \mathrm{E}+03$

$1.05 \mathrm{E}+03$

$1.05 \mathrm{E}+03$

$1.05 \mathrm{E}+03$

$1.05 \mathrm{E}+03$

$1.05 \mathrm{E}+03$

$1.05 \mathrm{E}+03$
Summary of dose at graphical times, reptition 1 (continued)

Dose statistics at graphical times, mrem/yr

\begin{tabular}{|c|c|c|c|c|c|c|c|}
\hline Minimum & Maximum & Mean & Median & $90 \%$ & $95 \%$ & $97.5 \%$ & $99 \%$ \\
\hline $1.94 \mathrm{E}-07$ & $5.70 \mathrm{E}-06$ & $1.63 E-06$ & $1.46 \mathrm{E}-06$ & $2.93 E-06$ & $3.38 E-06$ & $3.71 \mathrm{E}-06$ & $4.15 \mathrm{E}-06$ \\
\hline $1.95 \mathrm{E}-07$ & $5.69 \mathrm{E}-06$ & $1.63 \mathrm{E}-06$ & $1.46 \mathrm{E}-06$ & $2.94 \mathrm{E}-06$ & $3.38 \mathrm{E}-06$ & $3.71 \mathrm{E}-06$ & $4.15 \mathrm{E}-06$ \\
\hline $1.95 \mathrm{E}-07$ & $5.69 \mathrm{E}-06$ & $1.63 E-06$ & $1.46 \mathrm{E}-06$ & $2.94 \mathrm{E}-06$ & $3.38 \mathrm{E}-06$ & $3.70 \mathrm{E}-06$ & $4.14 \mathrm{E}-06$ \\
\hline $96 \mathrm{E}-07$ & $69 \mathrm{E}-06$ & $1.63 \mathrm{E}-06$ & $1.46 \mathrm{E}-06$ & $2.94 \mathrm{E}-06$ & $3.38 \mathrm{E}-06$ & $3.70 \mathrm{E}-06$ & $4.14 \mathrm{E}-06$ \\
\hline $.96 \mathrm{E}-07$ & $.68 E-06$ & $1.63 E-06$ & $1.46 \mathrm{E}-06$ & $94 E-06$ & $38 E-06$ & $E-06$ & -06 \\
\hline $1.96 \mathrm{E}-07$ & $5.68 \mathrm{E}-06$ & $1.63 E-06$ & $1.46 \mathrm{E}-06$ & $2.94 \mathrm{E}-06$ & $3.38 \mathrm{E}-06$ & $3.70 \mathrm{E}-06$ & $4.14 \mathrm{E}-06$ \\
\hline $1.97 \mathrm{E}-07$ & $5.68 \mathrm{E}-06$ & $1.63 \mathrm{E}-06$ & $1.46 \mathrm{E}-06$ & $2.94 E-06$ & $3.38 E-06$ & $3.70 \mathrm{E}-06$ & $4.14 \mathrm{E}-06$ \\
\hline $1.97 \mathrm{E}-07$ & $5.67 \mathrm{E}-06$ & $1.63 E-06$ & $1.46 \mathrm{E}-06$ & $2.94 \mathrm{E}-06$ & $3.38 E-06$ & $3.69 \mathrm{E}-06$ & $4.14 \mathrm{E}-06$ \\
\hline $1.98 \mathrm{E}-07$ & $5.67 \mathrm{E}-06$ & $1.64 \mathrm{E}-06$ & $1.46 \mathrm{E}-06$ & $2.94 \mathrm{E}-06$ & $3.38 \mathrm{E}-06$ & $3.69 \mathrm{E}-06$ & $4.14 \mathrm{E}-06$ \\
\hline $1.98 \mathrm{E}-07$ & $5.66 \mathrm{E}-06$ & 1. $64 \mathrm{E}-06$ & $1.47 \mathrm{E}-06$ & $2.94 \mathrm{E}-06$ & $3.38 E-06$ & $E-06$ & $4.13 E-06$ \\
\hline $1.98 \mathrm{E}-07$ & $5.66 \mathrm{E}-06$ & $1.64 \mathrm{E}-06$ & $1.47 E-06$ & $2.94 E-06$ & $3.38 E-06$ & $3.69 E-06$ & $4.13 E-06$ \\
\hline $1.99 \mathrm{E}-07$ & $5.66 \mathrm{E}-06$ & $1.64 \mathrm{E}-06$ & $1.47 \mathrm{E}-06$ & $2.94 \mathrm{E}-06$ & $3.38 E-06$ & $3.68 \mathrm{E}-06$ & $4.13 \mathrm{E}-06$ \\
\hline $1.99 \mathrm{E}-07$ & $5.65 \mathrm{E}-06$ & $1.64 \mathrm{E}-06$ & $1.47 \mathrm{E}-06$ & $2.94 \mathrm{E}-06$ & $3.38 \mathrm{E}-06$ & $3.68 \mathrm{E}-06$ & $4.13 \mathrm{E}-06$ \\
\hline $2.00 \mathrm{E}-07$ & $.65 E-06$ & $1.64 \mathrm{E}-06$ & $1.47 \mathrm{E}-06$ & $2.94 \mathrm{E}-06$ & $3.38 \mathrm{E}-06$ & $3.68 \mathrm{E}-06$ & $4.13 \mathrm{E}-06$ \\
\hline $2.00 \mathrm{E}-07$ & $.64 E-06$ & $1.64 \mathrm{E}-06$ & $1.47 \mathrm{E}-06$ & $2.94 \mathrm{E}-06$ & $3.37 E-06$ & $3.68 \mathrm{E}-06$ & $4.13 E-06$ \\
\hline $2.00 \mathrm{E}-07$ & $5.64 \mathrm{E}-06$ & $1.64 \mathrm{E}-06$ & $1.47 \mathrm{E}-06$ & $2.94 \mathrm{E}-06$ & $3.37 \mathrm{E}-06$ & $3.68 \mathrm{E}-06$ & $4.12 \mathrm{E}-06$ \\
\hline $2.01 E-07$ & $5.64 \mathrm{E}-06$ & $1.64 \mathrm{E}-06$ & $1.47 E-06$ & $2.94 E-06$ & $37 E-06$ & $E-06$ & $12 E-06$ \\
\hline $2.01 \mathrm{E}-07$ & $5.63 E-06$ & $1.64 E-06$ & $1.47 E-06$ & $2.94 E-06$ & $3.37 E-06$ & $3.68 E-06$ & $4.12 \mathrm{E}-06$ \\
\hline $2.02 \mathrm{E}-07$ & $5.63 \mathrm{E}-06$ & $1.64 E-06$ & $1.47 E-06$ & $2.94 E-06$ & $3.37 E-06$ & $3.68 \mathrm{E}-06$ & $4.12 \mathrm{E}-06$ \\
\hline $2.02 \mathrm{E}-07$ & $5.63 E-06$ & $1.64 \mathrm{E}-06$ & $1.48 E-06$ & $2.94 \mathrm{E}-06$ & $3.37 \mathrm{E}-06$ & $3.68 \mathrm{E}-06$ & $4.11 \mathrm{E}-06$ \\
\hline $2.02 \mathrm{E}-07$ & $5.62 \mathrm{E}-06$ & 1. $64 \mathrm{E}-06$ & $1.48 \mathrm{E}-06$ & $2.94 \mathrm{E}-06$ & $3.37 \mathrm{E}-06$ & $3.68 \mathrm{E}-06$ & $4.11 \mathrm{E}-06$ \\
\hline $2.03 E-07$ & $5.62 \mathrm{E}-06$ & $1.64 E-06$ & $1.48 E-06$ & $2.94 \mathrm{E}-06$ & $3.37 E-06$ & $3.68 \mathrm{E}-06$ & $4.11 \mathrm{E}-06$ \\
\hline $2.03 E-07$ & $5.61 \mathrm{E}-06$ & $1.64 \mathrm{E}-06$ & $1.48 E-06$ & $2.01+$ & . & $3.68 \mathrm{E}-06$ & $4.11 \mathrm{E}-06$ \\
\hline $2.04 \mathrm{E}-07$ & $5.61 \mathrm{E}-06$ & $1.65 E-06$ & $1.48 \mathrm{E}-06$ & $2.94 \mathrm{E}-06$ & $3.37 E-06$ & $3.68 E-06$ & $4.11 E-06$ \\
\hline $2.04 \mathrm{E}-07$ & $5.61 \mathrm{E}-06$ & $1.65 \mathrm{E}-06$ & 1. $48 \mathrm{E}-06$ & $2.94 E-06$ & $3.37 \mathrm{E}-06$ & $3.68 \mathrm{E}-06$ & $4.11 \mathrm{E}-06$ \\
\hline
\end{tabular}


RESRAD-OFFSITE, Version 2.5

$\mathrm{T}^{1 / 2}$ Limit $=180$ days

Title : RESRAD-OFFSITE External Gamma, Inhalation, and Soil Ingestion for Offsite Reside

File : PBA-1_TC99-DOE-5-1.ROF

Time

Years

$0.00 \mathrm{E}+00$

$5.13 \mathrm{E}-01$

1. $03 \mathrm{E}+00$

$1.54 \mathrm{E}+00$

$2.05 \mathrm{E}+00$

$2.56 \mathrm{E}+00$

$3.08 \mathrm{E}+00$

$3.59 \mathrm{E}+00$

$4.10 \mathrm{E}+00$

$4.61 \mathrm{E}+00$

$5.13 \mathrm{E}+00$

$5.64 \mathrm{E}+00$

$6.15 \mathrm{E}+00$

$6.67 \mathrm{E}+00$

$7.18 \mathrm{E}+00$

$7.69 \mathrm{E}+00$

$8.20 \mathrm{E}+00$

$8.72 \mathrm{E}+00$

$9.23 \mathrm{E}+00$

$9.74 \mathrm{E}+00$

$1.03 E+01$

$1.08 \mathrm{E}+01$

$1.13 \mathrm{E}+01$

$1.18 \mathrm{E}+01$

1. $23 \mathrm{E}+01$

$1.28 \mathrm{E}+01$

$1.33 \mathrm{E}+01$

$1.38 \mathrm{E}+01$

$1.44 \mathrm{E}+01$

$1.49 \mathrm{E}+01$

$1.54 \mathrm{E}+01$

$1.59 \mathrm{E}+01$

1. $64 \mathrm{E}+01$

$1.69 \mathrm{E}+01$

$1.74 \mathrm{E}+01$

$1.79 \mathrm{E}+01$

$1.85 \mathrm{E}+01$

1. $90 \mathrm{E}+01$

1. $95 \mathrm{E}+01$

2. $00 \mathrm{E}+01$

2. $05 \mathrm{E}+01$

$2.10 \mathrm{E}+01$

$2.15 \mathrm{E}+01$

2. $20 \mathrm{E}+01$

$2.26 \mathrm{E}+01$

$2.31 \mathrm{E}+01$
Summary of dose at graphical times, reptition 2

Dose statistics at graphical times, mrem/yr

\begin{tabular}{|c|c|c|c|c|c|c|c|}
\hline nimum & aximum & lean & edian & 5 & $\%$ & $\%$ & $\circ$ \\
\hline & 32 & $48 E-32$ & $1.48 \mathrm{E}-32$ & 32 & 32 & -32 & se \\
\hline $6 E-32$ & -32 & $9 E-32$ & $9 E-32$ & $49 E-32$ & $49 E-32$ & -32 & $49 E-32$ \\
\hline 32 & 32 & 32 & 32 & 32 & & 32 & -32 \\
\hline-32 & 32 & 32 & & 32 & 32 & -32 & -32 \\
\hline $43 E-32$ & -32 & $3 E-32$ & $3 E-32$ & $.53 E-32$ & -32 & $.53 E-32$ & $E-32$ \\
\hline$\cdot 43 E-32$ & $1.55 E-32$ & -32 & -32 & & 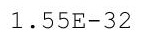 & -32 & $E-32$ \\
\hline-32 & 1.00 & 24 עل & $1.56 \mathrm{E}-32$ & 1.00 & 2 & -32 & 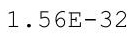 \\
\hline 32 & 32 & 32 & $7 E-32$ & 32 & $57 E-32$ & -32 & $58 E-32$ \\
\hline 32 & $E-32$ & $8 E-32$ & $8 E-32$ & 32 & 32 & -32 & $59 E-32$ \\
\hline $.40 \mathrm{E}-32$ & $0 E-32$ & $9 E-32$ & $9 E-32$ & $.60 \mathrm{E}-32$ & .601 & -32 & $.60 E-32$ \\
\hline-32 & -32 & $E-32$ & $E-32$ & 32 & $2 E-32$ & -32 & $62 E-32$ \\
\hline-32 & 32 & $61 E-32$ & $62 E-32$ & 32 & 32 & -32 & $3 E-32$ \\
\hline 32 & 32 & 32 & 32 & 2 & 2 & 32 & -32 \\
\hline 年 & 2 & 2 & 2 & 2 & 2 & 2 & $E-32$ \\
\hline $.37 E-32$ & -32 & -32 & $1.66 \mathrm{E}-32$ & 32 & 32 & -32 & -32 \\
\hline $.36 \mathrm{E}-32$ & $1.69 \mathrm{E}-32$ & $1.66 \mathrm{E}-32$ & $1.68 E-32$ & $1.69 \mathrm{E}-32$ & $1.69 \mathrm{E}-32$ & $.69 \mathrm{E}-32$ & $69 \mathrm{E}-32$ \\
\hline $.35 E-32$ & $1.71 \mathrm{E}-32$ & $1.68 \mathrm{E}-32$ & $1.69 \mathrm{E}-32$ & $1.70 E-32$ & $1.70 \mathrm{E}-32$ & $E-32$ & $.70 E-32$ \\
\hline$E-32$ & $2 E-32$ & $.69 E-32$ & $0 E-32$ & $72 E-32$ & $1.72 E-32$ & $E-32$ & $72 E-32$ \\
\hline 2 & & & 2 & 2 & 2 & -32 & $74 \mathrm{E}-32$ \\
\hline 2 & 32 & 32 & 2 & 2 & & 2 & 32 \\
\hline 2 & $1.77 \mathrm{E}-32$ & & 2 & & & 2 & 32 \\
\hline $.32 E-32$ & 2 & & 2 & 2 & تص० & -32 & $78 E-32$ \\
\hline $1=-32$ & $.80 \mathrm{E}-32$ & $.76 \mathrm{E}-32$ & $77 E-32$ & $79 E-32$ & $79=-32$ & $80 E-32$ & $80 E-32$ \\
\hline $5=32$ & $1.81 \mathrm{E}-32$ & $77 E-32$ & $9 E-32$ & $81 E-32$ & $81=32$ & -32 & $81 E-32$ \\
\hline 32 & $1.83 E-32$ & $79 E-32$ & $0 E-32$ & 32 & $83 E-32$ & -32 & $33 E-32$ \\
\hline & -32 & $.80 E-32$ & & & & & \\
\hline & & & & & & 2 & 32 \\
\hline $.20 E-32$ & $1.00 \pm-32$ & $.83 E-32$ & $5 E-32$ & $.87 \mathrm{E}-32$ & $.87 E-32$ & $88 E-32$ & $88 E-32$ \\
\hline e & (2) & $84 E-32$ & $86 \mathrm{E}-$ & (1) & $89 \mathrm{E}-$ & $89 E-32$ & $89 E-32$ \\
\hline $27 F-32$ & $1.91 \mathrm{E}-32$ & $.86 E-32$ & $88 E-32$ & & & $E-32$ & $91 \mathrm{E}-32$ \\
\hline $65-32$ & & & & & & -32 & $3 F-32=5$ \\
\hline 2 & & & & & & 32 & -32 \\
\hline & & & & & & & 32 \\
\hline $25 E-32$ & $1.98 E-32$ & $1.92 E-32$ & $1.94 E-32$ & $1.97 \mathrm{E}-32$ & $91 \pm-32$ & -32 & $98 E-32$ \\
\hline $.24 E-32$ & $2.00 \pm-32$ & •.93E-32 & & & & & $00 \mathrm{E}-25$ \\
\hline & & & & & & & 32 \\
\hline $35-32$ & 2 & 2 & 2 & & & & 32 \\
\hline $2 E-32$ & & & & & & & 32 \\
\hline $22 \mathrm{E}-32$ & $2.07 E-32$ & $1.99 \mathrm{E}-32$ & $2.02 E-32$ & $2.06 \mathrm{E}-32$ & $06 \mathrm{E}-32$ & $7 E-32$ & $07 E-32$ \\
\hline •.21E-32 & 2.0 & $E-32$ & $E-32$ & 2 & 2 & -32 & $9 E-32$ \\
\hline 32 & $2 \cdot 1 \perp E-32$ & $.03 E-32$ & $2.06 E-32$ & $2 \cdot \pm 0$ & $2 \cdot \pm 0+$ & $E-32$ & $\cdot 10 \pm-32$ \\
\hline 2 & $2 \cdot 1$ & $4 E-32$ & $7 E-32$ & & $12 \mathrm{~F}$ & 32 & $12 E-3 \angle$ \\
\hline 2 & $2 \cdot 14 \mathrm{E}-$ & .00 & $2 \cdot 001$ & 2. & $2 \cdot 14 \mathrm{E}-32$ & 2 & $\cdot+1+$ \\
\hline 2 & & & & & & & 32 \\
\hline$E-32$ & $E-32$ & $E-32$ & $2.13 E-32$ & $2.17 \mathrm{E}-32$ & $2.17 \mathrm{E}-32$ & 32 & 32 \\
\hline $18 \mathrm{E}-32$ & $.20 E-32$ & $2.11 E-32$ & $.14 \mathrm{E}-32$ & $.19 E-32$ & $2.19 E-32$ & $.20 E-32$ & $.20 E-32$ \\
\hline
\end{tabular}


RESRAD-OFFSITE, Version 2.5

$\mathrm{T}^{1 / 2}$ Limit $=180$ days

Title : RESRAD-OFFSITE External Gamma, Inhalation, and Soil Ingestion for Offsite Reside File : PBA-1_TC99-DOE-5-1.ROF

Summary of dose at graphical times, reptition 2 (continued)

Time

Years

$2.36 \mathrm{E}+01$

2. $41 \mathrm{E}+01$

$2.46 \mathrm{E}+01$

2. $51 \mathrm{E}+01$

2. $56 \mathrm{E}+01$

2. $61 \mathrm{E}+01$

2. $67 \mathrm{E}+01$

2. $72 \mathrm{E}+01$

2. $77 E+01$

$2.82 \mathrm{E}+01$

$2.87 \mathrm{E}+01$

2. $92 \mathrm{E}+01$

2. $97 \mathrm{E}+01$

3. $02 \mathrm{E}+01$

3. $08 \mathrm{E}+01$

3. $13 \mathrm{E}+01$

3. $18 \mathrm{E}+01$

3. $23 \mathrm{E}+01$

3. $28 \mathrm{E}+01$

3. $33 \mathrm{E}+01$

3. $38 \mathrm{E}+01$

3. $44 \mathrm{E}+01$

3. $49 \mathrm{E}+01$

3. $54 \mathrm{E}+01$

3. $59 \mathrm{E}+01$

3. $64 \mathrm{E}+01$

3. $69 \mathrm{E}+01$

$3.74 \mathrm{E}+01$

3. $79 \mathrm{E}+01$

$3.85 \mathrm{E}+01$

$3.90 \mathrm{E}+01$

$3.95 \mathrm{E}+01$

$4.00 \mathrm{E}+01$

4. $05 \mathrm{E}+01$

4. $10 \mathrm{E}+01$

4. $15 \mathrm{E}+01$

4. $20 \mathrm{E}+01$

$4.26 \mathrm{E}+01$

4. $31 \mathrm{E}+01$

$4.36 \mathrm{E}+01$

4. $41 \mathrm{E}+01$

$4.46 \mathrm{E}+01$

4. $51 \mathrm{E}+01$

$4.56 \mathrm{E}+01$

4. $61 \mathrm{E}+01$

$4.67 \mathrm{E}+01$
Dose statistics at graphical times, mrem/yr

\begin{tabular}{|c|c|c|c|c|c|c|c|}
\hline inimum & aximum & Mean & ledian & $0 \%$ & $5 \%$ & $97.5 \%$ & $\%$ \\
\hline 2 & -32 & $E-32$ & $E-32$ & 32 & 32 & 32 & 32 \\
\hline 32 & -32 & 2 & 2 & $.23 E-$ & 32 & 32 & $E-32$ \\
\hline-32 & $E-32$ & $E-32$ & $E-32$ & $5 E-32$ & 32 & -32 & $26 E-32$ \\
\hline$E-32$ & $8 E-32$ & $E-32$ & $E-32$ & 2 & 32 & 32 & $28 E-32$ \\
\hline-32 & -32 & 2 & 32 & 32 & 32 & -32 & $30 E-32$ \\
\hline-32 & 32 & -32 & -32 & 32 & 32 & 32 & -32 \\
\hline 32 & 2 & ? & -32 & 2.02 & 0 & -32 & -32 \\
\hline $13 E-32$ & $2.36 E-32$ & $2.25 E-32$ & $2.29 E-32$ & $2.35 E-32$ & $2.35 E-32$ & -32 & $.36 \mathrm{E}-32$ \\
\hline 32 & 32 & 32 & 32 & 32 & 32 & -32 & $38 E-32$ \\
\hline $12 \mathrm{E}-32$ & 32 & -32 & 32 & 32 & 32 & -32 & $40 E-32$ \\
\hline-32 & -32 & 2 & & & 32 & -32 & $42 E-32$ \\
\hline & & & & & & & -32 \\
\hline $.10 \mathrm{E}-32$ & $2.47 E-32$ & $E-32$ & $E-32$ & $2.45 E-32$ & -32 & -32 & $-3-32$ \\
\hline $10 \mathrm{E}-32$ & -32 & $E-32$ & -32 & $2.47 \mathrm{E}-32$ & & -32 & -32 \\
\hline $.09 E-32$ & -32 & -32 & 32 & 32 & 32 & 32 & -32 \\
\hline $.09 E-32$ & -32 & -32 & 2 . & 32 & 32 & -32 & -32 \\
\hline $.08 E-32$ & $E-32$ & $E-32$ & $E-32$ & $2.54 \mathrm{E}$ & $54 \mathrm{E}-32$ & -32 & $55 E-32$ \\
\hline-32 & $8 E-32$ & $3 E-32$ & $9 E-32$ & 32 & & -32 & $E-32$ \\
\hline 32 & -32 & -32 & 32 & & & 32 & -32 \\
\hline $.07 E-32$ & -32 & $E-32$ & -32 & -32 & -32 & -32 & $62 \mathrm{E}-32$ \\
\hline $.06 \mathrm{E}-32$ & -32 & -32 & -32 & & & -32 & -32 \\
\hline $.06 \mathrm{E}-32$ & $2.67 \mathrm{E}-32$ & -32 & 32 & 2.00 & & 32 & -32 \\
\hline $.05 E-32$ & $2.70 \mathrm{E}-32$ & $2.53 E-32$ & $2.59 \mathrm{E}-32$ & $2.67 \mathrm{E}-32$ & 2.004 & $.69 E-32$ & $.69 E-32$ \\
\hline$E-32$ & $2.72 E-32$ & $2.55 E-32$ & $1 E-32$ & $69 E-32$ & $70 E-32$ & $71 \mathrm{E}-32$ & $71 E-32$ \\
\hline 32 & 32 & $E-32$ & 32 & & & 32 & -32 \\
\hline 32 & 32 & -32 & 32 & & & 32 & $E-32$ \\
\hline $3 E-32$ & $E-32$ & $E-32$ & -32 & 32 & $77 E-32$ & -32 & $79 E-32$ \\
\hline $03 E-32$ & $2.82 E-32$ & $2.63 E-32$ & $2.70 E-32$ & 2. & $.00 \mathrm{D}-22$ & $.81 E-32$ & $.81 E-32$ \\
\hline $.02 E-32$ & $2.84 E-32$ & $2.65 E-32$ & $2.72 E-32$ & $2.81 E-32$ & 2 & -32 & $.84 E-32$ \\
\hline (6 & $2.87 E-32$ & $2.67 E-32$ & & & & 32 & $86 E-32$ \\
\hline 32 & $E-32$ & $9 E-32$ & $E-32$ & 32 & 32 & 32 & $E-32$ \\
\hline$E-32$ & $E-32$ & $E-32$ & -32 & 32 & 32 & 32 & -32 \\
\hline $.00 E-32$ & $2.94 \mathrm{E}-32$ & $2.74 \mathrm{E}-32$ & $2.81 E-32$ & $2.91 \mathrm{E}-$ & $2.92 \mathrm{E}-32$ & -32 & $94 \mathrm{E}-32$ \\
\hline $.98 E-33$ & $2.97 E-32$ & $2.76 \mathrm{E}-32$ & $2.84 E-32$ & $2.94 \mathrm{E}-32$ & $2.95 E-32$ & $.96 \mathrm{E}-32$ & $.96 E-32$ \\
\hline • & $3.00 \mathrm{E}-32$ & & & & & & . \\
\hline & & & & & & & \\
\hline $.84 E-33$ & 2 & & & & & & 32 \\
\hline 3 & 2 & 2 & 2 & 2 & 2 & 2 & 32 \\
\hline & & & & & & 32 & 32 \\
\hline $.69 E-33$ & $3.13 E-32$ & $2.89 E-32$ & & 2 & & 32 & $2 E-32$ \\
\hline 3 & & 2 & & & & & -32 \\
\hline-33 & $.19 E-32$ & $.94 E-32$ & & $.15 E-32$ & & & $18 E-32$ \\
\hline & 3 & 2 & 2 & & & 2 & $3.21 E-32$ \\
\hline 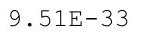 & -5 & & 2 & F & 2 & 32 & 32 \\
\hline-33 & 3.2 & 3.0 & 3. & 3.2 & 3. & 32 & 32 \\
\hline $.42 E-33$ & $3.30 E-32$ & $3.03 E-32$ & $3.13 E-32$ & $3.26 E-32$ & $3.27 E-32$ & $3.28 E-32$ & $3.29 \mathrm{E}-32$ \\
\hline
\end{tabular}


RESRAD-OFFSITE, Version 2.5

$\mathrm{T}^{1 / 2}$ Limit $=180$ days

Title : RESRAD-OFFSITE External Gamma, Inhalation, and Soil Ingestion for Offsite Reside

File : PBA-1_TC99-DOE-5-1.ROF

Summary of dose at graphical times, reptition 2 (continued)

Time

Years

$4.72 \mathrm{E}+01$

$4.77 \mathrm{E}+01$

4. $82 \mathrm{E}+01$

$4.87 \mathrm{E}+01$

4. $92 \mathrm{E}+01$

4. $97 \mathrm{E}+01$

$5.02 \mathrm{E}+01$

$5.08 \mathrm{E}+01$

$5.13 \mathrm{E}+01$

$5.18 \mathrm{E}+01$

$5.23 \mathrm{E}+01$

$5.28 \mathrm{E}+01$

$5.33 \mathrm{E}+01$

$5.38 \mathrm{E}+01$

$5.43 \mathrm{E}+01$

$5.49 \mathrm{E}+01$

$5.54 \mathrm{E}+01$

$5.59 \mathrm{E}+01$

$5.64 \mathrm{E}+01$

$5.69 \mathrm{E}+01$

$5.74 \mathrm{E}+01$

$5.79 \mathrm{E}+01$

$5.84 \mathrm{E}+01$

$5.90 \mathrm{E}+01$

$5.95 \mathrm{E}+01$

$6.00 \mathrm{E}+01$

$6.05 \mathrm{E}+01$

$6.10 \mathrm{E}+01$

$6.15 \mathrm{E}+01$

$6.20 \mathrm{E}+01$

$6.25 \mathrm{E}+01$

$6.31 \mathrm{E}+01$

$6.36 \mathrm{E}+01$

$6.41 \mathrm{E}+01$

$6.46 \mathrm{E}+01$

$6.51 \mathrm{E}+01$

$6.56 \mathrm{E}+01$

$6.61 \mathrm{E}+01$

$6.67 \mathrm{E}+01$

$6.72 \mathrm{E}+01$

$6.77 \mathrm{E}+01$

$6.82 \mathrm{E}+01$

$6.87 \mathrm{E}+01$

$6.92 \mathrm{E}+01$

$6.97 \mathrm{E}+01$

$7.02 \mathrm{E}+01$
Dose statistics at graphical times, mrem/yr

\begin{tabular}{|c|c|c|c|c|c|c|c|}
\hline inimum & aximum & Mean & ledian & $90 \%$ & $5 \%$ & $97.5 \%$ & \\
\hline 33 & -32 & $3.06 \mathrm{E}-32$ & $3.16 \mathrm{E}-32$ & $3.29 E-32$ & $3.30 E-32$ & $.31 E-32$ & $E-32$ \\
\hline 33 & 32 & 2 & 2 & 32 & 32 & 32 & -32 \\
\hline-33 & -32 & $E-32$ & -32 & 32 & 32 & -32 & -32 \\
\hline-33 & $E-32$ & 32 & 2 & 2 & & 32 & -32 \\
\hline-33 & 32 & & & & & 32 & $44 \mathrm{E}-32$ \\
\hline-33 & -32 & -32 & $E-32$ & -32 & $3<$ & 32 & -32 \\
\hline 3 & 32 & $3.21 E-32$ & 2 & 2 & 2 & 32 & -32 \\
\hline $.06 E-33$ & $4 E-32$ & $3.23 E-32$ & & & & -32 & $53 E-32$ \\
\hline 33 & 32 & 32 & 32 & 32 & 32 & -32 & $6 E E-32$ \\
\hline $.97 E-33$ & $61 E-32$ & $8 E-32$ & $0 \mathrm{E}-32$ & $55 E-32$ & $57 E-32$ & -32 & $E-32$ \\
\hline-33 & 32 & & & & & -32 & $E-32$ \\
\hline & & & & & & 32 & -32 \\
\hline $.84 \mathrm{E}-33$ & $0 E-32$ & $6 \pm-32$ & $8 E-32$ & $3.65 \mathrm{E}-32$ & $1 \mathrm{E}-32$ & -32 & $\mathrm{e}-3 \mathrm{~s}^{2}+x$ \\
\hline $.80 E-33$ & $3.73 E-32$ & $E-32$ & -32 & 32 & & -32 & $72 E-32$ \\
\hline 33 & -32 & -32 & 32 & 32 & 32 & -32 & -32 \\
\hline $.72 E-33$ & -32 & -32 & -32 & 32 & 32 & -32 & -32 \\
\hline $67 E-33$ & $3.83 E-32$ & $7 E-32$ & $0 \mathrm{E}-32$ & $78 E-32$ & $80 E-32$ & -32 & $82 E-32$ \\
\hline-33 & $7 E-32$ & $0 E-32$ & $3 E-32$ & 32 & & -32 & $E-32$ \\
\hline-33 & -32 & -32 & 32 & 2 & & -32 & -32 \\
\hline $5 E-33$ & $3.94 E-32$ & -32 & -32 & 32 & 32 & -32 & -32 \\
\hline $.51 \mathrm{E}-33$ & - & & & & & -32 & $E-32$ \\
\hline$E-33$ & 32 & 2 & 2 & & & 2 & -32 \\
\hline $45-33$ & $.04 E-32$ & $3.64 \mathrm{E}-32$ & $8 E-32$ & $98 E-32$ & $00 E-32$ & $2 E-32$ & $03 E-32$ \\
\hline $39 E-33$ & $08 E-32$ & $3.67 \mathrm{E}-32$ & $1 E-32$ & $01 E-32$ & $03 E-32$ & $5 E-32$ & $06 E-32$ \\
\hline 33 & $11 \mathrm{E}-32$ & $70 E-32$ & & & $E-32$ & $E-32$ & $10 E-32$ \\
\hline-33 & $E-32$ & -32 & 32 & 2 & & 32 & -32 \\
\hline $26 E-33$ & -32 & $E-32$ & 32 & & & 32 & $E-32$ \\
\hline $.825-20$ & $4.22 E-32$ & $9 E-32$ & $4 E-32$ & $15 E-32$ & $18 E-32$ & $20 E-32$ & $21 E-32$ \\
\hline 33 & 2 & 2 & 2 & 2 & 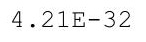 & $3 E-32$ & $.24 \mathrm{E}-32$ \\
\hline - & - & 然 & 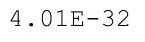 & -5 & & $27 E-32$ & $28 E-32$ \\
\hline-33 & $=-32$ & $8 F-32$ & & & & -32 & $32 E-32$ \\
\hline$F-33$ & $38 E-32$ & $E-32$ & $7 F-32$ & & & -32 & $E-32$ \\
\hline $3 E-33$ & $E-32$ & $E-32$ & 32 & 32 & 32 & 32 & $0 E-32$ \\
\hline $.99 E-33$ & $4.45 E-32$ & $3.98 E-32$ & $4.14 \mathrm{E}-32$ & $4.38 E-32$ & $40 E-32$ & $2 E-32$ & $43 E-32$ \\
\hline . $275-23$ & $4.49 E-32$ & $4.01 E-32$ & & & & $46 E-32$ & $.47 E-32$ \\
\hline (3) & & & & & & & $51 E-32$ \\
\hline $.87 E-33$ & 2 & & & & & 2 & 32 \\
\hline $7.84 \mathrm{E}-33$ & & & & 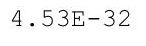 & & & 32 \\
\hline-33 & & & & & & -32 & 32 \\
\hline $.76 E-33$ & $4.70 E-32$ & $7 E-32$ & $5 E-32$ & 2 & 2 & 32 & $7 E-32$ \\
\hline 3 & & & & & & & -32 \\
\hline 3 & 32 & & & 2 & $2<$ & $74 \mathrm{E}-32$ & $\cdot 10 \pm-32$ \\
\hline 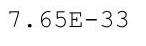 & 2 & 2 & $E-32$ & एक 28 & 2 & 32 & -32 \\
\hline $761 F-33$ & 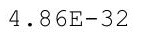 & - & 2 & 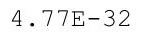 & & -32 & 32 \\
\hline$E-33$ & $4.91 E-32$ & $4.34 \mathrm{E}-32$ & $4.53 E-32$ & $4.81 \mathrm{E}$ & $4.84 \mathrm{E}-32$ & 32 & $.88 E-32$ \\
\hline 3 & 4. $95 E-32$ & $.37 E-32$ & $.57 E-32$ & $4.86 E-32$ & $4.89 E-32$ & $4.91 E-32$ & $4.93 E-32$ \\
\hline
\end{tabular}


RESRAD-OFFSITE, Version 2.5

$\mathrm{T}^{1 / 2}$ Limit $=180$ days

Title : RESRAD-OFFSITE External Gamma, Inhalation, and Soil Ingestion for Offsite Reside File : PBA-1_TC99-DOE-5-1.ROF

Summary of dose at graphical times, reptition 2 (continued)

Time

Years

$7.08 \mathrm{E}+01$

7. $13 \mathrm{E}+01$

7. $18 \mathrm{E}+01$

7. $23 \mathrm{E}+01$

7. $28 \mathrm{E}+01$

7. $33 \mathrm{E}+01$

7. $38 \mathrm{E}+01$

7. $43 \mathrm{E}+01$

$7.49 \mathrm{E}+01$

$7.54 \mathrm{E}+01$

$7.59 \mathrm{E}+01$

7. $64 \mathrm{E}+01$

$7.69 \mathrm{E}+01$

$7.74 \mathrm{E}+01$

$7.79 \mathrm{E}+01$

$7.84 \mathrm{E}+01$

7. $90 \mathrm{E}+01$

7. $95 \mathrm{E}+01$

$8.00 \mathrm{E}+01$

$8.05 \mathrm{E}+01$

8. $10 \mathrm{E}+01$

$8.15 \mathrm{E}+01$

$8.20 \mathrm{E}+01$

$8.25 \mathrm{E}+01$

$8.31 \mathrm{E}+01$

$8.36 \mathrm{E}+01$

$8.41 \mathrm{E}+01$

$8.46 \mathrm{E}+01$

$8.51 \mathrm{E}+01$

$8.56 \mathrm{E}+01$

8. $61 \mathrm{E}+01$

$8.66 \mathrm{E}+01$

$8.72 \mathrm{E}+01$

$8.77 \mathrm{E}+01$

$8.82 \mathrm{E}+01$

8. $87 \mathrm{E}+01$

$8.92 \mathrm{E}+01$

$8.97 \mathrm{E}+01$

9. $02 \mathrm{E}+01$

$9.07 \mathrm{E}+01$

$9.13 \mathrm{E}+01$

9. $18 \mathrm{E}+01$

9. $23 \mathrm{E}+01$

$9.28 \mathrm{E}+01$

$9.33 \mathrm{E}+01$

$9.38 \mathrm{E}+01$
Dose statistics at graphical times, mrem/yr

\begin{tabular}{|c|c|c|c|c|c|c|c|}
\hline inimum & Maximum & Mean & Median & $90 \%$ & $95 \%$ & $7.5 \%$ & $9 \%$ \\
\hline $7.50 \mathrm{E}-33$ & $4.99 \mathrm{E}-32$ & $4.41 \mathrm{E}-32$ & $4.61 E-32$ & $4.90 \mathrm{E}-32$ & $4.93 E-32$ & $4.96 \mathrm{E}-32$ & $4.97 \mathrm{E}-32$ \\
\hline $7.47 E-33$ & $5.04 \mathrm{E}-32$ & $4.44 \mathrm{E}-32$ & $4.65 E-32$ & $4.94 \mathrm{E}-32$ & $4.97 E-32$ & $5.00 \mathrm{E}-32$ & $5.01 \mathrm{E}-32$ \\
\hline $7.43 \mathrm{E}-33$ & $5.08 \mathrm{E}-32$ & $4.48 \mathrm{E}-32$ & $4.68 \mathrm{E}-32$ & $4.98 \mathrm{E}-32$ & $5.02 \mathrm{E}-32$ & $5.04 \mathrm{E}-32$ & $5.06 \mathrm{E}-32$ \\
\hline $7.39 \mathrm{E}-33$ & $5.13 E-32$ & $4.52 \mathrm{E}-32$ & $4.72 \mathrm{E}-32$ & $5.03 E-32$ & $5.06 \mathrm{E}-32$ & $5.09 \mathrm{E}-32$ & $.10 \mathrm{E}-32$ \\
\hline $7.36 \mathrm{E}-33$ & $5.17 \mathrm{E}-32$ & $4.55 \mathrm{E}-32$ & $4.76 \mathrm{E}-32$ & $5.07 \mathrm{E}-32$ & $10 \mathrm{E}-32$ & $5.13 \mathrm{E}-32$ & $5.15 \mathrm{E}-32$ \\
\hline $7.32 E-33$ & $5.22 \mathrm{E}-32$ & $4.59 \mathrm{E}-32$ & $4.80 E-32$ & $5.12 \mathrm{E}-32$ & $5.15 \mathrm{E}-32$ & $5.18 \mathrm{E}-32$ & $5.19 \mathrm{E}-32$ \\
\hline $7.29 \mathrm{E}-33$ & $5.26 \mathrm{E}-32$ & $4.63 \mathrm{E}-32$ & $4.84 \mathrm{E}-32$ & $5.16 \mathrm{E}-32$ & $19 \mathrm{E}-32$ & $5.22 \mathrm{E}-32$ & $24 E-32$ \\
\hline $.25 \mathrm{E}-33$ & $5.31 E-32$ & $4.66 \mathrm{E}-32$ & $4.88 E-32$ & $5.20 \mathrm{E}-32$ & $.24 \mathrm{E}-32$ & $5.27 \mathrm{E}-32$ & $5.29 \mathrm{E}-32$ \\
\hline $.22 \mathrm{E}-33$ & $5.36 \mathrm{E}-32$ & $4.70 \mathrm{E}-32$ & $4.92 E-32$ & $5.25 \mathrm{E}-32$ & $5.29 \mathrm{E}-32$ & $5.32 \mathrm{E}-32$ & $5.33 \mathrm{E}-32$ \\
\hline $7.18 \mathrm{E}-33$ & $5.41 E-32$ & $4.74 \mathrm{E}-32$ & $4.96 \mathrm{E}-32$ & $5.30 \mathrm{E}-32$ & $5.33 E-32$ & $5.36 \mathrm{E}-32$ & $5.38 \mathrm{E}-32$ \\
\hline $7.15 \mathrm{E}-33$ & $5.45 E-32$ & $4.78 \mathrm{E}-32$ & $5.00 \mathrm{E}-32$ & $5.34 \mathrm{E}-32$ & $5.38 \mathrm{E}-32$ & $5.41 \mathrm{E}-32$ & $5.43 \mathrm{E}-32$ \\
\hline $7.11 \mathrm{E}-33$ & $5.50 \mathrm{E}-32$ & $4.81 \mathrm{E}-32$ & $5.04 \mathrm{E}-32$ & $5.39 \mathrm{E}-32$ & $5.43 E-32$ & $5.46 \mathrm{E}-32$ & $.47 \mathrm{E}-32$ \\
\hline $7.08 \mathrm{E}-33$ & $5.55 E-32$ & $4.85 \mathrm{E}-32$ & $5.09 E-32$ & $5.44 \mathrm{E}-32$ & $5.47 \mathrm{E}-32$ & $5.50 \mathrm{E}-32$ & $5.52 \mathrm{E}-32$ \\
\hline $7.05 \mathrm{E}-33$ & $5.60 \mathrm{E}-32$ & $4.89 \mathrm{E}-32$ & $5.13 E-32$ & $5.48 \mathrm{E}-32$ & $5.52 \mathrm{E}-32$ & $5.55 \mathrm{E}-32$ & $5.57 \mathrm{E}-32$ \\
\hline $7.01 \mathrm{E}-33$ & $5.65 E-32$ & $4.93 \mathrm{E}-32$ & $5.17 E-32$ & $5.53 \mathrm{E}-32$ & $5.57 \mathrm{E}-32$ & $5.60 \mathrm{E}-32$ & $5.62 \mathrm{E}-32$ \\
\hline $6.98 \mathrm{E}-33$ & $5.70 \mathrm{E}-32$ & $4.97 \mathrm{E}-32$ & $5.21 E-32$ & $5.58 \mathrm{E}-32$ & $5.62 \mathrm{E}-32$ & $5.65 \mathrm{E}-32$ & $5.67 \mathrm{E}-32$ \\
\hline $6.94 \mathrm{E}-33$ & $5.75 E-32$ & $5.01 \mathrm{E}-32$ & $5.26 \mathrm{E}-32$ & $5.63 \mathrm{E}-32$ & $5.67 \mathrm{E}-32$ & $5.70 \mathrm{E}-32$ & $5.72 \mathrm{E}-32$ \\
\hline $6.91 \mathrm{E}-33$ & $5.80 \mathrm{E}-32$ & $5.05 \mathrm{E}-32$ & $5.30 \mathrm{E}-32$ & $5.68 \mathrm{E}-32$ & $5.72 \mathrm{E}-32$ & $5.75 \mathrm{E}-32$ & $5.77 \mathrm{E}-32$ \\
\hline $6.88 E-33$ & $5.85 E-32$ & $5.09 \mathrm{E}-32$ & $5.34 E-32$ & $5.73 E-32$ & $5.77 \mathrm{E}-32$ & $5.80 \mathrm{E}-32$ & $5.82 \mathrm{E}-32$ \\
\hline $.84 E-33$ & $5.90 \mathrm{E}-32$ & $5.13 \mathrm{E}-32$ & $5.39 E-32$ & $5.78 \mathrm{E}-32$ & 5825 & $5.85 \mathrm{E}-32$ & $87 E-32$ \\
\hline 8 & 5 & 2 & & 2 & 2 & 2 & \\
\hline 3 & 6.01 & 5. & 2 & 2 & 32 & 32 & -32 \\
\hline $6.75 \mathrm{E}-33$ & $6.06 \mathrm{E}-32$ & $5.26 \mathrm{E}-32$ & $5.52 \mathrm{E}-32$ & $5.93 \mathrm{E}-32$ & $5.97 \mathrm{E}-32$ & $6.01 \mathrm{E}-32$ & $6.03 E-32$ \\
\hline $6.71 \mathrm{E}-33$ & $6.11 \mathrm{E}-32$ & $5.30 \mathrm{E}-32$ & $5.57 E-32$ & $5.98 \mathrm{E}-32$ & $6.02 \mathrm{E}-32$ & $6.06 \mathrm{E}-32$ & $6.08 \mathrm{E}-32$ \\
\hline $6.68 \mathrm{E}-33$ & $6.17 \mathrm{E}-32$ & $5.34 \mathrm{E}-32$ & $5.61 \mathrm{E}-32$ & $6.03 E-32$ & $6.08 \mathrm{E}-32$ & $6.11 \mathrm{E}-32$ & $6.14 \mathrm{E}-32$ \\
\hline $6.65 \mathrm{E}-33$ & $6.22 \mathrm{E}-32$ & $5.38 \mathrm{E}-32$ & $5.66 \mathrm{E}-32$ & $6.08 \mathrm{E}-32$ & $6.13 \mathrm{E}-32$ & $6.17 \mathrm{E}-32$ & $6.19 \mathrm{E}-32$ \\
\hline $6.62 \mathrm{E}-33$ & $6.28 \mathrm{E}-32$ & $5.43 \mathrm{E}-32$ & $5.71 \mathrm{E}-32$ & $6.14 \mathrm{E}-32$ & $6.18 \mathrm{E}-32$ & $6.22 \mathrm{E}-32$ & $6.24 \mathrm{E}-32$ \\
\hline $6.58 \mathrm{E}-33$ & $6.33 E-32$ & $5.47 \mathrm{E}-32$ & $5.75 E-32$ & $6.19 \mathrm{E}-32$ & $6.24 \mathrm{E}-32$ & $6.28 \mathrm{E}-32$ & $6.30 \mathrm{E}-32$ \\
\hline $6.55 \mathrm{E}-33$ & $6.39 \mathrm{E}-32$ & $5.52 \mathrm{E}-32$ & $5.80 \mathrm{E}-32$ & $6.24 \mathrm{E}-32$ & $6.29 \mathrm{E}-32$ & $6.33 E-32$ & $6.35 \mathrm{E}-32$ \\
\hline $6.52 \mathrm{E}-33$ & $6.45 \mathrm{E}-$ & 5.561 & $5.85 \mathrm{E}$ & 32 & 32 & 0.39 & $6.41 \mathrm{E}-32$ \\
\hline $0.49 E-33$ & 6. & 5.6 & 2 & 2 & 2 & 32 & $6.47 \mathrm{E}-32$ \\
\hline $6.46 \mathrm{E}-33$ & $6.56 \mathrm{E}-32$ & $5.65 \mathrm{E}-32$ & $5.95 E-32$ & $6.41 \mathrm{E}-32$ & $6.46 \mathrm{E}-32$ & $6.50 \mathrm{E}-32$ & $6.52 \mathrm{E}-32$ \\
\hline $6.43 \mathrm{E}-33$ & $6.62 \mathrm{E}-32$ & $5.70 \mathrm{E}-32$ & $5.99 \mathrm{E}-32$ & $6.46 \mathrm{E}-32$ & $6.51 \mathrm{E}-32$ & $6.56 \mathrm{E}-32$ & $6.58 \mathrm{E}-32$ \\
\hline $6.40 \mathrm{E}-33$ & $6.68 \mathrm{E}-32$ & $5.74 \mathrm{E}-32$ & $6.04 \mathrm{E}-32$ & $6.52 \mathrm{E}-32$ & $6.57 E-32$ & $6.62 \mathrm{E}-32$ & $6.64 \mathrm{E}-32$ \\
\hline $6.37 E-33$ & $6.74 \mathrm{E}-32$ & $5.79 \mathrm{E}-32$ & $6.09 E-32$ & $6.58 \mathrm{E}-32$ & $6.63 \mathrm{E}-32$ & $6.67 \mathrm{E}-32$ & $6.70 \mathrm{E}-32$ \\
\hline $6.33 \mathrm{E}-33$ & $6.80 \mathrm{E}-32$ & $5.83 E-32$ & $6.14 \mathrm{E}-32$ & $6.63 \mathrm{E}-32$ & $6.69 \mathrm{E}-32$ & $6.73 E-32$ & $6.76 \mathrm{E}-32$ \\
\hline $6.30 \mathrm{E}-33$ & $6.86 \mathrm{E}-32$ & $5.88 \mathrm{E}-32$ & $6.19 \mathrm{E}-32$ & $6.69 \mathrm{E}-32$ & $6.75 E-32$ & $6.79 \mathrm{E}-32$ & $6.82 \mathrm{E}-32$ \\
\hline $6.27 \mathrm{E}-33$ & $6.92 \mathrm{E}-32$ & $5.93 \mathrm{E}-32$ & $6.25 E-32$ & $6.75 \mathrm{E}-32$ & $6.80 \mathrm{E}-32$ & $6.85 \mathrm{E}-32$ & $6.88 \mathrm{E}-32$ \\
\hline $6.24 \mathrm{E}-33$ & $6.98 \mathrm{E}-32$ & $5.98 \mathrm{E}-32$ & $6.30 \mathrm{E}-32$ & $6.81 \mathrm{E}-32$ & $6.86 \mathrm{E}-32$ & $6.91 \mathrm{E}-32$ & $6.94 \mathrm{E}-32$ \\
\hline $6.21 \mathrm{E}-33$ & $7.04 \mathrm{E}-32$ & $6.02 \mathrm{E}-32$ & $6.35 E-32$ & $6.87 \mathrm{E}-32$ & $6.92 \mathrm{E}-32$ & $6.97 \mathrm{E}-32$ & $7.00 \mathrm{E}-32$ \\
\hline $6.18 \mathrm{E}-33$ & $7.10 \mathrm{E}-32$ & $6.07 \mathrm{E}-32$ & $6.40 E-32$ & $6.93 \mathrm{E}-32$ & $6.98 \mathrm{E}-32$ & $7.03 E-32$ & $7.06 \mathrm{E}-32$ \\
\hline $6.15 \mathrm{E}-33$ & $7.16 \mathrm{E}-32$ & $6.12 \mathrm{E}-32$ & $6.45 E-32$ & $6.99 \mathrm{E}-32$ & $7.05 \mathrm{E}-32$ & $7.09 \mathrm{E}-32$ & $7.12 \mathrm{E}-32$ \\
\hline $6.12 \mathrm{E}-33$ & $7.23 \mathrm{E}-32$ & $6.17 \mathrm{E}-32$ & $6.51 \mathrm{E}-32$ & $7.05 E-32$ & $7.11 \mathrm{E}-32$ & $7.16 \mathrm{E}-32$ & $7.18 \mathrm{E}-32$ \\
\hline $6.09 \mathrm{E}-33$ & $7.29 \mathrm{E}-32$ & $6.22 \mathrm{E}-32$ & $6.56 \mathrm{E}-32$ & $7.11 \mathrm{E}-32$ & $7.17 \mathrm{E}-32$ & $7.22 \mathrm{E}-32$ & $7.25 \mathrm{E}-32$ \\
\hline $6.06 \mathrm{E}-33$ & $7.36 \mathrm{E}-32$ & $6.27 \mathrm{E}-32$ & $6.62 \mathrm{E}-32$ & $7.17 \mathrm{E}-32$ & $7.23 E-32$ & $7.28 \mathrm{E}-32$ & $7.31 \mathrm{E}-32$ \\
\hline $.04 E-33$ & $7.42 \mathrm{E}-32$ & $6.32 \mathrm{E}-32$ & $6.67 E-32$ & $7.23 E-32$ & $7.30 \mathrm{E}-32$ & $7.35 E-32$ & $7.38 \mathrm{E}-32$ \\
\hline
\end{tabular}


RESRAD-OFFSITE, Version 2.5

$\mathrm{T}^{1 / 2}$ Limit $=180$ days

Title : RESRAD-OFFSITE External Gamma, Inhalation, and Soil Ingestion for Offsite Reside

File : PBA-1_TC99-DOE-5-1.ROF

Summary of dose at graphical times, reptition 2 (continued)

Time

Years

$9.43 E+01$

$9.48 \mathrm{E}+01$

$9.54 \mathrm{E}+01$

$9.59 \mathrm{E}+01$

$9.64 \mathrm{E}+01$

$9.69 \mathrm{E}+01$

$9.74 \mathrm{E}+01$

$9.79 \mathrm{E}+01$

$9.84 \mathrm{E}+01$

$9.90 \mathrm{E}+01$

$9.95 \mathrm{E}+01$

$1.00 \mathrm{E}+02$

$1.00 \mathrm{E}+02$

$1.01 \mathrm{E}+02$

$1.02 \mathrm{E}+02$

$1.02 \mathrm{E}+02$

$1.03 \mathrm{E}+02$

$1.03 \mathrm{E}+02$

$1.04 \mathrm{E}+02$

$1.04 \mathrm{E}+02$

$1.05 \mathrm{E}+02$

$1.05 \mathrm{E}+02$

$1.06 \mathrm{E}+02$

$1.06 \mathrm{E}+02$

$1.07 \mathrm{E}+02$

$1.07 \mathrm{E}+02$

$1.08 \mathrm{E}+02$

$1.08 \mathrm{E}+02$

$1.09 \mathrm{E}+02$

$1.09 \mathrm{E}+02$

$1.10 \mathrm{E}+02$

$1.10 \mathrm{E}+02$

$1.11 \mathrm{E}+02$

1. $11 \mathrm{E}+02$

$1.12 \mathrm{E}+02$

$1.12 \mathrm{E}+02$

$1.13 \mathrm{E}+02$

$1.13 \mathrm{E}+02$

1. $14 \mathrm{E}+02$

1. $14 \mathrm{E}+02$

$1.15 \mathrm{E}+02$

1. $15 \mathrm{E}+02$

$1.16 \mathrm{E}+02$

$1.16 \mathrm{E}+02$

$1.17 \mathrm{E}+02$

$1.17 \mathrm{E}+02$
Dose statistics at graphical times, mrem/yr

\begin{tabular}{|c|c|c|c|c|c|c|c|}
\hline um & Maximum & thit & Median & . & & : & \\
\hline $01 E-33$ & $.49 \mathrm{E}-32$ & $6.37 E-32$ & $6.73 E-32$ & $7.30 \mathrm{E}-32$ & $7.36 \mathrm{E}-32$ & $7.41 \mathrm{E}-32$ & $7.44 \mathrm{E}-32$ \\
\hline $.98 E-33$ & $7.55 \mathrm{E}-32$ & $6.42 \mathrm{E}-32$ & $6.78 \mathrm{E}-32$ & $7.36 \mathrm{E}-32$ & $7.42 \mathrm{E}-32$ & $7.48 \mathrm{E}-32$ & $7.51 \mathrm{E}-32$ \\
\hline $.95 E-33$ & $7.62 \mathrm{E}-32$ & $6.47 \mathrm{E}-32$ & $6.84 \mathrm{E}-32$ & $7.43 E-32$ & $7.49 \mathrm{E}-32$ & $7.54 \mathrm{E}-32$ & $7.57 \mathrm{E}-32$ \\
\hline $.92 \mathrm{E}-33$ & $7.69 \mathrm{E}-32$ & $6.53 \mathrm{E}-32$ & $6.89 \mathrm{E}-32$ & $7.49 \mathrm{E}-32$ & $7.55 \mathrm{E}-32$ & $7.61 \mathrm{E}-32$ & $7.64 \mathrm{E}-32$ \\
\hline $5.89 \mathrm{E}-33$ & $7.76 \mathrm{E}-32$ & $6.58 \mathrm{E}-32$ & $6.95 E-32$ & $7.56 \mathrm{E}-32$ & $7.62 \mathrm{E}-32$ & $7.68 \mathrm{E}-32$ & $7.71 \mathrm{E}-32$ \\
\hline $5.86 \mathrm{E}-33$ & $7.82 \mathrm{E}-32$ & $6.63 \mathrm{E}-32$ & $7.01 \mathrm{E}-32$ & $7.62 \mathrm{E}-32$ & $7.69 \mathrm{E}-32$ & $7.74 \mathrm{E}-32$ & $7.77 \mathrm{E}-32$ \\
\hline $5.83 \mathrm{E}-33$ & $7.89 \mathrm{E}-32$ & $6.69 \mathrm{E}-32$ & $7.07 \mathrm{E}-32$ & $7.69 \mathrm{E}-32$ & $7.75 \mathrm{E}-32$ & $7.81 \mathrm{E}-32$ & $7.84 \mathrm{E}-32$ \\
\hline $5.81 \mathrm{E}-33$ & $7.96 \mathrm{E}-32$ & $6.74 \mathrm{E}-32$ & $7.12 \mathrm{E}-32$ & $7.75 \mathrm{E}-32$ & $7.82 \mathrm{E}-32$ & $7.88 \mathrm{E}-32$ & $7.91 \mathrm{E}-32$ \\
\hline $5.78 \mathrm{E}-33$ & $8.03 E-32$ & $6.79 \mathrm{E}-32$ & $7.18 \mathrm{E}-32$ & $7.82 \mathrm{E}-32$ & $7.89 \mathrm{E}-32$ & $7.95 E-32$ & $7.98 E-32$ \\
\hline $75 E-33$ & $8.10 \mathrm{E}-32$ & $6.85 E-32$ & $7.24 \mathrm{E}-32$ & $7.89 \mathrm{E}-32$ & $7.96 \mathrm{E}-32$ & $8.02 \mathrm{E}-32$ & $8.05 E-32$ \\
\hline $.72 E-33$ & $8.18 \mathrm{E}-32$ & $6.90 \mathrm{E}-32$ & $7.30 \mathrm{E}-32$ & $7.96 \mathrm{E}-32$ & $8.03 E-32$ & $8.09 \mathrm{E}-32$ & $8.12 \mathrm{E}-32$ \\
\hline $70 E-33$ & $8.25 E-32$ & $6.96 \mathrm{E}-32$ & $7.36 \mathrm{E}-32$ & $8.03 E-32$ & $8.10 \mathrm{E}-32$ & $8.16 \mathrm{E}-32$ & $.19 \mathrm{E}-32$ \\
\hline $.67 \mathrm{E}-33$ & $8.32 \mathrm{E}-32$ & $7.02 \mathrm{E}-32$ & $7.42 \mathrm{E}-32$ & $8.10 \mathrm{E}-32$ & $8.17 \mathrm{E}-32$ & $8.23 E-32$ & $.27 E-32$ \\
\hline $.64 \mathrm{E}-33$ & $8.39 \mathrm{E}-32$ & $7.07 \mathrm{E}-32$ & $7.48 \mathrm{E}-32$ & $8.17 \mathrm{E}-32$ & $8.24 E-32$ & $8.31 E-32$ & $8.34 \mathrm{E}-32$ \\
\hline $5.61 \mathrm{E}-33$ & $8.47 \mathrm{E}-32$ & $7.13 \mathrm{E}-32$ & $7.55 \mathrm{E}-32$ & $8.24 \mathrm{E}-32$ & $8.31 E-32$ & $8.38 E-32$ & $8.41 \mathrm{E}-32$ \\
\hline $5.59 \mathrm{E}-33$ & $8.54 \mathrm{E}-32$ & $7.19 \mathrm{E}-32$ & $7.61 \mathrm{E}-32$ & $8.31 \mathrm{E}-32$ & $8.39 \mathrm{E}-32$ & $8.45 E-32$ & $8.49 \mathrm{E}-32$ \\
\hline $5.56 \mathrm{E}-33$ & $8.62 \mathrm{E}-32$ & $7.24 \mathrm{E}-32$ & $7.67 \mathrm{E}-32$ & $8.38 \mathrm{E}-32$ & $8.46 E-32$ & $8.53 E-32$ & $8.56 \mathrm{E}-32$ \\
\hline $5.53 \mathrm{E}-33$ & $8.70 \mathrm{E}-32$ & $7.30 \mathrm{E}-32$ & $7.74 \mathrm{E}-32$ & $8.46 \mathrm{E}-32$ & $8.53 E-32$ & $8.60 \mathrm{E}-32$ & $8.64 \mathrm{E}-32$ \\
\hline $5.51 \mathrm{E}-33$ & $8.77 \mathrm{E}-32$ & $7.36 \mathrm{E}-32$ & $7.80 \mathrm{E}-32$ & $8.53 E-32$ & $8.61 \mathrm{E}-32$ & $8.68 \mathrm{E}-32$ & $8.71 \mathrm{E}-32$ \\
\hline $5.48 \mathrm{E}-33$ & $8.85 E-32$ & $7.42 \mathrm{E}-32$ & $7.86 \mathrm{E}-32$ & $8.60 \mathrm{E}-32$ & $8.68 \mathrm{E}-32$ & $8.75 E-32$ & $8.79 \mathrm{E}-32$ \\
\hline $45 \mathrm{E}-33$ & $8.93 E-32$ & $7.48 \mathrm{E}-32$ & $7.93 \mathrm{E}-32$ & $8.68 \mathrm{E}-32$ & $8.76 \mathrm{E}-32$ & $8.83 E-32$ & $8.87 \mathrm{E}-32$ \\
\hline $43 E-33$ & $9.01 \mathrm{E}-32$ & $7.54 \mathrm{E}-32$ & $7.99 \mathrm{E}-32$ & $8.75 E-32$ & $8.84 \mathrm{E}-32$ & $8.91 \mathrm{E}-32$ & $.95 E-32$ \\
\hline $40 E-33$ & 9. & 7. & 32 & 2 & 32 & 32 & 32 \\
\hline 3 & 9 & & 2 & & & & 32 \\
\hline $35 E-33$ & $9.25 \mathrm{E}-32$ & $7.73 \mathrm{E}-32$ & $8.19 \mathrm{E}-32$ & $8.99 \mathrm{E}-32$ & $9.07 \mathrm{E}-32$ & -32 & $18 E-32$ \\
\hline $5.32 \mathrm{E}-33$ & $9.33 E-32$ & $7.79 \mathrm{E}-32$ & $8.26 \mathrm{E}-32$ & $9.06 \mathrm{E}-32$ & $9.15 \mathrm{E}-32$ & $9.22 \mathrm{E}-32$ & $9.27 \mathrm{E}-32$ \\
\hline $5.30 \mathrm{E}-33$ & $9.41 \mathrm{E}-32$ & $7.85 E-32$ & $8.33 E-32$ & $9.14 \mathrm{E}-32$ & $9.23 \mathrm{E}-32$ & $9.31 \mathrm{E}-32$ & $9.35 \mathrm{E}-32$ \\
\hline $5.27 \mathrm{E}-33$ & $9.50 \mathrm{E}-32$ & $7.91 \mathrm{E}-32$ & $8.40 \mathrm{E}-32$ & $9.22 \mathrm{E}-32$ & $9.31 \mathrm{E}-32$ & $9.39 \mathrm{E}-32$ & $9.43 \mathrm{E}-32$ \\
\hline $5.25 \mathrm{E}-33$ & $9.58 \mathrm{E}-32$ & $7.98 \mathrm{E}-32$ & $8.47 \mathrm{E}-32$ & $9.30 \mathrm{E}-32$ & $9.39 \mathrm{E}-32$ & $9.47 \mathrm{E}-32$ & $9.51 \mathrm{E}-32$ \\
\hline $5.22 \mathrm{E}-33$ & $9.66 \mathrm{E}-32$ & $8.04 \mathrm{E}-32$ & $8.54 \mathrm{E}-32$ & $9.38 \mathrm{E}-32$ & $9.48 \mathrm{E}-32$ & $9.55 E-32$ & $9.60 \mathrm{E}-32$ \\
\hline $5.20 \mathrm{E}-33$ & $9.75 E-32$ & $8.11 \mathrm{E}-32$ & $8.61 \mathrm{E}-32$ & $9.46 \mathrm{E}-32$ & $9.56 \mathrm{E}-32$ & $9.64 \mathrm{E}-32$ & $9.68 \mathrm{E}-32$ \\
\hline $5.17 \mathrm{E}-33$ & $9.84 \mathrm{E}-32$ & $8.17 \mathrm{E}-32$ & $8.68 \mathrm{E}-32$ & $9.55 E-32$ & $9.64 \mathrm{E}-32$ & $9.72 \mathrm{E}-32$ & $9.77 \mathrm{E}-32$ \\
\hline $0.15 E-33$ & $2.52 \mathrm{E}-$ & $8.25 \mathrm{E}$ & $8.15 \mathrm{E}$ & 32 & 32 & 32 & $9.86 \mathrm{E}-32$ \\
\hline $5.12 \mathrm{E}-33$ & $7.72 \mathrm{E}-29$ & $1.22 \mathrm{E}-31$ & $8.83 E-32$ & $9.71 \mathrm{E}-32$ & $9.81 \mathrm{E}-32$ & $9.89 \mathrm{E}-32$ & $9.94 \mathrm{E}-32$ \\
\hline $10 E-33$ & $6.95 E-27$ & $3.56 \mathrm{E}-30$ & $8.90 \mathrm{E}-32$ & $9.80 \mathrm{E}-32$ & $9.90 \mathrm{E}-32$ & $9.98 \mathrm{E}-32$ & $1.00 \mathrm{E}-31$ \\
\hline$E-33$ & $2.76 \mathrm{E}-25$ & 1. & 32 & 2 & 32 & 31 & 31 \\
\hline $5 E-33$ & $6.25 \mathrm{E}-24$ & $3.13 \mathrm{E}-27$ & $9.05 \mathrm{E}$ & 9. & 1 & $1 . c$ & $02 E-31$ \\
\hline $5.02 \mathrm{E}-33$ & $9.31 \mathrm{E}-23$ & $4.66 \mathrm{E}-26$ & $9.13 \mathrm{E}-32$ & $1.01 \mathrm{E}-31$ & $1.02 \mathrm{E}-31$ & $1.02 \mathrm{E}-31$ & $1.03 \mathrm{E}-31$ \\
\hline $5.00 \mathrm{E}-33$ & $9.92 \mathrm{E}-22$ & $4.96 \mathrm{E}-25$ & $9.20 \mathrm{E}-32$ & $1.01 \mathrm{E}-31$ & $1.02 \mathrm{E}-31$ & $1.03 \mathrm{E}-31$ & $1.04 \mathrm{E}-31$ \\
\hline $4.97 E-33$ & $8.02 \mathrm{E}-21$ & $4.01 \mathrm{E}-24$ & $9.28 \mathrm{E}-32$ & $1.02 \mathrm{E}-31$ & $1.03 \mathrm{E}-31$ & $1.04 \mathrm{E}-31$ & $1.05 \mathrm{E}-31$ \\
\hline $4.95 E-33$ & $5.13 \mathrm{E}-20$ & $2.57 \mathrm{E}-23$ & $9.36 \mathrm{E}-32$ & $1.03 \mathrm{E}-31$ & $1.04 \mathrm{E}-31$ & $1.05 \mathrm{E}-31$ & $1.06 \mathrm{E}-31$ \\
\hline $4.93 E-33$ & $2.69 \mathrm{E}-19$ & $1.35 \mathrm{E}-22$ & $9.44 \mathrm{E}-32$ & $1.04 \mathrm{E}-31$ & $1.05 \mathrm{E}-31$ & $1.06 \mathrm{E}-31$ & $1.07 \mathrm{E}-31$ \\
\hline $4.90 \mathrm{E}-33$ & $1.19 \mathrm{E}-18$ & $5.95 \mathrm{E}-22$ & $9.51 \mathrm{E}-32$ & $1.05 \mathrm{E}-31$ & $1.06 \mathrm{E}-31$ & $1.07 \mathrm{E}-31$ & $1.08 \mathrm{E}-31$ \\
\hline $4.88 \mathrm{E}-33$ & $4.50 \mathrm{E}-18$ & $2.26 \mathrm{E}-21$ & $9.59 \mathrm{E}-32$ & $1.06 \mathrm{E}-31$ & $1.07 \mathrm{E}-31$ & $1.08 \mathrm{E}-31$ & $1.09 \mathrm{E}-31$ \\
\hline $4.86 \mathrm{E}-33$ & $1.50 \mathrm{E}-17$ & $7.57 \mathrm{E}-21$ & $9.67 \mathrm{E}-32$ & $1.07 \mathrm{E}-31$ & $1.08 \mathrm{E}-31$ & $1.09 \mathrm{E}-31$ & $1.10 \mathrm{E}-31$ \\
\hline $4.83 E-33$ & $4.46 \mathrm{E}-17$ & $2.26 \mathrm{E}-20$ & $9.75 E-32$ & $1.08 \mathrm{E}-31$ & $1.09 \mathrm{E}-31$ & $1.10 \mathrm{E}-31$ & $1.11 \mathrm{E}-31$ \\
\hline
\end{tabular}


RESRAD-OFFSITE, Version 2.5

Title : RESRAD-OFFSITE External Gamma, Inhalation, and Soil Ingestion for Offsite Reside File : PBA-1_TC99-DOE-5-1.ROF

Summary of dose at graphical times, reptition 2 (continued)

Time

Years

$1.18 \mathrm{E}+02$

$1.18 \mathrm{E}+02$

$1.19 \mathrm{E}+02$

$1.19 \mathrm{E}+02$

$1.20 \mathrm{E}+02$

$1.20 \mathrm{E}+02$

$1.21 \mathrm{E}+02$

$1.22 \mathrm{E}+02$

$1.22 \mathrm{E}+02$

$1.23 \mathrm{E}+02$

$1.23 \mathrm{E}+02$

$1.24 \mathrm{E}+02$

$1.24 \mathrm{E}+02$

$1.25 \mathrm{E}+02$

$1.25 \mathrm{E}+02$

$1.26 \mathrm{E}+02$

$1.26 \mathrm{E}+02$

$1.27 \mathrm{E}+02$

$1.27 \mathrm{E}+02$

$1.28 \mathrm{E}+02$

$1.28 \mathrm{E}+02$

$1.29 \mathrm{E}+02$

$1.29 \mathrm{E}+02$

$1.30 \mathrm{E}+02$

$1.30 \mathrm{E}+02$

$1.31 \mathrm{E}+02$

$1.31 \mathrm{E}+02$

$1.32 \mathrm{E}+02$

$1.32 \mathrm{E}+02$

$1.33 \mathrm{E}+02$

$1.33 \mathrm{E}+02$

1. $34 \mathrm{E}+02$

$1.34 \mathrm{E}+02$

1. $35 \mathrm{E}+02$

1. $35 \mathrm{E}+02$

$1.36 \mathrm{E}+02$

1. $36 \mathrm{E}+02$

$1.37 \mathrm{E}+02$

1. $37 \mathrm{E}+02$

1. $38 \mathrm{E}+02$

$1.38 \mathrm{E}+02$

$1.39 \mathrm{E}+02$

1. $39 \mathrm{E}+02$

1. $40 \mathrm{E}+02$

1. $40 \mathrm{E}+02$

1. $41 \mathrm{E}+02$
Dose statistics at graphical times, mrem/yr

\begin{tabular}{|c|c|c|c|c|c|c|c|}
\hline inimum & Maximum & Mean & Median & $90 \%$ & $95 \frac{\circ}{\circ}$ & $7.5 \%$ & $9 \%$ \\
\hline $.81 E-33$ & $1.20 \mathrm{E}-16$ & $6.10 \mathrm{E}-20$ & $9.84 \mathrm{E}-32$ & $1.09 \mathrm{E}-31$ & $1.10 \mathrm{E}-31$ & $1.11 \mathrm{E}-31$ & $1.12 \mathrm{E}-31$ \\
\hline $4.79 \mathrm{E}-33$ & $2.96 \mathrm{E}-16$ & $1.51 \mathrm{E}-19$ & $9.92 \mathrm{E}-32$ & $1.10 \mathrm{E}-31$ & $1.11 \mathrm{E}-31$ & $1.12 \mathrm{E}-31$ & $1.13 \mathrm{E}-31$ \\
\hline $4.76 \mathrm{E}-33$ & $6.76 \mathrm{E}-16$ & $3.47 \mathrm{E}-19$ & $1.00 \mathrm{E}-31$ & $1.11 \mathrm{E}-31$ & $1.12 \mathrm{E}-31$ & $1.13 \mathrm{E}-31$ & $1.14 \mathrm{E}-31$ \\
\hline $4.74 \mathrm{E}-33$ & $1.44 \mathrm{E}-15$ & $7.45 \mathrm{E}-19$ & $1.01 \mathrm{E}-31$ & $1.12 \mathrm{E}-31$ & $13 E-31$ & $1.14 \mathrm{E}-31$ & $15 E-31$ \\
\hline $4.72 \mathrm{E}-33$ & $2.91 \mathrm{E}-15$ & $1.51 \mathrm{E}-18$ & $1.02 \mathrm{E}-31$ & $1.13 \mathrm{E}$ & $14 \mathrm{E}$ & 1.15 & $16 \mathrm{E}-31$ \\
\hline $4.69 \mathrm{E}-33$ & $5.55 E-15$ & $2.90 \mathrm{E}-18$ & $1.03 \mathrm{E}-31$ & $1.14 \mathrm{E}-31$ & $.15 \mathrm{E}-31$ & $1.16 \mathrm{E}-31$ & $1.17 \mathrm{E}-31$ \\
\hline $4.67 \mathrm{E}-33$ & $1.01 \mathrm{E}-14$ & $5.32 \mathrm{E}-18$ & $1.03 \mathrm{E}-31$ & $1.15 \mathrm{E}-31$ & $16 \mathrm{E}-31$ & $1.17 \mathrm{E}-31$ & $1.18 \mathrm{E}-31$ \\
\hline $.65 E-33$ & $1.77 \mathrm{E}-14$ & $9.36 \mathrm{E}-18$ & $1.04 \mathrm{E}-31$ & $1.16 \mathrm{E}-31$ & $.17 \mathrm{E}-31$ & $1.18 \mathrm{E}-31$ & $1.19 \mathrm{E}-31$ \\
\hline $4.63 E-33$ & $2.99 \mathrm{E}-14$ & $1.59 \mathrm{E}-17$ & $1.05 \mathrm{E}-31$ & $1.17 \mathrm{E}-31$ & $1.18 \mathrm{E}-31$ & $1.19 \mathrm{E}-31$ & $1.20 \mathrm{E}-31$ \\
\hline $4.60 \mathrm{E}-33$ & $4.88 E-14$ & $2.61 \mathrm{E}-17$ & $1.06 \mathrm{E}-31$ & $1.18 \mathrm{E}-31$ & $1.19 \mathrm{E}-31$ & $1.20 \mathrm{E}-31$ & $1.21 \mathrm{E}-31$ \\
\hline $4.58 \mathrm{E}-33$ & $7.74 \mathrm{E}-14$ & $4.17 \mathrm{E}-17$ & $1.07 \mathrm{E}-31$ & $1.19 \mathrm{E}-31$ & $1.20 \mathrm{E}-31$ & $1.21 \mathrm{E}-31$ & $1.22 \mathrm{E}-31$ \\
\hline $4.56 \mathrm{E}-33$ & $1.19 \mathrm{E}-13$ & $6.47 \mathrm{E}-17$ & $1.08 \mathrm{E}-31$ & $1.20 \mathrm{E}-31$ & $1.21 \mathrm{E}-31$ & $1.22 \mathrm{E}-31$ & $1.23 \mathrm{E}-31$ \\
\hline $4.54 \mathrm{E}-33$ & $1.80 \mathrm{E}-13$ & $9.81 \mathrm{E}-17$ & $1.09 \mathrm{E}-31$ & $1.21 \mathrm{E}-31$ & $1.22 \mathrm{E}-31$ & $1.23 \mathrm{E}-31$ & $1.25 \mathrm{E}-31$ \\
\hline $4.52 \mathrm{E}-33$ & $2.65 \mathrm{E}-13$ & $1.45 \mathrm{E}-16$ & $1.10 \mathrm{E}-31$ & $1.22 \mathrm{E}-31$ & $1.23 \mathrm{E}-31$ & $1.24 \mathrm{E}-31$ & $1.26 \mathrm{E}-31$ \\
\hline $4.49 \mathrm{E}-33$ & $3.82 \mathrm{E}-13$ & $2.11 \mathrm{E}-16$ & $1.11 \mathrm{E}-31$ & $1.23 \mathrm{E}-31$ & $1.25 \mathrm{E}-31$ & $1.26 \mathrm{E}-31$ & $1.27 \mathrm{E}-31$ \\
\hline $4.47 \mathrm{E}-33$ & $5.40 \mathrm{E}-13$ & $3.01 \mathrm{E}-16$ & $1.11 \mathrm{E}-31$ & $1.24 \mathrm{E}-31$ & $1.26 \mathrm{E}-31$ & $1.27 \mathrm{E}-31$ & $1.28 \mathrm{E}-31$ \\
\hline $4.45 E-33$ & $7.52 \mathrm{E}-13$ & $4.22 \mathrm{E}-16$ & $1.12 \mathrm{E}-31$ & $1.25 \mathrm{E}-31$ & $1.27 \mathrm{E}-31$ & $1.28 \mathrm{E}-31$ & $1.29 \mathrm{E}-31$ \\
\hline $4.43 \mathrm{E}-33$ & $1.03 \mathrm{E}-12$ & $5.83 E-16$ & $1.13 \mathrm{E}-31$ & $1.26 \mathrm{E}-31$ & $1.28 \mathrm{E}-31$ & $1.29 \mathrm{E}-31$ & $1.30 \mathrm{E}-31$ \\
\hline $4.41 \mathrm{E}-33$ & $1.39 \mathrm{E}-12$ & $7.93 \mathrm{E}-16$ & $1.14 \mathrm{E}-31$ & $1.27 \mathrm{E}-31$ & $1.29 \mathrm{E}-31$ & $1.30 \mathrm{E}-31$ & $1.32 \mathrm{E}-31$ \\
\hline $4.39 E-33$ & $1.85 \mathrm{E}-12$ & $1.06 \mathrm{E}-15$ & $1.15 \mathrm{E}-31$ & $1.28 \mathrm{E}-31$ & $1.30 \mathrm{E}-31$ & $1.31 \mathrm{E}-31$ & $.49 \mathrm{E}-31$ \\
\hline $4.37 \mathrm{E}-33$ & 2 & 5 & 1 & 1 & 1 & 1 & 29 \\
\hline $4.34 \mathrm{E}-33$ & 3. & 1.8 & 1 & 31 & 31 & 31 & 27 \\
\hline $4.32 \mathrm{E}-33$ & $5 \mathrm{E}-12$ & $2.39 \mathrm{E}-15$ & $1.18 \mathrm{E}-31$ & $1.32 \mathrm{E}-31$ & $1.34 \mathrm{E}-31$ & 1.35 & -25 \\
\hline $4.30 \mathrm{E}-33$ & $5.14 \mathrm{E}-12$ & $3.06 \mathrm{E}-15$ & $1.19 \mathrm{E}-31$ & $1.33 \mathrm{E}-31$ & $1.35 \mathrm{E}-31$ & $1.36 \mathrm{E}-31$ & $2.85 \mathrm{E}-24$ \\
\hline $4.28 \mathrm{E}-33$ & $6.46 \mathrm{E}-12$ & $3.89 \mathrm{E}-15$ & $1.20 \mathrm{E}-31$ & $1.34 \mathrm{E}-31$ & $1.36 \mathrm{E}-31$ & $1.37 \mathrm{E}-31$ & $3.88 \mathrm{E}-23$ \\
\hline $4.26 \mathrm{E}-33$ & $8.05 E-12$ & $4.90 \mathrm{E}-15$ & $1.21 \mathrm{E}-31$ & $1.35 \mathrm{E}-31$ & $1.37 \mathrm{E}-31$ & $1.38 \mathrm{E}-31$ & $3.83 \mathrm{E}-22$ \\
\hline $4.24 \mathrm{E}-33$ & $9.95 \mathrm{E}-12$ & $6.12 \mathrm{E}-15$ & $1.22 \mathrm{E}-31$ & $1.37 \mathrm{E}-31$ & $1.39 \mathrm{E}-31$ & $1.40 \mathrm{E}-31$ & $2.89 \mathrm{E}-21$ \\
\hline $4.22 \mathrm{E}-33$ & $1.22 \mathrm{E}-11$ & $7.58 \mathrm{E}-15$ & $1.23 \mathrm{E}-31$ & $1.38 \mathrm{E}-31$ & $1.40 \mathrm{E}-31$ & $1.41 \mathrm{E}-31$ & $1.75 \mathrm{E}-20$ \\
\hline $4.20 \mathrm{E}-33$ & $1.48 \mathrm{E}-11$ & $9.33 E-15$ & $1.24 \mathrm{E}-31$ & $1.39 \mathrm{E}-31$ & $1.41 \mathrm{E}-31$ & $1.42 \mathrm{E}-31$ & $8.71 \mathrm{E}-20$ \\
\hline $4.18 \mathrm{E}-33$ & $1.79 \mathrm{E}-11$ & 1.14 & $1.25 \mathrm{E}$ & 1.40 & 31 & 1.44 & $3.67 \mathrm{E}-19$ \\
\hline $4.16 E-33$ & 54 & $1.38 \mathrm{E}$ & 1 & $1.41 \mathrm{E}-31$ & $1.44 \mathrm{E}-31$ & $1.45 \mathrm{E}-31$ & $1.34 \mathrm{E}-18$ \\
\hline $4.14 \mathrm{E}-33$ & $2.55 \mathrm{E}-11$ & $1.67 \mathrm{E}-14$ & $1.28 \mathrm{E}-31$ & $1.43 \mathrm{E}-31$ & $1.45 \mathrm{E}-31$ & $1.46 \mathrm{E}-31$ & $4.32 \mathrm{E}-18$ \\
\hline $4.12 \mathrm{E}-33$ & $3.02 \mathrm{E}-11$ & $2.00 \mathrm{E}-14$ & $1.29 \mathrm{E}-31$ & $1.44 \mathrm{E}-31$ & $1.46 \mathrm{E}-31$ & $1.48 \mathrm{E}-31$ & $1.23 \mathrm{E}-17$ \\
\hline $4.10 \mathrm{E}-33$ & $3.55 \mathrm{E}-11$ & $2.39 \mathrm{E}-14$ & $1.30 \mathrm{E}-31$ & $1.45 \mathrm{E}-31$ & $1.48 \mathrm{E}-31$ & $1.49 \mathrm{E}-31$ & $3.02 \mathrm{E}-17$ \\
\hline $4.08 \mathrm{E}-33$ & $4.15 \mathrm{E}-11$ & $2.84 \mathrm{E}-14$ & $1.31 \mathrm{E}-31$ & $1.47 \mathrm{E}-31$ & $1.49 \mathrm{E}-31$ & $1.50 \mathrm{E}-31$ & $6.94 \mathrm{E}-17$ \\
\hline $4.06 \mathrm{E}-33$ & $4.83 \mathrm{E}-11$ & $3.35 \mathrm{E}-14$ & $1.32 \mathrm{E}-31$ & $1.48 \mathrm{E}-31$ & $1.50 \mathrm{E}-31$ & $1.52 \mathrm{E}-31$ & $1.50 \mathrm{E}-16$ \\
\hline $4.04 \mathrm{E}-33$ & $5.60 \mathrm{E}-11$ & $3.94 \mathrm{E}-14$ & $1.33 \mathrm{E}-31$ & $1.49 \mathrm{E}-31$ & $1.52 \mathrm{E}-31$ & $1.53 \mathrm{E}-31$ & $3.12 \mathrm{E}-16$ \\
\hline $4.02 \mathrm{E}-33$ & $6.45 \mathrm{E}-11$ & $4.61 \mathrm{E}-14$ & $1.34 \mathrm{E}-31$ & $1.50 \mathrm{E}-31$ & $1.53 \mathrm{E}-31$ & $1.55 \mathrm{E}-31$ & $6.29 \mathrm{E}-16$ \\
\hline $4.00 \mathrm{E}-33$ & $7.40 \mathrm{E}-11$ & $5.38 \mathrm{E}-14$ & $1.35 \mathrm{E}-31$ & $1.52 \mathrm{E}-31$ & $1.54 \mathrm{E}-31$ & $1.57 \mathrm{E}-31$ & $1.21 \mathrm{E}-15$ \\
\hline $3.98 \mathrm{E}-33$ & $8.46 \mathrm{E}-11$ & $6.24 \mathrm{E}-14$ & $1.36 \mathrm{E}-31$ & $1.53 \mathrm{E}-31$ & $1.56 \mathrm{E}-31$ & $1.58 \mathrm{E}-31$ & $2.25 \mathrm{E}-15$ \\
\hline $3.96 \mathrm{E}-33$ & $9.62 \mathrm{E}-11$ & $7.22 \mathrm{E}-14$ & $1.38 \mathrm{E}-31$ & $1.54 \mathrm{E}-31$ & $1.57 \mathrm{E}-31$ & $1.60 \mathrm{E}-31$ & $4.00 \mathrm{E}-15$ \\
\hline $3.94 \mathrm{E}-33$ & $1.09 \mathrm{E}-10$ & $8.33 E-14$ & $1.39 \mathrm{E}-31$ & $1.56 \mathrm{E}-31$ & $1.58 \mathrm{E}-31$ & $1.61 \mathrm{E}-31$ & $6.88 \mathrm{E}-15$ \\
\hline $3.93 E-33$ & $1.23 \mathrm{E}-10$ & $9.56 \mathrm{E}-14$ & $1.40 \mathrm{E}-31$ & $1.57 \mathrm{E}-31$ & $1.60 \mathrm{E}-31$ & $1.67 \mathrm{E}-31$ & $1.15 \mathrm{E}-14$ \\
\hline $3.91 \mathrm{E}-33$ & $1.39 \mathrm{E}-10$ & $1.09 \mathrm{E}-13$ & $1.41 \mathrm{E}-31$ & $1.59 \mathrm{E}-31$ & $1.62 \mathrm{E}-31$ & $3.82 E-30$ & $1.85 \mathrm{E}-14$ \\
\hline $3.89 \mathrm{E}-33$ & $1.56 \mathrm{E}-10$ & $1.25 \mathrm{E}-13$ & $1.42 \mathrm{E}-31$ & $1.60 \mathrm{E}-31$ & $1.63 \mathrm{E}-31$ & $3.48 \mathrm{E}-28$ & $2.90 \mathrm{E}-14$ \\
\hline $.87 E-33$ & $1.74 \mathrm{E}-10$ & $1.42 \mathrm{E}-13$ & $1.43 \mathrm{E}-31$ & $1.61 \mathrm{E}-31$ & $1.64 \mathrm{E}-31$ & $1.48 \mathrm{E}-26$ & $4.44 \mathrm{E}-14$ \\
\hline
\end{tabular}


RESRAD-OFFSITE, Version 2.5

$\mathrm{T}^{1 / 2}$ Limit $=180$ days

Title : RESRAD-OFFSITE External Gamma, Inhalation, and Soil Ingestion for Offsite Reside File : PBA-1_TC99-DOE-5-1.ROF

Summary of dose at graphical times, reptition 2 (continued)

Time

Years

1. $42 \mathrm{E}+02$

1. $42 \mathrm{E}+02$

1. $43 \mathrm{E}+02$

1. $43 \mathrm{E}+02$

1. $44 \mathrm{E}+02$

1. $44 \mathrm{E}+02$

1. $45 \mathrm{E}+02$

1. $45 \mathrm{E}+02$

1. $46 \mathrm{E}+02$

1. $46 \mathrm{E}+02$

1. $47 \mathrm{E}+02$

1. $47 \mathrm{E}+02$

1. $48 \mathrm{E}+02$

1. $48 \mathrm{E}+02$

1. $49 \mathrm{E}+02$

1. $49 \mathrm{E}+02$

1. $50 \mathrm{E}+02$

1. $50 \mathrm{E}+02$

1. $51 \mathrm{E}+02$

1. $51 \mathrm{E}+02$

1. $52 \mathrm{E}+02$

1. $52 \mathrm{E}+02$

$1.53 \mathrm{E}+02$

$1.53 \mathrm{E}+02$

$1.54 \mathrm{E}+02$

$1.54 \mathrm{E}+02$

1. $55 \mathrm{E}+02$

1. $55 \mathrm{E}+02$

1. $56 \mathrm{E}+02$

1. $56 \mathrm{E}+02$

1. $57 \mathrm{E}+02$

1. $57 \mathrm{E}+02$

1. $58 \mathrm{E}+02$

1. $58 \mathrm{E}+02$

1. $59 \mathrm{E}+02$

1. $59 \mathrm{E}+02$

1. $60 \mathrm{E}+02$

1. $60 \mathrm{E}+02$

1. $61 \mathrm{E}+02$

1. $61 \mathrm{E}+02$

1. $62 \mathrm{E}+02$

1. $63 \mathrm{E}+02$

1. $63 \mathrm{E}+02$

1. $64 \mathrm{E}+02$

1. $64 \mathrm{E}+02$

1. $65 \mathrm{E}+02$

Dose statistics at graphical times, mrem/yr

\begin{tabular}{|c|c|c|c|c|c|c|c|}
\hline $\mathrm{m}$ & um & az & ledian & & & & \\
\hline 33 & 10 & 13 & 31 & 31 & 31 & -25 & -1 \\
\hline $83 E-33$ & $2.16 \mathrm{E}-10$ & $33 E-13$ & 31 & $4 E-31$ & $7 E-31$ & -24 & $36 E-14$ \\
\hline-33 & $.39 \mathrm{E}-10$ & $.06 \mathrm{E}-13$ & 1. $47 \mathrm{E}-31$ & $1.66 \mathrm{E}-31$ & $1.69 \mathrm{E}-31$ & -23 & -13 \\
\hline-33 & $65 \mathrm{p}-2 \mathrm{cos}$ & $32 F-13$ & $48 E-31$ & $.67 \mathrm{E}-31$ & $70 F-31$ & -22 & -1 \\
\hline 33 & 10 & 3 & 31 & 31 & 31 & 21 & 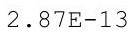 \\
\hline 33 & 10 & & & & & & \\
\hline $74 \mathrm{E}-33$ & $3.53 E-10$ & & & $1.72 \mathrm{E}$ & $.75 \mathrm{E}$ & & -13 \\
\hline $.72 E-33$ & -10 & -13 & & 31 & $1.77 \mathrm{E}-31$ & -19 & -13 \\
\hline $.70 E-33$ & -10 & -13 & 31 & $1.75 E-31$ & $79 E-31$ & -18 & -13 \\
\hline-33 & -10 & $49 E-13$ & 1 & 1 & $\perp$ & -18 & -12 \\
\hline$E-33$ & $\mathrm{~F}-\mathrm{s}+2.0$ & $5-13$ & $E-31$ & 1 & -31 & & 1 \\
\hline$E-33$ & $5.45 \mathrm{~F}-10$ & $1 F-13$ & 1 & 1 & 1 & 17 & -12 \\
\hline $63 E-33$ & $5.92 \mathrm{E}-10$ & $6.08 E-13$ & & $1.81 E-31$ & $1.85 \mathrm{E}-31$ & $66 \mathrm{E}-17$ & $10 \mathrm{E}-12$ \\
\hline $62 E-33$ & $6.41 \mathrm{E}-10$ & $6.70 \mathrm{E}-13$ & $1.61 \mathrm{E}-31$ & $1.83 \mathrm{E}-31$ & $1.87 \mathrm{E}-31$ & $.47 \mathrm{E}-16$ & $E-12$ \\
\hline-33 & $93 E-10$ & -13 & & & $\perp$ & -16 & -12 \\
\hline o & $9 E-10$ & $D E-13$ & & & & 6 & 12 \\
\hline$E-33$ & & & & & & & 2 \\
\hline 33 & 0 & 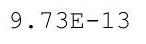 & 1 & & & 5 & 12 \\
\hline $.53 E-33$ & $9.35 \mathrm{E}-10$ & $1.06 \mathrm{E}-12$ & 1. $68 \mathrm{E}-31$ & 1. $91 \mathrm{E}-31$ & $1.96 \mathrm{E}-31$ & $.34 \mathrm{E}-15$ & $.59 \mathrm{E}-12$ \\
\hline$F-33$ & $.00 E-09$ & $1.16 \mathrm{E}-12$ & $1.70 \mathrm{E}-31$ & $1.93 \mathrm{E}-$ & $.98 \mathrm{E}-31$ & $E-15$ & $68 E-12$ \\
\hline-33 & $.08 \mathrm{E}-09$ & $1.27 \mathrm{E}-12$ & & $.95 \mathrm{~B}$ & & -14 & 12 \\
\hline 33 & & & & & & & 11 \\
\hline se & 0 & & & & & & 11 \\
\hline 33 & 1.02 & $.63 E-12$ & 1 & 1 & - & 4 & -11 \\
\hline 10 & $41 E-09$ & (1) & 1 & 1 & $2.98 E-27$ & 14 & -11 \\
\hline $41 F-3=$ & $.50 E-09$ & 1. $92 \mathrm{E}-12$ & $1.79 E-31$ & $2.04 \mathrm{E}-31$ & $1.02 \mathrm{E}-2$ & $.14 \mathrm{E}-13$ & $79 E-11$ \\
\hline-33 & $1.60 \mathrm{E}-09$ & $.07 E-12$ & $1.80 \mathrm{E}-31$ & & & $56 E-13$ & $05 E-11$ \\
\hline & & & & & & & \\
\hline & & & & & & 13 & \\
\hline & & $2.61 \mathrm{E}-12$ & & $2 \cdot 12$ & 2.50 & -13 & -11 \\
\hline eda & $2.04 \mathrm{E}-09$ & $82 E-12$ & $1.87 E-31$ & $2.14 \mathrm{E}-31$ & 舟 & $5 E-13$ & $39 E-11$ \\
\hline 等 & $2.16 \mathrm{E}-09$ & $3.03 E-12$ & $1.88 \mathrm{E}-31$ & 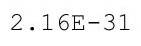 & 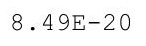 & $33 E-13$ & $.81 E-11$ \\
\hline 3 & $29 F-09$ & & & & & $E-13$ & $\theta-11$ \\
\hline & & & & & & & \\
\hline-33 & $2.56 \mathrm{E}-09$ & $3.76 \mathrm{E}-12$ & & & $4.61 E-18$ & $7 E-12$ & \\
\hline 0 & & & & & & -12 & 11 \\
\hline 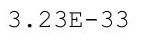 & $2.86 \mathrm{E}-09$ & $.33 E-12$ & $6 E-31$ & $.26 \mathrm{E}$ & $61 \mathrm{E}-$ & -12 & -11 \\
\hline 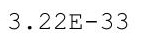 & & & & & & & $.84 \mathrm{E}-11$ \\
\hline $.20 E-33$ & 9 & 2 & 1 & 1 & 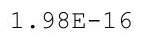 & 2 & 11 \\
\hline & & & & & & & \\
\hline-33 & 09 & & & & $827=$ & -12 & 11 \\
\hline-33 & $3.71 \mathrm{E}-09$ & $05 E-12$ & $2.05 E-31$ & $37 E-31$ & $6 E-15$ & $E-12$ & -11 \\
\hline-33 & & & & & & & \\
\hline & & & & & 1. 1 t & $07 E-12$ & $\cdot 1 U E-10$ \\
\hline & & & & 2. & • $\perp$ H & $6 E-12$ & $\cdot 10 \mathrm{D}-10$ \\
\hline 3 & $E-09$ & $E-12$ & $E-31$ & $.46 E-31$ & -14 & $9 E-12$ & -10 \\
\hline
\end{tabular}


RESRAD-OFFSITE, Version 2.5

Title : RESRAD-OFFSITE External Gamma, Inhalation, and Soil Ingestion for Offsite Reside File : PBA-1_TC99-DOE-5-1.ROF

Summary of dose at graphical times, reptition 2 (continued)

Time

Years

$1.65 \mathrm{E}+02$

$1.66 \mathrm{E}+02$

$1.66 \mathrm{E}+02$

$1.67 \mathrm{E}+02$

$1.67 \mathrm{E}+02$

1. $68 \mathrm{E}+02$

$1.68 \mathrm{E}+02$

$1.69 \mathrm{E}+02$

$1.69 \mathrm{E}+02$

$1.70 \mathrm{E}+02$

$1.70 \mathrm{E}+02$

$1.71 \mathrm{E}+02$

$1.71 \mathrm{E}+02$

$1.72 \mathrm{E}+02$

$1.72 \mathrm{E}+02$

$1.73 \mathrm{E}+02$

$1.73 \mathrm{E}+02$

$1.74 \mathrm{E}+02$

$1.74 \mathrm{E}+02$

$1.75 \mathrm{E}+02$

$1.75 \mathrm{E}+02$

$1.76 \mathrm{E}+02$

$1.76 \mathrm{E}+02$

$1.77 \mathrm{E}+02$

$1.77 \mathrm{E}+02$

$1.78 \mathrm{E}+02$

$1.78 \mathrm{E}+02$

$1.79 \mathrm{E}+02$

$1.79 \mathrm{E}+02$

$1.80 \mathrm{E}+02$

1. $80 \mathrm{E}+02$

1. $81 \mathrm{E}+02$

1. $81 \mathrm{E}+02$

1. $82 \mathrm{E}+02$

1. $83 \mathrm{E}+02$

1. $83 \mathrm{E}+02$

$1.84 \mathrm{E}+02$

$1.84 \mathrm{E}+02$

$1.85 \mathrm{E}+02$

$1.85 \mathrm{E}+02$

$1.86 \mathrm{E}+02$

1. $86 \mathrm{E}+02$

$1.87 \mathrm{E}+02$

$1.87 \mathrm{E}+02$

1. $88 \mathrm{E}+02$

$1.88 \mathrm{E}+02$
Dose statistics at graphical times, mrem/yr

\begin{tabular}{|c|c|c|c|c|c|c|c|}
\hline inimum & aximum & Mean & ledian & $0 \%$ & $5 \%$ & $97.5 \%$ & \\
\hline 33 & -09 & $8.30 \mathrm{E}-12$ & $2.14 \mathrm{E}-31$ & $2.48 E-31$ & $1.74 \mathrm{E}-14$ & $.13 \mathrm{E}-11$ & . \\
\hline 33 & -09 & 2 & 1 & 1 & 4 & 1 & 10 \\
\hline-33 & -09 & $E-12$ & 31 & $B 1$ & 14 & 1 & -10 \\
\hline-33 & $E-09$ & $E-12$ & $E-31$ & & -14 & -11 & -10 \\
\hline $2 E-33$ & 09 & 11 & & & & -11 & $79 E-10$ \\
\hline כ & -09 & -11 & 31 & 20 & 13 & -11 & -10 \\
\hline ك & -09 & $.19 \mathrm{E}-11$ & $5 E-31$ & 2.00 & 13 & -11 & 10 \\
\hline $98 E-33$ & -09 & $.26 \mathrm{E}-11$ & & & -13 & -11 & $18 \mathrm{E}-10$ \\
\hline 33 & 09 & 11 & 1 & 1 & 13 & -11 & 10 \\
\hline $.95 E-33$ & -09 & $1 \mathrm{E}-11$ & $2 E-31$ & $E-31$ & $06 E-13$ & -11 & -10 \\
\hline-33 & -09 & $E-11$ & & & & -11 & $E-10$ \\
\hline 33 & -09 & -11 & & & & 1 & 10 \\
\hline $.91 \mathrm{E}-33$ & $8.11 \mathrm{E}-09$ & $.67 \mathrm{E}-11$ & $2.38 E-31$ & $2.00 \mathrm{~L}-3 \mathrm{I}$ & $97 E-13$ & -11 & -10 \\
\hline $.89 E-33$ & -09 & 1. $76 \mathrm{E}-11$ & -31 & & -12 & -11 & -10 \\
\hline $3 E-33$ & 09 & $6 E-11$ & -31 & 28 & 12 & -11 & 10 \\
\hline $.87 E-33$ & -09 & -11 & -31 & -27 & 12 & -11 & -10 \\
\hline $.85 E-33$ & E-09 & $2.07 \mathrm{E}-11$ & $7 E-31$ & $2.20 \mathrm{E}-25$ & $15 \mathrm{E}-12$ & $.39 E-11$ & $90 \mathrm{E}-10$ \\
\hline-33 & $6 E-09$ & $8 E-11$ & $9 E-31$ & $0 E-24$ & $52 E-12$ & -11 & $E-10$ \\
\hline-33 & 08 & 11 & 31 & 3 & 12 & -11 & -10 \\
\hline $.81 E-33$ & -08 & $2.42 \mathrm{E}-11$ & -31 & 22 & -12 & -11 & -10 \\
\hline$E-33$ & -08 & $2.55 \mathrm{E}-11$ & -31 & & & 10 & -10 \\
\hline $.78 E-33$ & $1.17 \mathrm{E}-08$ & $.68 \mathrm{E}-11$ & 2.00 & 20 & 12 & -10 & -10 \\
\hline $775-33$ & $1.21 \mathrm{E}-08$ & $2.82 \mathrm{E}-11$ & $2.61 E-31$ & $01 E-20$ & $5.44 \mathrm{E}-12$ & $25 E-10$ & $73 E-10$ \\
\hline $.76 \mathrm{E}-33$ & $1.26 \mathrm{E}-08$ & $.96 \mathrm{E}-11$ & $2.63 E-31$ & $66 \mathrm{E}-19$ & $44 \mathrm{E}-12$ & $37 E-10$ & $4 E-10$ \\
\hline$E-33$ & 1. $31 E-08$ & $.11 \mathrm{E}-11$ & $5 E-31$ & $29 \mathrm{E}-18$ & $41 E-12$ & $E-10$ & $7 E-10$ \\
\hline$E-33$ & $E-08$ & $E-11$ & $E-31$ & $4 E-18$ & 12 & - & 10 \\
\hline $.72 E-33$ & -08 & $E-11$ & 1 & 7 & -1 & 0 & -10 \\
\hline$\cdot 1 / \mathrm{E}-32$ & $1.46 \mathrm{E}-08$ & $.60 \mathrm{E}-11$ & $3 E-31$ & $90 E-17$ & $.17 \mathrm{E}-11$ & $85 E-10$ & $42 E-10$ \\
\hline 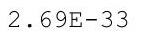 & 8 & 1 & 1 & 7 & 11 & $E-10$ & 10 \\
\hline 然 & -5 & - & - & - & 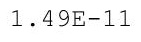 & 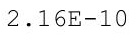 & 10 \\
\hline 3 & $53 E-08$ & $5 E-11$ & & $0 E-16$ & & $E-10$ & 10 \\
\hline$F-33$ & $1.69 E-08$ & $5 E-11$ & $3 E-31$ & $6 E-16$ & $87 E-11$ & $E-10$ & $E-10$ \\
\hline & & & & & & & \\
\hline $.63 E-33$ & $1.81 E-08$ & $4.77 E-11$ & $2.88 E-31$ & $1.96 \mathrm{E}-15$ & $2.32 \mathrm{E}-11$ & $98 E-10$ & $05 E-09$ \\
\hline $.025-23$ & $1.01 \mathrm{~T}-\mathrm{O}$ & $4 \cdot 99 E-11$ & & & & $.21 E-10$ & $.13 E-09$ \\
\hline 政 & & & & & & & $2+10$ \\
\hline $.59 E-33$ & & & & & & & 09 \\
\hline 3 & & & & & & & 09 \\
\hline 3 & & & & & & -10 & 09 \\
\hline $.55 E-33$ & $2.22 E-08$ & $3 E-11$ & $E-31$ & $9 \mathrm{E}-14$ & 1 & -10 & $9 E-09$ \\
\hline 3 & 08 & $1 E-11$ & & 4 & 1 & & 0 \\
\hline 3 & $2.37 E-08$ & $79 \mathrm{E}-11$ & 31 & 14 & 1 & & $025-09$ \\
\hline 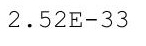 & 0 & 1 & 31 & -4 & & 0 & ces \\
\hline $5.50 \pi-23$ & - & & 1 & 2 & .00 & 0 & the \\
\hline-33 & $E-08$ & $E-11$ & 3. & 13 & 11 & -10 & -09 \\
\hline $.48 E-33$ & $2.69 E-08$ & $8.03 E-11$ & $3.21 E-31$ & $2.10 \mathrm{E}-13$ & 7. $58 \mathrm{E}-11$ & $.85 E-10$ & 1. $92 \mathrm{E}-09$ \\
\hline
\end{tabular}


RESRAD-OFFSITE, Version 2.5

Title : RESRAD-OFFSITE External Gamma, Inhalation, and Soil Ingestion for Offsite Reside File : PBA-1_TC99-DOE-5-1.ROF

Summary of dose at graphical times, reptition 2 (continued)

Time

Years

$1.89 \mathrm{E}+02$

1. $89 \mathrm{E}+02$

$.90 \mathrm{E}+02$

$.90 \mathrm{E}+02$

$91 \mathrm{E}+02$

$.91 \mathrm{E}+02$

1. $92 \mathrm{E}+02$

$.92 \mathrm{E}+02$

1. $93 \mathrm{E}+02$

$.93 \mathrm{E}+02$

. $94 \mathrm{E}+02$

1. $94 \mathrm{E}+02$

1. $95 \mathrm{E}+02$

1. $95 \mathrm{E}+02$

1. $96 \mathrm{E}+02$

1. $96 \mathrm{E}+02$

$1.97 \mathrm{E}+02$

$1.97 \mathrm{E}+02$

1. $98 \mathrm{E}+02$

1. $98 \mathrm{E}+02$

$1.99 \mathrm{E}+02$

1. $99 \mathrm{E}+02$

$2.00 \mathrm{E}+02$

$2.00 \mathrm{E}+02$

$2.01 \mathrm{E}+02$

$2.01 \mathrm{E}+02$

2. $02 \mathrm{E}+02$

$2.03 \mathrm{E}+02$

$2.03 E+02$

$2.04 \mathrm{E}+02$

$2.04 \mathrm{E}+02$

$2.05 \mathrm{E}+02$

$2.05 \mathrm{E}+02$

$2.06 \mathrm{E}+02$

$2.06 \mathrm{E}+02$

$2.07 \mathrm{E}+02$

$2.07 \mathrm{E}+02$

$2.08 \mathrm{E}+02$

$2.08 \mathrm{E}+02$

$2.09 \mathrm{E}+02$

$2.09 \mathrm{E}+02$

$2.10 \mathrm{E}+02$

$2.10 \mathrm{E}+02$

$2.11 E+02$

$2.11 \mathrm{E}+02$

$2.12 \mathrm{E}+02$
Dose statistics at graphical times, mrem/yr

\begin{tabular}{|c|c|c|c|c|c|c|c|}
\hline inimum & aximum & Mean & ledian & $90 \%$ & $5 \%$ & $97.5 \%$ & $\%$ \\
\hline 3 & -08 & 1 & -31 & 13 & 1 & 0 & nce \\
\hline 33 & -08 & 1 & 1 & 3 & 1 & 10 & -09 \\
\hline $44 E-33$ & $6 \mathrm{E}-08$ & $E-11$ & $E-31$ & $1 E-13$ & 11 & 10 & -09 \\
\hline $43 E-33$ & $5 E-08$ & 1 & & & & & -09 \\
\hline-33 & -08 & & & & & 10 & $36 E-09$ \\
\hline $41 E-33$ & -08 & 10 & $E-31$ & $E-13$ & $E-10$ & -10 & $6 \mathrm{E}-09$ \\
\hline 33 & -08 & -10 & -31 & $1.17 \mathrm{E}-12$ & 10 & -10 & $E-09$ \\
\hline $.39 E-33$ & $4 E-08$ & $.11 \mathrm{E}-10$ & & 1. $44 \mathrm{E}-12$ & -10 & -10 & $67 E-09$ \\
\hline 33 & 08 & 0 & 1 & $5 E-12$ & 10 & -10 & -09 \\
\hline $.36 \mathrm{E}-33$ & -08 & $0 E-10$ & $1 E-31$ & $11 \mathrm{E}-12$ & $61 E-10$ & -10 & -09 \\
\hline-33 & -08 & & 1 & 2 & & 10 & $E-09$ \\
\hline 3 & -08 & & & & & & -09 \\
\hline $.33 E-33$ & $3.98 \mathrm{E}-08$ & $.34 \mathrm{E}-10$ & $3.62 E-31$ & $3.56 \mathrm{E}-12$ & -10 & -09 & -0 \\
\hline $.32 E-33$ & -08 & -10 & $5 E-31$ & $4.18 \mathrm{E}-12$ & 10 & -09 & -09 \\
\hline 33 & 08 & 10 & 31 & $86 E-12$ & 10 & 09 & -09 \\
\hline $.30 E-33$ & -08 & -10 & -31 & -12 & -10 & -09 & -09 \\
\hline $.28 \mathrm{E}-33$ & $5 E-08$ & $5 E-10$ & $5 E-31$ & $66 \mathrm{E}-12$ & $52 \mathrm{E}-10$ & $.23 E-09$ & $95 E-09$ \\
\hline $27 E-33$ & $9 E-08$ & $1 E-10$ & -31 & -12 & $67 E-10$ & $3 E-09$ & $E-09$ \\
\hline-33 & -08 & 10 & 31 & -12 & 10 & 9 & -09 \\
\hline $.25 E-33$ & $4.85 E-08$ & -10 & -31 & -12 & -10 & 09 & -09 \\
\hline $.24 \mathrm{E}-33$ & $4.90 \mathrm{D}-00$ & 1. $79 \mathrm{E}-10$ & & 1. $12 \mathrm{E}-11$ & & & -09 \\
\hline $23 E-33$ & -08 & $1.86 \mathrm{E}-10$ & -31 & 11 & 10 & -09 & -09 \\
\hline $225-32$ & $5.26 \mathrm{E}-08$ & $1.92 \mathrm{E}-10$ & $3.96 E-31$ & $1.46 \mathrm{E}-11$ & $65 E-10$ & $59 E-09$ & $93 E-09$ \\
\hline $21 E-33$ & $40 \mathrm{E}-08$ & $1.99 \mathrm{E}-10$ & $0 E-31$ & $1.64 \mathrm{E}-11$ & $83 E-10$ & $66 \mathrm{E}-09$ & $11 \mathrm{E}-09$ \\
\hline-33 & $5 E-08$ & $.06 \mathrm{E}-10$ & $3 E-31$ & -11 & -10 & & $E-09$ \\
\hline$E-33$ & 08 & 10 & & -11 & -10 & & 09 \\
\hline $18 \mathrm{E}-33$ & $5.85 E-08$ & $2.21 E-10$ & -31 & 1 & & 9 & 09 \\
\hline$\cdot 8 / 2-23$ & $6.00 \mathrm{E}-08$ & $2 \cdot 28 \mathrm{E}-10$ & $4.14 E-31$ & $2.58 \mathrm{E}-11$ & $4.64 \mathrm{E}-10$ & $.96 E-09$ & $.87 E-09$ \\
\hline 我 & 8 & 年 & $18 E-31$ & 1 & . & $05 E-09$ & $08 E-09$ \\
\hline tes & 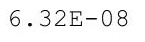 & -5 & $=$ & 1 & - & -5 & -5 \\
\hline $5-33$ & $F-08$ & $2.52 E-10$ & & & & $E-09$ & $0 E-09$ \\
\hline-33 & $6.65 E-08$ & $1 E-10$ & $0 E-31$ & $9 E-11$ & $E-10$ & & $E-09$ \\
\hline $11 \mathrm{E}-33$ & $6.82 \mathrm{E}-08$ & $9 E-10$ & $4 E-31$ & $6 \mathrm{E}-11$ & 0 & & $5 E-09$ \\
\hline $10 \mathrm{E}-33$ & $6.99 E-08$ & $2.78 E-10$ & $4.38 E-31$ & $4.76 E-11$ & $7 E-10$ & $51 E-09$ & $.18 E-09$ \\
\hline $.025-23$ & $7.16 \mathrm{E}-08$ & $2.87 E-10$ & & $5.18 \mathrm{E}-11$ & & & $.42 \mathrm{E}-09$ \\
\hline 然 & & & & & & & \\
\hline $.07 E-33$ & 8 & 0 & & & & & he \\
\hline 3 & & & & & & & 09 \\
\hline$E-33$ & & & & & & -09 & 09 \\
\hline $.04 \mathrm{E}-33$ & $8.09 \mathrm{E}-08$ & $E-10$ & 31 & 1 & 0 & 99 & $2 E-09$ \\
\hline 3 & & $E-10$ & & 1 & & & -09 \\
\hline 3 & 08 & $58 E-10$ & $72 E-31$ & 11 & 10 & & $25-09$ \\
\hline 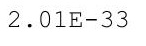 & 8 & 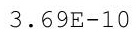 & 1 & 1 & 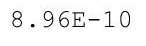 & & 0 \\
\hline ( & & 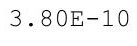 & $80 E-31$ & 0 & 0 & 9 & 09 \\
\hline $.99 E-33$ & $9.10 E-08$ & $3.92 \mathrm{E}-10$ & 4.8 & $1.12 \mathrm{E}$ & -10 & -09 & $E-08$ \\
\hline $.99 \mathrm{E}-$ & $9.31 E-08$ & $4.04 \mathrm{E}-10$ & $.89 E-31$ & 1. $20 \mathrm{E}-10$ & $1.01 \mathrm{E}-09$ & $3.91 \mathrm{E}-09$ & $1.04 \mathrm{E}-08$ \\
\hline
\end{tabular}


RESRAD-OFFSITE, Version 2.5

$\mathrm{T}^{1 / 2}$ Limit $=180$ days

Title : RESRAD-OFFSITE External Gamma, Inhalation, and Soil Ingestion for offsite Reside File : PBA-1_TC99-DOE-5-1.ROF

Summary of dose at graphical times, reptition 2 (continued)

Time

Years

$2.12 \mathrm{E}+02$

$2.13 \mathrm{E}+02$

$2.13 E+02$

$2.14 \mathrm{E}+02$

$2.14 \mathrm{E}+02$

$2.15 \mathrm{E}+02$

$2.15 \mathrm{E}+02$

$2.16 \mathrm{E}+02$

$2.16 \mathrm{E}+02$

$2.17 \mathrm{E}+02$

$2.17 \mathrm{E}+02$

$2.18 \mathrm{E}+02$

$2.18 \mathrm{E}+02$

$2.19 \mathrm{E}+02$

$2.19 \mathrm{E}+02$

$2.20 \mathrm{E}+02$

$2.20 \mathrm{E}+02$

$2.21 \mathrm{E}+02$

$2.21 \mathrm{E}+02$

2. $22 \mathrm{E}+02$

$2.23 \mathrm{E}+02$

2. $23 E+02$

$2.24 \mathrm{E}+02$

$2.24 \mathrm{E}+02$

$2.25 \mathrm{E}+02$

$2.25 \mathrm{E}+02$

$2.26 \mathrm{E}+02$

$2.26 \mathrm{E}+02$

$2.27 \mathrm{E}+02$

$2.27 \mathrm{E}+02$

$2.28 \mathrm{E}+02$

$2.28 \mathrm{E}+02$

$2.29 \mathrm{E}+02$

$2.29 \mathrm{E}+02$

$2.30 \mathrm{E}+02$

2. $30 \mathrm{E}+02$

2. $31 \mathrm{E}+02$

$2.31 E+02$

2. $32 \mathrm{E}+02$

2. $32 \mathrm{E}+02$

$2.33 \mathrm{E}+02$

$2.33 \mathrm{E}+02$

2. $34 \mathrm{E}+02$

2. $34 \mathrm{E}+02$

$2.35 \mathrm{E}+02$

$2.35 E+02$
Dose statistics at graphical times, mrem/yr

\begin{tabular}{|c|c|c|c|c|c|c|c|}
\hline m & $\mathrm{am}$ & a & ledian & & & & \\
\hline 33 & 08 & 10 & 31 & 10 & 09 & 09 & -0 \\
\hline $.97 E-33$ & $5 E-08$ & $9 \mathrm{E}-10$ & 31 & $=10$ & 09 & -09 & $10 E-08$ \\
\hline $.96 \mathrm{E}-33$ & $97 E-08$ & $.42 \mathrm{E}-10$ & $5.03 E-31$ & 1. $49 \mathrm{E}-10$ & $1.15 \mathrm{E}-09$ & -09 & -08 \\
\hline-33 & -07 & $55 F-10$ & $08 E-31$ & $59 F-10$ & $21 \mathrm{~F}-0 \mathrm{~g}$ & 09 & 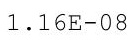 \\
\hline 33 & 7 & 10 & 31 & 10 & 09 & 09 & -08 \\
\hline 33 & 07 & 0 & & & & & -08 \\
\hline $92 E-33$ & 07 & & & 10 & & & -08 \\
\hline $91 E-33$ & -07 & -10 & 31 & -10 & -09 & -09 & -08 \\
\hline $90 E-33$ & -07 & $6 \mathrm{E}-10$ & 31 & $.21 E-10$ & $E-09$ & -09 & -08 \\
\hline-33 & $6 E-07$ & 10 & 1 & -10 & 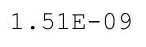 & 9 & 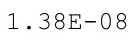 \\
\hline 33 & 1 & $5.56 \mathrm{E}-10$ & 1 & 0 & $1.56 \mathrm{E}-09$ & 9 & 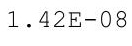 \\
\hline $87 E-33$ & $122 \mathrm{~F}-07$ & $2 F-10$ & 1 & $65 E-10$ & & 9 & -08 \\
\hline $.86 E-33$ & $1.24 \mathrm{E}-07$ & $5.88 \mathrm{E}-10$ & $5.54 \mathrm{E}-31$ & $2.82 E-10$ & $1.67 \mathrm{E}-09$ & & -08 \\
\hline $86 \mathrm{E}-33$ & $1.27 \mathrm{E}-07$ & $6.05 \mathrm{E}-10$ & $5.60 \mathrm{E}-31$ & $3.00 \mathrm{E}-10$ & $1.72 \mathrm{E}-09$ & $5-09$ & $z-08$ \\
\hline-33 & $E-07$ & $2 E-10$ & & -10 & 9 & -09 & -08 \\
\hline .8 & $32 E-07$ & 1 & & 0 & 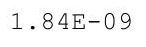 & 9 & 08 \\
\hline - c & 1 & & $\perp$ & 0 & & 9 & 8 \\
\hline 3 & 7 & 5 & 1 & & & 9 & 08 \\
\hline $.81 E-33$ & $1.41 \mathrm{E}-07$ & $6.93 E-10$ & $5.87 E-31$ & $3.96 \mathrm{E}-10$ & $2.02 \mathrm{E}-09$ & $29 E-09$ & $.77 E-08$ \\
\hline $.80 E-33$ & $1.44 \mathrm{E}-07$ & $.12 \mathrm{E}-10$ & $.92 E-31$ & $4.15 \mathrm{E}-10$ & $.08 E-09$ & $E-09$ & $E-08$ \\
\hline-33 & $.47 \mathrm{E}-07$ & $.31 \mathrm{E}-10$ & & $42 E-10$ & & 09 & -08 \\
\hline 33 & & & & & & & \\
\hline 30 & 1 & & & & & & 08 \\
\hline $.77 E-33$ & -07 & $.91 \mathrm{E}-10$ & 1 & 0 & & 09 & 08 \\
\hline 政 & 7 & $12 \mathrm{E}-$ & 1 & 0 & 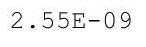 & 9 & $0 \varepsilon$ \\
\hline $75 F-33$ & $.62 \mathrm{E}-07$ & $.34 E-10$ & $6.29 E-31$ & $58 E-10$ & $66 \mathrm{E}-09$ & $7 E-09$ & $11 \mathrm{~F}-08 \mathrm{C}$ \\
\hline $5-33$ & $165 \mathrm{~F}-07$ & $.55 \mathrm{E}-10$ & $6.35 E-31$ & $93 E-10$ & & $6 \mathrm{E}-09$ & $17 \mathrm{~F}-08 \mathrm{r}-\mathrm{s}$ \\
\hline $3 E-33$ & & & & & & & \\
\hline & & & & & & & \\
\hline $.72 E-33$ & $1.75 \mathrm{E}-07$ & $9.24 E-10$ & $6.53 E-31$ & $6.66 \mathrm{E}-10$ & $3.01 \mathrm{E}-09$ & $E-09$ & $.33 E-08$ \\
\hline • & $1.78 \mathrm{E}-07$ & $.47 \mathrm{E}-10$ & $6.61 \mathrm{E}-31$ & $.90 \mathrm{E}-10$ & $\cdot 1 U E-U 2$ & $.57 E-09$ & •rum \\
\hline 年 & $1.82 \mathrm{E}-07$ & $9.71 \mathrm{E}-10$ & $6.68 \mathrm{E}-31$ & $7.14 \mathrm{E}-10$ & & $8 E-09$ & in \\
\hline 3 & $85 \mathrm{~F}-07$ & $.96 E-10$ & & & & & $F-08-2-25$ \\
\hline & & & & & & & \\
\hline 3 & & & & & & & \\
\hline $67 E-33$ & $1.96 \mathrm{E}-07$ & $.07 E-09$ & $95 E-31$ & $8.32 E-10$ & $3.55 \mathrm{E}-09$ & 08 & $67 E-08$ \\
\hline $.00 \mathrm{n}-32$ & $2.00 \pm-01$ & $\cdot 10 E-09$ & $.02 E-31$ & $8.01 E-10$ & 09 & & 00 \\
\hline | & & & & & & & • \\
\hline $645-33$ & 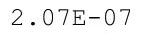 & 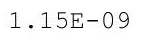 & & & 9 & 8 & 88 \\
\hline & & & & & & & \\
\hline $63 F-33$ & & & & $1.01 \mathrm{E}-09$ & 9 & 08 & \\
\hline $62 E-33$ & $2.18 \mathrm{E}-07$ & $.24 \mathrm{E}-09$ & $38 E-31$ & $04 E-09$ & 09 & 08 & -08 \\
\hline & 07 & 09 & & & & & \\
\hline & $2 \cdot 201$ & $1.30 E-09$ & $\cdot 00$ & 09 & 09 & -08 & -00 \\
\hline & & 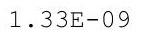 & $.60 E-31$ & $1.16 \mathrm{E}-09$ & 1.100 & 08 & $\begin{array}{c}\text { • } 27+400 \\
0\end{array}$ \\
\hline 3 & $34 E-07$ & $E-09$ & $3 E-31$ & $.20 E-09$ & -09 & $.37 E-08$ & $.31 E-08$ \\
\hline
\end{tabular}


RESRAD-OFFSITE, Version 2.5

Title : RESRAD-OFFSITE External Gamma, Inhalation, and Soil Ingestion for offsite Reside File : PBA-1_TC99-DOE-5-1.ROF

Summary of dose at graphical times, reptition 2 (continued)

Time

Years

$2.36 \mathrm{E}+02$

$2.36 \mathrm{E}+02$

$2.37 \mathrm{E}+02$

2. $37 \mathrm{E}+02$

$2.38 \mathrm{E}+02$

2. $38 \mathrm{E}+02$

$2.39 \mathrm{E}+02$

2. $39 \mathrm{E}+02$

2. $40 \mathrm{E}+02$

2. $40 \mathrm{E}+02$

2. $41 \mathrm{E}+02$

2. $41 E+02$

2. $42 \mathrm{E}+02$

$2.43 E+02$

2. $43 \mathrm{E}+02$

2. $44 \mathrm{E}+02$

2. $44 \mathrm{E}+02$

2. $45 \mathrm{E}+02$

2. $45 \mathrm{E}+02$

2. $46 \mathrm{E}+02$

2. $46 \mathrm{E}+02$

$2.47 \mathrm{E}+02$

2. $47 \mathrm{E}+02$

$2.48 \mathrm{E}+02$

$2.48 \mathrm{E}+02$

2. $49 \mathrm{E}+02$

2. $49 \mathrm{E}+02$

$2.50 \mathrm{E}+02$

2. $50 \mathrm{E}+02$

$2.51 \mathrm{E}+02$

2. $51 \mathrm{E}+02$

2. $52 \mathrm{E}+02$

$2.52 \mathrm{E}+02$

2. $53 \mathrm{E}+02$

$2.53 \mathrm{E}+02$

2. $54 \mathrm{E}+02$

$2.54 \mathrm{E}+02$

$2.55 \mathrm{E}+02$

$2.55 \mathrm{E}+02$

$2.56 \mathrm{E}+02$

$2.56 \mathrm{E}+02$

$2.57 \mathrm{E}+02$

$2.57 \mathrm{E}+02$

$2.58 \mathrm{E}+02$

$2.58 \mathrm{E}+02$

$2.59 \mathrm{E}+02$

Dose statistics at graphical times, mrem/yr

\begin{tabular}{|c|c|c|c|c|c|c|c|}
\hline inimum & aximum & Mean & ledian & $0 \%$ & $5 \%$ & $97.5 \%$ & $\%$ \\
\hline 3 & -07 & $9 E-09$ & $E-31$ & $1.24 \mathrm{E}-09$ & 09 & 08 & 08 \\
\hline-33 & -07 & $E-09$ & $E-31$ & $1.29 \mathrm{E}-09$ & 09 & .08 & -08 \\
\hline $7 E-33$ & $7 E-07$ & $E-09$ & $E-31$ & $33 E-09$ & $7 E-09$ & 08 & -08 \\
\hline $5 E-33$ & $E-07$ & $E-09$ & 1 & 9 & & 8 & -08 \\
\hline-33 & -07 & -09 & & & 9 & 08 & $67 E-08$ \\
\hline $.54 E-33$ & -07 & $6 E-09$ & 31 & 09 & 09 & .08 & -08 \\
\hline ك & T & ك & -31 & $1.50 \mathrm{E}-09$ & 09 & -08 & -08 \\
\hline $.53 E-33$ & $2.69 E-07$ & 1. $63 E-09$ & $8.34 E-31$ & $1.54 \mathrm{E}-09$ & -09 & -08 & $90 E-08$ \\
\hline 33 & -07 & 09 & 31 & 09 & 9 & -08 & -08 \\
\hline $.51 E-33$ & -07 & $1 \mathrm{E}-09$ & 1 & 1.6 & 09 & -08 & $E-08$ \\
\hline-33 & -07 & $E-09$ & 1 & 9 & & .08 & $E-08$ \\
\hline & 07 & 09 & & & & & -08 \\
\hline $.49 E-33$ & $2.92 \mathrm{E}-07$ & $1.83 E-09$ & $E-31$ & $1.77 \mathrm{E}-09$ & $32 E-09$ & $.85 \mathrm{E}-08$ & $E-08$ \\
\hline $.49 E-33$ & -07 & $1.87 \mathrm{E}-09$ & -31 & $1.83 \mathrm{E}-09$ & S & -08 & $E-08$ \\
\hline $3 E-33$ & -07 & 09 & -31 & 09 & 09 & 08 & -08 \\
\hline$E-33$ & -07 & -09 & -31 & 09 & 09 & -08 & -08 \\
\hline $.31 E-33$ & $E-07$ & $9 E-09$ & $E-31$ & $1 E-09$ & $93 E-09$ & $E-08$ & $69 \mathrm{E}-08$ \\
\hline-33 & $6 \mathrm{E}-07$ & $3 E-09$ & $E-31$ & $E-09$ & 09 & -08 & $79 E-08$ \\
\hline$E-33$ & $3.21 \mathrm{E}-07$ & $8 E-09$ & $D E-31$ & & & -08 & -08 \\
\hline$E-33$ & -07 & $E-09$ & -31 & & & -08 & $E-08$ \\
\hline$E-33$ & 7 & -09 & -31 & 09 & & -08 & -08 \\
\hline $27 E-33$ & -07 & 09 & 1 & & 9 & 08 & -08 \\
\hline $.26 \mathrm{E}-33$ & $3.41 \mathrm{E}-07$ & $2.26 \mathrm{E}-09$ & $.82 E-31$ & $2.41 E-09$ & $.93 E-09$ & $.26 \mathrm{E}-08$ & $.31 E-08$ \\
\hline $.25 E-33$ & $3.47 E-07$ & $2.31 E-09$ & $6 E-31$ & $48 E-09$ & $10 E-09$ & $31 E-08$ & $42 E-08$ \\
\hline$E-33$ & $3.52 \mathrm{E}-07$ & $2.35 E-09$ & $E-30$ & $5 E-09$ & & -08 & $E-08$ \\
\hline-33 & -07 & 09 & -30 & 9 & & 08 & 08 \\
\hline $3 E-33$ & $E-07$ & $E-09$ & -30 & $0 E-09$ & & -08 & $76 \mathrm{E}-08$ \\
\hline $22 E-33$ & $3.68 \mathrm{E}-07$ & $2.50 E-09$ & $1.05 E-30$ & $2.77 \mathrm{E}-09$ & $93 E-09$ & $.52 E-08$ & $.88 E-08$ \\
\hline • LIE Uك & 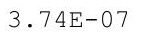 & $2.55 E-09$ & $1.07 E-30$ & $2.07 \mathrm{~L}$ & -09 & -08 & $0 E-08$ \\
\hline $20 E-33$ & $3.79 \mathrm{E}-07$ & $2.61 E-09$ & $9 E-30$ & $2.92 \mathrm{E}-09$ & 09 & -08 & $12 \mathrm{E}-0$ \\
\hline 33 & $E-07$ & $2.66 E-09$ & 29 & $0 E-09$ & 9 & $E-08$ & -08 \\
\hline$E-33$ & $0 E-07$ & $E-09$ & $E-27$ & $E-09$ & 9 & 08 & 08 \\
\hline $.17 \mathrm{E}-33$ & $3.96 \mathrm{E}-07$ & $2.77 E-09$ & $2 E-26$ & $3.16 \mathrm{E}-$ & 9 & $.80 \mathrm{E}-08$ & $9 \mathrm{E}-08$ \\
\hline $.16 \mathrm{E}-33$ & $4.02 E-07$ & $2.82 E-09$ & $8.35 E-25$ & $3.24 \mathrm{E}-09$ & $.03 E-08$ & $.85 E-08$ & $62 \mathrm{E}-08$ \\
\hline •. & $4.08 \mathrm{E}-07$ & $2.88 \mathrm{E}-09$ & & & & & $.76 \mathrm{E}-08$ \\
\hline 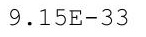 & & & & & & & $89 \mathrm{E}-08$ \\
\hline 3 & 7 & a & & 9 & 8 & 8 & 08 \\
\hline-33 & 07 & $E-09$ & $E-21$ & 9 & 8 & 8 & -08 \\
\hline-33 & $E-07$ & $E-09$ & $E-20$ & $E-09$ & 08 & 08 & $31 \mathrm{E}-08$ \\
\hline 33 & 07 & $7 E-09$ & & 9 & 8 & & -08 \\
\hline 3 & $44 E-07$ & $23 E-09$ & & - & & & -08 \\
\hline & & $.30 E-09$ & & $3.96 \mathrm{E}-09$ & $.22 E-08$ & & $.75 E-08$ \\
\hline & & $3.36 \mathrm{E}-09$ & & $4.06 \mathrm{E}-09$ & & 8 & $7.89 \mathrm{E}-08$ \\
\hline 08F-33 & 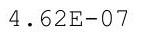 & & 17 & $4.16 \mathrm{E}-09$ & 8 & 8 & 0 \\
\hline-33 & $E-07$ & $3.49 E-09$ & 2.8 & 4 & 08 & -08 & $6 E-08$ \\
\hline $.06 E-33$ & $4.75 E-07$ & $.55 E-09$ & $38 E-17$ & $4.37 E-09$ & $.32 E-08$ & $3.54 \mathrm{E}-08$ & $8.30 \mathrm{E}-08$ \\
\hline
\end{tabular}


RESRAD-OFFSITE, Version 2.5

Title : RESRAD-OFFSITE External Gamma, Inhalation, and Soil Ingestion for offsite Reside File : PBA-1_TC99-DOE-5-1.ROF

Summary of dose at graphical times, reptition 2 (continued)

Time

Years

$2.59 \mathrm{E}+02$

$2.60 \mathrm{E}+02$

$2.60 \mathrm{E}+02$

2. $61 \mathrm{E}+02$

$2.61 E+02$

2. $62 \mathrm{E}+02$

2. $63 \mathrm{E}+02$

$2.63 \mathrm{E}+02$

$2.64 \mathrm{E}+02$

$2.64 \mathrm{E}+02$

$2.65 \mathrm{E}+02$

$2.65 \mathrm{E}+02$

$2.66 \mathrm{E}+02$

$2.66 \mathrm{E}+02$

$2.67 \mathrm{E}+02$

$2.67 \mathrm{E}+02$

$2.68 \mathrm{E}+02$

$2.68 \mathrm{E}+02$

$2.69 \mathrm{E}+02$

$2.69 \mathrm{E}+02$

$2.70 \mathrm{E}+02$

$2.70 \mathrm{E}+02$

$2.71 \mathrm{E}+02$

$2.71 \mathrm{E}+02$

2. $72 \mathrm{E}+02$

$2.72 \mathrm{E}+02$

$2.73 E+02$

$2.73 \mathrm{E}+02$

$2.74 \mathrm{E}+02$

$2.74 \mathrm{E}+02$

$2.75 \mathrm{E}+02$

$2.75 \mathrm{E}+02$

$2.76 \mathrm{E}+02$

$2.76 \mathrm{E}+02$

$2.77 \mathrm{E}+02$

$2.77 \mathrm{E}+02$

$2.78 \mathrm{E}+02$

$2.78 \mathrm{E}+02$

$2.79 \mathrm{E}+02$

$2.79 \mathrm{E}+02$

$2.80 \mathrm{E}+02$

$2.80 \mathrm{E}+02$

$2.81 \mathrm{E}+02$

$2.81 E+02$

$2.82 \mathrm{E}+02$

$2.82 \mathrm{E}+02$
Dose statistics at graphical times, mrem/yr

\begin{tabular}{|c|c|c|c|c|c|c|c|}
\hline inimum & Maximum & Mean & Median & $90 \%$ & $95 \frac{\circ}{\circ}$ & $7.5 \%$ & $9 \frac{\circ}{0}$ \\
\hline $9.05 E-33$ & $4.81 \mathrm{E}-07$ & $3.62 \mathrm{E}-09$ & $1.35 \mathrm{E}-16$ & $4.48 \mathrm{E}-09$ & $1.35 \mathrm{E}-08$ & $3.60 \mathrm{E}-08$ & $8.44 \mathrm{E}-08$ \\
\hline $9.04 \mathrm{E}-33$ & $4.88 E-07$ & $3.69 \mathrm{E}-09$ & $2.62 E-16$ & $4.59 \mathrm{E}-09$ & $1.38 \mathrm{E}-08$ & $3.66 \mathrm{E}-08$ & $8.58 E-08$ \\
\hline $9.03 \mathrm{E}-33$ & $4.94 \mathrm{E}-07$ & $3.76 \mathrm{E}-09$ & $4.89 \mathrm{E}-16$ & $4.71 \mathrm{E}-09$ & $1.41 \mathrm{E}-08$ & $3.73 E-08$ & $8.72 \mathrm{E}-08$ \\
\hline $9.02 \mathrm{E}-33$ & $5.01 \mathrm{E}-07$ & $3.83 \mathrm{E}-09$ & $8.81 \mathrm{E}-16$ & $4.84 \mathrm{E}-09$ & $1.44 \mathrm{E}-08$ & $3.79 \mathrm{E}-08$ & $8.86 \mathrm{E}-08$ \\
\hline $9.02 \mathrm{E}-33$ & $5.08 \mathrm{E}-07$ & $3.90 \mathrm{E}-09$ & $1.53 \mathrm{E}-15$ & $4.98 \mathrm{E}-09$ & $1.47 \mathrm{E}-08$ & $3.86 \mathrm{E}-08$ & $.01 \mathrm{E}-08$ \\
\hline $9.01 \mathrm{E}-33$ & $5.14 \mathrm{E}-07$ & $3.97 \mathrm{E}-09$ & $2.56 \mathrm{E}-15$ & $5.13 \mathrm{E}-09$ & $1.51 \mathrm{E}-08$ & $3.92 E-08$ & $9.16 \mathrm{E}-08$ \\
\hline $9.00 \mathrm{E}-33$ & $5.21 \mathrm{E}-07$ & $4.04 \mathrm{E}-09$ & $4.14 \mathrm{E}-15$ & $5.27 \mathrm{E}-09$ & $.54 \mathrm{E}-08$ & $3.99 \mathrm{E}-08$ & $31 \mathrm{E}-08$ \\
\hline $99 \mathrm{E}-33$ & $5.28 \mathrm{E}-07$ & $4.12 \mathrm{E}-09$ & $6.51 \mathrm{E}-15$ & $5.40 \mathrm{E}-09$ & $1.57 \mathrm{E}-08$ & $4.06 \mathrm{E}-08$ & $46 \mathrm{E}-08$ \\
\hline $8.98 \mathrm{E}-33$ & $5.35 \mathrm{E}-07$ & $4.19 \mathrm{E}-09$ & $9.99 \mathrm{E}-15$ & $5.52 \mathrm{E}-09$ & $1.61 \mathrm{E}-08$ & $4.13 E-08$ & $9.61 \mathrm{E}-08$ \\
\hline $3.97 \mathrm{E}-33$ & $5.42 \mathrm{E}-07$ & $4.27 \mathrm{E}-09$ & $1.52 \mathrm{E}-14$ & $5.64 \mathrm{E}-09$ & $1.64 \mathrm{E}-08$ & $4.20 \mathrm{E}-08$ & $9.76 \mathrm{E}-08$ \\
\hline $8.96 \mathrm{E}-33$ & $5.49 \mathrm{E}-07$ & $4.35 \mathrm{E}-09$ & $2.27 \mathrm{E}-14$ & $5.79 \mathrm{E}-09$ & $1.68 \mathrm{E}-08$ & $4.27 \mathrm{E}-08$ & $9.92 \mathrm{E}-08$ \\
\hline $8.96 \mathrm{E}-33$ & $5.56 \mathrm{E}-07$ & $4.42 \mathrm{E}-09$ & $3.25 \mathrm{E}-14$ & $5.93 \mathrm{E}-09$ & $1.71 \mathrm{E}-08$ & $4.34 \mathrm{E}-08$ & $1.01 \mathrm{E}-07$ \\
\hline $8.95 E-33$ & $5.63 \mathrm{E}-07$ & $4.50 \mathrm{E}-09$ & $4.63 \mathrm{E}-14$ & $6.09 \mathrm{E}-09$ & $1.75 \mathrm{E}-08$ & $4.41 \mathrm{E}-08$ & $1.02 \mathrm{E}-07$ \\
\hline $2.45 \mathrm{E}-32$ & $5.70 \mathrm{E}-07$ & $4.58 \mathrm{E}-09$ & $6.39 \mathrm{E}-14$ & $6.24 \mathrm{E}-09$ & $1.79 \mathrm{E}-08$ & $4.49 \mathrm{E}-08$ & $1.04 \mathrm{E}-07$ \\
\hline $2.45 \mathrm{E}-32$ & $5.77 \mathrm{E}-07$ & $4.66 \mathrm{E}-09$ & $8.68 \mathrm{E}-14$ & $6.40 \mathrm{E}-09$ & $1.83 \mathrm{E}-08$ & $4.56 \mathrm{E}-08$ & $1.06 \mathrm{E}-07$ \\
\hline $2.45 \mathrm{E}-32$ & $5.84 \mathrm{E}-07$ & $4.75 \mathrm{E}-09$ & $1.16 \mathrm{E}-13$ & $6.56 \mathrm{E}-09$ & $1.87 \mathrm{E}-08$ & $4.64 \mathrm{E}-08$ & $1.07 \mathrm{E}-07$ \\
\hline $2.45 \mathrm{E}-32$ & $5.91 \mathrm{E}-07$ & $4.83 \mathrm{E}-09$ & $1.55 \mathrm{E}-13$ & $6.72 \mathrm{E}-09$ & $1.90 \mathrm{E}-08$ & $4.72 \mathrm{E}-08$ & $1.09 \mathrm{E}-07$ \\
\hline $2.46 \mathrm{E}-32$ & $5.99 \mathrm{E}-07$ & $4.91 \mathrm{E}-09$ & $2.03 \mathrm{E}-13$ & $6.90 \mathrm{E}-09$ & $1.94 \mathrm{E}-08$ & $4.79 \mathrm{E}-08$ & $1.11 \mathrm{E}-07$ \\
\hline $2.46 \mathrm{E}-32$ & $6.06 \mathrm{E}-07$ & $5.00 \mathrm{E}-09$ & $2.61 \mathrm{E}-13$ & $7.09 \mathrm{E}-09$ & $1.98 \mathrm{E}-08$ & $4.87 \mathrm{E}-08$ & $1.12 \mathrm{E}-07$ \\
\hline $.46 \mathrm{E}-32$ & $6.13 \mathrm{E}-07$ & $5.09 \mathrm{E}-09$ & $3.31 \mathrm{E}-13$ & $7.26 \mathrm{E}-$ & $2.03 \mathrm{E}-08$ & $4.94 \mathrm{E}-08$ & $14 \mathrm{E}-07$ \\
\hline $.46 \mathrm{E}-$ & 6 & & & & & & \\
\hline 2 & 6 & 5 & 5 & 9 & 8 & 8 & 07 \\
\hline $2.47 \mathrm{E}-32$ & $6.36 \mathrm{E}-07$ & $5.35 \mathrm{E}-09$ & $6.39 \mathrm{E}-13$ & $7.76 \mathrm{E}-09$ & $2.15 \mathrm{E}-08$ & $5.17 \mathrm{E}-08$ & $1.19 \mathrm{E}-07$ \\
\hline $2.47 \mathrm{E}-32$ & $6.44 \mathrm{E}-07$ & $5.44 \mathrm{E}-09$ & $8.00 \mathrm{E}-13$ & $7.95 \mathrm{E}-09$ & $2.19 \mathrm{E}-08$ & $5.26 \mathrm{E}-08$ & $1.21 \mathrm{E}-07$ \\
\hline $2.47 \mathrm{E}-32$ & $6.51 \mathrm{E}-07$ & $5.54 \mathrm{E}-09$ & $1.00 \mathrm{E}-12$ & $8.14 \mathrm{E}-09$ & $2.23 \mathrm{E}-08$ & $5.34 \mathrm{E}-08$ & $1.23 \mathrm{E}-07$ \\
\hline $2.48 \mathrm{E}-32$ & $6.59 \mathrm{E}-07$ & $5.63 \mathrm{E}-09$ & $1.24 \mathrm{E}-12$ & $8.33 E-09$ & $2.27 \mathrm{E}-08$ & $5.42 \mathrm{E}-08$ & $1.25 \mathrm{E}-07$ \\
\hline $2.48 \mathrm{E}-32$ & $6.67 \mathrm{E}-07$ & $5.72 \mathrm{E}-09$ & $1.52 \mathrm{E}-12$ & $8.52 \mathrm{E}-09$ & $2.32 \mathrm{E}-08$ & $5.50 \mathrm{E}-08$ & $1.27 \mathrm{E}-07$ \\
\hline $2.48 \mathrm{E}-32$ & $6.75 \mathrm{E}-07$ & $5.82 \mathrm{E}-09$ & $1.84 \mathrm{E}-12$ & $8.71 \mathrm{E}-09$ & $2.37 \mathrm{E}-08$ & $5.59 \mathrm{E}-08$ & $1.28 \mathrm{E}-07$ \\
\hline $2.48 \mathrm{E}-32$ & $6.82 \mathrm{E}-07$ & $5.92 \mathrm{E}-09$ & $2.19 \mathrm{E}-12$ & $8.89 \mathrm{E}-09$ & $2.41 \mathrm{E}-08$ & $5.68 \mathrm{E}-08$ & $1.30 \mathrm{E}-07$ \\
\hline $2.49 \mathrm{E}-32$ & $6.90 \mathrm{E}-07$ & $6.02 \mathrm{E}-09$ & 2 & 19 & 8 & -08 & $1.32 \mathrm{E}-07$ \\
\hline $2.49 \mathrm{E}-32$ & $E-07$ & 6 & 3 & 9 & 8 & 8 & 1.04 \\
\hline $2.49 \mathrm{E}-32$ & $7.06 \mathrm{E}-07$ & $6.22 \mathrm{E}-09$ & $3.56 \mathrm{E}-12$ & $9.49 \mathrm{E}-09$ & $2.56 \mathrm{E}-08$ & $5.94 \mathrm{E}-08$ & $1.36 \mathrm{E}-07$ \\
\hline $2.49 \mathrm{E}-32$ & $7.14 \mathrm{E}-07$ & $6.32 \mathrm{E}-09$ & $4.14 \mathrm{E}-12$ & $9.69 \mathrm{E}-09$ & $2.61 \mathrm{E}-08$ & $6.03 E-08$ & $1.38 \mathrm{E}-07$ \\
\hline $2.50 \mathrm{E}-32$ & $7.22 \mathrm{E}-07$ & $6.42 \mathrm{E}-09$ & $4.86 \mathrm{E}-12$ & $9.92 \mathrm{E}-09$ & $2.66 \mathrm{E}-08$ & $6.12 \mathrm{E}-08$ & $1.40 \mathrm{E}-07$ \\
\hline $2.50 \mathrm{E}-32$ & $7.31 \mathrm{E}-07$ & $6.53 \mathrm{E}-09$ & $5.75 \mathrm{E}-12$ & $1.01 \mathrm{E}-08$ & $2.72 \mathrm{E}-08$ & $6.21 \mathrm{E}-08$ & $1.42 \mathrm{E}-07$ \\
\hline $2.50 \mathrm{E}-32$ & $7.39 \mathrm{E}-07$ & $6.63 \mathrm{E}-09$ & $6.70 \mathrm{E}-12$ & $1.03 \mathrm{E}-08$ & $2.77 \mathrm{E}-08$ & $6.30 \mathrm{E}-08$ & $1.44 \mathrm{E}-07$ \\
\hline $2.50 \mathrm{E}-32$ & $7.47 \mathrm{E}-07$ & $6.74 \mathrm{E}-09$ & $7.63 \mathrm{E}-12$ & $1.05 \mathrm{E}-08$ & $2.82 \mathrm{E}-08$ & $6.39 \mathrm{E}-08$ & $1.46 \mathrm{E}-07$ \\
\hline $2.51 \mathrm{E}-32$ & $7.55 \mathrm{E}-07$ & $6.85 \mathrm{E}-09$ & $8.68 \mathrm{E}-12$ & $1.08 \mathrm{E}-08$ & $2.88 \mathrm{E}-08$ & $6.49 \mathrm{E}-08$ & $1.48 \mathrm{E}-07$ \\
\hline $2.51 \mathrm{E}-32$ & $7.64 \mathrm{E}-07$ & $6.96 \mathrm{E}-09$ & $9.83 \mathrm{E}-12$ & $1.10 \mathrm{E}-08$ & $2.92 \mathrm{E}-08$ & $6.59 \mathrm{E}-08$ & $1.50 \mathrm{E}-07$ \\
\hline $2.51 \mathrm{E}-32$ & $7.72 \mathrm{E}-07$ & $7.07 \mathrm{E}-09$ & $1.10 \mathrm{E}-11$ & $1.13 \mathrm{E}-08$ & $2.97 \mathrm{E}-08$ & $6.70 \mathrm{E}-08$ & $1.52 \mathrm{E}-07$ \\
\hline $2.51 \mathrm{E}-32$ & $7.81 \mathrm{E}-07$ & $7.18 \mathrm{E}-09$ & $1.24 \mathrm{E}-11$ & $1.15 \mathrm{E}-08$ & $3.02 \mathrm{E}-08$ & $6.80 \mathrm{E}-08$ & $1.54 \mathrm{E}-07$ \\
\hline $2.52 \mathrm{E}-32$ & $7.89 \mathrm{E}-07$ & $7.29 \mathrm{E}-09$ & $1.39 \mathrm{E}-11$ & $1.18 \mathrm{E}-08$ & $3.07 \mathrm{E}-08$ & $6.91 \mathrm{E}-08$ & $1.56 \mathrm{E}-07$ \\
\hline $2.52 \mathrm{E}-32$ & $7.98 \mathrm{E}-07$ & $7.41 \mathrm{E}-09$ & $1.53 \mathrm{E}-11$ & $1.20 \mathrm{E}-08$ & $3.12 \mathrm{E}-08$ & $7.01 \mathrm{E}-08$ & $1.58 \mathrm{E}-07$ \\
\hline $2.52 \mathrm{E}-32$ & $8.06 \mathrm{E}-07$ & $7.52 \mathrm{E}-09$ & $1.71 \mathrm{E}-11$ & $1.23 \mathrm{E}-08$ & $3.16 \mathrm{E}-08$ & $7.12 \mathrm{E}-08$ & $1.60 \mathrm{E}-07$ \\
\hline $2.52 \mathrm{E}-32$ & $8.15 \mathrm{E}-07$ & $7.64 \mathrm{E}-09$ & $1.89 \mathrm{E}-11$ & $1.25 \mathrm{E}-08$ & $3.21 \mathrm{E}-$ & $7.23 \mathrm{E}-08$ & $1.63 \mathrm{E}-07$ \\
\hline $.52 \mathrm{E}-32$ & $8.24 \mathrm{E}-07$ & $7.76 \mathrm{E}-09$ & $2.12 \mathrm{E}-11$ & $1.28 \mathrm{E}-08$ & $3.26 \mathrm{E}-08$ & $7.33 E-08$ & $1.65 \mathrm{E}-07$ \\
\hline
\end{tabular}


RESRAD-OFFSITE, Version 2.5

$\mathrm{T}^{1 / 2}$ Limit $=180$ days

Title : RESRAD-OFFSITE External Gamma, Inhalation, and Soil Ingestion for Offsite Reside

File : PBA-1_TC99-DOE-5-1.ROF

Summary of dose at graphical times, reptition 2 (continued)

Time

Years

$2.83 \mathrm{E}+02$

$2.84 \mathrm{E}+02$

$2.84 \mathrm{E}+02$

$.85 \mathrm{E}+02$

$2.85 \mathrm{E}+02$

$2.86 \mathrm{E}+02$

$2.86 \mathrm{E}+02$

$2.87 \mathrm{E}+02$

$2.87 \mathrm{E}+02$

$2.88 \mathrm{E}+02$

$2.88 \mathrm{E}+02$

$2.89 \mathrm{E}+02$

$2.89 \mathrm{E}+02$

$2.90 \mathrm{E}+02$

$2.90 \mathrm{E}+02$

$2.91 \mathrm{E}+02$

$2.91 \mathrm{E}+02$

2. $92 \mathrm{E}+02$

$2.92 \mathrm{E}+02$

$2.93 \mathrm{E}+02$

$2.93 \mathrm{E}+02$

$2.94 \mathrm{E}+02$

$2.94 \mathrm{E}+02$

$2.95 \mathrm{E}+02$

2. $95 \mathrm{E}+02$

2. $96 \mathrm{E}+02$

$2.96 \mathrm{E}+02$

$2.97 \mathrm{E}+02$

$2.97 \mathrm{E}+02$

$2.98 \mathrm{E}+02$

$2.98 \mathrm{E}+02$

2. $99 \mathrm{E}+02$

2. $99 \mathrm{E}+02$

$3.00 \mathrm{E}+02$

$3.00 \mathrm{E}+02$

$3.01 \mathrm{E}+02$

$3.01 \mathrm{E}+02$

$3.02 \mathrm{E}+02$

$3.02 \mathrm{E}+02$

3. $03 \mathrm{E}+02$

3. $04 \mathrm{E}+02$

$3.04 \mathrm{E}+02$

$3.05 \mathrm{E}+02$

$3.05 \mathrm{E}+02$

$3.06 \mathrm{E}+02$

$3.06 \mathrm{E}+02$
Dose statistics at graphical times, mrem/yr

\begin{tabular}{|c|c|c|c|c|c|c|c|}
\hline inimum & aximum & Mean & ledian & $90 \%$ & $5 \%$ & $97.5 \%$ & \\
\hline 32 & -07 & $7.88 E-09$ & 2. $32 E-11$ & $1.31 \mathrm{E}-08$ & $3.32 \mathrm{E}-08$ & 7. $45 E-08$ & $E-0$ \\
\hline 32 & -07 & 09 & 1 & 8 & 08 & 08 & 07 \\
\hline$E-32$ & $E-07$ & -09 & 1 & $6 E-08$ & 08 & 08 & -07 \\
\hline$E-32$ & 07 & 9 & & & & & -07 \\
\hline-32 & -07 & 99 & & & 08 & $94 E-08$ & $75 E-07$ \\
\hline $54 E-32$ & -07 & $E-09$ & -11 & 08 & 08 & 08 & 07 \\
\hline $4 \mathrm{E}-32$ & ( & 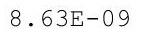 & -11 & -08 & 0 & -08 & -07 \\
\hline $.54 E-32$ & $8.95 E-07$ & 8 & & $1.52 \mathrm{E}-08$ & $69 E-08$ & -08 & $81 E-07$ \\
\hline 32 & 07 & 09 & 11 & 08 & 08 & -08 & -07 \\
\hline $.55 E-32$ & -07 & $E-09$ & $E-11$ & -08 & 08 & -08 & $86 E-07$ \\
\hline-32 & -07 & 09 & 1 & & & 08 & $E-07$ \\
\hline-32 & -07 & -09 & 11 & & & 08 & -07 \\
\hline $.56 \mathrm{E}-32$ & $9.41 \mathrm{E}-07$ & $.43 E-09$ & $5.65 E-11$ & $1.07 \pm-08$ & $00-08$ & $E-08$ & $E-07$ \\
\hline $.56 \mathrm{E}-32$ & $9.50 \mathrm{E}-07$ & $7 E-09$ & -11 & $1.10 \mathrm{~L}-0$ & 00 & -08 & $E-07$ \\
\hline$E-32$ & $D E-07$ & -09 & $6 E-11$ & 08 & 08 & 08 & -07 \\
\hline $.56 \mathrm{E}-32$ & -07 & -09 & -11 & -08 & -08 & -08 & -07 \\
\hline $.57 E-32$ & $9 E-07$ & $0 E-08$ & $0 E-11$ & 1.79E-08 & $27 E-08$ & $E-08$ & $01 E-07$ \\
\hline$E-32$ & $38 E-07$ & $01 E-08$ & $7 E-11$ & $2 E-08$ & $34 E-08$ & -08 & $04 E-07$ \\
\hline-32 & -07 & $E-08$ & -11 & 08 & & 8 & -07 \\
\hline $57 E-32$ & $1 E-06$ & -08 & 11 & 08 & & -08 & -07 \\
\hline $3 E-32$ & $2 E-06$ & $1.06 \mathrm{E}-08$ & & & & -07 & -07 \\
\hline $58 E-32$ & $1.03 E-06$ & $.07 E-08$ & $.00 \mathrm{E}-10$ & -08 & -08 & -07 & -07 \\
\hline $3 E-32$ & $1.04 \mathrm{E}-06$ & $1.09 E-08$ & $1.06 \mathrm{E}-10$ & $99 E-08$ & $66 \mathrm{E}-08$ & $04 E-07$ & $16 E-07$ \\
\hline$E-32$ & $1.05 \mathrm{E}-06$ & $1.10 \mathrm{E}-08$ & $2 E-10$ & $3 E-08$ & $73 E-08$ & $06 \mathrm{E}-07$ & $18 \mathrm{E}-07$ \\
\hline$E-32$ & $1.06 \mathrm{E}-06$ & $1.12 \mathrm{E}-08$ & $8 E-10$ & $6 \mathrm{E}-08$ & $E-08$ & $07 F-07$ & $21 E-07$ \\
\hline-32 & $E-06$ & $E-08$ & -10 & 08 & 08 & 07 & -07 \\
\hline $59 E-32$ & $1.08 \mathrm{E}-06$ & $5 E-08$ & 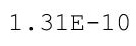 & 8 & & 07 & $E-07$ \\
\hline $60 \mathrm{E}-32$ & $1.09 \mathrm{E}-06$ & $.17 \mathrm{E}-08$ & $39 E-10$ & $6 E-08$ & $0 \perp \Sigma-00$ & $.12 \mathrm{E}-07$ & $.28 E-07$ \\
\hline 2 & 06 & $18 E-08$ & - & $20 E-08$ & 0 & $14 \mathrm{E}-07$ & $.31 E-07$ \\
\hline - & $1.11 \mathrm{E}-06$ & $.20 \mathrm{E}-08$ & - & -5 & - & . & - \\
\hline 32 & $2 E-06$ & $22 E-08$ & & & & $E-07$ & $36 E-07$ \\
\hline$E-32$ & $3 E-06$ & $.23 E-08$ & 35 & $1 E-08$ & 8 & $E-07$ & $9 E-07$ \\
\hline 32 & & & & & & 07 & \\
\hline $.61 E-32$ & $1.15 E-06$ & $.27 E-08$ & $1.89 E-10$ & $2.39 \mathrm{E}-08$ & $6 \mathrm{E}-08$ & $.22 \mathrm{E}-07$ & $.44 \mathrm{E}-07$ \\
\hline $61 E-32$ & $1.16 \mathrm{E}-06$ & $1.28 E-08$ & & & & $.23 E-07$ & $.47 E-07$ \\
\hline 2 & & & & & & & 西 \\
\hline 2 & & 8 & & & & & 07 \\
\hline 2 & & & & & & & 07 \\
\hline$E-32$ & & & & & & -07 & 07 \\
\hline $63 E-32$ & $1.21 \mathrm{E}-06$ & $.37 E-08$ & $8 E-10$ & $3 E-08$ & 8 & -07 & $51 \mathrm{E}-07$ \\
\hline $3 E-32$ & 06 & -08 & & 08 & & & $3 E-07$ \\
\hline$E-32$ & $1.23 E-06$ & $.41 \mathrm{E}-08$ & $2 \cdot 1+5$ & 08 & & $34 \mathrm{E}-07$ & $66 \mathrm{E}-07$ \\
\hline 2 & 1 & 0 & 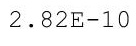 & 2. & 8 & 07 & $69 \mathrm{E}-01$ \\
\hline 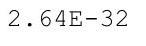 & 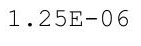 & 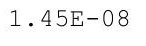 & & $2.00 \mathrm{t}$ & - & 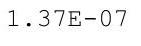 & $12+$ \\
\hline $4 E-32$ & 1.2 & $1.47 \mathrm{E}-08$ & 3. & 2. & 08 & 07 & -07 \\
\hline $.64 E-32$ & $1.27 \mathrm{E}-06$ & 1. $49 \mathrm{E}-08$ & $3.16 \mathrm{E}-10$ & $2.89 E-08$ & $6.41 \mathrm{E}-08$ & 1. $41 E-07$ & $2.78 \mathrm{E}-07$ \\
\hline
\end{tabular}


RESRAD-OFFSITE, Version 2.5

$\mathrm{T}^{1 / 2}$ Limit $=180$ days

Title : RESRAD-OFFSITE External Gamma, Inhalation, and Soil Ingestion for Offsite Reside

File : PBA-1_TC99-DOE-5-1.ROF

Summary of dose at graphical times, reptition 2 (continued)

Time

Years

$3.07 \mathrm{E}+02$

$3.07 \mathrm{E}+02$

$3.08 \mathrm{E}+02$

$3.08 \mathrm{E}+02$

$3.09 \mathrm{E}+02$

$3.09 \mathrm{E}+02$

$3.10 \mathrm{E}+02$

$3.10 \mathrm{E}+02$

$3.11 \mathrm{E}+02$

$3.11 E+02$

$3.12 \mathrm{E}+02$

$3.12 \mathrm{E}+02$

$3.13 \mathrm{E}+02$

$3.13 \mathrm{E}+02$

$3.14 \mathrm{E}+02$

$3.14 \mathrm{E}+02$

$3.15 \mathrm{E}+02$

$3.15 \mathrm{E}+02$

$3.16 \mathrm{E}+02$

$3.16 \mathrm{E}+02$

$3.17 \mathrm{E}+02$

$3.17 \mathrm{E}+02$

$3.18 \mathrm{E}+02$

$3.18 \mathrm{E}+02$

$3.19 \mathrm{E}+02$

$3.19 \mathrm{E}+02$

$3.20 \mathrm{E}+02$

$3.20 \mathrm{E}+02$

$3.21 \mathrm{E}+02$

$3.21 \mathrm{E}+02$

$3.22 \mathrm{E}+02$

$3.22 \mathrm{E}+02$

$3.23 \mathrm{E}+02$

$3.24 \mathrm{E}+02$

3. $24 \mathrm{E}+02$

$3.25 \mathrm{E}+02$

$3.25 \mathrm{E}+02$

$3.26 \mathrm{E}+02$

$3.26 \mathrm{E}+02$

$3.27 \mathrm{E}+02$

$3.27 \mathrm{E}+02$

3. $28 \mathrm{E}+02$

$3.28 \mathrm{E}+02$

$3.29 \mathrm{E}+02$

$3.29 \mathrm{E}+02$

$3.30 \mathrm{E}+02$
Dose statistics at graphical times, mrem/yr

\begin{tabular}{|c|c|c|c|c|c|c|c|}
\hline & aximum & - & teverest & . & & 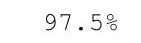 & \\
\hline $64 \mathrm{E}-32$ & $.28 \mathrm{E}-06$ & $1.50 \mathrm{E}-08$ & $3.29 \mathrm{E}-10$ & $2.94 \mathrm{E}-08$ & $6.50 \mathrm{E}-08$ & $1.43 \mathrm{E}-07$ & $2.81 \mathrm{E}-07$ \\
\hline $.65 E-32$ & $.29 \mathrm{E}-06$ & $1.52 \mathrm{E}-08$ & $3.41 \mathrm{E}-10$ & $2.99 \mathrm{E}-08$ & $6.59 \mathrm{E}-08$ & $1.45 \mathrm{E}-07$ & $2.84 \mathrm{E}-07$ \\
\hline $2.65 \mathrm{E}-32$ & $1.30 \mathrm{E}-06$ & $1.54 \mathrm{E}-08$ & $3.52 \mathrm{E}-10$ & $3.03 E-08$ & $6.68 \mathrm{E}-08$ & $1.46 \mathrm{E}-07$ & $2.86 \mathrm{E}-07$ \\
\hline $2.65 \mathrm{E}-32$ & $1.31 \mathrm{E}-06$ & $1.56 \mathrm{E}-08$ & $3.63 \mathrm{E}-10$ & $3.08 \mathrm{E}-08$ & $6.77 \mathrm{E}-08$ & $1.48 \mathrm{E}-07$ & $2.89 \mathrm{E}-07$ \\
\hline $2.65 \mathrm{E}-32$ & $1.33 \mathrm{E}-06$ & $1.58 \mathrm{E}-08$ & $3.77 \mathrm{E}-10$ & $3.13 \mathrm{E}-08$ & $6.87 \mathrm{E}-08$ & $1.50 \mathrm{E}-07$ & $2.92 \mathrm{E}-07$ \\
\hline $2.66 \mathrm{E}-32$ & $1.34 \mathrm{E}-06$ & $1.60 \mathrm{E}-08$ & $3.91 \mathrm{E}-10$ & $3.18 \mathrm{E}-08$ & $6.96 \mathrm{E}-08$ & $1.52 \mathrm{E}-07$ & $2.95 \mathrm{E}-07$ \\
\hline $2.66 \mathrm{E}-32$ & $1.35 \mathrm{E}-06$ & $1.62 \mathrm{E}-08$ & $4.04 \mathrm{E}-10$ & $3.23 \mathrm{E}-08$ & $7.05 \mathrm{E}-08$ & $1.53 \mathrm{E}-07$ & $2.98 \mathrm{E}-07$ \\
\hline $2.66 \mathrm{E}-32$ & $1.36 \mathrm{E}-06$ & $1.64 \mathrm{E}-08$ & $4.15 \mathrm{E}-10$ & $3.28 \mathrm{E}-08$ & $7.15 \mathrm{E}-08$ & $1.55 \mathrm{E}-07$ & $3.01 \mathrm{E}-07$ \\
\hline $2.66 \mathrm{E}-32$ & $1.37 \mathrm{E}-06$ & $1.67 \mathrm{E}-08$ & $4.29 \mathrm{E}-10$ & $3.33 \mathrm{E}-08$ & $7.24 \mathrm{E}-08$ & $1.57 \mathrm{E}-07$ & $3.04 \mathrm{E}-07$ \\
\hline $2.67 \mathrm{E}-32$ & $1.38 \mathrm{E}-06$ & $1.69 \mathrm{E}-08$ & $4.43 \mathrm{E}-10$ & $3.38 \mathrm{E}-08$ & 8 & 1.5 & $08 E-07$ \\
\hline $2.67 \mathrm{E}-32$ & $1.39 \mathrm{E}-06$ & $1.71 \mathrm{E}-08$ & $4.60 \mathrm{E}-10$ & $3.43 \mathrm{E}$ & 8 & 1.6 & 07 \\
\hline $2.67 \mathrm{E}-32$ & $1.40 \mathrm{E}-06$ & $1.73 \mathrm{E}-08$ & $4.75 \mathrm{E}-10$ & $3.48 \mathrm{E}-08$ & $7.54 \mathrm{E}-08$ & $1.62 \mathrm{E}-07$ & $3.14 \mathrm{E}-07$ \\
\hline $2.68 \mathrm{E}-32$ & $1.41 \mathrm{E}-06$ & $1.75 \mathrm{E}-08$ & $4.91 \mathrm{E}-10$ & $3.52 \mathrm{E}-08$ & $7.64 \mathrm{E}-08$ & $1.64 \mathrm{E}-07$ & $3.17 \mathrm{E}-07$ \\
\hline $.68 E-32$ & $1.42 \mathrm{E}-06$ & $1.77 \mathrm{E}-08$ & $5.07 \mathrm{E}-10$ & $3.57 \mathrm{E}-08$ & $7.74 \mathrm{E}-08$ & $1.66 \mathrm{E}-07$ & $3.20 \mathrm{E}-07$ \\
\hline $2.68 \mathrm{E}-32$ & $1.44 \mathrm{E}-06$ & $1.79 \mathrm{E}-08$ & $5.24 \mathrm{E}-10$ & $3.62 \mathrm{E}-08$ & $7.85 \mathrm{E}-08$ & $1.68 \mathrm{E}-07$ & $3.23 E-07$ \\
\hline $2.68 \mathrm{E}-32$ & $1.45 \mathrm{E}-06$ & $1.82 \mathrm{E}-08$ & $5.42 \mathrm{E}-10$ & $3.67 \mathrm{E}-08$ & $7.95 \mathrm{E}-08$ & $1.70 \mathrm{E}-07$ & $3.26 \mathrm{E}-07$ \\
\hline $2.69 \mathrm{E}-32$ & $1.46 \mathrm{E}-06$ & $1.84 \mathrm{E}-08$ & $5.59 \mathrm{E}-10$ & $3.72 \mathrm{E}-08$ & $8.05 E-08$ & $1.72 \mathrm{E}-07$ & $3.29 \mathrm{E}-07$ \\
\hline $2.69 \mathrm{E}-32$ & $1.47 \mathrm{E}-06$ & $1.86 \mathrm{E}-08$ & $5.76 \mathrm{E}-10$ & $3.78 \mathrm{E}-08$ & $8.15 \mathrm{E}-08$ & $1.74 \mathrm{E}-07$ & $3.33 \mathrm{E}-07$ \\
\hline $2.69 \mathrm{E}-32$ & $1.48 \mathrm{E}-06$ & $1.88 \mathrm{E}-08$ & $5.92 \mathrm{E}-10$ & $3.83 E-08$ & $8.26 E-08$ & $1.76 \mathrm{E}-07$ & $3.36 \mathrm{E}-07$ \\
\hline $2.69 \mathrm{E}-32$ & $1.49 \mathrm{E}-06$ & $1.91 \mathrm{E}-08$ & $6.10 \mathrm{E}-10$ & $3.89 \mathrm{E}-08$ & $8.37 \mathrm{E}-08$ & $1.78 \mathrm{E}-07$ & $3.39 \mathrm{E}-07$ \\
\hline $2.70 \mathrm{E}-32$ & $1.50 \mathrm{E}-06$ & $1.93 \mathrm{E}-08$ & $6.26 \mathrm{E}-10$ & $3.95 \mathrm{E}-08$ & $8.47 \mathrm{E}-08$ & $1.80 \mathrm{E}-07$ & $3.42 \mathrm{E}-07$ \\
\hline $2.70 \mathrm{E}-32$ & $1.51 \mathrm{E}-06$ & $1.95 \mathrm{E}-08$ & $6.46 \mathrm{E}-10$ & $4.02 \mathrm{E}-08$ & $8.58 \mathrm{E}-08$ & $1.81 \mathrm{E}-07$ & $3.46 \mathrm{E}-07$ \\
\hline $2.70 \mathrm{E}-32$ & $1.53 \mathrm{E}-06$ & 1.98 & 0 & 8 & 8 & $1.83 \mathrm{E}-07$ & $.49 \mathrm{E}-07$ \\
\hline 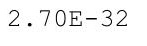 & 1 & 3 & 0 & 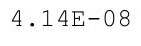 & & 7 & 1 \\
\hline $2.71 \mathrm{E}-32$ & $1.55 \mathrm{E}-06$ & $2.02 \mathrm{E}-08$ & $7.04 \mathrm{E}-10$ & $4.20 \mathrm{E}$ & 8 & 7 & 7 \\
\hline $2.71 \mathrm{E}-32$ & $1.56 \mathrm{E}-06$ & $2.05 \mathrm{E}-08$ & $7.27 \mathrm{E}-10$ & $4.26 \mathrm{E}-08$ & $9.02 \mathrm{E}-08$ & $1.90 \mathrm{E}-07$ & $3.59 \mathrm{E}-07$ \\
\hline $2.71 \mathrm{E}-32$ & $1.57 \mathrm{E}-06$ & $2.07 \mathrm{E}-08$ & $7.50 \mathrm{E}-10$ & $4.32 \mathrm{E}-08$ & $9.13 \mathrm{E}-08$ & $1.92 \mathrm{E}-07$ & $3.62 \mathrm{E}-07$ \\
\hline $2.72 \mathrm{E}-32$ & $1.58 \mathrm{E}-06$ & $2.10 \mathrm{E}-08$ & $7.73 \mathrm{E}-10$ & $4.38 \mathrm{E}-08$ & $9.24 \mathrm{E}-08$ & $1.94 \mathrm{E}-07$ & $3.66 \mathrm{E}-07$ \\
\hline $2.72 \mathrm{E}-32$ & $1.60 \mathrm{E}-06$ & $2.12 \mathrm{E}-08$ & $7.95 \mathrm{E}-10$ & $4.44 \mathrm{E}-08$ & $9.36 \mathrm{E}-08$ & $1.96 \mathrm{E}-07$ & $3.69 \mathrm{E}-07$ \\
\hline $2.72 \mathrm{E}-32$ & $1.61 \mathrm{E}-06$ & $2.14 \mathrm{E}-08$ & $8.14 \mathrm{E}-10$ & $4.50 \mathrm{E}-08$ & $9.49 \mathrm{E}-08$ & $1.98 \mathrm{E}-07$ & $3.72 \mathrm{E}-07$ \\
\hline $2.72 \mathrm{E}-32$ & $1.62 \mathrm{E}-06$ & $2.17 \mathrm{E}-08$ & $8.34 \mathrm{E}-10$ & $4.56 \mathrm{E}-08$ & $9.62 \mathrm{E}-08$ & $2.00 \mathrm{E}-07$ & $3.76 \mathrm{E}-07$ \\
\hline $2.73 E-32$ & $1.63 \mathrm{E}-06$ & $2.20 \mathrm{E}-08$ & $8.58 \mathrm{E}-10$ & $4.63 \mathrm{E}-08$ & $9.75 \mathrm{E}-08$ & $2.03 E-07$ & $3.79 \mathrm{E}-07$ \\
\hline $2.73 \mathrm{E}-32$ & $1.64 \mathrm{E}-06$ & $2.22 \mathrm{E}$ & 8 & 8 & 8 & 2.00 & $3.83 E-07$ \\
\hline $2.73 E-32$ & $1.65 \mathrm{E}-06$ & $2.25 \mathrm{E}-08$ & $9.15 \mathrm{E}-10$ & $4.74 \mathrm{E}-08$ & $1.00 \mathrm{E}-07$ & $2.07 \mathrm{E}-07$ & $3.86 \mathrm{E}-07$ \\
\hline $2.73 \mathrm{E}-32$ & $1.67 \mathrm{E}-06$ & $2.27 \mathrm{E}-08$ & $9.40 \mathrm{E}-10$ & $4.80 \mathrm{E}-08$ & $1.01 \mathrm{E}-07$ & $2.09 \mathrm{E}-07$ & $3.90 \mathrm{E}-07$ \\
\hline $2.74 \mathrm{E}-32$ & $1.68 \mathrm{E}-06$ & $2.30 \mathrm{E}-08$ & $9.63 \mathrm{E}-$ & $86 \mathrm{~F}-$ & $1.02 \mathrm{E}-07$ & $2.12 \mathrm{E}-07$ & 7 \\
\hline $2.74 \mathrm{E}-32$ & $1.69 \mathrm{E}-06$ & $2.32 \mathrm{E}-08$ & $9.85 \mathrm{E}-10$ & $4.93 \mathrm{E}-08$ & $1.04 \mathrm{E}-07$ & -07 & $7 E-07$ \\
\hline $2.74 \mathrm{E}-32$ & $1.70 \mathrm{E}-06$ & $2.35 \mathrm{E}-08$ & $1.01 \mathrm{E}-09$ & $5.00 \mathrm{E}-08$ & $1.05 \mathrm{E}-07$ & $2.16 \mathrm{E}-07$ & $4.00 \mathrm{E}-07$ \\
\hline $2.74 \mathrm{E}-32$ & $1.71 \mathrm{E}-06$ & $2.38 \mathrm{E}-08$ & $1.04 \mathrm{E}-09$ & $5.07 \mathrm{E}-08$ & $1.06 \mathrm{E}-07$ & $2.19 \mathrm{E}-07$ & $4.04 \mathrm{E}-07$ \\
\hline $2.75 E-32$ & $1.72 \mathrm{E}-06$ & $2.40 \mathrm{E}-08$ & $1.07 \mathrm{E}-09$ & $5.14 \mathrm{E}-08$ & $1.07 \mathrm{E}-07$ & $2.21 \mathrm{E}-07$ & $4.07 \mathrm{E}-07$ \\
\hline $2.75 \mathrm{E}-32$ & $1.74 \mathrm{E}-06$ & $2.43 \mathrm{E}-08$ & $1.09 \mathrm{E}-09$ & $5.20 \mathrm{E}-08$ & $1.08 \mathrm{E}-07$ & $2.23 \mathrm{E}-07$ & $4.11 \mathrm{E}-07$ \\
\hline $2.75 \mathrm{E}-32$ & $1.75 \mathrm{E}-06$ & $2.46 \mathrm{E}-08$ & $1.12 \mathrm{E}-09$ & $5.26 \mathrm{E}-08$ & $1.10 \mathrm{E}-07$ & $2.26 \mathrm{E}-07$ & $4.14 \mathrm{E}-07$ \\
\hline $2.76 \mathrm{E}-32$ & $1.76 \mathrm{E}-06$ & $2.49 \mathrm{E}-08$ & $1.14 \mathrm{E}-09$ & $5.33 E-08$ & $1.11 \mathrm{E}-07$ & $2.28 \mathrm{E}-07$ & $4.18 \mathrm{E}-07$ \\
\hline $2.76 \mathrm{E}-32$ & $1.77 \mathrm{E}-06$ & $2.51 \mathrm{E}-08$ & $1.16 \mathrm{E}-09$ & $5.39 \mathrm{E}-08$ & $1.12 \mathrm{E}-07$ & $2.31 \mathrm{E}-07$ & $4.22 \mathrm{E}-07$ \\
\hline $2.76 \mathrm{E}-32$ & $1.78 \mathrm{E}-06$ & $2.54 \mathrm{E}-08$ & $1.20 \mathrm{E}-09$ & $5.46 \mathrm{E}-08$ & $1.13 \mathrm{E}-07$ & $2.33 E-07$ & $4.25 \mathrm{E}-07$ \\
\hline $2.76 \mathrm{E}-32$ & $1.80 \mathrm{E}-06$ & $2.57 \mathrm{E}-08$ & $1.23 \mathrm{E}-09$ & $5.52 \mathrm{E}-08$ & $1.14 \mathrm{E}-07$ & $2.35 \mathrm{E}-07$ & $4.29 \mathrm{E}-07$ \\
\hline
\end{tabular}


RESRAD-OFFSITE, Version 2.5

$\mathrm{T}^{1 / 2}$ Limit $=180$ days

Title : RESRAD-OFFSITE External Gamma, Inhalation, and Soil Ingestion for Offsite Reside

File : PBA-1_TC99-DOE-5-1.ROF

Summary of dose at graphical times, reptition 2 (continued)

Time

Years

$3.30 \mathrm{E}+02$

$3.31 \mathrm{E}+02$

$3.31 \mathrm{E}+02$

$3.32 \mathrm{E}+02$

$3.32 \mathrm{E}+02$

3. $33 \mathrm{E}+02$

$3.33 \mathrm{E}+02$

3. $34 \mathrm{E}+02$

$3.34 \mathrm{E}+02$

$3.35 \mathrm{E}+02$

3. $35 \mathrm{E}+02$

$3.36 \mathrm{E}+02$

3. $36 \mathrm{E}+02$

3. $37 \mathrm{E}+02$

3. $37 \mathrm{E}+02$

$3.38 \mathrm{E}+02$

3. $38 \mathrm{E}+02$

3. $39 \mathrm{E}+02$

3. $39 \mathrm{E}+02$

$3.40 \mathrm{E}+02$

$3.40 \mathrm{E}+02$

$3.41 \mathrm{E}+02$

3. $41 \mathrm{E}+02$

3. $42 \mathrm{E}+02$

$3.42 \mathrm{E}+02$

$3.43 \mathrm{E}+02$

$3.44 \mathrm{E}+02$

$3.44 \mathrm{E}+02$

$3.45 \mathrm{E}+02$

$3.45 \mathrm{E}+02$

$3.46 \mathrm{E}+02$

$3.46 \mathrm{E}+02$

$3.47 \mathrm{E}+02$

$3.47 \mathrm{E}+02$

$3.48 \mathrm{E}+02$

$3.48 \mathrm{E}+02$

$3.49 \mathrm{E}+02$

$3.49 \mathrm{E}+02$

$3.50 \mathrm{E}+02$

$3.50 \mathrm{E}+02$

3. $51 \mathrm{E}+02$

3. $51 \mathrm{E}+02$

3. $52 \mathrm{E}+02$

3. $52 \mathrm{E}+02$

$3.53 \mathrm{E}+02$

$3.53 \mathrm{E}+02$
Dose statistics at graphical times, mrem/yr

\begin{tabular}{|c|c|c|c|c|c|c|c|}
\hline inimum & aximum & Mean & ledian & $0 \%$ & $5 \%$ & $97.5 \%$ & \\
\hline 2 & -06 & $E-08$ & $E-09$ & 08 & 7 & 7 & 0 \\
\hline$E-32$ & -06 & 8 & $3 E-09$ & 8 & 07 & 7 & 07 \\
\hline $.77 E-32$ & $3 E-06$ & $E-08$ & $E-09$ & $5 E-08$ & 07 & 07 & -07 \\
\hline$E-32$ & 06 & 8 & & 8 & & 7 & -07 \\
\hline $.78 E-32$ & -06 & 8 & 9 & & 7 & & $47 E-07$ \\
\hline $.78 E-32$ & -06 & $E-08$ & $E-09$ & 08 & T & $E-07$ & 07 \\
\hline 32 & 06 & 年 & -09 & -08 & $0^{\circ}$ & -07 & -07 \\
\hline $.79 E-32$ & $1.89 \mathrm{E}-06$ & $.80 \mathrm{E}-08$ & $1.46 \mathrm{E}-09$ & $12 E-08$ & $1.2+4 y$ & -07 & $59 E-07$ \\
\hline 32 & 06 & 08 & 09 & 08 & $r$ & -07 & -07 \\
\hline $.79 E-32$ & $1.92 \mathrm{E}-06$ & $86 \mathrm{E}-08$ & $3 E-09$ & -08 & $.27 \mathrm{E}-$ & -07 & $E-07$ \\
\hline-32 & -06 & 8 & 9 & & 7 & 7 & $E-07$ \\
\hline & & & & & & & -07 \\
\hline $.80 E-32$ & $1.95 \mathrm{E}-06$ & $6 \mathrm{E}-08$ & $3 E-09$ & $50 E-08$ & 地 & -07 & $E-07$ \\
\hline-32 & -06 & $E-08$ & 09 & 08 & 1 & Ti & $82 E-07$ \\
\hline 32 & 06 & 08 & 09 & 08 & -0.0 & 1 & -07 \\
\hline $81 E-32$ & 1.9 & 0 & -09 & 08 & 7 & 07 & -07 \\
\hline $81 E-32$ & $2.00 \mathrm{E}-06$ & $8 E-08$ & $7 E-09$ & $1 E-08$ & $1.36 \mathrm{E}-07$ & $78 \mathrm{E}-07$ & $93 E-07$ \\
\hline-32 & $2 E-06$ & $1 E-08$ & $1 E-09$ & 08 & 7 & -07 & $E-07$ \\
\hline 32 & $E-06$ & $E-08$ & 09 & 08 & & 1 & -07 \\
\hline-32 & -06 & -08 & -09 & 08 & & (- & $E-07$ \\
\hline $.82 E-32$ & $2.05 \mathrm{E}-06$ & -08 & -09 & & & & -07 \\
\hline $.07 E-31$ & $2.07 \mathrm{E}-06$ & 08 & 09 & & 2 & 0 & -07 \\
\hline $.08 E-31$ & $E-06$ & $E-08$ & -09 & $1 E-08$ & .44 & -07 & $17 E-07$ \\
\hline $.08 \mathrm{E}-31$ & $2.09 E-06$ & $.31 E-08$ & $6 E-09$ & $40 E-08$ & $1.46 \mathrm{E}-07$ & $6 \mathrm{E}-07$ & $21 E-07$ \\
\hline 31 & $2.10 \mathrm{E}-06$ & $E-08$ & 09 & 08 & & & -07 \\
\hline-31 & 06 & 08 & 09 & 08 & & & -07 \\
\hline $.09 E-31$ & $2.13 E-06$ & -08 & 9 & 8 & 1 & 7 & -07 \\
\hline $.09 \mathrm{E}-31$ & $2.14 \mathrm{E}-06$ & $3.45 E-08$ & $2.23 E-09$ & $7.79 \mathrm{E}-08$ & $1.52 \mathrm{E}-07$ & $.06 \mathrm{E}-07$ & $.37 E-07$ \\
\hline 1 & 6 & 8 & 9 & 8 & 7 & $t$ & 07 \\
\hline 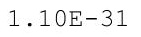 & $2.17 E-06$ & $3.52 \mathrm{E}-08$ & $2.32 \mathrm{E}-09$ & (5) & & r & $47 E-07$ \\
\hline 31 & $3 E-06$ & $5-08$ & $6 E-09$ & $7 E-08$ & 7 & 7 & $2 E-07$ \\
\hline-31 & $E-06$ & $E-08$ & & & & & 07 \\
\hline$E-31$ & $2.20 E-06$ & $E-08$ & 09 & 08 & 7 & 7 & $1 E-07$ \\
\hline $.11 E-31$ & $2.22 \mathrm{E}-06$ & $3.66 \mathrm{E}-08$ & $2.52 E-09$ & $5 E-08$ & $1.01 E-U /$ & $2 E-07$ & $66 E-07$ \\
\hline $12 \mathrm{E}-31$ & $2.23 E-06$ & $3.70 \mathrm{E}-08$ & & & & & • $1 \perp \mathrm{L}-\mathrm{U}$ \\
\hline $.12 \mathrm{E}-31$ & & & & & & & \\
\hline $.19 \mathrm{E}-31$ & 6 & & & 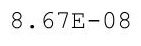 & & & 07 \\
\hline 1 & & & & 8 & 7 & 7 & -07 \\
\hline $4 E-31$ & $2.28 \mathrm{E}-06$ & $E-08$ & 09 & 08 & 7 & 07 & -07 \\
\hline $45 E-31$ & 2.2 & $E-08$ & 09 & 08 & 7 & & $6 E-07$ \\
\hline 1 & $2.31 E-06$ & & & & & & $U \perp E-U 1$ \\
\hline & $2.32 \mathrm{E}$ & 8 & & & & & 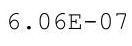 \\
\hline & 2 & & & 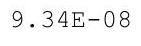 & 1 & & 1 \\
\hline 1 & 2 & $4.03 E-08$ & S & 8 & 7 & 07 & T \\
\hline $47 E-31$ & $2.36 E-06$ & $E-08$ & $E-09$ & 08 & 1. & 07 & -07 \\
\hline $.48 E-31$ & $37 E-06$ & $.11 \mathrm{E}-08$ & $.15 E-09$ & $69 E-08$ & $1.82 \mathrm{E}-07$ & $3.54 \mathrm{E}-07$ & $6.27 E-07$ \\
\hline
\end{tabular}


RESRAD-OFFSITE, Version 2.5

Title : RESRAD-OFFSITE External Gamma, Inhalation, and Soil Ingestion for Offsite Reside File : PBA-1_TC99-DOE-5-1.ROF

Summary of dose at graphical times, reptition 2 (continued)

Time

Years

$3.54 \mathrm{E}+02$

$3.54 \mathrm{E}+02$

$3.55 \mathrm{E}+02$

$3.55 \mathrm{E}+02$

$3.56 \mathrm{E}+02$

$3.56 \mathrm{E}+02$

$3.57 \mathrm{E}+02$

$3.57 \mathrm{E}+02$

$3.58 \mathrm{E}+02$

$3.58 \mathrm{E}+02$

$3.59 \mathrm{E}+02$

$3.59 \mathrm{E}+02$

$3.60 \mathrm{E}+02$

$3.60 \mathrm{E}+02$

$3.61 \mathrm{E}+02$

3. $61 \mathrm{E}+02$

$3.62 \mathrm{E}+02$

$3.62 \mathrm{E}+02$

$3.63 \mathrm{E}+02$

3. $64 \mathrm{E}+02$

$3.64 \mathrm{E}+02$

$3.65 \mathrm{E}+02$

$3.65 \mathrm{E}+02$

$3.66 \mathrm{E}+02$

$3.66 \mathrm{E}+02$

$3.67 \mathrm{E}+02$

3. $67 \mathrm{E}+02$

$3.68 \mathrm{E}+02$

$3.68 \mathrm{E}+02$

$3.69 \mathrm{E}+02$

$3.69 \mathrm{E}+02$

$3.70 \mathrm{E}+02$

$3.70 \mathrm{E}+02$

3. $71 \mathrm{E}+02$

$3.71 \mathrm{E}+02$

3. $72 \mathrm{E}+02$

$3.72 \mathrm{E}+02$

$3.73 \mathrm{E}+02$

$3.73 E+02$

$3.74 \mathrm{E}+02$

$3.74 \mathrm{E}+02$

$3.75 \mathrm{E}+02$

$3.75 \mathrm{E}+02$

$3.76 \mathrm{E}+02$

$3.76 \mathrm{E}+02$

$3.77 \mathrm{E}+02$
Dose statistics at graphical times, mrem/yr

\begin{tabular}{|c|c|c|c|c|c|c|c|}
\hline inimum & aximum & Mean & ledian & $90 \%$ & $5 \%$ & $97.5 \%$ & \\
\hline 1 & $E-06$ & $E-08$ & $q-09$ & -08 & -07 & -07 & 0 \\
\hline 31 & -06 & $E-08$ & $5-09$ & $3 E-$ & $6 E-07$ & -07 & 07 \\
\hline$E-31$ & $E-06$ & $E-08$ & $3 E-09$ & $1 E-07$ & \pm-07 & -07 & -07 \\
\hline $50 E-31$ & $E-06$ & $E-08$ & 9 & 7 & 7 & 07 & -07 \\
\hline-31 & -06 & -08 & 9 & 7 & 7 & 07 & $53 E-07$ \\
\hline-31 & -06 & $5 E-08$ & -09 & 07 & T & -07 & 07 \\
\hline PL & -06 & - & -09 & $1.05 \mathrm{E}-07$ & (1 & -07 & -07 \\
\hline $.52 E-31$ & $2.47 E-06$ & 4. $43 E-08$ & $3.62 \mathrm{E}-09$ & $1.07 \mathrm{E}-07$ & & -07 & $69 E-07$ \\
\hline 31 & -06 & 08 & 09 & 07 & 7 & -07 & -07 \\
\hline $.53 E-31$ & $0 E-06$ & $1 \mathrm{E}-08$ & -09 & -07 & 7 & -07 & $79 E-07$ \\
\hline 31 & -06 & 8 & 09 & & & 07 & $E-07$ \\
\hline & & & & & & & -07 \\
\hline $.54 \mathrm{E}-31$ & $E-06$ & $E-08$ & $E-09$ & $1.12 \mathrm{E}-07$ & 年 & -07 & $E-07$ \\
\hline $.30 \mathrm{E}-31$ & -06 & 要 & -09 & 07 & & -07 & -07 \\
\hline 31 & 06 & 08 & 09 & 07 & & ( & -07 \\
\hline $.32 E-31$ & -06 & 然 & -09 & 07 & 7 & -07 & -07 \\
\hline $.33 E-31$ & $9 \mathrm{E}-06$ & $0 \mathrm{E}-08$ & $E-09$ & $1.16 \mathrm{E}-07$ & $4 E-07$ & -07 & $.19 \mathrm{E}-07$ \\
\hline-31 & $50 E-06$ & $5 E-08$ & $7 E-09$ & 7 & $6 E-07$ & -07 & $25 E-07$ \\
\hline 31 & 06 & -08 & 09 & 7 & & 7 & -07 \\
\hline $36 E-31$ & -06 & $\mathrm{E}-08$ & -09 & 7 & 17 & -07 & -07 \\
\hline $.37 E-31$ & -06 & -08 & -09 & & & & -07 \\
\hline $38 E-31$ & $2.65 \mathrm{E}-06$ & -08 & 09 & 07 & & r & -07 \\
\hline $.39 E-31$ & $2.66 \mathrm{E}-06$ & $5.07 \mathrm{E}-08$ & 4. $62 \mathrm{E}-09$ & $1.23 \mathrm{E}-07$ & 2.20001 & $E-07$ & $.54 \mathrm{E}-07$ \\
\hline$E-31$ & $2.67 E-06$ & $1 E-08$ & $9 E-09$ & $1.25 \mathrm{E}-07$ & 7 & $7 E-07$ & $60 \mathrm{E}-07$ \\
\hline 31 & $2.69 \mathrm{E}-06$ & $6 E-08$ & 09 & & & 7 & -07 \\
\hline 31 & 06 & -08 & 09 & 7 & & & -07 \\
\hline$E-31$ & $1 E-06$ & $5.25 \mathrm{E}-08$ & -09 & $1.29 \mathrm{E}-07$ & & -07 & $78 \mathrm{E}-07$ \\
\hline $.43 E-31$ & $2.73 E-06$ & $5.29 E-08$ & $4.97 \mathrm{E}-09$ & $1.30 \mathrm{E}-07$ & $2.36 \mathrm{E}-07$ & $41 E-07$ & $.84 E-07$ \\
\hline $.44 E-31$ & $2.74 E-06$ & $5.34 \mathrm{E}-08$ & $4 E-09$ & $1.31 \mathrm{E}-07$ & 1 & -07 & $.90 E-07$ \\
\hline • & $2.75 E-06$ & 年 & $3 E-09$ & $1.03-4$ & - & -07 & $.96 \mathrm{E}-07$ \\
\hline 1 & $E-06$ & $E-08$ & $E-09$ & 7 & 7 & 7 & $E-07$ \\
\hline$E-31$ & $E-06$ & $E-08$ & $E-09$ & -07 & 7 & & $E-07$ \\
\hline $48 \mathrm{E}-31$ & $2.79 E-06$ & $3 E-08$ & $3 E-09$ & $1.37 E-07$ & 7 & 7 & $5 E-07$ \\
\hline $.49 \mathrm{E}-31$ & $2.80 \mathrm{E}-06$ & $5.57 \mathrm{E}-08$ & $5.47 \mathrm{E}-09$ & $1.38 \mathrm{E}-07$ & $2.50 \mathrm{E}-07$ & $50 E-07$ & $21 E-07$ \\
\hline $50 E-31$ & $2.82 E-06$ & $3.0<5-40$ & & & & & $.27 E-07$ \\
\hline$=$ & & & & & & & \\
\hline $.52 E-31$ & 2 & & & & & & 07 \\
\hline 1 & 2 & 8 & 9 & & 7 & 7 & -07 \\
\hline$E-31$ & $2.87 \mathrm{E}-06$ & $1 E-08$ & 09 & 07 & 7 & 7 & $2 E-07$ \\
\hline $5-31$ & $2.88 E-06$ & $E-08$ & 09 & 7 & & & $9 E-07$ \\
\hline 1 & 6 & & & 7 & & & -07 \\
\hline $57 E-31$ & $2.90 E-06$ & & & $1.50 \mathrm{E}-07$ & & & $.71 E-07$ \\
\hline $2.58 \mathrm{E}-31$ & 2 & 0 & & 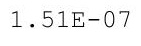 & & 7 & 1 \\
\hline $2597-31$ & 2 & & & 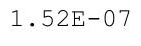 & 2 & 7 & T \\
\hline-31 & 2.9 & 08 & 09 & 1 . & 2 . & 07 & -07 \\
\hline $33 E-31$ & $2.96 E-06$ & $.16 \mathrm{E}-08$ & $50 E-09$ & $1.55 \mathrm{E}-07$ & $2.79 E-07$ & $.00 E-07$ & $8.96 \mathrm{E}-07$ \\
\hline
\end{tabular}


RESRAD-OFFSITE, Version 2.5

$\mathrm{T}^{1 / 2}$ Limit $=180$ days

Title : RESRAD-OFFSITE External Gamma, Inhalation, and Soil Ingestion for offsite Reside

File : PBA-1_TC99-DOE-5-1.ROF

Summary of dose at graphical times, reptition 2 (continued)

Time

Years

$3.77 \mathrm{E}+02$

$3.78 \mathrm{E}+02$

$3.78 \mathrm{E}+02$

$3.79 \mathrm{E}+02$

$3.79 \mathrm{E}+02$

$3.80 \mathrm{E}+02$

$3.80 \mathrm{E}+02$

$3.81 \mathrm{E}+02$

$3.81 \mathrm{E}+02$

$3.82 \mathrm{E}+02$

$3.82 \mathrm{E}+02$

$3.83 \mathrm{E}+02$

$3.83 \mathrm{E}+02$

$3.84 \mathrm{E}+02$

$3.85 \mathrm{E}+02$

$3.85 \mathrm{E}+02$

$3.86 \mathrm{E}+02$

3. $86 \mathrm{E}+02$

$3.87 \mathrm{E}+02$

$3.87 \mathrm{E}+02$

$3.88 \mathrm{E}+02$

$3.88 \mathrm{E}+02$

$3.89 \mathrm{E}+02$

$3.89 \mathrm{E}+02$

3. $90 \mathrm{E}+02$

$3.90 \mathrm{E}+02$

3. $91 \mathrm{E}+02$

3. $91 \mathrm{E}+02$

3. $92 \mathrm{E}+02$

3. $92 \mathrm{E}+02$

3. $93 \mathrm{E}+02$

3. $93 \mathrm{E}+02$

$3.94 \mathrm{E}+02$

3. $94 \mathrm{E}+02$

$3.95 \mathrm{E}+02$

$3.95 \mathrm{E}+02$

3. $96 \mathrm{E}+02$

$3.96 \mathrm{E}+02$

3. $97 \mathrm{E}+02$

3. $97 \mathrm{E}+02$

$3.98 \mathrm{E}+02$

3. $98 \mathrm{E}+02$

$3.99 \mathrm{E}+02$

3. $99 \mathrm{E}+02$

$4.00 \mathrm{E}+02$

$4.00 \mathrm{E}+02$
Dose statistics at graphical times, mrem/yr

\begin{tabular}{|c|c|c|c|c|c|c|c|}
\hline inimum & aximum & Mean & ledian & $0 \%$ & $5 \%$ & $97.5 \%$ & $3 \%$ \\
\hline 1 & -06 & -08 & $E-09$ & $6 E-07$ & 7 & 07 & 0 \\
\hline-31 & $3 E-06$ & $E-08$ & $8 E-09$ & $57 E-07$ & 07 & -07 & -07 \\
\hline $7 E-31$ & $2.99 E-06$ & $2 E-08$ & $7 E-09$ & $9 E-07$ & $6 E-07$ & -07 & -07 \\
\hline $2 E-31$ & 06 & $\mathrm{~F}-$ & & 7 & 7 & 07 & -07 \\
\hline-31 & -06 & 8 & 99 & 7 & 7 & 07 & $25 E-07$ \\
\hline-31 & -06 & $E-08$ & -09 & 07 & ( & -07 & -07 \\
\hline 31 & 06 & $E-08$ & -09 & 1.040 .01 & 1 & -07 & -07 \\
\hline $.71 E-31$ & $3.06 E-06$ & $6.58 \mathrm{E}-08$ & $7.27 E-09$ & 土 & & -07 & $E-07$ \\
\hline-31 & -06 & -08 & -09 & 7 & 7 & -07 & -07 \\
\hline $.80 E-31$ & -06 & -08 & 09 & 07 & 7 & -07 & -07 \\
\hline-31 & -06 & -08 & -09 & 7 & & -07 & $E-07$ \\
\hline & 06 & & & & & & -07 \\
\hline $.95 E-31$ & $3.12 \mathrm{E}-06$ & $.84 \mathrm{E}-08$ & $9 E-09$ & $1.12 \mathrm{E}-01$ & 年 & $52 E-07$ & $E-07$ \\
\hline $.00 \mathrm{E}-31$ & -06 & $E-08$ & -09 & I. & & -07 & -07 \\
\hline 31 & 06 & 08 & 09 & 07 & & -07 & -07 \\
\hline $.11 \mathrm{E}-31$ & -06 & -08 & -09 & -07 & 7 & -07 & -07 \\
\hline $.57 E-30$ & E-06 & $5 E-08$ & $E-09$ & $79 E-07$ & -07 & -07 & $95 E-07$ \\
\hline 30 & $3 E-06$ & $E-08$ & -09 & 7 & & 7 & $z-06$ \\
\hline $28 E-30$ & $3.20 \mathrm{E}-06$ & $.17 \mathrm{E}-08$ & $E-09$ & $2 E-07$ & & -07 & -06 \\
\hline $2 E-30$ & $3.21 \mathrm{E}-06$ & $E-08$ & -09 & $1.83 \mathrm{E}-01$ & & -07 & $z-06$ \\
\hline $5 E-30$ & -06 & -08 & -09 & -07 & & & -06 \\
\hline $\mathrm{E}-30$ & -06 & 08 & 09 & 07 & $3.26 \mathrm{E}-07$ & 7 & -06 \\
\hline $.44 \mathrm{E}-30$ & $3.25 \mathrm{E}-06$ & $7.40 \mathrm{E}-08$ & $8.94 \mathrm{E}-09$ & $1.88 \mathrm{E}-07$ & 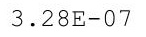 & ( & $.03 E-06$ \\
\hline $.49 \mathrm{E}-30$ & $3.26 \mathrm{E}-06$ & $7.46 \mathrm{E}-08$ & $5 E-09$ & $1.90 \mathrm{E}-07$ & $30 \mathrm{E}-07$ & $E-07$ & $04 \mathrm{E}-06$ \\
\hline $.53 E-30$ & $3.27 \mathrm{E}-06$ & $7.51 \mathrm{E}-08$ & $E-09$ & $2 E-07$ & & -07 & -06 \\
\hline 30 & -06 & $8-08$ & 09 & 7 & & 07 & -06 \\
\hline $5 E-30$ & $3.30 E-06$ & $E-08$ & -09 & $5 E-07$ & -01 & $E-07$ & $06 \mathrm{E}-06$ \\
\hline $.40 E-29$ & $3.31 E-06$ & $7.69 \mathrm{E}-08$ & $9.54 \mathrm{E}-09$ & $1.97 \mathrm{E}-07$ & $3.40 \mathrm{E}-07$ & $17 E-07$ & $.06 E-06$ \\
\hline $.95 E-27$ & $3.32 E-06$ & $7.75 \mathrm{E}-08$ & $9.67 E-09$ & I. & (2) & -07 & $E-06$ \\
\hline 要 & $3.33 E-06$ & $7.80 \mathrm{E}-08$ & $2 E-09$ & $0 E-07$ & - & -07 & $7 E-0$ \\
\hline 24 & $E-06$ & $86 E-08$ & $6 E-09$ & $2 E-07$ & 7 & 7 & -06 \\
\hline$E-23$ & $E-06$ & $2 E-08$ & $E-08$ & $3 E-07$ & 7 & 07 & -06 \\
\hline $.90 \mathrm{E}-22$ & $3.37 \mathrm{E}-06$ & $7.98 \mathrm{E}-08$ & $2 E-08$ & $2.05 \mathrm{E}-$ & 7 & $E-07$ & $9 \mathrm{E}-06$ \\
\hline $.44 \mathrm{E}-21$ & $3.38 \mathrm{E}-06$ & $8.04 \mathrm{E}-08$ & $1.04 \mathrm{E}-08$ & $2.06 \mathrm{E}-07$ & $3.55 \mathrm{E}-07$ & $3 E-07$ & $.10 \mathrm{E}-06$ \\
\hline $.72 E-21$ & $3.39 \mathrm{E}-00$ & $0 E-08$ & & & & & $10 \mathrm{~L}-\mathrm{n}$ \\
\hline 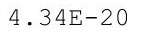 & & & & & & & - \\
\hline 9 & 6 & & 8 & 7 & & 7 & -0 \\
\hline 19 & $E-06$ & $E-08$ & 8 & 7 & 7 & 7 & -06 \\
\hline$E-18$ & $E-06$ & -08 & -08 & $5 E-07$ & 7 & 07 & $3 E-06$ \\
\hline$E-18$ & 6 & -08 & 08 & 7 & 7 & & -06 \\
\hline 17 & & & & & & & -00 \\
\hline $.74 E-17$ & & & & $2.19 E-07$ & & & $.15 E-06$ \\
\hline & & & & 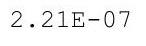 & & & $1.16 \mathrm{E}-06$ \\
\hline $725-16$ & -5 & & & 1 & 7 & 7 & \\
\hline-16 & -06 & 8. & 1 & 07 & 7 & 07 & 1.1 \\
\hline $27 E-16$ & $3.53 E-06$ & $.78 E-08$ & $.20 E-08$ & $2.26 \mathrm{E}-07$ & $3.90 \mathrm{E}-07$ & $7.01 \mathrm{E}-07$ & $1.18 \mathrm{E}-06$ \\
\hline
\end{tabular}


RESRAD-OFFSITE, Version 2.5

Title : RESRAD-OFFSITE External Gamma, Inhalation, and Soil Ingestion for Offsite Reside

File : PBA-1_TC99-DOE-5-1.ROF

Summary of dose at graphical times, reptition 2 (continued)

Time

Years

$4.01 \mathrm{E}+02$

$4.01 \mathrm{E}+02$

$4.02 \mathrm{E}+02$

$4.02 \mathrm{E}+02$

$4.03 E+02$

$4.03 \mathrm{E}+02$

$4.04 \mathrm{E}+02$

$4.05 \mathrm{E}+02$

$4.05 \mathrm{E}+02$

$4.06 \mathrm{E}+02$

$4.06 \mathrm{E}+02$

$4.07 \mathrm{E}+02$

$4.07 \mathrm{E}+02$

$4.08 \mathrm{E}+02$

$4.08 \mathrm{E}+02$

$4.09 \mathrm{E}+02$

$4.09 \mathrm{E}+02$

$4.10 \mathrm{E}+02$

$4.10 \mathrm{E}+02$

$4.11 \mathrm{E}+02$

$4.11 \mathrm{E}+02$

$4.12 \mathrm{E}+02$

$4.12 \mathrm{E}+02$

$4.13 \mathrm{E}+02$

$4.13 \mathrm{E}+02$

$4.14 \mathrm{E}+02$

$4.14 \mathrm{E}+02$

$4.15 \mathrm{E}+02$

$4.15 \mathrm{E}+02$

$4.16 \mathrm{E}+02$

$4.16 \mathrm{E}+02$

$4.17 \mathrm{E}+02$

$4.17 \mathrm{E}+02$

$4.18 \mathrm{E}+02$

$4.18 \mathrm{E}+02$

$4.19 \mathrm{E}+02$

$4.19 \mathrm{E}+02$

$4.20 \mathrm{E}+02$

$4.20 \mathrm{E}+02$

$4.21 \mathrm{E}+02$

4. $21 \mathrm{E}+02$

4. $22 \mathrm{E}+02$

4. $22 \mathrm{E}+02$

$4.23 \mathrm{E}+02$

$4.23 \mathrm{E}+02$

$4.24 \mathrm{E}+02$
Dose statistics at graphical times, mrem/yr

\begin{tabular}{|c|c|c|c|c|c|c|c|}
\hline inimum & Maximum & Mean & Median & $90 \%$ & $95 \frac{\circ}{\circ}$ & $7.5 \%$ & $9 \%$ \\
\hline $1.12 \mathrm{E}-15$ & $3.54 \mathrm{E}-06$ & $8.84 \mathrm{E}-08$ & $1.22 \mathrm{E}-08$ & $2.28 \mathrm{E}-07$ & $3.93 \mathrm{E}-07$ & $7.05 \mathrm{E}-07$ & $1.18 \mathrm{E}-06$ \\
\hline $1.91 \mathrm{E}-15$ & $3.55 E-06$ & $8.91 \mathrm{E}-08$ & $1.23 \mathrm{E}-08$ & $2.29 \mathrm{E}-07$ & $3.96 \mathrm{E}-07$ & $7.10 \mathrm{E}-07$ & $1.19 \mathrm{E}-06$ \\
\hline $3.15 \mathrm{E}-15$ & $3.56 \mathrm{E}-06$ & $8.97 \mathrm{E}-08$ & $1.25 \mathrm{E}-08$ & $2.31 \mathrm{E}-07$ & $3.99 \mathrm{E}-07$ & $7.14 \mathrm{E}-07$ & $1.20 \mathrm{E}-06$ \\
\hline $5.04 \mathrm{E}-15$ & $3.58 \mathrm{E}-06$ & $9.03 \mathrm{E}-08$ & $1.26 \mathrm{E}-08$ & $2.33 \mathrm{E}-07$ & $4.02 \mathrm{E}-07$ & $7.19 \mathrm{E}-07$ & $1.20 \mathrm{E}-06$ \\
\hline $7.84 \mathrm{E}-15$ & $3.59 \mathrm{E}-06$ & $9.10 \mathrm{E}-08$ & $1.28 \mathrm{E}-08$ & $2.35 \mathrm{E}-07$ & $4.06 \mathrm{E}-07$ & $7.24 \mathrm{E}-07$ & $.21 \mathrm{E}-06$ \\
\hline $1.19 \mathrm{E}-14$ & $3.60 \mathrm{E}-06$ & $9.16 \mathrm{E}-08$ & $1.30 \mathrm{E}-08$ & $2.37 \mathrm{E}-07$ & $.09 \mathrm{E}-07$ & $7.29 \mathrm{E}-07$ & $1.22 \mathrm{E}-06$ \\
\hline $1.75 \mathrm{E}-14$ & $3.61 \mathrm{E}-06$ & $9.23 \mathrm{E}-08$ & $1.31 \mathrm{E}-08$ & $2.39 \mathrm{E}-07$ & $12 \mathrm{E}-07$ & $7.34 \mathrm{E}-07$ & $1.22 \mathrm{E}-06$ \\
\hline $2.54 \mathrm{E}-14$ & $3.62 \mathrm{E}-06$ & $9.29 \mathrm{E}-08$ & $1.33 \mathrm{E}-08$ & $2.41 \mathrm{E}-07$ & $15 E-07$ & $7.39 \mathrm{E}-07$ & $1.23 \mathrm{E}-06$ \\
\hline $3.60 \mathrm{E}-14$ & $3.64 \mathrm{E}-06$ & $9.36 \mathrm{E}-08$ & $1.35 \mathrm{E}-08$ & $2.43 \mathrm{E}-07$ & $4.18 \mathrm{E}-07$ & $7.44 \mathrm{E}-07$ & $1.24 \mathrm{E}-06$ \\
\hline $02 \mathrm{E}-14$ & $3.65 E-06$ & $9.43 \mathrm{E}-08$ & $1.36 \mathrm{E}-08$ & $2.45 \mathrm{E}-07$ & $4.21 \mathrm{E}-07$ & $7.49 \mathrm{E}-07$ & $1.24 \mathrm{E}-06$ \\
\hline $6.87 E-14$ & $3.66 \mathrm{E}-06$ & $9.49 \mathrm{E}-08$ & $1.38 \mathrm{E}-08$ & $2.47 \mathrm{E}-07$ & $4.24 \mathrm{E}-07$ & $7.54 \mathrm{E}-07$ & $1.25 \mathrm{E}-06$ \\
\hline $9.26 \mathrm{E}-14$ & $3.67 \mathrm{E}-06$ & $9.56 \mathrm{E}-08$ & $1.40 \mathrm{E}-08$ & $2.48 \mathrm{E}-07$ & $4.27 \mathrm{E}-07$ & $7.59 \mathrm{E}-07$ & $1.26 \mathrm{E}-06$ \\
\hline $1.23 \mathrm{E}-13$ & $3.68 \mathrm{E}-06$ & $9.63 \mathrm{E}-08$ & $1.42 \mathrm{E}-08$ & $2.50 \mathrm{E}-07$ & $4.31 \mathrm{E}-07$ & $7.63 \mathrm{E}-07$ & $1.26 \mathrm{E}-06$ \\
\hline $1.61 \mathrm{E}-13$ & $3.70 \mathrm{E}-06$ & $9.69 \mathrm{E}-08$ & $1.43 \mathrm{E}-08$ & $2.51 \mathrm{E}-07$ & $4.34 \mathrm{E}-07$ & $7.68 \mathrm{E}-07$ & $1.27 \mathrm{E}-06$ \\
\hline $2.09 \mathrm{E}-13$ & $3.71 E-06$ & $9.76 \mathrm{E}-08$ & $1.45 \mathrm{E}-08$ & $2.53 \mathrm{E}-07$ & $4.37 \mathrm{E}-07$ & $7.72 \mathrm{E}-07$ & $1.28 \mathrm{E}-06$ \\
\hline $2.67 \mathrm{E}-13$ & $3.72 \mathrm{E}-06$ & $9.83 E-08$ & $1.47 \mathrm{E}-08$ & $2.54 \mathrm{E}-07$ & $4.40 \mathrm{E}-07$ & $7.76 \mathrm{E}-07$ & $1.29 \mathrm{E}-06$ \\
\hline $3.38 \mathrm{E}-13$ & $3.73 E-06$ & $9.89 \mathrm{E}-08$ & $1.48 \mathrm{E}-08$ & $2.56 \mathrm{E}-07$ & $4.44 \mathrm{E}-07$ & $7.81 \mathrm{E}-07$ & $1.29 \mathrm{E}-06$ \\
\hline $4.24 \mathrm{E}-13$ & $3.74 \mathrm{E}-06$ & $9.96 \mathrm{E}-08$ & $1.50 \mathrm{E}-08$ & $2.58 \mathrm{E}-07$ & $4.47 \mathrm{E}-07$ & $7.85 \mathrm{E}-07$ & $1.30 \mathrm{E}-06$ \\
\hline $5.26 \mathrm{E}-13$ & $3.75 E-06$ & $1.00 \mathrm{E}-07$ & $1.52 \mathrm{E}-08$ & $2.60 \mathrm{E}-07$ & $4.50 \mathrm{E}-07$ & $7.90 \mathrm{E}-07$ & $1.31 \mathrm{E}-06$ \\
\hline $47 \mathrm{E}-13$ & $3.77 \mathrm{E}-06$ & $1.01 \mathrm{E}-07$ & $1.53 \mathrm{E}$ & $2.62 \mathrm{E}-$ & 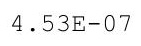 & 701 & $32 E-06$ \\
\hline .8 & & & 8 & & & & 06 \\
\hline 9.5 & 3 & 1 & 8 & 7 & 7 & 7 & 06 \\
\hline $1.14 \mathrm{E}-12$ & $3.80 \mathrm{E}-06$ & $1.03 \mathrm{E}-07$ & $1.59 \mathrm{E}-08$ & $2.68 \mathrm{E}-07$ & $4.63 \mathrm{E}-07$ & $8.08 \mathrm{E}-07$ & $1.34 \mathrm{E}-06$ \\
\hline $1.36 \mathrm{E}-12$ & $3.81 \mathrm{E}-06$ & $1.04 \mathrm{E}-07$ & $1.60 \mathrm{E}-08$ & $2.70 \mathrm{E}-07$ & $4.66 \mathrm{E}-07$ & $8.12 \mathrm{E}-07$ & $1.35 \mathrm{E}-06$ \\
\hline $1.61 \mathrm{E}-12$ & $3.82 \mathrm{E}-06$ & $1.04 \mathrm{E}-07$ & $1.62 \mathrm{E}-08$ & $2.72 \mathrm{E}-07$ & $4.69 \mathrm{E}-07$ & $8.17 \mathrm{E}-07$ & $1.35 \mathrm{E}-06$ \\
\hline $1.89 \mathrm{E}-12$ & $3.84 \mathrm{E}-06$ & $1.05 \mathrm{E}-07$ & $1.64 \mathrm{E}-08$ & $2.74 \mathrm{E}-07$ & $4.72 \mathrm{E}-07$ & $8.22 \mathrm{E}-07$ & $1.36 \mathrm{E}-06$ \\
\hline $2.21 \mathrm{E}-12$ & $3.85 \mathrm{E}-06$ & $1.06 \mathrm{E}-07$ & $1.66 \mathrm{E}-08$ & $2.76 \mathrm{E}-07$ & $4.75 \mathrm{E}-07$ & $8.27 \mathrm{E}-07$ & $1.37 \mathrm{E}-06$ \\
\hline $2.57 \mathrm{E}-12$ & $3.86 \mathrm{E}-06$ & $1.07 \mathrm{E}-07$ & $1.68 \mathrm{E}-08$ & $2.78 \mathrm{E}-07$ & $4.79 \mathrm{E}-07$ & $8.33 E-07$ & $1.37 \mathrm{E}-06$ \\
\hline $2.97 \mathrm{E}-12$ & $3.87 \mathrm{E}-06$ & $1.07 \mathrm{E}-07$ & $1.70 \mathrm{E}-08$ & $2.80 \mathrm{E}-07$ & $4.82 \mathrm{E}-07$ & $8.38 \mathrm{E}-07$ & $1.38 \mathrm{E}-06$ \\
\hline $3.41 \mathrm{E}-12$ & $3.88 \mathrm{E}-06$ & $1.08 \mathrm{E}-07$ & $1.72 \mathrm{E}$ & 2.02 & 7 & 0.44 & $1.39 \mathrm{E}-06$ \\
\hline $3.90 \mathrm{E}-12$ & 3 & 1 & 8 & 7 & 7 & 0.0 & $1.40 \mathrm{E}-06$ \\
\hline $4.44 \mathrm{E}-12$ & $3.90 \mathrm{E}-06$ & $1.09 \mathrm{E}-07$ & $1.76 \mathrm{E}-08$ & $2.86 \mathrm{E}-07$ & $4.92 \mathrm{E}-07$ & $8.55 \mathrm{E}-07$ & $1.41 \mathrm{E}-06$ \\
\hline $03 E-12$ & $3.92 \mathrm{E}-06$ & $1.10 \mathrm{E}-07$ & $1.78 \mathrm{E}-08$ & $2.87 \mathrm{E}-07$ & $4.95 \mathrm{E}-07$ & $8.60 \mathrm{E}-07$ & $1.41 \mathrm{E}-06$ \\
\hline $5.68 \mathrm{E}-12$ & $3.93 \mathrm{E}-06$ & $1.11 \mathrm{E}-07$ & $1.80 \mathrm{E}-08$ & $2.89 \mathrm{E}-07$ & $4.98 \mathrm{E}-07$ & $8.65 \mathrm{E}-07$ & $1.42 \mathrm{E}-06$ \\
\hline $6.38 \mathrm{E}-12$ & $3.94 \mathrm{E}-06$ & $1.12 \mathrm{E}-07$ & $1.82 \mathrm{E}-08$ & $2.91 \mathrm{E}-07$ & $5.00 \mathrm{E}-07$ & $8.69 \mathrm{E}-07$ & $1.43 \mathrm{E}-06$ \\
\hline $7.15 \mathrm{E}-12$ & $3.95 \mathrm{E}-06$ & $1.12 \mathrm{E}-07$ & $1.84 \mathrm{E}-08$ & $2.93 \mathrm{E}-07$ & $5.03 \mathrm{E}-07$ & $8.74 \mathrm{E}-07$ & $1.44 \mathrm{E}-06$ \\
\hline $7.97 \mathrm{E}-12$ & $3.96 \mathrm{E}-06$ & $1.13 \mathrm{E}-07$ & $1.86 \mathrm{E}-08$ & $2.96 \mathrm{E}-07$ & $5.06 \mathrm{E}-07$ & $8.78 \mathrm{E}-07$ & $1.44 \mathrm{E}-06$ \\
\hline $8.86 \mathrm{E}-12$ & $3.97 \mathrm{E}-06$ & $1.14 \mathrm{E}-07$ & $1.88 \mathrm{E}-08$ & $2.98 \mathrm{E}-07$ & $5.09 \mathrm{E}-07$ & $8.82 \mathrm{E}-07$ & $1.45 \mathrm{E}-06$ \\
\hline $9.82 \mathrm{E}-12$ & $3.98 \mathrm{E}-06$ & $1.15 \mathrm{E}-07$ & $1.91 \mathrm{E}-08$ & $3.01 \mathrm{E}-07$ & $5.11 \mathrm{E}-07$ & $8.87 \mathrm{E}-07$ & $1.46 \mathrm{E}-06$ \\
\hline $1.08 \mathrm{E}-11$ & $3.99 \mathrm{E}-06$ & $1.15 \mathrm{E}-07$ & $1.93 \mathrm{E}-08$ & $3.03 \mathrm{E}-07$ & $5.14 \mathrm{E}-07$ & $8.91 \mathrm{E}-07$ & $1.47 \mathrm{E}-06$ \\
\hline $1.19 \mathrm{E}-11$ & $4.01 \mathrm{E}-06$ & $1.16 \mathrm{E}-07$ & $1.95 \mathrm{E}-08$ & $3.05 \mathrm{E}-07$ & $5.17 \mathrm{E}-07$ & $8.96 \mathrm{E}-07$ & $1.47 \mathrm{E}-06$ \\
\hline $1.31 \mathrm{E}-11$ & $4.02 \mathrm{E}-06$ & $1.17 \mathrm{E}-07$ & $1.97 \mathrm{E}-08$ & $3.08 \mathrm{E}-07$ & $5.20 \mathrm{E}-07$ & $9.01 \mathrm{E}-07$ & $1.48 \mathrm{E}-06$ \\
\hline $1.44 \mathrm{E}-11$ & $4.03 E-06$ & $1.18 \mathrm{E}-07$ & $1.99 \mathrm{E}-08$ & $3.10 \mathrm{E}-07$ & $5.23 \mathrm{E}-07$ & $9.06 \mathrm{E}-07$ & $1.49 \mathrm{E}-06$ \\
\hline $1.57 \mathrm{E}-11$ & $4.04 \mathrm{E}-06$ & $1.18 \mathrm{E}-07$ & $2.01 \mathrm{E}-08$ & $3.12 \mathrm{E}-07$ & $5.25 \mathrm{E}-07$ & $9.12 \mathrm{E}-07$ & $1.50 \mathrm{E}-06$ \\
\hline $1.71 \mathrm{E}-11$ & $4.05 \mathrm{E}-06$ & $1.19 \mathrm{E}-07$ & $2.04 \mathrm{E}-08$ & $3.15 \mathrm{E}-07$ & $5.28 \mathrm{E}-07$ & $9.17 \mathrm{E}-07$ & $1.50 \mathrm{E}-06$ \\
\hline $.86 \mathrm{E}-11$ & $4.06 \mathrm{E}-06$ & $1.20 \mathrm{E}-07$ & $2.06 \mathrm{E}-08$ & $3.17 \mathrm{E}-07$ & $5.31 \mathrm{E}-07$ & $9.22 \mathrm{E}-07$ & $1.51 \mathrm{E}-06$ \\
\hline
\end{tabular}


RESRAD-OFFSITE, Version 2.5

Title : RESRAD-OFFSITE External Gamma, Inhalation, and Soil Ingestion for Offsite Reside

File : PBA-1_TC99-DOE-5-1.ROF

Summary of dose at graphical times, reptition 2 (continued)

Time

Years

$4.25 \mathrm{E}+02$

$4.25 \mathrm{E}+02$

$4.26 \mathrm{E}+02$

$4.26 \mathrm{E}+02$

$4.27 \mathrm{E}+02$

$4.27 \mathrm{E}+02$

$4.28 \mathrm{E}+02$

$4.28 \mathrm{E}+02$

$4.29 \mathrm{E}+02$

$4.29 \mathrm{E}+02$

4. $30 \mathrm{E}+02$

4. $30 \mathrm{E}+02$

$4.31 \mathrm{E}+02$

4. $31 \mathrm{E}+02$

4. $32 \mathrm{E}+02$

4. $32 \mathrm{E}+02$

$4.33 \mathrm{E}+02$

$4.33 \mathrm{E}+02$

$4.34 \mathrm{E}+02$

$4.34 \mathrm{E}+02$

$4.35 \mathrm{E}+02$

4. $35 \mathrm{E}+02$

$4.36 \mathrm{E}+02$

$4.36 \mathrm{E}+02$

$4.37 \mathrm{E}+02$

$4.37 \mathrm{E}+02$

$4.38 \mathrm{E}+02$

$4.38 \mathrm{E}+02$

$4.39 \mathrm{E}+02$

$4.39 \mathrm{E}+02$

$4.40 \mathrm{E}+02$

$4.40 \mathrm{E}+02$

$4.41 \mathrm{E}+02$

$4.41 \mathrm{E}+02$

$4.42 \mathrm{E}+02$

$4.42 \mathrm{E}+02$

$4.43 \mathrm{E}+02$

$4.43 \mathrm{E}+02$

$4.44 \mathrm{E}+02$

$4.45 \mathrm{E}+02$

4. $45 \mathrm{E}+02$

4. $46 \mathrm{E}+02$

$4.46 \mathrm{E}+02$

$4.47 \mathrm{E}+02$

$4.47 \mathrm{E}+02$

$4.48 \mathrm{E}+02$
Dose statistics at graphical times, mrem/yr

\begin{tabular}{|c|c|c|c|c|c|c|c|}
\hline inimum & aximum & Mean & ledian & $90 \%$ & $5 \%$ & $97.5 \%$ & $\%$ \\
\hline 1 & -06 & -07 & $E-08$ & -07 & 07 & 07 & 0 \\
\hline 11 & -06 & $E-07$ & $E-08$ & 7 & 07 & 7 & -06 \\
\hline E-11 & $9 E-06$ & $2 E-07$ & $E-08$ & $4 \mathrm{E}-07$ & 07 & 07 & -06 \\
\hline E-11 & $E-06$ & $23 \mathrm{E}-$ & 08 & 7 & & & -06 \\
\hline $2 E-11$ & -06 & -07 & -08 & 07 & 07 & -07 & $55 E-06$ \\
\hline $92 E-11$ & -06 & $.24 \mathrm{E}-07$ & -08 & $E-07$ & $O E-01$ & -07 & $.56 \mathrm{E}-06$ \\
\hline 11 & -06 & 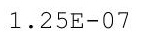 & -08 & $35-$ & $.51 \mathrm{E}-07$ & 7 & 06 \\
\hline $.35 E-11$ & $4.15 E-06$ & $\begin{array}{ll}0 \\
20\end{array}$ & $2.25 E-08$ & 至 & & -07 & $.57 E-06$ \\
\hline 11 & 06 & 1 & 08 & 07 & $r$ & -07 & $58 E-06$ \\
\hline $.82 E-11$ & $4.17 \mathrm{E}-06$ & $1.28 E-07$ & $9 E-08$ & $41 E-07$ & $9 E-07$ & -07 & $E-06$ \\
\hline-11 & -06 & $8 E-07$ & -08 & 7 & & 07 & $E-06$ \\
\hline-11 & 06 & -07 & & & & -07 & -06 \\
\hline $.58 \mathrm{E}-11$ & $4.20 \mathrm{E}-06$ & $.30 E-01$ & $7 \mathrm{E}-08$ & $\pm 8-01$ & (1) & $E-07$ & -0 \\
\hline-11 & $4.21 \mathrm{E}-06$ & t & -08 & (1) & & -07 & $E-06$ \\
\hline 11 & 06 & . & 08 & 07 & 1 & -07 & -06 \\
\hline $.44 \mathrm{E}-11$ & -06 & 1.08 & -08 & 7 & 7 & -06 & -06 \\
\hline $.74 \mathrm{E}-11$ & $4.24 \mathrm{E}-06$ & $.33 E-07$ & $6 \mathrm{E}-08$ & $58 E-07$ & $81 E-07$ & $E-06$ & $.64 \mathrm{E}-06$ \\
\hline$E-11$ & $6 E-06$ & $34 E-07$ & $9 E-08$ & $E-07$ & $E-07$ & $E-06$ & $65 E-06$ \\
\hline 11 & -06 & 1 & 08 & 1 & & -06 & -06 \\
\hline $.71 E-11$ & -06 & $1.36 \mathrm{E}$ & -08 & 7 & & -06 & -06 \\
\hline $.06 \mathrm{E}-11$ & $4.29 \mathrm{E}-06$ & 1. & -08 & -07 & & 0 & -06 \\
\hline-11 & 06 & $1.37 \mathrm{E}-07$ & 8 & 7 & & 6 & -06 \\
\hline $.77 E-11$ & $4.31 E-06$ & $1.38 E-07$ & $2.62 E-08$ & $72 E-07$ & $015=7$ & $4 E-06$ & $69 E-06$ \\
\hline $.04 \mathrm{E}-11$ & 4. $32 E-06$ & $1.39 \mathrm{E}-07$ & $2.64 \mathrm{E}-08$ & $75 E-07$ & $04 \mathrm{E}-07$ & $5 E-06$ & $70 \mathrm{E}-06$ \\
\hline$E-11$ & $4.33 E-06$ & $.40 \mathrm{E}-07$ & -08 & -07 & -07 & -06 & $E-06$ \\
\hline 11 & 06 & 7 & .08 & 07 & & & 06 \\
\hline $.85 E-11$ & $4.35 E-06$ & $1 \cdot 4+\infty-1$ & $3 E-08$ & 7 & & 6 & -06 \\
\hline $.13 E-11$ & $4.36 E-06$ & $\cdot 4 \angle 5-U 1$ & $5 E-08$ & $33 E-07$ & 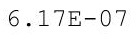 & $7 E-06$ & $.73 E-06$ \\
\hline 1 & 6 & the & $78 E-08$ & 7 & $20 E-01$ & $08 E-06$ & $74 \mathrm{E}-06$ \\
\hline 1 & - & - -5 & 8 & - & -5 & se & - \\
\hline 11 & $9 F-06$ & & $3 E-08$ & & & $E-06$ & $5 E-06$ \\
\hline$E-10$ & $0 F-06$ & $165-07$ & $6 E-08$ & $2 E-07$ & $D E-07$ & 6 & $76 E-06$ \\
\hline & & & & -07 & -07 & -06 & 06 \\
\hline $.09 E-10$ & $4.42 E-06$ & $1.47 \mathrm{E}-07$ & $2.92 E-08$ & $96 E-07$ & $37 E-07$ & $10 E-06$ & $.78 \mathrm{E}-06$ \\
\hline $12 \mathrm{E}-10$ & $4.43 E-06$ & $1.405-01$ & $2.94 E-08$ & & & $.11 \mathrm{E}-06$ & . \\
\hline-0 & & & & & & & \\
\hline $18 \mathrm{~F}-10$ & & $1.50 \mathrm{E}-07$ & & & & & 06 \\
\hline 0 & & & & & & & 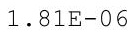 \\
\hline & & & & & 07 & .06 & 06 \\
\hline $28 E-10$ & $4.48 E-06$ & $1.53 E-07$ & $E-08$ & 7 & 7 & & $3 E-06$ \\
\hline $2 E-10$ & & $\pm \cdot$ & & & & & -0 \\
\hline 10 & & $1.34 E-01$ & & 1 & & & $045-00$ \\
\hline . $30 \mathrm{E}-10$ & & 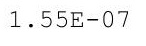 & & 1 & & & 00 \\
\hline the & 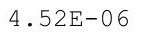 & & . & $20+$ & 7 & 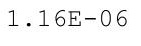 & . \\
\hline $4 E-10$ & -06 & $E-07$ & 08 & 4.2 & 07 & 06 & -06 \\
\hline $.48 E-10$ & $4.54 E-06$ & $1.58 \mathrm{E}-07$ & $.26 \mathrm{E}-08$ & $4.24 \mathrm{E}-07$ & $6.82 E-07$ & $1.17 \mathrm{E}-06$ & $1.87 \mathrm{E}-06$ \\
\hline
\end{tabular}


RESRAD-OFFSITE, Version 2.5

Title : RESRAD-OFFSITE External Gamma, Inhalation, and Soil Ingestion for offsite Reside File : PBA-1_TC99-DOE-5-1.ROF

Summary of dose at graphical times, reptition 2 (continued)

Time

Years

$4.48 \mathrm{E}+02$

$4.49 \mathrm{E}+02$

$4.49 \mathrm{E}+02$

$4.50 \mathrm{E}+02$

$4.50 \mathrm{E}+02$

4. $51 \mathrm{E}+02$

4. $51 \mathrm{E}+02$

4. $52 \mathrm{E}+02$

4. $52 \mathrm{E}+02$

$4.53 \mathrm{E}+02$

4. $53 \mathrm{E}+02$

4. $54 \mathrm{E}+02$

$4.54 \mathrm{E}+02$

4. $55 \mathrm{E}+02$

4. $55 \mathrm{E}+02$

4. $56 \mathrm{E}+02$

$4.56 \mathrm{E}+02$

4. $57 \mathrm{E}+02$

$4.57 \mathrm{E}+02$

$4.58 \mathrm{E}+02$

$4.58 \mathrm{E}+02$

$4.59 \mathrm{E}+02$

$4.59 \mathrm{E}+02$

$4.60 \mathrm{E}+02$

$4.60 \mathrm{E}+02$

$4.61 \mathrm{E}+02$

4. $61 \mathrm{E}+02$

$4.62 \mathrm{E}+02$

4. $62 \mathrm{E}+02$

4. $63 \mathrm{E}+02$

$4.63 \mathrm{E}+02$

4. $64 \mathrm{E}+02$

$4.65 \mathrm{E}+02$

$4.65 \mathrm{E}+02$

$4.66 \mathrm{E}+02$

$4.66 \mathrm{E}+02$

$4.67 \mathrm{E}+02$

$4.67 \mathrm{E}+02$

$4.68 \mathrm{E}+02$

$4.68 \mathrm{E}+02$

$4.69 \mathrm{E}+02$

$4.69 \mathrm{E}+02$

$4.70 \mathrm{E}+02$

$4.70 \mathrm{E}+02$

$4.71 \mathrm{E}+02$

$4.71 E+02$
Dose statistics at graphical times, mrem/yr

\begin{tabular}{|c|c|c|c|c|c|c|c|}
\hline inimum & aximum & Mean & ledian & $90 \%$ & $5 \%$ & $97.5 \%$ & $\%$ \\
\hline 0 & -06 & $E-07$ & -08 & -07 & 7 & 6 & 0 \\
\hline 10 & -06 & $E-07$ & $E-08$ & $4.29 E-07$ & 07 & 06 & -06 \\
\hline-10 & $E-06$ & $E-07$ & -08 & $1 \mathrm{E}-07$ & 07 & 06 & -06 \\
\hline$E-10$ & $3 E-06$ & $E-07$ & $E-08$ & $2 E-07$ & & & -06 \\
\hline $5 E-10$ & 06 & & & 7 & & 06 & $91 E-06$ \\
\hline $69 E-10$ & $E-06$ & $E-07$ & -08 & 07 & 4 1 & -06 & -06 \\
\hline 10 & -06 & 14 & -08 & i & 1 & -06 & -0 \\
\hline $.76 \mathrm{E}-10$ & $1 E-06$ & • & -08 & $4.43 E-07$ & & -06 & $.94 \mathrm{E}-06$ \\
\hline 10 & 06 & 1 & 08 & 07 & $r$ & .06 & -06 \\
\hline $.84 \mathrm{E}-10$ & $63 E-06$ & $57 E-07$ & $E-08$ & $49 E-07$ & 7 & -06 & $5 E-06$ \\
\hline-10 & -06 & & & 7 & & 06 & $E-06$ \\
\hline & 06 & & & & & & 06 \\
\hline $.96 \mathrm{E}-10$ & $4.66 \mathrm{E}-06$ & 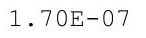 & $E-08$ & $4.59 \mathrm{E}-01$ & $21 \mathrm{~L}-0$ & -06 & $E-0$ \\
\hline$E-10$ & -06 & r & -08 & $4.0 \angle D-01$ & & -06 & $99 \mathrm{E}-06$ \\
\hline 10 & 06 & r & 08 & 07 & 1 & 06 & -06 \\
\hline $.08 \mathrm{E}-10$ & -06 & Lie & -08 & -07 & 7 & -06 & -06 \\
\hline $.12 \mathrm{E}-10$ & $0 E-06$ & $1.73 E-07$ & $1 \mathrm{E}-08$ & $4.71 E-07$ & $40 E-07$ & $.26 \mathrm{E}-06$ & $01 \mathrm{E}-06$ \\
\hline$E-10$ & $1 E-06$ & $4 E-07$ & $4 E-08$ & $4 E-07$ & $3 E-07$ & $E-06$ & $E-06$ \\
\hline 10 & $E-06$ & 1 & 08 & 1 & & 6 & -06 \\
\hline $25 E-10$ & -06 & 1.7 & -08 & $E-07$ & & 06 & -06 \\
\hline $9 E-10$ & $4.73 E-06$ & 土. & -08 & -07 & & 0 & -06 \\
\hline $3 E-10$ & -06 & 1. & 08 & 07 & & 06 & -06 \\
\hline $38 E-10$ & $.75 E-06$ & $1.79 \mathrm{E}-07$ & $1 E-08$ & $86 E-07$ & $625=07$ & $.29 E-06$ & $06 E-06$ \\
\hline$E-10$ & $6 \mathrm{E}-06$ & $1.80 \mathrm{E}-07$ & $4 \mathrm{E}-08$ & $88 E-07$ & ( & $.30 E-06$ & $7 E-06$ \\
\hline$E-10$ & $4.77 \mathrm{E}-06$ & $.81 \mathrm{E}-07$ & $8 E-08$ & & -07 & 6 & $E-06$ \\
\hline 10 & 06 & 7 & 08 & 7 & & & 06 \\
\hline $6 E-10$ & -06 & 4 & 08 & $97 E-07$ & & & -06 \\
\hline $.61 E-10$ & $4.79 E-06$ & $1.84 \mathrm{E}-07$ & $4.18 E-08$ & $5.00 \mathrm{E}-07$ & $7.84 \mathrm{E}-07$ & $1.32 \mathrm{E}-06$ & $.09 E-06$ \\
\hline 0 & 6 & 然 & $22 E-08$ & 7 & - & 政 & -06 \\
\hline $.71 \mathrm{E}-10$ & $4.81 E-06$ & 2.004 & 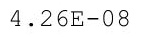 & r & ( & - & 等 \\
\hline$F-10$ & $2 F-06$ & & $E-08$ & & & $E-06$ & $E-06$ \\
\hline$E-10$ & $E-06$ & $88 \mathrm{~F}-07$ & $3 E-08$ & $2 E-07$ & $E-07$ & 6 & 06 \\
\hline $6 E-10$ & $E-06$ & $E-07$ & 08 & 7 & 7 & 6 & $2 E-06$ \\
\hline $91 \mathrm{E}-10$ & $4.84 \mathrm{E}-06$ & $1.90 \pm-01$ & $1 E-08$ & $.18 \mathrm{E}-07$ & $8.10 \mathrm{E}-07$ & $1.36 \mathrm{E}-06$ & $13 E-06$ \\
\hline $96 \mathrm{E}-10$ & $4.85 E-06$ & 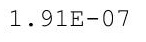 & $4.45 E-08$ & & & & $\cdot 14 \mathrm{~L}-0$ \\
\hline & & & & & & & \\
\hline $06 \mathrm{~F}-10$ & 6 & & & & & & he \\
\hline $.12 \mathrm{E}-10$ & & & & & 7 & 6 & 26 \\
\hline & & & & & -07 & -06 & \\
\hline $2 E-10$ & $4.90 E-06$ & $6 \mathrm{E}-07$ & $3 E-08$ & 7 & & 6 & $7 E-06$ \\
\hline 10 & & & & & & & -0 \\
\hline 0 & & & & & & & -00 \\
\hline & & 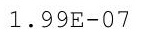 & & 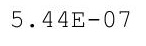 & & & $2.19 E-06$ \\
\hline & & & & 11 & 7 & 6 & cor \\
\hline-10 & $E-06$ & -07 & $E-08$ & 07 & 07 & 06 & $20 E-06$ \\
\hline $.56 E-10$ & $4.98 E-06$ & $2.02 E-07$ & $.86 \mathrm{E}-08$ & $5.54 \mathrm{E}-07$ & $8.54 \mathrm{E}-07$ & $1.43 E-06$ & $2.21 \mathrm{E}-06$ \\
\hline
\end{tabular}


RESRAD-OFFSITE, Version 2.5

Title : RESRAD-OFFSITE External Gamma, Inhalation, and Soil Ingestion for Offsite Reside File : PBA-1_TC99-DOE-5-1.ROF

Summary of dose at graphical times, reptition 2 (continued)

Time

Years

$4.72 \mathrm{E}+02$

$4.72 \mathrm{E}+02$

$4.73 \mathrm{E}+02$

$4.73 \mathrm{E}+02$

$4.74 \mathrm{E}+02$

$4.74 \mathrm{E}+02$

$4.75 E+02$

$4.75 \mathrm{E}+02$

$4.76 \mathrm{E}+02$

$4.76 \mathrm{E}+02$

$4.77 \mathrm{E}+02$

$4.77 \mathrm{E}+02$

$4.78 \mathrm{E}+02$

$4.78 \mathrm{E}+02$

$4.79 \mathrm{E}+02$

$4.79 \mathrm{E}+02$

$4.80 \mathrm{E}+02$

$4.80 \mathrm{E}+02$

$4.81 \mathrm{E}+02$

$4.81 \mathrm{E}+02$

$4.82 \mathrm{E}+02$

$4.82 \mathrm{E}+02$

$4.83 \mathrm{E}+02$

$4.83 \mathrm{E}+02$

$4.84 \mathrm{E}+02$

$4.84 \mathrm{E}+02$

$4.85 \mathrm{E}+02$

$4.86 \mathrm{E}+02$

$4.86 \mathrm{E}+02$

$4.87 \mathrm{E}+02$

$4.87 \mathrm{E}+02$

$4.88 \mathrm{E}+02$

$4.88 \mathrm{E}+02$

$4.89 \mathrm{E}+02$

$4.89 \mathrm{E}+02$

$4.90 \mathrm{E}+02$

$4.90 \mathrm{E}+02$

$4.91 \mathrm{E}+02$

$4.91 E+02$

$4.92 \mathrm{E}+02$

$4.92 \mathrm{E}+02$

$4.93 E+02$

4. $93 \mathrm{E}+02$

$4.94 \mathrm{E}+02$

4. $94 \mathrm{E}+02$

$4.95 \mathrm{E}+02$
Dose statistics at graphical times, mrem/yr

\begin{tabular}{|c|c|c|c|c|c|c|c|}
\hline inimum & aximum & Mean & ledian & $0 \%$ & $5 \%$ & $97.5 \%$ & \\
\hline 0 & -06 & -07 & -08 & 07 & 7 & 6 & O \\
\hline 10 & -06 & 7 & 8 & 7 & 07 & 6 & -06 \\
\hline-10 & -06 & $E-07$ & -08 & $3 E-07$ & 07 & 06 & -06 \\
\hline-10 & $3 E-06$ & & & & & & -06 \\
\hline $6 E-10$ & 06 & 7 & 88 & & & & $24 E-06$ \\
\hline-10 & -06 & $E-07$ & -08 & 1 & 政 & -06 & -06 \\
\hline 10 & -06 & - & -08 & F & 1 & -06 & -0 \\
\hline & $5.07 E-06$ & 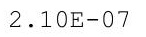 & $0 E-08$ & 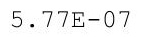 & & -06 & $.26 \mathrm{E}-06$ \\
\hline 10 & 06 & 1 & .08 & 7 & $r$ & .06 & -06 \\
\hline $.18 \mathrm{E}-10$ & $0 E-06$ & $2.12 \mathrm{E}-07$ & $E-08$ & $82 E-07$ & 7 & -06 & $27 E-06$ \\
\hline-10 & 06 & 7 & & & & 06 & $28 E-06$ \\
\hline-10 & & & & & & & -06 \\
\hline $.38 E-10$ & $5.13 E-06$ & $2 . \pm U$ & $E-08$ & $0 E-01$ & - & -06 & $E-0$ \\
\hline $.44 \mathrm{E}-10$ & -06 & i & -08 & T- & & -06 & -0 \\
\hline 10 & 06 & r & 08 & 07 & & 06 & -06 \\
\hline $.58 E-10$ & -06 & 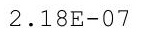 & -08 & 7 & 7 & -06 & -06 \\
\hline $65 E-10$ & $8 E-06$ & $2.19 \mathrm{E}-07$ & $1 E-08$ & $2 E-07$ & $4 E-07$ & $E-06$ & $.32 E-06$ \\
\hline-10 & $E-06$ & $.20 E-07$ & $5 E-08$ & $5 E-07$ & & $E-06$ & $32 E-06$ \\
\hline 10 & 06 & 1 & 08 & 1 & & 6 & -06 \\
\hline $6 E-10$ & -06 & $2 \cdot 0$ & -08 & 7 & & -06 & -06 \\
\hline $3 E-10$ & -06 & 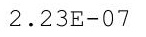 & & & & & -06 \\
\hline $.01 \mathrm{E}-10$ & -06 & $2.25 \mathrm{E}$ & 08 & 07 & & 06 & -06 \\
\hline $.08 E-10$ & $.25 E-06$ & $2.26 \mathrm{E}-07$ & $5.88 E-08$ & $21 E-07$ & 12 & $57 E-06$ & $36 E-06$ \\
\hline$E-10$ & $26 \mathrm{E}-06$ & $2.27 E-07$ & $3 E-08$ & $25 E-07$ & $47 E-07$ & $8 E-06$ & $36 \mathrm{E}-06$ \\
\hline-10 & $E-06$ & $28 E-07$ & $E-08$ & 7 & & -06 & -06 \\
\hline$E-10$ & -06 & 1 & 08 & & & & 06 \\
\hline $38 \mathrm{E}-10$ & $5.29 E-06$ & $2.500-1$ & -08 & $33 \pm-01$ & & & -06 \\
\hline $46 \mathrm{E}-10$ & 6 & $2.3 \perp[-U 1$ & $4 E-08$ & $6.36 \mathrm{E}-07$ & $9.045-01$ & $.60 \mathrm{E}-06$ & $.40 \mathrm{E}-06$ \\
\hline 0 & 6 & 年 & 8 & 然 & 1 & •.01+ vo & $.40 E-06$ \\
\hline 0 & 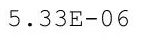 & 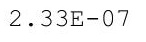 & -5 & - & - & 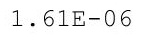 & - \\
\hline-10 & $1 F-06$ & 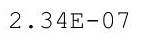 & $9 E-08$ & & & $7-06$ & $E-06$ \\
\hline$E-10$ & $E-06$ & $35 \mathrm{~F}-07$ & $E-08$ & $7 E-07$ & 07 & 6 & $E-06$ \\
\hline $6 \mathrm{E}-10$ & $6 E-06$ & $2.36 \mathrm{E}-07$ & $E-08$ & $0 E-07$ & 7 & & -06 \\
\hline $94 \mathrm{E}-10$ & $5.37 \mathrm{E}-06$ & $2.38 \pm-01$ & $2 E-08$ & $52 E-07$ & $9.88 \mathrm{E}-07$ & $1.64 \mathrm{E}-06$ & $2.45 \mathrm{E}-06$ \\
\hline $03 E-10$ & $38 E-06$ & $2.395-01$ & $6.47 E-08$ & & & & $-4=5-0$ \\
\hline & & & & & & & \\
\hline & 6 & & & & & & he \\
\hline $.28 \mathrm{E}-10$ & & & & & & 6 & 26 \\
\hline & & & & & & -06 & \\
\hline $5 E-10$ & $4 E-06$ & $E-07$ & 08 & 7 & 6 & & -06 \\
\hline$E-10$ & & 2. & & & & & . \\
\hline 0 & & 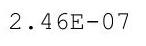 & & 1 & & & -00 \\
\hline 72F 10 & & 2 & & 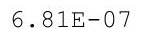 & & 0 & (t) \\
\hline $0.01 \mathrm{~L}-1 U$ & 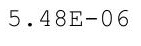 & . & 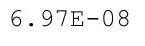 & 0.04 & 0 & 6 & ter \\
\hline $0 E-10$ & $5.49 E-06$ & -07 & 08 & 07 & 6 & 6 & -06 \\
\hline $.99 E-10$ & $5.50 \mathrm{E}-06$ & $2.51 E-07$ & $.08 E-08$ & $5.90 \mathrm{E}-07$ & $1.03 E-06$ & $1.72 \mathrm{E}-06$ & $2.54 \mathrm{E}-06$ \\
\hline
\end{tabular}


RESRAD-OFFSITE, Version 2.5

Title : RESRAD-OFFSITE External Gamma, Inhalation, and Soil Ingestion for offsite Reside File : PBA-1_TC99-DOE-5-1.ROF

Summary of dose at graphical times, reptition 2 (continued)

Time

Years

4. $95 \mathrm{E}+02$

$4.96 \mathrm{E}+02$

$4.96 \mathrm{E}+02$

$4.97 \mathrm{E}+02$

4. $97 \mathrm{E}+02$

$4.98 \mathrm{E}+02$

$4.98 \mathrm{E}+02$

4. $99 \mathrm{E}+02$

4. $99 \mathrm{E}+02$

$5.00 \mathrm{E}+02$

$5.00 \mathrm{E}+02$

$5.01 E+02$

$5.01 \mathrm{E}+02$

$5.02 \mathrm{E}+02$

$5.02 \mathrm{E}+02$

$5.03 E+02$

$5.03 E+02$

$5.04 \mathrm{E}+02$

$5.04 \mathrm{E}+02$

$5.05 \mathrm{E}+02$

$5.06 \mathrm{E}+02$

$5.06 \mathrm{E}+02$

$5.07 \mathrm{E}+02$

$5.07 \mathrm{E}+02$

$5.08 \mathrm{E}+02$

$5.08 \mathrm{E}+02$

$5.09 \mathrm{E}+02$

$5.09 \mathrm{E}+02$

$5.10 \mathrm{E}+02$

$5.10 \mathrm{E}+02$

$5.11 \mathrm{E}+02$

$5.11 \mathrm{E}+02$

$5.12 \mathrm{E}+02$

$5.12 \mathrm{E}+02$

$5.13 \mathrm{E}+02$

$5.13 \mathrm{E}+02$

$5.14 \mathrm{E}+02$

$5.14 \mathrm{E}+02$

$5.15 \mathrm{E}+02$

$5.15 \mathrm{E}+02$

$5.16 \mathrm{E}+02$

$5.16 \mathrm{E}+02$

$5.17 \mathrm{E}+02$

$5.17 \mathrm{E}+02$

$5.18 \mathrm{E}+02$

$5.18 \mathrm{E}+02$

Dose statistics at graphical times, mrem/yr

\begin{tabular}{|c|c|c|c|c|c|c|c|}
\hline m & um & az & ledian & & & & \\
\hline 10 & -06 & $2.52 \mathrm{E}-07$ & -08 & -07 & -06 & $1.73 \mathrm{E}-06$ & -06 \\
\hline-10 & $2 E-06$ & $3 E-07$ & -08 & 07 & 06 & -06 & $E-06$ \\
\hline $.28 \mathrm{E}-10$ & $3 E-06$ & $54 \mathrm{E}-07$ & -08 & $8 E-07$ & $1.05 \mathrm{E}-06$ & -06 & $\Xi-06$ \\
\hline$F-10$ & 06 & $55 \mathrm{~F}-07$ & $9 E-08$ & $1 F-07$ & $05 \mathrm{~F}-06$ & -06 & -0 \\
\hline 10 & 06 & 7 & 8 & 7 & 06 & 06 & -06 \\
\hline 10 & 06 & & & & & & -06 \\
\hline $67 \mathrm{E}-10$ & & 7 & & & & & -06 \\
\hline-10 & 06 & 7 & 8 & 7 & 6 & -06 & -06 \\
\hline $.87 \mathrm{E}-10$ & -06 & $1 E-07$ & -08 & 07 & 06 & -06 & -06 \\
\hline-10 & -06 & $62 \mathrm{E}-07$ & 8 & & & 6 & 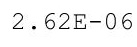 \\
\hline $7 E-10$ & 06 & $2.63 E-07$ & 8 & & & -06 & he \\
\hline $17 \mathrm{~F}-10$ & -06 & 5 & 8 & 7 & 6 & 06 & 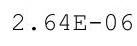 \\
\hline $28 \mathrm{E}-10$ & $5.63 E-06$ & $2.66 \mathrm{E}-07$ & & $7.30 \mathrm{E}-07$ & & $1.81 \mathrm{E}-06$ & -06 \\
\hline $38 \mathrm{E}-10$ & $.64 \mathrm{E}-06$ & $2.67 \mathrm{E}-07$ & $7.86 \mathrm{E}-08$ & $7.34 \mathrm{E}-07$ & & -06 & $z-06$ \\
\hline-10 & -06 & $3 E-07$ & -08 & $7 E-07$ & & -06 & -06 \\
\hline 10 & 6 & 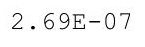 & & & & 6 & 06 \\
\hline$E-10$ & & & & 7 & & 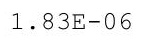 & $67 E-06$ \\
\hline 0 & & תרקר & 8 & 7 & & 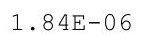 & 0 \\
\hline $92 \mathrm{E}-10$ & $5.69 \mathrm{E}-06$ & $2.73 E-07$ & $8.15 E-08$ & $7.49 E-07$ & 1. $12 \mathrm{E}-06$ & 1. $85 \mathrm{E}-06$ & $.68 E-06$ \\
\hline$E-10$ & $.70 E-06$ & $.74 \mathrm{E}-07$ & $8.21 E-08$ & $7.52 \mathrm{E}-07$ & $1.12 \mathrm{E}-06$ & L. $85 E-06$ & $9 E-06$ \\
\hline 10 & 06 & $.75 \mathrm{E}-\mathrm{C}$ & & 1 & & 6 & -06 \\
\hline 10 & & $76 \pi$ & & & & & 06 \\
\hline 0 & & & & & & & 0 \\
\hline 10 & 6 & $79 \mathrm{E}-$ & & 7 & 0 & 0 & -0 \\
\hline 0 & 6 & $80 \mathrm{E}-$ & 8 & 7 & $1.14 \mathrm{E}-06$ & -06 & 0 \\
\hline $72 \mathrm{E}-10$ & $.76 E-06$ & $2.81 \mathrm{E}-07$ & $56 E-08$ & $68 E-07$ & $1.15 \mathrm{E}-0$ & $.89 E-06$ & $3 F-06-2$ \\
\hline-10 & $.77 \mathrm{E}-06$ & $2.82 \mathrm{E}-07$ & $3 E-08$ & & & $89 F-06$ & $3 F-06-2$ \\
\hline & & & & & & & \\
\hline & & & & 7 & & & -0 \\
\hline $.02 E-09$ & $5.79 E-06$ & $2.86 \mathrm{E}-07$ & -08 & $7.80 \mathrm{E}-07$ & $\perp \cdot 1$ & $1.91 \mathrm{E}-06$ & $76 \mathrm{E}-06$ \\
\hline $03 E-09$ & $.80 \mathrm{E}-06$ & 2.010 ( & $.88 E-08$ & $7.82 \mathrm{E}-07$ & $\perp \cdot \perp 1$ U & 1.91L- & 700 \\
\hline $04 \mathrm{E}-09$ & $5.81 \mathrm{E}-06$ & . & & & & . $92 \mathrm{~L}$ - & 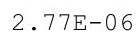 \\
\hline-09 & $F-06$ & & & & & & 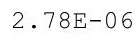 \\
\hline & & & & & & & 06 \\
\hline & & & & 7 & & & -06 \\
\hline $.09 E-09$ & $5.85 \mathrm{E}-06$ & $2.93 E-07$ & $E-08$ & $9 E-07$ & $1 .+21$ & 06 & -06 \\
\hline$\cdot 1 \perp E-U 9$ & 0.00 & $.945-01$ & 08 & 01 & $\cdot 19 \mathrm{~L}-\mathrm{U}$ & $1.95 \mathrm{E}-06$ & c \\
\hline & & & & & & & \\
\hline & & 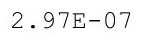 & & 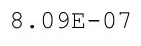 & & & $2.82 \mathrm{E}-06$ \\
\hline & & 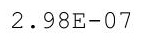 & & 7 & 6 & 6 & 0 \\
\hline-09 & & 2 ag & & $8.16 \mathrm{E}-07$ & $E-06$ & 06 & 06 \\
\hline 09 & $5.90 \mathrm{E}-06$ & $3.00 \mathrm{E}-07$ & $E-08$ & $9 E-07$ & 1.211 & 06 & -06 \\
\hline & & 1 & & & & & \\
\hline & & 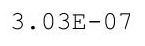 & & & $\perp \cdot \angle Z \mathrm{~L}$ & & -00 \\
\hline & $25-20$ & 年 & & $8.30 \mathrm{E}-07$ & $1 \cdot 2<$ & & $2.01+0$ \\
\hline-09 & $E-06$ & $E-07$ & $E-08$ & -07 & $.23 E-06$ & -06 & -06 \\
\hline
\end{tabular}


RESRAD-OFFSITE, Version 2.5

Title : RESRAD-OFFSITE External Gamma, Inhalation, and Soil Ingestion for offsite Reside File : PBA-1_TC99-DOE-5-1.ROF

Summary of dose at graphical times, reptition 2 (continued)

Time

Years

$5.19 \mathrm{E}+02$

$5.19 \mathrm{E}+02$

$5.20 \mathrm{E}+02$

$5.20 \mathrm{E}+02$

$5.21 \mathrm{E}+02$

$5.21 \mathrm{E}+02$

$5.22 \mathrm{E}+02$

$5.22 \mathrm{E}+02$

$5.23 \mathrm{E}+02$

$5.23 \mathrm{E}+02$

$5.24 \mathrm{E}+02$

$5.24 \mathrm{E}+02$

$5.25 \mathrm{E}+02$

$5.26 \mathrm{E}+02$

$5.26 \mathrm{E}+02$

$5.27 \mathrm{E}+02$

$5.27 \mathrm{E}+02$

$5.28 \mathrm{E}+02$

$5.28 \mathrm{E}+02$

$5.29 \mathrm{E}+02$

$5.29 \mathrm{E}+02$

$5.30 \mathrm{E}+02$

$5.30 \mathrm{E}+02$

$5.31 \mathrm{E}+02$

$5.31 \mathrm{E}+02$

$5.32 \mathrm{E}+02$

$5.32 \mathrm{E}+02$

$5.33 \mathrm{E}+02$

$5.33 \mathrm{E}+02$

$5.34 \mathrm{E}+02$

$5.34 \mathrm{E}+02$

$5.35 \mathrm{E}+02$

$5.35 \mathrm{E}+02$

$5.36 \mathrm{E}+02$

$5.36 \mathrm{E}+02$

$5.37 \mathrm{E}+02$

$5.37 \mathrm{E}+02$

$5.38 \mathrm{E}+02$

$5.38 \mathrm{E}+02$

$5.39 \mathrm{E}+02$

$5.39 \mathrm{E}+02$

$5.40 \mathrm{E}+02$

$5.40 \mathrm{E}+02$

$5.41 \mathrm{E}+02$

$5.41 \mathrm{E}+02$

$5.42 \mathrm{E}+02$
Dose statistics at graphical times, mrem/yr

\begin{tabular}{|c|c|c|c|c|c|c|c|}
\hline inimum & aximum & Mean & ledian & $0 \%$ & $5 \%$ & $97.5 \%$ & $\%$ \\
\hline 9 & -06 & $E-07$ & $E-08$ & $8 E-07$ & 06 & 06 & 0 \\
\hline $5 E-09$ & $E-06$ & $8 E-07$ & $7 E-08$ & $2 \mathrm{~F}$ & 06 & .06 & -06 \\
\hline $7 E-09$ & $E-06$ & $9 E-07$ & $E-07$ & $5 E-07$ & 06 & .06 & -06 \\
\hline $9 E-09$ & $E-06$ & 7 & 7 & 7 & & 66 & -06 \\
\hline $30 E-09$ & 06 & 7 & 7 & & 6 & 06 & $92 E-06$ \\
\hline 09 & 06 & -07 & -07 & - & 0 & $2 E-06$ & -06 \\
\hline $.33 E-09$ & 06 & 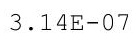 & -07 & 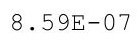 & 06 & -06 & -0 \\
\hline $.34 E-09$ & $6.00 E-06$ & ? & $1.03 E-07$ & ? & I. 20 U & -06 & $94 E-06$ \\
\hline 09 & -06 & $3.17 \mathrm{E}-07$ & 07 & $5 E-$ & 6 & -06 & -06 \\
\hline $.37 E-09$ & 06 & $E-07$ & $E-07$ & 7 & 06 & -06 & $E-06$ \\
\hline-09 & -06 & 7 & 7 & & 6 & .06 & $E-06$ \\
\hline 09 & & & & & & & 06 \\
\hline $.42 E-09$ & $6.04 \mathrm{E}-06$ & . & $E-07$ & $0.10 \mathrm{~L}$ & $1.28 \mathrm{E}-00$ & -06 & $E-06$ \\
\hline $.44 \mathrm{E}-09$ & -06 & . & -07 & 等 & (2) & -06 & $98 \mathrm{E}-06$ \\
\hline $45 E-09$ & 06 & 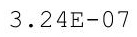 & 07 & 07 & 6 & 06 & -06 \\
\hline $.47 E-09$ & -06 & 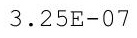 & -07 & 07 & 06 & -06 & -06 \\
\hline $.48 \mathrm{E}-09$ & $7 E-06$ & ( & $9 E-07$ & $2 E-07$ & $30 E-06$ & -06 & $00 E-06$ \\
\hline-09 & $8 E-06$ & $8 E-07$ & $0 E-07$ & $E-07$ & $E-06$ & -06 & $E-06$ \\
\hline $.52 \mathrm{E}-09$ & $9 \mathrm{E}-06$ & $9 E-07$ & $E-07$ & r & & -06 & -06 \\
\hline $3 E-09$ & -06 & -01 & -07 & $3 E-01$ & 0 & -06 & $E-06$ \\
\hline $.55 E-09$ & -06 & 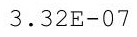 & -07 & 7 & & 00 & -06 \\
\hline $.57 E-09$ & $E-06$ & t & 07 & 7 & 20 & 6 & -06 \\
\hline $.58 \mathrm{E}-09$ & $6.12 \mathrm{E}-06$ & ? & $1.14 \mathrm{E}-07$ & $9.14 \mathrm{E}-07$ & $1.33 \mathrm{E}-06$ & $09 E-06$ & $.05 E-06$ \\
\hline$E-09$ & $E-06$ & $6 \mathrm{E}-07$ & $4 \mathrm{E}-07$ & $17 E-07$ & $1.34 \mathrm{E}-06$ & $0 E-06$ & $6 \mathrm{E}-06$ \\
\hline 09 & -06 & 7 & 7 & & & 06 & -06 \\
\hline$E-09$ & 06 & $E-$ & 07 & 07 & & & -06 \\
\hline $.65 E-09$ & $5 E-06$ & $E-07$ & -07 & $8 E-07$ & 6 & & $8 E-06$ \\
\hline $.67 E-09$ & $6.15 E-06$ & $3.41 \mathrm{E}-07$ & $1.18 \mathrm{E}-07$ & $9.32 \mathrm{E}-07$ & $1.36 \mathrm{E}-06$ & $.11 E-06$ & $09 E-06$ \\
\hline ים & $6.16 \mathrm{E}-06$ & . & $1.18 \mathrm{E}-07$ & $9.35 E-07$ & I. & -06 & H \\
\hline $.70 \mathrm{E}-09$ & $6.17 E-06$ & 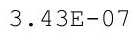 & r & ו & $-e^{-1}$ & -06 & -0 \\
\hline 09 & $E-06$ & $E-07$ & $E-07$ & $3 E-07$ & 06 & $E-06$ & -06 \\
\hline $1 E-09$ & $E-06$ & 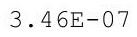 & $E-07$ & $5 E-07$ & 6 & 66 & 06 \\
\hline $.76 \mathrm{E}-09$ & $6.19 \mathrm{E}-06$ & $3.47 \mathrm{E}-07$ & 1. $22 \mathrm{E}-07$ & $0 \mathrm{E}-07$ & $1.38 \mathrm{E}-$ & & $2 E-06$ \\
\hline $.77 E-09$ & $6.20 \mathrm{E}-06$ & $3.49 \mathrm{E}-07$ & $1.22 \mathrm{E}-07$ & $9.54 \mathrm{E}-07$ & $1.39 \mathrm{E}-06$ & $.14 \mathrm{E}-06$ & $13 E-06$ \\
\hline $.79 E-09$ & $6.20 \mathrm{E}-06$ & & & & & & ت- \\
\hline 09 & & & & & & & 0 \\
\hline 9 & 6 & $3.52 \mathrm{E}-07$ & 7 & 7 & & & 0 \\
\hline$E-09$ & $E-06$ & $F-$ & 7 & -07 & 6 & 6 & 06 \\
\hline $.87 E-09$ & $6.23 E-06$ & $E-07$ & -07 & $E-07$ & 6 & -06 & -06 \\
\hline 9 & 06 & 7 & 7 & 7 & 6 & & -06 \\
\hline 9 & & & & - & & & .06 \\
\hline & $.25 E-06$ & $.59 \mathrm{E}-07$ & & $.83 E-07$ & & & $19 \mathrm{E}-06$ \\
\hline & & 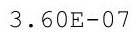 & & 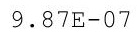 & 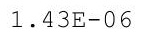 & & \\
\hline $.97 E-09$ & 06 & 1 & Pre & 7 & 6 & 6 & 0 \\
\hline$E-09$ & 6.2 & 3. & 1 . & 9. & 1.4 & 6 & 06 \\
\hline $.01 \mathrm{E}-\mathrm{C}$ & $6.28 E-06$ & $.64 \mathrm{E}-07$ & $1.32 E-07$ & $.99 E-07$ & $1.44 \mathrm{E}-06$ & $2.18 \mathrm{E}-06$ & $3.22 \mathrm{E}-06$ \\
\hline
\end{tabular}


RESRAD-OFFSITE, Version 2.5

Title : RESRAD-OFFSITE External Gamma, Inhalation, and Soil Ingestion for offsite Reside File : PBA-1_TC99-DOE-5-1.ROF

Summary of dose at graphical times, reptition 2 (continued)

Time

Years

$5.42 \mathrm{E}+02$

$5.43 \mathrm{E}+02$

$5.43 E+02$

$5.44 \mathrm{E}+02$

$5.44 \mathrm{E}+02$

$5.45 \mathrm{E}+02$

$5.46 \mathrm{E}+02$

$5.46 \mathrm{E}+02$

$5.47 \mathrm{E}+02$

$5.47 \mathrm{E}+02$

$5.48 \mathrm{E}+02$

$5.48 \mathrm{E}+02$

$5.49 \mathrm{E}+02$

$5.49 \mathrm{E}+02$

$5.50 \mathrm{E}+02$

$5.50 \mathrm{E}+02$

$5.51 \mathrm{E}+02$

$5.51 \mathrm{E}+02$

$5.52 \mathrm{E}+02$

$5.52 \mathrm{E}+02$

$5.53 \mathrm{E}+02$

$5.53 \mathrm{E}+02$

$5.54 \mathrm{E}+02$

$5.54 \mathrm{E}+02$

$5.55 \mathrm{E}+02$

$5.55 \mathrm{E}+02$

$5.56 \mathrm{E}+02$

$5.56 \mathrm{E}+02$

$5.57 \mathrm{E}+02$

$5.57 \mathrm{E}+02$

$5.58 \mathrm{E}+02$

$5.58 \mathrm{E}+02$

$5.59 \mathrm{E}+02$

$5.59 \mathrm{E}+02$

$5.60 \mathrm{E}+02$

$5.60 \mathrm{E}+02$

$5.61 E+02$

$5.61 \mathrm{E}+02$

$5.62 \mathrm{E}+02$

$5.62 \mathrm{E}+02$

$5.63 \mathrm{E}+02$

$5.63 \mathrm{E}+02$

$5.64 \mathrm{E}+02$

$5.64 \mathrm{E}+02$

$5.65 \mathrm{E}+02$

$5.66 \mathrm{E}+02$

Dose statistics at graphical times, mrem/yr

\begin{tabular}{|c|c|c|c|c|c|c|c|}
\hline inimum & aximum & Mean & ledian & $90 \%$ & $5 \%$ & $97.5 \%$ & \\
\hline 9 & 6 & 07 & -07 & 06 & 6 & 6 & 0 \\
\hline 09 & -06 & 7 & 7 & 6 & 6 & 6 & -06 \\
\hline$E-09$ & -06 & $E-07$ & 07 & 06 & 6 & 06 & -06 \\
\hline$E-09$ & $E-06$ & & & & & & -06 \\
\hline-09 & 06 & & & & 6 & 06 & $25 E-06$ \\
\hline-09 & -06 & -07 & -07 & $1.02 E-06$ & -06 & -06 & $26 E-06$ \\
\hline 09 & 06 & 07 & 7 & -06 & 6 & -06 & $27 E-0$ \\
\hline 09 & $6.33 E-06$ & (- & & $1.03 E-06$ & 10 & o & $27 E-06$ \\
\hline 09 & 06 & . & 7 & 06 & 6 & 06 & -06 \\
\hline $21 E-09$ & $E-06$ & $8 E-07$ & $10 \mathrm{E}-07$ & $04 E-06$ & $.49 \mathrm{E}-06$ & -06 & $8-06$ \\
\hline-09 & -06 & 7 & & & & 06 & $E-06$ \\
\hline-09 & 06 & -07 & 7 & & & -06 & $E-06$ \\
\hline $28 E-09$ & $E-06$ & $25-01$ & $E-07$ & $5 E-06$ & $1 \cdot 0$ & -06 & -0 \\
\hline-09 & 06 & $3 E-07$ & & 6 & 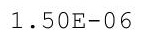 & 6 & 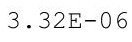 \\
\hline 09 & 06 & $r$ & 1 & 06 & & o & -06 \\
\hline $.35 E-09$ & -06 & $3.86 \mathrm{E}-07$ & 7 & 06 & 06 & -06 & -06 \\
\hline $.37 E-09$ & $3 E-06$ & $7 E-07$ & $6 E-07$ & $1.06 \mathrm{E}-06$ & $1.51 \mathrm{E}-06$ & $E-06$ & $.34 \mathrm{E}-06$ \\
\hline $9 E-09$ & $3 E-06$ & $9 E-07$ & $7 E-07$ & $\Xi-06$ & $E-06$ & $E-06$ & $E-06$ \\
\hline 09 & 06 & 1 & 7 & 06 & 6 & 6 & - o \\
\hline $.44 E-09$ & -06 & 1 & I. & & 6 & 06 & -06 \\
\hline $.46 \mathrm{E}-09$ & -06 & T & & & & o & -06 \\
\hline 09 & 06 & $3.94 \mathrm{E}-07$ & 7 & 6 & 6 & 6 & 6 \\
\hline$E-09$ & $E-06$ & م & 正 & 6 & 50 & $2.27 E-06$ & $.38 E-06$ \\
\hline$E-09$ & $.42 E-06$ & $7 E-07$ & $1.52 \mathrm{E}-07$ & $1.09 \mathrm{E}-06$ & $1.54 \mathrm{E}-06$ & $.27 E-06$ & $39 E-06$ \\
\hline 09 & $2 E-06$ & $98 \mathrm{~F}-07$ & & $E-06$ & 06 & -06 & -06 \\
\hline 09 & $E-06$ & $E-07$ & & 6 & & & 06 \\
\hline $.60 E-09$ & -06 & 1 & 7 & & 6 & 6 & 06 \\
\hline $.63 E-09$ & $44 E-06$ & $0<5-01$ & $5 E-07$ & $1.10 \mathrm{E}-06$ & $80 \mathrm{x}-20$ & $29 E-06$ & $41 E-06$ \\
\hline 09 & 6 & (5) & $56 E-07$ & 6 & 年 & • & $42 E-06$ \\
\hline - & - & -5 & - & 列 & - & - & - \\
\hline$F-09$ & $F-06$ & & & $2 E-06$ & & $E-06$ & $E-06$ \\
\hline$E-09$ & $E-06$ & 5 & $E-07$ & & 6 & & 06 \\
\hline $5 E-09$ & $E-06$ & $E-07$ & 7 & 06 & 6 & 6 & $5 E-06$ \\
\hline $.78 E-09$ & $6.47 E-06$ & $4 \cdot 10 E-01$ & 1. $61 \mathrm{E}-07$ & $1.13 \mathrm{E}-06$ & $1.58 \mathrm{E}-06$ & $2.31 \mathrm{E}-06$ & $45 E-06$ \\
\hline $.005-49$ & $6.47 E-06$ & $4 \cdot 1 \angle L-U 1$ & & & & & $.40-2-0$ \\
\hline & & & & & & & \\
\hline 86F-0 & 6 & & & & & & he \\
\hline 9 & & & & & & & 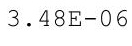 \\
\hline & & & & 6 & -06 & -06 & 06 \\
\hline $3 E-09$ & $E-06$ & $E-07$ & $6 E-07$ & 06 & 6 & & $9 E-06$ \\
\hline & & 1 & 7 & & & & -0 \\
\hline & & & & 6 & & & -00 \\
\hline $.01 \mathrm{E}-09$ & & 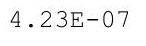 & & 0 & - & 6 & c \\
\hline $3.04 E-09$ & 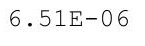 & $2+$ & & 6 & 6 & 6 & 0 \\
\hline E-09 & $6.52 E-06$ & -07 & $E-07$ & $1.17 \mathrm{E}$ & 1.63 & 2.3 & $.52 E-06$ \\
\hline $.10 \mathrm{E}-$ & $6.52 E-06$ & $.27 E-07$ & $1.72 E-07$ & $1.17 \mathrm{E}-06$ & $1.64 \mathrm{E}-06$ & $2.35 E-06$ & $3.52 E-06$ \\
\hline
\end{tabular}


RESRAD-OFFSITE, Version 2.5

Title : RESRAD-OFFSITE External Gamma, Inhalation, and Soil Ingestion for Offsite Reside File : PBA-1_TC99-DOE-5-1.ROF

Summary of dose at graphical times, reptition 2 (continued)

Time

Years

$5.66 \mathrm{E}+02$

$5.67 \mathrm{E}+02$

$5.67 \mathrm{E}+02$

$5.68 \mathrm{E}+02$

$5.68 \mathrm{E}+02$

$5.69 \mathrm{E}+02$

$5.69 \mathrm{E}+02$

$5.70 \mathrm{E}+02$

$5.70 \mathrm{E}+02$

$5.71 E+02$

$5.71 \mathrm{E}+02$

$5.72 \mathrm{E}+02$

$5.72 \mathrm{E}+02$

$5.73 \mathrm{E}+02$

$5.73 E+02$

$5.74 \mathrm{E}+02$

$5.74 \mathrm{E}+02$

$5.75 \mathrm{E}+02$

$5.75 \mathrm{E}+02$

$5.76 \mathrm{E}+02$

$5.76 \mathrm{E}+02$

$5.77 \mathrm{E}+02$

$5.77 \mathrm{E}+02$

$5.78 \mathrm{E}+02$

$5.78 \mathrm{E}+02$

$5.79 \mathrm{E}+02$

$5.79 \mathrm{E}+02$

$5.80 \mathrm{E}+02$

$5.80 \mathrm{E}+02$

$5.81 \mathrm{E}+02$

$5.81 \mathrm{E}+02$

$5.82 \mathrm{E}+02$

$5.82 \mathrm{E}+02$

$5.83 \mathrm{E}+02$

$5.83 \mathrm{E}+02$

$5.84 \mathrm{E}+02$

$5.84 \mathrm{E}+02$

$5.85 \mathrm{E}+02$

$5.85 \mathrm{E}+02$

$5.86 \mathrm{E}+02$

$5.87 \mathrm{E}+02$

$5.87 \mathrm{E}+02$

$5.88 \mathrm{E}+02$

$5.88 \mathrm{E}+02$

$5.89 \mathrm{E}+02$

$5.89 \mathrm{E}+02$
Dose statistics at graphical times, mrem/yr

\begin{tabular}{|c|c|c|c|c|c|c|c|}
\hline $\mathrm{m}$ & hum & ean & ed & & & & \\
\hline 09 & 6 & 7 & 7 & 06 & 6 & 6 & -06 \\
\hline$E-09$ & $.53 E-06$ & $30 E-07$ & $1.73 E-07$ & $1.18 \mathrm{E}-06$ & $1.65 \mathrm{E}-06$ & $2.36 \mathrm{E}-06$ & $53 E-06$ \\
\hline $3 E-09$ & -06 & $31 E-07$ & $.74 E-07$ & $1.19 \mathrm{E}-06$ & $1.65 E-06$ & 06 & -06 \\
\hline & & $3 E-07$ & & & & & -06 \\
\hline 09 & 06 & -07 & 7 & 06 & & & -06 \\
\hline $27 E-09$ & 06 & -07 & -07 & 66 & 6 & & -06 \\
\hline . & 06 & 7 & & & 6 & 06 & $56 E-06$ \\
\hline 09 & -06 & $E-07$ & $E-07$ & -06 & $58 E-06$ & -06 & $E-06$ \\
\hline (5 & $5 E-06$ & $E-07$ & $E-07$ & -06 & -06 & -06 & -06 \\
\hline $8 F-09$ & $.56 \mathrm{E}-06$ & & $81 \mathrm{E}-07$ & $.21 E-06$ & $.69 E-06$ & $.39 E-06$ & 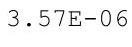 \\
\hline 09 & & & & & & & 06 \\
\hline-09 & E-06 & $E-07$ & $1.82 \mathrm{E}-07$ & $1.22 E-06$ & 06 & 06 & $E-06$ \\
\hline $.47 E-09$ & $6.58 E-06$ & $.46 E-07$ & $1.83 E-07$ & $1.22 E-06$ & $1.70 \mathrm{E}-06$ & $2.40 E-06$ & $E-06$ \\
\hline-09 & -06 & $E-07$ & & 06 & & 06 & -06 \\
\hline 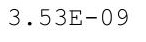 & & & & & & & -0 \\
\hline 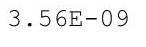 & & & & 6 & 6 & & 0 \\
\hline 09 & 6 & 1 & 7 & 6 & 6 & 6 & 06 \\
\hline $3 F-0-2-2$ & -06 & $4.53 \mathrm{E}-07$ & 7 & 124 & $1721-1$ & 6 & 06 \\
\hline $66 E-09$ & $.60 E-06$ & $.54 E-07$ & $1.89 E-07$ & $1.25 E-06$ & $1.73 E-06$ & $2.43 E-06$ & $E-06$ \\
\hline$E-09$ & $.60 E-06$ & $.56 E-07$ & $1.90 \mathrm{E}-07$ & $1.25 \mathrm{E}-06$ & $1.73 E-06$ & -06 & -06 \\
\hline & & & & & & & -06 \\
\hline & & & & & & & \\
\hline 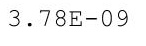 & & & & & & & 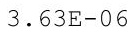 \\
\hline 9 & 06 & $1 \mathrm{E}-$ & 7 & 6 & 6 & 06 & -06 \\
\hline 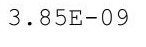 & $E-06$ & $.63 \mathrm{E}-07$ & $1.95 \mathrm{E}-$ & $.27 E-06$ & 1. $75 \mathrm{E}-06$ & $.45 \mathrm{E}-06$ & -06 \\
\hline 0 & $.62 E-06$ & $.64 \mathrm{E}-07$ & $1.96 \mathrm{E}-07$ & $1.28 \mathrm{E}-06$ & $1.75 \mathrm{E}-06$ & $2.46 \mathrm{E}-06$ & $F-0$ \\
\hline 09 & $62 E-06$ & & & & $76 F-06$ & $.46 E-06$ & -06 \\
\hline & & & & & & & \\
\hline & & & & & & & \\
\hline $.01 E-09$ & $6.63 E-06$ & 4. $70 \mathrm{E}-07$ & $2.00 \mathrm{E}-07$ & $1.30 \mathrm{E}-06$ & 土. & $2.47 \mathrm{E}-06$ & $E-06$ \\
\hline cos & $6.64 \mathrm{E}-06$ & 制 & $2.01 \mathrm{E}-07$ & $1.30 \mathrm{E}-06$ & $1.77 \mathrm{E}-06$ & . 100 o & $67 E-0$ \\
\hline 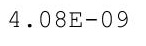 & & & & & & $2.48 E-06$ & 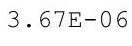 \\
\hline 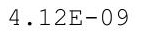 & $E-06$ & & $3 E-07$ & & & & 06 \\
\hline & & & & & & & \\
\hline & & & & & 6 & & \\
\hline $.22 \mathrm{E}-09$ & $6.65 E-06$ & $4.79 \mathrm{E}-07$ & $2.06 \mathrm{E}-07$ & $1.32 \mathrm{E}-06$ & $1.79 \mathrm{E}-06$ & $49 E-06$ & $69 E-06$ \\
\hline 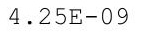 & $0.07 \mathrm{~L}-\mathrm{CO}$ & 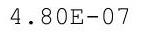 & 1 & te. & & & 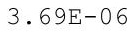 \\
\hline - & $66 \mathrm{E}-06$ & & & & & & -0 \\
\hline $.32 E-09$ & 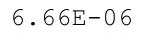 & 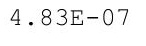 & 7 & 5 & & 6 & 06 \\
\hline $.36 E-09$ & & & & & 6 & 6 & 06 \\
\hline-09 & $.67 E-06$ & & & & -06 & -06 & 06 \\
\hline $3 E-09$ & $6.67 \mathrm{E}-06$ & $4.88 \mathrm{E}-07$ & $2.13 E-07$ & $1.34 \mathrm{E}$ & 1.81 & 06 & -06 \\
\hline & & & & & & & $.72 E-06$ \\
\hline & L- & ti & $.15 \mathrm{E}-07$ & (.) & $\pm .0<$ & 06 & . \\
\hline & 年 & & & & & & co \\
\hline-09 & $E-06$ & $E-07$ & $E-07$ & $.35 E-06$ & $3 E-06$ & $1 E-06$ & $3 E-06$ \\
\hline
\end{tabular}


RESRAD-OFFSITE, Version 2.5

Title : RESRAD-OFFSITE External Gamma, Inhalation, and Soil Ingestion for Offsite Reside File : PBA-1_TC99-DOE-5-1.ROF

Summary of dose at graphical times, reptition 2 (continued)

Time

Years

$5.90 \mathrm{E}+02$

$5.90 \mathrm{E}+02$

$5.91 \mathrm{E}+02$

5. $91 \mathrm{E}+02$

$5.92 \mathrm{E}+02$

$5.92 \mathrm{E}+02$

$5.93 \mathrm{E}+02$

$5.93 \mathrm{E}+02$

$5.94 \mathrm{E}+02$

$5.94 \mathrm{E}+02$

$5.95 \mathrm{E}+02$

$5.95 \mathrm{E}+02$

$5.96 \mathrm{E}+02$

$5.96 \mathrm{E}+02$

$5.97 \mathrm{E}+02$

$5.97 \mathrm{E}+02$

$5.98 \mathrm{E}+02$

$5.98 \mathrm{E}+02$

$5.99 \mathrm{E}+02$

$5.99 \mathrm{E}+02$

$6.00 \mathrm{E}+02$

$6.00 \mathrm{E}+02$

$6.01 \mathrm{E}+02$

$6.01 \mathrm{E}+02$

$6.02 \mathrm{E}+02$

$6.02 \mathrm{E}+02$

$6.03 E+02$

$6.03 \mathrm{E}+02$

$6.04 \mathrm{E}+02$

$6.04 \mathrm{E}+02$

$6.05 \mathrm{E}+02$

$6.05 \mathrm{E}+02$

$6.06 \mathrm{E}+02$

$6.07 \mathrm{E}+02$

$6.07 \mathrm{E}+02$

$6.08 \mathrm{E}+02$

$6.08 \mathrm{E}+02$

$6.09 \mathrm{E}+02$

$6.09 \mathrm{E}+02$

$6.10 \mathrm{E}+02$

$6.10 \mathrm{E}+02$

$6.11 \mathrm{E}+02$

$6.11 \mathrm{E}+02$

$6.12 \mathrm{E}+02$

$6.12 \mathrm{E}+02$

$6.13 \mathrm{E}+02$
Dose statistics at graphical times, mrem/yr

\begin{tabular}{|c|c|c|c|c|c|c|c|}
\hline inimum & Maximum & Mean & Median & $90 \%$ & $95 \frac{\circ}{\circ}$ & $7.5 \%$ & $9 \%$ \\
\hline $.62 \mathrm{E}-09$ & $6.68 \mathrm{E}-06$ & $4.95 \mathrm{E}-07$ & $2.18 \mathrm{E}-07$ & $1.36 \mathrm{E}-06$ & $1.83 \mathrm{E}-06$ & $2.55 \mathrm{E}-06$ & $3.73 \mathrm{E}-06$ \\
\hline $4.65 E-09$ & $6.68 \mathrm{E}-06$ & $4.96 \mathrm{E}-07$ & $2.19 \mathrm{E}-07$ & $1.36 \mathrm{E}-06$ & $1.84 \mathrm{E}-06$ & $2.55 E-06$ & $3.74 E-06$ \\
\hline $4.69 \mathrm{E}-09$ & $6.68 \mathrm{E}-06$ & $4.98 \mathrm{E}-07$ & $2.20 \mathrm{E}-07$ & $1.36 \mathrm{E}-06$ & $1.84 \mathrm{E}-06$ & $2.56 \mathrm{E}-06$ & $3.74 \mathrm{E}-06$ \\
\hline $4.73 \mathrm{E}-09$ & $6.69 \mathrm{E}-06$ & $4.99 \mathrm{E}-07$ & $2.21 \mathrm{E}-07$ & $1.36 \mathrm{E}-06$ & $85 E-06$ & $2.56 \mathrm{E}-06$ & $.74 \mathrm{E}-06$ \\
\hline $4.77 \mathrm{E}-09$ & $6.69 \mathrm{E}-06$ & $5.01 \mathrm{E}-07$ & $2.22 \mathrm{E}-07$ & $1.37 \mathrm{E}$ & $85 \mathrm{E}$ & $2.57 \mathrm{E}$ & $.75 \mathrm{E}-06$ \\
\hline $4.80 E-09$ & $6.69 \mathrm{E}-06$ & $5.02 \mathrm{E}-07$ & $2.22 \mathrm{E}-07$ & $1.37 \mathrm{E}-06$ & $1.86 \mathrm{E}-06$ & $2.58 \mathrm{E}-06$ & $3.75 \mathrm{E}-06$ \\
\hline $4.84 \mathrm{E}-09$ & $6.69 \mathrm{E}-06$ & $5.04 \mathrm{E}-07$ & $2.23 \mathrm{E}-07$ & $1.37 \mathrm{E}-06$ & $.86 \mathrm{E}-06$ & $2.58 \mathrm{E}-06$ & $75 E-06$ \\
\hline $88 \mathrm{E}-09$ & $6.70 \mathrm{E}-06$ & $5.05 \mathrm{E}-07$ & $2.24 \mathrm{E}-07$ & $1.38 \mathrm{E}-06$ & $87 E-06$ & $2.59 \mathrm{E}-06$ & $76 \mathrm{E}-06$ \\
\hline $4.92 \mathrm{E}-09$ & $6.70 \mathrm{E}-06$ & $5.07 \mathrm{E}-07$ & $2.25 \mathrm{E}-07$ & $1.38 \mathrm{E}-06$ & $1.87 \mathrm{E}-06$ & $2.59 \mathrm{E}-06$ & $3.76 \mathrm{E}-06$ \\
\hline $4.96 \mathrm{E}-09$ & $6.70 \mathrm{E}-06$ & $5.08 \mathrm{E}-07$ & $2.26 \mathrm{E}-07$ & $1.38 \mathrm{E}-06$ & $1.88 \mathrm{E}-06$ & $2.60 \mathrm{E}-06$ & $3.77 \mathrm{E}-06$ \\
\hline $.00 E-09$ & $6.70 \mathrm{E}-06$ & $5.10 \mathrm{E}-07$ & $2.27 \mathrm{E}-07$ & $1.39 \mathrm{E}-06$ & $1.88 \mathrm{E}-06$ & $2.60 \mathrm{E}-06$ & $3.77 \mathrm{E}-06$ \\
\hline $.04 \mathrm{E}-09$ & $6.70 \mathrm{E}-06$ & $5.11 \mathrm{E}-07$ & $2.28 \mathrm{E}-07$ & $1.39 \mathrm{E}-06$ & $1.89 \mathrm{E}-06$ & $2.61 \mathrm{E}-06$ & $3.77 \mathrm{E}-06$ \\
\hline $5.08 \mathrm{E}-09$ & $6.71 \mathrm{E}-06$ & $5.13 \mathrm{E}-07$ & $2.29 \mathrm{E}-07$ & $1.39 \mathrm{E}-06$ & $1.89 \mathrm{E}-06$ & $2.62 \mathrm{E}-06$ & $3.77 \mathrm{E}-06$ \\
\hline $5.12 \mathrm{E}-09$ & $6.71 \mathrm{E}-06$ & $5.14 \mathrm{E}-07$ & $2.30 \mathrm{E}-07$ & $1.39 \mathrm{E}-06$ & $1.90 \mathrm{E}-06$ & $2.62 \mathrm{E}-06$ & $3.78 \mathrm{E}-06$ \\
\hline $5.16 \mathrm{E}-09$ & $6.71 E-06$ & $5.16 \mathrm{E}-07$ & $2.31 \mathrm{E}-07$ & $1.40 \mathrm{E}-06$ & $1.90 \mathrm{E}-06$ & $2.63 \mathrm{E}-06$ & $3.78 \mathrm{E}-06$ \\
\hline $5.20 \mathrm{E}-09$ & $6.71 \mathrm{E}-06$ & $5.17 \mathrm{E}-07$ & $2.32 \mathrm{E}-07$ & $1.40 \mathrm{E}-06$ & $1.91 \mathrm{E}-06$ & $2.63 E-06$ & $3.79 \mathrm{E}-06$ \\
\hline $5.24 \mathrm{E}-09$ & $6.71 E-06$ & $5.19 \mathrm{E}-07$ & $2.34 \mathrm{E}-07$ & $1.40 \mathrm{E}-06$ & $1.91 \mathrm{E}-06$ & $2.64 \mathrm{E}-06$ & $3.80 \mathrm{E}-06$ \\
\hline $5.28 \mathrm{E}-09$ & $6.71 \mathrm{E}-06$ & $5.20 \mathrm{E}-07$ & $2.35 \mathrm{E}-07$ & $1.41 \mathrm{E}-06$ & $1.92 \mathrm{E}-06$ & $2.64 \mathrm{E}-06$ & $3.80 \mathrm{E}-06$ \\
\hline $32 E-09$ & $6.72 \mathrm{E}-06$ & $5.22 \mathrm{E}-07$ & $2.36 \mathrm{E}-07$ & $1.41 \mathrm{E}-06$ & $1.92 \mathrm{E}-06$ & $2.65 \mathrm{E}-06$ & $3.80 \mathrm{E}-06$ \\
\hline $36 \mathrm{E}-09$ & $6.72 \mathrm{E}-06$ & $5.23 \mathrm{E}-$ & $2.37 \mathrm{E}$ & $1.41 \mathrm{E}-06$ & $1.93 \mathrm{E}-$ & $2.66 \mathrm{E}-06$ & $81 E-06$ \\
\hline $40 \mathrm{E}-$ & 6 & 7 & & & 6 & 6 & \\
\hline $5 \mathrm{E}-$ & 6 & 5 & 2 & 6 & 6 & 6 & 06 \\
\hline $5.49 \mathrm{E}-09$ & $6.72 \mathrm{E}-06$ & $5.28 \mathrm{E}-07$ & $2.40 \mathrm{E}-07$ & $1.42 \mathrm{E}-06$ & $1.95 \mathrm{E}-06$ & $2.67 \mathrm{E}-06$ & $3.82 \mathrm{E}-06$ \\
\hline $5.53 \mathrm{E}-09$ & $6.72 \mathrm{E}-06$ & $5.29 \mathrm{E}-07$ & $2.41 \mathrm{E}-07$ & $1.43 \mathrm{E}-06$ & $1.95 \mathrm{E}-06$ & $2.68 \mathrm{E}-06$ & $3.82 \mathrm{E}-06$ \\
\hline $5.57 \mathrm{E}-09$ & $6.73 \mathrm{E}-06$ & $5.31 \mathrm{E}-07$ & $2.43 \mathrm{E}-07$ & $1.43 \mathrm{E}-06$ & $1.96 \mathrm{E}-06$ & $2.68 \mathrm{E}-06$ & $3.83 \mathrm{E}-06$ \\
\hline $5.62 \mathrm{E}-09$ & $6.73 E-06$ & $5.32 \mathrm{E}-07$ & $2.44 \mathrm{E}-07$ & $1.43 \mathrm{E}-06$ & $1.96 \mathrm{E}-06$ & $2.69 \mathrm{E}-06$ & $3.83 \mathrm{E}-06$ \\
\hline $5.66 \mathrm{E}-09$ & $6.73 \mathrm{E}-06$ & $5.34 \mathrm{E}-07$ & $2.45 \mathrm{E}-07$ & $1.44 \mathrm{E}-06$ & $1.97 \mathrm{E}-06$ & $2.70 \mathrm{E}-06$ & $3.84 \mathrm{E}-06$ \\
\hline $5.70 \mathrm{E}-09$ & $6.73 E-06$ & $5.35 \mathrm{E}-07$ & $2.46 \mathrm{E}-07$ & $1.44 \mathrm{E}-06$ & $1.97 \mathrm{E}-06$ & $2.70 \mathrm{E}-06$ & $3.84 \mathrm{E}-06$ \\
\hline $5.75 \mathrm{E}-09$ & $6.73 \mathrm{E}-06$ & $5.37 \mathrm{E}-07$ & $2.48 \mathrm{E}-07$ & $1.45 \mathrm{E}-06$ & $1.98 \mathrm{E}-06$ & $2.71 \mathrm{E}-06$ & $3.84 \mathrm{E}-06$ \\
\hline $5.79 \mathrm{E}-09$ & $6.73 \mathrm{E}-06$ & $5.38 \mathrm{E}-07$ & $2.49 \mathrm{E}-07$ & $1.45 \mathrm{E}$ & 6 & $2.71 \mathrm{E}-06$ & $.85 \mathrm{E}-06$ \\
\hline $3 E-c$ & 6 & $5.40 \mathrm{E}$ & 2 & $1.46 \mathrm{E}-$ & 1.3 & 06 & 06 \\
\hline $.88 \mathrm{E}-09$ & $6.73 \mathrm{E}-06$ & $5.41 \mathrm{E}-07$ & $2.51 \mathrm{E}-07$ & $1.46 \mathrm{E}-06$ & $1.99 \mathrm{E}-06$ & $2.72 \mathrm{E}-06$ & $3.86 \mathrm{E}-06$ \\
\hline $92 \mathrm{E}-09$ & $6.74 \mathrm{E}-06$ & $5.43 E-07$ & $2.53 \mathrm{E}-07$ & $1.47 \mathrm{E}-06$ & $2.00 \mathrm{E}-06$ & $2.73 E-06$ & $3.86 \mathrm{E}-06$ \\
\hline $5.97 \mathrm{E}-09$ & $6.74 \mathrm{E}-06$ & $5.44 \mathrm{E}-07$ & $2.54 \mathrm{E}-07$ & $1.47 \mathrm{E}-06$ & $2.00 \mathrm{E}-06$ & $2.73 E-06$ & $3.87 \mathrm{E}-06$ \\
\hline $6.01 \mathrm{E}-09$ & $6.74 \mathrm{E}-06$ & $5.46 \mathrm{E}-07$ & $2.55 \mathrm{E}-07$ & $1.48 \mathrm{E}-06$ & $2.01 \mathrm{E}-06$ & $2.74 \mathrm{E}-06$ & $3.87 \mathrm{E}-06$ \\
\hline $6.06 \mathrm{E}-09$ & $6.74 \mathrm{E}-06$ & $5.47 \mathrm{E}-07$ & $2.57 \mathrm{E}-07$ & $1.48 \mathrm{E}-06$ & $2.01 \mathrm{E}-06$ & $2.75 \mathrm{E}-06$ & $3.88 \mathrm{E}-06$ \\
\hline $6.10 \mathrm{E}-09$ & $6.74 \mathrm{E}-06$ & $5.49 \mathrm{E}-07$ & $2.58 \mathrm{E}-07$ & $1.49 \mathrm{E}-06$ & $2.02 \mathrm{E}-06$ & $2.75 \mathrm{E}-06$ & $3.88 \mathrm{E}-06$ \\
\hline $6.15 \mathrm{E}-09$ & $6.74 \mathrm{E}-06$ & $5.50 \mathrm{E}-07$ & $2.59 \mathrm{E}-07$ & $1.49 \mathrm{E}-06$ & $2.02 \mathrm{E}-06$ & $2.76 \mathrm{E}-06$ & $3.89 \mathrm{E}-06$ \\
\hline $6.19 \mathrm{E}-09$ & $6.74 \mathrm{E}-06$ & $5.52 \mathrm{E}-07$ & $2.60 \mathrm{E}-07$ & $1.49 \mathrm{E}-06$ & $2.02 \mathrm{E}-06$ & $2.76 \mathrm{E}-06$ & $3.89 \mathrm{E}-06$ \\
\hline $6.24 \mathrm{E}-09$ & $6.74 \mathrm{E}-06$ & $5.53 \mathrm{E}-07$ & $2.61 \mathrm{E}-07$ & $1.50 \mathrm{E}-06$ & $2.03 \mathrm{E}-06$ & $2.77 \mathrm{E}-06$ & $3.89 \mathrm{E}-06$ \\
\hline $6.29 \mathrm{E}-09$ & $6.74 \mathrm{E}-06$ & $5.55 \mathrm{E}-07$ & $2.62 \mathrm{E}-07$ & $1.50 \mathrm{E}-06$ & $2.03 \mathrm{E}-06$ & $2.77 \mathrm{E}-06$ & $3.90 \mathrm{E}-06$ \\
\hline $6.33 \mathrm{E}-09$ & $6.74 \mathrm{E}-06$ & $5.56 \mathrm{E}-07$ & $2.63 \mathrm{E}-07$ & $1.51 \mathrm{E}-06$ & $2.04 \mathrm{E}-06$ & $2.78 \mathrm{E}-06$ & $3.90 \mathrm{E}-06$ \\
\hline $6.38 \mathrm{E}-09$ & $6.75 \mathrm{E}-06$ & $5.58 \mathrm{E}-07$ & $2.64 \mathrm{E}-07$ & $1.51 \mathrm{E}-06$ & $2.04 \mathrm{E}-06$ & $2.78 \mathrm{E}-06$ & $3.91 \mathrm{E}-06$ \\
\hline $6.43 \mathrm{E}-09$ & $6.75 \mathrm{E}-06$ & $5.59 \mathrm{E}-07$ & $2.65 \mathrm{E}-07$ & $1.51 \mathrm{E}-06$ & $2.05 \mathrm{E}-06$ & $2.79 \mathrm{E}-06$ & $3.91 \mathrm{E}-06$ \\
\hline $6.48 \mathrm{E}-09$ & $6.75 \mathrm{E}-06$ & $5.61 \mathrm{E}-07$ & $2.66 \mathrm{E}-07$ & $1.52 \mathrm{E}-06$ & $2.05 \mathrm{E}-06$ & $2.80 \mathrm{E}-06$ & $3.92 \mathrm{E}-06$ \\
\hline $.52 \mathrm{E}-09$ & $6.75 E-06$ & $5.62 \mathrm{E}-07$ & $2.67 \mathrm{E}-07$ & $1.52 \mathrm{E}-06$ & $2.05 \mathrm{E}-06$ & $2.80 \mathrm{E}-06$ & $3.92 \mathrm{E}-06$ \\
\hline
\end{tabular}


RESRAD-OFFSITE, Version 2.5

Title : RESRAD-OFFSITE External Gamma, Inhalation, and Soil Ingestion for offsite Reside File : PBA-1_TC99-DOE-5-1.ROF

Summary of dose at graphical times, reptition 2 (continued)

Time

Years

$6.13 E+02$

$6.14 \mathrm{E}+02$

$6.14 \mathrm{E}+02$

$6.15 \mathrm{E}+02$

$6.15 \mathrm{E}+02$

$6.16 \mathrm{E}+02$

$6.16 \mathrm{E}+02$

$6.17 \mathrm{E}+02$

$6.17 \mathrm{E}+02$

$6.18 \mathrm{E}+02$

$6.18 \mathrm{E}+02$

$6.19 \mathrm{E}+02$

$6.19 \mathrm{E}+02$

$6.20 \mathrm{E}+02$

$6.20 \mathrm{E}+02$

$6.21 \mathrm{E}+02$

$6.21 \mathrm{E}+02$

$6.22 \mathrm{E}+02$

$6.22 \mathrm{E}+02$

$6.23 \mathrm{E}+02$

$6.23 \mathrm{E}+02$

$6.24 \mathrm{E}+02$

$6.24 \mathrm{E}+02$

$6.25 \mathrm{E}+02$

$6.25 \mathrm{E}+02$

$6.26 \mathrm{E}+02$

$6.27 \mathrm{E}+02$

$6.27 \mathrm{E}+02$

$6.28 \mathrm{E}+02$

$6.28 \mathrm{E}+02$

$6.29 \mathrm{E}+02$

$6.29 \mathrm{E}+02$

$6.30 \mathrm{E}+02$

$6.30 \mathrm{E}+02$

$6.31 \mathrm{E}+02$

$6.31 \mathrm{E}+02$

$6.32 \mathrm{E}+02$

$6.32 \mathrm{E}+02$

$6.33 \mathrm{E}+02$

$6.33 \mathrm{E}+02$

$6.34 \mathrm{E}+02$

$6.34 \mathrm{E}+02$

$6.35 \mathrm{E}+02$

$6.35 \mathrm{E}+02$

$6.36 \mathrm{E}+02$

$6.36 \mathrm{E}+02$

Dose statistics at graphical times, mrem/yr

\begin{tabular}{|c|c|c|c|c|c|c|c|}
\hline $\mathrm{m}$ & um & ea & ledian & & & & \\
\hline 09 & 06 & 07 & 7 & 06 & 06 & 06 & -06 \\
\hline $62 E-09$ & $5 E-06$ & $55 E-07$ & $E-07$ & $1.53 \mathrm{E}-06$ & $6 E-06$ & -06 & -06 \\
\hline $.67 E-09$ & $5 E-06$ & $.67 E-07$ & $2.71 E-07$ & $1.53 \mathrm{E}-06$ & $2.07 \mathrm{E}-06$ & -06 & -06 \\
\hline$F-09$ & -06 & $68 F-07$ & $72 \mathrm{~F}-07$ & $.54 E-06$ & $07 \mathrm{~F}-06$ & -06 & -0 \\
\hline 09 & 06 & 07 & 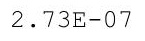 & 06 & 6 & 06 & -06 \\
\hline 09 & & & & & & & -06 \\
\hline $87 E-09$ & $E-06$ & 7 & & 6 & & & -06 \\
\hline-09 & -06 & 7 & 7 & 6 & 6 & 06 & -06 \\
\hline-09 & -06 & -07 & 7 & 06 & 06 & -06 & -06 \\
\hline-09 & -06 & $78=-07$ & 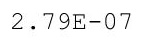 & 6 & & 6 & -06 \\
\hline 09 & 06 & 5 & $80 E-07$ & 6 & & 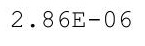 & -0 \\
\hline$E-09$ & $E-06$ & ${ }_{1}$ & $F_{-1}$ & 6 & 6 & 06 & 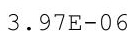 \\
\hline $.17 \mathrm{E}-09$ & $6.75 E-06$ & $5.82 \mathrm{E}-07$ & & & & & $98 E-06$ \\
\hline $.22 \mathrm{E}-09$ & $6.75 E-06$ & $.84 E-07$ & $2.83 E-07$ & $1.57 \mathrm{E}-06$ & $2.12 \mathrm{E}-06$ & $E-06$ & -06 \\
\hline-09 & -06 & $5 E-07$ & $F_{-}$ & $7 E-06$ & 6 & -06 & -06 \\
\hline 09 & $75 E-06$ & & & & & 6 & 06 \\
\hline $3 E-09$ & & & & & & & $00 E-06$ \\
\hline 9 & 6 & קת תم & 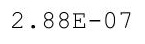 & & & 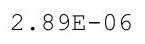 & 0 \\
\hline $48 E-09$ & $E-06$ & $91 \mathrm{~F}-07$ & $\mathrm{~F}-07$ & $8 E-06$ & $4 F-06$ & $E-06$ & -06 \\
\hline$E-09$ & $.75 E-06$ & $.93 E-07$ & $2.91 \mathrm{E}-07$ & $1.59 \mathrm{E}-06$ & $.14 \mathrm{E}-06$ & $9 E-06$ & $E-06$ \\
\hline-09 & -06 & $95 E-0$ & & & $5 \pi$ & 6 & -06 \\
\hline & & & & & & & 06 \\
\hline y & & & & & & & 0 \\
\hline $.75 E-09$ & 6 & - & 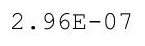 & 6 & & 0 & 0 \\
\hline 9 & 6 & o & + & 6 & $2.16 \mathrm{E}-06$ & - & 0 \\
\hline $86 E-09$ & $.75 E-06$ & $5.02 \mathrm{E}-07$ & $2.98 E-07$ & $1.60 \mathrm{E}-06$ & $17 \mathrm{E}-0$ & $.92 E-06$ & $3 F-06-2-2$ \\
\hline $91 F-09$ & $75 E-06$ & & & & & $.92 E-06$ & $F-06-2-25$ \\
\hline & & & & & & & \\
\hline & & & & & & & -0 \\
\hline $08 E-09$ & $6.75 E-06$ & $0.00 \mathrm{~L}-1$ & $3.035-4$ & $1.62 \mathrm{E}-06$ & $2 . \pm 0 \mathrm{~L}$ & $4-00$ & $E-06$ \\
\hline $14 \mathrm{E}-09$ & $6.75 \mathrm{E}-06$ & 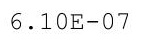 & t & $1.0<5-00$ & . & $2.935-00$ & $\begin{aligned} t \\
0\end{aligned}$ \\
\hline $19 \mathrm{E}-09$ & $6.75 E-06$ & 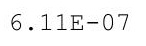 & 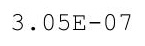 & 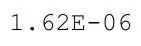 & & & 年 \\
\hline $7-0$ & $75 F-06$ & & & & & & -06 \\
\hline & & & & & & & 06 \\
\hline & & & & 06 & -06 & & -06 \\
\hline $2 E-09$ & $6.75 E-06$ & $6.18 \mathrm{E}-07$ & $3.10 \mathrm{E}-07$ & $\perp \cdot 04 \amalg$ & $2 \cdot 2 \perp \amalg$ & 06 & $7 E-06$ \\
\hline $8-09$ & $E-06$ & $25-01$ & 1 & . & $2+ \pm$ & & ce \\
\hline & & & & & & & \\
\hline 9 & 6 & - & & t & 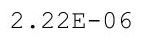 & & $4.09 \mathrm{E}-06$ \\
\hline 9 & & & & & 6 & 6 & 06 \\
\hline$E-09$ & & & & $6 E-06$ & -06 & 06 & 06 \\
\hline$E-09$ & $6.74 \mathrm{E}-06$ & $6.27 E-07$ & $3.18 \mathrm{E}-07$ & $6 E-06$ & $3 E-06$ & 06 & -06 \\
\hline & 06 & 7 & & & & & \\
\hline & & & & $1.67 \mathrm{E}-06$ & $2.24 \mathrm{E}-06$ & $97 E-06$ & -00 \\
\hline & & ( & & 土. & 2.201 & & 00 \\
\hline 9 & $E-06$ & $E-07$ & $3 E-07$ & $.67 E-06$ & -06 & -06 & -06 \\
\hline
\end{tabular}


RESRAD-OFFSITE, Version 2.5

Title : RESRAD-OFFSITE External Gamma, Inhalation, and Soil Ingestion for offsite Reside File : PBA-1_TC99-DOE-5-1.ROF

Summary of dose at graphical times, reptition 2 (continued)

Time

Years

$6.37 \mathrm{E}+02$

$6.37 \mathrm{E}+02$

$6.38 \mathrm{E}+02$

$6.38 \mathrm{E}+02$

$6.39 \mathrm{E}+02$

$6.39 \mathrm{E}+02$

$6.40 \mathrm{E}+02$

$6.40 \mathrm{E}+02$

$6.41 \mathrm{E}+02$

$6.41 \mathrm{E}+02$

$6.42 \mathrm{E}+02$

$6.42 \mathrm{E}+02$

$6.43 \mathrm{E}+02$

$6.43 \mathrm{E}+02$

$6.44 \mathrm{E}+02$

$6.44 \mathrm{E}+02$

$6.45 \mathrm{E}+02$

$6.45 \mathrm{E}+02$

$6.46 \mathrm{E}+02$

$6.47 \mathrm{E}+02$

$6.47 \mathrm{E}+02$

$6.48 \mathrm{E}+02$

$6.48 \mathrm{E}+02$

$6.49 \mathrm{E}+02$

$6.49 \mathrm{E}+02$

$6.50 \mathrm{E}+02$

$6.50 \mathrm{E}+02$

$6.51 \mathrm{E}+02$

$6.51 \mathrm{E}+02$

$6.52 \mathrm{E}+02$

$6.52 \mathrm{E}+02$

$6.53 \mathrm{E}+02$

$6.53 \mathrm{E}+02$

$6.54 \mathrm{E}+02$

$6.54 \mathrm{E}+02$

$6.55 \mathrm{E}+02$

$6.55 \mathrm{E}+02$

$6.56 \mathrm{E}+02$

$6.56 \mathrm{E}+02$

$6.57 \mathrm{E}+02$

$6.57 \mathrm{E}+02$

$6.58 \mathrm{E}+02$

$6.58 \mathrm{E}+02$

$6.59 \mathrm{E}+02$

$6.59 \mathrm{E}+02$

$6.60 \mathrm{E}+02$

Dose statistics at graphical times, mrem/yr

\begin{tabular}{|c|c|c|c|c|c|c|c|}
\hline inimum & aximum & Mean & ledian & $90 \%$ & $5 \%$ & $97.5 \%$ & $\%$ \\
\hline 9 & -06 & $E-07$ & $E-07$ & 06 & 06 & 6 & net \\
\hline 09 & -06 & -07 & 7 & 6 & 6 & 06 & -06 \\
\hline 09 & -06 & $E-07$ & -07 & $3 E-06$ & 06 & 06 & -06 \\
\hline-09 & 06 & & & 6 & & 06 & -06 \\
\hline-09 & -06 & 7 & & & 6 & 06 & $14 \mathrm{E}-06$ \\
\hline-09 & -06 & $E-07$ & -07 & -06 & $8 E-06$ & -06 & -06 \\
\hline-09 & $3 E-06$ & ( & 7 & -06 & 06 & -06 & -0 \\
\hline $.50 E-09$ & $6.73 E-06$ & 然 & & $1.69 \mathrm{E}-06$ & 2.20100 & -06 & $16 \mathrm{E}-06$ \\
\hline 09 & 06 & 1 & 7 & 06 & 6 & -06 & -06 \\
\hline $.63 E-09$ & $3 E-06$ & $9 E-07$ & $7 E-07$ & $.70 E-06$ & $30 E-06$ & -06 & $17 E-06$ \\
\hline-09 & -06 & 7 & & & 6 & & $.7 E-06$ \\
\hline-09 & 06 & & & & & & 06 \\
\hline $.82 E-09$ & $6.73 E-06$ & ا & $=-01$ & $1.71 \mathrm{E}-06$ & $2.31 \mathrm{E}-06$ & -06 & -0 \\
\hline $.89 E-09$ & $6.73 E-06$ & ו & 每 & 06 & 0 & -06 & -06 \\
\hline$E-09$ & 06 & T & 年 & 06 & 6 & 06 & $19 E-06$ \\
\hline $.00 \mathrm{E}-08$ & -06 & 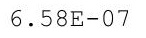 & 1 & 06 & 06 & -06 & -06 \\
\hline $.01 E-08$ & $2 E-06$ & $0 \mathrm{E}-07$ & $5 E-07$ & $1.72 \mathrm{E}-06$ & $33 E-06$ & $E-06$ & $.20 \mathrm{E}-06$ \\
\hline-08 & $2 E-06$ & $1 E-07$ & 7 & $E-06$ & $E-06$ & -06 & $20 E-06$ \\
\hline 08 & -06 & 1 & 1 & 06 & & 6 & -06 \\
\hline $.03 E-08$ & $6.72 E-06$ & -07 & 7 & 06 & 6 & -06 & -06 \\
\hline $3 E-08$ & $6.72 \mathrm{E}-06$ & . & & & & 0 & -06 \\
\hline $.04 \mathrm{E}-08$ & $6.71 \mathrm{E}-06$ & $E-07$ & & $1.73 \mathrm{E}-06$ & م5 & 6 & -06 \\
\hline $.05 E-08$ & $6.71 \mathrm{E}-06$ & $6.69 \mathrm{E}-07$ & 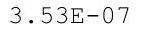 & $1.74 \mathrm{E}-06$ & $35 E-06$ & $6 \mathrm{E}-06$ & $23 E-06$ \\
\hline $.05 E-08$ & $6.71 \mathrm{E}-06$ & $6.71 \mathrm{E}-07$ & $4 \mathrm{E}-07$ & $1.74 \mathrm{E}-06$ & $35 E-06$ & $6 E-06$ & $23 E-06$ \\
\hline 08 & $1 E-06$ & $72 \mathrm{E}-07$ & & 06 & & 6 & -06 \\
\hline 08 & 06 & & 7 & 06 & & -06 & .06 \\
\hline $.08 E-08$ & $1 \pm-00$ & ( & 1 & 6 & & 6 & -06 \\
\hline $.08 E-08$ & $6.70 \mathrm{E}-06$ & $6.77 E-07$ & $3.60 \mathrm{E}-07$ & $1.75 \mathrm{E}-06$ & $2.37 \mathrm{E}-06$ & $.08 \mathrm{E}-06$ & $.25 E-06$ \\
\hline 08 & 6 & . & 年 & 6 & 年 & 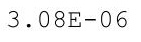 & $25 E-06$ \\
\hline $.10 \mathrm{E}-08$ & $6.70 \mathrm{E}-06$ & ? & the & $1.75 \mathrm{E}-06$ & 年 & 政 & . \\
\hline 08 & $E-06$ & $82 \mathrm{~F}-07$ & & $6 E-06$ & & $E-06$ & $26 \mathrm{E}-06$ \\
\hline 08 & $E-06$ & $.83 E-07$ & $E-07$ & 6 & 6 & 06 & $6 \mathrm{E}-06$ \\
\hline $2 E-08$ & $E-06$ & $5 E-07$ & 7 & 06 & 6 & & $27 E-06$ \\
\hline $.12 \mathrm{E}-08$ & $6.69 E-06$ & $.80 E-01$ & $3.08 \pm-01$ & $1.77 \mathrm{E}-06$ & $2.40 \mathrm{E}-06$ & $D E-06$ & $27 E-06$ \\
\hline $105-20$ & $6.69 E-06$ & $0.00 \mathrm{~L}-\mathrm{T}$ & & $1.77 \mathrm{E}-06$ & & & . $27 \mathrm{~L}-0$ \\
\hline 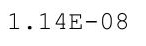 & & & & & & & \\
\hline 8 & 6 & & $3.72 \mathrm{E}-07$ & & & & 06 \\
\hline 8 & & & & 6 & 6 & 6 & 06 \\
\hline 08 & & & & 06 & -06 & -06 & 06 \\
\hline $.17 \mathrm{E}-08$ & $6.68 \mathrm{E}-06$ & $E-07$ & -07 & 06 & & & $29 E-06$ \\
\hline 08 & & 1 & & 6 & & & -0 \\
\hline 8 & & & & 6 & & & -00 \\
\hline & 6 & 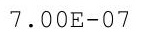 & & 0 & 6 & & 00 \\
\hline $20=-80$ & 06 & 07 & te & 6 & 6 & 6 & 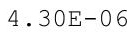 \\
\hline-08 & $6.67 E-06$ & $E-07$ & 3. & 66 & $2.45 \mathrm{E}$ & $E-06$ & $4.30 \mathrm{E}-06$ \\
\hline $.21 E-08$ & $6.67 E-06$ & $7.05 E-07$ & $.84 E-07$ & $1.80 \mathrm{E}-06$ & $2.45 E-06$ & $3.14 \mathrm{E}-06$ & $4.30 \mathrm{E}-06$ \\
\hline
\end{tabular}


RESRAD-OFFSITE, Version 2.5

Title : RESRAD-OFFSITE External Gamma, Inhalation, and Soil Ingestion for Offsite Reside File : PBA-1_TC99-DOE-5-1.ROF

Summary of dose at graphical times, reptition 2 (continued)

Time

Years

$6.60 \mathrm{E}+02$

$6.61 \mathrm{E}+02$

$6.61 \mathrm{E}+02$

$6.62 \mathrm{E}+02$

$6.62 \mathrm{E}+02$

$6.63 \mathrm{E}+02$

$6.63 \mathrm{E}+02$

$6.64 \mathrm{E}+02$

$6.64 \mathrm{E}+02$

$6.65 \mathrm{E}+02$

$6.65 \mathrm{E}+02$

$6.66 \mathrm{E}+02$

$6.67 \mathrm{E}+02$

$6.67 \mathrm{E}+02$

$6.68 \mathrm{E}+02$

$6.68 \mathrm{E}+02$

$6.69 \mathrm{E}+02$

$6.69 \mathrm{E}+02$

$6.70 \mathrm{E}+02$

$6.70 \mathrm{E}+02$

$6.71 \mathrm{E}+02$

$6.71 \mathrm{E}+02$

$6.72 \mathrm{E}+02$

$6.72 \mathrm{E}+02$

$6.73 \mathrm{E}+02$

$6.73 E+02$

$6.74 \mathrm{E}+02$

$6.74 \mathrm{E}+02$

$6.75 \mathrm{E}+02$

$6.75 \mathrm{E}+02$

$6.76 \mathrm{E}+02$

$6.76 \mathrm{E}+02$

$6.77 \mathrm{E}+02$

$6.77 \mathrm{E}+02$

$6.78 \mathrm{E}+02$

$6.78 \mathrm{E}+02$

$6.79 \mathrm{E}+02$

$6.79 \mathrm{E}+02$

$6.80 \mathrm{E}+02$

$6.80 \mathrm{E}+02$

$6.81 \mathrm{E}+02$

$6.81 \mathrm{E}+02$

$6.82 \mathrm{E}+02$

$6.82 \mathrm{E}+02$

$6.83 \mathrm{E}+02$

$6.83 \mathrm{E}+02$
Dose statistics at graphical times, mrem/yr

\begin{tabular}{|c|c|c|c|c|c|c|c|}
\hline inimum & aximum & Mean & ledian & $0 \%$ & $5 \%$ & $97.5 \%$ & $\%$ \\
\hline 08 & $6.67 E-06$ & $7.07 \mathrm{E}-07$ & $.85 \mathrm{E}-07$ & $1.80 \mathrm{E}-06$ & $.45 \mathrm{E}-06$ & $3.14 \mathrm{E}-06$ & $4.30 \mathrm{E}-0$ \\
\hline 08 & 06 & 07 & -07 & .801 & 6 & 06 & -06 \\
\hline $3 E-08$ & 06 & 07 & 07 & 06 & 06 & 06 & -06 \\
\hline $4 E-08$ & 06 & 07 & & & & 06 & -06 \\
\hline $25 E-08$ & $66 \mathrm{E}-06$ & $13 E-07$ & & 6 & $47 E-06$ & -06 & $31 E-06$ \\
\hline $.26 E-08$ & $65 E-06$ & $.15 \mathrm{E}-07$ & -07 & $.81 E-06$ & $48 E-06$ & -06 & $.31 E-06$ \\
\hline 08 & 06 & 07 & 7 & 6 & 6 & 06 & $2=$ \\
\hline 8 & 6 & $7.18 E-07$ & & $1.82 E-06$ & & -06 & $4.32 \mathrm{E}-06$ \\
\hline 08 & 06 & 07 & 1 & 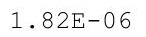 & 6 & 06 & $32 E-06$ \\
\hline $.29 E-08$ & $65 E-06$ & $.21 E-07$ & & $82 E-06$ & $50 E-06$ & -06 & $.32 E-06$ \\
\hline $.29 E-08$ & $.64 \mathrm{E}-06$ & $7.23 E-07$ & & & & $18 E-06$ & $.33 E-06$ \\
\hline-08 & 06 & -07 & & 6 & & -06 & $3 E-06$ \\
\hline $.31 E-08$ & $.64 \mathrm{E}-06$ & $1.20 \mathrm{E}-01$ & . & 1.000 & • & - & -06 \\
\hline 08 & 06 & 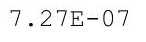 & & $1.83 E-06$ & & -06 & 06 \\
\hline 8 & 6 & 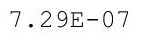 & & $33 E-06$ & • & -06 & 06 \\
\hline $.33 E-08$ & $6.63 \mathrm{E}-06$ & $7.30 \mathrm{E}-07$ & r & -06 & $.52 \mathrm{E}$ & -06 & -06 \\
\hline $.34 E-08$ & $6.63 \mathrm{E}-06$ & $7.32 E-07$ & $.06 E-07$ & $1.84 \mathrm{E}-06$ & $.52 E-06$ & $.22 \mathrm{E}-06$ & $.34 E-06$ \\
\hline $.35 E-08$ & $2 E-06$ & $34 E-07$ & & 6 & & $E-06$ & $34 E-06$ \\
\hline & 06 & & & & & -06 & -06 \\
\hline & -06 & & & & & -06 & -06 \\
\hline 8 & 6 & & & & & 0 & 06 \\
\hline $38 E-08$ & 6 & 7 & 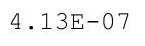 & 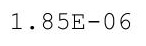 & 2. & $3.24 \mathrm{E}-06$ & 06 \\
\hline 8 & 6 & 7 & 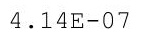 & 65 & F & -06 & -06 \\
\hline $40 E-08$ & $.61 \mathrm{E}-06$ & $7.43 E-07$ & $6 \mathrm{~F}-07$ & $86 F-06$ & 5 & $25 E-06$ & $.35 E-06$ \\
\hline $41 \mathrm{E}-08$ & $E-06$ & $5 E-07$ & & & & $E-06$ & $E-06$ \\
\hline $2 E-08$ & $\mathrm{E}-06$ & -07 & & & & & 06 \\
\hline & & & & & & & 06 \\
\hline $43 E-08$ & $60 E-06$ & $.49 \mathrm{E}-07$ & $2 \perp L-01$ & $1.01 \mathrm{~L}-0$ & 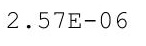 & 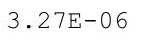 & $.36 E-06$ \\
\hline $44 \mathrm{E}-08$ & $59 E-06$ & $.51 E-07$ & (1) & 政 & 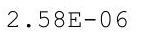 & -40 & $37 E-06$ \\
\hline $45 \mathrm{E}-08$ & $59 E-06$ & $52 E-07$ & 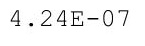 & - & & +2 & $.37 E-06$ \\
\hline $46 \mathrm{E}-08$ & $9 E-06$ & $.54 \mathrm{E}-07$ & & $88 \mathrm{~F}-06$ & & $E-06$ & $37 E-06$ \\
\hline $47 E-08$ & $E-06$ & $E-07$ & 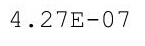 & & & & 06 \\
\hline $.47 E-08$ & & 7 & & & & & -06 \\
\hline $.48 E-08$ & $.58 E-06$ & $7.59 \mathrm{E}-07$ & $.30 E-07$ & $1.89 \mathrm{E}-06$ & $2.39 E-06$ & $\cdot 29 E-00$ & $.38 E-06$ \\
\hline $49 E-08$ & $.57 E-06$ & $7.60 \mathrm{E}-07$ & & $1.095-00$ & & $2-20$ & A. \\
\hline $.50 E-08$ & & & & & & & 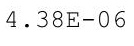 \\
\hline 8 & 6 & $7.64 \mathrm{E}-07$ & & 6 & & 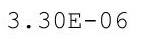 & 06 \\
\hline 8 & & & $.35 E-07$ & & & & 06 \\
\hline $.53 E-08$ & $E-06$ & & & & & & 06 \\
\hline $.54 \mathrm{E}-08$ & $.56 E-06$ & $.68 E-07$ & $8 E-07$ & $1.91 \mathrm{E}$ & 6 & -06 & $4.39 E-06$ \\
\hline $54 \mathrm{E}-08$ & $.56 \mathrm{E}-06$ & $0 \mathrm{E}-07$ & & 6 & & 00 & $.40 E-06$ \\
\hline $5 E-08$ & $5 E-06$ & - 10 & $1+\infty$ & $1.91 E-00$ & $0=$ & 06 & $4.40 E-06$ \\
\hline 0 & 0 & . & the & 0 & (1) & $31 E-06$ & $4.40 E-06$ \\
\hline 8 & 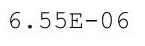 & & & & & & 1.100 \\
\hline $.58 \mathrm{E}-08$ & $.54 \mathrm{E}-06$ & $7.76 \mathrm{E}-07$ & $4.45 E-07$ & $1.92 \mathrm{E}-06$ & $2.62 \mathrm{E}-06$ & $3.32 E-06$ & 4.411 \\
\hline$E-08$ & $E-06$ & $E-07$ & $E-07$ & $.93 E-06$ & -06 & $E-06$ & 4. $41 E-06$ \\
\hline
\end{tabular}


RESRAD-OFFSITE, Version 2.5

robabilistic Dose and Risk Report

Title : RESRAD-OFFSITE External Gamma, Inhalation, and Soil Ingestion for offsite Reside File : PBA-1 TC99-DOE-5-1.ROF

Summary of dose at graphical times, reptition 2 (continued)

Time

Years

$6.84 \mathrm{E}+02$

$6.84 \mathrm{E}+02$

$6.85 \mathrm{E}+02$

$6.85 \mathrm{E}+02$

$6.86 \mathrm{E}+02$

$6.86 \mathrm{E}+02$

$6.87 \mathrm{E}+02$

$6.88 \mathrm{E}+02$

$6.88 \mathrm{E}+02$

$6.89 \mathrm{E}+02$

$6.89 \mathrm{E}+02$

$6.90 \mathrm{E}+02$

$6.90 \mathrm{E}+02$

$6.91 \mathrm{E}+02$

$6.91 \mathrm{E}+02$

$6.92 \mathrm{E}+02$

$6.92 \mathrm{E}+02$

$6.93 \mathrm{E}+02$

$6.93 \mathrm{E}+02$

$6.94 \mathrm{E}+02$

$6.94 \mathrm{E}+02$

$6.95 \mathrm{E}+02$

$6.95 \mathrm{E}+02$

$6.96 \mathrm{E}+02$

$6.96 \mathrm{E}+02$

$6.97 \mathrm{E}+02$

$6.97 \mathrm{E}+02$

$6.98 \mathrm{E}+02$

$6.98 \mathrm{E}+02$

$6.99 \mathrm{E}+02$

$6.99 \mathrm{E}+02$

$7.00 \mathrm{E}+02$

$7.00 \mathrm{E}+02$

$7.01 \mathrm{E}+02$

$7.01 \mathrm{E}+02$

$7.02 \mathrm{E}+02$

$7.02 \mathrm{E}+02$

$7.03 \mathrm{E}+02$

$7.03 E+02$

$7.04 \mathrm{E}+02$

$7.04 \mathrm{E}+02$

$7.05 \mathrm{E}+02$

$7.05 \mathrm{E}+02$

$7.06 \mathrm{E}+02$

$7.06 \mathrm{E}+02$

$7.07 \mathrm{E}+02$
Dose statistics at graphical times, mrem/yr

\begin{tabular}{|c|c|c|c|c|c|c|c|}
\hline m & um & ea & ledian & & & & \\
\hline 08 & 06 & 7 & 7 & 06 & 06 & 06 & -06 \\
\hline $61 E-08$ & $.53 E-06$ & $81 E-07$ & -07 & 06 & 06 & -06 & $41 E-06$ \\
\hline $62 \mathrm{E}-08$ & $.53 E-06$ & $.82 \mathrm{E}-07$ & $4.50 \mathrm{E}-07$ & $1.94 \mathrm{E}-06$ & $2.63 \mathrm{E}-06$ & -06 & -06 \\
\hline-08 & -06 & $84 F-07$ & $2 \mathrm{~F}-07$ & $.94 E-06$ & $6 \Delta \mathrm{F}-06$ & 06 & $-06=2-3 x$ \\
\hline 08 & 06 & $86 \mathrm{E}$ & 7 & 06 & 06 & 06 & -06 \\
\hline-08 & 06 & & & & & & -06 \\
\hline $65 E-08$ & 06 & & & & & & -06 \\
\hline-08 & 06 & 7 & & 6 & 6 & 06 & -06 \\
\hline $.67 \mathrm{E}-08$ & -06 & $92 \mathrm{E}-07$ & 7 & -06 & 06 & -06 & -06 \\
\hline $68 E-08$ & 06 & תמم: תמת & 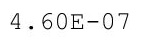 & 6 & & 6 & -06 \\
\hline 8 & 06 & $7.95 \mathrm{E}-07$ & $4.61 E-07$ & 6 & -06 & 6 & -0 \\
\hline $.70 \mathrm{E}-08$ & $6.50 \mathrm{E}-06$ & 075 & 4. & 6 & 6 & 06 & -06 \\
\hline $.71 \mathrm{E}-08$ & $6.49 E-06$ & $7.98 \mathrm{E}-07$ & & $1.97 \mathrm{E}-06$ & & & -06 \\
\hline-08 & $E-06$ & $0 E-07$ & $E-07$ & 6 & & 66 & $E-06$ \\
\hline $73 E-08$ & $E-06$ & $1 E-07$ & 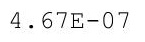 & $7 E-06$ & 6 & -06 & -06 \\
\hline 8 & 6 & & & & & & 06 \\
\hline - & & & & & & 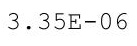 & $.45 E-06$ \\
\hline 8 & 6 & $8.06 \mathrm{E}-07$ & $4.71 \mathrm{E}-07$ & & & 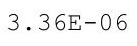 & 0 \\
\hline $.77 E-08$ & $6.47 E-06$ & $8.08 E-07$ & $4.73 E-07$ & $1.99 E-06$ & $2.68 \mathrm{E}-06$ & $36 E-06$ & $.46 \mathrm{E}-06$ \\
\hline $78 \mathrm{E}-08$ & $6.47 E-06$ & $.09 E-07$ & $4.74 \mathrm{E}-07$ & $1.99 \mathrm{E}-06$ & $.69 \mathrm{E}-06$ & -06 & $46 \mathrm{E}-06$ \\
\hline 08 & $5 E-06$ & 10 & & & & 6 & -06 \\
\hline 08 & & & & & & & 06 \\
\hline 8 & & & & & & & o \\
\hline $81 \mathrm{E}-08$ & 6 & t & 1 & 6 & & 0 & 0 \\
\hline 8 & 6 & $17 \mathrm{E}-$ & + & 6 & . & 0 & 0 \\
\hline $83 E-08$ & $.45 E-06$ & $.19 \mathrm{E}-07$ & $4.83 E-07$ & $1 E-06$ & $17=0$ & $8 E-06$ & $49 F-06-2$ \\
\hline-08 & $6.44 \mathrm{E}-06$ & & 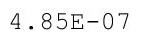 & & & & $49 F-06-2$ \\
\hline & & & & & & & \\
\hline 8 & & & & & & & -06 \\
\hline $.87 E-08$ & $6.44 E-06$ & $0.235-1$ & $4.095-4$ & $2.02 E-06$ & $2.125-00$ & $8 \pm-06$ & $50 \mathrm{E}-06$ \\
\hline $88 \mathrm{E}-08$ & $6.43 E-06$ & . 210 r & 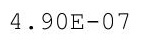 & $2.02 E-06$ & $2 \cdot 1000$ & $20 \mathrm{~m}-20$ & SID \\
\hline ( & $6.43 E-06$ & 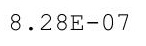 & ter & 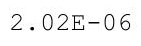 & & & 年 \\
\hline 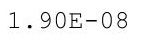 & $43 F-06$ & & $4.93 \mathrm{E}-$ & & & & -06 \\
\hline & & & & & & & 06 \\
\hline 08 & & & & & & & -06 \\
\hline $.94 \mathrm{E}-08$ & $6.43 E-06$ & $8.35 E-07$ & $4.97 E-07$ & $2.03 E-06$ & 6 & 06 & $53 E-06$ \\
\hline $.95 E-08$ & . 12 & $.30 \mathrm{D}-\mathrm{t}$ & t & 2.010 & 0 & 00 & c \\
\hline & & & & & & & • \\
\hline P & 6 & $8.39 \mathrm{E}-07$ & & & & & t \\
\hline & & & & & 6 & 6 & 66 \\
\hline $9 E-08$ & & & $5.05 E-07$ & $2.04 \mathrm{E}-06$ & 06 & $E-06$ & 06 \\
\hline $0 E-08$ & $6.41 E-06$ & $8.44 \mathrm{E}-07$ & $5.06 \mathrm{E}-07$ & $5 E-06$ & $6 E-06$ & 06 & -06 \\
\hline & 06 & 7 & & & & & \\
\hline & & & & 6 & & 06 & -00 \\
\hline & $1 E-06$ & 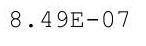 & 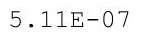 & 2.004 & & 6 & 0 \\
\hline 8 & $E-06$ & $E-07$ & $.13 E-07$ & -06 & $78 E-06$ & $2 E-06$ & -06 \\
\hline
\end{tabular}


RESRAD-OFFSITE, Version 2.5

Title : RESRAD-OFFSITE External Gamma, Inhalation, and Soil Ingestion for Offsite Reside File : PBA-1_TC99-DOE-5-1.ROF

Summary of dose at graphical times, reptition 2 (continued)

Time

Years

7. $08 \mathrm{E}+02$

7. $08 \mathrm{E}+02$

$7.09 \mathrm{E}+02$

$7.09 \mathrm{E}+02$

7. $10 \mathrm{E}+02$

7. $10 \mathrm{E}+02$

7. $11 \mathrm{E}+02$

7. $11 \mathrm{E}+02$

$7.12 \mathrm{E}+02$

$7.12 \mathrm{E}+02$

$7.13 \mathrm{E}+02$

7. $13 \mathrm{E}+02$

$7.14 \mathrm{E}+02$

$7.14 \mathrm{E}+02$

7. $15 \mathrm{E}+02$

7. $15 \mathrm{E}+02$

$7.16 \mathrm{E}+02$

$7.16 \mathrm{E}+02$

$7.17 \mathrm{E}+02$

$7.17 \mathrm{E}+02$

$7.18 \mathrm{E}+02$

$7.18 \mathrm{E}+02$

7. $19 \mathrm{E}+02$

$7.19 \mathrm{E}+02$

7. $20 \mathrm{E}+02$

$7.20 \mathrm{E}+02$

$7.21 \mathrm{E}+02$

$7.21 \mathrm{E}+02$

7. $22 \mathrm{E}+02$

$7.22 \mathrm{E}+02$

7. $23 \mathrm{E}+02$

7. $23 \mathrm{E}+02$

$7.24 \mathrm{E}+02$

7. $24 \mathrm{E}+02$

$7.25 \mathrm{E}+02$

7. $25 \mathrm{E}+02$

$7.26 \mathrm{E}+02$

$7.26 \mathrm{E}+02$

$7.27 \mathrm{E}+02$

$7.28 \mathrm{E}+02$

$7.28 \mathrm{E}+02$

$7.29 \mathrm{E}+02$

$7.29 \mathrm{E}+02$

7. $30 \mathrm{E}+02$

$7.30 \mathrm{E}+02$

$7.31 \mathrm{E}+02$
Dose statistics at graphical times, mrem/yr

\begin{tabular}{|c|c|c|c|c|c|c|c|}
\hline Minimum & aximum & Mean & ledian & $90 \%$ & $5 \%$ & $97.5 \%$ & $\%$ \\
\hline 08 & $40 E-06$ & $52 \mathrm{E}-07$ & $5.14 \mathrm{E}-07$ & $2.06 \mathrm{E}-06$ & $2.78 \mathrm{E}-06$ & $3.42 \mathrm{E}-06$ & $4.57 \mathrm{E}-06$ \\
\hline 8 & $E-06$ & $3 E-07$ & $E-07$ & $.07 \mathrm{E}$ & 6 & -06 & -06 \\
\hline F-08 & $40 E-06$ & $5 E-07$ & $E-07$ & $07 E-06$ & 06 & 06 & -06 \\
\hline$E-08$ & $40 E-06$ & 07 & 7 & & 6 & & -06 \\
\hline-08 & -06 & -07 & & 6 & -06 & 06 & -06 \\
\hline 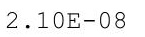 & -06 & L一 & T & -06 & -06 & 6 & -06 \\
\hline 年 & $39 E-06$ & 1 & - & $E-06$ & -06 & 0 & -06 \\
\hline 08 & 06 & ( & S & 06 & -06 & 06 & 06 \\
\hline 08 & -06 & -07 & r & $E-06$ & -06 & 06 & -06 \\
\hline $.15 E-08$ & $38 \mathrm{E}-06$ & -07 & 7 & -06 & -06 & & -06 \\
\hline-08 & 6 & -07 & & 6 & 6 & & -06 \\
\hline .08 & & & & & & & -06 \\
\hline$\cdot .8 \mathrm{E}-08$ & $38 \mathrm{E}-06$ & . & 年 & $\cdot .10 E-00$ & $83 \mathrm{E}-06$ & - & -06 \\
\hline 8 & 06 & $C_{0}$ & & 6 & 6 & 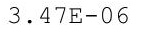 & 06 \\
\hline$E-08$ & $37 E-06$ & • & - & 06 & 06 & & -06 \\
\hline $.22 E-08$ & 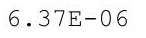 & (6) & & -06 & -06 & 06 & -06 \\
\hline $.23 E-08$ & $37 E-06$ & $7 E-07$ & $E-07$ & -06 & $34 \mathrm{E}-06$ & -06 & $.63 E-06$ \\
\hline-08 & $E-06$ & $78 E-07$ & $0 E-07$ & 06 & 06 & 06 & -06 \\
\hline $5 E-08$ & -06 & $E-U 1$ & 7 & 06 & 0 & & -06 \\
\hline $6 E-08$ & $36 E-06$ & $.82 E-07$ & S & 06 & -06 & 06 & -06 \\
\hline $.27 E-08$ & $36 \mathrm{E}-06$ & וע & & $2 E-06$ & & & -06 \\
\hline $28 \mathrm{E}-08$ & $36 \mathrm{E}-06$ & (4) & & -06 & -06 & $3.50 E-06$ & -06 \\
\hline $.30 E-08$ & $35 E-06$ & 7 & ( & $13 E-06$ & $87 E-06$ & ( & $66 E-06$ \\
\hline $31 E-08$ & -06 & $88 \mathrm{E}-07$ & 7 & $3 E-06$ & 06 & $E-06$ & -06 \\
\hline 08 & 06 & $89 E-07$ & 7 & 06 & -06 & & -06 \\
\hline 08 & 06 & .07 & + & 06 & & & -06 \\
\hline $.34 \mathrm{E}-08$ & $34 E-06$ & $.935-01$ & 4 - & $4 \mathrm{E}-06$ & $9 E-06$ & U & $57 E-06$ \\
\hline $.35 E-08$ & $34 \mathrm{E}-06$ & $8.94 \mathrm{E}-07$ & $5.57 \mathrm{E}-07$ & $2.14 \mathrm{E}-06$ & $.89 E-06$ & $52 E-06$ & $.67 \mathrm{E}-06$ \\
\hline $.37 E-08$ & $.34 E-06$ & $8.96 \mathrm{E}-07$ & $5.58 E-07$ & $2.14 E-06$ & $2.89 E-06$ & $.52 E-06$ & $.68 E-06$ \\
\hline $.38 \mathrm{E}-08$ & $33 E-06$ & 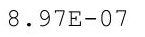 & 年 & $2.14 \pm-00$ & (1) & $2+00$ & $4.68 \mathrm{E}-06$ \\
\hline & -06 & ح تصم0 & & $5 E-06$ & 6 & 6 & -06 \\
\hline 08 & $E-06$ & $E-07$ & $3 E-07$ & $5 E-06$ & 06 & 6 & $8 E-06$ \\
\hline $1 E-08$ & $3 E-06$ & $E-U 1$ & $\mathrm{E}-\mathrm{C}$ & $5 E-06$ & 6 & 06 & $8 E-06$ \\
\hline $.42 \mathrm{E}-08$ & $.32 \mathrm{E}-06$ & $9.03 \mathrm{E}-01$ & $3.0 / E-01$ & $2.16 \mathrm{E}-06$ & $2.90 E-00$ & $3 E-06$ & $.69 E-06$ \\
\hline $.44 E-08$ & $32 E-06$ & $.03 \pm-4$ & & & & $.272-00$ & $.69 E-06$ \\
\hline & & & & & & & $69 E-06$ \\
\hline & 6 & & & & & & 06 \\
\hline 88 & 6 & 7 & 7 & 6 & 6 & 6 & 06 \\
\hline$E-08$ & $31 E-06$ & $E-07$ & 7 & 06 & 6 & 06 & $9 E-06$ \\
\hline $2.50 E-08$ & 6 & $3 E-07$ & 7 & 6 & 6 & & -06 \\
\hline 8 & 6 & & & & & & -06 \\
\hline $52 E-08$ & $30 E-06$ & $.16 E-07$ & $.79 E-07$ & $.18 \mathrm{E}-06$ & & & $0 E-06$ \\
\hline & & 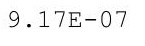 & 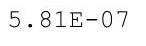 & & & & 06 \\
\hline & $6.30 E-06$ & & & & & & 06 \\
\hline 8 & 06 & 9.2 & 7 & 2.1 & 2.9 & 06 & -06 \\
\hline $.57 E-08$ & $.29 E-06$ & $.22 \mathrm{E}-07$ & $5.86 E-07$ & $.19 \mathrm{E}-06$ & $2.94 E-06$ & $3.56 \mathrm{E}-06$ & $4.70 \mathrm{E}-06$ \\
\hline
\end{tabular}


RESRAD-OFFSITE, Version 2.5

Title : RESRAD-OFFSITE External Gamma, Inhalation, and Soil Ingestion for offsite Reside File : PBA-1_TC99-DOE-5-1.ROF

Summary of dose at graphical times, reptition 2 (continued)

Time

Years

7. $31 \mathrm{E}+02$

7. $32 \mathrm{E}+02$

7. $32 \mathrm{E}+02$

7. $33 \mathrm{E}+02$

7. $33 \mathrm{E}+02$

7. $34 \mathrm{E}+02$

7. $34 \mathrm{E}+02$

7. $35 \mathrm{E}+02$

$7.35 \mathrm{E}+02$

7. $36 \mathrm{E}+02$

7. $36 \mathrm{E}+02$

7. $37 \mathrm{E}+02$

7. $37 \mathrm{E}+02$

7. $38 \mathrm{E}+02$

7. $38 \mathrm{E}+02$

7. $39 \mathrm{E}+02$

$7.39 \mathrm{E}+02$

$7.40 \mathrm{E}+02$

$7.40 \mathrm{E}+02$

$7.41 \mathrm{E}+02$

7. $41 \mathrm{E}+02$

7. $42 \mathrm{E}+02$

$7.42 \mathrm{E}+02$

$7.43 \mathrm{E}+02$

7. $43 \mathrm{E}+02$

$7.44 \mathrm{E}+02$

7. $44 \mathrm{E}+02$

$7.45 \mathrm{E}+02$

7. $45 \mathrm{E}+02$

$7.46 \mathrm{E}+02$

$7.46 \mathrm{E}+02$

$7.47 \mathrm{E}+02$

$7.48 \mathrm{E}+02$

$7.48 \mathrm{E}+02$

$7.49 \mathrm{E}+02$

$7.49 \mathrm{E}+02$

$7.50 \mathrm{E}+02$

$7.50 \mathrm{E}+02$

$7.51 \mathrm{E}+02$

$7.51 \mathrm{E}+02$

$7.52 \mathrm{E}+02$

7. $52 \mathrm{E}+02$

$7.53 \mathrm{E}+02$

$7.53 \mathrm{E}+02$

7. $54 \mathrm{E}+02$

$7.54 \mathrm{E}+02$
Dose statistics at graphical times, mrem/yr

\begin{tabular}{|c|c|c|c|c|c|c|c|}
\hline inimum & aximum & Mean & ledian & $90 \%$ & $5 \%$ & $97.5 \%$ & $\%$ \\
\hline-08 & $29 E-06$ & $9.24 E-07$ & $5.88 \mathrm{E}-07$ & $2.20 E-06$ & $E-06$ & $3.56 E-06$ & $E-0$ \\
\hline-08 & -06 & $E-07$ & 7 & 6 & 6 & 06 & $E-06$ \\
\hline$E-08$ & -06 & $E-07$ & -07 & $0 E-06$ & 6 & 06 & -06 \\
\hline $2 E-08$ & 06 & 7 & & 06 & & 66 & -06 \\
\hline $.63 E-08$ & -06 & 7 & & 66 & 6 & -06 & $70 E-06$ \\
\hline $.65 E-08$ & -06 & $\Xi-07$ & -07 & $2.21 \mathrm{E}-06$ & $5 E-06$ & -06 & $0 E-06$ \\
\hline-08 & -06 & 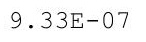 & 7 & $2 E-06$ & 06 & -06 & $1 E-0$ \\
\hline 08 & 06 & י & & 06 & ( & 06 & -06 \\
\hline 08 & -06 & 1 & 7 & $22 \mathrm{E}-$ & 6 & -06 & -06 \\
\hline $.70 \mathrm{E}-08$ & $26 E-06$ & $8 E-07$ & $2 E-07$ & $2.23 E-06$ & $5 E-06$ & -06 & -06 \\
\hline-08 & -06 & 7 & & 6 & & 06 & $71 E-06$ \\
\hline-08 & -06 & 7 & 7 & -06 & & -06 & $E-06$ \\
\hline $.74 \mathrm{E}-08$ & $E-06$ & - & $E-07$ & $24 E-06$ & 0 & -06 & -0 \\
\hline 08 & 06 & $9.44 \mathrm{E}-07$ & 7 & 6 & 0 & 6 & 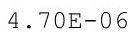 \\
\hline-08 & 06 & 政 & r & & & -06 & $.70 E-06$ \\
\hline $.78 \mathrm{E}-08$ & -06 & ? & 7 & 6 & 6 & 6 & -06 \\
\hline $.79 \mathrm{E}-08$ & $6.24 \mathrm{E}-06$ & $8 E-07$ & $5 E-07$ & $2.25 \mathrm{E}-06$ & $7 E-06$ & $E-06$ & $.70 E-06$ \\
\hline $0 E-08$ & $3 E-06$ & $0 E-07$ & $6 \mathrm{E}-07$ & $25 E-06$ & $8 E-06$ & $E-06$ & $70 E-06$ \\
\hline 08 & -06 & 1 & 7 & 06 & & -06 & -06 \\
\hline 08 & -06 & 1 & 7 & 06 & 6 & -06 & -06 \\
\hline $.84 \mathrm{E}-08$ & $6.22 \mathrm{E}-06$ & ( & & & & - & -06 \\
\hline $.85 E-08$ & $6.22 \mathrm{E}-06$ & $9.56 \mathrm{E}-07$ & & $2.26 \mathrm{E}-06$ & 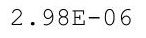 & -06 & -06 \\
\hline $7 E-08$ & $22 E-06$ & $8 \mathrm{E}-$ & 7 & $26 E-06$ & 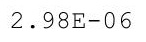 & 6 & $69 E-06$ \\
\hline $.88 \mathrm{E}-08$ & $.21 E-06$ & $.59 \mathrm{E}-07$ & $6 E-07$ & $.26 \mathrm{E}-06$ & $99 E-06$ & $3 E-06$ & $69 \mathrm{E}-06$ \\
\hline$E-08$ & $21 E-06$ & $51 F-07$ & 7 & $26 E-06$ & 06 & -06 & $69 E-06$ \\
\hline 08 & & & & & & & \\
\hline $.92 E-08$ & -06 & 4 & 7 & 6 & & 6 & -06 \\
\hline $.93 E-08$ & $6.20 E-06$ & O & $31 E-07$ & $2.27 E-06$ & (1- 0 & $4 E-06$ & $68 E-06$ \\
\hline 08 & 6 & - & - & 6 & 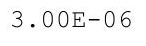 & -06 & $68 \mathrm{E}-06$ \\
\hline 8 & - & - & 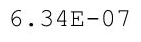 & 6 & 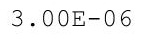 & - & 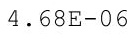 \\
\hline $98 F-08$ & $195-06$ & $0=07$ & & $28 E-06$ & & $E-06$ & $68 E-06$ \\
\hline$\Xi-08$ & $E-06$ & $5-c_{0}$ & 5 & & 6 & & -06 \\
\hline & & & & 06 & -06 & & -06 \\
\hline $.02 E-08$ & $6.18 E-06$ & $9.14 \mathrm{E}-01$ & $6.40 \mathrm{E}-07$ & $2.29 \mathrm{E}-06$ & $1 E-06$ & $5 E-06$ & $67 E-06$ \\
\hline $03 E-08$ & $6.18 E-06$ & . & & $2.29 E-06$ & & & . OTL- \\
\hline & & & & & & & \\
\hline 8 & 6 & & & & & & 06 \\
\hline 8 & & & & & & & 06 \\
\hline 8 & & & & 06 & -06 & -06 & .06 \\
\hline $0 E-08$ & $6.16 \mathrm{E}-06$ & $4 \mathrm{E}-07$ & $E-07$ & $L E-06$ & 6 & & $57 \mathrm{E}-06$ \\
\hline $1 E-08$ & -06 & L- t & & 6 & & & $8 / E-0$ \\
\hline & 6 & $.07 \mathrm{E}-\mathrm{T}$ & 7 & $2.01+$ & & & $.015-00$ \\
\hline 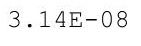 & 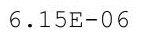 & 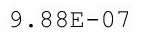 & 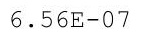 & $2.02 \Delta$ & & 06 & 年 \\
\hline $.10 \mathrm{E}-00$ & 06 & 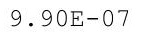 & 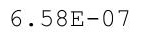 & 6 & 6 & 6 & 06 \\
\hline-08 & $6.14 E-06$ & $9.91 \mathrm{E}-07$ & -07 & $2.33 \mathrm{E}$ & 06 & $E-06$ & $4.68 E-06$ \\
\hline $.19 E-08$ & $6.14 E-06$ & $.93 E-07$ & $.61 E-07$ & $2.33 E-06$ & $3.04 \mathrm{E}-06$ & $3.66 \mathrm{E}-06$ & $4.68 E-06$ \\
\hline
\end{tabular}


RESRAD-OFFSITE, Version 2.5

Title : RESRAD-OFFSITE External Gamma, Inhalation, and Soil Ingestion for offsite Reside File : PBA-1_TC99-DOE-5-1.ROF

Summary of dose at graphical times, reptition 2 (continued)

Time

Years

$7.55 E+02$

$7.55 \mathrm{E}+02$

$7.56 \mathrm{E}+02$

$7.56 \mathrm{E}+02$

$7.57 \mathrm{E}+02$

$7.57 \mathrm{E}+02$

$7.58 \mathrm{E}+02$

7. $58 \mathrm{E}+02$

$7.59 \mathrm{E}+02$

$7.59 \mathrm{E}+02$

$7.60 \mathrm{E}+02$

$7.60 \mathrm{E}+02$

$7.61 \mathrm{E}+02$

7. $61 \mathrm{E}+02$

$7.62 \mathrm{E}+02$

7. $62 \mathrm{E}+02$

$7.63 \mathrm{E}+02$

$7.63 \mathrm{E}+02$

$7.64 \mathrm{E}+02$

$7.64 \mathrm{E}+02$

$7.65 \mathrm{E}+02$

7. $65 \mathrm{E}+02$

$7.66 \mathrm{E}+02$

$7.66 \mathrm{E}+02$

$7.67 \mathrm{E}+02$

$7.68 \mathrm{E}+02$

$7.68 \mathrm{E}+02$

$7.69 \mathrm{E}+02$

$7.69 \mathrm{E}+02$

$7.70 \mathrm{E}+02$

$7.70 \mathrm{E}+02$

$7.71 \mathrm{E}+02$

$7.71 \mathrm{E}+02$

7. $72 \mathrm{E}+02$

$7.72 \mathrm{E}+02$

$7.73 E+02$

$7.73 \mathrm{E}+02$

$7.74 \mathrm{E}+02$

$7.74 \mathrm{E}+02$

$7.75 \mathrm{E}+02$

$7.75 \mathrm{E}+02$

$7.76 \mathrm{E}+02$

$7.76 \mathrm{E}+02$

$7.77 \mathrm{E}+02$

$7.77 \mathrm{E}+02$

$7.78 \mathrm{E}+02$
Dose statistics at graphical times, mrem/yr

\begin{tabular}{|c|c|c|c|c|c|c|c|}
\hline inimum & aximum & Mean & ledian & $90 \%$ & $5 \%$ & $97.5 \%$ & $\%$ \\
\hline 8 & 6 & 07 & 7 & $2.33 E-06$ & $.04 \mathrm{E}-06$ & $3.66 \mathrm{E}-06$ & 4. $68 \mathrm{E}-0$ \\
\hline 08 & 06 & 07 & 07 & 06 & 06 & 06 & -06 \\
\hline$E-08$ & -06 & 07 & 07 & 06 & 06 & 06 & $3 E-06$ \\
\hline$E-08$ & -06 & 07 & & & 6 & 06 & -06 \\
\hline $26 E-08$ & $12 E-06$ & 6 & 07 & $35 E-06$ & $05 E-06$ & -06 & $68 E-06$ \\
\hline $27 E-08$ & $12 E-06$ & -06 & -07 & $36 E-06$ & $06 E-06$ & -06 & $.68 E-06$ \\
\hline 08 & $E-06$ & -06 & 7 & 6 & $6 \mathrm{~F}$ & -06 & 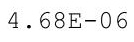 \\
\hline 08 & 06 & 0 & & ( & ( & 06 & $4.68 E-06$ \\
\hline 08 & 06 & 6 & 1 & 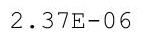 & 6 & 06 & $8 E-06$ \\
\hline $.33 E-08$ & $10 E-06$ & $.01 E-06$ & & $.37 E-06$ & 6 & -06 & $8 E-06$ \\
\hline $35 E-08$ & $.10 \mathrm{E}-06$ & $.01 \mathrm{E}-06$ & & $.38 E-06$ & $.07 E-06$ & $56 E-06$ & $.68 E-06$ \\
\hline 08 & -06 & -06 & & 6 & & -06 & $8 E-06$ \\
\hline $.37 E-08$ & $.09 \mathrm{E}-06$ & $.01 \mathrm{E}-06$ & (. & C. & 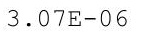 & - & -06 \\
\hline 08 & 06 & 6 & & $39 E-06$ & & 0 & 06 \\
\hline 8 & 6 & 6 & & $9 E-06$ & $775=6$ & -06 & 06 \\
\hline $42 \mathrm{E}-08$ & $6.08 \mathrm{E}-06$ & $.02 \mathrm{E}-06$ & r & $2.39 \mathrm{E}-06$ & 6 & -06 & -06 \\
\hline $43 E-08$ & $6.07 E-06$ & $1.02 E-06$ & $.89 E-07$ & $2.39 \mathrm{E}-06$ & $.07 E-06$ & $.65 E-06$ & $.68 E-06$ \\
\hline$E-08$ & $7 E-06$ & $.02 E-06$ & & -06 & & $E-06$ & $57 E-06$ \\
\hline & 06 & 06 & & & & -06 & -06 \\
\hline & -06 & -06 & & & & -06 & -06 \\
\hline 08 & 6 & 6 & & & & 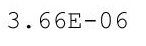 & -06 \\
\hline 08 & 6 & 6 & 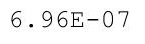 & $2.40 \mathrm{E}-06$ & 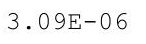 & $3.66 \mathrm{E}-06$ & -06 \\
\hline 8 & 6 & 6 & 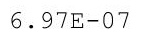 & 11 & تم & -06 & -06 \\
\hline $4 E-08$ & $.05 E-06$ & $.03 E-06$ & $3 E-07$ & $41 F-06$ & ل & $67 E-06$ & $.66 E-06$ \\
\hline$E-08$ & $E-06$ & $.03 E-06$ & & tit & & $7 E-06$ & $5 E-06$ \\
\hline$E-08$ & -06 & -06 & & & & & .06 \\
\hline & & & & & & & 06 \\
\hline $60 E-08$ & $.03 E-06$ & $.04 \mathrm{E}-06$ & $.045-1$ & $2.4 \perp E-00$ & $1 \perp E-U 0$ & 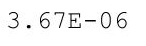 & $.65 E-06$ \\
\hline $2 E-08$ & $3 E-06$ & $04 E-06$ & 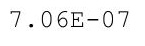 & $-1+$ & + & 我 & $4 E-06$ \\
\hline 然 & $02 E-06$ & $1.04 E-06$ & 至 & $(-5-5$ & & (c) & $64 E-06$ \\
\hline$E-08$ & $2 E-06$ & $1.04 \mathrm{E}-06$ & & & & $8 E-06$ & $4 E-06$ \\
\hline$E-08$ & $E-06$ & $E-06$ & ק & 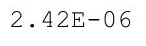 & & -06 & -06 \\
\hline & & & & & & $E-06$ & $53 E-06$ \\
\hline $.70 E-08$ & $.01 E-06$ & $.04 E-06$ & $7.14 \mathrm{E}-07$ & $2.42 \mathrm{E}-06$ & $12 \mathrm{E}-U \mathrm{O}$ & $9 E-06$ & $.63 E-06$ \\
\hline $71 E-08$ & $.00 E-06$ & $.05 E-06$ & & $\angle .4 \angle L-00$ & & $2 \pi-20$ & $.63 E-06$ \\
\hline & & & & & & & $.63 E-06$ \\
\hline 8 & 6 & 6 & & & & 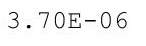 & e \\
\hline 8 & & & & & & 6 & 06 \\
\hline$E-08$ & $E-06$ & $5 E-06$ & 7 & 2 & 6 & -06 & $3 E-06$ \\
\hline $79 E-08$ & $98 E-06$ & $.05 E-06$ & 7 & 6 & & -06 & $4.63 E-06$ \\
\hline $1 E-08$ & $3 E-06$ & $5 E-06$ & & & & 00 & -06 \\
\hline$E-08$ & 0 & $.06 \mathrm{E}-06$ & -4 & $2 \cdot 104$ & 0 & 06 & -00 \\
\hline tito & 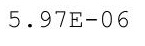 & . & .200 & 2. & $+\infty$ & $72 E-06$ & $4.045-00$ \\
\hline & . & +.00 & (. & 2. & & $.72 \mathrm{E}-06$ & $4.64 \mathrm{E}-06$ \\
\hline $7 E-08$ & $5.96 E-06$ & $6 E-06$ & 7.3 & $2.46 E-06$ & $3.16 \mathrm{E}-06$ & -06 & 4.64 \\
\hline-08 & 06 & $E-06$ & $3 E-07$ & $.46 E-06$ & -06 & $2 E-06$ & 4. $64 \mathrm{E}-06$ \\
\hline
\end{tabular}


RESRAD-OFFSITE, Version 2.5

Title : RESRAD-OFFSITE External Gamma, Inhalation, and Soil Ingestion for Offsite Reside File : PBA-1_TC99-DOE-5-1.ROF

Summary of dose at graphical times, reptition 2 (continued)

Time

Years

$7.78 \mathrm{E}+02$

$7.79 \mathrm{E}+02$

$7.79 \mathrm{E}+02$

$7.80 \mathrm{E}+02$

$7.80 \mathrm{E}+02$

$7.81 \mathrm{E}+02$

$7.81 \mathrm{E}+02$

$7.82 \mathrm{E}+02$

$7.82 \mathrm{E}+02$

$7.83 \mathrm{E}+02$

$7.83 \mathrm{E}+02$

$7.84 \mathrm{E}+02$

$7.84 \mathrm{E}+02$

$7.85 \mathrm{E}+02$

$7.85 \mathrm{E}+02$

$7.86 \mathrm{E}+02$

$7.86 \mathrm{E}+02$

$7.87 \mathrm{E}+02$

$7.88 \mathrm{E}+02$

$7.88 \mathrm{E}+02$

$7.89 \mathrm{E}+02$

$7.89 \mathrm{E}+02$

$7.90 \mathrm{E}+02$

$7.90 \mathrm{E}+02$

$7.91 \mathrm{E}+02$

$7.91 \mathrm{E}+02$

$7.92 \mathrm{E}+02$

$7.92 \mathrm{E}+02$

7. $93 \mathrm{E}+02$

7. $93 \mathrm{E}+02$

$7.94 \mathrm{E}+02$

$7.94 \mathrm{E}+02$

7. $95 \mathrm{E}+02$

$7.95 \mathrm{E}+02$

$7.96 \mathrm{E}+02$

7. $96 \mathrm{E}+02$

$7.97 \mathrm{E}+02$

$7.97 \mathrm{E}+02$

$7.98 \mathrm{E}+02$

$7.98 \mathrm{E}+02$

$7.99 \mathrm{E}+02$

$7.99 \mathrm{E}+02$

$8.00 \mathrm{E}+02$

$8.00 \mathrm{E}+02$

$8.01 \mathrm{E}+02$

$8.01 \mathrm{E}+02$
Dose statistics at graphical times, mrem/yr

\begin{tabular}{|c|c|c|c|c|c|c|c|}
\hline Iinimum & laximum & Mean & Median & $90 \%$ & $95 \%$ & $97.5 \%$ & \\
\hline 8 & 06 & 06 & $4 E-07$ & 6 & 06 & 06 & -06 \\
\hline $2 E-08$ & $5 E-06$ & $1.06 \mathrm{E}-06$ & $7.36 \mathrm{E}-07$ & 06 & $3.17 \mathrm{E}-06$ & $3.72 \mathrm{E}-06$ & $.64 \mathrm{E}-06$ \\
\hline-08 & $4 E-06$ & $E-06$ & 7 & 6 & 06 & 06 & -06 \\
\hline$E-08$ & $E-06$ & $7 E-06$ & $E-07$ & 06 & $7 E-06$ & 06 & -06 \\
\hline $.97 E-08$ & -06 & $7 E-06$ & -07 & $2.47 \mathrm{E}-06$ & -06 & & -06 \\
\hline $.98 E-08$ & -06 & -06 & 7 & 6 & $E-06$ & 06 & -06 \\
\hline $0 E-08$ & $3 E-06$ & $7 E-06$ & $6 E-07$ & $8 E-06$ & $z-06$ & 06 & $E-06$ \\
\hline $2 E-08$ & $92 E-06$ & $.07 E-06$ & $8 E-07$ & -06 & -06 & -06 & -06 \\
\hline $.03 E-08$ & $5.92 \mathrm{E}-06$ & $.08 \mathrm{E}-06$ & $7.49 \mathrm{E}-07$ & $2.48 \mathrm{E}-06$ & $18 \mathrm{E}-06$ & -06 & -06 \\
\hline$E-08$ & -06 & $3 E-06$ & -07 & 06 & 06 & 06 & -06 \\
\hline $.07 E-08$ & $5.91 E-06$ & $1.08 \mathrm{E}-06$ & $7.53 E-07$ & & $19 \mathrm{E}-06$ & & -06 \\
\hline-08 & -06 & $E-06$ & 7 & 6 & 6 & & 06 \\
\hline $.10 \mathrm{E}-08$ & $0 E-06$ & $3 E-06$ & $7 E-07$ & -06 & $19 \mathrm{E}-00$ & & \\
\hline $.12 \mathrm{E}-08$ & $5.90 \mathrm{E}-06$ & $1.08 \mathrm{E}-06$ & -07 & 0 & 6 & 6 & 06 \\
\hline $3 E-08$ & $E-06$ & $8 E-06$ & -07 & 06 & & 06 & -06 \\
\hline $.15 E-08$ & $9 E-06$ & $9 \mathrm{E}-06$ & -07 & 6 & 0 & 06 & -06 \\
\hline $.17 \mathrm{E}-08$ & $5.88 \mathrm{E}-06$ & $1.09 \mathrm{E}-06$ & $7.65 \mathrm{E}-07$ & $2.49 \mathrm{E}-06$ & $.20 E-06$ & $.75 E-06$ & -06 \\
\hline $.19 \mathrm{E}-08$ & $5.88 E-06$ & $1.09 \mathrm{E}-06$ & $7 E-07$ & $2.50 \mathrm{E}-06$ & $20 E-06$ & $76 E-06$ & $5 E-06$ \\
\hline $.20 \mathrm{E}-08$ & $7 E-06$ & $1.09 \mathrm{E}-06$ & $9 E-07$ & $0 E-06$ & $4-06$ & & \\
\hline $.22 \mathrm{E}-08$ & $5.87 \mathrm{E}-06$ & $.09 \mathrm{E}-06$ & -07 & 6 & 0 & & 06 \\
\hline $4 E-08$ & $5.86 \mathrm{E}-06$ & $1.09 \mathrm{E}-06$ & $2 E-07$ & & & & -06 \\
\hline . $20 \mathrm{~L}-00$ & $5.86 \mathrm{E}-06$ & $1.09 \mathrm{E}-06$ & $7.73 E-07$ & -06 & o & -06 & -06 \\
\hline F & $E-06$ & $0 E-06$ & $5 E-07$ & $1 E-06$ & 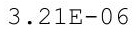 & -06 & 06 \\
\hline $.29 E-08$ & $E-06$ & $E-06$ & -07 & -06 & 6 & 06 & -06 \\
\hline $.30 \mathrm{E}-08$ & $5 E-06$ & $0 E-06$ & E-07 & $1 \mathrm{E}-06$ & $21 \mathrm{~F}-06$ & -06 & -06 \\
\hline$E-08$ & 06 & -06 & -07 & & & & -06 \\
\hline $4 \mathrm{E}-08$ & $E-06$ & $E-06$ & $2 E-07$ & 6 & & & -06 \\
\hline $.36 \mathrm{E}-08$ & $5.83 E-06$ & $1.10 \mathrm{E}-06$ & $7.83 \mathrm{E}-07$ & $2.52 \mathrm{E}-06$ & $22 E-06$ & $78 E-06$ & $.66 \mathrm{E}-06$ \\
\hline $.37 E-08$ & $5.83 E-06$ & $1.10 \mathrm{E}-06$ & $7.84 \mathrm{E}-07$ & $2.52 \mathrm{E}-06$ & $22 E-06$ & $.78 E-06$ & $.66 E-06$ \\
\hline • & $5.82 \mathrm{E}-06$ & $1.11 \mathrm{E}-06$ & $1.00 \mathrm{E}-\mathrm{T}$ & $2 \cdot 02+00$ & $\angle 25-00$ & -06 & $.00 \mathrm{E}-\mathrm{U}$ \\
\hline 08 & 6 & $E-06$ & 07 & 6 & 6 & 6 & 06 \\
\hline$E-08$ & $E-06$ & $E-06$ & $E-07$ & 6 & 6 & & 06 \\
\hline $.44 \mathrm{E}-08$ & $5.81 \mathrm{E}-06$ & $1.11 \mathrm{E}-06$ & $7.91 \mathrm{E}-07$ & 6 & 6 & 06 & -06 \\
\hline $.46 \mathrm{E}-08$ & $5.82 \mathrm{E}-06$ & $1.11 \mathrm{E}-06$ & $7.92 \mathrm{E}-07$ & $2.53 \mathrm{E}-06$ & $23 E-06$ & $79 E-06$ & $.66 \mathrm{E}-06$ \\
\hline $.40 E-00$ & $5.82 \mathrm{E}-06$ & $1.11 \mathrm{E}-06$ & & & & & $.66 \mathrm{E}-06$ \\
\hline ك & & & & & & & \\
\hline & & & & & & & \\
\hline 8 & 6 & 6 & 07 & 06 & 6 & 6 & -06 \\
\hline$E-08$ & $2 E-06$ & $2 E-06$ & $3 E-07$ & $5 E-06$ & 6 & 06 & -06 \\
\hline $7 E-08$ & 06 & $2 E-06$ & 07 & & & & 06 \\
\hline $94-08$ & $33 E-06$ & $12 \mathrm{E}-06$ & $0 E-07$ & 6 & & & $66 E-06$ \\
\hline $4.60 \mathrm{E}-08$ & $5.83 E-06$ & $1.12 \mathrm{E}-06$ & $8.02 \mathrm{E}-07$ & $2.55 \mathrm{E}-06$ & & & $.66 \mathrm{E}-06$ \\
\hline & & & & 0 & 6 & & $4.65 E-06$ \\
\hline A 6050 & & & 1 & 0 & 6 & 6 & 06 \\
\hline 08 & $5.83 \mathrm{E}$ & -06 & 8. & 2 . & 6 & 06 & -06 \\
\hline $.68 E-08$ & $5.83 E-06$ & $1.13 E-06$ & $.07 E-07$ & $2.56 \mathrm{E}-06$ & $3.24 \mathrm{E}-06$ & $3.82 \mathrm{E}-06$ & $4.65 E-06$ \\
\hline
\end{tabular}


RESRAD-OFFSITE, Version 2.5

Title : RESRAD-OFFSITE External Gamma, Inhalation, and Soil Ingestion for Offsite Reside File : PBA-1_TC99-DOE-5-1.ROF

Summary of dose at graphical times, reptition 2 (continued)

Time

Years

8. $02 \mathrm{E}+02$

$8.02 \mathrm{E}+02$

$8.03 E+02$

$8.03 \mathrm{E}+02$

$8.04 \mathrm{E}+02$

$8.04 \mathrm{E}+02$

$8.05 \mathrm{E}+02$

$8.05 \mathrm{E}+02$

$8.06 \mathrm{E}+02$

$8.06 \mathrm{E}+02$

$8.07 \mathrm{E}+02$

$8.07 \mathrm{E}+02$

$8.08 \mathrm{E}+02$

$8.09 \mathrm{E}+02$

$8.09 \mathrm{E}+02$

$8.10 \mathrm{E}+02$

$8.10 \mathrm{E}+02$

$8.11 \mathrm{E}+02$

$8.11 \mathrm{E}+02$

$8.12 \mathrm{E}+02$

$8.12 \mathrm{E}+02$

$8.13 \mathrm{E}+02$

$8.13 \mathrm{E}+02$

$8.14 \mathrm{E}+02$

$8.14 \mathrm{E}+02$

$8.15 \mathrm{E}+02$

$8.15 \mathrm{E}+02$

$8.16 \mathrm{E}+02$

$8.16 \mathrm{E}+02$

$8.17 \mathrm{E}+02$

$8.17 \mathrm{E}+02$

$8.18 \mathrm{E}+02$

$8.18 \mathrm{E}+02$

8. $19 \mathrm{E}+02$

$8.19 \mathrm{E}+02$

8. $20 \mathrm{E}+02$

$8.20 \mathrm{E}+02$

$8.21 E+02$

$8.21 E+02$

$8.22 \mathrm{E}+02$

$8.22 \mathrm{E}+02$

$8.23 \mathrm{E}+02$

$8.23 \mathrm{E}+02$

$8.24 \mathrm{E}+02$

$8.24 \mathrm{E}+02$

$8.25 E+02$

Dose statistics at graphical times, mrem/yr

\begin{tabular}{|c|c|c|c|c|c|c|c|}
\hline m & um & ean & ledian & & & & \\
\hline 08 & 06 & 06 & 7 & 66 & 06 & 06 & -06 \\
\hline $.71 E-08$ & $5.84 \mathrm{E}-06$ & $1.13 E-06$ & $8.10 E-07$ & $7 E-06$ & $5 E-06$ & -06 & $5 E-06$ \\
\hline $.73 E-08$ & $.84 \mathrm{E}-06$ & $.13 E-06$ & $8.12 \mathrm{E}-07$ & $2.57 \mathrm{E}-06$ & $3.25 \mathrm{E}-06$ & -06 & -06 \\
\hline-08 & -06 & $13 \mathrm{~F}-06$ & $13 \mathrm{~F}-07$ & $.57 E-06$ & $25 \mathrm{~F}-06$ & 06 & $-06=2-3 x$ \\
\hline 08 & 06 & 06 & 07 & 06 & 06 & 06 & -06 \\
\hline-08 & & & & & & & -06 \\
\hline $80 \mathrm{E}-08$ & $84 E-06$ & & & & & & -06 \\
\hline $.82 E-08$ & -06 & -06 & 7 & 6 & 6 & -06 & -06 \\
\hline $.84 \mathrm{E}-08$ & $85 E-06$ & $4 E-06$ & 7 & $9 E-06$ & -06 & -06 & -06 \\
\hline-08 & -06 & $14 \mathrm{E}-06$ & קח קח & & & 6 & -06 \\
\hline 8 & 06 & 6 & $E-07$ & 6 & & 6 & -0 \\
\hline-08 & -06 & $5 E-06$ & 7 & 6 & 6 & 06 & -06 \\
\hline $.92 \mathrm{E}-08$ & $5.85 E-06$ & $1.15 \mathrm{E}-06$ & & & & & -06 \\
\hline $.93 E-08$ & $5.85 \mathrm{E}-06$ & $1.15 \mathrm{E}-06$ & $8.32 E-07$ & $2.60 \mathrm{E}-06$ & & -06 & $z-06$ \\
\hline-08 & -06 & $E-06$ & & $\Xi-06$ & & -06 & -06 \\
\hline 08 & 6 & $.15 \mathrm{E}-06$ & & & 0 & 6 & 06 \\
\hline 8 & & & & & & 0 & 06 \\
\hline 8 & 6 & 6 & $8.38 E-07$ & & & 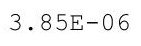 & 0 \\
\hline $.03 E-08$ & $5.86 \mathrm{E}-06$ & $1.16 \mathrm{E}-06$ & $8.40 E-07$ & $2.61 E-06$ & $3.27 \mathrm{E}-06$ & $85 E-06$ & $E-06$ \\
\hline$E-08$ & $.86 E-06$ & $1.16 \mathrm{E}-06$ & $8.41 E-07$ & $2.61 \mathrm{E}-06$ & $.27 E-06$ & $E-06$ & $E-06$ \\
\hline 08 & 06 & $.16 \mathrm{E}-06$ & & & & 6 & -06 \\
\hline & & & & & & & 06 \\
\hline 08 & & & & & & & o \\
\hline 08 & 6 & 6 & & 6 & 0 & 6 & -0 \\
\hline 8 & 6 & $16 \mathrm{E}-$ & . & 6 & . & 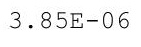 & 0 \\
\hline$E-08$ & $.87 E-06$ & $1.17 \mathrm{E}-06$ & $8.51 \mathrm{E}-07$ & $2.63 E-06$ & م & $E-06$ & $F-06$ \\
\hline$F-08$ & $.87 E-06$ & $1.17 \mathrm{E}-06$ & & & & $E-06$ & -06 \\
\hline & & & & & & & \\
\hline & 6 & & & & & & -06 \\
\hline $24 E-08$ & $5.87 \mathrm{E}-06$ & $1.17 \mathrm{E}-06$ & $0.015-4$ & $2.64 \mathrm{E}-06$ & $3.28 E-06$ & $E-06$ & $62 \mathrm{E}-06$ \\
\hline $26 \mathrm{E}-08$ & $.87 E-06$ & $.17 \mathrm{E}-06$ & 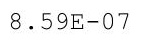 & $2.64 \mathrm{E}-06$ & $.20 \pi$ on & L- -0 & 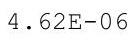 \\
\hline 8 & $.87 E-06$ & $1.17 \mathrm{E}-06$ & & $2.64 \mathrm{E}-06$ & & & 年 \\
\hline$F-08$ & $87 F-06$ & & & & & & $E-06-2-2$ \\
\hline & 6 & & & 6 & 6 & 6 & 06 \\
\hline & 06 & & & & 6 & & -06 \\
\hline $.36 \mathrm{E}-08$ & $5.87 \mathrm{E}-06$ & $1.18 \mathrm{E}-06$ & $8.65 E-07$ & $2.64 \mathrm{E}-06$ & 3.27 & 06 & $62 \mathrm{E}-06$ \\
\hline $38 E-08$ & $.88 E-06$ & $.18 \mathrm{E}-06$ & $.015-21$ & 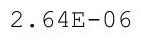 & 0 & & ce \\
\hline $40 \mathrm{E}-08$ & & & & & & & • U⿺辶一 \\
\hline 8 & & 6 & $8.70 \mathrm{E}-07$ & 2 & & & $4.62 \mathrm{E}-06$ \\
\hline & & & & & 6 & 6 & 06 \\
\hline-08 & & & $4 E-07$ & $5 E-06$ & $E-06$ & -06 & -06 \\
\hline $48 \mathrm{E}-08$ & $5.88 \mathrm{E}-06$ & $1.19 \mathrm{E}-06$ & $6 E-07$ & $5 E-06$ & $0 E-06$ & $E-06$ & -06 \\
\hline & & 06 & & & & & 06 \\
\hline & & $1.19 \mathrm{E}-06$ & & 6 & & 06 & 00 \\
\hline & & & & & & & •. \\
\hline 8 & $E-06$ & $.19 \mathrm{E}-06$ & $4 E-07$ & -06 & $31 E-06$ & $7 E-06$ & -06 \\
\hline
\end{tabular}


RESRAD-OFFSITE, Version 2.5

Title : RESRAD-OFFSITE External Gamma, Inhalation, and Soil Ingestion for Offsite Reside File : PBA-1_TC99-DOE-5-1.ROF

Summary of dose at graphical times, reptition 2 (continued)

Time

Years

$8.25 \mathrm{E}+02$

$8.26 \mathrm{E}+02$

$8.26 \mathrm{E}+02$

$8.27 \mathrm{E}+02$

$8.27 \mathrm{E}+02$

$8.28 \mathrm{E}+02$

$8.29 \mathrm{E}+02$

$8.29 \mathrm{E}+02$

$8.30 \mathrm{E}+02$

$8.30 \mathrm{E}+02$

$8.31 \mathrm{E}+02$

$8.31 \mathrm{E}+02$

8. $32 \mathrm{E}+02$

8. $32 \mathrm{E}+02$

$8.33 \mathrm{E}+02$

$8.33 \mathrm{E}+02$

$8.34 \mathrm{E}+02$

$8.34 \mathrm{E}+02$

$8.35 \mathrm{E}+02$

$8.35 \mathrm{E}+02$

$8.36 \mathrm{E}+02$

$8.36 \mathrm{E}+02$

$8.37 \mathrm{E}+02$

$8.37 \mathrm{E}+02$

$8.38 \mathrm{E}+02$

$8.38 \mathrm{E}+02$

$8.39 \mathrm{E}+02$

$8.39 \mathrm{E}+02$

$8.40 \mathrm{E}+02$

$8.40 \mathrm{E}+02$

$8.41 \mathrm{E}+02$

8. $41 \mathrm{E}+02$

$8.42 \mathrm{E}+02$

$8.42 \mathrm{E}+02$

$8.43 \mathrm{E}+02$

$8.43 \mathrm{E}+02$

$8.44 \mathrm{E}+02$

$8.44 \mathrm{E}+02$

$8.45 \mathrm{E}+02$

$8.45 \mathrm{E}+02$

$8.46 \mathrm{E}+02$

$8.46 \mathrm{E}+02$

$8.47 \mathrm{E}+02$

$8.47 \mathrm{E}+02$

$8.48 \mathrm{E}+02$

$8.49 \mathrm{E}+02$
Dose statistics at graphical times, mrem/yr

\begin{tabular}{|c|c|c|c|c|c|c|c|}
\hline & m & Mean & Median & & & & \\
\hline $58 \mathrm{E}-08$ & $5.88 \mathrm{E}-06$ & $1.19 \mathrm{E}-06$ & $8.86 \mathrm{E}-07$ & $2.65 \mathrm{E}-06$ & $3.31 \mathrm{E}-06$ & $3.87 \mathrm{E}-06$ & $4.62 \mathrm{E}-06$ \\
\hline $5.60 \mathrm{E}-08$ & $5.88 \mathrm{E}-06$ & $1.20 \mathrm{E}-06$ & $8.87 \mathrm{E}-07$ & $2.65 \mathrm{E}-06$ & $3.32 \mathrm{E}-06$ & $3.87 E-06$ & $4.62 \mathrm{E}-06$ \\
\hline $5.62 \mathrm{E}-08$ & $5.88 \mathrm{E}-06$ & $1.20 \mathrm{E}-06$ & $8.89 \mathrm{E}-07$ & $2.65 \mathrm{E}-06$ & $3.32 \mathrm{E}-06$ & $3.87 \mathrm{E}-06$ & $4.62 \mathrm{E}-06$ \\
\hline $.64 \mathrm{E}-08$ & $5.88 E-06$ & $1.20 \mathrm{E}-06$ & $8.91 \mathrm{E}-07$ & $2.65 \mathrm{E}-06$ & $3.32 \mathrm{E}-06$ & $3.87 \mathrm{E}-06$ & $4.61 \mathrm{E}-06$ \\
\hline $5.66 \mathrm{E}-08$ & $5.89 \mathrm{E}-06$ & $1.20 \mathrm{E}-06$ & $8.93 \mathrm{E}-07$ & $2.65 \mathrm{E}-06$ & $3.32 \mathrm{E}-06$ & $3.88 \mathrm{E}-06$ & $4.61 \mathrm{E}-06$ \\
\hline $.68 \mathrm{E}-08$ & $5.89 \mathrm{E}-06$ & $1.20 \mathrm{E}-06$ & $8.94 \mathrm{E}-07$ & $2.66 \mathrm{E}-06$ & $3.33 E-06$ & $3.88 \mathrm{E}-06$ & $4.61 \mathrm{E}-06$ \\
\hline $5.70 \mathrm{E}-08$ & $5.89 \mathrm{E}-06$ & $1.20 \mathrm{E}-06$ & $8.95 \mathrm{E}-07$ & $2.66 \mathrm{E}-06$ & $3.33 E-06$ & $3.88 \mathrm{E}-06$ & $4.61 \mathrm{E}-06$ \\
\hline $.72 E-08$ & $5.89 \mathrm{E}-06$ & $1.20 \mathrm{E}-06$ & $8.97 \mathrm{E}-07$ & $2.66 \mathrm{E}-06$ & $3.33 E-06$ & $3.88 \mathrm{E}-06$ & $4.61 \mathrm{E}-06$ \\
\hline $.74 \mathrm{E}-08$ & $5.89 \mathrm{E}-06$ & $1.21 \mathrm{E}-06$ & $8.98 \mathrm{E}-07$ & $2.66 \mathrm{E}-06$ & $3.33 E-06$ & $3.88 \mathrm{E}-06$ & $4.60 \mathrm{E}-06$ \\
\hline $76 \mathrm{E}-08$ & $5.89 \mathrm{E}-06$ & $1.21 \mathrm{E}-06$ & $8.99 \mathrm{E}$ & $6 \mathrm{E}$ & $33 \mathrm{E}$ & 3.88 & -06 \\
\hline $78 \mathrm{E}-08$ & $5.89 \mathrm{E}-06$ & $1.21 \mathrm{E}$ & $9.00 \mathrm{E}$ & 2. & 6 & 3.8 & $4.60 \mathrm{E}-06$ \\
\hline $80 E-08$ & $5.89 \mathrm{E}-06$ & $1.21 \mathrm{E}-06$ & $9.01 \mathrm{E}-07$ & $2.66 \mathrm{E}-06$ & $3.33 E-06$ & $3.88 \mathrm{E}-06$ & $4.60 \mathrm{E}-06$ \\
\hline $82 \mathrm{E}-08$ & $5.89 \mathrm{E}-06$ & $1.21 \mathrm{E}-06$ & $9.02 \mathrm{E}-07$ & $2.67 \mathrm{E}-06$ & $3.33 E-06$ & $3.88 \mathrm{E}-06$ & $4.59 \mathrm{E}-06$ \\
\hline $.84 \mathrm{E}-08$ & $5.89 \mathrm{E}-06$ & $1.21 \mathrm{E}-06$ & $9.04 \mathrm{E}-07$ & $2.67 \mathrm{E}-06$ & $3.33 \mathrm{E}-06$ & $3.88 \mathrm{E}-06$ & $59 E-06$ \\
\hline $86 \mathrm{E}-08$ & $5.89 E-06$ & $1.21 \mathrm{E}-06$ & $9.05 \mathrm{E}-07$ & $2.67 \mathrm{E}-06$ & $3.33 \mathrm{E}-06$ & $3.88 \mathrm{E}-06$ & $59 E-06$ \\
\hline $.88 \mathrm{E}-08$ & $5.89 \mathrm{E}-06$ & $1.22 \mathrm{E}-06$ & $9.06 \mathrm{E}-07$ & $2.67 \mathrm{E}$ & $3.33 E-06$ & $3.88 \mathrm{E}-06$ & $.59 E-06$ \\
\hline $5.90 \mathrm{E}-08$ & $5.89 \mathrm{E}-06$ & $1.22 \mathrm{E}-06$ & $9.07 \mathrm{E}-07$ & $2.67 \mathrm{E}-06$ & $3.33 E-06$ & $3.89 \mathrm{E}-06$ & $4.58 \mathrm{E}-06$ \\
\hline $5.92 \mathrm{E}-08$ & $5.89 \mathrm{E}-06$ & $1.22 \mathrm{E}-06$ & $9.08 \mathrm{E}-07$ & $2.68 \mathrm{E}-06$ & $3.34 \mathrm{E}-06$ & $3.89 \mathrm{E}-06$ & $4.58 \mathrm{E}-06$ \\
\hline $.95 E-08$ & $5.89 \mathrm{E}-06$ & $1.22 \mathrm{E}-06$ & $9.09 \mathrm{E}-07$ & $2.68 \mathrm{E}-06$ & $3.34 \mathrm{E}-06$ & $3.89 \mathrm{E}-06$ & $4.58 \mathrm{E}-06$ \\
\hline $.97 \mathrm{E}-08$ & $5.89 \mathrm{E}-06$ & $1.22 \mathrm{E}-06$ & $9.10 \mathrm{E}-07$ & $2.68 \mathrm{E}-06$ & $3.34 \mathrm{E}-06$ & $3.89 \mathrm{E}-06$ & $4.57 \mathrm{E}-06$ \\
\hline $.99 \mathrm{E}-08$ & $5.89 \mathrm{E}-06$ & $1.22 \mathrm{E}-06$ & $9.12 \mathrm{E}-07$ & $2.68 \mathrm{E}-06$ & $3.34 \mathrm{E}-06$ & $3.89 \mathrm{E}-06$ & $4.57 \mathrm{E}-06$ \\
\hline $6.01 \mathrm{E}-08$ & $5.89 \mathrm{E}-06$ & $1.22 \mathrm{E}-06$ & $9.13 \mathrm{E}-07$ & $2.69 \mathrm{E}-06$ & $3.34 \mathrm{E}-06$ & $3.89 \mathrm{E}-06$ & $4.57 \mathrm{E}-06$ \\
\hline $.03 E-08$ & $5.89 \mathrm{E}-06$ & $1.22 \mathrm{E}-06$ & $9.14 \mathrm{E}-07$ & $2.69 \mathrm{E}-06$ & $3.34 \mathrm{E}-06$ & $3.89 \mathrm{E}-06$ & $4.57 \mathrm{E}-06$ \\
\hline $5.05 \mathrm{E}-08$ & $5.89 E-06$ & 6 & 9. & 6 & 6 & 6 & -06 \\
\hline $.07 \mathrm{E}-08$ & 5 & 6 & 7 & 6 & 6 & 6 & 06 \\
\hline $6.09 \mathrm{E}-08$ & $5.89 \mathrm{E}-06$ & $1.23 E-06$ & $9.19 \mathrm{E}-07$ & $2.70 \mathrm{E}-06$ & $3.34 \mathrm{E}-06$ & $3.89 \mathrm{E}-06$ & $4.56 \mathrm{E}-06$ \\
\hline $6.11 E-08$ & $5.89 \mathrm{E}-06$ & $1.23 \mathrm{E}-06$ & $9.21 \mathrm{E}-07$ & $2.70 \mathrm{E}-06$ & $3.33 E-06$ & $3.89 \mathrm{E}-06$ & $4.56 \mathrm{E}-06$ \\
\hline $6.14 \mathrm{E}-08$ & $5.89 \mathrm{E}-06$ & $1.23 E-06$ & $9.22 \mathrm{E}-07$ & $2.70 \mathrm{E}-06$ & $3.34 \mathrm{E}-06$ & $3.89 \mathrm{E}-06$ & $4.55 \mathrm{E}-06$ \\
\hline $.16 \mathrm{E}-08$ & $5.89 \mathrm{E}-06$ & $1.23 \mathrm{E}-06$ & $9.24 \mathrm{E}-07$ & $2.70 \mathrm{E}-06$ & $3.34 \mathrm{E}-06$ & $3.89 \mathrm{E}-06$ & $4.55 \mathrm{E}-06$ \\
\hline $.18 \mathrm{E}-08$ & $5.90 \mathrm{E}-06$ & $1.23 E-06$ & $9.25 \mathrm{E}-07$ & $2.70 \mathrm{E}-06$ & $3.34 \mathrm{E}-06$ & $3.89 \mathrm{E}-06$ & $4.55 \mathrm{E}-06$ \\
\hline $5.20 \mathrm{E}-08$ & $5.90 \mathrm{E}-06$ & $1.24 \mathrm{E}-06$ & $9.26 \mathrm{E}-07$ & $2.70 \mathrm{E}-06$ & $3.34 \mathrm{E}-06$ & $3.89 \mathrm{E}-06$ & $4.54 \mathrm{E}-06$ \\
\hline $.22 \mathrm{E}-08$ & $5.90 \mathrm{E}-06$ & $1.24 \mathrm{E}-06$ & $9.28 \mathrm{E}-07$ & $2.70 \mathrm{E}-06$ & $3.35 E-06$ & $3.89 \mathrm{E}-06$ & $4.54 \mathrm{E}-06$ \\
\hline $6.24 \mathrm{E}-08$ & $5.90 \mathrm{E}-06$ & $1.24 \mathrm{E}-06$ & $9.29 \mathrm{E}-07$ & $2.70 \mathrm{E}-06$ & $3.35 \mathrm{E}-06$ & $3.89 \mathrm{E}-06$ & $4.53 \mathrm{E}-06$ \\
\hline $6.26 \mathrm{E}-08$ & $5.90 \mathrm{E}-06$ & $1.24 \mathrm{E}-06$ & $9.31 \mathrm{E}-07$ & $2.71 \mathrm{E}-06$ & $3.35 \mathrm{E}-06$ & $3.89 \mathrm{E}-06$ & $4.53 \mathrm{E}-06$ \\
\hline $6.29 \mathrm{E}-08$ & $5.90 \mathrm{E}-06$ & $1.24 \mathrm{E}-06$ & $9.32 \mathrm{E}-07$ & $2.71 \mathrm{E}-06$ & $3.35 E-06$ & $3.89 \mathrm{E}-06$ & $4.53 \mathrm{E}-06$ \\
\hline $.31 \mathrm{E}-08$ & $5.90 \mathrm{E}-06$ & $1.24 \mathrm{E}-06$ & $9.34 \mathrm{E}-07$ & $2.71 \mathrm{E}-06$ & $3.35 \mathrm{E}-06$ & $3.89 \mathrm{E}-06$ & $4.52 \mathrm{E}-06$ \\
\hline $.33 E-08$ & $5.90 \mathrm{E}-06$ & $1.24 \mathrm{E}-06$ & $9.35 \mathrm{E}-07$ & $2.71 \mathrm{E}-06$ & $3.36 \mathrm{E}-06$ & $3.90 \mathrm{E}-06$ & $4.52 \mathrm{E}-06$ \\
\hline $.35 E-08$ & $5.90 \mathrm{E}-06$ & $1.24 \mathrm{E}-06$ & $9.36 \mathrm{E}-07$ & $2.72 \mathrm{E}-06$ & $3.36 \mathrm{E}-06$ & $3.90 \mathrm{E}-06$ & $4.51 \mathrm{E}-06$ \\
\hline $.37 E-08$ & $5.90 \mathrm{E}-06$ & $1.25 \mathrm{E}-06$ & $9.38 \mathrm{E}-07$ & $2.72 E-06$ & $3.35 E-06$ & $3.90 \mathrm{E}-06$ & $4.51 \mathrm{E}-06$ \\
\hline $6.39 \mathrm{E}-08$ & $5.90 \mathrm{E}-06$ & $1.25 \mathrm{E}-06$ & $9.39 \mathrm{E}-07$ & $2.72 \mathrm{E}-06$ & $3.35 E-06$ & $3.90 \mathrm{E}-06$ & $4.51 \mathrm{E}-06$ \\
\hline $6.42 \mathrm{E}-08$ & $5.90 \mathrm{E}-06$ & $1.25 \mathrm{E}-06$ & $9.40 \mathrm{E}-07$ & $2.72 E-06$ & $3.35 E-06$ & $3.90 \mathrm{E}-06$ & $4.50 \mathrm{E}-06$ \\
\hline $6.44 \mathrm{E}-08$ & $5.90 \mathrm{E}-06$ & $1.25 \mathrm{E}-06$ & $9.41 \mathrm{E}-07$ & $2.73 E-06$ & $3.35 \mathrm{E}-06$ & $3.90 \mathrm{E}-06$ & $4.50 \mathrm{E}-06$ \\
\hline $6.46 \mathrm{E}-08$ & $5.90 \mathrm{E}$ & $25 E$ & 07 & 6 & $3.35 \mathrm{E}$ & $3.91 \mathrm{E}-06$ & $4.50 \mathrm{E}-06$ \\
\hline $6.48 \mathrm{E}-08$ & $5.90 E-06$ & $1.25 \mathrm{E}-06$ & $9.43 \mathrm{E}-07$ & $2.73 E-06$ & $3.35 E-06$ & $3.91 \mathrm{E}-06$ & $4.50 \mathrm{E}-06$ \\
\hline $6.50 \mathrm{E}-08$ & $5.90 \mathrm{E}-06$ & $1.25 \mathrm{E}-06$ & $9.45 \mathrm{E}-07$ & $2.74 \mathrm{E}-06$ & $3.36 \mathrm{E}-06$ & $3.91 \mathrm{E}-06$ & $4.50 \mathrm{E}-06$ \\
\hline $5.53 E-08$ & $5.90 \mathrm{E}-06$ & $1.25 \mathrm{E}-06$ & $9.46 \mathrm{E}-07$ & $2.74 \mathrm{E}-06$ & $3.36 \mathrm{E}-06$ & $3.91 \mathrm{E}-06$ & $4.50 \mathrm{E}-06$ \\
\hline
\end{tabular}


RESRAD-OFFSITE, Version 2.5

Title : RESRAD-OFFSITE External Gamma, Inhalation, and Soil Ingestion for Offsite Reside File : PBA-1 TC99-DOE-5-1.ROF

Summary of dose at graphical times, reptition 2 (continued)

Time

Years

8. $49 \mathrm{E}+02$

$8.50 \mathrm{E}+02$

$8.50 \mathrm{E}+02$

8. $51 \mathrm{E}+02$

$8.51 \mathrm{E}+02$

$8.52 \mathrm{E}+02$

$8.52 \mathrm{E}+02$

8. $53 \mathrm{E}+02$

8. $53 \mathrm{E}+02$

8. $54 \mathrm{E}+02$

$8.54 \mathrm{E}+02$

$8.55 \mathrm{E}+02$

8. $55 \mathrm{E}+02$

$8.56 \mathrm{E}+02$

$8.56 \mathrm{E}+02$

$8.57 \mathrm{E}+02$

$8.57 \mathrm{E}+02$

8. $58 \mathrm{E}+02$

8. $58 \mathrm{E}+02$

8. $59 \mathrm{E}+02$

8. $59 \mathrm{E}+02$

8. $60 \mathrm{E}+02$

$8.60 \mathrm{E}+02$

$8.61 \mathrm{E}+02$

8. $61 \mathrm{E}+02$

$8.62 \mathrm{E}+02$

8. $62 \mathrm{E}+02$

$8.63 \mathrm{E}+02$

$8.63 \mathrm{E}+02$

$8.64 \mathrm{E}+02$

$8.64 \mathrm{E}+02$

$8.65 \mathrm{E}+02$

$8.65 \mathrm{E}+02$

$8.66 \mathrm{E}+02$

$8.66 \mathrm{E}+02$

$8.67 \mathrm{E}+02$

$8.67 \mathrm{E}+02$

$8.68 \mathrm{E}+02$

$8.69 \mathrm{E}+02$

$8.69 \mathrm{E}+02$

$8.70 \mathrm{E}+02$

$8.70 \mathrm{E}+02$

$8.71 \mathrm{E}+02$

$8.71 E+02$

$8.72 \mathrm{E}+02$

$8.72 \mathrm{E}+02$
Dose statistics at graphical times, mrem/yr

\begin{tabular}{|c|c|c|c|c|c|c|c|}
\hline inimum & aximum & Mean & ledian & $0 \%$ & $5 \%$ & $97.5 \%$ & $\%$ \\
\hline-08 & $5.90 E-06$ & $1.26 \mathrm{E}-06$ & $8 E-07$ & $4 E-06$ & $6 E-06$ & $3.91 E-06$ & $50 \mathrm{E}-0$ \\
\hline 08 & -06 & 06 & $E-07$ & 6 & 06 & 06 & $E-06$ \\
\hline-08 & -06 & $E-06$ & -07 & $E-06$ & 6 & 06 & -06 \\
\hline$E-08$ & $E-06$ & 06 & 7 & 6 & & & -06 \\
\hline $4 E-08$ & 06 & 6 & & 06 & 6 & 06 & $49 E-06$ \\
\hline $5 E-08$ & -06 & $.26 E-06$ & $E-07$ & -06 & $7 E-06$ & -06 & $9 E-06$ \\
\hline-08 & -06 & $.26 \mathrm{E}-06$ & , & $5 E-06$ & 06 & -06 & -0 \\
\hline $.70 E-08$ & $5.90 \mathrm{E}-06$ & $.27 E-06$ & & $5 E-06$ & 0 & -06 & $.49 E-06$ \\
\hline 08 & 06 & 06 & 7 & 06 & 6 & -06 & -06 \\
\hline $.75 E-08$ & $E-06$ & $1.27 \mathrm{E}-06$ & $E-07$ & $5 E-06$ & -06 & -06 & -06 \\
\hline-08 & -06 & -06 & & & & & $E-06$ \\
\hline & & -06 & & & & & 06 \\
\hline $.82 E-08$ & $5.89 \mathrm{E}-06$ & $.27 E-06$ & E-U & $2.75 \mathrm{E}-06$ & $5-00$ & $E-06$ & -0 \\
\hline $4 \mathrm{E}-08$ & $5.89 \mathrm{E}-06$ & $1.27 \mathrm{E}-06$ & & $5 E-06$ & 0 & -06 & $E-06$ \\
\hline-08 & 06 & 06 & 1 & 06 & 6 & 06 & -06 \\
\hline $.88 \mathrm{E}-08$ & -06 & -06 & 7 & 06 & 06 & -06 & -06 \\
\hline $.91 \mathrm{E}-08$ & $9 E-06$ & $1.28 \mathrm{E}-06$ & $6 E-07$ & $6 E-06$ & $9 E-06$ & $E-06$ & $48 E-06$ \\
\hline-08 & $E-06$ & $28 E-06$ & $E-07$ & -06 & $E-06$ & -06 & $47 E-06$ \\
\hline 08 & -06 & 06 & 1 & 06 & & 6 & -06 \\
\hline $7 E-08$ & $E-06$ & $1.28 \mathrm{E}-06$ & 1 & 06 & & -06 & -06 \\
\hline $.00 \mathrm{E}-08$ & $5.89 \mathrm{E}-06$ & $1.28 \mathrm{E}-06$ & & & & o & -06 \\
\hline $.02 \mathrm{E}-08$ & $5.89 \mathrm{E}-06$ & $1.28 \mathrm{E}-06$ & & & & 06 & -06 \\
\hline $.04 E-08$ & $.89 E-06$ & $1.28 \mathrm{E}-06$ & ר 07 & $76 E-06$ & (10 & $0 E-06$ & $46 E-06$ \\
\hline $.07 \mathrm{E}-08$ & $9 E-06$ & $1.29 \mathrm{E}-06$ & $6 \mathrm{E}-07$ & $7 E-06$ & $40 E-06$ & $0 E-06$ & $46 \mathrm{E}-06$ \\
\hline-08 & -06 & $1.29 \mathrm{E}-06$ & & 06 & & 06 & -06 \\
\hline 08 & 06 & -06 & 07 & 06 & & .06 & \\
\hline $.14 \mathrm{E}-08$ & $5.89 \mathrm{E}-06$ & $1.29 \mathrm{E}-06$ & & $7 E-06$ & & & 06 \\
\hline $.16 \mathrm{E}-08$ & $5.89 \mathrm{E}-06$ & $1.29 \mathrm{E}-06$ & $9.93 E-07$ & $2.77 \mathrm{E}-06$ & $3.40 \mathrm{E}-06$ & $90 \mathrm{E}-06$ & $.45 E-06$ \\
\hline 08 & 6 & 6 & 年 & 6 & 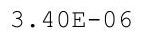 & 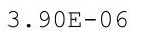 & $45 E-06$ \\
\hline $.21 \mathrm{E}-08$ & $5.89 \mathrm{E}-06$ & $1.29 \mathrm{E}-06$ & r & $7 E-06$ & 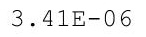 & 政 & 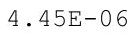 \\
\hline 08 & $F-06$ & $129 F-06$ & & $8 F-06$ & & $E-06$ & $5 E-06$ \\
\hline$E-08$ & $E-06$ & $.30 E-06$ & $E-06$ & $3 E-06$ & 6 & 6 & $44 E-06$ \\
\hline $3 E-08$ & $E-06$ & $1.30 \mathrm{E}-06$ & 06 & 06 & & & -06 \\
\hline $.30 E-08$ & $5.89 \mathrm{E}-06$ & 1. $30 \mathrm{E}-06$ & $.00 \mathrm{E}-06$ & $2.78 E-06$ & $3.42 \mathrm{E}-06$ & $91 E-06$ & $.44 E-06$ \\
\hline $32 E-08$ & $5.89 E-06$ & $1.30 E-06$ & & $2.78 E-06$ & & & $.445-0$ \\
\hline 0 & & & & & & & \\
\hline 8 & 6 & & & 6 & & & he \\
\hline 8 & & & & & & 6 & 06 \\
\hline 8 & & & & & -06 & -06 & 06 \\
\hline $.44 \mathrm{E}-08$ & $5.88 \mathrm{E}-06$ & $1.31 \mathrm{E}-06$ & $E-06$ & 06 & 6 & & $4 \mathrm{E}-06$ \\
\hline $5 E-08$ & & $E-06$ & & 6 & & & -0 \\
\hline 08 & 6 & $31 E-06$ & 0 & 6 & & & -00 \\
\hline 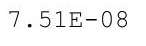 & 3 & 6 & 0 & 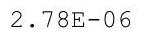 & - & 6 & 00 \\
\hline $1.04 \mathrm{E}-00$ & $2+\frac{1}{2}$ & +1 & $2+$ & 6 & 6 & 6 & 0 \\
\hline$E-08$ & 5.8 & 1.31 & 06 & 66 & 3 . & -06 & $4.4 \mathrm{~F}$ \\
\hline $.58 \mathrm{E}-08$ & $5.88 E-06$ & $1.31 \mathrm{E}-06$ & $.02 E-06$ & $2.79 E-06$ & $3.42 \mathrm{E}-06$ & $3.92 E-06$ & $4.44 \mathrm{E}-06$ \\
\hline
\end{tabular}


RESRAD-OFFSITE, Version 2.5

Title : RESRAD-OFFSITE External Gamma, Inhalation, and Soil Ingestion for offsite Reside File : PBA-1 TC99-DOE-5-1.ROF

Summary of dose at graphical times, reptition 2 (continued)

Time

Years

$8.73 E+02$

$8.73 \mathrm{E}+02$

$8.74 \mathrm{E}+02$

8. $74 \mathrm{E}+02$

$8.75 \mathrm{E}+02$

$8.75 \mathrm{E}+02$

$8.76 \mathrm{E}+02$

$8.76 \mathrm{E}+02$

8. $77 \mathrm{E}+02$

8. $77 \mathrm{E}+02$

$8.78 \mathrm{E}+02$

$8.78 \mathrm{E}+02$

$8.79 \mathrm{E}+02$

$8.79 \mathrm{E}+02$

$8.80 \mathrm{E}+02$

$8.80 \mathrm{E}+02$

$8.81 \mathrm{E}+02$

8. $81 \mathrm{E}+02$

$8.82 \mathrm{E}+02$

$8.82 \mathrm{E}+02$

$8.83 \mathrm{E}+02$

$8.83 \mathrm{E}+02$

$8.84 \mathrm{E}+02$

$8.84 \mathrm{E}+02$

$8.85 \mathrm{E}+02$

$8.85 \mathrm{E}+02$

$8.86 \mathrm{E}+02$

$8.86 \mathrm{E}+02$

$8.87 \mathrm{E}+02$

$8.87 \mathrm{E}+02$

$8.88 \mathrm{E}+02$

$8.89 \mathrm{E}+02$

$8.89 \mathrm{E}+02$

$8.90 \mathrm{E}+02$

8. $90 \mathrm{E}+02$

8. $91 \mathrm{E}+02$

8. $91 \mathrm{E}+02$

8. $92 \mathrm{E}+02$

8. $92 \mathrm{E}+02$

8. $93 \mathrm{E}+02$

$8.93 E+02$

$8.94 \mathrm{E}+02$

$8.94 \mathrm{E}+02$

$8.95 \mathrm{E}+02$

$8.95 \mathrm{E}+02$

$8.96 \mathrm{E}+02$
Dose statistics at graphical times, mrem/yr

\begin{tabular}{|c|c|c|c|c|c|c|c|}
\hline inimum & aximum & Mean & ledian & $90 \%$ & $5 \%$ & $97.5 \%$ & $\%$ \\
\hline 8 & $E-06$ & $31 E-06$ & $3 E-06$ & -06 & 6 & 06 & 0 \\
\hline-08 & $E-06$ & $E-06$ & $3 E-06$ & 6 & 06 & 06 & -06 \\
\hline$E-08$ & $E-06$ & $2 E-06$ & $3 E-06$ & $9 E-06$ & 06 & 06 & -06 \\
\hline $68 E-08$ & $8 E-06$ & $2 E-06$ & $E-06$ & 06 & 6 & 6 & -06 \\
\hline-08 & -06 & -06 & -06 & 6 & 6 & & $z-06$ \\
\hline $.73 E-08$ & -06 & $32 E-06$ & 06 & 06 & 06 & 06 & -06 \\
\hline $.75 E-08$ & -06 & -06 & -06 & 06 & 06 & -06 & -0 \\
\hline $.78 E-08$ & $5.87 E-06$ & 1. $32 E-06$ & -06 & $2.80 E-06$ & . ILL U & -06 & $.44 \mathrm{E}-06$ \\
\hline 08 & -06 & -06 & 06 & 06 & 6 & -06 & -06 \\
\hline $.83 E-08$ & 06 & $E-06$ & -06 & 06 & 06 & 06 & $44 \mathrm{E}-06$ \\
\hline-08 & -06 & -06 & -06 & & & 06 & $44 E-06$ \\
\hline-08 & & & & & & & 06 \\
\hline $.90 \mathrm{E}-08$ & $5.87 \mathrm{E}-06$ & $1.33 E-06$ & $1.04 \mathrm{E}-06$ & $1 \mathrm{E}-06$ & - 0 & $E-06$ & -0 \\
\hline $.92 \mathrm{E}-08$ & $5.87 \mathrm{E}-06$ & -06 & -06 & 06 & 0 & -06 & -06 \\
\hline $.95 E-08$ & 06 & 06 & 06 & 6 & 6 & 06 & -06 \\
\hline $.97 E-08$ & -06 & -06 & -06 & 06 & 06 & -06 & -06 \\
\hline$E-08$ & $E-06$ & $E-06$ & $E-06$ & $31 E-06$ & -06 & -06 & $.42 \mathrm{E}-06$ \\
\hline-08 & $E-06$ & $4 E-06$ & -06 & -06 & 06 & -06 & $42 E-06$ \\
\hline 08 & -06 & 06 & 06 & & 0 & 6 & -06 \\
\hline$E-08$ & -06 & -06 & -06 & 06 & 06 & -06 & $41 E-06$ \\
\hline$E-08$ & -06 & 06 & -06 & 06 & 0 & 0 & -06 \\
\hline$E-08$ & 06 & 06 & 06 & & $3.42 E-06$ & 6 & -06 \\
\hline $.15 E-08$ & $5.86 \mathrm{E}-06$ & $1.34 \mathrm{E}-06$ & $1.06 \mathrm{E}-06$ & $2.82 \mathrm{E}-06$ & ט & $0 E-06$ & $.40 \mathrm{E}-06$ \\
\hline-08 & $E-06$ & $4 E-06$ & $5-06$ & $82 E-06$ & $43 E-06$ & $E-06$ & $E-06$ \\
\hline 08 & $E-06$ & 06 & 06 & 06 & & -06 & -06 \\
\hline-08 & 06 & 06 & -06 & 6 & 6 & & 06 \\
\hline $.25 E-08$ & $E-06$ & $E-06$ & -06 & $32 E-06$ & 6 & & -06 \\
\hline $.27 E-08$ & $5.85 E-06$ & $1.35 E-06$ & $1.07 \mathrm{E}-06$ & $2.82 \mathrm{E}-06$ & $3.44 \mathrm{E}-06$ & $90 E-06$ & $.40 \mathrm{E}-06$ \\
\hline $.30 E-08$ & $5.85 E-06$ & $1.35 E-06$ & $1.07 E-06$ & $2.82 E-06$ & 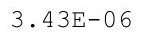 & 4 & $.39 E-06$ \\
\hline $32 E-08$ & $5.85 \mathrm{E}-06$ & $1.35 E-06$ & • & $2.02+0$ & - & 政 & $.39 \mathrm{E}-0$ \\
\hline 08 & $E-06$ & $E-06$ & $E-06$ & $3 E-06$ & 6 & 6 & -06 \\
\hline$E-08$ & $5-06$ & $E-06$ & $E-06$ & $3 E-06$ & 6 & 06 & -06 \\
\hline $.40 \mathrm{E}-08$ & $5.85 E-06$ & $1.35 \mathrm{E}-06$ & $8 E-06$ & $2.83 E-06$ & 6 & 06 & $39 E-06$ \\
\hline $.42 E-08$ & $5.85 E-06$ & $1.36 \mathrm{E}-06$ & $1.08 E-06$ & $2.83 \mathrm{E}-06$ & $3.44 \mathrm{E}-06$ & $0 E-06$ & $.39 E-06$ \\
\hline $.45 E-08$ & $5.85 E-06$ & & & & & & . \\
\hline . & & & & & & & \\
\hline 8 & 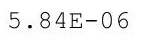 & & & & 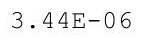 & & 0 \\
\hline$E-08$ & 6 & $E-06$ & $E-06$ & 6 & 6 & 6 & 06 \\
\hline$E-08$ & $E-06$ & $E-06$ & -06 & 06 & 6 & 6 & -06 \\
\hline $7 E-08$ & 06 & 06 & 06 & 6 & 6 & & -06 \\
\hline 08 & & & & & & & $38 \pm-06$ \\
\hline$E-08$ & & & & & & & $.38 \mathrm{E}-06$ \\
\hline $.65 E-08$ & & & & & & & $4.38 E-06$ \\
\hline $68 \mathrm{~F}-08$ & 0 & $1.37 \mathrm{E}-06$ & $1.09 \mathrm{E}-06$ & 0 & 6 & 0 & 0 \\
\hline 08 & 5.8 & 06 & 06 & 66 & 6 & 06 & -06 \\
\hline $.73 E-08$ & $83 E-06$ & $.37 E-06$ & $1.10 \mathrm{E}-06$ & $2.84 \mathrm{E}-06$ & $3.45 E-06$ & $3.88 \mathrm{E}-06$ & $4.38 \mathrm{E}-06$ \\
\hline
\end{tabular}


RESRAD-OFFSITE, Version 2.5

Title : RESRAD-OFFSITE External Gamma, Inhalation, and Soil Ingestion for offsite Reside File : PBA-1_TC99-DOE-5-1.ROF

Summary of dose at graphical times, reptition 2 (continued)

Time

Years

$8.96 \mathrm{E}+02$

$8.97 \mathrm{E}+02$

$8.97 \mathrm{E}+02$

$8.98 \mathrm{E}+02$

$8.98 \mathrm{E}+02$

$8.99 \mathrm{E}+02$

$8.99 \mathrm{E}+02$

9. $00 \mathrm{E}+02$

$9.00 \mathrm{E}+02$

9. $01 \mathrm{E}+02$

$9.01 \mathrm{E}+02$

$9.02 \mathrm{E}+02$

$9.02 \mathrm{E}+02$

$9.03 \mathrm{E}+02$

$9.03 \mathrm{E}+02$

$9.04 \mathrm{E}+02$

$9.04 \mathrm{E}+02$

$9.05 \mathrm{E}+02$

$9.05 \mathrm{E}+02$

$9.06 \mathrm{E}+02$

$9.06 \mathrm{E}+02$

$9.07 \mathrm{E}+02$

$9.07 \mathrm{E}+02$

$9.08 \mathrm{E}+02$

$9.08 \mathrm{E}+02$

$9.09 \mathrm{E}+02$

9. $10 \mathrm{E}+02$

$9.10 \mathrm{E}+02$

9. $11 \mathrm{E}+02$

$9.11 \mathrm{E}+02$

9. $12 \mathrm{E}+02$

9. $12 \mathrm{E}+02$

$9.13 \mathrm{E}+02$

$9.13 \mathrm{E}+02$

$9.14 \mathrm{E}+02$

9. $14 \mathrm{E}+02$

$9.15 \mathrm{E}+02$

$9.15 \mathrm{E}+02$

$9.16 \mathrm{E}+02$

$9.16 \mathrm{E}+02$

$9.17 \mathrm{E}+02$

$9.17 \mathrm{E}+02$

$9.18 \mathrm{E}+02$

$9.18 \mathrm{E}+02$

$9.19 \mathrm{E}+02$

$9.19 \mathrm{E}+02$
Dose statistics at graphical times, mrem/yr

\begin{tabular}{|c|c|c|c|c|c|c|c|}
\hline Inimum & laximum & Mean & Median & $90 \%$ & $95 \%$ & $97.5 \%$ & \\
\hline 8 & 06 & 06 & 06 & 06 & 06 & 6 & -06 \\
\hline $8 E-08$ & $3 E-06$ & $1.37 \mathrm{E}-06$ & 1.10E-06 & $2.85 \mathrm{E}-06$ & 06 & -06 & $.39 \mathrm{E}-06$ \\
\hline $1 E-08$ & $3 E-06$ & $7 E-06$ & -06 & 06 & 06 & 06 & $39 E-06$ \\
\hline$E-08$ & $E-06$ & $7 E-06$ & $E-06$ & $5 E-06$ & $5 E-06$ & 06 & $9 E-06$ \\
\hline $.86 \mathrm{E}-08$ & $3 E-06$ & $E-06$ & $10 E-06$ & -06 & 6 & 06 & $39 E-06$ \\
\hline $.88 E-08$ & -06 & $E-06$ & -06 & -06 & -06 & -06 & $39 E-06$ \\
\hline $1 E-08$ & $2 E-06$ & $8 \mathrm{E}-06$ & $E-06$ & $5 E-06$ & -06 & -06 & $E-06$ \\
\hline $4 E-08$ & $2 E-06$ & $8 E-06$ & $1 E-06$ & -06 & -06 & -06 & -06 \\
\hline $.96 \mathrm{E}-08$ & $5.82 \mathrm{E}-06$ & $1.38 \mathrm{E}-06$ & $1.11 \mathrm{E}-06$ & $2.86 \mathrm{E}-06$ & 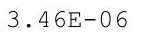 & $E-06$ & $40 E-06$ \\
\hline$E-08$ & -06 & $8 E-06$ & -06 & 06 & 06 & 06 & $E-06$ \\
\hline $.02 E-08$ & $5.82 \mathrm{E}-06$ & $1.38 \mathrm{E}-06$ & $11 E-06$ & & & & $41 E-06$ \\
\hline 08 & 06 & $E-06$ & $1 \mathrm{E}-06$ & 6 & 6 & 6 & -06 \\
\hline $.07 E-08$ & $1 E-06$ & $E-06$ & $1.11 E-06$ & -06 & & -06 & -06 \\
\hline $.09 E-08$ & $5.81 \mathrm{E}-06$ & 1. $39 \mathrm{E}-06$ & $1.11 E-06$ & -06 & 0 & -06 & $41 E-06$ \\
\hline$E-08$ & 06 & $E-06$ & $1.12 \mathrm{E}-06$ & 06 & & 06 & $40 E-06$ \\
\hline$E-08$ & -06 & $9 \mathrm{E}-06$ & 06 & 06 & ( & 06 & -06 \\
\hline $.17 E-08$ & $5.81 E-06$ & 1. $39 \mathrm{E}-06$ & $1.12 \mathrm{E}-06$ & $2.87 E-06$ & $46 E-06$ & $38 E-06$ & $.40 E-06$ \\
\hline $.20 E-08$ & $5.81 \mathrm{E}-06$ & $1.39 \mathrm{E}-06$ & $1.12 \mathrm{E}-06$ & $37 E-06$ & $46 E-06$ & $8 E-06$ & $39 E-06$ \\
\hline $3 E-08$ & $1 \mathrm{E}-06$ & $39 E-06$ & $1.12 \mathrm{E}-06$ & $7 E-06$ & & 06 & -06 \\
\hline $25 E-08$ & $5.80 \mathrm{E}-06$ & $9 E-06$ & -06 & 06 & 6 & 06 & -06 \\
\hline $3 E-08$ & $0 E-06$ & $1.39 E-06$ & $2 E-06$ & & & & $39 E-06$ \\
\hline . & $5.80 \mathrm{E}-06$ & $1.39 \mathrm{E}-06$ & $1.13 E-06$ & $2.87 \mathrm{E}-06$ & 50 & -06 & -06 \\
\hline 508 & $E-06$ & $40 E-06$ & $1.13 \mathrm{E}-06$ & $8 E-06$ & > & $3 E-06$ & $E-06$ \\
\hline $.36 E-08$ & $5.80 \mathrm{E}-06$ & $0 E-06$ & $3 E-06$ & -06 & 06 & -06 & -06 \\
\hline-08 & $E-06$ & $0 E-06$ & $1.13 E-06$ & 06 & 06 & -06 & -06 \\
\hline 08 & 06 & -06 & -06 & 06 & & 06 & -06 \\
\hline$E-08$ & $E-06$ & $E-06$ & -06 & 06 & & & $38 E-06$ \\
\hline $.47 \mathrm{E}-08$ & $5.79 \mathrm{E}-06$ & $1.40 \mathrm{E}-06$ & $1.14 \mathrm{E}-06$ & $2.88 \mathrm{E}-06$ & $46 \mathrm{E}-06$ & $89 \mathrm{E}-06$ & $.37 E-06$ \\
\hline $.49 E-08$ & $5.79 \mathrm{E}-06$ & $1.40 E-06$ & $1.14 \mathrm{E}-06$ & $2.88 \mathrm{E}-06$ & $.46 E-06$ & $39 E-06$ & $.37 E-06$ \\
\hline • & $5.79 E-06$ & 1. $40 \mathrm{E}-06$ & $1.14 \mathrm{E}-06$ & $2.89 \mathrm{E}-06$ & 五 & $9 E-06$ & $.30 \mathrm{E}-0$ \\
\hline 08 & 06 & $E-06$ & 06 & 6 & 6 & 6 & -06 \\
\hline-08 & $E-06$ & $E-06$ & -06 & $E-06$ & 6 & 66 & $5 E-06$ \\
\hline $.60 E-08$ & $8 E-06$ & $E-06$ & $4 E-06$ & $2.89 \mathrm{E}$ & 6 & 66 & $35 E-06$ \\
\hline $.63 E-08$ & $5.78 \mathrm{E}-06$ & $1.41 \mathrm{E}-06$ & $1.15 \mathrm{E}-06$ & $2.89 \mathrm{E}-06$ & $46 E-06$ & $9 E-06$ & $.35 E-06$ \\
\hline $.66 \mathrm{E}-08$ & $5.78 \mathrm{E}-06$ & $1.41 E-06$ & & & & & $.35 E-06$ \\
\hline & & & & & & & S \\
\hline 8 & & & & & & & 06 \\
\hline 8 & 6 & 6 & 6 & 6 & 6 & 6 & -06 \\
\hline$E-08$ & $E-06$ & $E-06$ & $E-06$ & 6 & 6 & -06 & -06 \\
\hline$E-08$ & 06 & $E-06$ & 06 & & 6 & & -06 \\
\hline $2+-U 8$ & $E-06$ & $42 \mathrm{E}-06$ & & & & & $34 E-06$ \\
\hline $85 E-08$ & $.77 E-06$ & $.42 E-06$ & & $.90 E-06$ & $.47 E-06$ & $0 E-06$ & $.34 E-06$ \\
\hline & & & & & 6 & & $4.34 \mathrm{E}-06$ \\
\hline $9.90 \mathrm{E}-00$ & & & 06 & 6 & 6 & 6 & 0 \\
\hline 8 & -06 & $E-06$ & 06 & 2 . & 6 & 6 & -06 \\
\hline $.96 E-08$ & $76 E-06$ & $.42 E-06$ & $1.17 E-06$ & $2.90 \mathrm{E}-06$ & $3.47 E-06$ & $3.89 \mathrm{E}-06$ & $4.34 \mathrm{E}-06$ \\
\hline
\end{tabular}


RESRAD-OFFSITE, Version 2.5

Title : RESRAD-OFFSITE External Gamma, Inhalation, and Soil Ingestion for Offsite Reside File : PBA-1_TC99-DOE-5-1.ROF

Summary of dose at graphical times, reptition 2 (continued)

Time

Years

$9.20 \mathrm{E}+02$

$9.20 \mathrm{E}+02$

$9.21 \mathrm{E}+02$

$9.21 \mathrm{E}+02$

$9.22 \mathrm{E}+02$

$9.22 \mathrm{E}+02$

$9.23 \mathrm{E}+02$

$9.23 \mathrm{E}+02$

$9.24 \mathrm{E}+02$

$9.24 \mathrm{E}+02$

$9.25 \mathrm{E}+02$

$9.25 \mathrm{E}+02$

$9.26 \mathrm{E}+02$

$9.26 \mathrm{E}+02$

$9.27 \mathrm{E}+02$

$9.27 \mathrm{E}+02$

$9.28 \mathrm{E}+02$

$9.28 \mathrm{E}+02$

$9.29 \mathrm{E}+02$

9. $30 \mathrm{E}+02$

9. $30 \mathrm{E}+02$

$9.31 \mathrm{E}+02$

$9.31 \mathrm{E}+02$

9. $32 \mathrm{E}+02$

9. $32 \mathrm{E}+02$

$9.33 \mathrm{E}+02$

9. $33 \mathrm{E}+02$

$9.34 \mathrm{E}+02$

9. $34 \mathrm{E}+02$

9. $35 \mathrm{E}+02$

9. $35 \mathrm{E}+02$

9. $36 \mathrm{E}+02$

9. $36 \mathrm{E}+02$

9. $37 \mathrm{E}+02$

9. $37 \mathrm{E}+02$

$9.38 \mathrm{E}+02$

9. $38 \mathrm{E}+02$

$9.39 \mathrm{E}+02$

9. $39 \mathrm{E}+02$

$9.40 \mathrm{E}+02$

$9.40 \mathrm{E}+02$

9. $41 \mathrm{E}+02$

9. $41 \mathrm{E}+02$

9. $42 \mathrm{E}+02$

$9.42 \mathrm{E}+02$

$9.43 \mathrm{E}+02$
Dose statistics at graphical times, mrem/yr

\begin{tabular}{|c|c|c|c|c|c|c|c|}
\hline inimum & Maximum & Mean & Median & $90 \%$ & $95 \frac{\circ}{\circ}$ & $7.5 \%$ & $9 \%$ \\
\hline $9.99 \mathrm{E}-08$ & $5.76 \mathrm{E}-06$ & $1.42 \mathrm{E}-06$ & $1.17 \mathrm{E}-06$ & $2.90 \mathrm{E}-06$ & $3.47 \mathrm{E}-06$ & $3.89 \mathrm{E}-06$ & $4.34 \mathrm{E}-06$ \\
\hline $1.00 \mathrm{E}-07$ & $5.76 \mathrm{E}-06$ & $1.42 \mathrm{E}-06$ & $1.17 \mathrm{E}-06$ & $2.90 \mathrm{E}-06$ & $3.47 \mathrm{E}-06$ & $3.89 \mathrm{E}-06$ & $4.34 E-06$ \\
\hline $1.00 \mathrm{E}-07$ & $5.75 \mathrm{E}-06$ & $1.42 \mathrm{E}-06$ & $1.17 \mathrm{E}-06$ & $2.90 \mathrm{E}-06$ & $3.47 \mathrm{E}-06$ & $3.89 \mathrm{E}-06$ & $4.34 \mathrm{E}-06$ \\
\hline $1.01 \mathrm{E}-07$ & $5.75 E-06$ & $1.43 \mathrm{E}-06$ & $1.17 \mathrm{E}-06$ & $2.90 \mathrm{E}-06$ & $3.47 \mathrm{E}-06$ & $3.90 \mathrm{E}-06$ & $4.34 \mathrm{E}-06$ \\
\hline $1.01 \mathrm{E}-07$ & $5.75 \mathrm{E}-06$ & $1.43 \mathrm{E}-06$ & $1.17 \mathrm{E}-06$ & $2.90 \mathrm{E}$ & $3.47 \mathrm{E}-06$ & $3.89 \mathrm{E}-06$ & $.34 \mathrm{E}-06$ \\
\hline $1.01 \mathrm{E}-07$ & $5.75 E-06$ & $1.43 \mathrm{E}-06$ & $1.17 \mathrm{E}-06$ & $2.90 \mathrm{E}-06$ & $3.47 \mathrm{E}-06$ & $3.89 \mathrm{E}-06$ & $4.34 \mathrm{E}-06$ \\
\hline $1.02 \mathrm{E}-07$ & $.75 \mathrm{E}-06$ & $1.43 \mathrm{E}-06$ & $1.18 \mathrm{E}-06$ & $2.90 \mathrm{E}-06$ & $47 \mathrm{E}-06$ & $3.89 \mathrm{E}-06$ & $34 \mathrm{E}-06$ \\
\hline $02 \mathrm{E}-07$ & $.75 \mathrm{E}-06$ & $1.43 \mathrm{E}-06$ & $1.18 \mathrm{E}-06$ & $2.90 \mathrm{E}-06$ & $47 \mathrm{E}-06$ & $3.89 \mathrm{E}-06$ & $34 \mathrm{E}-06$ \\
\hline $.02 \mathrm{E}-07$ & $5.74 \mathrm{E}-06$ & $1.43 \mathrm{E}-06$ & $1.18 \mathrm{E}-06$ & $2.90 \mathrm{E}-06$ & $3.47 \mathrm{E}-06$ & $3.89 \mathrm{E}-06$ & $4.35 \mathrm{E}-06$ \\
\hline $1.02 \mathrm{E}-07$ & $5.74 \mathrm{E}-06$ & $1.43 \mathrm{E}-06$ & $1.18 \mathrm{E}-06$ & $2.91 \mathrm{E}-06$ & $3.47 \mathrm{E}-06$ & $3.89 \mathrm{E}-06$ & $4.35 \mathrm{E}-06$ \\
\hline $1.03 \mathrm{E}-07$ & $5.74 \mathrm{E}-06$ & $1.43 \mathrm{E}-06$ & $1.18 \mathrm{E}-06$ & $2.91 \mathrm{E}-06$ & $3.47 \mathrm{E}-06$ & $3.89 \mathrm{E}-06$ & $4.35 \mathrm{E}-06$ \\
\hline $1.03 \mathrm{E}-07$ & $5.74 \mathrm{E}-06$ & $1.43 \mathrm{E}-06$ & $1.18 \mathrm{E}-06$ & $2.91 \mathrm{E}-06$ & $3.47 \mathrm{E}-06$ & $3.89 \mathrm{E}-06$ & $35 E-06$ \\
\hline $1.03 \mathrm{E}-07$ & $5.74 \mathrm{E}-06$ & $1.44 \mathrm{E}-06$ & $1.19 \mathrm{E}-06$ & $2.91 \mathrm{E}-06$ & $3.47 \mathrm{E}-06$ & $3.89 \mathrm{E}-06$ & $4.35 \mathrm{E}-06$ \\
\hline $1.03 \mathrm{E}-07$ & $5.73 \mathrm{E}-06$ & $1.44 \mathrm{E}-06$ & $1.19 \mathrm{E}-06$ & $2.91 \mathrm{E}-06$ & $3.48 \mathrm{E}-06$ & $3.89 \mathrm{E}-06$ & $4.35 \mathrm{E}-06$ \\
\hline $1.04 \mathrm{E}-07$ & $5.73 E-06$ & $1.44 \mathrm{E}-06$ & $1.19 \mathrm{E}-06$ & $2.91 \mathrm{E}-06$ & $3.48 \mathrm{E}-06$ & $3.89 \mathrm{E}-06$ & $4.35 \mathrm{E}-06$ \\
\hline $1.04 \mathrm{E}-07$ & $5.73 \mathrm{E}-06$ & $1.44 \mathrm{E}-06$ & $1.19 \mathrm{E}-06$ & $2.91 \mathrm{E}-06$ & $3.48 \mathrm{E}-06$ & $3.89 \mathrm{E}-06$ & $4.35 \mathrm{E}-06$ \\
\hline $1.04 \mathrm{E}-07$ & $5.73 E-06$ & $1.44 \mathrm{E}-06$ & $1.19 \mathrm{E}-06$ & $2.91 \mathrm{E}-06$ & $3.48 \mathrm{E}-06$ & $3.89 \mathrm{E}-06$ & $4.35 \mathrm{E}-06$ \\
\hline $1.05 \mathrm{E}-07$ & $5.73 \mathrm{E}-06$ & $1.44 \mathrm{E}-06$ & $1.19 \mathrm{E}-06$ & $2.91 \mathrm{E}-06$ & $3.48 \mathrm{E}-06$ & $3.89 \mathrm{E}-06$ & $4.35 \mathrm{E}-06$ \\
\hline $1.05 \mathrm{E}-07$ & $5.72 \mathrm{E}-06$ & $1.44 \mathrm{E}-06$ & $1.19 \mathrm{E}-06$ & $2.91 \mathrm{E}-06$ & $3.48 \mathrm{E}-06$ & $3.89 \mathrm{E}-06$ & $4.35 \mathrm{E}-06$ \\
\hline $.05 E-07$ & $5.72 \mathrm{E}-06$ & $1.44 \mathrm{E}-06$ & $1.19 \mathrm{E}$ & $2.91 \mathrm{E}-$ & $3.48 \mathrm{E}-06$ & $3.89 \mathrm{E}$ & $35 E-06$ \\
\hline $.05 \mathrm{E}-07$ & 5 & & & & & & \\
\hline $.06 \mathrm{E}-07$ & 5 & 1 & 6 & 6 & 6 & 6 & 06 \\
\hline $1.06 \mathrm{E}-07$ & $5.72 \mathrm{E}-06$ & $1.45 \mathrm{E}-06$ & $1.20 \mathrm{E}-06$ & $2.91 \mathrm{E}-06$ & $3.48 \mathrm{E}-06$ & $3.89 \mathrm{E}-06$ & $4.35 \mathrm{E}-06$ \\
\hline $1.06 \mathrm{E}-07$ & $5.71 \mathrm{E}-06$ & $1.45 \mathrm{E}-06$ & $1.20 \mathrm{E}-06$ & $2.91 \mathrm{E}-06$ & $3.48 \mathrm{E}-06$ & $3.89 \mathrm{E}-06$ & $4.35 \mathrm{E}-06$ \\
\hline $1.07 \mathrm{E}-07$ & $5.71 \mathrm{E}-06$ & $1.45 \mathrm{E}-06$ & $1.20 \mathrm{E}-06$ & $2.91 \mathrm{E}-06$ & $3.48 \mathrm{E}-06$ & $3.89 \mathrm{E}-06$ & $4.35 \mathrm{E}-06$ \\
\hline $1.07 \mathrm{E}-07$ & $5.71 E-06$ & $1.45 \mathrm{E}-06$ & $1.20 \mathrm{E}-06$ & $2.90 \mathrm{E}-06$ & $3.48 \mathrm{E}-06$ & $3.89 \mathrm{E}-06$ & $4.35 \mathrm{E}-06$ \\
\hline $1.07 \mathrm{E}-07$ & $5.71 \mathrm{E}-06$ & $1.45 \mathrm{E}-06$ & $1.20 \mathrm{E}-06$ & $2.90 \mathrm{E}-06$ & $3.48 \mathrm{E}-06$ & $3.89 \mathrm{E}-06$ & $4.35 \mathrm{E}-06$ \\
\hline $1.07 \mathrm{E}-07$ & $5.71 \mathrm{E}-06$ & $1.45 \mathrm{E}-06$ & $1.20 \mathrm{E}-06$ & $2.90 \mathrm{E}-06$ & $3.48 \mathrm{E}-06$ & $3.88 \mathrm{E}-06$ & $4.35 \mathrm{E}-06$ \\
\hline $1.08 \mathrm{E}-07$ & $5.70 \mathrm{E}-06$ & $1.45 \mathrm{E}-06$ & $1.20 \mathrm{E}-06$ & $2.90 \mathrm{E}-06$ & $3.47 \mathrm{E}-06$ & $3.88 \mathrm{E}-06$ & $4.35 \mathrm{E}-06$ \\
\hline $1.08 \mathrm{E}-07$ & 5. & $1.45 \mathrm{E}-06$ & $1.20 \mathrm{E}$ & $2.91 \mathrm{E}$ & 3.40 & -06 & 4.53 \\
\hline $1.08 \mathrm{E}-0$ & 5 & $1.45 \mathrm{E}-$ & 6 & 6 & 6 & 6 & 4.04 \\
\hline $1.09 \mathrm{E}-07$ & $5.70 \mathrm{E}-06$ & $1.46 \mathrm{E}-06$ & $1.21 \mathrm{E}-06$ & $2.91 \mathrm{E}-06$ & $3.48 \mathrm{E}-06$ & $3.88 \mathrm{E}-06$ & $4.34 \mathrm{E}-06$ \\
\hline $1.09 \mathrm{E}-07$ & $5.69 \mathrm{E}-06$ & $1.46 \mathrm{E}-06$ & $1.21 \mathrm{E}-06$ & $2.91 \mathrm{E}-06$ & $3.47 \mathrm{E}-06$ & $3.88 \mathrm{E}-06$ & $4.34 \mathrm{E}-06$ \\
\hline $1.09 \mathrm{E}-07$ & $5.69 \mathrm{E}-06$ & $1.46 \mathrm{E}-06$ & $1.21 \mathrm{E}-06$ & $2.90 \mathrm{E}-06$ & $3.47 \mathrm{E}-06$ & $3.89 \mathrm{E}-06$ & $4.34 \mathrm{E}-06$ \\
\hline $1.09 \mathrm{E}-07$ & $5.69 \mathrm{E}-06$ & $1.46 \mathrm{E}-06$ & $1.21 \mathrm{E}-06$ & $2.91 \mathrm{E}-06$ & $3.47 \mathrm{E}-06$ & $3.89 \mathrm{E}-06$ & $4.34 \mathrm{E}-06$ \\
\hline $1.10 \mathrm{E}-07$ & $5.69 \mathrm{E}-06$ & $1.46 \mathrm{E}-06$ & $1.21 \mathrm{E}-06$ & $2.91 \mathrm{E}-06$ & $3.47 \mathrm{E}-06$ & $3.89 \mathrm{E}-06$ & $4.33 \mathrm{E}-06$ \\
\hline $1.10 \mathrm{E}-07$ & $5.69 \mathrm{E}-06$ & $1.46 \mathrm{E}-06$ & $1.21 \mathrm{E}-06$ & $2.91 \mathrm{E}-06$ & $3.47 \mathrm{E}-06$ & $3.89 \mathrm{E}-06$ & $4.33 \mathrm{E}-06$ \\
\hline $1.10 \mathrm{E}-07$ & $5.68 \mathrm{E}-06$ & $1.46 \mathrm{E}-06$ & $1.21 \mathrm{E}-06$ & $2.91 \mathrm{E}-06$ & $3.47 \mathrm{E}-06$ & $3.88 \mathrm{E}-06$ & $4.34 \mathrm{E}-06$ \\
\hline $1.11 \mathrm{E}-07$ & $5.68 \mathrm{E}-06$ & $1.46 \mathrm{E}-06$ & $1.22 \mathrm{E}-06$ & $2.91 \mathrm{E}-06$ & $3.47 \mathrm{E}-06$ & $3.88 \mathrm{E}-06$ & $4.34 \mathrm{E}-06$ \\
\hline $1.11 \mathrm{E}-07$ & $5.68 \mathrm{E}-06$ & $1.46 \mathrm{E}-06$ & $1.22 \mathrm{E}-06$ & $2.92 \mathrm{E}-06$ & $3.47 \mathrm{E}-06$ & $3.88 \mathrm{E}-06$ & $4.34 \mathrm{E}-06$ \\
\hline $1.11 \mathrm{E}-07$ & $5.68 \mathrm{E}-06$ & $1.46 \mathrm{E}-06$ & $1.22 \mathrm{E}-06$ & $2.92 \mathrm{E}-06$ & $3.47 \mathrm{E}-06$ & $3.88 \mathrm{E}-06$ & $4.34 \mathrm{E}-06$ \\
\hline $1.12 \mathrm{E}-07$ & $5.67 \mathrm{E}-06$ & $1.47 \mathrm{E}-06$ & $1.22 \mathrm{E}-06$ & $2.92 \mathrm{E}-06$ & $3.47 \mathrm{E}-06$ & $3.88 \mathrm{E}-06$ & $4.34 \mathrm{E}-06$ \\
\hline $1.12 \mathrm{E}-07$ & $5.67 \mathrm{E}-06$ & $1.47 \mathrm{E}-06$ & $1.22 \mathrm{E}-06$ & $2.92 \mathrm{E}-06$ & $3.47 \mathrm{E}-06$ & $3.88 \mathrm{E}-06$ & $4.34 \mathrm{E}-06$ \\
\hline $1.12 \mathrm{E}-07$ & $5.67 \mathrm{E}-06$ & $1.47 \mathrm{E}-06$ & $1.22 \mathrm{E}-06$ & $2.92 \mathrm{E}-06$ & $3.48 \mathrm{E}-06$ & $3.88 \mathrm{E}-06$ & $4.34 \mathrm{E}-06$ \\
\hline $1.12 \mathrm{E}-07$ & $5.67 \mathrm{E}-06$ & $1.47 \mathrm{E}-06$ & $1.22 \mathrm{E}-06$ & $2.92 \mathrm{E}-06$ & $3.48 \mathrm{E}-06$ & $3.88 \mathrm{E}-06$ & $4.34 \mathrm{E}-06$ \\
\hline $.13 E-07$ & $5.67 \mathrm{E}-06$ & $1.47 \mathrm{E}-06$ & $1.22 \mathrm{E}-06$ & $2.92 \mathrm{E}-06$ & $3.48 \mathrm{E}-06$ & $3.88 \mathrm{E}-06$ & $4.34 \mathrm{E}-06$ \\
\hline
\end{tabular}


RESRAD-OFFSITE, Version 2.5

Title : RESRAD-OFFSITE External Gamma, Inhalation, and Soil Ingestion for Offsite Reside File : PBA-1_TC99-DOE-5-1.ROF

Summary of dose at graphical times, reptition 2 (continued)

Time

Years

9. $43 \mathrm{E}+02$

9. $44 \mathrm{E}+02$

9. $44 \mathrm{E}+02$

9. $45 \mathrm{E}+02$

9. $45 \mathrm{E}+02$

$9.46 \mathrm{E}+02$

$9.46 \mathrm{E}+02$

9. $47 \mathrm{E}+02$

$9.47 \mathrm{E}+02$

$9.48 \mathrm{E}+02$

9. $48 \mathrm{E}+02$

$9.49 \mathrm{E}+02$

$9.50 \mathrm{E}+02$

$9.50 \mathrm{E}+02$

9. $51 \mathrm{E}+02$

9. $51 \mathrm{E}+02$

9. $52 \mathrm{E}+02$

9. $52 \mathrm{E}+02$

9. $53 \mathrm{E}+02$

9. $53 \mathrm{E}+02$

9. $54 \mathrm{E}+02$

9. $54 \mathrm{E}+02$

9. $55 \mathrm{E}+02$

9. $55 \mathrm{E}+02$

9. $56 \mathrm{E}+02$

9. $56 \mathrm{E}+02$

9. $57 \mathrm{E}+02$

9. $57 \mathrm{E}+02$

9. $58 \mathrm{E}+02$

$9.58 \mathrm{E}+02$

$9.59 \mathrm{E}+02$

$9.59 \mathrm{E}+02$

$9.60 \mathrm{E}+02$

$9.60 \mathrm{E}+02$

$9.61 \mathrm{E}+02$

9. $61 \mathrm{E}+02$

$9.62 \mathrm{E}+02$

$9.62 \mathrm{E}+02$

$9.63 \mathrm{E}+02$

$9.63 \mathrm{E}+02$

$9.64 \mathrm{E}+02$

$9.64 \mathrm{E}+02$

$9.65 \mathrm{E}+02$

$9.65 \mathrm{E}+02$

$9.66 \mathrm{E}+02$

$9.66 \mathrm{E}+02$
Dose statistics at graphical times, mrem/yr

\begin{tabular}{|c|c|c|c|c|c|c|c|}
\hline num & aximum & lean & ledian & \% & & \% & \\
\hline $13 E-07$ & 6 & $\perp \cdot 4 / 5$ & 06 & 06 & 6 & 6 & -06 \\
\hline $.13 \mathrm{E}-07$ & $.66 \mathrm{E}-06$ & $.47 \mathrm{E}-06$ & $23 E-06$ & $.92 \mathrm{E}-06$ & $3.48 \mathrm{E}-06$ & $3.88 \mathrm{E}-06$ & $34 \mathrm{E}-06$ \\
\hline $.14 \mathrm{E}-07$ & $66 \mathrm{E}-06$ & $.47 \mathrm{E}-06$ & $.23 E-06$ & $.92 E-06$ & $48 E-06$ & $8 E-06$ & $4 \mathrm{E}-06$ \\
\hline & & 6 & & $.92 E-06$ & & 06 & -06 \\
\hline 07 & -06 & 06 & & 6 & 6 & & -06 \\
\hline $14 \mathrm{E}-07$ & $65 E-06$ & $.48 E-06$ & & $.93 E-06$ & 6 & & -06 \\
\hline $15 E-07$ & $65 E-06$ & $.48 E-06$ & $.23 E-06$ & $.93 E-06$ & $48 E-06$ & $E-06$ & $34 E-06$ \\
\hline $15 E-07$ & -06 & $8 E-06$ & -06 & $93 E-06$ & $8 E-06$ & -06 & $4 E-06$ \\
\hline $15 \mathrm{E}-07$ & $64 \mathrm{E}-06$ & $.48 E-06$ & $24 \mathrm{E}-06$ & $93 E-06$ & 6 & -06 & -06 \\
\hline $16 \mathrm{~F}-07$ & $64 E-06$ & $48 F-06$ & $24 \mathrm{~F}-06$ & $93 \mathrm{~F}-06$ & $8 E-06$ & -06 & -06 \\
\hline & 6 & 6 & & & & & 6 \\
\hline$E-07$ & $E-06$ & $.48 E-06$ & & 6 & 6 & 6 & $3 E-06$ \\
\hline $.17 \mathrm{E}-07$ & $.63 E-06$ & $.48 E-06$ & $.24 \mathrm{E}-06$ & $.94 E-06$ & $.48 E-06$ & $3.88 \mathrm{E}-06$ & $33 E-06$ \\
\hline $.17 \mathrm{E}-07$ & -06 & -06 & & -06 & -06 & 00 & -06 \\
\hline & & $.48 E-06$ & & & & o & -06 \\
\hline ה תר & & 0 & & & 6 & 0 & 06 \\
\hline 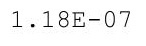 & 6 & 6 & & $90 \mathrm{~B}-2.25$ & 6 & 6 & -06 \\
\hline $18 \mathrm{~F}-07$ & $.62 \mathrm{E}-06$ & $.49 E-06$ & $5 E-06$ & $94 \mathrm{~F}-068-2$ & 06 & 6 & -06 \\
\hline $18 \mathrm{E}-07$ & $2 E-06$ & $.49 E-06$ & $5 E-06$ & $94 E-06$ & $7 E-06$ & -06 & $2 E-06$ \\
\hline $.19 \mathrm{E}-07$ & $.62 \mathrm{E}-06$ & $.49 \mathrm{E}-06$ & $.25 \mathrm{E}-06$ & $.95 E-06$ & $47 E-06$ & -06 & $.32 E-06$ \\
\hline & & & & c & & 06 & -06 \\
\hline & & & & & & & 06 \\
\hline & & & & & & & 06 \\
\hline $20 E-07$ & 06 & 6 & 6 & $05 \mathrm{~F}^{-2} \mathrm{C}$ & 6 & 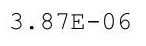 & -06 \\
\hline $20 E-07$ & $61 E-06$ & $.49 \mathrm{E}-06$ & $26 E-06$ & $05=-06$ & $6 E-06$ & $=0$ & $31 E-06$ \\
\hline $.20 \mathrm{E}-07$ & $60 F-06$ & $50 F-06$ & $F-06$ & $95 E-0$ & 6 & -06 & -06 \\
\hline $21 \mathrm{~F}-07$ & $50 \mathrm{E}-06$ & & & $95 E-06$ & $46 E-06$ & & -06 \\
\hline & & & & & & & 06 \\
\hline ת ת1 & & & & & & & -06 \\
\hline $.22 \mathrm{E}-07$ & $.59 E-06$ & $1.50 \mathrm{E}-06$ & $.27 E-06$ & 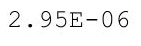 & $405-20$ & t & $30 E-06$ \\
\hline $.22 E-07$ & $.59 E-06$ & $.50 E-06$ & $.27 E-06$ & 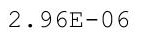 & $47 E-06$ & $7 E-06$ & $.30 E-06$ \\
\hline $.22 \mathrm{E}-$ & $59 E-06$ & $.50 \mathrm{E}-06$ & & & & $E-06$ & $E-06$ \\
\hline $.23 E-c$ & & & & & & & 06 \\
\hline $335-01$ & 6 & & & & & & -06 \\
\hline $.23 E-07$ & $.58 E-06$ & $1.50 \mathrm{E}-06$ & $.27 E-06$ & $2.96 \mathrm{E}-06$ & $3.47 E-06$ & $3.86 \mathrm{E}-06$ & $4.29 E-06$ \\
\hline • $20 \mathrm{E}-1$ & $.58 E-06$ & $1.31 E-06$ & $\cdot 215-06$ & . & $3.47 \mathrm{E}-06$ & 0 & $4.29 E-06$ \\
\hline . 240 प & $.3 / 2-00$ & $1.31 \mathrm{~L}-06$ & $\begin{array}{ll}-2 \\
210\end{array}$ & 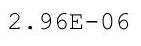 & $.475-00$ & .00世 vo & $4.29 E-00$ \\
\hline $.24 E-07$ & 6 & 6 & 6 & 6 & 6 & 6 & 06 \\
\hline $24 \mathrm{E}-0$ & & & & & & & 06 \\
\hline $.25 E-07$ & $.57 E-06$ & $.51 E-06$ & $28 F-06$ & $2.97 E-06$ & $46 E-06$ & -06 & $4.29 E-06$ \\
\hline $.25 \mathrm{E}-07$ & $.56 \mathrm{E}-06$ & $.51 E-06$ & $.28 E-06$ & $.97 E-06$ & 06 & 06 & $4.29 \mathrm{E}-06$ \\
\hline $.25 E-07$ & $6 E-06$ & $.51 \mathrm{E}$ & 6 & 6 & 6 & & $4.29 \mathrm{E}-06$ \\
\hline$\cdot 20 \mathrm{x}-1$ & 6 & $\perp \cdot 0 \perp$ & $205-00$ & 然 & . & & $4.29 E-06$ \\
\hline 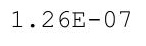 & $.30 E-00$ & 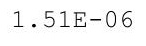 & $.205-00$ & $.9 / 2-00$ & $3.45 E-06$ & $3.86 \mathrm{E}-06$ & $4.29 E-06$ \\
\hline $.26 \mathrm{E}-07$ & e. & $1.51 \mathrm{E}-06$ & $.29 \mathrm{E}-06$ & $.97 E-06$ & $3.45 \mathrm{E}-06$ & & $4.29 \mathrm{E}-06$ \\
\hline $.27 E-07$ & $E-06$ & $51 E-06$ & $29 E-06$ & $97 E-06$ & $E-06$ & $6 E-06$ & $E-06$ \\
\hline
\end{tabular}


RESRAD-OFFSITE, Version 2.5

Title : RESRAD-OFFSITE External Gamma, Inhalation, and Soil Ingestion for Offsite Reside File : PBA-1_TC99-DOE-5-1.ROF

Summary of dose at graphical times, reptition 2 (continued)

Time

Years

9. $67 \mathrm{E}+02$

9. $67 \mathrm{E}+02$

$9.68 \mathrm{E}+02$

9. $68 \mathrm{E}+02$

9. $69 \mathrm{E}+02$

$9.70 \mathrm{E}+02$

$9.70 \mathrm{E}+02$

$9.71 \mathrm{E}+02$

9. $71 \mathrm{E}+02$

9. $72 \mathrm{E}+02$

9. $72 \mathrm{E}+02$

$9.73 \mathrm{E}+02$

$9.73 \mathrm{E}+02$

9. $74 \mathrm{E}+02$

$9.74 \mathrm{E}+02$

$9.75 \mathrm{E}+02$

$9.75 \mathrm{E}+02$

$9.76 \mathrm{E}+02$

$9.76 \mathrm{E}+02$

$9.77 \mathrm{E}+02$

$9.77 \mathrm{E}+02$

$9.78 \mathrm{E}+02$

$9.78 \mathrm{E}+02$

$9.79 \mathrm{E}+02$

$9.79 \mathrm{E}+02$

$9.80 \mathrm{E}+02$

$9.80 \mathrm{E}+02$

$9.81 \mathrm{E}+02$

$9.81 \mathrm{E}+02$

$9.82 \mathrm{E}+02$

$9.82 \mathrm{E}+02$

$9.83 \mathrm{E}+02$

$9.83 \mathrm{E}+02$

$9.84 \mathrm{E}+02$

$9.84 \mathrm{E}+02$

$9.85 \mathrm{E}+02$

$9.85 \mathrm{E}+02$

$9.86 \mathrm{E}+02$

$9.86 \mathrm{E}+02$

$9.87 \mathrm{E}+02$

$9.87 \mathrm{E}+02$

$9.88 \mathrm{E}+02$

$9.88 \mathrm{E}+02$

$9.89 \mathrm{E}+02$

9. $90 \mathrm{E}+02$

$9.90 \mathrm{E}+02$
Dose statistics at graphical times, mrem/yr

\begin{tabular}{|c|c|c|c|c|c|c|c|}
\hline Inimum & Maximum & Mean & Median & $90 \%$ & $95 \%$ & $97.5 \%$ & \\
\hline 07 & $5 E-06$ & $2 E-06$ & $29 E-06$ & 06 & 06 & 06 & -0 \\
\hline $.27 E-07$ & $5 E-06$ & $2 E-06$ & $1.29 \mathrm{E}-06$ & $2.97 \mathrm{E}-06$ & 06 & 06 & $29 E-06$ \\
\hline $7 E-07$ & $E-06$ & $2 E-06$ & 06 & 06 & 06 & 06 & $29 E-06$ \\
\hline$E-07$ & $E-06$ & $2 E-06$ & $9 E-06$ & $7 E-06$ & $5 E-06$ & 06 & $9 E-06$ \\
\hline $.28 \mathrm{E}-07$ & 06 & $2 E-06$ & -06 & $7 E-06$ & 6 & & $29 E-06$ \\
\hline $.28 \mathrm{E}-07$ & -06 & $E-06$ & -06 & $3 E-06$ & 6 & 06 & $29 E-06$ \\
\hline $.29 E-07$ & $E-06$ & $2 E-06$ & $1.30 E-06$ & $8 E-06$ & -06 & -06 & $E-06$ \\
\hline I & $3 E-06$ & $2 E-06$ & $.30 E-06$ & $8 E-06$ & 06 & -06 & -06 \\
\hline • & $5.53 E-06$ & $1.52 \mathrm{E}-06$ & $1.30 \mathrm{E}-06$ & $2.98 \mathrm{E}-06$ & $45 E-06$ & -06 & $.29 E-06$ \\
\hline $\mathrm{E}-07$ & -06 & $E-06$ & -06 & $8 E-06$ & 06 & 06 & $29 E-06$ \\
\hline $.30 E-07$ & $5.52 \mathrm{E}-06$ & $1.53 \mathrm{E}-06$ & $30 E-06$ & & & & $.29 E-06$ \\
\hline-07 & 06 & $E-06$ & -06 & 6 & 6 & 06 & -06 \\
\hline $.31 E-07$ & $2 E-06$ & $E-06$ & -06 & $8 E-06$ & & -06 & -06 \\
\hline 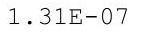 & $5.51 \mathrm{E}-06$ & $1.53 E-06$ & -06 & 6 & 10 & 6 & 06 \\
\hline$-5-1$ & 06 & $E-06$ & 06 & 06 & & 06 & $29 E-06$ \\
\hline • & 06 & $3 E-06$ & 06 & 06 & ( & 06 & -06 \\
\hline $.32 E-07$ & $5.50 \mathrm{E}-06$ & $1.53 \mathrm{E}-06$ & $1.31 \mathrm{E}-06$ & $2.98 E-06$ & $44 E-06$ & $5 E-06$ & $.29 E-06$ \\
\hline $.32 E-07$ & $5.50 \mathrm{E}-06$ & $1.53 E-06$ & $1.31 E-06$ & $8 E-06$ & $44 \mathrm{E}-06$ & $E-06$ & $29 E-06$ \\
\hline $.32 E-07$ & $0 \mathrm{E}-06$ & $1.53 E-06$ & $1.31 E-06$ & $8 E-06$ & & 6 & -06 \\
\hline $.33 E-07$ & $E-06$ & $E-06$ & -06 & 06 & & 06 & $z-06$ \\
\hline • & $E-06$ & $E-06$ & 1. $32 E-06$ & $8 E-06$ & & & $29 E-06$ \\
\hline $.33 E-07$ & D & $1.54 \mathrm{E}-06$ & $1.32 E-06$ & & & - & $.29 E-06$ \\
\hline - רמ & $E-06$ & $4 E-06$ & $32 E-06$ & $9 E-06$ & 1 & -06 & $29 E-06$ \\
\hline $.34 E-07$ & $3 E-06$ & $E-06$ & $1.32 \mathrm{E}$ & $9 E-06$ & 06 & -06 & -06 \\
\hline 07 & $E-06$ & $4 E-06$ & $2 E-06$ & 06 & 06 & 06 & -06 \\
\hline$E-07$ & 06 & 06 & 06 & 06 & & & -06 \\
\hline $5 E-07$ & $E-06$ & -06 & 1. $32 E-06$ & 6 & & & -06 \\
\hline $.35 E-07$ & $5.47 \mathrm{E}-06$ & $1.54 \mathrm{E}-06$ & 1. $32 \mathrm{E}-06$ & $2.99 \mathrm{E}-06$ & $44 \mathrm{E}-06$ & $84 \mathrm{E}-06$ & $.29 E-06$ \\
\hline . & $5.47 E-06$ & $1.54 \mathrm{E}-06$ & $1.32 \mathrm{E}-06$ & $2.99 \mathrm{E}-06$ & $.445-00$ & $34 E-06$ & $.29 \mathrm{E}-06$ \\
\hline • & $5.47 E-06$ & $1.54 \mathrm{E}-06$ & $1.33 E-06$ & $9 E-06$ & - & -06 & . \\
\hline 07 & 06 & 06 & 06 & 6 & 6 & 6 & -06 \\
\hline$E-07$ & $E-06$ & $E-06$ & $3 E-06$ & $9 E-06$ & 6 & 06 & $0 E-06$ \\
\hline $.37 E-07$ & $6 \mathrm{E}-06$ & $1.54 \mathrm{E}-06$ & $1.33 E-06$ & $8 E-06$ & 6 & & $30 E-06$ \\
\hline $.37 E-07$ & $5.46 \mathrm{E}-06$ & $1.55 \mathrm{E}-06$ & $1.33 E-06$ & $2.98 \mathrm{E}-06$ & $44 \mathrm{E}-06$ & $3 E-06$ & $.30 E-06$ \\
\hline $.30 \mathrm{E}-\mathrm{T}$ & $5.45 E-06$ & $1.55 E-06$ & $1.33 E-06$ & & & & $.30-06$ \\
\hline ? & & & & & & & \\
\hline 38507 & & & & & & & \\
\hline 7 & 6 & 6 & 6 & 6 & 6 & 6 & -06 \\
\hline$E-07$ & $E-06$ & $E-06$ & $3 E-06$ & $9 \mathrm{E}-$ & 6 & 6 & $0 E-06$ \\
\hline $.39 E-07$ & 06 & 06 & 06 & 06 & 6 & & -06 \\
\hline$E-U 1$ & 06 & $5 E-06$ & & 6 & & & -06 \\
\hline $.40 E-07$ & $.43 E-06$ & $1.55 \mathrm{E}-06$ & $1.33 E-06$ & $.99 \mathrm{E}-06$ & $45 E-06$ & & $4.30 \mathrm{E}-06$ \\
\hline & & & & & & & $4.30 E-06$ \\
\hline & & & 06 & 6 & 6 & 6 & 0 \\
\hline$E-07$ & $E-06$ & 06 & 06 & 6 & 6 & 6 & -06 \\
\hline $.41 E-07$ & $42 E-06$ & $.56 E-06$ & $1.34 \mathrm{E}-06$ & $2.99 \mathrm{E}-06$ & $3.45 E-06$ & $3.83 E-06$ & $4.30 E-06$ \\
\hline
\end{tabular}


RESRAD-OFFSITE, Version 2.5

robabilistic Dose and Risk Report

Title : RESRAD-OFFSITE External Gamma, Inhalation, and Soil Ingestion for Offsite Reside File : PBA-1_TC99-DOE-5-1.ROF

Summary of dose at graphical times, reptition 2 (continued)

Time

Years

$9.91 \mathrm{E}+02$

$9.91 \mathrm{E}+02$

$9.92 \mathrm{E}+02$

$9.92 \mathrm{E}+02$

$9.93 \mathrm{E}+02$

$9.93 \mathrm{E}+02$

$9.94 \mathrm{E}+02$

$9.94 \mathrm{E}+02$

$9.95 \mathrm{E}+02$

$9.95 \mathrm{E}+02$

$9.96 \mathrm{E}+02$

$9.96 \mathrm{E}+02$

$9.97 \mathrm{E}+02$

$9.97 \mathrm{E}+02$

$9.98 \mathrm{E}+02$

9. $98 \mathrm{E}+02$

$9.99 \mathrm{E}+02$

$9.99 \mathrm{E}+02$

$1.00 \mathrm{E}+03$

$1.00 \mathrm{E}+03$

$1.00 \mathrm{E}+03$

$1.00 \mathrm{E}+03$

$1.00 \mathrm{E}+03$

$1.00 \mathrm{E}+03$

$1.00 \mathrm{E}+03$

$1.00 \mathrm{E}+03$

$1.00 \mathrm{E}+03$

$1.00 \mathrm{E}+03$

$1.00 \mathrm{E}+03$

$1.01 \mathrm{E}+03$

$1.01 \mathrm{E}+03$

$1.01 \mathrm{E}+03$

$1.01 \mathrm{E}+03$

$1.01 \mathrm{E}+03$

$1.01 \mathrm{E}+03$

$1.01 \mathrm{E}+03$

$1.01 E+03$

$1.01 \mathrm{E}+03$

$1.01 \mathrm{E}+03$

$1.01 \mathrm{E}+03$

$1.01 \mathrm{E}+03$

1. $01 \mathrm{E}+03$

$1.01 \mathrm{E}+03$

$1.01 \mathrm{E}+03$

$1.01 \mathrm{E}+03$

$1.01 \mathrm{E}+03$
Dose statistics at graphical times, mrem/yr

\begin{tabular}{|c|c|c|c|c|c|c|c|}
\hline inimum & aximum & Mean & ledian & $0 \%$ & $5 \%$ & $97.5 \%$ & $\%$ \\
\hline 7 & -06 & $6 E-06$ & $E-06$ & $9 E-06$ & 06 & 06 & Oent \\
\hline-07 & $E-06$ & $6 E-06$ & $4 E-06$ & $9 E-06$ & 06 & 06 & -06 \\
\hline$E-07$ & $E-06$ & $E-06$ & $E-06$ & $9 E-06$ & 06 & 06 & -06 \\
\hline $2 E-07$ & $E-06$ & 06 & 06 & 06 & 6 & 6 & -06 \\
\hline $.43 E-07$ & 06 & 6 & 6 & & & 06 & $30 E-06$ \\
\hline-07 & -06 & $E-06$ & -06 & 06 & $E-06$ & -06 & 06 \\
\hline-07 & -06 & $6 E-06$ & $5 E-06$ & -06 & 06 & -06 & -06 \\
\hline $.44 E-07$ & $10 E-06$ & $1.56 \mathrm{E}-06$ & $1.35 E-06$ & $2.99 E-06$ & 06 & -06 & $30 E-06$ \\
\hline 07 & 06 & 06 & .06 & 06 & 6 & 06 & -06 \\
\hline $.44 \mathrm{E}-07$ & $E-06$ & $6 E-06$ & $5 E-06$ & -06 & 06 & 06 & -06 \\
\hline-07 & -06 & 06 & -06 & & & & $E-06$ \\
\hline 7 & & 06 & & & & & 06 \\
\hline $.45 E-07$ & $8 \mathrm{E}-06$ & $7 E-06$ & $5 E-06$ & $2.99 \mathrm{E}-06$ & -00 & -06 & -0 \\
\hline $.46 \mathrm{E}-07$ & -06 & $7 E-06$ & -06 & 06 & 0 & -06 & -06 \\
\hline-07 & 06 & 06 & 06 & 6 & 6 & 06 & -06 \\
\hline $.46 \mathrm{E}-07$ & -06 & -06 & 06 & 06 & 06 & -06 & -06 \\
\hline $.47 E-07$ & $E-06$ & $7 E-06$ & $6 E-06$ & $99 E-06$ & $44 \mathrm{E}-06$ & -06 & $28 E-06$ \\
\hline $.47 E-07$ & $5 E-06$ & $7 E-06$ & $E-06$ & 06 & 06 & 06 & $E-06$ \\
\hline $.47 E-07$ & $6 E-06$ & $7 E-06$ & $5 E-06$ & & & -06 & -06 \\
\hline $.48 \mathrm{E}-07$ & -06 & -06 & -06 & 06 & & -06 & $E-06$ \\
\hline $.48 \mathrm{E}-07$ & $5 E-06$ & $E-06$ & -06 & & & 0 & -06 \\
\hline $.48 E-07$ & -06 & 06 & 06 & & & 6 & -06 \\
\hline $.49 \mathrm{E}-07$ & $5.35 \mathrm{E}-06$ & $1.58 \mathrm{E}-06$ & $1.36 \mathrm{E}-06$ & $2.98 \mathrm{E}-06$ & $3.43 E-06$ & $3 E-06$ & $.27 E-06$ \\
\hline $.49 \mathrm{E}-07$ & $E-06$ & $8 \mathrm{E}-06$ & $6 \mathrm{E}-06$ & $98 \mathrm{E}-06$ & $43 E-06$ & $E-06$ & $27 E-06$ \\
\hline 07 & 06 & 06 & 06 & 06 & & 6 & -06 \\
\hline-07 & 06 & 06 & 06 & 6 & & & 06 \\
\hline $.50 \mathrm{E}-07$ & -06 & $8 E-06$ & -06 & & & & $6 \mathrm{E}-06$ \\
\hline $.50 E-07$ & $5.33 E-06$ & $1.58 \mathrm{E}-06$ & $1.37 \mathrm{E}-06$ & $2.98 \mathrm{E}-06$ & $3.44 \mathrm{E}-06$ & $33 E-06$ & $26 E-06$ \\
\hline • & $5.33 E-06$ & $1.58 E-06$ & $1.37 E-06$ & $2.98 E-06$ & . 1140 & 0 & . \\
\hline r & $33 E-06$ & $1.58 \mathrm{E}-06$ & $37 E-06$ & 06 & ( & 政 & -0 \\
\hline 07 & $E-06$ & $E-06$ & $E-06$ & $8 E-06$ & 6 & 6 & -06 \\
\hline $2 E-07$ & $E-06$ & $E-06$ & $E-06$ & $3 E-06$ & 6 & 66 & -06 \\
\hline $.52 E-07$ & $5.32 \mathrm{E}-06$ & $1.58 \mathrm{E}-06$ & $1.37 \mathrm{E}-06$ & $8 E-06$ & 6 & & $25 E-06$ \\
\hline $.52 \mathrm{E}-07$ & $5.31 E-06$ & $1.58 \mathrm{E}-06$ & $1.37 \mathrm{E}-06$ & $2.98 \mathrm{E}-06$ & $3.44 \mathrm{E}-06$ & $32 E-06$ & $.24 E-06$ \\
\hline • & $5.31 E-06$ & & & & & & $.245-00$ \\
\hline ים & & & & & & & \\
\hline 7 & 6 & & & 6 & 6 & & \\
\hline$E-07$ & -06 & $E-06$ & $E-06$ & 6 & 6 & 6 & 06 \\
\hline $.54 \mathrm{E}-07$ & $E-06$ & $E-06$ & $7 E-06$ & $3 E-06$ & 6 & 06 & $23 E-06$ \\
\hline $4 E-07$ & 06 & $5-06$ & 06 & 6 & 6 & & -06 \\
\hline 07 & & & & & & & $23 E-0$ \\
\hline $.55 E-07$ & $.29 \mathrm{E}-06$ & & & & & & $.23 E-06$ \\
\hline & & & 0 & & & & $4.23 E-06$ \\
\hline 07 & 0 & 0 & 0 & 0 & 6 & 0 & 0 \\
\hline$E-07$ & $E-06$ & -06 & 06 & 06 & 6 & -06 & $422 \mathrm{k}$ \\
\hline $.56 E-07$ & $27 E-06$ & $.59 E-06$ & $1.38 E-06$ & $.98 \mathrm{E}-06$ & $3.43 E-06$ & $3.81 E-06$ & $4.22 \mathrm{E}-06$ \\
\hline
\end{tabular}


RESRAD-OFFSITE, Version 2.5

Title : RESRAD-OFFSITE External Gamma, Inhalation, and Soil Ingestion for offsite Reside File : PBA-1_TC99-DOE-5-1.ROF

Summary of dose at graphical times, reptition 2 (continued)

Time

Years

$1.01 \mathrm{E}+03$

1. $01 \mathrm{E}+03$

1. $02 \mathrm{E}+03$

$02 \mathrm{E}+03$

1. $02 \mathrm{E}+03$

1. $02 \mathrm{E}+03$

1. $02 \mathrm{E}+03$

1. $02 \mathrm{E}+03$

1. $02 \mathrm{E}+03$

1. $02 \mathrm{E}+03$

1. $02 \mathrm{E}+03$

1. $02 \mathrm{E}+03$

1. $02 \mathrm{E}+03$

1. $02 \mathrm{E}+03$

1. $02 \mathrm{E}+03$

1. $02 \mathrm{E}+03$

1. $02 \mathrm{E}+03$

1. $02 \mathrm{E}+03$

1. $02 \mathrm{E}+03$

1. $02 \mathrm{E}+03$

1. $02 \mathrm{E}+03$

1. $02 \mathrm{E}+03$

1. $03 \mathrm{E}+03$

$1.03 \mathrm{E}+03$

$1.03 \mathrm{E}+03$

$1.03 \mathrm{E}+03$

$1.03 E+03$

$1.03 E+03$

$1.03 \mathrm{E}+03$

$1.03 \mathrm{E}+03$

$1.03 \mathrm{E}+03$

$1.03 \mathrm{E}+03$

$1.03 \mathrm{E}+03$

$1.03 \mathrm{E}+03$

$1.03 \mathrm{E}+03$

$1.03 \mathrm{E}+03$

$1.03 E+03$

$1.03 E+03$

$1.03 E+03$

$1.03 E+03$

$1.03 E+03$

$1.04 \mathrm{E}+03$

1. $04 \mathrm{E}+03$

$1.04 \mathrm{E}+03$

1. $04 \mathrm{E}+03$

$1.04 \mathrm{E}+03$
Dose statistics at graphical times, mrem/yr

\begin{tabular}{|c|c|c|c|c|c|c|c|}
\hline inimum & aximum & Mean & ledian & $0 \%$ & $5 \%$ & $97.5 \%$ & \\
\hline 7 & -06 & $9 E-06$ & $E-06$ & 06 & 06 & 6 & net \\
\hline 07 & $E-06$ & $E-06$ & $8 E-06$ & 6 & 06 & 06 & -06 \\
\hline E-07 & $E-06$ & $E-06$ & $3 E-06$ & $3 E-06$ & 06 & 06 & -06 \\
\hline$E-07$ & $E-06$ & $E-06$ & & 6 & & & -06 \\
\hline $3 E-07$ & 06 & 6 & 6 & & 6 & 06 & $22 E-06$ \\
\hline $.58 E-07$ & -06 & $0 E-06$ & -06 & 06 & 06 & 06 & -06 \\
\hline ז' & -06 & $.60 \mathrm{E}-06$ & -06 & -06 & 06 & -06 & -0 \\
\hline $.59 E-07$ & $5.25 E-06$ & $.60 E-06$ & $1.39 E-06$ & $2.98 E-06$ & 06 & -06 & $.22 E-06$ \\
\hline 07 & 06 & 06 & .06 & 06 & 6 & -06 & $22 E-06$ \\
\hline $.60 \mathrm{E}-07$ & $4 E-06$ & $50 E-06$ & $9 E-06$ & -06 & 06 & -06 & $22 E-06$ \\
\hline-07 & 06 & 06 & 06 & & & & $22 E-06$ \\
\hline-07 & & -06 & & & & & -06 \\
\hline $.0 \perp E-U 1$ & $5.23 E-06$ & $.60 \mathrm{E}-06$ & $1.39 E-06$ & $2.98 \mathrm{E}-06$ & 40 & -06 & $E-0$ \\
\hline • & -06 & -06 & -06 & 06 & 0 & -06 & -06 \\
\hline $2 E-07$ & 06 & 06 & 06 & 6 & 6 & 06 & -06 \\
\hline $2 E-07$ & -06 & -06 & 06 & 06 & 06 & -06 & -06 \\
\hline $.62 \mathrm{E}-07$ & $5.22 \mathrm{E}-06$ & $1 E-06$ & $0 \mathrm{E}-06$ & $8 E-06$ & $43 E-06$ & $E-06$ & $.20 \mathrm{E}-06$ \\
\hline $3 E-07$ & $1 E-06$ & $61 E-06$ & $0 E-06$ & $7 E-06$ & 06 & -06 & $E-06$ \\
\hline 07 & -06 & 06 & 06 & 06 & & 6 & -06 \\
\hline 07 & 06 & 06 & 06 & 06 & 6 & 06 & $E-06$ \\
\hline $\begin{array}{l}.04 \mathrm{~L}-0 \\
\end{array}$ & -06 & -06 & -06 & & & o & -06 \\
\hline 7 & 06 & 6 & 6 & 6 & $3.42 E-06$ & 6 & 06 \\
\hline $.64 \mathrm{E}-07$ & $5.20 \mathrm{E}-06$ & $1.61 \mathrm{E}-06$ & 1. $40 \mathrm{E}-06$ & $2.97 \mathrm{E}-06$ & $3.42 \mathrm{E}-06$ & $78 E-06$ & $.20 \mathrm{E}-06$ \\
\hline $.65 E-07$ & $20 E-06$ & $1.61 \mathrm{E}-06$ & $1.41 \mathrm{E}-06$ & $97 E-06$ & $42 E-06$ & $3 E-06$ & $20 \mathrm{E}-06$ \\
\hline 07 & 06 & $61 E-06$ & 06 & 06 & & 6 & -06 \\
\hline 07 & 06 & 06 & 06 & & & 6 & \\
\hline $.00 E-01$ & $19 \pm-06$ & $1.01 \mathrm{E}-06$ & -06 & & & & $19 \mathrm{E}-06$ \\
\hline $.66 \mathrm{E}-07$ & $5.19 \mathrm{E}-06$ & $1.62 \mathrm{E}-06$ & $1.41 E-06$ & $2.97 \mathrm{E}-06$ & $3.41 \mathrm{E}-06$ & $78 E-06$ & $.19 E-06$ \\
\hline 1 & 6 & 6 & $41 E-06$ & 6 & - & 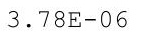 & 06 \\
\hline 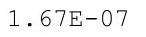 & $5.19 \mathrm{E}-06$ & 1. $62 \mathrm{E}-06$ & 1. $41 \mathrm{E}-06$ & $7 E-06$ & 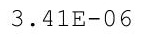 & 政 & 等 \\
\hline $67 \mathrm{~F}-07$ & $F-06$ & $62 E-06$ & & & & 6 & $9 E-06$ \\
\hline$E-07$ & $E-06$ & $1.62 \mathrm{E}-06$ & $1 E-06$ & $7 E-06$ & 6 & 06 & $19 \mathrm{E}-06$ \\
\hline $.68 \mathrm{E}-07$ & $3 E-06$ & $E-06$ & 06 & 06 & & 6 & $18 \mathrm{E}-06$ \\
\hline $.68 \mathrm{E}-07$ & $5.18 E-06$ & $1.62 \mathrm{E}-06$ & 1. $41 \mathrm{E}-06$ & $2.97 \mathrm{E}-06$ & $3.41 E-06$ & $78 E-06$ & $.18 \mathrm{E}-06$ \\
\hline $.00 \mathrm{~L}-01$ & $5.18 E-06$ & $1.62 E-06$ & & $2.97 E-06$ & & & $\cdot 10 \mathrm{~L}-\mathrm{C}$ \\
\hline - & & & & & & & \\
\hline $695-07$ & 6 & & & & & & he \\
\hline 7 & 5 & & & & & 6 & 06 \\
\hline 17 & & & & & -06 & -06 & 06 \\
\hline $.70 E-07$ & $16 \mathrm{E}-06$ & $1.62 \mathrm{E}-06$ & $1.42 \mathrm{E}$ & 6 & 6 & & $.7 E-06$ \\
\hline$E-07$ & & $E-06$ & 06 & & & & -0 \\
\hline $5-01$ & 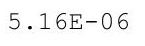 & $1.63 \mathrm{E}-06$ & 6 & 6 & & & $1 / E-00$ \\
\hline 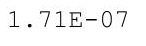 & & 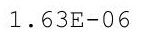 & 0 & 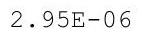 & 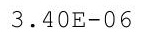 & 0 & c \\
\hline 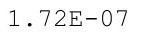 & t & 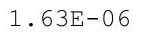 & th & o & 6 & 6 & the \\
\hline 07 & -06 & -06 & 06 & 66 & 06 & 06 & -06 \\
\hline $.72 E-07$ & $5.15 E-06$ & $1.63 \mathrm{E}-06$ & $1.43 E-06$ & $.95 E-06$ & $3.40 E-06$ & $3.77 \mathrm{E}-06$ & $4.16 \mathrm{E}-06$ \\
\hline
\end{tabular}


RESRAD-OFFSITE, Version 2.5

Title : RESRAD-OFFSITE External Gamma, Inhalation, and Soil Ingestion for offsite Reside File : PBA-1_TC99-DOE-5-1.ROF

Time

Years

$1.04 \mathrm{E}+03$

$1.04 \mathrm{E}+03$

1. $04 \mathrm{E}+03$

1. $04 \mathrm{E}+03$

1. $04 \mathrm{E}+03$

$1.04 \mathrm{E}+03$

1. $04 \mathrm{E}+03$

1. $04 \mathrm{E}+03$

1. $04 \mathrm{E}+03$

1. $04 \mathrm{E}+03$

1. $04 \mathrm{E}+03$

1. $04 \mathrm{E}+03$

1. $04 \mathrm{E}+03$

1. $04 \mathrm{E}+03$

1. $04 \mathrm{E}+03$

1. $05 \mathrm{E}+03$

1. $05 \mathrm{E}+03$

1. $05 \mathrm{E}+03$

1. $05 \mathrm{E}+03$

1. $05 \mathrm{E}+03$

1. $05 \mathrm{E}+03$

1. $05 \mathrm{E}+03$

1. $05 \mathrm{E}+03$

$1.05 \mathrm{E}+03$

$1.05 \mathrm{E}+03$
Summary of dose at graphical times, reptition 2 (continued)

Dose statistics at graphical times, mrem/yr

\begin{tabular}{|c|c|c|c|c|c|c|c|}
\hline Minimum & Maximum & Mean & Median & $90 \%$ & $95 \%$ & $97.5 \%$ & $99 \%$ \\
\hline $1.73 E-07$ & $5.15 E-06$ & $1.63 E-06$ & $1.43 E-06$ & $2.95 E-06$ & $3.40 \mathrm{E}-06$ & $3.77 \mathrm{E}-06$ & $4.16 \mathrm{E}-06$ \\
\hline $1.73 E-07$ & $5.15 E-06$ & $1.63 E-06$ & $1.43 E-06$ & $2.95 E-06$ & $3.40 \mathrm{E}-06$ & $3.77 \mathrm{E}-06$ & $4.16 \mathrm{E}-06$ \\
\hline $1.73 E-07$ & $5.14 \mathrm{E}-06$ & $1.63 \mathrm{E}-06$ & $1.43 \mathrm{E}-06$ & $2.95 \mathrm{E}-06$ & $3.40 \mathrm{E}-06$ & $3.77 \mathrm{E}-06$ & $4.16 \mathrm{E}-06$ \\
\hline $.74 \mathrm{E}-07$ & $5.14 \mathrm{E}-06$ & $1.63 \mathrm{E}-06$ & $1.43 E-06$ & $2.95 E-06$ & $.40 \mathrm{E}-06$ & $.77 E-06$ & $.16 \mathrm{E}-06$ \\
\hline $.74 \mathrm{E}-07$ & $5.14 \mathrm{E}-06$ & $1.63 \mathrm{E}-06$ & $1.43 E-06$ & $2.95 E-06$ & $.40 \mathrm{E}-06$ & $3.77 \mathrm{E}-06$ & $.16 \mathrm{E}-06$ \\
\hline $1.74 \mathrm{E}-07$ & $5.14 \mathrm{E}-06$ & $1.63 E-06$ & $1.43 E-06$ & $2.95 E-06$ & $3.40 \mathrm{E}-06$ & $3.77 \mathrm{E}-06$ & $4.15 E-06$ \\
\hline $1.75 \mathrm{E}-07$ & $5.13 E-06$ & $1.63 E-06$ & $1.43 E-06$ & $2.95 E-06$ & $3.40 \mathrm{E}-06$ & $3.77 \mathrm{E}-06$ & $4.15 E-06$ \\
\hline $1.75 \mathrm{E}-07$ & $5.13 \mathrm{E}-06$ & $1.63 \mathrm{E}-06$ & $1.44 \mathrm{E}-06$ & $2.95 E-06$ & $3.40 \mathrm{E}-06$ & $3.77 \mathrm{E}-06$ & $4.15 \mathrm{E}-06$ \\
\hline $1.75 \mathrm{E}-07$ & $5.13 E-06$ & $1.63 E-06$ & $1.44 \mathrm{E}-06$ & $2.95 E-06$ & $3.40 \mathrm{E}-06$ & $3.77 \mathrm{E}-06$ & $4.15 \mathrm{E}-06$ \\
\hline $1.76 \mathrm{E}-07$ & $5.13 E-06$ & $1.63 E-06$ & 1. $44 \mathrm{E}-06$ & $2.95 E-06$ & $.40 \mathrm{E}-06$ & $3.77 \mathrm{E}-06$ & $.15 E-06$ \\
\hline $1.76 \mathrm{E}-07$ & $5.13 E-06$ & $1.64 \mathrm{E}-06$ & $1.44 \mathrm{E}-06$ & $2.95 E-00$ & $3.405-00$ & $3.77 \mathrm{E}-06$ & $4.15 E-06$ \\
\hline 1. $76 \mathrm{E}-07$ & $5.12 \mathrm{E}-06$ & $1.64 \mathrm{E}-06$ & $1.44 \mathrm{E}-06$ & $2.95 E-06$ & $3.40 \mathrm{E}-06$ & $3.77 \mathrm{E}-06$ & $4.14 \mathrm{E}-06$ \\
\hline $1.77 \mathrm{E}-07$ & $5.12 \mathrm{E}-06$ & $1.64 \mathrm{E}-06$ & $1.44 \mathrm{E}-06$ & $2.95 E-06$ & $3.40 \mathrm{E}-06$ & $3.77 \mathrm{E}-06$ & $4.14 \mathrm{E}-06$ \\
\hline $1.77 \mathrm{E}-07$ & $5.12 \mathrm{E}-06$ & $1.64 \mathrm{E}-06$ & $1.44 \mathrm{E}-06$ & $2.95 E-06$ & $3.40 \mathrm{E}-06$ & $3.77 \mathrm{E}-06$ & $4.14 \mathrm{E}-06$ \\
\hline $1.78 \mathrm{E}-07$ & $5.12 \mathrm{E}-06$ & $1.64 \mathrm{E}-06$ & $1.44 \mathrm{E}-06$ & $2.95 E-06$ & $3.40 \mathrm{E}-06$ & $3.77 \mathrm{E}-06$ & $4.14 \mathrm{E}-06$ \\
\hline $1.78 \mathrm{E}-07$ & $5.11 \mathrm{E}-06$ & $1.64 \mathrm{E}-06$ & 1. $45 E-06$ & $2.95 E-06$ & $3.40 \mathrm{E}-06$ & $3.77 \mathrm{E}-06$ & $4.14 \mathrm{E}-06$ \\
\hline $1.78 \mathrm{E}-07$ & $5.11 E-06$ & $1.64 \mathrm{E}-06$ & $1.45 E-06$ & $2.95 E-06$ & $40 E-06$ & $5-06$ & $14 E-06$ \\
\hline $1.79 \mathrm{E}-07$ & $5.11 \mathrm{E}-06$ & $1.64 \mathrm{E}-06$ & $1.45 E-06$ & $2.95 E-06$ & $3.40 \mathrm{E}-06$ & $3.76 \mathrm{E}-06$ & $4.13 E-06$ \\
\hline $1.79 \mathrm{E}-07$ & $5.11 \mathrm{E}-06$ & $1.64 \mathrm{E}-06$ & $1.45 E-06$ & $2.95 E-06$ & $3.39 \mathrm{E}-06$ & $3.76 \mathrm{E}-06$ & $4.13 E-06$ \\
\hline $1.79 \mathrm{E}-07$ & $5.10 \mathrm{E}-06$ & $1.64 \mathrm{E}-06$ & $1.45 E-06$ & $2.95 E-06$ & $3.39 \mathrm{E}-06$ & $3.76 \mathrm{E}-06$ & $4.13 \mathrm{E}-06$ \\
\hline $1.80 \mathrm{E}-07$ & $5.10 \mathrm{E}-06$ & $1.64 \mathrm{E}-06$ & $1.45 E-06$ & $2.94 \mathrm{E}-06$ & $3.39 \mathrm{E}-06$ & $3.75 \mathrm{E}-06$ & $4.13 \mathrm{E}-06$ \\
\hline $1.80 \mathrm{E}-07$ & $5.10 \mathrm{E}-06$ & $1.64 \mathrm{E}-06$ & $1.45 E-06$ & $2.94 \mathrm{E}-06$ & $3.39 \mathrm{E}-06$ & $3.75 \mathrm{E}-06$ & $4.13 E-06$ \\
\hline $1.80 \mathrm{E}-07$ & $5.10 \mathrm{E}-06$ & $1.64 \mathrm{E}-06$ & $1.45 E-06$ & $2.94 \mathrm{E}-06$ & $3.39 \mathrm{E}-06$ & $3.75 \mathrm{E}-06$ & $4.13 \mathrm{E}-06$ \\
\hline $1.81 \mathrm{E}-07$ & $5.10 \mathrm{E}-06$ & $1.64 \mathrm{E}-06$ & $1.46 \mathrm{E}-06$ & $2.94 \mathrm{E}-06$ & $3.39 \mathrm{E}-06$ & $3.75 \mathrm{E}-06$ & $4.12 E-06$ \\
\hline $1.81 \mathrm{E}-07$ & $5.09 E-06$ & $1.64 \mathrm{E}-06$ & $1.46 \mathrm{E}-06$ & $2.94 \mathrm{E}-06$ & $3.39 E-06$ & $3.75 \mathrm{E}-06$ & $4.12 \mathrm{E}-06$ \\
\hline
\end{tabular}


RESRAD-OFFSITE, Version 2.5

$\mathrm{T}^{1 / 2}$ Limit $=180$ days

Title : RESRAD-OFFSITE External Gamma, Inhalation, and Soil Ingestion for Offsite Reside File : PBA-1_TC99-DOE-5-1.ROF

Time

Years

$0.00 \mathrm{E}+00$

$5.13 \mathrm{E}-01$

$1.03 \mathrm{E}+00$

$1.54 \mathrm{E}+00$

$2.05 \mathrm{E}+00$

$2.56 \mathrm{E}+00$

$3.08 \mathrm{E}+00$

$3.59 \mathrm{E}+00$

$4.10 \mathrm{E}+00$

$4.61 \mathrm{E}+00$

$5.13 \mathrm{E}+00$

$5.64 \mathrm{E}+00$

$6.15 \mathrm{E}+00$

$6.67 \mathrm{E}+00$

$7.18 \mathrm{E}+00$

$7.69 \mathrm{E}+00$

$8.20 \mathrm{E}+00$

$8.72 \mathrm{E}+00$

$9.23 \mathrm{E}+00$

$9.74 \mathrm{E}+00$

$1.03 \mathrm{E}+01$

$1.08 \mathrm{E}+01$

$1.13 \mathrm{E}+01$

$1.18 \mathrm{E}+01$

$1.23 \mathrm{E}+01$

$1.28 \mathrm{E}+01$

$1.33 \mathrm{E}+01$

$1.38 \mathrm{E}+01$

$1.44 \mathrm{E}+01$

$1.49 \mathrm{E}+01$

$1.54 \mathrm{E}+01$

$1.59 \mathrm{E}+01$

$1.64 \mathrm{E}+01$

$1.69 \mathrm{E}+01$

$1.74 \mathrm{E}+01$

1. $79 \mathrm{E}+01$

$1.85 \mathrm{E}+01$

1. $90 \mathrm{E}+01$

1. $95 \mathrm{E}+01$

$2.00 \mathrm{E}+01$

$2.05 \mathrm{E}+01$

$2.10 \mathrm{E}+01$

$2.15 \mathrm{E}+01$

$2.20 \mathrm{E}+01$

2. $26 \mathrm{E}+01$

$2.31 \mathrm{E}+01$
Summary of dose at graphical times, reptition 3

Dose statistics at graphical times, mrem/yr

\begin{tabular}{|c|c|c|c|c|c|c|c|}
\hline nimum & aximum & lean & edian & \% & $\%$ & $\%$ & $\circ$ \\
\hline 32 & 32 & 32 & $48 E-32$ & $1.48 \mathrm{E}$ & 32 & 32 & -3 \\
\hline-32 & $E-32$ & $9 E-32$ & $9 E-32$ & $49 E-32$ & $49 E-32$ & -32 & $49 E-32$ \\
\hline 32 & 32 & 32 & & 2 & 2 & 32 & -32 \\
\hline-32 & 2 & 32 & & 32 & 32 & -32 & -32 \\
\hline $39 E-32$ & -32 & -32 & -32 & 32 & $.53 E-32$ & $.53 E-32$ & $E-32$ \\
\hline (ט) & -32 & -32 & -32 & & 2 & -32 & -32 \\
\hline . & 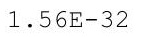 & ז & $1.30 \mathrm{E}-32$ & - o & 2 & -32 & 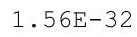 \\
\hline 32 & 32 & 32 & $7 E-32$ & 32 & $57 E-32$ & -32 & $58 E-32$ \\
\hline-32 & 32 & $8 E-32$ & $8 E-32$ & $59 E-32$ & -32 & -32 & -32 \\
\hline $.31 E-32$ & 32 & $9 E-32$ & $9 E-32$ & 1.601 & 32 & -32 & $.60 E-32$ \\
\hline 2 & -32 & 2 & $E-32$ & 2 & $2 E-32$ & -32 & $62 E-32$ \\
\hline $29 E-32$ & & $15-32$ & $62 E-32$ & & & $E-32$ & -3 \\
\hline $.27 \mathrm{E}-32$ & $1.65 \mathrm{E}-32$ & (1) & 1. $63 \mathrm{E}-32$ & $1 \cdot 0 \mathrm{~s}$ & 2 & -32 & $.65 E-32$ \\
\hline 32 & 32 & $.045-32$ & $1.65 E-32$ & $1.00 \mathrm{~T}-1$ & . & -32 & $.66 \mathrm{E}-32$ \\
\hline $.24 E-32$ & -32 & -0.0 & $1.66 \mathrm{E}-32$ & 32 & 32 & -32 & -32 \\
\hline $23 E-32$ & $1.69 \mathrm{E}-32$ & $1.66 \mathrm{E}-32$ & $1.68 \mathrm{E}-32$ & $1.69 \mathrm{E}-32$ & $.69 \mathrm{E}-32$ & $.69 \mathrm{E}-32$ & $69 E-32$ \\
\hline-32 & $1.71 E-32$ & $8 E-32$ & $9 E-32$ & $70 E-32$ & $70 E-32$ & $E-32$ & $70 E-32$ \\
\hline $20 E-32$ & $1.72 E-32$ & $69 E-32$ & $0 E-32$ & $2 E-32$ & $E-32$ & $E-32$ & $2 E-32$ \\
\hline$E-32$ & $E-32$ & $\mathrm{JE}-32$ & $2 E-32$ & 2 & 2 & -32 & $E-32$ \\
\hline $8+32$ & $1.75 E-32$ & $1.72 E-32$ & $1.73 E-32$ & $1.10 \mathrm{~s}$ & 32 & -32 & $E-32$ \\
\hline-32 & 1.7 & & $5 E-32$ & & & -32 & -32 \\
\hline $.15 E-32$ & $1.78 \mathrm{E}-32$ & $1.75 \mathrm{E}-32$ & $76 E-32$ & $78 E-32$ & $78 \mathrm{E}-32$ & $.78 \mathrm{E}-32$ & $78 E-32$ \\
\hline-32 & $1.80 E-32$ & $.76 E-32$ & $7 E-32$ & $79 E-32$ & $79 E-32$ & $.80 E-32$ & $.80 E-32$ \\
\hline-32 & $1.81 E-32$ & $1.77 E-32$ & $1.79 E-32$ & $1.81 \mathrm{E}-32$ & $.81 E-32$ & $.81 E-32$ & $81 E-32$ \\
\hline 32 & $1.83 E-32$ & $79 E-32$ & -32 & 32 & 32 & -32 & $3 E-32$ \\
\hline 32 & -32 & $E-32$ & $2 E-32$ & 32 & 32 & 32 & -32 \\
\hline $.09 E-32$ & $\mathrm{DE}-32$ & $1.82 E-32$ & $E-32$ & 2 & 32 & -32 & $6 E-32$ \\
\hline $.08 E-32$ & $1.88 \mathrm{E}-32$ & $1.83 E-32$ & $1.85 \mathrm{E}-32$ & $1.87 \mathrm{E}-32$ & $1.87 \mathrm{E}-32$ & $.88 E-32$ & $.88 E-32$ \\
\hline 3 & 然 & - & 2 & ? & $9 \mathrm{E}-$ & 然 & $89 E-32$ \\
\hline $05 F-32$ & $91 \mathrm{E}-$ & $.86 \mathrm{E}-$ & $88 E-32$ & & & $E-32$ & $=-32 x-15$ \\
\hline $5-32$ & 1. & $7 F-32$ & & & ברק & -32 & $5-32$ \\
\hline$E-32$ & & & & & & 32 & 32 \\
\hline & & & & & & 32 & \\
\hline $01 E-32$ & $1.98 E-32$ & $1.92 E-32$ & $4 E-32$ & 32 & 32 & -32 & $98 E-32$ \\
\hline 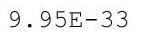 & $2.005-32$ & & & & & & . $.00 \pm-22$ \\
\hline $84=33$ & & & & & & & \\
\hline $735 \quad 33$ & 2 & $96 \mathrm{E}-$ & 2 & 2 & 2 & 2 & 32 \\
\hline $35=33$ & 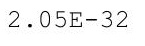 & 2 & 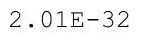 & 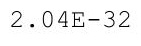 & & & \\
\hline $2 E-33$ & $2.07 E-32$ & $1.99 \mathrm{E}-32$ & $2 E-32$ & $06 \mathrm{E}$ & $6 E-32$ & -32 & $7 E-32$ \\
\hline+ & 2.0 & 32 & 2 & 2 & 2 & 32 & $9 E-32$ \\
\hline & & $2.03 E-32$ & $.06 \mathrm{E}-32$ & & $2 \cdot \pm 0+$ & & $\cdot 10 \pm-32$ \\
\hline & 2. & 2 & 2 & & 2 & & 32 \\
\hline P & 2 & . & & & the & 2 & + \\
\hline & & & & & & & 32 \\
\hline 33 & -32 & $E-32$ & $E-32$ & 2 . & 32 & 2 & 2.18 \\
\hline $.81 E-33$ & $.20 E-32$ & $2.11 E-32$ & $.14 E-32$ & $.19 \mathrm{E}-32$ & $2.19 E-32$ & $2.20 E-32$ & $2.20 E-32$ \\
\hline
\end{tabular}


RESRAD-OFFSITE, Version 2.5

$\mathrm{T}^{1 / 2}$ Limit $=180$ days

Title : RESRAD-OFFSITE External Gamma, Inhalation, and Soil Ingestion for Offsite Reside File : PBA-1_TC99-DOE-5-1.ROF

Summary of dose at graphical times, reptition 3 (continued)

Time

Years

2. $36 \mathrm{E}+01$

$2.41 \mathrm{E}+01$

$2.46 \mathrm{E}+01$

$2.51 \mathrm{E}+01$

2. $56 \mathrm{E}+01$

$2.61 \mathrm{E}+01$

$2.67 \mathrm{E}+01$

$2.72 \mathrm{E}+01$

$2.77 \mathrm{E}+01$

$2.82 \mathrm{E}+01$

$2.87 \mathrm{E}+01$

2. $92 \mathrm{E}+01$

$2.97 \mathrm{E}+01$

$3.02 \mathrm{E}+01$

$3.08 \mathrm{E}+01$

$3.13 \mathrm{E}+01$

3. $18 \mathrm{E}+01$

3. $23 \mathrm{E}+01$

3. $28 \mathrm{E}+01$

3. $33 \mathrm{E}+01$

3. $38 \mathrm{E}+01$

3. $44 \mathrm{E}+01$

3. $49 \mathrm{E}+01$

$3.54 \mathrm{E}+01$

$3.59 \mathrm{E}+01$

3. $64 \mathrm{E}+01$

$3.69 \mathrm{E}+01$

$3.74 \mathrm{E}+01$

3. $79 \mathrm{E}+01$

$3.85 \mathrm{E}+01$

3. $90 \mathrm{E}+01$

$3.95 \mathrm{E}+01$

$4.00 \mathrm{E}+01$

4. $05 \mathrm{E}+01$

$4.10 \mathrm{E}+01$

4. $15 \mathrm{E}+01$

$4.20 \mathrm{E}+01$

$4.26 \mathrm{E}+01$

$4.31 \mathrm{E}+01$

$4.36 \mathrm{E}+01$

4. $41 \mathrm{E}+01$

4. $46 \mathrm{E}+01$

$4.51 \mathrm{E}+01$

4. $56 \mathrm{E}+01$

4. $61 \mathrm{E}+01$

$4.67 \mathrm{E}+01$
Dose statistics at graphical times, mrem/yr

\begin{tabular}{|c|c|c|c|c|c|c|c|}
\hline Minimum & Maximum & Mean & Median & $90 \%$ & $95 \frac{\circ}{\circ}$ & $7.5 \%$ & $9 \frac{\circ}{0}$ \\
\hline $8.71 \mathrm{E}-33$ & $2.22 \mathrm{E}-32$ & $2.12 \mathrm{E}-32$ & $2.16 \mathrm{E}-32$ & $2.21 \mathrm{E}-32$ & $2.21 \mathrm{E}-32$ & $2.22 \mathrm{E}-32$ & $2.22 \mathrm{E}-32$ \\
\hline $8.61 E-33$ & $2.24 E-32$ & $2.14 \mathrm{E}-32$ & $2.18 \mathrm{E}-32$ & $2.23 E-32$ & $2.23 E-32$ & $2.23 E-32$ & $2.24 E-32$ \\
\hline $8.52 \mathrm{E}-33$ & $2.26 \mathrm{E}-32$ & $2.16 \mathrm{E}-32$ & $2.20 \mathrm{E}-32$ & $2.25 E-32$ & $2.25 E-32$ & $2.25 \mathrm{E}-32$ & $2.26 \mathrm{E}-32$ \\
\hline $8.42 \mathrm{E}-33$ & $2.28 \mathrm{E}-32$ & $2.18 \mathrm{E}-32$ & $2.22 \mathrm{E}-32$ & $2.27 \mathrm{E}-32$ & $2.27 \mathrm{E}-32$ & $2.27 \mathrm{E}-32$ & $.28 \mathrm{E}-32$ \\
\hline $8.33 \mathrm{E}-33$ & $2.30 \mathrm{E}-32$ & $2.19 \mathrm{E}-32$ & $2.23 E-32$ & $2.28 \mathrm{E}-32$ & $29 E-32$ & $2.29 \mathrm{E}-32$ & $2.30 \mathrm{E}-32$ \\
\hline $8.24 \mathrm{E}-33$ & $2.32 E-32$ & $2.21 E-32$ & $2.25 \mathrm{E}-32$ & $2.30 \mathrm{E}-32$ & $2.31 E-32$ & $2.31 E-32$ & $2.32 E-32$ \\
\hline $8.15 \mathrm{E}-33$ & $2.34 \mathrm{E}-32$ & $2.23 E-32$ & $2.27 \mathrm{E}-32$ & $2.32 \mathrm{E}-32$ & $2.33 E-32$ & $2.33 E-32$ & $34 \mathrm{E}-32$ \\
\hline $06 \mathrm{E}-33$ & $2.36 \mathrm{E}-32$ & $2.25 E-32$ & $2.29 \mathrm{E}-32$ & $2.35 E-32$ & $2.35 E-32$ & $2.36 \mathrm{E}-32$ & $36 \mathrm{E}-32$ \\
\hline $7.97 E-33$ & $2.38 \mathrm{E}-32$ & $2.26 \mathrm{E}-32$ & $2.31 \mathrm{E}-32$ & $2.37 E-32$ & $2.37 E-32$ & $2.38 \mathrm{E}-32$ & $2.38 E-32$ \\
\hline $7.88 \mathrm{E}-33$ & $2.41 E-32$ & $2.28 \mathrm{E}-32$ & $2.33 E-32$ & $2.39 \mathrm{E}-32$ & $2.39 \mathrm{E}-32$ & $2.40 \mathrm{E}-32$ & $2.40 \mathrm{E}-32$ \\
\hline $7.79 \mathrm{E}-33$ & $2.43 E-32$ & $2.30 \mathrm{E}-32$ & $2.35 \mathrm{E}-32$ & $2.41 \mathrm{E}-32$ & $2.41 \mathrm{E}-32$ & $2.42 E-32$ & $2.42 \mathrm{E}-32$ \\
\hline $7.70 \mathrm{E}-33$ & $2.45 \mathrm{E}-32$ & $2.32 \mathrm{E}-32$ & $2.37 E-32$ & $2.43 E-32$ & $2.43 E-32$ & $2.44 \mathrm{E}-32$ & $2.44 \mathrm{E}-32$ \\
\hline $7.62 \mathrm{E}-33$ & $2.47 E-32$ & $2.34 \mathrm{E}-32$ & $2.39 \mathrm{E}-32$ & $2.45 \mathrm{E}-32$ & $2.46 \mathrm{E}-32$ & $2.46 \mathrm{E}-32$ & $2.46 \mathrm{E}-32$ \\
\hline $7.53 E-33$ & $2.49 \mathrm{E}-32$ & $2.35 \mathrm{E}-32$ & $2.41 \mathrm{E}-32$ & $2.47 \mathrm{E}-32$ & $2.48 \mathrm{E}-32$ & $2.48 \mathrm{E}-32$ & $2.49 \mathrm{E}-32$ \\
\hline $7.45 \mathrm{E}-33$ & $2.51 E-32$ & $2.37 \mathrm{E}-32$ & $2.43 E-32$ & $2.49 \mathrm{E}-32$ & $2.50 \mathrm{E}-32$ & $2.50 \mathrm{E}-32$ & $2.51 \mathrm{E}-32$ \\
\hline $7.37 \mathrm{E}-33$ & $2.54 \mathrm{E}-32$ & $2.39 \mathrm{E}-32$ & $2.45 \mathrm{E}-32$ & $2.51 \mathrm{E}-32$ & $2.52 \mathrm{E}-32$ & $2.53 E-32$ & $2.53 E-32$ \\
\hline $7.29 \mathrm{E}-33$ & $2.56 \mathrm{E}-32$ & $2.41 \mathrm{E}-32$ & $2.47 \mathrm{E}-32$ & $2.54 \mathrm{E}-32$ & $2.54 \mathrm{E}-32$ & $2.55 \mathrm{E}-32$ & $2.55 \mathrm{E}-32$ \\
\hline $7.21 \mathrm{E}-33$ & $2.58 \mathrm{E}-32$ & $2.43 E-32$ & $2.49 \mathrm{E}-32$ & $2.56 \mathrm{E}-32$ & $2.57 \mathrm{E}-32$ & $2.57 E-32$ & $2.57 \mathrm{E}-32$ \\
\hline $7.13 E-33$ & $2.60 E-32$ & $2.45 \mathrm{E}-32$ & $2.51 \mathrm{E}-32$ & $2.58 \mathrm{E}-32$ & $2.59 \mathrm{E}-32$ & $2.59 \mathrm{E}-32$ & $2.60 \mathrm{E}-32$ \\
\hline $.05 E-33$ & $2.63 E-32$ & $2.47 \mathrm{E}-32$ & $2.53 E-32$ & $2.60 \mathrm{E}-32$ & $2.61 \mathrm{E}-32$ & $2.62 E-32$ & $.62 \mathrm{E}-32$ \\
\hline 6.9 & 2 & & & & & 32 & 32 \\
\hline $6.89 \mathrm{E}-33$ & 2 & 2 & 2 & 2 & 32 & 32 & -32 \\
\hline $6.82 \mathrm{E}-33$ & $2.70 \mathrm{E}-32$ & $2.53 E-32$ & $2.59 \mathrm{E}-32$ & $2.67 \mathrm{E}-32$ & $2.68 \mathrm{E}-32$ & $2.69 \mathrm{E}-32$ & $2.69 \mathrm{E}-32$ \\
\hline $6.74 \mathrm{E}-33$ & $2.72 \mathrm{E}-32$ & $2.55 E-32$ & $2.61 \mathrm{E}-32$ & $2.69 \mathrm{E}-32$ & $2.70 \mathrm{E}-32$ & $2.71 \mathrm{E}-32$ & $2.71 \mathrm{E}-32$ \\
\hline $6.67 \mathrm{E}-33$ & $2.75 \mathrm{E}-32$ & $2.57 \mathrm{E}-32$ & $2.63 E-32$ & $2.72 \mathrm{E}-32$ & $2.73 E-32$ & $2.73 E-32$ & $2.74 \mathrm{E}-32$ \\
\hline $6.59 \mathrm{E}-33$ & $2.77 E-32$ & $2.59 \mathrm{E}-32$ & $2.66 \mathrm{E}-32$ & $2.74 \mathrm{E}-32$ & $2.75 \mathrm{E}-32$ & $2.76 \mathrm{E}-32$ & $2.76 \mathrm{E}-32$ \\
\hline $6.52 E-33$ & $2.79 \mathrm{E}-32$ & $2.61 \mathrm{E}-32$ & $2.68 \mathrm{E}-32$ & $2.76 \mathrm{E}-32$ & $2.77 E-32$ & $2.78 \mathrm{E}-32$ & $2.79 \mathrm{E}-32$ \\
\hline $6.45 \mathrm{E}-33$ & $2.82 \mathrm{E}-32$ & $2.63 E-32$ & $2.70 \mathrm{E}-32$ & $2.79 \mathrm{E}-32$ & $2.80 \mathrm{E}-32$ & $2.81 \mathrm{E}-32$ & $2.81 \mathrm{E}-32$ \\
\hline $6.38 \mathrm{E}-33$ & $2.84 \mathrm{E}-32$ & $2.65 E-32$ & $2.72 \mathrm{E}-32$ & $2.81 \mathrm{E}-32$ & $2.82 \mathrm{E}-32$ & $2.83 E-32$ & $2.83 \mathrm{E}-32$ \\
\hline $6.31 \mathrm{E}-33$ & $2.87 \mathrm{E}$ & $2.67 \mathrm{E}-32$ & 2 . & 2 & 32 & -32 & -32 \\
\hline $6.24 \mathrm{E}-33$ & 2 & 2 & 32 & 2 & 2 & 32 & 32 \\
\hline $6.17 \mathrm{E}-33$ & $2.92 \mathrm{E}-32$ & $2.71 \mathrm{E}-32$ & $2.79 \mathrm{E}-32$ & $2.89 \mathrm{E}-32$ & $2.90 \mathrm{E}-32$ & $2.91 \mathrm{E}-32$ & $2.91 \mathrm{E}-32$ \\
\hline $6.10 \mathrm{E}-33$ & $2.95 E-32$ & $2.74 \mathrm{E}-32$ & $2.81 \mathrm{E}-32$ & $2.91 \mathrm{E}-32$ & $2.92 \mathrm{E}-32$ & $2.93 E-32$ & $2.94 \mathrm{E}-32$ \\
\hline $6.03 \mathrm{E}-33$ & $2.97 \mathrm{E}-32$ & $2.76 \mathrm{E}-32$ & $2.84 \mathrm{E}-32$ & $2.94 \mathrm{E}-32$ & $2.95 E-32$ & $2.96 \mathrm{E}-32$ & $2.96 \mathrm{E}-32$ \\
\hline $5.96 \mathrm{E}-33$ & $3.00 \mathrm{E}-32$ & $2.78 \mathrm{E}-32$ & $2.86 \mathrm{E}-32$ & $2.96 \mathrm{E}-32$ & $2.98 \mathrm{E}-32$ & $2.98 \mathrm{E}-32$ & $2.99 \mathrm{E}-32$ \\
\hline $5.90 \mathrm{E}-33$ & $3.02 \mathrm{E}-32$ & $2.80 \mathrm{E}-32$ & $2.88 \mathrm{E}-32$ & $2.99 \mathrm{E}-32$ & $3.00 \mathrm{E}-32$ & $3.01 \mathrm{E}-32$ & $3.01 \mathrm{E}-32$ \\
\hline $5.83 E-33$ & $3.05 E-32$ & $2.82 \mathrm{E}-32$ & $2.91 \mathrm{E}-32$ & $3.02 \mathrm{E}-32$ & $3.03 E-32$ & $3.04 \mathrm{E}-32$ & $3.04 \mathrm{E}-32$ \\
\hline $5.77 \mathrm{E}-33$ & $3.08 \mathrm{E}-32$ & $2.85 \mathrm{E}-32$ & $2.93 \mathrm{E}-32$ & $3.04 \mathrm{E}-32$ & $3.05 E-32$ & $3.06 \mathrm{E}-32$ & $3.07 \mathrm{E}-32$ \\
\hline $5.70 \mathrm{E}-33$ & $3.11 \mathrm{E}-32$ & $2.87 \mathrm{E}-32$ & $2.96 \mathrm{E}-32$ & $3.07 \mathrm{E}-32$ & $3.08 \mathrm{E}-32$ & $3.09 \mathrm{E}-32$ & $3.09 \mathrm{E}-32$ \\
\hline $5.64 \mathrm{E}-33$ & $3.13 \mathrm{E}-32$ & $2.89 \mathrm{E}-32$ & $2.98 \mathrm{E}-32$ & $3.09 \mathrm{E}-32$ & $3.11 \mathrm{E}-32$ & $3.12 \mathrm{E}-32$ & $3.12 \mathrm{E}-32$ \\
\hline $5.58 \mathrm{E}-33$ & $3.16 \mathrm{E}-32$ & $2.92 \mathrm{E}-32$ & $3.01 \mathrm{E}-32$ & $3.12 \mathrm{E}-32$ & $3.13 \mathrm{E}-32$ & $3.14 \mathrm{E}-32$ & $3.15 \mathrm{E}-32$ \\
\hline $5.52 \mathrm{E}-33$ & $3.19 \mathrm{E}-32$ & $2.94 \mathrm{E}-32$ & $3.03 E-32$ & $3.15 \mathrm{E}-32$ & $3.16 \mathrm{E}-32$ & $3.17 E-32$ & $3.18 \mathrm{E}-32$ \\
\hline $5.46 \mathrm{E}-33$ & $3.22 \mathrm{E}-32$ & $2.96 \mathrm{E}-32$ & $3.06 \mathrm{E}-32$ & $3.18 \mathrm{E}-32$ & $3.19 \mathrm{E}-32$ & $3.20 \mathrm{E}-32$ & $3.20 \mathrm{E}-32$ \\
\hline $5.40 \mathrm{E}-33$ & $3.25 \mathrm{E}-32$ & $2.99 \mathrm{E}-32$ & $3.08 \mathrm{E}-32$ & $3.20 \mathrm{E}-32$ & $3.22 \mathrm{E}-32$ & $3.23 E-32$ & $3.23 \mathrm{E}-32$ \\
\hline $.34 \mathrm{E}-33$ & $3.27 \mathrm{E}-32$ & $3.01 \mathrm{E}-32$ & $3.11 \mathrm{E}-32$ & $3.23 \mathrm{E}-$ & $3.25 \mathrm{E}-$ & $3.26 \mathrm{E}-32$ & $3.26 \mathrm{E}-32$ \\
\hline $.28 E-33$ & $3.30 \mathrm{E}-32$ & $3.03 E-32$ & $3.13 \mathrm{E}-32$ & $3.26 \mathrm{E}-32$ & $3.27 E-32$ & $3.28 \mathrm{E}-32$ & $3.29 \mathrm{E}-32$ \\
\hline
\end{tabular}


RESRAD-OFFSITE, Version 2.5

$\mathrm{T}^{1 / 2}$ Limit $=180$ days

Title : RESRAD-OFFSITE External Gamma, Inhalation, and Soil Ingestion for Offsite Reside

File : PBA-1_TC99-DOE-5-1.ROF

Summary of dose at graphical times, reptition 3 (continued)

Time

Years

$4.72 \mathrm{E}+01$

$4.77 \mathrm{E}+01$

4. $82 \mathrm{E}+01$

$4.87 \mathrm{E}+01$

4. $92 \mathrm{E}+01$

$4.97 \mathrm{E}+01$

$5.02 \mathrm{E}+01$

$5.08 \mathrm{E}+01$

$5.13 \mathrm{E}+01$

$5.18 \mathrm{E}+01$

$5.23 \mathrm{E}+01$

$5.28 \mathrm{E}+01$

$5.33 \mathrm{E}+01$

$5.38 \mathrm{E}+01$

$5.43 \mathrm{E}+01$

$5.49 \mathrm{E}+01$

$5.54 \mathrm{E}+01$

$5.59 \mathrm{E}+01$

$5.64 \mathrm{E}+01$

$5.69 \mathrm{E}+01$

$5.74 \mathrm{E}+01$

$5.79 \mathrm{E}+01$

$5.84 \mathrm{E}+01$

$5.90 \mathrm{E}+01$

$5.95 \mathrm{E}+01$

$6.00 \mathrm{E}+01$

$6.05 \mathrm{E}+01$

$6.10 \mathrm{E}+01$

$6.15 \mathrm{E}+01$

$6.20 \mathrm{E}+01$

$6.25 \mathrm{E}+01$

$6.31 \mathrm{E}+01$

$6.36 \mathrm{E}+01$

$6.41 \mathrm{E}+01$

$6.46 \mathrm{E}+01$

$6.51 \mathrm{E}+01$

$6.56 \mathrm{E}+01$

$6.61 \mathrm{E}+01$

$6.67 \mathrm{E}+01$

$6.72 \mathrm{E}+01$

$6.77 \mathrm{E}+01$

$6.82 \mathrm{E}+01$

$6.87 \mathrm{E}+01$

$6.92 \mathrm{E}+01$

$6.97 \mathrm{E}+01$

$7.02 \mathrm{E}+01$
Dose statistics at graphical times, mrem/yr

\begin{tabular}{|c|c|c|c|c|c|c|c|}
\hline um & aximum & ean & edi & & & & \\
\hline 33 & 32 & 32 & 32 & 32 & 32 & 2 & -32 \\
\hline $16 \mathrm{E}-33$ & $36 \mathrm{E}-32$ & $8 E-32$ & $3.18 E-32$ & $3.32 \mathrm{E}-32$ & $3.33 E-32$ & $.34 E-32$ & $35 E-32$ \\
\hline$E-33$ & $39 E-32$ & $1 E-32$ & $.21 E-32$ & $3.35 E-32$ & $36 E-32$ & -32 & $38 E-32$ \\
\hline & & -32 & & & & 32 & -32 \\
\hline-33 & 32 & 32 & 32 & & & & -32 \\
\hline $94 E-33$ & 32 & 32 & 32 & 32 & 32 & 32 & -32 \\
\hline 3 & 2 & 32 & 32 & & 32 & 32 & -32 \\
\hline (5) & -32 & $E-32$ & -32 & -32 & -32 & -32 & $E-32$ \\
\hline $.77 E-33$ & $8 E-32$ & $E-32$ & $7 E-32$ & 32 & -32 & -32 & $56 E-32$ \\
\hline $72 F-33$ & $61 E-32$ & $28 E-32$ & $40 E-32$ & & $57 E-32$ & $58 E-32$ & -32 \\
\hline $.67 E-33$ & & & & & & & -32 \\
\hline $62 E-33$ & $7 E-32$ & $E-32$ & -32 & 32 & 32 & 32 & $55 E-32$ \\
\hline $.57 E-33$ & $3.70 E-32$ & $3.36 E-32$ & $3.49 E-32$ & & & $68 E-32$ & $69 E-32$ \\
\hline 更 & 32 & -32 & & & & & -32 \\
\hline 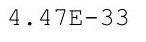 & & & & & & -32 & $75 E-32$ \\
\hline $5-3$ & & $44 \mathrm{E}-32$ & & & & 32 & -32 \\
\hline $.37 E-33$ & $3.84 \mathrm{E}-32$ & 2 & 2 & 2 & 2 & 2 & -32 \\
\hline $32 F-33$ & $8 F-$ & $E-32$ & -32 & & 32 & -32 & $E-32$ \\
\hline $.27 E-33$ & $.91 E-32$ & $3.53 E-32$ & $.66 E-32$ & $.84 E-32$ & $.86 E-32$ & $3 E-32$ & $89 E-32$ \\
\hline $22 E-33$ & $94 E-32$ & $.56 E-32$ & $.69 E-32$ & $88 E-32$ & -32 & -32 & $92 E-32$ \\
\hline & & & & & & 32 & -32 \\
\hline & & & & & & & 32 \\
\hline$B E-33$ & & & 32 & & & & -32 \\
\hline 3 & 2 & 32 & 2 & 2 & 2 & 32 & -32 \\
\hline 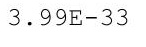 & $12 \mathrm{E}-$ & $70 E-32$ & $E-32$ & $5 E-32$ & $7 E-32$ & -32 & $E-32$ \\
\hline $5-32$ & $15 E-32$ & $.73 E-32$ & $88 E-32$ & $8 E-32$ & $4.11 E-32$ & -32 & $E-32$ \\
\hline$F-33$ & $19 E-32$ & $76 \mathrm{E}-32$ & & & & $E-32$ & $E-32$ \\
\hline & & & & & & & \\
\hline & & & & & & & \\
\hline $.78 E-33$ & $4.30 E-32$ & $3.85 E-32$ & $4.01 E-32$ & $4.23 E-32$ & $4.25 E-32$ & $27 E-32$ & $.28 E-32$ \\
\hline the & $4.34 E-32$ & $.88 E-32$ & $4.04 E-32$ & $4.26 \mathrm{E}-32$ & $4.29 E-32$ & $31 E-32$ & $32 E-32$ \\
\hline 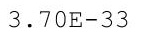 & - & & & & & -32 & $35 E-32$ \\
\hline-3 & $2 F-32$ & $94 E-32$ & & & & -32 & $E-32$ \\
\hline & & & & & & & -32 \\
\hline & & & & & & 32 & $47 E-32$ \\
\hline $.53 E-33$ & $4.54 \mathrm{E}-32$ & $4.04 E-32$ & $4.21 E-32$ & $4.45 E-32$ & $48 E-32$ & $50 E-32$ & $51 E-32$ \\
\hline 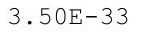 & न. & $7 E-32$ & (encos & 32 & (enter & 32 & $.02+28$ \\
\hline - & & & & & & & $.59 E-32$ \\
\hline & 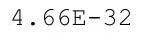 & (⿻上丨 & 2 & 2 & 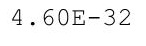 & 2 & 32 \\
\hline $.38 E-33$ & $4.70 E-32$ & & & & & 32 & -32 \\
\hline$E-33$ & $74 E-32$ & $4.20 \mathrm{E}-32$ & $4.39 E-32$ & $5 E-32$ & $58 E-32$ & $D E-32$ & $71 E-32$ \\
\hline-33 & $4.78 E-32$ & $4 E-32$ & $2 E-32$ & 4.65 & 32 & -32 & $5 E-32$ \\
\hline & & & & & & & $.80 E-32$ \\
\hline & $4.01 \mathrm{~L}-32$ & $E-32$ & $4.305-32$ & $4.77 E-32$ & 32 & $83 E-32$ & $4.04 \mathrm{~L}^{-32}$ \\
\hline & - & $E-32$ & & $31 E-32$ & & & क्षे \\
\hline-33 & $E-32$ & $7 E-32$ & $7 E-32$ & $6 E-32$ & $9 E-32$ & $1 E-32$ & $2 E-32$ \\
\hline
\end{tabular}


RESRAD-OFFSITE, Version 2.5

$\mathrm{T}^{1 / 2}$ Limit $=180$ days

Title : RESRAD-OFFSITE External Gamma, Inhalation, and Soil Ingestion for Offsite Reside File : PBA-1_TC99-DOE-5-1.ROF

Summary of dose at graphical times, reptition 3 (continued)

Time

Years

$7.08 \mathrm{E}+01$

7. $13 \mathrm{E}+01$

7. $18 \mathrm{E}+01$

7. $23 \mathrm{E}+01$

7. $28 \mathrm{E}+01$

7. $33 \mathrm{E}+01$

7. $38 \mathrm{E}+01$

7. $43 \mathrm{E}+01$

$7.49 \mathrm{E}+01$

$7.54 \mathrm{E}+01$

$7.59 \mathrm{E}+01$

7. $64 \mathrm{E}+01$

$7.69 \mathrm{E}+01$

7. $74 \mathrm{E}+01$

$7.79 \mathrm{E}+01$

$7.84 \mathrm{E}+01$

7. $90 \mathrm{E}+01$

7. $95 \mathrm{E}+01$

$8.00 \mathrm{E}+01$

$8.05 \mathrm{E}+01$

$8.10 \mathrm{E}+01$

$8.15 \mathrm{E}+01$

$8.20 \mathrm{E}+01$

$8.25 \mathrm{E}+01$

$8.31 \mathrm{E}+01$

$8.36 \mathrm{E}+01$

$8.41 \mathrm{E}+01$

$8.46 \mathrm{E}+01$

$8.51 \mathrm{E}+01$

$8.56 \mathrm{E}+01$

8. $61 \mathrm{E}+01$

$8.66 \mathrm{E}+01$

$8.72 \mathrm{E}+01$

$8.77 \mathrm{E}+01$

$8.82 \mathrm{E}+01$

8. $87 \mathrm{E}+01$

$8.92 \mathrm{E}+01$

$8.97 \mathrm{E}+01$

9. $02 \mathrm{E}+01$

9. $07 \mathrm{E}+01$

$9.13 \mathrm{E}+01$

9. $18 \mathrm{E}+01$

9. $23 \mathrm{E}+01$

$9.28 \mathrm{E}+01$

9. $33 \mathrm{E}+01$

$9.38 \mathrm{E}+01$
Dose statistics at graphical times, mrem/yr

\begin{tabular}{|c|c|c|c|c|c|c|c|}
\hline m & num & ean & ed & & & & \\
\hline 33 & 2 & 32 & 32 & 32 & 32 & 2 & -32 \\
\hline $.09 E-33$ & $.04 \mathrm{E}-32$ & $4 \mathrm{E}-32$ & $4.65 E-32$ & $4.94 \mathrm{E}-32$ & $4.98 E-32$ & $.00 \mathrm{E}-32$ & $01 E-32$ \\
\hline $5 E-33$ & -32 & $8 E-32$ & $4.69 E-32$ & 32 & $2 E-32$ & 32 & -32 \\
\hline & & & & & & & -32 \\
\hline 33 & 32 & $E-32$ & -32 & 2 & & & -32 \\
\hline $96 E-33$ & 32 & 32 & 32 & 32 & 32 & 32 & -32 \\
\hline 3 & 2 & 2 & & & & -32 & -32 \\
\hline EE-33 & -32 & $E-32$ & $8 E-32$ & 32 & -32 & -32 & $E-32$ \\
\hline $.86 E-33$ & $5 E-32$ & $E-32$ & $2 E-32$ & & -32 & -32 & $33 E-32$ \\
\hline $3 F-33$ & $41 \mathrm{E}-32$ & $4 E-32$ & $97 E-32$ & & $33 E-32$ & $36 E-32$ & -32 \\
\hline-33 & & & & & & & -32 \\
\hline $7 E-33$ & $E-32$ & $1 E-32$ & $5 E-32$ & 2 & 32 & 32 & $47 E-32$ \\
\hline $.74 E-33$ & $5.55 E-32$ & $4.85 E-32$ & $5.09 E-32$ & & & $.50 E-32$ & $52 E-32$ \\
\hline 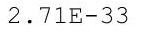 & & $E-32$ & & & & & -32 \\
\hline 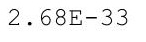 & & & & & & -32 & -32 \\
\hline $5 F-3$ & & $97 E-32$ & & & 2 & 32 & -32 \\
\hline $2.62 E-33$ & $5.75 E-32$ & 2 & 2 & 2 & 2 & 2 & 32 \\
\hline $9 F-33$ & 2 & -32 & -32 & & & 32 & $E-32$ \\
\hline $.56 E-33$ & $.86 E-32$ & $5.09 E-32$ & $5.35 E-32$ & $5.73 E-32$ & $.77 E-32$ & -32 & $82 E-32$ \\
\hline $.53 E-33$ & $91 E-32$ & $.13 E-32$ & $.39 E-32$ & $5.77 E-32$ & -32 & -32 & $37 E-32$ \\
\hline & & & & & & 32 & -32 \\
\hline & & & & & & & 32 \\
\hline 50 & & & $5.53 \mathrm{E}-$ & & & & 32 \\
\hline 3 & 2 & 32 & 32 & 2 & 2 & 32 & -32 \\
\hline$F-$ & $17 \mathrm{E}-$ & $E-32$ & $2 E-32$ & $E-32$ & $3 E-32$ & -32 & $E-32$ \\
\hline $37 E-33$ & $.23 E-32$ & $38 E-32$ & $66 E-32$ & $8 E-32$ & $13 E-32$ & $16 E-32$ & $E-32$ \\
\hline$F-33$ & $28 E-32$ & $3 E-32$ & $71 E-32$ & & $9 E-32$ & $E-32$ & $E-32$ \\
\hline & & & & & & & \\
\hline & & & & & & & 32 \\
\hline - 2 & & 2 & 32 & -32 & -32 & -32 & $40 E-32$ \\
\hline ch & $51 \mathrm{E}-32$ & $.60 E-32$ & $5.90 E-32$ & $6.35 E-32$ & $41 E-32$ & -32 & $E-32$ \\
\hline 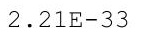 & 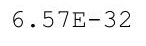 & & $5.95 E-32$ & & & -32 & 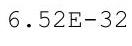 \\
\hline$F-3=5$ & $63 F-32$ & $0 \mathrm{E}-32$ & $6.00 E-32$ & $6 E-32$ & $2 E-32$ & -32 & $E-32$ \\
\hline & & & & & & 32 & \\
\hline $4 E-33$ & & & & & & -32 & \\
\hline $.12 E-33$ & $6.80 \mathrm{E}-32$ & $5.83 E-32$ & $6.15 E-32$ & $6.63 E-32$ & $6.69 \mathrm{E}-32$ & $6.73 E-32$ & $.75 E-32$ \\
\hline 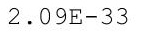 & . & $.88 E-32$ & $0.20 \mathrm{n}-22$ & $6.69 \mathrm{E}-32$ & - 1 & 32 & 25 \\
\hline $07 E-33$ & $92 E-32$ & & $6.25 E-32$ & & & & $87 E-32$ \\
\hline $05 F-33$ & 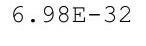 & 2 & 2 & 2 & 2 & 2 & 32 \\
\hline & & & & & & 32 & 32 \\
\hline $00 E-33$ & $11 F-32$ & $7 E-32$ & $6.41 E-32$ & & $E-32$ & -32 & $5 E-32$ \\
\hline $.98 E-33$ & $7.17 \mathrm{E}-32$ & $12 \mathrm{E}-32$ & $46 E-32$ & -32 & 32 & 32 & -32 \\
\hline tis & & & & & & & -32 \\
\hline 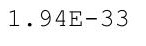 & 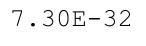 & 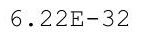 & $0.012-32$ & $1 E-32$ & 32 & -32 & $\cdot 245-32$ \\
\hline & & म $2 z^{2}$ & $6.62 \mathrm{E}-32$ & & & $28 E-32$ & . \\
\hline $89 \mathrm{E}-33$ & $E-32$ & $2 \mathrm{E}-32$ & $68 E-32$ & $3 E-32$ & $30 E-32$ & $E-32$ & $.37 E-32$ \\
\hline
\end{tabular}


RESRAD-OFFSITE, Version 2.5

$\mathrm{T}^{1 / 2}$ Limit $=180$ days

Title : RESRAD-OFFSITE External Gamma, Inhalation, and Soil Ingestion for Offsite Reside File : PBA-1_TC99-DOE-5-1.ROF

Summary of dose at graphical times, reptition 3 (continued)

Time

Years

$9.43 E+01$

9. $48 \mathrm{E}+01$

9. $54 \mathrm{E}+01$

$9.59 \mathrm{E}+01$

9. $64 \mathrm{E}+01$

$9.69 \mathrm{E}+01$

$9.74 \mathrm{E}+01$

$9.79 \mathrm{E}+01$

$9.84 \mathrm{E}+01$

9. $90 \mathrm{E}+01$

9. $95 \mathrm{E}+01$

$1.00 \mathrm{E}+02$

$1.00 \mathrm{E}+02$

$1.01 \mathrm{E}+02$

$1.02 \mathrm{E}+02$

$1.02 \mathrm{E}+02$

$1.03 \mathrm{E}+02$

$1.03 \mathrm{E}+02$

$1.04 \mathrm{E}+02$

$1.04 \mathrm{E}+02$

$1.05 \mathrm{E}+02$

$1.05 \mathrm{E}+02$

$1.06 \mathrm{E}+02$

$1.06 \mathrm{E}+02$

$1.07 \mathrm{E}+02$

$1.07 \mathrm{E}+02$

$1.08 \mathrm{E}+02$

$1.08 \mathrm{E}+02$

$1.09 \mathrm{E}+02$

$1.09 \mathrm{E}+02$

1. $10 \mathrm{E}+02$

$1.10 \mathrm{E}+02$

$1.11 \mathrm{E}+02$

1. $11 \mathrm{E}+02$

$1.12 \mathrm{E}+02$

1. $12 \mathrm{E}+02$

1. $13 \mathrm{E}+02$

1. $13 \mathrm{E}+02$

1. $14 \mathrm{E}+02$

1. $14 \mathrm{E}+02$

1. $15 \mathrm{E}+02$

1. $15 \mathrm{E}+02$

$1.16 \mathrm{E}+02$

1. $16 \mathrm{E}+02$

$1.17 \mathrm{E}+02$

$1.17 \mathrm{E}+02$
Dose statistics at graphical times, mrem/yr

\begin{tabular}{|c|c|c|c|c|c|c|c|}
\hline inimum & aximum & Mean & ledian & $0 \%$ & $5 \%$ & $97.5 \%$ & $\%$ \\
\hline 33 & -32 & $6.37 E-32$ & $3 E-32$ & $0 E-32$ & $7.36 \mathrm{E}-32$ & $.41 E-32$ & $E-32$ \\
\hline 33 & $6 E-32$ & 2 & 2 & $6 \mathrm{E}-$ & 32 & 32 & -32 \\
\hline$E-33$ & $3 E-32$ & $E-32$ & $E-32$ & -32 & 32 & -32 & $7 E-32$ \\
\hline$E-33$ & $E-32$ & $E-32$ & $E-32$ & -32 & & 32 & -32 \\
\hline-33 & 32 & & & 32 & & 32 & $70 E-32$ \\
\hline $.77 E-33$ & 32 & 2 & 32 & 32 & & 32 & -32 \\
\hline 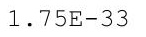 & 2 & -32 & 32 & 32 & 32 & 32 & -32 \\
\hline $.73 E-33$ & $7.97 E-32$ & $6.74 \mathrm{E}-32$ & $7.13 E-32$ & $7.75 E-32$ & 32 & -32 & $90 E-32$ \\
\hline 33 & 32 & 32 & 32 & 32 & 32 & -32 & -32 \\
\hline $.70 E-33$ & 32 & 2 & 2 & 32 & 32 & -32 & $4 E-32$ \\
\hline 33 & 32 & & & & & 32 & -32 \\
\hline 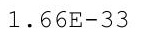 & & & & & & & 32 \\
\hline . & $E-32$ & $2 E-32$ & $E-32$ & $0 E-32$ & -32 & -32 & $4-32$ \\
\hline $62 E-33$ & -32 & $E-32$ & -32 & $7 E-32$ & -32 & -32 & $33 E-32$ \\
\hline$E-33$ & $3 E-32$ & 32 & -32 & 32 & 32 & -32 & -32 \\
\hline $9 E-33$ & -32 & -32 & 7. & 32 & 32 & -32 & -32 \\
\hline $.57 E-33$ & -32 & -32 & -32 & $8.38 E-32$ & -32 & -32 & $55 E-32$ \\
\hline-33 & -32 & $E-32$ & -32 & 32 & 32 & -32 & -32 \\
\hline-33 & -32 & -32 & -32 & 32 & 32 & -32 & -32 \\
\hline $.52 E-33$ & -32 & -32 & -32 & 32 & 32 & -32 & $E-32$ \\
\hline $.50 \mathrm{E}-33$ & -32 & -32 & & & 32 & -32 & $E-32$ \\
\hline $.48 E-33$ & $9.02 \mathrm{E}-32$ & -32 & 32 & & & 32 & -32 \\
\hline $47 E-33$ & $0 E-32$ & $0 E-32$ & $7 E-32$ & $33 E-32$ & $92 E-32$ & $3-32$ & $1 E-32$ \\
\hline$E-33$ & $E-32$ & $6 E-32$ & $4 E-32$ & 32 & 32 & -32 & $9 E-32$ \\
\hline 33 & $6 E-32$ & $3 E-32$ & 32 & 32 & 32 & -32 & -32 \\
\hline 33 & -32 & -32 & -32 & 32 & & 32 & -32 \\
\hline$E-33$ & $E-32$ & $E-32$ & -32 & & 32 & -32 & $E-32$ \\
\hline $.39 E-33$ & $9.51 E-32$ & $7.91 \mathrm{E}-32$ & $8.41 E-32$ & $9.22 \mathrm{E}-32$ & $9.32 \mathrm{E}-32$ & $38 \mathrm{E}-32$ & $.42 E-32$ \\
\hline $.37 E-33$ & $9.59 E-32$ & $7.98 \mathrm{E}-32$ & $8.48 E-32$ & $9.30 E-32$ & $9.40 \mathrm{E}-32$ & $46 \mathrm{E}-32$ & $50 E-32$ \\
\hline $.36 \mathrm{E}-33$ & $9.68 \mathrm{E}-32$ & $8.04 \mathrm{E}-32$ & $8.55 E-32$ & . & . & $.55 E-32$ & ل \\
\hline 3 & 1 & 2 & 2 & 2 & 2 & 32 & $E-32$ \\
\hline$E-33$ & $E-29$ & $E-31$ & $E-32$ & $5 E-32$ & $5 E-32$ & -32 & -32 \\
\hline $.31 E-33$ & $3.40 \mathrm{E}-27$ & $1.78 \mathrm{E}-30$ & $8.76 \mathrm{E}-32$ & $9.63 E-32$ & $9.74 \mathrm{E}-32$ & -32 & $4 E-32$ \\
\hline $.30 E-33$ & $9.89 E-26$ & $4.95 E-29$ & $8.83 E-32$ & $1 E-32$ & $9.82 \mathrm{E}-32$ & $89 E-32$ & $93 E-32$ \\
\hline $.50 \mathrm{x}-23$ & $1.79 E-24$ & $.96 E-28$ & & . & & & $.00 E-31$ \\
\hline 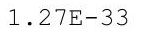 & & & & & & & \\
\hline & & & & & & & \\
\hline 3 & 1 & 5 & 2 & 1 & 1 & 31 & 31 \\
\hline 3 & 1 & 4 & 2 & 1 & & & \\
\hline $21 E-33$ & $E-20$ & $9 E-23$ & 2 & 1 & 1 & & $5 E-31$ \\
\hline 3 & 9 & & & & & & -31 \\
\hline$E-33$ & $.67 E-19$ & $.34 E-22$ & & $.04 \mathrm{E}-31$ & $.05 E-31$ & & $07 E-31$ \\
\hline$P$ & & 1 & & 1 & $\perp$ & & 0 \\
\hline 1. & 6 & & & 1 & $\perp$ & 1 & $p \perp$ \\
\hline 3 & 1.6 & -21 & 2 & 1 . & 31 & 31 & 31 \\
\hline $.14 \mathrm{E}-$ & $4.01 E-17$ & $.01 E-20$ & $.75 E-32$ & $.08 E-31$ & $1.09 \mathrm{E}-31$ & $1.10 \mathrm{E}-31$ & 1. $10 \mathrm{E}-31$ \\
\hline
\end{tabular}


RESRAD-OFFSITE, Version 2.5

Title : RESRAD-OFFSITE External Gamma, Inhalation, and Soil Ingestion for Offsite Reside File : PBA-1_TC99-DOE-5-1.ROF

Summary of dose at graphical times, reptition 3 (continued)

Time

Years

$1.18 \mathrm{E}+02$

$1.18 \mathrm{E}+02$

$1.19 \mathrm{E}+02$

$1.19 \mathrm{E}+02$

$1.20 \mathrm{E}+02$

$1.20 \mathrm{E}+02$

$1.21 \mathrm{E}+02$

$1.22 \mathrm{E}+02$

$1.22 \mathrm{E}+02$

$1.23 \mathrm{E}+02$

$1.23 \mathrm{E}+02$

$1.24 \mathrm{E}+02$

$1.24 \mathrm{E}+02$

$1.25 \mathrm{E}+02$

$1.25 \mathrm{E}+02$

$1.26 \mathrm{E}+02$

$1.26 \mathrm{E}+02$

$1.27 \mathrm{E}+02$

$1.27 \mathrm{E}+02$

$1.28 \mathrm{E}+02$

$1.28 \mathrm{E}+02$

$1.29 \mathrm{E}+02$

$1.29 \mathrm{E}+02$

$1.30 \mathrm{E}+02$

$1.30 \mathrm{E}+02$

$1.31 \mathrm{E}+02$

$1.31 \mathrm{E}+02$

$1.32 \mathrm{E}+02$

$1.32 \mathrm{E}+02$

$1.33 \mathrm{E}+02$

$1.33 \mathrm{E}+02$

1. $34 \mathrm{E}+02$

$1.34 \mathrm{E}+02$

1. $35 \mathrm{E}+02$

1. $35 \mathrm{E}+02$

$1.36 \mathrm{E}+02$

1. $36 \mathrm{E}+02$

$1.37 \mathrm{E}+02$

$1.37 \mathrm{E}+02$

1. $38 \mathrm{E}+02$

$1.38 \mathrm{E}+02$

$1.39 \mathrm{E}+02$

1. $39 \mathrm{E}+02$

$1.40 \mathrm{E}+02$

1. $40 \mathrm{E}+02$

1. $41 \mathrm{E}+02$
Dose statistics at graphical times, mrem/yr

\begin{tabular}{|c|c|c|c|c|c|c|c|}
\hline inimum & Maximum & Mean & Median & $90 \%$ & $95 \frac{\circ}{\circ}$ & $7.5 \%$ & $9 \frac{\circ}{0}$ \\
\hline $1.12 \mathrm{E}-33$ & $9.08 \mathrm{E}-17$ & $4.56 \mathrm{E}-20$ & $9.84 \mathrm{E}-32$ & $1.09 \mathrm{E}-31$ & $1.10 \mathrm{E}-31$ & $1.11 \mathrm{E}-31$ & $1.11 \mathrm{E}-31$ \\
\hline $1.11 \mathrm{E}-33$ & $1.93 \mathrm{E}-16$ & $9.70 \mathrm{E}-20$ & $9.92 \mathrm{E}-32$ & $1.10 \mathrm{E}-31$ & $1.11 \mathrm{E}-31$ & $1.12 \mathrm{E}-31$ & $1.12 \mathrm{E}-31$ \\
\hline $1.10 \mathrm{E}-33$ & $3.87 \mathrm{E}-16$ & $1.95 \mathrm{E}-19$ & $1.00 \mathrm{E}-31$ & $1.11 \mathrm{E}-31$ & $1.12 \mathrm{E}-31$ & $1.13 \mathrm{E}-31$ & $1.13 \mathrm{E}-31$ \\
\hline $1.09 \mathrm{E}-33$ & $7.39 \mathrm{E}-16$ & $3.74 \mathrm{E}-19$ & $1.01 \mathrm{E}-31$ & $1.12 \mathrm{E}-31$ & $13 E-31$ & $1.14 \mathrm{E}-31$ & $14 \mathrm{E}-31$ \\
\hline $1.07 \mathrm{E}-33$ & $1.35 \mathrm{E}-15$ & $6.88 \mathrm{E}-19$ & $1.02 \mathrm{E}-31$ & $1.13 \mathrm{E}$ & $14 \mathrm{E}$ & $1.15 \mathrm{E}$ & $15 \mathrm{E}-31$ \\
\hline $1.06 \mathrm{E}-33$ & $2.37 E-15$ & $1.22 \mathrm{E}-18$ & $1.03 \mathrm{E}-31$ & $1.14 \mathrm{E}-31$ & $.15 \mathrm{E}-31$ & $1.16 \mathrm{E}-31$ & $1.17 \mathrm{E}-31$ \\
\hline $1.05 \mathrm{E}-33$ & $4.00 \mathrm{E}-15$ & $2.08 \mathrm{E}-18$ & $1.03 \mathrm{E}-31$ & $1.15 \mathrm{E}-31$ & $16 \mathrm{E}-31$ & $1.17 \mathrm{E}-31$ & $1.18 \mathrm{E}-31$ \\
\hline $.04 E-33$ & $6.56 \mathrm{E}-15$ & $3.46 \mathrm{E}-18$ & $1.04 \mathrm{E}-31$ & $1.16 \mathrm{E}-31$ & $.17 \mathrm{E}-31$ & $1.18 \mathrm{E}-31$ & $1.19 \mathrm{E}-31$ \\
\hline $1.03 E-33$ & $1.05 \mathrm{E}-14$ & $5.59 \mathrm{E}-18$ & $1.05 \mathrm{E}-31$ & $1.17 \mathrm{E}-31$ & $1.18 \mathrm{E}-31$ & $1.19 \mathrm{E}-31$ & $1.20 \mathrm{E}-31$ \\
\hline $1.02 \mathrm{E}-33$ & $1.62 \mathrm{E}-14$ & $8.82 \mathrm{E}-18$ & $1.06 \mathrm{E}-31$ & $1.18 \mathrm{E}-31$ & $1.19 \mathrm{E}-31$ & $1.20 \mathrm{E}-31$ & $1.21 \mathrm{E}-31$ \\
\hline $1.00 \mathrm{E}-33$ & $2.45 E-14$ & $1.36 \mathrm{E}-17$ & $1.07 \mathrm{E}-31$ & $1.19 \mathrm{E}-31$ & $1.20 \mathrm{E}-31$ & $1.21 \mathrm{E}-31$ & $1.22 \mathrm{E}-31$ \\
\hline $9.94 \mathrm{E}-34$ & $3.64 \mathrm{E}-14$ & $2.06 \mathrm{E}-17$ & $1.08 \mathrm{E}-31$ & $1.20 \mathrm{E}-31$ & $1.21 \mathrm{E}-31$ & $1.22 \mathrm{E}-31$ & $1.23 \mathrm{E}-31$ \\
\hline $9.83 E-34$ & $5.28 \mathrm{E}-14$ & $3.06 \mathrm{E}-17$ & $1.09 \mathrm{E}-31$ & $1.21 \mathrm{E}-31$ & $1.22 \mathrm{E}-31$ & $1.23 \mathrm{E}-31$ & $1.24 \mathrm{E}-31$ \\
\hline $9.72 \mathrm{E}-34$ & $7.53 \mathrm{E}-14$ & $4.48 \mathrm{E}-17$ & $1.10 \mathrm{E}-31$ & $1.22 \mathrm{E}-31$ & $1.23 \mathrm{E}-31$ & $1.24 \mathrm{E}-31$ & $1.26 \mathrm{E}-31$ \\
\hline $9.61 \mathrm{E}-34$ & $1.05 E-13$ & $6.45 \mathrm{E}-17$ & $1.11 \mathrm{E}-31$ & $1.23 \mathrm{E}-31$ & $1.25 \mathrm{E}-31$ & $1.25 \mathrm{E}-31$ & $1.27 \mathrm{E}-31$ \\
\hline $9.50 \mathrm{E}-34$ & $1.45 \mathrm{E}-13$ & $9.16 \mathrm{E}-17$ & $1.12 \mathrm{E}-31$ & $1.24 \mathrm{E}-31$ & $1.26 \mathrm{E}-31$ & $1.27 \mathrm{E}-31$ & $1.28 \mathrm{E}-31$ \\
\hline $9.40 \mathrm{E}-34$ & $1.97 \mathrm{E}-13$ & $1.28 \mathrm{E}-16$ & $1.13 \mathrm{E}-31$ & $1.25 \mathrm{E}-31$ & $1.27 \mathrm{E}-31$ & $1.28 \mathrm{E}-31$ & $1.29 \mathrm{E}-31$ \\
\hline $9.29 \mathrm{E}-34$ & $2.65 E-13$ & $1.77 \mathrm{E}-16$ & $1.14 \mathrm{E}-31$ & $1.26 \mathrm{E}-31$ & $1.28 \mathrm{E}-31$ & $1.29 \mathrm{E}-31$ & $1.30 \mathrm{E}-31$ \\
\hline $9.19 \mathrm{E}-34$ & $3.50 \mathrm{E}-13$ & $2.43 E-16$ & $1.14 \mathrm{E}-31$ & $1.27 \mathrm{E}-31$ & $1.29 \mathrm{E}-31$ & $1.30 \mathrm{E}-31$ & $1.32 \mathrm{E}-31$ \\
\hline $.09 E-34$ & $4.57 \mathrm{E}-13$ & $3.28 \mathrm{E}-16$ & $1.15 \mathrm{E}-31$ & $1.28 \mathrm{E}-31$ & $1.30 \mathrm{E}-31$ & $1.31 \mathrm{E}-31$ & $.09 E-29$ \\
\hline $.99 \mathrm{E}-$ & & & & 1 & 1 & & 27 \\
\hline 4 & 7 & 5 & 1 & 1 & 1 & 31 & 26 \\
\hline $8.79 \mathrm{E}-34$ & $7 \mathrm{E}-13$ & $7.65 \mathrm{E}-16$ & $1.18 \mathrm{E}-31$ & $1.32 \mathrm{E}-31$ & $1.34 \mathrm{E}-31$ & 31 & -25 \\
\hline $8.69 \mathrm{E}-34$ & $1.20 \mathrm{E}-12$ & $9.97 \mathrm{E}-16$ & $1.19 \mathrm{E}-31$ & $1.33 \mathrm{E}-31$ & $1.35 \mathrm{E}-31$ & $1.36 \mathrm{E}-31$ & $9.88 \mathrm{E}-24$ \\
\hline $8.60 \mathrm{E}-34$ & $1.49 \mathrm{E}-12$ & $1.29 \mathrm{E}-15$ & $1.20 \mathrm{E}-31$ & $1.34 \mathrm{E}-31$ & $1.36 \mathrm{E}-31$ & $1.37 \mathrm{E}-31$ & $9.33 \mathrm{E}-23$ \\
\hline $8.50 \mathrm{E}-34$ & $1.84 \mathrm{E}-12$ & $1.65 \mathrm{E}-15$ & $1.21 \mathrm{E}-31$ & $1.35 \mathrm{E}-31$ & $1.37 \mathrm{E}-31$ & $1.38 \mathrm{E}-31$ & $6.90 \mathrm{E}-22$ \\
\hline $8.41 \mathrm{E}-34$ & $2.25 \mathrm{E}-12$ & $2.10 \mathrm{E}-15$ & $1.22 \mathrm{E}-31$ & $1.37 \mathrm{E}-31$ & $1.39 \mathrm{E}-31$ & $1.40 \mathrm{E}-31$ & $4.16 \mathrm{E}-21$ \\
\hline $8.31 \mathrm{E}-34$ & $2.73 E-12$ & $2.65 \mathrm{E}-15$ & $1.24 \mathrm{E}-31$ & $1.38 \mathrm{E}-31$ & $1.40 \mathrm{E}-31$ & $1.41 \mathrm{E}-31$ & $2.10 \mathrm{E}-20$ \\
\hline $8.22 \mathrm{E}-34$ & $3.29 \mathrm{E}-12$ & $3.32 \mathrm{E}-15$ & $1.25 \mathrm{E}-31$ & $1.39 \mathrm{E}-31$ & $1.41 \mathrm{E}-31$ & $1.42 \mathrm{E}-31$ & $9.17 \mathrm{E}-20$ \\
\hline $8.13 \mathrm{E}-34$ & $3.94 \mathrm{E}-12$ & 4.141 & $1.26 \mathrm{E}$ & $1.40 \mathrm{H}$ & $1.4 \angle \mathrm{E}$ & 1.43 & $3.51 \mathrm{E}-19$ \\
\hline $8.04 \mathrm{E}-34$ & $4.69 \mathrm{E}-$ & 5 & 1 & $1.41 \mathrm{E}-31$ & 1.440 & $1.45 \mathrm{E}-31$ & $1.20 \mathrm{E}-18$ \\
\hline $7.95 \mathrm{E}-34$ & $5.55 \mathrm{E}-12$ & $6.31 \mathrm{E}-15$ & $1.28 \mathrm{E}-31$ & $1.43 \mathrm{E}-31$ & $1.45 \mathrm{E}-31$ & $1.46 \mathrm{E}-31$ & $3.72 \mathrm{E}-18$ \\
\hline $7.86 \mathrm{E}-34$ & $6.53 \mathrm{E}-12$ & $7.72 \mathrm{E}-15$ & $1.29 \mathrm{E}-31$ & $1.44 \mathrm{E}-31$ & $1.46 \mathrm{E}-31$ & $1.47 \mathrm{E}-31$ & $1.05 \mathrm{E}-17$ \\
\hline $7.78 \mathrm{E}-34$ & $7.64 \mathrm{E}-12$ & $9.40 \mathrm{E}-15$ & $1.30 \mathrm{E}-31$ & $1.45 \mathrm{E}-31$ & $1.47 \mathrm{E}-31$ & $1.49 \mathrm{E}-31$ & $2.76 \mathrm{E}-17$ \\
\hline $7.69 \mathrm{E}-34$ & $8.89 \mathrm{E}-12$ & $1.14 \mathrm{E}-14$ & $1.31 \mathrm{E}-31$ & $1.46 \mathrm{E}-31$ & $1.49 \mathrm{E}-31$ & $1.50 \mathrm{E}-31$ & $6.69 \mathrm{E}-17$ \\
\hline $7.61 \mathrm{E}-34$ & $1.03 \mathrm{E}-11$ & $1.37 \mathrm{E}-14$ & $1.32 \mathrm{E}-31$ & $1.48 \mathrm{E}-31$ & $1.50 \mathrm{E}-31$ & $1.52 \mathrm{E}-31$ & $1.52 \mathrm{E}-16$ \\
\hline $7.52 \mathrm{E}-34$ & $1.19 \mathrm{E}-11$ & $1.65 \mathrm{E}-14$ & $1.33 \mathrm{E}-31$ & $1.49 \mathrm{E}-31$ & $1.51 \mathrm{E}-31$ & $1.53 \mathrm{E}-31$ & $3.26 \mathrm{E}-16$ \\
\hline $7.44 \mathrm{E}-34$ & $1.36 \mathrm{E}-11$ & $1.97 \mathrm{E}-14$ & $1.34 \mathrm{E}-31$ & $1.50 \mathrm{E}-31$ & $1.53 \mathrm{E}-31$ & $1.55 \mathrm{E}-31$ & $6.61 \mathrm{E}-16$ \\
\hline $7.36 \mathrm{E}-34$ & $1.56 \mathrm{E}-11$ & $2.34 \mathrm{E}-14$ & $1.35 \mathrm{E}-31$ & $1.52 \mathrm{E}-31$ & $1.54 \mathrm{E}-31$ & $1.56 \mathrm{E}-31$ & $1.32 \mathrm{E}-15$ \\
\hline $7.27 \mathrm{E}-34$ & $1.78 \mathrm{E}-11$ & $2.77 \mathrm{E}-14$ & $1.37 \mathrm{E}-31$ & $1.53 \mathrm{E}-31$ & $1.56 \mathrm{E}-31$ & $1.58 \mathrm{E}-31$ & $2.63 \mathrm{E}-15$ \\
\hline $7.19 \mathrm{E}-34$ & $2.01 \mathrm{E}-11$ & $3.27 \mathrm{E}-14$ & $1.38 \mathrm{E}-31$ & $1.54 \mathrm{E}-31$ & $1.57 \mathrm{E}-31$ & $1.59 \mathrm{E}-31$ & $4.98 \mathrm{E}-15$ \\
\hline $7.11 \mathrm{E}-34$ & $2.28 \mathrm{E}-11$ & $3.85 \mathrm{E}-14$ & $1.39 \mathrm{E}-31$ & $1.56 \mathrm{E}-31$ & $1.59 \mathrm{E}-31$ & $2.37 E-31$ & $9.03 \mathrm{E}-15$ \\
\hline $7.04 \mathrm{E}-34$ & $2.63 \mathrm{E}-11$ & $4.51 \mathrm{E}-14$ & $1.40 \mathrm{E}-31$ & $1.57 \mathrm{E}-31$ & $1.60 \mathrm{E}-31$ & $2.05 E-29$ & $1.57 \mathrm{E}-14$ \\
\hline $6.96 \mathrm{E}-34$ & $3.06 \mathrm{E}-11$ & $5.27 \mathrm{E}-14$ & $1.41 \mathrm{E}-31$ & $1.59 \mathrm{E}-31$ & $1.61 \mathrm{E}-31$ & $1.59 \mathrm{E}-27$ & $2.65 \mathrm{E}-14$ \\
\hline $6.88 \mathrm{E}-34$ & $3.55 \mathrm{E}-11$ & $6.13 \mathrm{E}-14$ & $1.42 \mathrm{E}-31$ & $1.60 \mathrm{E}-31$ & $1.63 \mathrm{E}-31$ & $5.77 \mathrm{E}-26$ & $4.32 \mathrm{E}-14$ \\
\hline $.80 E-34$ & $4.10 \mathrm{E}-11$ & $7.12 \mathrm{E}-14$ & $1.44 \mathrm{E}-31$ & $1.61 \mathrm{E}-31$ & $1.64 \mathrm{E}-31$ & $1.23 E-24$ & $6.66 \mathrm{E}-14$ \\
\hline
\end{tabular}


RESRAD-OFFSITE, Version 2.5

$\mathrm{T}^{1 / 2}$ Limit $=180$ days

Title : RESRAD-OFFSITE External Gamma, Inhalation, and Soil Ingestion for Offsite Reside File : PBA-1_TC99-DOE-5-1.ROF

Summary of dose at graphical times, reptition 3 (continued)

Time

Years

$1.42 \mathrm{E}+02$

$1.42 \mathrm{E}+02$

$1.43 \mathrm{E}+02$

$1.43 \mathrm{E}+02$

$1.44 \mathrm{E}+02$

$1.44 \mathrm{E}+02$

$1.45 \mathrm{E}+02$

$1.45 \mathrm{E}+02$

$1.46 \mathrm{E}+02$

$1.46 \mathrm{E}+02$

$1.47 \mathrm{E}+02$

$1.47 \mathrm{E}+02$

$1.48 \mathrm{E}+02$

$1.48 \mathrm{E}+02$

$1.49 \mathrm{E}+02$

$1.49 \mathrm{E}+02$

$1.50 \mathrm{E}+02$

$1.50 \mathrm{E}+02$

$1.51 \mathrm{E}+02$

$1.51 \mathrm{E}+02$

$1.52 \mathrm{E}+02$

$1.52 \mathrm{E}+02$

$1.53 \mathrm{E}+02$

$1.53 \mathrm{E}+02$

$1.54 \mathrm{E}+02$

$1.54 \mathrm{E}+02$

$1.55 \mathrm{E}+02$

$1.55 \mathrm{E}+02$

1. $56 \mathrm{E}+02$

$1.56 \mathrm{E}+02$

$1.57 \mathrm{E}+02$

1. $57 \mathrm{E}+02$

1. $58 \mathrm{E}+02$

1. $58 \mathrm{E}+02$

$1.59 \mathrm{E}+02$

$1.59 \mathrm{E}+02$

1. $60 \mathrm{E}+02$

$1.60 \mathrm{E}+02$

1. $61 \mathrm{E}+02$

1. $61 \mathrm{E}+02$

$1.62 \mathrm{E}+02$

1. $63 \mathrm{E}+02$

1. $63 \mathrm{E}+02$

1. $64 \mathrm{E}+02$

1. $64 \mathrm{E}+02$

1. $65 \mathrm{E}+02$
Dose statistics at graphical times, mrem/yr

\begin{tabular}{|c|c|c|c|c|c|c|c|}
\hline m & um & e & ledian & & & & \\
\hline $.73 E-34$ & 11 & -14 & -31 & -31 & $1.66 \mathrm{E}-31$ & -23 & $1-16$ \\
\hline $65 E-34$ & $5.39 \mathrm{E}-11$ & $9.50 \mathrm{E}-14$ & 31 & $4 E-31$ & $7 E-31$ & $.79 E-22$ & $36 E-13$ \\
\hline-34 & $.15 \mathrm{E}-11$ & $09 E-13$ & 1. $47 \mathrm{E}-31$ & $1.66 \mathrm{E}-31$ & $1.69 \mathrm{E}-31$ & -21 & -13 \\
\hline-34 & $08 \mathrm{~s}$ & $25 \mathrm{~F}-13$ & $48 E-31$ & $.67 \mathrm{E}-31$ & $70 F-31$ & -21 & -1 \\
\hline-34 & 11 & 13 & & 31 & 31 & -20 & -13 \\
\hline 34 & 11 & & & & & & \\
\hline $29 E-34$ & -11 & $87 \mathrm{E}$ & & $.72 \mathrm{H}$ & 31 & -19 & -13 \\
\hline $.22 E-34$ & -10 & $12 \mathrm{E}-13$ & & $1.73 E-31$ & $1.77 \mathrm{E}-31$ & -18 & -13 \\
\hline-34 & -10 & $41 E-13$ & -31 & $.75 E-31$ & $78 \mathrm{E}-31$ & -18 & -12 \\
\hline 34 & -10 & $72 E-13$ & 1 & 77 & 1 & -17 & -12 rat \\
\hline-34 & 10 & $F-13$ & 1 & 1 & $1.82 \mathrm{E}-31$ & 7 & 12 \\
\hline$E-34$ & 10 & $46 \mathrm{~F}-13$ & 1 & 1 & 1 & -17 & -12 \\
\hline $.89 E-34$ & $1.88 \mathrm{E}-10$ & $.89 E-13$ & & $1.81 E-31$ & $1.85 \mathrm{E}-31$ & $.72 E-16$ & -12 \\
\hline $82 E-34$ & $2.08 E-10$ & $4.37 \mathrm{E}-13$ & 1. $62 \mathrm{E}-31$ & $1.83 E-31$ & $1.87 \mathrm{E}-31$ & $.46 \mathrm{E}-16$ & -12 \\
\hline $76 E-34$ & $E-10$ & $9 E-13$ & & & & -16 & -12 \\
\hline 34 & $0 E-10$ & $46 E-13$ & & & & 15 & 12 \\
\hline 4 & & & & & & & 2 \\
\hline 4 & $99 F-10$ & 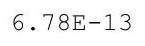 & 1 & & & 5 & 12 \\
\hline $51 E-34$ & $3.26 \mathrm{E}-10$ & $.54 E-13$ & 1. $69 \mathrm{E}-31$ & 1. $91 \mathrm{E}-31$ & $1.96 \mathrm{E}-31$ & $.86 E-15$ & $07 E-12$ \\
\hline-34 & $4 E-10$ & $.36 E-13$ & $1.71 E-31$ & $1.93 \mathrm{E}-$ & $1.98 \mathrm{E}-31$ & -15 & $E-12$ \\
\hline-34 & 10 & $26 \mathrm{E}-13$ & & 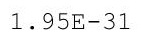 & & $44 \mathrm{E}-14$ & 11 \\
\hline 34 & & & & & & & \\
\hline 34 & & & & & & & 11 \\
\hline-34 & 10 & 2 & 1 & & $7.96 \mathrm{E}-28$ & 14 & -11 \\
\hline 4 & 10 & $.37 \mathrm{E}-$ & 1 & 1 & $3.61 \mathrm{E}-26$ & 14 & -11 \\
\hline$E-34$ & $.67 E-10$ & 1. $50 \mathrm{E}-12$ & $1.79 E-31$ & ? & मी० & $20 \mathrm{E}-14$ & $15 E-11$ \\
\hline-34 & $10 \mathrm{E}-10$ & $.65 E-12$ & $1.81 \mathrm{E}-31$ & & & $26 \mathrm{E}-13$ & $44 \mathrm{E}-11$ \\
\hline & & & & & & & \\
\hline & & & & & & & \\
\hline $7 E-34$ & & & & & $\pm \cdot 21$ & -13 & 11 \\
\hline $.82 E-34$ & $8.05 \mathrm{E}-10$ & $35 E-12$ & $1.87 E-31$ & $2.14 \mathrm{E}-31$ & $\begin{array}{ll}.0+1 \\
0\end{array}$ & $.90 E-13$ & $94 E-11$ \\
\hline $77 E-34$ & $8.61 \mathrm{E}-10$ & $2.56 \mathrm{E}-12$ & $1.89 \mathrm{E}-31$ & 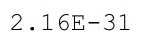 & & $.02 \mathrm{E}-13$ & $41 \mathrm{E}-11$ \\
\hline$E-34$ & $9.19 \mathrm{E}-10$ & $2.78 \mathrm{E}-12$ & & & & $E-13$ & $E-11$ \\
\hline 4 & & & & & & & \\
\hline & & $3.27 E-12$ & & & & 13 & \\
\hline & & & & & & 12 & 11 \\
\hline $51 E-34$ & $\cdot 18 \mathrm{E}-09$ & $.83 E-12$ & $1.97 E-31$ & $2.26 \mathrm{E}-$ & $4.35 E-$ & -12 & $.44 \mathrm{E}-11$ \\
\hline $46 \mathrm{E}-34$ & & & & $2.28 \mathrm{E}-31$ & & & $20 \mathrm{E}-11$ \\
\hline 3 & 9 & $4.47 E-12$ & & 2.00 & 5 & 2 & 11 \\
\hline & & & & & & & 11 \\
\hline-33 & & & $2.04 E-31$ & & $8.42 \mathrm{E}-16$ & & -10 \\
\hline-33 & $1.59 \mathrm{E}-09$ & $58 E-12$ & $2.06 E-31$ & $2.37 E-31$ & $7 E-15$ & $E-12$ & $E-10$ \\
\hline & 09 & $E-12$ & & & & & \\
\hline & $\perp \cdot T / \mathrm{L}-\mathrm{U}$ & $6.43 \mathrm{E}-12$ & $2 \cdot 0-1$ & $2 \cdot 1+4$ & . & $27 \mathrm{E}-12$ & $.40 \mathrm{E}-10$ \\
\hline & ק & $95-12$ & & $2.44 E-31$ & $0.40 \mathrm{E}-1 \mathrm{~J}$ & $.32 E-12$ & $\cdot 3 \angle D-10$ \\
\hline 33 & $98 E-09$ & $E-12$ & $3 E-31$ & $46 E-31$ & -14 & $E-12$ & $E-10$ \\
\hline
\end{tabular}


RESRAD-OFFSITE, Version 2.5

$\mathrm{T}^{1 / 2}$ Limit $=180$ days

Title : RESRAD-OFFSITE External Gamma, Inhalation, and Soil Ingestion for Offsite Reside File : PBA-1_TC99-DOE-5-1.ROF

Summary of dose at graphical times, reptition 3 (continued)

Time

Years

$1.65 \mathrm{E}+02$

1. $66 \mathrm{E}+02$

1. $66 \mathrm{E}+02$

1. $67 \mathrm{E}+02$

1. $67 \mathrm{E}+02$

1. $68 \mathrm{E}+02$

1. $68 \mathrm{E}+02$

1. $69 \mathrm{E}+02$

$1.69 \mathrm{E}+02$

1. $70 \mathrm{E}+02$

1. $70 \mathrm{E}+02$

1. $71 \mathrm{E}+02$

1. $71 \mathrm{E}+02$

1. $72 \mathrm{E}+02$

$1.72 \mathrm{E}+02$

$1.73 \mathrm{E}+02$

$1.73 \mathrm{E}+02$

$1.74 \mathrm{E}+02$

$1.74 \mathrm{E}+02$

$1.75 \mathrm{E}+02$

$1.75 \mathrm{E}+02$

1. $76 \mathrm{E}+02$

$1.76 \mathrm{E}+02$

$1.77 \mathrm{E}+02$

$1.77 \mathrm{E}+02$

$1.78 \mathrm{E}+02$

$1.78 \mathrm{E}+02$

$1.79 \mathrm{E}+02$

1. $79 \mathrm{E}+02$

$1.80 \mathrm{E}+02$

1. $80 \mathrm{E}+02$

1. $81 \mathrm{E}+02$

1. $81 \mathrm{E}+02$

1. $82 \mathrm{E}+02$

1. $83 \mathrm{E}+02$

1. $83 \mathrm{E}+02$

$1.84 \mathrm{E}+02$

$1.84 \mathrm{E}+02$

$1.85 \mathrm{E}+02$

$1.85 \mathrm{E}+02$

$1.86 \mathrm{E}+02$

1. $86 \mathrm{E}+02$

$1.87 \mathrm{E}+02$

$1.87 \mathrm{E}+02$

1. $88 \mathrm{E}+02$

$1.88 \mathrm{E}+02$
Dose statistics at graphical times, mrem/yr

\begin{tabular}{|c|c|c|c|c|c|c|c|}
\hline inimum & aximum & Mean & ledian & $0 \%$ & $5 \%$ & $97.5 \%$ & $3 \%$ \\
\hline 33 & -09 & $7.90 \mathrm{E}-12$ & $2.15 E-31$ & $2.48 E-31$ & $7 E-14$ & $.54 \mathrm{E}-12$ & ע \\
\hline 33 & 09 & 2 & 1 & 1 & 4 & 1 & 10 \\
\hline-33 & -09 & -12 & -31 & 31 & 14 & 11 & -10 \\
\hline$E-33$ & $E-09$ & $3 E-12$ & 1 & & & & 10 \\
\hline-33 & -09 & 11 & & & 14 & -11 & $42 E-10$ \\
\hline $96 E-33$ & -09 & $E-11$ & -31 & 1 & 13 & -11 & -10 \\
\hline כל ע ע & -09 & -11 & -31 & . & 13 & -11 & 10 \\
\hline $93 E-33$ & $2.97 E-09$ & $.24 \mathrm{E}-11$ & & $2.65 E-31$ & & -11 & $.89 E-10$ \\
\hline 33 & 09 & 11 & 1 & 1 & 13 & -11 & 10 \\
\hline $.90 E-33$ & $6 E-09$ & $40 E-11$ & $3 E-31$ & -31 & -13 & -11 & -10 \\
\hline-33 & -09 & -11 & 1 & & 13 & -11 & $E-10$ \\
\hline & -09 & -11 & & & & & \\
\hline $.80 \mathrm{E}-33$ & $.75 E-09$ & $7 E-11$ & $E-31$ & & -13 & -11 & 10 \\
\hline $.85 E-33$ & -09 & $1.77 \mathrm{E}-11$ & -31 & & -12 & -11 & -10 \\
\hline $3 E-33$ & 09 & $E-11$ & -31 & 30 & 12 & -11 & -10 \\
\hline $.82 E-33$ & -09 & -11 & -31 & -28 & -12 & -11 & -10 \\
\hline $.80 E-33$ & 4. 49E-09 & $2.09 \mathrm{E}-11$ & $7 E-31$ & $2.85 E-26$ & 1.92E-12 & $E-11$ & $08 \mathrm{E}-10$ \\
\hline-33 & $9 E-09$ & $1 E-11$ & $0 E-31$ & 25 & $31 E-12$ & -11 & $E-10$ \\
\hline-33 & -09 & $3 E-11$ & -31 & 24 & 12 & -11 & -10 \\
\hline $.76 E-33$ & -09 & -11 & -31 & 22 & -12 & -11 & -10 \\
\hline $.75 E-33$ & $5.33 E-09$ & $2.59 \mathrm{E}-11$ & -31 & & & $\perp \perp$ & -10 \\
\hline $.74 \mathrm{E}-33$ & $5.55 \mathrm{E}-09$ & $.73 E-11$ & 31 & 21 & 12 & -1 & -10 \\
\hline $725-33$ & $5.79 \mathrm{E}-09$ & $2.88 \mathrm{E}-11$ & $2.61 E-31$ & $88 E-20$ & $39 E-12$ & $03 E-10$ & $22 E-10$ \\
\hline $.71 \mathrm{E}-33$ & $.03 E-09$ & $.03 E-11$ & $2.63 E-31$ & $85 E-19$ & $38 E-12$ & $.13 \mathrm{E}-10$ & $63 E-10$ \\
\hline$E-33$ & $6.28 E-09$ & $19 \mathrm{E}-11$ & $E-31$ & $3 E-19$ & -12 & $E-10$ & $E-10$ \\
\hline-33 & $E-09$ & $E-11$ & $E-31$ & 8 & & 0 & -10 \\
\hline $67 E-33$ & -09 & 11 & 1 & & & .0 & -10 \\
\hline $.00 \mathrm{c}-32$ & $08 E-09$ & $.71 \mathrm{E}-11$ & $2 E-31$ & $.89 \mathrm{E}-17$ & $.23 E-11$ & $51 E-10$ & $31 E-10$ \\
\hline 33 & 9 & 1 & 1 & $9 E-17$ & - the & -10 & -10 \\
\hline 年 & - & $.09 E-11$ & - & - & - & - & - \\
\hline$F-33$ & $95 E-09$ & $9 \mathrm{E}-11$ & & & & & $E-09$ \\
\hline$F-33$ & $E-09$ & $0 E-11$ & $2 E-31$ & $3 E-16$ & $14 E-11$ & $E-10$ & 09 \\
\hline$E-33$ & & & & & & & \\
\hline $.58 E-33$ & $8.90 E-09$ & $4.94 E-11$ & $2.87 E-31$ & $1.54 \mathrm{E}-15$ & $70 \mathrm{E}-11$ & $7 E-10$ & $.23 E-09$ \\
\hline 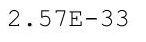 & $9.24 E-09$ & $5.17 E-11$ & & & & & $.29 \mathrm{E}-09$ \\
\hline & & & & & & & \\
\hline $.54 E-33$ & 9 & & & & & & 09 \\
\hline 3 & & & & & & & 09 \\
\hline 3 & & & & & & 10 & 09 \\
\hline $.51 \mathrm{E}-33$ & $1.11 \mathrm{E}-08$ & $8 E-11$ & $E-31$ & 4 & & 0 & $64 E-09$ \\
\hline 3 & 08 & $7 E-11$ & & 4 & & & t \\
\hline 3 & $19 E-08$ & $.08 E-11$ & $09 E-31$ & 14 & 然 & & $015-09$ \\
\hline 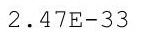 & 1 & 1 & 1 & 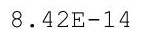 & $\perp$ & 0 & s \\
\hline 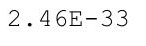 & - & $1+$ & 1 & $16 \mathrm{E}$ & 0 & 0 & or \\
\hline $5 E-33$ & $1.32 E-08$ & $8.05 E-11$ & 3. & 13 & -11 & -10 & -09 \\
\hline $.43 E-33$ & $1.36 E-08$ & $.39 \mathrm{E}-11$ & $.21 E-31$ & $.11 \mathrm{E}-13$ & $8.07 E-11$ & $5.35 E-10$ & $2.18 \mathrm{E}-09$ \\
\hline
\end{tabular}


RESRAD-OFFSITE, Version 2.5

$\mathrm{T}^{1 / 2}$ Limit $=180$ days

Title : RESRAD-OFFSITE External Gamma, Inhalation, and Soil Ingestion for Offsite Reside File : PBA-1_TC99-DOE-5-1.ROF

Summary of dose at graphical times, reptition 3 (continued)

Time

Years

$1.89 \mathrm{E}+02$

1. $89 \mathrm{E}+02$

$.90 \mathrm{E}+02$

$.90 \mathrm{E}+02$

$91 \mathrm{E}+02$

$.91 E+02$

1. $92 \mathrm{E}+02$

$.92 \mathrm{E}+02$

1. $93 \mathrm{E}+02$

1. $93 \mathrm{E}+02$

. $94 \mathrm{E}+02$

1. $94 \mathrm{E}+02$

1. $95 \mathrm{E}+02$

. $95 \mathrm{E}+02$

1. $96 \mathrm{E}+02$

1. $96 \mathrm{E}+02$

$1.97 \mathrm{E}+02$

$1.97 \mathrm{E}+02$

1. $98 \mathrm{E}+02$

1. $98 \mathrm{E}+02$

$1.99 \mathrm{E}+02$

1. $99 \mathrm{E}+02$

$2.00 \mathrm{E}+02$

$2.00 \mathrm{E}+02$

$2.01 \mathrm{E}+02$

$2.01 \mathrm{E}+02$

$2.02 E+02$

$2.03 \mathrm{E}+02$

$2.03 E+02$

$2.04 \mathrm{E}+02$

$2.04 \mathrm{E}+02$

$2.05 \mathrm{E}+02$

$2.05 \mathrm{E}+02$

$2.06 \mathrm{E}+02$

$2.06 \mathrm{E}+02$

$2.07 \mathrm{E}+02$

$2.07 \mathrm{E}+02$

$2.08 \mathrm{E}+02$

$2.08 \mathrm{E}+02$

$2.09 \mathrm{E}+02$

2. $09 \mathrm{E}+02$

$2.10 \mathrm{E}+02$

$2.10 \mathrm{E}+02$

$2.11 E+02$

$2.11 \mathrm{E}+02$

$2.12 \mathrm{E}+02$
Dose statistics at graphical times, mrem/yr

\begin{tabular}{|c|c|c|c|c|c|c|c|}
\hline inimum & aximum & Mean & ledian & $90 \%$ & $5 \%$ & $97.5 \%$ & $\%$ \\
\hline 3 & -08 & 1 & 31 & 13 & 1 & 0 & nce \\
\hline 33 & -08 & 1 & 1 & 3 & 1 & 10 & -09 \\
\hline-33 & $0 E-08$ & $E-11$ & -31 & $2 E-13$ & 10 & 10 & -09 \\
\hline $39 E-33$ & $6 E-08$ & 1 & 1 & 3 & & & -09 \\
\hline $.38 E-33$ & -08 & & & & 10 & $20 E-10$ & $72 E-09$ \\
\hline $36 E-33$ & -08 & $E-10$ & -31 & 13 & 10 & -10 & -09 \\
\hline (1) & -08 & -10 & -31 & 1.11E-12 & 10 & -10 & -09 \\
\hline $.34 E-33$ & $1.77 E-08$ & $.16 \mathrm{E}-10$ & & 1. $34 \mathrm{E}-12$ & $1.57 \mathrm{E}-10$ & -10 & $07 E-0$ \\
\hline 33 & 08 & 0 & 1 & -12 & 10 & -10 & 09 \\
\hline $.32 E-33$ & -08 & $6 E-10$ & -31 & $03 E-12$ & $79 \mathrm{E}-10$ & -10 & -09 \\
\hline-33 & -08 & 0 & & $1 E-12$ & & 10 & $E-09$ \\
\hline-33 & -08 & -10 & & & 10 & & $E-09$ \\
\hline $.28 \mathrm{E}-33$ & $2.07 E-08$ & $.41 \mathrm{E}-10$ & $E-31$ & $3.64 \mathrm{E}-12$ & -10 & -09 & $E-0$ \\
\hline $.27 E-33$ & -08 & -10 & -31 & 4. $27 \mathrm{E}-12$ & 10 & -09 & $83 E-09$ \\
\hline 33 & -08 & 10 & -31 & $97 E-12$ & 10 & 09 & -09 \\
\hline $.25 E-33$ & $2.26 \mathrm{E}-08$ & -10 & -31 & -12 & -10 & -09 & -09 \\
\hline $.24 \mathrm{E}-33$ & $2.33 E-08$ & $4 E-10$ & $4 E-31$ & $63 E-12$ & $71 \mathrm{E}-10$ & $E-09$ & $26 E-09$ \\
\hline $3 E-33$ & $40 E-08$ & $0 E-10$ & $E-31$ & $8 E-12$ & $85 E-10$ & $E-09$ & $E-09$ \\
\hline-33 & -08 & 10 & -31 & -12 & 10 & 9 & -09 \\
\hline $21 E-33$ & $2.55 E-08$ & -10 & -31 & -11 & -10 & 09 & -09 \\
\hline $.20 \mathrm{E}-33$ & $2.62 \mathrm{E}-08$ & $1.89 \mathrm{E}-10$ & -31 & -11 & & & -09 \\
\hline $.19 \mathrm{E}-33$ & $2.70 \mathrm{E}-08$ & $1.96 \mathrm{E}-10$ & -31 & 11 & 10 & -09 & -09 \\
\hline $18 E-33$ & $2.78 \mathrm{E}-08$ & $2.03 E-10$ & $95 E-31$ & $1.47 \mathrm{E}-11$ & $72 E-10$ & $72 E-09$ & $23 E-09$ \\
\hline $17 E-33$ & $2.87 E-08$ & $2.10 \mathrm{E}-10$ & $9 E-31$ & $1.63 \mathrm{E}-11$ & $89 \mathrm{E}-10$ & $80 E-09$ & $40 E-09$ \\
\hline $15 E-33$ & $2.96 \mathrm{E}-08$ & $.18 \mathrm{E}-10$ & $3 E-31$ & $84 \mathrm{E}-11$ & $E-10$ & $E-09$ & $59 \mathrm{E}-09$ \\
\hline 33 & -08 & $E-10$ & -31 & & & & 09 \\
\hline $13 E-33$ & $3.15 E-08$ & $2.33 E-10$ & 1 & 2. & & & -09 \\
\hline •.2LE-32 & $3.24 \mathrm{E}-08$ & $2.41 \mathrm{E}-10$ & $4.14 \mathrm{E}-31$ & $70 E-11$ & $4.80 \mathrm{E}-10$ & $.16 \mathrm{E}-09$ & $.16 \mathrm{E}-09$ \\
\hline 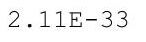 & 8 & 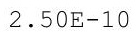 & $18 E-31$ & 1 & $\begin{array}{ll}0 \\
\end{array}$ & $26 E-09$ & $35 E-09$ \\
\hline - & 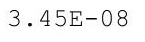 & 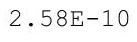 & 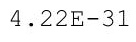 & - & - & 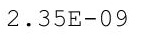 & 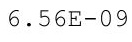 \\
\hline-33 & $E-08$ & $7 E-10$ & & & & -09 & $E-09$ \\
\hline-33 & $E-08$ & $.76 \mathrm{E}-10$ & $31 E-31$ & $7 E-11$ & $E-10$ & $\mathrm{E}-09$ & $8 E-09$ \\
\hline 33 & & & & & & -09 & \\
\hline $.06 E-33$ & $3.88 E-08$ & $2.95 E-10$ & $4.38 E-31$ & $4.84 \mathrm{E}-11$ & $5 E-10$ & $75 E-09$ & $.43 E-09$ \\
\hline 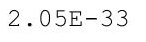 & $3.99 E-08$ & $3.05 E-10$ & & $5.26 E-11$ & & & $.66 \mathrm{E}-09$ \\
\hline - & & & & & & & \\
\hline $.03 E-33$ & & & & & & & he \\
\hline 3 & & & & & & & 09 \\
\hline$E-33$ & & & & & & & \\
\hline $.00 E-33$ & 4. $60 \mathrm{E}-08$ & $3.57 \mathrm{E}-10$ & $4 E-31$ & $9 E-11$ & 0 & 09 & $9 E-09$ \\
\hline 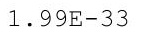 & 08 & $E-10$ & & $E-11$ & & & -09 \\
\hline 3 & $36 E-08$ & $30 E-10$ & $4.73 E-31$ & 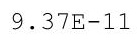 & 10 & 09 & $5 E-09$ \\
\hline 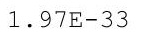 & 0 & 0 & 1 & 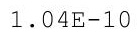 & & & o \\
\hline $965-32$ & $5.13 \mathrm{E}-08$ & & 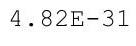 & 0 & +.0 & 9 & 3 \\
\hline-33 & -08 & $4.17 \mathrm{H}$ & 4.8 & 1 . & 09 & 09 & -08 \\
\hline $94 \mathrm{E}-1$ & $5.42 E-08$ & 4. $30 \mathrm{E}-10$ & $.90 E-31$ & 1. $32 \mathrm{E}-10$ & $1.13 E-09$ & $4.22 \mathrm{E}-09$ & $1.06 \mathrm{E}-08$ \\
\hline
\end{tabular}


RESRAD-OFFSITE, Version 2.5

$\mathrm{T}^{1 / 2}$ Limit $=180$ days

Title : RESRAD-OFFSITE External Gamma, Inhalation, and Soil Ingestion for Offsite Reside

File : PBA-1_TC99-DOE-5-1.ROF

Summary of dose at graphical times, reptition 3 (continued)

Time

Years

$2.12 \mathrm{E}+02$

$2.13 \mathrm{E}+02$

$2.13 \mathrm{E}+02$

$2.14 \mathrm{E}+02$

$2.14 \mathrm{E}+02$

$2.15 \mathrm{E}+02$

$2.15 \mathrm{E}+02$

$2.16 \mathrm{E}+02$

$2.16 \mathrm{E}+02$

$2.17 \mathrm{E}+02$

$2.17 \mathrm{E}+02$

$2.18 \mathrm{E}+02$

$2.18 \mathrm{E}+02$

$2.19 \mathrm{E}+02$

$2.19 \mathrm{E}+02$

$2.20 \mathrm{E}+02$

$2.20 \mathrm{E}+02$

$2.21 \mathrm{E}+02$

$2.21 \mathrm{E}+02$

$2.22 \mathrm{E}+02$

$2.23 \mathrm{E}+02$

$2.23 \mathrm{E}+02$

$2.24 \mathrm{E}+02$

$2.24 \mathrm{E}+02$

$2.25 \mathrm{E}+02$

$2.25 \mathrm{E}+02$

$2.26 \mathrm{E}+02$

$2.26 \mathrm{E}+02$

$2.27 \mathrm{E}+02$

$2.27 \mathrm{E}+02$

$2.28 \mathrm{E}+02$

$2.28 \mathrm{E}+02$

$2.29 \mathrm{E}+02$

$2.29 \mathrm{E}+02$

$2.30 \mathrm{E}+02$

2. $30 \mathrm{E}+02$

$2.31 E+02$

$2.31 \mathrm{E}+02$

2. $32 \mathrm{E}+02$

2. $32 \mathrm{E}+02$

$2.33 \mathrm{E}+02$

$2.33 \mathrm{E}+02$

$2.34 \mathrm{E}+02$

2. $34 \mathrm{E}+02$

$2.35 \mathrm{E}+02$

$2.35 E+02$
Dose statistics at graphical times, mrem/yr

\begin{tabular}{|c|c|c|c|c|c|c|c|}
\hline m & um & ea & ledian & & & & \\
\hline 33 & 08 & 10 & 31 & 10 & 09 & 09 & -0 \\
\hline $93 E-33$ & -08 & $4.56 \mathrm{E}-10$ & 31 & $1.50 \mathrm{E}-10$ & 09 & -09 & $12 E-08$ \\
\hline $92 E-33$ & $.87 E-08$ & $4.70 \mathrm{E}-10$ & $5.05 E-31$ & $1.58 \mathrm{E}-10$ & $1.29 \mathrm{E}-09$ & -09 & -08 \\
\hline-33 & -08 & $84 \mathrm{~F}-10$ & $10 E-31$ & $68 \mathrm{~F}-10$ & $3 \Delta \mathrm{F}-09$ & -09 & 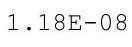 \\
\hline-33 & 08 & 10 & 31 & 10 & 09 & 09 & -08 \\
\hline 33 & & & & & & & -08 \\
\hline $88 E-33$ & & & & 10 & & & -08 \\
\hline $.87 E-33$ & -08 & -10 & & 10 & 9 & 09 & -08 \\
\hline $.86 \mathrm{E}-33$ & -08 & $0 E-10$ & & $22 E-10$ & 09 & -09 & $E-08$ \\
\hline-33 & 08 & 10 & 1 & -10 & & 9 & 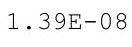 \\
\hline 33 & 8 & $5.92 \mathrm{E}-10$ & & & & & 08 \\
\hline $83 E-33$ & $E-08$ & $9 F-10$ & 1 & $66 \mathrm{E}-10$ & 9 & 9 & -08 \\
\hline $.82 E-33$ & $7.56 \mathrm{E}-08$ & $6.27 \mathrm{E}-10$ & & $2.83 E-10$ & & & -08 \\
\hline $.82 E-33$ & $7.75 \mathrm{E}-08$ & $6.44 \mathrm{E}-10$ & $5.59 \mathrm{E}-31$ & $3.00 \mathrm{E}-10$ & $1.94 \mathrm{E}-09$ & -09 & $z-08$ \\
\hline $81 E-33$ & -08 & $2 E-10$ & & -10 & & -09 & -08 \\
\hline P & $4 E-08$ & $81 \mathrm{E}-10$ & & 0 & & 9 & 08 \\
\hline 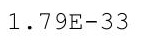 & & & $\perp$ & 0 & & 9 & 8 \\
\hline 33 & 8 & ק קת & 1 & 0 & & 9 & 08 \\
\hline $.77 E-33$ & $8.74 \mathrm{E}-08$ & 7. 39E-10 & $5.88 E-31$ & $3.80 \mathrm{E}-10$ & $2.30 \mathrm{E}-09$ & $40 E-09$ & $.75 E-08$ \\
\hline $.76 \mathrm{E}-33$ & $.95 E-08$ & $.59 E-10$ & $5.94 \mathrm{E}-31$ & 4. $00 \mathrm{E}-10$ & & -09 & $.79 E-08$ \\
\hline$-33 \cdot r \cdot r \cdot r$ & $E-08$ & $.79 E-10$ & & $4.22 \mathrm{E}-10$ & & -09 & -08 \\
\hline-33 & & & & & & & \\
\hline 30 & 08 & & & & & & 08 \\
\hline $.73 E-33$ & 8 & - & 1 & 0 & 9 & 9 & 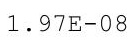 \\
\hline . & 7 & $66 \mathrm{E}$ & 1 & 0 & 9 & 9 & $0 \varepsilon$ \\
\hline $71 \mathrm{~F}-32$ & $.03 E-07$ & $.89 \mathrm{E}-10$ & $6.30 E-31$ & $23 E-10$ & $91 E-09$ & $98 E-09$ & $06 E-08$ \\
\hline $5-33$ & $105 \mathrm{~F}-07$ & $.12 \mathrm{E}-10$ & $6.37 E-31$ & $9 \mathrm{E}-10$ & & $2 E-09$ & $11 \mathrm{~F}-08$ \\
\hline & & & & & & & \\
\hline & & & & & & & \\
\hline $68 E-33$ & $1.12 \mathrm{E}-07$ & $9.84 \mathrm{E}-10$ & $6.56 \mathrm{E}-31$ & $3 E-10$ & $3.33 E-09$ & $E-09$ & $20 E-08$ \\
\hline • & $1.15 \mathrm{E}-07$ & $.01 E-09$ & $6.62 E-31$ & $6.47 E-10$ & $.405-09$ & $.03 E-08$ & 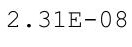 \\
\hline 年 & $1.18 \mathrm{E}-07$ & .04⿻- 0 & $6.68 \mathrm{E}-31$ & $6.73 E-10$ & & $5 E-08$ & 年 \\
\hline-3 & & & $5 E-31$ & & & $E-08$ & $-08+2 x+3$ \\
\hline & & & & & & & \\
\hline $5=33$ & & & & & & & \\
\hline $63 E-33$ & $1.28 \mathrm{E}-07$ & $.14 \mathrm{E}-09$ & $.97 E-31$ & $8.02 E-10$ & $3 E-09$ & 08 & $57 \mathrm{E}-08$ \\
\hline $.025-32$ & $1.31 \mathrm{E}-0 /$ & $.17 E-09$ & -31 & $8.3 \angle E-10$ & & 08 & 00 \\
\hline o & & & & & & & • \\
\hline $615-33$ & te & 9 & & 0 & & 8 & 88 \\
\hline & & & & & & & \\
\hline $9 F-33$ & & & & $9.66 \mathrm{E}-10$ & & 08 & \\
\hline $8 E-33$ & $1.45 \mathrm{E}-07$ & $.32 E-09$ & $.39 E-31$ & $00 E-09$ & $5 E-09$ & $3 E-08$ & -08 \\
\hline & & & & 9 & & & \\
\hline & & $1.38 E-09$ & 1 & 09 & & $39 E-08$ & -00 \\
\hline 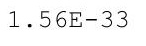 & $\perp \cdot 0$ & $25-09$ & $E-31$ & $1.13 E-09$ & & 08 & • \\
\hline 3 & $1.58 \mathrm{E}-07$ & $E-09$ & $E-31$ & -09 & $30 E-09$ & $45 E-08$ & -08 \\
\hline
\end{tabular}


RESRAD-OFFSITE, Version 2.5

Title : RESRAD-OFFSITE External Gamma, Inhalation, and Soil Ingestion for offsite Reside File : PBA-1_TC99-DOE-5-1.ROF

Summary of dose at graphical times, reptition 3 (continued)

Time

Years

$2.36 \mathrm{E}+02$

$2.36 \mathrm{E}+02$

$2.37 \mathrm{E}+02$

2. $37 \mathrm{E}+02$

2. $38 \mathrm{E}+02$

$2.38 \mathrm{E}+02$

$2.39 \mathrm{E}+02$

2. $39 \mathrm{E}+02$

2. $40 \mathrm{E}+02$

2. $40 \mathrm{E}+02$

2. $41 \mathrm{E}+02$

2. $41 E+02$

2. $42 \mathrm{E}+02$

$2.43 E+02$

2. $43 \mathrm{E}+02$

2. $44 \mathrm{E}+02$

2. $44 \mathrm{E}+02$

2. $45 \mathrm{E}+02$

2. $45 \mathrm{E}+02$

2. $46 \mathrm{E}+02$

2. $46 \mathrm{E}+02$

$2.47 \mathrm{E}+02$

2. $47 \mathrm{E}+02$

$2.48 \mathrm{E}+02$

$2.48 \mathrm{E}+02$

2. $49 \mathrm{E}+02$

2. $49 \mathrm{E}+02$

$2.50 \mathrm{E}+02$

2. $50 \mathrm{E}+02$

$2.51 \mathrm{E}+02$

2. $51 \mathrm{E}+02$

2. $52 \mathrm{E}+02$

$2.52 \mathrm{E}+02$

$2.53 E+02$

$2.53 \mathrm{E}+02$

2. $54 \mathrm{E}+02$

$2.54 \mathrm{E}+02$

$2.55 \mathrm{E}+02$

$2.55 \mathrm{E}+02$

$2.56 \mathrm{E}+02$

$2.56 \mathrm{E}+02$

$2.57 \mathrm{E}+02$

$2.57 \mathrm{E}+02$

$2.58 \mathrm{E}+02$

$2.58 \mathrm{E}+02$

$2.59 \mathrm{E}+02$
Dose statistics at graphical times, mrem/yr

\begin{tabular}{|c|c|c|c|c|c|c|c|}
\hline inimum & aximum & Mean & ledian & $90 \%$ & $5 \%$ & $97.5 \%$ & \\
\hline 3 & -07 & $E-09$ & 31 & 09 & 09 & 08 & 08 \\
\hline 33 & 07 & 09 & 1 & 9 & 9 & 08 & -08 \\
\hline-33 & $7 E-07$ & $E-09$ & -31 & $3 E-09$ & 9 & 08 & -08 \\
\hline$E-33$ & $E-07$ & 9 & & 9 & & & -08 \\
\hline $.52 E-33$ & -07 & & & 9 & & 08 & $54 E-08$ \\
\hline $51 E-33$ & $1.78 \mathrm{E}-07$ & $E-09$ & $E-31$ & -09 & 09 & $6 E-08$ & -08 \\
\hline a & $+D_{1}$ & . & $7 E-31$ & $1.41 \mathrm{~L}$ & J & -08 & -08 \\
\hline $.49 E-33$ & $1.85 E-07$ & 土. & & $1.53 E-09$ & & -08 & $77 E-08$ \\
\hline 33 & 07 & 09 & 31 & 09 & 9 & -08 & -08 \\
\hline $.48 E-33$ & $1.92 \mathrm{E}-07$ & $2 E-09$ & $E-31$ & $1.64 \mathrm{E}-09$ & 09 & -08 & -08 \\
\hline-33 & -07 & 9 & & 9 & & & $E-08$ \\
\hline 3 & -07 & -09 & & & & -08 & -08 \\
\hline $.46 \mathrm{E}-33$ & $2.03 E-07$ & $E-09$ & $E-31$ & L. & 19 & -08 & -08 \\
\hline $45 E-33$ & -07 & -09 & 1 & 9 & & 8 & 08 \\
\hline 33 & 07 & $3 E-09$ & -31 & 9 & 9 & 08 & -08 \\
\hline $.44 E-33$ & -07 & -09 & -31 & 09 & 09 & -08 & -08 \\
\hline $.43 E-33$ & $2.19 \mathrm{E}-07$ & $2.12 \mathrm{E}-09$ & $9 E-31$ & $2.05 E-09$ & $57 E-09$ & $E-08$ & $50 E-08$ \\
\hline-33 & $23 E-07$ & $6 E-09$ & $8 E-31$ & $2 E-09$ & $8 E-09$ & $E-08$ & $58 E-08$ \\
\hline-33 & -07 & -09 & -31 & 9 & & 8 & -08 \\
\hline $41 E-33$ & $2.31 E-07$ & -09 & -31 & 9 & & 08 & -08 \\
\hline $.40 \mathrm{E}-33$ & $2.35 E-07$ & & & & & 0 & -08 \\
\hline $.39 E-33$ & $2.39 \mathrm{E}-07$ & $.35 E-09$ & -31 & 9 & 09 & -08 & -08 \\
\hline $395-33$ & $2.44 \mathrm{E}-07$ & $2.40 E-09$ & $9.88 E-31$ & $2.46 \mathrm{E}-09$ & 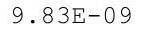 & $44 E-08$ & $03 E-08$ \\
\hline $.38 \mathrm{E}-33$ & $2.48 E-07$ & $2.45 E-09$ & $0 E-30$ & $.53 E-09$ & $00 \mathrm{E}-08$ & $49 E-08$ & $14 \mathrm{E}-08$ \\
\hline 33 & $2.52 \mathrm{E}-07$ & $50 E-09$ & & & & 08 & -08 \\
\hline 33 & 01 & 09 & -30 & & 08 & 08 & 08 \\
\hline $.36 \pm-33$ & $2.61 E-07$ & $2.01 \mathrm{E}-09$ & & & & 08 & -08 \\
\hline $.35 E-33$ & $2.66 \mathrm{E}-07$ & $2.66 \mathrm{E}-09$ & $1.05 E-30$ & $2.81 E-09$ & $1.10 \mathrm{E}-08$ & $.71 \mathrm{E}-08$ & $53 E-08$ \\
\hline 3 & 07 & 9 & 0 & - & 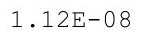 & $.77 \mathrm{E}-08$ & 08 \\
\hline $.34 \mathrm{E}-33$ & $2.75 E-07$ & $2.77 E-09$ & 年 & 2.000 & - & 年 & $.74 \mathrm{E}-0$ \\
\hline 33 & $2.80 E-07$ & $.83 E-09$ & & & & $F-08$ & $E-08$ \\
\hline$E-33$ & $2.84 E-07$ & $.88 E-09$ & 28 & 9 & 8 & 08 & $5 E-08$ \\
\hline $32 E-33$ & $E-07$ & $E-09$ & $9 E-26$ & 09 & 8 & 08 & $5 E-08$ \\
\hline $.32 E-33$ & $2.94 E-07$ & $3.00 E-09$ & $4.80 E-25$ & $3.29 \mathrm{E}-09$ & $.25 \mathrm{E}-08$ & $5 E-08$ & $17 E-08$ \\
\hline $.275-22$ & $2.99 E-07$ & $3.06 E-09$ & $5.95 E-24$ & $2.315-42$ & & $\cdot 1 \perp E-U 8$ & $.29 E-08$ \\
\hline 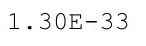 & & & & & & & \\
\hline $.30 E-33$ & 7 & 9 & & a & $1.34 \mathrm{E}-08$ & & 08 \\
\hline 3 & & & & & & & 08 \\
\hline$E-33$ & & & & & & .08 & 08 \\
\hline $28 E-33$ & $3.24 \mathrm{E}-07$ & $E-09$ & $E-19$ & 9 & 8 & & $2 E-08$ \\
\hline 3 & 07 & 99 & & & & & -08 \\
\hline 3 & 1 & $50 E-09$ & & 9 & 0 & 8 & $10 \mathrm{E}-00$ \\
\hline & 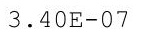 & 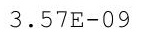 & & 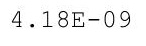 & 0 & & 5 \\
\hline $255-32$ & $3.46 \mathrm{E}-07$ & $3.63 E-09$ & 17 & 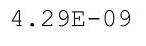 & 8 & 08 & 08 \\
\hline-33 & $3.51 \mathrm{E}-07$ & $E-09$ & $2.89 E-17$ & $4.41 \mathrm{E}$ & 1.6 & $E-08$ & -08 \\
\hline $.24 \mathrm{E}-$ & $3.57 E-07$ & $.77 E-09$ & $.53 E-17$ & $4.54 \mathrm{E}-09$ & $1.63 E-08$ & $3.80 \mathrm{E}-08$ & $7.74 \mathrm{E}-08$ \\
\hline
\end{tabular}


RESRAD-OFFSITE, Version 2.5

$\mathrm{T}^{1 / 2}$ Limit $=180$ days

Title : RESRAD-OFFSITE External Gamma, Inhalation, and Soil Ingestion for Offsite Reside File : PBA-1_TC99-DOE-5-1.ROF

Summary of dose at graphical times, reptition 3 (continued)

Time

Years

$2.59 \mathrm{E}+02$

$2.60 \mathrm{E}+02$

$2.60 \mathrm{E}+02$

$.61 \mathrm{E}+02$

$2.61 \mathrm{E}+02$

$.62 \mathrm{E}+02$

2. $63 \mathrm{E}+02$

$.63 \mathrm{E}+02$

$.64 \mathrm{E}+02$

$.64 \mathrm{E}+02$

$2.65 \mathrm{E}+02$

$.65 \mathrm{E}+02$

$2.66 \mathrm{E}+02$

$2.66 \mathrm{E}+02$

$2.67 \mathrm{E}+02$

$2.67 \mathrm{E}+02$

$2.68 \mathrm{E}+02$

$2.68 \mathrm{E}+02$

$2.69 \mathrm{E}+02$

$2.69 \mathrm{E}+02$

$2.70 \mathrm{E}+02$

$2.70 \mathrm{E}+02$

$2.71 \mathrm{E}+02$

$2.71 \mathrm{E}+02$

2. $72 \mathrm{E}+02$

2. $72 \mathrm{E}+02$

$2.73 E+02$

$2.73 \mathrm{E}+02$

$2.74 \mathrm{E}+02$

$2.74 \mathrm{E}+02$

$2.75 \mathrm{E}+02$

$2.75 \mathrm{E}+02$

$2.76 \mathrm{E}+02$

$2.76 \mathrm{E}+02$

$2.77 \mathrm{E}+02$

$2.77 \mathrm{E}+02$

$2.78 \mathrm{E}+02$

$2.78 \mathrm{E}+02$

$2.79 \mathrm{E}+02$

$2.79 \mathrm{E}+02$

$2.80 \mathrm{E}+02$

$2.80 \mathrm{E}+02$

$2.81 \mathrm{E}+02$

$2.81 E+02$

$2.82 \mathrm{E}+02$

$2.82 \mathrm{E}+02$
Dose statistics at graphical times, mrem/yr

\begin{tabular}{|c|c|c|c|c|c|c|c|}
\hline m & um & Mean & ledian & & & & \\
\hline 33 & 07 & 09 & 16 & 09 & 08 & 08 & - \\
\hline $23 E-33$ & $68 E-07$ & $92 E-09$ & $6 E-16$ & -09 & 08 & $.93 E-08$ & -08 \\
\hline-33 & $.74 \mathrm{E}-07$ & $99 E-09$ & $5.24 \mathrm{E}-16$ & $4.94 \mathrm{E}-09$ & $1.73 \mathrm{E}-08$ & -08 & $\Xi-08$ \\
\hline $22 F-33$ & $80 F-07$ & $06 \mathrm{~F}-09$ & $50 F-16$ & $.07 E-09$ & $77 \mathrm{~F}-08$ & 08 & 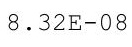 \\
\hline-33 & -07 & 09 & 15 & 9 & 08 & 08 & -08 \\
\hline 33 & 07 & 9 & & & & & -08 \\
\hline $20 E-33$ & $97 E-07$ & 99 & & & 08 & & -08 \\
\hline $.19 \mathrm{E}-33$ & -07 & -09 & -15 & 09 & 08 & -08 & -08 \\
\hline $.19 \mathrm{E}-33$ & $09 E-07$ & $45 E-09$ & -14 & $0 E-09$ & $94 \mathrm{E}-08$ & -08 & -08 \\
\hline-33 & $16 \mathrm{E}-07$ & $53 E-09$ & $63 E-14$ & 9 & 0 & 08 & 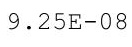 \\
\hline 33 & $4.22 E-07$ & 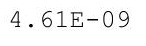 & 4 & 9 & $2.02 \mathrm{E}-08$ & 8 & 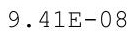 \\
\hline $17 \mathrm{E}-33$ & $4.28 F-07$ & $69 E-09$ & 4 & 9 & 8 & 08 & -08 \\
\hline $.16 \mathrm{E}-33$ & $4.34 E-07$ & $4.77 E-09$ & & & & & -08 \\
\hline $16 \mathrm{E}-33$ & $4.41 \mathrm{E}-07$ & $4.86 \mathrm{E}-09$ & $6.38 \mathrm{E}-14$ & $6.58 \mathrm{E}-09$ & $2.13 E-08$ & $82 E-08$ & $E-08$ \\
\hline-33 & $47 E-07$ & $4 E-09$ & -14 & & 8 & -08 & -07 \\
\hline 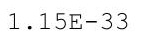 & $50-$ & $.03 E-09$ & 3 & 9 & 0 & & 07 \\
\hline $4 E-33$ & 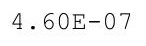 & & & & & 8 & 7 \\
\hline 3 & 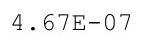 & 9 & 3 & & & & 07 \\
\hline $.13 E-33$ & $4.73 E-07$ & $5.29 E-09$ & $2.61 \mathrm{E}-13$ & $7.40 E-09$ & $2.33 E-08$ & $24 \mathrm{E}-08$ & $.08 E-07$ \\
\hline $13 E-33$ & $4.80 E-07$ & $.39 \mathrm{E}-09$ & $.30 E-13$ & $7.59 \mathrm{E}-09$ & & -08 & $E-07$ \\
\hline .33 & $.87 \mathrm{E}-07$ & $48 E-09$ & $18 \mathrm{E}-13$ & & & & -07 \\
\hline 33 & & & & & & & \\
\hline 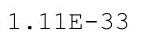 & & & & & & & \\
\hline 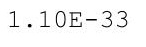 & 7 & (1) & 13 & 9 & 8 & 8 & 07 \\
\hline • & . 10 & $.86 \mathrm{E}-$ & 3 & 9 & 8 & 8 & 07 \\
\hline $09 F-3=$ & $.22 \mathrm{E}-07$ & $.96 \mathrm{E}-09$ & $1.20 \mathrm{E}-12$ & $.63 E-09$ & $64 \mathrm{E}-08$ & $5 E-08$ & $21 \mathrm{~F}-07 \mathrm{~T}$ \\
\hline-33 & $29 F-07$ & $.06 \mathrm{E}-09$ & 1. $44 \mathrm{E}-12$ & & & $E-08$ & $23 \mathrm{~F}-07$ \\
\hline & & & & & & & \\
\hline & & & & & & & -07 \\
\hline $.07 E-33$ & $5.50 \mathrm{E}-07$ & $6.36 E-09$ & $2.37 E-12$ & $9.42 \mathrm{E}-09$ & $2.83 E-08$ & $22 E-08$ & $.29 E-07$ \\
\hline 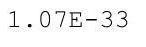 & $5.58 \mathrm{E}-07$ & $6.47 E-09$ & $.79 E-12$ & $.62 E-09$ & t.00世 & -08 & 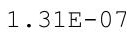 \\
\hline 年 & 年 & $6.57 E-09$ & $3.24 \mathrm{E}-12$ & 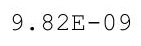 & & & \\
\hline$F-33$ & $73 F-07$ & & $86 F-12$ & & & & $F-07$ \\
\hline & & & & & & & \\
\hline $5 F-33$ & & & & & & & \\
\hline & & & & & & & 07 \\
\hline $.04 E-33$ & $6.03 E-07$ & $.12 \mathrm{E}-09$ & $.09 E-12$ & $9 E$ & 00 & & - \\
\hline ك & & & & & & & . \\
\hline $.03 E-33$ & 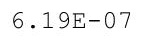 & . & 2 & ? & 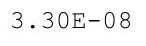 & & 07 \\
\hline & & & & & & & 07 \\
\hline $2 F-33$ & & & & & & 08 & \\
\hline $01 E-33$ & $6.43 E-07$ & $.70 E-09$ & $1.37 \mathrm{E}-11$ & $1.20 \mathrm{E}-08$ & $6 E-08$ & $2 E-08$ & $55-07$ \\
\hline 3 & $0.01 \mathrm{~L}$ & & & & & & -07 \\
\hline & 1 & $7.94 \mathrm{E}-09$ & 11 & $\perp \cdot 2 \sqrt{2}$ & $3.5 / \mathrm{E}-08$ & 08 & $-395-01$ \\
\hline क्ष & प & 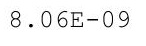 & $1.82 \mathrm{E}-11$ & 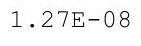 & $3.02 \mathrm{~L}-00$ & & $.01 \mathrm{~L}-0$ \\
\hline 4 & $E-07$ & $E-09$ & $02 E-11$ & $.30 E-08$ & $67 E-08$ & $9 E-08$ & -07 \\
\hline
\end{tabular}


RESRAD-OFFSITE, Version 2.5

Title : RESRAD-OFFSITE External Gamma, Inhalation, and Soil Ingestion for offsite Reside File : PBA-1_TC99-DOE-5-1.ROF

Summary of dose at graphical times, reptition 3 (continued)

Time

Years

$2.83 E+02$

$2.84 \mathrm{E}+02$

$2.84 \mathrm{E}+02$

$2.85 \mathrm{E}+02$

$2.85 \mathrm{E}+02$

$2.86 \mathrm{E}+02$

$2.86 \mathrm{E}+02$

$2.87 \mathrm{E}+02$

$2.87 \mathrm{E}+02$

$2.88 \mathrm{E}+02$

$2.88 \mathrm{E}+02$

$2.89 \mathrm{E}+02$

$2.89 \mathrm{E}+02$

2. $90 \mathrm{E}+02$

2. $90 \mathrm{E}+02$

$2.91 \mathrm{E}+02$

$2.91 \mathrm{E}+02$

2. $92 \mathrm{E}+02$

$2.92 \mathrm{E}+02$

$2.93 \mathrm{E}+02$

2. $93 \mathrm{E}+02$

2. $94 \mathrm{E}+02$

$2.94 \mathrm{E}+02$

2. $95 \mathrm{E}+02$

$2.95 \mathrm{E}+02$

$2.96 \mathrm{E}+02$

$2.96 \mathrm{E}+02$

$2.97 \mathrm{E}+02$

$2.97 \mathrm{E}+02$

$2.98 \mathrm{E}+02$

$2.98 \mathrm{E}+02$

2. $99 \mathrm{E}+02$

$2.99 \mathrm{E}+02$

$3.00 \mathrm{E}+02$

$3.00 \mathrm{E}+02$

$3.01 \mathrm{E}+02$

3. $01 \mathrm{E}+02$

$3.02 \mathrm{E}+02$

$3.02 \mathrm{E}+02$

$3.03 E+02$

$3.04 \mathrm{E}+02$

$3.04 \mathrm{E}+02$

$3.05 \mathrm{E}+02$

$3.05 \mathrm{E}+02$

$3.06 \mathrm{E}+02$

$3.06 \mathrm{E}+02$
Dose statistics at graphical times, mrem/yr

\begin{tabular}{|c|c|c|c|c|c|c|c|}
\hline inimum & Maximum & Mean & Median & $90 \%$ & $95 \frac{\circ}{\circ}$ & $7.5 \%$ & $9 \%$ \\
\hline $9.86 \mathrm{E}-34$ & $6.84 \mathrm{E}-07$ & $8.31 \mathrm{E}-09$ & $2.25 \mathrm{E}-11$ & $1.32 \mathrm{E}-08$ & $3.72 \mathrm{E}-08$ & $8.12 \mathrm{E}-08$ & $1.66 \mathrm{E}-07$ \\
\hline $9.81 \mathrm{E}-34$ & $6.93 E-07$ & $8.44 \mathrm{E}-09$ & $2.48 \mathrm{E}-11$ & $1.35 \mathrm{E}-08$ & $3.79 \mathrm{E}-08$ & $8.25 E-08$ & $1.68 \mathrm{E}-07$ \\
\hline $9.77 \mathrm{E}-34$ & $7.01 \mathrm{E}-07$ & $8.57 \mathrm{E}-09$ & $2.72 \mathrm{E}-11$ & $1.37 \mathrm{E}-08$ & $3.85 \mathrm{E}-08$ & $8.38 \mathrm{E}-08$ & $1.70 \mathrm{E}-07$ \\
\hline $9.72 \mathrm{E}-34$ & $7.10 \mathrm{E}-07$ & $8.70 \mathrm{E}-09$ & $2.98 \mathrm{E}-11$ & $1.40 \mathrm{E}-08$ & $3.91 \mathrm{E}-08$ & $8.52 \mathrm{E}-08$ & $1.72 \mathrm{E}-07$ \\
\hline $9.67 \mathrm{E}-34$ & $7.18 \mathrm{E}-07$ & $8.83 E-09$ & $3.27 \mathrm{E}-11$ & $1.42 \mathrm{E}$ & $3.97 \mathrm{E}$ & $8.66 \mathrm{E}-08$ & $.74 \mathrm{E}-07$ \\
\hline $9.62 \mathrm{E}-34$ & $7.27 \mathrm{E}-07$ & $8.96 \mathrm{E}-09$ & $3.66 \mathrm{E}-11$ & $1.45 \mathrm{E}-08$ & $.04 \mathrm{E}-08$ & $8.79 \mathrm{E}-08$ & $1.77 \mathrm{E}-07$ \\
\hline $9.58 \mathrm{E}-34$ & $7.36 \mathrm{E}-07$ & $9.10 \mathrm{E}-09$ & $4.04 \mathrm{E}-11$ & $1.48 \mathrm{E}-08$ & $10 \mathrm{E}-08$ & $8.91 \mathrm{E}-08$ & $1.79 \mathrm{E}-07$ \\
\hline $53 E-34$ & $7.44 \mathrm{E}-07$ & $9.23 E-09$ & $4.38 \mathrm{E}-11$ & $1.50 \mathrm{E}-08$ & $17 E-08$ & $9.03 E-08$ & $.81 E-07$ \\
\hline $9.48 \mathrm{E}-34$ & $7.53 \mathrm{E}-07$ & $9.37 \mathrm{E}-09$ & $4.67 \mathrm{E}-11$ & $1.53 \mathrm{E}-08$ & $4.24 \mathrm{E}-08$ & $9.15 \mathrm{E}-08$ & $1.84 \mathrm{E}-07$ \\
\hline $9.44 \mathrm{E}-34$ & $7.62 \mathrm{E}-07$ & $9.51 \mathrm{E}-09$ & $5.04 \mathrm{E}-11$ & $1.56 \mathrm{E}-08$ & $4.30 \mathrm{E}-08$ & $9.27 \mathrm{E}-08$ & $1.86 \mathrm{E}-07$ \\
\hline $9.39 \mathrm{E}-34$ & $7.71 \mathrm{E}-07$ & $9.65 \mathrm{E}-09$ & $5.45 \mathrm{E}-11$ & $1.59 \mathrm{E}-08$ & $4.37 \mathrm{E}-08$ & $9.39 \mathrm{E}-08$ & $1.88 \mathrm{E}-07$ \\
\hline $9.35 \mathrm{E}-34$ & $7.80 \mathrm{E}-07$ & $9.79 \mathrm{E}-09$ & $5.82 \mathrm{E}-11$ & $1.62 \mathrm{E}-08$ & $4.44 \mathrm{E}-08$ & $9.52 \mathrm{E}-08$ & $1.91 \mathrm{E}-07$ \\
\hline $9.30 \mathrm{E}-34$ & $7.89 \mathrm{E}-07$ & $9.94 \mathrm{E}-09$ & $6.23 \mathrm{E}-11$ & $1.65 \mathrm{E}-08$ & $4.50 \mathrm{E}-08$ & $9.66 \mathrm{E}-08$ & $1.93 \mathrm{E}-07$ \\
\hline $9.25 \mathrm{E}-34$ & $7.98 \mathrm{E}-07$ & $1.01 \mathrm{E}-08$ & $6.64 \mathrm{E}-11$ & $1.68 \mathrm{E}-08$ & $4.57 \mathrm{E}-08$ & $9.80 \mathrm{E}-08$ & $1.96 \mathrm{E}-07$ \\
\hline $9.21 \mathrm{E}-34$ & $8.07 E-07$ & $1.02 \mathrm{E}-08$ & $7.16 \mathrm{E}-11$ & $1.71 \mathrm{E}-08$ & $4.63 \mathrm{E}-08$ & $9.94 \mathrm{E}-08$ & $1.99 \mathrm{E}-07$ \\
\hline $9.16 \mathrm{E}-34$ & $8.17 \mathrm{E}-07$ & $1.04 \mathrm{E}-08$ & $7.69 \mathrm{E}-11$ & $1.74 \mathrm{E}-08$ & $4.69 \mathrm{E}-08$ & $1.01 \mathrm{E}-07$ & $2.01 \mathrm{E}-07$ \\
\hline $9.12 \mathrm{E}-34$ & $8.26 \mathrm{E}-07$ & $1.05 \mathrm{E}-08$ & $8.20 \mathrm{E}-11$ & $1.77 \mathrm{E}-08$ & $4.76 \mathrm{E}-08$ & $1.02 \mathrm{E}-07$ & $2.04 \mathrm{E}-07$ \\
\hline $9.08 \mathrm{E}-34$ & $8.35 E-07$ & $1.07 \mathrm{E}-08$ & $8.66 \mathrm{E}-11$ & $1.80 \mathrm{E}-08$ & $4.82 \mathrm{E}-08$ & $1.04 \mathrm{E}-07$ & $2.06 \mathrm{E}-07$ \\
\hline $9.03 E-34$ & $8.45 E-07$ & $1.08 \mathrm{E}-08$ & $9.10 \mathrm{E}-11$ & $1.84 \mathrm{E}-08$ & $4.89 \mathrm{E}-08$ & $1.05 \mathrm{E}-07$ & $2.09 \mathrm{E}-07$ \\
\hline $.99 E-34$ & $8.54 \mathrm{E}-07$ & $1.10 \mathrm{E}-08$ & $9.60 \mathrm{E}-11$ & $1.87 \mathrm{E}-08$ & $.95 \mathrm{E}-08$ & $1.07 \mathrm{E}-07$ & $12 \mathrm{E}-07$ \\
\hline $.94 \mathrm{E}-$ & 8 & & & & & & \\
\hline . & 8 & 1 & 0 & 8 & 8 & 7 & 07 \\
\hline $8.86 \mathrm{E}-34$ & $8.83 \mathrm{E}-07$ & $1.15 \mathrm{E}-08$ & $1.13 \mathrm{E}-10$ & $1.97 \mathrm{E}-08$ & $5.16 \mathrm{E}-08$ & $1.11 \mathrm{E}-07$ & $2.20 \mathrm{E}-07$ \\
\hline $1.80 \mathrm{E}-32$ & $8.93 \mathrm{E}-07$ & $1.16 \mathrm{E}-08$ & $1.19 \mathrm{E}-10$ & $2.01 \mathrm{E}-08$ & $5.23 \mathrm{E}-08$ & $1.13 \mathrm{E}-07$ & $2.22 \mathrm{E}-07$ \\
\hline $1.80 \mathrm{E}-32$ & $9.03 \mathrm{E}-07$ & $1.18 \mathrm{E}-08$ & $1.25 \mathrm{E}-10$ & $2.05 \mathrm{E}-08$ & $5.30 \mathrm{E}-08$ & $1.14 \mathrm{E}-07$ & $2.25 \mathrm{E}-07$ \\
\hline $1.80 \mathrm{E}-32$ & $9.13 \mathrm{E}-07$ & $1.19 \mathrm{E}-08$ & $1.33 \mathrm{E}-10$ & $2.08 \mathrm{E}-08$ & $5.37 \mathrm{E}-08$ & $1.16 \mathrm{E}-07$ & $2.27 \mathrm{E}-07$ \\
\hline $1.80 \mathrm{E}-32$ & $9.22 \mathrm{E}-07$ & $1.21 \mathrm{E}-08$ & $1.39 \mathrm{E}-10$ & $2.12 \mathrm{E}-08$ & $5.44 \mathrm{E}-08$ & $1.18 \mathrm{E}-07$ & $2.29 \mathrm{E}-07$ \\
\hline $1.80 \mathrm{E}-32$ & $9.32 \mathrm{E}-07$ & $1.23 \mathrm{E}-08$ & $1.47 \mathrm{E}-10$ & $2.16 \mathrm{E}-08$ & $5.51 \mathrm{E}-08$ & $1.19 \mathrm{E}-07$ & $2.32 \mathrm{E}-07$ \\
\hline $1.81 \mathrm{E}-32$ & $9.42 \mathrm{E}-07$ & $1.24 \mathrm{E}-08$ & $1.54 \mathrm{E}-10$ & $2.20 \mathrm{E}-08$ & $5.58 \mathrm{E}-08$ & $1.21 \mathrm{E}-07$ & $2.34 \mathrm{E}-07$ \\
\hline $1.81 \mathrm{E}-32$ & $9.53 \mathrm{E}-07$ & 1. & 10 & 8 & 8 & 1.23 & $.37 \mathrm{E}-07$ \\
\hline $1.81 \mathrm{E}-32$ & $E-07$ & 1 & 0 & 2.2 & 8 & 7 & $.40 \mathrm{E}-07$ \\
\hline $1.81 \mathrm{E}-32$ & $9.73 \mathrm{E}-07$ & $1.30 \mathrm{E}-08$ & $1.75 \mathrm{E}-10$ & $2.31 \mathrm{E}-08$ & $5.80 \mathrm{E}-08$ & $1.26 \mathrm{E}-07$ & $2.42 \mathrm{E}-07$ \\
\hline $81 E-32$ & $9.83 \mathrm{E}-07$ & $1.31 \mathrm{E}-08$ & $1.84 \mathrm{E}-10$ & $2.34 \mathrm{E}-08$ & $5.88 \mathrm{E}-08$ & $1.28 \mathrm{E}-07$ & $2.45 \mathrm{E}-07$ \\
\hline $1.81 \mathrm{E}-32$ & $9.93 \mathrm{E}-07$ & $1.33 \mathrm{E}-08$ & $1.92 \mathrm{E}-10$ & $2.38 \mathrm{E}-08$ & $5.96 \mathrm{E}-08$ & $1.29 \mathrm{E}-07$ & $2.48 \mathrm{E}-07$ \\
\hline $1.81 \mathrm{E}-32$ & $1.00 \mathrm{E}-06$ & $1.35 \mathrm{E}-08$ & $2.02 \mathrm{E}-10$ & $2.42 \mathrm{E}-08$ & $6.04 \mathrm{E}-08$ & $1.31 \mathrm{E}-07$ & $2.50 \mathrm{E}-07$ \\
\hline $1.81 \mathrm{E}-32$ & $1.01 \mathrm{E}-06$ & $1.37 \mathrm{E}-08$ & $2.12 \mathrm{E}-10$ & $2.45 \mathrm{E}-08$ & $6.12 \mathrm{E}-08$ & $1.33 \mathrm{E}-07$ & $2.53 \mathrm{E}-07$ \\
\hline $1.81 \mathrm{E}-32$ & $1.02 \mathrm{E}-06$ & $1.38 \mathrm{E}-08$ & $2.21 \mathrm{E}-10$ & $2.49 \mathrm{E}-08$ & $6.21 \mathrm{E}-08$ & $1.34 \mathrm{E}-07$ & $2.56 \mathrm{E}-07$ \\
\hline $1.81 \mathrm{E}-32$ & $1.04 \mathrm{E}-06$ & $1.40 \mathrm{E}-08$ & $2.29 \mathrm{E}-10$ & $2.53 \mathrm{E}-08$ & $6.29 \mathrm{E}-08$ & $1.36 \mathrm{E}-07$ & $2.59 \mathrm{E}-07$ \\
\hline $1.81 \mathrm{E}-32$ & $1.05 \mathrm{E}-06$ & $1.42 \mathrm{E}-08$ & $2.38 \mathrm{E}-10$ & $2.57 \mathrm{E}-08$ & $6.37 \mathrm{E}-08$ & $1.38 \mathrm{E}-07$ & $2.61 \mathrm{E}-07$ \\
\hline $1.81 \mathrm{E}-32$ & $1.06 \mathrm{E}-06$ & $1.44 \mathrm{E}-08$ & $2.47 \mathrm{E}-10$ & $2.61 \mathrm{E}-08$ & $6.46 \mathrm{E}-08$ & $1.39 \mathrm{E}-07$ & $2.65 \mathrm{E}-07$ \\
\hline $1.81 \mathrm{E}-32$ & $1.07 \mathrm{E}-06$ & $1.46 \mathrm{E}-08$ & $2.58 \mathrm{E}-10$ & $2.65 \mathrm{E}-08$ & $6.55 \mathrm{E}-08$ & $1.41 \mathrm{E}-07$ & $2.68 \mathrm{E}-07$ \\
\hline $1.81 \mathrm{E}-32$ & $1.08 \mathrm{E}-06$ & $1.48 \mathrm{E}-08$ & $2.69 \mathrm{E}-10$ & $2.69 \mathrm{E}-08$ & $6.63 \mathrm{E}-08$ & $1.43 E-07$ & $2.71 \mathrm{E}-07$ \\
\hline $1.81 \mathrm{E}-32$ & $1.09 \mathrm{E}-06$ & $1.50 \mathrm{E}-08$ & $2.80 \mathrm{E}-10$ & $2.73 \mathrm{E}-08$ & $6.72 \mathrm{E}-08$ & $1.44 \mathrm{E}-07$ & $2.75 \mathrm{E}-07$ \\
\hline $1.81 \mathrm{E}-32$ & $1.10 \mathrm{E}-06$ & $1.52 \mathrm{E}-08$ & $2.89 \mathrm{E}-10$ & $2.78 \mathrm{E}-08$ & $6.81 \mathrm{E}-08$ & $1.46 \mathrm{E}-07$ & $2.78 \mathrm{E}-07$ \\
\hline $1.82 \mathrm{E}-32$ & $1.11 \mathrm{E}-06$ & $1.54 \mathrm{E}-08$ & $2.99 \mathrm{E}-10$ & $2.83 \mathrm{E}-08$ & $6.90 \mathrm{E}-08$ & $1.47 \mathrm{E}-07$ & $2.81 \mathrm{E}-07$ \\
\hline $.82 E-32$ & $1.12 \mathrm{E}-06$ & $1.56 \mathrm{E}-08$ & $3.09 \mathrm{E}-10$ & $2.88 \mathrm{E}-08$ & $6.99 \mathrm{E}-08$ & $1.49 \mathrm{E}-07$ & $2.85 E-07$ \\
\hline
\end{tabular}


RESRAD-OFFSITE, Version 2.5

Title : RESRAD-OFFSITE External Gamma, Inhalation, and Soil Ingestion for Offsite Reside File : PBA-1_TC99-DOE-5-1.ROF

Summary of dose at graphical times, reptition 3 (continued)

Time

Years

$3.07 \mathrm{E}+02$

$3.07 \mathrm{E}+02$

$3.08 \mathrm{E}+02$

$3.08 \mathrm{E}+02$

$3.09 \mathrm{E}+02$

$3.09 \mathrm{E}+02$

$3.10 \mathrm{E}+02$

$3.10 \mathrm{E}+02$

$3.11 \mathrm{E}+02$

$3.11 E+02$

$3.12 \mathrm{E}+02$

$3.12 \mathrm{E}+02$

$3.13 \mathrm{E}+02$

$3.13 \mathrm{E}+02$

$3.14 \mathrm{E}+02$

$3.14 \mathrm{E}+02$

$3.15 \mathrm{E}+02$

$3.15 \mathrm{E}+02$

$3.16 \mathrm{E}+02$

$3.16 \mathrm{E}+02$

$3.17 \mathrm{E}+02$

$3.17 \mathrm{E}+02$

$3.18 \mathrm{E}+02$

$3.18 \mathrm{E}+02$

$3.19 \mathrm{E}+02$

$3.19 \mathrm{E}+02$

$3.20 \mathrm{E}+02$

$3.20 \mathrm{E}+02$

$3.21 \mathrm{E}+02$

$3.21 \mathrm{E}+02$

$3.22 \mathrm{E}+02$

$3.22 \mathrm{E}+02$

$3.23 \mathrm{E}+02$

$3.24 \mathrm{E}+02$

$3.24 \mathrm{E}+02$

$3.25 \mathrm{E}+02$

$3.25 \mathrm{E}+02$

$3.26 \mathrm{E}+02$

$3.26 \mathrm{E}+02$

$3.27 \mathrm{E}+02$

$3.27 \mathrm{E}+02$

3. $28 \mathrm{E}+02$

$3.28 \mathrm{E}+02$

$3.29 \mathrm{E}+02$

$3.29 \mathrm{E}+02$

$3.30 \mathrm{E}+02$
Dose statistics at graphical times, mrem/yr

\begin{tabular}{|c|c|c|c|c|c|c|c|}
\hline inimum & Maximum & Mean & Median & $90 \%$ & $95 \frac{\circ}{\circ}$ & $7.5 \%$ & $9 \%$ \\
\hline $.82 E-32$ & $1.13 \mathrm{E}-06$ & $1.58 \mathrm{E}-08$ & $3.19 \mathrm{E}-10$ & $2.93 E-08$ & $7.08 \mathrm{E}-08$ & $1.50 \mathrm{E}-07$ & $2.88 \mathrm{E}-07$ \\
\hline $1.82 \mathrm{E}-32$ & $1.14 \mathrm{E}-06$ & $1.60 \mathrm{E}-08$ & $3.29 \mathrm{E}-10$ & $2.98 \mathrm{E}-08$ & $7.17 \mathrm{E}-08$ & $1.52 \mathrm{E}-07$ & $2.91 \mathrm{E}-07$ \\
\hline $1.82 \mathrm{E}-32$ & $1.16 \mathrm{E}-06$ & $1.62 \mathrm{E}-08$ & $3.39 \mathrm{E}-10$ & $3.03 \mathrm{E}-08$ & $7.26 \mathrm{E}-08$ & $1.53 \mathrm{E}-07$ & $2.95 \mathrm{E}-07$ \\
\hline $1.82 \mathrm{E}-32$ & $1.17 \mathrm{E}-06$ & $1.64 \mathrm{E}-08$ & $3.52 \mathrm{E}-10$ & $3.07 \mathrm{E}-08$ & $7.35 \mathrm{E}-08$ & $1.55 \mathrm{E}-07$ & $.98 \mathrm{E}-07$ \\
\hline $1.82 \mathrm{E}-32$ & $1.18 \mathrm{E}-06$ & $1.66 \mathrm{E}-08$ & $3.64 \mathrm{E}-10$ & $3.12 \mathrm{E}-08$ & $7.45 \mathrm{E}$ & $1.57 \mathrm{E}-07$ & $.01 \mathrm{E}-07$ \\
\hline $1.82 \mathrm{E}-32$ & $1.19 \mathrm{E}-06$ & $1.68 \mathrm{E}-08$ & $3.76 \mathrm{E}-10$ & $3.16 \mathrm{E}-08$ & $7.54 \mathrm{E}-08$ & $1.58 \mathrm{E}-07$ & $3.04 \mathrm{E}-07$ \\
\hline $1.82 \mathrm{E}-32$ & $.20 E-06$ & $1.70 \mathrm{E}-08$ & $3.92 \mathrm{E}-10$ & $3.21 \mathrm{E}-08$ & $.64 \mathrm{E}-08$ & $1.60 \mathrm{E}-07$ & $3.07 \mathrm{E}-07$ \\
\hline $82 \mathrm{E}-32$ & $1.21 \mathrm{E}-06$ & $1.72 \mathrm{E}-08$ & $4.06 \mathrm{E}-10$ & $3.25 \mathrm{E}-08$ & $73 E-08$ & $1.62 \mathrm{E}-07$ & $11 \mathrm{E}-07$ \\
\hline $1.82 \mathrm{E}-32$ & $1.22 \mathrm{E}-06$ & $1.74 \mathrm{E}-08$ & $4.22 \mathrm{E}-10$ & $3.30 \mathrm{E}-08$ & $7.83 \mathrm{E}-08$ & $1.64 \mathrm{E}-07$ & $3.14 \mathrm{E}-07$ \\
\hline $1.82 \mathrm{E}-32$ & $1.23 \mathrm{E}-06$ & $1.76 \mathrm{E}-08$ & $4.36 \mathrm{E}-10$ & $3.35 \mathrm{E}-08$ & $7.93 \mathrm{E}-08$ & $1.66 \mathrm{E}-07$ & $3.17 \mathrm{E}-07$ \\
\hline $1.82 \mathrm{E}-32$ & $1.25 \mathrm{E}-06$ & $1.79 \mathrm{E}-08$ & $4.49 \mathrm{E}-10$ & $3.40 \mathrm{E}-08$ & $8.02 \mathrm{E}-08$ & $1.68 \mathrm{E}-07$ & $3.20 \mathrm{E}-07$ \\
\hline $1.82 \mathrm{E}-32$ & $1.26 \mathrm{E}-06$ & $1.81 \mathrm{E}-08$ & $4.64 \mathrm{E}-10$ & $3.46 \mathrm{E}-08$ & $8.12 \mathrm{E}-08$ & $1.70 \mathrm{E}-07$ & $3.23 \mathrm{E}-07$ \\
\hline $1.82 \mathrm{E}-32$ & $1.27 \mathrm{E}-06$ & $1.83 \mathrm{E}-08$ & $4.80 \mathrm{E}-10$ & $3.51 \mathrm{E}-08$ & $8.22 \mathrm{E}-08$ & $1.72 \mathrm{E}-07$ & $3.27 \mathrm{E}-07$ \\
\hline $1.83 \mathrm{E}-32$ & $1.28 \mathrm{E}-06$ & $1.85 \mathrm{E}-08$ & $4.95 \mathrm{E}-10$ & $3.57 \mathrm{E}-08$ & $8.32 \mathrm{E}-08$ & $1.74 \mathrm{E}-07$ & $3.31 \mathrm{E}-07$ \\
\hline $1.83 E-32$ & $1.29 \mathrm{E}-06$ & $1.88 \mathrm{E}-08$ & $5.12 \mathrm{E}-10$ & $3.62 \mathrm{E}-08$ & $8.43 \mathrm{E}-08$ & $1.76 \mathrm{E}-07$ & $3.34 \mathrm{E}-07$ \\
\hline $1.83 \mathrm{E}-32$ & $1.31 \mathrm{E}-06$ & $1.90 \mathrm{E}-08$ & $5.31 \mathrm{E}-10$ & $3.68 \mathrm{E}-08$ & $8.53 \mathrm{E}-08$ & $1.79 \mathrm{E}-07$ & $3.38 \mathrm{E}-07$ \\
\hline $1.83 E-32$ & $1.32 \mathrm{E}-06$ & $1.92 \mathrm{E}-08$ & $5.48 \mathrm{E}-10$ & $3.73 \mathrm{E}-08$ & $8.63 E-08$ & $1.81 \mathrm{E}-07$ & $3.42 \mathrm{E}-07$ \\
\hline $1.83 \mathrm{E}-32$ & $1.33 \mathrm{E}-06$ & $1.94 \mathrm{E}-08$ & $5.68 \mathrm{E}-10$ & $3.79 \mathrm{E}-08$ & $8.74 \mathrm{E}-08$ & $1.83 \mathrm{E}-07$ & $3.46 \mathrm{E}-07$ \\
\hline $1.83 \mathrm{E}-32$ & $1.34 \mathrm{E}-06$ & $1.97 \mathrm{E}-08$ & $5.87 \mathrm{E}-10$ & $3.85 \mathrm{E}-08$ & $8.85 \mathrm{E}-08$ & $1.85 \mathrm{E}-07$ & $3.49 \mathrm{E}-07$ \\
\hline $83 E-32$ & $1.35 \mathrm{E}-06$ & $1.99 \mathrm{E}-08$ & $6.07 \mathrm{E}$ & $3.91 \mathrm{E}$ & 8 & $1.87 \mathrm{E}-07$ & $.53 E-07$ \\
\hline $1.83 \mathrm{E}-$ & 1 & 2 & & & & 7 & 07 \\
\hline $3 E-32$ & 1 & 2 & 6 & 8 & 8 & 7 & 07 \\
\hline $1.83 \mathrm{E}-32$ & $1.39 \mathrm{E}-06$ & $2.06 \mathrm{E}-08$ & $6.71 \mathrm{E}-10$ & $4.08 \mathrm{E}-08$ & $9.35 \mathrm{E}-08$ & $1.94 \mathrm{E}-07$ & $3.65 \mathrm{E}-07$ \\
\hline $1.83 \mathrm{E}-32$ & $1.40 \mathrm{E}-06$ & $2.09 \mathrm{E}-08$ & $6.91 \mathrm{E}-10$ & $4.14 \mathrm{E}-08$ & $9.47 \mathrm{E}-08$ & $1.96 \mathrm{E}-07$ & $3.69 \mathrm{E}-07$ \\
\hline $1.83 \mathrm{E}-32$ & $1.41 \mathrm{E}-06$ & $2.11 \mathrm{E}-08$ & $7.09 \mathrm{E}-10$ & $4.20 \mathrm{E}-08$ & $9.60 \mathrm{E}-08$ & $1.98 \mathrm{E}-07$ & $3.73 \mathrm{E}-07$ \\
\hline $1.83 \mathrm{E}-32$ & $1.43 \mathrm{E}-06$ & $2.14 \mathrm{E}-08$ & $7.31 \mathrm{E}-10$ & $4.26 \mathrm{E}-08$ & $9.71 \mathrm{E}-08$ & $2.01 \mathrm{E}-07$ & $3.77 \mathrm{E}-07$ \\
\hline $1.83 \mathrm{E}-32$ & $1.44 \mathrm{E}-06$ & $2.16 \mathrm{E}-08$ & $7.55 \mathrm{E}-10$ & $4.32 \mathrm{E}-08$ & $9.83 \mathrm{E}-08$ & $2.03 E-07$ & $3.81 \mathrm{E}-07$ \\
\hline $1.83 \mathrm{E}-32$ & $1.45 \mathrm{E}-06$ & $2.19 \mathrm{E}-08$ & $7.79 \mathrm{E}-10$ & $4.38 \mathrm{E}-08$ & $9.94 \mathrm{E}-08$ & $2.06 \mathrm{E}-07$ & $3.85 \mathrm{E}-07$ \\
\hline $1.84 \mathrm{E}-32$ & $1.46 \mathrm{E}-06$ & $2.21 \mathrm{E}-08$ & $7.98 \mathrm{E}-10$ & $4.44 \mathrm{E}-08$ & $1.01 \mathrm{E}-07$ & $2.08 \mathrm{E}-07$ & $3.89 \mathrm{E}-07$ \\
\hline $1.84 \mathrm{E}-32$ & $1.48 \mathrm{E}-06$ & 2. & 10 & 8 & 07 & 2.11 & $.93 \mathrm{E}-07$ \\
\hline $1.84 \mathrm{E}-32$ & 6 & $2.26 \mathrm{E}$ & 0 & 4.00 & 7 & 7 & $.97 \mathrm{E}-07$ \\
\hline $1.84 \mathrm{E}-32$ & $1.50 \mathrm{E}-06$ & $2.29 \mathrm{E}-08$ & $8.59 \mathrm{E}-10$ & $4.62 \mathrm{E}-08$ & $1.04 \mathrm{E}-07$ & $2.16 \mathrm{E}-07$ & $4.01 \mathrm{E}-07$ \\
\hline $1.84 \mathrm{E}-32$ & $1.51 \mathrm{E}-06$ & $2.32 \mathrm{E}-08$ & $8.87 \mathrm{E}-10$ & $4.69 \mathrm{E}-08$ & $1.05 \mathrm{E}-07$ & $2.19 \mathrm{E}-07$ & $4.05 \mathrm{E}-07$ \\
\hline $1.84 \mathrm{E}-32$ & $1.53 \mathrm{E}-06$ & $2.34 \mathrm{E}-08$ & $9 \cdot 12 \mathrm{E}-10$ & $4.75 \mathrm{E}-08$ & $1.07 \mathrm{E}-07$ & $2.21 \mathrm{E}-07$ & $4.09 \mathrm{E}-07$ \\
\hline $1.84 \mathrm{E}-32$ & $1.54 \mathrm{E}-06$ & $2.37 E-08$ & $9.37 \mathrm{E}-10$ & $4.81 \mathrm{E}-08$ & $1.08 \mathrm{E}-07$ & $2.23 E-07$ & $4.14 \mathrm{E}-07$ \\
\hline $1.84 \mathrm{E}-32$ & $1.55 \mathrm{E}-06$ & $2.40 \mathrm{E}-08$ & $9.65 \mathrm{E}-10$ & $4.87 \mathrm{E}-08$ & $1.09 \mathrm{E}-07$ & $2.26 \mathrm{E}-07$ & $4.18 \mathrm{E}-07$ \\
\hline $1.84 \mathrm{E}-32$ & $1.57 \mathrm{E}-06$ & $2.42 \mathrm{E}-08$ & $9.90 \mathrm{E}-10$ & $4.93 \mathrm{E}-08$ & $1.10 \mathrm{E}-07$ & $2.28 \mathrm{E}-07$ & $4.22 \mathrm{E}-07$ \\
\hline $1.84 \mathrm{E}-32$ & $1.58 \mathrm{E}-06$ & $2.45 \mathrm{E}-08$ & $1.01 \mathrm{E}-09$ & $5.00 \mathrm{E}-08$ & $1.12 \mathrm{E}-07$ & $2.31 \mathrm{E}-07$ & $4.26 \mathrm{E}-07$ \\
\hline $1.84 \mathrm{E}-32$ & $1.59 \mathrm{E}-06$ & $2.48 \mathrm{E}-08$ & $1.04 \mathrm{E}-09$ & $5.07 \mathrm{E}-08$ & $1.13 \mathrm{E}-07$ & $2.33 E-07$ & $4.31 \mathrm{E}-07$ \\
\hline $1.84 \mathrm{E}-32$ & $1.60 \mathrm{E}-06$ & $2.51 \mathrm{E}-08$ & $1.07 \mathrm{E}-09$ & $5.14 \mathrm{E}-08$ & $1.14 \mathrm{E}-07$ & $2.36 \mathrm{E}-07$ & $4.35 \mathrm{E}-07$ \\
\hline $1.84 \mathrm{E}-32$ & $1.62 \mathrm{E}-06$ & $2.53 \mathrm{E}-08$ & $1.09 \mathrm{E}-09$ & $5.21 \mathrm{E}-08$ & $1.16 \mathrm{E}-07$ & $2.38 \mathrm{E}-07$ & $4.39 \mathrm{E}-07$ \\
\hline $1.84 \mathrm{E}-32$ & $1.63 \mathrm{E}-06$ & $2.56 \mathrm{E}-08$ & $1.12 \mathrm{E}-09$ & $5.28 \mathrm{E}-08$ & $1.17 \mathrm{E}-07$ & $2.41 \mathrm{E}-07$ & $4.44 \mathrm{E}-07$ \\
\hline $1.84 \mathrm{E}-32$ & $1.64 \mathrm{E}-06$ & $2.59 \mathrm{E}-08$ & $1.15 \mathrm{E}-09$ & $5.36 \mathrm{E}-08$ & $1.19 \mathrm{E}-07$ & $2.43 E-07$ & $4.48 \mathrm{E}-07$ \\
\hline $1.84 \mathrm{E}-32$ & $1.66 \mathrm{E}-06$ & $2.62 \mathrm{E}-08$ & $1.17 \mathrm{E}-09$ & $5.44 \mathrm{E}-08$ & $1.20 \mathrm{E}-07$ & $2.46 \mathrm{E}-07$ & $4.52 \mathrm{E}-07$ \\
\hline $1.85 \mathrm{E}-32$ & $1.67 \mathrm{E}-06$ & $2.65 \mathrm{E}-08$ & $1.20 \mathrm{E}-09$ & $5.51 \mathrm{E}-08$ & $1.22 \mathrm{E}-07$ & $2.48 \mathrm{E}-07$ & $4.57 \mathrm{E}-07$ \\
\hline $1.85 \mathrm{E}-32$ & $1.68 \mathrm{E}-06$ & $2.68 \mathrm{E}-08$ & $1.23 \mathrm{E}-09$ & $5.59 \mathrm{E}-08$ & $1.23 \mathrm{E}-07$ & $2.50 \mathrm{E}-07$ & $4.61 \mathrm{E}-07$ \\
\hline
\end{tabular}


RESRAD-OFFSITE, Version 2.5

$\mathrm{T}^{1 / 2}$ Limit $=180$ days

Title : RESRAD-OFFSITE External Gamma, Inhalation, and Soil Ingestion for Offsite Reside

File : PBA-1_TC99-DOE-5-1.ROF

Summary of dose at graphical times, reptition 3 (continued)

Time

Years

$3.30 \mathrm{E}+02$

$3.31 \mathrm{E}+02$

$3.31 \mathrm{E}+02$

$3.32 \mathrm{E}+02$

$3.32 \mathrm{E}+02$

$3.33 \mathrm{E}+02$

$3.33 \mathrm{E}+02$

$3.34 \mathrm{E}+02$

$3.34 \mathrm{E}+02$

$3.35 E+02$

$3.35 \mathrm{E}+02$

$3.36 \mathrm{E}+02$

$3.36 \mathrm{E}+02$

$3.37 \mathrm{E}+02$

$3.37 \mathrm{E}+02$

$3.38 \mathrm{E}+02$

$3.38 \mathrm{E}+02$

$3.39 \mathrm{E}+02$

$3.39 \mathrm{E}+02$

$3.40 \mathrm{E}+02$

$3.40 \mathrm{E}+02$

$3.41 \mathrm{E}+02$

$3.41 \mathrm{E}+02$

$3.42 \mathrm{E}+02$

$3.42 \mathrm{E}+02$

$3.43 \mathrm{E}+02$

$3.44 \mathrm{E}+02$

$3.44 \mathrm{E}+02$

$3.45 \mathrm{E}+02$

$3.45 \mathrm{E}+02$

$3.46 \mathrm{E}+02$

$3.46 \mathrm{E}+02$

$3.47 \mathrm{E}+02$

$3.47 \mathrm{E}+02$

$3.48 \mathrm{E}+02$

$3.48 \mathrm{E}+02$

$3.49 \mathrm{E}+02$

3. $49 \mathrm{E}+02$

$3.50 \mathrm{E}+02$

$3.50 \mathrm{E}+02$

3. $51 \mathrm{E}+02$

3. $51 \mathrm{E}+02$

3. $52 \mathrm{E}+02$

3. $52 \mathrm{E}+02$

$3.53 \mathrm{E}+02$

$3.53 \mathrm{E}+02$
Dose statistics at graphical times, mrem/yr

\begin{tabular}{|c|c|c|c|c|c|c|c|}
\hline m & aximum & ean & ed & & & & \\
\hline 32 & 6 & 8 & 9 & 8 & 07 & 7 & o \\
\hline $85 E-32$ & $.71 \mathrm{E}-06$ & $2.73 E-08$ & 1.29E-09 & $4 E-08$ & $1.26 \mathrm{E}-07$ & $55 E-07$ & $70 \mathrm{E}-07$ \\
\hline$E-32$ & $2 F-06$ & $76 E-08$ & $32 E-09$ & $81 E-08$ & $28 \mathrm{~F}-07$ & 7 & $75 E-07$ \\
\hline $5 F-32$ & 6 & $.79 \mathrm{E}-08$ & $1.35 E-09$ & & & & 07 \\
\hline 32 & 06 & -08 & 09 & 8 & & & -07 \\
\hline $85 E-32$ & -06 & $E-08$ & 09 & -08 & ${ }^{-1}$ & & -07 \\
\hline $85 E-32$ & 06 & 8 & 09 & 08 & 1 & & $93 E-07$ \\
\hline-32 & $E-06$ & $E-08$ & $3 E-09$ & $E-08$ & 7 & 07 & $E-07$ \\
\hline$E-32$ & $81 E-06$ & $5 E-08$ & $1 E-09$ & -08 & . & 07 & $\Xi-07$ \\
\hline $35-32$ & $82 E-06$ & $98 E-08$ & $.55 E-09$ & $32 E-08$ & $38 F-0$ & & 7 \\
\hline-32 & & & & & & & 07 \\
\hline $85 E-32$ & $E-06$ & $E-08$ & $1.62 \mathrm{E}-09$ & & & & $17 \mathrm{E}-07$ \\
\hline $.85 E-32$ & $1.86 \mathrm{E}-06$ & $3.07 E-08$ & $1.65 E-09$ & $6.56 E-08$ & & & $.22 E-07$ \\
\hline 32 & -06 & $E-08$ & $E-09$ & & & & -07 \\
\hline 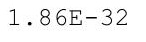 & 06 & & & & & & 07 \\
\hline 2 & $90 E-06$ & & $1.76 \mathrm{E}-$ & 8 & 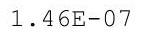 & & $36 \mathrm{E}-07$ \\
\hline $.86 E-32$ & 6 & $3.20 \mathrm{E}-08$ & 9 & 8 & $1.48 E-07$ & $2.93 E-07$ & 07 \\
\hline $86 F-32$ & $3 E-06$ & $3 F-08$ & $3 E-09$ & & $1.49 \mathrm{E}-07$ & 7 & 07 \\
\hline $86 \mathrm{E}-32$ & $1.94 \mathrm{E}-06$ & $.27 E-08$ & $1.86 \mathrm{E}-09$ & $2 E-08$ & $.51 \mathrm{E}-07$ & $.99 E-07$ & $51 \mathrm{E}-07$ \\
\hline $86 E-32$ & $1.96 \mathrm{E}-06$ & $.30 E-08$ & $1.90 E-09$ & $0 E-08$ & & & $56 E-07$ \\
\hline & & & & & & & \\
\hline & & & & & & & -07 \\
\hline $86 \mathrm{E}-32$ & 2.000 & & & & & & 07 \\
\hline 2 & 6 & 8 & 9 & 8 & $1.59 \mathrm{E}-07$ & & -07 \\
\hline $5-3-3$ & $.03 E-06$ & $.47 \mathrm{E}-08$ & $2.11 \mathrm{E}-09$ & $3 E-08$ & $6 \cap 5=$ & $5 \mathrm{~F}$ & $81 F-07$ \\
\hline 32 & $.04 E-06$ & $51 E-08$ & $2.15 E-09$ & $3 E-08$ & $625-0$ & & $86 E-07$ \\
\hline $86 \mathrm{E}-32$ & $2.06 \mathrm{E}-06$ & $4 E-08$ & & & & & \\
\hline & & & & & & & \\
\hline H & $2.09 \mathrm{E}-$ & 00 & & & + & & -07 \\
\hline 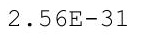 & $2 \cdot \perp U-40$ & $3.65 E-08$ & $2.31 E-09$ & $8.00 \mathrm{E}-08$ & t. & . & $06 E-07$ \\
\hline $.57 E-31$ & $2.12 \mathrm{E}-06$ & $3.68 \mathrm{E}-08$ & $2.36 E-09$ & $8.10 \mathrm{E}-08$ & 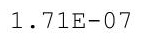 & th & $12 \mathrm{E}-07$ \\
\hline - & $2.13 E-06$ & & & & & & \\
\hline-3 & $5-06$ & $E-08$ & $E-09$ & & & & 07 \\
\hline 1 & 06 & & & & & & \\
\hline $3 E-31$ & $2.18 E-06$ & $3 E-08$ & 09 & 08 & $\perp$ & & $3 E-07$ \\
\hline $.905-31$ & $2.19 \mathrm{E}-06$ & $3.87 \mathrm{E}-08$ & $2.59 \mathrm{E}-09$ & $8.55 \mathrm{E}-08$ & 1.000 & -07 & $.38 E-07$ \\
\hline . & $2.20 \mathrm{E}-0$ & & $2.64 \mathrm{E}-09$ & & & & . \\
\hline $95 E-31$ & $2.22 E-06$ & & $2.68 E-09$ & 8 & & & 07 \\
\hline $98 F-31$ & 6 & 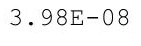 & 9 & 8 & ( & & 07 \\
\hline-31 & 06 & 08 & 09 & 8 & 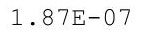 & 7 & -07 \\
\hline $3 E-31$ & $2.26 \mathrm{E}-06$ & $4.05 E-08$ & $6 E-09$ & -08 & & & -07 \\
\hline$E-31$ & $2.28 E-06$ & $E-08$ & -09 & $5 E-08$ & 1 & 07 & -07 \\
\hline & & & & & & & $.74 \mathrm{E}-07$ \\
\hline+ & 2. & 8 & 09 & 8 & \pm & & t \\
\hline & $2 \cdot$ & & & & & & i \\
\hline-31 & $34 E-06$ & $E-08$ & $2 E-09$ & $5 E-08$ & $9 \mathrm{E}-07$ & $3 E-07$ & -07 \\
\hline
\end{tabular}


RESRAD-OFFSITE, Version 2.5

Title : RESRAD-OFFSITE External Gamma, Inhalation, and Soil Ingestion for offsite Reside File : PBA-1_TC99-DOE-5-1.ROF

Summary of dose at graphical times, reptition 3 (continued)

Time

Years

$3.54 \mathrm{E}+02$

$3.54 \mathrm{E}+02$

$3.55 \mathrm{E}+02$

$3.55 \mathrm{E}+02$

$3.56 \mathrm{E}+02$

$3.56 \mathrm{E}+02$

$3.57 \mathrm{E}+02$

$3.57 \mathrm{E}+02$

$3.58 \mathrm{E}+02$

$3.58 \mathrm{E}+02$

$3.59 \mathrm{E}+02$

$3.59 \mathrm{E}+02$

3. $60 \mathrm{E}+02$

$3.60 \mathrm{E}+02$

3. $61 \mathrm{E}+02$

$3.61 \mathrm{E}+02$

3. $62 \mathrm{E}+02$

$3.62 \mathrm{E}+02$

3. $63 \mathrm{E}+02$

$3.64 \mathrm{E}+02$

$3.64 \mathrm{E}+02$

3. $65 \mathrm{E}+02$

$3.65 \mathrm{E}+02$

$3.66 \mathrm{E}+02$

$3.66 \mathrm{E}+02$

$3.67 \mathrm{E}+02$

3. $67 \mathrm{E}+02$

$3.68 \mathrm{E}+02$

$3.68 \mathrm{E}+02$

$3.69 \mathrm{E}+02$

$3.69 \mathrm{E}+02$

$3.70 \mathrm{E}+02$

$3.70 \mathrm{E}+02$

$3.71 \mathrm{E}+02$

$3.71 \mathrm{E}+02$

3. $72 \mathrm{E}+02$

$3.72 \mathrm{E}+02$

$3.73 \mathrm{E}+02$

$3.73 E+02$

$3.74 \mathrm{E}+02$

$3.74 \mathrm{E}+02$

$3.75 \mathrm{E}+02$

$3.75 \mathrm{E}+02$

$3.76 \mathrm{E}+02$

$3.76 \mathrm{E}+02$

$3.77 \mathrm{E}+02$
Dose statistics at graphical times, mrem/yr

\begin{tabular}{|c|c|c|c|c|c|c|c|}
\hline inimum & aximum & Mean & ledian & $90 \%$ & $5 \%$ & $97.5 \%$ & $3 \%$ \\
\hline-31 & $35 E-06$ & $4.29 E-08$ & $3.17 E-09$ & $9.67 \mathrm{E}-08$ & $1 E-07$ & $.76 \mathrm{E}-07$ & $E-0^{-}$ \\
\hline 31 & -06 & $E-08$ & $E-09$ & 8 & 07 & 07 & 07 \\
\hline-31 & $2.38 E-06$ & $7 E-08$ & $E-09$ & $0 E-08$ & 07 & -07 & -07 \\
\hline$E-31$ & $0 E-06$ & 08 & 9 & 7 & 7 & 07 & -07 \\
\hline $30 E-31$ & -06 & -08 & 09 & 7 & 7 & 07 & $15 E-07$ \\
\hline-31 & -06 & $E-08$ & -09 & 07 & T & 07 & 07 \\
\hline 31 & -06 & 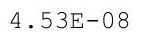 & 9 & 7 & $2.13 E-07$ & 7 & 7 \\
\hline $.38 E-31$ & $2.46 E-06$ & $4.57 \mathrm{E}-08$ & $3.56 \mathrm{E}-09$ & 土 & & -07 & $.31 E-07$ \\
\hline 31 & 06 & 08 & 09 & 7 & $r$ & -07 & -07 \\
\hline $43 E-31$ & $2.49 \mathrm{E}-06$ & $66 \mathrm{E}-08$ & $58 E-09$ & $07 E-07$ & 7 & -07 & $43 E-07$ \\
\hline 31 & -06 & $E-08$ & -09 & 7 & & -07 & $E-07$ \\
\hline & & & & & & & -07 \\
\hline $.3<\mathrm{E}-31$ & $2.54 \mathrm{E}-06$ & $4.79 E-08$ & $7 E-09$ & $1 \cdot \perp \perp E-U /$ & $2.20 \pm-41$ & -07 & $60 E-07$ \\
\hline $.55 E-31$ & -06 & $4.83 E-08$ & -09 & 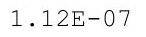 & & -07 & -07 \\
\hline$E-31$ & 06 & -08 & 09 & 07 & $2 \cdot 20$ & -07 & -07 \\
\hline $.60 E-31$ & $2.58 \mathrm{E}-06$ & -08 & -09 & 07 & 7 & -07 & -07 \\
\hline $63 E-31$ & $0 E-06$ & $6 \mathrm{E}-08$ & $5 E-09$ & $1.15 \mathrm{E}-07$ & $33 E-07$ & $E-07$ & $84 E-07$ \\
\hline 31 & $61 E-06$ & $0 E-08$ & $2 E-09$ & 7 & $35 E-07$ & $E-07$ & $90 \mathrm{E}-07$ \\
\hline 31 & -06 & -08 & -09 & 1 & & 7 & -07 \\
\hline $72 E-31$ & -06 & -08 & -09 & 7 & 7 & -07 & -07 \\
\hline $.75 E-31$ & $2.66 \mathrm{E}-06$ & 00 & -09 & & & 7 & -07 \\
\hline $78 E-31$ & $2.67 \mathrm{E}-06$ & -08 & -09 & $1.21 \mathrm{~F}$ & & -07 & -07 \\
\hline $81 E-31$ & $2.69 \mathrm{E}-06$ & $5.23 E-08$ & $4.60 E-09$ & $1.22 \mathrm{E}-07$ & $2.45 E-07$ & $49 E-07$ & $21 E-07$ \\
\hline $4 E-31$ & $2.70 \mathrm{E}-06$ & $.27 E-08$ & $58 E-09$ & $1.24 \mathrm{E}-07$ & $47 E-07$ & $53 E-07$ & $27 E-07$ \\
\hline 31 & $2.72 \mathrm{E}-06$ & $32 E-08$ & 09 & 7 & & -07 & -07 \\
\hline 31 & 06 & -08 & .09 & 7 & & 07 & -07 \\
\hline $.93 E-31$ & $2.75 E-06$ & $-4-08$ & -09 & $1.28 \mathrm{E}-07$ & & -07 & $45 E-07$ \\
\hline $.96 \mathrm{E}-31$ & $2.77 \mathrm{E}-06$ & $5.46 \mathrm{E}-08$ & $5.02 E-09$ & $1.29 \mathrm{E}-07$ & $2.56 \mathrm{E}-07$ & $68 \mathrm{E}-07$ & $.52 \mathrm{E}-07$ \\
\hline 1 & 6 & 20 & 9 & 7 & t & . $120 \quad 01$ & 07 \\
\hline • & $2.80 \mathrm{E}-06$ & 至 & $60-03$ & I. & 2. & T & $64 \mathrm{E}-07$ \\
\hline 31 & $2.81 \mathrm{E}-06$ & $E-08$ & $8 E-09$ & & & 7 & $0 E-07$ \\
\hline-31 & $2.83 E-06$ & $5 E-08$ & $E-09$ & 7 & & -07 & -07 \\
\hline $2 E-31$ & $2.85 E-06$ & $E-08$ & $5 E-09$ & $1.36 \mathrm{E}$ & 7 & 7 & $33 E-07$ \\
\hline $.15 \mathrm{E}-31$ & $2.86 \mathrm{E}-06$ & $5.74 E-08$ & $53 E-09$ & $1.38 \mathrm{E}-07$ & $2 \cdot T \perp E-U$ & $91 \mathrm{E}-07$ & $.89 E-07$ \\
\hline $18 E-31$ & $2.88 E-06$ & $5.79 E-08$ & & & & & $.96 E-07$ \\
\hline & & & & & & & \\
\hline $.25 E-31$ & 6 & & & & & & 07 \\
\hline 1 & 6 & & & & 7 & 07 & 07 \\
\hline & & & & & 7 & -07 & 07 \\
\hline $34 \mathrm{E}-31$ & $2.96 \mathrm{E}-06$ & $E-08$ & 09 & 7 & 7 & 7 & $8 E-07$ \\
\hline 1 & 06 & & & & & & -01 \\
\hline & $2.99 \mathrm{E}$ & & & -2 & & & $41 \mathrm{E}-07$ \\
\hline $.44 \mathrm{E}-31$ & 3 & & $y$ & 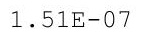 & 1 & 1 & 07 \\
\hline $54 F-31$ & 3 & & + & 1 & 7 & 07 & 07 \\
\hline-30 & 3.0 & -08 & 09 & 07 & 07 & 07 & -07 \\
\hline $66 E-30$ & $3.05 E-06$ & $.34 E-08$ & $.66 E-09$ & $1.55 \mathrm{E}-07$ & $3.02 E-07$ & $.34 E-07$ & $9.67 \mathrm{E}-07$ \\
\hline
\end{tabular}


RESRAD-OFFSITE, Version 2.5

Title : RESRAD-OFFSITE External Gamma, Inhalation, and Soil Ingestion for Offsite Reside File : PBA-1_TC99-DOE-5-1.ROF

Summary of dose at graphical times, reptition 3 (continued)

Time

Years

$3.77 \mathrm{E}+02$

$3.78 \mathrm{E}+02$

$3.78 \mathrm{E}+02$

$3.79 \mathrm{E}+02$

$3.79 \mathrm{E}+02$

$3.80 \mathrm{E}+02$

$3.80 \mathrm{E}+02$

$3.81 \mathrm{E}+02$

$3.81 \mathrm{E}+02$

$3.82 \mathrm{E}+02$

$3.82 \mathrm{E}+02$

$3.83 \mathrm{E}+02$

$3.83 \mathrm{E}+02$

$3.84 \mathrm{E}+02$

$3.85 \mathrm{E}+02$

$3.85 \mathrm{E}+02$

$3.86 \mathrm{E}+02$

$3.86 \mathrm{E}+02$

$3.87 \mathrm{E}+02$

$3.87 \mathrm{E}+02$

$3.88 \mathrm{E}+02$

$3.88 \mathrm{E}+02$

$3.89 \mathrm{E}+02$

$3.89 \mathrm{E}+02$

3. $90 \mathrm{E}+02$

$3.90 \mathrm{E}+02$

3. $91 \mathrm{E}+02$

3. $91 \mathrm{E}+02$

3. $92 \mathrm{E}+02$

3. $92 \mathrm{E}+02$

3. $93 \mathrm{E}+02$

3. $93 \mathrm{E}+02$

$3.94 \mathrm{E}+02$

3. $94 \mathrm{E}+02$

$3.95 \mathrm{E}+02$

$3.95 \mathrm{E}+02$

$3.96 \mathrm{E}+02$

$3.96 \mathrm{E}+02$

3. $97 \mathrm{E}+02$

3. $97 \mathrm{E}+02$

$3.98 \mathrm{E}+02$

3. $98 \mathrm{E}+02$

$3.99 \mathrm{E}+02$

$3.99 \mathrm{E}+02$

$4.00 \mathrm{E}+02$

$4.00 \mathrm{E}+02$
Dose statistics at graphical times, mrem/yr

\begin{tabular}{|c|c|c|c|c|c|c|c|}
\hline inimum & Iaximum & Mean & ledian & $90 \%$ & $5 \%$ & $97.5 \%$ & $3 \%$ \\
\hline-30 & $3.07 E-06$ & $6.39 E-08$ & $6.76 E-09$ & $1.57 \mathrm{E}-07$ & $3.04 \mathrm{E}-07$ & $.38 E-07$ & $E-0^{-}$ \\
\hline 30 & $3 E-06$ & $E-08$ & $5-09$ & $58 \mathrm{E}-$ & 07 & 07 & -07 \\
\hline $69 E-30$ & $E-06$ & $E-08$ & $E-09$ & $0 \mathrm{E}-07$ & $9 E-07$ & -07 & -07 \\
\hline $.70 E-30$ & 06 & 8 & & 7 & & 07 & -07 \\
\hline-30 & -06 & 8 & 9 & 7 & 7 & 07 & $00 E-06$ \\
\hline $.72 E-30$ & -06 & -08 & -09 & 07 & 1 & 07 & 06 \\
\hline $.73 E-30$ & -06 & ك & -09 & - 1 & 1 & -07 & -06 \\
\hline $.75 E-30$ & $3.18 E-06$ & $6.76 \mathrm{E}-08$ & $7.46 \mathrm{E}-09$ & 工. & & -07 & $.02 E-06$ \\
\hline 30 & 06 & -08 & 09 & 7 & $r$ & 07 & -06 \\
\hline $.77 \mathrm{E}-30$ & $1 E-06$ & $E-08$ & -09 & $71 E-07$ & 7 & -07 & $8-06$ \\
\hline-30 & -06 & 8 & 09 & 7 & & 07 & $E-06$ \\
\hline 30 & & & & & & & -06 \\
\hline $.83 E-30$ & $3.26 \mathrm{E}-06$ & $E-08$ & $E-09$ & $1.10 \mathrm{E}-01$ & ( & -07 & $E-06$ \\
\hline $.24 \mathrm{E}-30$ & $3.27 \mathrm{E}-06$ & $E-08$ & -09 & 土. & & & $E-06$ \\
\hline 30 & 06 & 08 & 09 & 07 & & 07 & -06 \\
\hline $.34 \mathrm{E}-30$ & -06 & 然 & -09 & -07 & 7 & -07 & -06 \\
\hline $.39 E-30$ & $2 E-06$ & $5 E-08$ & $7 E-09$ & $1.81 \mathrm{E}-07$ & $46 \mathrm{E}-07$ & -07 & $08 E-06$ \\
\hline-30 & $E-06$ & $0 \mathrm{E}-08$ & $9 E-09$ & 7 & 7 & -07 & $E-06$ \\
\hline-30 & -06 & -08 & 09 & 1 & & 17 & -06 \\
\hline $.55 E-30$ & $3.37 E-06$ & $E-08$ & -09 & 7 & & 07 & -06 \\
\hline $.60 \mathrm{E}-30$ & $3.39 \mathrm{E}-06$ & $7.47 E-08$ & -09 & & & & -06 \\
\hline $.66 \mathrm{E}-30$ & -06 & $.53 E-08$ & 09 & 07 & & - & -06 \\
\hline $25 E-30$ & $3.42 \mathrm{E}-06$ & $7.59 \mathrm{E}-08$ & $1 E-09$ & $1.90 \mathrm{E}-07$ & - & $4 E-07$ & $12 E-06$ \\
\hline $.32 \mathrm{E}-30$ & $3.43 E-06$ & $7.65 \mathrm{E}-08$ & $4 E-09$ & $1.92 \mathrm{E}-07$ & $65 E-07$ & $8 E-07$ & $13 \mathrm{E}-06$ \\
\hline-30 & $E-06$ & $E-08$ & 09 & & & 7 & -06 \\
\hline 30 & 06 & -08 & 09 & 7 & & & -06 \\
\hline $.53 E-30$ & $3.48 E-06$ & $7.82 \mathrm{E}-08$ & -09 & $1.97 \mathrm{E}-07$ & & -07 & $15 \mathrm{E}-06$ \\
\hline $60 E-30$ & $3.50 \mathrm{E}-06$ & $7.88 E-08$ & $9.87 E-09$ & $1.98 \mathrm{E}-07$ & $.77 E-07$ & $.43 E-07$ & $.16 \mathrm{E}-06$ \\
\hline 0 & 6 & 8 & 8 & 7 & 然 & $7 E-07$ & 06 \\
\hline $.75 E-30$ & $3.53 E-06$ & . & $.01 E-08$ & $2.01+8$ & $.02 \mathrm{D}-0$ & $1 E-07$ & 然 \\
\hline 0 & $E-06$ & $06 E-08$ & $3 E-08$ & $2 E-07$ & 7 & 7 & $E-06$ \\
\hline$E-29$ & $E-06$ & $2 E-08$ & $4 E-08$ & -07 & 7 & & -06 \\
\hline $37 E-27$ & $3 E-06$ & $3 E-08$ & $6 E-08$ & $5 E-07$ & 7 & 7 & $9 E-06$ \\
\hline $.32 E-25$ & $3.60 E-06$ & $8.24 E-08$ & $.07 E-08$ & $2.07 E-07$ & $94 \mathrm{E}-01$ & $57 E-07$ & $.20 E-06$ \\
\hline $44 \mathrm{E}-24$ & $3.61 E-06$ & $8.30 E-08$ & & $2.00 \mathrm{D}-01$ & & & $.205-20$ \\
\hline & & & & & & & $2+\infty<0$ \\
\hline $.81 E-22$ & 6 & & & $2.12 \mathrm{E}-07$ & & & 06 \\
\hline 1 & & & & & & 07 & 06 \\
\hline 0 & & & & & 07 & -07 & 06 \\
\hline $31 E-20$ & $3.69 E-06$ & $0 E-08$ & $5 E-08$ & 7 & 7 & & $.24 E-06$ \\
\hline $2 E-19$ & & $E-08$ & & 1 & & & -00 \\
\hline-19 & 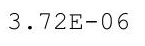 & $73 E-08$ & & . & & & $25 E-06$ \\
\hline 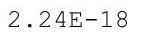 & 3 & 0 & 0 & 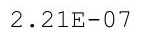 & & 7 & 0 \\
\hline $0.10[-10$ & 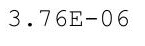 & $8.85 E-08$ & & 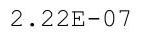 & 200 & 7 & the \\
\hline $4 \mathrm{E}-17$ & -06 & $E-08$ & -08 & 07 & 07 & 07 & 1.281 \\
\hline $.55 E-17$ & $3.79 E-06$ & $.98 E-08$ & $1.24 \mathrm{E}-08$ & $2.25 E-07$ & $4.31 E-07$ & $7.17 \mathrm{E}-07$ & $1.28 \mathrm{E}-06$ \\
\hline
\end{tabular}


RESRAD-OFFSITE, Version 2.5

Title : RESRAD-OFFSITE External Gamma, Inhalation, and Soil Ingestion for offsite Reside File : PBA-1_TC99-DOE-5-1.ROF

Summary of dose at graphical times, reptition 3 (continued)

Time

Years

4. $01 \mathrm{E}+02$

$4.01 \mathrm{E}+02$

$4.02 \mathrm{E}+02$

$4.02 \mathrm{E}+02$

$4.03 E+02$

$4.03 \mathrm{E}+02$

$4.04 \mathrm{E}+02$

$4.05 \mathrm{E}+02$

$4.05 \mathrm{E}+02$

$4.06 \mathrm{E}+02$

$4.06 \mathrm{E}+02$

$4.07 \mathrm{E}+02$

$4.07 \mathrm{E}+02$

$4.08 \mathrm{E}+02$

$4.08 \mathrm{E}+02$

$4.09 \mathrm{E}+02$

$4.09 \mathrm{E}+02$

$4.10 \mathrm{E}+02$

$4.10 \mathrm{E}+02$

4. $11 \mathrm{E}+02$

$4.11 \mathrm{E}+02$

$4.12 \mathrm{E}+02$

$4.12 \mathrm{E}+02$

$4.13 \mathrm{E}+02$

$4.13 \mathrm{E}+02$

$4.14 \mathrm{E}+02$

$4.14 \mathrm{E}+02$

$4.15 \mathrm{E}+02$

$4.15 \mathrm{E}+02$

$4.16 \mathrm{E}+02$

$4.16 \mathrm{E}+02$

$4.17 \mathrm{E}+02$

$4.17 \mathrm{E}+02$

$4.18 \mathrm{E}+02$

$4.18 \mathrm{E}+02$

4. $19 \mathrm{E}+02$

$4.19 \mathrm{E}+02$

$4.20 \mathrm{E}+02$

$4.20 \mathrm{E}+02$

$4.21 E+02$

4. $21 \mathrm{E}+02$

4. $22 \mathrm{E}+02$

4. $22 \mathrm{E}+02$

$4.23 E+02$

$4.23 \mathrm{E}+02$

$4.24 \mathrm{E}+02$
Dose statistics at graphical times, mrem/yr

\begin{tabular}{|c|c|c|c|c|c|c|c|}
\hline m & um & Mean & ledian & & & & \\
\hline 17 & 06 & 08 & 8 & 07 & 07 & 07 & - \\
\hline-16 & $.82 E-06$ & $1 \mathrm{E}-08$ & -08 & -07 & 07 & 07 & $30 E-06$ \\
\hline-16 & $84 \mathrm{E}-06$ & $7 E-08$ & $.29 \mathrm{E}-08$ & $30 E-07$ & $40 \mathrm{E}-07$ & -07 & -06 \\
\hline-16 & $85 E-06$ & $4 F-08$ & $30 E-08$ & $31 \mathrm{~F}-07$ & $35-07$ & 7 & 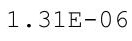 \\
\hline 16 & 06 & 08 & 08 & 07 & 07 & 07 & -06 \\
\hline 15 & 06 & 8 & & & & & -06 \\
\hline $53 E-15$ & -06 & 8 & & & & & -06 \\
\hline 15 & 06 & 8 & 8 & 7 & & 07 & -06 \\
\hline $.07 \mathrm{E}-15$ & -06 & $E-08$ & $E-08$ & $9 E-07$ & 07 & -07 & -06 \\
\hline 15 & -06 & 08 & $10 \mathrm{E}-08$ & 7 & & & 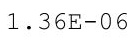 \\
\hline 14 & 06 & $9.70 \mathrm{E}-08$ & 8 & & & -07 & -0 \\
\hline $88 E-14$ & $98 E-06$ & $E-08$ & -08 & 7 & 7 & 7 & -06 \\
\hline $64 \mathrm{E}-14$ & $4.00 E-06$ & $9.83 E-08$ & & 7 & & 7 & -06 \\
\hline $63 E-14$ & $4.01 \mathrm{E}-06$ & $9.90 \mathrm{E}-08$ & $1.48 \mathrm{E}-08$ & $2.48 \mathrm{E}-07$ & $4.76 \mathrm{E}-07$ & $.83 E-07$ & -06 \\
\hline $91 \mathrm{E}-14$ & $3 E-06$ & $E-08$ & $E-08$ & $0 E-07$ & 7 & -07 & -06 \\
\hline 14 & 06 & & & & & & 0 \\
\hline 4 & & & & & & & $.41 \mathrm{E}-06$ \\
\hline 3 & & תרת & 8 & & & & 0 \\
\hline $43 E-13$ & $9 E-06$ & $2 E-07$ & $7 E-08$ & $9 E-07$ & $4 F-07$ & $E-07$ & -06 \\
\hline$E-13$ & $4.11 E-06$ & $.03 E-07$ & $1.59 \mathrm{E}-08$ & $2.61 \mathrm{E}-07$ & $.97 E-07$ & $E-07$ & $43 E-06$ \\
\hline 13 & $.12 \mathrm{E}-06$ & $.04 E-07$ & -08 & $3 F-0$ & & & -06 \\
\hline 13 & & $.04 E-07$ & & & & & \\
\hline 13 & & & & & & & o \\
\hline 3 & 6 & 7 & 08 & & & t & -0 \\
\hline 3 & 6 & ( & 8 & 7 & • & 7 & 0 \\
\hline$E-13$ & $.20 E-06$ & $1.07 \mathrm{E}-07$ & $1.71 E-08$ & $3 E-07$ & $6 \nabla_{0} 0$ & $40 \mathrm{E}-07$ & $47 \mathrm{E}-0$ \\
\hline-13 & $.22 E-06$ & $.08 E-07$ & $1.73 E-08$ & $75 E-07$ & & & $48 F-06$ \\
\hline & & & & & & & \\
\hline & & & & 07 & & & \\
\hline & & & & -07 & -07 & -07 & -06 \\
\hline $40 \mathrm{E}-12$ & $4.28 E-06$ & $1.11 \mathrm{E}-07$ & $.81 E-08$ & $2.83 E-07$ & $\begin{array}{ll} \\
\end{array}$ & 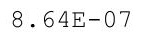 & -0 \\
\hline $61 \mathrm{E}-12$ & $4.30 \mathrm{E}-06$ & $1.12 \mathrm{E}-07$ & $1.83 E-08$ & $2.00 \mathrm{D}-1$ & & & . \\
\hline $7-12$ & $31 F-06$ & & & & & & $E-06-2-2$ \\
\hline & & & & & & & \\
\hline & & & & & & -07 & 06 \\
\hline $74 \mathrm{E}-12$ & & & & & & -07 & 06 \\
\hline $09 \mathrm{E}-12$ & $4.37 E-06$ & $5 E-07$ & 08 & 07 & 1 & & .00 \\
\hline & & & & & & & . \\
\hline 2 & 6 & $1.17 \mathrm{E}-07$ & & 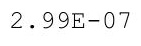 & 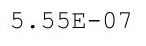 & $t$ & 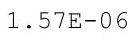 \\
\hline & & & & & & & 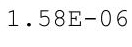 \\
\hline & & & & & -07 & -07 & 06 \\
\hline $4 \mathrm{E}-12$ & $4.45 E-06$ & $1.19 \mathrm{E}-07$ & $2.04 \mathrm{E}-08$ & $05 E-07$ & $5 E-07$ & 07 & -06 \\
\hline & & & & & & & \\
\hline & & & & $E-07$ & $\angle E-U \mid$ & 07 & $.0 \perp-4$ \\
\hline & & & & & & $9.29 \mathrm{E}-07$ & •.णZL \\
\hline$E-12$ & $E-06$ & $22 E-07$ & $.13 E-08$ & -07 & $9 E-07$ & $E-07$ & -06 \\
\hline
\end{tabular}


RESRAD-OFFSITE, Version 2.5

Title : RESRAD-OFFSITE External Gamma, Inhalation, and Soil Ingestion for Offsite Reside

File : PBA-1_TC99-DOE-5-1.ROF

Summary of dose at graphical times, reptition 3 (continued)

Time

Years

4. $25 E+02$

$4.25 \mathrm{E}+02$

4. $26 \mathrm{E}+02$

$4.26 \mathrm{E}+02$

$4.27 \mathrm{E}+02$

$4.27 \mathrm{E}+02$

$4.28 \mathrm{E}+02$

$4.28 \mathrm{E}+02$

$4.29 \mathrm{E}+02$

$4.29 \mathrm{E}+02$

$4.30 \mathrm{E}+02$

4. $30 \mathrm{E}+02$

4. $31 \mathrm{E}+02$

4. $31 \mathrm{E}+02$

4. $32 \mathrm{E}+02$

4. $32 \mathrm{E}+02$

4. $33 \mathrm{E}+02$

4. $33 \mathrm{E}+02$

4. $34 \mathrm{E}+02$

4. $34 \mathrm{E}+02$

4. $35 \mathrm{E}+02$

4. $35 \mathrm{E}+02$

4. $36 \mathrm{E}+02$

$4.36 \mathrm{E}+02$

4. $37 \mathrm{E}+02$

$4.37 \mathrm{E}+02$

$4.38 \mathrm{E}+02$

$4.38 \mathrm{E}+02$

4. $39 \mathrm{E}+02$

$4.39 \mathrm{E}+02$

$4.40 \mathrm{E}+02$

$4.40 \mathrm{E}+02$

$4.41 \mathrm{E}+02$

4. $41 \mathrm{E}+02$

4. $42 \mathrm{E}+02$

4. $42 \mathrm{E}+02$

$4.43 E+02$

$4.43 \mathrm{E}+02$

4. $44 \mathrm{E}+02$

$4.45 \mathrm{E}+02$

4. $45 \mathrm{E}+02$

$4.46 \mathrm{E}+02$

$4.46 \mathrm{E}+02$

$4.47 \mathrm{E}+02$

4. $47 \mathrm{E}+02$

$4.48 \mathrm{E}+02$
Dose statistics at graphical times, mrem/yr

\begin{tabular}{|c|c|c|c|c|c|c|c|}
\hline inimum & aximum & Mean & ledian & $90 \%$ & $5 \%$ & $97.5 \%$ & $\%$ \\
\hline 12 & $53 E-06$ & $1.23 \mathrm{E}-07$ & $E-08$ & 07 & 7 & 7 & $.63 E-0$ \\
\hline-12 & -06 & $E-07$ & $3 E-08$ & $9 E-07$ & 07 & 7 & -06 \\
\hline$E-11$ & $E-06$ & $4 E-07$ & $E-08$ & $1 E-07$ & 07 & 07 & -06 \\
\hline$E-11$ & $3 E-06$ & $5 E-07$ & $E-08$ & $24 \mathrm{E}$ & 7 & 07 & -06 \\
\hline $.18 \mathrm{E}-11$ & -06 & -07 & -08 & $26 E-07$ & 7 & $6 E-07$ & $66 E-06$ \\
\hline $28 E-11$ & -06 & $.27 E-07$ & -08 & 07 & 07 & -07 & -06 \\
\hline $38 \mathrm{E}-11$ & -06 & $.27 \mathrm{E}-07$ & $2.30 \mathrm{E}-08$ & (3) & ( & -07 & -06 \\
\hline $.48 E-11$ & $4.64 \mathrm{E}-06$ & $\begin{array}{ll}0 \\
20\end{array}$ & $2.33 E-08$ & ; & ( & -07 & $.69 E-06$ \\
\hline-11 & -06 & 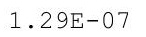 & -08 & $36 E-07$ & 7 & -07 & -06 \\
\hline $.70 \mathrm{E}-11$ & $67 E-06$ & $30 E-07$ & $7 E-08$ & $3 E-07$ & 07 & -07 & $.70 \mathrm{E}-06$ \\
\hline-11 & -06 & $E-07$ & -08 & $E-07$ & & 07 & $71 E-06$ \\
\hline 11 & 06 & 7 & & & & & -06 \\
\hline $.07 E-11$ & $4.71 E-06$ & $.3 \angle E-U 1$ & -08 & $\pm 4 \mathrm{E}-01$ & T & -07 & -06 \\
\hline $20 \mathrm{E}-11$ & $4.73 E-06$ & ו & -08 & $=1 \mathrm{~L}-0$ & & -07 & $.73 E-06$ \\
\hline 11 & 06 & 1 & 08 & 07 & T & -06 & -06 \\
\hline $9 E-11$ & -06 & -07 & -08 & -07 & 7 & -06 & -06 \\
\hline $.63 E-11$ & $E-06$ & $5 E-07$ & $4 \mathrm{E}-08$ & $54 \mathrm{E}-07$ & $1 E-07$ & -06 & $.75 \mathrm{E}-06$ \\
\hline$E-11$ & $9 E-06$ & $6 E-07$ & $7 E-08$ & $7 E-07$ & $E-07$ & -06 & $76 E-06$ \\
\hline 11 & -06 & 7 & 08 & -01 & & -06 & -06 \\
\hline $11 \mathrm{E}-11$ & -06 & $E-07$ & -08 & -07 & 7 & -06 & $78 E-06$ \\
\hline $.28 \mathrm{E}-11$ & $4.83 E-06$ & ז & -08 & -07 & & 0 & $.79 E-06$ \\
\hline $46 \mathrm{E}-11$ & $4.85 \mathrm{E}-06$ & 1 & 08 & -07 & & -06 & -06 \\
\hline $.64 \mathrm{E}-11$ & $4.86 \mathrm{E}-06$ & 1.700 t & $2.71 E-08$ & $3.69 \mathrm{E}-07$ & ( & $.04 \mathrm{E}-06$ & $.80 \mathrm{E}-06$ \\
\hline $.82 \mathrm{E}-11$ & $8 E-06$ & $1.41 \mathrm{E}-07$ & $74 \mathrm{E}-08$ & $72 E-07$ & 7 & $5 E-06$ & $81 \mathrm{E}-06$ \\
\hline 11 & $4.89 \mathrm{E}-06$ & $2 E-07$ & -08 & -07 & 07 & -06 & -06 \\
\hline 11 & 06 & 7 & .08 & $7 E-07$ & & 06 & 06 \\
\hline $2 E-11$ & $2 E-06$ & -01 & -08 & 9E-01 & & -06 & $83 E-06$ \\
\hline $.62 E-11$ & $4.94 \mathrm{E}-06$ & $1.44 \mathrm{E}-07$ & $2.87 E-08$ & $3.81 \mathrm{E}-07$ & $82 E-07$ & $07 E-06$ & $.84 E-06$ \\
\hline $.84 \mathrm{E}-11$ & $4.95 E-06$ & 土.尹U & $2.90 E-08$ & . & ו & 年 & $.85 E-06$ \\
\hline • & $4.97 \mathrm{E}-06$ & 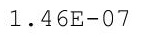 & $2.93 E-08$ & r & t & 年 & . \\
\hline-11 & $E-06$ & $E-07$ & $E-08$ & 7 & 7 & 6 & -06 \\
\hline-11 & $E-06$ & $E-07$ & $E-08$ & 7 & 7 & 6 & $7 E-06$ \\
\hline $75 E-11$ & $1 E-06$ & $E-07$ & 08 & 7 & 7 & 6 & $38 \mathrm{E}-06$ \\
\hline $.99 \mathrm{E}-11$ & $5.03 E-06$ & $1.50 \mathrm{E}-07$ & $3.05 E-08$ & $3.95 \mathrm{E}-07$ & $.06 \mathrm{E}-07$ & $10 E-06$ & $.89 \mathrm{E}-06$ \\
\hline $24 E-11$ & $5.04 \mathrm{E}-06$ & . & & & & & $.025-2$ \\
\hline & & & & & & & \\
\hline $75 F-11$ & & & & & & & he \\
\hline 1 & 5 & 5 & 8 & & 7 & 6 & 26 \\
\hline & & & & & -07 & -06 & \\
\hline $56 \mathrm{E}-11$ & $E-06$ & $55 E-07$ & 08 & 7 & & & -06 \\
\hline 11 & & tis & & & & & - e \\
\hline & & & & $.15 E-07$ & & & $.95 E-06$ \\
\hline $.42 E-11$ & & 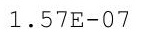 & 0 & 1 & & & 0 \\
\hline $0.7 \angle E-11$ & & & 0 & - & 7 & 6 & the \\
\hline 11 & 06 & $E-07$ & 08 & 07 & 07 & 06 & -06 \\
\hline $.34 E-11$ & $5.20 E-06$ & 1. $60 \mathrm{E}-07$ & $.42 E-08$ & $4.25 E-07$ & 7. $58 \mathrm{E}-07$ & $1.16 \mathrm{E}-06$ & $1.97 \mathrm{E}-06$ \\
\hline
\end{tabular}


RESRAD-OFFSITE, Version 2.5

Title : RESRAD-OFFSITE External Gamma, Inhalation, and Soil Ingestion for Offsite Reside File : PBA-1_TC99-DOE-5-1.ROF

Summary of dose at graphical times, reptition 3 (continued)

Time

Years

$4.48 \mathrm{E}+02$

$4.49 \mathrm{E}+02$

$4.49 \mathrm{E}+02$

$4.50 \mathrm{E}+02$

$4.50 \mathrm{E}+02$

$4.51 \mathrm{E}+02$

4. $51 \mathrm{E}+02$

4. $52 \mathrm{E}+02$

4. $52 \mathrm{E}+02$

4. $53 \mathrm{E}+02$

4. $53 \mathrm{E}+02$

4. $54 \mathrm{E}+02$

$4.54 \mathrm{E}+02$

4. $55 \mathrm{E}+02$

4. $55 \mathrm{E}+02$

4. $56 \mathrm{E}+02$

$4.56 \mathrm{E}+02$

4. $57 \mathrm{E}+02$

$4.57 \mathrm{E}+02$

$4.58 \mathrm{E}+02$

$4.58 \mathrm{E}+02$

$4.59 \mathrm{E}+02$

$4.59 \mathrm{E}+02$

$4.60 \mathrm{E}+02$

$4.60 \mathrm{E}+02$

$4.61 \mathrm{E}+02$

4. $61 \mathrm{E}+02$

$4.62 \mathrm{E}+02$

4. $62 \mathrm{E}+02$

$4.63 E+02$

$4.63 \mathrm{E}+02$

$4.64 \mathrm{E}+02$

$4.65 \mathrm{E}+02$

$4.65 \mathrm{E}+02$

$4.66 \mathrm{E}+02$

$4.66 \mathrm{E}+02$

$4.67 \mathrm{E}+02$

$4.67 \mathrm{E}+02$

$4.68 \mathrm{E}+02$

$4.68 \mathrm{E}+02$

$4.69 \mathrm{E}+02$

$4.69 \mathrm{E}+02$

$4.70 \mathrm{E}+02$

$4.70 \mathrm{E}+02$

$4.71 \mathrm{E}+02$

$4.71 E+02$
Dose statistics at graphical times, mrem/yr

\begin{tabular}{|c|c|c|c|c|c|c|c|}
\hline inimum & aximum & Mean & ledian & $90 \%$ & $5 \%$ & $97.5 \%$ & $\%$ \\
\hline 1 & -06 & $E-07$ & $E-08$ & $8 E-07$ & 07 & 06 & 0 \\
\hline 11 & -06 & $2 E-07$ & $E-08$ & 7 & 07 & 06 & -06 \\
\hline $3 E-10$ & $E-06$ & $3 E-07$ & $3 E-08$ & $3 E-07$ & 07 & 06 & -06 \\
\hline $5 E-10$ & $E-06$ & $E-07$ & $E-08$ & 7 & 7 & 6 & -06 \\
\hline-10 & 06 & 7 & & & 7 & 06 & $01 E-06$ \\
\hline-10 & -06 & $E-07$ & .08 & 07 & T & 06 & -06 \\
\hline $.17 \mathrm{E}-10$ & -06 & T & -08 & i & 1 & -06 & -06 \\
\hline $.20 E-10$ & $1 E-06$ & (4) & $0 E-08$ & $4.46 E-07$ & & -06 & $03 E-06$ \\
\hline 10 & 06 & - & 08 & 07 & 7 & -06 & -06 \\
\hline $.28 \mathrm{E}-10$ & $E-06$ & $59 E-07$ & -08 & $E-07$ & 7 & -06 & $E-06$ \\
\hline-10 & -06 & 7 & 8 & 7 & & 06 & $E-06$ \\
\hline-10 & & 7 & & & & & -06 \\
\hline $.38 E-10$ & $3 E-06$ & $1 \cdot 12 \mathrm{E}-01$ & $8 E-08$ & $4.59 \mathrm{E}-07$ & - & -06 & $E-06$ \\
\hline $41 \mathrm{E}-10$ & -06 & ו & -08 & . & & -06 & $E-06$ \\
\hline $5-10$ & 06 & 1 & 08 & 07 & 1 & 06 & -06 \\
\hline $3 E-10$ & -06 & 土. & -08 & 7 & 7 & -06 & -06 \\
\hline $.52 E-10$ & $E-06$ & $5 E-07$ & $1 E-08$ & $8 E-07$ & $26 \mathrm{E}-07$ & $E-06$ & $9 \mathrm{E}-06$ \\
\hline-10 & $E-06$ & $6 E-07$ & $4 \mathrm{E}-08$ & $E-07$ & 07 & -06 & $E-06$ \\
\hline 10 & 06 & 1 & 08 & 7 & & 6 & -06 \\
\hline $.62 E-10$ & -06 & 1. & -08 & -07 & 17 & 06 & -06 \\
\hline $.66 \mathrm{E}-10$ & -06 & T & -08 & -07 & & 0 & -06 \\
\hline $69 \mathrm{E}-10$ & -06 & 1.00 & 08 & 07 & & 6 & -06 \\
\hline $.73 E-10$ & $5.52 \mathrm{E}-06$ & t. & $4.24 \mathrm{E}-08$ & $4.83 E-07$ & 1 & $.29 E-06$ & $.14 \mathrm{E}-06$ \\
\hline $.77 E-10$ & $4 E-06$ & $1.82 \mathrm{E}-$ & $3 E-08$ & $86 E-07$ & 7 & $29 E-06$ & $15 E-06$ \\
\hline 10 & $E-06$ & $3 E-07$ & 08 & & & 06 & -06 \\
\hline$E-10$ & 06 & 7 & 08 & 07 & & & 06 \\
\hline $9 \mathrm{E}-10$ & $E-06$ & $E-01$ & -08 & -07 & & - & -06 \\
\hline $.93 E-10$ & $5.59 \mathrm{E}-06$ & $1.86 \mathrm{E}-07$ & $4.45 E-08$ & $4.96 \mathrm{E}-07$ & $8.68 \mathrm{E}-07$ & $.31 E-06$ & $18 E-06$ \\
\hline $.97 E-10$ & . & 土. & $9 E-08$ & 1. & I & 0 & $19 E-06$ \\
\hline $.01 \mathrm{E}-10$ & $62 E-06$ & t. & (4. & 更 & ( & 0 & $19 \mathrm{E}-0$ \\
\hline 10 & $E-06$ & $9 E-07$ & $E-08$ & 7 & 7 & 6 & -06 \\
\hline-10 & $E-06$ & $E-07$ & $E-08$ & $6 E-07$ & 7 & 6 & 06 \\
\hline $.13 \mathrm{E}-10$ & $5.66 \mathrm{E}-06$ & $1.91 \mathrm{E}-07$ & $6 \mathrm{E}-08$ & $8 E-07$ & 7 & -06 & $22 \mathrm{E}-06$ \\
\hline $.17 \mathrm{E}-10$ & $5.67 \mathrm{E}-06$ & $1.92 \mathrm{E}-07$ & $4.71 E-08$ & $5.10 \mathrm{E}-07$ & $8.93 E-07$ & $.33 E-06$ & $.22 E-06$ \\
\hline $.22 \mathrm{E}-10$ & $5.68 \mathrm{E}-06$ & 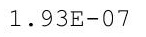 & & & & & $235-00$ \\
\hline 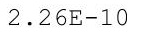 & & & & & & & \\
\hline $315-10$ & 6 & & & & & & 0 \\
\hline 0 & 6 & 7 & 8 & 7 & 7 & 6 & -06 \\
\hline$E-10$ & $E-06$ & $5-07$ & 08 & 07 & 7 & -06 & $6 E-06$ \\
\hline $.44 \mathrm{E}-10$ & $E-06$ & $E-07$ & 08 & 7 & & & -06 \\
\hline $9 E-10$ & & د・r & & -5 & & & $\cdot 28 E-00$ \\
\hline $.54 \mathrm{E}-10$ & & $.00 E-07$ & & $.29 E-07$ & & & $.28 E-06$ \\
\hline $2585-10$ & & 2 & 0 & 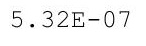 & & & $2.29 \mathrm{E}-06$ \\
\hline $2625-10$ & & & & $35 \mathrm{E}$ & 7 & 0 & . \\
\hline-10 & 5.8 & 2. & -08 & 07 & 07 & 66 & 06 \\
\hline $.73 E-10$ & $5.83 E-06$ & $2.04 E-07$ & $.19 \mathrm{E}-08$ & $5.42 \mathrm{E}-07$ & $9.55 E-07$ & 1. 39E-06 & $2.31 \mathrm{E}-06$ \\
\hline
\end{tabular}


RESRAD-OFFSITE, Version 2.5

Title : RESRAD-OFFSITE External Gamma, Inhalation, and Soil Ingestion for offsite Reside File : PBA-1_TC99-DOE-5-1.ROF

Summary of dose at graphical times, reptition 3 (continued)

Time

Years

$4.72 \mathrm{E}+02$

$4.72 \mathrm{E}+02$

$4.73 \mathrm{E}+02$

$4.73 \mathrm{E}+02$

$4.74 \mathrm{E}+02$

$4.74 \mathrm{E}+02$

$4.75 \mathrm{E}+02$

$4.75 \mathrm{E}+02$

$4.76 \mathrm{E}+02$

$4.76 \mathrm{E}+02$

$4.77 \mathrm{E}+02$

$4.77 \mathrm{E}+02$

$4.78 \mathrm{E}+02$

$4.78 \mathrm{E}+02$

$4.79 \mathrm{E}+02$

$4.79 \mathrm{E}+02$

$4.80 \mathrm{E}+02$

$4.80 \mathrm{E}+02$

$4.81 \mathrm{E}+02$

$4.81 \mathrm{E}+02$

$4.82 \mathrm{E}+02$

$4.82 \mathrm{E}+02$

$4.83 \mathrm{E}+02$

$4.83 \mathrm{E}+02$

$4.84 \mathrm{E}+02$

$4.84 \mathrm{E}+02$

$4.85 \mathrm{E}+02$

$4.86 \mathrm{E}+02$

$4.86 \mathrm{E}+02$

$4.87 \mathrm{E}+02$

$4.87 \mathrm{E}+02$

$4.88 \mathrm{E}+02$

$4.88 \mathrm{E}+02$

$4.89 \mathrm{E}+02$

$4.89 \mathrm{E}+02$

$4.90 \mathrm{E}+02$

$4.90 \mathrm{E}+02$

$4.91 \mathrm{E}+02$

$4.91 \mathrm{E}+02$

$4.92 \mathrm{E}+02$

$4.92 \mathrm{E}+02$

$4.93 \mathrm{E}+02$

4. $93 \mathrm{E}+02$

$4.94 \mathrm{E}+02$

$4.94 \mathrm{E}+02$

$4.95 \mathrm{E}+02$
Dose statistics at graphical times, mrem/yr

\begin{tabular}{|c|c|c|c|c|c|c|c|}
\hline inimum & aximum & Mean & ledian & $90 \%$ & $5 \%$ & $97.5 \%$ & $\%$ \\
\hline 0 & 6 & $E-07$ & -08 & -07 & 7 & 06 & 0 \\
\hline-10 & $E-06$ & $E-07$ & $3 E-08$ & 7 & 07 & 06 & -06 \\
\hline$E-10$ & $E-06$ & $7 E-07$ & -08 & $2 E-07$ & 7 & 06 & -06 \\
\hline$E-10$ & $38 E-06$ & $08=5-5$ & 8 & 7 & & & -06 \\
\hline $98 E-10$ & -06 & -07 & 88 & 7 & 7 & 06 & $35 E-06$ \\
\hline-10 & 06 & -07 & -08 & 造- & L- T & $E-06$ & $6 E-06$ \\
\hline 10 & 06 & 要 & -08 & $5 E-07$ & (1) & -06 & -0 \\
\hline$E-10$ & $5.93 E-06$ & 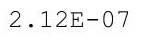 & $9 E-08$ & & & -06 & $37 E-06$ \\
\hline 10 & 06 & 1 & 08 & 7 & 6 & 06 & -06 \\
\hline $25 E-10$ & $5 E-06$ & $2.14 \mathrm{E}-07$ & $E-08$ & $6 E-07$ & 06 & -06 & $39 \mathrm{E}-06$ \\
\hline-10 & -06 & 7 & 8 & & & 06 & $E-06$ \\
\hline-10 & & & & & & & -06 \\
\hline $.42 E-10$ & $9 E-06$ & $2.17 \mathrm{~L}$ & $E-08$ & $7 \mathrm{E}-\mathrm{U}$ & $1.0<\mathrm{E}-06$ & -06 & $E-0$ \\
\hline $48 \mathrm{E}-10$ & -06 & i & -08 & T & & -06 & -06 \\
\hline 10 & 06 & r & 08 & 07 & 0 & 06 & -06 \\
\hline $.60 \mathrm{E}-10$ & -06 & 2.2 & -08 & -07 & 06 & -06 & -06 \\
\hline $.66 \mathrm{E}-10$ & $4 E-06$ & $2.21 E-07$ & $1 E-08$ & $1 E-07$ & $4 E-06$ & $.49 \mathrm{E}-06$ & $44 E-06$ \\
\hline-10 & $5 E-06$ & $.22 E-07$ & $5 E-08$ & 7 & $E-06$ & $E-06$ & $45 E-06$ \\
\hline 10 & -06 & 1 & 08 & 1 & & 6 & -06 \\
\hline $84 \mathrm{E}-10$ & -06 & 1 & -08 & 7 & & -06 & -06 \\
\hline $90 \mathrm{E}-10$ & -06 & (- & -08 & & & 0 & -06 \\
\hline $.96 \mathrm{E}-10$ & DE-06 & $2.26 \mathrm{E}-$ & -08 & 07 & 06 & 06 & -06 \\
\hline $.03 E-10$ & $6.11 \mathrm{E}-06$ & $2=28=-07$ & $6 E-08$ & $19 E-07$ & $1975-\cap 6$ & $52 E-06$ & $48 E-06$ \\
\hline$E-10$ & $2 E-06$ & $2.29 \mathrm{E}-07$ & $0 \mathrm{E}-08$ & $22 \mathrm{E}-07$ & $1.08 \mathrm{E}-06$ & $53 E-06$ & $49 \mathrm{E}-06$ \\
\hline 10 & $E-06$ & $30 E-07$ & 08 & 07 & & 6 & -06 \\
\hline-10 & 06 & 7 & 08 & 07 & & & 06 \\
\hline $.29 \mathrm{E}-10$ & $6.16 \mathrm{E}-06$ & $2.5 \angle D-4$ & -08 & 7 & & 6 & 06 \\
\hline $.35 E-10$ & $6.17 \mathrm{E}-06$ & $2.33 E-07$ & $6.49 E-08$ & $6.32 \mathrm{E}-07$ & $1.09 \mathrm{E}-06$ & $.55 E-06$ & $.52 E-06$ \\
\hline 10 & 6 & 每 & 8 & 7 & 年 & . & -06 \\
\hline $.49 \mathrm{E}-10$ & $19 E-06$ & r & D -0 & r & - & 0 & ل \\
\hline 0 & $F-06$ & 365 & $3 E-08$ & & & 6 & $E-06$ \\
\hline-10 & -06 & $2.37 E-07$ & $E-08$ & 7 & & $E-06$ & $55 E-06$ \\
\hline$D-10$ & $3 E-06$ & $3 E-07$ & 08 & 7 & 6 & 6 & $6 E E-06$ \\
\hline $.77 \mathrm{E}-10$ & $6.24 E-06$ & $2.39 \mathrm{E}-01$ & $6.77 \mathrm{E}-08$ & $6.49 \mathrm{E}-07$ & $1.12 \mathrm{E}-06$ & $.58 \mathrm{E}-06$ & $.56 E-06$ \\
\hline $84 E-10$ & $6.25 E-06$ & 2.900 t & & & & & .JIL- \\
\hline-0 & & & & & & & \\
\hline 0 & $6.27 E-06$ & & & & & & 06 \\
\hline 0 & & & & & 6 & 6 & 06 \\
\hline-10 & & & & 07 & -06 & -06 & \\
\hline $1 \mathrm{E}-10$ & $E-06$ & $5-07$ & 08 & 7 & 6 & & -06 \\
\hline 10 & & $2.4 / L-U 1$ & & ( & & & . $025-06$ \\
\hline 0 & & 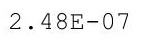 & & 1 & & & -00 \\
\hline$\triangle \wedge$ F 10 & & 2 & & 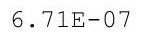 & 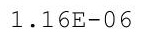 & & ste \\
\hline 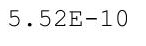 & 0 & 0 & 8 & 7 & 6 & 6 & 0 \\
\hline$E-10$ & $E-06$ & -07 & 08 & 07 & 1 . & $E-06$ & -06 \\
\hline $68 E-10$ & $6.37 E-06$ & $2.53 E-07$ & $7.35 E-08$ & $5.78 \mathrm{E}-07$ & $1.17 \mathrm{E}-06$ & $1.65 E-06$ & $2.66 \mathrm{E}-06$ \\
\hline
\end{tabular}


RESRAD-OFFSITE, Version 2.5

Title : RESRAD-OFFSITE External Gamma, Inhalation, and Soil Ingestion for offsite Reside File : PBA-1_TC99-DOE-5-1.ROF

Summary of dose at graphical times, reptition 3 (continued)

Time

Years

4. $95 \mathrm{E}+02$

$4.96 \mathrm{E}+02$

$4.96 \mathrm{E}+02$

$4.97 \mathrm{E}+02$

4. $97 \mathrm{E}+02$

4. $98 \mathrm{E}+02$

$4.98 \mathrm{E}+02$

4. $99 \mathrm{E}+02$

4. $99 \mathrm{E}+02$

$5.00 \mathrm{E}+02$

$5.00 \mathrm{E}+02$

$5.01 \mathrm{E}+02$

$5.01 \mathrm{E}+02$

$5.02 \mathrm{E}+02$

$5.02 \mathrm{E}+02$

$5.03 E+02$

$5.03 E+02$

$5.04 \mathrm{E}+02$

$5.04 \mathrm{E}+02$

$5.05 \mathrm{E}+02$

$5.06 \mathrm{E}+02$

$5.06 \mathrm{E}+02$

$5.07 \mathrm{E}+02$

$5.07 \mathrm{E}+02$

$5.08 \mathrm{E}+02$

$5.08 \mathrm{E}+02$

$5.09 \mathrm{E}+02$

$5.09 \mathrm{E}+02$

$5.10 \mathrm{E}+02$

$5.10 \mathrm{E}+02$

$5.11 \mathrm{E}+02$

$5.11 \mathrm{E}+02$

$5.12 \mathrm{E}+02$

$5.12 \mathrm{E}+02$

$5.13 \mathrm{E}+02$

$5.13 \mathrm{E}+02$

$5.14 \mathrm{E}+02$

$5.14 \mathrm{E}+02$

$5.15 \mathrm{E}+02$

$5.15 \mathrm{E}+02$

$5.16 \mathrm{E}+02$

$5.16 \mathrm{E}+02$

$5.17 \mathrm{E}+02$

$5.17 \mathrm{E}+02$

$5.18 \mathrm{E}+02$

$5.18 \mathrm{E}+02$

Dose statistics at graphical times, mrem/yr

\begin{tabular}{|c|c|c|c|c|c|c|c|}
\hline inimum & aximum & Mean & ledian & $0 \%$ & $5 \%$ & $97.5 \%$ & \\
\hline 10 & -06 & $4 E-07$ & $E-08$ & $0 E-07$ & $1.18 \mathrm{E}-06$ & $1.65 \mathrm{E}-06$ & $E-0$ \\
\hline 10 & 06 & -07 & 8 & 7 & 6 & 06 & -06 \\
\hline 10 & -06 & $E-07$ & .08 & $E-07$ & 6 & 06 & -06 \\
\hline-10 & 06 & 1 & & & & & -06 \\
\hline $.09 E-10$ & -06 & 7 & & & 06 & $.67 E-06$ & $71 E-06$ \\
\hline-10 & -06 & -07 & -08 & 71 & -06 & -06 & $71 E-06$ \\
\hline 0 & 06 & 7 & 8 & $6.97 \mathrm{E}-07$ & 6 & -06 & 0 \\
\hline & 06 & 1 & 08 & & 年 & 66 & 06 \\
\hline 10 & 06 & 1 & 08 & 7 & 6 & 06 & -06 \\
\hline $.52 \mathrm{E}-10$ & $48 \mathrm{E}-06$ & $.64 \mathrm{E}-07$ & $2 \mathrm{E}-08$ & $7 E-07$ & $.21 E-06$ & -06 & $74 E-06$ \\
\hline-10 & -06 & 7 & 8 & & 6 & 06 & $75 E-06$ \\
\hline-10 & 06 & 7 & 08 & & & -06 & $76 E-06$ \\
\hline$E-10$ & $E-06$ & +01 & $E-08$ & $8 \pm-01$ & 00 & -06 & -0 \\
\hline 10 & 06 & $9 E-07$ & 8 & 7 & 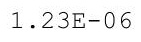 & 0 & 0 \\
\hline 10 & 06 & $r$ & 08 & 7 & & o & -06 \\
\hline $.07 E-10$ & -06 & $-x_{1}$ & 8 & 7 & 6 & 06 & -06 \\
\hline $.16 \mathrm{E}-10$ & $5 E-06$ & $2.72 \mathrm{E}-07$ & $4 \mathrm{E}-08$ & $32 E-07$ & $1.24 \mathrm{E}-06$ & $E-06$ & $.80 E-06$ \\
\hline-10 & $E-06$ & $.73 E-07$ & $0 E-08$ & $5 E-07$ & $24 E-06$ & $.74 E-06$ & $80 E-06$ \\
\hline-10 & -06 & 1 & 08 & 1 & 10 & -06 & $8-0$ \\
\hline 10 & -06 & 1 & 08 & 1 & 6 & -06 & -06 \\
\hline 0 & 6 & $2.77 \mathrm{E}-07$ & & & & 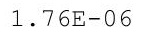 & 26 \\
\hline-10 & 06 & $2.78 \mathrm{E}-07$ & 8 & 7 & . & 6 & 06 \\
\hline$E-10$ & $E-06$ & $9 \mathrm{E}-$ & 8 & 7 & 261 & -06 & $84 E-06$ \\
\hline$E-10$ & $.62 E-06$ & $2.80 \mathrm{E}-07$ & $6 \mathrm{E}-08$ & $6 \mathrm{E}-07$ & $1.27 \mathrm{E}-06$ & $.78 E-06$ & $85 \mathrm{E}-06$ \\
\hline-10 & $3 E-06$ & $81 \mathrm{~F}-07$ & $E-08$ & $E-07$ & & $78 \mathrm{~F}-06$ & $85 \mathrm{E}-06$ \\
\hline 10 & & 7 & & & & & -06 \\
\hline & & & & & 6 & 6 & -06 \\
\hline $26 \mathrm{E}-10$ & $66 E-06$ & $2.00 \mathrm{D}-1$ & $3 E-08$ & $0 E-07$ & 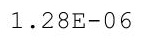 & $.80 E-06$ & $88 E-06$ \\
\hline 10 & 6 & ( & $9 E-08$ & 7 & cot & 0 & $88 E-06$ \\
\hline 0 & - & 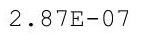 & $16 E-08$ & - & - & 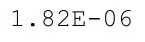 & - \\
\hline-10 & $69 F-06$ & $2.89 \mathrm{E}-07$ & $3 E-08$ & & & $82 E-06$ & $0 E-06$ \\
\hline 10 & $F-06$ & 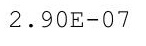 & $F-08$ & & & & 06 \\
\hline & & & & & & & \\
\hline $90 E-10$ & $6.72 E-06$ & $2.92 \mathrm{E}-07$ & $3 E-08$ & $1 E-07$ & $\perp \cdot J \perp 5$ & -06 & $92 \mathrm{E}-06$ \\
\hline $01 \mathrm{E}-10$ & $3 E-06$ & 2.000 t & & $25-21$ & & & $23 \mathrm{E}-\mathrm{C}$ \\
\hline & & & & & & & \\
\hline & 6 & & & $8.00 E-07$ & & & he \\
\hline 0 & & & & & & & 06 \\
\hline & & & & -07 & -06 & -06 & .06 \\
\hline $3 E-10$ & $7 E-06$ & $.99 E-07$ & 08 & 7 & 6 & 6 & $6 \mathrm{E}-06$ \\
\hline 10 & & L- t & 08 & 1 & & & -0 \\
\hline & 0 & 等 & & 1 & & & 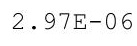 \\
\hline & & 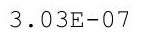 & 1 & 1 & $34 E-06$ & $.00 \mathrm{E}-06$ & ser \\
\hline+ & . & 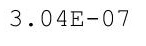 & -0 & . $2<1$ & $1.34 \mathrm{E}-06$ & . & 皮 \\
\hline $2 E-09$ & $6.82 E-06$ & $5 E-07$ & $E-07$ & 07 & 1.3 & -06 & $3.00 E-06$ \\
\hline $.03 E-09$ & $6.83 E-06$ & $.07 E-07$ & $.03 E-07$ & $3.29 \mathrm{E}-07$ & $1.35 \mathrm{E}-06$ & $1.89 \mathrm{E}-06$ & $3.00 \mathrm{E}-06$ \\
\hline
\end{tabular}


RESRAD-OFFSITE, Version 2.5

Title : RESRAD-OFFSITE External Gamma, Inhalation, and Soil Ingestion for offsite Reside File : PBA-1_TC99-DOE-5-1.ROF

Summary of dose at graphical times, reptition 3 (continued)

Time

Years

$5.19 \mathrm{E}+02$

$5.19 \mathrm{E}+02$

$5.20 \mathrm{E}+02$

$5.20 \mathrm{E}+02$

$5.21 \mathrm{E}+02$

$5.21 \mathrm{E}+02$

$5.22 \mathrm{E}+02$

$5.22 \mathrm{E}+02$

$5.23 \mathrm{E}+02$

$5.23 \mathrm{E}+02$

$5.24 \mathrm{E}+02$

$5.24 \mathrm{E}+02$

$5.25 \mathrm{E}+02$

$5.26 \mathrm{E}+02$

$5.26 \mathrm{E}+02$

$5.27 \mathrm{E}+02$

$5.27 \mathrm{E}+02$

$5.28 \mathrm{E}+02$

$5.28 \mathrm{E}+02$

$5.29 \mathrm{E}+02$

$5.29 \mathrm{E}+02$

$5.30 \mathrm{E}+02$

$5.30 \mathrm{E}+02$

$5.31 \mathrm{E}+02$

$5.31 \mathrm{E}+02$

$5.32 \mathrm{E}+02$

$5.32 \mathrm{E}+02$

$5.33 \mathrm{E}+02$

$5.33 \mathrm{E}+02$

$5.34 \mathrm{E}+02$

$5.34 \mathrm{E}+02$

$5.35 \mathrm{E}+02$

$5.35 \mathrm{E}+02$

$5.36 \mathrm{E}+02$

$5.36 \mathrm{E}+02$

$5.37 \mathrm{E}+02$

$5.37 \mathrm{E}+02$

$5.38 \mathrm{E}+02$

$5.38 \mathrm{E}+02$

$5.39 \mathrm{E}+02$

$5.39 \mathrm{E}+02$

$5.40 \mathrm{E}+02$

$5.40 \mathrm{E}+02$

$5.41 \mathrm{E}+02$

$5.41 \mathrm{E}+02$

$5.42 \mathrm{E}+02$

Dose statistics at graphical times, mrem/yr

\begin{tabular}{|c|c|c|c|c|c|c|c|}
\hline$m$ & $\operatorname{axi}$ & a & edian & & & & \\
\hline 09 & $6.84 \mathrm{E}-06$ & $3.08 E-07$ & $1.03 E-07$ & $8.32 \mathrm{E}-07$ & $.35 E-06$ & $.90 \mathrm{E}-06$ & $3.01 E-06$ \\
\hline 9 & 06 & -07 & 7 & 7 & $.35 E-06$ & $.90 \mathrm{E}-06$ & -06 \\
\hline $.07 E-09$ & $.86 \mathrm{E}-06$ & $.10 \mathrm{E}-07$ & $.05 E-07$ & $.39 \mathrm{E}-07$ & $36 \mathrm{E}-06$ & -06 & $02 E-06$ \\
\hline $08 F-09$ & 06 & -07 & 061 & $42 \mathrm{~F}$ & $36 \mathrm{~F}-$ & -06 & $3 F-06$ \\
\hline 9 & 6 & प्रा & 7 & 07 & 6 & 06 & 06 \\
\hline 09 & 06 & & & & & & -06 \\
\hline $12 \mathrm{E}-09$ & $89 E-06$ & & & $\begin{array}{c}-32 \mathrm{E}-01 \\
\end{array}$ & & & $E-06$ \\
\hline $.13 E-09$ & 06 & 7 & & $0 \pm-01$ & -06 & -06 & -06 \\
\hline $.14 \mathrm{E}-09$ & $91 E-06$ & -07 & 07 & $59 E-07$ & $8 E-06$ & -06 & $E-06$ \\
\hline $16 E-09$ & -06 & -07 & 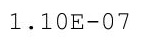 & 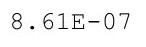 & 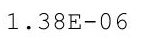 & -06 & 06 \\
\hline $17 F-09$ & $92 E-06$ & $20 E-07$ & $11 \mathrm{~F}_{\mathrm{H}}$ & $60 \mathrm{~F}-\mathrm{s}-2$ & $39=-8$ & -06 & -06 \\
\hline $19 E-09$ & $.93 E-06$ & 7 & 7 & 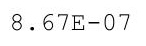 & $F$ & 06 & -06 \\
\hline $20 E-09$ & -06 & 7 & & & & & $E-06$ \\
\hline $.21 E-09$ & $6.95 \mathrm{E}-06$ & $.24 \mathrm{E}-07$ & $.13 \mathrm{E}-07$ & $3.72 \mathrm{E}-07$ & $.40 \mathrm{E}-06$ & $.97 \mathrm{E}-06$ & $E-06$ \\
\hline $.23 E-09$ & $6.96 \mathrm{E}-06$ & $.25 E-07$ & & $.75 E-07$ & $.40 \mathrm{E}-06$ & $4-0$ & -06 \\
\hline $24 E-09$ & 6 & 7 & & 2 & -1 & 0 & -06 \\
\hline Dr & & & & & & & 06 \\
\hline & & & & $883 F-07$ & & & -06 \\
\hline $28 E-09$ & $.99 E-06$ & $30 E-07$ & 07 & $6 E-07$ & $42 F-06$ & -06 & $2 E-06$ \\
\hline $30 E-09$ & $0 E-06$ & $E-07$ & $8 E-07$ & $9 \mathrm{~F}-07$ & $2 F-06$ & $E-06$ & $3 E-06$ \\
\hline $31 E-09$ & -06 & -07 & & $8.93 E-07$ & & -00 & -06 \\
\hline 09 & & & & & & & -06 \\
\hline & & & & & & & 06 \\
\hline $36 F-09$ & & & & & & & -06 \\
\hline $37 E-09$ & $04 \mathrm{E}-$ & 07 & $22 E-07$ & 7 & $45 E-$ & 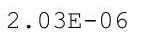 & -06 \\
\hline $39 E-09$ & $.05 E-06$ & $.39 E-07$ & $1.23 E-07$ & - & $45 E-$ & $.03 E-06$ & $6 \mathrm{E}-06$ \\
\hline $40 E-09$ & $.05 E-06$ & $40 E-07$ & $.24 \mathrm{E}-0$ & م & $45 \mathrm{E}-0$ & $E-06$ & $7 F-06$ \\
\hline & & & & & & & $E-06$ \\
\hline & & & & & & & -06 \\
\hline (15) & & & & & & & 06 \\
\hline $46 \mathrm{E}-09$ & $.08 E-06$ & $.46 \mathrm{E}-07$ & 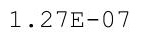 & . & $.47 E-06$ & 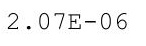 & $19 \mathrm{E}-06$ \\
\hline $48 E-09$ & $7.09 E-06$ & $3.47 E-07$ & 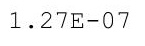 & (-) & the & & $0 E-06$ \\
\hline $50 E-09$ & & T & & & & & $F-06$ \\
\hline 09 & & & & & & & 06 \\
\hline $.53 E-09$ & $.11 E-06$ & $.51 E-07$ & & & & & $21 E-06$ \\
\hline $.55 E-09$ & $.12 \mathrm{E}-06$ & $3.52 \mathrm{E}-07$ & $1.31 E-07$ & $9.51 \mathrm{E}-07$ & $49 E-06$ & $.10 E-00$ & $22 E-06$ \\
\hline $.56 E-09$ & $\cdot 13 E-06$ & $3.53 E-01$ & 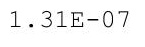 & $9.04 \mathrm{~L}-1$ & 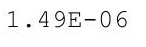 & & $\cdot 2 \angle E-U 6$ \\
\hline $58 E-09$ & $.14 \mathrm{E}-06$ & $.55 \mathrm{E}-07$ & $\begin{array}{ll}0 \\
\text {. }\end{array}$ & & & & $23 E-0$ \\
\hline 9 & 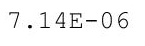 & 7 & +.0 & 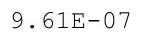 & - & 6 & 06 \\
\hline & 6 & & & & & & 06 \\
\hline $63 E-09$ & $.16 \mathrm{E}-06$ & -07 & & & & & $24 E-06$ \\
\hline $65 E-09$ & $.16 \mathrm{E}-06$ & $.60 E-07$ & $1.36 \mathrm{E}-07$ & 7 & 6 & $2.15 \mathrm{E}-06$ & $.25 E-06$ \\
\hline $6 E-09$ & $.17 \mathrm{E}-06$ & $.61 \mathrm{E}-07$ & & & & & 06 \\
\hline & $1.18 \mathrm{E}-06$ & . & I.JIL-Ut & $9.17 \mathrm{E}-01$ & . & $2.16 \mathrm{E}-06$ & $3.26 \mathrm{E}-06$ \\
\hline 9 & 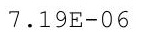 & .0नि & $\begin{array}{c}1.00 \mathrm{H} \\
\end{array}$ & $9.00 \mathrm{D}-1$ & $.53 E-06$ & $2.17 E-06$ & 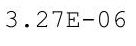 \\
\hline$E-0$ & $19 E-06$ & $E-07$ & $E-07$ & $84 \mathrm{E}-07$ & $53 E-06$ & $.17 E-06$ & $\cdot 21$ \\
\hline
\end{tabular}


RESRAD-OFFSITE, Version 2.5

Title : RESRAD-OFFSITE External Gamma, Inhalation, and Soil Ingestion for Offsite Reside File : PBA-1_TC99-DOE-5-1.ROF

Summary of dose at graphical times, reptition 3 (continued)

Time

Years

$5.42 \mathrm{E}+02$

$5.43 \mathrm{E}+02$

$5.43 \mathrm{E}+02$

$5.44 \mathrm{E}+02$

$5.44 \mathrm{E}+02$

$5.45 \mathrm{E}+02$

$5.46 \mathrm{E}+02$

$5.46 \mathrm{E}+02$

$5.47 \mathrm{E}+02$

$5.47 \mathrm{E}+02$

$5.48 \mathrm{E}+02$

$5.48 \mathrm{E}+02$

$5.49 \mathrm{E}+02$

$5.49 \mathrm{E}+02$

$5.50 \mathrm{E}+02$

$5.50 \mathrm{E}+02$

$5.51 \mathrm{E}+02$

$5.51 \mathrm{E}+02$

$5.52 \mathrm{E}+02$

$5.52 \mathrm{E}+02$

$5.53 \mathrm{E}+02$

$5.53 \mathrm{E}+02$

$5.54 \mathrm{E}+02$

$5.54 \mathrm{E}+02$

$5.55 \mathrm{E}+02$

$5.55 \mathrm{E}+02$

$5.56 \mathrm{E}+02$

$5.56 \mathrm{E}+02$

$5.57 \mathrm{E}+02$

$5.57 \mathrm{E}+02$

$5.58 \mathrm{E}+02$

$5.58 \mathrm{E}+02$

$5.59 \mathrm{E}+02$

$5.59 \mathrm{E}+02$

$5.60 \mathrm{E}+02$

$5.60 \mathrm{E}+02$

$5.61 E+02$

$5.61 \mathrm{E}+02$

$5.62 \mathrm{E}+02$

$5.62 \mathrm{E}+02$

$5.63 \mathrm{E}+02$

$5.63 \mathrm{E}+02$

$5.64 \mathrm{E}+02$

$5.64 \mathrm{E}+02$

$5.65 \mathrm{E}+02$

$5.66 \mathrm{E}+02$
Dose statistics at graphical times, mrem/yr

\begin{tabular}{|c|c|c|c|c|c|c|c|}
\hline num & aximum & Mean & ledian & \% & & $\%$ & \\
\hline $74 E-09$ & 6 & 7 & 07 & 07 & 6 & 06 & -06 \\
\hline $75 E-09$ & $.21 \mathrm{E}-06$ & $.68 \mathrm{E}-07$ & $41 E-07$ & $90 E-07$ & $1.54 \mathrm{E}-06$ & $.18 \mathrm{E}-06$ & $3.28 \mathrm{E}-06$ \\
\hline $77 \mathrm{~F}-09$ & $1 F-06$ & $69 F-07$ & $42 \mathrm{~F}-07$ & $93 F-07$ & $54 \mathrm{E}-06$ & $F-06$ & $99 F-06$ \\
\hline & 6 & 7 & & $97 E-07$ & $.55 E-06$ & 06 & -06 \\
\hline 09 & 06 & 07 & & 6 & 6 & & -06 \\
\hline $83 E-09$ & $.23 E-06$ & $73 E-07$ & & 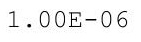 & & & -06 \\
\hline $.075-49$ & $.24 E-06$ & & 1 & $01 E-06$ & $.56 \mathrm{E}-06$ & $.21 \mathrm{E}-06$ & $31 E-06$ \\
\hline $.87 E-09$ & $25 E-06$ & $6 \mathrm{E}-07$ & $E-07$ & $01 E-06$ & $.57 \mathrm{E}-06$ & -06 & $E-06$ \\
\hline $88 E-09$ & $.25 E-06$ & $.77 \mathrm{E}-07$ & 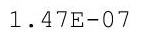 & $01 E-06$ & $.57 \mathrm{E}-06$ & -06 & $32 E-06$ \\
\hline $9 \cap F-09$ & $26 E-06$ & & & $02 F-06$ & $58 E-06$ & -06 & 6 \\
\hline Fכ & 6 & & & & & & 6 \\
\hline $.94 E-09$ & $.27 E-06$ & $E-07$ & & $3 \mathrm{~F}-$ & & 6 & -06 \\
\hline $.96 \mathrm{E}-09$ & $.28 E-06$ & $82 \mathrm{E}-07$ & $.50 \mathrm{E}-07$ & $.03 E-06$ & $1.59 \mathrm{E}-06$ & $.25 E-06$ & $34 E-06$ \\
\hline $98 E-09$ & $.28 \mathrm{E}-06$ & $E-07$ & & $3 E-$ & -06 & 00 & -06 \\
\hline & $29 E-06$ & & & & & o & -06 \\
\hline & 6 & & & F F & 6 & 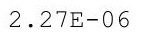 & -06 \\
\hline 5 & 6 & 07 & $154 \mathrm{~F}-07$ & F & 6 & 6 & -06 \\
\hline $06 \mathrm{~F}-09$ & $.31 E-06$ & $E-07$ & $5 \mathrm{~F}-0$ & $05 \mathrm{~F}-$ & $.61 \mathrm{E}-06$ & 0 & -06 \\
\hline $.08 E-09$ & $.32 \mathrm{E}-06$ & $90 E-07$ & $.55 E-07$ & $.05 E-06$ & $.62 E-06$ & $E-06$ & $7 E-06$ \\
\hline $.10 \mathrm{E}-09$ & $.32 E-06$ & $92 \mathrm{E}-07$ & & $.06 \mathrm{E}-0$ & $.62 \mathrm{E}-06$ & -06 & $.37 E-06$ \\
\hline & 06 & & & & 06 & 06 & -06 \\
\hline & & & & & & & 06 \\
\hline & & & & & 0 & & -06 \\
\hline $19 \mathrm{E}-$ & 06 & 7 & $6 c^{2}$ & ה7 & 6 & $2.32 E-06$ & -06 \\
\hline $21 E-09$ & $.35 E-06$ & $98 E-07$ & $61 \mathrm{E}-07$ & $07 F_{-}-0$ & $.64 \mathrm{E}-06$ & $\mathrm{~F}-0$ & $39 E-06$ \\
\hline $235-09$ & $36 E-06$ & $00 E-07$ & $61 E-07$ & $.08 \mathrm{E}-0$ & $.64 \mathrm{E}-06$ & -06 & -06 \\
\hline $5 E-09$ & $.36 E-06$ & $01 E-07$ & & $08 E-0$ & $65 E-06$ & -06 & -06 \\
\hline & & & & & & & 06 \\
\hline ג תمמ & 6 & & & & & & 06 \\
\hline $.32 E-09$ & $7.38 \mathrm{E}-06$ & $.05 E-07$ & cont & .0तa vo & $1.00 \mathrm{~L}-00$ & tro & $41 E-06$ \\
\hline $34 E-09$ & $38 E-06$ & $.07 E-07$ & (c) & -2 & $.67 E-06$ & - & $.42 E-06$ \\
\hline $36 \mathrm{E}-$ & $.39 E-06$ & $.08 E-07$ & & $10 \mathrm{E}-$ & $.67 E-06$ & $E-06$ & $E-06$ \\
\hline 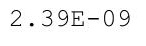 & & & & & 6 & & 06 \\
\hline $11 \mathrm{~F}-0 \mathrm{~g}$ & & & & & 6 & & -06 \\
\hline $.43 E-09$ & $.41 E-06$ & $12 \mathrm{E}-07$ & $69 E-07$ & 1.11E-06 & $1.68 E-06$ & $2.30 E-00$ & $43 E-06$ \\
\hline •. 40 - & $7.41 \mathrm{E}-06$ & $\cdot .3 E-U 1$ & - & 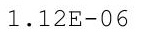 & $1.69 \mathrm{E}-06$ & 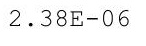 & $44 \mathrm{E}-06$ \\
\hline . & $1.4 \angle E-06$ & •.JE-U1 & 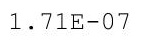 & 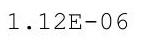 & $1.09 E-00$ & 年 & $3.445-00$ \\
\hline - & 6 & 7 & $1.72 \mathrm{E}-07$ & - & 6 & 6 & 06 \\
\hline $.53 E-09$ & & & & & & & 06 \\
\hline $55 \mathrm{~F}-09$ & $.43 E-06$ & 07 & & $.13 E-06$ & 06 & -06 & -06 \\
\hline $.57 E-09$ & $.44 \mathrm{E}-06$ & $20 E-07$ & $1.75 E-07$ & $1.13 E-06$ & 06 & 06 & $6 E-06$ \\
\hline $60 E-09$ & $.44 \mathrm{E}-06$ & 7 & 7 & 6 & 6 & & $.46 \mathrm{E}-06$ \\
\hline $0 \angle 5-0=$ & 06 & $23 E-01$ & 列 & $.14 \mathrm{E}-06$ & $1.71 \mathrm{E}-06$ & $2.425-00$ & $3.47 E-06$ \\
\hline 年 & $7.45 \mathrm{E}-06$ & • $245-01$ & . & $.14 \mathrm{E}-00$ & $1.71 \mathrm{E}-06$ & $2.42 E-06$ & $3.47 E-06$ \\
\hline $.67 E-09$ & . & & 土. & $.14 \mathrm{E}-06$ & $1.72 \mathrm{E}-06$ & & $3.47 E-06$ \\
\hline $70 E-09$ & $E-06$ & E-07 & $.80 E-07$ & $.15 E-06$ & $.72 E-06$ & $.43 E-06$ & $.48 E-06$ \\
\hline
\end{tabular}


RESRAD-OFFSITE, Version 2.5

Title : RESRAD-OFFSITE External Gamma, Inhalation, and Soil Ingestion for offsite Reside File : PBA-1_TC99-DOE-5-1.ROF

Summary of dose at graphical times, reptition 3 (continued)

Time

Years

$5.66 \mathrm{E}+02$

$5.67 \mathrm{E}+02$

$5.67 \mathrm{E}+02$

$5.68 \mathrm{E}+02$

$5.68 \mathrm{E}+02$

$5.69 \mathrm{E}+02$

$5.69 \mathrm{E}+02$

$5.70 \mathrm{E}+02$

$5.70 \mathrm{E}+02$

$5.71 \mathrm{E}+02$

$5.71 \mathrm{E}+02$

$5.72 \mathrm{E}+02$

$5.72 \mathrm{E}+02$

$5.73 \mathrm{E}+02$

$5.73 E+02$

$5.74 \mathrm{E}+02$

$5.74 \mathrm{E}+02$

$5.75 \mathrm{E}+02$

$5.75 \mathrm{E}+02$

$5.76 \mathrm{E}+02$

$5.76 \mathrm{E}+02$

$5.77 \mathrm{E}+02$

$5.77 \mathrm{E}+02$

$5.78 \mathrm{E}+02$

$5.78 \mathrm{E}+02$

$5.79 \mathrm{E}+02$

$5.79 \mathrm{E}+02$

$5.80 \mathrm{E}+02$

$5.80 \mathrm{E}+02$

$5.81 \mathrm{E}+02$

$5.81 \mathrm{E}+02$

$5.82 \mathrm{E}+02$

$5.82 \mathrm{E}+02$

$5.83 \mathrm{E}+02$

$5.83 \mathrm{E}+02$

$5.84 \mathrm{E}+02$

$5.84 \mathrm{E}+02$

$5.85 \mathrm{E}+02$

$5.85 \mathrm{E}+02$

$5.86 \mathrm{E}+02$

$5.87 \mathrm{E}+02$

$5.87 \mathrm{E}+02$

$5.88 \mathrm{E}+02$

$5.88 \mathrm{E}+02$

$5.89 \mathrm{E}+02$

$5.89 \mathrm{E}+02$
Dose statistics at graphical times, mrem/yr

\begin{tabular}{|c|c|c|c|c|c|c|c|}
\hline inimum & aximum & Mean & ledian & $0 \%$ & $5 \%$ & $97.5 \%$ & $\%$ \\
\hline 9 & -06 & $E-07$ & -07 & 06 & 6 & 6 & 0 \\
\hline 09 & -06 & 07 & 7 & 6 & 6 & 6 & -06 \\
\hline 7E-09 & $E-06$ & -07 & $3 E-07$ & $5 E-06$ & 6 & 06 & -06 \\
\hline$E-09$ & $3 E-06$ & $E-07$ & & & & 06 & -06 \\
\hline $.82 E-09$ & -06 & 7 & & & 6 & 06 & $50 E-06$ \\
\hline-09 & -06 & $E-07$ & $E-07$ & 06 & . & -06 & $0 E-06$ \\
\hline-09 & -06 & 1 & , & -06 & 06 & -06 & -0 \\
\hline $.90 E-09$ & $7.50 \mathrm{E}-06$ & 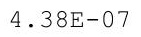 & & $1.17 \mathrm{E}-06$ & Der & -06 & -0 \\
\hline 09 & 06 & r & 1 & 06 & 6 & 06 & -06 \\
\hline $.96 \mathrm{E}-09$ & $1 E-06$ & $1 \mathrm{E}-07$ & $0 \mathrm{E}-07$ & $18 E-06$ & $.76 \mathrm{E}-06$ & -06 & -06 \\
\hline-09 & -06 & -07 & 7 & 6 & 6 & 06 & $E-06$ \\
\hline-09 & 06 & & 7 & & & & -06 \\
\hline $.04 \mathrm{E}-09$ & $7.52 \mathrm{E}-06$ & ( & $-0-01$ & $1.19 \mathrm{E}-06$ & $1.71 \mathrm{E}-00$ & -06 & -0 \\
\hline $5 E-09$ & $7.53 \mathrm{E}-06$ & r & & 06 & & -06 & -06 \\
\hline 09 & 06 & 1 & 年 & 6 & 0 & 0 & -06 \\
\hline $.12 \mathrm{E}-09$ & -06 & 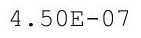 & 1 . & 06 & 06 & -06 & -06 \\
\hline $.15 \mathrm{E}-09$ & $E-06$ & $1 \mathrm{E}-07$ & $7 E-07$ & $1.20 \mathrm{E}-06$ & $1.80 \mathrm{E}-06$ & $.52 \mathrm{E}-06$ & $.54 \mathrm{E}-06$ \\
\hline-09 & -06 & $3 E-07$ & 7 & $20 E-06$ & $80 E-06$ & $E-06$ & $E-06$ \\
\hline 09 & -06 & 17 & 1 & 6 & & 6 & -06 \\
\hline $3 E-09$ & -06 & 1 & 2 . & 06 & & 06 & -06 \\
\hline $.26 \mathrm{E}-09$ & $7.55 \mathrm{E}-06$ & -07 & 1 & 06 & & -06 & -06 \\
\hline EE-09 & $7.56 \mathrm{E}-06$ & $.58 E-07$ & & $1.22 \mathrm{E}-06$ & >P & 06 & -06 \\
\hline $2 E-09$ & $7.56 \mathrm{E}-06$ & $4.60 \mathrm{E}-07$ & $2.03 E-07$ & $1.22 \mathrm{E}-06$ & 1 & $5 E-06$ & $56 \mathrm{E}-06$ \\
\hline$E-09$ & $E-06$ & $61 \mathrm{E}-07$ & $4 \mathrm{E}-07$ & $1.22 \mathrm{E}-06$ & $1.83 \mathrm{E}-06$ & $56 \mathrm{E}-06$ & $57 E-06$ \\
\hline 09 & $E-06$ & & & & 06 & -06 & -06 \\
\hline 09 & 06 & 7 & & & & & 06 \\
\hline $44 \mathrm{E}-09$ & $7.58 \mathrm{E}-06$ & $20-01$ & 1 & $\perp \cdot 2 J \amalg$ & • & 6 & -06 \\
\hline $.47 E-09$ & $7.58 E-06$ & $4.67 E-07$ & $2.012-01$ & $1.24 \mathrm{E}-06$ & $1.86 \mathrm{E}-06$ & $58 E-06$ & $.58 E-06$ \\
\hline 09 & 6 & 然 & 然 & 6 & 年 & $58 E-06$ & $59 \mathrm{E}-06$ \\
\hline 9 & - & - & - & - & - & - & 年 \\
\hline 9 & $F-06$ & & 吅 & & & $E-06$ & $E-06$ \\
\hline 09 & $E-06$ & $73 F-07$ & $E-07$ & $25 E-06$ & 6 & 6 & -06 \\
\hline $2 E-09$ & $E-06$ & 7 & 7 & $1.25 \mathrm{E}$ & 6 & & -06 \\
\hline $.65 E-09$ & $7.60 \mathrm{E}-06$ & $4.75 E-07$ & $2 \cdot 13 \pm-01$ & $1.26 \mathrm{E}-06$ & $1.89 \mathrm{E}-06$ & $1 E-06$ & $62 \mathrm{E}-06$ \\
\hline $68 E-09$ & $7.61 E-06$ & $4.77 E-07$ & & & & & . $0 \angle 5-0$ \\
\hline 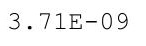 & & & & & & & \\
\hline $.75 E-09$ & 6 & & & & & & 06 \\
\hline 9 & & & & & & 6 & 06 \\
\hline 9 & & & & 06 & -06 & -06 & \\
\hline $4 E-09$ & $7.62 \mathrm{E}-06$ & $4.84 \mathrm{E}-07$ & $9 E-07$ & $1.27 \mathrm{E}-06$ & 6 & & -06 \\
\hline & & 7 & & & & & -0 \\
\hline & 6 & $.87 \mathrm{E}-07$ & & $+\cdot 201$ & & & -00 \\
\hline & & 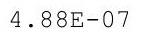 & 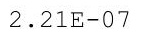 & 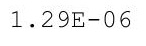 & 0 & 0 & ( \\
\hline & - & & $2<-$ & 6 & - 1 & 6 & or \\
\hline$E-09$ & $E-06$ & $4.91 \mathrm{E}-07$ & 2.23 & 06 & 1.95 & 06 & $68 E-06$ \\
\hline $.04 \mathrm{E}-\mathrm{C}$ & $7.64 \mathrm{E}-06$ & $.93 E-07$ & $.24 E-07$ & 1. $30 \mathrm{E}-06$ & $1.95 \mathrm{E}-06$ & $2.66 \mathrm{E}-06$ & $3.68 E-06$ \\
\hline
\end{tabular}


RESRAD-OFFSITE, Version 2.5

Title : RESRAD-OFFSITE External Gamma, Inhalation, and Soil Ingestion for offsite Reside File : PBA-1_TC99-DOE-5-1.ROF

Summary of dose at graphical times, reptition 3 (continued)

Time

Years

$5.90 \mathrm{E}+02$

$5.90 \mathrm{E}+02$

$5.91 \mathrm{E}+02$

$5.91 E+02$

$5.92 \mathrm{E}+02$

$5.92 \mathrm{E}+02$

$5.93 \mathrm{E}+02$

$5.93 \mathrm{E}+02$

$5.94 \mathrm{E}+02$

$5.94 \mathrm{E}+02$

$5.95 \mathrm{E}+02$

$5.95 \mathrm{E}+02$

$5.96 \mathrm{E}+02$

$5.96 \mathrm{E}+02$

$5.97 \mathrm{E}+02$

$5.97 \mathrm{E}+02$

$5.98 \mathrm{E}+02$

$5.98 \mathrm{E}+02$

$5.99 \mathrm{E}+02$

$5.99 \mathrm{E}+02$

$6.00 \mathrm{E}+02$

$6.00 \mathrm{E}+02$

$6.01 \mathrm{E}+02$

$6.01 \mathrm{E}+02$

$6.02 \mathrm{E}+02$

$6.02 \mathrm{E}+02$

$6.03 E+02$

$6.03 \mathrm{E}+02$

$6.04 \mathrm{E}+02$

$6.04 \mathrm{E}+02$

$6.05 \mathrm{E}+02$

$6.05 \mathrm{E}+02$

$6.06 \mathrm{E}+02$

$6.07 \mathrm{E}+02$

$6.07 \mathrm{E}+02$

$6.08 \mathrm{E}+02$

$6.08 \mathrm{E}+02$

$6.09 \mathrm{E}+02$

$6.09 \mathrm{E}+02$

$6.10 \mathrm{E}+02$

$6.10 \mathrm{E}+02$

$6.11 \mathrm{E}+02$

$6.11 \mathrm{E}+02$

$6.12 \mathrm{E}+02$

$6.12 \mathrm{E}+02$

$6.13 \mathrm{E}+02$
Dose statistics at graphical times, mrem/yr

\begin{tabular}{|c|c|c|c|c|c|c|c|}
\hline inimum & Maximum & Mean & Median & $90 \%$ & $95 \frac{\circ}{\circ}$ & $7.5 \%$ & $9 \%$ \\
\hline $.07 E-09$ & $7.64 \mathrm{E}-06$ & $4.94 \mathrm{E}-07$ & $2.25 \mathrm{E}-07$ & $1.30 \mathrm{E}-06$ & $1.96 \mathrm{E}-06$ & $2.66 \mathrm{E}-06$ & $3.69 \mathrm{E}-06$ \\
\hline $4.11 \mathrm{E}-09$ & $7.65 E-06$ & $4.96 \mathrm{E}-07$ & $2.26 \mathrm{E}-07$ & $1.30 \mathrm{E}-06$ & $1.96 \mathrm{E}-06$ & $2.67 \mathrm{E}-06$ & $3.69 \mathrm{E}-06$ \\
\hline $4.14 \mathrm{E}-09$ & $7.65 \mathrm{E}-06$ & $4.97 \mathrm{E}-07$ & $2.27 \mathrm{E}-07$ & $1.31 \mathrm{E}-06$ & $1.97 \mathrm{E}-06$ & $2.67 \mathrm{E}-06$ & $3.70 \mathrm{E}-06$ \\
\hline $4.18 \mathrm{E}-09$ & $7.65 \mathrm{E}-06$ & $4.99 \mathrm{E}-07$ & $2.28 \mathrm{E}-07$ & $1.31 \mathrm{E}-06$ & $1.97 \mathrm{E}-06$ & $2.67 \mathrm{E}-06$ & $.70 \mathrm{E}-06$ \\
\hline $4.21 \mathrm{E}-09$ & $7.65 \mathrm{E}-06$ & $5.00 \mathrm{E}-07$ & $2.30 \mathrm{E}-07$ & $1.31 \mathrm{E}$ & $1.97 \mathrm{E}$ & $2.68 \mathrm{E}$ & $.71 \mathrm{E}-06$ \\
\hline $4.25 \mathrm{E}-09$ & $7.66 \mathrm{E}-06$ & $5.01 \mathrm{E}-07$ & $2.31 E-07$ & $1.32 \mathrm{E}-06$ & $.98 \mathrm{E}-06$ & $2.68 \mathrm{E}-06$ & $3.71 \mathrm{E}-06$ \\
\hline $4.28 \mathrm{E}-09$ & $7.66 \mathrm{E}-06$ & $5.03 E-07$ & $2.32 \mathrm{E}-07$ & $1.32 \mathrm{E}-06$ & $.98 E-06$ & $2.69 \mathrm{E}-06$ & $72 \mathrm{E}-06$ \\
\hline $32 E-09$ & $7.66 \mathrm{E}-06$ & $5.04 \mathrm{E}-07$ & $2.33 \mathrm{E}-07$ & $1.32 \mathrm{E}-06$ & $.99 E-06$ & $2.69 \mathrm{E}-06$ & $72 \mathrm{E}-06$ \\
\hline $4.35 E-09$ & $7.66 \mathrm{E}-06$ & $5.06 \mathrm{E}-07$ & $2.34 \mathrm{E}-07$ & $1.33 \mathrm{E}-06$ & $1.99 \mathrm{E}-06$ & $2.69 \mathrm{E}-06$ & $3.73 \mathrm{E}-06$ \\
\hline $4.39 \mathrm{E}-09$ & $7.67 \mathrm{E}-06$ & $5.07 \mathrm{E}-07$ & $2.35 E-07$ & $1.33 \mathrm{E}-06$ & $1.99 \mathrm{E}-06$ & $2.70 \mathrm{E}-06$ & $3.73 \mathrm{E}-06$ \\
\hline $4.42 \mathrm{E}-09$ & $7.67 \mathrm{E}-06$ & $5.09 \mathrm{E}-07$ & $2.36 \mathrm{E}-07$ & $1.33 \mathrm{E}-06$ & $2.00 \mathrm{E}-06$ & $2.70 \mathrm{E}-06$ & $3.74 \mathrm{E}-06$ \\
\hline $4.46 \mathrm{E}-09$ & $7.67 \mathrm{E}-06$ & $5.10 \mathrm{E}-07$ & $2.37 \mathrm{E}-07$ & $1.34 \mathrm{E}-06$ & $2.00 \mathrm{E}-06$ & $2.71 \mathrm{E}-06$ & $3.74 \mathrm{E}-06$ \\
\hline $4.50 \mathrm{E}-09$ & $7.67 \mathrm{E}-06$ & $5.12 \mathrm{E}-07$ & $2.38 \mathrm{E}-07$ & $1.34 \mathrm{E}-06$ & $2.00 \mathrm{E}-06$ & $2.71 \mathrm{E}-06$ & $3.75 \mathrm{E}-06$ \\
\hline $4.53 \mathrm{E}-09$ & $7.68 \mathrm{E}-06$ & $5.13 \mathrm{E}-07$ & $2.39 \mathrm{E}-07$ & $1.34 \mathrm{E}-06$ & $2.01 \mathrm{E}-06$ & $2.71 \mathrm{E}-06$ & $3.75 \mathrm{E}-06$ \\
\hline $4.57 E-09$ & $7.68 \mathrm{E}-06$ & $5.15 \mathrm{E}-07$ & $2.40 \mathrm{E}-07$ & $1.35 \mathrm{E}-06$ & $2.01 \mathrm{E}-06$ & $2.72 \mathrm{E}-06$ & $3.76 \mathrm{E}-06$ \\
\hline $4.61 \mathrm{E}-09$ & $7.68 \mathrm{E}-06$ & $5.16 \mathrm{E}-07$ & $2.41 E-07$ & $1.35 \mathrm{E}-06$ & $2.01 \mathrm{E}-06$ & $2.72 \mathrm{E}-06$ & $3.76 \mathrm{E}-06$ \\
\hline $4.64 \mathrm{E}-09$ & $7.68 \mathrm{E}-06$ & $5.18 \mathrm{E}-07$ & $2.42 E-07$ & $1.35 \mathrm{E}-06$ & $2.01 \mathrm{E}-06$ & $2.73 \mathrm{E}-06$ & $3.77 \mathrm{E}-06$ \\
\hline $4.68 \mathrm{E}-09$ & $7.69 \mathrm{E}-06$ & $5.19 \mathrm{E}-07$ & $2.44 \mathrm{E}-07$ & $1.36 \mathrm{E}-06$ & $2.02 \mathrm{E}-06$ & $2.73 E-06$ & $3.78 \mathrm{E}-06$ \\
\hline $4.72 \mathrm{E}-09$ & $7.69 \mathrm{E}-06$ & $5.21 \mathrm{E}-07$ & $2.45 E-07$ & $1.36 \mathrm{E}-06$ & $2.02 \mathrm{E}-06$ & $2.73 E-06$ & $3.78 \mathrm{E}-06$ \\
\hline $.76 \mathrm{E}-09$ & $7.69 \mathrm{E}-06$ & $5.22 \mathrm{E}-$ & $2.46 \mathrm{E}$ & $1.36 \mathrm{E}-$ & $2.03 \mathrm{E}$ & 2705 & -06 \\
\hline $80 \mathrm{E}-$ & & 7 & & 6 & & 6 & \\
\hline . & 7 & 5 & 2 & 6 & 6 & 6 & 06 \\
\hline $4.87 \mathrm{E}-09$ & $7.70 \mathrm{E}-06$ & $5.26 \mathrm{E}-07$ & $2.50 \mathrm{E}-07$ & $1.37 \mathrm{E}-06$ & $2.04 \mathrm{E}-06$ & $2.75 \mathrm{E}-06$ & $3.81 \mathrm{E}-06$ \\
\hline $4.91 \mathrm{E}-09$ & $7.70 \mathrm{E}-06$ & $5.28 \mathrm{E}-07$ & $2.51 E-07$ & $1.37 \mathrm{E}-06$ & $2.04 \mathrm{E}-06$ & $2.75 \mathrm{E}-06$ & $3.81 \mathrm{E}-06$ \\
\hline $4.95 \mathrm{E}-09$ & $7.70 \mathrm{E}-06$ & $5.29 \mathrm{E}-07$ & $2.51 \mathrm{E}-07$ & $1.38 \mathrm{E}-06$ & $2.05 E-06$ & $2.76 \mathrm{E}-06$ & $3.82 \mathrm{E}-06$ \\
\hline $4.99 \mathrm{E}-09$ & $7.70 \mathrm{E}-06$ & $5.31 \mathrm{E}-07$ & $2.52 E-07$ & $1.38 \mathrm{E}-06$ & $2.05 \mathrm{E}-06$ & $2.76 \mathrm{E}-06$ & $3.82 \mathrm{E}-06$ \\
\hline $5.03 \mathrm{E}-09$ & $7.70 \mathrm{E}-06$ & $5.32 \mathrm{E}-07$ & $2.53 \mathrm{E}-07$ & $1.38 \mathrm{E}-06$ & $2.05 \mathrm{E}-06$ & $2.77 \mathrm{E}-06$ & $3.83 \mathrm{E}-06$ \\
\hline $5.07 \mathrm{E}-09$ & $7.71 \mathrm{E}-06$ & $5.34 \mathrm{E}-07$ & $2.54 \mathrm{E}-07$ & $1.39 \mathrm{E}-06$ & $2.06 \mathrm{E}-06$ & $2.77 E-06$ & $3.84 \mathrm{E}-06$ \\
\hline $5.11 \mathrm{E}-09$ & $7.71 \mathrm{E}-06$ & $5.35 \mathrm{E}-07$ & $2.55 \mathrm{E}-07$ & $1.39 \mathrm{E}-06$ & $2.06 \mathrm{E}-06$ & $2.77 \mathrm{E}-06$ & $3.84 \mathrm{E}-06$ \\
\hline $5.15 \mathrm{E}-09$ & $7.71 \mathrm{E}-06$ & $5.37 \mathrm{E}-07$ & 2 . & 1.39 & 6 & -06 & -06 \\
\hline $4-09$ & $E-06$ & $5.38 \mathrm{E}$ & 2 & 1 & 6 & 6 & .06 \\
\hline $23 E-09$ & $7.71 \mathrm{E}-06$ & $5.40 \mathrm{E}-07$ & $2.58 \mathrm{E}-07$ & $1.40 \mathrm{E}-06$ & $2.07 \mathrm{E}-06$ & $2.79 \mathrm{E}-06$ & $3.86 \mathrm{E}-06$ \\
\hline $27 E-09$ & $7.72 \mathrm{E}-06$ & $5.41 \mathrm{E}-07$ & $2.59 \mathrm{E}-07$ & $1.41 \mathrm{E}-06$ & $2.07 \mathrm{E}-06$ & $2.79 \mathrm{E}-06$ & $3.87 \mathrm{E}-06$ \\
\hline $5.31 \mathrm{E}-09$ & $7.72 \mathrm{E}-06$ & $5.43 \mathrm{E}-07$ & $2.60 \mathrm{E}-07$ & $1.41 \mathrm{E}-06$ & $2.08 \mathrm{E}-06$ & $2.80 \mathrm{E}-06$ & $3.87 \mathrm{E}-06$ \\
\hline $5.35 \mathrm{E}-09$ & $7.72 \mathrm{E}-06$ & $5.44 \mathrm{E}-07$ & $2.61 E-07$ & $1.42 \mathrm{E}-06$ & $2.08 \mathrm{E}-06$ & $2.80 \mathrm{E}-06$ & $3.88 \mathrm{E}-06$ \\
\hline $5.40 \mathrm{E}-09$ & $7.72 \mathrm{E}-06$ & $5.46 \mathrm{E}-07$ & $2.62 \mathrm{E}-07$ & $1.42 \mathrm{E}-06$ & $2.09 \mathrm{E}-06$ & $2.81 \mathrm{E}-06$ & $3.88 \mathrm{E}-06$ \\
\hline $5.44 \mathrm{E}-09$ & $7.72 \mathrm{E}-06$ & $5.47 \mathrm{E}-07$ & $2.63 E-07$ & $1.42 \mathrm{E}-06$ & $2.09 \mathrm{E}-06$ & $2.81 \mathrm{E}-06$ & $3.89 \mathrm{E}-06$ \\
\hline $5.48 \mathrm{E}-09$ & $7.72 \mathrm{E}-06$ & $5.49 \mathrm{E}-07$ & $2.64 \mathrm{E}-07$ & $1.43 \mathrm{E}-06$ & $2.09 \mathrm{E}-06$ & $2.82 \mathrm{E}-06$ & $3.89 \mathrm{E}-06$ \\
\hline $5.52 \mathrm{E}-09$ & $7.72 \mathrm{E}-06$ & $5.50 \mathrm{E}-07$ & $2.65 \mathrm{E}-07$ & $1.43 \mathrm{E}-06$ & $2.09 \mathrm{E}-06$ & $2.82 \mathrm{E}-06$ & $3.89 \mathrm{E}-06$ \\
\hline $5.56 \mathrm{E}-09$ & $7.73 \mathrm{E}-06$ & $5.52 \mathrm{E}-07$ & $2.66 \mathrm{E}-07$ & $1.43 \mathrm{E}-06$ & $2.10 \mathrm{E}-06$ & $2.83 E-06$ & $3.90 \mathrm{E}-06$ \\
\hline $5.61 \mathrm{E}-09$ & $7.73 \mathrm{E}-06$ & $5.53 \mathrm{E}-07$ & $2.67 E-07$ & $1.43 \mathrm{E}-06$ & $2.10 \mathrm{E}-06$ & $2.83 \mathrm{E}-06$ & $3.90 \mathrm{E}-06$ \\
\hline $5.65 \mathrm{E}-09$ & $7.73 \mathrm{E}-06$ & $5.55 \mathrm{E}-07$ & $2.68 \mathrm{E}-07$ & $1.44 \mathrm{E}-06$ & $2.10 \mathrm{E}-06$ & $2.84 \mathrm{E}-06$ & $3.91 \mathrm{E}-06$ \\
\hline $5.69 \mathrm{E}-09$ & $7.73 \mathrm{E}-06$ & $5.56 \mathrm{E}-07$ & $2.69 \mathrm{E}-07$ & $1.44 \mathrm{E}-06$ & $2.10 \mathrm{E}-06$ & $2.84 \mathrm{E}-06$ & $3.91 \mathrm{E}-06$ \\
\hline $5.74 \mathrm{E}-09$ & $7.73 \mathrm{E}-06$ & $5.58 \mathrm{E}-07$ & $2.70 \mathrm{E}-07$ & $1.44 \mathrm{E}-06$ & $2.11 \mathrm{E}-06$ & $2.85 \mathrm{E}-06$ & $3.91 \mathrm{E}-06$ \\
\hline $.78 \mathrm{E}-09$ & $7.73 E-06$ & $5.59 \mathrm{E}-07$ & $2.71 \mathrm{E}-07$ & $1.44 \mathrm{E}-06$ & $2.11 \mathrm{E}-06$ & $2.85 \mathrm{E}-06$ & $3.92 \mathrm{E}-06$ \\
\hline $.82 E-09$ & $7.73 E-06$ & $5.61 \mathrm{E}-07$ & $2.72 \mathrm{E}-07$ & $1.45 \mathrm{E}-06$ & $2.11 \mathrm{E}-06$ & $2.86 \mathrm{E}-06$ & $3.92 \mathrm{E}-06$ \\
\hline
\end{tabular}


RESRAD-OFFSITE, Version 2.5

Title : RESRAD-OFFSITE External Gamma, Inhalation, and Soil Ingestion for offsite Reside File : PBA-1_TC99-DOE-5-1.ROF

Summary of dose at graphical times, reptition 3 (continued)

Time

Years

$6.13 E+02$

$6.14 \mathrm{E}+02$

$6.14 \mathrm{E}+02$

$6.15 \mathrm{E}+02$

$6.15 \mathrm{E}+02$

$6.16 \mathrm{E}+02$

$6.16 \mathrm{E}+02$

$6.17 \mathrm{E}+02$

$6.17 \mathrm{E}+02$

$6.18 \mathrm{E}+02$

$6.18 \mathrm{E}+02$

$6.19 \mathrm{E}+02$

$6.19 \mathrm{E}+02$

$6.20 \mathrm{E}+02$

$6.20 \mathrm{E}+02$

$6.21 \mathrm{E}+02$

$6.21 \mathrm{E}+02$

$6.22 \mathrm{E}+02$

$6.22 \mathrm{E}+02$

$6.23 \mathrm{E}+02$

$6.23 \mathrm{E}+02$

$6.24 \mathrm{E}+02$

$6.24 \mathrm{E}+02$

$6.25 \mathrm{E}+02$

$6.25 \mathrm{E}+02$

$6.26 \mathrm{E}+02$

$6.27 \mathrm{E}+02$

$6.27 \mathrm{E}+02$

$6.28 \mathrm{E}+02$

$6.28 \mathrm{E}+02$

$6.29 \mathrm{E}+02$

$6.29 \mathrm{E}+02$

$6.30 \mathrm{E}+02$

$6.30 \mathrm{E}+02$

$6.31 \mathrm{E}+02$

$6.31 \mathrm{E}+02$

$6.32 \mathrm{E}+02$

$6.32 \mathrm{E}+02$

$6.33 \mathrm{E}+02$

$6.33 \mathrm{E}+02$

$6.34 \mathrm{E}+02$

$6.34 \mathrm{E}+02$

$6.35 \mathrm{E}+02$

$6.35 \mathrm{E}+02$

$6.36 \mathrm{E}+02$

$6.36 \mathrm{E}+02$

Dose statistics at graphical times, mrem/yr

\begin{tabular}{|c|c|c|c|c|c|c|c|}
\hline $\mathrm{m}$ & um & a & ledian & & & & \\
\hline-09 & -06 & $5.62 \mathrm{E}-07$ & -07 & -06 & -06 & $2.86 \mathrm{E}-06$ & -06 \\
\hline $91 E-09$ & -06 & $4 \mathrm{E}-07$ & -07 & 06 & 06 & $2.87 \mathrm{E}-06$ & -06 \\
\hline $.96 \mathrm{E}-09$ & $.74 \mathrm{E}-06$ & $.65 E-07$ & $5 E-07$ & $1.46 \mathrm{E}-06$ & $2.12 \mathrm{E}-06$ & -06 & -06 \\
\hline 09 & 06 & $67 \mathrm{~F}-07$ & $76 \mathrm{~F}-07$ & $46 \mathrm{E}-06$ & $13 \mathrm{~F}-06$ & 06 & $-0 \Leftrightarrow$ \\
\hline 09 & 06 & 7 & & 06 & 06 & 06 & -06 \\
\hline 09 & 06 & 7 & & & & & -06 \\
\hline $.14 \mathrm{E}-09$ & $.74 \mathrm{E}-06$ & & & & & & -06 \\
\hline-09 & -06 & 7 & & 6 & 6 & 06 & -06 \\
\hline-09 & -06 & $4 E-07$ & 7 & $48 E-06$ & 06 & -06 & -06 \\
\hline 09 & -06 & $76 \pi$ & 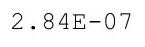 & 6 & & 06 & -06 \\
\hline 09 & 06 & $5.77 \mathrm{E}-07$ & 5 & 5 & -06 & 6 & $7 E-06$ \\
\hline-09 & 06 & $79 \mathrm{E}-$ & 7 & 6 & 6 & 06 & 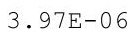 \\
\hline $.42 E-09$ & $7.74 \mathrm{E}-06$ & $5.80 \mathrm{E}-07$ & & & & & -06 \\
\hline $.47 \mathrm{E}-09$ & $7.75 \mathrm{E}-06$ & $5.82 \mathrm{E}-07$ & $2.89 \mathrm{E}-07$ & $1.50 \mathrm{E}-06$ & $2.17 \mathrm{E}-06$ & $5-06$ & -06 \\
\hline-09 & -06 & $3 E-07$ & 11 & $0 \mathrm{E}-06$ & & -06 & -06 \\
\hline 09 & $5 E-06$ & - & & & & 6 & 06 \\
\hline $1 E-09$ & & & & 6 & & 0 & $99 \mathrm{E}-06$ \\
\hline 9 & 6 & تصن & ק & 6 & & 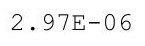 & 0 \\
\hline $.71 E-09$ & $5 E-06$ & $89 F-07$ & $5-07$ & $1 E-06$ & $20 E-06$ & $E-06$ & -06 \\
\hline $.76 E-09$ & $.75 E-06$ & $.91 E-07$ & $2.96 \mathrm{E}-07$ & $1.52 \mathrm{E}-06$ & $.20 \mathrm{E}-06$ & $3 E-06$ & $E-06$ \\
\hline 09 & -06 & $.92 \mathrm{E}-$ & & 6 & & 6 & -06 \\
\hline 09 & 06 & & & & & & \\
\hline 9 & & & & & & & 0 \\
\hline 09 & 6 & - & 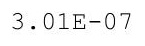 & 6 & 0 & 0 & 0 \\
\hline 9 & 6 & . & $2+$ & 6 & - & - & 0 \\
\hline $.06 \mathrm{E}-09$ & $7.75 E-06$ & $5.00 \mathrm{E}-07$ & $03 E-07$ & $4 E-06$ & $24 \mathrm{E}-0$ & $1 \mathrm{E}-06$ & $F-06-2-2$ \\
\hline $11 F-09$ & $7.75 \mathrm{E}-06$ & $.02 \mathrm{E}-07$ & & $1.54 \mathrm{E}-06$ & & $2 E-06$ & $3 F-06$ \\
\hline & & & & & & & 06 \\
\hline & & & & & & & -0 \\
\hline $.26 \mathrm{E}-09$ & $7.75 \mathrm{E}-06$ & $0.00 \mathrm{~L}-1$ & $3.005-4$ & 1. $55 \mathrm{E}-06$ & $2.205-00$ & -06 & $E-06$ \\
\hline $.31 E-09$ & $7.75 \mathrm{E}-06$ & .00m & $\begin{array}{ll}0 \\
\text {. }\end{array}$ & $1.55 \mathrm{E}-06$ & 2. & - & 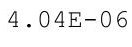 \\
\hline $.37 E-09$ & $7.75 \mathrm{E}-06$ & (6) & & $1.56 \mathrm{E}-06$ & & & 等 \\
\hline$F-09$ & $775 \mathrm{~F}-06$ & & & & & & -06 \\
\hline & & & & & & & 06 \\
\hline & & & & & & & \\
\hline & & & & & & 06 & \\
\hline $.63 E-09$ & $7.75 \mathrm{E}-06$ & 2IL-O & 1 & $1.57 \mathrm{E}$ & 0 & 06 & c \\
\hline & & & & & & & $\begin{array}{c}0 \\
0\end{array}$ \\
\hline 9 & 6 & $6.20 \mathrm{E}-07$ & $3.19 \mathrm{E}-07$ & te & & & $4.07 \mathrm{E}-06$ \\
\hline & & & & & & 6 & 66 \\
\hline & & & & $3 E-06$ & -06 & -06 & 06 \\
\hline $0 E-09$ & $7.75 E-06$ & $6.25 E-07$ & $3.22 \mathrm{E}-07$ & $1.58 \mathrm{E}-06$ & $31 E-06$ & $E-06$ & $\Xi-06$ \\
\hline & & 7 & & & & & \\
\hline & & & & $1.59 \mathrm{E}-06$ & $2.3 \angle \mathrm{E}-06$ & $9 E-06$ & 00 \\
\hline & & & & $\perp \cdot 0$ & 2.021 & & $\begin{array}{ll}+ \\
\end{array}$ \\
\hline 9 & $E-06$ & $E-07$ & $27 E-07$ & $.60 E-06$ & $2 E-06$ & $0 E-06$ & -06 \\
\hline
\end{tabular}


RESRAD-OFFSITE, Version 2.5

Title : RESRAD-OFFSITE External Gamma, Inhalation, and Soil Ingestion for offsite Reside File : PBA-1_TC99-DOE-5-1.ROF

Summary of dose at graphical times, reptition 3 (continued)

Time

Years

$6.37 \mathrm{E}+02$

$6.37 \mathrm{E}+02$

$6.38 \mathrm{E}+02$

$6.38 \mathrm{E}+02$

$6.39 \mathrm{E}+02$

$6.39 \mathrm{E}+02$

$6.40 \mathrm{E}+02$

$6.40 \mathrm{E}+02$

$6.41 \mathrm{E}+02$

$6.41 \mathrm{E}+02$

$6.42 \mathrm{E}+02$

$6.42 \mathrm{E}+02$

$6.43 \mathrm{E}+02$

$6.43 \mathrm{E}+02$

$6.44 \mathrm{E}+02$

$6.44 \mathrm{E}+02$

$6.45 \mathrm{E}+02$

$6.45 \mathrm{E}+02$

$6.46 \mathrm{E}+02$

$6.47 \mathrm{E}+02$

$6.47 \mathrm{E}+02$

$6.48 \mathrm{E}+02$

$6.48 \mathrm{E}+02$

$6.49 \mathrm{E}+02$

$6.49 \mathrm{E}+02$

$6.50 \mathrm{E}+02$

$6.50 \mathrm{E}+02$

$6.51 \mathrm{E}+02$

$6.51 \mathrm{E}+02$

$6.52 \mathrm{E}+02$

$6.52 \mathrm{E}+02$

$6.53 \mathrm{E}+02$

$6.53 \mathrm{E}+02$

$6.54 \mathrm{E}+02$

$6.54 \mathrm{E}+02$

$6.55 \mathrm{E}+02$

$6.55 \mathrm{E}+02$

$6.56 \mathrm{E}+02$

$6.56 \mathrm{E}+02$

$6.57 \mathrm{E}+02$

$6.57 \mathrm{E}+02$

$6.58 \mathrm{E}+02$

$6.58 \mathrm{E}+02$

$6.59 \mathrm{E}+02$

$6.59 \mathrm{E}+02$

$6.60 \mathrm{E}+02$

Dose statistics at graphical times, mrem/yr

\begin{tabular}{|c|c|c|c|c|c|c|c|}
\hline m & aximum & ean & ed & & & & \\
\hline 9 & 6 & 7 & 7 & 06 & 6 & 6 & -06 \\
\hline $4 E-09$ & $5 E-06$ & $4 E-07$ & $3.30 \mathrm{E}-07$ & $1.60 \mathrm{E}-06$ & $2.33 E-06$ & $3.11 \mathrm{E}-06$ & $11 \mathrm{E}-06$ \\
\hline$E-09$ & $E-06$ & $35 E-07$ & $.31 E-07$ & $1.61 \mathrm{E}-06$ & $33 E-06$ & 06 & -06 \\
\hline & & & & & & & -06 \\
\hline-09 & 06 & -07 & 7 & & & & -06 \\
\hline $47 E-09$ & 06 & -07 & 7 & 66 & 6 & & -06 \\
\hline 09 & 06 & 7 & & 6 & & & -06 \\
\hline$E-09$ & -06 & E-07 & $E-07$ & $3 E-06$ & $5-06$ & -06 & $E-06$ \\
\hline $4 E-09$ & $E-06$ & $E-07$ & $3 E-07$ & -06 & -06 & -06 & -06 \\
\hline $0 E-09$ & $74 E-06$ & & $39 E-07$ & $63 E-06$ & & & 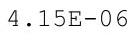 \\
\hline 9 & & & & & & & -06 \\
\hline$F-09$ & $E-06$ & $9 \mathrm{E}-07$ & -07 & 06 & 6 & 06 & -06 \\
\hline $88 E-09$ & $7.74 \mathrm{E}-06$ & $6.51 E-07$ & $3.43 E-07$ & $1.64 E-06$ & & $5 E-06$ & $16 E-06$ \\
\hline$E-09$ & -06 & $E-07$ & & 06 & & & -06 \\
\hline & 06 & & & & & & -0 \\
\hline 9 & $74 \mathrm{E}-06$ & & (6匚 & 6 & & & 06 \\
\hline 9 & 6 & $6.57 \mathrm{E}-07$ & 7 & 6 & 6 & $17 E-06$ & 06 \\
\hline$F-0$ & $F-06$ & $3 F-07$ & 7 & $166 \mathrm{E}-\mathrm{r}$ & & 6 & 06 \\
\hline $.25 E-09$ & $7.73 E-06$ & $6.60 E-07$ & $3.49 E-07$ & $1.66 \mathrm{E}-06$ & $2.39 E-06$ & -06 & $9 E-06$ \\
\hline $31 E-09$ & $.73 E-06$ & $5.61 \mathrm{E}-07$ & $3.51 \mathrm{E}-07$ & $1.67 \mathrm{E}-06$ & $2.39 \mathrm{E}-06$ & -06 & $E-06$ \\
\hline & & & & & & & -06 \\
\hline & & & & 6 & & & -06 \\
\hline 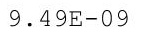 & & & & & & & 06 \\
\hline 9 & 06 & 7 & 7 & 6 & 6 & 66 & -06 \\
\hline 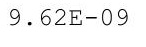 & $.73 E-06$ & $5.69 \mathrm{E}-07$ & $7 E-07$ & $8 E-06$ & $2.42 \mathrm{E}-06$ & 6 & -06 \\
\hline$F-0$ & $7.73 E-06$ & $.71 E-07$ & $58 E-07$ & $1.69 \mathrm{E}-06$ & $2.42 \mathrm{E}-06$ & -06 & $22 F-06$ \\
\hline-09 & $.72 E-06$ & & & & $3 E-06$ & $E-06$ & $E-06$ \\
\hline & & & & & & & 06 \\
\hline & & & & & & & \\
\hline 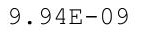 & $7.72 \mathrm{E}-06$ & $6.77 E-07$ & $3.63 \mathrm{E}-07$ & $1.70 \mathrm{E}-06$ & $2.445-00$ & $2+-00$ & $.24 E-06$ \\
\hline $.00 \mathrm{E}-08$ & $7.72 E-06$ & 位 & $.65 E-07$ & $1.70 \mathrm{E}-06$ & . & . & $.24 \mathrm{E}-0$ \\
\hline 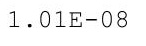 & $7.72 \mathrm{E}-06$ & & & & & & 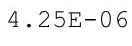 \\
\hline 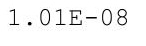 & $7.72 \mathrm{E}-06$ & $.82 \mathrm{E}-07$ & 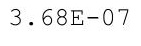 & $E-06$ & & & 06 \\
\hline & & & & & 6 & & 06 \\
\hline & & & & & -06 & 66 & \\
\hline $.03 E-08$ & $7.71 \mathrm{E}-06$ & $.00 E-01$ & $3.72 \mathrm{E}-07$ & $1.72 \mathrm{E}-06$ & $2.48 E-06$ & -06 & $.27 E-06$ \\
\hline 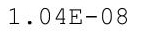 & $1.1+\mathrm{L}-00$ & 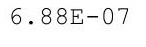 & & $1.72 \mathrm{E}$ & 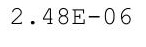 & & c \\
\hline 8 & & - & & & & & 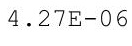 \\
\hline $05 \mathrm{~F}-08$ & . & 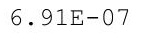 & 7 & 6 & 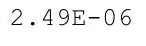 & 6 & 06 \\
\hline 8 & & & 07 & 6 & 6 & 6 & 06 \\
\hline $7 E-08$ & $.70 E-06$ & & $8 E-07$ & $3 E-06$ & $0 E-06$ & & -06 \\
\hline $.07 E-08$ & $7.70 \mathrm{E}-06$ & $96 \mathrm{E}-07$ & $E-07$ & 1 . & 06 & 06 & -06 \\
\hline & & & & & & & -00 \\
\hline & 0 & 1 & & 6 & 0 & 06 & - \\
\hline & . & ( & & & & & cos \\
\hline-08 & $E-06$ & $E-07$ & $5-07$ & $75 E-06$ & $3 E-06$ & $9 E-06$ & -06 \\
\hline
\end{tabular}


RESRAD-OFFSITE, Version 2.5

$\mathrm{T}^{1 / 2}$ Limit $=180$ days

Title : RESRAD-OFFSITE External Gamma, Inhalation, and Soil Ingestion for Offsite Reside

File : PBA-1_TC99-DOE-5-1.ROF

Summary of dose at graphical times, reptition 3 (continued)

Time

Years

$6.60 \mathrm{E}+02$

$6.61 \mathrm{E}+02$

$6.61 \mathrm{E}+02$

$6.62 \mathrm{E}+02$

$6.62 \mathrm{E}+02$

$6.63 \mathrm{E}+02$

$6.63 \mathrm{E}+02$

$6.64 \mathrm{E}+02$

$6.64 \mathrm{E}+02$

$6.65 \mathrm{E}+02$

$6.65 \mathrm{E}+02$

$6.66 \mathrm{E}+02$

$6.67 \mathrm{E}+02$

$6.67 \mathrm{E}+02$

$6.68 \mathrm{E}+02$

$6.68 \mathrm{E}+02$

$6.69 \mathrm{E}+02$

$6.69 \mathrm{E}+02$

$6.70 \mathrm{E}+02$

$6.70 \mathrm{E}+02$

$6.71 \mathrm{E}+02$

$6.71 \mathrm{E}+02$

$6.72 \mathrm{E}+02$

$6.72 \mathrm{E}+02$

$6.73 \mathrm{E}+02$

$6.73 \mathrm{E}+02$

$6.74 \mathrm{E}+02$

$6.74 \mathrm{E}+02$

$6.75 \mathrm{E}+02$

$6.75 \mathrm{E}+02$

$6.76 \mathrm{E}+02$

$6.76 \mathrm{E}+02$

$6.77 \mathrm{E}+02$

$6.77 \mathrm{E}+02$

$6.78 \mathrm{E}+02$

$6.78 \mathrm{E}+02$

$6.79 \mathrm{E}+02$

$6.79 \mathrm{E}+02$

$6.80 \mathrm{E}+02$

$6.80 \mathrm{E}+02$

$6.81 \mathrm{E}+02$

$6.81 \mathrm{E}+02$

$6.82 \mathrm{E}+02$

$6.82 \mathrm{E}+02$

$6.83 \mathrm{E}+02$

$6.83 \mathrm{E}+02$
Dose statistics at graphical times, mrem/yr

\begin{tabular}{|c|c|c|c|c|c|c|c|}
\hline inimum & aximum & Mean & ledian & $0 \%$ & $5 \%$ & $97.5 \%$ & $\%$ \\
\hline 8 & $9 E-06$ & $E-07$ & $E-07$ & $5 E-06$ & 06 & 06 & (ne \\
\hline 08 & $E-06$ & $E-07$ & $3 E-07$ & 6 & 06 & 06 & -06 \\
\hline$E-08$ & $9 E-06$ & $E-07$ & $E-07$ & $6 E-06$ & 06 & 06 & -06 \\
\hline$E-08$ & $9 E-06$ & 7 & & 6 & & & -06 \\
\hline $.14 \mathrm{E}-08$ & 06 & & & & 6 & 06 & $31 E-06$ \\
\hline $.14 \mathrm{E}-08$ & 06 & 1 & 07 & -06 & $5 E-06$ & $2 E-06$ & 06 \\
\hline $.15 \mathrm{E}-08$ & 06 & - & 7 & $1.77 \mathrm{E}-06$ & 06 & -06 & -06 \\
\hline $.16 \mathrm{E}-08$ & $7.68 \mathrm{E}-06$ & 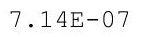 & & $1.77 \mathrm{E}-06$ & 乙. & -06 & $32 E-06$ \\
\hline 08 & -06 & $r$ & 1 & 06 & 6 & -06 & -06 \\
\hline $.17 \mathrm{E}-08$ & $7 E-06$ & $7 E-07$ & $1 \mathrm{E}-07$ & -06 & 06 & 06 & $32 E-06$ \\
\hline-08 & -06 & 7 & 7 & & & & $E-06$ \\
\hline-08 & 06 & & & & & & 06 \\
\hline $.20 E-08$ & $7.67 \mathrm{E}-06$ & . $2 \angle \mathrm{D}-01$ & $5 E-07$ & $1.79 \mathrm{E}-06$ & $2-06$ & -06 & -0 \\
\hline $.20 \mathrm{E}-08$ & -06 & . & . & 06 & 0 & -06 & -06 \\
\hline-08 & 06 & 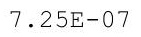 & 年 & 6 & 6 & 06 & -06 \\
\hline $.22 E-08$ & -06 & 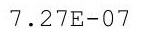 & 7 & 06 & 06 & -06 & -06 \\
\hline $.23 E-08$ & $6 E-06$ & $8 E-07$ & $0 \mathrm{E}-07$ & $1.80 \mathrm{E}-06$ & $9 E-06$ & -06 & $.34 \mathrm{E}-06$ \\
\hline-08 & $E-06$ & E-07 & $2 E-07$ & 06 & 06 & 06 & $E-06$ \\
\hline $.24 \mathrm{E}-08$ & $5 E-06$ & $E-07$ & & & & -06 & -06 \\
\hline $.25 E-08$ & -06 & -01 & & 06 & & -06 & $E-06$ \\
\hline $.26 \mathrm{E}-08$ & -06 & 急 & 1 & & & 0 & -06 \\
\hline $.26 \mathrm{E}-08$ & -06 & 年 & 1. & 06 & & 6 & -06 \\
\hline $.27 E-08$ & $7.64 \mathrm{E}-06$ & 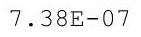 & . & $1.81 \mathrm{E}-06$ & $2.61 \mathrm{E}-06$ & $.39 E-06$ & $.35 E-06$ \\
\hline $.28 \mathrm{E}-08$ & $7.64 \mathrm{E}-06$ & $39 E-07$ & 7 & $1.82 \mathrm{E}-06$ & $61 \mathrm{E}-06$ & $9 E-06$ & $5 E-06$ \\
\hline 08 & 06 & 07 & & 06 & & 6 & -06 \\
\hline$E-08$ & 06 & 7 & 07 & 6 & & & 06 \\
\hline $0 E-08$ & $E-06$ & 1 & & -06 & & & $36 \mathrm{E}-06$ \\
\hline $.31 E-08$ & $7.63 \mathrm{E}-06$ & $7.45 \mathrm{E}-07$ & $4.25 E-07$ & $1.83 \mathrm{E}-06$ & $2.62 \mathrm{E}-06$ & $41 E-06$ & $36 E-06$ \\
\hline $.32 E-08$ & $7.63 E-06$ & 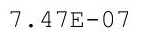 & . 20101 & $1.83 E-06$ & (2) & 0 & $.36 \mathrm{E}-06$ \\
\hline $.33 E-08$ & $7.62 \mathrm{E}-06$ & E t r t & 2.ever & $1.04 \mathrm{~L}-00$ & - & 政 & $.36 \mathrm{E}-0$ \\
\hline 08 & $E-06$ & $E-07$ & 7 & 06 & 6 & 6 & -06 \\
\hline$E-08$ & $E-06$ & $E-07$ & 7 & 6 & 6 & 66 & -06 \\
\hline $.35 E-08$ & $7.62 \mathrm{E}-06$ & $7.53 \mathrm{E}-07$ & 4. $32 \mathrm{E}-07$ & $1.85 \mathrm{E}-06$ & & & -06 \\
\hline $.36 \mathrm{E}-08$ & $7.61 \mathrm{E}-06$ & $7.55 \mathrm{E}-07$ & $4.33 E-07$ & $1.85 \mathrm{E}-06$ & $2.65 \mathrm{E}-06$ & $3 E-06$ & $.37 E-06$ \\
\hline $.37 E-08$ & $7.61 \mathrm{E}-06$ & 政 & & & & & . \\
\hline ט & & & & & & & \\
\hline $.38 E-08$ & 6 & & & 6 & & & 0 \\
\hline 8 & 6 & $E-07$ & $E-07$ & 6 & 6 & 6 & 06 \\
\hline$E-08$ & $E-06$ & 7 & 77 & 06 & 6 & 6 & $38 \mathrm{E}-06$ \\
\hline $.41 E-08$ & 06 & 7 & 7 & 06 & & & -06 \\
\hline 8 & & & & 6 & & & \\
\hline$E-08$ & & $.67 E-07$ & & $.87 E-06$ & & & $E-06$ \\
\hline & & $7.69 \mathrm{E}-07$ & & $1.88 \mathrm{E}-06$ & 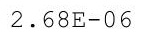 & & $4.38 E-06$ \\
\hline 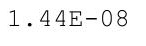 & $7.58 \mathrm{E}-06$ & $7.70 \mathrm{E}-07$ & 1 & 0 & 6 & 0 & 0 \\
\hline $5 E-08$ & 7.5 & 07 & 4.4 & 1 . & 2 . & 06 & 06 \\
\hline $.46 E-08$ & $7.58 \mathrm{E}-06$ & $7.74 \mathrm{E}-07$ & $.51 E-07$ & $1.89 \mathrm{E}-06$ & $2.69 E-06$ & $3.48 E-06$ & $4.39 \mathrm{E}-06$ \\
\hline
\end{tabular}


RESRAD-OFFSITE, Version 2.5

Title : RESRAD-OFFSITE External Gamma, Inhalation, and Soil Ingestion for offsite Reside File : PBA-1_TC99-DOE-5-1.ROF

Summary of dose at graphical times, reptition 3 (continued)

Time

Years

$6.84 \mathrm{E}+02$

$6.84 \mathrm{E}+02$

$6.85 \mathrm{E}+02$

$6.85 \mathrm{E}+02$

$6.86 \mathrm{E}+02$

$6.86 \mathrm{E}+02$

$6.87 \mathrm{E}+02$

$6.88 \mathrm{E}+02$

$6.88 \mathrm{E}+02$

$6.89 \mathrm{E}+02$

$6.89 \mathrm{E}+02$

$6.90 \mathrm{E}+02$

$6.90 \mathrm{E}+02$

$6.91 E+02$

$6.91 \mathrm{E}+02$

$6.92 \mathrm{E}+02$

$6.92 \mathrm{E}+02$

$6.93 \mathrm{E}+02$

$6.93 E+02$

$6.94 \mathrm{E}+02$

$6.94 \mathrm{E}+02$

$6.95 \mathrm{E}+02$

$6.95 \mathrm{E}+02$

$6.96 \mathrm{E}+02$

$6.96 \mathrm{E}+02$

$6.97 \mathrm{E}+02$

$6.97 \mathrm{E}+02$

$6.98 \mathrm{E}+02$

$6.98 \mathrm{E}+02$

$6.99 \mathrm{E}+02$

$6.99 \mathrm{E}+02$

$7.00 \mathrm{E}+02$

$7.00 \mathrm{E}+02$

7. $01 \mathrm{E}+02$

$7.01 \mathrm{E}+02$

7. $02 \mathrm{E}+02$

$7.02 \mathrm{E}+02$

$7.03 \mathrm{E}+02$

7. $03 E+02$

$7.04 \mathrm{E}+02$

$7.04 \mathrm{E}+02$

$7.05 \mathrm{E}+02$

$7.05 \mathrm{E}+02$

$7.06 \mathrm{E}+02$

$7.06 \mathrm{E}+02$

$7.07 \mathrm{E}+02$
Dose statistics at graphical times, mrem/yr

\begin{tabular}{|c|c|c|c|c|c|c|c|}
\hline Iinimum & Iaximum & Mean & Median & $90 \%$ & $95 \%$ & $97.5 \%$ & \\
\hline 08 & 06 & $5 E-07$ & $52 E-07$ & 1.891 & 06 & 6 & -0 \\
\hline $7 E-08$ & -06 & $7 E-07$ & $3 E-07$ & $1.89 \mathrm{E}-06$ & $0 E-06$ & 06 & $39 E-06$ \\
\hline$E-08$ & E-06 & $3 E-07$ & 7 & 06 & $0 E-06$ & 06 & $39 E-06$ \\
\hline$E-08$ & $E-06$ & $E-07$ & $6 E-07$ & $0 E-06$ & $1 E-06$ & 06 & $E-06$ \\
\hline $.50 \mathrm{E}-08$ & -06 & -07 & -07 & -06 & 6 & & $39 \mathrm{E}-06$ \\
\hline-08 & -06 & 7 & $E-07$ & 6 & 6 & 06 & $E-06$ \\
\hline $.52 E-08$ & $6 E-06$ & $4 E-07$ & $0 E-07$ & -06 & $2 E-06$ & -06 & $E-06$ \\
\hline $.53 E-08$ & $5 E-06$ & 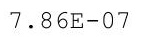 & $4.01+4$ & $1.91 E-06$ & $2.72 \mathrm{E}-06$ & -06 & $.40 E-06$ \\
\hline $.54 \mathrm{E}-08$ & $5 E-06$ & 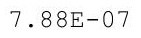 & 1. & $1.92 \mathrm{E}-06$ & 2.100 & -06 & $40 E-06$ \\
\hline $4 E-08$ & -06 & -07 & 7 & $92 E-06$ & 6 & 06 & $40 E-06$ \\
\hline $.55 E-08$ & $4 E-06$ & $1 \mathrm{E}-07$ & $5 E-07$ & & $73 E-06$ & & $40 E-06$ \\
\hline 08 & 06 & 7 & -07 & 6 & 6 & & -06 \\
\hline $7 E-08$ & $4 E-06$ & 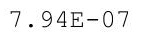 & & -06 & & 06 & -06 \\
\hline . & $7.53 \mathrm{E}-06$ & 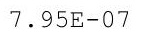 & $4.095-01$ & $1.93 \mathrm{E}-06$ & $45-00$ & -06 & $40 E-06$ \\
\hline $9 E-08$ & -06 & 1 & 07 & 06 & 6 & 06 & -06 \\
\hline $.60 E-08$ & 06 & 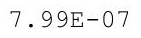 & 1 & 6 & 0 & 06 & -06 \\
\hline $.61 E-08$ & $7.52 \mathrm{E}-06$ & $8.00 \mathrm{E}-07$ & $4.74 E-07$ & -06 & $5 E-06$ & -06 & $.41 E-06$ \\
\hline$E-08$ & $E-06$ & $E-07$ & $E-07$ & -06 & $E-06$ & -06 & $42 E-06$ \\
\hline $.63 E-08$ & $1 \mathrm{E}-06$ & $3 E-07$ & & & & 6 & -06 \\
\hline $.63 E-08$ & $7.51 \mathrm{E}-06$ & $5 E-07$ & 4. & -06 & 6 & 06 & -06 \\
\hline $4 E-08$ & $E-06$ & 至 & 1 & & & & $3 E-06$ \\
\hline $55 E-08$ & 06 & $8.08 E-07$ & 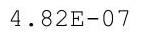 & 6 & & 6 & -06 \\
\hline $.66 E-08$ & $7.50 \mathrm{E}-06$ & r & 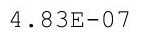 & $1.95 \mathrm{E}-06$ & 2.190 & 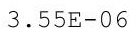 & $.44 E-06$ \\
\hline $.67 E-08$ & -06 & 7 & $E-07$ & -06 & 06 & -06 & -06 \\
\hline $.68 \mathrm{E}-08$ & $7.49 \mathrm{E}-06$ & $3 E-07$ & $7 E-07$ & & $7 E-06$ & -06 & $44 E-06$ \\
\hline$E-08$ & 06 & -07 & $E-07$ & -06 & 6 & 06 & $5 E-06$ \\
\hline$D E-08$ & $E-06$ & $E-01$ & $E-U 1$ & & 6 & & $45 E-06$ \\
\hline $.71 E-08$ & $7.48 \mathrm{E}-06$ & $8.17 \mathrm{E}-07$ & 4. $92 \mathrm{E}-07$ & $1.97 \mathrm{E}-06$ & $2.78 \mathrm{E}-06$ & $5 E-06$ & $.45 \mathrm{E}-06$ \\
\hline • & (1. & r & 年 & $1.97 \mathrm{E}-06$ & 年 & -06 & $.46 \mathrm{E}-06$ \\
\hline • & $7 E-06$ & r & tr & 06 & ( & 06 & -0 \\
\hline 28 & 06 & -07 & 7 & 06 & 6 & 6 & -06 \\
\hline$E-08$ & $E-06$ & $E-07$ & $3 E-07$ & $8 E-06$ & 6 & 6 & $6 E-06$ \\
\hline $.76 \mathrm{E}-08$ & $7.46 \mathrm{E}-06$ & $8.25 \mathrm{E}-07$ & 07 & $1.98 \mathrm{E}-06$ & 6 & 6 & -06 \\
\hline $.77 \mathrm{E}-08$ & $7.46 \mathrm{E}-06$ & $8.27 \mathrm{E}-07$ & $5.01 \mathrm{E}-07$ & $1.99 \mathrm{E}-06$ & $2.80 \mathrm{E}-06$ & $5 E-06$ & $.46 \mathrm{E}-06$ \\
\hline $.10 \mathrm{E}-00$ & $7.45 \mathrm{E}-06$ & . 2040 & & & & & $46 \mathrm{E}-06$ \\
\hline 正 & 6 & & & & & & $4.46 \mathrm{E}-06$ \\
\hline 08 & 06 & 7 & 7 & 6 & 6 & & 06 \\
\hline $.81 E-08$ & $E-06$ & $E-07$ & $E-07$ & 06 & 6 & 6 & $E-06$ \\
\hline $.82 E-08$ & $7.44 \mathrm{E}-06$ & $4 \mathrm{E}-07$ & $8 E-07$ & $1 E-06$ & $E-06$ & -06 & $46 \mathrm{E}-06$ \\
\hline $.83 E-08$ & & & & & & & -06 \\
\hline $1.84 \mathrm{E}-08$ & & & & & & & $16 \pm-06$ \\
\hline $.85 E-08$ & $7.43 E-06$ & & & $2.02 \mathrm{E}-06$ & $2.82 \mathrm{E}-06$ & & $.46 \mathrm{E}-06$ \\
\hline 8 & t & $8.41 \mathrm{E}-07$ & $5.13 \mathrm{E}-07$ & 2 & $2.83 E-06$ & 6 & $4.46 \mathrm{E}-06$ \\
\hline $.87 E-08$ & $7.42 \mathrm{E}-06$ & $8.42 \mathrm{E}-07$ & $5.14 \mathrm{E}-07$ & $2.02 \mathrm{E}$ & $2.83 E-06$ & $56 E-06$ & $4.46 \mathrm{E}-06$ \\
\hline$E-08$ & -06 & -07 & -07 & $z-06$ & 6 & -06 & $4.46 \mathrm{E}-06$ \\
\hline $.89 \mathrm{E}-08$ & $7.41 \mathrm{E}-06$ & $45 E-07$ & $.17 \mathrm{E}-07$ & $2.03 E-06$ & $2.84 \mathrm{E}-06$ & $3.55 \mathrm{E}-06$ & $4.46 \mathrm{E}-06$ \\
\hline
\end{tabular}


RESRAD-OFFSITE, Version 2.5

Title : RESRAD-OFFSITE External Gamma, Inhalation, and Soil Ingestion for Offsite Reside File : PBA-1_TC99-DOE-5-1.ROF

Summary of dose at graphical times, reptition 3 (continued)

Time

Years

7. $08 \mathrm{E}+02$

$7.08 \mathrm{E}+02$

$7.09 \mathrm{E}+02$

$7.09 \mathrm{E}+02$

$7.10 \mathrm{E}+02$

$7.10 \mathrm{E}+02$

7. $11 \mathrm{E}+02$

7. $11 \mathrm{E}+02$

$7.12 \mathrm{E}+02$

$7.12 \mathrm{E}+02$

$7.13 \mathrm{E}+02$

$7.13 \mathrm{E}+02$

$7.14 \mathrm{E}+02$

$7.14 \mathrm{E}+02$

7. $15 \mathrm{E}+02$

7. $15 \mathrm{E}+02$

7. $16 \mathrm{E}+02$

$7.16 \mathrm{E}+02$

$7.17 \mathrm{E}+02$

$7.17 \mathrm{E}+02$

$7.18 \mathrm{E}+02$

$7.18 \mathrm{E}+02$

$7.19 \mathrm{E}+02$

$7.19 \mathrm{E}+02$

$7.20 \mathrm{E}+02$

$7.20 \mathrm{E}+02$

7. $21 \mathrm{E}+02$

$7.21 \mathrm{E}+02$

7. $22 \mathrm{E}+02$

$7.22 \mathrm{E}+02$

7. $23 \mathrm{E}+02$

7. $23 \mathrm{E}+02$

$7.24 \mathrm{E}+02$

7. $24 \mathrm{E}+02$

$7.25 \mathrm{E}+02$

7. $25 \mathrm{E}+02$

$7.26 \mathrm{E}+02$

$7.26 \mathrm{E}+02$

$7.27 \mathrm{E}+02$

$7.28 \mathrm{E}+02$

$7.28 \mathrm{E}+02$

$7.29 \mathrm{E}+02$

$7.29 \mathrm{E}+02$

7. $30 \mathrm{E}+02$

$7.30 \mathrm{E}+02$

$7.31 \mathrm{E}+02$
Dose statistics at graphical times, mrem/yr

\begin{tabular}{|c|c|c|c|c|c|c|c|}
\hline $\mathrm{m}$ & $\operatorname{axi}$ & ea & ledian & $90 \%$ & & $\%$ & \\
\hline $90 \mathrm{E}-08$ & $41 \mathrm{E}-06$ & $.47 \mathrm{E}-07$ & $.18 \mathrm{E}-07$ & $.03 E-06$ & $2.84 \mathrm{E}-06$ & $3.56 \mathrm{E}-06$ & -00 \\
\hline-08 & $40 E-06$ & $E-07$ & -07 & $.03 E-06$ & $2.84 \mathrm{E}-06$ & $3.56 \mathrm{E}-06$ & $4.47 \mathrm{E}-06$ \\
\hline $.92 E-08$ & $40 \mathrm{E}-06$ & $.50 \mathrm{E}-07$ & $.20 \mathrm{E}-07$ & $.04 \mathrm{E}-06$ & $2.85 \mathrm{E}-06$ & $3.56 \mathrm{E}-06$ & -06 \\
\hline 8 & $39 F-06$ & $51 \mathrm{~F}-07$ & $21 \mathrm{~F}-07$ & $4 \mathrm{~F}-06$ & $5 \mathrm{~F}-06$ & -06 & $47 F_{-}=$ \\
\hline 8 & 06 & $3 E-07$ & 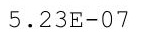 & 06 & 6 & 06 & -06 \\
\hline-08 & $39 E-06$ & -07 & & & & & 06 \\
\hline $.96 \mathrm{E}-08$ & $38 E-06$ & & & $05 E-06$ & & & -06 \\
\hline $.97 E-08$ & $38 E-06$ & & & $E-06$ & 06 & -06 & -06 \\
\hline $.98 E-08$ & $37 E-06$ & $.59 \mathrm{E}-07$ & $.29 \mathrm{E}-07$ & $6 E-06$ & $87 E-06$ & -06 & -06 \\
\hline 08 & 06 & $8615-07$ & $50 \pi$ & 6 & 6 & -06 & 6 \\
\hline 0 & 6 & 然 & ( & 6 & $2.88 E-06$ & 6 & 6 \\
\hline 08 & 6 & $F$ & $F^{2}$ & 6 & 6 & 6 & -06 \\
\hline $.02 E-08$ & $36 E-06$ & $.65 E-07$ & $5.35 E-07$ & $2.07 E-06$ & & $9 E-06$ & $4.47 \mathrm{E}-06$ \\
\hline $.03 E-08$ & $35 E-06$ & $.67 \mathrm{E}-07$ & $.36 \mathrm{E}-07$ & $.07 E-06$ & $.89 \mathrm{E}-06$ & -06 & $4.47 E-06$ \\
\hline 08 & -06 & $F-0$ & & $3 E-06$ & 0 & -06 & -06 \\
\hline-08 & 6 & 1 & & 10 & 0 & 0 & -06 \\
\hline $.06 \mathrm{E}-08$ & & & & & & 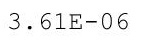 & 6 \\
\hline 8 & & & קתר & 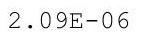 & $90 E-06$ & $2 E-06$ & 06 \\
\hline $.09 E-08$ & $33 E-06$ & $75 \mathrm{~F}-07$ & $5=-0$ & $9 E-06$ & $0 E-06$ & $5-06$ & -06 \\
\hline $.10 \mathrm{E}-08$ & $32 \mathrm{E}-06$ & $.76 \mathrm{E}-07$ & $.46 \mathrm{E}-0$ & $10 E-06$ & $.91 \mathrm{E}-06$ & $E-06$ & 4. $47 \mathrm{E}-06$ \\
\hline 08 & -06 & $\mathrm{~F}_{-}$ & & 6 & & 06 & $.47 \mathrm{E}-06$ \\
\hline & 06 & 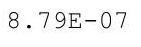 & & & & 06 & -06 \\
\hline & & & & & & & 06 \\
\hline 8 & $21+1$ & & & & & & -06 \\
\hline$E-08$ & 30 & 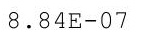 & 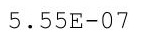 & 6 & 6 & 6 & $=0$ \\
\hline $16 \mathrm{E}-08$ & $30 E-06$ & $86 \mathrm{E}-0$ & $56 \mathrm{E}-0$ & $1 E-06$ & $3 E-06$ & -06 & $.47 \mathrm{E}-06$ \\
\hline-08 & $29 E-06$ & $87 F_{-}$ & & $1 E-06$ & $3 E-06$ & $F-06$ & $.47 \mathrm{E}-06$ \\
\hline-08 & & & & & & & -06 \\
\hline & & & & & & & 06 \\
\hline 08 & 6 & & & & & 0 & 4.47 \\
\hline $.22 \mathrm{E}-08$ & $27 E-06$ & • & 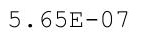 & $.12 \mathrm{E}-06$ & $2 \mathrm{~L}-\mathrm{O}$ & 30 & $4.47 \mathrm{E}-06$ \\
\hline $23 E-08$ & $27 E-06$ & . & & 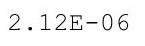 & • & (6) & . $41 \mathrm{~L}-0 \mathrm{c}$ \\
\hline & & & & $3 E-06$ & & & -06 \\
\hline-08 & & & & & & & 06 \\
\hline$E-08$ & -06 & & & & & & -06 \\
\hline $28 E-08$ & $25 E-06$ & $.01 \mathrm{E}-07$ & $5.72 E-07$ & $2.13 E-06$ & $2.96 \mathrm{E}-06$ & $3.67 \mathrm{E}-06$ & $4.47 E-06$ \\
\hline $.29 E-08$ & $24 E-06$ & 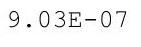 & tक & $.14 \mathrm{E}-06$ & 0 & $4-0$ & -06 \\
\hline $30 E-08$ & $24 E-06$ & 然 & & $.14 \mathrm{~L}-00$ & & & $4.4 / 5-00$ \\
\hline 8 & 6 & $\cdot$ & - is & 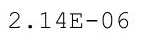 & 6 & 6 & $\cdots$ \\
\hline & & & & & & & 06 \\
\hline $.34 E-08$ & -06 & & & 6 & & -06 & -06 \\
\hline $35 E-08$ & $.22 \mathrm{E}-06$ & $.10 E-07$ & $5.82 E-07$ & $2.16 E-06$ & 6 & $8 E-06$ & -06 \\
\hline 08 & 66 & $.12 \mathrm{E}-07$ & & & & & 06 \\
\hline 8 & 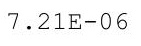 & 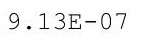 & . & +0 & $2.98 \mathrm{E}-06$ & $3.68 \mathrm{E}-06$ & $4.46 \mathrm{E}-06$ \\
\hline 8 & & & & $\begin{array}{c}-1 / 2-00 \\
0\end{array}$ & $.90 \mathrm{E}-20$ & $.68 E-06$ & $5 E-06$ \\
\hline 00 & He & $E-07$ & $88 E-07$ & -06 & $E-06$ & $8 E-06$ & $E-06$ \\
\hline
\end{tabular}


RESRAD-OFFSITE, Version 2.5

Title : RESRAD-OFFSITE External Gamma, Inhalation, and Soil Ingestion for Offsite Reside File : PBA-1_TC99-DOE-5-1.ROF

Summary of dose at graphical times, reptition 3 (continued)

Time

Years

$7.31 \mathrm{E}+02$

$7.32 \mathrm{E}+02$

$7.32 \mathrm{E}+02$

7. $33 \mathrm{E}+02$

$7.33 \mathrm{E}+02$

7. $34 \mathrm{E}+02$

7. $34 \mathrm{E}+02$

7. $35 \mathrm{E}+02$

7. $35 \mathrm{E}+02$

7. $36 \mathrm{E}+02$

7. $36 \mathrm{E}+02$

7. $37 \mathrm{E}+02$

7. $37 \mathrm{E}+02$

7. $38 \mathrm{E}+02$

7. $38 \mathrm{E}+02$

7. $39 \mathrm{E}+02$

$7.39 \mathrm{E}+02$

$7.40 \mathrm{E}+02$

$7.40 \mathrm{E}+02$

$7.41 \mathrm{E}+02$

7. $41 \mathrm{E}+02$

7. $42 \mathrm{E}+02$

$7.42 \mathrm{E}+02$

$7.43 \mathrm{E}+02$

7. $43 \mathrm{E}+02$

$7.44 \mathrm{E}+02$

7. $44 \mathrm{E}+02$

$7.45 \mathrm{E}+02$

7. $45 \mathrm{E}+02$

$7.46 \mathrm{E}+02$

$7.46 \mathrm{E}+02$

$7.47 \mathrm{E}+02$

$7.48 \mathrm{E}+02$

$7.48 \mathrm{E}+02$

$7.49 \mathrm{E}+02$

7. $49 \mathrm{E}+02$

7. $50 \mathrm{E}+02$

7. $50 \mathrm{E}+02$

$7.51 \mathrm{E}+02$

$7.51 \mathrm{E}+02$

$7.52 \mathrm{E}+02$

7. $52 \mathrm{E}+02$

$7.53 \mathrm{E}+02$

$7.53 \mathrm{E}+02$

7. $54 \mathrm{E}+02$

$7.54 \mathrm{E}+02$
Dose statistics at graphical times, mrem/yr

\begin{tabular}{|c|c|c|c|c|c|c|c|}
\hline inimum & aximum & Mean & ledian & $90 \%$ & $5 \%$ & $97.5 \%$ & $\%$ \\
\hline 8 & -06 & $E-07$ & -07 & 06 & 6 & 6 & net \\
\hline 08 & -06 & $E-07$ & 7 & 6 & 6 & 06 & -06 \\
\hline $3 E-08$ & -06 & $E-07$ & $3 E-07$ & $3 E-06$ & 6 & 06 & -06 \\
\hline-08 & 06 & 7 & & 6 & & & -06 \\
\hline-08 & -06 & 7 & & 06 & & 06 & $46 E-06$ \\
\hline-08 & -06 & -07 & 07 & -06 & -06 & -06 & $46 E-06$ \\
\hline-08 & 06 & $=07$ & 7 & -06 & 06 & -06 & $46 \mathrm{E}-0$ \\
\hline $.49 E-08$ & $7.16 \mathrm{E}-06$ & 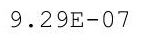 & & $2.20 E-06$ & & -06 & $46 \mathrm{E}-06$ \\
\hline 08 & 06 & 1 & 1 & 06 & 6 & -06 & -06 \\
\hline $.52 E-08$ & $E-06$ & $2 E-07$ & $E-07$ & $20 E-06$ & 06 & -06 & -06 \\
\hline-08 & -06 & 7 & & & & & $E-06$ \\
\hline-08 & 06 & -07 & 1 & & & -06 & $E-06$ \\
\hline $.55 E-08$ & $E-06$ & L- 1 & $E-U 1$ & -06 & 0 & -06 & -0 \\
\hline $.57 E-08$ & -06 & , & & 06 & 0 & -06 & $47 \mathrm{E}-06$ \\
\hline $.58 E-08$ & 06 & ( & 年 & 6 & 0 & o & -06 \\
\hline $.59 \mathrm{E}-08$ & -06 & -0 & 1 & 06 & 06 & -06 & -06 \\
\hline $.60 \mathrm{E}-08$ & $7.11 \mathrm{E}-06$ & $2 \mathrm{E}-07$ & $6 E-07$ & $2.22 \mathrm{E}-06$ & $4 E-06$ & $E-06$ & $.48 E-06$ \\
\hline $62 E-08$ & $1 \mathrm{E}-06$ & $4 \mathrm{E}-07$ & $8 E-07$ & $22 E-06$ & $E-06$ & $E-06$ & $48 E-06$ \\
\hline 08 & $E-06$ & 1 & 1 & 06 & & 6 & -06 \\
\hline $.64 \mathrm{E}-08$ & -06 & 1 & 1 & 06 & & -06 & -06 \\
\hline $.65 E-08$ & $7.09 \mathrm{E}-06$ & & & & & o & -06 \\
\hline $.67 E-08$ & $7.09 \mathrm{E}-06$ & $.50 \mathrm{E}-07$ & & $3 E-06$ & ( & -06 & -06 \\
\hline $68 \mathrm{E}-08$ & $E-06$ & ק & $6.27 \mathrm{E}-07$ & $3 E-06$ & $3.06 \mathrm{E}-06$ & 6 & $48 E-06$ \\
\hline $.69 \mathrm{E}-08$ & $7.08 \mathrm{E}-06$ & $9.53 \mathrm{E}-07$ & $6.29 \mathrm{E}-07$ & $23 E-06$ & $7 E-06$ & $5 E-06$ & $49 E-06$ \\
\hline $71 \mathrm{E}-08$ & $.07 E-06$ & $5 E-07$ & & & 06 & -06 & $49 E-06$ \\
\hline 08 & 06 & & & & & & 06 \\
\hline $.73 E-08$ & $7.06 \mathrm{E}-06$ & . 0001 & & 6 & & 6 & -06 \\
\hline $.74 \mathrm{E}-08$ & $7.06 \mathrm{E}-06$ & $9.392-01$ & $0.025-41$ & $2.24 \mathrm{E}-06$ & $2.00 \mathrm{x}-00$ & $76 \mathrm{E}-06$ & $.49 E-06$ \\
\hline 08 & 6 & 年 & . & $24 E-06$ & - & 的 00 & $.49 E-06$ \\
\hline 8 & 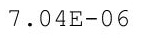 & 然 & 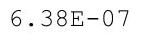 & -5 & - & -5 & - \\
\hline $78 \mathrm{~F}-08$ & $7.04 \mathrm{E}-06$ & & & & & $E-06$ & $50 E-06$ \\
\hline$E-08$ & & $E-07$ & 7 & & & & 06 \\
\hline $.81 E-08$ & $7.03 E-06$ & $E-07$ & 7 & 06 & 6 & 06 & $50 \mathrm{E}-06$ \\
\hline $.82 \mathrm{E}-08$ & $7.02 E-06$ & $9.08 \pm-01$ & $4 \mathrm{E}-\mathrm{U}$ & $2.25 E-06$ & $0 E-06$ & $78 E-06$ & $50 \mathrm{E}-06$ \\
\hline $84 \mathrm{E}-08$ & $7.02 E-06$ & $\begin{array}{ll}.100 \\
0\end{array}$ & & & & & $.20 \mathrm{~L}-2$ \\
\hline 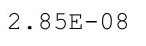 & & & & & & & \\
\hline 8 & 6 & & & & & & he \\
\hline 8 & & & & & & 6 & 06 \\
\hline 08 & & & 07 & 06 & 6 & -06 & 06 \\
\hline $.90 \mathrm{E}-08$ & $6.99 \mathrm{E}-06$ & $7 E-07$ & -07 & 06 & 6 & & $52 \mathrm{E}-06$ \\
\hline 08 & & & & & & & -0 \\
\hline 8 & & . & & 6 & & & -00 \\
\hline 0 & 6 & . & 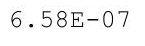 & 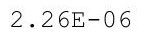 & 0 & 06 & . \\
\hline $9065=0$ & 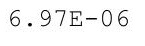 & $9.83 \mathrm{E}-07$ & 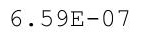 & 6 & 6 & 6 & 0 \\
\hline $97 E-08$ & $6.96 \mathrm{E}-06$ & $9.85 E-07$ & $6.61 \mathrm{E}-07$ & $2.27 \mathrm{E}$ & 3.12 & $E-06$ & $4.53 E-06$ \\
\hline $.99 E-08$ & $6.96 E-06$ & $.86 E-07$ & $.62 E-07$ & $2.27 E-06$ & $3.12 \mathrm{E}-06$ & $3.81 \mathrm{E}-06$ & $4.53 E-06$ \\
\hline
\end{tabular}


RESRAD-OFFSITE, Version 2.5

Title : RESRAD-OFFSITE External Gamma, Inhalation, and Soil Ingestion for Offsite Reside

File : PBA-1_TC99-DOE-5-1.ROF

Summary of dose at graphical times, reptition 3 (continued)

Time

Years

$7.55 E+02$

$7.55 \mathrm{E}+02$

$7.56 \mathrm{E}+02$

$7.56 \mathrm{E}+02$

$7.57 \mathrm{E}+02$

$7.57 \mathrm{E}+02$

$7.58 \mathrm{E}+02$

7. $58 \mathrm{E}+02$

$7.59 \mathrm{E}+02$

$7.59 \mathrm{E}+02$

$7.60 \mathrm{E}+02$

$7.60 \mathrm{E}+02$

$7.61 \mathrm{E}+02$

$7.61 \mathrm{E}+02$

$7.62 \mathrm{E}+02$

7. $62 \mathrm{E}+02$

$7.63 \mathrm{E}+02$

$7.63 \mathrm{E}+02$

$7.64 \mathrm{E}+02$

$7.64 \mathrm{E}+02$

$7.65 \mathrm{E}+02$

$7.65 \mathrm{E}+02$

$7.66 \mathrm{E}+02$

$7.66 \mathrm{E}+02$

$7.67 \mathrm{E}+02$

$7.68 \mathrm{E}+02$

$7.68 \mathrm{E}+02$

$7.69 \mathrm{E}+02$

7. $69 \mathrm{E}+02$

$7.70 \mathrm{E}+02$

$7.70 \mathrm{E}+02$

$7.71 \mathrm{E}+02$

$7.71 \mathrm{E}+02$

7. $72 \mathrm{E}+02$

$7.72 \mathrm{E}+02$

$7.73 E+02$

$7.73 \mathrm{E}+02$

$7.74 \mathrm{E}+02$

$7.74 \mathrm{E}+02$

$7.75 \mathrm{E}+02$

$7.75 \mathrm{E}+02$

$7.76 \mathrm{E}+02$

$7.76 \mathrm{E}+02$

$7.77 \mathrm{E}+02$

$7.77 \mathrm{E}+02$

$7.78 \mathrm{E}+02$
Dose statistics at graphical times, mrem/yr

\begin{tabular}{|c|c|c|c|c|c|c|c|}
\hline inimum & aximum & Mean & ledian & $0 \%$ & $5 \%$ & $97.5 \%$ & $\%$ \\
\hline 8 & 6 & $E-07$ & 07 & $2.27 E-06$ & $.13 E-06$ & $3.81 \mathrm{E}-06$ & $E-0$ \\
\hline 08 & 06 & 07 & 07 & $2.28 \mathrm{E}$ & 06 & 06 & -06 \\
\hline$E-08$ & -06 & $E-07$ & 07 & 06 & $3 E-06$ & 06 & -06 \\
\hline$E-08$ & $E-06$ & $E-07$ & & & & 6 & -06 \\
\hline$E-08$ & $3 E-06$ & 7 & 1 & 6 & -06 & -06 & $54 E-06$ \\
\hline $07 E-08$ & -06 & -07 & -07 & $.29 E-06$ & $E-06$ & $E-06$ & $4 E-06$ \\
\hline$E-08$ & $E-06$ & $7 E-07$ & 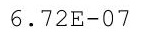 & $.29 \mathrm{E}-06$ & 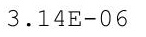 & -06 & 0 \\
\hline 08 & 06 & ( & & (2) & 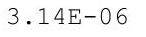 & 06 & $4.54 E-06$ \\
\hline-08 & 06 & 6 & 1 & $20+$ & 6 & 06 & $5 E-06$ \\
\hline $13 E-08$ & $E-06$ & $.00 E-06$ & & -06 & 6 & -06 & $.55 E-06$ \\
\hline $.14 \mathrm{E}-08$ & $.89 \mathrm{E}-06$ & $.00 \mathrm{E}-06$ & & $.30 \mathrm{E}-06$ & & $.81 \mathrm{E}-06$ & $.55 E-06$ \\
\hline-08 & -06 & -06 & & 6 & & -06 & $E-06$ \\
\hline $.17 \mathrm{E}-08$ & $.88 \mathrm{E}-06$ & $.01 \mathrm{E}-06$ & $.0 \angle D-01$ & C. & $-4 \pm-00$ & - & -06 \\
\hline 08 & 06 & 6 & & $2.31 \mathrm{E}-06$ & & 0 & 06 \\
\hline 8 & 6 & 6 & & $31 E-06$ & $4 \mathrm{~F}-06$ & $E-06$ & 06 \\
\hline $21 E-08$ & $6.86 \mathrm{E}-06$ & -06 & (1) & -06 & -1 & -06 & -06 \\
\hline $23 E-08$ & $6.86 \mathrm{E}-06$ & $.01 E-06$ & $.88 E-07$ & $2.31 E-06$ & $.15 E-06$ & $.83 E-06$ & $.56 E-06$ \\
\hline$E-08$ & $E-06$ & $.01 E-06$ & & $2 E-06$ & & $E-06$ & $6 E-06$ \\
\hline & $E-06$ & $.01 E-06$ & & -06 & 0 & -06 & $57 E-06$ \\
\hline 08 & 06 & 06 & & 0 & o & -06 & -06 \\
\hline 08 & 06 & & & & & 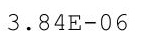 & -06 \\
\hline 08 & 6 & 6 & 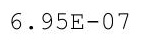 & $2.32 \mathrm{E}-06$ & 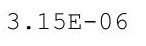 & $3.85 E-06$ & -06 \\
\hline 8 & 6 & 6 & 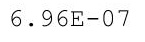 & (325 & $3.15 E-06$ & 06 & -06 \\
\hline$E-08$ & $82 E-06$ & $1.02 E-06$ & $75-07$ & $32 E-C$ & 55 & $85 E-06$ & $57 E-06$ \\
\hline$\exists-08$ & $E-06$ & $1.02 \mathrm{E}-06$ & & קרק & & $E-06$ & $57 E-06$ \\
\hline-08 & -06 & -06 & & 6 & 6 & -06 & $7 E-06$ \\
\hline 08 & & & & & & & 06 \\
\hline $39 E-08$ & $9 E-06$ & $.03 E-06$ & 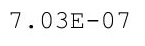 & $2.35 \mathrm{E}-00$ & 10ए- & $00 \mathrm{x}-20$ & $.57 E-06$ \\
\hline $0 E-08$ & $E-06$ & $3 E-06$ & 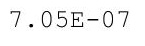 & 然 & . 10 D vo & tro & $57 E-06$ \\
\hline $2 E-08$ & $78 E-06$ & $1.03 E-06$ & 西 & $-2-5$ & 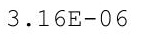 & (2) & $57 E-06$ \\
\hline-08 & $F-06$ & $03 E-06$ & & & & $7 E-06$ & $56 E-06$ \\
\hline$E-08$ & $E-06$ & $E-06$ & $=$ & 305 & 6 & $E-06$ & $E-06$ \\
\hline & & & & & & & \\
\hline $48 E-08$ & $.76 \mathrm{E}-06$ & $1.04 \mathrm{E}-06$ & $7.14 \mathrm{E}-07$ & $2.35 E-06$ & $1 / E-06$ & $.88 \mathrm{E}-00$ & $.56 E-06$ \\
\hline $49 E-08$ & $.75 E-06$ & $.04 E-06$ & & $5.30 \mathrm{D}-00$ & & $0 \mathrm{~L}-20$ & $.365-06$ \\
\hline & & & & & & & $.55 E-06$ \\
\hline 8 & & 6 & & & & 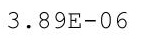 & 0 \\
\hline 8 & & & $7.22 \mathrm{E}-07$ & & & & 06 \\
\hline$E-08$ & $E-06$ & $4 E-06$ & 7 & 06 & 6 & 06 & $4 E-06$ \\
\hline $57 E-08$ & $72 E-06$ & $.05 E-06$ & 7 & 2.001 & 6 & 06 & $4.54 \mathrm{E}-06$ \\
\hline $9 E-08$ & $72 E-06$ & $5 E-06$ & & the & & 06 & $4 E-06$ \\
\hline$E-08$ & 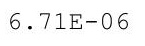 & $.05 E-06$ & -4 & 2. & & $.90 E-06$ & 1.0 \\
\hline$E-08$ & $E-$ & 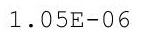 & $.0+5$ & ( & - & $905-06$ & $4.345-06$ \\
\hline & . & 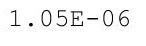 & $1.0<+$ & - & & $3.90 \mathrm{E}-06$ & $4.54 \mathrm{E}-06$ \\
\hline$E-08$ & 06 & $E-06$ & 7.3 & $2.36 E-06$ & $3.18 \mathrm{E}-06$ & -06 & 4.54 \\
\hline $.66 \mathrm{E}-08$ & $68 E-06$ & $1.05 E-06$ & $.36 E-07$ & $2.36 \mathrm{E}-06$ & $3.19 \mathrm{E}-06$ & $3.91 \mathrm{E}-06$ & $4.54 \mathrm{E}-06$ \\
\hline
\end{tabular}


RESRAD-OFFSITE, Version 2.5

Title : RESRAD-OFFSITE External Gamma, Inhalation, and Soil Ingestion for Offsite Reside File : PBA-1_TC99-DOE-5-1.ROF

Summary of dose at graphical times, reptition 3 (continued)

Time

Years

$7.78 \mathrm{E}+02$

$7.79 \mathrm{E}+02$

$7.79 \mathrm{E}+02$

7. $80 \mathrm{E}+02$

$7.80 \mathrm{E}+02$

$7.81 \mathrm{E}+02$

$7.81 \mathrm{E}+02$

$7.82 \mathrm{E}+02$

$7.82 \mathrm{E}+02$

$7.83 \mathrm{E}+02$

$7.83 \mathrm{E}+02$

$7.84 \mathrm{E}+02$

$7.84 \mathrm{E}+02$

$7.85 \mathrm{E}+02$

$7.85 \mathrm{E}+02$

$7.86 \mathrm{E}+02$

$7.86 \mathrm{E}+02$

$7.87 \mathrm{E}+02$

$7.88 \mathrm{E}+02$

$7.88 \mathrm{E}+02$

$7.89 \mathrm{E}+02$

$7.89 \mathrm{E}+02$

$7.90 \mathrm{E}+02$

$7.90 \mathrm{E}+02$

7. $91 \mathrm{E}+02$

7. $91 \mathrm{E}+02$

7. $92 \mathrm{E}+02$

7. $92 \mathrm{E}+02$

7. $93 \mathrm{E}+02$

7. $93 \mathrm{E}+02$

7. $94 \mathrm{E}+02$

$7.94 \mathrm{E}+02$

7. $95 \mathrm{E}+02$

7. $95 \mathrm{E}+02$

$7.96 \mathrm{E}+02$

7. $96 \mathrm{E}+02$

$7.97 \mathrm{E}+02$

7. $97 \mathrm{E}+02$

7. $98 \mathrm{E}+02$

7. $98 \mathrm{E}+02$

$7.99 \mathrm{E}+02$

7. $99 \mathrm{E}+02$

$8.00 \mathrm{E}+02$

$8.00 \mathrm{E}+02$

$8.01 \mathrm{E}+02$

$8.01 \mathrm{E}+02$
Dose statistics at graphical times, mrem/yr

\begin{tabular}{|c|c|c|c|c|c|c|c|}
\hline Iinimum & laximum & Mean & Median & $90 \%$ & $95 \%$ & $97.5 \%$ & \\
\hline 8 & 06 & $6 E-06$ & $38 E-07$ & 6 & 06 & 06 & -06 \\
\hline $0 E-08$ & $7 E-06$ & $1.06 \mathrm{E}-06$ & $7.40 \mathrm{E}-07$ & $2.37 \mathrm{E}-06$ & $3.19 \mathrm{E}-06$ & -06 & -06 \\
\hline$E-08$ & $.67 E-06$ & $E-06$ & 7 & 06 & $20 E-06$ & 06 & -06 \\
\hline$E-08$ & $6.66 \mathrm{E}-06$ & $5-06$ & -07 & $7 E-06$ & $20 E-06$ & & -06 \\
\hline $4 \mathrm{E}-08$ & -06 & $6 E-06$ & -07 & 6 & -06 & & -06 \\
\hline $.76 \mathrm{E}-08$ & $E-06$ & -06 & -07 & 6 & $1 E-06$ & 06 & -06 \\
\hline $.78 E-08$ & $4 E-06$ & $7 E-06$ & $9 E-07$ & -06 & -06 & 06 & -06 \\
\hline $9 E-08$ & $4 E-06$ & $.07 E-06$ & $7.50 \mathrm{E}-07$ & -06 & -06 & 06 & -06 \\
\hline $.81 E-08$ & $6.63 E-06$ & $1.07 \mathrm{E}-06$ & $7.52 \mathrm{E}-07$ & $2.38 \mathrm{E}-06$ & $21 \mathrm{E}-06$ & -06 & -06 \\
\hline $2 E-08$ & -06 & $E-06$ & -07 & 06 & $21 E-06$ & 06 & -06 \\
\hline $.84 \mathrm{E}-08$ & $6.62 \mathrm{E}-06$ & $1.07 \mathrm{E}-06$ & $7.55 \mathrm{E}-07$ & & $.22 E-06$ & & -06 \\
\hline-08 & 06 & $E-06$ & 7 & 6 & 6 & & -06 \\
\hline $.8 / \mathrm{E}-08$ & $0 E-06$ & $7 E-06$ & $3 E-07$ & & $\angle 25-00$ & & \\
\hline $.095-00$ & $6.60 \mathrm{E}-06$ & $1.08 \mathrm{E}-06$ & $7.59 \mathrm{E}-07$ & -06 & $.22 E-06$ & -06 & -06 \\
\hline$E-08$ & $9 E-06$ & $8 E-06$ & -07 & 06 & 06 & & -06 \\
\hline $.92 E-08$ & $8 E-06$ & $8 E-06$ & 07 & 06 & 0 & 06 & -06 \\
\hline $.94 \mathrm{E}-08$ & $6.58 \mathrm{E}-06$ & $1.08 \mathrm{E}-06$ & $7.63 \mathrm{E}-07$ & $2.40 \mathrm{E}-06$ & $.22 \mathrm{E}-06$ & $.93 E-06$ & $E-06$ \\
\hline$E-08$ & $E-06$ & $3 E-06$ & $E-07$ & & 6 & & 06 \\
\hline $7 \mathrm{E}-08$ & $7 E-06$ & $1.08 \mathrm{E}-06$ & $6 E-07$ & -06 & $25-06$ & & -06 \\
\hline $9 E-08$ & $6.56 \mathrm{E}-06$ & $1.08 \mathrm{E}-06$ & -07 & 6 & 0 & 06 & 06 \\
\hline $15-00$ & $E-06$ & $1.09 \mathrm{E}-06$ & $9 \mathrm{E}-07$ & & $\angle S E-0$ & & -06 \\
\hline 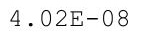 & $6.55 E-06$ & $1.09 \mathrm{E}-06$ & $7.71 \mathrm{E}-07$ & -06 & 20 & -06 & -06 \\
\hline $4 E-08$ & $4 E-06$ & $9 E-06$ & $3 E-07$ & $42 E-06$ & מ 0 ת תמת & -06 & -06 \\
\hline $.06 E-08$ & $53 E-06$ & $9 E-06$ & -07 & -06 & 06 & 06 & -06 \\
\hline$E-08$ & $E-06$ & $.09 E-06$ & $E-07$ & -06 & -06 & 06 & -06 \\
\hline 08 & 06 & -06 & -07 & 06 & & & -06 \\
\hline$E-08$ & $2 E-06$ & $9 E-06$ & $3 E-07$ & & T & & -06 \\
\hline $.12 \mathrm{E}-08$ & $6.51 \mathrm{E}-06$ & $1.10 \mathrm{E}-06$ & $7.80 \mathrm{E}-07$ & $2.43 E-06$ & $25 E-06$ & $.94 \mathrm{E}-06$ & $.50 \mathrm{E}-06$ \\
\hline 0 & 6 & 6 & 7 & 6 & 6 & 6 & 06 \\
\hline . & $6.50 \mathrm{E}-06$ & $1.10 \mathrm{E}-06$ & $1.03 \mathrm{E}-\mathrm{T}$ & $2.43 E-06$ & $\angle 0-00$ & 0 & $20 \mathrm{~L}-0$ \\
\hline 08 & 06 & $E-06$ & 07 & 6 & 6 & 6 & 06 \\
\hline$E-08$ & $E-06$ & $E-06$ & $E-07$ & 6 & 6 & & 06 \\
\hline $.21 \mathrm{E}-08$ & $8 E-06$ & $1.10 \mathrm{E}-06$ & $7.87 \mathrm{E}-07$ & $2.44 \mathrm{E}$ & $26 E-$ & & -06 \\
\hline $.23 E-08$ & $6.47 \mathrm{E}-06$ & $1.10 \mathrm{E}-06$ & $7.88 \mathrm{E}-07$ & $2.44 \mathrm{E}-06$ & $26 \mathrm{E}-06$ & $94 \mathrm{E}-06$ & $49 E-06$ \\
\hline . $\angle 4 E-00$ & $6.46 \mathrm{E}-06$ & $1.11 \mathrm{E}-06$ & & & & & $49 E-06$ \\
\hline & & & & & & & \\
\hline & & & & & & & \\
\hline $.29 \mathrm{E}-08$ & 6 & 6 & 7 & 06 & 6 & 6 & -06 \\
\hline$E-08$ & $E-06$ & $E-06$ & $3 E-07$ & 2 . & 6 & 06 & -06 \\
\hline $3 E-08$ & 06 & $E-06$ & 07 & 6 & 6 & & 06 \\
\hline $5+-08$ & $3 E-06$ & $11 \mathrm{E}-06$ & & & & & $49 E-06$ \\
\hline $36 E-08$ & & 6 & 7 & 6 & 6 & & $.49 \mathrm{E}-06$ \\
\hline & 6 & & & & & & \\
\hline & & & 1 & 6 & 6 & 6 & 0 \\
\hline$E-08$ & $E-06$ & $1.12 \mathrm{E}-06$ & 8 & 2. & 66 & 06 & -06 \\
\hline $.43 E-08$ & $6.39 E-06$ & $1.12 \mathrm{E}-06$ & $8.07 E-07$ & $2.46 E-06$ & $3.28 E-06$ & $3.96 \mathrm{E}-06$ & $4.50 \mathrm{E}-06$ \\
\hline
\end{tabular}


RESRAD-OFFSITE, Version 2.5

Title : RESRAD-OFFSITE External Gamma, Inhalation, and Soil Ingestion for offsite Reside File : PBA-1_TC99-DOE-5-1.ROF

Summary of dose at graphical times, reptition 3 (continued)

Time

Years

8. $02 \mathrm{E}+02$

$8.02 \mathrm{E}+02$

$8.03 E+02$

$8.03 \mathrm{E}+02$

$8.04 \mathrm{E}+02$

$8.04 \mathrm{E}+02$

$8.05 \mathrm{E}+02$

$8.05 \mathrm{E}+02$

$8.06 \mathrm{E}+02$

$8.06 \mathrm{E}+02$

$8.07 \mathrm{E}+02$

$8.07 \mathrm{E}+02$

$8.08 \mathrm{E}+02$

$8.09 \mathrm{E}+02$

$8.09 \mathrm{E}+02$

$8.10 \mathrm{E}+02$

$8.10 \mathrm{E}+02$

$8.11 \mathrm{E}+02$

$8.11 \mathrm{E}+02$

$8.12 \mathrm{E}+02$

$8.12 \mathrm{E}+02$

$8.13 \mathrm{E}+02$

$8.13 \mathrm{E}+02$

$8.14 \mathrm{E}+02$

$8.14 \mathrm{E}+02$

$8.15 \mathrm{E}+02$

$8.15 \mathrm{E}+02$

$8.16 \mathrm{E}+02$

$8.16 \mathrm{E}+02$

$8.17 \mathrm{E}+02$

$8.17 \mathrm{E}+02$

$8.18 \mathrm{E}+02$

$8.18 \mathrm{E}+02$

8. $19 \mathrm{E}+02$

$8.19 \mathrm{E}+02$

8. $20 \mathrm{E}+02$

$8.20 \mathrm{E}+02$

$8.21 E+02$

$8.21 E+02$

$8.22 \mathrm{E}+02$

$8.22 \mathrm{E}+02$

$8.23 \mathrm{E}+02$

$8.23 \mathrm{E}+02$

$8.24 \mathrm{E}+02$

$8.24 \mathrm{E}+02$

$8.25 E+02$

Dose statistics at graphical times, mrem/yr

\begin{tabular}{|c|c|c|c|c|c|c|c|}
\hline m & um & ean & ledian & & & $\%$ & \\
\hline 08 & 06 & 06 & 7 & 66 & 06 & 06 & -06 \\
\hline $.47 E-08$ & $6.38 \mathrm{E}-06$ & $1.12 \mathrm{E}-06$ & $8.10 E-07$ & $6 E-06$ & $28 E-06$ & $96 E-06$ & $50 E-06$ \\
\hline $.49 \mathrm{E}-08$ & $.37 E-06$ & $.13 \mathrm{E}-06$ & $8.12 \mathrm{E}-07$ & $2.46 \mathrm{E}-06$ & $3.28 \mathrm{E}-06$ & -06 & $\Xi-06$ \\
\hline $51 \mathrm{E}-08$ & $37 E-06$ & $13 \mathrm{~F}-06$ & $14 \mathrm{~F}-07$ & $.46 \mathrm{E}-06$ & $28 \mathrm{~F}-06$ & 06 & $-06+2+3$ \\
\hline 08 & 06 & 06 & 07 & 06 & 06 & 06 & -06 \\
\hline 08 & & & & & & & -06 \\
\hline $56 \mathrm{E}-08$ & -06 & & & & & & -06 \\
\hline-08 & 06 & -06 & 7 & 6 & 6 & 06 & -06 \\
\hline $.60 \mathrm{E}-08$ & -06 & $13 E-06$ & 7 & $7 E-06$ & -06 & -06 & -06 \\
\hline 08 & -06 & $14 \mathrm{E}-06$ & ח & 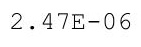 & & -06 & -06 \\
\hline 8 & 06 & 6 & $E-07$ & o & & 6 & -0 \\
\hline$E-08$ & $F-06$ & $4 E-06$ & 8 & 6 & 6 & 06 & -06 \\
\hline $.67 \mathrm{E}-08$ & $6.31 E-06$ & $1.14 \mathrm{E}-06$ & & & & & -06 \\
\hline-08 & -06 & $E-06$ & 7 & 6 & & -06 & -06 \\
\hline $.71 \mathrm{E}-08$ & -06 & $4 E-06$ & & $9 \mathrm{E}-06$ & & -06 & -06 \\
\hline 08 & 6 & $.14 \mathrm{E}-06$ & & 6 & 0 & 6 & 06 \\
\hline 8 & & 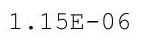 & & & & 0 & $53 E-06$ \\
\hline 8 & 6 & 6 & & 6 & & 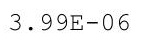 & 0 \\
\hline $.78 E-08$ & $6.27 \mathrm{E}-06$ & $1.15 E-06$ & $8.35 E-07$ & $2.51 E-06$ & $3.29 \mathrm{E}-06$ & $9 E-06$ & $.52 \mathrm{E}-06$ \\
\hline-08 & $.26 E-06$ & $1.15 \mathrm{E}-06$ & $8.37 \mathrm{E}-07$ & $2.51 \mathrm{E}-06$ & $.29 E-06$ & $E-06$ & $2 E-06$ \\
\hline 08 & -06 & $.15 \mathrm{E}-06$ & & & & -06 & -06 \\
\hline 08 & & $.15 E-06$ & & & & & \\
\hline 08 & & & & & & & o \\
\hline$E-08$ & 6 & 6 & . & 6 & 0 & 6 & -06 \\
\hline 8 & 6 & $.16 \mathrm{E}$ & e & 6 & . & 6 & 0 \\
\hline $91 E-08$ & $.22 E-06$ & $1.16 \mathrm{E}-06$ & $8.46 E-07$ & $.51 E-06$ & م & $E-06$ & $=-06$ \\
\hline $93 F-08$ & $.21 \mathrm{E}-06$ & $1.16 \mathrm{E}-06$ & & & & $E-06$ & $9 F-06$ \\
\hline & & & & & & & \\
\hline & & & & & & & -0 \\
\hline $.99 E-08$ & $6.19 E-06$ & $1.16 \mathrm{E}-06$ & $0.0 \angle 5-41$ & $2.52 \mathrm{E}-06$ & $2.30 \mathrm{~L}-00$ & $0 E-00$ & $48 E-06$ \\
\hline $.01 \mathrm{E}-08$ & $6.19 \mathrm{E}-06$ & $.16 \mathrm{E}-06$ & 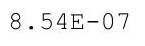 & $2.52 \mathrm{E}-06$ & . & $20-0$ & $.40 \mathrm{D}-\mathrm{U}$ \\
\hline 8 & $6.18 \mathrm{E}-06$ & $1.17 \mathrm{E}-06$ & 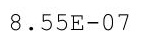 & $2.52 \mathrm{E}-06$ & & $0 E-06$ & 年 \\
\hline$F-08$ & $5.17 F-06$ & & & & & & $F-06-25-5$ \\
\hline & & & & & 6 & 6 & 06 \\
\hline & & & & $E-06$ & 6 & -06 & -06 \\
\hline $0 E-08$ & $6.15 \mathrm{E}-06$ & $1.17 \mathrm{E}-06$ & $8.62 \mathrm{E}-07$ & $2.53 E-06$ & $3.00 \mathrm{~L}$ & 06 & $8 E-06$ \\
\hline$E-08$ & 06 & $.17 E-06$ & 1 & 2.000 & & 06 & ce \\
\hline $4 E-08$ & & & & & & & •.tula \\
\hline 8 & 6 & 6 & $8.67 \mathrm{E}-07$ & & & 6 & $4.48 \mathrm{E}-06$ \\
\hline & & & & 6 & 6 & 6 & 06 \\
\hline 08 & & & $O E-07$ & 2. & 6 & -06 & 06 \\
\hline$E-08$ & $6.11 \mathrm{E}-06$ & $1.18 \mathrm{E}-06$ & $2 E-07$ & $4 E-06$ & 6 & $8 E-06$ & -06 \\
\hline & 06 & 06 & & 6 & & & \\
\hline & & & 1 & $5 E-06$ & & 06 & -00 \\
\hline & & & . & 2.00 & & & 0 \\
\hline-08 & $E-06$ & -06 & $9 E-07$ & $55 E-06$ & $2 E-06$ & $8 E-06$ & -06 \\
\hline
\end{tabular}


RESRAD-OFFSITE, Version 2.5

Title : RESRAD-OFFSITE External Gamma, Inhalation, and Soil Ingestion for Offsite Reside File : PBA-1_TC99-DOE-5-1.ROF

Summary of dose at graphical times, reptition 3 (continued)

Time

Years

$8.25 \mathrm{E}+02$

$8.26 \mathrm{E}+02$

$8.26 \mathrm{E}+02$

$8.27 \mathrm{E}+02$

$8.27 \mathrm{E}+02$

$8.28 \mathrm{E}+02$

$8.29 \mathrm{E}+02$

$8.29 \mathrm{E}+02$

$8.30 \mathrm{E}+02$

$8.30 \mathrm{E}+02$

$8.31 \mathrm{E}+02$

$8.31 \mathrm{E}+02$

$8.32 \mathrm{E}+02$

8. $32 \mathrm{E}+02$

$8.33 E+02$

$8.33 \mathrm{E}+02$

$8.34 \mathrm{E}+02$

$8.34 \mathrm{E}+02$

$8.35 \mathrm{E}+02$

$8.35 \mathrm{E}+02$

$8.36 \mathrm{E}+02$

$8.36 \mathrm{E}+02$

$8.37 \mathrm{E}+02$

$8.37 \mathrm{E}+02$

$8.38 \mathrm{E}+02$

$8.38 \mathrm{E}+02$

$8.39 \mathrm{E}+02$

$8.39 \mathrm{E}+02$

$8.40 \mathrm{E}+02$

$8.40 \mathrm{E}+02$

$8.41 \mathrm{E}+02$

8. $41 \mathrm{E}+02$

$8.42 \mathrm{E}+02$

$8.42 \mathrm{E}+02$

$8.43 \mathrm{E}+02$

$8.43 \mathrm{E}+02$

$8.44 \mathrm{E}+02$

$8.44 \mathrm{E}+02$

$8.45 \mathrm{E}+02$

$8.45 \mathrm{E}+02$

$8.46 \mathrm{E}+02$

$8.46 \mathrm{E}+02$

$8.47 \mathrm{E}+02$

$8.47 \mathrm{E}+02$

$8.48 \mathrm{E}+02$

$8.49 \mathrm{E}+02$
Dose statistics at graphical times, mrem/yr

\begin{tabular}{|c|c|c|c|c|c|c|c|}
\hline um & aximum & Mean & Median & $90 \%$ & $95 \%$ & $7.5 \%$ & $\frac{\circ}{\circ}$ \\
\hline $32 E-08$ & $6.08 \mathrm{E}-06$ & $1.19 \mathrm{E}-06$ & $8.81 E-07$ & $2.55 \mathrm{E}-06$ & $3.32 E-06$ & $3.98 \mathrm{E}-06$ & $4.49 \mathrm{E}-06$ \\
\hline $34 \mathrm{E}-08$ & $6.07 \mathrm{E}-06$ & $1.19 \mathrm{E}-06$ & $8.83 E-07$ & $2.55 \mathrm{E}-06$ & $3.32 \mathrm{E}-06$ & $3.98 \mathrm{E}-06$ & $4.49 \mathrm{E}-06$ \\
\hline $36 \mathrm{E}-08$ & $6.07 \mathrm{E}-06$ & $1.19 \mathrm{E}-06$ & $8.85 E-07$ & $2.56 \mathrm{E}-06$ & $3.32 \mathrm{E}-06$ & $3.98 \mathrm{E}-06$ & $4.49 \mathrm{E}-06$ \\
\hline $5.38 \mathrm{E}-08$ & $6.06 \mathrm{E}-06$ & $1.19 \mathrm{E}-06$ & $8.87 \mathrm{E}-07$ & $2.56 \mathrm{E}-06$ & $3.32 \mathrm{E}-06$ & $3.98 \mathrm{E}-06$ & $4.49 \mathrm{E}-06$ \\
\hline $40 \mathrm{E}-08$ & $6.05 \mathrm{E}-06$ & $1.19 \mathrm{E}-$ & $8.88 \mathrm{E}-$ & $2.56 \mathrm{E}-$ & $3.32 \mathrm{E}$ & $98 \mathrm{E}$ & $49 E-06$ \\
\hline $42 \mathrm{E}-08$ & $6.05 \mathrm{E}-06$ & $1.19 \mathrm{E}-06$ & $8.90 E-07$ & $2.56 \mathrm{E}-06$ & $3.33 E-06$ & $3.98 \mathrm{E}-06$ & $4.49 \mathrm{E}-06$ \\
\hline $44 \mathrm{E}-08$ & $6.04 \mathrm{E}-06$ & $.20 \mathrm{E}-06$ & $8.91 \mathrm{E}-07$ & $2.57 E-06$ & $3.33 \mathrm{E}-06$ & $.98 \mathrm{E}-06$ & $.49 \mathrm{E}-06$ \\
\hline $46 \mathrm{E}-08$ & $6.03 E-06$ & $.20 \mathrm{E}-06$ & $8.92 E-07$ & $2.57 E-06$ & $3.33 E-06$ & $3.99 \mathrm{E}-06$ & $4.49 \mathrm{E}-06$ \\
\hline $48 \mathrm{E}-08$ & $6.03 E-06$ & $1.20 \mathrm{E}-06$ & $8.94 \mathrm{E}-07$ & $2.57 E-06$ & $3.33 E-06$ & $3.99 \mathrm{E}-06$ & $4.49 \mathrm{E}-06$ \\
\hline $50 \mathrm{E}-08$ & $6.02 \mathrm{E}-06$ & $1.20 \mathrm{E}-06$ & $8.95 E-07$ & $2.57 E-06$ & $3.33 E-06$ & $3.99 \mathrm{E}-06$ & $4.49 \mathrm{E}-06$ \\
\hline $52 \mathrm{E}-08$ & $6.01 \mathrm{E}-06$ & $1.20 \mathrm{E}-06$ & $8.97 E-07$ & $2.58 \mathrm{E}-06$ & $3.33 E-06$ & $3.99 \mathrm{E}-06$ & $4.49 \mathrm{E}-06$ \\
\hline $.54 \mathrm{E}-08$ & $6.01 \mathrm{E}-06$ & $1.20 \mathrm{E}-06$ & $8.98 \mathrm{E}-07$ & $2.58 \mathrm{E}-06$ & $3.34 \mathrm{E}-06$ & $3.99 \mathrm{E}-06$ & $4.49 \mathrm{E}-06$ \\
\hline $5.56 \mathrm{E}-08$ & $6.00 \mathrm{E}-06$ & $1.20 \mathrm{E}-06$ & $8.99 \mathrm{E}-07$ & $2.58 \mathrm{E}-06$ & $3.34 \mathrm{E}$ & $3.99 \mathrm{E}-06$ & $4.49 \mathrm{E}-06$ \\
\hline $5.58 \mathrm{E}-08$ & $5.99 \mathrm{E}-06$ & $1.20 \mathrm{E}-06$ & $9.01 \mathrm{E}-07$ & $2.58 \mathrm{E}-06$ & $3.34 \mathrm{E}-06$ & $3.99 \mathrm{E}-06$ & $4.49 \mathrm{E}-06$ \\
\hline $5.60 \mathrm{E}-08$ & $5.99 \mathrm{E}-06$ & $1.21 \mathrm{E}-06$ & $9.02 E-07$ & $2.58 \mathrm{E}-06$ & $3.34 \mathrm{E}-06$ & $3.99 \mathrm{E}-06$ & $4.50 \mathrm{E}-06$ \\
\hline $5.62 \mathrm{E}-08$ & $5.98 \mathrm{E}-06$ & $1.21 \mathrm{E}-06$ & $9.04 \mathrm{E}-07$ & $2.59 \mathrm{E}-06$ & $3.34 \mathrm{E}-06$ & $3.99 \mathrm{E}-06$ & $4.50 \mathrm{E}-06$ \\
\hline $5.64 \mathrm{E}-08$ & $5.97 \mathrm{E}-06$ & $1.21 \mathrm{E}-06$ & $9.05 E-07$ & $2.59 \mathrm{E}-06$ & $3.34 \mathrm{E}-06$ & $3.99 \mathrm{E}-06$ & $4.50 \mathrm{E}-06$ \\
\hline $66 \mathrm{E}-08$ & $5.97 \mathrm{E}-06$ & $1.21 \mathrm{E}-06$ & $9.07 E-07$ & $2.59 \mathrm{E}-06$ & $3.35 \mathrm{E}-06$ & $3.99 \mathrm{E}-06$ & $4.50 \mathrm{E}-06$ \\
\hline $68 \mathrm{E}-08$ & $5.96 \mathrm{E}-06$ & $1.21 \mathrm{E}-06$ & $9.08 E-07$ & $2.59 \mathrm{E}-06$ & $3.35 \mathrm{E}-06$ & $3.99 \mathrm{E}-06$ & $4.50 \mathrm{E}-06$ \\
\hline $70 \mathrm{E}-08$ & $5.95 \mathrm{E}-06$ & $1.21 \mathrm{E}-$ & $E-07$ & 2 & $3.35 \mathrm{E}-$ & 6 & $.50 \mathrm{E}-06$ \\
\hline 72 & & & & & & & \\
\hline - & 5.94 & 6 & 9 & 2.60 & 6 & 6 & -06 \\
\hline $5.76 \mathrm{E}-08$ & $5.94 \mathrm{E}-06$ & $1.22 \mathrm{E}-06$ & $9.14 \mathrm{E}-07$ & $2.60 \mathrm{E}-06$ & $3.35 \mathrm{E}-06$ & $3.99 \mathrm{E}-06$ & $4.50 \mathrm{E}-06$ \\
\hline $5.78 \mathrm{E}-08$ & $5.93 \mathrm{E}-06$ & $1.22 \mathrm{E}-06$ & $9.16 \mathrm{E}-07$ & $2.60 \mathrm{E}-06$ & $3.36 \mathrm{E}-06$ & $3.99 \mathrm{E}-06$ & $4.50 \mathrm{E}-06$ \\
\hline $5.81 \mathrm{E}-08$ & $5.93 \mathrm{E}-06$ & $1.22 \mathrm{E}-06$ & $9.18 \mathrm{E}-07$ & $2.60 \mathrm{E}-06$ & $3.36 \mathrm{E}-06$ & $3.99 \mathrm{E}-06$ & $4.50 \mathrm{E}-06$ \\
\hline $5.83 \mathrm{E}-08$ & $5.93 \mathrm{E}-06$ & $1.22 \mathrm{E}-06$ & $9.19 \mathrm{E}-07$ & $2.60 E-06$ & $3.36 \mathrm{E}-06$ & $3.99 \mathrm{E}-06$ & $4.50 \mathrm{E}-06$ \\
\hline $5.85 \mathrm{E}-08$ & $5.93 \mathrm{E}-06$ & $1.22 \mathrm{E}-06$ & $9.21 \mathrm{E}-07$ & $2.61 E-06$ & $3.36 \mathrm{E}-06$ & $3.99 \mathrm{E}-06$ & $4.50 \mathrm{E}-06$ \\
\hline $5.87 \mathrm{E}-08$ & $5.93 \mathrm{E}-06$ & $1.22 \mathrm{E}-06$ & $9.22 \mathrm{E}-07$ & $2.61 E-06$ & $3.36 \mathrm{E}-06$ & $3.99 \mathrm{E}-06$ & $4.50 \mathrm{E}-06$ \\
\hline $5.89 \mathrm{E}-08$ & $5.92 \mathrm{E}-06$ & $1.22 \mathrm{E}-06$ & $9.24 \mathrm{E}-07$ & $2.61 E-06$ & $3.37 \mathrm{E}-06$ & $3.99 \mathrm{E}-06$ & $4.50 \mathrm{E}-06$ \\
\hline $5.91 \mathrm{E}-08$ & $5.92 \mathrm{E}-06$ & $1.23 \mathrm{E}-06$ & 9.25 & 2.61 & 06 & 3.991 & $4.50 \mathrm{E}-06$ \\
\hline $.93 E-08$ & $5.92 \mathrm{E}-$ & $1.23 \mathrm{E}-$ & 9.26 & 2.6 & 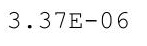 & $3.99 \mathrm{E}-06$ & $4.50 \mathrm{E}-06$ \\
\hline $5.95 \mathrm{E}-08$ & $5.92 \mathrm{E}-06$ & $1.23 \mathrm{E}-06$ & $9.28 \mathrm{E}-07$ & $2.62 \mathrm{E}-06$ & $3.37 \mathrm{E}-06$ & $3.99 \mathrm{E}-06$ & $4.51 \mathrm{E}-06$ \\
\hline $5.97 \mathrm{E}-08$ & $5.92 \mathrm{E}-06$ & $1.23 \mathrm{E}-06$ & $9.29 \mathrm{E}-07$ & $2.62 E-06$ & $3.37 \mathrm{E}-06$ & $3.99 \mathrm{E}-06$ & $4.51 \mathrm{E}-06$ \\
\hline $5.99 \mathrm{E}-08$ & $5.91 \mathrm{E}-06$ & $1.23 \mathrm{E}-06$ & $9.30 \mathrm{E}-07$ & $2.63 E-06$ & $3.37 \mathrm{E}-06$ & $3.99 \mathrm{E}-06$ & $4.51 \mathrm{E}-06$ \\
\hline $6.02 \mathrm{E}-08$ & $5.91 \mathrm{E}-06$ & $1.23 \mathrm{E}-06$ & $9.32 \mathrm{E}-07$ & $2.63 E-06$ & $3.37 \mathrm{E}-06$ & $3.99 \mathrm{E}-06$ & $4.51 \mathrm{E}-06$ \\
\hline $6.04 \mathrm{E}-08$ & $5.91 \mathrm{E}-06$ & $1.23 \mathrm{E}-06$ & $9.33 \mathrm{E}-07$ & $2.63 E-06$ & $3.37 \mathrm{E}-06$ & $3.99 \mathrm{E}-06$ & $4.52 \mathrm{E}-06$ \\
\hline $6.06 \mathrm{E}-08$ & $5.91 \mathrm{E}-06$ & $1.24 \mathrm{E}-06$ & $9.35 E-07$ & $2.63 E-06$ & $3.37 E-06$ & $3.99 \mathrm{E}-06$ & $4.52 \mathrm{E}-06$ \\
\hline $6.08 \mathrm{E}-08$ & $5.91 \mathrm{E}-06$ & $1.24 \mathrm{E}-06$ & $9.37 \mathrm{E}-07$ & $2.64 \mathrm{E}-06$ & $3.38 \mathrm{E}-06$ & $3.99 \mathrm{E}-06$ & $4.52 \mathrm{E}-06$ \\
\hline $6.10 \mathrm{E}-08$ & $5.90 \mathrm{E}-06$ & $1.24 \mathrm{E}-06$ & $9.38 \mathrm{E}-07$ & $2.64 \mathrm{E}-06$ & $3.38 \mathrm{E}-06$ & $3.99 \mathrm{E}-06$ & $4.52 \mathrm{E}-06$ \\
\hline $6.12 \mathrm{E}-08$ & $5.90 \mathrm{E}-06$ & $1.24 \mathrm{E}-06$ & $9.40 \mathrm{E}-07$ & $2.64 \mathrm{E}-06$ & $3.38 \mathrm{E}-06$ & $3.99 \mathrm{E}-06$ & $4.52 \mathrm{E}-06$ \\
\hline $6.14 \mathrm{E}-08$ & $5.90 \mathrm{E}-06$ & $1.24 \mathrm{E}-06$ & $9.41 \mathrm{E}-07$ & $2.64 \mathrm{E}-06$ & $3.38 \mathrm{E}-06$ & $4.00 \mathrm{E}-06$ & $4.53 \mathrm{E}-06$ \\
\hline $6.17 \mathrm{E}-08$ & $5.90 \mathrm{E}-06$ & $1.24 \mathrm{E}-06$ & $9.43 E-07$ & $2.64 \mathrm{E}-06$ & $3.38 \mathrm{E}-06$ & $4.00 \mathrm{E}-06$ & $4.53 \mathrm{E}-06$ \\
\hline $6.19 \mathrm{E}-08$ & $5.90 \mathrm{E}-06$ & $1.24 \mathrm{E}-06$ & $9.44 \mathrm{E}-07$ & $2.65 \mathrm{E}-06$ & $3.38 \mathrm{E}-06$ & $4.00 \mathrm{E}-06$ & $4.53 \mathrm{E}-06$ \\
\hline $6.21 \mathrm{E}-08$ & $5.89 \mathrm{E}-06$ & $1.24 \mathrm{E}-06$ & $9.46 \mathrm{E}-07$ & $2.65 E-06$ & $3.38 \mathrm{E}-06$ & $4.00 \mathrm{E}-06$ & $4.53 \mathrm{E}-06$ \\
\hline $6.23 \mathrm{E}-08$ & $5.89 \mathrm{E}-06$ & $1.25 \mathrm{E}-06$ & $9.48 \mathrm{E}-07$ & $2.65 \mathrm{E}-06$ & $3.38 \mathrm{E}-06$ & $4.00 \mathrm{E}-06$ & $4.54 \mathrm{E}-06$ \\
\hline $6.25 \mathrm{E}-08$ & $5.89 \mathrm{E}-06$ & $.25 \mathrm{E}-06$ & $9.49 \mathrm{E}-07$ & $2.65 E-06$ & $3.38 \mathrm{E}-06$ & $4.00 \mathrm{E}-$ & $4.54 \mathrm{E}-06$ \\
\hline
\end{tabular}


RESRAD-OFFSITE, Version 2.5

Title : RESRAD-OFFSITE External Gamma, Inhalation, and Soil Ingestion for offsite Reside File : PBA-1_TC99-DOE-5-1.ROF

Summary of dose at graphical times, reptition 3 (continued)

Time

Years

8. $49 \mathrm{E}+02$

$8.50 \mathrm{E}+02$

$8.50 \mathrm{E}+02$

8. $51 \mathrm{E}+02$

$8.51 \mathrm{E}+02$

8. $52 \mathrm{E}+02$

8. $52 \mathrm{E}+02$

8. $53 \mathrm{E}+02$

8. $53 \mathrm{E}+02$

8. $54 \mathrm{E}+02$

$8.54 \mathrm{E}+02$

$8.55 \mathrm{E}+02$

8. $55 \mathrm{E}+02$

$8.56 \mathrm{E}+02$

$8.56 \mathrm{E}+02$

$8.57 \mathrm{E}+02$

$8.57 \mathrm{E}+02$

8. $58 \mathrm{E}+02$

8. $58 \mathrm{E}+02$

8. $59 \mathrm{E}+02$

8. $59 \mathrm{E}+02$

8. $60 \mathrm{E}+02$

$8.60 \mathrm{E}+02$

$8.61 \mathrm{E}+02$

$8.61 \mathrm{E}+02$

$8.62 \mathrm{E}+02$

8. $62 \mathrm{E}+02$

$8.63 \mathrm{E}+02$

$8.63 \mathrm{E}+02$

$8.64 \mathrm{E}+02$

8. $64 \mathrm{E}+02$

$8.65 \mathrm{E}+02$

$8.65 \mathrm{E}+02$

$8.66 \mathrm{E}+02$

$8.66 \mathrm{E}+02$

$8.67 \mathrm{E}+02$

$8.67 \mathrm{E}+02$

$8.68 \mathrm{E}+02$

$8.69 \mathrm{E}+02$

$8.69 \mathrm{E}+02$

$8.70 \mathrm{E}+02$

$8.70 \mathrm{E}+02$

$8.71 \mathrm{E}+02$

$8.71 E+02$

$8.72 \mathrm{E}+02$

$8.72 \mathrm{E}+02$
Dose statistics at graphical times, mrem/yr

\begin{tabular}{|c|c|c|c|c|c|c|c|}
\hline num & aximum & Mean & ledian & ? & & & \\
\hline $27 E-08$ & 6 & 06 & $E-07$ & 06 & 6 & 06 & -00 \\
\hline $30 E-08$ & $.89 E-06$ & $.25 E-06$ & $3 E-07$ & $65 E-06$ & $3.38 \mathrm{E}-06$ & $4.01 \mathrm{E}-06$ & $4.54 \mathrm{E}-06$ \\
\hline-08 & $88 E-06$ & $.25 E-06$ & $55 E-07$ & $.66 \mathrm{E}-06$ & $.38 E-06$ & $.01 E-06$ & $54 \mathrm{E}-06$ \\
\hline & & $.25 E-06$ & & $.66 \mathrm{E}-06$ & & 06 & -06 \\
\hline 08 & 06 & 6 & & & 6 & & 06 \\
\hline $38 E-08$ & $88 E-06$ & $.25 E-06$ & & 6 & & & -06 \\
\hline $41 \mathrm{E}-08$ & $87 E-06$ & -06 & & -06 & -06 & -06 & $55 E-06$ \\
\hline $43 E-08$ & $E-06$ & -06 & 07 & $66 \mathrm{E}-06$ & $39 E-06$ & -06 & $E-06$ \\
\hline $45 E-08$ & $87 E-06$ & $.26 \mathrm{E}-06$ & 年 & $66 E-06$ & $39 E-06$ & -06 & -06 \\
\hline $7 E-08$ & $87 E-06$ & $26 \mathrm{~F}-06$ & $675-07$ & $66 F-06$ & $39 F-06$ & -06 & -06 \\
\hline$F-08$ & 6 & 6 & & & & & 06 \\
\hline $2 E-08$ & $E-06$ & .2 & & & 6 & & -06 \\
\hline $.54 \mathrm{E}-08$ & $.86 \mathrm{E}-06$ & $.26 E-06$ & & $.66 E-06$ & $.39 E-06$ & $.99 E-06$ & $57 E-06$ \\
\hline $56 E-08$ & -06 & -06 & & & -06 & 0 & -06 \\
\hline & & •राम vo & & & & 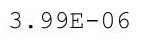 & -06 \\
\hline ل1 & & 27 & & $67 \mathrm{~F}_{0}$ & 6 & & -06 \\
\hline 35 & & 6 & & $7 F_{-1}$ & 6 & 6 & -06 \\
\hline $5 E-08$ & $5 E-06$ & $.27 E-06$ & 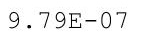 & $67 \mathrm{~F}-06 \mathrm{r}-\mathrm{s}$ & 06 & $3.99 \mathrm{E}-06$ & $E-06$ \\
\hline $7 E-08$ & $5 E-06$ & $.27 E-06$ & $1 \mathrm{~F}-07$ & $67 E-06$ & $9 E-06$ & -06 & $6 E-06$ \\
\hline $.70 \mathrm{E}-08$ & $.84 \mathrm{E}-06$ & $.27 \mathrm{E}-06$ & & $.67 \mathrm{E}-06$ & $39 E-06$ & -06 & $.56 \mathrm{E}-06$ \\
\hline & & & & & & & -06 \\
\hline & & & & & & & 06 \\
\hline & & & & & & & -06 \\
\hline $9 \mathrm{E}-$ & 06 & 6 & $9.88 \mathrm{E}-07$ & 685 & 6 & 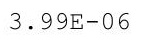 & -06 \\
\hline $1 E-08$ & $3 E-06$ & $.28 E-06$ & 7 & $68=-06$ & $39 E-06$ & $=0$ & $55 E-06$ \\
\hline$F-08$ & $E-06$ & .28 & & $68 E-06$ & -06 & -06 & -06 \\
\hline$E-08$ & E-0 6 & $28 \mathrm{~F}-06$ & & $69 F-06$ & $9 E-06$ & 06 & -06 \\
\hline & & & & & & & 06 \\
\hline & & & & & & & 06 \\
\hline $.93 E-08$ & $.82 E-06$ & $1.29 \mathrm{E}-06$ & 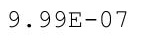 & . & $39 E-06$ & 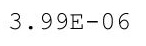 & $54 \mathrm{E}-06$ \\
\hline $95 E-08$ & $.82 \mathrm{E}-06$ & $1.29 \mathrm{E}-06$ & 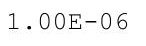 & . & $39 E-06$ & $.99 E-06$ & $.54 \mathrm{E}-06$ \\
\hline (2) & $E-06$ & $.29 E-06$ & & & & $5-06$ & -06 \\
\hline $.00 \mathrm{E}-08$ & 6 & & & & & & 06 \\
\hline-08 & 6 & 6 & & & 6 & & -06 \\
\hline $04 \mathrm{E}-08$ & $.81 E-06$ & $1.29 \mathrm{E}-06$ & $01 E-06$ & $2.70 E-06$ & $3.39 E-06$ & $3.99 \mathrm{E}-06$ & $4.53 E-06$ \\
\hline $.01 \mathrm{E}-08$ & $.81 E-06$ & $1.29 \mathrm{E}-06$ & orta & . & $3.39 \mathrm{E}-06$ & 0 & $53 E-06$ \\
\hline 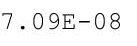 & $.00 \pm-00$ & $1.29 E-06$ & . & 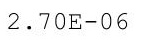 & $.39 E-00$ & 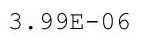 & $4.35 E-00$ \\
\hline 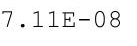 & 6 & 6 & 6 & 6 & 6 & 6 & 06 \\
\hline $.14 \mathrm{E}-08$ & & & & & & & 06 \\
\hline $16 \mathrm{~F}-08$ & $E-06$ & 06 & 06 & $.70 E-06$ & 06 & 06 & -06 \\
\hline $.18 \mathrm{E}-08$ & $.80 \mathrm{E}-06$ & $.30 \mathrm{E}-06$ & $.02 E-06$ & $70 E-06$ & 06 & 06 & $4.53 E-06$ \\
\hline $21 E-08$ & $79 E-06$ & $.30 \mathrm{E}$ & 6 & 6 & 6 & 06 & $4.53 E-06$ \\
\hline VI-UO & 6 & $\pm \cdot 00$ & - & & ( & $3.97 \mathrm{E}-06$ & $4.53 E-06$ \\
\hline टणम & $195-06$ & I. & $0<\mathrm{-}-0$ & $.10=-00$ & $3.39 E-06$ & $3.97 \mathrm{E}-06$ & $4.52 E-06$ \\
\hline . 20000 & & $+\cdot 00$ & & $.70 E-06$ & & $E-06$ & $4.52 \mathrm{E}-06$ \\
\hline $30 E-08$ & $E-06$ & $1 E-06$ & $02 E-06$ & $0 E-06$ & $38 E-06$ & $7 E-06$ & $52 E-06$ \\
\hline
\end{tabular}


RESRAD-OFFSITE, Version 2.5

Title : RESRAD-OFFSITE External Gamma, Inhalation, and Soil Ingestion for offsite Reside File : PBA-1_TC99-DOE-5-1.ROF

Summary of dose at graphical times, reptition 3 (continued)

Time

Years

$8.73 E+02$

$8.73 \mathrm{E}+02$

$8.74 \mathrm{E}+02$

$8.74 \mathrm{E}+02$

$8.75 \mathrm{E}+02$

$8.75 \mathrm{E}+02$

$8.76 \mathrm{E}+02$

$8.76 \mathrm{E}+02$

$8.77 E+02$

$8.77 \mathrm{E}+02$

$8.78 \mathrm{E}+02$

$8.78 \mathrm{E}+02$

8. $79 \mathrm{E}+02$

$8.79 \mathrm{E}+02$

$8.80 \mathrm{E}+02$

$8.80 \mathrm{E}+02$

$8.81 E+02$

8. $81 \mathrm{E}+02$

$8.82 \mathrm{E}+02$

8. $82 \mathrm{E}+02$

$8.83 \mathrm{E}+02$

$8.83 \mathrm{E}+02$

$8.84 \mathrm{E}+02$

$8.84 \mathrm{E}+02$

$8.85 \mathrm{E}+02$

$8.85 \mathrm{E}+02$

$8.86 \mathrm{E}+02$

$8.86 \mathrm{E}+02$

$8.87 \mathrm{E}+02$

$8.87 \mathrm{E}+02$

$8.88 \mathrm{E}+02$

$8.89 \mathrm{E}+02$

$8.89 \mathrm{E}+02$

8. $90 \mathrm{E}+02$

8. $90 \mathrm{E}+02$

8. $91 \mathrm{E}+02$

8. $91 \mathrm{E}+02$

8. $92 \mathrm{E}+02$

8. $92 \mathrm{E}+02$

8. $93 \mathrm{E}+02$

$8.93 E+02$

8. $94 \mathrm{E}+02$

$8.94 \mathrm{E}+02$

$8.95 \mathrm{E}+02$

$8.95 \mathrm{E}+02$

$8.96 \mathrm{E}+02$
Dose statistics at graphical times, mrem/yr

\begin{tabular}{|c|c|c|c|c|c|c|c|}
\hline inimum & aximum & Mean & ledian & $90 \%$ & $5 \%$ & $97.5 \%$ & $\%$ \\
\hline-08 & $8 E-06$ & $1.31 \mathrm{E}-06$ & $3 E-06$ & -06 & 6 & 06 & 0 \\
\hline$\Xi-08$ & $E-06$ & $E-06$ & $3 E-06$ & $1 E-06$ & 06 & 06 & -06 \\
\hline $7 E-08$ & $E-06$ & $1 \mathrm{E}-06$ & $3 E-06$ & $1 E-06$ & 06 & 06 & $E-06$ \\
\hline$E-08$ & $E-06$ & $1 E-06$ & $3 E-06$ & 06 & 6 & 6 & -06 \\
\hline-08 & -06 & -06 & -06 & 6 & & 06 & $51 E-06$ \\
\hline-08 & -06 & -06 & 06 & 06 & 06 & 06 & -06 \\
\hline-08 & $7 E-06$ & -06 & -06 & -06 & 06 & -06 & -06 \\
\hline $.49 E-08$ & $5.77 E-06$ & 1. $32 E-06$ & -06 & $2.71 E-06$ & $8 E-06$ & -06 & $51 \mathrm{E}-06$ \\
\hline-08 & -06 & 06 & 06 & 06 & 6 & -06 & $50 E-06$ \\
\hline $.54 \mathrm{E}-08$ & $E-06$ & $2 E-06$ & -06 & $1 E-06$ & 06 & 06 & $E-06$ \\
\hline-08 & -06 & -06 & 06 & 6 & & 06 & $E-06$ \\
\hline-08 & & 06 & & & & & 06 \\
\hline $.61 \mathrm{E}-08$ & $6 \mathrm{E}-06$ & $1.32 \mathrm{E}-06$ & $1.04 \mathrm{E}-06$ & $2.71 E-06$ & $2-06$ & -06 & $E-06$ \\
\hline $.64 \mathrm{E}-08$ & -06 & 1. $32 \mathrm{E}-06$ & -06 & 06 & 06 & -06 & $E-06$ \\
\hline $5 E-08$ & 06 & 06 & 06 & 6 & 6 & .06 & -06 \\
\hline$E-08$ & -06 & -06 & -06 & 06 & 06 & -06 & -06 \\
\hline $.71 \mathrm{E}-08$ & $E-06$ & $E-06$ & $E-06$ & $2.71 E-06$ & -06 & -06 & $49 E-06$ \\
\hline $4 E-08$ & $E-06$ & $3 E-06$ & -06 & 06 & & -06 & -06 \\
\hline$E-08$ & -06 & 06 & 06 & 06 & & 06 & -06 \\
\hline $.79 E-08$ & -06 & -06 & -06 & $72 E-06$ & -06 & -06 & $E-06$ \\
\hline $1 E-08$ & -06 & -06 & -06 & 06 & & 00 & -06 \\
\hline $4 E-08$ & -06 & 06 & 06 & 06 & & 6 & -06 \\
\hline $.86 E-08$ & $5.76 \mathrm{E}-06$ & $1.33 E-06$ & $1.06 \mathrm{E}-06$ & $2.72 \mathrm{E}-06$ & 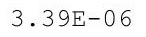 & $5 E-06$ & $48 E-06$ \\
\hline$E-08$ & $6 E-06$ & $1.34 \mathrm{E}-06$ & $5-06$ & $73 E-06$ & $E-06$ & -06 & $8 \mathrm{E}-06$ \\
\hline 08 & $E-06$ & 06 & 06 & 06 & & -06 & $E-06$ \\
\hline$E-08$ & 06 & 06 & 06 & 6 & & & -06 \\
\hline $.96 \mathrm{E}-08$ & $E-06$ & -06 & -06 & $3 E-06$ & & & $7 \mathrm{E}-06$ \\
\hline $.99 E-08$ & $5.75 \mathrm{E}-06$ & $1.34 \mathrm{E}-06$ & $1.07 \mathrm{E}-06$ & $2.73 E-06$ & $3.39 E-06$ & $4 E-06$ & $.47 E-06$ \\
\hline $.01 E-08$ & $5.75 E-06$ & $1.34 \mathrm{E}-06$ & $1.07 E-06$ & $2.73 E-06$ & 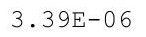 & -06 & $.47 \mathrm{E}-06$ \\
\hline $.04 \mathrm{E}-08$ & $5 E-06$ & $1.34 \mathrm{E}-06$ & $7 \mathrm{~L}-00$ & 南 & ( & -06 & $47 E-0$ \\
\hline 08 & $E-06$ & $4 \mathrm{E}-06$ & $E-06$ & $4 E-06$ & 6 & 6 & \pm-06 \\
\hline$E-08$ & $E-06$ & $E-06$ & $E-06$ & $E-06$ & 6 & 66 & -06 \\
\hline $.11 \mathrm{E}-08$ & $5.75 E-06$ & $1.35 \mathrm{E}-06$ & $8 E-06$ & $4 E-06$ & 6 & & -06 \\
\hline $.14 \mathrm{E}-08$ & $5.75 \mathrm{E}-06$ & $1.35 E-06$ & $1.08 E-06$ & $2.74 \mathrm{E}-06$ & $3.39 \mathrm{E}-06$ & $E-06$ & $46 E-06$ \\
\hline $.16 \mathrm{E}-08$ & $5 E-06$ & & & & & & 年 \\
\hline 8 & & & & & & & \\
\hline 08 & 6 & 6 & 6 & 6 & & 6 & n \\
\hline-08 & $E-06$ & -06 & 06 & 06 & 6 & -06 & 06 \\
\hline$E-08$ & $E-06$ & $E-06$ & -06 & 06 & 6 & 06 & -06 \\
\hline E-08 & 06 & $5 E-06$ & 06 & 06 & & & -06 \\
\hline 08 & & & & 6 & & & .06 \\
\hline & & & & & & & $45 E-06$ \\
\hline & & & & $2.75 E-06$ & & & $4.45 E-06$ \\
\hline 0 & 0 & 06 & 0 & 0 & 6 & 6 & 0 \\
\hline 08 & -06 & 06 & 06 & 06 & 6 & 06 & 06 \\
\hline $.44 E-08$ & $E-06$ & $.36 E-06$ & $1.10 \mathrm{E}-06$ & $.75 E-06$ & $3.39 E-06$ & $3.92 \mathrm{E}-06$ & $4.44 \mathrm{E}-06$ \\
\hline
\end{tabular}


RESRAD-OFFSITE, Version 2.5

Title : RESRAD-OFFSITE External Gamma, Inhalation, and Soil Ingestion for offsite Reside File : PBA-1_TC99-DOE-5-1.ROF

Summary of dose at graphical times, reptition 3 (continued)

Time

Years

$8.96 \mathrm{E}+02$

$8.97 \mathrm{E}+02$

$8.97 \mathrm{E}+02$

$8.98 \mathrm{E}+02$

$8.98 \mathrm{E}+02$

$8.99 \mathrm{E}+02$

8. $99 \mathrm{E}+02$

9. $00 \mathrm{E}+02$

$9.00 \mathrm{E}+02$

$9.01 \mathrm{E}+02$

$9.01 \mathrm{E}+02$

$9.02 \mathrm{E}+02$

$9.02 \mathrm{E}+02$

$9.03 \mathrm{E}+02$

$9.03 \mathrm{E}+02$

$9.04 \mathrm{E}+02$

$9.04 \mathrm{E}+02$

$9.05 \mathrm{E}+02$

$9.05 \mathrm{E}+02$

$9.06 \mathrm{E}+02$

$9.06 \mathrm{E}+02$

$9.07 \mathrm{E}+02$

$9.07 \mathrm{E}+02$

$9.08 \mathrm{E}+02$

$9.08 \mathrm{E}+02$

$9.09 \mathrm{E}+02$

9. $10 \mathrm{E}+02$

$9.10 \mathrm{E}+02$

9. $11 \mathrm{E}+02$

9. $11 \mathrm{E}+02$

9. $12 \mathrm{E}+02$

9. $12 \mathrm{E}+02$

$9.13 \mathrm{E}+02$

$9.13 \mathrm{E}+02$

$9.14 \mathrm{E}+02$

9. $14 \mathrm{E}+02$

$9.15 \mathrm{E}+02$

$9.15 \mathrm{E}+02$

$9.16 \mathrm{E}+02$

$9.16 \mathrm{E}+02$

$9.17 \mathrm{E}+02$

$9.17 \mathrm{E}+02$

$9.18 \mathrm{E}+02$

$9.18 \mathrm{E}+02$

$9.19 \mathrm{E}+02$

$9.19 \mathrm{E}+02$
Dose statistics at graphical times, mrem/yr

\begin{tabular}{|c|c|c|c|c|c|c|c|}
\hline inimum & aximum & Mean & ledian & $0 \%$ & $5 \%$ & $97.5 \%$ & $\%$ \\
\hline 8 & -06 & $E-06$ & $E-06$ & 06 & 06 & 6 & net \\
\hline 08 & -06 & 06 & $E-06$ & 6 & 06 & 06 & -06 \\
\hline-08 & -06 & -06 & -06 & $5 E-06$ & 6 & 06 & -06 \\
\hline$E-08$ & $E-06$ & $E-06$ & 6 & 6 & & & -06 \\
\hline-08 & 06 & -06 & 6 & 06 & & 06 & $43 E-06$ \\
\hline $60 E-08$ & -06 & $E-06$ & -06 & 06 & 06 & $2 E-06$ & -06 \\
\hline-08 & -06 & $7 E-06$ & -06 & -06 & 06 & -06 & -06 \\
\hline $65 E-08$ & $3 E-06$ & $.37 E-06$ & -06 & $2.76 \mathrm{E}-06$ & - & -06 & $.43 E-06$ \\
\hline 08 & 06 & 06 & 06 & 06 & 6 & -06 & -06 \\
\hline $.70 E-08$ & $3 E-06$ & $7 E-06$ & $11 E-06$ & $6 E-06$ & 06 & -06 & -06 \\
\hline-08 & -06 & $E-06$ & 06 & 6 & & & $42 E-06$ \\
\hline-08 & -06 & -06 & & & & & 06 \\
\hline $.78 \mathrm{E}-08$ & $5.72 \mathrm{E}-06$ & $1.38 E-06$ & $1.12 \mathrm{E}-06$ & $2.77 \mathrm{E}-06$ & -00 & $E-06$ & -0 \\
\hline $.81 \mathrm{E}-08$ & $5.72 \mathrm{E}-06$ & $1.38 \mathrm{E}-06$ & -06 & $2.77 \mathrm{E}-06$ & & -06 & -06 \\
\hline$E-08$ & 06 & $8 \mathrm{E}-06$ & 06 & 06 & 6 & 0 & -06 \\
\hline $.86 \mathrm{E}-08$ & -06 & -06 & -06 & -06 & 06 & -06 & -06 \\
\hline $.89 E-08$ & $2 E-06$ & $8 \mathrm{E}-06$ & $1.12 \mathrm{E}-06$ & $7 E-06$ & $40 E-06$ & $E-06$ & $.41 \mathrm{E}-06$ \\
\hline-08 & $2 E-06$ & $8 \mathrm{E}-06$ & $2 E-06$ & $7 E-06$ & $10 E-06$ & -06 & $41 E-06$ \\
\hline 08 & -06 & 06 & 06 & 06 & & 6 & -06 \\
\hline $.97 E-08$ & -06 & $E-06$ & -06 & 06 & & -06 & -06 \\
\hline $9 E-08$ & -06 & $9 E-06$ & & & & - & -06 \\
\hline $.02 E-08$ & $1 E-06$ & $1.39 \mathrm{E}-06$ & $3 E-06$ & $7 E-06$ & & -06 & -06 \\
\hline $.05 E-08$ & $.71 E-06$ & $1.39 E-06$ & $1.13 E-06$ & $78 E-06$ & (1) & $4 E-06$ & $39 E-06$ \\
\hline$E-08$ & $1 E-06$ & $1.39 \mathrm{E}-06$ & $1.13 \mathrm{E}-06$ & $78 E-06$ & $41 \mathrm{E}-06$ & $1 E-06$ & $38 \mathrm{E}-06$ \\
\hline 08 & $1 E-06$ & $.39 E-06$ & $3 E-06$ & 06 & & 6 & -06 \\
\hline$E-08$ & 06 & 06 & -06 & 6 & & .06 & 06 \\
\hline $15 \mathrm{E}-08$ & $E-06$ & $1.39 \mathrm{E}-06$ & -06 & & & & 06 \\
\hline $.18 \mathrm{E}-08$ & $5.71 \mathrm{E}-06$ & $1.39 E-06$ & $1.14 \mathrm{E}-06$ & $2.78 \mathrm{E}-06$ & $3.42 \mathrm{E}-06$ & $95 E-06$ & $.38 E-06$ \\
\hline 08 & 6 & 6 & $14 E-06$ & 6 & 政 & 00 & $38 E-06$ \\
\hline 8 & 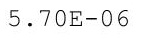 & $40 E-06$ & $14 \mathrm{E}-06$ & - & 政 & 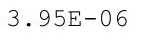 & - \\
\hline 8 & $F-06$ & $F-06$ & & $8 F-06$ & & -06 & $E-06$ \\
\hline 08 & $E-06$ & $E-06$ & $E-06$ & $9 E-06$ & 6 & -06 & $37 E-06$ \\
\hline $2 E-08$ & $E-06$ & $E-06$ & $5 E-06$ & 06 & 6 & & -06 \\
\hline $.34 \mathrm{E}-08$ & $5.70 E-06$ & $1.40 E-06$ & $1.15 \mathrm{E}-06$ & $2.79 \mathrm{E}-06$ & $3.42 \mathrm{E}-06$ & $95 E-06$ & $.37 E-06$ \\
\hline $37 E-08$ & $.70 E-06$ & $1.40 E-06$ & & $2.79 E-06$ & & & . 31 L- \\
\hline & & & & & & & \\
\hline $.42 \mathrm{E}-08$ & 6 & & & & & & 06 \\
\hline 8 & & & & & & & 26 \\
\hline & & & & & -06 & -06 & 06 \\
\hline $1 E-08$ & $E-06$ & $E-06$ & 06 & 6 & 6 & & -06 \\
\hline 08 & & -06 & & 6 & & & -0 \\
\hline & & & & & & & -00 \\
\hline & & & & 0 & 0 & 0 & ( \\
\hline $9.0 \angle E-00$ & $5.68 \mathrm{E}-06$ & & - & 6 & 6 & 6 & 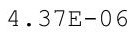 \\
\hline$E-08$ & -06 & $1.41 \mathrm{E}-06$ & $E-06$ & 2. & 06 & 06 & -06 \\
\hline $.67 E-08$ & $5.68 E-06$ & 1. $41 E-06$ & $1.16 \mathrm{E}-06$ & $2.80 \mathrm{E}-06$ & $3.43 E-06$ & $3.94 \mathrm{E}-06$ & $4.37 E-06$ \\
\hline
\end{tabular}


RESRAD-OFFSITE, Version 2.5

Title : RESRAD-OFFSITE External Gamma, Inhalation, and Soil Ingestion for Offsite Reside File : PBA-1_TC99-DOE-5-1.ROF

Summary of dose at graphical times, reptition 3 (continued)

Time

Years

$9.20 \mathrm{E}+02$

$9.20 \mathrm{E}+02$

$9.21 \mathrm{E}+02$

$9.21 \mathrm{E}+02$

$9.22 \mathrm{E}+02$

$9.22 \mathrm{E}+02$

$9.23 \mathrm{E}+02$

$9.23 \mathrm{E}+02$

$9.24 \mathrm{E}+02$

$9.24 \mathrm{E}+02$

$9.25 \mathrm{E}+02$

$9.25 \mathrm{E}+02$

$9.26 \mathrm{E}+02$

$9.26 \mathrm{E}+02$

$9.27 \mathrm{E}+02$

$9.27 \mathrm{E}+02$

$9.28 \mathrm{E}+02$

$9.28 \mathrm{E}+02$

$9.29 \mathrm{E}+02$

9. $30 \mathrm{E}+02$

9. $30 \mathrm{E}+02$

9. $31 \mathrm{E}+02$

$9.31 \mathrm{E}+02$

9. $32 \mathrm{E}+02$

9. $32 \mathrm{E}+02$

$9.33 \mathrm{E}+02$

9. $33 \mathrm{E}+02$

$9.34 \mathrm{E}+02$

9. $34 \mathrm{E}+02$

9. $35 \mathrm{E}+02$

9. $35 \mathrm{E}+02$

9. $36 \mathrm{E}+02$

9. $36 \mathrm{E}+02$

9. $37 \mathrm{E}+02$

9. $37 \mathrm{E}+02$

$9.38 \mathrm{E}+02$

$9.38 \mathrm{E}+02$

$9.39 \mathrm{E}+02$

9. $39 \mathrm{E}+02$

$9.40 \mathrm{E}+02$

$9.40 \mathrm{E}+02$

9. $41 \mathrm{E}+02$

9. $41 \mathrm{E}+02$

9. $42 \mathrm{E}+02$

$9.42 \mathrm{E}+02$

$9.43 \mathrm{E}+02$
Dose statistics at graphical times, mrem/yr

\begin{tabular}{|c|c|c|c|c|c|c|c|}
\hline inimum & Maximum & Mean & Median & $90 \%$ & $95 \%$ & $7.5 \%$ & $9 \%$ \\
\hline $9.70 \mathrm{E}-08$ & $5.68 \mathrm{E}-06$ & $1.41 \mathrm{E}-06$ & $1.17 \mathrm{E}-06$ & $2.80 \mathrm{E}-06$ & $3.43 E-06$ & $3.94 \mathrm{E}-06$ & $4.36 \mathrm{E}-06$ \\
\hline $9.73 E-08$ & $5.68 \mathrm{E}-06$ & $1.42 \mathrm{E}-06$ & $1.17 \mathrm{E}-06$ & $2.80 \mathrm{E}-06$ & $3.43 E-06$ & $3.94 \mathrm{E}-06$ & $4.36 \mathrm{E}-06$ \\
\hline $9.76 \mathrm{E}-08$ & $5.68 \mathrm{E}-06$ & $1.42 \mathrm{E}-06$ & $1.17 \mathrm{E}-06$ & $2.80 \mathrm{E}-06$ & $3.43 \mathrm{E}-06$ & $3.94 \mathrm{E}-06$ & $4.36 \mathrm{E}-06$ \\
\hline $9.78 \mathrm{E}-08$ & $5.68 \mathrm{E}-06$ & $1.42 \mathrm{E}-06$ & $1.17 \mathrm{E}-06$ & $2.80 \mathrm{E}-06$ & $3.43 \mathrm{E}-06$ & $3.94 \mathrm{E}-06$ & $4.36 \mathrm{E}-06$ \\
\hline $9.81 \mathrm{E}-08$ & $5.67 \mathrm{E}-06$ & $1.42 \mathrm{E}-06$ & $1.17 \mathrm{E}-06$ & $2.80 \mathrm{E}-06$ & $3.42 \mathrm{E}-06$ & $3.94 \mathrm{E}-06$ & $.36 \mathrm{E}-06$ \\
\hline $9.84 \mathrm{E}-08$ & $5.67 \mathrm{E}-06$ & $1.42 \mathrm{E}-06$ & $1.17 \mathrm{E}-06$ & $2.80 \mathrm{E}-06$ & $3.42 \mathrm{E}-06$ & $3.94 \mathrm{E}-06$ & $4.36 \mathrm{E}-06$ \\
\hline $9.87 \mathrm{E}-08$ & $5.67 \mathrm{E}-06$ & $1.42 \mathrm{E}-06$ & $1.18 \mathrm{E}-06$ & $2.81 \mathrm{E}-06$ & $3.42 \mathrm{E}-06$ & $3.94 \mathrm{E}-06$ & $4.35 \mathrm{E}-06$ \\
\hline $90 \mathrm{E}-08$ & $5.67 \mathrm{E}-06$ & $1.42 \mathrm{E}-06$ & $1.18 \mathrm{E}-06$ & $2.80 \mathrm{E}-06$ & $3.42 \mathrm{E}-06$ & $3.94 \mathrm{E}-06$ & $.35 E-06$ \\
\hline $.92 \mathrm{E}-08$ & $5.67 \mathrm{E}-06$ & $1.42 \mathrm{E}-06$ & $1.18 \mathrm{E}-06$ & $2.80 \mathrm{E}-06$ & $3.42 \mathrm{E}-06$ & $3.94 \mathrm{E}-06$ & $4.35 \mathrm{E}-06$ \\
\hline $9.95 \mathrm{E}-08$ & $5.67 \mathrm{E}-06$ & $1.42 \mathrm{E}-06$ & $1.18 \mathrm{E}-06$ & $2.81 \mathrm{E}-06$ & $3.42 \mathrm{E}-06$ & $3.94 \mathrm{E}-06$ & $4.35 \mathrm{E}-06$ \\
\hline $9.98 \mathrm{E}-08$ & $5.67 \mathrm{E}-06$ & $1.43 \mathrm{E}-06$ & $1.18 \mathrm{E}-06$ & $2.81 \mathrm{E}-06$ & $3.41 \mathrm{E}-06$ & $3.94 \mathrm{E}-06$ & $4.35 \mathrm{E}-06$ \\
\hline $1.00 \mathrm{E}-07$ & $5.66 \mathrm{E}-06$ & $1.43 \mathrm{E}-06$ & $1.18 \mathrm{E}-06$ & $2.81 \mathrm{E}-06$ & $3.41 \mathrm{E}-06$ & $3.94 \mathrm{E}-06$ & $4.35 \mathrm{E}-06$ \\
\hline $1.00 \mathrm{E}-07$ & $5.66 \mathrm{E}-06$ & $1.43 \mathrm{E}-06$ & $1.19 \mathrm{E}-06$ & $2.81 \mathrm{E}-06$ & $3.41 \mathrm{E}-06$ & $3.93 E-06$ & $4.35 \mathrm{E}-06$ \\
\hline $1.01 \mathrm{E}-07$ & $5.66 \mathrm{E}-06$ & $1.43 \mathrm{E}-06$ & $1.19 \mathrm{E}-06$ & $2.81 \mathrm{E}-06$ & $3.41 \mathrm{E}-06$ & $3.94 \mathrm{E}-06$ & $4.34 \mathrm{E}-06$ \\
\hline $1.01 \mathrm{E}-07$ & $5.66 \mathrm{E}-06$ & $1.43 \mathrm{E}-06$ & $1.19 \mathrm{E}-06$ & $2.81 \mathrm{E}-06$ & $3.41 \mathrm{E}-06$ & $3.93 E-06$ & $4.34 \mathrm{E}-06$ \\
\hline $1.01 \mathrm{E}-07$ & $5.66 \mathrm{E}-06$ & $1.43 \mathrm{E}-06$ & $1.19 \mathrm{E}-06$ & $2.81 \mathrm{E}-06$ & $3.41 \mathrm{E}-06$ & $3.93 E-06$ & $4.34 \mathrm{E}-06$ \\
\hline $1.01 \mathrm{E}-07$ & $5.66 \mathrm{E}-06$ & $1.43 \mathrm{E}-06$ & $1.19 \mathrm{E}-06$ & $2.81 \mathrm{E}-06$ & $3.40 \mathrm{E}-06$ & $3.93 E-06$ & $4.34 \mathrm{E}-06$ \\
\hline $1.02 \mathrm{E}-07$ & $5.65 \mathrm{E}-06$ & $1.43 \mathrm{E}-06$ & $1.19 \mathrm{E}-06$ & $2.81 \mathrm{E}-06$ & $3.40 \mathrm{E}-06$ & $3.93 E-06$ & $4.34 \mathrm{E}-06$ \\
\hline $1.02 \mathrm{E}-07$ & $5.65 \mathrm{E}-06$ & $1.43 \mathrm{E}-06$ & $1.20 \mathrm{E}-06$ & $2.81 \mathrm{E}-06$ & $3.40 \mathrm{E}-06$ & $3.94 \mathrm{E}-06$ & $4.34 \mathrm{E}-06$ \\
\hline $.02 \mathrm{E}-07$ & $5.65 \mathrm{E}-06$ & $1.44 \mathrm{E}-06$ & $1.20 \mathrm{E}-06$ & $2.81 \mathrm{E}-06$ & $3.40 \mathrm{E}-06$ & $3.94 \mathrm{E}-06$ & $34 \mathrm{E}-06$ \\
\hline $.03 E-07$ & 5 & 6 & & & & & \\
\hline $.03 E-07$ & 5 & 1 & 6 & 6 & 6 & 6 & 06 \\
\hline $1.03 \mathrm{E}-07$ & $5.65 \mathrm{E}-06$ & $1.44 \mathrm{E}-06$ & $1.20 \mathrm{E}-06$ & $2.81 \mathrm{E}-06$ & $3.39 \mathrm{E}-06$ & $3.94 \mathrm{E}-06$ & $4.34 \mathrm{E}-06$ \\
\hline $1.03 \mathrm{E}-07$ & $5.64 \mathrm{E}-06$ & $1.44 \mathrm{E}-06$ & $1.20 \mathrm{E}-06$ & $2.81 \mathrm{E}-06$ & $3.39 \mathrm{E}-06$ & $3.94 \mathrm{E}-06$ & $4.34 \mathrm{E}-06$ \\
\hline $1.04 \mathrm{E}-07$ & $5.64 \mathrm{E}-06$ & $1.44 \mathrm{E}-06$ & $1.20 \mathrm{E}-06$ & $2.81 \mathrm{E}-06$ & $3.39 \mathrm{E}-06$ & $3.94 \mathrm{E}-06$ & $4.34 \mathrm{E}-06$ \\
\hline $1.04 \mathrm{E}-07$ & $5.64 \mathrm{E}-06$ & $1.44 \mathrm{E}-06$ & $1.20 \mathrm{E}-06$ & $2.81 \mathrm{E}-06$ & $3.39 \mathrm{E}-06$ & $3.94 \mathrm{E}-06$ & $4.34 \mathrm{E}-06$ \\
\hline $1.04 \mathrm{E}-07$ & $5.64 \mathrm{E}-06$ & $1.44 \mathrm{E}-06$ & $1.21 \mathrm{E}-06$ & $2.82 \mathrm{E}-06$ & $3.39 \mathrm{E}-06$ & $3.94 \mathrm{E}-06$ & $4.34 \mathrm{E}-06$ \\
\hline $1.05 \mathrm{E}-07$ & $5.64 \mathrm{E}-06$ & $1.44 \mathrm{E}-06$ & $1.21 \mathrm{E}-06$ & $2.81 \mathrm{E}-06$ & $3.38 \mathrm{E}-06$ & $3.94 \mathrm{E}-06$ & $4.33 \mathrm{E}-06$ \\
\hline $1.05 \mathrm{E}-07$ & $5.64 \mathrm{E}-06$ & $1.44 \mathrm{E}-06$ & $1.21 \mathrm{E}-06$ & $2.81 \mathrm{E}-06$ & $3.38 \mathrm{E}-06$ & $3.94 \mathrm{E}-06$ & $4.33 \mathrm{E}-06$ \\
\hline $1.05 \mathrm{E}-07$ & $5.63 \mathrm{E}-06$ & $1.45 \mathrm{E}-06$ & $1.21 \mathrm{E}$ & $2.81 \mathrm{E}-06$ & 3.30 & -06 & $4.33 \mathrm{E}-06$ \\
\hline $1.06 \mathrm{E}-07$ & 5 & $1.45 \mathrm{E}-$ & 6 & 6 & 6 & $3.94 \mathrm{E}-06$ & $4.33 \mathrm{E}-06$ \\
\hline $1.06 \mathrm{E}-07$ & $5.63 \mathrm{E}-06$ & $1.45 \mathrm{E}-06$ & $1.21 \mathrm{E}-06$ & $2.81 \mathrm{E}-06$ & $3.38 \mathrm{E}-06$ & $3.94 \mathrm{E}-06$ & $4.33 \mathrm{E}-06$ \\
\hline $1.06 \mathrm{E}-07$ & $5.63 \mathrm{E}-06$ & $1.45 \mathrm{E}-06$ & $1.22 \mathrm{E}-06$ & $2.81 \mathrm{E}-06$ & $3.38 \mathrm{E}-06$ & $3.94 \mathrm{E}-06$ & $4.33 \mathrm{E}-06$ \\
\hline $1.06 \mathrm{E}-07$ & $5.63 \mathrm{E}-06$ & $1.45 \mathrm{E}-06$ & $1.22 \mathrm{E}-06$ & $2.81 \mathrm{E}-06$ & $3.38 \mathrm{E}-06$ & $3.94 \mathrm{E}-06$ & $4.33 \mathrm{E}-06$ \\
\hline $1.07 \mathrm{E}-07$ & $5.63 \mathrm{E}-06$ & $1.45 \mathrm{E}-06$ & $1.22 \mathrm{E}-06$ & $2.82 \mathrm{E}-06$ & $3.38 \mathrm{E}-06$ & $3.94 \mathrm{E}-06$ & $4.33 \mathrm{E}-06$ \\
\hline $1.07 \mathrm{E}-07$ & $5.62 \mathrm{E}-06$ & $1.45 \mathrm{E}-06$ & $1.22 \mathrm{E}-06$ & $2.82 \mathrm{E}-06$ & $3.38 \mathrm{E}-06$ & $3.94 \mathrm{E}-06$ & $4.33 \mathrm{E}-06$ \\
\hline $1.07 \mathrm{E}-07$ & $5.62 \mathrm{E}-06$ & $1.45 \mathrm{E}-06$ & $1.22 \mathrm{E}-06$ & $2.82 \mathrm{E}-06$ & $3.38 \mathrm{E}-06$ & $3.94 \mathrm{E}-06$ & $4.33 \mathrm{E}-06$ \\
\hline $1.08 \mathrm{E}-07$ & $5.62 \mathrm{E}-06$ & $1.45 \mathrm{E}-06$ & $1.22 \mathrm{E}-06$ & $2.82 \mathrm{E}-06$ & $3.38 \mathrm{E}-06$ & $3.94 \mathrm{E}-06$ & $4.33 \mathrm{E}-06$ \\
\hline $1.08 \mathrm{E}-07$ & $5.62 \mathrm{E}-06$ & $1.46 \mathrm{E}-06$ & $1.23 \mathrm{E}-06$ & $2.82 \mathrm{E}-06$ & $3.38 \mathrm{E}-06$ & $3.93 E-06$ & $4.33 \mathrm{E}-06$ \\
\hline $1.08 \mathrm{E}-07$ & $5.62 \mathrm{E}-06$ & $1.46 \mathrm{E}-06$ & $1.23 \mathrm{E}-06$ & $2.82 \mathrm{E}-06$ & $3.38 \mathrm{E}-06$ & $3.93 E-06$ & $4.33 \mathrm{E}-06$ \\
\hline $1.08 \mathrm{E}-07$ & $5.61 \mathrm{E}-06$ & $1.46 \mathrm{E}-06$ & $1.23 \mathrm{E}-06$ & $2.82 \mathrm{E}-06$ & $3.38 \mathrm{E}-06$ & $3.93 E-06$ & $4.33 \mathrm{E}-06$ \\
\hline $1.09 \mathrm{E}-07$ & $5.61 \mathrm{E}-06$ & $1.46 \mathrm{E}-06$ & $1.23 \mathrm{E}-06$ & $2.82 \mathrm{E}-06$ & $3.38 \mathrm{E}-06$ & $3.93 E-06$ & $4.33 \mathrm{E}-06$ \\
\hline $1.09 \mathrm{E}-07$ & $5.61 \mathrm{E}-06$ & $1.46 \mathrm{E}-06$ & $1.23 \mathrm{E}-06$ & $2.82 \mathrm{E}-06$ & $3.38 \mathrm{E}-06$ & $3.93 E-06$ & $4.33 \mathrm{E}-06$ \\
\hline $1.09 \mathrm{E}-07$ & $5.61 \mathrm{E}-06$ & $1.46 \mathrm{E}-06$ & $1.23 \mathrm{E}-06$ & $2.83 \mathrm{E}-06$ & $3.38 \mathrm{E}-06$ & $3.93 \mathrm{E}-06$ & $4.32 \mathrm{E}-06$ \\
\hline $1.10 \mathrm{E}-07$ & $5.61 \mathrm{E}-06$ & $1.46 \mathrm{E}-06$ & $1.23 \mathrm{E}-06$ & $2.83 \mathrm{E}-06$ & $3.38 \mathrm{E}-06$ & $3.93 E-06$ & $4.32 \mathrm{E}-06$ \\
\hline $.10 \mathrm{E}-07$ & $5.61 \mathrm{E}-06$ & $1.46 \mathrm{E}-06$ & $1.23 \mathrm{E}-06$ & $2.83 \mathrm{E}-06$ & $3.39 \mathrm{E}-06$ & $3.93 E-06$ & $4.32 \mathrm{E}-06$ \\
\hline
\end{tabular}


RESRAD-OFFSITE, Version 2.5

Title : RESRAD-OFFSITE External Gamma, Inhalation, and Soil Ingestion for offsite Reside File : PBA-1_TC99-DOE-5-1.ROF

Summary of dose at graphical times, reptition 3 (continued)

Time

Years

9. $43 \mathrm{E}+02$

9. $44 \mathrm{E}+02$

9. $44 \mathrm{E}+02$

$9.45 \mathrm{E}+02$

9. $45 \mathrm{E}+02$

$9.46 \mathrm{E}+02$

$9.46 \mathrm{E}+02$

$9.47 \mathrm{E}+02$

$9.47 \mathrm{E}+02$

9. $48 \mathrm{E}+02$

9. $48 \mathrm{E}+02$

$9.49 \mathrm{E}+02$

$9.50 \mathrm{E}+02$

$9.50 \mathrm{E}+02$

9. $51 \mathrm{E}+02$

9. $51 \mathrm{E}+02$

9. $52 \mathrm{E}+02$

9. $52 \mathrm{E}+02$

$9.53 \mathrm{E}+02$

9. $53 \mathrm{E}+02$

9. $54 \mathrm{E}+02$

9. $54 \mathrm{E}+02$

9. $55 \mathrm{E}+02$

9. $55 \mathrm{E}+02$

9. $56 \mathrm{E}+02$

9. $56 \mathrm{E}+02$

9. $57 \mathrm{E}+02$

9. $57 \mathrm{E}+02$

9. $58 \mathrm{E}+02$

$9.58 \mathrm{E}+02$

$9.59 \mathrm{E}+02$

$9.59 \mathrm{E}+02$

$9.60 \mathrm{E}+02$

$9.60 \mathrm{E}+02$

$9.61 \mathrm{E}+02$

9. $61 \mathrm{E}+02$

$9.62 \mathrm{E}+02$

$9.62 \mathrm{E}+02$

$9.63 \mathrm{E}+02$

$9.63 \mathrm{E}+02$

$9.64 \mathrm{E}+02$

$9.64 \mathrm{E}+02$

$9.65 \mathrm{E}+02$

$9.65 \mathrm{E}+02$

$9.66 \mathrm{E}+02$

$9.66 \mathrm{E}+02$
Dose statistics at graphical times, mrem/yr

\begin{tabular}{|c|c|c|c|c|c|c|c|}
\hline num & aximum & lean & ledian & \% & & & \\
\hline $10 E-07$ & 6 & 06 & 06 & 06 & 6 & 6 & -06 \\
\hline $.10 \mathrm{E}-07$ & $.60 \mathrm{E}-06$ & $.46 \mathrm{E}-06$ & $24 \mathrm{E}-06$ & $.83 E-06$ & $3.39 \mathrm{E}-06$ & $3.93 E-06$ & $4.32 E-06$ \\
\hline $.11 \mathrm{E}-07$ & $60 E-06$ & $.47 \mathrm{E}-06$ & $.24 \mathrm{E}-06$ & $.83 E-06$ & $.39 E-06$ & $E-06$ & $32 E-06$ \\
\hline & & 6 & & 6 & & 6 & 06 \\
\hline$F-07$ & -06 & 06 & & 6 & 6 & & -06 \\
\hline $12 \mathrm{E}-07$ & $59 E-06$ & $.47 E-06$ & & 6 & 6 & & -06 \\
\hline $12 \mathrm{E}-07$ & $59 E-06$ & $.47 \mathrm{E}-06$ & $.25 E-06$ & $.04 \Sigma-00$ & $.38 \mathrm{E}-06$ & -06 & $31 E-06$ \\
\hline $.12 \mathrm{E}-07$ & $59 E-06$ & $.47 \mathrm{E}-06$ & -06 & $84 E-06$ & $E-06$ & -06 & $1 E-06$ \\
\hline $13 E-07$ & $59 E-06$ & $.47 \mathrm{E}-06$ & $25 E-06$ & $84 E-06$ & 6 & -06 & -06 \\
\hline $13 F-07$ & $59 E-06$ & $47 F-06$ & $25 F-06$ & $84 \mathrm{~F}-06$ & $8 F-06$ & -06 & -06 \\
\hline & & 6 & & & & & 6 \\
\hline $13 E-07$ & $E-06$ & $.47 E-06$ & & 6 & & 6 & -06 \\
\hline $.14 \mathrm{E}-07$ & $.59 E-06$ & $.48 E-06$ & $.26 \mathrm{E}-06$ & $.84 \mathrm{E}-06$ & $.38 E-06$ & $E-06$ & $30 E-06$ \\
\hline $.14 \mathrm{E}-07$ & -06 & -06 & & $84 \mathrm{E}-06$ & -06 & 00 & -06 \\
\hline & & 06 & & 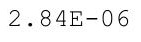 & & 0 & -06 \\
\hline م5 & & $48=0$ & & $80 \mathrm{~F}$ & 6 & 0 & -0 \\
\hline & & 6 & 6 & F1 & 6 & 6 & -06 \\
\hline $15 \mathrm{~F}-07$ & $8 E-06$ & $.48 E-06$ & & $84 \mathrm{~F}-06$ & $8 E-06$ & 6 & -06 \\
\hline $16 \mathrm{E}-07$ & $8 E-06$ & $.48 E-06$ & $6 E-06$ & $84 F-06$ & $38 E-06$ & -06 & $E-06$ \\
\hline $.16 \mathrm{E}-07$ & $.58 E-06$ & $.48 E-06$ & $.26 \mathrm{E}-06$ & $.84 \mathrm{E}-06$ & $38 E-06$ & -06 & $30 E-06$ \\
\hline & & & & & & 06 & -06 \\
\hline & & & & & & & 06 \\
\hline & & & & & & & 06 \\
\hline $.17 \mathrm{E}-07$ & 06 & 6 & 6 & تص人 & 6 & $3.90 E-06$ & -06 \\
\hline $.17 \mathrm{E}-07$ & $57 E-06$ & $.49 \mathrm{E}-06$ & $27 E-06$ & $84=-06$ & $8 E-06$ & r & $30 E-06$ \\
\hline $.18 \mathrm{E}-07$ & $57 F-06$ & $.49 E-06$ & $27 E-06$ & $84 E-06$ & 6 & -06 & -06 \\
\hline $18 \mathrm{~F}-07$ & $7 E-06$ & $.49 \mathrm{E}-06$ & & $84 E-06$ & $8 E-06$ & & -06 \\
\hline & & & & & & & 06 \\
\hline תم & & & & & & & 06 \\
\hline $.19 \mathrm{E}-07$ & $.57 E-06$ & $1.49 \mathrm{E}-06$ & $.28 E-06$ & . & 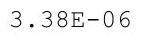 & tro & $29 E-06$ \\
\hline $.19 E-07$ & $.56 E-06$ & $1.49 \mathrm{E}-06$ & $.28 E-06$ & 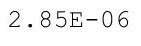 & $38 E-06$ & the & $.29 E-06$ \\
\hline $20 \mathrm{E}-$ & & $.49 \mathrm{E}-06$ & & $05 \Gamma-8$ & & & $F-06$ \\
\hline $.20 \mathrm{E}-$ & 6 & & & & & & 06 \\
\hline $20 \mathrm{~F}-07$ & 6 & & & & & & -06 \\
\hline $.20 \mathrm{E}-07$ & $.56 E-06$ & $1.50 \mathrm{E}-06$ & $.29 E-06$ & $2.85 E-06$ & $3.39 E-06$ & $3.90 \mathrm{E}-06$ & $4.29 E-06$ \\
\hline 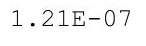 & $.56 E-06$ & $1.30 \pm-06$ & 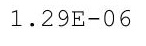 & . & $3.38 \mathrm{E}-06$ & o & -06 \\
\hline 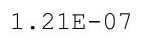 & $.30=-00$ & $1.30 \pm-06$ & 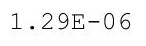 & 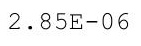 & $.30 E-40$ & . & $4.20 E-00$ \\
\hline $.21 E-07$ & 6 & 6 & 6 & 6 & 6 & 6 & 06 \\
\hline $22 E-0$ & & & & & & & 06 \\
\hline $.22 E-07$ & $.55 E-06$ & $.50 E-06$ & & $.86 \mathrm{E}-06$ & $3.38 E-06$ & -06 & -06 \\
\hline $.22 \mathrm{E}-07$ & $.55 E-06$ & $.50 E-06$ & $.30 E-06$ & $.86 E-06$ & $38 E-06$ & 06 & $4.27 \mathrm{E}-06$ \\
\hline $.23 E-07$ & $5 E-06$ & $.50 \mathrm{E}$ & 6 & 6 & . 00 & & $4.27 E-06$ \\
\hline • $20 \mathrm{E}-1$ & 6 & . & & 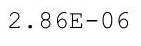 & ( & $E-06$ & $4.27 E-06$ \\
\hline 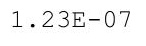 & $.55 E-06$ & 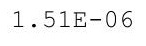 & $.30-00$ & $.005-00$ & $3.38 E-06$ & $3.89 E-06$ & $4.27 \mathrm{E}-06$ \\
\hline $.24 \mathrm{E}-07$ & e. & $1.51 \mathrm{E}-06$ & $.30 \mathrm{E}-06$ & $.86 \mathrm{E}-06$ & & & $4.27 E-06$ \\
\hline $.24 E-07$ & $E-06$ & $E-06$ & $.30 E-06$ & $86 E-06$ & $38 E-06$ & $3 E-06$ & $E-06$ \\
\hline
\end{tabular}


RESRAD-OFFSITE, Version 2.5

Title : RESRAD-OFFSITE External Gamma, Inhalation, and Soil Ingestion for offsite Reside File : PBA-1_TC99-DOE-5-1.ROF

Summary of dose at graphical times, reptition 3 (continued)

Time

Years

9. $67 \mathrm{E}+02$

9. $67 \mathrm{E}+02$

$9.68 \mathrm{E}+02$

$9.68 \mathrm{E}+02$

$9.69 \mathrm{E}+02$

$9.70 \mathrm{E}+02$

$9.70 \mathrm{E}+02$

$9.71 \mathrm{E}+02$

9. $71 \mathrm{E}+02$

9. $72 \mathrm{E}+02$

9. $72 \mathrm{E}+02$

$9.73 \mathrm{E}+02$

$9.73 \mathrm{E}+02$

9. $74 \mathrm{E}+02$

$9.74 \mathrm{E}+02$

$9.75 \mathrm{E}+02$

$9.75 \mathrm{E}+02$

$9.76 \mathrm{E}+02$

$9.76 \mathrm{E}+02$

$9.77 \mathrm{E}+02$

$9.77 \mathrm{E}+02$

$9.78 \mathrm{E}+02$

$9.78 \mathrm{E}+02$

$9.79 \mathrm{E}+02$

$9.79 \mathrm{E}+02$

$9.80 \mathrm{E}+02$

$9.80 \mathrm{E}+02$

$9.81 \mathrm{E}+02$

$9.81 \mathrm{E}+02$

$9.82 \mathrm{E}+02$

$9.82 \mathrm{E}+02$

$9.83 \mathrm{E}+02$

$9.83 \mathrm{E}+02$

$9.84 \mathrm{E}+02$

$9.84 \mathrm{E}+02$

$9.85 \mathrm{E}+02$

$9.85 \mathrm{E}+02$

$9.86 \mathrm{E}+02$

$9.86 \mathrm{E}+02$

$9.87 \mathrm{E}+02$

$9.87 \mathrm{E}+02$

$9.88 \mathrm{E}+02$

$9.88 \mathrm{E}+02$

$9.89 \mathrm{E}+02$

9. $90 \mathrm{E}+02$

$9.90 \mathrm{E}+02$
Dose statistics at graphical times, mrem/yr

\begin{tabular}{|c|c|c|c|c|c|c|c|}
\hline tum & aximum & ean & ledian & \% & & $\because$ & \\
\hline $24 E-07$ & 6 & 06 & 06 & 6 & 6 & 6 & -06 \\
\hline $25 E-07$ & $.54 \mathrm{E}-06$ & $.51 E-06$ & $31 E-06$ & $.87 \mathrm{E}-06$ & $3.38 \mathrm{E}-06$ & $3.88 \mathrm{E}-06$ & $4.26 \mathrm{E}-06$ \\
\hline $25 E-07$ & -06 & $.51 E-06$ & $.31 E-06$ & $.87 \mathrm{E}-06$ & $.38 E-06$ & $E-06$ & $26 \mathrm{E}-06$ \\
\hline & & 6 & & $.87 E-06$ & & 06 & -06 \\
\hline 07 & 06 & & & 6 & 6 & & -06 \\
\hline $26 \mathrm{E}-07$ & $54 E-06$ & $.51 \mathrm{E}-06$ & & $86 E-06$ & 6 & & -06 \\
\hline $26 \mathrm{E}-07$ & $3 E-06$ & $.51 \mathrm{E}-06$ & $31 \mathrm{E}-06$ & $.86 \mathrm{E}-06$ & $.38 \mathrm{E}-06$ & -06 & $25 E-06$ \\
\hline $26 \mathrm{E}-07$ & $3 E-06$ & $1 E-06$ & -06 & $86 E-06$ & $38 E-06$ & -06 & $25 E-06$ \\
\hline $27 E-07$ & $53 E-06$ & $.52 E-06$ & $2 E-06$ & $86 E-06$ & 6 & -06 & -06 \\
\hline $27 \mathrm{~F}-07$ & $53 E-06$ & $52 F-06$ & $32 F-06$ & $86 F-06$ & $8 F-06$ & -06 & -06 \\
\hline $275-07-2$ & & 6 & & & & & -06 \\
\hline $28 E-07$ & $E-06$ & -06 & & 6 & 6 & & $5 E-06$ \\
\hline $28 \mathrm{E}-07$ & $.52 \mathrm{E}-06$ & $.52 E-06$ & $.32 \mathrm{E}-06$ & $.86 E-06$ & $38 E-06$ & $.86 E-06$ & $.24 \mathrm{E}-06$ \\
\hline $28 E-07$ & -06 & -06 & & $6 E-06$ & -06 & 00 & -06 \\
\hline $29 E-07$ & & $.52 E-06$ & & & & o & -06 \\
\hline ת תמת & & & & $86 \mathrm{~F}-\mathrm{C}$ & 6 & 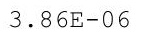 & 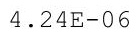 \\
\hline $20=0$ & & 6 & & & 6 & 6 & -06 \\
\hline $.30 \mathrm{E}-07$ & $2 E-06$ & $2 E-06$ & $33 E-06$ & $86 \mathrm{~F}-06$ & $8 E-06$ & 6 & $3 E-06$ \\
\hline $30 F-07$ & $1 E-06$ & $3 E-06$ & $3 E-06$ & $36 E-06$ & $8 E-06$ & -06 & $23 E-06$ \\
\hline $.30 \mathrm{E}-07$ & $.51 E-06$ & $.53 E-06$ & $.33 E-06$ & $.86 \mathrm{E}-06$ & $38 E-06$ & -06 & $23 E-06$ \\
\hline & & & & $6 \mathrm{~F}^{2}-10$ & & 06 & -06 \\
\hline & & & & & & & 06 \\
\hline & & & & & & & 06 \\
\hline $32 E-07$ & 06 & 6 & 6 & $86 F_{-1}$ & 6 & 6 & -06 \\
\hline $32 E-07$ & $50 E-06$ & $.53 E-06$ & $34 E-06$ & $865=0$ & $38 E-06$ & -0 & $.22 \mathrm{E}-06$ \\
\hline $32 E-07$ & $50 F-06$ & $E-06$ & $34 E-06$ & $86 E-06$ & 6 & -06 & $22 F-06$ \\
\hline $32 E-07$ & $E-06$ & & & $87 E-06$ & $7 E-06$ & & -06 \\
\hline & & & & & & & 06 \\
\hline $33 E-c$ & & & & & & & -06 \\
\hline $.33 E-07$ & $.50 E-06$ & $1.54 \mathrm{E}-06$ & 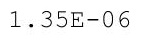 & $.87 E-06$ & 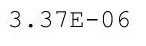 & t5 & $21 E-06$ \\
\hline $.34 E-07$ & $.49 E-06$ & $1.54 \mathrm{E}-06$ & $.35 E-06$ & 年 & $.37 E-06$ & $3 E-06$ & $.21 E-06$ \\
\hline $34 \mathrm{E}-$ & 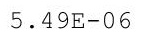 & $.54 \mathrm{E}-06$ & & $87 \mathrm{E}-\mathrm{C}$ & $37 E-06$ & 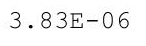 & $21 F-06$ \\
\hline . & & & & & & & 06 \\
\hline $35 E-0$ & 6 & 6 & & & 6 & & -06 \\
\hline $.35 E-07$ & $.49 \mathrm{E}-06$ & $1.54 \mathrm{E}-06$ & $.35 E-06$ & $2.87 E-06$ & $3.37 E-06$ & $3.83 \mathrm{E}-06$ & $4.20 E-06$ \\
\hline . & $.49 E-06$ & $1.34 E-06$ & 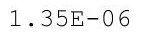 & . 01 th & $3.37 \mathrm{E}-06$ & 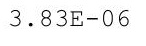 & $4.20 E-06$ \\
\hline 政 & $.40 \pm-00$ & $1.345-06$ & 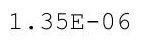 & 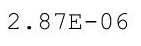 & $.3 / 4-00$ & .0 & $\begin{array}{l}7.205-00 \\
0\end{array}$ \\
\hline (c) & 6 & 6 & 6 & 6 & 6 & 6 & 06 \\
\hline (- & & & & & & & 06 \\
\hline $.37 E-07$ & $.48 E-06$ & $.54 E-06$ & & $.88 \mathrm{E}-06$ & $3.37 \mathrm{E}-06$ & -06 & -06 \\
\hline $.37 E-07$ & $.48 E-06$ & $.54 \mathrm{E}-06$ & $.36 \mathrm{E}-$ & $.88 E-06$ & 06 & 06 & $4.19 \mathrm{E}-06$ \\
\hline $.37 E-07$ & $47 E-06$ & $.55 \mathrm{E}$ & 6 & 6 & e. & & $4.19 \mathrm{E}-06$ \\
\hline 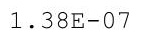 & $47 E-06$ & (1) & & - & $3.37 E-06$ & $3.82 \mathrm{E}-06$ & $4.19 E-06$ \\
\hline (1) & $.47 E-06$ & $1.35-06$ & $.31 \mathrm{E}-00$ & $.00 \mathrm{E}-00$ & $3.37 E-06$ & $3.82 E-06$ & $4.19 E-06$ \\
\hline $38 E-07$ & & $1.55 \mathrm{E}-06$ & $.37 \mathrm{E}-06$ & $.88 E-06$ & $3.37 \mathrm{E}-06$ & & $4.19 \mathrm{E}-06$ \\
\hline $.39 E-07$ & $E-06$ & $5 E-06$ & $.37 E-06$ & $88 E-06$ & $37 E-06$ & $E-06$ & $E-06$ \\
\hline
\end{tabular}


RESRAD-OFFSITE, Version 2.5

Title : RESRAD-OFFSITE External Gamma, Inhalation, and Soil Ingestion for offsite Reside File : PBA-1_TC99-DOE-5-1.ROF

Summary of dose at graphical times, reptition 3 (continued)

Time

Years

$9.91 \mathrm{E}+02$

9. $91 \mathrm{E}+02$

9. $92 \mathrm{E}+02$

9. $92 \mathrm{E}+02$

9. $93 \mathrm{E}+02$

9. $93 \mathrm{E}+02$

9. $94 \mathrm{E}+02$

9. $94 \mathrm{E}+02$

9. $95 \mathrm{E}+02$

9. $95 \mathrm{E}+02$

9. $96 \mathrm{E}+02$

9. $96 \mathrm{E}+02$

9. $97 \mathrm{E}+02$

9. $97 \mathrm{E}+02$

9. $98 \mathrm{E}+02$

9. $98 \mathrm{E}+02$

9. $99 \mathrm{E}+02$

9. $99 \mathrm{E}+02$

$1.00 \mathrm{E}+03$

$1.00 \mathrm{E}+03$

$1.00 \mathrm{E}+03$

$1.00 \mathrm{E}+03$

$1.00 \mathrm{E}+03$

$1.00 \mathrm{E}+03$

$1.00 \mathrm{E}+03$

$1.00 \mathrm{E}+03$

$1.00 \mathrm{E}+03$

$1.00 \mathrm{E}+03$

$1.00 \mathrm{E}+03$

$1.01 \mathrm{E}+03$

$1.01 \mathrm{E}+03$

$1.01 \mathrm{E}+03$

$1.01 \mathrm{E}+03$

$1.01 \mathrm{E}+03$

$1.01 \mathrm{E}+03$

$1.01 \mathrm{E}+03$

$1.01 E+03$

$1.01 \mathrm{E}+03$

$1.01 \mathrm{E}+03$

$1.01 \mathrm{E}+03$

$1.01 \mathrm{E}+03$

$1.01 \mathrm{E}+03$

$1.01 \mathrm{E}+03$

$1.01 \mathrm{E}+03$

$1.01 \mathrm{E}+03$

$1.01 \mathrm{E}+03$
Dose statistics at graphical times, mrem/yr

\begin{tabular}{|c|c|c|c|c|c|c|c|}
\hline inimum & aximum & Mean & ledian & $0 \%$ & $5 \%$ & $97.5 \%$ & $\%$ \\
\hline $.39 E-07$ & $47 E-06$ & $5 E-06$ & $E-06$ & $8 E-06$ & 06 & 6 & Oent \\
\hline 07 & $E-06$ & $5 E-06$ & $7 E-06$ & 6 & 06 & 06 & -06 \\
\hline-07 & $E-06$ & $E-06$ & $7 E-06$ & $3 E-06$ & 06 & 06 & -06 \\
\hline$E-07$ & $E-06$ & $E-06$ & 06 & 06 & & 06 & -06 \\
\hline-07 & 06 & 6 & 6 & 06 & 6 & 06 & $18 E-06$ \\
\hline $41 E-07$ & -06 & $E-06$ & $E-06$ & $E-06$ & $7 E-06$ & -06 & 06 \\
\hline $.4 \perp$ & -06 & $6 \mathrm{E}-06$ & $8 E-06$ & -06 & 06 & -06 & -0 \\
\hline $.41 E-07$ & $5 E-06$ & $.56 E-06$ & $1.38 E-06$ & $2.89 E-06$ & $37 E-06$ & -06 & $18 \mathrm{E}-06$ \\
\hline 07 & 06 & 06 & .06 & 06 & 6 & -06 & -06 \\
\hline $.42 E-07$ & $E-06$ & $6 E-06$ & $8 \mathrm{E}-06$ & -06 & -06 & -06 & $18 E-06$ \\
\hline $2 E-07$ & -06 & 06 & -06 & & & & $18 E-06$ \\
\hline-07 & & 06 & & & & & 06 \\
\hline $.43 E-07$ & $E-06$ & $.56 \mathrm{E}-06$ & $9 E-06$ & $2.89 \mathrm{E}-06$ & $5-00$ & -06 & -0 \\
\hline • & -06 & -06 & -06 & 06 & 0 & -06 & -06 \\
\hline 07 & 06 & 06 & 06 & 6 & 0 & 06 & -06 \\
\hline $.44 \mathrm{E}-07$ & -06 & -06 & -06 & 06 & 06 & -06 & -06 \\
\hline $.44 \mathrm{E}-07$ & $E-06$ & $1.56 \mathrm{E}-06$ & $9 E-06$ & $9 E-06$ & $6 E-06$ & $E-06$ & $.18 \mathrm{E}-06$ \\
\hline $5-07$ & $E-06$ & $6 E-06$ & $9 E-06$ & 06 & 06 & -06 & $18 E-06$ \\
\hline 07 & 06 & 06 & 06 & 06 & & 6 & -06 \\
\hline $.45 E-07$ & -06 & -06 & -06 & 06 & 6 & -06 & -06 \\
\hline $.46 \mathrm{E}-07$ & -06 & $1.57 \mathrm{E}-06$ & -06 & & & o & -06 \\
\hline $.46 \mathrm{E}-07$ & -06 & $1.57 \mathrm{E}-06$ & 06 & 06 & & 6 & -06 \\
\hline $.46 \mathrm{E}-07$ & $5.42 \mathrm{E}-06$ & $1.57 \mathrm{E}-06$ & 1. $40 \mathrm{E}-06$ & $2.89 \mathrm{E}-06$ & $3.36 \mathrm{E}-06$ & $82 E-06$ & $.18 \mathrm{E}-06$ \\
\hline $.47 \mathrm{E}-07$ & $2 \mathrm{E}-06$ & $1.57 \mathrm{E}-06$ & $1.40 \mathrm{E}-06$ & $9 E-06$ & $6 E-06$ & $2 E-06$ & $18 \mathrm{E}-06$ \\
\hline 07 & 06 & $7 E-06$ & 06 & 06 & & -06 & -06 \\
\hline 07 & 06 & 06 & 06 & 06 & & 06 & 06 \\
\hline $8 \pm-4$ & -06 & $7 E-06$ & -06 & $0 E-06$ & & & $18 \mathrm{E}-06$ \\
\hline $.48 \mathrm{E}-07$ & $5.41 E-06$ & $1.57 \mathrm{E}-06$ & $1.40 \mathrm{E}-06$ & $2.90 \mathrm{E}-06$ & $3.36 \mathrm{E}-06$ & $81 E-06$ & $.18 E-06$ \\
\hline ton & 6 & 6 & 6 & 6 & 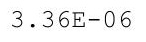 & 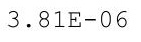 & 06 \\
\hline • & $5.41 E-06$ & $1.57 \mathrm{E}-06$ & -06 & $0 E-06$ & 政 & 政 & . \\
\hline 07 & $E-06$ & $8 E-06$ & & 6 & & 6 & $18 \mathrm{E}-06$ \\
\hline$E-07$ & $E-06$ & $3 E-06$ & $1 E-06$ & 6 & 6 & 6 & -06 \\
\hline $.50 E-07$ & $E-06$ & $3 E-06$ & 06 & 06 & 6 & & $18 \mathrm{E}-06$ \\
\hline $.50 \mathrm{E}-07$ & $5.40 \mathrm{E}-06$ & $1.58 \mathrm{E}-06$ & $1.41 \mathrm{E}-06$ & $2.90 \mathrm{E}-06$ & $3.37 \mathrm{E}-06$ & $1 E-06$ & $.18 \mathrm{E}-06$ \\
\hline $.20 \mathrm{E}-0 t$ & $5.40 E-06$ & $1.58 E-06$ & & $2.90 E-06$ & & & $\cdot 10 \mathrm{~L}$ \\
\hline t & & & & & & & \\
\hline $515-07$ & 6 & & & & & & he \\
\hline 7 & & & & & 6 & 6 & 26 \\
\hline 7 & & & & & 6 & -06 & 06 \\
\hline $.52 \mathrm{E}-07$ & $9 \mathrm{E}-06$ & $E-06$ & $1.42 \mathrm{E}$ & 6 & 6 & & $17 \mathrm{E}-06$ \\
\hline $2 E-07$ & & 06 & & 6 & & & - e \\
\hline $\begin{array}{c}\mathrm{E}-01 \\
\mathrm{~s}\end{array}$ & 6 & $1.58 \mathrm{E}-06$ & & 6 & & & -00 \\
\hline & & 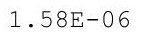 & & 0 & & & c \\
\hline $54=-07$ & 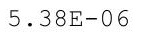 & $1.59 \mathrm{E}-06$ & - & 6 & ( & 6 & $x^{2}$ \\
\hline $4 \mathrm{E}-07$ & 5.3 & $E-06$ & $1.43 E-06$ & 66 & 3. & 06 & 4.171 \\
\hline $.54 E-07$ & $5.37 E-06$ & $1.59 \mathrm{E}-06$ & $1.43 E-06$ & $2.90 \mathrm{E}-06$ & $3.37 E-06$ & $3.80 \mathrm{E}-06$ & $4.17 \mathrm{E}-06$ \\
\hline
\end{tabular}


RESRAD-OFFSITE, Version 2.5

Title : RESRAD-OFFSITE External Gamma, Inhalation, and Soil Ingestion for offsite Reside File : PBA-1_TC99-DOE-5-1.ROF

Summary of dose at graphical times, reptition 3 (continued)

Time

Years

1. $01 \mathrm{E}+03$

1. $01 \mathrm{E}+03$

1. $02 \mathrm{E}+03$

1. $02 \mathrm{E}+03$

1. $02 \mathrm{E}+03$

1. $02 \mathrm{E}+03$

1. $02 \mathrm{E}+03$

1. $02 \mathrm{E}+03$

1. $02 \mathrm{E}+03$

1. $02 \mathrm{E}+03$

1. $02 \mathrm{E}+03$

1. $02 \mathrm{E}+03$

1. $02 \mathrm{E}+03$

1. $02 \mathrm{E}+03$

1. $02 \mathrm{E}+03$

1. $02 \mathrm{E}+03$

1. $02 \mathrm{E}+03$

1. $02 \mathrm{E}+03$

1. $02 \mathrm{E}+03$

1. $02 \mathrm{E}+03$

1. $02 \mathrm{E}+03$

1. $02 \mathrm{E}+03$

1. $03 \mathrm{E}+03$

$1.03 E+03$

$1.03 \mathrm{E}+03$

$1.03 \mathrm{E}+03$

$1.03 E+03$

$1.03 E+03$

$1.03 \mathrm{E}+03$

$1.03 \mathrm{E}+03$

$1.03 \mathrm{E}+03$

$1.03 \mathrm{E}+03$

$1.03 \mathrm{E}+03$

$1.03 \mathrm{E}+03$

$1.03 \mathrm{E}+03$

$1.03 \mathrm{E}+03$

$1.03 E+03$

$1.03 E+03$

$1.03 E+03$

$1.03 E+03$

$1.03 E+03$

$1.04 \mathrm{E}+03$

1. $04 \mathrm{E}+03$

$1.04 \mathrm{E}+03$

1. $04 \mathrm{E}+03$

$1.04 \mathrm{E}+03$
Dose statistics at graphical times, mrem/yr

\begin{tabular}{|c|c|c|c|c|c|c|c|}
\hline Inimum & Maximum & Mean & Median & $90 \%$ & $95 \%$ & $97.5 \%$ & \\
\hline 07 & 06 & $9 E-06$ & $43 E-06$ & 06 & 06 & 06 & $-06 r a r a r$ \\
\hline $5 E-07$ & $37 E-06$ & $1.59 \mathrm{E}-06$ & $.43 E-06$ & $2.90 \mathrm{E}-06$ & $3.37 \mathrm{E}-06$ & $9 E-06$ & $E-06$ \\
\hline $5-07$ & E-06 & $E-06$ & 06 & 06 & $7 E-06$ & 06 & $7 E-06$ \\
\hline$E-07$ & $E-06$ & $E-06$ & -06 & $1 E-06$ & $7 E-06$ & 06 & $7 E-06$ \\
\hline $.56 \mathrm{E}-07$ & -06 & $E-06$ & -06 & $91 E-06$ & 6 & & $17 E-06$ \\
\hline $.56 E-07$ & -06 & -06 & -06 & 6 & 6 & 06 & $17 E-06$ \\
\hline $.57 E-07$ & $6 E-06$ & $59 E-06$ & -06 & $90 E-06$ & $E-06$ & -06 & $E-06$ \\
\hline 1 & $5 E-06$ & $9 E-06$ & -06 & -06 & -06 & -06 & -06 \\
\hline (ט) & $5.35 E-06$ & $1.59 \mathrm{E}-06$ & -06 & -06 & 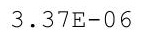 & $78 E-06$ & $16 \mathrm{E}-06$ \\
\hline $3 E-07$ & -06 & $E-06$ & 06 & 06 & 06 & 06 & $E-06$ \\
\hline $.58 E-07$ & $5.35 E-06$ & $1.60 \mathrm{E}-06$ & $E-06$ & & $37 E-06$ & & $16 \mathrm{E}-06$ \\
\hline 1 & -06 & $E-06$ & -06 & 6 & 6 & 6 & -06 \\
\hline $.59 E-07$ & $E-06$ & $0 E-06$ & -06 & -06 & $7 \pm-06$ & -06 & $E-06$ \\
\hline . $39 \mathrm{E}-01$ & $5.34 \mathrm{E}-06$ & $1.60 \mathrm{E}-06$ & -06 & 0 & 0 & 6 & 06 \\
\hline 年 & 06 & $E-06$ & 06 & 06 & 06 & 06 & $16 E-06$ \\
\hline ( & 06 & $0 E-06$ & 06 & 06 & 0 & 06 & -06 \\
\hline $.60 E-07$ & $5.33 E-06$ & 1. $60 \mathrm{E}-06$ & $1.45 E-06$ & -06 & $8 E-06$ & $8 E-06$ & $.16 \mathrm{E}-06$ \\
\hline $.60 E-07$ & $3 E-06$ & $1.60 \mathrm{E}-06$ & $5 E-06$ & $1 E-06$ & $8 E-06$ & $3 E-06$ & $16 \mathrm{E}-06$ \\
\hline $.61 E-07$ & $3 E-06$ & $0 E-06$ & $5 E-06$ & & & 6 & -06 \\
\hline $61 E-07$ & $5.33 E-06$ & -06 & -06 & 06 & 6 & 06 & $E-06$ \\
\hline $.0 \angle \mathrm{E}-\mathrm{T}$ & $2 E-06$ & $E-06$ & $5 E-06$ & & $0 \mathrm{E}-40$ & & $5 E-06$ \\
\hline $.62 E-07$ & $5.32 \mathrm{E}-06$ & $1.60 \mathrm{E}-06$ & $1.45 E-06$ & & & -06 & -06 \\
\hline - ד & $2 E-06$ & $1 E-06$ & $5 E-06$ & $1 E-06$ & ح > קم & $E-06$ & $15 E-06$ \\
\hline $.63 E-07$ & $2 E-06$ & $1 \mathrm{E}-06$ & -06 & 06 & 06 & -06 & -06 \\
\hline$E-07$ & $E-06$ & $1 E-06$ & 06 & 06 & & -06 & -06 \\
\hline$E-07$ & 06 & 06 & -06 & 06 & 6 & 06 & -06 \\
\hline $4 \mathrm{E}-07$ & $E-06$ & -06 & 06 & & & & $E-06$ \\
\hline $.64 \mathrm{E}-07$ & $5.31 \mathrm{E}-06$ & $1.61 \mathrm{E}-06$ & $1.46 \mathrm{E}-06$ & $2.92 \mathrm{E}-06$ & $3.38 \mathrm{E}-06$ & $77 \mathrm{E}-06$ & $.15 E-06$ \\
\hline $.04 \mathrm{~L}-1$ & $5.30 \mathrm{E}-06$ & $1.61 \mathrm{E}-06$ & $1.46 \mathrm{E}-06$ & $2.92 \mathrm{E}-06$ & 正 0 & $77 E-06$ & $.15 \mathrm{E}-06$ \\
\hline • & $5.30 E-06$ & $1.61 E-06$ & $1.46 \mathrm{E}-06$ & $2.02 \mathrm{CO}$ & 乎 & -06 & $.15 \mathrm{E}-06$ \\
\hline 77 & 06 & $E-06$ & 06 & 6 & 6 & 6 & -06 \\
\hline $5 E-07$ & $E-06$ & $E-06$ & $E-06$ & $2 E-06$ & 6 & 6 & -06 \\
\hline $.66 \mathrm{E}-07$ & $5.30 \mathrm{E}-06$ & $1.61 \mathrm{E}-06$ & $6 E-06$ & 06 & 6 & & $5 E-06$ \\
\hline $.66 \mathrm{E}-07$ & $5.29 \mathrm{E}-06$ & $1.61 \mathrm{E}-06$ & $1.47 \mathrm{E}-06$ & $2.92 \mathrm{E}-06$ & $3.38 \mathrm{E}-06$ & $7 E-06$ & $.15 \mathrm{E}-06$ \\
\hline $.00 \mathrm{E}-\mathrm{C}$ & $5.29 E-06$ & 1. $61 E-06$ & & & & & $\cdot 13 E-06$ \\
\hline 1 & & & & & & & \\
\hline $1.67 \mathrm{E}-07$ & & & & & & & 06 \\
\hline 07 & 6 & $E-06$ & 06 & 6 & 6 & 6 & -06 \\
\hline$E-07$ & $3 E-06$ & $2 E-06$ & $E-06$ & 06 & 6 & 6 & -06 \\
\hline $.68 E-07$ & 06 & 06 & 06 & & 6 & & -06 \\
\hline $.69 \mathrm{E}-01$ & & $62 E-06$ & & & & & -06 \\
\hline $.69 \mathrm{E}-07$ & $.27 \mathrm{E}-06$ & $1.62 \mathrm{E}-06$ & $1.48 \mathrm{E}-06$ & & & & $4.14 \mathrm{E}-06$ \\
\hline & & & & & & & $4.14 \mathrm{E}-06$ \\
\hline & & 06 & 0 & 0 & 6 & 6 & 0 \\
\hline 07 & 5.2 & 06 & 06 & 06 & 6 & 6 & 4.1 \\
\hline $.70 E-07$ & $26 E-06$ & 1. $62 E-06$ & $1.48 E-06$ & $.91 E-06$ & $3.38 E-06$ & $3.75 \mathrm{E}-06$ & $4.14 \mathrm{E}-06$ \\
\hline
\end{tabular}


RESRAD-OFFSITE, Version 2.5

$T^{1 / 2}$ Limit $=180$ days

robabilistic Dose and Risk Report

Title : RESRAD-OFFSITE External Gamma, Inhalation, and Soil Ingestion for offsite Reside File : PBA-1_TC99-DOE-5-1.ROF

Time

Years

$1.04 \mathrm{E}+03$

$1.04 \mathrm{E}+03$

$1.04 \mathrm{E}+03$

$1.04 \mathrm{E}+03$

$1.04 \mathrm{E}+03$

$1.04 \mathrm{E}+03$

$1.04 \mathrm{E}+03$

$1.04 \mathrm{E}+03$

$1.04 \mathrm{E}+03$

$1.04 \mathrm{E}+03$

$1.04 \mathrm{E}+03$

$1.04 \mathrm{E}+03$

$1.04 \mathrm{E}+03$

$1.04 \mathrm{E}+03$

$1.04 \mathrm{E}+03$

$1.05 \mathrm{E}+03$

$1.05 \mathrm{E}+03$

$1.05 \mathrm{E}+03$

$1.05 \mathrm{E}+03$

$1.05 \mathrm{E}+03$

$1.05 \mathrm{E}+03$

$1.05 \mathrm{E}+03$

$1.05 \mathrm{E}+03$

$1.05 \mathrm{E}+03$

$1.05 \mathrm{E}+03$
Summary of dose at graphical times, reptition

3 (continued)

Dose statistics at graphical times, mrem/yr

\begin{tabular}{|c|c|c|c|c|c|c|c|}
\hline Minimum & Maximum & Mean & Median & $90 \%$ & $95 \%$ & $97.5 \%$ & $99 \%$ \\
\hline $1.71 \mathrm{E}-07$ & $5.26 \mathrm{E}-06$ & $1.62 \mathrm{E}-06$ & $1.48 \mathrm{E}-06$ & $2.91 E-06$ & $3.37 \mathrm{E}-06$ & $3.75 E-06$ & $4.14 \mathrm{E}-06$ \\
\hline $1.71 \mathrm{E}-07$ & $5.26 \mathrm{E}-06$ & $1.62 \mathrm{E}-06$ & $1.48 \mathrm{E}-06$ & $2.91 E-06$ & $3.37 \mathrm{E}-06$ & $3.75 \mathrm{E}-06$ & $4.13 E-06$ \\
\hline $1.72 \mathrm{E}-07$ & $5.25 \mathrm{E}-06$ & $1.62 \mathrm{E}-06$ & $1.48 \mathrm{E}-06$ & $2.91 E-06$ & $3.37 \mathrm{E}-06$ & $3.74 \mathrm{E}-06$ & $4.13 E-06$ \\
\hline $.72 \mathrm{E}-07$ & $25 E-06$ & $1.62 \mathrm{E}-06$ & $1.48 \mathrm{E}-06$ & $2.91 \mathrm{E}-06$ & $3.37 \mathrm{E}-06$ & $3.74 \mathrm{E}-06$ & $4.13 E-06$ \\
\hline $.72 \mathrm{E}-07$ & $25 E-06$ & $1.63 E-06$ & $8 E-06$ & $91 E-06$ & $37 E-06$ & -06 & -06 \\
\hline $1.73 E-07$ & $5.25 \mathrm{E}-06$ & $1.63 E-06$ & $1.49 \mathrm{E}-06$ & $2.91 E-06$ & $3.37 \mathrm{E}-06$ & $3.74 \mathrm{E}-06$ & $4.13 E-06$ \\
\hline $1.73 E-07$ & $5.24 \mathrm{E}-06$ & $1.63 \mathrm{E}-06$ & 1. $49 \mathrm{E}-06$ & $2.91 E-06$ & $3.37 \mathrm{E}-06$ & $3.74 \mathrm{E}-06$ & $4.13 E-06$ \\
\hline $1.73 \mathrm{E}-07$ & $5.24 \mathrm{E}-06$ & $1.63 E-06$ & $1.49 \mathrm{E}-06$ & $2.91 \mathrm{E}-06$ & $3.37 \mathrm{E}-06$ & $3.73 E-06$ & $4.13 E-06$ \\
\hline $1.74 \mathrm{E}-07$ & $5.24 \mathrm{E}-06$ & $1.63 \mathrm{E}-06$ & $1.49 \mathrm{E}-06$ & $2.91 E-06$ & $3.36 \mathrm{E}-06$ & $3.73 E-06$ & $4.13 E-06$ \\
\hline $1.74 \mathrm{E}-07$ & $5.24 \mathrm{E}-06$ & 1. $63 \mathrm{E}-06$ & $1.49 \mathrm{E}-06$ & $2.91 E-06$ & $3.36 \mathrm{E}-06$ & $3.73 E-06$ & $4.13 E-06$ \\
\hline $1.74 \mathrm{E}-07$ & $5.23 E-06$ & $1.63 E-06$ & $1.49 E-06$ & $2.91 E-06$ & $3.36 E-06$ & $3.73 E-06$ & $4.13 E-06$ \\
\hline $1.75 \mathrm{E}-07$ & $5.23 \mathrm{E}-06$ & $1.63 E-06$ & $1.49 \mathrm{E}-06$ & $2.91 E-06$ & $3.36 \mathrm{E}-06$ & $3.72 \mathrm{E}-06$ & $4.13 E-06$ \\
\hline $1.75 \mathrm{E}-07$ & $5.23 E-06$ & $1.63 \mathrm{E}-06$ & $1.50 \mathrm{E}-06$ & $2.91 \mathrm{E}-06$ & $3.36 \mathrm{E}-06$ & $3.72 \mathrm{E}-06$ & $4.13 E-06$ \\
\hline $1.75 \mathrm{E}-07$ & $5.23 \mathrm{E}-06$ & $1.63 \mathrm{E}-06$ & $1.50 \mathrm{E}-06$ & $2.91 \mathrm{E}-06$ & $3.36 \mathrm{E}-06$ & $3.72 \mathrm{E}-06$ & $4.13 E-06$ \\
\hline $1.76 \mathrm{E}-07$ & $5.22 \mathrm{E}-06$ & $1.63 E-06$ & $1.50 \mathrm{E}-06$ & $2.91 \mathrm{E}-06$ & $3.36 \mathrm{E}-06$ & $3.72 \mathrm{E}-06$ & $4.13 E-06$ \\
\hline $1.76 \mathrm{E}-07$ & $5.22 \mathrm{E}-06$ & $1.63 \mathrm{E}-06$ & $1.50 \mathrm{E}-06$ & $2.91 \mathrm{E}-06$ & $3.35 E-06$ & $3.72 \mathrm{E}-06$ & $4.13 E-06$ \\
\hline $1.77 \mathrm{E}-07$ & $5.22 \mathrm{E}-06$ & $1.63 E-06$ & $1.50 \mathrm{E}-06$ & $2.91 E-06$ & $35 E-06$ & $E-06$ & $13 E-06$ \\
\hline $1.77 \mathrm{E}-07$ & $5.22 E-06$ & $1.63 E-06$ & $1.50 \mathrm{E}-06$ & $2.91 E-06$ & $3.35 E-06$ & $3.72 \mathrm{E}-06$ & $4.13 E-06$ \\
\hline $1.77 \mathrm{E}-07$ & $5.21 E-06$ & $1.64 E-06$ & $1.50 \mathrm{E}-06$ & $2.91 E-06$ & $3.35 E-06$ & $3.72 \mathrm{E}-06$ & $4.13 E-06$ \\
\hline $1.78 \mathrm{E}-07$ & $5.21 \mathrm{E}-06$ & $1.64 \mathrm{E}-06$ & $1.50 E-06$ & $2.91 E-06$ & $3.35 E-06$ & $3.72 \mathrm{E}-06$ & $4.13 E-06$ \\
\hline $1.78 \mathrm{E}-07$ & $5.21 \mathrm{E}-06$ & 1. $64 \mathrm{E}-06$ & $1.50 \mathrm{E}-06$ & $2.90 E-06$ & $3.35 E-06$ & $3.72 \mathrm{E}-06$ & $4.13 E-06$ \\
\hline $1.78 \mathrm{E}-07$ & $5.20 E-06$ & $1.64 E-06$ & $1.51 \mathrm{E}-06$ & $2.90 E-06$ & $3.35 E-06$ & $3.71 E-06$ & $4.13 E-06$ \\
\hline $1.79 \mathrm{E}-07$ & $5.20 \mathrm{E}-06$ & $1.64 \mathrm{E}-06$ & $1.51 \mathrm{E}-06$ & $2.90 E-06$ & $3.35 E-06$ & $3.71 E-06$ & $4.13 E-06$ \\
\hline $1.79 \mathrm{E}-07$ & $5.20 E-06$ & $1.64 \mathrm{E}-06$ & $1.51 \mathrm{E}-06$ & $2.90 E-06$ & $3.35 E-06$ & $3.71 E-06$ & $4.13 E-06$ \\
\hline 1. $79 \mathrm{E}-07$ & $5.20 \mathrm{E}-06$ & $1.64 \mathrm{E}-06$ & 1. $51 \mathrm{E}-06$ & $2.90 E-06$ & $3.35 E-06$ & $3.71 \mathrm{E}-06$ & $4.13 E-06$ \\
\hline
\end{tabular}




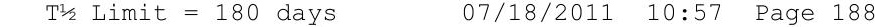

Probabilistic Dose and Risk Report

Title : RESRAD-OFFSITE External Gamma, Inhalation, and Soil Ingestion for Offsite Reside File : PBA-1_TC99-DOE-5-1.ROF

Repetition

1

2

3

$\begin{array}{cc}\begin{array}{c}\text { Peak of the mean dose (averaged over ob } \\ \text { Time of peak mean dose } \\ \text { Years }\end{array} & \begin{array}{c}\text { Peak mean dose } \\ \text { mrem/yr }\end{array} \\ 1.050 \mathrm{E}+03 & 1.646 \mathrm{E}-06 \\ 1.050 \mathrm{E}+03 & 1.644 \mathrm{E}-06 \\ 1.050 \mathrm{E}+03 & 1.638 \mathrm{E}-06\end{array}$


RESRAD-OFFSITE Regression and Correlation output 07/18/11 16:15 Page: Coef 1
Title : RESRAD-OFFSITE External Gamma, Inhalation, and Soil Ingestion for offsite Reside

File : PBA-1_TC99-DOE-5-1.ROF

Coefficients for peak All Pathways Dose

\section{Coefficient $=$}

Repetition =

Description of Probabilistic Variable

\footnotetext{
-R-SQUARE varies between 0 and 1 and is called the coefficient of determination; it provides a measure of the variation in the dependent variable (Dose) explained by regression on the independent variables.

-Sig is set to zero if the dose or risk is zero or the correlation matrix is singular.
}

Sig Coeff Sig Coeff Sig Coeff Sig Coeff Sig Co

Kd of Tc-99 in Contaminated Zone

$2-0.86$

Total porosity of saturated zone

Effective porosity of saturated zone

Hydraulic Conductivity of saturated zone

$5-0.02$

$2-0.87$

$2-0.86$

$2-0.61$

50.02

60.01

$5-0.02$

60.02

$6-0.02$

$5-0.02$

60.01

$3-0.67$

$3-0.66$

$3-0.66$

$3-0.33$

40.24

40.25

40.26

40.09

Effective Porosity of Unsaturated zone 5

$-$

$$
\overline{0.87}
$$

$$
0.88
$$

$1-0.87$

$1-0.61$

0.87

0.87 
ATTACHMENT 2 
RESRAD Table of Input Parameters for the C-746-U Landfill Onsite Receptor Scenarios

\begin{tabular}{|c|c|c|c|c|c|c|c|c|c|}
\hline $\begin{array}{c}\text { Input Screen Title } \\
\text { and Parameter } \\
\text { Name }\end{array}$ & Unit & $\begin{array}{c}\text { Code } \\
\text { Default } \\
\text { Value }\end{array}$ & $\begin{array}{c}\text { Code- } \\
\text { Accepted } \\
\text { Values }^{a}\end{array}$ & Receptor $^{b}$ & $\begin{array}{c}\text { Deterministic } \\
\text { Value }\end{array}$ & Type $^{c}$ & Priority $^{d}$ & Justification & References \\
\hline \multicolumn{10}{|l|}{ Source } \\
\hline $\begin{array}{c}\text { Radionuclide } \\
\text { concentration }\end{array}$ & $\mathrm{pCi} / \mathrm{g}$ & $\begin{array}{l}100 \text { (Nuclide } \\
\text { specific) }\end{array}$ & Site specific & All & $\begin{array}{c}\text { Unit } \\
\text { concentration for: } \\
\text { Am-241 } \\
\text { Cs-137 } \\
\text { Np-237 } \\
\text { Pu-238 } \\
\text { Pu-239 } \\
\text { Pu-240 } \\
\text { Tc-99 } \\
\text { Th-228 } \\
\text { Th-230 } \\
\text { Th-232 } \\
\text { U-234 } \\
\text { U-235 } \\
\text { U-238 }\end{array}$ & $P$ & 2 & $\begin{array}{l}\text { The radionuclide concentration used is } 1 \mathrm{pCi} / \mathrm{g} \\
\text { for each parent radionuclide listed. Site- } \\
\text { specific values for the 6-year waste inventory } \\
\text { (May } 2003 \text { - May 2009) were not used as } \\
\text { input values. The list of radionuclides used } \\
\text { was provided to ORISE by DOE. Radioactive } \\
\text { secular equilibrium was not assumed in the } \\
\text { analysis for the uranium, actinium, and } \\
\text { thorium decay series due to the nature of the } \\
\text { PGDP's uranium enrichment mission. }\end{array}$ & $\begin{array}{l}\text { DOE 2003a } \\
\text { DOE SOW for } \\
\text { C-746-U landfill } \\
\text { and DOE } \\
\text { Project } \\
\text { Communication } \\
\text { (May 2010) }\end{array}$ \\
\hline
\end{tabular}

Transport Factors

\begin{tabular}{|c|c|c|c|c|c|c|c|c|c|}
\hline $\begin{array}{c}\text { Distribution } \\
\text { coefficients: } \\
\text { contaminated zone }\end{array}$ & $\mathrm{cm}^{3} / \mathrm{g}$ & $\begin{array}{l}\text { Nuclide } \\
\text { Specific } \\
\text { (Default } \\
\text { values } \\
\text { available) }\end{array}$ & $\begin{array}{l}\text { Nuclide } \\
\text { Specific }\end{array}$ & All & $\begin{array}{l}\text { Nuclide Specific } \\
\text { (See Attachment I) }\end{array}$ & $P$ & 1 & $\begin{array}{l}\text { Tables with site-specific distribution } \\
\text { coefficients for the parent and progeny } \\
\text { radionuclides are available in } \\
\text { Attachment I immediately following this table } \\
\text { of parameters. }\end{array}$ & $\begin{array}{c}\text { DOE 2003b } \\
\text { Table Att. 1, } \\
\text { page C3-314, } \\
\text { Table C.3.1., } \\
\text { page C3-301 } \\
\\
\text { DOE Project } \\
\text { Communication } \\
\text { (March 2010) }\end{array}$ \\
\hline $\begin{array}{c}\text { Distribution } \\
\text { coefficients: } \\
\text { unsaturated zones }\end{array}$ & $\mathrm{cm}^{3} / \mathrm{g}$ & $\begin{array}{l}\text { Nuclide } \\
\text { Specific } \\
\text { (Default } \\
\text { values } \\
\text { available) }\end{array}$ & $\begin{array}{l}\text { Nuclide } \\
\text { Specific }\end{array}$ & All & $\begin{array}{l}\text { Nuclide Specific } \\
\text { (See Attachment I) }\end{array}$ & $P$ & 1 & $\begin{array}{l}\text { Tables with site-specific distribution } \\
\text { coefficients for the parent and progeny } \\
\text { radionuclides are available in } \\
\text { Attachment I immediately following this table } \\
\text { of parameters. }\end{array}$ & $\begin{array}{c}\text { DOE 2003b } \\
\text { Table Att. 1, } \\
\text { page C3-314, } \\
\text { Table C.3.1., } \\
\text { page C3-301 } \\
\\
\text { DOE Project } \\
\text { Communication } \\
\text { (March 2010) }\end{array}$ \\
\hline $\begin{array}{c}\text { Distribution } \\
\text { coefficients: saturated } \\
\text { zones }\end{array}$ & $\mathrm{cm}^{3} / \mathrm{g}$ & $\begin{array}{l}\text { Nuclide } \\
\text { Specific } \\
\text { (Default } \\
\text { values }\end{array}$ & $\begin{array}{l}\text { Nuclide } \\
\text { Specific }\end{array}$ & All & $\begin{array}{l}\text { Nuclide Specific } \\
\text { (See Attachment I) }\end{array}$ & $P$ & 1 & $\begin{array}{l}\text { Tables with site-specific distribution } \\
\text { coefficients for the parent and daughter } \\
\text { radionuclides are available in } \\
\text { Attachment I immediately following this table }\end{array}$ & $\begin{array}{l}\text { DOE 2003b } \\
\text { Table Att. 1, } \\
\text { page C3-314, } \\
\text { Table C.3.1., }\end{array}$ \\
\hline
\end{tabular}


RESRAD Table of Input Parameters for the C-746-U Landfill Onsite Receptor Scenarios

\begin{tabular}{|c|c|c|c|c|c|c|c|c|c|}
\hline $\begin{array}{c}\text { Input Screen Title } \\
\text { and Parameter } \\
\text { Name }\end{array}$ & Unit & $\begin{array}{c}\text { Code } \\
\text { Default } \\
\text { Value }\end{array}$ & $\begin{array}{c}\text { Code- } \\
\text { Accepted } \\
\text { Values }^{a}\end{array}$ & Receptor ${ }^{b}$ & $\begin{array}{l}\text { Deterministic } \\
\text { Value }\end{array}$ & Type $^{c}$ & Priority $^{d}$ & Justification & References \\
\hline & & available) & & & & & & of parameters. & $\begin{array}{c}\text { page C3-301, } \\
\text { Table 4.7, } \\
\text { page 4-21 } \\
\text { DOE Project } \\
\text { Communication } \\
\text { (March 2010) }\end{array}$ \\
\hline $\begin{array}{c}\text { Number of } \\
\text { unsaturated zones }\end{array}$ & $-{ }^{e}$ & 1 & $\begin{array}{l}0-5 \\
\text { (integer } \\
\text { value) }\end{array}$ & All & 5 & P & 3 & $\begin{array}{l}\text { There are five unsaturated zones (UZ) } \\
\text { considered for receptors evaluated during the } \\
\text { Operational Period and the Post-Institutional } \\
\text { Control Period. These correspond to the } \\
\text { layers under waste. The maximum number of } \\
\text { layers accepted by the code is five. } \\
\text { Only the Landfill Worker and the Trespasser } \\
\text { are evaluated during the Operational Period, } \\
\text { the other receptors are evaluated during the } \\
\text { Post-Institutional Control Period. } \\
\text { It is important to note that even though the } \\
\text { UZ values input into the code correspond to } \\
\text { each receptor in accordance to its period of } \\
\text { evaluation, the UZ parameters will not be } \\
\text { applicable for the Trespasser, Outdoor } \\
\text { Worker, Recreational User or the Landfill } \\
\text { Worker. This is because the pathways } \\
\text { considering the UZ are suppressed as per the } \\
\text { conceptual site model. } \\
\text { Below are the five zones considered: } \\
\text { UZ 1= Protective layer (native soil) } \\
\text { UZ } 2=\text { Gravel layer } \\
\text { UZ } 3=\text { Clay barrier } \\
\text { UZ } 4=\text { Alluvium soils (native/subgrade) } \\
\text { UZ } 5=\text { Clay confining unit (native) }\end{array}$ & $\begin{array}{c}\text { DOE } 2003 \mathrm{~b} \\
\text { Fig. 4.3, } \\
\text { page 4-16, } \\
\text { Table 4.4, } \\
\text { page 4-9, } \\
\text { Fig. 4.5, } \\
\text { page 4-18, } \\
\text { Table Att.2, } \\
\text { page C3-315, }\end{array}$ \\
\hline $\begin{array}{l}\text { Time since placement } \\
\text { of material }\end{array}$ & $\mathrm{yr}$ & 0 & $0-100$ & All & 27 & P & 3 & $\begin{array}{l}\text { It is assumed that waste material was initially } \\
\text { placed in the landfill on May } 2003 \text { and that } \\
\text { the landfill will close in } 2030 .\end{array}$ & $\begin{array}{c}\text { DOE Project } \\
\text { Communication } \\
\text { with DOE-PPPO } \\
\text { (May 2010) } \\
\end{array}$ \\
\hline $\begin{array}{l}\text { Groundwater } \\
\text { concentration }\end{array}$ & $\mathrm{pCi} / \mathrm{L}$ & $\begin{array}{l}0^{\mathrm{f}} \text { (Nuclide } \\
\text { specific) }\end{array}$ & $0-1 E+34$ & All & 0 & P & 3 & $\begin{array}{l}\text { The default value is assigned; however, it is } \\
\text { not used by the code. This parameter is one of } \\
\text { the options in RESRAD to derive distribution }\end{array}$ & Yu et al. 2001 \\
\hline
\end{tabular}


RESRAD Table of Input Parameters for the C-746-U Landfill Onsite Receptor Scenarios

\begin{tabular}{|c|c|c|c|c|c|c|c|c|c|}
\hline $\begin{array}{c}\text { Input Screen Title } \\
\text { and Parameter } \\
\text { Name }\end{array}$ & Unit & $\begin{array}{c}\text { Code } \\
\text { Default } \\
\text { Value }\end{array}$ & $\begin{array}{c}\text { Code- } \\
\text { Accepted } \\
\text { Values }^{a}\end{array}$ & Receptor ${ }^{b}$ & $\begin{array}{c}\text { Deterministic } \\
\text { Value }\end{array}$ & Type $^{c}$ & Priority $^{d}$ & Justification & References \\
\hline & & & & & & & & $\begin{array}{l}\text { coefficients (Kds) when site-specific data is } \\
\text { not available. In this case site-specific Kds are } \\
\text { available and are used by the code; therefore, } \\
\text { there was no need to use this option to derive } \\
\text { them. }\end{array}$ & \\
\hline Leach rate ${ }^{g}$ & $1 / \mathrm{yr}$ & $\begin{array}{l}0 \text { (Nuclide } \\
\text { specific) }\end{array}$ & $0-1 E+34$ & All & 0 & $\mathrm{P}$ & 3 & $\begin{array}{l}\text { The default value is assigned; however, it is } \\
\text { not used by the code. This parameter is one of } \\
\text { the options in RESRAD to derive distribution } \\
\text { coefficients (Kds) when site-specific data is } \\
\text { not available. In this case site-specific Kds are } \\
\text { available and are used by the code; therefore, } \\
\text { there was no need to use this option to derive } \\
\text { them. }\end{array}$ & Yu et al. 2001 \\
\hline Solubility limit & $\mathrm{mol} / \mathrm{L}$ & $\begin{array}{l}0 \text { (Nuclide } \\
\text { specific) }\end{array}$ & $0-1 E+34$ & All & 0 & $\mathrm{P}$ & 3 & $\begin{array}{l}\text { The default value is assigned; however, it is } \\
\text { not used by the code. This parameter is one of } \\
\text { the options in RESRAD to derive distribution } \\
\text { coefficients (Kds) when site-specific data is } \\
\text { not available. In this case site-specific Kds are } \\
\text { available and are used by the code; therefore, } \\
\text { there was no need to use this option to derive } \\
\text { them. }\end{array}$ & Yu et al. 2001 \\
\hline Use plant/soil ratio & check box & Yes/No & $N A^{h}$ & All & $\begin{array}{l}\text { Box checked for } \\
\text { all except Np-237 }\end{array}$ & NA & 3 & $\begin{array}{l}\text { The default value is "checked", but the code } \\
\text { will not allow input of site specific distribution } \\
\text { coefficients for Np- } 237 \text { unless the box is } \\
\text { unchecked. Confirmed that this approach was } \\
\text { appropriate with Dr. Charley Yu, ANL. }\end{array}$ & $\begin{array}{c}\text { Project } \\
\text { Communication } \\
\text { with } \\
\text { Dr. Charley Yu } \\
\text { (April 2010) }\end{array}$ \\
\hline
\end{tabular}

Calculation Parameters

\begin{tabular}{|c|c|c|c|c|c|c|c|c|c|}
\hline \multirow{2}{*}{$\begin{array}{l}\text { Basic radiation dose } \\
\text { limit }\end{array}$} & \multirow{2}{*}{$\mathrm{mrem} / \mathrm{yr}$} & \multirow{2}{*}{25} & \multirow{2}{*}{$\begin{array}{l}1 \mathrm{E}-2- \\
1 \mathrm{E}+4\end{array}$} & $\begin{array}{c}\text { RF } \\
\text { RG } \\
\mathrm{T} \\
\mathrm{L}\end{array}$ & 100 & \multirow{2}{*}{ NA } & \multirow{2}{*}{3} & \multirow{2}{*}{$\begin{array}{l}\text { Three target dose constraints of } 1,15,25 \\
\mathrm{mrem} / \mathrm{yr} \text { and a primary dose limit of } 100 \\
\mathrm{mrem} / \mathrm{yr} \text { are considered in this project. } \\
\text { However, a target dose constraint of } 1 \\
\mathrm{mrem} / \mathrm{yr} \text { and a primary dose limit of } 100 \\
\mathrm{mrem} / \mathrm{yr} \text { are used for the RESRAD runs. } \\
\\
\text { Note that changing the basic radiation dose } \\
\text { limit in the code will not change the Dose to } \\
\text { Source Ratio (DSR) which is used in the } \\
\text { calculation for single radionuclide soil } \\
\text { guidelines. }\end{array}$} & \multirow[t]{2}{*}{$\begin{array}{l}\text { DOE SOW to } \\
\text { ORISE for } \\
\text { C-746-U } \\
\text { landfill, } \\
\text { Section 2, } \\
\text { Item 3 }\end{array}$} \\
\hline & & & & $\begin{array}{l}\text { W } \\
\mathrm{RU}\end{array}$ & 1 & & & & \\
\hline
\end{tabular}


RESRAD Table of Input Parameters for the C-746-U Landfill Onsite Receptor Scenarios

\begin{tabular}{|c|c|c|c|c|c|c|c|c|c|}
\hline $\begin{array}{c}\text { Input Screen Title } \\
\text { and Parameter } \\
\text { Name }\end{array}$ & Unit & $\begin{array}{c}\text { Code } \\
\text { Default } \\
\text { Value }\end{array}$ & $\begin{array}{l}\text { Code- } \\
\text { Accepted } \\
\text { Values }^{a}\end{array}$ & Receptor ${ }^{b}$ & $\begin{array}{c}\text { Deterministic } \\
\text { Value }\end{array}$ & Type $e^{c}$ & Priority $^{d}$ & Justification & References \\
\hline & & & & $\begin{array}{l}\text { RF } \\
\text { RG } \\
W \\
\text { RU } \\
\end{array}$ & $\begin{array}{c}1,50,100,500 \\
1050\end{array}$ & & & $\begin{array}{l}\text { A time horizon of } 1,050 \text { years is used in order } \\
\text { to calculate single radionuclide soil guidelines. } \\
\text { This is assumed to allow for in- growth and } \\
\text { decay since PGDP has been in operation for } \\
\text { about } 50 \text { years (since about } 1960 \text { to2010). }\end{array}$ & $\begin{array}{l}\mathrm{DOE} / \mathrm{CH} / 8901 \\
\text { and } \\
\text { DOE Order } \\
5400.5\end{array}$ \\
\hline Times for calculations & $\mathrm{yr}$ & $\begin{array}{c}1,3,10,30 \\
100,300 \\
1000\end{array}$ & $0-1 \mathrm{E}+5$ & $\begin{array}{l}\mathrm{T} \\
\mathrm{L}\end{array}$ & $1,50,70$ & P & 3 & $\begin{array}{l}\text { A time horizon of } 70 \text { years is used for the } \\
\text { Landfill Worker and the Trespasser since } \\
\text { these receptors are modeled during the } \\
\text { Operational Period of the Landfill. The } \\
\text { Operational Period of the Landfill is } \\
\text { considered to be } 20 \text { years per DOE } 2003 \mathrm{~b} \text { and } \\
50 \text { years are included to allow for in- growth } \\
\text { and decay due to PGDP being in operation for } \\
\text { about } 50 \text { years. }\end{array}$ & $\begin{array}{l}\text { Communication } \\
\text { (May 2010 and } \\
\text { July 2010) } \\
\text { DOE 2003b }\end{array}$ \\
\hline
\end{tabular}

Contaminated Zone Parameters

\begin{tabular}{|c|c|c|c|c|c|c|c|c|c|}
\hline $\begin{array}{l}\text { Area of contaminated } \\
\text { zone }\end{array}$ & $\mathrm{m}^{2}$ & 10,000 & $\begin{array}{l}1 \mathrm{E}-4- \\
1 \mathrm{E}+15\end{array}$ & All & 89,436 & $P$ & 2 & $\begin{array}{l}\text { The contaminated zone is composed of four } \\
\text { different waste forms. The waste forms types } \\
\text { are soil, concrete, metal, and organic (lumber } \\
\text { and debris). The total waste disposal area of } \\
\text { the landfill is used as the area of the } \\
\text { contaminated zone. When filled the landfill } \\
\text { disposal area will encompass } 22.1 \text { acres } \\
\text { (approximately } 89,436 \text { square meters). } \\
\text { However, the total permitted landfill site will } \\
\text { encompass } 59.7 \text { acres. }\end{array}$ & $\begin{array}{l}\text { DOE SOW for } \\
\text { C-746-U landfill } \\
\\
\text { DOE 2003b } \\
\text { Section 3.2, } \\
\text { page 3-11, } \\
\text { Table 4.5, } \\
\text { page 4-13 }\end{array}$ \\
\hline $\begin{array}{l}\text { Thickness of } \\
\text { contaminated zone }\end{array}$ & $\mathrm{m}$ & 2 & $\begin{array}{l}1 \mathrm{E}-5- \\
1 \mathrm{E}+3\end{array}$ & All & 13.4 & $P$ & 2 & $\begin{array}{l}\text { This value is the average thickness for the } \\
\text { waste forms when the landfill is full. }\end{array}$ & $\begin{array}{c}\text { DOE 2003b } \\
\text { Table 4.5, } \\
\text { page 4-13, } \\
\text { Table Att.3, } \\
\text { page C3-315 }\end{array}$ \\
\hline $\begin{array}{l}\text { Length parallel to } \\
\text { aquifer flow }\end{array}$ & $\mathrm{m}$ & 100 & $\begin{array}{l}1 \mathrm{E}-4- \\
1 \mathrm{E}+6\end{array}$ & All & 399 & $P$ & 2 & $\begin{array}{l}\text { This value of } 399 \mathrm{~m} \text { is the conservative longest } \\
\text { dimension between the upgradient edge of } \\
\text { the contaminated zone and the downgradient } \\
\text { edge, parallel to the aquifer. }\end{array}$ & $\begin{array}{l}\text { Lee et al. } 1995 \\
\text { Fig 2-4, page } 17\end{array}$ \\
\hline
\end{tabular}

Cover and Contaminated Zone Hydrological Data 
RESRAD Table of Input Parameters for the C-746-U Landfill Onsite Receptor Scenarios

\begin{tabular}{|c|c|c|c|c|c|c|c|c|c|}
\hline $\begin{array}{l}\text { Input Screen Title } \\
\text { and Parameter } \\
\text { Name }\end{array}$ & Unit & $\begin{array}{l}\text { Code } \\
\text { Default } \\
\text { Value }\end{array}$ & $\begin{array}{l}\text { Code- } \\
\text { Accepted } \\
\text { Values }^{a}\end{array}$ & Receptor ${ }^{b}$ & $\begin{array}{l}\text { Deterministic } \\
\text { Value }\end{array}$ & Type ${ }^{c}$ & Priority $^{d}$ & Justification & References \\
\hline Cover depth & $\mathrm{m}$ & 0 & $0-100$ & $\begin{array}{l}\text { RF } \\
\text { RG } \\
\text { W } \\
\text { RU }\end{array}$ & 0.152 & $P$ & 2 & $\begin{array}{l}\text { For receptors exposed during the Post- } \\
\text { Institutional Control Period this value is the } \\
\text { depth of the final cover planned for the } \\
\text { landfill. The landfill cover will have six layers } \\
\text { with a total thickness of } 5 \mathrm{ft} \text { ( } 1.52 \text { meters). This } \\
\text { applies to all receptors except for the } \\
\text { Trespasser and Landfill Worker. The } \\
\text { Trespasser and the Landfill Worker are } \\
\text { exposed during the Operational Period. } \\
\text { During this period the cover has a layer of } \\
\text { vegetative soil and its depth is expected to be } \\
6 \text { in ( } 0.152 \text { meters) A cover is assumed for the } \\
\text { Trespasser; however, no cover is assumed for } \\
\text { the Landfill Worker. }\end{array}$ & $\begin{array}{c}\text { DOE } 2003 b \\
\text { Section } 3.2, \\
\text { page } 3-11, \\
\text { page } 3-13, \\
\text { Fig. } 4.3, \\
\text { page } 4-16, \\
\text { Fig. } 4.5, \\
\text { page } 4-18\end{array}$ \\
\hline $\begin{array}{l}\text { Density of cover } \\
\text { material }\end{array}$ & $\mathrm{g} / \mathrm{cm} 3$ & 1.5 & $1 E-3-22.5$ & All & 1.5 & $P$ & 1 & $\begin{array}{l}\text { For receptors exposed during the Post- } \\
\text { Institutional Control Period the value for the } \\
\text { density of the cover was obtained from the } \\
\text { previous RESRAD study for the landfill } \\
\text { described in DOE } 2003 \mathrm{~b} \text {. This applies to all } \\
\text { receptors except for the Trespasser and the } \\
\text { Landfill Worker. This value was also confirmed } \\
\text { with DOE to be a site specific value for the } \\
\text { final cover. The Trespasser is exposed during } \\
\text { the operational period and the density of the } \\
\text { cover is also } 1.5 \mathrm{~g} / \mathrm{cm}^{3} \text { as provided by geologist } \\
\text { and engineer. This parameter is not applicable } \\
\text { to the Landfill Worker since no cover is } \\
\text { assumed for this receptor. }\end{array}$ & $\begin{array}{c}\text { DOE 2003b } \\
\text { Table Att.5, } \\
\text { page C3-316 } \\
\text { DOE Project } \\
\text { Communication } \\
\text { with geologist } \\
\text { and engineer } \\
\text { (April 2010) }\end{array}$ \\
\hline Cover erosion rate & $\mathrm{m} / \mathrm{yr}$ & 0.001 & $0-5$ & All & 0.0006 & $P, B$ & 2 & $\begin{array}{l}\text { This value was obtained from the previous } \\
\text { RESRAD study for the landfill described in DOE } \\
\text { 2003b. }\end{array}$ & $\begin{array}{l}\text { DOE 2003b } \\
\text { Table Att.5, } \\
\text { page C3-316 }\end{array}$ \\
\hline $\begin{array}{c}\text { Density of } \\
\text { contaminated zone }\end{array}$ & $\mathrm{g} / \mathrm{cm} 3$ & 1.5 & $1 E-3-22.5$ & All & 1.89 & $\mathrm{P}$ & 1 & $\begin{array}{l}\text { The densities of the waste forms were used to } \\
\text { calculate the weighted average density for the } \\
\text { contaminated zone which is approximately } \\
1.89 \mathrm{~g} / \mathrm{cm}^{3} \text {. }\end{array}$ & $\begin{array}{l}\text { DOE } 2003 b \\
\text { Table } 4.5 \\
\text { page } 4-13\end{array}$ \\
\hline $\begin{array}{l}\text { Contaminated zone } \\
\text { total porosity }\end{array}$ & - & 0.4 & $1 E-5-1$ & All & 0.17 & $P$ & 2 & $\begin{array}{l}\text { The site-specific value available is } 0.168 \\
\mathrm{vol} / \mathrm{vol} \text {. }\end{array}$ & $\begin{array}{l}\text { DOE 2003b } \\
\text { Table 4.4, } \\
\text { page 4-9 }\end{array}$ \\
\hline $\begin{array}{l}\text { Contaminated zone } \\
\text { field capacity }\end{array}$ & - & 0.2 & $1 E-34-1$ & All & 0.07 & $P$ & 3 & $\begin{array}{l}\text { The site-specific value available is } 0.073 \\
\mathrm{vol} / \mathrm{vol} \text {. }\end{array}$ & $\begin{array}{l}\text { DOE 2003b } \\
\text { Table 4.4, } \\
\text { page 4-9 }\end{array}$ \\
\hline Contaminated zone & $\mathrm{m} / \mathrm{yr}$ & 0.001 & $0-5$ & All & 0.0006 & $P, B$ & 2 & This value was obtained from the previous & DOE 2003b \\
\hline
\end{tabular}


RESRAD Table of Input Parameters for the C-746-U Landfill Onsite Receptor Scenarios

\begin{tabular}{|c|c|c|c|c|c|c|c|c|c|}
\hline $\begin{array}{l}\text { Input Screen Title } \\
\text { and Parameter } \\
\text { Name }\end{array}$ & Unit & $\begin{array}{l}\text { Code } \\
\text { Default } \\
\text { Value }\end{array}$ & $\begin{array}{l}\text { Code- } \\
\text { Accepted } \\
\text { Values }^{a}\end{array}$ & Receptor $^{b}$ & $\begin{array}{l}\text { Deterministic } \\
\text { Value }\end{array}$ & Type $^{c}$ & Priority $^{d}$ & Justification & References \\
\hline erosion rate & & & & & & & & $\begin{array}{l}\text { RESRAD study for the landfill described in DOE } \\
\text { 2003b. }\end{array}$ & $\begin{array}{l}\text { Table Att.3, } \\
\text { page C3-315 }\end{array}$ \\
\hline $\begin{array}{l}\text { Contaminated zone } \\
\text { hydraulic conductivity }\end{array}$ & $\mathrm{m} / \mathrm{yr}$ & 10 & $\begin{array}{l}1 \mathrm{E}-3- \\
1 \mathrm{E}+10\end{array}$ & All & 315.4 & $P$ & 2 & $\begin{array}{l}\text { The hydraulic conductivity for waste forms 1-4 } \\
\text { is } 1.0 \mathrm{E}-3 \mathrm{~cm} / \mathrm{s} \text { (approximately } 315.4 \mathrm{~m} / \mathrm{yr} \text { ). }\end{array}$ & $\begin{array}{l}\text { DOE 2003b } \\
\text { Fig. } 4.5, \\
\text { page } 4-18\end{array}$ \\
\hline $\begin{array}{l}\text { Contaminated zone b } \\
\text { parameter }\end{array}$ & - & 5.3 & $0-15$ & All & 4.05 & $\mathrm{P}$ & 2 & $\begin{array}{l}\text { DOE geologist determined that the most } \\
\text { appropriate value for the contaminated zone } \\
\text { b parameter available in Yu et al. } 1993 \text { is the } \\
\text { one for sand. It is known that the } \\
\text { contaminated zone (waste) will have high } \\
\text { porosity and high permeability. When } \\
\text { selecting a deterministic value for this input } \\
\text { parameter, the closest material and } \\
\text { corresponding Soil b Parameter, as developed } \\
\text { by Clapp and Hornberger (Yu et al. 1993), for } \\
\text { concrete, steel and soil waste is sand. Clapp \& } \\
\text { Hornberger do not offer a corresponding Soil } \\
\text { b Parameter for landfill waste. }\end{array}$ & $\begin{array}{c}\text { Yu et al. } 1993 \\
\text { page } 83 \\
\text { DOE Project } \\
\text { Communication } \\
\text { with geologist } \\
\text { (July 2010) }\end{array}$ \\
\hline \multirow{4}{*}{$\begin{array}{l}\text { Evapotranspiration } \\
\text { coefficient }\end{array}$} & \multirow{4}{*}{-} & \multirow{4}{*}{0.5} & \multirow{4}{*}{$0-0.999$} & $\begin{array}{l}\mathrm{RF} \\
\mathrm{RG}\end{array}$ & 0.74 & \multirow{4}{*}{$P$} & \multirow{4}{*}{2} & $\begin{array}{l}\text { The value for the Resident Farmer, Resident } \\
\text { Gardener, Worker and Recreational User were } \\
\text { calculated using the HELP Output data for the } \\
\text { Post-Institutional Control Period. }\end{array}$ & \multirow{4}{*}{$\begin{array}{c}\text { DOE 2003b } \\
\text { pages, C3-93, } \\
\text { C3-243 } \\
\text { Yu et al. } 1993 \\
\text { page } 78\end{array}$} \\
\hline & & & & $\begin{array}{l}\text { W } \\
\text { RU }\end{array}$ & 0.83 & & & $\begin{array}{l}\text { The value for the Trespasser and the Landfill } \\
\text { Worker was calculated using the HELP Output } \\
\text { data for the Operational Period. }\end{array}$ & \\
\hline & & & & & & & & $\begin{array}{l}\text { The equation used to calculate these values is } \\
\text { available in Yu et al. } 1993 \text {. } \\
\text { The calculations are available in Attachment II } \\
\text { following this table. }\end{array}$ & \\
\hline & & & & $\begin{array}{l}\mathrm{T} \\
\mathrm{L}\end{array}$ & 0.69 & & & $\begin{array}{l}\text { The code initially did not run when using an } \\
\text { irrigation rate of } 0.1 \mathrm{~m} / \mathrm{yr} \text { and an } \\
\text { evapotranspiration coefficient of } 0.74 \text { for the } \\
\text { Resident Farmer. It generated an output file } \\
\text { with instructions to make appropriate } \\
\text { changes in order for it run. Adjustments had } \\
\text { to be made to the code's graphic points and } \\
\text { the number of dose points. The RESRAD } \\
\text { output file with the instructions is available in } \\
\text { Attachment III following this table. }\end{array}$ & \\
\hline
\end{tabular}


RESRAD Table of Input Parameters for the C-746-U Landfill Onsite Receptor Scenarios

\begin{tabular}{|c|c|c|c|c|c|c|c|c|c|}
\hline $\begin{array}{c}\text { Input Screen Title } \\
\text { and Parameter } \\
\text { Name }\end{array}$ & Unit & $\begin{array}{c}\text { Code } \\
\text { Default } \\
\text { Value }\end{array}$ & $\begin{array}{c}\text { Code- } \\
\text { Accepted } \\
\text { Values }^{a}\end{array}$ & Receptor $^{b}$ & $\begin{array}{l}\text { Deterministic } \\
\text { Value }\end{array}$ & Type ${ }^{c}$ & Priority $^{d}$ & Justification & References \\
\hline Wind speed & $\mathrm{m} / \mathrm{s}$ & 2 & $1 E-4-20$ & All & 4.5 & $P$ & 2 & $\begin{array}{l}\text { The average prevailing wind at the PGDP is } \\
\text { from the south to southwest at approximately } \\
10 \mathrm{mph} \text { ( } 4.5 \text { meters/seconds). }\end{array}$ & $\begin{array}{l}\text { PRS } 2008 \\
\text { page 1-4 }\end{array}$ \\
\hline Precipitation rate & $\mathrm{m} / \mathrm{yr}$ & 1 & $0-10$ & All & 1.24 & $P$ & 2 & $\begin{array}{l}\text { The yearly precipitation averages about } 49 \\
\text { inches ( } 1.24 \text { meters). }\end{array}$ & $\begin{array}{l}\text { PRS } 2008 \\
\text { page 1-4 }\end{array}$ \\
\hline Irrigation rate & $\mathrm{m} / \mathrm{yr}$ & 0.2 & $0-10$ & $\begin{array}{l}\text { W } \\
\text { RU } \\
T \\
\text { L }\end{array}$ & 0.1 & B & 3 & $\begin{array}{l}\text { Irrigation in the Paducah, Kentucky area is } \\
\text { considered to be unlikely. In the event } \\
\text { irrigation is necessary, the water will primarily } \\
\text { come from uncontaminated surface water } \\
\text { and not from groundwater (well). Information } \\
\text { from the USGS shows that surface water is the } \\
\text { main source of water used in Kentucky for } \\
\text { irrigation (Kenny et al. 2009). The Paducah } \\
\text { area (i.e., where PGDP is located) receives } \\
\text { about an average of } 49 \text { inches (1.24 m) of } \\
\text { precipitation per year (PRS 2008). According } \\
\text { to ATSDR 2002, the farms in McCracken } \\
\text { County, KY (i.e., where Paducah is located) } \\
\text { rely on rainfall to water their crops. For } \\
\text { conservatism in the modeling, and as } \\
\text { recommended by DOE-PPPO, it was assumed } \\
\text { that the Resident Farmer uses contaminated } \\
\text { well water for irrigation of agricultural areas } \\
\text { (i.e., fruit, grain, non-leafy and leafy } \\
\text { vegetables). However, due to limitations in } \\
\text { the RESRAD (onsite) code, the Resident } \\
\text { Farmer (onsite) scenario includes irrigation of } \\
\text { fodder besides the agricultural areas. } \\
\text { Alternatively, the Resident Gardener uses } \\
\text { water for irrigation of plants (i.e., fruit, grain, } \\
\text { non-leafy and leafy vegetables) from an } \\
\text { uncontaminated source (e.g., municipal water } \\
\text { source). Even though this receptor is modeled } \\
\text { with RESRAD (onsite), irrigation of fodder will } \\
\text { not be included for this receptor because the } \\
\text { meat and milk ingestion pathways are } \\
\text { excluded in this receptor scenario. An } \\
\text { irrigation rate of } 0.1 \mathrm{~m} / \mathrm{yr} \text { is used for the } \\
\text { Resident Farmer (onsite), and the Resident } \\
\text { Gardener. } \\
\text { An irrigation rate of } 0 \text { m/yr or no irrigation is }\end{array}$ & $\begin{array}{c}\text { DOE Project } \\
\text { Communication } \\
\text { with DOE-PPPO } \\
\text { (April 2011) } \\
\text { Kenny et al. } \\
2009 \\
\text { ATSDR } 2002 \\
\text { page } 8\end{array}$ \\
\hline
\end{tabular}


RESRAD Table of Input Parameters for the C-746-U Landfill Onsite Receptor Scenarios

\begin{tabular}{|c|c|c|c|c|c|c|c|c|c|}
\hline $\begin{array}{c}\text { Input Screen Title } \\
\text { and Parameter } \\
\text { Name }\end{array}$ & Unit & $\begin{array}{c}\text { Code } \\
\text { Default } \\
\text { Value }\end{array}$ & $\begin{array}{l}\text { Code- } \\
\text { Accepted }^{a} \\
\text { Values }^{a}\end{array}$ & Receptor ${ }^{b}$ & $\begin{array}{c}\text { Deterministic } \\
\text { Value }\end{array}$ & Type $^{c}$ & Priority $^{d}$ & Justification & References \\
\hline & & & & & & & & $\begin{array}{l}\text { assumed for the Landfill Worker, Trespasser, } \\
\text { Recreational User, and Outdoor Worker. } \\
\text { The code initially did not run when using an } \\
\text { irrigation rate of } 0.1 \mathrm{~m} / \mathrm{yr} \text { and an } \\
\text { evapotranspiration coefficient of } 0.74 \text { for the } \\
\text { Resident Farmer. It generated an output file } \\
\text { with instructions to make appropriate } \\
\text { changes in order for it run. Adjustments had } \\
\text { to be made to the code's graphic points and } \\
\text { the number of dose points. The RESRAD } \\
\text { output file with the instructions is available in } \\
\text { Attachment III following this table. }\end{array}$ & \\
\hline Irrigation mode & - & Overhead & $\begin{array}{l}\text { Overhead/ } \\
\text { ditch }\end{array}$ & All & Overhead & B & 3 & $\begin{array}{l}\text { The default input is used. } \\
\text { Irrigation is not applicable for the Workers, } \\
\text { Recreational User, or the Trespasser. In order } \\
\text { to suppress this parameter for these } \\
\text { receptors only the following pathways are } \\
\text { used: external gamma, inhalation, and soil } \\
\text { ingestion. }\end{array}$ & Yu et al. 2001 \\
\hline Runoff coefficient & - & 0.2 & $0-1$ & $\begin{array}{l}\text { RF } \\
\text { RG } \\
\text { W } \\
\text { RU }\end{array}$ & 0.34 & & 2 & $\begin{array}{l}\text { The values for the Resident Farmer, Resident } \\
\text { Gardener, Outdoor Worker and Recreational } \\
\text { User were calculated using the HELP Output } \\
\text { data for the Post-Institutional Control Period. } \\
\text { The value for the Trespasser and Landfill } \\
\text { Worker was calculated using the HELP Output } \\
\text { data for the Operational Period. } \\
\text { The equation used to calculate these values is } \\
\text { available in Yu et al. 1993. } \\
\text { The calculations are available in Attachment II } \\
\text { following this table. }\end{array}$ & $\begin{array}{c}\text { DOE } 2003 \mathrm{~b} \\
\text { pages C3-93, } \\
\text { C3-243 } \\
\text { Yu et al. } 1993 \\
\text { page } 73\end{array}$ \\
\hline $\begin{array}{l}\text { Watershed area for } \\
\text { nearby stream or pond }\end{array}$ & $\mathrm{m}^{2}$ & $1,000,000$ & $\begin{array}{l}1 E-4- \\
1 E+34\end{array}$ & All & $1,000,000$ & & 3 & $\begin{array}{l}\text { This parameter refers to the site-specific area } \\
\text { that drains into the nearby pond. } \\
\text { A default value is assumed. } \\
\text { No site-specific value available. }\end{array}$ & Yu et al. 2001 \\
\hline $\begin{array}{l}\text { Accuracy for water } \\
\text { soil computation }\end{array}$ & - & 0.001 & $0-0.1$ & All & 0.001 & NA & 3 & $\begin{array}{l}\text { This parameter refers to the fractional } \\
\text { accuracy desired (convergence criterion) in } \\
\text { the Romberg integration used to obtain } \\
\text { water/soil concentration ratios. }\end{array}$ & Yu et al. 2001 \\
\hline
\end{tabular}


RESRAD Table of Input Parameters for the C-746-U Landfill Onsite Receptor Scenarios

\begin{tabular}{|c|c|c|c|c|c|c|c|c|}
\hline $\begin{array}{c}\text { Input Screen Title } \\
\text { and Parameter } \\
\text { Name }\end{array}$ & Unit & $\begin{array}{c}\text { Code } \\
\text { Default } \\
\text { Value }\end{array}$ & $\begin{array}{c}\text { Code- } \\
\text { Accepted } \\
\text { Values }^{a}\end{array}$ & Receptor $^{b}$ & $\begin{array}{c}\text { Deterministic } \\
\text { Value }\end{array}$ & Type $^{c}$ & Priority & Justification \\
\hline & & & & & & & $\begin{array}{c}\text { A default value is assumed. No site-specific } \\
\text { value available. }\end{array}$ & \\
\hline
\end{tabular}

Saturated Zone Hydrological Data

\begin{tabular}{|c|c|c|c|c|c|c|c|c|c|}
\hline $\begin{array}{l}\text { Density of saturated } \\
\text { zone }\end{array}$ & $\mathrm{g} / \mathrm{cm}^{3}$ & 1.5 & $1 E-3-22.5$ & All & 1.67 & $P$ & 1 & $\begin{array}{l}\text { This value was obtained from the previous } \\
\text { RESRAD study for the landfill described in DOE } \\
\text { 2003b. }\end{array}$ & $\begin{array}{c}\text { DOE 2003b } \\
\text { Table 4.7, page } \\
\text { 4-21, Table } \\
\text { Att.4., page C3- } \\
315 \\
\end{array}$ \\
\hline $\begin{array}{l}\text { Saturated zone total } \\
\text { porosity }\end{array}$ & - & 0.4 & $1 \mathrm{E}-5-1$ & All & 0.34 & $P$ & 1 & $\begin{array}{l}\text { This value was obtained from the previous } \\
\text { RESRAD study for the landfill described in DOE } \\
\text { 2003b. }\end{array}$ & $\begin{array}{l}\text { DOE 2003b } \\
\text { Table Att.4., } \\
\text { page C3-315 }\end{array}$ \\
\hline $\begin{array}{l}\text { Saturated zone } \\
\text { effective porosity }\end{array}$ & - & 0.2 & $1 \mathrm{E}-34-1$ & All & 0.3 & $\mathrm{P}$ & 1 & $\begin{array}{l}\text { This value was obtained from the previous } \\
\text { RESRAD study for the landfill described in DOE } \\
\text { 2003b. }\end{array}$ & $\begin{array}{c}\text { DOE 2003b } \\
\text { Table 4.7, page } \\
\text { 4-21, Table } \\
\text { Att.4., page C3- } \\
315 \\
\end{array}$ \\
\hline $\begin{array}{l}\text { Saturated zone field } \\
\text { capacity }\end{array}$ & - & 0.2 & $1 E-34-1$ & All & 0.04 & $P$ & 3 & $\begin{array}{l}\text { This value was obtained from the previous } \\
\text { RESRAD study for the landfill described in DOE } \\
\text { 2003b. }\end{array}$ & $\begin{array}{l}\text { DOE 2003b } \\
\text { Table Att.4., } \\
\text { page C3-315 }\end{array}$ \\
\hline $\begin{array}{c}\text { Saturated zone } \\
\text { hydraulic conductivity }\end{array}$ & $\mathrm{m} / \mathrm{yr}$ & 100 & $\begin{array}{l}1 E-3- \\
1 E+10\end{array}$ & All & 55630 & $P$ & 1 & $\begin{array}{l}\text { This value was obtained from the previous } \\
\text { RESRAD study for the landfill described in DOE } \\
\text { 2003b. This value was verified by DOE } \\
\text { geologist. }\end{array}$ & $\begin{array}{c}\text { DOE 2003b } \\
\text { Table Att.4., } \\
\text { page C3-315 } \\
\\
\text { DOE Project } \\
\text { Communication } \\
\text { with geologist } \\
\text { and engineer } \\
\text { (April 2010) }\end{array}$ \\
\hline $\begin{array}{l}\text { Saturated zone } \\
\text { hydraulic gradient }\end{array}$ & - & 0.02 & $1 \mathrm{E}-10-10$ & All & 0.0011 & $\mathrm{P}$ & 2 & $\begin{array}{l}\text { This value was obtained from the previous } \\
\text { RESRAD study for the landfill described in DOE } \\
\text { 2003b. }\end{array}$ & $\begin{array}{l}\text { DOE 2003b } \\
\text { Table Att.4., } \\
\text { page C3-315 }\end{array}$ \\
\hline $\begin{array}{l}\text { Saturated zone } b \\
\text { parameter }\end{array}$ & - & 5.3 & $1 E-34-15$ & All & 4.05 & $P$ & 2 & $\begin{array}{l}\text { DOE geologist determined that saturated zone } \\
\text { consists of a mixture of gravel and sand and } \\
\text { recommended a value from Yu et al. } 1993 \\
\text { based on sand. }\end{array}$ & $\begin{array}{l}\text { Yu et al. } 1993 \\
\text { DOE Project } \\
\text { Communication } \\
\text { with geologist } \\
\text { (April 2010) }\end{array}$ \\
\hline Water table drop rate & $\mathrm{m} / \mathrm{yr}$ & 0.001 & $0-5$ & All & 0.001 & $P$ & 3 & $\begin{array}{l}\text { The default value is used. } \\
\text { No site-specific value was available. }\end{array}$ & Yu et al. 2001 \\
\hline Well pump intake & $\mathrm{m}$ & 10 & $1 \mathrm{E}-5-$ & All & 9.1 & $P$ & 2 & The value of $9.1 \mathrm{~m}$ is used for the Resident & DOE Project \\
\hline
\end{tabular}


RESRAD Table of Input Parameters for the C-746-U Landfill Onsite Receptor Scenarios

\begin{tabular}{|c|c|c|c|c|c|c|c|c|c|}
\hline $\begin{array}{c}\text { Input Screen Title } \\
\text { and Parameter } \\
\text { Name }\end{array}$ & Unit & $\begin{array}{c}\text { Code } \\
\text { Default } \\
\text { Value }\end{array}$ & $\begin{array}{c}\text { Code- } \\
\text { Accepted } \\
\text { Values }^{a}\end{array}$ & Receptor $^{b}$ & $\begin{array}{c}\text { Deterministic } \\
\text { Value }\end{array}$ & $T_{y p e^{c}}$ & Priority $^{d}$ & Justification & References \\
\hline $\begin{array}{c}\text { depth (below water } \\
\text { table) }\end{array}$ & & & 1,000 & & & & & $\begin{array}{l}\text { Farmer since this value was recommended by } \\
\text { LATA (Los Alamos Technical Associates) } \\
\text { Kentucky. In addition, the value for the well } \\
\text { pump intake depth in RESRAD was modified in } \\
\text { order to achieve consistency with the depth } \\
\text { of aquifer contributing to well in RESRAD- } \\
\text { OFFSITE as suggested by Argonne National } \\
\text { Laboratory (ANL) expert. } \\
\text { This parameter is suppressed for the Resident } \\
\text { Gardener, Workers, Recreational User and the } \\
\text { Trespasser by choosing the applicable } \\
\text { pathways. }\end{array}$ & $\begin{array}{c}\text { Communication } \\
\text { with DOE } \\
\text { consultant } \\
\text { (November } \\
\text { 2010) }\end{array}$ \\
\hline $\begin{array}{l}\text { Model: nondispersion } \\
\text { (ND) or mass-balance } \\
\text { (MB) }\end{array}$ & - & ND & $\mathrm{ND} / \mathrm{MB}$ & All & ND & $P$ & 3 & $\begin{array}{l}\text { A default model was assumed for the } \\
\text { Resident Farmer, since this is the only } \\
\text { receptor that will have a well and site specific } \\
\text { information is not available. } \\
\text { The meat, milk, plant and drinking water } \\
\text { ingestion pathways are suppressed for the } \\
\text { Workers, Recreational User, and Trespasser } \\
\text { since these pathways are not considered in } \\
\text { the conceptual site model for these receptors. } \\
\text { The meat, milk, and drinking water ingestion } \\
\text { pathways are suppressed for Resident } \\
\text { Gardener. T he plant ingestion pathway is } \\
\text { active for this receptor; however, the water is } \\
\text { obtained from uncontaminated sources. }\end{array}$ & Yu et al. 2001 \\
\hline Well pumping rate & $\mathrm{m}^{3} / \mathrm{yr}$ & 250 & $0-1 E+10$ & All & 685 & $B, P$ & 2 & $\begin{array}{l}\text { This value is modified to achieve consistency } \\
\text { with the calculated well pumping rate in } \\
\text { RESRAD-OFFSITE. This applies to the Resident } \\
\text { Farmer and Resident Gardener. The value } \\
\text { calculated by RESRAD-OFFSITE for the well } \\
\text { pumping rate corresponds to } 685 \mathrm{~m}^{3} / \mathrm{yr} \text {. This } \\
\text { approach was suggested by ANL. } \\
\text { The meat, milk, plant and drinking water } \\
\text { ingestion pathways are suppressed for the } \\
\text { Workers, Recreational User, and Trespasser } \\
\text { since these pathways are not considered in } \\
\text { the conceptual site model for these receptors. }\end{array}$ & $\begin{array}{l}\text { DOE Project } \\
\text { Communication } \\
\text { with DOE } \\
\text { consultant } \\
\text { (November } \\
\text { 2010) }\end{array}$ \\
\hline
\end{tabular}


RESRAD Table of Input Parameters for the C-746-U Landfill Onsite Receptor Scenarios

\begin{tabular}{|c|c|c|c|c|c|c|c|c|c|}
\hline $\begin{array}{c}\text { Input Screen Title } \\
\text { and Parameter } \\
\text { Name }\end{array}$ & Unit & $\begin{array}{c}\text { Code } \\
\text { Default } \\
\text { Value }\end{array}$ & $\begin{array}{c}\text { Code- } \\
\text { Accepted } \\
\text { Values }^{a}\end{array}$ & Receptor ${ }^{b}$ & $\begin{array}{c}\text { Deterministic } \\
\text { Value }\end{array}$ & Type $^{c}$ & Priority $^{d}$ & Justification & References \\
\hline & & & & & & & & $\begin{array}{l}\text { The meat, milk, and drinking water ingestion } \\
\text { pathways are suppressed for Resident } \\
\text { Gardener. The plant ingestion pathway is } \\
\text { active for this receptor; however, the water is } \\
\text { obtained from uncontaminated sources. }\end{array}$ & \\
\hline
\end{tabular}

Uncontaminated Unsaturated Zone Parameters

\begin{tabular}{|c|c|c|c|c|c|c|c|c|c|}
\hline $\begin{array}{l}\text { Unsaturated zone } \\
\text { thickness }\end{array}$ & $\mathrm{m}$ & 4 & $0-10,000$ & All & $\begin{array}{l}\text { Zone } 1=0.3 \\
\text { Zone } 2=0.3 \\
\text { Zone } 3=0.9 \\
\text { Zone } 4=2.0 \\
\text { Zone } 5=8.4\end{array}$ & $P$ & 1 & $\begin{array}{l}\text { These values were obtained from the previous } \\
\text { RESRAD study for the landfill described in DOE } \\
\text { 2003b. }\end{array}$ & $\begin{array}{l}\text { DOE 2003b } \\
\text { Table Att.2, } \\
\text { page C3-315 }\end{array}$ \\
\hline $\begin{array}{l}\text { Unsaturated zone } \\
\text { density }\end{array}$ & $\mathrm{g} / \mathrm{cm}^{3}$ & 1.5 & $1 \mathrm{E}-3-22.5$ & All & $\begin{array}{c}\text { Zone } 1=1.2 \\
\text { Zone } 2=1.5 \\
\text { Zone } 3=1.8 \\
\text { Zone } 4=1.5 \\
\text { Zone } 5=1.76 \\
\end{array}$ & $P$ & 2 & $\begin{array}{l}\text { These values were obtained from the previous } \\
\text { RESRAD study for the landfill described in DOE } \\
\text { 2003b. }\end{array}$ & $\begin{array}{l}\text { DOE 2003b } \\
\text { Table Att.2, } \\
\text { page C3-315 }\end{array}$ \\
\hline $\begin{array}{l}\text { Unsaturated zone } \\
\text { total porosity }\end{array}$ & - & 0.4 & $1 E-5-1$ & All & $\begin{array}{c}\text { Zone } 1=0.45 \\
\text { Zone } 2=0.4 \\
\text { Zone } 3=0.43 \\
\text { Zone } 4=0.4 \\
\text { Zone } 5=0.45\end{array}$ & $P$ & 2 & $\begin{array}{l}\text { These values were obtained from the previous } \\
\text { RESRAD study for the landfill described in DOE } \\
\text { 2003b. } \\
\text { The values for UZ1 and UZ2 were transposed } \\
\text { as recommended by DOE. }\end{array}$ & $\begin{array}{c}\text { DOE 2003b } \\
\text { Table Att.2, } \\
\text { page C3-315 } \\
\text { DOE Project } \\
\text { Communication } \\
\text { with DOE-PPPO } \\
\text { (October 2010) }\end{array}$ \\
\hline $\begin{array}{l}\text { Unsaturated zone } \\
\text { effective porosity }\end{array}$ & - & 0.2 & $1 E-34-1$ & All & $\begin{array}{c}\text { Zone } 1=0.2 \\
\text { Zone } 2=0.2 \\
\text { Zone } 3=0.08 \\
\text { Zone } 4=0.2 \\
\text { Zone } 5=0.15\end{array}$ & $P$ & 2 & $\begin{array}{l}\text { These values were calculated using equation } \\
4.4 \text { from Yu et al. } 1993 \text { as this approach was } \\
\text { accepted by ANL rather than using the values } \\
\text { available in DOE 2003b. This approach was } \\
\text { taken to ensure that the effective porosity } \\
\text { was less than the total porosity. }\end{array}$ & $\begin{array}{l}\text { Yu et al. } 1993 \\
\text { Project } \\
\text { Communication } \\
\text { with DOE } \\
\text { consultant } \\
\text { (October 2010) } \\
\end{array}$ \\
\hline $\begin{array}{l}\text { Unsaturated zone } \\
\text { field capacity }\end{array}$ & - & 0.2 & $1 E-34-1$ & All & $\begin{aligned} & \text { Zone } 1=0.25 \\
& \text { Zone } 2=0.2 \\
& \text { Zone } 3=0.35 \\
& \text { Zone } 4=0.2 \\
& \text { Zone } 5=0.3\end{aligned}$ & $P$ & 3 & $\begin{array}{l}\text { These values were obtained from the previous } \\
\text { RESRAD study for the landfill described in DOE } \\
\text { 2003b. } \\
\text { The values for UZ1 and UZ2 were transposed } \\
\text { as recommended by DOE. }\end{array}$ & $\begin{array}{c}\text { DOE 2003b } \\
\text { Table Att.2, } \\
\text { page C3-315 } \\
\text { Project } \\
\text { Communication } \\
\text { with DOE-PPPO } \\
\text { (October 2010) }\end{array}$ \\
\hline $\begin{array}{l}\text { Unsaturated zone, } \\
\text { soil-specific b } \\
\text { parameter }\end{array}$ & - & 5.3 & $0-15$ & All & $\begin{array}{l}\text { Zone } 1=7.75 \\
\text { Zone } 2=7.75 \\
\text { Zone } 3=11.4\end{array}$ & $P$ & 2 & $\begin{array}{l}\text { DOE evaluated the unsaturated zone and } \\
\text { determined that the value for Silty Clay Loam } \\
\text { from Yu et al. } 1993 \text { was most appropriate for }\end{array}$ & $\begin{array}{l}\text { Yu et al. } 1993 \\
\text { DOE Project }\end{array}$ \\
\hline
\end{tabular}


RESRAD Table of Input Parameters for the C-746-U Landfill Onsite Receptor Scenarios

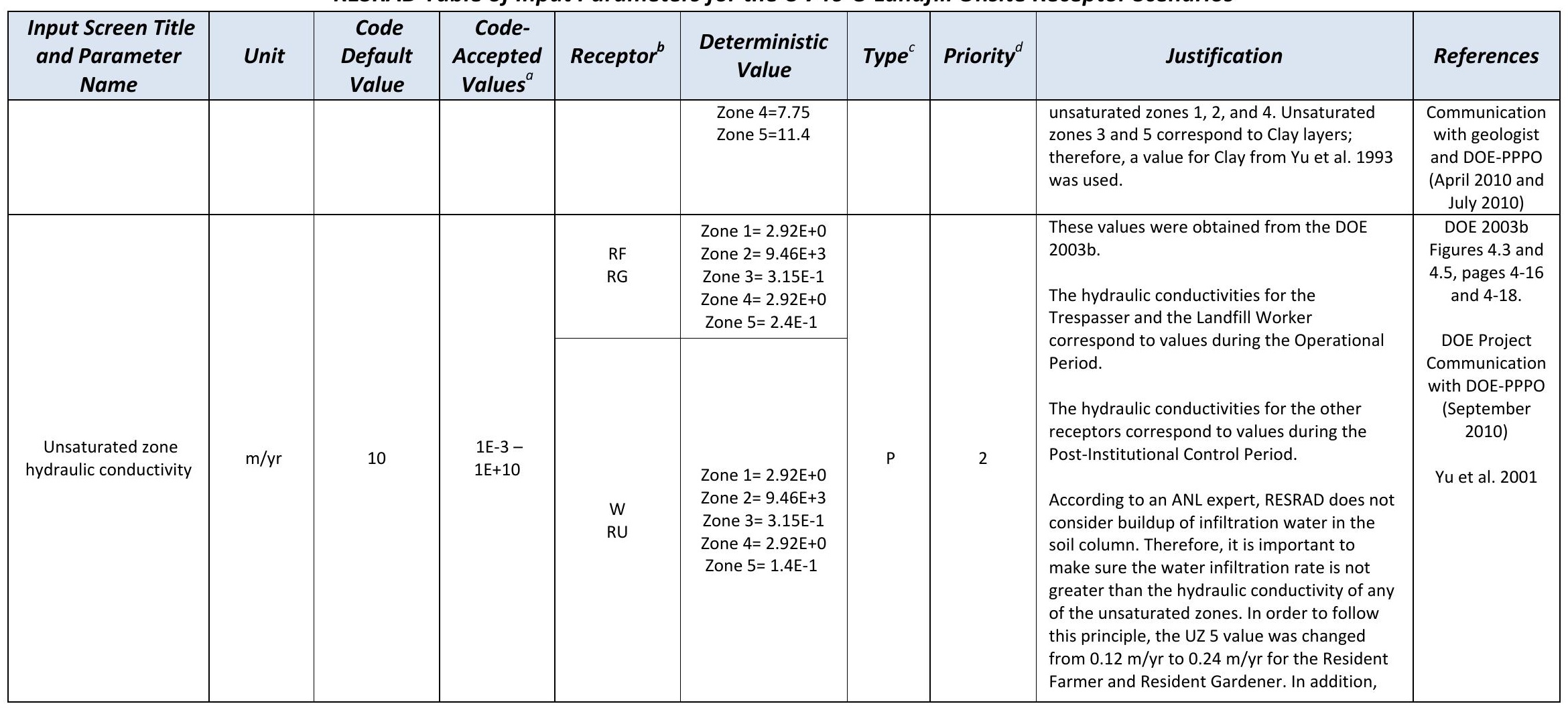


RESRAD Table of Input Parameters for the C-746-U Landfill Onsite Receptor Scenarios

\begin{tabular}{|c|c|c|c|c|c|c|c|c|c|}
\hline $\begin{array}{c}\text { Input Screen Title } \\
\text { and Parameter } \\
\text { Name }\end{array}$ & Unit & $\begin{array}{c}\text { Code } \\
\text { Default } \\
\text { Value }\end{array}$ & $\begin{array}{c}\text { Code- } \\
\text { Accepted } \\
\text { Values }^{a}\end{array}$ & Receptor ${ }^{b}$ & $\begin{array}{c}\text { Deterministic } \\
\text { Value }\end{array}$ & Type $^{c}$ & Priority $^{d}$ & Justification & References \\
\hline & & & & $\begin{array}{l}\mathrm{T} \\
\mathrm{L}\end{array}$ & 更 & & & $\begin{array}{l}\text { the UZ } 5 \text { value was changed from } 0.12 \mathrm{~m} / \mathrm{yr} \text { to } \\
0.14 \mathrm{~m} / \mathrm{yr} \text { for the Outdoor Worker and } \\
\text { Recreational User. For the Trespasser and } \\
\text { Landfill Worker the UZ } 3 \text { value was changed } \\
\text { besides the value of UZ } 5 \text { value since the } \\
\text { infiltration rate calculated was greater than } \\
\text { the value of the hydraulic conductivities for } \\
\text { these zones. The value for UZ } 3 \text { was changed } \\
\text { from } 0.0315 \mathrm{~m} / \mathrm{yr} \text { to } 0.281 \mathrm{~m} / \mathrm{yr} \text { and the value } \\
\text { for UZ } 5 \text { was changed from } 0.12 \mathrm{~m} / \mathrm{yr} \text { to } 0.281 \\
\mathrm{~m} / \mathrm{yr} \text {. } \\
\text { Although all the receptors have corresponding } \\
\text { hydraulic conductivities (that are greater than } \\
\text { the infiltration rate), these are only used by } \\
\text { the code in the Resident Farmer and Gardener } \\
\text { scenarios. In these scenarios, the code uses } \\
\text { the hydraulic conductivities (besides other } \\
\text { parameters related to the unsaturated zones), } \\
\text { when at least one of the following ingestion } \\
\text { pathways is active; drinking water, plant, milk, } \\
\text { and/or meat. In the case of the Resident } \\
\text { Farmer, all of these pathways are active and } \\
\text { in the case of the Resident Gardener the plant } \\
\text { ingestion pathway is active. For the Workers, } \\
\text { Recreational User and the Trespasser, these } \\
\text { ingestion pathways mentioned are } \\
\text { suppressed; therefore, the unsaturated zones } \\
\text { parameters are not used by the code. } \\
\text { The infiltration rate calculations are in } \\
\text { Attachment II following this table. }\end{array}$ & \\
\hline
\end{tabular}

Occupancy, Inhalation, and External Gamma Parameters

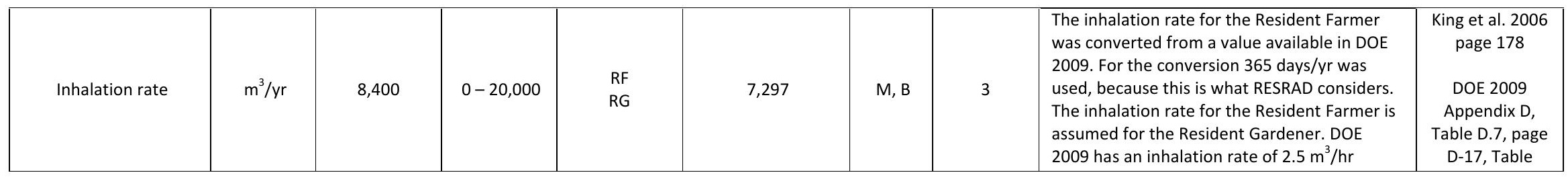


RESRAD Table of Input Parameters for the C-746-U Landfill Onsite Receptor Scenarios

\begin{tabular}{|c|c|c|c|c|c|c|c|c|c|}
\hline $\begin{array}{c}\text { Input Screen Title } \\
\text { and Parameter } \\
\text { Name }\end{array}$ & Unit & $\begin{array}{c}\text { Code } \\
\text { Default } \\
\text { Value }\end{array}$ & $\begin{array}{c}\text { Code- } \\
\text { Accepted } \\
\text { Values }^{a}\end{array}$ & Receptor ${ }^{b}$ & $\begin{array}{c}\text { Deterministic } \\
\text { Value }\end{array}$ & Type $^{c}$ & Priority $^{d}$ & Justification & References \\
\hline & & & & $\begin{array}{l}\text { W } \\
\text { RU } \\
\text { T } \\
\text { L }\end{array}$ & 20,000 & & & $\begin{array}{l}\left.\text { (21,900 } \mathrm{m}^{3} / \mathrm{yr}\right) \text { for the Workers, Recreational } \\
\text { User, and the Trespasser. The maximum value } \\
\text { allowed by RESRAD is } 20,000 \mathrm{~m}^{3} / \mathrm{yr} \text {, thus this } \\
\text { value is used. } \\
\text { See Attachment II following this table of } \\
\text { parameters. }\end{array}$ & $\begin{array}{c}\text { D.38, pages D- } \\
\text { 48, Table D.17, } \\
\text { page D-27 }\end{array}$ \\
\hline $\begin{array}{l}\text { Mass loading for } \\
\text { inhalation }\end{array}$ & $\mathrm{g} / \mathrm{m}^{3}$ & $1.00 \mathrm{E}-04$ & $0-2$ & $\begin{array}{l}\text { RF } \\
\text { RG } \\
\text { RU } \\
T\end{array}$ & 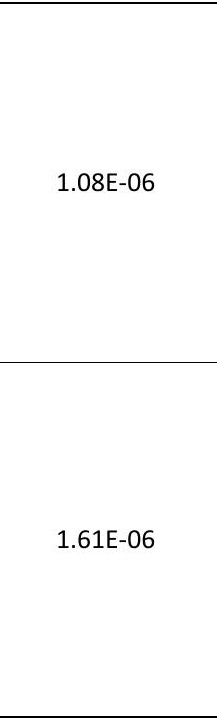 & $P, B$ & 2 & $\begin{array}{l}\text { The following equation was used to calculate } \\
\text { the Mass Loading for Inhalation or Air-to-Soil } \\
\text { concentration ratio (ASR): } \\
\text { ASR = 1/ PEF; PEF is the particulate emission } \\
\text { factor. } \\
\text { The PEF values used to calculate the mass } \\
\text { loading for inhalation are available in DOE } \\
\text { 2009. The PEF values were converted into } \\
\text { RESRAD compatible units. } \\
\text { The mass loading for inhalation for the } \\
\text { Resident Farmer is assumed for the Resident } \\
\text { Gardener. } \\
\text { The mass loading for inhalation for the } \\
\text { Recreational User is assumed for the } \\
\text { Trespasser. } \\
\text { See Attachment II following this table of } \\
\text { parameters }\end{array}$ & $\begin{array}{l}\text { King et al. } 2006 \\
\text { page } 178 \\
\text { DOE } 2009 \\
\text { Appendix D, } \\
\text { Table D.7, page } \\
\text { D-17, Table } \\
\text { D.38, pages D- } \\
\text { 48, Table D.17, } \\
\text { page D-27 }\end{array}$ \\
\hline Exposure duration & $\mathrm{yr}$ & 30 & $1-1,000$ & $\begin{array}{l}\mathrm{RF} \\
\mathrm{RG}\end{array}$ & 24 & B & 3 & $\begin{array}{l}\text { The exposure duration is the span of time, in } \\
\text { years, during which an individual is expected } \\
\text { to spend time on the site. This value is used in } \\
\text { calculating lifetime cancer risk from exposure } \\
\text { to radionuclide contamination. It is also used } \\
\text { to calculate time-integrated dose if the } \\
\text { exposure duration is less than a year. }\end{array}$ & $\begin{array}{c}\text { DOE } 2009 \\
\text { Appendix D, } \\
\text { Table D.8, page } \\
\text { D-18, Table } \\
\text { D.18, page D- } \\
\text { 28, Table D.40, } \\
\text { page D-50 }\end{array}$ \\
\hline
\end{tabular}


RESRAD Table of Input Parameters for the C-746-U Landfill Onsite Receptor Scenarios

\begin{tabular}{|c|c|c|c|c|c|c|c|c|c|}
\hline $\begin{array}{c}\text { Input Screen Title } \\
\text { and Parameter } \\
\text { Name }\end{array}$ & Unit & $\begin{array}{c}\text { Code } \\
\text { Default } \\
\text { Value }\end{array}$ & $\begin{array}{l}\text { Code- } \\
\text { Accepted } \\
\text { Values }^{a}\end{array}$ & Receptor $^{b}$ & $\begin{array}{l}\text { Deterministic } \\
\text { Value }\end{array}$ & Type $^{c}$ & Priority $^{d}$ & Justification & References \\
\hline & & & & $\begin{array}{l}\text { W } \\
\text { L }\end{array}$ & 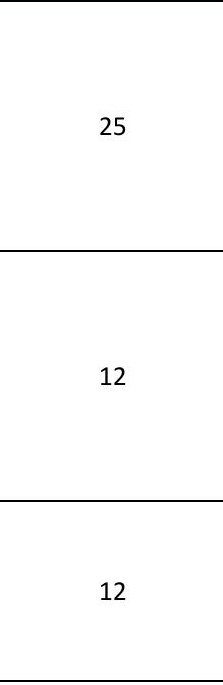 & & & $\begin{array}{l}\text { These values were obtained from DOE } 2009 . \\
\text { The exposure duration is available in the } \\
\text { tables of Appendix D. } \\
\text { For the Resident Farmer and the Resident } \\
\text { Gardener the adult value for "Rural Resident" } \\
\text { is used. } \\
\text { For the Workers the value for "Industrial } \\
\text { Worker or Excavation Worker" is used since } \\
\text { these values are equivalent. } \\
\text { For the Recreational User the value for the } \\
\text { "Recreational User (Teen)" is used. } \\
\text { For the Trespasser the value for the } \\
\text { "Recreational User (adult)" is used. } \\
\text { See Attachment II following this table of } \\
\text { parameters. }\end{array}$ & \\
\hline $\begin{array}{l}\text { Indoor dust filtration } \\
\text { factor }\end{array}$ & - & 0.4 & $0-1$ & All & 0.4 & $P, B$ & 2 & $\begin{array}{l}\text { The default value is used. Indoor time fraction } \\
\text { is the driver for application of this parameter. } \\
\text { In instances where there is no indoor } \\
\text { occupancy, this parameter will not be applied. }\end{array}$ & Yu et al. 2001 \\
\hline $\begin{array}{l}\text { External gamma } \\
\text { shielding factor }\end{array}$ & - & 0.7 & $0-1$ & $\begin{array}{l}\text { RF } \\
\text { RG } \\
W \\
L\end{array}$ & 0.8 & $\mathrm{P}$ & 2 & $\begin{array}{l}\text { The external gamma shielding factors are } \\
\text { available for the Resident Farmer, Workers, } \\
\text { and Recreational User in DOE } 2009 \text {. The value } \\
\text { is } 0.2 \text { for all these receptors except for the } \\
\text { Recreational User which is } 0 \text {. The RESRAD } \\
\text { input values correspond to } 0.8 \text { and } 1 \text {. The } \\
\text { shielding factor of } 0.8 \text { implies that the indoor } \\
\text { levels of external radiation are } 20 \% \text { lower } \\
\text { than the outdoor levels. A shielding factor of } 1 \\
\text { implies that there is no shielding. } \\
\text { The Resident Gardener is assumed to have the } \\
\text { same shielding factor as the Resident Farmer. } \\
\text { The Trespasser is assumed to have the same } \\
\text { shielding factor as the Recreational User. } \\
\text { See Attachment II following this table of }\end{array}$ & $\begin{array}{c}\text { DOE } 2009 \\
\text { Appendix D, } \\
\text { Table D.8, page } \\
\text { D-18, Table } \\
\text { D.18, page D- } \\
\text { 28, and Table } \\
\text { D.40, page D-50 }\end{array}$ \\
\hline
\end{tabular}


RESRAD Table of Input Parameters for the C-746-U Landfill Onsite Receptor Scenarios

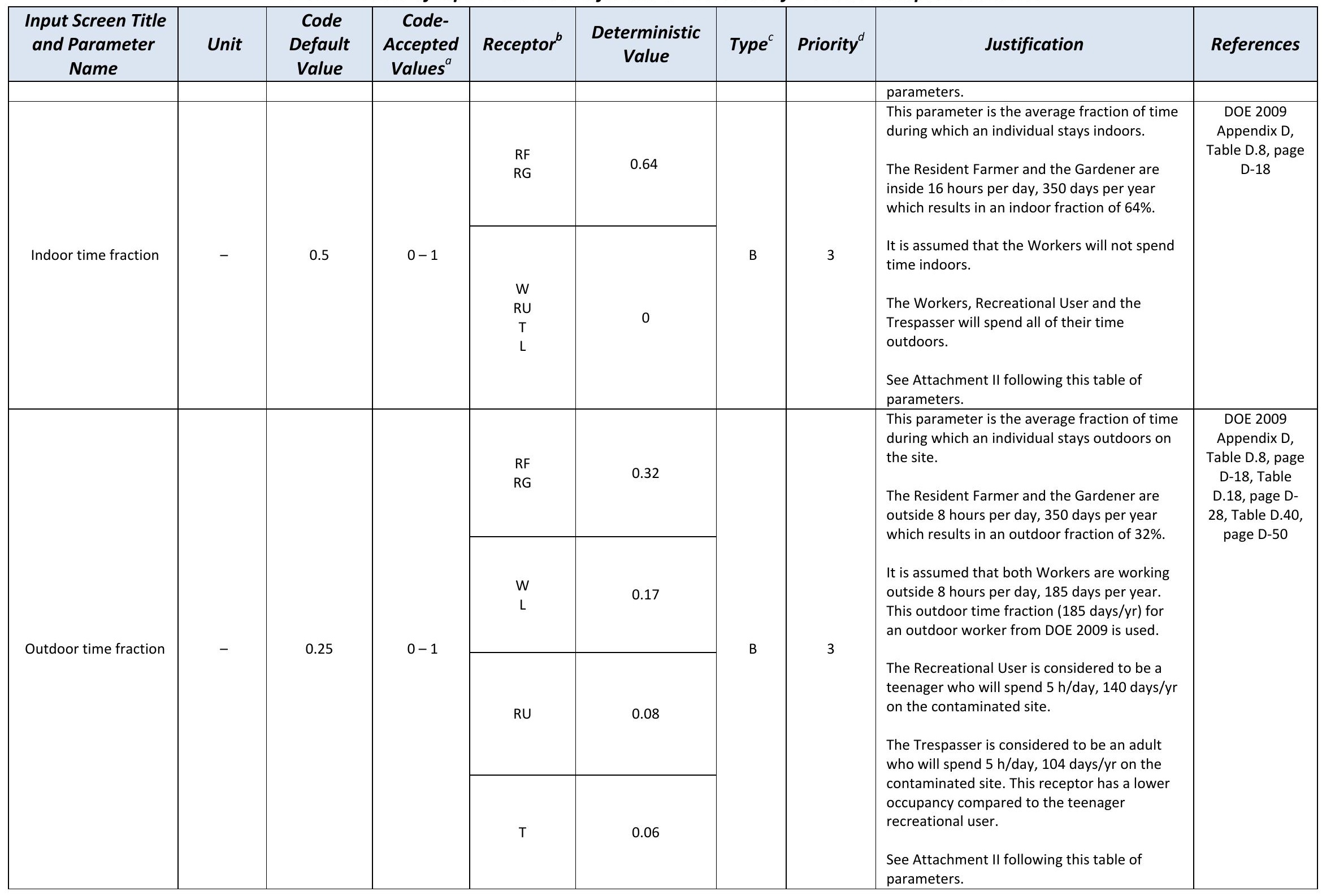


RESRAD Table of Input Parameters for the C-746-U Landfill Onsite Receptor Scenarios

\begin{tabular}{|c|c|c|c|c|c|c|c|c|c|}
\hline $\begin{array}{c}\text { Input Screen Title } \\
\text { and Parameter } \\
\text { Name }\end{array}$ & Unit & $\begin{array}{c}\text { Code } \\
\text { Default } \\
\text { Value }\end{array}$ & $\begin{array}{c}\text { Code- } \\
\text { Accepted } \\
\text { Values }^{a}\end{array}$ & Receptor ${ }^{b}$ & $\begin{array}{c}\text { Deterministic } \\
\text { Value }\end{array}$ & Type ${ }^{c}$ & Priority $^{d}$ & Justification & References \\
\hline $\begin{array}{l}\text { Shape of the } \\
\text { contaminated zone } \\
\text { (shape factor flag) }\end{array}$ & - & Circular & $\begin{array}{l}\text { Circular/ } \\
\text { non- } \\
\text { circular }\end{array}$ & All & Circular & $P$ & 3 & $\begin{array}{l}\text { It is assumed that the receptor is located in } \\
\text { the middle of the contaminated zone. } \\
\text { Therefore, the circular shape was assumed } \\
\text { instead of the noncircular shape. By default, } \\
\text { the receptor is assumed to be placed in the } \\
\text { middle of a circularly shaped contaminated } \\
\text { zone. }\end{array}$ & Yu et al. 2001 \\
\hline
\end{tabular}

Ingestion Pathway, Dietary Data

\begin{tabular}{|c|c|c|c|c|c|c|c|c|c|}
\hline $\begin{array}{l}\text { Fruit, vegetable, and } \\
\text { grain consumption }\end{array}$ & $\mathrm{kg} / \mathrm{yr}$ & 160 & $0-1,000$ & All & 231.7 & $\mathrm{M}, \mathrm{B}$ & 2 & $\begin{array}{l}\text { The value was converted from Table D.9 in } \\
\text { DOE 2009, which is for home grown } \\
\text { vegetables. It does not specify fruit, and grain, } \\
\text { thus for RESRAD a ratio was obtained to } \\
\text { assign a value for fruit, vegetable and grain } \\
\text { consumption and a value for leafy vegetable } \\
\text { consumption. } \\
\text { The calculation is included in Attachment II. } \\
\text { This parameter applies to the Resident Farmer } \\
\text { and Resident Gardener since the ingestion } \\
\text { pathway for plants/ home-grown produce is } \\
\text { applicable for these receptors. } \\
\text { The plant ingestion pathway is suppressed for } \\
\text { the Workers, Recreational User, and } \\
\text { Trespasser since this pathway is not } \\
\text { considered in the conceptual site model for } \\
\text { these receptors. } \\
\text { See Attachment II following this table of } \\
\text { parameters. }\end{array}$ & $\begin{array}{c}\text { DOE } 2009 \\
\text { Appendix D, } \\
\text { Table D.9, page } \\
\text { D-19 }\end{array}$ \\
\hline $\begin{array}{l}\text { Leafy vegetable } \\
\text { consumption }\end{array}$ & $\mathrm{kg} / \mathrm{yr}$ & 14 & $0-100$ & All & 20.3 & $M, B$ & 3 & $\begin{array}{l}\text { The value was converted from Table D.9 in } \\
\text { DOE 2009, which is for home grown } \\
\text { vegetables. It does not specify fruit, and grain, } \\
\text { thus for RESRAD a ratio was obtained to } \\
\text { assign a value for fruit, vegetable and grain } \\
\text { consumption and a value for leafy vegetable } \\
\text { consumption. } \\
\text { The calculation is included in Attachment II. } \\
\text { This parameter applies to the Resident Farmer } \\
\text { and Resident Gardener since the ingestion }\end{array}$ & $\begin{array}{c}\text { DOE } 2009 \\
\text { Appendix D, } \\
\text { Table D.9, page } \\
\text { D-19 }\end{array}$ \\
\hline
\end{tabular}


RESRAD Table of Input Parameters for the C-746-U Landfill Onsite Receptor Scenarios

\begin{tabular}{|c|c|c|c|c|c|c|c|c|c|}
\hline $\begin{array}{c}\text { Input Screen Title } \\
\text { and Parameter } \\
\text { Name }\end{array}$ & Unit & $\begin{array}{c}\text { Code } \\
\text { Default } \\
\text { Value }\end{array}$ & $\begin{array}{c}\text { Code- } \\
\text { Accepted } \\
\text { Values }^{a}\end{array}$ & Receptor ${ }^{b}$ & $\begin{array}{c}\text { Deterministic } \\
\text { Value }\end{array}$ & Type ${ }^{c}$ & Priority $^{d}$ & Justification & References \\
\hline & & & & & & & & $\begin{array}{l}\text { pathway for plants/ home-grown produce is } \\
\text { applicable for these receptors. } \\
\text { The plant ingestion pathway is suppressed for } \\
\text { the Workers, Recreational User, and } \\
\text { Trespasser since this pathway is not } \\
\text { considered in the conceptual site model for } \\
\text { these receptors. } \\
\text { See Attachment II following this table of } \\
\text { parameters. }\end{array}$ & \\
\hline Milk consumption & $L / y r$ & 92 & $0-1,000$ & All & 425 & $M, B$ & 2 & $\begin{array}{l}\text { This value was converted from Table D.11 in } \\
\text { DOE } 2009 . \\
\text { The density of whole milk, } 1030 \mathrm{~kg} / \mathrm{cubic} \\
\text { meter, was used to convert the value into } \\
\text { L/yr. } \\
\text { This parameter is applicable for the Resident } \\
\text { Farmer. } \\
\text { This parameter is not applicable for the } \\
\text { Resident Gardener, Workers, Recreational } \\
\text { User, or the Trespasser; therefore, the milk } \\
\text { ingestion pathway is suppressed. } \\
\text { See Attachment II following this table of } \\
\text { parameters. }\end{array}$ & $\begin{array}{l}\text { DOE } 2009 \\
\text { Appendix D, } \\
\text { Table D.11, } \\
\text { page D-21 }\end{array}$ \\
\hline $\begin{array}{l}\text { Meat and poultry } \\
\text { consumption }\end{array}$ & $\mathrm{kg} / \mathrm{yr}$ & 63 & $0-300$ & All & 154 & $\mathrm{M}, \mathrm{B}$ & 3 & $\begin{array}{l}\text { This value was converted from Table D.10, } \\
\text { D.12, and D.13 in DOE } 2009 \text {. The value is the } \\
\text { sum of the values obtained for beef, pork and } \\
\text { poultry, since they are in separate tables. The } \\
\text { value for eggs is available, but eggs are not } \\
\text { considered poultry. } \\
\text { This parameter is applicable for the Resident } \\
\text { Farmer. } \\
\text { This parameter is not applicable for the } \\
\text { Resident Gardener, Workers, Recreational } \\
\text { User or the Trespasser; therefore, the meat } \\
\text { ingestion pathway is suppressed. } \\
\text { See Attachment II following this table of }\end{array}$ & $\begin{array}{c}\text { DOE } 2009 \\
\text { Appendix D, } \\
\text { Table D.10, } \\
\text { D.12, and D.13, } \\
\text { pages D-20, D- } \\
22 \text { and D-23 }\end{array}$ \\
\hline
\end{tabular}


RESRAD Table of Input Parameters for the C-746-U Landfill Onsite Receptor Scenarios

\begin{tabular}{|c|c|c|c|c|c|c|c|c|c|}
\hline $\begin{array}{l}\text { Input Screen Title } \\
\text { and Parameter } \\
\text { Name }\end{array}$ & Unit & $\begin{array}{l}\text { Code } \\
\text { Default } \\
\text { Value }\end{array}$ & $\begin{array}{l}\text { Code- } \\
\text { Accepted } \\
\text { Values }^{a}\end{array}$ & Receptor ${ }^{b}$ & $\begin{array}{c}\text { Deterministic } \\
\text { Value }\end{array}$ & Type $^{c}$ & Priority $^{d}$ & Justification & References \\
\hline & & & & & & & & parameters. & \\
\hline Fish consumption & $\mathrm{kg} / \mathrm{yr}$ & 5.4 & $0-1,000$ & All & 5.4 & $M, B$ & 3 & $\begin{array}{l}\text { The aquatic foods ingestion pathway is } \\
\text { suppressed in RESRAD for all receptors } \\
\text { because it is not considered part of the } \\
\text { conceptual site model. }\end{array}$ & Yu et al. 2001 \\
\hline $\begin{array}{l}\text { Other seafood } \\
\text { consumption }\end{array}$ & $\mathrm{kg} / \mathrm{yr}$ & 0.9 & $0-100$ & All & 0.9 & $M, B$ & 3 & $\begin{array}{l}\text { The aquatic foods ingestion pathway is } \\
\text { suppressed in RESRAD for all receptors } \\
\text { because it is not considered part of the } \\
\text { conceptual site model. }\end{array}$ & Yu et al. 2001 \\
\hline \multirow[b]{2}{*}{ Soil ingestion rate } & \multirow[b]{2}{*}{$\mathrm{g} / \mathrm{yr}$} & \multirow[b]{2}{*}{36.5} & \multirow[b]{2}{*}{$0-10,000$} & $\begin{array}{l}\text { RF } \\
\text { RG } \\
\text { RU } \\
\text { T }\end{array}$ & 36.5 & \multirow[b]{2}{*}{$\mathrm{M}, \mathrm{B}$} & \multirow[b]{2}{*}{2} & \multirow{2}{*}{$\begin{array}{l}\text { This value was converted from Table D.5 in } \\
\text { DOE } 2009 . \\
\text { Reference DOE } 2009 \text { assumes a lower } \\
\text { ingestion rate for workers who spend part of } \\
\text { the day outdoors. It is assumed the Workers } \\
\text { are working outside and perform duties that } \\
\text { result in a higher soil ingestion rate. } \\
\text { For the Recreational User the value available } \\
\text { in Table D.15 in DOE } 2009 \text { is for ingestion of } \\
\text { sediment. This value was assumed for the soil } \\
\text { ingestion rate. } \\
\text { See Attachment II following this table of } \\
\text { parameters. }\end{array}$} & \multirow[t]{2}{*}{$\begin{array}{c}\text { DOE } 2009 \\
\text { Appendix D, } \\
\text { Table D.5, page } \\
\text { D-15, Table } \\
\text { D.15, page D- } \\
\text { 25, Table D.37, } \\
\text { page D-47 }\end{array}$} \\
\hline & & & & $\begin{array}{l}\text { W } \\
\mathrm{L}\end{array}$ & 175.2 & & & & \\
\hline Drinking water intake & $\mathrm{L} / \mathrm{yr}$ & 510 & $0-10,000$ & All & 700 & $M, B$ & 2 & $\begin{array}{l}\text { This value was converted from Table D. } 1 \text { in } \\
\text { DOE } 2009 \\
\text { This parameter is applicable for the Resident } \\
\text { Farmer. } \\
\text { This parameter is not applicable for the } \\
\text { Resident Gardener, Workers, Recreational } \\
\text { User or the Trespasser; therefore, the drinking } \\
\text { water ingestion pathway is suppressed. } \\
\text { See Attachment II following this table of } \\
\text { parameters. }\end{array}$ & $\begin{array}{c}\text { DOE } 2009 \\
\text { Appendix D, } \\
\text { Table D.1, page } \\
\text { D-11 }\end{array}$ \\
\hline $\begin{array}{c}\text { Drinking water } \\
\text { contaminated fraction }\end{array}$ & - & 1 & $0-1$ & All & 1 & $B, P$ & 3 & $\begin{array}{l}\text { This parameter allows specification of the } \\
\text { fraction of contaminated intake for the } \\
\text { drinking water pathway. The remaining } \\
\text { balance (if value }<1 \text { ) of the drinking water is }\end{array}$ & Yu et al. 2001 \\
\hline
\end{tabular}


RESRAD Table of Input Parameters for the C-746-U Landfill Onsite Receptor Scenarios

\begin{tabular}{|c|c|c|c|c|c|c|c|c|c|}
\hline $\begin{array}{c}\text { Input Screen Title } \\
\text { and Parameter } \\
\text { Name }\end{array}$ & Unit & $\begin{array}{c}\text { Code } \\
\text { Default } \\
\text { Value }\end{array}$ & $\begin{array}{c}\text { Code- } \\
\text { Accepted } \\
\text { Values }^{a}\end{array}$ & Receptor $^{b}$ & $\begin{array}{c}\text { Deterministic } \\
\text { Value }\end{array}$ & Type $^{c}$ & Priority $^{d}$ & Justification & References \\
\hline & & & & & & & & $\begin{array}{l}\text { from off-site sources, which are assumed to } \\
\text { be uncontaminated. } \\
\text { A default value of } 1 \text { was assumed for the } \\
\text { Resident Farmer. } \\
\text { This parameter is not applicable for the } \\
\text { Resident Gardener, Workers, Recreational } \\
\text { User or the Trespasser; therefore, the drinking } \\
\text { water ingestion pathway is suppressed. }\end{array}$ & \\
\hline $\begin{array}{l}\text { Household water } \\
\text { contaminated fraction }\end{array}$ & - & 1 & $0-1$ & All & 1 & $B, P$ & 3 & $\begin{array}{l}\text { A default value of } 1 \text { is assumed. This default } \\
\text { value of } 1 \text { indicates that all household water is } \\
\text { from an on-site source. However, this } \\
\text { parameter is not used by the code since it is } \\
\text { related to the radon pathway and this } \\
\text { pathway is deactivated. }\end{array}$ & Yu et al. 2001 \\
\hline $\begin{array}{l}\text { Livestock water } \\
\text { contaminated fraction }\end{array}$ & - & 1 & $0-1$ & All & 1 & $B, P$ & 3 & $\begin{array}{l}\text { A default value of } 1 \text { is assumed for the } \\
\text { Resident Farmer. This default value of } 1 \\
\text { indicates that all livestock water is from an } \\
\text { on-site source. } \\
\text { This parameter is related to the milk and meat } \\
\text { ingestion pathways and these pathways are } \\
\text { not applicable for the Resident Gardener, } \\
\text { Workers, Recreational User, or the } \\
\text { Trespasser. Therefore, the meat and milk } \\
\text { ingestion pathways are deactivated for these } \\
\text { receptors. }\end{array}$ & Yu et al. 2001 \\
\hline \multirow{2}{*}{$\begin{array}{c}\text { Irrigation water } \\
\text { contaminated fraction }\end{array}$} & \multirow{2}{*}{-} & \multirow{2}{*}{1} & \multirow{2}{*}{$0-1$} & $\begin{array}{l}\text { RF } \\
\text { W } \\
\text { RU } \\
\text { T } \\
\text { L }\end{array}$ & 1 & \multirow{2}{*}{$B, P$} & \multirow{2}{*}{3} & $\begin{array}{l}\text { The default value of } 1 \text { is assumed for the } \\
\text { Resident Farmer. This default value of } 1 \\
\text { indicates that all irrigation water is from an } \\
\text { on-site source. } \\
\text { A value of " } 0 \text { " is used for the Resident }\end{array}$ & \multirow[t]{2}{*}{$\begin{array}{l}\text { DOE Project } \\
\text { Communicatior } \\
\text { with DOE-PPPO } \\
\text { (September } \\
\text { 2010) }\end{array}$} \\
\hline & & & & RG & 0 & & & $\begin{array}{l}\text { Gardener since this receptor will use an oft- } \\
\text { site water source. } \\
\text { This parameter is related to the plant, meat, } \\
\text { and milk ingestion pathways and these are } \\
\text { not applicable for the Workers, Recreational } \\
\text { User, and the Trespasser. Therefore, the }\end{array}$ & \\
\hline
\end{tabular}


RESRAD Table of Input Parameters for the C-746-U Landfill Onsite Receptor Scenarios

\begin{tabular}{|c|c|c|c|c|c|c|c|c|c|}
\hline $\begin{array}{c}\text { Input Screen Title } \\
\text { and Parameter } \\
\text { Name }\end{array}$ & Unit & $\begin{array}{c}\text { Code } \\
\text { Default } \\
\text { Value }\end{array}$ & $\begin{array}{c}\text { Code- } \\
\text { Accepted } \\
\text { Values }^{a}\end{array}$ & Receptor $^{b}$ & $\begin{array}{c}\text { Deterministic } \\
\text { Value }\end{array}$ & Type & Priority $^{d}$ & Justification & References \\
\hline & & & & & & & & $\begin{array}{l}\text { plant, meat and milk ingestion pathways are } \\
\text { suppressed for these receptors. }\end{array}$ & \\
\hline $\begin{array}{c}\text { Aquatic food } \\
\text { contaminated fraction }\end{array}$ & - & 0.5 & $0-1$ & All & 0.5 & $\mathrm{~B}, \mathrm{P}$ & 2 & $\begin{array}{l}\text { A default value of } 0.5 \text { indicates that } 50 \% \text { of } \\
\text { aquatic food is being obtained from on-site } \\
\text { sources. } \\
\text { The aquatic food pathway is not considered in } \\
\text { the conceptual site model and it is } \\
\text { deactivated for all receptors. Therefore, this } \\
\text { parameter is not used by the code. }\end{array}$ & Yu et al. 2001 \\
\hline $\begin{array}{c}\text { Plant food } \\
\text { contaminated fraction }\end{array}$ & - & -1 & 0 to 1 or -1 & All & -1 & $\mathrm{~B}, \mathrm{P}$ & 3 & $\begin{array}{l}\text { The default value of }-1 \text { specifies that the } \\
\text { contaminated fraction of plant food is } \\
\text { calculated from the appropriate area factor in } \\
\text { the code (see page A-8 of Yu et al. 2001). } \\
\text { The plant ingestion pathway is suppressed for } \\
\text { the Workers, Recreational User, and } \\
\text { Trespasser since this pathway is not } \\
\text { considered in the conceptual site model for } \\
\text { these receptors. }\end{array}$ & Yu et al. 2001 \\
\hline $\begin{array}{l}\text { Meat contaminated } \\
\text { fraction }\end{array}$ & - & -1 & 0 to 1 or -1 & All & -1 & $\mathrm{~B}, \mathrm{P}$ & 3 & $\begin{array}{l}\text { A default value of - } 1 \text { was assumed for the } \\
\text { Resident Farmer. The default value of }-1 \\
\text { specifies that the contaminated fraction of } \\
\text { meat is calculated from the appropriate area } \\
\text { factor in the code. } \\
\text { The meat ingestion pathway is suppressed for } \\
\text { the Resident Gardener, Workers, Recreational } \\
\text { User, and Trespasser since this pathway is not } \\
\text { considered in the conceptual site model for } \\
\text { these receptors. }\end{array}$ & Yu et al. 2001 \\
\hline $\begin{array}{l}\text { Milk contaminated } \\
\text { fraction }\end{array}$ & - & -1 & 0 to 1 or -1 & All & -1 & $\mathrm{~B}, \mathrm{P}$ & 3 & $\begin{array}{l}\text { The default value of }-1 \text { specifies that the } \\
\text { contaminated fraction of milk is calculated } \\
\text { from the appropriate area factor in the code. } \\
\text { The milk ingestion pathway is suppressed for } \\
\text { the Resident Gardener, Workers, Recreational } \\
\text { User, and Trespasser since this pathway is not }\end{array}$ & Yu et al. 2001 \\
\hline
\end{tabular}


RESRAD Table of Input Parameters for the C-746-U Landfill Onsite Receptor Scenarios

\begin{tabular}{|c|c|c|c|c|c|c|c|c|}
\hline $\begin{array}{c}\text { Input Screen Title } \\
\text { and Parameter } \\
\text { Name }\end{array}$ & Unit & $\begin{array}{c}\text { Code } \\
\text { Default } \\
\text { Value }\end{array}$ & $\begin{array}{c}\text { Code- } \\
\text { Accepted } \\
\text { Values }^{a}\end{array}$ & Receptor $^{b}$ & $\begin{array}{c}\text { Deterministic } \\
\text { Value }\end{array}$ & Type $^{c}$ & Priority & Justification \\
\hline & & & & & & & $\begin{array}{c}\text { considered in the conceptual site model for } \\
\text { these receptors. }\end{array}$ \\
\hline
\end{tabular}

Ingestion Pathway, Nondietary Data

\begin{tabular}{|c|c|c|c|c|c|c|c|c|c|}
\hline $\begin{array}{l}\text { Livestock fodder } \\
\text { intake for meat }\end{array}$ & $\mathrm{kg} / \mathrm{d}$ & 68 & $0-300$ & All & 25 & $\mathrm{M}$ & 3 & $\begin{array}{l}\text { This parameter is for the daily intake of } \\
\text { fodder by livestock kept for meat } \\
\text { consumption. The code uses the area factor to } \\
\text { calculate the contaminated intake. } \\
\text { The meat ingestion pathway is suppressed for } \\
\text { the Resident Gardener, Workers, Recreational } \\
\text { User, and Trespasser since this pathway is not } \\
\text { considered in the conceptual site model for } \\
\text { these receptors. }\end{array}$ & $\begin{array}{c}\text { DOE } 2009 \\
\text { Appendix D, } \\
\text { Table D.46, } \\
\text { page D-56 }\end{array}$ \\
\hline $\begin{array}{l}\text { Livestock fodder } \\
\text { intake for milk }\end{array}$ & $\mathrm{kg} / \mathrm{d}$ & 55 & $0-300$ & All & 25 & $M$ & 3 & $\begin{array}{l}\text { This parameter is for the daily intake of } \\
\text { fodder by livestock kept for milk consumption. } \\
\text { The code uses the area factor to calculate the } \\
\text { contaminated intake. } \\
\text { The milk ingestion pathway is suppressed for } \\
\text { the Resident Gardener, Workers, Recreational } \\
\text { User, and Trespasser since this pathway is not } \\
\text { considered in the conceptual site model for } \\
\text { these receptors. }\end{array}$ & $\begin{array}{c}\text { DOE } 2009 \\
\text { Appendix D, } \\
\text { Table D.47, } \\
\text { page D-57 }\end{array}$ \\
\hline $\begin{array}{l}\text { Livestock water intake } \\
\text { for meat }\end{array}$ & $\mathrm{L} / \mathrm{d}$ & 50 & $0-500$ & All & 50 & $\mathrm{M}$ & 3 & $\begin{array}{l}\text { This parameter is for the daily intake of water } \\
\text { by livestock kept for meat consumption. } \\
\text { The code uses the area factor to calculate the } \\
\text { contaminated intake. } \\
\text { The meat ingestion pathway is suppressed for } \\
\text { the Resident Gardener, Workers, Recreational } \\
\text { User, and Trespasser since this pathway is not } \\
\text { considered in the conceptual site model for } \\
\text { these receptors. }\end{array}$ & $\begin{array}{c}\text { DOE } 2009 \\
\text { Appendix D, } \\
\text { Table D.46, } \\
\text { page D-56 }\end{array}$ \\
\hline $\begin{array}{l}\text { Livestock water intake } \\
\text { for milk }\end{array}$ & $\mathrm{L} / \mathrm{d}$ & 160 & $0-500$ & All & 160 & $M$ & 3 & $\begin{array}{l}\text { The default value is used for the Resident } \\
\text { Farmer. } \\
\text { The milk ingestion pathway is suppressed for } \\
\text { the Resident Gardener, Workers, Recreational } \\
\text { User, and Trespasser since this pathway is not } \\
\text { considered in the conceptual site model for }\end{array}$ & Yu et al. 2001 \\
\hline
\end{tabular}


RESRAD Table of Input Parameters for the C-746-U Landfill Onsite Receptor Scenarios

\begin{tabular}{|c|c|c|c|c|c|c|c|c|c|}
\hline $\begin{array}{c}\text { Input Screen Title } \\
\text { and Parameter } \\
\text { Name }\end{array}$ & Unit & $\begin{array}{c}\text { Code } \\
\text { Default } \\
\text { Value }\end{array}$ & $\begin{array}{c}\text { Code- } \\
\text { Accepted } \\
\text { Values }^{a}\end{array}$ & Receptor ${ }^{b}$ & $\begin{array}{c}\text { Deterministic } \\
\text { Value }\end{array}$ & Type $^{c}$ & Priority $^{d}$ & Justification & References \\
\hline & & & & & & & & these receptors. & \\
\hline Livestock intake of soil & $\mathrm{kg} / \mathrm{d}$ & 0.5 & $0-10$ & All & 1 & $M$ & 3 & $\begin{array}{l}\text { This parameter reflects the daily intake of soil } \\
\text { by livestock kept for meat or milk } \\
\text { consumption. } \\
\text { DOE } 2009 \text { has separate tables for livestock soil } \\
\text { ingestion. A value of } 1 \mathrm{~kg} / \mathrm{d} \text { is listed for beef } \\
\text { and dairy in each table, thus for the Resident } \\
\text { Farmer, this value will be used. } \\
\text { The meat and milk ingestion pathways are } \\
\text { suppressed for the Resident Gardener, } \\
\text { Workers, Recreational User, and Trespasser } \\
\text { since these pathways are not considered in } \\
\text { the conceptual site model for these receptors. }\end{array}$ & $\begin{array}{c}\text { DOE } 2009 \\
\text { Appendix D, } \\
\text { Table D.46 and } \\
\text { D.47, page D-56 } \\
\text { and D-57 }\end{array}$ \\
\hline $\begin{array}{l}\text { Mass loading for foliar } \\
\text { deposition }\end{array}$ & $\mathrm{g} / \mathrm{m}^{3}$ & $1.00 \mathrm{E}-04$ & $0-1$ & All & $1.00 \mathrm{E}-04$ & $P$ & 3 & $\begin{array}{l}\text { The average mass loading of airborne } \\
\text { contaminated soil particles in a garden during } \\
\text { the growing season. } \\
\text { A default value was assumed for the Resident } \\
\text { Farmer and the Resident Gardener, since } \\
\text { plant ingestion is a pathway for these } \\
\text { receptors and site specific information is not } \\
\text { available. } \\
\text { The plant ingestion pathway is suppressed for } \\
\text { the Workers, Recreational User, and } \\
\text { Trespasser since this pathway is not } \\
\text { considered in the conceptual site model for } \\
\text { these receptors. }\end{array}$ & Yu et al. 2001 \\
\hline $\begin{array}{c}\text { Depth of soil mixing } \\
\text { layer }\end{array}$ & $\mathrm{m}$ & 0.15 & $0-1$ & All & 0.15 & $P$ & 2 & $\begin{array}{l}\text { Used in calculating the depth factor for dust } \\
\text { inhalation and soil ingestion pathways and for } \\
\text { foliar deposition for the plant, meat, and milk } \\
\text { ingestion pathways. The depth factor is the } \\
\text { fraction of the resuspendable soil particles at } \\
\text { the ground surface that are contaminated. It } \\
\text { is calculated by assuming that mixing of soil } \\
\text { will occur in the soil mixing layer. } \\
\text { A default value was assumed and is applied to } \\
\text { all receptors since the inhalation and soil } \\
\text { ingestion pathways apply to all receptors and }\end{array}$ & Yu et al. 2001 \\
\hline
\end{tabular}


RESRAD Table of Input Parameters for the C-746-U Landfill Onsite Receptor Scenarios

\begin{tabular}{|c|c|c|c|c|c|c|c|c|c|}
\hline $\begin{array}{c}\text { Input Screen Title } \\
\text { and Parameter } \\
\text { Name }\end{array}$ & Unit & $\begin{array}{c}\text { Code } \\
\text { Default } \\
\text { Value }\end{array}$ & $\begin{array}{c}\text { Code- } \\
\text { Accepted } \\
\text { Values }^{a}\end{array}$ & Receptor $^{b}$ & $\begin{array}{l}\text { Deterministic } \\
\text { Value }\end{array}$ & Type $^{c}$ & Priority $^{d}$ & Justification & References \\
\hline & & & & & & & & $\begin{array}{l}\text { site specific information is not available. } \\
\text { The meat, milk, and plant ingestion pathways } \\
\text { are suppressed for the Workers, Recreational } \\
\text { User, and Trespasser since these pathways } \\
\text { are not considered in the conceptual site } \\
\text { model for these receptors. } \\
\text { The meat and milk ingestion pathways are } \\
\text { suppressed for the Resident Gardener since } \\
\text { these pathways are not considered in the } \\
\text { conceptual site model for this receptor. }\end{array}$ & \\
\hline Depth of roots & $\mathrm{m}$ & 0.9 & $0-100$ & All & 0.9 & $P$ & 1 & $\begin{array}{l}\text { The maximum root depth below the ground } \\
\text { surface. } \\
\text { A default value was assumed for the Resident } \\
\text { Farmer, since meat, milk, and plant ingestion } \\
\text { are pathways for this receptor and site } \\
\text { specific information is not available. } \\
\text { The meat, milk, and plant ingestion pathways } \\
\text { are suppressed for the Workers, Recreational } \\
\text { User, and Trespasser since these pathways } \\
\text { are not considered in the conceptual site } \\
\text { model for these receptors. } \\
\text { The meat and milk ingestion pathways are } \\
\text { suppressed for the Resident Gardener since } \\
\text { these pathways are not considered in the } \\
\text { conceptual site model for this receptor. }\end{array}$ & Yu et al. 2001 \\
\hline $\begin{array}{l}\text { Groundwater } \\
\text { fractional usage for } \\
\text { drinking water }\end{array}$ & - & 1 & $0-1$ & All & 1 & $B, P$ & 3 & $\begin{array}{l}\text { The four groundwater fractional usage } \\
\text { parameters (drinking water, household water, } \\
\text { livestock water, and irrigation water) are } \\
\text { included primarily for all groundwater (well or } \\
\text { spring) and surface water (pond or river) } \\
\text { scenarios. Hence, the fractions will usually be } \\
\text { set at } 1 \text { or } 0 \text {. A value of } 1 \text { specifies } 100 \% \\
\text { groundwater usage and } 0 \text { specifies } 100 \% \\
\text { surface water usage. } \\
\text { A default value was assumed for the Resident } \\
\text { Farmer, since drinking water ingestion is a }\end{array}$ & Yu et al. 2001 \\
\hline
\end{tabular}


RESRAD Table of Input Parameters for the C-746-U Landfill Onsite Receptor Scenarios

\begin{tabular}{|c|c|c|c|c|c|c|c|c|c|}
\hline $\begin{array}{c}\text { Input Screen Title } \\
\text { and Parameter } \\
\text { Name }\end{array}$ & Unit & $\begin{array}{c}\text { Code } \\
\text { Default } \\
\text { Value }\end{array}$ & $\begin{array}{c}\text { Code- } \\
\text { Accepted } \\
\text { Values }^{a}\end{array}$ & Receptor $^{b}$ & $\begin{array}{l}\text { Deterministic } \\
\text { Value }\end{array}$ & Type $^{c}$ & Priority $^{d}$ & Justification & References \\
\hline & & & & & & & & $\begin{array}{l}\text { pathway for this receptor and site specific } \\
\text { information is not available. } \\
\text { The drinking water ingestion pathway is } \\
\text { suppressed for the Resident Gardener, } \\
\text { Workers, Recreational User, and Trespasser } \\
\text { since this pathway is not considered in the } \\
\text { conceptual site model for these receptors. }\end{array}$ & \\
\hline $\begin{array}{l}\text { Groundwater } \\
\text { fractional usage for } \\
\text { household water }\end{array}$ & - & 1 & $0-1$ & All & 1 & $B, P$ & 3 & $\begin{array}{l}\text { The four groundwater fractional usage } \\
\text { parameters (drinking water, household water, } \\
\text { livestock water, and irrigation water) are } \\
\text { included primarily for all groundwater (well or } \\
\text { spring) and surface water (pond or river) } \\
\text { scenarios. Hence, the fractions will usually be } \\
\text { set at } 1 \text { or } 0 \text {. A value of } 1 \text { specifies } 100 \% \\
\text { groundwater usage and } 0 \text { specifies } 100 \% \\
\text { surface water usage. } \\
\text { A default value was assumed for the Resident } \\
\text { Farmer, since it is reflected in the pathways } \\
\text { for this receptor and site specific information } \\
\text { is not available. } \\
\text { The meat, milk, and plant ingestion pathways } \\
\text { are suppressed for the Workers, Recreational } \\
\text { User, and Trespasser since these pathways } \\
\text { are not considered in the conceptual site } \\
\text { model for these receptors. } \\
\text { The meat and milk ingestion pathways are } \\
\text { suppressed for the Resident Gardener since } \\
\text { these pathways are not considered in the } \\
\text { conceptual site model for this receptor. }\end{array}$ & Yu et al. 2001 \\
\hline $\begin{array}{l}\text { Groundwater } \\
\text { fractional usage for } \\
\text { livestock water }\end{array}$ & - & 1 & $0-1$ & All & 1 & $B, P$ & 3 & $\begin{array}{l}\text { The four groundwater fractional usage } \\
\text { parameters (drinking water, household water, } \\
\text { livestock water, and irrigation water) are } \\
\text { included primarily for all groundwater (well or } \\
\text { spring) and surface water (pond or river) } \\
\text { scenarios. Hence, the fractions will usually be } \\
\text { set at } 1 \text { or } 0 \text {. A value of } 1 \text { specifies } 100 \% \\
\text { groundwater usage and } 0 \text { specifies } 100 \% \\
\text { surface water usage. }\end{array}$ & Yu et al. 2001 \\
\hline
\end{tabular}


RESRAD Table of Input Parameters for the C-746-U Landfill Onsite Receptor Scenarios

\begin{tabular}{|c|c|c|c|c|c|c|c|c|c|}
\hline $\begin{array}{c}\text { Input Screen Title } \\
\text { and Parameter } \\
\text { Name }\end{array}$ & Unit & $\begin{array}{c}\text { Code } \\
\text { Default } \\
\text { Value }\end{array}$ & $\begin{array}{c}\text { Code- } \\
\text { Accepted } \\
\text { Values }^{a}\end{array}$ & Receptor $^{b}$ & $\begin{array}{l}\text { Deterministic } \\
\text { Value }\end{array}$ & Type $^{c}$ & Priority $^{d}$ & Justification & References \\
\hline & & & & & & & & $\begin{array}{l}\text { A default value was assumed for the Resident } \\
\text { Farmer since it is reflected in the pathways for } \\
\text { this receptor and site specific information is } \\
\text { not available. } \\
\text { The meat and milk ingestion pathways are } \\
\text { suppressed for the Resident Gardener, } \\
\text { Workers, Recreational User, and Trespasser } \\
\text { since these pathways are not considered in } \\
\text { the conceptual site model. }\end{array}$ & \\
\hline $\begin{array}{l}\text { Groundwater } \\
\text { fractional usage for } \\
\text { irrigation water }\end{array}$ & - & 1 & $0-1$ & $\begin{array}{l}\text { RF } \\
\text { W } \\
\text { RU } \\
\text { T } \\
\text { L }\end{array}$ & 1 & $B, P$ & 3 & $\begin{array}{l}\text { The four groundwater fractional usage } \\
\text { parameters (drinking water, household water, } \\
\text { livestock water, and irrigation water) are } \\
\text { included primarily for all groundwater (well or } \\
\text { spring) and surface water (pond or river) } \\
\text { scenarios. Hence, the fractions will usually be } \\
\text { set at } 1 \text { or } 0 \text {. A value of } 1 \text { specifies } 100 \% \\
\text { groundwater usage and } 0 \text { specifies } 100 \% \\
\text { surface water usage. } \\
\text { A value of } 1 \text { is used for the Resident Farmer } \\
\text { and because the conceptual site model } \\
\text { assumed this individual will obtain irrigation } \\
\text { water from groundwater. } \\
\text { A value of } 0 \text { is used the Resident Gardener } \\
\text { because the conceptual site model assumes } \\
\text { this individual will obtain uncontaminated } \\
\text { irrigation water from offsite (e.g., a municipal } \\
\text { water source). } \\
\text { The plant ingestion pathway is suppressed for } \\
\text { the Workers, Recreational User, and } \\
\text { Trespasser since this pathway is not } \\
\text { considered in the conceptual site model for } \\
\text { these receptors. }\end{array}$ & $\begin{array}{l}\text { Yu et al. } 2001 \\
\text { DOE Project } \\
\text { Communication } \\
\text { with DOE-PPPO } \\
\text { (September } \\
\text { 2010) }\end{array}$ \\
\hline
\end{tabular}

Plant Factors 
RESRAD Table of Input Parameters for the C-746-U Landfill Onsite Receptor Scenarios

\begin{tabular}{|c|c|c|c|c|c|c|c|c|c|}
\hline $\begin{array}{c}\text { Input Screen Title } \\
\text { and Parameter } \\
\text { Name }\end{array}$ & Unit & $\begin{array}{c}\text { Code } \\
\text { Default } \\
\text { Value }\end{array}$ & $\begin{array}{l}\text { Code- } \\
\text { Accepted } \\
\text { Values }^{a}\end{array}$ & Receptor ${ }^{b}$ & $\begin{array}{c}\text { Deterministic } \\
\text { Value }\end{array}$ & Type $^{c}$ & Priority $^{d}$ & Justification & References \\
\hline $\begin{array}{l}\text { Wet-weight crop } \\
\text { yields for non-leafy } \\
\text { vegetables }\end{array}$ & $\mathrm{kg} / \mathrm{m}^{2}$ & 0.7 & $0.01-3$ & All & 0.7 & $P$ & 2 & $\begin{array}{l}\text { The weight of the edible portion of plant food } \\
\text { produced per unit land area for different food } \\
\text { classes. The code has wet weight crop yield } \\
\text { for non-leafy, leafy, and fodder. Non-leafy and } \\
\text { leafy vegetables are for human consumption; } \\
\text { fodder is for animal consumption. } \\
\text { A default value was assumed for the Resident } \\
\text { Farmer and Resident Gardener since it is } \\
\text { reflected in the pathway for these receptors } \\
\text { and site specific information is not available. } \\
\text { The plant ingestion pathway is suppressed for } \\
\text { the Workers, Recreational User, and } \\
\text { Trespasser since this pathway is not } \\
\text { considered in the conceptual site model for } \\
\text { these receptors. }\end{array}$ & Yu et al. 2001 \\
\hline $\begin{array}{l}\text { Wet-weight crop } \\
\text { yields for leafy } \\
\text { vegetables }\end{array}$ & $\mathrm{kg} / \mathrm{m}^{2}$ & 1.5 & $0.01-3$ & All & 1.5 & $P$ & 3 & $\begin{array}{l}\text { A default value was assumed for the Resident } \\
\text { Farmer and Resident Gardener since the } \\
\text { ingestion pathway for home-grown produce is } \\
\text { applicable for these receptors and site specific } \\
\text { information is not available. } \\
\text { The plant ingestion pathway is suppressed for } \\
\text { the Workers, Recreational User, and } \\
\text { Trespasser since this pathway is not } \\
\text { considered in the conceptual site model for } \\
\text { these receptors. }\end{array}$ & Yu et al. 2001 \\
\hline $\begin{array}{l}\text { Wet-weight crop } \\
\text { yields for fodder }\end{array}$ & $\mathrm{kg} / \mathrm{m}^{2}$ & 1.1 & $0.01-3$ & All & 1.1 & $P$ & 3 & $\begin{array}{l}\text { A default value was assumed for the Resident } \\
\text { Farmer since meat and milk ingestion is } \\
\text { applicable and a site specific value is not } \\
\text { available. } \\
\text { The meat and milk ingestion pathways are } \\
\text { suppressed for the Resident Gardener, } \\
\text { Workers, Recreational User, and Trespasser } \\
\text { since these pathways are not considered in } \\
\text { the conceptual site model for these receptors. }\end{array}$ & Yu et al. 2001 \\
\hline $\begin{array}{l}\text { Length of growing } \\
\text { season for non-leafy } \\
\text { vegetables }\end{array}$ & $\mathrm{yr}$ & 0.17 & $0.01-1$ & All & 0.17 & $P$ & 3 & $\begin{array}{l}\text { The exposure time to contamination for the } \\
\text { plant food during the growing season. The } \\
\text { contamination can reach the edible portion of } \\
\text { the plant food through foliar deposition, root }\end{array}$ & Yu et al. 2001 \\
\hline
\end{tabular}


RESRAD Table of Input Parameters for the C-746-U Landfill Onsite Receptor Scenarios

\begin{tabular}{|c|c|c|c|c|c|c|c|c|c|}
\hline $\begin{array}{c}\text { Input Screen Title } \\
\text { and Parameter } \\
\text { Name }\end{array}$ & Unit & $\begin{array}{c}\text { Code } \\
\text { Default } \\
\text { Value }\end{array}$ & $\begin{array}{c}\text { Code- } \\
\text { Accepted } \\
\text { Values }^{a}\end{array}$ & Receptor $^{b}$ & $\begin{array}{l}\text { Deterministic } \\
\text { Value }\end{array}$ & Type $^{c}$ & Priority $^{d}$ & Justification & References \\
\hline & & & & & & & & $\begin{array}{l}\text { uptake, and water irrigation. } \\
\text { The code has length of growing season for } \\
\text { non-leafy vegetables, leafy vegetables, and } \\
\text { fodder. } \\
\text { A default value was assumed for the Resident } \\
\text { Farmer and Resident Gardener since plant } \\
\text { ingestion is applicable and a site specific value } \\
\text { is not available. } \\
\text { The plant ingestion pathway is suppressed for } \\
\text { the Workers, Recreational User, and } \\
\text { Trespasser since this pathway is not } \\
\text { considered in the conceptual site model for } \\
\text { these receptors. }\end{array}$ & \\
\hline $\begin{array}{l}\text { Length of growing } \\
\text { season for leafy } \\
\text { vegetables }\end{array}$ & $\mathrm{yr}$ & 0.25 & $0.01-1$ & All & 0.25 & $\mathrm{P}$ & 3 & $\begin{array}{l}\text { The exposure time to contamination for the } \\
\text { plant food during the growing season. The } \\
\text { contamination can reach the edible portion of } \\
\text { the plant food through foliar deposition, root } \\
\text { uptake, and water irrigation. } \\
\text { The code has length of growing season for } \\
\text { non-leafy vegetables, leafy vegetables, and } \\
\text { fodder. } \\
\text { A default value was assumed for the Resident } \\
\text { Farmer and Resident Gardener since plant } \\
\text { ingestion is applicable and a site specific value } \\
\text { is not available. } \\
\text { The plant ingestion pathway is suppressed for } \\
\text { the Workers, Recreational User, and } \\
\text { Trespasser since this pathway is not } \\
\text { considered in the conceptual site model for } \\
\text { these receptors. }\end{array}$ & Yu et al. 2001 \\
\hline $\begin{array}{l}\text { Length of growing } \\
\text { season for fodder }\end{array}$ & $\mathrm{yr}$ & 0.08 & $0.01-1$ & All & 0.08 & $P$ & 3 & $\begin{array}{l}\text { The exposure time to contamination for the } \\
\text { plant food during the growing season. The } \\
\text { contamination can reach the edible portion of } \\
\text { the plant food through foliar deposition, root } \\
\text { uptake, and water irrigation. }\end{array}$ & Yu et al. 2001 \\
\hline
\end{tabular}


RESRAD Table of Input Parameters for the C-746-U Landfill Onsite Receptor Scenarios

\begin{tabular}{|c|c|c|c|c|c|c|c|c|c|}
\hline $\begin{array}{c}\text { Input Screen Title } \\
\text { and Parameter } \\
\text { Name }\end{array}$ & Unit & $\begin{array}{c}\text { Code } \\
\text { Default } \\
\text { Value }\end{array}$ & $\begin{array}{c}\text { Code- } \\
\text { Accepted } \\
\text { Values }^{a}\end{array}$ & Receptor $^{b}$ & $\begin{array}{l}\text { Deterministic } \\
\text { Value }\end{array}$ & Type $^{c}$ & Priority $^{d}$ & Justification & References \\
\hline & & & & & & & & $\begin{array}{l}\text { The code has length of growing season for } \\
\text { non-leafy vegetables, leafy vegetables, and } \\
\text { fodder. } \\
\text { A default value was assumed for the Resident } \\
\text { Farmer because meat and milk ingestion are } \\
\text { applicable and a site specific value is not } \\
\text { available. } \\
\text { The meat and milk ingestion pathways are } \\
\text { suppressed for the Resident Gardener, } \\
\text { Workers, Recreational User, and Trespasser } \\
\text { since these pathways are not considered in } \\
\text { the conceptual site model for these receptors. }\end{array}$ & \\
\hline $\begin{array}{l}\text { Translocation factor } \\
\text { for non-leafy } \\
\text { vegetables }\end{array}$ & - & 0.1 & $0-1$ & All & 0.1 & $P$ & 3 & $\begin{array}{l}\text { The fraction of the contamination that is } \\
\text { retained on the foliage that is transferred to } \\
\text { the edible portion of the plant. } \\
\text { The code has three food categories, non-leafy } \\
\text { (includes non-leafy vegetables, fruit, and } \\
\text { grain) and leafy vegetables for human and } \\
\text { fodder for animal consumption. } \\
\text { A default value was assumed for the Resident } \\
\text { Farmer and Resident Gardener since plant } \\
\text { ingestion is applicable and a site specific value } \\
\text { is not available. } \\
\text { The plant ingestion pathway is suppressed for } \\
\text { the Workers, Recreational User, and } \\
\text { Trespasser since this pathway is not } \\
\text { considered in the conceptual site model for } \\
\text { these receptors. }\end{array}$ & Yu et al. 2001 \\
\hline $\begin{array}{l}\text { Translocation factor } \\
\text { for leafy vegetables }\end{array}$ & - & 1 & $0-1$ & All & 1 & $P$ & 3 & $\begin{array}{l}\text { The fraction of the contamination that is } \\
\text { retained on the foliage that is transferred to } \\
\text { the edible portion of the plant. } \\
\text { The code has three food categories, non-leafy } \\
\text { (includes non-leafy vegetables, fruit, and } \\
\text { grain) and leafy vegetables for human and } \\
\text { fodder for animal consumption. }\end{array}$ & Yu et al. 2001 \\
\hline
\end{tabular}


RESRAD Table of Input Parameters for the C-746-U Landfill Onsite Receptor Scenarios

\begin{tabular}{|c|c|c|c|c|c|c|c|c|c|}
\hline $\begin{array}{c}\text { Input Screen Title } \\
\text { and Parameter } \\
\text { Name }\end{array}$ & Unit & $\begin{array}{c}\text { Code } \\
\text { Default } \\
\text { Value }\end{array}$ & $\begin{array}{c}\text { Code- } \\
\text { Accepted } \\
\text { Values }^{a}\end{array}$ & Receptor ${ }^{b}$ & $\begin{array}{c}\text { Deterministic } \\
\text { Value }\end{array}$ & Type $^{c}$ & Priority $^{d}$ & Justification & References \\
\hline & & & & & & & & $\begin{array}{l}\text { A default value was assumed for the Resident } \\
\text { Farmer and Resident Gardener since plant } \\
\text { ingestion is applicable and a site specific value } \\
\text { is not available. } \\
\text { The plant ingestion pathway is suppressed for } \\
\text { the Workers, Recreational User, and } \\
\text { Trespasser since this pathway is not } \\
\text { considered in the conceptual site model for } \\
\text { these receptors. }\end{array}$ & \\
\hline $\begin{array}{l}\text { Translocation factor } \\
\text { for fodder }\end{array}$ & - & 1 & $0-1$ & All & 1 & $P$ & 3 & $\begin{array}{l}\text { The fraction of the contamination that is } \\
\text { retained on the foliage that is transferred to } \\
\text { the edible portion of the plant. The code has } \\
\text { three food categories, non-leafy (includes } \\
\text { non-leafy vegetables, fruit, and grain) and } \\
\text { leafy vegetables for human and fodder for } \\
\text { animal consumption (in all three values). } \\
\text { A default value was assumed for the Resident } \\
\text { Farmer because meat and milk ingestion are } \\
\text { applicable and a site specific value is not } \\
\text { available. } \\
\text { The meat and milk ingestion pathways are } \\
\text { suppressed for the Resident Gardener, } \\
\text { Workers, Recreational User, and Trespasser } \\
\text { since these pathways are not considered in } \\
\text { the conceptual site model for these receptors. }\end{array}$ & Yu et al. 2001 \\
\hline $\begin{array}{l}\text { Weathering removal } \\
\text { constant }\end{array}$ & $1 / \mathrm{yr}$ & 20 & $1-40$ & All & 20 & $\mathrm{P}$ & 2 & $\begin{array}{l}\text { The weathering process would remove } \\
\text { contaminants from foliage of the plant food. } \\
\text { The process is characterized by a removal } \\
\text { constant and reduces the amount of } \\
\text { contaminants on foliage exponentially during } \\
\text { the exposure period. } \\
\text { A default value was assumed for the Resident } \\
\text { Farmer and Resident Gardener since plant } \\
\text { ingestion is applicable and a site specific value } \\
\text { is not available. } \\
\text { The plant ingestion pathway is suppressed for } \\
\text { the Workers, Recreational User, and }\end{array}$ & Yu et al. 2001 \\
\hline
\end{tabular}


RESRAD Table of Input Parameters for the C-746-U Landfill Onsite Receptor Scenarios

\begin{tabular}{|c|c|c|c|c|c|c|c|c|c|}
\hline $\begin{array}{c}\text { Input Screen Title } \\
\text { and Parameter } \\
\text { Name }\end{array}$ & Unit & $\begin{array}{c}\text { Code } \\
\text { Default } \\
\text { Value }\end{array}$ & $\begin{array}{c}\text { Code- } \\
\text { Accepted } \\
\text { Values }^{a}\end{array}$ & Receptor $^{b}$ & $\begin{array}{l}\text { Deterministic } \\
\text { Value }\end{array}$ & Type $^{c}$ & Priority $^{d}$ & Justification & References \\
\hline & & & & & & & & $\begin{array}{l}\text { Trespasser since this pathway is not } \\
\text { considered in the conceptual site model for } \\
\text { these receptors. }\end{array}$ & \\
\hline $\begin{array}{l}\text { Wet foliar } \\
\text { interception fraction } \\
\text { for non-leafy } \\
\text { vegetables }\end{array}$ & - & 0.25 & $0-1$ & All & 0.25 & $P$ & 3 & $\begin{array}{l}\text { The fraction of deposited radionuclides that is } \\
\text { retained on the foliage of the plant food. Both } \\
\text { dry deposition (from airborne particulates) } \\
\text { and the wet deposition processes (from } \\
\text { irrigation) are considered. } \\
\text { The code has wet as well as dry foliar } \\
\text { interception fraction for non-leafy, leafy (for } \\
\text { human consumption), and fodder (for animal } \\
\text { consumption). } \\
\text { A default value was assumed for the Resident } \\
\text { Farmer and Resident Gardener since plant } \\
\text { ingestion is applicable and a site specific value } \\
\text { is not available. } \\
\text { The plant ingestion pathway is suppressed for } \\
\text { the Workers, Recreational User, and } \\
\text { Trespasser since this pathway is not } \\
\text { considered in the conceptual site model for } \\
\text { these receptors. }\end{array}$ & Yu et al. 2001 \\
\hline $\begin{array}{l}\text { Wet foliar } \\
\text { interception fraction } \\
\text { for leafy vegetables }\end{array}$ & - & 0.25 & $0-1$ & All & 0.25 & $P$ & 2 & $\begin{array}{l}\text { The fraction of deposited radionuclides that is } \\
\text { retained on the foliage of the plant food. Both } \\
\text { dry deposition (from airborne particulates) } \\
\text { and the wet deposition processes (from } \\
\text { irrigation) are considered. } \\
\text { The code has wet as well as dry foliar } \\
\text { interception fraction for non-leafy, leafy (for } \\
\text { human consumption), and fodder (for animal } \\
\text { consumption). } \\
\text { A default value was assumed for the Resident } \\
\text { Farmer and Resident Gardener since plant } \\
\text { ingestion is applicable and a site specific value } \\
\text { is not available. } \\
\text { The plant ingestion pathway is suppressed for } \\
\text { the Workers, Recreational User, and }\end{array}$ & Yu et al. 2001 \\
\hline
\end{tabular}


RESRAD Table of Input Parameters for the C-746-U Landfill Onsite Receptor Scenarios

\begin{tabular}{|c|c|c|c|c|c|c|c|c|c|}
\hline $\begin{array}{c}\text { Input Screen Title } \\
\text { and Parameter } \\
\text { Name }\end{array}$ & Unit & $\begin{array}{c}\text { Code } \\
\text { Default } \\
\text { Value }\end{array}$ & $\begin{array}{c}\text { Code- } \\
\text { Accepted } \\
\text { Values }^{a}\end{array}$ & Receptor $^{b}$ & $\begin{array}{l}\text { Deterministic } \\
\text { Value }\end{array}$ & Type $^{c}$ & Priority $^{d}$ & Justification & References \\
\hline & & & & & & & & $\begin{array}{l}\text { Trespasser since this pathway is not } \\
\text { considered in the conceptual site model for } \\
\text { these receptors. }\end{array}$ & \\
\hline $\begin{array}{l}\text { Wet foliar } \\
\text { interception fraction } \\
\text { for fodder }\end{array}$ & - & 0.25 & $0-1$ & All & 0.25 & $\mathrm{P}$ & 3 & $\begin{array}{l}\text { The fraction of deposited radionuclides that is } \\
\text { retained on the foliage of the plant food. Both } \\
\text { dry deposition (from airborne particulates) } \\
\text { and the wet deposition processes (from } \\
\text { irrigation) are considered. } \\
\text { The code has wet as well as dry foliar } \\
\text { interception fraction for non-leafy, leafy (for } \\
\text { human consumption), and fodder (for animal } \\
\text { consumption). } \\
\text { A default value was assumed for the Resident } \\
\text { Farmer because meat and milk ingestion are } \\
\text { applicable and a site specific value is not } \\
\text { available. } \\
\text { The meat and milk ingestion pathways are } \\
\text { suppressed for the Resident Gardener, } \\
\text { Workers, Recreational User, and Trespasser } \\
\text { since these pathways are not considered in } \\
\text { the conceptual site model for these receptors. }\end{array}$ & Yu et al. 2001 \\
\hline $\begin{array}{l}\text { Dry foliar interception } \\
\text { fraction for non-leafy } \\
\text { vegetables }\end{array}$ & - & 0.25 & $0-1$ & All & 0.25 & $P$ & 3 & $\begin{array}{l}\text { The fraction of deposited radionuclides that is } \\
\text { retained on the foliage of the plant food. Both } \\
\text { the dry deposition (from airborne } \\
\text { particulates) and the wet deposition } \\
\text { processes (from irrigation) are considered. } \\
\text { The code has wet as well as dry foliar } \\
\text { interception fraction for non-leafy, leafy (for } \\
\text { human consumption), and fodder (for animal } \\
\text { consumption). } \\
\text { A default value was assumed for the Resident } \\
\text { Farmer and Resident Gardener since plant } \\
\text { ingestion is applicable and a site specific value } \\
\text { is not available. } \\
\text { The plant ingestion pathway is suppressed for } \\
\text { the Workers, Recreational User, and }\end{array}$ & Yu et al. 2001 \\
\hline
\end{tabular}


RESRAD Table of Input Parameters for the C-746-U Landfill Onsite Receptor Scenarios

\begin{tabular}{|c|c|c|c|c|c|c|c|c|c|}
\hline $\begin{array}{c}\text { Input Screen Title } \\
\text { and Parameter } \\
\text { Name }\end{array}$ & Unit & $\begin{array}{c}\text { Code } \\
\text { Default } \\
\text { Value }\end{array}$ & $\begin{array}{c}\text { Code- } \\
\text { Accepted } \\
\text { Values }^{a}\end{array}$ & Receptor $^{b}$ & $\begin{array}{l}\text { Deterministic } \\
\text { Value }\end{array}$ & Type $^{c}$ & Priority $^{d}$ & Justification & References \\
\hline & & & & & & & & $\begin{array}{l}\text { Trespasser since this pathway is not } \\
\text { considered in the conceptual site model for } \\
\text { these receptors. }\end{array}$ & \\
\hline $\begin{array}{l}\text { Dry foliar interception } \\
\text { fraction for leafy } \\
\text { vegetables }\end{array}$ & - & 0.25 & $0-1$ & All & 0.25 & $\mathrm{P}$ & 3 & $\begin{array}{l}\text { The fraction of deposited radionuclides that is } \\
\text { retained on the foliage of the plant food. Both } \\
\text { the dry deposition (from airborne } \\
\text { particulates) and the wet deposition } \\
\text { processes (from irrigation) are considered. } \\
\text { The code has wet as well as dry foliar } \\
\text { interception fraction for non-leafy, leafy (for } \\
\text { human consumption), and fodder (for animal } \\
\text { consumption). } \\
\text { A default value was assumed for the Resident } \\
\text { Farmer and Resident Gardener since plant } \\
\text { ingestion is applicable and a site specific value } \\
\text { is not available. } \\
\text { The plant ingestion pathway is suppressed for } \\
\text { the Workers, Recreational User, and } \\
\text { Trespasser since this pathway is not } \\
\text { considered in the conceptual site model for } \\
\text { these receptors. }\end{array}$ & Yu et al. 2001 \\
\hline $\begin{array}{l}\text { Dry foliar interception } \\
\text { fraction for fodder }\end{array}$ & - & 0.25 & $0-1$ & All & 0.25 & $P$ & 3 & $\begin{array}{l}\text { The fraction of deposited radionuclides that is } \\
\text { retained on the foliage of the plant food. Both } \\
\text { the dry deposition (from airborne } \\
\text { particulates) and the wet deposition } \\
\text { processes (from irrigation) are considered. } \\
\text { The code has wet as well as dry foliar } \\
\text { interception fraction for non-leafy, leafy (for } \\
\text { human consumption), and fodder (for animal } \\
\text { consumption). } \\
\text { A default value was assumed for the Resident } \\
\text { Farmer because meat and milk ingestion are } \\
\text { applicable and a site specific value is not } \\
\text { available. } \\
\text { The meat and milk ingestion pathways are } \\
\text { suppressed for the Resident Gardener, }\end{array}$ & Yu et al. 2001 \\
\hline
\end{tabular}


RESRAD Table of Input Parameters for the C-746-U Landfill Onsite Receptor Scenarios

\begin{tabular}{|c|c|c|c|c|c|c|c|c|c|}
\hline $\begin{array}{c}\text { Input Screen Title } \\
\text { and Parameter } \\
\text { Name }\end{array}$ & Unit & $\begin{array}{c}\text { Code } \\
\text { Default } \\
\text { Value }\end{array}$ & $\begin{array}{c}\text { Code- } \\
\text { Accepted } \\
\text { Values }^{a}\end{array}$ & Receptor ${ }^{b}$ & $\begin{array}{l}\text { Deterministic } \\
\text { Value }\end{array}$ & Type $e^{c}$ & Priority $^{d}$ & Justification & References \\
\hline & & & & & & & & $\begin{array}{l}\text { Workers, Recreational User, and Trespasser } \\
\text { since these pathways are not considered in } \\
\text { the conceptual site model for these receptors. }\end{array}$ & \\
\hline
\end{tabular}

Storage Times before Use Data

\begin{tabular}{|c|c|c|c|c|c|c|c|c|c|}
\hline $\begin{array}{l}\text { Storage times for } \\
\text { fruits, non-leafy } \\
\text { vegetables, and grain }\end{array}$ & $d$ & 14 & $0-1 E+34$ & All & 14 & B & 3 & $\begin{array}{l}\text { The storage times are used to calculate } \\
\text { radioactive ingrowth and decay adjustment } \\
\text { factors for food and feed due to storage. } \\
\text { The code has values for fruits, non-leafy } \\
\text { vegetables, and grain (one category), leafy } \\
\text { vegetables, milk, well and surface water, } \\
\text { livestock fodder, meat, fish and crustacea; } \\
\text { and mollusks. } \\
\text { A default value was assumed for the Resident } \\
\text { Farmer and Resident Gardener since plant } \\
\text { ingestion is applicable and a site specific value } \\
\text { is not available. } \\
\text { The plant ingestion pathway is suppressed for } \\
\text { the Workers, Recreational User, and } \\
\text { Trespasser since this pathway is not } \\
\text { considered in the conceptual site model for } \\
\text { these receptors. }\end{array}$ & Yu et al. 2001 \\
\hline $\begin{array}{l}\text { Storage times for leafy } \\
\text { vegetables }\end{array}$ & $d$ & 1 & $0-1 E+34$ & All & 1 & B & 3 & $\begin{array}{l}\text { The storage times are used to calculate } \\
\text { radioactive ingrowth and decay adjustment } \\
\text { factors for food and feed due to storage. } \\
\text { The code has values for fruits, non-leafy } \\
\text { vegetables, and grain (one category), leafy } \\
\text { vegetables, milk, well and surface water, } \\
\text { livestock fodder, meat, fish and crustacea; } \\
\text { and mollusks. } \\
\text { A default value was assumed for the Resident } \\
\text { Farmer and Resident Gardener since plant } \\
\text { ingestion is applicable and a site specific value } \\
\text { is not available. } \\
\text { The plant ingestion pathway is suppressed for } \\
\text { the Workers, Recreational User, and }\end{array}$ & Yu et al. 2001 \\
\hline
\end{tabular}


RESRAD Table of Input Parameters for the C-746-U Landfill Onsite Receptor Scenarios

\begin{tabular}{|c|c|c|c|c|c|c|c|c|c|}
\hline $\begin{array}{c}\text { Input Screen Title } \\
\text { and Parameter } \\
\text { Name }\end{array}$ & Unit & $\begin{array}{c}\text { Code } \\
\text { Default } \\
\text { Value }\end{array}$ & $\begin{array}{l}\text { Code- } \\
\text { Accepted } \\
\text { Values }^{a}\end{array}$ & Receptor ${ }^{b}$ & $\begin{array}{l}\text { Deterministic } \\
\text { Value }\end{array}$ & Type $^{c}$ & Priority $^{d}$ & Justification & References \\
\hline & & & & & & & & $\begin{array}{l}\text { Trespasser since this pathway is not } \\
\text { considered in the conceptual site model for } \\
\text { these receptors. }\end{array}$ & \\
\hline Storage times for milk & d & 1 & $0-1 E+34$ & All & 1 & B & 3 & $\begin{array}{l}\text { The storage times are used to calculate } \\
\text { radioactive ingrowth and decay adjustment } \\
\text { factors for food and feed due to storage. } \\
\text { The code has values for fruits, non-leafy } \\
\text { vegetables, and grain (one category), leafy } \\
\text { vegetables, milk, well and surface water, } \\
\text { livestock fodder, meat, fish and crustacea; } \\
\text { and mollusks. } \\
\text { A default value was assumed for the Resident } \\
\text { Farmer since milk ingestion is applicable and a } \\
\text { site specific value is not available. } \\
\text { The milk ingestion pathway is suppressed for } \\
\text { the Residential Gardener, Workers, } \\
\text { Recreational User, and Trespasser since this } \\
\text { pathway is not considered in the conceptual } \\
\text { site model for these receptors. }\end{array}$ & Yu et al. 2001 \\
\hline $\begin{array}{l}\text { Storage times for } \\
\text { meat }\end{array}$ & d & 20 & $0-1 E+34$ & All & 20 & B & 3 & $\begin{array}{l}\text { The storage times are used to calculate } \\
\text { radioactive ingrowth and decay adjustment } \\
\text { factors for food and feed due to storage. } \\
\text { The code has values for fruits, non-leafy } \\
\text { vegetables, and grain (one category), leafy } \\
\text { vegetables, milk, well and surface water, } \\
\text { livestock fodder, meat, fish and crustacea; } \\
\text { and mollusks. } \\
\text { A default value was assumed for the Resident } \\
\text { Farmer since meat ingestion is applicable and } \\
\text { a site specific value is not available. } \\
\text { The meat ingestion pathway is suppressed for } \\
\text { the Resident Gardner, Workers, Recreational } \\
\text { User, and Trespasser since this pathway is not } \\
\text { considered in the conceptual site model for } \\
\text { these receptors. }\end{array}$ & Yu et al. 2001 \\
\hline Storage times for fish & d & 7 & $0-1 E+34$ & All & 7 & B & 3 & The storage times are used to calculate & Yu et al. 2001 \\
\hline
\end{tabular}


RESRAD Table of Input Parameters for the C-746-U Landfill Onsite Receptor Scenarios

\begin{tabular}{|c|c|c|c|c|c|c|c|c|c|}
\hline $\begin{array}{c}\text { Input Screen Title } \\
\text { and Parameter } \\
\text { Name }\end{array}$ & Unit & $\begin{array}{c}\text { Code } \\
\text { Default } \\
\text { Value }\end{array}$ & $\begin{array}{c}\text { Code- } \\
\text { Accepted } \\
\text { Values }^{a}\end{array}$ & Receptor ${ }^{b}$ & $\begin{array}{c}\text { Deterministic } \\
\text { Value }\end{array}$ & Type $^{c}$ & Priority $^{d}$ & Justification & References \\
\hline & & & & & & & & $\begin{array}{l}\text { radioactive ingrowth and decay adjustment } \\
\text { factors for food and feed due to storage. } \\
\text { The code has values for fruits, non-leafy } \\
\text { vegetables, and grain (one category), leafy } \\
\text { vegetables, milk, well and surface water, } \\
\text { livestock fodder, meat, fish and crustacea; } \\
\text { and mollusks. } \\
\text { A default value was assumed; however, the } \\
\text { aquatic foods ingestion pathway is suppressed } \\
\text { for all receptors since this pathway is not } \\
\text { considered in the conceptual site model. }\end{array}$ & \\
\hline $\begin{array}{l}\text { Storage times for } \\
\text { crustacea and mollusks }\end{array}$ & $d$ & 7 & $0-1 E+34$ & All & 7 & B & 3 & $\begin{array}{l}\text { The storage times are used to calculate } \\
\text { radioactive ingrowth and decay adjustment } \\
\text { factors for food and feed due to storage. } \\
\text { The code has values for fruits, non-leafy } \\
\text { vegetables, and grain (one category), leafy } \\
\text { vegetables, milk, well and surface water, } \\
\text { livestock fodder, meat, fish and crustacea; } \\
\text { and mollusks. } \\
\text { A default value was assumed; however, the } \\
\text { aquatic foods ingestion pathway is suppressed } \\
\text { for all receptors since this pathway is not } \\
\text { considered in the conceptual site model. }\end{array}$ & Yu et al. 2001 \\
\hline $\begin{array}{l}\text { Storage times for well } \\
\text { water }\end{array}$ & $d$ & 1 & $0-1 E+34$ & All & 1 & B & 3 & $\begin{array}{l}\text { The storage times are used to calculate } \\
\text { radioactive ingrowth and decay adjustment } \\
\text { factors for food and feed due to storage. } \\
\text { The code has values for fruits, non-leafy } \\
\text { vegetables, and grain (one category), leafy } \\
\text { vegetables, milk, well and surface water, } \\
\text { livestock fodder, meat, fish and crustacea; } \\
\text { and mollusks. } \\
\text { A default value was assumed for the Resident } \\
\text { Farmer since this receptor would be } \\
\text { potentially affected by contaminated well } \\
\text { water and a site specific value is not available. }\end{array}$ & Yu et al. 2001 \\
\hline
\end{tabular}


RESRAD Table of Input Parameters for the C-746-U Landfill Onsite Receptor Scenarios

\begin{tabular}{|c|c|c|c|c|c|c|c|c|c|}
\hline $\begin{array}{c}\text { Input Screen Title } \\
\text { and Parameter } \\
\text { Name }\end{array}$ & Unit & $\begin{array}{c}\text { Code } \\
\text { Default } \\
\text { Value }\end{array}$ & $\begin{array}{c}\text { Code- } \\
\text { Accepted } \\
\text { Values }^{a}\end{array}$ & Receptor $^{b}$ & $\begin{array}{c}\text { Deterministic } \\
\text { Value }\end{array}$ & Type $^{c}$ & Priority $^{d}$ & Justification & References \\
\hline & & & & & & & & $\begin{array}{l}\text { The meat, milk, plant, and drinking water } \\
\text { ingestion pathways are suppressed for the } \\
\text { Workers, Recreational User, and Trespasser } \\
\text { since these pathways are not considered in } \\
\text { the conceptual site model for these receptors. } \\
\text { The meat, milk, and drinking water ingestion } \\
\text { pathways are suppressed for the Resident } \\
\text { Gardener since these pathways are not } \\
\text { considered in the conceptual site model for } \\
\text { this receptor. }\end{array}$ & \\
\hline $\begin{array}{l}\text { Storage times for } \\
\text { surface water }\end{array}$ & $d$ & 1 & $0-1 E+34$ & All & 1 & B & 3 & $\begin{array}{l}\text { The storage times are used to calculate } \\
\text { radioactive ingrowth and decay adjustment } \\
\text { factors for food and feed due to storage. } \\
\text { The code has values for fruits, non-leafy } \\
\text { vegetables, and grain (one category), leafy } \\
\text { vegetables, milk, well and surface water, } \\
\text { livestock fodder, meat, fish and crustacea; } \\
\text { and mollusks. } \\
\text { A default value was assumed for the Resident } \\
\text { Farmer since this receptor would be } \\
\text { potentially affected by contaminated surface } \\
\text { water and a site specific value is not available. } \\
\text { The meat, milk, plant, and drinking water } \\
\text { ingestion pathways are suppressed for the } \\
\text { Workers, Recreational User, and Trespasser } \\
\text { since these pathways are not considered in } \\
\text { the conceptual site model for these receptors. } \\
\text { The meat, milk, and drinking water ingestion } \\
\text { pathways are suppressed for the Resident } \\
\text { Gardener since these pathways are not } \\
\text { considered in the conceptual site model for } \\
\text { this receptor. }\end{array}$ & Yu et al. 2001 \\
\hline $\begin{array}{l}\text { Storage times for } \\
\text { livestock fodder }\end{array}$ & $d$ & 45 & $0-1 E+34$ & All & 45 & B & 3 & $\begin{array}{l}\text { For livestock fodder the storage time is an } \\
\text { annual average. The default value is obtained } \\
\text { by assuming } 6 \text { months of outside gazing and } 6 \\
\text { months of silage fodder with an average silo } \\
\text { time of } 3 \text { months. }\end{array}$ & Yu et al. 2001 \\
\hline
\end{tabular}


RESRAD Table of Input Parameters for the C-746-U Landfill Onsite Receptor Scenarios

\begin{tabular}{|c|c|c|c|c|c|c|c|c|c|}
\hline $\begin{array}{c}\text { Input Screen Title } \\
\text { and Parameter } \\
\text { Name }\end{array}$ & Unit & $\begin{array}{c}\text { Code } \\
\text { Default } \\
\text { Value }\end{array}$ & $\begin{array}{c}\text { Code- } \\
\text { Accepted } \\
\text { Values }^{a}\end{array}$ & Receptor ${ }^{b}$ & $\begin{array}{c}\text { Deterministic } \\
\text { Value }\end{array}$ & Type $^{c}$ & Priority $^{d}$ & Justification & References \\
\hline & & & & & & & & $\begin{array}{l}\text { A default value was assumed for the Resident } \\
\text { Farmer because meat and milk ingestion are } \\
\text { applicable and a site specific value is not } \\
\text { available. } \\
\text { The meat and milk ingestion pathways are } \\
\text { suppressed for the Resident Gardener, } \\
\text { Workers, Recreational User, and Trespasser } \\
\text { since these pathways are not considered in } \\
\text { the conceptual site model for these receptors. }\end{array}$ & \\
\hline \multirow{2}{*}{$\begin{array}{l}\text { Inhalation dose } \\
\text { conversion factors }\end{array}$} & \multirow{2}{*}{$\mathrm{mrem} / \mathrm{pCi}$} & \multirow{2}{*}{$\begin{array}{c}\text { Nuclide } \\
\text { Specific } \\
\text { (Default } \\
\text { values } \\
\text { available) }\end{array}$} & \multirow{2}{*}{$\begin{array}{l}\text { Nuclide } \\
\text { Specific }\end{array}$} & $\begin{array}{c}\text { RF } \\
\text { RG } \\
W \\
T \\
L\end{array}$ & $\begin{array}{l}\text { Nuclide Specific } \\
\text { (ICRP } 72 \text { (Adult)) }\end{array}$ & \multirow[t]{2}{*}{ M } & \multirow[t]{2}{*}{3} & \multirow{2}{*}{$\begin{array}{l}\text { The ICRP } 72 \text { Adult and Age } 15 \text { (internal dose } \\
\text { conversion factors) libraries are selected in } \\
\text { conjunction with the ICRP } 60 \text { (external dose } \\
\text { conversion factors) library to obtain results in } \\
\text { Total Effective Dose (TED). } \\
\text { The Recreational User is the only receptor } \\
\text { who is a teenager; therefore, the applicable } \\
\text { library is ICRP } 72 \text { (Age 15). }\end{array}$} & \multirow[t]{2}{*}{ Yu et al. 2001} \\
\hline & & & & RU & $\begin{array}{l}\text { Nuclide Specific } \\
\text { (ICRP } 72 \text { (Age 15)) }\end{array}$ & & & & \\
\hline \multirow[t]{2}{*}{$\begin{array}{l}\text { Ingestion dose } \\
\text { conversion factors }\end{array}$} & \multirow{2}{*}{$\mathrm{mrem} / \mathrm{pCi}$} & \multirow{2}{*}{$\begin{array}{l}\text { Nuclide } \\
\text { Specific } \\
\text { (Default } \\
\text { values } \\
\text { available) }\end{array}$} & \multirow[t]{2}{*}{$\begin{array}{l}\text { Nuclide } \\
\text { Specific }\end{array}$} & $\begin{array}{l}\text { RF } \\
\text { RG } \\
W \\
T \\
L \\
\end{array}$ & $\begin{array}{l}\text { Nuclide Specific } \\
\text { (ICRP } 72 \text { (Adult)) }\end{array}$ & \multirow[t]{2}{*}{ M } & \multirow[t]{2}{*}{3} & \multirow{2}{*}{$\begin{array}{l}\text { The ICRP } 72 \text { Adult and Age } 15 \text { (internal dose } \\
\text { conversion factors) libraries are selected in } \\
\text { conjunction with the ICRP } 60 \text { (external dose } \\
\text { conversion factors) library to obtain results in } \\
\text { Total Effective Dose (TED). } \\
\text { The Recreational User is the only receptor } \\
\text { who is a teenager; therefore, the applicable } \\
\text { library is ICRP } 72 \text { (Age 15). }\end{array}$} & \multirow[t]{2}{*}{ Yu et al. 2001} \\
\hline & & & & RU & $\begin{array}{c}\text { Nuclide Specific } \\
\text { (ICRP } 72 \text { (Age 15)) }\end{array}$ & & & & \\
\hline Slope factor- external & $\begin{array}{l}\text { (risk/yr)/ } \\
(\mathrm{pCi} / \mathrm{g})\end{array}$ & $\begin{array}{c}\text { Nuclide } \\
\text { Specific } \\
\text { (Default } \\
\text { values } \\
\text { available) }\end{array}$ & $\begin{array}{l}\text { Nuclide } \\
\text { Specific }\end{array}$ & All & $\begin{array}{l}\text { Nuclide Specific } \\
\text { (Default values) }\end{array}$ & M & 3 & Default value is used. & Yu et al. 2001 \\
\hline $\begin{array}{l}\text { Slope factor - } \\
\text { inhalation }\end{array}$ & risk/pCi & $\begin{array}{c}\text { Nuclide } \\
\text { Specific } \\
\text { (Default } \\
\text { values } \\
\text { available) }\end{array}$ & $\begin{array}{l}\text { Nuclide } \\
\text { Specific }\end{array}$ & All & $\begin{array}{l}\text { Nuclide Specific } \\
\text { (Default values) }\end{array}$ & M & 3 & Default value is used. & Yu et al. 2001 \\
\hline
\end{tabular}


RESRAD Table of Input Parameters for the C-746-U Landfill Onsite Receptor Scenarios

\begin{tabular}{|c|c|c|c|c|c|c|c|c|c|}
\hline $\begin{array}{c}\text { Input Screen Title } \\
\text { and Parameter } \\
\text { Name }\end{array}$ & Unit & $\begin{array}{c}\text { Code } \\
\text { Default } \\
\text { Value }\end{array}$ & $\begin{array}{c}\text { Code- } \\
\text { Accepted } \\
\text { Values }^{a}\end{array}$ & Receptor ${ }^{b}$ & $\begin{array}{c}\text { Deterministic } \\
\text { Value }\end{array}$ & Type ${ }^{c}$ & Priority $^{d}$ & Justification & References \\
\hline $\begin{array}{l}\text { Slope factor - } \\
\text { ingestion }\end{array}$ & risk/pCi & $\begin{array}{c}\text { Nuclide } \\
\text { Specific } \\
\text { (Default } \\
\text { values } \\
\text { available) } \\
\end{array}$ & $\begin{array}{l}\text { Nuclide } \\
\text { Specific }\end{array}$ & All & $\begin{array}{l}\text { Nuclide Specific } \\
\text { (Default values) }\end{array}$ & M & 3 & Default value is used. & Yu et al. 2001 \\
\hline Plant transfer factor & - & $\begin{array}{c}\text { Element } \\
\text { Specific } \\
\text { (Default } \\
\text { values } \\
\text { available) }\end{array}$ & $\begin{array}{l}\text { Element } \\
\text { Specific }\end{array}$ & All & $\begin{array}{l}\text { Nuclide Specific } \\
\text { (Default values) }\end{array}$ & $P$ & 1 & Default value is used. & Yu et al. 2001 \\
\hline Meat transfer factor & $\begin{array}{l}(\mathrm{pCi} / \mathrm{kg}) / \\
(\mathrm{pCi} / \mathrm{d})\end{array}$ & $\begin{array}{l}\text { Element } \\
\text { Specific } \\
\text { (Default } \\
\text { values } \\
\text { available) }\end{array}$ & $\begin{array}{l}\text { Element } \\
\text { Specific }\end{array}$ & All & $\begin{array}{l}\text { Nuclide Specific } \\
\text { (Default values) }\end{array}$ & $P$ & 2 & Default value is used. & Yu et al. 2001 \\
\hline Milk transfer factor & $\begin{array}{l}(\mathrm{pCi} / \mathrm{L}) / \\
(\mathrm{pCi} / \mathrm{d})\end{array}$ & $\begin{array}{c}\text { Element } \\
\text { Specific } \\
\text { (Default } \\
\text { values } \\
\text { available) } \\
\end{array}$ & $\begin{array}{l}\text { Element } \\
\text { Specific }\end{array}$ & All & $\begin{array}{l}\text { Nuclide Specific } \\
\text { (Default values) }\end{array}$ & $P$ & 2 & Default value is used. & Yu et al. 2001 \\
\hline $\begin{array}{l}\text { Bioaccumulation } \\
\text { factor for fish }\end{array}$ & $\begin{array}{l}(\mathrm{pCi} / \mathrm{kg}) / \\
(\mathrm{pCi} / \mathrm{L})\end{array}$ & $\begin{array}{c}\text { Element } \\
\text { Specific } \\
\text { (Default } \\
\text { values } \\
\text { available) }\end{array}$ & $\begin{array}{l}\text { Element } \\
\text { Specific }\end{array}$ & All & $\begin{array}{l}\text { Nuclide Specific } \\
\text { (Default values) }\end{array}$ & $P$ & 2 & Default value is used. & Yu et al. 2001 \\
\hline $\begin{array}{l}\text { Bioaccumulation } \\
\text { factor for crustacea } \\
\text { and mollusks }\end{array}$ & $\begin{array}{l}(\mathrm{pCi} / \mathrm{kg}) / \\
(\mathrm{pCi} / \mathrm{L})\end{array}$ & $\begin{array}{c}\text { Element } \\
\text { Specific } \\
\text { (Default } \\
\text { values } \\
\text { available) }\end{array}$ & $\begin{array}{l}\text { Element } \\
\text { Specific }\end{array}$ & All & $\begin{array}{l}\text { Nuclide Specific } \\
\text { (Default values }\end{array}$ & $P$ & 3 & Default value is used. & Yu et al. 2001 \\
\hline
\end{tabular}


a RESRAD does not provide code-accepted values for element- or nuclide-specific parameters

b The receptors considered for the selection of parameters are the Resident Farmer (RF), Resident Gardener (RG), Outdoor Worker (W), Recreational User (RU) Trespasser $(T)$ and the Landfill Worker $(L)$

c $\mathrm{P}=$ physical, $\mathrm{B}=$ behavioral, $\mathrm{M}=$ metabolic; when more than one type is listed, the first is primary and the next is secondary. The RESRAD parameters that are not classified, because of their function in the code are considered as "NA= not applicable" in this table.

d According to NUREG/CR-6697, it is necessary to establish priorities about which parameters to collect data for and use for distribution analysis. The parameters were ranked into three levels of priority: 1 (high priority), 2 (medium priority), and 3 (low priority).

e " $\_$" indicates that the parameter is dimensionless.

$f$ Groundwater concentration can be input only if time since placement of material is $>0$.

$\mathrm{g}$ This parameter should be used only if radionuclide leach rates are known.

h $\quad \mathrm{NA}=$ not applicable.

The Radon and Carbon-14 parameters are not included as part of this table because these radionuclides are not included in the contaminants of concern for this project. RESRAD allows the user to edit radon parameters only when a radon parent for either Rn-222 (U-238, U-234, Th-230, or Ra-226) or Rn-220 (Th-232, Ra-228, or Th-228) is present as a contaminant. Similarly, a user will have access to carbon-14 (C-14) parameters only if C-14 is a contaminant.

Notes:

The template for the table of parameters was created based on information available in NUREG/CR-6697 ANL/EAD/TM-98 "Development of Probabilistic RESRAD 6.0 and RESRAD-Build 3.0 Computer Codes" and the RESRAD 6.0 Manual. 
Attachment I

Distribution Coefficients 


\section{Distribution Coefficients $\left(\mathrm{Kds}, \mathrm{cm}^{3} / \mathrm{g}\right)^{\mathrm{a}, \mathrm{b}}$ for parent radionuclides in the contaminated zone, the unsaturated zones, and the saturated zone}

\begin{tabular}{|c|c|c|c|c|c|c|c|c|c|c|c|c|}
\hline Radionuclide & Am-241 & Cs-137 & Np-237 & Pu-238 & Pu-239/240 & Tc-99 & Th-228 & Th-230 & Th-232 & U-234 & U-235 & U-238 \\
\hline Contaminated Zone $^{c}$ & 1900 & 280 & 70 & 550 & 550 & 1 & 3200 & 3200 & 3200 & 410 & 410 & 410 \\
\hline $\begin{array}{c}\text { Unsaturated Zone } 1 \\
\text { (Protective layer } \\
\text { (native soil)) }\end{array}$ & 1900 & 280 & 70 & 550 & 550 & 0.2 & 3200 & 3200 & 3200 & 66.8 & 66.8 & 66.8 \\
\hline $\begin{array}{c}\text { Unsaturated Zone } 2 \\
\text { (Gravel layer) }\end{array}$ & 1900 & 280 & 70 & 550 & 550 & 0.2 & 3200 & 3200 & 3200 & 66.8 & 66.8 & 66.8 \\
\hline $\begin{array}{l}\text { Unsaturated Zone } 3 \\
\text { (Clay barrier) }\end{array}$ & 8400 & 1900 & 144 & 5100 & 5100 & 20 & 5800 & 5800 & 5800 & 3640 & 3640 & 3640 \\
\hline $\begin{array}{l}\text { Unsaturated Zone } 4 \\
\text { (Alluvium soils } \\
\text { (native/subgrade)) }\end{array}$ & 1900 & 280 & 70 & 550 & 550 & 0.2 & 3200 & 3200 & 3200 & 66.8 & 66.8 & 66.8 \\
\hline $\begin{array}{c}\text { Unsaturated Zone } 5 \\
\text { (Clay confining unit } \\
\text { (native)) }\end{array}$ & 8400 & 1900 & 144 & 5100 & 5100 & 20 & 5800 & 5800 & 5800 & 3640 & 3640 & 3640 \\
\hline Saturated Zone(RGA) & 1900 & 280 & 70 & 550 & 550 & 0.2 & 3200 & 3200 & 3200 & 66.8 & 66.8 & 66.8 \\
\hline
\end{tabular}

\footnotetext{
a Distribution coefficients for Am-241, Np-237, Th-230, Th-232, U-234 and U-238 were obtained from DOE 2003b, page C3-313 and Table Att. 1. Distribution coefficient of radionuclides and their daughter products in different zones, page C3-314. It was assumed that the Kd for U-235 was similar to the Kd for U-234 and U-238 since the Kds are chemical specific.

${ }^{b}$ Distribution coefficients for Cs-137, Th-228, Pu-238, Pu-239, and Pu-240 were obtained through "Project Communication" with the Waste Disposal Options Project Team from Paducah, KY. The distribution coefficients for Tc-99 are available in Table C.3.1. Chemical and physical properties of different classes of chemicals identified as COPCs for the C-746-U Landfill of DOE 2003b, page C3301. Table 4.5 DUST model input parameters, page 4-12, has Kds for Tc-99 and Uranium.

${ }^{c}$ The contaminated zone includes four Waste Forms such as: Soil (Waste Form 1), Concrete (Waste Form 2), Metal (Waste Form 3), and Organic (Waste Form 4). This information was obtained from figure Fig. 4.5. Schematic diagram of DUST model layers and materials for the Post-Institutional Control Period under the gradual failure and immediate failure scenarios of DOE 2003b, page 4-18.
} 


\section{Distribution Coefficients $\left(\mathrm{Kds}, \mathrm{cm}^{3} / \mathrm{g}\right)^{\mathrm{d}}$ for progeny radionuclides in the contaminated zone, the unsaturated zones and the saturated zone}

\begin{tabular}{|c|c|c|c|c|c|c|c|c|}
\hline Radionuclide & Ac-227 & Pa-231 & Pb-210 & Ra-226 & Ra-228 & Th-229 & U-233 & U-236 \\
\hline Contaminated Zone & 450 & 550 & 270 & 500 & 500 & 3200 & 410 & 410 \\
\hline $\begin{array}{c}\text { Unsaturated Zone 1 } \\
\text { (Protective layer } \\
\text { (native soil)) }\end{array}$ & 450 & 550 & 270 & 500 & 500 & 3200 & 66.8 & 66.8 \\
\hline $\begin{array}{c}\text { Unsaturated Zone 2 } \\
\text { (Gravel layer) }\end{array}$ & 450 & 550 & 270 & 500 & 500 & 3200 & 66.8 & 66.8 \\
\hline $\begin{array}{c}\text { Unsaturated Zone 3 } \\
\text { (Clay barrier) }\end{array}$ & 2400 & 2700 & 550 & 9100 & 9100 & 5800 & 3640 & 3640 \\
\hline $\begin{array}{c}\text { Unsaturated Zone 4 } \\
\text { (Alluvium soils } \\
\text { (native/subgrade)) }\end{array}$ & 450 & 550 & 270 & 500 & 500 & 3200 & 66.8 & 66.8 \\
\hline $\begin{array}{c}\text { Unsaturated Zone 5 } \\
\text { (Clay confining unit } \\
\text { (native)) }\end{array}$ & 2400 & 2700 & 550 & 9100 & 9100 & 5800 & 3640 & 3640 \\
\hline Saturated Zone(RGA) & 450 & 550 & 270 & 500 & 500 & 3200 & 66.8 & 66.8 \\
\hline
\end{tabular}

\footnotetext{
d Distribution coefficients for Ac-227, Pa-231, Pb-210, Ra-226, Ra-228, Th-229, and U-236 were obtained through "Project Communication" with the Waste Disposal Options Project Team from Paducah, KY. It was assumed that the Kds for U-233 was similar to the Kds for the other uranium isotopes (i.e. U-234, U-235, U-236 and U-238), since the Kds are chemical specific.

e The contaminated zone includes four Waste Forms such as: Soil (Waste Form 1), Concrete (Waste Form 2), Metal (Waste Form 3), and Organic (Waste Form 4). This information was obtained from figure Fig. 4.5. Schematic diagram of DUST model layers and materials for the Post Institutional Control Period under the gradual failure and immediate failure scenarios of DOE $2003 \mathrm{~b}$, page $4-18$.
} 
Attachment II

Calculations and Applicable Parameters from DOE 2009, Appendix D, Converted into RESRAD Compatible Units 


\section{Section A. Runoff Coefficient and Evapotranspiration Coefficient Calculations}

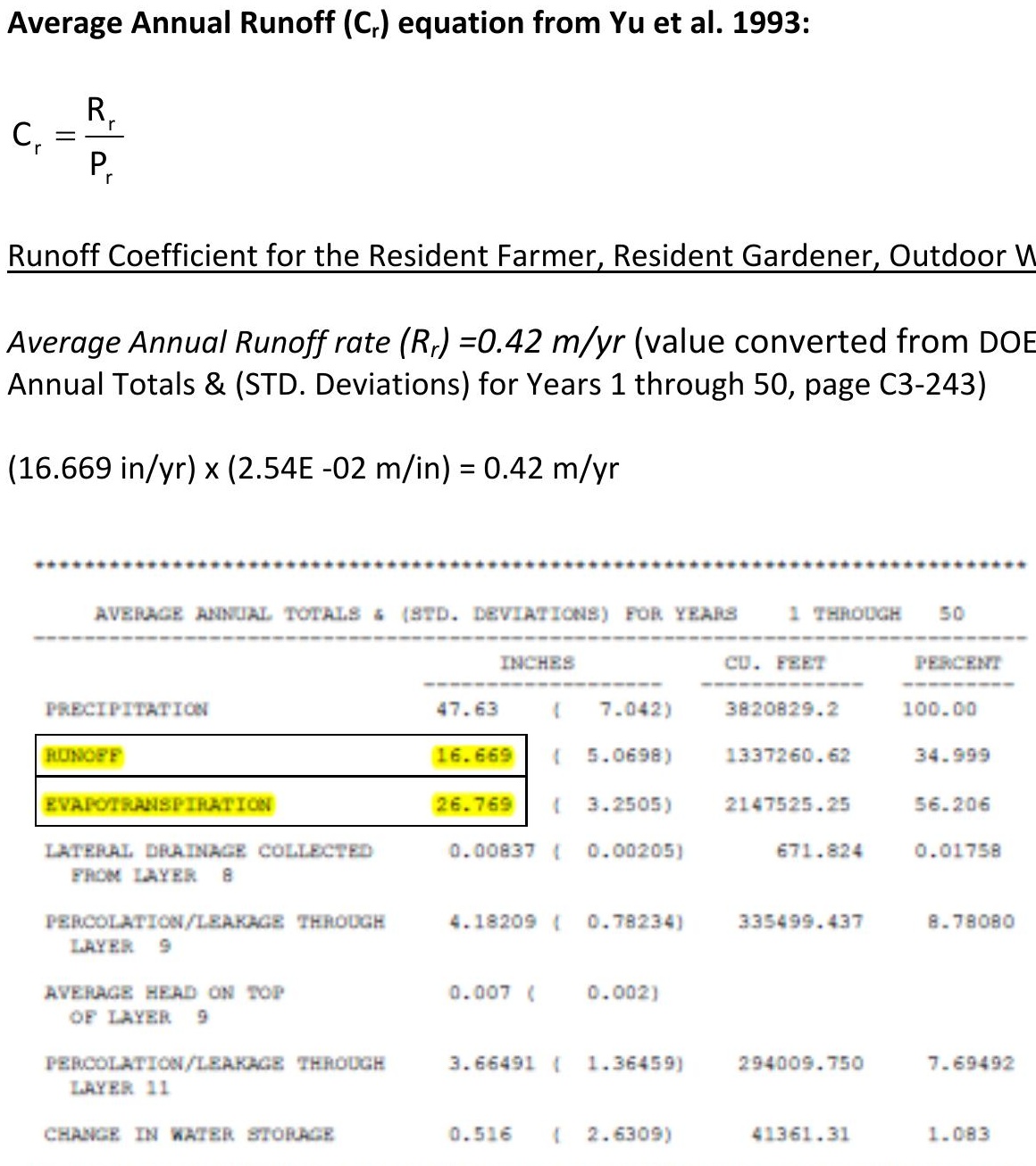

Values from the HELP Output List 3 that were used to determine input parameters are highlighted. 


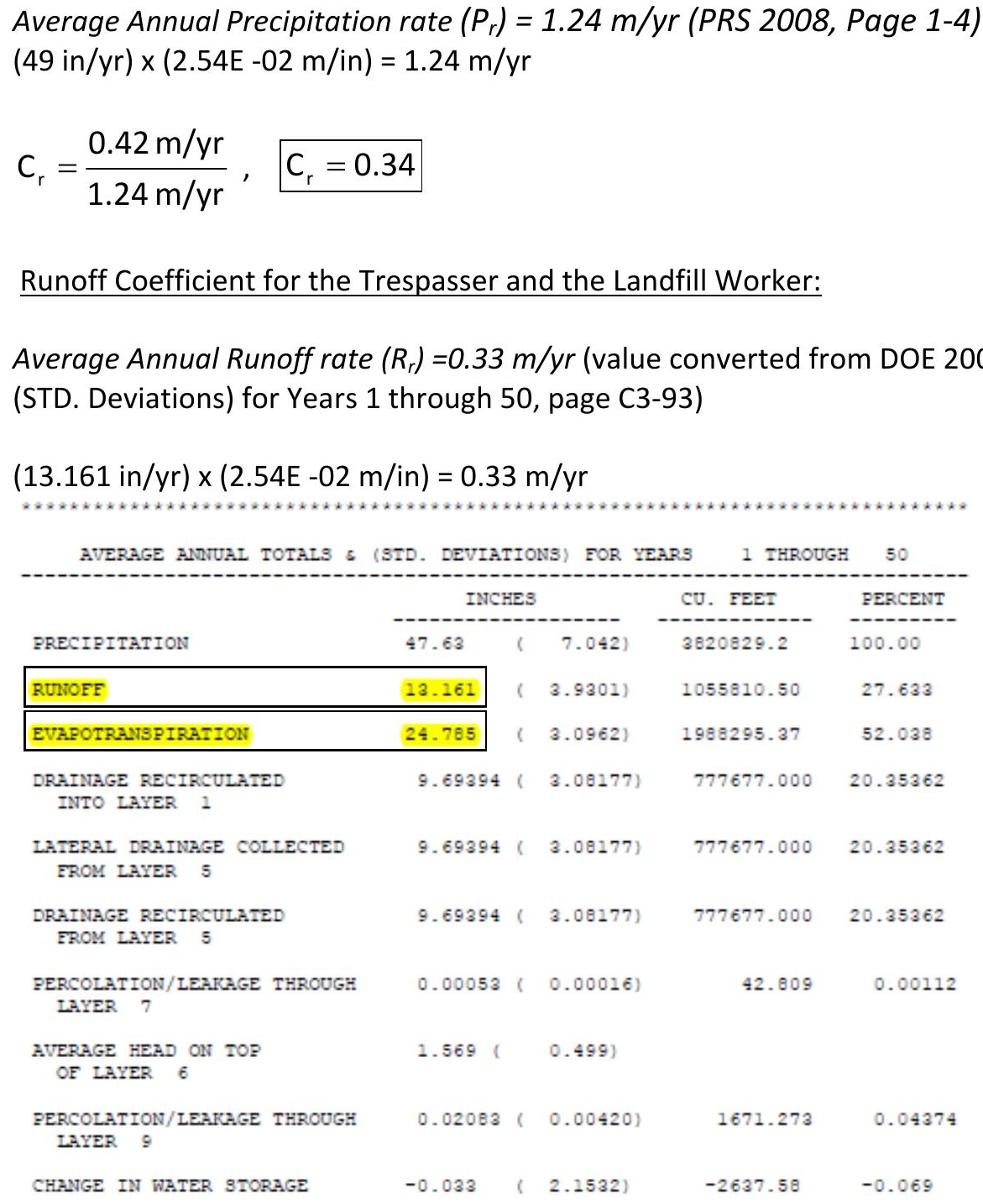

Cathe

Values from the HELP Output List 1 that were used to determine input parameters are highlighted. 


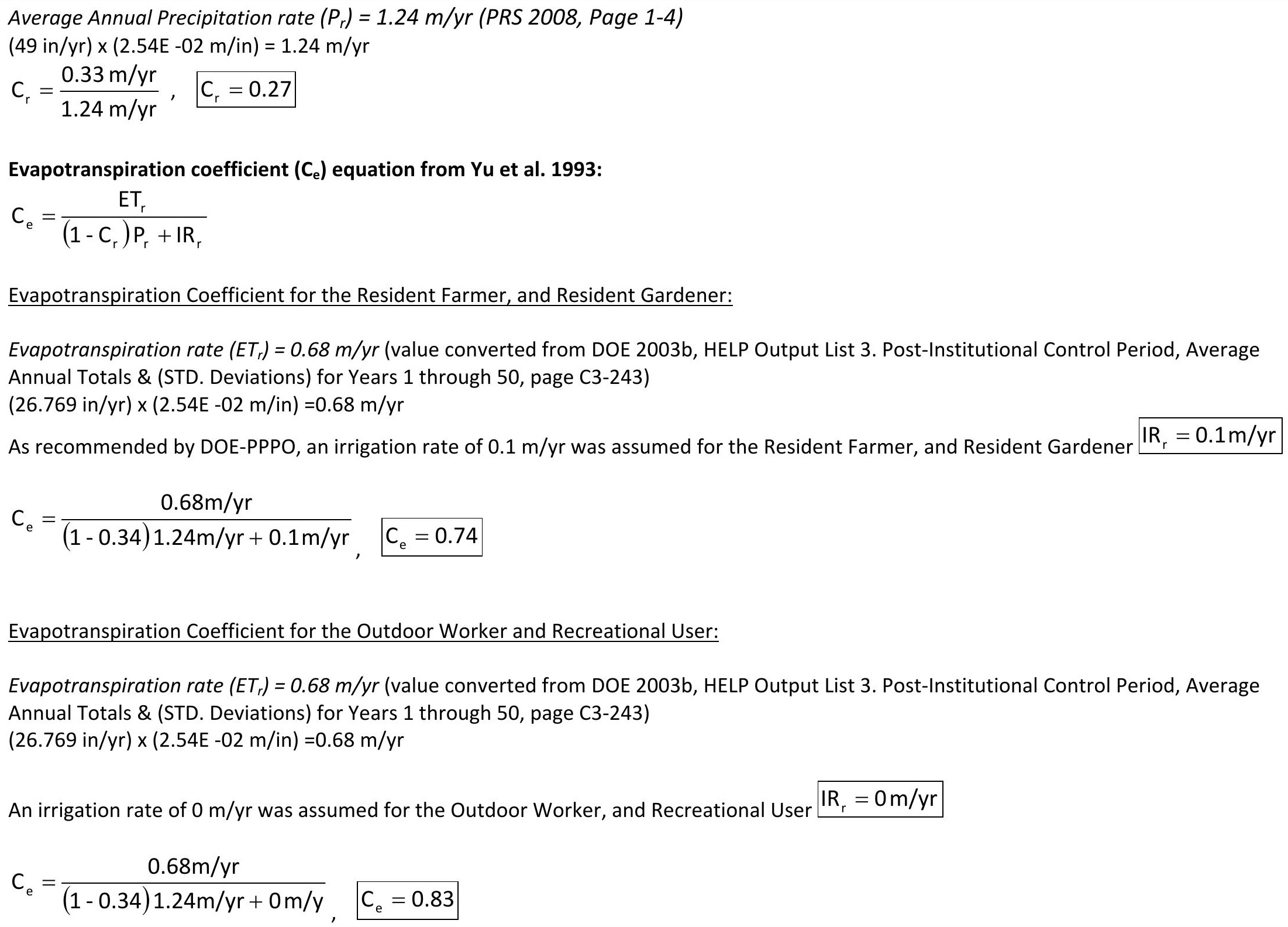




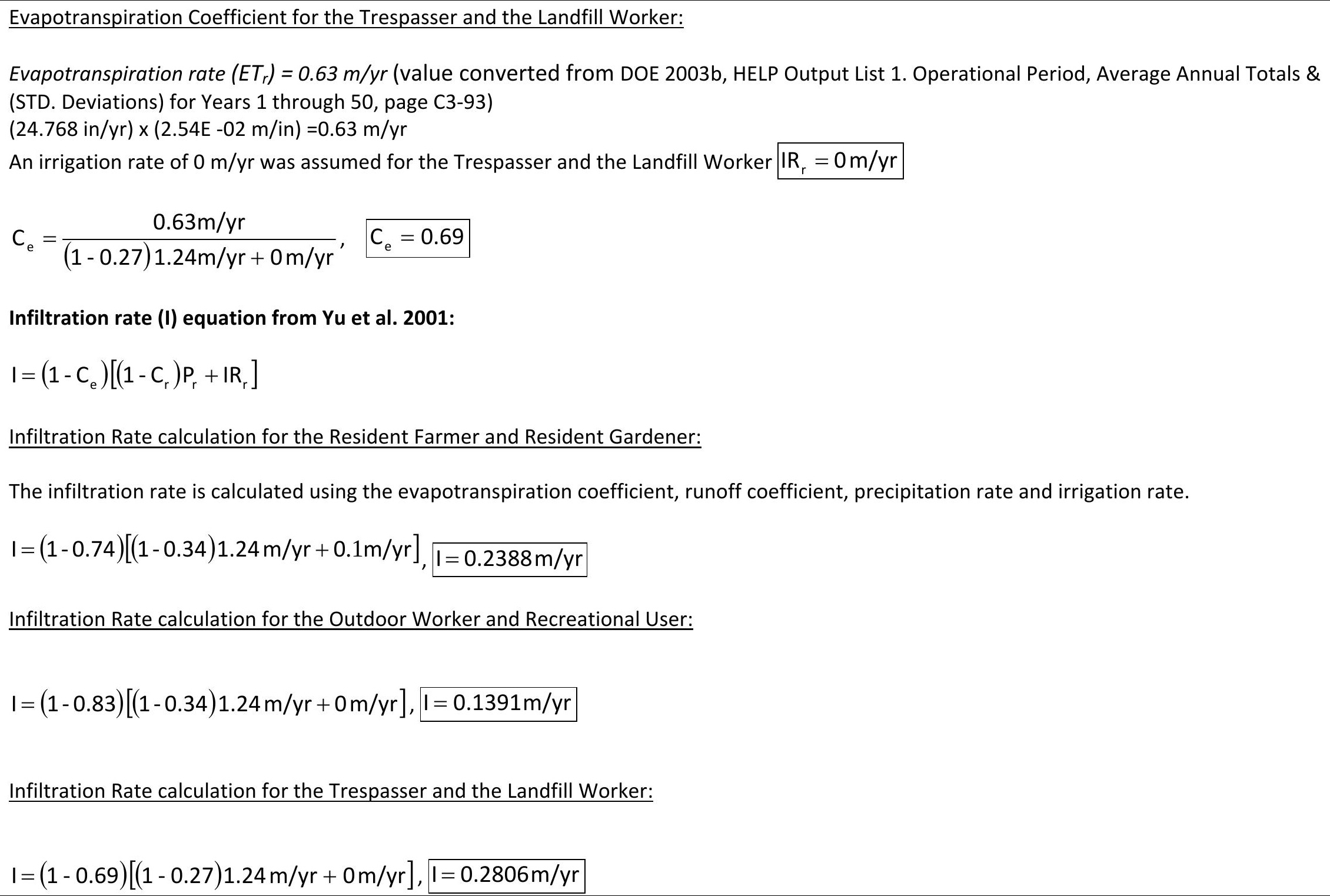




\section{Section B. Parameters Applicable to the Resident Farmer and the Resident Gardener (In Some Cases)}

\section{Drinking Water Intake}

\begin{tabular}{|c|c|c|c|c|c|c|c|c|}
\hline \multicolumn{5}{|c|}{$\begin{array}{l}\text { Parameters from the Risk Methods Document (DOE 2009), Appendix D } \\
\text { Table D.l. Reasonable maximum exposure assumptions and human intake factors for ingestion of water by a } \\
\text { rural resident }^{\mathrm{a}}\end{array}$} & \multicolumn{4}{|c|}{$\begin{array}{l}\text { Conversion of Parameter Units into RESRAD } \\
\text { Compatible Units }\end{array}$} \\
\hline \multicolumn{5}{|c|}{ Equations: } & $\begin{array}{l}\text { Ingestion } \\
\text { Rate = IR } \\
\text { (L/day) }\end{array}$ & $\begin{array}{l}\text { Exposure } \\
\text { frequency } \\
=\mathrm{EF} \text { in } \\
\text { (days/yr) }\end{array}$ & $\begin{array}{c}\text { RESRAD- } \\
\text { Drinking } \\
\text { water } \\
\text { intake (L/yr) } \\
\text { obtained by } \\
\text { multiplying } \\
\text { IR X EF }\end{array}$ & Receptor \\
\hline & $\begin{array}{l}\text { Parameter } \\
\text { Chemical concentration in water }=\mathrm{C}_{\pi} \\
\text { Radiological activity }=\mathrm{A}_{\pi} \\
\text { Ingestion Rate }=\mathrm{IR} \\
\text { Exposure frequency }=\mathrm{EF} \\
\text { Exposure duration }=\mathrm{ED}\end{array}$ & $\begin{array}{c}\text { Units } \\
\mathrm{mg} / \mathrm{L} \\
\mathrm{pCiL} \\
\mathrm{L} / \mathrm{d} \\
\\
\mathrm{d} / \text { year } \\
\text { years }\end{array}$ & $\begin{array}{c}\text { Value used } \\
\text { Chemical-specific } \\
\text { Chemical-specific } \\
2 \text { (acult) } \\
1.5 \text { (child) } \\
350 \\
24 \text { (adult) } \\
6 \text { (child) }\end{array}$ & $\begin{array}{c}\text { References }^{b} \\
-- \\
- \\
-114]\end{array}$ & 2 & 350 & 700 & $\begin{array}{l}\text { Adult Rural } \\
\text { Resident } \\
\text { which } \\
\text { corresponds } \\
\text { to the } \\
\text { "Resident } \\
\text { Farmer" }\end{array}$ \\
\hline & $\begin{array}{l}\text { Body weight }=\text { BW } \\
\text { Averaging time = AT }\end{array}$ & $\begin{array}{c}\mathrm{kg} \\
\mathrm{yr} \times \text { day } / \mathrm{yr} .\end{array}$ & $\begin{array}{c}70 \text { (adult) } \\
15 \text { (child) } \\
70 \times 365 \text { (carcinogen) } \\
\mathrm{ED} \times 365 \text { (noncarcinoge }\end{array}$ & $\begin{array}{l}\text { [14] } \\
{[14]}\end{array}$ & & & & \\
\hline a & $\begin{array}{l}\text { Equation from [1]. } \\
\text { References follow Table D. } 50 .\end{array}$ & & & & & & & \\
\hline
\end{tabular}




\section{Soil Ingestion Rate}

Parameters from the Risk Methods Document (DOE 2009), Appendix D

Table D.5. Reasonable maximum exposure assumptions and human intake factors for incidental ingestion soil by a rural resident ${ }^{2}$

\section{Equations:}

Chemical Intake $\left[\mathrm{mg} /(\mathrm{kg} \times\right.$ day $]=\frac{C_{s} \times C F \times E F \times F I \times E D \times I R}{B W \times A T}$

Radionuclide Intake $(\mathrm{pCi})=A_{s} \times C F_{\text {rad }} \times E F \times F I \times E D \times I R$

\begin{tabular}{|c|c|c|c|}
\hline Parameter & Units & Value used & References $^{b}$ \\
\hline Chemical concentration in soil $=\mathrm{C}_{3}$ & $\mathrm{mg} / \mathrm{kg}$ & Chemical-specific & - \\
\hline Radiological activity $=A_{s}$ & $\mathrm{pCi} / \mathrm{g}$ & Chemical-specific & $\ldots$ \\
\hline Conversion factor $=\mathbf{C F}$ & $\mathrm{kg} / \mathrm{mg}$ & $10^{-5}$ & $\ldots$ \\
\hline Conversion factor $=\mathbf{C F}_{\text {rad }}$ & $\mathrm{g} / \mathrm{mg}$ & $10^{-3}$ & $\ldots$ \\
\hline Exposure frequency $=\mathbf{E F}$ & days $/ y r$ & 350 & [14] \\
\hline Fraction ingested $=\mathbf{F I}$ & unitless & 1 & [14] \\
\hline \multirow[t]{2}{*}{ Exposure curation $=\mathrm{ED}$} & years & 24 (adult) & [14] \\
\hline & & 6 (child) & \\
\hline \multirow[t]{2}{*}{ Ingestion rate of soil = IR } & $\mathrm{mg} / \mathrm{d}$ & 100 (adult) & [14] \\
\hline & & 200 (child) & \\
\hline \multirow[t]{2}{*}{ Body weight $=$ BW } & $\mathrm{kg}$ & 70 (adult) & [14] \\
\hline & & 15 (child) & \\
\hline \multirow[t]{2}{*}{ Averaging time $=\mathrm{AT}$} & $\mathrm{yr} \times \mathrm{day} / \mathrm{yr}$ & $70 \times 365$ (carcinogen) & [14] \\
\hline & & $\mathrm{ED} \times 365$ (noncarcinogen) & \\
\hline
\end{tabular}

Equation from [1]
Conversion of Parameter Units into RESRAD Compatible Units

\begin{tabular}{|c|c|c|c|c|}
\hline $\begin{array}{c}\text { Conversion } \\
\text { factor }= \\
\mathrm{Cf}_{\mathrm{rad}} \\
(\mathrm{g} / \mathrm{mg})\end{array}$ & $\begin{array}{l}\text { Ingestion } \\
\text { rate of } \\
\text { soil = IR } \\
\text { (mg/day) }\end{array}$ & $\begin{array}{c}\text { Exposure } \\
\text { frequency = } \\
\text { EF (days/yr) }\end{array}$ & $\begin{array}{c}\text { RESRAD - } \\
\text { Soil } \\
\text { ingestion } \\
\text { (g/yr) } \\
\text { obtained by } \\
\text { multiplying } \\
\text { Cf }_{\text {rad }} \text { X IR X } \\
\text { EF }\end{array}$ & Receptor \\
\hline $1.00 \mathrm{E}-03$ & 100 & 365 & 36.5 & $\begin{array}{l}\text { Adult Rural } \\
\text { Resident } \\
\text { which } \\
\text { corresponds } \\
\text { to the } \\
\text { "Resident } \\
\text { Farmer" }\end{array}$ \\
\hline \multicolumn{5}{|c|}{$\begin{array}{l}\text { Note: The exposure frequency of } 365 \text { days/yr is used in the conversion, } \\
\text { instead of } 350 \text { days/yr since RESRAD uses time fractions to correct for } \\
\text { occupancy. }\end{array}$} \\
\hline
\end{tabular}


Inhalation Rate and Mass Loading for Inhalation

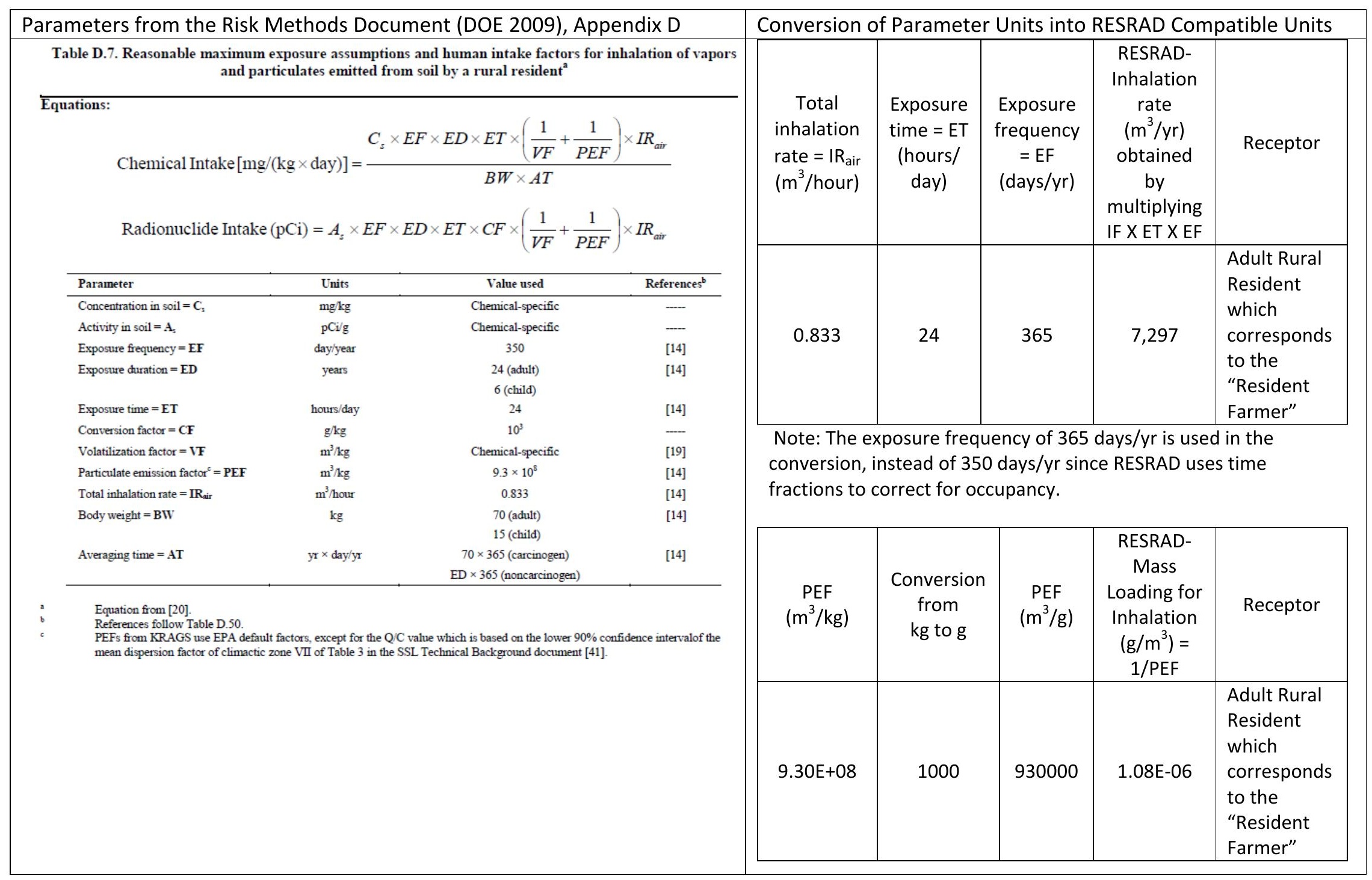


External Gamma Shielding Factor and Exposure Duration

\begin{tabular}{|c|c|c|c|c|c|c|c|}
\hline \multirow{2}{*}{\multicolumn{4}{|c|}{$\begin{array}{l}\text { Parameters from the Risk Methods Document (DOE 2009), Appendix D } \\
\text { Table D.8. Reasonable maximum exposure assumptions and human intake factors for external exposure to } \\
\text { ionizing radiation from soil by a rural resident }{ }^{\mathrm{a}}\end{array}$}} & \multicolumn{4}{|c|}{$\begin{array}{l}\text { Conversion of Parameter Units into RESRAD } \\
\text { Compatible Units }\end{array}$} \\
\hline & & & & \multirow{4}{*}{$\begin{array}{c}\text { Exposure } \\
\text { duration = ED } \\
\text { (years) -no } \\
\text { conversion } \\
\text { required since } \\
\text { it is in RESRAD } \\
\text { units }\end{array}$} & \multirow{4}{*}{$\begin{array}{l}\text { Gamma } \\
\text { shielding } \\
\text { factor }= \\
\text { Se } \\
\text { (unitless) }\end{array}$} & \multirow{4}{*}{ Receptor } & \multirow{4}{*}{$\begin{array}{l}\text { RESRAD } \\
\text { external } \\
\text { gamma } \\
\text { shielding } \\
\text { factor }\end{array}$} \\
\hline \multicolumn{4}{|c|}{ Absorbed Dose $[(\mathrm{pCi} \times$ year $) / \mathrm{g}]=A_{s} \times E D \times E F \times\left(1-S_{e}\right) \times T_{\epsilon}$} & & & & \\
\hline Parameter & Units & Value used & References $^{\mathrm{b}}$ & & & & \\
\hline Activity in soil $=A_{8}$ & $\mathrm{pCi} / \mathrm{g}$ & Chemical-specific & - & & & & \\
\hline Exposure duration = ED & year & $\begin{array}{l}24 \text { (adult) } \\
6 \text { (child) }\end{array}$ & [14] & \multirow{5}{*}{24} & \multirow{5}{*}{0.2} & \multirow{5}{*}{$\begin{array}{l}\text { Adult Rural } \\
\text { Resident } \\
\text { which } \\
\text { corresponds } \\
\text { to the } \\
\text { "Resident } \\
\text { Farmer" }\end{array}$} & \multirow{5}{*}{$1-0.2=0.8$} \\
\hline Exposure frequency $=\mathbf{E F}$ & day/day & $350 / 365$ & [14] & & & & \\
\hline Gamma shielding factor $=\mathrm{S}_{\mathrm{e}}$ & unitless & 0.2 & {$[20]$} & & & & \\
\hline Gamma exposure time factor $=T_{\text {e }}$ & $\mathrm{hr} / \mathrm{hr}$ & $24 / 24$ & [20] & & & & \\
\hline $\begin{array}{l}\text { a Equation from [20]. } \\
\text { b References follow Table D. } 50 .\end{array}$ & & & & & & & \\
\hline
\end{tabular}

Indoor and Outdoor occupancy fractions

\begin{tabular}{|c|c|c|}
\hline \multicolumn{3}{|c|}{ Resident Farmer Occupancy fractions } \\
\hline & Days & Fractions for RESRAD \\
\hline $1 / 3$ of the time outdoors & 117 & 0.32 \\
\hline $2 / 3$ of the time indoors & 233 & 0.64 \\
\hline Total Days Onsite & 350 & \\
\hline Total Fraction & & 0.96 \\
\hline
\end{tabular}

Note: The Resident Farmer spends 350 days on site. 
Fruit, non-leafy vegetable, and grain consumption and Leafy vegetables consumption

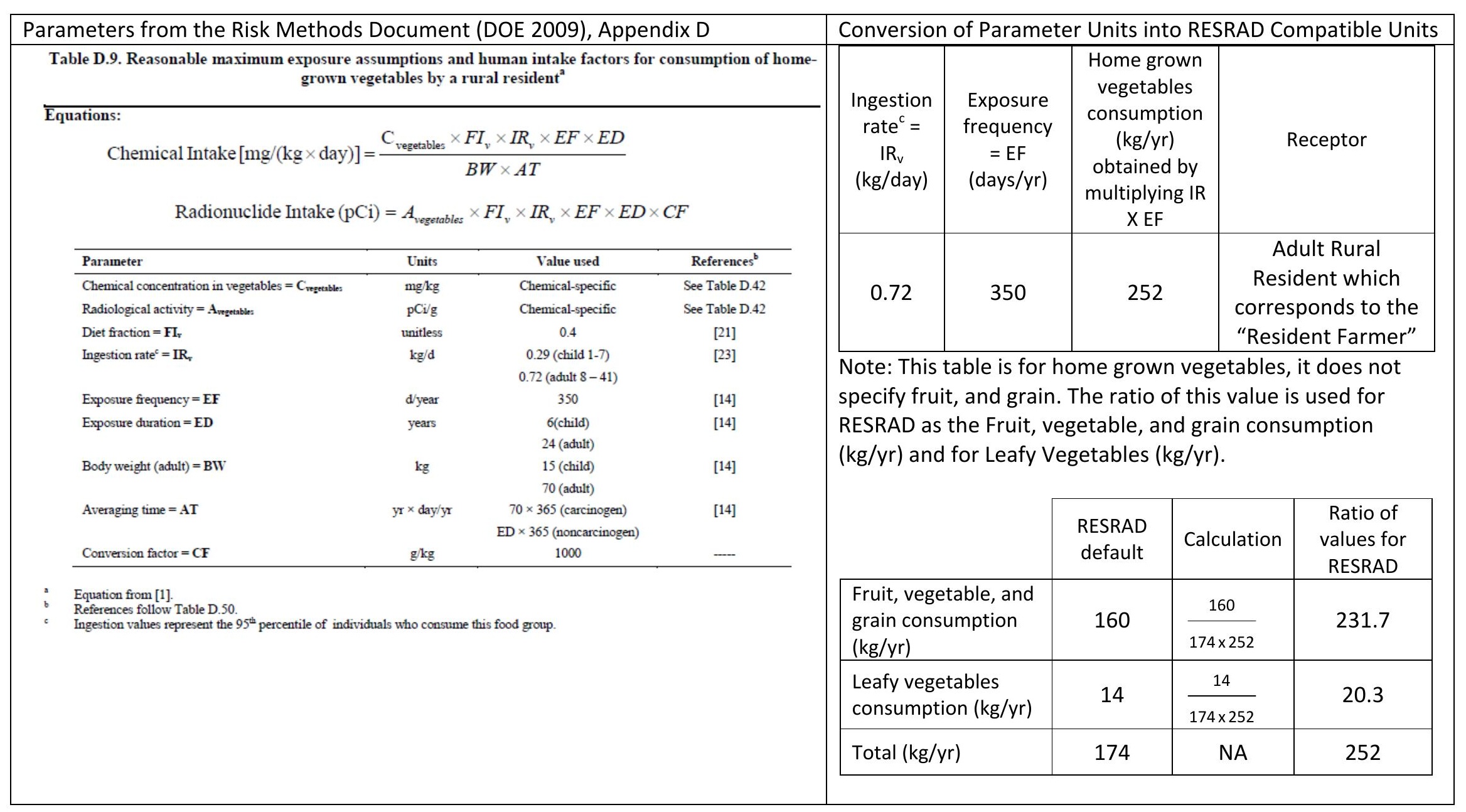




\section{Milk Consumption}

\begin{tabular}{|c|c|c|c|}
\hline \multirow{2}{*}{\multicolumn{4}{|c|}{$\begin{array}{l}\text { Parameters from the Risk Methods Document (DOE 2009), Appendix D } \\
\text { Table D.11. Reasonable maximum exposure assumptions and human intake factors for consumption of mi } \\
\text { by a rural resident }^{a}\end{array}$}} \\
\hline & & & \\
\hline \multicolumn{4}{|l|}{ Equations: } \\
\hline \multicolumn{4}{|c|}{ Chemical Intake $[\mathrm{mg} /(\mathrm{kg} \times$ day $)]=\frac{C_{\text {milk }} \times F I_{m} \times I R_{m} \times E F \times E D}{B W \times A T}$} \\
\hline \multicolumn{4}{|c|}{ Radionuclide Intake $(\mathrm{pCi})=A_{m i l k} \times F I_{m} \times I R_{m} \times E F \times E D$} \\
\hline Parameter & Units & Value used & References $^{b}$ \\
\hline Chemical concentration in milk $=\mathrm{C}_{\text {mill }}$ & $\mathrm{mg} / \mathrm{kg}$ & Chemical-specific & See Table D.47 \\
\hline Radiological activity in milk $=A_{\text {mill }}$ & $\mathrm{pCi} / \mathrm{kg}$ & Chemical-specific & See Table D.47 \\
\hline \multirow[t]{2}{*}{ Milk ingestion rate ${ }^{c}=\mathrm{IR}_{\mathrm{m}}$} & $\mathrm{kg} / \mathrm{day}$ & 0.9 (child $1-7$ ) & [23] \\
\hline & & 1.25 (adult $8-41$ ) & \\
\hline Diet fraction $=\mathbf{F I}_{\mathbf{m}}$ & unitless & 1 & [21] \\
\hline Exposure frequency $=\mathbf{E F}$ & $d$ /year & 350 & [14] \\
\hline \multirow[t]{2}{*}{ Exposure duration $=\mathrm{ED}$} & years & 6 (child) & [14] \\
\hline & & 24 (adult) & \\
\hline \multirow[t]{2}{*}{ Body weight $($ adult) $=\mathrm{BW}$} & $\mathrm{kg}$ & 15 (child) & [14] \\
\hline & & 70 (adult) & \\
\hline \multirow[t]{2}{*}{ Averaging time $=\mathrm{AT}$} & $\mathrm{yr} \times$ day $/ \mathrm{yr}$ & $70 \times 365$ (carcinogen) & [14] \\
\hline & & $\mathrm{ED} \times 365$ (noncarcinogen) & \\
\hline
\end{tabular}

\begin{tabular}{|c|c|c|c|c|}
\hline \multicolumn{5}{|c|}{ Conversion of Parameter Units into RESRAD Compatible Units } \\
\hline $\begin{array}{c}\text { Milk } \\
\text { ingestion } \\
\text { rate }^{c}=I_{\mathrm{b}} \\
(\mathrm{kg} / \text { day) }\end{array}$ & $\begin{array}{l}\text { Exposure } \\
\text { frequency } \\
=\mathrm{EF} \\
\text { (days/yr) }\end{array}$ & $\begin{array}{c}\text { Milk } \\
\text { consumption } \\
\text { (kg/yr) } \\
\text { obtained by } \\
\text { multiplying IR } \\
\text { X EF }\end{array}$ & $\begin{array}{l}\text { RESRAD-Milk } \\
\text { consumption } \\
\text { (L/yr) obtained } \\
\text { by diving the } \\
\text { milk } \\
\text { consumption } \\
\text { (kg/yr) by the } \\
\text { density of milk } \\
\text { and then } \\
\text { multiplying by } \\
1000\end{array}$ & Receptor \\
\hline 1.25 & 350 & 437.5 & 425 & $\begin{array}{l}\text { Adult Rural } \\
\text { Resident } \\
\text { which } \\
\text { corresponds } \\
\text { to the } \\
\text { "Resident } \\
\text { Farmer" }\end{array}$ \\
\hline
\end{tabular}

Equation from [1].

References follow Table D. 50 .
Ingestion values represent the $95^{\text {t }}$ percentile of individuals who consume this food group

Density of milk, cow, whole $=1030 \mathrm{~kg} / \mathrm{m}^{3}$

1 cubic meter $=1000$ liters

This density was obtained from an online

source: http://physics.info/density/ 
Meat and Poultry Consumption

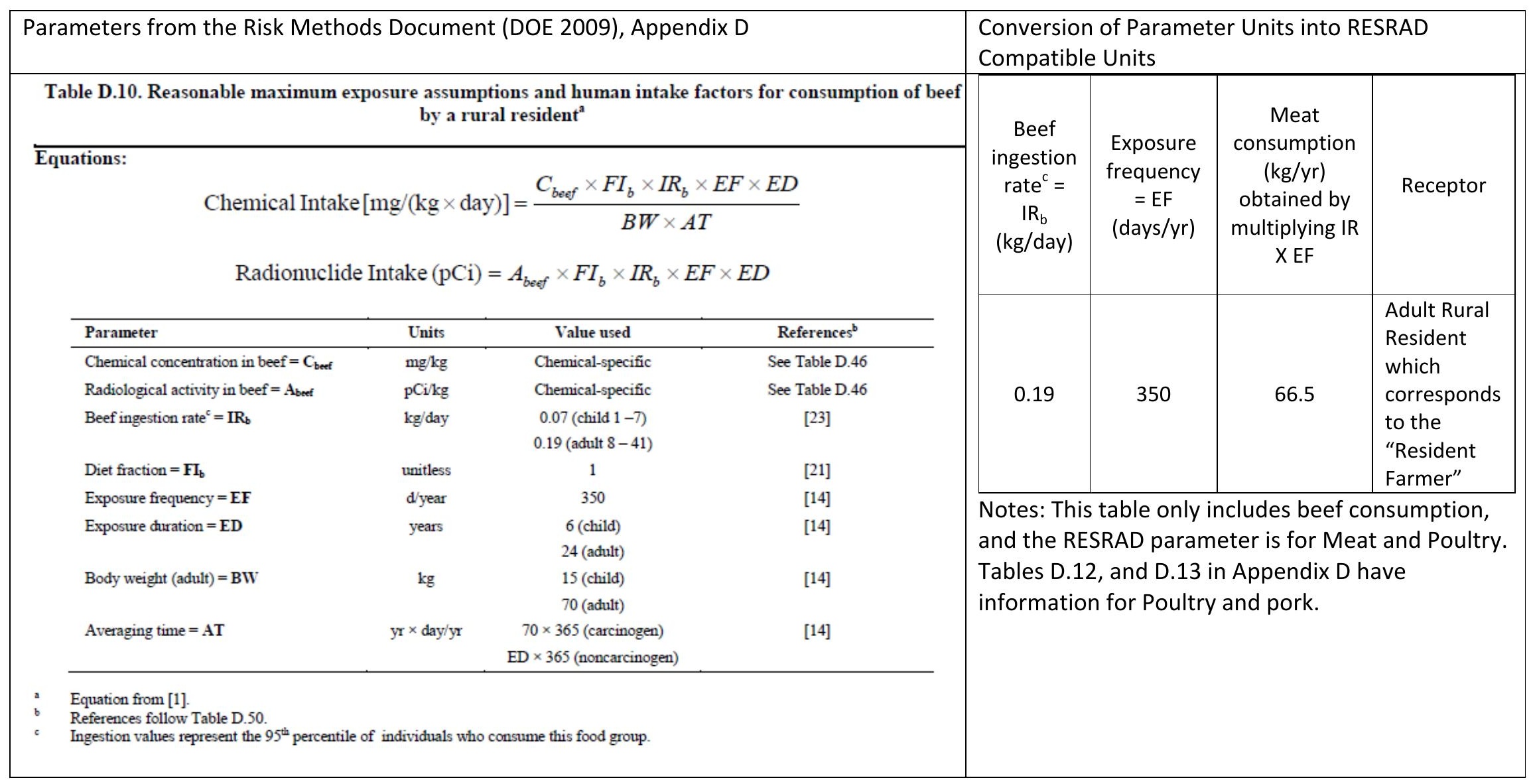


Meat and Poultry Consumption (cont.)

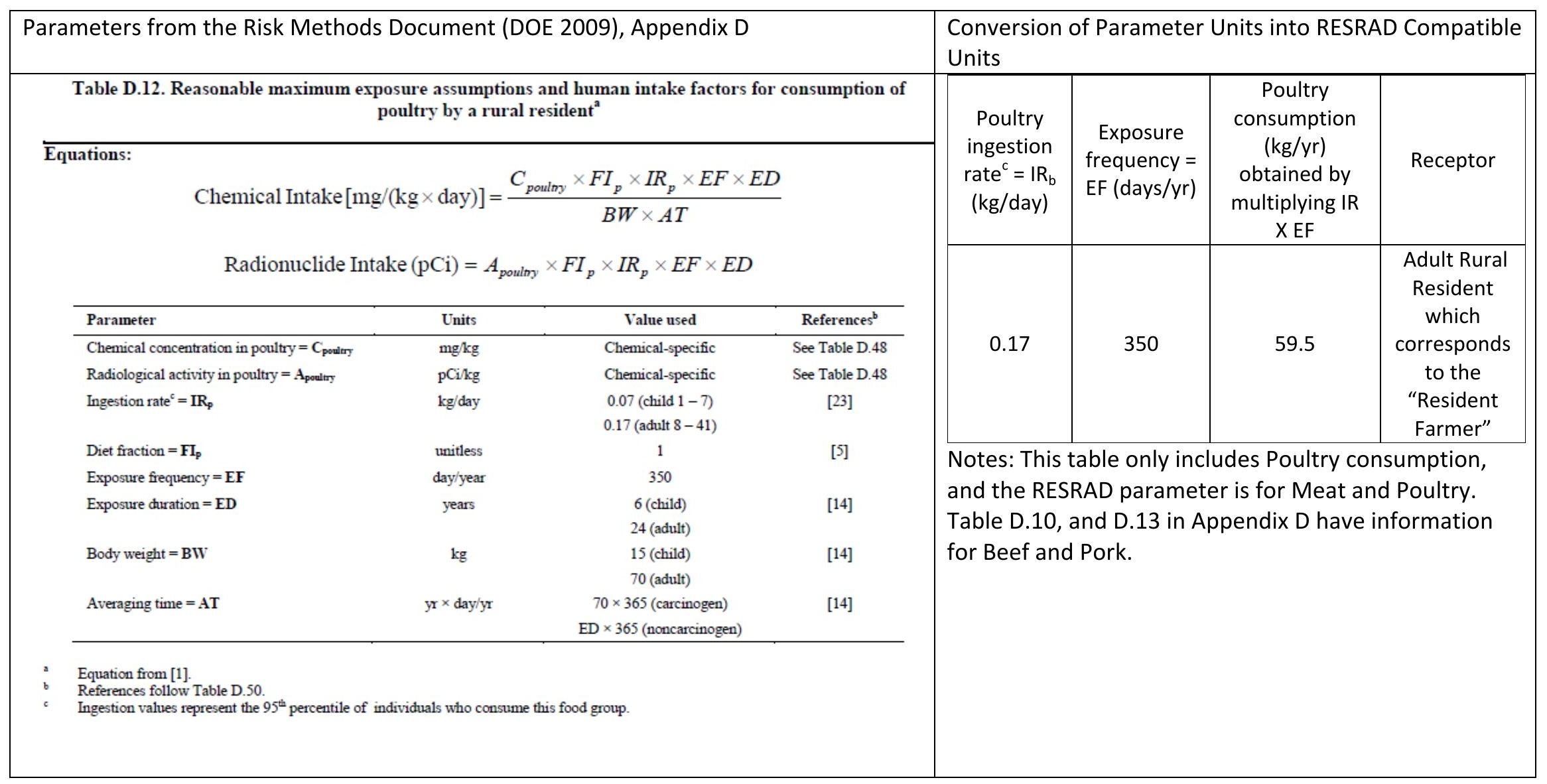


Meat and Poultry Consumption (cont.)

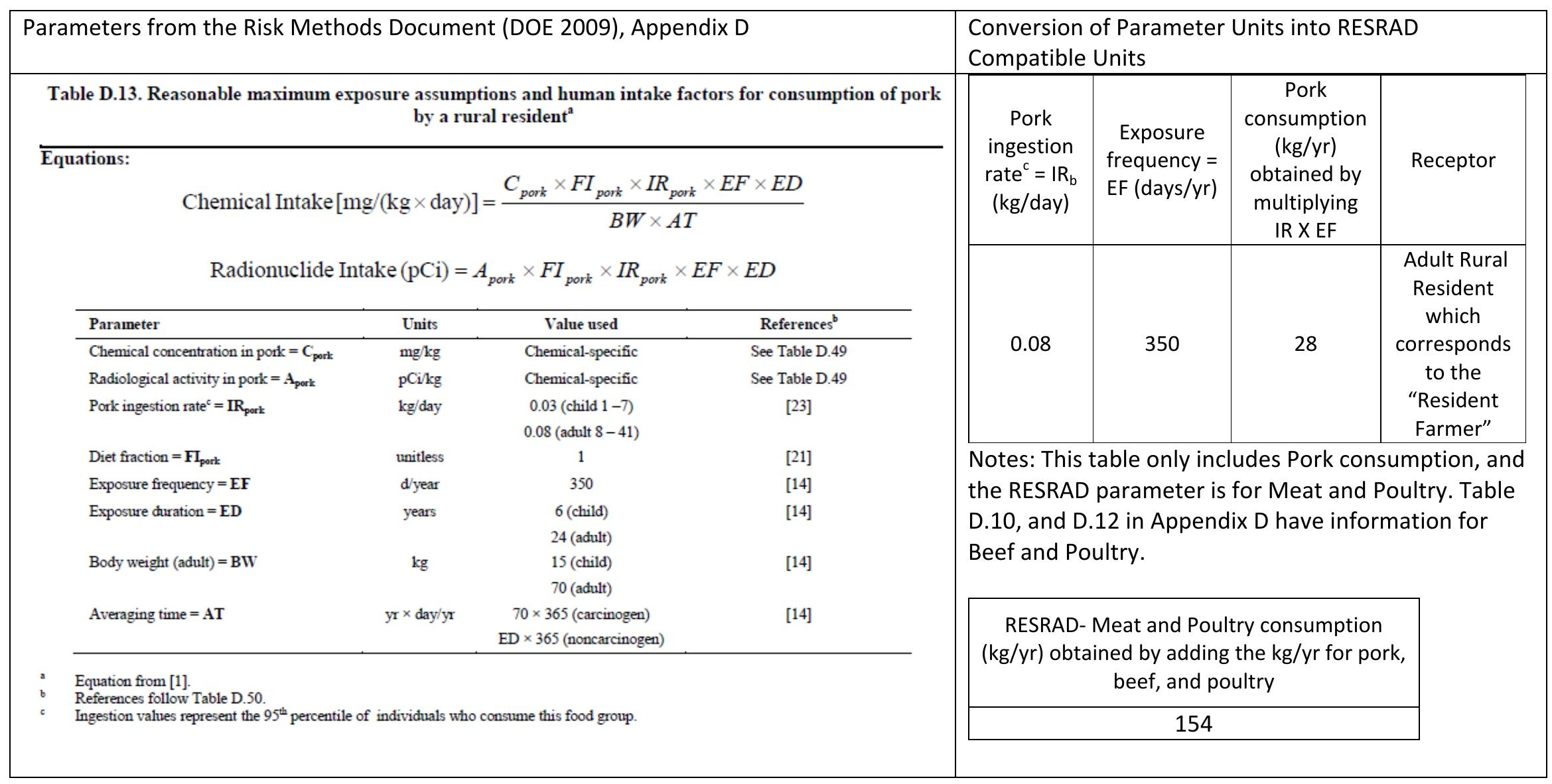




\section{Section C. Parameters Applicable to the Outdoor Worker and the Landfill Worker}

\section{Soil Ingestion Rate}

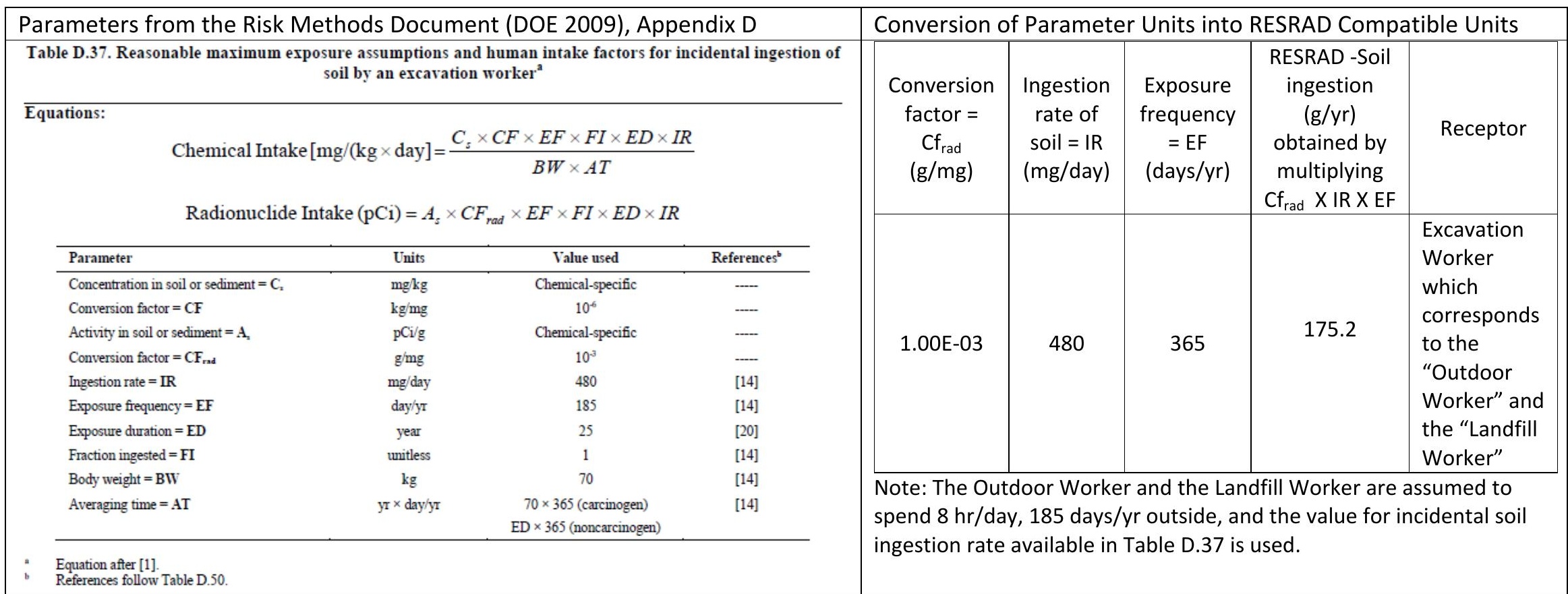


Inhalation Rate and Mass Loading for Inhalation

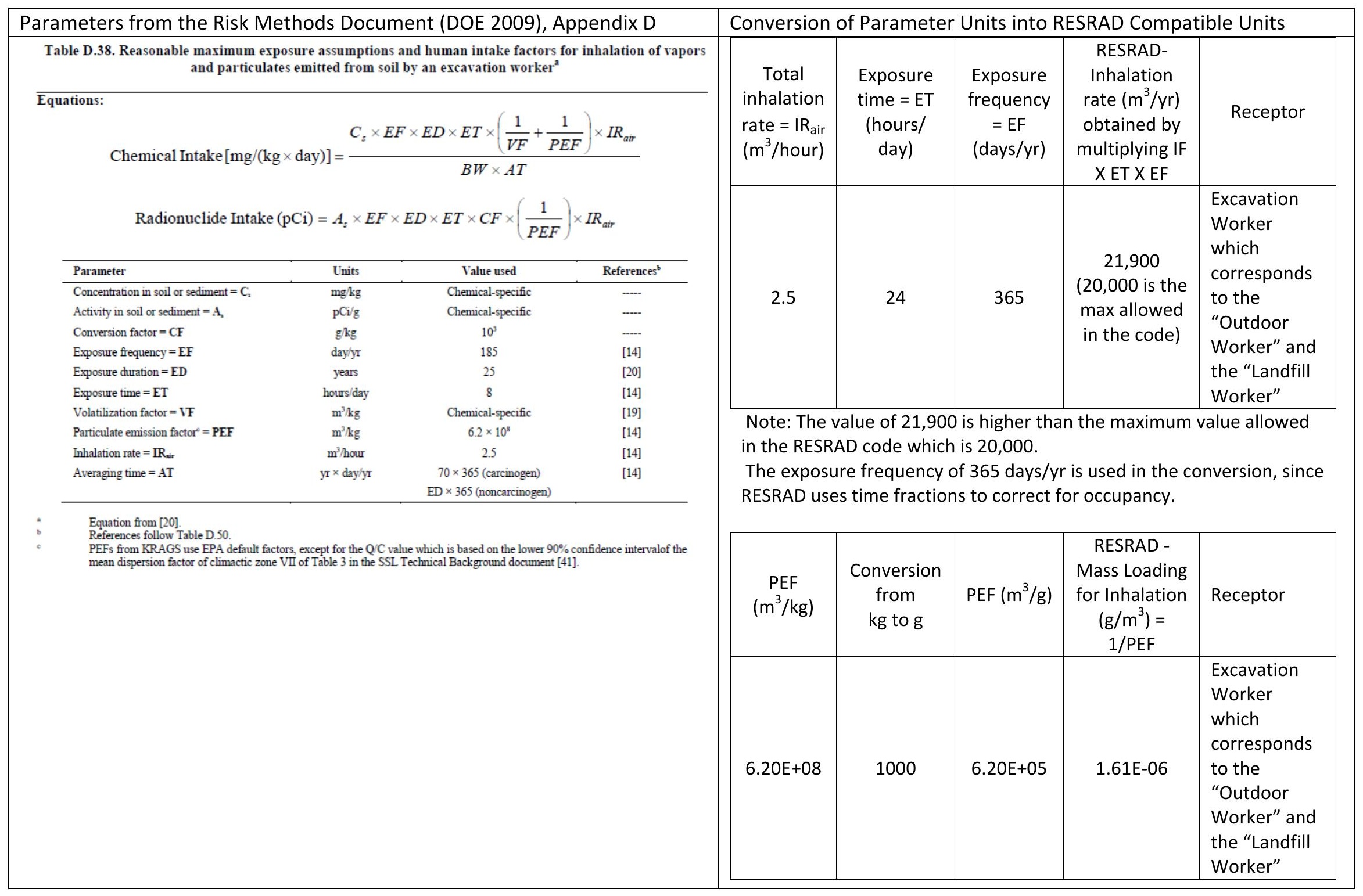


External Gamma Shielding Factor and Exposure Duration

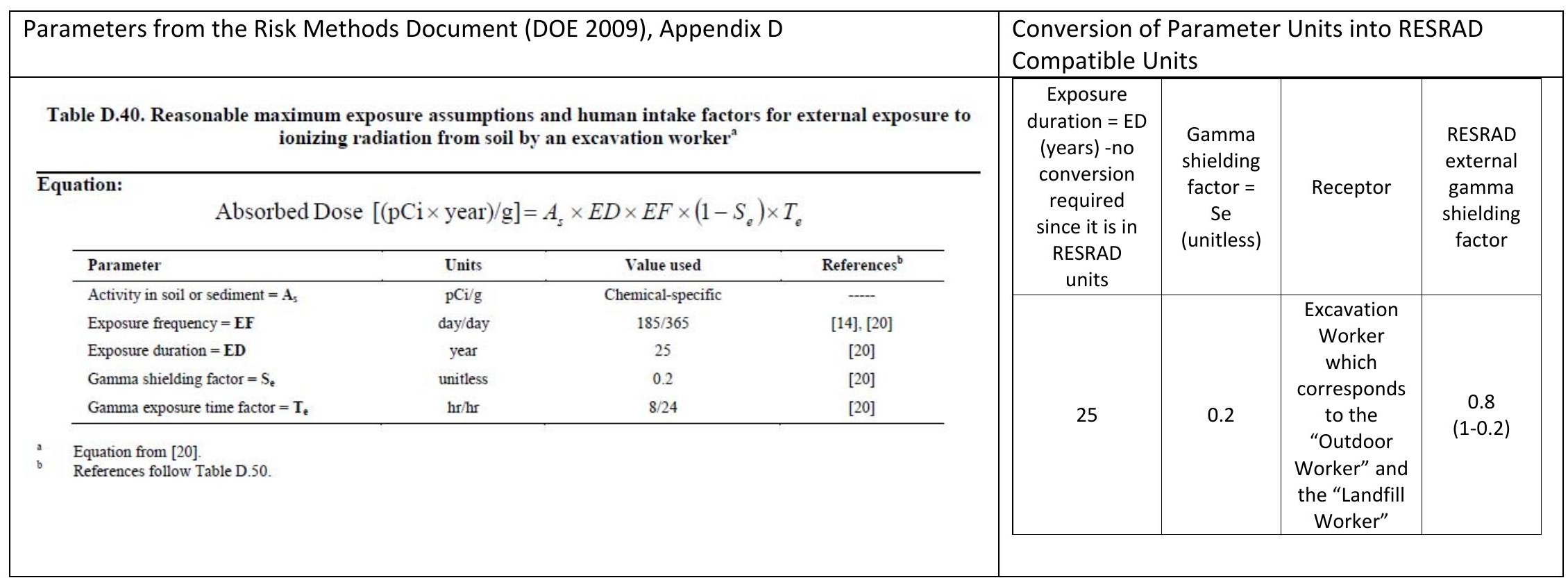




\section{Outdoor Time Fraction}

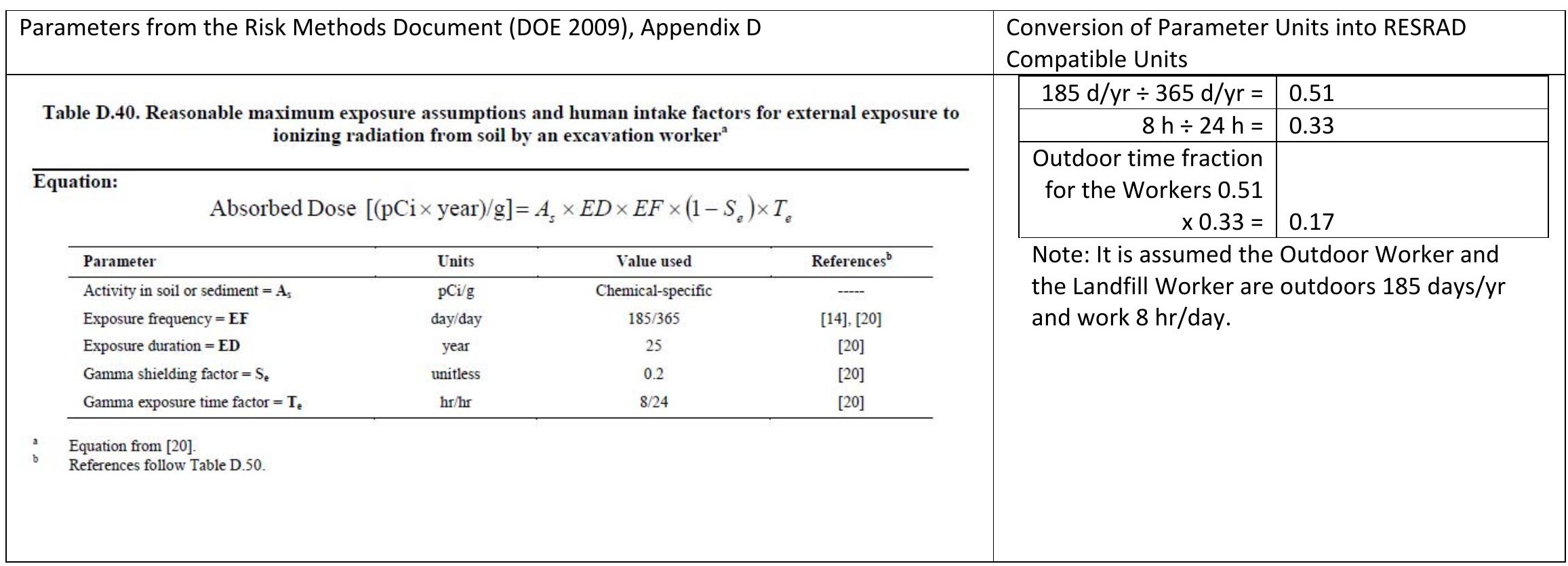




\section{Section D. Parameters Applicable to the Recreational User and Trespasser (In Some Cases)}

\section{Soil Ingestion Rate}

\begin{tabular}{|c|c|c|c|c|c|c|c|c|}
\hline \multirow{2}{*}{\multicolumn{4}{|c|}{$\begin{array}{l}\text { Parameters from the Risk Methods Document (DOE 2009), Appendix D } \\
\begin{array}{c}\text { Table D.15. Reasonable maximum exposure assumptions and human intake factors for incidental ingestion of } \\
\text { sediment by a recreational user }\end{array} \\
\end{array}$}} & \multicolumn{5}{|c|}{ Conversion of Parameter Units into RESRAD Compatible Units } \\
\hline & & & & \multirow[b]{2}{*}{$\begin{array}{l}\text { Conversion } \\
\text { factor }= \\
\mathrm{Cf}_{\text {rad }} \\
(\mathrm{g} / \mathrm{mg})\end{array}$} & \multirow[b]{2}{*}{$\begin{array}{l}\text { Ingestion } \\
\text { rate of } \\
\text { soil = IR } \\
\text { (mg/day) }\end{array}$} & \multirow[b]{2}{*}{$\begin{array}{l}\text { Exposure } \\
\text { frequency } \\
\quad=\mathrm{EF} \\
\text { (days/yr) }\end{array}$} & \multirow{2}{*}{$\begin{array}{c}\text { RESRAD -Soil } \\
\text { ingestion } \\
\text { (g/yr) } \\
\text { obtained by } \\
\text { multiplying } \\
\text { Cf }_{\text {rad }} \text { X IR X } \\
\text { EF }\end{array}$} & \multirow[b]{2}{*}{ Receptor } \\
\hline $\begin{array}{l}\text { Equations: } \\
\text { Chemical Intake }[1 \\
\text { Radionuclide Int } \\
\end{array}$ & $\begin{array}{l}\text { lay }]=\frac{C_{s e}}{=A_{s e d}} \times C\end{array}$ & $\begin{aligned} & F \times E D \times E T \times C F \\
& B W \times A T \\
& E D \times E T \times C F_{2}\end{aligned}$ & $\frac{\times F I}{F I}$ & & & & & \\
\hline Parameter & Units & Value used & References $^{b}$ & \multirow{7}{*}{ 1.00E-03 } & \multirow{7}{*}{100} & \multirow{7}{*}{365} & \multirow{7}{*}{36.5} & \multirow{7}{*}{$\begin{array}{l}\text { Recreational } \\
\text { User which } \\
\text { corresponds } \\
\text { to the } \\
\text { "Recreational } \\
\text { User" }\end{array}$} \\
\hline Concentration in sediment $=C_{x d}$ & $\mathrm{mg} / \mathrm{kg}$ & Chemical-specific & -- & & & & & \\
\hline Conversion factor $=\mathbf{C F}$ & $\mathrm{kg} / \mathrm{mg}$ & $10^{-5}$ & - & & & & & \\
\hline Activity in soil $=A_{\text {sed }}$ & $\mathrm{pCi} i \mathrm{~g}$ & Chemical-specific & - & & & & & \\
\hline Conversion factor $=\mathrm{CF}_{\mathrm{rad}}$ & $g / \mathrm{mg}$ & $10^{-3}$ & - & & & & & \\
\hline Exposure frequency $=\mathbf{E F}$ & day/yr & 104 (adult) & [14] & & & & & \\
\hline \multirow{3}{*}{ Exposure duration $=\mathrm{ED}$} & \multirow{3}{*}{ year } & 140 (child and teen) & \multirow{3}{*}{ [14] } & & & & & \\
\hline & & 12 (teen) & & \multirow{4}{*}{\multicolumn{5}{|c|}{$\begin{array}{l}\text { Notes: The exposure frequency of } 365 \text { days/yr is used in the } \\
\text { conversion, instead of } 140 \text { days/yr (teen) or } 104 \text { days/yr (adult) since } \\
\text { RESRAD uses time fractions to correct for occupancy. }\end{array}$}} \\
\hline & & 6 (child) & & & & & & \\
\hline Exposure time $=\mathbf{E T}$ & hr/day & 5 & [14] & & & & & \\
\hline Conversion factor $=\mathbf{C F}_{2}$ & day/hr & $1 / 24$ & - & & & & & \\
\hline \multirow[t]{3}{*}{ Ingestion rate $=$ IR } & $\mathrm{mg} / \mathrm{day}$ & 100 (adult) & [14] & & & & & \\
\hline & & 100 (teen) & & & & & & \\
\hline & & 200 (child) & & & & & & \\
\hline Fraction ingested $=\mathbf{F I}$ & unitless & 1 & [14] & & & & & \\
\hline \multirow[t]{3}{*}{ Body weight $=\mathrm{BW}$} & $\mathrm{kg}$ & 70 (adult) & [14] & & & & & \\
\hline & & 43 (teen) & & & & & & \\
\hline & & 15 (child) & & & & & & \\
\hline \multirow[t]{2}{*}{ Averaging time $=\mathrm{AT}$} & $\mathrm{yr} \times$ day $/ \mathrm{yr}$ & $70 \times 365$ (carcinogen) & [14] & & & & & \\
\hline & & ED $\times 365$ (noncarcinogen) & & & & & & \\
\hline $\begin{array}{l}\text { Equation after [1]. } \\
\text { References follow Table D. } 50 \text {. }\end{array}$ & & & & & & & & \\
\hline
\end{tabular}


Inhalation Rate and Mass Loading for Inhalation

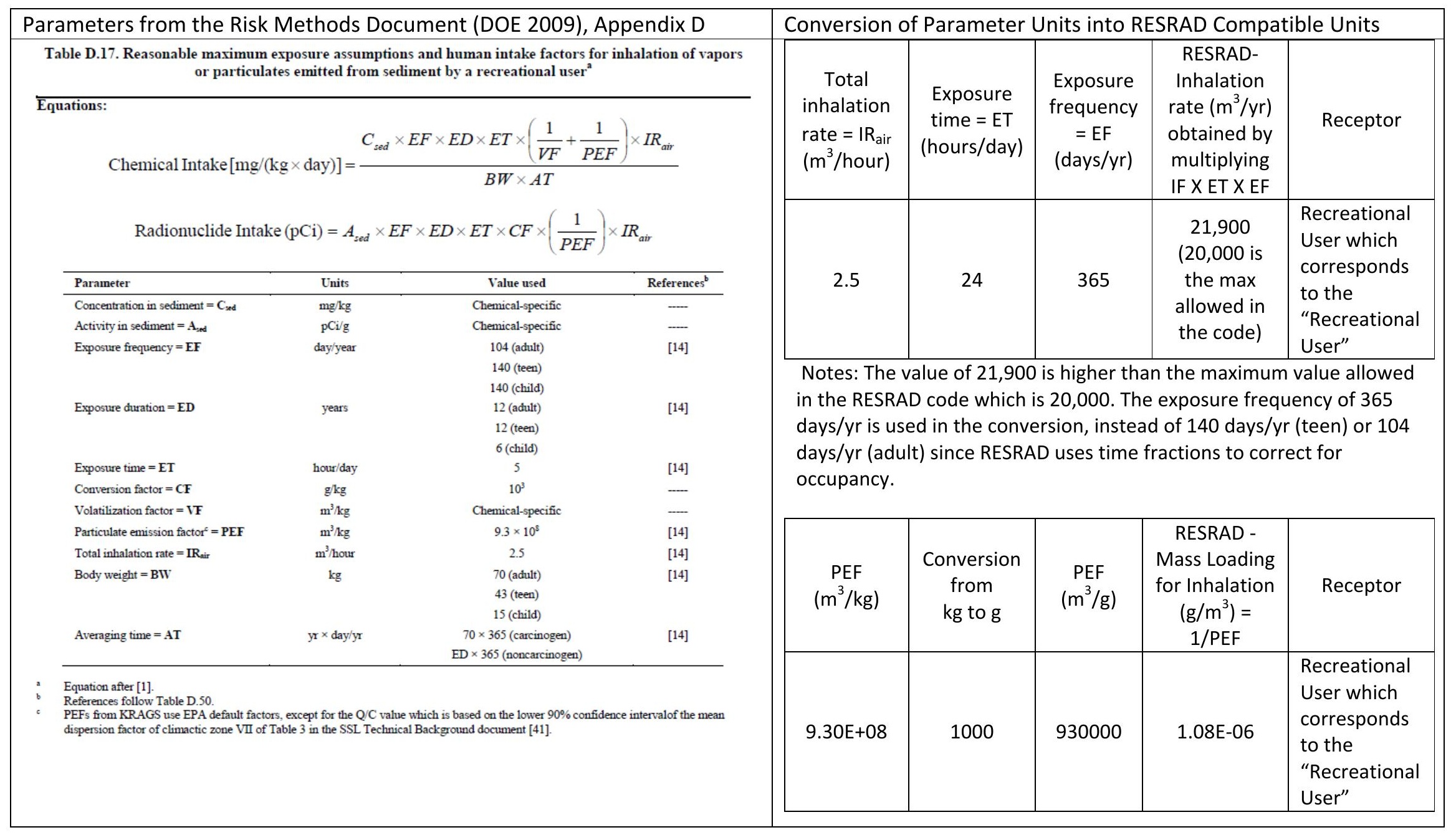


External Gamma Shielding Factor and Exposure Duration

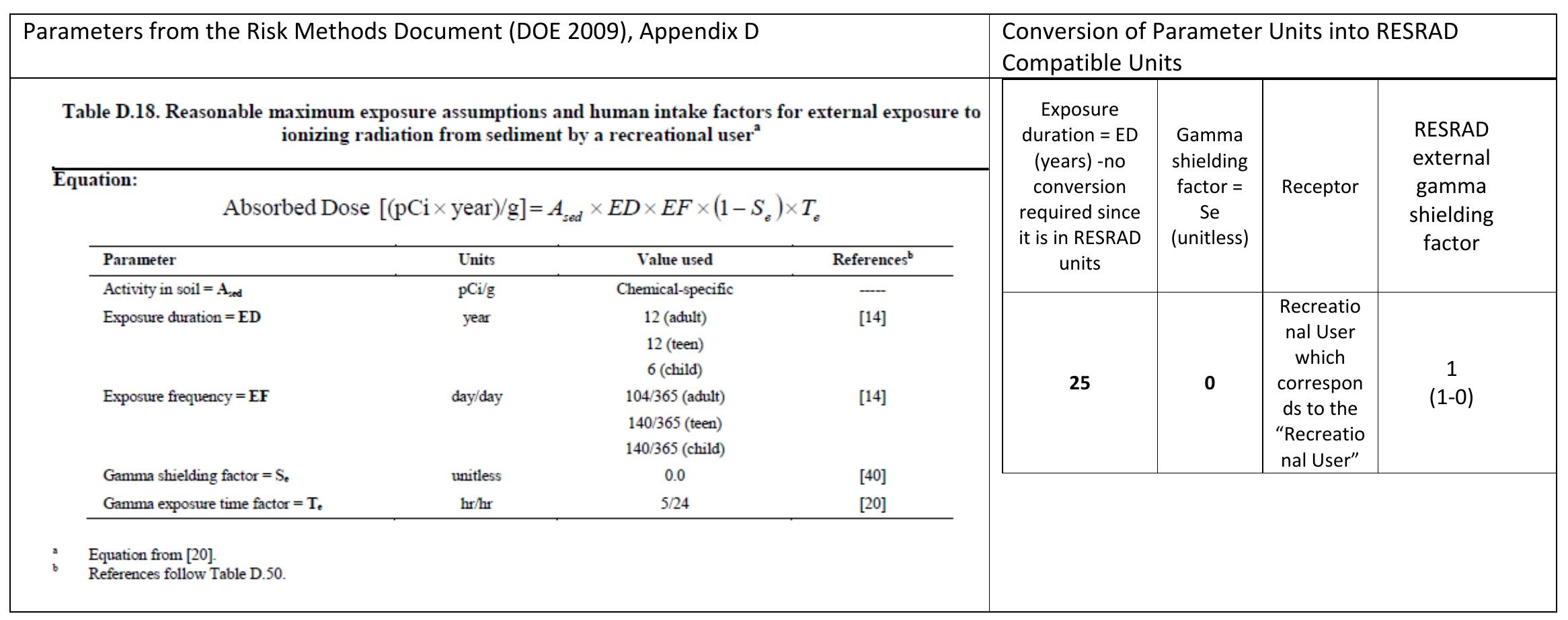

Outdoor Time Fraction (Recreational User-Teenager)

\begin{tabular}{|r|l|}
\hline $140 \mathrm{~d} / \mathrm{yr} \div 365 \mathrm{~d} / \mathrm{yr}=$ & 0.38 \\
\hline $5 \mathrm{~h} \div 24 \mathrm{~h}=$ & 0.21 \\
\hline Outdoor time fraction for & \\
the RU-teenager & \\
$0.38 \times 0.21=$ & 0.08 \\
\hline
\end{tabular}

Note: The Recreational User is considered to be a teenager who will spend $5 \mathrm{~h} /$ day, 140 days/yr on the contaminated site. 
Outdoor Time Fraction (Trespasser-Adult)

\begin{tabular}{|c|c|}
\hline $104 d / y r \div 365 d / y r=$ & 0.28 \\
\hline $5 \mathrm{~h} \div 24 \mathrm{~h}=$ & 0.21 \\
\hline $\begin{array}{r}\text { Outdoor time fraction for } \\
\text { the Trespasser-Adult } \\
0.28 \times 0.21=\end{array}$ & 0.06 \\
\hline $\begin{array}{l}\text { Note: The Trespasser is consid } \\
\text { spend } 5 \text { h/day, } 104 \text { days/yr on } \\
\text { receptor has a lower occupanc } \\
\text { User. }\end{array}$ & $\begin{array}{l}\text { ered to be an adult who will } \\
\text { the contaminated site. This } \\
y \text { than the teen Recreational }\end{array}$ \\
\hline
\end{tabular}




\section{Section E. Parameters applicable to beef and dairy from the Risk Methods Document (DOE 2009), Appendix D}

Table D.46. Reasonable maximum exposure assumptions for concentration or activity of COPCs in beef ${ }^{a}$

\begin{tabular}{|c|c|c|c|}
\hline \multicolumn{4}{|l|}{$\begin{array}{l}\text { Equations: } \\
\qquad C_{\text {beef }}=F_{b e}\end{array}$} \\
\hline Parameter & Units & Value used & References $^{b}$ \\
\hline Chemical concentration in beef $=\mathrm{C}_{\text {beef }}$ & $\mathrm{mg} / \mathrm{kg}$ or $\mathrm{pCi} / \mathrm{g}$ & Chemical-specific & Calculated \\
\hline Forage-beef transfer factor $=\mathbf{F}_{\text {beef }}$ & day $/ \mathrm{kg}$ & Chemical-specific & --- \\
\hline Chemical concentration in pasture $=\mathrm{C}_{\text {forage }}$ & $\mathrm{mg} / \mathrm{kg}$ or $\mathrm{pCi} / \mathrm{g}$ & Chemical-specific & Calculated \\
\hline Area of contact $^{c}=\mathbf{A C}$ & unitless & $\mathrm{AS} / \mathrm{AD}$ & $-\ldots$ \\
\hline Area of $\mathrm{SWMU}=\mathrm{AS}$ & acres & SWMU-specific & - \\
\hline Area of beef range $=\mathbf{A D}$ & acres & 2 & [29] \\
\hline Fraction of beef's food from site when on site $=f_{s}$ & unitless & 1.0 & [5] \\
\hline Quantity of pasture ingested daily by beef $=Q_{f}$ & $\mathrm{~kg} /$ day & 25 & [25] \\
\hline Chemical concentration in soil or sediment $=\mathrm{C}_{\mathrm{s}}$ & $\mathrm{mg} / \mathrm{kg}$ or $\mathrm{pCi} / \mathrm{g}$ & Chemical-specific & 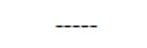 \\
\hline Quantity of soil ingested daily by beef $=Q_{s}$ & $\mathrm{~kg} /$ day & 1 & [26] \\
\hline Contaminant concentration in water $=\mathrm{C}_{\mathrm{w}}$ & $\mathrm{mg} / \mathrm{L}$ or $\mathrm{pCi} / \mathrm{L}$ & Chemical-specific & - \\
\hline Conversion factor for radionuclides $=\mathrm{CF}_{\mathrm{rad}}$ & $\mathrm{kg} / \mathrm{g}$ & $10^{-3}$ & $\ldots$ \\
\hline Quantity of water ingested daily by beef $=Q_{w}$ & L/day & 50 & [25] \\
\hline Soil to plant uptake (dry) $=\mathbf{R}_{\text {upp }}$ & unitless & $\begin{array}{l}\text { Chemical-specific } \\
\text { or } 38 \times \mathrm{K}_{\text {ow }}^{-0.58}\end{array}$ & [8] \\
\hline Soil resuspension multiplier $=\mathbf{R}_{e s}$ & unitless & 0.25 & [3] \\
\hline
\end{tabular}

Equations after [1], [2], [3], [4].

AC cerences follow Table D.s.

$\mathrm{AC}$ cannot be greater than 1.
All ingested water is considered to be from SWMU or SWMU area.

Values that were used to determine input parameters are highlighted. 
Table D.47. Reasonable maximum exposure assumptions for concentration or activity of COPCs in milk

\begin{tabular}{|c|c|c|c|}
\hline \multicolumn{4}{|l|}{ Equations: } \\
\hline Parameter & Units & Value used & References $^{b}$ \\
\hline Chemical concentration in milk $=\mathrm{C}_{\text {milk }}$ & $\mathrm{mg} / \mathrm{kg}$ or $\mathrm{pCi} / \mathrm{g}$ & Chemical-specific & Calculated \\
\hline Forage-milk transfer factor $=\mathbf{F}_{\text {milk }}$ & day $/ \mathrm{kg}$ & Chemical-specific & $\ldots$ \\
\hline Chemical concentration in pasture $=\mathrm{C}_{\text {forage }}$ & $\mathrm{mg} / \mathrm{kg}$ or $\mathrm{pCi} / \mathrm{g}$ & Chemical-specific & Calculated \\
\hline Area of contact $^{c}=\mathrm{AC}$ & unitless & $\mathrm{AS} / \mathrm{AD}$ & $\ldots$ \\
\hline Area of SWMU $=$ AS & acres & SWMU-specific & $\ldots$ \\
\hline Area of dairy range $=\mathrm{AD}$ & acres & 2 & [29] \\
\hline Fraction of dairy's food from site when on site $=\mathbf{f}_{s}$ & unitless & 1.0 & [5] \\
\hline Quantity of pasture ingested daily by dairy $=Q_{f}$ & $\mathrm{~kg} /$ day & 25 & [25] \\
\hline Chemical concentration in soil or sediment $=\mathrm{C}_{5}$ & $\mathrm{mg} / \mathrm{kg}$ or $\mathrm{pCi} / \mathrm{g}$ & Chemical-specific & $\ldots$ \\
\hline Quantity of soil ingested daily by dairy $=Q_{s}$ & $\mathrm{~kg} /$ day & 1 & [26] \\
\hline Contaminant concentration in water $=\mathrm{C}_{\mathrm{w}}$ & $\mathrm{mg} / \mathrm{L}$ or $\mathrm{pCi} / \mathrm{L}$ & Chemical-specific & $\ldots$ \\
\hline Conversion factor for radionuclides $=\mathbf{C F}_{\text {rad }}$ & $\mathrm{kg} / \mathrm{g}$ & $10^{-3}$ & $\ldots$ \\
\hline Quantity of water ingested daily by dairy $=Q_{w}$ & L/day & 60 & [25] \\
\hline Soil to plant uptake (dry) $=R_{\mathrm{upp}}$ & unitless & $\begin{array}{l}\text { Chemical-specific } \\
\text { or } 38 \times \mathrm{K}_{\mathrm{ow}}^{-0.58}\end{array}$ & [8] \\
\hline Soil resuspension multiplier $=R_{e s}$ & unitless & 0.25 & [3] \\
\hline
\end{tabular}

Equations after [1], [2], [3], [4].

All references follow Table D.50.

AC cannot be greater than 1 .
All ingested water is considered to be from SWMU or SWMU area.

Values that were used to determine input parameters are highlighted. 


\section{Attachment III \\ RESRAD Error/OUTPUT File for the Resident Farmer}


The code displayed an error message for the Resident Farmer when running it with an irrigation rate of $0.1 \mathrm{~m} / \mathrm{yr}$ and an evapotranspiration coefficient of 0.74 . The message is below:
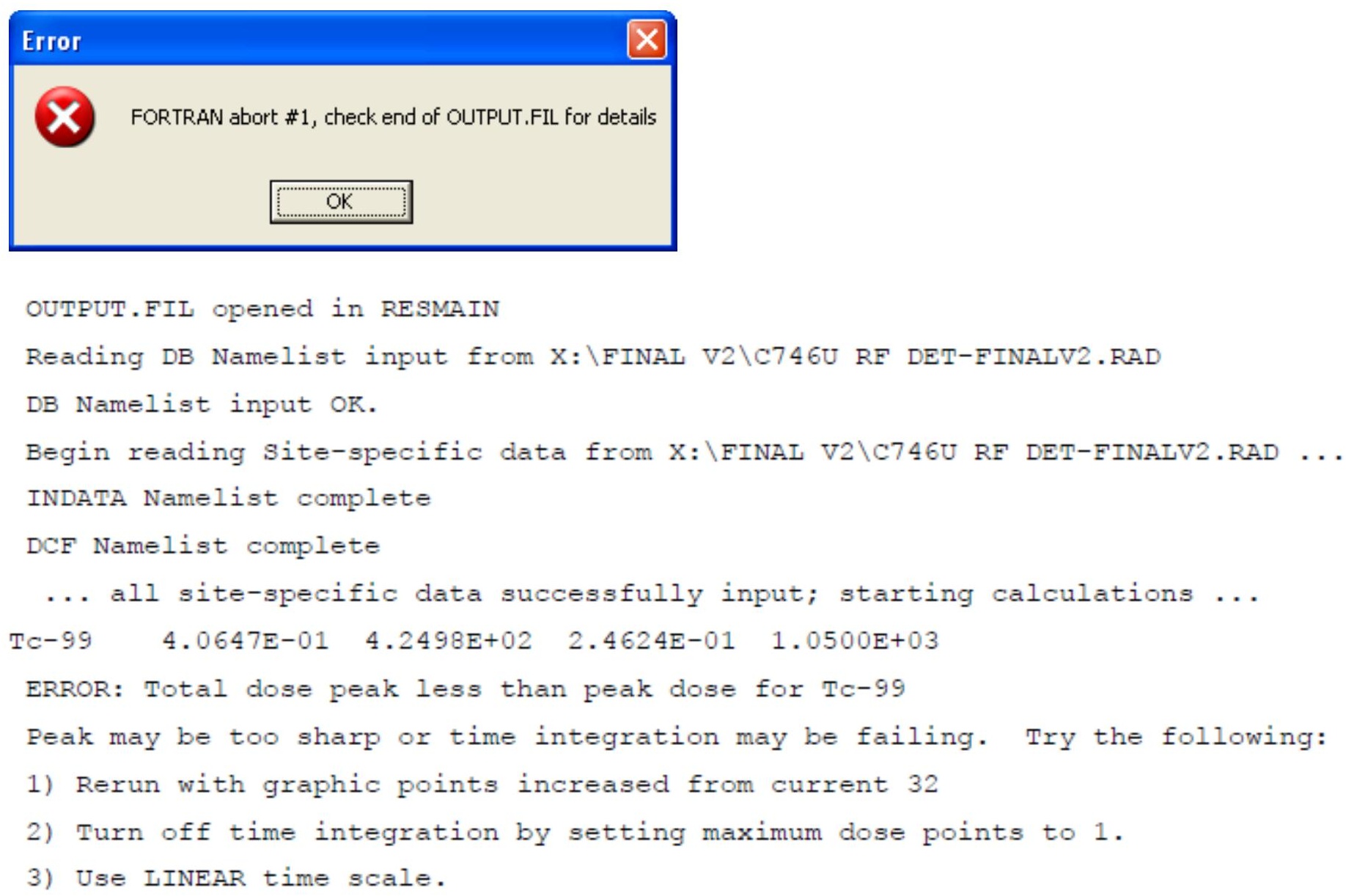

The code ran successfully after increasing the graphic points from 32 (default) to 64 and setting the maximum dose points from 17 (default) to 1 as indicated in the output file above. 


\section{References}

ATSDR 2002, Public Health Assessment for the Paducah Gaseous Diffusion Plant (USDOE) Paducah, McCracken County, Kentucky (May 2002).

DOE 2003a. Authorized Limits Request for Solid Waste Disposal at Landfill C-746-U at the Paducah Gaseous Diffusion Plant, (November 2002; revised January 2003).

DOE 2003b. Risk and Performance Evaluation of the C-746-U Landfill at the Paducah Gaseous Diffusion Plant, Paducah, Kentucky, DOE/OR/072041\&D2R1 (2003).

DOE 2009. Methods for Conducting Risk Assessments and Risk Evaluations at the Paducah Gaseous Diffusion Plant Paducah, Kentucky Volume 1. Human Health, DOE/LX/07-0107\&D1/V1 (2009).

DOE Statement of Work (SOW) for C-746-U Landfill provided to ORISE on December 2009.

DOE C-746-U landfill inventory spreadsheet for total waste disposed from May 2003 through May 2009.

DOE Project Communication with the Waste Disposal Operations Project Team from Paducah, KY, March 2010 (Email correspondence 03/29/2010 from Rich Bonczek).

DOE Project Communication with the Geologist from Paducah, KY, April 2010 (Email correspondence 04/05/2010 from Raulie Casteel).

DOE Project Communication with Geologist and Engineer from Paducah, KY, April 2010 (Email correspondence 04/07/2010 from Raulie Casteel).

DOE Project Communication with the Facility Representative DOE-PPPO from Paducah, KY, May 2010 (Email correspondence 05/05/2010 from Don Dihel).

DOE Project Communication May, 2010 (Discussion between ORISE and Rich Bonczek during a meeting held at ORISE on 05/17/2010).

DOE Project Communication June, 2010 (Email correspondence 06/02/2010 from ORISE to DOE).

DOE Project Communication July, 2010 (Discussion between ORISE and DOE-PPPO during a meeting held at ORISE on 07/12/2010).

DOE Project Communication September, 2010 (Discussion between ORISE and DOE-PPPO during a conference call held on 09/29/2010). 
DOE Project Communication October, 2010 (Discussion between ORISE and DOE-PPPO during a conference call held on 10/7/2010). DOE Project Communication November, 2010 (Email correspondence 11/03/2010 from ORISE to DOE consultant).

DOE Project Communication April, 2011 (ORISE and DOE-PPPO biweekly conference call on 04/13/2011 and email correspondence 04/14/2011 from ORISE to DOE-PPPO).

DOE Order 458.1, Radiation Protection of the Public and the Environment (DOE 2011).

DOE Order 5400.5, Radiation Protection of the Public and the Environment (DOE 1993).

Kenny, J. F. et al. 2009. Estimated Use of Water in the United States in 2005, Circular 1344, U.S. Department of Interior, U.S. Geological Survey (2009).

King, David A. and Karen Keil, 2006. Comparison of Standard Radiological Risk Models and Using RESRAD to Derive Generic Risk-Based Area Factors for Final Status Surveys, Risk Analysis, Vol. 26, No. 1.

Lee, D. W., J. C. Wang, and D. C. Kocher, 1995. Operating Limit Study for the Proposed Solid Waste Landfill at Paducah Gaseous Diffusion Plant, ORNL/TM-13008.

PRS 2008. 2006 Paducah Site Annual Site Environmental Report for Calendar Year 2006, PRS-ENM-0034 Volume I, Paducah Remediation Services (September 2008).

Yu, C., C. Loureiro, J. J. Cheng, L.G. Jones, Y.Y. Wang, Y.P. Chia, and E. Faillace, 1993. Data Collection Handbook to Support Modeling Impacts of Radioactive Material in Soil.

Yu C., D. LePoire, E. Gnanapragasam, J. Arnish, S. Kamboj, B.M. Biwer, J.-J. Cheng, A. Zielen, and S.Y. Chen, 2000. Development of Probabilistic RESRAD 6.0 and RESRAD-Build 3.0 Computer Codes, NUREG/CR-6697 ANL/EAD/TM-98.

Yu, C., A.J. Zielen, J.J. Cheng, D.J. LePoire, E. Gnanapragasam, S. Kamboj, J. Arnish, A. Wallo, III, W.A. Williams, and H. Peterson, 2001. User's Manual for RESRAD Version 6, ANL/EAD-4, Argonne National Laboratory. 
RESRAD-OFFSITE Table of Input Parameters for the C-746-U Landfill Offsite Resident Farmer Scenario

\begin{tabular}{|c|c|c|c|c|c|c|c|}
\hline $\begin{array}{c}\text { Input Screen Title } \\
\text { and Parameter } \\
\text { Name }\end{array}$ & Units & $\begin{array}{l}\text { Default } \\
\text { Value }^{\text {a }}\end{array}$ & $\begin{array}{l}\text { Code-Accepted } \\
\text { Values }^{b} \\
\text { Physical or } \\
\text { Numerical }^{\mathrm{C}} \text { (N) } \\
\text { Range }\end{array}$ & $\begin{array}{c}\text { Deterministic } \\
\text { Value }\end{array}$ & Type $^{d} \quad$ Priority & Justification & References \\
\hline
\end{tabular}

\section{Preliminary Inputs}

\begin{tabular}{|c|c|c|c|c|c|c|c|c|c|}
\hline $\begin{array}{l}\text { Radiological units } \\
\text { for activity }\end{array}$ & $\begin{array}{c}\mathrm{Ci}, \mathrm{Bq} \\
\mathrm{dps}, \mathrm{dpm}\end{array}$ & $\mathrm{pCi}$ & $\begin{array}{l}\mathrm{Ci}, \mathrm{Bq}, \mathrm{dps} \\
\mathrm{dpm}\end{array}$ & & $\mathrm{pCi}$ & $N A^{f}$ & & Default units are used. & Yu et al. 2007 \\
\hline $\begin{array}{l}\text { Radiological units } \\
\text { for dose }\end{array}$ & $\begin{array}{l}\text { rem and } \\
\text { Sv }\end{array}$ & mrem & rem, Sv & & mrem & NA & & Default units are used. & Yu et al. 2007 \\
\hline $\begin{array}{l}\text { Basic radiation dose } \\
\text { limit }\end{array}$ & $\mathrm{mrem} / \mathrm{yr}$ & 25 & $\begin{array}{l}1 \mathrm{E}-34- \\
1 \mathrm{E}+34\end{array}$ & $\mathrm{~N}$ & 1 & NA & 3 & $\begin{array}{l}\text { The target dose constraints of } 1,15,25 \text { and } 100 \\
\text { mrem/yr are considered in this project. However, the } \\
\text { basic radiation dose constraint used for the RESRAD } \\
\text { run is } 1 \mathrm{mrem} / \mathrm{yr} \text {. If the basic radiation dose limit is } \\
\text { changed it will not change the Dose to Source Ratio } \\
\text { (DSR) which is used in the calculation for single } \\
\text { radionuclide soil guidelines. }\end{array}$ & $\begin{array}{l}\text { DOE SOW for C- } \\
746-U \text { landfill, } \\
\text { Section } 2 \text {, item } 3\end{array}$ \\
\hline Exposure duration & $\mathrm{yr}$ & 30 & $1-1,000$ & & 24 & B & 3 & $\begin{array}{l}\text { The exposure duration is the span of time, in years, } \\
\text { during which an individual is expected to spend time } \\
\text { on the site. This value is used in calculating lifetime } \\
\text { cancer risk from exposure to radionuclide } \\
\text { contamination. It is also used to calculate time- } \\
\text { integrated dose if exposure duration is less than a } \\
\text { year. This value is obtained from DOE 2009. The } \\
\text { exposure duration is available in the tables of } \\
\text { Appendix D. For the Resident Farmer, the value for } \\
\text { "Rural Resident" is used. }\end{array}$ & $\begin{array}{c}\text { DOE } 2009 \\
\text { Appendix D,Table } \\
\text { D.8, page D-18 }\end{array}$ \\
\hline $\begin{array}{l}\text { Number of } \\
\text { unsaturated zone }\end{array}$ & $--\mathrm{g}$ & 1 & $0-5$ & $\mathrm{~N}$ & 5 & $P$ & 3 & $\begin{array}{l}\text { There are five unsaturated zones (UZ) considered. } \\
\text { These correspond to the layers under waste during } \\
\text { the Post-Institutional Control Period. Below are the } \\
\text { five zones: } \\
\text { UZ } 1=\text { Protective layer (native soil) } \\
\text { UZ } 2 \text { = Gravel layer } \\
\text { UZ } 3 \text { = Clay barrier } \\
\text { UZ } 4=\text { Alluvium soils (native/subgrade) } \\
\text { UZ } 5 \text { = Clay confining unit (native) }\end{array}$ & $\begin{array}{c}\text { DOE 2003b } \\
\text { Table 4.4, page 4- } \\
\text { 9, Fig. 4.5, page 4- } \\
\text { 18, Table Att.2, } \\
\text { page C3-315 }\end{array}$ \\
\hline \multicolumn{10}{|l|}{ Site Layout } \\
\hline Bearing of $X$ axis & degrees & 90 & $0-360$ & $P$ & 90 & $P$ & & Default value is used. & Yu et al. 2007 \\
\hline $\begin{array}{l}X \text { dimension of } \\
\text { Primary }\end{array}$ & $\mathrm{m}$ & 100 & $\begin{array}{l}-80,000- \\
+80,000\end{array}$ & & 256 & $P$ & 2 & $\begin{array}{l}\text { The primary contamination is modeled as a rectangle } \\
\text { for atmospheric release and transport calculations. }\end{array}$ & Lee et al. 1995 \\
\hline
\end{tabular}


RESRAD-OFFSITE Table of Input Parameters for the C-746-U Landfill Offsite Resident Farmer Scenario

\begin{tabular}{|c|c|c|c|c|c|c|c|c|}
\hline $\begin{array}{c}\text { Input Screen Title } \\
\text { and Parameter } \\
\text { Name }\end{array}$ & Units & $\begin{array}{l}\text { Default } \\
\text { Value }^{\mathrm{a}}\end{array}$ & $\begin{array}{l}\text { Code-Accepted } \\
\text { Values }^{b} \\
\text { Physical or } \\
\text { Numerical }{ }^{\mathrm{C}} \text { (N) } \\
\text { Range } \\
\end{array}$ & $\begin{array}{c}\text { Deterministic } \\
\text { Value }\end{array}$ & Type $^{d}$ & Priority & Justification & References \\
\hline contamination & & & & & & & $\begin{array}{l}\text { The lengths of the sides of the rectangle are used to } \\
\text { define the rectangular region for the atmospheric } \\
\text { transport calculations. The area is no longer an input, } \\
\text { but is obtained as the product of these two } \\
\text { perpendicular dimensions. The landfill does not have } \\
\text { a rectangular shape ;therefore, the two sides }(x, y) \text { of } \\
\text { the pentagon with maximum length were selected. }\end{array}$ & Yu et al. 2007 \\
\hline $\begin{array}{l}\text { Y dimension of } \\
\text { Primary } \\
\text { contamination }\end{array}$ & $\mathrm{m}$ & 100 & $\begin{array}{l}-80,000- \\
+80,000\end{array}$ & 399 & $P$ & 2 & $\begin{array}{l}\text { The primary contamination is modeled as a rectangle } \\
\text { for atmospheric release and transport calculations. } \\
\text { The lengths of the sides of the rectangle are used to } \\
\text { define the rectangular region for the atmospheric } \\
\text { transport calculations. The area is no longer an input, } \\
\text { but is obtained as the product of these two } \\
\text { perpendicular dimensions. The landfill does not have } \\
\text { a rectangular shape; therefore, the two sides }(x, y) \text { of } \\
\text { the pentagon with maximum length were selected. }\end{array}$ & $\begin{array}{l}\text { Lee et al. } 1995 \\
\text { Yu et al. } 2007\end{array}$ \\
\hline $\begin{array}{l}\text { Smaller } x \\
\text { coordinate of the } \\
\text { fruit, grain, } \\
\text { nonleafy vegetables } \\
\text { plot } \\
\end{array}$ & $\mathrm{m}$ & 34.375 & $\begin{array}{l}-80,000- \\
+80,000\end{array}$ & 34.375 & $P$ & 3 & \multirow[t]{4}{*}{$\begin{array}{l}\text { A plot, with an area }=1,000 \text { square meters (RESRAD } \\
\text { OFFSITE default), is located north of the } \\
\text { contaminated zone near the well (which is located } \\
407 \text { meters north/downgradient of the contaminated } \\
\text { zone). }\end{array}$} & \multirow[t]{4}{*}{ Yu et al. 2007} \\
\hline $\begin{array}{l}\text { Larger } x \text { coordinate } \\
\text { of the fruit, grain, } \\
\text { nonleafy vegetables } \\
\text { plot }\end{array}$ & $\mathrm{m}$ & 65.625 & $\begin{array}{l}-80,000- \\
+80,000\end{array}$ & 65.625 & $P$ & 3 & & \\
\hline $\begin{array}{l}\text { Smaller y } \\
\text { coordinate of the } \\
\text { fruit, grain, } \\
\text { nonleafy vegetables } \\
\text { plot }\end{array}$ & $\mathrm{m}$ & 234 & $\begin{array}{l}-80,000- \\
+80,000\end{array}$ & 806 & P & 3 & & \\
\hline $\begin{array}{l}\text { Larger y coordinate } \\
\text { of the fruit, grain, } \\
\text { nonleafy vegetables } \\
\text { plot }\end{array}$ & $\mathrm{m}$ & 266 & $\begin{array}{l}-80,000- \\
+80,000\end{array}$ & 838 & $P$ & 3 & & \\
\hline $\begin{array}{c}\text { Smaller } x \\
\text { coordinate of the } \\
\text { leafy vegetables } \\
\text { plot }\end{array}$ & $\mathrm{m}$ & 34.375 & $\begin{array}{l}-80,000- \\
+80,000\end{array}$ & 34.375 & $P$ & 3 & $\begin{array}{l}\text { A plot, with an area }=1,000 \text { square meters (RESRAD } \\
\text { OFFSITE default), is located north of the } \\
\text { contaminated zone near the well (which is located } \\
407 \text { meters north/downgradient of the contaminated } \\
\text { zone). }\end{array}$ & Yu et al. 2007 \\
\hline
\end{tabular}


RESRAD-OFFSITE Table of Input Parameters for the C-746-U Landfill Offsite Resident Farmer Scenario

\begin{tabular}{|c|c|c|c|c|c|c|c|c|}
\hline $\begin{array}{c}\text { Input Screen Title } \\
\text { and Parameter } \\
\text { Name }\end{array}$ & Units & $\begin{array}{l}\text { Default } \\
\text { Value }^{\mathrm{a}}\end{array}$ & $\begin{array}{r}\text { Code-Acce } \\
\text { Values } \\
\text { Physical } \\
\text { Numerical } \\
\text { Range }\end{array}$ & $\begin{array}{l}\text { Deterministic } \\
\text { Value }\end{array}$ & Type $^{d}$ & Priority $^{e}$ & Justification & References \\
\hline $\begin{array}{c}\text { Larger } x \text { coordinate } \\
\text { of the leafy } \\
\text { vegetables plot }\end{array}$ & $\mathrm{m}$ & 65.625 & $\begin{array}{l}-80,000- \\
+80,000\end{array}$ & 65.625 & $P$ & 3 & & \\
\hline $\begin{array}{c}\text { Smaller y } \\
\text { coordinate of the } \\
\text { leafy vegetables } \\
\text { plot }\end{array}$ & $\mathrm{m}$ & 268 & $\begin{array}{l}-80,000- \\
+80,000\end{array}$ & 840 & $P$ & 3 & & \\
\hline $\begin{array}{l}\text { Larger y coordinate } \\
\text { of the leafy } \\
\text { vegetables plot }\end{array}$ & $\mathrm{m}$ & 300 & $\begin{array}{l}-80,000- \\
+80,000\end{array}$ & 872 & $P$ & 3 & & \\
\hline $\begin{array}{l}\text { Smaller } x \\
\text { coordinate of the } \\
\text { pasture, silage } \\
\text { growing area }\end{array}$ & $\mathrm{m}$ & 0 & $\begin{array}{l}-80,000- \\
+80,000\end{array}$ & 0 & $P$ & 3 & \multirow{4}{*}{$\begin{array}{l}\text { A plot, with an area }=10,000 \text { square meters (RESRAD } \\
\text { OFFSITE default), is located north of the } \\
\text { contaminated zone near the well (which is located } \\
407 \text { meters north/downgradient of the contaminated } \\
\text { zone). }\end{array}$} & \multirow[t]{4}{*}{ Yu et al. 2007} \\
\hline $\begin{array}{l}\text { Larger } x \text { coordinate } \\
\text { of the pasture, } \\
\text { silage growing area }\end{array}$ & $\mathrm{m}$ & 100 & $\begin{array}{l}-80,000- \\
+80,000\end{array}$ & 100 & $P$ & 3 & & \\
\hline $\begin{array}{l}\text { Smaller y } \\
\text { coordinate of the } \\
\text { pasture, silage } \\
\text { growing area }\end{array}$ & $\mathrm{m}$ & 450 & $\begin{array}{l}-80,000- \\
+80,000\end{array}$ & 706 & $P$ & 3 & & \\
\hline $\begin{array}{l}\text { Larger y coordinate } \\
\text { of the pasture, } \\
\text { silage growing area }\end{array}$ & $\mathrm{m}$ & 550 & $\begin{array}{l}-80,000- \\
+80,000\end{array}$ & 806 & $P$ & 3 & & \\
\hline $\begin{array}{l}\text { Smaller } x \\
\text { coordinate of the } \\
\text { grain fields }\end{array}$ & $\mathrm{m}$ & 0 & $\begin{array}{l}-80,000- \\
+80,000\end{array}$ & 192 & $\mathrm{P}$ & 3 & \multirow{4}{*}{$\begin{array}{l}\text { A plot, with an area }=10,000 \text { square meters (RESRAD } \\
\text { OFFSITE default), is located north of the } \\
\text { contaminated zone near the well (which is located } \\
407 \text { meters north/downgradient of the contaminated } \\
\text { zone). }\end{array}$} & \multirow[t]{4}{*}{ Yu et al. 2007} \\
\hline $\begin{array}{l}\text { Larger } x \text { coordinate } \\
\text { of the grain fields }\end{array}$ & $\mathrm{m}$ & 100 & $\begin{array}{l}-80,000- \\
+80,000\end{array}$ & 292 & $P$ & 3 & & \\
\hline $\begin{array}{l}\text { Smaller y } \\
\text { coordinate of the } \\
\text { grain fields }\end{array}$ & $\mathrm{m}$ & 300 & $\begin{array}{l}-80,000- \\
+80,000\end{array}$ & 700 & $P$ & 3 & & \\
\hline $\begin{array}{l}\text { Larger y coordinate } \\
\text { of the grain fields }\end{array}$ & $\mathrm{m}$ & 400 & $\begin{array}{l}-80,000- \\
+80,000\end{array}$ & 800 & $P$ & 3 & & \\
\hline $\begin{array}{c}\text { Smaller } x \\
\text { coordinate of the } \\
\text { dwelling site }\end{array}$ & $\mathrm{m}$ & 34.375 & $\begin{array}{l}-80,000- \\
+80,000\end{array}$ & 34.375 & $\mathrm{P}$ & 3 & \multirow{2}{*}{$\begin{array}{l}\text { A plot, with an area }=1,000 \text { square meters (RESRAD } \\
\text { OFFSITE default), is located north of the } \\
\text { contaminated zone near the well (which is located } \\
407 \text { meters north/downgradient of the contaminated } \\
\text { zone). }\end{array}$} & \multirow[t]{2}{*}{ Yu et al. 200} \\
\hline $\begin{array}{l}\text { Larger } x \text { coordinate } \\
\text { of the dwelling site }\end{array}$ & $\mathrm{m}$ & 65.625 & $\begin{array}{l}-80,000- \\
+80,000\end{array}$ & 65.625 & $\mathrm{P}$ & 3 & & \\
\hline
\end{tabular}


RESRAD-OFFSITE Table of Input Parameters for the C-746-U Landfill Offsite Resident Farmer Scenario

\begin{tabular}{|c|c|c|c|c|c|c|c|c|}
\hline $\begin{array}{l}\text { Input Screen Title } \\
\text { and Parameter } \\
\text { Name }\end{array}$ & Units & $\begin{array}{l}\text { Default } \\
\text { Value }^{\mathrm{a}}\end{array}$ & $\begin{array}{c}\text { Code-Accepted } \\
\text { Values }^{b} \\
\text { Physical or } \\
\text { Numerical }^{\mathrm{C}}(\mathrm{N}) \\
\text { Range }^{\text {Rang }}\end{array}$ & $\begin{array}{l}\text { Deterministic } \\
\text { Value }\end{array}$ & Type $^{d}$ & Priority & Justification & References \\
\hline $\begin{array}{c}\text { Smaller y } \\
\text { coordinate of the } \\
\text { dwelling site }\end{array}$ & $\mathrm{m}$ & 134 & $\begin{array}{l}-80,000- \\
+80,000\end{array}$ & 636 & $P$ & 3 & & \\
\hline $\begin{array}{l}\text { Larger y coordinate } \\
\text { of the dwelling site }\end{array}$ & $\mathrm{m}$ & 166 & $\begin{array}{l}-80,000- \\
+80,000\end{array}$ & 670 & $P$ & 3 & & \\
\hline $\begin{array}{c}\text { Smaller } x \\
\text { coordinate of the } \\
\text { surface-water body }\end{array}$ & $\mathrm{m}$ & -100 & $\begin{array}{l}-80,000- \\
+80,000\end{array}$ & -100 & $P$ & 3 & \multirow{4}{*}{$\begin{array}{l}\text { A plot, with an area }=90,000 \text { square meters (RESRAD } \\
\text { OFFSITE default), is located south of the } \\
\text { contaminated zone/upgradient. The surface water } \\
\text { body is not included in the CSM. }\end{array}$} & \multirow[t]{4}{*}{ Yu et al. 2007} \\
\hline $\begin{array}{l}\text { Larger } \mathrm{x} \text { coordinate } \\
\text { of the surface- } \\
\text { water body }\end{array}$ & $\mathrm{m}$ & 200 & $\begin{array}{l}-80,000- \\
+80,000\end{array}$ & 200 & $P$ & 3 & & \\
\hline $\begin{array}{c}\text { Smaller y } \\
\text { coordinate of the } \\
\text { surface-water body }\end{array}$ & $\mathrm{m}$ & 550 & $\begin{array}{l}-80,000- \\
+80,000\end{array}$ & -850 & P & 3 & & \\
\hline $\begin{array}{l}\text { Larger y coordinate } \\
\text { of the surface- } \\
\text { water body }\end{array}$ & $\mathrm{m}$ & 850 & $\begin{array}{l}-80,000- \\
+80,000\end{array}$ & -550 & $P$ & 3 & & \\
\hline
\end{tabular}

Source

\begin{tabular}{|c|c|c|c|c|c|c|c|c|c|}
\hline $\begin{array}{c}\text { Nuclide } \\
\text { concentration }\end{array}$ & $\mathrm{pCi} / \mathrm{g}$ & 100 & $0-1 \mathrm{E}+34$ & $\mathrm{~N}$ & $\begin{array}{c}\text { Unit } \\
\text { concentration } \\
\text { for: } \\
\text { Am-241 } \\
\text { Cs-137 } \\
\text { Np-237 } \\
\text { Pu-238 } \\
\text { Pu-239 } \\
\text { Pu-240 } \\
\text { Tc-99 } \\
\text { Th-228 } \\
\text { Th-230 } \\
\text { Th-232 } \\
\text { U-234 } \\
\text { U-235 } \\
\text { U-238 } \\
\end{array}$ & $P$ & 2 & $\begin{array}{l}\text { The radionuclide concentration used is } 1 \mathrm{pCi} / \mathrm{g} \text { for } \\
\text { each parent radionuclide listed. Site-specific values } \\
\text { for the 6-year waste inventory (May 2003- May 2009) } \\
\text { were not used as input values. The list of } \\
\text { radionuclides used was provided to ORISE by DOE. } \\
\text { Radioactive secular equilibrium was not assumed in } \\
\text { the analysis for the uranium, actinium, and thorium } \\
\text { decay series due to the nature of the PGDP's uranium } \\
\text { enrichment mission. }\end{array}$ & $\begin{array}{c}\text { DOE 2003a } \\
\text { DOE SOW for C- } \\
746-U \text { landfill and } \\
\text { DOE Project } \\
\text { Communication } \\
\text { (May2010) }\end{array}$ \\
\hline \multicolumn{10}{|c|}{ Source Release and Deposition Velocity } \\
\hline $\begin{array}{c}\text { Release to } \\
\text { groundwater, leach }\end{array}$ & $1 / \mathrm{yr}$ & 0 & $0-1 E+34$ & $\mathrm{~N}$ & 0 & $P$ & 3 & $\begin{array}{l}\text { The fraction of the available radionuclide leached out } \\
\text { from the contaminated zone per unit of time. If a }\end{array}$ & Yu et al. 2007 \\
\hline
\end{tabular}


RESRAD-OFFSITE Table of Input Parameters for the C-746-U Landfill Offsite Resident Farmer Scenario

\begin{tabular}{|c|c|c|c|c|c|c|c|c|c|}
\hline \multirow{2}{*}{$\begin{array}{c}\text { Input Screen Title } \\
\text { and Parameter } \\
\text { Name } \\
\text { rate }\end{array}$} & \multirow[t]{2}{*}{ Units } & \multirow[t]{2}{*}{$\begin{array}{l}\text { Default } \\
\text { Value }^{a}\end{array}$} & \multicolumn{2}{|c|}{$\begin{array}{l}\text { Code-Accepted } \\
\text { Values }^{b} \\
\text { Physical or } \\
\text { Numerical }^{c} \text { (N) } \\
\text { Range }\end{array}$} & \multirow[t]{2}{*}{$\begin{array}{l}\text { Deterministic } \\
\text { Value }\end{array}$} & \multirow[t]{2}{*}{ Type } & Priority ${ }^{e}$ & Justification & \multirow[t]{2}{*}{ References } \\
\hline & & & & & & & & $\begin{array}{l}\text { zero is entered, the code will estimate a release rate } \\
\text { on the basis of the equilibrium desorption } \\
\text { concentration. The default value is used. }\end{array}$ & \\
\hline Deposition velocity & $\mathrm{m} / \mathrm{s}$ & $\begin{array}{c}0.001 \\
0.01(\mathrm{Cl}, \mathrm{l}) \\
0(\mathrm{Xe})\end{array}$ & $0-1 E+34$ & $\mathrm{~N}$ & 0.001 & $P$ & 2 & $\begin{array}{l}\text { For nuclides that are transported by contaminated } \\
\text { dust, it is the settling velocity of dust. If the nuclide is } \\
\text { being transported in the form of a gas (water vapor, } \\
\text { carbon dioxide, radon, etc.), a value of zero may be } \\
\text { entered. The default value is used. }\end{array}$ & Yu et al. 2007 \\
\hline
\end{tabular}

Distribution Coefficients

\begin{tabular}{|c|c|c|c|c|c|c|c|c|c|}
\hline Contaminated zone & $\mathrm{cm}^{3} / \mathrm{g}$ & $\begin{array}{l}\text { Nuclide- } \\
\text { dependent } \\
\text { (Default values } \\
\text { available) }\end{array}$ & $0-1 E+34$ & $\mathrm{~N}$ & $\begin{array}{l}\text { Nuclide- } \\
\text { dependent (see } \\
\text { Attachment I) }\end{array}$ & $P$ & 1 & $\begin{array}{l}\text { Tables with site-specific distribution coefficients for } \\
\text { the parent and daughter radionuclides are available } \\
\text { immediately following this table of parameters. }\end{array}$ & $\begin{array}{c}\text { DOE 2003b } \\
\text { Table Att. 1, page } \\
\text { C3-314, Table } \\
\text { C.3.1., page C3- } \\
301 \\
\\
\text { DOE Project } \\
\text { Communication } \\
\text { (March 2010) } \\
\text { Yu et al. } 2001 \\
\end{array}$ \\
\hline Unsaturated zone & $\mathrm{cm}^{3} / \mathrm{g}$ & $\begin{array}{l}\text { Nuclide- } \\
\text { dependent } \\
\text { (Default values } \\
\text { available) }\end{array}$ & $0-1 E+34$ & $\mathrm{~N}$ & $\begin{array}{l}\text { Nuclide- } \\
\text { dependent (see } \\
\text { Attachment I) }\end{array}$ & $P$ & 1 & $\begin{array}{l}\text { Tables with site-specific distribution coefficients for } \\
\text { the parent and daughter radionuclides are available } \\
\text { immediately following this table of parameters. }\end{array}$ & $\begin{array}{c}\text { DOE 2003b } \\
\text { Table Att. 1, page } \\
\text { C3-314, Table } \\
\text { C.3.1., page C3- } \\
301 \\
\\
\text { DOE Project } \\
\text { Communication } \\
\text { (March 2010) } \\
\text { Yu et al. } 2001\end{array}$ \\
\hline Saturated zone & $\mathrm{cm}^{3} / \mathrm{g}$ & $\begin{array}{l}\text { Nuclide- } \\
\text { dependent } \\
\text { (Default values } \\
\text { available) }\end{array}$ & $0-1 E+34$ & $\mathrm{~N}$ & $\begin{array}{l}\text { Nuclide- } \\
\text { dependent (see } \\
\text { Attachment I) }\end{array}$ & $P$ & 1 & $\begin{array}{l}\text { Tables with site-specific distribution coefficients for } \\
\text { the parent and daughter radionuclides are available } \\
\text { immediately following this table of parameters. }\end{array}$ & $\begin{array}{c}\text { DOE 2003b } \\
\text { Table Att. 1, page } \\
\text { C3-314, Table } \\
\text { C.3.1., page C3- } \\
\text { 301, } \\
\text { Table 4.7., page 4- } \\
21\end{array}$ \\
\hline
\end{tabular}


RESRAD-OFFSITE Table of Input Parameters for the C-746-U Landfill Offsite Resident Farmer Scenario

\begin{tabular}{|c|c|c|c|c|c|c|c|c|c|}
\hline \multirow[t]{2}{*}{$\begin{array}{l}\text { Input Screen Title } \\
\text { and Parameter } \\
\text { Name }\end{array}$} & \multirow[t]{2}{*}{ Units } & \multirow[t]{2}{*}{$\begin{array}{l}\text { Default } \\
\text { Value }^{a}\end{array}$} & \multicolumn{2}{|c|}{$\begin{array}{l}\text { Code-Accepted } \\
\text { Values }^{b} \\
\text { Physical or } \\
\text { Numerical }{ }^{\mathrm{C}} \text { (N) } \\
\text { Range }\end{array}$} & \multirow[t]{2}{*}{$\begin{array}{l}\text { Deterministic } \\
\text { Value }\end{array}$} & \multirow[t]{2}{*}{ Type $^{d}$} & \multirow[t]{2}{*}{ Priority ${ }^{e}$} & \multirow[t]{2}{*}{ Justification } & \multirow{2}{*}{$\begin{array}{c}\text { References } \\
\text { DOE Project } \\
\text { Communication } \\
\text { (March 2010) }\end{array}$} \\
\hline & & & & & & & & & \\
\hline $\begin{array}{l}\text { Sediment in surface } \\
\text { water body }\end{array}$ & $\mathrm{cm}^{3} / \mathrm{g}$ & $\begin{array}{l}\text { Nuclide- } \\
\text { dependent } \\
\text { (Default values } \\
\text { available) }\end{array}$ & $0-1 E+34$ & $\mathrm{~N}$ & $\begin{array}{l}\text { Nuclide- } \\
\text { dependent (see } \\
\text { Attachment I) }\end{array}$ & $P$ & 1 & $\begin{array}{l}\text { Tables with site-specific distribution coefficients for } \\
\text { the parent and daughter radionuclides are available } \\
\text { immediately following this table of parameters. }\end{array}$ & $\begin{array}{l}\text { DOE Project } \\
\text { Communication } \\
\text { (March 2010) }\end{array}$ \\
\hline $\begin{array}{l}\text { Fruit, grain, } \\
\text { nonleafy fields }\end{array}$ & $\mathrm{cm}^{3} / \mathrm{g}$ & $\begin{array}{c}\text { Nuclide- } \\
\text { dependent } \\
\text { (Default values } \\
\text { available) }\end{array}$ & $0-1 E+34$ & $\mathrm{~N}$ & $\begin{array}{l}\text { Nuclide- } \\
\text { dependent (see } \\
\text { Attachment I) }\end{array}$ & $P$ & 1 & $\begin{array}{l}\text { Tables with site-specific distribution coefficients for } \\
\text { the parent and daughter radionuclides are available } \\
\text { immediately following this table of parameters. }\end{array}$ & $\begin{array}{l}\text { DOE Project } \\
\text { Communication } \\
\text { (March 2010) }\end{array}$ \\
\hline $\begin{array}{l}\text { Leafy vegetable } \\
\text { fields }\end{array}$ & $\mathrm{cm}^{3} / \mathrm{g}$ & $\begin{array}{c}\text { Nuclide- } \\
\text { dependent } \\
\text { (Default values } \\
\text { available) }\end{array}$ & $0-1 E+34$ & $\mathrm{~N}$ & $\begin{array}{l}\text { Nuclide- } \\
\text { dependent (see } \\
\text { Attachment I) }\end{array}$ & $P$ & 1 & $\begin{array}{l}\text { Tables with site-specific distribution coefficients for } \\
\text { the parent and daughter radionuclides are available } \\
\text { immediately following this table of parameters. }\end{array}$ & $\begin{array}{c}\text { DOE Project } \\
\text { Communication } \\
\text { (March 2010) }\end{array}$ \\
\hline $\begin{array}{l}\text { Pasture, silage } \\
\text { growing areas }\end{array}$ & $\mathrm{cm}^{3} / \mathrm{g}$ & $\begin{array}{l}\text { Nuclide- } \\
\text { dependent } \\
\text { (Default values } \\
\text { available) }\end{array}$ & $0-1 E+34$ & $\mathrm{~N}$ & $\begin{array}{l}\text { Nuclide- } \\
\text { dependent (see } \\
\text { Attachment I) }\end{array}$ & $P$ & 1 & $\begin{array}{l}\text { Tables with site-specific distribution coefficients for } \\
\text { the parent and daughter radionuclides are available } \\
\text { immediately following this table of parameters. }\end{array}$ & $\begin{array}{l}\text { DOE Project } \\
\text { Communication } \\
\text { (March 2010) }\end{array}$ \\
\hline $\begin{array}{l}\text { Livestock feed grain } \\
\text { fields }\end{array}$ & $\mathrm{cm}^{3} / \mathrm{g}$ & $\begin{array}{c}\text { Nuclide- } \\
\text { dependent } \\
\text { (Default values } \\
\text { available) }\end{array}$ & $0-1 E+34$ & $\mathrm{~N}$ & $\begin{array}{l}\text { Nuclide- } \\
\text { dependent (see } \\
\text { Attachment I) }\end{array}$ & $P$ & 1 & $\begin{array}{l}\text { Tables with site-specific distribution coefficients for } \\
\text { the parent and daughter radionuclides are available } \\
\text { immediately following this table of parameters. }\end{array}$ & $\begin{array}{l}\text { DOE Project } \\
\text { Communication } \\
\text { (March 2010) }\end{array}$ \\
\hline Offsite dwelling site & $\mathrm{cm}^{3} / \mathrm{g}$ & $\begin{array}{c}\text { Nuclide- } \\
\text { dependent } \\
\text { (Default values } \\
\text { available) }\end{array}$ & $0-1 E+34$ & $\mathrm{~N}$ & $\begin{array}{l}\text { Nuclide- } \\
\text { dependent (see } \\
\text { Attachment I) }\end{array}$ & $P$ & 1 & $\begin{array}{l}\text { Tables with site-specific distribution coefficients for } \\
\text { the parent and daughter radionuclides are available } \\
\text { immediately following this table of parameters. }\end{array}$ & $\begin{array}{l}\text { DOE Project } \\
\text { Communication } \\
\text { (March 2010) }\end{array}$ \\
\hline
\end{tabular}

Dose Conversion and Slope Factors

\begin{tabular}{|c|c|c|c|c|c|c|c|c|}
\hline $\begin{array}{l}\text { External dose } \\
\text { conversion factors }\end{array}$ & $\begin{array}{c}\text { (mrem/yr) } \\
\text { per } \\
\text { (pCi/g) }\end{array}$ & $\begin{array}{l}\text { Nuclide- } \\
\text { specific } \\
\text { (default values } \\
\text { available) }\end{array}$ & $\begin{array}{c}\text { Nuclide- } \\
\text { specific } \\
\text { (default } \\
\text { values } \\
\text { available) }\end{array}$ & $\begin{array}{c}\text { Nuclide-specific } \\
\text { (ICRP } 60 \text { values } \\
\text { available) }\end{array}$ & $M$ & 3 & $\begin{array}{l}\text { The ICRP } 60 \text { (external dose conversion factors) library } \\
\text { is selected in conjunction with the ICRP } 72 \text { Adult } \\
\text { (internal dose conversion factors) library to obtain } \\
\text { results in Total Effective Dose (TED). }\end{array}$ & Yu et al. 2007 \\
\hline $\begin{array}{l}\text { Inhalation dose } \\
\text { conversion factors }\end{array}$ & $\mathrm{mrem} / \mathrm{pCi}$ & $\begin{array}{l}\text { Nuclide- } \\
\text { specific } \\
\text { (default values } \\
\text { available) }\end{array}$ & $\begin{array}{c}\text { Nuclide- } \\
\text { specific } \\
\text { (default } \\
\text { values } \\
\text { available) }\end{array}$ & $\begin{array}{c}\text { Nuclide-specific } \\
\text { (ICRP } 72 \text { values } \\
\text { available) }\end{array}$ & $M$ & 3 & $\begin{array}{l}\text { The ICRP } 72 \text { Adult (internal dose conversion factors) } \\
\text { library is selected in conjunction with the ICRP } 60 \\
\text { (external dose conversion factors) library to obtain } \\
\text { results in Total Effective Dose (TED). }\end{array}$ & Yu et al. 2007 \\
\hline
\end{tabular}


RESRAD-OFFSITE Table of Input Parameters for the C-746-U Landfill Offsite Resident Farmer Scenario

\begin{tabular}{|c|c|c|c|c|c|c|c|c|}
\hline $\begin{array}{c}\text { Input Screen Title } \\
\text { and Parameter } \\
\text { Name }\end{array}$ & Units & $\begin{array}{l}\text { Default } \\
\text { Value }^{\mathrm{a}}\end{array}$ & $\begin{array}{r}\text { Code-Acce } \\
\text { Values } \\
\text { Physical } \\
\text { Numerical } \\
\text { Range } \\
\end{array}$ & $\begin{array}{l}\text { Deterministic } \\
\text { Value }\end{array}$ & Type $^{d}$ & Priority $^{\mathrm{e}}$ & Justification & References \\
\hline $\begin{array}{l}\text { Ingestion dose } \\
\text { conversion factors }\end{array}$ & $\mathrm{mrem} / \mathrm{pCi}$ & $\begin{array}{l}\text { Nuclide- } \\
\text { specific } \\
\text { (default values } \\
\text { available) }\end{array}$ & $\begin{array}{c}\text { Nuclide- } \\
\text { specific } \\
\text { (default } \\
\text { values } \\
\text { available) } \\
\end{array}$ & $\begin{array}{c}\text { Nuclide-specific } \\
\text { (ICRP } 72 \text { values } \\
\text { available) }\end{array}$ & $M$ & 3 & $\begin{array}{l}\text { The ICRP } 72 \text { Adult (internal dose conversion factors) } \\
\text { library is selected in conjunction with the ICRP } 60 \\
\text { (external dose conversion factors) library to obtain } \\
\text { results in Total Effective Dose (TED). }\end{array}$ & Yu et al. 2007 \\
\hline $\begin{array}{l}\text { Slope factor -- } \\
\text { external }\end{array}$ & $\begin{array}{l}\text { (risk/yr) } \\
\text { per } \\
(\mathrm{pCi} / \mathrm{g})\end{array}$ & $\begin{array}{l}\text { Nuclide- } \\
\text { specific } \\
\text { (default values } \\
\text { available) }\end{array}$ & $\begin{array}{c}\text { Nuclide- } \\
\text { specific } \\
\text { (default } \\
\text { values } \\
\text { available) } \\
\end{array}$ & $\begin{array}{l}\text { Nuclide-specific } \\
\text { (default values } \\
\text { available) }\end{array}$ & $M$ & 3 & Default values are used. & Yu et al. 2007 \\
\hline $\begin{array}{l}\text { Slope factor -- } \\
\text { inhalation }\end{array}$ & risk/pCi & $\begin{array}{l}\text { Nuclide- } \\
\text { specific } \\
\text { (default values } \\
\text { available) }\end{array}$ & $\begin{array}{c}\text { Nuclide- } \\
\text { specific } \\
\text { (default } \\
\text { values } \\
\text { available) } \\
\end{array}$ & $\begin{array}{l}\text { Nuclide-specific } \\
\text { (default values } \\
\text { available) }\end{array}$ & M & 3 & Default values are used. & Yu et al. 2007 \\
\hline $\begin{array}{l}\text { Slope factor -- food } \\
\text { ingestion }\end{array}$ & risk/pCi & $\begin{array}{l}\text { Nuclide- } \\
\text { specific } \\
\text { (default values } \\
\text { available) }\end{array}$ & $\begin{array}{c}\text { Nuclide- } \\
\text { specific } \\
\text { (default } \\
\text { values } \\
\text { available) } \\
\end{array}$ & $\begin{array}{l}\text { Nuclide-specific } \\
\text { (default values } \\
\text { available) }\end{array}$ & $M$ & 3 & Default values are used. & Yu et al. 2007 \\
\hline $\begin{array}{l}\text { Slope factor -- } \\
\text { water ingestion }\end{array}$ & risk/pCi & $\begin{array}{l}\text { Nuclide- } \\
\text { specific } \\
\text { (default values } \\
\text { available) }\end{array}$ & $\begin{array}{c}\text { Nuclide- } \\
\text { specific } \\
\text { (default } \\
\text { values } \\
\text { available) } \\
\end{array}$ & $\begin{array}{l}\text { Nuclide-specific } \\
\text { (default values } \\
\text { available) }\end{array}$ & M & 3 & Default values are used. & Yu et al. 2007 \\
\hline $\begin{array}{l}\text { Slope factor -- soil } \\
\text { ingestion }\end{array}$ & risk/pCi & $\begin{array}{l}\text { Nuclide- } \\
\text { specific } \\
\text { (default values } \\
\text { available) }\end{array}$ & $\begin{array}{l}\text { Nuclide- } \\
\text { specific } \\
\text { (default } \\
\text { values } \\
\text { available) }\end{array}$ & $\begin{array}{l}\text { Nuclide-specific } \\
\text { (default values } \\
\text { available) }\end{array}$ & M & 3 & Default values are used. & Yu et al. 2007 \\
\hline
\end{tabular}

Transfer Factors

\begin{tabular}{|c|c|c|c|c|c|c|c|c|c|}
\hline $\begin{array}{l}\text { Fruit, grain, } \\
\text { nonleafy vegetables } \\
\text { transfer factor }\end{array}$ & $\begin{array}{l}(\mathrm{pCi} / \mathrm{kg}) / \\
(\mathrm{pCi} / \mathrm{kg})\end{array}$ & $\begin{array}{c}\text { Element- } \\
\text { dependent } \\
\text { (Default values } \\
\text { available) }\end{array}$ & $0-1 E+34$ & $\mathrm{~N}$ & $\begin{array}{c}\text { Element- } \\
\text { dependent } \\
\text { (default values } \\
\text { available) }\end{array}$ & $P$ & 1 & Default values are used. & Yu et al. 2007 \\
\hline $\begin{array}{l}\text { Leafy vegetables } \\
\text { transfer factor }\end{array}$ & $\begin{array}{l}(\mathrm{pCi} / \mathrm{kg}) / \\
(\mathrm{pCi} / \mathrm{kg})\end{array}$ & $\begin{array}{c}\text { Element- } \\
\text { dependent } \\
\text { (Default values } \\
\text { available) }\end{array}$ & $0-1 E+34$ & $\mathrm{~N}$ & $\begin{array}{c}\text { Element- } \\
\text { dependent } \\
\text { (default values } \\
\text { available) }\end{array}$ & $P$ & 1 & Default values are used. & Yu et al. 2007 \\
\hline
\end{tabular}


RESRAD-OFFSITE Table of Input Parameters for the C-746-U Landfill Offsite Resident Farmer Scenario

\begin{tabular}{|c|c|c|c|c|c|c|c|c|c|}
\hline $\begin{array}{c}\text { Input Screen Title } \\
\text { and Parameter } \\
\text { Name }\end{array}$ & Units & $\begin{array}{l}\text { Default } \\
\text { Value }^{a}\end{array}$ & $\begin{array}{r}\text { Code-Accep } \\
\text { Values } \\
\text { Physical } \\
\text { Numerical } \\
\text { Range } \\
\end{array}$ & & $\begin{array}{l}\text { Deterministic } \\
\text { Value }\end{array}$ & Type $^{d}$ & Priority $^{\mathrm{e}}$ & Justification & References \\
\hline $\begin{array}{l}\text { Pasture and silage } \\
\text { transfer factor }\end{array}$ & $\begin{array}{l}(\mathrm{pCi} / \mathrm{kg}) / \\
(\mathrm{pCi} / \mathrm{kg})\end{array}$ & $\begin{array}{c}\text { Element- } \\
\text { dependent } \\
\text { (Default values } \\
\text { available) }\end{array}$ & $0-1 E+34$ & $\mathrm{~N}$ & $\begin{array}{c}\text { Element- } \\
\text { dependent } \\
\text { (default values } \\
\text { available) } \\
\end{array}$ & $P$ & 1 & Default values are used. & Yu et al. 2007 \\
\hline $\begin{array}{l}\text { Livestock feed grain } \\
\text { transfer factor }\end{array}$ & $\begin{array}{l}(\mathrm{pCi} / \mathrm{kg}) / \\
(\mathrm{pCi} / \mathrm{kg})\end{array}$ & $\begin{array}{c}\text { Element- } \\
\text { dependent } \\
\text { (Default values } \\
\text { available) } \\
\end{array}$ & $0-1 E+34$ & $\mathrm{~N}$ & $\begin{array}{c}\text { Element- } \\
\text { dependent } \\
\text { (default values } \\
\text { available) } \\
\end{array}$ & $P$ & 1 & Default values are used. & Yu et al. 2007 \\
\hline $\begin{array}{l}\text { Meat transfer } \\
\text { factor }\end{array}$ & $\begin{array}{l}(\mathrm{pCi} / \mathrm{kg}) / \\
(\mathrm{pCi} / \mathrm{d})\end{array}$ & $\begin{array}{c}\text { Element- } \\
\text { dependent } \\
\text { (Default values } \\
\text { available) } \\
\end{array}$ & $0-1 E+34$ & $\mathrm{~N}$ & $\begin{array}{c}\text { Element- } \\
\text { dependent } \\
\text { (default values } \\
\text { available) } \\
\end{array}$ & $P$ & 2 & Default values are used. & Yu et al. 2007 \\
\hline Milk transfer factor & $\begin{array}{l}(\mathrm{pCi} / \mathrm{L}) / \\
(\mathrm{pCi} / \mathrm{d})\end{array}$ & $\begin{array}{c}\text { Element- } \\
\text { dependent } \\
\text { (Default values } \\
\text { available) }\end{array}$ & $0-1 E+34$ & $\mathrm{~N}$ & $\begin{array}{c}\text { Element- } \\
\text { dependent } \\
\text { (default values } \\
\text { available) } \\
\end{array}$ & $P$ & 2 & Default values are used. & Yu et al. 2007 \\
\hline $\begin{array}{l}\text { Bioaccumulation } \\
\text { factor for fish }\end{array}$ & $\begin{array}{l}(\mathrm{pCi} / \mathrm{kg}) / \\
(\mathrm{pCi} / \mathrm{L})\end{array}$ & $\begin{array}{c}\text { Element- } \\
\text { dependent } \\
\text { (Default values } \\
\text { available) } \\
\end{array}$ & $0-1 E+34$ & $\mathrm{~N}$ & $\begin{array}{c}\text { Element- } \\
\text { dependent } \\
\text { (default values } \\
\text { available) } \\
\end{array}$ & $P$ & 2 & Default values are used. & Yu et al. 2007 \\
\hline $\begin{array}{l}\text { Bioaccumulation } \\
\text { factor for crustacea } \\
\text { and mollusks }\end{array}$ & $\begin{array}{l}(\mathrm{pCi} / \mathrm{kg}) / \\
(\mathrm{pCi} / \mathrm{L})\end{array}$ & $\begin{array}{c}\text { Element- } \\
\text { dependent } \\
\text { (Default values } \\
\text { available) } \\
\end{array}$ & $0-1 E+34$ & $\mathrm{~N}$ & $\begin{array}{c}\text { Element- } \\
\text { dependent } \\
\text { (default values } \\
\text { available) } \\
\end{array}$ & $P$ & 3 & Default values are used. & Yu et al. 2007 \\
\hline
\end{tabular}

Reporting Times

\begin{tabular}{|c|c|c|c|c|c|c|c|c|}
\hline $\begin{array}{l}\text { Times at which } \\
\text { output is reported }\end{array}$ & $\mathrm{yr}$ & $\begin{array}{c}1,3,6,12,30 \\
75,175,420 \\
970\end{array}$ & $0-1 \mathrm{E}+5$ & $\begin{array}{c}1,50,100,500 \\
1026\end{array}$ & $P$ & 3 & $\begin{array}{l}\text { A time horizon of } 1,050 \text { years is used to calculate soil } \\
\text { guidelines. This is assumed to allow for in- growth } \\
\text { and decay since the plant has been in operation for } \\
\text { about } 50 \text { years (since about } 1960 \text { to 2010). } \\
\text { The time horizon is the sum of the maximum user- } \\
\text { specified reporting time and the exposure duration. } \\
\text { For instance, in this case for a time horizon of } 1050 \\
\text { yrs, the maximum reporting time is } 1026 \text { yrs for an } \\
\text { exposure duration of } 24 \text { yrs. }\end{array}$ & $\begin{array}{c}\text { DOE/CH/8901 and } \\
\text { DOE Order } 5400.5 \\
\text { DOE Project } \\
\text { Communication } \\
\text { (May 2010) }\end{array}$ \\
\hline
\end{tabular}

Storage Times

Storage time for d 1 $0-1 \mathrm{E}+34$

\begin{tabular}{l|l}
$\mathrm{N}$ & 1
\end{tabular}

\begin{tabular}{l|l}
1 & B \\
\hline
\end{tabular}

3 Default value is used. 
RESRAD-OFFSITE Table of Input Parameters for the C-746-U Landfill Offsite Resident Farmer Scenario

\begin{tabular}{|c|c|c|c|c|c|c|c|c|c|}
\hline $\begin{array}{c}\text { Input Screen Title } \\
\text { and Parameter } \\
\text { Name }\end{array}$ & Units & $\begin{array}{l}\text { Default } \\
\text { Value }^{\text {a }}\end{array}$ & $\begin{array}{r}\text { Code-Acce } \\
\text { Values } \\
\text { Physical } \\
\text { Numerica } \\
\text { Range }\end{array}$ & & $\begin{array}{l}\text { Deterministic } \\
\text { Value }\end{array}$ & Type $^{d}$ & Priority $^{e}$ & Justification & References \\
\hline surface water & & & & & & & & & \\
\hline $\begin{array}{l}\text { Storage time for } \\
\text { well water }\end{array}$ & $d$ & 1 & $0-1 E+34$ & $\mathrm{~N}$ & 1 & B & 3 & Default value is used. & Yu et al. 2007 \\
\hline $\begin{array}{c}\text { Storage time for } \\
\text { fruits, grain, and } \\
\text { nonleafy vegetables }\end{array}$ & $d$ & 14 & $0-1 E+34$ & $\mathrm{~N}$ & 14 & B & 3 & Default value is used. & Yu et al. 2007 \\
\hline $\begin{array}{l}\text { Storage time for } \\
\text { leafy vegetables }\end{array}$ & $d$ & 1 & $0-1 E+34$ & $\mathrm{~N}$ & 1 & B & 3 & Default value is used. & Yu et al. 2007 \\
\hline $\begin{array}{l}\text { Storage time for } \\
\text { pasture and silage }\end{array}$ & $d$ & 1 & $0-1 E+34$ & $\mathrm{~N}$ & 1 & B & 3 & Default value is used. & Yu et al. 2007 \\
\hline $\begin{array}{l}\text { Storage time for } \\
\text { livestock feed grain }\end{array}$ & $d$ & 45 & $0-1 E+34$ & $\mathrm{~N}$ & 45 & B & 3 & Default value is used. & Yu et al. 2007 \\
\hline $\begin{array}{c}\text { Storage time for } \\
\text { meat }\end{array}$ & $d$ & 20 & $0-1 E+34$ & $\mathrm{~N}$ & 20 & B & 3 & Default value is used. & Yu et al. 2007 \\
\hline $\begin{array}{l}\text { Storage time for } \\
\text { milk }\end{array}$ & $d$ & 1 & $0-1 E+34$ & $\mathrm{~N}$ & 1 & B & 3 & Default value is used. & Yu et al. 2007 \\
\hline $\begin{array}{l}\text { Storage time for } \\
\text { fish }\end{array}$ & $d$ & 7 & $0-1 E+34$ & $\mathrm{~N}$ & 7 & B & 3 & Default value is used. & Yu et al. 2007 \\
\hline $\begin{array}{c}\text { Storage time for } \\
\text { crustacea and } \\
\text { mollusks }\end{array}$ & $d$ & 7 & $0-1 E+34$ & $\mathrm{~N}$ & 7 & B & 3 & Default value is used. & Yu et al. 2007 \\
\hline \multicolumn{10}{|l|}{$\begin{array}{l}\text { Physical and } \\
\text { Hydrological }\end{array}$} \\
\hline Precipitation & $\mathrm{m} / \mathrm{yr}$ & 1 & $0-10$ & & 1.24 & $\mathrm{P}$ & 2 & $\begin{array}{l}\text { The yearly precipitation averages about } 49 \text { inches } \\
\text { (approximately } 1.24 \text { meters). }\end{array}$ & $\begin{array}{l}\text { PRS 2008a } \\
\text { page 1-4 } \\
\text { DOE 2003b } \\
\text { page 2-5 }\end{array}$ \\
\hline Wind speed & $\mathrm{m} / \mathrm{s}$ & 2 & $1 E-4-20$ & & $\begin{array}{l}\text { Actual values } \\
\text { will be from } \\
\text { Paducah read } \\
\text { meteorological } \\
\text { star file }\end{array}$ & $\mathrm{P}$ & 2 & $\begin{array}{l}\text { The STAR file selected from the RESRAD-OFFSITE } \\
\text { code is called KY_Paducah.str. } \\
\text { The wind speed is divided into six intervals in order to } \\
\text { specify the joint frequency distribution of wind speed } \\
\text { and atmospheric stability in each direction of a wind } \\
\text { rose. This is the average wind speed for the wind } \\
\text { speed interval. }\end{array}$ & Yu et al. 2007 \\
\hline \multicolumn{10}{|l|}{$\begin{array}{l}\text { Primary } \\
\text { Contamination }\end{array}$} \\
\hline Area of primary & $\mathrm{m}^{2}$ & 10,000 & Calculated & & Calculated & $\mathrm{P}$ & 2 & The contaminated zone is composed of four different & DOE SOW for $\mathrm{C}$ \\
\hline
\end{tabular}


RESRAD-OFFSITE Table of Input Parameters for the C-746-U Landfill Offsite Resident Farmer Scenario

\begin{tabular}{|c|c|c|c|c|c|c|c|c|}
\hline $\begin{array}{l}\text { Input Screen Title } \\
\text { and Parameter } \\
\text { Name }\end{array}$ & Units & $\begin{array}{l}\text { Default } \\
\text { Value }^{\mathrm{a}}\end{array}$ & $\begin{array}{c}\text { Code-Accepted } \\
\text { Values }^{b} \\
\text { Physical or } \\
\text { Numerical }^{\mathrm{C}}(\mathrm{N}) \\
\text { Range }^{\text {Rang }}\end{array}$ & $\begin{array}{l}\text { Deterministic } \\
\text { Value }\end{array}$ & Type $^{d}$ & Priority ${ }^{e}$ & Justification & References \\
\hline contamination & & & & & & & $\begin{array}{l}\text { waste forms. The waste forms types are soil, } \\
\text { concrete, metal, and organic (lumber and debris). The } \\
\text { total waste disposal area of the landfill is calculated } \\
\text { by the code, it is not an input. The calculated area of } \\
\text { the contaminated zone is approximately } 91,000 \\
\text { square meters (not exactly } 89,436 \text { square meters } \\
\text { which is the total disposal area when the landfill is } \\
\text { filled). The code calculated this area based on input } \\
\text { values from dimensions of the waste disposal area } \\
\text { available in Lee et al. } 1995 \text {. }\end{array}$ & $\begin{array}{l}\text { 746-U landfill } \\
\text { DOE 2003b } \\
\text { Section } 3.2 \text {, } \\
\text { page } 3-11 \text {, } \\
\text { Table 4.5, } \\
\text { page } 4-13 \\
\text { Lee et al. } 1995 \\
\text { Fig } 2-4 \text {, } \\
\text { page } 17\end{array}$ \\
\hline $\begin{array}{l}\text { Length of } \\
\text { contamination } \\
\text { parallel to aquifer } \\
\text { flow }\end{array}$ & $\mathrm{m}$ & 100 & $1 E-4-1 E+6$ & 399 & $P$ & 2 & $\begin{array}{l}\text { This value of } 399 \mathrm{~m} \text { is the conservative longest } \\
\text { dimension between the upgradient edge of the } \\
\text { contaminated zone and the downgradient edge, } \\
\text { parallel to the aquifer. }\end{array}$ & $\begin{array}{l}\text { Lee et al. } 1995 \\
\text { Fig 2-4, } \\
\text { page } 17\end{array}$ \\
\hline $\begin{array}{l}\text { Depth of soil mixing } \\
\text { layer }(\mathrm{m})\end{array}$ & $\mathrm{m}$ & 0.15 & $0-1$ & 0.15 & $P, B$ & 2 & Default value is used. & Yu et al. 2007 \\
\hline $\begin{array}{l}\text { Deposition velocity } \\
\text { of dust ( } \mathrm{m} / \mathrm{s})\end{array}$ & $\mathrm{m} / \mathrm{s}$ & 0.001 & $0-0.01$ & 0.001 & $\mathrm{P}$ & & $\begin{array}{l}\text { This is the average velocity with which dust settles } \\
\text { onto the contaminated zone. It is used to calculate } \\
\text { the release to the atmosphere. The default value is } \\
\text { used per communication with DOE geologist. }\end{array}$ & $\begin{array}{l}\text { Yu et al. } 2007 \\
\text { DOE Project } \\
\text { Communication } \\
\text { with geologist } \\
\text { (April 2010) }\end{array}$ \\
\hline $\begin{array}{l}\text { Irrigation applied } \\
\text { per year }(\mathrm{m} / \mathrm{yr})\end{array}$ & $\mathrm{m} / \mathrm{yr}$ & 0.2 & $0-10$ & 0 & B & 3 & $\begin{array}{l}\text { The irrigation rate for the contaminated zone is set to } \\
\text { "0" since the Resident Farmer is located offsite. }\end{array}$ & Yu et al. 2007 \\
\hline $\begin{array}{l}\text { Evapotranspiration } \\
\text { coefficient }\end{array}$ & -- & 0.5 & $0-0.999$ & 0.83 & $P$ & 2 & $\begin{array}{l}\text { This value was calculated from the HELP Output data } \\
\text { for the Post-Institutional Control Period. The } \\
\text { equation used to calculate the value is available in Yu } \\
\text { et al. } 1993 . \\
\text { The calculations are available in Attachment II } \\
\text { following this table. }\end{array}$ & $\begin{array}{c}\text { DOE 2003b } \\
\text { page C3-243 } \\
\text { Yu et al.1993 } \\
\text { page } 78\end{array}$ \\
\hline Runoff coefficient & -- & 0.2 & $0-1$ & 0.34 & $\mathrm{P}$ & 2 & $\begin{array}{l}\text { This value was calculated from the HELP Output data } \\
\text { for the Post-Institutional Control Period. The } \\
\text { equation used to calculate the value is available in Yu } \\
\text { et al. } 1993 . \\
\text { The calculations are available in Attachment II } \\
\text { following this table. }\end{array}$ & $\begin{array}{l}\text { DOE 2003b } \\
\text { Page C3-243 } \\
\text { Yu et al. } 1993 \\
\text { page } 73\end{array}$ \\
\hline Rainfall and runoff & -- & 160 & $0-1,000$ & 250 & $P$ & 2 & This value was obtained from Wischmeier et al. 1978 & Wischmeier et al. \\
\hline
\end{tabular}


RESRAD-OFFSITE Table of Input Parameters for the C-746-U Landfill Offsite Resident Farmer Scenario

\begin{tabular}{|c|c|c|c|c|c|c|c|c|}
\hline $\begin{array}{c}\text { Input Screen Title } \\
\text { and Parameter } \\
\text { Name }\end{array}$ & Units & $\begin{array}{l}\text { Default } \\
\text { Value }^{\mathrm{a}}\end{array}$ & $\begin{array}{c}\text { Code-Accepted } \\
\text { Values }^{b} \\
\text { Physical or } \\
\text { Numerical' (N) } \\
\text { Range }\end{array}$ & $\begin{array}{l}\text { Deterministic } \\
\text { Value }\end{array}$ & Type $^{d}$ & Priority ${ }^{e}$ & Justification & References \\
\hline & & & & & & & and agreed upon by DOE geologist. & $\begin{array}{c}1978 \\
\text { Figure 1, page } 5 \\
\text { (Predicting } \\
\text { Rainfall Erosion } \\
\text { Losses) } \\
\\
\text { DOE Project } \\
\text { Communication } \\
\text { with geologist } \\
\text { (April 2010) }\end{array}$ \\
\hline $\begin{array}{l}\text { Slope-length- } \\
\text { steepness factor }\end{array}$ & -- & 0.4 & $0-10$ & 0.4 & $P$ & 2 & $\begin{array}{l}\text { DOE geologist recommended a value of } 0.4 \text { based on } \\
\text { site topography. }\end{array}$ & $\begin{array}{c}\text { Yu et al. } 2007 \\
\text { DOE Project } \\
\text { Communication } \\
\text { with geologist } \\
\text { (April 2010) }\end{array}$ \\
\hline $\begin{array}{l}\text { Cover and } \\
\text { management factor }\end{array}$ & -- & 0.003 & $0-1$ & 0.2 & $B, P$ & 2 & $\begin{array}{l}\text { DOE geologist recommended value based on no } \\
\text { appreciable canopy and } 20 \% \text { ground cover. }\end{array}$ & $\begin{array}{l}\text { Yu et al. } 2007 \\
\text { DOE Project } \\
\text { Communication } \\
\text { with geologist } \\
\text { (April 2010) }\end{array}$ \\
\hline $\begin{array}{l}\text { Support practice } \\
\text { factor }\end{array}$ & -- & 1 & $0-1$ & 0.5 & $B, P$ & 2 & DOE geologist recommended value. & $\begin{array}{l}\text { Yu et al. } 2007 \\
\text { DOE Project } \\
\text { Communication } \\
\text { with geologist } \\
\text { (July 2010) }\end{array}$ \\
\hline
\end{tabular}

Contaminated Zone

\begin{tabular}{|c|c|c|c|c|c|c|c|c|}
\hline $\begin{array}{c}\text { Thickness of } \\
\text { contaminated zone }\end{array}$ & $\mathrm{m}$ & 2 & $\begin{array}{c}1 \mathrm{E}-5- \\
1,000\end{array}$ & 13.4 & $\mathrm{P}$ & 2 & $\begin{array}{c}\text { This value is the average thickness for the waste } \\
\text { forms when the landfill is full. }\end{array}$ & $\begin{array}{c}\text { Table 4.5, } \\
\text { page 4-13, } \\
\text { Table Att.3, } \\
\text { page C3-315 }\end{array}$ \\
\hline $\begin{array}{c}\text { Total porosity of } \\
\text { contaminated zone }\end{array}$ & -- & 0.4 & $1 \mathrm{E}-5-1$ & & 0.17 & $\mathrm{P}$ & 2 & $\begin{array}{c}\text { The site-specific value available is 0.168 vol/vol. } \\
\text { Table } 4.4, \\
\text { page 4-9 }\end{array}$ \\
\hline $\begin{array}{c}\text { Dry bulk density of } \\
\text { contaminated zone }\end{array}$ & $\mathrm{g} / \mathrm{cm}^{3}$ & 1.5 & $1 \mathrm{E}-3-22.5$ & & 1.89 & $\mathrm{P}$ & 1 & $\begin{array}{c}\text { The densities of the waste forms were used to } \\
\text { calculate the weighted average density for the }\end{array}$ \\
\hline
\end{tabular}


RESRAD-OFFSITE Table of Input Parameters for the C-746-U Landfill Offsite Resident Farmer Scenario

\begin{tabular}{|c|c|c|c|c|c|c|c|c|}
\hline $\begin{array}{c}\text { Input Screen Title } \\
\text { and Parameter } \\
\text { Name }\end{array}$ & Units & $\begin{array}{l}\text { Default } \\
\text { Value }^{\mathrm{a}}\end{array}$ & 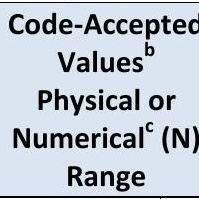 & $\begin{array}{l}\text { Deterministic } \\
\text { Value }\end{array}$ & Type $^{d}$ & Priority ${ }^{\mathrm{e}}$ & Justification & References \\
\hline & & & & & & & $\begin{array}{l}\text { contaminated zone which is approximately } \\
1.89 \mathrm{~g} / \mathrm{cm}^{3} \text {. }\end{array}$ & page $4-13$ \\
\hline $\begin{array}{l}\text { Soil erodibility } \\
\text { factor of } \\
\text { contaminated zone }\end{array}$ & tons/acre & 0.4 & $0-0.5$ & 0.37 & P & 2 & $\begin{array}{l}\text { DOE geologist recommended value based on silty clay } \\
\text { loam and } 0.5 \% \text { organic matter. }\end{array}$ & $\begin{array}{c}\text { Yu et al. } 2007 \\
\text { Table } 2.4-2, \\
\text { page B-31 } \\
\\
\text { DOE Project } \\
\text { Communication } \\
\text { with geologist } \\
\text { (May 2010) }\end{array}$ \\
\hline $\begin{array}{l}\text { Field capacity of } \\
\text { contaminated zone }\end{array}$ & -- & 0.3 & $1 E-5-1$ & 0.07 & P & 3 & The site-specific value available is $0.073 \mathrm{vol} / \mathrm{vol}$. & $\begin{array}{l}\text { DOE 2003b } \\
\text { Table 4.4, } \\
\text { page 4-9 }\end{array}$ \\
\hline $\begin{array}{l}\text { Soil b parameter of } \\
\text { contaminated zone }\end{array}$ & -- & 5.3 & $0-15$ & 4.05 & $\mathrm{P}$ & 2 & $\begin{array}{l}\text { DOE geologist determined that the most appropriate } \\
\text { value for the contaminated zone b available in Yu et } \\
\text { al. } 1993 \text { is the one for sand. It is known that the } \\
\text { contaminated zone (waste) will have high porosity } \\
\text { and high permeability. When selecting a } \\
\text { deterministic value for this input parameter, the } \\
\text { closest material and corresponding Soil b Parameter, } \\
\text { as developed by Clapp \& and Hornberger (Yu et al. } \\
\text { 1993), for concrete, steel and soil waste is sand. } \\
\text { Clapp \& Hornberger do not offer a corresponding Soil } \\
\text { b Parameter for landfill waste material. This value } \\
\text { according to the geologist should be low. }\end{array}$ & $\begin{array}{l}\text { Yu et al. } 1993 \\
\text { page } 83 \\
\\
\text { DOE project } \\
\text { Communication } \\
\text { with geologist } \\
\text { (July 2010) }\end{array}$ \\
\hline $\begin{array}{c}\text { Hydraulic } \\
\text { conductivity of } \\
\text { contaminated zone }\end{array}$ & $\mathrm{m} / \mathrm{yr}$ & 10 & $\begin{array}{l}1 E-3- \\
1 E+10\end{array}$ & 315.4 & P & 2 & $\begin{array}{l}\text { The hydraulic conductivity for waste forms } 1-4 \text { is } \\
1.0 \mathrm{E}^{-3} \mathrm{~cm} / \mathrm{s}(315.4 \mathrm{~m} / \mathrm{yr}) \text {. }\end{array}$ & $\begin{array}{l}\text { DOE 2003b } \\
\text { Fig. } 4.5 \text {, page } 4-18\end{array}$ \\
\hline
\end{tabular}

Clean Cover

\begin{tabular}{|c|c|c|c|c|c|c|c|c|}
\hline $\begin{array}{l}\text { Thickness of clean } \\
\text { cover }\end{array}$ & $\mathrm{m}$ & 0 & $0-100$ & 1.52 & $P$ & 2 & $\begin{array}{l}\text { For receptors exposed during the post-institutional } \\
\text { control period this value is the depth of the final } \\
\text { cover planned for the landfill. The landfill cover will } \\
\text { have six layers with a total thickness of } 5 \mathrm{ft} \text { ( } 1.52 \\
\text { meters). }\end{array}$ & $\begin{array}{c}\text { DOE 2003b } \\
\text { Section 3.2, page } \\
\text { 3-11, Fig. 4.3, } \\
\text { page 4-16 } \\
\\
\text { DOE Project } \\
\text { Communication } \\
\text { with geologist and } \\
\text { engineer } \\
\text { (April 2010) }\end{array}$ \\
\hline
\end{tabular}


RESRAD-OFFSITE Table of Input Parameters for the C-746-U Landfill Offsite Resident Farmer Scenario

\begin{tabular}{|c|c|c|c|c|c|c|c|c|}
\hline $\begin{array}{c}\text { Input Screen Title } \\
\text { and Parameter } \\
\text { Name }\end{array}$ & Units & $\begin{array}{l}\text { Default } \\
\text { Value }^{a}\end{array}$ & $\begin{array}{r}\text { Code-Accep }^{\text {Values }^{b}} \\
\text { Physical } \\
\text { Numerical } \\
\text { Range } \\
\end{array}$ & $\begin{array}{l}\text { Deterministic } \\
\text { Value }\end{array}$ & Type $^{d}$ & Priority & Justification & References \\
\hline $\begin{array}{l}\text { Total porosity of } \\
\text { clean cover }\end{array}$ & -- & 0.4 & $1 E-5-1$ & 0.3 & P & 2 & $\begin{array}{l}\text { DOE geologist recommended a value for vegetative } \\
\text { soil cover (root zone, layer } 1 \text { ) available in DOE 2003b. }\end{array}$ & $\begin{array}{l}\text { DOE Project } \\
\text { Communication } \\
\text { with geologist } \\
\text { (May 2010) and } \\
\text { DOE 2003b } \\
\text { Table 4.4 } \\
\end{array}$ \\
\hline $\begin{array}{l}\text { Dry bulk density of } \\
\text { clean cover }\end{array}$ & $\mathrm{g} / \mathrm{cm}^{3}$ & 1.5 & $1 E-3-22.5$ & 1.5 & $P$ & 2 & $\begin{array}{l}\text { The value for the density of the cover was obtained } \\
\text { from the previous RESRAD study for the landfill } \\
\text { described in DOE 2003b. This value was also } \\
\text { confirmed with DOE to be a site specific value for the } \\
\text { final cover. }\end{array}$ & $\begin{array}{c}\text { DOE 2003b } \\
\text { Table Att.5, page } \\
\text { C3-316 } \\
\text { DOE Project } \\
\text { Communication } \\
\text { with geologist and } \\
\text { engineer } \\
\text { (April 2010) } \\
\end{array}$ \\
\hline $\begin{array}{l}\text { Soil erodibility } \\
\text { factor of clean } \\
\text { cover }\end{array}$ & tons/acre & 0.4 & $0-0.5$ & 0.37 & $\mathrm{P}$ & 2 & $\begin{array}{l}\text { DOE geologist recommended value based on silty clay } \\
\text { loam and } 0.5 \% \text { organic matter. }\end{array}$ & $\begin{array}{c}\text { Yu et al. } 2007 \\
\text { Table 2.4-2, page } \\
\text { B-31 } \\
\\
\text { DOE Project } \\
\text { Communication } \\
\text { with geologist } \\
\text { (May 2010) } \\
\end{array}$ \\
\hline $\begin{array}{l}\text { Volumetric water } \\
\text { content of clean } \\
\text { cover }\end{array}$ & -- & 0.05 & $0-1$ & 0.347 & $\mathrm{P}$ & 2 & $\begin{array}{l}\text { DOE geologist recommended value based on silty clay } \\
\text { loam and normal distribution. However, this } \\
\text { parameter is only used by the code when the radon } \\
\text { pathway is active and radon is included in the } \\
\text { conceptual site model. }\end{array}$ & $\begin{array}{l}\text { Yu et al. } 2007 \\
\text { DOE Project } \\
\text { Communication } \\
\text { with geologist } \\
\text { (April 2010) }\end{array}$ \\
\hline
\end{tabular}

Agriculture Area Parameters

Fruit, Grain, and Non-leafy Vegetables Field

\begin{tabular}{|c|c|c|c|c|c|c|c|c|}
\hline $\begin{array}{l}\text { Area for fruit, grain, } \\
\text { and non-leafy } \\
\text { vegetables field }\end{array}$ & $\mathrm{m}^{2}$ & 1,000 & Calculated & $\begin{array}{l}\text { Calculated by } \\
\text { the code }\end{array}$ & B & 3 & $\begin{array}{l}\text { The fruit, grain and non-leafy vegetable growing area, } \\
\text { the leafy vegetable growing area, the pasture and } \\
\text { silage growing area, the livestock feed grain growing } \\
\text { area, and the dwelling site are all approximated by } \\
\text { rectangular shapes in the atmospheric transport } \\
\text { model. The sides of these rectangles must be parallel }\end{array}$ & Yu et al. 2007 \\
\hline
\end{tabular}


RESRAD-OFFSITE Table of Input Parameters for the C-746-U Landfill Offsite Resident Farmer Scenario

\begin{tabular}{|c|c|c|c|c|c|c|c|c|}
\hline $\begin{array}{c}\text { Input Screen Title } \\
\text { and Parameter } \\
\text { Name }\end{array}$ & Units & $\begin{array}{l}\text { Default } \\
\text { Value }^{\mathrm{a}}\end{array}$ & $\begin{array}{c}\text { Code-Accepted } \\
\text { Values }^{b} \\
\text { Physical or } \\
\text { Numerical }^{c} \text { (N) } \\
\text { Range }^{\text {Rumed }}\end{array}$ & $\begin{array}{l}\text { Deterministic } \\
\text { Value }\end{array}$ & Type $^{d}$ & Priority ${ }^{e}$ & Justification & References \\
\hline & & & & & & & to the sides of the primary contamination. & \\
\hline $\begin{array}{l}\text { Fraction of area } \\
\text { directly over } \\
\text { primary } \\
\text { contamination for } \\
\text { fruit, grain, and } \\
\text { nonleafy vegetables } \\
\text { field }\end{array}$ & -- & 0 & $0-1$ & 0 & $B, P$ & 3 & $\begin{array}{l}\text { Default value is used since the receptor is outside of } \\
\text { the contaminated zone. }\end{array}$ & Yu et al. 2007 \\
\hline $\begin{array}{l}\text { Irrigation applied } \\
\text { per year for fruit, } \\
\text { grain, and nonleafy } \\
\text { vegetables field }\end{array}$ & $\mathrm{m} / \mathrm{yr}$ & 0.2 & $0-10$ & 0.1 & B & 3 & $\begin{array}{l}\text { Irrigation in the Paducah, Kentucky area is considered } \\
\text { to be unlikely. In the event irrigation is necessary, the } \\
\text { water will primarily come from uncontaminated } \\
\text { surface water and not from groundwater (well). } \\
\text { Information from the USGS shows that surface water } \\
\text { is the main source of water used in Kentucky for } \\
\text { irrigation (Kenny et al. 2009). The Paducah area (i.e., } \\
\text { where PGDP is located) receives about an average of } \\
49 \text { inches (1.24 m) of precipitation per year (PRS } \\
2008 \text { a). According to ATSDR 2002, the farms in } \\
\text { McCracken County, KY (i.e., where Paducah is } \\
\text { located) rely on rainfall to water their crops. For } \\
\text { conservatism in the modeling, and as recommended } \\
\text { by DOE-PPPO, it was assumed that the Offsite } \\
\text { Resident Farmer uses contaminated well water for } \\
\text { irrigation of agricultural areas (i.e., fruit, grain, non- } \\
\text { leafy and leafy vegetables). An irrigation rate of } 0.1 \\
\text { m/yr is used for the Offsite Resident Farmer's } \\
\text { agricultural areas (i.e., fruit, grain, non-leafy and leafy } \\
\text { vegetables). } \\
\text { The fruits, grains, non-leafy vegetables, and leafy } \\
\text { vegetables are for human consumption. }\end{array}$ & $\begin{array}{c}\text { DOE Project } \\
\text { Communication } \\
\text { with DOE-PPPO } \\
\text { (April 2011) } \\
\text { PRS 2008a } \\
\text { page 1-4 } \\
\text { ATSDR } 2002 \\
\begin{array}{c}\text { Yu et al. } 1993 \\
\text { page } 75\end{array} \\
\text { Yu et al. } 2007 \\
\text { Kenny et al. } 2009\end{array}$ \\
\hline $\begin{array}{l}\text { Evapotranspiration } \\
\text { coefficient for fruit, } \\
\text { grain, and nonleafy } \\
\text { vegetables field }\end{array}$ & -- & 0.5 & $0-0.999$ & 0.74 & $P$ & 2 & $\begin{array}{l}\text { This value was calculated from the HELP Output data } \\
\text { for the Post-Institutional Control Period. The } \\
\text { equation used to calculate the value is available in Yu } \\
\text { et al. } 1993 . \\
\text { The calculations are available in Attachment II } \\
\text { following this table. }\end{array}$ & $\begin{array}{l}\text { DOE } 2003 \mathrm{~b} \\
\text { page C3-243 } \\
\text { Yu et al. } 1993 \\
\text { page } 78\end{array}$ \\
\hline $\begin{array}{l}\text { Runoff coefficient } \\
\text { for fruit, grain, and }\end{array}$ & -- & 0.2 & $0-1$ & 0.34 & P & 2 & $\begin{array}{l}\text { This value was calculated from the HELP Output data } \\
\text { for the Post-Institutional Control Period. The }\end{array}$ & $\begin{array}{l}\text { DOE 2003b } \\
\text { page C3-243 }\end{array}$ \\
\hline
\end{tabular}


RESRAD-OFFSITE Table of Input Parameters for the C-746-U Landfill Offsite Resident Farmer Scenario

\begin{tabular}{|c|c|c|c|c|c|c|c|c|}
\hline $\begin{array}{c}\text { Input Screen Title } \\
\text { and Parameter } \\
\text { Name }\end{array}$ & Units & $\begin{array}{l}\text { Default } \\
\text { Value }^{\mathrm{a}}\end{array}$ & $\begin{array}{l}\text { Code-Accepted } \\
\text { Values }^{b} \\
\text { Physical or } \\
\text { Numerical }{ }^{\mathrm{C}} \text { (N) } \\
\text { Range }\end{array}$ & $\begin{array}{l}\text { Deterministic } \\
\text { Value }\end{array}$ & Type $^{d}$ & Priority $^{e}$ & Justification & References \\
\hline $\begin{array}{l}\text { nonleafy vegetables } \\
\text { field }\end{array}$ & & & & & & & $\begin{array}{l}\text { calculated value is } 0.34 \text {. The equation used to } \\
\text { calculate the value is available in Yu et al. } 1993 . \\
\text { The calculations are available in Attachment II } \\
\text { following this table. }\end{array}$ & $\begin{array}{l}\text { Yu et al. } 1993 \\
\text { page } 73\end{array}$ \\
\hline $\begin{array}{l}\text { Depth of soil mixing } \\
\text { layer or plow layer } \\
\text { for fruit, grain, and } \\
\text { nonleafy vegetables } \\
\text { field } \\
\end{array}$ & $\mathrm{m}$ & 0.15 & $0-1$ & 0.15 & $P, B$ & 2 & Default value is used. & Yu et al. 2007 \\
\hline $\begin{array}{l}\text { Volumetric water } \\
\text { content for fruit, } \\
\text { grain, and nonleafy } \\
\text { vegetables field }\end{array}$ & -- & 0.3 & $1 E-5-1$ & 0.347 & $P$ & 2 & $\begin{array}{l}\text { DOE geologist recommended value based on silty clay } \\
\text { loam and normal distribution. }\end{array}$ & $\begin{array}{l}\text { Yu et al. } 2007 \\
\text { DOE project } \\
\text { communication } \\
\text { with geologist } \\
\text { (April 2010) }\end{array}$ \\
\hline $\begin{array}{l}\text { Dry bulk density of } \\
\text { soil for fruit, grain, } \\
\text { and nonleafy } \\
\text { vegetables field }\end{array}$ & $\mathrm{g} / \mathrm{cm}^{3}$ & 1.5 & $1 E-3-22.5$ & 1.5 & $P$ & 2 & Default value is used. & Yu et al. 2007 \\
\hline $\begin{array}{l}\text { Soil erodibility } \\
\text { factor for fruit, } \\
\text { grain, and nonleafy } \\
\text { vegetables field }\end{array}$ & tons/acre & 0.4 & $0-0.5$ & 0.37 & P & 2 & $\begin{array}{l}\text { DOE geologist recommended value based on silty clay } \\
\text { loam and } 0.5 \% \text { organic matter. }\end{array}$ & $\begin{array}{c}\text { Yu et al. } 2007 \\
\text { Table 2.4-2, page } \\
\text { B-31 } \\
\text { DOE Project } \\
\text { Communication } \\
\text { with geologist } \\
\text { (May 2010) }\end{array}$ \\
\hline $\begin{array}{l}\text { Slope-length- } \\
\text { steepness factor for } \\
\text { fruit, grain, and } \\
\text { nonleafy vegetables } \\
\text { field }\end{array}$ & -- & 0.4 & $0-10$ & 0.4 & $P$ & 2 & $\begin{array}{l}\text { DOE geologist recommended to use } 0.4 \text { based on site } \\
\text { topography. }\end{array}$ & $\begin{array}{l}\text { Yu et al. } 2007 \\
\text { DOE Project } \\
\text { Communication } \\
\text { with geologist } \\
\text { (April 2010) } \\
\end{array}$ \\
\hline $\begin{array}{l}\text { Cover and } \\
\text { management factor } \\
\text { for fruit, grain, and } \\
\text { nonleafy vegetables } \\
\text { field }\end{array}$ & -- & 0.003 & $0-1$ & 0.2 & $B, P$ & 2 & $\begin{array}{l}\text { DOE geologist recommended value based on no } \\
\text { appreciable canopy and } 20 \% \text { ground cover. }\end{array}$ & $\begin{array}{l}\text { Yu et al. } 2007 \\
\text { DOE Project } \\
\text { Communication } \\
\text { with geologist } \\
\text { (April 2010) }\end{array}$ \\
\hline
\end{tabular}


RESRAD-OFFSITE Table of Input Parameters for the C-746-U Landfill Offsite Resident Farmer Scenario

\begin{tabular}{|c|c|c|c|c|c|c|c|c|}
\hline $\begin{array}{c}\text { Input Screen Title } \\
\text { and Parameter } \\
\text { Name }\end{array}$ & Units & $\begin{array}{l}\text { Default } \\
\text { Value }^{\mathrm{a}}\end{array}$ & $\begin{array}{c}\text { Code-Accepted } \\
\text { Values }^{\mathrm{b}} \\
\text { Physical or } \\
\text { Numerical }^{\mathrm{c}}(\mathrm{N}) \\
\text { Range } \\
\end{array}$ & $\begin{array}{l}\text { Deterministic } \\
\text { Value }\end{array}$ & Type $^{d}$ & Priority ${ }^{e}$ & Justification & References \\
\hline $\begin{array}{l}\text { Support practice } \\
\text { factor for fruit, } \\
\text { grain, and nonleafy } \\
\text { vegetables field }\end{array}$ & -- & 1 & $0-1$ & 0.5 & $B, P$ & 2 & DOE geologist recommended value. & $\begin{array}{l}\text { Yu et al. } 2007 \\
\text { DOE Project } \\
\text { Communication } \\
\text { with geologist } \\
\text { (July 2010) }\end{array}$ \\
\hline
\end{tabular}

Leafy Vegetable Field

\begin{tabular}{|c|c|c|c|c|c|c|c|c|}
\hline $\begin{array}{l}\text { Area for leafy } \\
\text { vegetable field }\end{array}$ & $\mathrm{m}^{2}$ & 1,000 & Calculated & $\begin{array}{l}\text { Calculated by } \\
\text { the code }\end{array}$ & B & 3 & $\begin{array}{l}\text { The fruit, grain and non-leafy vegetable growing area, } \\
\text { the leafy vegetable growing area, the pasture and } \\
\text { silage growing area, the livestock feed grain growing } \\
\text { area, and the dwelling site are all approximated by } \\
\text { rectangular shapes in the atmospheric transport } \\
\text { model. The sides of these rectangles must be parallel } \\
\text { to the sides of the primary contamination. }\end{array}$ & Yu et al. 2007 \\
\hline $\begin{array}{c}\text { Fraction of area } \\
\text { directly over } \\
\text { primary } \\
\text { contamination for } \\
\text { leafy vegetable field } \\
\end{array}$ & -- & 0 & $0-1$ & 0 & $B, P$ & 3 & $\begin{array}{l}\text { Default value is used since the receptor is located } \\
\text { outside the contaminated zone. }\end{array}$ & Yu et al. 2007 \\
\hline $\begin{array}{l}\text { Irrigation applied } \\
\text { per year for leafy } \\
\text { vegetable field }\end{array}$ & $\mathrm{m} / \mathrm{yr}$ & 0.2 & $0-10$ & 0.1 & B & 3 & $\begin{array}{l}\text { Irrigation in the Paducah, Kentucky area is considered } \\
\text { to be unlikely. In the event irrigation is necessary, the } \\
\text { water will primarily come from uncontaminated } \\
\text { surface water and not from groundwater (well). } \\
\text { Information from the USGS shows that surface water } \\
\text { is the main source of water used in Kentucky for } \\
\text { irrigation (Kenny et al. 2009). The Paducah area (i.e., } \\
\text { where PGDP is located) receives about an average of } \\
49 \text { inches (1.24 m) of precipitation per year (PRS } \\
2008 \text { a). According to ATSDR 2002, the farms in } \\
\text { McCracken County, KY (i.e., where Paducah is } \\
\text { located) rely on rainfall to water their crops. For } \\
\text { conservatism in the modeling, and as recommended } \\
\text { by DOE-PPPO, it was assumed that the Offsite } \\
\text { Resident Farmer uses contaminated well water for } \\
\text { irrigation of agricultural areas (i.e., fruit, grain, non- } \\
\text { leafy and leafy vegetables). An irrigation rate of 0.1 } \\
\text { m/yr is used for the Offsite Resident Farmer's } \\
\text { agricultural areas (i.e., fruit, grain, non-leafy and leafy } \\
\text { vegetables). }\end{array}$ & $\begin{array}{c}\text { DOE Project } \\
\text { Communication } \\
\text { with DOE-PPPO } \\
\text { (April 2011) } \\
\text { PRS 2008a } \\
\text { page 1-4 } \\
\text { ATSDR } 2002 \\
\text { page } 8 \\
\text { Yu et al. } 1993 \\
\text { page } 75 \\
\text { Yu et al. } 2007 \\
\text { Kenny et al. } 2009\end{array}$ \\
\hline
\end{tabular}


RESRAD-OFFSITE Table of Input Parameters for the C-746-U Landfill Offsite Resident Farmer Scenario

\begin{tabular}{|c|c|c|c|c|c|c|c|c|}
\hline $\begin{array}{c}\text { Input Screen Title } \\
\text { and Parameter } \\
\text { Name }\end{array}$ & Units & $\begin{array}{l}\text { Default } \\
\text { Value }^{\mathrm{a}}\end{array}$ & $\begin{array}{c}\text { Code-Accepted } \\
\text { Values }^{b} \\
\text { Physical or } \\
\text { Numerical }^{\mathrm{C}}(\mathrm{N}) \\
\text { Range }^{\text {Rang }}\end{array}$ & $\begin{array}{l}\text { Deterministic } \\
\text { Value }\end{array}$ & Type $^{d}$ & Priority ${ }^{e}$ & Justification & References \\
\hline & & & & & & & $\begin{array}{l}\text { The fruits, grains, non-leafy vegetables, and leafy } \\
\text { vegetables are for human consumption. }\end{array}$ & \\
\hline $\begin{array}{l}\text { Evapotranspiration } \\
\text { coefficient for leafy } \\
\text { vegetable field }\end{array}$ & -- & 0.5 & $0-0.999$ & 0.74 & $P$ & 2 & $\begin{array}{l}\text { This value was calculated using the HELP Output data } \\
\text { for the Post-Institutional Control Period. The } \\
\text { equation used to calculate the value is available in Yu } \\
\text { et al. } 1993 . \\
\text { The calculations are available in Attachment II } \\
\text { following this table. }\end{array}$ & $\begin{array}{c}\text { DOE } 2003 b \\
\text { page C3-243 } \\
\text { Yu et al. } 1993 \\
\text { page } 78\end{array}$ \\
\hline $\begin{array}{l}\text { Runoff coefficient } \\
\text { for leafy vegetable } \\
\text { field }\end{array}$ & -- & 0.2 & $0-1$ & 0.34 & $P$ & 2 & $\begin{array}{l}\text { This value was calculated from the HELP Output data } \\
\text { for the Post-Institutional Control Period. The } \\
\text { calculated value is } 0.34 \text {. The equation used to } \\
\text { calculate the value is available in Yu et al. } 1993 \text {. } \\
\text { The calculations are available in Attachment II } \\
\text { following this table. }\end{array}$ & $\begin{array}{l}\text { DOE 2003b } \\
\text { page C3-243 } \\
\text { Yu et al. } 1993 \\
\text { page } 73\end{array}$ \\
\hline $\begin{array}{l}\text { Depth of soil mixing } \\
\text { layer or plow layer } \\
\text { for leafy vegetable } \\
\text { field }\end{array}$ & $\mathrm{m}$ & 0.15 & $0-1$ & 0.15 & $P, B$ & 2 & Default value is used. & Yu et al. 2007 \\
\hline $\begin{array}{l}\text { Volumetric water } \\
\text { content for leafy } \\
\text { vegetable field }\end{array}$ & -- & 0.3 & $1 E-5-1$ & 0.347 & $P$ & 2 & $\begin{array}{l}\text { DOE geologist recommended value based on silty clay } \\
\text { loam and normal distribution. }\end{array}$ & $\begin{array}{l}\text { Yu et al. } 2007 \\
\text { DOE Project } \\
\text { Communication } \\
\text { with geologist } \\
\text { (April 2010) }\end{array}$ \\
\hline $\begin{array}{l}\text { Dry bulk density of } \\
\text { soil for leafy } \\
\text { vegetable field }\end{array}$ & $\mathrm{g} / \mathrm{cm}^{3}$ & 1.5 & $1 E-3-22.5$ & 1.5 & $\mathrm{P}$ & 2 & Default value is used. & Yu et al. 2007 \\
\hline $\begin{array}{l}\text { Soil erodibility } \\
\text { factor for leafy } \\
\text { vegetable field }\end{array}$ & tons/acre & 0.4 & $0-0.5$ & 0.37 & $P$ & 2 & $\begin{array}{l}\text { DOE geologist recommended value based on silty clay } \\
\text { loam and } 0.5 \% \text { organic matter. }\end{array}$ & $\begin{array}{l}\text { Yu et al. } 2007 \\
\text { Table 2.4-2, page } \\
\text { B-31 } \\
\text { DOE Project } \\
\text { Communication } \\
\text { with geologist } \\
\text { (May 2010) }\end{array}$ \\
\hline $\begin{array}{l}\text { Slope-length- } \\
\text { steepness factor for }\end{array}$ & -- & 0.4 & $0-10$ & 0.4 & $P$ & 2 & $\begin{array}{l}\text { DOE geologist recommended a value of } 0.4 \text { based on } \\
\text { site topography. }\end{array}$ & Yu et al. 2007 \\
\hline
\end{tabular}


RESRAD-OFFSITE Table of Input Parameters for the C-746-U Landfill Offsite Resident Farmer Scenario

\begin{tabular}{|c|c|c|c|c|c|c|c|c|}
\hline $\begin{array}{c}\text { Input Screen Title } \\
\text { and Parameter } \\
\text { Name }\end{array}$ & Units & $\begin{array}{l}\text { Default } \\
\text { Value }^{a}\end{array}$ & $\begin{array}{l}\text { Code-Accepted } \\
\text { Values }^{b} \\
\text { Physical or } \\
\text { Numerical }^{c}(\mathrm{~N}) \\
\text { Range }\end{array}$ & $\begin{array}{l}\text { Deterministic } \\
\text { Value }\end{array}$ & Type $^{d}$ & Priority $^{\mathrm{e}}$ & Justification & References \\
\hline leafy vegetable field & & & & & & & & $\begin{array}{c}\text { DOE Project } \\
\text { Communication } \\
\text { with geologist } \\
\text { (April 2010) }\end{array}$ \\
\hline $\begin{array}{c}\text { Cover and } \\
\text { management factor } \\
\text { for leafy vegetable } \\
\text { field }\end{array}$ & -- & 0.003 & $0-1$ & 0.2 & $B, P$ & 2 & $\begin{array}{l}\text { DOE geologist recommended value based on no } \\
\text { appreciable canopy and } 20 \% \text { ground cover. }\end{array}$ & $\begin{array}{l}\text { Yu et al. } 2007 \\
\text { DOE Project } \\
\text { Communication } \\
\text { with geologist } \\
\text { (April 2010) }\end{array}$ \\
\hline $\begin{array}{l}\text { Support practice } \\
\text { factor for leafy } \\
\text { vegetable field }\end{array}$ & -- & 1 & $0-1$ & 0.5 & $B, P$ & 2 & DOE geologist recommended value. & $\begin{array}{l}\text { Yu et al. } 2007 \\
\text { DOE Project } \\
\text { Communication } \\
\text { with geologist } \\
\text { (July 2010) }\end{array}$ \\
\hline
\end{tabular}

Livestock Feed Growing Area Parameters

Pasture and Silage Field

\begin{tabular}{|c|c|c|c|c|c|c|c|c|}
\hline $\begin{array}{l}\text { Area for pasture } \\
\text { and silage field }\end{array}$ & $\mathrm{m}^{2}$ & 10,000 & Calculated & $\begin{array}{l}\text { Calculated by } \\
\text { the code }\end{array}$ & B & 3 & $\begin{array}{l}\text { The fruit, grain and non-leafy vegetable growing area, } \\
\text { the leafy vegetable growing area, the pasture and } \\
\text { silage growing area, the livestock feed grain growing } \\
\text { area, and the dwelling site are all approximated by } \\
\text { rectangular shapes in the atmospheric transport } \\
\text { model. The sides of these rectangles must be parallel } \\
\text { to the sides of the primary contamination. }\end{array}$ & Yu et al. 2007 \\
\hline $\begin{array}{l}\text { Fraction of area } \\
\text { directly over } \\
\text { primary } \\
\text { contamination for } \\
\text { pasture and silage } \\
\text { field }\end{array}$ & -- & 0 & $0-1$ & 0 & $B, P$ & 3 & $\begin{array}{l}\text { Default is used since the receptor is located outside } \\
\text { the contaminated zone. }\end{array}$ & Yu et al. 2007 \\
\hline $\begin{array}{l}\text { Irrigation applied } \\
\text { per year for pasture } \\
\text { and silage field }\end{array}$ & $\mathrm{m} / \mathrm{yr}$ & 0.2 & $0-10$ & 0 & B & 3 & $\begin{array}{l}\text { The irrigation rate was set to } 0 \mathrm{~m} / \mathrm{yr} \text { as requested by } \\
\text { DOE-PPPO, since no irrigation is being considered for } \\
\text { the pasture and silage field. Irrigation in the Paducah, } \\
\text { Kentucky area is considered to be unlikely. In the } \\
\text { event irrigation is necessary, the water will primarily } \\
\text { come from uncontaminated surface water and not }\end{array}$ & $\begin{array}{c}\text { DOE Project } \\
\text { Communication } \\
\text { with DOE-PPPO } \\
\text { (September 2010) } \\
\text { DOE Project }\end{array}$ \\
\hline
\end{tabular}


RESRAD-OFFSITE Table of Input Parameters for the C-746-U Landfill Offsite Resident Farmer Scenario

\begin{tabular}{|c|c|c|c|c|c|c|c|c|}
\hline $\begin{array}{c}\text { Input Screen Title } \\
\text { and Parameter } \\
\text { Name }\end{array}$ & Units & $\begin{array}{l}\text { Default } \\
\text { Value }^{\mathrm{a}}\end{array}$ & $\begin{array}{l}\text { Code-Acceptec } \\
\text { Values }^{b} \\
\text { Physical or } \\
\text { Numerical }{ }^{c}(\mathrm{~N}) \\
\text { Range }\end{array}$ & $\begin{array}{l}\text { Deterministic } \\
\text { Value }\end{array}$ & Type $^{d}$ & Priority $^{e}$ & Justification & References \\
\hline & & & & & & & $\begin{array}{l}\text { from groundwater (well). Information from the USGS } \\
\text { shows that surface water is the main source of water } \\
\text { used in Kentucky for irrigation (Kenny et al. 2009). } \\
\text { The pasture and silage and livestock feed grain are } \\
\text { for livestock consumption. }\end{array}$ & $\begin{array}{c}\text { Communication } \\
\text { with DOE-PPPO } \\
\text { (April 2011) } \\
\text { Kenny et al. } 2009\end{array}$ \\
\hline $\begin{array}{l}\text { Evapotranspiration } \\
\text { coefficient for } \\
\text { pasture and silage } \\
\text { field }\end{array}$ & -- & 0.5 & $0-0.999$ & 0.83 & $P$ & 2 & $\begin{array}{l}\text { This value was calculated using the HELP Output data } \\
\text { for the Post-Institutional Control Period. The } \\
\text { equation used to calculate the value is available in Yu } \\
\text { et al. } 1993 . \\
\text { The calculations are available in Attachment II } \\
\text { following this table. }\end{array}$ & $\begin{array}{l}\text { DOE } 2003 b \\
\text { page C3-243 } \\
\text { Yu et al. } 1993 \\
\text { page } 78\end{array}$ \\
\hline $\begin{array}{l}\text { Runoff coefficient } \\
\text { for pasture and } \\
\text { silage field }\end{array}$ & -- & 0.2 & $0-1$ & 0.34 & $P$ & 2 & $\begin{array}{l}\text { This value was calculated from the HELP Output data } \\
\text { for the Post-Institutional Control Period. The } \\
\text { calculated value is } 0.34 \text {. The equation used to } \\
\text { calculate the value is available in Yu et al. 1993. } \\
\text { The calculations are available in Attachment II } \\
\text { following this table. }\end{array}$ & $\begin{array}{l}\text { DOE } 2003 b \\
\text { page C3-243 } \\
\text { Yu et al. } 1993 \\
\text { page } 73\end{array}$ \\
\hline $\begin{array}{l}\text { Depth of soil mixing } \\
\text { layer or plow layer } \\
\text { for pasture and } \\
\text { silage field }\end{array}$ & $\mathrm{m}$ & 0.15 & $0-1$ & 0.15 & $P, B$ & 2 & Default value is used. & Yu et al. 2007 \\
\hline $\begin{array}{l}\text { Volumetric water } \\
\text { content for pasture } \\
\text { and silage field }\end{array}$ & -- & 0.3 & $1 E-5-1$ & 0.347 & $P$ & 2 & $\begin{array}{l}\text { DOE geologist recommended value based on silty clay } \\
\text { loam and normal distribution. }\end{array}$ & $\begin{array}{l}\text { Yu et al. } 2007 \\
\text { DOE project } \\
\text { Communication } \\
\text { with geologist } \\
\text { (April 2010) }\end{array}$ \\
\hline $\begin{array}{l}\text { Dry bulk density of } \\
\text { soil for pasture and } \\
\text { silage field }\end{array}$ & $\mathrm{g} / \mathrm{cm}^{3}$ & 1.5 & $1 E-3-22.5$ & 1.5 & $P$ & 2 & Default value is used. & Yu et al. 2007 \\
\hline $\begin{array}{l}\text { Soil erodibility } \\
\text { factor for pasture } \\
\text { and silage field }\end{array}$ & tons/acre & 0.4 & $0-0.5$ & 0.37 & $P$ & 2 & $\begin{array}{l}\text { DOE geologist recommended value based on silty clay } \\
\text { loam and } 0.5 \% \text { organic matter. }\end{array}$ & $\begin{array}{c}\text { Yu et al. } 2007 \\
\text { Table 2.4-2, page } \\
\text { B-31 } \\
\text { DOE Project } \\
\text { Communication } \\
\text { with geologist }\end{array}$ \\
\hline
\end{tabular}


RESRAD-OFFSITE Table of Input Parameters for the C-746-U Landfill Offsite Resident Farmer Scenario

\begin{tabular}{|c|c|c|c|c|c|c|c|c|}
\hline $\begin{array}{c}\text { Input Screen Title } \\
\text { and Parameter } \\
\text { Name }\end{array}$ & Units & $\begin{array}{l}\text { Default } \\
\text { Value }^{a}\end{array}$ & $\begin{array}{c}\text { Code-Accepted } \\
\text { Values }^{b} \\
\text { Physical or } \\
\text { Numerical }^{\mathrm{C}} \text { (N) } \\
\text { Range }^{\text {Rang }}\end{array}$ & $\begin{array}{l}\text { Deterministic } \\
\text { Value }\end{array}$ & Type $^{d}$ & Priority $^{\mathrm{e}}$ & Justification & References \\
\hline & & & & & & & & (May 2010) \\
\hline $\begin{array}{c}\text { Slope-length- } \\
\text { steepness factor for } \\
\text { pasture and silage } \\
\text { field }\end{array}$ & -- & 0.4 & $0-10$ & 0.4 & P & 2 & $\begin{array}{l}\text { DOE geologist recommended to use } 0.4 \text { based on site } \\
\text { topography. }\end{array}$ & $\begin{array}{l}\text { Yu et al. } 2007 \\
\text { DOE Project } \\
\text { Communication } \\
\text { with geologist } \\
\text { (April 2010) }\end{array}$ \\
\hline $\begin{array}{l}\text { Cover and } \\
\text { management factor } \\
\text { for pasture and } \\
\text { silage field }\end{array}$ & -- & 0.003 & $0-1$ & 0.2 & $B, P$ & 2 & $\begin{array}{l}\text { DOE geologist recommended value based on no } \\
\text { appreciable canopy and } 20 \% \text { ground cover. }\end{array}$ & $\begin{array}{l}\text { Yu et al. } 2007 \\
\text { DOE Project } \\
\text { Communication } \\
\text { with geologist } \\
\text { (April 2010) }\end{array}$ \\
\hline $\begin{array}{l}\text { Support practice } \\
\text { factor for pasture } \\
\text { and silage field }\end{array}$ & -- & 1 & $0-1$ & 0.5 & $B, P$ & 2 & DOE geologist recommended value. & $\begin{array}{l}\text { Yu et al. } 2007 \\
\\
\text { DOE Project } \\
\text { Communication } \\
\text { with geologist } \\
\text { (July 2010) }\end{array}$ \\
\hline
\end{tabular}

Grain Field

\begin{tabular}{|c|c|c|c|c|c|c|c|c|}
\hline Area for grain field & $\mathrm{m}^{2}$ & 10,000 & Calculated & $\begin{array}{l}\text { Calculated by } \\
\text { the code }\end{array}$ & B & & $\begin{array}{l}\text { The fruit, grain and non-leafy vegetable growing area, } \\
\text { the leafy vegetable growing area, the pasture and } \\
\text { silage growing area, the livestock feed grain growing } \\
\text { area, and the dwelling site are all approximated by } \\
\text { rectangular shapes in the atmospheric transport } \\
\text { model. The sides of these rectangles must be parallel } \\
\text { to the sides of the primary contamination. }\end{array}$ & Yu et al. 2007 \\
\hline $\begin{array}{l}\text { Fraction of area } \\
\text { directly over } \\
\text { primary } \\
\text { contamination for } \\
\text { grain field } \\
\end{array}$ & -- & 0 & $0-1$ & 0 & $B, P$ & & $\begin{array}{l}\text { Default value is used since the receptor is outside the } \\
\text { contaminated zone. }\end{array}$ & Yu et al. 2007 \\
\hline $\begin{array}{l}\text { Irrigation applied } \\
\text { per year for grain } \\
\text { field }\end{array}$ & $\mathrm{m} / \mathrm{yr}$ & 0.2 & $0-10$ & 0 & B & 3 & $\begin{array}{l}\text { The irrigation rate was set to } 0 \mathrm{~m} / \mathrm{yr} \text { as requested by } \\
\text { DOE-PPPO, since no irrigation is being considered for } \\
\text { the grain field. Irrigation in the Paducah, Kentucky } \\
\text { area is considered to be unlikely. In the event } \\
\text { irrigation is necessary, the water will primarily come } \\
\text { from uncontaminated surface water and not from } \\
\text { groundwater (well). Information from the USGS }\end{array}$ & $\begin{array}{c}\text { DOE Project } \\
\text { Communication } \\
\text { with DOE-PPPO } \\
\text { (September 2010) } \\
\\
\text { DOE Project } \\
\text { Communication }\end{array}$ \\
\hline
\end{tabular}


RESRAD-OFFSITE Table of Input Parameters for the C-746-U Landfill Offsite Resident Farmer Scenario

\begin{tabular}{|c|c|c|c|c|c|c|c|c|}
\hline $\begin{array}{c}\text { Input Screen Title } \\
\text { and Parameter } \\
\text { Name }\end{array}$ & Units & $\begin{array}{l}\text { Default } \\
\text { Value }^{a}\end{array}$ & $\begin{array}{r}\text { Code-Accep } \\
\text { Values }^{b} \\
\text { Physical } \\
\text { Numerical }^{c} \\
\text { Range }\end{array}$ & $\begin{array}{l}\text { Deterministic } \\
\text { Value }\end{array}$ & Type $^{d}$ & Priority $^{\mathrm{e}}$ & Justification & References \\
\hline & & & & & & & $\begin{array}{l}\text { shows that surface water is the main source of water } \\
\text { used in Kentucky for irrigation (Kenny et al. 2009). } \\
\text { The pasture and silage and livestock feed grain are } \\
\text { for livestock consumption. }\end{array}$ & $\begin{array}{l}\text { with DOE-PPPO } \\
\text { (April 2011) } \\
\text { Kenny et al. } 2009 \\
\text { Yu et al. } 2007 \\
\end{array}$ \\
\hline $\begin{array}{l}\text { Evapotranspiration } \\
\text { coefficient for grain } \\
\text { field }\end{array}$ & -- & 0.5 & $0-0.999$ & 0.83 & $\mathrm{P}$ & 2 & $\begin{array}{l}\text { This value was calculated using the HELP Output data } \\
\text { for the Post-Institutional Control Period. The } \\
\text { equation used to calculate the value is available in Yu } \\
\text { et al. } 1993 . \\
\text { The calculations are available in Attachment II } \\
\text { following this table. }\end{array}$ & $\begin{array}{l}\text { DOE } 2003 \mathrm{~b} \\
\text { page C3-243 } \\
\text { Yu et al. } 1993 \\
\text { page } 78\end{array}$ \\
\hline $\begin{array}{l}\text { Runoff coefficient } \\
\text { for grain field }\end{array}$ & -- & 0.2 & $0-1$ & 0.34 & $\mathrm{P}$ & 2 & $\begin{array}{l}\text { This value was calculated from the HELP Output data } \\
\text { for the Post-Institutional Control Period. The } \\
\text { calculated value is } 0.34 \text {. The equation used to } \\
\text { calculate the value is available in Yu et al. } 1993 \text {. } \\
\text { The calculations are available in Attachment II } \\
\text { following this table. }\end{array}$ & $\begin{array}{l}\text { DOE } 2003 \mathrm{~b} \\
\text { page C3-243 } \\
\text { Yu et al. } 1993 \\
\text { page } 73\end{array}$ \\
\hline $\begin{array}{l}\text { Depth of soil mixing } \\
\text { layer or plow layer } \\
\text { for grain field }\end{array}$ & $\mathrm{m}$ & 0.15 & $0-1$ & 0.15 & $P, B$ & 2 & Default value is used. & Yu et al. 2007 \\
\hline $\begin{array}{l}\text { Volumetric water } \\
\text { content for grain } \\
\text { field }\end{array}$ & -- & 0.3 & $1 E-5-1$ & 0.347 & $P$ & 2 & $\begin{array}{l}\text { DOE geologist recommended value based on silty clay } \\
\text { loam and normal distribution. }\end{array}$ & $\begin{array}{l}\text { Yu et al. } 2007 \\
\text { DOE Project } \\
\text { Communication } \\
\text { with geologist } \\
\text { (April 2010) } \\
\end{array}$ \\
\hline $\begin{array}{l}\text { Dry bulk density of } \\
\text { soil for grain field }\end{array}$ & $\mathrm{g} / \mathrm{cm}^{3}$ & 1.5 & $1 E-3-22.5$ & 1.5 & $\mathrm{P}$ & 2 & Default value is used. & Yu et al. 2007 \\
\hline $\begin{array}{l}\text { Soil erodibility } \\
\text { factor for grain field }\end{array}$ & tons/acre & 0.4 & $0-0.5$ & 0.37 & $P$ & 2 & $\begin{array}{l}\text { DOE geologist recommended value based on silty clay } \\
\text { loam and } 0.5 \% \text { organic matter. }\end{array}$ & $\begin{array}{l}\text { Yu et al. } 2007 \\
\text { Table 2.4-2, page } \\
\text { B-31 } \\
\text { DOE Project } \\
\text { Communication } \\
\text { with geologist } \\
\text { (May 2010) }\end{array}$ \\
\hline Slope-length- & -- & 0.4 & $0-10$ & 0.4 & $P$ & 2 & DOE geologist recommended a value of 0.4 based on & Yu et al. 2007 \\
\hline
\end{tabular}


RESRAD-OFFSITE Table of Input Parameters for the C-746-U Landfill Offsite Resident Farmer Scenario

\begin{tabular}{|c|c|c|c|c|c|c|c|c|}
\hline $\begin{array}{c}\text { Input Screen Title } \\
\text { and Parameter } \\
\text { Name }\end{array}$ & Units & $\begin{array}{l}\text { Default } \\
\text { Value }^{a}\end{array}$ & $\begin{array}{c}\text { Code-Accepted } \\
\text { Values }^{b} \\
\text { Physical or } \\
\text { Numerical }^{\mathrm{C}} \text { (N) } \\
\text { Range }^{\text {Rang }}\end{array}$ & $\begin{array}{l}\text { Deterministic } \\
\text { Value }\end{array}$ & Type $^{d}$ & Priority ${ }^{e}$ & Justification & References \\
\hline $\begin{array}{l}\text { steepness factor for } \\
\text { grain field }\end{array}$ & & & & & & & site topography. & $\begin{array}{l}\text { DOE Project } \\
\text { Communication } \\
\text { with geologist } \\
\text { (April 2010) }\end{array}$ \\
\hline $\begin{array}{l}\text { Cover and } \\
\text { management factor } \\
\text { for grain field }\end{array}$ & -- & 0.003 & $0-1$ & 0.2 & $B, P$ & 2 & $\begin{array}{l}\text { DOE geologist recommended value based on no } \\
\text { appreciable canopy and } 20 \% \text { ground cover. }\end{array}$ & $\begin{array}{l}\text { Yu et al. } 2007 \\
\text { DOE Project } \\
\text { Communication } \\
\text { with geologist } \\
\text { (April 2010) }\end{array}$ \\
\hline $\begin{array}{l}\text { Support practice } \\
\text { factor for grain field }\end{array}$ & -- & 1 & $0-1$ & 0.5 & $B, P$ & 2 & DOE geologist recommended value. & $\begin{array}{l}\text { Yu et al. } 2007 \\
\text { DOE Project } \\
\text { Communication } \\
\text { with geologist } \\
\text { (July 2010) }\end{array}$ \\
\hline
\end{tabular}

Offsite Dwelling Area Parameters

\begin{tabular}{|c|c|c|c|c|c|c|c|c|}
\hline $\begin{array}{l}\text { Area of offsite } \\
\text { dwelling site }\end{array}$ & $\mathrm{m}^{2}$ & 1,000 & Calculated & $\begin{array}{l}\text { Calculated by } \\
\text { the code }\end{array}$ & B & 3 & $\begin{array}{l}\text { The fruit, grain and non-leafy vegetable growing area, } \\
\text { the leafy vegetable growing area, the pasture and } \\
\text { silage growing area, the livestock feed grain growing } \\
\text { area, and the dwelling site are all approximated by } \\
\text { rectangular shapes in the atmospheric transport } \\
\text { model. The sides of these rectangles must be parallel } \\
\text { to the sides of the primary contamination. }\end{array}$ & Yu et al. 2007 \\
\hline $\begin{array}{l}\text { Irrigation applied } \\
\text { per year to home } \\
\text { garden or lawn }\end{array}$ & $\mathrm{m} / \mathrm{yr}$ & 0.2 & $0-10$ & 0 & B & 3 & $\begin{array}{l}\text { The irrigation rate was set to } 0 \mathrm{~m} / \mathrm{yr} \text { as requested by } \\
\text { DOE-PPPO, since no irrigation is being considered for } \\
\text { the dwelling site. Irrigation in the Paducah, Kentucky } \\
\text { area is considered to be unlikely. In the event } \\
\text { irrigation is necessary, the water will primarily come } \\
\text { from uncontaminated surface water and not from } \\
\text { groundwater (well). Information from the USGS } \\
\text { shows that surface water is the main source of water } \\
\text { used in Kentucky for irrigation (Kenny et al. 2009). }\end{array}$ & $\begin{array}{c}\text { DOE Project } \\
\text { Communication } \\
\text { with DOE-PPPO } \\
\text { (September 2010) } \\
\text { Kenny et al. } 2009\end{array}$ \\
\hline $\begin{array}{l}\text { Evapotranspiration } \\
\text { coefficient for } \\
\text { dwelling site }\end{array}$ & -- & 0.5 & $0-0.999$ & 0.83 & $P$ & 2 & $\begin{array}{l}\text { This value was calculated using the HELP Output data } \\
\text { for the Post-Institutional Control Period. The } \\
\text { equation used to calculate the value is available in Yu } \\
\text { et al. } 1993 \text {. }\end{array}$ & $\begin{array}{l}\text { DOE } 2003 \mathrm{~b} \\
\text { page C3-243 } \\
\text { Yu et al. } 1993\end{array}$ \\
\hline
\end{tabular}


RESRAD-OFFSITE Table of Input Parameters for the C-746-U Landfill Offsite Resident Farmer Scenario

\begin{tabular}{|c|c|c|c|c|c|c|c|c|}
\hline $\begin{array}{c}\text { Input Screen Title } \\
\text { and Parameter } \\
\text { Name }\end{array}$ & Units & $\begin{array}{l}\text { Default } \\
\text { Value }^{\mathrm{a}}\end{array}$ & $\begin{array}{c}\text { Code-Accepted } \\
\text { Values }^{b} \\
\text { Physical or } \\
\text { Numerical }{ }^{\mathrm{C}} \text { (N) } \\
\text { Range }^{\text {Rang }}\end{array}$ & $\begin{array}{l}\text { Deterministic } \\
\text { Value }\end{array}$ & Type $^{d}$ & Priority & Justification & References \\
\hline & & & & & & & $\begin{array}{l}\text { The calculations are available in Attachment II } \\
\text { following this table. }\end{array}$ & page 78 \\
\hline $\begin{array}{l}\text { Runoff coefficient } \\
\text { for dwelling site }\end{array}$ & -- & 0.2 & $0-1$ & 0.34 & $P$ & 2 & $\begin{array}{l}\text { This value was calculated from the HELP Output data } \\
\text { for the Post-Institutional Control Period. The } \\
\text { calculated value is } 0.34 \text {. The equation used to } \\
\text { calculate the value is available in Yu et al. } 1993 . \\
\text { The calculations are available in Attachment II } \\
\text { following this table. }\end{array}$ & $\begin{array}{l}\text { DOE } 2003 \mathrm{~b} \\
\text { page C3-243 } \\
\text { Yu et al. } 1993 \\
\text { page } 73\end{array}$ \\
\hline $\begin{array}{c}\text { Depth of soil mixing } \\
\text { layer for dwelling } \\
\text { site }\end{array}$ & $\mathrm{m}$ & 0.15 & $0-1$ & 0.15 & $P, B$ & 2 & Default value is used. & Yu et al. 2007 \\
\hline $\begin{array}{l}\text { Volumetric water } \\
\text { content for dwelling } \\
\text { site }\end{array}$ & -- & 0.3 & $1 E-5-1$ & 0.347 & $P$ & 2 & $\begin{array}{l}\text { DOE geologist recommended value based on silty clay } \\
\text { loam and normal distribution. }\end{array}$ & $\begin{array}{l}\text { Yu et al. } 2007 \\
\\
\text { DOE Project } \\
\text { Communication } \\
\text { with geologist } \\
\text { (April 2010) }\end{array}$ \\
\hline $\begin{array}{l}\text { Dry bulk density of } \\
\text { soil for dwelling site }\end{array}$ & $\mathrm{g} / \mathrm{cm}^{3}$ & 1.5 & $1 \mathrm{E}-3-22.5$ & 1.5 & $\mathrm{P}$ & 2 & Default value is used. & Yu et al. 2007 \\
\hline $\begin{array}{c}\text { Soil erodibility } \\
\text { factor for dwelling } \\
\text { site }\end{array}$ & tons/acre & 0 & $0-0.5$ & 0.37 & $\mathrm{P}$ & 2 & $\begin{array}{l}\text { DOE geologist recommended value based on silty clay } \\
\text { loam and } 0.5 \% \text { organic matter. }\end{array}$ & $\begin{array}{l}\text { Yu et al. } 2007 \\
\text { Table 2.4-2, page } \\
\text { B-31 } \\
\text { DOE Project } \\
\text { Communication } \\
\text { with geologist } \\
\text { (May 2010) }\end{array}$ \\
\hline $\begin{array}{l}\text { Slope-length- } \\
\text { steepness factor for } \\
\text { dwelling site }\end{array}$ & -- & 0.4 & $0-10$ & 0.4 & $\mathrm{P}$ & 2 & $\begin{array}{l}\text { DOE geologist recommended a value of } 0.4 \text { based on } \\
\text { site topography. }\end{array}$ & $\begin{array}{l}\text { Yu et al. } 2007 \\
\\
\text { DOE Project } \\
\text { Communication } \\
\text { with geologist } \\
\text { (April 2010) }\end{array}$ \\
\hline $\begin{array}{c}\text { Cover and } \\
\text { management factor } \\
\text { for dwelling site }\end{array}$ & -- & 0.003 & $0-1$ & 0.2 & $B, P$ & 2 & $\begin{array}{l}\text { DOE geologist recommended value based on no } \\
\text { appreciable canopy and } 20 \% \text { ground cover. }\end{array}$ & $\begin{array}{l}\text { Yu et al. } 2007 \\
\text { DOE Project } \\
\text { Communication } \\
\text { with geologist }\end{array}$ \\
\hline
\end{tabular}


RESRAD-OFFSITE Table of Input Parameters for the C-746-U Landfill Offsite Resident Farmer Scenario

\begin{tabular}{|c|c|c|c|c|c|c|c|c|}
\hline $\begin{array}{c}\text { Input Screen Title } \\
\text { and Parameter } \\
\text { Name }\end{array}$ & Units & $\begin{array}{l}\text { Default } \\
\text { Value }^{\mathrm{a}}\end{array}$ & $\begin{array}{c}\text { Code-Accepted } \\
\text { Values }^{b} \\
\text { Physical or }^{\text {Pacal }} \\
\text { Numerical }^{\mathrm{C}} \text { (N) } \\
\text { Range }\end{array}$ & $\begin{array}{l}\text { Deterministic } \\
\text { Value }\end{array}$ & Type $^{d}$ & Priority ${ }^{e}$ & Justification & References \\
\hline & & & & & & & & (April 2010) \\
\hline $\begin{array}{l}\text { Support practice } \\
\text { factor for dwelling } \\
\text { site }\end{array}$ & -- & 1 & $0-1$ & 0.5 & $B, P$ & 2 & DOE geologist recommended value. & $\begin{array}{l}\text { Yu et al. } 2007 \\
\text { DOE Project } \\
\text { Communication } \\
\text { with geologist } \\
\text { (July 2010) }\end{array}$ \\
\hline
\end{tabular}

Atmospheric Transport

\begin{tabular}{|c|c|c|c|c|c|c|c|c|}
\hline Release height & $\mathrm{m}$ & 1 & $0-100$ & 0.1 & $\mathrm{P}$ & 2 & $\begin{array}{l}\text { The code does not allow a value of less than } 0.1 \text { thus } \\
\text { this value is selected because the release height is } \\
\text { assumed to be at ground level. }\end{array}$ & Yu et al. 2007 \\
\hline Release heat flux & $\mathrm{cal} / \mathrm{s}$ & 0 & $0-1 \mathrm{E}+10$ & 0 & & 2 & Default value is used. & Yu et al. 2007 \\
\hline Anemometer height & $\mathrm{m}$ & 10 & $0-100$ & 10 & $\mathrm{P}$ & 2 & Default value is used. & Yu et al. 2007 \\
\hline $\begin{array}{l}\text { Ambient } \\
\text { temperature }\end{array}$ & $\mathrm{K}$ & 285 & $250-320$ & 285 & $\mathrm{P}$ & 2 & Default value is used. & Yu et al. 2007 \\
\hline $\begin{array}{l}\text { AM atmospheric } \\
\text { mixing height }\end{array}$ & $\mathrm{m}$ & 400 & $0-3,000$ & 400 & $P$ & 2 & Default value is used. & Yu et al. 2007 \\
\hline $\begin{array}{l}\text { PM atmospheric } \\
\text { mixing height }\end{array}$ & $\mathrm{m}$ & 1,600 & $0-3,000$ & 1600 & $P$ & 2 & Default value is used. & Yu et al. 2007 \\
\hline $\begin{array}{l}\text { Dispersion model } \\
\text { coefficients }\end{array}$ & -- & Pasquill-Gifford & $\begin{array}{c}\text { Briggs } \\
\text { rural/urban, } \\
\text { Pasquill- } \\
\text { Gifford } \\
\end{array}$ & Pasquill-Gifford & $\mathrm{P}$ & 2 & $\begin{array}{l}\text { Pasquill-Gifford should be used for releases at or near } \\
\text { ground level. }\end{array}$ & Yu et al. 2007 \\
\hline Windspeed Terrain & -- & Rural & $\begin{array}{l}\text { Rural, } \\
\text { urban }\end{array}$ & Rural & $\mathrm{P}$ & 2 & Rural is appropriate for the terrain. & Yu et al. 2007 \\
\hline $\begin{array}{l}\text { Fruit, grain, } \\
\text { nonleafy vegetable } \\
\text { plot }\end{array}$ & $\mathrm{m}$ & 0 & $0-100$ & 0 & $P$ & 2 & Default value is used. & Yu et al. 2007 \\
\hline Leafy vegetable plot & $\mathrm{m}$ & 0 & $0-100$ & 0 & $\mathrm{P}$ & 2 & Default value is used. & Yu et al. 2007 \\
\hline $\begin{array}{l}\text { Pasture, silage } \\
\text { growing area }\end{array}$ & $\mathrm{m}$ & 0 & $0-100$ & 0 & $\mathrm{P}$ & 2 & Default value is used. & Yu et al. 2007 \\
\hline Grain fields & $\mathrm{m}$ & 0 & $0-100$ & 0 & $\mathrm{P}$ & 2 & Default value is used. & Yu et al. 2007 \\
\hline Dwelling site & $\mathrm{m}$ & 0 & $0-100$ & 0 & $\mathrm{P}$ & 2 & Default value is used. & Yu et al. 2007 \\
\hline Surface water body & $\mathrm{m}$ & 0 & $0-100$ & 0 & $\mathrm{P}$ & 2 & Default value is used. & Yu et al. 2007 \\
\hline $\begin{array}{l}\text { Grid spacing for } \\
\text { areal integration }\end{array}$ & $\mathrm{m}$ & 10 & $0-500$ & 10 & $P$ & 2 & Default value is used. & Yu et al. 2007 \\
\hline $\begin{array}{l}\text { Joint frequency of } \\
\text { wind speed and }\end{array}$ & -- & 1 (S to $N)$ & $0-1$ & $\begin{array}{l}\text { Actual values } \\
\text { will be from }\end{array}$ & $P$ & 3 & $\begin{array}{l}\text { When a star file is read in the information for all } 16 \\
\text { sectors is read in. This parameter indicates the joint }\end{array}$ & Yu et al. 2007 \\
\hline
\end{tabular}


RESRAD-OFFSITE Table of Input Parameters for the C-746-U Landfill Offsite Resident Farmer Scenario

\begin{tabular}{|c|c|c|c|c|c|c|c|c|}
\hline $\begin{array}{c}\text { Input Screen Title } \\
\text { and Parameter } \\
\text { Name }\end{array}$ & Units & $\begin{array}{l}\text { Default } \\
\text { Value }^{a}\end{array}$ & $\begin{array}{l}\text { Code-Accepted } \\
\text { Values }^{\mathrm{b}} \\
\text { Physical or } \\
\text { Numerical }^{\mathrm{C}} \text { (N) } \\
\text { Range }\end{array}$ & $\begin{array}{l}\text { Deterministic } \\
\text { Value }\end{array}$ & Type $^{d}$ & Priority ${ }^{\mathrm{e}}$ & Justification & References \\
\hline $\begin{array}{l}\text { stability class for a } \\
16 \text { sector windrose }\end{array}$ & & & & $\begin{array}{l}\text { Paducah, KY } \\
\quad \text { read } \\
\text { metereological } \\
\text { STAR file }\end{array}$ & & & $\begin{array}{l}\text { frequency that is displayed on the input screen; } \\
\text { however all } 16 \text { sectors are used in the model. The } \\
\text { STAR file selected is called KY_Paducah.str. }\end{array}$ & \\
\hline Wind speed & $\mathrm{m} / \mathrm{s}$ & $\begin{array}{c}0.89,2.46 \\
4.47,6.93,9.61 \\
12.52\end{array}$ & $0.001-20$ & $\begin{array}{r}0.89,2.46,4.47 \\
6.93,9.61,12.52\end{array}$ & $P$ & 2 & $\begin{array}{l}\text { Default values are used. The wind speed is divided } \\
\text { into six intervals in order to specify the joint } \\
\text { frequency distribution of wind speed and } \\
\text { atmospheric stability in each direction of a wind rose. } \\
\text { This is the average wind speed for the wind speed } \\
\text { interval. }\end{array}$ & Yu et al. 2007 \\
\hline
\end{tabular}

Unsaturated Zone Parameters

\begin{tabular}{|c|c|c|c|c|c|c|c|c|}
\hline \multirow{5}{*}{$\begin{array}{l}\text { Unsaturated zone } \\
\text { thickness }\end{array}$} & \multirow{5}{*}{$\mathrm{m}$} & \multirow{5}{*}{4} & \multirow{5}{*}{$\begin{array}{r}0.01- \\
10,000\end{array}$} & Zone $1=0.3$ & \multirow{5}{*}{$\mathrm{P}$} & \multirow{5}{*}{1} & \multirow{5}{*}{$\begin{array}{l}\text { This value was obtained from the previous RESRAD } \\
\text { study for the landfill described in DOE 2003b. }\end{array}$} & \multirow{5}{*}{$\begin{array}{c}\text { DOE 2003b } \\
\text { Table Att.2, page } \\
\text { C3-315 }\end{array}$} \\
\hline & & & & Zone $2=0.3$ & & & & \\
\hline & & & & Zone $3=0.9$ & & & & \\
\hline & & & & Zone $4=2.0$ & & & & \\
\hline & & & & Zone $5=8.4$ & & & & \\
\hline \multirow{5}{*}{$\begin{array}{l}\text { Unsaturated zone } \\
\text { dry bulk density }\end{array}$} & \multirow{5}{*}{$\mathrm{g} / \mathrm{cm}^{3}$} & \multirow{5}{*}{1.5} & \multirow{5}{*}{$1 \mathrm{E}-3-22.5$} & Zone $1=1.2$ & \multirow{5}{*}{$P$} & \multirow{5}{*}{2} & \multirow{5}{*}{$\begin{array}{l}\text { This value was obtained from the previous RESRAD } \\
\text { study for the landfill described in DOE 2003b. }\end{array}$} & \multirow{5}{*}{$\begin{array}{c}\text { DOE 2003b } \\
\text { Table Att.2, page } \\
\text { C3-315 }\end{array}$} \\
\hline & & & & Zone $2=1.5$ & & & & \\
\hline & & & & Zone $3=1.8$ & & & & \\
\hline & & & & Zone $4=1.5$ & & & & \\
\hline & & & & Zone $5=1.76$ & & & & \\
\hline \multirow{5}{*}{$\begin{array}{l}\text { Unsaturated zone } \\
\text { total porosity }\end{array}$} & \multirow{5}{*}{--} & \multirow{5}{*}{0.4} & \multirow{5}{*}{$1 \mathrm{E}-5-1$} & Zone $1=0.45$ & \multirow{5}{*}{$\mathrm{P}$} & \multirow{5}{*}{2} & \multirow{5}{*}{$\begin{array}{l}\text { This value was obtained from the previous RESRAD } \\
\text { study for the landfill described in DOE 2003b. } \\
\text { The values for UZ1 and UZ2 were transposed as } \\
\text { recommended by DOE. }\end{array}$} & \multirow{5}{*}{$\begin{array}{c}\text { DOE 2003b } \\
\text { Table Att.2, page } \\
\text { C3-315 } \\
\text { DOE Project } \\
\text { Communication } \\
\text { with DOE-PPPO } \\
\text { (October 2010) }\end{array}$} \\
\hline & & & & Zone $2=0.4$ & & & & \\
\hline & & & & Zone $3=0.43$ & & & & \\
\hline & & & & Zone $4=0.4$ & & & & \\
\hline & & & & Zone $5=0.45$ & & & & \\
\hline \multirow{5}{*}{$\begin{array}{l}\text { Unsaturated zone } \\
\text { effective porosity }\end{array}$} & \multirow{5}{*}{--} & \multirow{5}{*}{0.2} & \multirow{5}{*}{$1 \mathrm{E}-5-1$} & Zone $1=0.2$ & \multirow{5}{*}{$\mathrm{P}$} & \multirow{5}{*}{2} & \multirow{5}{*}{$\begin{array}{l}\text { These values were calculated using equation } 4.4 \text { from } \\
\text { Yu et al. } 1993 \text { as this approach was accepted by ANL } \\
\text { rather than using the values available in DOE 2003b. } \\
\text { This approach was taken to ensure that the effective } \\
\text { porosity was less than the total porosity. }\end{array}$} & \multirow{5}{*}{$\begin{array}{c}\text { Yu et al. } 1993 \\
\text { Project } \\
\text { Communication } \\
\text { with DOE } \\
\text { consultant } \\
\text { (October 2010) }\end{array}$} \\
\hline & & & & Zone $2=0.2$ & & & & \\
\hline & & & & Zone $3=0.08$ & & & & \\
\hline & & & & Zone $4=0.2$ & & & & \\
\hline & & & & Zone $5=0.15$ & & & & \\
\hline Unsaturated zone & - & 0.3 & $1 \mathrm{E}-5-1$ & Zone $1=0.25$ & $P$ & 3 & These values were obtained from the previous & DOE 2003b \\
\hline
\end{tabular}


RESRAD-OFFSITE Table of Input Parameters for the C-746-U Landfill Offsite Resident Farmer Scenario

\begin{tabular}{|c|c|c|c|c|c|c|c|c|}
\hline $\begin{array}{l}\text { Input Screen Title } \\
\text { and Parameter } \\
\text { Name }\end{array}$ & Units & $\begin{array}{l}\text { Default } \\
\text { Value }^{a}\end{array}$ & $\begin{array}{r}\text { Code-Accep } \\
\text { Values }^{b} \\
\text { Physical c } \\
\text { Numerical }^{c} \\
\text { Range }\end{array}$ & $\begin{array}{c}\text { Deterministic } \\
\text { Value }\end{array}$ & Type $^{d}$ & Priority ${ }^{\mathrm{e}}$ & Justification & References \\
\hline \multirow[t]{4}{*}{ field capacity } & & & & Zone $2=0.2$ & & & \multirow{4}{*}{$\begin{array}{l}\text { RESRAD study for the landfill described in DOE 2003b. } \\
\text { The values for UZ1 and UZ2 were transposed as } \\
\text { recommended by DOE. }\end{array}$} & \multirow{2}{*}{$\begin{array}{l}\text { Table Att.2, page } \\
\text { C3-315 }\end{array}$} \\
\hline & & & & Zone $3=0.35$ & & & & \\
\hline & & & & Zone $4=0.2$ & & & & DOE Project \\
\hline & & & & Zone $5=0.3$ & & & & $\begin{array}{c}\text { with DOE-PPPO } \\
\text { (July 2010) }\end{array}$ \\
\hline \multirow{5}{*}{$\begin{array}{l}\text { Unsaturated zone } \\
\text { hydraulic } \\
\text { conductivity }\end{array}$} & \multirow{5}{*}{$\mathrm{m} / \mathrm{yr}$} & \multirow{5}{*}{10} & \multirow{5}{*}{$1 E-3-1 E+6$} & Zone $1=2.92 \mathrm{E} 0$ & \multirow{5}{*}{$\mathrm{P}$} & \multirow{5}{*}{2} & \multirow{5}{*}{$\begin{array}{l}\text { This value was obtained from the previous RESRAD } \\
\text { study for the landfill described in DOE } 2003 \mathrm{~b} \text {. The } \\
\text { value for unsaturated zone } 5 \text { was changed from } 0.12 \\
\mathrm{~m} / \mathrm{yr} \text { to } 0.14 \mathrm{~m} / \mathrm{yr} \text { to allow the code to run as agreed } \\
\text { with DOE. }\end{array}$} & DOE 2003b \\
\hline & & & & Zone $2=9.46 \mathrm{E}+3$ & & & & Table Att.2, page \\
\hline & & & & Zone $3=3.15 \mathrm{E}-1$ & & & & C3-315 \\
\hline & & & & Zone $4=2.92 \mathrm{E} 0$ & & & & \\
\hline & & & & Zone $5=1.4 \mathrm{E}-1$ & & & & $\begin{array}{c}\text { Communication } \\
\text { (June 2010) }\end{array}$ \\
\hline \multirow{5}{*}{$\begin{array}{l}\text { Unsaturated zone } \\
\text { soil b parameter }\end{array}$} & \multirow{5}{*}{--} & \multirow{5}{*}{5.3} & \multirow{5}{*}{$0-15$} & Zone $1=7.75$ & \multirow{5}{*}{$P$} & \multirow{5}{*}{2} & \multirow{5}{*}{$\begin{array}{l}\text { DOE geologist evaluated the unsaturated zone and } \\
\text { determined that the value for Silty Clay Loam from Yu } \\
\text { et al. } 1993 \text { was most appropriate. }\end{array}$} & Yu et al. 1993 \\
\hline & & & & Zone $2=7.75$ & & & & \\
\hline & & & & Zone $3=11.4$ & & & & $\begin{array}{l}\text { DOE Project } \\
\text { Communication }\end{array}$ \\
\hline & & & & Zone $4=7.75$ & & & & with geologist \\
\hline & & & & Zone $5=11.4$ & & & & (April 2010) \\
\hline \multirow{5}{*}{$\begin{array}{l}\text { Unsaturated zone } \\
\text { longitudinal } \\
\text { dispersivity }\end{array}$} & \multirow{5}{*}{$\mathrm{m}$} & \multirow{5}{*}{0.1} & \multirow{5}{*}{$0-100$} & Zone $1=0.03$ & \multirow{5}{*}{$P$} & \multirow{5}{*}{2} & \multirow{5}{*}{$\begin{array}{l}\text { According to ANL expert, in general, the value of this } \\
\text { parameter is dependent on the thickness of the } \\
\text { unsaturated zone, and ranges from one hundredth of } \\
\text { the thickness to the order of the thickness. A value of } \\
1 / 10 \text { of the thickness might be more appropriate for } \\
\text { this parameter. } \\
\text { A value of } 1 / 10 \text { of the thickness was used for each } \\
\text { unsaturated zone as suggested. }\end{array}$} & Yu et al. 2007 \\
\hline & & & & Zone $2=0.03$ & & & & ROE Proiect \\
\hline & & & & Zone $3=0.09$ & & & & Communication \\
\hline & & & & Zone $4=0.2$ & & & & $\begin{array}{l}\text { with DOE } \\
\text { consultant }\end{array}$ \\
\hline & & & & Zone $5=0.84$ & & & & (November 2010) \\
\hline
\end{tabular}

Saturated Zone Hydrological Data

\begin{tabular}{|c|c|c|c|c|c|c|c|c|}
\hline $\begin{array}{c}\text { Thickness of } \\
\text { saturated zone }\end{array}$ & $\mathrm{m}$ & 100 & $0-1,000$ & & 14 & $\mathrm{P}$ & 2 & YOE geologist recommended value. \\
\hline $\begin{array}{c}\text { Dry bulk density of } \\
\text { saturated zone }\end{array}$ & $\mathrm{g} / \mathrm{cm}^{3}$ & 1.5 & $1 \mathrm{E}-3-22.5$ & & 1.67 & $\mathrm{P}$ & 1 & $\begin{array}{c}\text { This value was obtained from the previous RESRAD } \\
\text { study for the landfill described in DOE 2003b. } \\
\text { (April 2010) }\end{array}$ \\
\hline
\end{tabular}


RESRAD-OFFSITE Table of Input Parameters for the C-746-U Landfill Offsite Resident Farmer Scenario

\begin{tabular}{|c|c|c|c|c|c|c|c|c|}
\hline $\begin{array}{l}\text { Input Screen Title } \\
\text { and Parameter } \\
\text { Name }\end{array}$ & Units & $\begin{array}{l}\text { Default } \\
\text { Value }^{\mathrm{a}}\end{array}$ & $\begin{array}{c}\text { Code-Acceptec } \\
\text { Values }^{b} \\
\text { Physical or } \\
\text { Numerical' (N) } \\
\text { Range }\end{array}$ & $\begin{array}{l}\text { Deterministic } \\
\text { Value }\end{array}$ & Type $^{d}$ & Priority & Justification & References \\
\hline & & & & & & & & page C3-315 \\
\hline $\begin{array}{l}\text { Saturated zone } \\
\text { total porosity }\end{array}$ & -- & 0.4 & $1 E-5-1$ & 0.34 & $\mathrm{P}$ & 1 & $\begin{array}{l}\text { This value was obtained from the previous RESRAD } \\
\text { study for the landfill described in DOE 2003b. }\end{array}$ & $\begin{array}{c}\text { DOE 2003b } \\
\text { Table Att.4., page } \\
\text { C3-315 }\end{array}$ \\
\hline $\begin{array}{l}\text { Saturated zone } \\
\text { effective porosity }\end{array}$ & -- & 0.2 & $1 E-5-1$ & 0.3 & $\mathrm{P}$ & 1 & $\begin{array}{l}\text { This value was obtained from the previous RESRAD } \\
\text { study for the landfill described in DOE 2003b. }\end{array}$ & $\begin{array}{l}\text { DOE 2003b } \\
\text { Table 4.7, page 4- } \\
\text { 21, Table Att.4., } \\
\text { page C3-315 }\end{array}$ \\
\hline $\begin{array}{l}\text { Saturated zone } \\
\text { hydraulic } \\
\text { conductivity }\end{array}$ & $\mathrm{m} / \mathrm{yr}$ & 100 & $\begin{array}{l}1 E-3- \\
1 E+10\end{array}$ & 55630 & $P$ & 1 & $\begin{array}{l}\text { This value was obtained from the previous RESRAD } \\
\text { study for the landfill described in DOE 2003b. This } \\
\text { value was verified by DOE geologist. }\end{array}$ & $\begin{array}{l}\text { DOE 2003b } \\
\text { Table Att.4., page } \\
\text { C3-315 } \\
\text { DOE Project } \\
\text { Communication } \\
\text { with geologist and } \\
\text { engineer (April } \\
\text { 2010) }\end{array}$ \\
\hline $\begin{array}{c}\text { Saturated zone } \\
\text { hydraulic gradient } \\
\text { to well }\end{array}$ & -- & 0.02 & $1 \mathrm{E}-10-10$ & 0.0011 & $P$ & 2 & $\begin{array}{l}\text { This value was obtained from the previous RESRAD } \\
\text { study for the landfill described in DOE 2003b. }\end{array}$ & $\begin{array}{c}\text { DOE 2003b } \\
\text { Table Att.4., page } \\
\text { C3-315 }\end{array}$ \\
\hline $\begin{array}{c}\text { Saturated } \\
\text { zone longitudinal } \\
\text { dispersivity to well }\end{array}$ & $\mathrm{m}$ & 3 & $0-1,000$ & 15 & $\mathrm{P}$ & 2 & $\begin{array}{l}\text { This value was obtained from DOE 2003b and agreed } \\
\text { upon by DOE geologist. } \\
\text { In addition, this value was provided by site modeling } \\
\text { experts in Paducah (i.e., the values for saturated zone } \\
\text { longitudinal, horizontal lateral and vertical lateral } \\
\text { dispersivity were provided by Chad Drummond, and } \\
\text { are used by Los Alamos Technical Associates (LATA) } \\
\text { KY for their modeling). }\end{array}$ & $\begin{array}{c}\text { DOE 2003b } \\
\text { Table 4.7, page 4- } \\
21 \\
\text { DOE Project } \\
\text { Communication } \\
\text { with geologist } \\
\text { (April 2010) } \\
\text { PRS 2008b } \\
\text { Table 3.5, page 3- } \\
36 \\
\text { DOE Project } \\
\text { Communication } \\
\text { with DOE } \\
\text { consultant } \\
\text { (November 2010) } \\
\text { DOE Project } \\
\end{array}$ \\
\hline
\end{tabular}


RESRAD-OFFSITE Table of Input Parameters for the C-746-U Landfill Offsite Resident Farmer Scenario

\begin{tabular}{|c|c|c|c|c|c|c|c|c|}
\hline $\begin{array}{c}\text { Input Screen Title } \\
\text { and Parameter } \\
\text { Name }\end{array}$ & Units & $\begin{array}{l}\text { Default } \\
\text { Value }^{\mathrm{a}}\end{array}$ & $\begin{array}{l}\text { Code-Accepted } \\
\text { Values }^{b} \\
\text { Physical or } \\
\text { Numerical }{ }^{\mathrm{C}} \text { (N) } \\
\text { Range }\end{array}$ & $\begin{array}{l}\text { Deterministic } \\
\text { Value }\end{array}$ & Type $^{d}$ & Priority & Justification & References \\
\hline & & & & & & & & $\begin{array}{c}\text { Communication } \\
\text { with DOE-PPPO } \\
\text { (April 2011) }\end{array}$ \\
\hline $\begin{array}{l}\text { Saturated zone } \\
\text { horizontal lateral } \\
\text { dispersivity to well }\end{array}$ & $\mathrm{m}$ & 0.4 & $0-1,000$ & 1.5 & $\mathrm{P}$ & 2 & $\begin{array}{l}\text { This value was provided by site modeling experts in } \\
\text { Paducah (i.e., the values for saturated zone } \\
\text { longitudinal, horizontal lateral and vertical lateral } \\
\text { dispersivity were provided by Chad Drummond, and } \\
\text { are used by Los Alamos Technical Associates (LATA) } \\
\text { KY for their modeling). }\end{array}$ & $\begin{array}{c}\text { DOE Project } \\
\text { Communication } \\
\text { with DOE-PPPO } \\
\text { (April 2011) }\end{array}$ \\
\hline $\begin{array}{c}\text { Saturated zone } \\
\text { vertical lateral } \\
\text { dispersivity to well }\end{array}$ & $\mathrm{m}$ & 0.02 & $0-1,000$ & 0.15 & $\mathrm{P}$ & 2 & $\begin{array}{l}\text { This value was provided by site modeling experts in } \\
\text { Paducah (i.e., the values for saturated zone } \\
\text { longitudinal, horizontal lateral and vertical lateral } \\
\text { dispersivity were provided by Chad Drummond, and } \\
\text { are used by Los Alamos Technical Associates (LATA) } \\
\text { KY for their modeling). }\end{array}$ & $\begin{array}{c}\text { DOE Project } \\
\text { Communication } \\
\text { with DOE-PPPO } \\
\text { (April 2011) }\end{array}$ \\
\hline $\begin{array}{l}\text { Depth of aquifer } \\
\text { contributing to well }\end{array}$ & $\mathrm{m}$ & 10 & $\begin{array}{l}1 \mathrm{E}-4- \\
1,000\end{array}$ & 9.1 & $\mathrm{P}$ & 2 & $\begin{array}{l}\text { The value of } 9.1 \mathrm{~m} \text { is used for the Resident Farmer } \\
\text { since this value was recommended by LATA (Los } \\
\text { Alamos Technical Associates) Kentucky. In addition, } \\
\text { the value for the well pump intake depth in RESRAD } \\
\text { was modified in order to achieve consistency with the } \\
\text { depth of aquifer contributing to well in RESRAD- } \\
\text { OFFSITE as suggested by Argonne National } \\
\text { Laboratory (ANL) expert. }\end{array}$ & $\begin{array}{c}\text { DOE Project } \\
\text { Communication } \\
\text { with DOE } \\
\text { consultant } \\
\text { (November 2010) }\end{array}$ \\
\hline $\begin{array}{c}\text { Saturated zone } \\
\text { hydraulic gradient } \\
\text { to surface water } \\
\text { body }\end{array}$ & -- & 0.02 & $1 \mathrm{E}-10-10$ & 0.0011 & $\mathrm{P}$ & 3 & $\begin{array}{l}\text { Assumed to be the same as hydraulic gradient to the } \\
\text { well. }\end{array}$ & $\begin{array}{c}\text { DOE 2003b } \\
\text { Table Att.4., page } \\
\text { C3-315 }\end{array}$ \\
\hline $\begin{array}{l}\text { Saturated zone } \\
\text { longitudinal } \\
\text { dispersivity to } \\
\text { surface water body }\end{array}$ & $\mathrm{m}$ & 10 & $0-1,000$ & 15 & $P$ & 3 & $\begin{array}{l}\text { This value was obtained from DOE 2003b and agreed } \\
\text { upon by DOE geologist. } \\
\text { In addition, this value was recommended by Chad } \\
\text { Drummond (Los Alamos Technical Associates (LATA) } \\
\text { KY) in April } 2011 \text {. }\end{array}$ & $\begin{array}{c}\text { DOE 2003b } \\
\text { Table 4.7, page 4- } \\
21 \\
\text { DOE Project } \\
\text { Communication } \\
\text { with geologist } \\
\text { (April 2010) } \\
\text { DOE Project } \\
\text { Communication } \\
\text { with DOE-PPPO } \\
\text { (April 2011) }\end{array}$ \\
\hline
\end{tabular}


RESRAD-OFFSITE Table of Input Parameters for the C-746-U Landfill Offsite Resident Farmer Scenario

\begin{tabular}{|c|c|c|c|c|c|c|c|c|}
\hline $\begin{array}{c}\text { Input Screen Title } \\
\text { and Parameter } \\
\text { Name }\end{array}$ & Units & $\begin{array}{l}\text { Default } \\
\text { Value }^{\mathrm{a}}\end{array}$ & $\begin{array}{c}\text { Code-Accepted } \\
\text { Values }^{b} \\
\text { Physical or } \\
\text { Numerical }^{c} \text { (N) } \\
\text { Range }^{\text {Rang }}\end{array}$ & $\begin{array}{l}\text { Deterministic } \\
\text { Value }\end{array}$ & Type $^{d}$ & Priority $^{\mathrm{e}}$ & Justification & References \\
\hline $\begin{array}{l}\text { Saturated zone } \\
\text { horizontal lateral } \\
\text { dispersivity to } \\
\text { surface water body }\end{array}$ & $\mathrm{m}$ & 1 & $0-1,000$ & 1.5 & $\mathrm{P}$ & 3 & $\begin{array}{l}\text { This value was recommended by Chad Drummond } \\
\text { (Los Alamos Technical Associates (LATA) KY) in April } \\
2011 .\end{array}$ & $\begin{array}{l}\text { DOE Project } \\
\text { Communication } \\
\text { with DOE-PPPO } \\
\text { (April 2011) }\end{array}$ \\
\hline $\begin{array}{l}\text { Saturated zone } \\
\text { vertical lateral } \\
\text { dispersivity to } \\
\text { surface water body }\end{array}$ & $\mathrm{m}$ & 0.06 & $0-1,000$ & 0.15 & $P$ & 3 & $\begin{array}{l}\text { This value was recommended by Chad Drummond } \\
\text { (Los Alamos Technical Associates (LATA) KY) in April } \\
2011 .\end{array}$ & $\begin{array}{c}\text { DOE Project } \\
\text { Communication } \\
\text { with DOE-PPPO } \\
\text { (April 2011) } \\
\end{array}$ \\
\hline $\begin{array}{l}\text { Depth of aquifer } \\
\text { contributing to } \\
\text { surface water body }\end{array}$ & $\mathrm{m}$ & 10 & $0-1,000$ & 9.1 & $\mathrm{P}$ & 3 & $\begin{array}{l}\text { The value of } 9.1 \mathrm{~m} \text { was recommended by LATA (Los } \\
\text { Alamos Technical Associates) Kentucky for the depth } \\
\text { of aquifer contributing to well. However, this value is } \\
\text { assumed for the depth of aquifer contributing to } \\
\text { surface water body. This modification will not impact } \\
\text { the results since the surface water body is not } \\
\text { considered in the CSM. }\end{array}$ & $\begin{array}{c}\text { DOE Project } \\
\text { Communication } \\
\text { with DOE } \\
\text { consultant } \\
\text { (November 2010) }\end{array}$ \\
\hline
\end{tabular}

Surface Water Body Parameters

\begin{tabular}{|c|c|c|c|c|c|c|c|c|c|}
\hline $\begin{array}{l}\text { Sediment delivery } \\
\text { ratio }\end{array}$ & -- & 1 & $0-1$ & & 0 & $P$ & 3 & $\begin{array}{l}\text { DOE geologist recommended a value of } 0 \text { since this is } \\
\text { the fraction of the contaminated soil that is eroded } \\
\text { from the area of primary contamination that reaches } \\
\text { the surface water body. }\end{array}$ & $\begin{array}{l}\text { Yu et al. } 2007 \\
\text { DOE Project } \\
\text { Communication } \\
\text { with geologist } \\
\text { (April 2010) }\end{array}$ \\
\hline $\begin{array}{l}\text { Volume of surface } \\
\text { water body }\end{array}$ & $\mathrm{m}^{3}$ & 150,000 & $1-1 E+34$ & $\mathrm{~N}$ & 150000 & $P$ & 3 & Default value is used. & Yu et al. 2007 \\
\hline $\begin{array}{c}\text { Mean residence } \\
\text { time of water in } \\
\text { surface water body }\end{array}$ & $\mathrm{yr}$ & 1 & $\begin{array}{l}1 E-4- \\
1 E+34\end{array}$ & $\mathrm{~N}$ & 1 & $\mathrm{P}$ & 3 & Default value is used. & Yu et al. 2007 \\
\hline
\end{tabular}

Groundwater Transport Parameters

Distance from Downgradient Edge of Contamination to:

\begin{tabular}{|c|c|c|c|c|c|c|c|c|}
\hline $\begin{array}{c}\text { Well in the } \\
\text { direction parallel to } \\
\text { aquifer flow }\end{array}$ & $\mathrm{m}$ & 100 & $\begin{array}{c}-16,000- \\
+16,000\end{array}$ & 407 & $\mathrm{P}, \mathrm{B}$ & 2 & $\begin{array}{l}\text { This is the distance, in meters, between two lines that } \\
\text { are perpendicular to the direction of aquifer flow, } \\
\text { one at the down gradient edge of the primary }\end{array}$ & $\begin{array}{c}\text { Yu et at. 2007 } \\
\text { DOE 2003b }\end{array}$ \\
\hline
\end{tabular}


RESRAD-OFFSITE Table of Input Parameters for the C-746-U Landfill Offsite Resident Farmer Scenario

\begin{tabular}{|c|c|c|c|c|c|c|c|c|}
\hline $\begin{array}{c}\text { Input Screen Title } \\
\text { and Parameter } \\
\text { Name }\end{array}$ & Units & $\begin{array}{l}\text { Default } \\
\text { Value }^{a}\end{array}$ & $\begin{array}{l}\text { Code-Accepted } \\
\text { Values }^{b} \\
\text { Physical or } \\
\text { Numerical }{ }^{\mathrm{C}} \text { (N) } \\
\text { Range }\end{array}$ & $\begin{array}{l}\text { Deterministic } \\
\text { Value }\end{array}$ & Type $^{d}$ & Priority $^{e}$ & Justification & References \\
\hline & & & & & & & $\begin{array}{l}\text { contamination and the other at the well. This value is } \\
\text { set at "0" for onsite receptors to put the well at } \\
\text { downgradient edge of the primary contaminated } \\
\text { zone. For the offsite receptor, the well is located at } \\
407 \mathrm{~m} \text { from the downgradient edge of the } \\
\text { contaminated zone. This point corresponds to an } \\
\text { exposure point previously evaluated by DOE at the } \\
\text { property boundary. }\end{array}$ & page 4-1 \\
\hline $\begin{array}{l}\text { Surface water body } \\
\text { in the direction } \\
\text { parallel to aquifer } \\
\text { flow }\end{array}$ & $\mathrm{m}$ & 600 & $\begin{array}{l}-16,000- \\
+16,000\end{array}$ & -1249 & $\mathrm{P}$ & 3 & $\begin{array}{l}\text { Setting this to a negative value will cause the code to } \\
\text { skip the groundwater transport calculations to the } \\
\text { surface water body. } \\
\text { Surface water is not considered in the CSM. }\end{array}$ & Yu et at. 2007 \\
\hline $\begin{array}{c}\text { Well in the } \\
\text { direction } \\
\text { perpendicular to } \\
\text { aquifer flow }\end{array}$ & $\mathrm{m}$ & 0 & $\begin{array}{l}-16,000- \\
+16,000\end{array}$ & 0 & $P, B$ & 2 & $\begin{array}{l}\text { The well is located } 407 \text { meters downgradient to the } \\
\text { primary contaminated zone. }\end{array}$ & Yu et at. 2007 \\
\hline $\begin{array}{l}\text { Near edge of } \\
\text { surface water body } \\
\text { in the direction } \\
\text { perpendicular to } \\
\text { aquifer flow }\end{array}$ & $\mathrm{m}$ & -150 & $\begin{array}{l}-16,000- \\
+16,000\end{array}$ & -72 & $P$ & 3 & $\begin{array}{l}\text { The surface water body is located upgradient to the } \\
\text { primary contaminated zone since it is not considered } \\
\text { in the CSM. }\end{array}$ & Yu et at. 2007 \\
\hline $\begin{array}{l}\text { Far edge of surface } \\
\text { water body in the } \\
\text { direction } \\
\text { perpendicular to } \\
\text { aquifer flow } \\
\end{array}$ & $\mathrm{m}$ & 150 & $\begin{array}{l}-16,000- \\
+16,000\end{array}$ & 228 & $P$ & 3 & $\begin{array}{l}\text { The surface water body is located upgradient to the } \\
\text { primary contaminated zone since it is not considered } \\
\text { in the CSM. }\end{array}$ & Yu et at. 2007 \\
\hline $\begin{array}{l}\text { Convergence } \\
\text { criterion (fractional } \\
\text { accuracy desired) }\end{array}$ & -- & 0.001 & $0-0.1$ & 0.001 & $\mathrm{P}$ & 3 & $\begin{array}{l}\text { Default value is used. The surface water body is } \\
\text { located upgradient to the primary contaminated zone } \\
\text { since it is not considered in the CSM. }\end{array}$ & Yu et at. 2007 \\
\hline $\begin{array}{l}\text { Main subzones in } \\
\text { saturated zone }\end{array}$ & -- & 1 & $1-1024$ & 1 & NA & 3 & Default value is used. & Yu et al. 2007 \\
\hline $\begin{array}{l}\text { Main subzones in } \\
\text { each partially } \\
\text { saturated zone }\end{array}$ & -- & 1 & $1-1024$ & 1 & NA & 3 & Default value is used. & Yu et al. 2007 \\
\hline
\end{tabular}


RESRAD-OFFSITE Table of Input Parameters for the C-746-U Landfill Offsite Resident Farmer Scenario

\begin{tabular}{|c|c|c|c|c|c|c|c|c|}
\hline $\begin{array}{l}\text { Input Screen Title } \\
\text { and Parameter } \\
\text { Name }\end{array}$ & Units & $\begin{array}{l}\text { Default } \\
\text { Value }^{a}\end{array}$ & $\begin{array}{c}\text { Code-Accepted } \\
\text { Values }^{b} \\
\text { Physical or } \\
\text { Numerical } \\
\text { Range } \\
\text { Ra) } \\
\end{array}$ & $\begin{array}{c}\text { Deterministic } \\
\text { Value }\end{array}$ & Type $^{d}$ & Priority & Justification & References \\
\hline $\begin{array}{l}\text { Nuclide-specific } \\
\text { retardation in all } \\
\text { subzones, } \\
\text { longitudinal } \\
\text { dispersion in all but } \\
\text { the subzone of } \\
\text { transformation? }\end{array}$ & -- & Yes & Yes/No & Yes & NA & 3 & Default value is used. & Yu et at. 2007 \\
\hline $\begin{array}{l}\text { Longitudinal } \\
\text { dispersion in all } \\
\text { subzones, nuclide- } \\
\text { specific retardation } \\
\text { in all but the } \\
\text { subzone of } \\
\text { transformation, } \\
\text { parent retardation } \\
\text { in zone of } \\
\text { transformation? }\end{array}$ & -- & No & Yes/No & No & NA & 3 & Default value is used. & Yu et at. 2007 \\
\hline $\begin{array}{c}\text { Longitudinal } \\
\text { dispersion in all } \\
\text { subzones, nuclide- } \\
\text { specific retardation } \\
\text { in all but the } \\
\text { subzone of } \\
\text { transformation, } \\
\text { progeny retardation } \\
\text { in zone of } \\
\text { transformation? } \\
\end{array}$ & -- & No & Yes/No & No & NA & 3 & Default value is used. & Yu et at. 2007 \\
\hline $\begin{array}{l}\text { Quantity of water } \\
\text { consumed by an } \\
\text { individual }\end{array}$ & $\mathrm{L} / \mathrm{yr}$ & 510 & $0-1,000$ & 700 & $\mathrm{M}, \mathrm{B}$ & 2 & $\begin{array}{l}\text { This value was converted from Table D.1 in DOE } \\
2009 . \\
\text { See Attachment II following this table of parameters. }\end{array}$ & $\begin{array}{c}\text { DOE } 2009 \\
\text { Appendix D, } \\
\text { Table D.1, page D- } \\
11 \\
\end{array}$ \\
\hline $\begin{array}{l}\text { Fraction of water } \\
\text { from surface body } \\
\text { for human } \\
\text { consumption }\end{array}$ & -- & 0 & $0-1$ & 0 & B, P & 3 & $\begin{array}{l}\text { This parameter is the fraction of water that is } \\
\text { obtained from the contaminated surface water body } \\
\text { for the specific use. If water is obtained from other } \\
\text { sources (contaminated well, uncontaminated outside } \\
\text { source), the fraction will be less than one. } \\
\text { It is assumed that all drinking water will come from } \\
\text { the well; therefore, the fraction of water from } \\
\text { contaminated surface water body is } 0 \text {. }\end{array}$ & Yu et al. 2007 \\
\hline
\end{tabular}


RESRAD-OFFSITE Table of Input Parameters for the C-746-U Landfill Offsite Resident Farmer Scenario

\begin{tabular}{|c|c|c|c|c|c|c|c|c|}
\hline $\begin{array}{c}\text { Input Screen Title } \\
\text { and Parameter } \\
\text { Name }\end{array}$ & Units & $\begin{array}{l}\text { Default } \\
\text { Value }^{a}\end{array}$ & $\begin{array}{l}\text { Code-Acceptec } \\
\text { Values }^{b} \\
\text { Physical or } \\
\text { Numerical }{ }^{c} \text { (N) } \\
\text { Range }\end{array}$ & $\begin{array}{l}\text { Deterministic } \\
\text { Value }\end{array}$ & Type $^{d}$ & Priority $^{\mathbf{e}}$ & Justification & References \\
\hline $\begin{array}{l}\text { Fraction of water } \\
\text { from well for } \\
\text { human } \\
\text { consumption }\end{array}$ & -- & 1 & $0-1$ & 1 & $B, P$ & 2 & $\begin{array}{l}\text { This parameter is the fraction of water that is } \\
\text { obtained from the contaminated well for the specific } \\
\text { use. If water is obtained from other sources } \\
\text { (contaminated surface water body, uncontaminated } \\
\text { outside source), the fraction will be less than one. } \\
\text { It is assumed that all drinking water will come from } \\
\text { the well; therefore, the fraction of water from the } \\
\text { contaminated well is } 1 .\end{array}$ & Yu et al. 2007 \\
\hline $\begin{array}{l}\text { Number of } \\
\text { household } \\
\text { individuals } \\
\text { consuming and } \\
\text { using water } \\
\end{array}$ & -- & 4 & $0-1,000$ & 4 & B & 3 & $\begin{array}{l}\text { Default value is used. The number of individuals } \\
\text { consuming and using water from the well is used to } \\
\text { estimate the minimum amount of water that is being } \\
\text { extracted from the well. This is not used in the } \\
\text { computational code. }\end{array}$ & Yu et al. 2007 \\
\hline $\begin{array}{l}\text { Quantity of water } \\
\text { for use indoors of } \\
\text { dwelling per } \\
\text { individual }\end{array}$ & $L / d$ & 225 & $0-1,000$ & 225 & $M, B$ & 3 & $\begin{array}{l}\text { Default value is used. This is the total amount of } \\
\text { water used in the house. It includes water used for } \\
\text { cleaning, washing, showering/bathing, etc. } \\
\text { It is also used by the interface to estimate the volume } \\
\text { of water that needs to be extracted from the well to } \\
\text { satisfy the specified needs. }\end{array}$ & Yu et al. 2007 \\
\hline $\begin{array}{l}\text { Fraction of water } \\
\text { from surface body } \\
\text { for use indoors of } \\
\text { dwelling }\end{array}$ & -- & 0 & $0-1$ & 0 & $B, P$ & 3 & $\begin{array}{l}\text { This parameter is the fraction of water that is } \\
\text { obtained from the contaminated surface water body } \\
\text { for the specific use. If water is obtained from other } \\
\text { sources (contaminated well, uncontaminated outside } \\
\text { source), the fraction will be less than one. } \\
\text { It is assumed that all water will come from a } \\
\text { contaminated well. }\end{array}$ & Yu et al. 2007 \\
\hline $\begin{array}{l}\text { Fraction of water } \\
\text { from well for use } \\
\text { indoors of dwelling }\end{array}$ & -- & 1 & $0-1$ & 1 & $B, P$ & 2 & $\begin{array}{l}\text { This parameter is the fraction of water that is } \\
\text { obtained from the contaminated well for the specific } \\
\text { use. If water is obtained from other sources } \\
\text { (contaminated surface water body, uncontaminated } \\
\text { outside source), the fraction will be less than one. } \\
\text { It is assumed that all water will come from a } \\
\text { contaminated well. }\end{array}$ & Yu et al. 2007 \\
\hline \multicolumn{9}{|l|}{ Beef Cattle } \\
\hline $\begin{array}{l}\text { Quantity of water } \\
\text { for beef cattle }\end{array}$ & $L / d$ & 50 & $0-500$ & 50 & $M, B$ & 2 & $\begin{array}{l}\text { The value used corresponds to the quantity of water } \\
\text { ingested daily by beef, available in DOE } 2009 \text {. }\end{array}$ & $\begin{array}{c}\text { DOE } 2009 \\
\text { Appendix D, Table }\end{array}$ \\
\hline
\end{tabular}


RESRAD-OFFSITE Table of Input Parameters for the C-746-U Landfill Offsite Resident Farmer Scenario

\begin{tabular}{|c|c|c|c|c|c|c|c|c|}
\hline $\begin{array}{c}\text { Input Screen Title } \\
\text { and Parameter } \\
\text { Name }\end{array}$ & Units & $\begin{array}{l}\text { Default } \\
\text { Value }^{\mathrm{a}}\end{array}$ & 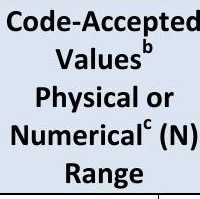 & $\begin{array}{c}\text { Deterministic } \\
\text { Value }\end{array}$ & Type $^{d}$ & Priority & Justification & References \\
\hline & & & & & & & See Attachment II following this table of parameters. & D.46, Page D-56. \\
\hline $\begin{array}{l}\text { Fraction of water } \\
\text { from surface body } \\
\text { for beef cattle }\end{array}$ & -- & 0 & $0-1$ & 0 & $B, P$ & 3 & $\begin{array}{l}\text { This parameter is the fraction of water that is } \\
\text { obtained from the contaminated surface water body } \\
\text { for the specific use. If water is obtained from other } \\
\text { sources (contaminated well, uncontaminated outside } \\
\text { source), the fraction will be less than one. } \\
\text { It is assumed that all water will come from a } \\
\text { contaminated well. }\end{array}$ & Yu et al. 2007 \\
\hline $\begin{array}{l}\text { Fraction of water } \\
\text { from well for beef } \\
\text { cattle }\end{array}$ & -- & 1 & $0-1$ & 1 & $B, P$ & 2 & $\begin{array}{l}\text { This parameter is the fraction of water that is } \\
\text { obtained from the contaminated well for the specific } \\
\text { use. If water is obtained from other sources } \\
\text { (contaminated surface water body, uncontaminated } \\
\text { outside source), the fraction will be less than one. } \\
\text { It is assumed that all water will come from a } \\
\text { contaminated well. }\end{array}$ & Yu et al. 2007 \\
\hline $\begin{array}{l}\text { Number of cattle } \\
\text { for beef cattle }\end{array}$ & -- & 2 & $0-10$ & 2 & B & 3 & Default value is used. & Yu et al. 2007 \\
\hline
\end{tabular}

\section{Dairy Cows}

\begin{tabular}{|c|c|c|c|c|c|c|c|c|}
\hline $\begin{array}{l}\text { Quantity of water } \\
\text { for dairy cows }\end{array}$ & $L / d$ & 160 & $0-1,000$ & 160 & $M, B$ & 2 & The default value is used. & Yu et al. 2007 \\
\hline $\begin{array}{l}\text { Fraction of water } \\
\text { from surface body } \\
\text { for dairy cows }\end{array}$ & -- & 0 & $0-1$ & 0 & $B, P$ & 3 & $\begin{array}{l}\text { This parameter is the fraction of water that is } \\
\text { obtained from the contaminated surface water body } \\
\text { for the specific use. If water is obtained from other } \\
\text { sources (contaminated well, uncontaminated outside } \\
\text { source), the fraction will be less than one. } \\
\text { It is assumed that all water will come from a } \\
\text { contaminated well. }\end{array}$ & Yu et al. 2007 \\
\hline $\begin{array}{l}\text { Fraction of water } \\
\text { from well for dairy } \\
\text { cows }\end{array}$ & -- & 1 & $0-1$ & 1 & $B, P$ & 2 & $\begin{array}{l}\text { This parameter is the fraction of water that is } \\
\text { obtained from the contaminated well for the specific } \\
\text { use. If water is obtained from other sources } \\
\text { (contaminated surface water body, uncontaminated } \\
\text { outside source), the fraction will be less than one. } \\
\text { It is assumed that all water will come from a } \\
\text { contaminated well. }\end{array}$ & Yu et al. 2007 \\
\hline
\end{tabular}


RESRAD-OFFSITE Table of Input Parameters for the C-746-U Landfill Offsite Resident Farmer Scenario

\begin{tabular}{|c|c|c|c|c|c|c|c|c|}
\hline $\begin{array}{c}\text { Input Screen Title } \\
\text { and Parameter } \\
\text { Name }\end{array}$ & Units & $\begin{array}{l}\text { Default } \\
\text { Value }^{a}\end{array}$ & $\begin{array}{l}\text { Code-Accepted } \\
\text { Values }^{b} \\
\text { Physical or }^{\mathrm{C}} \\
\text { Numerical } \\
\text { Range }\end{array}$ & $\begin{array}{l}\text { Deterministic } \\
\text { Value }\end{array}$ & Type $^{d}$ & Priority $^{\mathrm{e}}$ & Justification & References \\
\hline $\begin{array}{c}\text { Number of cows for } \\
\text { dairy cows }\end{array}$ & -- & 2 & $0-10$ & 2 & B & 3 & Default value is used. & Yu et al. 2007 \\
\hline $\begin{array}{l}\text { Fraction of water } \\
\text { from surface body } \\
\text { for fruit, grain, and } \\
\text { nonleafy vegetables }\end{array}$ & -- & 0 & $0-1$ & 0 & $B, P$ & 3 & $\begin{array}{l}\text { This parameter is the fraction of water that is } \\
\text { obtained from the contaminated surface water body } \\
\text { for the specific use. If water is obtained from other } \\
\text { sources (contaminated well, uncontaminated outside } \\
\text { source), the fraction will be less than one. } \\
\text { It is assumed that all water will come from a } \\
\text { contaminated well. }\end{array}$ & $\begin{array}{c}\text { DOE Project } \\
\text { Communication } \\
\text { with DOE-PPPO } \\
\text { (April 2011) } \\
\text { Yu et al. } 2007\end{array}$ \\
\hline $\begin{array}{l}\text { Fraction of water } \\
\text { from well for fruit, } \\
\text { grain, and nonleafy } \\
\text { vegetables }\end{array}$ & -- & 1 & $0-1$ & 1 & $B, P$ & 2 & $\begin{array}{l}\text { This parameter is the fraction of water that is } \\
\text { obtained from the contaminated well for the specific } \\
\text { use. If water is obtained from other sources } \\
\text { (contaminated surface water body, uncontaminated } \\
\text { outside source), the fraction will be less than one. } \\
\text { It is assumed that all water will come from a } \\
\text { contaminated well. }\end{array}$ & $\begin{array}{c}\text { DOE Project } \\
\text { Communication } \\
\text { with DOE-PPPO } \\
\text { (April 2011) } \\
\text { Yu et al. } 2007\end{array}$ \\
\hline
\end{tabular}

Leafy Vegetables

\begin{tabular}{|c|c|c|c|c|c|c|c|c|}
\hline $\begin{array}{l}\text { Fraction of water } \\
\text { from surface body } \\
\text { for leafy vegetables }\end{array}$ & -- & 0 & $0-1$ & 0 & $\mathrm{~B}, \mathrm{P}$ & 3 & $\begin{array}{l}\text { This parameter is the fraction of water that is } \\
\text { obtained from the contaminated surface water body } \\
\text { for the specific use. If water is obtained from other } \\
\text { sources (contaminated well, uncontaminated outside } \\
\text { source), the fraction will be less than one. } \\
\text { It is assumed that all water will come from a } \\
\text { contaminated well. }\end{array}$ & $\begin{array}{c}\text { DOE Project } \\
\text { Communication } \\
\text { with DOE-PPPO } \\
\text { (April 2011) } \\
\text { Yu et al. } 2007\end{array}$ \\
\hline $\begin{array}{l}\text { Fraction of water } \\
\text { from well for leafy } \\
\text { vegetables }\end{array}$ & -- & 1 & $0-1$ & 1 & $\mathrm{~B}, \mathrm{P}$ & 2 & $\begin{array}{l}\text { This parameter is the fraction of water that is } \\
\text { obtained from the contaminated well for the specific } \\
\text { use. If water is obtained from other sources } \\
\text { (contaminated surface water body, uncontaminated } \\
\text { outside source), the fraction will be less than one. } \\
\text { It is assumed that all water will come from a } \\
\text { contaminated well. }\end{array}$ & $\begin{array}{c}\text { DOE Project } \\
\text { Communication } \\
\text { with DOE-PPPO } \\
\text { (April 2011) } \\
\text { Yu et al. } 2007\end{array}$ \\
\hline
\end{tabular}

Pasture and Silage

Fraction of water


RESRAD-OFFSITE Table of Input Parameters for the C-746-U Landfill Offsite Resident Farmer Scenario

\begin{tabular}{|c|c|c|c|c|c|c|c|c|}
\hline $\begin{array}{c}\text { Input Screen Title } \\
\text { and Parameter } \\
\text { Name }\end{array}$ & Units & $\begin{array}{l}\text { Default } \\
\text { Value }^{a}\end{array}$ & $\begin{array}{l}\text { Code-Accepted } \\
\text { Values }^{b} \\
\text { Physical or } \\
\text { Numerical }^{\mathrm{C}}(\mathrm{N}) \\
\text { Range }^{2}\end{array}$ & $\begin{array}{l}\text { Deterministic } \\
\text { Value }\end{array}$ & Type $^{d}$ & Priority ${ }^{e}$ & Justification & References \\
\hline $\begin{array}{c}\text { from surface body } \\
\text { for pasture and } \\
\text { silage }\end{array}$ & & & & & & & $\begin{array}{l}\text { contaminated surface water body for the specific use. } \\
\text { If water is obtained from other sources } \\
\text { (contaminated well, uncontaminated outside source), } \\
\text { the fraction will be less than one. } \\
\text { It is assumed that all water will come from an } \\
\text { uncontaminated outside source. }\end{array}$ & $\begin{array}{l}\text { Communication } \\
\text { with DOE-PPPO } \\
\text { (October 2010) } \\
\text { Yu et al. } 2007\end{array}$ \\
\hline $\begin{array}{l}\text { Fraction of water } \\
\text { from well for } \\
\text { pasture and silage }\end{array}$ & -- & 1 & $0-1$ & 0 & $B, P$ & 2 & $\begin{array}{l}\text { This parameter is the fraction of water that is } \\
\text { obtained from the contaminated well for the specific } \\
\text { use. If water is obtained from other sources } \\
\text { (contaminated surface water body, uncontaminated } \\
\text { outside source), the fraction will be less than one. } \\
\text { It is assumed that all water will come from an } \\
\text { uncontaminated outside source. }\end{array}$ & $\begin{array}{c}\text { DOE Project } \\
\text { Communication } \\
\text { with DOE-PPPO } \\
\text { (October 2010) } \\
\text { Yu et al. } 2007\end{array}$ \\
\hline
\end{tabular}

Livestock Feed Grain

\begin{tabular}{|c|c|c|c|c|c|c|c|c|}
\hline $\begin{array}{c}\text { Fraction of water } \\
\text { from surface body } \\
\text { for livestock feed } \\
\text { grain }\end{array}$ & -- & 0 & $0-1$ & 0 & $\mathrm{~B}, \mathrm{P}$ & 3 & $\begin{array}{l}\text { This is the fraction of water that is obtained from the } \\
\text { contaminated surface water body for the specific use. } \\
\text { If water is obtained from other sources } \\
\text { (contaminated well, uncontaminated outside source), } \\
\text { the fraction will be less than one. } \\
\text { It is assumed that all water will come from an } \\
\text { uncontaminated outside source. }\end{array}$ & $\begin{array}{c}\text { DOE Project } \\
\text { Communication } \\
\text { with DOE-PPPO } \\
\text { (October 2010) } \\
\text { Yu et al. } 2007\end{array}$ \\
\hline $\begin{array}{l}\text { Fraction of water } \\
\text { from well for } \\
\text { livestock feed grain }\end{array}$ & -- & 1 & $0-1$ & 0 & $B, P$ & 2 & $\begin{array}{l}\text { This parameter is the fraction of water that is } \\
\text { obtained from the contaminated well for the specific } \\
\text { use. If water is obtained from other sources } \\
\text { (contaminated surface water body, uncontaminated } \\
\text { outside source), the fraction will be less than one. } \\
\text { It is assumed that all water will come from an } \\
\text { uncontaminated outside source. }\end{array}$ & $\begin{array}{c}\text { DOE Project } \\
\text { Communication } \\
\text { with DOE-PPPO } \\
\text { (October 2010) } \\
\text { Yu et al. } 2007\end{array}$ \\
\hline
\end{tabular}

Offsite Dwelling Site

\begin{tabular}{|c|c|c|c|c|c|c|c|c|}
\hline $\begin{array}{c}\text { Fraction of water } \\
\text { from surface body } \\
\text { for offsite dwelling } \\
\text { site }\end{array}$ & -- & 0 & $0-1$ & & 0 & B, P & 3 & $\begin{array}{l}\text { This is the fraction of water that is obtained from the } \\
\text { contaminated surface water body for the specific use. } \\
\text { If water is obtained from other sources } \\
\text { (contaminated well, uncontaminated outside source), }\end{array}$ \\
$\begin{array}{c}\text { Communication } \\
\text { with DOE-PPPO } \\
\text { (October 2010) }\end{array}$ \\
\hline
\end{tabular}


RESRAD-OFFSITE Table of Input Parameters for the C-746-U Landfill Offsite Resident Farmer Scenario

\begin{tabular}{|c|c|c|c|c|c|c|c|c|}
\hline $\begin{array}{l}\text { Input Screen Title } \\
\text { and Parameter } \\
\text { Name }\end{array}$ & Units & $\begin{array}{l}\text { Default } \\
\text { Value }^{\mathrm{a}}\end{array}$ & $\begin{array}{r}\text { Code-Acce } \\
\text { Values } \\
\text { Physical } \\
\text { Numerical } \\
\text { Range }\end{array}$ & $\begin{array}{l}\text { Deterministic } \\
\text { Value }\end{array}$ & Type $^{d}$ & Priority ${ }^{e}$ & Justification & References \\
\hline & & & & & & & $\begin{array}{l}\text { the fraction will be less than one. } \\
\text { It is assumed that all water will come from an } \\
\text { uncontaminated outside source. }\end{array}$ & Yu et al. 2007 \\
\hline $\begin{array}{l}\text { Fraction of water } \\
\text { from well for offsite } \\
\text { dwelling site }\end{array}$ & -- & 1 & $0-1$ & 0 & $B, P$ & 2 & $\begin{array}{l}\text { This parameter is the fraction of water that is } \\
\text { obtained from the contaminated well for the specific } \\
\text { use. If water is obtained from other sources } \\
\text { (contaminated surface water body, uncontaminated } \\
\text { outside source), the fraction will be less than one. } \\
\text { It is assumed that all water will come from an } \\
\text { uncontaminated outside source. }\end{array}$ & $\begin{array}{c}\text { DOE Project } \\
\text { Communication } \\
\text { with DOE-PPPO } \\
\text { (October 2010) } \\
\text { Yu et al. } 2007\end{array}$ \\
\hline Well pumping rate & $\mathrm{m}^{3} / \mathrm{yr}$ & 5,100 & $0-100,000$ & $\begin{array}{l}\text { Calculated by } \\
\text { the code }\end{array}$ & $B, P$ & 2 & Default is used. & Yu et al. 2007 \\
\hline $\begin{array}{l}\text { Well pumping rate } \\
\text { needed to specified } \\
\text { water use for } \\
\text { livestock feed grain }\end{array}$ & $\mathrm{m}^{3} / \mathrm{yr}$ & $5,084.17$ & Calculated & $\begin{array}{l}\text { Calculated by } \\
\text { the code }\end{array}$ & $B, P$ & 3 & Default value is used. & Yu et al. 2007 \\
\hline
\end{tabular}

\section{Ingestion Rates}

Consumption Rate

\begin{tabular}{|c|c|c|c|c|c|c|c|c|}
\hline $\begin{array}{l}\text { Drinking water } \\
\text { intake }\end{array}$ & $\mathrm{L} / \mathrm{yr}$ & 510 & $0-1,000$ & 700 & $M, B$ & 2 & $\begin{array}{l}\text { This value was converted from Table D.1 in DOE } \\
2009 . \\
\text { See Attachment II following this table of parameters. }\end{array}$ & $\begin{array}{c}\text { DOE } 2009 \\
\text { Appendix D, } \\
\text { Table D.1, page D- } \\
11\end{array}$ \\
\hline Fish consumption & $\mathrm{kg} / \mathrm{yr}$ & 5.4 & $0-1,000$ & 5.4 & $\mathrm{M}, \mathrm{B}$ & 3 & $\begin{array}{l}\text { The aquatic foods ingestion pathway is suppressed in } \\
\text { RESRAD OFFSITE for all receptors because it is not } \\
\text { considered part of the conceptual site model. }\end{array}$ & Yu et el. 2007 \\
\hline $\begin{array}{l}\text { Other aquatic food } \\
\text { consumption }\end{array}$ & $\mathrm{kg} / \mathrm{yr}$ & 0.9 & $0-100$ & 0.9 & $\mathrm{M}, \mathrm{B}$ & 3 & $\begin{array}{l}\text { The aquatic foods ingestion pathway is suppressed in } \\
\text { RESRAD OFFSITE for all receptors because it is not } \\
\text { considered part of the conceptual site model. }\end{array}$ & Yu et el. 2007 \\
\hline $\begin{array}{l}\text { Fruit, grain, } \\
\text { nonleafy vegetables } \\
\text { consumption }\end{array}$ & $\mathrm{kg} / \mathrm{yr}$ & 160 & $0-1,000$ & 231.7 & $\mathrm{M}, \mathrm{B}$ & 2 & $\begin{array}{l}\text { The value was converted from Table D.9 in DOE 2009, } \\
\text { which is for home grown vegetables. It does not } \\
\text { specify fruit, and grain, thus for RESRAD a ratio was } \\
\text { obtained to assign a value for fruit, vegetable and } \\
\text { grain consumption and a value for leafy vegetable } \\
\text { consumption. }\end{array}$ & $\begin{array}{c}\text { DOE } 2009 \\
\text { Appendix D, } \\
\text { Table D.9, page D- } \\
19\end{array}$ \\
\hline
\end{tabular}


RESRAD-OFFSITE Table of Input Parameters for the C-746-U Landfill Offsite Resident Farmer Scenario

\begin{tabular}{|c|c|c|c|c|c|c|c|c|}
\hline $\begin{array}{l}\text { Input Screen Title } \\
\text { and Parameter } \\
\text { Name }\end{array}$ & Units & $\begin{array}{l}\text { Default } \\
\text { Value }^{a}\end{array}$ & $\begin{array}{r}\text { Code-Accep } \\
\text { Values }^{b} \\
\text { Physical } \\
\text { Numerical } \\
\text { Range }\end{array}$ & $\begin{array}{l}\text { Deterministic } \\
\text { Value }\end{array}$ & Type $^{d}$ & Priority ${ }^{e}$ & Justification & References \\
\hline & & & & & & & The calculation is included in Attachment II. & \\
\hline $\begin{array}{l}\text { Leafy vegetables } \\
\text { consumption }\end{array}$ & $\mathrm{kg} / \mathrm{yr}$ & 14 & $0-100$ & 20.3 & $M, B$ & 3 & $\begin{array}{l}\text { The value was converted from Table D.9 in DOE 2009, } \\
\text { which is for home grown vegetables. It does not } \\
\text { specify fruit, and grain, thus for RESRAD a ratio was } \\
\text { obtained to assign a value for fruit, vegetable and } \\
\text { grain consumption and a value for leafy vegetable } \\
\text { consumption. } \\
\text { The calculation is included in Attachment II. }\end{array}$ & $\begin{array}{c}\text { DOE } 2009 \\
\text { Appendix D, Table } \\
\text { D.9, page D-19 }\end{array}$ \\
\hline Meat consumption & $\mathrm{kg} / \mathrm{yr}$ & 63 & $0-300$ & 154 & $\mathrm{M}, \mathrm{B}$ & 3 & $\begin{array}{l}\text { This value was converted from Table D.10, D.12, and } \\
\text { D.13 in DOE } 2009 \text {. The value is the sum of the values } \\
\text { obtained for beef, pork and poultry, since they are in } \\
\text { separate tables. The value for eggs is available, but } \\
\text { eggs are not considered poultry. } \\
\text { See Attachment II following this table of parameters. }\end{array}$ & $\begin{array}{l}\text { DOE } 2009 \\
\text { Appendix D, Table } \\
\text { D.10, D.12, and } \\
\text { D.13, pages D-20, } \\
\text { D-22 and D-23 }\end{array}$ \\
\hline Milk consumption & $\mathrm{L} / \mathrm{yr}$ & 92 & $0-1,000$ & 425 & $\mathrm{M}, \mathrm{B}$ & 2 & $\begin{array}{l}\text { This value was converted from Table D.11 in DOE } \\
\text { 2009. The density of whole milk, } 1030 \mathrm{~kg} / \mathrm{cubic} \\
\text { meter, was used to convert the value into L/yr. } \\
\text { See Attachment II following this table of parameters. }\end{array}$ & $\begin{array}{c}\text { DOE } 2009 \\
\text { Appendix D, } \\
\text { Table D.11, page } \\
\text { D-21 }\end{array}$ \\
\hline $\begin{array}{l}\text { Soil (incidental) } \\
\text { ingestion rate }\end{array}$ & $g / y r$ & 36.5 & $0-10,000$ & 36.5 & $M, B$ & 2 & $\begin{array}{l}\text { This value was converted from Table D.5 in DOE } \\
2009 . \\
\text { See Attachment II following this table of parameters. }\end{array}$ & $\begin{array}{c}\text { DOE } 2009 \\
\text { Appendix D,Table } \\
\text { D.5, page D-15 }\end{array}$ \\
\hline $\begin{array}{l}\text { Drinking water } \\
\text { intake from } \\
\text { affected area }\end{array}$ & -- & 1 & $0-1$ & 1 & $B, P$ & 3 & $\begin{array}{l}\text { This is the fraction of drinking water consumed by an } \\
\text { individual that is obtained from the contaminated } \\
\text { source. }\end{array}$ & Yu et al. 2007 \\
\hline $\begin{array}{l}\text { Fish consumption } \\
\text { from affected area }\end{array}$ & -- & 0.5 & $0-1$ & 0.5 & $B, P$ & 2 & $\begin{array}{l}\text { This is the fraction of fish consumed by an individual } \\
\text { that is obtained from the contaminated surface water } \\
\text { body. } \\
\text { This parameter is suppressed by turning off the } \\
\text { aquatic food pathway because it is not considered in } \\
\text { the conceptual site model. }\end{array}$ & Yu et al. 2007 \\
\hline $\begin{array}{l}\text { Other aquatic food } \\
\text { consumption from } \\
\text { affected area }\end{array}$ & -- & 0.5 & $0-1$ & 0.5 & $B, P$ & 2 & $\begin{array}{l}\text { This is the fraction of the other aquatic food } \\
\text { consumed by an individual that is obtained from the } \\
\text { contaminated surface water body. The aquatic foods } \\
\text { ingestion pathway is suppressed in RESRAD for all } \\
\text { receptors because it is not considered part of the }\end{array}$ & Yu et al. 2007 \\
\hline
\end{tabular}


RESRAD-OFFSITE Table of Input Parameters for the C-746-U Landfill Offsite Resident Farmer Scenario

\begin{tabular}{|c|c|c|c|c|c|c|c|c|}
\hline $\begin{array}{c}\text { Input Screen Title } \\
\text { and Parameter } \\
\text { Name }\end{array}$ & Units & $\begin{array}{l}\text { Default } \\
\text { Value }^{\mathrm{a}}\end{array}$ & $\begin{array}{c}\text { Code-Accepted } \\
\text { Values }^{b} \\
\text { Physical or }^{\text {Pacal }} \\
\text { Numerical }^{\mathrm{C}} \text { (N) } \\
\text { Range }\end{array}$ & $\begin{array}{l}\text { Deterministic } \\
\text { Value }\end{array}$ & Type $^{d}$ & Priority $^{e}$ & Justification & References \\
\hline & & & & & & & conceptual site model. & \\
\hline $\begin{array}{c}\text { Fruit, grain, } \\
\text { nonleafy vegetables } \\
\text { consumption from } \\
\text { affected area }\end{array}$ & -- & 0.5 & $0-1$ & 0.5 & $B, P$ & 3 & $\begin{array}{l}\text { This is the fraction of fruit, nonleafy vegetables, or } \\
\text { grain consumed by an individual that is obtained } \\
\text { from contaminated agricultural areas. }\end{array}$ & Yu et al. 2007 \\
\hline $\begin{array}{l}\text { Leafy vegetables } \\
\text { consumption from } \\
\text { affected area }\end{array}$ & -- & 0.5 & $0-1$ & 0.5 & $B, P$ & 3 & $\begin{array}{l}\text { This is the fraction of leafy vegetables consumed by } \\
\text { an individual that is obtained from contaminated } \\
\text { agricultural areas. }\end{array}$ & Yu et al. 2007 \\
\hline $\begin{array}{l}\text { Meat consumption } \\
\text { from affected area }\end{array}$ & -- & 1 & $0-1$ & 1 & $B, P$ & 3 & $\begin{array}{l}\text { This is the fraction of meat consumed by an } \\
\text { individual that is produced using contaminated feed } \\
\text { and water. }\end{array}$ & Yu et al. 2007 \\
\hline $\begin{array}{l}\text { Milk consumption } \\
\text { from affected area }\end{array}$ & -- & 1 & $0-1$ & 1 & $B, P$ & 3 & $\begin{array}{l}\text { This is the fraction of milk consumed by an individual } \\
\text { that is produced using contaminated feed and water. }\end{array}$ & Yu et al. 2007 \\
\hline
\end{tabular}

\section{Livestock Intakes}

\begin{tabular}{|c|c|c|c|c|c|c|c|c|}
\hline \multicolumn{9}{|l|}{ Beef Cattle } \\
\hline $\begin{array}{l}\text { Water intake for } \\
\text { beef cattle }\end{array}$ & $L / d$ & 50 & $0-500$ & 50 & $M$ & 3 & $\begin{array}{l}\text { The value used corresponds to the quantity of water } \\
\text { ingested daily by beef, available in DOE } 2009 . \\
\text { See Attachment II following this table of parameters. }\end{array}$ & $\begin{array}{c}\text { DOE } 2009 \\
\text { Appendix D, Table } \\
\text { D.46, Page D-56. }\end{array}$ \\
\hline $\begin{array}{l}\text { Pasture and silage } \\
\text { intake for beef } \\
\text { cattle }\end{array}$ & $\mathrm{kg} / \mathrm{d}$ & 14 & $0-300$ & 25 & $M$ & 3 & $\begin{array}{l}\text { The value used corresponds to the quantity of } \\
\text { pasture ingested daily by beef, available in DOE } 2009 . \\
\text { See Attachment II following this table of parameters. }\end{array}$ & $\begin{array}{c}\text { DOE } 2009 \\
\text { Appendix D, Table } \\
\text { D.46, Page D-56. }\end{array}$ \\
\hline $\begin{array}{l}\text { Grain intake for } \\
\text { beef cattle }\end{array}$ & $\mathrm{kg} / \mathrm{d}$ & 54 & $0-300$ & 54 & $M$ & 3 & $\begin{array}{l}\text { Default value is used because there is no site specific } \\
\text { value. }\end{array}$ & Yu et al. 2007 \\
\hline $\begin{array}{l}\text { Soil from pasture } \\
\text { and silage intake for } \\
\text { beef cattle }\end{array}$ & $\mathrm{kg} / \mathrm{d}$ & 0.1 & $0-10$ & 0.2 & M & 3 & $\begin{array}{l}\text { DOE } 2009 \text { specifies a value of } 1 \mathrm{~kg} / \mathrm{d} \text { for soil ingested } \\
\text { daily by beef. The default values were used to } \\
\text { develop a ratio, by which this value was calculated. } \\
\text { See Attachment II following this table of parameters. }\end{array}$ & $\begin{array}{c}\text { DOE 2009, } \\
\text { Appendix D, Table } \\
\text { D.46, page D-56 }\end{array}$ \\
\hline $\begin{array}{l}\text { Soil from grain } \\
\text { intake for beef } \\
\quad \text { cattle }\end{array}$ & $\mathrm{kg} / \mathrm{d}$ & 0.4 & $0-10$ & 0.8 & $M$ & 3 & $\begin{array}{l}\text { DOE } 2009 \text { specifies a value of } 1 \mathrm{~kg} / \mathrm{d} \text { for soil ingested } \\
\text { daily by beef. The default values were used to } \\
\text { develop a ratio, by which this value was calculated. } \\
\text { See Attachment II following this table of parameters. }\end{array}$ & $\begin{array}{c}\text { DOE 2009, } \\
\text { Appendix D, Table } \\
\text { D.46, page D-56 }\end{array}$ \\
\hline
\end{tabular}

Dairy Cows 
RESRAD-OFFSITE Table of Input Parameters for the C-746-U Landfill Offsite Resident Farmer Scenario

\begin{tabular}{|c|c|c|c|c|c|c|c|c|}
\hline $\begin{array}{c}\text { Input Screen Title } \\
\text { and Parameter } \\
\text { Name }\end{array}$ & Units & $\begin{array}{l}\text { Default } \\
\text { Value }^{a}\end{array}$ & $\begin{array}{l}\text { Code-Accepted } \\
\text { Values }^{b} \\
\text { Physical or } \\
\text { Numerical }{ }^{\mathrm{C}} \text { (N) } \\
\text { Range }\end{array}$ & $\begin{array}{l}\text { Deterministic } \\
\text { Value }\end{array}$ & Type $^{d}$ & Priority & Justification & References \\
\hline $\begin{array}{l}\text { Water intake for } \\
\text { dairy cows }\end{array}$ & $L / d$ & 160 & $0-500$ & 160 & M & 3 & The default value is used. & Yu et al. 2007 \\
\hline $\begin{array}{l}\text { Pasture and silage } \\
\text { intake for dairy } \\
\text { cows }\end{array}$ & $\mathrm{kg} / \mathrm{d}$ & 44 & $0-300$ & 25 & M & 3 & $\begin{array}{l}\text { The value used corresponds to the quantity of } \\
\text { pasture ingested daily by dairy, available in DOE } \\
2009 \text {. } \\
\text { See Attachment II following this table of parameters. }\end{array}$ & $\begin{array}{c}\text { DOE } 2009 \\
\text { Appendix D, Table } \\
\text { D.47, Page D-57 }\end{array}$ \\
\hline $\begin{array}{l}\text { Grain intake for } \\
\text { dairy cows }\end{array}$ & $\mathrm{kg} / \mathrm{d}$ & 11 & $0-300$ & 11 & M & 3 & $\begin{array}{l}\text { Default value is used because there is no site specific } \\
\text { value. }\end{array}$ & Yu et al. 2007 \\
\hline $\begin{array}{l}\text { Soil from pasture } \\
\text { and silage intake for } \\
\text { dairy cows }\end{array}$ & $\mathrm{kg} / \mathrm{d}$ & 0.4 & $0-10$ & 0.8 & M & 3 & $\begin{array}{l}\text { DOE } 2009 \text { specifies a value of } 1 \mathrm{~kg} / \mathrm{d} \text { for soil ingested } \\
\text { daily by dairy. The default values were used to } \\
\text { develop a ratio, by which this value was calculated. } \\
\text { See Attachment II following this table of parameters. }\end{array}$ & $\begin{array}{c}\text { DOE 2009, } \\
\text { Appendix D, Table } \\
\text { D.47, page D-57 }\end{array}$ \\
\hline $\begin{array}{l}\text { Soil from grain } \\
\text { intake for dairy } \\
\text { cows }\end{array}$ & $\mathrm{kg} / \mathrm{d}$ & 0.1 & $0-10$ & 0.2 & M & 3 & $\begin{array}{l}\text { DOE } 2009 \text { specifies a value of } 1 \mathrm{~kg} / \mathrm{d} \text { for soil ingested } \\
\text { daily by dairy. The default values were used to } \\
\text { develop a ratio, by which this value was calculated. } \\
\text { See Attachment II following this table of parameters. }\end{array}$ & $\begin{array}{c}\text { DOE 2009, } \\
\text { Appendix D, Table } \\
\text { D.47, page D-57 }\end{array}$ \\
\hline
\end{tabular}

Livestock Feed Factors

Pasture and Silage
\begin{tabular}{|c|c|c|c|c|c|c|c|c|}
\hline $\begin{array}{c}\text { Wet weight crop } \\
\text { yield of pasture and } \\
\text { silage }\end{array}$ & $\mathrm{kg} / \mathrm{m}^{2}$ & 1.1 & $0.01-3$ & & 1.1 & $\mathrm{P}$ & 3 & Default value is used. \\
\hline $\begin{array}{c}\text { Duration of growing } \\
\text { season of pasture } \\
\text { and silage }\end{array}$ & $\mathrm{yr}$ & 0.08 & $0.01-1$ & & 0.08 & $\mathrm{P}$ & 3 & Default value is used. \\
\hline $\begin{array}{c}\text { Foliage to food } \\
\text { transfer coefficient } \\
\text { of pasture and } \\
\text { silage }\end{array}$ & -- & 1 & $0-1$ & 1 & & $\mathrm{P}$ & 3 & Ye07 et al. 2007 \\
\hline $\begin{array}{c}\text { Weathering } \\
\text { removal constant of } \\
\text { pasture and silage }\end{array}$ & $1 / \mathrm{yr}$ & 20 & $1-40$ & & 20 & $\mathrm{P}$ & 2 & Default value is used. \\
\hline $\begin{array}{c}\text { Foliar interception } \\
\text { factor for irrigation } \\
\text { of pasture and }\end{array}$ & -- & 0.25 & $0-1$ & & 0.25 & $\mathrm{P}$ & 3 & Default value is used. \\
\hline
\end{tabular}


RESRAD-OFFSITE Table of Input Parameters for the C-746-U Landfill Offsite Resident Farmer Scenario

\begin{tabular}{|c|c|c|c|c|c|c|c|c|}
\hline $\begin{array}{c}\text { Input Screen Title } \\
\text { and Parameter } \\
\text { Name }\end{array}$ & Units & $\begin{array}{l}\text { Default } \\
\text { Value }^{a}\end{array}$ & $\begin{array}{c}\text { Code-Accepted } \\
\text { Values }^{\mathrm{b}} \\
\text { Physical or } \\
\text { Numerical }^{\mathrm{c}}(\mathrm{N}) \\
\text { Range } \\
\end{array}$ & $\begin{array}{l}\text { Deterministic } \\
\text { Value }\end{array}$ & Type $^{d}$ & Priority $^{e}$ & Justification & References \\
\hline \multicolumn{9}{|l|}{ silage } \\
\hline $\begin{array}{l}\text { Foliar interception } \\
\text { factor for dust of } \\
\text { pasture and silage }\end{array}$ & -- & 0.25 & $0-1$ & 0.25 & $P$ & 3 & Default value is used. & Yu et al. 2007 \\
\hline $\begin{array}{c}\text { Root depth of } \\
\text { pasture and silage }\end{array}$ & $\mathrm{m}$ & 0.9 & $0-3$ & 0.9 & P & 1 & Default value is used. & Yu et al. 2007 \\
\hline
\end{tabular}

Grain

\begin{tabular}{|c|c|c|c|c|c|c|c|c|}
\hline $\begin{array}{c}\text { Wet weight crop } \\
\text { yield of grain }\end{array}$ & $\mathrm{kg} / \mathrm{m}^{2}$ & 0.7 & $0.01-3$ & 0.7 & $\mathrm{P}$ & 3 & Default value is used. \\
\hline $\begin{array}{c}\text { Duration of growing } \\
\text { season of grain }\end{array}$ & $\mathrm{yr}$ & 0.17 & $0.01-1$ & 0.17 & $\mathrm{P}$ & 3 & Default value is used. \\
\hline $\begin{array}{c}\text { Foliage to food } \\
\text { transfer coefficient } \\
\text { of grain }\end{array}$ & -- & 0.1 & $0-1$ & 0.1 & $\mathrm{P}$ & 3 & Default value is used. \\
\hline $\begin{array}{c}\text { Weathering } \\
\text { removal constant of } \\
\text { grain }\end{array}$ & $1 / \mathrm{yr}$ & 20 & $1-40$ & 0.20 & $\mathrm{P}$ & 2 & Default value is used. \\
\hline $\begin{array}{c}\text { Foliar interception } \\
\text { factor for irrigation } \\
\text { of grain }\end{array}$ & -- & 0.25 & $0-1$ & 0.25 & $\mathrm{P}$ & 3 & Yefault value is used. \\
\hline $\begin{array}{c}\text { Foliar interception } \\
\text { factor for dust of } \\
\text { grain }\end{array}$ & -- & 0.25 & $0-1$ & & 0.25 & $\mathrm{P}$ & 3 & Yu et al. 2007 \\
\hline Root depth of grain & $\mathrm{m}$ & 1.2 & $0-10$ & & 1.2 & $\mathrm{P}$ & 1 & Default value is used. \\
\hline
\end{tabular}

\section{Plant Factors}

\begin{tabular}{|c|c|c|c|c|c|c|c|c|}
\hline $\begin{array}{l}\text { Wet weight crop } \\
\text { yield of fruit, grain, } \\
\text { and nonleafy } \\
\text { vegetables }\end{array}$ & $\mathrm{kg} / \mathrm{m}^{2}$ & 0.7 & $0.01-3$ & 0.7 & $P$ & 3 & $\begin{array}{l}\text { The weight of the edible portion of plant food } \\
\text { produced per unit land area for different food } \\
\text { classes. The code has wet weight crop yield for non- } \\
\text { leafy, leafy, and fodder. Non-leafy and leafy } \\
\text { vegetables are for human consumption; fodder is for } \\
\text { animal consumption. } \\
\text { Default value is used. }\end{array}$ & Yu et al. 2007 \\
\hline $\begin{array}{l}\text { Duration of growing } \\
\text { season of fruit, } \\
\text { grain, and nonleafy } \\
\text { vegetables }\end{array}$ & $\mathrm{yr}$ & 0.17 & $0.01-1$ & 0.17 & $P$ & 3 & $\begin{array}{l}\text { This is the period of time over which the crop is } \\
\text { grown. It is assumed that the plant is exposed to } \\
\text { contamination by foliar interception during this } \\
\text { period and that all the irrigation is applied during this }\end{array}$ & Yu et al. 2007 \\
\hline
\end{tabular}


RESRAD-OFFSITE Table of Input Parameters for the C-746-U Landfill Offsite Resident Farmer Scenario

\begin{tabular}{|c|c|c|c|c|c|c|c|c|}
\hline $\begin{array}{c}\text { Input Screen Title } \\
\text { and Parameter } \\
\text { Name }\end{array}$ & Units & $\begin{array}{l}\text { Default } \\
\text { Value }^{a}\end{array}$ & $\begin{array}{l}\text { Code-Accepted } \\
\text { Values }^{b} \\
\text { Physical or }^{c} \\
\text { Numerical }{ }^{\mathrm{C}} \text { (N) } \\
\text { Range }^{\text {Nang }}\end{array}$ & $\begin{array}{l}\text { Deterministic } \\
\text { Value }\end{array}$ & Type $^{d}$ & Priority ${ }^{\mathrm{e}}$ & Justification & References \\
\hline & & & & & & & $\begin{array}{l}\text { period. } \\
\text { Default value is used. }\end{array}$ & \\
\hline $\begin{array}{l}\text { Foliage to food } \\
\text { transfer coefficient } \\
\text { of fruit, grain, and } \\
\text { nonleafy vegetables }\end{array}$ & -- & 0.1 & $0-1$ & 0.1 & $P$ & 3 & Default value is used. & Yu et al. 2007 \\
\hline $\begin{array}{l}\text { Weathering } \\
\text { removal constant of } \\
\text { fruit, grain, and } \\
\text { nonleafy vegetables }\end{array}$ & $1 / \mathrm{yr}$ & 20 & $1-40$ & 20 & $P$ & 2 & Default value is used. & Yu et al. 2007 \\
\hline $\begin{array}{l}\text { Foliar interception } \\
\text { factor for irrigation } \\
\text { of fruit, grain, and } \\
\text { nonleafy vegetables }\end{array}$ & -- & 0.25 & $0-1$ & 0.25 & $P$ & 2 & Default value is used. & Yu et al. 2007 \\
\hline $\begin{array}{l}\text { Foliar interception } \\
\text { factor for dust of } \\
\text { fruit, grain, and } \\
\text { nonleafy vegetables }\end{array}$ & -- & 0.25 & $0-1$ & 0.25 & $P$ & 3 & Default value is used. & Yu et al. 2007 \\
\hline $\begin{array}{l}\text { Root depth of fruit, } \\
\text { grain, and nonleafy } \\
\text { vegetables }\end{array}$ & $\mathrm{m}$ & 1.2 & $0-10$ & 1.2 & $P$ & 1 & Default value is used. & Yu et al. 2007 \\
\hline
\end{tabular}

\section{Leafy Vegetables}

\begin{tabular}{|c|c|c|c|c|c|c|c|c|}
\hline $\begin{array}{c}\text { Wet weight crop } \\
\text { yield of leafy } \\
\text { vegetables }\end{array}$ & $\mathrm{kg} / \mathrm{m}^{2}$ & 1.5 & $0.01-3$ & 1.5 & $\mathrm{P}$ & 3 & Yu et al. 2007 \\
\hline $\begin{array}{c}\text { Duration of growing } \\
\text { season of leafy } \\
\text { vegetables }\end{array}$ & $\mathrm{yr}$ & 0.25 & $0.01-1$ & 0.25 & $\mathrm{P}$ & 3 & Default value is used. \\
\hline $\begin{array}{c}\text { Foliage to food } \\
\text { transfer coefficient } \\
\text { of leafy vegetables }\end{array}$ & -- & 1 & $0-1$ & 1 & $\mathrm{P}$ & 3 & Default value is used. \\
\hline $\begin{array}{c}\text { Weathering } \\
\text { removal constant of } \\
\text { leafy vegetables }\end{array}$ & $1 / \mathrm{yr}$ & 20 & $1-40$ & 2007 & Yu et al. 2007 \\
\hline $\begin{array}{c}\text { Foliar interception } \\
\text { factor for irrigation } \\
\text { of leafy vegetables }\end{array}$ & -- & 0.25 & $0-1$ & & 0.25 & $\mathrm{P}$ & 2 & Default value is used. \\
\hline
\end{tabular}


RESRAD-OFFSITE Table of Input Parameters for the C-746-U Landfill Offsite Resident Farmer Scenario

\begin{tabular}{|c|c|c|c|c|c|c|c|c|}
\hline $\begin{array}{c}\text { Input Screen Title } \\
\text { and Parameter } \\
\text { Name }\end{array}$ & Units & $\begin{array}{l}\text { Default } \\
\text { Value }^{a}\end{array}$ & $\begin{array}{l}\text { Code-Accepted } \\
\text { Values }^{b} \\
\text { Physical or } \\
\text { Numerical }{ }^{\mathrm{C}} \text { (N) } \\
\text { Range }\end{array}$ & $\begin{array}{l}\text { Deterministic } \\
\text { Value }\end{array}$ & Type $^{d}$ & Priority $^{e}$ & Justification & References \\
\hline $\begin{array}{l}\text { Foliar interception } \\
\text { factor for dust of } \\
\text { leafy vegetables }\end{array}$ & -- & 0.25 & $0-1$ & 0.25 & $P$ & 3 & Default value is used. & Yu et al. 2007 \\
\hline $\begin{array}{l}\text { Root depth of leafy } \\
\text { vegetables }\end{array}$ & $\mathrm{m}$ & 0.9 & $0-3$ & 0.9 & $\mathrm{P}$ & 1 & Default value is used. & Yu et al. 2007 \\
\hline
\end{tabular}

Inhalation and External Gamma Data

\begin{tabular}{|c|c|c|c|c|c|c|c|c|}
\hline Inhalation rate & $\mathrm{m}^{3} / \mathrm{yr}$ & 8,400 & $0-20,000$ & 7,297 & $M, B$ & 3 & $\begin{array}{l}\text { The inhalation rate for the Resident Farmer was } \\
\text { converted from a value available in DOE 2009. For } \\
\text { the conversion } 365 \text { days/yr were used, because this is } \\
\text { what RESRAD considers. }\end{array}$ & $\begin{array}{c}\text { DOE } 2009 \\
\text { Appendix D, Table } \\
\text { D.7, page D-17 } \\
\\
\text { King et al. } 2006 \\
\text { Page } 178\end{array}$ \\
\hline $\begin{array}{l}\text { Mass loading for } \\
\text { inhalation }\end{array}$ & $\mathrm{g} / \mathrm{m}^{3}$ & 0.0001 & $0-2$ & $1.08 \mathrm{E}-06$ & $P, B$ & 2 & $\begin{array}{l}\text { The following equation was used to calculate the } \\
\text { Mass Loading for Inhalation or Air-to-Soil } \\
\text { Concentration Ratio (ASR): ASR = 1/ PEF. } \\
\text { The PEF values used to calculate the mass loading for } \\
\text { inhalation are available in DOE 2009. The PEF value } \\
\text { was converted into RESRAD compatible units. } \\
\text { See Attachment II following this table of parameters. }\end{array}$ & $\begin{array}{l}\text { King et al. } 2006 \\
\text { page } 178 \\
\\
\text { DOE } 2009 \\
\text { Appendix D, Table } \\
\text { D.7 (Resident } \\
\text { Farmer = Rural } \\
\text { Resident), page D- } \\
17 \\
\end{array}$ \\
\hline $\begin{array}{l}\text { Mean onsite mass } \\
\text { loading }\end{array}$ & $\mathrm{g} / \mathrm{m}^{3}$ & 0.0001 & $0-2$ & $1.08 \mathrm{E}-06$ & $P, B$ & 2 & $\begin{array}{l}\text { This is the average mass loading of airborne } \\
\text { contaminated soil particles, above the primary } \\
\text { contamination. It is used to estimate the contaminant } \\
\text { release rate to the atmosphere. }\end{array}$ & Yu et al. 2007 \\
\hline $\begin{array}{l}\text { Indoor dust } \\
\text { filtration factor } \\
\text { (indoor to outdoor } \\
\text { dust concentration) }\end{array}$ & -- & 0.4 & $0-1$ & 0.4 & $P, B$ & 2 & $\begin{array}{l}\text { The default value is used. Indoor time fraction is the } \\
\text { driver for application of this parameter. In instances } \\
\text { where there is no indoor occupancy, this parameter } \\
\text { will not be applied. }\end{array}$ & Yu et al. 2007 \\
\hline $\begin{array}{l}\text { External gamma } \\
\text { shielding } \\
\text { (penetration) factor }\end{array}$ & -- & 0.7 & $0-1$ & 0.8 & $P$ & 2 & $\begin{array}{l}\text { The external gamma shielding factor is available for } \\
\text { the Resident Farmer in DOE } 2009 \text {. } \\
\text { The value used in the code is actually the fraction of } \\
\text { outdoor gamma radiation that penetrates the } \\
\text { building. } \\
\text { See Attachment II following this table of parameters. }\end{array}$ & $\begin{array}{c}\text { DOE } 2009 \\
\text { Appendix D, Table } \\
\text { D.8, page D-18 } \\
\text { Yu et al. } 2007\end{array}$ \\
\hline
\end{tabular}


RESRAD-OFFSITE Table of Input Parameters for the C-746-U Landfill Offsite Resident Farmer Scenario

\begin{tabular}{|c|c|c|c|c|c|c|c|c|}
\hline $\begin{array}{c}\text { Input Screen Title } \\
\text { and Parameter } \\
\text { Name }\end{array}$ & Units & $\begin{array}{l}\text { Default } \\
\text { Value }^{\mathrm{a}}\end{array}$ & $\begin{array}{l}\text { Code-Accepted } \\
\text { Values }^{b} \\
\text { Physical or } \\
\text { Numerical' }{ }^{\mathrm{C}} \text { (N) } \\
\text { Range }^{\text {Rang }}\end{array}$ & $\begin{array}{l}\text { Deterministic } \\
\text { Value }\end{array}$ & Type $^{d}$ & Priority $^{e}$ & Justification & References \\
\hline
\end{tabular}

External Radiation Shape and Area Factors

\begin{tabular}{|c|c|c|c|c|c|c|c|c|}
\hline Dwelling location & & Offsite & $\begin{array}{l}\text { Onsite or } \\
\text { offsite }\end{array}$ & Offsite & $\mathrm{P}$ & 3 & $\begin{array}{l}\text { The receptor is located outside the contaminated } \\
\text { zone. }\end{array}$ & Yu et al. 2007 \\
\hline Scale & $\mathrm{m}$ & 200 & $>0-32,000$ & 1000 & $\mathrm{P}$ & 3 & $\begin{array}{l}\text { This scale is chosen to fully encompass the primary } \\
\text { contamination. }\end{array}$ & Yu et al. 2007 \\
\hline $\begin{array}{l}\text { Dwelling location } \\
\text { coordinate in X- } \\
\text { direction }\end{array}$ & $\mathrm{m}$ & 100 & $\begin{array}{l}-16,000- \\
+16,000\end{array}$ & 190.375 & $\mathrm{P}$ & 3 & $\begin{array}{l}\text { The dwelling is located near the well, north of the } \\
\text { contaminated zone. }\end{array}$ & \\
\hline $\begin{array}{l}\text { Dwelling location } \\
\text { coordinate in } y^{-} \\
\text {direction }\end{array}$ & $\mathrm{m}$ & 0 & $\begin{array}{l}-16,000- \\
+16,000\end{array}$ & 670 & $\mathrm{P}$ & 3 & $\begin{array}{l}\text { The dwelling is located near the well, } 300 \text { meters } \\
\text { north of the north edge of the contaminated zone. }\end{array}$ & \\
\hline \multirow{12}{*}{ Radius } & \multirow{12}{*}{$\mathrm{m}$} & 13.25 & \multirow{12}{*}{ Calculated } & Calculated & \multirow{12}{*}{$P$} & \multirow{12}{*}{3} & \multirow[t]{12}{*}{ Calculated by the code. } & \multirow[t]{12}{*}{ Yu et al. 2007} \\
\hline & & 26.5 & & Calculated & & & & \\
\hline & & 39.75 & & Calculated & & & & \\
\hline & & 53 & & Calculated & & & & \\
\hline & & 66.25 & & Calculated & & & & \\
\hline & & 79.5 & & Calculated & & & & \\
\hline & & 92.75 & & Calculated & & & & \\
\hline & & 106 & & Calculated & & & & \\
\hline & & 119.25 & & Calculated & & & & \\
\hline & & 132.5 & & Calculated & & & & \\
\hline & & 145.75 & & Calculated & & & & \\
\hline & & 159 & & Calculated & & & & \\
\hline \multirow{12}{*}{ Fraction } & \multirow{12}{*}{--} & 0 & \multirow{12}{*}{ Calculated } & Calculated & \multirow{12}{*}{$P$} & \multirow{12}{*}{3} & \multirow[t]{12}{*}{ Calculated by the code. } & \multirow[t]{12}{*}{ Yu et al. 2007} \\
\hline & & 0 & & Calculated & & & & \\
\hline & & 0 & & Calculated & & & & \\
\hline & & 0.024 & & Calculated & & & & \\
\hline & & 0.19 & & Calculated & & & & \\
\hline & & 0.24 & & Calculated & & & & \\
\hline & & 0.2 & & Calculated & & & & \\
\hline & & 0.17 & & Calculated & & & & \\
\hline & & 0.15 & & Calculated & & & & \\
\hline & & 0.13 & & Calculated & & & & \\
\hline & & 0.12 & & Calculated & & & & \\
\hline & & 0.052 & & Calculated & & & & \\
\hline
\end{tabular}


RESRAD-OFFSITE Table of Input Parameters for the C-746-U Landfill Offsite Resident Farmer Scenario

\begin{tabular}{|c|c|c|c|c|c|c|c|c|}
\hline $\begin{array}{c}\text { Input Screen Title } \\
\text { and Parameter } \\
\text { Name }\end{array}$ & Units & $\begin{array}{l}\text { Default } \\
\text { Value }^{\mathrm{a}}\end{array}$ & $\begin{array}{r}\text { Code-Acce } \\
\text { Values } \\
\text { Physical } \\
\text { Numerical } \\
\text { Range }\end{array}$ & $\begin{array}{l}\text { Deterministic } \\
\text { Value }\end{array}$ & Type $^{d}$ & Priority & Justification & References \\
\hline $\begin{array}{l}\text { Shape of the } \\
\text { primary } \\
\text { contamination }\end{array}$ & -- & Polygonal & $\begin{array}{l}\text { Circular or } \\
\text { polygonal }\end{array}$ & Polygonal & $P$ & 3 & $\begin{array}{l}\text { The coordinates of the waste area were used to } \\
\text { create the shape of the contaminated area. }\end{array}$ & $\begin{array}{l}\text { Yu et al. } 2007 \\
\text { Lee et al. } 1995\end{array}$ \\
\hline $\begin{array}{l}\mathrm{X} \text { coordinate of the } \\
\text { vertices of polygon } \\
\text { of the primary } \\
\text { contamination }\end{array}$ & $\mathrm{m}$ & none & $\begin{array}{l}-16,000- \\
+16,000\end{array}$ & $\begin{array}{r}X 1=98, \\
X 2=256, \\
X 3=256, \\
X 4=0, \\
X 5=0, \\
X 6=98\end{array}$ & $P$ & 3 & $\begin{array}{l}\text { The coordinates of the waste area were used to } \\
\text { create the shape of the contaminated area. }\end{array}$ & Lee et al. 1995 \\
\hline $\begin{array}{l}Y \text { coordinate of the } \\
\text { vertices of polygon } \\
\text { of the primary } \\
\text { contamination }\end{array}$ & $\mathrm{m}$ & none & $\begin{array}{l}-16,000- \\
+16,000\end{array}$ & $\begin{array}{c}Y 1=0, \\
Y 2=0, \\
Y 3=399, \\
Y 4=399, \\
Y 5=210, \\
Y 6=0\end{array}$ & $P$ & 3 & $\begin{array}{l}\text { The coordinates of the waste area were used to } \\
\text { create the shape of the contaminated area. }\end{array}$ & Lee et al. 1995 \\
\hline
\end{tabular}

Occupancy Factors

\begin{tabular}{|c|c|c|c|c|c|c|c|c|}
\hline $\begin{array}{l}\text { Indoor time fraction } \\
\text { on primary } \\
\text { contamination }\end{array}$ & -- & 0 & $0-1$ & 0 & B & 3 & $\begin{array}{l}\text { This parameter is the average fraction of time during } \\
\text { which an individual stays indoors. } \\
\text { The default value is used. The Resident Farmer does } \\
\text { not spend any time onsite. }\end{array}$ & Yu et al. 2007 \\
\hline $\begin{array}{l}\text { Outdoor time } \\
\text { fraction on primary } \\
\text { contamination }\end{array}$ & -- & 0 & $0-1$ & 0 & B & 3 & $\begin{array}{l}\text { This parameter is the average fraction of time during } \\
\text { which an individual stays outdoors on the site. } \\
\text { The default value is used. The Resident Farmer does } \\
\text { not spend any time onsite. }\end{array}$ & Yu et al. 2007 \\
\hline $\begin{array}{l}\text { Indoor time fraction } \\
\text { on offsite dwelling } \\
\text { site }\end{array}$ & -- & 0.5 & $0-1$ & 0.64 & B & 3 & $\begin{array}{l}\text { This parameter is the average fraction of time during } \\
\text { which an individual stays indoors. } \\
\text { The Resident Farmer is inside } 16 \text { hours per day, } 350 \\
\text { days per year which results in an indoor fraction of } \\
64 \% \text {. }\end{array}$ & $\begin{array}{c}\text { DOE } 2009 \\
\text { Appendix D, } \\
\text { Table D.8, page D- } \\
18\end{array}$ \\
\hline $\begin{array}{l}\text { Outdoor time } \\
\text { fraction on offsite } \\
\text { dwelling site }\end{array}$ & -- & 0.1 & $0-1$ & 0.064 & B & 3 & $\begin{array}{l}\text { This parameter is the average fraction of time during } \\
\text { which an individual stays outdoors on the site. } \\
\text { The Resident Farmer is outside } 8 \text { hours per day, } 350 \\
\text { days per year which results in an outdoor fraction of } \\
32 \% \text {. }\end{array}$ & $\begin{array}{c}\text { DOE } 2009 \\
\text { Appendix D, Table } \\
\text { D.8, page D-18 }\end{array}$ \\
\hline
\end{tabular}


RESRAD-OFFSITE Table of Input Parameters for the C-746-U Landfill Offsite Resident Farmer Scenario

\begin{tabular}{|c|c|c|c|c|c|c|c|c|}
\hline $\begin{array}{c}\text { Input Screen Title } \\
\text { and Parameter } \\
\text { Name }\end{array}$ & Units & $\begin{array}{l}\text { Default } \\
\text { Value }^{a}\end{array}$ & $\begin{array}{c}\text { Code-Accepted } \\
\text { Values }^{b} \\
\text { Physical or } \\
\text { Numerical }{ }^{\mathrm{C}} \text { (N) } \\
\text { Range }\end{array}$ & $\begin{array}{l}\text { Deterministic } \\
\text { Value }\end{array}$ & Type $^{d}$ & Priority $^{e}$ & Justification & References \\
\hline & & & & & & & $\begin{array}{l}\text { The outdoor fraction of } 0.32 \text { is divided by the number } \\
\text { of outdoor locations (5) to determine the time } \\
\text { fraction. }\end{array}$ & \\
\hline $\begin{array}{c}\text { Time fraction in } \\
\text { fruit, grain, and } \\
\text { nonleafy vegetable } \\
\text { fields }\end{array}$ & -- & 0.1 & $0-1$ & 0.064 & B & 3 & $\begin{array}{l}\text { This parameter is the average fraction of time during } \\
\text { which an individual stays outdoors on the site. } \\
\text { The Resident Farmer is outside } 8 \text { hours per day, } 350 \\
\text { days per year which results in an outdoor fraction of } \\
32 \% \text {. } \\
\text { The outdoor fraction of } 0.32 \text { is divided by the number } \\
\text { of outdoor locations (5) to determine the time } \\
\text { fraction. }\end{array}$ & $\begin{array}{c}\text { DOE } 2009 \\
\text { Appendix D, Table } \\
\text { D.8, page D-18 }\end{array}$ \\
\hline $\begin{array}{l}\text { Time fraction in } \\
\text { leafy vegetable } \\
\text { fields }\end{array}$ & -- & 0.1 & $0-1$ & 0.064 & B & 3 & $\begin{array}{l}\text { This parameter is the average fraction of time during } \\
\text { which an individual stays outdoors on the site. } \\
\text { The Resident Farmer is outside } 8 \text { hours per day, } 350 \\
\text { days per year which results in an outdoor fraction of } \\
32 \% \text {. } \\
\text { The outdoor fraction of } 0.32 \text { is divided by the number } \\
\text { of outdoor locations (5) to determine the time } \\
\text { fraction. }\end{array}$ & $\begin{array}{c}\text { DOE } 2009 \\
\text { Appendix D, Table } \\
\text { D.8, page D-18 }\end{array}$ \\
\hline $\begin{array}{l}\text { Time fraction in } \\
\text { pasture and silage } \\
\text { fields }\end{array}$ & -- & 0.1 & $0-1$ & 0.064 & B & 3 & $\begin{array}{l}\text { This parameter is the average fraction of time during } \\
\text { which an individual stays outdoors on the site. } \\
\text { The Resident Farmer is outside } 8 \text { hours per day, } 350 \\
\text { days per year which results in an outdoor fraction of } \\
32 \% \text {. } \\
\text { The outdoor fraction of } 0.32 \text { is divided by the number } \\
\text { of outdoor locations (5) to determine the time } \\
\text { fraction. }\end{array}$ & $\begin{array}{c}\text { DOE } 2009 \\
\text { Appendix D, Table } \\
\text { D.8, page D-18 }\end{array}$ \\
\hline
\end{tabular}


RESRAD-OFFSITE Table of Input Parameters for the C-746-U Landfill Offsite Resident Farmer Scenario

\begin{tabular}{|c|c|c|c|c|c|c|c|c|}
\hline $\begin{array}{c}\text { Input Screen Title } \\
\text { and Parameter } \\
\text { Name }\end{array}$ & Units & $\begin{array}{l}\text { Default } \\
\text { Value }^{a}\end{array}$ & $\begin{array}{l}\text { Code-Accepted } \\
\text { Values }^{b} \\
\text { Physical or } \\
\text { Numerical }^{\mathrm{C}} \text { (N) } \\
\text { Range }\end{array}$ & $\begin{array}{l}\text { Deterministic } \\
\text { Value }\end{array}$ & Type $^{d}$ & Priority ${ }^{e}$ & Justification & References \\
\hline $\begin{array}{l}\text { Time fraction in } \\
\text { livestock grain fields }\end{array}$ & -- & 0.1 & $0-1$ & 0.064 & B & 3 & $\begin{array}{l}\text { This parameter is the average fraction of time during } \\
\text { which an individual stays outdoors on the site. } \\
\text { The Resident Farmer is outside } 8 \text { hours per day, } 350 \\
\text { days per year which results in an outdoor fraction of } \\
32 \% \text {. } \\
\text { The outdoor fraction of } 0.32 \text { is divided by the number } \\
\text { of outdoor locations (5) to determine the time } \\
\text { fraction. }\end{array}$ & $\begin{array}{c}\text { DOE } 2009 \\
\text { Appendix D, Table } \\
\text { D.8, page D-18 }\end{array}$ \\
\hline
\end{tabular}

a The default values listed in this table are the default values in the RESRAD-OFFSITE code Version 2.

b RESRAD-OFFSITE does not provide code-accepted values for element- or nuclide-specific parameters.

c Numerical range is the range defined in a program file to prevent code crashes.

d $\quad P=$ physical, $B=$ behavioral, $M=$ metabolic; when more than one type is listed, the first is primary and the next is secondary.

e According to NUREG/CR-6697, it is necessary to establish priorities about which parameters to collect data for and use for distribution analysis. The parameters were ranked into three levels of priority: 1 (high priority), 2 (medium priority), and 3 (low priority).

f $\quad \mathrm{NA}=$ not applicable.

g Two hyphens indicate that the parameter is dimensionless.

Notes: According to the RESRAD-OFFSITE manual, the Radon parameters can be changed only if a radon precursor is selected in the radionuclide list and the radon pathway is turned on. Similarly, a user will have access to carbon-14 (C-14) or tritium (H-3) parameters only if C-14 or $\mathrm{H}-3$ radionuclides are selected as a contaminant.

The information in this table was obtained from the User's Manual for RESRAD-OFFSITE Version 2 
Attachment I

Distribution Coefficients 
Distribution Coefficients $\left(\mathrm{Kds}, \mathrm{cm}^{3} / \mathrm{g}\right)^{\mathrm{a}, \mathrm{b}}$ for parent radionuclides in the contaminated zone, the unsaturated zone, and the saturated zone

\begin{tabular}{|c|c|c|c|c|c|c|c|c|c|c|c|c|}
\hline Radionuclide & Am-241 & Cs-137 & Np-237 & Pu-238 & Pu-239/240 & Tc-99 & Th-228 & Th-230 & Th-232 & U-234 & U-235 & U-238 \\
\hline Contaminated Zone ${ }^{c}$ & 1900 & 280 & 70 & 550 & 550 & 1 & 3200 & 3200 & 3200 & 410 & 410 & 410 \\
\hline $\begin{array}{l}\text { Unsaturated Zone } 1 \\
\text { (Protective layer } \\
\text { (native soil)) }\end{array}$ & 1900 & 280 & 70 & 550 & 550 & 0.2 & 3200 & 3200 & 3200 & 66.8 & 66.8 & 66.8 \\
\hline $\begin{array}{l}\text { Unsaturated Zone } 2 \\
\text { (Gravel layer (no } \\
\text { collection)) }\end{array}$ & 1900 & 280 & 70 & 550 & 550 & 0.2 & 3200 & 3200 & 3200 & 66.8 & 66.8 & 66.8 \\
\hline $\begin{array}{c}\text { Unsaturated Zone } 3 \\
\text { (Clay barrier) }\end{array}$ & 8400 & 1900 & 144 & 5100 & 5100 & 20 & 5800 & 5800 & 5800 & 3640 & 3640 & 3640 \\
\hline $\begin{array}{l}\text { Unsaturated Zone } 4 \\
\text { (Alluvium soils } \\
\text { (native/subgrade)) }\end{array}$ & 1900 & 280 & 70 & 550 & 550 & 0.2 & 3200 & 3200 & 3200 & 66.8 & 66.8 & 66.8 \\
\hline $\begin{array}{c}\text { Unsaturated Zone } 5 \\
\text { (Clay confining unit } \\
\text { (native)) }\end{array}$ & 8400 & 1900 & 144 & 5100 & 5100 & 20 & 5800 & 5800 & 5800 & 3640 & 3640 & 3640 \\
\hline Saturated Zone(RGA) & 1900 & 280 & 70 & 550 & 550 & 0.2 & 3200 & 3200 & 3200 & 66.8 & 66.8 & 66.8 \\
\hline
\end{tabular}

\footnotetext{
a Distribution coefficients for Am-241, Np-237, Th-230, Th-232, U-234 and U-238 were obtained from DOE 2003b, page C3-313 and Table Att. 1. Distribution coefficient of radionuclides and their daughter products in different zones, page C3-314. It was assumed that the Kd for U-235 was similar to the Kd for U-234 and U-238 since the Kds are chemical specific.

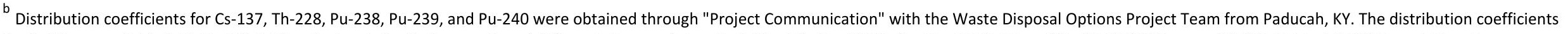
for Tc-99 are available in Table C.3.1. Chemical and physical properties of different classes of chemicals identified as COPCs for the C-746-U Landfill of DOE 2003b, page C3-301. Table 4.5 DUST model input parameters, page 4-12, has Kds for Tc-99 and Uranium.

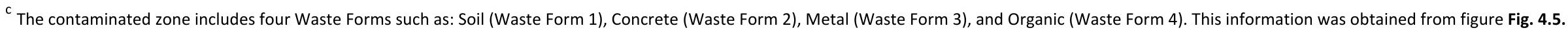
Schematic diagram of DUST model layers and materials for the Post-Institutional Control Period under the gradual failure and immediate failure scenarios of DOE 2003b, page 4-18.
} 
Distribution Coefficients $\left(\mathrm{Kds}, \mathrm{cm}^{3} / \mathrm{g}\right)^{\mathrm{d}}$ for progeny radionuclides in the contaminated zone, the unsaturated zones, and the saturated zone

\begin{tabular}{|c|c|c|c|c|c|c|c|c|}
\hline Radionuclide & Ac-227 & Pa-231 & Pb-210 & Ra-226 & Ra-228 & Th-229 & U-233 & U-236 \\
\hline $\begin{array}{c}\text { Contaminated Zone } \\
\text { e }\end{array}$ & 450 & 550 & 270 & 500 & 500 & 3200 & 410 & 410 \\
\hline $\begin{array}{c}\text { Unsaturated Zone 1 } \\
\text { (Protective layer } \\
\text { (native soi)) }\end{array}$ & 450 & 550 & 270 & 500 & 500 & 3200 & 66.8 & 66.8 \\
\hline $\begin{array}{c}\text { Unsaturated Zone 2 } \\
\text { (Gravel layer (no } \\
\text { collection)) }\end{array}$ & 450 & 550 & 270 & 500 & 500 & 3200 & 66.8 & 66.8 \\
\hline $\begin{array}{c}\text { Unsaturated Zone 3 } \\
\text { (Clay barrier) }\end{array}$ & 2400 & 2700 & 550 & 9100 & 9100 & 5800 & 3640 & 3640 \\
\hline $\begin{array}{c}\text { Unsaturated Zone 4 } \\
\text { (Alluvium soils } \\
\text { (native/subgrade)) }\end{array}$ & 450 & 550 & 270 & 500 & 500 & 3200 & 66.8 & 66.8 \\
\hline $\begin{array}{c}\text { Unsaturated Zone 5 } \\
\text { (Clay confining unit } \\
\text { (native)) }\end{array}$ & 2400 & 2700 & 550 & 9100 & 9100 & 5800 & 3640 & 3640 \\
\hline \begin{tabular}{c} 
Saturated Zone (RGA) \\
\hline
\end{tabular} & 450 & 550 & 270 & 500 & 500 & 3200 & 66.8 & 66.8 \\
\hline
\end{tabular}

\footnotetext{
d Distribution coefficients for Ac-227, Pa-231, Pb-210, Ra-226, Ra-228, Th-229, and U-236 were obtained through "Project Communication" with the Waste Disposal Options Project Team from Paducah, KY. It was assumed that the Kds for U-233 was similar to the Kds for the other uranium isotopes (i.e. U-234, U-235, U-236 and U-238), since the Kds are chemical specific.

e The contaminated zone includes four Waste Forms such as: Soil (Waste Form 1), Concrete (Waste Form 2), Metal (Waste Form 3), and Organic (Waste Form 4). This information was obtained from figure Fig. 4.5. Schematic diagram of DUST model layers and materials for the Post Institutional Control Period under the gradual failure and immediate failure scenarios of DOE $2003 \mathrm{~b}$, page 4-18.
} 
Distribution Coefficients ( $\mathrm{Kds}, \mathrm{cm}^{3} / \mathrm{g}$ ) for parent radionuclides in the sediment in surface water body; fruit, grain, nonleafy fields; leafy vegetable fields; pasture, silage growing areas; livestock feed grain fields; and dwelling site ${ }^{f}$

\begin{tabular}{|c|c|c|c|c|c|c|c|c|c|c|c|c|}
\hline Radionuclide & Am-241 & Cs-137 & Np-237 & Pu-238 & $\mathrm{Pu}-239 / 240$ & Tc-99 & Th-228 & Th-230 & Th-232 & U-234 & U-235 & U-238 \\
\hline $\begin{array}{c}\text { Sediment in } \\
\text { Surface Water } \\
\text { Body }\end{array}$ & 1900 & 280 & 70 & 550 & 550 & 0.2 & 3200 & 3200 & 3200 & 66.8 & 66.8 & 66.8 \\
\hline $\begin{array}{l}\text { Fruit, Grain, } \\
\text { Nonleafy Fields }\end{array}$ & 1900 & 280 & 70 & 550 & 550 & 0.2 & 3200 & 3200 & 3200 & 66.8 & 66.8 & 66.8 \\
\hline $\begin{array}{l}\text { Leafy Vegetable } \\
\text { Fields }\end{array}$ & 1900 & 280 & 70 & 550 & 550 & 0.2 & 3200 & 3200 & 3200 & 66.8 & 66.8 & 66.8 \\
\hline $\begin{array}{l}\text { Pasture, Silage } \\
\text { Growing Areas }\end{array}$ & 1900 & 280 & 70 & 550 & 550 & 0.2 & 3200 & 3200 & 3200 & 66.8 & 66.8 & 66.8 \\
\hline $\begin{array}{l}\text { Livestock Feed } \\
\text { Grain Fields }\end{array}$ & 1900 & 280 & 70 & 550 & 550 & 0.2 & 3200 & 3200 & 3200 & 66.8 & 66.8 & 66.8 \\
\hline Dwelling Site & 1900 & 280 & 70 & 550 & 550 & 0.2 & 3200 & 3200 & 3200 & 66.8 & 66.8 & 66.8 \\
\hline
\end{tabular}

\footnotetext{
${ }^{f}$ The Kds for native soil (Unsaturated Zone 2) were assumed for these areas.
} 
Distribution Coefficients ( $\mathrm{Kds}, \mathrm{cm}^{3} / \mathrm{g}$ ) for progeny in the sediment in surface water body; fruit, grain, nonleafy fields; leafy vegetable fields; pasture, silage growing areas; livestock feed grain fields; and dwelling site

\begin{tabular}{|c|c|c|c|c|c|c|c|c|}
\hline Radionuclide & Ac-227 & $\mathrm{Pa}-231$ & $\mathrm{~Pb}-210$ & Ra-226 & Ra-228 & Th-229 & U-233 & U-236 \\
\hline Sediment in Surface Water Body & 450 & 550 & 270 & 500 & 500 & 3200 & 66.8 & 66.8 \\
\hline Fruit, Grain, Nonleafy Fields & 450 & 550 & 270 & 500 & 500 & 3200 & 66.8 & 66.8 \\
\hline Pasture, Silage Growing Areas & 450 & 550 & 270 & 500 & 500 & 3200 & 66.8 & 66.8 \\
\hline Livestock Feed Grain Fields & 450 & 550 & 270 & 500 & 500 & 3200 & 66.8 & 66.8 \\
\hline Dwelling Site & 450 & 550 & 270 & 500 & 500 & 3200 & 66.8 & 66.8 \\
\hline
\end{tabular}


Attachment II

Calculations and Applicable Parameters from DOE 2009, Appendix D, Converted into RESRAD Compatible Units 


\section{Section A. Runoff Coefficient and Evapotranspiration Coefficient Calculations}

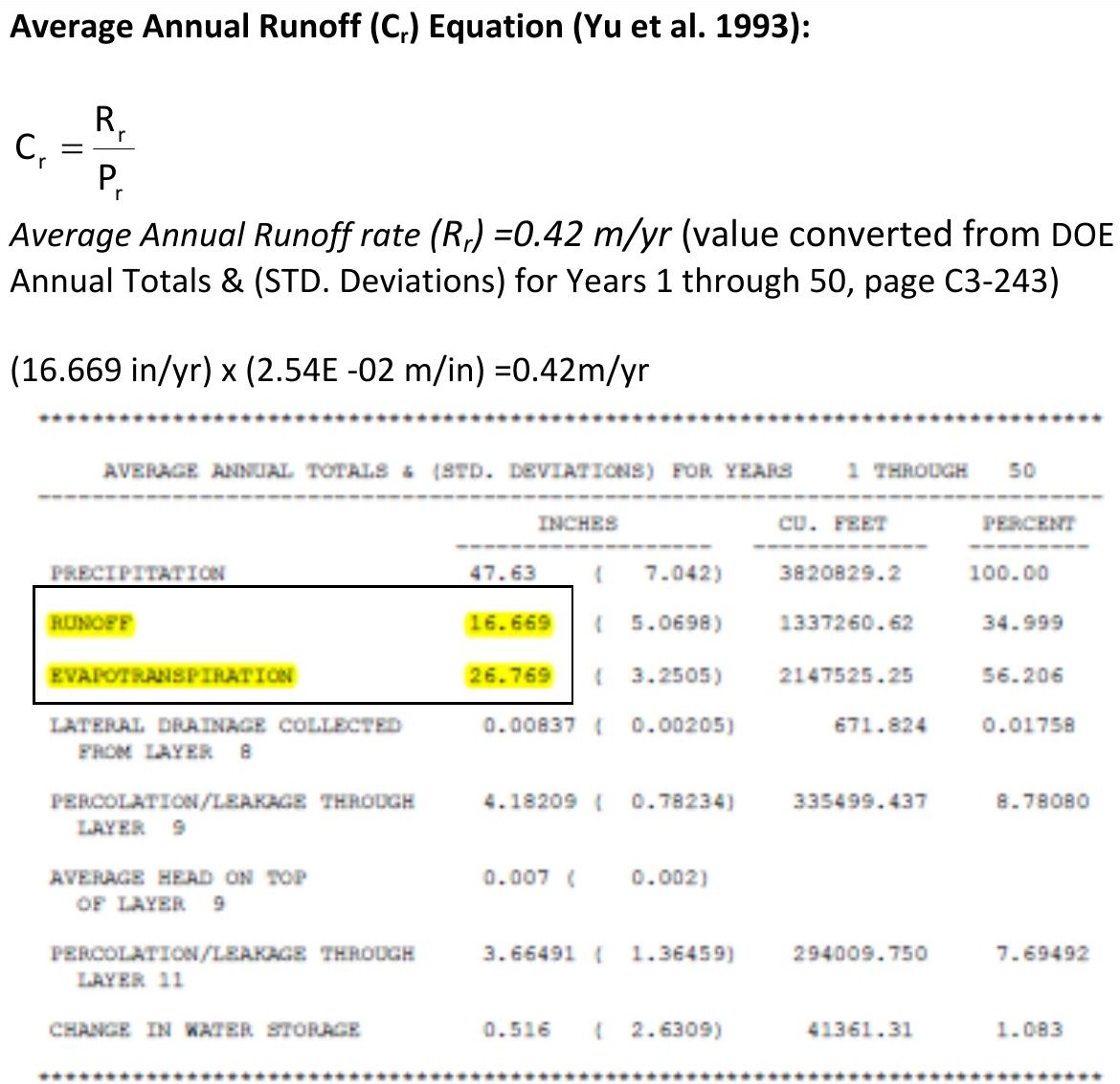




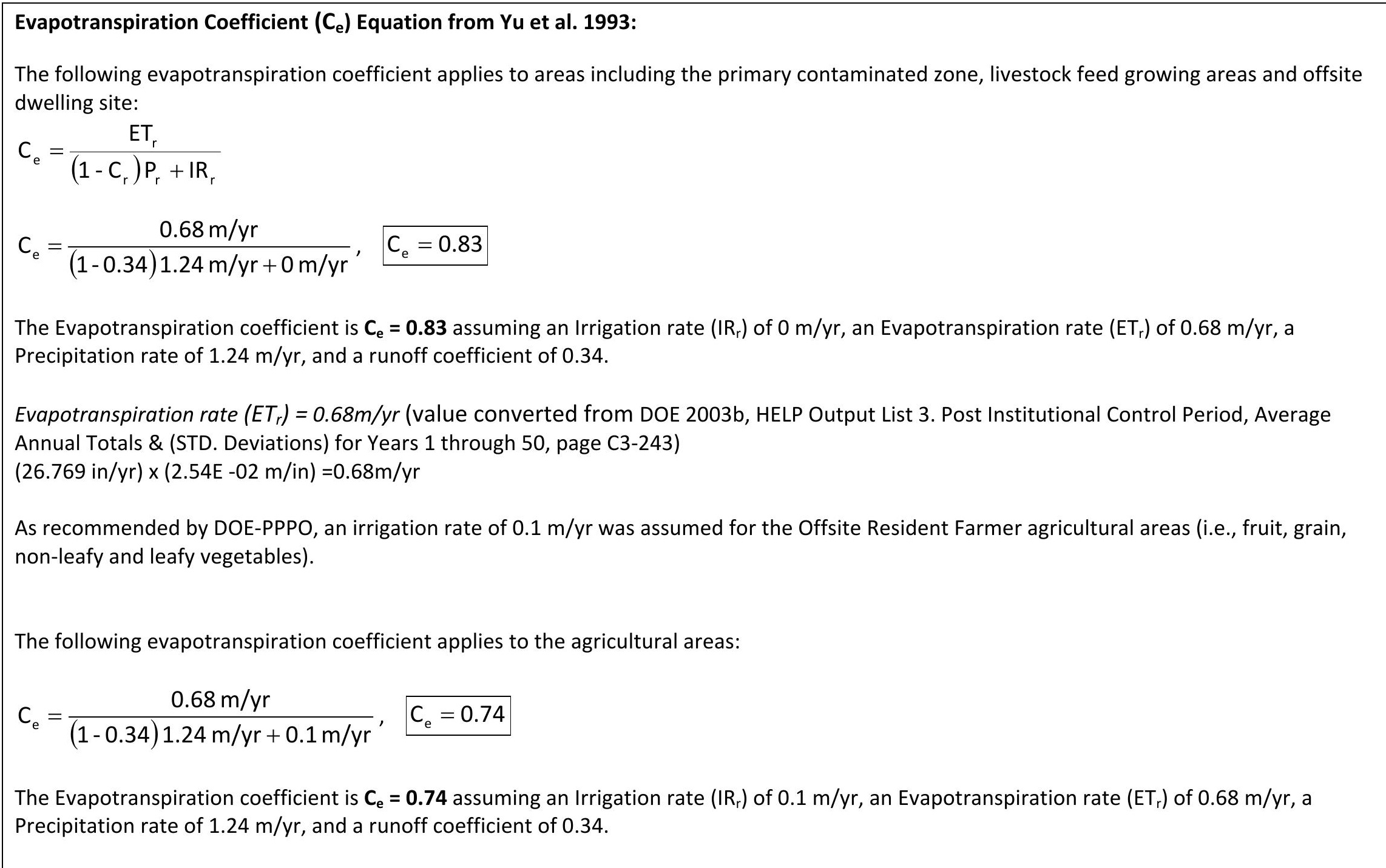




\section{Section B. Parameters Applicable to the Resident Farmer from DOE 2009, Appendix D Converted into RESRAD Compatible Units}

\section{Drinking Water Intake}

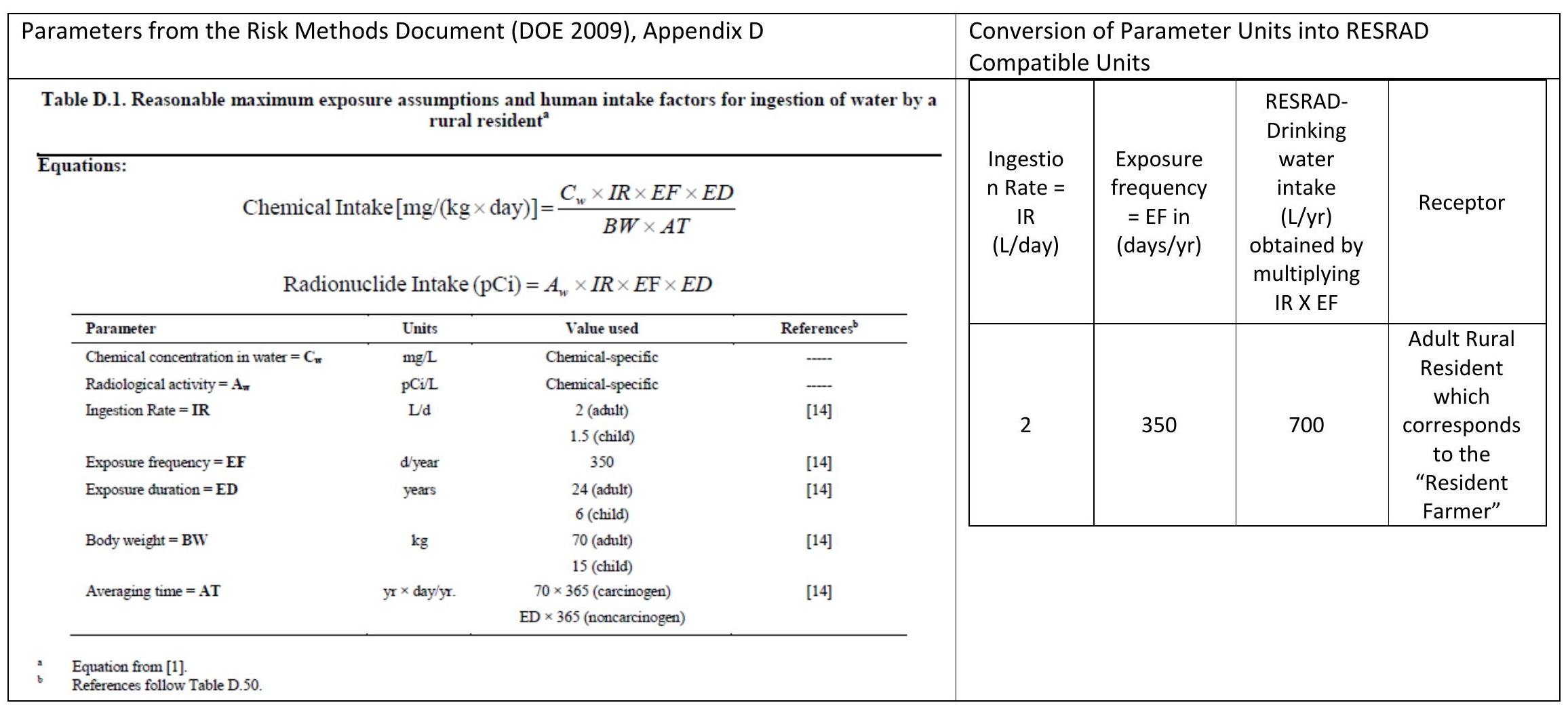




\section{Soil Ingestion Rate}

Parameters from the Risk Methods Document (DOE 2009), Appendix D

Table D.5. Reasonable maximum exposure assumptions and human intake factors for incidental ingestion soil by a rural resident ${ }^{a}$

$$
\text { Equations: }
$$$$
\text { Chemical Intake }\left[\mathrm{mg} /(\mathrm{kg} \times \text { day }]=\frac{C_{s} \times C F \times E F \times F I \times E D \times I R}{B W \times A T}\right.
$$

Radionuclide Intake $(\mathrm{pCi})=A_{s} \times C F_{\text {rad }} \times E F \times F I \times E D \times I R$

\begin{tabular}{|c|c|c|c|}
\hline Parameter & Units & Value used & References $^{\mathrm{b}}$ \\
\hline Chemical concentration in soil $=\mathrm{C}_{\mathrm{F}}$ & $\mathrm{mg} / \mathrm{kg}$ & Chemical-specific & $\ldots$ \\
\hline Radiological activity $=\mathbf{A}_{\mathbf{s}}$ & pCi/g & Chemical-specific & $\ldots$ \\
\hline Conversion factor $=\mathbf{C F}$ & $\mathrm{kg} / \mathrm{mg}$ & $10^{-6}$ & - \\
\hline Conversion factor $=\mathbf{C F}_{\mathrm{rad}}$ & $\mathrm{g} / \mathrm{mg}$ & $10^{-3}$ & $\ldots$ \\
\hline Exposure frequency $=\mathbf{E F}$ & days/yr & 350 & [14] \\
\hline Fraction ingested = FI & unitless & 1 & [14] \\
\hline \multirow[t]{2}{*}{ Exposure curation = ED } & years & 24 (adult) & [14] \\
\hline & & 6 (child) & \\
\hline \multirow[t]{2}{*}{ Ingestion rate of soil = IR } & $\mathrm{mg} / \mathrm{d}$ & 100 (adult) & [14] \\
\hline & & 200 (child) & \\
\hline \multirow[t]{2}{*}{ Body weight $=$ BW } & $\mathrm{kg}$ & 70 (adult) & [14] \\
\hline & & 15 (child) & \\
\hline \multirow{2}{*}{ Averaging time $=\mathrm{AT}$} & $\mathrm{yr} \times \mathrm{day} / \mathrm{yr}$ & $70 \times 365$ (carcinogen) & [14] \\
\hline & & $\mathrm{ED} \times 365$ (noncarcinogen) & \\
\hline
\end{tabular}

Conversion of Parameter Units into RESRAD Compatible Units

\begin{tabular}{|c|c|c|c|l|}
\hline $\begin{array}{c}\text { Conversion } \\
\text { factor }= \\
\begin{array}{c}\mathrm{Cf}_{\text {rad }} \\
(\mathrm{g} / \mathrm{mg})\end{array}\end{array}$ & $\begin{array}{c}\text { Ingestion } \\
\text { rate of } \\
\text { soil = IR } \\
(\mathrm{mg} / \text { day) }\end{array}$ & $\begin{array}{c}\text { Exposure } \\
\text { frequenc } \\
\mathrm{y}=\mathrm{EF} \\
\text { (days/yr) }\end{array}$ & $\begin{array}{c}\text { RESRAD -Soil } \\
\text { ingestion } \\
\text { (g/yr) } \\
\text { obtained by } \\
\text { multiplying } \\
\mathrm{Cf}_{\text {rad }} \text { X IR X EF }\end{array}$ & Receptor \\
\hline $1.00 \mathrm{E}-03$ & 100 & 365 & 36.5 & $\begin{array}{l}\text { Adult Rural } \\
\text { Resident } \\
\text { which } \\
\text { corresponds } \\
\text { to the } \\
\text { "Resident } \\
\text { Farmer" }\end{array}$ \\
\hline
\end{tabular}

Note: The exposure frequency of $365 \mathrm{~d} / \mathrm{yr}$ is used in the conversion, instead of $350 \mathrm{~d} / \mathrm{yr}$ since RESRAD uses time fractions to correct for occupancy. 
Inhalation Rate and Mass Loading for Inhalation

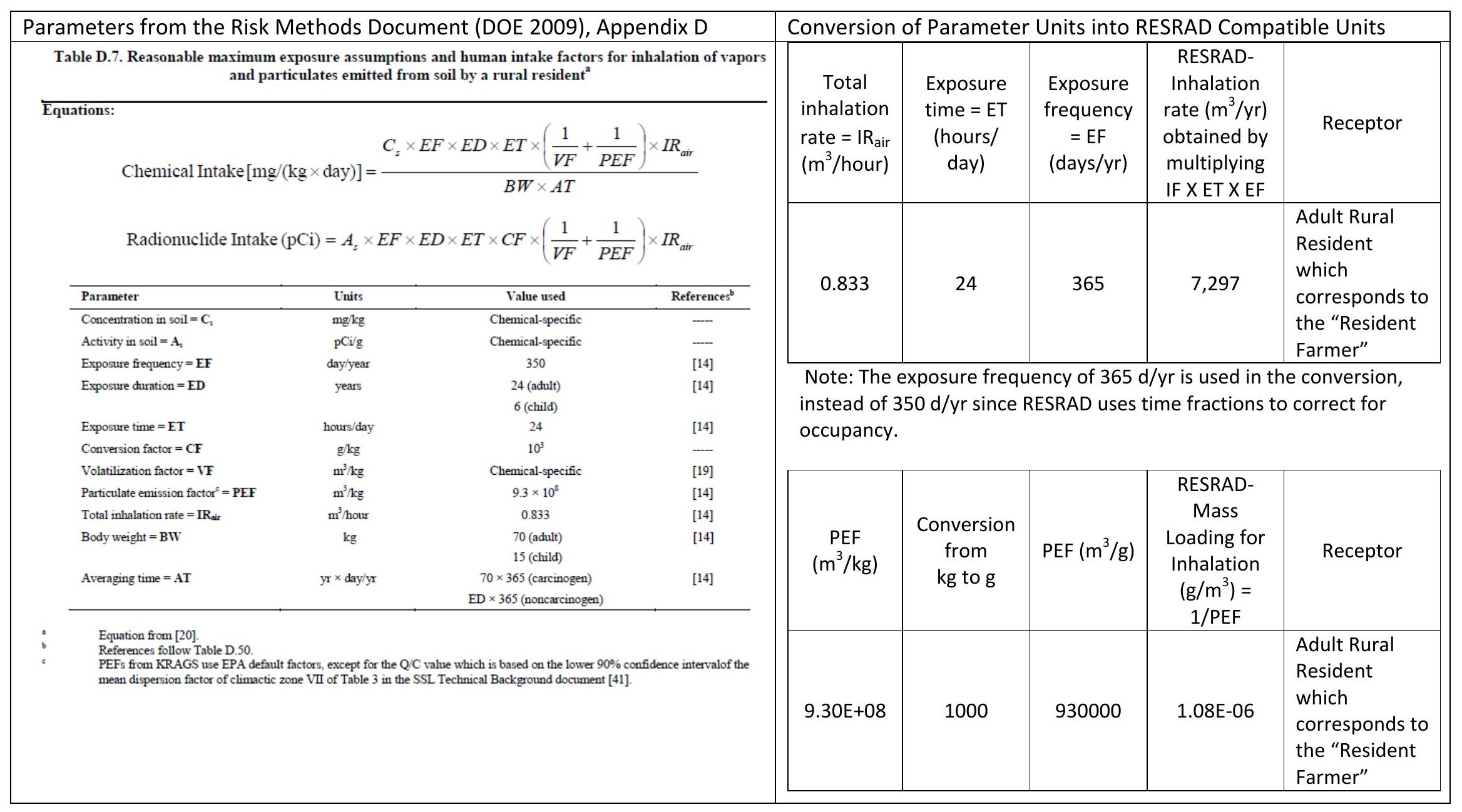


External Gamma Shielding Factor and Exposure Duration

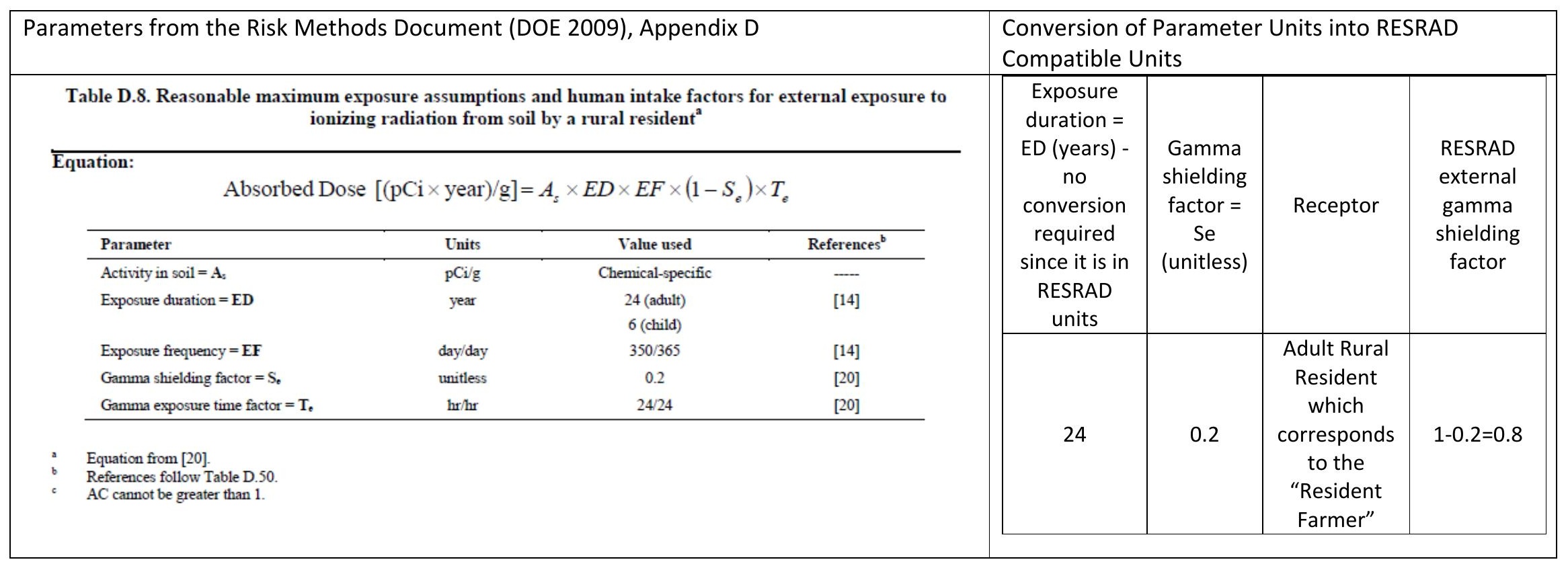

\section{Indoor and Outdoor Occupancy Fractions}

\begin{tabular}{|c|c|c|}
\hline \multicolumn{3}{|c|}{ Resident Farmer Occupancy fractions } \\
\hline & Days & Fractions for RESRAD \\
\hline $1 / 3$ of the time outdoors & 117 & 0.32 \\
\hline $2 / 3$ of the time indoors & 233 & 0.64 \\
\hline Total Days Onsite & 350 & \\
\hline Total Fraction & & 0.96 \\
\hline
\end{tabular}

Note: The Resident Farmer spends 350 days on site.

The fraction of time spent outdoors was divided by 5 , in order to equally distribute the time spent outdoors and in the different farm areas. This fraction was 0.064 . 
Fruit, Non-Leafy Vegetable, and Grain Consumption and Leafy Vegetables Consumption

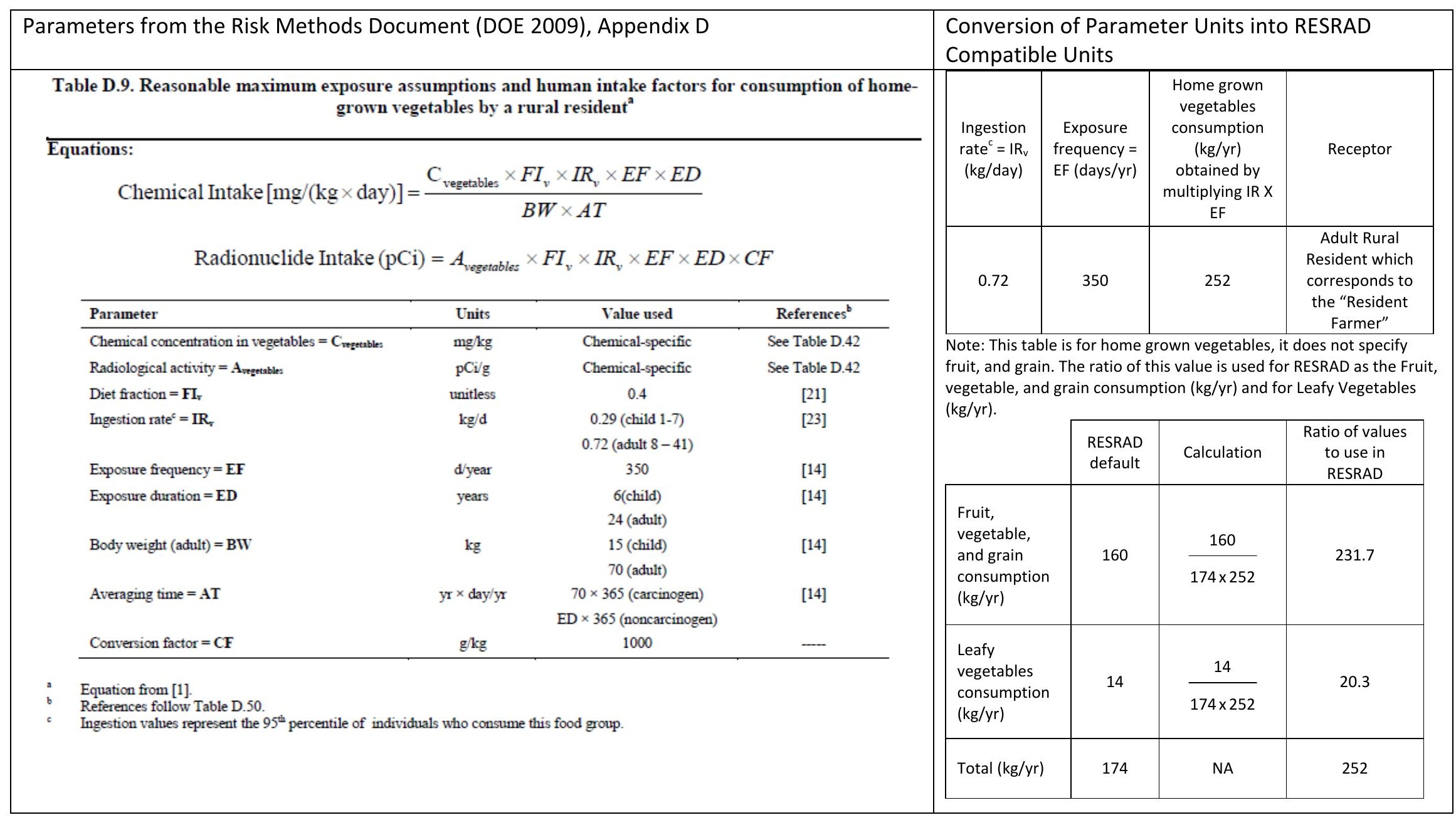




\section{Milk Consumption}

\section{Parameters from the Risk Methods Document (DOE 2009), Appendix D}

Table D.11. Reasonable maximum exposure assumptions and human intake factors for consumption of mil by a rural resident ${ }^{\mathrm{a}}$

$$
\text { Equations: }
$$

Chemical Intake $[\mathrm{mg} /(\mathrm{kg} \times$ day $)]=\frac{C_{\text {milk }} \times F I_{m} \times I R_{m} \times E F \times E D}{B W \times A T}$

Radionuclide Intake $(\mathrm{pCi})=A_{m i k} \times F I_{m} \times I R_{m} \times E F \times E D$

\begin{tabular}{|c|c|c|c|}
\hline Parameter & Units & Value used & References $^{b}$ \\
\hline Chemical concentration in milk $=\mathrm{C}_{\text {mill }}$ & $\mathrm{mg} / \mathrm{kg}$ & Chemical-specific & See Table D.47 \\
\hline Radiological activity in milk $=\mathbf{A}_{\operatorname{mill}}$ & $\mathrm{pCi} / \mathrm{kg}$ & Chemical-specific & See Table D.47 \\
\hline Milk ingestion rate ${ }^{c}=\mathrm{IR}_{\mathrm{m}}$ & $\mathrm{kg} /$ day & $\begin{array}{c}0.9 \text { (child } 1-7 \text { ) } \\
1.25 \text { (adult } 8-41 \text { ) }\end{array}$ & [23] \\
\hline Diet fraction $=\mathbf{F I}_{\mathbf{m}}$ & unitless & 1 & [21] \\
\hline Exposure frequency $=\mathbf{E F}$ & $d /$ year & 350 & [14] \\
\hline Exposure duration $=\mathrm{ED}$ & years & $\begin{array}{l}6 \text { (child) } \\
24 \text { (adult) }\end{array}$ & [14] \\
\hline Body weight (adult) $=\mathrm{BW}$ & $\mathrm{kg}$ & $\begin{array}{l}15 \text { (child) } \\
70 \text { (adult) }\end{array}$ & [14] \\
\hline Averaging time $=\mathrm{AT}$ & $\mathrm{yr} \times$ day $/ \mathrm{yr}$ & $\begin{array}{c}70 \times 365 \text { (carcinogen) } \\
\text { ED } \times 365 \text { (noncarcinogen) }\end{array}$ & [14] \\
\hline
\end{tabular}

\section{Equation from [1]}

References follow Table D. 50 .
ingestion values represent the $95^{\text {t }}$ percentile of individuals who consume this food group.

\begin{tabular}{|c|c|c|c|c|}
\hline \multicolumn{5}{|c|}{ Conversion of Parameter Units into RESRAD Compatible Units } \\
\hline $\begin{array}{c}\text { Milk } \\
\text { ingestion } \\
\text { rate }^{\mathrm{c}}= \\
\mathrm{IR}_{\mathrm{b}} \\
\text { (kg/day) }\end{array}$ & $\begin{array}{l}\text { Exposure } \\
\text { frequency } \\
=\mathrm{EF} \\
\text { (days/yr) }\end{array}$ & $\begin{array}{l}\text { Milk } \\
\text { consumption } \\
(\mathrm{kg} / \mathrm{yr}) \\
\text { obtained by } \\
\text { multiplying IR } \\
\text { X EF }\end{array}$ & $\begin{array}{l}\text { RESRAD-Milk } \\
\text { consumption } \\
\text { (L/yr) } \\
\text { obtained by } \\
\text { diving the } \\
\text { milk } \\
\text { consumption } \\
\text { (kg/yr) by the } \\
\text { density of } \\
\text { milk and then } \\
\text { multiplying by } \\
1000\end{array}$ & Receptor \\
\hline 1.25 & 350 & 437.5 & 425 & $\begin{array}{l}\text { Adult Rural } \\
\text { Resident } \\
\text { which } \\
\text { corresponds } \\
\text { to the } \\
\text { "Resident } \\
\text { Farmer" }\end{array}$ \\
\hline
\end{tabular}

Density of milk, cow, whole $=1030 \mathrm{~kg} / \mathrm{m}^{3}$

1 cubic meter $=1000$ liters

This density was obtained from an online source: http://physics.info/density/ 
Meat and Poultry Consumption

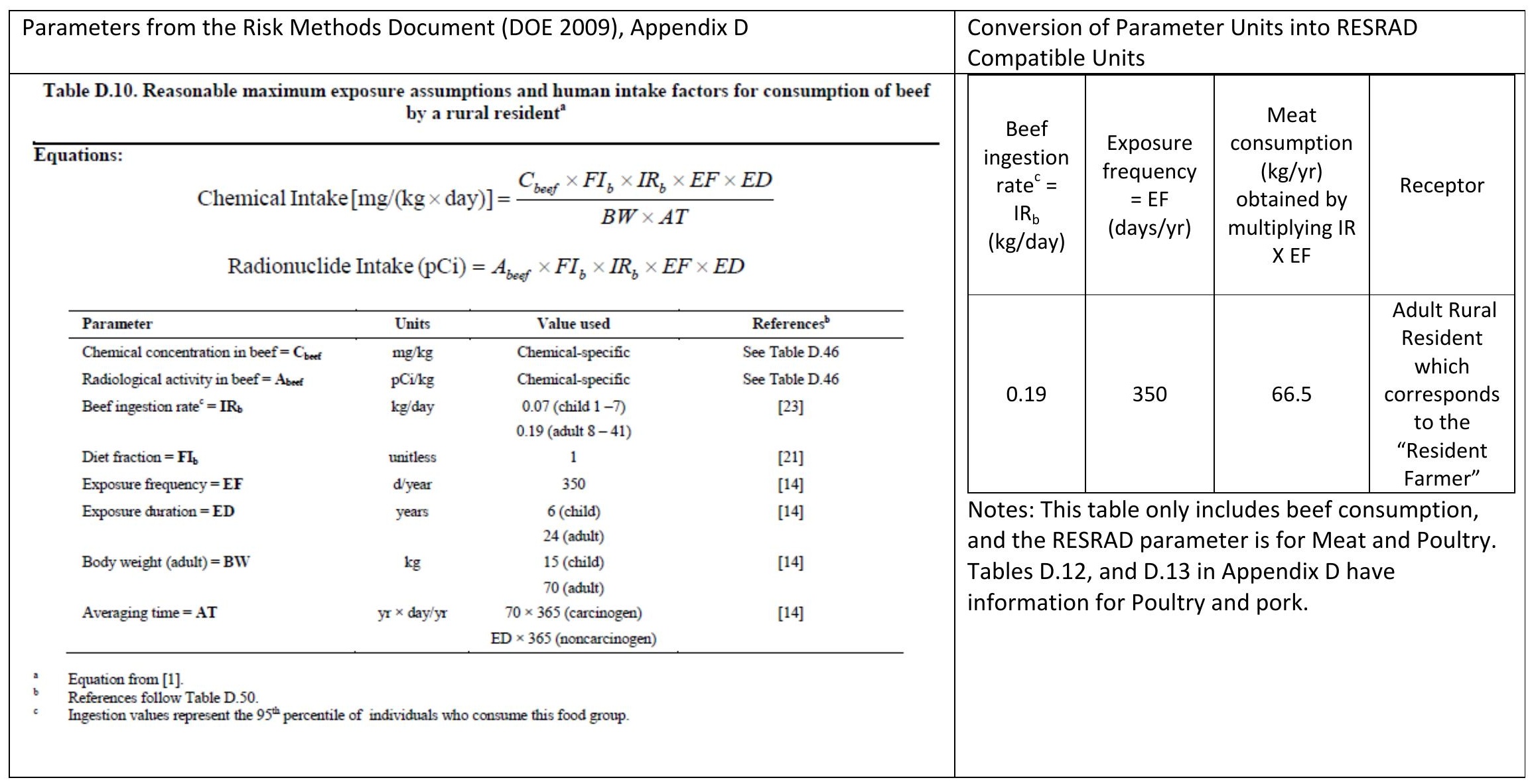


Meat and Poultry Consumption (cont.)

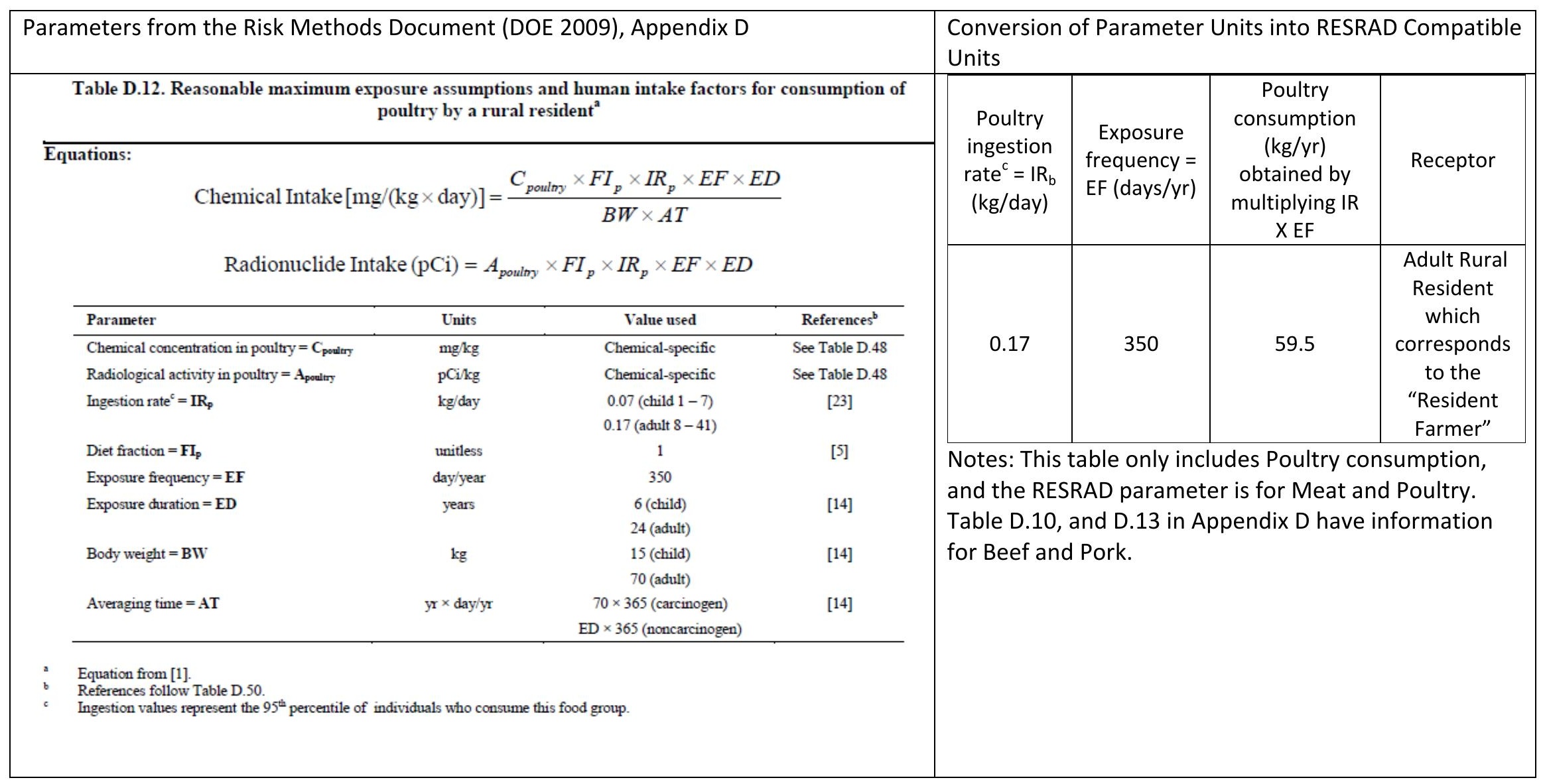


Meat and Poultry Consumption (cont.)

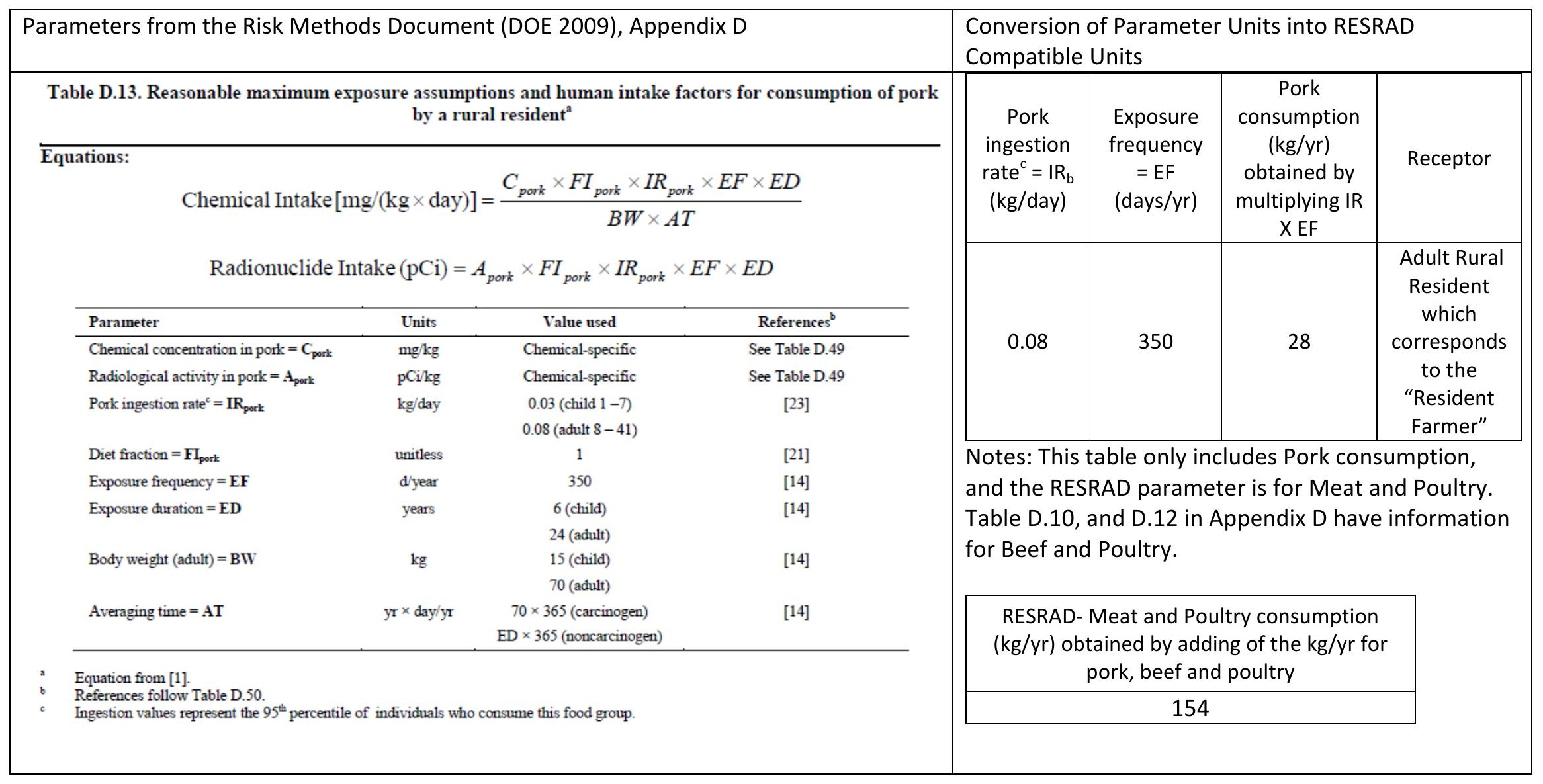




\section{Section C. Parameters Applicable to Beef and Dairy from DOE 2009, Appendix D}

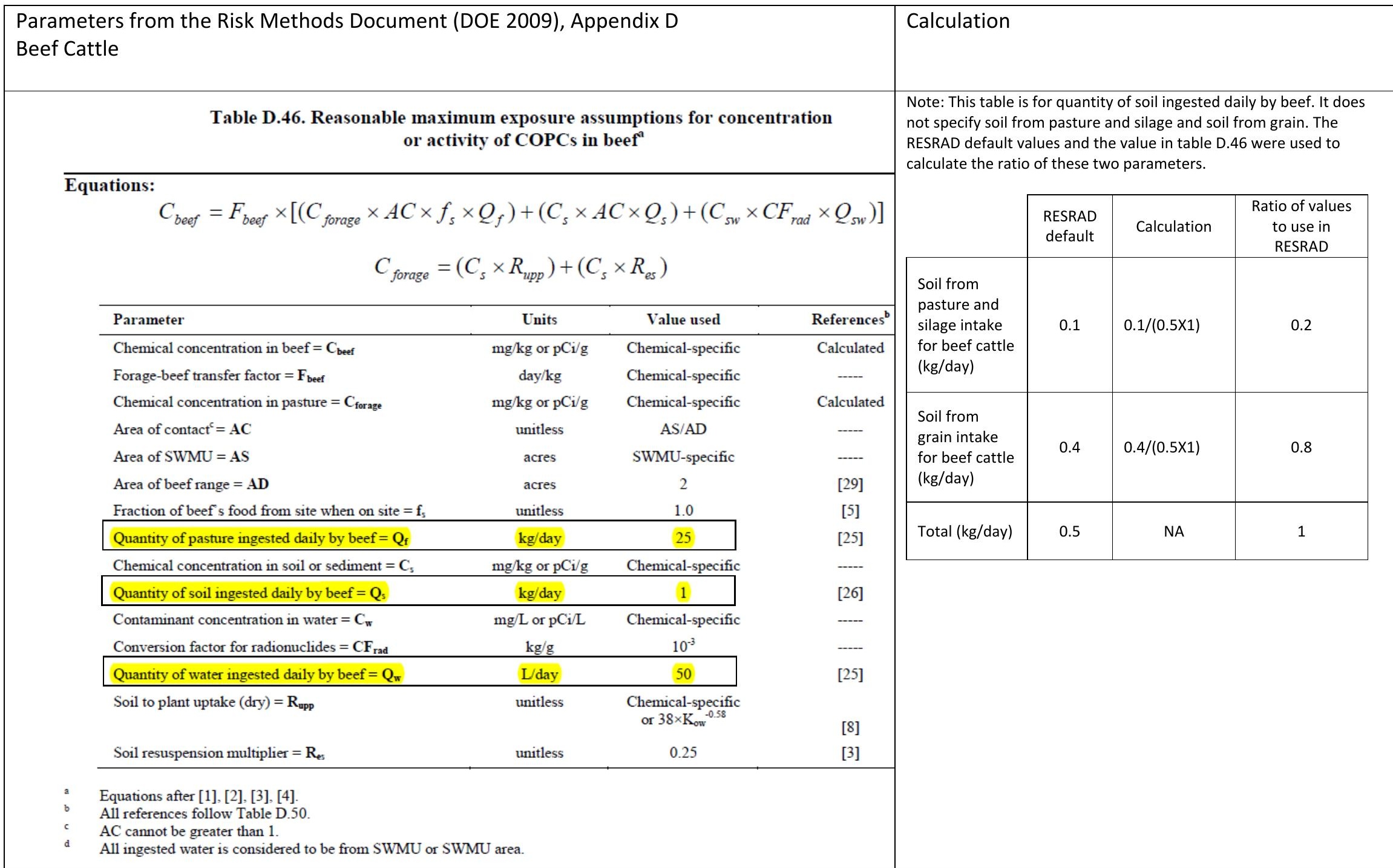

Values that were used to determine input parameters are highlighted. 


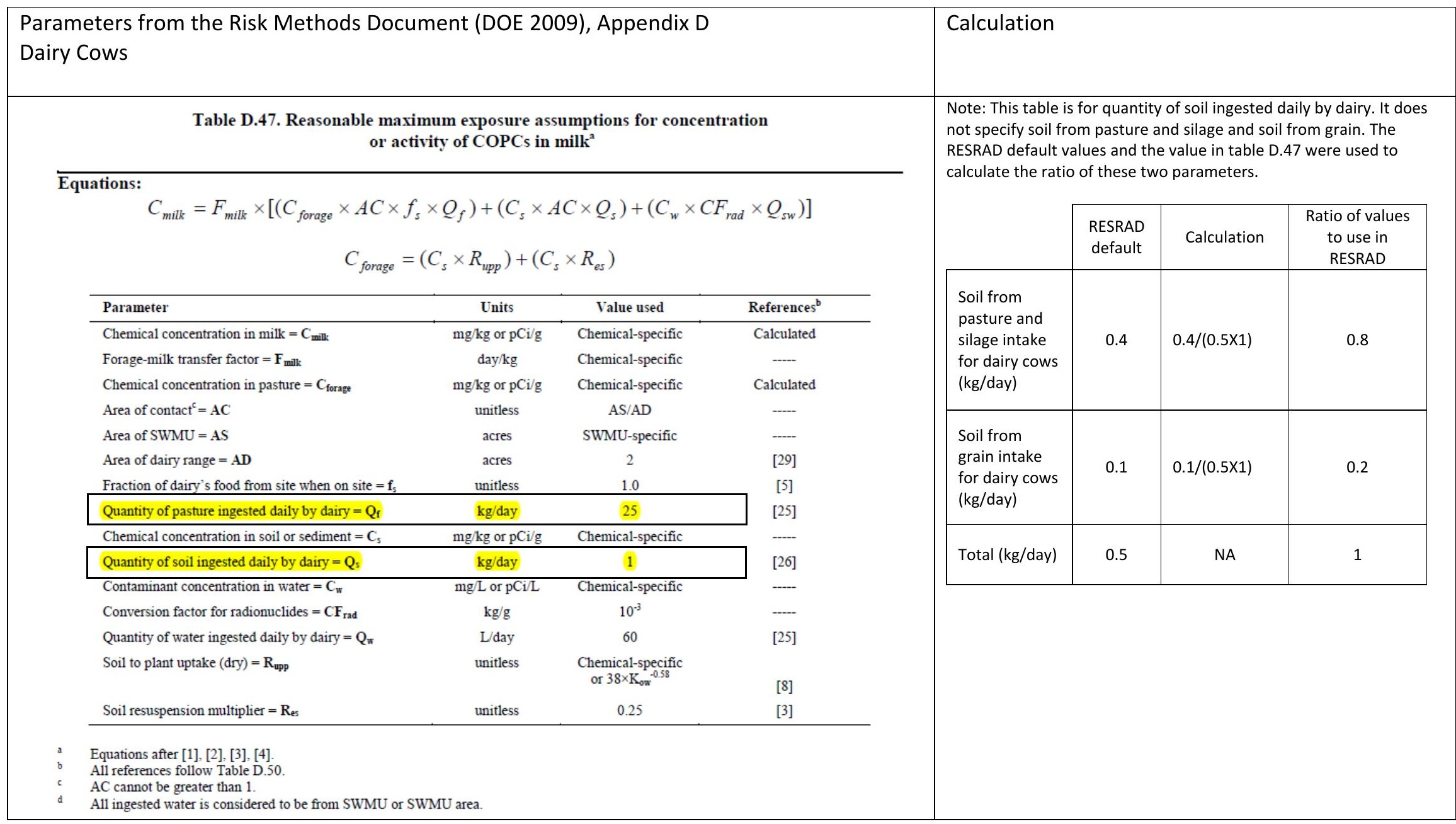

Values that were used to determine input parameters are highlighted. 


\section{References}

ATSDR 2002, Public Health Assessment for the Paducah Gaseous Diffusion Plant (USDOE) Paducah, McCracken County, Kentucky (May 2002).

DOE 2003a. Authorized Limits Request for Solid Waste Disposal at Landfill C-746-U at the Paducah Gaseous Diffusion Plant, (November 2002; revised January 2003).

DOE 2003b. Risk and Performance Evaluation of the C-746-U Landfill at the Paducah Gaseous Diffusion Plant, Paducah, Kentucky, DOE/OR/072041\&D2R1 (2003).

DOE 2009. Methods for Conducting Risk Assessments and Risk Evaluations at the Paducah Gaseous Diffusion Plant Paducah, Kentucky Volume 1. Human Health, DOE/LX/07-0107\&D1/V1 (2009).

DOE Statement of Work (SOW) for C-746-U Landfill provided to ORISE on December 2009.

DOE C-746-U landfill inventory spreadsheet for total waste disposed from May 2003 through May 2009.

DOE Project Communication with the Waste Disposal Options Project Team from Paducah, KY, March 2010 (Latest email correspondence 03/29/2010 from Rich Bonczek).

DOE Project Communication with the Geologist from Paducah, KY, April 2010 (Latest email correspondence 04/05/2010 from Raulie Casteel).

DOE Project Communication with Geologist and Engineer from Paducah, KY, April 2010 (Latest email correspondence 04/07/2010 from Raulie Casteel).

DOE Project Communication with the Geologist from Paducah, KY, April 2010 (Latest email correspondence 04/28/2010 from Raulie Casteel). DOE Project Communication May, 2010 (Discussion between ORISE and Rich Bonczek during a meeting held at ORISE on 05/17/2010).

DOE Project Communication June, 2010 (Email correspondence 06/02/2010 from ORISE to DOE).

DOE Project Communication July, 2010 (Discussion between ORISE and DOE-PPPO during a meeting held at ORISE on 07/12/2010).

DOE Project Communication September, 2010 (Discussion between ORISE and DOE-PPPO during a conference call held on 09/29/2010). 
DOE Project Communication October, 2010 (Discussion between ORISE and DOE-PPPO during a conference call held on 10/7/2010).

DOE Project Communication November, 2010 (Email correspondence 11/03/2010 from ORISE to DOE consultant).

DOE Project Communication April, 2011 (ORISE and DOE-PPPO biweekly conference call on 04/13/2011 and email correspondence 04/14/2011 from ORISE to DOE-PPPO).

DOE Project Communication April, 2011 (ORISE and DOE-PPPO email correspondence 04/8/2011 from Chad Drummond to DOE-PPPO from DOEPPPO to ORISE).

DOE Order 458.1, Radiation Protection of the Public and the Environment (DOE 2011).

DOE Order 5400.5, Radiation Protection of the Public and the Environment (DOE 1993).

Kenny, J. F. et al. 2009. Estimated Use of Water in the United States in 2005, Circular 1344, U.S. Department of Interior, U.S. Geological Survey (2009).

King, David A. and Karen Keil, 2006. Comparison of Standard Radiological Risk Models and Using RESRAD to Derive Generic Risk-Based Area Factors for Final Status Surveys, Risk Analysis, Vol. 26, No. 1.

Lee, D. W., J. C. Wang, and D. C. Kocher, 1995. Operating Limit Study for the Proposed Solid Waste Landfill at Paducah Gaseous Diffusion Plant, ORNL/TM-13008.

PRS 2008a. 2006 Paducah Site Annual Site Environmental Report for Calendar Year 2006, PRS-ENM-0034 Volume I, Paducah Remediation Services (September 2008).

PRS 2008b. 2008 Update of the Paducah Gaseous Diffusion Plant Site Wide Groundwater Flow Model, PRS-ENR-0028.

Wischmeier, W.H., and D.D. Smith 1978. Predicting Rainfall Erosion Losses: A Guide to Conservation Planning, AH537/12/78.

Yu, C., C. Loureiro, J. J. Cheng, L.G. Jones, Y.Y. Wang, Y.P. Chia, and E. Faillace, 1993. Data Collection Handbook to Support Modeling Impacts of Radioactive Material in Soil.

Yu C., D. LePoire, E. Gnanapragasam, J. Arnish, S. Kamboj, B.M. Biwer, J.-J. Cheng, A. Zielen, and S.Y. Chen, 2000. Development of Probabilistic RESRAD 6.0 and RESRAD-Build 3.0 Computer Codes, NUREG/CR-6697 ANL/EAD/TM-98. 
Yu, C., A.J. Zielen, J.J. Cheng, D.J. LePoire, E. Gnanapragasam, S. Kamboj, J. Arnish, A. Wallo, III, W.A. Williams, and H. Peterson, 2007. User's Manual for RESRAD OFFSITE Version 2, ANL/EVS/TM/07-1, DOE /HS-0005, NUREG/CR-6937, Argonne National Laboratory. 
ATTACHMENT 3 


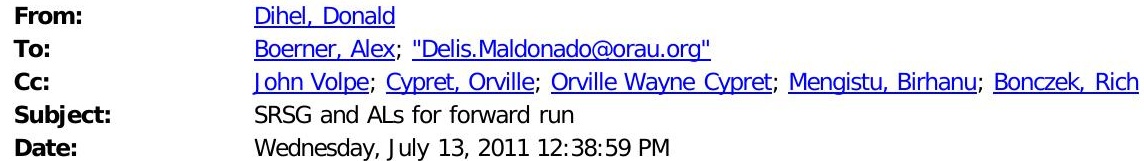

Here is what will be in the AL Request.

\begin{tabular}{|llll|}
\hline Radionuclide & $\begin{array}{l}\text { PPPO Proposed Single } \\
\text { Radionuclide Soil } \\
\text { Guideline }\end{array}$ & $\begin{array}{l}\text { PPPO Proposed ALs } \\
\text { Volumetric } \\
\text { (pCi/g) }\end{array}$ & \multicolumn{1}{c|}{$\begin{array}{l}\text { (pCi/g) } \\
\text { PPPO Proposed ALs } \\
\text { Surface } \\
\mathbf{( d p m} / \mathbf{1 0 0} \mathbf{c m}^{2} \text { ) }\end{array}$} \\
${ }^{241} \mathrm{Am}$ & 35 & 70 & 14,000 \\
${ }^{137} \mathrm{Cs}$ & 19 & 38 & 7,600 \\
${ }^{237} \mathrm{~Np}$ & 5.5 & 11 & 2,200 \\
${ }^{238} \mathrm{Pu}$ & 39 & 78 & 15,600 \\
${ }^{239} \mathrm{Pu}$ & 36 & 72 & 14,400 \\
${ }^{240} \mathrm{Pu}$ & 36 & 72 & 14,400 \\
${ }^{99} \mathrm{Tc}$ & 52 & 104 & 20,800 \\
${ }^{228} \mathrm{Th}$ & 4 & 8 & 1,600 \\
${ }^{230} \mathrm{Th}$ & 100 & 200 & 40,000 \\
${ }^{232} \mathrm{Th}$ & 4 & 8 & 1,600 \\
${ }^{234} \mathrm{U}$ & 160 & 320 & 64,000 \\
${ }^{235} \mathrm{U}$ & 6.5 & 13 & 2,600 \\
${ }^{238 \mathrm{U}}$ & 160 & 320 & 64,000 \\
\hline
\end{tabular}

Donald L Dihel, CHMM

Facility Representative/ Health Physicist

US Department of Energy

PPPO Paducah Site Office

5600 Hobbs Road

MS-103

Kevil, KY 42053

Office $270-441-6824$

Cell 270-217-9904

Fax 270-441-6801

From: Dihel, Donald

Sent: Tuesday, J uly 12, 2011 12:53 PM

To: 'Delis.Maldonado@orau.org'; 'Boerner, Alex'; Bonczek, Rich; 'John Volpe'; Cypret, Orville; 'Orville Wayne Cypret' Subject: SRSG for forward run

Below is the PPPO Proposed SRSG for performing the forward run. The 99TC for the offsite resident farmer will need to be a probabilistic analysis.

\section{Donald L Dihel, CHMM}

Facility Representative/ Health Physicist US Department of Energy 
PPPO Paducah Site Office

5600 Hobbs Road

MS-103

Kevil, KY 42053

Office $270-441-6824$

Cell 270-217-9904

Fax 270-441-6801 
ATTACHMENT 4 
QC of ORISE Forward Runs - RESRAD and RESRAD OFFSITE Deterministic Forward Runs and RESRAD OFFSITE Probabilistic Risk Assessment Forward Runs

Resident Farmer (onsite), Resident Gardener, Recreational User, Outdoor Worker and Offsite Resident Farmer

\begin{tabular}{|c|c|c|c|c|c|}
\hline \multicolumn{6}{|c|}{ Peak Dose from DOE-PPPO Proposed Single Radionuclide Soil Guidelines (mrem/yr) } \\
\hline \multirow{2}{*}{$\begin{array}{c}\text { Target } \\
\text { Dose }\end{array}$} & \multicolumn{4}{|c|}{$100 \mathrm{mrem} / \mathrm{yr}$} & \multirow{2}{*}{$\begin{array}{c}\mathrm{mrem} / \mathrm{yr} \\
\text { Offsite Resident } \\
\text { Farmer }\end{array}$} \\
\hline & $\begin{array}{c}\text { Resident } \\
\text { Farmer } \\
\text { (onsite) }\end{array}$ & $\begin{array}{l}\text { Resident } \\
\text { Gardener }\end{array}$ & $\begin{array}{c}\text { Recreational } \\
\text { User }\end{array}$ & Outdoor Worker & \\
\hline \multicolumn{6}{|c|}{ ORISE FORWARD RUNS } \\
\hline $\begin{array}{l}\text { Peak Dose } \\
(\mathrm{mrem} / \mathrm{yr})\end{array}$ & 21 & 6.8 & 0.0012 & 0.0026 & 1.9 \\
\hline Time $(y r)$ & $425.2 \pm 0.9$ & 1,050 & 1,050 & 1,050 & 772 \\
\hline \multicolumn{6}{|c|}{ QC FORWARD RUNS } \\
\hline $\begin{array}{l}\text { Peak Dose } \\
\text { (mrem/yr) }\end{array}$ & 21 & 6.8 & 0.0012 & 0.0026 & 1.9 \\
\hline Time $(\mathrm{yr})$ & $424.6 \pm 0.8$ & 1,050 & 1,050 & 1,050 & 772 \\
\hline \multicolumn{6}{|c|}{ ORISE FORWARD RUNS 10,000 YEARS } \\
\hline $\begin{array}{l}\text { Peak Dose } \\
\text { (mrem/yr) }\end{array}$ & 2,700 & 2,400 & 95 & 220 & 2.2 \\
\hline Time $(y r)$ & 10,000 & 10,000 & 10,000 & 10,000 & 10,000 \\
\hline \multicolumn{6}{|c|}{ OC FORWARD RUNS 10,000 YEARS } \\
\hline $\begin{array}{l}\text { Peak Dose } \\
(\mathrm{mrem} / \mathrm{yr})\end{array}$ & 2,719 & 2,359 & 95 & 218 & 2.2 \\
\hline Time $(y r)$ & 10,000 & 10,000 & 10,000 & 10,000 & 10,024 \\
\hline \multicolumn{6}{|c|}{ ORISE FORWARD RUNS 100,000 YEARS } \\
\hline $\begin{array}{l}\text { Peak Dose } \\
\text { (mrem/yr) }\end{array}$ & 2,700 & 2,400 & 96 & 220 & 2.2 \\
\hline Time $(y r)$ & 12,773 & 12,931 & 19,739 & 19,045 & 10,065 \\
\hline \multicolumn{6}{|c|}{ QC FORWARD RUNS 100,000 YEARS } \\
\hline $\begin{array}{l}\text { Peak Dose } \\
(\mathrm{mrem} / \mathrm{yr})\end{array}$ & 2731 & 2,370 & 96 & 221 & 2.2 \\
\hline Time $(y r)$ & 12,780 & 12,931 & 19,703 & 19,046 & 10,061 \\
\hline
\end{tabular}




\section{Landfill Worker and Trespasser}

\begin{tabular}{|c|c|c|}
\hline \multicolumn{3}{|c|}{$\begin{array}{l}\text { Peak Dose from DOE-PPPO Proposed Single } \\
\text { Radionuclide Soil Guidelines (mrem/yr) }\end{array}$} \\
\hline $\begin{array}{l}\text { Target } \\
\text { Dose }\end{array}$ & \multicolumn{2}{|c|}{$100 \mathrm{mrem} / \mathrm{yr}$} \\
\hline Receptor & Trespasser & Landfill Worker \\
\hline \multicolumn{3}{|c|}{ ORISE FORWARD RUNS AT SRSG } \\
\hline $\begin{array}{l}\text { Peak Dose } \\
(\mathrm{mrem} / \mathrm{yr})^{*}\end{array}$ & 2.1 & 32 \\
\hline Time $(\mathrm{yr})$ & 70 & 70 \\
\hline \multicolumn{3}{|c|}{ QC FORWARD RUNS AT SRSG } \\
\hline $\begin{array}{l}\text { Peak Dose } \\
(\mathrm{mrem} / \mathrm{yr})^{*}\end{array}$ & 2.1 & 32 \\
\hline Time $(y r)$ & 70 & 70 \\
\hline \multicolumn{3}{|c|}{ ORISE FORWARD RUNS AT PROPOSED AUTHORIZED LIMITS } \\
\hline $\begin{array}{l}\text { Peak Dose } \\
(\mathrm{mrem} / \mathrm{yr})^{*}\end{array}$ & 4.1 & 64 \\
\hline Time $(\mathrm{yr})$ & 70 & 70 \\
\hline \multicolumn{3}{|c|}{ QC FORWARD RUNS AT PROPOSED AUTHORIZED LIMITS } \\
\hline $\begin{array}{l}\text { Peak Dose } \\
(\mathrm{mrem} / \mathrm{yr})^{*}\end{array}$ & 4.1 & 63 \\
\hline Time (yr) & 70 & 70 \\
\hline
\end{tabular}




\section{Tc-99 Probabilistic Analysis for the Offsite Resident Farmer}

\begin{tabular}{|c|c|c|c|c|}
\hline \multicolumn{5}{|c|}{$\begin{array}{l}\text { Peak of the Mean Dose from DOE-PPPO Propos } \\
\text { Guideline for Tc- } 99\end{array}$} \\
\hline \multicolumn{5}{|c|}{ Offsite Resident Farmer } \\
\hline \multicolumn{5}{|c|}{ Active Pathways: Drinking Water, Plant, Milk, and Meat Ingestion } \\
\hline \multirow{3}{*}{$\begin{array}{l}\text { Peak of the } \\
\text { Mean Dose } \\
(\mathrm{mrem} / \mathrm{yr})\end{array}$} & & Repetitions & & \multirow{4}{*}{0.98} \\
\hline & 1 & 2 & 3 & \\
\hline & 0.9794 & 0.9773 & 0.9772 & \\
\hline $\begin{array}{l}\text { Time of Peak of } \\
\text { the Mean Dose } \\
(\mathrm{yr})\end{array}$ & 1,050 & 1,050 & 1,050 & \\
\hline \multicolumn{5}{|c|}{ QC FORWARD RUNS } \\
\hline \multirow{3}{*}{$\begin{array}{l}\text { Peak of the } \\
\text { Mean Dose } \\
(\mathrm{mrem} / \mathrm{yr})\end{array}$} & \multicolumn{3}{|c|}{ Repetitions } & \multirow{4}{*}{0.97} \\
\hline & 1 & 2 & 3 & \\
\hline & 0.9762 & 0.9754 & 0.9719 & \\
\hline $\begin{array}{l}\text { Time of Peak of } \\
\text { the Mean Dose } \\
(\mathrm{yr})\end{array}$ & 1,050 & 1,050 & 1,050 & \\
\hline \multicolumn{5}{|c|}{ Active Pathways: External Gamma, Inhalation of Dust, and Soil Ingestion } \\
\hline \multirow{3}{*}{$\begin{array}{l}\text { Peak of the } \\
\text { Mean Dose } \\
(\text { mrem/yr) }\end{array}$} & & Repetitions & & \multirow{4}{*}{0.0} \\
\hline & 1 & 2 & 3 & \\
\hline & $1.651 \mathrm{E}-06$ & $1.648 \mathrm{E}-06$ & $1.647 \mathrm{E}-06$ & \\
\hline $\begin{array}{l}\text { Time of Peak of } \\
\text { the Mean Dose } \\
(y r)\end{array}$ & 1,050 & 1,050 & 1,050 & \\
\hline \multicolumn{5}{|c|}{ QC FORWARD RUNS } \\
\hline \multirow{3}{*}{$\begin{array}{l}\text { Peak of the } \\
\text { Mean Dose } \\
(\mathrm{mrem} / \mathrm{yr})\end{array}$} & & Repetitions & & \multirow{4}{*}{0.0} \\
\hline & 1 & 2 & 3 & \\
\hline & $1.646 \mathrm{E}-6$ & $1.644 \mathrm{E}-6$ & $1.638 \mathrm{E}-6$ & \\
\hline $\begin{array}{l}\text { Time of Peak of } \\
\text { the Mean Dose } \\
(\mathrm{yr})\end{array}$ & 1,050 & 1,050 & 1,050 & \\
\hline & & & & \\
\hline
\end{tabular}

